Supplemental Table S2.txt

\begin{tabular}{|c|c|c|c|c|c|c|}
\hline CompoundID & AssayID & \multicolumn{2}{|c|}{ expt_pIC50 } & \multicolumn{2}{|l|}{ max2-pQSAR_pIC50 } & Clustering \\
\hline CHEMBL 2323521 & 941825 & $4.25 \overline{7}$ & 4.5689 & TRN & & \\
\hline CHEMBL178687 & 941825 & 4.2477 & 4.4279 & TRN & & \\
\hline CHEMBL 2323490 & 941825 & 4.2999 & 4.1577 & TRN & & \\
\hline CHEMBL 2323493 & 941825 & 4.8162 & 5.0078 & TRN & & \\
\hline CHEMBL 2323484 & 941825 & 3.0 & 3.1545 & TRN & & \\
\hline CHEMBL 2323478 & 941825 & 4.3606 & 3.5512 & TRN & & \\
\hline CHEMBL2323500 & 941825 & 4.3989 & 4.3875 & TRN & & \\
\hline CHEMBL2323497 & 941825 & 4.7617 & 4.6396 & TRN & & \\
\hline CHEMBL2323481 & 941825 & 4.0918 & 4.2558 & TRN & & \\
\hline CHEMBL 2323482 & 941825 & 4.8681 & 5.0159 & TRN & & \\
\hline CHEMBL 2323494 & 941825 & 4.4177 & 4.4666 & TRN & & \\
\hline CHEMBL2323522 & 941825 & 4.2704 & 4.2696 & TST & & \\
\hline CHEMBL2323512 & 941825 & 3.9363 & 4.2781 & TRN & & \\
\hline CHEMBL2323485 & 941825 & 3.0 & 3.417 & TRN & & \\
\hline CHEMBL 2323525 & 941825 & 4.317 & 4.3377 & TST & & \\
\hline CHEMBL2323486 & 941825 & 3.0 & 3.5334 & TRN & & \\
\hline CHEMBL2323498 & 941825 & 5.1024 & 4.8426 & TRN & & \\
\hline CHEMBL 2172787 & 941825 & 4.1845 & 4.1584 & TRN & & \\
\hline CHEMBL2323472 & 941825 & 4.39 & 4.5969 & TRN & & \\
\hline CHEMBL2323480 & 941825 & 3.0 & 3.0562 & TRN & & \\
\hline CHEMBL2323475 & 941825 & 4.7097 & 4.7657 & TRN & & \\
\hline CHEMBL1058 & 941825 & 4.0 & 3.6136 & TST & & \\
\hline CHEMBL2323509 & 941825 & 5.0079 & 4.5912 & TRN & & \\
\hline CHEMBL 73572 & 941825 & 3.0 & 3.5274 & TRN & & \\
\hline CHEMBL2323483 & 941825 & 4.62 & 3.7138 & TST & & \\
\hline CHEMBL 2323511 & 941825 & 4.0315 & 3.8415 & TRN & & \\
\hline CHEMBL 2323508 & 941825 & 4.3048 & 4.3509 & TRN & & \\
\hline CHEMBL2323488 & 941825 & 4.6336 & 4.5445 & TST & & \\
\hline CHEMBL2323520 & 941825 & 4.563 & 4.3726 & TRN & & \\
\hline CHEMBL2323507 & 941825 & 4.8401 & 4.2217 & TRN & & \\
\hline CHEMBL 2323505 & 941825 & 4.0 & 3.3734 & TST & & \\
\hline CHEMBL178499 & 941825 & 4.2149 & 4.0308 & TRN & & \\
\hline CHEMBL2323504 & 941825 & 4.7156 & 4.8263 & TRN & & \\
\hline CHEMBL2323523 & 941825 & 4.0 & 4.4995 & TST & & \\
\hline CHEMBL2323491 & 941825 & 4.3692 & 4.8563 & TRN & & \\
\hline CHEMBL 2323496 & 941825 & 4.8210 & 000000000 & 4.6624 & TRN & \\
\hline CHEMBL 2323474 & 941825 & 4.447 & 4.1274 & TRN & & \\
\hline CHEMBL2323502 & 941825 & 4.4816 & 4.5433 & TRN & & \\
\hline CHEMBL2323515 & 941825 & 4.1409 & 4.4989 & TRN & & \\
\hline CHEMBL2323499 & 941825 & 4.399 & 4.406000 & 0000000001 & TRN & \\
\hline CHEMBL 2323487 & 941825 & 4.0 & 4.1972 & TRN & & \\
\hline CHEMBL2323506 & 941825 & 3.0 & 3.0468 & TST & & \\
\hline CHEMBL 2323516 & 941825 & 4.6751 & 4.7397 & TRN & & \\
\hline CHEMBL2323510 & 941825 & 4.9108 & 4.5478 & TRN & & \\
\hline CHEMBL2323518 & 941825 & 4.3933 & 4.2907 & TRN & & \\
\hline CHEMBL2323517 & 941825 & 4.4719 & 4.2435 & TRN & & \\
\hline CHEMBL 2323492 & 941825 & 4.7739 & 4.7637 & TRN & & \\
\hline
\end{tabular}




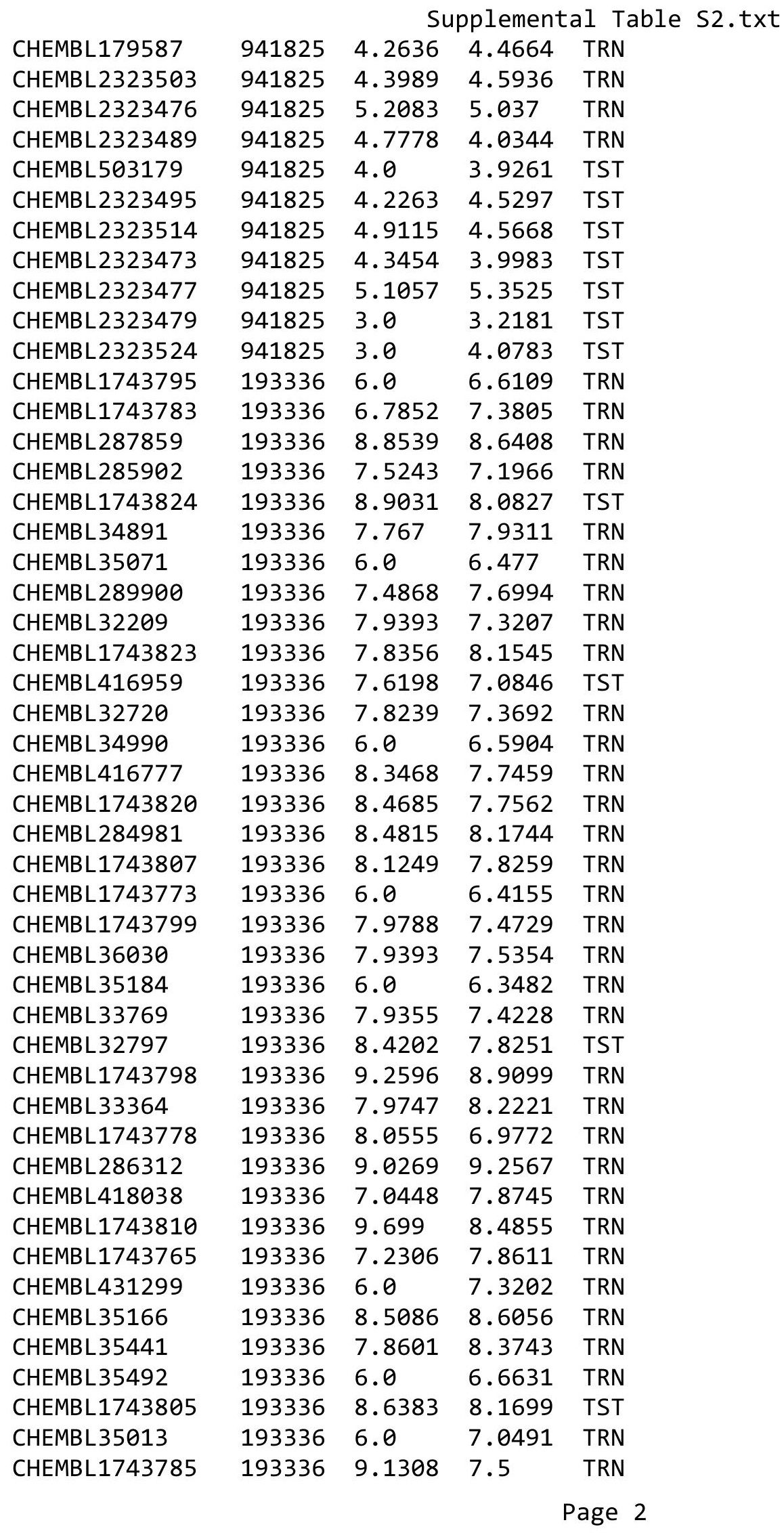




\begin{tabular}{|c|c|c|c|c|c|c|}
\hline \multicolumn{7}{|c|}{ 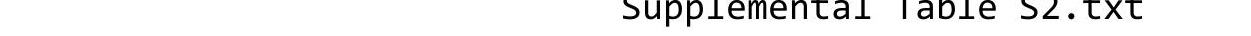 } \\
\hline CHEMBL1743819 & 193336 & 6.0 & 6.4558 & TRN & & \\
\hline CHEMBL1743767 & 193336 & 8.8539 & 8.3408 & TRN & & \\
\hline CHEMBL431898 & 193336 & 8.2518 & 7.7354 & TRN & & \\
\hline CHEMBL1743793 & 193336 & 6.0 & 6.6369 & TRN & & \\
\hline CHEMBL1743791 & 193336 & 8.8239 & 8.3877 & TRN & & \\
\hline CHEMBL1743790 & 193336 & 6.0 & 8.5413 & TRN & & \\
\hline CHEMBL1743821 & 193336 & 7.5129 & 7.4996 & TST & & \\
\hline CHEMBL32497 & 193336 & 7.8633 & 5.945 & TRN & & \\
\hline CHEMBL1743812 & 193336 & 8.4685 & 8.133 & TRN & & \\
\hline CHEMBL286455 & 193336 & 8.2518 & 7.5094 & TST & & \\
\hline CHEMBL1743803 & 193336 & 6.0 & 6.5594 & TST & & \\
\hline CHEMBL284513 & 193336 & 7.9788 & 6.2047 & TST & & \\
\hline CHEMBL1743786 & 193336 & 9.2076 & 8.7207 & TST & & \\
\hline CHEMBL1743804 & 193336 & 7.27 & 6.4525 & TST & & \\
\hline CHEMBL1743814 & 193336 & 7.0915 & 6.9935 & TST & & \\
\hline CHEMBL 284367 & 193336 & 6.0 & 6.2535 & TST & & \\
\hline CHEMBL32726 & 193336 & 6.0 & 7.6841 & TST & & \\
\hline CHEMBL1743822 & 193336 & 6.0 & 6.6322 & TST & & \\
\hline CHEMBL391597 & 457234 & 6.4597 & 6.1288 & TRN & & \\
\hline CHEMBL249061 & 457234 & 6.38200 & 00000000 & $\partial 1$ & 6.1795 & TRN \\
\hline CHEMBL248047 & 457234 & 6.1427 & 5.989 & TRN & & \\
\hline CHEMBL248218 & 457234 & 8.0458 & 8.003 & TRN & & \\
\hline CHEMBL397519 & 457234 & 4.0 & 4.1281 & TRN & & \\
\hline CHEMBL248389 & 457234 & 7.3468 & 7.6131 & TRN & & \\
\hline CHEMBL247645 & 457234 & 7.4815 & 7.358 & TRN & & \\
\hline CHEMBL247016 & 457234 & 6.9208 & 5.8098 & TRN & & \\
\hline CHEMBL399073 & 457234 & 4.0 & 4.9047 & TST & & \\
\hline CHEMBL249063 & 457234 & 7.0 & 6.7909 & TRN & & \\
\hline CHEMBL245794 & 457234 & 7.3665 & 7.4217 & TRN & & \\
\hline CHEMBL249471 & 457234 & 7.8861 & 7.6673 & TRN & & \\
\hline CHEMBL398466 & 457234 & 5.6576 & 5.0492 & TRN & & \\
\hline CHEMBL246619 & 457234 & 6.3788 & 6.4162 & TRN & & \\
\hline CHEMBL247606 & 457234 & 7.4949 & 6.806 & TRN & & \\
\hline CHEMBL248026 & 457234 & 4.0 & 4.1679 & TRN & & \\
\hline CHEMBL248192 & 457234 & 6.6126 & 6.1447 & TRN & & \\
\hline CHEMBL247655 & 457234 & 4.0 & 3.778 & TRN & & \\
\hline CHEMBL248388 & 457234 & 6.7447 & 6.7859 & TRN & & \\
\hline CHEMBL247198 & 457234 & 5.7959 & 5.6353 & TRN & & \\
\hline CHEMBL247818 & 457234 & 6.2924 & 6.0557 & TRN & & \\
\hline CHEMBL245795 & 457234 & 7.5686 & 7.1901 & TST & & \\
\hline CHEMBL247607 & 457234 & 5.8729 & 5.0182 & TRN & & \\
\hline CHEMBL248054 & 457234 & 4.0 & 5.1078 & TRN & & \\
\hline CHEMBL248241 & 457234 & 4.0 & 3.9342 & TRN & & \\
\hline CHEMBL438874 & 457234 & 6.3979 & 5.6829 & TST & & \\
\hline CHEMBL247017 & 457234 & 7.2676 & 7.2421 & TRN & & \\
\hline CHEMBL399357 & 457234 & 6.8539 & 6.4249 & TST & & \\
\hline CHEMBL248217 & 457234 & 7.6383 & 7.7066 & TRN & & \\
\hline CHEMBL248053 & 457234 & 6.3872 & 5.9152 & TRN & & \\
\hline
\end{tabular}




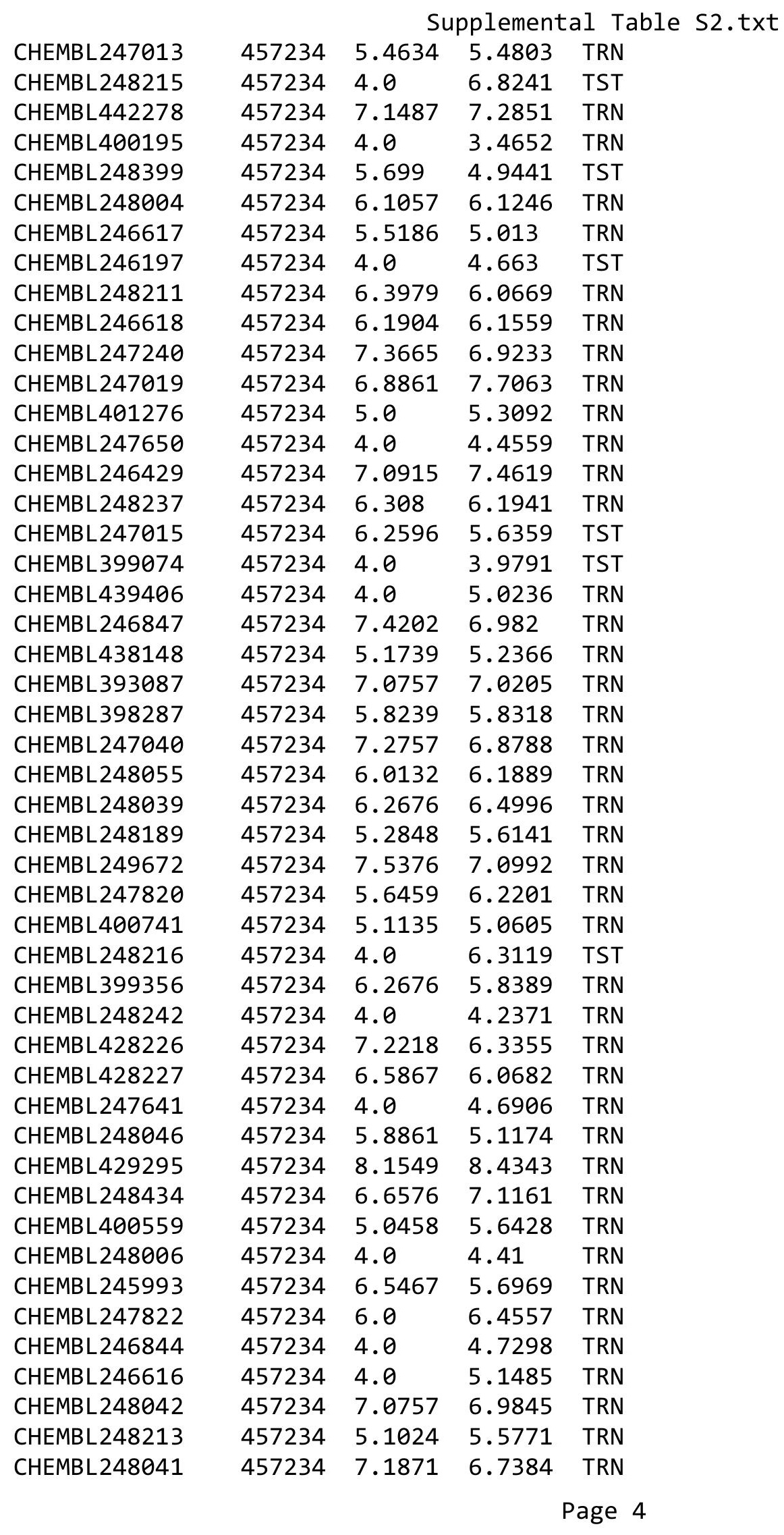




\begin{tabular}{|c|c|c|c|c|}
\hline \multicolumn{5}{|c|}{ Supplemental Table S2.txt } \\
\hline CHEMBL247461 & 457234 & 4.0 & 3.1391 & TRN \\
\hline CHEMBL249062 & 457234 & 6.2132 & 6.6761 & TRN \\
\hline CHEMBL248426 & 457234 & 5.1024 & 6.1815 & TRN \\
\hline CHEMBL247643 & 457234 & 6.5406 & 5.5674 & TRN \\
\hline CHEMBL436633 & 457234 & 5.6383 & 6.4672 & TST \\
\hline CHEMBL245793 & 457234 & 4.0 & 4.0821 & TRN \\
\hline CHEMBL440231 & 457234 & 7.6576 & 7.356 & TRN \\
\hline CHEMBL251095 & 457234 & 7.5528 & 4.0335 & TST \\
\hline CHEMBL246843 & 457234 & 6.4949 & 6.6485 & TRN \\
\hline CHEMBL398286 & 457234 & 4.0 & 5.6189 & TRN \\
\hline CHEMBL246428 & 457234 & 6.8861 & 7.3013 & TRN \\
\hline CHEMBL393268 & 457234 & 6.6345 & 5.8219 & TRN \\
\hline CHEMBL245792 & 457234 & 4.0 & 5.3222 & TST \\
\hline CHEMBL400869 & 457234 & 5.3565 & 5.6726 & TRN \\
\hline CHEMBL248035 & 457234 & 5.1643 & 5.3137 & TRN \\
\hline CHEMBL399767 & 457234 & 4.0 & 4.3153 & TRN \\
\hline CHEMBL399768 & 457234 & 5.8539 & 4.6102 & TST \\
\hline CHEMBL247644 & 457234 & 7.0605 & 7.0571 & TST \\
\hline CHEMBL246196 & 457234 & 4.0 & 4.3821 & TST \\
\hline CHEMBL247041 & 457234 & 7.4559 & 6.1112 & TST \\
\hline CHEMBL395701 & 457234 & 6.8447 & 6.1452 & TST \\
\hline CHEMBL247605 & 457234 & 5.5045 & 5.5967 & TST \\
\hline CHEMBL246846 & 457234 & 4.0 & 4.4646 & TST \\
\hline CHEMBL398549 & 457234 & 4.0 & 4.5874 & TST \\
\hline CHEMBL248428 & 457234 & 7.5229 & 6.5143 & TST \\
\hline CHEMBL245995 & 457234 & 5.9208 & 5.7937 & TST \\
\hline CHEMBL247014 & 457234 & 5.7959 & 4.3761 & TST \\
\hline CHEMBL246421 & 457234 & 4.0 & 3.6921 & TST \\
\hline CHEMBL248390 & 457234 & 7.9586 & 6.5668 & TST \\
\hline CHEMBL245994 & 457234 & 5.5918 & 5.6316 & TST \\
\hline CHEMBL248037 & 457234 & 5.0655 & 6.2545 & TST \\
\hline CHEMBL377852 & 467683 & 8.1 & 7.6422 & TST \\
\hline CHEMBL402326 & 467683 & 6.4 & 6.4726 & TRN \\
\hline CHEMBL257969 & 467683 & 6.8 & 6.731 & TRN \\
\hline CHEMBL255485 & 467683 & 6.6 & 6.5978 & TRN \\
\hline CHEMBL255701 & 467683 & 7.2 & 7.1666 & TRN \\
\hline CHEMBL255876 & 467683 & 7.3 & 7.29700 & 2000000001 \\
\hline CHEMBL258183 & 467683 & 7.3 & 7.2705 & TRN \\
\hline CHEMBL402770 & 467683 & 7.5 & 7.5267 & TRN \\
\hline CHEMBL429321 & 467683 & 7.1 & 7.1418 & TRN \\
\hline CHEMBL258439 & 467683 & 6.7 & 6.7153 & TRN \\
\hline CHEMBL258226 & 467683 & 7.1 & 7.1175 & TRN \\
\hline CHEMBL256560 & 467683 & 7.6 & 7.5957 & TRN \\
\hline CHEMBL253538 & 467683 & 7.1 & 7.0721 & TRN \\
\hline CHEMBL254963 & 467683 & 7.1 & 7.1138 & TRN \\
\hline CHEMBL256092 & 467683 & 7.5 & 7.5496 & TRN \\
\hline CHEMBL258199 & 467683 & 7.6 & 7.584 & TRN \\
\hline CHEMBL258413 & 467683 & 7.6 & 7.6197 & TRN \\
\hline
\end{tabular}




\begin{tabular}{|c|c|c|c|c|}
\hline & & & olem & \\
\hline CHEMBL 258200 & 467683 & 7.5 & 7.522 & TRN \\
\hline CHEMBL403580 & 467683 & 7.6 & 7.6147 & TRN \\
\hline CHEMBL254558 & 467683 & 7.4 & 7.3988 & TRN \\
\hline CHEMBL437796 & 467683 & 7.8 & 7.776 & TRN \\
\hline CHEMBL 254559 & 467683 & 7.2 & 7.2092 & TRN \\
\hline CHEMBL404481 & 467683 & 7.3 & 7.3771 & TRN \\
\hline CHEMBL 257544 & 467683 & 7.4 & 7.3998 & TRN \\
\hline CHEMBL 257138 & 467683 & 7.7 & 7.6336 & TRN \\
\hline CHEMBL 256933 & 467683 & 7.9 & 7.8931 & TRN \\
\hline CHEMBL404026 & 467683 & 7.9 & 7.893 & TRN \\
\hline CHEMBL 254990 & 467683 & 7.8 & 7.7847 & TRN \\
\hline CHEMBL403939 & 467683 & 7.2 & 7.2529 & TRN \\
\hline CHEMBL403940 & 467683 & 7.4 & 7.349 & TRN \\
\hline CHEMBL 256731 & 467683 & 7.4 & 7.3856 & TRN \\
\hline CHEMBL404297 & 467683 & 8.2 & 8.1984 & TRN \\
\hline CHEMBL 254151 & 467683 & 7.8 & 7.7594 & TRN \\
\hline CHEMBL 254150 & 467683 & 8.0 & 7.9957 & TRN \\
\hline CHEMBL 254152 & 467683 & 7.6 & 7.5773 & TRN \\
\hline CHEMBL402604 & 467683 & 6.5 & 6.4885 & TRN \\
\hline CHEMBL402202 & 467683 & 6.6 & 7.4304 & TST \\
\hline CHEMBL 256532 & 467683 & 6.7 & 7.5543 & TST \\
\hline CHEMBL 256737 & 467683 & 6.9 & 6.8882 & TRN \\
\hline CHEMBL 256736 & 467683 & 7.1 & 7.0008 & TRN \\
\hline CHEMBL 254553 & 467683 & 7.3 & 7.2654 & TRN \\
\hline CHEMBL 254554 & 467683 & 7.6 & 7.6282 & TRN \\
\hline CHEMBL 257146 & 467683 & 7.4 & 7.5285 & TRN \\
\hline CHEMBL 257147 & 467683 & 6.9 & 6.9085 & TRN \\
\hline CHEMBL404711 & 467683 & 8.0 & 7.5282 & TST \\
\hline CHEMBL 256579 & 467683 & 7.1 & 7.8939 & TST \\
\hline CHEMBL 254958 & 467683 & 6.7 & 7.5026 & TST \\
\hline CHEMBL404698 & 467683 & 7.4 & 7.3262 & TST \\
\hline CHEMBL 257970 & 467683 & 6.9 & 7.5662 & TST \\
\hline CHEMBL 258171 & 467683 & 7.0 & 7.2572 & TST \\
\hline CHEMBL437399 & 467683 & 6.9 & 6.9367 & TST \\
\hline CHEMBL 256785 & 467683 & 0.2 & 7.1906 & TST \\
\hline CHEMBL 258184 & 467683 & 8.2 & 7.2568 & TST \\
\hline CHEMBL 232117 & 467683 & 8.6 & 7.8165 & TST \\
\hline CHEMBL233140 & 467683 & 7.6 & 7.8091 & TST \\
\hline CHEMBL2288902 & 925615 & 8.07 & 8.7288 & TRN \\
\hline CHEMBL 2288901 & 925615 & 4.09 & 4.1636 & TRN \\
\hline CHEMBL2288900 & 925615 & 4.09 & 4.1765 & TRN \\
\hline CHEMBL2288899 & 925615 & 5.32 & 5.2036 & TRN \\
\hline CHEMBL2288898 & 925615 & 9.06 & 8.3911 & TRN \\
\hline CHEMBL 2288897 & 925615 & 6.31 & 5.7324 & TST \\
\hline CHEMBL 257071 & 925615 & 7.21 & 7.0339 & TRN \\
\hline CHEMBL 272075 & 925615 & 7.36 & 7.0339 & TRN \\
\hline CHEMBL 273139 & 925615 & 6.9 & 7.0339 & TRN \\
\hline CHEMBL155621 & 925615 & 6.83 & 7.0339 & TRN \\
\hline
\end{tabular}




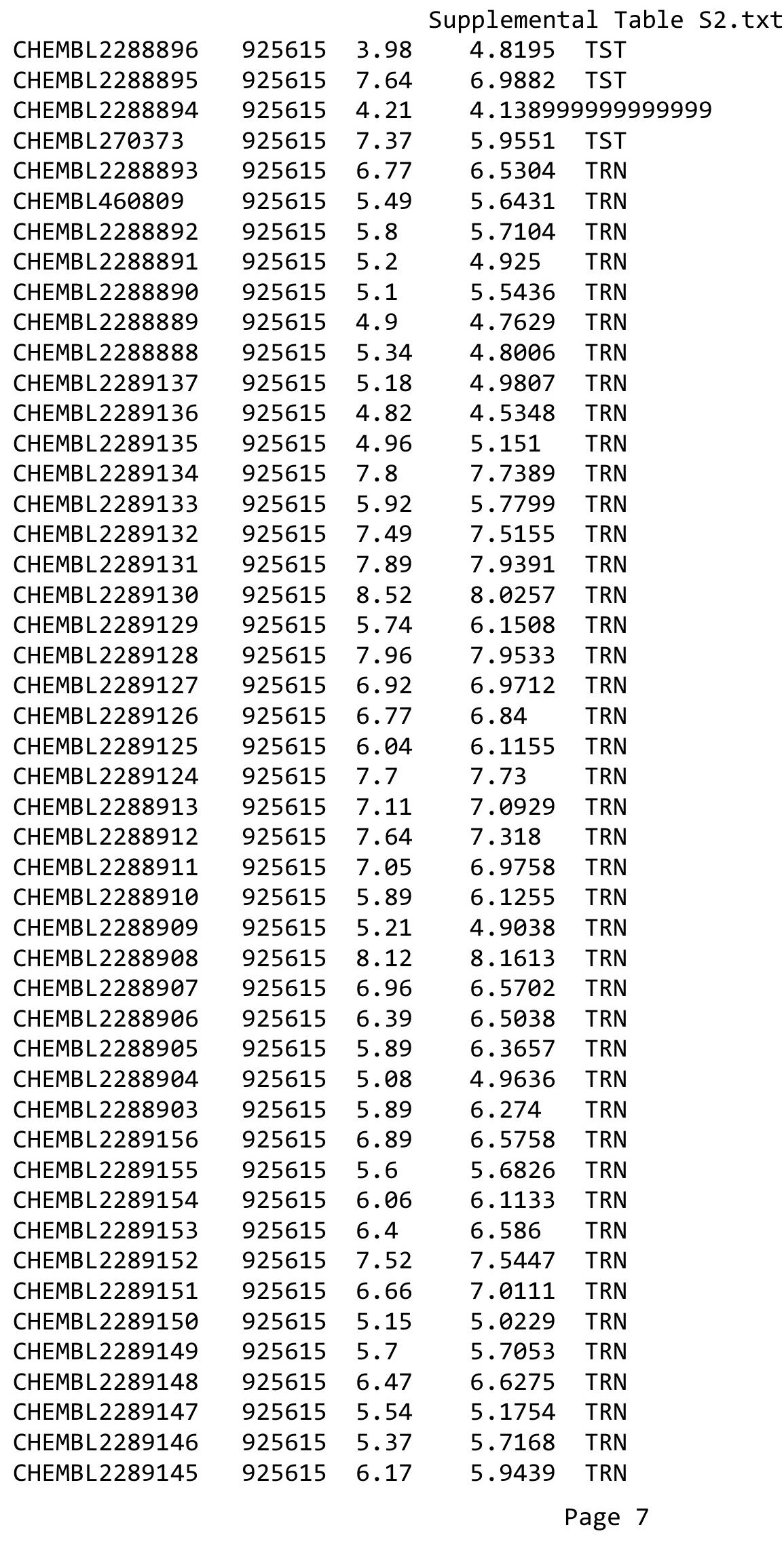




\begin{tabular}{|c|c|c|c|c|}
\hline \multicolumn{5}{|c|}{ Supplemental Table S2.txt } \\
\hline CHEMBL 2289144 & 925615 & 5.68 & 6.1976 & TRN \\
\hline CHEMBL 2289143 & 925615 & 5.06 & 5.043 & TRN \\
\hline CHEMBL2289142 & 925615 & 8.49 & 8.4908 & TRN \\
\hline CHEMBL 2289141 & 925615 & 8.51 & 8.3128 & TRN \\
\hline CHEMBL 2289140 & 925615 & 8.12 & 8.0657 & TRN \\
\hline CHEMBL 2289139 & 925615 & 8.35 & 8.4219 & TRN \\
\hline CHEMBL 2289138 & 925615 & 5.28 & \multicolumn{2}{|c|}{6.7989999999999995} \\
\hline CHEMBL2289184 & 925615 & 5.01 & 6.6548 & TST \\
\hline CHEMBL 2289183 & 925615 & 6.3 & 7.3665 & TRN \\
\hline CHEMBL 2289182 & 925615 & 6.2 & 7.3665 & TRN \\
\hline CHEMBL 2289181 & 925615 & 6.4 & 7.3665 & TRN \\
\hline CHEMBL 2289180 & 925615 & 7.35 & 7.3665 & TRN \\
\hline CHEMBL2289179 & 925615 & 7.16 & 7.7451 & TRN \\
\hline CHEMBL270375 & 925615 & 7.82 & 7.3665 & TRN \\
\hline CHEMBL 2289178 & 925615 & 7.89 & 7.5939 & TRN \\
\hline CHEMBL 2289177 & 925615 & 7.37 & 7.3665 & TRN \\
\hline CHEMBL 2289176 & 925615 & 8.24 & 8.2783 & TRN \\
\hline CHEMBL 270374 & 925615 & 7.7 & 7.3665 & TRN \\
\hline CHEMBL 2289175 & 925615 & 9.77 & 9.6849 & TRN \\
\hline CHEMBL 2289174 & 925615 & 8.43 & 7.3665 & TRN \\
\hline CHEMBL 2289173 & 925615 & 7.98 & 7.3864 & TST \\
\hline CHEMBL89506 & 925615 & 8.62 & 7.3665 & TRN \\
\hline CHEMBL 2289172 & 925615 & 8.09 & 7.3665 & TRN \\
\hline CHEMBL440542 & 925615 & 7.51 & 7.3665 & TRN \\
\hline CHEMBL 2289171 & 925615 & 5.6 & 5.6901 & TRN \\
\hline CHEMBL 2289170 & 925615 & 5.8 & 6.435 & TST \\
\hline CHEMBL 2289169 & 925615 & 5.3 & 6.1706 & TST \\
\hline CHEMBL 2289168 & 925615 & 6.11 & 6.4581 & TRN \\
\hline CHEMBL402615 & 925615 & 5.82 & 5.9462 & TRN \\
\hline CHEMBL 2289167 & 925615 & 5.27 & 4.7583 & TST \\
\hline CHEMBL 2289166 & 925615 & 8.0 & 6.4066 & TST \\
\hline CHEMBL 2289165 & 925615 & 7.57 & 6.4066 & TST \\
\hline CHEMBL 2289164 & 925615 & 7.24 & 6.4066 & TST \\
\hline CHEMBL356917 & 925615 & 6.4 & 6.4066 & TST \\
\hline CHEMBL 2289163 & 925615 & 5.49 & 5.2547 & TST \\
\hline CHEMBL 2289162 & 925615 & 6.06 & 6.8705 & TST \\
\hline CHEMBL 2289160 & 925615 & 3.3 & 6.7628 & TST \\
\hline CHEMBL 2289159 & 925615 & 6.7 & 8.8047 & TST \\
\hline CHEMBL 2289158 & 925615 & 6.52 & 7.5691 & TST \\
\hline CHEMBL 2289157 & 925615 & 4.15 & 4.399 & TST \\
\hline CHEMBL 293277 & 925615 & 3.04 & 3.7993 & TST \\
\hline CHEMBL89946 & 925615 & 4.85 & 5.3095 & TRN \\
\hline CHEMBL 86674 & 925615 & 5.14 & 5.3095 & TRN \\
\hline CHEMBL89508 & 925615 & 5.41 & 5.3095 & TRN \\
\hline CHEMBL89613 & 925615 & 7.0 & 5.3095 & TST \\
\hline CHEMBL86668 & 925615 & 6.66 & 5.3095 & TST \\
\hline CHEMBL152843 & 925615 & 5.17 & 5.3095 & TST \\
\hline CHEMBL93675 & 925615 & 4.17 & 5.3095 & TST \\
\hline
\end{tabular}




\begin{tabular}{|c|c|c|c|c|c|c|}
\hline \multicolumn{7}{|c|}{ Supplemental Table s2.txt } \\
\hline CHEMBL90719 & 925615 & 3.66 & 5.3095 & TST & & \\
\hline CHEMBL3919487 & 1641573 & 8.9872 & 7.8014 & TRN & & \\
\hline CHEMBL3904101 & 1641573 & 5.0 & 8.71 & TRN & & \\
\hline CHEMBL 3911435 & 1641573 & 8.9884 & 8.2738 & TRN & & \\
\hline CHEMBL3956912 & 1641573 & 8.6271 & 8.4563 & TRN & & \\
\hline CHEMBL3979379 & 1641573 & 9.3098 & 8.9619 & TRN & & \\
\hline CHEMBL3895177 & 1641573 & 9.5251 & 8.3317 & TRN & & \\
\hline CHEMBL3895387 & 1641573 & 8.5017 & 8.3056 & TRN & & \\
\hline CHEMBL3910917 & 1641573 & 7.8413 & 8.647 & TRN & & \\
\hline CHEMBL3981422 & 1641573 & 8.0862 & 8.4088 & TRN & & \\
\hline CHEMBL 3943285 & 1641573 & 6.0 & 7.9144 & TRN & & \\
\hline CHEMBL3934011 & 1641573 & 8.9031 & 8.6877 & TRN & & \\
\hline CHEMBL3895877 & 1641573 & 8.2281 & 8.9076 & TST & & \\
\hline CHEMBL 3904155 & 1641573 & 6.0 & 8.9187 & TST & & \\
\hline CHEMBL3911652 & 1641573 & 5.0 & 8.9341 & TST & & \\
\hline CHEMBL3948240 & 1641573 & 9.6576 & 9.1561 & TST & & \\
\hline CHEMBL3923484 & 1641573 & 6.0 & 8.4354 & TRN & & \\
\hline CHEMBL3947651 & 1641573 & 9.2676 & 9.2344 & TRN & & \\
\hline CHEMBL3914825 & 1641573 & 8.2636 & 8.3389 & TRN & & \\
\hline CHEMBL3920436 & 1641573 & 9.2757 & 9.0699 & TRN & & \\
\hline CHEMBL3962329 & 1641573 & 9.0 & 8.5854 & TRN & & \\
\hline CHEMBL3893418 & 1641573 & 8.85700 & 20000000 & $\partial 1$ & 8.2507 & TRN \\
\hline CHEMBL3916337 & 1641573 & 8.9914 & 9.0456 & TST & & \\
\hline CHEMBL 3928641 & 1641573 & 8.9666 & 9.0222 & TST & & \\
\hline CHEMBL3928579 & 1641573 & 8.8239 & 8.73899 & 9999999999 & & TST \\
\hline CHEMBL3981749 & 1641573 & 9.2291 & 9.1323 & TRN & & \\
\hline CHEMBL3955543 & 1641573 & 9.3768 & 8.6861 & TRN & & \\
\hline CHEMBL3960181 & 1641573 & 7.9318 & 8.7735 & TRN & & \\
\hline CHEMBL3953315 & 1641573 & 8.6716 & 8.6897 & TRN & & \\
\hline CHEMBL3923015 & 1641573 & 8.7282 & 8.8585 & TST & & \\
\hline CHEMBL3968048 & 1641573 & 5.0 & 8.7623 & TST & & \\
\hline CHEMBL3938530 & 1641573 & 7.8931 & 8.5166 & TRN & & \\
\hline CHEMBL3960386 & 1641573 & 8.98299 & 99999999 & 99 & 9.0215 & TS \\
\hline CHEMBL3895498 & 1641573 & 9.3468 & 9.043 & TRN & & \\
\hline CHEMBL3900767 & 1641573 & 9.6198 & 8.7762 & TRN & & \\
\hline CHEMBL3939459 & 1641573 & 9.1249 & 8.9321 & TST & & \\
\hline CHEMBL3976590 & 1641573 & 5.0 & 8.2325 & TRN & & \\
\hline CHEMBL3956338 & 1641573 & 9.4815 & 9.1203 & TRN & & \\
\hline CHEMBL 3966488 & 1641573 & 9.1273 & 8.8411 & TST & & \\
\hline CHEMBL3965964 & 1641573 & 8.6383 & 9.0375 & TRN & & \\
\hline CHEMBL3920451 & 1641573 & 8.4112 & 8.7457 & TRN & & \\
\hline CHEMBL3896919 & 1641573 & 8.9566 & 8.9818 & TST & & \\
\hline CHEMBL3960503 & 1641573 & 9.1537 & 8.0759 & TRN & & \\
\hline CHEMBL3942335 & 1641573 & 8.8601 & 8.5814 & TRN & & \\
\hline CHEMBL3893818 & 1641573 & 9.1079 & 9.0118 & TRN & & \\
\hline CHEMBL3925327 & 1641573 & 8.2549 & 8.3708 & TRN & & \\
\hline CHEMBL3947167 & 1641573 & 9.1249 & 9.1069 & TST & & \\
\hline CHEMBL3890732 & 1641573 & 5.0 & 7.6411 & TRN & & \\
\hline
\end{tabular}


Supplemental Table S2.txt

\begin{tabular}{|c|c|c|c|c|c|}
\hline CHEMBL3897074 & 1641573 & 8.9281 & 8.7706 & TST & \\
\hline CHEMBL3894103 & 1641573 & 8.8665 & 8.4203 & TRN & \\
\hline CHEMBL3928064 & 1641573 & 8.3179 & 8.2877 & TRN & \\
\hline CHEMBL3920500 & 1641573 & 7.4669 & 7.5532 & TRN & \\
\hline CHEMBL3892459 & 1641573 & 6.0 & 7.6832 & TRN & \\
\hline CHEMBL3980976 & 1641573 & 8.5017 & 9.0807 & TST & \\
\hline CHEMBL 3894276 & 1641573 & 8.4306 & 8.7148 & TRN & \\
\hline CHEMBL3917810 & 1641573 & 9.0242 & 8.5389 & TST & \\
\hline CHEMBL3943927 & 1641573 & 5.0 & 7.8075 & TRN & \\
\hline CHEMBL3909121 & 1641573 & 8.6326 & 7.8916 & TRN & \\
\hline CHEMBL3925926 & 1641573 & 9.0506 & 8.8211 & TRN & \\
\hline CHEMBL3938528 & 1641573 & 9.3814 & 8.7946 & TST & \\
\hline CHEMBL3913903 & 1641573 & 8.1124 & 8.8348 & TRN & \\
\hline CHEMBL3947310 & 1641573 & 8.51 & 8.8159 & TRN & \\
\hline CHEMBL3949515 & 1641573 & 8.6655 & 8.7703 & TRN & \\
\hline CHEMBL3932951 & 1641573 & 8.9788 & 7.7036 & TRN & \\
\hline CHEMBL3984660 & 1641573 & 9.1669 & 8.8157 & TRN & \\
\hline CHEMBL3936101 & 1641573 & 8.8239 & 8.9538 & TRN & \\
\hline CHEMBL3911488 & 1641573 & 9.1805 & 8.7226 & TRN & \\
\hline CHEMBL3940685 & 1641573 & 8.3883 & 8.671 & TST & \\
\hline CHEMBL3933362 & 1641573 & 9.699 & 9.1438 & TST & \\
\hline CHEMBL3924093 & 1641573 & 9.3979 & \multicolumn{2}{|c|}{8.097999999999999} & TRN \\
\hline CHEMBL3930754 & 1641573 & 7.61799 & 999999999 & 7.6328 & TRN \\
\hline CHEMBL3960233 & 1641573 & 8.9872 & 9.2587 & TST & \\
\hline CHEMBL3971611 & 1641573 & 9.2147 & 8.3652 & TRN & \\
\hline CHEMBL3968902 & 1641573 & 8.8996 & 8.868 & TRN & \\
\hline CHEMBL3962464 & 1641573 & 9.2237 & 8.9711 & TRN & \\
\hline CHEMBL3918054 & 1641573 & 8.8539 & 9.1792 & TST & \\
\hline CHEMBL 3943065 & 1641573 & 8.7423 & 8.0115 & TRN & \\
\hline CHEMBL 3919672 & 1641573 & 8.757 & 8.8849 & TRN & \\
\hline CHEMBL3934819 & 1641573 & 9.3565 & 8.9234 & TRN & \\
\hline CHEMBL3982898 & 1641573 & 9.3979 & 8.091000 & 0000000001 & TRN \\
\hline CHEMBL3905503 & 1641573 & 5.0 & 8.0809 & TST & \\
\hline CHEMBL 3921737 & 1641573 & 6.0 & 8.2162 & TRN & \\
\hline CHEMBL3985721 & 1641573 & 8.9337 & 8.9542 & TST & \\
\hline CHEMBL3935292 & 1641573 & 9.2218 & 8.5113 & TRN & \\
\hline CHEMBL3977239 & 1641573 & 8.3575 & 8.7622 & TST & \\
\hline CHEMBL3912693 & 1641573 & 8.8447 & 7.8435 & TRN & \\
\hline CHEMBL 3896879 & 1641573 & 7.9788 & 7.9903 & TRN & \\
\hline CHEMBL3955200 & 1641573 & 9.1308 & 9.0494 & TRN & \\
\hline CHEMBL3966678 & 1641573 & 8.9136 & 7.951000 & 00000000005 & TRN \\
\hline CHEMBL 3984877 & 1641573 & 9.301 & 8.3782 & TRN & \\
\hline CHEMBL3958157 & 1641573 & 9.0655 & 8.6252 & TST & \\
\hline CHEMBL3978355 & 1641573 & 6.0 & 8.798 & TRN & \\
\hline CHEMBL3984294 & 1641573 & 8.8697 & 7.7044 & TRN & \\
\hline CHEMBL3979838 & 1641573 & 9.4841 & 8.4241 & TRN & \\
\hline CHEMBL 3952673 & 1641573 & 5.0 & 7.5826 & TRN & \\
\hline CHEMBL3960051 & 1641573 & 9.4089 & 8.4475 & TRN & \\
\hline
\end{tabular}


Supplemental Table S2.txt

\begin{tabular}{|c|c|c|c|c|}
\hline CHEMBL3894667 & 1641573 & 8.7011 & 8.9079 & TRN \\
\hline CHEMBL3895876 & 1641573 & 8.3915 & 8.4862 & TRN \\
\hline CHEMBL3930983 & 1641573 & 8.9706 & 8.125 & TRN \\
\hline CHEMBL3973732 & 1641573 & 9.0757 & 8.4389 & TRN \\
\hline CHEMBL3904293 & 1641573 & 6.0 & 8.1489 & TRN \\
\hline CHEMBL3968090 & 1641573 & 9.5376 & 8.9095 & TRN \\
\hline CHEMBL3945299 & 1641573 & 8.251 & 8.6157 & TRN \\
\hline CHEMBL3948391 & 1641573 & 9.3979 & 8.1335 & TRN \\
\hline CHEMBL 3891400 & 1641573 & 6.0 & 8.3538 & TRN \\
\hline CHEMBL3929017 & 1641573 & 9.3979 & 8.4954 & TRN \\
\hline CHEMBL3956047 & 1641573 & 9.2757 & 9.1306 & TST \\
\hline CHEMBL3951304 & 1641573 & 9.0655 & 8.3299 & TRN \\
\hline CHEMBL3894914 & 1641573 & 8.6055 & 9.0216 & TRN \\
\hline CHEMBL3906341 & 1641573 & 8.9747 & 7.8547 & TRN \\
\hline CHEMBL3923885 & 1641573 & 8.9586 & 8.7817 & TRN \\
\hline CHEMBL3905347 & 1641573 & 8.8894 & 8.5691 & TRN \\
\hline CHEMBL3920932 & 1641573 & 9.0458 & 9.1168 & TST \\
\hline CHEMBL3909661 & 1641573 & 9.0605 & 8.3531 & TRN \\
\hline CHEMBL3902773 & 1641573 & 8.7399 & 7.5719 & TRN \\
\hline CHEMBL3960290 & 1641573 & 8.7852 & 8.9904 & TST \\
\hline CHEMBL3986850 & 1641573 & 6.0 & 7.8318 & TRN \\
\hline CHEMBL3891620 & 1641573 & 9.3372 & 9.0262 & TRN \\
\hline CHEMBL3979389 & 1641573 & 9.6383 & 8.3034 & TRN \\
\hline CHEMBL3947319 & 1641573 & 8.9512 & 8.6454 & TRN \\
\hline CHEMBL3984662 & 1641573 & 8.4923 & 8.7271 & TRN \\
\hline CHEMBL3973304 & 1641573 & 9.3098 & 8.1943 & TRN \\
\hline CHEMBL3951841 & 1641573 & 8.8962 & 9.0692 & TRN \\
\hline CHEMBL3919866 & 1641573 & 9.0506 & \multicolumn{2}{|c|}{8.892999999999999} \\
\hline CHEMBL 3925843 & 1641573 & 9.0315 & 9.2232 & TST \\
\hline CHEMBL3941887 & 1641573 & 9.3979 & 8.83 & TST \\
\hline CHEMBL3906022 & 1641573 & 8.5143 & 8.6599 & TST \\
\hline CHEMBL3929838 & 1641573 & 8.9788 & 7.7746 & TRN \\
\hline CHEMBL3984661 & 1641573 & 8.4881 & 9.0904 & TST \\
\hline CHEMBL3933042 & 1641573 & 8.567 & 8.7803 & TRN \\
\hline CHEMBL3909570 & 1641573 & 9.1249 & 8.3517 & TRN \\
\hline CHEMBL3915317 & 1641573 & 8.4449 & 8.5479 & TRN \\
\hline CHEMBL3971761 & 1641573 & 8.7423 & 7.9326 & TRN \\
\hline CHEMBL3915089 & 1641573 & 8.9285 & 8.0522 & TRN \\
\hline CHEMBL3896008 & 1641573 & 6.0 & 8.2881 & TRN \\
\hline CHEMBL3957067 & 1641573 & 8.8145 & 8.9525 & TST \\
\hline CHEMBL3942973 & 1641573 & 8.7905 & 8.9179 & TRN \\
\hline CHEMBL3927586 & 1641573 & 9.2676 & 8.0324 & TRN \\
\hline CHEMBL3944258 & 1641573 & 8.7399 & 8.2662 & TRN \\
\hline CHEMBL3962958 & 1641573 & 7.8861 & 8.5299 & TRN \\
\hline CHEMBL3973438 & 1641573 & 8.5391 & 8.8766 & TST \\
\hline CHEMBL3902436 & 1641573 & 8.6851 & 8.5111 & TRN \\
\hline CHEMBL3916920 & 1641573 & 9.7447 & 9.0871 & TRN \\
\hline CHEMBL3948251 & 1641573 & 5.0 & 9.0628 & TST \\
\hline
\end{tabular}




$$
\text { Supplemental Table S2.txt }
$$

\begin{tabular}{|c|c|c|c|c|}
\hline CHEMBL3959461 & 1641573 & 9.0391 & 8.7618 & TRN \\
\hline CHEMBL1550970 & 688436 & 5.9 & 6.3531 & TRN \\
\hline CHEMBL1389845 & 688436 & 5.6 & 5.8135 & TRN \\
\hline CHEMBL1367254 & 688436 & 5.35 & 5.2638 & TRN \\
\hline CHEMBL 259848 & 688436 & 4.65 & 5.297006 & 0000000001 \\
\hline CHEMBL1672258 & 688436 & 5.1 & 5.0656 & TRN \\
\hline CHEMBL1441203 & 688436 & 6.2 & 6.586 & TRN \\
\hline CHEMBL1356231 & 688436 & 5.25 & 5.334 & TRN \\
\hline CHEMBL1393949 & 688436 & 5.1 & 5.3305 & TRN \\
\hline CHEMBL1523867 & 688436 & 5.5 & 6.1544 & TST \\
\hline CHEMBL1512531 & 688436 & 7.3497 & 5.6731 & TRN \\
\hline CHEMBL259853 & 688436 & 5.55 & 5.5058 & TRN \\
\hline CHEMBL1405552 & 688436 & 4.4 & 4.8497 & TRN \\
\hline CHEMBL1354095 & 688436 & 6.1 & 6.1156 & TRN \\
\hline CHEMBL1511846 & 688436 & 5.15 & 5.3057 & TRN \\
\hline CHEMBL1354148 & 688436 & 6.4 & 6.4797 & TRN \\
\hline CHEMBL1408238 & 688436 & 7.4498 & 5.2604 & TST \\
\hline CHEMBL103769 & 688436 & 6.0 & 5.729 & TST \\
\hline CHEMBL1336452 & 688436 & 6.5 & 6.1755 & TRN \\
\hline CHEMBL1386329 & 688436 & 4.9 & 4.8373 & TRN \\
\hline CHEMBL1396821 & 688436 & 6.3 & 5.5326 & TRN \\
\hline CHEMBL1474623 & 688436 & 6.0 & 5.7008 & TRN \\
\hline CHEMBL1552164 & 688436 & 5.35 & 5.1148 & TRN \\
\hline CHEMBL1450529 & 688436 & 5.3 & 5.4908 & TRN \\
\hline CHEMBL1314058 & 688436 & 6.25 & 5.999 & TRN \\
\hline CHEMBL1516025 & 688436 & 4.75 & 5.1505 & TRN \\
\hline CHEMBL1436910 & 688436 & 5.4 & 5.4485 & TRN \\
\hline CHEMBL1527485 & 688436 & 4.7 & 4.8237 & TRN \\
\hline CHEMBL1354202 & 688436 & 5.05 & 5.4484 & TRN \\
\hline CHEMBL 1433316 & 688436 & 5.95 & 6.0045 & TRN \\
\hline CHEMBL1592410 & 688436 & 5.65 & 5.0651 & TRN \\
\hline CHEMBL1522474 & 688436 & 4.35 & 5.395 & TST \\
\hline CHEMBL259330 & 688436 & 4.95 & 5.4268 & TST \\
\hline CHEMBL1553985 & 688436 & 5.6 & 5.5212 & TRN \\
\hline CHEMBL1554954 & 688436 & 4.95 & 4.9812 & TRN \\
\hline CHEMBL129795 & 688436 & 5.4 & 5.0773 & TST \\
\hline CHEMBL 1363295 & 688436 & 4.85 & 4.9289 & TRN \\
\hline CHEMBL1474062 & 688436 & 6.1 & 5.99 & TRN \\
\hline CHEMBL1474012 & 688436 & 4.85 & 5.4919 & TST \\
\hline CHEMBL1325666 & 688436 & 5.0 & 5.5284 & TST \\
\hline CHEMBL1315035 & 688436 & 6.1 & 6.2218 & TRN \\
\hline CHEMBL429079 & 688436 & 5.0 & 5.3467 & TST \\
\hline CHEMBL1361379 & 688436 & 6.6 & 6.374 & TRN \\
\hline CHEMBL1393971 & 688436 & 6.3 & 6.1896 & TRN \\
\hline CHEMBL1435323 & 688436 & 6.6499 & 6.6159 & TRN \\
\hline CHEMBL1446531 & 688436 & 5.45 & 5.4286 & TRN \\
\hline CHEMBL 1316340 & 688436 & 5.5 & 5.6539 & TST \\
\hline \multirow[t]{2}{*}{ CHEMBL1442507 } & 688436 & 4.5 & \multicolumn{2}{|c|}{5.1770000000000005} \\
\hline & & & \multicolumn{2}{|c|}{ Page 12} \\
\hline
\end{tabular}




\begin{tabular}{|c|c|c|c|c|}
\hline \multicolumn{5}{|c|}{ Supplemental Table S2.txt } \\
\hline CHEMBL1436605 & 688436 & 5.4 & 5.2985 & TRN \\
\hline CHEMBL1381698 & 688436 & 5.85 & 6.2756 & TST \\
\hline CHEMBL117108 & 688436 & 5.0 & 5.4128 & TRN \\
\hline CHEMBL1357878 & 688436 & 6.5 & 6.1901 & TRN \\
\hline CHEMBL1393924 & 688436 & 4.75 & 5.1157 & TRN \\
\hline CHEMBL1672334 & 688436 & 5.65 & 5.9298 & TRN \\
\hline CHEMBL1393882 & 688436 & 5.95 & 6.2226 & TRN \\
\hline CHEMBL1314132 & 688436 & 5.15 & 5.2988 & TRN \\
\hline CHEMBL1354978 & 688436 & 6.1 & 6.2604 & TRN \\
\hline CHEMBL259854 & 688436 & 6.35 & 5.4881 & TST \\
\hline CHEMBL1550940 & 688436 & 6.1 & 6.3009 & TRN \\
\hline CHEMBL1396417 & 688436 & 5.95 & 5.871 & TRN \\
\hline CHEMBL258515 & 688436 & 4.8 & 5.5398 & TST \\
\hline CHEMBL1299329 & 688436 & 5.7 & 5.7636 & TRN \\
\hline CHEMBL1433940 & 688436 & 5.85 & 5.9994 & TRN \\
\hline CHEMBL1433310 & 688436 & 5.6 & 5.3565 & TRN \\
\hline CHEMBL406121 & 688436 & 4.6 & 5.1785 & TST \\
\hline CHEMBL1355818 & 688436 & 5.4 & 5.4961 & TRN \\
\hline CHEMBL1472511 & 688436 & 6.1 & 6.1349 & TRN \\
\hline CHEMBL 260582 & 688436 & 4.85 & 5.2523 & TST \\
\hline CHEMBL1317425 & 688436 & 5.4 & 6.0705 & TRN \\
\hline CHEMBL1513215 & 688436 & 4.8 & 5.2078 & TRN \\
\hline CHEMBL 260290 & 688436 & 5.1 & 5.5902 & TST \\
\hline CHEMBL1374352 & 688436 & 4.45 & 5.5222 & TST \\
\hline CHEMBL1354092 & 688436 & 5.9 & 6.1079 & TRN \\
\hline CHEMBL406704 & 688436 & 5.3 & 5.5553 & TST \\
\hline CHEMBL1433363 & 688436 & 5.1 & 5.2726 & TRN \\
\hline CHEMBL1393956 & 688436 & 6.6499 & 6.5279 & TRN \\
\hline CHEMBL1415959 & 688436 & 5.65 & 5.3234 & TRN \\
\hline CHEMBL1476627 & 688436 & 6.25 & 6.1187 & TRN \\
\hline CHEMBL1314035 & 688436 & 6.5501 & 6.1871 & TRN \\
\hline CHEMBL1433408 & 688436 & 5.5 & 5.47 & TRN \\
\hline CHEMBL1397594 & 688436 & 5.95 & 6.2841 & TRN \\
\hline CHEMBL1551656 & 688436 & 6.45 & 6.3524 & TRN \\
\hline CHEMBL1584975 & 688436 & 4.5 & 4.8976 & TST \\
\hline CHEMBL1610733 & 688436 & 4.9 & 4.6786 & TST \\
\hline CHEMBL1315685 & 688436 & 4.8 & 5.5288 & TRN \\
\hline CHEMBL1356723 & 688436 & 5.05 & 5.2742 & TRN \\
\hline CHEMBL1550968 & 688436 & 5.95 & 5.8462 & TRN \\
\hline CHEMBL1423516 & 688436 & 5.0 & 5.0429 & TRN \\
\hline CHEMBL1576168 & 688436 & 5.85 & 5.6244 & TRN \\
\hline CHEMBL3211678 & 688436 & 4.5 & 5.1625 & TST \\
\hline CHEMBL1411146 & 688436 & 5.4 & 4.93199 & 99999999995 \\
\hline CHEMBL1358203 & 688436 & 5.7 & 5.4478 & TRN \\
\hline CHEMBL236275 & 688436 & 4.95 & 5.1403 & TST \\
\hline CHEMBL1317395 & 688436 & 5.1 & 5.2244 & TRN \\
\hline CHEMBL1511986 & 688436 & 4.9 & 5.025 & TRN \\
\hline CHEMBL1370189 & 688436 & 4.85 & 4.6355 & TRN \\
\hline
\end{tabular}




\begin{tabular}{|c|c|c|c|c|c|c|}
\hline & & \multicolumn{5}{|c|}{ Supplemental Table S2.txt } \\
\hline CHEMBL1433409 & 688436 & 6.8499 & 6.2107 & TRN & & \\
\hline CHEMBL260291 & 688436 & 4.9 & 5.4647 & TST & & \\
\hline CHEMBL1358037 & 688436 & 5.35 & 5.2656 & TRN & & \\
\hline CHEMBL1242028 & 654923 & 7.0458 & 7.0372 & TRN & & \\
\hline CHEMBL1242118 & 654923 & 5.7696 & 5.9376 & TRN & & \\
\hline CHEMBL1241679 & 654923 & 6.1938 & 5.7979 & TRN & & \\
\hline CHEMBL1242109 & 654923 & 6.3279 & 6.5526 & TRN & & \\
\hline CHEMBL1242476 & 654923 & 7.1675 & 7.1428 & TRN & & \\
\hline CHEMBL1242031 & 654923 & 6.6778 & 6.2424 & TRN & & \\
\hline CHEMBL1242206 & 654923 & 4.0 & 4.9158 & TST & & \\
\hline CHEMBL1241860 & 654923 & 6.6716 & 6.2683 & TRN & & \\
\hline CHEMBL1242032 & 654923 & 6.6198 & 6.0463 & TRN & & \\
\hline CHEMBL1242381 & 654923 & 6.0 & 6.5894 & TRN & & \\
\hline CHEMBL1241775 & 654923 & 6.3883 & 5.6237 & TRN & & \\
\hline CHEMBL1241355 & 654923 & 4.0 & 4.5589 & TST & & \\
\hline CHEMBL1242750 & 654923 & 7.1308 & 6.505 & TRN & & \\
\hline CHEMBL1233882 & 654923 & 8.2218 & 7.6631 & TRN & & \\
\hline CHEMBL1242851 & 654923 & 6.1249 & 5.3226 & TRN & & \\
\hline CHEMBL1242657 & 654923 & 6.0 & 6.6132 & TRN & & \\
\hline CHEMBL1241357 & 654923 & 4.0862 & 5.0339 & TST & & \\
\hline CHEMBL1242383 & 654923 & 5.5229 & 5.2027 & TRN & & \\
\hline CHEMBL1242203 & 654923 & 6.6676 & 6.6519 & TRN & & \\
\hline CHEMBL1240566 & 654923 & 6.1805 & 6.3002 & TRN & & \\
\hline CHEMBL1240545 & 654923 & 5.9208 & 5.319 & TRN & & \\
\hline CHEMBL1241943 & 654923 & 6.8069 & 5.9308 & TRN & & \\
\hline CHEMBL1242475 & 654923 & 6.8477 & 7.1884 & TRN & & \\
\hline CHEMBL1242844 & 654923 & 5.7022 & 5.8349 & TRN & & \\
\hline CHEMBL1241770 & 654923 & 6.684 & 6.0618 & TRN & & \\
\hline CHEMBL1242117 & 654923 & 5.4089 & 5.9259 & TRN & & \\
\hline CHEMBL1241390 & 654923 & 5.7212 & 5.4935 & TRN & & \\
\hline CHEMBL1240594 & 654923 & 5.9208 & 5.9268 & TST & & \\
\hline CHEMBL1241945 & 654923 & 6.7932 & 7.1997 & TRN & & \\
\hline CHEMBL1241771 & 654923 & 5.8539 & 5.6106 & TRN & & \\
\hline CHEMBL1242572 & 654923 & 6.7212 & 7.0103 & TRN & & \\
\hline CHEMBL1241492 & 654923 & 5.4318 & 6.3283 & TRN & & \\
\hline CHEMBL1242113 & 654923 & 7.3279 & 7.0293 & TRN & & \\
\hline CHEMBL1242470 & 654923 & 6.1451 & 7.0434 & TST & & \\
\hline CHEMBL1241490 & 654923 & 6.3605 & 6.1985 & TRN & & \\
\hline CHEMBL1242290 & 654923 & 7.3188 & 7.24799 & 9999999999 & & TRN \\
\hline CHEMBL1241944 & 654923 & 7.0555 & 7.3613 & TRN & & \\
\hline CHEMBL1241680 & 654923 & 5.2007 & 5.4644 & TRN & & \\
\hline CHEMBL1242386 & 654923 & 7.0 & 7.3206 & TRN & & \\
\hline CHEMBL1241299 & 654923 & 7.6383 & 7.8799 & TRN & & \\
\hline CHEMBL1242659 & 654923 & 6.75200 & 30000000 & & 6.8437 & TRN \\
\hline CHEMBL1241482 & 654923 & 5.9706 & 4.8856 & TST & & \\
\hline CHEMBL1241769 & 654923 & 5.26200 & 90000000 & 205 & 5.9486 & TRN \\
\hline CHEMBL1242208 & 654923 & 7.0706 & 6.5622 & TRN & & \\
\hline CHEMBL1242376 & 654923 & 6.9508 & 7.8237 & TRN & & \\
\hline
\end{tabular}




\begin{tabular}{|c|c|c|c|c|c|c|}
\hline \multirow[b]{2}{*}{ CHEMBL1242758 } & & \multicolumn{5}{|c|}{ Supplemental Table S2.txt } \\
\hline & 654923 & 6.3507 & 6.0212 & TST & & \\
\hline CHEMBL1241949 & 654923 & 6.426 & 7.2219 & TRN & & \\
\hline CHEMBL1241145 & 654923 & 4.9586 & 4.9501 & TST & & \\
\hline CHEMBL1233881 & 654923 & 8.3979 & 7.9585 & TRN & & \\
\hline CHEMBL1241356 & 654923 & 4.9586 & 4.9852 & TST & & \\
\hline CHEMBL1241942 & 654923 & 4.0 & 5.4577 & TRN & & \\
\hline CHEMBL1241391 & 654923 & 4.0 & 4.8979 & TRN & & \\
\hline CHEMBL1240554 & 654923 & 7.7696 & 7.3387 & TRN & & \\
\hline CHEMBL1241772 & 654923 & 5.1612 & 5.6605 & TRN & & \\
\hline CHEMBL1242198 & 654923 & 7.3372 & 7.1267 & TRN & & \\
\hline CHEMBL1242748 & 654923 & 6.0 & 6.6312 & TRN & & \\
\hline CHEMBL1241491 & 654923 & 6.3675 & 6.31 & TRN & & \\
\hline CHEMBL1241487 & 654923 & 6.5986 & 6.4885 & TRN & & \\
\hline CHEMBL1081312 & 654923 & 6.8239 & 7.0102 & TRN & & \\
\hline CHEMBL1241270 & 654923 & 6.1805 & 6.0942 & TST & & \\
\hline CHEMBL1230790 & 654923 & 6.6021 & 6.2745 & TRN & & \\
\hline CHEMBL1241947 & 654923 & 6.8539 & 5.9337 & TST & & \\
\hline CHEMBL1241104 & 654923 & 4.9031 & 4.7421 & TST & & \\
\hline CHEMBL1242110 & 654923 & 6.1694 & 6.1938 & TRN & & \\
\hline CHEMBL1241862 & 654923 & 6.3098 & 6.2844 & TRN & & \\
\hline CHEMBL1242847 & 654923 & 6.9031 & 6.2188 & TRN & & \\
\hline CHEMBL1242852 & 654923 & 5.6055 & 5.7741 & TRN & & \\
\hline CHEMBL1242472 & 654923 & 7.3768 & 6.565 & TRN & & \\
\hline CHEMBL1242474 & 654923 & 4.9208 & 4.9955 & TRN & & \\
\hline CHEMBL1242291 & 654923 & 5.2007 & 4.7161 & TST & & \\
\hline CHEMBL1242569 & 654923 & 6.5591 & 6.5093 & TRN & & \\
\hline CHEMBL1242574 & 654923 & 6.4685 & 6.358 & TRN & & \\
\hline CHEMBL1241676 & 654923 & 6.9872 & 7.2921 & TRN & & \\
\hline CHEMBL1241948 & 654923 & 6.1871 & 6.1119 & TRN & & \\
\hline CHEMBL1242661 & 654923 & 5.4318 & 5.6744 & TRN & & \\
\hline CHEMBL1242656 & 654923 & 7.2366 & 7.0628 & TRN & & \\
\hline CHEMBL1241300 & 654923 & 6.7033 & 6.4759 & TST & & \\
\hline CHEMBL1242294 & 654923 & 6.76200 & 00000000 & 205 & 6.7028 & TRN \\
\hline CHEMBL1241271 & 654923 & 6.6778 & 6.7746 & TRN & & \\
\hline CHEMBL1241489 & 654923 & 5.9208 & 5.6207 & TRN & & \\
\hline CHEMBL1242286 & 654923 & 6.6861 & 6.3699 & TRN & & \\
\hline CHEMBL1242201 & 654923 & 8.0 & 7.4916 & TRN & & \\
\hline CHEMBL1242663 & 654923 & 5.7447 & 5.16 & TST & & \\
\hline CHEMBL1242209 & 654923 & 6.9586 & 6.8153 & TRN & & \\
\hline CHEMBL1241587 & 654923 & 6.1918 & 6.1401 & TST & & \\
\hline CHEMBL1241358 & 654923 & 4.0 & 4.3114 & TST & & \\
\hline CHEMBL1242666 & 654923 & 6.9031 & 6.7639 & TRN & & \\
\hline CHEMBL1242753 & 654923 & 5.6198 & 6.0105 & TRN & & \\
\hline CHEMBL1242378 & 654923 & 6.0 & 6.7056 & TRN & & \\
\hline CHEMBL1241584 & 654923 & 5.1739 & 5.4866 & TRN & & \\
\hline CHEMBL1231371 & 654923 & 4.0 & 4.7644 & TRN & & \\
\hline CHEMBL1242200 & 654923 & 5.5272 & 5.7118 & TRN & & \\
\hline CHEMBL1242029 & 654923 & 6.1367 & 5.686 & TRN & & \\
\hline
\end{tabular}




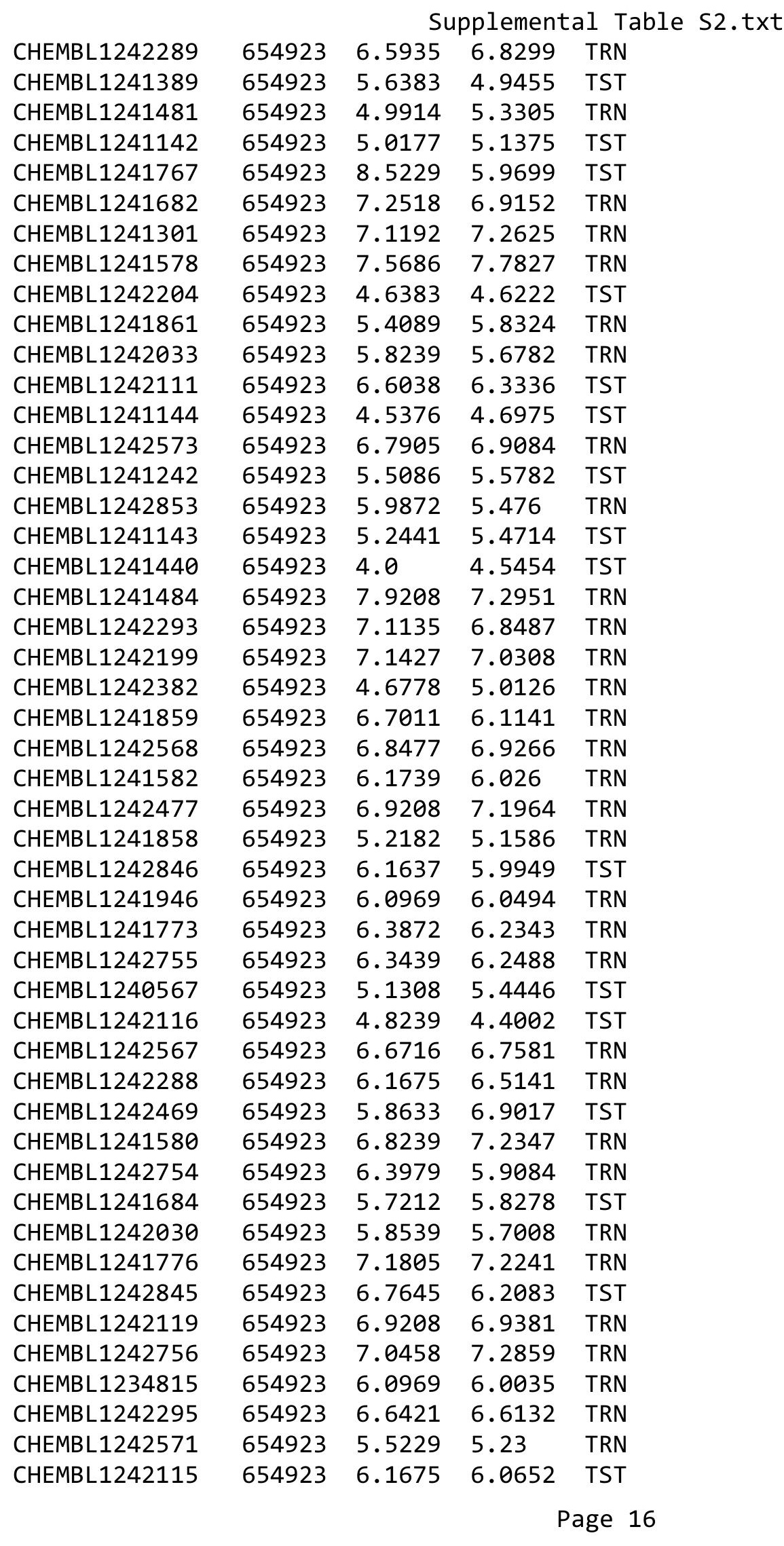


Supplemental Table S2.txt

\begin{tabular}{|c|c|c|c|c|}
\hline 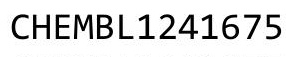 & & 583 & - & \\
\hline HEMBL1241677 & 54923 & 6925 & 6.8746 & \\
\hline HEMBL1241486 & 923 & 8 & 3114 & \\
\hline 752 & & & 21 & \\
\hline AEMBL1241588 & & 861 & 997 & \\
\hline AEMBL1241683 & 54923 & 101 & .8008 & \\
\hline HEMBL1242665 & 54923 & .1427 & .1013 & \\
\hline HEMBL1241681 & & & 0284 & \\
\hline HEMBL124 & & & 86 & \\
\hline IEMBL124 & & & & \\
\hline HEMBL1241950 & 54923 & 6.0 & .5767 & \\
\hline HEMBL1240565 & 23 & 39 & 5.8672 & \\
\hline HEMBL124 & & 51 & 9826 & \\
\hline HEMBL 12 & & & 86 & \\
\hline HEMBL 124 & & & 3341 & \\
\hline HEMBL1242114 & 3 & 08 & 7.1811 & \\
\hline HEMBL1242287 & & & & \\
\hline HEMBL 124 & & 4. & 4.7847 & \\
\hline HEMBL 12 & & & 302 & \\
\hline HEMBL $12 \angle$ & & & & \\
\hline HEMBL1241774 & & 098 & 9765 & \\
\hline HEMBL1241483 & & & & \\
\hline HEMBL12 & & 2 & 53 & \\
\hline HEMBL12 & & & 72 & \\
\hline HEMBL 12 & & & & \\
\hline HEMBL 124 & & 21 & & \\
\hline AEMBL1241269 & & & & 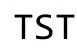 \\
\hline HEMBL12 & & & & \\
\hline L12 & & & & \\
\hline HEMBL124 & & 4 & 06 & RN \\
\hline HEMBL 124 & & & & $\mathrm{RN}$ \\
\hline HEMBL1241488 & & & & RN \\
\hline AEMBL12 & & & & \\
\hline 11 & & & & ST \\
\hline $3 \mathrm{~L} 12$ & & 7. & & ST \\
\hline HEMBL1242660 & & & 541 & RN \\
\hline HEMBL1242384 & & & & $2 \mathrm{~N}$ \\
\hline 7 & & & & RIN \\
\hline НᄃMP 12 & & & 78 & RIN \\
\hline HEMBL1241241 & & & 559 & RN \\
\hline AEMBL1242751 & & 4. & 358 & RN \\
\hline HEMBL 124 & & & & RN \\
\hline 6 & & & & \\
\hline HEMBL124 & & & & NIV \\
\hline HEMBL 124 & & & 3665 & RN \\
\hline HEMBL 124 & & 5.7447 & 27 & \\
\hline HEMBL124 & & & & \\
\hline CHEM & 654923 & 6.1096 & & \\
\hline
\end{tabular}

Page 17 


\begin{tabular}{|c|c|c|c|c|c|}
\hline \multirow[b]{2}{*}{ CHEMBL1242662 } & \multicolumn{5}{|c|}{ Supplemental Table S2.txt } \\
\hline & 654923 & 7.2291 & 6.5051 & TRN & \\
\hline CHEMBL1241863 & 654923 & 4.0 & 4.9224 & TRN & \\
\hline CHEMBL1241240 & 654923 & 4.7447 & 4.864 & TST & \\
\hline CHEMBL1241441 & 654923 & 6.0915 & 5.4252 & TST & \\
\hline CHEMBL1241485 & 654923 & 6.5528 & 6.4726 & TRN & \\
\hline CHEMBL1242034 & 654923 & 5.284 & 5.9327 & TST & \\
\hline CHEMBL1242664 & 654923 & 6.015 & 6.3019 & TST & \\
\hline CHEMBL3126880 & 1294965 & 3.0 & 3.3512 & TRN & \\
\hline CHEMBL 3126867 & 1294965 & 3.0 & 2.98100 & 00000000003 & TRN \\
\hline CHEMBL3126875 & 1294965 & 3.0 & 3.0655 & TRN & \\
\hline CHEMBL3126911 & 1294965 & 4.0137 & 3.6569 & TRN & \\
\hline CHEMBL3126872 & 1294965 & 3.0 & 2.6952 & TST & \\
\hline CHEMBL 3126884 & 1294965 & 3.0 & 2.8484 & TRN & \\
\hline CHEMBL3126891 & 1294965 & 3.0 & 3.0717 & TRN & \\
\hline CHEMBL3126865 & 1294965 & 4.6091 & 5.1733 & TST & \\
\hline CHEMBL3126894 & 1294965 & 3.0 & 3.0493 & TRN & \\
\hline CHEMBL3127063 & 1294965 & 4.1215 & 4.0321 & TRN & \\
\hline CHEMBL3126873 & 1294965 & 3.0 & 3.0743 & TRN & \\
\hline CHEMBL3126877 & 1294965 & 3.0 & 3.1992 & TRN & \\
\hline CHEMBL3126914 & 1294965 & 7.301 & 7.0155 & TST & \\
\hline CHEMBL3127051 & 1294965 & 4.0137 & 4.0407 & TRN & \\
\hline CHEMBL3127059 & 1294965 & 4.0164 & 3.847 & TRN & \\
\hline CHEMBL3127065 & 1294965 & 6.3665 & 6.3718 & TRN & \\
\hline CHEMBL3126901 & 1294965 & 3.0 & 2.7791 & TRN & \\
\hline CHEMBL 3127047 & 1294965 & 4.007 & 3.7845 & TST & \\
\hline CHEMBL3126902 & 1294965 & 3.0 & 3.2299 & TRN & \\
\hline CHEMBL403715 & 1294965 & 3.0 & 2.4861 & TST & \\
\hline CHEMBL3127066 & 1294965 & 4.5406 & 4.5562 & TRN & \\
\hline CHEMBL3126909 & 1294965 & 4.0496 & 4.402 & TRN & \\
\hline CHEMBL3126907 & 1294965 & 4.3401 & 4.7928 & TST & \\
\hline CHEMBL 3127061 & 1294965 & 3.0 & 3.2021 & TRN & \\
\hline CHEMBL 3127044 & 1294965 & 3.0 & 3.8697 & TST & \\
\hline CHEMBL1814767 & 1294965 & 4.7375 & 4.7747 & TRN & \\
\hline CHEMBL3126899 & 1294965 & 3.0 & 3.3141 & TRN & \\
\hline CHEMBL1814768 & 1294965 & 4.1831 & 4.0506 & TRN & \\
\hline CHEMBL3126895 & 1294965 & 3.0 & 3.105 & TRN & \\
\hline CHEMBL3126897 & 1294965 & 3.0 & 3.1161 & TST & \\
\hline CHEMBL3126905 & 1294965 & 6.3872 & 5.9986 & TST & \\
\hline CHEMBL3127060 & 1294965 & 3.0 & 3.1779 & TRN & \\
\hline CHEMBL3126886 & 1294965 & 3.0 & 3.1684 & TRN & \\
\hline CHEMBL3126900 & 1294965 & 4.0035 & 4.0142 & TRN & \\
\hline CHEMBL 3127057 & 1294965 & 4.065 & 3.3146 & TST & \\
\hline CHEMBL3126883 & 1294965 & 4.2027 & 4.0379 & TRN & \\
\hline CHEMBL3127052 & 1294965 & 4.0186 & 3.9064 & TRN & \\
\hline CHEMBL3126906 & 1294965 & 5.2757 & 4.9863 & TST & \\
\hline CHEMBL 3126882 & 1294965 & 3.0 & 2.8835 & TRN & \\
\hline CHEMBL 3127064 & 1294965 & 4.0655 & 3.8853 & TST & \\
\hline CHEMBL3126892 & 1294965 & 3.0 & 3.0954 & TRN & \\
\hline
\end{tabular}




\begin{tabular}{|c|c|c|c|c|c|}
\hline \multicolumn{6}{|c|}{ Supplemental Table S2.txt } \\
\hline CHEMBL3126888 & 1294965 & 3.0 & 3.0553 & TRN & \\
\hline CHEMBL3127046 & 1294965 & 4.6498 & 4.603 & TRN & \\
\hline CHEMBL319177 & 1294965 & 3.0 & 2.8748 & TST & \\
\hline CHEMBL3126896 & 1294965 & 3.0 & 3.7696 & TST & \\
\hline CHEMBL 3126878 & 1294965 & 3.0 & 3.1984 & TRN & \\
\hline CHEMBL 3126874 & 1294965 & 4.6676 & 4.3873 & TRN & \\
\hline CHEMBL3127049 & 1294965 & 6.585 & 6.63700 & 00000000005 & TRN \\
\hline CHEMBL3126912 & 1294965 & 3.0 & 2.7988 & TRN & \\
\hline CHEMBL1269812 & 1294965 & 7.1549 & 7.5591 & TST & \\
\hline CHEMBL3127053 & 1294965 & 3.0 & 3.2538 & TRN & \\
\hline CHEMBL3126908 & 1294965 & 7.1549 & 6.9685 & TRN & \\
\hline CHEMBL 3126910 & 1294965 & 3.0 & 2.9009 & TRN & \\
\hline CHEMBL3126879 & 1294965 & 3.0 & 2.9269 & TRN & \\
\hline CHEMBL 3126870 & 1294965 & 3.0 & 3.0837 & TRN & \\
\hline CHEMBL3126904 & 1294965 & 3.0 & 3.0268 & TRN & \\
\hline CHEMBL3126893 & 1294965 & 3.0 & 2.9599 & TRN & \\
\hline CHEMBL3126903 & 1294965 & 3.0 & 2.7205 & TRN & \\
\hline CHEMBL3126898 & 1294965 & 4.0391 & 3.9799 & TST & \\
\hline CHEMBL 3127055 & 1294965 & 4.1637 & 4.4772 & TST & \\
\hline CHEMBL3127067 & 1294965 & 4.202 & 4.538 & TRN & \\
\hline CHEMBL3126889 & 1294965 & 3.0 & 2.9562 & TRN & \\
\hline CHEMBL3126869 & 1294965 & 3.0 & 2.8841 & TRN & \\
\hline CHEMBL 3127062 & 1294965 & 3.0 & 3.262 & TRN & \\
\hline CHEMBL 3126868 & 1294965 & 4.0004 & 3.8017 & TRN & \\
\hline CHEMBL3126866 & 1294965 & 3.0 & 3.1917 & TRN & \\
\hline CHEMBL3124960 & 1294965 & 3.0 & 2.9086 & TRN & \\
\hline CHEMBL3126876 & 1294965 & 3.0 & 2.9068 & TRN & \\
\hline CHEMBL3126890 & 1294965 & 3.0 & 2.8179 & TRN & \\
\hline CHEMBL 3126887 & 1294965 & 3.0 & 2.8312 & TRN & \\
\hline CHEMBL 3127050 & 1294965 & 4.0052 & 3.8348 & TRN & \\
\hline CHEMBL3126871 & 1294965 & 4.5918 & 4.5872 & TRN & \\
\hline CHEMBL 3127056 & 1294965 & 3.0 & 3.9945 & TST & \\
\hline CHEMBL 3127048 & 1294965 & 4.041 & 3.1268 & TST & \\
\hline CHEMBL3126915 & 1294965 & 3.0 & 4.9531 & TST & \\
\hline CHEMBL3127045 & 1294965 & 3.0 & 2.645 & TRN & \\
\hline CHEMBL3127058 & 1294965 & 5.2976 & 5.1082 & TRN & \\
\hline CHEMBL3126881 & 1294965 & 3.0 & 2.862 & TST & \\
\hline CHEMBL 3127054 & 1294965 & 4.1726 & 4.3315 & TRN & \\
\hline CHEMBL 3126885 & 1294965 & 3.0 & 3.1425 & TRN & \\
\hline CHEMBL3126913 & 1294965 & 4.0273 & 3.9161 & TRN & \\
\hline CHEMBL3127068 & 1294965 & 4.1918 & 4.3428 & TRN & \\
\hline CHEMBL1329725 & 688662 & 2.8239 & 4.1412 & TRN & \\
\hline CHEMBL1995045 & 688662 & 5.5923 & 5.2779 & TST & \\
\hline CHEMBL1393689 & 688662 & 4.4523 & 4.5352 & TRN & \\
\hline CHEMBL1466523 & 688662 & 4.735 & 5.2469 & TRN & \\
\hline CHEMBL1584468 & 688662 & 4.6378 & 4.4034 & TRN & \\
\hline CHEMBL373137 & 688662 & 3.9186 & 4.9839 & TRN & \\
\hline CHEMBL1518085 & 688662 & 4.5384 & 5.0617 & TRN & \\
\hline
\end{tabular}




\begin{tabular}{|c|c|c|c|c|c|}
\hline \multirow[b]{2}{*}{ CHEMBL1523954 } & \multicolumn{5}{|c|}{ Supplemental Table S2.txt } \\
\hline & 688662 & 2.8239 & 3.3706 & TRN & \\
\hline CHEMBL1362687 & 688662 & 6.1555 & 5.71299 & 9999999999 & TRN \\
\hline CHEMBL1531170 & 688662 & 2.8239 & 4.5069 & TRN & \\
\hline CHEMBL585502 & 688662 & 5.5496 & 6.2649 & TRN & \\
\hline CHEMBL1987454 & 688662 & 4.4071 & 5.6312 & TRN & \\
\hline CHEMBL1514474 & 688662 & 4.1494 & 3.4084 & TRN & \\
\hline CHEMBL3196139 & 688662 & 5.3394 & 5.4367 & TRN & \\
\hline CHEMBL1608077 & 688662 & 4.9979 & 4.582 & TRN & \\
\hline CHEMBL1598561 & 688662 & 5.3716 & 4.7507 & TRN & \\
\hline CHEMBL3195477 & 688662 & 5.4588 & 5.0806 & TRN & \\
\hline CHEMBL1580848 & 688662 & 4.6167 & 4.841 & TRN & \\
\hline CHEMBL1546134 & 688662 & 5.3421 & 4.5941 & TRN & \\
\hline CHEMBL1363578 & 688662 & 2.8239 & 3.4481 & TST & \\
\hline CHEMBL1451921 & 688662 & 6.0278 & 5.2432 & TRN & \\
\hline CHEMBL1302089 & 688662 & 5.5589 & 5.4604 & TRN & \\
\hline CHEMBL 2094567 & 688662 & 5.8645 & 6.0243 & TRN & \\
\hline CHEMBL1971248 & 688662 & 4.2387 & 4.7106 & TRN & \\
\hline CHEMBL1403148 & 688662 & 5.3473 & 5.2557 & TRN & \\
\hline CHEMBL592600 & 688662 & 5.6405 & 5.49700 & 0000000001 & TRN \\
\hline CHEMBL1548492 & 688662 & 5.4666 & 5.6699 & TRN & \\
\hline CHEMBL1608301 & 688662 & 4.7029 & 4.5452 & TRN & \\
\hline CHEMBL1399543 & 688662 & 5.63899 & 99999999 & 5.647 & TRN \\
\hline CHEMBL1520346 & 688662 & 6.4622 & 5.5785 & TRN & \\
\hline CHEMBL1322738 & 688662 & 4.9176 & 5.07100 & 0000000001 & TRN \\
\hline CHEMBL1340089 & 688662 & 4.805 & 4.6043 & TRN & \\
\hline CHEMBL1353341 & 688662 & 5.4372 & 5.0694 & TRN & \\
\hline CHEMBL1497939 & 688662 & 5.2684 & 5.228 & TRN & \\
\hline CHEMBL1887153 & 688662 & 5.5879 & 5.1396 & TRN & \\
\hline CHEMBL1428163 & 688662 & 5.5634 & 5.1319 & TRN & \\
\hline CHEMBL1491711 & 688662 & 2.8239 & 3.7669 & TRN & \\
\hline CHEMBL1318088 & 688662 & 5.0195 & 4.8394 & TRN & \\
\hline CHEMBL1511179 & 688662 & 5.6931 & 5.6273 & TRN & \\
\hline CHEMBL1613639 & 688662 & 5.4996 & 5.0867 & TRN & \\
\hline CHEMBL1431376 & 688662 & 4.4823 & 4.7406 & TRN & \\
\hline CHEMBL1440862 & 688662 & 4.7981 & 4.2525 & TRN & \\
\hline CHEMBL1572278 & 688662 & 4.1561 & 5.3269 & TRN & \\
\hline CHEMBL1511219 & 688662 & 5.8996 & 5.7015 & TRN & \\
\hline CHEMBL1536118 & 688662 & 4.5938 & 5.2997 & TRN & \\
\hline CHEMBL1368683 & 688662 & 4.4137 & 5.112 & TRN & \\
\hline CHEMBL578944 & 688662 & 5.3785 & 5.2617 & TST & \\
\hline CHEMBL523200 & 688662 & 5.0895 & 4.5737 & TRN & \\
\hline CHEMBL1572624 & 688662 & 4.164 & 4.9966 & TRN & \\
\hline CHEMBL1458479 & 688662 & 5.2818 & 5.0871 & TRN & \\
\hline CHEMBL1602759 & 688662 & 5.1451 & 5.0683 & TRN & \\
\hline CHEMBL86464 & 688662 & 5.3194 & 4.8128 & TRN & \\
\hline CHEMBL1470728 & 688662 & 5.2917 & 5.098 & TST & \\
\hline CHEMBL1360484 & 688662 & 5.5453 & 4.976 & TRN & \\
\hline CHEMBL1567256 & 688662 & 4.2494 & 4.8328 & TRN & \\
\hline
\end{tabular}




\begin{tabular}{|c|c|c|c|c|c|c|}
\hline & & \multicolumn{5}{|c|}{ Supplemental Table S2.txt } \\
\hline CHEMBL1507407 & 688662 & 4.925 & 4.5601 & TRN & & \\
\hline CHEMBL513150 & 688662 & 4.0839 & 4.9209 & TRN & & \\
\hline CHEMBL1317682 & 688662 & 2.8239 & 3.6331 & TRN & & \\
\hline CHEMBL3190594 & 688662 & 5.6728 & 5.7729 & TRN & & \\
\hline CHEMBL1483312 & 688662 & 3.9669 & 4.6331 & TRN & & \\
\hline CHEMBL1353271 & 688662 & 4.7234 & 4.6461 & TRN & & \\
\hline CHEMBL1382517 & 688662 & 2.8239 & 5.0443 & TST & & \\
\hline CHEMBL1431587 & 688662 & 4.2349 & 4.9053 & TRN & & \\
\hline CHEMBL1319307 & 688662 & 4.2832 & 4.5858 & TRN & & \\
\hline CHEMBL1606557 & 688662 & 5.5099 & 3.4031 & TRN & & \\
\hline CHEMBL1378769 & 688662 & 4.8192 & 4.9912 & TRN & & \\
\hline CHEMBL1417726 & 688662 & 4.6219 & 3.6472 & TRN & & \\
\hline CHEMBL1419227 & 688662 & 2.8239 & 3.0176 & TRN & & \\
\hline CHEMBL1408486 & 688662 & 4.967 & 5.3136 & TRN & & \\
\hline CHEMBL1587981 & 688662 & 5.1377 & 3.8759 & TRN & & \\
\hline CHEMBL1487460 & 688662 & 4.6861 & 4.2103 & TRN & & \\
\hline CHEMBL3194964 & 688662 & 5.3854 & 5.434 & TRN & & \\
\hline CHEMBL 290077 & 688662 & 5.8684 & 5.83700 & 0000000001 & & TST \\
\hline CHEMBL1543836 & 688662 & 2.8239 & 3.721 & TST & & \\
\hline CHEMBL1492289 & 688662 & 4.459 & 4.9871 & TRN & & \\
\hline CHEMBL1342728 & 688662 & 4.0542 & 4.6998 & TRN & & \\
\hline CHEMBL3193510 & 688662 & 5.4337 & 5.995 & TRN & & \\
\hline CHEMBL1369945 & 688662 & 4.9147 & 4.7971 & TRN & & \\
\hline CHEMBL1532887 & 688662 & 4.2936 & 3.9901 & TRN & & \\
\hline CHEMBL1419266 & 688662 & 2.8239 & 3.5742 & TRN & & \\
\hline CHEMBL1524929 & 688662 & 5.25200 & 00000000 & $\partial 1$ & 5.2259 & TRN \\
\hline CHEMBL1341442 & 688662 & 4.6861 & 5.045 & TRN & & \\
\hline CHEMBL1411266 & 688662 & 2.8239 & 3.3392 & TRN & & \\
\hline CHEMBL1530741 & 688662 & 2.8239 & 3.6658 & TRN & & \\
\hline CHEMBL1606861 & 688662 & 5.4527 & 4.5217 & TRN & & \\
\hline CHEMBL1391582 & 688662 & 4.5238 & 4.8808 & TST & & \\
\hline CHEMBL1372199 & 688662 & 4.8464 & 5.1634 & TRN & & \\
\hline CHEMBL1994372 & 688662 & 4.3099 & 5.4875 & TRN & & \\
\hline CHEMBL1567841 & 688662 & 5.2961 & 5.044 & TRN & & \\
\hline CHEMBL1417428 & 688662 & 4.624 & 4.8633 & TST & & \\
\hline CHEMBL576208 & 688662 & 4.8748 & 4.6127 & TRN & & \\
\hline CHEMBL1426871 & 688662 & 3.9947 & 4.4869 & TRN & & \\
\hline CHEMBL1489824 & 688662 & 5.5789 & 4.7522 & TST & & \\
\hline CHEMBL1609605 & 688662 & 2.8239 & 3.7589 & TRN & & \\
\hline CHEMBL3195455 & 688662 & 5.0316 & 4.6857 & TRN & & \\
\hline CHEMBL1378118 & 688662 & 5.4527 & 5.2482 & TST & & \\
\hline CHEMBL585071 & 688662 & 5.9957 & 5.5626 & TRN & & \\
\hline CHEMBL1406462 & 688662 & 2.8239 & 3.0476 & TRN & & \\
\hline CHEMBL1386838 & 688662 & 4.5406 & 4.5783 & TST & & \\
\hline CHEMBL3209451 & 688662 & 4.43199 & 99999999 & 995 & 4.5092 & TRN \\
\hline CHEMBL1373253 & 688662 & 4.3342 & 5.3556 & TRN & & \\
\hline CHEMBL1353737 & 688662 & 2.8239 & 3.3423 & TRN & & \\
\hline CHEMBL1472126 & 688662 & 5.5272 & 4.8948 & TRN & & \\
\hline
\end{tabular}




\begin{tabular}{|c|c|c|c|c|c|}
\hline & & \multicolumn{4}{|c|}{ Supplemental Table S2.txt } \\
\hline CHEMBL1473676 & 688662 & 2.8239 & 5.693 & TST & \\
\hline CHEMBL1522007 & 688662 & 4.5843 & 4.5768 & TRN & \\
\hline CHEMBL3199512 & 688662 & 5.561 & 5.3203 & TRN & \\
\hline CHEMBL528791 & 688662 & 5.2555 & 4.9781 & TST & \\
\hline CHEMBL 1537340 & 688662 & 2.8239 & 2.9783 & TRN & \\
\hline CHEMBL3199050 & 688662 & 5.4782 & 5.1556 & TRN & \\
\hline CHEMBL 2004475 & 688662 & 5.1717 & 4.6323 & TST & \\
\hline CHEMBL1370884 & 688662 & 5.2119 & 5.3432 & TRN & \\
\hline CHEMBL1600146 & 688662 & 4.7993 & 4.4009 & TST & \\
\hline CHEMBL1323313 & 688662 & 4.3691 & 4.8408 & TRN & \\
\hline CHEMBL3198332 & 688662 & 5.2561 & 5.61799 & 9999999999 & TRN \\
\hline CHEMBL1500581 & 688662 & 4.8256 & 5.0293 & TST & \\
\hline CHEMBL1399388 & 688662 & 6.1141 & 4.8836 & TRN & \\
\hline CHEMBL1523206 & 688662 & 5.2899 & 4.9776 & TST & \\
\hline CHEMBL1484547 & 688662 & 5.5122 & 5.0741 & TRN & \\
\hline CHEMBL1359327 & 688662 & 2.8239 & 3.2602 & TRN & \\
\hline CHEMBL1977018 & 688662 & 4.1362 & 4.8201 & TRN & \\
\hline CHEMBL1999480 & 688662 & 5.4917 & 5.0808 & TST & \\
\hline CHEMBL1432727 & 688662 & 2.8239 & 3.217 & TRN & \\
\hline CHEMBL1602637 & 688662 & 5.8133 & 5.5581 & TRN & \\
\hline CHEMBL1610733 & 688662 & 4.6486 & 4.0807 & TST & \\
\hline CHEMBL1564522 & 688662 & 5.5835 & 5.2338 & TRN & \\
\hline CHEMBL1373586 & 688662 & 4.7041 & 4.5919 & TRN & \\
\hline CHEMBL1975754 & 688662 & 4.2255 & 4.8402 & TRN & \\
\hline CHEMBL1533067 & 688662 & 5.3009 & 4.8011 & TST & \\
\hline CHEMBL3145305 & 688662 & 5.6182 & 5.1511 & TRN & \\
\hline CHEMBL1479316 & 688662 & 4.8869 & 5.0418 & TRN & \\
\hline CHEMBL1998716 & 688662 & 6.2457 & 5.6187 & TRN & \\
\hline CHEMBL1586255 & 688662 & 5.2477 & 4.4364 & TRN & \\
\hline CHEMBL1346796 & 688662 & 4.9531 & 3.7847 & TRN & \\
\hline CHEMBL1448054 & 688662 & 5.4291 & 5.5323 & TRN & \\
\hline CHEMBL600778 & 688662 & 5.159 & 5.6452 & TRN & \\
\hline CHEMBL1427790 & 688662 & 4.8154 & 4.5246 & TRN & \\
\hline CHEMBL1483593 & 688662 & 6.1959 & 5.7028 & TRN & \\
\hline CHEMBL1970422 & 688662 & 6.2692 & 5.5123 & TST & \\
\hline CHEMBL1403322 & 688662 & 4.7154 & 5.4116 & TRN & \\
\hline CHEMBL1611472 & 688662 & 2.8239 & 3.284 & TRN & \\
\hline CHEMBL1311226 & 688662 & 4.7917 & 4.3678 & TST & \\
\hline CHEMBL1544726 & 688662 & 4.3521 & 4.5116 & TRN & \\
\hline CHEMBL 2006168 & 688662 & 5.6635 & 5.6168 & TRN & \\
\hline CHEMBL1572446 & 688662 & 2.8239 & 3.3639 & TST & \\
\hline CHEMBL1471587 & 688662 & 4.4666 & 4.3541 & TRN & \\
\hline CHEMBL1967952 & 688662 & 5.3973 & 4.6649 & TRN & \\
\hline CHEMBL1584364 & 688662 & 5.5429 & 4.4898 & TRN & \\
\hline CHEMBL1486176 & 688662 & 4.5856 & 4.658 & TRN & \\
\hline CHEMBL1576251 & 688662 & 6.1811 & 5.6215 & TRN & \\
\hline CHEMBL1441122 & 688662 & 5.0603 & 4.2935 & TST & \\
\hline CHEMBL1387238 & 688662 & 4.6649 & 3.9512 & TRN & \\
\hline
\end{tabular}




\begin{tabular}{|c|c|c|c|c|c|c|}
\hline & & \multicolumn{5}{|c|}{ Supplemental Table S2.txt } \\
\hline CHEMBL1611744 & 688662 & 4.2645 & 5.0272 & TRN & & \\
\hline CHEMBL1453099 & 688662 & 2.8239 & 4.7323 & TST & & \\
\hline CHEMBL1605614 & 688662 & 2.8239 & 3.5352 & TRN & & \\
\hline CHEMBL1342448 & 688662 & 4.6318 & 5.2654 & TRN & & \\
\hline CHEMBL1500190 & 688662 & 4.3611 & 4.9096 & TRN & & \\
\hline CHEMBL1581425 & 688662 & 4.8421 & 4.2114 & TRN & & \\
\hline CHEMBL1991136 & 688662 & 4.3279 & 4.5744 & TRN & & \\
\hline CHEMBL1586439 & 688662 & 2.8239 & 4.0479 & TRN & & \\
\hline CHEMBL1344025 & 688662 & 2.8239 & 3.512 & TST & & \\
\hline CHEMBL1321427 & 688662 & \multicolumn{3}{|c|}{4.4239999999999995} & 5.8071 & TRN \\
\hline CHEMBL1506351 & 688662 & 2.8239 & 3.4983 & TRN & & \\
\hline CHEMBL1350780 & 688662 & 4.7723 & 5.4773 & TRN & & \\
\hline CHEMBL1982032 & 688662 & 5.1017 & 5.0829 & TRN & & \\
\hline CHEMBL1596681 & 688662 & 5.684 & 5.4716 & TRN & & \\
\hline CHEMBL1531500 & 688662 & 4.8426 & 4.9643 & TRN & & \\
\hline CHEMBL1497549 & 688662 & 5.8496 & 5.1883 & TRN & & \\
\hline CHEMBL1550486 & 688662 & 4.643 & 4.5479 & TRN & & \\
\hline CHEMBL1333449 & 688662 & 5.9512 & 5.1732 & TRN & & \\
\hline CHEMBL1597716 & 688662 & 2.8239 & 3.6013 & TRN & & \\
\hline CHEMBL1583955 & 688662 & 2.8239 & 5.5688 & TRN & & \\
\hline CHEMBL1520030 & 688662 & 5.0757 & 4.1322 & TST & & \\
\hline CHEMBL1430460 & 688662 & 2.8239 & 3.6223 & TRN & & \\
\hline CHEMBL1335248 & 688662 & 2.8239 & 3.9425 & TRN & & \\
\hline CHEMBL1549611 & 688662 & 4.2324 & 4.7828 & TST & & \\
\hline CHEMBL1423192 & 688662 & 5.1409 & 4.3975 & TRN & & \\
\hline CHEMBL1544797 & 688662 & 5.3565 & 5.2249 & TRN & & \\
\hline CHEMBL1541441 & 688662 & 5.2052 & 4.7704 & TST & & \\
\hline CHEMBL1505813 & 688662 & 5.8791 & 4.5362 & TRN & & \\
\hline CHEMBL1563136 & 688662 & 2.8239 & 3.7356 & TRN & & \\
\hline CHEMBL1446306 & 688662 & 4.271 & 5.2215 & TRN & & \\
\hline CHEMBL1469642 & 688662 & 4.4422 & 3.895 & TST & & \\
\hline CHEMBL533602 & 688662 & 5.4339 & 5.2631 & TST & & \\
\hline CHEMBL1462373 & 688662 & 5.3513 & 5.4709 & TRN & & \\
\hline CHEMBL1303910 & 688662 & 5.8496 & 5.3166 & TRN & & \\
\hline CHEMBL1376068 & 688662 & 2.8239 & 3.8332 & TRN & & \\
\hline CHEMBL1586371 & 688662 & 6.2262 & 4.8789 & TRN & & \\
\hline CHEMBL1436988 & 688662 & 5.0606 & 4.7297 & TRN & & \\
\hline CHEMBL1511371 & 688662 & 5.5455 & 4.9449 & TST & & \\
\hline CHEMBL1492222 & 688662 & 3.9827 & 4.7897 & TRN & & \\
\hline CHEMBL3195943 & 688662 & 4.808 & 3.9567 & TRN & & \\
\hline CHEMBL1586263 & 688662 & 5.0175 & 4.4716 & TRN & & \\
\hline CHEMBL1462938 & 688662 & 7.9208 & 5.4989 & TRN & & \\
\hline CHEMBL1368681 & 688662 & 2.8239 & 3.76 & TRN & & \\
\hline CHEMBL1458812 & 688662 & 2.8239 & 4.6324 & TRN & & \\
\hline CHEMBL3191874 & 688662 & 6.6517 & 5.1745 & TRN & & \\
\hline CHEMBL31840 & 688662 & 5.8861 & 5.0587 & TRN & & \\
\hline CHEMBL 1563712 & 688662 & 2.8239 & 3.696 & TRN & & \\
\hline CHEMBL15968 & 688662 & 4.7034 & 5.3658 & TRN & & \\
\hline
\end{tabular}




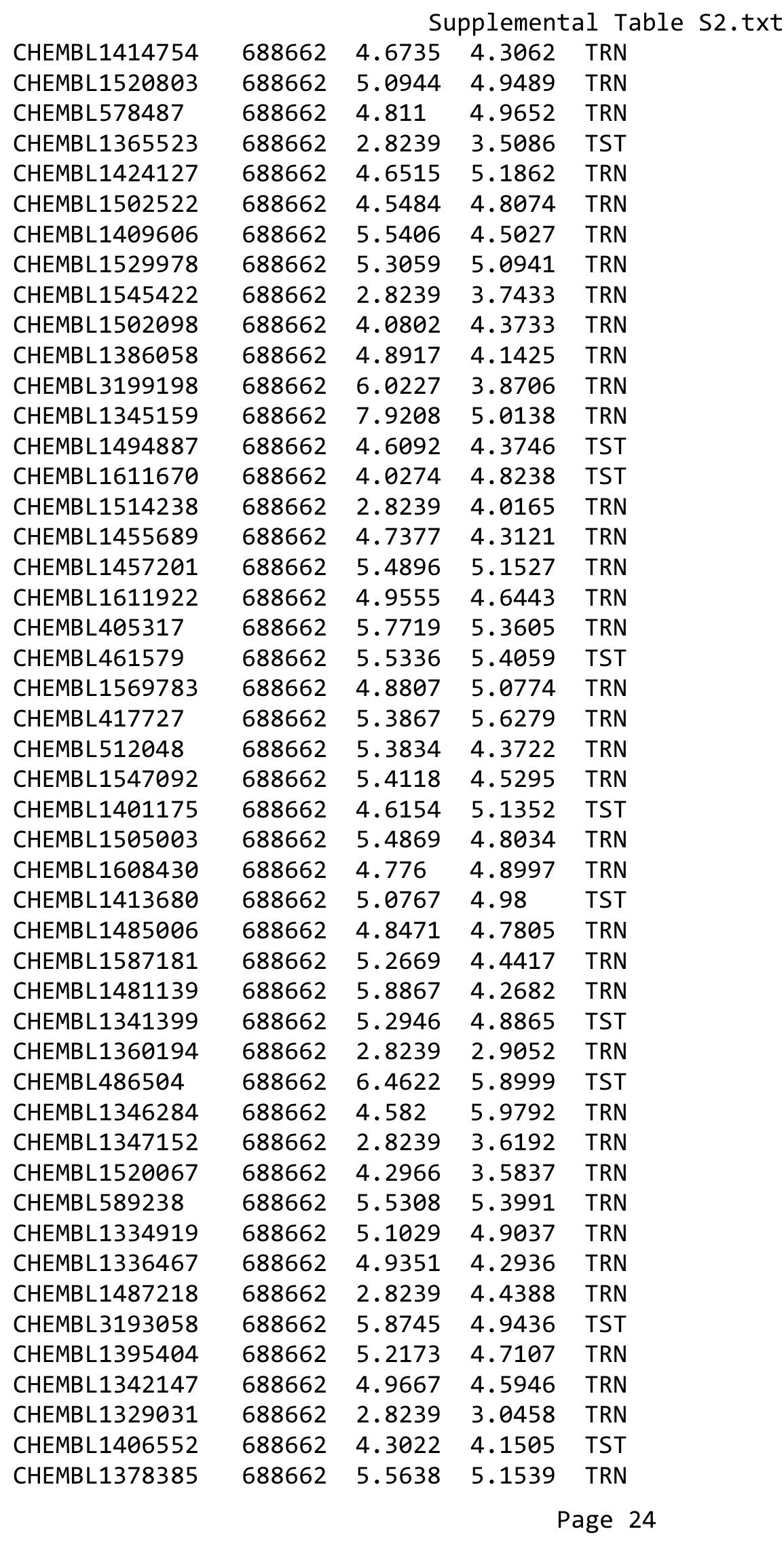




\begin{tabular}{|c|c|c|c|c|c|}
\hline & & \multicolumn{4}{|c|}{ Supplemental Table S2.txt } \\
\hline CHEMBL1582519 & 688662 & 2.8239 & 3.0087 & TRN & \\
\hline CHEMBL1541779 & 688662 & 4.4331 & 4.5381 & TRN & \\
\hline CHEMBL1396519 & 688662 & 4.9098 & 4.9269 & TRN & \\
\hline CHEMBL1990919 & 688662 & 5.5896 & 5.6563 & TRN & \\
\hline CHEMBL 1389248 & 688662 & 4.5618 & 5.2085 & TRN & \\
\hline CHEMBL1300069 & 688662 & 4.5987 & 4.7371 & TST & \\
\hline CHEMBL453974 & 688662 & 6.51 & 4.94300 & 00000000005 & TST \\
\hline CHEMBL1338243 & 688662 & 2.8239 & 3.7986 & TRN & \\
\hline CHEMBL3214583 & 688662 & 2.8239 & 4.4326 & TRN & \\
\hline CHEMBL 1358722 & 688662 & 6.15 & 5.4544 & TST & \\
\hline CHEMBL3197908 & 688662 & 5.2935 & 5.227 & TRN & \\
\hline CHEMBL1600963 & 688662 & 2.8239 & 3.5604 & TRN & \\
\hline CHEMBL1498509 & 688662 & 5.5607 & 5.6881 & TRN & \\
\hline CHEMBL1303916 & 688662 & 4.8962 & 4.218 & TRN & \\
\hline CHEMBL1366104 & 688662 & 2.8239 & 3.5989 & TRN & \\
\hline CHEMBL1987894 & 688662 & 5.5293 & 5.2702 & TRN & \\
\hline CHEMBL1990093 & 688662 & 5.9165 & 5.6666 & TRN & \\
\hline CHEMBL1425008 & 688662 & 2.8239 & 2.9206 & TRN & \\
\hline CHEMBL1459394 & 688662 & 4.5975 & 4.20100 & 00000000005 & TRN \\
\hline CHEMBL1493225 & 688662 & 2.8239 & 4.1469 & TRN & \\
\hline CHEMBL600121 & 688662 & 4.8507 & 4.5678 & TRN & \\
\hline CHEMBL1462919 & 688662 & 2.8239 & 4.5074 & TST & \\
\hline CHEMBL1371028 & 688662 & 4.6092 & 3.9081 & TRN & \\
\hline CHEMBL1314208 & 688662 & 4.7134 & 4.3628 & TST & \\
\hline CHEMBL1485562 & 688662 & 2.8239 & 3.9638 & TRN & \\
\hline CHEMBL1503190 & 688662 & 4.9935 & 4.5433 & TRN & \\
\hline CHEMBL3208035 & 688662 & 2.8239 & 4.1016 & TRN & \\
\hline CHEMBL1985575 & 688662 & 5.5025 & 5.4307 & TRN & \\
\hline CHEMBL1310508 & 688662 & 5.4322 & 4.7286 & TRN & \\
\hline CHEMBL1399212 & 688662 & 4.7311 & 4.1997 & TRN & \\
\hline CHEMBL1472773 & 688662 & 5.204 & 5.2639 & TST & \\
\hline CHEMBL1403980 & 688662 & 5.2147 & 4.5966 & TRN & \\
\hline CHEMBL1546843 & 688662 & 2.8239 & 4.7703 & TRN & \\
\hline CHEMBL1596609 & 688662 & 4.5174 & 3.7184 & TRN & \\
\hline CHEMBL3209306 & 688662 & 5.3961 & 5.2204 & TRN & \\
\hline CHEMBL1527380 & 688662 & 4.6746 & 5.584 & TRN & \\
\hline CHEMBL1528258 & 688662 & 5.1112 & 4.6202 & TRN & \\
\hline CHEMBL1494636 & 688662 & 4.3542 & 3.6575 & TST & \\
\hline CHEMBL1569918 & 688662 & 5.0302 & 4.355 & TRN & \\
\hline CHEMBL1412002 & 688662 & 5.506 & 5.8057 & TRN & \\
\hline CHEMBL1439210 & 688662 & 5.4547 & 5.0793 & TRN & \\
\hline CHEMBL1506210 & 688662 & 4.7718 & 4.2333 & TRN & \\
\hline CHEMBL3189320 & 688662 & 2.8239 & 4.2864 & TST & \\
\hline CHEMBL1546722 & 688662 & 4.6695 & 5.3301 & TST & \\
\hline CHEMBL1575441 & 688662 & 3.9063 & 5.3639 & TST & \\
\hline CHEMBL3192181 & 688662 & 5.6686 & 5.5812 & TRN & \\
\hline CHEMBL1444020 & 688662 & 5.5805 & 5.2798 & TRN & \\
\hline CHEMBL1563623 & 688662 & 5.3874 & 4.2093 & TRN & \\
\hline
\end{tabular}




\begin{tabular}{|c|c|c|c|c|c|}
\hline & & \multicolumn{4}{|c|}{ Supplemental Table S2.txt } \\
\hline CHEMBL1567896 & 688662 & 2.8239 & 3.5296 & TRN & \\
\hline CHEMBL1343823 & 688662 & 5.5032 & 5.6259 & TRN & \\
\hline CHEMBL1437683 & 688662 & 4.9189 & 4.6805 & TRN & \\
\hline CHEMBL1349455 & 688662 & 4.632 & 4.5312 & TRN & \\
\hline CHEMBL1380406 & 688662 & 4.6113 & 4.6222 & TRN & \\
\hline CHEMBL1476358 & 688662 & 2.8239 & 4.5251 & TRN & \\
\hline CHEMBL1448905 & 688662 & 5.0953 & 4.8282 & TRN & \\
\hline CHEMBL603129 & 688662 & 4.7672 & 5.0044 & TRN & \\
\hline CHEMBL1595169 & 688662 & 6.5654 & 4.9103 & TRN & \\
\hline CHEMBL1342029 & 688662 & 6.1096 & 5.7087 & TRN & \\
\hline CHEMBL1489856 & 688662 & 4.6516 & 4.0133 & TRN & \\
\hline CHEMBL1543268 & 688662 & 4.1664 & 4.9966 & TRN & \\
\hline CHEMBL1328050 & 688662 & 4.4221 & 4.7251 & TRN & \\
\hline CHEMBL1462630 & 688662 & 6.0334 & 5.4313 & TRN & \\
\hline CHEMBL1380239 & 688662 & 4.4983 & 4.3242 & TRN & \\
\hline CHEMBL1516533 & 688662 & 4.6942 & 5.433 & TRN & \\
\hline CHEMBL1455421 & 688662 & 4.9509 & 4.6646 & TRN & \\
\hline CHEMBL1600403 & 688662 & 4.0344 & 3.4692 & TRN & \\
\hline CHEMBL1341518 & 688662 & 3.9531 & 4.5525 & TST & \\
\hline CHEMBL1566559 & 688662 & 2.8239 & 2.9089 & TRN & \\
\hline CHEMBL1543337 & 688662 & 5.1719 & 5.1904 & TRN & \\
\hline CHEMBL1341680 & 688662 & 4.3302 & 4.3079 & TRN & \\
\hline CHEMBL1339289 & 688662 & 5.5136 & 5.4665 & TST & \\
\hline CHEMBL590184 & 688662 & 4.7416 & 4.7204 & TRN & \\
\hline CHEMBL1335177 & 688662 & 4.0476 & 4.8177 & TRN & \\
\hline CHEMBL1539572 & 688662 & 4.1211 & 4.8672 & TRN & \\
\hline CHEMBL1340058 & 688662 & 4.882 & 5.2843 & TRN & \\
\hline CHEMBL1609270 & 688662 & 4.5844 & 4.221 & TRN & \\
\hline CHEMBL1490339 & 688662 & 6.0119 & 5.5581 & TRN & \\
\hline CHEMBL1544508 & 688662 & 5.5596 & 4.54899 & 99999999995 & TRN \\
\hline CHEMBL1411388 & 688662 & 4.8858 & 5.1118 & TRN & \\
\hline CHEMBL1977480 & 688662 & 4.016 & 4.8017 & TRN & \\
\hline CHEMBL1567957 & 688662 & 4.1957 & 4.2046 & TRN & \\
\hline CHEMBL 267099 & 688662 & 5.2636 & 5.4674 & TST & \\
\hline CHEMBL1457139 & 688662 & 4.8563 & 5.2796 & TRN & \\
\hline CHEMBL1349116 & 688662 & 4.9604 & 5.4306 & TRN & \\
\hline CHEMBL1359872 & 688662 & 4.5355 & 5.5353 & TRN & \\
\hline CHEMBL1407169 & 688662 & 5.6863 & 4.7612 & TRN & \\
\hline CHEMBL199868 & 688662 & 5.4764 & 5.4485 & TRN & \\
\hline CHEMBL1523841 & 688662 & 5.6295 & 4.9742 & TST & \\
\hline CHEMBL528694 & 688662 & 5.6613 & 5.4794 & TRN & \\
\hline CHEMBL1345208 & 688662 & 2.8239 & 4.0827 & TST & \\
\hline CHEMBL1305972 & 688662 & 4.4773 & 4.5431 & TST & \\
\hline CHEMBL1519014 & 688662 & 4.2611 & 4.3535 & TRN & \\
\hline CHEMBL1535665 & 688662 & 5.2165 & 4.9144 & TRN & \\
\hline CHEMBL1404086 & 688662 & 4.8426 & 3.8278 & TRN & \\
\hline CHEMBL1546374 & 688662 & 5.7724 & 5.6574 & TST & \\
\hline CHEMBL1468200 & 688662 & 2.8239 & 3.9424 & TST & \\
\hline
\end{tabular}


Supplemental Table S2.txt

\begin{tabular}{|c|c|c|c|c|}
\hline CHEMBL1523306 & 688662 & 4.5701 & 4.7268 & TRN \\
\hline CHEMBL1986514 & 688662 & 4.8067 & 4.7191 & TRN \\
\hline CHEMBL 2135351 & 688662 & 5.7528 & 5.4324 & TST \\
\hline CHEMBL1583292 & 688662 & 4.8922 & 5.0962 & TST \\
\hline CHEMBL600862 & 688662 & 5.6182 & 5.7473 & TRN \\
\hline CHEMBL81782 & 688662 & 5.7742 & 5.8047 & TRN \\
\hline CHEMBL1332450 & 688662 & 4.8952 & 4.7205 & TRN \\
\hline CHEMBL1504035 & 688662 & 4.5694 & 4.8249 & TRN \\
\hline CHEMBL1439227 & 688662 & 4.7221 & 5.0349 & TRN \\
\hline CHEMBL1576132 & 688662 & 5.397 & 5.1973 & TRN \\
\hline CHEMBL1424269 & 688662 & 5.2397 & 5.1129 & TRN \\
\hline CHEMBL1321538 & 688662 & 5.5504 & 4.8252 & TRN \\
\hline CHEMBL1369513 & 688662 & 4.3676 & 3.2883 & TRN \\
\hline CHEMBL1490060 & 688662 & 4.6055 & 5.1016 & TRN \\
\hline CHEMBL1333830 & 688662 & 5.3474 & 4.678999 & 999999999 \\
\hline CHEMBL1548898 & 688662 & 4.7853 & 4.2503 & TRN \\
\hline CHEMBL1993380 & 688662 & 5.5642 & 4.9813 & TRN \\
\hline CHEMBL1376166 & 688662 & 5.9194 & 5.0919 & TRN \\
\hline CHEMBL1491324 & 688662 & 5.7345 & 5.1314 & TRN \\
\hline CHEMBL 3210375 & 688662 & 2.8239 & 3.3982 & TRN \\
\hline CHEMBL1576754 & 688662 & 5.3152 & 4.6104 & TRN \\
\hline CHEMBL1462074 & 688662 & 6.1701 & 5.2129 & TST \\
\hline CHEMBL1392026 & 688662 & 4.4725 & 4.5901 & TRN \\
\hline CHEMBL1520080 & 688662 & 2.8239 & 3.8433 & TRN \\
\hline CHEMBL1197556 & 688662 & 5.5643 & 5.9152 & TRN \\
\hline CHEMBL1455654 & 688662 & 2.8239 & 3.4458 & TRN \\
\hline CHEMBL1312720 & 688662 & 3.9555 & 4.1995 & TRN \\
\hline CHEMBL1533621 & 688662 & 5.5156 & 5.1846 & TRN \\
\hline CHEMBL 3191855 & 688662 & 5.49299 & 999999999 & 5.546 \\
\hline CHEMBL 3145285 & 688662 & 5.519 & 5.233 & TRN \\
\hline CHEMBL1587877 & 688662 & 4.2524 & 4.7161 & TRN \\
\hline CHEMBL1996752 & 688662 & 4.8706 & 4.6428 & TRN \\
\hline CHEMBL1577495 & 688662 & 4.1126 & 4.7404 & TRN \\
\hline CHEMBL1605372 & 688662 & 5.4003 & 4.4692 & TST \\
\hline CHEMBL1324061 & 688662 & 4.712 & 5.1463 & TRN \\
\hline CHEMBL1385375 & 688662 & 2.8239 & 3.5857 & TRN \\
\hline CHEMBL89445 & 688662 & 5.3121 & 5.6404 & TRN \\
\hline CHEMBL1414465 & 688662 & 2.8239 & 3.8392 & TRN \\
\hline CHEMBL1978117 & 688662 & 6.1024 & 5.4143 & TRN \\
\hline CHEMBL1405453 & 688662 & 6.1993 & 5.3155 & TRN \\
\hline CHEMBL568092 & 688662 & 5.5456 & 5.1407 & TRN \\
\hline CHEMBL1361005 & 688662 & 2.8239 & 3.1235 & TRN \\
\hline CHEMBL1466997 & 688662 & 5.0587 & 4.8037 & TRN \\
\hline CHEMBL1404493 & 688662 & 5.6313 & 5.9238 & TRN \\
\hline CHEMBL1484332 & 688662 & 5.1422 & 4.9182 & TRN \\
\hline CHEMBL1457480 & 688662 & 4.3109 & 4.2035 & TRN \\
\hline CHEMBL1380801 & 688662 & 5.2695 & 4.9249 & TRN \\
\hline CHEMBL1311094 & 688662 & 5.5346 & 5.0643 & TRN \\
\hline
\end{tabular}




\begin{tabular}{|c|c|c|c|c|c|}
\hline \multicolumn{6}{|c|}{ Supplemental Table s2.txt } \\
\hline CHEMBL1983871 & 688662 & 5.0013 & 4.431 & TRN & \\
\hline CHEMBL1518905 & 688662 & 6.1778 & 5.7928 & TRN & \\
\hline CHEMBL1498488 & 688662 & 6.5952 & 5.294 & TRN & \\
\hline CHEMBL1414345 & 688662 & 5.1572 & 4.1904 & TRN & \\
\hline CHEMBL1583976 & 688662 & 4.4132 & 5.1672 & TRN & \\
\hline CHEMBL1556239 & 688662 & 5.9555 & 5.2743 & TST & \\
\hline CHEMBL1528030 & 688662 & 2.8239 & 3.2573 & TRN & \\
\hline CHEMBL1343525 & 688662 & 4.7423 & 3.4799 & TRN & \\
\hline CHEMBL1501508 & 688662 & 4.7619 & 4.8872 & TRN & \\
\hline CHEMBL1987938 & 688662 & 5.6836 & 5.6239 & TRN & \\
\hline CHEMBL1452391 & 688662 & 4.8073 & 5.2019 & TRN & \\
\hline CHEMBL1450116 & 688662 & 4.7457 & 4.7822 & TRN & \\
\hline CHEMBL1353528 & 688662 & 4.274 & 4.6336 & TRN & \\
\hline CHEMBL1319676 & 688662 & 5.5018 & 4.6902 & TRN & \\
\hline CHEMBL1301647 & 688662 & 4.3832 & 4.2559 & TRN & \\
\hline CHEMBL1526174 & 688662 & 5.3527 & 5.0216 & TRN & \\
\hline CHEMBL518292 & 688662 & 5.2386 & 5.1115 & TST & \\
\hline CHEMBL473721 & 688662 & 5.0868 & 5.2898 & TRN & \\
\hline CHEMBL1307506 & 688662 & 4.8747 & 4.4812 & TRN & \\
\hline CHEMBL1464824 & 688662 & 2.8239 & 3.3668 & TRN & \\
\hline CHEMBL1508051 & 688662 & 4.8628 & 4.8785 & TST & \\
\hline CHEMBL1388469 & 688662 & 5.1596 & 4.9036 & TRN & \\
\hline CHEMBL1325021 & 688662 & 5.2488 & 4.3836 & TRN & \\
\hline CHEMBL1608727 & 688662 & 5.6251 & 5.1736 & TRN & \\
\hline CHEMBL1410102 & 688662 & 4.6872 & 5.0192 & TRN & \\
\hline CHEMBL1395962 & 688662 & 5.8649 & 4.5851 & TRN & \\
\hline CHEMBL1548433 & 688662 & 4.6148 & 4.3824 & TRN & \\
\hline CHEMBL1328504 & 688662 & 5.2863 & 4.4181 & TRN & \\
\hline CHEMBL1372163 & 688662 & 5.8077 & 5.4605 & TRN & \\
\hline CHEMBL1565526 & 688662 & 4.6776 & 5.1996 & TRN & \\
\hline CHEMBL1524734 & 688662 & 5.2346 & 4.9708 & TRN & \\
\hline CHEMBL1566211 & 688662 & 5.4149 & 4.7796 & TRN & \\
\hline CHEMBL1611686 & 688662 & 5.1169 & 5.6594 & TRN & \\
\hline CHEMBL1430094 & 688662 & 5.2392 & 5.0923 & TRN & \\
\hline CHEMBL1589042 & 688662 & 4.4166 & 4.5952 & TRN & \\
\hline CHEMBL1558993 & 688662 & 4.7689 & 4.0344 & TRN & \\
\hline CHEMBL1577016 & 688662 & 2.8239 & 4.7536 & TST & \\
\hline CHEMBL3212654 & 688662 & 4.6398 & 4.3602 & TRN & \\
\hline CHEMBL1525300 & 688662 & 4.7394 & 4.7077 & TRN & \\
\hline CHEMBL1987820 & 688662 & 5.5216 & 5.7474 & TRN & \\
\hline CHEMBL1337416 & 688662 & 4.9282 & 5.343999 & 9999999999 & TST \\
\hline CHEMBL1502738 & 688662 & 5.3577 & 4.6492 & TRN & \\
\hline CHEMBL3191962 & 688662 & 5.1927 & 5.4782 & TRN & \\
\hline CHEMBL1488760 & 688662 & 3.9833 & 4.9055 & TST & \\
\hline CHEMBL1330793 & 688662 & 5.1098 & 5.0947 & TST & \\
\hline CHEMBL570345 & 688662 & 5.4465 & 4.916 & TST & \\
\hline CHEMBL1392509 & 688662 & 4.4924 & 4.0486 & TRN & \\
\hline CHEMBL1401327 & 688662 & 2.8239 & 3.7691 & TRN & \\
\hline
\end{tabular}




\begin{tabular}{|c|c|c|c|c|c|c|}
\hline & & \multicolumn{5}{|c|}{ Supplemental Table S2.txt } \\
\hline CHEMBL1385053 & 688662 & 4.448 & 5.033 & TRN & & \\
\hline CHEMBL1308404 & 688662 & 5.276 & 5.0915 & TRN & & \\
\hline CHEMBL1540682 & 688662 & 5.5373 & 5.1602 & TST & & \\
\hline CHEMBL1309860 & 688662 & 4.633 & 4.3603 & TRN & & \\
\hline CHEMBL1993058 & 688662 & 3.8551 & 4.40600 & 00000000 & & TRN \\
\hline CHEMBL1361866 & 688662 & 4.2812 & 5.0591 & TST & & \\
\hline CHEMBL1417620 & 688662 & 4.0429 & 4.9656 & TRN & & \\
\hline CHEMBL1321754 & 688662 & 4.7494 & 4.3342 & TRN & & \\
\hline CHEMBL1307663 & 688662 & 5.246 & 4.4151 & TRN & & \\
\hline CHEMBL493863 & 688662 & 5.0432 & 5.2598 & TST & & \\
\hline CHEMBL1573883 & 688662 & 5.4815 & 4.5056 & TRN & & \\
\hline CHEMBL1598569 & 688662 & 4.5449 & 4.6323 & TRN & & \\
\hline CHEMBL1547278 & 688662 & 2.8239 & 3.8712 & TRN & & \\
\hline CHEMBL379179 & 688662 & 4.7185 & 5.7373 & TRN & & \\
\hline CHEMBL1308497 & 688662 & 2.8239 & 4.3026 & TRN & & \\
\hline CHEMBL1503006 & 688662 & 3.87899 & 99999999 & 996 & 4.1217 & TRN \\
\hline CHEMBL1989225 & 688662 & 4.7402 & 5.1922 & TRN & & \\
\hline CHEMBL3182775 & 688662 & 6.3224 & 5.1099 & TST & & \\
\hline CHEMBL1466445 & 688662 & 5.2609 & 4.776 & TRN & & \\
\hline CHEMBL1548542 & 688662 & 4.8729 & 4.5759 & TRN & & \\
\hline CHEMBL1544486 & 688662 & 5.5772 & 5.35 & TRN & & \\
\hline CHEMBL1567899 & 688662 & 4.3204 & 5.3852 & TRN & & \\
\hline CHEMBL1544445 & 688662 & 6.0899 & 5.5584 & TRN & & \\
\hline CHEMBL1337592 & 688662 & 6.0057 & 5.3235 & TRN & & \\
\hline CHEMBL1451142 & 688662 & 2.8239 & 3.1262 & TRN & & \\
\hline CHEMBL1365332 & 688662 & 4.5591 & 4.8574 & TRN & & \\
\hline CHEMBL3199216 & 688662 & 5.3296 & 5.7408 & TRN & & \\
\hline CHEMBL1611182 & 688662 & 5.2505 & 4.9851 & TRN & & \\
\hline CHEMBL1407996 & 688662 & 4.8319 & 3.6154 & TRN & & \\
\hline CHEMBL1547706 & 688662 & 4.1951 & 5.0994 & TRN & & \\
\hline CHEMBL1587596 & 688662 & 4.5867 & 4.5503 & TRN & & \\
\hline CHEMBL1312644 & 688662 & 2.8239 & 2.8828 & TRN & & \\
\hline CHEMBL1479953 & 688662 & 2.8239 & 2.9976 & TRN & & \\
\hline CHEMBL1351755 & 688662 & 5.5998 & 5.3726 & TRN & & \\
\hline CHEMBL1404448 & 688662 & 5.3319 & 5.0278 & TRN & & \\
\hline CHEMBL1392025 & 688662 & 5.0987 & 3.8158 & TRN & & \\
\hline CHEMBL602126 & 688662 & 4.6894 & 4.8889 & TRN & & \\
\hline CHEMBL1569667 & 688662 & 5.2273 & 5.4159 & TRN & & \\
\hline CHEMBL3196976 & 688662 & 5.5349 & 5.23 & TRN & & \\
\hline CHEMBL1442452 & 688662 & 2.8239 & 3.6032 & TRN & & \\
\hline CHEMBL1603293 & 688662 & 2.8239 & 3.1536 & TRN & & \\
\hline CHEMBL1488923 & 688662 & 5.9817 & 5.5507 & TRN & & \\
\hline CHEMBL1361821 & 688662 & 4.5732 & 4.4454 & TRN & & \\
\hline CHEMBL1993287 & 688662 & 4.2669 & 5.03 & TRN & & \\
\hline CHEMBL1928491 & 688662 & 5.2946 & 4.6166 & TRN & & \\
\hline CHEMBL1365006 & 688662 & 5.0859 & 4.7589 & TRN & & \\
\hline CHEMBL 1487444 & 688662 & 5.0463 & 4.8109 & TRN & & \\
\hline CHEMBL3194449 & 688662 & 5.3677 & 5.341 & TRN & & \\
\hline
\end{tabular}




\begin{tabular}{|c|c|c|c|c|c|}
\hline \multicolumn{6}{|c|}{ Supplemental Table s2.txt } \\
\hline CHEMBL1503930 & 688662 & 5.0455 & 4.5897 & TRN & \\
\hline CHEMBL1327703 & 688662 & 4.8206 & 5.2523 & TRN & \\
\hline CHEMBL1419779 & 688662 & 4.5001 & 4.6119 & TRN & \\
\hline CHEMBL1420007 & 688662 & 4.6539 & 4.5165 & TRN & \\
\hline CHEMBL1337130 & 688662 & 2.8239 & 3.6132 & TRN & \\
\hline CHEMBL1987461 & 688662 & 5.1283 & 5.4384 & TRN & \\
\hline CHEMBL1422078 & 688662 & 4.82 & 5.0395 & TRN & \\
\hline CHEMBL1319113 & 688662 & 4.6771 & 4.3836 & TST & \\
\hline CHEMBL1607187 & 688662 & 4.2858 & 4.1943 & TRN & \\
\hline CHEMBL1442056 & 688662 & 5.2934 & 4.8876 & TST & \\
\hline CHEMBL1384373 & 688662 & 4.8663 & 4.2759 & TRN & \\
\hline CHEMBL1386941 & 688662 & 2.8239 & 3.8236 & TRN & \\
\hline CHEMBL1501238 & 688662 & 5.0811 & 4.4318 & TST & \\
\hline CHEMBL1335650 & 688662 & 2.8239 & 3.0544 & TST & \\
\hline CHEMBL1343458 & 688662 & 4.7683 & 4.7435 & TST & \\
\hline CHEMBL1535161 & 688662 & 2.8239 & 3.0855 & TRN & \\
\hline CHEMBL1971142 & 688662 & 5.0773 & 4.8129 & TRN & \\
\hline CHEMBL1610540 & 688662 & 4.6295 & 4.9576 & TRN & \\
\hline CHEMBL602722 & 688662 & 4.808 & 5.1836 & TRN & \\
\hline CHEMBL1560590 & 688662 & 4.8772 & 4.5375 & TRN & \\
\hline CHEMBL193872 & 688662 & 5.2211 & 5.4327 & TRN & \\
\hline CHEMBL1582760 & 688662 & 6.4672 & 5.4757 & TRN & \\
\hline CHEMBL1476215 & 688662 & 4.8245 & 5.5859 & TRN & \\
\hline CHEMBL1341845 & 688662 & 2.8239 & 4.3176 & TRN & \\
\hline CHEMBL1553717 & 688662 & 5.1285 & 4.5876 & TRN & \\
\hline CHEMBL1530673 & 688662 & 4.8228 & 4.9763 & TST & \\
\hline CHEMBL1549860 & 688662 & 4.6617 & 4.1944 & TST & \\
\hline CHEMBL3209269 & 688662 & 2.8239 & 4.3996 & TRN & \\
\hline CHEMBL1384771 & 688662 & 4.9421 & 4.4718 & TST & \\
\hline CHEMBL1982575 & 688662 & 4.9369 & 4.6196 & TRN & \\
\hline CHEMBL 3199573 & 688662 & 2.8239 & 4.1328 & TRN & \\
\hline CHEMBL1373992 & 688662 & 2.8239 & 4.1227 & TST & \\
\hline CHEMBL1985165 & 688662 & 5.2945 & 4.7578 & TRN & \\
\hline CHEMBL1468340 & 688662 & 4.6986 & 5.3269 & TRN & \\
\hline CHEMBL51931 & 688662 & 5.2227 & 5.67299 & 9999999999 & TRN \\
\hline CHEMBL1543387 & 688662 & 4.6928 & 5.3609 & TRN & \\
\hline CHEMBL1430987 & 688662 & 2.8239 & 3.1218 & TRN & \\
\hline CHEMBL1543383 & 688662 & 4.4689 & 4.8238 & TRN & \\
\hline CHEMBL1444065 & 688662 & 4.525 & 4.6308 & TRN & \\
\hline CHEMBL1486332 & 688662 & 5.2745 & 5.2266 & TRN & \\
\hline CHEMBL1482760 & 688662 & 5.4252 & 4.7469 & TRN & \\
\hline CHEMBL1580075 & 688662 & 6.2882 & 4.7926 & TRN & \\
\hline CHEMBL1415336 & 688662 & 2.8239 & 2.9552 & TRN & \\
\hline CHEMBL1971727 & 688662 & 5.2317 & 5.0315 & TRN & \\
\hline CHEMBL1967031 & 688662 & 4.912 & 4.9092 & TRN & \\
\hline CHEMBL1613644 & 688662 & 4.2113 & 4.1455 & TRN & \\
\hline CHEMBL1610510 & 688662 & 4.7521 & 5.0762 & TRN & \\
\hline CHEMBL1353184 & 688662 & 4.4635 & 3.8341 & TRN & \\
\hline
\end{tabular}




\begin{tabular}{|c|c|c|c|c|c|c|}
\hline & & & & & & \\
\hline CHEMBL330320 & 688662 & 6.2027 & 5.9066 & TST & & \\
\hline CHEMBL1374527 & 688662 & 4.2178 & 5.0838 & TRN & & \\
\hline CHEMBL1608333 & 688662 & 5.1743 & 5.0323 & TRN & & \\
\hline CHEMBL1368526 & 688662 & 4.44300 & 0000000 & 205 & 4.9917 & TRN \\
\hline CHEMBL1596798 & 688662 & 5.6008 & 5.5754 & TRN & & \\
\hline CHEMBL1430227 & 688662 & 4.4783 & 4.2759 & TRN & & \\
\hline CHEMBL1429789 & 688662 & 4.854 & 4.4479 & TRN & & \\
\hline CHEMBL257286 & 688662 & 4.7643 & 3.9886 & TRN & & \\
\hline CHEMBL1457561 & 688662 & 4.8292 & 4.912 & TRN & & \\
\hline CHEMBL1588722 & 688662 & 2.8239 & 4.7172 & TST & & \\
\hline CHEMBL1575588 & 688662 & 5.0439 & 5.1966 & TRN & & \\
\hline CHEMBL1577840 & 688662 & 5.2194 & 5.1152 & TST & & \\
\hline CHEMBL1537106 & 688662 & 5.1764 & 5.1991 & TST & & \\
\hline CHEMBL1477197 & 688662 & 5.0094 & 4.6645 & TRN & & \\
\hline CHEMBL1498959 & 688662 & 4.5244 & 4.422 & TRN & & \\
\hline CHEMBL1329069 & 688662 & 4.9201 & 5.0821 & TRN & & \\
\hline CHEMBL1426340 & 688662 & 5.0934 & 5.3498 & TRN & & \\
\hline CHEMBL1309463 & 688662 & 5.1661 & 4.1138 & TRN & & \\
\hline CHEMBL80799 & 688662 & 4.3349 & 5.0353 & TRN & & \\
\hline CHEMBL1997978 & 688662 & 4.3481 & 4.14 & TRN & & \\
\hline CHEMBL3194752 & 688662 & 4.7574 & 4.4414 & TRN & & \\
\hline CHEMBL1487099 & 688662 & 5.8661 & 5.4944 & TST & & \\
\hline CHEMBL3145303 & 688662 & 5.51399 & 99999999 & 99 & 5.3609 & TRN \\
\hline CHEMBL1392473 & 688662 & 4.3884 & 4.8407 & TRN & & \\
\hline CHEMBL1500296 & 688662 & 2.8239 & 3.299 & TRN & & \\
\hline CHEMBL1462711 & 688662 & 4.3312 & 3.9918 & TRN & & \\
\hline CHEMBL1330780 & 688662 & 2.8239 & 3.6542 & TRN & & \\
\hline CHEMBL1575428 & 688662 & 4.7739 & 4.2978 & TRN & & \\
\hline CHEMBL1549738 & 688662 & 5.0797 & 4.8655 & TST & & \\
\hline CHEMBL3196369 & 688662 & 5.2348 & 3.8678 & TRN & & \\
\hline CHEMBL1301313 & 688662 & 2.8239 & 3.1496 & TRN & & \\
\hline CHEMBL1469827 & 688662 & 2.8239 & 4.5577 & TRN & & \\
\hline CHEMBL323668 & 688662 & 6.8996 & 6.1338 & TST & & \\
\hline CHEMBL1519655 & 688662 & 4.9584 & 4.551 & TRN & & \\
\hline CHEMBL82134 & 688662 & 4.7488 & 5.5395 & TRN & & \\
\hline CHEMBL1489779 & 688662 & 4.3901 & 5.9367 & TRN & & \\
\hline CHEMBL1373252 & 688662 & 4.5922 & 4.2155 & TRN & & \\
\hline CHEMBL1363437 & 688662 & 6.5258 & 6.2042 & TRN & & \\
\hline CHEMBL1981103 & 688662 & 5.1866 & 4.9723 & TST & & \\
\hline CHEMBL1522827 & 688662 & 5.0934 & 4.9902 & TRN & & \\
\hline CHEMBL1500284 & 688662 & 4.456 & 4.6704 & TST & & \\
\hline CHEMBL3210936 & 688662 & 2.8239 & 4.128 & TST & & \\
\hline CHEMBL578915 & 688662 & 4.6831 & 4.087 & TRN & & \\
\hline CHEMBL1313990 & 688662 & 5.1552 & 4.7642 & TST & & \\
\hline CHEMBL1995692 & 688662 & 4.5613 & 5.5124 & TRN & & \\
\hline CHEMBL1606328 & 688662 & 4.4464 & 4.5118 & TST & & \\
\hline CHEMBL1547295 & 688662 & 4.8401 & 3.532 & TRN & & \\
\hline CHEMBL1514691 & 688662 & 5.6144 & 4.5606 & TRN & & \\
\hline
\end{tabular}




\begin{tabular}{|c|c|c|c|c|c|c|}
\hline & & \multicolumn{5}{|c|}{ Supplemental Table S2.txt } \\
\hline CHEMBL1587031 & 688662 & 3.1249 & 4.4392 & TST & & \\
\hline CHEMBL1585706 & 688662 & 4.8618 & 3.835 & TRN & & \\
\hline CHEMBL1422429 & 688662 & 5.8595 & 5.7871 & TRN & & \\
\hline CHEMBL1397089 & 688662 & 5.2373 & 5.0902 & TRN & & \\
\hline CHEMBL1995769 & 688662 & 4.3343 & 5.1789 & TRN & & \\
\hline CHEMBL1366838 & 688662 & 5.5772 & 5.3508 & TRN & & \\
\hline CHEMBL353764 & 688662 & 5.319 & 4.6201 & TRN & & \\
\hline CHEMBL1447885 & 688662 & 5.385 & 4.0127 & TRN & & \\
\hline CHEMBL1595952 & 688662 & 5.7905 & 5.5141 & TRN & & \\
\hline CHEMBL 2004304 & 688662 & 5.0376 & 5.0434 & TRN & & \\
\hline CHEMBL598883 & 688662 & 5.2223 & 4.5724 & TRN & & \\
\hline CHEMBL1994078 & 688662 & 5.1329 & 4.9013 & TRN & & \\
\hline CHEMBL1323872 & 688662 & 5.5945 & 5.8454 & TRN & & \\
\hline CHEMBL1374957 & 688662 & 4.502 & 4.5314 & TST & & \\
\hline CHEMBL1389427 & 688662 & 4.7841 & 4.5192 & TRN & & \\
\hline CHEMBL1392527 & 688662 & 6.08200 & 000000000 & $\partial 1$ & 5.1544 & TRN \\
\hline CHEMBL1336535 & 688662 & 4.5125 & 4.3797 & TRN & & \\
\hline CHEMBL1599070 & 688662 & 2.8239 & 3.9484 & TRN & & \\
\hline CHEMBL1417929 & 688662 & 5.4844 & 4.2861 & TST & & \\
\hline CHEMBL1569975 & 688662 & 6.0701 & 5.1143 & TRN & & \\
\hline CHEMBL1602792 & 688662 & 5.0448 & 4.8932 & TST & & \\
\hline CHEMBL1572157 & 688662 & 5.3391 & 4.0089 & TRN & & \\
\hline CHEMBL1466699 & 688662 & 2.8239 & 4.8544 & TST & & \\
\hline CHEMBL1438717 & 688662 & 2.8239 & 4.6485 & TRN & & \\
\hline CHEMBL1461027 & 688662 & 5.6598 & 4.3311 & TRN & & \\
\hline CHEMBL3198970 & 688662 & 4.4545 & 5.5777 & TRN & & \\
\hline CHEMBL1568793 & 688662 & 2.8239 & 3.6516 & TRN & & \\
\hline CHEMBL1330279 & 688662 & 5.5728 & 5.7778 & TRN & & \\
\hline CHEMBL1452795 & 688662 & 6.2314 & 5.4147 & TST & & \\
\hline CHEMBL1558285 & 688662 & 4.6263 & 5.1661 & TRN & & \\
\hline CHEMBL1325943 & 688662 & 5.0291 & 5.0308 & TRN & & \\
\hline CHEMBL1323828 & 688662 & 2.8239 & 3.5125 & TRN & & \\
\hline CHEMBL1505209 & 688662 & 5.6782 & 5.5038 & TST & & \\
\hline CHEMBL1514187 & 688662 & 4.6848 & 3.7939 & TRN & & \\
\hline CHEMBL1555066 & 688662 & 5.0722 & 4.9882 & TRN & & \\
\hline CHEMBL19954 & 688662 & 5.0323 & 5.2241 & TRN & & \\
\hline CHEMBL1350192 & 688662 & 6.3468 & 5.9581 & TRN & & \\
\hline CHEMBL1376974 & 688662 & 7.3372 & 5.0825 & TST & & \\
\hline CHEMBL1566835 & 688662 & 4.9379 & 4.6584 & TRN & & \\
\hline CHEMBL1998521 & 688662 & 6.015 & 5.9352 & TRN & & \\
\hline CHEMBL1535055 & 688662 & 3.1249 & 3.7715 & TRN & & \\
\hline CHEMBL1369671 & 688662 & 4.8405 & 4.0899 & TRN & & \\
\hline CHEMBL1491358 & 688662 & 5.4453 & 3.4998 & TRN & & \\
\hline CHEMBL1576791 & 688662 & 4.6549 & 4.5102 & TRN & & \\
\hline CHEMBL1541834 & 688662 & 4.9641 & 4.8952 & TRN & & \\
\hline CHEMBL1992918 & 688662 & 4.8488 & 4.8733 & TST & & \\
\hline CHEMBL1547901 & 688662 & 4.3761 & 4.3195 & TST & & \\
\hline CHEMBL1497078 & 688662 & 4.6575 & 4.3939 & TRN & & \\
\hline
\end{tabular}




\begin{tabular}{|c|c|c|c|c|c|}
\hline \multicolumn{6}{|c|}{ Supplemental Table s2.txt } \\
\hline CHEMBL1312489 & 688662 & 2.8239 & 3.0412 & TRN & \\
\hline CHEMBL1586895 & 688662 & 5.1538 & 4.8314 & TRN & \\
\hline CHEMBL1393195 & 688662 & 6.1759 & 5.4297 & TRN & \\
\hline CHEMBL1524921 & 688662 & 5.8297 & 4.9307 & TRN & \\
\hline CHEMBL1317322 & 688662 & 4.9966 & 4.9579 & TRN & \\
\hline CHEMBL1469676 & 688662 & 5.3389 & 4.6898 & TRN & \\
\hline CHEMBL1613679 & 688662 & 2.8239 & 3.23 & TRN & \\
\hline CHEMBL 3199403 & 688662 & 5.2258 & 5.3346 & TRN & \\
\hline CHEMBL585591 & 688662 & 5.8794 & 5.6169 & TRN & \\
\hline CHEMBL1387436 & 688662 & 4.8703 & 4.2861 & TRN & \\
\hline CHEMBL1417496 & 688662 & 4.6736 & 3.9645 & TRN & \\
\hline CHEMBL1358473 & 688662 & 4.5708 & 3.6655 & TRN & \\
\hline CHEMBL1596197 & 688662 & 2.8239 & 3.9627 & TRN & \\
\hline CHEMBL1324319 & 688662 & 4.6704 & 4.9252 & TRN & \\
\hline CHEMBL1399938 & 688662 & 5.4425 & 4.5883 & TRN & \\
\hline CHEMBL1582024 & 688662 & 2.8239 & 3.5862 & TRN & \\
\hline CHEMBL328834 & 688662 & 5.8962 & 5.5469 & TST & \\
\hline CHEMBL1447125 & 688662 & 5.6957 & 4.7027 & TRN & \\
\hline CHEMBL1346521 & 688662 & 2.8239 & 3.9774 & TRN & \\
\hline CHEMBL1385784 & 688662 & 5.6019 & 5.2735 & TRN & \\
\hline CHEMBL1464645 & 688662 & 5.0431 & 4.7259 & TRN & \\
\hline CHEMBL1517325 & 688662 & 5.3182 & 5.4629 & TRN & \\
\hline CHEMBL1586531 & 688662 & 5.1912 & 4.8978 & TST & \\
\hline CHEMBL1448625 & 688662 & 4.4491 & 4.5303 & TRN & \\
\hline CHEMBL1570706 & 688662 & 4.9992 & 4.9195 & TRN & \\
\hline CHEMBL1551000 & 688662 & 2.8239 & 4.9749 & TRN & \\
\hline CHEMBL1519279 & 688662 & 4.6903 & 4.7394 & TRN & \\
\hline CHEMBL1421333 & 688662 & 2.8239 & 3.1169 & TRN & \\
\hline CHEMBL1558695 & 688662 & 4.2997 & 5.0103 & TRN & \\
\hline CHEMBL1991242 & 688662 & 5.1141 & 5.3693 & TRN & \\
\hline CHEMBL1464686 & 688662 & 4.3633 & 4.2684 & TRN & \\
\hline CHEMBL1596740 & 688662 & 4.2696 & 5.3734 & TRN & \\
\hline CHEMBL1323140 & 688662 & 4.5146 & 4.6689 & TRN & \\
\hline CHEMBL 2007313 & 688662 & 4.6943 & 4.4989 & TRN & \\
\hline CHEMBL1605299 & 688662 & 5.4793 & 4.3738 & TRN & \\
\hline CHEMBL1388137 & 688662 & 5.8216 & 5.1339 & TRN & \\
\hline CHEMBL1345835 & 688662 & 4.8293 & 4.2259 & TRN & \\
\hline CHEMBL1411142 & 688662 & 4.5411 & 4.5262 & TST & \\
\hline CHEMBL599098 & 688662 & 5.5896 & 4.5623 & TRN & \\
\hline CHEMBL1331514 & 688662 & 5.1814 & 4.6669 & TRN & \\
\hline CHEMBL3190965 & 688662 & 5.5408 & 5.28600 & 00000000005 & TRN \\
\hline CHEMBL1529883 & 688662 & 5.3474 & 5.1403 & TRN & \\
\hline CHEMBL1320414 & 688662 & 5.1046 & 4.3513 & TRN & \\
\hline CHEMBL1583715 & 688662 & 5.4681 & 4.6879 & TRN & \\
\hline CHEMBL1544114 & 688662 & 5.5524 & 5.3242 & TRN & \\
\hline CHEMBL1393126 & 688662 & 5.8626 & 5.4529 & TST & \\
\hline CHEMBL1460869 & 688662 & 5.3022 & 5.3248 & TRN & \\
\hline CHEMBL1462675 & 688662 & 4.5311 & 4.33 & TRN & \\
\hline & & & & e 33 & \\
\hline
\end{tabular}




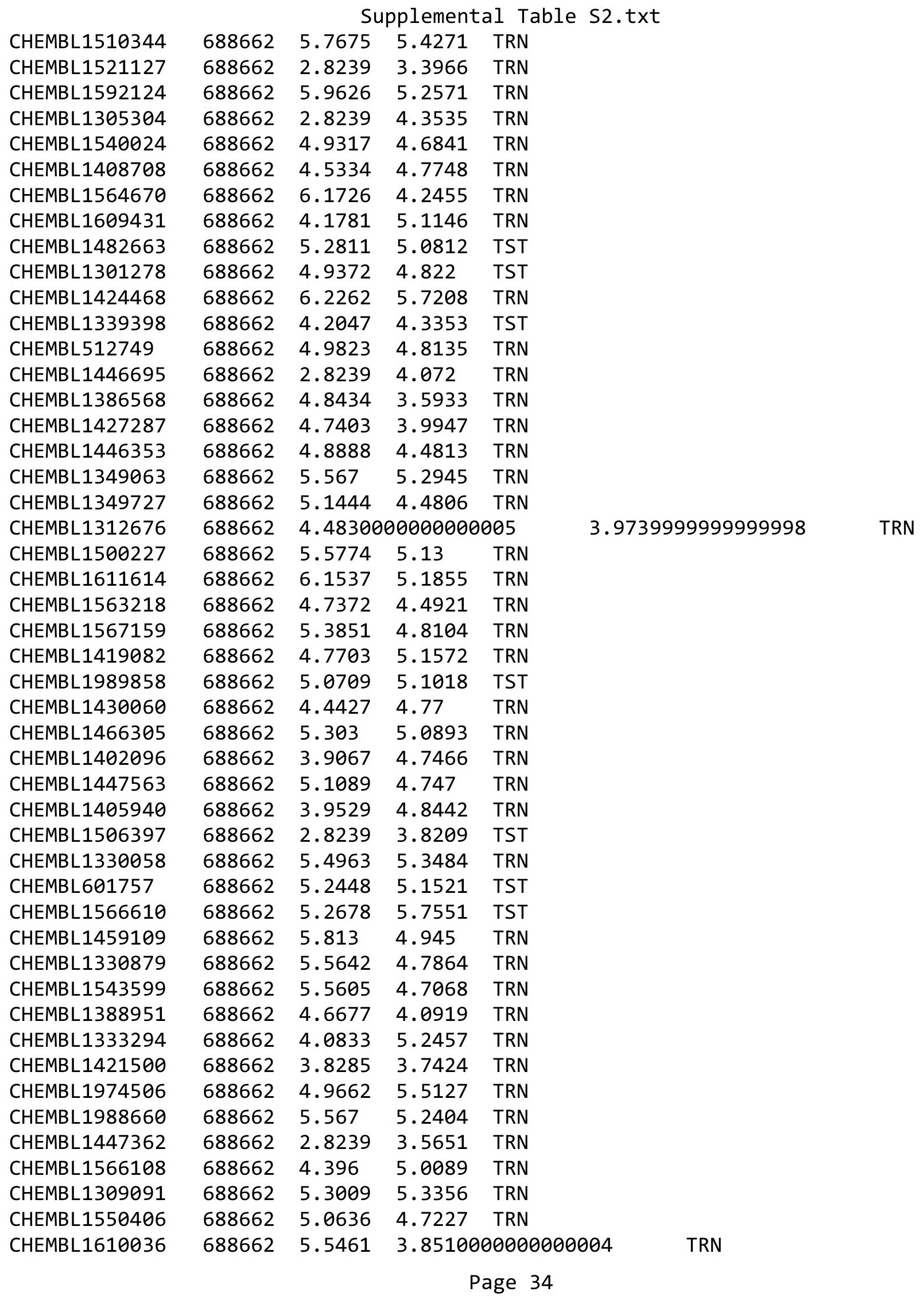


Supplemental Table S2.txt

\begin{tabular}{|c|c|c|c|c|}
\hline CHEMBL 3208365 & 688662 & 5.6351 & 5.3126 & TST \\
\hline CHEMBL1537417 & 688662 & 5.1209 & 4.8943 & TST \\
\hline CHEMBL1475774 & 688662 & 4.7552 & 4.4799 & TRN \\
\hline CHEMBL1583677 & 688662 & 3.8771 & 4.9498 & TRN \\
\hline CHEMBL1487639 & 688662 & 4.4722 & 4.8081 & TRN \\
\hline CHEMBL1982774 & 688662 & 4.9624 & 5.0886 & TRN \\
\hline CHEMBL1313766 & 688662 & 3.8574 & 3.6498 & TRN \\
\hline CHEMBL492468 & 688662 & 5.2842 & 4.5598 & TST \\
\hline CHEMBL1400319 & 688662 & 2.8239 & 3.7739 & TRN \\
\hline CHEMBL1347156 & 688662 & 2.8239 & \multicolumn{2}{|c|}{4.4430000000000005} \\
\hline CHEMBL1521348 & 688662 & 5.4477 & 4.9079 & TRN \\
\hline CHEMBL1579277 & 688662 & 2.8239 & 4.3082 & TRN \\
\hline CHEMBL604321 & 688662 & 5.225 & 5.3264 & TST \\
\hline CHEMBL 225903 & 688662 & 5.1166 & 4.9395 & TRN \\
\hline CHEMBL1542809 & 688662 & 4.8723 & 4.4846 & TRN \\
\hline CHEMBL1481030 & 688662 & 5.5771 & 5.1119 & TRN \\
\hline CHEMBL546170 & 688662 & 4.9153 & 5.0715 & TRN \\
\hline CHEMBL1348389 & 688662 & 4.6657 & 5.5804 & TRN \\
\hline CHEMBL1364681 & 688662 & 4.5849 & 4.8168 & TRN \\
\hline CHEMBL1544837 & 688662 & 2.8239 & 3.0904 & TRN \\
\hline CHEMBL117966 & 688662 & 2.8239 & 4.5036 & TRN \\
\hline CHEMBL1426410 & 688662 & 4.0264 & 4.7338 & TRN \\
\hline CHEMBL1541554 & 688662 & 5.5585 & 4.9814 & TRN \\
\hline CHEMBL1385516 & 688662 & 4.9953 & 4.4841 & TRN \\
\hline CHEMBL1612556 & 688662 & 5.0896 & 3.6731 & TRN \\
\hline CHEMBL1970286 & 688662 & 4.4262 & 5.0732 & TRN \\
\hline CHEMBL585622 & 688662 & 5.0676 & 4.8798 & TRN \\
\hline CHEMBL1581233 & 688662 & 2.8239 & 3.9584 & TRN \\
\hline CHEMBL1341756 & 688662 & 5.2564 & 4.9118 & TRN \\
\hline CHEMBL1500188 & 688662 & 6.2154 & 5.7165 & TRN \\
\hline CHEMBL1978479 & 688662 & 4.7452 & 3.9882 & TRN \\
\hline CHEMBL1520297 & 688662 & 2.8239 & 3.4841 & TRN \\
\hline CHEMBL1388358 & 688662 & 5.9038 & 5.4356 & TRN \\
\hline CHEMBL1528867 & 688662 & 4.1903 & 3.9825 & TRN \\
\hline CHEMBL1368103 & 688662 & 4.9321 & 5.2268 & TRN \\
\hline CHEMBL1445297 & 688662 & 6.0044 & 6.1282 & TRN \\
\hline CHEMBL1429164 & 688662 & 4.1965 & 4.4568 & TRN \\
\hline CHEMBL1242180 & 688662 & 5.9223 & 5.6967 & TRN \\
\hline CHEMBL1548695 & 688662 & 2.8239 & 3.7659 & TRN \\
\hline CHEMBL1326464 & 688662 & 5.0686 & 5.0217 & TST \\
\hline CHEMBL1347192 & 688662 & 4.8432 & 4.4256 & TST \\
\hline CHEMBL1383090 & 688662 & 5.9535 & 5.3866 & TRN \\
\hline CHEMBL1535695 & 688662 & 2.8239 & 4.4686 & TST \\
\hline CHEMBL1789993 & 688662 & 2.8239 & 5.083 & TST \\
\hline CHEMBL1459746 & 688662 & 5.8697 & 5.3884 & TRN \\
\hline CHEMBL1997171 & 688662 & 6.2182 & 5.5462 & TRN \\
\hline CHEMBL1445776 & 688662 & 5.2959 & 4.3731 & TRN \\
\hline CHEMBL1586733 & 688662 & 4.4278 & 5.1637 & TRN \\
\hline
\end{tabular}




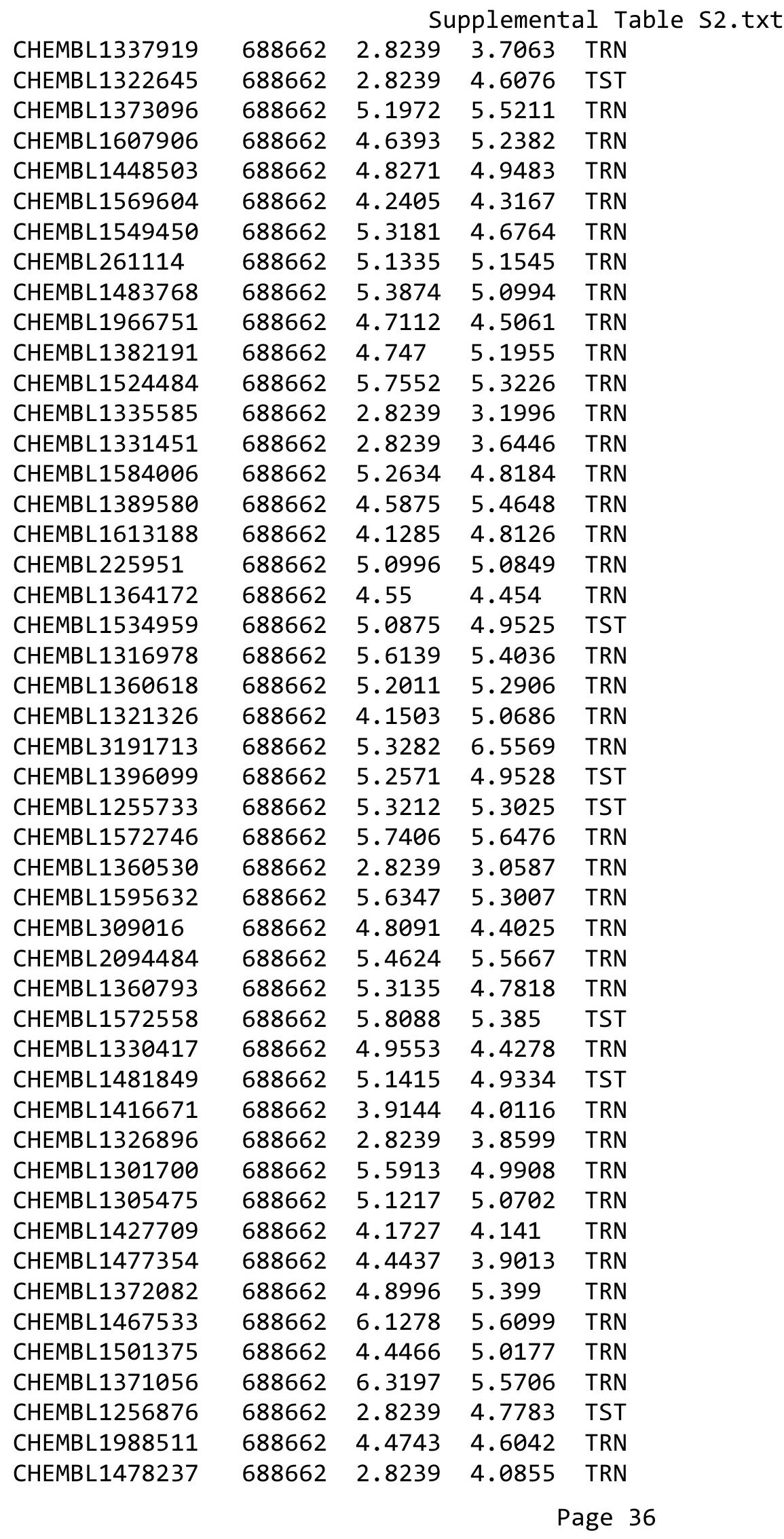


Supplemental Table S2.txt

\begin{tabular}{|c|c|c|c|c|c|}
\hline CHEMBL1578061 & 688662 & 5.4053 & 4.4821 & TRN & \\
\hline CHEMBL1328069 & 688662 & 4.8549 & 4.6503 & TRN & \\
\hline CHEMBL1545099 & 688662 & 6.1752 & 5.138999 & 9999999999 & TRN \\
\hline CHEMBL581251 & 688662 & 6.4535 & 5.7558 & TRN & \\
\hline CHEMBL1405749 & 688662 & 6.1244 & 5.5936 & TRN & \\
\hline CHEMBL1460522 & 688662 & 2.8239 & 3.8455 & TST & \\
\hline CHEMBL1450195 & 688662 & 4.5774 & 4.9431 & TRN & \\
\hline CHEMBL1481328 & 688662 & 5.3754 & 4.3136 & TRN & \\
\hline CHEMBL1334804 & 688662 & 4.4813 & 4.7805 & TST & \\
\hline CHEMBL1609900 & 688662 & 2.8239 & 2.8987 & TRN & \\
\hline CHEMBL1350673 & 688662 & 4.1318 & 4.9205 & TRN & \\
\hline CHEMBL3189245 & 688662 & 4.87 & 5.1948 & TRN & \\
\hline CHEMBL1301125 & 688662 & 5.5683 & 5.1112 & TST & \\
\hline CHEMBL1606521 & 688662 & 5.6319 & 5.1549 & TRN & \\
\hline CHEMBL1321240 & 688662 & 5.2519 & 4.9103 & TRN & \\
\hline CHEMBL1469579 & 688662 & 4.6032 & 3.8062 & TRN & \\
\hline CHEMBL57013 & 688662 & 5.3409 & 4.822 & TST & \\
\hline CHEMBL1413355 & 688662 & 4.8668 & 4.9412 & TRN & \\
\hline CHEMBL1408307 & 688662 & 4.7071 & 4.1826 & TRN & \\
\hline CHEMBL1324197 & 688662 & 6.3288 & 5.8633 & TRN & \\
\hline CHEMBL1393671 & 688662 & 4.2734 & 4.6595 & TRN & \\
\hline CHEMBL3190220 & 688662 & 2.8239 & 4.6636 & TRN & \\
\hline CHEMBL1372924 & 688662 & 4.2894 & 4.5698 & TST & \\
\hline CHEMBL1328466 & 688662 & 5.0646 & 5.3207 & TRN & \\
\hline CHEMBL1996068 & 688662 & 5.5891 & 5.0984 & TRN & \\
\hline CHEMBL1368290 & 688662 & 3.9944 & 4.85 & TRN & \\
\hline CHEMBL1445386 & 688662 & 5.8345 & 4.9792 & TST & \\
\hline CHEMBL1303034 & 688662 & 3.963 & 5.4658 & TST & \\
\hline CHEMBL1347277 & 688662 & 4.8264 & 4.356 & TRN & \\
\hline CHEMBL1501191 & 688662 & 4.8907 & 4.2791 & TRN & \\
\hline CHEMBL1416406 & 688662 & 5.0012 & \multicolumn{2}{|c|}{3.8369999999999997} & TRN \\
\hline CHEMBL1454029 & 688662 & 4.8225 & 4.9594 & TRN & \\
\hline CHEMBL1505604 & 688662 & 4.1068 & 4.9909 & TRN & \\
\hline CHEMBL1611041 & 688662 & 4.9208 & 4.4756 & TST & \\
\hline CHEMBL1589457 & 688662 & 2.8239 & 4.2793 & TRN & \\
\hline CHEMBL1524798 & 688662 & 4.6646 & 4.9566 & TRN & \\
\hline CHEMBL3196853 & 688662 & 3.9872 & 4.3128 & TRN & \\
\hline CHEMBL1539486 & 688662 & 4.6975 & 5.3541 & TRN & \\
\hline CHEMBL1584985 & 688662 & 6.064 & 5.2635 & TRN & \\
\hline CHEMBL1393156 & 688662 & 2.8239 & 3.077 & TRN & \\
\hline CHEMBL1352313 & 688662 & 5.5091 & 4.8211 & TRN & \\
\hline CHEMBL1311809 & 688662 & 4.8546 & 4.739 & TST & \\
\hline CHEMBL1440293 & 688662 & 4.6305 & 4.9063 & TST & \\
\hline CHEMBL1311879 & 688662 & 5.5586 & 5.7724 & TRN & \\
\hline CHEMBL1367034 & 688662 & 4.7768 & 5.2548 & TST & \\
\hline CHEMBL1479319 & 688662 & 5.1099 & 4.0393 & TST & \\
\hline CHEMBL1467284 & 688662 & 5.1076 & 4.7002 & TRN & \\
\hline CHEMBL1455468 & 688662 & 5.5654 & 5.2623 & TRN & \\
\hline
\end{tabular}




\begin{tabular}{|c|c|c|c|c|c|c|}
\hline & & \multicolumn{5}{|c|}{ Supplemental Table S2.txt } \\
\hline CHEMBL1342336 & 688662 & 7.9208 & 5.6094 & TRN & & \\
\hline CHEMBL1335846 & 688662 & 5.6739 & 5.9767 & TRN & & \\
\hline CHEMBL1612044 & 688662 & 5.3065 & 5.3046 & TRN & & \\
\hline CHEMBL1428662 & 688662 & 2.8239 & 3.9083 & TRN & & \\
\hline CHEMBL1369594 & 688662 & 5.0299 & 4.9069 & TRN & & \\
\hline CHEMBL1588716 & 688662 & 2.8239 & 3.5377 & TRN & & \\
\hline CHEMBL 2359072 & 688662 & 4.4587 & 5.7526 & TRN & & \\
\hline CHEMBL1393820 & 688662 & 4.9271 & 4.4534 & TRN & & \\
\hline CHEMBL1378489 & 688662 & 4.2653 & 4.6708 & TST & & \\
\hline CHEMBL1524034 & 688662 & 4.8809 & 4.9069 & TRN & & \\
\hline CHEMBL1352850 & 688662 & 5.5005 & 4.5103 & TRN & & \\
\hline CHEMBL1864040 & 688662 & 3.9583 & 4.9797 & TRN & & \\
\hline CHEMBL1492548 & 688662 & 2.8239 & 3.6563 & TRN & & \\
\hline CHEMBL1326803 & 688662 & 5.5591 & 5.2334 & TRN & & \\
\hline CHEMBL1588452 & 688662 & 4.3479 & 4.8514 & TRN & & \\
\hline CHEMBL1392556 & 688662 & 4.2131 & 3.9906 & TRN & & \\
\hline CHEMBL1388459 & 688662 & 2.8239 & 3.11 & TRN & & \\
\hline CHEMBL1588661 & 688662 & 5.2601 & 5.5104 & TRN & & \\
\hline CHEMBL1404792 & 688662 & \multicolumn{3}{|c|}{5.922999999999999} & 6.0475 & TRN \\
\hline CHEMBL1584727 & 688662 & 2.8239 & 2.9551 & TRN & & \\
\hline CHEMBL1443513 & 688662 & 2.8239 & 3.5963 & TRN & & \\
\hline CHEMBL1344300 & 688662 & 4.2133 & 3.7336 & TST & & \\
\hline CHEMBL224869 & 688662 & 2.8239 & 4.0709 & TRN & & \\
\hline CHEMBL1310861 & 688662 & 5.3365 & 4.5793 & TST & & \\
\hline CHEMBL1404547 & 688662 & 5.1837 & 5.1438 & TRN & & \\
\hline CHEMBL3193945 & 688662 & 2.8239 & 4.296 & TRN & & \\
\hline CHEMBL3196518 & 688662 & 6.4179 & 5.7804 & TRN & & \\
\hline CHEMBL1305612 & 688662 & 4.8737 & 4.5777 & TRN & & \\
\hline CHEMBL1544402 & 688662 & 4.8317 & 4.1421 & TRN & & \\
\hline CHEMBL1464984 & 688662 & 4.4442 & 4.3377 & TRN & & \\
\hline CHEMBL391123 & 688662 & 4.0638 & 4.6312 & TST & & \\
\hline CHEMBL1523845 & 688662 & 4.2976 & 4.2385 & TRN & & \\
\hline CHEMBL1418867 & 688662 & 2.8239 & 4.507 & TRN & & \\
\hline CHEMBL1374715 & 688662 & 4.744 & 5.1863 & TST & & \\
\hline CHEMBL1315921 & 688662 & 4.8515 & 5.0262 & TRN & & \\
\hline CHEMBL3197070 & 688662 & 5.7036 & 5.973 & TRN & & \\
\hline CHEMBL1583767 & 688662 & 2.8239 & 4.4459 & TRN & & \\
\hline CHEMBL1460991 & 688662 & 4.4488 & 3.4152 & TRN & & \\
\hline CHEMBL1993934 & 688662 & 4.5012 & 5.2182 & TRN & & \\
\hline CHEMBL3189712 & 688662 & 5.3763 & 5.2684 & TRN & & \\
\hline CHEMBL1344556 & 688662 & 2.8239 & 3.1983 & TRN & & \\
\hline CHEMBL1501720 & 688662 & 4.1756 & 4.1808 & TST & & \\
\hline CHEMBL1461858 & 688662 & 2.8239 & 3.0918 & TRN & & \\
\hline CHEMBL1329255 & 688662 & 5.1102 & 3.5524 & TRN & & \\
\hline CHEMBL3191127 & 688662 & 4.5847 & 4.9874 & TRN & & \\
\hline CHEMBL1372356 & 688662 & 2.8239 & 3.9904 & TRN & & \\
\hline CHEMBL1560237 & 688662 & 4.3484 & 5.4034 & TST & & \\
\hline CHEMBL601933 & 688662 & 4.9259 & 5.1407 & TRN & & \\
\hline
\end{tabular}




\begin{tabular}{|c|c|c|c|c|c|}
\hline \multicolumn{6}{|c|}{ Supplemental Table S2.txt } \\
\hline CHEMBL1324082 & 688662 & 5.4626 & 4.4211 & TRN & \\
\hline CHEMBL1483324 & 688662 & 4.6224 & 4.12 & TRN & \\
\hline CHEMBL1441181 & 688662 & 5.2642 & 4.2568 & TRN & \\
\hline CHEMBL1526851 & 688662 & 4.3828 & 4.8297 & TST & \\
\hline CHEMBL1408268 & 688662 & 4.8691 & 5.2965 & TRN & \\
\hline CHEMBL6742 & 688662 & 5.0888 & 4.5937 & TRN & \\
\hline CHEMBL1402510 & 688662 & 5.0526 & 4.6189 & TRN & \\
\hline CHEMBL1453212 & 688662 & 5.3388 & 4.6716 & TRN & \\
\hline CHEMBL 3145088 & 688662 & 4.9892 & 5.0235 & TRN & \\
\hline CHEMBL131037 & 688662 & 5.2761 & 5.1315 & TRN & \\
\hline CHEMBL1556634 & 688662 & 2.8239 & 4.6215 & TST & \\
\hline CHEMBL1480475 & 688662 & 4.1891 & 4.8585 & TST & \\
\hline CHEMBL1967436 & 688662 & 5.0705 & 5.0696 & TST & \\
\hline CHEMBL1568243 & 688662 & 2.8239 & 4.3895 & TRN & \\
\hline CHEMBL3192894 & 688662 & 5.9014 & 5.4962 & TRN & \\
\hline CHEMBL 2000499 & 688662 & 5.3855 & 4.4082 & TRN & \\
\hline CHEMBL1504701 & 688662 & 5.8742 & 5.5619 & TRN & \\
\hline CHEMBL1366347 & 688662 & 4.7945 & 4.5419 & TRN & \\
\hline CHEMBL1516407 & 688662 & 2.8239 & 3.4819 & TRN & \\
\hline CHEMBL1414112 & 688662 & 5.9176 & 5.5098 & TRN & \\
\hline CHEMBL1520801 & 688662 & 2.8239 & 4.2172 & TRN & \\
\hline CHEMBL1347563 & 688662 & 4.6929 & 4.8939 & TRN & \\
\hline CHEMBL1485865 & 688662 & 4.8421 & 4.8564 & TRN & \\
\hline CHEMBL1386418 & 688662 & 2.8239 & 4.3939 & TRN & \\
\hline CHEMBL1383793 & 688662 & 2.8239 & 4.8787 & TRN & \\
\hline CHEMBL1363706 & 688662 & 5.0388 & 4.8948 & TRN & \\
\hline CHEMBL1301094 & 688662 & 5.4139 & 4.0571 & TRN & \\
\hline CHEMBL1380592 & 688662 & 3.9971 & 4.8577 & TRN & \\
\hline CHEMBL1396209 & 688662 & 5.9097 & 5.71399 & 99999999995 & TRN \\
\hline CHEMBL1357063 & 688662 & 4.7888 & 4.8968 & TRN & \\
\hline CHEMBL1484195 & 688662 & 4.4305 & 4.4792 & TRN & \\
\hline CHEMBL 37570 & 688662 & 5.7247 & 5.3114 & TRN & \\
\hline CHEMBL1493731 & 688662 & 4.4562 & 5.4627 & TRN & \\
\hline CHEMBL1454183 & 688662 & 2.8239 & 4.7675 & TST & \\
\hline CHEMBL1576851 & 688662 & 3.9626 & 5.2002 & TRN & \\
\hline CHEMBL1369126 & 688662 & 5.047 & 3.9309 & TRN & \\
\hline CHEMBL1969992 & 688662 & 5.1036 & 5.2944 & TRN & \\
\hline CHEMBL1608535 & 688662 & 4.676 & 4.3159 & TRN & \\
\hline CHEMBL1419369 & 688662 & 4.3444 & 5.2683 & TRN & \\
\hline CHEMBL1390868 & 688662 & 4.8432 & 5.1251 & TRN & \\
\hline CHEMBL1394314 & 688662 & 4.854 & 5.091 & TRN & \\
\hline CHEMBL 2002262 & 688662 & 3.8436 & 4.8869 & TRN & \\
\hline CHEMBL1379740 & 688662 & 5.5154 & 5.5588 & TRN & \\
\hline CHEMBL1442431 & 688662 & 5.5539 & 4.5483 & TST & \\
\hline CHEMBL1318350 & 688662 & 6.015 & 6.1407 & TRN & \\
\hline CHEMBL3199665 & 688662 & 5.4334 & 5.5774 & TRN & \\
\hline CHEMBL1349067 & 688662 & 4.6998 & 4.4839 & TRN & \\
\hline CHEMBL1479010 & 688662 & 5.1525 & 5.0131 & TST & \\
\hline
\end{tabular}




\begin{tabular}{|c|c|c|c|c|c|}
\hline & & \multicolumn{4}{|c|}{ Supplemental Table S2.txt } \\
\hline CHEMBL1368752 & 688662 & 2.8239 & 3.3404 & TRN & \\
\hline CHEMBL1514534 & 688662 & 2.8239 & 4.4952 & TRN & \\
\hline CHEMBL1587116 & 688662 & 6.6421 & 5.2317 & TRN & \\
\hline CHEMBL1375740 & 688662 & 5.6521 & 5.2211 & TRN & \\
\hline CHEMBL3199428 & 688662 & 4.9815 & 5.3413 & TRN & \\
\hline CHEMBL1332139 & 688662 & 6.0218 & 5.6057 & TRN & \\
\hline CHEMBL1421396 & 688662 & 4.675 & 4.5347 & TRN & \\
\hline CHEMBL1424118 & 688662 & 6.1445 & 5.53799 & 9999999999 & TRN \\
\hline CHEMBL1389728 & 688662 & 4.6354 & 3.9185 & TST & \\
\hline CHEMBL1391387 & 688662 & 6.0066 & 5.5944 & TRN & \\
\hline CHEMBL1504036 & 688662 & 5.2798 & 4.8749 & TRN & \\
\hline CHEMBL1996625 & 688662 & 4.217 & 4.5045 & TRN & \\
\hline CHEMBL1521217 & 688662 & 4.8663 & 5.4823 & TRN & \\
\hline CHEMBL1455485 & 688662 & 4.9638 & 5.0414 & TRN & \\
\hline CHEMBL260342 & 688662 & 5.7469 & 5.46899 & 9999999999 & TRN \\
\hline CHEMBL1310355 & 688662 & 4.728 & 4.4303 & TRN & \\
\hline CHEMBL1994221 & 688662 & 4.9709 & 4.7264 & TRN & \\
\hline CHEMBL1565600 & 688662 & 5.1381 & 4.3654 & TST & \\
\hline CHEMBL3199286 & 688662 & 5.5482 & 5.6527 & TRN & \\
\hline CHEMBL1332756 & 688662 & 4.9698 & 5.28700 & 0000000001 & TRN \\
\hline CHEMBL1523997 & 688662 & 5.0372 & 4.1576 & TRN & \\
\hline CHEMBL452328 & 688662 & 2.8239 & 4.3865 & TRN & \\
\hline CHEMBL1609770 & 688662 & 4.5539 & 5.4395 & TRN & \\
\hline CHEMBL1257013 & 688662 & 4.4505 & 4.7249 & TST & \\
\hline CHEMBL1564519 & 688662 & 5.2481 & 5.1406 & TRN & \\
\hline CHEMBL1522486 & 688662 & 5.0515 & 5.2386 & TRN & \\
\hline CHEMBL1418818 & 688662 & 4.7734 & 4.343 & TRN & \\
\hline CHEMBL1387610 & 688662 & 5.8324 & 5.4168 & TRN & \\
\hline CHEMBL29711 & 688662 & 4.5433 & 3.8772 & TST & \\
\hline CHEMBL1491847 & 688662 & 5.2887 & 4.769 & TST & \\
\hline CHEMBL1588704 & 688662 & 4.1898 & 3.6643 & TRN & \\
\hline CHEMBL19980 & 688662 & 2.8239 & 5.7492 & TST & \\
\hline CHEMBL1573720 & 688662 & 4.8409 & 4.4531 & TRN & \\
\hline CHEMBL1599438 & 688662 & 5.7279 & 5.6424 & TRN & \\
\hline CHEMBL1393193 & 688662 & 2.8239 & 4.4039 & TRN & \\
\hline CHEMBL1530911 & 688662 & 5.5327 & 5.3505 & TRN & \\
\hline CHEMBL1332955 & 688662 & 5.5991 & 4.8143 & TRN & \\
\hline CHEMBL1429086 & 688662 & 2.8239 & 3.4339 & TRN & \\
\hline CHEMBL1349146 & 688662 & 5.7275 & 5.6161 & TRN & \\
\hline CHEMBL1545480 & 688662 & 2.8239 & 4.0256 & TRN & \\
\hline CHEMBL1544633 & 688662 & 6.1972 & 5.3658 & TRN & \\
\hline CHEMBL1553246 & 688662 & 4.0618 & 5.1758 & TRN & \\
\hline CHEMBL533226 & 688662 & 5.3276 & 4.9213 & TRN & \\
\hline CHEMBL 1448895 & 688662 & 2.8239 & 3.7258 & TST & \\
\hline CHEMBL1329221 & 688662 & 6.4763 & 5.1963 & TRN & \\
\hline CHEMBL1876078 & 688662 & 6.4202 & 4.6956 & TRN & \\
\hline CHEMBL1539678 & 688662 & 4.3587 & 4.6599 & TST & \\
\hline CHEMBL1569585 & 688662 & 5.0926 & 5.2142 & TST & \\
\hline
\end{tabular}


Supplemental Table S2.txt

\begin{tabular}{|c|c|c|c|c|}
\hline 228 & & .7929 & & \\
\hline HEMBL1374860 & 88662 & 5.3203 & & \\
\hline & & & & \\
\hline 164 & 662 & 8239 & 1994 & \\
\hline IEMBL1 & 38662 & 852 & 8153 & \\
\hline IEMBL3198544 & 38662 & 5934 & 5742 & \\
\hline AEMBL1550485 & 662 & .8239 & 8388 & \\
\hline & & 64 & & \\
\hline IEMBL & 662 & .9803 & 5011 & \\
\hline IEMBL1373967 & 38662 & 1316 & 7848 & S \\
\hline AEMBL1471808 & 38662 & 5928 & 8777 & \\
\hline IEMBL31 & 662 & 391 & 308 & \\
\hline 500 & & & & $S T$ \\
\hline IEMBL32 & 662 & 28 & 8021 & \\
\hline IEMBL14 & 8662 & 902 & 8135 & \\
\hline EMBL1546005 & 662 & 39 & 956 & 31 \\
\hline IEMBL1380099 & 62 & 51 & 45 & \\
\hline IEMBL144 & & & & \\
\hline IEMBL15 & 62 & & & \\
\hline IEMBL1491717 & & & 99 & 3 \\
\hline 02160 & 62 & 87 & 597 & $S$ \\
\hline EMBL1986214 & 52 & 31 & & 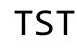 \\
\hline 55 & & & & \\
\hline 505 & & & & \\
\hline EMBL1 & & & $\partial 9$ & $S$ \\
\hline EMBL & & & 756 & $S$ \\
\hline 559 & & & 531 & וכ \\
\hline 5 & & & & ST \\
\hline 94 & & & 58 & ST \\
\hline EMBL583 & & & 57 & 31 \\
\hline EMBL1: & & 39 & 389 & ST \\
\hline 266 & & & & ST \\
\hline & & & & ST \\
\hline EMBL1437888 & & & 74 & ST \\
\hline IEMBL1486214 & 62 & & 537 & IST \\
\hline EMBLI & 52 & 4. & 669 & ST \\
\hline 8 & & & & ST \\
\hline & & & 4.3663 & ST \\
\hline AEMBL3199311 & & & 5.51 & $\mathrm{~S}$ \\
\hline EMBL14 & 62 & & 4.8789 & IST \\
\hline AEMBL13 & & 39 & 3.2455 & ST \\
\hline & & & 4.2753 & ST \\
\hline AEMBL1491893 & & & 5.357 & ST \\
\hline EMBL1529669 & 8662 & .8239 & 4.1107 & 5 \\
\hline & & .7905 & 4.1678 & $S$ \\
\hline CHEMBL1302639 & & & 4.385 & 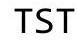 \\
\hline CHEMBL1363614 & & 2.8239 & 4.6233 & SI \\
\hline CHEMBL1455137 & 688662 & 5.4587 & 4.8699 & TS \\
\hline
\end{tabular}

Page 41 


\begin{tabular}{|c|c|c|c|c|c|c|}
\hline & & \multicolumn{5}{|c|}{ Supplemental Table S2.txt } \\
\hline CHEMBL1416693 & 688662 & 2.8239 & 2.9219 & TST & & \\
\hline CHEMBL1459468 & 688662 & 6.2168 & 5.6575 & TST & & \\
\hline CHEMBL1481347 & 688662 & 5.6094 & 5.4716 & TST & & \\
\hline CHEMBL3189519 & 688662 & 5.3004 & 5.7009 & TST & & \\
\hline CHEMBL1487345 & 688662 & 2.8239 & 4.4725 & TST & & \\
\hline CHEMBL1373969 & 688662 & 5.2965 & 5.2057 & TST & & \\
\hline CHEMBL1372889 & 688662 & 5.1755 & 5.308 & TST & & \\
\hline CHEMBL3207906 & 688662 & 2.8239 & 4.6294 & TST & & \\
\hline CHEMBL1342038 & 688662 & 5.3208 & 5.1817 & TST & & \\
\hline CHEMBL3194563 & 688662 & 4.9724 & 5.1434 & TST & & \\
\hline CHEMBL1334307 & 688662 & 2.8239 & 5.1267 & TST & & \\
\hline CHEMBL1200512 & 688662 & 5.3722 & 4.2811 & TST & & \\
\hline CHEMBL1540795 & 688662 & 5.0248 & 4.2699 & TST & & \\
\hline CHEMBL1416089 & 688662 & 5.1953 & 5.1425 & TST & & \\
\hline CHEMBL1449669 & 688662 & 4.5395 & 4.6907 & TST & & \\
\hline CHEMBL1407944 & 688662 & 5.6893 & 5.455 & TST & & \\
\hline CHEMBL1592917 & 688662 & 5.2896 & 4.8311 & TST & & \\
\hline CHEMBL1555271 & 688662 & 5.1249 & 5.5301 & TST & & \\
\hline CHEMBL1519965 & 688662 & 5.643 & 5.4052 & TST & & \\
\hline CHEMBL1430068 & 688662 & 5.2847 & 5.2643 & TST & & \\
\hline CHEMBL1549192 & 688662 & 3.8592 & 4.7247 & TST & & \\
\hline CHEMBL1451736 & 688662 & 4.6989 & 5.4754 & TST & & \\
\hline CHEMBL3198720 & 688662 & 5.3781 & 5.2094 & TST & & \\
\hline CHEMBL1420037 & 688662 & 5.4238 & 5.4351 & TST & & \\
\hline CHEMBL3194013 & 688662 & 4.9667 & 5.0808 & TST & & \\
\hline CHEMBL601135 & 688662 & 4.6697 & 4.0907 & TST & & \\
\hline CHEMBL3189394 & 688662 & 4.3936 & 4.6418 & TST & & \\
\hline CHEMBL1977570 & 688662 & 4.9588 & 4.7382 & TST & & \\
\hline CHEMBL1460638 & 688662 & 2.8239 & 3.7666 & TST & & \\
\hline CHEMBL124006 & 688662 & 5.4936 & 5.3149 & TST & & \\
\hline CHEMBL586135 & 688662 & 4.8534 & 4.9626 & TST & & \\
\hline CHEMBL1524608 & 688662 & 2.8239 & 3.3834 & TST & & \\
\hline CHEMBL1361740 & 688662 & 5.1386 & 4.8104 & TST & & \\
\hline CHEMBL1966241 & 688662 & 5.6649 & 5.5635 & TST & & \\
\hline CHEMBL1541771 & 688662 & 5.6229 & 4.7169 & TST & & \\
\hline CHEMBL1445372 & 688662 & 5.2148 & 4.9658 & TST & & \\
\hline CHEMBL1597628 & 688662 & 4.0289 & 3.6671 & TST & & \\
\hline CHEMBL587801 & 688662 & 5.0656 & 4.6953 & TST & & \\
\hline CHEMBL1376861 & 688662 & 5.0061 & 4.3354 & TST & & \\
\hline CHEMBL1542833 & 688662 & 5.1513 & 4.8469 & TST & & \\
\hline CHEMBL1404398 & 688662 & $5.2810 e$ & 000000000 & $\partial 1$ & 3.8059 & TST \\
\hline CHEMBL1525381 & 688662 & 4.7003 & 4.706 & TST & & \\
\hline CHEMBL1539745 & 688662 & 2.8239 & 2.9546 & TST & & \\
\hline CHEMBL1456851 & 688662 & 4.8045 & 5.4244 & TST & & \\
\hline CHEMBL1513325 & 688662 & 4.3343 & 5.2542 & TST & & \\
\hline CHEMBL1900055 & 688662 & 4.2809 & 4.4534 & TST & & \\
\hline CHEMBL1361550 & 688662 & 2.8239 & 4.5426 & TST & & \\
\hline CHEMBL1516637 & 688662 & 4.78 & 4.5264 & TST & & \\
\hline
\end{tabular}




\begin{tabular}{|c|c|c|c|c|}
\hline \multicolumn{5}{|c|}{ Supplemental Table } \\
\hline CHEMBL1993731 & 688662 & 4.4258 & 4.9681 & TST \\
\hline CHEMBL1458951 & 688662 & 2.8239 & 3.0824 & TST \\
\hline CHEMBL1481538 & 688662 & 4.6879 & 5.6449 & TST \\
\hline CHEMBL1335176 & 688662 & 5.5331 & 5.0795 & TST \\
\hline CHEMBL1579636 & 688662 & 4.7531 & 5.3569 & TST \\
\hline CHEMBL1394035 & 688662 & 2.8239 & 3.3659 & TST \\
\hline CHEMBL1469534 & 688662 & 5.7328 & 3.6869 & TST \\
\hline CHEMBL1550640 & 688662 & 4.2667 & 3.7284 & TST \\
\hline CHEMBL530609 & 688662 & 5.0839 & 4.7238 & TST \\
\hline CHEMBL1581648 & 688662 & 4.7523 & 4.0159 & TST \\
\hline CHEMBL1979662 & 688662 & 2.8239 & 3.6941 & TST \\
\hline CHEMBL1569698 & 688662 & 5.6866 & 5.0258 & TST \\
\hline CHEMBL1393944 & 688662 & 2.8239 & 4.2038 & TST \\
\hline CHEMBL1327496 & 688662 & 5.4706 & 4.8792 & TST \\
\hline CHEMBL1580774 & 688662 & 4.9061 & 4.7615 & TST \\
\hline CHEMBL1967744 & 688662 & 5.3446 & 4.561 & TST \\
\hline CHEMBL1488712 & 688662 & 4.9671 & 4.6629 & TST \\
\hline CHEMBL3191151 & 688662 & 5.0689 & 5.3024 & TST \\
\hline CHEMBL1509637 & 688662 & 2.8239 & 3.2333 & TST \\
\hline CHEMBL 2354875 & 688662 & 4.9679 & 5.0654 & TST \\
\hline CHEMBL1495325 & 688662 & 4.2856 & 4.6712 & TST \\
\hline CHEMBL1527242 & 688662 & 2.8239 & 4.567 & TST \\
\hline CHEMBL242555 & 326139 & 7.2984 & 6.8944 & TRN \\
\hline CHEMBL3706834 & 326139 & 5.0 & 5.044 & TRN \\
\hline CHEMBL3706840 & 326139 & 7.7305 & 7.7125 & TRN \\
\hline CHEMBL3706825 & 326139 & 6.2529 & 5.7883 & TRN \\
\hline CHEMBL 2113171 & 326139 & 7.1494 & 7.3064 & TRN \\
\hline CHEMBL 200818 & 326139 & 6.5677 & 5.1986 & TST \\
\hline CHEMBL 2113186 & 326139 & 5.0 & 6.0824 & TST \\
\hline CHEMBL 2113172 & 326139 & 7.6799 & 6.8068 & TRN \\
\hline CHEMBL3706826 & 326139 & 8.1612 & 7.2617 & TST \\
\hline CHEMBL3706816 & 326139 & 8.0555 & 7.8156 & TRN \\
\hline CHEMBL3706838 & 326139 & 5.0 & 4.2905 & TRN \\
\hline CHEMBL3706837 & 326139 & 8.0915 & 8.5983 & TRN \\
\hline CHEMBL3706843 & 326139 & 7.5302 & 7.0109 & TST \\
\hline CHEMBL 2113180 & 326139 & 5.0 & 5.0675 & TST \\
\hline CHEMBL 2113176 & 326139 & 6.9566 & 6.7638 & TRN \\
\hline CHEMBL 2113173 & 326139 & 5.0 & 5.7197 & TST \\
\hline CHEMBL199455 & 326139 & 6.3912 & 6.5546 & TRN \\
\hline CHEMBL 2113193 & 326139 & 7.8928 & 7.6679 & TRN \\
\hline CHEMBL 2113191 & 326139 & 5.0 & 4.9023 & TRN \\
\hline CHEMBL 2113184 & 326139 & 7.8153 & 7.0861 & TST \\
\hline CHEMBL3706817 & 326139 & 8.0458 & 7.9783 & TRN \\
\hline CHEMBL 2113163 & 326139 & 8.2924 & 7.9636 & TRN \\
\hline CHEMBL3706831 & 326139 & 5.0 & 4.993 & TST \\
\hline CHEMBL 2113170 & 326139 & 6.9017 & 5.5449 & TST \\
\hline CHEMBL3706815 & 326139 & 7.3757 & 7.2047 & TRN \\
\hline CHEMBL3706828 & 326139 & 5.0 & 5.7654 & TST \\
\hline
\end{tabular}




\begin{tabular}{|c|c|c|c|c|c|}
\hline \multicolumn{6}{|c|}{ Supplemental Table S2.txt } \\
\hline CHEMBL 2113166 & 326139 & 5.0 & 5.5657 & TRN & \\
\hline CHEMBL 2113199 & 326139 & 7.8210 & 00000000 & 7.5903 & TRN \\
\hline CHEMBL3706818 & 326139 & 5.0 & 5.1412 & TRN & \\
\hline CHEMBL 2113164 & 326139 & 7.7375 & 8.123 & TRN & \\
\hline CHEMBL3706841 & 326139 & 8.2007 & 8.26799 & 9999999999 & TRN \\
\hline CHEMBL3706829 & 326139 & 6.0547 & 5.9636 & TRN & \\
\hline CHEMBL 2113165 & 326139 & 6.6349 & 5.003 & TST & \\
\hline CHEMBL3706824 & 326139 & 5.0 & 4.8513 & TRN & \\
\hline CHEMBL396472 & 326139 & 7.3778 & 7.5943 & TRN & \\
\hline CHEMBL 2113175 & 326139 & 7.6716 & 7.2323 & TRN & \\
\hline CHEMBL3706823 & 326139 & 8.1675 & 8.09 & TRN & \\
\hline CHEMBL 2113188 & 326139 & 6.4366 & 7.2821 & TST & \\
\hline CHEMBL 2113167 & 326139 & 5.301 & 4.5187 & TRN & \\
\hline CHEMBL3706819 & 326139 & 8.3188 & 7.6931 & TRN & \\
\hline CHEMBL3706830 & 326139 & 5.0 & 5.6164 & TRN & \\
\hline CHEMBL 2113192 & 326139 & 5.0 & 5.5352 & TRN & \\
\hline CHEMBL3706839 & 326139 & 5.0 & 5.92399 & 99999999995 & TST \\
\hline CHEMBL3706835 & 326139 & 7.5986 & 7.5225 & TRN & \\
\hline CHEMBL200387 & 326139 & 5.0 & 6.0593 & TRN & \\
\hline CHEMBL200765 & 326139 & 7.6716 & 7.018 & TRN & \\
\hline CHEMBL200723 & 326139 & 6.6203 & 6.0606 & TST & \\
\hline CHEMBL3706820 & 326139 & 5.0 & 5.0878 & TST & \\
\hline CHEMBL 2113169 & 326139 & 5.0 & 5.5354 & TRN & \\
\hline CHEMBL 2113190 & 326139 & 7.1549 & 7.1264 & TRN & \\
\hline CHEMBL3706814 & 326139 & 7.0804 & 7.2397 & TRN & \\
\hline CHEMBL 2113174 & 326139 & 5.0 & 6.3277 & TRN & \\
\hline CHEMBL371551 & 326139 & 6.3239 & 6.4241 & TRN & \\
\hline CHEMBL3706822 & 326139 & 5.0 & 5.1847 & TRN & \\
\hline CHEMBL3706842 & 326139 & 8.7447 & 9.0676 & TRN & \\
\hline CHEMBL3706832 & 326139 & 5.0 & 4.9789 & TRN & \\
\hline CHEMBL 2113182 & 326139 & 7.4855 & 7.3281 & TRN & \\
\hline CHEMBL3706836 & 326139 & 7.4976 & 7.5332 & TRN & \\
\hline CHEMBL3661386 & 1528693 & 7.1549 & 7.1367 & TRN & \\
\hline CHEMBL3661399 & 1528693 & 6.1549 & 6.3636 & TRN & \\
\hline CHEMBL3661381 & 1528693 & 7.2218 & 6.9946 & TRN & \\
\hline CHEMBL3657191 & 1528693 & 5.9586 & 7.0761 & TST & \\
\hline CHEMBL3657189 & 1528693 & 6.0044 & 6.8291 & TRN & \\
\hline CHEMBL1546415 & 1528693 & 6.7696 & 6.6896 & TRN & \\
\hline CHEMBL3661406 & 1528693 & 6.2924 & 6.2114 & TST & \\
\hline CHEMBL3661416 & 1528693 & 5.8861 & 6.5159 & TST & \\
\hline CHEMBL3661332 & 1528693 & 6.0 & 6.4932 & TRN & \\
\hline CHEMBL10835 & 1528693 & 6.1549 & 6.6559 & TST & \\
\hline CHEMBL3661364 & 1528693 & 6.3768 & 6.9129 & TST & \\
\hline CHEMBL3657188 & 1528693 & 7.2218 & 7.1494 & TRN & \\
\hline CHEMBL3661396 & 1528693 & 7.0458 & 6.8088 & TRN & \\
\hline CHEMBL3661380 & 1528693 & 7.0969 & 6.9822 & TRN & \\
\hline CHEMBL3661370 & 1528693 & 7.301 & 7.2713 & TRN & \\
\hline CHEMBL3661409 & 1528693 & 6.3188 & 6.1247 & TST & \\
\hline
\end{tabular}


Supplemental Table S2.txt

\begin{tabular}{|c|c|c|c|c|}
\hline CHEMBL 3661320 & 1528693 & 7.301 & 7.025 & TRN \\
\hline CHEMBL3661389 & 1528693 & 7.301 & 6.7339 & TRN \\
\hline CHEMBL3661402 & 1528693 & 5.4559 & 6.2705 & TST \\
\hline CHEMBL1231909 & 1528693 & 7.3979 & 6.9503 & TRN \\
\hline CHEMBL3661401 & 1528693 & 4.8996 & 5.7765 & TST \\
\hline CHEMBL3661342 & 1528693 & 6.699 & 6.5293 & TRN \\
\hline CHEMBL3661365 & 1528693 & 7.301 & \multicolumn{2}{|c|}{7.207999999999999} \\
\hline CHEMBL 3661372 & 1528693 & 7.301 & 7.0445 & TRN \\
\hline CHEMBL 2031931 & 1528693 & 7.301 & 7.1336 & TRN \\
\hline CHEMBL3661327 & 1528693 & 7.2218 & 6.86 & TRN \\
\hline CHEMBL3661321 & 1528693 & 5.5229 & 6.8173 & TRN \\
\hline CHEMBL1231797 & 1528693 & 7.1549 & 7.1559 & TRN \\
\hline CHEMBL3661390 & 1528693 & 6.7696 & 6.8462 & TRN \\
\hline CHEMBL 2031928 & 1528693 & 7.2218 & 7.1284 & TRN \\
\hline CHEMBL3661338 & 1528693 & 5.6402 & 6.3602 & TRN \\
\hline CHEMBL3661385 & 1528693 & 7.301 & 6.9842 & TRN \\
\hline CHEMBL 3661318 & 1528693 & 7.2218 & 7.2862 & TRN \\
\hline CHEMBL1568999 & 1528693 & 7.301 & 6.8508 & TRN \\
\hline CHEMBL 242255 & 1528693 & 7.301 & 7.3326 & TRN \\
\hline CHEMBL3661366 & 1528693 & 6.0458 & 6.4156 & TRN \\
\hline CHEMBL3661410 & 1528693 & 7.0 & 6.6981 & TST \\
\hline CHEMBL3661378 & 1528693 & 7.1549 & 7.091 & TRN \\
\hline CHEMBL1533919 & 1528693 & 7.301 & 7.1785 & TRN \\
\hline CHEMBL3661336 & 1528693 & 6.284 & 6.2349 & TRN \\
\hline CHEMBL3657187 & 1528693 & 6.4815 & 6.3182 & TST \\
\hline CHEMBL3661334 & 1528693 & 5.9747 & 6.1661 & TRN \\
\hline CHEMBL3661348 & 1528693 & 6.9208 & 6.6476 & TRN \\
\hline CHEMBL3661413 & 1528693 & 5.1871 & 5.5897 & TST \\
\hline CHEMBL3661369 & 1528693 & 7.301 & 7.1836 & TRN \\
\hline CHEMBL11522 & 1528693 & 6.1024 & 6.3255 & TRN \\
\hline CHEMBL162598 & 1528693 & 6.6021 & 6.8878 & TST \\
\hline CHEMBL3661368 & 1528693 & 7.301 & 7.1836 & TRN \\
\hline CHEMBL2031923 & 1528693 & 7.301 & 6.9799 & TST \\
\hline CHEMBL 3661376 & 1528693 & 7.2218 & 6.7996 & TRN \\
\hline CHEMBL3661388 & 1528693 & 7.301 & 6.6592 & TRN \\
\hline CHEMBL3661341 & 1528693 & 6.9208 & 6.7088 & TRN \\
\hline CHEMBL2031927 & 1528693 & 7.2218 & 7.1223 & TRN \\
\hline CHEMBL1330191 & 1528693 & 7.301 & 7.1836 & TRN \\
\hline CHEMBL 3661394 & 1528693 & 6.2291 & 6.2335 & TRN \\
\hline CHEMBL2098452 & 1528693 & 7.301 & 7.0329 & TRN \\
\hline CHEMBL3661367 & 1528693 & 7.301 & 7.2556 & TRN \\
\hline CHEMBL1713120 & 1528693 & 6.0706 & 6.7983 & TRN \\
\hline CHEMBL11524 & 1528693 & 7.1549 & 6.65 & TRN \\
\hline CHEMBL3661331 & 1528693 & 6.5086 & 6.7088 & TRN \\
\hline CHEMBL3661407 & 1528693 & 4.3768 & 5.8228 & TST \\
\hline CHEMBL3661360 & 1528693 & 7.301 & 7.2666 & TRN \\
\hline CHEMBL3661325 & 1528693 & 7.301 & 7.0132 & TRN \\
\hline CHEMBL3661398 & 1528693 & 7.0 & 6.5268 & TST \\
\hline
\end{tabular}




\begin{tabular}{|c|c|c|c|c|c|}
\hline \multicolumn{6}{|c|}{ Supplemental Table S2.txt } \\
\hline CHEMBL3661343 & 1528693 & 7.301 & 6.6274 & TRN & \\
\hline CHEMBL 3661397 & 1528693 & 6.4089 & 6.2122 & TRN & \\
\hline CHEMBL 1458 & 1528693 & 7.0458 & 7.1836 & TRN & \\
\hline CHEMBL3661339 & 1528693 & 6.9208 & 6.7088 & TRN & \\
\hline CHEMBL3661411 & 1528693 & 7.0458 & 6.6369 & TST & \\
\hline CHEMBL1609005 & 1528693 & 7.301 & 7.2927 & TRN & \\
\hline CHEMBL3661387 & 1528693 & 6.7696 & 7.1901 & TRN & \\
\hline CHEMBL3661359 & 1528693 & 7.0 & 7.1836 & TRN & \\
\hline CHEMBL67158 & 1528693 & 7.2218 & 7.2935 & TRN & \\
\hline CHEMBL3661393 & 1528693 & 6.6021 & 6.2585 & TRN & \\
\hline CHEMBL1469609 & 1528693 & 6.0706 & 6.3602 & TRN & \\
\hline CHEMBL1360431 & 1528693 & 7.0458 & 7.1764 & TRN & \\
\hline CHEMBL3661379 & 1528693 & 7.301 & 7.1182 & TST & \\
\hline CHEMBL3661358 & 1528693 & 6.9586 & 7.2935 & TRN & \\
\hline CHEMBL3661404 & 1528693 & 3.9872 & 5.7349 & TST & \\
\hline CHEMBL1573741 & 1528693 & 6.1079 & 6.8391 & TRN & \\
\hline CHEMBL3661330 & 1528693 & 6.0 & 6.4506 & TRN & \\
\hline CHEMBL 3661375 & 1528693 & 7.301 & 7.28299 & 99999999995 & TRN \\
\hline CHEMBL3661417 & 1528693 & 6.8539 & 6.6571 & TST & \\
\hline CHEMBL3661418 & 1528693 & 6.3098 & 6.4132 & TST & \\
\hline CHEMBL3661400 & 1528693 & 7.301 & 7.2165 & TRN & \\
\hline CHEMBL3661356 & 1528693 & 7.301 & 7.2161 & TRN & \\
\hline CHEMBL11405 & 1528693 & 6.7212 & 6.9809 & TRN & \\
\hline CHEMBL3661377 & 1528693 & 7.301 & 6.901 & TRN & \\
\hline CHEMBL3657190 & 1528693 & 6.0 & 6.9897 & TST & \\
\hline CHEMBL3657193 & 1528693 & 7.0 & 7.0233 & TRN & \\
\hline CHEMBL1379831 & 1528693 & 7.301 & 6.5844 & TRN & \\
\hline CHEMBL 3661328 & 1528693 & 6.0969 & 6.8224 & TRN & \\
\hline CHEMBL3661362 & 1528693 & 7.2218 & 7.1568 & TRN & \\
\hline CHEMBL193888 & 1528693 & 7.2218 & 7.035 & TRN & \\
\hline CHEMBL3661355 & 1528693 & 7.301 & 7.2935 & TRN & \\
\hline CHEMBL 3661344 & 1528693 & 6.301 & 5.9998 & TRN & \\
\hline CHEMBL 77250 & 1528693 & 6.6778 & 6.9151 & TST & \\
\hline CHEMBL3661383 & 1528693 & 7.2218 & 7.0858 & TRN & \\
\hline CHEMBL3657192 & 1528693 & 6.9208 & 7.0444 & TST & \\
\hline CHEMBL1733373 & 1528693 & 5.5376 & 6.6184 & TST & \\
\hline CHEMBL3661384 & 1528693 & 7.2218 & 7.018 & TRN & \\
\hline CHEMBL3661371 & 1528693 & 7.301 & 7.0784 & TRN & \\
\hline CHEMBL3661403 & 1528693 & 5.6383 & 6.3683 & TST & \\
\hline CHEMBL3661322 & 1528693 & 6.3188 & 6.5445 & TRN & \\
\hline CHEMBL3661353 & 1528693 & 7.301 & 7.2935 & TRN & \\
\hline CHEMBL 2031932 & 1528693 & 7.301 & 7.1413 & TRN & \\
\hline CHEMBL3657186 & 1528693 & 6.9586 & 6.5388 & TRN & \\
\hline CHEMBL3661350 & 1528693 & 7.2218 & 6.9212 & TRN & \\
\hline CHEMBL1413197 & 1528693 & 6.6778 & 6.499 & TRN & \\
\hline CHEMBL2029374 & 1528693 & 7.2218 & 7.0122 & TRN & \\
\hline CHEMBL3661357 & 1528693 & 7.301 & 7.2935 & TRN & \\
\hline CHEMBL1451424 & 1528693 & 6.1549 & 6.3886 & TST & \\
\hline
\end{tabular}


Supplemental Table S2.txt

\begin{tabular}{|c|c|c|c|c|c|}
\hline CHEMBL3661324 & 1528693 & 6.7212 & 7.0865 & TRN & \\
\hline CHEMBL3661373 & 1528693 & 6.0 & 6.7658 & TRN & \\
\hline CHEMBL3661349 & 1528693 & 7.301 & 7.0967 & TRN & \\
\hline CHEMBL3661323 & 1528693 & 6.5686 & 6.989 & TRN & \\
\hline CHEMBL3661326 & 1528693 & 6.6021 & 6.71 & TRN & \\
\hline CHEMBL 3661354 & 1528693 & 7.301 & 7.2935 & TRN & \\
\hline CHEMBL3661337 & 1528693 & 7.2218 & 7.2935 & TRN & \\
\hline CHEMBL3661352 & 1528693 & 7.301 & 6.7852 & TRN & \\
\hline CHEMBL365939 & 1528693 & 6.1192 & 6.6813 & TRN & \\
\hline CHEMBL3661329 & 1528693 & 6.7447 & 6.8116 & TRN & \\
\hline CHEMBL191968 & 1528693 & 6.1487 & 6.9535 & TRN & \\
\hline CHEMBL3661392 & 1528693 & 6.2291 & 6.1419 & TRN & \\
\hline CHEMBL3661351 & 1528693 & 6.9586 & 7.2935 & TRN & \\
\hline CHEMBL 3661408 & 1528693 & 4.1367 & 5.7093 & TST & \\
\hline CHEMBL3661391 & 1528693 & 7.301 & 7.3326 & TRN & \\
\hline CHEMBL3661347 & 1528693 & 6.2218 & 6.4876 & TRN & \\
\hline CHEMBL3661346 & 1528693 & 6.0969 & 6.2349 & TRN & \\
\hline CHEMBL 3661345 & 1528693 & 6.8539 & 6.5293 & TRN & \\
\hline CHEMBL3661405 & 1528693 & 4.1427 & 5.6993 & TST & \\
\hline CHEMBL 3661317 & 1528693 & 6.3468 & 7.0626 & TRN & \\
\hline CHEMBL3661333 & 1528693 & 7.0458 & 6.6332 & TRN & \\
\hline CHEMBL3661340 & 1528693 & 6.6778 & 6.3602 & TRN & \\
\hline CHEMBL3263303 & 1528693 & 7.301 & 7.0733 & TRN & \\
\hline CHEMBL1557995 & 1528693 & 6.1367 & 6.576006 & 00000000005 & TRN \\
\hline CHEMBL192293 & 1528693 & 7.1549 & 6.9981 & TST & \\
\hline CHEMBL3661361 & 1528693 & 7.301 & 7.2599 & TST & \\
\hline CHEMBL3661363 & 1528693 & 7.301 & 7.2654 & TST & \\
\hline CHEMBL3661412 & 1528693 & 3.7878 & 5.4359 & TST & \\
\hline CHEMBL3639602 & 1528693 & 5.6383 & 6.4618 & TST & \\
\hline CHEMBL 3661382 & 1528693 & 6.8861 & 7.0335 & TST & \\
\hline CHEMBL3661395 & 1528693 & 6.699 & 6.4877 & TST & \\
\hline CHEMBL3910925 & 1642439 & 6.3979 & 6.3851 & TRN & \\
\hline CHEMBL3894733 & 1642439 & 5.699 & 5.8008 & TRN & \\
\hline CHEMBL3925064 & 1642439 & 5.644 & 5.9857 & TRN & \\
\hline CHEMBL3968026 & 1642439 & 4.5436 & 5.6825 & TST & \\
\hline CHEMBL3938953 & 1642439 & 6.0 & 5.4858 & TRN & \\
\hline CHEMBL3941839 & 1642439 & 4.301 & 4.6848 & TRN & \\
\hline CHEMBL3944360 & 1642439 & 4.6778 & 4.8804 & TRN & \\
\hline CHEMBL3932194 & 1642439 & 5.1838 & 5.0879 & TRN & \\
\hline CHEMBL3900163 & 1642439 & 5.1805 & 5.2934 & TST & \\
\hline CHEMBL3908347 & 1642439 & 6.0 & 5.6475 & TRN & \\
\hline CHEMBL3918930 & 1642439 & 4.301 & 4.8011 & TRN & \\
\hline CHEMBL3943001 & 1642439 & 5.1445 & 5.1469 & TRN & \\
\hline CHEMBL3907457 & 1642439 & 4.9872 & 4.8043 & TRN & \\
\hline CHEMBL3968531 & 1642439 & 5.5003 & 5.5677 & TRN & \\
\hline CHEMBL3913852 & 1642439 & 6.0 & 5.4535 & TRN & \\
\hline CHEMBL 3943875 & 1642439 & 4.301 & 4.4288 & TRN & \\
\hline CHEMBL3901984 & 1642439 & 6.0 & 5.2415 & TST & \\
\hline
\end{tabular}




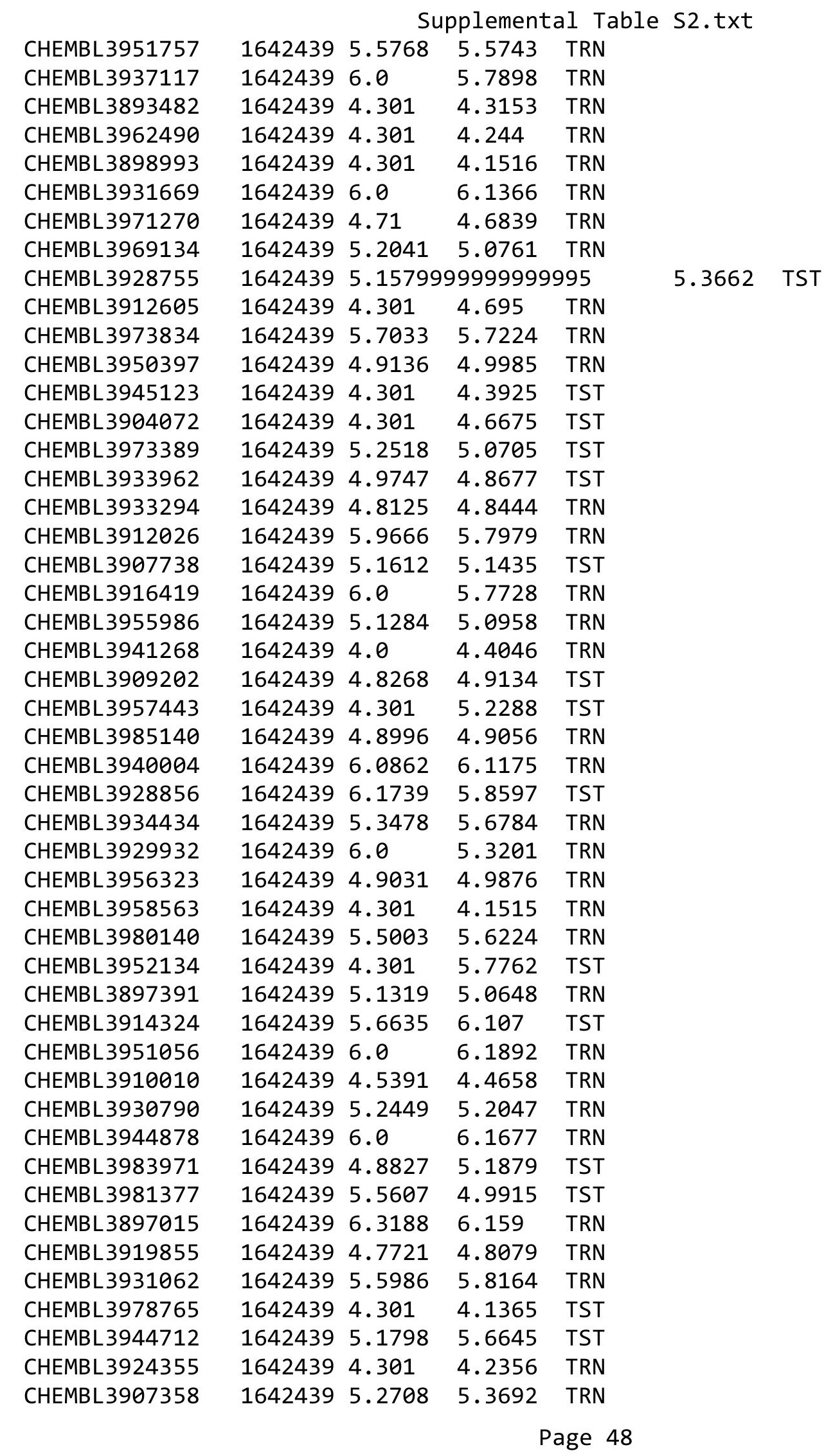


Supplemental Table S2.txt

\begin{tabular}{|c|c|c|c|c|c|}
\hline CHEMBL3936804 & 1642439 & 4.6326 & 4.5915 & TRN & \\
\hline CHEMBL3942322 & 1642439 & 5.7773 & 5.8831 & TRN & \\
\hline CHEMBL3948778 & 1642439 & 5.6498 & 5.6624 & TRN & \\
\hline CHEMBL3908893 & 1642439 & 4.301 & 4.0694 & TRN & \\
\hline CHEMBL258995 & 474639 & 7.041 & 7.0351 & TRN & \\
\hline CHEMBL259408 & 474639 & 7.3768 & 7.2272 & TRN & \\
\hline CHEMBL260076 & 474639 & 6.3468 & 6.3753 & TRN & \\
\hline CHEMBL259626 & 474639 & 7.0969 & 7.0458 & TRN & \\
\hline CHEMBL 261100 & 474639 & 5.6198 & 5.7459 & TRN & \\
\hline CHEMBL260514 & 474639 & 6.9586 & 7.1186 & TRN & \\
\hline CHEMBL410043 & 474639 & 6.0362 & 5.5425 & TRN & \\
\hline CHEMBL258956 & 474639 & 7.0132 & 7.0807 & TRN & \\
\hline CHEMBL409358 & 474639 & 6.3979 & 6.4033 & TRN & \\
\hline CHEMBL261433 & 474639 & 6.2076 & 6.3684 & TRN & \\
\hline CHEMBL411868 & 474639 & 5.9586 & 5.6315 & TRN & \\
\hline CHEMBL428781 & 474639 & 7.6778 & 7.5053 & TRN & \\
\hline CHEMBL 259001 & 474639 & 7.3188 & 7.4202 & TRN & \\
\hline CHEMBL261232 & 474639 & 5.699 & 5.6197 & TRN & \\
\hline CHEMBL261187 & 474639 & 6.1135 & 6.1812 & TRN & \\
\hline CHEMBL261102 & 474639 & 7.1249 & 6.6084 & TST & \\
\hline CHEMBL260022 & 474639 & 7.2596 & 7.1793 & TRN & \\
\hline CHEMBL262589 & 474639 & 5.1367 & 2.7906 & TST & \\
\hline CHEMBL261654 & 474639 & 6.0269 & 6.2484 & TRN & \\
\hline CHEMBL 260250 & 474639 & 6.1367 & 6.0597 & TRN & \\
\hline CHEMBL436700 & 474639 & 7.3468 & 7.386 & TRN & \\
\hline CHEMBL260023 & 474639 & 6.1487 & 6.4165 & TRN & \\
\hline CHEMBL261149 & 474639 & 6.699 & 6.6573 & TRN & \\
\hline CHEMBL258525 & 474639 & 6.4318 & 6.6136 & TRN & \\
\hline CHEMBL259236 & 474639 & 6.4559 & 6.6372 & TRN & \\
\hline CHEMBL258524 & 474639 & 5.8861 & 5.8535 & TRN & \\
\hline CHEMBL410922 & 474639 & 5.0458 & 4.8245 & TRN & \\
\hline CHEMBL260804 & 474639 & 6.6383 & 6.8809 & TRN & \\
\hline CHEMBL259199 & 474639 & 7.3098 & 7.3135 & TRN & \\
\hline CHEMBL259619 & 474639 & 6.1675 & 6.037006 & 0000000001 & TRN \\
\hline CHEMBL261742 & 474639 & 7.7959 & 7.6627 & TRN & \\
\hline CHEMBL260903 & 474639 & 6.2291 & 6.0044 & TST & \\
\hline CHEMBL260906 & 474639 & 7.1308 & 6.8998 & TST & \\
\hline CHEMBL261572 & 474639 & 6.3279 & 6.3668 & TRN & \\
\hline CHEMBL260907 & 474639 & 7.9208 & 7.898 & TRN & \\
\hline CHEMBL261019 & 474639 & 7.0362 & 6.419 & TST & \\
\hline CHEMBL260901 & 474639 & 5.9586 & 5.746 & TST & \\
\hline CHEMBL260706 & 474639 & 6.7959 & 6.8619 & TRN & \\
\hline CHEMBL259776 & 474639 & 6.9208 & 7.1108 & TRN & \\
\hline CHEMBL261653 & 474639 & 6.301 & 5.5697 & TST & \\
\hline CHEMBL260971 & 474639 & 6.1135 & 6.1926 & TRN & \\
\hline CHEMBL407966 & 474639 & 6.5686 & 6.5613 & TRN & \\
\hline CHEMBL 260650 & 474639 & 4.0 & 4.13 & TRN & \\
\hline CHEMBL261018 & 474639 & 6.1675 & 6.0921 & TRN & \\
\hline
\end{tabular}


Supplemental Table S2.txt

\begin{tabular}{|c|c|c|c|c|}
\hline CHEMBL 260648 & 474639 & 6.3768 & 6.415 & TRN \\
\hline CHEMBL260705 & 474639 & 7.0706 & 6.9623 & TRN \\
\hline CHEMBL260073 & 474639 & 6.9586 & 7.001 & TRN \\
\hline CHEMBL409156 & 474639 & 7.1024 & 6.7465 & TRN \\
\hline CHEMBL407154 & 474639 & 4.0 & 4.3899 & TRN \\
\hline CHEMBL412153 & 474639 & 6.1938 & 6.2309 & TST \\
\hline CHEMBL411442 & 474639 & 6.0 & 5.8837 & TRN \\
\hline CHEMBL260003 & 474639 & 5.6576 & 5.6368 & TRN \\
\hline CHEMBL259625 & 474639 & 5.8539 & 5.6303 & TRN \\
\hline CHEMBL409157 & 474639 & 6.3468 & 6.2229 & TRN \\
\hline CHEMBL 258785 & 474639 & 7.7212 & 7.8303 & TRN \\
\hline CHEMBL408717 & 474639 & 7.5376 & 7.3923 & TRN \\
\hline CHEMBL260756 & 474639 & 7.5376 & 7.5357 & TRN \\
\hline CHEMBL260969 & 474639 & 5.9208 & 5.7714 & TRN \\
\hline CHEMBL260029 & 474639 & 6.3768 & 6.1079 & TST \\
\hline CHEMBL411105 & 474639 & 6.7212 & 6.6762 & TRN \\
\hline CHEMBL261099 & 474639 & 6.0269 & 6.2908 & TST \\
\hline CHEMBL260249 & 474639 & 6.1871 & 5.7229 & TRN \\
\hline CHEMBL260902 & 474639 & 6.6778 & 6.869 & TRN \\
\hline CHEMBL410042 & 474639 & 6.2924 & 7.9427 & TST \\
\hline CHEMBL260970 & 474639 & 6.8861 & 6.9143 & TRN \\
\hline CHEMBL410075 & 474639 & 6.0315 & 6.1607 & TRN \\
\hline CHEMBL259407 & 474639 & 6.7212 & 6.7765 & TRN \\
\hline CHEMBL261573 & 474639 & 6.4559 & 6.6719 & TST \\
\hline CHEMBL261434 & 474639 & 7.2596 & 6.6874 & TST \\
\hline CHEMBL407411 & 474639 & 7.0088 & 6.9607 & TRN \\
\hline CHEMBL410722 & 474639 & 5.8239 & 6.4588 & TST \\
\hline CHEMBL 261151 & 474639 & 6.301 & 5.49 & TST \\
\hline CHEMBL259414 & 474639 & 6.1612 & 5.7184 & TST \\
\hline CHEMBL260704 & 474639 & 4.0 & 4.2784 & TRN \\
\hline CHEMBL261231 & 474639 & 7.585 & 7.6734 & TRN \\
\hline CHEMBL261291 & 474639 & 7.0223 & 6.3155 & TST \\
\hline CHEMBL405892 & 474639 & 6.699 & 6.8132 & TRN \\
\hline CHEMBL 261337 & 474639 & 6.2291 & 6.3689 & TRN \\
\hline CHEMBL406221 & 474639 & 7.7959 & 7.6946 & TRN \\
\hline CHEMBL411104 & 474639 & 6.585 & 6.5302 & TST \\
\hline CHEMBL260074 & 474639 & 6.8861 & 7.7678 & TST \\
\hline CHEMBL409107 & 474639 & 5.6021 & 5.6436 & TRN \\
\hline CHEMBL259827 & 474639 & 6.699 & 5.2164 & TST \\
\hline CHEMBL261233 & 474639 & 4.0 & 3.0692 & TST \\
\hline CHEMBL259415 & 474639 & 6.3372 & 6.0132 & TST \\
\hline CHEMBL372052 & 688619 & 4.9 & 5.2335 & TRN \\
\hline CHEMBL2374062 & 688619 & 4.8 & 5.6979 & TST \\
\hline CHEMBL48449 & 688619 & 5.5 & 5.6765 & TST \\
\hline CHEMBL2374027 & 688619 & 4.9 & 5.0531 & TRN \\
\hline CHEMBL539947 & 688619 & 5.0 & 5.3305 & TRN \\
\hline CHEMBL596674 & 688619 & 5.6 & 5.4869 & TRN \\
\hline CHEMBL1256687 & 688619 & 4.6 & 4.81 & TRN \\
\hline
\end{tabular}




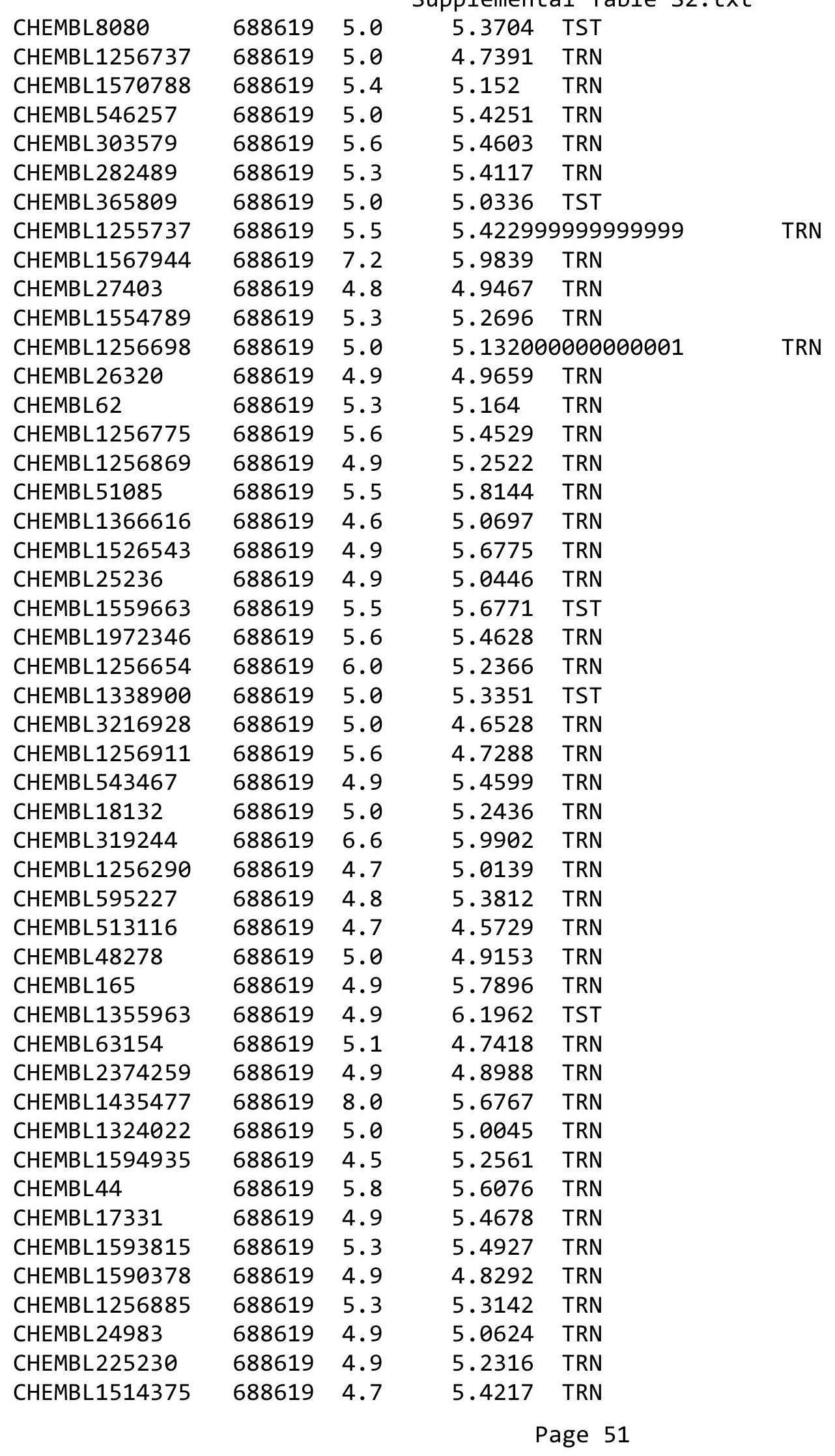




\begin{tabular}{|c|c|c|c|c|c|}
\hline \multicolumn{6}{|c|}{ Supplemental Table S2.txt } \\
\hline CHEMBL544115 & 688619 & 5.6 & 5.2217 & TRN & \\
\hline CHEMBL328710 & 688619 & 7.2 & 6.155 & TRN & \\
\hline CHEMBL 21260 & 688619 & 7.4001 & 6.5475 & TRN & \\
\hline CHEMBL153036 & 688619 & 6.0 & 5.1756 & TRN & \\
\hline CHEMBL520992 & 688619 & 5.0 & 4.9682 & TRN & \\
\hline CHEMBL1256751 & 688619 & 4.9 & 4.9904 & TRN & \\
\hline CHEMBL1284 & 688619 & 5.0 & 5.1612 & TRN & \\
\hline CHEMBL52 & 688619 & 5.3 & 5.0354 & TRN & \\
\hline CHEMBL1380684 & 688619 & 4.9 & 5.5834 & TRN & \\
\hline CHEMBL1595524 & 688619 & 4.9 & 5.2689 & TRN & \\
\hline CHEMBL1255649 & 688619 & 5.9 & 5.2136 & TRN & \\
\hline CHEMBL310798 & 688619 & 4.7 & 5.1282 & TRN & \\
\hline CHEMBL1255755 & 688619 & 7.0 & 5.44799 & 99999999995 & TRN \\
\hline CHEMBL 8145 & 688619 & 5.6 & 5.4654 & TRN & \\
\hline CHEMBL500996 & 688619 & 4.6 & 4.9432 & TRN & \\
\hline CHEMBL1515691 & 688619 & 7.6003 & 6.1093 & TST & \\
\hline CHEMBL60718 & 688619 & 5.0 & 5.1071 & TRN & \\
\hline CHEMBL1522486 & 688619 & 5.6 & 5.9711 & TRN & \\
\hline CHEMBL1415777 & 688619 & 5.1 & 5.4499 & TRN & \\
\hline CHEMBL1256646 & 688619 & 4.9 & 4.8688 & TRN & \\
\hline CHEMBL1493117 & 688619 & 5.0 & 5.3189 & TRN & \\
\hline CHEMBL1256666 & 688619 & 5.0 & 5.1127 & TRN & \\
\hline CHEMBL68534 & 688619 & 5.5 & 5.4029 & TRN & \\
\hline CHEMBL113830 & 688619 & 4.9 & 5.1607 & TRN & \\
\hline CHEMBL1315457 & 688619 & 5.6 & 5.1749 & TST & \\
\hline CHEMBL53898 & 688619 & 5.8 & 5.4849 & TRN & \\
\hline CHEMBL441282 & 688619 & 5.1 & 5.0546 & TRN & \\
\hline CHEMBL262083 & 688619 & 5.4 & 5.5693 & TRN & \\
\hline CHEMBL1256147 & 688619 & 4.7 & 5.2242 & TRN & \\
\hline CHEMBL1255656 & 688619 & 5.0 & 5.1424 & TRN & \\
\hline CHEMBL275938 & 688619 & 5.5 & 5.5695 & TRN & \\
\hline CHEMBL1234696 & 688619 & 5.2 & 5.7879 & TRN & \\
\hline CHEMBL1529009 & 688619 & 4.6 & 5.1612 & TRN & \\
\hline CHEMBL260374 & 688619 & 5.4 & 5.1521 & TRN & \\
\hline CHEMBL1527442 & 688619 & 4.6 & 5.2649 & TST & \\
\hline CHEMBL347862 & 688619 & 5.3 & 5.4873 & TRN & \\
\hline CHEMBL1412842 & 688619 & 5.2 & 5.8893 & TRN & \\
\hline CHEMBL1513654 & 688619 & 4.9 & 5.3012 & TRN & \\
\hline CHEMBL1480136 & 688619 & 5.3 & 5.0609 & TRN & \\
\hline CHEMBL1255866 & 688619 & 4.9 & 5.2844 & TRN & \\
\hline CHEMBL1605605 & 688619 & 5.0 & 5.1198 & TRN & \\
\hline CHEMBL164 & 688619 & 5.0 & 5.2001 & TRN & \\
\hline CHEMBL517986 & 688619 & 5.0 & 5.2522 & TRN & \\
\hline CHEMBL1200450 & 688619 & 5.4 & 5.2347 & TRN & \\
\hline CHEMBL 322970 & 688619 & 6.7001 & 5.7798 & TRN & \\
\hline CHEMBL45891 & 688619 & 5.2 & 5.4746 & TRN & \\
\hline CHEMBL67311 & 688619 & 4.9 & 5.6056 & TST & \\
\hline CHEMBL542700 & 688619 & 4.8 & 5.0795 & TRN & \\
\hline
\end{tabular}




\begin{tabular}{|c|c|c|c|c|c|}
\hline \multicolumn{6}{|c|}{ oplemental } \\
\hline CHEMBL1527722 & 688619 & 6.9 & 5.9016 & TRN & \\
\hline CHEMBL587714 & 688619 & 4.9 & 4.8311 & TRN & \\
\hline CHEMBL279556 & 688619 & 4.6 & 5.1537 & TRN & \\
\hline CHEMBL123 & 688619 & 5.0 & 5.59399 & 9999999999 & TRN \\
\hline CHEMBL1256740 & 688619 & 5.0 & 5.0111 & TRN & \\
\hline CHEMBL539027 & 688619 & 5.1 & 4.5918 & TRN & \\
\hline CHEMBL1256727 & 688619 & 5.0 & 5.0853 & TRN & \\
\hline CHEMBL428768 & 688619 & 5.0 & 4.8261 & TRN & \\
\hline CHEMBL258893 & 688619 & 5.7 & 6.1768 & TRN & \\
\hline CHEMBL1224512 & 688619 & 4.9 & 5.4644 & TRN & \\
\hline CHEMBL177820 & 688619 & 5.5 & 5.1619 & TST & \\
\hline CHEMBL1257013 & 688619 & 5.4 & 5.5055 & TRN & \\
\hline CHEMBL542493 & 688619 & 5.0 & 4.9911 & TRN & \\
\hline CHEMBL297784 & 688619 & 6.0 & 5.3266 & TRN & \\
\hline CHEMBL1490919 & 688619 & 4.8 & 5.3037 & TST & \\
\hline CHEMBL1355762 & 688619 & 4.9 & 5.2175 & TRN & \\
\hline CHEMBL1440857 & 688619 & 5.7 & 6.0462 & TRN & \\
\hline CHEMBL536950 & 688619 & 5.6 & 5.5529 & TRN & \\
\hline CHEMBL1329033 & 688619 & 5.0 & 5.2607 & TRN & \\
\hline CHEMBL1357558 & 688619 & 4.9 & 5.0229 & TRN & \\
\hline CHEMBL1256995 & 688619 & 4.8 & 5.0742 & TRN & \\
\hline CHEMBL1338358 & 688619 & 5.0 & 5.2333 & TRN & \\
\hline CHEMBL554311 & 688619 & 5.0 & 5.715 & TRN & \\
\hline CHEMBL1437846 & 688619 & 5.9 & 5.83200 & 0000000001 & TST \\
\hline CHEMBL1528565 & 688619 & 5.0 & 5.0114 & TRN & \\
\hline CHEMBL23194 & 688619 & 5.1 & 5.0537 & TRN & \\
\hline CHEMBL293749 & 688619 & 5.9 & 5.428 & TRN & \\
\hline CHEMBL285819 & 688619 & 4.8 & 5.3438 & TRN & \\
\hline CHEMBL13647 & 688619 & 5.1 & 5.3223 & TRN & \\
\hline CHEMBL30432 & 688619 & 5.0 & 5.2869 & TST & \\
\hline CHEMBL 275516 & 688619 & 5.3 & 5.1818 & TST & \\
\hline CHEMBL188 & 688619 & 4.9 & 5.3816 & TRN & \\
\hline CHEMBL1257041 & 688619 & 5.0 & 5.1097 & TRN & \\
\hline CHEMBL1514440 & 688619 & 6.0 & 5.4063 & TRN & \\
\hline CHEMBL13790 & 688619 & 5.5 & 5.25799 & 9999999999 & TRN \\
\hline CHEMBL1256759 & 688619 & 5.5 & 5.5034 & TRN & \\
\hline CHEMBL1256660 & 688619 & 4.6 & 4.6094 & TRN & \\
\hline CHEMBL250711 & 688619 & 6.3 & 5.3899 & TRN & \\
\hline CHEMBL1256661 & 688619 & 4.8 & 5.0646 & TRN & \\
\hline CHEMBL1448979 & 688619 & 8.3979 & 5.7835 & TRN & \\
\hline CHEMBL371811 & 688619 & 5.5 & 4.9707 & TRN & \\
\hline CHEMBL1355710 & 688619 & 5.6 & 5.056 & TRN & \\
\hline CHEMBL1257083 & 688619 & 6.6 & 5.0953 & TRN & \\
\hline CHEMBL1256364 & 688619 & 4.7 & 5.5772 & TRN & \\
\hline CHEMBL14276 & 688619 & 4.8 & 5.1367 & TRN & \\
\hline CHEMBL 2374058 & 688619 & 4.9 & 5.6151 & TST & \\
\hline CHEMBL1256180 & 688619 & 5.3 & 5.4375 & TRN & \\
\hline CHEMBL1256659 & 688619 & 5.0 & 5.0676 & TRN & \\
\hline
\end{tabular}




\begin{tabular}{|c|c|c|c|c|c|}
\hline \multicolumn{6}{|c|}{ Supplemental Table S2.txt } \\
\hline CHEMBL275311 & 688619 & 5.0 & 5.4373 & TRN & \\
\hline CHEMBL402468 & 688619 & 5.4 & 5.46 & TRN & \\
\hline CHEMBL56543 & 688619 & 6.0 & 5.3573 & TRN & \\
\hline CHEMBL19439 & 688619 & 6.1 & 5.3863 & TRN & \\
\hline CHEMBL1316314 & 688619 & 4.9 & 5.0515 & TRN & \\
\hline CHEMBL98350 & 688619 & 5.0 & 5.931 & TRN & \\
\hline CHEMBL26915 & 688619 & 5.3 & 5.319 & TRN & \\
\hline CHEMBL1331383 & 688619 & 5.0 & 5.2411 & TRN & \\
\hline CHEMBL28140 & 688619 & 5.0 & 5.3967 & TRN & \\
\hline CHEMBL1472703 & 688619 & 4.9 & 5.2943 & TRN & \\
\hline CHEMBL567175 & 688619 & 4.8 & 4.6603 & TRN & \\
\hline CHEMBL1256693 & 688619 & 5.5 & 4.7259 & TRN & \\
\hline CHEMBL19612 & 688619 & 5.2 & 5.1273 & TRN & \\
\hline CHEMBL1476170 & 688619 & 8.3979 & 6.3475 & TRN & \\
\hline CHEMBL448741 & 688619 & 4.9 & 5.1495 & TRN & \\
\hline CHEMBL299052 & 688619 & 4.5 & 5.0054 & TRN & \\
\hline CHEMBL1335406 & 688619 & 4.9 & 5.5141 & TRN & \\
\hline CHEMBL1161525 & 688619 & 5.5 & 5.73600 & 0000000001 & TRN \\
\hline CHEMBL576349 & 688619 & 5.1 & 5.8257 & TRN & \\
\hline CHEMBL78150 & 688619 & 5.8 & 5.2561 & TRN & \\
\hline CHEMBL1436882 & 688619 & 4.8 & 5.5679 & TRN & \\
\hline CHEMBL276727 & 688619 & 5.5 & 5.2723 & TRN & \\
\hline CHEMBL1725279 & 688619 & 5.3 & 5.2497 & TRN & \\
\hline CHEMBL16687 & 688619 & 4.9 & 5.2984 & TST & \\
\hline CHEMBL47940 & 688619 & 4.9 & 5.4355 & TRN & \\
\hline CHEMBL258767 & 688619 & 6.0 & 5.8693 & TRN & \\
\hline CHEMBL1336166 & 688619 & 5.8 & 5.23600 & 0000000001 & TRN \\
\hline CHEMBL604119 & 688619 & 5.0 & 5.4802 & TST & \\
\hline CHEMBL1256910 & 688619 & 5.4 & 5.7943 & TRN & \\
\hline CHEMBL 278041 & 688619 & 4.5 & 5.3298 & TRN & \\
\hline CHEMBL320820 & 688619 & 5.0 & 5.2174 & TST & \\
\hline CHEMBL 903 & 688619 & 6.9 & 5.2214 & TRN & \\
\hline CHEMBL268868 & 688619 & 4.6 & 5.4747 & TRN & \\
\hline CHEMBL110739 & 688619 & 5.9 & 5.2635 & TRN & \\
\hline CHEMBL288096 & 688619 & 5.0 & 4.9802 & TRN & \\
\hline CHEMBL1255837 & 688619 & 5.0 & 5.7105 & TRN & \\
\hline CHEMBL104264 & 688619 & 5.0 & 5.2093 & TRN & \\
\hline CHEMBL1256797 & 688619 & 5.0 & 4.9244 & TRN & \\
\hline CHEMBL1255867 & 688619 & 6.2 & 4.6454 & TRN & \\
\hline CHEMBL 34241 & 688619 & 5.6 & 5.3985 & TRN & \\
\hline CHEMBL102714 & 688619 & 4.8 & 5.2565 & TRN & \\
\hline CHEMBL1598680 & 688619 & 4.9 & 5.1988 & TRN & \\
\hline CHEMBL289277 & 688619 & 4.9 & 5.53 & TRN & \\
\hline CHEMBL310310 & 688619 & 4.9 & 5.2822 & TRN & \\
\hline CHEMBL1453208 & 688619 & 5.0 & 5.3475 & TRN & \\
\hline CHEMBL76904 & 688619 & 4.9 & 5.4682 & TRN & \\
\hline CHEMBL269733 & 688619 & 5.4 & 5.2212 & TRN & \\
\hline CHEMBL1373007 & 688619 & 5.0 & 5.7268 & TRN & \\
\hline
\end{tabular}




\begin{tabular}{|c|c|c|c|c|}
\hline \multicolumn{5}{|c|}{ Supplemental Table S2.txt } \\
\hline CHEMBL1256647 & 688619 & 4.9 & 4.5966 & TRN \\
\hline CHEMBL56393 & 688619 & 4.5 & 5.1414 & TRN \\
\hline CHEMBL35482 & 688619 & 6.4 & 5.4822 & TRN \\
\hline CHEMBL1256876 & 688619 & 5.0 & 4.8855 & TRN \\
\hline CHEMBL28626 & 688619 & 5.5 & 5.2886 & TRN \\
\hline CHEMBL1515334 & 688619 & 4.9 & 5.0733 & TRN \\
\hline CHEMBL3392050 & 688619 & 4.9 & 5.4726 & TST \\
\hline CHEMBL408982 & 688619 & 5.6 & 5.2079 & TRN \\
\hline CHEMBL376505 & 688619 & 5.9 & 5.2383 & TST \\
\hline CHEMBL545184 & 688619 & 5.1 & 5.2996 & TRN \\
\hline CHEMBL391997 & 688619 & 5.0 & 5.1026 & TRN \\
\hline CHEMBL85139 & 688619 & 6.5 & 5.5327 & TRN \\
\hline CHEMBL429095 & 688619 & 5.9 & 6.0905 & TRN \\
\hline CHEMBL274438 & 688619 & 5.0 & 5.5247 & TRN \\
\hline CHEMBL40998 & 688619 & 5.1 & 5.6174 & TRN \\
\hline CHEMBL1256749 & 688619 & 4.9 & 4.7134 & TRN \\
\hline CHEMBL 28 & 688619 & 6.3 & 5.9999 & TRN \\
\hline CHEMBL405358 & 688619 & 7.1002 & 6.0145 & TRN \\
\hline CHEMBL1396661 & 688619 & 4.9 & 5.5739 & TRN \\
\hline CHEMBL22870 & 688619 & 4.9 & 4.9501 & TRN \\
\hline CHEMBL416657 & 688619 & 5.0 & 5.0463 & TRN \\
\hline CHEMBL1256913 & 688619 & 4.9 & 5.1769 & TRN \\
\hline CHEMBL1208858 & 688619 & 4.6 & 5.0862 & TST \\
\hline CHEMBL45244 & 688619 & 5.5 & 5.1177 & TRN \\
\hline CHEMBL95606 & 688619 & 6.0 & 5.7308 & TRN \\
\hline CHEMBL1365553 & 688619 & 6.3 & 5.8668 & TRN \\
\hline CHEMBL407232 & 688619 & 5.7 & 5.3144 & TRN \\
\hline CHEMBL365739 & 688619 & 7.4001 & 6.5223 & TRN \\
\hline CHEMBL1456417 & 688619 & 5.0 & 5.6092 & TRN \\
\hline CHEMBL60518 & 688619 & 5.7 & 4.9833 & TRN \\
\hline CHEMBL1521453 & 688619 & 5.3 & 5.3617 & TST \\
\hline CHEMBL1608159 & 688619 & 4.9 & 5.245 & TRN \\
\hline CHEMBL1256663 & 688619 & 5.0 & 4.7189 & TRN \\
\hline CHEMBL112816 & 688619 & 5.2 & 5.2399 & TRN \\
\hline CHEMBL101168 & 688619 & 6.0 & 5.1632 & TRN \\
\hline CHEMBL280998 & 688619 & 5.3 & 5.2967 & TRN \\
\hline CHEMBL109037 & 688619 & 4.9 & 5.4894 & TRN \\
\hline CHEMBL1405759 & 688619 & 5.0 & 5.3207 & TRN \\
\hline CHEMBL1554131 & 688619 & 5.0 & 5.4009 & TRN \\
\hline CHEMBL 290943 & 688619 & 6.8 & 5.2215 & TST \\
\hline CHEMBL129795 & 688619 & 5.5 & 5.555 & TRN \\
\hline CHEMBL 244948 & 688619 & 4.9 & 5.3594 & TRN \\
\hline CHEMBL1434950 & 688619 & 5.4 & 5.0092 & TRN \\
\hline CHEMBL1600780 & 688619 & 5.1 & 5.2738 & TRN \\
\hline CHEMBL445102 & 688619 & 5.0 & 5.1098 & TRN \\
\hline CHEMBL429711 & 688619 & 5.5 & 5.0166 & TRN \\
\hline CHEMBL1256484 & 688619 & 4.9 & 4.7429 & TRN \\
\hline CHEMBL1255778 & 688619 & 4.6 & 5.3848 & TRN \\
\hline
\end{tabular}




\begin{tabular}{|c|c|c|c|c|c|}
\hline \multicolumn{6}{|c|}{ Supplemental Table S2.txt } \\
\hline CHEMBL1461491 & 688619 & 5.0 & 5.385 & TRN & \\
\hline CHEMBL1256024 & 688619 & 4.9 & 5.1624 & TRN & \\
\hline CHEMBL399491 & 688619 & 5.4 & 5.8552 & TST & \\
\hline CHEMBL 1322702 & 688619 & 4.9 & 5.4692 & TRN & \\
\hline CHEMBL288174 & 688619 & 5.3 & 5.2418 & TRN & \\
\hline CHEMBL1255940 & 688619 & 5.2 & 5.3374 & TRN & \\
\hline CHEMBL 2374063 & 688619 & 5.6 & 5.954 & TST & \\
\hline CHEMBL1413371 & 688619 & 5.4 & 5.5151 & TRN & \\
\hline CHEMBL1256191 & 688619 & 4.9 & 4.7988 & TRN & \\
\hline CHEMBL1256750 & 688619 & 4.6 & 5.0137 & TRN & \\
\hline CHEMBL1079460 & 688619 & 5.0 & 4.8381 & TRN & \\
\hline CHEMBL65 & 688619 & 6.9 & 7.0314 & TRN & \\
\hline CHEMBL1367076 & 688619 & 6.5 & 5.3318 & TRN & \\
\hline CHEMBL 11348 & 688619 & 4.9 & 5.4988 & TST & \\
\hline CHEMBL1554098 & 688619 & 6.4 & 5.9192 & TST & \\
\hline CHEMBL1255657 & 688619 & 5.0 & 5.3625 & TST & \\
\hline CHEMBL323356 & 688619 & 5.8 & 5.1962 & TST & \\
\hline CHEMBL34704 & 688619 & 4.9 & 4.953 & TST & \\
\hline CHEMBL66654 & 688619 & 6.0 & 5.5696 & TST & \\
\hline CHEMBL126077 & 688619 & 6.0 & 5.2943 & TST & \\
\hline CHEMBL1398031 & 688619 & 5.0 & 4.9541 & TST & \\
\hline CHEMBL428496 & 688619 & 5.5 & 5.8045 & TST & \\
\hline CHEMBL1318166 & 688619 & 5.3 & 5.6793 & TST & \\
\hline CHEMBL664 & 688619 & 5.4 & 5.3195 & TST & \\
\hline CHEMBL 24510 & 688619 & 5.7 & 5.309 & TST & \\
\hline CHEMBL268609 & 688619 & 5.0 & 5.1981 & TST & \\
\hline CHEMBL429023 & 688619 & 7.5003 & 6.9309 & TST & \\
\hline CHEMBL556001 & 688619 & 5.0 & 5.3517 & TST & \\
\hline CHEMBL288591 & 688619 & 5.0 & 5.1436 & TST & \\
\hline CHEMBL559612 & 688619 & 4.9 & 4.8899 & TST & \\
\hline CHEMBL3186408 & 688619 & 5.0 & 5.8705 & TST & \\
\hline CHEMBL375270 & 688619 & 5.8 & 5.1964 & TST & \\
\hline CHEMBL 284028 & 688619 & 4.9 & 4.9093 & TST & \\
\hline CHEMBL553503 & 688619 & 5.0 & 4.9068 & TST & \\
\hline CHEMBL299613 & 688619 & 5.0 & 5.695 & TST & \\
\hline CHEMBL336467 & 688619 & 5.4 & 5.3771 & TST & \\
\hline CHEMBL 1256678 & 688619 & 5.7 & 5.78299 & 99999999995 & TST \\
\hline CHEMBL1256656 & 688619 & 5.0 & 5.4921 & TST & \\
\hline CHEMBL1256754 & 688619 & 5.4 & 5.0265 & TST & \\
\hline CHEMBL1526455 & 688619 & 5.0 & 4.5751 & TST & \\
\hline CHEMBL1237212 & 688619 & 4.9 & 5.4049 & TST & \\
\hline CHEMBL1523894 & 688619 & 4.9 & 5.5827 & TST & \\
\hline CHEMBL15192 & 688619 & 5.8 & 5.7987 & TST & \\
\hline CHEMBL1255936 & 688619 & 5.6 & 5.5012 & TST & \\
\hline CHEMBL 8211 & 688619 & 5.8 & 5.3327 & TST & \\
\hline CHEMBL1256686 & 688619 & 5.5 & 5.5484 & TST & \\
\hline CHEMBL 73188 & 688619 & 5.0 & 5.3953 & TST & \\
\hline CHEMBL541543 & 688619 & 5.1 & 5.48 & TST & \\
\hline & & & & age 56 & \\
\hline
\end{tabular}




\begin{tabular}{|c|c|c|c|c|c|}
\hline \multicolumn{6}{|c|}{ Supplemental Table S2.txt } \\
\hline CHEMBL1473612 & 688619 & 4.9 & 5.1543 & TST & \\
\hline CHEMBL1256873 & 688619 & 5.4 & 5.3404 & TST & \\
\hline CHEMBL296586 & 688619 & 6.8 & 6.0607 & TST & \\
\hline CHEMBL501701 & 688619 & 4.6 & 5.4247 & TST & \\
\hline CHEMBL355496 & 688619 & 6.6 & 5.2503 & TST & \\
\hline CHEMBL574181 & 688619 & 4.7 & 5.2254 & TST & \\
\hline CHEMBL 294590 & 688619 & 5.0 & 5.0583 & TST & \\
\hline CHEMBL270299 & 688619 & 6.1 & 5.6959 & TST & \\
\hline CHEMBL1255659 & 688619 & 5.3 & 5.4901 & TST & \\
\hline CHEMBL250892 & 688619 & 5.2 & 5.2887 & TST & \\
\hline CHEMBL402063 & 688619 & 5.1 & 5.5804 & TST & \\
\hline CHEMBL541585 & 688619 & 5.5 & 4.885 & TST & \\
\hline CHEMBL1554717 & 688619 & 5.0 & 4.6489 & TST & \\
\hline CHEMBL34730 & 688619 & 4.6 & 5.3813 & TST & \\
\hline CHEMBL192566 & 688619 & 7.3002 & 6.4068 & TST & \\
\hline CHEMBL1256878 & 688619 & 4.9 & 5.1766 & TST & \\
\hline CHEMBL443652 & 1555048 & 6.0915 & 6.0912 & TRN & \\
\hline CHEMBL 3764803 & 1555048 & 6.3872 & 6.3867 & TRN & \\
\hline CHEMBL3764712 & 1555048 & 4.699 & 4.854 & TST & \\
\hline CHEMBL3763371 & 1555048 & 5.8539 & 5.8536 & TRN & \\
\hline CHEMBL456807 & 1555048 & 6.6383 & 5.3328 & TST & \\
\hline CHEMBL3764903 & 1555048 & 5.0506 & 5.0502 & TRN & \\
\hline CHEMBL 3764023 & 1555048 & 5.8861 & 5.8861 & TRN & \\
\hline CHEMBL3764796 & 1555048 & 5.6021 & 5.6023 & TRN & \\
\hline CHEMBL3764504 & 1555048 & 6.0 & 6.0011 & TRN & \\
\hline CHEMBL320474 & 1555048 & 5.0362 & 5.06800 & 00000000005 & TST \\
\hline CHEMBL3764351 & 1555048 & 4.6198 & 4.62 & TRN & \\
\hline CHEMBL3763639 & 1555048 & 6.3098 & 6.3098 & TRN & \\
\hline CHEMBL3765389 & 1555048 & 5.0 & 5.5801 & TST & \\
\hline CHEMBL1231544 & 1555048 & 4.1487 & 5.7591 & TST & \\
\hline CHEMBL3765088 & 1555048 & 6.2441 & 6.2443 & TRN & \\
\hline CHEMBL3763730 & 1555048 & 5.6198 & 5.6195 & TRN & \\
\hline CHEMBL 3763481 & 1555048 & 6.2441 & 6.2437 & TRN & \\
\hline CHEMBL3765123 & 1555048 & 5.5686 & 5.5686 & TRN & \\
\hline CHEMBL3763593 & 1555048 & 5.3372 & 5.3376 & TRN & \\
\hline CHEMBL3763498 & 1555048 & 4.9208 & 4.9209 & TRN & \\
\hline CHEMBL3763688 & 1555048 & 6.6778 & 6.6778 & TRN & \\
\hline CHEMBL 3764868 & 1555048 & 4.8239 & 4.8236 & TRN & \\
\hline CHEMBL3764053 & 1555048 & 5.7959 & 5.7952 & TRN & \\
\hline CHEMBL1441489 & 1555048 & 5.2218 & 5.2246 & TST & \\
\hline CHEMBL3764515 & 1555048 & 5.0 & 5.3672 & TST & \\
\hline CHEMBL3764039 & 1555048 & 5.6778 & 5.6775 & TRN & \\
\hline CHEMBL3765086 & 1555048 & 5.9586 & 5.9596 & TRN & \\
\hline CHEMBL3765396 & 1555048 & 6.0088 & 6.0091 & TRN & \\
\hline CHEMBL3764152 & 1555048 & 5.5686 & 5.5682 & TRN & \\
\hline CHEMBL3765142 & 1555048 & 6.2007 & 6.2005 & TRN & \\
\hline CHEMBL3763696 & 1555048 & 4.2596 & 4.2597 & TRN & \\
\hline CHEMBL 3764222 & 1555048 & 5.0223 & 5.0222 & TRN & \\
\hline
\end{tabular}


Supplemental Table S2.txt

\begin{tabular}{|c|c|c|c|c|}
\hline 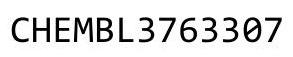 & 48 & 3468 & 6.3471 & TR \\
\hline HEMBL3764514 & .555048 & 5.1487 & 5.149 & \\
\hline 5654 & 5048 & & 693 & \\
\hline HEMBL3764480 & 5048 & 4.0862 & 0863 & 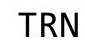 \\
\hline HEMBL3764137 & 555048 & 5.3768 & .3767 & \\
\hline HEMBL 3763237 & 555048 & 5.4685 & 5.4678 & \\
\hline HEMBL16300 & 555048 & 4.7959 & .7963 & \\
\hline HEMBL37 & 5048 & & .2146 & \\
\hline HEMBL3765807 & 555048 & 6.5229 & 6.5227 & \\
\hline HEMBL3763210 & 555048 & 5.2676 & 5.2679 & \\
\hline HEMBL 3765107 & 555048 & 4.585 & 5.7981 & \\
\hline HEMBL3764500 & 5048 & 212 & .7213 & \\
\hline HEMBL37 & & & & RN \\
\hline HEMBL3 & 5048 & 5.284 & 4.8028 & \\
\hline HEMBL37 & 5048 & 539 & 5.8534 & \\
\hline AEMBL3763469 & 5048 & 6.4949 & 6.495 & \\
\hline HEMBL37 & 5048 & 59 & 5.7964 & RIV \\
\hline HEMBL37 & 5048 & & 34 & \\
\hline HEMBL37 & 5048 & & 39 & \\
\hline HEMBL 37 & 5048 & & 91 & TST \\
\hline HEMBL14 & 192 & 7. & 975 & RIV \\
\hline HEMBL15 & 192 & 8 & 5.4896 & $R N$ \\
\hline HEMBL35 & 92 & & 6.76 & \\
\hline HEMBL15 & 192 & & 7.0602 & RN \\
\hline HEMBL 14 & 192 & & 323 & I RIV \\
\hline HEMBL35 & 192 & & 7.478 & RN \\
\hline HEMBL14 & 92 & & 6 . & RN \\
\hline HEMBL14 & 92 & & 52 & \\
\hline HEMBL34 & 192 & & & RIV \\
\hline HEMBL35 & 192 & 4 & 5 . & IRN \\
\hline HEMBL14 & 192 & & 207 & $\mathrm{RN}$ \\
\hline HEMBL14 & 92 & & 4. & RN \\
\hline HEMBL 35 & 192 & & 253 & TRN \\
\hline HEMBL146198 & 192 & & 783 & TRN \\
\hline HEMBL346679 & 56192 & 56 & 6. & 「RN \\
\hline HEMBL34 & 192 & & 7. & RN \\
\hline HEMBL3: & 92 & & & RN \\
\hline HEMBL 35 & 56192 & & 5.1815 & TRN \\
\hline HEMBL148773 & 56192 & 5. & 6.1437 & TRN \\
\hline HEMBL 357003 & 56192 & & 7.0233 & TRN \\
\hline HEMBL148741 & 56192 & & 6.2722 & TRN \\
\hline CHEMBL345756 & 156192 & & 7.6108 & RIN \\
\hline HEMBL149880 & 56192 & 6.8097 & 6.7312 & TRN \\
\hline HEMBL149654 & 56192 & 5.4724 & 5.7675 & $\mathrm{TR}$ \\
\hline HEMBL15 & 56192 & & 7.2012 & IRIV \\
\hline CHEMBL358380 & 56192 & 7.4815 & 7.3253 & \\
\hline CHEMBL14 & 56192 & 6.7447 & 6.5087 & I \\
\hline CHEMBL146189 & 156192 & 5.7471 & 5.9757 & ГRN \\
\hline
\end{tabular}




\begin{tabular}{|c|c|c|c|c|}
\hline \multicolumn{5}{|c|}{ Supplemental Table S2.txt } \\
\hline CHEMBL356729 & 156192 & 6.3747 & 6.5439 & TRN \\
\hline CHEMBL423205 & 156192 & 7.6576 & 7.7577 & TRN \\
\hline CHEMBL356752 & 156192 & 6.8182 & 6.2667 & TRN \\
\hline CHEMBL355966 & 156192 & 7.2366 & 7.3829 & TRN \\
\hline CHEMBL148682 & 156192 & 5.9914 & 6.1922 & TRN \\
\hline CHEMBL342549 & 156192 & 6.2557 & 6.6447 & TRN \\
\hline CHEMBL151886 & 156192 & 5.2343 & 5.2886 & TRN \\
\hline CHEMBL 2112028 & 156192 & 4.7747 & 7.0226 & TST \\
\hline CHEMBL356724 & 156192 & 7.2924 & 7.5905 & TRN \\
\hline CHEMBL356814 & 156192 & 5.082 & 5.5145 & TST \\
\hline CHEMBL146267 & 156192 & 6.9281 & 6.8018 & TRN \\
\hline CHEMBL357808 & 156192 & 5.8962 & 5.722 & TRN \\
\hline CHEMBL341672 & 156192 & 7.0706 & 6.9445 & TST \\
\hline CHEMBL146214 & 156192 & 5.7212 & 5.4813 & TRN \\
\hline CHEMBL146962 & 156192 & 4.4685 & 4.3273 & TRN \\
\hline CHEMBL356607 & 156192 & 6.8447 & 6.8059 & TST \\
\hline CHEMBL148924 & 156192 & 6.6925 & 7.0975 & TST \\
\hline CHEMBL359067 & 156192 & 5.8894 & 6.535 & TST \\
\hline CHEMBL149075 & 156192 & 7.3979 & 7.4171 & TRN \\
\hline CHEMBL146055 & 156192 & 6.1844 & 6.3213 & TST \\
\hline CHEMBL148479 & 156192 & 7.284 & 7.222 & TST \\
\hline CHEMBL359304 & 156192 & 7.8239 & 7.8742 & TRN \\
\hline CHEMBL359388 & 156192 & 6.2782 & 6.2076 & TRN \\
\hline CHEMBL358049 & 156192 & 7.4815 & 7.6032 & TRN \\
\hline CHEMBL149330 & 156192 & 6.2132 & 7.7703 & TST \\
\hline CHEMBL356160 & 156192 & 5.7375 & 5.9742 & TRN \\
\hline CHEMBL147247 & 156192 & 6.4214 & 6.6776 & TRN \\
\hline CHEMBL148601 & 156192 & 7.7959 & 7.8926 & TRN \\
\hline CHEMBL262564 & 156192 & 7.6576 & 7.4611 & TRN \\
\hline CHEMBL150059 & 156192 & 7.0315 & 6.7133 & TRN \\
\hline CHEMBL148887 & 156192 & 6.3468 & 5.9235 & TRN \\
\hline CHEMBL359294 & 156192 & 6.4935 & 6.2439 & TST \\
\hline CHEMBL149562 & 156192 & 7.2291 & 7.2978 & TRN \\
\hline CHEMBL348695 & 156192 & 5.9914 & 6.029 & TRN \\
\hline CHEMBL423762 & 156192 & 8.0 & 7.1834 & TST \\
\hline CHEMBL146186 & 156192 & 7.6383 & 7.1775 & TRN \\
\hline CHEMBL149889 & 156192 & 6.9172 & 7.176 & TST \\
\hline CHEMBL 357394 & 156192 & 5.2306 & 6.4747 & TST \\
\hline CHEMBL262428 & 156192 & 6.5143 & 5.8318 & TRN \\
\hline CHEMBL149030 & 156192 & 7.301 & 7.3636 & TRN \\
\hline CHEMBL423947 & 156192 & 6.8125 & 6.933 & TST \\
\hline CHEMBL145978 & 156192 & 7.3565 & 6.9952 & TRN \\
\hline CHEMBL424500 & 156192 & 7.284 & 6.402 & TST \\
\hline CHEMBL146568 & 156192 & 6.71 & 7.0768 & TRN \\
\hline CHEMBL 357620 & 156192 & 6.7905 & 6.9088 & TRN \\
\hline CHEMBL 2112027 & 156192 & 5.1593 & 5.1506 & TRN \\
\hline CHEMBL343906 & 156192 & 5.4342 & 6.4737 & TST \\
\hline CHEMBL146572 & 156192 & 6.399 & 6.5812 & TST \\
\hline
\end{tabular}




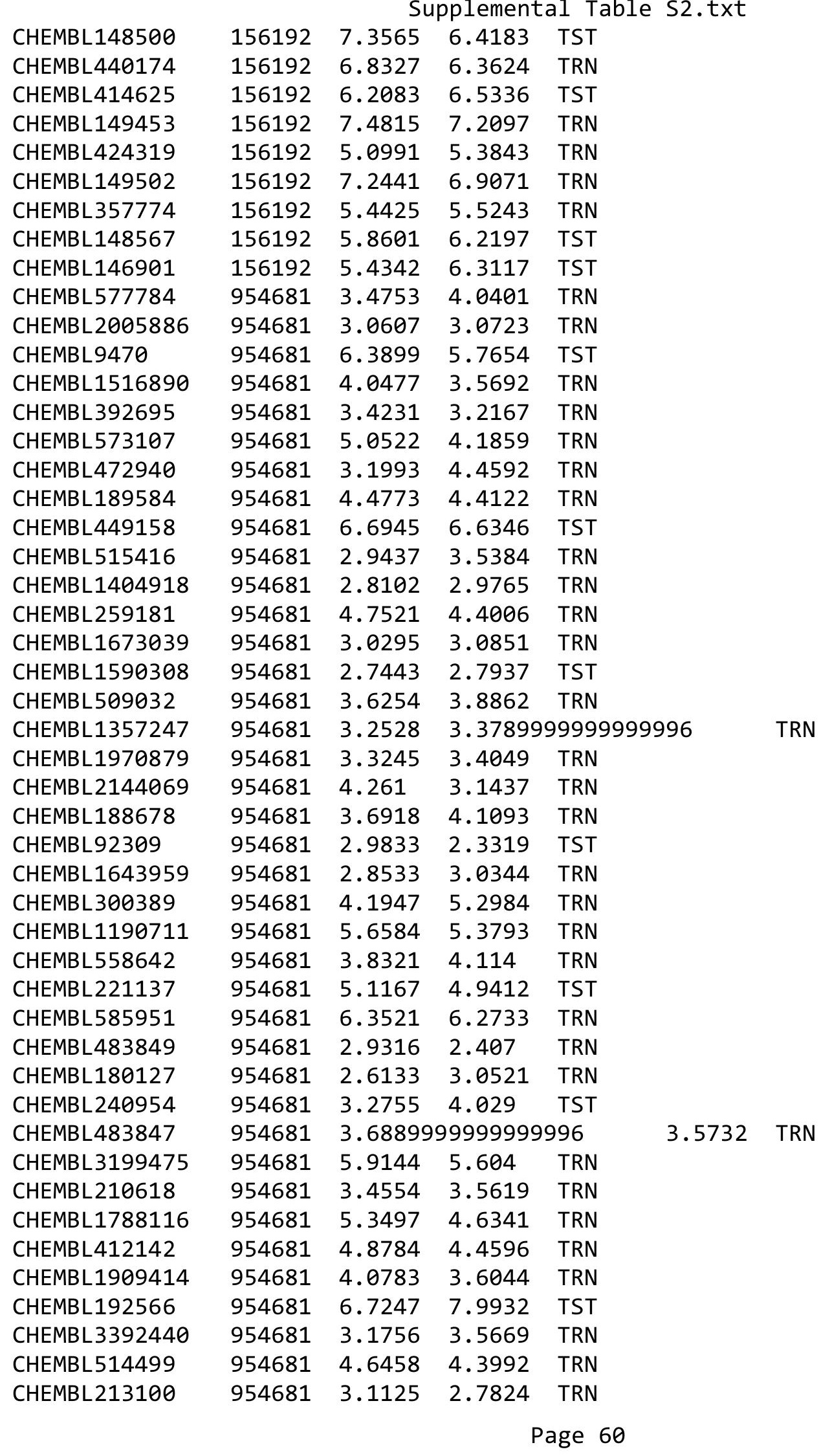


Supplemental Table S2.txt

\begin{tabular}{|c|c|c|c|c|c|}
\hline CHEMBL3186408 & 954681 & 4.2752 & 2.9445 & TST & \\
\hline CHEMBL1242367 & 954681 & 3.4071 & 3.5052 & TRN & \\
\hline CHEMBL1256459 & 954681 & 3.9288 & 4.0729 & TRN & \\
\hline CHEMBL512504 & 954681 & 7.1792 & 7.2105 & TRN & \\
\hline CHEMBL220241 & 954681 & 3.6105 & 3.6433 & TRN & \\
\hline CHEMBL1230020 & 954681 & 3.3146 & 3.4085 & TRN & \\
\hline CHEMBL209148 & 954681 & 2.7796 & 2.9512 & TRN & \\
\hline CHEMBL202721 & 954681 & 3.4865 & 3.7943 & TRN & \\
\hline CHEMBL65 & 954681 & 7.3822 & 7.0513 & TRN & \\
\hline CHEMBL393929 & 954681 & 3.3795 & 3.4133 & TRN & \\
\hline CHEMBL373751 & 954681 & 3.3809 & 3.28800 & 00000000003 & TRN \\
\hline CHEMBL3349342 & 954681 & 3.3814 & 3.5509 & TRN & \\
\hline CHEMBL 379300 & 954681 & 4.2779 & 4.1567 & TRN & \\
\hline CHEMBL135561 & 954681 & 4.0227 & 4.3521 & TST & \\
\hline CHEMBL 2363137 & 954681 & 5.2149 & 4.5508 & TST & \\
\hline CHEMBL222102 & 954681 & 3.4311 & 3.4978 & TST & \\
\hline CHEMBL258844 & 954681 & 3.4747 & 4.8573 & TST & \\
\hline CHEMBL191334 & 954681 & 3.9607 & 3.9435 & TST & \\
\hline CHEMBL102714 & 954681 & 3.7856 & 4.0209 & TST & \\
\hline CHEMBL379975 & 954681 & 4.3096 & 4.9476 & TST & \\
\hline CHEMBL570455 & 596087 & 5.0 & 5.5841 & TRN & \\
\hline CHEMBL570454 & 596087 & 9.0 & 9.2395 & TRN & \\
\hline CHEMBL570650 & 596087 & 5.0 & 4.5978 & TRN & \\
\hline CHEMBL570874 & 596087 & 6.8601 & 7.2043 & TRN & \\
\hline CHEMBL571773 & 596087 & 8.7447 & 8.9482 & TRN & \\
\hline CHEMBL571999 & 596087 & 8.6778 & 9.1282 & TST & \\
\hline CHEMBL570660 & 596087 & 6.7423 & 7.0733 & TRN & \\
\hline CHEMBL569300 & 596087 & 8.5528 & 8.5705 & TRN & \\
\hline CHEMBL569082 & 596087 & 10.0458 & 9.6256 & TRN & \\
\hline CHEMBL571344 & 596087 & 6.7212 & 6.6482 & TRN & \\
\hline CHEMBL570877 & 596087 & 8.5376 & 8.0723 & TRN & \\
\hline CHEMBL569994 & 596087 & 9.8539 & 9.3739 & TRN & \\
\hline CHEMBL570908 & 596087 & 8.4318 & 8.6535 & TRN & \\
\hline CHEMBL584105 & 596087 & 9.0044 & 9.1977 & TRN & \\
\hline CHEMBL571131 & 596087 & 9.1487 & 8.9728 & TRN & \\
\hline CHEMBL579240 & 596087 & 5.0 & 5.6336 & TRN & \\
\hline CHEMBL571346 & 596087 & 5.0 & 4.5035 & TRN & \\
\hline CHEMBL576485 & 596087 & 5.0 & 4.9055 & TRN & \\
\hline CHEMBL584738 & 596087 & 7.7959 & 8.3239 & TRN & \\
\hline CHEMBL570907 & 596087 & 7.9586 & 8.6685 & TRN & \\
\hline CHEMBL569993 & 596087 & 8.7212 & 8.6375 & TRN & \\
\hline CHEMBL571330 & 596087 & 9.3188 & 8.3118 & TRN & \\
\hline CHEMBL408430 & 596087 & 7.9393 & 7.8525 & TST & \\
\hline CHEMBL569301 & 596087 & 9.3979 & 9.8522 & TRN & \\
\hline CHEMBL576706 & 596087 & 8.6576 & 8.2531 & TRN & \\
\hline CHEMBL568807 & 596087 & 8.2366 & 7.7177 & TRN & \\
\hline CHEMBL570909 & 596087 & 5.0 & 5.4873 & TRN & \\
\hline CHEMBL571549 & 596087 & 5.0 & 4.8289 & TRN & \\
\hline
\end{tabular}




\begin{tabular}{|c|c|c|c|c|c|}
\hline \multirow[b]{2}{*}{ CHEMBL569992 } & \multicolumn{5}{|c|}{ Supplemental Table S2.txt } \\
\hline & 596087 & 8.2291 & 9.7821 & TST & \\
\hline CHEMBL 271158 & 596087 & 9.6778 & 9.4929 & TRN & \\
\hline CHEMBL570198 & 596087 & 8.7447 & 8.1591 & TRN & \\
\hline CHEMBL572000 & 596087 & 8.8861 & 9.1959 & TRN & \\
\hline CHEMBL568755 & 596087 & 6.7959 & 6.2659 & TRN & \\
\hline CHEMBL568796 & 596087 & 8.0809 & 7.4847 & TST & \\
\hline CHEMBL262865 & 596087 & 8.3372 & 7.8165 & TRN & \\
\hline CHEMBL576920 & 596087 & 7.2518 & 6.7792 & TRN & \\
\hline CHEMBL583472 & 596087 & 5.0 & 5.4942 & TRN & \\
\hline CHEMBL306764 & 596087 & 7.4559 & 8.1255 & TST & \\
\hline CHEMBL 3085421 & 596087 & 7.4559 & 7.11 & TRN & \\
\hline CHEMBL570876 & 596087 & 8.6383 & 8.4471 & TRN & \\
\hline CHEMBL570875 & 596087 & 5.0 & 5.7149 & TRN & \\
\hline CHEMBL584534 & 596087 & 5.0 & 5.6635 & TRN & \\
\hline CHEMBL583244 & 596087 & 7.2596 & 7.3573 & TRN & \\
\hline CHEMBL571973 & 596087 & 5.0 & 4.9013 & TRN & \\
\hline CHEMBL571097 & 596087 & 6.6576 & 6.4656 & TRN & \\
\hline CHEMBL188 & 596087 & 8.8861 & 8.2157 & TST & \\
\hline CHEMBL584742 & 596087 & 9.7447 & 9.521 & TRN & \\
\hline CHEMBL582810 & 596087 & 7.1675 & 8.0771 & TRN & \\
\hline CHEMBL578179 & 596087 & 7.699 & 7.8634 & TRN & \\
\hline CHEMBL571342 & 596087 & 8.7447 & 8.7847 & TST & \\
\hline CHEMBL570659 & 596087 & 7.9586 & 7.2043 & TRN & \\
\hline CHEMBL572192 & 596087 & 8.5528 & 8.1461 & TRN & \\
\hline CHEMBL571559 & 596087 & 7.585 & 8.4471 & TRN & \\
\hline CHEMBL571776 & 596087 & 5.0 & 4.5419 & TRN & \\
\hline CHEMBL569524 & 596087 & 7.5086 & 7.9876 & TRN & \\
\hline CHEMBL583473 & 596087 & 7.6383 & 6.9315 & TST & \\
\hline CHEMBL571550 & 596087 & 8.699 & 8.7456 & TRN & \\
\hline CHEMBL579241 & 596087 & 8.0362 & 8.1037 & TRN & \\
\hline CHEMBL 3085420 & 596087 & 8.585 & 8.9778 & TST & \\
\hline CHEMBL571095 & 596087 & 7.7447 & 9.5684 & TST & \\
\hline CHEMBL578178 & 596087 & 7.5229 & 8.7625 & TST & \\
\hline CHEMBL570690 & 596087 & 8.5086 & 9.3987 & TST & \\
\hline CHEMBL569299 & 596087 & 8.6778 & 8.3954 & TST & \\
\hline CHEMBL571774 & 596087 & 8.0862 & 8.3244 & TST & \\
\hline CHEMBL584528 & 596087 & 7.3279 & 7.577006 & 0000000001 & TST \\
\hline CHEMBL584321 & 596087 & 5.0 & 6.9613 & TST & \\
\hline CHEMBL570679 & 596087 & 6.7696 & 6.6157 & TST & \\
\hline CHEMBL86613 & 36944 & 7.5686 & 7.6979 & TRN & \\
\hline CHEMBL315012 & 36944 & 7.6198 & 7.8813 & TRN & \\
\hline CHEMBL87650 & 36944 & 7.5686 & 7.6936 & TST & \\
\hline CHEMBL 278741 & 36944 & 8.2366 & 8.2505 & TRN & \\
\hline CHEMBL 87778 & 36944 & 8.5376 & 8.3839 & TRN & \\
\hline CHEMBL87129 & 36944 & 7.9208 & 7.9544 & TRN & \\
\hline CHEMBL 83248 & 36944 & 8.1805 & 8.1723 & TRN & \\
\hline CHEMBL86741 & 36944 & 7.1024 & 6.9028 & TRN & \\
\hline CHEMBL312921 & 36944 & 7.9586 & 7.6936 & TRN & \\
\hline
\end{tabular}




\begin{tabular}{|c|c|c|c|c|c|}
\hline & & \multicolumn{4}{|c|}{ Supplemental Table s2.txt } \\
\hline CHEMBL83194 & 36944 & 8.5086 & 8.379 & TRN & \\
\hline CHEMBL86986 & 36944 & 7.5686 & 7.4308 & TRN & \\
\hline CHEMBL87363 & 36944 & 7.9586 & 7.7502 & TRN & \\
\hline CHEMBL87513 & 36944 & 8.699 & 8.8577 & TRN & \\
\hline CHEMBL19202 & 36944 & 8.6778 & 8.2032 & TRN & \\
\hline CHEMBL86906 & 36944 & 7.7959 & 7.9649 & TRN & \\
\hline CHEMBL907 & 36944 & 8.2218 & 7.4061 & TST & \\
\hline CHEMBL420970 & 36944 & 7.3665 & 7.1206 & TRN & \\
\hline CHEMBL315776 & 36944 & 8.4437 & 8.6013 & TRN & \\
\hline CHEMBL87073 & 36944 & 7.4815 & 7.4872 & TRN & \\
\hline CHEMBL419483 & 36944 & 9.1308 & 8.9507 & TRN & \\
\hline CHEMBL85596 & 36944 & 7.6778 & 7.5929 & TRN & \\
\hline CHEMBL313696 & 36944 & 8.0 & 7.9611 & TRN & \\
\hline CHEMBL18287 & 36944 & 8.6198 & 8.5343 & TRN & \\
\hline CHEMBL315615 & 36944 & 7.7447 & 7.7481 & TRN & \\
\hline CHEMBL316052 & 36944 & 8.2441 & 8.3332 & TRN & \\
\hline CHEMBL87957 & 36944 & 7.2218 & 8.1189 & TST & \\
\hline CHEMBL87057 & 36944 & 8.4949 & 8.5806 & TRN & \\
\hline CHEMBL87964 & 36944 & 8.7447 & 8.5543 & TRN & \\
\hline CHEMBL424053 & 36944 & 7.0 & 6.7322 & TRN & \\
\hline CHEMBL87682 & 36944 & 7.0223 & 7.2806 & TRN & \\
\hline CHEMBL 87276 & 36944 & 7.0 & 7.6039 & TRN & \\
\hline CHEMBL88002 & 36944 & 7.284 & 7.29299 & 9999999999 & TRN \\
\hline CHEMBL314436 & 36944 & 7.6383 & 7.6699 & TRN & \\
\hline CHEMBL446152 & 36944 & 7.1549 & 7.2892 & TRN & \\
\hline CHEMBL85765 & 36944 & 7.4949 & 7.6974 & TRN & \\
\hline CHEMBL87074 & 36944 & 9.0706 & 9.0043 & TRN & \\
\hline CHEMBL313017 & 36944 & 7.1549 & 7.4441 & TRN & \\
\hline CHEMBL 86143 & 36944 & 7.1675 & 7.0798 & TRN & \\
\hline CHEMBL315077 & 36944 & 7.7959 & 7.8533 & TRN & \\
\hline CHEMBL69508 & 36944 & 7.2218 & 7.5397 & TST & \\
\hline CHEMBL86084 & 36944 & 8.0 & 8.0086 & TRN & \\
\hline CHEMBL87669 & 36944 & 7.7959 & 8.0232 & TRN & \\
\hline CHEMBL87890 & 36944 & 6.6021 & 8.0582 & TST & \\
\hline CHEMBL84630 & 36944 & 7.0969 & 6.9536 & TRN & \\
\hline CHEMBL86232 & 36944 & 6.1675 & 6.2483 & TRN & \\
\hline CHEMBL82920 & 36944 & 7.4318 & 7.2561 & TRN & \\
\hline CHEMBL85659 & 36944 & 6.2441 & 7.65600 & 2000000001 & TST \\
\hline CHEMBL 85545 & 36944 & 8.3098 & 8.57 & TRN & \\
\hline CHEMBL86314 & 36944 & 8.7447 & 8.1436 & TRN & \\
\hline CHEMBL87780 & 36944 & 7.1192 & 7.6339 & TRN & \\
\hline CHEMBL82797 & 36944 & 8.0862 & 8.0951 & TRN & \\
\hline CHEMBL87985 & 36944 & 8.1135 & 8.1247 & TRN & \\
\hline CHEMBL422593 & 36944 & 8.3372 & 8.2566 & TRN & \\
\hline CHEMBL313025 & 36944 & 8.4949 & 8.4616 & TRN & \\
\hline CHEMBL314810 & 36944 & 7.7959 & 7.8197 & TRN & \\
\hline CHEMBL85876 & 36944 & 7.6576 & 7.7111 & TRN & \\
\hline CHEMBL314447 & 36944 & 7.9586 & 7.9336 & TRN & \\
\hline
\end{tabular}




\begin{tabular}{|c|c|c|c|c|}
\hline & & & pplement & al $\mathrm{Tc}$ \\
\hline CHEMBL87354 & 36944 & 7.301 & 7.7693 & TST \\
\hline CHEMBL87275 & 36944 & 6.9208 & 6.8656 & TRN \\
\hline CHEMBL313579 & 36944 & 8.1135 & 7.99 & TRN \\
\hline CHEMBL87330 & 36944 & 7.8539 & 8.0663 & TST \\
\hline CHEMBL85704 & 36944 & 6.9393 & 6.9921 & TRN \\
\hline CHEMBL19018 & 36944 & 8.9208 & 8.7752 & TRN \\
\hline CHEMBL 313837 & 36944 & 7.5229 & 8.0114 & TST \\
\hline CHEMBL87942 & 36944 & 7.9208 & 7.8432 & TRN \\
\hline CHEMBL87392 & 36944 & 8.0223 & 8.1342 & TRN \\
\hline CHEMBL87798 & 36944 & 7.9208 & 7.8666 & TRN \\
\hline CHEMBL 313222 & 36944 & 7.9586 & 8.4735 & TRN \\
\hline CHEMBL431411 & 36944 & 8.8539 & 8.9179 & TRN \\
\hline CHEMBL 313371 & 36944 & 9.0458 & 8.7215 & TRN \\
\hline CHEMBL 313435 & 36944 & 8.1308 & 7.9725 & TST \\
\hline CHEMBL312913 & 36944 & 9.0315 & 8.9294 & TRN \\
\hline CHEMBL87341 & 36944 & 7.9208 & 7.9765 & TRN \\
\hline CHEMBL314179 & 36944 & 7.7696 & 7.7852 & TRN \\
\hline CHEMBL 86255 & 36944 & 7.8239 & 7.6476 & TRN \\
\hline CHEMBL 83180 & 36944 & 8.3872 & 8.5577 & TRN \\
\hline CHEMBL407827 & 36944 & 7.9586 & 8.0325 & TRN \\
\hline CHEMBL84627 & 36944 & 8.301 & 8.0935 & TST \\
\hline CHEMBL87239 & 36944 & 8.5376 & 8.7983 & TST \\
\hline CHEMBL 314333 & 36944 & 6.8861 & 8.3012 & TST \\
\hline CHEMBL86440 & 36944 & 7.1612 & 7.3618 & TST \\
\hline CHEMBL87885 & 36944 & 7.6383 & 7.3076 & TST \\
\hline CHEMBL315128 & 36944 & 7.699 & 7.8361 & TST \\
\hline CHEMBL 314042 & 36944 & 8.2518 & 8.1452 & TST \\
\hline CHEMBL 315469 & 36944 & 7.585 & 7.6056 & TST \\
\hline CHEMBL87184 & 36944 & 7.4815 & 7.485 & TST \\
\hline CHEMBL 86853 & 36944 & 7.0223 & 8.2696 & TST \\
\hline CHEMBL 314590 & 36944 & 6.3098 & 6.2851 & TST \\
\hline CHEMBL83182 & 36944 & 6.9586 & 7.1464 & TST \\
\hline CHEMBL 85541 & 36944 & 7.7696 & 7.4778 & TST \\
\hline CHEMBL111951 & 623652 & 4.7959 & 4.7056 & TST \\
\hline CHEMBL1092095 & 623652 & 3.2596 & 3.3488 & TRN \\
\hline CHEMBL1089893 & 623652 & 4.2218 & 3.2152 & TRN \\
\hline CHEMBL1090901 & 623652 & 3.0 & 2.9835 & TRN \\
\hline CHEMBL1093826 & 623652 & 3.0 & 3.8759 & TRN \\
\hline CHEMBL209918 & 623652 & 3.0 & 2.7354 & TRN \\
\hline CHEMBL1093875 & 623652 & 4.8539 & 4.2856 & TRN \\
\hline CHEMBL1093508 & 623652 & 5.8861 & 5.2463 & TRN \\
\hline CHEMBL1092938 & 623652 & 3.0 & 3.3361 & TRN \\
\hline CHEMBL1092674 & 623652 & 3.5528 & 3.3593 & TRN \\
\hline CHEMBL1092947 & 623652 & 3.6383 & 3.8416 & TRN \\
\hline CHEMBL1092966 & 623652 & 3.0 & 2.9384 & TRN \\
\hline CHEMBL341112 & 623652 & 4.0458 & 4.4309 & TRN \\
\hline CHEMBL1092978 & 623652 & 3.7959 & 3.9968 & TRN \\
\hline CHEMBL1091953 & 623652 & 3.0 & 2.781 & TRN \\
\hline
\end{tabular}




\begin{tabular}{|c|c|c|c|c|c|}
\hline \multicolumn{6}{|c|}{ Supplemental Table S2.txt } \\
\hline CHEMBL1093919 & 623652 & 6.0 & 4.8882 & TRN & \\
\hline CHEMBL1093920 & 623652 & 3.5528 & 3.4707 & TRN & \\
\hline CHEMBL1095562 & 623652 & 5.0 & 4.9744 & TRN & \\
\hline CHEMBL1090567 & 623652 & 3.0 & 2.8565 & TRN & \\
\hline CHEMBL1090902 & 623652 & 5.1549 & 5.0047 & TRN & \\
\hline CHEMBL1091257 & 623652 & 4.3979 & 4.4691 & TRN & \\
\hline CHEMBL1090903 & 623652 & 5.2218 & 4.8811 & TRN & \\
\hline CHEMBL1093876 & 623652 & 3.0 & 3.4813 & TRN & \\
\hline CHEMBL1091258 & 623652 & 4.2218 & 4.5989 & TRN & \\
\hline CHEMBL1091651 & 623652 & 3.0 & 3.0932 & TRN & \\
\hline CHEMBL1090692 & 623652 & 3.0 & 3.213 & TRN & \\
\hline CHEMBL1093988 & 623652 & 4.8239 & 5.2015 & TRN & \\
\hline CHEMBL1092936 & 623652 & 3.2518 & 4.6327 & TST & \\
\hline CHEMBL1092985 & 623652 & 4.3768 & 3.0546 & TST & \\
\hline CHEMBL418899 & 623652 & 5.7696 & 3.5125 & TST & \\
\hline CHEMBL1094254 & 623652 & 3.4948 & 3.7311 & TRN & \\
\hline CHEMBL159895 & 623652 & 5.8239 & 4.9573 & TST & \\
\hline CHEMBL1093507 & 623652 & 3.1135 & 2.9496 & TRN & \\
\hline CHEMBL1092673 & 623652 & 4.6021 & 5.2721 & TRN & \\
\hline CHEMBL1093493 & 623652 & 5.699 & 5.4079 & TRN & \\
\hline CHEMBL1092984 & 623652 & 3.0 & 2.8413 & TST & \\
\hline CHEMBL1093512 & 623652 & 5.6021 & 5.9582 & TRN & \\
\hline CHEMBL1092613 & 623652 & 5.0 & 5.2759 & TRN & \\
\hline CHEMBL1090566 & 623652 & 3.0 & 3.2936 & TRN & \\
\hline CHEMBL1091652 & 623652 & 3.0 & 3.3562 & TRN & \\
\hline CHEMBL1089235 & 623652 & 3.699 & 3.6135 & TRN & \\
\hline CHEMBL1093853 & 623652 & 3.0862 & 3.6602 & TRN & \\
\hline CHEMBL1093492 & 623652 & 5.5229 & 5.0559 & TRN & \\
\hline CHEMBL1093233 & 623652 & 5.699 & 5.8908 & TRN & \\
\hline CHEMBL1093907 & 623652 & 5.3979 & 5.6793 & TRN & \\
\hline CHEMBL1093263 & 623652 & 4.3279 & 3.8141 & TRN & \\
\hline CHEMBL1092746 & 623652 & 3.9586 & 4.0899 & TRN & \\
\hline CHEMBL1093511 & 623652 & 6.0 & 5.1349 & TRN & \\
\hline CHEMBL1091037 & 623652 & 3.3372 & 4.0693 & TRN & \\
\hline CHEMBL1090678 & 623652 & 3.0 & 3.39 & TRN & \\
\hline CHEMBL1095561 & 623652 & 3.0 & 2.6639 & TRN & \\
\hline CHEMBL1089234 & 623652 & 4.1612 & 4.3197 & TRN & \\
\hline CHEMBL1092614 & 623652 & 5.1549 & 5.157 & TRN & \\
\hline CHEMBL1092937 & 623652 & 3.3665 & 3.2977 & TST & \\
\hline CHEMBL1093874 & 623652 & 4.8239 & 4.7197 & TRN & \\
\hline CHEMBL1093220 & 623652 & 3.0 & 2.9511 & TST & \\
\hline CHEMBL1089907 & 623652 & 3.0 & 3.40199 & 99999999997 & TRN \\
\hline CHEMBL1088991 & 623652 & 6.0969 & 4.8097 & TST & \\
\hline CHEMBL1094255 & 623652 & 3.0 & 2.8277 & TRN & \\
\hline CHEMBL1091653 & 623652 & 3.0 & 3.0584 & TRN & \\
\hline CHEMBL1093513 & 623652 & 5.699 & 5.7961 & TRN & \\
\hline CHEMBL1090936 & 623652 & 3.7447 & 3.427 & TRN & \\
\hline CHEMBL 98778 & 623652 & 4.4202 & 3.4836 & TST & \\
\hline
\end{tabular}




\begin{tabular}{|c|c|c|c|c|}
\hline & & & oplement & al Ta \\
\hline CHEMBL1093827 & 623652 & 3.7696 & 3.8776 & TRN \\
\hline CHEMBL1092935 & 623652 & 4.1871 & 4.101 & TRN \\
\hline CHEMBL1092703 & 623652 & 5.1549 & 4.363 & TRN \\
\hline CHEMBL1093520 & 623652 & 3.7447 & 2.9037 & TST \\
\hline CHEMBL1093553 & 623652 & 6.0 & 5.7083 & TST \\
\hline CHEMBL1092701 & 623652 & 3.7696 & 4.016 & TST \\
\hline CHEMBL1092702 & 623652 & 3.7447 & 3.3065 & TST \\
\hline CHEMBL1092967 & 623652 & 4.3468 & 3.0277 & TST \\
\hline CHEMBL1091736 & 623652 & 3.2924 & 4.2869 & TST \\
\hline CHEMBL1092979 & 623652 & 3.7212 & 4.4312 & TST \\
\hline CHEMBL1093873 & 623652 & 5.0969 & 3.5355 & TST \\
\hline CHEMBL564201 & 623652 & 3.0 & 2.5331 & TST \\
\hline CHEMBL1802502 & 755721 & 7.2676 & 7.0703 & TRN \\
\hline CHEMBL1802578 & 755721 & 6.301 & 6.2739 & TRN \\
\hline CHEMBL1802495 & 755721 & 5.0 & 5.2206 & TRN \\
\hline CHEMBL1800100 & 755721 & 6.7447 & 6.8159 & TRN \\
\hline CHEMBL1803002 & 755721 & 7.2596 & 7.341 & TRN \\
\hline CHEMBL441724 & 755721 & 6.3768 & 6.5552 & TST \\
\hline CHEMBL1802504 & 755721 & 7.2218 & 6.8941 & TRN \\
\hline CHEMBL1802994 & 755721 & 7.1487 & 7.1872 & TRN \\
\hline CHEMBL1802993 & 755721 & 7.2147 & 7.2338 & TRN \\
\hline CHEMBL1802565 & 755721 & 6.7696 & 6.6239 & TRN \\
\hline CHEMBL1802496 & 755721 & 5.0 & 4.8922 & TRN \\
\hline CHEMBL1802583 & 755721 & 6.6576 & 6.9109 & TRN \\
\hline CHEMBL1802999 & 755721 & 7.1805 & 7.3381 & TRN \\
\hline CHEMBL1802501 & 755721 & 7.8861 & 7.7739 & TRN \\
\hline CHEMBL 1802580 & 755721 & 5.0 & 5.2314 & TRN \\
\hline CHEMBL1802509 & 755721 & 8.0 & 8.0167 & TRN \\
\hline CHEMBL1802514 & 755721 & 7.041 & 7.2317 & TRN \\
\hline CHEMBL1802575 & 755721 & 7.2441 & 7.0876 & TRN \\
\hline CHEMBL1802572 & 755721 & 5.0 & 4.9256 & TRN \\
\hline CHEMBL1802498 & 755721 & 7.2924 & 7.3468 & TRN \\
\hline CHEMBL1802505 & 755721 & 6.5686 & 6.4352 & TRN \\
\hline CHEMBL1802569 & 755721 & 6.4815 & 6.7598 & TST \\
\hline CHEMBL1803059 & 755721 & 5.0 & 4.837 & TRN \\
\hline CHEMBL1802566 & 755721 & 6.6778 & 6.6179 & TRN \\
\hline CHEMBL1802557 & 755721 & 6.7212 & 6.7258 & TRN \\
\hline CHEMBL1802494 & 755721 & 6.1367 & 6.3222 & TRN \\
\hline CHEMBL1802570 & 755721 & 7.0 & 6.9931 & TST \\
\hline CHEMBL1802511 & 755721 & 7.7447 & 7.9039 & TRN \\
\hline CHEMBL1802512 & 755721 & 7.0 & 7.115 & TRN \\
\hline CHEMBL1802571 & 755721 & 6.1135 & 6.2223 & TST \\
\hline CHEMBL1803061 & 755721 & 5.0 & 4.9782 & TRN \\
\hline CHEMBL1802499 & 755721 & 7.4685 & 7.3744 & TRN \\
\hline CHEMBL1803003 & 755721 & 7.4949 & 7.4254 & TRN \\
\hline CHEMBL1802558 & 755721 & 6.9586 & 6.8669 & TRN \\
\hline CHEMBL1803001 & 755721 & 6.7696 & 6.8328 & TRN \\
\hline CHEMBL1802563 & 755721 & 5.0 & 4.996 & TST \\
\hline
\end{tabular}


Supplemental Table S2.txt

\begin{tabular}{|c|c|c|c|c|}
\hline HEMBL18 & 55721 & 7.0555 & 6.7612 & \\
\hline & 55721 & 7.0605 & 6.9786 & \\
\hline 0 & 721 & & & \\
\hline IEMBL] & 5721 & 01 & 3 & \\
\hline IEMBL1802559 & 5721 & & & \\
\hline AEMBL1803065 & 55721 & 5.0 & 885 & \\
\hline 02507 & 5721 & & & \\
\hline 503 & 5721 & & & \\
\hline 302995 & 55721 & 686 & & \\
\hline AEMBL1802500 & 55721 & 212 & 92 & \\
\hline AEMBL1802508 & 55721 & 555 & & \\
\hline 02506 & 55721 & 279 & & \\
\hline 02992 & 55721 & & & \\
\hline 02579 & 55721 & 5.0 & & \\
\hline 02582 & 55721 & 7. & & \\
\hline 02567 & 755721 & 5.0 & & \\
\hline 02497 & 55721 & ת & & \\
\hline 03063 & 55721 & & & \\
\hline 02576 & 755721 & & & \\
\hline 3058 & 55721 & & & \\
\hline 02584 & 755721 & 99 & & \\
\hline 2561 & 55721 & 39 & & \\
\hline 2996 & 55721 & & & \\
\hline 562 & & 506 & & \\
\hline 066 & & & & \\
\hline 02573 & 55721 & & & \\
\hline 03057 & 55721 & 5 & & \\
\hline 560 & 755721 & & & \\
\hline 998 & 21 & & & \\
\hline 2568 & 755721 & & & \\
\hline 02510 & 755721 & & & \\
\hline 02513 & 755721 & & & \\
\hline 62 & גז & & & \\
\hline & & & & \\
\hline 02574 & 755721 & & & \\
\hline 7 & 5721 & & & \\
\hline 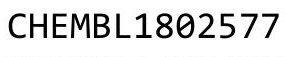 & 755721 & 6. & & \\
\hline & & & & \\
\hline 515 & & & & \\
\hline 184306 & 688222 & & & \\
\hline 26 & 688222 & 65 & & \\
\hline 4011 & 688222 & 3. & & \\
\hline & & & & \\
\hline 387605 & 0002 & 3. & 86 & $\pi$ \\
\hline 62568 & 688222 & 4.1534 & 3. & \\
\hline & 688 & 3. & & \\
\hline - & 688222 & 3. & 2.7533 & \\
\hline MBL130360 & 688222 & 4. & 3.3906 & \\
\hline
\end{tabular}

Page 67 


\begin{tabular}{|c|c|c|c|c|}
\hline \multicolumn{5}{|c|}{ Supplemental Table S2.txt } \\
\hline CHEMBL1452628 & 688222 & 3.0 & 3.1754 & TRN \\
\hline CHEMBL1540933 & 688222 & 4.3773 & 3.6057 & TRN \\
\hline CHEMBL1353925 & 688222 & 3.0 & 3.3328 & TST \\
\hline CHEMBL 3210104 & 688222 & 3.0 & 3.221 & TRN \\
\hline CHEMBL1403029 & 688222 & 4.0899 & 3.4535 & TRN \\
\hline CHEMBL1971458 & 688222 & 3.0 & 3.0159 & TRN \\
\hline CHEMBL1576891 & 688222 & 3.0 & 3.2088 & TST \\
\hline CHEMBL3190601 & 688222 & 3.0 & 3.0508 & TRN \\
\hline CHEMBL1310989 & 688222 & 4.5406 & 4.6644 & TRN \\
\hline CHEMBL1574799 & 688222 & 3.0 & 3.0639 & TRN \\
\hline CHEMBL1333676 & 688222 & 3.0 & 3.2834 & TRN \\
\hline CHEMBL1571540 & 688222 & 4.6716 & 4.6458 & TRN \\
\hline CHEMBL1569592 & 688222 & 4.1791 & 4.0421 & TRN \\
\hline CHEMBL1414074 & 688222 & 3.0 & 3.2604 & TRN \\
\hline CHEMBL1601313 & 688222 & 4.2328 & 3.7158 & TRN \\
\hline CHEMBL122360 & 688222 & 3.0 & 3.2536 & TRN \\
\hline CHEMBL1379508 & 688222 & 3.0 & 3.19 & TRN \\
\hline CHEMBL1459610 & 688222 & 3.0 & 3.0968 & TRN \\
\hline CHEMBL1509308 & 688222 & 3.0 & 3.3137 & TRN \\
\hline CHEMBL1410618 & 688222 & 3.0 & 3.0659 & TRN \\
\hline CHEMBL1589162 & 688222 & 3.0 & 2.9388 & TRN \\
\hline CHEMBL1574359 & 688222 & 4.4908 & 4.5716 & TRN \\
\hline CHEMBL1445742 & 688222 & 3.0 & 4.0003 & TRN \\
\hline CHEMBL1362878 & 688222 & 3.0 & 2.7946 & TRN \\
\hline CHEMBL1467093 & 688222 & 3.0 & 3.0639 & TRN \\
\hline CHEMBL3198326 & 688222 & 3.0 & 2.9412 & TRN \\
\hline CHEMBL1463081 & 688222 & 3.0 & 2.9761 & TRN \\
\hline CHEMBL1420184 & 688222 & 3.0 & 3.2503 & TRN \\
\hline CHEMBL 3145330 & 688222 & 3.0 & 2.9716 & TRN \\
\hline CHEMBL1498425 & 688222 & 3.0 & 3.4505 & TRN \\
\hline CHEMBL1379122 & 688222 & 3.0 & 3.6498 & TRN \\
\hline CHEMBL3192395 & 688222 & 3.0 & 3.0326 & TRN \\
\hline CHEMBL1366491 & 688222 & 3.0 & 3.3171 & TST \\
\hline CHEMBL1419329 & 688222 & 4.2803 & 4.1673 & TRN \\
\hline CHEMBL1308206 & 688222 & 4.1772 & 3.2096 & TRN \\
\hline CHEMBL1508524 & 688222 & 3.0 & 2.9457 & TRN \\
\hline CHEMBL1547948 & 688222 & 4.1308 & 4.082 & TRN \\
\hline CHEMBL1530781 & 688222 & 4.5031 & 4.6348 & TRN \\
\hline CHEMBL1477087 & 688222 & 3.0 & 3.6762 & TRN \\
\hline CHEMBL1465015 & 688222 & 3.0 & 2.8737 & TRN \\
\hline CHEMBL1401053 & 688222 & 4.8794 & 4.1734 & TRN \\
\hline CHEMBL1385222 & 688222 & 4.1169 & 3.7393 & TRN \\
\hline CHEMBL1536448 & 688222 & 3.0 & 3.2483 & TRN \\
\hline CHEMBL1522133 & 688222 & 4.3497 & 3.3103 & TST \\
\hline CHEMBL1477085 & 688222 & 3.0 & 3.7857 & TST \\
\hline CHEMBL1341036 & 688222 & 3.0 & 3.2096 & TST \\
\hline CHEMBL1523682 & 688222 & 3.0 & 3.3937 & TST \\
\hline CHEMBL1468826 & 688222 & 3.0 & 3.0699 & TST \\
\hline
\end{tabular}




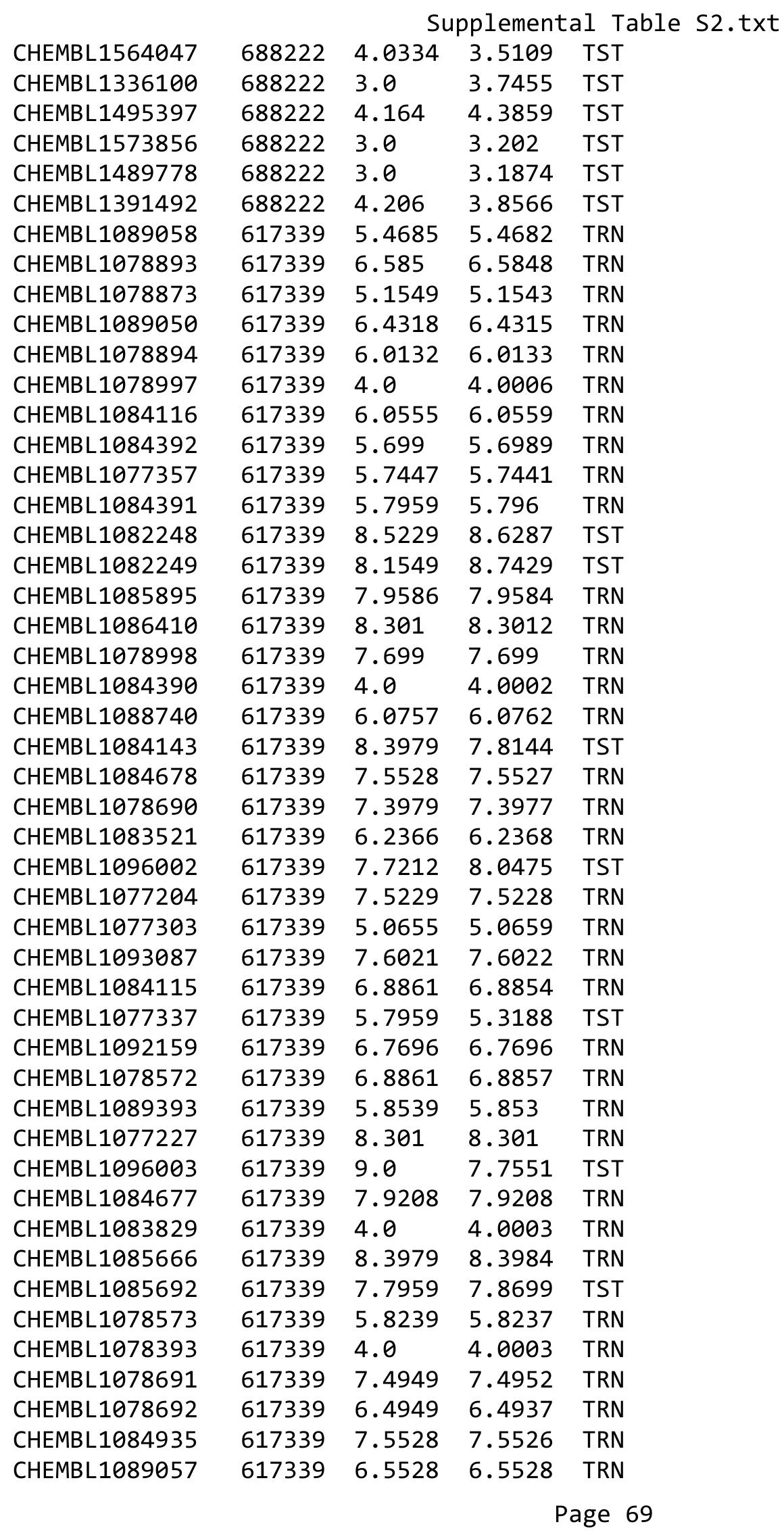


Supplemental Table S2.txt

\begin{tabular}{|c|c|c|c|c|}
\hline CHEMBL1084676 & 617339 & 6.9586 & 6.9735 & TST \\
\hline CHEMBL1078774 & 617339 & 7.7212 & 7.7228 & TRN \\
\hline CHEMBL1089056 & 617339 & 6.6021 & 6.6025 & TRN \\
\hline CHEMBL1093088 & 617339 & 7.6198 & 7.7665 & TST \\
\hline CHEMBL1089051 & 617339 & 5.7447 & 5.7448 & TRN \\
\hline CHEMBL1086409 & 617339 & 6.7212 & 7.0592 & TST \\
\hline CHEMBL1084431 & 617339 & 7.6383 & 6.8433 & TST \\
\hline CHEMBL1083517 & 617339 & 7.5376 & 8.4049 & TST \\
\hline CHEMBL1083836 & 617339 & 8.0969 & 8.0054 & TST \\
\hline CHEMBL1863217 & 774024 & 6.3665 & 6.4783 & TRN \\
\hline CHEMBL1863031 & 774024 & 5.0 & 4.7099 & TRN \\
\hline CHEMBL1863179 & 774024 & 7.1549 & 6.8144 & TRN \\
\hline CHEMBL 29904 & 774024 & 6.6504 & 6.1018 & TRN \\
\hline CHEMBL1863374 & 774024 & 7.4685 & 7.4233 & TRN \\
\hline CHEMBL1863003 & 774024 & 7.1308 & 7.125 & TRN \\
\hline CHEMBL1862904 & 774024 & 6.699 & 6.8423 & TRN \\
\hline CHEMBL1863422 & 774024 & 6.4151 & 6.8505 & TRN \\
\hline CHEMBL1863062 & 774024 & 7.6383 & 7.38299 & 9999999999 \\
\hline CHEMBL1863473 & 774024 & 7.75700 & 300000006 & 7.4893 \\
\hline CHEMBL1862860 & 774024 & 5.7235 & 5.3897 & TRN \\
\hline CHEMBL1863420 & 774024 & 6.585 & 6.4018 & TRN \\
\hline CHEMBL1863337 & 774024 & 6.9066 & 6.9627 & TST \\
\hline CHEMBL1863027 & 774024 & 7.4089 & 7.3093 & TRN \\
\hline CHEMBL1863103 & 774024 & 4.0 & 4.4325 & TRN \\
\hline CHEMBL1863406 & 774024 & 6.6003 & 5.58899 & 99999999995 \\
\hline CHEMBL1863185 & 774024 & 7.2076 & 7.0366 & TRN \\
\hline CHEMBL1863114 & 774024 & 5.0 & 5.6735 & TRN \\
\hline CHEMBL1862923 & 774024 & 7.5901 & 7.2857 & TRN \\
\hline CHEMBL135115 & 774024 & 7.0458 & 6.9644 & TRN \\
\hline CHEMBL1862926 & 774024 & 5.0 & 6.0657 & TRN \\
\hline CHEMBL519873 & 774024 & 5.1898 & 5.9624 & TST \\
\hline CHEMBL1863457 & 774024 & 5.9431 & 5.9459 & TRN \\
\hline CHEMBL1862963 & 774024 & 7.0605 & 7.6095 & TRN \\
\hline CHEMBL1863140 & 774024 & 6.699 & 6.4648 & TST \\
\hline CHEMBL1863299 & 774024 & 6.3979 & 6.6571 & TRN \\
\hline CHEMBL1862792 & 774024 & 7.6198 & 7.1729 & TRN \\
\hline CHEMBL1863071 & 774024 & 7.1249 & 7.2606 & TRN \\
\hline CHEMBL1862959 & 774024 & 4.125 & 5.6646 & TST \\
\hline CHEMBL1863132 & 774024 & 6.3468 & 6.2452 & TRN \\
\hline CHEMBL1863441 & 774024 & 4.0 & 6.3484 & TST \\
\hline CHEMBL1863315 & 774024 & 6.0 & 6.3874 & TST \\
\hline CHEMBL1862921 & 774024 & 6.6778 & 6.6057 & TRN \\
\hline CHEMBL1863141 & 774024 & 6.2441 & 6.7254 & TRN \\
\hline CHEMBL1863455 & 774024 & 7.5229 & 7.4878 & TRN \\
\hline CHEMBL1863200 & 774024 & 5.0 & 6.0802 & TRN \\
\hline CHEMBL1863241 & 774024 & 6.0 & 6.4897 & TRN \\
\hline CHEMBL1231667 & 774024 & 4.6496 & 6.0823 & TST \\
\hline CHEMBL1862979 & 774024 & 6.2076 & 6.001 & TRN \\
\hline
\end{tabular}




\begin{tabular}{|c|c|c|c|c|}
\hline \multicolumn{5}{|c|}{ Supplemental Table S2.txt } \\
\hline CHEMBL1862845 & 774024 & 4.0 & 5.9518 & TST \\
\hline CHEMBL1863144 & 774024 & 6.8861 & 6.8622 & TRN \\
\hline CHEMBL1863007 & 774024 & 8.1135 & 7.8959 & TRN \\
\hline CHEMBL1862955 & 774024 & 7.2218 & 7.6376 & TRN \\
\hline CHEMBL1863421 & 774024 & 6.4225 & 6.6102 & TST \\
\hline CHEMBL1862997 & 774024 & 5.0 & 6.5036 & TST \\
\hline CHEMBL 230001 & 774024 & 5.4873 & 6.1394 & TST \\
\hline CHEMBL1863046 & 774024 & 7.699 & 7.9222 & TRN \\
\hline CHEMBL1863214 & 774024 & 6.4437 & 6.1887 & TRN \\
\hline CHEMBL1863465 & 774024 & 7.4437 & 7.2477 & TRN \\
\hline CHEMBL1862876 & 774024 & 6.6605 & 6.4541 & TRN \\
\hline CHEMBL1863297 & 774024 & 6.301 & 7.0 & TRN \\
\hline CHEMBL1863284 & 774024 & 6.0 & 7.3239 & TRN \\
\hline CHEMBL1863412 & 774024 & 6.1675 & 6.2288 & TRN \\
\hline CHEMBL1863424 & 774024 & 8.1549 & 8.035 & TRN \\
\hline CHEMBL1863305 & 774024 & 6.8239 & 6.5454 & TRN \\
\hline CHEMBL1863033 & 774024 & 7.0044 & 7.1501 & TRN \\
\hline CHEMBL1863355 & 774024 & 7.4089 & 6.7742 & TRN \\
\hline CHEMBL1863260 & 774024 & 6.301 & 6.1481 & TRN \\
\hline CHEMBL1863447 & 774024 & 6.8539 & 7.1922 & TRN \\
\hline CHEMBL1863016 & 774024 & 6.0 & 6.3173 & TRN \\
\hline CHEMBL1863011 & 774024 & 8.0 & 7.4765 & TRN \\
\hline CHEMBL1863245 & 774024 & 7.2218 & 7.3063 & TRN \\
\hline CHEMBL1862990 & 774024 & 7.6778 & 7.586 & TRN \\
\hline CHEMBL1863378 & 774024 & 6.2741 & 7.2455 & TRN \\
\hline CHEMBL1863041 & 774024 & 7.5686 & 7.5171 & TRN \\
\hline CHEMBL1863417 & 774024 & 6.9119 & 7.0376 & TRN \\
\hline CHEMBL1863128 & 774024 & 7.7825 & 7.2437 & TST \\
\hline CHEMBL1862945 & 774024 & 7.2366 & 6.7895 & TRN \\
\hline CHEMBL1862912 & 774024 & 7.7447 & 7.5419 & TRN \\
\hline CHEMBL1862801 & 774024 & 7.2218 & 7.0824 & TRN \\
\hline CHEMBL1863292 & 774024 & 6.7632 & 7.2571 & TRN \\
\hline CHEMBL1863045 & 774024 & 6.2291 & 6.585 & TRN \\
\hline CHEMBL1863334 & 774024 & 7.7696 & 7.8845 & TRN \\
\hline CHEMBL1863443 & 774024 & 5.9706 & 5.5725 & TST \\
\hline CHEMBL1862970 & 774024 & 7.6478 & 6.8392 & TRN \\
\hline CHEMBL1862816 & 774024 & 7.5376 & 7.4761 & TRN \\
\hline CHEMBL1863250 & 774024 & 6.1549 & 5.8717 & TRN \\
\hline CHEMBL1863023 & 774024 & 6.7305 & 6.5094 & TRN \\
\hline CHEMBL1863087 & 774024 & 5.9431 & 6.0211 & TRN \\
\hline CHEMBL1863289 & 774024 & 7.3372 & 7.1705 & TRN \\
\hline CHEMBL1863118 & 774024 & 6.5331 & 7.1137 & TRN \\
\hline CHEMBL1863073 & 774024 & 7.4949 & 7.3961 & TRN \\
\hline CHEMBL1863390 & 774024 & 7.1249 & 7.3007 & TRN \\
\hline CHEMBL1862898 & 774024 & 6.4835 & 6.4793 & TRN \\
\hline CHEMBL1863298 & 774024 & 7.1079 & 7.0117 & TRN \\
\hline CHEMBL1863043 & 774024 & 5.5143 & 6.6325 & TRN \\
\hline CHEMBL1862940 & 774024 & 7.7212 & 8.0557 & TST \\
\hline
\end{tabular}


Supplemental Table S2.txt

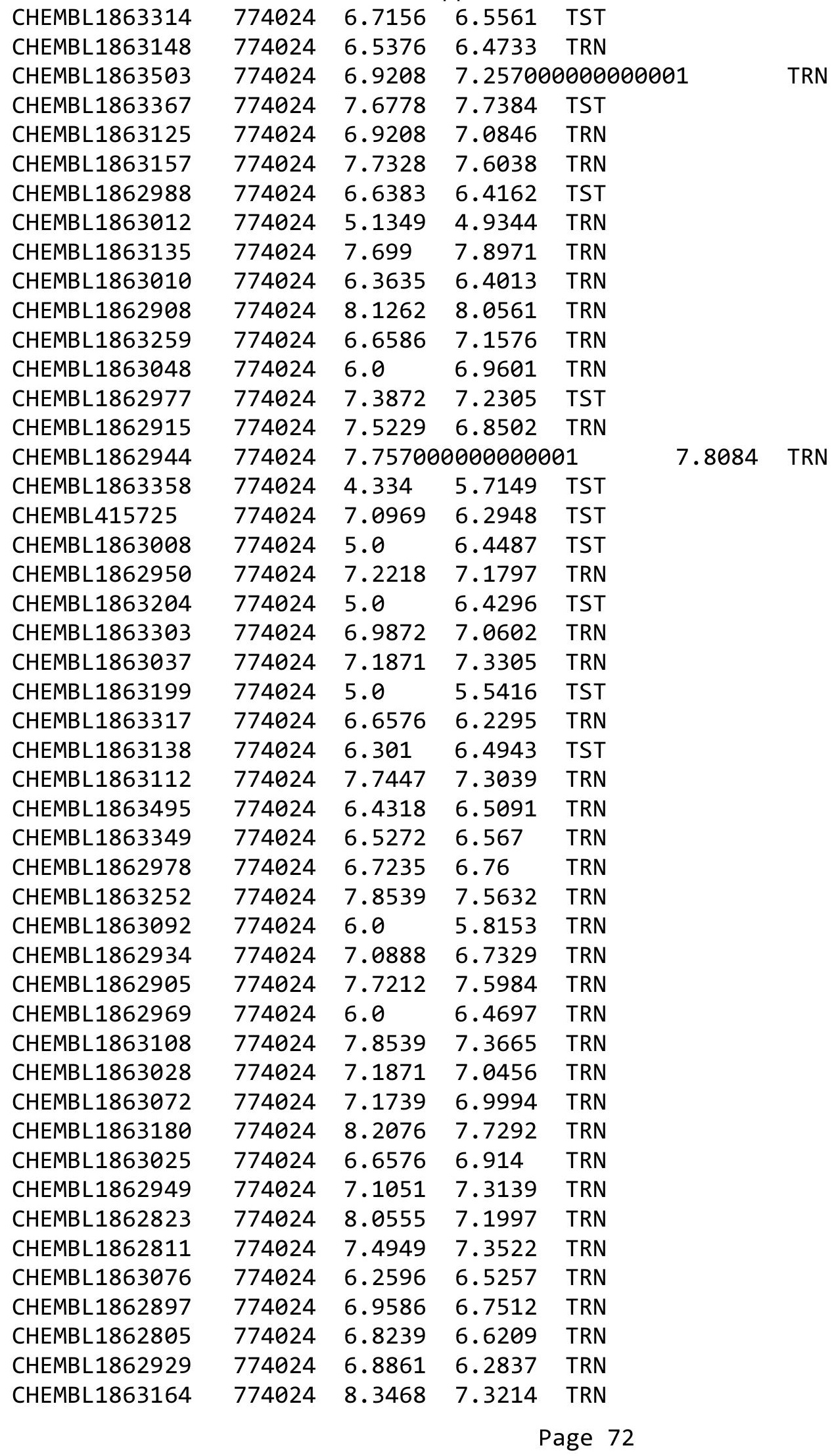


Supplemental Table S2.txt

\begin{tabular}{|c|c|c|c|c|c|}
\hline CHEMBL1863215 & 774024 & 7.4377 & 7.2598 & TST & \\
\hline CHEMBL1863440 & 774024 & 7.2076 & 7.0567 & TRN & \\
\hline CHEMBL1862892 & 774024 & 8.1549 & 7.4131 & TRN & \\
\hline CHEMBL1863261 & 774024 & 6.8125 & 6.3808 & TST & \\
\hline CHEMBL1863362 & 774024 & 7.5376 & 7.5426 & TRN & \\
\hline CHEMBL1863394 & 774024 & 7.1192 & 7.2948 & TRN & \\
\hline CHEMBL1863095 & 774024 & 6.6383 & 6.4176 & TRN & \\
\hline CHEMBL1863040 & 774024 & 8.0458 & 7.5977 & TRN & \\
\hline CHEMBL1863379 & 774024 & 6.0 & 7.3466 & TRN & \\
\hline CHEMBL1863066 & 774024 & 7.6021 & 7.8259 & TRN & \\
\hline CHEMBL1863170 & 774024 & 6.9706 & 7.3634 & TRN & \\
\hline CHEMBL1863107 & 774024 & 7.7212 & 7.3742 & TRN & \\
\hline CHEMBL1863377 & 774024 & 7.4202 & 7.0496 & TRN & \\
\hline CHEMBL1862798 & 774024 & 8.0706 & 7.6403 & TRN & \\
\hline CHEMBL1863365 & 774024 & 7.699 & 7.492000 & 000000001 & $T B$ \\
\hline CHEMBL1862976 & 774024 & 5.0 & 6.6482 & TST & \\
\hline CHEMBL1862919 & 774024 & 6.6198 & 6.5207 & TRN & \\
\hline CHEMBL1863243 & 774024 & 5.0 & 5.8058 & TRN & \\
\hline CHEMBL1863504 & 774024 & 6.9586 & 6.6947 & TRN & \\
\hline CHEMBL1863459 & 774024 & 6.0969 & 6.6288 & TRN & \\
\hline CHEMBL1862967 & 774024 & 5.1296 & 6.1169 & TST & \\
\hline CHEMBL1862932 & 774024 & 6.3372 & 6.7391 & TRN & \\
\hline CHEMBL1863285 & 774024 & 6.4949 & 6.5104 & TRN & \\
\hline CHEMBL1862828 & 774024 & 6.5686 & 6.7514 & TRN & \\
\hline CHEMBL1863509 & 774024 & 5.0 & 5.6942 & TRN & \\
\hline CHEMBL1863481 & 774024 & 7.2882 & 6.8321 & TRN & \\
\hline CHEMBL1863078 & 774024 & 4.0 & 5.9425 & TST & \\
\hline CHEMBL1863492 & 774024 & 7.0044 & 7.0488 & TRN & \\
\hline CHEMBL1863136 & 774024 & 6.6198 & 6.757000 & 000000001 & TST \\
\hline CHEMBL1863469 & 774024 & 6.7471 & 6.9911 & TRN & \\
\hline CHEMBL1863263 & 774024 & 5.0 & 4.7882 & TRN & \\
\hline CHEMBL1862954 & 774024 & 7.5376 & 7.0033 & TRN & \\
\hline CHEMBL1863036 & 774024 & 5.0 & 5.8773 & TST & \\
\hline CHEMBL280558 & 774024 & 4.67899 & 999999999 & 5.593 & ISI \\
\hline CHEMBL1863106 & 774024 & 7.9586 & 7.3112 & TRN & \\
\hline CHEMBL1863115 & 774024 & 7.4559 & 7.0478 & TST & \\
\hline CHEMBL 282325 & 774024 & 6.1931 & 6.3385 & TRN & \\
\hline CHEMBL1862911 & 774024 & 7.1192 & 7.4588 & TRN & \\
\hline CHEMBL1862818 & 774024 & 6.9208 & 6.8994 & TRN & \\
\hline CHEMBL1863464 & 774024 & 6.5768 & 7.1619 & TRN & \\
\hline CHEMBL1863229 & 774024 & 6.2899 & 6.3831 & TRN & \\
\hline CHEMBL1862927 & 774024 & 6.5376 & 6.6077 & TRN & \\
\hline CHEMBL286965 & 774024 & 6.0757 & 6.4592 & TRN & \\
\hline CHEMBL1862813 & 774024 & 8.0706 & 7.9287 & TRN & \\
\hline CHEMBL1862881 & 774024 & 7.2967 & 6.9165 & TRN & \\
\hline CHEMBL1863431 & 774024 & 6.5528 & 6.4048 & TRN & \\
\hline CHEMBL1863009 & 774024 & 6.5686 & 6.2163 & TRN & \\
\hline CHEMBL1863463 & 774024 & 7.5086 & 6.9944 & TRN & \\
\hline
\end{tabular}




\begin{tabular}{|c|c|c|c|c|c|c|}
\hline & & & & & & \\
\hline CHEMBL1863444 & 774024 & 7.4685 & 7.5911 & TRN & & \\
\hline CHEMBL1863196 & 774024 & 6.4056 & 5.6691 & TRN & & \\
\hline CHEMBL1863279 & 774024 & 7.7959 & 7.789 & TRN & & \\
\hline CHEMBL1863058 & 774024 & 6.0555 & 6.0753 & TRN & & \\
\hline CHEMBL1863171 & 774024 & 6.6021 & 6.0527 & TRN & & \\
\hline CHEMBL1863247 & 774024 & 7.1549 & 6.4431 & TRN & & \\
\hline CHEMBL1862936 & 774024 & 6.2518 & 6.5418 & TRN & & \\
\hline CHEMBL1863385 & 774024 & 7.1549 & 7.1227 & TRN & & \\
\hline CHEMBL1863021 & 774024 & 7.3665 & 8.0633 & TST & & \\
\hline CHEMBL1863208 & 774024 & 6.7328 & 6.6602 & TRN & & \\
\hline CHEMBL1863249 & 774024 & 6.3468 & 7.0149 & TST & & \\
\hline CHEMBL1862802 & 774024 & 7.3768 & 6.9326 & TRN & & \\
\hline CHEMBL1863195 & 774024 & 7.15799 & 99999999 & 995 & 6.8392 & TRN \\
\hline CHEMBL1862822 & 774024 & 6.2328 & 6.2728 & TRN & & \\
\hline CHEMBL1863437 & 774024 & 7.4559 & 7.0185 & TRN & & \\
\hline CHEMBL1862849 & 774024 & 7.2596 & 7.6022 & TRN & & \\
\hline CHEMBL1863139 & 774024 & 6.0 & 6.5141 & TRN & & \\
\hline CHEMBL1863137 & 774024 & 7.4949 & 7.5117 & TRN & & \\
\hline CHEMBL1863428 & 774024 & 6.5952 & 6.5219 & TRN & & \\
\hline CHEMBL1863470 & 774024 & 5.8041 & 5.2227 & TRN & & \\
\hline CHEMBL1863122 & 774024 & 7.6289 & 7.426 & TRN & & \\
\hline CHEMBL1862855 & 774024 & 7.1675 & 7.4202 & TRN & & \\
\hline CHEMBL1862886 & 774024 & 7.7033 & 7.6577 & TRN & & \\
\hline CHEMBL1863126 & 774024 & 7.15799 & 99999999 & 995 & 7.1364 & TRN \\
\hline CHEMBL1863110 & 774024 & 8.2076 & 7.9903 & TRN & & \\
\hline CHEMBL1863022 & 774024 & 6.2976 & 6.8254 & TRN & & \\
\hline CHEMBL1863501 & 774024 & 6.2518 & 6.2992 & TRN & & \\
\hline CHEMBL1863373 & 774024 & 6.0969 & 5.8956 & TRN & & \\
\hline CHEMBL1862791 & 774024 & 8.4815 & 8.0484 & TRN & & \\
\hline CHEMBL1863360 & 774024 & 6.7122 & 7.2644 & TRN & & \\
\hline CHEMBL1863239 & 774024 & 7.063 & 6.3815 & TRN & & \\
\hline CHEMBL1862992 & 774024 & 6.0706 & 6.0699 & TRN & & \\
\hline CHEMBL1862874 & 774024 & 6.2007 & 5.8253 & TRN & & \\
\hline CHEMBL1863209 & 774024 & 7.5452 & 7.2473 & TRN & & \\
\hline CHEMBL1863270 & 774024 & 6.8539 & 6.6517 & TRN & & \\
\hline CHEMBL1863165 & 774024 & 5.0 & 4.8052 & TRN & & \\
\hline CHEMBL1862829 & 774024 & 5.4377 & 4.8591 & TRN & & \\
\hline CHEMBL1862909 & 774024 & 8.2218 & 7.8671 & TRN & & \\
\hline CHEMBL1863391 & 774024 & 6.9626 & 7.2879 & TST & & \\
\hline CHEMBL1863184 & 774024 & 8.301 & 8.2908 & TRN & & \\
\hline CHEMBL1863290 & 774024 & 7.0757 & 6.9061 & TRN & & \\
\hline CHEMBL1862965 & 774024 & 4.0 & 5.6473 & TST & & \\
\hline CHEMBL 28971 & 774024 & 6.0 & 5.7977 & TRN & & \\
\hline CHEMBL1863201 & 774024 & 6.8239 & 6.9217 & TRN & & \\
\hline CHEMBL1863403 & 774024 & 6.0969 & 5.635 & TRN & & \\
\hline CHEMBL1863142 & 774024 & 7.2291 & 7.5317 & TST & & \\
\hline CHEMBL1863183 & 774024 & 5.8153 & 6.5615 & TRN & & \\
\hline CHEMBL1862928 & 774024 & 6.5842 & 6.8253 & TRN & & \\
\hline
\end{tabular}




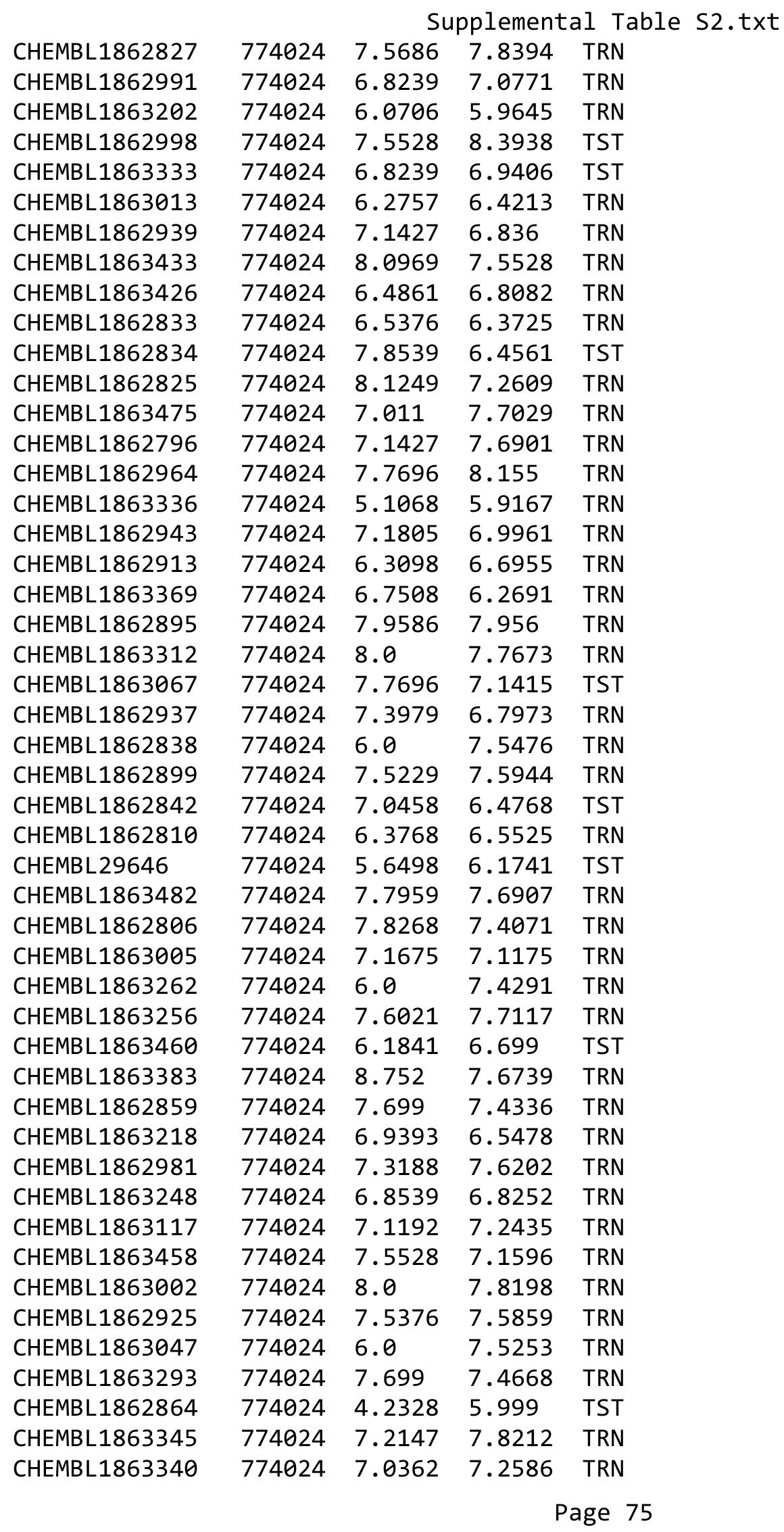




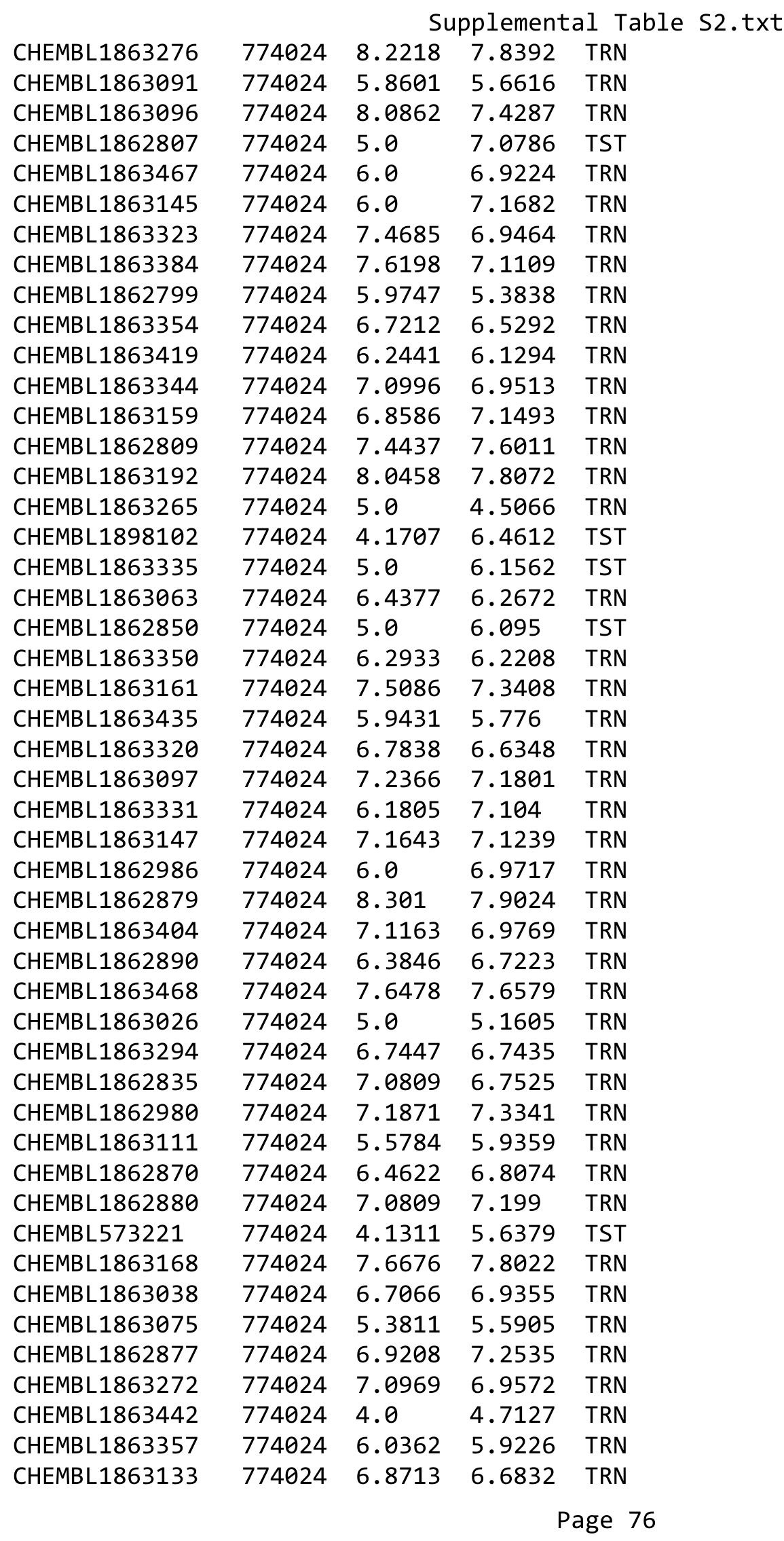




\begin{tabular}{|c|c|c|c|c|c|c|}
\hline \\
\hline CHEMBL1863456 & 774024 & 5.0 & 6.324 & TST & & \\
\hline CHEMBL1863134 & 774024 & 7.0 & 7.1339 & TRN & & \\
\hline CHEMBL1863100 & 774024 & 5.0 & 5.4345 & TRN & & \\
\hline CHEMBL1862996 & 774024 & 7.4202 & 6.9341 & TRN & & \\
\hline CHEMBL1863070 & 774024 & 6.4685 & 6.3018 & TRN & & \\
\hline CHEMBL1863004 & 774024 & 8.4283 & 8.1631 & TRN & & \\
\hline CHEMBL1862883 & 774024 & 8.3468 & 7.9557 & TRN & & \\
\hline CHEMBL1863085 & 774024 & 5.0 & 5.8701 & TRN & & \\
\hline CHEMBL1863236 & 774024 & 7.699 & 7.6255 & TRN & & \\
\hline CHEMBL1862968 & 774024 & 6.1938 & 6.9965 & TST & & \\
\hline CHEMBL1863368 & 774024 & 6.5376 & 7.0411 & TRN & & \\
\hline CHEMBL1863006 & 774024 & 7.1772 & 6.7736 & TRN & & \\
\hline CHEMBL1863014 & 774024 & 7.2218 & 6.9889 & TRN & & \\
\hline CHEMBL1863287 & 774024 & 7.2596 & 6.9966 & TRN & & \\
\hline CHEMBL1863068 & 774024 & 6.9263 & 7.0205 & TRN & & \\
\hline CHEMBL1863396 & 774024 & 5.0 & 5.0937 & TST & & \\
\hline CHEMBL1862814 & 774024 & 7.301 & 7.2036 & TRN & & \\
\hline CHEMBL1863393 & 774024 & 7.5528 & 7.6181 & TRN & & \\
\hline CHEMBL1862851 & 774024 & 6.6021 & 6.0774 & TRN & & \\
\hline CHEMBL1863296 & 774024 & 6.7959 & 6.8637 & TRN & & \\
\hline CHEMBL1863116 & 774024 & 8.1871 & 8.3004 & TRN & & \\
\hline CHEMBL1863273 & 774024 & 6.9586 & 6.6257 & TRN & & \\
\hline CHEMBL1863035 & 774024 & 7.6576 & 7.3822 & TST & & \\
\hline CHEMBL1862989 & 774024 & 7.0088 & 7.4061 & TST & & \\
\hline CHEMBL1863233 & 774024 & 6.585 & 6.3548 & TRN & & \\
\hline CHEMBL1862808 & 774024 & 8.0458 & 7.4322 & TRN & & \\
\hline CHEMBL1863119 & 774024 & 7.6576 & 7.6737 & TRN & & \\
\hline CHEMBL1863466 & 774024 & 6.4622 & 7.5727 & TRN & & \\
\hline CHEMBL1863472 & 774024 & 7.7696 & 6.7678 & TST & & \\
\hline CHEMBL1863471 & 774024 & 5.6696 & 6.2831 & TST & & \\
\hline CHEMBL1863194 & 774024 & 5.0 & 5.0586 & TRN & & \\
\hline CHEMBL1862938 & 774024 & 7.0942 & 6.9694 & TRN & & \\
\hline CHEMBL1863427 & 774024 & 7.5376 & 7.3952 & TST & & \\
\hline CHEMBL1862847 & 774024 & 6.0 & 6.0856 & TRN & & \\
\hline CHEMBL1863415 & 774024 & 6.2218 & 5.9545 & TRN & & \\
\hline CHEMBL1863054 & 774024 & 5.0 & 6.6353 & TRN & & \\
\hline CHEMBL1863267 & 774024 & 6.0 & 7.3845 & TRN & & \\
\hline CHEMBL1863232 & 774024 & 8.0 & 8.0706 & TRN & & \\
\hline CHEMBL1863042 & 774024 & 5.0 & 5.5432 & TRN & & \\
\hline CHEMBL1862931 & 774024 & 7.1549 & 6.5085 & TST & & \\
\hline CHEMBL1862840 & 774024 & 7.0862 & 6.3132 & TRN & & \\
\hline CHEMBL1863346 & 774024 & 7.5528 & 6.8664 & TRN & & \\
\hline CHEMBL1862956 & 774024 & 6.6021 & 6.5597 & TRN & & \\
\hline CHEMBL1863175 & 774024 & 6.62799 & 999999999 & 99 & 6.9479 & TRN \\
\hline CHEMBL1862961 & 774024 & 6.6576 & 6.9895 & TRN & & \\
\hline CHEMBL1863177 & 774024 & 4.0 & 6.0138 & TST & & \\
\hline CHEMBL1863281 & 774024 & 7.2291 & 7.4522 & TRN & & \\
\hline CHEMBL1862885 & 774024 & 7.1427 & 7.4497 & TRN & & \\
\hline
\end{tabular}




\begin{tabular}{|c|c|c|c|c|c|c|}
\hline & & \multicolumn{5}{|c|}{ Supplemental Table S2.txt } \\
\hline CHEMBL1863327 & 774024 & 7.8239 & 7.2758 & TST & & \\
\hline CHEMBL1862793 & 774024 & 7.6778 & 7.3722 & TST & & \\
\hline CHEMBL1862946 & 774024 & 7.6021 & 7.9155 & TRN & & \\
\hline CHEMBL1863057 & 774024 & 7.2328 & 7.1845 & TRN & & \\
\hline CHEMBL1863124 & 774024 & 6.4089 & 6.3002 & TRN & & \\
\hline CHEMBL1863493 & 774024 & 7.3279 & 7.0034 & TRN & & \\
\hline CHEMBL1862812 & 774024 & 7.3768 & 6.6045 & TST & & \\
\hline CHEMBL1863153 & 774024 & 6.24799 & 99999999 & 99 & 6.4566 & TRN \\
\hline CHEMBL1863487 & 774024 & 7.4685 & 7.1377 & TRN & & \\
\hline CHEMBL1863056 & 774024 & 7.5528 & 7.2847 & TRN & & \\
\hline CHEMBL1863274 & 774024 & 5.0 & 6.7303 & TST & & \\
\hline CHEMBL138538 & 774024 & 7.7696 & 7.0657 & TST & & \\
\hline CHEMBL1863162 & 774024 & 6.9154 & 7.4121 & TRN & & \\
\hline CHEMBL29669 & 774024 & 6.1659 & 5.895 & TST & & \\
\hline CHEMBL1862999 & 774024 & 7.5086 & 7.5224 & TST & & \\
\hline CHEMBL1862971 & 774024 & 5.0 & 7.2156 & TST & & \\
\hline CHEMBL1863474 & 774024 & 8.0 & 7.8721 & TRN & & \\
\hline CHEMBL1863392 & 774024 & 7.8239 & 7.7426 & TRN & & \\
\hline CHEMBL1863228 & 774024 & 6.7447 & 7.4297 & TST & & \\
\hline CHEMBL1863277 & 774024 & 6.4202 & 6.8694 & TRN & & \\
\hline CHEMBL1863364 & 774024 & 7.2366 & 7.2768 & TRN & & \\
\hline CHEMBL1863188 & 774024 & 7.1871 & 7.1664 & TRN & & \\
\hline CHEMBL1863500 & 774024 & 7.4685 & 7.5924 & TRN & & \\
\hline CHEMBL1863313 & 774024 & 6.4815 & 6.2947 & TRN & & \\
\hline CHEMBL1862894 & 774024 & 7.8097 & 7.6903 & TRN & & \\
\hline CHEMBL1863024 & 774024 & 6.3492 & 6.8897 & TRN & & \\
\hline CHEMBL1863051 & 774024 & 6.3188 & 6.9057 & TRN & & \\
\hline CHEMBL1863402 & 774024 & 7.0655 & 7.7885 & TST & & \\
\hline CHEMBL337750 & 774024 & 7.1739 & 7.1599 & TST & & \\
\hline CHEMBL1863225 & 774024 & 6.857 & 5.8447 & TST & & \\
\hline CHEMBL1862917 & 774024 & 5.0 & 6.3248 & TRN & & \\
\hline CHEMBL1863197 & 774024 & 7.2147 & 6.7372 & TST & & \\
\hline CHEMBL1862994 & 774024 & 7.7447 & 7.739 & TRN & & \\
\hline CHEMBL1863155 & 774024 & 7.5528 & 7.6906 & TRN & & \\
\hline CHEMBL1863352 & 774024 & 6.5086 & 6.4909 & TRN & & \\
\hline CHEMBL1863187 & 774024 & 6.301 & 6.0646 & TRN & & \\
\hline CHEMBL1862837 & 774024 & 6.0809 & 5.9791 & TRN & & \\
\hline CHEMBL1863338 & 774024 & 7.7447 & 7.8117 & TRN & & \\
\hline CHEMBL1863231 & 774024 & 7.1192 & 7.0156 & TRN & & \\
\hline CHEMBL1863234 & 774024 & 7.2366 & 6.8246 & TRN & & \\
\hline CHEMBL1863079 & 774024 & 6.5309 & 6.8659 & TRN & & \\
\hline CHEMBL1863060 & 774024 & 7.301 & 7.3473 & TRN & & \\
\hline CHEMBL1863491 & 774024 & 4.0 & 4.698 & TRN & & \\
\hline CHEMBL1863129 & 774024 & 6.7696 & 6.8358 & TRN & & \\
\hline CHEMBL1863212 & 774024 & 7.6576 & 7.3858 & TRN & & \\
\hline CHEMBL1863032 & 774024 & 8.2596 & 7.7745 & TRN & & \\
\hline CHEMBL1863166 & 774024 & 7.1549 & 7.4975 & TRN & & \\
\hline CHEMBL1863019 & 774024 & 6.0132 & 5.7507 & TRN & & \\
\hline
\end{tabular}




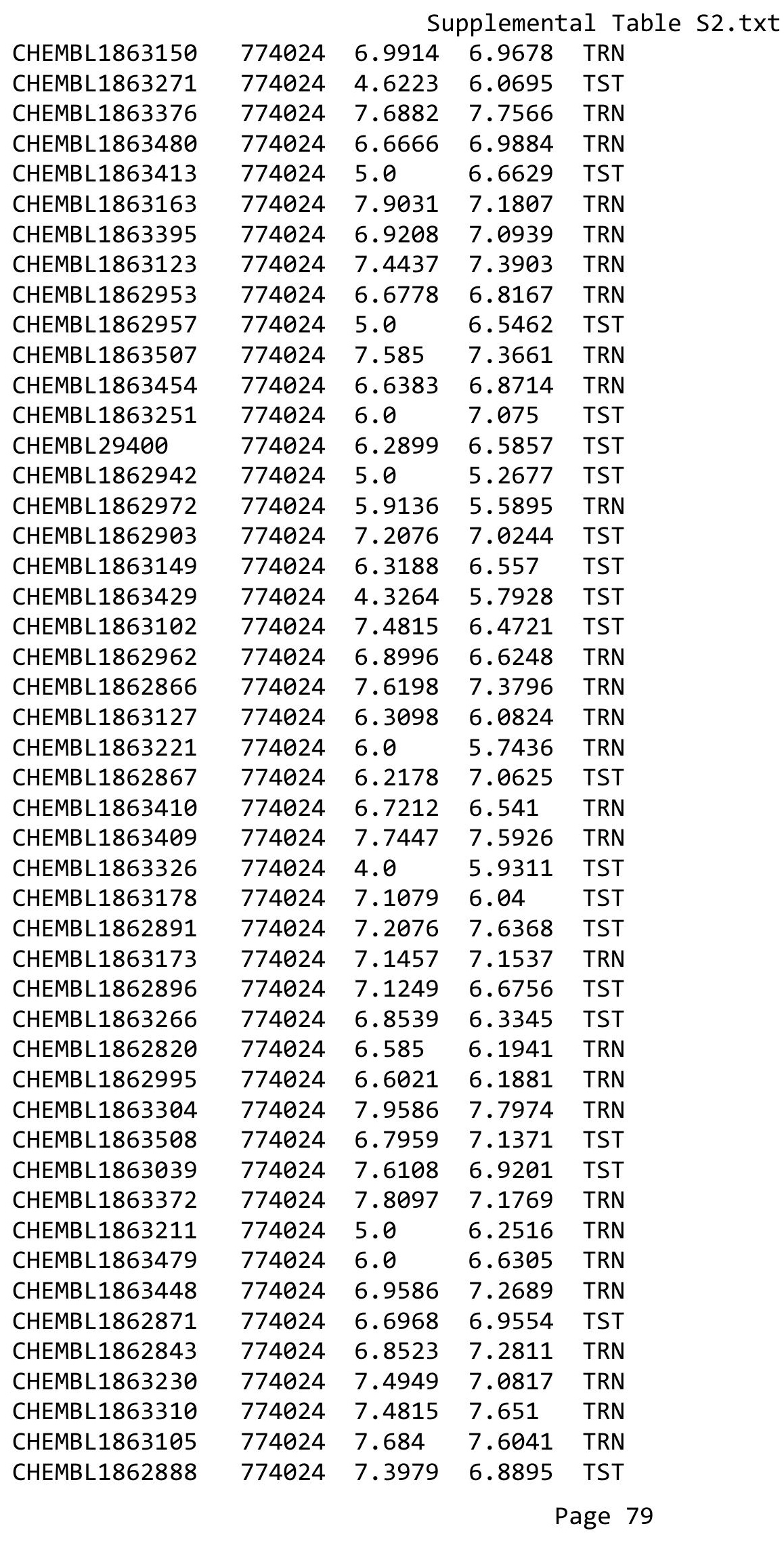




\begin{tabular}{|c|c|c|c|c|c|}
\hline & & \multicolumn{4}{|c|}{ Supplemental Table S2.txt } \\
\hline CHEMBL1863307 & 774024 & 7.3188 & 7.6304 & TST & \\
\hline CHEMBL1862983 & 774024 & 7.1135 & 6.9113 & TST & \\
\hline CHEMBL1863001 & 774024 & 8.3468 & 7.5472 & TRN & \\
\hline CHEMBL1862920 & 774024 & 7.1192 & 7.6542 & TRN & \\
\hline CHEMBL1863418 & 774024 & 7.5768 & 7.6378 & TST & \\
\hline CHEMBL1863109 & 774024 & 6.2076 & 6.4211 & TRN & \\
\hline CHEMBL1862900 & 774024 & 5.0 & 6.3378 & TRN & \\
\hline CHEMBL1863064 & 774024 & 6.2291 & 5.7442 & TRN & \\
\hline CHEMBL1863198 & 774024 & 5.6757 & 5.3777 & TST & \\
\hline CHEMBL1863371 & 774024 & 5.0 & 6.2923 & TST & \\
\hline CHEMBL1863104 & 774024 & 5.5467 & 6.1895 & TST & \\
\hline CHEMBL1863318 & 774024 & 5.0 & 5.7414 & TRN & \\
\hline CHEMBL1863291 & 774024 & 7.7212 & 6.8616 & TST & \\
\hline CHEMBL1863237 & 774024 & 8.0835 & 8.1137 & TRN & \\
\hline CHEMBL1863494 & 774024 & 8.5229 & 8.254 & TRN & \\
\hline CHEMBL1863445 & 774024 & 8.0458 & 7.8937 & TRN & \\
\hline CHEMBL1862857 & 774024 & 8.2218 & 7.9944 & TRN & \\
\hline CHEMBL1862916 & 774024 & 7.6198 & 7.7658 & TRN & \\
\hline CHEMBL1863366 & 774024 & 7.0132 & 6.9869 & TRN & \\
\hline CHEMBL1862889 & 774024 & 6.7688 & 6.3444 & TST & \\
\hline CHEMBL1863397 & 774024 & 7.2007 & 7.0233 & TRN & \\
\hline CHEMBL1862794 & 774024 & 6.6383 & 6.2586 & TRN & \\
\hline CHEMBL1863275 & 774024 & 6.0 & 6.9734 & TRN & \\
\hline CHEMBL1863017 & 774024 & 7.699 & 7.4036 & TRN & \\
\hline CHEMBL1863322 & 774024 & 6.6383 & 6.769 & TRN & \\
\hline CHEMBL1863257 & 774024 & 5.0 & 5.5763 & TRN & \\
\hline CHEMBL1863088 & 774024 & 6.2288 & 6.7855 & TRN & \\
\hline CHEMBL1863389 & 774024 & 8.0706 & 7.6746 & TRN & \\
\hline CHEMBL1863499 & 774024 & 8.8861 & 8.3997 & TST & \\
\hline CHEMBL1863030 & 774024 & 7.5528 & 7.9901 & TRN & \\
\hline CHEMBL1863309 & 774024 & 6.2676 & 6.3684 & TRN & \\
\hline CHEMBL1863425 & 774024 & 7.7212 & 7.4698 & TRN & \\
\hline CHEMBL1862848 & 774024 & 7.3468 & 7.7882 & TRN & \\
\hline CHEMBL1863203 & 774024 & 6.8996 & 6.5707 & TST & \\
\hline CHEMBL1862803 & 774024 & 6.4318 & 7.0147 & TST & \\
\hline CHEMBL1863080 & 774024 & 8.3486 & 7.3276 & TRN & \\
\hline CHEMBL1863172 & 774024 & 6.6383 & 6.1697 & TST & \\
\hline CHEMBL1863321 & 774024 & 8.4949 & 8.3486 & TST & \\
\hline CHEMBL1862832 & 774024 & 5.0 & 6.365 & TRN & \\
\hline CHEMBL1863408 & 774024 & 6.0 & 6.38399 & 99999999995 & TRN \\
\hline CHEMBL1862800 & 774024 & 7.5918 & 7.5824 & TRN & \\
\hline CHEMBL1862907 & 774024 & 6.4191 & 6.76399 & 9999999999 & TST \\
\hline CHEMBL1863181 & 774024 & 7.0022 & 7.0312 & TRN & \\
\hline CHEMBL1863130 & 774024 & 7.1938 & 6.5414 & TST & \\
\hline CHEMBL1862815 & 774024 & 6.5792 & 6.5961 & TRN & \\
\hline CHEMBL1863235 & 774024 & 7.2076 & 7.119 & TRN & \\
\hline CHEMBL1862817 & 774024 & 6.8239 & 7.5616 & TST & \\
\hline CHEMBL1862872 & 774024 & 7.1772 & 7.42 & TRN & \\
\hline
\end{tabular}


Supplemental Table S2.txt

\begin{tabular}{|c|c|c|c|c|c|}
\hline CHEMBL1862947 & 774024 & 7.1079 & 7.5051 & TRN & \\
\hline CHEMBL1863242 & 774024 & 7.3188 & 7.6311 & TST & \\
\hline CHEMBL1863356 & 774024 & 6.2596 & 6.1457 & TRN & \\
\hline CHEMBL1863069 & 774024 & 7.5452 & 7.2466 & TRN & \\
\hline CHEMBL1863300 & 774024 & 7.1192 & 7.5983 & TRN & \\
\hline CHEMBL1863082 & 774024 & 7.2676 & 7.5276 & TST & \\
\hline CHEMBL1863143 & 774024 & 7.1938 & 7.1203 & TRN & \\
\hline CHEMBL1863190 & 774024 & 6.8239 & 6.9724 & TRN & \\
\hline CHEMBL1863113 & 774024 & 7.8539 & 7.9193 & TRN & \\
\hline CHEMBL1863264 & 774024 & 5.8601 & 5.2014 & TRN & \\
\hline CHEMBL1863050 & 774024 & 7.0 & 7.6138 & TST & \\
\hline CHEMBL1863423 & 774024 & 5.0 & \multicolumn{2}{|c|}{5.212000000000001} & TRN \\
\hline CHEMBL1863361 & 774024 & 4.0 & 4.9085 & TRN & \\
\hline CHEMBL1863099 & 774024 & 7.5768 & 6.5689 & TRN & \\
\hline CHEMBL1862868 & 774024 & 5.8416 & 5.8682 & TRN & \\
\hline CHEMBL1863167 & 774024 & 6.0655 & 5.5394 & TRN & \\
\hline CHEMBL1862873 & 774024 & 7.3979 & 6.8314 & TST & \\
\hline CHEMBL1863306 & 774024 & 7.6198 & 7.4143 & TRN & \\
\hline CHEMBL 2028156 & 774024 & 8.0223 & \multicolumn{2}{|c|}{8.152000000000001} & TRN \\
\hline CHEMBL1862804 & 774024 & 6.4949 & 7.1028 & TRN & \\
\hline CHEMBL1862918 & 774024 & 7.2716 & 6.973 & TRN & \\
\hline CHEMBL1863052 & 774024 & 5.0 & 5.5812 & TRN & \\
\hline CHEMBL1863486 & 774024 & 6.0 & 7.4748 & TST & \\
\hline CHEMBL1863400 & 774024 & 7.7696 & 7.6653 & TRN & \\
\hline CHEMBL1862973 & 774024 & 6.3102 & 6.3257 & TRN & \\
\hline CHEMBL1863462 & 774024 & 7.585 & 7.0532 & TRN & \\
\hline CHEMBL1863059 & 774024 & 7.301 & 6.6031 & TRN & \\
\hline CHEMBL1863506 & 774024 & 7.9208 & 7.7097 & TRN & \\
\hline CHEMBL1863258 & 774024 & 7.2218 & 7.3466 & TST & \\
\hline CHEMBL1863176 & 774024 & 8.163 & 7.7299 & TRN & \\
\hline CHEMBL1863282 & 774024 & 7.301 & 6.568 & TST & \\
\hline CHEMBL1862826 & 774024 & 5.9393 & 6.3027 & TST & \\
\hline CHEMBL1863055 & 774024 & 6.5513 & 6.1748 & TRN & \\
\hline CHEMBL1863461 & 774024 & 6.4935 & 7.0974 & TRN & \\
\hline CHEMBL1862922 & 774024 & 6.9208 & 6.9684 & TST & \\
\hline CHEMBL421035 & 774024 & 3.0 & 5.5991 & TST & \\
\hline CHEMBL1862836 & 774024 & 7.0 & 6.8511 & TRN & \\
\hline CHEMBL1863156 & 774024 & 6.0706 & 6.0171 & TRN & \\
\hline CHEMBL1863174 & 774024 & 6.3507 & 7.5589 & TST & \\
\hline CHEMBL1863502 & 774024 & 7.0 & 7.2011 & TST & \\
\hline CHEMBL1863193 & 774024 & 5.0 & 6.3699 & TST & \\
\hline CHEMBL1863269 & 774024 & 6.699 & 6.6552 & TST & \\
\hline CHEMBL1863434 & 774024 & 7.3054 & 7.0251 & TST & \\
\hline CHEMBL1863053 & 774024 & 7.9208 & 7.3826 & TRN & \\
\hline CHEMBL1863308 & 774024 & 6.7696 & 6.6124 & TRN & \\
\hline CHEMBL1862878 & 774024 & 5.1858 & 5.859 & TRN & \\
\hline CHEMBL1863189 & 774024 & 7.3188 & 6.9824 & TRN & \\
\hline CHEMBL1863497 & 774024 & 7.699 & 7.3063 & TST & \\
\hline
\end{tabular}




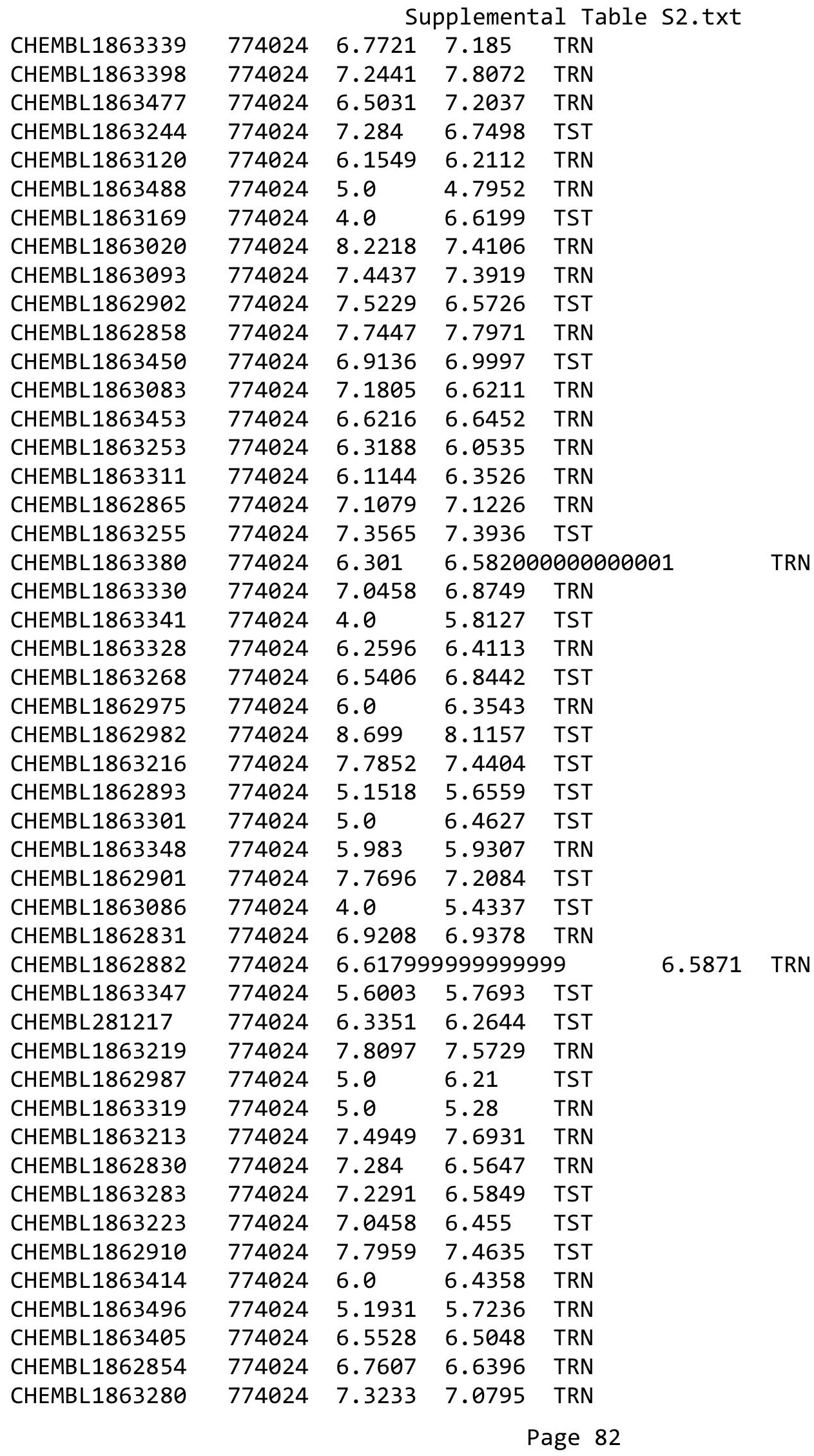




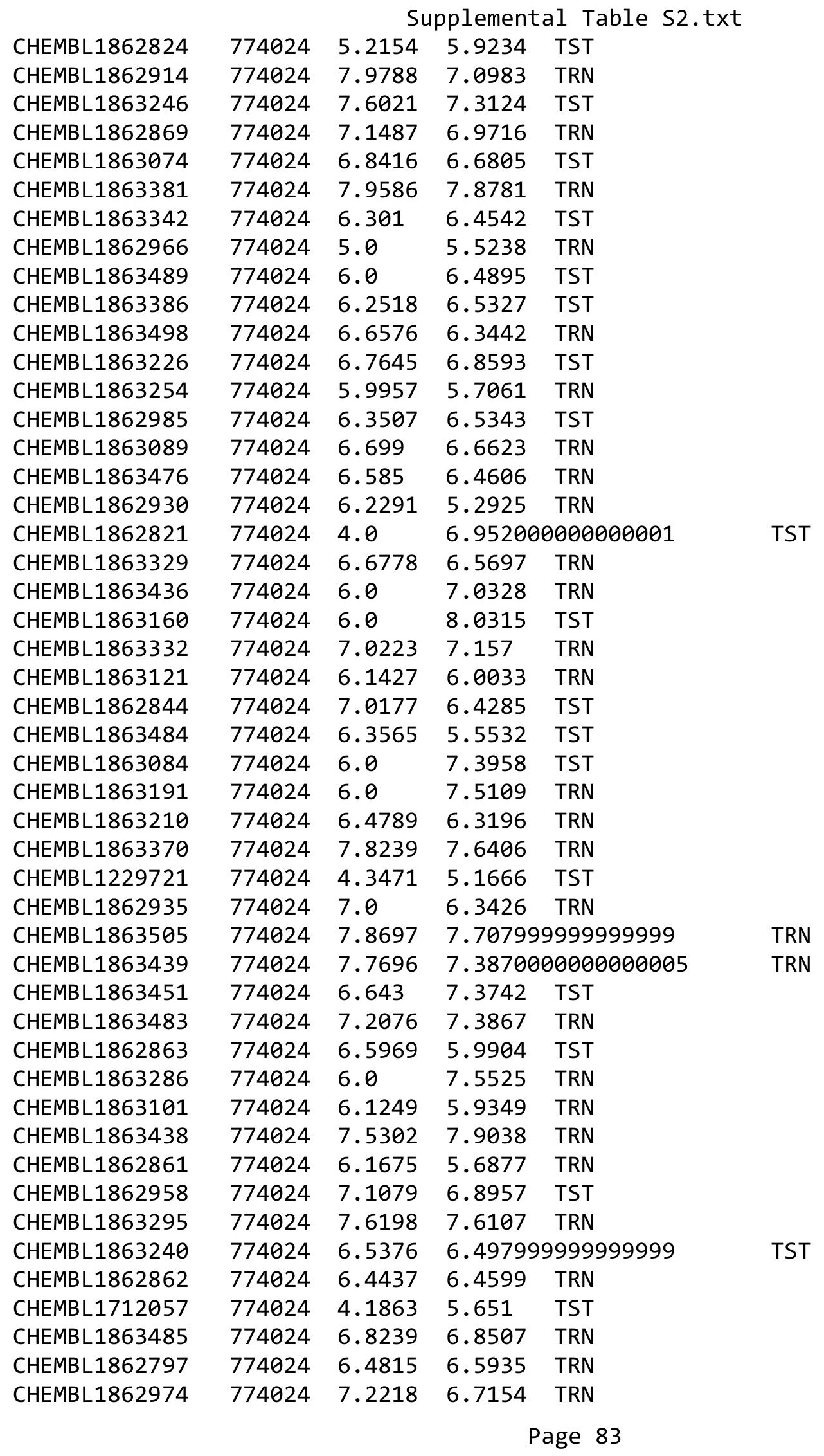




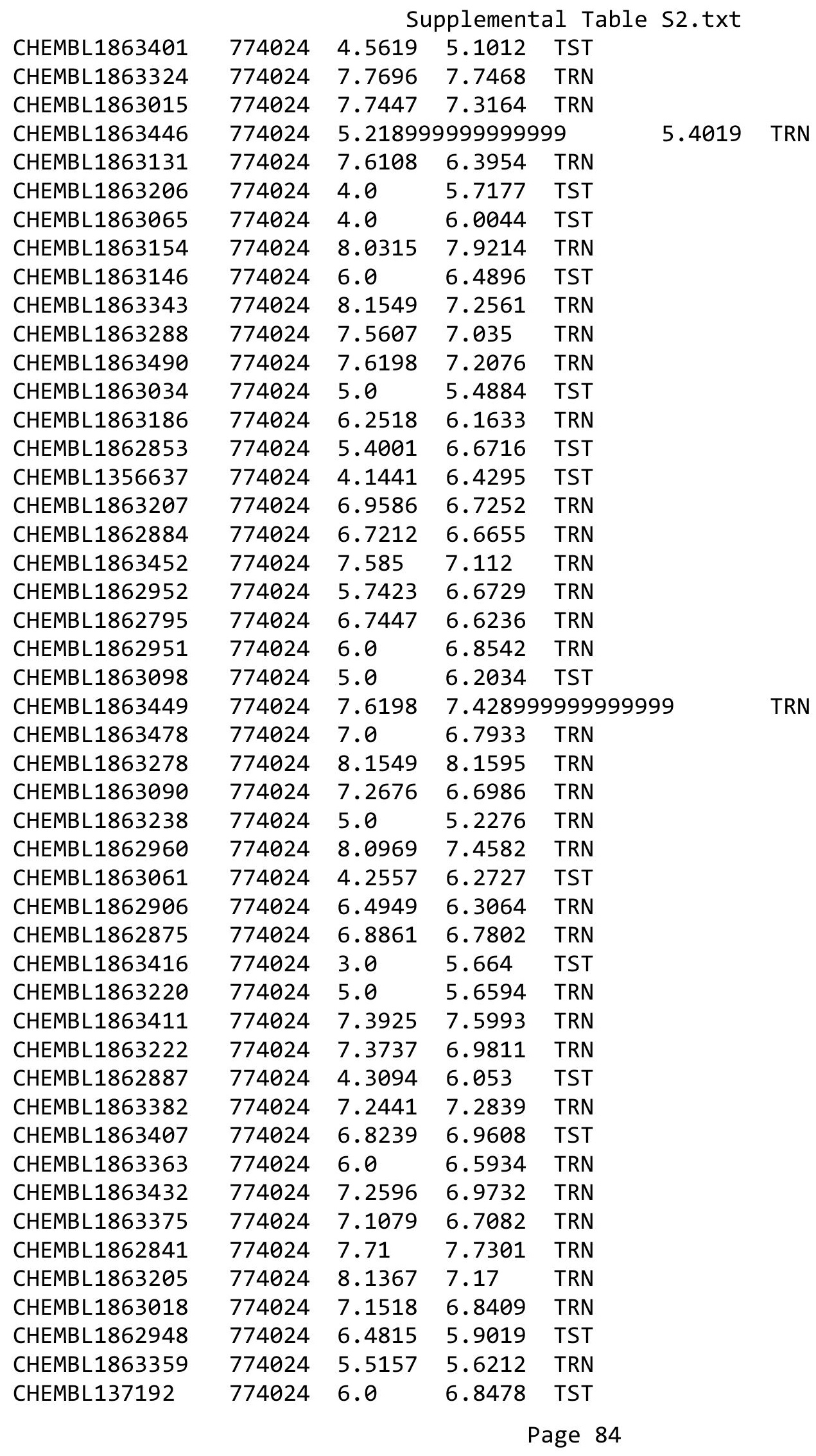




\begin{tabular}{|c|c|c|c|c|c|}
\hline \multicolumn{6}{|c|}{ Supplemental Table s2.txt } \\
\hline CHEMBL1863387 & 774024 & 6.3565 & 6.5156 & TRN & \\
\hline CHEMBL1863029 & 774024 & 6.301 & 6.4743 & TRN & \\
\hline CHEMBL1863302 & 774024 & 6.4401 & 6.6616 & TRN & \\
\hline CHEMBL1862839 & 774024 & 4.8377 & 5.5299 & TST & \\
\hline CHEMBL1863353 & 774024 & 7.6198 & 7.2203 & TRN & \\
\hline CHEMBL1862852 & 774024 & 5.0501 & 5.2309 & TRN & \\
\hline CHEMBL1863316 & 774024 & 7.4949 & 6.9261 & TRN & \\
\hline CHEMBL1863224 & 774024 & 7.585 & 7.0284 & TST & \\
\hline CHEMBL1863158 & 774024 & 7.2291 & 6.9972 & TRN & \\
\hline CHEMBL1863000 & 774024 & 7.7696 & 7.8468 & TRN & \\
\hline CHEMBL1863399 & 774024 & 5.3233 & 6.2171 & TST & \\
\hline CHEMBL1862924 & 774024 & 6.3615 & 5.9521 & TST & \\
\hline CHEMBL1863182 & 774024 & 6.284 & 6.2525 & TRN & \\
\hline CHEMBL1863044 & 774024 & 6.7375 & 6.7711 & TRN & \\
\hline CHEMBL1862933 & 774024 & 7.585 & 7.4404 & TRN & \\
\hline CHEMBL1863081 & 774024 & 6.9412 & 6.9569 & TRN & \\
\hline CHEMBL1862846 & 774024 & 4.6402 & 5.2969 & TST & \\
\hline CHEMBL1863077 & 774024 & 5.0 & 5.2794 & TRN & \\
\hline CHEMBL1862941 & 774024 & 7.6289 & 7.4073 & TRN & \\
\hline CHEMBL1862819 & 774024 & 6.3279 & 5.7889 & TRN & \\
\hline CHEMBL1863152 & 774024 & 6.6383 & 6.0796 & TRN & \\
\hline CHEMBL1862984 & 774024 & 6.7212 & 6.6788 & TRN & \\
\hline CHEMBL 3649400 & 1535447 & 6.8548 & 6.8699 & TRN & \\
\hline CHEMBL 3649371 & 1535447 & 6.0816 & 6.0934 & TRN & \\
\hline CHEMBL 3649402 & 1535447 & 6.7279 & 6.7337 & TRN & \\
\hline CHEMBL 3649378 & 1535447 & 6.9714 & 6.9773 & TRN & \\
\hline CHEMBL 3649370 & 1535447 & 7.3635 & 7.4109 & TRN & \\
\hline CHEMBL 3649381 & 1535447 & 6.6105 & 6.6063 & TRN & \\
\hline CHEMBL 3649404 & 1535447 & 6.9496 & 6.886 & TRN & \\
\hline CHEMBL 3649417 & 1535447 & 7.0306 & 7.0317 & TRN & \\
\hline CHEMBL 3649389 & 1535447 & 7.0119 & 6.9957 & TRN & \\
\hline CHEMBL 3649383 & 1535447 & 6.8428 & 6.8824 & TRN & \\
\hline CHEMBL 3649395 & 1535447 & 6.3986 & 6.3865 & TRN & \\
\hline CHEMBL 3649365 & 1535447 & 5.5349 & 5.2258 & TST & \\
\hline CHEMBL 3649411 & 1535447 & 7.1624 & 7.1585 & TRN & \\
\hline CHEMBL 3649387 & 1535447 & 4.6021 & 5.2103 & TST & \\
\hline CHEMBL3649393 & 1535447 & 7.5317 & 7.4827 & TRN & \\
\hline CHEMBL 3649384 & 1535447 & 5.9104 & 5.92299 & 9999999999 & TRN \\
\hline CHEMBL 3649398 & 1535447 & 6.6092 & 6.6061 & TRN & \\
\hline CHEMBL3649391 & 1535447 & 6.6778 & 6.6737 & TRN & \\
\hline CHEMBL 3649422 & 1535447 & 6.9208 & 6.8578 & TRN & \\
\hline CHEMBL3649394 & 1535447 & 7.1135 & 7.15 & TRN & \\
\hline CHEMBL 3649364 & 1535447 & 5.4974 & 5.1428 & TST & \\
\hline CHEMBL3649405 & 1535447 & 6.9682 & 7.0477 & TRN & \\
\hline CHEMBL 3649388 & 1535447 & 4.6021 & 5.2843 & TST & \\
\hline CHEMBL 3649366 & 1535447 & 3.9767 & 4.3745 & TST & \\
\hline CHEMBL3649413 & 1535447 & 6.7249 & 6.7098 & TRN & \\
\hline CHEMBL3649392 & 1535447 & 7.3206 & 7.2849 & TRN & \\
\hline
\end{tabular}


Supplemental Table S2.txt

\begin{tabular}{|c|c|c|c|c|c|c|}
\hline CHEMBL 3649367 & 1535447 & 5.8866 & 5.7955 & TST & & \\
\hline CHEMBL 3649363 & 1535447 & 4.6454 & 5.4347 & TST & & \\
\hline CHEMBL 3649380 & 1535447 & 6.3723 & 6.3676 & TRN & & \\
\hline CHEMBL 3649412 & 1535447 & 6.414 & 6.4369 & TRN & & \\
\hline CHEMBL 3649406 & 1535447 & 6.4747 & 6.5338 & TRN & & \\
\hline CHEMBL 3649408 & 1535447 & 5.8133 & 5.8034 & TRN & & \\
\hline CHEMBL 3649401 & 1535447 & 6.4363 & 6.4184 & TRN & & \\
\hline CHEMBL 3649386 & 1535447 & 6.5996 & 6.5384 & TRN & & \\
\hline CHEMBL 3649385 & 1535447 & 6.7222 & 6.7542 & TRN & & \\
\hline CHEMBL 3649403 & 1535447 & 6.9378 & 6.9765 & TRN & & \\
\hline CHEMBL 3649409 & 1535447 & 7.0799 & 7.0879 & TRN & & \\
\hline CHEMBL 3649420 & 1535447 & 6.4509 & 6.5407 & TRN & & \\
\hline CHEMBL 3649414 & 1535447 & 7.0685 & 7.0805 & TRN & & \\
\hline CHEMBL 3649376 & 1535447 & 7.0066 & 7.0425 & TRN & & \\
\hline CHEMBL 3649421 & 1535447 & 6.76399 & 99999999 & 99 & 6.733 & TRN \\
\hline CHEMBL 3649374 & 1535447 & 6.8471 & 6.852 & TRN & & \\
\hline CHEMBL 3649397 & 1535447 & 6.4566 & 6.4534 & TRN & & \\
\hline CHEMBL 3649362 & 1535447 & 4.9559 & 5.2769 & TST & & \\
\hline CHEMBL 3649407 & 1535447 & 6.6501 & 6.5919 & TRN & & \\
\hline CHEMBL 3649415 & 1535447 & 7.2104 & 7.2287 & TRN & & \\
\hline CHEMBL 3649369 & 1535447 & 7.2027 & 7.216 & TRN & & \\
\hline CHEMBL 3649375 & 1535447 & 6.82299 & 99999999 & 995 & 6.8131 & TRN \\
\hline CHEMBL 3649377 & 1535447 & 7.3429 & 7.2868 & TRN & & \\
\hline CHEMBL 3649419 & 1535447 & 6.2853 & 6.2973 & TRN & & \\
\hline CHEMBL 3649399 & 1535447 & 6.8119 & 6.7585 & TRN & & \\
\hline CHEMBL 3649418 & 1535447 & 6.4903 & 6.4964 & TRN & & \\
\hline CHEMBL 3649373 & 1535447 & 6.7385 & 5.9422 & TST & & \\
\hline CHEMBL 3649382 & 1535447 & 6.7825 & 6.7687 & TRN & & \\
\hline CHEMBL 3649372 & 1535447 & \multicolumn{3}{|c|}{6.5360000000000005} & 6.5167 & TRN \\
\hline CHEMBL 3649416 & 1535447 & 6.9952 & 6.9314 & TST & & \\
\hline CHEMBL 3649368 & 1535447 & 5.7322 & 5.9229 & TST & & \\
\hline CHEMBL 3649390 & 1535447 & 6.7491 & 6.885 & TST & & \\
\hline CHEMBL 3649379 & 1535447 & 7.1543 & 7.1447 & TST & & \\
\hline CHEMBL 3649396 & 1535447 & 7.5086 & 7.3535 & TST & & \\
\hline CHEMBL 3639482 & 1535447 & 6.7635 & 6.9099 & TST & & \\
\hline CHEMBL 3649410 & 1535447 & 7.52 & 7.4885 & TST & & \\
\hline CHEMBL 3633226 & 1526993 & 9.5229 & 9.5053 & TRN & & \\
\hline CHEMBL 3632977 & 1526993 & 7.4815 & 7.4637 & TRN & & \\
\hline CHEMBL 3633407 & 1526993 & 8.9208 & 8.8869 & TRN & & \\
\hline CHEMBL 3633230 & 1526993 & 8.9208 & 8.9081 & TRN & & \\
\hline CHEMBL 3633229 & 1526993 & 9.301 & 9.255 & TRN & & \\
\hline CHEMBL 3633413 & 1526993 & 8.9586 & 8.9222 & TRN & & \\
\hline CHEMBL 3633215 & 1526993 & 6.8633 & 6.8661 & TRN & & \\
\hline CHEMBL 3633224 & 1526993 & 8.9586 & 8.958 & TRN & & \\
\hline CHEMBL 3632968 & 1526993 & 8.6778 & 8.6915 & TRN & & \\
\hline CHEMBL 3633409 & 1526993 & 8.9586 & 8.9677 & TRN & & \\
\hline CHEMBL 3632970 & 1526993 & 7.8539 & 7.8522 & TRN & & \\
\hline CHEMBL 3633225 & 1526993 & 8.0862 & 8.1158 & TRN & & \\
\hline
\end{tabular}


Supplemental Table S2.txt

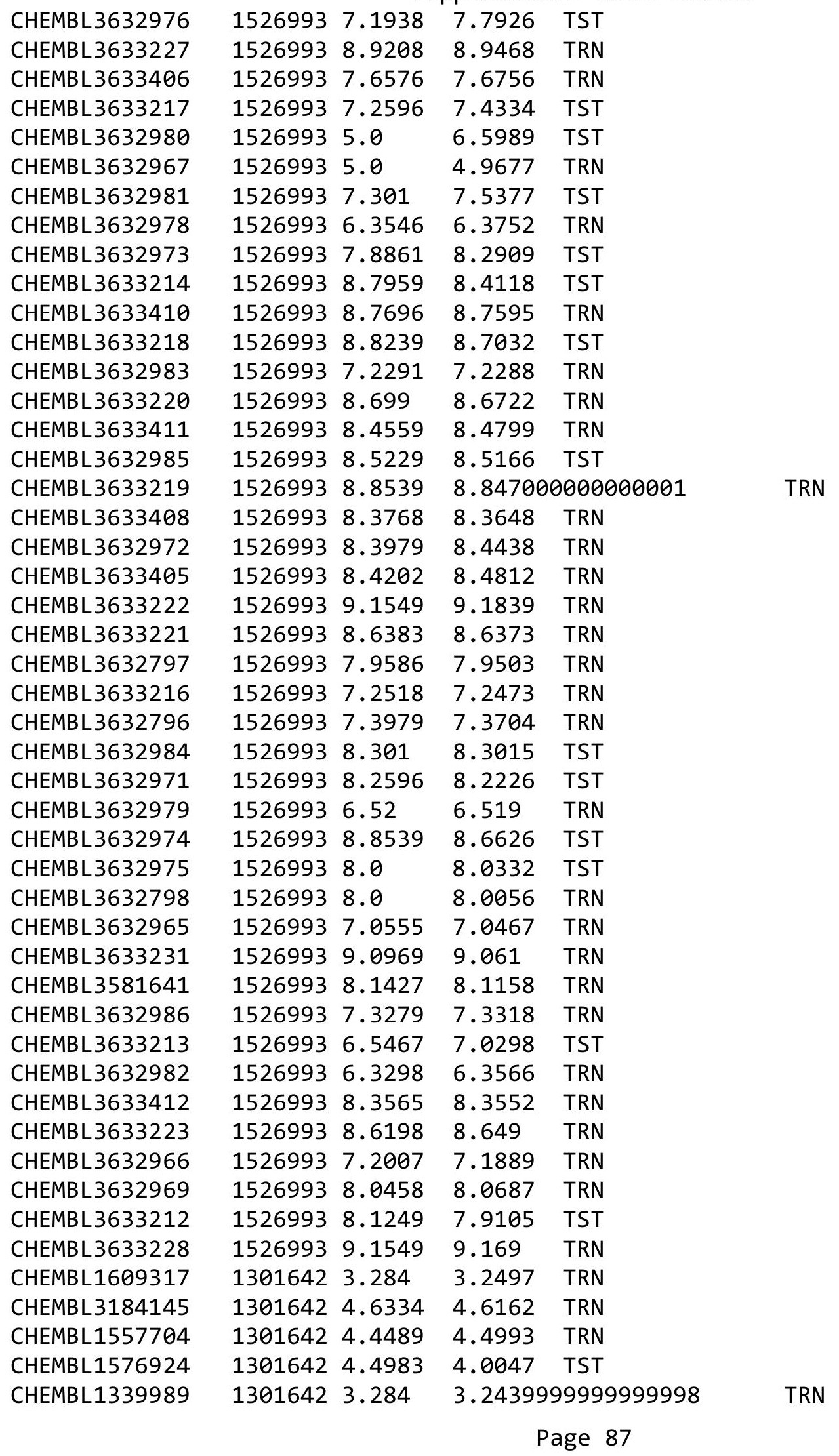


Supplemental Table S2.txt

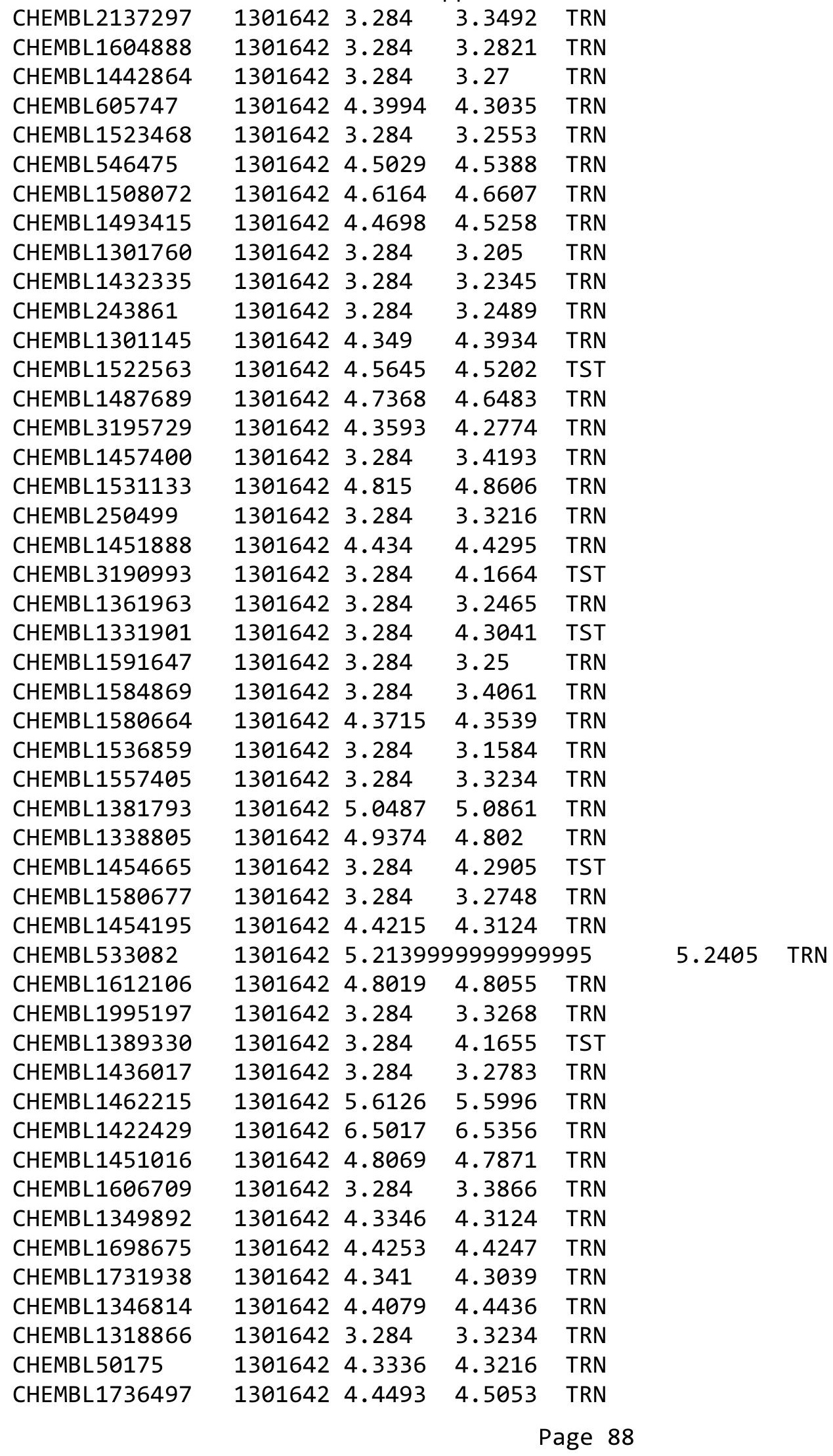




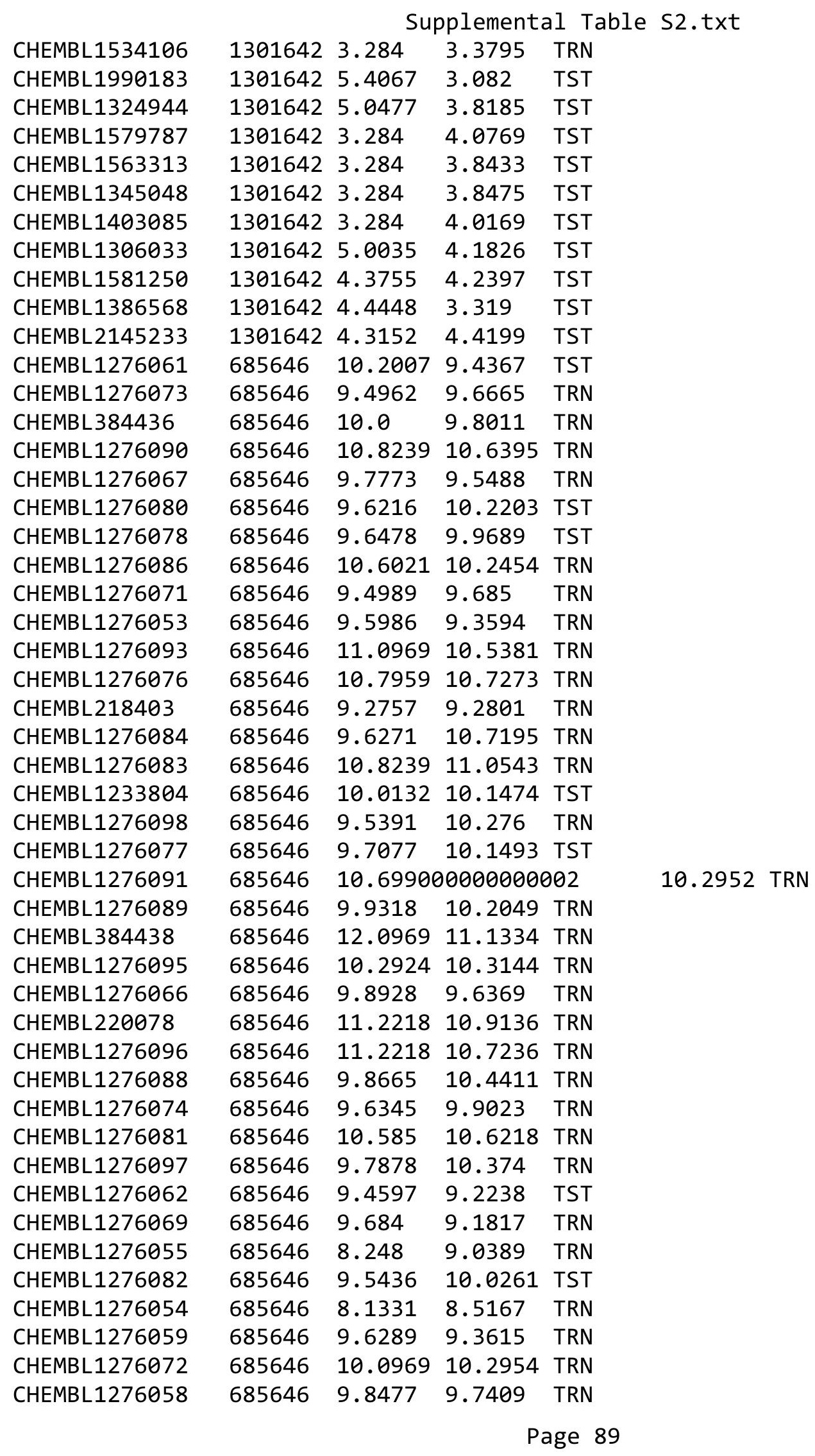




\begin{tabular}{|c|c|c|c|c|c|}
\hline \multirow[b]{2}{*}{ CHEMBL1276092 } & \multicolumn{5}{|c|}{ Supplemental Table s2.txt } \\
\hline & 685646 & 9.9469 & 10.1034 & TRN & \\
\hline CHEMBL1276056 & 685646 & 9.8665 & 9.2933 & TRN & \\
\hline CHEMBL1276057 & 685646 & 10.0655 & 9.7611 & TRN & \\
\hline CHEMBL1276060 & 685646 & 9.4145 & 8.947006 & 0000000001 & TST \\
\hline CHEMBL1276085 & 685646 & 10.3098 & 10.4241 & TRN & \\
\hline CHEMBL1276099 & 685646 & 10.585 & 10.6984 & TRN & \\
\hline CHEMBL1276094 & 685646 & 9.9136 & 10.4825 & TRN & \\
\hline CHEMBL1276052 & 685646 & 10.4815 & 10.2206 & TRN & \\
\hline CHEMBL1276063 & 685646 & 9.8239 & 9.6544 & TST & \\
\hline CHEMBL1276075 & 685646 & 9.4815 & 9.2497 & TRN & \\
\hline CHEMBL1276065 & 685646 & 9.3487 & 9.115 & TRN & \\
\hline CHEMBL1276079 & 685646 & 9.8861 & 10.3171 & TST & \\
\hline CHEMBL1276087 & 685646 & 11.5229 & 10.6733 & TST & \\
\hline CHEMBL1276051 & 685646 & 9.6861 & 9.7585 & TRN & \\
\hline CHEMBL1276068 & 685646 & 9.8761 & 9.9616 & TST & \\
\hline CHEMBL1276070 & 685646 & 10.1367 & 10.4958 & TST & \\
\hline CHEMBL1233803 & 685646 & 8.8327 & 8.9988 & TRN & \\
\hline CHEMBL1276064 & 685646 & 9.6737 & 9.0206 & TST & \\
\hline CHEMBL1914753 & 786095 & 7.301 & 6.4762 & TRN & \\
\hline CHEMBL1915030 & 786095 & 6.7077 & 5.9352 & TRN & \\
\hline CHEMBL1915051 & 786095 & 6.4248 & 6.4293 & TRN & \\
\hline CHEMBL1914789 & 786095 & 6.0 & 7.8414 & TST & \\
\hline CHEMBL1915027 & 786095 & 6.4401 & 6.1126 & TRN & \\
\hline CHEMBL1915025 & 786095 & 4.0 & 4.7039 & TRN & \\
\hline CHEMBL1915046 & 786095 & 6.0531 & 6.5589 & TRN & \\
\hline CHEMBL1914534 & 786095 & 7.2757 & 7.3083 & TST & \\
\hline CHEMBL1915044 & 786095 & 7.4815 & 7.6036 & TRN & \\
\hline CHEMBL1914764 & 786095 & 6.3565 & 7.3187 & TRN & \\
\hline CHEMBL1914779 & 786095 & 4.0 & 6.3249 & TRN & \\
\hline CHEMBL1914540 & 786095 & 8.9586 & 8.4143 & TRN & \\
\hline CHEMBL1915053 & 786095 & 4.0 & 4.934 & TRN & \\
\hline CHEMBL1915047 & 786095 & 7.4318 & 6.9214 & TRN & \\
\hline CHEMBL1914542 & 786095 & 8.9586 & 8.9759 & TRN & \\
\hline CHEMBL1914791 & 786095 & 6.0 & 7.7864 & TST & \\
\hline CHEMBL1914769 & 786095 & 6.8386 & 7.1667 & TRN & \\
\hline CHEMBL1914785 & 786095 & 8.0969 & 7.6752 & TRN & \\
\hline CHEMBL1915034 & 786095 & 6.5654 & 6.1303 & TRN & \\
\hline CHEMBL1914776 & 786095 & 8.4685 & 8.2695 & TRN & \\
\hline CHEMBL1915041 & 786095 & 5.4912 & 5.3108 & TST & \\
\hline CHEMBL1914755 & 786095 & 9.0969 & 8.8082 & TRN & \\
\hline CHEMBL1915039 & 786095 & 6.4609 & 5.45 & TST & \\
\hline CHEMBL1914767 & 786095 & 7.6778 & 8.3465 & TRN & \\
\hline CHEMBL1914761 & 786095 & 7.7212 & 7.5149 & TRN & \\
\hline CHEMBL1915032 & 786095 & 6.0535 & 4.3302 & TRN & \\
\hline CHEMBL1914546 & 786095 & 7.7212 & 7.652 & TRN & \\
\hline CHEMBL1915023 & 786095 & 4.0 & 4.6502 & TRN & \\
\hline CHEMBL1914774 & 786095 & 8.1135 & 7.2569 & TRN & \\
\hline CHEMBL1914788 & 786095 & 6.0 & 7.9207 & TST & \\
\hline
\end{tabular}




\begin{tabular}{|c|c|c|c|c|}
\hline \multicolumn{5}{|c|}{ Supplemental Table S2.txt } \\
\hline CHEMBL1914539 & 786095 & 4.0 & 6.7332 & TST \\
\hline CHEMBL1914752 & 786095 & 7.6778 & 7.3399 & TRN \\
\hline CHEMBL1914756 & 786095 & 7.9208 & 8.3783 & TRN \\
\hline CHEMBL1914757 & 786095 & 8.1135 & 7.4533 & TRN \\
\hline CHEMBL1915028 & 786095 & 4.0 & 4.9604 & TRN \\
\hline CHEMBL1914760 & 786095 & 9.0 & 8.1066 & TRN \\
\hline CHEMBL1915029 & 786095 & 4.0 & 4.8463 & TRN \\
\hline CHEMBL1914765 & 786095 & 6.7447 & 7.0124 & TRN \\
\hline CHEMBL1915042 & 786095 & 6.0545 & 5.1765 & TST \\
\hline CHEMBL1914751 & 786095 & 7.1308 & 7.0769 & TRN \\
\hline CHEMBL1914545 & 786095 & 7.3372 & 8.0863 & TRN \\
\hline CHEMBL1914745 & 786095 & 8.4437 & 7.7402 & TST \\
\hline CHEMBL1914777 & 786095 & 7.3979 & 6.8952 & TRN \\
\hline CHEMBL1915024 & 786095 & 4.0 & 4.0885 & TRN \\
\hline CHEMBL1914535 & 786095 & 4.0 & 6.2047 & TST \\
\hline CHEMBL1914537 & 786095 & 4.0 & 6.5099 & TST \\
\hline CHEMBL1915037 & 786095 & 4.0 & 4.6459 & TRN \\
\hline CHEMBL1091874 & 786095 & 6.0 & 8.9027 & TRN \\
\hline CHEMBL232421 & 786095 & 7.2518 & 8.0347 & TRN \\
\hline CHEMBL1914754 & 786095 & 7.5229 & 6.9883 & TRN \\
\hline CHEMBL1914543 & 786095 & 8.6198 & 7.6135 & TRN \\
\hline CHEMBL1915049 & 786095 & 7.7959 & 6.1407 & TRN \\
\hline CHEMBL1914544 & 786095 & 7.1249 & 8.3724 & TRN \\
\hline CHEMBL1914770 & 786095 & 6.9172 & 6.3544 & TRN \\
\hline CHEMBL1914766 & 786095 & 5.8928 & 8.0293 & TST \\
\hline CHEMBL1914771 & 786095 & 7.3279 & 6.9381 & TRN \\
\hline CHEMBL1914538 & 786095 & 5.6882 & 7.4259 & TST \\
\hline CHEMBL1914790 & 786095 & 7.5086 & 7.3342 & TST \\
\hline CHEMBL1914775 & 786095 & 6.8069 & 7.1313 & TRN \\
\hline CHEMBL1914782 & 786095 & 8.699 & 8.4421 & TRN \\
\hline CHEMBL1914794 & 786095 & 6.0 & 6.8728 & TST \\
\hline CHEMBL1914780 & 786095 & 7.699 & 6.7886 & TRN \\
\hline CHEMBL1914772 & 786095 & 7.8861 & 8.6691 & TRN \\
\hline CHEMBL1914778 & 786095 & 8.0 & 7.166 & TRN \\
\hline CHEMBL1914746 & 786095 & 6.0 & 7.1495 & TST \\
\hline CHEMBL1915031 & 786095 & 6.3536 & 4.8356 & TRN \\
\hline CHEMBL1914784 & 786095 & 7.9586 & 8.1911 & TRN \\
\hline CHEMBL1915035 & 786095 & 6.3809 & 5.8113 & TRN \\
\hline CHEMBL1914773 & 786095 & 6.8601 & 7.7195 & TST \\
\hline CHEMBL1914541 & 786095 & 10.0 & 9.1543 & TRN \\
\hline CHEMBL1914462 & 786095 & 9.5229 & 8.0644 & TRN \\
\hline CHEMBL1915026 & 786095 & 7.3768 & 6.4128 & TRN \\
\hline CHEMBL1915052 & 786095 & 6.857 & 6.3248 & TST \\
\hline CHEMBL1914768 & 786095 & 5.9792 & 6.9093 & TRN \\
\hline CHEMBL1914762 & 786095 & 7.3665 & 7.961 & TRN \\
\hline CHEMBL1915033 & 786095 & 4.0 & 4.8742 & TRN \\
\hline CHEMBL1914536 & 786095 & 4.0 & 7.2746 & TST \\
\hline CHEMBL1915038 & 786095 & 4.0 & 4.6041 & TRN \\
\hline
\end{tabular}


Supplemental Table S2.txt

\begin{tabular}{|c|c|c|c|c|c|}
\hline CHEMBL1915040 & 786095 & 6.0773 & \multicolumn{2}{|c|}{5.388999999999999} & TST \\
\hline CHEMBL1914533 & 786095 & 6.9208 & 6.7387 & TST & \\
\hline CHEMBL1914547 & 786095 & 8.4685 & 7.9042 & TRN & \\
\hline CHEMBL1914758 & 786095 & 6.8069 & 7.3386 & TRN & \\
\hline CHEMBL1915043 & 786095 & 4.0 & 4.7877 & TST & \\
\hline CHEMBL1914786 & 786095 & 8.0 & 7.2428 & TRN & \\
\hline CHEMBL1914759 & 786095 & 7.5376 & 7.4485 & TST & \\
\hline CHEMBL1093180 & 786095 & 8.3279 & 8.6626 & TRN & \\
\hline CHEMBL1915050 & 786095 & 6.2125 & 6.1389 & TRN & \\
\hline CHEMBL1914744 & 786095 & 6.8633 & 8.003 & TRN & \\
\hline CHEMBL1914763 & 786095 & 7.7447 & 7.8419 & TST & \\
\hline CHEMBL1914748 & 786095 & 6.0 & 6.3122 & TRN & \\
\hline CHEMBL1914787 & 786095 & 7.4089 & 7.1162 & TRN & \\
\hline CHEMBL1915045 & 786095 & 7.4559 & 7.4655 & TRN & \\
\hline CHEMBL1915048 & 786095 & 8.0269 & 7.4549 & TRN & \\
\hline CHEMBL1914783 & 786095 & 9.0 & 8.6298 & TRN & \\
\hline CHEMBL1914781 & 786095 & 9.1549 & 8.9818 & TRN & \\
\hline CHEMBL1915036 & 786095 & 4.0 & 5.0957 & TRN & \\
\hline CHEMBL421582 & 97281 & 6.3372 & 6.186 & TRN & \\
\hline CHEMBL133968 & 97281 & 4.7447 & 4.5928 & TRN & \\
\hline CHEMBL132992 & 97281 & 5.585 & 5.8366 & TRN & \\
\hline CHEMBL131013 & 97281 & 6.8539 & 6.8414 & TRN & \\
\hline CHEMBL130418 & 97281 & 4.4815 & 4.3326 & TRN & \\
\hline CHEMBL335937 & 97281 & 5.2518 & 6.5818 & TST & \\
\hline CHEMBL127552 & 97281 & 6.0177 & 5.8798 & TRN & \\
\hline CHEMBL131513 & 97281 & 6.2757 & 6.1229 & TRN & \\
\hline CHEMBL131178 & 97281 & 4.7905 & 4.8878 & TRN & \\
\hline CHEMBL129870 & 97281 & 5.4202 & 5.487 & TRN & \\
\hline CHEMBL131260 & 97281 & 3.0 & 2.8917 & TRN & \\
\hline CHEMBL128109 & 97281 & 6.3768 & 6.6654 & TRN & \\
\hline CHEMBL128305 & 97281 & 6.9586 & 7.0736 & TRN & \\
\hline CHEMBL130992 & 97281 & 3.0 & 3.3931 & TST & \\
\hline CHEMBL129963 & 97281 & 3.699 & 4.5641 & TRN & \\
\hline CHEMBL422802 & 97281 & 6.7696 & 6.8608 & TRN & \\
\hline CHEMBL131466 & 97281 & 6.2291 & 5.2911 & TRN & \\
\hline CHEMBL101416 & 97281 & 6.8539 & 6.4529 & TRN & \\
\hline CHEMBL130488 & 97281 & 3.699 & 3.7263 & TRN & \\
\hline CHEMBL262940 & 97281 & 7.0 & 7.0238 & TRN & \\
\hline CHEMBL131314 & 97281 & 6.9208 & 6.7672 & TRN & \\
\hline CHEMBL131562 & 97281 & 6.2147 & 5.7021 & TRN & \\
\hline CHEMBL130311 & 97281 & 4.0862 & 5.3853 & TST & \\
\hline CHEMBL129929 & 97281 & 6.1249 & 6.05 & TRN & \\
\hline CHEMBL128368 & 97281 & 4.0 & 4.3503 & TRN & \\
\hline CHEMBL128584 & 97281 & 6.2076 & 6.2511 & TRN & \\
\hline CHEMBL131368 & 97281 & 4.7825 & 4.95 & TRN & \\
\hline CHEMBL335444 & 97281 & 5.1549 & 5.3714 & TRN & \\
\hline CHEMBL130468 & 97281 & 6.8239 & 6.8835 & TRN & \\
\hline CHEMBL338870 & 97281 & 6.7447 & 6.477 & TRN & \\
\hline
\end{tabular}




\begin{tabular}{|c|c|c|c|c|c|}
\hline \multicolumn{6}{|c|}{ Supplemental Table S2.txt } \\
\hline CHEMBL334396 & 97281 & 4.0 & 4.0333 & TRN & \\
\hline CHEMBL128805 & 97281 & 5.9208 & 5.5986 & TRN & \\
\hline CHEMBL128509 & 97281 & 5.6778 & 5.5461 & TST & \\
\hline CHEMBL339871 & 97281 & 6.5086 & 6.7043 & TRN & \\
\hline CHEMBL131348 & 97281 & 5.8539 & 6.3747 & TRN & \\
\hline CHEMBL129869 & 97281 & 7.0458 & 7.029 & TRN & \\
\hline CHEMBL19677 & 97281 & 7.3565 & 7.142 & TRN & \\
\hline CHEMBL130292 & 97281 & 7.2218 & 7.3258 & TRN & \\
\hline CHEMBL423895 & 97281 & 3.699 & 3.6036 & TRN & \\
\hline CHEMBL131594 & 97281 & 5.4815 & 5.8931 & TRN & \\
\hline CHEMBL 334414 & 97281 & 5.4089 & 5.6009 & TRN & \\
\hline CHEMBL133178 & 97281 & 6.585 & 6.6673 & TRN & \\
\hline CHEMBL128482 & 97281 & 4.8239 & 4.6735 & TST & \\
\hline CHEMBL133411 & 97281 & 4.2147 & 5.0764 & TST & \\
\hline CHEMBL316691 & 97281 & 6.2596 & 6.182 & TRN & \\
\hline CHEMBL319484 & 97281 & 5.9586 & 6.145 & TRN & \\
\hline CHEMBL130486 & 97281 & 7.1871 & 7.0504 & TRN & \\
\hline CHEMBL 267203 & 97281 & 6.0362 & 5.8814 & TRN & \\
\hline CHEMBL 338062 & 97281 & 4.9208 & 4.6076 & TRN & \\
\hline CHEMBL132287 & 97281 & 4.7212 & 4.7925 & TRN & \\
\hline CHEMBL131769 & 97281 & 6.1487 & 5.9797 & TST & \\
\hline CHEMBL130110 & 97281 & 7.0 & 7.0898 & TRN & \\
\hline CHEMBL424446 & 97281 & 6.7447 & 6.707999 & э999999999 & TRI \\
\hline CHEMBL131576 & 97281 & 6.1871 & 6.2154 & TRN & \\
\hline CHEMBL419958 & 97281 & 5.0088 & 3.9878 & TST & \\
\hline CHEMBL132221 & 97281 & 3.0 & 5.0472 & TST & \\
\hline CHEMBL334782 & 97281 & 5.6383 & 5.1235 & TST & \\
\hline CHEMBL339361 & 97281 & 5.585 & 4.9873 & TST & \\
\hline CHEMBL131563 & 97281 & 4.8097 & 5.4203 & TST & \\
\hline CHEMBL435596 & 97281 & 5.3468 & 5.085 & TST & \\
\hline CHEMBL130446 & 97281 & 3.699 & 4.4578 & TST & \\
\hline CHEMBL422262 & 97281 & 3.0 & 3.1821 & TST & \\
\hline CHEMBL339317 & 97281 & 5.7959 & 5.4415 & TST & \\
\hline CHEMBL1452646 & 752395 & 5.3729 & 5.3694 & TRN & \\
\hline CHEMBL1486109 & 752395 & 4.6894 & 5.1019 & TRN & \\
\hline CHEMBL 3144906 & 752395 & 5.1052 & 5.1404 & TRN & \\
\hline CHEMBL1509975 & 752395 & 5.3471 & 5.7426 & TRN & \\
\hline CHEMBL1728153 & 752395 & 5.8265 & 5.8826 & TRN & \\
\hline CHEMBL1721015 & 752395 & 5.3712 & 5.3529 & TRN & \\
\hline CHEMBL1502004 & 752395 & 5.3682 & 5.3766 & TRN & \\
\hline CHEMBL1426440 & 752395 & 5.7698 & 5.5144 & TST & \\
\hline CHEMBL1461236 & 752395 & 5.1188 & 5.1944 & TRN & \\
\hline CHEMBL1536248 & 752395 & 7.71 & 6.7756 & TRN & \\
\hline CHEMBL1332450 & 752395 & 5.3382 & 5.3189 & TRN & \\
\hline CHEMBL591126 & 752395 & 5.21899 & 999999999 & 5.4319 & TRN \\
\hline CHEMBL1409985 & 752395 & 5.3444 & 5.461 & TST & \\
\hline CHEMBL1388119 & 752395 & 5.0534 & 5.0703 & TRN & \\
\hline CHEMBL1509060 & 752395 & 5.2548 & 5.3193 & TST & \\
\hline
\end{tabular}




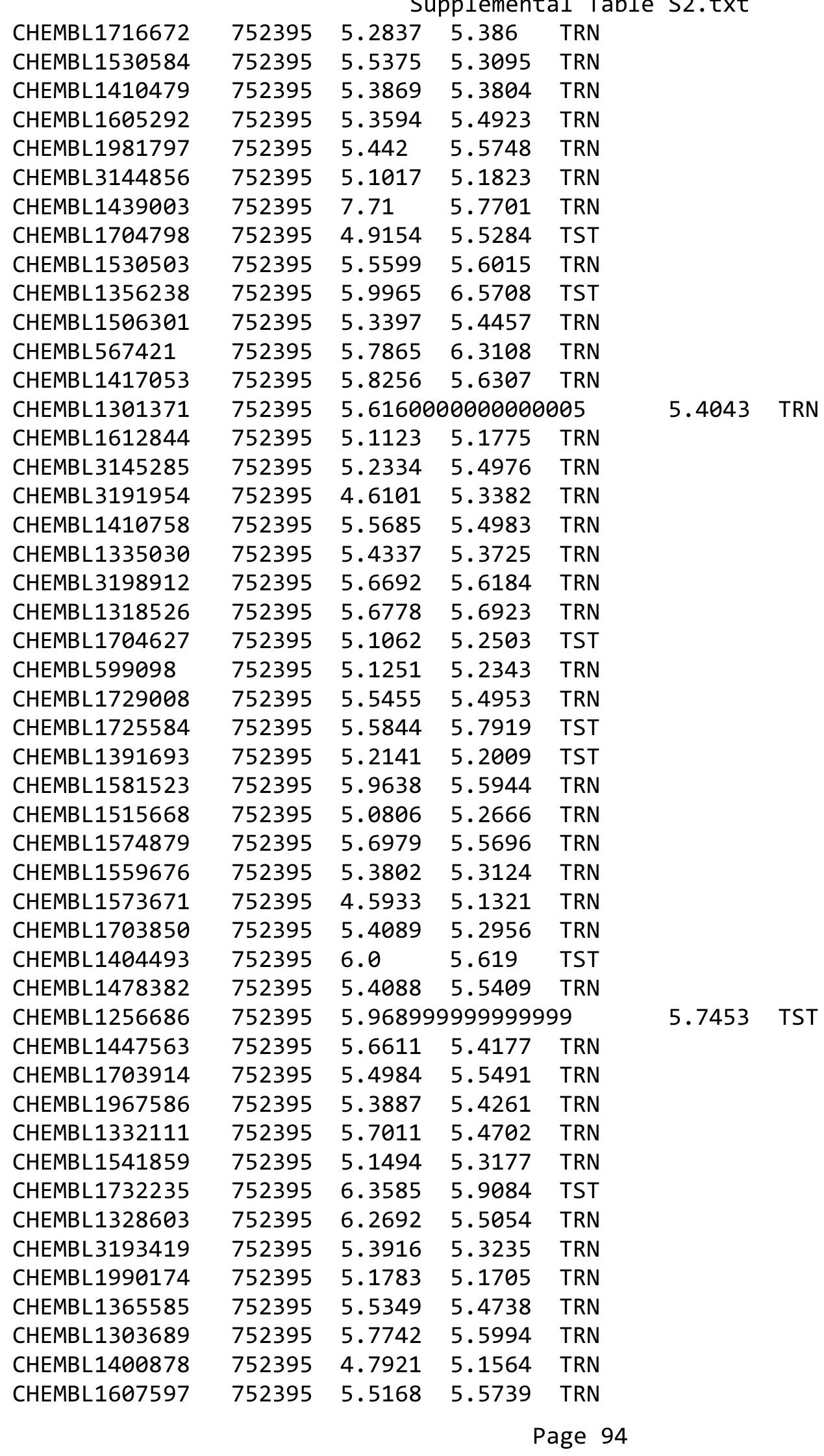


Supplemental Table S2.txt

\begin{tabular}{|c|c|c|c|c|}
\hline CHEMBL1711925 & 752395 & 4.7991 & 5.4596 & TST \\
\hline CHEMBL3198994 & 752395 & 4.9756 & 5.553 & TRN \\
\hline CHEMBL1991277 & 752395 & 6.1959 & 5.4838 & TRN \\
\hline CHEMBL1407401 & 752395 & 5.6902 & 5.6172 & TRN \\
\hline CHEMBL1711441 & 752395 & 4.8257 & 5.11 & TRN \\
\hline CHEMBL1415813 & 752395 & 5.7744 & 5.3419 & TRN \\
\hline CHEMBL1306556 & 752395 & 5.1301 & 5.1896 & TRN \\
\hline CHEMBL 2002776 & 752395 & 4.7626 & 4.9755 & TRN \\
\hline CHEMBL1973042 & 752395 & 5.3816 & 5.3475 & TRN \\
\hline CHEMBL1319984 & 752395 & 5.4496 & 5.4187 & TRN \\
\hline CHEMBL1582831 & 752395 & 5.6944 & 5.6508 & TRN \\
\hline CHEMBL1356395 & 752395 & 5.5589 & 5.3859 & TRN \\
\hline CHEMBL1370183 & 752395 & 4.5653 & 5.7215 & TRN \\
\hline CHEMBL69612 & 752395 & 5.7617 & 5.5043 & TRN \\
\hline CHEMBL1697947 & 752395 & 5.0858 & 5.4478 & TST \\
\hline CHEMBL1362061 & 752395 & 5.0903 & 5.1905 & TST \\
\hline CHEMBL1727063 & 752395 & 5.2866 & 5.4261 & TST \\
\hline CHEMBL1328504 & 752395 & 5.4725 & 5.2959 & TRN \\
\hline CHEMBL1986678 & 752395 & 5.5724 & 5.5106 & TRN \\
\hline CHEMBL1736490 & 752395 & 5.8 & 5.5458 & TRN \\
\hline CHEMBL 363491 & 752395 & 6.0061 & 5.6118 & TRN \\
\hline CHEMBL1584597 & 752395 & 6.068 & 5.7438 & TRN \\
\hline CHEMBL1541834 & 752395 & 5.1153 & 5.3134 & TRN \\
\hline CHEMBL1478024 & 752395 & 4.5955 & 5.004 & TRN \\
\hline CHEMBL1328511 & 752395 & 5.5085 & \multicolumn{2}{|c|}{5.542000000000001} \\
\hline CHEMBL1348836 & 752395 & 6.0097 & 5.6647 & TRN \\
\hline CHEMBL 282489 & 752395 & 5.1993 & 5.1741 & TST \\
\hline CHEMBL1589118 & 752395 & 5.6 & \multicolumn{2}{|c|}{5.127000000000001} \\
\hline CHEMBL523200 & 752395 & 5.6533 & 5.3936 & TRN \\
\hline CHEMBL1423096 & 752395 & 5.1078 & 5.1816 & TST \\
\hline CHEMBL1448285 & 752395 & 5.4055 & 5.4217 & TRN \\
\hline CHEMBL1417329 & 752395 & 5.088 & 5.2168 & TRN \\
\hline CHEMBL1310234 & 752395 & 5.1739 & 5.2495 & TRN \\
\hline CHEMBL1481836 & 752395 & 5.3916 & 5.3462 & TRN \\
\hline CHEMBL1443383 & 752395 & 5.1065 & 5.2537 & TRN \\
\hline CHEMBL1718737 & 752395 & 5.0461 & 5.2143 & TST \\
\hline CHEMBL1536493 & 752395 & 5.5669 & 5.5031 & TRN \\
\hline CHEMBL592600 & 752395 & 5.4461 & 5.4938 & TRN \\
\hline CHEMBL1550794 & 752395 & 5.4448 & 5.2555 & TRN \\
\hline CHEMBL1790039 & 752395 & 6.1226 & 5.7667 & TST \\
\hline CHEMBL1720801 & 752395 & 5.7053 & 5.5554 & TRN \\
\hline CHEMBL1597768 & 752395 & 4.9718 & 5.2061 & TRN \\
\hline CHEMBL1532232 & 752395 & 5.3933 & 5.5121 & TRN \\
\hline CHEMBL1529236 & 752395 & 5.0557 & 5.2348 & TRN \\
\hline CHEMBL89445 & 752395 & 5.8693 & 5.6746 & TRN \\
\hline CHEMBL1993788 & 752395 & 4.8073 & 5.3291 & TRN \\
\hline CHEMBL1359384 & 752395 & 4.7332 & 5.2036 & TST \\
\hline CHEMBL3192475 & 752395 & 5.7036 & 5.5952 & TRN \\
\hline
\end{tabular}


Supplemental Table S2.txt

\begin{tabular}{|c|c|c|c|c|c|}
\hline CHEMBL1726247 & 752395 & 6.0106 & 5.6996 & TRN & \\
\hline CHEMBL 3207561 & 752395 & 5.2115 & 5.3053 & TRN & \\
\hline CHEMBL1335220 & 752395 & 5.3655 & 5.45200 & 0000000001 & TST \\
\hline CHEMBL1382617 & 752395 & 5.3229 & 5.1387 & TRN & \\
\hline CHEMBL591361 & 752395 & 5.421 & 5.1953 & TRN & \\
\hline CHEMBL1372112 & 752395 & 5.5452 & 5.436 & TRN & \\
\hline CHEMBL1594483 & 752395 & 5.7406 & 5.8744 & TST & \\
\hline CHEMBL 260342 & 752395 & 5.6946 & 5.2982 & TRN & \\
\hline CHEMBL1339522 & 752395 & 5.8047 & 5.4648 & TRN & \\
\hline CHEMBL1468982 & 752395 & 4.9953 & 5.3365 & TRN & \\
\hline CHEMBL1488095 & 752395 & 6.5302 & 6.8601 & TRN & \\
\hline CHEMBL1966872 & 752395 & 5.087 & 5.1075 & TST & \\
\hline CHEMBL1392793 & 752395 & 5.1019 & 5.2654 & TRN & \\
\hline CHEMBL1515267 & 752395 & 5.102 & 5.185 & TRN & \\
\hline CHEMBL1996730 & 752395 & 5.4018 & 5.4391 & TRN & \\
\hline CHEMBL1717138 & 752395 & 5.4575 & 5.4098 & TRN & \\
\hline CHEMBL1502605 & 752395 & 5.9104 & 5.7859 & TRN & \\
\hline CHEMBL1439210 & 752395 & 5.3012 & 5.3033 & TRN & \\
\hline CHEMBL1398937 & 752395 & 5.0882 & 5.2452 & TRN & \\
\hline CHEMBL582099 & 752395 & 5.5698 & 5.4016 & TRN & \\
\hline CHEMBL1708074 & 752395 & 5.3761 & 5.2508 & TST & \\
\hline CHEMBL1382917 & 752395 & 5.1107 & 5.1622 & TST & \\
\hline CHEMBL1324303 & 752395 & 5.0768 & 5.2169 & TRN & \\
\hline CHEMBL1458812 & 752395 & 5.8289 & 5.5667 & TRN & \\
\hline CHEMBL1732556 & 752395 & 5.064 & 5.2642 & TRN & \\
\hline CHEMBL528694 & 752395 & 5.3326 & 5.3269 & TRN & \\
\hline CHEMBL1560628 & 752395 & 5.1567 & 5.1809 & TRN & \\
\hline CHEMBL 3197424 & 752395 & 5.3426 & 5.3743 & TRN & \\
\hline CHEMBL1448722 & 752395 & 5.5207 & 5.2188 & TRN & \\
\hline CHEMBL1563370 & 752395 & 5.0713 & 5.4192 & TST & \\
\hline CHEMBL3192152 & 752395 & 5.414 & \multicolumn{2}{|c|}{5.337000000000001} & TRN \\
\hline CHEMBL1520716 & 752395 & 4.7528 & 5.2556 & TRN & \\
\hline CHEMBL1439833 & 752395 & 5.4667 & 5.2908 & TRN & \\
\hline CHEMBL1715463 & 752395 & 5.6619 & 5.7333 & TST & \\
\hline CHEMBL1587031 & 752395 & 5.0887 & 5.2616 & TST & \\
\hline CHEMBL1416493 & 752395 & 4.9057 & 4.9966 & TRN & \\
\hline CHEMBL1362832 & 752395 & 5.521 & 5.46899 & 9999999999 & TRN \\
\hline CHEMBL1370387 & 752395 & 5.0936 & 5.1964 & TRN & \\
\hline CHEMBL1471900 & 752395 & 5.6562 & 5.6941 & TRN & \\
\hline CHEMBL1490222 & 752395 & 5.4535 & 5.3098 & TRN & \\
\hline CHEMBL3196732 & 752395 & 5.3644 & 5.5034 & TRN & \\
\hline CHEMBL1488021 & 752395 & 5.216 & 5.4819 & TST & \\
\hline CHEMBL1526174 & 752395 & 6.2411 & 5.9265 & TRN & \\
\hline CHEMBL1523997 & 752395 & 5.8914 & 5.9632 & TRN & \\
\hline CHEMBL1726787 & 752395 & 5.0851 & 5.1786 & TRN & \\
\hline CHEMBL203695 & 752395 & 5.2884 & 5.1468 & TRN & \\
\hline CHEMBL1725990 & 752395 & 4.7903 & 5.0156 & TRN & \\
\hline CHEMBL1327183 & 752395 & 4.5822 & 4.9927 & TRN & \\
\hline
\end{tabular}




\begin{tabular}{|c|c|c|c|c|c|}
\hline & & & & & \\
\hline CHEMBL1986557 & 752395 & 5.4604 & 5.329 & TST & \\
\hline CHEMBL601768 & 752395 & 5.3934 & 5.1521 & TRN & \\
\hline CHEMBL1459468 & 752395 & 6.2557 & 5.6266 & TRN & \\
\hline CHEMBL1875929 & 752395 & 5.3245 & 5.2406 & TST & \\
\hline CHEMBL1565674 & 752395 & 5.9876 & 5.5852 & TRN & \\
\hline CHEMBL1393385 & 752395 & 5.3752 & 5.3491 & TRN & \\
\hline CHEMBL505670 & 752395 & 5.4077 & 5.3313 & TRN & \\
\hline CHEMBL1527151 & 752395 & 5.2386 & 5.3647 & TRN & \\
\hline CHEMBL560579 & 752395 & 7.71 & 6.7481 & TRN & \\
\hline CHEMBL1520254 & 752395 & 5.6297 & 5.3593 & TRN & \\
\hline CHEMBL1526505 & 752395 & 5.4713 & 5.5097 & TRN & \\
\hline CHEMBL473721 & 752395 & 4.3565 & 4.6376 & TRN & \\
\hline CHEMBL1440300 & 752395 & 7.71 & 5.8366 & TRN & \\
\hline CHEMBL1363361 & 752395 & 5.6815 & 5.3634 & TRN & \\
\hline CHEMBL1710307 & 752395 & 5.1451 & 5.2055 & TRN & \\
\hline CHEMBL1713454 & 752395 & 5.2884 & 5.2977 & TRN & \\
\hline CHEMBL1567272 & 752395 & 5.3703 & 5.4257 & TRN & \\
\hline CHEMBL1494120 & 752395 & 6.0531 & 5.8139 & TRN & \\
\hline CHEMBL1418299 & 752395 & 5.5203 & 5.5196 & TRN & \\
\hline CHEMBL1539339 & 752395 & 5.4569 & 5.29899 & 99999999995 & TST \\
\hline CHEMBL1378295 & 752395 & 5.1097 & 5.1293 & TRN & \\
\hline CHEMBL1709779 & 752395 & 5.1409 & 5.1707 & TRN & \\
\hline CHEMBL1369441 & 752395 & 5.3736 & 5.3538 & TRN & \\
\hline CHEMBL1708706 & 752395 & 5.3806 & 5.4237 & TST & \\
\hline CHEMBL1985598 & 752395 & 5.569 & 5.4067 & TRN & \\
\hline CHEMBL567622 & 752395 & 6.4225 & 6.7559 & TRN & \\
\hline CHEMBL 86104 & 752395 & 5.8781 & 5.4484 & TRN & \\
\hline CHEMBL64391 & 752395 & 7.71 & 6.8711 & TRN & \\
\hline CHEMBL1443126 & 752395 & 6.1367 & 6.0706 & TRN & \\
\hline CHEMBL1506580 & 752395 & 5.6572 & 5.5971 & TRN & \\
\hline CHEMBL1733848 & 752395 & 5.5317 & 5.3732 & TRN & \\
\hline CHEMBL1503864 & 752395 & 5.3969 & 5.294 & TST & \\
\hline CHEMBL1308170 & 752395 & 5.2699 & 5.2919 & TST & \\
\hline CHEMBL590927 & 752395 & 5.3896 & 5.2195 & TRN & \\
\hline CHEMBL1542436 & 752395 & 5.3004 & 5.3163 & TRN & \\
\hline CHEMBL1511593 & 752395 & 5.3374 & 5.0496 & TRN & \\
\hline CHEMBL 240332 & 752395 & 5.4121 & 5.3759 & TRN & \\
\hline CHEMBL1338958 & 752395 & 5.3605 & 5.2771 & TRN & \\
\hline CHEMBL269163 & 752395 & 5.3503 & 5.3248 & TRN & \\
\hline CHEMBL1700268 & 752395 & 6.5287 & 5.7333 & TST & \\
\hline CHEMBL1483252 & 752395 & 5.7989 & 5.9684 & TRN & \\
\hline CHEMBL1561738 & 752395 & 5.1632 & 5.3063 & TST & \\
\hline CHEMBL1384790 & 752395 & 5.3865 & 5.4475 & TRN & \\
\hline CHEMBL1709364 & 752395 & 5.8005 & 5.5373 & TRN & \\
\hline CHEMBL3196691 & 752395 & 5.2756 & 5.4054 & TRN & \\
\hline CHEMBL1311826 & 752395 & 5.8044 & 5.6362 & TRN & \\
\hline CHEMBL1492677 & 752395 & 5.78600 & 00000000 & 5.7172 & TRN \\
\hline CHEMBL1549128 & 752395 & 5.1055 & 5.2734 & TST & \\
\hline
\end{tabular}


Supplemental Table S2.txt

\begin{tabular}{|c|c|c|c|c|c|c|}
\hline CHEMBL1353112 & 752395 & 3.7676 & 5.4239 & TRN & & \\
\hline CHEMBL 3196404 & 752395 & 5.2427 & 5.2545 & TRN & & \\
\hline CHEMBL265699 & 752395 & 4.785 & 4.9424 & TRN & & \\
\hline CHEMBL1491279 & 752395 & 5.1931 & 5.3914 & TRN & & \\
\hline CHEMBL1894226 & 752395 & 5.5677 & 6.6659 & TRN & & \\
\hline CHEMBL1870867 & 752395 & 5.0704 & 5.1886 & TRN & & \\
\hline CHEMBL1708852 & 752395 & 5.0868 & 5.2054 & TRN & & \\
\hline CHEMBL1555271 & 752395 & 5.3885 & 5.2974 & TRN & & \\
\hline CHEMBL1350780 & 752395 & 5.2434 & 5.4521 & TRN & & \\
\hline CHEMBL1499893 & 752395 & 5.3857 & 5.3211 & TRN & & \\
\hline CHEMBL1698845 & 752395 & 6.2441 & 5.8469 & TST & & \\
\hline CHEMBL1464948 & 752395 & 5.1223 & 5.1893 & TST & & \\
\hline CHEMBL1589298 & 752395 & 6.3526 & 5.876 & TRN & & \\
\hline CHEMBL1554214 & 752395 & 5.9485 & 5.6463 & TRN & & \\
\hline CHEMBL1348468 & 752395 & 5.1115 & 5.3434 & TRN & & \\
\hline CHEMBL1410739 & 752395 & 5.0399 & 5.3025 & TRN & & \\
\hline CHEMBL1733942 & 752395 & 5.519 & 5.593 & TRN & & \\
\hline CHEMBL492886 & 752395 & 5.4488 & 5.4734 & TRN & & \\
\hline CHEMBL131037 & 752395 & 5.5187 & 5.6313 & TRN & & \\
\hline CHEMBL1474684 & 752395 & 5.4212 & 5.4535 & TST & & \\
\hline CHEMBL 2000750 & 752395 & 4.8537 & 5.0523 & TRN & & \\
\hline CHEMBL1707960 & 752395 & 4.8394 & 5.3717 & TRN & & \\
\hline CHEMBL1483235 & 752395 & 4.4881 & 4.9269 & TRN & & \\
\hline CHEMBL 3190808 & 752395 & 5.5168 & 5.4876 & TRN & & \\
\hline CHEMBL1400298 & 752395 & 5.5688 & 5.4415 & TRN & & \\
\hline CHEMBL251369 & 752395 & 5.4395 & 5.3004 & TRN & & \\
\hline CHEMBL1333737 & 752395 & \multicolumn{3}{|c|}{5.997000000000001} & 5.6412 & $\mathrm{TP}$ \\
\hline CHEMBL1404602 & 752395 & 4.978 & 5.5425 & TRN & & \\
\hline CHEMBL1559558 & 752395 & 5.0947 & 5.209 & TST & & \\
\hline CHEMBL1502038 & 752395 & 5.7796 & 5.4761 & TST & & \\
\hline CHEMBL 3199364 & 752395 & 5.0402 & 5.1483 & TST & & \\
\hline CHEMBL1711095 & 752395 & 5.0985 & 5.1515 & TRN & & \\
\hline CHEMBL1569871 & 752395 & \multicolumn{3}{|c|}{6.007000000000001} & 5.7141 & TRN \\
\hline CHEMBL1722821 & 752395 & 5.7975 & 5.5257 & TRN & & \\
\hline CHEMBL570345 & 752395 & 5.4559 & 5.4989 & TRN & & \\
\hline CHEMBL1471612 & 752395 & 5.1915 & 5.2265 & TRN & & \\
\hline CHEMBL1570705 & 752395 & 5.7865 & 5.6166 & TRN & & \\
\hline CHEMBL1422477 & 752395 & 4.8268 & 5.1458 & TRN & & \\
\hline CHEMBL585071 & 752395 & 5.374 & 5.4514 & TRN & & \\
\hline CHEMBL1378952 & 752395 & 6.1135 & 5.9554 & TRN & & \\
\hline CHEMBL1719994 & 752395 & 5.5262 & 5.4392 & TRN & & \\
\hline CHEMBL1507679 & 752395 & 6.2472 & 5.894 & TRN & & \\
\hline CHEMBL1369200 & 752395 & \multicolumn{3}{|c|}{5.5360000000000005} & 5.3342 & TRN \\
\hline CHEMBL1605052 & 752395 & 5.2612 & 5.2515 & TST & & \\
\hline CHEMBL1506823 & 752395 & \multicolumn{3}{|c|}{5.547000000000001} & 5.4281 & I RN \\
\hline CHEMBL1699691 & 752395 & 5.6392 & 5.5417 & TST & & \\
\hline CHEMBL1535361 & 752395 & 5.1887 & 5.4119 & TRN & & \\
\hline CHEMBL1519630 & 752395 & \multicolumn{3}{|c|}{ 5.343999999999999 } & 5.4272 & N \\
\hline
\end{tabular}

Page 98 
Supplemental Table S2.txt

\begin{tabular}{|c|c|c|c|c|}
\hline CHEMBL1303810 & 752395 & 5.0772 & 5.3759 & TRN \\
\hline CHEMBL1403802 & 752395 & 5.5991 & 5.5002 & TST \\
\hline CHEMBL1385989 & 752395 & 5.3818 & 5.2601 & TST \\
\hline CHEMBL1506041 & 752395 & 4.7634 & 5.46 & TRN \\
\hline CHEMBL1441485 & 752395 & 5.3233 & 5.2492 & TRN \\
\hline CHEMBL1442280 & 752395 & 4.6163 & 4.9601 & TRN \\
\hline CHEMBL1300370 & 752395 & 5.476 & 5.6813 & TRN \\
\hline CHEMBL1469916 & 752395 & 5.4347 & 5.4634 & TRN \\
\hline CHEMBL1487183 & 752395 & 5.3923 & 5.3883 & TST \\
\hline CHEMBL1362566 & 752395 & 5.074 & 5.3278 & TRN \\
\hline CHEMBL1986690 & 752395 & 5.2109 & 5.1831 & TRN \\
\hline CHEMBL1447284 & 752395 & 5.4757 & 5.3671 & TRN \\
\hline CHEMBL 239275 & 752395 & 4.9054 & 5.2317 & TRN \\
\hline CHEMBL1403191 & 752395 & 5.8207 & 5.4405 & TRN \\
\hline CHEMBL1718805 & 752395 & 6.3625 & 6.6239 & TRN \\
\hline CHEMBL1332139 & 752395 & 5.6404 & 5.4795 & TRN \\
\hline CHEMBL1338045 & 752395 & 6.1249 & 6.0853 & TRN \\
\hline CHEMBL1531308 & 752395 & 5.5161 & 5.5909 & TRN \\
\hline CHEMBL1722933 & 752395 & 4.7812 & 5.1908 & TRN \\
\hline CHEMBL1534390 & 752395 & 5.48 & 5.3979 & TRN \\
\hline CHEMBL1688556 & 752395 & 5.4066 & 6.6051 & TRN \\
\hline CHEMBL1699845 & 752395 & 5.5693 & 6.6423 & TRN \\
\hline CHEMBL1577064 & 752395 & 5.9706 & 5.8625 & TRN \\
\hline CHEMBL1605668 & 752395 & 5.0313 & 5.3114 & TRN \\
\hline CHEMBL1594984 & 752395 & 4.8087 & 5.235 & TRN \\
\hline CHEMBL1698281 & 752395 & 6.2832 & 5.3456 & TST \\
\hline CHEMBL1309364 & 752395 & 4.4527 & 5.4599 & TRN \\
\hline CHEMBL1569910 & 752395 & 7.71 & 6.6723 & TRN \\
\hline CHEMBL1991736 & 752395 & 5.0976 & 5.1698 & TRN \\
\hline CHEMBL1468684 & 752395 & 5.6313 & 5.331 & TRN \\
\hline CHEMBL1539001 & 752395 & 5.4263 & 5.4744 & TRN \\
\hline CHEMBL578944 & 752395 & 5.2693 & 5.4395 & TRN \\
\hline CHEMBL1437683 & 752395 & 5.7357 & 5.4611 & TRN \\
\hline CHEMBL1531377 & 752395 & 5.6247 & 5.747999 & 999999999 \\
\hline CHEMBL1309484 & 752395 & 5.5432 & 5.4118 & TRN \\
\hline CHEMBL1343392 & 752395 & 5.3683 & 5.4268 & TRN \\
\hline CHEMBL453974 & 752395 & 6.4461 & 5.5717 & TST \\
\hline CHEMBL1447124 & 752395 & 5.8236 & 6.0339 & TRN \\
\hline CHEMBL1382939 & 752395 & 5.3016 & 5.2569 & TRN \\
\hline CHEMBL3192061 & 752395 & 5.8216 & 6.0697 & TRN \\
\hline CHEMBL140425 & 752395 & 5.7296 & 5.5571 & TRN \\
\hline CHEMBL1400457 & 752395 & 6.0773 & 5.8416 & TRN \\
\hline CHEMBL1727678 & 752395 & 5.1193 & 5.1708 & TRN \\
\hline CHEMBL3189712 & 752395 & 5.6786 & 5.3609 & TRN \\
\hline CHEMBL1446971 & 752395 & 5.4363 & 5.4812 & TRN \\
\hline CHEMBL1407812 & 752395 & 5.364 & 5.4059 & TRN \\
\hline CHEMBL1719093 & 752395 & 4.6258 & 5.0467 & TRN \\
\hline CHEMBL1374672 & 752395 & 5.5455 & 5.4064 & TRN \\
\hline
\end{tabular}




\begin{tabular}{|c|c|c|c|c|c|c|}
\hline CHEMBL1357277 & 752395 & \multicolumn{4}{|c|}{ Supplemental Table S2.txt } & TRN \\
\hline CHEMBL1582091 & 752395 & 5.1867 & \multicolumn{3}{|c|}{5.332999999999999} & TRN \\
\hline CHEMBL478791 & 752395 & 5.0956 & 5.2641 & TST & & \\
\hline CHEMBL1578641 & 752395 & 6.1605 & 5.858 & TRN & & \\
\hline CHEMBL3196754 & 752395 & 4.6103 & 4.9894 & TRN & & \\
\hline CHEMBL1330109 & 752395 & 5.6249 & 5.5072 & TRN & & \\
\hline CHEMBL1374860 & 752395 & 6.0325 & 5.6783 & TRN & & \\
\hline CHEMBL1333830 & 752395 & 5.3436 & 5.388 & TST & & \\
\hline CHEMBL1706082 & 752395 & 5.4743 & 5.412999 & 999999999 & & TRN \\
\hline CHEMBL 280065 & 752395 & 5.1154 & 5.3755 & TRN & & \\
\hline CHEMBL1988042 & 752395 & 5.6507 & 5.3902 & TRN & & \\
\hline CHEMBL1727268 & 752395 & 6.3019 & 6.7427 & TRN & & \\
\hline CHEMBL1608016 & 752395 & 4.9926 & 5.0484 & TRN & & \\
\hline CHEMBL1544423 & 752395 & 5.379 & 5.3326 & TRN & & \\
\hline CHEMBL1519298 & 752395 & 6.1605 & 6.7654 & TRN & & \\
\hline CHEMBL1606097 & 752395 & 5.4861 & 5.1743 & TRN & & \\
\hline CHEMBL3193391 & 752395 & 5.524 & 5.5297 & TRN & & \\
\hline CHEMBL1542804 & 752395 & 5.7582 & 5.3819 & TRN & & \\
\hline CHEMBL1549308 & 752395 & 5.1714 & 5.1647 & TRN & & \\
\hline CHEMBL1431608 & 752395 & 5.3787 & 5.3955 & TRN & & \\
\hline CHEMBL1901693 & 752395 & \multicolumn{3}{|c|}{6.082999999999999} & 5.7909 & TRN \\
\hline CHEMBL1598569 & 752395 & 4.9339 & 4.9817 & TRN & & \\
\hline CHEMBL1540682 & 752395 & 5.5613 & 5.4725 & TST & & \\
\hline CHEMBL1327737 & 752395 & 5.0967 & 5.3603 & TRN & & \\
\hline CHEMBL1584720 & 752395 & 5.1229 & 5.1945 & TRN & & \\
\hline CHEMBL1568996 & 752395 & 5.3127 & 5.3176 & TST & & \\
\hline CHEMBL1519239 & 752395 & 5.6225 & 5.523 & TRN & & \\
\hline CHEMBL1608255 & 752395 & 6.1878 & 5.8121 & TST & & \\
\hline CHEMBL2006168 & 752395 & 5.4501 & 5.4832 & TRN & & \\
\hline CHEMBL1698608 & 752395 & 5.6615 & 5.3948 & TRN & & \\
\hline CHEMBL1712384 & 752395 & 5.0755 & 5.4553 & TST & & \\
\hline CHEMBL1458022 & 752395 & 5.8598 & 5.6514 & TRN & & \\
\hline CHEMBL1339979 & 752395 & 4.1589 & 5.3352 & TRN & & \\
\hline CHEMBL1897901 & 752395 & 5.121 & 5.1644 & TST & & \\
\hline CHEMBL1542748 & 752395 & 5.5444 & 5.3816 & TST & & \\
\hline CHEMBL582983 & 752395 & 7.71 & 6.9541 & TST & & \\
\hline CHEMBL1459279 & 752395 & 5.2463 & 5.4229 & TST & & \\
\hline CHEMBL1976308 & 752395 & 5.7361 & 5.5324 & TRN & & \\
\hline CHEMBL1477640 & 752395 & 5.4253 & 5.3088 & TRN & & \\
\hline CHEMBL1499792 & 752395 & 5.5089 & 6.584 & TRN & & \\
\hline CHEMBL1986664 & 752395 & 5.5099 & 5.2988 & TRN & & \\
\hline CHEMBL1438881 & 752395 & \multicolumn{3}{|c|}{5.542000000000001} & 5.4751 & TRN \\
\hline CHEMBL1518799 & 752395 & 5.4008 & 5.4167 & TRN & & \\
\hline CHEMBL1720380 & 752395 & 5.3879 & 5.474 & TST & & \\
\hline CHEMBL1375884 & 752395 & 5.7622 & 5.4057 & TRN & & \\
\hline CHEMBL1466186 & 752395 & \multicolumn{3}{|c|}{5.412999999999999} & 5.2939 & TRN \\
\hline CHEMBL1540985 & 752395 & 5.3859 & 5.2041 & TRN & & \\
\hline CHEMBL1418885 & 752395 & 5.5207 & 5.6131 & TRN & & \\
\hline
\end{tabular}




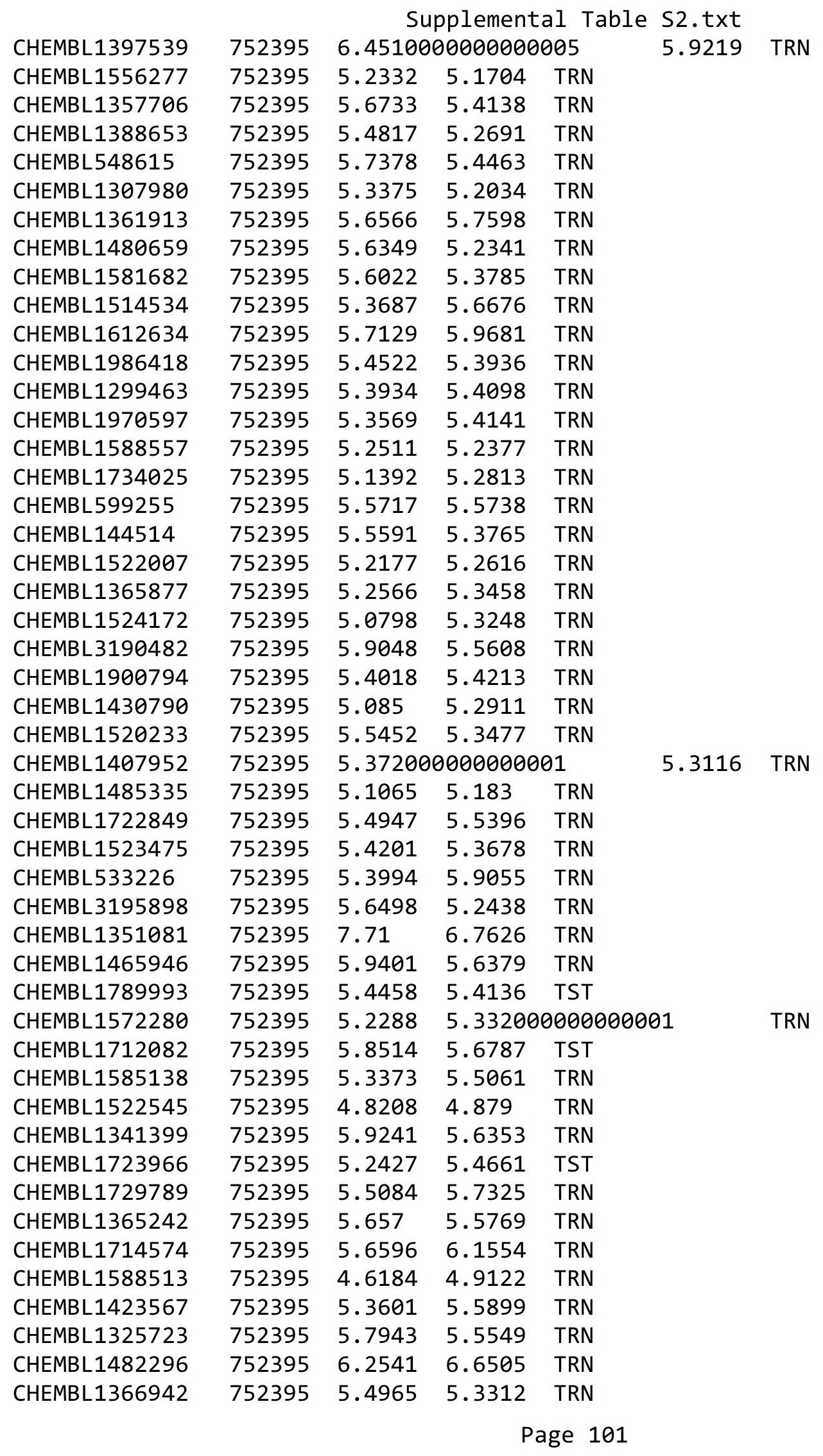




\begin{tabular}{|c|c|c|c|c|c|c|}
\hline & & \multicolumn{5}{|c|}{ Supplemental Table S2.txt } \\
\hline CHEMBL1555652 & 752395 & 5.0931 & 5.1828 & TRN & & \\
\hline CHEMBL1463563 & 752395 & 4.9467 & 5.0426 & TRN & & \\
\hline CHEMBL1412167 & 752395 & 5.5373 & 5.3535 & TRN & & \\
\hline CHEMBL1417204 & 752395 & 6.2277 & 6.0353 & TRN & & \\
\hline CHEMBL1478237 & 752395 & \multicolumn{3}{|c|}{5.622000000000001} & 5.8044 & TRN \\
\hline CHEMBL1700323 & 752395 & 6.0448 & 5.7524 & TRN & & \\
\hline CHEMBL1348175 & 752395 & 5.3979 & 5.4916 & TRN & & \\
\hline CHEMBL1557704 & 752395 & 6.3224 & 5.8433 & TRN & & \\
\hline CHEMBL1499233 & 752395 & 5.36 & 5.2767 & TRN & & \\
\hline CHEMBL1224755 & 752395 & 5.0604 & 5.4053 & TRN & & \\
\hline CHEMBL 3197113 & 752395 & 5.9594 & 6.5927 & TRN & & \\
\hline CHEMBL 1441486 & 752395 & 5.1494 & 5.3172 & TRN & & \\
\hline CHEMBL1378300 & 752395 & 5.3997 & 5.186 & TRN & & \\
\hline CHEMBL1345979 & 752395 & 5.4107 & 5.465 & TST & & \\
\hline CHEMBL1575502 & 752395 & 5.1119 & 5.1596 & TST & & \\
\hline CHEMBL1458695 & 752395 & 5.0592 & 5.0236 & TRN & & \\
\hline CHEMBL3198438 & 752395 & 5.7967 & 5.6917 & TRN & & \\
\hline CHEMBL1359580 & 752395 & 5.2812 & 5.2925 & TRN & & \\
\hline CHEMBL459022 & 752395 & 4.4197 & 5.4423 & TST & & \\
\hline CHEMBL1571835 & 752395 & 6.2565 & 6.2457 & TRN & & \\
\hline CHEMBL1703975 & 752395 & 5.7989 & 5.6905 & TRN & & \\
\hline CHEMBL1557782 & 752395 & 5.0987 & 5.6551 & TRN & & \\
\hline CHEMBL1472307 & 752395 & 5.5972 & 5.5958 & TRN & & \\
\hline CHEMBL1333896 & 752395 & 4.9665 & 6.5487 & TRN & & \\
\hline CHEMBL2004056 & 752395 & 5.5935 & 5.4961 & TRN & & \\
\hline CHEMBL1578482 & 752395 & 4.6333 & 5.0344 & TRN & & \\
\hline CHEMBL 3194161 & 752395 & 4.3051 & 5.3662 & TRN & & \\
\hline CHEMBL1376163 & 752395 & 5.2055 & 5.209 & TRN & & \\
\hline CHEMBL1408544 & 752395 & 5.3684 & 5.4387 & TRN & & \\
\hline CHEMBL596674 & 752395 & 5.0278 & 5.0301 & TRN & & \\
\hline CHEMBL1361420 & 752395 & 5.3228 & 5.3083 & TRN & & \\
\hline CHEMBL1336054 & 752395 & 5.688 & 5.5748 & TRN & & \\
\hline CHEMBL1350851 & 752395 & 5.3816 & 5.5186 & TRN & & \\
\hline CHEMBL1488169 & 752395 & 5.1007 & 5.221 & TRN & & \\
\hline CHEMBL1969300 & 752395 & 5.3773 & 5.7748 & TRN & & \\
\hline CHEMBL1459024 & 752395 & 5.1062 & 5.182 & TRN & & \\
\hline CHEMBL1480448 & 752395 & 4.5955 & 4.9898 & TRN & & \\
\hline CHEMBL1360535 & 752395 & 5.1278 & 5.4233 & TST & & \\
\hline CHEMBL585827 & 752395 & 4.5943 & 4.8903 & TRN & & \\
\hline CHEMBL1533351 & 752395 & 5.5827 & 5.4285 & TRN & & \\
\hline CHEMBL591363 & 752395 & 5.5722 & 5.4292 & TRN & & \\
\hline CHEMBL1305708 & 752395 & 5.1615 & 5.2422 & TRN & & \\
\hline CHEMBL1556062 & 752395 & 5.0425 & 5.3845 & TRN & & \\
\hline CHEMBL1606685 & 752395 & 5.4841 & 5.3699 & TRN & & \\
\hline CHEMBL1303373 & 752395 & 5.7142 & 5.32100 & 0000000001 & & TRN \\
\hline CHEMBL1606074 & 752395 & 5.5117 & 5.4398 & TRN & & \\
\hline CHEMBL1427459 & 752395 & 5.2401 & 5.2186 & TRN & & \\
\hline CHEMBL1608776 & 752395 & 5.8595 & 5.6301 & TRN & & \\
\hline
\end{tabular}


Supplemental Table S2.txt

\begin{tabular}{|c|c|c|c|c|c|}
\hline CHEMBL1966952 & 752395 & 5.7921 & 6.1305 & TRN & \\
\hline CHEMBL1409883 & 752395 & 5.65799 & 999999999 & 5.9753 & TRN \\
\hline CHEMBL1522486 & 752395 & 5.1484 & \multicolumn{2}{|c|}{5.2410000000000005} & TRN \\
\hline CHEMBL1431036 & 752395 & 5.0707 & 5.2617 & TRN & \\
\hline CHEMBL1401989 & 752395 & 5.7109 & 5.7193 & TRN & \\
\hline CHEMBL1457995 & 752395 & 5.7525 & 5.6751 & TRN & \\
\hline CHEMBL1413208 & 752395 & 5.1325 & 5.3607 & TRN & \\
\hline CHEMBL157707 & 752395 & 5.4636 & 5.5159 & TRN & \\
\hline CHEMBL1566835 & 752395 & 5.3715 & 5.4168 & TRN & \\
\hline CHEMBL1422849 & 752395 & 5.8668 & 5.6054 & TRN & \\
\hline CHEMBL1386366 & 752395 & 5.0669 & 5.4234 & TRN & \\
\hline CHEMBL1487639 & 752395 & 6.2581 & 6.4629 & TRN & \\
\hline CHEMBL1385558 & 752395 & 5.3639 & 5.3222 & TRN & \\
\hline CHEMBL1418428 & 752395 & 5.3534 & 5.3457 & TRN & \\
\hline CHEMBL565893 & 752395 & 5.5042 & 5.9237 & TRN & \\
\hline CHEMBL1868450 & 752395 & 5.2969 & 5.2259 & TST & \\
\hline CHEMBL1598383 & 752395 & 5.0771 & 5.2029 & TRN & \\
\hline CHEMBL1474113 & 752395 & 4.9885 & 5.3203 & TRN & \\
\hline CHEMBL1507251 & 752395 & 5.0959 & 5.1567 & TRN & \\
\hline CHEMBL1354360 & 752395 & 5.1846 & 5.1613 & TRN & \\
\hline CHEMBL1866014 & 752395 & 5.5784 & 5.4299 & TST & \\
\hline CHEMBL1400118 & 752395 & 5.5646 & 5.3191 & TRN & \\
\hline CHEMBL1607437 & 752395 & 5.9872 & 5.7341 & TRN & \\
\hline CHEMBL1465039 & 752395 & 5.0544 & 5.303 & TRN & \\
\hline CHEMBL1712666 & 752395 & 5.9817 & 5.6155 & TRN & \\
\hline CHEMBL1538215 & 752395 & 5.2317 & 5.4013 & TRN & \\
\hline CHEMBL 2002008 & 752395 & 5.9914 & 5.632999 & 9999999999 & TRN \\
\hline CHEMBL1986259 & 752395 & 6.2565 & 5.8776 & TRN & \\
\hline CHEMBL1467765 & 752395 & 5.3888 & 5.4394 & TRN & \\
\hline CHEMBL1502351 & 752395 & 5.3479 & 5.3225 & TRN & \\
\hline CHEMBL1736432 & 752395 & 5.7905 & 5.713999 & 99999999995 & TRN \\
\hline CHEMBL1882206 & 752395 & 6.4067 & 5.8052 & TST & \\
\hline CHEMBL1571123 & 752395 & 5.494 & 5.3333 & TRN & \\
\hline CHEMBL1571901 & 752395 & 5.3986 & 5.3365 & TRN & \\
\hline CHEMBL1874920 & 752395 & 5.6247 & 5.5019 & TRN & \\
\hline CHEMBL1384108 & 752395 & 5.4768 & 5.2956 & TST & \\
\hline CHEMBL1502723 & 752395 & 5.6749 & 5.6697 & TRN & \\
\hline CHEMBL1572553 & 752395 & 5.7423 & 5.3627 & TRN & \\
\hline CHEMBL1873093 & 752395 & 5.0918 & 5.3544 & TRN & \\
\hline CHEMBL1528216 & 752395 & 4.60800 & 000000000 & 5.5425 & TRN \\
\hline CHEMBL1600855 & 752395 & 5.0794 & 5.191 & TRN & \\
\hline CHEMBL1388339 & 752395 & 5.05 & 5.4107 & TRN & \\
\hline CHEMBL1349480 & 752395 & 5.365 & 5.3877 & TRN & \\
\hline CHEMBL1591223 & 752395 & 5.1075 & 5.3376 & TRN & \\
\hline CHEMBL1208858 & 752395 & 5.1509 & 5.3156 & TST & \\
\hline CHEMBL 3189217 & 752395 & 6.1244 & 5.8367 & TRN & \\
\hline CHEMBL1724453 & 752395 & 5.3535 & 6.6106 & TRN & \\
\hline CHEMBL1723955 & 752395 & 5.4704 & 5.9378 & TRN & \\
\hline
\end{tabular}




\begin{tabular}{|c|c|c|c|c|c|}
\hline & & & & & \\
\hline CHEMBL1451491 & 752395 & 5.4475 & 6.0226 & TST & \\
\hline CHEMBL469546 & 752395 & 7.71 & 5.7479 & TST & \\
\hline CHEMBL1476029 & 752395 & 4.9634 & 5.2361 & TRN & \\
\hline CHEMBL1560954 & 752395 & 7.71 & 6.938 & TRN & \\
\hline CHEMBL1511179 & 752395 & 6.0306 & 5.7834 & TRN & \\
\hline CHEMBL1467867 & 752395 & 5.087 & 5.2111 & TRN & \\
\hline CHEMBL1315169 & 752395 & 5.8147 & 5.3866 & TRN & \\
\hline CHEMBL1538339 & 752395 & 6.1046 & 5.9079 & TRN & \\
\hline CHEMBL1712047 & 752395 & 5.2351 & 6.7078 & TRN & \\
\hline CHEMBL1309765 & 752395 & 5.4759 & 5.5569 & TST & \\
\hline CHEMBL1518073 & 752395 & 6.0 & 5.6651 & TRN & \\
\hline CHEMBL1420826 & 752395 & 5.3744 & 5.4612 & TRN & \\
\hline CHEMBL1597289 & 752395 & 5.4202 & 5.3192 & TRN & \\
\hline CHEMBL1510339 & 752395 & 5.8996 & 5.3649 & TRN & \\
\hline CHEMBL1490080 & 752395 & 5.3569 & 5.32100 & 0000000001 & TRN \\
\hline CHEMBL1511171 & 752395 & 5.3059 & 5.2073 & TRN & \\
\hline CHEMBL1501726 & 752395 & 5.4989 & 5.6251 & TRN & \\
\hline CHEMBL3197024 & 752395 & 5.4168 & 5.4242 & TRN & \\
\hline CHEMBL428496 & 752395 & 6.4401 & 6.17 & TST & \\
\hline CHEMBL1596594 & 752395 & 5.2052 & 5.3561 & TST & \\
\hline CHEMBL1562846 & 752395 & 5.5882 & 5.7437 & TRN & \\
\hline CHEMBL1576260 & 752395 & 5.3563 & 5.2171 & TST & \\
\hline CHEMBL1465511 & 752395 & 4.5911 & 5.3182 & TRN & \\
\hline CHEMBL1469579 & 752395 & 5.3745 & 5.2848 & TRN & \\
\hline CHEMBL1733265 & 752395 & 5.5035 & 5.63 & TRN & \\
\hline CHEMBL1413680 & 752395 & 5.8265 & 5.4328 & TST & \\
\hline CHEMBL1597585 & 752395 & 5.1063 & 5.15 & TRN & \\
\hline CHEMBL1598785 & 752395 & 5.3327 & 5.2285 & TRN & \\
\hline CHEMBL1448161 & 752395 & 5.6362 & 5.5337 & TRN & \\
\hline CHEMBL1508175 & 752395 & 5.32 & 5.3487 & TRN & \\
\hline CHEMBL1715042 & 752395 & 5.3581 & 5.313 & TRN & \\
\hline CHEMBL1526855 & 752395 & 6.2807 & 6.7108 & TRN & \\
\hline CHEMBL1715330 & 752395 & 5.3953 & 5.2787 & TST & \\
\hline CHEMBL1508067 & 752395 & 5.1395 & 5.2236 & TRN & \\
\hline CHEMBL1375045 & 752395 & 5.9374 & 5.2946 & TRN & \\
\hline CHEMBL1511219 & 752395 & 5.8462 & 5.5157 & TRN & \\
\hline CHEMBL1486503 & 752395 & 5.5897 & 5.5915 & TRN & \\
\hline CHEMBL1368477 & 752395 & 5.4377 & 5.3954 & TRN & \\
\hline CHEMBL1372951 & 752395 & 6.5591 & 5.3817 & TRN & \\
\hline CHEMBL1338466 & 752395 & 6.1972 & 5.7447 & TRN & \\
\hline CHEMBL1721165 & 752395 & 6.3696 & 6.1432 & TRN & \\
\hline CHEMBL1484777 & 752395 & 5.6304 & 5.3858 & TRN & \\
\hline CHEMBL1452421 & 752395 & 5.3586 & 5.2423 & TRN & \\
\hline CHEMBL1427185 & 752395 & 6.317 & 5.8954 & TRN & \\
\hline CHEMBL1316838 & 752395 & 5.2716 & 5.1539 & TRN & \\
\hline CHEMBL1520962 & 752395 & 5.5627 & 5.6041 & TRN & \\
\hline CHEMBL1501376 & 752395 & 5.6809 & 5.4792 & TRN & \\
\hline CHEMBL1539520 & 752395 & 5.5258 & 5.3812 & TST & \\
\hline
\end{tabular}




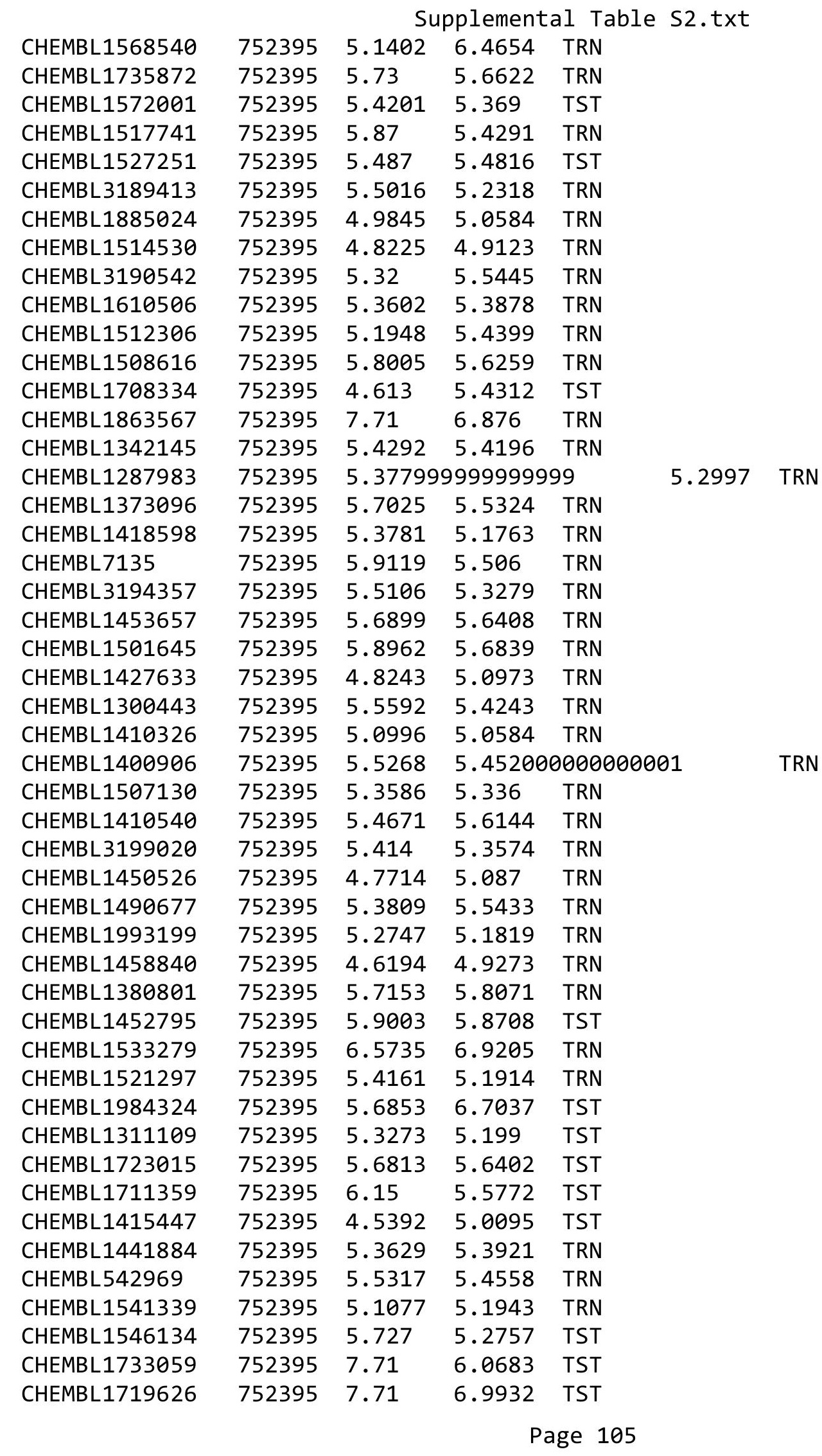




\begin{tabular}{|c|c|c|c|c|c|c|}
\hline & & \multicolumn{5}{|c|}{ Supplemental Table S2.txt } \\
\hline CHEMBL1404277 & 752395 & 5.5049 & 5.6379 & TST & & \\
\hline CHEMBL1332969 & 752395 & 5.3326 & 5.4638 & TRN & & \\
\hline CHEMBL1714971 & 752395 & \multicolumn{3}{|c|}{5.406000000000001} & 5.2352 & TRN \\
\hline CHEMBL1481281 & 752395 & 5.8489 & 5.4717 & TRN & & \\
\hline CHEMBL1304402 & 752395 & 5.1844 & 5.3141 & TRN & & \\
\hline CHEMBL488140 & 752395 & 4.6133 & 6.4094 & TRN & & \\
\hline CHEMBL1442788 & 752395 & 7.71 & 6.6997 & TRN & & \\
\hline CHEMBL1484618 & 752395 & 5.4203 & 5.3714 & TRN & & \\
\hline CHEMBL1098875 & 752395 & 5.4286 & 5.4525 & TRN & & \\
\hline CHEMBL1699284 & 752395 & 4.6019 & 5.1527 & TRN & & \\
\hline CHEMBL1968273 & 752395 & 5.0692 & 5.1308 & TRN & & \\
\hline CHEMBL1464949 & 752395 & 5.2132 & 5.421 & TRN & & \\
\hline CHEMBL1447219 & 752395 & 5.4333 & 5.4673 & TRN & & \\
\hline CHEMBL 3194762 & 752395 & 5.1323 & 5.1444 & TRN & & \\
\hline CHEMBL45152 & 752395 & 4.7283 & 5.2417 & TRN & & \\
\hline CHEMBL1699032 & 752395 & 5.7331 & 6.7968 & TRN & & \\
\hline CHEMBL1723625 & 752395 & 5.0846 & 5.1964 & TRN & & \\
\hline CHEMBL1469379 & 752395 & \multicolumn{3}{|c|}{5.582000000000001} & 5.3198 & TRN \\
\hline CHEMBL1974389 & 752395 & 5.7945 & 5.7048 & TRN & & \\
\hline CHEMBL1578341 & 752395 & \multicolumn{3}{|c|}{5.367999999999999} & 5.3555 & TRN \\
\hline CHEMBL1331822 & 752395 & 6.2581 & 6.0376 & TRN & & \\
\hline CHEMBL1540525 & 752395 & 5.3319 & 5.3078 & TRN & & \\
\hline CHEMBL1576094 & 752395 & 6.3526 & 6.0356 & TRN & & \\
\hline CHEMBL1439593 & 752395 & 5.3945 & 5.3498 & TRN & & \\
\hline CHEMBL1212972 & 752395 & 6.5817 & 6.5335 & TST & & \\
\hline CHEMBL1516922 & 752395 & 5.4947 & 5.4186 & TRN & & \\
\hline CHEMBL1528425 & 752395 & 7.71 & 5.7497 & TRN & & \\
\hline CHEMBL 3197786 & 752395 & 5.1062 & 5.1753 & TRN & & \\
\hline CHEMBL1578946 & 752395 & 5.3787 & 5.4026 & TRN & & \\
\hline CHEMBL 1447350 & 752395 & 5.4388 & 5.7175 & TRN & & \\
\hline CHEMBL1734361 & 752395 & 5.8114 & 5.7096 & TRN & & \\
\hline CHEMBL1413321 & 752395 & 4.9602 & 5.2238 & TRN & & \\
\hline CHEMBL1554169 & 752395 & 4.7802 & 4.994 & TRN & & \\
\hline CHEMBL1448592 & 752395 & 5.4583 & 5.447 & TRN & & \\
\hline CHEMBL1370513 & 752395 & 5.1024 & 5.2064 & TRN & & \\
\hline CHEMBL1388509 & 752395 & 4.6902 & 5.7053 & TST & & \\
\hline CHEMBL1460705 & 752395 & 5.4482 & 5.3166 & TRN & & \\
\hline CHEMBL1353371 & 752395 & 5.5211 & 5.4643 & TRN & & \\
\hline CHEMBL1321398 & 752395 & 5.1217 & 5.2889 & TRN & & \\
\hline CHEMBL1432633 & 752395 & 5.6607 & 5.6199 & TST & & \\
\hline CHEMBL1586817 & 752395 & 5.1015 & 6.4634 & TRN & & \\
\hline CHEMBL1325873 & 752395 & 5.6517 & 5.5057 & TRN & & \\
\hline CHEMBL1393829 & 752395 & 5.4227 & 5.3831 & TRN & & \\
\hline CHEMBL590184 & 752395 & 4.8906 & 4.9366 & TRN & & \\
\hline CHEMBL2369316 & 752395 & 5.7349 & 5.652 & TST & & \\
\hline CHEMBL1887153 & 752395 & 5.3967 & 5.5828 & TRN & & \\
\hline CHEMBL1529146 & 752395 & 5.7997 & 5.5455 & TST & & \\
\hline CHEMBL1511794 & 752395 & 5.7655 & 5.4855 & TRN & & \\
\hline
\end{tabular}




\begin{tabular}{|c|c|c|c|c|c|}
\hline & & & & & \\
\hline CHEMBL1895647 & 752395 & 5.2827 & 5.3075 & TRN & \\
\hline CHEMBL1701797 & 752395 & 4.7723 & 5.0988 & TRN & \\
\hline CHEMBL1365431 & 752395 & 5.5025 & 5.4448 & TST & \\
\hline CHEMBL1301082 & 752395 & 5.5424 & 5.4297 & TRN & \\
\hline CHEMBL1699003 & 752395 & 5.3629 & 5.5236 & TST & \\
\hline CHEMBL1703955 & 752395 & 5.5519 & 5.54 & TRN & \\
\hline CHEMBL1998606 & 752395 & 5.2525 & 5.332999 & 999999999 & TRN \\
\hline CHEMBL1568277 & 752395 & 5.1199 & 5.1916 & TRN & \\
\hline CHEMBL1701401 & 752395 & 5.3007 & 5.3348 & TRN & \\
\hline CHEMBL1496705 & 752395 & 4.7155 & 4.8482 & TRN & \\
\hline CHEMBL1364999 & 752395 & 7.71 & 6.5258 & TRN & \\
\hline CHEMBL530499 & 752395 & 5.8315 & 5.5443 & TRN & \\
\hline CHEMBL1346822 & 752395 & 5.4721 & 5.6976 & TRN & \\
\hline CHEMBL1585527 & 752395 & 5.4763 & 5.3721 & TRN & \\
\hline CHEMBL1448282 & 752395 & 5.4755 & 5.375 & TRN & \\
\hline CHEMBL1328820 & 752395 & 5.4064 & 5.3064 & TRN & \\
\hline CHEMBL534423 & 752395 & 5.4608 & 5.3711 & TRN & \\
\hline CHEMBL1731730 & 752395 & 5.5156 & 5.8448 & TST & \\
\hline CHEMBL1546228 & 752395 & 5.6953 & 5.5933 & TRN & \\
\hline CHEMBL1528479 & 752395 & 5.6861 & 5.525 & TST & \\
\hline CHEMBL 2000342 & 752395 & 5.7617 & 5.4499 & TST & \\
\hline CHEMBL1454102 & 752395 & 5.381 & 5.4827 & TRN & \\
\hline CHEMBL1510979 & 752395 & 5.4359 & 5.3983 & TRN & \\
\hline CHEMBL1425137 & 752395 & 5.9796 & 5.72 & TRN & \\
\hline CHEMBL1364435 & 752395 & 6.0079 & 5.7604 & TRN & \\
\hline CHEMBL1719154 & 752395 & 5.0949 & 5.1589 & TRN & \\
\hline CHEMBL1345195 & 752395 & 4.873 & 5.2221 & TRN & \\
\hline CHEMBL1502104 & 752395 & 5.9307 & 5.7127 & TST & \\
\hline CHEMBL1581146 & 752395 & 5.3721 & 5.342000 & 0000000005 & TRN \\
\hline CHEMBL1325640 & 752395 & 5.36100 & 00000000 & 5.3608 & TRN \\
\hline CHEMBL548540 & 752395 & 5.4432 & 5.354 & TRN & \\
\hline CHEMBL1415154 & 752395 & 5.3786 & 5.3609 & TRN & \\
\hline CHEMBL1726134 & 752395 & 5.2476 & 5.4197 & TRN & \\
\hline CHEMBL1501558 & 752395 & 5.3782 & 5.2192 & TRN & \\
\hline CHEMBL1382884 & 752395 & 6.0 & 5.6992 & TRN & \\
\hline CHEMBL1998521 & 752395 & 5.6156 & 5.5061 & TRN & \\
\hline CHEMBL1576291 & 752395 & 5.1232 & 5.411000 & 0000000005 & TRN \\
\hline CHEMBL1487546 & 752395 & 5.6855 & 5.64 & TRN & \\
\hline CHEMBL1878494 & 752395 & 5.4089 & 5.3698 & TRN & \\
\hline CHEMBL428064 & 752395 & 7.71 & 5.7183 & TRN & \\
\hline CHEMBL1547395 & 752395 & 5.7118 & 5.5052 & TRN & \\
\hline CHEMBL1883941 & 752395 & 6.1409 & 5.7174 & TRN & \\
\hline CHEMBL1333510 & 752395 & 6.5331 & 5.9558 & TRN & \\
\hline CHEMBL1313412 & 752395 & 5.0971 & 5.1851 & TST & \\
\hline CHEMBL1567814 & 752395 & 5.2911 & 5.3384 & TST & \\
\hline CHEMBL1539483 & 752395 & 5.5976 & 5.535 & TST & \\
\hline CHEMBL1987579 & 752395 & 5.1024 & 5.1333 & TRN & \\
\hline CHEMBL1340519 & 752395 & 5.6611 & 5.5623 & TRN & \\
\hline & & & & 107 & \\
\hline
\end{tabular}


Supplemental Table S2.txt

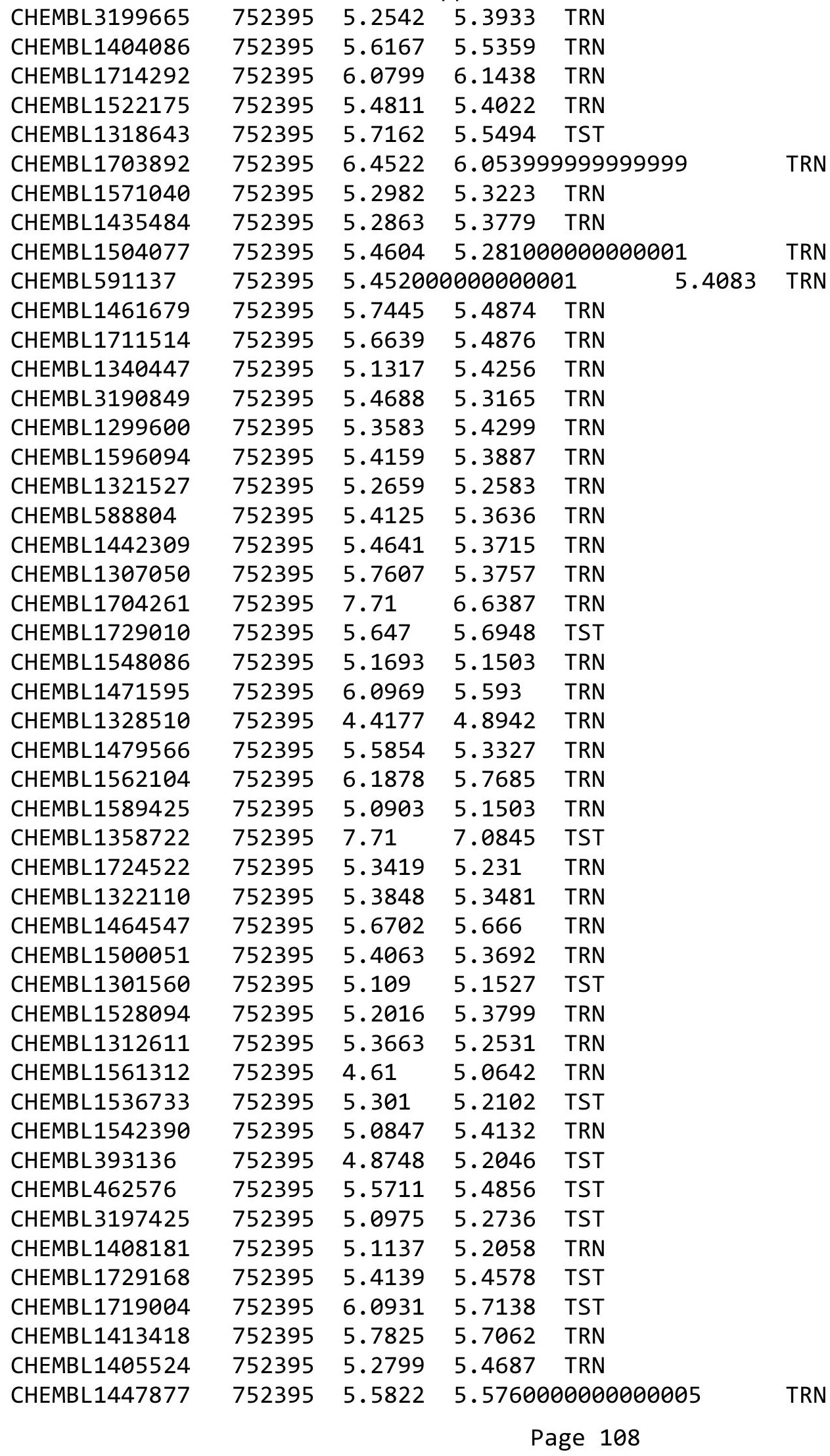


Supplemental Table S2.txt

\begin{tabular}{|c|c|c|c|c|}
\hline CHEMBL1583264 & 752395 & 5.8729 & 5.476 & TRN \\
\hline CHEMBL1413988 & 752395 & 4.7541 & 4.9684 & TRN \\
\hline CHEMBL1447697 & 752395 & 5.5862 & 5.5297 & TRN \\
\hline CHEMBL1337445 & 752395 & 5.3707 & 5.4065 & TRN \\
\hline CHEMBL1730243 & 752395 & 5.7862 & 5.5596 & TRN \\
\hline CHEMBL1349566 & 752395 & 5.3521 & \multicolumn{2}{|c|}{5.452000000000001} \\
\hline CHEMBL1890411 & 752395 & 6.4473 & 5.8034 & TRN \\
\hline CHEMBL591876 & 752395 & 4.5928 & 5.0248 & TRN \\
\hline CHEMBL1399287 & 752395 & 5.0811 & 5.2264 & TRN \\
\hline CHEMBL520275 & 752395 & 6.5376 & 6.9479 & TRN \\
\hline CHEMBL1578142 & 752395 & 5.5077 & 5.3305 & TRN \\
\hline CHEMBL1313141 & 752395 & 5.5109 & 5.9649 & TRN \\
\hline CHEMBL1569107 & 752395 & 5.4142 & 5.2629 & TRN \\
\hline CHEMBL1333169 & 752395 & 5.3842 & 5.4328 & TRN \\
\hline CHEMBL1424562 & 752395 & 7.71 & 6.7226 & TRN \\
\hline CHEMBL1543433 & 752395 & 5.6167 & 5.3357 & TST \\
\hline CHEMBL1406911 & 752395 & 5.1454 & 5.2166 & TRN \\
\hline CHEMBL568092 & 752395 & 4.9673 & 5.2053 & TRN \\
\hline CHEMBL1730870 & 752395 & 5.521 & 5.6436 & TRN \\
\hline CHEMBL1404578 & 752395 & 5.5306 & 5.3876 & TRN \\
\hline CHEMBL1322089 & 752395 & 5.3946 & 5.9123 & TRN \\
\hline CHEMBL1449794 & 752395 & 4.6177 & 5.1178 & TRN \\
\hline CHEMBL1413626 & 752395 & 5.0837 & 5.2639 & TRN \\
\hline CHEMBL1602759 & 752395 & 5.5381 & 5.4254 & TST \\
\hline CHEMBL1384167 & 752395 & 5.4045 & \multicolumn{2}{|c|}{5.707000000000001} \\
\hline CHEMBL1709153 & 752395 & 5.6472 & 5.2532 & TRN \\
\hline CHEMBL1392673 & 752395 & 5.3582 & 5.2976 & TRN \\
\hline CHEMBL1609354 & 752395 & 5.2494 & 5.2984 & TRN \\
\hline CHEMBL1458548 & 752395 & 6.2204 & 5.8664 & TRN \\
\hline CHEMBL1400889 & 752395 & 5.0557 & 5.1248 & TRN \\
\hline CHEMBL1889980 & 752395 & 5.6574 & 5.6841 & TST \\
\hline CHEMBL1453089 & 752395 & 5.4666 & 5.3114 & TRN \\
\hline CHEMBL1312208 & 752395 & 5.3891 & 6.6192 & TRN \\
\hline CHEMBL1700106 & 752395 & 5.7924 & 5.4408 & TRN \\
\hline CHEMBL1495939 & 752395 & 5.2061 & 5.4229 & TST \\
\hline CHEMBL1256761 & 752395 & 5.856 & 5.6861 & TST \\
\hline CHEMBL1303320 & 752395 & 5.5852 & 5.4548 & TST \\
\hline CHEMBL1717770 & 752395 & 5.3462 & 6.0002 & TST \\
\hline CHEMBL1488923 & 752395 & 5.3038 & 5.5672 & TST \\
\hline CHEMBL1383414 & 752395 & 5.4751 & 5.5167 & TST \\
\hline CHEMBL169811 & 752395 & 5.5875 & 5.4868 & TST \\
\hline CHEMBL1545702 & 752395 & 5.5013 & 5.4587 & TST \\
\hline CHEMBL1563898 & 752395 & 5.5372 & \multicolumn{2}{|c|}{5.4110000000000005} \\
\hline CHEMBL1405150 & 752395 & 5.4429 & 5.3734 & TST \\
\hline CHEMBL1308313 & 752395 & 6.0 & 5.6826 & TST \\
\hline CHEMBL1502607 & 752395 & 6.0269 & 5.7534 & TST \\
\hline CHEMBL1477528 & 752395 & 5.6189 & 5.352 & TST \\
\hline CHEMBL1608392 & 752395 & 5.0621 & 5.3109 & TST \\
\hline
\end{tabular}


Supplemental Table S2.txt

\begin{tabular}{|c|c|c|c|c|c|c|}
\hline CHEMBL1736537 & 752395 & 6.1675 & 6.2674 & TST & & \\
\hline CHEMBL1399492 & 752395 & 5.2135 & 5.4971 & TST & & \\
\hline CHEMBL1379068 & 752395 & 5.7962 & 5.7354 & TST & & \\
\hline CHEMBL1307271 & 752395 & 5.1425 & 5.4379 & TST & & \\
\hline CHEMBL1439384 & 752395 & 6.1232 & 5.6425 & TST & & \\
\hline CHEMBL1387248 & 752395 & 5.5648 & 5.7495 & TST & & \\
\hline CHEMBL1578411 & 752395 & 5.3661 & 5.3858 & TST & & \\
\hline CHEMBL1339270 & 752395 & 5.40799 & 999999999 & 995 & 5.5059 & TST \\
\hline CHEMBL3189590 & 752395 & 5.2226 & 5.2946 & TST & & \\
\hline CHEMBL1719096 & 752395 & 5.1135 & 5.4232 & TST & & \\
\hline CHEMBL1533963 & 752395 & 5.3594 & 5.4379 & TST & & \\
\hline CHEMBL1880070 & 752395 & 5.7742 & 5.4177 & TST & & \\
\hline CHEMBL1895325 & 752395 & 5.3872 & 5.4746 & TST & & \\
\hline CHEMBL1484318 & 752395 & 5.3613 & 5.3826 & TST & & \\
\hline CHEMBL1445658 & 752395 & 5.0952 & 5.2586 & TST & & \\
\hline CHEMBL1383799 & 752395 & 5.7491 & 5.468 & TST & & \\
\hline CHEMBL1709889 & 752395 & 5.4055 & 5.4218 & TST & & \\
\hline CHEMBL602363 & 752395 & 5.3943 & 5.3759 & TST & & \\
\hline CHEMBL1698715 & 752395 & 5.5547 & 5.4855 & TST & & \\
\hline CHEMBL1477770 & 752395 & 5.6631 & 5.5157 & TST & & \\
\hline CHEMBL1337219 & 752395 & 5.5081 & 5.4204 & TST & & \\
\hline CHEMBL1447796 & 752395 & 5.5786 & 5.4019 & TST & & \\
\hline CHEMBL1403586 & 752395 & 5.7747 & 5.3478 & TST & & \\
\hline CHEMBL1570845 & 752395 & 5.7815 & 6.1465 & TST & & \\
\hline CHEMBL1549568 & 752395 & 5.7082 & 5.143 & TST & & \\
\hline CHEMBL1404113 & 752395 & 5.8831 & 5.7207 & TST & & \\
\hline CHEMBL1524958 & 752395 & 7.71 & 6.7198 & TST & & \\
\hline CHEMBL1724645 & 752395 & 5.8972 & 5.7019 & TST & & \\
\hline CHEMBL1408715 & 752395 & 5.5077 & 5.3256 & TST & & \\
\hline CHEMBL1585779 & 752395 & 5.8435 & 5.8557 & TST & & \\
\hline CHEMBL1386711 & 752395 & 5.3677 & 5.3432 & TST & & \\
\hline CHEMBL1443660 & 752395 & 5.852 & 5.5564 & TST & & \\
\hline CHEMBL1544114 & 752395 & 5.3972 & 5.412000 & 0000000001 & & בו \\
\hline CHEMBL1582708 & 752395 & 5.6916 & 5.7112 & TST & & \\
\hline CHEMBL1452264 & 752395 & 4.8964 & 5.2041 & TST & & \\
\hline CHEMBL1730502 & 752395 & 5.0865 & 5.3391 & TST & & \\
\hline CHEMBL1539545 & 752395 & 5.3989 & 5.4598 & TST & & \\
\hline CHEMBL1330279 & 752395 & 5.267 & 5.0994 & TST & & \\
\hline CHEMBL1575756 & 752395 & 5.3207 & 5.5562 & TST & & \\
\hline CHEMBL1315731 & 752395 & \multicolumn{3}{|c|}{6.2139999999999995} & 6.0524 & כו \\
\hline CHEMBL1602792 & 752395 & 5.0995 & 5.1753 & TST & & \\
\hline CHEMBL1391094 & 752395 & 6.2284 & 6.2193 & TST & & \\
\hline CHEMBL1586593 & 752395 & 5.4493 & 5.2646 & TST & & \\
\hline CHEMBL1567571 & 752395 & 5.0974 & 5.2743 & TST & & \\
\hline CHEMBL1466490 & 752395 & 5.4024 & 5.3433 & TST & & \\
\hline CHEMBL1704558 & 752395 & 5.0556 & 5.1628 & TST & & \\
\hline CHEMBL1334584 & 752395 & 5.3672 & 5.3944 & TST & & \\
\hline CHEMBL1450086 & 752395 & 5.05699 & 79999999 & 995 & 5.3411 & \\
\hline
\end{tabular}


Supplemental Table S2.txt

\begin{tabular}{|c|c|c|c|c|}
\hline 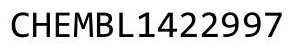 & & & & \\
\hline AEMBL1431189 & 2395 & 4.7756 & & \\
\hline AEMBL1532068 & 52395 & 5.4921 & 275 & \\
\hline HEMBL1528768 & 52395 & .5563 & .5727 & \\
\hline HEMBL1411314 & 2395 & & 3871 & \\
\hline AEMBL1426695 & 2395 & 3689 & 4395 & \\
\hline AEMBL3199016 & 52395 & 2969 & . 1591 & \\
\hline HEMBL1726290 & 52395 & .482 & .4596 & \\
\hline HEMBL1337745 & 52395 & 5.5896 & .4042 & \\
\hline IEMBL1495443 & 52395 & 572 & .3014 & \\
\hline AEMBL1466593 & 52395 & & .3821 & \\
\hline HEMBL1423633 & 52395 & 256 & 5.2696 & \\
\hline HEMBL1485259 & 52395 & 562 & & \\
\hline AEMBL1544548 & 52395 & & 5. & \\
\hline IEMBL1533511 & 95 & & & \\
\hline IEMBL1547078 & 95 & & & \\
\hline AEMBL547285 & 52395 & & 5.3442 & \\
\hline AEMBL1580272 & & & & \\
\hline L1394747 & 5 & & 47 & \\
\hline L1491222 & 5 & & & \\
\hline EMBL1703209 & 5 & & 351 & \\
\hline HEMBL 296527 & 95 & 003 & 5.301 & \\
\hline AEMBL1367860 & & & & \\
\hline AEMBL1480517 & 5 & & 76 & \\
\hline L1509380 & 5 & & & \\
\hline L3191762 & 5 & 15 & & \\
\hline L1327667 & 95 & 585 & & \\
\hline AEMBL1326083 & & & & \\
\hline AEMBL 2387398 & 331 & 872 & 6.7258 & \\
\hline L3658911 & 31 & 724 & 49 & \\
\hline 3911419 & 31 & 7. & 45 & \\
\hline AEMBL3965143 & & 6 & & \\
\hline AEMBL2387405 & 31 & & & \\
\hline HEMBL3981721 & 31 & 665 & & \\
\hline L2387401 & 31 & & & \\
\hline 89 & & 04 & & \\
\hline AEMBL 2387523 & 528331 & 7.2924 & 361 & \\
\hline AEMBL 2387524 & 528331 & 7.2924 & & \\
\hline HEMBL 2387510 & 31 & 461 & & \\
\hline HEMBL3899283 & 31 & & & \\
\hline 509 & & 6. & & \\
\hline HEMBL 2387513 & 528331 & 6.6038 & 26 & \\
\hline AEMBL2387417 & 528331 & 362 & & \\
\hline HEMBL 3898080 & & 6. & & \\
\hline HEMBL3979643 & & & & \\
\hline HEMBL3949516 & 331 & 7.1367 & 7.6393 & \\
\hline HEMBL3945696 & 528331 & 5.4776 & 5.6624 & \\
\hline CHEMBL3977139 & 1528331 & 6.8827 & 7.3318 & \\
\hline
\end{tabular}

Page 111 
Supplemental Table S2.txt

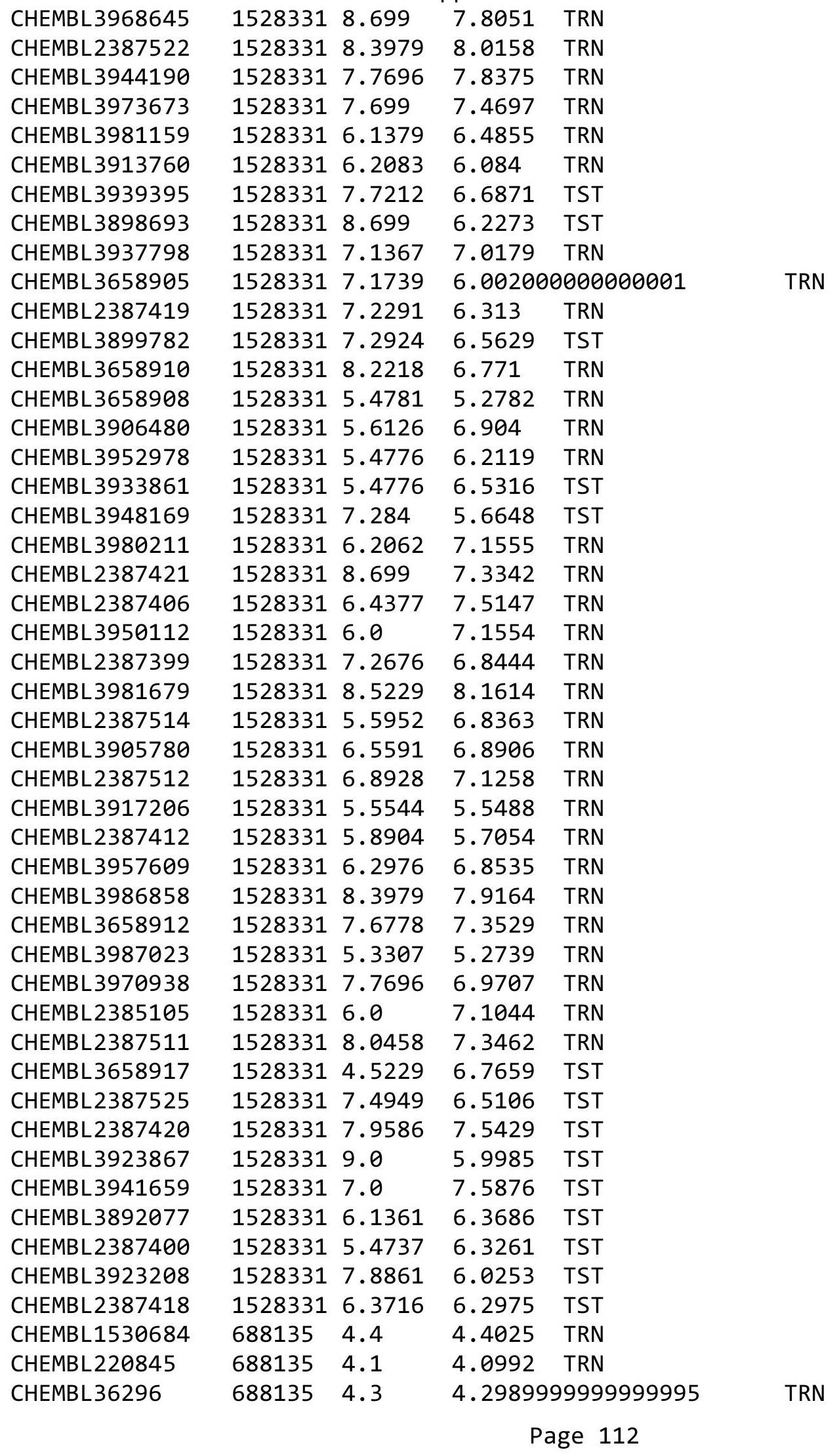




\begin{tabular}{|c|c|c|c|c|}
\hline \multicolumn{5}{|c|}{ Supplemental Table S2.txt } \\
\hline CHEMBL509531 & 688135 & 5.1 & 5.1001 & TRN \\
\hline CHEMBL1407826 & 688135 & 4.4 & 4.721 & TST \\
\hline CHEMBL1527567 & 688135 & 4.1 & 4.1006 & TRN \\
\hline CHEMBL105712 & 688135 & 4.3 & 4.3004 & TRN \\
\hline CHEMBL1545634 & 688135 & 6.1 & 6.0987 & TRN \\
\hline CHEMBL935 & 688135 & 4.3 & 4.2984 & TRN \\
\hline CHEMBL1303139 & 688135 & 4.8 & 4.7995 & TRN \\
\hline CHEMBL1489064 & 688135 & 4.3 & 4.3 & TRN \\
\hline CHEMBL1492884 & 688135 & 4.4 & 4.3995 & TRN \\
\hline CHEMBL1600998 & 688135 & 5.1 & 5.1 & TRN \\
\hline CHEMBL1447588 & 688135 & 5.0 & 5.001 & TRN \\
\hline CHEMBL334255 & 688135 & 4.8 & 4.7985 & TRN \\
\hline CHEMBL1450607 & 688135 & 4.1 & 4.4252 & TST \\
\hline CHEMBL1408847 & 688135 & 4.6 & 4.6001 & TRN \\
\hline CHEMBL194399 & 688135 & 4.4 & 4.3991 & TRN \\
\hline CHEMBL3391990 & 688135 & 4.1 & 4.0996 & TRN \\
\hline CHEMBL402063 & 688135 & 4.3 & 5.1876 & TST \\
\hline CHEMBL1496957 & 688135 & 4.7 & 4.6964 & TRN \\
\hline CHEMBL1448387 & 688135 & 4.4 & 4.3997 & TRN \\
\hline CHEMBL1409985 & 688135 & 4.8 & 4.7978 & TRN \\
\hline CHEMBL1495381 & 688135 & 5.8 & 5.7997 & TRN \\
\hline CHEMBL328910 & 688135 & 4.5 & 4.5007 & TRN \\
\hline CHEMBL1519327 & 688135 & 5.7 & 5.7013 & TRN \\
\hline CHEMBL196590 & 688135 & 4.3 & 4.3002 & TRN \\
\hline CHEMBL 28 & 688135 & 4.1 & 4.1013 & TRN \\
\hline CHEMBL1142 & 688135 & 4.4 & 4.4002 & TRN \\
\hline CHEMBL195953 & 688135 & 4.4 & 4.4013 & TRN \\
\hline CHEMBL1535689 & 688135 & 4.4 & 4.3993 & TRN \\
\hline CHEMBL1562104 & 688135 & 4.9 & 4.9009 & TRN \\
\hline CHEMBL1499545 & 688135 & 5.5 & 5.5006 & TRN \\
\hline CHEMBL1449018 & 688135 & 4.5 & 4.5023 & TRN \\
\hline CHEMBL1517425 & 688135 & 4.3 & 4.3002 & TRN \\
\hline CHEMBL1558796 & 688135 & 4.4 & 4.4 & TRN \\
\hline CHEMBL1602699 & 688135 & 5.4 & 5.4005 & TRN \\
\hline CHEMBL1526319 & 688135 & 4.5 & 4.4996 & TRN \\
\hline CHEMBL1609459 & 688135 & 4.9 & 4.8992 & TRN \\
\hline CHEMBL1566504 & 688135 & 4.3 & 4.3006 & TRN \\
\hline CHEMBL140 & 688135 & 4.4 & 4.4005 & TRN \\
\hline CHEMBL1559341 & 688135 & 4.4 & 4.401 & TRN \\
\hline CHEMBL1569493 & 688135 & 5.4 & 5.4015 & TRN \\
\hline CHEMBL1366408 & 688135 & 4.4 & 4.399 & TRN \\
\hline CHEMBL1569226 & 688135 & 4.8 & 4.4686 & TST \\
\hline CHEMBL1308088 & 688135 & 4.7 & 4.6046 & TST \\
\hline CHEMBL1561876 & 688135 & 4.4 & 4.482 & TST \\
\hline CHEMBL1200471 & 688135 & 6.2 & 5.8009 & TST \\
\hline CHEMBL44072 & 688135 & 4.9 & 4.4678 & TST \\
\hline CHEMBL 388676 & 688135 & 5.1 & 4.8182 & TST \\
\hline CHEMBL1524617 & 688135 & 4.9 & 4.9957 & TST \\
\hline
\end{tabular}




\begin{tabular}{|c|c|c|c|c|c|}
\hline \multicolumn{6}{|c|}{ premer } \\
\hline CHEMBL194400 & 688135 & 4.6 & 4.3837 & TST & \\
\hline CHEMBL192627 & 688135 & 4.4 & 4.427 & TST & \\
\hline CHEMBL1522486 & 688135 & 4.5 & 4.6405 & TST & \\
\hline CHEMBL1579130 & 688135 & 6.0 & 5.4455 & TST & \\
\hline CHEMBL470530 & 499309 & 6.1871 & 5.7065 & TRN & \\
\hline CHEMBL475424 & 499309 & 6.1549 & 6.0668 & TRN & \\
\hline CHEMBL166031 & 499309 & 6.6383 & 6.2464 & TRN & \\
\hline CHEMBL94487 & 499309 & 5.9586 & 6.0942 & TRN & \\
\hline CHEMBL19148 & 499309 & 4.7696 & 5.0077 & TRN & \\
\hline CHEMBL328143 & 499309 & 5.699 & 4.9191 & TRN & \\
\hline CHEMBL470529 & 499309 & 5.0 & 5.7124 & TRN & \\
\hline CHEMBL471768 & 499309 & 5.8239 & 5.8914 & TRN & \\
\hline CHEMBL471723 & 499309 & 6.6383 & 5.7682 & TST & \\
\hline CHEMBL 279560 & 499309 & 4.7447 & 4.9452 & TRN & \\
\hline CHEMBL475410 & 499309 & 6.0605 & 6.0857 & TRN & \\
\hline CHEMBL18852 & 499309 & 5.301 & 5.2363 & TST & \\
\hline CHEMBL96383 & 499309 & 5.2218 & 5.1283 & TRN & \\
\hline CHEMBL92934 & 499309 & 4.8861 & 5.1163 & TRN & \\
\hline CHEMBL513409 & 499309 & 5.0223 & 5.8013 & TRN & \\
\hline CHEMBL94581 & 499309 & 4.699 & 4.9371 & TRN & \\
\hline CHEMBL471902 & 499309 & 5.9586 & 6.08799 & 9999999999 & TRN \\
\hline CHEMBL93185 & 499309 & 5.0915 & 4.9692 & TRN & \\
\hline CHEMBL166030 & 499309 & 6.9208 & 6.1274 & TRN & \\
\hline CHEMBL475411 & 499309 & 5.5686 & 5.8863 & TRN & \\
\hline CHEMBL96077 & 499309 & 5.0969 & 4.9626 & TRN & \\
\hline CHEMBL94156 & 499309 & 4.8239 & 5.0539 & TRN & \\
\hline CHEMBL475425 & 499309 & 6.0862 & 6.1231 & TRN & \\
\hline CHEMBL317305 & 499309 & 4.9208 & 5.2701 & TST & \\
\hline CHEMBL 255819 & 499309 & 5.3565 & 6.0639 & TRN & \\
\hline CHEMBL93264 & 499309 & 5.1192 & 4.9514 & TRN & \\
\hline CHEMBL92721 & 499309 & 4.9586 & 4.937 & TRN & \\
\hline CHEMBL164292 & 499309 & 7.2757 & 5.8416 & TST & \\
\hline CHEMBL318248 & 499309 & 4.699 & 4.9541 & TRN & \\
\hline CHEMBL96536 & 499309 & 5.1739 & 4.9881 & TRN & \\
\hline CHEMBL472620 & 499309 & 6.0969 & 6.0557 & TRN & \\
\hline CHEMBL475571 & 499309 & 6.3565 & 6.1296 & TRN & \\
\hline CHEMBL95114 & 499309 & 4.7959 & 4.9688 & TRN & \\
\hline CHEMBL279377 & 499309 & 5.7696 & 4.9939 & TRN & \\
\hline CHEMBL514505 & 499309 & 6.0 & 6.0277 & TRN & \\
\hline CHEMBL321312 & 499309 & 4.6576 & 4.872 & TRN & \\
\hline CHEMBL18764 & 499309 & 5.5229 & 5.3184 & TST & \\
\hline CHEMBL471756 & 499309 & 6.2291 & 5.9714 & TRN & \\
\hline CHEMBL470703 & 499309 & 5.1249 & 5.9873 & TRN & \\
\hline CHEMBL18848 & 499309 & 5.3979 & 5.1195 & TST & \\
\hline CHEMBL512329 & 499309 & 6.9208 & 6.1453 & TRN & \\
\hline CHEMBL514343 & 499309 & 6.301 & 6.0312 & TRN & \\
\hline CHEMBL448264 & 499309 & 6.7959 & 5.8541 & TST & \\
\hline CHEMBL475417 & 499309 & 5.3565 & 5.8904 & TST & \\
\hline
\end{tabular}




\begin{tabular}{|c|c|c|c|c|c|c|}
\hline & & \multicolumn{5}{|c|}{ Supplemental Table S2.txt } \\
\hline CHEMBL511830 & 499309 & 5.8539 & 5.8791 & TRN & & \\
\hline CHEMBL350747 & 499309 & 8.2218 & 5.858 & TST & & \\
\hline CHEMBL350129 & 499309 & 7.585 & 5.7897 & TST & & \\
\hline CHEMBL165327 & 499309 & 7.1367 & 5.7889 & TST & & \\
\hline CHEMBL475781 & 499309 & 7.0555 & 5.6796 & TST & & \\
\hline CHEMBL514806 & 499309 & 7.3565 & 5.9531 & TST & & \\
\hline CHEMBL1357247 & 954797 & 3.5405 & 3.489 & TRN & & \\
\hline CHEMBL210618 & 954797 & 4.0834 & 4.067 & TRN & & \\
\hline CHEMBL3186408 & 954797 & 5.1953 & 4.1674 & TST & & \\
\hline CHEMBL180127 & 954797 & 4.2934 & 4.459 & TRN & & \\
\hline CHEMBL259181 & 954797 & 4.842 & 5.2832 & TRN & & \\
\hline CHEMBL515416 & 954797 & 4.9932 & 5.0761 & TRN & & \\
\hline CHEMBL 379300 & 954797 & 6.6355 & 6.8421 & TRN & & \\
\hline CHEMBL1970879 & 954797 & 5.1093 & 5.269 & TRN & & \\
\hline CHEMBL1643959 & 954797 & 3.1685 & 3.3905 & TRN & & \\
\hline CHEMBL1190711 & 954797 & 5.5127 & 6.0714 & TRN & & \\
\hline CHEMBL 209148 & 954797 & 4.9667 & 5.17 & TRN & & \\
\hline CHEMBL412142 & 954797 & 3.1544 & 3.8048 & TRN & & \\
\hline CHEMBL 373751 & 954797 & 3.2626 & 3.8384 & TRN & & \\
\hline CHEMBL92309 & 954797 & 4.141 & 3.2583 & TST & & \\
\hline CHEMBL483847 & 954797 & 4.0682 & 3.9834 & TRN & & \\
\hline CHEMBL392695 & 954797 & 5.851 & 5.974 & TRN & & \\
\hline CHEMBL221137 & 954797 & 4.9813 & 5.1843 & TST & & \\
\hline CHEMBL585951 & 954797 & 6.5394 & 6.9782 & TRN & & \\
\hline CHEMBL 2144069 & 954797 & 3.6209 & 3.3478 & TRN & & \\
\hline CHEMBL449158 & 954797 & 6.5676 & 7.0513 & TST & & \\
\hline CHEMBL558642 & 954797 & $5.2920 e$ & 000000000 & $\partial 1$ & 5.3812 & TRN \\
\hline CHEMBL300389 & 954797 & 7.5877 & 7.619 & TRN & & \\
\hline CHEMBL573107 & 954797 & 5.2684 & 5.2255 & TRN & & \\
\hline CHEMBL1788116 & 954797 & 5.2047 & 4.7863 & TRN & & \\
\hline CHEMBL3392440 & 954797 & 3.3194 & 3.6924 & TRN & & \\
\hline CHEMBL1516890 & 954797 & 4.3621 & 4.29 & TRN & & \\
\hline CHEMBL3349342 & 954797 & 4.8647 & 4.4537 & TRN & & \\
\hline CHEMBL1404918 & 954797 & 3.0894 & 2.9706 & TRN & & \\
\hline CHEMBL188678 & 954797 & 5.6279 & 5.2993 & TRN & & \\
\hline CHEMBL220241 & 954797 & 5.1537 & 4.7761 & TRN & & \\
\hline CHEMBL512504 & 954797 & 6.6416 & 6.5626 & TRN & & \\
\hline CHEMBL379975 & 954797 & 6.3142 & 6.3426 & TRN & & \\
\hline CHEMBL65 & 954797 & 9.0885 & 8.7132 & TRN & & \\
\hline CHEMBL189584 & 954797 & 4.6782 & 4.9099 & TRN & & \\
\hline CHEMBL577784 & 954797 & 5.5598 & 5.6059 & TRN & & \\
\hline CHEMBL472940 & 954797 & 5.0161 & 5.1702 & TRN & & \\
\hline CHEMBL509032 & 954797 & 9.033 & 8.3114 & TRN & & \\
\hline CHEMBL192566 & 954797 & 7.9855 & 9.139 & TST & & \\
\hline CHEMBL202721 & 954797 & 5.5613 & 5.2191 & TRN & & \\
\hline CHEMBL1230020 & 954797 & 4.8117 & 3.9333 & TRN & & \\
\hline CHEMBL1256459 & 954797 & 7.5505 & 7.8564 & TRN & & \\
\hline CHEMBL191334 & 954797 & 4.3184 & 4.1847 & TRN & & \\
\hline
\end{tabular}


Supplemental Table S2.txt

\begin{tabular}{|c|c|c|c|c|}
\hline CHEMBL3199475 & 954797 & 5.3069 & 5.5496 & TRN \\
\hline CHEMBL135561 & 954797 & 5.0964 & 4.6181 & TRN \\
\hline CHEMBL222102 & 954797 & 4.5713 & 4.3372 & TRN \\
\hline CHEMBL393929 & 954797 & 4.7355 & 4.54 & TRN \\
\hline CHEMBL1590308 & 954797 & 4.6958 & 3.4862 & TST \\
\hline CHEMBL102714 & 954797 & 4.5369 & 4.338 & TRN \\
\hline CHEMBL1242367 & 954797 & 3.9641 & 4.3199 & TRN \\
\hline CHEMBL240954 & 954797 & 4.2053 & 4.325 & TST \\
\hline CHEMBL514499 & 954797 & 7.7003 & 7.8463 & TRN \\
\hline CHEMBL 2005886 & 954797 & 5.5694 & 6.7701 & TST \\
\hline CHEMBL1673039 & 954797 & 4.9472 & 5.8117 & TST \\
\hline CHEMBL483849 & 954797 & 3.6353 & 2.3678 & TST \\
\hline CHEMBL9470 & 954797 & 6.813 & 6.5265 & TST \\
\hline CHEMBL1909414 & 954797 & 4.8876 & 3.723999 & 9999999998 \\
\hline CHEMBL213100 & 954797 & 3.6156 & 4.9553 & TST \\
\hline CHEMBL258844 & 954797 & 4.2162 & 4.8309 & TST \\
\hline CHEMBL 2363137 & 954797 & 5.1751 & 4.7517 & TST \\
\hline CHEMBL93544 & 66586 & 5.699 & 5.6796 & TRN \\
\hline CHEMBL92937 & 66586 & 9.1612 & 9.0904 & TRN \\
\hline CHEMBL93966 & 66586 & 8.699 & 8.7308 & TRN \\
\hline CHEMBL328106 & 66586 & 9.0177 & 9.0572 & TRN \\
\hline CHEMBL94432 & 66586 & 4.0 & 5.3252 & TST \\
\hline CHEMBL94275 & 66586 & 6.0 & 6.061 & TST \\
\hline CHEMBL418967 & 66586 & 9.7696 & 9.8262 & TRN \\
\hline CHEMBL420624 & 66586 & 10.0 & 10.1829 & TRN \\
\hline CHEMBL321511 & 66586 & 4.0 & 5.1128 & TST \\
\hline CHEMBL92709 & 66586 & 6.9469 & 7.061 & TRN \\
\hline CHEMBL290096 & 66586 & 7.5686 & 7.7063 & TRN \\
\hline CHEMBL329183 & 66586 & 5.2147 & 5.0965 & TST \\
\hline CHEMBL330224 & 66586 & 7.0 & 7.0693 & TRN \\
\hline CHEMBL328879 & 66586 & 7.2596 & 7.2405 & TRN \\
\hline CHEMBL328295 & 66586 & 5.301 & 4.8222 & TST \\
\hline CHEMBL96627 & 66586 & 5.8642 & 5.8531 & TRN \\
\hline CHEMBL52765 & 66586 & 9.1079 & 8.9829 & TRN \\
\hline CHEMBL66409 & 66586 & 7.6021 & 7.6439 & TRN \\
\hline CHEMBL93461 & 66586 & 7.3979 & 7.5181 & TRN \\
\hline CHEMBL447230 & 66586 & 6.8182 & 6.5894 & TST \\
\hline CHEMBL96780 & 66586 & 8.4202 & 8.3896 & TRN \\
\hline CHEMBL93284 & 66586 & 6.2676 & 5.8773 & TST \\
\hline CHEMBL329672 & 66586 & 7.6383 & 7.6549 & TRN \\
\hline CHEMBL93302 & 66586 & 8.3279 & 8.2144 & TRN \\
\hline CHEMBL93545 & 66586 & 7.2757 & 7.2561 & TRN \\
\hline CHEMBL65038 & 66586 & 7.8239 & 7.7978 & TRN \\
\hline CHEMBL93181 & 66586 & 8.0 & 7.9418 & TRN \\
\hline CHEMBL94191 & 66586 & 7.5376 & 7.5466 & TRN \\
\hline CHEMBL92824 & 66586 & 6.2388 & 6.1845 & TRN \\
\hline CHEMBL96065 & 66586 & 9.0506 & 9.2212 & TRN \\
\hline CHEMBL328216 & 66586 & 9.9208 & 9.9959 & TRN \\
\hline
\end{tabular}




\begin{tabular}{|c|c|c|c|c|c|}
\hline \multirow[b]{2}{*}{ CHEMBL93032 } & \multicolumn{5}{|c|}{ Supplemental Table S2.txt } \\
\hline & 66586 & 9.7696 & 9.8002 & TRN & \\
\hline CHEMBL420254 & 66586 & 7.9208 & 7.8855 & TRN & \\
\hline CHEMBL327307 & 66586 & 10.1427 & 10.1094 & TRN & \\
\hline CHEMBL91914 & 66586 & 4.9208 & 4.4767 & TST & \\
\hline CHEMBL93346 & 66586 & 4.0 & 4.0532 & TRN & \\
\hline CHEMBL92985 & 66586 & 7.2518 & 7.1183 & TRN & \\
\hline CHEMBL92174 & 66586 & 6.8928 & 6.6132 & TST & \\
\hline CHEMBL318736 & 66586 & 6.9788 & 6.9473 & TRN & \\
\hline CHEMBL91980 & 66586 & 9.4559 & 9.3385 & TRN & \\
\hline CHEMBL328955 & 66586 & 9.6021 & 9.6075 & TRN & \\
\hline CHEMBL431811 & 66586 & 4.0 & 3.9037 & TRN & \\
\hline CHEMBL90013 & 66586 & 7.9586 & 7.8992 & TRN & \\
\hline CHEMBL317925 & 66586 & 9.1739 & 9.2549 & TRN & \\
\hline CHEMBL433205 & 66586 & 8.4815 & 8.4016 & TRN & \\
\hline CHEMBL 93051 & 66586 & 7.8239 & 8.5943 & TST & \\
\hline CHEMBL329161 & 66586 & 6.0458 & 6.376 & TST & \\
\hline CHEMBL35820 & 66586 & 11.2218 & 11.2358 & TRN & \\
\hline CHEMBL63469 & 66586 & 8.1871 & 8.1998 & TRN & \\
\hline CHEMBL 94431 & 66586 & 8.4202 & 8.4977 & TRN & \\
\hline CHEMBL89940 & 66586 & 6.1135 & 6.0088 & TRN & \\
\hline CHEMBL92812 & 66586 & 8.1549 & 8.1168 & TRN & \\
\hline CHEMBL316064 & 66586 & 9.6198 & 9.5738 & TRN & \\
\hline CHEMBL29197 & 66586 & 10.6021 & 10.2514 & TRN & \\
\hline CHEMBL328691 & 66586 & 7.9208 & 8.0368 & TST & \\
\hline CHEMBL92398 & 66586 & 6.9208 & 6.879 & TRN & \\
\hline CHEMBL52197 & 66586 & 7.5229 & 7.6679 & TRN & \\
\hline CHEMBL93635 & 66586 & 6.0915 & 6.2499 & TST & \\
\hline CHEMBL93734 & 66586 & 7.5528 & 7.5382 & TRN & \\
\hline CHEMBL 289959 & 66586 & 6.4634 & 5.9105 & TST & \\
\hline CHEMBL328244 & 66586 & 6.2411 & 6.4183 & TRN & \\
\hline CHEMBL50344 & 66586 & 8.3979 & 8.431000 & 0000000001 & TRN \\
\hline CHEMBL96489 & 66586 & 6.7986 & 6.7718 & TRN & \\
\hline CHEMBL52015 & 66586 & 7.0757 & 7.0812 & TRN & \\
\hline CHEMBL93295 & 66586 & 6.3344 & 6.9502 & TST & \\
\hline CHEMBL294769 & 66586 & 4.0 & 6.6283 & TST & \\
\hline CHEMBL92825 & 66586 & 7.0969 & 7.1537 & TRN & \\
\hline CHEMBL 7917 & 66586 & 9.5086 & 9.6441 & TST & \\
\hline CHEMBL92936 & 66586 & 7.1675 & 7.4852 & TST & \\
\hline CHEMBL 3912471 & 1640574 & 8.8239 & 8.7082 & TRN & \\
\hline CHEMBL 3894577 & 1640574 & 7.699 & 7.4884 & TRN & \\
\hline CHEMBL 3896892 & 1640574 & 8.1192 & 8.0844 & TRN & \\
\hline CHEMBL 3932390 & 1640574 & 8.3872 & 8.4132 & TRN & \\
\hline CHEMBL3936329 & 1640574 & 7.0757 & 7.2796 & TRN & \\
\hline CHEMBL 3976090 & 1640574 & 7.2596 & 7.2853 & TRN & \\
\hline CHEMBL3976678 & 1640574 & 7.9586 & 7.6585 & TRN & \\
\hline CHEMBL 3946371 & 1640574 & 7.3768 & 7.7558 & TRN & \\
\hline CHEMBL3904672 & 1640574 & 8.2007 & 8.004 & TRN & \\
\hline CHEMBL3899716 & 1640574 & 10.0 & 9.8323 & TRN & \\
\hline
\end{tabular}


Supplemental Table S2.txt

\begin{tabular}{|c|c|c|}
\hline הם & 1640574 & \\
\hline HEMBL3979190 & 1640574 & \\
\hline HEMBL3974201 & 1640574 & \\
\hline AEMBL3905494 & 1640574 & \\
\hline HEMBL3980785 & 1640574 & \\
\hline HEMBL3928074 & 1640574 & \\
\hline HEMBL3948660 & 1640574 & \\
\hline HEMBL3894291 & 1640574 & \\
\hline HEMBL3913464 & 1640574 & \\
\hline HEMBL3907714 & 1640574 & \\
\hline HEMBL3890965 & 1640574 & 6.0 \\
\hline AEMBL3984446 & 1640574 & \\
\hline HEMBL3952282 & 1640574 & \\
\hline HEMBL3925183 & 1640574 & \\
\hline HEMBL3979925 & 1640574 & \\
\hline HEMBL3919089 & 1640574 & 9. \\
\hline AEMBL3889930 & 1640574 & \\
\hline HEMBL3956468 & 1640574 & \\
\hline HEMBL3966806 & 1640574 & \\
\hline HEMBL3987123 & 1640574 & \\
\hline HEMBL3897066 & 1640574 & \\
\hline HEMBL3969229 & 1640574 & \\
\hline HEMBL3979122 & 1640574 & 4. \\
\hline HEMBL3895400 & 1640574 & \\
\hline HEMBL3925234 & 1640574 & \\
\hline HEMBL3965271 & 1640574 & 8 . \\
\hline HEMBL3906695 & 1640574 & \\
\hline HEMBL3976254 & 164 & \\
\hline HEMBL3901997 & 1640574 & \\
\hline HEMBL3971381 & 1640574 & 6. \\
\hline HEMBL3964726 & 1640574 & \\
\hline HEMBL3974022 & 1640574 & 7. \\
\hline HEMBL3918965 & 1640574 & \\
\hline CHEMBL3961056 & 1640574 & 8. \\
\hline HEMBL 3897534 & 1640574 & 6. \\
\hline HEMBL3968856 & 1640574 & 6. \\
\hline HEMBL3975126 & 1640574 & 6 . \\
\hline CHEMBL 3940535 & 16 & \\
\hline HEMBL3949501 & 1640574 & \\
\hline HEMBL3977710 & 1640574 & 7. \\
\hline CHEMBL3927446 & 1640574 & 8. \\
\hline CHEMBL 3954717 & 1640574 & \\
\hline CHEMBL3919344 & 1640574 & \\
\hline CHEMBL3906488 & 1640574 & 8.3 \\
\hline HEMBL 3890270 & 1640574 & 7. \\
\hline CHEMBL3976391 & 1640574 & \\
\hline CHEMBL3965033 & 1640574 & \\
\hline CHEMBL 3909180 & 1640574 & \\
\hline
\end{tabular}

8

7.6229 TST

7.5968 TRN

8.3661 TRN

8.1311 TRN

5.3734 TST

7.7976 TRN

7.6136 TRN

6.7615 TST

7.0409 TRN

6.1737 TST

5.506 TST

4.8626 TRN

7.3251 TST

8.0224 TRN

6.9254 TST

8.9479 TRN

6.1718 TST

8.3184 TRN

9.3262 TST

8.3206 TRN

5.9886 TST

7.23 TRN

4.599 TST

5.9245 TST

7.1769 TST

8.3681 TRN

7.8712 TST

8.1557 TRN

6.6798 TRN

6.1338 TRN

6.0473 TRN

7.3852 TRN

7.9969 TRN

8.8173 TRN

6.4719 TRN

7.0292 TST

6.1041 TRN

6.0633 TST

7.8515 TRN

7.3859 TRN

8.1619 TRN

8.0841 TRN

8.0319 TRN

8.172 TRN

7.2728 TRN

6.8009 TRN

7.582000000000001 TRN

8.5566 TRN

Page 118 
Supplemental Table S2.txt

\begin{tabular}{|c|c|c|}
\hline HEMBL3896152 & 0574 & \\
\hline HEMBL3901741 & 640574 & \\
\hline HEMBL3976022 & 574 & \\
\hline HEMBL3986416 & 1640574 & \\
\hline HEMBL3982217 & 1640574 & \\
\hline CHEMBL3901580 & 1640574 & \\
\hline HEMBL3932445 & 1640574 & \\
\hline HEMBL3956421 & 1640574 & \\
\hline HEMBL3966203 & 1640574 & \\
\hline HEMBL3952076 & 1640574 & \\
\hline CHEMBL3910308 & 1640574 & 8.0 \\
\hline HEMBL3929608 & 1640574 & \\
\hline HEMBL 3964344 & 164 & \\
\hline HEMBL3926903 & 1640574 & \\
\hline CHEMBL3962807 & 1640574 & \\
\hline CHEMBL3927385 & 1640574 & \\
\hline HEMBL3940462 & 164 & \\
\hline CHEMBL3903026 & 164 & \\
\hline HEMBL3966620 & 1640574 & \\
\hline CHEMBL3963232 & 574 & \\
\hline CHEMBL3933596 & 164 & \\
\hline HEMBL3931709 & 164 & \\
\hline CHEMBL 3908831 & 16 & \\
\hline CHEMBL 3919834 & 1640574 & \\
\hline CHEMBL 3967750 & 164 & \\
\hline CHEMBL3962020 & 164 & \\
\hline HEMBL3972635 & 164 & \\
\hline CHEMBL3907940 & 164 & \\
\hline CHEMBL3891980 & 1640574 & \\
\hline CHEMBL 3913252 & 1640574 & \\
\hline CHEMBL 3974191 & 1640574 & \\
\hline CHEMBL3928144 & 164 & \\
\hline CHEMBL 3890225 & 164 & \\
\hline CHEMBL3969159 & 1640574 & 7.6 \\
\hline CHEMBL 3899177 & 1640574 & 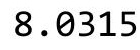 \\
\hline CHEMBL3947929 & 164 & \\
\hline CHEMBL3913969 & 164 & \\
\hline CHEMBL3967166 & 1640574 & \\
\hline CHEMBL3899490 & 1640574 & 8.8 \\
\hline CHEMBL 3938237 & 1640574 & \\
\hline CHEMBL3971598 & 1640574 & \\
\hline CHEMBL3912632 & 1640574 & 8.4 \\
\hline CHEMBL3945304 & 1640574 & 6.7 \\
\hline CHEMBL3941283 & 1640574 & 9.0 \\
\hline CHEMBL 3917410 & 1640574 & 8.1 \\
\hline CHEMBL3931262 & 1640574 & \\
\hline CHEMBL3894578 & 1640574 & \\
\hline CHEMBL3901251 & 1640574 & \\
\hline
\end{tabular}

.

7.3266 TRN

8.0672 TRN

6.8124 TRN

5.9451 TRN

5.7638 TST

5.856 TST

6.8726 TRN

7.1381 TST

8.9433 TRN

6.6277 TST

7.8844 TRN

6.1378 TST

7.2481 TRN

7.1756 TST

8.599 TRN

5.6688 TST

7.8921 TRN

7.2806 TRN

8.1639 TST

5.9743 TST

6.0209 TRN

6.1912 TRN

6.5655 TRN

8.2747 TRN

8.2797 TRN

8.1174 TRN

8.5106 TRN

7.7481 TRN

8.4491 TST

6.7596 TST

7.6784 TRN

7.3422 TST

8.1967 TRN

7.7748 TRN

8.1332 TRN

6.751 TRN

7.7709 TRN

7.8585 TRN

8.8519 TRN

8.4287 TRN

8.7274 TRN

8.4168 TRN

6.7585 TRN

8.9433 TRN

8.0298 TRN

6.9734 TRN

8.5603 TRN

7.0360000000000005 TRN

Page 119 
Supplemental Table S2.txt

\begin{tabular}{|c|c|c|c|c|c|}
\hline CHEMBL3912087 & 1640574 & 7.1192 & 7.1991 & TRN & \\
\hline CHEMBL3961556 & 1640574 & 8.5229 & 8.5447 & TRN & \\
\hline CHEMBL3900963 & 1640574 & 7.9208 & 7.8732 & TRN & \\
\hline CHEMBL 3904694 & 1640574 & 5.5686 & 5.6332 & TST & \\
\hline CHEMBL3933645 & 1640574 & 6.6383 & 6.8277 & TRN & \\
\hline CHEMBL3926535 & 1640574 & 7.8239 & 7.6872 & TRN & \\
\hline CHEMBL3927877 & 1640574 & 8.6383 & 8.484 & TRN & \\
\hline CHEMBL 3899515 & 1640574 & 4.8861 & 5.3332 & TRN & \\
\hline CHEMBL 3899172 & 1640574 & 7.8861 & 7.846 & TRN & \\
\hline CHEMBL3939144 & 1640574 & 6.3872 & 6.3985 & TST & \\
\hline CHEMBL3955055 & 1640574 & 6.9788 & 7.131 & TST & \\
\hline CHEMBL3965676 & 1640574 & 7.3188 & 7.3515 & TRN & \\
\hline CHEMBL3932866 & 1640574 & 7.8861 & 8.008 & TRN & \\
\hline CHEMBL3916864 & 1640574 & 8.041 & 8.0982 & TRN & \\
\hline CHEMBL3922652 & 1640574 & 6.3468 & 6.4906 & TRN & \\
\hline CHEMBL3950595 & 1640574 & 6.7447 & 6.4914 & TRN & \\
\hline CHEMBL3895789 & 1640574 & 7.6383 & 7.425 & TRN & \\
\hline CHEMBL3937511 & 1640574 & 7.0223 & 7.2086 & TRN & \\
\hline CHEMBL3967010 & 1640574 & 8.8239 & 8.7916 & TRN & \\
\hline CHEMBL3942559 & 1640574 & 7.1192 & 6.9504 & TRN & \\
\hline CHEMBL3892286 & 1640574 & 7.7212 & 7.8531 & TRN & \\
\hline CHEMBL3983708 & 1640574 & 7.8861 & 7.9425 & TRN & \\
\hline CHEMBL3923651 & 1640574 & 5.2441 & 5.3838 & TST & \\
\hline CHEMBL3916178 & 1640574 & 8.6778 & \multicolumn{2}{|c|}{8.783999999999999} & TRN \\
\hline CHEMBL3977191 & 1640574 & 6.8861 & 7.1369 & TRN & \\
\hline CHEMBL3957354 & 1640574 & 7.1904 & 7.3428 & TRN & \\
\hline CHEMBL 3985874 & 1640574 & 6.284 & 6.1635 & TST & \\
\hline CHEMBL3961106 & 1640574 & 8.0315 & 8.0468 & TRN & \\
\hline CHEMBL3975500 & 1640574 & 8.1367 & 7.3453 & TST & \\
\hline CHEMBL3919026 & 1640574 & 6.7212 & 6.6125 & TRN & \\
\hline CHEMBL 3984164 & 1640574 & 8.7212 & 8.5905 & TRN & \\
\hline CHEMBL 3977344 & 1640574 & 7.0915 & 7.5295 & TRN & \\
\hline CHEMBL3969016 & 1640574 & 8.7696 & 8.8779 & TRN & \\
\hline CHEMBL3939239 & 1640574 & 8.0506 & 8.1129 & TRN & \\
\hline CHEMBL 3968002 & 1640574 & 6.3768 & 6.9617 & TST & \\
\hline CHEMBL3941846 & 1640574 & 5.4437 & \multicolumn{2}{|c|}{6.0520000000000005} & TST \\
\hline CHEMBL3907965 & 1640574 & 6.9586 & 6.9683 & TRN & \\
\hline CHEMBL 3982415 & 1640574 & 7.8539 & 8.2499 & TRN & \\
\hline CHEMBL3916957 & 1640574 & 6.8539 & 7.0754 & TRN & \\
\hline CHEMBL3912088 & 1640574 & 6.0044 & 5.9443 & TRN & \\
\hline CHEMBL3947888 & 1640574 & 8.0132 & 8.2495 & TRN & \\
\hline CHEMBL3974777 & 1640574 & 7.2518 & 7.2222 & TRN & \\
\hline CHEMBL3904712 & 1640574 & 8.1024 & 8.3989 & TRN & \\
\hline CHEMBL3927590 & 1640574 & 8.5686 & 8.7463 & TST & \\
\hline CHEMBL3913487 & 1640574 & 5.7212 & 5.7895 & TRN & \\
\hline CHEMBL3950150 & 1640574 & 7.5086 & 7.5505 & TRN & \\
\hline CHEMBL3944209 & 1640574 & 8.3768 & 8.052 & TST & \\
\hline CHEMBL3987000 & 1640574 & 7.3665 & 7.3793 & TRN & \\
\hline
\end{tabular}

Page 120 
Supplemental Table S2.txt

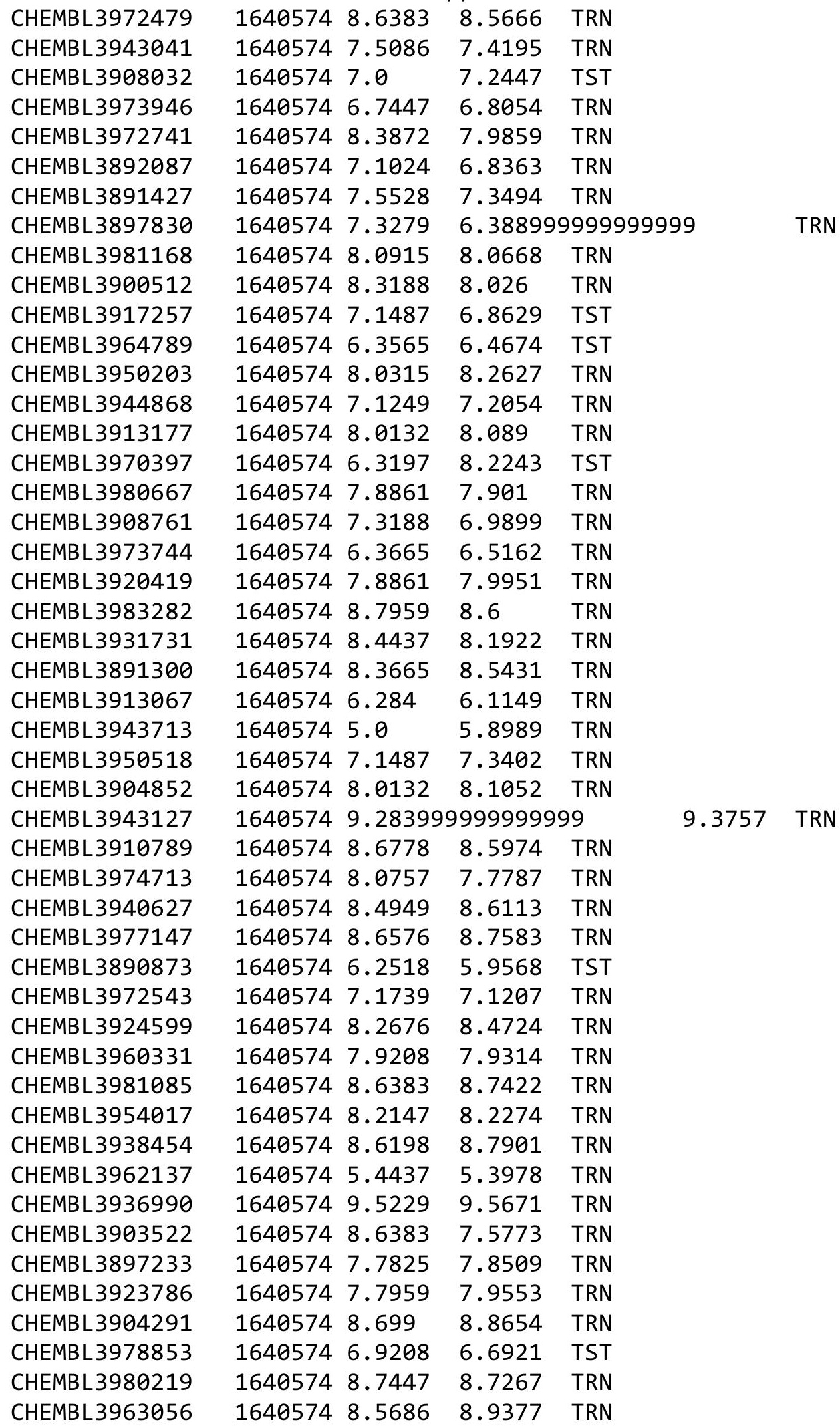


Supplemental Table S2.txt

\begin{tabular}{|c|c|c|c|c|}
\hline HEMBL3924930 & 74 & 35 & 78 & \\
\hline & 640574 & 7.7959 & 7.6403 & \\
\hline 19 & & & & \\
\hline AEMBL & 574 & 5.0 & & \\
\hline AEMBL3892575 & 574 & 586 & 7824 & \\
\hline HEMBL 3978595 & 640574 & 8.0915 & 4414 & \\
\hline & 54 & 239 & & \\
\hline |FMRI & & 192 & & \\
\hline HEMBL3948454 & 640574 & 3539 & & \\
\hline HEMBL3897494 & 640574 & 586 & 094 & \\
\hline HEMBL3921412 & 640574 & 7.7447 & 24 & \\
\hline IEMBL38 & 74 & 437 & 226 & \\
\hline AEMBL3 & & & & \\
\hline HEMBL 39 & 54 & 8.2291 & & \\
\hline AEMBL38 & 74 & 376 & & \\
\hline AEMBL3906990 & 74 & 979 & & \\
\hline AEMBL38 & 74 & 38 & & \\
\hline HEMBL38 & & 21 & & \\
\hline HEMBL39 & 74 & 208 & & \\
\hline AEMBL3S & 74 & 96 & & $\mathrm{~T}$ \\
\hline HEIMBLSל & 4 & 39 & & \\
\hline AEMBL: & 4 & 86 & & \\
\hline HEMBL; & & 25 & & \\
\hline 216 & & 08 & & NTI \\
\hline AEMBL39 & & & & RN \\
\hline HEMBL & 4 & & 57 & RI \\
\hline HEMBL3 & & 66 & & \\
\hline$A F M B$ & & 39 & & ST \\
\hline HEMBL3S & & & & RIV \\
\hline HEMBL 393 & 64 & & & RN \\
\hline HEMBL3S & 64 & & & ST \\
\hline HEMBL 3 & 4 & & & RN \\
\hline 96 & & 67 & & RN \\
\hline HEMBL3903066 & 74 & 21 & & RN \\
\hline HEMBL3980922 & 640 & 8.6021 & & RN \\
\hline HEMBL3\& & 74 & 65 & & \\
\hline HFMRI & & & & RN \\
\hline HEMBL3 & & & & RN \\
\hline HEMBL3904322 & 640574 & 6.7959 & 397 & TST \\
\hline IEMBL3 & 74 & & & RN \\
\hline HEMBL39 & 74 & 62 & 11 & \\
\hline CHEMBL390 & & & & RN \\
\hline HEMBL3895450 & 574 & 8.1805 & 392 & RN \\
\hline AEMBL3960833 & 640574 & 7.6383 & 083 & RN \\
\hline$M B L$ & & & & \\
\hline HEMBL 398 & 64 & 686 & 4094 & \\
\hline CHEMBL 3905309 & 16405 & & .9163 & \\
\hline THEMBL389182e & 1640574 & 3.58 & 8.6012 & ГRN \\
\hline
\end{tabular}

Page 122 
Supplemental Table S2.txt

\begin{tabular}{|c|c|c|c|c|c|}
\hline CHEMBL3899565 & 1640574 & 7.2882 & 7.5204 & TRN & \\
\hline CHEMBL3936879 & 1640574 & 7.8239 & 8.0143 & TRN & \\
\hline CHEMBL3973734 & 1640574 & 7.8539 & 7.7962 & TRN & \\
\hline CHEMBL3933597 & 1640574 & 8.6198 & 8.1 & TRN & \\
\hline CHEMBL3923440 & 1640574 & 7.7825 & 7.541 & TST & \\
\hline CHEMBL3968774 & 1640574 & 8.0506 & 8.0395 & TRN & \\
\hline CHEMBL3986943 & 1640574 & 9.0969 & 8.8286 & TRN & \\
\hline CHEMBL3941307 & 1640574 & 6.9586 & 6.6979 & TRN & \\
\hline CHEMBL3968742 & 1640574 & 7.6383 & 7.7513 & TRN & \\
\hline CHEMBL3900809 & 1640574 & 8.1805 & 8.2864 & TRN & \\
\hline CHEMBL3957688 & 1640574 & 7.1739 & 7.2813 & TRN & \\
\hline CHEMBL3934916 & 1640574 & 8.2518 & 8.0749 & TRN & \\
\hline CHEMBL3957616 & 1640574 & 8.2076 & 8.1474 & TRN & \\
\hline CHEMBL3971435 & 1640574 & 5.6021 & 6.5474 & TST & \\
\hline CHEMBL3929885 & 1640574 & 6.1192 & 4.837 & TST & \\
\hline CHEMBL3943038 & 1640574 & 7.8239 & 7.6159 & TRN & \\
\hline CHEMBL3954781 & 1640574 & 8.0862 & 8.168 & TRN & \\
\hline CHEMBL3983416 & 1640574 & 6.3279 & 6.8595 & TRN & \\
\hline CHEMBL3950042 & 1640574 & 6.0 & 5.7287 & TRN & \\
\hline CHEMBL3955405 & 1640574 & 6.6576 & 6.4357 & TRN & \\
\hline CHEMBL3922949 & 1640574 & 8.2596 & 7.9679 & TRN & \\
\hline CHEMBL3895898 & 1640574 & 8.7212 & 8.7738 & TRN & \\
\hline CHEMBL3952378 & 1640574 & 8.3098 & 8.4975 & TRN & \\
\hline CHEMBL3951639 & 1640574 & 8.0757 & 8.3243 & TRN & \\
\hline CHEMBL3899097 & 1640574 & 7.7959 & 7.1567 & TST & \\
\hline CHEMBL3904876 & 1640574 & 6.0269 & 6.2825 & TST & \\
\hline CHEMBL3941240 & 1640574 & 7.2147 & 6.7269 & TST & \\
\hline CHEMBL3920410 & 1640574 & 6.3768 & 6.933 & TRN & \\
\hline CHEMBL3900331 & 1640574 & 6.3565 & 6.8081 & TRN & \\
\hline CHEMBL3927358 & 1640574 & 9.1549 & 9.0506 & TRN & \\
\hline CHEMBL3922482 & 1640574 & 5.7212 & 6.7955 & TST & \\
\hline CHEMBL3975681 & 1640574 & 7.8239 & 8.0369 & TRN & \\
\hline CHEMBL3980688 & 1640574 & 7.7959 & 7.6456 & TRN & \\
\hline CHEMBL3968352 & 1640574 & 8.5376 & 8.1645 & TRN & \\
\hline CHEMBL3913659 & 1640574 & 8.585 & 8.6713 & TRN & \\
\hline CHEMBL3955767 & 1640574 & 7.8239 & 7.5851 & TRN & \\
\hline CHEMBL3983786 & 1640574 & 6.8239 & 7.0774 & TRN & \\
\hline CHEMBL3906193 & 1640574 & 7.5086 & 7.33899 & & TRN \\
\hline CHEMBL 3944201 & 1640574 & 8.7696 & 8.4264 & TRN & \\
\hline CHEMBL3954981 & 1640574 & 8.8539 & 8.8359 & TRN & \\
\hline CHEMBL3985709 & 1640574 & 6.8539 & 6.9219 & TRN & \\
\hline CHEMBL3948085 & 1640574 & 8.7696 & 8.6573 & TRN & \\
\hline CHEMBL3966878 & 1640574 & 6.4202 & 6.4178 & TRN & \\
\hline CHEMBL 3927542 & 1640574 & 6.6576 & 6.8648 & TRN & \\
\hline CHEMBL3948379 & 1640574 & 7.2291 & 7.3485 & TRN & \\
\hline CHEMBL3908333 & 1640574 & 6.6021 & 6.5725 & TST & \\
\hline CHEMBL3906804 & 1640574 & 6.6576 & 6.7069 & TST & \\
\hline CHEMBL3891763 & 1640574 & 6.6198 & 7.2561 & TST & \\
\hline
\end{tabular}


Supplemental Table S2.txt

\begin{tabular}{|c|c|c|c|c|}
\hline-1 & 574 & & & \\
\hline & 640574 & 8.7696 & & \\
\hline$H E N$ & & & & \\
\hline AEMBL & 574 & 6778 & 8639 & $\mathrm{MI}$ \\
\hline AEMBL3985540 & 640574 & 362 & 3782 & \\
\hline HEMBL3943569 & 540574 & . 1805 & .3809 & \\
\hline 291 & & 007 & 525 & \\
\hline IEMBL 3890352 & & & & \\
\hline AEMBL3926246 & 574 & 1079 & 1187 & \\
\hline AEMBL3910716 & 640574 & 5021 & 5207 & \\
\hline AEMBL3970663 & 574 & 2596 & .2398 & \\
\hline EMBL & 74 & 79 & 437 & \\
\hline IEMBL3 & & & & \\
\hline HEMBL3900660 & 574 & 301 & 7.7891 & \\
\hline AEMBL3960355 & 74 & 969 & .967 & \\
\hline HEMBL3970947 & 74 & 7 & 7.8661 & \\
\hline AEMBL3 & 74 & 65 & 062 & \\
\hline AEMBL3 & & & & \\
\hline HEMBL3917106 & 74 & & 9707 & \\
\hline AEMBL39 & 74 & 98 & & \\
\hline HEMBL= & 4 & 12 & 47 & \\
\hline AEMBL: & & 2 & 15 & ודים \\
\hline HEMBL; & & 55 & 17 & \\
\hline 72161 & & 362 & 3095 & \\
\hline AEMBL39 & & & & ISI \\
\hline HEMBL & 4 & & 402 & RN \\
\hline AEMBL; & & & & NIV \\
\hline HFMBI : & & & 503 & \\
\hline AEMBL39 & & 612 & & in \\
\hline HEMBL39616 & & 39 & 34 & 15 \\
\hline HEMBL3 & 74 & 7. & 558 & RN \\
\hline HEMBL & & 79 & & RN \\
\hline AEMBL: & & 39 & 909 & 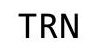 \\
\hline HEMBL3911853 & & 76 & 253 & R \\
\hline HEMBL3922798 & 74 & 872 & 8.2264 & TRN \\
\hline HEMBL3S & 74 & 447 & 382 & RN \\
\hline HFMRI & & & & RN \\
\hline HEMBL3 & & & 485 & ST \\
\hline HEMBL3890310 & 574 & 778 & 7.869 & $\Gamma \mathrm{RN}$ \\
\hline AEMBL3 & & 212 & 7341 & $\mathrm{RN}$ \\
\hline HEMBL3S & 4 & 59 & 3302 & 80 \\
\hline HEMBL 39 & & & & NIV \\
\hline HEMBL3931504 & 574 & 768 & 8.1799 & TRN \\
\hline AEMBL3922125 & 540574 & 198 & .6243 & TR \\
\hline $\mathrm{MBL}=$ & & & 8.4644 & $\mathrm{~N}$ \\
\hline HEMBL3S & 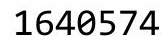 & 177 & .7553 & \\
\hline HEMBL3925871 & & & 5.6881 & \\
\hline THEMBL3905622 & 1640574 & 6.8539 & 7.0314 & IST \\
\hline
\end{tabular}

Page 124 
Supplemental Table S2.txt

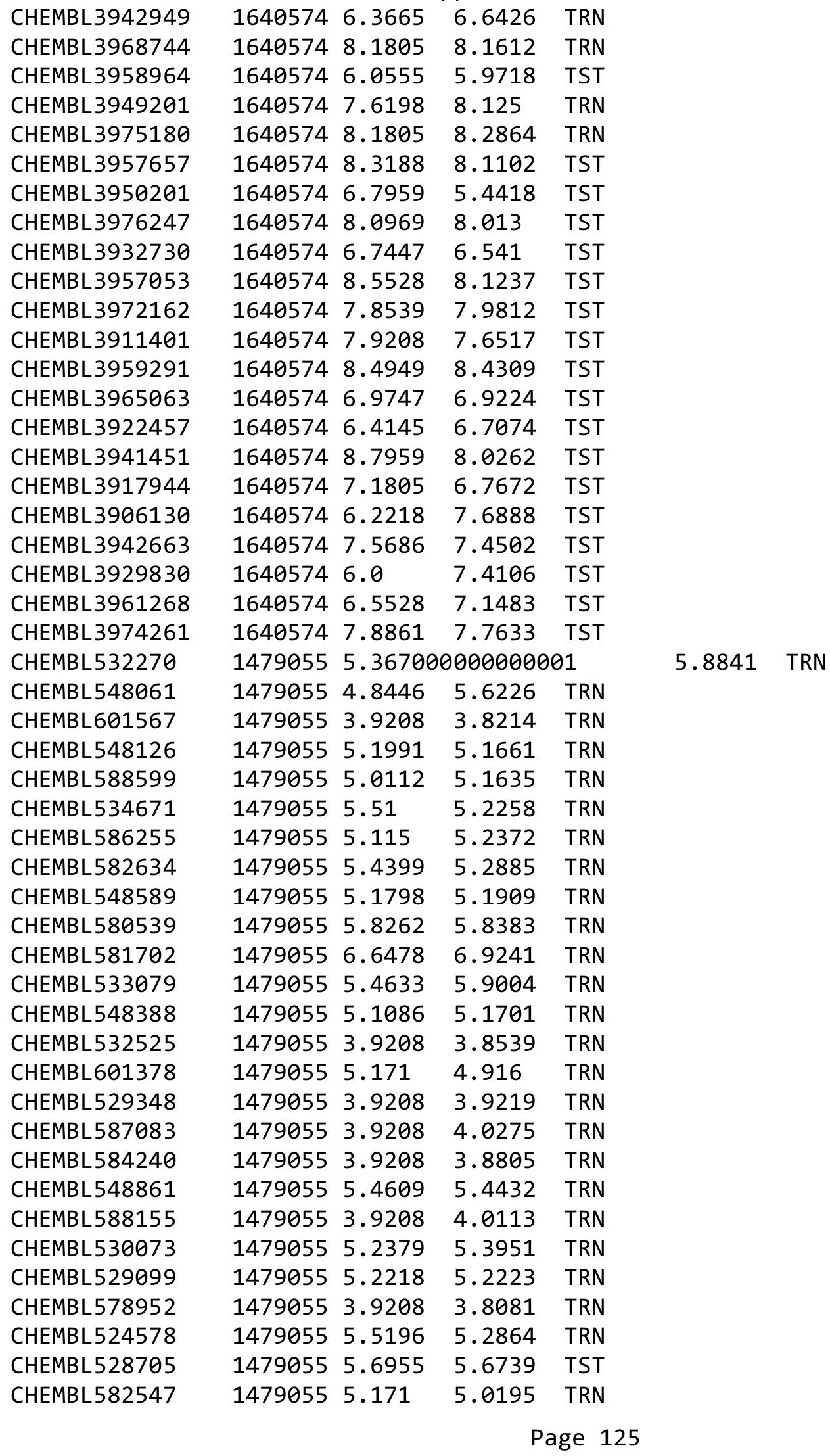


Supplemental Table S2.txt

\begin{tabular}{|c|c|c|c|c|}
\hline HEMBL 579584 & 1479055 & 5.2655 & 5.4368 & Tru \\
\hline CHEMBL601158 & 479055 & 3.9208 & 4.1483 & \\
\hline HEMBL 592808 & 479055 & 9208 & & \\
\hline AEMBL475813 & 479055 & 9208 & & \\
\hline HEMBL 588641 & 479055 & 8099 & 9351 & \\
\hline HEMBL 528480 & 479055 & 5.7655 & 28 & \\
\hline HEMBL2028064 & 479055 & 3.9208 & & \\
\hline AEMBL 547184 & 479055 & 5.0722 & & \\
\hline HEMBL 2028053 & 479055 & 5.171 & 021 & RN \\
\hline HEMBL591623 & 479055 & 3.9208 & & \\
\hline HEMBL5 & 479055 & 5.1421 & & \\
\hline AEMBL: & 055 & 5.2483 & & \\
\hline HEMBL: & 055 & 3.9208 & & \\
\hline JEMBL 548002 & 479055 & 5.7881 & 562 & \\
\hline HEMBL3 & 055 & 5.9821 & & \\
\hline HEMBL: & 1479055 & 3.9208 & & \\
\hline HEMBL & 55 & 5.7086 & & RN \\
\hline HEMBL & 055 & 3.9208 & & \\
\hline AEMBL5 & .479055 & 3.9208 & & \\
\hline HEMBL5 & & 3.9208 & & \\
\hline HEMBL & 47 & 5.6308 & & RIV \\
\hline AEMBL & 14 & 3.9208 & & RN \\
\hline AEMBL & 055 & 5.2641 & & RN \\
\hline AEMBL: & 055 & 5.7176 & & $\mathrm{RN}$ \\
\hline HEMBL5 & 55 & 3.5 & & RN \\
\hline HEMBL: & 5 & 5 . & & RIN \\
\hline AEMBL & 5 & 3 . & & RN \\
\hline IEMB & 55 & 3.9208 & & BN \\
\hline AEMBL & & 208 & & RN \\
\hline HEMBL: & 55 & 6.1524 & & ГRN \\
\hline AEMBL: & & & & 传 \\
\hline AEMB & 5 & 38 & & 「RN \\
\hline HEMBL & 55 & 4.87 & & TRN \\
\hline HEMBL & 55 & 208 & & $\mathrm{RI}$ \\
\hline HEMBL5 & 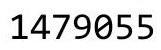 & 3.9208 & & TRI \\
\hline AEME & & $\partial 8$ & & ובנו \\
\hline HEME & 5 & 8 & & TRN \\
\hline HEMBL & 1479055 & 5.4238 & & RN \\
\hline HEMBL & 479055 & 5.2217 & & ГRN \\
\hline HEMBL & 1799 & 58 & & RI \\
\hline CHEMBL & & & & IRI \\
\hline CHEMBL: & 1479055 & 3.9208 & $3 . \varepsilon$ & TRI \\
\hline CHEMBL548777 & 1479055 & 5.232 & 5.3262 & TR \\
\hline HEMBL & 479055 & 3.9208 & 3. & $\mathrm{TR}$ \\
\hline CHEMBL & & 5.1309 & & w \\
\hline CHEMBL 5 & 4790 & 4.9767 & 5.0937 & (n) \\
\hline CHEMBL580353 & 479055 & 3.9208 & 4.2174 & TR \\
\hline CHEMBL580876 & 1479055 & 3.9208 & 3.903 & TR \\
\hline
\end{tabular}

Page 126 
Supplemental Table S2.txt

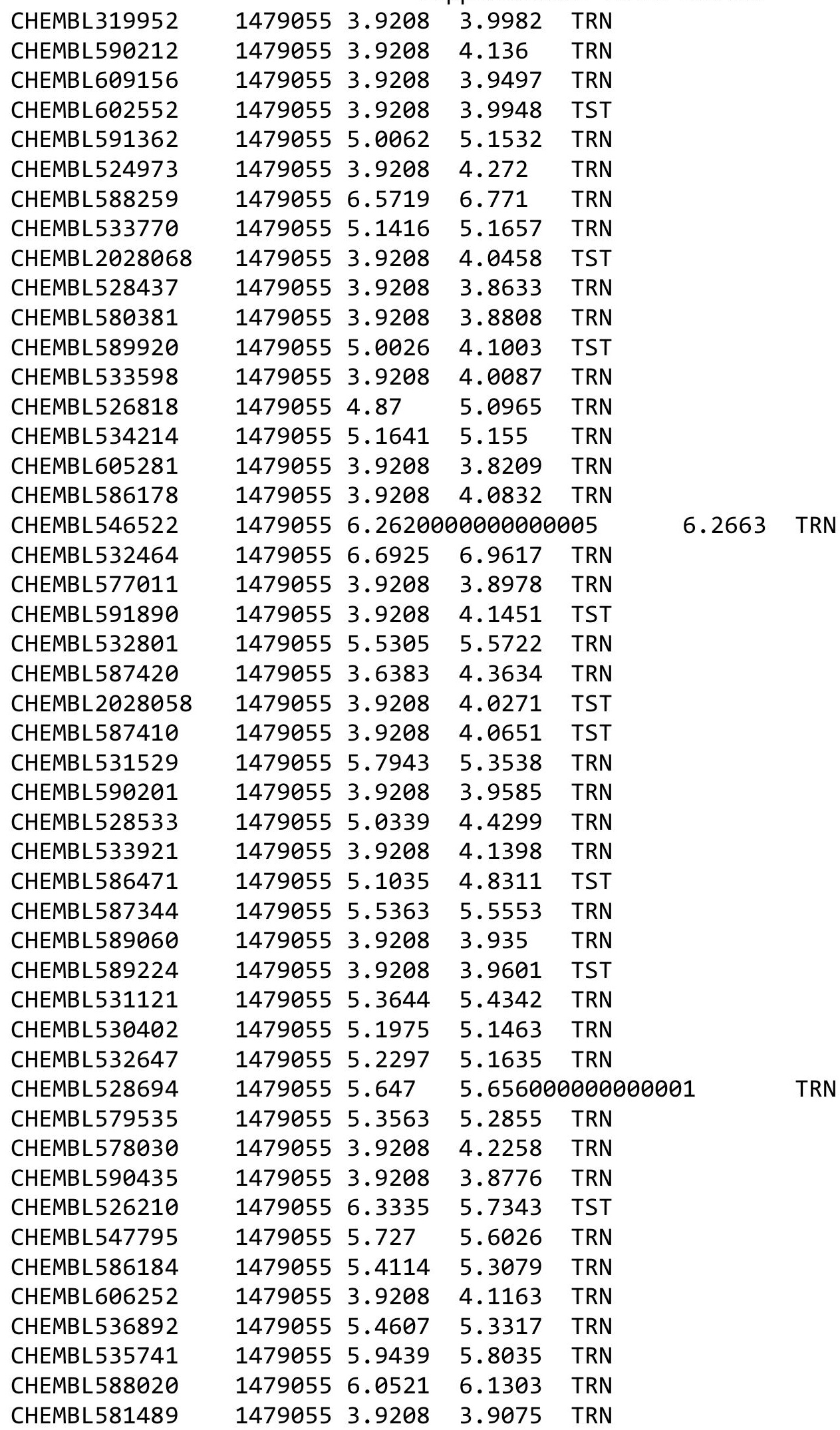


Supplemental Table S2.txt

\begin{tabular}{|c|c|c|c|c|c|}
\hline CHEMBL581860 & 1479055 & 5.171 & 4.0993 & TRN & \\
\hline CHEMBL601814 & 1479055 & 3.9208 & 3.8724 & TRN & \\
\hline CHEMBL527730 & 1479055 & 3.9208 & 3.8884 & TRN & \\
\hline CHEMBL533085 & 1479055 & 5.0536 & 5.0046 & TST & \\
\hline CHEMBL579300 & 1479055 & 3.9208 & 4.0042 & TRN & \\
\hline CHEMBL546531 & 1479055 & 3.9208 & 4.1862 & TRN & \\
\hline CHEMBL588855 & 1479055 & 5.171 & 3.9723 & TRN & \\
\hline CHEMBL588127 & 1479055 & 5.0916 & 5.2992 & TRN & \\
\hline CHEMBL10835 & 1479055 & 3.9208 & 3.9314 & TRN & \\
\hline CHEMBL601528 & 1479055 & 3.9208 & 4.0479 & TRN & \\
\hline CHEMBL598279 & 1479055 & 5.349 & 5.0787 & TRN & \\
\hline CHEMBL582552 & 1479055 & 3.9208 & 4.0276 & TRN & \\
\hline CHEMBL537379 & 1479055 & 5.3384 & 5.3975 & TRN & \\
\hline CHEMBL537564 & 1479055 & 5.7964 & \multicolumn{2}{|c|}{5.627000000000001} & TRN \\
\hline CHEMBL590919 & 1479055 & 4.9325 & 4.1385 & TRN & \\
\hline CHEMBL536165 & 1479055 & 3.6383 & 3.9118 & TRN & \\
\hline CHEMBL533563 & 1479055 & 3.9208 & 4.0248 & TST & \\
\hline CHEMBL579315 & 1479055 & 3.9208 & 3.9848 & TRN & \\
\hline CHEMBL602127 & 1479055 & 3.9208 & 3.9975 & TRN & \\
\hline CHEMBL535475 & 1479055 & \multicolumn{3}{|c|}{6.162999999999999} & TRN \\
\hline CHEMBL596652 & 1479055 & 3.9208 & 3.8691 & TRN & \\
\hline CHEMBL585983 & 1479055 & 3.9208 & 4.0425 & TRN & \\
\hline CHEMBL588473 & 1479055 & 5.5906 & 5.6401 & TRN & \\
\hline CHEMBL532155 & 1479055 & 3.9208 & 4.1333 & TRN & \\
\hline CHEMBL532890 & 1479055 & 5.1476 & 5.2718 & TST & \\
\hline CHEMBL590686 & 1479055 & 3.9208 & 3.9576 & TRN & \\
\hline CHEMBL588516 & 1479055 & 3.9208 & 3.9879 & TRN & \\
\hline CHEMBL527541 & 1479055 & 5.353 & 4.8066 & TRN & \\
\hline CHEMBL580264 & 1479055 & 5.1404 & 5.3035 & TRN & \\
\hline CHEMBL547476 & 1479055 & 3.9208 & 3.9994 & TRN & \\
\hline CHEMBL586031 & 1479055 & 3.9208 & 4.0355 & TST & \\
\hline CHEMBL530399 & 1479055 & 5.0069 & 4.9867 & TRN & \\
\hline CHEMBL2028059 & 1479055 & 3.9208 & 3.8939 & TST & \\
\hline CHEMBL581135 & 1479055 & 6.4461 & 6.7491 & TRN & \\
\hline CHEMBL586093 & 1479055 & 5.56 & 5.4808 & TRN & \\
\hline CHEMBL598881 & 1479055 & 3.9208 & 4.0993 & TST & \\
\hline CHEMBL607688 & 1479055 & 3.9208 & 4.0467 & TRN & \\
\hline CHEMBL580191 & 1479055 & 5.3648 & 5.5418 & TRN & \\
\hline CHEMBL534605 & 1479055 & 5.6291 & 5.757000 & 0000000001 & TS \\
\hline CHEMBL547127 & 1479055 & 5.3139 & 5.2668 & TRN & \\
\hline CHEMBL579331 & 1479055 & 3.9208 & 3.9854 & TRN & \\
\hline CHEMBL468963 & 1479055 & 6.2366 & 6.5505 & TRN & \\
\hline CHEMBL527221 & 1479055 & 3.6383 & 4.1095 & TRN & \\
\hline CHEMBL547442 & 1479055 & 5.3118 & 5.3548 & TRN & \\
\hline CHEMBL533429 & 1479055 & 5.1086 & 5.2922 & TRN & \\
\hline CHEMBL529792 & 1479055 & 5.8586 & 5.4939 & TST & \\
\hline CHEMBL527902 & 1479055 & 5.3473 & 5.3404 & TRN & \\
\hline CHEMBL582356 & 1479055 & 5.4314 & 5.2377 & TRN & \\
\hline
\end{tabular}

Page 128 
Supplemental Table S2.txt

\begin{tabular}{|c|c|c|c|c|c|}
\hline CHEMBL527593 & 1479055 & 3.9208 & 3.9715 & TST & \\
\hline CHEMBL589422 & 1479055 & 3.9208 & 3.9665 & TST & \\
\hline CHEMBL598263 & 1479055 & 6.4935 & 5.855 & TST & \\
\hline CHEMBL583555 & 1479055 & 3.9208 & 4.0886 & TST & \\
\hline CHEMBL534612 & 1479055 & 3.9208 & 3.9037 & TRN & \\
\hline CHEMBL1237253 & 1479055 & 4.6984 & 4.3404 & TRN & \\
\hline CHEMBL599100 & 1479055 & 3.9208 & 4.0346 & TRN & \\
\hline CHEMBL533333 & 1479055 & 5.6212 & 5.6978 & TRN & \\
\hline CHEMBL586000 & 1479055 & 4.937 & 4.4282 & TRN & \\
\hline CHEMBL547140 & 1479055 & 5.6792 & 5.809 & TRN & \\
\hline CHEMBL587989 & 1479055 & 3.9208 & 3.9801 & TST & \\
\hline CHEMBL529452 & 1479055 & 5.8817 & 6.0882 & TRN & \\
\hline CHEMBL587824 & 1479055 & 5.4097 & 5.1636 & TST & \\
\hline CHEMBL525826 & 1479055 & 3.9208 & 4.1441 & TRN & \\
\hline CHEMBL535091 & 1479055 & 5.6765 & 5.5449 & TRN & \\
\hline CHEMBL581933 & 1479055 & 5.2187 & 5.3808 & TRN & \\
\hline CHEMBL585686 & 1479055 & 3.9208 & 4.0756 & TST & \\
\hline CHEMBL546826 & 1479055 & 5.3857 & 5.3092 & TRN & \\
\hline CHEMBL525692 & 1479055 & 3.9208 & 3.8419 & TRN & \\
\hline CHEMBL579443 & 1479055 & 3.9208 & 3.9681 & TRN & \\
\hline CHEMBL602234 & 1479055 & 3.9208 & 4.2167 & TRN & \\
\hline CHEMBL605751 & 1479055 & 3.9208 & 4.0064 & TRN & \\
\hline CHEMBL525462 & 1479055 & 5.0248 & 4.8386 & TRN & \\
\hline CHEMBL533917 & 1479055 & 5.171 & 5.0361 & TRN & \\
\hline CHEMBL580159 & 1479055 & 3.9208 & 3.9236 & TRN & \\
\hline CHEMBL585243 & 1479055 & 3.9208 & 3.9996 & TRN & \\
\hline CHEMBL588636 & 1479055 & 5.4681 & 5.2686 & TST & \\
\hline CHEMBL593290 & 1479055 & 6.4179 & 6.0129 & TRN & \\
\hline CHEMBL580809 & 1479055 & 5.1307 & 5.1162 & TST & \\
\hline CHEMBL579920 & 1479055 & 5.0969 & 5.1728 & TRN & \\
\hline CHEMBL596643 & 1479055 & 3.9208 & 3.8225 & TRN & \\
\hline CHEMBL597248 & 1479055 & 3.9208 & 4.2372 & TRN & \\
\hline CHEMBL535077 & 1479055 & 6.9136 & 6.7704 & TRN & \\
\hline CHEMBL580149 & 1479055 & 5.2822 & 5.2179 & TST & \\
\hline CHEMBL601612 & 1479055 & 3.9208 & 4.0781 & TRN & \\
\hline CHEMBL546309 & 1479055 & 5.9161 & 5.7732 & TRN & \\
\hline CHEMBL532483 & 1479055 & 5.0837 & 5.186 & TRN & \\
\hline CHEMBL 2028057 & 1479055 & 3.9208 & 3.8783 & TST & \\
\hline CHEMBL261693 & 1479055 & 3.9208 & 3.83600 & 00000000003 & TRN \\
\hline CHEMBL609036 & 1479055 & 3.9208 & 4.1402 & TRN & \\
\hline CHEMBL586130 & 1479055 & 5.228 & 5.1879 & TRN & \\
\hline CHEMBL1616787 & 1479055 & 3.9208 & 3.9765 & TRN & \\
\hline CHEMBL529081 & 1479055 & 3.6383 & 4.0319 & TRN & \\
\hline CHEMBL585264 & 1479055 & 3.9208 & 4.0835 & TST & \\
\hline CHEMBL1460047 & 1479055 & 3.9208 & 4.2789 & TST & \\
\hline CHEMBL537153 & 1479055 & 5.2865 & 5.1224 & TRN & \\
\hline CHEMBL546168 & 1479055 & 3.9208 & 3.9044 & TRN & \\
\hline CHEMBL580967 & 1479055 & 5.4053 & 5.5174 & TRN & \\
\hline
\end{tabular}


Supplemental Table S2.txt

\begin{tabular}{|c|c|c|c|c|}
\hline CHEMBL587371 & 479055 & 3.9208 & 3.931 & TR \\
\hline HEMBL548918 & 479055 & 5.3411 & 5.3408 & TR \\
\hline HEMBL 5 & 9955 & 5.3089 & & \\
\hline HEMBL547443 & 479055 & 3.9208 & 0198 & $R N$ \\
\hline HEMBL600235 & 479055 & 1949 & 9939 & \\
\hline HEMBL601348 & 479055 & 3.9208 & 4.0969 & \\
\hline HEMBL579802 & 4790 & 4.8825 & 5.1681 & \\
\hline HEMBL 602764 & 1 & 3.9208 & & RN \\
\hline HEMBL 587802 & 479055 & 4.7431 & 5.1623 & RN \\
\hline HEMBL582767 & 479055 & 5.2062 & 4.4709 & ST \\
\hline HEMBL532141 & 479055 & 3.9208 & 3.9259 & \\
\hline HEMBL528336 & 479 & 4.87 & 7664 & \\
\hline HEMBL5 & & 3.9208 & & RN \\
\hline HEMBL601566 & 1479055 & 3.9208 & 4.0593 & $\mathrm{RN}$ \\
\hline HEMBL581187 & 295 & 08 & .0285 & \\
\hline HEMBL533564 & 4796 & 5.3093 & 5.3349 & ST \\
\hline HEMBL54 & 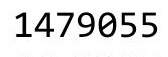 & 5.734 & 5854 & RN \\
\hline HEMBL5\& & & 5.3172 & 816 & \\
\hline HEMBL 587120 & 1479055 & 6.4461 & 5.9958 & TRN \\
\hline HEMBL52 & & 3.5 & 3095 & TRN \\
\hline HEMBL6 & 4 & 3 . & 665 & ST \\
\hline HEMBLS & $4 /$ & 38 & 665 & $\Gamma \mathrm{RN}$ \\
\hline HEMBL5 & 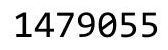 & 08 & 94 & IRN \\
\hline HEMBL529924 & 1479055 & 5 . & 9955 & TRN \\
\hline HEMBL5 & & 4.5 & 59 & TST \\
\hline HEMBL5 & 96 & 48 & 4294 & RN \\
\hline HEMBL 5 & 55 & 3 . & 3828 & $\Gamma \mathrm{RN}$ \\
\hline HEMBL5 & 55 & 14 & 502 & IST \\
\hline LHEMBL586962 & & 3.9208 & 4.0986 & TRN \\
\hline HEMBL529984 & & 3.9208 & 345 & TRN \\
\hline HEMBL 5 & 90 & 3 . & 8312 & ГRN \\
\hline HEMBL5 & 14 & $\partial 8$ & 353 & TRN \\
\hline CHEMBL5 & 55 & 5 . & 807 & TRN \\
\hline HEMBL527906 & 479055 & 5.6815 & 5.5587 & TRN \\
\hline HEMBL1485159 & 47905 & 3.9208 & 4.0916 & TRN \\
\hline CHEMBL5 & 5 & & 8162 & $\Gamma \mathrm{RN}$ \\
\hline CHEMBL5 & 5 & 87 & 1003 & $\Gamma \mathrm{RN}$ \\
\hline CHEMBL548469 & 1479055 & 5.171 & 4.4432 & TRN \\
\hline CHEMBL1744512 & 1479055 & 3.9208 & 3.9096 & TRN \\
\hline CHEMBL588501 & 7905 & 5 & 5.0308 & TRN \\
\hline CHEMBL586175 & 1479055 & 5.2128 & 5.1656 & TRN \\
\hline CHEMBL533069 & 1479055 & 5.0523 & 5.0052 & TRN \\
\hline CHEMBL607975 & 1479055 & 3.9208 & 4.1897 & TRN \\
\hline CHEMBL529990 & 1479055 & 5.6885 & 5.7485 & TRN \\
\hline CHEMBL529424 & 147905 & 3.6383 & 3.8203 & TST \\
\hline CHEMBL527904 & 1479055 & 5.8502 & 6.3871 & \\
\hline CHEMBL587759 & 147905 & 3.6383 & 3.7558 & RN \\
\hline CHEMBL601580 & 1479055 & 5.171 & 4.9781 & ГRN \\
\hline
\end{tabular}


Supplemental Table S2.txt

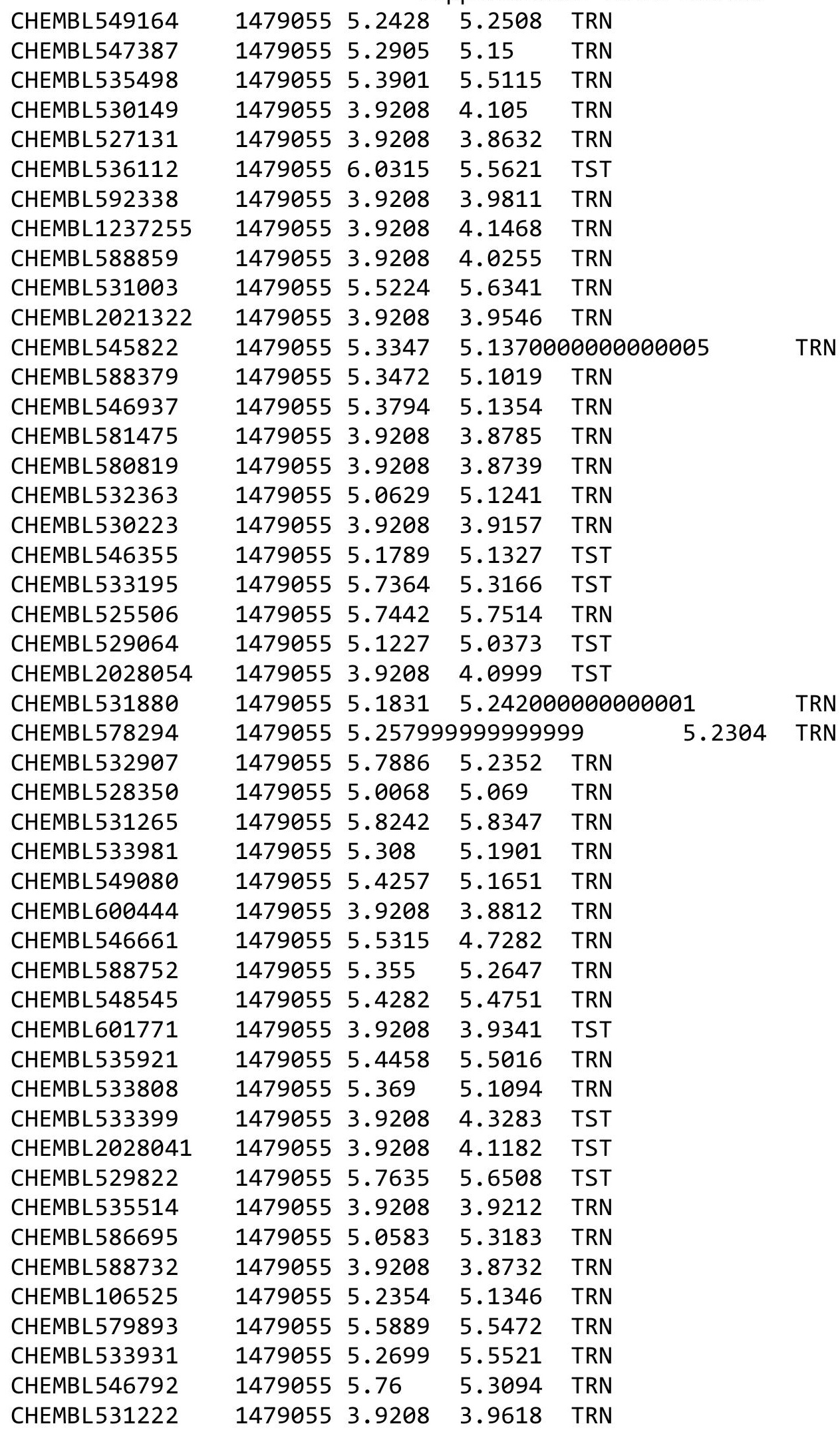


Supplemental Table S2.txt

\begin{tabular}{|c|c|c|c|c|c|}
\hline CHEMBL586553 & 1479055 & 5.3143 & 5.1959 & TRN & \\
\hline CHEMBL529919 & 1479055 & 3.9208 & 3.9739 & TRN & \\
\hline CHEMBL530649 & 1479055 & 5.6326 & 5.4997 & TRN & \\
\hline CHEMBL581175 & 1479055 & 3.9208 & 3.9544 & TRN & \\
\hline CHEMBL586937 & 1479055 & 5.5157 & 5.3639 & TRN & \\
\hline CHEMBL548482 & 1479055 & 3.6383 & 4.0643 & TRN & \\
\hline CHEMBL590888 & 1479055 & 3.9208 & 4.0529 & TRN & \\
\hline CHEMBL588011 & 1479055 & 4.998 & 5.046 & TST & \\
\hline CHEMBL 2028051 & 1479055 & 3.9208 & 3.9228 & TRN & \\
\hline CHEMBL599885 & 1479055 & 3.9208 & 3.9059 & TRN & \\
\hline CHEMBL588939 & 1479055 & 5.3192 & 5.2795 & TRN & \\
\hline CHEMBL580609 & 1479055 & 5.657 & 5.5418 & TRN & \\
\hline CHEMBL1237217 & 1479055 & 5.2387 & 5.1223 & TST & \\
\hline CHEMBL548422 & 1479055 & 5.5027 & 5.2664 & TRN & \\
\hline CHEMBL586095 & 1479055 & 5.2715 & 5.5188 & TRN & \\
\hline CHEMBL546162 & 1479055 & 4.9656 & 4.7385 & TRN & \\
\hline CHEMBL529823 & 1479055 & 5.3292 & 5.0856 & TRN & \\
\hline CHEMBL586344 & 1479055 & 3.9208 & 4.0513 & TST & \\
\hline CHEMBL586026 & 1479055 & 3.9208 & 4.1287 & TST & \\
\hline CHEMBL537039 & 1479055 & 5.5494 & 5.4447 & TRN & \\
\hline CHEMBL591641 & 1479055 & 3.9208 & 3.9099 & TRN & \\
\hline CHEMBL525149 & 1479055 & 6.5952 & 6.8142 & TRN & \\
\hline CHEMBL92137 & 1479055 & 5.3472 & 5.0225 & TRN & \\
\hline CHEMBL548721 & 1479055 & 5.35 & 5.2782 & TRN & \\
\hline CHEMBL533788 & 1479055 & 5.3991 & 5.3721 & TRN & \\
\hline CHEMBL546632 & 1479055 & 5.4911 & 5.1545 & TRN & \\
\hline CHEMBL604982 & 1479055 & 3.9208 & 3.9988 & TRN & \\
\hline CHEMBL548901 & 1479055 & 3.9208 & 4.0706 & TRN & \\
\hline CHEMBL584841 & 1479055 & 3.9208 & 4.0488 & TRN & \\
\hline CHEMBL587612 & 1479055 & 5.9983 & 6.4119 & TRN & \\
\hline CHEMBL 2028048 & 1479055 & 3.9208 & 3.9398 & TRN & \\
\hline CHEMBL532060 & 1479055 & 5.3528 & 5.346 & TRN & \\
\hline CHEMBL588184 & 1479055 & 5.2558 & 5.3214 & TRN & \\
\hline CHEMBL606159 & 1479055 & 3.9208 & 3.8583 & TRN & \\
\hline CHEMBL525879 & 1479055 & 5.4506 & 5.3956 & TRN & \\
\hline CHEMBL581874 & 1479055 & 3.9208 & 3.9983 & TRN & \\
\hline CHEMBL587029 & 1479055 & 6.6383 & 6.2298 & TRN & \\
\hline CHEMBL580580 & 1479055 & 5.8592 & 5.246 & TRN & \\
\hline CHEMBL588481 & 1479055 & 3.9208 & 4.0461 & TRN & \\
\hline CHEMBL603686 & 1479055 & 3.9208 & 3.9305 & TRN & \\
\hline CHEMBL600305 & 1479055 & 3.9208 & 3.9236 & TRN & \\
\hline CHEMBL535730 & 1479055 & 3.9208 & 4.0626 & TST & \\
\hline CHEMBL537087 & 1479055 & 4.9581 & \multicolumn{2}{|c|}{3.9330000000000003} & TRN \\
\hline CHEMBL1198307 & 1479055 & 5.171 & 5.0758 & TRN & \\
\hline CHEMBL1237267 & 1479055 & 4.87 & 4.9165 & TRN & \\
\hline CHEMBL514409 & 1479055 & 5.8435 & \multicolumn{2}{|c|}{5.502999999999999} & TRN \\
\hline CHEMBL 2028049 & 1479055 & 3.9208 & 3.9884 & TRN & \\
\hline CHEMBL526064 & 1479055 & 5.2511 & 5.2409 & TRN & \\
\hline
\end{tabular}

Page 132 


\begin{tabular}{|c|c|c|c|c|c|}
\hline \multirow{3}{*}{$\begin{array}{l}\text { CHEMBL548750 } \\
\text { CHEMBL2028047 }\end{array}$} & \multicolumn{5}{|c|}{ Supplemental Table s2.txt } \\
\hline & 1479055 & 4.87 & 4.99100 & 20000000005 & TRN \\
\hline & 1479055 & 3.9208 & 4.0212 & TRN & \\
\hline CHEMBL589922 & 1479055 & 3.9208 & 3.8798 & TRN & \\
\hline CHEMBL537082 & 1479055 & 5.0757 & 4.8935 & TST & \\
\hline CHEMBL581191 & 1479055 & 5.4743 & 5.2645 & TRN & \\
\hline CHEMBL586253 & 1479055 & 5.1581 & 5.269 & TRN & \\
\hline CHEMBL585839 & 1479055 & 3.9208 & 3.8532 & TRN & \\
\hline CHEMBL532987 & 1479055 & 3.9208 & 3.87 & TRN & \\
\hline CHEMBL546994 & 1479055 & 3.9208 & 3.9346 & TRN & \\
\hline CHEMBL548338 & 1479055 & 3.9208 & 4.0757 & TST & \\
\hline CHEMBL584829 & 1479055 & 3.9208 & 4.0345 & TRN & \\
\hline CHEMBL532103 & 1479055 & 5.3465 & 5.4675 & TRN & \\
\hline CHEMBL547552 & 1479055 & 5.5805 & 5.5611 & TRN & \\
\hline CHEMBL547614 & 1479055 & 3.9208 & 4.0147 & TST & \\
\hline CHEMBL589946 & 1479055 & 3.9208 & 3.9055 & TRN & \\
\hline CHEMBL527400 & 1479055 & 5.2552 & 5.3611 & TRN & \\
\hline CHEMBL547607 & 1479055 & 5.3647 & 5.2252 & TRN & \\
\hline CHEMBL581619 & 1479055 & 4.7375 & 5.2355 & TRN & \\
\hline CHEMBL579105 & 1479055 & 5.3567 & 5.2713 & TRN & \\
\hline CHEMBL601492 & 1479055 & 3.9208 & 4.0576 & TST & \\
\hline CHEMBL603945 & 1479055 & 3.9208 & 4.1192 & TRN & \\
\hline CHEMBL528508 & 1479055 & 5.3578 & 5.57100 & 0000000001 & TRN \\
\hline CHEMBL 2028056 & 1479055 & 3.9208 & 4.101 & TRN & \\
\hline CHEMBL581194 & 1479055 & 3.9208 & 3.91399 & 99999999997 & TRN \\
\hline CHEMBL531695 & 1479055 & 5.5281 & 5.4181 & TST & \\
\hline CHEMBL549093 & 1479055 & 5.4764 & 5.4118 & TRN & \\
\hline CHEMBL592305 & 1479055 & 3.9208 & 3.8868 & TST & \\
\hline CHEMBL125044 & 1479055 & 3.9208 & 3.8608 & TRN & \\
\hline CHEMBL601156 & 1479055 & 3.9208 & 4.0849 & TST & \\
\hline CHEMBL580534 & 1479055 & 4.8464 & 5.1158 & TRN & \\
\hline CHEMBL597855 & 1479055 & 3.9208 & 3.90100 & 00000000002 & TRN \\
\hline CHEMBL528447 & 1479055 & 5.0017 & 5.0999 & TST & \\
\hline CHEMBL 2028055 & 1479055 & 3.9208 & 3.918 & TRN & \\
\hline CHEMBL527691 & 1479055 & 4.87 & 5.2751 & TRN & \\
\hline CHEMBL533252 & 1479055 & 5.2372 & 4.9804 & TRN & \\
\hline CHEMBL124006 & 1479055 & 5.8074 & 5.693 & TRN & \\
\hline CHEMBL607308 & 1479055 & 3.9208 & 4.0694 & TRN & \\
\hline CHEMBL534803 & 1479055 & 5.1789 & 5.2855 & TRN & \\
\hline CHEMBL583682 & 1479055 & 3.9208 & 3.8534 & TRN & \\
\hline CHEMBL546955 & 1479055 & 5.7582 & 5.8045 & TRN & \\
\hline CHEMBL592123 & 1479055 & 5.1218 & 5.1913 & TRN & \\
\hline CHEMBL586310 & 1479055 & 3.9208 & 4.0154 & TRN & \\
\hline CHEMBL584676 & 1479055 & 3.9208 & 3.8389 & TRN & \\
\hline CHEMBL1545915 & 1479055 & 3.9208 & 3.9236 & TST & \\
\hline CHEMBL582478 & 1479055 & 5.171 & 5.06 & TRN & \\
\hline CHEMBL592550 & 1479055 & 3.9208 & 3.9434 & TRN & \\
\hline CHEMBL549003 & 1479055 & 5.4923 & 5.5839 & TRN & \\
\hline CHEMBL602409 & 1479055 & 3.9208 & 3.9204 & TRN & \\
\hline
\end{tabular}


Supplemental Table S2.txt

\begin{tabular}{|c|c|c|c|c|}
\hline CHEMBL532472 & 1479055 & 6.3279 & 6.2163 & TRN \\
\hline CHEMBL527419 & 1479055 & 4.7875 & 4.3372 & TST \\
\hline CHEMBL549075 & 1479055 & 5.1888 & 5.053 & TRN \\
\hline CHEMBL106772 & 1479055 & 5.2687 & 5.3381 & TRN \\
\hline CHEMBL536424 & 1479055 & 5.2077 & 5.2702 & TRN \\
\hline CHEMBL526110 & 1479055 & 6.6778 & 6.5935 & TRN \\
\hline CHEMBL532148 & 1479055 & 4.87 & 5.0812 & TRN \\
\hline CHEMBL579790 & 1479055 & 5.3005 & 5.5728 & TRN \\
\hline CHEMBL586700 & 1479055 & 5.4569 & 5.1716 & TRN \\
\hline CHEMBL549208 & 1479055 & 3.9208 & 4.0209 & TST \\
\hline CHEMBL529603 & 1479055 & 3.9208 & 4.0599 & TRN \\
\hline CHEMBL580307 & 1479055 & 6.1791 & 6.4824 & TRN \\
\hline CHEMBL524580 & 1479055 & 5.8327 & 5.8878 & TRN \\
\hline CHEMBL528245 & 1479055 & 3.9208 & 3.8959 & TRN \\
\hline CHEMBL546211 & 1479055 & 4.9705 & 4.9962 & TRN \\
\hline CHEMBL532808 & 1479055 & 5.8306 & 5.8363 & TRN \\
\hline CHEMBL535079 & 1479055 & 4.9605 & 3.969 & TRN \\
\hline CHEMBL582079 & 1479055 & 3.9208 & 3.9338 & TRN \\
\hline CHEMBL586942 & 1479055 & 5.2509 & 5.2101 & TRN \\
\hline CHEMBL530291 & 1479055 & 6.6003 & 6.6193 & TRN \\
\hline CHEMBL580199 & 1479055 & 5.1716 & 5.1657 & TRN \\
\hline CHEMBL533110 & 1479055 & 3.6383 & 3.9015 & TRN \\
\hline CHEMBL590159 & 1479055 & 3.9208 & 3.8909 & TRN \\
\hline CHEMBL526981 & 1479055 & 3.9208 & 3.9249 & TRN \\
\hline CHEMBL532775 & 1479055 & 5.3896 & 5.289 & TRN \\
\hline CHEMBL546912 & 1479055 & 5.4593 & 5.3171 & TRN \\
\hline CHEMBL531744 & 1479055 & 5.657 & 5.5172 & TRN \\
\hline CHEMBL532254 & 1479055 & 5.8047 & 5.6677 & TST \\
\hline CHEMBL578933 & 1479055 & 3.9208 & 3.8494 & TRN \\
\hline CHEMBL602211 & 1479055 & 3.9208 & 4.1322 & TRN \\
\hline CHEMBL600488 & 1479055 & 3.9208 & 3.9949 & TRN \\
\hline CHEMBL580698 & 1479055 & 5.7383 & 5.4763 & TRN \\
\hline CHEMBL549034 & 1479055 & 5.6782 & 5.757006 & 0000000001 \\
\hline CHEMBL601957 & 1479055 & 3.9208 & 4.0357 & TRN \\
\hline CHEMBL529968 & 1479055 & 3.9208 & 3.9938 & TRN \\
\hline CHEMBL577012 & 1479055 & 3.9208 & 3.9914 & TRN \\
\hline CHEMBL587980 & 1479055 & 5.1179 & 5.2156 & TRN \\
\hline CHEMBL536671 & 1479055 & 5.2492 & 5.2266 & TRN \\
\hline CHEMBL534797 & 1479055 & 4.87 & 5.1114 & TRN \\
\hline CHEMBL587892 & 1479055 & 3.9208 & 4.23600 & 0000000001 \\
\hline CHEMBL170760 & 1479055 & 5.9952 & 5.8452 & TRN \\
\hline CHEMBL587104 & 1479055 & 3.9208 & 3.8348 & TRN \\
\hline CHEMBL1237214 & 1479055 & 5.7555 & 5.5809 & TRN \\
\hline CHEMBL585431 & 1479055 & 3.9208 & 3.9443 & TST \\
\hline CHEMBL524764 & 1479055 & 5.18 & 5.4143 & TRN \\
\hline CHEMBL532510 & 1479055 & 3.9208 & $3.92100 t$ & 30000000003 \\
\hline CHEMBL586468 & 1479055 & 3.9208 & 4.1467 & TRN \\
\hline CHEMBL352960 & 1479055 & 3.6383 & 4.3538 & TRN \\
\hline
\end{tabular}




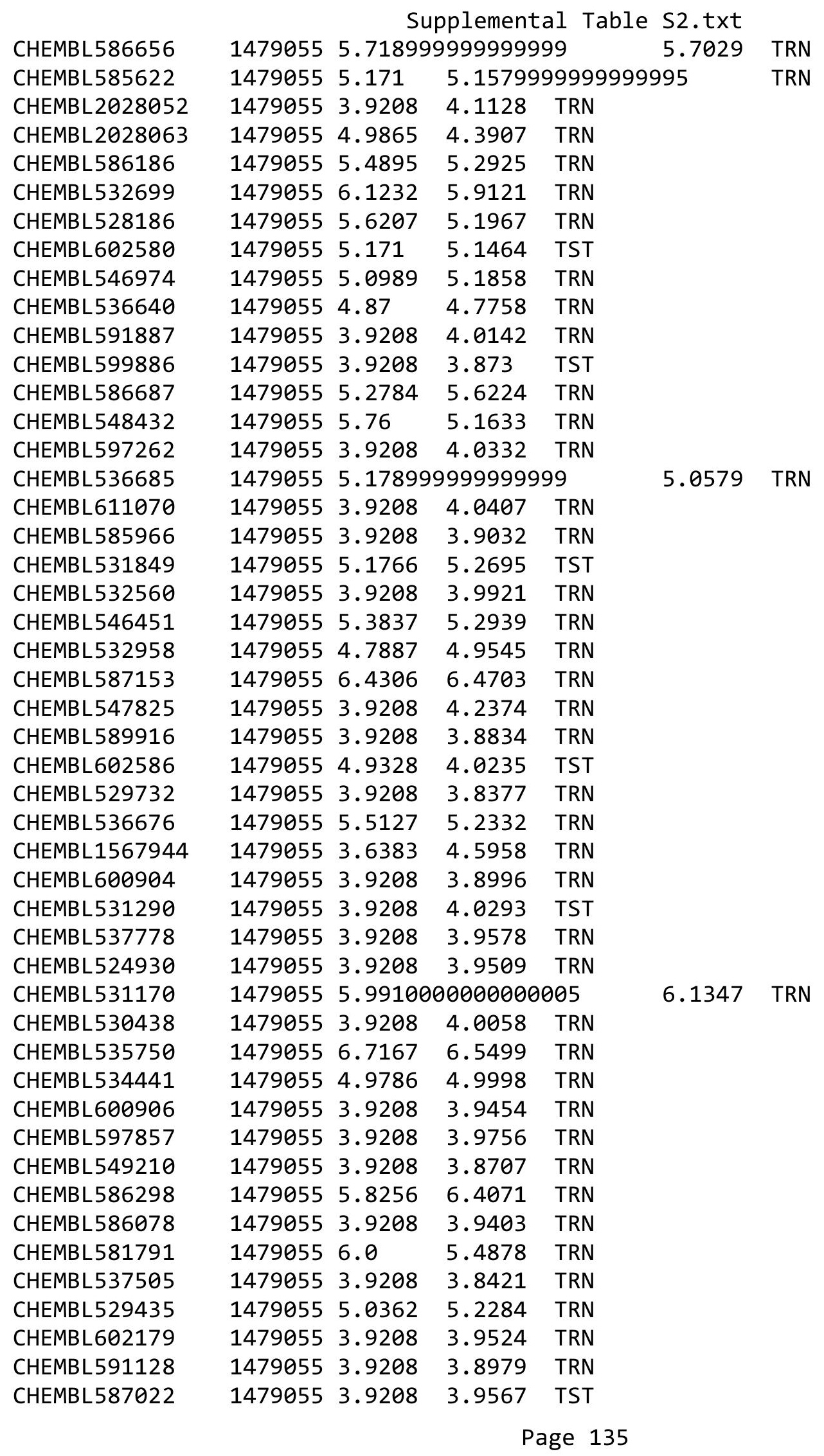


Supplemental Table S2.txt

\begin{tabular}{|c|c|c|c|c|c|}
\hline CHEMBL525519 & 1479055 & 3.9208 & 4.0422 & TRN & \\
\hline CHEMBL586704 & 1479055 & 3.9208 & 3.918 & TRN & \\
\hline CHEMBL537576 & 1479055 & 5.34 & 5.5932 & TRN & \\
\hline CHEMBL609628 & 1479055 & 5.0452 & 4.8776 & TRN & \\
\hline CHEMBL529957 & 1479055 & 5.0768 & 5.0294 & TRN & \\
\hline CHEMBL589733 & 1479055 & 5.1809 & 4.7873 & TRN & \\
\hline CHEMBL588062 & 1479055 & 5.2534 & 5.3866 & TRN & \\
\hline CHEMBL532762 & 1479055 & 5.49 & 5.1546 & TRN & \\
\hline CHEMBL549241 & 1479055 & 5.2476 & 5.3282 & TRN & \\
\hline CHEMBL1623028 & 1479055 & 3.9208 & 4.1728 & TRN & \\
\hline CHEMBL582486 & 1479055 & 3.9208 & 3.9601 & TST & \\
\hline CHEMBL535680 & 1479055 & 5.3326 & 5.4321 & TRN & \\
\hline CHEMBL527390 & 1479055 & 5.5289 & 5.5012 & TRN & \\
\hline CHEMBL586135 & 1479055 & 4.7997 & 4.6772 & TRN & \\
\hline CHEMBL589205 & 1479055 & 3.9208 & 3.9348 & TRN & \\
\hline CHEMBL593052 & 1479055 & 6.2366 & 6.6193 & TRN & \\
\hline CHEMBL602413 & 1479055 & 5.3 & 4.9212 & TRN & \\
\hline CHEMBL 2028066 & 1479055 & 3.9208 & 4.0801 & TST & \\
\hline CHEMBL586888 & 1479055 & 3.9208 & 3.8668 & TRN & \\
\hline CHEMBL530547 & 1479055 & 5.3461 & 5.3992 & TST & \\
\hline CHEMBL1594640 & 1479055 & 3.9208 & 4.1374 & TRN & \\
\hline CHEMBL1615697 & 1479055 & 3.9208 & 4.0584 & TST & \\
\hline CHEMBL527911 & 1479055 & 5.7994 & 5.8388 & TRN & \\
\hline CHEMBL547266 & 1479055 & 4.9325 & 4.263999 & 9999999999 & TRN \\
\hline CHEMBL591147 & 1479055 & 3.9208 & 3.9057 & TRN & \\
\hline CHEMBL588786 & 1479055 & 5.53299 & 799999999 & 5.5434 & TRN \\
\hline CHEMBL591183 & 1479055 & 5.171 & 5.1829 & TRN & \\
\hline CHEMBL581065 & 1479055 & 5.5712 & 5.3799 & TST & \\
\hline CHEMBL580043 & 1479055 & 5.4553 & 5.3341 & TRN & \\
\hline CHEMBL533883 & 1479055 & 5.8811 & 5.6823 & TST & \\
\hline CHEMBL494669 & 1479055 & 3.9208 & 4.1624 & TRN & \\
\hline CHEMBL591395 & 1479055 & 3.9208 & 4.0039 & TRN & \\
\hline CHEMBL604389 & 1479055 & 3.9208 & 4.0321 & TRN & \\
\hline CHEMBL586375 & 1479055 & 5.7937 & 5.615 & TRN & \\
\hline CHEMBL459199 & 1479055 & 3.9208 & 3.8852 & TRN & \\
\hline CHEMBL529140 & 1479055 & 5.978 & 6.346 & TRN & \\
\hline CHEMBL529612 & 1479055 & 5.3852 & 4.9247 & TRN & \\
\hline CHEMBL590933 & 1479055 & 5.171 & 4.8353 & TRN & \\
\hline CHEMBL577014 & 1479055 & 3.9208 & 4.0443 & TRN & \\
\hline CHEMBL525308 & 1479055 & 5.3512 & 5.2326 & TRN & \\
\hline CHEMBL589951 & 1479055 & 3.9208 & 4.028000 & 00000000005 & TRN \\
\hline CHEMBL587090 & 1479055 & 6.0209 & 5.5994 & TST & \\
\hline CHEMBL546544 & 1479055 & 5.1142 & 5.0174 & TRN & \\
\hline CHEMBL533017 & 1479055 & 3.9208 & 3.9544 & TRN & \\
\hline CHEMBL579457 & 1479055 & 4.87 & 5.1298 & TRN & \\
\hline CHEMBL528734 & 1479055 & 3.9208 & 3.9627 & TRN & \\
\hline CHEMBL582420 & 1479055 & 3.9208 & 3.8635 & TRN & \\
\hline CHEMBL601534 & 1479055 & 3.9208 & 4.123 & TST & \\
\hline
\end{tabular}


Supplemental Table S2.txt

\begin{tabular}{|c|c|c|c|c|}
\hline CHEMBL586632 & 1479055 & 5.7397 & 5.5916 & TRN \\
\hline CHEMBL 2028045 & 1479055 & 3.9208 & 4.0703 & TRN \\
\hline CHEMBL531611 & 1479055 & 3.9208 & 4.0 & TRN \\
\hline CHEMBL589236 & 1479055 & 3.9208 & 3.9391 & TRN \\
\hline CHEMBL530308 & 1479055 & 3.9208 & 3.965 & TST \\
\hline CHEMBL547470 & 1479055 & 7.2007 & 6.684 & TRN \\
\hline CHEMBL534283 & 1479055 & 3.9208 & 4.2976 & TRN \\
\hline CHEMBL535323 & 1479055 & 5.2095 & 5.4277 & TRN \\
\hline CHEMBL528794 & 1479055 & 5.0938 & 5.0498 & TRN \\
\hline CHEMBL587825 & 1479055 & 3.9208 & 4.1669 & TRN \\
\hline CHEMBL601825 & 1479055 & 3.9208 & 3.9401 & TRN \\
\hline CHEMBL527234 & 1479055 & 3.9208 & 3.8297 & TRN \\
\hline CHEMBL527213 & 1479055 & 5.3432 & \multicolumn{2}{|c|}{5.377999999999999} \\
\hline CHEMBL531184 & 1479055 & 5.1231 & 5.1178 & TRN \\
\hline CHEMBL525486 & 1479055 & 3.9208 & 3.9896 & TRN \\
\hline CHEMBL588280 & 1479055 & 4.87 & 5.2562 & TRN \\
\hline CHEMBL529312 & 1479055 & 5.3906 & 5.1946 & TRN \\
\hline CHEMBL579467 & 1479055 & 5.7734 & 5.8589 & TRN \\
\hline CHEMBL528147 & 1479055 & 5.5725 & 5.3463 & TST \\
\hline CHEMBL529055 & 1479055 & 5.3472 & 5.0974 & TRN \\
\hline CHEMBL338094 & 1479055 & 3.9208 & 3.8601 & TRN \\
\hline CHEMBL532597 & 1479055 & 3.9208 & 4.143 & TST \\
\hline CHEMBL534374 & 1479055 & 5.6444 & 5.4766 & TST \\
\hline CHEMBL 2028043 & 1479055 & 3.9208 & 4.0676 & TRN \\
\hline CHEMBL546799 & 1479055 & 3.9208 & 3.8768 & TRN \\
\hline CHEMBL534123 & 1479055 & 5.0962 & 5.4001 & TRN \\
\hline CHEMBL535557 & 1479055 & 5.1377 & 5.1979 & TRN \\
\hline CHEMBL579294 & 1479055 & 3.9208 & 3.9107 & TRN \\
\hline CHEMBL588673 & 1479055 & 5.2054 & 5.0053 & TST \\
\hline CHEMBL526243 & 1479055 & 6.1096 & 6.4508 & TRN \\
\hline CHEMBL536115 & 1479055 & 6.1002 & 5.9529 & TRN \\
\hline CHEMBL600549 & 1479055 & 3.9208 & 3.9751 & TST \\
\hline CHEMBL590944 & 1479055 & 3.9208 & 4.1065 & TRN \\
\hline CHEMBL532879 & 1479055 & 3.9208 & 4.0042 & TRN \\
\hline CHEMBL591393 & 1479055 & 5.171 & 4.334 & TRN \\
\hline CHEMBL173617 & 1479055 & 5.5336 & 5.74100 & 00000000005 \\
\hline CHEMBL531060 & 1479055 & 3.9208 & 4.1211 & TRN \\
\hline CHEMBL598369 & 1479055 & 3.9208 & 3.8424 & TRN \\
\hline CHEMBL528032 & 1479055 & 5.3367 & 5.1781 & TRN \\
\hline CHEMBL577445 & 1479055 & 3.9208 & 3.9794 & TRN \\
\hline CHEMBL586933 & 1479055 & 3.9208 & 3.8092 & TRN \\
\hline CHEMBL534288 & 1479055 & 3.9208 & 3.8718 & TRN \\
\hline CHEMBL548288 & 1479055 & 5.3569 & 4.3309 & TRN \\
\hline CHEMBL530139 & 1479055 & 5.4572 & 5.4941 & TRN \\
\hline CHEMBL582010 & 1479055 & 5.2063 & 5.3783 & TRN \\
\hline CHEMBL529869 & 1479055 & 5.8176 & 5.5412 & TRN \\
\hline CHEMBL95606 & 1479055 & 3.9208 & 4.1041 & TST \\
\hline CHEMBL1619026 & 1479055 & 3.9208 & 3.8504 & TRN \\
\hline
\end{tabular}




\begin{tabular}{|c|c|c|c|c|c|c|}
\hline \multicolumn{7}{|c|}{ Supplemental Table s2.txt } \\
\hline CHEMBL532650 & 1479055 & 6.0391 & 6.2086 & TRN & & \\
\hline CHEMBL530513 & 1479055 & 5.684 & 5.5633 & TRN & & \\
\hline CHEMBL527132 & 1479055 & 5.0851 & 5.2202 & TST & & \\
\hline CHEMBL580757 & 1479055 & 3.9208 & 3.9539 & TRN & & \\
\hline CHEMBL534384 & 1479055 & 5.4087 & 5.1986 & TRN & & \\
\hline CHEMBL587923 & 1479055 & 5.0139 & 4.0505 & TRN & & \\
\hline CHEMBL600356 & 1479055 & 3.9208 & 4.0404 & TST & & \\
\hline CHEMBL586033 & 1479055 & 5.171 & 4.8662 & TRN & & \\
\hline CHEMBL602940 & 1479055 & 3.9208 & 4.0903 & TST & & \\
\hline CHEMBL582180 & 1479055 & 3.9208 & 3.9166 & TRN & & \\
\hline CHEMBL535659 & 1479055 & 5.2688 & 5.3501 & TRN & & \\
\hline CHEMBL580388 & 1479055 & 3.9208 & 4.0988 & TST & & \\
\hline CHEMBL369258 & 1479055 & 5.7009 & 5.8292 & TRN & & \\
\hline CHEMBL586821 & 1479055 & 3.6383 & 4.3219 & TRN & & \\
\hline CHEMBL588566 & 1479055 & 5.4231 & 5.4532 & TRN & & \\
\hline CHEMBL587288 & 1479055 & 3.9208 & 4.0051 & TRN & & \\
\hline CHEMBL549216 & 1479055 & 3.9208 & 3.9103 & TRN & & \\
\hline CHEMBL547367 & 1479055 & 5.3957 & 5.2464 & TST & & \\
\hline CHEMBL600439 & 1479055 & 3.9208 & 4.1253 & TRN & & \\
\hline CHEMBL581162 & 1479055 & 5.2702 & 5.2767 & TRN & & \\
\hline CHEMBL533999 & 1479055 & 3.9208 & 3.9878 & TRN & & \\
\hline CHEMBL530720 & 1479055 & 5.34399 & 99999999 & 99 & .8415 & TRN \\
\hline CHEMBL532570 & 1479055 & 5.5139 & 5.8412 & TRN & & \\
\hline CHEMBL530978 & 1479055 & 3.9208 & 3.8198 & TRN & & \\
\hline CHEMBL547180 & 1479055 & 5.4759 & 5.3971 & TRN & & \\
\hline CHEMBL596856 & 1479055 & 3.9208 & 4.1743 & TRN & & \\
\hline CHEMBL580252 & 1479055 & 5.3049 & 5.1902 & TST & & \\
\hline CHEMBL590182 & 1479055 & 3.9208 & 3.8069 & TRN & & \\
\hline CHEMBL601325 & 1479055 & 3.9208 & 4.02800 & 00000000005 & & TST \\
\hline CHEMBL537071 & 1479055 & 3.9208 & 3.9641 & TRN & & \\
\hline CHEMBL548374 & 1479055 & 5.1629 & 5.0067 & TRN & & \\
\hline CHEMBL535556 & 1479055 & 3.9208 & 4.0762 & TRN & & \\
\hline CHEMBL592344 & 1479055 & 3.9208 & 3.8229 & TRN & & \\
\hline CHEMBL533070 & 1479055 & 4.8966 & 5.0873 & TRN & & \\
\hline CHEMBL2028050 & 1479055 & 5.2956 & 5.2672 & TRN & & \\
\hline CHEMBL600030 & 1479055 & 3.9208 & 3.8837 & TRN & & \\
\hline CHEMBL548356 & 1479055 & 5.3608 & 5.3631 & TRN & & \\
\hline CHEMBL600706 & 1479055 & 3.9208 & 3.9955 & TRN & & \\
\hline CHEMBL339050 & 1479055 & 5.3893 & 5.4024 & TRN & & \\
\hline CHEMBL582610 & 1479055 & 5.1858 & 5.5332 & TRN & & \\
\hline CHEMBL170758 & 1479055 & 5.6942 & 5.7225 & TRN & & \\
\hline CHEMBL580812 & 1479055 & 5.1942 & 5.3332 & TRN & & \\
\hline CHEMBL534279 & 1479055 & 4.87 & 4.9814 & TRN & & \\
\hline CHEMBL548176 & 1479055 & 5.38700 & 00000000 & 005 & .2733 & TRN \\
\hline CHEMBL600174 & 1479055 & 3.9208 & 3.98199 & 99999999998 & & TST \\
\hline CHEMBL533389 & 1479055 & 3.6383 & 3.9644 & TST & & \\
\hline CHEMBL530989 & 1479055 & 5.1796 & 4.9852 & TRN & & \\
\hline CHEMBL536166 & 1479055 & 6.21899 & 99999999 & & .3871 & TRN \\
\hline
\end{tabular}


Supplemental Table S2.txt

\begin{tabular}{|c|c|c|c|c|c|}
\hline CHEMBL546472 & 1479055 & 4.9854 & 5.0848 & TRN & \\
\hline CHEMBL547775 & 1479055 & 5.5683 & 5.3787 & TRN & \\
\hline CHEMBL528458 & 1479055 & 3.6383 & 3.8995 & TRN & \\
\hline CHEMBL587432 & 1479055 & 5.6423 & 5.4332 & TRN & \\
\hline CHEMBL524606 & 1479055 & 5.4542 & 5.2483 & TRN & \\
\hline CHEMBL584015 & 1479055 & 5.171 & 4.9947 & TRN & \\
\hline CHEMBL587611 & 1479055 & 5.1227 & 5.0261 & TRN & \\
\hline CHEMBL533268 & 1479055 & 5.3062 & 5.4368 & TRN & \\
\hline CHEMBL534210 & 1479055 & 5.3093 & 5.2237 & TRN & \\
\hline CHEMBL587968 & 1479055 & 5.7151 & 5.8372 & TRN & \\
\hline CHEMBL528063 & 1479055 & 4.87 & 5.1709 & TRN & \\
\hline CHEMBL526587 & 1479055 & 3.9208 & 3.9577 & TRN & \\
\hline CHEMBL548111 & 1479055 & 5.4305 & 5.1041 & TRN & \\
\hline CHEMBL526800 & 1479055 & 3.9208 & 3.8584 & TRN & \\
\hline CHEMBL580654 & 1479055 & 3.9208 & 3.8111 & TRN & \\
\hline CHEMBL588253 & 1479055 & 5.6428 & 5.5528 & TRN & \\
\hline CHEMBL528043 & 1479055 & 5.5638 & 5.3256 & TRN & \\
\hline CHEMBL546871 & 1479055 & 5.3783 & 4.9425 & TRN & \\
\hline CHEMBL534151 & 1479055 & 5.841 & 5.5402 & TST & \\
\hline CHEMBL532015 & 1479055 & 3.9208 & 3.9455 & TST & \\
\hline CHEMBL531829 & 1479055 & 5.1724 & 5.0758 & TST & \\
\hline CHEMBL49055 & 1479055 & 5.1476 & 5.1237 & TRN & \\
\hline CHEMBL588743 & 1479055 & 5.2369 & 5.2666 & TRN & \\
\hline CHEMBL530531 & 1479055 & 3.9208 & 4.2235 & TST & \\
\hline CHEMBL548005 & 1479055 & 5.9485 & 5.649 & TRN & \\
\hline CHEMBL592044 & 1479055 & 3.9208 & 4.2963 & TRN & \\
\hline CHEMBL532079 & 1479055 & 3.9208 & 3.965 & TRN & \\
\hline CHEMBL529385 & 1479055 & 3.9208 & 4.1104 & TRN & \\
\hline CHEMBL580140 & 1479055 & 3.9208 & 4.1923 & TRN & \\
\hline CHEMBL590914 & 1479055 & 3.9208 & 3.9969 & TRN & \\
\hline CHEMBL526987 & 1479055 & 5.2367 & 5.3196 & TRN & \\
\hline CHEMBL536161 & 1479055 & 5.1061 & 5.0966 & TRN & \\
\hline CHEMBL529640 & 1479055 & 3.9208 & 3.9054 & TRN & \\
\hline CHEMBL589723 & 1479055 & 3.9208 & 3.9982 & TRN & \\
\hline CHEMBL536627 & 1479055 & 3.6383 & 4.07100 & 0000000001 & TRN \\
\hline CHEMBL531938 & 1479055 & 5.215 & 5.2116 & TRN & \\
\hline CHEMBL531534 & 1479055 & 5.6021 & 5.4965 & TRN & \\
\hline CHEMBL590680 & 1479055 & 3.9208 & 3.9059 & TRN & \\
\hline CHEMBL534589 & 1479055 & 3.9208 & 3.8612 & TRN & \\
\hline CHEMBL604323 & 1479055 & 3.9208 & 4.0957 & TRN & \\
\hline CHEMBL584235 & 1479055 & 3.9208 & 3.9195 & TRN & \\
\hline CHEMBL529372 & 1479055 & 5.3802 & 5.6517 & TRN & \\
\hline CHEMBL527620 & 1479055 & 3.9208 & 3.8891 & TST & \\
\hline CHEMBL584237 & 1479055 & 3.9208 & 3.9576 & TST & \\
\hline CHEMBL582495 & 1479055 & 3.9208 & 4.0725 & TST & \\
\hline CHEMBL580730 & 1479055 & 5.364 & 5.2595 & TST & \\
\hline CHEMBL602946 & 1479055 & 4.9325 & 4.5464 & TST & \\
\hline CHEMBL 2028067 & 1479055 & 3.9208 & 4.2941 & TST & \\
\hline
\end{tabular}


Supplemental Table S2.txt

\begin{tabular}{|c|c|c|c|c|}
\hline CHEMBL548372 & 1479055 & 5.3516 & 5.4664 & TST \\
\hline CHEMBL547488 & 1479055 & 3.9208 & 4.0435 & TST \\
\hline CHEMBL526234 & 1479055 & 5.5033 & 5.478 & TST \\
\hline CHEMBL582070 & 1479055 & 3.9208 & 4.1492 & TST \\
\hline CHEMBL580567 & 1479055 & 5.3868 & 5.0883 & TST \\
\hline CHEMBL601806 & 1479055 & 3.9208 & 3.9889 & TST \\
\hline CHEMBL580496 & 1479055 & 5.0475 & 5.0943 & TST \\
\hline CHEMBL533283 & 1479055 & 5.4021 & 5.6071 & TST \\
\hline CHEMBL528761 & 1479055 & 5.437 & 5.4629 & TST \\
\hline CHEMBL586442 & 1479055 & 3.9208 & 3.8578 & TST \\
\hline CHEMBL545880 & 1479055 & 3.9208 & 4.0032 & TST \\
\hline CHEMBL581225 & 1479055 & 3.9208 & 4.0251 & TST \\
\hline CHEMBL 2028062 & 1479055 & 3.9208 & 4.0097 & TST \\
\hline CHEMBL580249 & 1479055 & 3.9208 & 3.8571 & TST \\
\hline CHEMBL602312 & 1479055 & 5.171 & 4.9733 & TST \\
\hline CHEMBL581359 & 1479055 & 5.2551 & 5.047 & TST \\
\hline CHEMBL535027 & 1479055 & 5.2447 & 5.2474 & TST \\
\hline CHEMBL601122 & 1479055 & 5.0921 & 4.8786 & TST \\
\hline CHEMBL 2028060 & 1479055 & 3.9208 & 4.0362 & TST \\
\hline CHEMBL580918 & 1479055 & 6.2132 & 6.3871 & TST \\
\hline CHEMBL1459149 & 1479055 & 3.9208 & 4.0884 & TST \\
\hline CHEMBL 2028046 & 1479055 & 3.9208 & 3.9418 & TST \\
\hline CHEMBL581349 & 1479055 & 3.9208 & 3.9258 & TST \\
\hline CHEMBL579411 & 1479055 & 5.5907 & 5.5766 & TST \\
\hline CHEMBL530372 & 1479055 & 5.4541 & 5.4382 & TST \\
\hline CHEMBL590683 & 1479055 & 5.171 & 5.0011 & TST \\
\hline CHEMBL586234 & 1479055 & 5.4519 & 5.7947 & TST \\
\hline CHEMBL580914 & 1479055 & 6.5317 & 6.3506 & TST \\
\hline CHEMBL579809 & 1479055 & 5.396 & 5.2618 & TST \\
\hline CHEMBL 2028061 & 1479055 & 3.9208 & 4.0498 & TST \\
\hline CHEMBL1437888 & 1479055 & 5.171 & 5.0989 & TST \\
\hline CHEMBL582042 & 1479055 & 6.0209 & 5.8759 & TST \\
\hline CHEMBL525710 & 1479055 & 5.1007 & 5.3778 & TST \\
\hline CHEMBL533284 & 1479055 & 5.3004 & 5.2867 & TST \\
\hline CHEMBL580275 & 1479055 & 5.4455 & 5.4261 & TST \\
\hline CHEMBL547715 & 1479055 & 5.6639 & 5.03600 & 00000000005 \\
\hline CHEMBL548334 & 1479055 & 3.9208 & 3.9785 & TST \\
\hline CHEMBL582119 & 1479055 & 3.9208 & 4.0357 & TST \\
\hline CHEMBL582072 & 1479055 & 3.9208 & 4.0354 & TST \\
\hline CHEMBL579459 & 1479055 & 3.9208 & 4.0108 & TST \\
\hline CHEMBL586109 & 1479055 & 5.2315 & 5.2409 & TST \\
\hline CHEMBL533377 & 1479055 & 5.6317 & 5.4611 & TST \\
\hline CHEMBL590675 & 1479055 & 3.9208 & 3.9932 & TST \\
\hline CHEMBL588318 & 1479055 & 5.6148 & 5.13700 & 00000000005 \\
\hline CHEMBL530217 & 1479055 & 5.49 & 5.2338 & TST \\
\hline CHEMBL606531 & 1479055 & 3.9208 & 3.9819 & TST \\
\hline CHEMBL531046 & 1479055 & 5.8213 & 5.3657 & TST \\
\hline CHEMBL533000 & 1479055 & 5.4109 & 5.3023 & TST \\
\hline
\end{tabular}


Supplemental Table S2.txt

\begin{tabular}{|c|c|c|}
\hline CHEMBI & 55 & \\
\hline CHEMBL533226 & 1479055 & \\
\hline CHEMBL603943 & 1479055 & \\
\hline CHEMBL580188 & 1479055 & \\
\hline CHEMBL608855 & 1479055 & \\
\hline CHEMBL587934 & 1479055 & \\
\hline CHEMBL526944 & 1479055 & \\
\hline CHEMBL535029 & 1479055 & \\
\hline CHEMBL528849 & 1479055 & \\
\hline CHEMBL580474 & 1479055 & \\
\hline CHEMBL600132 & 1479055 & \\
\hline CHEMBL529874 & 1479055 & \\
\hline CHEMBL1740701 & 1479055 & \\
\hline CHEMBL577440 & 1479055 & \\
\hline CHEMBL533941 & 1479055 & \\
\hline CHEMBL547448 & 1479055 & \\
\hline CHEMBL534190 & 1479055 & \\
\hline CHEMBL580345 & 1479055 & \\
\hline CHEMBL547269 & 1479055 & \\
\hline CHEMBL546383 & 1479055 & 5.3 \\
\hline CHEMBL592332 & 1479055 & \\
\hline CHEMBL529773 & 1479055 & \\
\hline CHEMBL546565 & 1479055 & \\
\hline CHEMBL524784 & 1479055 & \\
\hline CHEMBL547136 & 1479055 & \\
\hline CHEMBL582286 & 1479055 & \\
\hline CHEMBL526627 & 1479055 & \\
\hline CHEMBL527924 & 1479055 & \\
\hline CHEMBL353161 & 1479055 & \\
\hline CHEMBL601743 & 1479055 & \\
\hline CHEMBL579760 & 1479055 & \\
\hline CHEMBL527374 & 1479055 & \\
\hline CHEMBL601786 & 1479055 & \\
\hline CHEMBL582430 & 1479055 & \\
\hline CHEMBL206540 & 1479055 & \\
\hline CHEMBL577874 & 1479055 & \\
\hline CHEMBL581771 & 1479055 & \\
\hline CHEMBL549067 & 1479055 & \\
\hline CHEMBL261095 & 1479055 & \\
\hline CHEMBL 3925549 & 1641380 & \\
\hline CHEMBL 3980611 & 1641380 & \\
\hline CHEMBL 3967858 & 1641380 & \\
\hline CHEMBL3956452 & 1641380 & \\
\hline CHEMBL3913738 & 1641380 & 4.1 \\
\hline CHEMBL 3896064 & 1641380 & \\
\hline CHEMBL3920351 & 1641380 & \\
\hline CHEMBL 3908929 & 1641380 & \\
\hline CHEMBL 3958029 & 1641380 & \\
\hline
\end{tabular}

\begin{tabular}{ll}
3.9886 & TST \\
5.4602 & TST \\
3.9843 & TST \\
3.8482 & TST \\
3.943 & TST \\
5.3965 & TST \\
5.4505 & TST \\
4.9787 & TST \\
6.1717 & TST \\
5.322 & TST \\
4.6743 & TST \\
3.8884 & TST \\
3.9935 & TST \\
4.1798 & TST \\
5.4212 & TST \\
5.0885 & TST \\
3.9412 & TST \\
4.8857 & TST \\
3.9127 & TST \\
5.1998 & TST \\
3.9755 & TST \\
3.955 & TST \\
5.2833 & TST \\
4.0276 & TST \\
5.6207 & TST \\
3.9166 & TST \\
5.7047 & TST \\
5.3632 & TST \\
5.1814 & TST \\
3.973000000000003 \\
4.1737 & TST \\
5.4423 & TST \\
3.9913 & TST \\
5.4156 & TST \\
3.9545 & TST \\
3.9505 & TST \\
4.9449 & TST \\
5.3704 & TST \\
3.9019 & TST \\
6.7544 & TST \\
7.1231 & TST \\
5.3498 & TRN \\
6.7026 & TRN \\
4.1369 & TRN \\
5.9526 & TRN \\
8.516 & TRN \\
6.1838 & TRN \\
& TRN \\
\hline .2984 & TST \\
\hline 5
\end{tabular}


Supplemental Table S2.txt

\begin{tabular}{|c|c|c|c|c|c|}
\hline CHEMBL3979632 & 1641380 & 6.7799 & 6.7459 & TST & \\
\hline CHEMBL3920000 & 1641380 & 8.0458 & 7.9407 & TRN & \\
\hline CHEMBL3926069 & 1641380 & 7.3468 & 7.2026 & TRN & \\
\hline CHEMBL3914375 & 1641380 & 6.6904 & 6.6568 & TRN & \\
\hline CHEMBL3911680 & 1641380 & 6.0283 & 5.9594 & TST & \\
\hline CHEMBL3929379 & 1641380 & 6.5361 & 6.4648 & TRN & \\
\hline CHEMBL3986515 & 1641380 & 6.6799 & 6.6116 & TRN & \\
\hline CHEMBL3928515 & 1641380 & 6.8416 & 6.84 & TRN & \\
\hline CHEMBL3897928 & 1641380 & 5.9586 & 5.9511 & TRN & \\
\hline CHEMBL3892527 & 1641380 & 7.6198 & 7.3454 & TRN & \\
\hline CHEMBL3972690 & 1641380 & 6.7375 & 6.661000 & 00000000005 & TRN \\
\hline CHEMBL3981586 & 1641380 & 4.2027 & 4.2265 & TRN & \\
\hline CHEMBL3942460 & 1641380 & 6.4647 & 6.4905 & TRN & \\
\hline CHEMBL3958813 & 1641380 & 8.0458 & 6.1157 & TST & \\
\hline CHEMBL 3970447 & 1641380 & 7.2147 & 7.0144 & TRN & \\
\hline CHEMBL3914910 & 1641380 & 8.5229 & 8.4764 & TRN & \\
\hline CHEMBL3982813 & 1641380 & 10.3979 & 10.3801 & TRN & \\
\hline CHEMBL3898179 & 1641380 & 4.2832 & 5.3551 & TST & \\
\hline CHEMBL3924742 & 1641380 & 5.2757 & 5.3684 & TRN & \\
\hline CHEMBL3898446 & 1641380 & 8.585 & 8.5963 & TRN & \\
\hline CHEMBL3902186 & 1641380 & 7.3372 & 7.3469 & TRN & \\
\hline CHEMBL3953631 & 1641380 & 10.0 & 10.0121 & TRN & \\
\hline CHEMBL3933020 & 1641380 & 7.0088 & 7.0419 & TRN & \\
\hline CHEMBL3893209 & 1641380 & 9.8729 & 10.0803 & TRN & \\
\hline CHEMBL 3899266 & 1641380 & 7.1249 & 7.1311 & TRN & \\
\hline CHEMBL3932426 & 1641380 & 6.9626 & 7.0253 & TRN & \\
\hline CHEMBL3920206 & 1641380 & 5.9586 & 6.0852 & TRN & \\
\hline CHEMBL3983153 & 1641380 & 6.6038 & 6.6119 & TRN & \\
\hline CHEMBL3905723 & 1641380 & 5.1549 & 4.6587 & TST & \\
\hline CHEMBL 3981086 & 1641380 & 5.7447 & 5.6607 & TRN & \\
\hline CHEMBL3916406 & 1641380 & 6.062 & 6.0586 & TRN & \\
\hline CHEMBL3905642 & 1641380 & 6.1713 & 6.2421 & TRN & \\
\hline CHEMBL3959891 & 1641380 & 7.1487 & 6.3879 & TST & \\
\hline CHEMBL3966340 & 1641380 & 6.6517 & 6.67 & TRN & \\
\hline CHEMBL3927009 & 1641380 & 5.3872 & 5.278 & TRN & \\
\hline CHEMBL3911042 & 1641380 & 6.6055 & 6.6714 & TRN & \\
\hline CHEMBL3985779 & 1641380 & 8.699 & 8.6529 & TRN & \\
\hline CHEMBL3910071 & 1641380 & 5.6925 & 4.9757 & TST & \\
\hline CHEMBL3960720 & 1641380 & 7.8539 & 7.8388 & TRN & \\
\hline CHEMBL3983542 & 1641380 & 4.0665 & 4.0296 & TRN & \\
\hline CHEMBL3925585 & 1641380 & 5.7447 & 5.8811 & TRN & \\
\hline CHEMBL3903169 & 1641380 & 6.1925 & 4.2964 & TST & \\
\hline CHEMBL3966267 & 1641380 & 8.5086 & 8.5008 & TRN & \\
\hline CHEMBL3924942 & 1641380 & 6.5391 & 6.5548 & TRN & \\
\hline CHEMBL 3984242 & 1641380 & 6.8182 & 6.7169 & TRN & \\
\hline CHEMBL3913467 & 1641380 & 7.1549 & 7.0993 & TRN & \\
\hline CHEMBL3939169 & 1641380 & 6.5817 & 6.6609 & TRN & \\
\hline CHEMBL3907471 & 1641380 & 9.699 & 9.45 & TRN & \\
\hline
\end{tabular}


Supplemental Table S2.txt

\begin{tabular}{|c|c|c|c|c|c|}
\hline CHEMBL3977668 & 1641380 & 6.7055 & 6.6937 & TRN & \\
\hline CHEMBL3906944 & 1641380 & 7.1487 & 6.4737 & TST & \\
\hline CHEMBL3984898 & 1641380 & 5.2366 & 4.3341 & TST & \\
\hline CHEMBL3893071 & 1641380 & 5.3979 & 5.3928 & TRN & \\
\hline CHEMBL3922057 & 1641380 & 6.4214 & 6.4556 & TRN & \\
\hline CHEMBL3928042 & 1641380 & 6.7212 & 6.5812 & TRN & \\
\hline CHEMBL3969639 & 1641380 & 10.6498 & 10.6911 & TRN & \\
\hline CHEMBL3913547 & 1641380 & 6.9469 & 6.9522 & TRN & \\
\hline CHEMBL3900042 & 1641380 & 6.38200 & 000000000 & 91 & 6.3757 \\
\hline CHEMBL3934318 & 1641380 & 7.8861 & 7.8446 & TRN & \\
\hline CHEMBL3952256 & 1641380 & 5.3872 & 5.3595 & TRN & \\
\hline CHEMBL3949519 & 1641380 & 6.9318 & 6.9485 & TRN & \\
\hline CHEMBL3955577 & 1641380 & 5.3565 & 5.3488 & TRN & \\
\hline CHEMBL3908961 & 1641380 & 8.301 & 8.1623 & TRN & \\
\hline CHEMBL3916019 & 1641380 & 9.0362 & 8.9902 & TRN & \\
\hline CHEMBL3941528 & 1641380 & 6.8386 & 6.9074 & TRN & \\
\hline CHEMBL3943842 & 1641380 & 3.0 & 2.9799 & TRN & \\
\hline CHEMBL3974230 & 1641380 & 7.1549 & 7.1891 & TRN & \\
\hline CHEMBL3913783 & 1641380 & 6.8962 & 6.9677 & TRN & \\
\hline CHEMBL3906342 & 1641380 & 8.0 & 7.9761 & TRN & \\
\hline CHEMBL3904551 & 1641380 & 6.1681 & 6.1504 & TRN & \\
\hline CHEMBL3899045 & 1641380 & 5.4949 & 5.8731 & TST & \\
\hline CHEMBL3902482 & 1641380 & 7.7959 & 7.9958 & TRN & \\
\hline CHEMBL3930368 & 1641380 & 6.4881 & 6.5513 & TST & \\
\hline CHEMBL3901955 & 1641380 & 10.04 & 10.1385 & TRN & \\
\hline CHEMBL3969120 & 1641380 & 7.0506 & 7.0544 & TRN & \\
\hline CHEMBL3969677 & 1641380 & 5.8861 & 5.8494 & TRN & \\
\hline CHEMBL3893365 & 1641380 & 9.699 & 9.5375 & TRN & \\
\hline CHEMBL3915747 & 1641380 & 6.1979 & 6.222 & TRN & \\
\hline CHEMBL3895331 & 1641380 & 4.8013 & 4.8772 & TST & \\
\hline CHEMBL3953335 & 1641380 & 6.7747 & 6.6354 & TRN & \\
\hline CHEMBL3929263 & 1641380 & 6.8761 & 6.9429 & TRN & \\
\hline CHEMBL3934425 & 1641380 & 9.699 & 9.8093 & TRN & \\
\hline CHEMBL3963639 & 1641380 & 5.7696 & 5.8142 & TRN & \\
\hline CHEMBL3922722 & 1641380 & 4.3468 & 4.8104 & TST & \\
\hline CHEMBL3983867 & 1641380 & 4.9136 & 4.2745 & TST & \\
\hline CHEMBL3950261 & 1641380 & 6.6676 & 6.7408 & TRN & \\
\hline CHEMBL3935224 & 1641380 & 6.0227 & 6.0546 & TRN & \\
\hline CHEMBL3933485 & 1641380 & 7.7212 & 7.6296 & TRN & \\
\hline CHEMBL3903259 & 1641380 & 6.9666 & 6.899 & TRN & \\
\hline CHEMBL3970657 & 1641380 & 7.9586 & 7.3061 & TST & \\
\hline CHEMBL3928692 & 1641380 & 6.1669 & 6.1874 & TST & \\
\hline CHEMBL3908313 & 1641380 & 7.2218 & 7.0211 & TRN & \\
\hline CHEMBL3921914 & 1641380 & 8.1079 & 8.3462 & TRN & \\
\hline CHEMBL3912319 & 1641380 & 7.5229 & 7.6275 & TRN & \\
\hline CHEMBL3979287 & 1641380 & 7.5229 & 7.403 & TRN & \\
\hline CHEMBL3951070 & 1641380 & 5.6778 & 5.6731 & TRN & \\
\hline CHEMBL3925963 & 1641380 & 5.7447 & 5.9253 & TST & \\
\hline
\end{tabular}


Supplemental Table S2.txt

\begin{tabular}{|c|c|c|c|c|}
\hline HEMB I & 541380 & 6.3862 & & \\
\hline HEMPI 2006107 & & 5.2007 & 5.0038 & \\
\hline 743 & & & & \\
\hline AEMBL: & & 3872 & 18 & \\
\hline AEMBL3905475 & 380 & 6778 & 5838 & \\
\hline HEMBL3944733 & 641380 & 6.8239 & 0548 & \\
\hline 503 & 380 & 549 & 588 & \\
\hline IFMRI 395 & & & & \\
\hline AEMBL3935946 & & 3861 & 0054 & \\
\hline HEMBL3968138 & 380 & 18 & 402 & \\
\hline HEMBL3909446 & 380 & 7.7212 & 9258 & \\
\hline IEMBL392 & 80 & 79 & 397 & \\
\hline IEMBL39 & & & 301 & \\
\hline HEMBL392 & & 08 & 5965 & \\
\hline HEMBL393 & 80 & & 575 & \\
\hline IEMBL397 & 80 & 6. & & \\
\hline HEMBL39 & 30 & & 017 & \\
\hline HEMBL39 & & & 581 & \\
\hline HEMBL39 & & & 3488 & \\
\hline AEMBL3S & & 3. & 87 & 151 \\
\hline HEMBLS & 50 & 8 & 3524 & $\mathrm{IRIV}$ \\
\hline AEMBL: & & & 888 & RN \\
\hline AEMBL & & & 49 & \\
\hline HEMBL 39 & & & 3677 & \\
\hline AEMBL39 & & & & I RIV \\
\hline HEMBL3S & 6 & & 97 & RN \\
\hline HEMBL; & & & 41 & ודים \\
\hline$H F M B I=$ & & & 851 & $c T$ \\
\hline HEMBL39 & & & 1441 & TS \\
\hline HEMBL3916 & & & & is \\
\hline HEMBL 388 & & & 958 & TST \\
\hline HEMBL & & & 519 & ГST \\
\hline HEMBL3 & & & 377 & ГST \\
\hline HEMBL 391 & & & 5684 & $\mathrm{IR}$ \\
\hline HEMBL3958591 & 30 & & 5084 & TRN \\
\hline HEMBL3S & & & 987 & RN \\
\hline HFMRI $=2$ & & & 093 & $\Gamma \mathrm{RN}$ \\
\hline HEMBL3 & & & 656 & IRN \\
\hline HEMBL3894719 & 30 & 8.3979 & 2457 & TST \\
\hline HEMBL 390 & & 7 & 9638 & TRN \\
\hline HEMBL39 & 30 & & 266 & \\
\hline HEMBL39 & & & & N \\
\hline HEMBL391 & 30 & & 4375 & TRN \\
\hline HEMBL3984116 & 80 & 26 & 2254 & TS \\
\hline MBL3 & & & & IRN \\
\hline HEMBL3S & & & 5228 & \\
\hline CHEMBL 3938510 & & & .664 & \\
\hline LHEMBL3961259 & 164138 & 6.8239 & 6.7388 & ГRN \\
\hline
\end{tabular}

Page 144 
Supplemental Table S2.txt

\begin{tabular}{|c|c|c|c|c|c|}
\hline CHEMBL3898498 & 1641380 & 6.098 & 6.0354 & TRN & \\
\hline CHEMBL3890188 & 1641380 & 8.9208 & 8.9215 & TRN & \\
\hline CHEMBL3898754 & 1641380 & 8.2218 & 8.1945 & TRN & \\
\hline CHEMBL3928632 & 1641380 & 6.6402 & 6.6729 & TRN & \\
\hline CHEMBL3924837 & 1641380 & 6.0915 & 6.8328 & TST & \\
\hline CHEMBL3950654 & 1641380 & 4.9957 & 5.9747 & TST & \\
\hline CHEMBL3963734 & 1641380 & 6.1688 & 6.1248 & TRN & \\
\hline CHEMBL3936475 & 1641380 & 6.2255 & 5.8786 & TST & \\
\hline CHEMBL3913930 & 1641380 & 5.5952 & 5.7073 & TRN & \\
\hline CHEMBL3897372 & 1641380 & 10.5229 & 10.2652 & TRN & \\
\hline CHEMBL3959212 & 1641380 & 7.1427 & 7.1745 & TRN & \\
\hline CHEMBL3949814 & 1641380 & 7.3372 & 7.1303 & TST & \\
\hline CHEMBL3959079 & 1641380 & 8.6778 & 8.4272 & TRN & \\
\hline CHEMBL3975557 & 1641380 & 9.3979 & 7.5398 & TST & \\
\hline CHEMBL3982066 & 1641380 & 6.9469 & 5.4138 & TST & \\
\hline CHEMBL3911260 & 1641380 & 5.3468 & 4.997 & TST & \\
\hline CHEMBL3968534 & 1641380 & 5.2441 & 4.1167 & TST & \\
\hline CHEMBL3985055 & 1641380 & 4.4498 & 5.2344 & TST & \\
\hline CHEMBL3984312 & 1641380 & 6.3143 & 6.362 & TRN & \\
\hline CHEMBL3956826 & 1641380 & 5.699 & 5.7417 & TRN & \\
\hline CHEMBL3945655 & 1641380 & 7.2218 & 6.7011 & TST & \\
\hline CHEMBL3982336 & 1641380 & 8.5229 & 8.6333 & TRN & \\
\hline CHEMBL3912934 & 1641380 & 10.0 & 10.0945 & TRN & \\
\hline CHEMBL3951075 & 1641380 & 8.4815 & 8.5778 & TRN & \\
\hline CHEMBL3981345 & 1641380 & 8.301 & 8.1144 & TRN & \\
\hline CHEMBL3984186 & 1641380 & 6.8447 & 6.8808 & TRN & \\
\hline CHEMBL3974025 & 1641380 & 5.9208 & 5.8826 & TRN & \\
\hline CHEMBL3963195 & 1641380 & 6.433 & 6.516 & TRN & \\
\hline CHEMBL473368 & 1508819 & 5.6198 & 5.3585 & TRN & \\
\hline CHEMBL3601810 & 1508819 & 2.699 & 3.163999 & 99999999997 & TRN \\
\hline CHEMBL3600923 & 1508819 & 4.9469 & 4.6309 & TRN & \\
\hline CHEMBL3601819 & 1508819 & 2.699 & 2.6242 & TRN & \\
\hline CHEMBL3600624 & 1508819 & 5.9208 & 4.2766 & TRN & \\
\hline CHEMBL3600621 & 1508819 & 4.9586 & 4.442 & TRN & \\
\hline CHEMBL3600610 & 1508819 & 5.1871 & 5.4642 & TRN & \\
\hline CHEMBL65 & 1508819 & 7.0 & -1.3509 & TST & \\
\hline CHEMBL3601807 & 1508819 & 5.4572 & 5.667000 & 0000000001 & TRN \\
\hline CHEMBL3601816 & 1508819 & 7.301 & 6.0188 & TRN & \\
\hline CHEMBL3600622 & 1508819 & 2.699 & 3.6278 & TRN & \\
\hline CHEMBL3601814 & 1508819 & 5.0223 & 4.7319 & TRN & \\
\hline CHEMBL 3601808 & 1508819 & 2.699 & 3.1648 & TRN & \\
\hline CHEMBL3601672 & 1508819 & 4.2041 & 3.8223 & TRN & \\
\hline CHEMBL3601804 & 1508819 & 2.699 & 3.7255 & TST & \\
\hline CHEMBL3601824 & 1508819 & 4.5467 & 4.3293 & TRN & \\
\hline CHEMBL3600606 & 1508819 & 4.757 & 4.2416 & TRN & \\
\hline CHEMBL3601659 & 1508819 & 4.5452 & 3.9827 & TST & \\
\hline CHEMBL3601677 & 1508819 & 5.1805 & 4.4913 & TRN & \\
\hline CHEMBL3601664 & 1508819 & 2.699 & 3.5231 & TST & \\
\hline
\end{tabular}


Supplemental Table S2.txt

\begin{tabular}{|c|c|c|c|c|}
\hline CHEMBL3601821 & 1508819 & 2.699 & 3.3197 & TRN \\
\hline CHEMBL3600616 & 1508819 & 5.7447 & 5.4685 & TRN \\
\hline CHEMBL3601827 & 1508819 & 3.7615 & 3.1605 & TRN \\
\hline CHEMBL3600611 & 1508819 & 4.8327 & 4.3578 & TRN \\
\hline CHEMBL3601675 & 1508819 & 4.0223 & 3.6252 & TRN \\
\hline CHEMBL3600607 & 1508819 & 4.7905 & 5.1745 & TRN \\
\hline CHEMBL3601668 & 1508819 & 5.3979 & 4.8685 & TRN \\
\hline CHEMBL3601817 & 1508819 & 5.585 & 5.7361 & TRN \\
\hline CHEMBL3601811 & 1508819 & 4.2967 & 3.9295 & TRN \\
\hline CHEMBL3600931 & 1508819 & 6.1549 & 7.1155 & TRN \\
\hline CHEMBL3601818 & 1508819 & 2.699 & 2.3609 & TRN \\
\hline CHEMBL3601679 & 1508819 & 5.7959 & 6.218 & TRN \\
\hline CHEMBL3600930 & 1508819 & 6.5229 & 6.8895 & TRN \\
\hline CHEMBL3600926 & 1508819 & 2.699 & 3.3432 & TST \\
\hline CHEMBL3601522 & 1508819 & 4.8013 & 3.4821 & TST \\
\hline CHEMBL3601523 & 1508819 & 4.5702 & 4.21399 & 99999999995 \\
\hline CHEMBL3600388 & 1508819 & 5.284 & 6.7632 & TRN \\
\hline CHEMBL3600618 & 1508819 & 5.5086 & 4.261 & TRN \\
\hline CHEMBL3601673 & 1508819 & 4.5884 & 4.5309 & TRN \\
\hline CHEMBL3601670 & 1508819 & 4.5719 & 4.0732 & TRN \\
\hline CHEMBL3601658 & 1508819 & 2.699 & 4.1375 & TST \\
\hline CHEMBL3601666 & 1508819 & 5.2076 & 4.4049 & TST \\
\hline CHEMBL3600608 & 1508819 & 2.699 & 3.373 & TRN \\
\hline CHEMBL3600605 & 1508819 & 3.9859 & 3.7205 & TRN \\
\hline CHEMBL3601812 & 1508819 & 2.699 & 3.2392 & TRN \\
\hline CHEMBL3600617 & 1508819 & 5.2518 & 4.5827 & TRN \\
\hline CHEMBL3601820 & 1508819 & 2.699 & 3.94 & TRN \\
\hline CHEMBL3601822 & 1508819 & 5.5686 & 5.3429 & TRN \\
\hline CHEMBL 3600625 & 1508819 & 5.6383 & 5.3883 & TRN \\
\hline CHEMBL3601680 & 1508819 & 2.699 & 2.7869 & TRN \\
\hline CHEMBL3600924 & 1508819 & 5.0862 & 5.4624 & TRN \\
\hline CHEMBL3600612 & 1508819 & 5.4202 & 5.4219 & TRN \\
\hline CHEMBL3601674 & 1508819 & 3.759 & 4.0018 & TRN \\
\hline CHEMBL3600613 & 1508819 & 4.5361 & 5.3586 & TRN \\
\hline CHEMBL3600932 & 1508819 & 2.699 & 3.6132 & TST \\
\hline CHEMBL3601825 & 1508819 & 4.6968 & 4.9238 & TRN \\
\hline CHEMBL3601662 & 1508819 & 2.699 & 3.2073 & TST \\
\hline CHEMBL3601669 & 1508819 & 7.301 & 6.4664 & TRN \\
\hline CHEMBL472784 & 1508819 & 2.699 & 3.6015 & TRN \\
\hline CHEMBL 3600620 & 1508819 & 4.1858 & 4.2012 & TRN \\
\hline CHEMBL3601676 & 1508819 & 4.8297 & 4.5872 & TRN \\
\hline CHEMBL3601671 & 1508819 & 4.2321 & 5.2035 & TRN \\
\hline CHEMBL3600619 & 1508819 & 5.1135 & 5.6511 & TRN \\
\hline CHEMBL 3601829 & 1508819 & 2.699 & 3.332 & TRN \\
\hline CHEMBL3601661 & 1508819 & 2.699 & \multicolumn{2}{|c|}{3.9530000000000003} \\
\hline CHEMBL486598 & 1508819 & 2.699 & 4.2732 & TST \\
\hline CHEMBL3600929 & 1508819 & 7.699 & 7.5881 & TRN \\
\hline CHEMBL3600614 & 1508819 & 7.2218 & 7.4631 & TRN \\
\hline
\end{tabular}


Supplemental Table S2.txt

\begin{tabular}{|c|c|c|c|c|c|c|}
\hline CHEMBL3601520 & 1508819 & 2.699 & 3.4661 & TST & & \\
\hline CHEMBL3601524 & 1508819 & 4.4908 & 3.9665 & TST & & \\
\hline CHEMBL3600609 & 1508819 & 4.9747 & 4.9068 & TRN & & \\
\hline CHEMBL3601806 & 1508819 & 2.699 & 3.6538 & TRN & & \\
\hline CHEMBL3601828 & 1508819 & 2.699 & 2.8508 & TRN & & \\
\hline CHEMBL3601823 & 1508819 & 3.9442 & 4.4696 & TRN & & \\
\hline CHEMBL3601525 & 1508819 & 5.4089 & 3.9442 & TST & & \\
\hline CHEMBL3601813 & 1508819 & 2.699 & 3.1022 & TRN & & \\
\hline CHEMBL3601667 & 1508819 & 2.699 & 3.4668 & TST & & \\
\hline CHEMBL3601663 & 1508819 & 3.7142 & 3.7338 & TST & & \\
\hline CHEMBL3600928 & 1508819 & 5.9208 & 6.4222 & TRN & & \\
\hline CHEMBL3601678 & 1508819 & 7.301 & 6.421 & TRN & & \\
\hline CHEMBL3601805 & 1508819 & 4.4547 & 4.1741 & TRN & & \\
\hline CHEMBL3601803 & 1508819 & 5.7447 & 4.9807 & TRN & & \\
\hline CHEMBL3601826 & 1508819 & 2.699 & 3.1908 & TRN & & \\
\hline CHEMBL3601815 & 1508819 & 4.8827 & 4.0756 & TRN & & \\
\hline CHEMBL3601660 & 1508819 & 5.301 & 3.9691 & TST & & \\
\hline CHEMBL 3601665 & 1508819 & 4.4895 & 3.7433 & TST & & \\
\hline CHEMBL3600925 & 1508819 & 2.699 & 3.9076 & TST & & \\
\hline CHEMBL3600623 & 1508819 & 5.6778 & 5.4394 & TRN & & \\
\hline CHEMBL3601809 & 1508819 & 5.4202 & 5.0349 & TRN & & \\
\hline CHEMBL3600615 & 1508819 & 5.0655 & 4.7901 & TRN & & \\
\hline CHEMBL3601521 & 1508819 & 3.9559 & 3.8585 & TST & & \\
\hline CHEMBL 3600927 & 1508819 & 2.699 & 3.8432 & TST & & \\
\hline CHEMBL 2336120 & 943499 & \multicolumn{3}{|c|}{4.9830000000000005} & 4.9395 & TRN \\
\hline CHEMBL 2335656 & 943499 & 4.4283 & 4.7592 & TRN & & \\
\hline CHEMBL 2335682 & 943499 & 5.1013 & 4.9785 & TRN & & \\
\hline CHEMBL 2336114 & 943499 & 5.1397 & 4.7709 & TRN & & \\
\hline CHEMBL 2335654 & 943499 & 5.0141 & 4.8106 & TRN & & \\
\hline CHEMBL 2336125 & 943499 & 4.9318 & 4.7645 & TRN & & \\
\hline CHEMBL 2336596 & 943499 & 5.5017 & 4.7768 & TST & & \\
\hline CHEMBL 2336115 & 943499 & 5.2211 & 4.8494 & TRN & & \\
\hline CHEMBL 2336111 & 943499 & 5.5498 & 5.0225 & TRN & & \\
\hline CHEMBL 2336606 & 943499 & 5.7471 & 4.9023 & TRN & & \\
\hline CHEMBL 2336093 & 943499 & 5.6021 & 5.5639 & TRN & & \\
\hline CHEMBL2335679 & 943499 & 5.4622 & 4.9839 & TRN & & \\
\hline CHEMBL 2336593 & 943499 & 5.4214 & 4.7979 & TST & & \\
\hline CHEMBL 2335658 & 943499 & 5.3507 & 5.1768 & TRN & & \\
\hline CHEMBL 2336122 & 943499 & 4.7799 & 4.8392 & TRN & & \\
\hline CHEMBL2336609 & 943499 & 4.7496 & 4.6273 & TRN & & \\
\hline CHEMBL 2336604 & 943499 & \multicolumn{3}{|c|}{4.1530000000000005} & 4.7857 & TRN \\
\hline CHEMBL 2335649 & 943499 & 4.4179 & 4.7473 & TRN & & \\
\hline CHEMBL 2336108 & 943499 & 4.5287 & 4.7102 & TRN & & \\
\hline CHEMBL 2336128 & 943499 & 5.0066 & 4.7703 & TRN & & \\
\hline CHEMBL 2336588 & 943499 & 4.295 & 4.7022 & TRN & & \\
\hline CHEMBL 2335660 & 943499 & 4.9626 & 5.0862 & TRN & & \\
\hline CHEMBL 2335667 & 943499 & 4.567 & 5.0845 & TRN & & \\
\hline CHEMBL 2336124 & 943499 & 4.7447 & 4.6831 & TRN & & \\
\hline
\end{tabular}




\begin{tabular}{|c|c|c|c|c|c|}
\hline & & \multicolumn{4}{|c|}{ Supplemental Table s2.txt } \\
\hline CHEMBL2336094 & 943499 & 5.3206 & 5.5146 & TRN & \\
\hline CHEMBL 2335678 & 943499 & 5.3605 & 4.9875 & TRN & \\
\hline CHEMBL2336592 & 943499 & 5.6904 & 4.9888 & TST & \\
\hline CHEMBL2335675 & 943499 & 5.2612 & 5.0877 & TRN & \\
\hline CHEMBL2336112 & 943499 & 3.0 & 4.6537 & TRN & \\
\hline CHEMBL2336102 & 943499 & 3.0 & 5.2888 & TST & \\
\hline CHEMBL2336589 & 943499 & 5.699 & 4.6235 & TST & \\
\hline CHEMBL1477081 & 943499 & 5.9586 & 4.9828 & TST & \\
\hline CHEMBL2336598 & 943499 & 5.4461 & 4.9969 & TST & \\
\hline CHEMBL2336099 & 943499 & 5.5129 & 5.7481 & TRN & \\
\hline CHEMBL2335648 & 943499 & 4.4202 & 4.8903 & TRN & \\
\hline CHEMBL2336601 & 943499 & 5.7144 & 4.8704 & TST & \\
\hline CHEMBL 2336095 & 943499 & 4.9706 & 4.9606 & TRN & \\
\hline CHEMBL 2336117 & 943499 & \multicolumn{3}{|c|}{5.1579999999999995} & 4.9523 \\
\hline CHEMBL2335661 & 943499 & 5.1203 & 5.2019 & TRN & \\
\hline CHEMBL2336109 & 943499 & 3.0 & 4.8937 & TST & \\
\hline CHEMBL2335670 & 943499 & 5.289 & 5.1929 & TRN & \\
\hline CHEMBL 2336100 & 943499 & 4.4572 & 4.8937 & TST & \\
\hline CHEMBL2336602 & 943499 & 4.4214 & 4.9307 & TST & \\
\hline CHEMBL2336104 & 943499 & 4.9914 & 4.9837 & TRN & \\
\hline CHEMBL 2336600 & 943499 & 6.1549 & 4.817 & TST & \\
\hline CHEMBL2335680 & 943499 & 5.2472 & 5.0543 & TRN & \\
\hline CHEMBL 2336106 & 943499 & 5.3726 & 4.9574 & TRN & \\
\hline CHEMBL2335663 & 943499 & 5.6676 & 5.4406 & TRN & \\
\hline CHEMBL2336595 & 943499 & 5.6737 & 4.6458 & TST & \\
\hline CHEMBL 2336097 & 943499 & 5.6716 & 5.5304 & TRN & \\
\hline CHEMBL2336098 & 943499 & 4.52 & 5.3176 & TRN & \\
\hline CHEMBL 2336118 & 943499 & 4.4449 & 5.0248 & TRN & \\
\hline CHEMBL2336105 & 943499 & 5.0701 & 5.0685 & TRN & \\
\hline CHEMBL2335651 & 943499 & 5.1068 & 4.8056 & TRN & \\
\hline CHEMBL2336113 & 943499 & 5.6655 & 4.7765 & TST & \\
\hline CHEMBL2336119 & 943499 & 5.0665 & 4.9192 & TRN & \\
\hline CHEMBL2335671 & 943499 & 5.0937 & 5.266 & TRN & \\
\hline CHEMBL2336116 & 943499 & 5.5086 & 4.9314 & TRN & \\
\hline CHEMBL2335647 & 943499 & 5.0391 & 4.9736 & TRN & \\
\hline CHEMBL2335665 & 943499 & 5.1343 & 5.1849 & TRN & \\
\hline CHEMBL2335659 & 943499 & 4.4401 & 4.7348 & TRN & \\
\hline CHEMBL2335650 & 943499 & 4.6882 & 4.717 & TRN & \\
\hline CHEMBL 2336121 & 943499 & 4.762 & 4.9305 & TRN & \\
\hline CHEMBL 2335673 & 943499 & 4.9788 & 5.1738 & TRN & \\
\hline CHEMBL2335655 & 943499 & 4.8297 & 4.7604 & TRN & \\
\hline CHEMBL2336123 & 943499 & 4.762 & 4.7133 & TRN & \\
\hline CHEMBL2336590 & 943499 & 5.0742 & 4.7599 & TST & \\
\hline CHEMBL2335662 & 943499 & 4.8268 & 4.9946 & TRN & \\
\hline CHEMBL2336130 & 943499 & 4.2351 & 4.7391 & TRN & \\
\hline CHEMBL2335676 & 943499 & 5.2007 & 4.9434 & TRN & \\
\hline CHEMBL2335669 & 943499 & 5.0752 & 5.1762 & TRN & \\
\hline CHEMBL 2336597 & 943499 & 4.8416 & 4.7483 & TST & \\
\hline
\end{tabular}




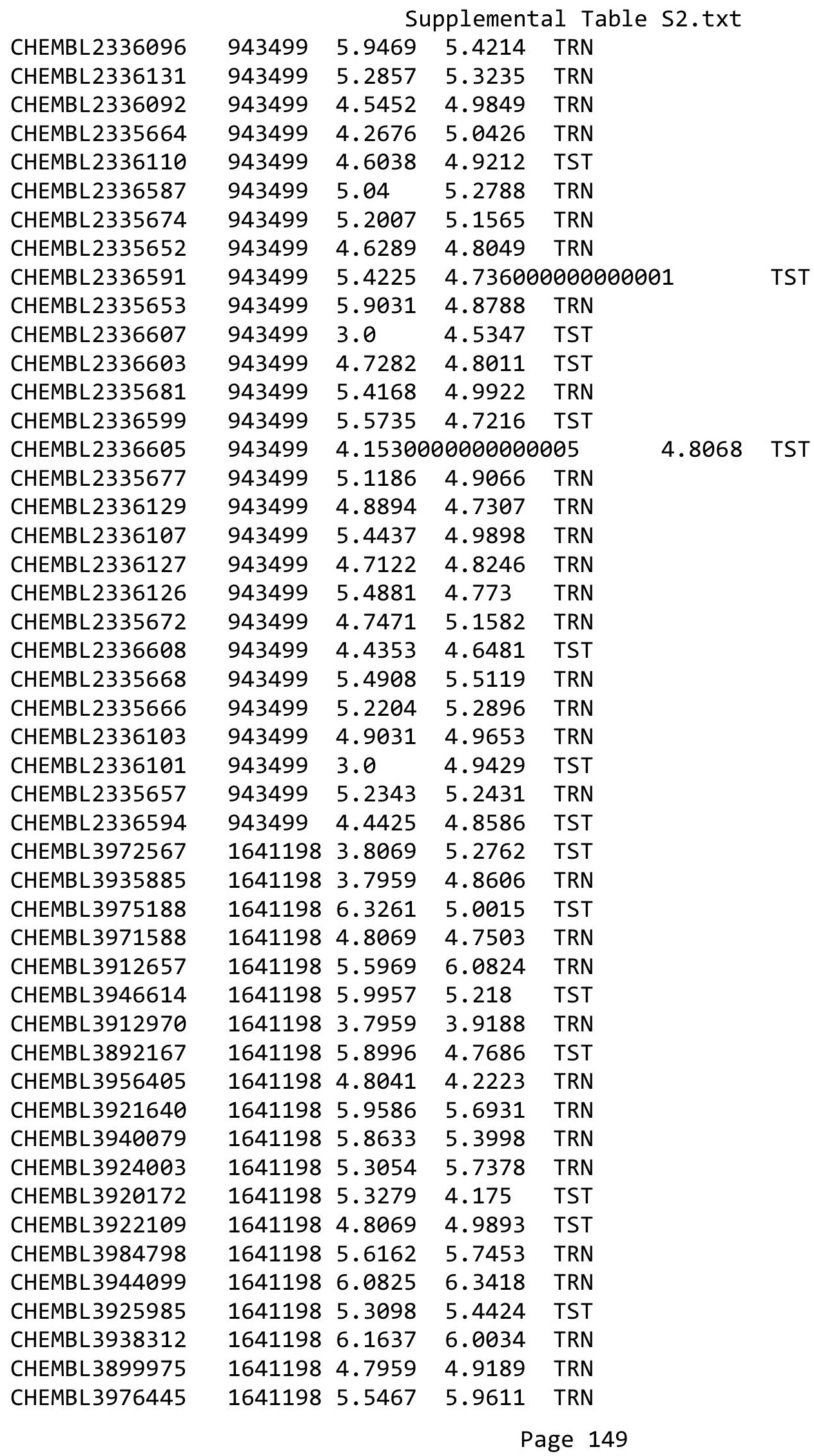


Supplemental Table S2.txt

\begin{tabular}{|c|c|c|c|c|c|}
\hline CHEMBL3926692 & 1641198 & 3.8069 & 4.2524 & TRN & \\
\hline CHEMBL3958297 & 1641198 & 4.9031 & 4.7153 & TRN & \\
\hline CHEMBL3972709 & 1641198 & 5.9172 & 5.4488 & TRN & \\
\hline CHEMBL3933021 & 1641198 & 5.8477 & 6.1201 & TRN & \\
\hline CHEMBL3894106 & 1641198 & 4.7959 & 4.9786 & TRN & \\
\hline CHEMBL3901628 & 1641198 & 6.2449 & 6.2818 & TRN & \\
\hline CHEMBL3973916 & 1641198 & 4.8069 & 4.6891 & TRN & \\
\hline CHEMBL 3932522 & 1641198 & 4.7959 & 4.5555 & TST & \\
\hline CHEMBL 3900304 & 1641198 & 5.5171 & 5.3952 & TST & \\
\hline CHEMBL3958384 & 1641198 & 5.6778 & 5.2473 & TRN & \\
\hline CHEMBL3964537 & 1641198 & 3.7959 & 4.6343 & TRN & \\
\hline CHEMBL3921479 & 1641198 & 6.0773 & 4.5613 & TST & \\
\hline CHEMBL3931027 & 1641198 & 5.4101 & 5.5668 & TRN & \\
\hline CHEMBL 3984472 & 1641198 & 4.8069 & 4.2085 & TRN & \\
\hline CHEMBL3901815 & 1641198 & 5.6615 & 4.9383 & TRN & \\
\hline CHEMBL3957923 & 1641198 & 5.6326 & 6.2326 & TRN & \\
\hline CHEMBL3950258 & 1641198 & 6.3904 & \multicolumn{2}{|c|}{5.8020000000000005} & TRN \\
\hline CHEMBL3909641 & 1641198 & 6.1367 & 6.1173 & TRN & \\
\hline CHEMBL3893816 & 1641198 & 4.9469 & 5.1473 & TRN & \\
\hline CHEMBL3966684 & 1641198 & 5.8697 & 5.2858 & TST & \\
\hline CHEMBL3922538 & 1641198 & 6.0419 & 4.7803 & TST & \\
\hline CHEMBL3915395 & 1641198 & 3.8697 & 4.518 & TRN & \\
\hline CHEMBL3933807 & 1641198 & 6.0716 & 5.9133 & TRN & \\
\hline CHEMBL3953685 & 1641198 & 4.8182 & 4.7531 & TRN & \\
\hline CHEMBL3920935 & 1641198 & 5.7033 & 5.3943 & TRN & \\
\hline CHEMBL3928618 & 1641198 & 3.7932 & 4.0992 & TRN & \\
\hline CHEMBL3960029 & 1641198 & 5.7932 & 5.4322 & TRN & \\
\hline CHEMBL3969828 & 1641198 & 5.7696 & 5.8963 & TRN & \\
\hline CHEMBL3955192 & 1641198 & 5.15 & 4.8954 & TRN & \\
\hline CHEMBL 3964270 & 1641198 & 3.7932 & \multicolumn{2}{|c|}{3.9789999999999996} & TRN \\
\hline CHEMBL3914683 & 1641198 & 6.3595 & 5.8924 & TRN & \\
\hline CHEMBL 3949420 & 1641198 & 5.6144 & 6.4653 & TRN & \\
\hline CHEMBL3927937 & 1641198 & 6.6925 & 5.5828 & TRN & \\
\hline CHEMBL3935126 & 1641198 & 6.556 & 5.9209 & TRN & \\
\hline CHEMBL3961674 & 1641198 & 5.556 & 5.8363 & TRN & \\
\hline CHEMBL3960541 & 1641198 & 5.7447 & 4.9265 & TRN & \\
\hline CHEMBL3918561 & 1641198 & 5.6402 & 5.8964 & TRN & \\
\hline CHEMBL3936257 & 1641198 & 5.5171 & 5.8352 & TST & \\
\hline CHEMBL3907109 & 1641198 & 3.8041 & 4.9107 & TRN & \\
\hline CHEMBL3980630 & 1641198 & 5.4634 & 5.8571 & TRN & \\
\hline CHEMBL 3898242 & 1641198 & 3.8761 & \multicolumn{2}{|c|}{4.7410000000000005} & TRN \\
\hline CHEMBL3962324 & 1641198 & 6.2351 & 5.9035 & TRN & \\
\hline CHEMBL3958953 & 1641198 & 6.3143 & 5.4295 & TRN & \\
\hline CHEMBL3919242 & 1641198 & 6.5214 & 5.0655 & TRN & \\
\hline CHEMBL3695569 & 1641198 & 7.3468 & 3.9723 & TST & \\
\hline CHEMBL 3890213 & 1641198 & 6.7352 & 6.1288 & TRN & \\
\hline CHEMBL3986904 & 1641198 & 6.5735 & 6.5343 & TRN & \\
\hline CHEMBL 3978244 & 1641198 & 3.7959 & 3.8052 & TRN & \\
\hline
\end{tabular}


Supplemental Table S2.txt

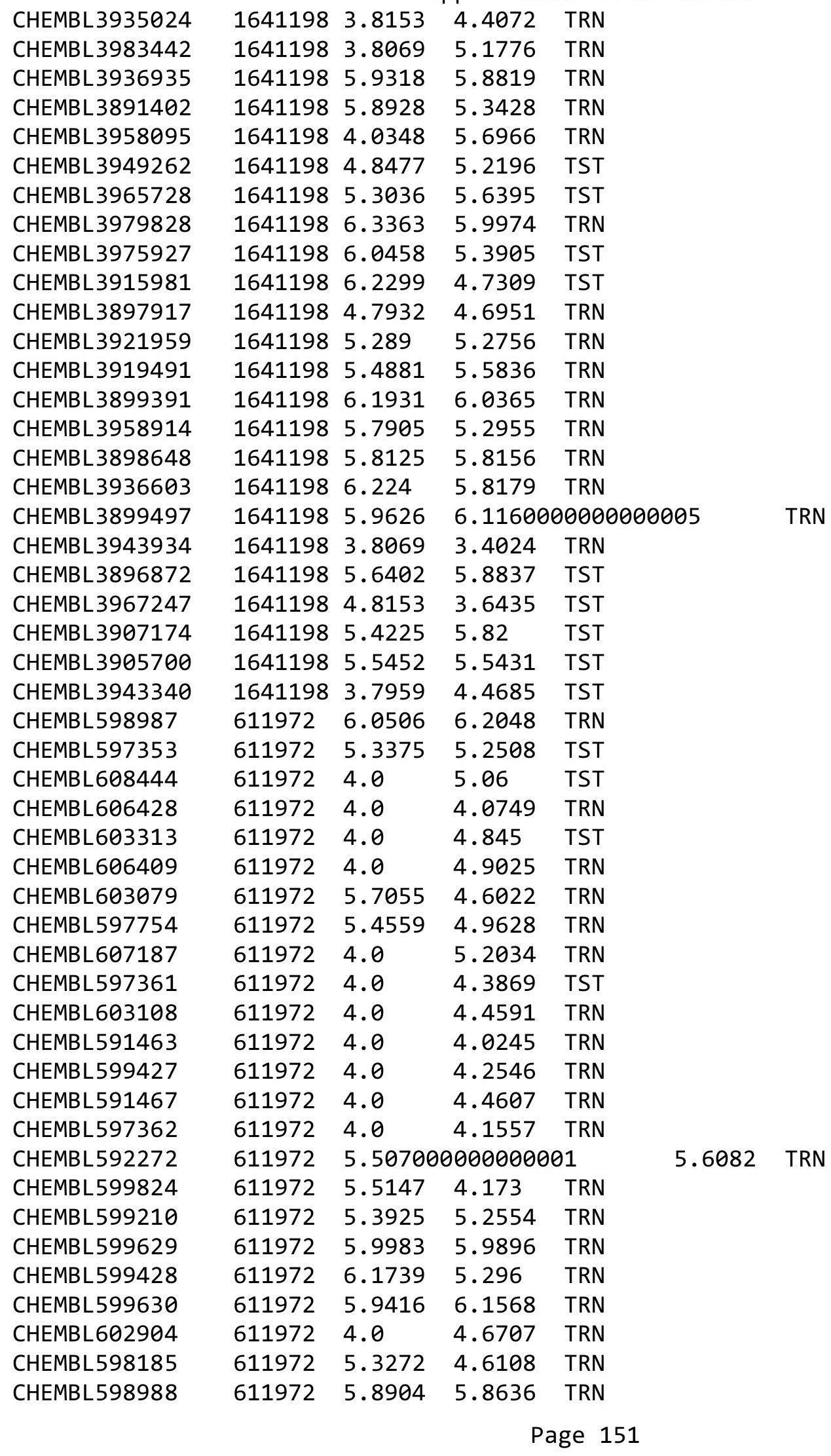




\begin{tabular}{|c|c|c|c|c|c|c|}
\hline & & \multicolumn{5}{|c|}{ Supplemental Table S2.txt } \\
\hline CHEMBL605153 & 611972 & 5.636 & 5.3131 & TRN & & \\
\hline CHEMBL605350 & 611972 & 5.6704 & 5.9762 & TST & & \\
\hline CHEMBL603080 & 611972 & 4.0 & 4.5126 & TRN & & \\
\hline CHEMBL597977 & 611972 & 4.0 & 4.9567 & TRN & & \\
\hline CHEMBL592256 & 611972 & 5.8901 & 5.9466 & TRN & & \\
\hline CHEMBL605774 & 611972 & 5.3407 & 4.8559 & TST & & \\
\hline CHEMBL599631 & 611972 & 5.8395 & 5.9557 & TST & & \\
\hline CHEMBL598186 & 611972 & 4.0 & 4.1654 & TRN & & \\
\hline CHEMBL597753 & 611972 & 5.9076 & 5.3243 & TRN & & \\
\hline CHEMBL599401 & 611972 & 4.0 & 4.6315 & TRN & & \\
\hline CHEMBL591230 & 611972 & 5.716 & 5.6028 & TST & & \\
\hline CHEMBL610218 & 611972 & 5.7726 & 5.6172 & TST & & \\
\hline CHEMBL597379 & 611972 & 4.0 & 4.7205 & TRN & & \\
\hline CHEMBL599224 & 611972 & 4.0 & 4.7048 & TRN & & \\
\hline CHEMBL599607 & 611972 & 4.0 & 4.494 & TRN & & \\
\hline CHEMBL604092 & 611972 & 4.0 & 4.1264 & TRN & & \\
\hline CHEMBL597352 & 611972 & 5.6371 & 5.777 & TST & & \\
\hline CHEMBL600876 & 611972 & 5.21899 & 99999999 & 99 & 4.6774 & TRN \\
\hline CHEMBL598382 & 611972 & 4.0 & 4.0229 & TRN & & \\
\hline CHEMBL605208 & 611972 & 4.0 & 5.2132 & TST & & \\
\hline CHEMBL600394 & 611972 & 4.0 & 4.0488 & TRN & & \\
\hline CHEMBL598401 & 611972 & 5.8834 & 5.0419 & TRN & & \\
\hline CHEMBL606000 & 611972 & 6.3546 & 5.442 & TRN & & \\
\hline CHEMBL598986 & 611972 & 6.1726 & 5.7798 & TST & & \\
\hline CHEMBL605781 & 611972 & 5.4158 & 4.2056 & TRN & & \\
\hline CHEMBL607852 & 611972 & 5.3332 & 5.6207 & TST & & \\
\hline CHEMBL3898990 & 1641181 & 6.0002 & 6.4816 & TRN & & \\
\hline CHEMBL3916506 & 1641181 & 8.0591 & 8.0578 & TRN & & \\
\hline CHEMBL 3925412 & 1641181 & 8.567 & 8.5881 & TRN & & \\
\hline CHEMBL3891570 & 1641181 & 7.4182 & 7.3503 & TRN & & \\
\hline CHEMBL3909768 & 1641181 & 7.6343 & 7.7348 & TRN & & \\
\hline CHEMBL3919958 & 1641181 & 8.0076 & 7.6749 & TRN & & \\
\hline CHEMBL 3966448 & 1641181 & 8.0252 & 7.8526 & TRN & & \\
\hline CHEMBL3916832 & 1641181 & 6.8262 & 6.9519 & TRN & & \\
\hline CHEMBL3979684 & 1641181 & 8.4841 & 8.0273 & TRN & & \\
\hline CHEMBL3901068 & 1641181 & 8.6737 & 8.2656 & TRN & & \\
\hline CHEMBL 3898085 & 1641181 & 7.8684 & 7.8861 & TRN & & \\
\hline CHEMBL3952645 & 1641181 & 8.1872 & 8.1449 & TRN & & \\
\hline CHEMBL3984708 & 1641181 & 8.6386 & 8.381 & TRN & & \\
\hline CHEMBL3951179 & 1641181 & 5.8374 & 6.5259 & TRN & & \\
\hline CHEMBL3928933 & 1641181 & 7.7542 & 7.9879 & TRN & & \\
\hline CHEMBL3963380 & 1641181 & 7.5786 & 7.4944 & TRN & & \\
\hline CHEMBL3954958 & 1641181 & 7.3328 & 8.5867 & TRN & & \\
\hline CHEMBL3954719 & 1641181 & 7.2446 & 6.8141 & TRN & & \\
\hline CHEMBL3964172 & 1641181 & 8.3796 & 8.0882 & TRN & & \\
\hline CHEMBL3975918 & 1641181 & 7.7627 & 7.7136 & TRN & & \\
\hline CHEMBL3987045 & 1641181 & 7.159 & 6.8064 & TRN & & \\
\hline CHEMBL3986737 & 1641181 & 7.5683 & 7.6374 & TRN & & \\
\hline
\end{tabular}


Supplemental Table S2.txt

\begin{tabular}{|c|c|c|c|c|c|c|}
\hline CHEMBL 3980752 & 1641181 & 5.6735 & 5.8934 & TRN & & \\
\hline CHEMBL 3952529 & 1641181 & 7.9859 & 7.6764 & TRN & & \\
\hline CHEMBL3935437 & 1641181 & 7.9694 & 8.0394 & TRN & & \\
\hline CHEMBL 3974839 & 1641181 & 7.5599 & 7.9388 & TRN & & \\
\hline CHEMBL 3930219 & 1641181 & 6.0 & 5.7745 & TRN & & \\
\hline CHEMBL 3937778 & 1641181 & 7.4685 & 8.0134 & TRN & & \\
\hline CHEMBL 3921087 & 1641181 & 7.2569 & 7.1128 & TRN & & \\
\hline CHEMBL 3937501 & 1641181 & 8.5707 & 8.2546 & TRN & & \\
\hline CHEMBL 3971484 & 1641181 & 8.3683 & 7.8852 & TST & & \\
\hline CHEMBL 3895519 & 1641181 & 8.7607 & 8.5776 & TRN & & \\
\hline CHEMBL3911893 & 1641181 & 8.604 & 8.1887 & TRN & & \\
\hline CHEMBL 3970019 & 1641181 & 8.3435 & 8.2645 & TRN & & \\
\hline CHEMBL 3901207 & 1641181 & 9.0129 & 8.1858 & TRN & & \\
\hline CHEMBL 3893835 & 1641181 & 8.3629 & 8.5707 & TRN & & \\
\hline CHEMBL3916536 & 1641181 & 6.0 & 5.4061 & TRN & & \\
\hline CHEMBL3901862 & 1641181 & 7.0279 & 6.8709 & TST & & \\
\hline CHEMBL3932687 & 1641181 & 8.0863 & 7.8993 & TRN & & \\
\hline CHEMBL 3946696 & 1641181 & 7.7747 & 7.8956 & TRN & & \\
\hline CHEMBL 3904688 & 1641181 & 6.0 & 6.1255 & TRN & & \\
\hline CHEMBL 3945828 & 1641181 & 7.5574 & 7.8028 & TST & & \\
\hline CHEMBL 3980765 & 1641181 & 8.0501 & 7.1721 & TST & & \\
\hline CHEMBL3976190 & 1641181 & 6.0 & 5.5563 & TST & & \\
\hline CHEMBL 3947779 & 1641181 & 8.5239 & 8.5136 & TRN & & \\
\hline CHEMBL3948171 & 1641181 & 8.7533 & 8.8667 & TRN & & \\
\hline CHEMBL 3956485 & 1641181 & 6.2362 & 6.7923 & TRN & & \\
\hline CHEMBL 3901713 & 1641181 & 8.5399 & 8.1605 & TST & & \\
\hline CHEMBL3914135 & 1641181 & 8.1028 & 7.9837 & TRN & & \\
\hline CHEMBL 3977462 & 1641181 & 8.4306 & 8.2931 & TRN & & \\
\hline CHEMBL 3891323 & 1641181 & 6.0 & 5.2582 & TST & & \\
\hline CHEMBL 3937875 & 1641181 & 8.1556 & 7.9622 & TRN & & \\
\hline CHEMBL3917306 & 1641181 & 8.0396 & 7.501 & TRN & & \\
\hline CHEMBL 3936821 & 1641181 & 8.1406 & 8.5091 & TRN & & \\
\hline CHEMBL3917905 & 1641181 & 5.2613 & 6.1858 & TRN & & \\
\hline CHEMBL 3983945 & 1641181 & 6.7683 & 7.31 & TST & & \\
\hline CHEMBL 3904284 & 1641181 & 6.67299 & 999999999 & 99 & 6.6754 & TRN \\
\hline CHEMBL3985345 & 1641181 & 6.5418 & 7.0122 & TRN & & \\
\hline CHEMBL3895952 & 1641181 & 8.7655 & 8.3986 & TST & & \\
\hline CHEMBL3931991 & 1641181 & 8.1141 & 8.1751 & TRN & & \\
\hline CHEMBL3955411 & 1641181 & 6.0 & 5.6313 & TRN & & \\
\hline CHEMBL 3922375 & 1641181 & 8.4135 & 8.6279 & TRN & & \\
\hline CHEMBL 3932372 & 1641181 & 8.6792 & 8.3584 & TRN & & \\
\hline CHEMBL 3909941 & 1641181 & 8.1 & 7.7966 & TRN & & \\
\hline CHEMBL 3947746 & 1641181 & 7.6611 & 7.3694 & TRN & & \\
\hline CHEMBL3910891 & 1641181 & 7.5538 & 8.3708 & TRN & & \\
\hline CHEMBL 3895909 & 1641181 & 7.38 & 6.9599 & TST & & \\
\hline CHEMBL 3964267 & 1641181 & 8.3382 & 7.8558 & TST & & \\
\hline CHEMBL 3919141 & 1641181 & 7.6996 & 7.4581 & TST & & \\
\hline CHEMBL 3908585 & 1641181 & 6.7071 & 7.3531 & TST & & \\
\hline
\end{tabular}


Supplemental Table S2.txt

\begin{tabular}{|c|c|c|c|c|c|}
\hline CHEMBL3972307 & 1641181 & 7.9767 & 8.3125 & TST & \\
\hline CHEMBL3977884 & 1641181 & 6.6855 & 7.6814 & TRN & \\
\hline CHEMBL3967409 & 1641181 & 8.4674 & 8.1545 & TST & \\
\hline CHEMBL3942882 & 1641181 & 6.0 & 4.9737 & TST & \\
\hline CHEMBL 3972841 & 1641181 & 7.7809 & 7.7417 & TST & \\
\hline CHEMBL3941278 & 1641181 & 6.1672 & 6.5719 & TST & \\
\hline CHEMBL3923062 & 1641181 & 8.4411 & 7.8286 & TRN & \\
\hline CHEMBL3939908 & 1641181 & 8.3677 & 8.0924 & TST & \\
\hline CHEMBL3954156 & 1641181 & 8.2688 & 8.202 & TST & \\
\hline CHEMBL 3900877 & 1641181 & 8.422 & 8.3003 & TST & \\
\hline CHEMBL3964630 & 1641181 & 6.4288 & 6.3078 & TRN & \\
\hline CHEMBL 3900278 & 1641181 & 6.0 & 6.0616 & TRN & \\
\hline CHEMBL409669 & 472995 & 7.1805 & 6.3702 & TST & \\
\hline CHEMBL 270955 & 472995 & 6.6904 & 5.5619 & TRN & \\
\hline CHEMBL 271838 & 472995 & 7.8861 & 7.5815 & TRN & \\
\hline CHEMBL271837 & 472995 & 4.0 & 4.3553 & TRN & \\
\hline CHEMBL411631 & 472995 & 7.3468 & 7.616006 & 00000000005 & TRN \\
\hline CHEMBL270546 & 472995 & 7.4815 & 6.7369 & TRN & \\
\hline CHEMBL 269851 & 472995 & 7.3979 & 7.6183 & TRN & \\
\hline CHEMBL 270125 & 472995 & 6.1062 & 6.6403 & TRN & \\
\hline CHEMBL 272176 & 472995 & 6.4034 & 5.9644 & TRN & \\
\hline CHEMBL409491 & 472995 & 4.5229 & 5.5099 & TRN & \\
\hline CHEMBL 271527 & 472995 & 5.8962 & 6.2823 & TRN & \\
\hline CHEMBL410676 & 472995 & 6.2907 & 7.2947 & TRN & \\
\hline CHEMBL 271553 & 472995 & 4.0 & 3.8789 & TRN & \\
\hline CHEMBL409647 & 472995 & 5.4781 & 5.6886 & TRN & \\
\hline CHEMBL259463 & 472995 & 5.7144 & 6.3443 & TRN & \\
\hline CHEMBL 272882 & 472995 & 6.5498 & 6.3405 & TRN & \\
\hline CHEMBL411674 & 472995 & 7.8539 & 7.9196 & TRN & \\
\hline CHEMBL 271565 & 472995 & 5.9606 & 5.941 & TRN & \\
\hline CHEMBL271814 & 472995 & 4.4559 & 4.7529 & TRN & \\
\hline CHEMBL410441 & 472995 & 7.1549 & 7.1907 & TRN & \\
\hline CHEMBL188 & 472995 & 7.8761 & 6.2134 & TST & \\
\hline CHEMBL259253 & 472995 & 6.4112 & 5.8763 & TRN & \\
\hline CHEMBL410677 & 472995 & 5.9172 & 6.1779 & TRN & \\
\hline CHEMBL406918 & 472995 & 4.0 & 4.3016 & TRN & \\
\hline CHEMBL272189 & 472995 & 5.727 & 5.4705 & TRN & \\
\hline CHEMBL408430 & 472995 & 5.8965 & 5.5068 & TST & \\
\hline CHEMBL259462 & 472995 & 5.0 & 5.3386 & TRN & \\
\hline CHEMBL410842 & 472995 & 4.0 & 4.798 & TRN & \\
\hline CHEMBL271158 & 472995 & 7.9208 & 7.0151 & TRN & \\
\hline CHEMBL262865 & 472995 & 6.0731 & 6.0881 & TRN & \\
\hline CHEMBL408964 & 472995 & 5.9626 & 6.0269 & TRN & \\
\hline CHEMBL411673 & 472995 & 4.0 & 3.9457 & TRN & \\
\hline CHEMBL409265 & 472995 & 5.8911 & 6.0119 & TRN & \\
\hline CHEMBL409231 & 472995 & 4.4559 & 4.7377 & TRN & \\
\hline CHEMBL410313 & 472995 & 4.0 & 3.98 & TRN & \\
\hline CHEMBL272876 & 472995 & 6.6234 & 5.9042 & TRN & \\
\hline
\end{tabular}




\begin{tabular}{|c|c|c|c|c|c|}
\hline \multicolumn{6}{|c|}{ Supplemental Table S2.txt } \\
\hline CHEMBL1203961 & 472995 & 4.0 & 5.6668 & TST & \\
\hline CHEMBL411888 & 472995 & 4.0 & 3.8096 & TRN & \\
\hline CHEMBL270987 & 472995 & 5.5522 & 5.6486 & TRN & \\
\hline CHEMBL409537 & 472995 & 5.3897 & 4.5181 & TRN & \\
\hline CHEMBL270968 & 472995 & 5.0 & 4.9061 & TRN & \\
\hline CHEMBL411937 & 472995 & 6.0061 & 5.7419 & TRN & \\
\hline CHEMBL272868 & 472995 & 7.5528 & 7.0179 & TRN & \\
\hline CHEMBL270082 & 472995 & 6.6091 & 6.7491 & TRN & \\
\hline CHEMBL271839 & 472995 & 7.5528 & 7.629 & TST & \\
\hline CHEMBL272658 & 472995 & 4.0 & 5.2041 & TST & \\
\hline CHEMBL410655 & 472995 & 7.5086 & 6.6661 & TST & \\
\hline CHEMBL411244 & 472995 & 6.6421 & 7.0602 & TST & \\
\hline CHEMBL272659 & 472995 & 4.0 & 4.8738 & TST & \\
\hline CHEMBL271810 & 472995 & 7.6021 & 6.501 & TST & \\
\hline CHEMBL271805 & 472995 & 4.0 & 4.5459 & TST & \\
\hline CHEMBL406399 & 472995 & 5.769 & 4.5312 & TST & \\
\hline CHEMBL408174 & 472995 & 4.6576 & 4.3635 & TST & \\
\hline CHEMBL306764 & 472995 & 5.9194 & 6.24299 & 9999999999 & TST \\
\hline CHEMBL222102 & 954716 & 3.2161 & 3.28800 & 00000000003 & TRN \\
\hline CHEMBL300389 & 954716 & 5.7321 & 5.8789 & TRN & \\
\hline CHEMBL191334 & 954716 & 3.6212 & 3.7147 & TRN & \\
\hline CHEMBL192566 & 954716 & 8.5358 & 7.4691 & TST & \\
\hline CHEMBL412142 & 954716 & 3.4281 & 3.5767 & TRN & \\
\hline CHEMBL483847 & 954716 & 3.5089 & 3.5755 & TRN & \\
\hline CHEMBL1190711 & 954716 & $5.3270 e$ & 0000000 & 5.1325 & TRN \\
\hline CHEMBL515416 & 954716 & 4.0901 & 4.0901 & TRN & \\
\hline CHEMBL373751 & 954716 & 3.2008 & 3.3912 & TRN & \\
\hline CHEMBL472940 & 954716 & 3.4383 & 3.4774 & TRN & \\
\hline CHEMBL259181 & 954716 & 3.8035 & 3.8758 & TRN & \\
\hline CHEMBL1590308 & 954716 & 2.5046 & 3.1739 & TST & \\
\hline CHEMBL180127 & 954716 & 4.0698 & 3.963 & TRN & \\
\hline CHEMBL3392440 & 954716 & 3.2928 & 3.3191 & TRN & \\
\hline CHEMBL210618 & 954716 & 2.8718 & 3.1012 & TRN & \\
\hline CHEMBL1673039 & 954716 & 4.2095 & 4.3825 & TRN & \\
\hline CHEMBL 202721 & 954716 & 5.546 & 5.3227 & TRN & \\
\hline CHEMBL1230020 & 954716 & 3.6209 & 3.5335 & TRN & \\
\hline CHEMBL258844 & 954716 & 4.0984 & 3.9327 & TRN & \\
\hline CHEMBL221137 & 954716 & 4.4774 & 4.3574 & TST & \\
\hline CHEMBL1970879 & 954716 & 4.0186 & 4.0746 & TRN & \\
\hline CHEMBL1357247 & 954716 & 3.029 & 2.904 & TRN & \\
\hline CHEMBL209148 & 954716 & 4.3998 & 4.2714 & TRN & \\
\hline CHEMBL509032 & 954716 & 5.7598 & 5.6303 & TRN & \\
\hline CHEMBL1643959 & 954716 & 2.7582 & 2.7959 & TRN & \\
\hline CHEMBL1516890 & 954716 & 3.8088 & 3.7184 & TRN & \\
\hline CHEMBL577784 & 954716 & 4.6951 & 4.7985 & TRN & \\
\hline CHEMBL512504 & 954716 & 6.3931 & 6.6485 & TRN & \\
\hline CHEMBL1256459 & 954716 & 6.8779 & 6.7968 & TRN & \\
\hline CHEMBL573107 & 954716 & 5.3363 & 5.2545 & TRN & \\
\hline
\end{tabular}




\begin{tabular}{|c|c|c|c|c|c|c|}
\hline & & \multicolumn{5}{|c|}{ supplemental lable s2.txt } \\
\hline CHEMBL585951 & 954716 & 6.0547 & 6.0165 & TRN & & \\
\hline CHEMBL 379300 & 954716 & 5.7396 & 5.7155 & TRN & & \\
\hline CHEMBL1909414 & 954716 & 4.3785 & 4.3001 & TRN & & \\
\hline CHEMBL240954 & 954716 & 3.5047 & 3.5593 & TST & & \\
\hline CHEMBL189584 & 954716 & 4.1432 & 4.2328 & TRN & & \\
\hline CHEMBL1788116 & 954716 & 4.0894 & 3.9909 & TRN & & \\
\hline CHEMBL 2144069 & 954716 & 4.4104 & 4.7818 & TRN & & \\
\hline CHEMBL65 & 954716 & \multicolumn{3}{|c|}{7.1579999999999995} & 7.1268 & TRN \\
\hline CHEMBL135561 & 954716 & 4.1673 & 3.9489 & TRN & & \\
\hline CHEMBL393929 & 954716 & 3.9907 & 3.9524 & TRN & & \\
\hline CHEMBL3186408 & 954716 & 3.3813 & 3.4521 & TST & & \\
\hline CHEMBL188678 & 954716 & 3.8239 & 3.8764 & TRN & & \\
\hline CHEMBL9470 & 954716 & 6.1706 & 5.3682 & TST & & \\
\hline CHEMBL1404918 & 954716 & 2.6646 & 2.4587 & TRN & & \\
\hline CHEMBL2005886 & 954716 & 4.6657 & 4.7836 & TRN & & \\
\hline CHEMBL92309 & 954716 & 1.8691 & 2.4979 & TST & & \\
\hline CHEMBL558642 & 954716 & 3.2874 & 3.2676 & TRN & & \\
\hline CHEMBL2363137 & 954716 & 4.6395 & 4.4521 & TRN & & \\
\hline CHEMBL 213100 & 954716 & 3.3236 & 3.3364 & TRN & & \\
\hline CHEMBL483849 & 954716 & 2.1041 & 2.1325 & TRN & & \\
\hline CHEMBL3199475 & 954716 & 4.2393 & 4.2107 & TRN & & \\
\hline CHEMBL220241 & 954716 & 3.8463 & 4.2395 & TST & & \\
\hline CHEMBL449158 & 954716 & 5.8263 & 6.3244 & TST & & \\
\hline CHEMBL1242367 & 954716 & 3.7936 & 3.4984 & TST & & \\
\hline CHEMBL3349342 & 954716 & 4.6418 & 4.6495 & TST & & \\
\hline CHEMBL102714 & 954716 & 4.6803 & 3.3069 & TST & & \\
\hline CHEMBL514499 & 954716 & 7.1563 & 6.59 & TST & & \\
\hline CHEMBL379975 & 954716 & 5.2086 & 4.9454 & TST & & \\
\hline CHEMBL392695 & 954716 & 5.319 & 4.6619 & TST & & \\
\hline CHEMBL221396 & 425772 & 3.8239 & 2.8675 & TST & & \\
\hline CHEMBL 219433 & 425772 & 8.041 & 8.2376 & TRN & & \\
\hline CHEMBL218036 & 425772 & 8.2676 & 8.4689 & TRN & & \\
\hline CHEMBL 220753 & 425772 & 8.6021 & 8.5924 & TRN & & \\
\hline CHEMBL376846 & 425772 & 3.5229 & 7.3027 & TST & & \\
\hline CHEMBL217979 & 425772 & 7.2933 & 7.267 & TRN & & \\
\hline CHEMBL220701 & 425772 & 8.6576 & 8.3984 & TRN & & \\
\hline CHEMBL218374 & 425772 & 9.7696 & 9.7051 & TRN & & \\
\hline CHEMBL221789 & 425772 & 7.4214 & 7.4562 & TRN & & \\
\hline CHEMBL426207 & 425772 & 7.7852 & 7.6507 & TRN & & \\
\hline CHEMBL 222110 & 425772 & 5.7545 & 6.4155 & TST & & \\
\hline CHEMBL 386987 & 425772 & 5.6919 & 5.704 & TRN & & \\
\hline CHEMBL 221345 & 425772 & 7.4935 & 7.4626 & TRN & & \\
\hline CHEMBL 219588 & 425772 & 6.2381 & 6.426 & TRN & & \\
\hline CHEMBL 218640 & 425772 & 4.301 & 4.3648 & TRN & & \\
\hline CHEMBL221638 & 425772 & 6.7011 & 7.4624 & TRN & & \\
\hline CHEMBL 221078 & 425772 & 6.9431 & 6.75799 & 9999999999 & & TRN \\
\hline CHEMBL221977 & 425772 & 8.1739 & 8.2236 & TRN & & \\
\hline CHEMBL218218 & 425772 & 8.2007 & 8.2542 & TRN & & \\
\hline
\end{tabular}




\begin{tabular}{|c|c|c|c|c|c|c|}
\hline \multicolumn{7}{|c|}{ 2.tx } \\
\hline CHEMBL218366 & 425772 & 7.1487 & 7.1612 & TRN & & \\
\hline CHEMBL218207 & 425772 & 5.11100 & 000000006 & $\partial 1$ & 7.3321 & TST \\
\hline CHEMBL385288 & 425772 & 7.1113 & 7.3717 & TRN & & \\
\hline CHEMBL 217908 & 425772 & 3.5229 & 7.9568 & TST & & \\
\hline CHEMBL221961 & 425772 & 7.8013 & 7.621 & TRN & & \\
\hline CHEMBL 376910 & 425772 & 8.7959 & 8.9768 & TRN & & \\
\hline CHEMBL 375880 & 425772 & 7.341 & 7.3892 & TRN & & \\
\hline CHEMBL376069 & 425772 & 3.3565 & 1.6259 & TST & & \\
\hline CHEMBL 218502 & 425772 & 3.3565 & 7.7974 & TST & & \\
\hline CHEMBL373504 & 425772 & 6.6144 & 6.4913 & TRN & & \\
\hline CHEMBL 374979 & 425772 & 8.1427 & 8.0768 & TRN & & \\
\hline CHEMBL222111 & 425772 & 6.6325 & 7.5354 & TST & & \\
\hline CHEMBL385108 & 425772 & 8.3768 & 8.6763 & TRN & & \\
\hline CHEMBL221904 & 425772 & 8.3872 & 8.3388 & TRN & & \\
\hline CHEMBL412116 & 425772 & 7.3706 & 5.4051 & TST & & \\
\hline CHEMBL 221251 & 425772 & 8.3768 & 8.3293 & TRN & & \\
\hline CHEMBL387161 & 425772 & 6.9666 & 6.9128 & TRN & & \\
\hline CHEMBL218503 & 425772 & 8.3565 & 8.2637 & TRN & & \\
\hline CHEMBL218375 & 425772 & 8.7959 & 8.9126 & TRN & & \\
\hline CHEMBL 385287 & 425772 & 5.4845 & 7.6806 & TST & & \\
\hline CHEMBL 221865 & 425772 & 9.1549 & 9.27799 & 9999999999 & & TRN \\
\hline CHEMBL220703 & 425772 & 7.9469 & 8.3021 & TRN & & \\
\hline CHEMBL219327 & 425772 & 7.4647 & 7.7516 & TRN & & \\
\hline CHEMBL375315 & 425772 & 8.2832 & 8.0821 & TRN & & \\
\hline CHEMBL221867 & 425772 & 8.7959 & 8.2541 & TRN & & \\
\hline CHEMBL 218350 & 425772 & 7.1096 & 6.9275 & TRN & & \\
\hline CHEMBL222058 & 425772 & 7.4473 & 7.7059 & TRN & & \\
\hline CHEMBL373739 & 425772 & 8.9586 & 8.5744 & TRN & & \\
\hline CHEMBL 384534 & 425772 & 3.5229 & 7.3149 & TST & & \\
\hline CHEMBL 373893 & 425772 & 3.3565 & 4.3546 & TST & & \\
\hline CHEMBL 221130 & 425772 & 8.4559 & 8.3608 & TRN & & \\
\hline CHEMBL374916 & 425772 & 4.301 & 4.1612 & TRN & & \\
\hline CHEMBL374939 & 425772 & 9.5229 & 9.0811 & TRN & & \\
\hline CHEMBL 375854 & 425772 & 8.8239 & 8.6956 & TRN & & \\
\hline CHEMBL218037 & 425772 & 8.6383 & 8.9041 & TRN & & \\
\hline CHEMBL376076 & 425772 & 7.8182 & 7.7132 & TRN & & \\
\hline CHEMBL221021 & 425772 & 8.0223 & 7.7945 & TRN & & \\
\hline CHEMBL219589 & 425772 & 6.901 & 8.1547 & TST & & \\
\hline CHEMBL 387451 & 425772 & 7.091 & 8.166 & TST & & \\
\hline CHEMBL219487 & 425772 & 6.2468 & 9.0158 & TST & & \\
\hline CHEMBL3086172 & 1276354 & 6.0 & 6.0006 & TRN & & \\
\hline CHEMBL 3085980 & 1276354 & 6.301 & 6.3871 & TRN & & \\
\hline CHEMBL 3086314 & 1276354 & 7.2218 & 7.1814 & TRN & & \\
\hline CHEMBL 3086170 & 1276354 & 5.5229 & 6.9207 & TST & & \\
\hline CHEMBL 3086317 & 1276354 & 7.8861 & 7.8536 & TRN & & \\
\hline CHEMBL 3086168 & 1276354 & 6.6778 & 6.6691 & TRN & & \\
\hline CHEMBL 3086321 & 1276354 & 8.0088 & 8.0003 & TRN & & \\
\hline CHEMBL3085986 & 1276354 & 5.5229 & 6.7608 & TST & & \\
\hline
\end{tabular}


Supplemental Table S2.txt

\begin{tabular}{|c|c|c|c|c|}
\hline HEN & & 7.4949 & & \\
\hline & & 7.6778 & 7.6675 & \\
\hline & & 7696 & & \\
\hline AEMBL & 276354 & 3979 & & \\
\hline AEMBL3086316 & . & 7447 & 7614 & \\
\hline HEMBL3085976 & 276354 & 8.2366 & .2455 & \\
\hline & & 188 & 3284 & \\
\hline |FMRI: & & & & \\
\hline HEMBL3085834 & & 8.1135 & 8.1282 & \\
\hline HEMBL3085982 & 354 & 2676 & 2632 & \\
\hline HEMBL3085833 & & 8.2147 & .2326 & \\
\hline IEMBL3E & & 15 & 573 & \\
\hline AEMBL3 & & & & \\
\hline HEMBL 30 & & 258 & 7.9982 & \\
\hline AEMBL30 & & 518 & 2427 & \\
\hline AEMBL308 & & 7 & 7.7035 & \\
\hline HEMBL3E & & 021 & 008 & \\
\hline HEMBL3E & & 7. & & \\
\hline HEMBL3e & & 7.4685 & 6.7715 & \\
\hline AEMBL3C & & 24 & & \\
\hline HEMBL= & & 5 & 583 & Niv \\
\hline AEMBL & & & & RN \\
\hline HEMBL; & & & 33 & \\
\hline 161 & & & & \\
\hline AEMBL36 & & & & I RIV \\
\hline HEMBL3 & & 91 & 11 & RN \\
\hline HEMBL & & 12 & 57 & 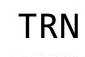 \\
\hline HFMBI : & & 7. & 366 & \\
\hline HEMBL3 & & 5383 & 501 & IRIN \\
\hline HEMBL 30 & & 7. & 5557 & I RN \\
\hline HEMBL3C & & 8 & 347 & RN \\
\hline HEMBL & & 96 & 779 & RN \\
\hline 78 & & & 765 & TRN \\
\hline HEMBL 30 & & & 5518 & $\mathrm{IR}$ \\
\hline HEMBL3085981 & & 7.6021 & 5283 & TRN \\
\hline HEMBL3E & & 29 & 105 & TRN \\
\hline HCMP - & & - & & ST \\
\hline HEMBL3 & & & 5.8438 & IR \\
\hline HEMBL3086179 & & 7.8861 & 9253 & TRI \\
\hline AEMBL30 & & & 244 & TST \\
\hline HEMBL3e & & 655 & 3263 & . \\
\hline HEMBL $3 e$ & & & & ST \\
\hline HEMBL 30 & & 7.5086 & 7.9527 & TST \\
\hline AEMBL3085973 & 635 & 7.8861 & .5554 & TS \\
\hline MRI $=$ & & 4949 & 35 & IS \\
\hline HEMBL3E & & & .7267 & \\
\hline CHEMBL 308 & & .5229 & 6.3962 & \\
\hline HEMBL3085832 & 1276354 & 7.8861 & 7.5838 & IST \\
\hline
\end{tabular}

Page 158 
Supplemental Table S2.txt

\begin{tabular}{|c|c|c|c|c|c|}
\hline CHEMBL3736497 & 1537874 & 3.0 & 2.8845 & TST & \\
\hline CHEMBL3735937 & 1537874 & 3.0 & 2.7862 & TST & \\
\hline CHEMBL3735786 & 1537874 & 3.0 & 3.0708 & TST & \\
\hline CHEMBL 3736487 & 1537874 & 3.0 & 3.2678 & TRN & \\
\hline CHEMBL3736357 & 1537874 & 3.0 & 3.2022 & TRN & \\
\hline CHEMBL1515627 & 1537874 & 4.1249 & 3.5742 & TRN & \\
\hline CHEMBL3735922 & 1537874 & 3.0 & 3.1214 & TRN & \\
\hline CHEMBL 3735807 & 1537874 & 3.0 & 2.8219 & TRN & \\
\hline CHEMBL3735328 & 1537874 & 3.0 & 2.9394 & TRN & \\
\hline CHEMBL98778 & 1537874 & 3.0 & 3.2934 & TST & \\
\hline CHEMBL 3735377 & 1537874 & 3.0 & 3.2151 & TRN & \\
\hline CHEMBL 3734841 & 1537874 & 4.7696 & 4.1591 & TRN & \\
\hline CHEMBL3736284 & 1537874 & 3.0 & 3.0448 & TRN & \\
\hline CHEMBL 3734766 & 1537874 & 3.0 & 2.9561 & TRN & \\
\hline CHEMBL3736362 & 1537874 & 3.0 & $3.14300 t$ & 00000000002 & TRN \\
\hline CHEMBL 3736087 & 1537874 & 3.0 & 3.7474 & TRN & \\
\hline CHEMBL 2007435 & 1537874 & 3.0 & 3.2735 & TST & \\
\hline CHEMBL3735084 & 1537874 & 3.0 & 2.8552 & TRN & \\
\hline CHEMBL 3736259 & 1537874 & 3.0 & 3.0748 & TRN & \\
\hline CHEMBL3735685 & 1537874 & 3.0 & 2.8305 & TRN & \\
\hline CHEMBL418899 & 1537874 & 5.8239 & 3.4486 & TST & \\
\hline CHEMBL3735233 & 1537874 & 3.0 & 3.0312 & TRN & \\
\hline CHEMBL3734945 & 1537874 & 3.0 & 3.0616 & TRN & \\
\hline CHEMBL 2007235 & 1537874 & 3.0 & \multicolumn{2}{|c|}{3.3080000000000003} & TST \\
\hline CHEMBL3735788 & 1537874 & 3.0 & 3.5769 & TRN & \\
\hline CHEMBL 3734808 & 1537874 & 3.0 & 3.0495 & TRN & \\
\hline CHEMBL 3734874 & 1537874 & 3.0 & 3.069 & TRN & \\
\hline CHEMBL3735443 & 1537874 & 3.0 & 3.0313 & TRN & \\
\hline CHEMBL 3735742 & 1537874 & 3.0 & 2.9559 & TRN & \\
\hline CHEMBL3735747 & 1537874 & 3.0 & 2.9434 & TRN & \\
\hline CHEMBL564201 & 1537874 & 4.585 & 3.3125 & TST & \\
\hline CHEMBL3735292 & 1537874 & 3.0 & 2.9885 & TRN & \\
\hline CHEMBL3735636 & 1537874 & 3.0 & 2.9546 & TRN & \\
\hline CHEMBL1964543 & 1537874 & 3.0 & 3.1569 & TST & \\
\hline CHEMBL3736219 & 1537874 & 3.0 & 2.8628 & TRN & \\
\hline CHEMBL3735258 & 1537874 & 3.0 & 3.3712 & TST & \\
\hline CHEMBL3736249 & 1537874 & 5.2218 & 4.3024 & TRN & \\
\hline CHEMBL3734848 & 1537874 & 3.0 & 3.1395 & TRN & \\
\hline CHEMBL 3735262 & 1537874 & 3.0 & 2.9606 & TRN & \\
\hline CHEMBL3735946 & 1537874 & 3.0 & 2.9524 & TRN & \\
\hline CHEMBL3735299 & 1537874 & 3.0809 & 3.9427 & TRN & \\
\hline CHEMBL3736492 & 1537874 & 3.0 & 2.8628 & TRN & \\
\hline CHEMBL3735442 & 1537874 & 3.0 & 3.1006 & TST & \\
\hline CHEMBL 3735768 & 1537874 & 3.0 & 3.0961 & TRN & \\
\hline CHEMBL1994493 & 1537874 & 3.0 & 3.2304 & TST & \\
\hline CHEMBL3736351 & 1537874 & 3.0 & 2.9579 & TRN & \\
\hline CHEMBL 2007490 & 1537874 & 3.0 & 3.3381 & TST & \\
\hline CHEMBL3735182 & 1537874 & 3.0 & 3.0089 & TRN & \\
\hline
\end{tabular}




\begin{tabular}{|c|c|c|c|c|}
\hline \multicolumn{5}{|c|}{ Supplemental Table S2.txt } \\
\hline CHEMBL 3736258 & 1537874 & 3.0 & 3.0376 & TRN \\
\hline CHEMBL3736102 & 1537874 & 3.0 & 3.0258 & TRN \\
\hline CHEMBL3735729 & 1537874 & 3.0 & 2.9446 & TRN \\
\hline CHEMBL3735011 & 1537874 & 3.0 & 3.0292 & TRN \\
\hline CHEMBL3734996 & 1537874 & 3.0 & 2.986 & TRN \\
\hline CHEMBL3735551 & 1537874 & 3.0 & 2.766 & TRN \\
\hline CHEMBL3735991 & 1537874 & 3.0 & 3.1212 & TRN \\
\hline CHEMBL 3735248 & 1537874 & 4.5686 & 3.1597 & TST \\
\hline CHEMBL3735430 & 1537874 & 3.0 & 2.8826 & TRN \\
\hline CHEMBL3734762 & 1537874 & 3.0 & 2.8559 & TRN \\
\hline CHEMBL3735313 & 1537874 & 3.0 & 2.9615 & TRN \\
\hline CHEMBL3735595 & 1537874 & 3.0 & 3.0019 & TRN \\
\hline CHEMBL 3735615 & 1537874 & 3.0 & 2.9386 & TST \\
\hline CHEMBL1979981 & 1537874 & 3.0 & 3.343 & TST \\
\hline CHEMBL3734886 & 1537874 & 3.0 & 3.037 & TRN \\
\hline CHEMBL3735111 & 1537874 & 3.0 & 2.847 & TRN \\
\hline CHEMBL378596 & 347197 & 5.9208 & 6.0636 & TRN \\
\hline CHEMBL 205942 & 347197 & 6.1549 & 5.1496 & TRN \\
\hline CHEMBL438623 & 347197 & 4.0 & 5.5404 & TRN \\
\hline CHEMBL208169 & 347197 & 4.0 & 3.4395 & TRN \\
\hline CHEMBL205034 & 347197 & 4.0 & 3.826 & TRN \\
\hline CHEMBL205588 & 347197 & 6.301 & 5.4035 & TRN \\
\hline CHEMBL382608 & 347197 & 7.0 & 4.3554 & TST \\
\hline CHEMBL205943 & 347197 & 4.0 & 4.7554 & TRN \\
\hline CHEMBL426673 & 347197 & 4.0 & 4.3331 & TRN \\
\hline CHEMBL383300 & 347197 & 6.699 & 5.115 & TST \\
\hline CHEMBL205587 & 347197 & 4.0 & 5.4857 & TRN \\
\hline CHEMBL207820 & 347197 & 6.0969 & 5.6131 & TRN \\
\hline CHEMBL207935 & 347197 & 6.1549 & 5.6694 & TRN \\
\hline CHEMBL381161 & 347197 & 5.0458 & 5.8112 & TRN \\
\hline CHEMBL205316 & 347197 & 6.5229 & 5.9311 & TRN \\
\hline CHEMBL206506 & 347197 & 4.0 & 4.0495 & TST \\
\hline CHEMBL381282 & 347197 & 4.0 & 5.3631 & TRN \\
\hline CHEMBL 383241 & 347197 & 7.0 & 4.3869 & TST \\
\hline CHEMBL426311 & 347197 & 6.699 & 4.7862 & TST \\
\hline CHEMBL206322 & 347197 & 6.1549 & 6.3594 & TRN \\
\hline CHEMBL206504 & 347197 & 4.0 & 5.1562 & TRN \\
\hline CHEMBL383672 & 347197 & 6.0969 & 5.4576 & TRN \\
\hline CHEMBL 203675 & 347197 & 4.0 & 5.7436 & TRN \\
\hline CHEMBL379118 & 347197 & 6.3979 & 5.9493 & TRN \\
\hline CHEMBL425599 & 347197 & 5.1249 & 4.1851 & TRN \\
\hline CHEMBL380116 & 347197 & 4.0 & 4.9339 & TRN \\
\hline CHEMBL203676 & 347197 & 5.0969 & 5.6768 & TRN \\
\hline CHEMBL207147 & 347197 & 6.0969 & 5.6688 & TRN \\
\hline CHEMBL207032 & 347197 & 4.0 & 4.9517 & TRN \\
\hline CHEMBL 208042 & 347197 & 6.2218 & 5.935 & TRN \\
\hline CHEMBL207736 & 347197 & 4.0 & 4.6688 & TST \\
\hline CHEMBL206796 & 347197 & 4.0 & 3.9241 & TST \\
\hline
\end{tabular}




\begin{tabular}{|c|c|c|c|c|c|}
\hline \multirow[b]{2}{*}{ CHEMBL381308 } & \multicolumn{5}{|c|}{ Supplemental Table S2.txt } \\
\hline & 347197 & 6.0 & 5.4096 & TRN & \\
\hline CHEMBL205368 & 347197 & 4.0 & 4.4628 & TST & \\
\hline CHEMBL206853 & 347197 & 6.2218 & 5.2792 & TRN & \\
\hline CHEMBL383006 & 347197 & 6.301 & 5.6577 & TRN & \\
\hline CHEMBL382809 & 347197 & 6.5229 & 6.29799 & 9999999999 & TRN \\
\hline CHEMBL382637 & 347197 & 6.0458 & 5.3559 & TRN & \\
\hline CHEMBL383834 & 347197 & 5.5229 & 6.2305 & TRN & \\
\hline CHEMBL205911 & 347197 & 4.0 & 4.3746 & TRN & \\
\hline CHEMBL426131 & 347197 & 5.1024 & 4.9486 & TRN & \\
\hline CHEMBL204933 & 347197 & 6.699 & 3.1168 & TST & \\
\hline CHEMBL206797 & 347197 & 6.301 & 6.2113 & TRN & \\
\hline CHEMBL377957 & 347197 & 6.699 & 6.277 & TRN & \\
\hline CHEMBL381609 & 347197 & 5.699 & 5.0711 & TRN & \\
\hline CHEMBL205098 & 347197 & 6.699 & 5.7917 & TRN & \\
\hline CHEMBL381998 & 347197 & 4.0 & 4.2368 & TRN & \\
\hline CHEMBL205642 & 347197 & 4.0 & 4.3797 & TST & \\
\hline CHEMBL203020 & 347197 & 5.8239 & 5.8906 & TRN & \\
\hline CHEMBL208054 & 347197 & 4.0 & 3.3151 & TST & \\
\hline CHEMBL378811 & 347197 & 7.0 & 5.8916 & TRN & \\
\hline CHEMBL204982 & 347197 & 4.0 & 4.2876 & TST & \\
\hline CHEMBL203178 & 347197 & 5.1549 & 5.2089 & TST & \\
\hline CHEMBL207312 & 347197 & 4.0 & 4.224 & TST & \\
\hline CHEMBL111417 & 200254 & 4.9393 & 4.8138 & TRN & \\
\hline CHEMBL107707 & 200254 & 5.6576 & 5.649 & TST & \\
\hline CHEMBL144088 & 200254 & 6.2757 & 6.1519 & TRN & \\
\hline CHEMBL144334 & 200254 & 5.0809 & 5.0352 & TRN & \\
\hline CHEMBL144386 & 200254 & 5.6289 & 5.6487 & TRN & \\
\hline CHEMBL144617 & 200254 & 5.585 & 5.7663 & TRN & \\
\hline CHEMBL91163 & 200254 & 5.1427 & 5.3319 & TRN & \\
\hline CHEMBL344072 & 200254 & 5.0 & 5.0784 & TRN & \\
\hline CHEMBL343445 & 200254 & 4.4202 & 5.0206 & TST & \\
\hline CHEMBL110044 & 200254 & 5.5229 & 5.7562 & TST & \\
\hline CHEMBL422120 & 200254 & 5.6576 & 5.4817 & TRN & \\
\hline CHEMBL145575 & 200254 & 5.284 & 5.5341 & TRN & \\
\hline CHEMBL146602 & 200254 & 5.3279 & 5.4954 & TST & \\
\hline CHEMBL33618 & 200254 & 5.3979 & 5.446006 & 0000000001 & TST \\
\hline CHEMBL144756 & 200254 & 5.3979 & 5.5246 & TRN & \\
\hline CHEMBL144827 & 200254 & 4.6778 & 4.3725 & TRN & \\
\hline CHEMBL444347 & 200254 & 5.5376 & 5.4277 & TRN & \\
\hline CHEMBL144984 & 200254 & 5.7825 & 5.9114 & TRN & \\
\hline CHEMBL144134 & 200254 & 5.699 & 5.4954 & TST & \\
\hline CHEMBL444340 & 200254 & 5.9208 & 5.8199 & TRN & \\
\hline CHEMBL142900 & 200254 & 5.5376 & 5.5752 & TRN & \\
\hline CHEMBL356077 & 200254 & 6.2076 & 6.1701 & TRN & \\
\hline CHEMBL144999 & 200254 & 5.5302 & 5.7562 & TST & \\
\hline CHEMBL14832 & 200254 & 5.6576 & 5.649 & TST & \\
\hline CHEMBL145311 & 200254 & 5.3372 & 5.1547 & TRN & \\
\hline CHEMBL343238 & 200254 & 5.3372 & 5.2446 & TRN & \\
\hline
\end{tabular}




\begin{tabular}{|c|c|c|c|c|c|}
\hline & & \multicolumn{4}{|c|}{ Supplemental Table s2.txt } \\
\hline CHEMBL34683 & 200254 & 5.5017 & 5.3319 & TRN & \\
\hline CHEMBL141831 & 200254 & 5.8539 & 5.6985 & TRN & \\
\hline CHEMBL91898 & 200254 & 3.0 & 4.2393 & TST & \\
\hline CHEMBL359443 & 200254 & 5.6198 & 5.9692 & TRN & \\
\hline CHEMBL344274 & 200254 & 5.0 & 5.067 & TRN & \\
\hline CHEMBL423017 & 200254 & 5.699 & 5.2999 & TRN & \\
\hline CHEMBL144664 & 200254 & 6.2076 & 5.9989 & TRN & \\
\hline CHEMBL33505 & 200254 & 3.6021 & 4.2393 & TST & \\
\hline CHEMBL144411 & 200254 & 3.6021 & 3.5021 & TRN & \\
\hline CHEMBL345004 & 200254 & 6.4089 & 6.6354 & TRN & \\
\hline CHEMBL89977 & 200254 & \multicolumn{3}{|c|}{5.382000000000001} & TRN \\
\hline CHEMBL109617 & 200254 & 5.3565 & 5.5246 & TRN & \\
\hline CHEMBL144208 & 200254 & 3.6021 & 3.6543 & TRN & \\
\hline CHEMBL 300584 & 200254 & 6.4437 & 6.2165 & TRN & \\
\hline CHEMBL322704 & 200254 & 5.0706 & 5.1218 & TRN & \\
\hline CHEMBL146111 & 200254 & 5.1938 & 5.2999 & TST & \\
\hline CHEMBL109890 & 200254 & 4.4881 & 4.3645 & TRN & \\
\hline CHEMBL144848 & 200254 & 6.0862 & 5.9788 & TRN & \\
\hline CHEMBL143452 & 200254 & 4.4318 & 4.4441 & TRN & \\
\hline CHEMBL144303 & 200254 & 3.6021 & 4.2666 & TRN & \\
\hline CHEMBL145490 & 200254 & 5.2366 & 5.4079 & TRN & \\
\hline CHEMBL144219 & 200254 & 5.301 & 5.2715 & TRN & \\
\hline CHEMBL 89250 & 200254 & 5.4318 & 5.446006 & 0000000001 & TST \\
\hline CHEMBL144757 & 200254 & 5.6383 & 5.0206 & TST & \\
\hline CHEMBL1300237 & 688686 & 3.3997 & 4.20100 & 00000000005 & TST \\
\hline CHEMBL1535225 & 688686 & 4.4914 & 4.5087 & TRN & \\
\hline CHEMBL1325413 & 688686 & 3.3997 & 3.5542 & TRN & \\
\hline CHEMBL1397452 & 688686 & 4.4259 & 4.4709 & TST & \\
\hline CHEMBL1600399 & 688686 & 3.3997 & 3.741 & TST & \\
\hline CHEMBL1558065 & 688686 & 5.1993 & 4.8891 & TRN & \\
\hline CHEMBL1977301 & 688686 & 4.9044 & 4.7191 & TRN & \\
\hline CHEMBL1442500 & 688686 & 4.9718 & 5.7739 & TRN & \\
\hline CHEMBL1472681 & 688686 & 3.3997 & 3.867 & TST & \\
\hline CHEMBL1539359 & 688686 & 4.718 & 4.4434 & TRN & \\
\hline CHEMBL1975754 & 688686 & 4.6907 & 4.5373 & TRN & \\
\hline CHEMBL1312928 & 688686 & 4.8495 & 4.3831 & TRN & \\
\hline CHEMBL3197344 & 688686 & 4.789 & 4.4958 & TRN & \\
\hline CHEMBL1330145 & 688686 & 4.4907 & 3.6206 & TST & \\
\hline CHEMBL3196263 & 688686 & 3.3997 & 3.9822 & TRN & \\
\hline CHEMBL1338085 & 688686 & 4.556 & 4.6994 & TRN & \\
\hline CHEMBL3198763 & 688686 & 4.9945 & 4.7069 & TRN & \\
\hline CHEMBL1582665 & 688686 & 3.3997 & 3.30899 & 99999999997 & TRN \\
\hline CHEMBL1525789 & 688686 & 3.3997 & 3.5808 & TRN & \\
\hline CHEMBL1331514 & 688686 & 4.4603 & 4.0416 & TRN & \\
\hline CHEMBL1427072 & 688686 & 3.8768 & 3.9748 & TRN & \\
\hline CHEMBL1491705 & 688686 & 3.3997 & 3.9481 & TRN & \\
\hline CHEMBL1559529 & 688686 & 3.3997 & 3.3056 & TRN & \\
\hline CHEMBL1383991 & 688686 & 3.3997 & 4.3337 & TRN & \\
\hline
\end{tabular}




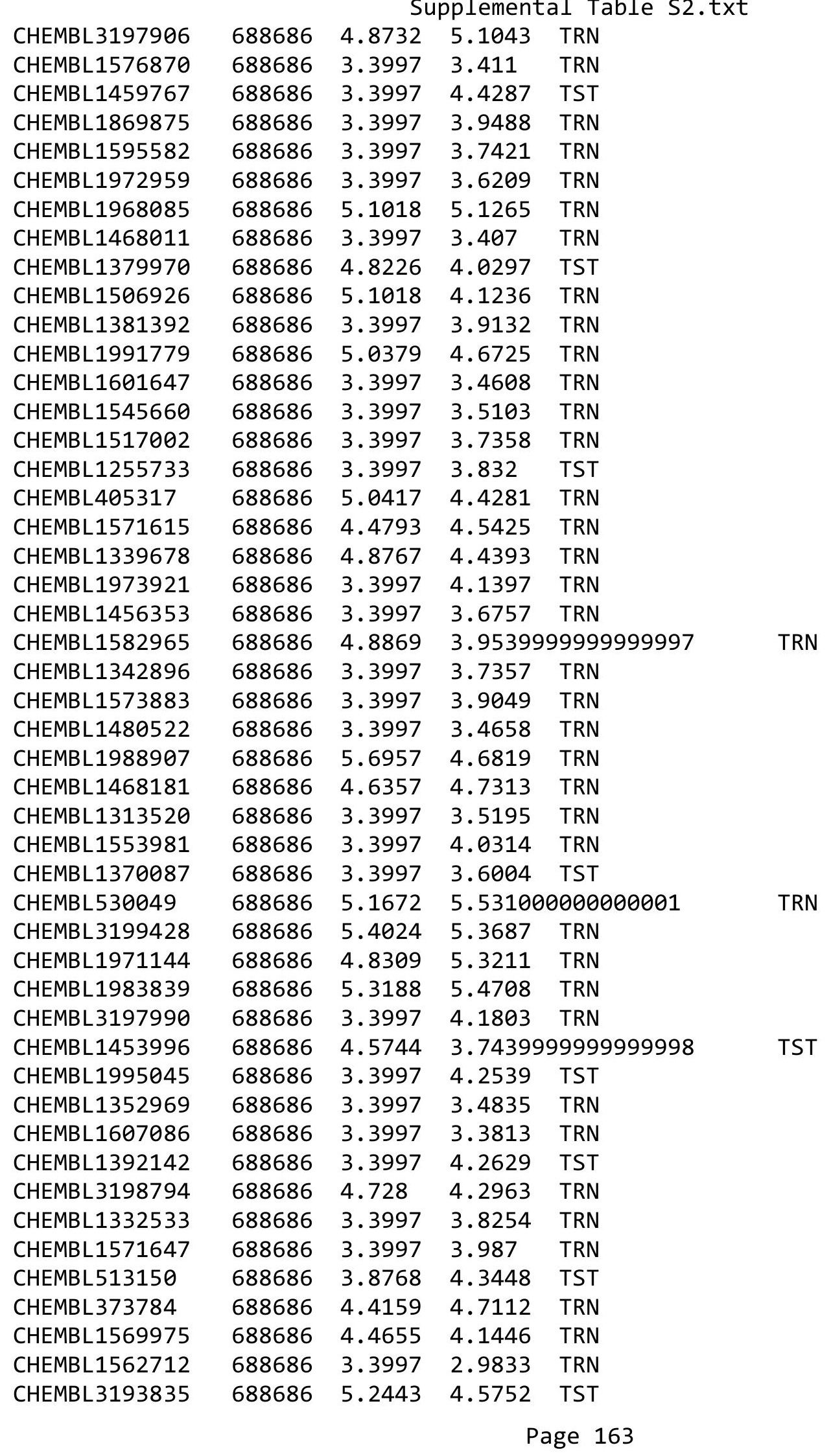




\begin{tabular}{|c|c|c|c|c|c|}
\hline \multicolumn{6}{|c|}{ Supplemental Table S2.txt } \\
\hline CHEMBL1372203 & 688686 & 5.2886 & 4.6951 & TRN & \\
\hline CHEMBL1982569 & 688686 & 5.3175 & 5.1573 & TRN & \\
\hline CHEMBL3194013 & 688686 & 4.6068 & 4.4747 & TRN & \\
\hline CHEMBL1383534 & 688686 & 3.3997 & 3.9091 & TRN & \\
\hline CHEMBL1384292 & 688686 & 3.3997 & 3.5194 & TRN & \\
\hline CHEMBL3189791 & 688686 & 5.2552 & 5.4425 & TRN & \\
\hline CHEMBL1371650 & 688686 & 4.7951 & 4.1298 & TRN & \\
\hline CHEMBL3199673 & 688686 & 3.3997 & 3.8638 & TRN & \\
\hline CHEMBL1470568 & 688686 & 4.6967 & 4.8405 & TRN & \\
\hline CHEMBL 2007601 & 688686 & 5.0156 & 4.7616 & TRN & \\
\hline CHEMBL1581759 & 688686 & 4.4977 & 3.852 & TST & \\
\hline CHEMBL1495977 & 688686 & 3.3997 & 3.7192 & TRN & \\
\hline CHEMBL3195997 & 688686 & 5.5016 & 5.1432 & TRN & \\
\hline CHEMBL1990786 & 688686 & 4.9133 & 4.8883 & TRN & \\
\hline CHEMBL1998606 & 688686 & 4.5713 & 4.1689 & TRN & \\
\hline CHEMBL1559811 & 688686 & 3.3997 & 3.37600 & 00000000003 & TRN \\
\hline CHEMBL1303280 & 688686 & 4.75 & 3.9572 & TRN & \\
\hline CHEMBL1333987 & 688686 & 5.2028 & 5.3959 & TRN & \\
\hline CHEMBL1510389 & 688686 & 3.3997 & 3.6967 & TRN & \\
\hline CHEMBL1605021 & 688686 & 3.3997 & 3.9839 & TST & \\
\hline CHEMBL3199020 & 688686 & 4.7916 & 4.375 & TRN & \\
\hline CHEMBL1359871 & 688686 & 4.8035 & 5.0003 & TRN & \\
\hline CHEMBL1481543 & 688686 & 4.8843 & 4.9247 & TRN & \\
\hline CHEMBL1371507 & 688686 & 3.3997 & 3.2653 & TRN & \\
\hline CHEMBL1492399 & 688686 & 3.3997 & 3.4492 & TRN & \\
\hline CHEMBL3196134 & 688686 & 4.4313 & 4.0591 & TRN & \\
\hline CHEMBL1971379 & 688686 & 4.9024 & 4.5615 & TRN & \\
\hline CHEMBL602218 & 688686 & 5.4357 & 5.5113 & TRN & \\
\hline CHEMBL1970422 & 688686 & 3.3997 & 4.0339 & TST & \\
\hline CHEMBL1378232 & 688686 & 3.3997 & 3.4278 & TRN & \\
\hline CHEMBL1569988 & 688686 & 5.2389 & 3.9339 & TRN & \\
\hline CHEMBL578905 & 688686 & 3.3997 & 3.682 & TRN & \\
\hline CHEMBL1390450 & 688686 & 3.3997 & 3.5112 & TRN & \\
\hline CHEMBL1427279 & 688686 & 3.3997 & 3.9711 & TRN & \\
\hline CHEMBL1430094 & 688686 & 5.1142 & 3.7545 & TRN & \\
\hline CHEMBL1519239 & 688686 & 5.319 & 4.8865 & TST & \\
\hline CHEMBL1526738 & 688686 & 3.3997 & 3.8378 & TST & \\
\hline CHEMBL1525220 & 688686 & 3.3997 & 3.5383 & TST & \\
\hline CHEMBL1983939 & 688686 & 5.0291 & 5.0869 & TST & \\
\hline CHEMBL1972347 & 688686 & 5.2228 & 4.8482 & TST & \\
\hline CHEMBL1382820 & 688686 & 3.3997 & 4.4616 & TST & \\
\hline CHEMBL1360928 & 688686 & 4.6548 & 3.8846 & TST & \\
\hline CHEMBL1468323 & 688686 & 3.3997 & 3.1446 & TST & \\
\hline CHEMBL3192873 & 688686 & 3.3997 & 3.4261 & TST & \\
\hline CHEMBL265686 & 688686 & 4.4961 & 4.5203 & TST & \\
\hline CHEMBL1461730 & 688686 & 3.3997 & 4.0883 & TST & \\
\hline CHEMBL1979727 & 688686 & 4.7735 & 5.1886 & TST & \\
\hline CHEMBL1488730 & 688686 & 4.6685 & 3.6039 & TST & \\
\hline
\end{tabular}




\begin{tabular}{|c|c|c|c|c|c|}
\hline \multirow[b]{2}{*}{ CHEMBL1334514 } & & \multicolumn{4}{|c|}{ Supplemental Table S2.txt } \\
\hline & 688686 & 3.3997 & \multicolumn{2}{|c|}{4.6930000000000005} & TST \\
\hline CHEMBL6685 & 219472 & 8.0969 & 8.1291 & TRN & \\
\hline CHEMBL32836 & 219472 & 7.1249 & 7.2383 & TRN & \\
\hline CHEMBL34317 & 219472 & 9.0969 & 9.076 & TRN & \\
\hline CHEMBL6784 & 219472 & 6.9586 & 6.4182 & TST & \\
\hline CHEMBL32732 & 219472 & 7.8861 & \multicolumn{2}{|c|}{8.017000000000001} & TRN \\
\hline CHEMBL269628 & 219472 & 7.5528 & 6.6231 & TST & \\
\hline CHEMBL286549 & 219472 & 6.6021 & 6.6633 & TRN & \\
\hline CHEMBL408857 & 219472 & 7.3665 & 7.2529 & TRN & \\
\hline CHEMBL35118 & 219472 & 8.0458 & 8.1048 & TRN & \\
\hline CHEMBL2112274 & 219472 & 9.301 & 9.4223 & TRN & \\
\hline CHEMBL35338 & 219472 & 8.1549 & \multicolumn{2}{|c|}{8.017000000000001} & TRN \\
\hline CHEMBL32160 & 219472 & 7.699 & 7.7257 & TRN & \\
\hline CHEMBL6753 & 219472 & 7.7212 & 7.6334 & TST & \\
\hline CHEMBL6705 & 219472 & 6.5302 & 5.859 & TST & \\
\hline CHEMBL30168 & 219472 & 8.0458 & 7.8982 & TRN & \\
\hline CHEMBL287117 & 219472 & 8.1549 & 8.2379 & TRN & \\
\hline CHEMBL32606 & 219472 & 9.0458 & 8.9899 & TRN & \\
\hline CHEMBL 290348 & 219472 & 7.9208 & 7.9192 & TRN & \\
\hline CHEMBL6919 & 219472 & 6.9031 & 6.3598 & TST & \\
\hline CHEMBL 2111218 & 219472 & 9.3979 & 9.3188 & TRN & \\
\hline CHEMBL 2112276 & 219472 & 8.0458 & 8.1577 & TRN & \\
\hline CHEMBL284617 & 219472 & 8.0 & 7.9824 & TRN & \\
\hline CHEMBL6853 & 219472 & 7.2218 & 6.7383 & TST & \\
\hline CHEMBL284398 & 219472 & 7.8239 & 7.7257 & TRN & \\
\hline CHEMBL268177 & 219472 & 7.1549 & \multicolumn{2}{|c|}{6.593999999999999} & TST \\
\hline CHEMBL 286586 & 219472 & 9.301 & 9.2544 & TRN & \\
\hline CHEMBL34974 & 219472 & 7.0969 & 7.2529 & TRN & \\
\hline CHEMBL34852 & 219472 & 9.2218 & 9.175 & TRN & \\
\hline CHEMBL 266240 & 219472 & 7.1249 & 6.5156 & TST & \\
\hline CHEMBL 36525 & 219472 & 6.7447 & 6.7387 & TRN & \\
\hline CHEMBL32096 & 219472 & 7.8239 & 7.7103 & TRN & \\
\hline CHEMBL32208 & 219472 & 8.0458 & 7.9824 & TRN & \\
\hline CHEMBL35385 & 219472 & 7.4685 & 7.3885 & TRN & \\
\hline CHEMBL 286449 & 219472 & 7.7212 & 7.693 & TRN & \\
\hline CHEMBL287145 & 219472 & 6.8097 & 6.7387 & TRN & \\
\hline CHEMBL432083 & 219472 & 9.0 & 8.9899 & TRN & \\
\hline CHEMBL415466 & 219472 & 9.0969 & 9.2544 & TRN & \\
\hline CHEMBL408856 & 219472 & 9.2218 & 9.076 & TRN & \\
\hline CHEMBL286297 & 219472 & 7.6383 & 7.693 & TRN & \\
\hline CHEMBL262389 & 219472 & 6.6676 & 6.6633 & TRN & \\
\hline CHEMBL416410 & 219472 & 9.0 & 9.1627 & TRN & \\
\hline CHEMBL287316 & 219472 & 8.0 & 7.9122 & TRN & \\
\hline CHEMBL 285516 & 219472 & 9.2218 & 9.1627 & TRN & \\
\hline CHEMBL7204 & 219472 & 6.4949 & 6.0086 & TST & \\
\hline CHEMBL 289888 & 219472 & 8.699 & 8.889 & TRN & \\
\hline CHEMBL 32982 & 219472 & 7.7959 & 7.8982 & TRN & \\
\hline CHEMBL2112275 & 219472 & 7.7959 & 7.6758 & TRN & \\
\hline
\end{tabular}




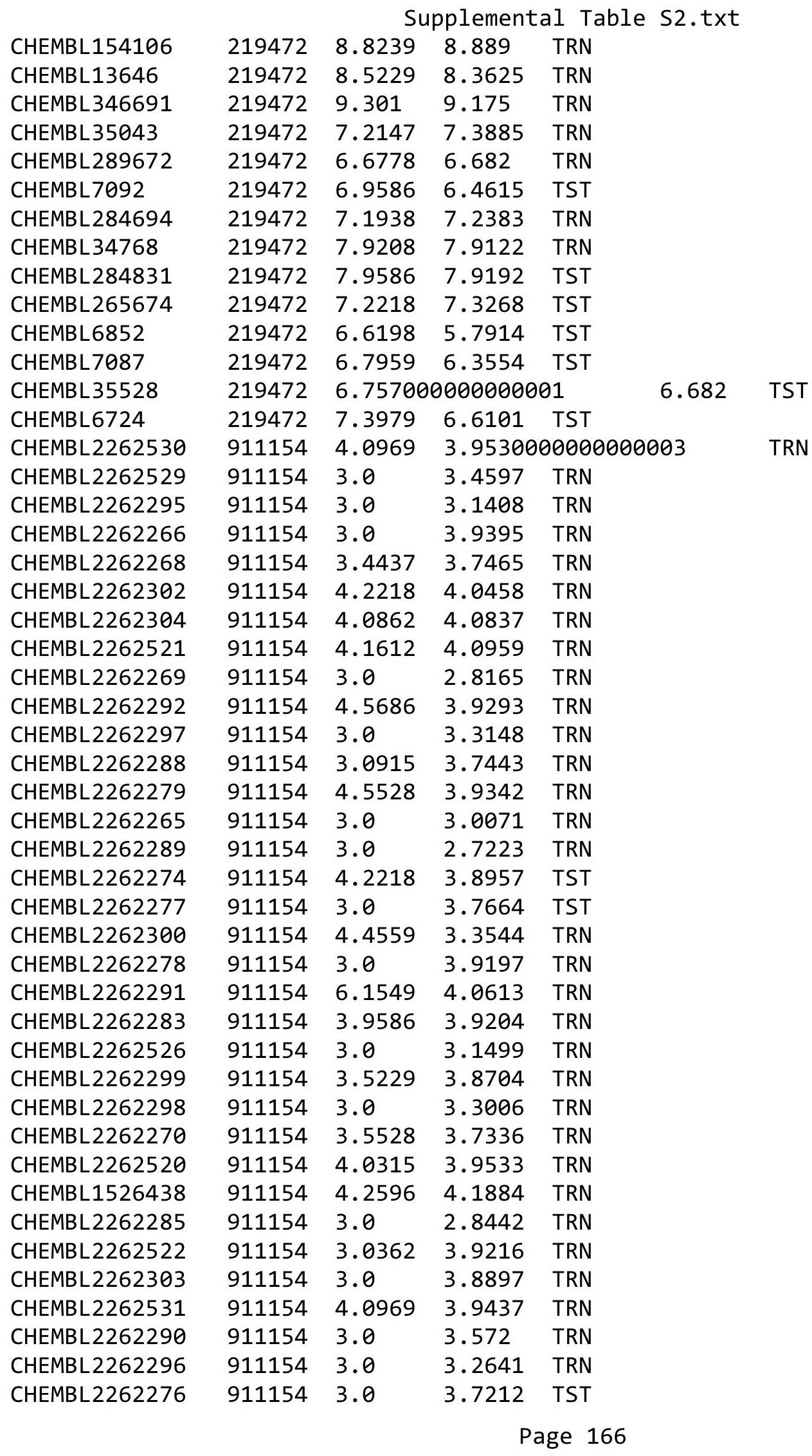




\begin{tabular}{|c|c|c|c|c|c|}
\hline \multicolumn{6}{|c|}{ Supplemental Table S2.txt } \\
\hline CHEMBL 2262281 & 911154 & 3.0 & 4.0049 & TRN & \\
\hline CHEMBL 2262284 & 911154 & 3.0 & 2.8739 & TRN & \\
\hline CHEMBL 2262286 & 911154 & 3.4685 & 3.77600 & 00000000002 & TRN \\
\hline CHEMBL 2262275 & 911154 & 3.0 & 3.77399 & 99999999996 & TST \\
\hline CHEMBL 2262525 & 911154 & 3.0 & 3.3868 & TRN & \\
\hline CHEMBL 2262523 & 911154 & 4.8539 & 4.1313 & TRN & \\
\hline CHEMBL 2262273 & 911154 & 3.7212 & 4.0996 & TST & \\
\hline CHEMBL 2262282 & 911154 & 3.0 & 2.9762 & TRN & \\
\hline CHEMBL 2262280 & 911154 & 4.7959 & 3.9739 & TST & \\
\hline CHEMBL 2262528 & 911154 & 4.3098 & 3.5528 & TRN & \\
\hline CHEMBL 2262519 & 911154 & 4.1249 & 3.6128 & TRN & \\
\hline CHEMBL 2262287 & 911154 & 3.0 & 2.8345 & TRN & \\
\hline CHEMBL 2262293 & 911154 & 4.8239 & 3.9032 & TRN & \\
\hline CHEMBL 2262301 & 911154 & 6.1549 & 3.9839 & TST & \\
\hline CHEMBL 2262272 & 911154 & 3.3279 & 3.7494 & TST & \\
\hline CHEMBL 2262524 & 911154 & 3.0 & 4.0647 & TST & \\
\hline CHEMBL363306 & 911154 & 4.301 & 4.0309 & TST & \\
\hline CHEMBL 2262267 & 911154 & 3.0 & 2.8196 & TST & \\
\hline CHEMBL 2262527 & 911154 & 6.699 & 3.0389 & TST & \\
\hline CHEMBL 2262294 & 911154 & 4.3279 & 3.2786 & TST & \\
\hline CHEMBL 2262271 & 911154 & 3.2291 & 3.7296 & TST & \\
\hline CHEMBL122394 & 47518 & 5.8239 & 6.3276 & TST & \\
\hline CHEMBL35118 & 47518 & 7.1549 & 7.1171 & TRN & \\
\hline CHEMBL6753 & 47518 & 5.0315 & 5.8478 & TST & \\
\hline CHEMBL 6784 & 47518 & 4.7447 & 5.019 & TST & \\
\hline CHEMBL123878 & 47518 & 6.2676 & 6.2426 & TRN & \\
\hline CHEMBL334088 & 47518 & 6.284 & 6.2313 & TRN & \\
\hline CHEMBL124399 & 47518 & 6.2147 & 6.2325 & TRN & \\
\hline CHEMBL333033 & 47518 & 6.2798 & 6.3521 & TRN & \\
\hline CHEMBL333954 & 47518 & 6.0 & 6.51399 & 9999999999 & TST \\
\hline CHEMBL331331 & 47518 & 7.2076 & 7.2462 & TRN & \\
\hline CHEMBL121782 & 47518 & 7.2924 & 7.3019 & TRN & \\
\hline CHEMBL125729 & 47518 & 6.301 & 6.2853 & TRN & \\
\hline CHEMBL7204 & 47518 & 4.1051 & 4.28100 & 0000000001 & TST \\
\hline CHEMBL333874 & 47518 & 7.8239 & 7.8391 & TRN & \\
\hline CHEMBL332222 & 47518 & 8.0 & 7.9017 & TRN & \\
\hline CHEMBL123047 & 47518 & 6.5528 & 6.6899 & TRN & \\
\hline CHEMBL122817 & 47518 & 6.1107 & 6.1263 & TRN & \\
\hline CHEMBL 2112599 & 47518 & 7.0088 & 6.6258 & TST & \\
\hline CHEMBL331002 & 47518 & 4.6289 & 4.6468 & TRN & \\
\hline CHEMBL122838 & 47518 & 6.0969 & 6.0366 & TRN & \\
\hline CHEMBL123482 & 47518 & 7.3468 & 7.3169 & TRN & \\
\hline CHEMBL6853 & 47518 & 5.0809 & 5.2098 & TST & \\
\hline CHEMBL265674 & 47518 & 5.0655 & 5.2949 & TST & \\
\hline CHEMBL331697 & 47518 & 7.9586 & 7.8923 & TRN & \\
\hline CHEMBL 287117 & 47518 & 7.301 & 7.3671 & TRN & \\
\hline CHEMBL121922 & 47518 & 4.7905 & 4.7772 & TRN & \\
\hline CHEMBL124224 & 47518 & 6.0862 & 6.1469 & TRN & \\
\hline
\end{tabular}




\begin{tabular}{|c|c|c|c|c|c|c|}
\hline & & \multicolumn{5}{|c|}{ Supplemental Table S2.txt } \\
\hline CHEMBL14182 & 47518 & 7.3565 & 7.4197 & TRN & & \\
\hline CHEMBL269122 & 47518 & 7.3768 & 7.5096 & TRN & & \\
\hline CHEMBL122961 & 47518 & 6.2218 & 6.1949 & TRN & & \\
\hline CHEMBL122249 & 47518 & 5.8539 & 5.8498 & TRN & & \\
\hline CHEMBL122953 & 47518 & 6.2596 & 6.2514 & TRN & & \\
\hline CHEMBL123603 & 47518 & 5.9208 & 6.3707 & TST & & \\
\hline CHEMBL451190 & 47518 & 7.8539 & 7.92 & TRN & & \\
\hline CHEMBL125776 & 47518 & 6.2924 & 6.2616 & TRN & & \\
\hline CHEMBL 7087 & 47518 & 4.6778 & 4.8898 & TST & & \\
\hline CHEMBL121696 & 47518 & 7.2757 & 7.2148 & TRN & & \\
\hline CHEMBL13646 & 47518 & \multicolumn{3}{|c|}{6.3420000000000005} & 6.4496 & TRN \\
\hline CHEMBL 7092 & 47518 & 5.0088 & 5.1185 & TST & & \\
\hline CHEMBL123398 & 47518 & 7.3372 & 7.2605 & TRN & & \\
\hline CHEMBL123982 & 47518 & 4.6576 & 4.6885 & TRN & & \\
\hline CHEMBL6919 & 47518 & 4.6198 & 4.8502 & TST & & \\
\hline CHEMBL 6705 & 47518 & 4.3429 & 3.7644 & TST & & \\
\hline CHEMBL122336 & 47518 & 5.7447 & 6.2655 & TST & & \\
\hline CHEMBL332648 & 47518 & 7.6778 & 7.7213 & TRN & & \\
\hline CHEMBL124046 & 47518 & 4.8239 & 4.9042 & TRN & & \\
\hline CHEMBL268439 & 47518 & 8.2218 & 7.9921 & TRN & & \\
\hline CHEMBL122730 & 47518 & 6.0223 & 5.9805 & TRN & & \\
\hline CHEMBL122390 & 47518 & 8.0458 & 8.0236 & TRN & & \\
\hline CHEMBL122786 & 47518 & 7.9208 & 7.9349 & TRN & & \\
\hline CHEMBL122280 & 47518 & 4.5986 & 4.7023 & TRN & & \\
\hline CHEMBL331932 & 47518 & 4.7799 & 4.673 & TRN & & \\
\hline CHEMBL122839 & 47518 & 5.8665 & 5.8977 & TRN & & \\
\hline CHEMBL330755 & 47518 & 8.0458 & 8.0108 & TRN & & \\
\hline CHEMBL123827 & 47518 & 7.2676 & 7.2062 & TRN & & \\
\hline CHEMBL123539 & 47518 & 7.6778 & 7.7736 & TRN & & \\
\hline CHEMBL 2112600 & 47518 & 7.1249 & 6.666 & TST & & \\
\hline CHEMBL 340503 & 47518 & 7.7959 & 7.8275 & TRN & & \\
\hline CHEMBL268177 & 47518 & 5.2218 & 5.3315 & TST & & \\
\hline CHEMBL121364 & 47518 & 6.475 & 6.3552 & TST & & \\
\hline CHEMBL6685 & 47518 & 7.2596 & 7.1621 & TRN & & \\
\hline CHEMBL125338 & 47518 & 7.9208 & 7.9005 & TRN & & \\
\hline CHEMBL331727 & 47518 & 7.2218 & 7.1605 & TRN & & \\
\hline CHEMBL541990 & 47518 & 7.9586 & 7.9735 & TRN & & \\
\hline CHEMBL121726 & 47518 & 6.2676 & 6.2316 & TRN & & \\
\hline CHEMBL332225 & 47518 & 6.2924 & 6.2798 & TRN & & \\
\hline CHEMBL 332527 & 47518 & 5.7696 & 6.4314 & TST & & \\
\hline CHEMBL338513 & 47518 & 7.2218 & 7.2982 & TRN & & \\
\hline CHEMBL122444 & 47518 & 6.5376 & 6.6583 & TST & & \\
\hline CHEMBL331386 & 47518 & 7.6778 & 7.697 & TRN & & \\
\hline CHEMBL122756 & 47518 & 6.4559 & 6.4743 & TRN & & \\
\hline CHEMBL419604 & 47518 & 7.9208 & 7.9622 & TRN & & \\
\hline CHEMBL332549 & 47518 & 4.6021 & 4.6231 & TRN & & \\
\hline CHEMBL121662 & 47518 & 6.284 & 6.2955 & TRN & & \\
\hline CHEMBL123066 & 47518 & 4.6819 & 4.6697 & TRN & & \\
\hline
\end{tabular}




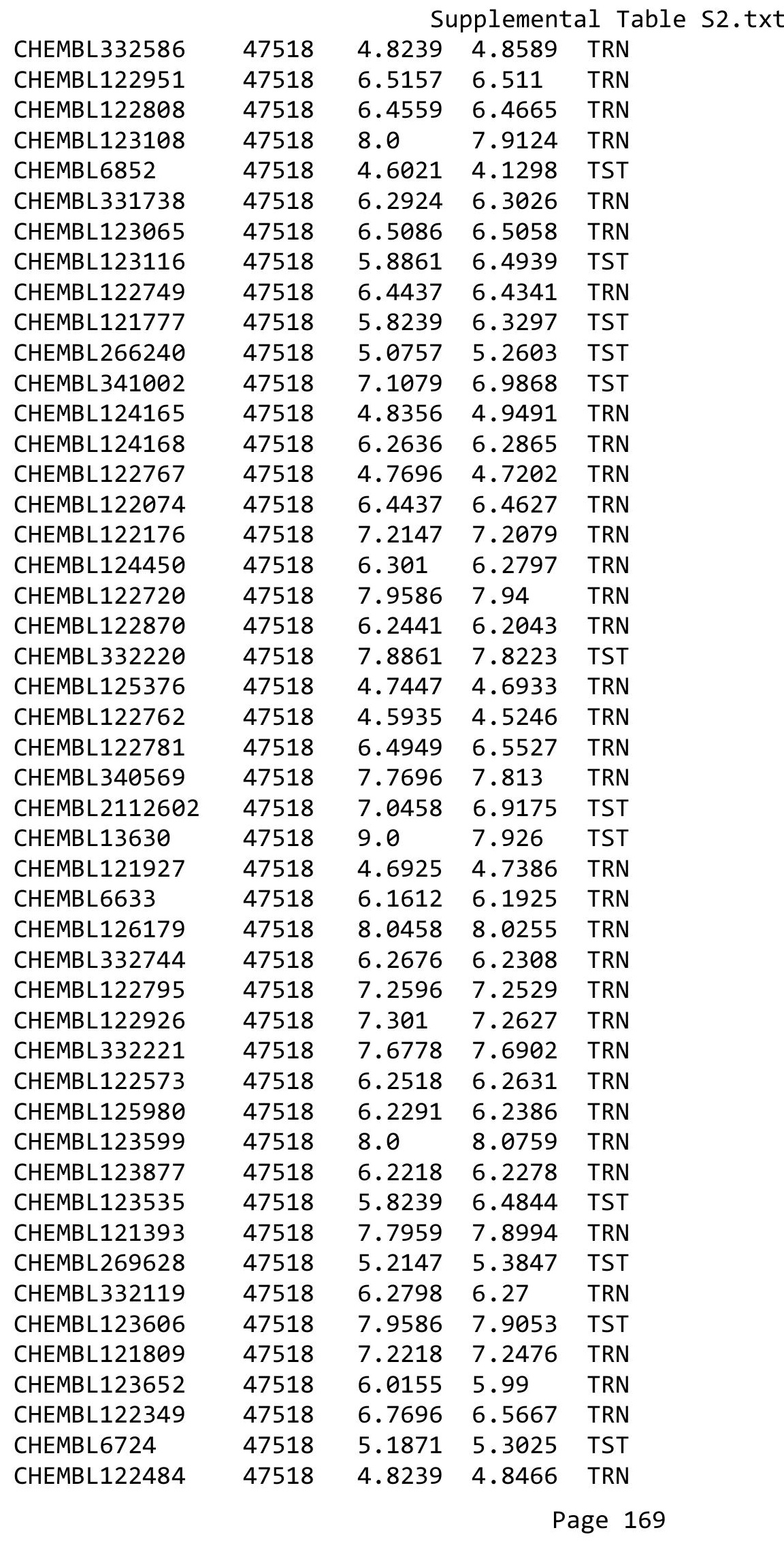




\begin{tabular}{|c|c|c|c|c|c|}
\hline & & \multicolumn{4}{|c|}{ Supplemental Table s2.txt } \\
\hline CHEMBL332200 & 47518 & 4.6925 & 4.6279 & TRN & \\
\hline CHEMBL331527 & 47518 & 7.8861 & 7.9352 & TRN & \\
\hline CHEMBL122395 & 47518 & 6.0706 & 6.0204 & TRN & \\
\hline CHEMBL333692 & 47518 & 6.7212 & 6.4528 & TST & \\
\hline CHEMBL1334484 & 688177 & 4.6 & 4.7305 & TRN & \\
\hline CHEMBL1481914 & 688177 & 4.5 & 4.5001 & TRN & \\
\hline CHEMBL1330961 & 688177 & 5.4 & 5.2238 & TRN & \\
\hline CHEMBL2003304 & 688177 & 4.5 & 4.8826 & TRN & \\
\hline CHEMBL516616 & 688177 & 6.5 & 5.3138 & TRN & \\
\hline CHEMBL109037 & 688177 & 4.8 & 5.0854 & TRN & \\
\hline CHEMBL72365 & 688177 & 4.5 & 4.9132 & TRN & \\
\hline CHEMBL 1450165 & 688177 & 5.2 & 4.5743 & TRN & \\
\hline CHEMBL1724937 & 688177 & 4.6 & 4.934 & TRN & \\
\hline CHEMBL1596090 & 688177 & 4.4 & 4.4391 & TRN & \\
\hline CHEMBL1316831 & 688177 & 5.0 & 5.2772 & TRN & \\
\hline CHEMBL1478 & 688177 & 4.4 & 4.7952 & TST & \\
\hline CHEMBL1488393 & 688177 & 5.0 & 5.1294 & TRN & \\
\hline CHEMBL1334633 & 688177 & 4.5 & 4.4182 & TRN & \\
\hline CHEMBL584759 & 688177 & 5.0 & 5.2939 & TRN & \\
\hline CHEMBL1368261 & 688177 & 4.7 & 5.0229 & TST & \\
\hline CHEMBL1607905 & 688177 & 4.4 & 5.0253 & TST & \\
\hline CHEMBL1416218 & 688177 & 4.5 & 4.6109 & TRN & \\
\hline CHEMBL1567682 & 688177 & 4.5 & 4.4787 & TRN & \\
\hline CHEMBL1313353 & 688177 & 5.0 & 4.6996 & TST & \\
\hline CHEMBL1461420 & 688177 & 4.5 & 4.4907 & TRN & \\
\hline CHEMBL1566406 & 688177 & 5.0 & 4.7586 & TRN & \\
\hline CHEMBL1309430 & 688177 & 4.4 & 4.9747 & TRN & \\
\hline CHEMBL1379677 & 688177 & 6.2 & 5.176 & TRN & \\
\hline CHEMBL41092 & 688177 & 4.4 & 4.9685 & TRN & \\
\hline CHEMBL294264 & 688177 & 4.4 & 5.1391 & TRN & \\
\hline CHEMBL1515691 & 688177 & 4.9 & 5.2273 & TRN & \\
\hline CHEMBL1526171 & 688177 & 4.5 & 4.3099 & TRN & \\
\hline CHEMBL1334684 & 688177 & 4.4 & 4.4877 & TRN & \\
\hline CHEMBL1317415 & 688177 & 5.5 & 5.3049 & TRN & \\
\hline CHEMBL1418094 & 688177 & 5.4 & 5.1733 & TRN & \\
\hline CHEMBL1340515 & 688177 & 4.4 & 4.5508 & TRN & \\
\hline CHEMBL1256623 & 688177 & 5.2 & 5.1215 & TRN & \\
\hline CHEMBL1732424 & 688177 & 4.5 & 4.6605 & TST & \\
\hline CHEMBL1487801 & 688177 & 6.0 & 5.5051 & TRN & \\
\hline CHEMBL1476362 & 688177 & 4.5 & 4.8764 & TST & \\
\hline CHEMBL1408894 & 688177 & 4.4 & 4.9086 & TRN & \\
\hline CHEMBL1384172 & 688177 & 5.3 & 4.4846 & TRN & \\
\hline CHEMBL1485984 & 688177 & 5.1 & 5.2077 & TRN & \\
\hline CHEMBL1479781 & 688177 & 4.4 & 4.6963 & TST & \\
\hline CHEMBL1580759 & 688177 & 5.6 & 5.2636 & TRN & \\
\hline CHEMBL1345866 & 688177 & 4.5 & 4.46899 & 9999999999 & TRN \\
\hline CHEMBL1430764 & 688177 & 5.0 & 4.6473 & TRN & \\
\hline CHEMBL 29898 & 688177 & 4.5 & 5.2256 & TRN & \\
\hline
\end{tabular}




\begin{tabular}{|c|c|c|c|c|}
\hline \multicolumn{5}{|c|}{ Supplemental Table S2.txt } \\
\hline CHEMBL310396 & 688177 & 4.5 & 4.9258 & TRN \\
\hline CHEMBL1514486 & 688177 & 5.4 & 5.2036 & TRN \\
\hline CHEMBL1606751 & 688177 & 6.2 & 5.7217 & TRN \\
\hline CHEMBL269733 & 688177 & 4.5 & 5.1039 & TRN \\
\hline CHEMBL1306960 & 688177 & 4.6 & 4.4671 & TRN \\
\hline CHEMBL43612 & 688177 & 5.5 & 5.1781 & TRN \\
\hline CHEMBL1481974 & 688177 & 5.4 & 5.521 & TRN \\
\hline CHEMBL1450838 & 688177 & 4.6 & 4.4791 & TRN \\
\hline CHEMBL1522300 & 688177 & 4.4 & 4.5667 & TST \\
\hline CHEMBL1501053 & 688177 & 4.9 & 4.5909 & TST \\
\hline CHEMBL1362935 & 688177 & 5.2 & 5.1378 & TST \\
\hline CHEMBL1481028 & 688177 & 4.4 & 4.5902 & TST \\
\hline CHEMBL1376870 & 688177 & 4.5 & 4.4604 & TST \\
\hline CHEMBL1314469 & 688177 & 4.4 & 5.0504 & TST \\
\hline CHEMBL1566165 & 688177 & 4.4 & 4.3513 & TST \\
\hline CHEMBL1361000 & 688177 & 5.5 & 5.4118 & TST \\
\hline CHEMBL2151485 & 851668 & 4.0 & 4.0756 & TRN \\
\hline CHEMBL 2151622 & 851668 & 5.4685 & 4.9608 & TRN \\
\hline CHEMBL 2151476 & 851668 & 6.0362 & 6.2877 & TRN \\
\hline CHEMBL 2151481 & 851668 & 5.9586 & 5.9775 & TRN \\
\hline CHEMBL 2151620 & 851668 & 4.0 & 3.7633 & TRN \\
\hline CHEMBL2151629 & 851668 & 4.0 & 4.7332 & TRN \\
\hline CHEMBL 2151475 & 851668 & 4.0 & 4.2374 & TRN \\
\hline CHEMBL 2151484 & 851668 & 4.0 & 4.428 & TRN \\
\hline CHEMBL 2151474 & 851668 & 4.0 & 4.0447 & TRN \\
\hline CHEMBL 2151471 & 851668 & 4.0 & 4.359 & TRN \\
\hline CHEMBL 2151473 & 851668 & 4.0 & 3.9768 & TRN \\
\hline CHEMBL 2151624 & 851668 & 4.0 & 4.0011 & TRN \\
\hline CHEMBL2151635 & 851668 & 4.0 & 4.132 & TST \\
\hline CHEMBL 2151494 & 851668 & 4.0 & 4.3805 & TRN \\
\hline CHEMBL2151619 & 851668 & 4.0 & 3.6619 & TRN \\
\hline CHEMBL2151627 & 851668 & 6.0044 & 5.4144 & TRN \\
\hline CHEMBL 2151626 & 851668 & 5.7375 & 5.1383 & TRN \\
\hline CHEMBL2151469 & 851668 & 5.6778 & 5.7406 & TRN \\
\hline CHEMBL 2151500 & 851668 & 4.0 & 4.0531 & TRN \\
\hline CHEMBL 2151486 & 851668 & 4.0 & 4.1766 & TRN \\
\hline CHEMBL 2151490 & 851668 & 5.8861 & 6.2182 & TRN \\
\hline CHEMBL 2151470 & 851668 & 5.8539 & 5.2315 & TST \\
\hline CHEMBL2151496 & 851668 & 6.0506 & 5.8313 & TRN \\
\hline CHEMBL 2151479 & 851668 & 6.4089 & 6.099 & TST \\
\hline CHEMBL 2151477 & 851668 & 6.7696 & 6.2124 & TST \\
\hline CHEMBL2151493 & 851668 & 4.0 & 4.075 & TRN \\
\hline CHEMBL2151632 & 851668 & 5.7447 & 5.3269 & TST \\
\hline CHEMBL 2151618 & 851668 & 4.0 & 3.8312 & TRN \\
\hline CHEMBL 2151634 & 851668 & 5.8539 & 5.1921 & TST \\
\hline CHEMBL 2151483 & 851668 & 6.1871 & 5.8433 & TST \\
\hline CHEMBL 2151465 & 851668 & 5.3979 & 5.0602 & TRN \\
\hline CHEMBL 2151498 & 851668 & 4.0 & 4.2679 & TRN \\
\hline
\end{tabular}




\begin{tabular}{|c|c|c|c|c|}
\hline & & & pplement & at \\
\hline CHEMBL2151497 & 851668 & 4.0 & 3.9968 & TRN \\
\hline CHEMBL 2151489 & 851668 & 6.0 & 5.553 & TRN \\
\hline CHEMBL2151501 & 851668 & 4.0 & 4.4625 & TRN \\
\hline CHEMBL 2151480 & 851668 & 6.1739 & 6.1829 & TST \\
\hline CHEMBL2151482 & 851668 & 6.0223 & 5.7629 & TST \\
\hline CHEMBL 2151468 & 851668 & 4.0 & 3.8226 & TRN \\
\hline CHEMBL 2151491 & 851668 & 5.7212 & 5.6185 & TRN \\
\hline CHEMBL 2151045 & 851668 & 4.0 & 4.2144 & TST \\
\hline CHEMBL2151628 & 851668 & 4.0 & 3.7633 & TRN \\
\hline CHEMBL 2151472 & 851668 & 4.0 & 3.9508 & TRN \\
\hline CHEMBL2151623 & 851668 & 4.0 & 4.0344 & TRN \\
\hline CHEMBL2151631 & 851668 & 6.0362 & 5.1975 & TST \\
\hline CHEMBL 2151487 & 851668 & 4.0 & 3.8604 & TRN \\
\hline CHEMBL 2151633 & 851668 & 4.0 & 4.3128 & TST \\
\hline CHEMBL 2151492 & 851668 & 5.7447 & 5.9713 & TRN \\
\hline CHEMBL 2151488 & 851668 & 5.6021 & 5.2573 & TRN \\
\hline CHEMBL2151502 & 851668 & 4.0 & 3.9579 & TRN \\
\hline CHEMBL 2151478 & 851668 & 6.8861 & 6.1579 & TST \\
\hline CHEMBL 2151466 & 851668 & 6.1079 & 6.0869 & TRN \\
\hline CHEMBL 2151467 & 851668 & 6.1739 & 5.5467 & TST \\
\hline CHEMBL 2151625 & 851668 & 4.0 & 4.8569 & TRN \\
\hline CHEMBL2151616 & 851668 & 4.0 & 3.7414 & TRN \\
\hline CHEMBL 2151495 & 851668 & 5.8239 & 5.5454 & TRN \\
\hline CHEMBL 2151630 & 851668 & 4.0 & 3.9562 & TST \\
\hline CHEMBL 2151621 & 851668 & 4.0 & 3.8285 & TRN \\
\hline CHEMBL 2151617 & 851668 & 4.0 & 3.911 & TRN \\
\hline CHEMBL2151499 & 851668 & 4.0 & 4.3041 & TRN \\
\hline CHEMBL373751 & 954564 & 3.7712 & 3.8228 & TRN \\
\hline CHEMBL1357247 & 954564 & 3.2327 & 3.2437 & TRN \\
\hline CHEMBL577784 & 954564 & 5.7815 & 5.7674 & TRN \\
\hline CHEMBL92309 & 954564 & 3.0105 & 2.8116 & TST \\
\hline CHEMBL515416 & 954564 & 4.6603 & 4.6835 & TRN \\
\hline CHEMBL 258844 & 954564 & 4.3172 & 4.2865 & TRN \\
\hline CHEMBL192566 & 954564 & 7.7978 & 8.2129 & TST \\
\hline CHEMBL220241 & 954564 & 4.7558 & 4.7124 & TRN \\
\hline CHEMBL210618 & 954564 & 4.0069 & 3.9794 & TRN \\
\hline CHEMBL102714 & 954564 & 4.2333 & 4.2329 & TRN \\
\hline CHEMBL1190711 & 954564 & 5.3436 & 5.3311 & TRN \\
\hline CHEMBL472940 & 954564 & 3.7673 & 3.7898 & TRN \\
\hline CHEMBL509032 & 954564 & 6.6285 & 6.5929 & TRN \\
\hline CHEMBL1643959 & 954564 & 3.1732 & 3.1302 & TRN \\
\hline CHEMBL1230020 & 954564 & 4.6042 & 4.6054 & TRN \\
\hline CHEMBL135561 & 954564 & 4.1468 & 4.1352 & TRN \\
\hline CHEMBL393929 & 954564 & 4.9306 & 4.9776 & TRN \\
\hline CHEMBL1909414 & 954564 & 4.8082 & 4.8325 & TRN \\
\hline CHEMBL 379300 & 954564 & 6.2851 & 6.2702 & TRN \\
\hline CHEMBL 2363137 & 954564 & 4.7178 & 4.6917 & TRN \\
\hline CHEMBL558642 & 954564 & 3.8909 & 3.9323 & TRN \\
\hline
\end{tabular}




\begin{tabular}{|c|c|c|c|c|c|c|}
\hline \multicolumn{7}{|c|}{ Supplemental Table S2.txt } \\
\hline CHEMBL1256459 & 954564 & 6.7931 & 6.8276 & TRN & & \\
\hline CHEMBL9470 & 954564 & 5.9661 & 5.4617 & TST & & \\
\hline CHEMBL189584 & 954564 & 5.0715 & 5.0684 & TRN & & \\
\hline CHEMBL573107 & 954564 & 5.6895 & 5.7073 & TRN & & \\
\hline CHEMBL1788116 & 954564 & 4.4216 & 4.4007 & TRN & & \\
\hline CHEMBL1242367 & 954564 & 4.335 & 4.3478 & TRN & & \\
\hline CHEMBL 3392440 & 954564 & 4.188 & 4.2014 & TRN & & \\
\hline CHEMBL 3186408 & 954564 & 4.7701 & 4.1502 & TST & & \\
\hline CHEMBL449158 & 954564 & 5.8813 & 6.8866 & TST & & \\
\hline CHEMBL1673039 & 954564 & 4.9389 & 4.8847 & TRN & & \\
\hline CHEMBL 2144069 & 954564 & 6.3258 & 6.289 & TRN & & \\
\hline CHEMBL 3349342 & 954564 & 4.0092 & 3.9409 & TRN & & \\
\hline CHEMBL240954 & 954564 & 4.6217 & 4.4631 & TST & & \\
\hline CHEMBL483849 & 954564 & 3.2139 & 3.2567 & TRN & & \\
\hline CHEMBL 209148 & 954564 & 3.7682 & 3.7544 & TRN & & \\
\hline CHEMBL392695 & 954564 & 5.7303 & 5.7202 & TRN & & \\
\hline CHEMBL65 & 954564 & 8.9112 & 8.9082 & TRN & & \\
\hline CHEMBL1970879 & 954564 & 4.3143 & 4.3029 & TRN & & \\
\hline CHEMBL585951 & 954564 & 6.2596 & 6.3599 & TRN & & \\
\hline CHEMBL 222102 & 954564 & 4.42399 & 99999999 & 995 & 4.3557 & TRN \\
\hline CHEMBL 213100 & 954564 & 4.65300 & 00000000 & 005 & 4.688 & TRN \\
\hline CHEMBL514499 & 954564 & 7.7833 & 7.7856 & TRN & & \\
\hline CHEMBL483847 & 954564 & 4.0327 & 4.1244 & TRN & & \\
\hline CHEMBL512504 & 954564 & 6.7325 & 6.6827 & TRN & & \\
\hline CHEMBL180127 & 954564 & 4.0361 & 4.0485 & TRN & & \\
\hline CHEMBL379975 & 954564 & 5.645 & 5.6521 & TRN & & \\
\hline CHEMBL1590308 & 954564 & 4.2725 & 3.5085 & TST & & \\
\hline CHEMBL300389 & 954564 & 7.0923 & 7.1254 & TRN & & \\
\hline CHEMBL412142 & 954564 & 3.7501 & 3.7663 & TRN & & \\
\hline CHEMBL259181 & 954564 & 4.8623 & 4.8201 & TRN & & \\
\hline CHEMBL 221137 & 954564 & 4.8218 & 4.6497 & TST & & \\
\hline CHEMBL 202721 & 954564 & 5.8649 & 5.5916 & TST & & \\
\hline CHEMBL 3199475 & 954564 & 4.3905 & 4.668 & TST & & \\
\hline CHEMBL 2005886 & 954564 & 3.4845 & 5.0737 & TST & & \\
\hline CHEMBL1404918 & 954564 & 2.7888 & 3.2229 & TST & & \\
\hline CHEMBL188678 & 954564 & 5.62200 & 00000000 & 01 & 5.085 & TST \\
\hline CHEMBL191334 & 954564 & 4.0338 & 4.5094 & TST & & \\
\hline CHEMBL1516890 & 954564 & 4.5317 & 4.4847 & TST & & \\
\hline CHEMBL 3325895 & 1454020 & 5.4815 & 5.715 & TRN & & \\
\hline CHEMBL 3325653 & 1454020 & 6.0 & 6.1851 & TRN & & \\
\hline CHEMBL 3325625 & 1454020 & 4.7959 & 4.5286 & TST & & \\
\hline CHEMBL 3325657 & 1454020 & 6.0458 & 6.0791 & TRN & & \\
\hline CHEMBL 3325658 & 1454020 & 6.0458 & 6.0867 & TRN & & \\
\hline CHEMBL 3325644 & 1454020 & 6.0969 & 5.9542 & TRN & & \\
\hline CHEMBL 3325647 & 1454020 & 6.301 & 6.1558 & TRN & & \\
\hline CHEMBL 3325652 & 1454020 & 5.8539 & 5.8718 & TST & & \\
\hline CHEMBL 3325782 & 1454020 & 6.3979 & 6.2453 & TRN & & \\
\hline CHEMBL 3325792 & 1454020 & 6.3979 & 6.1101 & TRN & & \\
\hline
\end{tabular}


Supplemental Table S2.txt

\begin{tabular}{|c|c|c|c|c|c|}
\hline CHEMBL3326906 & 1454020 & 4.7447 & 4.702 & TRN & \\
\hline CHEMBL 3325784 & 1454020 & 5.9586 & 6.1556 & TRN & \\
\hline CHEMBL3325891 & 1454020 & 7.2218 & 6.5921 & TRN & \\
\hline CHEMBL3325797 & 1454020 & 5.4318 & 5.859 & TRN & \\
\hline CHEMBL3325650 & 1454020 & 5.9586 & 6.1232 & TRN & \\
\hline CHEMBL3326903 & 1454020 & 3.5229 & 4.9047 & TST & \\
\hline CHEMBL3325783 & 1454020 & 6.301 & 6.3305 & TRN & \\
\hline CHEMBL3325654 & 1454020 & 5.8539 & 5.9771 & TRN & \\
\hline CHEMBL3325635 & 1454020 & 5.3979 & 6.0032 & TST & \\
\hline CHEMBL3325628 & 1454020 & 5.4559 & 5.8649 & TRN & \\
\hline CHEMBL3325651 & 1454020 & 6.301 & 5.8933 & TST & \\
\hline CHEMBL3325794 & 1454020 & 5.6383 & 5.654 & TRN & \\
\hline CHEMBL3325800 & 1454020 & 5.2291 & 5.4552 & TRN & \\
\hline CHEMBL3325631 & 1454020 & 6.301 & 5.8867 & TRN & \\
\hline CHEMBL3325893 & 1454020 & 6.8239 & 6.3217 & TST & \\
\hline CHEMBL3325662 & 1454020 & 6.0969 & 6.0686 & TRN & \\
\hline CHEMBL3325641 & 1454020 & 6.0 & 5.9836 & TRN & \\
\hline CHEMBL3325786 & 1454020 & 6.301 & 6.0911 & TST & \\
\hline CHEMBL3325897 & 1454020 & 5.0177 & 5.2784 & TRN & \\
\hline CHEMBL3326905 & 1454020 & 4.6021 & 4.6873 & TRN & \\
\hline CHEMBL3325630 & 1454020 & 6.5229 & 5.9361 & TRN & \\
\hline CHEMBL 3325898 & 1454020 & 5.8239 & $5.74200 t$ & 0000000001 & TRN \\
\hline CHEMBL3325807 & 1454020 & 6.1549 & 6.3569 & TRN & \\
\hline CHEMBL3325799 & 1454020 & 5.2676 & 5.6799 & TRN & \\
\hline CHEMBL3326908 & 1454020 & 3.5229 & 4.1628 & TST & \\
\hline CHEMBL3325646 & 1454020 & 5.9586 & 6.0908 & TRN & \\
\hline CHEMBL3325781 & 1454020 & 6.0 & 6.1494 & TRN & \\
\hline CHEMBL3325632 & 1454020 & 6.0969 & 6.1987 & TRN & \\
\hline CHEMBL3326904 & 1454020 & 3.5229 & 4.5358 & TST & \\
\hline CHEMBL3325788 & 1454020 & 6.3979 & 6.4434 & TRN & \\
\hline CHEMBL3325795 & 1454020 & 5.7696 & 5.8438 & TRN & \\
\hline CHEMBL3325793 & 1454020 & 6.2218 & 6.102 & TRN & \\
\hline CHEMBL3325643 & 1454020 & 6.2218 & 5.921 & TRN & \\
\hline CHEMBL3325798 & 1454020 & 5.5686 & 5.7172 & TRN & \\
\hline CHEMBL3325636 & 1454020 & 6.0 & 5.9608 & TST & \\
\hline CHEMBL3325785 & 1454020 & 6.301 & 6.0727 & TST & \\
\hline CHEMBL3325780 & 1454020 & 6.0969 & 6.351 & TRN & \\
\hline CHEMBL3325789 & 1454020 & 6.301 & 6.2567 & TRN & \\
\hline CHEMBL 3325640 & 1454020 & 6.0969 & 6.1107 & TST & \\
\hline CHEMBL3325664 & 1454020 & 6.3979 & 6.2221 & TRN & \\
\hline CHEMBL3325663 & 1454020 & 6.1549 & 6.1202 & TRN & \\
\hline CHEMBL3325634 & 1454020 & 6.0 & 5.8644 & TST & \\
\hline CHEMBL3325660 & 1454020 & 6.5229 & 6.4605 & TRN & \\
\hline CHEMBL3325661 & 1454020 & 5.7696 & 5.9789 & TRN & \\
\hline CHEMBL3325649 & 1454020 & 6.0 & 6.0414 & TRN & \\
\hline CHEMBL3325642 & 1454020 & 6.0458 & 5.9198 & TST & \\
\hline CHEMBL3325626 & 1454020 & 3.5229 & 3.8279 & TRN & \\
\hline CHEMBL3325645 & 1454020 & 6.3979 & 6.1121 & TRN & \\
\hline
\end{tabular}


Supplemental Table S2.txt

\begin{tabular}{|c|c|c|c|c|c|}
\hline CHEMBL3325787 & 1454020 & 5.9208 & 6.1441 & TST & \\
\hline CHEMBL3325666 & 1454020 & 6.3979 & 6.1001 & TRN & \\
\hline CHEMBL3325899 & 1454020 & 5.0315 & 6.0297 & TST & \\
\hline CHEMBL3325665 & 1454020 & 6.1549 & 6.2544 & TRN & \\
\hline CHEMBL3325779 & 1454020 & 6.3979 & 6.3706 & TRN & \\
\hline CHEMBL3325627 & 1454020 & 5.3372 & 4.8331 & TRN & \\
\hline CHEMBL3325629 & 1454020 & 5.6576 & 5.8235 & TRN & \\
\hline CHEMBL3326907 & 1454020 & 5.0132 & 4.7955 & TRN & \\
\hline CHEMBL3325801 & 1454020 & 6.3979 & \multicolumn{2}{|c|}{6.912999999999999} & TRN \\
\hline CHEMBL3325637 & 1454020 & 5.7696 & 5.7912 & TST & \\
\hline CHEMBL3325638 & 1454020 & 5.7447 & 5.9275 & TST & \\
\hline CHEMBL3325633 & 1454020 & 5.8239 & 5.8446 & TST & \\
\hline CHEMBL3325656 & 1454020 & 6.1549 & 6.1187 & TRN & \\
\hline CHEMBL3325803 & 1454020 & 6.5229 & 6.676 & TRN & \\
\hline CHEMBL3325655 & 1454020 & 6.3979 & 6.3003 & TRN & \\
\hline CHEMBL3325452 & 1454020 & 6.3979 & 6.3322 & TRN & \\
\hline CHEMBL3325894 & 1454020 & 7.699 & \multicolumn{2}{|c|}{6.2139999999999995} & TST \\
\hline CHEMBL3325659 & 1454020 & 6.3979 & 6.2146 & TRN & \\
\hline CHEMBL3325892 & 1454020 & 5.8861 & 6.385 & TRN & \\
\hline CHEMBL3325639 & 1454020 & 6.0 & 6.0253 & TRN & \\
\hline CHEMBL3325804 & 1454020 & 6.699 & 6.7617 & TRN & \\
\hline CHEMBL3325790 & 1454020 & 6.5229 & 6.182 & TRN & \\
\hline CHEMBL3325791 & 1454020 & 6.3979 & 6.02 & TRN & \\
\hline CHEMBL3325648 & 1454020 & 5.9586 & 5.9795 & TRN & \\
\hline CHEMBL3325896 & 1454020 & 6.3979 & 5.8306 & TRN & \\
\hline CHEMBL3325802 & 1454020 & 6.699 & 6.6904 & TRN & \\
\hline CHEMBL3325796 & 1454020 & 5.699 & 5.9274 & TRN & \\
\hline CHEMBL3325806 & 1454020 & 6.2218 & 6.3922 & TST & \\
\hline CHEMBL3325808 & 1454020 & 5.0969 & 6.2988 & TST & \\
\hline CHEMBL 2094197 & 842684 & 7.2 & 7.1513 & TRN & \\
\hline CHEMBL 2094198 & 842684 & 6.6 & 6.6758 & TRN & \\
\hline CHEMBL 2094199 & 842684 & 6.7 & 6.7522 & TRN & \\
\hline CHEMBL 2094200 & 842684 & 6.0 & 5.9217 & TRN & \\
\hline CHEMBL 2094201 & 842684 & 7.5 & 7.4129 & TRN & \\
\hline CHEMBL 2094202 & 842684 & 7.8 & 7.8842 & TRN & \\
\hline CHEMBL 2094203 & 842684 & 6.4 & 6.4137 & TRN & \\
\hline CHEMBL 2094204 & 842684 & 6.8 & 6.7992 & TRN & \\
\hline CHEMBL 2094205 & 842684 & 6.8 & 6.8425 & TRN & \\
\hline CHEMBL 2094206 & 842684 & 8.3 & 8.1936 & TRN & \\
\hline CHEMBL 2094207 & 842684 & 6.8 & 6.8212 & TRN & \\
\hline CHEMBL 2094208 & 842684 & 6.5 & 6.50200 & 0000000001 & TRN \\
\hline CHEMBL 2094209 & 842684 & 7.6 & 7.5476 & TRN & \\
\hline CHEMBL 2094210 & 842684 & 7.6 & 7.7916 & TRN & \\
\hline CHEMBL 2094211 & 842684 & 6.5 & 6.4805 & TRN & \\
\hline CHEMBL 2094212 & 842684 & 6.3 & 6.3418 & TRN & \\
\hline CHEMBL 2094213 & 842684 & 7.0 & 6.9435 & TRN & \\
\hline CHEMBL 2094214 & 842684 & 6.4 & 6.4201 & TRN & \\
\hline CHEMBL 2094215 & 842684 & 7.2 & 7.0389 & TRN & \\
\hline
\end{tabular}




\begin{tabular}{|c|c|c|c|c|c|}
\hline & & & & & \\
\hline CHEMBL558293 & 842684 & 7.3 & 7.3441 & TRN & \\
\hline CHEMBL 2094216 & 842684 & 6.8 & 6.7995 & TRN & \\
\hline CHEMBL2094217 & 842684 & 6.7 & 6.7136 & TRN & \\
\hline CHEMBL 2094218 & 842684 & 6.4 & 6.3256 & TRN & \\
\hline CHEMBL 2094196 & 842684 & 7.0 & 6.3597 & TST & \\
\hline CHEMBL2094219 & 842684 & 7.3 & 7.1806 & TRN & \\
\hline CHEMBL 2094220 & 842684 & 7.5 & 7.5217 & TRN & \\
\hline CHEMBL 2094221 & 842684 & 6.3 & 6.3765 & TRN & \\
\hline CHEMBL 2094222 & 842684 & 7.5 & 7.57799 & 9999999999 & TRN \\
\hline CHEMBL2094223 & 842684 & 6.3 & 6.4347 & TRN & \\
\hline CHEMBL2094224 & 842684 & 6.8 & 6.8445 & TRN & \\
\hline CHEMBL 2094225 & 842684 & 7.1 & 7.1208 & TRN & \\
\hline CHEMBL 2094226 & 842684 & 7.3 & $7.3260 e$ & 00000000005 & TRN \\
\hline CHEMBL 2094227 & 842684 & 6.1 & 6.2079 & TRN & \\
\hline CHEMBL 2094228 & 842684 & 6.6 & 6.631 & TRN & \\
\hline CHEMBL2094229 & 842684 & 6.2 & 6.2031 & TRN & \\
\hline CHEMBL 2094230 & 842684 & 6.1 & 6.1345 & TRN & \\
\hline CHEMBL2094231 & 842684 & 7.6 & 7.5525 & TRN & \\
\hline CHEMBL 2094232 & 842684 & 7.0 & 6.9981 & TRN & \\
\hline CHEMBL 2094233 & 842684 & 6.0 & 5.9578 & TRN & \\
\hline CHEMBL 2094234 & 842684 & 6.8 & 6.6035 & TRN & \\
\hline CHEMBL 2094235 & 842684 & 6.7 & 6.6116 & TRN & \\
\hline CHEMBL 2094236 & 842684 & 6.7 & 6.8332 & TST & \\
\hline CHEMBL 2094237 & 842684 & 6.8 & 6.6884 & TST & \\
\hline CHEMBL 2094238 & 842684 & 6.4 & 6.7228 & TST & \\
\hline CHEMBL2094239 & 842684 & 7.5 & 6.6504 & TST & \\
\hline CHEMBL 2094240 & 842684 & 6.7 & 7.097 & TST & \\
\hline CHEMBL 2094241 & 842684 & 7.4 & 7.0606 & TST & \\
\hline CHEMBL 2094242 & 842684 & 8.0 & 6.9023 & TST & \\
\hline CHEMBL 2094243 & 842684 & 7.4 & 7.1307 & TST & \\
\hline CHEMBL 2094244 & 842684 & 6.8 & 7.1147 & TST & \\
\hline CHEMBL 2094245 & 842684 & 7.5 & 7.0423 & TST & \\
\hline CHEMBL 2094246 & 842684 & 6.8 & 7.1901 & TST & \\
\hline CHEMBL 2094247 & 842684 & 8.6 & 7.7987 & TST & \\
\hline CHEMBL 2094248 & 842684 & 8.3 & 7.83899 & 99999999995 & TST \\
\hline CHEMBL1978271 & 809169 & 4.4 & 4.3224 & TRN & \\
\hline CHEMBL 2007266 & 809169 & 4.4 & 3.8265 & TRN & \\
\hline CHEMBL 202721 & 809169 & 4.4 & 5.0246 & TRN & \\
\hline CHEMBL1985469 & 809169 & 4.4 & 4.6776 & TST & \\
\hline CHEMBL 2000568 & 809169 & 5.4 & 4.7298 & TRN & \\
\hline CHEMBL1994308 & 809169 & 4.4 & 4.6123 & TRN & \\
\hline CHEMBL1973516 & 809169 & 4.4 & 5.9898 & TRN & \\
\hline CHEMBL1974328 & 809169 & 4.4 & 5.932 & TRN & \\
\hline CHEMBL509032 & 809169 & 8.0 & 6.8472 & TRN & \\
\hline CHEMBL388311 & 809169 & 6.1 & 6.494 & TRN & \\
\hline CHEMBL1964948 & 809169 & 4.4 & 4.1314 & TRN & \\
\hline CHEMBL1973013 & 809169 & 5.4 & 5.4758 & TRN & \\
\hline CHEMBL1987430 & 809169 & 5.7 & 5.6271 & TRN & \\
\hline & & & & e 176 & \\
\hline
\end{tabular}




\begin{tabular}{|c|c|c|c|c|c|}
\hline \\
\hline CHEMBL1993413 & 809169 & 4.4 & 4.7546 & TRN & \\
\hline CHEMBL 205415 & 809169 & 4.4 & 4.5866 & TRN & \\
\hline CHEMBL1975927 & 809169 & 4.4 & 5.5305 & TRN & \\
\hline CHEMBL1986943 & 809169 & 5.9 & 5.4154 & TRN & \\
\hline CHEMBL 289959 & 809169 & 4.3 & 4.535 & TRN & \\
\hline CHEMBL1977138 & 809169 & 6.1 & 6.2495 & TRN & \\
\hline CHEMBL1978448 & 809169 & 4.4 & 4.57 & TST & \\
\hline CHEMBL1969483 & 809169 & 4.4 & 4.4017 & TRN & \\
\hline CHEMBL1980329 & 809169 & 5.5 & 5.8199 & TRN & \\
\hline CHEMBL2004515 & 809169 & 5.1 & 4.9925 & TRN & \\
\hline CHEMBL1992042 & 809169 & 4.4 & 5.2199 & TRN & \\
\hline CHEMBL1986265 & 809169 & 4.4 & 4.343 & TRN & \\
\hline CHEMBL1991734 & 809169 & 6.3 & 6.1781 & TRN & \\
\hline CHEMBL 21156 & 809169 & 4.4 & 4.559 & TRN & \\
\hline CHEMBL1994724 & 809169 & 5.6 & 4.7962 & TRN & \\
\hline CHEMBL1989267 & 809169 & 5.9 & 7.1068 & TRN & \\
\hline CHEMBL1991782 & 809169 & 3.1 & 3.9902 & TRN & \\
\hline CHEMBL2002105 & 809169 & 4.4 & 4.6633 & TRN & \\
\hline CHEMBL1983348 & 809169 & 4.4 & 5.0032 & TRN & \\
\hline CHEMBL1974574 & 809169 & 4.4 & 4.8002 & TRN & \\
\hline CHEMBL1970290 & 809169 & 5.7 & 5.0681 & TRN & \\
\hline CHEMBL1993877 & 809169 & 6.1 & 5.4942 & TRN & \\
\hline CHEMBL 2000934 & 809169 & 6.1 & 5.5365 & TRN & \\
\hline CHEMBL1996500 & 809169 & 4.4 & 4.5654 & TRN & \\
\hline CHEMBL1980671 & 809169 & 6.3 & 5.2666 & TRN & \\
\hline CHEMBL1986177 & 809169 & 4.4 & 4.5014 & TRN & \\
\hline CHEMBL1989708 & 809169 & 6.6 & 6.3556 & TRN & \\
\hline CHEMBL1976420 & 809169 & 7.4 & 6.3124 & TRN & \\
\hline CHEMBL1998253 & 809169 & 4.4 & 4.6827 & TRN & \\
\hline CHEMBL1981744 & 809169 & 6.0 & 5.4922 & TRN & \\
\hline CHEMBL1985367 & 809169 & 6.2 & 5.3227 & TRN & \\
\hline CHEMBL1996510 & 809169 & 4.4 & 4.7992 & TRN & \\
\hline CHEMBL 2000029 & 809169 & 4.4 & 5.5224 & TRN & \\
\hline CHEMBL1995172 & 809169 & 4.4 & 4.3445 & TST & \\
\hline CHEMBL 2001584 & 809169 & 4.4 & 4.5869 & TRN & \\
\hline CHEMBL1973961 & 809169 & 4.4 & 5.1089 & TRN & \\
\hline CHEMBL1967998 & 809169 & 6.9 & 6.38399 & 99999999995 & TRN \\
\hline CHEMBL1978562 & 809169 & 4.4 & 4.2999 & TRN & \\
\hline CHEMBL1994977 & 809169 & 4.4 & 4.2558 & TRN & \\
\hline CHEMBL 2001149 & 809169 & 4.4 & 5.1063 & TRN & \\
\hline CHEMBL2000078 & 809169 & 4.4 & 4.4123 & TRN & \\
\hline CHEMBL1974875 & 809169 & 4.7 & 4.652 & TST & \\
\hline CHEMBL 2005478 & 809169 & 4.4 & 4.3036 & TRN & \\
\hline CHEMBL1996646 & 809169 & 4.4 & 5.2058 & TRN & \\
\hline CHEMBL1979773 & 809169 & 4.4 & 4.4784 & TRN & \\
\hline CHEMBL1989471 & 809169 & 6.8 & 5.5233 & TST & \\
\hline CHEMBL 2002099 & 809169 & 4.4 & 5.05 & TRN & \\
\hline CHEMBL1992723 & 809169 & 4.1 & 4.8133 & TRN & \\
\hline
\end{tabular}




\begin{tabular}{|c|c|c|c|c|c|}
\hline \\
\hline CHEMBL1996702 & 809169 & 8.5 & 6.7079 & TRN & \\
\hline CHEMBL 2005482 & 809169 & 4.4 & 5.2338 & TRN & \\
\hline CHEMBL1997909 & 809169 & 4.4 & 4.0536 & TRN & \\
\hline CHEMBL2007124 & 809169 & 4.4 & 3.7932 & TRN & \\
\hline CHEMBL1978195 & 809169 & 5.9 & 5.2596 & TRN & \\
\hline CHEMBL 2006439 & 809169 & 4.4 & 5.0982 & TRN & \\
\hline CHEMBL1985681 & 809169 & 5.7 & 4.6654 & TRN & \\
\hline CHEMBL1966842 & 809169 & 4.4 & 5.0661 & TRN & \\
\hline CHEMBL1991674 & 809169 & 4.4 & 4.8475 & TRN & \\
\hline CHEMBL1982711 & 809169 & 6.2 & 5.4349 & TRN & \\
\hline CHEMBL262623 & 809169 & 5.0 & 4.7311 & TRN & \\
\hline CHEMBL1984842 & 809169 & 4.4 & 4.894 & TRN & \\
\hline CHEMBL2004118 & 809169 & 4.4 & 4.4034 & TRN & \\
\hline CHEMBL1996345 & 809169 & 4.4 & 4.9061 & TRN & \\
\hline CHEMBL 2004025 & 809169 & 4.4 & 4.9618 & TRN & \\
\hline CHEMBL1996048 & 809169 & 4.4 & 5.0421 & TRN & \\
\hline CHEMBL50894 & 809169 & 7.2 & 6.2239 & TRN & \\
\hline CHEMBL1976158 & 809169 & 4.7 & 5.0486 & TRN & \\
\hline CHEMBL1995211 & 809169 & 4.4 & 5.5006 & TRN & \\
\hline CHEMBL1965033 & 809169 & 4.4 & 3.6396 & TRN & \\
\hline CHEMBL461876 & 809169 & 4.4 & 5.4786 & TRN & \\
\hline CHEMBL1982753 & 809169 & 4.4 & 4.8597 & TRN & \\
\hline CHEMBL2006299 & 809169 & 4.4 & 4.6165 & TRN & \\
\hline CHEMBL1972346 & 809169 & 6.3 & 6.0728 & TST & \\
\hline CHEMBL1971519 & 809169 & 6.0 & 4.7708 & TRN & \\
\hline CHEMBL1997335 & 809169 & 6.2 & 5.9439 & TRN & \\
\hline CHEMBL1965169 & 809169 & 4.4 & 4.68199 & 99999999995 & TRN \\
\hline CHEMBL1991818 & 809169 & 4.4 & 5.1444 & TRN & \\
\hline CHEMBL1081312 & 809169 & 7.2 & 7.4475 & TRN & \\
\hline CHEMBL1971132 & 809169 & 4.4 & 4.5486 & TRN & \\
\hline CHEMBL1965170 & 809169 & 4.4 & 6.1456 & TRN & \\
\hline CHEMBL2005792 & 809169 & 4.4 & 5.0052 & TRN & \\
\hline CHEMBL1991867 & 809169 & 5.2 & 4.6668 & TRN & \\
\hline CHEMBL1986503 & 809169 & 4.4 & 4.7173 & TST & \\
\hline CHEMBL1972355 & 809169 & 5.9 & 5.7551 & TRN & \\
\hline CHEMBL1997892 & 809169 & 4.4 & 4.0799 & TRN & \\
\hline CHEMBL2001641 & 809169 & 4.1 & 4.9897 & TRN & \\
\hline CHEMBL1991377 & 809169 & 4.4 & 4.3942 & TRN & \\
\hline CHEMBL1997193 & 809169 & 4.4 & 4.4588 & TST & \\
\hline CHEMBL1964902 & 809169 & 4.4 & 4.1445 & TRN & \\
\hline CHEMBL1973868 & 809169 & 6.2 & 4.7181 & TRN & \\
\hline CHEMBL1972462 & 809169 & 4.4 & 4.6953 & TRN & \\
\hline CHEMBL1983715 & 809169 & 7.4 & 6.6365 & TRN & \\
\hline CHEMBL1984500 & 809169 & 3.1 & 4.032 & TRN & \\
\hline CHEMBL2002992 & 809169 & 6.0 & 4.9497 & TRN & \\
\hline CHEMBL1982700 & 809169 & 4.4 & 4.4934 & TRN & \\
\hline CHEMBL10 & 809169 & 4.4 & 4.6817 & TRN & \\
\hline CHEMBL1980763 & 809169 & 4.4 & 4.4989 & TRN & \\
\hline & & & & 178 & \\
\hline
\end{tabular}




\begin{tabular}{|c|c|c|c|c|}
\hline & & & pplement & $d \perp$ \\
\hline CHEMBL1977634 & 809169 & 4.4 & 4.2622 & TRN \\
\hline CHEMBL1969156 & 809169 & 5.5 & 4.5358 & TRN \\
\hline CHEMBL2007479 & 809169 & 4.4 & 5.0557 & TRN \\
\hline CHEMBL1998953 & 809169 & 4.4 & 4.7697 & TRN \\
\hline CHEMBL1971606 & 809169 & 4.4 & 4.9055 & TRN \\
\hline CHEMBL1971223 & 809169 & 4.4 & 4.3384 & TRN \\
\hline CHEMBL1999120 & 809169 & 4.4 & 4.6119 & TRN \\
\hline CHEMBL1972220 & 809169 & 7.0 & 6.7674 & TRN \\
\hline CHEMBL1981215 & 809169 & 6.9 & 5.7195 & TRN \\
\hline CHEMBL 2003785 & 809169 & 4.4 & 4.5337 & TRN \\
\hline CHEMBL1973720 & 809169 & 6.2 & 4.9445 & TRN \\
\hline CHEMBL1999414 & 809169 & 7.3 & 6.1873 & TRN \\
\hline CHEMBL1967336 & 809169 & 4.4 & 5.6648 & TRN \\
\hline CHEMBL 2001228 & 809169 & 4.4 & 4.7635 & TRN \\
\hline CHEMBL 2001923 & 809169 & 4.4 & 4.7733 & TRN \\
\hline CHEMBL 2003514 & 809169 & 4.4 & 4.5667 & TRN \\
\hline CHEMBL1970340 & 809169 & 6.2 & 4.6345 & TRN \\
\hline CHEMBL1967992 & 809169 & 4.4 & 4.8964 & TRN \\
\hline CHEMBL1989043 & 809169 & 4.4 & 5.4768 & TRN \\
\hline CHEMBL1981671 & 809169 & 4.4 & 4.7573 & TRN \\
\hline CHEMBL 2006450 & 809169 & 4.4 & 4.6669 & TRN \\
\hline CHEMBL 2001987 & 809169 & 7.2 & 5.2473 & TRN \\
\hline CHEMBL1994555 & 809169 & 7.0 & 5.9889 & TRN \\
\hline CHEMBL1164180 & 809169 & 5.5 & 5.7041 & TST \\
\hline CHEMBL1975121 & 809169 & 4.4 & 4.9182 & TRN \\
\hline CHEMBL1983640 & 809169 & 4.4 & 4.6185 & TRN \\
\hline CHEMBL1997611 & 809169 & 5.6 & 5.3625 & TST \\
\hline CHEMBL1971943 & 809169 & 4.4 & 4.925 & TRN \\
\hline CHEMBL1997924 & 809169 & 6.8 & 7.2228 & TRN \\
\hline CHEMBL1984686 & 809169 & 4.4 & 4.9612 & TST \\
\hline CHEMBL1978267 & 809169 & 4.4 & 4.2352 & TRN \\
\hline CHEMBL1973793 & 809169 & 4.4 & 4.6866 & TRN \\
\hline CHEMBL1992073 & 809169 & 4.4 & 5.0085 & TRN \\
\hline CHEMBL1990254 & 809169 & 4.4 & 5.1 & TRN \\
\hline CHEMBL1986143 & 809169 & 4.4 & 4.8532 & TRN \\
\hline CHEMBL 2007559 & 809169 & 4.4 & 4.9422 & TRN \\
\hline CHEMBL1992581 & 809169 & 4.4 & 5.0569 & TRN \\
\hline CHEMBL 2004290 & 809169 & 6.7 & 6.2451 & TRN \\
\hline CHEMBL1975921 & 809169 & 4.6 & 4.6391 & TRN \\
\hline CHEMBL1975923 & 809169 & 4.7 & 5.5187 & TST \\
\hline CHEMBL 2005449 & 809169 & 6.0 & 5.928 & TRN \\
\hline CHEMBL1996576 & 809169 & 4.4 & 4.4205 & TST \\
\hline CHEMBL1988076 & 809169 & 4.4 & 4.359 & TRN \\
\hline CHEMBL1991678 & 809169 & 4.4 & 4.7925 & TRN \\
\hline CHEMBL1987998 & 809169 & 6.9 & 4.1795 & TRN \\
\hline CHEMBL1971534 & 809169 & 4.1 & 4.8556 & TRN \\
\hline CHEMBL1990496 & 809169 & 4.4 & 4.5229 & TRN \\
\hline CHEMBL 242865 & 809169 & 6.1 & 6.5438 & TRN \\
\hline
\end{tabular}




\begin{tabular}{|c|c|c|c|c|}
\hline \multicolumn{5}{|c|}{ Supplemental Table S2.txt } \\
\hline CHEMBL235157 & 809169 & 4.4 & 4.2838 & TST \\
\hline CHEMBL 2002480 & 809169 & 4.4 & 4.6063 & TRN \\
\hline CHEMBL1983884 & 809169 & 3.1 & 4.2805 & TRN \\
\hline CHEMBL 2004159 & 809169 & 4.4 & 4.1744 & TRN \\
\hline CHEMBL1978371 & 809169 & 4.4 & 5.14 & TST \\
\hline CHEMBL440084 & 809169 & 4.4 & 4.7885 & TRN \\
\hline CHEMBL1998110 & 809169 & 4.4 & 4.394 & TRN \\
\hline CHEMBL1978166 & 809169 & 5.5 & 5.8877 & TRN \\
\hline CHEMBL1977814 & 809169 & 4.4 & 4.573 & TST \\
\hline CHEMBL1974617 & 809169 & 4.7 & 5.0484 & TRN \\
\hline CHEMBL86755 & 809169 & 4.4 & 4.7154 & TRN \\
\hline CHEMBL1965660 & 809169 & 5.7 & 5.9086 & TRN \\
\hline CHEMBL1992125 & 809169 & 5.9 & 5.5426 & TRN \\
\hline CHEMBL1966175 & 809169 & 4.4 & 4.5214 & TRN \\
\hline CHEMBL 2007375 & 809169 & 4.4 & 5.5332 & TRN \\
\hline CHEMBL379975 & 809169 & 7.0 & 5.2303 & TST \\
\hline CHEMBL1967612 & 809169 & 4.1 & 4.6052 & TST \\
\hline CHEMBL1973016 & 809169 & 4.4 & 4.511 & TRN \\
\hline CHEMBL1965387 & 809169 & 4.4 & 3.8378 & TRN \\
\hline CHEMBL 2001539 & 809169 & 4.2 & 4.6094 & TST \\
\hline CHEMBL 388978 & 809169 & 7.2 & 7.3451 & TST \\
\hline CHEMBL1997041 & 809169 & 4.9 & 4.8218 & TRN \\
\hline CHEMBL550418 & 809169 & 7.8 & 5.9282 & TRN \\
\hline CHEMBL398951 & 809169 & 4.4 & 4.2192 & TST \\
\hline CHEMBL1971289 & 809169 & 4.4 & 4.8464 & TST \\
\hline CHEMBL1988437 & 809169 & 4.4 & 5.6325 & TST \\
\hline CHEMBL 2007603 & 809169 & 5.8 & 5.4864 & TRN \\
\hline CHEMBL1421720 & 809169 & 5.5 & 4.9655 & TRN \\
\hline CHEMBL1233887 & 809169 & 4.4 & 4.6449 & TRN \\
\hline CHEMBL1968130 & 809169 & 4.9 & 4.8596 & TST \\
\hline CHEMBL2003689 & 809169 & 4.4 & 4.2174 & TRN \\
\hline CHEMBL576113 & 809169 & 4.4 & 4.9917 & TRN \\
\hline CHEMBL1996649 & 809169 & 7.0 & 5.8403 & TRN \\
\hline CHEMBL1986756 & 809169 & 6.9 & 5.5697 & TRN \\
\hline CHEMBL1949855 & 809169 & 6.5 & 5.0414 & TRN \\
\hline CHEMBL3109278 & 809169 & 4.4 & 4.1183 & TRN \\
\hline CHEMBL1727312 & 809169 & 4.2 & 3.9653 & TRN \\
\hline CHEMBL1974998 & 809169 & 4.4 & 4.2106 & TRN \\
\hline CHEMBL1990223 & 809169 & 4.4 & 4.4424 & TRN \\
\hline CHEMBL 2004438 & 809169 & 4.4 & 3.7234 & TRN \\
\hline CHEMBL1964382 & 809169 & 4.4 & 4.4495 & TST \\
\hline CHEMBL101311 & 809169 & 7.3 & 6.439 & TRN \\
\hline CHEMBL191003 & 809169 & 5.5 & 5.9653 & TRN \\
\hline CHEMBL1973359 & 809169 & 6.7 & 6.4427 & TST \\
\hline CHEMBL1988581 & 809169 & 6.9 & 6.5929 & TST \\
\hline CHEMBL 2005699 & 809169 & 4.4 & 4.1599 & TRN \\
\hline CHEMBL 2006564 & 809169 & 6.3 & 6.2997 & TRN \\
\hline CHEMBL1979690 & 809169 & 7.0 & 6.4579 & TRN \\
\hline
\end{tabular}




\begin{tabular}{|c|c|c|c|c|c|}
\hline \multicolumn{6}{|c|}{ Supplemental Table S2.txt } \\
\hline CHEMBL1991008 & 809169 & 4.1 & 4.2616 & TRN & \\
\hline CHEMBL 234085 & 809169 & 4.4 & 4.1581 & TRN & \\
\hline CHEMBL1978167 & 809169 & 4.4 & 4.3118 & TRN & \\
\hline CHEMBL418203 & 809169 & 5.7 & 5.1798 & TST & \\
\hline CHEMBL225519 & 809169 & 6.0 & 5.2582 & TST & \\
\hline CHEMBL1994159 & 809169 & 4.2 & 4.7535 & TRN & \\
\hline CHEMBL1976376 & 809169 & 5.4 & 5.4717 & TRN & \\
\hline CHEMBL1983575 & 809169 & 7.4 & 5.9772 & TRN & \\
\hline CHEMBL1968868 & 809169 & 6.7 & 5.6898 & TRN & \\
\hline CHEMBL1981047 & 809169 & 6.9 & 6.7586 & TRN & \\
\hline CHEMBL1998470 & 809169 & 4.4 & 4.4831 & TRN & \\
\hline CHEMBL1976196 & 809169 & 5.5 & 4.9565 & TRN & \\
\hline CHEMBL1997197 & 809169 & 4.4 & 4.9938 & TRN & \\
\hline CHEMBL1975903 & 809169 & 6.7 & 5.5764 & TRN & \\
\hline CHEMBL1522508 & 809169 & 5.0 & 4.6724 & TRN & \\
\hline CHEMBL1988805 & 809169 & 4.4 & 4.8866 & TRN & \\
\hline CHEMBL458997 & 809169 & 4.4 & 5.9079 & TRN & \\
\hline CHEMBL1969942 & 809169 & 4.4 & 4.5247 & TRN & \\
\hline CHEMBL1982660 & 809169 & 6.2 & 6.2808 & TRN & \\
\hline CHEMBL1978567 & 809169 & 4.4 & 4.394 & TRN & \\
\hline CHEMBL1995765 & 809169 & 4.8 & 4.8748 & TRN & \\
\hline CHEMBL1984760 & 809169 & 4.4 & 4.3551 & TRN & \\
\hline CHEMBL1997846 & 809169 & 4.4 & 4.6727 & TRN & \\
\hline CHEMBL424872 & 809169 & 4.4 & $4.1560 e$ & 0000000001 & TRN \\
\hline CHEMBL 2007073 & 809169 & 4.4 & 4.1979 & TRN & \\
\hline CHEMBL 360847 & 809169 & 4.4 & 4.2942 & TRN & \\
\hline CHEMBL1995811 & 809169 & 5.4 & 5.6425 & TRN & \\
\hline CHEMBL1987240 & 809169 & 4.3 & 4.8551 & TRN & \\
\hline CHEMBL1983111 & 809169 & 6.4 & 6.9909 & TRN & \\
\hline CHEMBL1988141 & 809169 & 4.4 & 5.8659 & TST & \\
\hline CHEMBL1992937 & 809169 & 4.4 & 4.8256 & TRN & \\
\hline CHEMBL1977134 & 809169 & 4.4 & 4.8183 & TRN & \\
\hline CHEMBL1970873 & 809169 & 4.0 & 4.1938 & TRN & \\
\hline CHEMBL1985206 & 809169 & 4.4 & 4.1942 & TRN & \\
\hline CHEMBL1991078 & 809169 & 6.0 & 5.9244 & TRN & \\
\hline CHEMBL1977749 & 809169 & 5.9 & 5.0301 & TST & \\
\hline CHEMBL1975212 & 809169 & 6.2 & 5.1362 & TRN & \\
\hline CHEMBL 2001613 & 809169 & 5.1 & 4.8966 & TRN & \\
\hline CHEMBL261849 & 809169 & 4.4 & 4.1618 & TST & \\
\hline CHEMBL1983923 & 809169 & 7.5 & 5.8583 & TRN & \\
\hline CHEMBL1993904 & 809169 & 4.4 & 5.3443 & TRN & \\
\hline CHEMBL1997275 & 809169 & 4.4 & 4.1713 & TRN & \\
\hline CHEMBL1967513 & 809169 & 5.8 & 5.4788 & TRN & \\
\hline CHEMBL1980376 & 809169 & 5.5 & 4.5979 & TRN & \\
\hline CHEMBL1982413 & 809169 & 4.4 & 5.3129 & TRN & \\
\hline CHEMBL1985042 & 809169 & 4.1 & 4.8961 & TRN & \\
\hline CHEMBL1987535 & 809169 & 5.9 & 4.643 & TRN & \\
\hline CHEMBL1983393 & 809169 & 4.4 & 4.5997 & TRN & \\
\hline
\end{tabular}




\begin{tabular}{|c|c|c|c|c|}
\hline & & & & al lable \\
\hline CHEMBL1981792 & 809169 & 5.5 & 5.0653 & TRN \\
\hline CHEMBL2002586 & 809169 & 4.4 & 5.1891 & TRN \\
\hline CHEMBL2006674 & 809169 & 4.4 & 5.0109 & TST \\
\hline CHEMBL1984236 & 809169 & 4.4 & 4.5097 & TST \\
\hline CHEMBL383264 & 809169 & 4.4 & 5.0127 & TRN \\
\hline CHEMBL1992371 & 809169 & 5.6 & 5.8497 & TRN \\
\hline CHEMBL 2007421 & 809169 & 5.8 & 5.7459 & TRN \\
\hline CHEMBL1973138 & 809169 & 4.4 & 4.559 & TRN \\
\hline CHEMBL2002599 & 809169 & 5.5 & 5.8169 & TRN \\
\hline CHEMBL1992673 & 809169 & 4.1 & 4.8655 & TST \\
\hline CHEMBL1969151 & 809169 & 5.6 & 4.5898 & TRN \\
\hline CHEMBL1967252 & 809169 & 5.4 & 4.8515 & TRN \\
\hline CHEMBL1993335 & 809169 & 4.4 & 4.3188 & TRN \\
\hline CHEMBL1981492 & 809169 & 4.3 & 4.9632 & TST \\
\hline CHEMBL1988692 & 809169 & 5.4 & 5.4638 & TST \\
\hline CHEMBL 2007574 & 809169 & 4.4 & 5.33200 & 0000000001 \\
\hline CHEMBL2004637 & 809169 & 5.7 & 5.1186 & TST \\
\hline CHEMBL1993374 & 809169 & 4.4 & 4.7062 & TST \\
\hline CHEMBL1994318 & 809169 & 4.4 & 4.4668 & TST \\
\hline CHEMBL1998680 & 809169 & 4.4 & 4.1973 & TST \\
\hline CHEMBL592030 & 809169 & 4.5 & 5.2443 & TST \\
\hline CHEMBL1999506 & 809169 & 4.4 & 4.215 & TST \\
\hline CHEMBL1970317 & 809169 & 6.7 & 6.0924 & TST \\
\hline CHEMBL1985232 & 809169 & 5.9 & 5.5662 & TST \\
\hline CHEMBL1605605 & 809169 & 4.4 & 4.7421 & TST \\
\hline CHEMBL1996208 & 809169 & 4.4 & 4.6243 & TST \\
\hline CHEMBL 2002736 & 809169 & 4.4 & 4.8368 & TST \\
\hline CHEMBL1997007 & 809169 & 4.4 & 4.5036 & TST \\
\hline CHEMBL1970352 & 809169 & 5.4 & 5.1674 & TST \\
\hline CHEMBL1964444 & 809169 & 6.5 & 5.5379 & TST \\
\hline CHEMBL 2002690 & 809169 & 4.4 & 4.4108 & TST \\
\hline CHEMBL1980167 & 809169 & 4.4 & 4.8952 & TST \\
\hline CHEMBL 377408 & 809169 & 4.4 & 4.1777 & TST \\
\hline CHEMBL 278041 & 809169 & 4.5 & 4.6631 & TST \\
\hline CHEMBL 215152 & 809169 & 4.4 & 4.4899 & TST \\
\hline CHEMBL1997051 & 809169 & 4.4 & 5.0317 & TST \\
\hline CHEMBL 2006765 & 809169 & 4.4 & 5.5036 & TST \\
\hline CHEMBL1986590 & 809169 & 4.4 & 4.2214 & TST \\
\hline CHEMBL1870106 & 809169 & 4.4 & 4.5703 & TST \\
\hline CHEMBL406845 & 809169 & 7.2 & 5.9376 & TST \\
\hline CHEMBL1980246 & 809169 & 5.8 & 4.9585 & TST \\
\hline CHEMBL1983980 & 809169 & 5.5 & 5.598 & TST \\
\hline CHEMBL482538 & 809169 & 4.7 & 4.8609 & TST \\
\hline CHEMBL1999484 & 809169 & 7.4 & 6.3884 & TST \\
\hline CHEMBL1984296 & 809169 & 5.5 & 5.4338 & TST \\
\hline CHEMBL1986899 & 809169 & 4.4 & 4.3378 & TST \\
\hline CHEMBL1996837 & 809169 & 4.6 & 4.7528 & TST \\
\hline CHEMBL1984038 & 809169 & 4.4 & 4.6976 & TST \\
\hline
\end{tabular}




\begin{tabular}{|c|c|c|c|c|c|c|}
\hline & & & & & & \\
\hline CHEMBL1964718 & 809169 & 4.4 & 4.7603 & TST & & \\
\hline CHEMBL1993661 & 809169 & 6.8 & 7.5522 & TST & & \\
\hline CHEMBL1968705 & 809169 & 5.4 & 4.7897 & TST & & \\
\hline CHEMBL1964441 & 809169 & 4.4 & 5.3874 & TST & & \\
\hline CHEMBL1991410 & 809169 & 4.4 & 4.8011 & TST & & \\
\hline CHEMBL1986684 & 809169 & 4.8 & 4.9574 & TST & & \\
\hline CHEMBL546797 & 809169 & 4.4 & 4.9445 & TST & & \\
\hline CHEMBL3934893 & 1642489 & 6.3372 & 6.8814 & TST & & \\
\hline CHEMBL3935932 & 1642489 & 7.5528 & 6.68 & TST & & \\
\hline CHEMBL3926184 & 1642489 & 7.3098 & 6.8603 & TRN & & \\
\hline CHEMBL3960636 & 1642489 & 7.5086 & 6.7517 & TRN & & \\
\hline CHEMBL3907515 & 1642489 & 7.2366 & 6.4388 & TRN & & \\
\hline CHEMBL3904213 & 1642489 & 7.4949 & 6.8267 & TRN & & \\
\hline CHEMBL3937782 & 1642489 & 5.4631 & 6.5454 & TST & & \\
\hline CHEMBL3962559 & 1642489 & 6.82100 & 00000000 & & 6.8349 & TRN \\
\hline CHEMBL3960996 & 1642489 & 6.8697 & 6.8205 & TRN & & \\
\hline CHEMBL3952914 & 1642489 & 7.2518 & 6.9181 & TRN & & \\
\hline CHEMBL3931988 & 1642489 & 7.1024 & 6.4307 & TRN & & \\
\hline CHEMBL3953982 & 1642489 & 6.3372 & 6.352 & TST & & \\
\hline CHEMBL3980183 & 1642489 & 6.4377 & 6.5843 & TRN & & \\
\hline CHEMBL3983931 & 1642489 & 7.6778 & 6.8947 & TST & & \\
\hline CHEMBL3979262 & 1642489 & 6.0 & 6.7726 & TRN & & \\
\hline CHEMBL3903417 & 1642489 & 6.7282 & 6.8062 & TRN & & \\
\hline CHEMBL3902053 & 1642489 & 6.2076 & 6.803 & TRN & & \\
\hline CHEMBL3976029 & 1642489 & 6.9208 & 6.7967 & TRN & & \\
\hline CHEMBL3901225 & 1642489 & 7.2218 & 6.7551 & TRN & & \\
\hline CHEMBL3939223 & 1642489 & 6.6038 & 6.796 & TST & & \\
\hline CHEMBL3970533 & 1642489 & 6.0 & 6.9234 & TST & & \\
\hline CHEMBL3935581 & 1642489 & 5.556 & 6.7885 & TST & & \\
\hline CHEMBL3925043 & 1642489 & 6.0 & 6.7921 & TRN & & \\
\hline CHEMBL3966968 & 1642489 & 6.8633 & 6.8342 & TST & & \\
\hline CHEMBL3967063 & 1642489 & 6.0 & 6.7164 & TRN & & \\
\hline CHEMBL3954746 & 1642489 & 7.1805 & 6.7617 & TRN & & \\
\hline CHEMBL3896975 & 1642489 & 7.0177 & 6.6706 & TRN & & \\
\hline CHEMBL3920892 & 1642489 & 6.2336 & 6.8264 & TST & & \\
\hline CHEMBL3923945 & 1642489 & 7.0506 & 6.8354 & TRN & & \\
\hline CHEMBL3891328 & 1642489 & 6.0 & 6.79200 & 0000000001 & & TRN \\
\hline CHEMBL3936662 & 1642489 & 6.4711 & 6.7696 & TST & & \\
\hline CHEMBL3979964 & 1642489 & 6.5391 & 6.8827 & TRN & & \\
\hline CHEMBL3972272 & 1642489 & 6.5686 & 6.2337 & TRN & & \\
\hline CHEMBL3967544 & 1642489 & 6.0 & 6.6392 & TRN & & \\
\hline CHEMBL3941302 & 1642489 & 5.5504 & 6.6358 & TST & & \\
\hline CHEMBL3980531 & 1642489 & 7.585 & 6.9838 & TRN & & \\
\hline CHEMBL3909447 & 1642489 & 6.0 & 6.8372 & TST & & \\
\hline CHEMBL3987163 & 1642489 & 6.0 & 6.8084 & TRN & & \\
\hline CHEMBL3982317 & 1642489 & 7.4815 & 6.8542 & TRN & & \\
\hline CHEMBL3909683 & 1642489 & 6.8761 & 6.9918 & TRN & & \\
\hline CHEMBL3906859 & 1642489 & 6.4498 & 6.87700 & 0000000001 & & וכן \\
\hline & & & & 183 & & \\
\hline
\end{tabular}


Supplemental Table S2.txt

\begin{tabular}{|c|c|c|c|c|c|}
\hline CHEMBL 3938923 & 1642489 & 6.0186 & 6.9136 & TST & \\
\hline CHEMBL 3893562 & 1642489 & 5.8074 & 6.5099 & TST & \\
\hline CHEMBL3929177 & 1642489 & 7.1308 & 6.6761 & TRN & \\
\hline CHEMBL 3984126 & 1642489 & 7.3188 & 6.8838 & TRN & \\
\hline CHEMBL3911996 & 1642489 & 6.0 & 6.824 & TRN & \\
\hline CHEMBL3970002 & 1642489 & 6.8697 & 6.981 & TRN & \\
\hline CHEMBL 3927278 & 1642489 & 6.0 & 6.8003 & TRN & \\
\hline CHEMBL 3960897 & 1642489 & 7.1612 & 6.859 & TRN & \\
\hline CHEMBL 3979443 & 1642489 & 6.6326 & 6.8166 & TRN & \\
\hline CHEMBL3903285 & 1642489 & 6.9355 & 6.357 & TRN & \\
\hline CHEMBL 3958293 & 1642489 & 6.6655 & 6.6029 & TRN & \\
\hline CHEMBL 3940145 & 1642489 & 6.75200 & 000000000 & 6.8636 & TRN \\
\hline CHEMBL 3986458 & 1642489 & 7.1487 & 6.705 & TRN & \\
\hline CHEMBL 3971479 & 1642489 & 7.3872 & 6.7832 & TRN & \\
\hline CHEMBL3937697 & 1642489 & 6.0 & 6.8389 & TRN & \\
\hline CHEMBL 3963478 & 1642489 & 6.8508 & 6.7466 & TRN & \\
\hline CHEMBL3926707 & 1642489 & 6.6861 & 6.9553 & TRN & \\
\hline CHEMBL3970757 & 1642489 & 5.8735 & 6.8842 & TST & \\
\hline CHEMBL 3977738 & 1642489 & 7.4089 & 6.9988 & TRN & \\
\hline CHEMBL3934991 & 1642489 & 7.0362 & 6.6337 & TST & \\
\hline CHEMBL3905964 & 1642489 & 7.0555 & 6.6049 & TRN & \\
\hline CHEMBL3960791 & 1642489 & 6.7077 & 6.6201 & TRN & \\
\hline CHEMBL3891426 & 1642489 & 7.4685 & 6.7373 & TRN & \\
\hline CHEMBL3977998 & 1642489 & 6.9626 & 6.8809 & TST & \\
\hline CHEMBL 3978284 & 1642489 & 7.5086 & 6.8631 & TRN & \\
\hline CHEMBL 3906848 & 1642489 & 6.7399 & 6.8629 & TRN & \\
\hline CHEMBL 3944207 & 1642489 & 7.4815 & 7.241000 & 00000000005 & ובנו \\
\hline CHEMBL3984575 & 1642489 & 7.2291 & 7.0616 & TRN & \\
\hline CHEMBL 3914873 & 1642489 & 6.9355 & 6.8036 & TRN & \\
\hline CHEMBL3905551 & 1642489 & 6.6946 & 6.8585 & TRN & \\
\hline CHEMBL 3966690 & 1642489 & 6.7645 & 6.7109 & TRN & \\
\hline CHEMBL3961479 & 1642489 & 6.5952 & 6.7831 & TRN & \\
\hline CHEMBL3963442 & 1642489 & 6.7747 & 6.6601 & TRN & \\
\hline CHEMBL 3949148 & 1642489 & 7.3565 & 6.9036 & TRN & \\
\hline CHEMBL3976103 & 1642489 & 5.8861 & 6.7652 & TRN & \\
\hline CHEMBL3953813 & 1642489 & 6.8297 & 6.4724 & TRN & \\
\hline CHEMBL3949171 & 1642489 & 7.4949 & 7.0005 & TRN & \\
\hline CHEMBL3911767 & 1642489 & 6.3507 & 6.9431 & TRN & \\
\hline CHEMBL 3908527 & 1642489 & 6.0 & 6.7731 & TRN & \\
\hline CHEMBL 3919574 & 1642489 & 7.1871 & 6.916 & TRN & \\
\hline CHEMBL3939344 & 1642489 & 6.0835 & 6.2947 & TRN & \\
\hline CHEMBL3986994 & 1642489 & 7.1249 & 6.754 & TRN & \\
\hline CHEMBL3983591 & 1642489 & 7.2676 & 7.1531 & TST & \\
\hline CHEMBL 3896395 & 1642489 & 7.0362 & \multicolumn{2}{|c|}{6.877000000000001} & rRN \\
\hline CHEMBL3916472 & 1642489 & 6.32700 & 000000000 & 6.5612 & TRN \\
\hline CHEMBL 3963898 & 1642489 & 6.5735 & 6.8269 & TRN & \\
\hline CHEMBL 3909302 & 1642489 & 5.8164 & 6.3879 & TRN & \\
\hline CHEMBL 3923268 & 1642489 & 6.6716 & 6.7442 & TRN & \\
\hline
\end{tabular}


Supplemental Table S2.txt

\begin{tabular}{|c|c|c|c|c|c|c|}
\hline CHEMBL3947596 & 1642489 & 6.5513 & 6.8718 & TRN & & \\
\hline CHEMBL3940963 & 1642489 & 6.6108 & 6.8347 & TRN & & \\
\hline CHEMBL3916560 & 1642489 & 6.5952 & 6.7494 & TRN & & \\
\hline CHEMBL3966674 & 1642489 & 7.2924 & 6.9011 & TRN & & \\
\hline CHEMBL3895753 & 1642489 & 5.8807 & 6.7471 & TRN & & \\
\hline CHEMBL3924604 & 1642489 & 7.301 & 7.2877 & TRN & & \\
\hline CHEMBL3941709 & 1642489 & 7.4949 & 6.8552 & TRN & & \\
\hline CHEMBL3976636 & 1642489 & \multicolumn{3}{|c|}{6.821000000000001} & 6.7326 & TRN \\
\hline CHEMBL 3891890 & 1642489 & 6.8477 & 6.8179 & TRN & & \\
\hline CHEMBL3897789 & 1642489 & 6.0 & 6.5711 & TRN & & \\
\hline CHEMBL3915171 & 1642489 & 6.0 & 6.7671 & TRN & & \\
\hline CHEMBL3949304 & 1642489 & 5.8389 & 6.975 & TRN & & \\
\hline CHEMBL3981461 & 1642489 & 6.8327 & 7.065 & TRN & & \\
\hline CHEMBL3895017 & 1642489 & 5.8496 & 6.8247 & TST & & \\
\hline CHEMBL3964850 & 1642489 & 6.2175 & 6.3169 & TRN & & \\
\hline CHEMBL3939114 & 1642489 & 7.2596 & 6.6409 & TRN & & \\
\hline CHEMBL3948471 & 1642489 & \multicolumn{3}{|c|}{6.327000000000001} & 6.5557 & TRN \\
\hline CHEMBL3973011 & 1642489 & 7.585 & 7.0065 & TRN & & \\
\hline CHEMBL3903114 & 1642489 & 7.2924 & 6.9865 & TRN & & \\
\hline CHEMBL3946416 & 1642489 & 6.341 & 6.8966 & TRN & & \\
\hline CHEMBL3953110 & 1642489 & 6.0 & 6.6331 & TRN & & \\
\hline CHEMBL3911153 & 1642489 & 6.1739 & 6.7063 & TRN & & \\
\hline CHEMBL 3985252 & 1642489 & 6.0 & 6.6636 & TRN & & \\
\hline CHEMBL 3898943 & 1642489 & 6.8633 & 6.9208 & TRN & & \\
\hline CHEMBL3945774 & 1642489 & 6.9469 & 6.6644 & TST & & \\
\hline CHEMBL3918507 & 1642489 & 5.5921 & 6.5515 & TRN & & \\
\hline CHEMBL3934640 & 1642489 & 7.4089 & 6.8151 & TRN & & \\
\hline CHEMBL3954915 & 1642489 & 6.9547 & 6.8342 & TRN & & \\
\hline CHEMBL3904321 & 1642489 & 7.1739 & 6.9449 & TRN & & \\
\hline CHEMBL3940769 & 1642489 & 6.9747 & 6.9821 & TRN & & \\
\hline CHEMBL3968130 & 1642489 & 6.9355 & 6.5294 & TRN & & \\
\hline CHEMBL3958654 & 1642489 & 6.6556 & 6.7306 & TRN & & \\
\hline CHEMBL3890204 & 1642489 & 7.2291 & 7.2599 & TRN & & \\
\hline CHEMBL 3942524 & 1642489 & 6.0 & 6.8648 & TRN & & \\
\hline CHEMBL3975132 & 1642489 & 6.9393 & 6.9475 & TRN & & \\
\hline CHEMBL3943498 & 1642489 & 7.1192 & 6.683 & TRN & & \\
\hline CHEMBL3927570 & 1642489 & 6.5784 & 6.9041 & TRN & & \\
\hline CHEMBL3916711 & 1642489 & 7.3279 & 6.672999 & 9999999999 & & TRN \\
\hline CHEMBL3929536 & 1642489 & 7.2924 & 6.9214 & TRN & & \\
\hline CHEMBL3938369 & 1642489 & 6.5421 & 6.874 & TRN & & \\
\hline CHEMBL3916412 & 1642489 & 6.8894 & 6.6886 & TRN & & \\
\hline CHEMBL3893081 & 1642489 & 7.3372 & 7.1599 & TRN & & \\
\hline CHEMBL3907460 & 1642489 & 6.7986 & 6.8845 & TRN & & \\
\hline CHEMBL3940388 & 1642489 & 6.4225 & 6.8085 & TRN & & \\
\hline CHEMBL3920325 & 1642489 & 6.0 & 6.7706 & TRN & & \\
\hline CHEMBL3939324 & 1642489 & 6.9626 & 6.6096 & TRN & & \\
\hline CHEMBL3980624 & 1642489 & 6.71 & 6.9799 & TRN & & \\
\hline CHEMBL3964069 & 1642489 & 6.9393 & 6.4766 & TRN & & \\
\hline
\end{tabular}


Supplemental Table S2.txt

\begin{tabular}{|c|c|c|c|c|}
\hline CHEMBL 3946754 & 1642489 & 6.8447 & 6.4703 & TRN \\
\hline CHEMBL 3925307 & 1642489 & 7.3872 & 6.7453 & TRN \\
\hline CHEMBL3956805 & 1642489 & 6.7122 & 6.7105 & TRN \\
\hline CHEMBL 3975870 & 1642489 & 6.5346 & 6.7867 & TRN \\
\hline CHEMBL3892832 & 1642489 & 6.0 & 6.7039 & TRN \\
\hline CHEMBL 3897923 & 1642489 & 6.8097 & 6.9587 & TST \\
\hline CHEMBL 3968027 & 1642489 & 7.6021 & 6.8406 & TRN \\
\hline CHEMBL3909792 & 1642489 & 6.8268 & 6.8368 & TRN \\
\hline CHEMBL 3890912 & 1642489 & 7.0132 & 6.7976 & TRN \\
\hline CHEMBL3907312 & 1642489 & 6.0 & 6.8862 & TST \\
\hline CHEMBL3926907 & 1642489 & 6.3925 & 6.4356 & TRN \\
\hline CHEMBL 3926624 & 1642489 & 6.0386 & 7.0489 & TST \\
\hline CHEMBL3890017 & 1642489 & 6.6383 & 6.7111 & TRN \\
\hline CHEMBL3905813 & 1642489 & 7.4949 & 6.9875 & TRN \\
\hline CHEMBL3976293 & 1642489 & 7.2441 & 6.7828 & TRN \\
\hline CHEMBL3977039 & 1642489 & 5.3353 & 6.2314 & TRN \\
\hline CHEMBL3934548 & 1642489 & 6.0 & 6.8042 & TRN \\
\hline CHEMBL3938756 & 1642489 & 7.5376 & 6.8811 & TRN \\
\hline CHEMBL3899064 & 1642489 & 7.585 & 6.8707 & TRN \\
\hline CHEMBL3924735 & 1642489 & 6.8761 & 6.6678 & TRN \\
\hline CHEMBL3955302 & 1642489 & 6.2984 & 6.3547 & TRN \\
\hline CHEMBL 3940289 & 1642489 & 6.5331 & 6.9634 & TST \\
\hline CHEMBL3963811 & 1642489 & 6.0 & 6.6506 & TRN \\
\hline CHEMBL3916423 & 1642489 & 7.2924 & 6.9349 & TRN \\
\hline CHEMBL3972511 & 1642489 & 7.284 & 6.8568 & TRN \\
\hline CHEMBL3944436 & 1642489 & 6.8894 & 6.7769 & TRN \\
\hline CHEMBL3917571 & 1642489 & 7.7959 & 6.7282 & TRN \\
\hline CHEMBL 3901578 & 1642489 & 7.2757 & 6.8768 & TRN \\
\hline CHEMBL3911690 & 1642489 & 7.2076 & \multicolumn{2}{|c|}{6.6979999999999995} \\
\hline CHEMBL3909964 & 1642489 & 6.0 & 6.7126 & TRN \\
\hline CHEMBL3985738 & 1642489 & 6.8761 & 6.7732 & TRN \\
\hline CHEMBL 3951814 & 1642489 & 6.767 & 6.7941 & TRN \\
\hline CHEMBL3980094 & 1642489 & 7.1249 & 6.8747 & TRN \\
\hline CHEMBL3934023 & 1642489 & 7.2924 & 6.8449 & TRN \\
\hline CHEMBL3945732 & 1642489 & 5.6105 & 6.5932 & TRN \\
\hline CHEMBL3893400 & 1642489 & 6.2343 & 6.7399 & TRN \\
\hline CHEMBL3912593 & 1642489 & 7.3372 & 6.7231 & TRN \\
\hline CHEMBL 3974483 & 1642489 & 5.5947 & \multicolumn{2}{|c|}{6.5089999999999995} \\
\hline CHEMBL 3894387 & 1642489 & 6.5751 & 6.862 & TRN \\
\hline CHEMBL3939103 & 1642489 & 6.9706 & 6.813 & TRN \\
\hline CHEMBL3912442 & 1642489 & 7.1308 & 6.6264 & TRN \\
\hline CHEMBL3906561 & 1642489 & 7.301 & 6.7559 & TRN \\
\hline CHEMBL3957191 & 1642489 & 6.9547 & 6.8747 & TRN \\
\hline CHEMBL3889628 & 1642489 & 7.0915 & 6.6715 & TRN \\
\hline CHEMBL3918938 & 1642489 & 7.1308 & \multicolumn{2}{|c|}{6.611000000000001} \\
\hline CHEMBL3933290 & 1642489 & 7.3188 & 6.8351 & TRN \\
\hline CHEMBL3962476 & 1642489 & 6.8097 & 6.6953 & TRN \\
\hline CHEMBL3965360 & 1642489 & 7.3979 & 6.9251 & TRN \\
\hline
\end{tabular}


Supplemental Table S2.txt

\begin{tabular}{|c|c|c|c|c|c|}
\hline CHEMBL 3932867 & 1642489 & 6.5421 & 7.0355 & TST & \\
\hline CHEMBL 3908886 & 1642489 & 7.3665 & 6.6144 & TRN & \\
\hline CHEMBL3937232 & 1642489 & 7.2676 & 6.9012 & TRN & \\
\hline CHEMBL 3911569 & 1642489 & 6.8539 & 6.8236 & TRN & \\
\hline CHEMBL 3925386 & 1642489 & 6.3595 & 6.7644 & TST & \\
\hline CHEMBL 3974468 & 1642489 & 6.8013 & 7.0189 & TST & \\
\hline CHEMBL3919097 & 1642489 & 6.9172 & 6.8223 & TRN & \\
\hline CHEMBL3929156 & 1642489 & 7.0969 & 6.7915 & TRN & \\
\hline CHEMBL3933276 & 1642489 & 6.0 & 6.6819 & TRN & \\
\hline CHEMBL 3923534 & 1642489 & 7.2366 & 6.7458 & TRN & \\
\hline CHEMBL 3898148 & 1642489 & 6.6655 & 6.9704 & TRN & \\
\hline CHEMBL 3890394 & 1642489 & 6.9245 & 6.6827 & TST & \\
\hline CHEMBL 3904356 & 1642489 & 7.2924 & 6.3417 & TRN & \\
\hline CHEMBL3977183 & 1642489 & 7.3872 & 6.7138 & TRN & \\
\hline CHEMBL 3912529 & 1642489 & 6.7305 & 6.6629 & TST & \\
\hline CHEMBL 3976833 & 1642489 & 5.7627 & 6.7938 & TST & \\
\hline CHEMBL3976521 & 1642489 & 6.3401 & 6.906000 & 0000000001 & TST \\
\hline CHEMBL3920994 & 1642489 & 6.0 & 6.6468 & TRN & \\
\hline CHEMBL3917116 & 1642489 & 6.0 & 6.7017 & TRN & \\
\hline CHEMBL 3890902 & 1642489 & 6.9393 & 6.789 & TRN & \\
\hline CHEMBL 3971288 & 1642489 & 6.8508 & 6.7672 & TRN & \\
\hline CHEMBL3909617 & 1642489 & 6.6108 & 6.5963 & TRN & \\
\hline CHEMBL3933657 & 1642489 & 6.6556 & 6.7908 & TRN & \\
\hline CHEMBL 3971973 & 1642489 & 6.8794 & 6.8654 & TRN & \\
\hline CHEMBL 3960341 & 1642489 & 7.2596 & 6.9634 & TRN & \\
\hline CHEMBL 3934381 & 1642489 & 6.0 & 6.8494 & TST & \\
\hline CHEMBL 3955462 & 1642489 & 6.0273 & 6.4303 & TRN & \\
\hline CHEMBL3899800 & 1642489 & 7.5086 & 6.8689 & TRN & \\
\hline CHEMBL3954992 & 1642489 & 6.75700 & 000000000 & 6.9151 & TRN \\
\hline CHEMBL 3951828 & 1642489 & 6.5544 & 6.7994 & TRN & \\
\hline CHEMBL 3890349 & 1642489 & 7.3979 & 6.9746 & TRN & \\
\hline CHEMBL 3969201 & 1642489 & 7.4202 & 6.9446 & TRN & \\
\hline CHEMBL3899603 & 1642489 & 6.7773 & 6.9566 & TST & \\
\hline CHEMBL3963077 & 1642489 & 6.1713 & 6.4026 & TST & \\
\hline CHEMBL 3914776 & 1642489 & 7.1308 & 6.2356 & TRN & \\
\hline CHEMBL3951267 & 1642489 & 6.7645 & 6.6108 & TRN & \\
\hline CHEMBL 3922071 & 1642489 & 6.6383 & 6.9219 & TRN & \\
\hline CHEMBL 3947899 & 1642489 & 7.1427 & 6.7531 & TRN & \\
\hline CHEMBL 3897888 & 1642489 & 6.6757 & 6.6762 & TST & \\
\hline CHEMBL 3919910 & 1642489 & 6.9626 & 6.5461 & TRN & \\
\hline CHEMBL3908690 & 1642489 & 6.1524 & 6.6104 & TRN & \\
\hline CHEMBL 3948511 & 1642489 & 7.2291 & 6.9127 & TRN & \\
\hline CHEMBL 3921611 & 1642489 & 7.041 & 6.8528 & TRN & \\
\hline CHEMBL 3937244 & 1642489 & 5.7948 & 6.8308 & TRN & \\
\hline CHEMBL3902474 & 1642489 & 6.0 & 6.6659 & TRN & \\
\hline CHEMBL3920379 & 1642489 & 7.1308 & 6.7629 & TRN & \\
\hline CHEMBL 3934759 & 1642489 & 6.9747 & 6.8678 & TST & \\
\hline CHEMBL3956521 & 1642489 & 6.8239 & 6.8256 & TRN & \\
\hline
\end{tabular}


Supplemental Table S2.txt

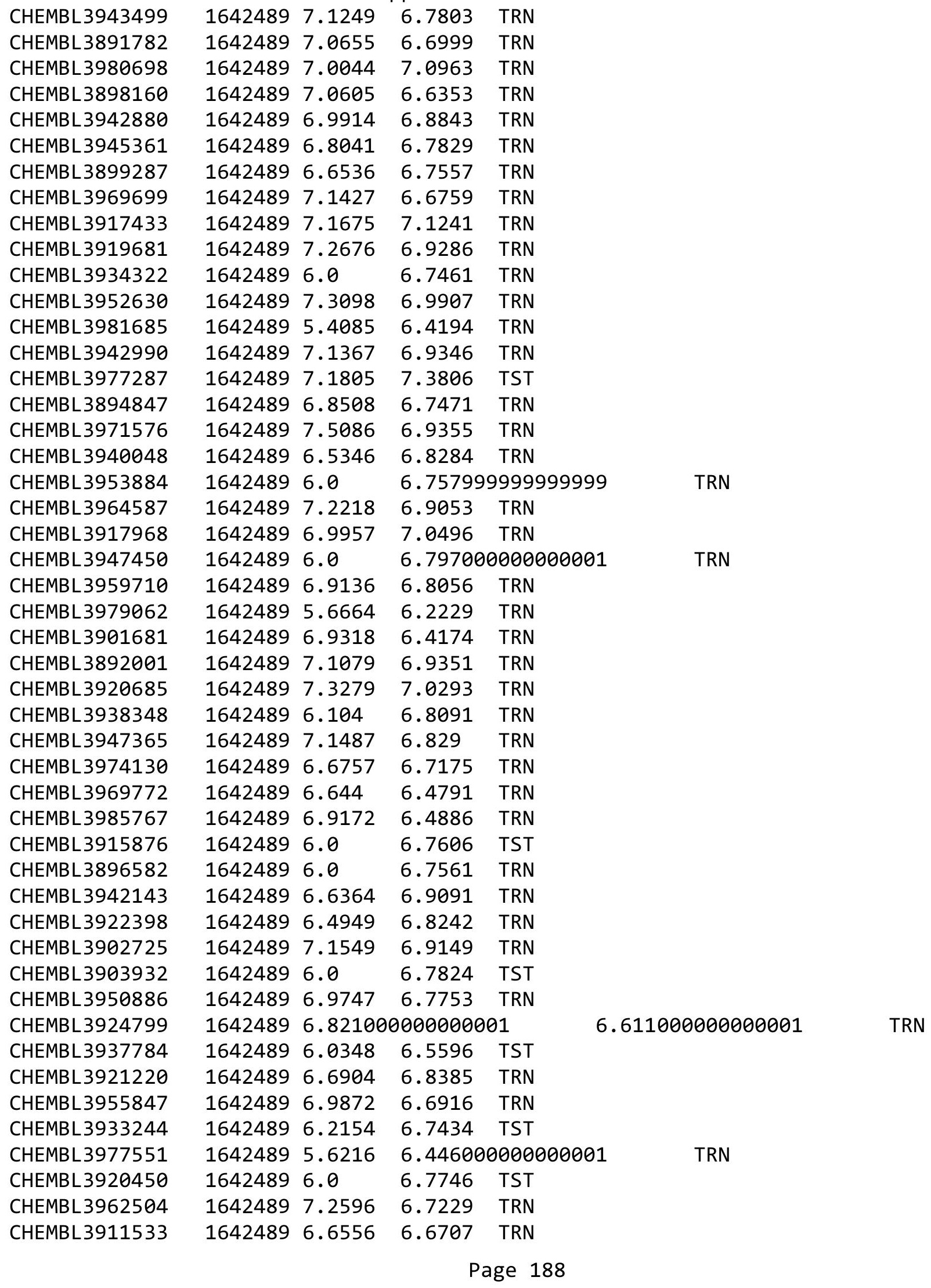


Supplemental Table S2.txt

\begin{tabular}{|c|c|c|c|c|c|}
\hline CHEMBL3965369 & 1642489 & 6.2111 & 6.6155 & TST & \\
\hline CHEMBL3911707 & 1642489 & 6.0 & 6.7749 & TRN & \\
\hline CHEMBL3958063 & 1642489 & 6.1506 & 6.7123 & TRN & \\
\hline CHEMBL3931974 & 1642489 & 7.1675 & 6.9037 & TRN & \\
\hline CHEMBL3966124 & 1642489 & 6.6819 & 6.6928 & TRN & \\
\hline CHEMBL3951210 & 1642489 & 7.2441 & 6.815 & TRN & \\
\hline CHEMBL3963595 & 1642489 & 7.0506 & 6.79 & TRN & \\
\hline CHEMBL3966588 & 1642489 & 6.7852 & 6.9362 & TRN & \\
\hline CHEMBL3921565 & 1642489 & 6.7471 & 6.5554 & TRN & \\
\hline CHEMBL3900217 & 1642489 & 6.4191 & 6.7202 & TRN & \\
\hline CHEMBL3954543 & 1642489 & 7.0915 & 7.1886 & TRN & \\
\hline CHEMBL3973076 & 1642489 & 6.1487 & 6.8451 & TST & \\
\hline CHEMBL3945514 & 1642489 & 5.9259 & 6.7441 & TRN & \\
\hline CHEMBL3939682 & 1642489 & 6.9747 & 6.7344 & TRN & \\
\hline CHEMBL3943083 & 1642489 & 7.4089 & 6.9197 & TRN & \\
\hline CHEMBL3984292 & 1642489 & 6.58 & 7.0212 & TRN & \\
\hline CHEMBL3979378 & 1642489 & 7.1024 & 6.8784 & TRN & \\
\hline CHEMBL3963852 & 1642489 & 6.8508 & 6.8755 & TRN & \\
\hline CHEMBL3944273 & 1642489 & 6.767 & 6.8862 & TRN & \\
\hline CHEMBL3894298 & 1642489 & 7.0969 & 6.6987 & TRN & \\
\hline CHEMBL3900442 & 1642489 & 6.2526 & 6.7991 & TST & \\
\hline CHEMBL3978825 & 1642489 & 6.6364 & 6.7302 & TST & \\
\hline CHEMBL3967963 & 1642489 & 7.6198 & 6.8303 & TRN & \\
\hline CHEMBL3902250 & 1642489 & 6.0742 & 6.8374 & TRN & \\
\hline CHEMBL3955878 & 1642489 & 7.1805 & 6.729 & TRN & \\
\hline CHEMBL3922665 & 1642489 & 7.0706 & 6.8486 & TRN & \\
\hline CHEMBL3921279 & 1642489 & 5.9796 & 6.6153 & TRN & \\
\hline CHEMBL3901079 & 1642489 & 7.1612 & 6.7236 & TRN & \\
\hline CHEMBL3928244 & 1642489 & 7.1871 & 6.9264 & TRN & \\
\hline CHEMBL3910136 & 1642489 & 7.2924 & 6.7625 & TRN & \\
\hline CHEMBL3948462 & 1642489 & 7.1427 & 6.4455 & TRN & \\
\hline CHEMBL3929300 & 1642489 & 7.0177 & 6.8474 & TRN & \\
\hline CHEMBL3931949 & 1642489 & 6.7328 & 6.8432 & TRN & \\
\hline CHEMBL3907922 & 1642489 & 7.1024 & 6.587999 & 9999999999 & TRN \\
\hline CHEMBL3942150 & 1642489 & 6.4023 & 7.0242 & TRN & \\
\hline CHEMBL3954971 & 1642489 & 6.3143 & 6.8574 & TST & \\
\hline CHEMBL3915437 & 1642489 & 7.1367 & 6.8796 & TRN & \\
\hline CHEMBL3916614 & 1642489 & 5.4911 & 6.4072 & TRN & \\
\hline CHEMBL3962989 & 1642489 & 6.8827 & 7.1932 & TST & \\
\hline CHEMBL3954489 & 1642489 & 6.9031 & 6.6977 & TST & \\
\hline CHEMBL3953200 & 1642489 & 5.3745 & 6.5389 & TRN & \\
\hline CHEMBL3975708 & 1642489 & 6.9626 & 6.9714 & TRN & \\
\hline CHEMBL3889631 & 1642489 & 6.8268 & 6.925 & TRN & \\
\hline CHEMBL 3895007 & 1642489 & 7.5528 & 6.8729 & TRN & \\
\hline CHEMBL3919668 & 1642489 & 6.0 & 6.5915 & TRN & \\
\hline CHEMBL3906418 & 1642489 & 6.5918 & 6.8426 & TRN & \\
\hline CHEMBL 3928440 & 1642489 & 6.7258 & 6.9073 & TRN & \\
\hline CHEMBL 3972578 & 1642489 & 7.0315 & 6.9711 & TRN & \\
\hline
\end{tabular}




\begin{tabular}{|c|c|c|c|c|c|c|}
\hline \multicolumn{6}{|c|}{ Supplemental Table S2.txt } & \\
\hline CHEMBL3949200 & 1642489 & 7.3565 & 6.6727 & TRN & & \\
\hline CHEMBL3896132 & 1642489 & 6.0 & 6.8496 & TST & & \\
\hline CHEMBL3973995 & 1642489 & 6.5129 & 6.881 & TST & & \\
\hline CHEMBL 3899223 & 1642489 & 7.301 & 6.843 & TRN & & \\
\hline CHEMBL3912299 & 1642489 & 5.6936 & 6.7777 & TST & & \\
\hline CHEMBL3926512 & 1642489 & 7.1308 & 6.7335 & TRN & & \\
\hline CHEMBL 3941091 & 1642489 & 6.16299 & 999999999 & 99 & 6.8528 TST & \\
\hline CHEMBL3986158 & 1642489 & 6.0 & 6.7651 & TRN & & \\
\hline CHEMBL 3925142 & 1642489 & 6.0888 & 6.9663 & TRN & & \\
\hline CHEMBL3956926 & 1642489 & 5.8901 & 6.3932 & TRN & & \\
\hline CHEMBL3936287 & 1642489 & 6.8153 & 6.6889 & TRN & & \\
\hline CHEMBL3911101 & 1642489 & 5.4297 & 6.8181 & TST & & \\
\hline CHEMBL3935843 & 1642489 & 7.0655 & 6.562 & TRN & & \\
\hline CHEMBL 3920720 & 1642489 & 7.3188 & 6.8014 & TRN & & \\
\hline CHEMBL 3899729 & 1642489 & 6.9469 & 6.8782 & TRN & & \\
\hline CHEMBL3980562 & 1642489 & 6.0 & 6.8088 & TRN & & \\
\hline CHEMBL3953288 & 1642489 & 6.0 & 6.9221 & TRN & & \\
\hline CHEMBL3941113 & 1642489 & 6.9666 & 6.9206 & TRN & & \\
\hline CHEMBL3944607 & 1642489 & 6.9547 & 6.96 & TRN & & \\
\hline CHEMBL3938802 & 1642489 & 5.53299 & 999999999 & 995 & 6.382999999999999 & TRN \\
\hline CHEMBL 3957820 & 1642489 & 6.7721 & 7.0131 & TRN & & \\
\hline CHEMBL3947567 & 1642489 & 7.4559 & 6.7228 & TRN & & \\
\hline CHEMBL3962725 & 1642489 & 6.0339 & 6.5531 & TST & & \\
\hline CHEMBL3960923 & 1642489 & 6.0 & 6.5635 & TST & & \\
\hline CHEMBL3962636 & 1642489 & 6.0 & 6.8889 & TRN & & \\
\hline CHEMBL3963391 & 1642489 & 6.0 & 6.7806 & TST & & \\
\hline CHEMBL 3894675 & 1642489 & 7.284 & 6.7558 & TRN & & \\
\hline CHEMBL3960709 & 1642489 & 6.7595 & 6.7639 & TRN & & \\
\hline CHEMBL 3896604 & 1642489 & 6.8097 & 6.5484 & TRN & & \\
\hline CHEMBL3978670 & 1642489 & 7.0177 & 6.733 & TRN & & \\
\hline CHEMBL 3895840 & 1642489 & 7.2924 & 6.8074 & TRN & & \\
\hline CHEMBL3907973 & 1642489 & 6.8928 & 6.5671 & TRN & & \\
\hline CHEMBL3971882 & 1642489 & 7.0809 & 6.4597 & TRN & & \\
\hline CHEMBL3918253 & 1642489 & 6.8477 & 7.097 & TRN & & \\
\hline CHEMBL3960372 & 1642489 & 6.7282 & 6.8849 & TRN & & \\
\hline CHEMBL 3947804 & 1642489 & 6.9245 & 6.7089 & TRN & & \\
\hline CHEMBL3962245 & 1642489 & 6.0 & 6.8162 & TRN & & \\
\hline CHEMBL3892990 & 1642489 & 7.1024 & 6.8346 & TRN & & \\
\hline CHEMBL3969836 & 1642489 & 7.2291 & 6.809 & TRN & & \\
\hline CHEMBL3909316 & 1642489 & 6.8665 & 6.7368 & TRN & & \\
\hline CHEMBL3956058 & 1642489 & 7.3279 & 6.7604 & TRN & & \\
\hline CHEMBL3907148 & 1642489 & 6.0 & 6.7495 & TRN & & \\
\hline CHEMBL3944393 & 1642489 & 6.7799 & 6.6389 & TRN & & \\
\hline CHEMBL3931609 & 1642489 & 7.3372 & 6.7893 & TRN & & \\
\hline CHEMBL3931010 & 1642489 & 6.0 & 6.605 & TRN & & \\
\hline CHEMBL 3960578 & 1642489 & 6.7328 & 7.0165 & TRN & & \\
\hline CHEMBL3905745 & 1642489 & 6.0 & 6.8104 & TRN & & \\
\hline CHEMBL3956838 & 1642489 & 6.4377 & 6.9609 & TRN & & \\
\hline
\end{tabular}


Supplemental Table S2.txt

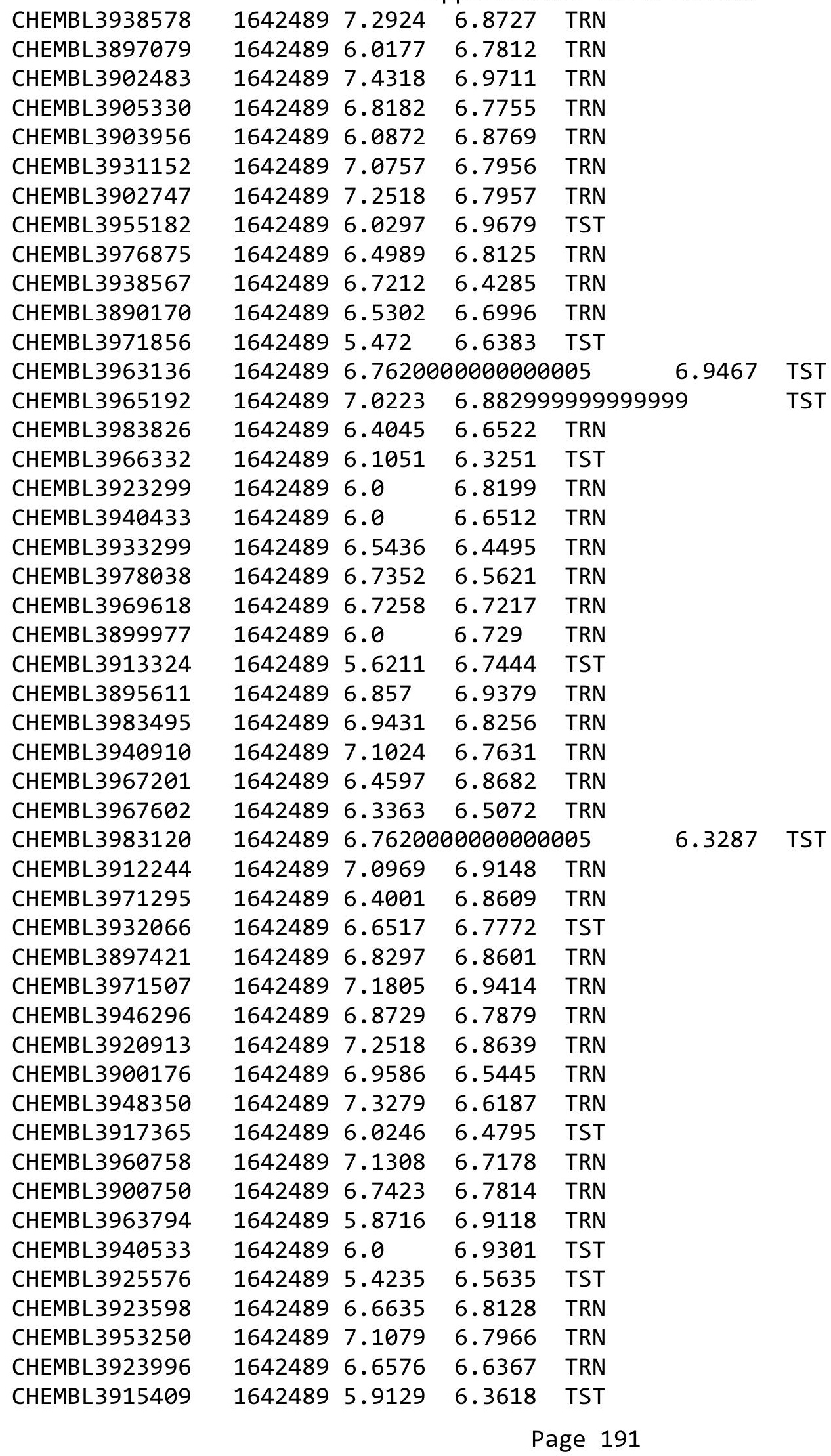


Supplemental Table S2.txt

\begin{tabular}{|c|c|c|}
\hline (1) & & \\
\hline CHEMBL & & \\
\hline AEMBL3974842 & 642489 & \\
\hline HEMBL3929630 & 642489 & 86 \\
\hline HEMBL 3897094 & 642489 & 5.857 \\
\hline HEMBL 3952470 & 89 & 7.193 \\
\hline AEMBL3934081 & 489 & 7.301 \\
\hline HEMBL3935828 & 642489 & 6.847 \\
\hline AEMBL 3957920 & 1642489 & 6.987 \\
\hline AEMBL3921780 & 89 & \\
\hline L3982505 & & 71 \\
\hline AEMBL3985682 & 489 & 6.943 \\
\hline HEMBL391 & 89 & 7.397 \\
\hline HEMBL 392 & 16 & 6.73 \\
\hline AEMBL3918723 & 16 & \\
\hline 3934871 & & 386 \\
\hline AEMBL3925966 & 16 & 6.679 \\
\hline HEMBL 394 & 39 & 267 \\
\hline 984 & & 6 \\
\hline 62 & 16 & 5 \\
\hline 51 & & 18 \\
\hline 011 & 39 & 514 \\
\hline L395 & 16 & 31 \\
\hline L394 & & 102 \\
\hline 394 & 16 & \\
\hline 694 & 16 & 3979 \\
\hline 3937841 & 39 & 218 \\
\hline L3933059 & 16 & \\
\hline AEMBL3921112 & 16 & 267 \\
\hline 383 & & 7. \\
\hline 97 & 39 & 43 \\
\hline L391 & & 337 \\
\hline HEMBL3926113 & 16 & 7.387 \\
\hline HEMBL3961438 & 164 & 6.0 \\
\hline L394 & 16 & 6.0 \\
\hline 1 & 16 & 7.356 \\
\hline HEMBL3960485 & 16 & 6. \\
\hline HEMBL 3957808 & 16 & 6.630 \\
\hline HEMBL3965595 & 16 & 6.243 \\
\hline IEMBL3951777 & 16 & 7.481 \\
\hline 389 & & 7.050 \\
\hline HEMBL 3902743 & 164 & 7.251 \\
\hline CHEMBL3895003 & 16 & 7.017 \\
\hline CHEMBL3917666 & 16 & 7.036 \\
\hline CHEMBL3897999 & 164 & 5.422 \\
\hline CHEMBL 3932870 & 164 & 6.694 \\
\hline HEMBL 3946378 & 1642489 & 7.744 \\
\hline CHEMBL3907746 & 1642489 & 6.632 \\
\hline
\end{tabular}

$\begin{array}{ll}6.8249 & \text { TRN } \\ 6.7951 & \text { TRN } \\ 6.7346 & \text { TRN } \\ 6.6417 & \text { TRN } \\ 6.8146 & \text { TRN } \\ 6.7768 & \text { TRN } \\ 6.7423 & \text { TRN } \\ 6.7512 & \text { TRN } \\ 6.4897 & \text { TRN } \\ 6.7307 & \text { TRN } \\ 6.6942 & \text { TRN } \\ 6.801 & \text { TRN } \\ 7.1754 & \text { TRN } \\ 6.6871 & \text { TRN } \\ 6.9307 & \text { TRN } \\ 6.5865 & \text { TRN } \\ 6.7211 & \text { TRN } \\ 6.751 & \text { TRN } \\ 6.6765 & \text { TRN } \\ 6.4543 & \text { TST } \\ 6.598 & \text { TST } \\ 7.0829 & \text { TST } \\ 6.95 & \text { TST } \\ 6.8660000000000005 \\ 6.82 & \text { TST } \\ 6.7399 & \text { TST } \\ 6.6208 & \text { TST } \\ 6.8636 & \text { TST } \\ 6.8816 & \text { TST } \\ 6.8687 & \text { TST } \\ 6.7778 & \text { TST } \\ 6.7853 & \text { TST } \\ 6.8032 & \text { TST } \\ 6.8661 & \text { TST } \\ 6.8562 & \text { TST } \\ 6.7849 & \text { TST } \\ 6.7177 & \text { TST } \\ 6.4174 & \text { TST } \\ 6.8256 & \text { TST } \\ 6.8036 & \text { TST } \\ 6.8062 & \text { TST } \\ 7.0766 & \text { TST } \\ 6.9355 & \text { TST } \\ 6.4857 & \text { TST } \\ 6.6739 & \text { TST } \\ 6.862 & \text { TST } \\ 6.8777 & \text { TST } \\ 6.9911 & \text { TST } \\ & \\ 6.90 \\ 6.90\end{array}$

TST 
Supplemental Table S2.txt

\begin{tabular}{|c|c|c|c|c|}
\hline CHEMBL3918451 & 1642489 & 6.8386 & 7.0384 & TST \\
\hline CHEMBL 3967043 & 1642489 & 6.0 & 6.9148 & TST \\
\hline CHEMBL3960267 & 1642489 & 6.7721 & 6.7761 & TST \\
\hline CHEMBL 3909484 & 1642489 & 5.8416 & 6.855 & TST \\
\hline CHEMBL 3961912 & 1642489 & 6.9957 & 7.0633 & TST \\
\hline CHEMBL 3934892 & 1642489 & 6.6576 & 6.6518 & TST \\
\hline CHEMBL3966534 & 1642489 & 6.0 & 6.9158 & TST \\
\hline CHEMBL 3942267 & 1642489 & 7.0969 & 7.1119 & TST \\
\hline CHEMBL3915572 & 1642489 & 6.4168 & 7.0431 & TST \\
\hline CHEMBL3925385 & 1642489 & 6.7305 & 6.8703 & TST \\
\hline CHEMBL 3933140 & 1642489 & 6.2373 & 6.8149 & TST \\
\hline CHEMBL 3894396 & 1642489 & 6.1818 & 6.8167 & TST \\
\hline CHEMBL3974995 & 1642489 & 7.1487 & 6.7572 & TST \\
\hline CHEMBL3927190 & 1642489 & 6.6946 & 6.6621 & TST \\
\hline CHEMBL 3922648 & 1642489 & 6.8861 & 6.8469 & TST \\
\hline CHEMBL 3943865 & 1642489 & 5.4069 & 6.7996 & TST \\
\hline CHEMBL3963439 & 1642489 & 6.6861 & 6.7932 & TST \\
\hline CHEMBL 3965066 & 1642489 & 7.5528 & 6.7731 & TST \\
\hline CHEMBL3901535 & 1642489 & 7.2291 & 6.4209 & TST \\
\hline CHEMBL 3917500 & 1642489 & 7.1367 & 6.8803 & TST \\
\hline CHEMBL3930894 & 1642489 & 6.8894 & 6.7787 & TST \\
\hline CHEMBL 3927313 & 1642489 & 5.9646 & 6.8941 & TST \\
\hline CHEMBL506225 & 555772 & 7.9586 & 7.9748 & TRN \\
\hline CHEMBL362146 & 555772 & 8.5686 & 8.7524 & TRN \\
\hline CHEMBL503307 & 555772 & 7.1938 & 7.2376 & TRN \\
\hline CHEMBL454022 & 555772 & 8.2366 & 8.4044 & TRN \\
\hline CHEMBL510098 & 555772 & 7.6925 & 8.0612 & TRN \\
\hline CHEMBL448640 & 555772 & 8.6198 & 8.7984 & TRN \\
\hline CHEMBL447258 & 555772 & 7.7645 & 8.0757 & TST \\
\hline CHEMBL506777 & 555772 & 7.8239 & 7.5679 & TST \\
\hline CHEMBL450892 & 555772 & 7.8297 & 8.2837 & TST \\
\hline CHEMBL475137 & 555772 & 8.3872 & 8.5535 & TRN \\
\hline CHEMBL505186 & 555772 & 8.1739 & 8.0856 & TRN \\
\hline CHEMBL453709 & 555772 & 7.8601 & 8.1871 & TRN \\
\hline CHEMBL498935 & 555772 & 7.8239 & 7.9926 & TST \\
\hline CHEMBL452738 & 555772 & 8.2676 & 8.3819 & TRN \\
\hline CHEMBL445708 & 555772 & 8.9208 & 8.4086 & TST \\
\hline CHEMBL502417 & 555772 & 7.8182 & 8.0415 & TRN \\
\hline CHEMBL503845 & 555772 & 7.9208 & 7.8873 & TRN \\
\hline CHEMBL510577 & 555772 & 7.8861 & 8.0299 & TRN \\
\hline CHEMBL503601 & 555772 & 8.8861 & 8.7281 & TRN \\
\hline CHEMBL504170 & 555772 & 8.2924 & 8.3937 & TRN \\
\hline CHEMBL447645 & 555772 & 9.0458 & 8.8684 & TRN \\
\hline CHEMBL507683 & 555772 & 8.7447 & 8.3354 & TRN \\
\hline CHEMBL504333 & 555772 & 8.9586 & 8.5869 & TST \\
\hline CHEMBL502695 & 555772 & 7.3768 & \multicolumn{2}{|c|}{7.928999999999999} \\
\hline CHEMBL442936 & 555772 & 8.6198 & 8.4339 & TST \\
\hline CHEMBL445812 & 555772 & 8.6778 & 8.7684 & TRN \\
\hline
\end{tabular}




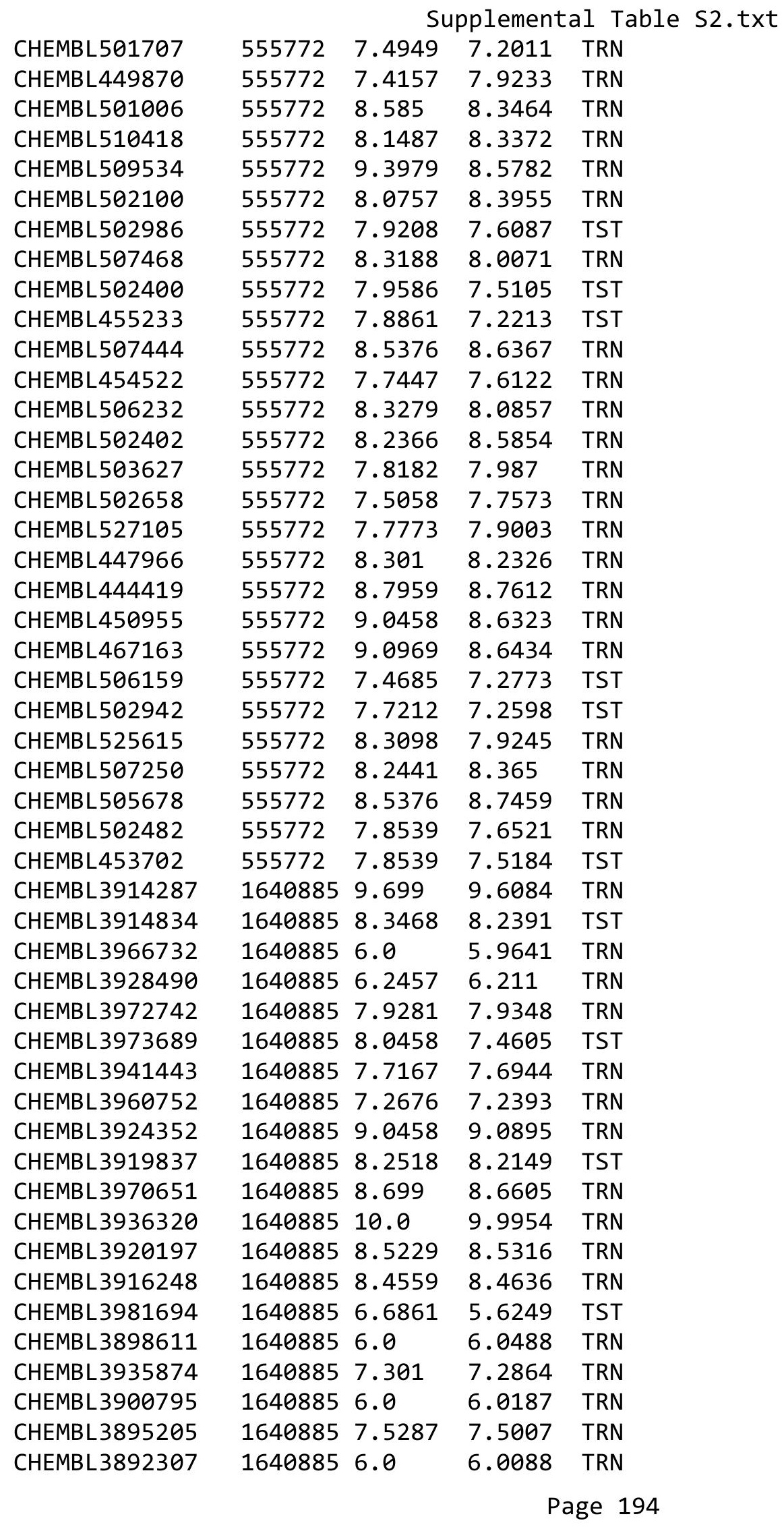


Supplemental Table S2.txt

\begin{tabular}{|c|c|c|c|c|}
\hline CHEMBL3922469 & 1640885 & 9.699 & 9.6981 & TRN \\
\hline CHEMBL3910008 & 1640885 & 9.0 & 9.0467 & TRN \\
\hline CHEMBL3937943 & 1640885 & 7.8539 & 8.2271 & TST \\
\hline CHEMBL 3918076 & 1640885 & 9.699 & 9.6965 & TRN \\
\hline CHEMBL 3924011 & 1640885 & 8.6198 & 9.2116 & TST \\
\hline CHEMBL 3904472 & 1640885 & 5.0 & 5.0 & TRN \\
\hline CHEMBL 3947580 & 1640885 & 9.0 & 9.4497 & TST \\
\hline CHEMBL 3900463 & 1640885 & 9.5229 & 9.5112 & TRN \\
\hline CHEMBL3963604 & 1640885 & 6.8239 & \multicolumn{2}{|c|}{6.388999999999999} \\
\hline CHEMBL 3928216 & 1640885 & 9.5229 & 9.4856 & TRN \\
\hline CHEMBL 3955725 & 1640885 & 7.4711 & 6.0224 & TST \\
\hline CHEMBL 3952051 & 1640885 & 6.9706 & 6.9702 & TRN \\
\hline CHEMBL3969621 & 1640885 & 7.4168 & 7.7301 & TST \\
\hline CHEMBL3974415 & 1640885 & 8.6576 & 8.6824 & TRN \\
\hline CHEMBL 3950192 & 1640885 & 7.6021 & 7.5962 & TRN \\
\hline CHEMBL3982322 & 1640885 & 8.3979 & 7.5198 & TST \\
\hline CHEMBL3940201 & 1640885 & 6.0 & 6.3928 & TST \\
\hline CHEMBL 3890530 & 1640885 & 10.0 & 9.9779 & TRN \\
\hline CHEMBL3959100 & 1640885 & 7.4559 & \multicolumn{2}{|c|}{7.497000000000001} \\
\hline CHEMBL 3921064 & 1640885 & 8.6576 & 8.6309 & TRN \\
\hline CHEMBL3932460 & 1640885 & 9.699 & 9.7509 & TRN \\
\hline CHEMBL 3966144 & 1640885 & 7.4145 & 7.43 & TRN \\
\hline CHEMBL 3923683 & 1640885 & 6.0 & 6.0156 & TRN \\
\hline CHEMBL3936842 & 1640885 & 7.8539 & 7.8572 & TRN \\
\hline CHEMBL3957474 & 1640885 & 8.9208 & 8.9223 & TRN \\
\hline CHEMBL3952938 & 1640885 & 8.7959 & 8.7925 & TST \\
\hline CHEMBL 3949500 & 1640885 & 8.0655 & 8.5228 & TST \\
\hline CHEMBL3893193 & 1640885 & 9.0969 & 9.0965 & TRN \\
\hline CHEMBL3919646 & 1640885 & 6.0 & 6.0296 & TRN \\
\hline CHEMBL3915354 & 1640885 & 8.0969 & 8.1006 & TRN \\
\hline CHEMBL3965074 & 1640885 & 6.0 & 5.9797 & TRN \\
\hline CHEMBL 3902922 & 1640885 & 7.4202 & \multicolumn{2}{|c|}{7.1770000000000005} \\
\hline CHEMBL3936992 & 1640885 & 9.5229 & 9.5342 & TRN \\
\hline CHEMBL3922101 & 1640885 & 8.1549 & 8.0111 & TST \\
\hline CHEMBL3951503 & 1640885 & 7.0044 & 7.0235 & TRN \\
\hline CHEMBL3914768 & 1640885 & 6.7167 & 6.6688 & TRN \\
\hline CHEMBL 3986154 & 1640885 & 10.0 & 9.993 & TRN \\
\hline CHEMBL 3927505 & 1640885 & 8.4685 & 8.4742 & TRN \\
\hline CHEMBL 3944210 & 1640885 & 6.2725 & \multicolumn{2}{|c|}{5.696000000000001} \\
\hline CHEMBL 3942827 & 1640885 & 9.5229 & 9.5553 & TRN \\
\hline CHEMBL3912242 & 1640885 & 8.699 & 8.7075 & TRN \\
\hline CHEMBL3905239 & 1640885 & 9.0458 & 9.0417 & TRN \\
\hline CHEMBL 3937423 & 1640885 & 8.8239 & 8.8254 & TRN \\
\hline CHEMBL3931386 & 1640885 & 9.3979 & 9.4209 & TRN \\
\hline CHEMBL3920733 & 1640885 & 9.0458 & 9.0516 & TRN \\
\hline CHEMBL281065 & 155208 & 7.3979 & 7.4883 & TRN \\
\hline CHEMBL 280699 & 155208 & 8.1871 & 8.1734 & TRN \\
\hline CHEMBL24552 & 155208 & 7.2596 & 7.6094 & TST \\
\hline
\end{tabular}




\begin{tabular}{|c|c|c|c|c|c|}
\hline \multicolumn{6}{|c|}{ Supplemental Table S2.txt } \\
\hline CHEMBL26775 & 155208 & 8.5528 & 8.3829 & TRN & \\
\hline CHEMBL488322 & 155208 & 7.3188 & 7.2773 & TRN & \\
\hline CHEMBL26229 & 155208 & 8.6778 & 8.7941 & TRN & \\
\hline CHEMBL23123 & 155208 & 8.7959 & 8.5782 & TRN & \\
\hline CHEMBL279903 & 155208 & 8.6576 & 8.7328 & TRN & \\
\hline CHEMBL283242 & 155208 & 8.2007 & 8.471 & TST & \\
\hline CHEMBL440786 & 155208 & 7.2366 & 7.5673 & TRN & \\
\hline CHEMBL283562 & 155208 & 8.3468 & 7.5529 & TST & \\
\hline CHEMBL 24691 & 155208 & 6.2596 & 6.1603 & TRN & \\
\hline CHEMBL25985 & 155208 & 8.0809 & 7.87799 & 9999999999 & TST \\
\hline CHEMBL432657 & 155208 & 8.8239 & 8.8331 & TRN & \\
\hline CHEMBL25419 & 155208 & 8.5528 & 8.9594 & TST & \\
\hline CHEMBL177716 & 155208 & 8.3979 & 8.4067 & TRN & \\
\hline CHEMBL 23308 & 155208 & 8.8861 & 9.1792 & TST & \\
\hline CHEMBL24536 & 155208 & 8.5086 & 8.6126 & TRN & \\
\hline CHEMBL23375 & 155208 & 8.8861 & 8.7919 & TRN & \\
\hline CHEMBL24815 & 155208 & 8.699 & 8.7825 & TRN & \\
\hline CHEMBL286723 & 155208 & 9.0458 & 8.9895 & TRN & \\
\hline CHEMBL23992 & 155208 & 8.4089 & 8.1824 & TRN & \\
\hline CHEMBL26396 & 155208 & 9.5229 & 9.4706 & TRN & \\
\hline CHEMBL282528 & 155208 & 6.8861 & 6.9628 & TRN & \\
\hline CHEMBL282189 & 155208 & 8.7447 & 8.7656 & TRN & \\
\hline CHEMBL26102 & 155208 & 8.6383 & 8.586 & TRN & \\
\hline CHEMBL23513 & 155208 & 7.3665 & 9.3489 & TST & \\
\hline CHEMBL24653 & 155208 & 8.301 & 8.2561 & TRN & \\
\hline CHEMBL282709 & 155208 & 9.2147 & 8.6263 & TST & \\
\hline CHEMBL 23572 & 155208 & 8.7212 & 9.0095 & TST & \\
\hline CHEMBL281087 & 155208 & 8.0969 & 8.14 & TRN & \\
\hline CHEMBL24228 & 155208 & 7.9586 & 8.8898 & TST & \\
\hline CHEMBL423838 & 155208 & 6.7959 & 6.959 & TRN & \\
\hline CHEMBL280993 & 155208 & 7.6576 & 7.6122 & TRN & \\
\hline CHEMBL441223 & 155208 & 8.2676 & 8.3073 & TRN & \\
\hline CHEMBL282114 & 155208 & 8.7959 & 8.9199 & TRN & \\
\hline CHEMBL 285573 & 155208 & 8.1675 & 8.2396 & TRN & \\
\hline CHEMBL285610 & 155208 & 8.9586 & 8.8582 & TRN & \\
\hline CHEMBL26445 & 155208 & 7.8861 & 7.8539 & TRN & \\
\hline CHEMBL25311 & 155208 & 8.301 & 8.2587 & TRN & \\
\hline CHEMBL280576 & 155208 & 7.7447 & 7.8926 & TRN & \\
\hline CHEMBL 280525 & 155208 & 9.0458 & 8.86 & TRN & \\
\hline CHEMBL280624 & 155208 & 8.6778 & 8.9901 & TRN & \\
\hline CHEMBL 24543 & 155208 & 8.6778 & 8.6719 & TRN & \\
\hline CHEMBL281772 & 155208 & 8.2007 & 8.1591 & TRN & \\
\hline CHEMBL436144 & 155208 & 7.3372 & 7.3223 & TRN & \\
\hline CHEMBL 277692 & 155208 & 7.699 & 7.386 & TRN & \\
\hline CHEMBL280578 & 155208 & 8.1871 & 8.0239 & TST & \\
\hline CHEMBL446663 & 155208 & 7.4089 & 7.3882 & TST & \\
\hline CHEMBL487704 & 155208 & 8.1549 & 8.1868 & TRN & \\
\hline CHEMBL 24587 & 155208 & 8.5229 & 8.9897 & TST & \\
\hline
\end{tabular}




\begin{tabular}{|c|c|c|c|c|c|}
\hline \multicolumn{6}{|c|}{ Supplemental Table S2.txt } \\
\hline CHEMBL92476 & 42968 & 4.2596 & 4.1437 & TRN & \\
\hline CHEMBL354829 & 42968 & 5.9586 & 5.7212 & TST & \\
\hline CHEMBL170162 & 42968 & 5.3665 & 5.6379 & TST & \\
\hline CHEMBL354616 & 42968 & 5.4089 & 5.403 & TRN & \\
\hline CHEMBL37755 & 42968 & 5.4318 & 5.1048 & TST & \\
\hline CHEMBL170117 & 42968 & 5.6198 & 5.3942 & TRN & \\
\hline CHEMBL354803 & 42968 & 5.7447 & 5.5304 & TRN & \\
\hline CHEMBL287361 & 42968 & 5.8539 & 5.7153 & TRN & \\
\hline CHEMBL305204 & 42968 & 6.1549 & 6.1242 & TRN & \\
\hline CHEMBL312293 & 42968 & 6.1549 & 6.0778 & TRN & \\
\hline CHEMBL169119 & 42968 & 5.7959 & 5.6987 & TST & \\
\hline CHEMBL171786 & 42968 & 5.7959 & 5.5212 & TRN & \\
\hline CHEMBL171720 & 42968 & 5.7447 & 5.9406 & TRN & \\
\hline CHEMBL86226 & 42968 & 5.7447 & 5.7361 & TST & \\
\hline CHEMBL169391 & 42968 & 5.7959 & 5.9023 & TRN & \\
\hline CHEMBL67867 & 42968 & 6.0969 & 6.1564 & TRN & \\
\hline CHEMBL354499 & 42968 & 5.3372 & 5.6598 & TRN & \\
\hline CHEMBL168269 & 42968 & 5.6198 & 5.6401 & TRN & \\
\hline CHEMBL169849 & 42968 & 5.7959 & 5.6099 & TRN & \\
\hline CHEMBL171229 & 42968 & 5.7212 & 5.3514 & TST & \\
\hline CHEMBL171873 & 42968 & 5.9586 & 5.9651 & TRN & \\
\hline CHEMBL172271 & 42968 & 5.4815 & 5.5927 & TRN & \\
\hline CHEMBL354783 & 42968 & 5.7696 & 5.7165 & TRN & \\
\hline CHEMBL169543 & 42968 & 5.7959 & 5.9659 & TRN & \\
\hline CHEMBL 2110204 & 42968 & 6.0 & 5.8966 & TRN & \\
\hline CHEMBL169142 & 42968 & 5.6198 & 5.5244 & TRN & \\
\hline CHEMBL168384 & 42968 & 5.2007 & 5.3276 & TRN & \\
\hline CHEMBL171434 & 42968 & 4.2366 & 4.7302 & TST & \\
\hline CHEMBL3350251 & 42968 & 6.0 & 5.9751 & TRN & \\
\hline CHEMBL355438 & 42968 & 3.2291 & 5.6142 & TST & \\
\hline CHEMBL70986 & 42968 & 6.0 & 6.0041 & TRN & \\
\hline CHEMBL169871 & 42968 & 5.2518 & 5.1955 & TRN & \\
\hline CHEMBL168270 & 42968 & 5.284 & 5.13200 & 0000000001 & TRN \\
\hline CHEMBL169278 & 42968 & 5.6021 & 5.7201 & TRN & \\
\hline CHEMBL354867 & 42968 & 5.2366 & 5.5151 & TRN & \\
\hline CHEMBL433616 & 42968 & 5.3565 & 5.2528 & TST & \\
\hline CHEMBL 306421 & 42968 & 6.0969 & 6.1867 & TRN & \\
\hline CHEMBL169256 & 42968 & 4.7959 & 5.0065 & TST & \\
\hline CHEMBL169878 & 42968 & 5.3768 & 5.4592 & TST & \\
\hline CHEMBL354173 & 42968 & 4.7212 & 4.8035 & TRN & \\
\hline CHEMBL355735 & 42968 & 5.0223 & 5.8757 & TST & \\
\hline CHEMBL168369 & 42968 & 5.301 & 5.3194 & TRN & \\
\hline CHEMBL169381 & 42968 & 6.1549 & 5.8547 & TRN & \\
\hline CHEMBL354615 & 42968 & 5.8539 & 5.8665 & TRN & \\
\hline CHEMBL351155 & 42968 & 5.6778 & 5.7274 & TRN & \\
\hline CHEMBL263268 & 42968 & 5.4559 & 5.4678 & TRN & \\
\hline CHEMBL169714 & 42968 & 5.3872 & 5.6902 & TRN & \\
\hline CHEMBL171729 & 42968 & 5.7447 & 5.824 & TST & \\
\hline
\end{tabular}




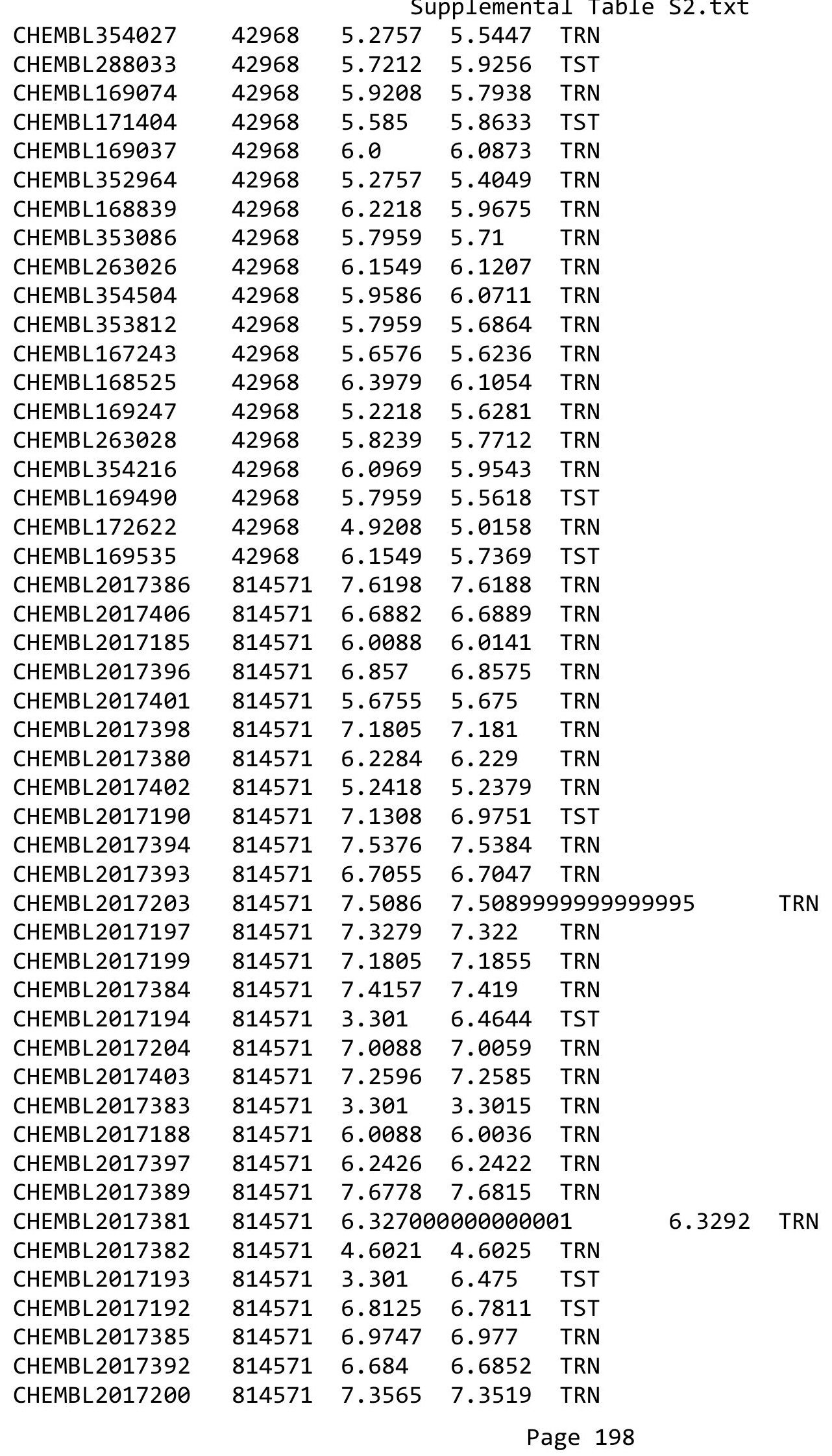


Supplemental Table S2.txt

\begin{tabular}{|c|c|c|c|c|}
\hline CHEMBL2017186 & 14571 & 6.0232 & 6.2825 & TST \\
\hline HEMBL2017399 & 314571 & 7.1427 & 7.1436 & TRN \\
\hline HEMBL 201739 & 14571 & 6.9666 & 6.972 & N \\
\hline HEMBL 2017182 & 14571 & 3125 & 6666 & \\
\hline HEMBL2017390 & 314571 & .5229 & 5215 & RN \\
\hline HEMBL2017407 & 814571 & 6.0835 & .084 & \\
\hline HEMBL2017196 & 14571 & 6.8729 & .8739 & RN \\
\hline HEMBL 2017400 & 314571 & .3116 & .3124 & DN \\
\hline HEMBL2017388 & 814571 & 7.9208 & 7.9044 & RN \\
\hline HEMBL2017180 & 314571 & 4.3372 & 5.7962 & ST \\
\hline HEMBL2017391 & 314571 & 7.6198 & 7.6206 & RN \\
\hline HEMBL2017404 & 314 & 431 & .9385 & $\mathrm{RN}$ \\
\hline HEMBL 201 & 314 & & 3067 & \\
\hline HEMBL2017405 & 814571 & 6.7144 & 6.7122 & IRIN \\
\hline HEMBL2017205 & 14 & 77 & 6.8466 & . \\
\hline HEMBL 201 & 314 & 5. & 6. & \\
\hline HEMBL 201 & 71 & 56 & 39 & ST \\
\hline HEMBL 201 & 814 & 6. & 14 & ST \\
\hline HEMBL 201 & 71 & 6 . & 6.0032 & 13 \\
\hline HEMBL 201 & 314 & 5. & 52 & 151 \\
\hline HEMBL 20 & 314 & 7.69 & 7.7145 & 「RN \\
\hline HEMBL19 & 46 & 4 & 96 & RN \\
\hline HEMBL $20 \Theta$ & 809 & 4. & 417 & RN \\
\hline HEMBL 202 & 309 & & 4.5433 & RN \\
\hline HEMBL 200 & 305 & & 251 & IRN \\
\hline HEMBL19 & $30 s$ & & 5952 & TRN \\
\hline HEMBL19 & 805 & 4 & 88 & $\mathrm{RN}$ \\
\hline HEMBL19 & 805 & 4. & 4.7818 & TRN \\
\hline HEMBL509 & 809 & & 57 & TRN \\
\hline HEMBL388 & 809146 & & 7.4988 & TRN \\
\hline HEMBL19 & 309 & 4 & 486 & 「RN \\
\hline HEMBL 19 & 16 & 4. & 65 & TRN \\
\hline HEMBL 19 & 800 & 3. & & TRN \\
\hline HEMBL198 & 809 & 4 . & 365 & TRN \\
\hline HEMBL1993413 & 809 & 4 & 0054 & TRN \\
\hline HEMBL 20 & 809 & 4 & 434 & TRN \\
\hline CHEMBL1S & 16 & 6. & 195 & TRN \\
\hline CHEMBL198 & 809 & 6.0 & 5.9498 & TRN \\
\hline CHEMBL2001920 & 809 & 4 & 802 & TRN \\
\hline LHEMBL197 & 809 & 5 & 24 & TRN \\
\hline CHEMBL197 & 809 & 4 . & 4.3646 & ונדי \\
\hline CHEMBL198 & 809146 & 5.9 & 5.7996 & TRN \\
\hline CHEMBL1992042 & 809146 & 5 . & 5.2425 & TRN \\
\hline CHEMBL1986265 & 809 & 4. & 99 & $\mathrm{TR}$ \\
\hline CHEMBL1 & 809 & 4 & & TIV \\
\hline CHEMBL1991734 & 809146 & 6.5 & 5.641 & \\
\hline CHEMBL 21156 & 809146 & 6.7 & 5.7156 & ГRN \\
\hline CHEMBL1994724 & 809146 & 4.5 & 4.6879 & RN \\
\hline
\end{tabular}

Page 199 


\begin{tabular}{|c|c|c|c|c|}
\hline \multicolumn{5}{|c|}{ lemental T } \\
\hline CHEMBL1989267 & 809146 & 5.6 & 5.1269 & TRN \\
\hline CHEMBL1991782 & 809146 & 3.2 & 2.8537 & TRN \\
\hline CHEMBL1983348 & 809146 & 6.5 & 6.1325 & TRN \\
\hline CHEMBL1970290 & 809146 & 4.5 & 5.1366 & TRN \\
\hline CHEMBL1993877 & 809146 & 4.5 & 4.7601 & TRN \\
\hline CHEMBL1996500 & 809146 & 4.5 & 4.6279 & TRN \\
\hline CHEMBL1986177 & 809146 & 4.5 & 4.3114 & TRN \\
\hline CHEMBL1989708 & 809146 & 4.5 & 4.9908 & TRN \\
\hline CHEMBL1976420 & 809146 & 4.5 & 4.5435 & TRN \\
\hline CHEMBL1981744 & 809146 & 4.5 & 4.712 & TRN \\
\hline CHEMBL1985367 & 809146 & 4.5 & 4.5782 & TRN \\
\hline CHEMBL1996510 & 809146 & 4.5 & 5.1987 & TRN \\
\hline CHEMBL497151 & 809146 & 5.9 & 4.9422 & TRN \\
\hline CHEMBL 2000029 & 809146 & 6.5 & 5.9865 & TRN \\
\hline CHEMBL1995172 & 809146 & 4.5 & 4.1038 & TRN \\
\hline CHEMBL 2001584 & 809146 & 4.5 & 4.3891 & TRN \\
\hline CHEMBL1973961 & 809146 & 4.5 & 5.0693 & TRN \\
\hline CHEMBL1967998 & 809146 & 6.5 & 6.7423 & TRN \\
\hline CHEMBL1978562 & 809146 & 4.5 & 4.8536 & TRN \\
\hline CHEMBL1994977 & 809146 & 4.5 & 4.4403 & TRN \\
\hline CHEMBL 2001149 & 809146 & 4.5 & 4.6135 & TRN \\
\hline CHEMBL1974875 & 809146 & 4.1 & 4.2148 & TRN \\
\hline CHEMBL 2005478 & 809146 & 5.5 & 4.9733 & TRN \\
\hline CHEMBL1996646 & 809146 & 5.5 & 5.4784 & TRN \\
\hline CHEMBL1979773 & 809146 & 4.5 & 4.4525 & TRN \\
\hline CHEMBL1989471 & 809146 & 5.9 & 5.0343 & TST \\
\hline CHEMBL1977346 & 809146 & 4.8 & 4.7904 & TRN \\
\hline CHEMBL 2002099 & 809146 & 4.5 & 4.5305 & TRN \\
\hline CHEMBL1996702 & 809146 & 4.5 & 5.2067 & TRN \\
\hline CHEMBL 2007124 & 809146 & 4.5 & 4.5759 & TRN \\
\hline CHEMBL1978195 & 809146 & 4.5 & 4.9722 & TRN \\
\hline CHEMBL 2006439 & 809146 & 4.5 & 4.6953 & TRN \\
\hline CHEMBL1985681 & 809146 & 6.1 & 5.3037 & TRN \\
\hline CHEMBL1991674 & 809146 & 4.5 & 5.2582 & TRN \\
\hline CHEMBL1982711 & 809146 & 6.1 & 4.8504 & TRN \\
\hline CHEMBL262623 & 809146 & 4.4 & 4.1336 & TRN \\
\hline CHEMBL1984842 & 809146 & 4.5 & 4.8581 & TRN \\
\hline CHEMBL2004118 & 809146 & 6.3 & 5.3503 & TRN \\
\hline CHEMBL1996345 & 809146 & 4.5 & 4.27 & TRN \\
\hline CHEMBL 2004025 & 809146 & 4.5 & 5.1286 & TRN \\
\hline CHEMBL1996048 & 809146 & 4.5 & 4.6657 & TRN \\
\hline CHEMBL50894 & 809146 & 4.5 & 4.5805 & TRN \\
\hline CHEMBL1995211 & 809146 & 4.5 & 4.4303 & TRN \\
\hline CHEMBL1965033 & 809146 & 4.5 & 4.349 & TRN \\
\hline CHEMBL461876 & 809146 & 4.5 & 5.329 & TRN \\
\hline CHEMBL1982753 & 809146 & 4.5 & 4.7186 & TRN \\
\hline CHEMBL2006299 & 809146 & 4.5 & 4.386 & TRN \\
\hline CHEMBL1972346 & 809146 & 6.2 & 5.1012 & TST \\
\hline
\end{tabular}




\begin{tabular}{|c|c|c|c|c|c|}
\hline \\
\hline CHEMBL1997335 & 809146 & 6.2 & 5.5813 & TRN & \\
\hline CHEMBL1965169 & 809146 & 4.5 & 4.2544 & TRN & \\
\hline CHEMBL1081312 & 809146 & 4.5 & 4.9044 & TRN & \\
\hline CHEMBL1965170 & 809146 & 4.5 & 4.6457 & TRN & \\
\hline CHEMBL2005792 & 809146 & 4.5 & 4.7615 & TRN & \\
\hline CHEMBL1972355 & 809146 & 5.8 & 5.7344 & TRN & \\
\hline CHEMBL1997892 & 809146 & 4.5 & 4.4967 & TRN & \\
\hline CHEMBL2001641 & 809146 & 4.1 & 4.6193 & TRN & \\
\hline CHEMBL1997193 & 809146 & 4.5 & 4.8178 & TST & \\
\hline CHEMBL1964902 & 809146 & 4.5 & 4.3882 & TRN & \\
\hline CHEMBL1973868 & 809146 & 4.5 & 4.3749 & TRN & \\
\hline CHEMBL1972462 & 809146 & 4.5 & 4.4458 & TRN & \\
\hline CHEMBL1983715 & 809146 & 7.0 & 6.7326 & TRN & \\
\hline CHEMBL1984500 & 809146 & 3.2 & 3.0821 & TRN & \\
\hline CHEMBL2002992 & 809146 & 4.5 & 4.8019 & TRN & \\
\hline CHEMBL560813 & 809146 & 4.8 & 4.6031 & TRN & \\
\hline CHEMBL1982700 & 809146 & 4.5 & 4.5033 & TRN & \\
\hline CHEMBL10 & 809146 & 4.5 & 4.3408 & TRN & \\
\hline CHEMBL1980763 & 809146 & 5.5 & 5.3259 & TRN & \\
\hline CHEMBL1977634 & 809146 & 4.5 & 4.2766 & TRN & \\
\hline CHEMBL1977931 & 809146 & 4.2 & 4.0672 & TRN & \\
\hline CHEMBL 2007479 & 809146 & 4.5 & 4.5703 & TRN & \\
\hline CHEMBL1998953 & 809146 & 4.5 & 4.2206 & TRN & \\
\hline CHEMBL1971606 & 809146 & 4.5 & 4.4053 & TRN & \\
\hline CHEMBL1972125 & 809146 & 4.8 & 5.4796 & TRN & \\
\hline CHEMBL1972220 & 809146 & 4.5 & 4.9761 & TRN & \\
\hline CHEMBL1981215 & 809146 & 4.5 & 4.6138 & TRN & \\
\hline CHEMBL2003785 & 809146 & 4.2 & 4.3617 & TRN & \\
\hline CHEMBL1973720 & 809146 & 5.7 & 5.8177 & TRN & \\
\hline CHEMBL1999414 & 809146 & 4.5 & 4.7989 & TRN & \\
\hline CHEMBL1967336 & 809146 & 4.5 & 4.6278 & TRN & \\
\hline CHEMBL2001923 & 809146 & 4.5 & 4.7149 & TRN & \\
\hline CHEMBL1983070 & 809146 & 4.5 & 4.3823 & TRN & \\
\hline CHEMBL 2003514 & 809146 & 4.5 & 4.4108 & TRN & \\
\hline CHEMBL1967992 & 809146 & 4.5 & 4.5834 & TRN & \\
\hline CHEMBL1989043 & 809146 & 4.5 & 4.8807 & TRN & \\
\hline CHEMBL 2006450 & 809146 & 4.5 & 4.14199 & 99999999995 & TRN \\
\hline CHEMBL1975534 & 809146 & 5.9 & 4.3772 & TRN & \\
\hline CHEMBL2001987 & 809146 & 4.5 & 4.4644 & TRN & \\
\hline CHEMBL1994555 & 809146 & 4.5 & 4.6181 & TRN & \\
\hline CHEMBL1164180 & 809146 & 4.5 & 5.2832 & TST & \\
\hline CHEMBL1975121 & 809146 & 4.5 & 4.5137 & TRN & \\
\hline CHEMBL1983640 & 809146 & 4.5 & 4.6446 & TRN & \\
\hline CHEMBL1997611 & 809146 & 4.5 & 4.9925 & TST & \\
\hline CHEMBL1971943 & 809146 & 4.5 & 4.3484 & TRN & \\
\hline CHEMBL1984686 & 809146 & 4.5 & 4.2182 & TST & \\
\hline CHEMBL1973793 & 809146 & 4.5 & 4.1957 & TRN & \\
\hline CHEMBL1992073 & 809146 & 4.5 & 4.9277 & TRN & \\
\hline
\end{tabular}




\begin{tabular}{|c|c|c|c|c|}
\hline & & & ipplemen & $d \perp 1$ \\
\hline CHEMBL1990254 & 809146 & 4.5 & 4.7422 & TRN \\
\hline CHEMBL1986143 & 809146 & 4.5 & 4.5243 & TRN \\
\hline CHEMBL 2007559 & 809146 & 4.5 & 4.6627 & TRN \\
\hline CHEMBL1992581 & 809146 & 6.7 & 4.9291 & TRN \\
\hline CHEMBL 2004290 & 809146 & 4.5 & 4.4987 & TRN \\
\hline CHEMBL1975921 & 809146 & 4.1 & 4.1506 & TRN \\
\hline CHEMBL1992634 & 809146 & 4.8 & 4.3688 & TRN \\
\hline CHEMBL1975923 & 809146 & 4.8 & 4.8725 & TST \\
\hline CHEMBL1984847 & 809146 & 4.5 & 4.5542 & TST \\
\hline CHEMBL2005449 & 809146 & 4.5 & 5.5378 & TRN \\
\hline CHEMBL1996576 & 809146 & 4.5 & 4.5409 & TST \\
\hline CHEMBL1991678 & 809146 & 4.5 & 4.6843 & TRN \\
\hline CHEMBL1987998 & 809146 & 4.5 & 4.1817 & TRN \\
\hline CHEMBL1971534 & 809146 & 4.1 & 4.5213 & TRN \\
\hline CHEMBL1990496 & 809146 & 4.5 & 4.4964 & TRN \\
\hline CHEMBL242865 & 809146 & 6.4 & 6.1158 & TRN \\
\hline CHEMBL235157 & 809146 & 4.5 & 4.3714 & TST \\
\hline CHEMBL1991725 & 809146 & 7.1 & 5.7275 & TRN \\
\hline CHEMBL 2004159 & 809146 & 4.5 & 4.2395 & TRN \\
\hline CHEMBL1978371 & 809146 & 4.5 & 5.1448 & TST \\
\hline CHEMBL440084 & 809146 & 4.5 & 4.3019 & TRN \\
\hline CHEMBL1998110 & 809146 & 4.5 & 4.3239 & TRN \\
\hline CHEMBL1978166 & 809146 & 5.8 & 5.4751 & TRN \\
\hline CHEMBL 2000832 & 809146 & 6.2 & 5.4379 & TRN \\
\hline CHEMBL1990590 & 809146 & 4.5 & 4.3831 & TRN \\
\hline CHEMBL1977814 & 809146 & 4.5 & 4.5757 & TST \\
\hline CHEMBL1974617 & 809146 & 4.3 & 4.6537 & TRN \\
\hline CHEMBL 86755 & 809146 & 4.5 & 5.09 & TRN \\
\hline CHEMBL1965660 & 809146 & 4.5 & 5.4051 & TRN \\
\hline CHEMBL1992125 & 809146 & 5.5 & 5.4273 & TRN \\
\hline CHEMBL1966175 & 809146 & 4.5 & 4.8062 & TRN \\
\hline CHEMBL1974702 & 809146 & 4.8 & 4.6374 & TST \\
\hline CHEMBL1965589 & 809146 & 4.8 & 4.8962 & TRN \\
\hline CHEMBL 2007375 & 809146 & 4.5 & 4.6556 & TRN \\
\hline CHEMBL1970104 & 809146 & 6.8 & 5.5651 & TRN \\
\hline CHEMBL379975 & 809146 & 4.5 & 5.0685 & TRN \\
\hline CHEMBL1965387 & 809146 & 4.5 & 4.3405 & TRN \\
\hline CHEMBL 388978 & 809146 & 8.9 & 7.138 & TST \\
\hline CHEMBL1997041 & 809146 & 4.3 & 4.6444 & TRN \\
\hline CHEMBL550418 & 809146 & 4.5 & 4.9174 & TRN \\
\hline CHEMBL1972584 & 809146 & 4.8 & 5.117 & TRN \\
\hline CHEMBL398951 & 809146 & 4.5 & 4.7459 & TST \\
\hline CHEMBL1971289 & 809146 & 4.5 & 4.7122 & TRN \\
\hline CHEMBL1988437 & 809146 & 5.8 & 4.8967 & TST \\
\hline CHEMBL1985406 & 809146 & 4.8 & 5.3067 & TRN \\
\hline CHEMBL1421720 & 809146 & 5.6 & 5.2552 & TRN \\
\hline CHEMBL1233887 & 809146 & 4.5 & 4.4507 & TRN \\
\hline CHEMBL1992607 & 809146 & 4.3 & 4.2002 & TRN \\
\hline
\end{tabular}




\begin{tabular}{|c|c|c|c|c|c|}
\hline \\
\hline CHEMBL1996649 & 809146 & 4.5 & 4.7115 & TRN & \\
\hline CHEMBL1986756 & 809146 & 4.5 & 4.6403 & TRN & \\
\hline CHEMBL1949855 & 809146 & 4.1 & 4.4626 & TRN & \\
\hline CHEMBL3109278 & 809146 & 4.5 & 4.657 & TRN & \\
\hline CHEMBL1990223 & 809146 & 4.5 & 4.2037 & TRN & \\
\hline CHEMBL 2004438 & 809146 & 4.5 & 4.1812 & TRN & \\
\hline CHEMBL1964382 & 809146 & 4.5 & 4.5895 & TST & \\
\hline CHEMBL101311 & 809146 & 4.5 & 4.9138 & TRN & \\
\hline CHEMBL191003 & 809146 & 4.5 & 5.2948 & TRN & \\
\hline CHEMBL1973359 & 809146 & 6.3 & 6.0382 & TST & \\
\hline CHEMBL1988581 & 809146 & 6.9 & 6.405 & TST & \\
\hline CHEMBL1975500 & 809146 & 4.8 & 5.2392 & TRN & \\
\hline CHEMBL2005699 & 809146 & 4.5 & 4.3096 & TRN & \\
\hline CHEMBL 2006564 & 809146 & 7.1 & 5.9783 & TRN & \\
\hline CHEMBL1979690 & 809146 & 7.0 & 6.7749 & TRN & \\
\hline CHEMBL 234085 & 809146 & 4.5 & 4.8037 & TRN & \\
\hline CHEMBL1978167 & 809146 & 4.5 & 4.6557 & TRN & \\
\hline CHEMBL418203 & 809146 & 5.5 & 4.7317 & TRN & \\
\hline CHEMBL225519 & 809146 & 4.5 & 4.7959 & TST & \\
\hline CHEMBL1976376 & 809146 & 4.5 & 4.1065 & TRN & \\
\hline CHEMBL1983575 & 809146 & 6.1 & 5.92899 & 9999999999 & TRN \\
\hline CHEMBL1968868 & 809146 & 4.5 & 4.6078 & TRN & \\
\hline CHEMBL1981047 & 809146 & 4.5 & 5.4967 & TRN & \\
\hline CHEMBL1998470 & 809146 & 4.5 & 4.291 & TRN & \\
\hline CHEMBL1976196 & 809146 & 4.5 & 4.859 & TRN & \\
\hline CHEMBL1997197 & 809146 & 4.5 & 4.5962 & TRN & \\
\hline CHEMBL1975903 & 809146 & 4.5 & 4.81800 & 00000000005 & TRN \\
\hline CHEMBL1983630 & 809146 & 4.1 & 4.2073 & TRN & \\
\hline CHEMBL1988805 & 809146 & 4.5 & 4.3112 & TRN & \\
\hline CHEMBL458997 & 809146 & 5.9 & 5.8951 & TRN & \\
\hline CHEMBL1969942 & 809146 & 4.5 & 4.3934 & TRN & \\
\hline CHEMBL1974310 & 809146 & 5.9 & 5.0087 & TRN & \\
\hline CHEMBL1978567 & 809146 & 4.5 & 4.3239 & TRN & \\
\hline CHEMBL1995765 & 809146 & 5.1 & 4.3658 & TST & \\
\hline CHEMBL1975138 & 809146 & 4.8 & 4.7899 & TRN & \\
\hline CHEMBL1984760 & 809146 & 4.5 & 5.221 & TRN & \\
\hline CHEMBL1997846 & 809146 & 4.5 & 4.646 & TRN & \\
\hline CHEMBL424872 & 809146 & 4.5 & 4.4359 & TST & \\
\hline CHEMBL360847 & 809146 & 6.3 & 5.0279 & TRN & \\
\hline CHEMBL1995811 & 809146 & 6.1 & 6.1209 & TRN & \\
\hline CHEMBL1983111 & 809146 & 7.9 & 6.5659 & TRN & \\
\hline CHEMBL1988141 & 809146 & 4.5 & 5.8791 & TST & \\
\hline CHEMBL1992937 & 809146 & 4.5 & 4.5776 & TRN & \\
\hline CHEMBL1977134 & 809146 & 4.5 & 4.4397 & TRN & \\
\hline CHEMBL1985206 & 809146 & 4.5 & 4.3775 & TRN & \\
\hline CHEMBL1991078 & 809146 & 7.6 & 6.523 & TRN & \\
\hline CHEMBL1090356 & 809146 & 4.8 & 5.3138 & TRN & \\
\hline CHEMBL1977749 & 809146 & 5.6 & 4.9972 & TST & \\
\hline & & & & 203 & \\
\hline
\end{tabular}




\begin{tabular}{|c|c|c|c|c|c|}
\hline \\
\hline CHEMBL2001613 & 809146 & 4.5 & 4.3901 & TRN & \\
\hline CHEMBL261849 & 809146 & 4.5 & 4.2001 & TST & \\
\hline CHEMBL1983923 & 809146 & 6.8 & 5.706 & TRN & \\
\hline CHEMBL1993904 & 809146 & 4.5 & 4.9439 & TRN & \\
\hline CHEMBL1997275 & 809146 & 4.5 & 4.5551 & TRN & \\
\hline CHEMBL1999112 & 809146 & 4.8 & 4.6225 & TST & \\
\hline CHEMBL1967513 & 809146 & 4.5 & 4.6772 & TRN & \\
\hline CHEMBL2000724 & 809146 & 4.5 & 4.1979 & TRN & \\
\hline CHEMBL1982660 & 809146 & 4.5 & 4.7523 & TRN & \\
\hline CHEMBL1982413 & 809146 & 4.5 & 5.0511 & TRN & \\
\hline CHEMBL1985042 & 809146 & 4.3 & 4.3955 & TST & \\
\hline CHEMBL1987535 & 809146 & 4.5 & 4.7611 & TRN & \\
\hline CHEMBL1983393 & 809146 & 4.5 & 4.4745 & TRN & \\
\hline CHEMBL1981792 & 809146 & 4.5 & 4.8671 & TRN & \\
\hline CHEMBL 2002586 & 809146 & 4.5 & 4.8029 & TRN & \\
\hline CHEMBL 2006674 & 809146 & 4.5 & 4.7271 & TST & \\
\hline CHEMBL383264 & 809146 & 4.5 & 6.0348 & TRN & \\
\hline CHEMBL1992371 & 809146 & 4.5 & 5.0455 & TRN & \\
\hline CHEMBL1984236 & 809146 & 4.5 & 4.185 & TST & \\
\hline CHEMBL 2007421 & 809146 & 4.5 & 5.4514 & TST & \\
\hline CHEMBL1973138 & 809146 & 4.5 & 4.2993 & TST & \\
\hline CHEMBL2002599 & 809146 & 4.5 & 4.9078 & TST & \\
\hline CHEMBL1969151 & 809146 & 5.7 & 5.5862 & TST & \\
\hline CHEMBL1967252 & 809146 & 4.4 & 5.0738 & TST & \\
\hline CHEMBL1993335 & 809146 & 6.0 & 5.1487 & TST & \\
\hline CHEMBL 2007574 & 809146 & 4.5 & 4.9289 & TST & \\
\hline CHEMBL1988692 & 809146 & 4.5 & 4.6543 & TST & \\
\hline CHEMBL 2004637 & 809146 & 4.5 & 4.937 & TST & \\
\hline CHEMBL1993374 & 809146 & 4.5 & 4.6703 & TST & \\
\hline CHEMBL1994318 & 809146 & 4.5 & 4.6836 & TST & \\
\hline CHEMBL 2000354 & 809146 & 4.8 & 4.76399 & 9999999999 & TST \\
\hline CHEMBL1998680 & 809146 & 4.5 & 4.46899 & 9999999999 & TST \\
\hline CHEMBL592030 & 809146 & 4.8 & 4.9862 & TST & \\
\hline CHEMBL1999506 & 809146 & 4.5 & 4.4527 & TST & \\
\hline CHEMBL1605605 & 809146 & 4.5 & 4.499 & TST & \\
\hline CHEMBL1989029 & 809146 & 4.8 & 4.5626 & TST & \\
\hline CHEMBL1997007 & 809146 & 5.6 & 5.1558 & TST & \\
\hline CHEMBL1970352 & 809146 & 4.5 & $5.0280 e$ & 00000000005 & TST \\
\hline CHEMBL 2002690 & 809146 & 4.5 & 4.3749 & TST & \\
\hline CHEMBL1980167 & 809146 & 4.5 & 5.2132 & TST & \\
\hline CHEMBL377408 & 809146 & 4.5 & 4.4618 & TST & \\
\hline CHEMBL 278041 & 809146 & 4.5 & 4.3147 & TST & \\
\hline CHEMBL215152 & 809146 & 4.5 & 4.6581 & TST & \\
\hline CHEMBL 2006765 & 809146 & 6.3 & 5.9735 & TST & \\
\hline CHEMBL1986590 & 809146 & 4.5 & 4.5056 & TST & \\
\hline CHEMBL1870106 & 809146 & 4.5 & 4.9407 & TST & \\
\hline CHEMBL406845 & 809146 & 4.5 & 4.1318 & TST & \\
\hline CHEMBL1980246 & 809146 & 4.5 & 4.4049 & TST & \\
\hline
\end{tabular}




\begin{tabular}{|c|c|c|c|c|c|c|c|}
\hline \\
\hline CHEMBL1983980 & 809146 & 5.5 & 5.6907 & TST & & & \\
\hline CHEMBL1999484 & 809146 & 6.8 & 6.6014 & TST & & & \\
\hline CHEMBL1984296 & 809146 & 4.5 & 5.3408 & TST & & & \\
\hline CHEMBL1986899 & 809146 & 4.5 & 4.3519 & TST & & & \\
\hline CHEMBL1984038 & 809146 & 4.5 & 4.5166 & TST & & & \\
\hline CHEMBL1993661 & 809146 & 7.4 & 6.6999 & TST & & & \\
\hline CHEMBL1968705 & 809146 & 4.5 & 4.6967 & TST & & & \\
\hline CHEMBL1991410 & 809146 & 4.5 & 3.9233 & TST & & & \\
\hline CHEMBL1964441 & 809146 & 4.5 & 4.5526 & TST & & & \\
\hline CHEMBL546797 & 809146 & 4.5 & 4.4822 & TST & & & \\
\hline CHEMBL 273825 & 28023 & 6.301 & 6.4557 & TRN & & & \\
\hline CHEMBL11526 & 28023 & 6.2007 & 5.874 & TRN & & & \\
\hline CHEMBL269463 & 28023 & 4.6021 & 4.6224 & TRN & & & \\
\hline CHEMBL11238 & 28023 & 5.1244 & 5.4731 & TRN & & & \\
\hline CHEMBL 273510 & 28023 & 6.4685 & $6.78100 e$ & 0000000001 & & TRN & \\
\hline CHEMBL11232 & 28023 & 8.3979 & 7.6966 & TRN & & & \\
\hline CHEMBL11316 & 28023 & 6.4437 & 6.4814 & TRN & & & \\
\hline CHEMBL10307 & 28023 & 7.0969 & 7.2179 & TRN & & & \\
\hline CHEMBL11091 & 28023 & 7.0969 & 6.69 & TRN & & & \\
\hline CHEMBL269386 & 28023 & 6.0044 & 5.86 & TRN & & & \\
\hline CHEMBL 273532 & 28023 & 6.0269 & 6.0174 & TRN & & & \\
\hline CHEMBL11631 & 28023 & 5.1649 & 5.2816 & TRN & & & \\
\hline CHEMBL 273369 & 28023 & 5.7645 & 5.7488 & TRN & & & \\
\hline CHEMBL11201 & 28023 & 7.7959 & 6.7378 & TST & & & \\
\hline CHEMBL11130 & 28023 & 5.1713 & 5.0751 & TRN & & & \\
\hline CHEMBL 268478 & 28023 & 5.75700 & 000000000 & & $5.7810 e$ & 0000000001 & TRN \\
\hline CHEMBL11071 & 28023 & 7.4949 & 7.6292 & TST & & & \\
\hline CHEMBL11400 & 28023 & 5.5622 & 5.3134 & TRN & & & \\
\hline CHEMBL 275332 & 28023 & 5.52 & 5.5073 & TRN & & & \\
\hline CHEMBL 273824 & 28023 & 6.4437 & 6.4807 & TRN & & & \\
\hline CHEMBL 269470 & 28023 & 5.8729 & 6.474 & TRN & & & \\
\hline CHEMBL10916 & 28023 & 6.3468 & 6.6084 & TRN & & & \\
\hline CHEMBL416705 & 28023 & 5.6162 & 5.8977 & TRN & & & \\
\hline CHEMBL11197 & 28023 & 5.8327 & 6.122000 & 0000000001 & & TRN & \\
\hline CHEMBL418529 & 28023 & 6.0555 & 5.9709 & TRN & & & \\
\hline CHEMBL 274214 & 28023 & 5.6946 & 5.6183 & TRN & & & \\
\hline CHEMBL 11422 & 28023 & 5.4001 & 5.4187 & TRN & & & \\
\hline CHEMBL268700 & 28023 & 6.2366 & 6.0765 & TST & & & \\
\hline CHEMBL268699 & 28023 & 5.6615 & 5.7452 & TRN & & & \\
\hline CHEMBL11110 & 28023 & 5.20200 & 00000000 & & 5.4952 & TRN & \\
\hline CHEMBL11267 & 28023 & 6.0757 & 5.7612 & TRN & & & \\
\hline CHEMBL10954 & 28023 & 6.1938 & 6.084 & TST & & & \\
\hline CHEMBL11379 & 28023 & 6.5376 & 6.6086 & TRN & & & \\
\hline CHEMBL11204 & 28023 & 5.6478 & 5.5796 & TRN & & & \\
\hline CHEMBL11612 & 28023 & 7.5376 & 7.4796 & TST & & & \\
\hline CHEMBL11445 & 28023 & 5.4559 & 6.5242 & TRN & & & \\
\hline CHEMBL11303 & 28023 & 7.2218 & 7.2572 & TST & & & \\
\hline CHEMBL11254 & 28023 & 6.1938 & 6.1981 & TST & & & \\
\hline
\end{tabular}




\begin{tabular}{|c|c|c|c|c|c|}
\hline \multirow[b]{2}{*}{ CHEMBL11248 } & \multicolumn{5}{|c|}{ Supplemental Table S2.txt } \\
\hline & 28023 & 7.3979 & 5.8318 & TST & \\
\hline CHEMBL 275308 & 28023 & 6.0757 & 6.2557 & TST & \\
\hline CHEMBL273826 & 28023 & 8.5229 & 6.8424 & TST & \\
\hline CHEMBL269469 & 28023 & 6.0757 & 5.9584 & TRN & \\
\hline CHEMBL268024 & 28023 & 6.0 & 6.9939 & TST & \\
\hline CHEMBL11072 & 28023 & 5.684 & 5.2819 & TRN & \\
\hline CHEMBL 274166 & 28023 & 5.5686 & 6.0809 & TST & \\
\hline CHEMBL 275265 & 28023 & 6.6021 & 6.1694 & TRN & \\
\hline CHEMBL 275479 & 28023 & 7.301 & 6.7048 & TRN & \\
\hline CHEMBL10844 & 28023 & 5.3969 & 5.1417 & TRN & \\
\hline CHEMBL11192 & 28023 & 5.3233 & 5.4919 & TRN & \\
\hline CHEMBL439720 & 28023 & 5.6198 & 6.5769 & TST & \\
\hline CHEMBL1975523 & 752541 & 3.0044 & 3.6306 & TRN & \\
\hline CHEMBL1606773 & 752541 & 3.0044 & 3.7631 & TST & \\
\hline CHEMBL1432585 & 752541 & 4.5654 & 3.5847 & TRN & \\
\hline CHEMBL1322281 & 752541 & 4.0701 & 3.3132 & TST & \\
\hline CHEMBL1480971 & 752541 & 3.0044 & 3.3844 & TRN & \\
\hline CHEMBL1497574 & 752541 & 3.0044 & 3.3478 & TRN & \\
\hline CHEMBL1574438 & 752541 & 4.3585 & 3.7121 & TRN & \\
\hline CHEMBL1573304 & 752541 & 3.0044 & 3.7859 & TRN & \\
\hline CHEMBL1457252 & 752541 & 4.426 & 3.5823 & TRN & \\
\hline CHEMBL1504624 & 752541 & 4.3778 & 3.6127 & TST & \\
\hline CHEMBL1385897 & 752541 & 3.0044 & 3.3271 & TRN & \\
\hline CHEMBL1431919 & 752541 & 4.6216 & 3.6231 & TRN & \\
\hline CHEMBL1486531 & 752541 & 3.0044 & 3.3476 & TRN & \\
\hline CHEMBL1984348 & 752541 & 4.0531 & 3.5177 & TST & \\
\hline CHEMBL1598441 & 752541 & 4.9747 & 3.4891 & TRN & \\
\hline CHEMBL1896512 & 752541 & 4.0438 & 3.6925 & TRN & \\
\hline CHEMBL1459196 & 752541 & 3.0044 & 3.8229 & TRN & \\
\hline CHEMBL1602261 & 752541 & 4.8386 & 3.8038 & TRN & \\
\hline CHEMBL1419027 & 752541 & 3.0044 & 3.1663 & TRN & \\
\hline CHEMBL1523597 & 752541 & 3.0044 & 3.57800 & 00000000003 & TRN \\
\hline CHEMBL1362667 & 752541 & 3.0044 & 3.2472 & TST & \\
\hline CHEMBL1529418 & 752541 & 3.0044 & 3.7254 & TST & \\
\hline CHEMBL1972014 & 752541 & 3.0044 & 3.6503 & TRN & \\
\hline CHEMBL1971324 & 752541 & 3.0044 & 3.6123 & TRN & \\
\hline CHEMBL1313936 & 752541 & 4.3152 & 3.472 & TRN & \\
\hline CHEMBL2001481 & 752541 & 4.2472 & 3.9053 & TRN & \\
\hline CHEMBL1500423 & 752541 & 3.0044 & 3.6723 & TRN & \\
\hline CHEMBL1518508 & 752541 & 3.0044 & 3.4685 & TRN & \\
\hline CHEMBL1548789 & 752541 & 3.0044 & 3.2086 & TRN & \\
\hline CHEMBL1403913 & 752541 & 3.0044 & 3.7323 & TST & \\
\hline CHEMBL1528991 & 752541 & 4.5143 & 3.8258 & TRN & \\
\hline CHEMBL1366593 & 752541 & 4.7055 & 3.35699 & 99999999998 & TRN \\
\hline CHEMBL1307648 & 752541 & 4.3188 & 3.49399 & 99999999998 & TRN \\
\hline CHEMBL1393284 & 752541 & 3.0044 & 3.5263 & TRN & \\
\hline CHEMBL1407274 & 752541 & 3.0044 & 3.4502 & TRN & \\
\hline CHEMBL1382089 & 752541 & 4.6021 & 3.3205 & TRN & \\
\hline
\end{tabular}


Supplemental Table S2.txt

\begin{tabular}{|c|c|c|c|c|c|}
\hline CHEMBL1523192 & 752541 & 3.0044 & 3.7048 & TRN & \\
\hline CHEMBL1710856 & 752541 & 3.0044 & 3.7814 & TRN & \\
\hline CHEMBL1878187 & 752541 & 3.0044 & 3.4046 & TST & \\
\hline CHEMBL1402149 & 752541 & 4.7077 & 3.6293 & TRN & \\
\hline CHEMBL1973694 & 752541 & 4.3556 & 3.4905 & TRN & \\
\hline CHEMBL1573198 & 752541 & 3.0044 & 3.1713 & TRN & \\
\hline CHEMBL1523044 & 752541 & 3.0044 & 3.0958 & TST & \\
\hline CHEMBL1964868 & 752541 & 4.7167 & 3.6278 & TRN & \\
\hline CHEMBL1698604 & 752541 & 3.0044 & 3.4557 & TRN & \\
\hline CHEMBL1469032 & 752541 & 3.0044 & 3.2863 & TRN & \\
\hline CHEMBL1991136 & 752541 & 3.0044 & \multicolumn{2}{|c|}{3.8689999999999998} & TRN \\
\hline CHEMBL1483095 & 752541 & 4.295 & 3.3784 & TRN & \\
\hline CHEMBL1463714 & 752541 & 4.4377 & 3.6688 & TST & \\
\hline CHEMBL1406911 & 752541 & 3.0044 & 3.1678 & TRN & \\
\hline CHEMBL1587434 & 752541 & 3.0044 & 3.7748 & TRN & \\
\hline CHEMBL3196160 & 752541 & 4.3716 & 3.8607 & TRN & \\
\hline CHEMBL1469894 & 752541 & 3.0044 & 3.0807 & TRN & \\
\hline CHEMBL1601846 & 752541 & 3.0044 & 3.3885 & TST & \\
\hline CHEMBL1522724 & 752541 & 3.0044 & 3.505 & TRN & \\
\hline CHEMBL1351618 & 752541 & 4.0535 & 3.3882 & TRN & \\
\hline CHEMBL1595871 & 752541 & 3.0044 & 3.9627 & TRN & \\
\hline CHEMBL1304092 & 752541 & 4.5017 & 3.5952 & TRN & \\
\hline CHEMBL3197965 & 752541 & 3.0044 & 3.6673 & TRN & \\
\hline CHEMBL3190691 & 752541 & 3.0044 & 3.3367 & TST & \\
\hline CHEMBL1598538 & 752541 & 3.0044 & 3.6834 & TRN & \\
\hline CHEMBL1352343 & 752541 & 4.6308 & 3.8078 & TRN & \\
\hline CHEMBL1444979 & 752541 & 3.0044 & 3.8062 & TRN & \\
\hline CHEMBL1488551 & 752541 & 3.0044 & 3.4898 & TRN & \\
\hline CHEMBL 2007056 & 752541 & 4.6596 & 3.576 & TST & \\
\hline CHEMBL1325286 & 752541 & 5.3872 & 3.3598 & TST & \\
\hline CHEMBL3194152 & 752541 & 5.1018 & 3.5664 & TRN & \\
\hline CHEMBL1582131 & 752541 & 4.7959 & 3.7718 & TRN & \\
\hline CHEMBL1514705 & 752541 & 3.0044 & 3.6334 & TRN & \\
\hline CHEMBL1970711 & 752541 & 3.0044 & 3.3978 & TRN & \\
\hline CHEMBL1416570 & 752541 & 3.0044 & 3.2783 & TRN & \\
\hline CHEMBL3195184 & 752541 & 3.0044 & 2.9804 & TRN & \\
\hline CHEMBL 3209848 & 752541 & 3.0044 & 3.5053 & TST & \\
\hline CHEMBL1408741 & 752541 & 4.2168 & 3.9806 & TRN & \\
\hline CHEMBL1409207 & 752541 & 3.0044 & 3.3394 & TRN & \\
\hline CHEMBL1582996 & 752541 & 3.0044 & 3.0447 & TRN & \\
\hline CHEMBL1543005 & 752541 & 4.4449 & 3.7604 & TRN & \\
\hline CHEMBL1499361 & 752541 & 4.0742 & 3.2117 & TRN & \\
\hline CHEMBL1405274 & 752541 & 3.0044 & 3.5563 & TRN & \\
\hline CHEMBL3191412 & 752541 & 5.2612 & 3.3946 & TRN & \\
\hline CHEMBL1863914 & 752541 & 4.4225 & 4.0044 & TRN & \\
\hline CHEMBL1713837 & 752541 & 4.684 & 3.9375 & TRN & \\
\hline CHEMBL1524630 & 752541 & 3.0044 & 3.5325 & TRN & \\
\hline CHEMBL3211804 & 752541 & 3.0044 & 3.3971 & TRN & \\
\hline
\end{tabular}




\begin{tabular}{|c|c|c|c|c|}
\hline \multicolumn{5}{|c|}{ Supplemental Table S2.txt } \\
\hline CHEMBL1323828 & 752541 & 3.0044 & 3.6693 & TRN \\
\hline CHEMBL1447988 & 752541 & 3.0044 & 3.4359 & TRN \\
\hline CHEMBL1488420 & 752541 & 3.0044 & 3.8107 & TRN \\
\hline CHEMBL1481671 & 752541 & 4.056 & 3.7138 & TRN \\
\hline CHEMBL1473591 & 752541 & 4.6757 & 3.7847 & TRN \\
\hline CHEMBL1539653 & 752541 & 5.153 & 3.5201 & TRN \\
\hline CHEMBL1407873 & 752541 & 3.0044 & 3.0651 & TRN \\
\hline CHEMBL1364211 & 752541 & 3.0044 & 3.7225 & TRN \\
\hline CHEMBL1386020 & 752541 & 3.0044 & 3.3992 & TRN \\
\hline CHEMBL1728023 & 752541 & 3.0044 & 3.5848 & TRN \\
\hline CHEMBL1389963 & 752541 & 3.0044 & 3.3331 & TRN \\
\hline CHEMBL1532783 & 752541 & 3.0044 & 3.4922 & TRN \\
\hline CHEMBL1325819 & 752541 & 3.0044 & 3.2817 & TRN \\
\hline CHEMBL1559324 & 752541 & 3.0044 & 3.5833 & TST \\
\hline CHEMBL1540841 & 752541 & 3.0044 & 3.2458 & TRN \\
\hline CHEMBL1377943 & 752541 & 3.0044 & 3.6636 & TRN \\
\hline CHEMBL1325293 & 752541 & 4.1463 & 3.6529 & TRN \\
\hline CHEMBL1992719 & 752541 & 4.0246 & 3.1061 & TRN \\
\hline CHEMBL1976839 & 752541 & 3.0044 & 3.5498 & TRN \\
\hline CHEMBL1454807 & 752541 & 3.0044 & 3.4223 & TRN \\
\hline CHEMBL1200847 & 752541 & 3.0044 & 3.4619 & TRN \\
\hline CHEMBL 268584 & 752541 & 3.0044 & 3.6051 & TST \\
\hline CHEMBL1420548 & 752541 & 3.0044 & 3.8329 & TRN \\
\hline CHEMBL1462918 & 752541 & 4.7852 & 3.6164 & TRN \\
\hline CHEMBL1408828 & 752541 & 3.0044 & 3.4066 & TRN \\
\hline CHEMBL1337221 & 752541 & 3.0044 & 3.6549 & TRN \\
\hline CHEMBL1546791 & 752541 & 4.2526 & 3.7583 & TRN \\
\hline CHEMBL1539384 & 752541 & 3.0044 & 3.6276 & TRN \\
\hline CHEMBL1342798 & 752541 & 4.7825 & 3.5283 & TRN \\
\hline CHEMBL1566130 & 752541 & 5.2573 & 3.6103 & TRN \\
\hline CHEMBL1440463 & 752541 & 3.0044 & 3.4538 & TRN \\
\hline CHEMBL1584115 & 752541 & 3.0044 & 3.2439 & TST \\
\hline CHEMBL518575 & 752541 & 4.6216 & 3.8622 & TRN \\
\hline CHEMBL1521250 & 752541 & 4.5591 & 3.4778 & TRN \\
\hline CHEMBL1558977 & 752541 & 4.3904 & 3.4349 & TRN \\
\hline CHEMBL1313945 & 752541 & 3.0044 & 3.4942 & TRN \\
\hline CHEMBL1576642 & 752541 & 3.0044 & 3.1586 & TST \\
\hline CHEMBL1341350 & 752541 & 4.0472 & 3.449 & TRN \\
\hline CHEMBL1972346 & 752541 & 3.0044 & 3.6261 & TRN \\
\hline CHEMBL1339765 & 752541 & 3.0044 & 3.2673 & TRN \\
\hline CHEMBL1394008 & 752541 & 4.2104 & 3.5987 & TRN \\
\hline CHEMBL1577333 & 752541 & 3.0044 & 3.6335 & TRN \\
\hline CHEMBL1343099 & 752541 & 3.0044 & 3.6311 & TRN \\
\hline CHEMBL1423836 & 752541 & 3.0044 & 3.5614 & TRN \\
\hline CHEMBL1491210 & 752541 & 4.5719 & 3.2996 & TRN \\
\hline CHEMBL1516186 & 752541 & 3.0044 & 3.595 & TRN \\
\hline CHEMBL1427044 & 752541 & 3.0044 & 3.2897 & TRN \\
\hline CHEMBL1503442 & 752541 & 4.2984 & 3.8621 & TRN \\
\hline
\end{tabular}




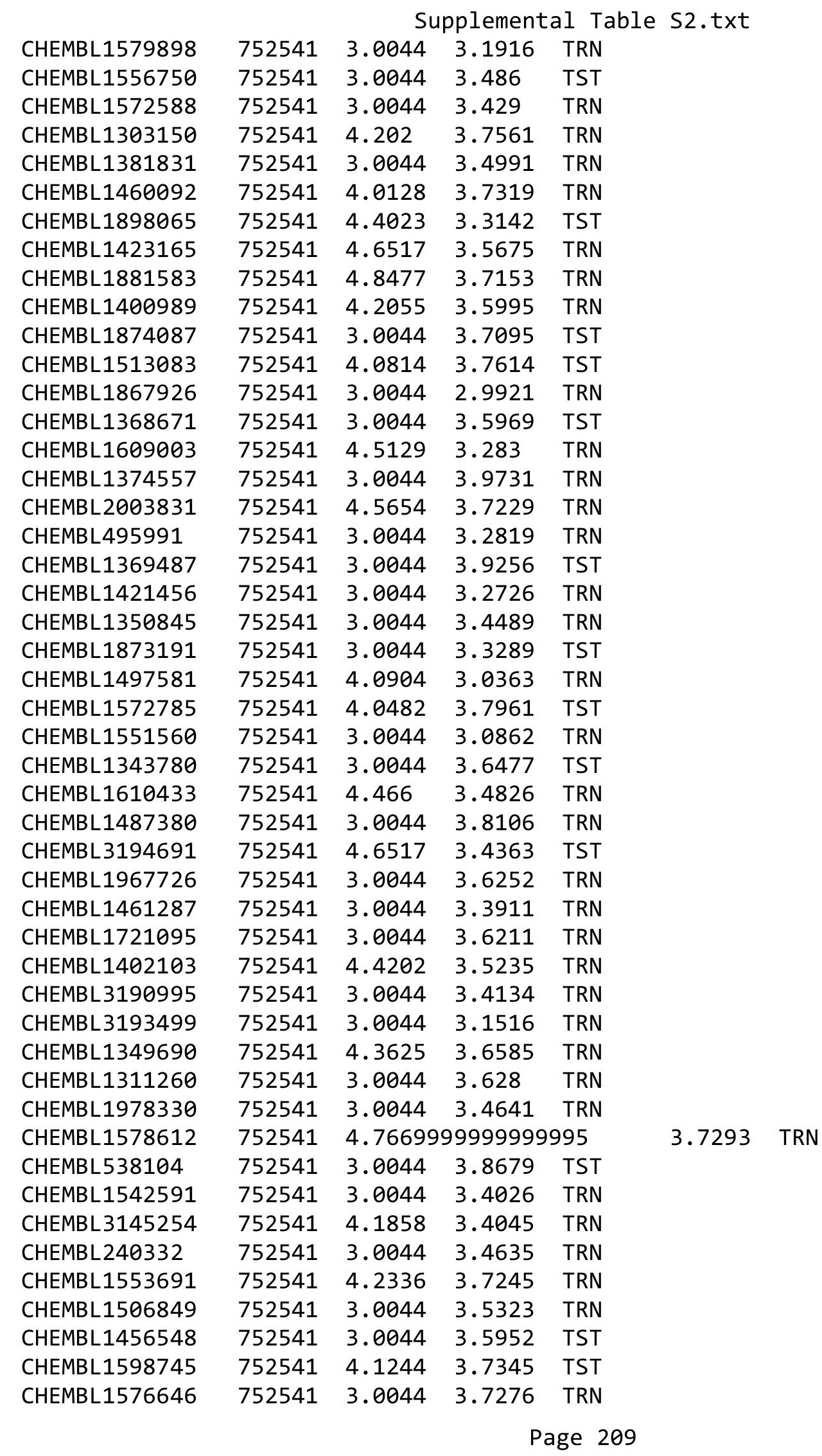


Supplemental Table S2.txt

\begin{tabular}{|c|c|c|c|c|}
\hline CHEMBL1439958 & 752541 & 3.0044 & 3.8824 & TST \\
\hline CHEMBL1901790 & 752541 & 3.0044 & 3.8592 & TRN \\
\hline CHEMBL1444791 & 752541 & 3.0044 & 3.5774 & TRN \\
\hline CHEMBL1501108 & 752541 & 3.0044 & 3.3048 & TRN \\
\hline CHEMBL1705345 & 752541 & 3.0044 & 3.5711 & TRN \\
\hline CHEMBL1512498 & 752541 & 4.2848 & 3.6863 & TRN \\
\hline CHEMBL1578806 & 752541 & 3.0044 & 3.4905 & TRN \\
\hline CHEMBL1585764 & 752541 & 3.0044 & 3.4587 & TRN \\
\hline CHEMBL1431810 & 752541 & 4.857 & \multicolumn{2}{|c|}{3.9019999999999997} \\
\hline CHEMBL1536490 & 752541 & 3.0044 & 3.4684 & TRN \\
\hline CHEMBL1393396 & 752541 & 3.0044 & 3.2294 & TRN \\
\hline CHEMBL1578039 & 752541 & 4.251 & 3.7348 & TRN \\
\hline CHEMBL1486503 & 752541 & 4.6234 & 3.8118 & TRN \\
\hline CHEMBL1604953 & 752541 & 3.0044 & 3.4071 & TRN \\
\hline CHEMBL1327721 & 752541 & 4.3556 & 3.7261 & TRN \\
\hline CHEMBL1430935 & 752541 & 4.3655 & 3.5977 & TRN \\
\hline CHEMBL1466606 & 752541 & 4.4078 & 3.8431 & TRN \\
\hline CHEMBL1411354 & 752541 & 3.0044 & 3.7677 & TRN \\
\hline CHEMBL1501146 & 752541 & 3.0044 & 3.4691 & TRN \\
\hline CHEMBL1578643 & 752541 & 4.0535 & 3.2698 & TRN \\
\hline CHEMBL1333238 & 752541 & 3.0044 & 3.6183 & TRN \\
\hline CHEMBL1543229 & 752541 & 4.2636 & 3.463 & TRN \\
\hline CHEMBL1487625 & 752541 & 3.0044 & 3.4794 & TST \\
\hline CHEMBL1582416 & 752541 & 3.0044 & 3.3829 & TRN \\
\hline CHEMBL521762 & 752541 & 4.3391 & 3.6646 & TRN \\
\hline CHEMBL1505608 & 752541 & 4.0696 & 3.8725 & TRN \\
\hline CHEMBL1558832 & 752541 & 3.0044 & 3.3838 & TST \\
\hline CHEMBL1987483 & 752541 & 3.0044 & 3.313 & TRN \\
\hline CHEMBL1416018 & 752541 & 3.0044 & 3.2375 & TRN \\
\hline CHEMBL1380580 & 752541 & 3.0044 & 3.647 & TRN \\
\hline CHEMBL3211738 & 752541 & 3.0044 & 3.3725 & TRN \\
\hline CHEMBL1561287 & 752541 & 3.0044 & 3.1447 & TRN \\
\hline CHEMBL1533337 & 752541 & 4.1427 & 3.8003 & TRN \\
\hline CHEMBL1523652 & 752541 & 3.0044 & 3.5872 & TRN \\
\hline CHEMBL1610395 & 752541 & 3.0044 & 3.7668 & TRN \\
\hline CHEMBL1595909 & 752541 & 3.0044 & 3.7805 & TRN \\
\hline CHEMBL1866444 & 752541 & 3.0044 & 3.5256 & TRN \\
\hline CHEMBL1359137 & 752541 & 3.0044 & 3.0641 & TRN \\
\hline CHEMBL1421924 & 752541 & 4.8761 & 3.5633 & TST \\
\hline CHEMBL1365068 & 752541 & 3.0044 & 3.9701 & TST \\
\hline CHEMBL1531495 & 752541 & 4.2628 & 3.6584 & TRN \\
\hline CHEMBL1604510 & 752541 & 3.0044 & 3.7497 & TRN \\
\hline CHEMBL1421105 & 752541 & 3.0044 & 3.3125 & TRN \\
\hline CHEMBL1567518 & 752541 & 3.0044 & 3.4882 & TRN \\
\hline CHEMBL1545489 & 752541 & 3.0044 & 3.5003 & TST \\
\hline CHEMBL1502526 & 752541 & 4.2487 & 3.9242 & TRN \\
\hline CHEMBL1583907 & 752541 & 3.0044 & 3.6255 & TST \\
\hline CHEMBL1576943 & 752541 & 4.7212 & 3.5101 & TRN \\
\hline
\end{tabular}


Supplemental Table S2.txt

\begin{tabular}{|c|c|c|c|c|c|}
\hline CHEMBL1499390 & 752541 & 3.0044 & 3.5441 & TRN & \\
\hline CHEMBL1605468 & 752541 & 3.0044 & 3.6089 & TRN & \\
\hline CHEMBL1309404 & 752541 & 4.1904 & 3.7417 & TRN & \\
\hline CHEMBL1503639 & 752541 & 4.2676 & 3.2127 & TRN & \\
\hline CHEMBL1517176 & 752541 & 3.0044 & 3.1641 & TRN & \\
\hline CHEMBL1995385 & 752541 & 3.0044 & 3.4103 & TRN & \\
\hline CHEMBL1499508 & 752541 & 4.2343 & 3.8227 & TRN & \\
\hline CHEMBL1447058 & 752541 & 3.0044 & 3.4506 & TRN & \\
\hline CHEMBL1318179 & 752541 & 4.6925 & 3.7937 & TRN & \\
\hline CHEMBL1720248 & 752541 & 4.1537 & 3.7808 & TRN & \\
\hline CHEMBL1324227 & 752541 & 6.567 & 3.5339 & TST & \\
\hline CHEMBL1342485 & 752541 & 3.0044 & 3.6633 & TST & \\
\hline CHEMBL1569865 & 752541 & 3.0044 & 3.5873 & TRN & \\
\hline CHEMBL1612672 & 752541 & 3.0044 & 3.595 & TRN & \\
\hline CHEMBL1465106 & 752541 & 5.0227 & 3.997 & TRN & \\
\hline CHEMBL1597246 & 752541 & 3.0044 & 3.5064 & TRN & \\
\hline CHEMBL1366122 & 752541 & 4.5157 & 3.4116 & TST & \\
\hline CHEMBL1425931 & 752541 & 4.6536 & 3.1619 & TST & \\
\hline CHEMBL1303193 & 752541 & 4.4609 & 3.909 & TRN & \\
\hline CHEMBL1432052 & 752541 & 4.2487 & 3.4618 & TST & \\
\hline CHEMBL1477749 & 752541 & 5.3487 & 3.6646 & TRN & \\
\hline CHEMBL3208853 & 752541 & 3.0044 & 3.6571 & TRN & \\
\hline CHEMBL1578178 & 752541 & 3.0044 & 3.6453 & TRN & \\
\hline CHEMBL1482878 & 752541 & 3.0044 & 3.3356 & TST & \\
\hline CHEMBL1328405 & 752541 & 3.0044 & 3.5364 & TRN & \\
\hline CHEMBL3212018 & 752541 & 3.0044 & 3.3237 & TST & \\
\hline CHEMBL1483453 & 752541 & 3.0044 & 3.3145 & TRN & \\
\hline CHEMBL1463624 & 752541 & 3.0044 & 3.1666 & TRN & \\
\hline CHEMBL2003840 & 752541 & 4.4498 & 3.5531 & TRN & \\
\hline CHEMBL1594756 & 752541 & 3.0044 & \multicolumn{2}{|c|}{3.37399999999999997} & TST \\
\hline CHEMBL1487921 & 752541 & 3.0044 & 3.5545 & TRN & \\
\hline CHEMBL1482959 & 752541 & 3.0044 & 3.5599 & TRN & \\
\hline CHEMBL1307956 & 752541 & 3.0044 & 3.5027 & TST & \\
\hline CHEMBL1885471 & 752541 & 3.0044 & 3.423 & TST & \\
\hline CHEMBL1605813 & 752541 & 3.0044 & 4.0745 & TRN & \\
\hline CHEMBL1405729 & 752541 & 3.0044 & 3.8558 & TRN & \\
\hline CHEMBL66953 & 752541 & 3.0044 & 3.4273 & TST & \\
\hline CHEMBL1459316 & 752541 & 3.0044 & 3.8265 & TRN & \\
\hline CHEMBL1583552 & 752541 & 5.7144 & 3.437 & TRN & \\
\hline CHEMBL1393310 & 752541 & 3.0044 & 3.7224 & TRN & \\
\hline CHEMBL481577 & 752541 & 3.0044 & 3.3516 & TRN & \\
\hline CHEMBL3214439 & 752541 & 3.0044 & 3.3309 & TRN & \\
\hline CHEMBL3191182 & 752541 & 3.0044 & \multicolumn{2}{|c|}{3.43399999999999997} & TRN \\
\hline CHEMBL1379898 & 752541 & 3.0044 & 3.8885 & TRN & \\
\hline CHEMBL1884882 & 752541 & 3.0044 & 3.8216 & TRN & \\
\hline CHEMBL1370184 & 752541 & 3.0044 & 3.6288 & TRN & \\
\hline CHEMBL1428087 & 752541 & 3.0044 & 3.597 & TRN & \\
\hline CHEMBL1533083 & 752541 & 3.0044 & 3.5736 & TRN & \\
\hline
\end{tabular}

Page 211 


\begin{tabular}{|c|c|c|c|c|c|}
\hline \multirow[b]{2}{*}{ CHEMBL1580472 } & \multicolumn{5}{|c|}{ Supplemental Table S2.txt } \\
\hline & 752541 & 3.0044 & 3.613 & TRN & \\
\hline CHEMBL1372505 & 752541 & 4.51 & 3.5609 & TRN & \\
\hline CHEMBL1538590 & 752541 & 4.3391 & 3.4877 & TRN & \\
\hline CHEMBL1375904 & 752541 & 3.0044 & 3.3744 & TRN & \\
\hline CHEMBL1328741 & 752541 & 4.4989 & 3.6263 & TRN & \\
\hline CHEMBL1535241 & 752541 & 4.2967 & 3.6673 & TRN & \\
\hline CHEMBL1985338 & 752541 & 3.0044 & 3.7697 & TRN & \\
\hline CHEMBL1723047 & 752541 & 3.0044 & 3.4562 & TRN & \\
\hline CHEMBL1864111 & 752541 & 5.153 & 3.8901 & TRN & \\
\hline CHEMBL1537639 & 752541 & 3.0044 & 3.4832 & TST & \\
\hline CHEMBL1401048 & 752541 & 3.0044 & 3.3421 & TRN & \\
\hline CHEMBL1492819 & 752541 & 4.0757 & 3.8361 & TRN & \\
\hline CHEMBL428496 & 752541 & 3.0044 & 3.6974 & TST & \\
\hline CHEMBL1594826 & 752541 & 3.0044 & 3.6981 & TRN & \\
\hline CHEMBL1361805 & 752541 & 3.0044 & 3.433999 & 99999999997 & TRN \\
\hline CHEMBL600034 & 752541 & 3.0044 & 3.7272 & TRN & \\
\hline CHEMBL1405900 & 752541 & 3.0044 & 3.2329 & TRN & \\
\hline CHEMBL1608989 & 752541 & 3.0044 & 2.9701 & TRN & \\
\hline CHEMBL584246 & 752541 & 4.0675 & 3.7901 & TST & \\
\hline CHEMBL1375292 & 752541 & 3.0044 & 3.2308 & TRN & \\
\hline CHEMBL1599761 & 752541 & 3.0044 & 3.5603 & TRN & \\
\hline CHEMBL1734383 & 752541 & 3.0044 & 3.4884 & TRN & \\
\hline CHEMBL1360793 & 752541 & 5.0825 & 3.697 & TRN & \\
\hline CHEMBL1423797 & 752541 & 3.0044 & 3.413999 & 99999999997 & TRN \\
\hline CHEMBL512216 & 752541 & 4.6326 & 3.835 & TRN & \\
\hline CHEMBL1500904 & 752541 & 3.0044 & 3.5896 & TRN & \\
\hline CHEMBL1303157 & 752541 & 4.9245 & 3.7346 & TRN & \\
\hline CHEMBL1338930 & 752541 & 3.0044 & 3.2563 & TRN & \\
\hline CHEMBL1611002 & 752541 & 3.0044 & 3.793999 & 99999999996 & TRN \\
\hline CHEMBL1468444 & 752541 & 3.0044 & 3.4415 & TRN & \\
\hline CHEMBL1445858 & 752541 & 3.0044 & 3.3503 & TST & \\
\hline CHEMBL 3192243 & 752541 & 3.0044 & 3.5283 & TRN & \\
\hline CHEMBL1505747 & 752541 & 3.0044 & 3.5267 & TRN & \\
\hline CHEMBL1998893 & 752541 & 4.5784 & 3.4367 & TRN & \\
\hline CHEMBL1506476 & 752541 & 3.0044 & 3.7279 & TRN & \\
\hline CHEMBL1416556 & 752541 & 3.0044 & 3.9708 & TRN & \\
\hline CHEMBL1457774 & 752541 & 4.2097 & 3.8404 & TRN & \\
\hline CHEMBL1517376 & 752541 & 3.0044 & 3.5474 & TRN & \\
\hline CHEMBL1382001 & 752541 & 4.3507 & 3.8207 & TRN & \\
\hline CHEMBL1339921 & 752541 & 3.0044 & 3.4341 & TRN & \\
\hline CHEMBL1868444 & 752541 & 4.6198 & 3.6729 & TST & \\
\hline CHEMBL1338689 & 752541 & 4.4449 & 3.7704 & TRN & \\
\hline CHEMBL1379877 & 752541 & 3.0044 & 3.315 & TRN & \\
\hline CHEMBL1381340 & 752541 & 3.0044 & 3.6955 & TRN & \\
\hline CHEMBL1572627 & 752541 & 3.0044 & 3.5872 & TRN & \\
\hline CHEMBL1465727 & 752541 & 3.0044 & 3.2498 & TRN & \\
\hline CHEMBL1611662 & 752541 & 3.0044 & 3.5429 & TRN & \\
\hline CHEMBL1333151 & 752541 & 3.0044 & 3.3256 & TRN & \\
\hline
\end{tabular}




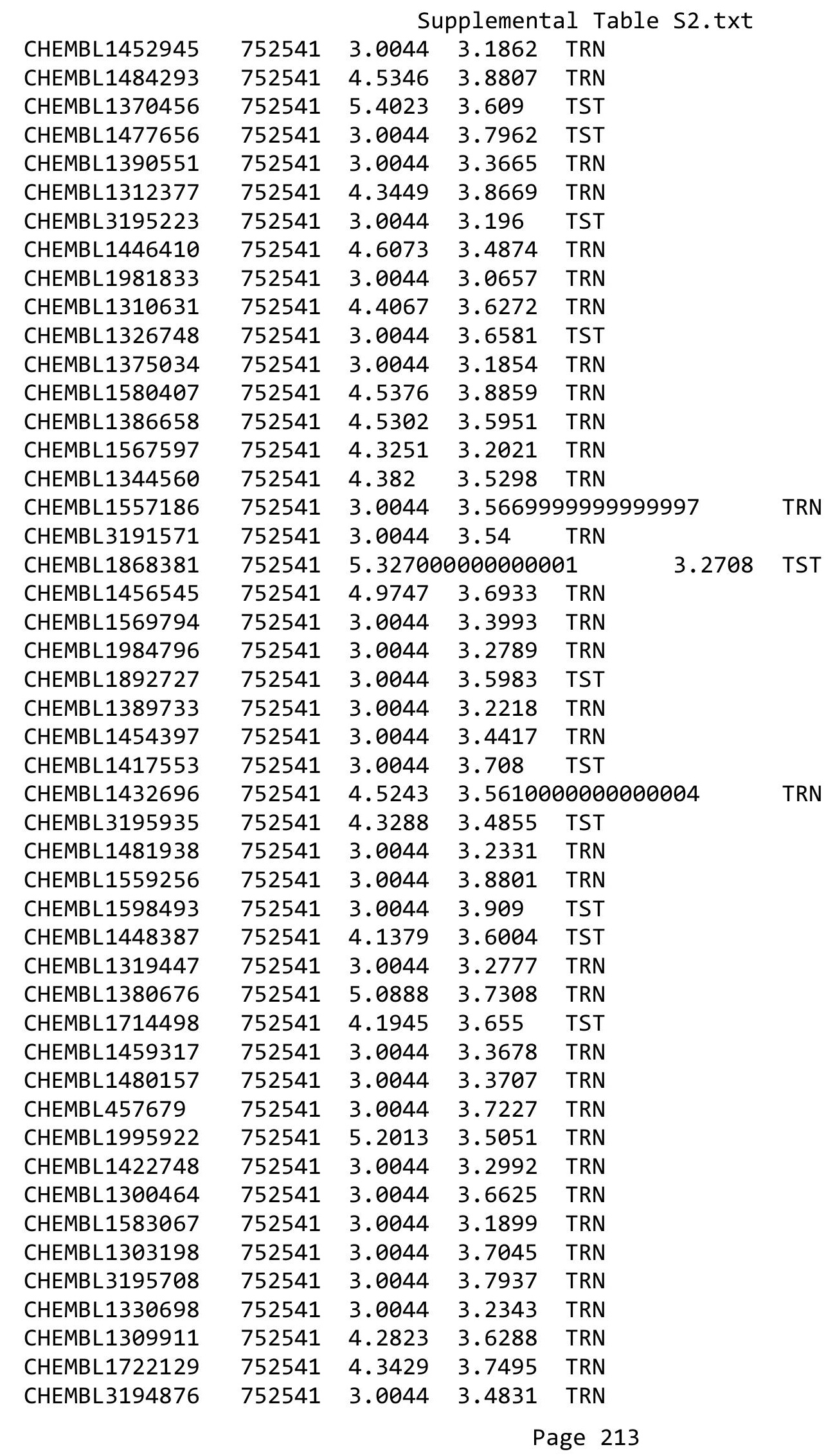


Supplemental Table S2.txt

\begin{tabular}{|c|c|c|c|c|}
\hline CHEMBL1580198 & 752541 & 4.6904 & 3.2278 & TRN \\
\hline CHEMBL1897572 & 752541 & 4.5346 & 3.0457 & TRN \\
\hline CHEMBL1462803 & 752541 & 4.2612 & 3.7483 & TRN \\
\hline CHEMBL1360606 & 752541 & 3.0044 & 3.0445 & TST \\
\hline CHEMBL1323268 & 752541 & 3.0044 & 3.4679 & TRN \\
\hline CHEMBL1578141 & 752541 & 4.3536 & 3.5677 & TRN \\
\hline CHEMBL1863847 & 752541 & 3.0044 & \multicolumn{2}{|c|}{3.3080000000000003} \\
\hline CHEMBL1555050 & 752541 & 4.158 & 3.6171 & TRN \\
\hline CHEMBL1428271 & 752541 & 3.0044 & 3.2507 & TRN \\
\hline CHEMBL1573707 & 752541 & 3.0044 & 3.3977 & TRN \\
\hline CHEMBL1484508 & 752541 & 3.0044 & 3.4327 & TST \\
\hline CHEMBL1309683 & 752541 & 3.0044 & 3.6499 & TST \\
\hline CHEMBL1492158 & 752541 & 3.0044 & \multicolumn{2}{|c|}{3.3160000000000003} \\
\hline CHEMBL3211284 & 752541 & 3.0044 & 3.2766 & TRN \\
\hline CHEMBL1411784 & 752541 & 3.0044 & 3.4165 & TRN \\
\hline CHEMBL1300370 & 752541 & 4.1361 & 3.9244 & TST \\
\hline CHEMBL1421166 & 752541 & 3.0044 & 3.7566 & TRN \\
\hline CHEMBL1419935 & 752541 & 4.4949 & 3.9497 & TRN \\
\hline CHEMBL1408986 & 752541 & 3.0044 & 3.9934 & TRN \\
\hline CHEMBL1981303 & 752541 & 3.0044 & 3.4427 & TRN \\
\hline CHEMBL1579116 & 752541 & 4.6216 & 3.5854 & TRN \\
\hline CHEMBL1446234 & 752541 & 3.0044 & 3.3208 & TRN \\
\hline CHEMBL1462078 & 752541 & 3.0044 & 3.5613 & TRN \\
\hline CHEMBL1546706 & 752541 & 4.0565 & 3.5382 & TRN \\
\hline CHEMBL1497357 & 752541 & 3.0044 & 3.5685 & TST \\
\hline CHEMBL1534294 & 752541 & 5.1314 & 3.7507 & TRN \\
\hline CHEMBL1419680 & 752541 & 4.5086 & 4.127 & TRN \\
\hline CHEMBL1333548 & 752541 & 3.0044 & 3.6295 & TRN \\
\hline CHEMBL1476029 & 752541 & 4.3344 & 3.7553 & TRN \\
\hline CHEMBL1414655 & 752541 & 3.0044 & 3.0108 & TRN \\
\hline CHEMBL1420252 & 752541 & 4.1858 & 3.2588 & TRN \\
\hline CHEMBL3214600 & 752541 & 3.0044 & 3.3267 & TRN \\
\hline CHEMBL1583844 & 752541 & 3.0044 & 3.362 & TRN \\
\hline CHEMBL1386791 & 752541 & 3.0044 & 3.2652 & TRN \\
\hline CHEMBL1445617 & 752541 & 3.0044 & 3.5698 & TRN \\
\hline CHEMBL1422285 & 752541 & 3.0044 & 3.7515 & TRN \\
\hline CHEMBL1613256 & 752541 & 4.5287 & 3.8745 & TRN \\
\hline CHEMBL1521461 & 752541 & 3.0044 & 3.4903 & TRN \\
\hline CHEMBL1398060 & 752541 & 4.4202 & 3.4447 & TST \\
\hline CHEMBL1429367 & 752541 & 3.0044 & 3.7484 & TRN \\
\hline CHEMBL1883085 & 752541 & 3.0044 & 3.5728 & TRN \\
\hline CHEMBL3199198 & 752541 & 3.0044 & 3.0419 & TRN \\
\hline CHEMBL1577981 & 752541 & 3.0044 & 3.8425 & TRN \\
\hline CHEMBL1398190 & 752541 & 4.7878 & 3.6646 & TST \\
\hline CHEMBL1605363 & 752541 & 4.3468 & 3.4768 & TST \\
\hline CHEMBL3191091 & 752541 & 3.0044 & 3.48 & TST \\
\hline CHEMBL505670 & 752541 & 3.0044 & 3.8309 & TST \\
\hline CHEMBL1499248 & 752541 & 3.0044 & 3.6867 & TST \\
\hline
\end{tabular}

Page 214 
Supplemental Table S2.txt

\begin{tabular}{|c|c|c|c|c|}
\hline CHEMBL1310269 & 752541 & 4.4711 & 3.5694 & TST \\
\hline CHEMBL1352376 & 752541 & 3.0044 & 3.3769 & TST \\
\hline CHEMBL1996363 & 752541 & 4.4191 & 3.175 & TST \\
\hline CHEMBL1702248 & 752541 & 3.0044 & 3.8856 & TST \\
\hline CHEMBL1723854 & 752541 & 5.4498 & 3.8969 & TST \\
\hline CHEMBL1393520 & 752541 & 3.0044 & 3.7232 & TST \\
\hline CHEMBL1336930 & 752541 & 3.0044 & 3.7328 & TST \\
\hline CHEMBL1346297 & 752541 & 3.0044 & 3.5419 & TST \\
\hline CHEMBL1885064 & 752541 & 3.0044 & 3.2043 & TST \\
\hline CHEMBL1386952 & 752541 & 3.0044 & 3.5159 & TST \\
\hline CHEMBL1490734 & 752541 & 3.0044 & 4.0458 & TST \\
\hline CHEMBL1983116 & 752541 & 4.5072 & \multicolumn{2}{|c|}{3.6630000000000003} \\
\hline CHEMBL1442704 & 752541 & 3.0044 & 3.4717 & TST \\
\hline CHEMBL1410465 & 752541 & 3.0044 & 3.3634 & TST \\
\hline CHEMBL1463189 & 752541 & 3.0044 & 3.7688 & TST \\
\hline CHEMBL1339166 & 752541 & 3.0044 & 3.6254 & TST \\
\hline CHEMBL1465435 & 752541 & 3.0044 & 3.0254 & TST \\
\hline CHEMBL1421207 & 752541 & 4.8386 & 3.5075 & TST \\
\hline CHEMBL1371472 & 752541 & 3.0044 & 3.5696 & TST \\
\hline CHEMBL1724655 & 752541 & 3.0044 & 3.5305 & TST \\
\hline CHEMBL1340895 & 752541 & 4.7773 & 3.6824 & TST \\
\hline CHEMBL3196874 & 752541 & 3.0044 & 3.4271 & TST \\
\hline CHEMBL1453623 & 752541 & 4.8297 & 3.1223 & TST \\
\hline CHEMBL1522986 & 752541 & 3.0044 & 3.5293 & TST \\
\hline CHEMBL1727519 & 752541 & 3.0044 & 3.5324 & TST \\
\hline CHEMBL1601348 & 752541 & 3.0044 & \multicolumn{2}{|c|}{3.9730000000000003} \\
\hline CHEMBL1372792 & 752541 & 3.0044 & 2.9853 & TST \\
\hline CHEMBL1540094 & 752541 & 3.0044 & 3.5876 & TST \\
\hline CHEMBL1997740 & 752541 & 5.0742 & 3.8566 & TST \\
\hline CHEMBL1441958 & 752541 & 4.5498 & 3.6911 & TST \\
\hline CHEMBL3209076 & 752541 & 3.0044 & 3.2017 & TST \\
\hline CHEMBL1428589 & 752541 & 4.4425 & 3.5371 & TST \\
\hline CHEMBL1317867 & 752541 & 3.0044 & \multicolumn{2}{|c|}{ 3.2319999999999998 } \\
\hline CHEMBL1431909 & 752541 & 3.0044 & 3.458 & TST \\
\hline CHEMBL1558403 & 752541 & 3.0044 & 3.2318 & TST \\
\hline CHEMBL179544 & 1527963 & 3.6021 & 3.7259 & TRN \\
\hline CHEMBL156679 & 1527963 & 4.4225 & 4.3094 & TRN \\
\hline CHEMBL179610 & 1527963 & 3.9281 & 3.9362 & TRN \\
\hline CHEMBL1522291 & 1527963 & 5.6576 & 5.1368 & TRN \\
\hline CHEMBL 3640785 & 1527963 & 6.0 & 4.5428 & TRN \\
\hline CHEMBL368048 & 1527963 & 4.2299 & 4.0539 & TRN \\
\hline CHEMBL180524 & 1527963 & 4.475 & 4.422 & TRN \\
\hline CHEMBL179618 & 1527963 & 6.0 & 5.0442 & TRN \\
\hline CHEMBL 3640780 & 1527963 & 4.2118 & 4.5471 & TST \\
\hline CHEMBL178090 & 1527963 & 6.0 & \multicolumn{2}{|c|}{6.2589999999999995} \\
\hline CHEMBL179005 & 1527963 & 5.2336 & 5.0015 & TRN \\
\hline CHEMBL178527 & 1527963 & 3.7825 & 4.6038 & TRN \\
\hline CHEMBL 3640774 & 1527963 & 3.6021 & 5.0419 & TRN \\
\hline
\end{tabular}


Supplemental Table S2.txt

\begin{tabular}{|c|c|c|c|c|c|c|}
\hline CHEMBL360068 & 1527963 & 3.6757 & 3.7812 & TRN & & \\
\hline CHEMBL179398 & 1527963 & 5.3215 & 5.0574 & TRN & & \\
\hline CHEMBL3640766 & 1527963 & 5.0969 & 4.9398 & TRN & & \\
\hline CHEMBL179762 & 1527963 & 3.7825 & 3.9009 & TRN & & \\
\hline CHEMBL178878 & 1527963 & 4.9634 & 4.655 & TRN & & \\
\hline CHEMBL359657 & 1527963 & 6.0 & 6.5779 & TRN & & \\
\hline CHEMBL3640786 & 1527963 & 5.7144 & 5.0084 & TRN & & \\
\hline CHEMBL 3640768 & 1527963 & 4.9393 & 4.7428 & TRN & & \\
\hline CHEMBL3640769 & 1527963 & 4.8894 & 4.8445 & TRN & & \\
\hline CHEMBL3640763 & 1527963 & 5.2388 & 5.0424 & TST & & \\
\hline CHEMBL178708 & 1527963 & 2.3979 & 2.6444 & TRN & & \\
\hline CHEMBL1230982 & 1527963 & 3.9208 & 4.8486 & TRN & & \\
\hline CHEMBL 3640770 & 1527963 & 6.0 & 4.9316 & TST & & \\
\hline CHEMBL361969 & 1527963 & 3.8761 & 3.8069 & TRN & & \\
\hline CHEMBL 3640781 & 1527963 & 4.1871 & 5.2357 & TRN & & \\
\hline CHEMBL1601461 & 1527963 & 2.3979 & 4.7255 & TRN & & \\
\hline CHEMBL361153 & 1527963 & 5.8633 & 5.5624 & TRN & & \\
\hline CHEMBL 3640783 & 1527963 & 2.3979 & 5.0441 & TST & & \\
\hline CHEMBL368434 & 1527963 & 4.7212 & 4.6738 & TRN & & \\
\hline CHEMBL423429 & 1527963 & 3.7282 & 4.8123 & TRN & & \\
\hline CHEMBL179365 & 1527963 & 3.4101 & 3.3389 & TRN & & \\
\hline CHEMBL178196 & 1527963 & 5.0506 & 4.728 & TRN & & \\
\hline CHEMBL 6200 & 1527963 & 2.3979 & 4.9939 & TST & & \\
\hline CHEMBL440464 & 1527963 & 4.58 & 5.037 & TST & & \\
\hline CHEMBL361364 & 1527963 & 5.5031 & 5.4361 & TRN & & \\
\hline CHEMBL 3640784 & 1527963 & 2.3979 & 4.5986 & TRN & & \\
\hline CHEMBL425519 & 1527963 & 4.8013 & 4.8979 & TRN & & \\
\hline CHEMBL 3640773 & 1527963 & 4.6676 & 4.6439 & TRN & & \\
\hline CHEMBL178946 & 1527963 & 5.0655 & 5.2698 & TRN & & \\
\hline CHEMBL 3640778 & 1527963 & 4.3372 & 4.7113 & TST & & \\
\hline CHEMBL369285 & 1527963 & 5.9586 & 5.6771 & TRN & & \\
\hline CHEMBL179763 & 1527963 & 5.1805 & 4.851 & TRN & & \\
\hline CHEMBL 3640762 & 1527963 & 5.4547 & 5.2347 & TRN & & \\
\hline CHEMBL3640760 & 1527963 & 6.0 & 4.8479 & TRN & & \\
\hline CHEMBL 3640782 & 1527963 & 3.719 & 4.5079 & TRN & & \\
\hline CHEMBL359672 & 1527963 & 2.3979 & 2.5518 & TRN & & \\
\hline CHEMBL178516 & 1527963 & 5.82100 & 30000000 & $\partial 1$ & 5.4079999999999995 & TRN \\
\hline CHEMBL179366 & 1527963 & 3.3893 & 2.8124 & TST & & \\
\hline CHEMBL 3640767 & 1527963 & 5.0 & 5.2147 & TST & & \\
\hline CHEMBL360541 & 1527963 & 6.289 & 5.949 & TST & & \\
\hline CHEMBL3640776 & 1527963 & 4.4908 & 4.5171 & TRN & & \\
\hline CHEMBL179704 & 1527963 & 5.7328 & 5.6718 & TRN & & \\
\hline CHEMBL1373373 & 1527963 & 5.3768 & 4.4554 & TST & & \\
\hline CHEMBL178780 & 1527963 & 5.857 & 5.5954 & TRN & & \\
\hline CHEMBL179628 & 1527963 & 4.4001 & 3.9537 & TRN & & \\
\hline CHEMBL3640771 & 1527963 & 4.6946 & 5.225 & TST & & \\
\hline CHEMBL360998 & 1527963 & 4.5482 & 3.5201 & TRN & & \\
\hline CHEMBL 3640775 & 1527963 & 4.5735 & 4.8435 & TRN & & \\
\hline
\end{tabular}


Supplemental Table S2.txt

\begin{tabular}{|c|c|c|c|c|}
\hline CHEMBL 362702 & 1527963 & 5.065 & 4.9481 & TRN \\
\hline CHEMBL178348 & 1527963 & 4.3363 & 4.1445 & TRN \\
\hline CHEMBL359736 & 1527963 & 4.5171 & 4.4398 & TRN \\
\hline CHEMBL179962 & 1527963 & 4.1805 & 4.4134 & TRN \\
\hline CHEMBL3544719 & 1527963 & 3.5622 & 4.9288 & TST \\
\hline CHEMBL178938 & 1527963 & 5.7825 & 5.3595 & TRN \\
\hline CHEMBL3640779 & 1527963 & 4.2132 & 5.224 & TST \\
\hline CHEMBL313833 & 1527963 & 6.0 & 5.0645 & TST \\
\hline CHEMBL3640761 & 1527963 & 5.7878 & 4.7637 & TRN \\
\hline CHEMBL180270 & 1527963 & 3.8665 & \multicolumn{2}{|c|}{3.8139999999999996} \\
\hline CHEMBL3640765 & 1527963 & 6.0 & 4.7772 & TST \\
\hline CHEMBL 368883 & 1527963 & 5.8239 & 5.4693 & TST \\
\hline CHEMBL179669 & 1527963 & 6.2062 & 5.8937 & TRN \\
\hline CHEMBL179200 & 1527963 & 3.5817 & 3.6826 & TRN \\
\hline CHEMBL149808 & 1527963 & 5.2708 & 5.0824 & TST \\
\hline CHEMBL1526229 & 1527963 & 4.4895 & 4.9939 & TST \\
\hline CHEMBL360999 & 1527963 & 6.1261 & 5.7991 & TRN \\
\hline CHEMBL360779 & 1527963 & 4.4306 & 4.2164 & TRN \\
\hline CHEMBL3640772 & 1527963 & 4.6383 & 5.0085 & TST \\
\hline CHEMBL178453 & 1527963 & 3.5735 & 3.5805 & TRN \\
\hline CHEMBL179589 & 1527963 & 4.7825 & 4.5152 & TRN \\
\hline CHEMBL3640777 & 1527963 & 4.4789 & 5.1647 & TRN \\
\hline CHEMBL179621 & 1527963 & 5.8894 & 5.2682 & TRN \\
\hline CHEMBL188430 & 313055 & 5.2291 & 4.8739 & TST \\
\hline CHEMBL187192 & 313055 & 6.6021 & 6.4955 & TRN \\
\hline CHEMBL189026 & 313055 & 5.0 & 5.0757 & TST \\
\hline CHEMBL188610 & 313055 & 5.4089 & 5.1747 & TRN \\
\hline CHEMBL186217 & 313055 & 5.8539 & 5.7583 & TRN \\
\hline CHEMBL359783 & 313055 & 4.8539 & 6.3032 & TST \\
\hline CHEMBL360177 & 313055 & 6.0132 & 6.1209 & TRN \\
\hline CHEMBL187565 & 313055 & 4.7959 & 4.7032 & TRN \\
\hline CHEMBL186209 & 313055 & 5.2291 & \multicolumn{2}{|c|}{5.377000000000001} \\
\hline CHEMBL186707 & 313055 & 4.9586 & 4.8409 & TRN \\
\hline CHEMBL188198 & 313055 & 5.0044 & 5.0732 & TRN \\
\hline CHEMBL363763 & 313055 & 4.7447 & 4.4212 & TST \\
\hline CHEMBL363071 & 313055 & 5.699 & 5.5943 & TRN \\
\hline CHEMBL189826 & 313055 & 4.8539 & 4.6797 & TRN \\
\hline CHEMBL187977 & 313055 & 6.0315 & 5.9537 & TRN \\
\hline CHEMBL187200 & 313055 & 3.8239 & 3.8605 & TRN \\
\hline CHEMBL186420 & 313055 & 5.8861 & 6.0309 & TRN \\
\hline CHEMBL189605 & 313055 & 6.699 & 5.9929 & TRN \\
\hline CHEMBL433578 & 313055 & 3.699 & 4.3883 & TST \\
\hline CHEMBL1161726 & 313055 & 3.8239 & \multicolumn{2}{|c|}{3.9189999999999996} \\
\hline CHEMBL181855 & 313055 & 6.2757 & 6.5586 & TRN \\
\hline CHEMBL188533 & 313055 & 4.8539 & 4.0875 & TST \\
\hline CHEMBL363735 & 313055 & 6.3872 & 6.148 & TRN \\
\hline CHEMBL188611 & 313055 & 5.5686 & 5.5313 & TRN \\
\hline CHEMBL189757 & 313055 & 4.7959 & 4.2434 & TST \\
\hline
\end{tabular}




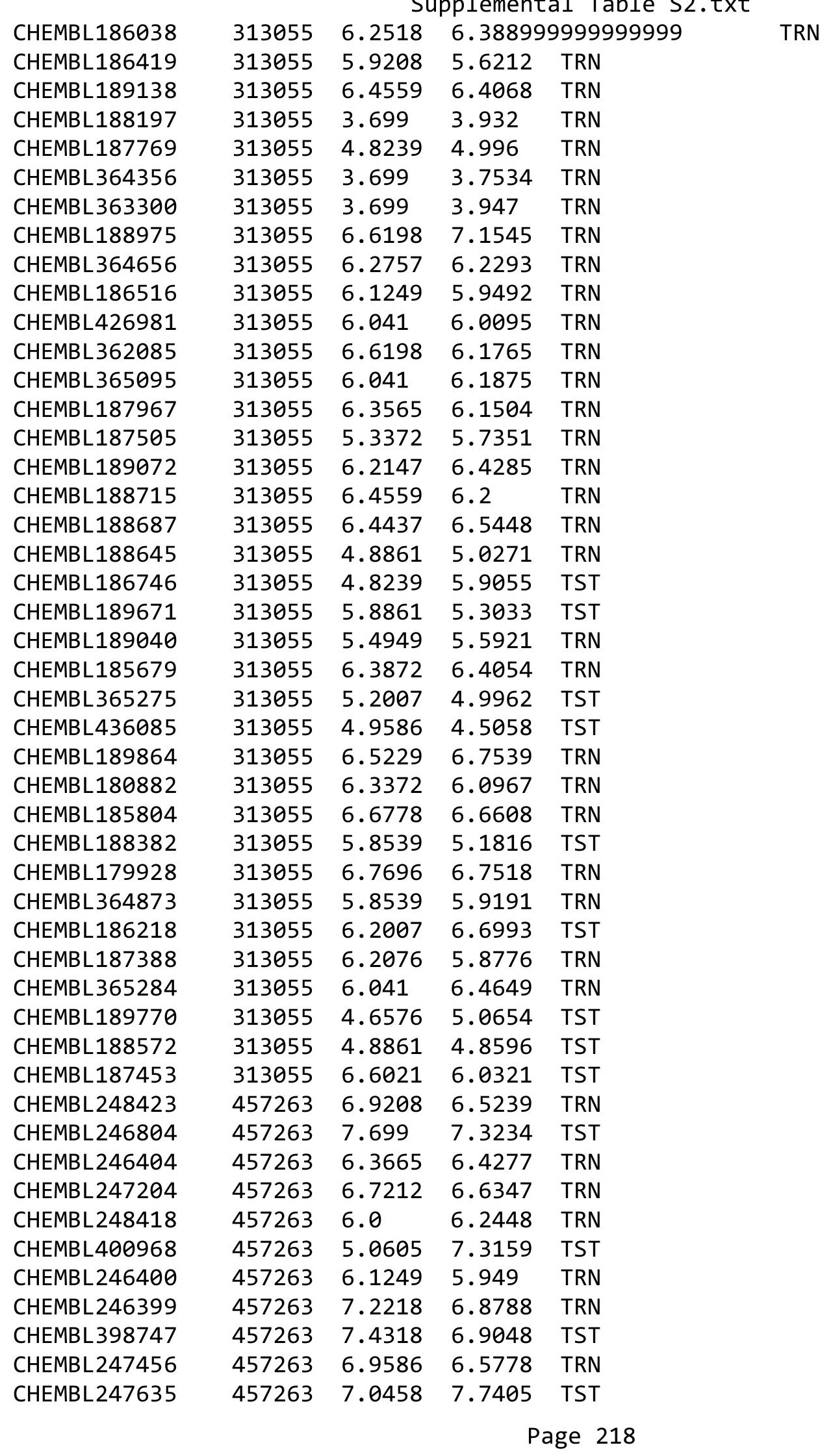




\begin{tabular}{|c|c|c|c|c|c|}
\hline \multicolumn{6}{|c|}{ Supplemental Table S2.txt } \\
\hline CHEMBL247621 & 457263 & 7.6383 & 7.5869 & TRN & \\
\hline CHEMBL246401 & 457263 & 6.3979 & 6.3537 & TRN & \\
\hline CHEMBL247210 & 457263 & 6.585 & 6.3942 & TRN & \\
\hline CHEMBL400196 & 457263 & 6.0 & 6.6038 & TRN & \\
\hline CHEMBL246218 & 457263 & 4.8239 & 6.3415 & TST & \\
\hline CHEMBL246417 & 457263 & 6.8239 & 6.8569 & TRN & \\
\hline CHEMBL400793 & 457263 & 6.8239 & 6.6816 & TRN & \\
\hline CHEMBL402055 & 457263 & 6.0458 & 6.5414 & TRN & \\
\hline CHEMBL400158 & 457263 & 6.9586 & 6.6376 & TRN & \\
\hline CHEMBL246397 & 457263 & 5.9208 & 5.8262 & TRN & \\
\hline CHEMBL398134 & 457263 & 7.7959 & 7.6434 & TRN & \\
\hline CHEMBL246406 & 457263 & 7.3279 & 6.8632 & TRN & \\
\hline CHEMBL398354 & 457263 & 6.0 & 6.1485 & TRN & \\
\hline CHEMBL402056 & 457263 & 7.4437 & 7.1346 & TRN & \\
\hline CHEMBL427705 & 457263 & 6.8861 & 7.6269 & TRN & \\
\hline CHEMBL247407 & 457263 & 6.1135 & 6.4991 & TRN & \\
\hline CHEMBL246398 & 457263 & 5.1549 & 5.5727 & TRN & \\
\hline CHEMBL392814 & 457263 & 7.7212 & 7.6059 & TRN & \\
\hline CHEMBL248421 & 457263 & 6.6021 & 6.5505 & TRN & \\
\hline CHEMBL246221 & 457263 & 6.8861 & 6.4143 & TST & \\
\hline CHEMBL400383 & 457263 & 6.3872 & 6.3611 & TRN & \\
\hline CHEMBL248417 & 457263 & 5.2596 & 5.8265 & TRN & \\
\hline CHEMBL246409 & 457263 & 6.1739 & 6.1332 & TRN & \\
\hline CHEMBL247205 & 457263 & 7.0555 & 6.8712 & TRN & \\
\hline CHEMBL247214 & 457263 & 5.7696 & 5.9287 & TRN & \\
\hline CHEMBL247207 & 457263 & 7.0044 & 6.9687 & TRN & \\
\hline CHEMBL401009 & 457263 & 6.7696 & 6.5722 & TRN & \\
\hline CHEMBL247245 & 457263 & 7.9586 & 7.4576 & TST & \\
\hline CHEMBL246098 & 457263 & 6.5086 & 7.62200 & 0000000001 & TRN \\
\hline CHEMBL246405 & 457263 & 6.7959 & 6.6499 & TRN & \\
\hline CHEMBL337246 & 457263 & 7.7696 & 6.7435 & TST & \\
\hline CHEMBL246410 & 457263 & 6.9208 & 6.3904 & TRN & \\
\hline CHEMBL393267 & 457263 & 7.8861 & 7.481 & TST & \\
\hline CHEMBL248420 & 457263 & 6.6383 & 6.4492 & TRN & \\
\hline CHEMBL247439 & 457263 & 7.1871 & 7.4453 & TST & \\
\hline CHEMBL401463 & 457263 & 6.3979 & 6.8566 & TRN & \\
\hline CHEMBL400160 & 457263 & 5.9586 & 6.1308 & TRN & \\
\hline CHEMBL246415 & 457263 & 7.1871 & 6.8112 & TRN & \\
\hline CHEMBL400159 & 457263 & 6.4202 & 6.1415 & TRN & \\
\hline CHEMBL247209 & 457263 & 7.2596 & 6.5037 & TRN & \\
\hline CHEMBL246411 & 457263 & 6.1612 & 6.6339 & TRN & \\
\hline CHEMBL400382 & 457263 & 4.6576 & 6.398 & TST & \\
\hline CHEMBL401011 & 457263 & 6.699 & 6.5871 & TRN & \\
\hline CHEMBL247211 & 457263 & 6.3098 & 6.30200 & 00000000005 & TRN \\
\hline CHEMBL247608 & 457263 & 7.7212 & 6.4662 & TST & \\
\hline CHEMBL247206 & 457263 & 7.0132 & 6.9622 & TRN & \\
\hline CHEMBL247208 & 457263 & 6.8239 & 6.9834 & TRN & \\
\hline CHEMBL247455 & 457263 & 7.8239 & 7.517 & TST & \\
\hline
\end{tabular}


Supplemental Table S2.txt

\begin{tabular}{|c|c|c|c|c|}
\hline HEMBL 247203 & 57263 & 6.9208 & & 策 \\
\hline HEMBL401010 & 57263 & 7.0 & & \\
\hline HFMRI 2 & 263 & 2518 & & \\
\hline IEMBL2 & 263 & 427 & & \\
\hline HEMBL 246403 & 57263 & 2757 & 9261 & \\
\hline HEMBL 24 & 57263 & .5528 & 6791 & \\
\hline HEMBL 2 & 7263 & 212 & 3785 & \\
\hline AEMBL2 24 & 263 & 8861 & & $C T$ \\
\hline HEMBL 248188 & 57263 & 7.6383 & 4984 & \\
\hline HEMBL 246407 & .57263 & 37 & 4864 & 1 \\
\hline HEMBL2 & 263 & & & \\
\hline HEMBL1 & 50 & 29 & 301 & RN \\
\hline HEMBL1 & & & & \\
\hline HEMBL23 & 48150 & .1085 & 127 & I RIN \\
\hline HEMBL6S & 150 & 89 & & \\
\hline HEMBL4 & 50 & 74 & & ונס \\
\hline HEMBL 2 & & & & RN \\
\hline HEMBL 2 & 50 & & & RN \\
\hline HEMBL2 & 50 & & 4729 & $1 \mathrm{KIV}$ \\
\hline HEMBL2 & & & & 131 \\
\hline HEMBL 2 & & & & RN \\
\hline HEMBL & & & & ST \\
\hline HEMBL 2 & 50 & & 87 & RN \\
\hline HEMBL1 & 50 & & & TST \\
\hline HEMBL1 & & & 63 & IRIN \\
\hline HEMBL1 & & & 39 & 「RN \\
\hline HEMBL & & & & RN \\
\hline 789 & & & 95 & TST \\
\hline HEMBL6 & & & & TST \\
\hline HEMBL1 & & & & TRN \\
\hline HEMBL: & & & & 「RN \\
\hline HFM & & & & 「RN \\
\hline 785 & & & & TRN \\
\hline HEMBL1 & & & & 「RN \\
\hline HEMBL2 & 50 & 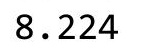 & 212 & ГRN \\
\hline 335 & & & 51 & TRN \\
\hline 57 & & & & TRN \\
\hline HEMBL2 & & & & TST \\
\hline HEMBL 2 & 50 & & & TRN \\
\hline HEMBL & & & & TST \\
\hline HEMBL 2 & & 34 & & TST \\
\hline HEMBL 2 & & 32 & 7784 & TRN \\
\hline HEMBL 2 & 150 & . 7189 & & ГRN \\
\hline HEMBL2 & 50 & & & TR \\
\hline 62 & & & & RN \\
\hline HEMBL23 & & & & \\
\hline HEMBL11 & 48150 & 8.2464 & 7.9001 & ST \\
\hline CHEMBL1165241 & 948150 & 5.756 & 5.7401 & TRN \\
\hline
\end{tabular}

Page 220 


\begin{tabular}{|c|c|c|c|c|c|c|}
\hline & & \multicolumn{5}{|c|}{ Supplemental Table S2.txt } \\
\hline CHEMBL1163867 & 948150 & 8.0867 & 8.1102 & TST & & \\
\hline CHEMBL2336366 & 948150 & 5.8064 & 5.8034 & TRN & & \\
\hline CHEMBL2336348 & 948150 & 5.7882 & 5.7632 & TRN & & \\
\hline CHEMBL2336358 & 948150 & 8.1319 & 8.1487 & TRN & & \\
\hline CHEMBL1830131 & 948150 & 5.7416 & 5.744 & TRN & & \\
\hline CHEMBL2336783 & 948150 & 8.2284 & 8.2677 & TST & & \\
\hline CHEMBL2336337 & 948150 & 8.1068 & 8.1153 & TST & & \\
\hline CHEMBL1830143 & 948150 & 5.7401 & 5.7557 & TRN & & \\
\hline CHEMBL 145 & 948150 & 7.6733 & 7.9406 & TST & & \\
\hline CHEMBL2336359 & 948150 & 8.1952 & \multicolumn{3}{|c|}{8.197000000000001} & TRN \\
\hline CHEMBL2336347 & 948150 & 8.0491 & 8.0573 & TRN & & \\
\hline CHEMBL1998736 & 948150 & 7.9755 & 7.9681 & TRN & & \\
\hline CHEMBL2336361 & 948150 & 7.9889 & 7.9794 & TRN & & \\
\hline CHEMBL 229844 & 948150 & 8.2083 & 8.227 & TRN & & \\
\hline CHEMBL68427 & 948150 & 5.7846 & 5.8092 & TRN & & \\
\hline CHEMBL 2336356 & 948150 & 5.704 & 5.7145 & TRN & & \\
\hline CHEMBL2336354 & 948150 & 5.7455 & 5.729 & TRN & & \\
\hline CHEMBL325749 & 948150 & 8.1062 & 8.0937 & TST & & \\
\hline CHEMBL 2336364 & 948150 & 8.1175 & 8.0865 & TST & & \\
\hline CHEMBL2336336 & 948150 & 8.0851 & 8.0863 & TRN & & \\
\hline CHEMBL 2336340 & 948150 & 8.3716 & 8.3956 & TRN & & \\
\hline CHEMBL1981977 & 948150 & 7.8579 & 7.8816 & TRN & & \\
\hline CHEMBL 2336339 & 948150 & 5.7998 & 5.7789 & TRN & & \\
\hline CHEMBL1830129 & 948150 & \multicolumn{3}{|c|}{8.097999999999999} & 8.101 & TRN \\
\hline CHEMBL2336353 & 948150 & 8.1439 & 8.1283 & TRN & & \\
\hline CHEMBL 2336350 & 948150 & 8.0297 & 7.9934 & TRN & & \\
\hline CHEMBL2336782 & 948150 & \multicolumn{3}{|c|}{8.466000000000001} & 8.5019 & TIN \\
\hline CHEMBL1165574 & 948150 & 8.1073 & 8.1729 & TST & & \\
\hline CHEMBL1163455 & 948150 & 8.4776 & 8.5041 & TST & & \\
\hline CHEMBL2336351 & 948150 & 8.0367 & 8.0431 & TRN & & \\
\hline CHEMBL1830141 & 948150 & 5.7103 & 5.7136 & TRN & & \\
\hline CHEMBL1165106 & 948150 & 8.4389 & 8.4446 & TRN & & \\
\hline CHEMBL 2336784 & 948150 & 5.7548 & 5.7739 & TRN & & \\
\hline CHEMBL2336342 & 948150 & 5.7799 & 5.7674 & TRN & & \\
\hline CHEMBL275362 & 948150 & 8.1463 & 8.1676 & TRN & & \\
\hline CHEMBL2336786 & 948150 & 8.0958 & 8.1103 & TST & & \\
\hline CHEMBL3963052 & 1640573 & 8.2007 & 8.1282 & TRN & & \\
\hline CHEMBL3950595 & 1640573 & 7.9208 & 7.9915 & TRN & & \\
\hline CHEMBL3948379 & 1640573 & 8.585 & 8.3788 & TRN & & \\
\hline CHEMBL3983416 & 1640573 & 7.8861 & 7.8758 & TRN & & \\
\hline CHEMBL3974777 & 1640573 & 8.6021 & 8.7004 & TRN & & \\
\hline CHEMBL3901242 & 1640573 & 8.1024 & 8.1024 & TRN & & \\
\hline CHEMBL3901251 & 1640573 & 8.0 & 7.9976 & TRN & & \\
\hline CHEMBL3918796 & 1640573 & 6.8697 & 6.8792 & TRN & & \\
\hline CHEMBL3922125 & 1640573 & 7.6021 & 7.6846 & TRN & & \\
\hline CHEMBL3965271 & 1640573 & 9.1549 & 9.1586 & TRN & & \\
\hline CHEMBL3977710 & 1640573 & 8.3979 & 8.4478 & TRN & & \\
\hline \multirow[t]{2}{*}{ CHEMBL3912123 } & 1640573 & 8.4202 & 8.55299 & 999999999 & & \\
\hline & & \multicolumn{4}{|c|}{ Page 221} & \\
\hline
\end{tabular}


Supplemental Table S2.txt

\begin{tabular}{|c|c|c|c|c|c|}
\hline CHEMBL3957616 & 1640573 & 8.3872 & 8.3975 & TRN & \\
\hline CHEMBL3925183 & 1640573 & 8.2291 & 8.3662 & TRN & \\
\hline CHEMBL3931848 & 1640573 & 8.5686 & 8.6488 & TRN & \\
\hline CHEMBL 3909655 & 1640573 & 7.9586 & 9.0133 & TST & \\
\hline CHEMBL3923651 & 1640573 & 5.8861 & 6.1838 & TST & \\
\hline CHEMBL 3977147 & 1640573 & 9.301 & 9.1624 & TRN & \\
\hline CHEMBL3927385 & 1640573 & 8.6576 & 8.7962 & TST & \\
\hline CHEMBL 3909180 & 1640573 & 8.6576 & 8.6395 & TRN & \\
\hline CHEMBL3967166 & 1640573 & 8.4685 & 8.561 & TRN & \\
\hline CHEMBL3938454 & 1640573 & 9.0 & 9.1867 & TRN & \\
\hline CHEMBL 3965676 & 1640573 & 8.7959 & 8.7272 & TRN & \\
\hline CHEMBL3912769 & 1640573 & 8.9586 & 9.0555 & TRN & \\
\hline CHEMBL3975180 & 1640573 & 8.4089 & 8.6696 & TRN & \\
\hline CHEMBL 3927446 & 1640573 & 8.3098 & 8.261000 & 0000000001 & TRN \\
\hline CHEMBL3950150 & 1640573 & 8.5086 & 8.4288 & TRN & \\
\hline CHEMBL3973987 & 1640573 & 8.7212 & 8.6965 & TRN & \\
\hline CHEMBL3900512 & 1640573 & 8.4949 & 8.5027 & TRN & \\
\hline CHEMBL3910789 & 1640573 & 9.2218 & 8.976 & TRN & \\
\hline CHEMBL3954073 & 1640573 & 8.301 & 8.3571 & TRN & \\
\hline CHEMBL3974191 & 1640573 & 8.5376 & 8.622 & TRN & \\
\hline CHEMBL3913487 & 1640573 & 8.0757 & 7.9047 & TRN & \\
\hline CHEMBL3984164 & 1640573 & 8.8861 & 8.8331 & TRN & \\
\hline CHEMBL3924194 & 1640573 & 7.8539 & 8.1721 & TST & \\
\hline CHEMBL3941240 & 1640573 & 8.4318 & 8.4928 & TRN & \\
\hline CHEMBL 3897830 & 1640573 & 8.5528 & 8.7756 & TRN & \\
\hline CHEMBL3918747 & 1640573 & 8.2596 & 8.2467 & TRN & \\
\hline CHEMBL3906419 & 1640573 & 8.0088 & 8.4434 & TST & \\
\hline CHEMBL3980688 & 1640573 & 8.6383 & 8.6061 & TRN & \\
\hline CHEMBL3941307 & 1640573 & 8.8239 & 8.91 & TRN & \\
\hline CHEMBL 3900809 & 1640573 & 8.1675 & 8.4641 & TRN & \\
\hline CHEMBL3896910 & 1640573 & 8.5686 & 8.5947 & TRN & \\
\hline CHEMBL 3949232 & 1640573 & 8.7959 & 8.7394 & TRN & \\
\hline CHEMBL3972162 & 1640573 & 8.699 & 8.5135 & TRN & \\
\hline CHEMBL 3935451 & 1640573 & 8.5229 & 8.8246 & TST & \\
\hline CHEMBL 3940823 & 1640573 & 7.8539 & 7.9651 & TRN & \\
\hline CHEMBL3895789 & 1640573 & 7.6383 & 7.6081 & TRN & \\
\hline CHEMBL3901741 & 1640573 & 8.2441 & 8.3489 & TRN & \\
\hline CHEMBL 3899565 & 1640573 & 7.9747 & 7.9341 & TRN & \\
\hline CHEMBL3977596 & 1640573 & 8.585 & 8.3615 & TRN & \\
\hline CHEMBL3957688 & 1640573 & 8.3979 & 8.2332 & TRN & \\
\hline CHEMBL 3968742 & 1640573 & 8.7696 & 8.9793 & TRN & \\
\hline CHEMBL3974022 & 1640573 & 8.4685 & 8.5254 & TRN & \\
\hline CHEMBL3961268 & 1640573 & 8.28399 & 999999999 & 8.1891 & $1 \mathrm{~N}$ \\
\hline CHEMBL3949795 & 1640573 & 8.8861 & 9.0822 & TRN & \\
\hline CHEMBL3969016 & 1640573 & 9.0458 & 9.0892 & TRN & \\
\hline CHEMBL3976090 & 1640573 & 7.6021 & 7.7605 & TRN & \\
\hline CHEMBL3956421 & 1640573 & 8.2596 & 8.2 & TRN & \\
\hline CHEMBL3912632 & 1640573 & 9.0969 & 9.0532 & TRN & \\
\hline
\end{tabular}


Supplemental Table S2.txt

\begin{tabular}{|c|c|c|c|c|}
\hline CHEMBL3933596 & 1640573 & 7.585 & 7.7519 & TRN \\
\hline CHEMBL3980667 & 1640573 & 8.8861 & 8.9758 & TRN \\
\hline CHEMBL3917678 & 1640573 & 7.6778 & 8.171 & TST \\
\hline CHEMBL 3891300 & 1640573 & 8.7696 & 8.7452 & TRN \\
\hline CHEMBL3950518 & 1640573 & 8.2007 & 8.2192 & TRN \\
\hline CHEMBL3963881 & 1640573 & 8.5229 & 8.5526 & TRN \\
\hline CHEMBL3931731 & 1640573 & 8.5528 & 8.5125 & TRN \\
\hline CHEMBL3932421 & 1640573 & 8.6021 & 8.5511 & TRN \\
\hline CHEMBL3944209 & 1640573 & 8.7212 & 8.92799 & 999999999 \\
\hline CHEMBL3907506 & 1640573 & 8.2757 & 8.6897 & TST \\
\hline CHEMBL3931709 & 1640573 & 7.3279 & 7.34 & TRN \\
\hline CHEMBL3986416 & 1640573 & 7.6778 & 7.7347 & TRN \\
\hline CHEMBL3935483 & 1640573 & 8.6576 & 8.8802 & TRN \\
\hline CHEMBL3951221 & 1640573 & 8.3468 & 8.3016 & TRN \\
\hline CHEMBL 3947888 & 1640573 & 8.8239 & 8.7448 & TRN \\
\hline CHEMBL3912513 & 1640573 & 8.2007 & 8.5717 & TST \\
\hline CHEMBL3974201 & 1640573 & 8.9586 & 8.8349 & TRN \\
\hline CHEMBL 3920410 & 1640573 & 8.3979 & 8.4265 & TRN \\
\hline CHEMBL3919663 & 1640573 & 7.0605 & 8.1611 & TST \\
\hline CHEMBL3904672 & 1640573 & 7.9208 & 7.9929 & TRN \\
\hline CHEMBL 3894577 & 1640573 & 8.6383 & 8.4557 & TRN \\
\hline CHEMBL3955405 & 1640573 & 8.0 & 8.1234 & TRN \\
\hline CHEMBL3970397 & 1640573 & 8.6778 & 8.3548 & TRN \\
\hline CHEMBL3948232 & 1640573 & 5.5686 & 5.8099 & TRN \\
\hline CHEMBL 3913252 & 1640573 & 7.9586 & 7.9714 & TRN \\
\hline CHEMBL 3929830 & 1640573 & 8.0 & 7.7949 & TRN \\
\hline CHEMBL3920419 & 1640573 & 8.5686 & 8.709 & TRN \\
\hline CHEMBL 3940867 & 1640573 & 9.0 & 9.041 & TRN \\
\hline CHEMBL3922417 & 1640573 & 8.6778 & 8.3639 & TST \\
\hline CHEMBL3969229 & 1640573 & 8.4437 & 8.4552 & TRN \\
\hline CHEMBL 3932324 & 1640573 & 6.5017 & 6.3523 & TST \\
\hline CHEMBL3968655 & 1640573 & 8.4815 & 8.6236 & TRN \\
\hline CHEMBL3900963 & 1640573 & 8.5686 & 8.5755 & TRN \\
\hline CHEMBL3924930 & 1640573 & 8.4559 & 8.4514 & TRN \\
\hline CHEMBL3921412 & 1640573 & 8.4949 & 8.5615 & TRN \\
\hline CHEMBL3978888 & 1640573 & 8.5229 & 8.3345 & TST \\
\hline CHEMBL3958964 & 1640573 & 8.6383 & 8.1969 & TST \\
\hline CHEMBL3966203 & 1640573 & 9.0969 & 9.0194 & TRN \\
\hline CHEMBL 3960355 & 1640573 & 8.9586 & 9.01700 & 000000001 \\
\hline CHEMBL3925121 & 1640573 & 6.6021 & 9.0839 & TST \\
\hline CHEMBL 3906488 & 1640573 & 8.6576 & 8.7908 & TRN \\
\hline CHEMBL3951747 & 1640573 & 9.0 & 8.9297 & TRN \\
\hline CHEMBL3970947 & 1640573 & 8.585 & 9.1349 & TST \\
\hline CHEMBL3976022 & 1640573 & 8.2441 & 8.2902 & TRN \\
\hline CHEMBL 3899333 & 1640573 & 8.0458 & 6.4633 & TST \\
\hline CHEMBL 3973744 & 1640573 & 8.5528 & 8.3916 & TRN \\
\hline CHEMBL3913969 & 1640573 & 8.2291 & 8.2812 & TRN \\
\hline CHEMBL3960833 & 1640573 & 8.3872 & 8.7653 & TRN \\
\hline
\end{tabular}

Page 223 
Supplemental Table S2.txt

\begin{tabular}{|c|c|c|c|c|c|c|}
\hline CHEMBL3892575 & 1640573 & 8.1871 & \multicolumn{2}{|c|}{8.152999999999999} & & TRN \\
\hline CHEMBL3954781 & 1640573 & 8.9586 & 8.6349 & TRN & & \\
\hline CHEMBL3922482 & 1640573 & 8.2218 & 8.2409 & TRN & & \\
\hline CHEMBL3926249 & 1640573 & 8.0458 & 8.1227 & TRN & & \\
\hline CHEMBL3986943 & 1640573 & 8.6198 & 8.5778 & TRN & & \\
\hline CHEMBL3903026 & 1640573 & 7.9208 & 7.8214 & TRN & & \\
\hline CHEMBL3917410 & 1640573 & 8.4437 & 8.5212 & TRN & & \\
\hline CHEMBL3966806 & 1640573 & 9.9586 & 9.7994 & TRN & & \\
\hline CHEMBL3922457 & 1640573 & 7.9208 & 7.9105 & TRN & & \\
\hline CHEMBL3973946 & 1640573 & 8.4559 & 8.4884 & TRN & & \\
\hline CHEMBL3897576 & 1640573 & 8.0362 & 7.9997 & TRN & & \\
\hline CHEMBL3982706 & 1640573 & 8.4559 & 8.5475 & TRN & & \\
\hline CHEMBL3927590 & 1640573 & 8.8539 & 8.4562 & TST & & \\
\hline CHEMBL3894578 & 1640573 & 8.8239 & 8.8417 & TRN & & \\
\hline CHEMBL3970663 & 1640573 & 8.5528 & 8.4631 & TRN & & \\
\hline CHEMBL3932730 & 1640573 & 7.301 & 7.2579 & TST & & \\
\hline CHEMBL3951639 & 1640573 & 8.8539 & 8.6948 & TRN & & \\
\hline CHEMBL3931262 & 1640573 & 8.2441 & 8.2978 & TRN & & \\
\hline CHEMBL3900331 & 1640573 & 8.7447 & 8.6181 & TRN & & \\
\hline CHEMBL3960331 & 1640573 & 8.2366 & 8.184 & TRN & & \\
\hline CHEMBL3895898 & 1640573 & 8.8861 & 8.906 & TRN & & \\
\hline CHEMBL3916864 & 1640573 & 8.7447 & 8.6655 & TRN & & \\
\hline CHEMBL3987189 & 1640573 & 6.7212 & 8.367 & TST & & \\
\hline CHEMBL3973441 & 1640573 & 7.6576 & 8.5458 & TST & & \\
\hline CHEMBL3913301 & 1640573 & 7.6778 & 7.4826 & TST & & \\
\hline CHEMBL3897494 & 1640573 & 8.2076 & 8.1193 & TRN & & \\
\hline CHEMBL3968002 & 1640573 & 7.6021 & 8.0896 & TST & & \\
\hline CHEMBL3967750 & 1640573 & 8.6778 & 9.1595 & TRN & & \\
\hline CHEMBL3927440 & 1640573 & 8.4949 & 8.6016 & TRN & & \\
\hline CHEMBL3951912 & 1640573 & 8.4559 & 7.9522 & TST & & \\
\hline CHEMBL3939318 & 1640573 & 8.3665 & 8.4581 & TST & & \\
\hline CHEMBL3963056 & 1640573 & 9.0969 & 8.9353 & TRN & & \\
\hline CHEMBL3925871 & 1640573 & 8.4685 & 8.277999 & 9999999995 & & TST \\
\hline CHEMBL3923786 & 1640573 & 8.1739 & 8.0574 & TRN & & \\
\hline CHEMBL3895298 & 1640573 & 8.5229 & 8.5428 & TRN & & \\
\hline CHEMBL3907714 & 1640573 & 7.6021 & 7.5757 & TST & & \\
\hline CHEMBL3952076 & 1640573 & 7.7959 & 7.9007 & TST & & \\
\hline CHEMBL3983282 & 1640573 & 8.9586 & 9.1095 & TRN & & \\
\hline CHEMBL 3949201 & 1640573 & 9.0969 & 9.0421 & TRN & & \\
\hline CHEMBL3891980 & 1640573 & 9.1549 & 9.1926 & TRN & & \\
\hline CHEMBL3957053 & 1640573 & 8.28399 & 999999999 & 99 & 8.3841 & TRN \\
\hline CHEMBL3964789 & 1640573 & 8.6778 & 8.9044 & TST & & \\
\hline CHEMBL3932390 & 1640573 & 8.6198 & 8.4763 & TRN & & \\
\hline CHEMBL3949523 & 1640573 & 8.8539 & 9.003 & TRN & & \\
\hline CHEMBL3917257 & 1640573 & 7.6778 & 7.5377 & TST & & \\
\hline CHEMBL3981168 & 1640573 & 8.2007 & 8.1199 & TRN & & \\
\hline CHEMBL3939239 & 1640573 & 8.0 & 8.222999 & 999999999 & & $\mathrm{KI}$ \\
\hline CHEMBL3899490 & 1640573 & 8.8861 & 9.043 & TRN & & \\
\hline
\end{tabular}




\begin{tabular}{|c|c|c|c|c|c|}
\hline \multicolumn{6}{|c|}{ Supplemental Table S2.txt } \\
\hline CHEMBL3899716 & 1640573 & 10.0 & 9.5732 & TRN & \\
\hline CHEMBL3939144 & 1640573 & 6.9586 & 7.0667 & TST & \\
\hline CHEMBL3956468 & 1640573 & 8.5528 & 8.381 & TRN & \\
\hline CHEMBL3968352 & 1640573 & 8.7447 & 8.6943 & TRN & \\
\hline CHEMBL3936990 & 1640573 & 10.2218 & 9.8936 & TRN & \\
\hline CHEMBL3936879 & 1640573 & 8.8539 & 8.8754 & TRN & \\
\hline CHEMBL3899515 & 1640573 & 7.0 & 6.9957 & TRN & \\
\hline CHEMBL 3987000 & 1640573 & 7.9586 & 7.9939 & TRN & \\
\hline CHEMBL3961623 & 1640573 & 7.0223 & 7.9406 & TST & \\
\hline CHEMBL3943041 & 1640573 & 8.0809 & 8.0286 & TRN & \\
\hline CHEMBL3890352 & 1640573 & 9.0 & 9.1701 & TRN & \\
\hline CHEMBL3976247 & 1640573 & 8.585 & 8.5617 & TRN & \\
\hline CHEMBL3904291 & 1640573 & 8.8861 & 8.6264 & TRN & \\
\hline CHEMBL 3944201 & 1640573 & 8.8861 & 9.0381 & TRN & \\
\hline CHEMBL3982217 & 1640573 & 6.5086 & 7.5503 & TST & \\
\hline CHEMBL3964344 & 1640573 & 8.3565 & 8.0283 & TRN & \\
\hline CHEMBL3942949 & 1640573 & 7.4318 & 7.3542 & TRN & \\
\hline CHEMBL 3954717 & 1640573 & 8.699 & 8.6315 & TRN & \\
\hline CHEMBL3980521 & 1640573 & 9.699 & 9.1379 & TRN & \\
\hline CHEMBL3911853 & 1640573 & 8.8539 & 8.9916 & TRN & \\
\hline CHEMBL3981085 & 1640573 & 9.585 & 9.53 & TRN & \\
\hline CHEMBL3937511 & 1640573 & 8.0915 & 8.037 & TRN & \\
\hline CHEMBL3949501 & 1640573 & 8.699 & 8.6533 & TRN & \\
\hline CHEMBL3928772 & 1640573 & 9.0969 & 8.7996 & TRN & \\
\hline CHEMBL 3890873 & 1640573 & 7.0969 & 7.4619 & TST & \\
\hline CHEMBL 3966878 & 1640573 & 7.6778 & 7.68 & TRN & \\
\hline CHEMBL3912088 & 1640573 & 7.0605 & 7.0425 & TRN & \\
\hline CHEMBL3922798 & 1640573 & 8.6778 & 8.7524 & TRN & \\
\hline CHEMBL 3897066 & 1640573 & 8.5686 & 9.6077 & TST & \\
\hline CHEMBL 3975681 & 1640573 & 8.6198 & 8.5097 & TRN & \\
\hline CHEMBL3974713 & 1640573 & 8.4815 & 8.4714 & TRN & \\
\hline CHEMBL3931504 & 1640573 & 8.585 & 8.7467 & TRN & \\
\hline CHEMBL3913809 & 1640573 & 8.1249 & 8.4284 & TST & \\
\hline CHEMBL3961976 & 1640573 & 6.0 & 7.9871 & TST & \\
\hline CHEMBL3926334 & 1640573 & 8.5686 & 7.6171 & TST & \\
\hline CHEMBL3961556 & 1640573 & 8.4318 & 8.5014 & TRN & \\
\hline CHEMBL3932445 & 1640573 & 7.7447 & 7.6456 & TRN & \\
\hline CHEMBL3972226 & 1640573 & 7.0088 & 7.2809 & TRN & \\
\hline CHEMBL3971435 & 1640573 & 7.5229 & 7.4967 & TST & \\
\hline CHEMBL3912964 & 1640573 & 8.7959 & 8.5276 & TST & \\
\hline CHEMBL3962465 & 1640573 & 7.6778 & 7.5997 & TRN & \\
\hline CHEMBL3903522 & 1640573 & 8.6198 & 8.797 & TRN & \\
\hline CHEMBL3933645 & 1640573 & 8.1367 & 8.11399 & 9999999999 & TRN \\
\hline CHEMBL 3892087 & 1640573 & 7.6021 & 7.7166 & TRN & \\
\hline CHEMBL3965063 & 1640573 & 8.0605 & 8.1418 & TRN & \\
\hline CHEMBL 3959379 & 1640573 & 8.6198 & 8.3743 & TRN & \\
\hline CHEMBL3919089 & 1640573 & 9.2218 & 9.0512 & TRN & \\
\hline CHEMBL3898856 & 1640573 & 8.301 & 8.933 & TST & \\
\hline
\end{tabular}


Supplemental Table S2.txt

\begin{tabular}{|c|c|c|c|c|}
\hline 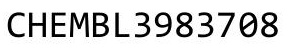 & & & & \\
\hline AEM & 0573 & 8.6576 & & \\
\hline IEMBL 3890270 & 540573 & 3768 & 1273 & \\
\hline AEMBL3 & 640573 & 0458 & 0662 & \\
\hline & & 8.6021 & 103 & \\
\hline 450 & 573 & 8.3768 & 3798 & \\
\hline IEMBL 3906193 & 640573 & 8.4202 & 4363 & \\
\hline AEMBL3950509 & 640573 & 7.9208 & 8037 & \\
\hline HEMBL 39 & 640573 & 4.0 & 8312 & \\
\hline 178 & 73 & 208 & 106 & \\
\hline EMBL3967010 & 573 & 969 & 002 & \\
\hline AEMBL3968744 & 640573 & 8.9586 & 8.8965 & \\
\hline AEMBL3942663 & 640573 & 8.6576 & 1153 & \\
\hline IEMBL3905865 & 640 & 366 & 142 & \\
\hline 161 & 73 & 7.8861 & 006 & \\
\hline EMBL 3941283 & & 9.2218 & 837 & \\
\hline IEMBL 3948454 & 640573 & 8.699 & 8.8413 & \\
\hline IEMBL 3927877 & 640573 & 212 & 7304 & \\
\hline 3595 & 64 & 9 . & 042 & \\
\hline 427 & 3 & 212 & 819 & \\
\hline 1598 & & 01 & 924 & \\
\hline AEMBL3919026 & 640573 & 8.0 & 7.9695 & \\
\hline IEMBL 3908032 & 3 & 696 & 069 & \\
\hline IEMBL38 & 64 & 8. & 7257 & \\
\hline 349 & 3 & 79 & 457 & \\
\hline 106 & 3 & 576 & 7224 & \\
\hline 056 & 573 & 9.1549 & 3452 & \\
\hline IEMBL 3908761 & & 7. & 772 & \\
\hline IEMBL39 & 640 & 367 & 147 & RN \\
\hline 967 & 3 & 96 & 572 & KIV \\
\hline 999 & 3 & 68 & 448 & ST \\
\hline IEMBL38 & 73 & 239 & 3875 & RN \\
\hline IEMBL 3892286 & 5405 & 576 & 883 & RN \\
\hline IEMBL39 & $64 t$ & 279 & 066 & ST \\
\hline 346 & 3 & 318 & 027 & ST \\
\hline 85 & & 9 . & 375 & $\mathrm{RN}$ \\
\hline AEMBL3946371 & 640573 & 8.2076 & 815 & RN \\
\hline IEMBL 3959291 & 5405 & 8.7212 & 643 & $2 \mathrm{~N}$ \\
\hline AEMBL3 & 64 & 298 & 547 & RN \\
\hline 464 & & 969 & 979 & NIV \\
\hline & & 83 & 622 & RN \\
\hline IEMBL 3962807 & 640573 & 8.9208 & 9001 & RN \\
\hline IEMBL 3929608 & $r$ & 686 & 696 & ST \\
\hline HEIMIBL3 3 & & & 404 & \\
\hline HEMBL3S & & 8.4685 & & \\
\hline HEMBL 3894252 & & 372 & 4361 & RN \\
\hline 3902751 & 640573 & 8.3468 & 8.3495 & ST \\
\hline HEMBL 3949829 & 1640573 & 8.3565 & 8.2449 & \\
\hline
\end{tabular}

Page 226 
Supplemental Table S2.txt

\begin{tabular}{|c|c|c|c|c|c|}
\hline CHEMBL 3911401 & 1640573 & 8.4318 & 8.6345 & TRN & \\
\hline CHEMBL 3972741 & 1640573 & 8.7447 & 8.8905 & TRN & \\
\hline CHEMBL 3952282 & 1640573 & 7.9208 & 8.0982 & TST & \\
\hline CHEMBL 3908831 & 1640573 & 8.0 & 8.127 & TRN & \\
\hline CHEMBL3894291 & 1640573 & 7.7696 & 7.7076 & TST & \\
\hline CHEMBL 3941855 & 1640573 & 7.0757 & 6.9953 & TRN & \\
\hline CHEMBL 3894443 & 1640573 & 7.6778 & 7.7659 & TRN & \\
\hline CHEMBL3904876 & 1640573 & 7.1904 & 7.124 & TRN & \\
\hline CHEMBL 3908552 & 1640573 & 8.5376 & 9.0074 & TST & \\
\hline CHEMBL 3987123 & 1640573 & 8.4685 & 8.5545 & TRN & \\
\hline CHEMBL 3932866 & 1640573 & 8.6198 & 8.5714 & TRN & \\
\hline CHEMBL 3940627 & 1640573 & 9.0458 & 8.9831 & TRN & \\
\hline CHEMBL 3908333 & 1640573 & 7.9586 & 7.9855 & TRN & \\
\hline CHEMBL 3899177 & 1640573 & 8.5528 & 8.4931 & TRN & \\
\hline CHEMBL3976391 & 1640573 & 7.9586 & 7.9239 & TRN & \\
\hline CHEMBL 3901997 & 1640573 & 8.28399 & 799999999 & 99 & 8.3684 \\
\hline CHEMBL 3917106 & 1640573 & 7.7447 & 7.7586 & TRN & \\
\hline CHEMBL 3980219 & 1640573 & 8.8539 & 9.0252 & TRN & \\
\hline CHEMBL 3906130 & 1640573 & 8.7696 & 7.7817 & TST & \\
\hline CHEMBL 3950203 & 1640573 & 8.7959 & 8.8098 & TRN & \\
\hline CHEMBL 3899097 & 1640573 & 8.4685 & 7.4409 & TST & \\
\hline CHEMBL3918965 & 1640573 & 8.6383 & 8.7275 & TRN & \\
\hline CHEMBL 3975500 & 1640573 & 8.0655 & 7.5292 & TST & \\
\hline CHEMBL 3943127 & 1640573 & 9.3565 & 9.2178 & TRN & \\
\hline CHEMBL 3904383 & 1640573 & 8.0315 & 8.0538 & TRN & \\
\hline CHEMBL 3940462 & 1640573 & 8.6021 & 8.4295 & TRN & \\
\hline CHEMBL 3926903 & 1640573 & 8.2076 & 7.6454 & TST & \\
\hline CHEMBL 3904694 & 1640573 & 8.6383 & 8.6002 & TST & \\
\hline CHEMBL 3897233 & 1640573 & 8.3188 & 8.3173 & TRN & \\
\hline CHEMBL 3900157 & 1640573 & 8.1739 & 8.3574 & TRN & \\
\hline CHEMBL 3904712 & 1640573 & 8.2757 & 8.2323 & TRN & \\
\hline CHEMBL 3890076 & 1640573 & 8.8861 & 8.9204 & TRN & \\
\hline CHEMBL 3928144 & 1640573 & 8.4202 & 8.2932 & TRN & \\
\hline CHEMBL 3972635 & 1640573 & 8.5528 & 8.8512 & TRN & \\
\hline CHEMBL 3955767 & 1640573 & 8.3372 & 8.5418 & TRN & \\
\hline CHEMBL 3954017 & 1640573 & 8.6576 & 8.8296 & TRN & \\
\hline CHEMBL 3890965 & 1640573 & 6.4437 & 6.8358 & TST & \\
\hline CHEMBL 3950042 & 1640573 & 7.7959 & 8.0587 & TRN & \\
\hline CHEMBL 3952378 & 1640573 & 8.3979 & 8.285 & TRN & \\
\hline CHEMBL 3915684 & 1640573 & 8.699 & 8.1138 & TST & \\
\hline CHEMBL 3972479 & 1640573 & 9.0969 & 9.0807 & TRN & \\
\hline CHEMBL 3912087 & 1640573 & 8.3872 & 8.4805 & TRN & \\
\hline CHEMBL 3938237 & 1640573 & 8.4202 & 8.5251 & TRN & \\
\hline CHEMBL 3891763 & 1640573 & 8.1938 & 8.0614 & TST & \\
\hline CHEMBL 3896892 & 1640573 & 8.6383 & 8.5676 & TRN & \\
\hline CHEMBL 3983786 & 1640573 & 7.8894 & 7.7402 & TRN & \\
\hline CHEMBL 3926246 & 1640573 & 7.6778 & 7.7385 & TRN & \\
\hline CHEMBL 3919344 & 1640573 & 8.5376 & 8.619 & TRN & \\
\hline
\end{tabular}


Supplemental Table S2.txt

\begin{tabular}{|c|c|c|c|c|}
\hline 3975 & 540573 & & .4043 & \\
\hline HEMBL3955055 & 640573 & 7.6576 & & \\
\hline & & & & \\
\hline IEMBL3 & 2573 & & & \\
\hline AEMBL & 573 & & & \\
\hline AEMBL3947929 & 540573 & 2605 & 177 & \\
\hline AEMBL: & 573 & 86 & & \\
\hline 322 & & & & \\
\hline AEMBL3968856 & 573 & & & \\
\hline AEMBL3973291 & 573 & 447 & & \\
\hline AEMBL 3913177 & 573 & & & \\
\hline IEMBL: & 573 & & & \\
\hline 965 & & & & \\
\hline AEMBL3965033 & 573 & & & \\
\hline IEMBL3 & 573 & & & \\
\hline IEMBL3976254 & 164 & & & \\
\hline AEMBL: & 73 & & & \\
\hline IEMBL: & 73 & & & \\
\hline IEMBL3912226 & 573 & & & \\
\hline IEMBL & 573 & & & \\
\hline 187 & $-6<$ & & & \\
\hline 540 & 3 & & & \\
\hline 066 & 73 & & & \\
\hline 981 & 573 & & & \\
\hline IEMBL: & & & & \\
\hline IEMBL & 16 & & & \\
\hline 716 & 73 & & & \\
\hline 16 & 73 & & & \\
\hline 40 & & & & \\
\hline IEMBL 3910308 & 73 & & & \\
\hline AEMBL: & 16 & & & \\
\hline 72 & 73 & & & \\
\hline 59 & 73 & & & \\
\hline IEMBL3925234 & 164 & & & \\
\hline IEMBL3978717 & 573 & & & S1 \\
\hline IEMBL: & 3 & & & \\
\hline 0 & & & & \\
\hline & & & & \\
\hline AEMBL 3924599 & 1640573 & & & \\
\hline IEMBL3S & 73 & & & -1 \\
\hline 534 & 164 & & & \\
\hline 659 & & & & \\
\hline HEMBL3986793 & 573 & & & \\
\hline IEMBL3940535 & 640573 & 487 & & \\
\hline AEMBL & 6195 & & & \\
\hline HEMBL3982415 & 573 & & & \\
\hline CHEMBL3964726 & 640573 & & 8.5401 & \\
\hline CHEMBL3889927 & 1640573 & 7.2441 & 8.0873 & \\
\hline
\end{tabular}

Page 228 
Supplemental Table S2.txt

\begin{tabular}{|c|c|c|c|c|}
\hline CHEMBL3972543 & 1640573 & 7.6778 & 7.8505 & TRN \\
\hline CHEMBL3980785 & 1640573 & 8.1367 & 7.8726 & TST \\
\hline CHEMBL3969159 & 1640573 & 8.3979 & 8.2606 & TRN \\
\hline CHEMBL3980922 & 1640573 & 8.9586 & 8.8588 & TRN \\
\hline CHEMBL3896152 & 1640573 & 8.3188 & 8.3075 & TRN \\
\hline CHEMBL3929885 & 1640573 & 6.0655 & 7.5095 & TST \\
\hline CHEMBL3962137 & 1640573 & 7.3372 & 7.2232 & TRN \\
\hline CHEMBL3972216 & 1640573 & 8.2596 & 8.3864 & TRN \\
\hline CHEMBL3926535 & 1640573 & 8.8239 & 8.738 & TRN \\
\hline CHEMBL 3917944 & 1640573 & 8.6778 & 8.8632 & TST \\
\hline CHEMBL3973734 & 1640573 & 8.4437 & 8.461 & TRN \\
\hline CHEMBL3953761 & 1640573 & 7.7959 & 7.8556 & TRN \\
\hline CHEMBL3943713 & 1640573 & 7.7959 & 7.6028 & TRN \\
\hline CHEMBL3978853 & 1640573 & 6.7696 & 8.096 & TST \\
\hline CHEMBL 3928074 & 1640573 & 9.0458 & 8.7429 & TRN \\
\hline CHEMBL3936329 & 1640573 & 8.4559 & 8.3259 & TRN \\
\hline CHEMBL3980207 & 1640573 & 8.4559 & 8.5242 & TRN \\
\hline CHEMBL3979190 & 1640573 & 8.1367 & 8.2309 & TRN \\
\hline CHEMBL3919834 & 1640573 & 9.0458 & 9.0222 & TRN \\
\hline CHEMBL3961562 & 1640573 & 8.1612 & 8.1421 & TRN \\
\hline CHEMBL3966620 & 1640573 & 8.7696 & 8.8451 & TRN \\
\hline CHEMBL3933597 & 1640573 & 9.0 & 8.8942 & TRN \\
\hline CHEMBL3930731 & 1640573 & 7.7447 & 8.0044 & TST \\
\hline CHEMBL3975126 & 1640573 & 7.0044 & 6.6933 & TRN \\
\hline CHEMBL3976678 & 1640573 & 8.1938 & 8.3554 & TRN \\
\hline CHEMBL3957354 & 1640573 & 7.8861 & 8.043 & TRN \\
\hline CHEMBL3916957 & 1640573 & 8.0862 & 7.9144 & TRN \\
\hline CHEMBL3909262 & 1640573 & 8.2007 & 8.0196 & TRN \\
\hline CHEMBL3979925 & 1640573 & 8.6198 & 7.5133 & TST \\
\hline CHEMBL3905622 & 1640573 & 7.8539 & 8.6912 & TST \\
\hline CHEMBL 3891820 & 1640573 & 8.7959 & 8.6232 & TRN \\
\hline CHEMBL 3895400 & 1640573 & 7.4962 & 6.5396 & TST \\
\hline CHEMBL3906695 & 1640573 & 9.0458 & 8.0254 & TST \\
\hline CHEMBL3904852 & 1640573 & 8.699 & 8.7136 & TRN \\
\hline CHEMBL3968301 & 1640573 & 8.2676 & 7.4884 & TST \\
\hline CHEMBL3984446 & 1640573 & 5.5686 & 5.58899 & 9999999995 \\
\hline CHEMBL3941451 & 1640573 & 9.0458 & 8.9218 & TRN \\
\hline CHEMBL3927542 & 1640573 & 8.4089 & 8.2362 & TRN \\
\hline CHEMBL3912471 & 1640573 & 8.6778 & 8.7339 & TST \\
\hline CHEMBL3977191 & 1640573 & 8.2924 & 8.3026 & TST \\
\hline CHEMBL3907940 & 1640573 & 8.1192 & 8.1915 & TST \\
\hline CHEMBL3922949 & 1640573 & 8.3565 & 8.6214 & TST \\
\hline CHEMBL3943038 & 1640573 & 8.1308 & 8.616 & TST \\
\hline CHEMBL3922652 & 1640573 & 8.2518 & 7.9189 & TST \\
\hline CHEMBL3962020 & 1640573 & 9.0458 & 8.5403 & TST \\
\hline CHEMBL3950201 & 1640573 & 7.0088 & 7.31 & TST \\
\hline CHEMBL3906990 & 1640573 & 9.699 & 9.2227 & TST \\
\hline CHEMBL3934633 & 1640573 & 7.8861 & 7.9183 & TST \\
\hline
\end{tabular}

Page 229 


\begin{tabular}{|c|c|c|c|c|}
\hline \multicolumn{5}{|c|}{ Supplemental Table S2.txt } \\
\hline CHEMBL 2012975 & 810094 & 4.6021 & 5.1832 & TST \\
\hline CHEMBL 2012968 & 810094 & 5.1249 & 5.1179 & TRN \\
\hline CHEMBL2013115 & 810094 & 7.0969 & 7.0595 & TRN \\
\hline CHEMBL 2013117 & 810094 & 6.699 & 6.6989 & TRN \\
\hline CHEMBL1771374 & 810094 & 4.699 & 4.7638 & TRN \\
\hline CHEMBL 2012984 & 810094 & 4.6021 & 4.6032 & TRN \\
\hline CHEMBL 2012999 & 810094 & 6.6021 & 6.5986 & TRN \\
\hline CHEMBL2012980 & 810094 & 5.1249 & 5.9424 & TST \\
\hline CHEMBL 2012977 & 810094 & 7.6021 & 7.4324 & TST \\
\hline CHEMBL 2013116 & 810094 & 6.6021 & 6.5964 & TRN \\
\hline CHEMBL 2012988 & 810094 & 4.6021 & 4.6004 & TRN \\
\hline CHEMBL 2013118 & 810094 & 7.8239 & 7.8312 & TRN \\
\hline CHEMBL 2012996 & 810094 & 4.5229 & 4.4823 & TRN \\
\hline CHEMBL1771372 & 810094 & 5.6021 & 5.5738 & TRN \\
\hline CHEMBL 2012973 & 810094 & 6.1249 & 6.1098 & TRN \\
\hline CHEMBL 2013001 & 810094 & 6.0969 & 6.1037 & TRN \\
\hline CHEMBL 2013112 & 810094 & 7.1249 & 7.1591 & TRN \\
\hline CHEMBL2013006 & 810094 & 6.8239 & 6.8265 & TRN \\
\hline CHEMBL 2013007 & 810094 & 5.5229 & 5.5256 & TRN \\
\hline CHEMBL 2012972 & 810094 & 6.301 & 6.2972 & TRN \\
\hline CHEMBL 2012995 & 810094 & 7.0 & 7.0213 & TRN \\
\hline CHEMBL 2013003 & 810094 & 6.0969 & 6.1185 & TRN \\
\hline CHEMBL 2012993 & 810094 & 4.8239 & 5.0555 & TST \\
\hline CHEMBL 2012979 & 810094 & 6.6021 & 6.6324 & TRN \\
\hline CHEMBL 2013000 & 810094 & 6.6021 & 6.5853 & TRN \\
\hline CHEMBL 2012982 & 810094 & 6.5229 & 6.5531 & TRN \\
\hline CHEMBL 2013113 & 810094 & 8.1249 & 8.1097 & TRN \\
\hline CHEMBL 2012986 & 810094 & 8.0 & 8.0012 & TRN \\
\hline CHEMBL 2013111 & 810094 & 6.8239 & 6.8174 & TRN \\
\hline CHEMBL 1771378 & 810094 & 7.301 & 7.2328 & TRN \\
\hline CHEMBL 2013008 & 810094 & 5.301 & 5.2938 & TRN \\
\hline CHEMBL 2012991 & 810094 & 4.8239 & 4.8418 & TRN \\
\hline CHEMBL 2012997 & 810094 & 6.0 & 6.0279 & TRN \\
\hline CHEMBL 2013110 & 810094 & 7.8239 & 7.8354 & TRN \\
\hline CHEMBL 2012978 & 810094 & 6.6021 & 6.6177 & TRN \\
\hline CHEMBL 2012998 & 810094 & 6.699 & 6.5619 & TST \\
\hline CHEMBL 2013114 & 810094 & 7.8239 & 8.1857 & TST \\
\hline CHEMBL 2012981 & 810094 & 5.301 & 5.26 & TRN \\
\hline CHEMBL 2013002 & 810094 & 7.5229 & 7.2217 & TST \\
\hline CHEMBL 2012989 & 810094 & 5.6021 & 5.608 & TRN \\
\hline CHEMBL 2012971 & 810094 & 4.301 & 4.3 & TRN \\
\hline CHEMBL 2012994 & 810094 & 7.5229 & 7.6451 & TST \\
\hline CHEMBL 2012976 & 810094 & 4.699 & 4.7027 & TRN \\
\hline CHEMBL 2013005 & 810094 & 6.699 & 5.9976 & TST \\
\hline CHEMBL1771376 & 810094 & 8.6021 & 8.6117 & TRN \\
\hline CHEMBL 2012983 & 810094 & 4.699 & 4.6992 & TRN \\
\hline CHEMBL 2012990 & 810094 & 6.0969 & 6.0943 & TRN \\
\hline CHEMBL 2012974 & 810094 & 6.1249 & 6.2771 & TST \\
\hline
\end{tabular}


Supplemental Table S2.txt

\begin{tabular}{|c|c|c|c|c|}
\hline CHEMBL 2012967 & 810094 & 4.699 & 4.7045 & TRN \\
\hline CHEMBL 2012969 & 810094 & 4.6021 & 4.5985 & TRN \\
\hline HEMBL2012985 & 10094 & 6.1249 & 6.1089 & \\
\hline HEMBL2012970 & 10094 & 5.6021 & .6012 & 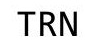 \\
\hline HEMBL2012987 & 310094 & 5.6021 & 5.6338 & $T$ \\
\hline HEMBL2013004 & 10094 & 6.699 & .9022 & \\
\hline HEMBL1771387 & 10094 & 7.699 & 7.62 & \\
\hline HEMBL2012992 & 810094 & 5.301 & 5.3008 & \\
\hline HEMBL3898372 & 1638894 & 8.0 & 8.0039 & RN \\
\hline HEMBL3907491 & 1638894 & 8.0 & 7.2225 & \\
\hline HEMBL 3898480 & 1638894 & 7.0 & 7.4476 & - \\
\hline HEMBL604094 & 1638894 & 8.0 & 7.6853 & \\
\hline HEMBL3897865 & 1638894 & 4.0 & 7.562 & \\
\hline HEMBL3898444 & 1638894 & 8.0 & 7.9181 & RN \\
\hline HEMBL 3901144 & L638894 & 8.0 & .031 & NI \\
\hline HEMBL3901210 & 1638894 & 8.0 & 0645 & 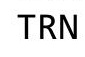 \\
\hline HEMBL3 & 1638894 & 8.0 & 7778 & RN \\
\hline HEMBL3901236 & 1638894 & 8.0 & 7.4476 & RN \\
\hline HEMBL3916142 & 1638894 & 8.0 & 7.6288 & RN \\
\hline HEMBL3945421 & L638894 & 8.0 & 7.7438 & SI \\
\hline HEMBL5 & 1638894 & 8 . & 0761 & $\mathrm{RN}$ \\
\hline HEMBL3 & 1638894 & 8.6 & 2416 & RN \\
\hline CHEMBL 3984055 & 1638894 & 8.0 & 7.8875 & RN \\
\hline HEMBL3902161 & 1638894 & 8.0 & 7.8551 & TRN \\
\hline HEMBL3914322 & 1638894 & 7.0 & 7.6635 & I RN \\
\hline HEMBL3 & 1638894 & 8 . & 6483 & I \\
\hline HEMBL3 & 1638894 & 8.0 & 8335 & RN \\
\hline HEMBL 3 & 1638894 & 8.0 & 8.1638 & TRN \\
\hline HEMBL3S & 1638894 & 8.0 & 265 & is \\
\hline HEMBL3972249 & 1638894 & 8.0 & 7.6972 & TST \\
\hline HEMBL3 & 1638894 & 8 . & 7.9767 & RN \\
\hline CHEMBL3 & 1638894 & 8.0 & 325 & ST \\
\hline CHEMBL3 & 1638894 & 8.0 & 7.3199 & TRN \\
\hline CHEMBL3928197 & 1638894 & 8.0 & 2857 & TRN \\
\hline HEMBL3932057 & 1638894 & 8.0 & 7.5557 & TRN \\
\hline HEMBL 3 & 1638894 & 8 . & 7.9797 & TRN \\
\hline CHEMBL3 & 1638894 & 8.0 & 8.0384 & RN \\
\hline CHEMBL597569 & 1638894 & 8.0 & 8.0645 & TRN \\
\hline CHEMBL598164 & 1638894 & 8.0 & .9156 & TRN \\
\hline CHEMBL 3 & 1638894 & 8. & 7.9944 & TRN \\
\hline CHEMBL3910297 & 1638894 & 6.0 & 6.9351 & TRN \\
\hline CHEMBL3953871 & 1638894 & 8.0 & 8.2008 & TST \\
\hline CHEMBL3952709 & 1638894 & 8.0 & 8.1095 & TRN \\
\hline CHEMBL 3984008 & 1638894 & 7.0 & 7.5331 & TS \\
\hline CHEMBL 3977186 & 1638894 & 8.0 & 7.745 & TRI \\
\hline CHEMBL 3930226 & 1638894 & 8.0 & 7.5696 & \\
\hline CHEMBL3905086 & 1638894 & 8.0 & 7.651 & \\
\hline CHEMBL3985245 & 1638894 & 8.0 & 8.2357 & 11 \\
\hline
\end{tabular}

Page 231 


\begin{tabular}{|c|c|c|c|c|}
\hline & & & ient & al Ta \\
\hline CHEMBL 3890344 & 1638894 & 8.0 & 8.0899 & TRN \\
\hline CHEMBL3980430 & 1638894 & 8.0 & 7.8325 & TST \\
\hline CHEMBL3914607 & 1638894 & 7.0 & 7.1448 & TRN \\
\hline CHEMBL 3944171 & 1638894 & 8.0 & 8.1706 & TRN \\
\hline CHEMBL 3892811 & 1638894 & 8.0 & 8.1138 & TST \\
\hline CHEMBL 3970892 & 1638894 & 8.0 & 8.2694 & TRN \\
\hline CHEMBL3909900 & 1638894 & 8.0 & 7.9525 & TRN \\
\hline CHEMBL 3950023 & 1638894 & 7.0 & 7.7944 & TRN \\
\hline CHEMBL597773 & 1638894 & 8.0 & 8.1932 & TRN \\
\hline CHEMBL3900967 & 1638894 & 8.0 & 7.6845 & TRN \\
\hline CHEMBL 3967530 & 1638894 & 8.0 & 7.2595 & TRN \\
\hline CHEMBL3936547 & 1638894 & 8.0 & 7.4476 & TRN \\
\hline CHEMBL3896110 & 1638894 & 8.0 & 7.8803 & TRN \\
\hline CHEMBL 3924787 & 1638894 & 7.0 & 7.5331 & TST \\
\hline CHEMBL598163 & 1638894 & 8.0 & 8.1736 & TRN \\
\hline CHEMBL 3907094 & 1638894 & 8.0 & 7.7227 & TST \\
\hline CHEMBL3917105 & 1638894 & 7.0 & 7.2093 & TST \\
\hline CHEMBL598799 & 1638894 & 8.0 & 8.1385 & TRN \\
\hline CHEMBL596754 & 1638894 & 8.0 & 8.2691 & TRN \\
\hline CHEMBL3971713 & 1638894 & 4.0 & 5.8049 & TRN \\
\hline CHEMBL 3893111 & 1638894 & 8.0 & 7.9181 & TRN \\
\hline CHEMBL 3959855 & 1638894 & 8.0 & 7.4362 & TRN \\
\hline CHEMBL 3922584 & 1638894 & 8.0 & 7.5295 & TST \\
\hline CHEMBL598611 & 1638894 & 8.0 & 7.9156 & TRN \\
\hline CHEMBL3976961 & 1638894 & 8.0 & 8.0365 & TRN \\
\hline CHEMBL596964 & 1638894 & 7.0 & 7.1849 & TRN \\
\hline CHEMBL 3985004 & 1638894 & 7.0 & 7.0256 & TST \\
\hline CHEMBL3951191 & 1638894 & 8.0 & 7.9972 & TRN \\
\hline CHEMBL3905131 & 1638894 & 8.0 & 8.1615 & TRN \\
\hline CHEMBL 3929290 & 1638894 & 8.0 & 6.5579 & TRN \\
\hline CHEMBL 3951620 & 1638894 & 8.0 & 7.8551 & TRN \\
\hline CHEMBL3943805 & 1638894 & 8.0 & 7.0283 & TRN \\
\hline CHEMBL 3979482 & 1638894 & 7.0 & 7.4628 & TRN \\
\hline CHEMBL3917951 & 1638894 & 7.0 & 7.4077 & TRN \\
\hline CHEMBL 3937516 & 1638894 & 8.0 & 8.0125 & TST \\
\hline CHEMBL 3899385 & 1638894 & 8.0 & 7.81 & TRN \\
\hline CHEMBL 3915273 & 1638894 & 8.0 & 7.5302 & TRN \\
\hline CHEMBL596761 & 1638894 & 8.0 & 7.2532 & TRN \\
\hline CHEMBL3976436 & 1638894 & 8.0 & 7.8171 & TRN \\
\hline CHEMBL596736 & 1638894 & 8.0 & 8.1444 & TRN \\
\hline CHEMBL 3975710 & 1638894 & 6.0 & 6.6389 & TRN \\
\hline CHEMBL3903506 & 1638894 & 8.0 & 7.7393 & TST \\
\hline CHEMBL3928963 & 1638894 & 8.0 & 7.6853 & TST \\
\hline CHEMBL3939206 & 1638894 & 8.0 & 7.9376 & TRN \\
\hline CHEMBL 3922068 & 1638894 & 7.0 & 7.5789 & TST \\
\hline CHEMBL 3916600 & 1638894 & 8.0 & 7.7765 & TST \\
\hline CHEMBL 3912598 & 1638894 & 7.0 & 7.5669 & TRN \\
\hline CHEMBL 3938265 & 1638894 & 8.0 & 7.7765 & TST \\
\hline
\end{tabular}




\begin{tabular}{|c|c|c|c|c|c|c|}
\hline \multicolumn{7}{|c|}{ Supplemental Table S2.txt } \\
\hline CHEMBL599398 & 1638894 & 8.0 & 7.89 & TRN & & \\
\hline CHEMBL597551 & 1638894 & 8.0 & 8.0454 & TRN & & \\
\hline CHEMBL2309506 & 1638894 & 7.0 & 7.7191 & TST & & \\
\hline CHEMBL 3986286 & 1638894 & 8.0 & 8.2857 & TRN & & \\
\hline CHEMBL3975990 & 1638894 & 7.0 & 7.5669 & TRN & & \\
\hline CHEMBL3924346 & 1638894 & 8.0 & 8.0562 & TRN & & \\
\hline CHEMBL598377 & 1638894 & 8.5086 & 8.1736 & TRN & & \\
\hline CHEMBL3949197 & 1638894 & 8.0 & 8.0156 & TRN & & \\
\hline CHEMBL3976389 & 1638894 & 8.0 & 7.8565 & TRN & & \\
\hline CHEMBL3930003 & 1638894 & 8.0 & 8.1176 & TRN & & \\
\hline CHEMBL2309507 & 1638894 & 7.0 & 7.7186 & TST & & \\
\hline CHEMBL3956995 & 1638894 & 8.0 & 8.1104 & TRN & & \\
\hline CHEMBL3959043 & 1638894 & 8.0 & 7.9928 & TRN & & \\
\hline CHEMBL3909214 & 1638894 & 7.0 & 7.5964 & TST & & \\
\hline CHEMBL3906200 & 1638894 & 7.0 & 7.1999 & TRN & & \\
\hline CHEMBL3939306 & 1638894 & 8.0 & 8.1615 & TRN & & \\
\hline CHEMBL3609221 & 1513932 & 11.1675 & 10.6388 & TRN & & \\
\hline CHEMBL3609034 & 1513932 & 11.6383 & 10.3618 & TRN & & \\
\hline CHEMBL3609077 & 1513932 & 11.3979 & 10.6388 & TRN & & \\
\hline CHEMBL3609073 & 1513932 & 8.6304 & 10.121 & TRN & & \\
\hline CHEMBL3609255 & 1513932 & 7.4772 & 7.7831 & TRN & & \\
\hline CHEMBL3609274 & 1513932 & 11.3468 & 10.3618 & TRN & & \\
\hline CHEMBL3609264 & 1513932 & 10.3979 & 10.8775 & TRN & & \\
\hline CHEMBL 3609023 & 1513932 & 10.7423 & 11.1624 & TST & & \\
\hline CHEMBL 3609071 & 1513932 & 11.3009 & 999999999 & 998 & 11.2691 & TRN \\
\hline CHEMBL3609252 & 1513932 & 7.4772 & 9.9921 & TRN & & \\
\hline CHEMBL 3609022 & 1513932 & 11.1079 & 11.3737 & TRN & & \\
\hline CHEMBL3609089 & 1513932 & 10.8239 & 10.8254 & TST & & \\
\hline CHEMBL3609085 & 1513932 & 9.1308 & 10.0672 & TRN & & \\
\hline CHEMBL3609272 & 1513932 & 11.3768 & 10.3618 & TRN & & \\
\hline CHEMBL 3609234 & 1513932 & 9.3507 & 10.6388 & TRN & & \\
\hline CHEMBL3609225 & 1513932 & 11.2757 & 11.2578 & TST & & \\
\hline CHEMBL 3609042 & 1513932 & 11.5686 & 10.6388 & TRN & & \\
\hline CHEMBL 3609082 & 1513932 & 9.7595 & 10.6388 & TRN & & \\
\hline CHEMBL3609256 & 1513932 & 11.0409 & 999999999 & 999 & 11.1661 & TRN \\
\hline CHEMBL 3609243 & 1513932 & 9.5157 & 9.2726 & TRN & & \\
\hline CHEMBL3609052 & 1513932 & 7.4772 & 10.6388 & TRN & & \\
\hline CHEMBL3609245 & 1513932 & 12.0458 & 9.9921 & TRN & & \\
\hline CHEMBL 3609048 & 1513932 & 11.4202 & 10.6388 & TRN & & \\
\hline CHEMBL3609259 & 1513932 & 7.4772 & 9.9921 & TRN & & \\
\hline CHEMBL3609254 & 1513932 & 7.4772 & 9.9921 & TRN & & \\
\hline CHEMBL3608997 & 1513932 & 11.5528 & 10.8782 & TST & & \\
\hline CHEMBL3609030 & 1513932 & 10.5528 & 10.3618 & TRN & & \\
\hline CHEMBL3608994 & 1513932 & 11.5686 & 11.3764 & TRN & & \\
\hline CHEMBL3609251 & 1513932 & 11.4815 & 11.1423 & TST & & \\
\hline CHEMBL 3609070 & 1513932 & 11.3565 & 10.6388 & TRN & & \\
\hline CHEMBL3609066 & 1513932 & 7.4772 & 9.7847 & TRN & & \\
\hline CHEMBL 3609067 & 1513932 & 11.3009 & 999999999 & 998 & 10.8782 & TST \\
\hline
\end{tabular}


Supplemental Table S2.txt

\begin{tabular}{|c|c|c|c|c|c|c|}
\hline CHEMBL 3609065 & 1513932 & 11.585 & 10.9681 & TRN & & \\
\hline CHEMBL3609246 & 1513932 & 10.5622 & 9.9921 & TRN & & \\
\hline CHEMBL3609275 & 1513932 & 10.2924 & 10.314 & TRN & & \\
\hline CHEMBL 3609036 & 1513932 & 11.0809 & 11.1849 & TRN & & \\
\hline CHEMBL3609220 & 1513932 & 11.6990 & 00000006 & 302 & 10.6388 & TRN \\
\hline CHEMBL 3609242 & 1513932 & 10.5528 & 10.3592 & TRN & & \\
\hline CHEMBL 3609078 & 1513932 & 11.5528 & 11.2694 & TRN & & \\
\hline CHEMBL 3609044 & 1513932 & 10.71 & 10.6388 & TRN & & \\
\hline CHEMBL 3609261 & 1513932 & 11.2147 & 9.9921 & TRN & & \\
\hline CHEMBL3609269 & 1513932 & 10.4949 & 9.7738 & TRN & & \\
\hline CHEMBL 3609091 & 1513932 & 7.8788 & 9.6292 & TST & & \\
\hline CHEMBL3609037 & 1513932 & 12.0 & 11.4319 & TRN & & \\
\hline CHEMBL3609043 & 1513932 & 11.5229 & 10.6388 & TRN & & \\
\hline CHEMBL3609056 & 1513932 & 10.1549 & 10.6388 & TRN & & \\
\hline CHEMBL3609035 & 1513932 & 11.3098 & 11.4172 & TST & & \\
\hline CHEMBL3609060 & 1513932 & 11.4437 & 11.2262 & TST & & \\
\hline CHEMBL3609045 & 1513932 & 11.7447 & 11.2691 & TRN & & \\
\hline CHEMBL3609226 & 1513932 & 10.7399 & 10.6388 & TRN & & \\
\hline CHEMBL3609263 & 1513932 & 11.3565 & 11.134 & TRN & & \\
\hline CHEMBL3609032 & 1513932 & 11.7447 & 10.3618 & TRN & & \\
\hline CHEMBL3608317 & 1513932 & 10.7645 & 9.7847 & TRN & & \\
\hline CHEMBL 3609228 & 1513932 & 9.1192 & 10.6388 & TRN & & \\
\hline CHEMBL3609267 & 1513932 & 8.9208 & 8.8106 & TRN & & \\
\hline CHEMBL3609075 & 1513932 & 11.6778 & 10.6388 & TRN & & \\
\hline CHEMBL 3609058 & 1513932 & 11.0969 & 10.6388 & TRN & & \\
\hline CHEMBL3609270 & 1513932 & 11.1367 & 10.9802 & TST & & \\
\hline CHEMBL 3609031 & 1513932 & 8.7447 & 10.3618 & TRN & & \\
\hline CHEMBL3609265 & 1513932 & 11.8239 & 11.5241 & TRN & & \\
\hline CHEMBL 3609248 & 1513932 & 10.3107 & 11.2691 & TRN & & \\
\hline CHEMBL 3608991 & 1513932 & 11.1739 & 9.9921 & TRN & & \\
\hline CHEMBL 3609229 & 1513932 & 7.4772 & 7.4918 & TRN & & \\
\hline CHEMBL 3609277 & 1513932 & 10.3768 & 11.1624 & TST & & \\
\hline CHEMBL 3609241 & 1513932 & 7.4772 & 8.9279 & TRN & & \\
\hline CHEMBL 3609024 & 1513932 & 7.4772 & 10.3618 & TRN & & \\
\hline CHEMBL 3609230 & 1513932 & 11.3009 & 799999995 & 998 & 10.6388 & TRN \\
\hline CHEMBL3609260 & 1513932 & 11.4949 & 9.9921 & TRN & & \\
\hline CHEMBL 3609257 & 1513932 & 8.9923 & 9.9921 & TRN & & \\
\hline CHEMBL 3609080 & 1513932 & 10.1249 & 10.6388 & TRN & & \\
\hline CHEMBL3609276 & 1513932 & 11.3979 & 10.3618 & TRN & & \\
\hline CHEMBL 3608992 & 1513932 & 11.1135 & 10.9981 & TST & & \\
\hline CHEMBL 3609084 & 1513932 & 11.2924 & 11.0644 & TRN & & \\
\hline CHEMBL3609063 & 1513932 & 11.3768 & 11.3764 & TRN & & \\
\hline CHEMBL3609247 & 1513932 & 10.8041 & 9.9921 & TRN & & \\
\hline CHEMBL3609266 & 1513932 & 11.1192 & 11.2775 & TRN & & \\
\hline CHEMBL3609062 & 1513932 & 11.5086 & 11.0938 & TRN & & \\
\hline CHEMBL 3609227 & 1513932 & 11.8539 & 10.1747 & TST & & \\
\hline CHEMBL3609039 & 1513932 & 8.4843 & 8.3516 & TRN & & \\
\hline CHEMBL 3609268 & 1513932 & 10.5918 & 11.0523 & TRN & & \\
\hline
\end{tabular}

Page 234 
Supplemental Table S2.txt

CHEMBL3609033

CHEMBL 3609055

CHEMBL 3609069

CHEMBL3609025

CHEMBL 3609088

CHEMBL 3609090

CHEMBL 3609236

CHEMBL3609224

CHEMBL 3608318

CHEMBL3609061

CHEMBL3609029

CHEMBL3609081

CHEMBL 3609050

CHEMBL3609047

CHEMBL3609026

CHEMBL 3609074

CHEMBL3609244

CHEMBL3609235

CHEMBL 3609231

CHEMBL 3609092

CHEMBL 3609250

CHEMBL3609093

CHEMBL 3609232

CHEMBL 3608998

CHEMBL 3609051

CHEMBL 3609086

CHEMBL 3609222

CHEMBL 3609068

CHEMBL 3609027

CHEMBL3609239

CHEMBL3609262

CHEMBL3609253

CHEMBL3609054

CHEMBL 3608996

CHEMBL 3609049

CHEMBL3609059

CHEMBL 3609258

CHEMBL 3608995

CHEMBL 3609087

CHEMBL 3608993

CHEMBL 3609233

CHEMBL 3609046

CHEMBL3608999

CHEMBL 3609057

CHEMBL 3609040

CHEMBL 3609238

CHEMBL 3609041

CHEMBL 3609237 $\begin{array}{lll}1513932 & 11.2441 & 10.3618 \text { TRN }\end{array}$

$\begin{array}{llll}1513932 & 11.7447 & 11.2694 \text { TRN }\end{array}$

$\begin{array}{lll}1513932 & 11.6198 & 10.6388 \text { TRN }\end{array}$

$\begin{array}{lll}1513932 & 9.3098 & 9.392000000000001\end{array}$

$\begin{array}{lll}1513932 & 8.0223 & 10.1231\end{array}$

$\begin{array}{llll}1513932 & 7.5337 & 9.5677 & \text { TST }\end{array}$

$\begin{array}{lll}1513932 & 11.3979 & 10.6388 \text { TRN }\end{array}$

$\begin{array}{lll}1513932 & 11.4559 & 10.6388 \text { TRN }\end{array}$

$\begin{array}{lll}1513932 & 11.2218 & 10.5782 \\ 1 S T\end{array}$

151393211.699000000000002

151393210.699000000000002

$\begin{array}{lll}1513932 & 9.5751 & 10.6388 \\ 1 R N\end{array}$

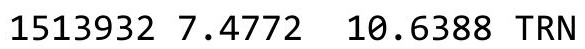

$\begin{array}{lll}1513932 & 10.2596 & 10.121\end{array}$

$\begin{array}{lll}1513932 & 7.4772 & 10.3618 \text { TRN }\end{array}$

$\begin{array}{lll}1513932 & 11.7696 & 11.2578 \text { TST }\end{array}$

$\begin{array}{lll}1513932 & 10.9586 & 9.9921 \\ \text { TRN }\end{array}$

151393211.300999999999998

$\begin{array}{lll}1513932 & 11.8539 & 11.2694 \text { TRN }\end{array}$

$\begin{array}{llll}1513932 & 6.4772 & 9.804 & \text { TST }\end{array}$

$\begin{array}{llll}1513932 & 7.4772 & 8.9307 & \text { TST }\end{array}$

151393210.699000000000002

$\begin{array}{lll}1513932 & 11.9586 & 10.6388 \text { TRN }\end{array}$

$\begin{array}{lll}1513932 & 10.9586 & 10.6388 \text { TRN }\end{array}$

$\begin{array}{lll}1513932 & 10.4895 & 10.1747\end{array}$

$\begin{array}{lll}1513932 & 10.9586 & 10.121 \\ \text { TRN }\end{array}$

151393211.300999999999998

$\begin{array}{lll}1513932 & 11.4815 & 10.6388 \text { TRN }\end{array}$

$\begin{array}{llll}1513932 & 7.4772 & 7.1009 & \text { TRN }\end{array}$

$\begin{array}{lll}1513932 & 11.2218 & 10.7935\end{array}$

$\begin{array}{lll}1513932 & 11.2147 & 10.8705\end{array}$

$\begin{array}{llll}1513932 & 10.5817 & 9.7451 & \text { TST }\end{array}$

$\begin{array}{lll}1513932 & 11.0605 & 11.445\end{array}$

$\begin{array}{lll}1513932 & 11.0223 & 10.2868\end{array}$

$\begin{array}{lll}1513932 & 11.5528 & 11.2578\end{array}$

$\begin{array}{lll}1513932 & 9.2291 & 10.6388 \\ 1 R N\end{array}$

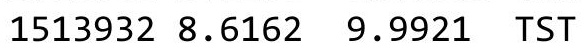

$\begin{array}{lll}1513932 & 11.1079 & 10.6388 \text { TRN }\end{array}$

$\begin{array}{lll}1513932 & 9.2218 & 10.0392\end{array}$

$\begin{array}{lll}1513932 & 11.4685 & 11.3552 \\ \text { TST }\end{array}$

$\begin{array}{lll}1513932 & 11.4685 & 10.6388 \text { TRN }\end{array}$

$\begin{array}{lll}1513932 & 10.8125 & 11.2578\end{array}$

$\begin{array}{lll}1513932 & 9.5114 & 10.6388 \text { TRN }\end{array}$

$\begin{array}{lll}1513932 & 7.4772 & 10.6388\end{array}$

$\begin{array}{lll}1513932 & 10.3372 & 10.9681 \\ \text { TRN }\end{array}$

$\begin{array}{lll}1513932 & 11.4318 & 11.282\end{array}$

$\begin{array}{lll}1513932 & 11.3979 & 10.8782\end{array}$

151393211.300999999999998
11.0644 TRN

11.0019 TRN

10.6388 TRN

10.6388 TRN

10.6388 TRN

11.2262 TST

Page 235 
Supplemental Table S2.txt

CHEMBL3609249

CHEMBL 3609028

CHEMBL 3609271

CHEMBL 3609079

CHEMBL 3609053

CHEMBL3609273

CHEMBL 3609240

CHEMBL3609064

CHEMBL 3609083

CHEMBL3609076

CHEMBL3609038

CHEMBL3609223

CHEMBL3609072

CHEMBL3677790

CHEMBL3677777

CHEMBL3677796

CHEMBL3677765

CHEMBL3677827

CHEMBL 3677773

CHEMBL 3677748

CHEMBL3677810

CHEMBL3677754

CHEMBL3677759

CHEMBL 3677815

CHEMBL 3677744

CHEMBL 3677774

CHEMBL 3593998

CHEMBL3677809

CHEMBL3677819

CHEMBL3677814

CHEMBL3677818

CHEMBL3677747

CHEMBL3677821

CHEMBL 3677755

CHEMBL 3677770

CHEMBL3677734

CHEMBL3677741

CHEMBL 3677780

CHEMBL3677813

CHEMBL 3677772

CHEMBL 3677800

CHEMBL 3677816

CHEMBL3677793

CHEMBL 3677803

CHEMBL3677787

CHEMBL 3677830

CHEMBL3677798

CHEMBL 3677732

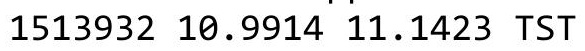

$\begin{array}{lll}1513932 & 10.8539 & 10.3618 \text { TRN }\end{array}$

$\begin{array}{lll}1513932 & 11.2291 & 10.3618 \text { TRN }\end{array}$

$\begin{array}{lll}1513932 & 10.475 & 10.6388\end{array}$

$\begin{array}{llll}1513932 & 7.4772 & 7.4918 & \text { TRN }\end{array}$

$\begin{array}{lll}1513932 & 10.5376 & 10.3618 \text { TRN }\end{array}$

$\begin{array}{lll}1513932 & 11.3768 & 10.6435\end{array}$

$\begin{array}{llll}1513932 & 9.3391 & 8.3516 & \text { TRN }\end{array}$

151393211.300999999999998

$\begin{array}{lll}1513932 & 10.3979 & 10.1747\end{array}$

$\begin{array}{lll}1513932 & 11.1549 & 11.3764 \text { TRN }\end{array}$

$\begin{array}{lll}1513932 & 11.6576 & 10.121 \\ \text { TRN }\end{array}$

$\begin{array}{lll}1513932 & 10.2782 & 11.2578\end{array}$

$\begin{array}{llll}1528876 & 7.8665 & 7.8487 & \text { TRN }\end{array}$

$\begin{array}{llll}1528876 & 5.178 & 5.1943 & \text { TRN }\end{array}$

$\begin{array}{lllll}1528876 & 6.8097 & 6.8046 & \text { TRN }\end{array}$

$\begin{array}{llll}1528876 & 5.4179 & 5.4274 & \text { TRN }\end{array}$

$\begin{array}{llll}1528876 & 5.9101 & 5.9 & \text { TRN }\end{array}$

$\begin{array}{llll}1528876 & 5.7873 & 5.715 & \text { TRN }\end{array}$

$\begin{array}{llll}1528876 & 8.1675 & 8.1703 & \text { TRN }\end{array}$

$\begin{array}{llll}1528876 & 7.5498 & 7.5775 & \text { TRN }\end{array}$

$\begin{array}{llll}1528876 & 6.0467 & 6.0591 & \text { TRN }\end{array}$

$\begin{array}{llll}1528876 & 6.3904 & 6.4324 & \text { TRN }\end{array}$

$\begin{array}{llll}1528876 & 5.9136 & 6.01 & \text { TRN }\end{array}$

$\begin{array}{llll}1528876 & 6.2055 & 6.2951 & \text { TRN }\end{array}$

$\begin{array}{llll}1528876 & 6.1599 & 6.1256 & \text { TRN }\end{array}$

$\begin{array}{llll}1528876 & 6.0996 & 6.1219 & \text { TRN }\end{array}$

$\begin{array}{llll}1528876 & 6.301 & 6.2853 & \text { TRN }\end{array}$

$\begin{array}{llll}1528876 & 6.9281 & 6.8904 & \text { TRN }\end{array}$

$\begin{array}{llll}1528876 & 7.699 & 7.5799 & \text { TRN }\end{array}$

$\begin{array}{llll}1528876 & 6.0926 & 6.0618 & \text { TRN }\end{array}$

$\begin{array}{llll}1528876 & 6.0026 & 6.646 & \text { TST }\end{array}$

$\begin{array}{lllll}1528876 & 6.5498 & 6.5488 & \text { TRN }\end{array}$

$\begin{array}{llll}1528876 & 5.1506 & 5.1755 & \text { TRN }\end{array}$

$\begin{array}{llll}1528876 & 7.2518 & 7.3429 & \text { TRN }\end{array}$

$\begin{array}{llll}1528876 & 5.4214 & 5.4469 & \text { TRN }\end{array}$

$\begin{array}{lllll}1528876 & 6.4283 & 6.5277 & \text { TRN }\end{array}$

$\begin{array}{llll}1528876 & 5.2208 & 5.2465 & \text { TRN }\end{array}$

$\begin{array}{llll}1528876 & 6.6799 & 6.6515 & \text { TRN }\end{array}$

$\begin{array}{llll}1528876 & 5.5196 & 5.5025 & \text { TRN }\end{array}$

$\begin{array}{llll}1528876 & 5.9208 & 6.0372 & \text { TRN }\end{array}$

$\begin{array}{llll}1528876 & 7.7447 & 7.7792 & \text { TRN }\end{array}$

$\begin{array}{llll}1528876 & 4.7986 & 3.8678 & \text { TST }\end{array}$

$\begin{array}{llll}1528876 & 5.8861 & 5.8553 & \text { TRN }\end{array}$

$\begin{array}{llll}1528876 & 6.3507 & 6.3417 & \text { TRN }\end{array}$

$\begin{array}{llll}1528876 & 7.6778 & 7.7263 & \text { TRN }\end{array}$

$\begin{array}{llll}1528876 & 6.9355 & 8.2912 & \text { TST }\end{array}$

$\begin{array}{llll}1528876 & 6.5171 & 6.5009 & \text { TRN }\end{array}$
11.2262 TST 
Supplemental Table S2.txt

\begin{tabular}{|c|c|c|c|c|c|}
\hline CHEMBL 3677806 & 1528876 & 6.3969 & 6.3492 & TRN & \\
\hline CHEMBL 3677778 & 1528876 & 5.3198 & 6.8944 & TST & \\
\hline CHEMBL 3677768 & 1528876 & 7.1079 & 7.105 & TRN & \\
\hline CHEMBL 3677829 & 1528876 & 6.5031 & 6.4132 & TRN & \\
\hline CHEMBL3677763 & 1528876 & 6.5591 & 6.5597 & TRN & \\
\hline CHEMBL 3677769 & 1528876 & 4.9427 & 4.9395 & TRN & \\
\hline CHEMBL 3677801 & 1528876 & 6.0645 & 6.0943 & TRN & \\
\hline CHEMBL3677746 & 1528876 & 5.8477 & 5.8406 & TRN & \\
\hline CHEMBL 3677832 & 1528876 & 6.6615 & 6.7451 & TRN & \\
\hline CHEMBL3677784 & 1528876 & 5.5086 & 5.5414 & TRN & \\
\hline CHEMBL 3677745 & 1528876 & 5.9957 & 6.017 & TRN & \\
\hline CHEMBL 3677728 & 1528876 & 6.2411 & 6.2104 & TRN & \\
\hline CHEMBL 3677736 & 1528876 & 5.5186 & 6.4084 & TST & \\
\hline CHEMBL 3677785 & 1528876 & 7.2218 & 7.1848 & TRN & \\
\hline CHEMBL3677811 & 1528876 & 8.0526 & 7.987999 & э9999999995 & TRN \\
\hline CHEMBL 3677817 & 1528876 & 6.4225 & 6.4685 & TRN & \\
\hline CHEMBL 3677805 & 1528876 & 6.1221 & 6.1271 & TRN & \\
\hline CHEMBL 3677791 & 1528876 & 5.8239 & 5.8223 & TRN & \\
\hline CHEMBL 3677751 & 1528876 & 5.9281 & 5.8619 & TRN & \\
\hline CHEMBL3677767 & 1528876 & 8.2518 & 8.2741 & TRN & \\
\hline CHEMBL 3677789 & 1528876 & 7.8697 & 8.1147 & TST & \\
\hline CHEMBL 3677828 & 1528876 & 6.3556 & 6.3874 & TRN & \\
\hline CHEMBL 3677797 & 1528876 & 5.6925 & 5.6995 & TRN & \\
\hline CHEMBL 3677764 & 1528876 & 5.3585 & 5.3252 & TRN & \\
\hline CHEMBL 3677766 & 1528876 & 6.4634 & 6.8025 & TST & \\
\hline CHEMBL 3677735 & 1528876 & 5.8996 & 5.8261 & TRN & \\
\hline CHEMBL 3677729 & 1528876 & 5.7959 & 7.1561 & TST & \\
\hline CHEMBL 3677795 & 1528876 & 6.9586 & 7.6896 & TST & \\
\hline CHEMBL 3677833 & 1528876 & 5.7747 & 5.8017 & TRN & \\
\hline CHEMBL 3677808 & 1528876 & 8.5229 & 8.3306 & TST & \\
\hline CHEMBL 3677739 & 1528876 & 6.0155 & 6.8211 & TST & \\
\hline CHEMBL 3677786 & 1528876 & 6.1506 & 6.5638 & TST & \\
\hline CHEMBL 3677761 & 1528876 & 5.7352 & 6.3307 & TST & \\
\hline CHEMBL 3677783 & 1528876 & 5.6576 & 6.9302 & TST & \\
\hline CHEMBL 3677823 & 1528876 & 5.4202 & 5.6888 & TST & \\
\hline CHEMBL 3677822 & 1528876 & 5.6498 & 5.6945 & TRN & \\
\hline CHEMBL 3677726 & 1528876 & 5.3054 & 5.3142 & TRN & \\
\hline CHEMBL 3677752 & 1528876 & 6.75200 & 000000000 & 6.7378 & TRN \\
\hline CHEMBL 3677733 & 1528876 & 6.3098 & 6.1719 & TRN & \\
\hline CHEMBL 3639766 & 1528876 & 8.4559 & 8.4641 & TRN & \\
\hline CHEMBL3677799 & 1528876 & 5.76200 & 000000000 & 5.7998 & IRI \\
\hline CHEMBL 3677825 & 1528876 & 7.4949 & 7.5221 & TRN & \\
\hline CHEMBL 3677781 & 1528876 & 7.7959 & 8.2611 & TST & \\
\hline CHEMBL 3677812 & 1528876 & 7.3188 & 7.2641 & TRN & \\
\hline CHEMBL 3677779 & 1528876 & 7.1079 & 7.905 & TST & \\
\hline CHEMBL 3677820 & 1528876 & 5.7986 & 5.8397 & TRN & \\
\hline CHEMBL 3677737 & 1528876 & 6.011 & 6.0474 & TRN & \\
\hline CHEMBL 3677740 & 1528876 & 6.7645 & 6.9437 & TST & \\
\hline
\end{tabular}


Supplemental Table S2.txt

\begin{tabular}{|c|c|c|c|c|}
\hline- & & & & \\
\hline HEMBL3677750 & 528876 & 6.0227 & 0993 & \\
\hline 30 & & & & \\
\hline 77782 & 3876 & 36 & 381 & \\
\hline IEMBL 3677826 & 528876 & 788 & 9215 & \\
\hline AEMBL3677804 & 528876 & 6517 & 6285 & \\
\hline HEMBL 367 & 528876 & 3947 & 5405 & \\
\hline 57 & 76 & 3041 & 121 & \\
\hline AEMBL & 528876 & 9208 & .1549 & \\
\hline AEMBL3677831 & 528876 & 5.0731 & 2585 & \\
\hline HEMBL 3677788 & 528876 & 5.9208 & 3232 & \\
\hline AEMBL: & 528876 & 811 & 1098 & \\
\hline 92 & & & & \\
\hline AEMBL & 528876 & 672 & 2445 & \\
\hline AEMBL3 & 528876 & 7.301 & 2897 & \\
\hline AEMBL36 & 528876 & 329 & 49 & \\
\hline HEMBL & 528876 & 67 & 627 & \\
\hline HEMBL & 528876 & & & \\
\hline 94 & 528876 & & 351 & \\
\hline AEMBL3 & 8876 & & & \\
\hline$A \in M B L 36$ & $5288 / 6$ & 88 & b5 & MT \\
\hline HEMBL3 & 28876 & 2 & 381 & \\
\hline HEMBL; & 76 & & & \\
\hline 53 & & & 2009 & \\
\hline AEMBL3 & 76 & 4 & 784 & SI \\
\hline$M B L$ & 28876 & 5 & 308 & ГST \\
\hline HEM & 7383 & 1 & 973 & \\
\hline 3 & 83 & & 75 & RN \\
\hline AEMBL1 & 37383 & & & RN \\
\hline AEMBL1 & 33 & 1 & 83 & RN \\
\hline IEMBL1 & 7383 & 674 & 503 & \\
\hline 6 & 33 & 34 & 391 & RN \\
\hline 94 & & & & RN \\
\hline HEMBL17 & 37383 & & & RN \\
\hline AEMBL1 & 37383 & 19 & 127 & RN \\
\hline AEMBL1 & 83 & 104 & 184 & \\
\hline $45 M I^{-7}$ & 33 & & & RN \\
\hline & 37383 & & 6.1801 & $\mathrm{RN}$ \\
\hline HEMBL153 & 37383 & 75 & 3664 & TRN \\
\hline AEMBL1 & 373 & & 1793 & IST \\
\hline HEMBL1; & 37383 & 904 & 6.2207 & $\mathrm{RN}$ \\
\hline HEMBL 32 & & & & RN \\
\hline HEMBL31 & 737383 & 153 & 213 & $\mathrm{RN}$ \\
\hline HEMBL170 & 37383 & 5121 & 8631 & RN \\
\hline 1 & 37383 & & .9552 & \\
\hline HEMBL1 & 737383 & & 5411 & \\
\hline HEMBL14 & 737383 & 7.0132 & 6.1665 & \\
\hline CHEMBL1462827 & 737383 & 7.4949 & 6.3051 & \\
\hline
\end{tabular}

Page 238 


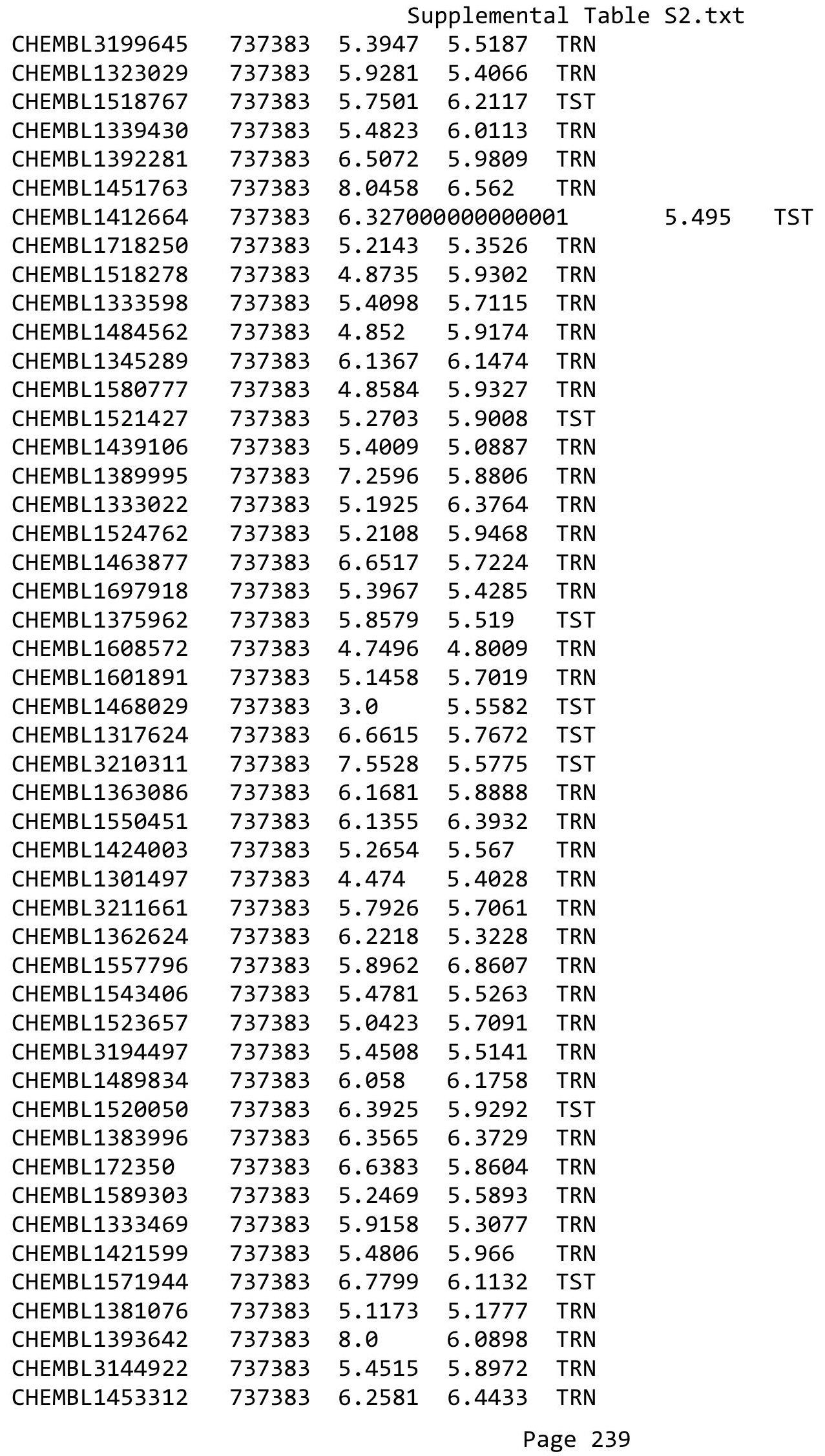




\begin{tabular}{|c|c|c|c|c|c|}
\hline \multirow[b]{2}{*}{ CHEMBL1305415 } & \multicolumn{5}{|c|}{ Supplemental Table S2.txt } \\
\hline & 737383 & 4.6111 & 5.6392 & TRN & \\
\hline CHEMBL 3213852 & 737383 & 6.757006 & 000000000 & 5.7204 & TRN \\
\hline CHEMBL1340668 & 737383 & 5.0831 & 5.747000 & 0000000001 & TST \\
\hline CHEMBL1511009 & 737383 & 5.2024 & 5.3848 & TRN & \\
\hline CHEMBL1716241 & 737383 & 5.5596 & 5.4224 & TRN & \\
\hline CHEMBL1467650 & 737383 & 4.5447 & 5.4553 & TST & \\
\hline CHEMBL1540380 & 737383 & 5.1814 & 5.5391 & TST & \\
\hline CHEMBL1567637 & 737383 & 6.2882 & 6.182 & TRN & \\
\hline CHEMBL473107 & 737383 & 5.5809 & 6.0493 & TRN & \\
\hline CHEMBL1312887 & 737383 & 5.6527 & 4.9978 & TRN & \\
\hline CHEMBL1573328 & 737383 & 4.9817 & 5.4832 & TRN & \\
\hline CHEMBL1445777 & 737383 & 5.6041 & 5.6134 & TRN & \\
\hline CHEMBL1449167 & 737383 & 5.7481 & 6.008999 & 99999999995 & TRN \\
\hline CHEMBL1702245 & 737383 & 9.301 & 6.2031 & TRN & \\
\hline CHEMBL1459961 & 737383 & 6.066 & 6.4666 & TRN & \\
\hline CHEMBL1702507 & 737383 & 5.7174 & 5.3763 & TRN & \\
\hline CHEMBL1345959 & 737383 & 8.8539 & 5.6008 & TST & \\
\hline CHEMBL1406188 & 737383 & 5.4199 & 5.2935 & TRN & \\
\hline CHEMBL1567939 & 737383 & 4.1748 & 5.5243 & TRN & \\
\hline CHEMBL1353082 & 737383 & 5.2828 & 5.8307 & TST & \\
\hline CHEMBL1311211 & 737383 & 4.8721 & 5.5062 & TRN & \\
\hline CHEMBL576932 & 737383 & 5.246 & 6.091 & TST & \\
\hline CHEMBL1459528 & 737383 & 5.36 & 5.343999 & 9999999999 & TRN \\
\hline CHEMBL1425884 & 737383 & 5.4806 & 6.4422 & TRN & \\
\hline CHEMBL1349538 & 737383 & 4.6058 & 5.4571 & TRN & \\
\hline CHEMBL1452020 & 737383 & 5.4795 & 5.6041 & TRN & \\
\hline CHEMBL1543146 & 737383 & 4.7711 & 5.5223 & TRN & \\
\hline CHEMBL2369297 & 737383 & 6.6421 & 5.7696 & TRN & \\
\hline CHEMBL1406756 & 737383 & 3.0 & 5.6387 & TRN & \\
\hline CHEMBL3192686 & 737383 & 5.9133 & 5.9801 & TRN & \\
\hline CHEMBL1352596 & 737383 & 5.5226 & 5.4167 & TRN & \\
\hline CHEMBL3198324 & 737383 & 5.2812 & 6.3345 & TRN & \\
\hline CHEMBL1351560 & 737383 & 5.8318 & 5.9098 & TRN & \\
\hline CHEMBL1367670 & 737383 & 5.346 & 6.0567 & TRN & \\
\hline CHEMBL1580517 & 737383 & 5.6914 & 5.37 & TRN & \\
\hline CHEMBL1582027 & 737383 & 6.1694 & 5.5855 & TRN & \\
\hline CHEMBL1445541 & 737383 & 4.9857 & 5.915 & TRN & \\
\hline CHEMBL1700162 & 737383 & 5.7647 & 5.5936 & TRN & \\
\hline CHEMBL1494935 & 737383 & 5.3015 & 5.8625 & TRN & \\
\hline CHEMBL1725556 & 737383 & 5.0802 & 5.7984 & TRN & \\
\hline CHEMBL1403039 & 737383 & 5.4835 & 6.035 & TRN & \\
\hline CHEMBL1977858 & 737383 & 5.6392 & 6.0546 & TRN & \\
\hline CHEMBL1393567 & 737383 & 6.8069 & 5.7616 & TRN & \\
\hline CHEMBL1564025 & 737383 & 5.3416 & 6.3815 & TRN & \\
\hline CHEMBL1327249 & 737383 & 4.9189 & 5.3094 & TRN & \\
\hline CHEMBL1353997 & 737383 & 5.6507 & 5.2498 & TRN & \\
\hline CHEMBL1711677 & 737383 & 5.0939 & 5.3297 & TRN & \\
\hline CHEMBL1391076 & 737383 & 5.022 & 5.8672 & TST & \\
\hline
\end{tabular}




\begin{tabular}{|c|c|c|c|c|c|}
\hline \multirow[b]{2}{*}{ CHEMBL1732951 } & \multicolumn{5}{|c|}{ Supplemental Table S2.txt } \\
\hline & 737383 & 5.8633 & 5.9227 & TRN & \\
\hline CHEMBL3192488 & 737383 & 6.041 & 5.8235 & TRN & \\
\hline CHEMBL1469126 & 737383 & 4.1778 & 6.1012 & TRN & \\
\hline CHEMBL1443752 & 737383 & 7.3372 & 5.9035 & TRN & \\
\hline CHEMBL1369610 & 737383 & 6.4067 & 5.8945 & TST & \\
\hline CHEMBL1582553 & 737383 & 5.6488 & 6.1167 & TRN & \\
\hline CHEMBL1395013 & 737383 & 5.9226 & 5.772 & TRN & \\
\hline CHEMBL1700296 & 737383 & 6.6478 & 6.48600 & 0000000001 & TRN \\
\hline CHEMBL1426576 & 737383 & 5.348 & 5.2255 & TRN & \\
\hline CHEMBL3196995 & 737383 & 5.6906 & 5.8766 & TRN & \\
\hline CHEMBL1351592 & 737383 & 5.7162 & 5.2808 & TRN & \\
\hline CHEMBL1586957 & 737383 & 7.4815 & 6.0957 & TST & \\
\hline CHEMBL1498113 & 737383 & 5.3407 & 5.859 & TRN & \\
\hline CHEMBL1334762 & 737383 & 5.8511 & 5.7401 & TRN & \\
\hline CHEMBL1509728 & 737383 & 5.5771 & 6.0978 & TRN & \\
\hline CHEMBL3208690 & 737383 & 5.6753 & 5.0646 & TRN & \\
\hline CHEMBL1602010 & 737383 & 5.24299 & 99999999 & 5.9303 & TST \\
\hline CHEMBL1408610 & 737383 & 5.6523 & 5.5092 & TRN & \\
\hline CHEMBL1724886 & 737383 & 6.1463 & 5.5906 & TRN & \\
\hline CHEMBL1468273 & 737383 & 5.6882 & 5.70299 & 9999999999 & TRN \\
\hline CHEMBL3199715 & 737383 & 6.8861 & 5.9541 & TRN & \\
\hline CHEMBL1981002 & 737383 & 6.0964 & 6.1331 & TST & \\
\hline CHEMBL1383107 & 737383 & 4.971 & 5.7391 & TRN & \\
\hline CHEMBL1527022 & 737383 & 6.475 & 6.0033 & TST & \\
\hline CHEMBL1332506 & 737383 & 6.9586 & 6.1574 & TRN & \\
\hline CHEMBL1604961 & 737383 & 4.7987 & 5.0181 & TRN & \\
\hline CHEMBL1698033 & 737383 & 6.8729 & 5.6026 & TRN & \\
\hline CHEMBL1570641 & 737383 & 5.0139 & 5.7879 & TRN & \\
\hline CHEMBL1587448 & 737383 & 5.3175 & 5.5377 & TST & \\
\hline CHEMBL3197799 & 737383 & 5.6171 & 5.5984 & TRN & \\
\hline CHEMBL1438517 & 737383 & 5.2436 & 6.1748 & TRN & \\
\hline CHEMBL1580609 & 737383 & 7.6778 & 6.4166 & TRN & \\
\hline CHEMBL1439767 & 737383 & 5.0209 & 5.5038 & TRN & \\
\hline CHEMBL1468323 & 737383 & 5.8645 & 5.2683 & TRN & \\
\hline CHEMBL1381845 & 737383 & 5.3231 & 5.7723 & TRN & \\
\hline CHEMBL1352953 & 737383 & 4.7095 & 5.1962 & TRN & \\
\hline CHEMBL1538030 & 737383 & 5.2162 & 5.6162 & TRN & \\
\hline CHEMBL1727714 & 737383 & 5.4787 & 5.4135 & TRN & \\
\hline CHEMBL1590193 & 737383 & 6.4134 & 5.6202 & TRN & \\
\hline CHEMBL1399281 & 737383 & 5.0879 & 5.58200 & 0000000001 & TST \\
\hline CHEMBL1467771 & 737383 & 4.8714 & 5.6785 & TRN & \\
\hline CHEMBL1328677 & 737383 & 5.4751 & 5.6539 & TRN & \\
\hline CHEMBL1613591 & 737383 & 4.8796 & 5.6193 & TRN & \\
\hline CHEMBL1509253 & 737383 & 9.301 & 6.5542 & TRN & \\
\hline CHEMBL1336011 & 737383 & 4.8408 & 5.6589 & TRN & \\
\hline CHEMBL1699194 & 737383 & 5.3563 & 5.5387 & TRN & \\
\hline CHEMBL1502286 & 737383 & 5.4479 & 5.8447 & TRN & \\
\hline CHEMBL1332645 & 737383 & 5.0966 & 5.4137 & TRN & \\
\hline
\end{tabular}


Supplemental Table S2.txt

\begin{tabular}{|c|c|c|c|c|c|}
\hline CHEMBL 3189366 & 737383 & 6.5986 & 5.7839 & TST & \\
\hline CHEMBL1403049 & 737383 & 5.2273 & 5.0774 & TRN & \\
\hline CHEMBL1332684 & 737383 & 6.1694 & 5.7175 & TST & \\
\hline CHEMBL1490944 & 737383 & 5.4553 & 6.1005 & TST & \\
\hline CHEMBL3194699 & 737383 & 8.301 & 5.6802 & TRN & \\
\hline CHEMBL1307237 & 737383 & 5.7567 & 6.3523 & TRN & \\
\hline CHEMBL1389728 & 737383 & 5.1944 & 5.7146 & TRN & \\
\hline CHEMBL1201074 & 737383 & 5.9642 & 6.0595 & TST & \\
\hline CHEMBL1582927 & 737383 & \multicolumn{2}{|c|}{5.6370000000000005} & 5.9283 & \\
\hline CHEMBL1533994 & 737383 & 5.4584 & 5.3318 & TRN & \\
\hline CHEMBL1385794 & 737383 & 6.3716 & 5.813 & TST & \\
\hline CHEMBL1980031 & 737383 & 6.8539 & 6.1336 & TRN & \\
\hline CHEMBL1412423 & 737383 & 6.6819 & 6.3264 & TRN & \\
\hline CHEMBL1430953 & 737383 & 5.9205 & 6.277 & TRN & \\
\hline CHEMBL1300856 & 737383 & 6.9245 & 6.7067 & TRN & \\
\hline CHEMBL1333659 & 737383 & 5.9767 & 6.2538 & TRN & \\
\hline CHEMBL1403847 & 737383 & 4.9097 & 5.4729 & TRN & \\
\hline CHEMBL1346753 & 737383 & 5.8499 & 5.531000 & 0000000001 & \\
\hline CHEMBL1391665 & 737383 & 7.7959 & 5.2416 & TRN & \\
\hline CHEMBL499363 & 737383 & 5.3406 & 6.0536 & TST & \\
\hline CHEMBL1715421 & 737383 & 5.3582 & 6.0037 & TRN & \\
\hline CHEMBL1368927 & 737383 & 5.2548 & 5.5995 & TST & \\
\hline CHEMBL1702217 & 737383 & 5.7208 & 6.3972 & TRN & \\
\hline CHEMBL1548073 & 737383 & 4.9549 & 5.7059 & TRN & \\
\hline CHEMBL3195719 & 737383 & 5.5769 & 5.5823 & TRN & \\
\hline CHEMBL1435749 & 737383 & 6.3768 & 5.9823 & TRN & \\
\hline CHEMBL1721801 & 737383 & 7.3098 & 6.2897 & TRN & \\
\hline CHEMBL1356238 & 737383 & 6.3645 & 5.7786 & TST & \\
\hline CHEMBL1312974 & 737383 & 5.8125 & 5.7024 & TST & \\
\hline CHEMBL3210893 & 737383 & 4.9614 & 6.1665 & TRN & \\
\hline CHEMBL1503192 & 737383 & 4.8695 & 5.7353 & TRN & \\
\hline CHEMBL1531891 & 737383 & 5.2596 & 5.1428 & TRN & \\
\hline CHEMBL1430289 & 737383 & 5.0577 & 5.803 & TST & \\
\hline CHEMBL1714907 & 737383 & 4.4291 & 5.9332 & TRN & \\
\hline CHEMBL1488901 & 737383 & 6.0846 & 5.7892 & TRN & \\
\hline CHEMBL1510485 & 737383 & 6.4179 & 6.1991 & TRN & \\
\hline CHEMBL1567547 & 737383 & 6.75700 & 000000000 & 6.0542 & \\
\hline CHEMBL1527186 & 737383 & 6.0768 & 5.8031 & TRN & \\
\hline CHEMBL1320828 & 737383 & 5.9978 & 5.3271 & TRN & \\
\hline CHEMBL3189790 & 737383 & 5.4176 & 5.3665 & TRN & \\
\hline CHEMBL1716535 & 737383 & 5.2224 & 5.3562 & TRN & \\
\hline CHEMBL1421614 & 737383 & 9.301 & 5.7719 & TRN & \\
\hline CHEMBL1717338 & 737383 & 5.4667 & 5.388999 & 7999999999 & \\
\hline CHEMBL1345687 & 737383 & 6.6716 & 5.5036 & TRN & \\
\hline CHEMBL 269928 & 737383 & 5.9578 & 5.7395 & TRN & \\
\hline CHEMBL1733476 & 737383 & 5.0882 & 5.2893 & TRN & \\
\hline CHEMBL1468601 & 737383 & 6.4157 & 6.4592 & TRN & \\
\hline CHEMBL1504851 & 737383 & 5.2743 & 5.9106 & TRN & \\
\hline
\end{tabular}




\begin{tabular}{|c|c|c|c|c|c|c|}
\hline & & \multicolumn{5}{|c|}{ Supplemental Table S2.txt } \\
\hline CHEMBL1339948 & 737383 & 5.0928 & 5.2343 & TRN & & \\
\hline CHEMBL1328312 & 737383 & 6.8125 & 6.4769 & TRN & & \\
\hline CHEMBL1559614 & 737383 & 5.504 & 6.0953 & TRN & & \\
\hline CHEMBL1499401 & 737383 & 5.0428 & 5.5475 & TRN & & \\
\hline CHEMBL1467899 & 737383 & 5.9212 & 6.1965 & TRN & & \\
\hline CHEMBL3190156 & 737383 & 6.2055 & 5.9842 & TRN & & \\
\hline CHEMBL1370267 & 737383 & 5.2745 & 6.2333 & TRN & & \\
\hline CHEMBL1422185 & 737383 & 6.2733 & 6.0144 & TRN & & \\
\hline CHEMBL 1458572 & 737383 & 5.1383 & 5.4146 & TRN & & \\
\hline CHEMBL1390701 & 737383 & 5.5521 & 5.5393 & TRN & & \\
\hline CHEMBL1327238 & 737383 & 5.8465 & 6.0261 & TST & & \\
\hline CHEMBL1704827 & 737383 & \multicolumn{3}{|c|}{5.622000000000001} & 5.2789 & TRN \\
\hline CHEMBL1390773 & 737383 & 4.8079 & 5.5398 & TRN & & \\
\hline CHEMBL 1444580 & 737383 & 6.7825 & 5.9108 & TRN & & \\
\hline CHEMBL1489339 & 737383 & 5.8262 & 6.0202 & TRN & & \\
\hline CHEMBL1367860 & 737383 & 5.2303 & 5.8669 & TST & & \\
\hline CHEMBL1714089 & 737383 & 4.8282 & 5.8431 & TST & & \\
\hline CHEMBL1470024 & 737383 & 5.4678 & 5.8084 & TRN & & \\
\hline CHEMBL1452084 & 737383 & 5.4112 & 6.1261 & TRN & & \\
\hline CHEMBL1409013 & 737383 & 5.6778 & 5.5296 & TRN & & \\
\hline CHEMBL 3191854 & 737383 & 5.768 & 5.58700 & 0000000001 & & TRN \\
\hline CHEMBL1393480 & 737383 & 5.7053 & 6.0007 & TRN & & \\
\hline CHEMBL341473 & 737383 & 5.4168 & 5.771 & TRN & & \\
\hline CHEMBL 1450386 & 737383 & 6.7258 & 6.015 & TRN & & \\
\hline CHEMBL1468277 & 737383 & 5.8595 & 6.2203 & TRN & & \\
\hline CHEMBL 3189145 & 737383 & 5.9367 & 6.5117 & TRN & & \\
\hline CHEMBL3208497 & 737383 & 4.4745 & 5.5085 & TRN & & \\
\hline CHEMBL1368662 & 737383 & 5.2013 & 5.5889 & TRN & & \\
\hline CHEMBL1998824 & 737383 & 5.6332 & 6.0031 & TRN & & \\
\hline CHEMBL1466798 & 737383 & 4.9196 & 5.6063 & TRN & & \\
\hline CHEMBL1323281 & 737383 & 5.1291 & 5.6858 & TRN & & \\
\hline CHEMBL1344269 & 737383 & 5.1565 & 5.7418 & TST & & \\
\hline CHEMBL1453077 & 737383 & 5.6087 & 5.876 & TRN & & \\
\hline CHEMBL1572168 & 737383 & 5.6772 & 4.9991 & TRN & & \\
\hline CHEMBL3208177 & 737383 & 4.6423 & 5.4554 & TRN & & \\
\hline CHEMBL83527 & 737383 & 6.109 & 5.7876 & TRN & & \\
\hline CHEMBL1333101 & 737383 & 5.7545 & 5.9136 & TRN & & \\
\hline CHEMBL1441487 & 737383 & 5.1575 & 5.0423 & TRN & & \\
\hline CHEMBL1562264 & 737383 & 6.3595 & 6.0953 & TST & & \\
\hline CHEMBL1353098 & 737383 & 7.699 & 6.1471 & TRN & & \\
\hline CHEMBL1413585 & 737383 & 6.6289 & 5.9969 & TRN & & \\
\hline CHEMBL1391464 & 737383 & 6.6271 & 6.2994 & TRN & & \\
\hline CHEMBL1611164 & 737383 & 5.2352 & 5.9185 & TRN & & \\
\hline CHEMBL1462751 & 737383 & 6.032 & 6.4004 & TRN & & \\
\hline CHEMBL1497149 & 737383 & 6.6498 & 5.6723 & TRN & & \\
\hline CHEMBL1378661 & 737383 & 5.6874 & 5.5118 & TRN & & \\
\hline CHEMBL1372098 & 737383 & 4.6658 & 5.4307 & TST & & \\
\hline CHEMBL1367933 & 737383 & 6.5686 & 6.0067 & TRN & & \\
\hline
\end{tabular}




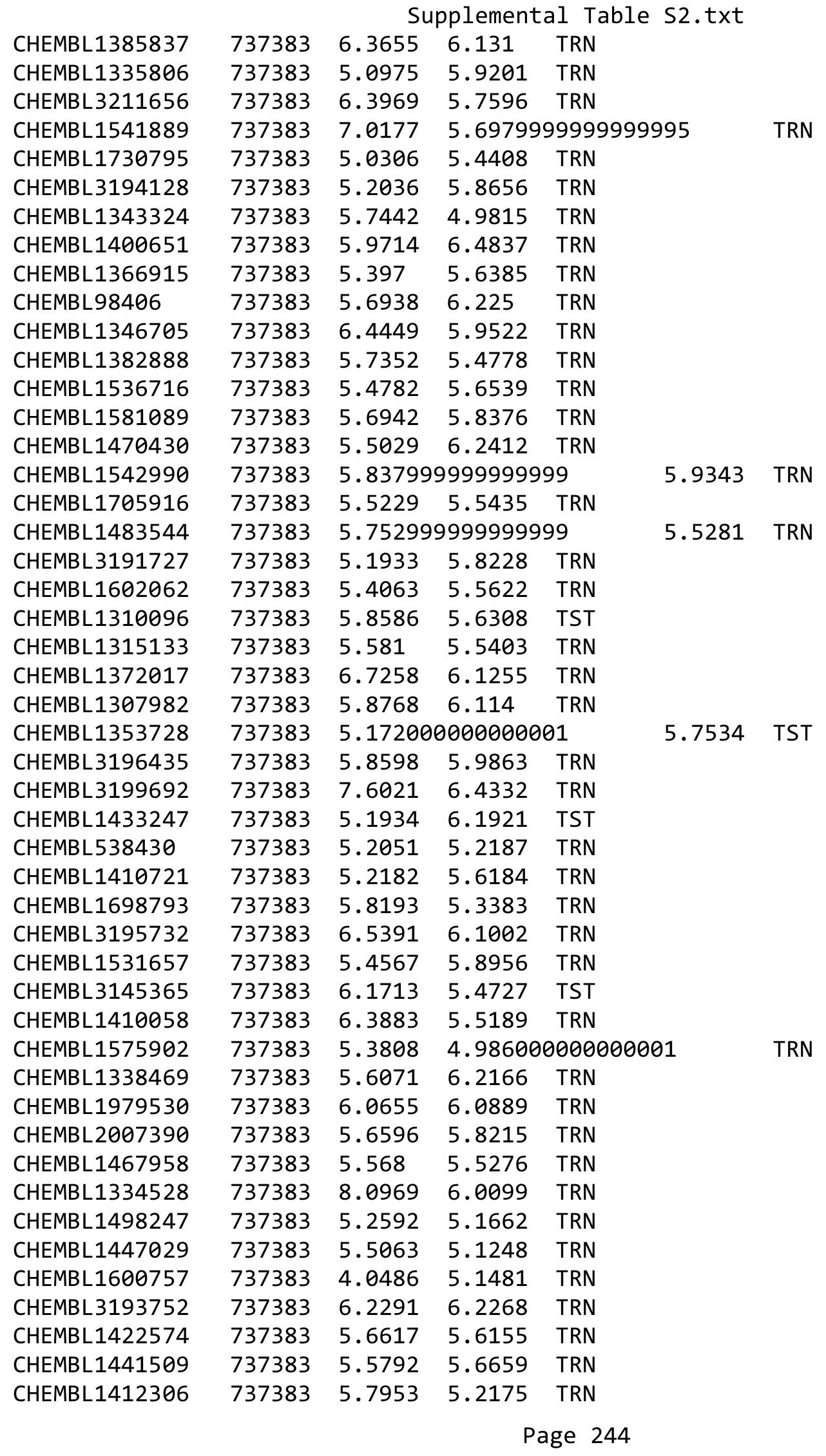




\begin{tabular}{|c|c|c|c|c|c|c|}
\hline & & \multicolumn{5}{|c|}{ Supplemental Table S2.txt } \\
\hline CHEMBL1422970 & 737383 & 6.2916 & 5.9747 & TRN & & \\
\hline CHEMBL1585417 & 737383 & 5.1321 & 5.5959 & TST & & \\
\hline CHEMBL1382220 & 737383 & 4.8582 & 5.7888 & TRN & & \\
\hline CHEMBL1712388 & 737383 & 5.7565 & 5.2675 & TRN & & \\
\hline CHEMBL1347556 & 737383 & 6.1778 & 5.6129 & TRN & & \\
\hline CHEMBL1389127 & 737383 & 4.7698 & 5.9832 & TRN & & \\
\hline CHEMBL1390541 & 737383 & 5.6031 & 5.9843 & TRN & & \\
\hline CHEMBL1547557 & 737383 & 5.9314 & 5.6905 & TRN & & \\
\hline CHEMBL1584901 & 737383 & 5.6043 & 5.4654 & TRN & & \\
\hline CHEMBL1710519 & 737383 & 5.7567 & 5.6255 & TRN & & \\
\hline CHEMBL1362257 & 737383 & 3.0 & 5.0529 & TRN & & \\
\hline CHEMBL1404704 & 737383 & \multicolumn{3}{|c|}{5.2139999999999995} & .8239 & TRN \\
\hline CHEMBL1482957 & 737383 & 6.8069 & 6.6148 & TRN & & \\
\hline CHEMBL1451435 & 737383 & 5.1361 & 5.5976 & TRN & & \\
\hline CHEMBL333985 & 737383 & 4.9995 & 5.5556 & TST & & \\
\hline CHEMBL1390024 & 737383 & 5.3869 & 5.3691 & TRN & & \\
\hline CHEMBL1602731 & 737383 & 5.4553 & 5.8291 & TST & & \\
\hline CHEMBL3189512 & 737383 & 4.9654 & 5.2046 & TRN & & \\
\hline CHEMBL1558836 & 737383 & 5.0184 & 5.9576 & TRN & & \\
\hline CHEMBL1605436 & 737383 & 6.057 & 5.8573 & TRN & & \\
\hline CHEMBL1698633 & 737383 & 6.3575 & 5.4542 & TRN & & \\
\hline CHEMBL1580977 & 737383 & \multicolumn{3}{|c|}{5.622000000000001} & 6.0688 & TRN \\
\hline CHEMBL3210929 & 737383 & 5.6807 & 5.9296 & TRN & & \\
\hline CHEMBL 233347 & 737383 & 5.2533 & 5.4898 & TRN & & \\
\hline CHEMBL1404929 & 737383 & 7.2076 & 5.6598 & TRN & & \\
\hline CHEMBL1347862 & 737383 & 5.3903 & 5.1989 & TRN & & \\
\hline CHEMBL1567356 & 737383 & 5.3393 & 5.5534 & TRN & & \\
\hline CHEMBL1726481 & 737383 & 5.7142 & 5.6934 & TRN & & \\
\hline CHEMBL1339120 & 737383 & 7.3468 & 5.7866 & TRN & & \\
\hline CHEMBL3190653 & 737383 & 6.0773 & 6.024 & TRN & & \\
\hline CHEMBL3213497 & 737383 & 5.6643 & 5.744 & TRN & & \\
\hline CHEMBL1333617 & 737383 & 5.4872 & 6.1976 & TRN & & \\
\hline CHEMBL1417176 & 737383 & 5.3146 & 5.9395 & TRN & & \\
\hline CHEMBL1730929 & 737383 & 5.0303 & 5.1933 & TRN & & \\
\hline CHEMBL1407628 & 737383 & 9.301 & 6.6913 & TRN & & \\
\hline CHEMBL1445346 & 737383 & 5.4584 & 6.3301 & TRN & & \\
\hline CHEMBL239103 & 737383 & 5.5061 & 6.1668 & TRN & & \\
\hline CHEMBL1994738 & 737383 & 5.1043 & 5.9047 & TRN & & \\
\hline CHEMBL1595067 & 737383 & 5.3183 & 5.7813 & TRN & & \\
\hline CHEMBL1527997 & 737383 & 5.3744 & 6.3296 & TRN & & \\
\hline CHEMBL1448877 & 737383 & 5.2729 & 5.3192 & TST & & \\
\hline CHEMBL1320510 & 737383 & 5.5053 & 5.5949 & TRN & & \\
\hline CHEMBL1467908 & 737383 & 6.3116 & 5.3313 & TST & & \\
\hline CHEMBL3190152 & 737383 & 6.4789 & 5.9651 & TRN & & \\
\hline CHEMBL1343516 & 737383 & 6.6556 & 5.5257 & TST & & \\
\hline CHEMBL3208482 & 737383 & 4.1705 & 5.3176 & TRN & & \\
\hline CHEMBL1588970 & 737383 & 6.4179 & 5.3475 & TRN & & \\
\hline CHEMBL3198126 & 737383 & 5.67 & 5.7318 & TRN & & \\
\hline
\end{tabular}




\begin{tabular}{|c|c|c|c|c|c|c|}
\hline & & \multicolumn{5}{|c|}{ Supplemental Table S2.txt } \\
\hline CHEMBL1302810 & 737383 & 5.2259 & 5.2617 & TRN & & \\
\hline CHEMBL1483585 & 737383 & 5.9318 & 6.0508 & TRN & & \\
\hline CHEMBL544115 & 737383 & 5.3247 & 5.7528 & TST & & \\
\hline CHEMBL 3189872 & 737383 & 5.5865 & 6.397 & TRN & & \\
\hline CHEMBL1569188 & 737383 & 5.9555 & 6.1646 & TRN & & \\
\hline CHEMBL 3192210 & 737383 & 5.5539 & 6.1056 & TRN & & \\
\hline CHEMBL1277546 & 737383 & 5.6813 & 5.4127 & TST & & \\
\hline CHEMBL1352830 & 737383 & 7.0132 & 5.83899 & 9999999999 & 95 & TRN \\
\hline CHEMBL1599130 & 737383 & 5.0652 & 5.3862 & TRN & & \\
\hline CHEMBL1558183 & 737383 & 5.6857 & 6.0272 & TRN & & \\
\hline CHEMBL1353843 & 737383 & 3.0 & 5.6664 & TRN & & \\
\hline CHEMBL1470913 & 737383 & 5.7062 & 5.194 & TRN & & \\
\hline CHEMBL3194208 & 737383 & 4.87 & 5.5891 & TRN & & \\
\hline CHEMBL1542232 & 737383 & 5.1769 & 5.5497 & TRN & & \\
\hline CHEMBL1493247 & 737383 & 5.3874 & 5.7521 & TST & & \\
\hline CHEMBL3212696 & 737383 & 5.721 & 5.8477 & TRN & & \\
\hline CHEMBL1387244 & 737383 & 5.2391 & 5.808 & TST & & \\
\hline CHEMBL1495260 & 737383 & 5.5547 & 5.4858 & TRN & & \\
\hline CHEMBL1402410 & 737383 & 5.4296 & 5.9432 & TST & & \\
\hline CHEMBL1389969 & 737383 & 5.0994 & 5.3105 & TRN & & \\
\hline CHEMBL1308971 & 737383 & 7.0969 & 5.6453 & TRN & & \\
\hline CHEMBL1477749 & 737383 & 7.1024 & 5.5377 & TST & & \\
\hline CHEMBL1532785 & 737383 & 7.1249 & 6.1511 & TST & & \\
\hline CHEMBL1450363 & 737383 & 5.9255 & 6.6101 & TRN & & \\
\hline CHEMBL1407992 & 737383 & 5.5092 & 5.9316 & TST & & \\
\hline CHEMBL1492366 & 737383 & 5.8199 & 5.9283 & TRN & & \\
\hline CHEMBL1433919 & 737383 & 6.585 & 6.1482 & TRN & & \\
\hline CHEMBL3191810 & 737383 & 6.9355 & 6.2639 & TRN & & \\
\hline CHEMBL1532900 & 737383 & 4.7873 & 4.9598 & TRN & & \\
\hline CHEMBL1414675 & 737383 & 5.98799 & 99999999 & 995 & 5.9547 & TRN \\
\hline CHEMBL1730656 & 737383 & 5.1714 & 6.0226 & TRN & & \\
\hline CHEMBL1408826 & 737383 & 5.8401 & 5.6778 & TRN & & \\
\hline CHEMBL3194668 & 737383 & 5.0298 & 5.8278 & TRN & & \\
\hline CHEMBL1722349 & 737383 & 4.9534 & 5.9239 & TST & & \\
\hline CHEMBL1604427 & 737383 & 5.9241 & 5.1488 & TRN & & \\
\hline CHEMBL1407081 & 737383 & 7.3565 & 6.2143 & TRN & & \\
\hline CHEMBL1256484 & 737383 & 5.3862 & 5.4943 & TRN & & \\
\hline CHEMBL1479410 & 737383 & 5.6293 & 5.8632 & TST & & \\
\hline CHEMBL1321939 & 737383 & 8.0458 & 5.5338 & TRN & & \\
\hline CHEMBL1590507 & 737383 & 8.0969 & 6.0452 & TST & & \\
\hline CHEMBL1384845 & 737383 & 5.4032 & 5.7322 & TRN & & \\
\hline CHEMBL1612858 & 737383 & 5.0048 & 6.0438 & TST & & \\
\hline CHEMBL1411415 & 737383 & 4.7601 & 5.8962 & TRN & & \\
\hline CHEMBL1443228 & 737383 & 5.76399 & 99999999 & & 5.7728 & TRN \\
\hline CHEMBL1613189 & 737383 & 6.1325 & 6.079 & TRN & & \\
\hline CHEMBL1479624 & 737383 & 3.0 & 5.82299 & 9999999999 & 95 & TRN \\
\hline CHEMBL1528830 & 737383 & 6.6345 & 5.9911 & TRN & & \\
\hline CHEMBL3197360 & 737383 & 6.5243 & 6.3522 & TRN & & \\
\hline
\end{tabular}




\begin{tabular}{|c|c|c|c|c|c|c|}
\hline & & \multicolumn{5}{|c|}{ Supplemental Table S2.txt } \\
\hline CHEMBL1520203 & 737383 & 6.4815 & 5.9319 & TRN & & \\
\hline CHEMBL3190856 & 737383 & 5.4395 & 5.5279 & TRN & & \\
\hline CHEMBL1484850 & 737383 & 5.1932 & 5.737 & TRN & & \\
\hline CHEMBL1606517 & 737383 & 5.1345 & 6.1482 & TRN & & \\
\hline CHEMBL1414274 & 737383 & 5.0399 & 5.8658 & TRN & & \\
\hline CHEMBL3208276 & 737383 & 7.5528 & 6.21 & TRN & & \\
\hline CHEMBL1429819 & 737383 & 6.3872 & 5.9308 & TRN & & \\
\hline CHEMBL1411837 & 737383 & 5.794 & 5.2603 & TRN & & \\
\hline CHEMBL3213363 & 737383 & 6.0835 & 5.7908 & TRN & & \\
\hline CHEMBL1503539 & 737383 & 6.7055 & 5.9809 & TRN & & \\
\hline CHEMBL1460083 & 737383 & 5.5467 & 5.8335 & TRN & & \\
\hline CHEMBL585222 & 737383 & 6.5452 & 6.5732 & TRN & & \\
\hline CHEMBL1335589 & 737383 & \multicolumn{3}{|c|}{5.7379999999999995} & 5.8108 & TRN \\
\hline CHEMBL1530492 & 737383 & 5.0394 & 5.6212 & TRN & & \\
\hline CHEMBL1501205 & 737383 & \multicolumn{3}{|c|}{5.622000000000001} & 5.3711 & TRN \\
\hline CHEMBL1613285 & 737383 & 5.2653 & 5.8264 & TRN & & \\
\hline CHEMBL1319671 & 737383 & 5.6861 & \multicolumn{3}{|c|}{5.367000000000001} & TRN \\
\hline CHEMBL1306923 & 737383 & 5.4751 & 6.1432 & TRN & & \\
\hline CHEMBL1419743 & 737383 & 5.7815 & 5.9914 & TST & & \\
\hline CHEMBL1455265 & 737383 & 5.2719 & 5.8301 & TST & & \\
\hline CHEMBL1548423 & 737383 & 5.3627 & 6.7345 & TST & & \\
\hline CHEMBL1477800 & 737383 & 5.4276 & 6.0122 & TRN & & \\
\hline CHEMBL607979 & 737383 & 6.0809 & 5.9872 & TRN & & \\
\hline CHEMBL1488983 & 737383 & \multicolumn{3}{|c|}{5.6370000000000005} & 5.5667 & TRN \\
\hline CHEMBL1569284 & 737383 & 6.1361 & 5.8092 & TRN & & \\
\hline CHEMBL1599312 & 737383 & 5.9355 & 5.999 & TRN & & \\
\hline CHEMBL1302239 & 737383 & 5.688 & 5.9346 & TRN & & \\
\hline CHEMBL1330989 & 737383 & 5.6605 & 6.0735 & TRN & & \\
\hline CHEMBL1577459 & 737383 & 5.813 & 6.3303 & TRN & & \\
\hline CHEMBL1565488 & 737383 & 5.5181 & 5.0979 & TRN & & \\
\hline CHEMBL1420166 & 737383 & 4.8683 & 5.0407 & TRN & & \\
\hline CHEMBL1496338 & 737383 & 5.0148 & 5.529 & TRN & & \\
\hline CHEMBL3199240 & 737383 & 5.2319 & 5.6378 & TRN & & \\
\hline CHEMBL3199415 & 737383 & 6.6038 & 6.5143 & TRN & & \\
\hline CHEMBL1391622 & 737383 & 5.0645 & 5.4486 & TST & & \\
\hline CHEMBL1455993 & 737383 & 6.7696 & 6.8571 & TRN & & \\
\hline CHEMBL1527929 & 737383 & 5.5541 & 5.6145 & TST & & \\
\hline CHEMBL1400492 & 737383 & 5.0239 & 5.8768 & TRN & & \\
\hline CHEMBL1440255 & 737383 & 6.5638 & 5.8226 & TRN & & \\
\hline CHEMBL1392299 & 737383 & 4.5243 & 5.8859 & TRN & & \\
\hline CHEMBL1319645 & 737383 & 5.87 & 5.9061 & TRN & & \\
\hline CHEMBL1522586 & 737383 & 5.6137 & 5.3264 & TRN & & \\
\hline CHEMBL1480703 & 737383 & 4.8728 & 4.9095 & TRN & & \\
\hline CHEMBL1712627 & 737383 & 6.1331 & 6.0265 & TRN & & \\
\hline CHEMBL1522898 & 737383 & 5.1754 & 5.4176 & TRN & & \\
\hline CHEMBL1558417 & 737383 & 5.4751 & 5.8124 & TRN & & \\
\hline CHEMBL1424687 & 737383 & 6.7122 & 6.3617 & TRN & & \\
\hline CHEMBL1425542 & 737383 & 5.937 & 5.9752 & TRN & & \\
\hline
\end{tabular}


Supplemental Table S2.txt

\begin{tabular}{|c|c|c|c|c|}
\hline CHEMBL1608593 & 737383 & 6.5702 & 6.1223 & TRN \\
\hline CHEMBL1312649 & 737383 & 5.9488 & 5.5257 & TRN \\
\hline CHEMBL3191285 & 737383 & 6.1221 & 5.7562 & TRN \\
\hline CHEMBL1522482 & 737383 & 5.561 & 5.9267 & TRN \\
\hline CHEMBL1310535 & 737383 & 5.3709 & 5.3715 & TRN \\
\hline CHEMBL 3209473 & 737383 & 5.1159 & 5.419 & TRN \\
\hline CHEMBL1440037 & 737383 & 5.2001 & 5.7682 & TRN \\
\hline CHEMBL3207730 & 737383 & 6.6073 & 5.6899 & TRN \\
\hline CHEMBL1368428 & 737383 & 6.3809 & 5.6917 & TRN \\
\hline CHEMBL1375807 & 737383 & 5.155 & 5.5809 & TRN \\
\hline CHEMBL1425154 & 737383 & 5.2983 & 5.6796 & TRN \\
\hline CHEMBL1333250 & 737383 & 6.6144 & 5.6122 & TRN \\
\hline CHEMBL1455053 & 737383 & 3.0 & 5.3278 & TRN \\
\hline CHEMBL1601724 & 737383 & 5.2053 & 6.0337 & TRN \\
\hline CHEMBL1452933 & 737383 & 6.4935 & 6.3325 & TRN \\
\hline CHEMBL1326159 & 737383 & 6.9031 & 6.0503 & TRN \\
\hline CHEMBL1458859 & 737383 & 5.6586 & 5.5217 & TRN \\
\hline CHEMBL1607166 & 737383 & 6.5719 & 5.9991 & TRN \\
\hline CHEMBL3207965 & 737383 & 5.4597 & 5.5477 & TRN \\
\hline CHEMBL1535395 & 737383 & 5.0332 & 5.8547 & TST \\
\hline CHEMBL1492549 & 737383 & 6.0443 & 5.6066 & TRN \\
\hline CHEMBL1432570 & 737383 & 5.8993 & 5.4711 & TRN \\
\hline CHEMBL 3214200 & 737383 & 6.2388 & 5.7696 & TRN \\
\hline CHEMBL1431608 & 737383 & 4.8161 & 5.8444 & TST \\
\hline CHEMBL1710802 & 737383 & 5.2576 & 5.8942 & TRN \\
\hline CHEMBL1503500 & 737383 & 4.8062 & 5.3998 & TRN \\
\hline CHEMBL1600360 & 737383 & 5.0041 & 5.8838 & TST \\
\hline CHEMBL1322576 & 737383 & 4.8887 & 5.9191 & TRN \\
\hline CHEMBL1562810 & 737383 & 5.0791 & 5.4948 & TRN \\
\hline CHEMBL1585742 & 737383 & 6.2967 & 5.4244 & TRN \\
\hline CHEMBL1428882 & 737383 & 8.8539 & 5.84200 & 0000000005 \\
\hline CHEMBL1537681 & 737383 & 5.3458 & 5.9152 & TST \\
\hline CHEMBL1464800 & 737383 & 6.4045 & 5.6684 & TRN \\
\hline CHEMBL1462337 & 737383 & 6.9318 & 5.5215 & TRN \\
\hline CHEMBL3209646 & 737383 & 5.5268 & 5.7406 & TRN \\
\hline CHEMBL1510509 & 737383 & 7.2366 & 5.7015 & TRN \\
\hline CHEMBL1334885 & 737383 & 4.16 & 5.4103 & TRN \\
\hline CHEMBL1713525 & 737383 & 6.1367 & 5.7163 & TST \\
\hline CHEMBL1332718 & 737383 & 5.2487 & 5.462006 & 000000001 \\
\hline CHEMBL 3199006 & 737383 & 5.5068 & 5.4682 & TRN \\
\hline CHEMBL1540100 & 737383 & 4.958 & 5.681 & TRN \\
\hline CHEMBL1419870 & 737383 & 6.2269 & 6.0041 & TRN \\
\hline CHEMBL1372336 & 737383 & 6.3325 & 5.7326 & TRN \\
\hline CHEMBL1389463 & 737383 & 6.7144 & 6.5884 & TRN \\
\hline CHEMBL1390246 & 737383 & 6.295 & 6.0456 & TRN \\
\hline CHEMBL1970615 & 737383 & 5.9763 & 5.6895 & TRN \\
\hline CHEMBL1332357 & 737383 & 5.5293 & 6.2267 & TRN \\
\hline CHEMBL 3208621 & 737383 & 6.065 & 5.7157 & TRN \\
\hline
\end{tabular}


Supplemental Table S2.txt

\begin{tabular}{|c|c|c|c|c|c|}
\hline CHEMBL1497487 & 737383 & 5.4802 & 5.519 & TRN & \\
\hline CHEMBL1421018 & 737383 & 5.4344 & 5.6582 & TRN & \\
\hline CHEMBL1466652 & 737383 & 5.3932 & 5.7848 & TRN & \\
\hline CHEMBL 3189538 & 737383 & 4.5911 & 5.8631 & TRN & \\
\hline CHEMBL1589011 & 737383 & 5.2428 & 5.6148 & TRN & \\
\hline CHEMBL1498152 & 737383 & 6.5214 & 5.8787 & TRN & \\
\hline CHEMBL95862 & 737383 & 6.2464 & 5.7873 & TRN & \\
\hline CHEMBL1338533 & 737383 & 5.1324 & 6.1623 & TRN & \\
\hline CHEMBL1986394 & 737383 & 6.8601 & 6.193 & TRN & \\
\hline CHEMBL1323368 & 737383 & 5.7256 & 5.6611 & TRN & \\
\hline CHEMBL1607208 & 737383 & 6.0487 & 5.9094 & TRN & \\
\hline CHEMBL1582181 & 737383 & 6.6615 & 6.4292 & TRN & \\
\hline CHEMBL3193304 & 737383 & 7.0044 & 6.1431 & TRN & \\
\hline CHEMBL1612401 & 737383 & 5.3181 & 5.6997 & TRN & \\
\hline CHEMBL1458437 & 737383 & 5.7642 & 5.463999 & & TRN \\
\hline CHEMBL1490634 & 737383 & 6.4001 & 6.0456 & TRN & \\
\hline CHEMBL1335546 & 737383 & 4.948 & 5.6886 & TST & \\
\hline CHEMBL1491091 & 737383 & 4.5945 & 5.3021 & TRN & \\
\hline CHEMBL1431998 & 737383 & 6.6459 & 5.5249 & TRN & \\
\hline CHEMBL1577794 & 737383 & 6.9666 & 6.3453 & TRN & \\
\hline CHEMBL 3145312 & 737383 & 5.9066 & 6.3678 & TST & \\
\hline CHEMBL1539736 & 737383 & 5.7416 & 4.864 & TRN & \\
\hline CHEMBL1728167 & 737383 & 5.96299 & 99999999 & 5.5703 & \\
\hline CHEMBL1568298 & 737383 & 8.0 & 6.1875 & TRN & \\
\hline CHEMBL1572363 & 737383 & 5.0925 & 5.3154 & TRN & \\
\hline CHEMBL 3214541 & 737383 & 5.5144 & 5.9445 & TRN & \\
\hline CHEMBL1508355 & 737383 & 5.7055 & 5.0516 & TRN & \\
\hline CHEMBL1385638 & 737383 & 6.3116 & 5.2754 & TRN & \\
\hline CHEMBL1362247 & 737383 & 7.6198 & 6.2634 & TRN & \\
\hline CHEMBL 367741 & 737383 & 6.1057 & 5.6749 & TST & \\
\hline CHEMBL1419016 & 737383 & 5.9547 & 6.1696 & TST & \\
\hline CHEMBL1543497 & 737383 & 5.481 & 5.9385 & TST & \\
\hline CHEMBL1466601 & 737383 & 6.1226 & 5.7975 & TRN & \\
\hline CHEMBL1371624 & 737383 & 4.0916 & 5.9211 & TRN & \\
\hline CHEMBL1452174 & 737383 & 5.7755 & 5.6604 & TRN & \\
\hline CHEMBL1579092 & 737383 & 5.5085 & 5.2222 & TRN & \\
\hline CHEMBL 3191171 & 737383 & 6.0424 & 5.9061 & TRN & \\
\hline CHEMBL1529010 & 737383 & 6.7959 & 5.8314 & TRN & \\
\hline CHEMBL1483419 & 737383 & 5.6326 & 5.9455 & TRN & \\
\hline CHEMBL1612078 & 737383 & 4.5569 & 5.7288 & TRN & \\
\hline CHEMBL1500343 & 737383 & 7.1427 & 6.6272 & TRN & \\
\hline CHEMBL1529007 & 737383 & 7.1192 & 6.257999 & 9999999999 & TRN \\
\hline CHEMBL1574724 & 737383 & 5.7428 & 6.3649 & TST & \\
\hline CHEMBL1399143 & 737383 & 5.8348 & 5.5848 & TRN & \\
\hline CHEMBL1482681 & 737383 & 5.1653 & 6.1265 & TRN & \\
\hline CHEMBL 3192368 & 737383 & 6.5784 & 5.955 & TRN & \\
\hline CHEMBL1375811 & 737383 & 5.8739 & 6.1125 & TRN & \\
\hline CHEMBL1448179 & 737383 & 5.0601 & 5.4758 & TRN & \\
\hline
\end{tabular}


Supplemental Table S2.txt

\begin{tabular}{|c|c|c|c|c|c|}
\hline CHEMBL1428495 & 737383 & 5.8871 & 6.0115 & TRN & \\
\hline CHEMBL1363679 & 737383 & 6.7852 & 5.2501 & TRN & \\
\hline CHEMBL1549268 & 737383 & 5.002 & 5.4828 & TRN & \\
\hline CHEMBL 3190647 & 737383 & 6.341 & 6.1223 & TRN & \\
\hline CHEMBL1508164 & 737383 & 6.056 & 6.1139 & TRN & \\
\hline CHEMBL1606971 & 737383 & 5.3455 & 5.722 & TRN & \\
\hline CHEMBL 3209332 & 737383 & 6.5654 & 5.9651 & TRN & \\
\hline CHEMBL1601518 & 737383 & 4.5886 & 6.0097 & TRN & \\
\hline CHEMBL1718075 & 737383 & 5.3694 & 5.1348 & TRN & \\
\hline CHEMBL1323454 & 737383 & 5.3589 & 5.6098 & TRN & \\
\hline CHEMBL1456900 & 737383 & 6.6882 & 5.9048 & TRN & \\
\hline CHEMBL1432259 & 737383 & 5.2611 & 4.9727 & TRN & \\
\hline CHEMBL1406520 & 737383 & 5.1226 & 5.751 & TST & \\
\hline CHEMBL1712248 & 737383 & 7.3665 & 6.7392 & TRN & \\
\hline CHEMBL1968326 & 737383 & 6.9626 & 5.6149 & TRN & \\
\hline CHEMBL1503102 & 737383 & 5.1877 & 6.0359 & TRN & \\
\hline CHEMBL1445527 & 737383 & 5.3111 & 5.2756 & TRN & \\
\hline CHEMBL1560906 & 737383 & 5.6824 & 5.5073 & TRN & \\
\hline CHEMBL 3189888 & 737383 & 6.20200 & 000000000 & 6.21 & TRN \\
\hline CHEMBL1584444 & 737383 & 5.8268 & 5.7106 & TRN & \\
\hline CHEMBL1492148 & 737383 & 6.6021 & 6.2613 & TST & \\
\hline CHEMBL1380161 & 737383 & 6.5391 & 6.2591 & TRN & \\
\hline CHEMBL1527214 & 737383 & 5.8804 & 6.0009 & TRN & \\
\hline CHEMBL1327715 & 737383 & 5.8447 & 6.4812 & TRN & \\
\hline CHEMBL1433997 & 737383 & 6.1707 & 5.893 & TRN & \\
\hline CHEMBL1565980 & 737383 & 5.13399 & 999999999 & 5.3708 & TRN \\
\hline CHEMBL1324930 & 737383 & 4.3859 & \multicolumn{2}{|c|}{5.372000000000001} & TRN \\
\hline CHEMBL1720415 & 737383 & 6.1778 & 5.936 & TST & \\
\hline CHEMBL1391048 & 737383 & 5.5965 & 6.1328 & TRN & \\
\hline CHEMBL1382192 & 737383 & 5.5664 & 5.5807 & TRN & \\
\hline CHEMBL1350320 & 737383 & 5.8674 & 5.2961 & TRN & \\
\hline CHEMBL1576166 & 737383 & 5.2125 & 5.9384 & TRN & \\
\hline CHEMBL 3191670 & 737383 & 5.3663 & \multicolumn{2}{|c|}{5.7620000000000005} & TRN \\
\hline CHEMBL1576236 & 737383 & 5.5621 & 6.1588 & TRN & \\
\hline CHEMBL1365007 & 737383 & 4.9733 & 5.6233 & TRN & \\
\hline CHEMBL 3196840 & 737383 & 6.3706 & 6.4676 & TRN & \\
\hline CHEMBL3189300 & 737383 & 5.2765 & 5.6375 & TRN & \\
\hline CHEMBL1443454 & 737383 & 5.4282 & \multicolumn{2}{|c|}{5.662999999999999} & TRN \\
\hline CHEMBL1328941 & 737383 & 5.563 & 5.5883 & TRN & \\
\hline CHEMBL 3192061 & 737383 & 7.0555 & 5.147 & TST & \\
\hline CHEMBL1374567 & 737383 & 5.6404 & 6.2748 & TRN & \\
\hline CHEMBL444357 & 737383 & 5.7595 & 6.0929 & TRN & \\
\hline CHEMBL1470571 & 737383 & 7.0706 & 5.6757 & TRN & \\
\hline CHEMBL585651 & 737383 & 6.2604 & 5.6487 & TRN & \\
\hline CHEMBL1325470 & 737383 & 5.2322 & \multicolumn{2}{|c|}{5.7620000000000005} & TRN \\
\hline CHEMBL1353712 & 737383 & 5.8891 & 5.7921 & TST & \\
\hline CHEMBL1335687 & 737383 & 6.3002 & 5.8555 & TRN & \\
\hline CHEMBL2005764 & 737383 & 7.6021 & 5.8431 & TRN & \\
\hline
\end{tabular}


Supplemental Table S2.txt

\begin{tabular}{|c|c|c|c|c|}
\hline CHEMBL1722303 & 737383 & 5.5959 & 5.3333 & TRN \\
\hline CHEMBL1542566 & 737383 & 6.5986 & 6.5338 & TRN \\
\hline CHEMBL1365351 & 737383 & 5.2397 & 5.3115 & TRN \\
\hline CHEMBL 3193233 & 737383 & 6.1931 & 5.8285 & TRN \\
\hline CHEMBL1585213 & 737383 & 6.6757 & 5.5035 & TRN \\
\hline CHEMBL1338759 & 737383 & 5.5511 & 5.8793 & TST \\
\hline CHEMBL1421400 & 737383 & 5.7003 & 6.0593 & TRN \\
\hline CHEMBL1455708 & 737383 & 5.0571 & 5.4203 & TRN \\
\hline CHEMBL1565254 & 737383 & 5.5109 & 5.9282 & TRN \\
\hline CHEMBL1425107 & 737383 & 4.3731 & 5.4874 & TRN \\
\hline CHEMBL1351821 & 737383 & 5.7251 & 5.4008 & TRN \\
\hline CHEMBL1507055 & 737383 & 5.2475 & 5.491000 & 0000000005 \\
\hline CHEMBL1310413 & 737383 & 5.8122 & 5.1101 & TRN \\
\hline CHEMBL1422152 & 737383 & 5.1328 & 5.6465 & TRN \\
\hline CHEMBL1557166 & 737383 & 5.2444 & 5.1487 & TRN \\
\hline CHEMBL3191045 & 737383 & 5.4144 & 6.4519 & TRN \\
\hline CHEMBL1698418 & 737383 & 5.25200 & 00000000 & 5.7648 \\
\hline CHEMBL1556947 & 737383 & 5.7857 & 5.5516 & TRN \\
\hline CHEMBL1613045 & 737383 & 4.6992 & 5.5801 & TRN \\
\hline CHEMBL1441098 & 737383 & 5.3633 & 5.7641 & TRN \\
\hline CHEMBL1449978 & 737383 & 4.8347 & 5.6935 & TRN \\
\hline CHEMBL1440054 & 737383 & 6.0783 & 5.7306 & TRN \\
\hline CHEMBL1564636 & 737383 & 6.2034 & 5.7868 & TRN \\
\hline CHEMBL1728840 & 737383 & 6.15799 & 99999999 & 5.5937 \\
\hline CHEMBL1577045 & 737383 & 5.5564 & 5.4229 & TRN \\
\hline CHEMBL 71851 & 737383 & 5.3563 & 5.9899 & TRN \\
\hline CHEMBL1393021 & 737383 & 5.4138 & 6.3468 & TST \\
\hline CHEMBL1427896 & 737383 & 4.9665 & 5.5925 & TRN \\
\hline CHEMBL3214106 & 737383 & 5.7698 & 5.6645 & TRN \\
\hline CHEMBL3190136 & 737383 & 6.0453 & 5.9728 & TRN \\
\hline CHEMBL1490559 & 737383 & 5.978 & 5.6973 & TRN \\
\hline CHEMBL1972346 & 737383 & 6.1618 & 5.9872 & TRN \\
\hline CHEMBL1379073 & 737383 & 5.8794 & 5.6699 & TRN \\
\hline CHEMBL1994372 & 737383 & 8.0458 & 6.095 & TRN \\
\hline CHEMBL3190975 & 737383 & 6.4789 & 5.9634 & TRN \\
\hline CHEMBL1494344 & 737383 & 5.5574 & 5.4001 & TRN \\
\hline CHEMBL1452050 & 737383 & 5.43 & 5.4032 & TST \\
\hline CHEMBL1518691 & 737383 & 5.5498 & 5.4981 & TRN \\
\hline CHEMBL1400717 & 737383 & 5.3873 & 5.8019 & TST \\
\hline CHEMBL1412545 & 737383 & 7.4685 & 5.9871 & TRN \\
\hline CHEMBL1362893 & 737383 & 6.0857 & 5.6296 & TRN \\
\hline CHEMBL3207542 & 737383 & 5.7683 & 5.66 & TRN \\
\hline CHEMBL1726783 & 737383 & 7.7696 & 6.466 & TRN \\
\hline CHEMBL1509295 & 737383 & 4.8025 & 5.4204 & TRN \\
\hline CHEMBL1491681 & 737383 & 6.0386 & 5.6175 & TRN \\
\hline CHEMBL1476215 & 737383 & 4.7904 & 5.6822 & TRN \\
\hline CHEMBL1345948 & 737383 & 4.1231 & 5.2961 & TRN \\
\hline CHEMBL1544456 & 737383 & 5.2212 & 5.9463 & TRN \\
\hline
\end{tabular}




\begin{tabular}{|c|c|c|c|c|c|}
\hline & & \multicolumn{4}{|c|}{ Supplemental Table S2.txt } \\
\hline CHEMBL1359781 & 737383 & 7.0088 & 5.8688 & TRN & \\
\hline CHEMBL1731110 & 737383 & 5.687 & 6.7501 & TRN & \\
\hline CHEMBL1551228 & 737383 & 5.6836 & 6.0951 & TRN & \\
\hline CHEMBL1565575 & 737383 & 6.0255 & 5.6702 & TST & \\
\hline CHEMBL1384636 & 737383 & 8.0 & 5.5806 & TRN & \\
\hline CHEMBL1584225 & 737383 & 5.6517 & 5.7599 & TRN & \\
\hline CHEMBL1370612 & 737383 & 3.0 & 5.8493 & TRN & \\
\hline CHEMBL1577873 & 737383 & 6.1778 & 6.2142 & TRN & \\
\hline CHEMBL578487 & 737383 & 5.8649 & 5.6434 & TRN & \\
\hline CHEMBL1508413 & 737383 & 5.2533 & 5.2751 & TRN & \\
\hline CHEMBL1545389 & 737383 & 6.153 & 5.8894 & TRN & \\
\hline CHEMBL1354038 & 737383 & 6.9101 & 6.319 & TRN & \\
\hline CHEMBL1443770 & 737383 & 5.26 & 5.6445 & TRN & \\
\hline CHEMBL1606786 & 737383 & 5.3285 & 6.2573 & TRN & \\
\hline CHEMBL1353528 & 737383 & 5.4148 & 4.9433 & TRN & \\
\hline CHEMBL1350525 & 737383 & 5.4614 & 5.5476 & TRN & \\
\hline CHEMBL1418360 & 737383 & 5.8824 & 5.7605 & TRN & \\
\hline CHEMBL1587766 & 737383 & 5.8948 & 5.7865 & TRN & \\
\hline CHEMBL1256655 & 737383 & 4.7954 & 5.9484 & TRN & \\
\hline CHEMBL1423986 & 737383 & 6.5768 & 5.6457 & TST & \\
\hline CHEMBL3195917 & 737383 & 6.0799 & 5.9768 & TRN & \\
\hline CHEMBL1491577 & 737383 & 7.3979 & 6.3162 & TRN & \\
\hline CHEMBL1365341 & 737383 & 5.9614 & 5.5693 & TRN & \\
\hline CHEMBL1598581 & 737383 & 6.7721 & 6.21299 & & TRN \\
\hline CHEMBL1573801 & 737383 & 5.4425 & 5.4329 & TRN & \\
\hline CHEMBL1507162 & 737383 & 4.7359 & 5.2999 & TRN & \\
\hline CHEMBL1329366 & 737383 & 5.7481 & 6.0241 & TST & \\
\hline CHEMBL1340228 & 737383 & 6.2233 & 6.0379 & TST & \\
\hline CHEMBL1488395 & 737383 & 6.5686 & 5.8735 & TST & \\
\hline CHEMBL1385093 & 737383 & 7.0458 & 5.7496 & TST & \\
\hline CHEMBL1423157 & 737383 & 4.6767 & 5.4564 & TRN & \\
\hline CHEMBL1307247 & 737383 & 6.3288 & 6.0247 & TRN & \\
\hline CHEMBL1540272 & 737383 & 5.9727 & 5.4267 & TST & \\
\hline CHEMBL1574229 & 737383 & 6.2865 & 6.7932 & TRN & \\
\hline CHEMBL1351342 & 737383 & 6.1319 & 5.4198 & TRN & \\
\hline CHEMBL1707416 & 737383 & 5.0797 & 5.517 & TRN & \\
\hline CHEMBL1506617 & 737383 & 4.562 & 5.5339 & TST & \\
\hline CHEMBL1393850 & 737383 & 6.0227 & 5.7813 & TST & \\
\hline CHEMBL3199413 & 737383 & 6.3575 & 5.9952 & TRN & \\
\hline CHEMBL1321420 & 737383 & 6.209 & 5.7162 & TRN & \\
\hline CHEMBL1722117 & 737383 & 5.432 & 5.7337 & TRN & \\
\hline CHEMBL3190604 & 737383 & 5.443 & 5.9381 & TRN & \\
\hline CHEMBL3196317 & 737383 & 5.567 & 5.8729 & TRN & \\
\hline CHEMBL3209637 & 737383 & 5.6035 & 6.1885 & TRN & \\
\hline CHEMBL1455660 & 737383 & 6.3036 & 5.5026 & TRN & \\
\hline CHEMBL1470270 & 737383 & 5.5556 & 5.6949 & TST & \\
\hline CHEMBL1441773 & 737383 & 6.3862 & 5.7803 & TRN & \\
\hline CHEMBL1468747 & 737383 & 5.5095 & 5.5188 & TRN & \\
\hline
\end{tabular}




\begin{tabular}{|c|c|c|c|c|c|c|}
\hline & & \multicolumn{5}{|c|}{ Supplemental Table S2.txt } \\
\hline CHEMBL1597261 & 737383 & 5.76399 & 79999999 & & 5.8377 & TRN \\
\hline CHEMBL 3213665 & 737383 & 5.9863 & 5.9861 & TRN & & \\
\hline CHEMBL1577621 & 737383 & 5.6187 & 5.9004 & TRN & & \\
\hline CHEMBL1562224 & 737383 & 5.4072 & 5.4746 & TRN & & \\
\hline CHEMBL1607366 & 737383 & 5.96899 & 99999999 & 99 & 5.8834 & TRN \\
\hline CHEMBL3190833 & 737383 & 5.6897 & 5.8283 & TRN & & \\
\hline CHEMBL1701300 & 737383 & 4.249 & 5.2745 & TRN & & \\
\hline CHEMBL1568762 & 737383 & 5.7077 & 5.699 & TRN & & \\
\hline CHEMBL1733285 & 737383 & 5.118 & 4.9711 & TRN & & \\
\hline CHEMBL1447142 & 737383 & 5.1133 & 5.2343 & TRN & & \\
\hline CHEMBL165 & 737383 & 5.3957 & 5.8675 & TRN & & \\
\hline CHEMBL 2062336 & 737383 & 5.902 & 5.67899 & 9999999999 & & TST \\
\hline CHEMBL1468011 & 737383 & 6.0762 & 6.362 & TRN & & \\
\hline CHEMBL1576053 & 737383 & 5.2987 & 5.8089 & TRN & & \\
\hline CHEMBL1332551 & 737383 & 4.9494 & 5.2464 & TRN & & \\
\hline CHEMBL3194873 & 737383 & 4.8956 & 5.4574 & TRN & & \\
\hline CHEMBL1311932 & 737383 & 5.4052 & 5.7647 & TRN & & \\
\hline CHEMBL304953 & 737383 & 6.0521 & 6.1987 & TRN & & \\
\hline CHEMBL52101 & 737383 & 7.7959 & 5.9834 & TRN & & \\
\hline CHEMBL3213321 & 737383 & 5.67 & 5.7568 & TRN & & \\
\hline CHEMBL1370095 & 737383 & 5.3463 & 5.6091 & TRN & & \\
\hline CHEMBL1730847 & 737383 & 7.6576 & 5.3611 & TRN & & \\
\hline CHEMBL1990685 & 737383 & 5.4619 & 5.9962 & TRN & & \\
\hline CHEMBL1588310 & 737383 & 5.9226 & 5.9124 & TRN & & \\
\hline CHEMBL1429712 & 737383 & 3.0 & 5.0315 & TRN & & \\
\hline CHEMBL1334161 & 737383 & 4.9751 & 5.4521 & TRN & & \\
\hline CHEMBL1338732 & 737383 & 3.0 & 5.3279 & TRN & & \\
\hline CHEMBL1478588 & 737383 & 5.6047 & 5.6216 & TRN & & \\
\hline CHEMBL3196072 & 737383 & 5.9367 & 6.6134 & TRN & & \\
\hline CHEMBL1318901 & 737383 & 5.8072 & 4.9593 & TRN & & \\
\hline CHEMBL1413740 & 737383 & 5.761 & 5.4477 & TRN & & \\
\hline CHEMBL1584895 & 737383 & 6.5575 & 6.1001 & TRN & & \\
\hline CHEMBL1358818 & 737383 & 6.4622 & 5.6504 & TRN & & \\
\hline CHEMBL1332872 & 737383 & 6.4855 & 6.4401 & TRN & & \\
\hline CHEMBL1608959 & 737383 & 5.8374 & 5.49100 & 0000000000 & & TRN \\
\hline CHEMBL1500927 & 737383 & 5.0925 & 5.2449 & TRN & & \\
\hline CHEMBL1723584 & 737383 & 5.1153 & 5.5719 & TRN & & \\
\hline CHEMBL1506094 & 737383 & 6.4685 & 6.5579 & TRN & & \\
\hline CHEMBL3196437 & 737383 & 5.3152 & 5.4818 & TRN & & \\
\hline CHEMBL1425603 & 737383 & 6.1688 & 5.9699 & TRN & & \\
\hline CHEMBL1428108 & 737383 & 5.7665 & 6.1653 & TRN & & \\
\hline CHEMBL1413719 & 737383 & 5.0434 & 5.4774 & TRN & & \\
\hline CHEMBL1574283 & 737383 & 5.0973 & 5.5787 & TRN & & \\
\hline CHEMBL1483904 & 737383 & 5.7929 & 6.2803 & TRN & & \\
\hline CHEMBL 208005 & 737383 & 5.3948 & 5.6033 & TRN & & \\
\hline CHEMBL3191988 & 737383 & 5.3937 & 5.4027 & TRN & & \\
\hline CHEMBL1494735 & 737383 & 5.4808 & 6.0119 & TRN & & \\
\hline CHEMBL1512486 & 737383 & 5.9385 & 5.5184 & TRN & & \\
\hline
\end{tabular}




\begin{tabular}{|c|c|c|c|c|c|}
\hline & & \multicolumn{4}{|c|}{ Supplemental Table S2.txt } \\
\hline CHEMBL1599537 & 737383 & 5.2839 & 6.0309 & TRN & \\
\hline CHEMBL1369476 & 737383 & 5.1927 & 5.7905 & TRN & \\
\hline CHEMBL1544946 & 737383 & 5.6356 & 6.147 & TRN & \\
\hline CHEMBL1464646 & 737383 & 5.3566 & 5.7204 & TST & \\
\hline CHEMBL1733170 & 737383 & 6.0605 & 6.3453 & TRN & \\
\hline CHEMBL 2002332 & 737383 & 6.098 & 5.3732 & TRN & \\
\hline CHEMBL1726568 & 737383 & 5.8085 & 5.8245 & TRN & \\
\hline CHEMBL1382346 & 737383 & 5.3559 & 5.7203 & TRN & \\
\hline CHEMBL1386698 & 737383 & 5.4165 & 5.6324 & TRN & \\
\hline CHEMBL1390442 & 737383 & 5.6851 & 5.9034 & TST & \\
\hline CHEMBL1588746 & 737383 & 6.0851 & 5.449 & TRN & \\
\hline CHEMBL1434750 & 737383 & 5.8019 & 5.4031 & TRN & \\
\hline CHEMBL1334570 & 737383 & 5.5461 & 5.6388 & TRN & \\
\hline CHEMBL1462606 & 737383 & 4.9663 & 5.1788 & TRN & \\
\hline CHEMBL3211429 & 737383 & 5.9834 & 5.8786 & TRN & \\
\hline CHEMBL1506173 & 737383 & 5.2729 & 5.2571 & TRN & \\
\hline CHEMBL3210970 & 737383 & 5.1555 & 5.5469 & TRN & \\
\hline CHEMBL1532258 & 737383 & 4.9186 & 5.2397 & TRN & \\
\hline CHEMBL1391729 & 737383 & 5.1063 & 5.8515 & TRN & \\
\hline CHEMBL1584194 & 737383 & 5.6536 & 5.3924 & TST & \\
\hline CHEMBL1496160 & 737383 & 4.7155 & 6.0547 & TST & \\
\hline CHEMBL535331 & 737383 & 6.51 & 6.0072 & TRN & \\
\hline CHEMBL1437830 & 737383 & 5.2031 & 5.1239 & TRN & \\
\hline CHEMBL1418892 & 737383 & 7.0809 & 6.0599 & TST & \\
\hline CHEMBL1354480 & 737383 & 6.6021 & 6.4911 & TST & \\
\hline CHEMBL1494549 & 737383 & 6.3063 & 6.3419 & TRN & \\
\hline CHEMBL3197724 & 737383 & 5.8251 & 5.8144 & TST & \\
\hline CHEMBL1735257 & 737383 & 6.9066 & 6.7779 & TRN & \\
\hline CHEMBL1451046 & 737383 & 5.6254 & 5.9189 & TST & \\
\hline CHEMBL 223084 & 737383 & 5.5442 & 6.0333 & TRN & \\
\hline CHEMBL1577526 & 737383 & 5.2445 & 5.5631 & TRN & \\
\hline CHEMBL600287 & 737383 & 6.0013 & 6.4541 & TRN & \\
\hline CHEMBL3209009 & 737383 & 6.38299 & 999999999 & 5.4771 & TST \\
\hline CHEMBL1549226 & 737383 & 5.5328 & 5.3778 & TRN & \\
\hline CHEMBL1602759 & 737383 & 6.5513 & 6.4515 & TST & \\
\hline CHEMBL1455250 & 737383 & 5.397 & 5.1689 & TRN & \\
\hline CHEMBL1604540 & 737383 & 5.0706 & 5.7488 & TRN & \\
\hline CHEMBL1444451 & 737383 & 5.9292 & 5.9199 & TRN & \\
\hline CHEMBL1589467 & 737383 & 6.1694 & 5.9446 & TRN & \\
\hline CHEMBL1730480 & 737383 & 6.9469 & 5.6223 & TST & \\
\hline CHEMBL1571585 & 737383 & 5.3204 & 5.5399 & TRN & \\
\hline CHEMBL1548074 & 737383 & 6.3063 & 5.9318 & TRN & \\
\hline CHEMBL1429255 & 737383 & 6.1618 & 6.2202 & TRN & \\
\hline CHEMBL1375569 & 737383 & 5.9073 & 5.677000 & 00000000005 & TRN \\
\hline CHEMBL3194172 & 737383 & 5.36700 & 000000000 & 5.4932 & TRN \\
\hline CHEMBL1501911 & 737383 & 5.4493 & 5.0384 & TRN & \\
\hline CHEMBL3197207 & 737383 & 5.3002 & 6.1396 & TRN & \\
\hline CHEMBL1359054 & 737383 & 6.6421 & 5.9865 & TRN & \\
\hline
\end{tabular}




\begin{tabular}{|c|c|c|c|c|c|c|}
\hline & & \multicolumn{4}{|c|}{ Supplemental Table S2.txt } & \multirow[b]{2}{*}{ TST } \\
\hline CHEMBL1497146 & 737383 & 5.76399 & 99999999 & 99 & 5.8241 & \\
\hline CHEMBL1705882 & 737383 & 6.2381 & 5.3793 & TRN & & \\
\hline CHEMBL1340513 & 737383 & 4.4211 & 5.5406 & TRN & & \\
\hline CHEMBL1368543 & 737383 & 6.4157 & 5.9496 & TRN & & \\
\hline CHEMBL1339206 & 737383 & 4.797 & 5.3808 & TRN & & \\
\hline CHEMBL1387497 & 737383 & 7.4559 & 5.7098 & TRN & & \\
\hline CHEMBL1419560 & 737383 & 6.2 & 5.9759 & TRN & & \\
\hline CHEMBL1340013 & 737383 & 4.1283 & 5.345 & TRN & & \\
\hline CHEMBL1323421 & 737383 & 5.2906 & 5.5976 & TRN & & \\
\hline CHEMBL1602460 & 737383 & 5.716 & 5.6841 & TRN & & \\
\hline CHEMBL3196316 & 737383 & 6.0985 & 5.5839 & TRN & & \\
\hline CHEMBL1700767 & 737383 & 5.1744 & 5.5394 & TRN & & \\
\hline CHEMBL1383770 & 737383 & 8.0458 & 6.7312 & TRN & & \\
\hline CHEMBL1445749 & 737383 & 4.8569 & 5.1245 & TRN & & \\
\hline CHEMBL1384300 & 737383 & 6.2941 & 5.8344 & TRN & & \\
\hline CHEMBL1455000 & 737383 & 7.0132 & 6.8544 & TRN & & \\
\hline CHEMBL1429290 & 737383 & 5.7726 & 5.5739 & TRN & & \\
\hline CHEMBL1487568 & 737383 & 5.7749 & 6.1823 & TRN & & \\
\hline CHEMBL3192164 & 737383 & 6.3893 & 6.0227 & TRN & & \\
\hline CHEMBL1300836 & 737383 & 6.0531 & 5.9516 & TRN & & \\
\hline CHEMBL1338809 & 737383 & 4.8862 & 5.3699 & TRN & & \\
\hline CHEMBL1713230 & 737383 & 5.3764 & 5.5893 & TST & & \\
\hline CHEMBL1596420 & 737383 & \multicolumn{3}{|c|}{6.327000000000001} & 5.8586 & TRN \\
\hline CHEMBL1483455 & 737383 & 6.1361 & 6.2053 & TRN & & \\
\hline CHEMBL3191317 & 737383 & 5.7464 & 5.5405 & TRN & & \\
\hline CHEMBL1385257 & 737383 & 6.1824 & 5.2924 & TRN & & \\
\hline CHEMBL1407882 & 737383 & 6.4908 & 6.3125 & TRN & & \\
\hline CHEMBL1458709 & 737383 & 6.7167 & 5.2502 & TRN & & \\
\hline CHEMBL1310834 & 737383 & 6.8827 & 6.0431 & TRN & & \\
\hline CHEMBL1393131 & 737383 & 6.1051 & 5.3583 & TRN & & \\
\hline CHEMBL583558 & 737383 & 4.1998 & 5.7025 & TST & & \\
\hline CHEMBL1324456 & 737383 & 6.6126 & 5.6192 & TRN & & \\
\hline CHEMBL1586235 & 737383 & 5.7688 & 6.4419 & TST & & \\
\hline CHEMBL1350981 & 737383 & 5.7222 & 5.9224 & TRN & & \\
\hline CHEMBL1093074 & 737383 & 7.5086 & 6.1599 & TRN & & \\
\hline CHEMBL1725519 & 737383 & \multicolumn{3}{|c|}{6.202000000000001} & 5.3072 & TRN \\
\hline CHEMBL1316222 & 737383 & 6.0757 & 5.1423 & TST & & \\
\hline CHEMBL1426212 & 737383 & 5.5585 & 5.5001 & TRN & & \\
\hline CHEMBL3209857 & 737383 & 7.699 & 6.6013 & TRN & & \\
\hline CHEMBL3195310 & 737383 & 6.1945 & 6.0531 & TRN & & \\
\hline CHEMBL1491246 & 737383 & 5.6786 & 5.4847 & TRN & & \\
\hline CHEMBL1493248 & 737383 & 5.3803 & 5.9135 & TRN & & \\
\hline CHEMBL1544163 & 737383 & 4.8361 & 5.9767 & TRN & & \\
\hline CHEMBL3193979 & 737383 & 7.041 & 6.4031 & TRN & & \\
\hline CHEMBL3194638 & 737383 & 5.3946 & 6.1837 & TST & & \\
\hline CHEMBL1421202 & 737383 & 8.0 & 6.1792 & TRN & & \\
\hline CHEMBL3196919 & 737383 & 5.3816 & 5.4486 & TRN & & \\
\hline CHEMBL3212126 & 737383 & 6.2708 & 6.2904 & TRN & & \\
\hline
\end{tabular}


Supplemental Table S2.txt

\begin{tabular}{|c|c|c|c|c|c|c|}
\hline CHEMBL1532624 & 737383 & 4.8965 & 5.0109 & TRN & & \\
\hline CHEMBL1527538 & 737383 & 5.6273 & 5.2613 & TRN & & \\
\hline CHEMBL1532958 & 737383 & 5.9914 & 5.6309 & TRN & & \\
\hline CHEMBL1376643 & 737383 & 5.7506 & 5.836 & TRN & & \\
\hline CHEMBL 3194804 & 737383 & 5.2503 & 5.8289 & TRN & & \\
\hline CHEMBL 3198449 & 737383 & 5.6289 & 5.5519 & TRN & & \\
\hline CHEMBL510132 & 737383 & 5.3596 & 5.7811 & TRN & & \\
\hline CHEMBL1529342 & 737383 & 5.8108 & 5.6239 & TRN & & \\
\hline CHEMBL1600756 & 737383 & 6.3585 & 5.8023 & TRN & & \\
\hline CHEMBL 3211733 & 737383 & 5.1902 & 5.8037 & TRN & & \\
\hline CHEMBL1509508 & 737383 & \multicolumn{3}{|c|}{5.627999999999999} & 5.8568 & TR \\
\hline CHEMBL 3212457 & 737383 & 5.9226 & 5.9239 & TRN & & \\
\hline CHEMBL3199792 & 737383 & 5.7525 & 6.1033 & TRN & & \\
\hline CHEMBL1326255 & 737383 & 4.796 & 5.9868 & TRN & & \\
\hline CHEMBL1353612 & 737383 & \multicolumn{3}{|c|}{5.071000000000001} & 5.9984 & \\
\hline CHEMBL1468967 & 737383 & 6.4881 & 5.5373 & TRN & & \\
\hline CHEMBL1428818 & 737383 & 5.4154 & 5.4066 & TRN & & \\
\hline CHEMBL1375496 & 737383 & 5.3264 & 5.497999 & 9999999999 & & \\
\hline CHEMBL 3209238 & 737383 & 5.5084 & 5.6746 & TRN & & \\
\hline CHEMBL3191185 & 737383 & 5.4312 & 5.603 & TRN & & \\
\hline CHEMBL1468104 & 737383 & 6.3036 & 5.9595 & TST & & \\
\hline CHEMBL1411640 & 737383 & 7.5086 & 5.6779 & TRN & & \\
\hline CHEMBL1600647 & 737383 & 5.419 & 5.6514 & TRN & & \\
\hline CHEMBL 3197383 & 737383 & 5.3406 & 5.757006 & 0000000001 & & \\
\hline CHEMBL1370010 & 737383 & 5.8794 & 5.6389 & TRN & & \\
\hline CHEMBL1332041 & 737383 & 7.1739 & 6.7191 & TRN & & \\
\hline CHEMBL1345333 & 737383 & 3.0 & 5.8354 & TRN & & \\
\hline CHEMBL 3211246 & 737383 & 6.9706 & 6.4227 & TRN & & \\
\hline CHEMBL1536153 & 737383 & 5.6755 & 5.2891 & TRN & & \\
\hline CHEMBL1488098 & 737383 & \multicolumn{3}{|c|}{6.172000000000001} & 5.8016 & \\
\hline CHEMBL1602070 & 737383 & 6.1409 & 5.9826 & TRN & & \\
\hline CHEMBL1547699 & 737383 & 6.0757 & 5.3624 & TRN & & \\
\hline CHEMBL1529823 & 737383 & 6.4976 & 6.1021 & TST & & \\
\hline CHEMBL 3145205 & 737383 & 5.2672 & 5.8103 & TRN & & \\
\hline CHEMBL1990259 & 737383 & 5.3847 & 5.9309 & TRN & & \\
\hline CHEMBL1699968 & 737383 & 5.7652 & 5.4794 & TRN & & \\
\hline CHEMBL 3196054 & 737383 & 4.9789 & 5.5519 & TRN & & \\
\hline CHEMBL1708210 & 737383 & 5.3552 & 5.8577 & TRN & & \\
\hline CHEMBL1584482 & 737383 & 4.3066 & 6.0077 & TST & & \\
\hline CHEMBL1379345 & 737383 & 5.6375 & 5.9302 & TRN & & \\
\hline CHEMBL81782 & 737383 & 6.2823 & 5.9213 & TST & & \\
\hline CHEMBL1978082 & 737383 & 5.4311 & 5.3769 & TRN & & \\
\hline CHEMBL1524410 & 737383 & 5.6366 & 6.1066 & TST & & \\
\hline CHEMBL3196097 & 737383 & 5.4353 & 6.0348 & TRN & & \\
\hline CHEMBL1440799 & 737383 & 5.9496 & 5.6052 & TRN & & \\
\hline CHEMBL 3211664 & 737383 & 6.5072 & 6.1253 & TRN & & \\
\hline CHEMBL1520374 & 737383 & 5.8303 & 5.813 & TRN & & \\
\hline CHEMBL3198816 & 737383 & 5.7106 & 5.4003 & TRN & & \\
\hline
\end{tabular}


Supplemental Table S2.txt

\begin{tabular}{|c|c|c|c|c|c|}
\hline CHEMBL1562643 & 737383 & 6.0074 & 5.7749 & TRN & \\
\hline CHEMBL1708186 & 737383 & 5.4866 & 5.7229 & TST & \\
\hline CHEMBL65675 & 737383 & 5.3062 & 5.2868 & TST & \\
\hline CHEMBL1509639 & 737383 & 6.2358 & 5.8803 & TRN & \\
\hline CHEMBL1584156 & 737383 & 5.624 & 5.6438 & TRN & \\
\hline CHEMBL1403064 & 737383 & 4.397 & 5.1556 & TRN & \\
\hline CHEMBL1424946 & 737383 & 4.6815 & 5.5519 & TRN & \\
\hline CHEMBL1587421 & 737383 & 6.2366 & 6.8222 & TRN & \\
\hline CHEMBL1433124 & 737383 & 5.3417 & 5.9466 & TST & \\
\hline CHEMBL1506906 & 737383 & 5.3384 & 5.5417 & TRN & \\
\hline CHEMBL1345455 & 737383 & 8.0 & 5.5136 & TRN & \\
\hline CHEMBL1722932 & 737383 & 5.3832 & 5.3037 & TRN & \\
\hline CHEMBL1378604 & 737383 & 5.3537 & 5.4725 & TRN & \\
\hline CHEMBL1391443 & 737383 & 6.0721 & 5.9612 & TRN & \\
\hline CHEMBL1500593 & 737383 & 7.0315 & 6.2677 & TRN & \\
\hline CHEMBL1499041 & 737383 & 6.9666 & 5.9372 & TRN & \\
\hline CHEMBL1701120 & 737383 & 5.5331 & 5.7505 & TRN & \\
\hline CHEMBL1335847 & 737383 & 5.7537 & 6.1454 & TRN & \\
\hline CHEMBL1353522 & 737383 & 6.9281 & 6.0745 & TRN & \\
\hline CHEMBL1305541 & 737383 & 5.9027 & 5.7094 & TRN & \\
\hline CHEMBL1416554 & 737383 & 5.3509 & 5.5881 & TRN & \\
\hline CHEMBL1358996 & 737383 & 6.6144 & 6.6863 & TRN & \\
\hline CHEMBL1485489 & 737383 & 5.4139 & 5.2591 & TRN & \\
\hline CHEMBL1585253 & 737383 & 5.3564 & 6.2733 & TRN & \\
\hline CHEMBL1477039 & 737383 & 6.3487 & 5.9346 & TRN & \\
\hline CHEMBL1335881 & 737383 & 6.2916 & 6.3764 & TST & \\
\hline CHEMBL1376053 & 737383 & 7.5686 & 5.506 & TST & \\
\hline CHEMBL1446322 & 737383 & 5.1219 & 5.2109 & TRN & \\
\hline CHEMBL1975457 & 737383 & 5.7857 & 5.6728 & TRN & \\
\hline CHEMBL1710832 & 737383 & 5.7918 & 5.3184 & TRN & \\
\hline CHEMBL3197120 & 737383 & \multicolumn{3}{|c|}{5.968999999999999} & TRN \\
\hline CHEMBL3197012 & 737383 & 5.4275 & 6.2463 & TRN & \\
\hline CHEMBL1309903 & 737383 & 5.751 & 6.2318 & TST & \\
\hline CHEMBL1510296 & 737383 & 5.937 & 5.7886 & TRN & \\
\hline CHEMBL1363900 & 737383 & 5.6325 & 5.8234 & TST & \\
\hline CHEMBL1594308 & 737383 & 4.9854 & 5.5051 & TST & \\
\hline CHEMBL1309361 & 737383 & 4.7432 & 5.9403 & TRN & \\
\hline CHEMBL3211417 & 737383 & 5.1273 & 5.6003 & TRN & \\
\hline CHEMBL1451922 & 737383 & 5.4089 & 5.867000 & 0000000001 & TRN \\
\hline CHEMBL1372242 & 737383 & 4.962 & 5.9425 & TST & \\
\hline CHEMBL1524714 & 737383 & 5.8359 & 5.9033 & TST & \\
\hline CHEMBL1491402 & 737383 & 5.7282 & 6.1273 & TRN & \\
\hline CHEMBL1588421 & 737383 & 4.3878 & 5.8337 & TST & \\
\hline CHEMBL1368368 & 737383 & \multicolumn{2}{|c|}{5.0089999999999995} & 5.8434 & TRN \\
\hline CHEMBL1700038 & 737383 & 5.9759 & 5.5683 & TRN & \\
\hline CHEMBL1328996 & 737383 & 5.4693 & 5.4767 & TRN & \\
\hline CHEMBL1733661 & 737383 & 4.477 & 5.2438 & TRN & \\
\hline CHEMBL1366111 & 737383 & 5.0374 & 5.244 & TRN & \\
\hline
\end{tabular}




\begin{tabular}{|c|c|c|c|c|c|c|}
\hline & & \multicolumn{5}{|c|}{ Supplemental Table S2.txt } \\
\hline CHEMBL542700 & 737383 & 5.2692 & 5.9594 & TST & & \\
\hline CHEMBL1241371 & 737383 & 5.306 & 6.1257 & TRN & & \\
\hline CHEMBL1390144 & 737383 & 5.8297 & 5.4545 & TRN & & \\
\hline CHEMBL1426938 & 737383 & 5.0889 & 5.3643 & TRN & & \\
\hline CHEMBL1576059 & 737383 & 5.5875 & 5.6195 & TRN & & \\
\hline CHEMBL1366239 & 737383 & 5.4368 & 5.8722 & TRN & & \\
\hline CHEMBL525103 & 737383 & 6.1331 & 6.0815 & TRN & & \\
\hline CHEMBL1470226 & 737383 & 5.1442 & 5.1308 & TRN & & \\
\hline CHEMBL1564800 & 737383 & 6.1433 & 5.2843 & TRN & & \\
\hline CHEMBL1459487 & 737383 & 4.8485 & 5.9709 & TRN & & \\
\hline CHEMBL3198618 & 737383 & 5.4176 & 5.5253 & TRN & & \\
\hline CHEMBL1580443 & 737383 & 6.8861 & 6.3427 & TRN & & \\
\hline CHEMBL1500638 & 737383 & 5.4408 & 5.9981 & TRN & & \\
\hline CHEMBL1722996 & 737383 & 5.1802 & 5.0148 & TRN & & \\
\hline CHEMBL455007 & 737383 & 6.3098 & 5.8152 & TST & & \\
\hline CHEMBL1558354 & 737383 & 5.3812 & 5.5606 & TRN & & \\
\hline CHEMBL1726371 & 737383 & 5.1889 & 5.9732 & TRN & & \\
\hline CHEMBL1530938 & 737383 & 6.8268 & 5.9013 & TRN & & \\
\hline CHEMBL1599886 & 737383 & 7.4089 & 6.0894 & TRN & & \\
\hline CHEMBL 289356 & 737383 & 5.7181 & 6.0741 & TRN & & \\
\hline CHEMBL1340836 & 737383 & 5.8008 & 6.1136 & TRN & & \\
\hline CHEMBL1509078 & 737383 & 5.0763 & 6.1078 & TST & & \\
\hline CHEMBL1607582 & 737383 & 4.0255 & 5.2626 & TST & & \\
\hline CHEMBL3196679 & 737383 & 5.647 & 5.9727 & TRN & & \\
\hline CHEMBL1384026 & 737383 & 5.1629 & 5.6184 & TRN & & \\
\hline CHEMBL1391082 & 737383 & 4.3861 & 5.7088 & TST & & \\
\hline CHEMBL1300764 & 737383 & 5.5196 & 5.1889 & TST & & \\
\hline CHEMBL1361898 & 737383 & 6.2495 & 6.6458 & TRN & & \\
\hline CHEMBL 3199548 & 737383 & 6.983 & 6.099 & TRN & & \\
\hline CHEMBL1702837 & 737383 & 5.4323 & 5.2343 & TRN & & \\
\hline CHEMBL3197109 & 737383 & 5.7007 & 5.7509 & TRN & & \\
\hline CHEMBL1448462 & 737383 & 6.5935 & 6.2902 & TRN & & \\
\hline CHEMBL1346425 & 737383 & 5.5 & 5.5158 & TRN & & \\
\hline CHEMBL1409617 & 737383 & 6.1046 & 5.4796 & TRN & & \\
\hline CHEMBL1319005 & 737383 & 5.9104 & 5.5653 & TRN & & \\
\hline CHEMBL1390362 & 737383 & 6.556 & 5.8559 & TRN & & \\
\hline CHEMBL1705550 & 737383 & 6.1555 & 5.835 & TRN & & \\
\hline CHEMBL1531720 & 737383 & 5.9076 & 5.7045 & TRN & & \\
\hline CHEMBL1472347 & 737383 & 6.7328 & 6.3517 & TRN & & \\
\hline CHEMBL1419835 & 737383 & 6.26200 & 00000000 & 005 & 6.0532 & TRN \\
\hline CHEMBL1313269 & 737383 & 5.601 & 5.4003 & TRN & & \\
\hline CHEMBL1417170 & 737383 & 5.7251 & 5.9773 & TRN & & \\
\hline CHEMBL1544818 & 737383 & 5.3149 & 5.79799 & 9999999999 & & TRN \\
\hline CHEMBL1471700 & 737383 & 6.1232 & 5.9096 & TST & & \\
\hline CHEMBL1564369 & 737383 & 5.8422 & 5.4854 & TRN & & \\
\hline CHEMBL1602894 & 737383 & 4.8782 & 5.3759 & TRN & & \\
\hline CHEMBL1710197 & 737383 & 6.3215 & 6.1592 & TRN & & \\
\hline CHEMBL1507892 & 737383 & 5.3042 & 6.3054 & TRN & & \\
\hline
\end{tabular}


Supplemental Table S2.txt

\begin{tabular}{|c|c|c|c|c|}
\hline CHEMBL1547549 & 737383 & 6.6556 & 5.7968 & TRN \\
\hline CHEMBL1302693 & 737383 & 4.8961 & 5.3851 & TRN \\
\hline CHEMBL584883 & 737383 & 5.9442 & 6.0648 & TST \\
\hline CHEMBL1549086 & 737383 & 7.6576 & 5.5559 & TRN \\
\hline CHEMBL1301245 & 737383 & 6.8633 & 5.4519 & TRN \\
\hline CHEMBL1402853 & 737383 & 5.5824 & 5.6855 & TST \\
\hline CHEMBL1542766 & 737383 & 5.9431 & 6.2702 & TST \\
\hline CHEMBL1347975 & 737383 & 5.8091 & 5.901 & TRN \\
\hline CHEMBL1606209 & 737383 & 4.8307 & 6.5255 & TST \\
\hline CHEMBL1441699 & 737383 & 5.0193 & 5.3955 & TRN \\
\hline CHEMBL1439531 & 737383 & 5.324 & 5.4266 & TRN \\
\hline CHEMBL1322274 & 737383 & 4.0638 & 5.7688 & TST \\
\hline CHEMBL1708249 & 737383 & 7.6021 & 6.8052 & TRN \\
\hline CHEMBL1551407 & 737383 & 5.4772 & 5.6467 & TRN \\
\hline CHEMBL1490262 & 737383 & 5.6028 & 5.7623 & TRN \\
\hline CHEMBL1731659 & 737383 & 6.1463 & 5.5656 & TRN \\
\hline CHEMBL1579679 & 737383 & 4.0673 & 5.4214 & TRN \\
\hline CHEMBL1702589 & 737383 & 5.6572 & 5.6537 & TRN \\
\hline CHEMBL1313488 & 737383 & 6.6198 & 5.32600 & 0000000005 \\
\hline CHEMBL1608677 & 737383 & 5.8102 & 5.4838 & TST \\
\hline CHEMBL1336543 & 737383 & 7.1192 & 6.4554 & TRN \\
\hline CHEMBL1481271 & 737383 & 5.2513 & 5.4451 & TRN \\
\hline CHEMBL1557147 & 737383 & 6.5421 & 5.859 & TRN \\
\hline CHEMBL1534434 & 737383 & 4.5654 & 5.3158 & TRN \\
\hline CHEMBL1563821 & 737383 & 5.6124 & 6.5535 & TRN \\
\hline CHEMBL 3195242 & 737383 & 6.8962 & 6.0621 & TRN \\
\hline CHEMBL1557403 & 737383 & 4.6789 & 5.3534 & TRN \\
\hline CHEMBL1362056 & 737383 & 6.0969 & 6.0806 & TST \\
\hline CHEMBL1450173 & 737383 & 5.9219 & 5.5489 & TRN \\
\hline CHEMBL1704543 & 737383 & 5.1203 & 5.7251 & TRN \\
\hline CHEMBL1399667 & 737383 & 4.6657 & 6.5324 & TRN \\
\hline CHEMBL1604837 & 737383 & 4.8841 & 4.9148 & TRN \\
\hline CHEMBL1301362 & 737383 & 5.345 & 5.6288 & TRN \\
\hline CHEMBL1531172 & 737383 & 6.1675 & 6.0943 & TRN \\
\hline CHEMBL1535814 & 737383 & 5.0566 & 5.1469 & TRN \\
\hline CHEMBL1359763 & 737383 & 7.3565 & 5.9348 & TRN \\
\hline CHEMBL1411518 & 737383 & 6.1586 & 5.7819 & TRN \\
\hline CHEMBL1311163 & 737383 & 5.3055 & 5.2373 & TRN \\
\hline CHEMBL1489115 & 737383 & 6.3152 & 5.9736 & TRN \\
\hline CHEMBL1540680 & 737383 & 6.1101 & 5.8289 & TRN \\
\hline CHEMBL1444178 & 737383 & 5.6407 & 5.79799 & 999999999 \\
\hline CHEMBL194594 & 737383 & 6.4881 & 6.1707 & TST \\
\hline CHEMBL1462105 & 737383 & 5.3833 & 5.7183 & TRN \\
\hline CHEMBL3197392 & 737383 & 7.9586 & 5.9387 & TRN \\
\hline CHEMBL1312932 & 737383 & 6.9626 & 6.028 & TST \\
\hline CHEMBL3213796 & 737383 & 4.8126 & 5.3811 & TRN \\
\hline CHEMBL3194203 & 737383 & 6.1675 & 5.8133 & TRN \\
\hline CHEMBL1564460 & 737383 & 5.8608 & 6.0003 & TRN \\
\hline
\end{tabular}

Page 259 


\begin{tabular}{|c|c|c|c|c|c|c|}
\hline & & \multicolumn{5}{|c|}{ Supplemental Table S2.txt } \\
\hline CHEMBL1716953 & 737383 & 4.5824 & 4.8949 & TRN & & \\
\hline CHEMBL1562995 & 737383 & 6.4881 & 5.6153 & TST & & \\
\hline CHEMBL1309568 & 737383 & 6.4935 & 5.9879 & TRN & & \\
\hline CHEMBL1366244 & 737383 & 5.2948 & 5.7244 & TRN & & \\
\hline CHEMBL1733497 & 737383 & 5.0755 & 5.8658 & TST & & \\
\hline CHEMBL1596399 & 737383 & 9.301 & 5.8828 & TRN & & \\
\hline CHEMBL3197323 & 737383 & 5.7219 & 5.7304 & TRN & & \\
\hline CHEMBL1388317 & 737383 & 5.32299 & 9999999 & 995 & 5.3273 & TRN \\
\hline CHEMBL3190662 & 737383 & 5.7807 & 5.8883 & TRN & & \\
\hline CHEMBL1531403 & 737383 & 6.0438 & 5.9168 & TRN & & \\
\hline CHEMBL1379556 & 737383 & 5.5632 & 5.3691 & TST & & \\
\hline CHEMBL1538567 & 737383 & 5.5068 & 5.2118 & TRN & & \\
\hline CHEMBL1384595 & 737383 & 6.5406 & 6.0974 & TRN & & \\
\hline CHEMBL3196744 & 737383 & 5.5245 & 6.0876 & TRN & & \\
\hline CHEMBL1468265 & 737383 & 4.256 & 5.8458 & TST & & \\
\hline CHEMBL1408033 & 737383 & 6.3516 & 5.6455 & TRN & & \\
\hline CHEMBL324389 & 737383 & 6.8665 & 6.3692 & TRN & & \\
\hline CHEMBL1455653 & 737383 & 6.0395 & 5.9256 & TRN & & \\
\hline CHEMBL1704183 & 737383 & 5.7199 & 5.5305 & TRN & & \\
\hline CHEMBL1727484 & 737383 & 5.0661 & 5.5628 & TRN & & \\
\hline CHEMBL1452754 & 737383 & 5.9266 & 6.6702 & TRN & & \\
\hline CHEMBL1323387 & 737383 & 5.624 & 6.1618 & TRN & & \\
\hline CHEMBL1460825 & 737383 & 5.9274 & 5.6242 & TRN & & \\
\hline CHEMBL1400505 & 737383 & 6.5406 & 5.9736 & TRN & & \\
\hline CHEMBL1391118 & 737383 & 5.6501 & 5.68 & TST & & \\
\hline CHEMBL 2369243 & 737383 & 7.1135 & 5.9659 & TRN & & \\
\hline CHEMBL1581468 & 737383 & 5.7647 & 6.148 & TRN & & \\
\hline CHEMBL1492242 & 737383 & 6.2933 & 5.8592 & TRN & & \\
\hline CHEMBL 1708341 & 737383 & 5.2778 & 5.3081 & TRN & & \\
\hline CHEMBL3193457 & 737383 & 5.2931 & 5.9908 & TRN & & \\
\hline CHEMBL1256291 & 737383 & 5.4946 & 5.3619 & TST & & \\
\hline CHEMBL1425819 & 737383 & 5.3166 & 6.0605 & TST & & \\
\hline CHEMBL1324092 & 737383 & 5.5552 & 5.8194 & TRN & & \\
\hline CHEMBL1312762 & 737383 & 5.2812 & 5.9846 & TRN & & \\
\hline CHEMBL1435811 & 737383 & 6.1911 & 5.6159 & TRN & & \\
\hline CHEMBL1613336 & 737383 & 5.2965 & 5.2641 & TRN & & \\
\hline CHEMBL1608563 & 737383 & 5.5602 & 5.8406 & TRN & & \\
\hline CHEMBL1408233 & 737383 & 6.8356 & 5.4648 & TRN & & \\
\hline CHEMBL1380398 & 737383 & 5.4372 & 5.4254 & TRN & & \\
\hline CHEMBL3194647 & 737383 & 5.7245 & 5.2658 & TRN & & \\
\hline CHEMBL553503 & 737383 & 5.4168 & 5.8947 & TST & & \\
\hline CHEMBL1430126 & 737383 & 6.062 & 6.2371 & TRN & & \\
\hline CHEMBL1420092 & 737383 & 5.0839 & 5.9449 & TRN & & \\
\hline CHEMBL1589340 & 737383 & 5.3275 & 5.5305 & TRN & & \\
\hline CHEMBL1350548 & 737383 & 6.5214 & 5.3873 & TRN & & \\
\hline CHEMBL1459929 & 737383 & 3.0 & 4.7445 & TRN & & \\
\hline CHEMBL1347768 & 737383 & 5.5017 & 5.7681 & TST & & \\
\hline CHEMBL1454784 & 737383 & 6.0381 & 5.8956 & TRN & & \\
\hline
\end{tabular}


Supplemental Table S2.txt

\begin{tabular}{|c|c|c|c|c|c|}
\hline CHEMBL1500570 & 737383 & 6.5719 & 6.6886 & TRN & \\
\hline CHEMBL1542738 & 737383 & 5.3037 & 5.7336 & TRN & \\
\hline CHEMBL1544223 & 737383 & 5.4141 & 5.7837 & TRN & \\
\hline CHEMBL1299433 & 737383 & 6.3197 & 5.7915 & TRN & \\
\hline CHEMBL1539508 & 737383 & 6.2916 & 5.5938 & TRN & \\
\hline CHEMBL1323804 & 737383 & 6.6055 & 6.1215 & TRN & \\
\hline CHEMBL1428600 & 737383 & 4.9784 & 5.5442 & TRN & \\
\hline CHEMBL1553077 & 737383 & 5.2906 & 5.4863 & TRN & \\
\hline CHEMBL1489087 & 737383 & 6.7399 & 6.226 & TRN & \\
\hline CHEMBL1311746 & 737383 & 5.7765 & 5.7465 & TRN & \\
\hline CHEMBL3194483 & 737383 & 5.6313 & 6.4486 & TRN & \\
\hline CHEMBL3209133 & 737383 & 5.2162 & 6.2518 & TRN & \\
\hline CHEMBL1484770 & 737383 & 5.4489 & 5.73 & TRN & \\
\hline CHEMBL1458203 & 737383 & 6.1518 & 6.3451 & TRN & \\
\hline CHEMBL1571182 & 737383 & 4.912 & 5.416 & TRN & \\
\hline CHEMBL1502225 & 737383 & 6.1415 & 5.4679 & TST & \\
\hline CHEMBL3210534 & 737383 & 5.4312 & 5.7114 & TRN & \\
\hline CHEMBL3190829 & 737383 & 5.7366 & 5.9706 & TRN & \\
\hline CHEMBL1573620 & 737383 & 5.0511 & 5.269 & TST & \\
\hline CHEMBL1417969 & 737383 & 5.6946 & 5.685 & TRN & \\
\hline CHEMBL1361397 & 737383 & 5.4685 & 5.1966 & TRN & \\
\hline CHEMBL1381136 & 737383 & 5.4679 & 6.1488 & TRN & \\
\hline CHEMBL1596373 & 737383 & 7.0605 & 5.9373 & TRN & \\
\hline CHEMBL1503893 & 737383 & 5.4544 & 5.4829 & TRN & \\
\hline CHEMBL1499541 & 737383 & 6.6459 & 5.957006 & 2000000001 & TRN \\
\hline CHEMBL1603830 & 737383 & 5.8623 & 5.6498 & TRN & \\
\hline CHEMBL1568582 & 737383 & 5.229 & 6.4996 & TRN & \\
\hline CHEMBL1460055 & 737383 & 3.0 & 4.6747 & TRN & \\
\hline CHEMBL1726198 & 737383 & 5.5411 & 5.3498 & TRN & \\
\hline CHEMBL1300779 & 737383 & 4.7232 & 5.8405 & TRN & \\
\hline CHEMBL1527451 & 737383 & 5.7256 & 5.9654 & TRN & \\
\hline CHEMBL3207601 & 737383 & 7.0088 & 5.7518 & TRN & \\
\hline CHEMBL1337365 & 737383 & 5.754 & 5.9704 & TRN & \\
\hline CHEMBL1325346 & 737383 & 6.2248 & 6.0088 & TST & \\
\hline CHEMBL1609286 & 737383 & 4.6393 & 5.8396 & TST & \\
\hline CHEMBL1585345 & 737383 & 5.4632 & 5.0894 & TRN & \\
\hline CHEMBL1547833 & 737383 & 5.2325 & 5.444 & TRN & \\
\hline CHEMBL1561144 & 737383 & 5.6207 & 5.2962 & TST & \\
\hline CHEMBL1707082 & 737383 & 5.0089 & 5.5204 & TRN & \\
\hline CHEMBL1333003 & 737383 & 5.4016 & 5.5009 & TRN & \\
\hline CHEMBL1564346 & 737383 & 5.7371 & 5.7334 & TRN & \\
\hline CHEMBL3209822 & 737383 & 5.3506 & 5.317 & TRN & \\
\hline CHEMBL1968928 & 737383 & 6.2652 & 5.8535 & TRN & \\
\hline CHEMBL1598721 & 737383 & 5.3937 & 5.5538 & TRN & \\
\hline CHEMBL1486521 & 737383 & 5.4073 & 5.9678 & TRN & \\
\hline CHEMBL1371049 & 737383 & 5.1869 & 5.2349 & TRN & \\
\hline CHEMBL3197393 & 737383 & 5.9893 & 5.5918 & TRN & \\
\hline CHEMBL1466338 & 737383 & 5.9311 & 6.224 & TRN & \\
\hline
\end{tabular}


Supplemental Table S2.txt

\begin{tabular}{|c|c|c|c|c|c|}
\hline CHEMBL1489074 & 737383 & 5.5928 & 6.1325 & TRN & \\
\hline CHEMBL1508595 & 737383 & 5.7455 & 5.6219 & TRN & \\
\hline CHEMBL124267 & 737383 & 5.3685 & 5.4356 & TRN & \\
\hline CHEMBL1305451 & 737383 & 6.1175 & 6.3533 & TRN & \\
\hline CHEMBL1519209 & 737383 & 5.6796 & 5.9552 & TRN & \\
\hline CHEMBL1580926 & 737383 & 5.1389 & 5.57 & TRN & \\
\hline CHEMBL1305117 & 737383 & 5.5674 & 5.8248 & TRN & \\
\hline CHEMBL1477798 & 737383 & 5.3834 & 5.1552 & TRN & \\
\hline CHEMBL1601574 & 737383 & 5.3666 & 5.5789 & TRN & \\
\hline CHEMBL1579020 & 737383 & 5.6605 & 5.9109 & TST & \\
\hline CHEMBL1513900 & 737383 & 5.6501 & 5.5571 & TRN & \\
\hline CHEMBL1374182 & 737383 & 5.8125 & 5.3192 & TRN & \\
\hline CHEMBL1494391 & 737383 & 5.4136 & 5.9524 & TRN & \\
\hline CHEMBL1711416 & 737383 & 5.3829 & 5.5439 & TRN & \\
\hline CHEMBL 3210165 & 737383 & 5.5748 & 5.9661 & TRN & \\
\hline CHEMBL1368821 & 737383 & 6.1118 & 5.7904 & TST & \\
\hline CHEMBL1583957 & 737383 & 4.9055 & 5.3504 & TRN & \\
\hline CHEMBL1346510 & 737383 & 6.8097 & 6.3911 & TRN & \\
\hline CHEMBL1372816 & 737383 & 5.9658 & 5.4897 & TST & \\
\hline CHEMBL 3145380 & 737383 & 5.2977 & 5.5948 & TST & \\
\hline CHEMBL1728404 & 737383 & 5.3654 & 6.1627 & TRN & \\
\hline CHEMBL1595983 & 737383 & 5.7333 & 5.8823 & TRN & \\
\hline CHEMBL1528722 & 737383 & 5.6078 & 5.9392 & TST & \\
\hline CHEMBL 3199002 & 737383 & 5.3836 & 6.2382 & TRN & \\
\hline CHEMBL1328835 & 737383 & 5.3242 & 5.9165 & TST & \\
\hline CHEMBL1708892 & 737383 & 6.6234 & 5.8134 & TRN & \\
\hline CHEMBL1380497 & 737383 & 5.5753 & 5.7565 & TRN & \\
\hline CHEMBL 3210294 & 737383 & 5.7948 & 5.7622 & TRN & \\
\hline CHEMBL1328633 & 737383 & 5.2799 & 5.0545 & TRN & \\
\hline CHEMBL 3195588 & 737383 & 6.6778 & 5.5943 & TRN & \\
\hline CHEMBL1469319 & 737383 & 5.7169 & 5.9881 & TRN & \\
\hline CHEMBL1521669 & 737383 & 5.5158 & 5.7847 & TRN & \\
\hline CHEMBL3189172 & 737383 & 5.6258 & 5.5506 & TRN & \\
\hline CHEMBL1718885 & 737383 & 5.0039 & 5.5566 & TRN & \\
\hline CHEMBL 3209723 & 737383 & 5.2563 & 5.3985 & TST & \\
\hline CHEMBL1525639 & 737383 & 4.7229 & 5.7442 & TRN & \\
\hline CHEMBL1610977 & 737383 & 7.4202 & 5.6845 & TRN & \\
\hline CHEMBL 3197063 & 737383 & 5.67700 & 000000000 & 05 & 5.1942 \\
\hline CHEMBL293776 & 737383 & 6.2426 & 5.9598 & TRN & \\
\hline CHEMBL1505824 & 737383 & 4.312 & 5.6009 & TRN & \\
\hline CHEMBL1595897 & 737383 & 6.5302 & 6.1602 & TRN & \\
\hline CHEMBL1585237 & 737383 & 9.301 & 6.1098 & TRN & \\
\hline CHEMBL1729824 & 737383 & 4.8605 & 4.9204 & TRN & \\
\hline CHEMBL1305204 & 737383 & 6.1831 & 5.5305 & TRN & \\
\hline CHEMBL1452516 & 737383 & 5.3711 & 5.7243 & TST & \\
\hline CHEMBL1461381 & 737383 & 5.813 & 5.7998 & TST & \\
\hline CHEMBL1344360 & 737383 & 4.7908 & 5.7738 & TRN & \\
\hline CHEMBL 3191946 & 737383 & 6.7167 & 5.6871 & TRN & \\
\hline
\end{tabular}




\begin{tabular}{|c|c|c|c|c|c|}
\hline & & \multicolumn{4}{|c|}{ Supplemental Table s2.txt } \\
\hline CHEMBL1390628 & 737383 & 6.3635 & 5.8829 & TRN & \\
\hline CHEMBL1599981 & 737383 & 6.5214 & 5.8902 & TRN & \\
\hline CHEMBL1432345 & 737383 & 6.7033 & 5.5005 & TRN & \\
\hline CHEMBL1736762 & 737383 & 7.0223 & 6.681 & TRN & \\
\hline CHEMBL1580480 & 737383 & 4.9934 & 5.9039 & TRN & \\
\hline CHEMBL1362904 & 737383 & 4.0905 & 5.4022 & TRN & \\
\hline CHEMBL3192107 & 737383 & 5.9566 & 6.0122 & TRN & \\
\hline CHEMBL1423096 & 737383 & 6.8894 & 5.5724 & TST & \\
\hline CHEMBL1301291 & 737383 & 3.0 & 5.0865 & TST & \\
\hline CHEMBL3193147 & 737383 & 5.3952 & 5.5161 & TRN & \\
\hline CHEMBL1537963 & 737383 & 5.5567 & 5.2121 & TRN & \\
\hline CHEMBL1469068 & 737383 & 5.3423 & 5.9911 & TST & \\
\hline CHEMBL1576118 & 737383 & 4.4653 & 5.4277 & TST & \\
\hline CHEMBL 2001554 & 737383 & 8.301 & 6.2946 & TRN & \\
\hline CHEMBL1373808 & 737383 & 4.1898 & 5.6183 & TRN & \\
\hline CHEMBL3199530 & 737383 & 5.409 & 6.2347 & TRN & \\
\hline CHEMBL1363799 & 737383 & 6.3904 & 5.4572 & TST & \\
\hline CHEMBL1313171 & 737383 & 5.806 & 5.8403 & TST & \\
\hline CHEMBL1561532 & 737383 & 6.1463 & 6.4713 & TRN & \\
\hline CHEMBL1431575 & 737383 & 9.301 & 5.7968 & TRN & \\
\hline CHEMBL1307432 & 737383 & 6.1002 & 6.2637 & TRN & \\
\hline CHEMBL1607103 & 737383 & 4.7234 & 5.8379 & TRN & \\
\hline CHEMBL1428539 & 737383 & 3.0 & 5.6498 & TRN & \\
\hline CHEMBL1526898 & 737383 & 5.4152 & 5.8481 & TRN & \\
\hline CHEMBL1491555 & 737383 & 7.5686 & 6.0634 & TRN & \\
\hline CHEMBL3195202 & 737383 & 6.6882 & 6.0549 & TRN & \\
\hline CHEMBL1430557 & 737383 & 6.1675 & 5.8275 & TRN & \\
\hline CHEMBL1444135 & 737383 & 5.3285 & 6.218 & TRN & \\
\hline CHEMBL1388116 & 737383 & 6.3575 & 5.6031 & TRN & \\
\hline CHEMBL1449587 & 737383 & 6.4001 & 6.29299 & 9999999999 & TRN \\
\hline CHEMBL1466541 & 737383 & 5.3246 & 6.225 & TRN & \\
\hline CHEMBL3208905 & 737383 & 5.919 & 5.877006 & 2000000001 & TRN \\
\hline CHEMBL1395951 & 737383 & 6.1029 & 5.4802 & TRN & \\
\hline CHEMBL1444846 & 737383 & 5.2915 & 5.8903 & TRN & \\
\hline CHEMBL3211095 & 737383 & 4.8714 & 5.4341 & TRN & \\
\hline CHEMBL1556476 & 737383 & 6.1296 & 5.9252 & TRN & \\
\hline CHEMBL1477639 & 737383 & 6.6091 & 5.7576 & TRN & \\
\hline CHEMBL3195077 & 737383 & 5.2205 & 6.025 & TRN & \\
\hline CHEMBL1319688 & 737383 & 4.9012 & 5.5391 & TRN & \\
\hline CHEMBL1337913 & 737383 & 5.4772 & 5.9033 & TRN & \\
\hline CHEMBL3199610 & 737383 & 5.9393 & 5.7982 & TRN & \\
\hline CHEMBL1489619 & 737383 & 4.8211 & 5.5 & TRN & \\
\hline CHEMBL3197936 & 737383 & 7.8861 & 6.0872 & TRN & \\
\hline CHEMBL1457360 & 737383 & 6.16299 & 99999999 & 6.4802 & TST \\
\hline CHEMBL1336799 & 737383 & 5.2627 & 5.4919 & TRN & \\
\hline CHEMBL1452406 & 737383 & 5.4605 & 5.994 & TRN & \\
\hline CHEMBL1312131 & 737383 & 6.3883 & 5.7835 & TST & \\
\hline CHEMBL3191382 & 737383 & 5.4244 & 5.2739 & TRN & \\
\hline
\end{tabular}


Supplemental Table S2.txt

\begin{tabular}{|c|c|c|c|c|c|}
\hline CHEMBL1432219 & 737383 & 5.5249 & 6.0587 & TRN & \\
\hline CHEMBL1699636 & 737383 & 5.9122 & 6.2463 & TRN & \\
\hline CHEMBL1355957 & 737383 & 5.1774 & 5.9616 & TRN & \\
\hline CHEMBL3198461 & 737383 & 5.5638 & 5.8979 & TST & \\
\hline CHEMBL1609453 & 737383 & 5.3584 & 6.2869 & TRN & \\
\hline CHEMBL111951 & 737383 & 5.8854 & 6.31 & TRN & \\
\hline CHEMBL1361574 & 737383 & 3.0 & 5.0846 & TRN & \\
\hline CHEMBL1373994 & 737383 & 4.7651 & 5.4503 & TRN & \\
\hline CHEMBL1469726 & 737383 & 7.2291 & 6.1349 & TRN & \\
\hline CHEMBL1547116 & 737383 & 5.942 & 6.0811 & TRN & \\
\hline CHEMBL1704789 & 737383 & 6.104 & 5.3067 & TRN & \\
\hline CHEMBL1519538 & 737383 & 3.0 & 5.6307 & TRN & \\
\hline CHEMBL1485299 & 737383 & 5.3321 & 5.8268 & TRN & \\
\hline CHEMBL1563751 & 737383 & 4.9275 & 5.0811 & TRN & \\
\hline CHEMBL1411520 & 737383 & 3.0 & 5.4032 & TRN & \\
\hline CHEMBL1359534 & 737383 & 6.6108 & 6.2266 & TRN & \\
\hline CHEMBL1537555 & 737383 & 5.5412 & 5.141 & TRN & \\
\hline CHEMBL1608601 & 737383 & 7.9586 & 6.1827 & TRN & \\
\hline CHEMBL1344530 & 737383 & 4.6693 & 5.2364 & TRN & \\
\hline CHEMBL1341926 & 737383 & 6.1244 & 6.3728 & TRN & \\
\hline CHEMBL1727245 & 737383 & 5.8697 & 5.4018 & TST & \\
\hline CHEMBL1584488 & 737383 & 5.6807 & 5.6023 & TRN & \\
\hline CHEMBL1300358 & 737383 & 5.4547 & 5.4467 & TRN & \\
\hline CHEMBL1399184 & 737383 & 5.7773 & 5.024 & TRN & \\
\hline CHEMBL1488756 & 737383 & 5.3583 & 5.3721 & TST & \\
\hline CHEMBL1214934 & 737383 & 5.2256 & 5.8829 & TRN & \\
\hline CHEMBL1341099 & 737383 & 6.4045 & 6.3261 & TRN & \\
\hline CHEMBL1550311 & 737383 & 5.8256 & 5.7628 & TRN & \\
\hline CHEMBL1354816 & 737383 & 6.129 & 5.6519 & TRN & \\
\hline CHEMBL1585432 & 737383 & 4.6334 & 5.2941 & TRN & \\
\hline CHEMBL3209753 & 737383 & 6.6271 & 5.8287 & TRN & \\
\hline CHEMBL1367754 & 737383 & 4.8129 & 5.33799 & 9999999999 & TRN \\
\hline CHEMBL3192850 & 737383 & 5.2746 & 6.2278 & TRN & \\
\hline CHEMBL1330954 & 737383 & 6.2055 & 5.5833 & TRN & \\
\hline CHEMBL1452930 & 737383 & 4.72 & 5.23600 & 0000000001 & TRN \\
\hline CHEMBL3192954 & 737383 & 4.4257 & 6.1327 & TRN & \\
\hline CHEMBL1599967 & 737383 & 5.2511 & 6.08799 & 7999999999 & TST \\
\hline CHEMBL1431163 & 737383 & 4.8103 & 5.8145 & TRN & \\
\hline CHEMBL1410034 & 737383 & 5.1334 & 5.2066 & TRN & \\
\hline CHEMBL1605103 & 737383 & 6.3883 & 6.5216 & TRN & \\
\hline CHEMBL1348853 & 737383 & 5.6981 & 5.7068 & TST & \\
\hline CHEMBL1382604 & 737383 & 5.505 & 5.8047 & TST & \\
\hline CHEMBL1459644 & 737383 & 5.1091 & 5.5439 & TST & \\
\hline CHEMBL1506131 & 737383 & 5.6611 & 5.84 & TST & \\
\hline CHEMBL1509580 & 737383 & 5.9038 & 5.7063 & TRN & \\
\hline CHEMBL1563481 & 737383 & 5.1579 & 5.3981 & TRN & \\
\hline CHEMBL3192390 & 737383 & 5.4873 & 6.4422 & TST & \\
\hline CHEMBL348267 & 737383 & 5.9788 & 6.0455 & TRN & \\
\hline
\end{tabular}




\begin{tabular}{|c|c|c|c|c|c|c|}
\hline & & & & & & \\
\hline CHEMBL1497998 & 737383 & 5.2845 & 5.9391 & TRN & & \\
\hline CHEMBL 2369291 & 737383 & 7.4559 & 5.8673 & TRN & & \\
\hline CHEMBL1330075 & 737383 & 6.699 & 5.1136 & TST & & \\
\hline CHEMBL 3213783 & 737383 & 6.8069 & 6.0888 & TRN & & \\
\hline CHEMBL1587584 & 737383 & 5.6319 & 5.4572 & TRN & & \\
\hline CHEMBL1418103 & 737383 & 6.3478 & 6.1314 & TRN & & \\
\hline CHEMBL1733966 & 737383 & 4.7923 & 5.3436 & TRN & & \\
\hline CHEMBL225230 & 737383 & 8.0458 & 5.8683 & TST & & \\
\hline CHEMBL1406283 & 737383 & 5.7402 & 6.3529 & TRN & & \\
\hline CHEMBL1323486 & 737383 & 6.2899 & 6.0671 & TRN & & \\
\hline CHEMBL1571316 & 737383 & 5.033 & 6.1094 & TRN & & \\
\hline CHEMBL1519731 & 737383 & 6.2534 & 5.9281 & TRN & & \\
\hline CHEMBL3190073 & 737383 & 6.556 & 6.358 & TRN & & \\
\hline CHEMBL1314092 & 737383 & 8.1549 & 6.1992 & TRN & & \\
\hline CHEMBL1320566 & 737383 & 5.82799 & 99999999 & & 5.2053 & TRN \\
\hline CHEMBL1422585 & 737383 & 6.75200 & 00000000 & & 5.6721 & TST \\
\hline CHEMBL1558087 & 737383 & 5.7698 & 5.7471 & TST & & \\
\hline CHEMBL1541297 & 737383 & 5.777 & 5.7422 & TST & & \\
\hline CHEMBL1992164 & 737383 & 6.9788 & 5.9847 & TST & & \\
\hline CHEMBL1409203 & 737383 & 7.4559 & 5.5294 & TST & & \\
\hline CHEMBL1382060 & 737383 & 6.71 & 5.3486 & TST & & \\
\hline CHEMBL1610461 & 737383 & 5.3711 & 5.9286 & TST & & \\
\hline CHEMBL 1490340 & 737383 & 5.9165 & 5.8046 & TST & & \\
\hline CHEMBL1329175 & 737383 & 5.6942 & 5.66299 & 9999999999 & & TST \\
\hline CHEMBL1431488 & 737383 & 4.9946 & 5.3749 & TST & & \\
\hline CHEMBL1461615 & 737383 & 6.767 & 6.7279 & TST & & \\
\hline CHEMBL1353353 & 737383 & 6.9101 & 6.1262 & TST & & \\
\hline CHEMBL1594342 & 737383 & 6.0334 & 5.7788 & TST & & \\
\hline CHEMBL1452158 & 737383 & 5.1686 & 5.9043 & TST & & \\
\hline CHEMBL1507790 & 737383 & 7.3372 & 6.5294 & TST & & \\
\hline CHEMBL1542087 & 737383 & 4.1402 & 5.1463 & TST & & \\
\hline CHEMBL1510332 & 737383 & 5.2843 & 5.19 & TST & & \\
\hline CHEMBL1563536 & 737383 & 6.2062 & 5.86700 & 0000000001 & & נכו \\
\hline CHEMBL3211732 & 737383 & 5.8268 & 5.7156 & TST & & \\
\hline CHEMBL1565833 & 737383 & 4.5413 & 5.404 & TST & & \\
\hline CHEMBL1528150 & 737383 & 4.6165 & 5.8257 & TST & & \\
\hline CHEMBL1398590 & 737383 & 6.0985 & 5.9247 & TST & & \\
\hline CHEMBL1382191 & 737383 & 6.3449 & 5.6488 & TST & & \\
\hline CHEMBL1304327 & 737383 & 5.6444 & 5.5913 & TST & & \\
\hline CHEMBL1409733 & 737383 & 7.1427 & 5.715 & TST & & \\
\hline CHEMBL1508937 & 737383 & 6.2211 & 6.4538 & TST & & \\
\hline CHEMBL1368921 & 737383 & 5.5408 & 5.9464 & TST & & \\
\hline CHEMBL3197651 & 737383 & 5.8665 & 5.4632 & TST & & \\
\hline CHEMBL3194820 & 737383 & 4.0691 & 5.6293 & TST & & \\
\hline CHEMBL1720650 & 737383 & 5.4292 & 5.6837 & TST & & \\
\hline CHEMBL1537389 & 737383 & 6.3904 & 5.4521 & TST & & \\
\hline CHEMBL 3196445 & 737383 & 5.58700 & 00000000 & & 5.5247 & IJ \\
\hline CHEMBL1467766 & 737383 & 5.3599 & 5.3269 & TST & & \\
\hline
\end{tabular}


Supplemental Table S2.txt

\begin{tabular}{|c|c|c|c|c|}
\hline & & & & \\
\hline AEMBL3191000 & 7383 & 1129 & 6.1894 & \\
\hline IEMBL3212241 & 37383 & 6526 & 776 & \\
\hline HEMBL1526866 & 37383 & 2976 & 2035 & \\
\hline & 7383 & 441 & & \\
\hline IEMBL1440792 & 7383 & 856 & 035 & \\
\hline AEMBL1391694 & 37383 & 0191 & 391 & \\
\hline AEMBL1722578 & 37383 & 6.4413 & 8855 & \\
\hline AEMBL1604438 & 37383 & .4403 & 58 & \\
\hline HEMBL1489492 & 37383 & & 889 & \\
\hline AEMBL1477861 & 37383 & & 361 & \\
\hline AEMBL3194974 & 37383 & 423 & 3151 & \\
\hline AEMBL1424888 & 37383 & & 52 & \\
\hline IEMBL1304738 & 7383 & 58 & 7771 & \\
\hline IEMBL1308435 & 383 & & 324 & \\
\hline IEMBL1460092 & 383 & & & \\
\hline AEMBL1481434 & 37383 & 3.0 & 1882 & \\
\hline AEMBL1977221 & 383 & & & \\
\hline IEMBL1442479 & 383 & 39 & 64 & \\
\hline IEMBL483 & 383 & & 68 & \\
\hline AEMBL13. & 383 & & 16 & \\
\hline AEMBL1518540 & 37383 & 88 & 621 & \\
\hline IEMBL1569243 & & & & \\
\hline IEMBL1357218 & 83 & & & \\
\hline EMMB 1472572 & 83 & & 69 & \\
\hline IEMBL1702854 & 83 & 44 & 366 & \\
\hline AEMBL1588341 & 7383 & & & \\
\hline AEMBL3190631 & & & & \\
\hline IEMBL1712503 & 7383 & 72 & 68 & \\
\hline 1596849 & 83 & 78 & 65 & \\
\hline 1301573 & 83 & 49 & 34 & \\
\hline AEMBL1531718 & & & & \\
\hline AEMBL1383482 & & & & \\
\hline IEMBL1344638 & 37383 & 248 & 55 & \\
\hline AEMBL1483284 & 83 & 24 & 59 & \\
\hline 29 & 33 & & & \\
\hline AEMBL1387308 & 37383 & & & \\
\hline AEMBL1327612 & 37383 & 082 & & \\
\hline EMBL1506961 & 83 & 24 & & \\
\hline IEMBL1490597 & 33 & & 97 & \\
\hline & & & & rST \\
\hline AEMBL1558470 & 37383 & 6.4045 & .7132 & S \\
\hline IEMBL1438870 & 37383 & & & \\
\hline HEMBL1544/64 & & & & \\
\hline HEMBL1372902 & & & & \\
\hline CHEMBL1364812 & 383 & & 197 & \\
\hline AEMBL1379466 & 37383 & 5.5941 & 5.8076 & \\
\hline HFMRI 3214566 & 737383 & 5.9462 & 5.6792 & \\
\hline
\end{tabular}

Page 266 


\begin{tabular}{|c|c|c|c|c|c|c|c|}
\hline \multicolumn{8}{|c|}{ Supplemental Table S2.txt } \\
\hline CHEMBL1709662 & 737383 & 3.0 & 5.2631 & TST & & & \\
\hline CHEMBL1507983 & 737383 & 4.6569 & 5.8066 & TST & & & \\
\hline CHEMBL1722434 & 737383 & 6.0367 & 5.5254 & TST & & & \\
\hline CHEMBL1509716 & 737383 & 7.8239 & 6.084 & TST & & & \\
\hline CHEMBL3210365 & 737383 & 5.782 & 6.0519 & TST & & & \\
\hline CHEMBL1450053 & 737383 & 5.416 & 7.0632 & TST & & & \\
\hline CHEMBL1312126 & 737383 & 4.7753 & 5.1663 & TST & & & \\
\hline CHEMBL1489892 & 737383 & 4.8555 & 6.2184 & TST & & & \\
\hline CHEMBL1554542 & 737383 & 4.836 & 5.8067 & TST & & & \\
\hline CHEMBL1386715 & 737383 & 4.766 & 5.6778 & TST & & & \\
\hline CHEMBL1387709 & 737383 & 5.6951 & 5.4209 & TST & & & \\
\hline CHEMBL1300599 & 737383 & 5.0703 & 5.5644 & TST & & & \\
\hline CHEMBL1391172 & 737383 & 6.1707 & 6.3569 & TST & & & \\
\hline CHEMBL1582872 & 737383 & 5.3796 & 5.5248 & TST & & & \\
\hline CHEMBL1299521 & 737383 & 5.4371 & 5.4568 & TST & & & \\
\hline CHEMBL1567500 & 737383 & 6.6946 & 5.9006 & TST & & & \\
\hline CHEMBL1327880 & 737383 & 5.3406 & 6.2141 & TST & & & \\
\hline CHEMBL1424746 & 737383 & 5.3726 & 5.9278 & TST & & & \\
\hline CHEMBL1461059 & 737383 & 7.7447 & 5.5024 & TST & & & \\
\hline CHEMBL1987655 & 737383 & 4.45 & 5.8453 & TST & & & \\
\hline CHEMBL1442502 & 737383 & 6.2351 & 6.00899 & 99999999995 & & TST & \\
\hline CHEMBL1710291 & 737383 & 5.82799 & 99999999 & & 5.9923 & TST & \\
\hline CHEMBL1319442 & 737383 & 5.2383 & 5.6696 & TST & & & \\
\hline CHEMBL3191937 & 737383 & 5.37799 & 79999999 & 99 & 5.53799 & 9999999999 & TST \\
\hline CHEMBL1701695 & 737383 & 4.6841 & 5.8637 & TST & & & \\
\hline CHEMBL1307716 & 737383 & 5.763 & 6.5414 & TST & & & \\
\hline CHEMBL3145369 & 737383 & 6.1068 & 5.5105 & TST & & & \\
\hline CHEMBL1592490 & 737383 & 6.6198 & 5.5085 & TST & & & \\
\hline CHEMBL1526851 & 737383 & 5.9144 & 6.4111 & TST & & & \\
\hline CHEMBL1461340 & 737383 & 5.3963 & 6.1925 & TST & & & \\
\hline CHEMBL3195919 & 737383 & 5.6467 & 5.3755 & TST & & & \\
\hline CHEMBL1492448 & 737383 & 6.7545 & 6.2791 & TST & & & \\
\hline CHEMBL1485338 & 737383 & 5.3393 & 5.1129 & TST & & & \\
\hline CHEMBL1479188 & 737383 & 5.7156 & 5.7036 & TST & & & \\
\hline CHEMBL3196677 & 737383 & 5.596 & 5.6103 & TST & & & \\
\hline CHEMBL1440476 & 737383 & 5.7296 & 5.7673 & TST & & & \\
\hline CHEMBL3193935 & 737383 & 5.0902 & 6.017 & TST & & & \\
\hline CHEMBL572994 & 737383 & 9.301 & 5.8977 & TST & & & \\
\hline CHEMBL1461809 & 737383 & 6.5638 & 5.8548 & TST & & & \\
\hline CHEMBL1502921 & 737383 & 5.6542 & 5.6248 & TST & & & \\
\hline CHEMBL601142 & 737383 & 5.9151 & 6.4237 & TST & & & \\
\hline CHEMBL1387122 & 737383 & 5.5507 & 5.5701 & TST & & & \\
\hline CHEMBL1324305 & 737383 & 5.2903 & 5.7458 & TST & & & \\
\hline CHEMBL1524483 & 737383 & 5.2988 & 5.3783 & TST & & & \\
\hline CHEMBL3196427 & 737383 & 7.4089 & 5.5699 & TST & & & \\
\hline CHEMBL1375445 & 737383 & 6.4067 & 5.547006 & 0000000001 & & TST & \\
\hline CHEMBL3192155 & 737383 & 5.4482 & 5.9784 & TST & & & \\
\hline CHEMBL1539795 & 737383 & 5.105 & 5.9876 & TST & & & \\
\hline
\end{tabular}


Supplemental Table S2.txt

\begin{tabular}{|c|c|c|c|c|}
\hline $\mathrm{HEI}$ & & 3703 & 5.6312 & 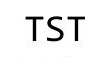 \\
\hline HEMPI 1725651 & & .2591 & 5.2148 & \\
\hline JFA & & & & \\
\hline AEMBLI & 383 & 78 & 8606 & \\
\hline AEMBL3198294 & 37383 & & & \\
\hline HEMBL1350147 & 37383 & 5387 & .8498 & \\
\hline HEMBL1548439 & 7383 & & 211 & \\
\hline 51903 & & & & \\
\hline AEMBL600100 & 383 & 76 & 6099 & \\
\hline HEMBL1504067 & 383 & 1785 & 4738 & \\
\hline HEMBL1401417 & 383 & 2207 & 9762 & \\
\hline IEMBL1346591 & 383 & 781 & 83 & \\
\hline IEMBL1 & & & & \\
\hline AEMBL1526325 & 383 & 3892 & 1279 & \\
\hline AEMBL1306033 & & 21 & 77 & \\
\hline AEMBL383918 & 83 & 94 & 7061 & \\
\hline HEMBL1 & 33 & 06 & 121 & \\
\hline HEMBL1 & & & & \\
\hline HEMBL1 & & & 5.7087 & \\
\hline IEMBL1 & & & & \\
\hline HEMBL: & 3 & & 88 & \\
\hline AEMBL & & & & \\
\hline HEMBL & & & & \\
\hline 5652 & & & & \\
\hline AEMBL1420412 & & & & \\
\hline HEMBLI & 33 & & 074 & \\
\hline AEMBL & & & 191 & \\
\hline AFMRI : & 83 & & 134 & \\
\hline HEMBL1 & & & 6611 & \\
\hline HEMBL1733417 & & & 5.6091 & 1 \\
\hline HEMBL1 & & 21 & 2875 & ST \\
\hline HEMBL 1 & 3 & 36 & 599 & ות \\
\hline 6 & 33 & & 304 & \\
\hline HEMBL1549362 & & & 812 & $\mid$ \\
\hline HEMBL1606512 & 37383 & & 5.8043 & TST \\
\hline HEMBL3 & 83 & 945 & 5.4034 & TST \\
\hline HFMRI $=2$ & & & & וס \\
\hline & & & 5756 & ST \\
\hline HEMBL1719552 & 37383 & 59 & 5.5591 & TST \\
\hline IEMBL1 & & & 5.1127 & TS \\
\hline HEMBL 2 & 83 & $\partial 02$ & 9622 & \\
\hline HEMBL1525122 & & & & ST \\
\hline HEMBL1538686 & 37383 & 1567 & 0206 & IST \\
\hline AEMBL1565125 & 38885 & & 9458 & $\mathrm{RI}$ \\
\hline EMBL2 & & & 512 & \\
\hline CHEMBL1437090 & 88885 & & & \\
\hline LHEMBL1374799 & 88885 & 5. & 5.5311 & \\
\hline SHEMBL1551477 & 688885 & 5.2 & 5.2203 & \\
\hline
\end{tabular}

Page 268 


\begin{tabular}{|c|c|c|c|c|}
\hline & & & oplement & al $\mathrm{Ta}$ \\
\hline CHEMBL14276 & 688885 & 6.0 & 6.3721 & TST \\
\hline CHEMBL1337691 & 688885 & 5.6 & 5.5377 & TRN \\
\hline CHEMBL1394187 & 688885 & 5.5 & 5.3954 & TRN \\
\hline CHEMBL1475338 & 688885 & 6.5 & 6.5395 & TRN \\
\hline CHEMBL1515131 & 688885 & 5.2 & 5.4505 & TST \\
\hline CHEMBL1514071 & 688885 & 6.1 & 5.9467 & TRN \\
\hline CHEMBL1493810 & 688885 & 4.5 & 4.7883 & TRN \\
\hline CHEMBL1395138 & 688885 & 5.5 & 5.5457 & TST \\
\hline CHEMBL1396142 & 688885 & 4.4 & 4.5402 & TRN \\
\hline CHEMBL1514640 & 688885 & 4.9 & 4.8066 & TRN \\
\hline CHEMBL1590886 & 688885 & 5.0 & 5.2729 & TRN \\
\hline CHEMBL 384903 & 688885 & 6.1 & 6.0196 & TST \\
\hline CHEMBL1433687 & 688885 & 7.6003 & 5.1168 & TRN \\
\hline CHEMBL1357982 & 688885 & 5.4 & 5.1915 & TRN \\
\hline CHEMBL172064 & 688885 & 5.7 & 5.9059 & TST \\
\hline CHEMBL1316953 & 688885 & 6.0 & 5.2992 & TST \\
\hline CHEMBL1355708 & 688885 & 4.8 & 5.0265 & TRN \\
\hline CHEMBL1436478 & 688885 & 5.9 & 5.3332 & TST \\
\hline CHEMBL1331363 & 688885 & 6.1 & 6.2255 & TRN \\
\hline CHEMBL1591731 & 688885 & 6.9 & 6.5419 & TST \\
\hline CHEMBL1318310 & 688885 & 5.8 & 6.0664 & TRN \\
\hline CHEMBL1611999 & 688885 & 4.4 & 4.434 & TRN \\
\hline CHEMBL1568129 & 688885 & 6.1 & 5.2006 & TRN \\
\hline CHEMBL1398351 & 688885 & 4.8 & 5.1158 & TST \\
\hline CHEMBL1477833 & 688885 & 4.8 & 4.9133 & TRN \\
\hline CHEMBL1596121 & 688885 & 4.5 & 5.1944 & TRN \\
\hline CHEMBL1378758 & 688885 & 5.4 & 5.3403 & TRN \\
\hline CHEMBL1592506 & 688885 & 5.0 & 5.0577 & TRN \\
\hline CHEMBL1479202 & 688885 & 8.0 & 4.8439 & TRN \\
\hline CHEMBL1476159 & 688885 & 5.5 & 5.6778 & TRN \\
\hline CHEMBL1396108 & 688885 & 5.0 & 5.0901 & TRN \\
\hline CHEMBL1327945 & 688885 & 6.7001 & 6.2306 & TRN \\
\hline CHEMBL1257076 & 688885 & 4.4 & 5.2925 & TST \\
\hline CHEMBL39 & 688885 & 4.8 & 4.7362 & TRN \\
\hline CHEMBL1356060 & 688885 & 6.1 & 6.2306 & TRN \\
\hline CHEMBL1566987 & 688885 & 6.4 & 6.1127 & TRN \\
\hline CHEMBL122701 & 688885 & 4.5 & 5.1855 & TRN \\
\hline CHEMBL1358116 & 688885 & 6.0 & 5.1692 & TST \\
\hline CHEMBL1374863 & 688885 & 5.0 & 5.0909 & TRN \\
\hline CHEMBL1512413 & 688885 & 5.6 & 5.8578 & TRN \\
\hline CHEMBL1415569 & 688885 & 5.2 & 5.2467 & TRN \\
\hline CHEMBL1436644 & 688885 & 4.9 & 4.8927 & TRN \\
\hline CHEMBL1354706 & 688885 & 5.4 & 5.2549 & TRN \\
\hline CHEMBL1256914 & 688885 & 4.4 & 5.2099 & TRN \\
\hline CHEMBL1411411 & 688885 & 6.0 & 5.5252 & TRN \\
\hline CHEMBL1376005 & 688885 & 5.5 & 5.349 & TRN \\
\hline CHEMBL 303516 & 688885 & 5.3 & 5.1997 & TST \\
\hline CHEMBL1325197 & 688885 & 5.2 & 5.5476 & TRN \\
\hline
\end{tabular}




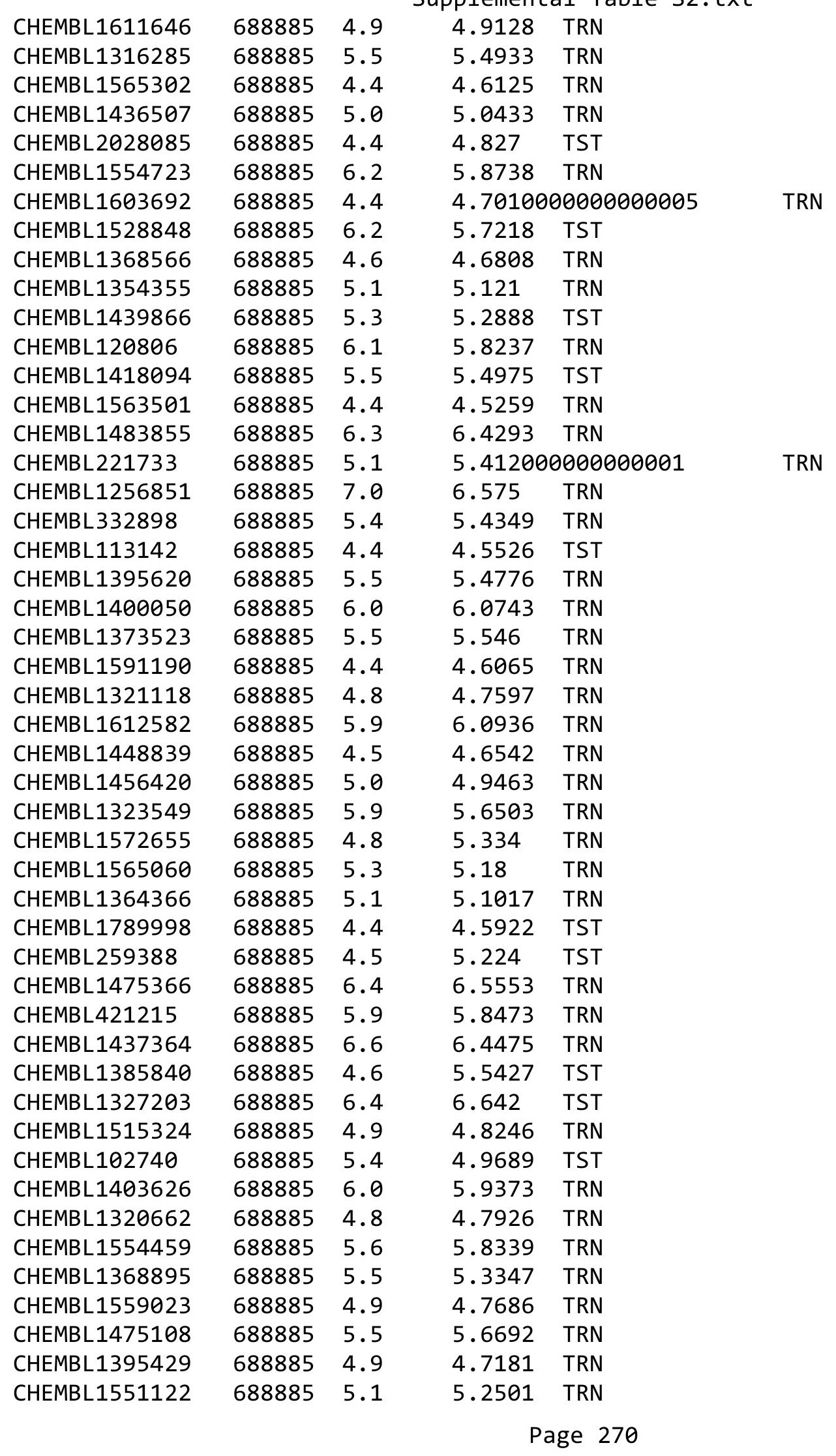




\begin{tabular}{|c|c|c|c|c|c|}
\hline \\
\hline CHEMBL1318553 & 688885 & 4.6 & 5.2324 & TST & \\
\hline CHEMBL304008 & 688885 & 5.1 & 5.1561 & TST & \\
\hline CHEMBL1436488 & 688885 & 4.7 & 5.1892 & TRN & \\
\hline CHEMBL1521167 & 688885 & 5.3 & 5.2764 & TST & \\
\hline CHEMBL1513431 & 688885 & 5.5 & 5.3649 & TRN & \\
\hline CHEMBL1318708 & 688885 & 5.0 & 5.1769 & TRN & \\
\hline CHEMBL3351063 & 688885 & 5.6 & 5.6211 & TRN & \\
\hline CHEMBL1566670 & 688885 & 4.4 & 4.593 & TRN & \\
\hline CHEMBL1318104 & 688885 & 5.4 & 5.3553 & TRN & \\
\hline CHEMBL1607885 & 688885 & 6.3 & 6.3982 & TRN & \\
\hline CHEMBL1515858 & 688885 & 4.8 & 5.2502 & TRN & \\
\hline CHEMBL3192674 & 688885 & 5.9 & 5.8859 & TRN & \\
\hline CHEMBL1355431 & 688885 & 5.5 & 5.3609 & TRN & \\
\hline CHEMBL1605632 & 688885 & 5.4 & 5.5356 & TRN & \\
\hline CHEMBL1476280 & 688885 & 4.6 & 5.0553 & TRN & \\
\hline CHEMBL1592760 & 688885 & 4.6 & 4.6817 & TRN & \\
\hline CHEMBL1323524 & 688885 & 5.8 & 5.4694 & TRN & \\
\hline CHEMBL541847 & 688885 & 6.0 & 6.0182 & TRN & \\
\hline CHEMBL1317932 & 688885 & 5.4 & 5.1605 & TRN & \\
\hline CHEMBL1361945 & 688885 & 4.4 & 5.07600 & 00000000005 & TRN \\
\hline CHEMBL1405001 & 688885 & 5.4 & 5.1692 & TRN & \\
\hline CHEMBL1397177 & 688885 & 5.0 & 5.1131 & TRN & \\
\hline CHEMBL1233960 & 688885 & 5.3 & 5.3803 & TRN & \\
\hline CHEMBL1515698 & 688885 & 5.8 & 5.7252 & TRN & \\
\hline CHEMBL3207894 & 688885 & 6.0 & 5.8885 & TRN & \\
\hline CHEMBL1327059 & 688885 & 5.0 & 5.0118 & TRN & \\
\hline CHEMBL1356055 & 688885 & 5.5 & 5.3105 & TRN & \\
\hline CHEMBL1410420 & 688885 & 5.4 & 5.6579 & TRN & \\
\hline CHEMBL1327619 & 688885 & 4.6 & 5.6574 & TST & \\
\hline CHEMBL1590980 & 688885 & 7.1002 & 6.9116 & TRN & \\
\hline CHEMBL1404451 & 688885 & 6.1 & 6.2656 & TRN & \\
\hline CHEMBL1326204 & 688885 & 5.5 & 5.2849 & TST & \\
\hline CHEMBL275809 & 688885 & 4.7 & 4.9566 & TRN & \\
\hline CHEMBL1474483 & 688885 & 5.2 & 5.1373 & TRN & \\
\hline CHEMBL 1375480 & 688885 & 5.6 & 5.3393 & TRN & \\
\hline CHEMBL1612675 & 688885 & 4.8 & 4.919 & TRN & \\
\hline CHEMBL1904453 & 688885 & 5.5 & 5.4199 & TRN & \\
\hline CHEMBL1358525 & 688885 & 4.4 & 4.6058 & TRN & \\
\hline CHEMBL1487860 & 688885 & 5.2 & 5.2839 & TST & \\
\hline CHEMBL1574390 & 688885 & 5.1 & 5.1257 & TRN & \\
\hline CHEMBL1365616 & 688885 & 4.6 & 4.7539 & TRN & \\
\hline CHEMBL1399528 & 688885 & 5.9 & 6.0788 & TRN & \\
\hline CHEMBL1567236 & 688885 & 5.3 & 5.36100 & 0000000001 & TRN \\
\hline CHEMBL1256814 & 688885 & 4.9 & 4.8617 & TRN & \\
\hline CHEMBL1317056 & 688885 & 4.9 & 5.0083 & TRN & \\
\hline CHEMBL1506225 & 688885 & 4.4 & 5.2613 & TRN & \\
\hline CHEMBL1356115 & 688885 & 4.7 & 5.3689 & TST & \\
\hline CHEMBL1413858 & 688885 & 4.8 & 4.9744 & TRN & \\
\hline
\end{tabular}




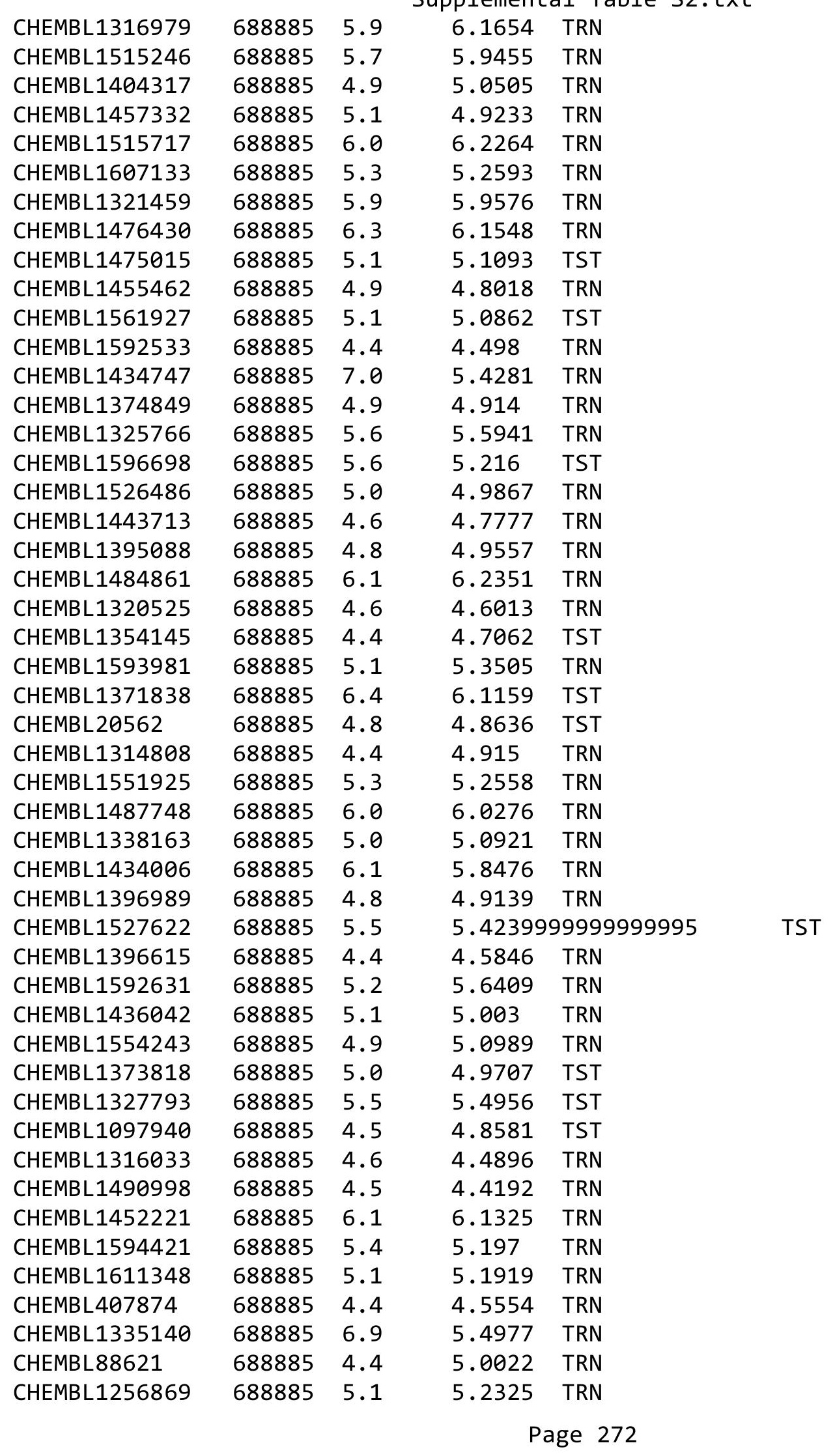




\begin{tabular}{|c|c|c|c|c|c|}
\hline \multicolumn{6}{|c|}{ Supplemental Table S2.txt } \\
\hline CHEMBL1398216 & 688885 & 5.5 & 5.7398 & TRN & \\
\hline CHEMBL1396049 & 688885 & 4.4 & 5.2882 & TRN & \\
\hline CHEMBL327708 & 688885 & 5.5 & 5.6653 & TRN & \\
\hline CHEMBL13790 & 688885 & 4.4 & 5.2505 & TRN & \\
\hline CHEMBL1334465 & 688885 & 5.2 & 5.4798 & TST & \\
\hline CHEMBL1593751 & 688885 & 5.6 & 5.4686 & TST & \\
\hline CHEMBL1363413 & 688885 & 6.0 & 6.1069 & TRN & \\
\hline CHEMBL1487205 & 688885 & 5.5 & 5.3565 & TST & \\
\hline CHEMBL1329026 & 688885 & 5.3 & 5.3668 & TST & \\
\hline CHEMBL1551041 & 688885 & 5.3 & 5.5075 & TRN & \\
\hline CHEMBL1318340 & 688885 & 6.3 & 6.4222 & TRN & \\
\hline CHEMBL1257002 & 688885 & 5.3 & 5.5153 & TST & \\
\hline CHEMBL1404598 & 688885 & 6.0 & 6.2332 & TRN & \\
\hline CHEMBL1486638 & 688885 & 4.8 & 4.7263 & TRN & \\
\hline CHEMBL1457499 & 688885 & 5.4 & 5.1726 & TRN & \\
\hline CHEMBL1489359 & 688885 & 5.6 & 5.5565 & TST & \\
\hline CHEMBL1552854 & 688885 & 6.0 & 5.7315 & TRN & \\
\hline CHEMBL1356391 & 688885 & 5.6 & 5.6937 & TRN & \\
\hline CHEMBL1356262 & 688885 & 5.0 & 5.1177 & TRN & \\
\hline CHEMBL317757 & 688885 & 5.3 & 5.1989 & TRN & \\
\hline CHEMBL1358272 & 688885 & 6.0 & 6.07700 & 0000000001 & TRN \\
\hline CHEMBL230056 & 688885 & 4.4 & 5.2396 & TST & \\
\hline CHEMBL1314416 & 688885 & 5.7 & 5.6068 & TRN & \\
\hline CHEMBL1492205 & 688885 & 5.4 & 5.4378 & TRN & \\
\hline CHEMBL1554236 & 688885 & 5.9 & 5.8582 & TRN & \\
\hline CHEMBL1568019 & 688885 & 6.7001 & 6.4259 & TRN & \\
\hline CHEMBL1474326 & 688885 & 4.9 & 4.9339 & TRN & \\
\hline CHEMBL1569592 & 688885 & 5.1 & 5.2108 & TRN & \\
\hline CHEMBL397565 & 688885 & 5.9 & 5.0587 & TRN & \\
\hline CHEMBL1601506 & 688885 & 5.4 & 5.7314 & TRN & \\
\hline CHEMBL50112 & 688885 & 4.4 & 4.6072 & TRN & \\
\hline CHEMBL1474479 & 688885 & 4.8 & 5.0211 & TRN & \\
\hline CHEMBL1355040 & 688885 & 8.4949 & 5.2943 & TST & \\
\hline CHEMBL1566428 & 688885 & 6.3 & 6.2826 & TRN & \\
\hline CHEMBL1213137 & 688885 & 7.1002 & 5.1023 & TST & \\
\hline CHEMBL1396261 & 688885 & 6.3 & 6.4457 & TRN & \\
\hline CHEMBL516075 & 688885 & 6.4 & 6.4859 & TRN & \\
\hline CHEMBL1372363 & 688885 & 4.6 & 4.7053 & TRN & \\
\hline CHEMBL1513824 & 688885 & 6.0 & 5.5758 & TRN & \\
\hline CHEMBL1494697 & 688885 & 6.5 & 6.0212 & TRN & \\
\hline CHEMBL1317916 & 688885 & 5.4 & 5.4067 & TRN & \\
\hline CHEMBL1554291 & 688885 & 5.9 & 5.6221 & TST & \\
\hline CHEMBL1613544 & 688885 & 4.9 & 5.0159 & TST & \\
\hline CHEMBL1314185 & 688885 & 4.7 & 4.7924 & TRN & \\
\hline CHEMBL1488918 & 688885 & 5.5 & 5.4569 & TRN & \\
\hline CHEMBL1437776 & 688885 & 4.4 & 4.4358 & TRN & \\
\hline CHEMBL1473430 & 688885 & 6.1 & 6.2558 & TRN & \\
\hline CHEMBL1316055 & 688885 & 6.0 & 6.1771 & TRN & \\
\hline
\end{tabular}




\begin{tabular}{|c|c|c|c|c|}
\hline & & & & al lable \\
\hline CHEMBL1608125 & 688885 & 6.0 & 6.0911 & TRN \\
\hline CHEMBL1439893 & 688885 & 5.8 & 6.1306 & TRN \\
\hline CHEMBL1396374 & 688885 & 6.0 & 6.0515 & TRN \\
\hline CHEMBL1474056 & 688885 & 5.5 & 5.4121 & TRN \\
\hline CHEMBL1359613 & 688885 & 5.0 & 5.0172 & TRN \\
\hline CHEMBL1437747 & 688885 & 4.8 & 4.9027 & TRN \\
\hline CHEMBL323197 & 688885 & 5.3 & 5.4149 & TRN \\
\hline CHEMBL34241 & 688885 & 6.2 & 5.2855 & TRN \\
\hline CHEMBL1437263 & 688885 & 5.9 & 5.8926 & TRN \\
\hline CHEMBL1474876 & 688885 & 4.7 & 4.8027 & TRN \\
\hline CHEMBL1398518 & 688885 & 5.1 & 5.5198 & TST \\
\hline CHEMBL1527466 & 688885 & 6.0 & 6.0697 & TRN \\
\hline CHEMBL16751 & 688885 & 5.4 & 5.2946 & TRN \\
\hline CHEMBL491547 & 688885 & 6.3 & 6.5218 & TRN \\
\hline CHEMBL1495071 & 688885 & 4.8 & 4.8887 & TST \\
\hline CHEMBL1482790 & 688885 & 7.2 & 5.7923 & TRN \\
\hline CHEMBL1434801 & 688885 & 5.0 & 5.1566 & TRN \\
\hline CHEMBL1338095 & 688885 & 6.0 & 6.0958 & TRN \\
\hline CHEMBL1335409 & 688885 & 5.1 & 5.1125 & TST \\
\hline CHEMBL455185 & 688885 & 4.8 & 4.9735 & TRN \\
\hline CHEMBL 76904 & 688885 & 6.0 & 5.143 & TRN \\
\hline CHEMBL274438 & 688885 & 5.4 & 5.4126 & TRN \\
\hline CHEMBL1478279 & 688885 & 4.5 & 4.4571 & TRN \\
\hline CHEMBL1514221 & 688885 & 5.5 & 5.4375 & TST \\
\hline CHEMBL1598680 & 688885 & 6.0 & 5.9888 & TRN \\
\hline CHEMBL1358588 & 688885 & 4.8 & 5.0104 & TRN \\
\hline CHEMBL1318316 & 688885 & 5.5 & 5.5622 & TRN \\
\hline CHEMBL1489705 & 688885 & 5.5 & 5.47 & TRN \\
\hline CHEMBL1438138 & 688885 & 5.1 & 5.6516 & TRN \\
\hline CHEMBL299683 & 688885 & 4.7 & 5.5696 & TRN \\
\hline CHEMBL1407962 & 688885 & 5.6 & 5.61700 & 0000000001 \\
\hline CHEMBL 222808 & 688885 & 6.5 & 6.3617 & TRN \\
\hline CHEMBL1481378 & 688885 & 4.9 & 4.9611 & TRN \\
\hline CHEMBL69367 & 688885 & 4.8 & 5.062 & TRN \\
\hline CHEMBL1331913 & 688885 & 5.2 & 5.2394 & TST \\
\hline CHEMBL1596186 & 688885 & 5.5 & 5.4047 & TRN \\
\hline CHEMBL1396630 & 688885 & 5.4 & 5.9525 & TRN \\
\hline CHEMBL395915 & 688885 & 4.4 & 4.9517 & TRN \\
\hline CHEMBL1611856 & 688885 & 4.8 & 4.7913 & TRN \\
\hline CHEMBL1437007 & 688885 & 4.9 & 5.0854 & TRN \\
\hline CHEMBL1395297 & 688885 & 5.0 & 4.9032 & TRN \\
\hline CHEMBL241862 & 688885 & 5.4 & 5.1811 & TRN \\
\hline CHEMBL1360942 & 688885 & 6.5 & 6.2736 & TRN \\
\hline CHEMBL1256659 & 688885 & 4.5 & 4.5515 & TST \\
\hline CHEMBL1315316 & 688885 & 5.5 & 5.6909 & TRN \\
\hline CHEMBL1489432 & 688885 & 4.7 & 5.1789 & TST \\
\hline CHEMBL1365994 & 688885 & 5.3 & 5.5037 & TRN \\
\hline CHEMBL1440157 & 688885 & 6.4 & 6.4664 & TRN \\
\hline
\end{tabular}




\begin{tabular}{|c|c|c|c|c|c|}
\hline \multicolumn{6}{|c|}{ splemental } \\
\hline CHEMBL1413701 & 688885 & 5.1 & 5.1529 & TRN & \\
\hline CHEMBL8747 & 688885 & 4.5 & 4.7196 & TRN & \\
\hline CHEMBL123904 & 688885 & 5.4 & 5.4302 & TST & \\
\hline CHEMBL1370480 & 688885 & 4.9 & 4.8897 & TRN & \\
\hline CHEMBL1433805 & 688885 & 5.3 & 5.3458 & TRN & \\
\hline CHEMBL1437176 & 688885 & 4.4 & 4.5506 & TRN & \\
\hline CHEMBL1437650 & 688885 & 5.1 & 5.1344 & TRN & \\
\hline CHEMBL1591847 & 688885 & 4.4 & 4.5815 & TRN & \\
\hline CHEMBL267458 & 688885 & 6.2 & 6.0169 & TST & \\
\hline CHEMBL1481029 & 688885 & 5.5 & 5.6684 & TRN & \\
\hline CHEMBL1397596 & 688885 & 4.4 & 4.2814 & TRN & \\
\hline CHEMBL1334255 & 688885 & 5.3 & 5.6024 & TRN & \\
\hline CHEMBL1335889 & 688885 & 4.7 & 4.8731 & TRN & \\
\hline CHEMBL1433752 & 688885 & 6.4 & 6.4691 & TRN & \\
\hline CHEMBL305881 & 688885 & 6.0 & 5.6497 & TRN & \\
\hline CHEMBL1404630 & 688885 & 5.6 & 5.2618 & TST & \\
\hline CHEMBL1376572 & 688885 & 4.9 & 4.9311 & TRN & \\
\hline CHEMBL1446743 & 688885 & 5.0 & 5.0978 & TST & \\
\hline CHEMBL1552542 & 688885 & 4.4 & 4.6298 & TRN & \\
\hline CHEMBL1356842 & 688885 & 7.1002 & 6.2029 & TRN & \\
\hline CHEMBL1444652 & 688885 & 5.7 & 5.6149 & TRN & \\
\hline CHEMBL1366961 & 688885 & 4.4 & 5.3253 & TRN & \\
\hline CHEMBL1516187 & 688885 & 6.0 & 5.7642 & TRN & \\
\hline CHEMBL1517172 & 688885 & 5.1 & 5.1978 & TRN & \\
\hline CHEMBL1437325 & 688885 & 4.9 & 4.8751 & TRN & \\
\hline CHEMBL1595282 & 688885 & 4.5 & 4.5579 & TRN & \\
\hline CHEMBL52 & 688885 & 6.0 & 4.9998 & TRN & \\
\hline CHEMBL1496125 & 688885 & 5.1 & 5.3107 & TRN & \\
\hline CHEMBL1357759 & 688885 & 5.5 & 5.3733 & TRN & \\
\hline CHEMBL72631 & 688885 & 4.4 & 5.3217 & TRN & \\
\hline CHEMBL539947 & 688885 & 7.0 & 6.9826 & TRN & \\
\hline CHEMBL1448138 & 688885 & 5.4 & 5.3309 & TRN & \\
\hline CHEMBL1514307 & 688885 & 6.2 & 6.17 & TRN & \\
\hline CHEMBL1590378 & 688885 & 6.0 & 5.775 & TST & \\
\hline CHEMBL1603803 & 688885 & 5.2 & 5.48799 & 99999999995 & TRN \\
\hline CHEMBL1408259 & 688885 & 6.0 & 6.0075 & TRN & \\
\hline CHEMBL1531727 & 688885 & 5.6 & 5.5501 & TRN & \\
\hline CHEMBL1315417 & 688885 & 4.6 & 4.672 & TST & \\
\hline CHEMBL1593765 & 688885 & 6.0 & 5.374 & TRN & \\
\hline CHEMBL1607106 & 688885 & 5.4 & 5.6212 & TRN & \\
\hline CHEMBL1513508 & 688885 & 8.6021 & 5.595 & TRN & \\
\hline CHEMBL145725 & 688885 & 6.4 & 6.2135 & TST & \\
\hline CHEMBL1590974 & 688885 & 5.3 & 5.3071 & TRN & \\
\hline CHEMBL 23327 & 688885 & 6.0 & 4.6407 & TRN & \\
\hline CHEMBL1593547 & 688885 & 5.4 & 5.4468 & TRN & \\
\hline CHEMBL1553373 & 688885 & 5.4 & 5.1944 & TRN & \\
\hline CHEMBL1411543 & 688885 & 6.5 & 4.8605 & TRN & \\
\hline CHEMBL1453216 & 688885 & 5.5 & 5.3543 & TRN & \\
\hline
\end{tabular}




\begin{tabular}{|c|c|c|c|c|c|}
\hline \\
\hline CHEMBL1435384 & 688885 & 4.9 & 4.8894 & TRN & \\
\hline CHEMBL1552623 & 688885 & 6.3 & 6.6658 & TRN & \\
\hline CHEMBL1865547 & 688885 & 5.4 & 5.4532 & TRN & \\
\hline CHEMBL1437733 & 688885 & 4.5 & 5.2311 & TRN & \\
\hline CHEMBL1519490 & 688885 & 6.0 & 5.8891 & TST & \\
\hline CHEMBL1354941 & 688885 & 4.9 & 4.9673 & TRN & \\
\hline CHEMBL313833 & 688885 & 6.0 & 5.648 & TST & \\
\hline CHEMBL1603371 & 688885 & 5.7 & 5.6478 & TRN & \\
\hline CHEMBL1591714 & 688885 & 5.4 & 5.2869 & TRN & \\
\hline CHEMBL1520976 & 688885 & 5.5 & 5.1952 & TST & \\
\hline CHEMBL1410491 & 688885 & 4.6 & 4.5603 & TRN & \\
\hline CHEMBL 7634 & 688885 & 6.0 & 5.6702 & TST & \\
\hline CHEMBL 2374087 & 688885 & 5.4 & 5.3708 & TRN & \\
\hline CHEMBL1478530 & 688885 & 4.9 & 5.0628 & TST & \\
\hline CHEMBL1476981 & 688885 & 4.9 & 4.80399 & 9999999999 & TRN \\
\hline CHEMBL1394638 & 688885 & 4.6 & 4.6362 & TRN & \\
\hline CHEMBL1555810 & 688885 & 4.4 & 4.6299 & TST & \\
\hline CHEMBL1405744 & 688885 & 5.1 & 5.2991 & TRN & \\
\hline CHEMBL611494 & 688885 & 6.0 & 5.9601 & TST & \\
\hline CHEMBL1354281 & 688885 & 5.0 & 5.0044 & TRN & \\
\hline CHEMBL1317234 & 688885 & 4.5 & 5.8626 & TRN & \\
\hline CHEMBL1415180 & 688885 & 4.8 & 5.1722 & TRN & \\
\hline CHEMBL429023 & 688885 & 6.0 & 4.8086 & TST & \\
\hline CHEMBL1475620 & 688885 & 4.9 & 4.749 & TRN & \\
\hline CHEMBL1481608 & 688885 & 4.9 & 5.0413 & TRN & \\
\hline CHEMBL1437088 & 688885 & 4.6 & 4.602 & TRN & \\
\hline CHEMBL18879 & 688885 & 5.1 & 4.9933 & TST & \\
\hline CHEMBL1327697 & 688885 & 4.9 & 4.8901 & TRN & \\
\hline CHEMBL1448192 & 688885 & 5.4 & 5.7894 & TRN & \\
\hline CHEMBL1361149 & 688885 & 4.5 & 4.44300 & 00000000005 & TRN \\
\hline CHEMBL1512683 & 688885 & 4.5 & 4.6669 & TRN & \\
\hline CHEMBL1365882 & 688885 & 5.4 & 5.7891 & TRN & \\
\hline CHEMBL1409830 & 688885 & 6.3 & 6.3191 & TRN & \\
\hline CHEMBL1601095 & 688885 & 4.5 & 4.6693 & TRN & \\
\hline CHEMBL270299 & 688885 & 6.0 & 5.3272 & TRN & \\
\hline CHEMBL153648 & 688885 & 4.5 & 4.7163 & TST & \\
\hline CHEMBL1526053 & 688885 & 6.0 & 5.3968 & TRN & \\
\hline CHEMBL1514458 & 688885 & 4.4 & 4.3615 & TRN & \\
\hline CHEMBL1329488 & 688885 & 5.5 & 5.5808 & TST & \\
\hline CHEMBL1552150 & 688885 & 4.8 & 4.9447 & TRN & \\
\hline CHEMBL3207783 & 688885 & 5.6 & 5.7206 & TRN & \\
\hline CHEMBL1558526 & 688885 & 5.0 & 5.0665 & TRN & \\
\hline CHEMBL1366754 & 688885 & 5.4 & 5.3166 & TRN & \\
\hline CHEMBL1595576 & 688885 & 5.9 & 6.0678 & TRN & \\
\hline CHEMBL1591272 & 688885 & 5.5 & 5.4731 & TRN & \\
\hline CHEMBL1371726 & 688885 & 6.0 & 5.6614 & TRN & \\
\hline CHEMBL1322414 & 688885 & 5.8 & 5.8588 & TRN & \\
\hline CHEMBL1314367 & 688885 & 6.0 & 6.166 & TRN & \\
\hline
\end{tabular}




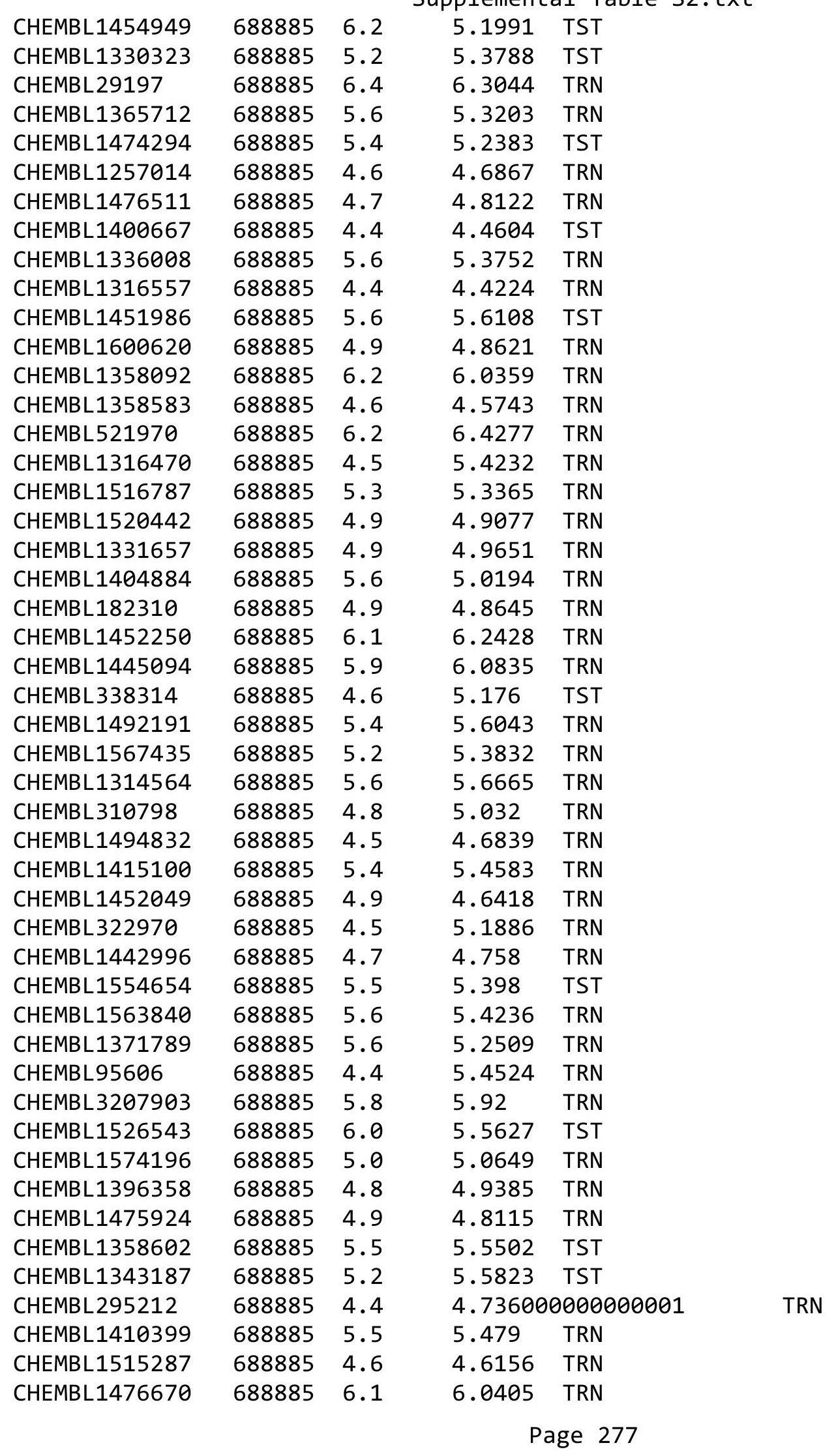




\begin{tabular}{|c|c|c|c|c|}
\hline \multicolumn{5}{|c|}{ Supplemental Table S2.txt } \\
\hline CHEMBL1595205 & 688885 & 4.5 & 4.5527 & TRN \\
\hline CHEMBL1449218 & 688885 & 4.9 & 5.0302 & TRN \\
\hline CHEMBL1314172 & 688885 & 4.9 & 4.8734 & TRN \\
\hline CHEMBL1574278 & 688885 & 5.4 & 5.5892 & TRN \\
\hline CHEMBL1590909 & 688885 & 6.0 & 6.1011 & TRN \\
\hline CHEMBL1358560 & 688885 & 4.9 & 5.0562 & TRN \\
\hline CHEMBL1524851 & 688885 & 4.7 & 4.7946 & TRN \\
\hline CHEMBL1512802 & 688885 & 4.8 & 4.8259 & TRN \\
\hline CHEMBL1571995 & 688885 & 5.4 & 5.7111 & TRN \\
\hline CHEMBL1564545 & 688885 & 4.7 & 4.7877 & TRN \\
\hline CHEMBL1514910 & 688885 & 5.0 & 5.2419 & TST \\
\hline CHEMBL1435834 & 688885 & 4.4 & 4.6787 & TRN \\
\hline CHEMBL1553926 & 688885 & 5.3 & 5.1446 & TRN \\
\hline CHEMBL1315743 & 688885 & 6.0 & 5.9008 & TRN \\
\hline CHEMBL1256719 & 688885 & 5.6 & 5.4636 & TST \\
\hline CHEMBL1356022 & 688885 & 5.9 & 5.6247 & TRN \\
\hline CHEMBL1475311 & 688885 & 5.8 & 6.1242 & TRN \\
\hline CHEMBL433461 & 688885 & 5.7 & 5.7809 & TRN \\
\hline CHEMBL1523594 & 688885 & 4.8 & 4.9972 & TRN \\
\hline CHEMBL165 & 688885 & 6.0 & 4.7297 & TRN \\
\hline CHEMBL1400521 & 688885 & 4.6 & 4.9614 & TRN \\
\hline CHEMBL83899 & 688885 & 6.6 & 6.4602 & TST \\
\hline CHEMBL1232474 & 688885 & 6.8 & 7.0005 & TST \\
\hline CHEMBL1410367 & 688885 & 5.6 & 5.4941 & TRN \\
\hline CHEMBL342375 & 688885 & 4.7 & 4.9496 & TRN \\
\hline CHEMBL1354841 & 688885 & 4.7 & 4.9042 & TRN \\
\hline CHEMBL1332636 & 688885 & 5.2 & 5.4575 & TRN \\
\hline CHEMBL1605255 & 688885 & 4.9 & 4.9674 & TRN \\
\hline CHEMBL1565965 & 688885 & 4.6 & 4.614 & TRN \\
\hline CHEMBL1365983 & 688885 & 5.0 & 5.0646 & TRN \\
\hline CHEMBL1317344 & 688885 & 4.5 & 4.6745 & TRN \\
\hline CHEMBL1398425 & 688885 & 5.2 & 4.9241 & TRN \\
\hline CHEMBL1324178 & 688885 & 5.4 & 5.4708 & TRN \\
\hline CHEMBL168461 & 688885 & 4.8 & 4.7732 & TRN \\
\hline CHEMBL1545634 & 688885 & 6.0 & 6.0287 & TRN \\
\hline CHEMBL198159 & 688885 & 4.4 & 4.5876 & TRN \\
\hline CHEMBL1518415 & 688885 & 6.4 & 6.3192 & TRN \\
\hline CHEMBL 225513 & 688885 & 5.8 & 4.747 & TRN \\
\hline CHEMBL1442987 & 688885 & 6.0 & 5.9774 & TRN \\
\hline CHEMBL129795 & 688885 & 6.0 & 4.8997 & TRN \\
\hline CHEMBL1593001 & 688885 & 4.8 & 4.9415 & TRN \\
\hline CHEMBL1591380 & 688885 & 4.8 & 5.0888 & TRN \\
\hline CHEMBL1484360 & 688885 & 4.5 & 5.522 & TRN \\
\hline CHEMBL1554791 & 688885 & 4.9 & 5.0537 & TRN \\
\hline CHEMBL78150 & 688885 & 7.5003 & 7.271 & TRN \\
\hline CHEMBL1591209 & 688885 & 4.9 & 5.2121 & TRN \\
\hline CHEMBL287689 & 688885 & 5.5 & 5.5265 & TRN \\
\hline CHEMBL1324405 & 688885 & 6.0 & 5.8048 & TRN \\
\hline
\end{tabular}




\begin{tabular}{|c|c|c|c|c|c|}
\hline \multicolumn{6}{|c|}{ Supplemental Table S2.txt } \\
\hline CHEMBL1553694 & 688885 & 6.2 & 6.2986 & TRN & \\
\hline CHEMBL1560445 & 688885 & 4.8 & 4.7419 & TRN & \\
\hline CHEMBL1552362 & 688885 & 4.5 & 4.6526 & TRN & \\
\hline CHEMBL445102 & 688885 & 4.4 & 4.9424 & TRN & \\
\hline CHEMBL1328324 & 688885 & 4.9 & 4.99 & TST & \\
\hline CHEMBL1398636 & 688885 & 5.5 & 5.6424 & TRN & \\
\hline CHEMBL1438566 & 688885 & 6.0 & 4.7468 & TRN & \\
\hline CHEMBL1613441 & 688885 & 7.8996 & 5.4259 & TST & \\
\hline CHEMBL1612410 & 688885 & 4.5 & 4.7275 & TRN & \\
\hline CHEMBL1570851 & 688885 & 5.1 & 5.20700 & 0000000001 & TRN \\
\hline CHEMBL1314182 & 688885 & 5.0 & 5.2446 & TRN & \\
\hline CHEMBL1434447 & 688885 & 5.3 & 5.6778 & TRN & \\
\hline CHEMBL3210947 & 688885 & 5.4 & 5.5141 & TRN & \\
\hline CHEMBL281622 & 688885 & 6.5 & 6.1039 & TRN & \\
\hline CHEMBL1320913 & 688885 & 5.6 & 5.3982 & TST & \\
\hline CHEMBL1473472 & 688885 & 6.7001 & 6.3791 & TRN & \\
\hline CHEMBL1336155 & 688885 & 5.5 & 5.4356 & TST & \\
\hline CHEMBL1454033 & 688885 & 5.5 & 5.7572 & TRN & \\
\hline CHEMBL1256835 & 688885 & 4.8 & 4.8469 & TRN & \\
\hline CHEMBL462880 & 688885 & 4.6 & 5.4137 & TRN & \\
\hline CHEMBL1450395 & 688885 & 5.2 & 5.2327 & TRN & \\
\hline CHEMBL37081 & 688885 & 4.8 & 4.9287 & TRN & \\
\hline CHEMBL1413962 & 688885 & 5.0 & 5.0104 & TRN & \\
\hline CHEMBL1554453 & 688885 & 4.9 & 4.842 & TRN & \\
\hline CHEMBL1326100 & 688885 & 4.8 & 5.0038 & TRN & \\
\hline CHEMBL1487944 & 688885 & 4.9 & 4.9168 & TST & \\
\hline CHEMBL1520727 & 688885 & 5.4 & 5.381 & TRN & \\
\hline CHEMBL1316464 & 688885 & 4.4 & 4.944 & TRN & \\
\hline CHEMBL1435447 & 688885 & 6.3 & 6.2884 & TRN & \\
\hline CHEMBL1441222 & 688885 & 5.4 & 5.3916 & TRN & \\
\hline CHEMBL1513030 & 688885 & 4.4 & 4.4676 & TRN & \\
\hline CHEMBL1474890 & 688885 & 6.1 & 6.1084 & TRN & \\
\hline CHEMBL1435702 & 688885 & 6.0 & 5.8178 & TRN & \\
\hline CHEMBL1553731 & 688885 & 5.5 & 5.3427 & TRN & \\
\hline CHEMBL1599748 & 688885 & 4.9 & 4.8342 & TRN & \\
\hline CHEMBL1448896 & 688885 & 5.9 & 5.8886 & TRN & \\
\hline CHEMBL1373587 & 688885 & 5.5 & 5.6829 & TRN & \\
\hline CHEMBL1433898 & 688885 & 5.4 & 5.6378 & TRN & \\
\hline CHEMBL1410602 & 688885 & 5.1 & 5.2803 & TRN & \\
\hline CHEMBL1331444 & 688885 & 4.4 & 4.4857 & TRN & \\
\hline CHEMBL276727 & 688885 & 4.4 & 4.5633 & TST & \\
\hline CHEMBL567332 & 688885 & 6.0 & 6.1495 & TRN & \\
\hline CHEMBL1442087 & 688885 & 5.5 & 5.51 & TRN & \\
\hline CHEMBL1484447 & 688885 & 4.8 & 5.04 & TRN & \\
\hline CHEMBL1532555 & 688885 & 4.8 & 4.6503 & TRN & \\
\hline CHEMBL1570716 & 688885 & 6.0 & 5.6793 & TRN & \\
\hline CHEMBL1494615 & 688885 & 5.5 & 5.6086 & TRN & \\
\hline CHEMBL 280822 & 688885 & 5.0 & 5.5886 & TST & \\
\hline
\end{tabular}




\begin{tabular}{|c|c|c|c|c|c|}
\hline \multicolumn{6}{|c|}{ Supplemental Table S2.txt } \\
\hline CHEMBL1512171 & 688885 & 4.6 & 4.6699 & TRN & \\
\hline CHEMBL1568086 & 688885 & 6.1 & 6.144 & TRN & \\
\hline CHEMBL 253765 & 688885 & 4.9 & 5.0174 & TRN & \\
\hline CHEMBL1551133 & 688885 & 5.3 & 5.4777 & TRN & \\
\hline CHEMBL149223 & 688885 & 6.5 & 6.2158 & TST & \\
\hline CHEMBL258405 & 688885 & 6.0 & 5.8587 & TST & \\
\hline CHEMBL1357909 & 688885 & 6.0 & 5.9568 & TRN & \\
\hline CHEMBL1440534 & 688885 & 6.4 & 5.4257 & TRN & \\
\hline CHEMBL1530982 & 688885 & 4.6 & 4.545 & TRN & \\
\hline CHEMBL1524370 & 688885 & 4.5 & 5.2196 & TRN & \\
\hline CHEMBL1517718 & 688885 & 5.5 & 5.4269 & TRN & \\
\hline CHEMBL1496315 & 688885 & 5.8 & 5.8621 & TRN & \\
\hline CHEMBL1564426 & 688885 & 6.4 & 5.6902 & TRN & \\
\hline CHEMBL1515310 & 688885 & 4.4 & 5.71299 & 7999999999 & TRN \\
\hline CHEMBL1396236 & 688885 & 5.8 & 5.8464 & TRN & \\
\hline CHEMBL491548 & 688885 & 6.1 & 6.0433 & TRN & \\
\hline CHEMBL1442992 & 688885 & 4.5 & 5.2339 & TRN & \\
\hline CHEMBL1496514 & 688885 & 6.0 & 5.6353 & TST & \\
\hline CHEMBL1318454 & 688885 & 4.9 & 5.025 & TRN & \\
\hline CHEMBL1369940 & 688885 & 5.5 & 5.5274 & TRN & \\
\hline CHEMBL1435200 & 688885 & 4.8 & 4.9132 & TST & \\
\hline CHEMBL1487532 & 688885 & 5.1 & 5.1625 & TST & \\
\hline CHEMBL472994 & 688885 & 5.7 & 5.6294 & TST & \\
\hline CHEMBL1551548 & 688885 & 4.8 & 4.802 & TRN & \\
\hline CHEMBL186872 & 688885 & 7.2 & 6.5341 & TST & \\
\hline CHEMBL1255870 & 688885 & 4.7 & 4.8969 & TST & \\
\hline CHEMBL111545 & 688885 & 5.1 & 5.2516 & TST & \\
\hline CHEMBL1180496 & 688885 & 4.4 & 4.9974 & TST & \\
\hline CHEMBL1474302 & 688885 & 4.8 & 4.7841 & TRN & \\
\hline CHEMBL1406879 & 688885 & 4.6 & 4.5941 & TRN & \\
\hline CHEMBL1367222 & 688885 & 5.3 & 5.2616 & TRN & \\
\hline CHEMBL1551065 & 688885 & 4.8 & 4.9042 & TRN & \\
\hline CHEMBL1361133 & 688885 & 5.1 & 5.0047 & TST & \\
\hline CHEMBL 294747 & 688885 & 7.4001 & 5.2481 & TRN & \\
\hline CHEMBL1535057 & 688885 & 5.1 & 5.1867 & TRN & \\
\hline CHEMBL1398467 & 688885 & 5.4 & 5.4344 & TRN & \\
\hline CHEMBL1591573 & 688885 & 4.7 & 4.6015 & TRN & \\
\hline CHEMBL1554569 & 688885 & 4.8 & 4.8772 & TRN & \\
\hline CHEMBL1612363 & 688885 & 4.4 & 4.3997 & TRN & \\
\hline CHEMBL598263 & 688885 & 4.9 & 5.0837 & TRN & \\
\hline CHEMBL323668 & 688885 & 4.8 & 5.2729 & TST & \\
\hline CHEMBL1513392 & 688885 & 5.9 & 5.6268 & TRN & \\
\hline CHEMBL1612694 & 688885 & 4.6 & 4.9137 & TRN & \\
\hline CHEMBL365739 & 688885 & 6.0 & 5.7284 & TST & \\
\hline CHEMBL1256737 & 688885 & 4.4 & 4.6997 & TST & \\
\hline CHEMBL1338311 & 688885 & 5.0 & 4.8501 & TRN & \\
\hline CHEMBL1475562 & 688885 & 6.1 & 5.7364 & TRN & \\
\hline CHEMBL285932 & 688885 & 5.7 & 5.6615 & TST & \\
\hline
\end{tabular}




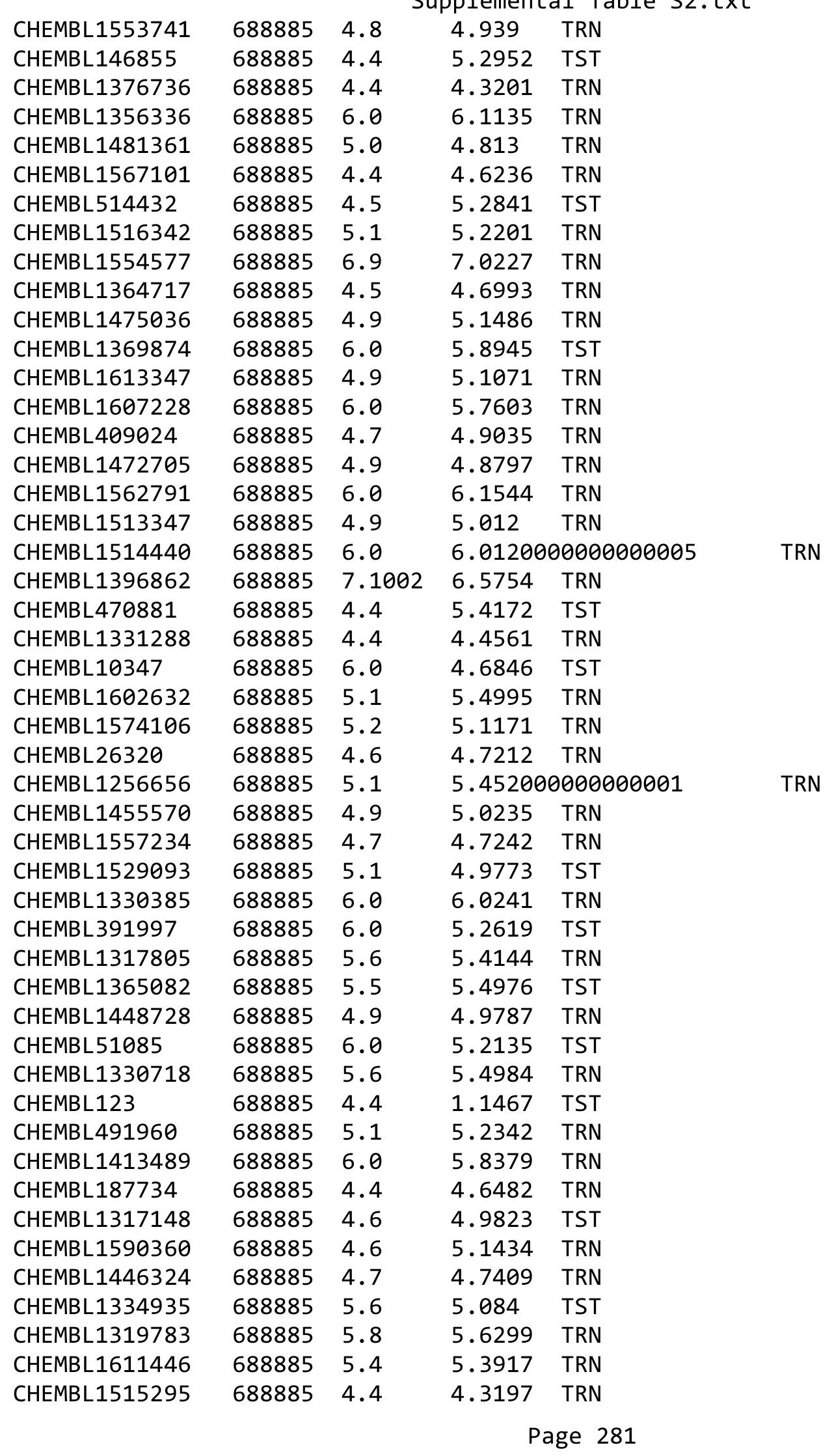




\begin{tabular}{|c|c|c|c|c|}
\hline \multicolumn{5}{|c|}{ Supplemental Table S2.txt } \\
\hline CHEMBL1520681 & 688885 & 4.9 & 4.8015 & TRN \\
\hline CHEMBL54909 & 688885 & 4.6 & 5.3351 & TRN \\
\hline CHEMBL1358462 & 688885 & 5.3 & 5.205 & TRN \\
\hline CHEMBL1316482 & 688885 & 5.9 & 5.3593 & TRN \\
\hline CHEMBL1330272 & 688885 & 5.3 & 5.6968 & TRN \\
\hline CHEMBL3198273 & 688885 & 5.8 & 5.7715 & TRN \\
\hline CHEMBL1256186 & 688885 & 4.9 & 4.9665 & TST \\
\hline CHEMBL1593837 & 688885 & 4.5 & 5.113 & TRN \\
\hline CHEMBL1569116 & 688885 & 6.1 & 5.3851 & TST \\
\hline CHEMBL1374544 & 688885 & 5.9 & 5.925 & TRN \\
\hline CHEMBL1316213 & 688885 & 5.4 & 5.5726 & TRN \\
\hline CHEMBL395808 & 688885 & 5.2 & 5.0082 & TRN \\
\hline CHEMBL1358796 & 688885 & 6.3 & 6.3747 & TRN \\
\hline CHEMBL1479771 & 688885 & 5.4 & 5.3466 & TRN \\
\hline CHEMBL1364972 & 688885 & 6.0 & 5.9525 & TRN \\
\hline CHEMBL1371604 & 688885 & 5.5 & 5.2142 & TST \\
\hline CHEMBL1569985 & 688885 & 5.9 & 5.8312 & TRN \\
\hline CHEMBL1601121 & 688885 & 6.4 & 6.0057 & TRN \\
\hline CHEMBL166161 & 688885 & 4.6 & 4.6561 & TRN \\
\hline CHEMBL1607244 & 688885 & 5.5 & 5.4637 & TRN \\
\hline CHEMBL369142 & 688885 & 4.8 & 5.0787 & TRN \\
\hline CHEMBL1605130 & 688885 & 4.4 & 4.4307 & TRN \\
\hline CHEMBL1512385 & 688885 & 4.9 & 4.976 & TRN \\
\hline CHEMBL1454730 & 688885 & 5.4 & 5.6135 & TRN \\
\hline CHEMBL1402049 & 688885 & 5.8 & 5.7632 & TRN \\
\hline CHEMBL1555132 & 688885 & 5.0 & 5.1444 & TRN \\
\hline CHEMBL126077 & 688885 & 6.0 & 4.6964 & TST \\
\hline CHEMBL1394626 & 688885 & 6.9 & 5.4617 & TRN \\
\hline CHEMBL1525813 & 688885 & 5.4 & 5.4999 & TRN \\
\hline CHEMBL164841 & 688885 & 5.6 & 5.5909 & TRN \\
\hline CHEMBL1256797 & 688885 & 4.5 & 4.5541 & TRN \\
\hline CHEMBL52387 & 688885 & 6.5 & 6.1604 & TRN \\
\hline CHEMBL1358359 & 688885 & 5.1 & 5.3054 & TST \\
\hline CHEMBL1435276 & 688885 & 4.5 & 4.5574 & TRN \\
\hline CHEMBL1551749 & 688885 & 4.8 & 5.1285 & TRN \\
\hline CHEMBL1364404 & 688885 & 5.2 & 5.3056 & TRN \\
\hline CHEMBL1096400 & 688885 & 4.9 & 5.1166 & TRN \\
\hline CHEMBL1516024 & 688885 & 4.8 & 4.9246 & TRN \\
\hline CHEMBL 2373608 & 688885 & 5.7 & 5.3423 & TRN \\
\hline CHEMBL1355139 & 688885 & 6.5 & 6.5822 & TRN \\
\hline CHEMBL1356628 & 688885 & 5.7 & 5.5785 & TRN \\
\hline CHEMBL1335668 & 688885 & 6.2 & 5.9998 & TRN \\
\hline CHEMBL1375127 & 688885 & 7.699 & 7.2231 & TRN \\
\hline CHEMBL1553404 & 688885 & 4.9 & 4.7792 & TRN \\
\hline CHEMBL1561829 & 688885 & 7.1002 & 6.6252 & TRN \\
\hline CHEMBL10284 & 688885 & 4.9 & 5.3365 & TRN \\
\hline CHEMBL45068 & 688885 & 6.0 & 5.0606 & TRN \\
\hline CHEMBL1396792 & 688885 & 5.1 & 5.1427 & TRN \\
\hline
\end{tabular}




\begin{tabular}{|c|c|c|c|c|}
\hline \multicolumn{5}{|c|}{ Supplemental Table S2.txt } \\
\hline CHEMBL1318307 & 688885 & 4.7 & 5.5078 & TST \\
\hline CHEMBL1368942 & 688885 & 6.0 & 6.0076 & TRN \\
\hline CHEMBL1488167 & 688885 & 5.5 & 5.5164 & TRN \\
\hline CHEMBL587849 & 688885 & 6.5 & 6.3371 & TRN \\
\hline CHEMBL1359713 & 688885 & 7.0 & 7.1225 & TST \\
\hline CHEMBL1455699 & 688885 & 5.4 & 5.3766 & TRN \\
\hline CHEMBL1314989 & 688885 & 6.4 & 5.2948 & TRN \\
\hline CHEMBL1257123 & 688885 & 4.8 & 4.9938 & TRN \\
\hline CHEMBL1354626 & 688885 & 5.5 & 5.6177 & TRN \\
\hline CHEMBL1370770 & 688885 & 5.0 & 5.0286 & TRN \\
\hline CHEMBL1593374 & 688885 & 5.5 & 5.0254 & TRN \\
\hline CHEMBL1554789 & 688885 & 6.0 & 5.3034 & TRN \\
\hline CHEMBL1477506 & 688885 & 5.2 & 5.4147 & TRN \\
\hline CHEMBL1452716 & 688885 & 4.8 & 5.4462 & TST \\
\hline CHEMBL1403905 & 688885 & 4.9 & 4.7929 & TRN \\
\hline CHEMBL 259140 & 688885 & 5.8 & 5.896 & TRN \\
\hline CHEMBL280563 & 688885 & 4.4 & 4.8983 & TST \\
\hline CHEMBL1556431 & 688885 & 4.9 & 4.9038 & TRN \\
\hline CHEMBL107528 & 688885 & 5.4 & 5.4043 & TRN \\
\hline CHEMBL1398321 & 688885 & 5.3 & 5.4681 & TRN \\
\hline CHEMBL1411578 & 688885 & 4.4 & 4.4791 & TST \\
\hline CHEMBL150 & 688885 & 6.0 & 8.5406 & TRN \\
\hline CHEMBL1357085 & 688885 & 5.2 & 5.4244 & TRN \\
\hline CHEMBL1317451 & 688885 & 4.6 & 4.709 & TRN \\
\hline CHEMBL 1255837 & 688885 & 6.0 & 5.875 & TST \\
\hline CHEMBL476833 & 688885 & 5.2 & 5.4054 & TST \\
\hline CHEMBL3351080 & 688885 & 5.8 & 5.6734 & TRN \\
\hline CHEMBL1415777 & 688885 & 5.7 & 5.2721 & TST \\
\hline CHEMBL1476711 & 688885 & 4.4 & 4.3762 & TRN \\
\hline CHEMBL 7463 & 688885 & 4.8 & 4.7249 & TRN \\
\hline CHEMBL553751 & 688885 & 4.8 & 4.8763 & TST \\
\hline CHEMBL1364243 & 688885 & 6.0 & 6.0725 & TRN \\
\hline CHEMBL1482582 & 688885 & 6.0 & 6.018 & TRN \\
\hline CHEMBL1490268 & 688885 & 4.7 & 4.7132 & TRN \\
\hline CHEMBL1316265 & 688885 & 4.5 & 5.2288 & TRN \\
\hline CHEMBL1603595 & 688885 & 4.5 & 4.4397 & TRN \\
\hline CHEMBL77030 & 688885 & 4.6 & 4.7748 & TRN \\
\hline CHEMBL1564178 & 688885 & 5.4 & 5.5469 & TST \\
\hline CHEMBL523167 & 688885 & 5.6 & 5.62 & TST \\
\hline CHEMBL1490386 & 688885 & 5.0 & 4.9767 & TRN \\
\hline CHEMBL1316190 & 688885 & 6.0 & 5.0844 & TRN \\
\hline CHEMBL1567600 & 688885 & 4.4 & 4.6864 & TRN \\
\hline CHEMBL1557821 & 688885 & 6.6 & 5.9892 & TRN \\
\hline CHEMBL1315091 & 688885 & 4.7 & 4.9405 & TRN \\
\hline CHEMBL1604377 & 688885 & 5.5 & 5.5758 & TRN \\
\hline CHEMBL1399994 & 688885 & 5.1 & 5.2044 & TRN \\
\hline CHEMBL411502 & 688885 & 4.6 & 4.6317 & TRN \\
\hline CHEMBL1354913 & 688885 & 7.8996 & 7.371 & TST \\
\hline
\end{tabular}




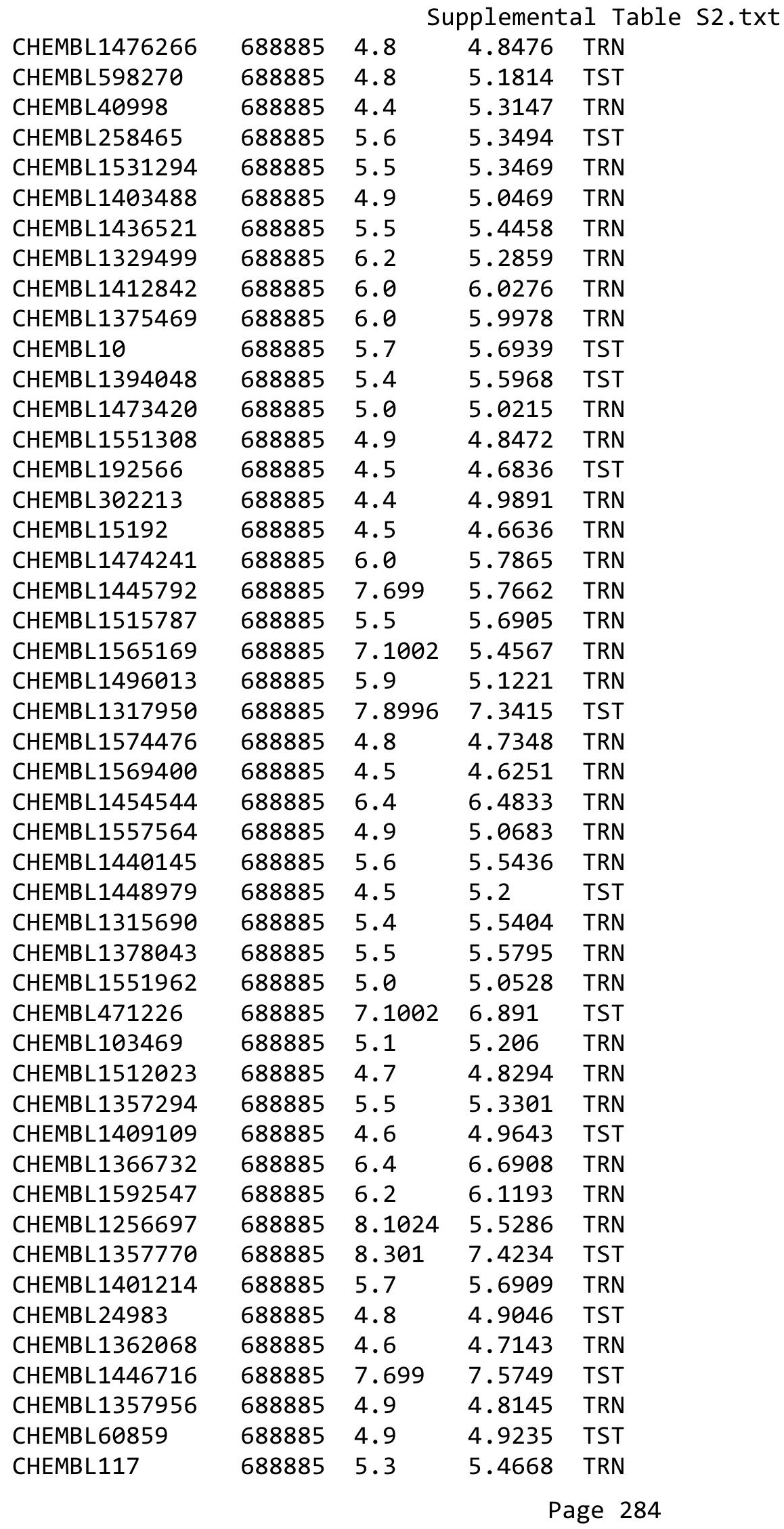




\begin{tabular}{|c|c|c|c|c|}
\hline & & & plement & \\
\hline CHEMBL16687 & 688885 & 4.5 & 4.6246 & TST \\
\hline CHEMBL253786 & 688885 & 4.6 & 5.0234 & TRN \\
\hline CHEMBL1361000 & 688885 & 5.1 & 5.1432 & TRN \\
\hline CHEMBL19980 & 688885 & 4.8 & 4.9471 & TST \\
\hline CHEMBL1606292 & 688885 & 5.1 & 5.1261 & TRN \\
\hline CHEMBL1337108 & 688885 & 5.0 & 4.9236 & TRN \\
\hline CHEMBL1486734 & 688885 & 6.1 & 6.0372 & TRN \\
\hline CHEMBL1323905 & 688885 & 4.9 & 4.9908 & TRN \\
\hline CHEMBL1354344 & 688885 & 5.4 & 5.7316 & TRN \\
\hline CHEMBL1475860 & 688885 & 5.0 & 4.8091 & TRN \\
\hline CHEMBL1354243 & 688885 & 4.5 & 5.2134 & TST \\
\hline CHEMBL1488679 & 688885 & 5.6 & 5.7451 & TST \\
\hline CHEMBL1473191 & 688885 & 6.0 & 5.6788 & TST \\
\hline CHEMBL476135 & 688885 & 5.3 & 5.2678 & TST \\
\hline CHEMBL1412519 & 688885 & 5.4 & 5.483 & TRN \\
\hline CHEMBL1182777 & 688885 & 6.8 & 6.4093 & TST \\
\hline CHEMBL1363467 & 688885 & 4.6 & 4.7638 & TRN \\
\hline CHEMBL1554982 & 688885 & 4.8 & 4.7809 & TRN \\
\hline CHEMBL399249 & 688885 & 4.9 & 5.1681 & TRN \\
\hline CHEMBL1453240 & 688885 & 4.7 & 4.8643 & TRN \\
\hline CHEMBL38576 & 688885 & 7.0 & 6.4752 & TRN \\
\hline CHEMBL1496243 & 688885 & 4.4 & 4.5622 & TRN \\
\hline CHEMBL1318421 & 688885 & 5.6 & 5.5335 & TRN \\
\hline CHEMBL1326341 & 688885 & 4.4 & 4.7191 & TRN \\
\hline CHEMBL1531299 & 688885 & 5.3 & 5.4854 & TRN \\
\hline CHEMBL1558135 & 688885 & 4.5 & 4.7527 & TRN \\
\hline CHEMBL1474498 & 688885 & 4.6 & 5.1092 & TST \\
\hline CHEMBL1369414 & 688885 & 6.2 & 5.9609 & TRN \\
\hline CHEMBL1477492 & 688885 & 5.3 & 5.0834 & TRN \\
\hline CHEMBL1551639 & 688885 & 5.1 & 5.2418 & TRN \\
\hline CHEMBL16671 & 688885 & 5.6 & 5.7068 & TRN \\
\hline CHEMBL1398185 & 688885 & 5.0 & 5.296 & TRN \\
\hline CHEMBL1316775 & 688885 & 4.4 & 4.5642 & TRN \\
\hline CHEMBL1483672 & 688885 & 5.3 & 5.5167 & TST \\
\hline CHEMBL1357676 & 688885 & 4.7 & 4.7482 & TRN \\
\hline CHEMBL1371710 & 688885 & 5.3 & 5.2426 & TRN \\
\hline CHEMBL1473755 & 688885 & 6.1 & 6.0937 & TRN \\
\hline CHEMBL269521 & 688885 & 5.7 & 5.5252 & TRN \\
\hline CHEMBL1399619 & 688885 & 5.8 & 5.7328 & TRN \\
\hline CHEMBL1482184 & 688885 & 4.8 & 5.2355 & TST \\
\hline CHEMBL1480903 & 688885 & 6.2 & 6.0588 & TRN \\
\hline CHEMBL1554659 & 688885 & 4.8 & 4.8035 & TRN \\
\hline CHEMBL1572988 & 688885 & 4.4 & 4.3905 & TRN \\
\hline CHEMBL1450004 & 688885 & 7.8996 & 5.5831 & TST \\
\hline CHEMBL1594372 & 688885 & 5.8 & 6.0502 & TRN \\
\hline CHEMBL1370553 & 688885 & 4.5 & 4.4016 & TRN \\
\hline CHEMBL1473055 & 688885 & 4.6 & 4.7218 & TRN \\
\hline CHEMBL1358487 & 688885 & 5.1 & 5.3151 & TRN \\
\hline
\end{tabular}




\begin{tabular}{|c|c|c|c|c|}
\hline & & & & $a \perp 1 a$ \\
\hline CHEMBL1529609 & 688885 & 5.2 & 5.2817 & TST \\
\hline CHEMBL1415728 & 688885 & 5.3 & 5.1398 & TRN \\
\hline CHEMBL1478772 & 688885 & 4.8 & 4.8187 & TRN \\
\hline CHEMBL1256364 & 688885 & 4.7 & 4.8061 & TRN \\
\hline CHEMBL1331618 & 688885 & 5.5 & 5.4792 & TRN \\
\hline CHEMBL1331301 & 688885 & 5.5 & 5.4474 & TRN \\
\hline CHEMBL1357044 & 688885 & 5.5 & 5.5134 & TST \\
\hline CHEMBL1533895 & 688885 & 4.4 & 5.4393 & TRN \\
\hline CHEMBL1451562 & 688885 & 4.5 & 4.6602 & TRN \\
\hline CHEMBL1332346 & 688885 & 5.0 & 5.0245 & TRN \\
\hline CHEMBL567331 & 688885 & 6.1 & 6.2809 & TRN \\
\hline CHEMBL1561402 & 688885 & 4.6 & 4.6734 & TRN \\
\hline CHEMBL1288013 & 688885 & 5.1 & 5.2684 & TRN \\
\hline CHEMBL1573532 & 688885 & 5.7 & 5.8859 & TRN \\
\hline CHEMBL1555369 & 688885 & 5.5 & 5.5229 & TRN \\
\hline CHEMBL93655 & 688885 & 5.6 & 5.4381 & TRN \\
\hline CHEMBL1480293 & 688885 & 4.8 & 4.9237 & TRN \\
\hline CHEMBL1334847 & 688885 & 4.7 & 4.7661 & TRN \\
\hline CHEMBL1358807 & 688885 & 5.2 & 5.1628 & TRN \\
\hline CHEMBL1567176 & 688885 & 4.5 & 4.4751 & TRN \\
\hline CHEMBL1598334 & 688885 & 5.0 & 4.9573 & TRN \\
\hline CHEMBL1333061 & 688885 & 4.8 & 4.7897 & TRN \\
\hline CHEMBL1551575 & 688885 & 5.8 & 5.3874 & TRN \\
\hline CHEMBL1336932 & 688885 & 4.6 & 4.6028 & TRN \\
\hline CHEMBL1354408 & 688885 & 5.8 & 5.6184 & TRN \\
\hline CHEMBL1526213 & 688885 & 5.7 & 5.7045 & TRN \\
\hline CHEMBL1373326 & 688885 & 6.2 & 6.1941 & TRN \\
\hline CHEMBL1589879 & 688885 & 5.2 & 5.4006 & TRN \\
\hline CHEMBL1552551 & 688885 & 5.3 & 5.4719 & TRN \\
\hline CHEMBL117405 & 688885 & 4.4 & 5.3263 & TRN \\
\hline CHEMBL1336787 & 688885 & 5.0 & 5.1321 & TRN \\
\hline CHEMBL 2028181 & 688885 & 5.7 & 5.6675 & TST \\
\hline CHEMBL1593068 & 688885 & 5.2 & 5.3782 & TRN \\
\hline CHEMBL3392050 & 688885 & 4.4 & 5.2815 & TRN \\
\hline CHEMBL1403280 & 688885 & 5.1 & 5.0687 & TRN \\
\hline CHEMBL1395567 & 688885 & 5.6 & 5.4431 & TRN \\
\hline CHEMBL3212645 & 688885 & 5.4 & 5.4717 & TRN \\
\hline CHEMBL3197283 & 688885 & 5.3 & 5.4941 & TRN \\
\hline CHEMBL1412390 & 688885 & 5.9 & 6.1874 & TRN \\
\hline CHEMBL1515526 & 688885 & 5.8 & 5.7572 & TRN \\
\hline CHEMBL1359843 & 688885 & 5.0 & 5.0416 & TRN \\
\hline CHEMBL1551515 & 688885 & 5.9 & 6.0337 & TRN \\
\hline CHEMBL1337629 & 688885 & 5.5 & 5.6217 & TRN \\
\hline CHEMBL1373464 & 688885 & 4.4 & 4.6079 & TRN \\
\hline CHEMBL1371944 & 688885 & 5.3 & 5.2948 & TRN \\
\hline CHEMBL1516179 & 688885 & 4.9 & 5.0007 & TRN \\
\hline CHEMBL1331583 & 688885 & 5.6 & 5.2661 & TRN \\
\hline CHEMBL1524331 & 688885 & 5.5 & 5.4134 & TRN \\
\hline
\end{tabular}




\begin{tabular}{|c|c|c|c|c|}
\hline \multirow[b]{2}{*}{ CHEMBL1475788 } & & & pplement & al $\mathrm{Ta}$ \\
\hline & 688885 & 4.9 & 4.9279 & TRN \\
\hline CHEMBL1314971 & 688885 & 5.0 & 4.8229 & TRN \\
\hline CHEMBL489534 & 688885 & 6.2 & 6.4546 & TRN \\
\hline CHEMBL1533335 & 688885 & 6.0 & 6.2003 & TRN \\
\hline CHEMBL1554936 & 688885 & 5.6 & 5.6035 & TRN \\
\hline CHEMBL1315833 & 688885 & 4.9 & 5.1013 & TRN \\
\hline CHEMBL447347 & 688885 & 5.7 & 5.6135 & TRN \\
\hline CHEMBL1407011 & 688885 & 4.8 & 4.9041 & TST \\
\hline CHEMBL1337713 & 688885 & 4.7 & 4.7683 & TRN \\
\hline CHEMBL1596241 & 688885 & 6.1 & 6.2078 & TRN \\
\hline CHEMBL1534872 & 688885 & 4.5 & 4.5319 & TST \\
\hline CHEMBL510275 & 688885 & 4.6 & 5.3411 & TST \\
\hline CHEMBL1491965 & 688885 & 4.9 & 5.1048 & TRN \\
\hline CHEMBL1256646 & 688885 & 4.5 & 4.5276 & TST \\
\hline CHEMBL1565914 & 688885 & 5.2 & 5.2846 & TRN \\
\hline CHEMBL1590975 & 688885 & 5.5 & 5.3359 & TRN \\
\hline CHEMBL1256727 & 688885 & 5.7 & 5.4113 & TRN \\
\hline CHEMBL42485 & 688885 & 6.1 & 6.0957 & TST \\
\hline CHEMBL1479088 & 688885 & 5.2 & 5.1552 & TRN \\
\hline CHEMBL1562088 & 688885 & 5.1 & 5.0436 & TST \\
\hline CHEMBL1553056 & 688885 & 7.1002 & 6.4414 & TRN \\
\hline CHEMBL1451794 & 688885 & 5.6 & 5.6041 & TRN \\
\hline CHEMBL 286722 & 688885 & 4.4 & 4.5853 & TRN \\
\hline CHEMBL1512702 & 688885 & 5.2 & 5.0117 & TRN \\
\hline CHEMBL1449838 & 688885 & 5.5 & 5.6202 & TRN \\
\hline CHEMBL1328286 & 688885 & 5.7 & 5.7016 & TRN \\
\hline CHEMBL1492577 & 688885 & 5.7 & 5.8502 & TRN \\
\hline CHEMBL1605152 & 688885 & 5.7 & 5.9345 & TRN \\
\hline CHEMBL1357429 & 688885 & 6.5 & 6.2052 & TRN \\
\hline CHEMBL1453244 & 688885 & 5.3 & 5.2317 & TRN \\
\hline CHEMBL1408013 & 688885 & 6.0 & 6.0845 & TRN \\
\hline CHEMBL1607623 & 688885 & 5.5 & 5.4312 & TRN \\
\hline CHEMBL1520347 & 688885 & 4.5 & 4.5134 & TRN \\
\hline CHEMBL140 & 688885 & 5.9 & 5.2803 & TRN \\
\hline CHEMBL1435509 & 688885 & 5.9 & 5.5838 & TRN \\
\hline CHEMBL1475146 & 688885 & 6.3 & 6.2519 & TRN \\
\hline CHEMBL1452910 & 688885 & 5.0 & 5.063 & TRN \\
\hline CHEMBL1417025 & 688885 & 5.5 & 5.566 & TRN \\
\hline CHEMBL1318222 & 688885 & 5.4 & 5.1936 & TRN \\
\hline CHEMBL1602112 & 688885 & 4.7 & 4.7558 & TRN \\
\hline CHEMBL1513643 & 688885 & 5.5 & 5.4948 & TRN \\
\hline CHEMBL475375 & 688885 & 6.4 & 6.7066 & TRN \\
\hline CHEMBL253998 & 688885 & 5.5 & 5.466 & TRN \\
\hline CHEMBL 330320 & 688885 & 4.4 & 5.2919 & TST \\
\hline CHEMBL1554721 & 688885 & 6.1 & 6.1596 & TRN \\
\hline CHEMBL1569972 & 688885 & 4.9 & 5.0654 & TRN \\
\hline CHEMBL1435381 & 688885 & 4.8 & 5.2649 & TRN \\
\hline CHEMBL1437436 & 688885 & 5.5 & 5.6143 & TRN \\
\hline
\end{tabular}




\begin{tabular}{|c|c|c|c|c|}
\hline & & & & al Table S2 \\
\hline CHEMBL1611946 & 688885 & 6.2 & 5.6198 & TRN \\
\hline CHEMBL 188 & 688885 & 5.9 & 5.8645 & TST \\
\hline CHEMBL1443628 & 688885 & 5.7 & 5.6762 & TRN \\
\hline CHEMBL512832 & 688885 & 5.5 & 5.5126 & TRN \\
\hline CHEMBL1357183 & 688885 & 4.4 & 5.0216 & TST \\
\hline CHEMBL486817 & 688885 & 4.8 & 5.0805 & TST \\
\hline CHEMBL151 & 688885 & 4.5 & 5.5026 & TRN \\
\hline CHEMBL288174 & 688885 & 4.9 & 5.0526 & TST \\
\hline CHEMBL1356113 & 688885 & 5.7 & 5.6798 & TRN \\
\hline CHEMBL242384 & 688885 & 4.9 & 5.1968 & TRN \\
\hline CHEMBL457665 & 688885 & 4.9 & 4.9126 & TRN \\
\hline CHEMBL1354414 & 688885 & 5.3 & 5.394 & TRN \\
\hline CHEMBL86676 & 688885 & 6.0 & 4.7988 & TRN \\
\hline CHEMBL1399511 & 688885 & 6.9 & 5.2264 & TST \\
\hline CHEMBL1395137 & 688885 & 5.0 & 4.8943 & TRN \\
\hline CHEMBL1487801 & 688885 & 5.1 & 5.0058 & TRN \\
\hline CHEMBL1367030 & 688885 & 5.1 & 5.1287 & TRN \\
\hline CHEMBL1552314 & 688885 & 4.8 & 4.6602 & TRN \\
\hline CHEMBL17002 & 688885 & 4.4 & 4.7996 & TRN \\
\hline CHEMBL1332591 & 688885 & 6.6 & 6.4111 & TRN \\
\hline CHEMBL1560095 & 688885 & 4.4 & 4.5718 & TRN \\
\hline CHEMBL186526 & 688885 & 4.8 & 5.6347 & TRN \\
\hline CHEMBL1401483 & 688885 & 4.4 & 4.4457 & TRN \\
\hline CHEMBL429711 & 688885 & 4.5 & 4.8944 & TRN \\
\hline CHEMBL 1356331 & 688885 & 5.8 & 5.7593 & TRN \\
\hline CHEMBL1367984 & 688885 & 5.2 & 5.26200 & 20000000005 \\
\hline CHEMBL491953 & 688885 & 6.3 & 6.4581 & TRN \\
\hline CHEMBL1605356 & 688885 & 5.0 & 4.9155 & TRN \\
\hline CHEMBL1589942 & 688885 & 5.4 & 5.5142 & TST \\
\hline CHEMBL1603627 & 688885 & 4.9 & 4.8659 & TRN \\
\hline CHEMBL1332964 & 688885 & 4.9 & 4.8928 & TRN \\
\hline CHEMBL1532016 & 688885 & 5.1 & 5.2674 & TRN \\
\hline CHEMBL1519978 & 688885 & 5.1 & 5.0567 & TRN \\
\hline CHEMBL577455 & 688885 & 4.5 & 4.6652 & TST \\
\hline CHEMBL1416639 & 688885 & 4.5 & 4.5896 & TRN \\
\hline CHEMBL1354398 & 688885 & 5.4 & 5.5522 & TRN \\
\hline CHEMBL1569585 & 688885 & 5.4 & 5.3399 & TRN \\
\hline CHEMBL1406556 & 688885 & 5.5 & 5.3464 & TRN \\
\hline CHEMBL1590397 & 688885 & 5.6 & 5.7092 & TRN \\
\hline CHEMBL 243664 & 688885 & 5.9 & 5.9132 & TRN \\
\hline CHEMBL1590663 & 688885 & 4.6 & 4.357 & TRN \\
\hline CHEMBL1397559 & 688885 & 4.6 & 4.5449 & TST \\
\hline CHEMBL321820 & 688885 & 4.9 & 4.9952 & TST \\
\hline CHEMBL1611449 & 688885 & 5.8 & 5.1789 & TRN \\
\hline CHEMBL1593827 & 688885 & 5.8 & 5.9638 & TRN \\
\hline CHEMBL1321338 & 688885 & 4.4 & 4.5962 & TRN \\
\hline CHEMBL1324022 & 688885 & 4.5 & 4.5691 & TRN \\
\hline CHEMBL1316463 & 688885 & 4.8 & 5.1005 & TRN \\
\hline
\end{tabular}




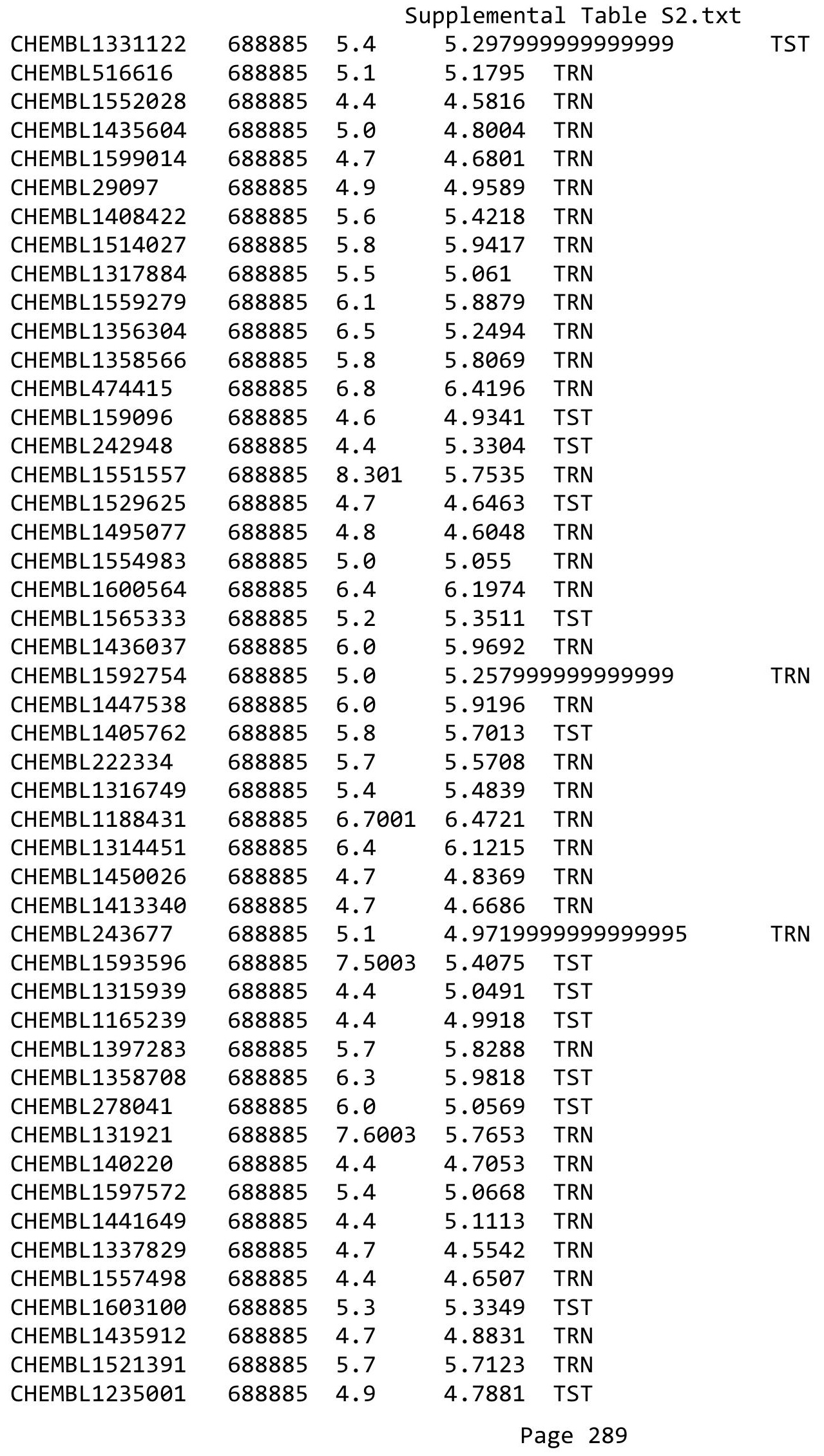




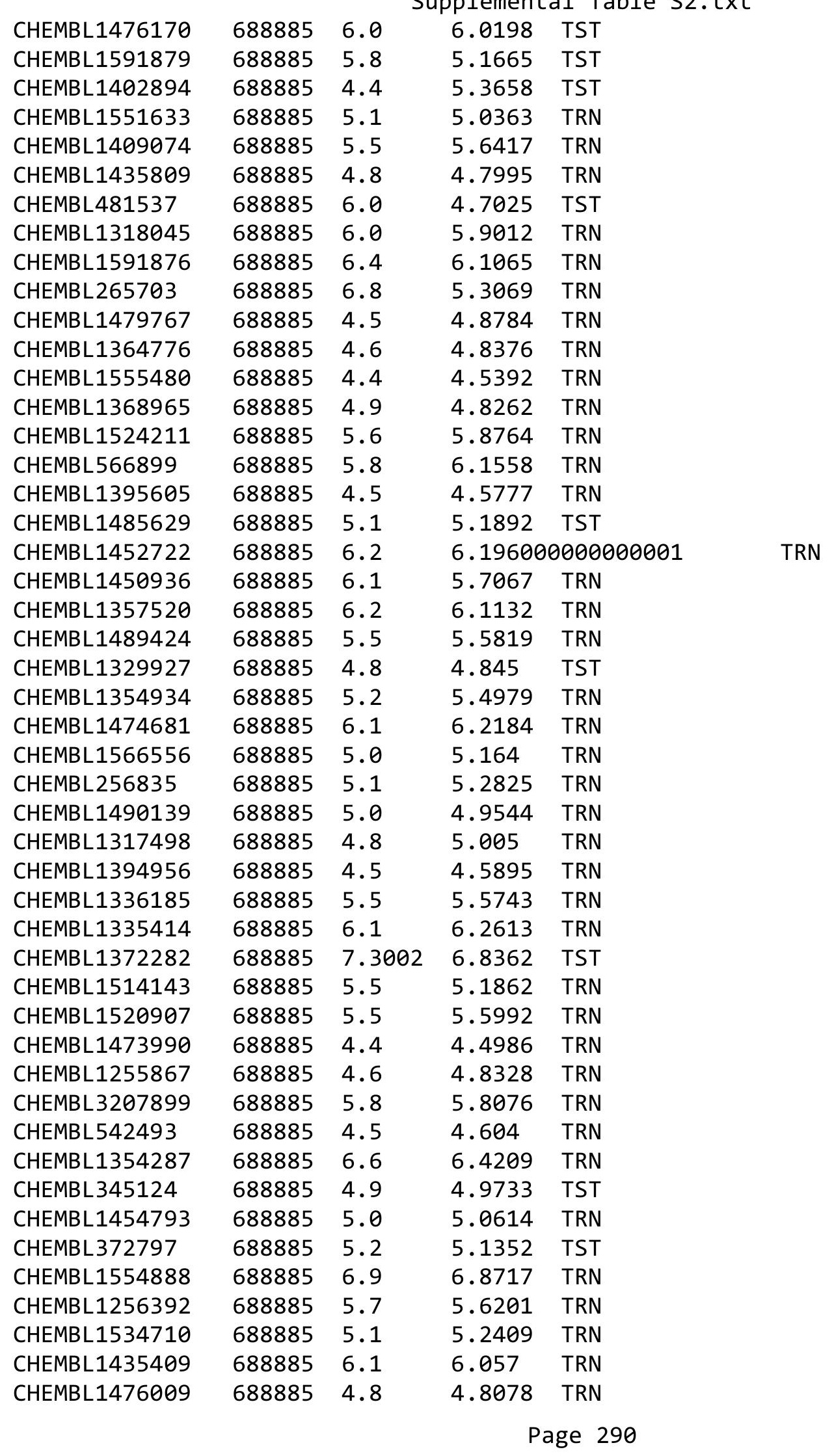




\begin{tabular}{|c|c|c|c|c|c|}
\hline & & & & & \\
\hline CHEMBL311489 & 688885 & 5.5 & 5.4924 & TRN & \\
\hline CHEMBL1608678 & 688885 & 5.1 & 5.0155 & TRN & \\
\hline CHEMBL317221 & 688885 & 5.7 & 5.2116 & TRN & \\
\hline CHEMBL1481127 & 688885 & 4.9 & 4.9288 & TRN & \\
\hline CHEMBL 39372 & 688885 & 4.8 & 5.0675 & TRN & \\
\hline CHEMBL1378764 & 688885 & 5.2 & 5.0496 & TRN & \\
\hline CHEMBL1356106 & 688885 & 5.0 & 5.0501 & TST & \\
\hline CHEMBL1405464 & 688885 & 5.6 & 5.74200 & 0000000001 & TRN \\
\hline CHEMBL1361731 & 688885 & 4.8 & 4.8472 & TRN & \\
\hline CHEMBL1354572 & 688885 & 5.2 & 5.1945 & TRN & \\
\hline CHEMBL1395882 & 688885 & 4.9 & 4.95 & TRN & \\
\hline CHEMBL1356744 & 688885 & 6.2 & 6.1953 & TRN & \\
\hline CHEMBL1525388 & 688885 & 4.4 & 5.2056 & TRN & \\
\hline CHEMBL1453542 & 688885 & 5.0 & 5.0753 & TRN & \\
\hline CHEMBL1521453 & 688885 & 6.0 & 5.5123 & TST & \\
\hline CHEMBL1326360 & 688885 & 4.8 & 4.7124 & TRN & \\
\hline CHEMBL23731 & 688885 & 4.9 & 4.9099 & TRN & \\
\hline CHEMBL1596743 & 688885 & 4.9 & 4.8999 & TRN & \\
\hline CHEMBL1358568 & 688885 & 6.0 & 5.9872 & TRN & \\
\hline CHEMBL1396090 & 688885 & 4.6 & 4.6687 & TRN & \\
\hline CHEMBL1412477 & 688885 & 6.5 & 6.0068 & TRN & \\
\hline CHEMBL1590181 & 688885 & 5.1 & 5.1 & TRN & \\
\hline CHEMBL1439839 & 688885 & 4.7 & 4.7708 & TRN & \\
\hline CHEMBL113180 & 688885 & 4.5 & 4.7316 & TRN & \\
\hline CHEMBL409902 & 688885 & 4.9 & 4.7777 & TRN & \\
\hline CHEMBL1593545 & 688885 & 7.8013 & 4.9176 & TRN & \\
\hline CHEMBL1473743 & 688885 & 5.3 & 5.2174 & TST & \\
\hline CHEMBL1551036 & 688885 & 4.8 & 4.6327 & TRN & \\
\hline CHEMBL1304918 & 688885 & 5.4 & 5.4899 & TRN & \\
\hline CHEMBL1363513 & 688885 & 4.4 & 4.466 & TRN & \\
\hline CHEMBL1314222 & 688885 & 6.3 & 6.3891 & TRN & \\
\hline CHEMBL1609528 & 688885 & 5.0 & 4.9431 & TRN & \\
\hline CHEMBL1495675 & 688885 & 4.4 & 5.1253 & TRN & \\
\hline CHEMBL1358012 & 688885 & 6.0 & 4.8595 & TST & \\
\hline CHEMBL1397623 & 688885 & 5.5 & 5.4143 & TRN & \\
\hline CHEMBL608555 & 688885 & 5.0 & 4.9652 & TRN & \\
\hline CHEMBL 276140 & 688885 & 8.2007 & 7.4616 & TST & \\
\hline CHEMBL567175 & 688885 & 6.0 & 5.5363 & TST & \\
\hline CHEMBL1474169 & 688885 & 4.9 & 5.0442 & TRN & \\
\hline CHEMBL1398022 & 688885 & 5.1 & 5.3708 & TRN & \\
\hline CHEMBL1484196 & 688885 & 5.4 & 5.4253 & TRN & \\
\hline CHEMBL1410398 & 688885 & 5.2 & 5.2968 & TST & \\
\hline CHEMBL294649 & 688885 & 4.9 & 5.2281 & TST & \\
\hline CHEMBL1414073 & 688885 & 4.9 & 4.9978 & TRN & \\
\hline CHEMBL1407527 & 688885 & 5.1 & 4.9848 & TRN & \\
\hline CHEMBL1514090 & 688885 & 4.8 & 4.8318 & TST & \\
\hline CHEMBL1361596 & 688885 & 4.9 & 5.7718 & TST & \\
\hline CHEMBL1554664 & 688885 & 5.9 & 6.16799 & 9999999999 & TRN \\
\hline & & & & se 291 & \\
\hline
\end{tabular}




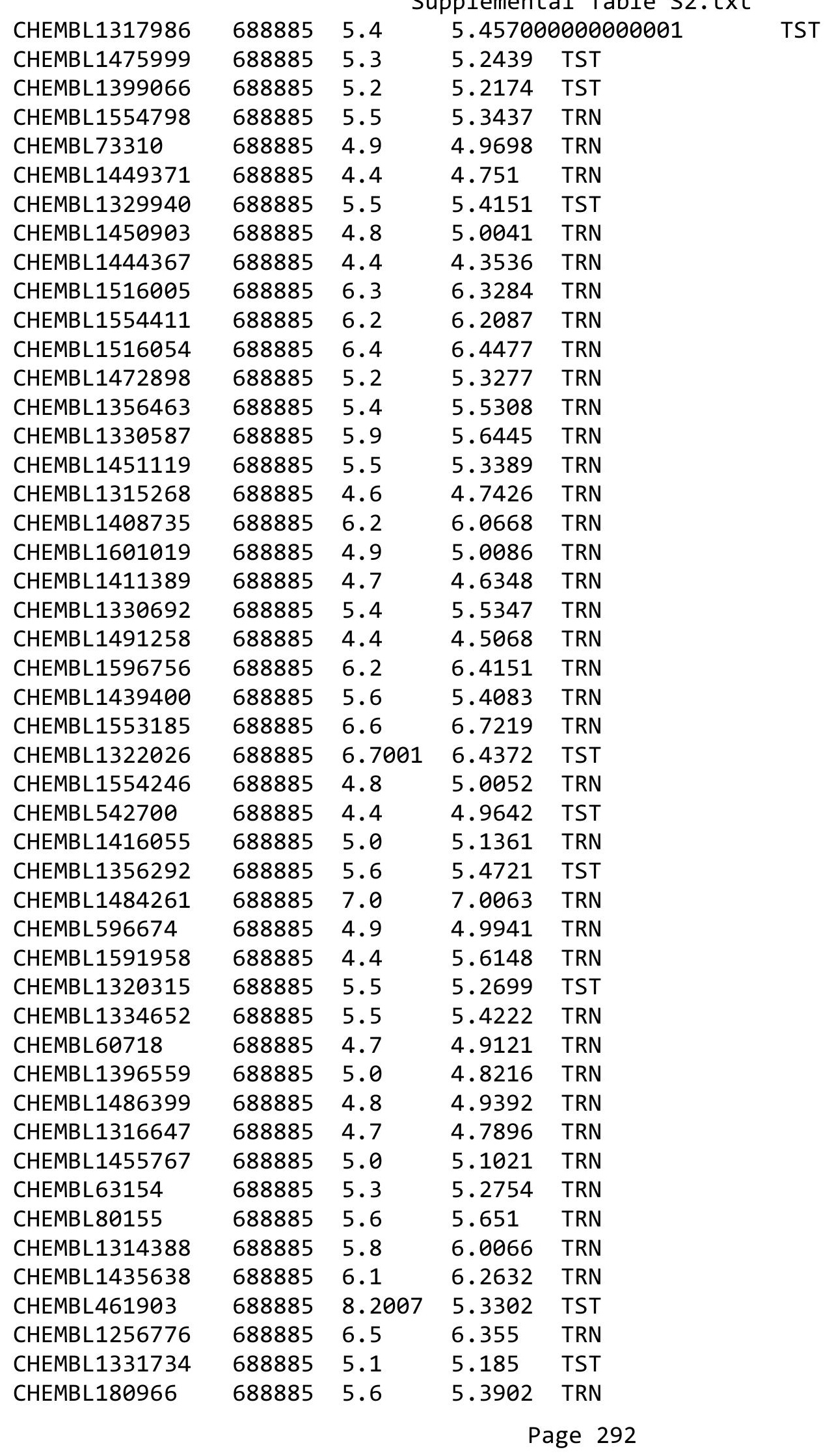




\begin{tabular}{|c|c|c|c|c|c|}
\hline \multirow{2}{*}{\multicolumn{2}{|c|}{ CHEMBL441282 }} & \\
\hline & & 5.5 & 5.0115 & TST & \\
\hline CHEMBL1499077 & 688885 & 6.5 & 6.5681 & TRN & \\
\hline CHEMBL1533232 & 688885 & 5.5 & 5.38399 & 99999999995 & TRN \\
\hline CHEMBL399491 & 688885 & 6.0 & 5.7299 & TST & \\
\hline CHEMBL1334357 & 688885 & 5.5 & 5.5619 & TRN & \\
\hline CHEMBL1354154 & 688885 & 6.1 & 6.3181 & TRN & \\
\hline CHEMBL1318480 & 688885 & 5.6 & 5.9601 & TRN & \\
\hline CHEMBL1490024 & 688885 & 5.3 & 5.1469 & TRN & \\
\hline CHEMBL1483625 & 688885 & 4.8 & 4.6563 & TRN & \\
\hline CHEMBL 275006 & 688885 & 5.9 & 5.5578 & TRN & \\
\hline CHEMBL44 & 688885 & 6.0 & 5.9613 & TRN & \\
\hline CHEMBL1409261 & 688885 & 5.5 & 5.5292 & TRN & \\
\hline CHEMBL 286615 & 688885 & 4.8 & 4.8849 & TRN & \\
\hline CHEMBL1590156 & 688885 & 6.5 & 6.5502 & TRN & \\
\hline CHEMBL1551818 & 688885 & 5.9 & 4.6909 & TRN & \\
\hline CHEMBL1270168 & 688885 & 5.5 & 5.3239 & TRN & \\
\hline CHEMBL1354693 & 688885 & 5.4 & 5.3824 & TRN & \\
\hline CHEMBL1594149 & 688885 & 4.5 & 4.5986 & TST & \\
\hline CHEMBL1411360 & 688885 & 8.3979 & 5.2847 & TRN & \\
\hline CHEMBL1417865 & 688885 & 5.4 & 5.1213 & TRN & \\
\hline CHEMBL1473707 & 688885 & 5.6 & 5.5225 & TRN & \\
\hline CHEMBL1409369 & 688885 & 5.5 & 5.5547 & TRN & \\
\hline CHEMBL1256359 & 688885 & 4.4 & 4.6618 & TRN & \\
\hline CHEMBL1447946 & 688885 & 5.0 & 4.9483 & TRN & \\
\hline CHEMBL1519435 & 688885 & 6.3 & 6.2419 & TRN & \\
\hline CHEMBL1478504 & 688885 & 5.3 & 5.3576 & TRN & \\
\hline CHEMBL1534630 & 688885 & 4.7 & 4.8046 & TST & \\
\hline CHEMBL1318512 & 688885 & 5.5 & 5.5355 & TRN & \\
\hline CHEMBL1485850 & 688885 & 4.8 & 4.7623 & TRN & \\
\hline CHEMBL1447746 & 688885 & 5.2 & 5.3935 & TRN & \\
\hline CHEMBL1517187 & 688885 & 4.9 & 5.2649 & TRN & \\
\hline CHEMBL1316796 & 688885 & 5.0 & 4.9393 & TRN & \\
\hline CHEMBL1172911 & 688885 & 5.5 & 5.5871 & TRN & \\
\hline CHEMBL1435654 & 688885 & 5.6 & 5.2952 & TRN & \\
\hline CHEMBL1554308 & 688885 & 5.5 & 5.0492 & TRN & \\
\hline CHEMBL1402656 & 688885 & 4.4 & 4.6811 & TRN & \\
\hline CHEMBL1434022 & 688885 & 4.7 & 4.6574 & TRN & \\
\hline CHEMBL1593019 & 688885 & 4.4 & 4.57600 & 20000000005 & TRN \\
\hline CHEMBL75967 & 688885 & 6.0 & 5.8081 & TST & \\
\hline CHEMBL 33884 & 688885 & 5.0 & 5.3086 & TST & \\
\hline CHEMBL1436506 & 688885 & 5.2 & 5.3138 & TST & \\
\hline CHEMBL1526455 & 688885 & 4.9 & 5.3496 & TRN & \\
\hline CHEMBL1525024 & 688885 & 5.6 & 5.4624 & TST & \\
\hline CHEMBL1527565 & 688885 & 5.9 & 5.8356 & TRN & \\
\hline CHEMBL1414185 & 688885 & 5.5 & 5.4515 & TST & \\
\hline CHEMBL1370229 & 688885 & 5.5 & 5.5469 & TRN & \\
\hline CHEMBL1476958 & 688885 & 4.5 & 4.3384 & TRN & \\
\hline CHEMBL1476762 & 688885 & 4.5 & 5.01399 & 9999999999 & TRN \\
\hline & & & & ge 293 & \\
\hline
\end{tabular}




\begin{tabular}{|c|c|c|c|c|}
\hline & & & lement & al Ta \\
\hline CHEMBL1329108 & 688885 & 4.9 & 5.0329 & TRN \\
\hline CHEMBL1417375 & 688885 & 5.5 & 5.5135 & TRN \\
\hline CHEMBL1603582 & 688885 & 4.8 & 4.7748 & TST \\
\hline CHEMBL1493707 & 688885 & 5.6 & 5.5636 & TRN \\
\hline CHEMBL1413165 & 688885 & 5.5 & 5.5415 & TRN \\
\hline CHEMBL1593918 & 688885 & 4.4 & 5.0883 & TRN \\
\hline CHEMBL1512434 & 688885 & 6.0 & 5.9103 & TRN \\
\hline CHEMBL1331112 & 688885 & 5.0 & 4.9003 & TST \\
\hline CHEMBL22870 & 688885 & 4.9 & 5.1036 & TRN \\
\hline CHEMBL1396203 & 688885 & 6.1 & 6.2745 & TRN \\
\hline CHEMBL1493496 & 688885 & 5.4 & 5.4386 & TRN \\
\hline CHEMBL1476146 & 688885 & 4.9 & 4.8221 & TRN \\
\hline CHEMBL1590968 & 688885 & 5.0 & 4.9317 & TRN \\
\hline CHEMBL1736254 & 688885 & 5.8 & 5.829 & TST \\
\hline CHEMBL1553498 & 688885 & 7.0 & 6.4665 & TRN \\
\hline CHEMBL1316337 & 688885 & 4.9 & 4.9022 & TRN \\
\hline CHEMBL1332504 & 688885 & 5.8 & 5.7077 & TRN \\
\hline CHEMBL1570196 & 688885 & 5.0 & 5.1943 & TST \\
\hline CHEMBL1594258 & 688885 & 5.5 & 5.1962 & TRN \\
\hline CHEMBL1475657 & 688885 & 5.1 & 5.1509 & TRN \\
\hline CHEMBL1364168 & 688885 & 4.8 & 4.8528 & TRN \\
\hline CHEMBL1407576 & 688885 & 5.1 & 5.2963 & TST \\
\hline CHEMBL1517765 & 688885 & 4.9 & 5.1123 & TRN \\
\hline CHEMBL489934 & 688885 & 6.8 & 6.9236 & TRN \\
\hline CHEMBL1474318 & 688885 & 6.6 & 5.1115 & TRN \\
\hline CHEMBL1326815 & 688885 & 5.5 & 5.5933 & TRN \\
\hline CHEMBL491578 & 688885 & 6.1 & 6.3093 & TRN \\
\hline CHEMBL1474230 & 688885 & 5.2 & 5.2784 & TST \\
\hline CHEMBL1329110 & 688885 & 6.1 & 5.6938 & TRN \\
\hline CHEMBL 2374062 & 688885 & 4.6 & 4.8731 & TST \\
\hline CHEMBL1609700 & 688885 & 4.7 & 4.8677 & TRN \\
\hline CHEMBL1408138 & 688885 & 5.4 & 5.3291 & TST \\
\hline CHEMBL1555537 & 688885 & 5.2 & 5.3322 & TST \\
\hline CHEMBL1409996 & 688885 & 5.0 & 5.2139 & TRN \\
\hline CHEMBL1410910 & 688885 & 5.7 & 5.6269 & TRN \\
\hline CHEMBL1435254 & 688885 & 5.7 & 5.7507 & TRN \\
\hline CHEMBL1314211 & 688885 & 6.4 & 6.5651 & TRN \\
\hline CHEMBL 7257 & 688885 & 4.4 & 5.3581 & TRN \\
\hline CHEMBL1365537 & 688885 & 5.4 & 5.6108 & TRN \\
\hline CHEMBL1603393 & 688885 & 5.1 & 4.9499 & TRN \\
\hline CHEMBL1414993 & 688885 & 5.2 & 5.2506 & TRN \\
\hline CHEMBL1314906 & 688885 & 5.0 & 4.8841 & TRN \\
\hline CHEMBL1396577 & 688885 & 5.2 & 5.1931 & TRN \\
\hline CHEMBL1373621 & 688885 & 5.0 & 5.0344 & TRN \\
\hline CHEMBL1730100 & 688885 & 5.4 & 5.3437 & TST \\
\hline CHEMBL1405909 & 688885 & 4.6 & 4.7851 & TRN \\
\hline CHEMBL 245121 & 688885 & 5.6 & 5.3276 & TRN \\
\hline CHEMBL1484689 & 688885 & 4.5 & 4.7033 & TRN \\
\hline
\end{tabular}




\begin{tabular}{|c|c|c|c|c|c|}
\hline & & \multicolumn{4}{|c|}{ Supplemental Table S2.txt } \\
\hline CHEMBL1570525 & 688885 & 8.6021 & 5.2157 & TST & \\
\hline CHEMBL1361855 & 688885 & 5.5 & 5.5347 & TRN & \\
\hline CHEMBL1524001 & 688885 & 5.0 & 4.9261 & TRN & \\
\hline CHEMBL1477140 & 688885 & 6.0 & 5.9343 & TRN & \\
\hline CHEMBL1395430 & 688885 & 5.4 & 5.2353 & TRN & \\
\hline CHEMBL1408703 & 688885 & 4.5 & 4.5838 & TRN & \\
\hline CHEMBL1526964 & 688885 & 5.6 & 5.4665 & TST & \\
\hline CHEMBL1436361 & 688885 & 4.6 & 4.8791 & TRN & \\
\hline CHEMBL1551980 & 688885 & 4.5 & 4.5653 & TRN & \\
\hline CHEMBL1395107 & 688885 & 6.2 & 5.7511 & TRN & \\
\hline CHEMBL1493939 & 688885 & 4.8 & 5.0865 & TRN & \\
\hline CHEMBL1531070 & 688885 & 5.1 & 5.1796 & TRN & \\
\hline CHEMBL1316408 & 688885 & 5.9 & 6.0847 & TRN & \\
\hline CHEMBL1395634 & 688885 & 6.0 & 6.0913 & TRN & \\
\hline CHEMBL1436272 & 688885 & 6.2 & 6.2561 & TRN & \\
\hline CHEMBL1456872 & 688885 & 6.9 & 7.0213 & TRN & \\
\hline CHEMBL1490869 & 688885 & 4.9 & 4.9639 & TRN & \\
\hline CHEMBL1604074 & 688885 & 5.0 & 4.9667 & TST & \\
\hline CHEMBL1611893 & 688885 & 8.1024 & 5.5376 & TRN & \\
\hline CHEMBL1409961 & 688885 & 5.1 & 5.2161 & TRN & \\
\hline CHEMBL1355262 & 688885 & 5.4 & 5.1691 & TRN & \\
\hline CHEMBL1611413 & 688885 & 6.1 & 5.6771 & TRN & \\
\hline CHEMBL1513241 & 688885 & 6.2 & 6.4038 & TRN & \\
\hline CHEMBL1456747 & 688885 & 5.4 & 5.3276 & TST & \\
\hline CHEMBL1608337 & 688885 & 5.1 & 5.0529 & TRN & \\
\hline CHEMBL1481781 & 688885 & 5.0 & 5.0771 & TRN & \\
\hline CHEMBL1519649 & 688885 & 5.8 & 6.0087 & TRN & \\
\hline CHEMBL1596347 & 688885 & 6.2 & 5.9256 & TST & \\
\hline CHEMBL 392394 & 688885 & 5.7 & 5.6668 & TST & \\
\hline CHEMBL 1438690 & 688885 & 6.3 & 6.6813 & TRN & \\
\hline CHEMBL 267548 & 688885 & 5.2 & 5.3084 & TST & \\
\hline CHEMBL1496590 & 688885 & 5.3 & 4.6638 & TRN & \\
\hline CHEMBL1255936 & 688885 & 4.9 & 5.1223 & TRN & \\
\hline CHEMBL1531108 & 688885 & 6.2 & 4.4919 & TRN & \\
\hline CHEMBL1411743 & 688885 & 5.0 & 5.09699 & 99999999995 & TRN \\
\hline CHEMBL1568767 & 688885 & 6.1 & 6.2801 & TRN & \\
\hline CHEMBL1330020 & 688885 & 5.2 & 5.4265 & TRN & \\
\hline CHEMBL1356132 & 688885 & 4.7 & 4.6516 & TRN & \\
\hline CHEMBL1364980 & 688885 & 4.7 & 4.7245 & TRN & \\
\hline CHEMBL1433726 & 688885 & 4.6 & 4.6981 & TST & \\
\hline CHEMBL1564813 & 688885 & 4.9 & 4.8761 & TRN & \\
\hline CHEMBL1318799 & 688885 & 5.4 & 5.3622 & TRN & \\
\hline CHEMBL1395527 & 688885 & 5.9 & 5.4503 & TRN & \\
\hline CHEMBL1476108 & 688885 & 4.7 & 4.7097 & TST & \\
\hline CHEMBL1450521 & 688885 & 7.0 & 7.1124 & TRN & \\
\hline CHEMBL1486808 & 688885 & 5.1 & 4.9711 & TRN & \\
\hline CHEMBL1335634 & 688885 & 6.0 & 4.8683 & TST & \\
\hline CHEMBL1481510 & 688885 & 6.8 & 6.5034 & TRN & \\
\hline
\end{tabular}




\begin{tabular}{|c|c|c|c|c|c|}
\hline \multicolumn{6}{|c|}{ Supplemental Table S2.txt } \\
\hline CHEMBL1328490 & 688885 & 5.5 & 5.5406 & TRN & \\
\hline CHEMBL1411164 & 688885 & 5.5 & 5.6047 & TRN & \\
\hline CHEMBL 277127 & 688885 & 5.1 & 5.265 & TRN & \\
\hline CHEMBL1554408 & 688885 & 5.4 & 5.4672 & TRN & \\
\hline CHEMBL1355881 & 688885 & 6.0 & 4.6158 & TRN & \\
\hline CHEMBL1592556 & 688885 & 6.5 & 6.2432 & TRN & \\
\hline CHEMBL1491332 & 688885 & 4.7 & 4.9306 & TRN & \\
\hline CHEMBL1397634 & 688885 & 5.5 & 5.6517 & TRN & \\
\hline CHEMBL1360650 & 688885 & 5.3 & 5.3682 & TRN & \\
\hline CHEMBL1324697 & 688885 & 4.5 & 4.6853 & TRN & \\
\hline CHEMBL1365427 & 688885 & 4.4 & 4.5102 & TRN & \\
\hline CHEMBL1410759 & 688885 & 5.5 & 5.2875 & TST & \\
\hline CHEMBL1408604 & 688885 & 5.3 & 5.3765 & TST & \\
\hline CHEMBL1256923 & 688885 & 4.7 & 4.9011 & TST & \\
\hline CHEMBL1449605 & 688885 & 6.9 & 5.0186 & TRN & \\
\hline CHEMBL1323204 & 688885 & 5.5 & 5.4294 & TRN & \\
\hline CHEMBL1593269 & 688885 & 5.3 & 5.2766 & TRN & \\
\hline CHEMBL1445772 & 688885 & 5.0 & 5.0718 & TRN & \\
\hline CHEMBL1592493 & 688885 & 5.4 & 5.3689 & TRN & \\
\hline CHEMBL1494529 & 688885 & 5.1 & 4.9409 & TRN & \\
\hline CHEMBL1358570 & 688885 & 5.1 & 5.0335 & TST & \\
\hline CHEMBL1411201 & 688885 & 4.7 & 4.7925 & TRN & \\
\hline CHEMBL1322864 & 688885 & 5.8 & 5.6839 & TST & \\
\hline CHEMBL1604914 & 688885 & 5.5 & 5.3427 & TST & \\
\hline CHEMBL1602476 & 688885 & 4.4 & 4.3769 & TRN & \\
\hline CHEMBL1316219 & 688885 & 4.8 & 5.0455 & TST & \\
\hline CHEMBL1485361 & 688885 & 4.4 & 4.6995 & TRN & \\
\hline CHEMBL1512359 & 688885 & 5.6 & 5.3827 & TST & \\
\hline CHEMBL1434643 & 688885 & 4.6 & 4.7518 & TRN & \\
\hline CHEMBL1363622 & 688885 & 5.3 & 5.2782 & TRN & \\
\hline CHEMBL136906 & 688885 & 5.1 & 5.0025 & TRN & \\
\hline CHEMBL1380212 & 688885 & 5.2 & 5.4362 & TRN & \\
\hline CHEMBL272005 & 688885 & 4.9 & 5.5146 & TRN & \\
\hline CHEMBL1600497 & 688885 & 5.1 & 5.0797 & TST & \\
\hline CHEMBL1416389 & 688885 & 6.0 & 5.9972 & TRN & \\
\hline CHEMBL164660 & 688885 & 5.1 & 5.3472 & TRN & \\
\hline CHEMBL1414477 & 688885 & 5.8 & 5.8017 & TRN & \\
\hline CHEMBL1594329 & 688885 & 6.7001 & 6.6246 & TRN & \\
\hline CHEMBL153057 & 688885 & 5.0 & 5.1792 & TRN & \\
\hline CHEMBL1490292 & 688885 & 6.0 & 5.3846 & TRN & \\
\hline CHEMBL 76897 & 688885 & 4.4 & 4.6153 & TRN & \\
\hline CHEMBL1331118 & 688885 & 4.8 & 4.7337 & TRN & \\
\hline CHEMBL1567251 & 688885 & 5.1 & 5.21200 & 0000000001 & TRN \\
\hline CHEMBL1358122 & 688885 & 5.4 & 5.3738 & TRN & \\
\hline CHEMBL1553941 & 688885 & 4.6 & 4.6343 & TRN & \\
\hline CHEMBL1570285 & 688885 & 5.4 & 5.4767 & TRN & \\
\hline CHEMBL1323529 & 688885 & 4.8 & 4.6665 & TRN & \\
\hline CHEMBL1331105 & 688885 & 5.0 & 5.1129 & TRN & \\
\hline
\end{tabular}




\begin{tabular}{|c|c|c|c|c|c|}
\hline & & & & & \\
\hline CHEMBL1437990 & 688885 & 5.4 & 5.3231 & TRN & \\
\hline CHEMBL1436054 & 688885 & 6.0 & 5.9597 & TRN & \\
\hline CHEMBL1436817 & 688885 & 4.5 & 4.4598 & TRN & \\
\hline CHEMBL1256718 & 688885 & 4.4 & 4.7738 & TST & \\
\hline CHEMBL1200766 & 688885 & 5.9 & 5.8787 & TRN & \\
\hline CHEMBL1398138 & 688885 & 5.8 & 5.2253 & TST & \\
\hline CHEMBL1454224 & 688885 & 5.5 & 5.3429 & TRN & \\
\hline CHEMBL282489 & 688885 & 5.5 & 5.3962 & TST & \\
\hline CHEMBL296586 & 688885 & 5.0 & 5.1486 & TST & \\
\hline CHEMBL1361285 & 688885 & 5.2 & 5.495 & TRN & \\
\hline CHEMBL1533121 & 688885 & 7.8013 & 5.7056 & TRN & \\
\hline CHEMBL1326787 & 688885 & 4.9 & 5.2024 & TRN & \\
\hline CHEMBL1551915 & 688885 & 4.5 & 5.2473 & TST & \\
\hline CHEMBL1397752 & 688885 & 5.0 & 5.03600 & 00000000005 & TRN \\
\hline CHEMBL1322959 & 688885 & 6.0 & 5.9372 & TST & \\
\hline CHEMBL512908 & 688885 & 5.8 & 5.6662 & TRN & \\
\hline CHEMBL1592470 & 688885 & 4.7 & 4.9172 & TRN & \\
\hline CHEMBL283196 & 688885 & 5.1 & 4.4963 & TRN & \\
\hline CHEMBL1610945 & 688885 & 5.2 & 5.1943 & TST & \\
\hline CHEMBL1323385 & 688885 & 5.5 & 5.6227 & TRN & \\
\hline CHEMBL1441415 & 688885 & 6.1 & 6.2301 & TRN & \\
\hline CHEMBL1592803 & 688885 & 6.3 & 6.4974 & TRN & \\
\hline CHEMBL1397406 & 688885 & 4.6 & 4.7513 & TRN & \\
\hline CHEMBL1433485 & 688885 & 5.5 & 5.8161 & TRN & \\
\hline CHEMBL1514016 & 688885 & 4.9 & 4.9189 & TRN & \\
\hline CHEMBL1436882 & 688885 & 6.1 & 5.9745 & TRN & \\
\hline CHEMBL1532103 & 688885 & 5.1 & 5.8096 & TRN & \\
\hline CHEMBL1433939 & 688885 & 5.1 & 5.1113 & TST & \\
\hline CHEMBL1442459 & 688885 & 5.5 & 5.4429 & TST & \\
\hline CHEMBL1331634 & 688885 & 6.0 & 5.6797 & TRN & \\
\hline CHEMBL1395165 & 688885 & 4.6 & 5.0064 & TRN & \\
\hline CHEMBL1592465 & 688885 & 4.5 & 4.7764 & TRN & \\
\hline CHEMBL1518301 & 688885 & 5.1 & 5.1719 & TRN & \\
\hline CHEMBL1365367 & 688885 & 5.7 & 5.8747 & TRN & \\
\hline CHEMBL1554590 & 688885 & 5.1 & 5.3075 & TRN & \\
\hline CHEMBL1417140 & 688885 & 6.3 & 5.7051 & TRN & \\
\hline CHEMBL1552133 & 688885 & 4.8 & 5.3063 & TRN & \\
\hline CHEMBL1335220 & 688885 & 5.1 & 5.1874 & TRN & \\
\hline CHEMBL1511972 & 688885 & 5.5 & 4.6179 & TRN & \\
\hline CHEMBL1516249 & 688885 & 4.9 & 4.8155 & TRN & \\
\hline CHEMBL1526068 & 688885 & 4.9 & 5.1406 & TRN & \\
\hline CHEMBL1597366 & 688885 & 4.6 & 4.6036 & TRN & \\
\hline CHEMBL1412825 & 688885 & 5.0 & 5.1905 & TRN & \\
\hline CHEMBL1325335 & 688885 & 4.4 & 4.3742 & TRN & \\
\hline CHEMBL1416009 & 688885 & 5.9 & 5.9541 & TST & \\
\hline CHEMBL1590038 & 688885 & 4.8 & 4.7119 & TRN & \\
\hline CHEMBL1370805 & 688885 & 5.6 & 5.7121 & TRN & \\
\hline CHEMBL274619 & 688885 & 4.4 & 5.35 & TST & \\
\hline & & & & 297 & \\
\hline
\end{tabular}




\begin{tabular}{|c|c|c|c|c|c|}
\hline \multicolumn{6}{|c|}{ Supplemental Table s2.txt } \\
\hline CHEMBL66654 & 688885 & 5.0 & 5.2827 & TRN & \\
\hline CHEMBL1374913 & 688885 & 4.5 & 4.668 & TRN & \\
\hline CHEMBL1558384 & 688885 & 4.9 & 5.0105 & TRN & \\
\hline CHEMBL1316839 & 688885 & 5.4 & 5.4596 & TRN & \\
\hline CHEMBL1400043 & 688885 & 4.8 & 5.0083 & TRN & \\
\hline CHEMBL1445578 & 688885 & 5.1 & 5.1479 & TRN & \\
\hline CHEMBL86931 & 688885 & 5.2 & 5.1348 & TRN & \\
\hline CHEMBL559934 & 688885 & 4.9 & 4.998 & TST & \\
\hline CHEMBL77287 & 688885 & 5.6 & 5.4527 & TRN & \\
\hline CHEMBL1496363 & 688885 & 5.5 & 5.1388 & TST & \\
\hline CHEMBL 77971 & 688885 & 5.4 & 5.3529 & TST & \\
\hline CHEMBL1445799 & 688885 & 4.7 & 4.8114 & TRN & \\
\hline CHEMBL491771 & 688885 & 6.3 & 6.3927 & TRN & \\
\hline CHEMBL406835 & 688885 & 4.5 & 5.19 & TRN & \\
\hline CHEMBL1594029 & 688885 & 5.5 & 5.4939 & TRN & \\
\hline CHEMBL1457043 & 688885 & 4.6 & 5.1688 & TRN & \\
\hline CHEMBL1318674 & 688885 & 5.4 & 5.1637 & TRN & \\
\hline CHEMBL1355547 & 688885 & 5.5 & 5.3677 & TRN & \\
\hline CHEMBL1437408 & 688885 & 4.8 & 4.9585 & TRN & \\
\hline CHEMBL1376723 & 688885 & 4.5 & 4.6934 & TRN & \\
\hline CHEMBL1370296 & 688885 & 6.0 & 6.1113 & TRN & \\
\hline CHEMBL1421016 & 688885 & 4.9 & 4.89 & TST & \\
\hline CHEMBL1315636 & 688885 & 5.5 & 5.3369 & TRN & \\
\hline CHEMBL1356497 & 688885 & 5.5 & 5.5175 & TRN & \\
\hline CHEMBL1491009 & 688885 & 5.4 & 5.4347 & TRN & \\
\hline CHEMBL1434334 & 688885 & 4.6 & 5.2683 & TST & \\
\hline CHEMBL1555436 & 688885 & 6.6 & 5.1606 & TST & \\
\hline CHEMBL1512701 & 688885 & 6.8 & 6.903 & TRN & \\
\hline CHEMBL1322137 & 688885 & 5.5 & 5.5249 & TST & \\
\hline CHEMBL1332759 & 688885 & 4.9 & 5.0103 & TRN & \\
\hline CHEMBL1234071 & 688885 & 4.4 & 4.9997 & TRN & \\
\hline CHEMBL543557 & 688885 & 5.1 & 5.2004 & TRN & \\
\hline CHEMBL1559912 & 688885 & 4.7 & 4.9827 & TRN & \\
\hline CHEMBL1395992 & 688885 & 6.4 & 6.4393 & TRN & \\
\hline CHEMBL491939 & 688885 & 7.8013 & 7.74799 & 7999999999 & TRN \\
\hline CHEMBL1474578 & 688885 & 5.7 & 5.1151 & TRN & \\
\hline CHEMBL1256873 & 688885 & 4.5 & 4.7769 & TST & \\
\hline CHEMBL352396 & 688885 & 5.2 & 5.2663 & TST & \\
\hline CHEMBL1590191 & 688885 & 5.1 & 4.9399 & TRN & \\
\hline CHEMBL1358137 & 688885 & 5.1 & 5.0398 & TRN & \\
\hline CHEMBL338790 & 688885 & 4.4 & 5.1202 & TST & \\
\hline CHEMBL1435080 & 688885 & 5.1 & 4.9469 & TRN & \\
\hline CHEMBL1417837 & 688885 & 5.8 & 5.90799 & 99999999995 & TRN \\
\hline CHEMBL1256910 & 688885 & 5.9 & 6.081 & TST & \\
\hline CHEMBL1449457 & 688885 & 6.9 & 6.1078 & TRN & \\
\hline CHEMBL448602 & 688885 & 5.7 & 5.7356 & TRN & \\
\hline CHEMBL1553488 & 688885 & 5.4 & 5.3618 & TRN & \\
\hline CHEMBL1451411 & 688885 & 5.2 & 5.2884 & TRN & \\
\hline
\end{tabular}




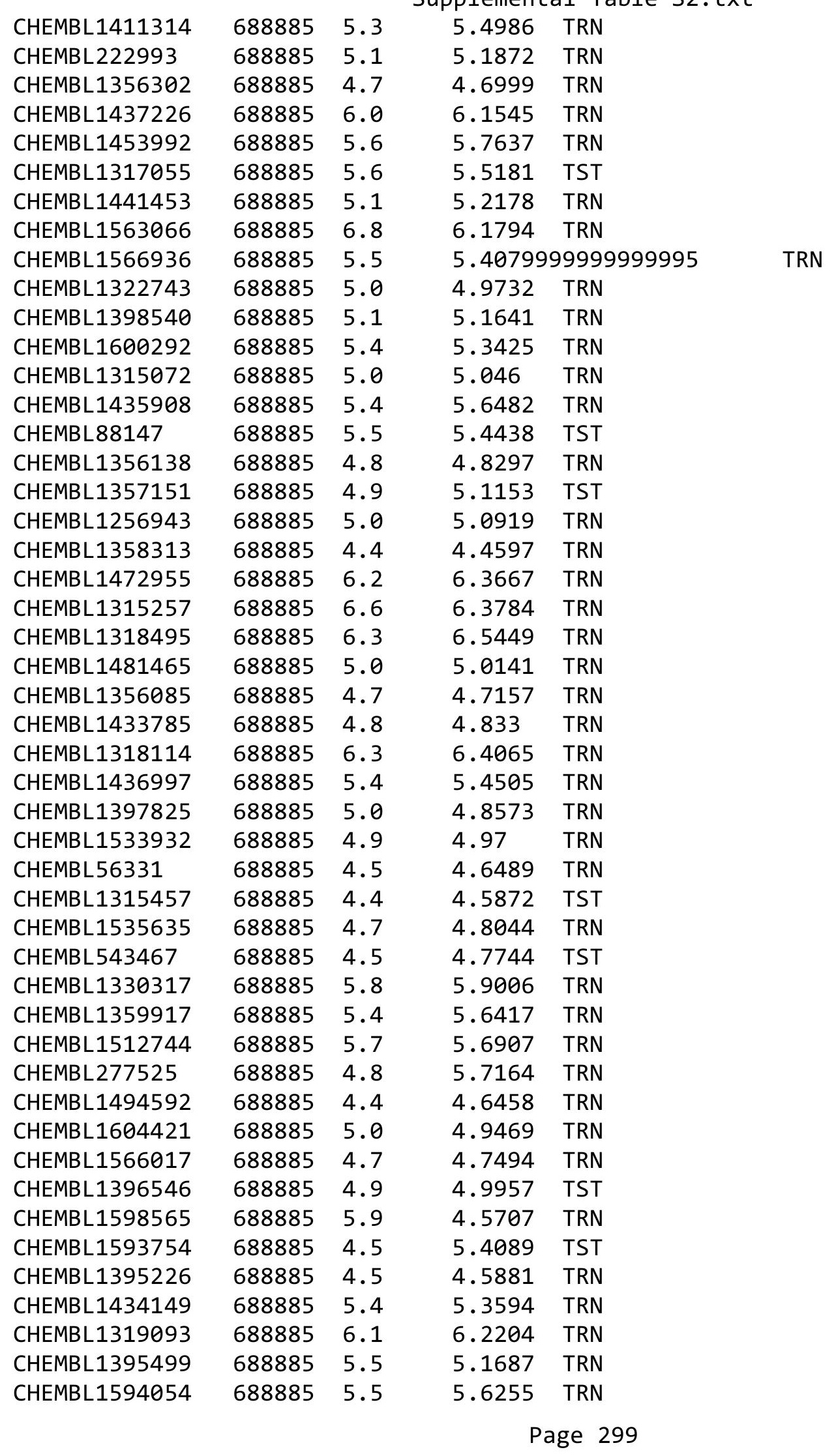




\begin{tabular}{|c|c|c|c|c|c|}
\hline \multicolumn{6}{|c|}{ plemental Table S2. } \\
\hline CHEMBL1362931 & 688885 & 5.8 & 5.6214 & TRN & \\
\hline CHEMBL1434833 & 688885 & 5.9 & 5.88399 & 99999999995 & TRN \\
\hline CHEMBL1410676 & 688885 & 6.0 & 6.3167 & TRN & \\
\hline CHEMBL1375753 & 688885 & 5.6 & 5.7071 & TRN & \\
\hline CHEMBL1533572 & 688885 & 7.4001 & 5.8973 & TRN & \\
\hline CHEMBL1513684 & 688885 & 4.9 & 4.9365 & TRN & \\
\hline CHEMBL1400309 & 688885 & 5.3 & 5.2788 & TRN & \\
\hline CHEMBL1395869 & 688885 & 5.4 & 5.7063 & TRN & \\
\hline CHEMBL1532597 & 688885 & 5.6 & 5.7449 & TRN & \\
\hline CHEMBL1418190 & 688885 & 4.4 & 4.8092 & TRN & \\
\hline CHEMBL1493369 & 688885 & 6.3 & 6.1365 & TRN & \\
\hline CHEMBL1413637 & 688885 & 4.8 & 4.6572 & TRN & \\
\hline CHEMBL490718 & 688885 & 6.4 & 6.6474 & TRN & \\
\hline CHEMBL1449373 & 688885 & 5.1 & 4.9933 & TST & \\
\hline CHEMBL1356318 & 688885 & 5.2 & 5.0959 & TST & \\
\hline CHEMBL1410016 & 688885 & 5.7 & 5.7262 & TRN & \\
\hline CHEMBL1532921 & 688885 & 5.5 & 5.4307 & TRN & \\
\hline CHEMBL242385 & 688885 & 5.3 & 5.4172 & TRN & \\
\hline CHEMBL1331066 & 688885 & 5.9 & 5.5912 & TST & \\
\hline CHEMBL1317378 & 688885 & 5.8 & 4.8514 & TRN & \\
\hline CHEMBL1481747 & 688885 & 5.7 & 5.6516 & TRN & \\
\hline CHEMBL 279841 & 688885 & 5.4 & 5.4092 & TRN & \\
\hline CHEMBL1356041 & 688885 & 6.6 & 6.6945 & TRN & \\
\hline CHEMBL1407035 & 688885 & 6.1 & 6.2249 & TRN & \\
\hline CHEMBL1486820 & 688885 & 6.2 & 5.2532 & TRN & \\
\hline CHEMBL 1403388 & 688885 & 7.0 & 6.5504 & TRN & \\
\hline CHEMBL1449490 & 688885 & 5.7 & 5.6429 & TRN & \\
\hline CHEMBL1255578 & 688885 & 6.0 & 4.7815 & TST & \\
\hline CHEMBL1552680 & 688885 & 4.6 & 4.4413 & TRN & \\
\hline CHEMBL 3350578 & 688885 & 5.2 & 5.3513 & TST & \\
\hline CHEMBL1406764 & 688885 & 5.6 & 5.6651 & TRN & \\
\hline CHEMBL1378237 & 688885 & 5.0 & 5.2017 & TRN & \\
\hline CHEMBL1324882 & 688885 & 5.6 & 5.5188 & TRN & \\
\hline CHEMBL1491574 & 688885 & 4.9 & 4.9282 & TRN & \\
\hline CHEMBL1490786 & 688885 & 5.0 & 5.2296 & TRN & \\
\hline CHEMBL1475509 & 688885 & 5.5 & 5.3608 & TRN & \\
\hline CHEMBL1592557 & 688885 & 6.2 & 6.2496 & TRN & \\
\hline CHEMBL1371781 & 688885 & 4.4 & 4.4991 & TRN & \\
\hline CHEMBL21241 & 688885 & 4.5 & 5.2493 & TST & \\
\hline CHEMBL95431 & 688885 & 6.3 & 5.2894 & TST & \\
\hline CHEMBL1565578 & 688885 & 5.1 & 5.7059 & TRN & \\
\hline CHEMBL1529330 & 688885 & 4.7 & 4.6908 & TRN & \\
\hline CHEMBL1610944 & 688885 & 5.0 & 5.1758 & TRN & \\
\hline CHEMBL1439631 & 688885 & 5.5 & 5.3116 & TRN & \\
\hline CHEMBL1160544 & 688885 & 6.2 & 5.9588 & TRN & \\
\hline CHEMBL1373954 & 688885 & 5.4 & 5.3549 & TRN & \\
\hline CHEMBL1366296 & 688885 & 4.6 & 4.6201 & TRN & \\
\hline CHEMBL1591860 & 688885 & 4.4 & 4.4114 & TRN & \\
\hline
\end{tabular}




\begin{tabular}{|c|c|c|c|c|c|}
\hline \\
\hline CHEMBL1404490 & 688885 & 4.5 & 5.2624 & TST & \\
\hline CHEMBL1593219 & 688885 & 5.1 & 5.41100 & 00000000005 & TRN \\
\hline CHEMBL1314286 & 688885 & 6.0 & 5.9314 & TST & \\
\hline CHEMBL1396936 & 688885 & 6.0 & 6.1727 & TRN & \\
\hline CHEMBL1472880 & 688885 & 5.7 & 5.4971 & TRN & \\
\hline CHEMBL1565342 & 688885 & 6.0 & 5.9106 & TRN & \\
\hline CHEMBL 242341 & 688885 & 8.0 & 5.4422 & TRN & \\
\hline CHEMBL28 & 688885 & 6.0 & 5.8184 & TRN & \\
\hline CHEMBL1562477 & 688885 & 4.6 & 4.8638 & TRN & \\
\hline CHEMBL1533672 & 688885 & 5.5 & 5.6311 & TRN & \\
\hline CHEMBL1361725 & 688885 & 4.9 & 4.9193 & TRN & \\
\hline CHEMBL1317373 & 688885 & 5.9 & 5.9901 & TRN & \\
\hline CHEMBL261011 & 688885 & 4.8 & 4.7637 & TRN & \\
\hline CHEMBL1214274 & 688885 & 5.7 & 5.8125 & TRN & \\
\hline CHEMBL1363367 & 688885 & 5.1 & 5.0958 & TST & \\
\hline CHEMBL164 & 688885 & 6.0 & 6.4719 & TRN & \\
\hline CHEMBL446315 & 688885 & 6.0 & 5.8671 & TST & \\
\hline CHEMBL1371160 & 688885 & 5.4 & 5.4288 & TST & \\
\hline CHEMBL1317300 & 688885 & 6.0 & 5.4143 & TST & \\
\hline CHEMBL1555567 & 688885 & 5.0 & 4.9653 & TRN & \\
\hline CHEMBL1476334 & 688885 & 6.4 & 5.5745 & TRN & \\
\hline CHEMBL1452561 & 688885 & 4.6 & 5.0272 & TRN & \\
\hline CHEMBL 3210244 & 688885 & 5.5 & 5.65799 & 99999999995 & TRN \\
\hline CHEMBL287045 & 688885 & 4.4 & 5.3478 & TST & \\
\hline CHEMBL1395089 & 688885 & 6.4 & 6.5963 & TRN & \\
\hline CHEMBL1514639 & 688885 & 4.6 & 4.8063 & TRN & \\
\hline CHEMBL1371572 & 688885 & 5.5 & 5.5044 & TRN & \\
\hline CHEMBL1362630 & 688885 & 4.8 & 4.9046 & TRN & \\
\hline CHEMBL288096 & 688885 & 4.4 & 4.6171 & TRN & \\
\hline CHEMBL1589897 & 688885 & 4.9 & 5.0601 & TRN & \\
\hline CHEMBL1365701 & 688885 & 5.9 & 6.0367 & TRN & \\
\hline CHEMBL1394579 & 688885 & 5.4 & 5.3322 & TRN & \\
\hline CHEMBL1489353 & 688885 & 5.0 & 4.9154 & TST & \\
\hline CHEMBL34704 & 688885 & 6.1 & 5.1318 & TST & \\
\hline CHEMBL491940 & 688885 & 6.2 & 6.3667 & TRN & \\
\hline CHEMBL1354272 & 688885 & 4.7 & 4.6261 & TRN & \\
\hline CHEMBL1365979 & 688885 & 4.4 & 4.8471 & TRN & \\
\hline CHEMBL1334104 & 688885 & 5.5 & 5.3198 & TRN & \\
\hline CHEMBL109037 & 688885 & 4.4 & 5.1345 & TRN & \\
\hline CHEMBL1315521 & 688885 & 4.4 & 4.427 & TRN & \\
\hline CHEMBL1556742 & 688885 & 5.8 & 5.6658 & TRN & \\
\hline CHEMBL1533214 & 688885 & 4.9 & 4.6029 & TRN & \\
\hline CHEMBL1590123 & 688885 & 6.0 & 6.0494 & TRN & \\
\hline CHEMBL489738 & 688885 & 5.8 & 6.1799 & TRN & \\
\hline CHEMBL1528688 & 688885 & 5.2 & 5.2088 & TST & \\
\hline CHEMBL1593805 & 688885 & 5.6 & 5.438 & TRN & \\
\hline CHEMBL1359108 & 688885 & 5.0 & 5.0279 & TRN & \\
\hline CHEMBL1378208 & 688885 & 5.0 & 5.0549 & TRN & \\
\hline
\end{tabular}




\begin{tabular}{|c|c|c|c|c|}
\hline \multicolumn{5}{|c|}{ ental Table s } \\
\hline CHEMBL47 & 688885 & 4.7 & 5.0314 & TST \\
\hline CHEMBL1332937 & 688885 & 6.1 & 6.2292 & TRN \\
\hline CHEMBL47940 & 688885 & 4.5 & 4.5305 & TRN \\
\hline CHEMBL1551834 & 688885 & 5.0 & 5.0212 & TRN \\
\hline CHEMBL1554693 & 688885 & 5.0 & 5.3333 & TRN \\
\hline CHEMBL1361226 & 688885 & 5.8 & 5.8532 & TRN \\
\hline CHEMBL1565311 & 688885 & 7.1002 & 6.9814 & TRN \\
\hline CHEMBL1376178 & 688885 & 5.7 & 5.8005 & TRN \\
\hline CHEMBL1433668 & 688885 & 4.4 & 4.8409 & TRN \\
\hline CHEMBL1515401 & 688885 & 5.6 & 5.6265 & TRN \\
\hline CHEMBL1331443 & 688885 & 6.0 & 5.77 & TRN \\
\hline CHEMBL1449528 & 688885 & 5.3 & 5.1662 & TRN \\
\hline CHEMBL1591757 & 688885 & 5.5 & 5.433 & TRN \\
\hline CHEMBL1600908 & 688885 & 5.5 & 5.5075 & TRN \\
\hline CHEMBL1475255 & 688885 & 6.5 & 6.473 & TRN \\
\hline CHEMBL1461491 & 688885 & 4.4 & 4.2705 & TST \\
\hline CHEMBL1475207 & 688885 & 4.9 & 5.0679 & TRN \\
\hline CHEMBL1602926 & 688885 & 5.5 & 5.6112 & TRN \\
\hline CHEMBL1565724 & 688885 & 5.6 & 5.8627 & TRN \\
\hline CHEMBL1511998 & 688885 & 6.3 & 5.2416 & TST \\
\hline CHEMBL1316760 & 688885 & 4.6 & 4.6577 & TRN \\
\hline CHEMBL1314371 & 688885 & 5.1 & 5.1999 & TRN \\
\hline CHEMBL1528654 & 688885 & 5.2 & 5.33799 & 9999999999 \\
\hline CHEMBL1593128 & 688885 & 4.8 & 4.7386 & TRN \\
\hline CHEMBL1355088 & 688885 & 5.5 & 5.3979 & TRN \\
\hline CHEMBL1451315 & 688885 & 6.1 & 5.7815 & TRN \\
\hline CHEMBL1513845 & 688885 & 4.4 & 5.2267 & TRN \\
\hline CHEMBL1397079 & 688885 & 5.0 & 4.4812 & TRN \\
\hline CHEMBL1320206 & 688885 & 5.1 & 5.099 & TRN \\
\hline CHEMBL1361839 & 688885 & 4.8 & 4.6767 & TRN \\
\hline CHEMBL1436536 & 688885 & 6.0 & 5.0014 & TRN \\
\hline CHEMBL1370467 & 688885 & 6.0 & 6.0768 & TRN \\
\hline CHEMBL1257075 & 688885 & 6.0 & 5.0975 & TRN \\
\hline CHEMBL1591198 & 688885 & 4.4 & 5.1034 & TRN \\
\hline CHEMBL1450162 & 688885 & 4.9 & 4.9202 & TRN \\
\hline CHEMBL1317802 & 688885 & 4.9 & 5.3988 & TRN \\
\hline CHEMBL 269550 & 688885 & 5.4 & 5.3037 & TRN \\
\hline CHEMBL 145 & 688885 & 4.8 & 4.8184 & TRN \\
\hline CHEMBL1396583 & 688885 & 4.4 & 4.4308 & TRN \\
\hline CHEMBL1411519 & 688885 & 4.7 & 4.8705 & TRN \\
\hline CHEMBL1592982 & 688885 & 6.9 & 6.8464 & TRN \\
\hline CHEMBL1256291 & 688885 & 5.9 & 5.8436 & TRN \\
\hline CHEMBL1333556 & 688885 & 4.9 & 4.8777 & TST \\
\hline CHEMBL1354262 & 688885 & 4.6 & 4.614 & TRN \\
\hline CHEMBL259389 & 688885 & 5.7 & 5.6028 & TST \\
\hline CHEMBL242172 & 688885 & 4.8 & 5.2101 & TRN \\
\hline CHEMBL280065 & 688885 & 4.5 & 4.9326 & TRN \\
\hline CHEMBL1394731 & 688885 & 5.7 & 5.6252 & TRN \\
\hline
\end{tabular}




\begin{tabular}{|c|c|c|c|c|}
\hline \multicolumn{5}{|c|}{ Supplemental Table S2.txt } \\
\hline CHEMBL472656 & 688885 & 5.9 & 5.9459 & TST \\
\hline CHEMBL1593707 & 688885 & 5.4 & 5.4256 & TRN \\
\hline CHEMBL1487191 & 688885 & 5.3 & 5.2748 & TRN \\
\hline CHEMBL1378800 & 688885 & 5.2 & 5.2677 & TST \\
\hline CHEMBL1559127 & 688885 & 5.0 & 4.9852 & TRN \\
\hline CHEMBL1512708 & 688885 & 6.0 & 6.2789 & TRN \\
\hline CHEMBL1406082 & 688885 & 6.0 & 5.5245 & TRN \\
\hline CHEMBL1528708 & 688885 & 5.0 & 4.8201 & TRN \\
\hline CHEMBL1454052 & 688885 & 4.8 & 4.8777 & TRN \\
\hline CHEMBL1555164 & 688885 & 5.8 & 5.9942 & TRN \\
\hline CHEMBL1356844 & 688885 & 4.6 & 4.6711 & TRN \\
\hline CHEMBL1518338 & 688885 & 5.5 & 5.4678 & TRN \\
\hline CHEMBL1256998 & 688885 & 4.4 & 5.3238 & TST \\
\hline CHEMBL471005 & 688885 & 5.1 & 5.3135 & TST \\
\hline CHEMBL1555014 & 688885 & 7.2 & 5.6788 & TRN \\
\hline CHEMBL1440509 & 688885 & 5.2 & 5.3473 & TRN \\
\hline CHEMBL1333783 & 688885 & 6.3 & 6.5898 & TRN \\
\hline CHEMBL1495213 & 688885 & 5.0 & 4.9077 & TRN \\
\hline CHEMBL1552517 & 688885 & 6.4 & 6.1754 & TRN \\
\hline CHEMBL1594058 & 688885 & 4.8 & 4.8424 & TRN \\
\hline CHEMBL1554465 & 688885 & 5.8 & 5.5714 & TRN \\
\hline CHEMBL1402106 & 688885 & 5.8 & 6.0391 & TRN \\
\hline CHEMBL1355216 & 688885 & 4.6 & 5.0451 & TRN \\
\hline CHEMBL1457544 & 688885 & 4.4 & 4.5387 & TRN \\
\hline CHEMBL1560551 & 688885 & 4.9 & 4.9526 & TRN \\
\hline CHEMBL1592327 & 688885 & 6.4 & 6.3461 & TRN \\
\hline CHEMBL311226 & 688885 & 4.6 & 4.6411 & TST \\
\hline CHEMBL1598994 & 688885 & 4.9 & 4.7092 & TRN \\
\hline CHEMBL1331410 & 688885 & 5.0 & 5.2122 & TRN \\
\hline CHEMBL1395974 & 688885 & 4.7 & 4.7874 & TRN \\
\hline CHEMBL491555 & 688885 & 6.0 & 6.3645 & TRN \\
\hline CHEMBL1395252 & 688885 & 4.5 & 5.6208 & TRN \\
\hline CHEMBL158507 & 688885 & 5.8 & 5.7009 & TRN \\
\hline CHEMBL1487111 & 688885 & 5.5 & 5.5498 & TRN \\
\hline CHEMBL1512562 & 688885 & 6.1 & 5.7803 & TRN \\
\hline CHEMBL1591107 & 688885 & 6.1 & 6.0199 & TRN \\
\hline CHEMBL 28626 & 688885 & 5.0 & 6.8174 & TRN \\
\hline CHEMBL1569001 & 688885 & 4.6 & 5.402 & TRN \\
\hline CHEMBL3195553 & 688885 & 5.5 & 5.6679 & TRN \\
\hline CHEMBL1440650 & 688885 & 4.8 & 4.9415 & TRN \\
\hline CHEMBL1479817 & 688885 & 5.3 & 5.271 & TRN \\
\hline CHEMBL10009 & 688885 & 5.9 & 5.7378 & TRN \\
\hline CHEMBL1473448 & 688885 & 4.8 & 4.8637 & TRN \\
\hline CHEMBL1448726 & 688885 & 4.7 & 4.7578 & TRN \\
\hline CHEMBL268609 & 688885 & 6.0 & 6.0928 & TRN \\
\hline CHEMBL1476206 & 688885 & 4.9 & 4.944 & TRN \\
\hline CHEMBL1335967 & 688885 & 7.8996 & 7.1266 & TRN \\
\hline CHEMBL19612 & 688885 & 4.9 & 4.9778 & TST \\
\hline
\end{tabular}




\begin{tabular}{|c|c|c|c|c|}
\hline \multicolumn{5}{|c|}{ Supplemental Table S2.t } \\
\hline CHEMBL1609178 & 688885 & 5.1 & 5.1771 & TRN \\
\hline CHEMBL1362562 & 688885 & 5.8 & 5.8629 & TRN \\
\hline CHEMBL1473996 & 688885 & 6.4 & 6.2302 & TRN \\
\hline CHEMBL1474475 & 688885 & 4.7 & 4.7257 & TRN \\
\hline CHEMBL1611630 & 688885 & 7.1002 & 5.4545 & TRN \\
\hline CHEMBL515505 & 688885 & 5.5 & 5.5305 & TRN \\
\hline CHEMBL1315382 & 688885 & 5.9 & 5.7797 & TRN \\
\hline CHEMBL1414943 & 688885 & 5.3 & 5.4619 & TRN \\
\hline CHEMBL1435788 & 688885 & 4.4 & 4.5321 & TRN \\
\hline CHEMBL1590048 & 688885 & 5.5 & 5.4994 & TRN \\
\hline CHEMBL523283 & 688885 & 5.9 & 6.1935 & TRN \\
\hline CHEMBL1437164 & 688885 & 6.9 & 4.7546 & TRN \\
\hline CHEMBL1447149 & 688885 & 5.9 & 5.7285 & TRN \\
\hline CHEMBL1601824 & 688885 & 5.4 & 5.6127 & TRN \\
\hline CHEMBL1603120 & 688885 & 5.7 & 5.2159 & TRN \\
\hline CHEMBL1530832 & 688885 & 6.0 & 5.8167 & TRN \\
\hline CHEMBL1555389 & 688885 & 5.6 & 5.4533 & TRN \\
\hline CHEMBL1357231 & 688885 & 6.1 & 6.2125 & TRN \\
\hline CHEMBL34730 & 688885 & 6.0 & 5.1675 & TRN \\
\hline CHEMBL265177 & 688885 & 5.8 & 5.6539 & TST \\
\hline CHEMBL1354563 & 688885 & 6.3 & 6.2981 & TRN \\
\hline CHEMBL1446731 & 688885 & 5.6 & 5.7687 & TRN \\
\hline CHEMBL1358538 & 688885 & 5.4 & 5.4899 & TST \\
\hline CHEMBL1161936 & 688885 & 5.8 & 5.8168 & TRN \\
\hline CHEMBL1555119 & 688885 & 5.5 & 5.4801 & TRN \\
\hline CHEMBL1331148 & 688885 & 7.3002 & 6.5188 & TRN \\
\hline CHEMBL507 & 688885 & 4.4 & 5.0071 & TST \\
\hline CHEMBL1456755 & 688885 & 5.2 & 5.3987 & TST \\
\hline CHEMBL1339209 & 688885 & 6.1 & 6.2754 & TRN \\
\hline CHEMBL1472732 & 688885 & 5.5 & 5.6109 & TRN \\
\hline CHEMBL1256663 & 688885 & 5.8 & 5.2939 & TST \\
\hline CHEMBL1443585 & 688885 & 5.2 & 5.1781 & TRN \\
\hline CHEMBL1334103 & 688885 & 4.5 & 4.6415 & TRN \\
\hline CHEMBL1375723 & 688885 & 5.4 & 5.4444 & TRN \\
\hline CHEMBL1443323 & 688885 & 6.3 & 5.6417 & TRN \\
\hline CHEMBL1447438 & 688885 & 4.5 & 4.5531 & TRN \\
\hline CHEMBL1319604 & 688885 & 4.6 & 5.228 & TRN \\
\hline CHEMBL85251 & 688885 & 4.6 & 5.69600 & 2000000001 \\
\hline CHEMBL1436228 & 688885 & 4.6 & 4.4774 & TRN \\
\hline CHEMBL1590769 & 688885 & 5.4 & 5.5959 & TRN \\
\hline CHEMBL1553804 & 688885 & 4.4 & 4.6219 & TRN \\
\hline CHEMBL1496744 & 688885 & 5.5 & 5.4542 & TRN \\
\hline CHEMBL1256667 & 688885 & 4.8 & 5.0505 & TST \\
\hline CHEMBL1412900 & 688885 & 4.9 & 5.0385 & TRN \\
\hline CHEMBL24909 & 688885 & 5.1 & 5.1578 & TRN \\
\hline CHEMBL1355849 & 688885 & 5.4 & 5.3311 & TST \\
\hline CHEMBL1562612 & 688885 & 5.4 & 5.1515 & TST \\
\hline CHEMBL1326152 & 688885 & 4.5 & 4.6626 & TRN \\
\hline
\end{tabular}




\begin{tabular}{|c|c|c|c|c|}
\hline & & & ipplemen & $\mathrm{a} \perp \mathrm{T}$ \\
\hline CHEMBL1552752 & 688885 & 6.1 & 6.1989 & TRN \\
\hline CHEMBL1513825 & 688885 & 4.4 & 4.9697 & TRN \\
\hline CHEMBL1317335 & 688885 & 6.9 & 5.7685 & TRN \\
\hline CHEMBL1369863 & 688885 & 4.4 & 4.505 & TRN \\
\hline CHEMBL1376952 & 688885 & 5.4 & 5.3156 & TRN \\
\hline CHEMBL1369966 & 688885 & 5.5 & 5.3551 & TRN \\
\hline CHEMBL1475358 & 688885 & 8.0 & 5.9194 & TRN \\
\hline CHEMBL1481847 & 688885 & 5.6 & 5.5111 & TRN \\
\hline CHEMBL1407670 & 688885 & 4.8 & 4.8607 & TRN \\
\hline CHEMBL1474231 & 688885 & 4.4 & 5.0822 & TRN \\
\hline CHEMBL1595404 & 688885 & 5.0 & 4.9867 & TRN \\
\hline CHEMBL1593371 & 688885 & 5.5 & 5.4941 & TRN \\
\hline CHEMBL876 & 688885 & 5.1 & 5.3662 & TRN \\
\hline CHEMBL 2373626 & 688885 & 4.7 & 5.2075 & TST \\
\hline CHEMBL1373723 & 688885 & 6.0 & 5.8894 & TRN \\
\hline CHEMBL1590259 & 688885 & 4.6 & 4.8209 & TRN \\
\hline CHEMBL1591381 & 688885 & 4.4 & 4.3276 & TRN \\
\hline CHEMBL1356617 & 688885 & 4.9 & 4.9715 & TRN \\
\hline CHEMBL1553173 & 688885 & 6.0 & 6.2498 & TRN \\
\hline CHEMBL1473753 & 688885 & 5.4 & 5.6427 & TRN \\
\hline CHEMBL1397902 & 688885 & 5.5 & 5.5518 & TRN \\
\hline CHEMBL6705 & 688885 & 5.4 & 5.206 & TRN \\
\hline CHEMBL1438916 & 688885 & 5.5 & 5.4503 & TRN \\
\hline CHEMBL1437447 & 688885 & 5.7 & 5.4936 & TRN \\
\hline CHEMBL522121 & 688885 & 6.1 & 6.4697 & TRN \\
\hline CHEMBL328710 & 688885 & 6.0 & 4.7508 & TRN \\
\hline CHEMBL1480806 & 688885 & 6.1 & 6.1176 & TRN \\
\hline CHEMBL1367656 & 688885 & 6.1 & 5.9133 & TRN \\
\hline CHEMBL1474185 & 688885 & 4.4 & 4.3705 & TRN \\
\hline CHEMBL1574160 & 688885 & 4.9 & 4.7126 & TRN \\
\hline CHEMBL1476383 & 688885 & 4.9 & 5.0239 & TST \\
\hline CHEMBL1372997 & 688885 & 4.5 & 4.6894 & TST \\
\hline CHEMBL1609324 & 688885 & 6.0 & 6.0813 & TRN \\
\hline CHEMBL1315700 & 688885 & 5.0 & 4.8927 & TRN \\
\hline CHEMBL64239 & 688885 & 4.4 & 4.9969 & TRN \\
\hline CHEMBL375270 & 688885 & 5.2 & 5.319 & TRN \\
\hline CHEMBL1325511 & 688885 & 5.1 & 5.0983 & TRN \\
\hline CHEMBL1604063 & 688885 & 5.2 & 5.1601 & TST \\
\hline CHEMBL1437491 & 688885 & 4.5 & 4.5127 & TRN \\
\hline CHEMBL1401672 & 688885 & 4.7 & 4.7735 & TRN \\
\hline CHEMBL1972346 & 688885 & 4.5 & 4.4788 & TRN \\
\hline CHEMBL1594761 & 688885 & 4.4 & 4.3673 & TRN \\
\hline CHEMBL1493851 & 688885 & 5.8 & 5.7286 & TRN \\
\hline CHEMBL1475381 & 688885 & 4.8 & 4.6498 & TRN \\
\hline CHEMBL495068 & 688885 & 6.1 & 6.3189 & TRN \\
\hline CHEMBL1434098 & 688885 & 4.7 & 4.7627 & TRN \\
\hline CHEMBL1317231 & 688885 & 6.2 & 6.0439 & TRN \\
\hline CHEMBL1375285 & 688885 & 6.0 & 5.9018 & TRN \\
\hline
\end{tabular}




\begin{tabular}{|c|c|c|c|c|}
\hline & & & & $a \perp 1$ \\
\hline CHEMBL269366 & 688885 & 5.3 & 5.4093 & TST \\
\hline CHEMBL1359181 & 688885 & 4.6 & 4.6569 & TRN \\
\hline CHEMBL1079460 & 688885 & 4.6 & 4.6849 & TST \\
\hline CHEMBL1440487 & 688885 & 5.9 & 6.0947 & TRN \\
\hline CHEMBL79140 & 688885 & 5.0 & 4.9488 & TRN \\
\hline CHEMBL1417789 & 688885 & 5.8 & 5.8239 & TRN \\
\hline CHEMBL1361977 & 688885 & 4.6 & 4.6674 & TRN \\
\hline CHEMBL559612 & 688885 & 4.6 & 5.1706 & TST \\
\hline CHEMBL1256749 & 688885 & 4.8 & 4.9344 & TST \\
\hline CHEMBL1316629 & 688885 & 5.6 & 5.4658 & TRN \\
\hline CHEMBL1473705 & 688885 & 4.7 & 5.2488 & TRN \\
\hline CHEMBL1570894 & 688885 & 6.6 & 6.3225 & TRN \\
\hline CHEMBL1436761 & 688885 & 4.8 & 5.1489 & TRN \\
\hline CHEMBL1315083 & 688885 & 6.3 & 6.4967 & TRN \\
\hline CHEMBL510009 & 688885 & 6.2 & 6.2302 & TRN \\
\hline CHEMBL1406410 & 688885 & 4.7 & 4.9249 & TRN \\
\hline CHEMBL1357247 & 688885 & 5.1 & 5.2679 & TST \\
\hline CHEMBL1437054 & 688885 & 8.0 & 7.3574 & TRN \\
\hline CHEMBL1173453 & 688885 & 5.6 & 5.6051 & TRN \\
\hline CHEMBL 259073 & 688885 & 5.1 & 4.9942 & TRN \\
\hline CHEMBL1552405 & 688885 & 5.1 & 5.0216 & TRN \\
\hline CHEMBL1574626 & 688885 & 5.5 & 5.34399 & 9999999999 \\
\hline CHEMBL1403154 & 688885 & 5.4 & 5.3597 & TRN \\
\hline CHEMBL1332803 & 688885 & 5.3 & 5.5213 & TST \\
\hline CHEMBL1323563 & 688885 & 6.0 & 5.8684 & TRN \\
\hline CHEMBL1454512 & 688885 & 5.3 & 5.4671 & TRN \\
\hline CHEMBL1533923 & 688885 & 6.0 & 5.8988 & TRN \\
\hline CHEMBL1507262 & 688885 & 5.4 & 5.3872 & TST \\
\hline CHEMBL1435293 & 688885 & 6.0 & 6.0819 & TRN \\
\hline CHEMBL1433950 & 688885 & 4.4 & 4.5727 & TRN \\
\hline CHEMBL1337740 & 688885 & 6.0 & 6.2805 & TRN \\
\hline CHEMBL1474828 & 688885 & 6.0 & 5.9622 & TST \\
\hline CHEMBL311389 & 688885 & 4.5 & 5.3341 & TRN \\
\hline CHEMBL1474970 & 688885 & 5.7 & 5.3016 & TRN \\
\hline CHEMBL1325408 & 688885 & 5.3 & 5.3736 & TRN \\
\hline CHEMBL1491288 & 688885 & 5.1 & 5.0334 & TRN \\
\hline CHEMBL1335826 & 688885 & 4.5 & 5.3583 & TRN \\
\hline CHEMBL1320722 & 688885 & 5.0 & 5.0468 & TRN \\
\hline CHEMBL1328536 & 688885 & 5.4 & 5.4411 & TST \\
\hline CHEMBL1394640 & 688885 & 6.0 & 6.0964 & TRN \\
\hline CHEMBL1487929 & 688885 & 5.8 & 5.6556 & TRN \\
\hline CHEMBL81977 & 688885 & 4.9 & 5.1257 & TRN \\
\hline CHEMBL1321655 & 688885 & 4.9 & 5.0629 & TRN \\
\hline CHEMBL 289277 & 688885 & 6.0 & 5.3997 & TST \\
\hline CHEMBL1475698 & 688885 & 4.9 & 4.9766 & TST \\
\hline CHEMBL1357381 & 688885 & 5.5 & 5.8555 & TRN \\
\hline CHEMBL1456660 & 688885 & 5.5 & 5.294 & TRN \\
\hline CHEMBL 8867 & 688885 & 6.0 & 5.8434 & TST \\
\hline
\end{tabular}




\begin{tabular}{|c|c|c|c|c|}
\hline & & & 15 & al Table \\
\hline CHEMBL1591508 & 688885 & 4.8 & 4.8186 & TST \\
\hline CHEMBL1396791 & 688885 & 5.5 & 5.55399 & 9999999999 \\
\hline CHEMBL1488197 & 688885 & 6.0 & 5.9288 & TRN \\
\hline CHEMBL1356372 & 688885 & 4.8 & 4.7792 & TRN \\
\hline CHEMBL1255940 & 688885 & 5.0 & 5.1039 & TRN \\
\hline CHEMBL1513966 & 688885 & 5.4 & 5.8451 & TRN \\
\hline CHEMBL1600340 & 688885 & 6.8 & 6.6265 & TRN \\
\hline CHEMBL1330614 & 688885 & 5.6 & 5.2714 & TRN \\
\hline CHEMBL1552922 & 688885 & 4.5 & 4.6518 & TRN \\
\hline CHEMBL1406851 & 688885 & 6.4 & 6.7147 & TRN \\
\hline CHEMBL1557048 & 688885 & 6.5 & 6.5775 & TRN \\
\hline CHEMBL1358033 & 688885 & 5.3 & 5.3844 & TRN \\
\hline CHEMBL1411049 & 688885 & 4.9 & 5.101 & TRN \\
\hline CHEMBL1514390 & 688885 & 5.6 & 5.3714 & TRN \\
\hline CHEMBL1357167 & 688885 & 6.2 & 6.3003 & TRN \\
\hline CHEMBL1372635 & 688885 & 5.2 & 4.9861 & TRN \\
\hline CHEMBL1319626 & 688885 & 5.5 & 5.3965 & TRN \\
\hline CHEMBL168276 & 688885 & 6.0 & 5.9328 & TRN \\
\hline CHEMBL1598717 & 688885 & 5.2 & 5.1689 & TRN \\
\hline CHEMBL1516388 & 688885 & 6.0 & 5.9165 & TST \\
\hline CHEMBL1373007 & 688885 & 5.0 & 5.0991 & TST \\
\hline CHEMBL1444141 & 688885 & 5.6 & 5.2376 & TRN \\
\hline CHEMBL1327466 & 688885 & 5.8 & 5.9387 & TRN \\
\hline CHEMBL 28992 & 688885 & 4.9 & 5.164 & TST \\
\hline CHEMBL1496246 & 688885 & 5.1 & 5.2246 & TRN \\
\hline CHEMBL1318597 & 688885 & 4.5 & 4.4608 & TRN \\
\hline CHEMBL1437448 & 688885 & 4.9 & 4.8545 & TRN \\
\hline CHEMBL1371547 & 688885 & 5.2 & 5.5385 & TRN \\
\hline CHEMBL1324032 & 688885 & 5.4 & 5.5318 & TST \\
\hline CHEMBL1476693 & 688885 & 4.6 & 4.8894 & TRN \\
\hline CHEMBL1255778 & 688885 & 4.9 & 4.856 & TST \\
\hline CHEMBL1533516 & 688885 & 5.1 & 5.3648 & TRN \\
\hline CHEMBL250711 & 688885 & 5.8 & 5.2338 & TRN \\
\hline CHEMBL400875 & 688885 & 6.1 & 6.0531 & TRN \\
\hline CHEMBL1327459 & 688885 & 5.2 & 5.1724 & TRN \\
\hline CHEMBL1451697 & 688885 & 6.0 & 5.5516 & TRN \\
\hline CHEMBL1554098 & 688885 & 4.4 & 5.2924 & TST \\
\hline CHEMBL311158 & 688885 & 6.0 & 5.5042 & TRN \\
\hline CHEMBL1489659 & 688885 & 5.1 & 5.0857 & TRN \\
\hline CHEMBL1318448 & 688885 & 4.4 & 4.5376 & TRN \\
\hline CHEMBL1488179 & 688885 & 4.9 & 4.888 & TRN \\
\hline CHEMBL604119 & 688885 & 4.6 & 4.7723 & TST \\
\hline CHEMBL1318020 & 688885 & 6.0 & 4.9269 & TST \\
\hline CHEMBL1551090 & 688885 & 4.7 & 4.6717 & TRN \\
\hline CHEMBL1397192 & 688885 & 5.8 & 5.706 & TRN \\
\hline CHEMBL1316973 & 688885 & 4.5 & 5.0029 & TRN \\
\hline CHEMBL1256984 & 688885 & 4.6 & 4.8104 & TRN \\
\hline CHEMBL1433686 & 688885 & 4.5 & 5.1991 & TST \\
\hline
\end{tabular}

TRN 


\begin{tabular}{|c|c|c|c|c|}
\hline & & & pplement & al $\mathrm{T}$ \\
\hline CHEMBL1448288 & 688885 & 6.1 & 6.1248 & TRN \\
\hline CHEMBL1404501 & 688885 & 4.4 & 4.5011 & TRN \\
\hline CHEMBL1594648 & 688885 & 7.1002 & 6.7593 & TRN \\
\hline CHEMBL1594020 & 688885 & 5.0 & 5.0353 & TRN \\
\hline CHEMBL1477557 & 688885 & 4.4 & 4.3738 & TRN \\
\hline CHEMBL1318411 & 688885 & 4.9 & 4.7886 & TRN \\
\hline CHEMBL1560502 & 688885 & 5.0 & 5.08 & TRN \\
\hline CHEMBL1395275 & 688885 & 4.6 & 5.2065 & TRN \\
\hline CHEMBL1605233 & 688885 & 4.6 & 4.8108 & TRN \\
\hline CHEMBL1514416 & 688885 & 5.7 & 5.7146 & TRN \\
\hline CHEMBL1554547 & 688885 & 4.4 & 5.0679 & TRN \\
\hline CHEMBL1609142 & 688885 & 5.0 & 5.0318 & TRN \\
\hline CHEMBL1688558 & 688885 & 5.2 & 5.4209 & TRN \\
\hline CHEMBL1397466 & 688885 & 4.9 & 4.9031 & TST \\
\hline CHEMBL1527132 & 688885 & 5.0 & 4.9251 & TRN \\
\hline CHEMBL1395219 & 688885 & 4.8 & 4.8722 & TRN \\
\hline CHEMBL1514045 & 688885 & 4.7 & 4.7804 & TRN \\
\hline CHEMBL1566105 & 688885 & 6.4 & 6.3022 & TST \\
\hline CHEMBL1607905 & 688885 & 5.1 & 5.3996 & TRN \\
\hline CHEMBL490913 & 688885 & 6.0 & 6.3969 & TRN \\
\hline CHEMBL1523959 & 688885 & 5.2 & 5.1927 & TRN \\
\hline CHEMBL1488010 & 688885 & 4.6 & 5.1296 & TRN \\
\hline CHEMBL1602812 & 688885 & 5.3 & 5.1289 & TRN \\
\hline CHEMBL1515452 & 688885 & 5.5 & 5.7925 & TRN \\
\hline CHEMBL388054 & 688885 & 4.4 & 4.5018 & TST \\
\hline CHEMBL1599163 & 688885 & 6.1 & 5.6371 & TRN \\
\hline CHEMBL1554976 & 688885 & 6.1 & 5.9478 & TRN \\
\hline CHEMBL1482527 & 688885 & 5.2 & 5.2711 & TRN \\
\hline CHEMBL1412847 & 688885 & 5.9 & 6.176 & TRN \\
\hline CHEMBL1611308 & 688885 & 5.5 & 5.5583 & TRN \\
\hline CHEMBL1408176 & 688885 & 5.5 & 5.6782 & TRN \\
\hline CHEMBL1208858 & 688885 & 4.5 & 5.004 & TST \\
\hline CHEMBL1529265 & 688885 & 5.5 & 5.4174 & TRN \\
\hline CHEMBL1551841 & 688885 & 6.0 & 5.9656 & TRN \\
\hline CHEMBL1415616 & 688885 & 5.2 & 5.2483 & TST \\
\hline CHEMBL1323927 & 688885 & 6.8 & 5.9671 & TRN \\
\hline CHEMBL1533413 & 688885 & 5.5 & 5.4573 & TST \\
\hline CHEMBL 2374058 & 688885 & 5.0 & 5.2141 & TST \\
\hline CHEMBL1453655 & 688885 & 6.8 & 5.2412 & TRN \\
\hline CHEMBL1323759 & 688885 & 6.0 & 5.6663 & TRN \\
\hline CHEMBL92387 & 688885 & 4.5 & 5.206 & TST \\
\hline CHEMBL552439 & 688885 & 5.9 & 6.0908 & TST \\
\hline CHEMBL1611012 & 688885 & 5.1 & 5.2604 & TRN \\
\hline CHEMBL 251647 & 688885 & 6.0 & 5.4537 & TST \\
\hline CHEMBL1321624 & 688885 & 4.9 & 5.0722 & TRN \\
\hline CHEMBL1449777 & 688885 & 5.5 & 5.4921 & TRN \\
\hline CHEMBL1317633 & 688885 & 4.5 & 5.0056 & TRN \\
\hline CHEMBL1435886 & 688885 & 4.5 & 4.5522 & TRN \\
\hline
\end{tabular}




\begin{tabular}{|c|c|c|c|c|c|}
\hline \\
\hline CHEMBL1451097 & 688885 & 4.7 & 4.7668 & TRN & \\
\hline CHEMBL1408334 & 688885 & 6.0 & 5.9737 & TRN & \\
\hline CHEMBL513116 & 688885 & 6.0 & 6.5188 & TRN & \\
\hline CHEMBL1563507 & 688885 & 5.2 & 5.5065 & TRN & \\
\hline CHEMBL1442106 & 688885 & 4.5 & 4.5226 & TRN & \\
\hline CHEMBL1173475 & 688885 & 6.0 & 6.3818 & TRN & \\
\hline CHEMBL1474471 & 688885 & 5.9 & 5.7749 & TRN & \\
\hline CHEMBL1524194 & 688885 & 5.5 & 5.5581 & TRN & \\
\hline CHEMBL1574115 & 688885 & 4.9 & 4.9068 & TRN & \\
\hline CHEMBL1315794 & 688885 & 5.1 & 5.1523 & TRN & \\
\hline CHEMBL1162521 & 688885 & 5.2 & 5.1922 & TST & \\
\hline CHEMBL1728023 & 688885 & 6.0 & 5.445 & TRN & \\
\hline CHEMBL1552095 & 688885 & 6.0 & 5.88 & TST & \\
\hline CHEMBL1335471 & 688885 & 4.5 & 4.5935 & TRN & \\
\hline CHEMBL1555368 & 688885 & 4.9 & 5.0829 & TRN & \\
\hline CHEMBL1400637 & 688885 & 4.4 & 4.9795 & TRN & \\
\hline CHEMBL1398608 & 688885 & 5.6 & 5.796 & TRN & \\
\hline CHEMBL1599647 & 688885 & 5.5 & 5.3836 & TRN & \\
\hline CHEMBL208484 & 688885 & 6.0 & 5.5679 & TRN & \\
\hline CHEMBL1487318 & 688885 & 5.5 & 5.5938 & TRN & \\
\hline CHEMBL1397892 & 688885 & 4.6 & 5.2822 & TRN & \\
\hline CHEMBL446774 & 688885 & 5.4 & 5.2389 & TST & \\
\hline CHEMBL1375967 & 688885 & 5.4 & 5.5466 & TRN & \\
\hline CHEMBL1355672 & 688885 & 5.0 & 5.1234 & TRN & \\
\hline CHEMBL1600489 & 688885 & 6.2 & 5.9645 & TRN & \\
\hline CHEMBL1358756 & 688885 & 5.1 & 5.2493 & TRN & \\
\hline CHEMBL1514782 & 688885 & 5.6 & 5.53299 & 99999999995 & TRN \\
\hline CHEMBL1553766 & 688885 & 4.5 & 4.5552 & TRN & \\
\hline CHEMBL35482 & 688885 & 4.5 & 4.7811 & TRN & \\
\hline CHEMBL1513665 & 688885 & 4.9 & 5.2288 & TRN & \\
\hline CHEMBL1370622 & 688885 & 6.0 & 6.1031 & TRN & \\
\hline CHEMBL1447392 & 688885 & 5.0 & 4.9166 & TRN & \\
\hline CHEMBL488803 & 688885 & 4.9 & 5.0578 & TST & \\
\hline CHEMBL1563032 & 688885 & 5.5 & 5.466 & TRN & \\
\hline CHEMBL1331031 & 688885 & 5.8 & 5.8504 & TRN & \\
\hline CHEMBL 236789 & 688885 & 4.7 & 4.869 & TRN & \\
\hline CHEMBL1256740 & 688885 & 7.8013 & 7.0874 & TST & \\
\hline CHEMBL1451768 & 688885 & 4.8 & 4.84699 & 99999999995 & TRN \\
\hline CHEMBL473136 & 688885 & 4.5 & 4.6734 & TST & \\
\hline CHEMBL1567365 & 688885 & 5.5 & 5.5299 & TRN & \\
\hline CHEMBL1318425 & 688885 & 4.5 & 5.3057 & TST & \\
\hline CHEMBL 221137 & 688885 & 4.6 & 5.1233 & TST & \\
\hline CHEMBL1555156 & 688885 & 4.9 & 5.0158 & TRN & \\
\hline CHEMBL1512222 & 688885 & 4.6 & 4.8053 & TRN & \\
\hline CHEMBL123433 & 688885 & 4.5 & 4.8146 & TST & \\
\hline CHEMBL1358628 & 688885 & 6.0 & 6.0222 & TST & \\
\hline CHEMBL1398137 & 688885 & 4.8 & 4.9377 & TRN & \\
\hline CHEMBL1513511 & 688885 & 5.9 & 6.0928 & TRN & \\
\hline
\end{tabular}




\begin{tabular}{|c|c|c|c|c|}
\hline \multicolumn{5}{|c|}{ Supplemental Table S2.txt } \\
\hline CHEMBL1317010 & 688885 & 7.8996 & 7.5682 & TRN \\
\hline CHEMBL1373998 & 688885 & 5.2 & 5.2531 & TRN \\
\hline CHEMBL1512307 & 688885 & 5.5 & 5.7369 & TRN \\
\hline CHEMBL1404882 & 688885 & 5.5 & 5.4769 & TRN \\
\hline CHEMBL1473554 & 688885 & 4.4 & 3.9662 & TRN \\
\hline CHEMBL393136 & 688885 & 5.5 & 5.421 & TST \\
\hline CHEMBL1489541 & 688885 & 5.5 & 5.5968 & TRN \\
\hline CHEMBL258893 & 688885 & 4.4 & 4.9004 & TST \\
\hline CHEMBL3661417 & 688885 & 4.9 & 5.0274 & TRN \\
\hline CHEMBL1489212 & 688885 & 4.6 & 4.6873 & TRN \\
\hline CHEMBL1572855 & 688885 & 6.2 & 6.0658 & TRN \\
\hline CHEMBL1552066 & 688885 & 5.4 & 5.3381 & TRN \\
\hline CHEMBL1378440 & 688885 & 4.9 & 4.921 & TRN \\
\hline CHEMBL137246 & 688885 & 5.2 & 5.3879 & TRN \\
\hline CHEMBL1444270 & 688885 & 5.4 & 5.5732 & TRN \\
\hline CHEMBL1441981 & 688885 & 5.3 & 5.2212 & TRN \\
\hline CHEMBL1494408 & 688885 & 4.9 & 4.845 & TRN \\
\hline CHEMBL1554170 & 688885 & 5.2 & 5.0373 & TRN \\
\hline CHEMBL1317924 & 688885 & 4.6 & 4.7957 & TRN \\
\hline CHEMBL87418 & 688885 & 4.9 & 5.0955 & TRN \\
\hline CHEMBL1317039 & 688885 & 5.8 & 5.7953 & TRN \\
\hline CHEMBL1369728 & 688885 & 5.3 & 5.4612 & TRN \\
\hline CHEMBL 9843 & 688885 & 4.9 & 5.4373 & TRN \\
\hline CHEMBL1451099 & 688885 & 5.5 & 5.5344 & TRN \\
\hline CHEMBL1257012 & 688885 & 4.4 & 4.4969 & TST \\
\hline CHEMBL1479727 & 688885 & 5.0 & 5.0573 & TRN \\
\hline CHEMBL1475487 & 688885 & 5.9 & 5.9844 & TRN \\
\hline CHEMBL1328265 & 688885 & 5.5 & 5.4875 & TST \\
\hline CHEMBL1331525 & 688885 & 6.1 & 6.3594 & TRN \\
\hline CHEMBL1558480 & 688885 & 5.0 & 5.0822 & TRN \\
\hline CHEMBL1362880 & 688885 & 4.8 & 4.6764 & TRN \\
\hline CHEMBL68534 & 688885 & 4.5 & 4.5731 & TRN \\
\hline CHEMBL1373773 & 688885 & 4.9 & 4.8891 & TRN \\
\hline CHEMBL1446112 & 688885 & 5.6 & 5.4925 & TRN \\
\hline CHEMBL1446649 & 688885 & 5.7 & 5.4097 & TRN \\
\hline CHEMBL1590081 & 688885 & 5.5 & 5.4924 & TRN \\
\hline CHEMBL1489708 & 688885 & 4.7 & 4.6223 & TRN \\
\hline CHEMBL1447317 & 688885 & 4.5 & 5.3264 & TST \\
\hline CHEMBL1316731 & 688885 & 4.4 & 4.8921 & TRN \\
\hline CHEMBL1395997 & 688885 & 6.4 & 6.1221 & TRN \\
\hline CHEMBL1606094 & 688885 & 5.5 & 5.5078 & TST \\
\hline CHEMBL1435765 & 688885 & 5.5 & 5.224 & TRN \\
\hline CHEMBL1488574 & 688885 & 6.5 & 6.3599 & TRN \\
\hline CHEMBL1332726 & 688885 & 4.9 & 4.956 & TRN \\
\hline CHEMBL1598228 & 688885 & 6.1 & 5.774 & TST \\
\hline CHEMBL1552249 & 688885 & 4.6 & 4.6326 & TST \\
\hline CHEMBL428814 & 688885 & 6.3 & 6.5465 & TRN \\
\hline CHEMBL1374696 & 688885 & 5.1 & 4.9954 & TRN \\
\hline
\end{tabular}




\begin{tabular}{|c|c|c|c|c|c|}
\hline \\
\hline CHEMBL1396809 & 688885 & 4.9 & 5.0121 & TRN & \\
\hline CHEMBL1515194 & 688885 & 4.7 & 4.3256 & TRN & \\
\hline CHEMBL1256759 & 688885 & 6.0 & 6.2375 & TRN & \\
\hline CHEMBL1484337 & 688885 & 4.7 & 4.7994 & TRN & \\
\hline CHEMBL1553322 & 688885 & 6.8 & 5.3012 & TRN & \\
\hline CHEMBL1357551 & 688885 & 4.5 & 4.7258 & TRN & \\
\hline CHEMBL 292477 & 688885 & 4.4 & 4.4059 & TRN & \\
\hline CHEMBL1456076 & 688885 & 4.9 & 5.0602 & TRN & \\
\hline CHEMBL1319251 & 688885 & 5.5 & 5.3535 & TRN & \\
\hline CHEMBL576349 & 688885 & 4.6 & 4.8522 & TRN & \\
\hline CHEMBL1568735 & 688885 & 5.9 & 6.1647 & TRN & \\
\hline CHEMBL153036 & 688885 & 4.6 & 5.79799 & 9999999999 & TRN \\
\hline CHEMBL1316562 & 688885 & 6.9 & $6.7070 e$ & 0000000001 & TRN \\
\hline CHEMBL1437488 & 688885 & 6.0 & 5.3901 & TRN & \\
\hline CHEMBL1256760 & 688885 & 4.6 & 4.396 & TST & \\
\hline CHEMBL1328319 & 688885 & 4.5 & 4.5149 & TRN & \\
\hline CHEMBL1269022 & 688885 & 5.6 & 5.614 & TST & \\
\hline CHEMBL1592220 & 688885 & 5.4 & 5.2222 & TRN & \\
\hline CHEMBL430893 & 688885 & 4.4 & 5.2996 & TST & \\
\hline CHEMBL1415053 & 688885 & 5.3 & 5.3326 & TST & \\
\hline CHEMBL1330057 & 688885 & 5.5 & 5.4503 & TST & \\
\hline CHEMBL489525 & 688885 & 4.9 & 5.4532 & TRN & \\
\hline CHEMBL1361406 & 688885 & 4.8 & 4.6166 & TRN & \\
\hline CHEMBL1355263 & 688885 & 4.4 & 4.4882 & TRN & \\
\hline CHEMBL1453749 & 688885 & 4.6 & 4.9922 & TRN & \\
\hline CHEMBL1333056 & 688885 & 6.0 & 5.8557 & TST & \\
\hline CHEMBL1590059 & 688885 & 6.0 & 5.6591 & TRN & \\
\hline CHEMBL1487219 & 688885 & 5.0 & 4.9272 & TST & \\
\hline CHEMBL 243676 & 688885 & 5.0 & 5.7462 & TRN & \\
\hline CHEMBL1476043 & 688885 & 5.5 & 5.5208 & TRN & \\
\hline CHEMBL 26915 & 688885 & 4.6 & 4.8109 & TST & \\
\hline CHEMBL1441192 & 688885 & 5.2 & 4.6584 & TRN & \\
\hline CHEMBL1474795 & 688885 & 4.6 & 4.6337 & TRN & \\
\hline CHEMBL1397151 & 688885 & 4.9 & 5.1521 & TRN & \\
\hline CHEMBL1554564 & 688885 & 4.9 & 4.79899 & 99999999995 & TRN \\
\hline CHEMBL1361847 & 688885 & 6.5 & 6.6254 & TRN & \\
\hline CHEMBL1435902 & 688885 & 5.1 & 5.5802 & TST & \\
\hline CHEMBL1398528 & 688885 & 4.8 & 4.8457 & TRN & \\
\hline CHEMBL1358297 & 688885 & 4.5 & 4.6209 & TST & \\
\hline CHEMBL1484032 & 688885 & 4.8 & 4.8931 & TST & \\
\hline CHEMBL1449598 & 688885 & 5.2 & 5.3972 & TRN & \\
\hline CHEMBL1317232 & 688885 & 5.5 & 5.5016 & TRN & \\
\hline CHEMBL 275938 & 688885 & 4.8 & 5.1899 & TRN & \\
\hline CHEMBL1358266 & 688885 & 4.9 & 4.9125 & TRN & \\
\hline CHEMBL1476362 & 688885 & 4.4 & 5.1986 & TST & \\
\hline CHEMBL1476632 & 688885 & 6.2 & 5.9821 & TRN & \\
\hline CHEMBL1495875 & 688885 & 4.5 & 4.527 & TRN & \\
\hline CHEMBL3209702 & 688885 & 5.5 & 5.5435 & TRN & \\
\hline
\end{tabular}




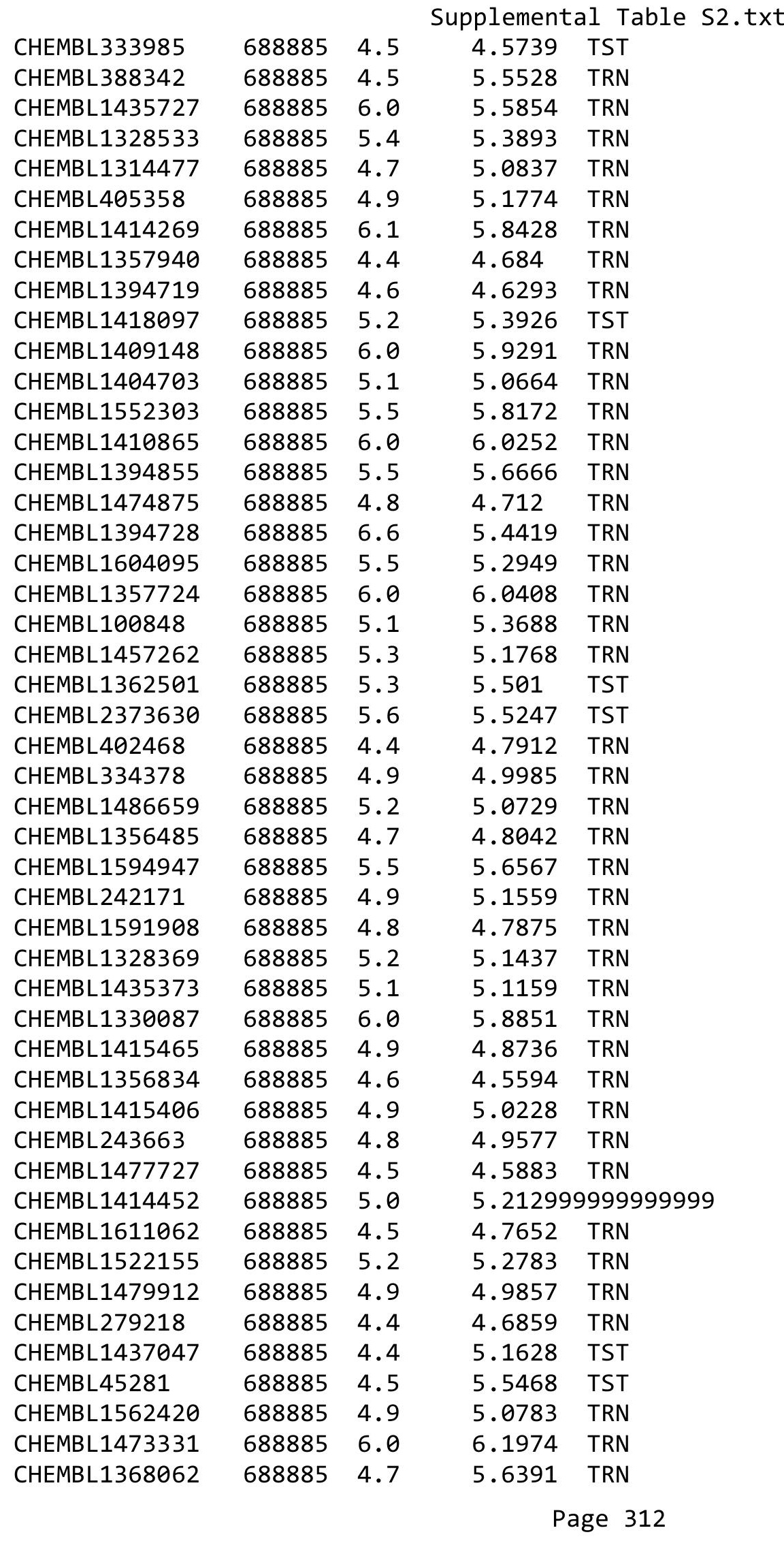




\begin{tabular}{|c|c|c|c|c|}
\hline \multicolumn{5}{|c|}{ lemental T } \\
\hline CHEMBL1591459 & 688885 & 5.4 & 5.506 & TRN \\
\hline CHEMBL1358449 & 688885 & 5.5 & 5.4095 & TST \\
\hline CHEMBL303579 & 688885 & 4.9 & 5.0175 & TRN \\
\hline CHEMBL1395281 & 688885 & 5.3 & 5.1978 & TRN \\
\hline CHEMBL1356941 & 688885 & 4.8 & 5.1724 & TRN \\
\hline CHEMBL1315184 & 688885 & 5.8 & 5.9824 & TRN \\
\hline CHEMBL1515802 & 688885 & 5.1 & 5.2348 & TST \\
\hline CHEMBL1512027 & 688885 & 4.5 & 4.5376 & TRN \\
\hline CHEMBL1556218 & 688885 & 4.4 & 4.3908 & TRN \\
\hline CHEMBL1569485 & 688885 & 5.5 & 5.4266 & TRN \\
\hline CHEMBL1515209 & 688885 & 5.5 & 5.5526 & TST \\
\hline CHEMBL1487561 & 688885 & 4.6 & 4.7698 & TRN \\
\hline CHEMBL23832 & 688885 & 4.8 & 4.9862 & TRN \\
\hline CHEMBL1374334 & 688885 & 5.5 & 5.2453 & TST \\
\hline CHEMBL1372850 & 688885 & 5.6 & 5.5835 & TRN \\
\hline CHEMBL1398319 & 688885 & 5.5 & 5.4635 & TRN \\
\hline CHEMBL1316317 & 688885 & 5.0 & 5.1012 & TRN \\
\hline CHEMBL1365553 & 688885 & 4.4 & 5.3593 & TST \\
\hline CHEMBL520107 & 688885 & 4.9 & 4.907 & TST \\
\hline CHEMBL1331980 & 688885 & 5.1 & 4.9925 & TST \\
\hline CHEMBL1414232 & 688885 & 4.4 & 5.6134 & TRN \\
\hline CHEMBL1355066 & 688885 & 5.4 & 5.2738 & TRN \\
\hline CHEMBL238624 & 688885 & 7.0 & 6.6672 & TRN \\
\hline CHEMBL1355010 & 688885 & 4.4 & 4.4729 & TRN \\
\hline CHEMBL1328979 & 688885 & 5.1 & 5.1027 & TRN \\
\hline CHEMBL1435028 & 688885 & 4.7 & 4.6519 & TRN \\
\hline CHEMBL1450169 & 688885 & 5.1 & 5.1812 & TST \\
\hline CHEMBL1355537 & 688885 & 4.8 & 4.9254 & TRN \\
\hline CHEMBL574181 & 688885 & 4.7 & 4.8784 & TRN \\
\hline CHEMBL1354751 & 688885 & 5.4 & 5.2652 & TRN \\
\hline CHEMBL1315380 & 688885 & 5.4 & 5.5547 & TRN \\
\hline CHEMBL1492411 & 688885 & 4.6 & 4.9688 & TRN \\
\hline CHEMBL90769 & 688885 & 4.7 & 4.907 & TST \\
\hline CHEMBL1319789 & 688885 & 6.0 & 5.8271 & TRN \\
\hline CHEMBL1437142 & 688885 & 5.4 & 4.9418 & TST \\
\hline CHEMBL1523108 & 688885 & 5.4 & 5.223 & TRN \\
\hline CHEMBL1412163 & 688885 & 6.1 & 5.4728 & TRN \\
\hline CHEMBL1395196 & 688885 & 6.0 & 5.0458 & TST \\
\hline CHEMBL1527157 & 688885 & 5.1 & 5.2021 & TST \\
\hline CHEMBL540294 & 688885 & 6.0 & 5.8638 & TST \\
\hline CHEMBL1557657 & 688885 & 5.3 & 5.4409 & TRN \\
\hline CHEMBL9352 & 688885 & 4.9 & 5.1548 & TRN \\
\hline CHEMBL1394419 & 688885 & 4.4 & 5.2424 & TRN \\
\hline CHEMBL1323124 & 688885 & 4.6 & 4.6661 & TRN \\
\hline CHEMBL1091971 & 688885 & 5.1 & 5.1801 & TST \\
\hline CHEMBL1592549 & 688885 & 5.3 & 4.758 & TRN \\
\hline CHEMBL 3084891 & 688885 & 4.4 & 5.1577 & TRN \\
\hline CHEMBL1517935 & 688885 & 5.2 & 5.1535 & TRN \\
\hline
\end{tabular}




\begin{tabular}{|c|c|c|c|c|c|}
\hline & & & & & \\
\hline CHEMBL402063 & 688885 & 4.4 & 4.5564 & TST & \\
\hline CHEMBL1397860 & 688885 & 5.1 & 5.1077 & TRN & \\
\hline CHEMBL1531754 & 688885 & 6.0 & 6.0445 & TRN & \\
\hline CHEMBL545050 & 688885 & 6.0 & 4.8329 & TRN & \\
\hline CHEMBL1411424 & 688885 & 4.4 & 4.5245 & TRN & \\
\hline CHEMBL1474695 & 688885 & 5.1 & 5.0327 & TRN & \\
\hline CHEMBL1395235 & 688885 & 5.4 & 5.3526 & TRN & \\
\hline CHEMBL1457550 & 688885 & 6.0 & 5.92200 & 0000000001 & TRN \\
\hline CHEMBL1527722 & 688885 & 6.0 & 5.7137 & TST & \\
\hline CHEMBL1397671 & 688885 & 4.7 & 4.921 & TRN & \\
\hline CHEMBL1568071 & 688885 & 4.6 & 4.7692 & TRN & \\
\hline CHEMBL1474272 & 688885 & 6.1 & 5.5812 & TRN & \\
\hline CHEMBL1516262 & 688885 & 4.7 & 4.7751 & TRN & \\
\hline CHEMBL1554141 & 688885 & 5.5 & 5.6762 & TRN & \\
\hline CHEMBL1398878 & 688885 & 6.0 & 5.3318 & TRN & \\
\hline CHEMBL1320141 & 688885 & 5.7 & 5.7899 & TRN & \\
\hline CHEMBL1395828 & 688885 & 6.9 & 5.3781 & TRN & \\
\hline CHEMBL1373610 & 688885 & 5.6 & 5.9528 & TRN & \\
\hline CHEMBL536950 & 688885 & 5.7 & 5.6052 & TST & \\
\hline CHEMBL1522752 & 688885 & 5.1 & 4.9833 & TST & \\
\hline CHEMBL1375214 & 688885 & 5.4 & 5.3827 & TRN & \\
\hline CHEMBL1256720 & 688885 & 4.4 & 5.3833 & TRN & \\
\hline CHEMBL 289233 & 688885 & 4.4 & 4.6222 & TRN & \\
\hline CHEMBL1371696 & 688885 & 5.5 & 5.4905 & TRN & \\
\hline CHEMBL1515614 & 688885 & 4.4 & 4.4308 & TRN & \\
\hline CHEMBL1515366 & 688885 & 6.6 & 5.568 & TRN & \\
\hline CHEMBL1409046 & 688885 & 5.2 & 5.313 & TST & \\
\hline CHEMBL1358731 & 688885 & 4.5 & 4.7424 & TRN & \\
\hline CHEMBL1321470 & 688885 & 5.4 & 5.6075 & TST & \\
\hline CHEMBL1516622 & 688885 & 5.4 & 5.556 & TRN & \\
\hline CHEMBL1449726 & 688885 & 5.4 & 5.5729 & TRN & \\
\hline CHEMBL1398600 & 688885 & 5.5 & 5.4342 & TRN & \\
\hline CHEMBL1410635 & 688885 & 4.9 & 4.8587 & TRN & \\
\hline CHEMBL1474468 & 688885 & 5.8 & 5.9035 & TRN & \\
\hline CHEMBL1437018 & 688885 & 4.5 & 5.1943 & TRN & \\
\hline CHEMBL137803 & 688885 & 4.4 & 5.2697 & TST & \\
\hline CHEMBL3209838 & 688885 & 5.5 & 5.6121 & TRN & \\
\hline CHEMBL605003 & 688885 & 5.0 & 5.0915 & TRN & \\
\hline CHEMBL1474503 & 688885 & 4.6 & 4.5887 & TRN & \\
\hline CHEMBL1358631 & 688885 & 5.5 & 5.3321 & TRN & \\
\hline CHEMBL1595377 & 688885 & 4.4 & 4.8044 & TRN & \\
\hline CHEMBL1476084 & 688885 & 6.5 & 6.2896 & TRN & \\
\hline CHEMBL1404660 & 688885 & 5.8 & 5.6484 & TRN & \\
\hline CHEMBL1491065 & 688885 & 4.8 & 4.82 & TRN & \\
\hline CHEMBL1571785 & 688885 & 7.5003 & 6.05399 & 9999999999 & TRN \\
\hline CHEMBL1318513 & 688885 & 5.5 & 5.5683 & TRN & \\
\hline CHEMBL 1473760 & 688885 & 6.1 & 5.6541 & TRN & \\
\hline CHEMBL1528491 & 688885 & 5.2 & 5.3806 & TRN & \\
\hline & & & & 314 & \\
\hline
\end{tabular}




\begin{tabular}{|c|c|c|c|c|c|}
\hline \\
\hline CHEMBL11684 & 688885 & 4.4 & 5.1179 & TST & \\
\hline CHEMBL1603394 & 688885 & 5.5 & 5.4046 & TRN & \\
\hline CHEMBL1398488 & 688885 & 4.6 & 4.6068 & TRN & \\
\hline CHEMBL1496576 & 688885 & 5.0 & 4.9431 & TRN & \\
\hline CHEMBL598952 & 688885 & 4.4 & 4.5584 & TST & \\
\hline CHEMBL25230 & 688885 & 5.4 & 5.30399 & 9999999999 & TST \\
\hline CHEMBL1482968 & 688885 & 4.4 & 4.5022 & TRN & \\
\hline CHEMBL1317769 & 688885 & 5.0 & 5.1064 & TRN & \\
\hline CHEMBL1356256 & 688885 & 4.7 & 4.7288 & TRN & \\
\hline CHEMBL1408520 & 688885 & 5.4 & 5.3631 & TRN & \\
\hline CHEMBL1330357 & 688885 & 4.4 & 5.32100 & 0000000001 & TST \\
\hline CHEMBL1590919 & 688885 & 4.9 & 4.8354 & TRN & \\
\hline CHEMBL1592452 & 688885 & 4.6 & 4.6062 & TRN & \\
\hline CHEMBL1532426 & 688885 & 4.4 & 4.6793 & TRN & \\
\hline CHEMBL1490528 & 688885 & 5.7 & 5.7212 & TRN & \\
\hline CHEMBL1515874 & 688885 & 4.5 & 4.7256 & TRN & \\
\hline CHEMBL1568744 & 688885 & 4.4 & 4.7042 & TRN & \\
\hline CHEMBL1479506 & 688885 & 6.7001 & 6.2169 & TRN & \\
\hline CHEMBL1446009 & 688885 & 7.8013 & 7.3768 & TRN & \\
\hline CHEMBL1533537 & 688885 & 4.9 & 4.8788 & TRN & \\
\hline CHEMBL1433704 & 688885 & 5.0 & 4.9974 & TRN & \\
\hline CHEMBL1476729 & 688885 & 4.9 & 4.8263 & TRN & \\
\hline CHEMBL1495395 & 688885 & 5.5 & 5.5355 & TRN & \\
\hline CHEMBL1591384 & 688885 & 4.8 & 4.9356 & TRN & \\
\hline CHEMBL1401520 & 688885 & 4.9 & 5.141 & TST & \\
\hline CHEMBL1357968 & 688885 & 4.7 & 4.5874 & TRN & \\
\hline CHEMBL1429478 & 688885 & 5.6 & 5.3479 & TST & \\
\hline CHEMBL323356 & 688885 & 5.6 & 5.7108 & TST & \\
\hline CHEMBL1335890 & 688885 & 5.8 & 5.898 & TRN & \\
\hline CHEMBL1372330 & 688885 & 6.0 & 5.9921 & TRN & \\
\hline CHEMBL1533680 & 688885 & 5.4 & 5.2402 & TRN & \\
\hline CHEMBL1518689 & 688885 & 5.5 & 5.5497 & TRN & \\
\hline CHEMBL1409720 & 688885 & 5.6 & 5.6981 & TRN & \\
\hline CHEMBL1357338 & 688885 & 4.7 & 4.8416 & TRN & \\
\hline CHEMBL1439882 & 688885 & 5.3 & 5.4333 & TRN & \\
\hline CHEMBL1527209 & 688885 & 4.6 & 4.8162 & TRN & \\
\hline CHEMBL1395839 & 688885 & 8.1024 & 5.6323 & TRN & \\
\hline CHEMBL1255647 & 688885 & 4.4 & 5.4058 & TST & \\
\hline CHEMBL1513115 & 688885 & 6.0 & 5.63200 & 0000000001 & TRN \\
\hline CHEMBL1516477 & 688885 & 4.6 & 4.933 & TST & \\
\hline CHEMBL1354864 & 688885 & 4.6 & 4.6648 & TRN & \\
\hline CHEMBL1322976 & 688885 & 5.2 & 5.2521 & TST & \\
\hline CHEMBL1552953 & 688885 & 5.6 & 5.7294 & TRN & \\
\hline CHEMBL492127 & 688885 & 6.1 & 6.3051 & TRN & \\
\hline CHEMBL1355935 & 688885 & 4.7 & 4.7519 & TRN & \\
\hline CHEMBL1569497 & 688885 & 4.9 & 4.9202 & TRN & \\
\hline CHEMBL1438323 & 688885 & 6.0 & 6.2459 & TRN & \\
\hline CHEMBL469309 & 688885 & 5.5 & 5.6285 & TRN & \\
\hline
\end{tabular}




\begin{tabular}{|c|c|c|c|c|c|}
\hline \multicolumn{6}{|c|}{ Supplemental Table S2.txt } \\
\hline CHEMBL1368773 & 688885 & 5.7 & 5.9253 & TST & \\
\hline CHEMBL1727680 & 688885 & 7.0 & 6.6779 & TRN & \\
\hline CHEMBL1487735 & 688885 & 6.4 & 6.2259 & TRN & \\
\hline CHEMBL1364808 & 688885 & 4.5 & 4.7583 & TST & \\
\hline CHEMBL 2068217 & 688885 & 5.5 & 5.3116 & TST & \\
\hline CHEMBL1257003 & 688885 & 6.3 & 6.0917 & TRN & \\
\hline CHEMBL1394095 & 688885 & 4.6 & 4.7314 & TRN & \\
\hline CHEMBL1492346 & 688885 & 5.3 & 5.1858 & TRN & \\
\hline CHEMBL1456688 & 688885 & 5.1 & 4.988 & TRN & \\
\hline CHEMBL77387 & 688885 & 4.5 & 4.8085 & TRN & \\
\hline CHEMBL1437906 & 688885 & 5.0 & 4.9932 & TRN & \\
\hline CHEMBL1515867 & 688885 & 4.4 & 4.8302 & TRN & \\
\hline CHEMBL1606796 & 688885 & 4.9 & 4.6644 & TRN & \\
\hline CHEMBL1592464 & 688885 & 6.7001 & 6.849 & TRN & \\
\hline CHEMBL362223 & 688885 & 6.3 & 5.2445 & TRN & \\
\hline CHEMBL1526170 & 688885 & 4.8 & 4.8922 & TRN & \\
\hline CHEMBL1488305 & 688885 & 4.6 & 4.6591 & TRN & \\
\hline CHEMBL 294989 & 688885 & 5.1 & 4.9897 & TRN & \\
\hline CHEMBL1488477 & 688885 & 4.8 & 4.6694 & TRN & \\
\hline CHEMBL1316759 & 688885 & 6.5 & 4.7633 & TRN & \\
\hline CHEMBL1327256 & 688885 & 4.5 & 5.4916 & TRN & \\
\hline CHEMBL1532319 & 688885 & 6.1 & 6.0215 & TST & \\
\hline CHEMBL608109 & 688885 & 5.8 & 5.8771 & TRN & \\
\hline CHEMBL1562337 & 688885 & 5.4 & 5.1831 & TRN & \\
\hline CHEMBL1399058 & 688885 & 5.3 & 5.3616 & TRN & \\
\hline CHEMBL1372106 & 688885 & 5.4 & 5.6123 & TRN & \\
\hline CHEMBL1481741 & 688885 & 4.9 & 4.8207 & TRN & \\
\hline CHEMBL1530613 & 688885 & 7.0 & 6.6498 & TST & \\
\hline CHEMBL416657 & 688885 & 5.2 & 5.1683 & TRN & \\
\hline CHEMBL1330114 & 688885 & 5.5 & 5.3882 & TRN & \\
\hline CHEMBL1593504 & 688885 & 4.9 & 4.7853 & TRN & \\
\hline CHEMBL1399481 & 688885 & 5.4 & 5.3388 & TRN & \\
\hline CHEMBL1356395 & 688885 & 6.0 & 5.9645 & TRN & \\
\hline CHEMBL3192742 & 688885 & 5.6 & 5.49100 & 00000000005 & TRN \\
\hline CHEMBL492193 & 688885 & 6.1 & 5.9456 & TST & \\
\hline CHEMBL1591745 & 688885 & 5.5 & 5.3993 & TST & \\
\hline CHEMBL1403333 & 688885 & 6.1 & 6.2205 & TRN & \\
\hline CHEMBL1172977 & 688885 & 5.5 & 5.4701 & TRN & \\
\hline CHEMBL1474523 & 688885 & 5.2 & 5.0605 & TST & \\
\hline CHEMBL1453715 & 688885 & 5.1 & 5.1796 & TST & \\
\hline CHEMBL1442770 & 688885 & 4.7 & 4.7764 & TST & \\
\hline CHEMBL309490 & 688885 & 5.5 & 7.0831 & TRN & \\
\hline CHEMBL428768 & 688885 & 6.0 & 5.9074 & TRN & \\
\hline CHEMBL1317860 & 688885 & 5.2 & 5.4574 & TRN & \\
\hline CHEMBL1355351 & 688885 & 4.9 & 4.9278 & TRN & \\
\hline CHEMBL1397595 & 688885 & 6.3 & 5.9018 & TRN & \\
\hline CHEMBL490706 & 688885 & 6.4 & 6.5697 & TRN & \\
\hline CHEMBL1515417 & 688885 & 5.9 & 5.8572 & TRN & \\
\hline
\end{tabular}




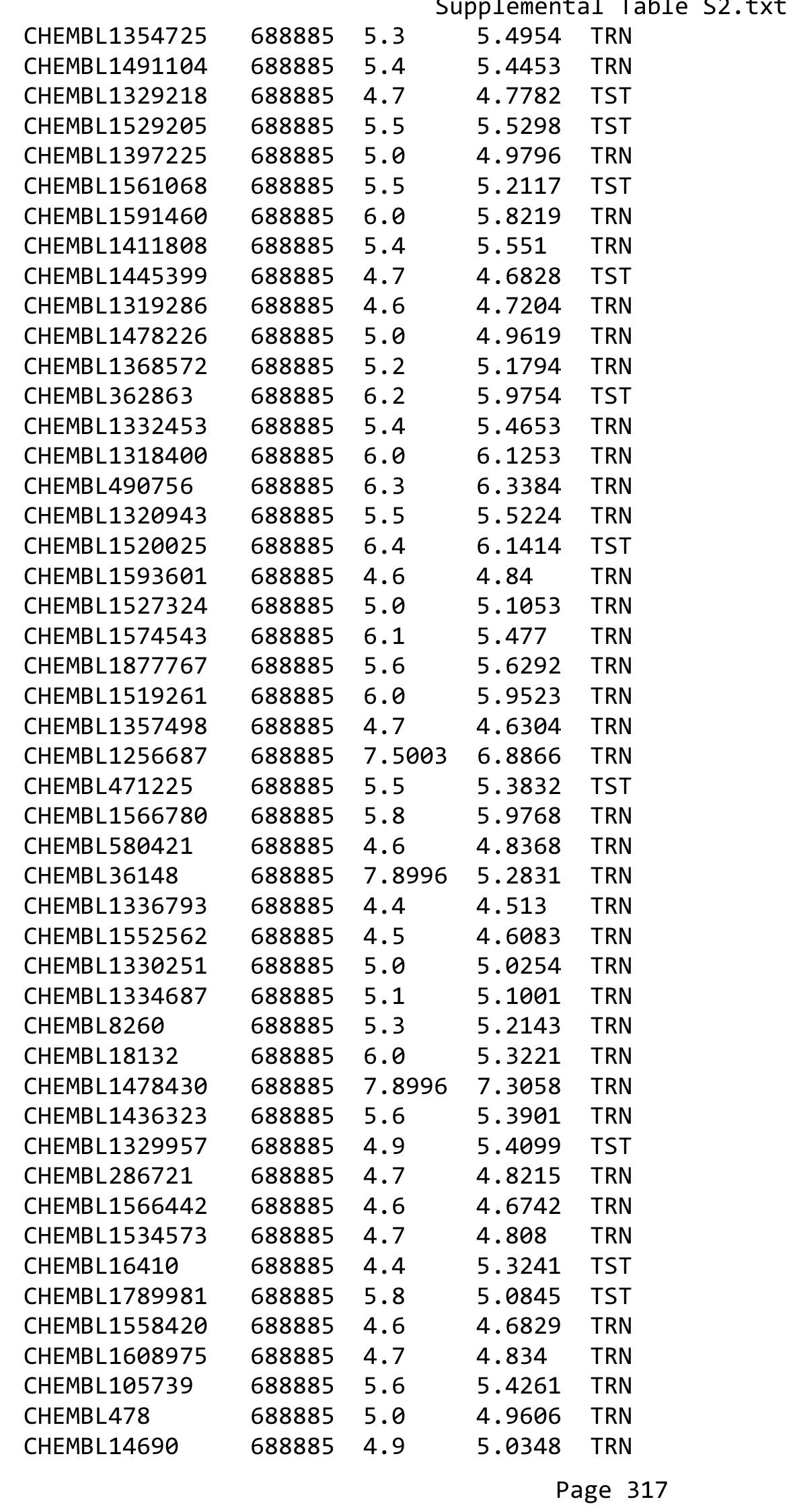




\begin{tabular}{|c|c|c|c|c|}
\hline \multicolumn{5}{|c|}{ Supplemental Table S2.txt } \\
\hline CHEMBL1325701 & 688885 & 5.2 & 5.3673 & TRN \\
\hline CHEMBL1484006 & 688885 & 6.0 & 6.1104 & TRN \\
\hline CHEMBL1534566 & 688885 & 8.7959 & 7.7015 & TRN \\
\hline CHEMBL56543 & 688885 & 6.6 & 5.0526 & TRN \\
\hline CHEMBL1358197 & 688885 & 5.0 & 4.995 & TRN \\
\hline CHEMBL1552161 & 688885 & 5.2 & 5.3146 & TRN \\
\hline CHEMBL1440842 & 688885 & 5.8 & 5.7636 & TRN \\
\hline CHEMBL1314516 & 688885 & 5.5 & 5.5841 & TRN \\
\hline CHEMBL1484944 & 688885 & 4.7 & 5.0243 & TRN \\
\hline CHEMBL1487003 & 688885 & 5.2 & 5.3062 & TRN \\
\hline CHEMBL1593815 & 688885 & 5.0 & 5.3922 & TRN \\
\hline CHEMBL1515449 & 688885 & 6.6 & 6.7303 & TRN \\
\hline CHEMBL1561452 & 688885 & 4.5 & 5.2866 & TRN \\
\hline CHEMBL1334959 & 688885 & 6.0 & 5.8926 & TRN \\
\hline CHEMBL1551503 & 688885 & 6.2 & 6.3177 & TRN \\
\hline CHEMBL1315820 & 688885 & 4.8 & 4.8175 & TRN \\
\hline CHEMBL1401324 & 688885 & 4.9 & 4.8631 & TRN \\
\hline CHEMBL1399922 & 688885 & 4.4 & 4.8412 & TST \\
\hline CHEMBL1355909 & 688885 & 4.7 & 4.8626 & TRN \\
\hline CHEMBL1486304 & 688885 & 5.4 & 5.4406 & TRN \\
\hline CHEMBL1368892 & 688885 & 5.6 & 5.555 & TRN \\
\hline CHEMBL1513656 & 688885 & 5.5 & 5.6679 & TRN \\
\hline CHEMBL1373151 & 688885 & 5.7 & 5.6682 & TRN \\
\hline CHEMBL1513490 & 688885 & 5.1 & 4.9935 & TST \\
\hline CHEMBL565856 & 688885 & 6.5 & 6.5122 & TRN \\
\hline CHEMBL242080 & 688885 & 5.1 & 5.1434 & TRN \\
\hline CHEMBL260374 & 688885 & 6.0 & 5.6861 & TST \\
\hline CHEMBL1331521 & 688885 & 4.6 & 5.4453 & TRN \\
\hline CHEMBL 319244 & 688885 & 4.4 & 4.6484 & TRN \\
\hline CHEMBL1568178 & 688885 & 7.699 & 5.8396 & TRN \\
\hline CHEMBL1316956 & 688885 & 6.6 & 6.8654 & TRN \\
\hline CHEMBL1396898 & 688885 & 5.9 & 5.6243 & TRN \\
\hline CHEMBL1451057 & 688885 & 5.6 & 5.8065 & TRN \\
\hline CHEMBL1318544 & 688885 & 4.9 & 4.9773 & TRN \\
\hline CHEMBL1355135 & 688885 & 4.8 & 4.9761 & TRN \\
\hline CHEMBL1397218 & 688885 & 6.5 & 6.1353 & TST \\
\hline CHEMBL1435259 & 688885 & 4.5 & 4.8143 & TRN \\
\hline CHEMBL 8145 & 688885 & 5.2 & 5.3522 & TRN \\
\hline CHEMBL1369212 & 688885 & 6.0 & 5.9317 & TRN \\
\hline CHEMBL410873 & 688885 & 4.6 & 4.7365 & TRN \\
\hline CHEMBL1411094 & 688885 & 5.1 & 5.0145 & TRN \\
\hline CHEMBL1357157 & 688885 & 4.9 & 4.984 & TRN \\
\hline CHEMBL1331579 & 688885 & 5.7 & 5.7164 & TRN \\
\hline CHEMBL1600520 & 688885 & 5.2 & 5.2518 & TRN \\
\hline CHEMBL242383 & 688885 & 5.0 & 5.9053 & TRN \\
\hline CHEMBL1253351 & 688885 & 5.1 & 5.3455 & TST \\
\hline CHEMBL1443425 & 688885 & 4.9 & 4.8402 & TRN \\
\hline CHEMBL1534591 & 688885 & 6.4 & 5.8352 & TRN \\
\hline
\end{tabular}




\begin{tabular}{|c|c|c|c|c|}
\hline \multicolumn{5}{|c|}{ Supplemental Table S2.txt } \\
\hline CHEMBL1331004 & 688885 & 4.7 & 4.7707 & TRN \\
\hline CHEMBL1568083 & 688885 & 8.6021 & 5.3847 & TST \\
\hline CHEMBL1369822 & 688885 & 5.1 & 5.1342 & TRN \\
\hline CHEMBL464859 & 688885 & 4.6 & 4.6087 & TRN \\
\hline CHEMBL1488845 & 688885 & 5.3 & 5.1641 & TRN \\
\hline CHEMBL539027 & 688885 & 6.0 & 5.6799 & TRN \\
\hline CHEMBL1592160 & 688885 & 5.0 & 5.5114 & TRN \\
\hline CHEMBL1521440 & 688885 & 5.5 & 5.4989 & TRN \\
\hline CHEMBL1408760 & 688885 & 4.7 & \multicolumn{2}{|c|}{4.8180000000000005} \\
\hline CHEMBL1332471 & 688885 & 5.5 & 5.4921 & TRN \\
\hline CHEMBL1447147 & 688885 & 5.7 & 5.4598 & TRN \\
\hline CHEMBL1606727 & 688885 & 7.2 & 7.1879 & TRN \\
\hline CHEMBL1591275 & 688885 & 4.5 & 4.6268 & TRN \\
\hline CHEMBL1320469 & 688885 & 5.8 & 5.9363 & TRN \\
\hline CHEMBL72365 & 688885 & 6.0 & 4.8901 & TRN \\
\hline CHEMBL1448552 & 688885 & 5.5 & 6.066 & TRN \\
\hline CHEMBL315268 & 688885 & 5.0 & 5.0825 & TRN \\
\hline CHEMBL1354341 & 688885 & 4.4 & 4.7374 & TRN \\
\hline CHEMBL1474111 & 688885 & 5.4 & 5.2848 & TRN \\
\hline CHEMBL1319049 & 688885 & 6.0 & 6.0262 & TRN \\
\hline CHEMBL1330422 & 688885 & 5.2 & 5.1016 & TRN \\
\hline CHEMBL1611906 & 688885 & 5.6 & 5.6128 & TRN \\
\hline CHEMBL1514161 & 688885 & 5.0 & 4.8236 & TRN \\
\hline CHEMBL1396949 & 688885 & 5.5 & 5.5019 & TRN \\
\hline CHEMBL1372627 & 688885 & 4.8 & 4.757 & TRN \\
\hline CHEMBL1524305 & 688885 & 4.5 & 4.5639 & TRN \\
\hline CHEMBL3194627 & 688885 & 5.5 & 5.6621 & TRN \\
\hline CHEMBL1476298 & 688885 & 4.7 & 4.798 & TRN \\
\hline CHEMBL1564927 & 688885 & 5.7 & 5.6512 & TST \\
\hline CHEMBL1570921 & 688885 & 5.0 & 4.9044 & TRN \\
\hline CHEMBL1397209 & 688885 & 7.0 & 5.3222 & TRN \\
\hline CHEMBL1364601 & 688885 & 5.3 & 5.5981 & TRN \\
\hline CHEMBL1417333 & 688885 & 5.3 & 5.3458 & TST \\
\hline CHEMBL1434783 & 688885 & 4.9 & 4.8289 & TRN \\
\hline CHEMBL1526229 & 688885 & 5.1 & 5.1168 & TST \\
\hline CHEMBL 258767 & 688885 & 6.0 & 5.1167 & TRN \\
\hline CHEMBL1442011 & 688885 & 7.5003 & 5.5638 & TRN \\
\hline CHEMBL1552677 & 688885 & 6.0 & \multicolumn{2}{|c|}{6.212000000000001} \\
\hline CHEMBL1325833 & 688885 & 4.6 & 4.8035 & TRN \\
\hline CHEMBL1597410 & 688885 & 5.0 & 5.0409 & TRN \\
\hline CHEMBL39878 & 688885 & 5.3 & 5.2403 & TRN \\
\hline CHEMBL1552270 & 688885 & 5.8 & 5.9048 & TRN \\
\hline CHEMBL1552519 & 688885 & 5.8 & 6.0616 & TRN \\
\hline CHEMBL1439126 & 688885 & 5.8 & 5.9686 & TST \\
\hline CHEMBL1527443 & 688885 & 5.5 & 5.4407 & TRN \\
\hline CHEMBL464176 & 688885 & 4.5 & 5.0868 & TST \\
\hline CHEMBL110739 & 688885 & 4.8 & 4.9494 & TST \\
\hline CHEMBL1256865 & 688885 & 4.9 & 4.9834 & TRN \\
\hline
\end{tabular}




\begin{tabular}{|c|c|c|c|c|}
\hline \multicolumn{5}{|c|}{ Supplemental Table S2.txt } \\
\hline CHEMBL540848 & 688885 & 4.5 & 5.3355 & TRN \\
\hline CHEMBL1411814 & 688885 & 5.5 & 5.4637 & TRN \\
\hline CHEMBL1319303 & 688885 & 5.4 & 5.4604 & TRN \\
\hline CHEMBL1453208 & 688885 & 4.4 & 4.5534 & TRN \\
\hline CHEMBL1555011 & 688885 & 4.9 & 4.8505 & TRN \\
\hline CHEMBL1369062 & 688885 & 4.4 & 4.5608 & TRN \\
\hline CHEMBL3213210 & 688885 & 5.4 & 5.4646 & TRN \\
\hline CHEMBL1411438 & 688885 & 5.1 & 5.166 & TRN \\
\hline CHEMBL 275854 & 688885 & 5.0 & 4.8574 & TRN \\
\hline CHEMBL1591965 & 688885 & 4.5 & 4.5678 & TRN \\
\hline CHEMBL1356843 & 688885 & 4.6 & 4.8497 & TRN \\
\hline CHEMBL1317823 & 688885 & 4.5 & 4.8529 & TRN \\
\hline CHEMBL1327243 & 688885 & 5.6 & 5.3439 & TST \\
\hline CHEMBL1559404 & 688885 & 4.6 & 4.8715 & TST \\
\hline CHEMBL 2373582 & 688885 & 5.5 & 5.1496 & TST \\
\hline CHEMBL 21260 & 688885 & 6.0 & 5.8599 & TST \\
\hline CHEMBL1318622 & 688885 & 6.3 & 6.1364 & TST \\
\hline CHEMBL1354426 & 688885 & 5.6 & 5.5969 & TST \\
\hline CHEMBL1552294 & 688885 & 4.5 & 4.4894 & TST \\
\hline CHEMBL434119 & 688885 & 4.4 & 4.4941 & TST \\
\hline CHEMBL3209943 & 688885 & 5.4 & 5.6618 & TST \\
\hline CHEMBL1603186 & 688885 & 5.7 & 5.6165 & TST \\
\hline CHEMBL1553274 & 688885 & 4.6 & 5.1062 & TST \\
\hline CHEMBL1396773 & 688885 & 4.9 & 4.9003 & TST \\
\hline CHEMBL1314273 & 688885 & 5.7 & 5.6494 & TST \\
\hline CHEMBL3211338 & 688885 & 6.0 & 6.0814 & TST \\
\hline CHEMBL443893 & 688885 & 4.4 & 5.1314 & TST \\
\hline CHEMBL1374610 & 688885 & 5.3 & 5.0187 & TST \\
\hline CHEMBL1610350 & 688885 & 5.9 & 5.8503 & TST \\
\hline CHEMBL1490497 & 688885 & 5.3 & 5.2009 & TST \\
\hline CHEMBL1358390 & 688885 & 5.1 & 5.1199 & TST \\
\hline CHEMBL544115 & 688885 & 4.5 & 4.2997 & TST \\
\hline CHEMBL1366061 & 688885 & 5.6 & 5.7904 & TST \\
\hline CHEMBL 582444 & 688885 & 8.301 & 7.5527 & TST \\
\hline CHEMBL1415957 & 688885 & 4.4 & 4.5227 & TST \\
\hline CHEMBL1413343 & 688885 & 6.3 & 5.5501 & TST \\
\hline CHEMBL1324334 & 688885 & 5.4 & 5.4587 & TST \\
\hline CHEMBL1572173 & 688885 & 4.8 & 5.0367 & TST \\
\hline CHEMBL1316808 & 688885 & 5.8 & 5.7932 & TST \\
\hline CHEMBL464467 & 688885 & 4.8 & 5.4321 & TST \\
\hline CHEMBL239439 & 688885 & 5.8 & 5.7933 & TST \\
\hline CHEMBL1398834 & 688885 & 5.0 & 4.9608 & TST \\
\hline CHEMBL475198 & 688885 & 6.2 & 6.2854 & TST \\
\hline CHEMBL 350343 & 688885 & 4.8 & 5.0165 & TST \\
\hline CHEMBL1363347 & 688885 & 8.3979 & 5.1904 & TST \\
\hline CHEMBL1396867 & 688885 & 5.1 & 5.4788 & TST \\
\hline CHEMBL1356630 & 688885 & 5.9 & 6.3013 & TST \\
\hline CHEMBL1553399 & 688885 & 4.6 & 4.7433 & TST \\
\hline
\end{tabular}




\begin{tabular}{|c|c|c|c|c|}
\hline & & & & \\
\hline CHEMBL475376 & 688885 & 6.1 & 6.2828 & TST \\
\hline CHEMBL1329939 & 688885 & 6.0 & 5.5779 & TST \\
\hline CHEMBL1608779 & 688885 & 5.5 & 5.523 & TST \\
\hline CHEMBL1562786 & 688885 & 4.9 & 4.7477 & TST \\
\hline CHEMBL1569638 & 688885 & 5.4 & 5.6373 & TST \\
\hline CHEMBL1565525 & 688885 & 6.3 & 6.46399 & 99999999995 \\
\hline CHEMBL1337781 & 688885 & 6.7001 & 6.4004 & TST \\
\hline CHEMBL1457317 & 688885 & 4.7 & 4.9707 & TST \\
\hline CHEMBL1224512 & 688885 & 4.6 & 4.666 & TST \\
\hline CHEMBL1604366 & 688885 & 5.5 & 5.439 & TST \\
\hline CHEMBL1451788 & 688885 & 4.9 & 4.8358 & TST \\
\hline CHEMBL269733 & 688885 & 5.0 & 5.1593 & TST \\
\hline CHEMBL1366297 & 688885 & 4.9 & 4.886 & TST \\
\hline CHEMBL50267 & 688885 & 4.4 & 5.3634 & TST \\
\hline CHEMBL1371311 & 688885 & 5.4 & 5.3445 & TST \\
\hline CHEMBL1591219 & 688885 & 4.4 & 5.0087 & TST \\
\hline CHEMBL1337163 & 688885 & 4.5 & 4.8021 & TST \\
\hline CHEMBL32142 & 688885 & 5.2 & 5.135 & TST \\
\hline CHEMBL102714 & 688885 & 6.0 & 4.4922 & TST \\
\hline CHEMBL1515341 & 688885 & 5.5 & 5.34399 & 9999999999 \\
\hline CHEMBL1452894 & 688885 & 4.9 & 5.1225 & TST \\
\hline CHEMBL1395899 & 688885 & 5.4 & 5.4854 & TST \\
\hline CHEMBL1319720 & 688885 & 5.2 & 5.4666 & TST \\
\hline CHEMBL1476139 & 688885 & 4.7 & 4.65 & TST \\
\hline CHEMBL1417135 & 688885 & 5.0 & 4.9997 & TST \\
\hline CHEMBL1398543 & 688885 & 4.6 & 4.5847 & TST \\
\hline CHEMBL1380684 & 688885 & 6.0 & 5.6545 & TST \\
\hline CHEMBL1529538 & 688885 & 4.4 & 5.012 & TST \\
\hline CHEMBL1437661 & 688885 & 5.1 & 4.6816 & TST \\
\hline CHEMBL1473715 & 688885 & 4.4 & 4.2981 & TST \\
\hline CHEMBL1409547 & 688885 & 4.9 & 4.9703 & TST \\
\hline CHEMBL1476791 & 688885 & 4.9 & 5.0388 & TST \\
\hline CHEMBL1515352 & 688885 & 5.6 & 5.3117 & TST \\
\hline CHEMBL1395421 & 688885 & 4.4 & 4.6937 & TST \\
\hline CHEMBL1519225 & 688885 & 4.5 & 4.746 & TST \\
\hline CHEMBL1551051 & 688885 & 4.8 & 4.8893 & TST \\
\hline CHEMBL1363142 & 688885 & 5.9 & 6.0084 & TST \\
\hline CHEMBL1513740 & 688885 & 5.1 & 5.01 & TST \\
\hline CHEMBL490577 & 688885 & 7.8013 & 4.9583 & TST \\
\hline CHEMBL1409320 & 688885 & 5.4 & 5.343 & TST \\
\hline CHEMBL1320619 & 688885 & 4.6 & 4.5034 & TST \\
\hline CHEMBL1595166 & 688885 & 5.1 & 5.0497 & TST \\
\hline CHEMBL1356466 & 688885 & 4.4 & 4.6492 & TST \\
\hline CHEMBL1555118 & 688885 & 5.1 & 5.152 & TST \\
\hline CHEMBL1394137 & 688885 & 5.2 & 5.2536 & TST \\
\hline CHEMBL1554854 & 688885 & 5.5 & 5.6024 & TST \\
\hline CHEMBL1593589 & 688885 & 6.9 & 6.1847 & TST \\
\hline CHEMBL1447333 & 688885 & 6.3 & 6.151 & TST \\
\hline
\end{tabular}




\begin{tabular}{|c|c|c|c|c|}
\hline \multicolumn{5}{|c|}{ Supplemental Table S2.txt } \\
\hline CHEMBL1328274 & 688885 & 5.7 & 5.2737 & TST \\
\hline CHEMBL1417771 & 688885 & 6.3 & 6.5327 & TST \\
\hline CHEMBL1554194 & 688885 & 6.5 & 6.5703 & TST \\
\hline CHEMBL1725279 & 688885 & 6.0 & 5.5807 & TST \\
\hline CHEMBL1435647 & 688885 & 5.0 & 4.9527 & TST \\
\hline CHEMBL 20730 & 688885 & 4.4 & 5.0556 & TST \\
\hline CHEMBL1493037 & 688885 & 4.7 & 4.8122 & TST \\
\hline CHEMBL1514149 & 688885 & 5.9 & 6.0365 & TST \\
\hline CHEMBL1590270 & 688885 & 5.2 & 5.0895 & TST \\
\hline CHEMBL1437128 & 688885 & 5.1 & 5.1661 & TST \\
\hline CHEMBL1590334 & 688885 & 5.1 & 5.2129 & TST \\
\hline CHEMBL1452111 & 688885 & 6.0 & 5.808 & TST \\
\hline CHEMBL1369374 & 688885 & 6.2 & 5.519 & TST \\
\hline CHEMBL407232 & 688885 & 5.4 & 5.2488 & TST \\
\hline CHEMBL1416476 & 688885 & 6.0 & 6.2999 & TST \\
\hline CHEMBL1608410 & 688885 & 5.5 & 5.2896 & TST \\
\hline CHEMBL1454049 & 688885 & 6.3 & 6.4726 & TST \\
\hline CHEMBL1354190 & 688885 & 5.6 & 5.4827 & TST \\
\hline CHEMBL1398538 & 688885 & 6.6 & 6.4149 & TST \\
\hline CHEMBL86313 & 688885 & 6.2 & 5.4372 & TST \\
\hline CHEMBL1443376 & 688885 & 4.4 & 4.6563 & TST \\
\hline CHEMBL30432 & 688885 & 4.9 & 5.1732 & TST \\
\hline CHEMBL1473754 & 688885 & 5.4 & 5.3156 & TST \\
\hline CHEMBL148296 & 688885 & 5.1 & 5.0832 & TST \\
\hline CHEMBL1436578 & 688885 & 5.9 & 5.3358 & TST \\
\hline CHEMBL1433725 & 688885 & 5.5 & 4.244 & TST \\
\hline CHEMBL1314641 & 688885 & 5.1 & 5.3613 & TST \\
\hline CHEMBL1324667 & 688885 & 5.6 & 5.5298 & TST \\
\hline CHEMBL98350 & 688885 & 4.4 & 4.503 & TST \\
\hline CHEMBL1534734 & 688885 & 4.4 & 4.2679 & TST \\
\hline CHEMBL565654 & 688885 & 6.2 & 6.3601 & TST \\
\hline CHEMBL1333445 & 688885 & 5.7 & 5.5485 & TST \\
\hline CHEMBL1571851 & 688885 & 6.0 & 4.8843 & TST \\
\hline CHEMBL1398066 & 688885 & 5.1 & 5.2049 & TST \\
\hline CHEMBL1605426 & 688885 & 4.9 & 4.8984 & TST \\
\hline CHEMBL39317 & 688885 & 4.5 & 4.8554 & TST \\
\hline CHEMBL15060 & 688885 & 4.8 & 4.8199 & TST \\
\hline CHEMBL1411081 & 688885 & 6.0 & 5.7829 & TST \\
\hline CHEMBL1374501 & 688885 & 5.4 & 5.2812 & TST \\
\hline CHEMBL1491744 & 688885 & 6.5 & 6.4702 & TST \\
\hline CHEMBL1564477 & 688885 & 4.9 & 4.9503 & TST \\
\hline CHEMBL3208021 & 688885 & 5.6 & 5.6574 & TST \\
\hline CHEMBL1573063 & 688885 & 6.3 & 6.5029 & TST \\
\hline CHEMBL1602633 & 688885 & 5.3 & 5.3696 & TST \\
\hline CHEMBL1449517 & 688885 & 5.6 & 5.5533 & TST \\
\hline CHEMBL32503 & 688885 & 5.5 & 5.4573 & TST \\
\hline CHEMBL1554851 & 688885 & 5.6 & 5.561 & TST \\
\hline CHEMBL1405325 & 688885 & 5.3 & 5.4091 & TST \\
\hline
\end{tabular}




\begin{tabular}{|c|c|c|c|c|}
\hline \multirow[b]{2}{*}{ CHEMBL1396015 } & & & pplement & al $\mathrm{T}$ \\
\hline & 688885 & 5.5 & 5.489 & TST \\
\hline CHEMBL1593321 & 688885 & 5.5 & 5.4476 & TST \\
\hline CHEMBL1568080 & 688885 & 5.3 & 5.2413 & TST \\
\hline CHEMBL1476687 & 688885 & 5.3 & 5.2461 & TST \\
\hline CHEMBL1371947 & 688885 & 5.2 & 5.3647 & TST \\
\hline CHEMBL86537 & 688885 & 5.1 & 5.1539 & TST \\
\hline CHEMBL1437138 & 688885 & 6.0 & 5.9362 & TST \\
\hline CHEMBL1369515 & 688885 & 6.3 & 6.1887 & TST \\
\hline CHEMBL398673 & 688885 & 5.1 & 5.2159 & TST \\
\hline CHEMBL574985 & 688885 & 5.4 & 5.4229 & TST \\
\hline CHEMBL1551295 & 688885 & 5.5 & 5.1523 & TST \\
\hline CHEMBL429095 & 688885 & 6.0 & 5.2157 & TST \\
\hline CHEMBL1371698 & 688885 & 5.4 & 5.532 & TST \\
\hline CHEMBL1397427 & 688885 & 4.6 & 5.0942 & TST \\
\hline CHEMBL1596246 & 688885 & 4.9 & 4.9107 & TST \\
\hline CHEMBL1479428 & 688885 & 4.4 & 4.8682 & TST \\
\hline CHEMBL1442250 & 688885 & 4.9 & 5.069 & TST \\
\hline CHEMBL1491776 & 688885 & 7.1002 & 6.8757 & TST \\
\hline CHEMBL1557809 & 688885 & 5.8 & 5.7237 & TST \\
\hline CHEMBL1475075 & 688885 & 5.6 & 5.7993 & TST \\
\hline CHEMBL1397782 & 688885 & 5.1 & 5.023 & TST \\
\hline CHEMBL1405894 & 688885 & 5.8 & 5.2575 & TST \\
\hline CHEMBL1354090 & 688885 & 4.4 & 5.0811 & TST \\
\hline CHEMBL1441593 & 688885 & 5.9 & 5.3496 & TST \\
\hline CHEMBL1329823 & 688885 & 8.301 & 5.532 & TST \\
\hline CHEMBL1396010 & 688885 & 4.6 & 4.5505 & TST \\
\hline CHEMBL434063 & 688885 & 6.0 & 4.8202 & TST \\
\hline CHEMBL1482575 & 688885 & 4.6 & 4.7065 & TST \\
\hline CHEMBL1590982 & 688885 & 5.0 & 5.0869 & TST \\
\hline CHEMBL1603446 & 688885 & 5.8 & 5.7264 & TST \\
\hline CHEMBL1553325 & 688885 & 5.9 & 5.3726 & TST \\
\hline CHEMBL1592500 & 688885 & 6.0 & 5.5927 & TST \\
\hline CHEMBL1553136 & 688885 & 7.699 & 5.1582 & TST \\
\hline CHEMBL554041 & 688885 & 4.7 & 4.8373 & TST \\
\hline CHEMBL1359291 & 688885 & 4.5 & 4.4348 & TST \\
\hline CHEMBL1593663 & 688885 & 4.8 & 4.8668 & TST \\
\hline CHEMBL1591181 & 688885 & 5.2 & 5.5993 & TST \\
\hline CHEMBL1602394 & 688885 & 5.2 & 5.305 & TST \\
\hline CHEMBL441618 & 688885 & 5.0 & 4.9708 & TST \\
\hline CHEMBL1372088 & 688885 & 6.7001 & 5.4198 & TST \\
\hline CHEMBL 9225 & 688885 & 5.3 & 5.1958 & TST \\
\hline CHEMBL1475375 & 688885 & 5.6 & 5.6538 & TST \\
\hline CHEMBL1366393 & 688885 & 5.9 & 6.0589 & TST \\
\hline CHEMBL1552181 & 688885 & 5.4 & 5.3717 & TST \\
\hline CHEMBL1491340 & 688885 & 6.0 & 5.774 & TST \\
\hline CHEMBL1513876 & 688885 & 4.8 & 4.7885 & TST \\
\hline CHEMBL1479372 & 688885 & 4.8 & 4.8664 & TST \\
\hline \multirow[t]{2}{*}{ CHEMBL1594227 } & 688885 & 5.2 & 5.2268 & TST \\
\hline & & & \multicolumn{2}{|c|}{ Page 32} \\
\hline
\end{tabular}




\begin{tabular}{|c|c|c|c|c|c|}
\hline \multicolumn{6}{|c|}{ Supplemental Table s2.txt } \\
\hline CHEMBL1433783 & 688885 & 4.7 & 4.6733 & TST & \\
\hline CHEMBL1333156 & 688885 & 5.7 & 5.5862 & TST & \\
\hline CHEMBL1527221 & 688885 & 6.1 & 6.2325 & TST & \\
\hline CHEMBL1366766 & 688885 & 5.2 & 5.3387 & TST & \\
\hline CHEMBL1554088 & 688885 & 4.5 & 4.7613 & TST & \\
\hline CHEMBL1591635 & 688885 & 5.4 & 5.2492 & TST & \\
\hline CHEMBL1412305 & 688885 & 8.1024 & 5.2618 & TST & \\
\hline CHEMBL399121 & 688885 & 6.0 & 5.3043 & TST & \\
\hline CHEMBL1477982 & 688885 & 6.7001 & 5.8469 & TST & \\
\hline CHEMBL1452850 & 688885 & 5.7 & 5.6276 & TST & \\
\hline CHEMBL595227 & 688885 & 6.1 & 5.20100 & 00000000005 & TST \\
\hline CHEMBL1512693 & 688885 & 5.5 & 5.5607 & TST & \\
\hline CHEMBL1517793 & 688885 & 8.6021 & 5.1698 & TST & \\
\hline CHEMBL1490383 & 688885 & 4.4 & 5.1115 & TST & \\
\hline CHEMBL1455438 & 688885 & 5.1 & 5.1019 & TST & \\
\hline CHEMBL1318278 & 688885 & 4.6 & 4.7784 & TST & \\
\hline CHEMBL1514779 & 688885 & 4.4 & 4.4432 & TST & \\
\hline CHEMBL1317885 & 688885 & 4.6 & 4.7413 & TST & \\
\hline CHEMBL1483716 & 688885 & 5.5 & 5.47 & TST & \\
\hline CHEMBL1317172 & 688885 & 4.7 & 5.2547 & TST & \\
\hline CHEMBL3113316 & 1290683 & 4.9469 & 4.3878 & TRN & \\
\hline CHEMBL3113323 & 1290683 & 3.301 & 3.4309 & TST & \\
\hline CHEMBL3113295 & 1290683 & 3.301 & 3.8457 & TRN & \\
\hline CHEMBL3113334 & 1290683 & 3.301 & 3.3456 & TST & \\
\hline CHEMBL3113292 & 1290683 & 3.301 & 4.2781 & TRN & \\
\hline CHEMBL3113320 & 1290683 & 4.5901 & 4.2433 & TRN & \\
\hline CHEMBL3113304 & 1290683 & 4.3298 & 3.4447 & TRN & \\
\hline CHEMBL550866 & 1290683 & 3.301 & 3.3449 & TRN & \\
\hline CHEMBL3113291 & 1290683 & 4.5969 & 4.2927 & TRN & \\
\hline CHEMBL 3113310 & 1290683 & 4.3799 & 4.4339 & TRN & \\
\hline CHEMBL 226093 & 1290683 & 4.3516 & 3.3935 & TRN & \\
\hline CHEMBL3113293 & 1290683 & 4.618 & 4.4939 & TRN & \\
\hline CHEMBL3113330 & 1290683 & 3.301 & 3.3221 & TST & \\
\hline CHEMBL3113311 & 1290683 & 4.9245 & 4.5099 & TRN & \\
\hline CHEMBL226142 & 1290683 & 3.301 & 3.4299 & TRN & \\
\hline CHEMBL3113308 & 1290683 & 4.6655 & 4.5382 & TRN & \\
\hline CHEMBL 3113101 & 1290683 & 4.6778 & 4.4385 & TRN & \\
\hline CHEMBL3113313 & 1290683 & 4.4214 & 4.4314 & TRN & \\
\hline CHEMBL3113332 & 1290683 & 3.301 & 3.1531 & TST & \\
\hline CHEMBL3113303 & 1290683 & 3.301 & 4.0715 & TRN & \\
\hline CHEMBL3113329 & 1290683 & 3.301 & 3.2811 & TRN & \\
\hline CHEMBL3113306 & 1290683 & 3.301 & 3.7056 & TRN & \\
\hline CHEMBL3113324 & 1290683 & 3.301 & 3.2538 & TST & \\
\hline CHEMBL3113305 & 1290683 & 4.5918 & 4.2352 & TRN & \\
\hline CHEMBL3113100 & 1290683 & 3.301 & 3.9834 & TRN & \\
\hline CHEMBL3113327 & 1290683 & 3.301 & 3.2308 & TRN & \\
\hline CHEMBL3113326 & 1290683 & 4.4001 & 3.5431 & TST & \\
\hline CHEMBL554939 & 1290683 & 4.5058 & 3.3826 & TST & \\
\hline
\end{tabular}


Supplemental Table S2.txt

\begin{tabular}{|c|c|c|c|c|c|}
\hline CHEMBL3113314 & 1290683 & 4.9172 & 4.5188 & TRN & \\
\hline CHEMBL3113300 & 1290683 & 3.301 & 3.8826 & TRN & \\
\hline CHEMBL3113331 & 1290683 & 3.301 & 3.2496 & TRN & \\
\hline CHEMBL3113322 & 1290683 & 3.301 & 3.2262 & TST & \\
\hline CHEMBL3113336 & 1290683 & 3.301 & 3.3249 & TRN & \\
\hline CHEMBL3113321 & 1290683 & 4.6716 & 4.3488 & TRN & \\
\hline CHEMBL3113312 & 1290683 & 4.4437 & 4.625 & TRN & \\
\hline CHEMBL3113096 & 1290683 & 3.301 & 3.2574 & TRN & \\
\hline CHEMBL564467 & 1290683 & 3.301 & 3.1799 & TST & \\
\hline CHEMBL558129 & 1290683 & 4.5622 & 3.3545 & TST & \\
\hline CHEMBL3113309 & 1290683 & 4.6308 & 4.3293 & TRN & \\
\hline CHEMBL3113325 & 1290683 & 3.301 & 3.2776 & TRN & \\
\hline CHEMBL3113099 & 1290683 & 4.4067 & 4.0335 & TRN & \\
\hline CHEMBL3113098 & 1290683 & 4.3197 & 4.0075 & TRN & \\
\hline CHEMBL3113315 & 1290683 & 5.284 & 4.5558 & TRN & \\
\hline CHEMBL3113298 & 1290683 & 3.301 & 4.1423 & TRN & \\
\hline CHEMBL3113328 & 1290683 & 4.6615 & 3.20399 & 99999999997 & TST \\
\hline CHEMBL3113299 & 1290683 & 4.6576 & 4.3538 & TRN & \\
\hline CHEMBL3113297 & 1290683 & 3.301 & 4.1529 & TRN & \\
\hline CHEMBL3113294 & 1290683 & 4.3615 & 3.8704 & TRN & \\
\hline CHEMBL3113296 & 1290683 & 4.6364 & 4.3123 & TRN & \\
\hline CHEMBL3113335 & 1290683 & 3.301 & 3.3158 & TRN & \\
\hline CHEMBL 3113307 & 1290683 & 4.475 & 4.3803 & TRN & \\
\hline CHEMBL3113337 & 1290683 & 3.301 & 3.2313 & TST & \\
\hline CHEMBL3113097 & 1290683 & 3.301 & 3.1516 & TST & \\
\hline CHEMBL3113319 & 1290683 & 3.301 & 4.373 & TRN & \\
\hline CHEMBL3113318 & 1290683 & 3.301 & 4.2192 & TRN & \\
\hline CHEMBL3113301 & 1290683 & 3.301 & 3.7589 & TRN & \\
\hline CHEMBL 3113302 & 1290683 & 4.6108 & 4.2259 & TRN & \\
\hline CHEMBL3113317 & 1290683 & 4.7167 & 4.3737 & TST & \\
\hline CHEMBL3113333 & 1290683 & 3.301 & 3.3592 & TST & \\
\hline CHEMBL439364 & 404278 & 4.3979 & 4.2468 & TRN & \\
\hline CHEMBL 217201 & 404278 & 7.4318 & 7.4224 & TRN & \\
\hline CHEMBL 213718 & 404278 & 7.3565 & 7.4753 & TRN & \\
\hline CHEMBL212072 & 404278 & 7.2291 & 7.2827 & TST & \\
\hline CHEMBL 215062 & 404278 & 4.3979 & 4.6361 & TRN & \\
\hline CHEMBL 212910 & 404278 & 6.4763 & 6.5473 & TRN & \\
\hline CHEMBL215219 & 404278 & 4.3979 & 4.8979 & TRN & \\
\hline CHEMBL215912 & 404278 & 4.3979 & 5.7975 & TST & \\
\hline CHEMBL384700 & 404278 & 6.6536 & 6.5799 & TRN & \\
\hline CHEMBL387433 & 404278 & 6.4365 & 5.9935 & TRN & \\
\hline CHEMBL215063 & 404278 & 7.0915 & 6.9521 & TRN & \\
\hline CHEMBL214590 & 404278 & 4.3979 & 5.4735 & TRN & \\
\hline CHEMBL214563 & 404278 & 6.8508 & \multicolumn{2}{|c|}{7.4079999999999995} & TRN \\
\hline CHEMBL214628 & 404278 & 8.301 & 7.7843 & TRN & \\
\hline CHEMBL 214658 & 404278 & 7.4685 & 6.9086 & TST & \\
\hline CHEMBL384966 & 404278 & 6.1169 & 5.3877 & TRN & \\
\hline CHEMBL215650 & 404278 & 6.58 & 6.1979 & TRN & \\
\hline
\end{tabular}




\begin{tabular}{|c|c|c|c|c|c|}
\hline \multicolumn{6}{|c|}{ Supplemental Table S2.txt } \\
\hline CHEMBL212564 & 404278 & 6.6308 & 6.6944 & TRN & \\
\hline CHEMBL215433 & 404278 & 6.2518 & 5.6004 & TRN & \\
\hline CHEMBL215777 & 404278 & 7.2218 & 7.5713 & TRN & \\
\hline CHEMBL183752 & 404278 & 8.699 & 8.3531 & TRN & \\
\hline CHEMBL384319 & 404278 & 6.1945 & 6.2593 & TRN & \\
\hline CHEMBL215751 & 404278 & 5.9813 & 5.2088 & TRN & \\
\hline CHEMBL378563 & 404278 & 7.585 & 7.8526 & TRN & \\
\hline CHEMBL386795 & 404278 & 6.5376 & 7.0548 & TRN & \\
\hline CHEMBL216882 & 404278 & 6.9872 & 6.76 & TRN & \\
\hline CHEMBL267538 & 404278 & 6.7986 & 6.9735 & TRN & \\
\hline CHEMBL217819 & 404278 & 5.6192 & 5.5243 & TRN & \\
\hline CHEMBL214686 & 404278 & 5.6938 & 5.5743 & TRN & \\
\hline CHEMBL215330 & 404278 & 7.4437 & 6.9487 & TRN & \\
\hline CHEMBL215422 & 404278 & 6.7167 & 6.8163 & TRN & \\
\hline CHEMBL385966 & 404278 & 5.8864 & 6.7461 & TRN & \\
\hline CHEMBL427052 & 404278 & 8.0458 & 8.10700 & 0000000001 & TRN \\
\hline CHEMBL214510 & 404278 & 7.4559 & 7.5756 & TRN & \\
\hline CHEMBL276153 & 404278 & 6.1586 & 6.5324 & TST & \\
\hline CHEMBL385717 & 404278 & 7.0555 & 7.1089 & TRN & \\
\hline CHEMBL214796 & 404278 & 8.8539 & 7.9342 & TST & \\
\hline CHEMBL384600 & 404278 & 6.7077 & 6.5247 & TRN & \\
\hline CHEMBL 386251 & 404278 & 8.3979 & 7.7727 & TRN & \\
\hline CHEMBL213660 & 404278 & 5.8005 & 5.9814 & TRN & \\
\hline CHEMBL 215482 & 404278 & 7.2518 & 7.6015 & TRN & \\
\hline CHEMBL386040 & 404278 & 7.8861 & 7.9071 & TRN & \\
\hline CHEMBL215047 & 404278 & 6.1415 & 6.1597 & TRN & \\
\hline CHEMBL 214852 & 404278 & 6.7212 & 6.7429 & TRN & \\
\hline CHEMBL183121 & 404278 & 8.0969 & 8.0424 & TST & \\
\hline CHEMBL425258 & 404278 & 6.4881 & 7.6407 & TRN & \\
\hline CHEMBL215966 & 404278 & 6.4584 & 6.71299 & 9999999999 & TRN \\
\hline CHEMBL214607 & 404278 & 7.9586 & 7.2725 & TST & \\
\hline CHEMBL 214989 & 404278 & 9.3979 & 8.7565 & TRN & \\
\hline CHEMBL214331 & 404278 & 9.0 & 8.6988 & TRN & \\
\hline CHEMBL180902 & 404278 & 8.3979 & 8.4832 & TRN & \\
\hline CHEMBL214274 & 404278 & 7.699 & 7.5175 & TRN & \\
\hline CHEMBL180138 & 404278 & 8.0458 & 7.8538 & TRN & \\
\hline CHEMBL183045 & 404278 & 8.301 & 8.4859 & TST & \\
\hline CHEMBL214927 & 404278 & 4.3979 & 4.8228 & TST & \\
\hline CHEMBL414867 & 404278 & 4.3979 & 5.6892 & TST & \\
\hline CHEMBL385241 & 404278 & 6.2343 & 6.6848 & TST & \\
\hline CHEMBL386017 & 404278 & 7.1871 & 7.349 & TST & \\
\hline CHEMBL215015 & 404278 & 4.3979 & 5.3785 & TST & \\
\hline CHEMBL213975 & 404278 & 7.3665 & 6.2201 & TST & \\
\hline CHEMBL215439 & 404278 & 6.0477 & 5.8052 & TST & \\
\hline CHEMBL214880 & 404278 & 6.7799 & 7.3833 & TST & \\
\hline CHEMBL1643959 & 954718 & 2.7265 & 2.6608 & TRN & \\
\hline CHEMBL483847 & 954718 & 3.6461 & 3.8249 & TRN & \\
\hline CHEMBL 2137530 & 954718 & 4.513 & 4.4501 & TRN & \\
\hline
\end{tabular}


Supplemental Table S2.txt

\begin{tabular}{|c|c|c|c|c|}
\hline HEMBL & 54718 & & 7274 & TP \\
\hline HEMBL102714 & 54718 & 3.1689 & 2.9958 & \\
\hline$\partial 69$ & 18 & & & \\
\hline HEMBL2005886 & 18 & & 1696 & $R N$ \\
\hline HEMBL 300389 & 54718 & 1048 & 1011 & \\
\hline HEMBL1256459 & 54718 & .2292 & 2084 & \\
\hline HEMBL180127 & 18 & 014 & 1445 & \\
\hline AEMBL472940 & & & 3466 & RN \\
\hline HEMBL 202721 & 18 & 588 & 6293 & RN \\
\hline HEMBL379300 & 18 & 4.7032 & .7996 & \\
\hline HEMBL 392695 & 8 & 3.6803 & 5634 & \\
\hline HEMBL 3349342 & 8 & 824 & 3359 & \\
\hline HEMBL189584 & & & & RN \\
\hline HEMBL1673039 & 18 & & 3.385 & \\
\hline HEMBL449158 & 18 & & 5667 & \\
\hline HEMBL1516890 & 8 & 3. & 596 & \\
\hline HEMBL483849 & 8 & 20 & 129 & \\
\hline HEMBL1404 & & & 9782 & \\
\hline HEMBL1909414 & 18 & 96 & 3.4283 & \\
\hline HEMBL573107 & 8 & & 1445 & \\
\hline AEMBL379 & 8 & & 2312 & NIV \\
\hline HEMBL515416 & & & 016 & RN \\
\hline HEMBL1788 & & & 1776 & \\
\hline HEMBL19708 & & & 8821 & \\
\hline HEMBL514499 & & & & N \\
\hline HEMBL65 & & & 694 & IV \\
\hline HEMBL2 2 & & & & ST \\
\hline HEMBL $33{ }^{\circ}$ & & & 82 & RN \\
\hline HEMBL3199475 & & & 1669 & IRIN \\
\hline HEMBL 217354 & & & 973 & IRN \\
\hline HEMBL5090 & & & 415 & RN \\
\hline HEMBL1S & & & 79 & TRN \\
\hline HEMBL5 & & & 425 & 「RN \\
\hline HEMBL123002 & & & 0335 & TRN \\
\hline HEMBL412142 & & & 3088 & IRN \\
\hline HEMBL92 & & & 835 & TST \\
\hline HEMBL3 & & & 205 & $\Gamma \mathrm{RN}$ \\
\hline HEMBL512504 & & & 888 & TRN \\
\hline HEMBL21061 & & & 6144 & TRN \\
\hline HEMBL9470 & & & 5287 & TST \\
\hline HEMBL 21342 & & 3 . & 3635 & TRN \\
\hline CHEMBL135561 & & 25 & 4.3935 & TRN \\
\hline CHEMBL 221137 & & & 4705 & TST \\
\hline HEMBL 31864 & 18 & 4.5 & 6108 & TST \\
\hline CHEMBL1886 & & & 81 & $T$ \\
\hline CHEMBL 25884 & & & 9098 & \\
\hline CHEMBL 213100 & & 2.9103 & 2.9664 & \\
\hline CHEMBL585951 & 954718 & 5.5635 & 5.5882 & ГRN \\
\hline
\end{tabular}

Page 327 


\begin{tabular}{|c|c|c|c|c|c|}
\hline & & \multicolumn{4}{|c|}{ Supplemental Table S2.txt } \\
\hline CHEMBL 222102 & 954718 & 3.0505 & 3.2861 & TRN & \\
\hline CHEMBL1186585 & 954718 & 4.2369 & 4.24337 & TRN & \\
\hline CHEMBL259181 & 954718 & 4.1972 & 4.03967 & TRN & \\
\hline CHEMBL1357247 & 954718 & 3.0166 & 3.0027 & TRN & \\
\hline CHEMBL255342 & 954718 & 3.7148 & 3.70767 & TST & \\
\hline CHEMBL577784 & 954718 & 4.9583 & 4.84287 & TST & \\
\hline CHEMBL1242367 & 954718 & 4.5711 & 3.13477 & TST & \\
\hline CHEMBL1190711 & 954718 & 4.823 & 4.22967 & TST & \\
\hline CHEMBL192566 & 954718 & 6.8801 & 7.2928 & TST & \\
\hline CHEMBL220241 & 954718 & 3.971 & 4.35747 & TST & \\
\hline CHEMBL 399530 & 954718 & 4.2334 & 4.8426 & TST & \\
\hline CHEMBL1590308 & 954718 & 2.588 & 3.23477 & TST & \\
\hline CHEMBL 209148 & 954718 & 3.8501 & 3.6162 & TST & \\
\hline CHEMBL393929 & 954718 & 3.5601 & 3.9691 & TST & \\
\hline CHEMBL3701032 & 1640748 & 7.9957 & 7.9957 & TRN & \\
\hline CHEMBL3701041 & 1640748 & 8.3279 & 8.3276 & TRN & \\
\hline CHEMBL3909511 & 1640748 & 8.2596 & 8.04717 & TST & \\
\hline CHEMBL 3947443 & 1640748 & 6.9252 & 6.9253 & TRN & \\
\hline CHEMBL418052 & 1640748 & 5.2289 & 5.1147 & TST & \\
\hline CHEMBL 3949741 & 1640748 & 7.9872 & 7.987 & TRN & \\
\hline CHEMBL3701038 & 1640748 & 6.9718 & 6.972 & TRN & \\
\hline CHEMBL 3940475 & 1640748 & 8.5376 & 8.5377 & TRN & \\
\hline CHEMBL3911120 & 1640748 & 8.3979 & 8.3977 & TRN & \\
\hline CHEMBL 3963830 & 1640748 & 8.1739 & 8.1738 & TRN & \\
\hline CHEMBL3701043 & 1640748 & 8.9586 & 8.9587 & TRN & \\
\hline CHEMBL 3945718 & 1640748 & 7.7496 & 7.7492 & TRN & \\
\hline CHEMBL3946689 & 1640748 & 6.4963 & 6.0007 & TST & \\
\hline CHEMBL3956266 & 1640748 & 8.3372 & 8.3375 & TRN & \\
\hline CHEMBL 3925098 & 1640748 & 7.6882 & 7.688 & TRN & \\
\hline CHEMBL3895049 & 1640748 & 7.767 & 7.7673 & TRN & \\
\hline CHEMBL 3918857 & 1640748 & 7.2226 & 6.9421 & TST & \\
\hline CHEMBL3701005 & 1640748 & 8.6778 & 8.6778 & TRN & \\
\hline CHEMBL 3942268 & 1640748 & 8.1192 & 8.1187 & TRN & \\
\hline CHEMBL3360855 & 1640748 & 8.0862 & 8.086 & TRN & \\
\hline CHEMBL3909934 & 1640748 & 8.1675 & 8.1675 & TRN & \\
\hline CHEMBL3933289 & 1640748 & 8.0177 & 8.0175 & TRN & \\
\hline CHEMBL3971862 & 1640748 & 8.4202 & 8.4203 & TRN & \\
\hline CHEMBL 3971620 & 1640748 & 8.0862 & 8.0865 & TRN & \\
\hline CHEMBL3939074 & 1640748 & 8.1487 & 8.1489 & TRN & \\
\hline CHEMBL3946376 & 1640748 & 7.0545 & 6.8897 & TST & \\
\hline CHEMBL3916617 & 1640748 & 8.5686 & 8.5687 & TRN & \\
\hline CHEMBL3701042 & 1640748 & 8.4437 & 8.44397 & TRN & \\
\hline CHEMBL3910693 & 1640748 & 8.5528 & 8.552999 & 9999999999 & TRN \\
\hline CHEMBL3979717 & 1640748 & 7.71899 & 999999999 & $99 \quad 7.803$ & TST \\
\hline CHEMBL3964569 & 1640748 & 7.644 & 7.644 & TRN & \\
\hline CHEMBL 3908410 & 1640748 & 8.7447 & 8.7452 & TRN & \\
\hline CHEMBL 3770184 & 1640748 & 8.2924 & 7.6286 & TST & \\
\hline CHEMBL3909279 & 1640748 & 8.4949 & 8.4951 & TRN & \\
\hline
\end{tabular}


Supplemental Table S2.txt

\begin{tabular}{|c|c|c|c|c|}
\hline CHEMBL3942740 & 1640748 & 6.0 & 6.0 & TRN \\
\hline CHEMBL3701035 & 1640748 & 8.0757 & 8.1315 & TST \\
\hline CHEMBL3941351 & 1640748 & 7.8928 & 7.8927 & TRN \\
\hline CHEMBL 3893981 & 1640748 & 8.1871 & 8.18700 & 0000000001 \\
\hline CHEMBL3918450 & 1640748 & 8.2924 & 8.2924 & TRN \\
\hline CHEMBL3701036 & 1640748 & 5.9142 & 5.0685 & TST \\
\hline CHEMBL3961483 & 1640748 & 6.0 & 6.0 & TRN \\
\hline CHEMBL3701037 & 1640748 & 8.1249 & 8.4057 & TST \\
\hline CHEMBL3984929 & 1640748 & 8.8539 & 8.8539 & TRN \\
\hline CHEMBL3938638 & 1640748 & 8.7696 & 8.7692 & TRN \\
\hline CHEMBL3769849 & 1640748 & 7.2976 & 6.9043 & TST \\
\hline CHEMBL3937573 & 1640748 & 7.6536 & 7.654 & TRN \\
\hline CHEMBL3931287 & 1640748 & 7.5575 & 7.5576 & TRN \\
\hline CHEMBL3701034 & 1640748 & 8.1427 & 8.1834 & TST \\
\hline CHEMBL 3701033 & 1640748 & 8.4089 & 8.2758 & TST \\
\hline CHEMBL3916086 & 1640748 & 7.7144 & 7.7144 & TRN \\
\hline CHEMBL475978 & 564965 & 5.1152 & 5.0949 & TRN \\
\hline CHEMBL449068 & 564965 & 4.6162 & 4.6228 & TRN \\
\hline CHEMBL476013 & 564965 & 3.9066 & 3.8048 & TRN \\
\hline CHEMBL449459 & 564965 & 5.2434 & 5.1946 & TRN \\
\hline CHEMBL478698 & 564965 & 3.8729 & 4.3851 & TST \\
\hline CHEMBL474880 & 564965 & 4.3757 & 4.5774 & TRN \\
\hline CHEMBL478128 & 564965 & 5.0227 & 5.0996 & TRN \\
\hline CHEMBL510241 & 564965 & 3.6091 & 3.8482 & TRN \\
\hline CHEMBL478325 & 564965 & 4.8894 & 4.4024 & TST \\
\hline CHEMBL514996 & 564965 & 4.9393 & 4.8422 & TRN \\
\hline CHEMBL478697 & 564965 & 3.9101 & 4.2656 & TST \\
\hline CHEMBL476027 & 564965 & 5.0655 & 4.9934 & TRN \\
\hline CHEMBL476068 & 564965 & 5.567 & 4.5797 & TST \\
\hline CHEMBL474471 & 564965 & 3.8477 & 4.1255 & TRN \\
\hline CHEMBL473670 & 564965 & 5.2958 & 5.1111 & TRN \\
\hline CHEMBL448334 & 564965 & 4.433 & 3.9697 & TRN \\
\hline CHEMBL478494 & 564965 & 3.9066 & 4.3873 & TST \\
\hline CHEMBL507262 & 564965 & 4.2692 & 4.5703 & TRN \\
\hline CHEMBL476653 & 564965 & 5.0083 & 4.9358 & TRN \\
\hline CHEMBL515300 & 564965 & 5.0752 & 4.5849 & TRN \\
\hline CHEMBL470445 & 564965 & 4.3161 & 4.3411 & TRN \\
\hline CHEMBL476654 & 564965 & 4.163 & 4.6076 & TRN \\
\hline CHEMBL478495 & 564965 & 3.8416 & 4.3221 & TST \\
\hline CHEMBL515931 & 564965 & 3.9393 & 3.9398 & TRN \\
\hline CHEMBL514018 & 564965 & 4.0851 & 4.1132 & TRN \\
\hline CHEMBL473051 & 564965 & 4.0004 & 3.9756 & TRN \\
\hline CHEMBL515961 & 564965 & 3.9431 & 4.0618 & TRN \\
\hline CHEMBL478515 & 564965 & 4.9747 & 5.0508 & TRN \\
\hline CHEMBL478061 & 564965 & 3.9788 & 4.0126 & TST \\
\hline CHEMBL509748 & 564965 & 3.6737 & 3.8238 & TRN \\
\hline CHEMBL515464 & 564965 & 3.6459 & 3.9398 & TRN \\
\hline CHEMBL499436 & 564965 & 5.5017 & 4.3583 & TST \\
\hline
\end{tabular}




\begin{tabular}{|c|c|c|c|c|c|}
\hline \multicolumn{6}{|c|}{ Supplemental Table s2.txt } \\
\hline CHEMBL476383 & 564965 & 4.9355 & 4.1171 & TRN & \\
\hline CHEMBL475886 & 564965 & 4.9136 & 4.8545 & TRN & \\
\hline CHEMBL476652 & 564965 & 4.6003 & 5.2477 & TRN & \\
\hline CHEMBL475979 & 564965 & 3.9626 & 4.1101 & TRN & \\
\hline CHEMBL516252 & 564965 & 4.8633 & 4.3702 & TRN & \\
\hline CHEMBL450904 & 564965 & 5.1062 & 4.9198 & TRN & \\
\hline CHEMBL476234 & 564965 & 5.3809 & 5.2515 & TRN & \\
\hline CHEMBL476390 & 564965 & 4.262 & 4.4353 & TRN & \\
\hline CHEMBL476061 & 564965 & 4.9666 & 4.9809 & TRN & \\
\hline CHEMBL478060 & 564965 & 3.8239 & 4.1427 & TRN & \\
\hline CHEMBL475985 & 564965 & 3.9318 & 4.1076 & TRN & \\
\hline CHEMBL514834 & 564965 & 4.2692 & 4.1359 & TST & \\
\hline CHEMBL476012 & 564965 & 4.2636 & 4.2066 & TRN & \\
\hline CHEMBL506941 & 564965 & 3.8996 & 4.0442 & TST & \\
\hline CHEMBL449379 & 564965 & 4.2083 & 4.2148 & TRN & \\
\hline CHEMBL514531 & 564965 & 4.2628 & 4.0873 & TRN & \\
\hline CHEMBL477869 & 564965 & 4.1618 & 3.8956 & TST & \\
\hline CHEMBL478075 & 564965 & 4.6946 & 5.0996 & TRN & \\
\hline CHEMBL477875 & 564965 & 5.1918 & 5.0374 & TRN & \\
\hline CHEMBL514628 & 564965 & 4.1858 & 4.1631 & TST & \\
\hline CHEMBL514079 & 564965 & 4.4157 & 4.2853 & TST & \\
\hline CHEMBL474071 & 564965 & 5.6478 & 5.2447 & TRN & \\
\hline CHEMBL515148 & 564965 & 3.9626 & 4.1521 & TST & \\
\hline CHEMBL514833 & 564965 & 4.2636 & 4.1872 & TRN & \\
\hline CHEMBL1964290 & 809181 & 4.9 & 4.8646 & TRN & \\
\hline CHEMBL 2001398 & 809181 & 4.2 & 4.66 & TRN & \\
\hline CHEMBL 213505 & 809181 & 4.9 & 4.9332 & TRN & \\
\hline CHEMBL 202721 & 809181 & 5.4 & 5.3916 & TRN & \\
\hline CHEMBL1987034 & 809181 & 6.8 & 6.274 & TRN & \\
\hline CHEMBL1993941 & 809181 & 7.6 & 7.0957 & TRN & \\
\hline CHEMBL 377383 & 809181 & 4.9 & 4.8554 & TST & \\
\hline CHEMBL 2005886 & 809181 & 7.0 & 6.0634 & TRN & \\
\hline CHEMBL481491 & 809181 & 4.9 & 4.6138 & TST & \\
\hline CHEMBL1973142 & 809181 & 4.9 & 4.9053 & TRN & \\
\hline CHEMBL388311 & 809181 & 5.4 & 5.4228 & TRN & \\
\hline CHEMBL1973145 & 809181 & 4.9 & 5.2151 & TRN & \\
\hline CHEMBL1982924 & 809181 & 4.9 & 4.84399 & 9999999999 & TRN \\
\hline CHEMBL2005936 & 809181 & 4.9 & 4.7644 & TRN & \\
\hline CHEMBL1807515 & 809181 & 4.9 & 4.4529 & TRN & \\
\hline CHEMBL1964948 & 809181 & 4.2 & 3.9206 & TRN & \\
\hline CHEMBL1971141 & 809181 & 4.9 & 4.7241 & TRN & \\
\hline CHEMBL1995813 & 809181 & 4.9 & 4.3967 & TRN & \\
\hline CHEMBL206236 & 809181 & 4.9 & 5.0705 & TRN & \\
\hline CHEMBL1989834 & 809181 & 3.3 & 4.04 & TRN & \\
\hline CHEMBL1987430 & 809181 & 4.2 & 4.2201 & TRN & \\
\hline CHEMBL 244378 & 809181 & 4.9 & 5.3225 & TRN & \\
\hline CHEMBL2001957 & 809181 & 4.9 & 4.8534 & TRN & \\
\hline CHEMBL1969372 & 809181 & 4.9 & 4.96399 & 99999999995 & TRN \\
\hline & & & & e 330 & \\
\hline
\end{tabular}




\begin{tabular}{|c|c|c|c|c|c|}
\hline & & \multicolumn{4}{|c|}{ Supplemental Table S2.txt } \\
\hline CHEMBL1993413 & 809181 & 4.2 & 4.297 & TRN & \\
\hline CHEMBL1986943 & 809181 & 4.9 & 4.2885 & TRN & \\
\hline CHEMBL 2006263 & 809181 & 4.9 & 5.0821 & TRN & \\
\hline CHEMBL1993584 & 809181 & 4.9 & 4.8432 & TRN & \\
\hline CHEMBL1986263 & 809181 & 4.9 & 4.7694 & TRN & \\
\hline CHEMBL2000114 & 809181 & 4.9 & 4.7255 & TRN & \\
\hline CHEMBL1986265 & 809181 & 4.2 & 4.0966 & TRN & \\
\hline CHEMBL1975647 & 809181 & 4.9 & 4.6702 & TRN & \\
\hline CHEMBL1968380 & 809181 & 4.9 & \multicolumn{2}{|c|}{5.542000000000001} & TRN \\
\hline CHEMBL1964644 & 809181 & 4.9 & \multicolumn{2}{|c|}{4.9319999999999995} & TRN \\
\hline CHEMBL1991734 & 809181 & 6.1 & 5.2632 & TST & \\
\hline CHEMBL1981782 & 809181 & 4.9 & 4.9157 & TRN & \\
\hline CHEMBL1970142 & 809181 & 4.9 & 6.7 & TRN & \\
\hline CHEMBL1990912 & 809181 & 4.9 & 4.8835 & TRN & \\
\hline CHEMBL1983348 & 809181 & 4.2 & 4.6393 & TRN & \\
\hline CHEMBL1975128 & 809181 & 4.9 & 4.7751 & TRN & \\
\hline CHEMBL1980671 & 809181 & 4.3 & 4.7727 & TRN & \\
\hline CHEMBL1986177 & 809181 & 4.2 & 4.6571 & TRN & \\
\hline CHEMBL1992323 & 809181 & 4.9 & 4.9041 & TRN & \\
\hline CHEMBL1969735 & 809181 & 4.9 & 4.963 & TRN & \\
\hline CHEMBL 2002649 & 809181 & 4.9 & 4.5491 & TRN & \\
\hline CHEMBL1985367 & 809181 & 4.2 & 4.8256 & TRN & \\
\hline CHEMBL1996510 & 809181 & 4.2 & 4.3062 & TRN & \\
\hline CHEMBL1995172 & 809181 & 4.0 & 4.3379 & TST & \\
\hline CHEMBL 2001584 & 809181 & 8.5 & 4.627 & TRN & \\
\hline CHEMBL1971227 & 809181 & 5.2 & 4.9199 & TST & \\
\hline CHEMBL1967998 & 809181 & 6.4 & 6.3195 & TRN & \\
\hline CHEMBL1978562 & 809181 & 4.2 & 4.7099 & TRN & \\
\hline CHEMBL229799 & 809181 & 4.9 & 4.6184 & TRN & \\
\hline CHEMBL1974875 & 809181 & 4.1 & \multicolumn{2}{|c|}{4.611000000000001} & TST \\
\hline CHEMBL1989471 & 809181 & 5.3 & 4.9254 & TST & \\
\hline CHEMBL2002099 & 809181 & 4.2 & 4.7297 & TRN & \\
\hline CHEMBL 2000508 & 809181 & 4.9 & 5.0164 & TRN & \\
\hline CHEMBL2001547 & 809181 & 4.9 & 4.9751 & TRN & \\
\hline CHEMBL 210928 & 809181 & 4.9 & 5.0624 & TST & \\
\hline CHEMBL1978195 & 809181 & 4.2 & 4.1344 & TRN & \\
\hline CHEMBL1977148 & 809181 & 6.6 & 7.3595 & TRN & \\
\hline CHEMBL1966842 & 809181 & 5.5 & 4.8949 & TRN & \\
\hline CHEMBL2003286 & 809181 & 4.9 & 4.8429 & TRN & \\
\hline CHEMBL1992306 & 809181 & 4.9 & 5.3659 & TRN & \\
\hline CHEMBL2002165 & 809181 & 7.7 & 7.135 & TRN & \\
\hline CHEMBL1998585 & 809181 & 6.2 & 6.1126 & TRN & \\
\hline CHEMBL519697 & 809181 & 4.9 & 4.7596 & TRN & \\
\hline CHEMBL2004934 & 809181 & 4.9 & 4.7566 & TRN & \\
\hline CHEMBL1996345 & 809181 & 4.2 & 4.5365 & TRN & \\
\hline CHEMBL2004025 & 809181 & 4.2 & 4.7076 & TRN & \\
\hline CHEMBL1996048 & 809181 & 4.2 & 4.6646 & TRN & \\
\hline CHEMBL1976158 & 809181 & 4.5 & 4.6505 & TST & \\
\hline
\end{tabular}




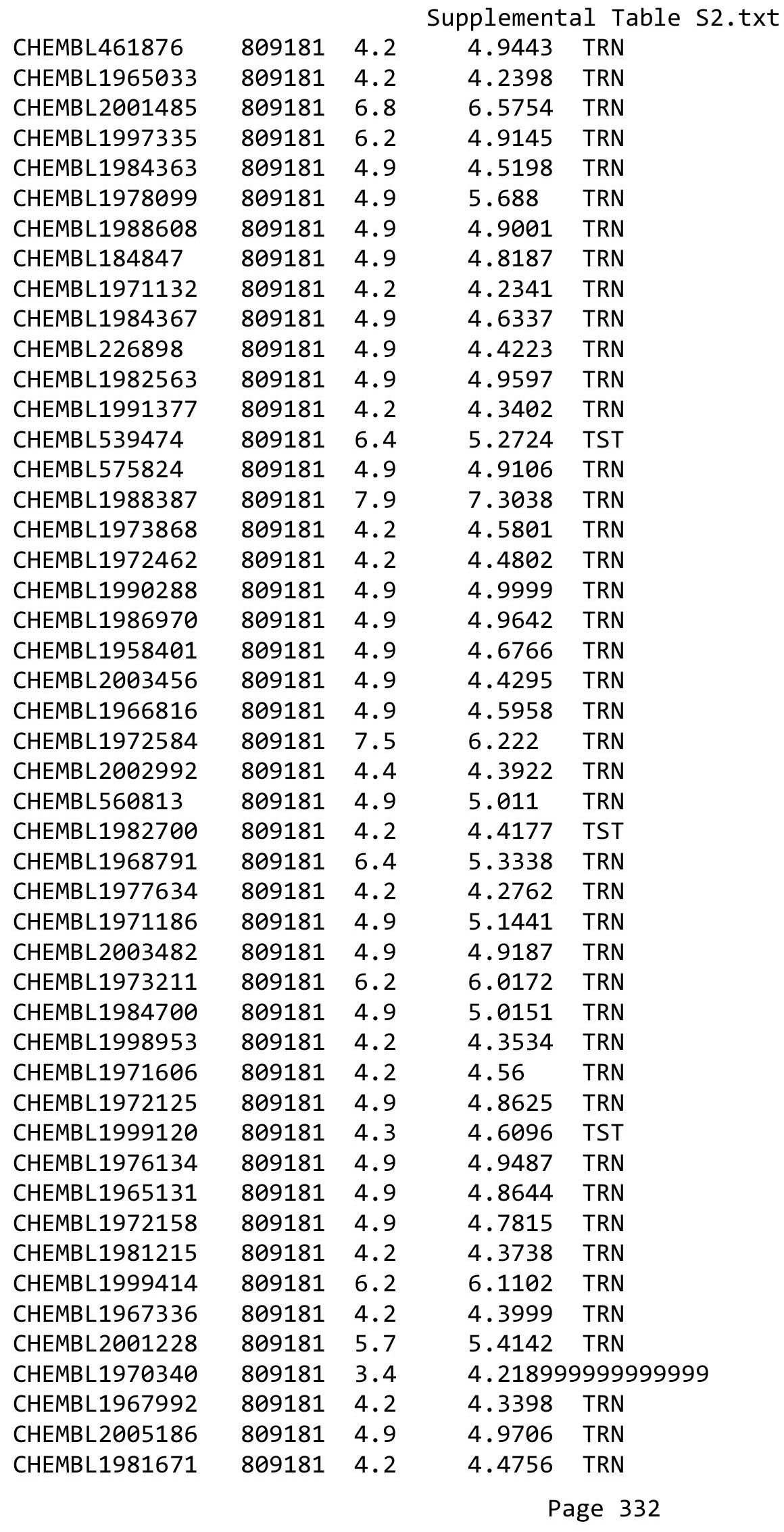

TRN 


\begin{tabular}{|c|c|c|c|c|c|}
\hline & & \multicolumn{4}{|c|}{ Supplemental Table S2.txt } \\
\hline CHEMBL2006450 & 809181 & 4.2 & 4.25899 & 99999999995 & TRN \\
\hline CHEMBL1975534 & 809181 & 4.9 & 4.9998 & TRN & \\
\hline CHEMBL1966703 & 809181 & 4.9 & 4.9269 & TST & \\
\hline CHEMBL 2001987 & 809181 & 4.2 & 4.3105 & TRN & \\
\hline CHEMBL1969561 & 809181 & 4.9 & 5.0055 & TRN & \\
\hline CHEMBL1994555 & 809181 & 4.2 & 4.9606 & TRN & \\
\hline CHEMBL1975121 & 809181 & 4.2 & 4.5914 & TRN & \\
\hline CHEMBL1983640 & 809181 & 5.7 & 5.4163 & TRN & \\
\hline CHEMBL1997023 & 809181 & 4.9 & 4.9333 & TST & \\
\hline CHEMBL1964687 & 809181 & 4.9 & 5.055 & TRN & \\
\hline CHEMBL1971943 & 809181 & 4.4 & 4.4768 & TRN & \\
\hline CHEMBL1974254 & 809181 & 7.1 & 7.2305 & TRN & \\
\hline CHEMBL1997924 & 809181 & 6.2 & 5.8309 & TRN & \\
\hline CHEMBL1988537 & 809181 & 4.9 & 4.8397 & TST & \\
\hline CHEMBL1969049 & 809181 & 4.9 & 4.7592 & TRN & \\
\hline CHEMBL2005828 & 809181 & 4.9 & 4.9026 & TRN & \\
\hline CHEMBL1971485 & 809181 & 4.2 & 4.6907 & TRN & \\
\hline CHEMBL1978267 & 809181 & 4.2 & 4.473 & TRN & \\
\hline CHEMBL1998611 & 809181 & 4.9 & 4.9036 & TRN & \\
\hline CHEMBL1975900 & 809181 & 4.9 & 4.8692 & TRN & \\
\hline CHEMBL1992334 & 809181 & 4.2 & 4.1888 & TRN & \\
\hline CHEMBL255822 & 809181 & 4.9 & 4.8444 & TRN & \\
\hline CHEMBL1972221 & 809181 & 4.9 & 4.9401 & TRN & \\
\hline CHEMBL378627 & 809181 & 4.9 & 4.9971 & TST & \\
\hline CHEMBL1996979 & 809181 & 6.9 & 5.9589 & TRN & \\
\hline CHEMBL1968406 & 809181 & 4.9 & 5.083 & TRN & \\
\hline CHEMBL1975921 & 809181 & 4.2 & 4.3045 & TRN & \\
\hline CHEMBL1998545 & 809181 & 4.9 & 4.88899 & 9999999999 & TRN \\
\hline CHEMBL1986869 & 809181 & 4.9 & 5.0905 & TRN & \\
\hline CHEMBL 2004033 & 809181 & 5.3 & 4.5891 & TST & \\
\hline CHEMBL1975923 & 809181 & 5.5 & 4.8664 & TST & \\
\hline CHEMBL 2005449 & 809181 & 5.4 & 5.1888 & TRN & \\
\hline CHEMBL1987998 & 809181 & 4.2 & 4.247 & TRN & \\
\hline CHEMBL1682558 & 809181 & 4.9 & 5.0326 & TRN & \\
\hline CHEMBL1990496 & 809181 & 4.4 & 4.7894 & TRN & \\
\hline CHEMBL 2002799 & 809181 & 4.2 & 4.5571 & TST & \\
\hline CHEMBL242865 & 809181 & 6.0 & 5.0954 & TRN & \\
\hline CHEMBL 2002479 & 809181 & 4.9 & 4.9994 & TRN & \\
\hline CHEMBL1967094 & 809181 & 4.9 & 4.4739 & TRN & \\
\hline CHEMBL 2003341 & 809181 & 4.9 & 4.9695 & TRN & \\
\hline CHEMBL1998110 & 809181 & 4.2 & 4.3524 & TRN & \\
\hline CHEMBL1999590 & 809181 & 4.9 & 5.4646 & TST & \\
\hline CHEMBL1981079 & 809181 & 4.9 & 4.7346 & TRN & \\
\hline CHEMBL1978166 & 809181 & 6.9 & 5.8347 & TRN & \\
\hline CHEMBL1980489 & 809181 & 4.9 & 4.8627 & TRN & \\
\hline CHEMBL 2000832 & 809181 & 4.9 & 4.7457 & TRN & \\
\hline CHEMBL1990590 & 809181 & 4.2 & 4.3149 & TRN & \\
\hline CHEMBL1977814 & 809181 & 4.2 & 4.8225 & TST & \\
\hline
\end{tabular}




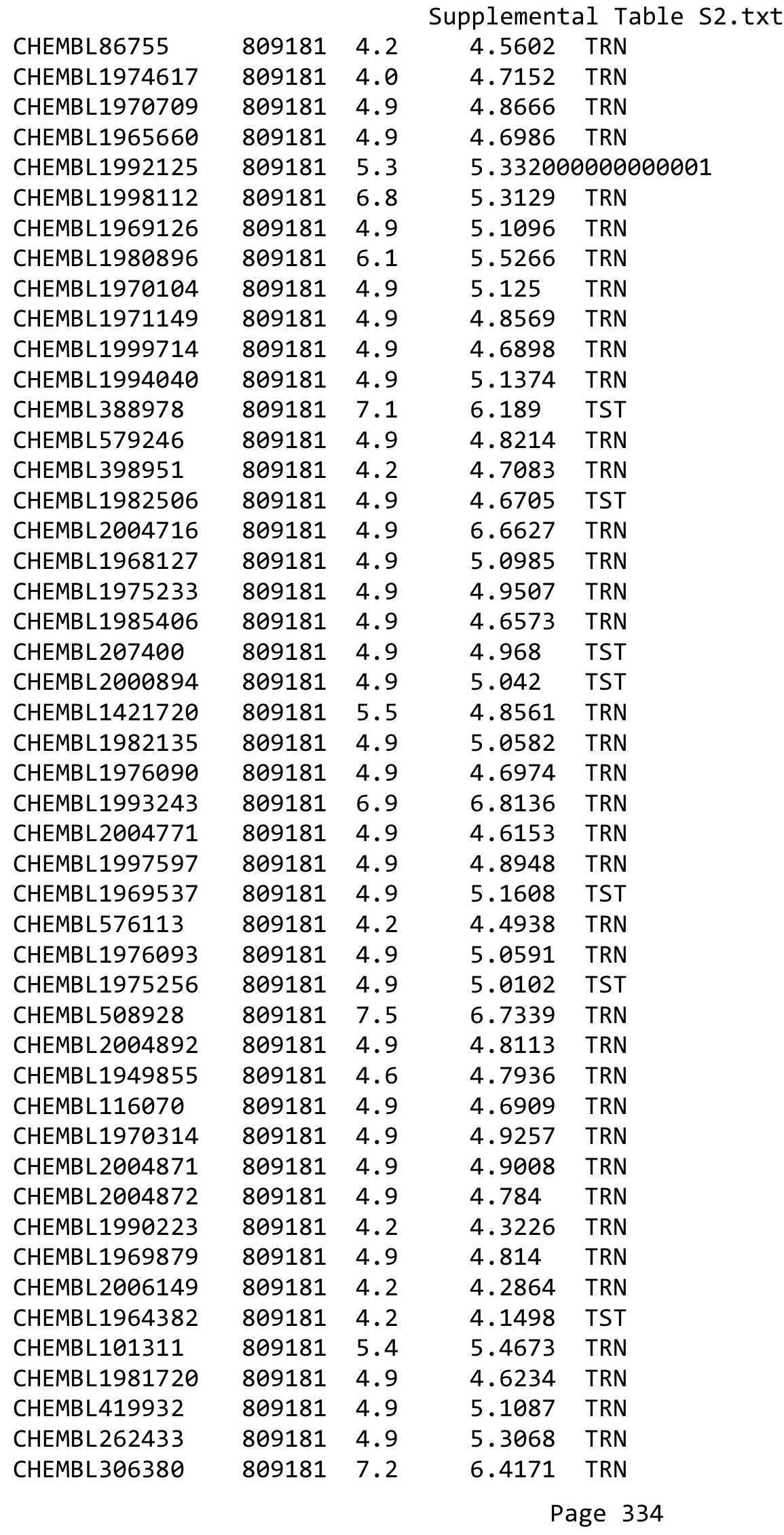

TRN 


\begin{tabular}{|c|c|c|c|c|c|}
\hline \multirow[b]{2}{*}{ CHEMBL1966722 } & \multirow[b]{2}{*}{809181} & \multicolumn{4}{|c|}{ Supplemental Table S2.txt } \\
\hline & & 4.9 & 4.6676 & TRN & \\
\hline CHEMBL1988581 & 809181 & 6.8 & 5.96700 & 00000000005 & TST \\
\hline CHEMBL 2005699 & 809181 & 4.2 & 4.1406 & TRN & \\
\hline CHEMBL1975500 & 809181 & 4.9 & 5.1526 & TRN & \\
\hline CHEMBL394619 & 809181 & 4.9 & 5.0407 & TRN & \\
\hline CHEMBL2006564 & 809181 & 6.8 & 5.8198 & TRN & \\
\hline CHEMBL1996831 & 809181 & 6.2 & 4.7406 & TST & \\
\hline CHEMBL411903 & 809181 & 4.9 & 5.1925 & TRN & \\
\hline CHEMBL1978167 & 809181 & 4.2 & 4.3811 & TRN & \\
\hline CHEMBL418203 & 809181 & 4.4 & 4.5784 & TST & \\
\hline CHEMBL1989646 & 809181 & 4.9 & 4.8321 & TRN & \\
\hline CHEMBL225519 & 809181 & 4.5 & 4.4052 & TRN & \\
\hline CHEMBL1978200 & 809181 & 4.9 & 4.9901 & TRN & \\
\hline CHEMBL1970522 & 809181 & 4.9 & 4.8039 & TRN & \\
\hline CHEMBL402846 & 809181 & 4.9 & 5.041 & TRN & \\
\hline CHEMBL1964692 & 809181 & 4.9 & 5.3443 & TRN & \\
\hline CHEMBL1971223 & 809181 & 4.2 & 4.13899 & 9999999999 & TRN \\
\hline CHEMBL1973483 & 809181 & 4.9 & 4.5525 & TRN & \\
\hline CHEMBL1998470 & 809181 & 4.2 & 4.2617 & TRN & \\
\hline CHEMBL1995428 & 809181 & 4.2 & 4.4718 & TRN & \\
\hline CHEMBL1975903 & 809181 & 4.2 & 4.6151 & TRN & \\
\hline CHEMBL1997340 & 809181 & 4.9 & 5.0093 & TRN & \\
\hline CHEMBL1522508 & 809181 & 4.9 & 4.5226 & TRN & \\
\hline CHEMBL210887 & 809181 & 4.9 & 4.8823 & TRN & \\
\hline CHEMBL1988805 & 809181 & 4.2 & 4.3157 & TRN & \\
\hline CHEMBL458997 & 809181 & 6.3 & 5.6813 & TRN & \\
\hline CHEMBL1971021 & 809181 & 4.9 & 4.5891 & TRN & \\
\hline CHEMBL227271 & 809181 & 4.9 & 4.7185 & TRN & \\
\hline CHEMBL583144 & 809181 & 6.2 & 5.0285 & TRN & \\
\hline CHEMBL1974310 & 809181 & 4.9 & 4.3479 & TRN & \\
\hline CHEMBL1969942 & 809181 & 4.2 & 4.5161 & TRN & \\
\hline CHEMBL1978567 & 809181 & 4.2 & 4.3524 & TRN & \\
\hline CHEMBL1982660 & 809181 & 4.9 & 4.627 & TRN & \\
\hline CHEMBL1994693 & 809181 & 4.9 & 5.0869 & TRN & \\
\hline CHEMBL1982957 & 809181 & 4.9 & 5.2536 & TRN & \\
\hline CHEMBL1725279 & 809181 & 4.9 & 4.7312 & TST & \\
\hline CHEMBL1975138 & 809181 & 4.9 & 4.5816 & TRN & \\
\hline CHEMBL424872 & 809181 & 4.2 & 4.6153 & TST & \\
\hline CHEMBL1980704 & 809181 & 4.9 & 4.8599 & TST & \\
\hline CHEMBL 2003271 & 809181 & 4.9 & 4.8267 & TRN & \\
\hline CHEMBL1966808 & 809181 & 4.9 & 4.9236 & TST & \\
\hline CHEMBL 2004447 & 809181 & 4.9 & 4.8031 & TST & \\
\hline CHEMBL1983111 & 809181 & 6.4 & 6.0615 & TRN & \\
\hline CHEMBL1973860 & 809181 & 4.9 & 5.131 & TRN & \\
\hline CHEMBL 260135 & 809181 & 4.9 & 4.5658 & TRN & \\
\hline CHEMBL 220241 & 809181 & 4.9 & 5.1471 & TRN & \\
\hline CHEMBL 2004544 & 809181 & 6.3 & 4.8289 & TST & \\
\hline CHEMBL1988141 & 809181 & 5.8 & 5.295 & TST & \\
\hline
\end{tabular}




\begin{tabular}{|c|c|c|c|c|}
\hline & & & Supplement & \\
\hline CHEMBL1982610 & 809181 & 4.9 & 5.2209 & TST \\
\hline CHEMBL1977134 & 809181 & 6.5 & 5.8097 & TRN \\
\hline CHEMBL1985206 & 809181 & 4.2 & 4.0407 & TST \\
\hline CHEMBL1988300 & 809181 & 6.0 & 6.1033 & TRN \\
\hline CHEMBL1991078 & 809181 & 4.4 & 5.3629 & TRN \\
\hline CHEMBL1987359 & 809181 & 4.9 & 4.7058 & TST \\
\hline CHEMBL1977749 & 809181 & 4.2 & 4.4549 & TST \\
\hline CHEMBL1975212 & 809181 & 4.5 & 4.9314 & TRN \\
\hline CHEMBL 2001613 & 809181 & 4.5 & 4.4751 & TRN \\
\hline CHEMBL1997275 & 809181 & 4.2 & 4.1571 & TRN \\
\hline CHEMBL1993904 & 809181 & 4.2 & 4.7118 & TRN \\
\hline CHEMBL1967513 & 809181 & 4.2 & 4.2143 & TRN \\
\hline CHEMBL 2000724 & 809181 & 4.2 & 4.2512 & TRN \\
\hline CHEMBL1982413 & 809181 & 5.3 & 4.5929 & TRN \\
\hline CHEMBL1969502 & 809181 & 6.5 & 5.6812 & TST \\
\hline CHEMBL1682553 & 809181 & 4.9 & 4.9228 & TRN \\
\hline CHEMBL1983963 & 809181 & 4.9 & 5.4246 & TRN \\
\hline CHEMBL1997764 & 809181 & 4.9 & 4.7327 & TRN \\
\hline CHEMBL1981792 & 809181 & 4.2 & 4.2669 & TRN \\
\hline CHEMBL1987535 & 809181 & 4.2 & 4.1892 & TRN \\
\hline CHEMBL1985092 & 809181 & 4.9 & 4.6459 & TRN \\
\hline CHEMBL1981410 & 809181 & 4.9 & 4.6508 & TRN \\
\hline CHEMBL 2002586 & 809181 & 4.2 & 4.9131 & TRN \\
\hline CHEMBL1996234 & 809181 & 4.9 & 4.9901 & TRN \\
\hline CHEMBL383264 & 809181 & 4.2 & 4.4441 & TRN \\
\hline CHEMBL 2007421 & 809181 & 6.0 & 5.8495 & TRN \\
\hline CHEMBL1967544 & 809181 & 4.9 & 4.9665 & TRN \\
\hline CHEMBL1973138 & 809181 & 7.7 & 4.5872 & TRN \\
\hline CHEMBL340384 & 809181 & 4.9 & 4.9771 & TST \\
\hline CHEMBL1969151 & 809181 & 4.2 & 3.8326 & TRN \\
\hline CHEMBL1996587 & 809181 & 4.9 & 5.0812 & TRN \\
\hline CHEMBL1993335 & 809181 & 4.2 & 4.794 & TRN \\
\hline CHEMBL1988692 & 809181 & 5.8 & 5.1232 & TRN \\
\hline CHEMBL 2007574 & 809181 & 4.2 & 3.8809 & TRN \\
\hline CHEMBL1964804 & 809181 & 4.9 & 4.9619 & TRN \\
\hline CHEMBL 2000354 & 809181 & 4.9 & 4.7553 & TRN \\
\hline CHEMBL1965507 & 809181 & 4.9 & 4.9695 & TRN \\
\hline CHEMBL1998680 & 809181 & 4.2 & 4.2123 & TRN \\
\hline CHEMBL1967564 & 809181 & 4.9 & 4.8082 & TRN \\
\hline CHEMBL592030 & 809181 & 4.4 & 4.3038 & TRN \\
\hline CHEMBL 2000071 & 809181 & 4.9 & 4.8021 & TRN \\
\hline CHEMBL1979176 & 809181 & 4.9 & 4.6079 & TRN \\
\hline CHEMBL 2000408 & 809181 & 4.9 & 4.9214 & TRN \\
\hline CHEMBL1978014 & 809181 & 4.9 & 5.0839 & TRN \\
\hline CHEMBL 2002736 & 809181 & 4.2 & 4.4033 & TRN \\
\hline CHEMBL1997007 & 809181 & 4.2 & 4.0678 & TRN \\
\hline CHEMBL1994538 & 809181 & 4.9 & 4.8933 & TRN \\
\hline CHEMBL1975490 & 809181 & 4.9 & 4.9277 & TRN \\
\hline
\end{tabular}




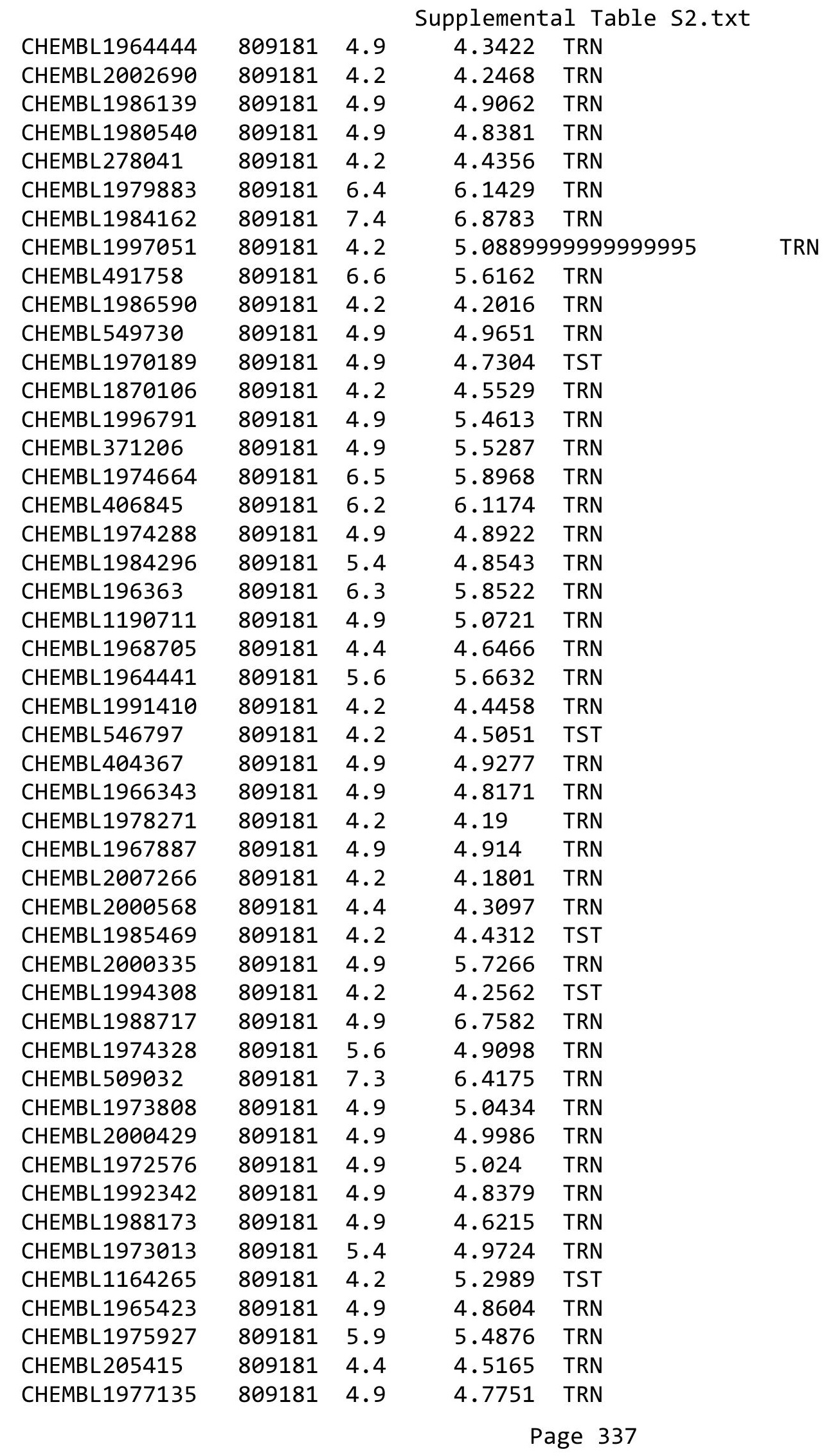




\begin{tabular}{|c|c|c|c|c|c|}
\hline \multicolumn{6}{|c|}{ Supplemental Table S2.txt } \\
\hline CHEMBL 2001920 & 809181 & 4.9 & 4.6708 & TRN & \\
\hline CHEMBL1977138 & 809181 & 5.6 & 5.6465 & TST & \\
\hline CHEMBL1978448 & 809181 & 4.5 & 4.6384 & TST & \\
\hline CHEMBL1969483 & 809181 & 4.2 & 4.4619 & TRN & \\
\hline CHEMBL 2001257 & 809181 & 6.1 & 5.7432 & TRN & \\
\hline CHEMBL1980329 & 809181 & 4.2 & 4.6431 & TRN & \\
\hline CHEMBL1992042 & 809181 & 5.3 & 4.5716 & TST & \\
\hline CHEMBL1992536 & 809181 & 4.9 & 4.9795 & TRN & \\
\hline CHEMBL21156 & 809181 & 4.2 & 4.5 & TST & \\
\hline CHEMBL1994724 & 809181 & 4.2 & 4.6271 & TRN & \\
\hline CHEMBL1989267 & 809181 & 7.9 & 6.92299 & 9999999999 & TRN \\
\hline CHEMBL439340 & 809181 & 4.9 & 4.9867 & TRN & \\
\hline CHEMBL 2006188 & 809181 & 4.9 & 4.937 & TRN & \\
\hline CHEMBL1970290 & 809181 & 5.3 & 4.8939 & TRN & \\
\hline CHEMBL1974574 & 809181 & 4.2 & 4.4637 & TST & \\
\hline CHEMBL1967531 & 809181 & 4.9 & 5.3972 & TRN & \\
\hline CHEMBL1970913 & 809181 & 4.9 & 4.9966 & TRN & \\
\hline CHEMBL1973893 & 809181 & 4.9 & 4.9465 & TRN & \\
\hline CHEMBL1997534 & 809181 & 4.9 & 4.7276 & TRN & \\
\hline CHEMBL1993877 & 809181 & 4.2 & 5.0587 & TRN & \\
\hline CHEMBL1996500 & 809181 & 4.3 & 4.5942 & TRN & \\
\hline CHEMBL1985095 & 809181 & 4.9 & 4.6238 & TRN & \\
\hline CHEMBL1682540 & 809181 & 4.9 & 4.9481 & TRN & \\
\hline CHEMBL1976420 & 809181 & 4.7 & 5.3155 & TRN & \\
\hline CHEMBL1998253 & 809181 & 4.2 & 4.1899 & TST & \\
\hline CHEMBL1981744 & 809181 & 4.2 & 4.3332 & TRN & \\
\hline CHEMBL497151 & 809181 & 4.9 & 4.68199 & 99999999995 & TRN \\
\hline CHEMBL 2000029 & 809181 & 4.2 & 4.4013 & TRN & \\
\hline CHEMBL1973961 & 809181 & 4.2 & 4.9901 & TRN & \\
\hline CHEMBL 246970 & 809181 & 4.9 & 4.8684 & TST & \\
\hline CHEMBL340921 & 809181 & 4.9 & 5.0195 & TST & \\
\hline CHEMBL1994977 & 809181 & 4.2 & 4.1742 & TRN & \\
\hline CHEMBL 2001149 & 809181 & 4.2 & 4.2598 & TRN & \\
\hline CHEMBL1999718 & 809181 & 4.9 & 4.8913 & TRN & \\
\hline CHEMBL 2000078 & 809181 & 4.2 & 4.8078 & TRN & \\
\hline CHEMBL 2005478 & 809181 & 4.2 & 4.8593 & TRN & \\
\hline CHEMBL1276446 & 809181 & 7.1 & 5.2861 & TST & \\
\hline CHEMBL1996646 & 809181 & 4.2 & 4.9924 & TRN & \\
\hline CHEMBL1979773 & 809181 & 4.2 & 3.9995 & TRN & \\
\hline CHEMBL1977346 & 809181 & 4.9 & 4.8319 & TRN & \\
\hline CHEMBL1971649 & 809181 & 4.9 & 4.9573 & TRN & \\
\hline CHEMBL 2005482 & 809181 & 4.2 & 5.2983 & TRN & \\
\hline CHEMBL1996702 & 809181 & 4.2 & 4.9203 & TRN & \\
\hline CHEMBL1997909 & 809181 & 4.2 & 4.1891 & TRN & \\
\hline CHEMBL 2007124 & 809181 & 4.2 & 4.2355 & TRN & \\
\hline CHEMBL 2006439 & 809181 & 4.4 & 4.4065 & TRN & \\
\hline CHEMBL1985681 & 809181 & 4.2 & 4.2919 & TRN & \\
\hline CHEMBL1969190 & 809181 & 4.9 & 5.5054 & TRN & \\
\hline
\end{tabular}




\begin{tabular}{|c|c|c|c|c|}
\hline \multicolumn{5}{|c|}{ Supplemental Table } \\
\hline CHEMBL2002660 & 809181 & 4.2 & 4.0541 & TRN \\
\hline CHEMBL1973937 & 809181 & 4.9 & 4.9 & TRN \\
\hline CHEMBL1991674 & 809181 & 4.6 & 3.7942 & TRN \\
\hline CHEMBL1982711 & 809181 & 4.4 & 4.2238 & TRN \\
\hline CHEMBL1984842 & 809181 & 4.2 & 4.6871 & TRN \\
\hline CHEMBL2004118 & 809181 & 4.2 & 4.0715 & TRN \\
\hline CHEMBL1996795 & 809181 & 4.2 & 4.5429 & TST \\
\hline CHEMBL50894 & 809181 & 4.2 & 4.5417 & TRN \\
\hline CHEMBL1995211 & 809181 & 4.2 & 4.2634 & TRN \\
\hline CHEMBL1988838 & 809181 & 6.8 & 6.0293 & TRN \\
\hline CHEMBL1981725 & 809181 & 7.0 & 6.2113 & TRN \\
\hline CHEMBL1982753 & 809181 & 4.2 & 4.6963 & TRN \\
\hline CHEMBL 2006299 & 809181 & 4.2 & 4.3798 & TRN \\
\hline CHEMBL1972346 & 809181 & 6.2 & 4.9645 & TST \\
\hline CHEMBL1965169 & 809181 & 4.2 & 4.2795 & TRN \\
\hline CHEMBL1991818 & 809181 & 5.4 & 4.4459 & TST \\
\hline CHEMBL1081312 & 809181 & 5.8 & 6.0308 & TRN \\
\hline CHEMBL1965170 & 809181 & 7.0 & 6.7603 & TRN \\
\hline CHEMBL1982866 & 809181 & 4.9 & 5.0497 & TRN \\
\hline CHEMBL 2005792 & 809181 & 4.2 & 4.7358 & TRN \\
\hline CHEMBL1986503 & 809181 & 4.2 & 4.3923 & TST \\
\hline CHEMBL1965570 & 809181 & 6.1 & 6.2432 & TRN \\
\hline CHEMBL 2007592 & 809181 & 4.9 & 4.9242 & TST \\
\hline CHEMBL1972355 & 809181 & 5.9 & 5.0999 & TST \\
\hline CHEMBL1997892 & 809181 & 4.2 & 4.3254 & TRN \\
\hline CHEMBL1997193 & 809181 & 4.2 & 4.632 & TST \\
\hline CHEMBL 210963 & 809181 & 4.9 & 4.9889 & TST \\
\hline CHEMBL1964902 & 809181 & 4.2 & 4.1171 & TRN \\
\hline CHEMBL1614705 & 809181 & 4.9 & 5.0364 & TRN \\
\hline CHEMBL1984633 & 809181 & 4.9 & 5.0611 & TRN \\
\hline CHEMBL1965845 & 809181 & 4.9 & 4.4754 & TRN \\
\hline CHEMBL1998228 & 809181 & 4.3 & 4.8059 & TST \\
\hline CHEMBL1983715 & 809181 & 5.8 & 5.8894 & TRN \\
\hline CHEMBL1986597 & 809181 & 4.9 & 4.9117 & TRN \\
\hline CHEMBL1990482 & 809181 & 4.9 & 4.8277 & TRN \\
\hline CHEMBL1990904 & 809181 & 4.9 & 5.0404 & TRN \\
\hline CHEMBL 2005475 & 809181 & 4.9 & 4.4883 & TRN \\
\hline CHEMBL183844 & 809181 & 4.9 & 4.6518 & TRN \\
\hline CHEMBL220057 & 809181 & 4.9 & 5.0016 & TRN \\
\hline CHEMBL1682545 & 809181 & 4.9 & 4.8579 & TRN \\
\hline CHEMBL 383541 & 809181 & 4.9 & 4.8527 & TRN \\
\hline CHEMBL 2001224 & 809181 & 4.9 & 4.9625 & TRN \\
\hline CHEMBL10 & 809181 & 4.2 & 4.5397 & TRN \\
\hline CHEMBL1976732 & 809181 & 4.9 & 5.1775 & TRN \\
\hline CHEMBL1969506 & 809181 & 4.9 & 5.227 & TRN \\
\hline CHEMBL1964937 & 809181 & 4.9 & 4.4915 & TRN \\
\hline CHEMBL1980763 & 809181 & 4.2 & 4.2877 & TRN \\
\hline CHEMBL1980163 & 809181 & 4.9 & 4.8633 & TRN \\
\hline
\end{tabular}




\begin{tabular}{|c|c|c|c|c|c|}
\hline \multicolumn{6}{|c|}{ Supplemental Table S2.txt } \\
\hline CHEMBL 2005899 & 809181 & 4.9 & 4.8413 & TRN & \\
\hline CHEMBL1682552 & 809181 & 4.9 & 4.8515 & TRN & \\
\hline CHEMBL 2007479 & 809181 & 4.2 & 4.329 & TRN & \\
\hline CHEMBL105739 & 809181 & 4.9 & 5.0503 & TRN & \\
\hline CHEMBL1972220 & 809181 & 7.2 & 7.2903 & TRN & \\
\hline CHEMBL 379300 & 809181 & 4.9 & 4.5852 & TRN & \\
\hline CHEMBL1973720 & 809181 & 4.2 & 4.01699 & 99999999995 & TRN \\
\hline CHEMBL 2003785 & 809181 & 4.2 & 4.4853 & TST & \\
\hline CHEMBL 2001923 & 809181 & 4.2 & 4.7622 & TST & \\
\hline CHEMBL1986781 & 809181 & 4.9 & 5.2379 & TRN & \\
\hline CHEMBL1983070 & 809181 & 4.2 & 4.2902 & TRN & \\
\hline CHEMBL526133 & 809181 & 4.9 & 4.8209 & TRN & \\
\hline CHEMBL 2003514 & 809181 & 4.2 & 4.4268 & TRN & \\
\hline CHEMBL1989043 & 809181 & 4.2 & 4.7459 & TRN & \\
\hline CHEMBL1979057 & 809181 & 4.9 & 4.5099 & TRN & \\
\hline CHEMBL387971 & 809181 & 4.9 & 5.2137 & TST & \\
\hline CHEMBL1164180 & 809181 & 4.2 & 5.2229 & TST & \\
\hline CHEMBL1999428 & 809181 & 4.9 & 4.7843 & TRN & \\
\hline CHEMBL1967560 & 809181 & 4.9 & 5.3895 & TRN & \\
\hline CHEMBL1997611 & 809181 & 4.2 & 4.7743 & TST & \\
\hline CHEMBL211378 & 809181 & 4.9 & 5.1442 & TRN & \\
\hline CHEMBL 2001751 & 809181 & 6.3 & 5.1009 & TRN & \\
\hline CHEMBL 2003420 & 809181 & 4.9 & 4.6734 & TRN & \\
\hline CHEMBL1984586 & 809181 & 4.9 & 4.9313 & TRN & \\
\hline CHEMBL1972659 & 809181 & 4.9 & 4.6152 & TST & \\
\hline CHEMBL272453 & 809181 & 4.9 & 4.9817 & TRN & \\
\hline CHEMBL1970217 & 809181 & 4.9 & 4.8684 & TRN & \\
\hline CHEMBL 2005528 & 809181 & 4.9 & 4.7814 & TST & \\
\hline CHEMBL1984686 & 809181 & 4.2 & 4.4697 & TRN & \\
\hline CHEMBL185569 & 809181 & 4.9 & 4.805 & TRN & \\
\hline CHEMBL1969843 & 809181 & 4.9 & 5.0512 & TRN & \\
\hline CHEMBL 2007002 & 809181 & 4.9 & 4.9761 & TRN & \\
\hline CHEMBL1987007 & 809181 & 4.9 & 4.6655 & TRN & \\
\hline CHEMBL1973793 & 809181 & 4.2 & 4.1789 & TST & \\
\hline CHEMBL1969588 & 809181 & 4.9 & 5.2305 & TRN & \\
\hline CHEMBL1992073 & 809181 & 4.2 & 4.6088 & TRN & \\
\hline CHEMBL484390 & 809181 & 4.9 & 4.7934 & TRN & \\
\hline CHEMBL1986143 & 809181 & 4.2 & 4.4521 & TRN & \\
\hline CHEMBL1979252 & 809181 & 4.9 & 4.8029 & TRN & \\
\hline CHEMBL 2007559 & 809181 & 4.2 & 4.5518 & TRN & \\
\hline CHEMBL1992581 & 809181 & 5.6 & 5.0504 & TRN & \\
\hline CHEMBL 2004290 & 809181 & 6.6 & 6.8803 & TRN & \\
\hline CHEMBL1986499 & 809181 & 4.9 & 4.7812 & TRN & \\
\hline CHEMBL1972937 & 809181 & 4.9 & 4.7564 & TRN & \\
\hline CHEMBL 2000393 & 809181 & 6.2 & 5.5434 & TST & \\
\hline CHEMBL 2004311 & 809181 & 4.9 & 4.6281 & TRN & \\
\hline CHEMBL1992634 & 809181 & 4.9 & 4.4653 & TRN & \\
\hline CHEMBL1242373 & 809181 & 4.9 & 5.223 & TRN & \\
\hline
\end{tabular}




\begin{tabular}{|c|c|c|c|c|}
\hline \multicolumn{5}{|c|}{ Supplemental Table S2.txt } \\
\hline CHEMBL1984847 & 809181 & 4.2 & 4.512 & TRN \\
\hline CHEMBL316264 & 809181 & 4.9 & 4.7356 & TRN \\
\hline CHEMBL1988075 & 809181 & 4.9 & 5.96200 & 0000000001 \\
\hline CHEMBL1996576 & 809181 & 4.2 & 4.3795 & TST \\
\hline CHEMBL1988076 & 809181 & 4.2 & 4.3358 & TRN \\
\hline CHEMBL1991678 & 809181 & 4.3 & 4.624 & TRN \\
\hline CHEMBL2001239 & 809181 & 6.1 & 4.9774 & TRN \\
\hline CHEMBL1988594 & 809181 & 4.9 & 5.059 & TRN \\
\hline CHEMBL 2001288 & 809181 & 4.9 & 5.0895 & TRN \\
\hline CHEMBL1999811 & 809181 & 4.9 & 5.0144 & TRN \\
\hline CHEMBL235157 & 809181 & 4.2 & 4.4151 & TST \\
\hline CHEMBL1985074 & 809181 & 4.9 & 4.845 & TST \\
\hline CHEMBL1982874 & 809181 & 4.9 & 4.9233 & TRN \\
\hline CHEMBL 2000481 & 809181 & 4.9 & 4.8012 & TRN \\
\hline CHEMBL1991725 & 809181 & 4.9 & 4.8781 & TRN \\
\hline CHEMBL 2007296 & 809181 & 4.9 & 4.7711 & TRN \\
\hline CHEMBL396523 & 809181 & 6.3 & 5.3843 & TRN \\
\hline CHEMBL 2004159 & 809181 & 4.2 & 4.3488 & TRN \\
\hline CHEMBL1978371 & 809181 & 5.6 & 4.774 & TST \\
\hline CHEMBL1970203 & 809181 & 4.9 & 4.8157 & TRN \\
\hline CHEMBL1986530 & 809181 & 4.9 & 4.7839 & TST \\
\hline CHEMBL440084 & 809181 & 4.2 & 4.5111 & TRN \\
\hline CHEMBL1999321 & 809181 & 4.9 & 4.7502 & TRN \\
\hline CHEMBL1968590 & 809181 & 6.2 & 6.4072 & TRN \\
\hline CHEMBL 2005375 & 809181 & 4.9 & 5.4524 & TRN \\
\hline CHEMBL1984191 & 809181 & 4.9 & 4.7661 & TRN \\
\hline CHEMBL1966501 & 809181 & 4.2 & 4.3246 & TRN \\
\hline CHEMBL394790 & 809181 & 4.9 & 4.8044 & TRN \\
\hline CHEMBL1974702 & 809181 & 4.9 & 5.0163 & TRN \\
\hline CHEMBL1996111 & 809181 & 4.9 & 4.8732 & TRN \\
\hline CHEMBL1966175 & 809181 & 4.2 & 4.5314 & TRN \\
\hline CHEMBL1965589 & 809181 & 4.9 & 5.0001 & TRN \\
\hline CHEMBL 2007375 & 809181 & 4.2 & 4.1877 & TRN \\
\hline CHEMBL1998193 & 809181 & 4.9 & 4.6706 & TRN \\
\hline CHEMBL379975 & 809181 & 4.2 & 4.5554 & TST \\
\hline CHEMBL1973016 & 809181 & 4.2 & 4.4013 & TRN \\
\hline CHEMBL1965387 & 809181 & 4.2 & 4.072 & TRN \\
\hline CHEMBL1997041 & 809181 & 4.3 & 4.5044 & TRN \\
\hline CHEMBL1988153 & 809181 & 4.9 & 4.7053 & TRN \\
\hline CHEMBL550418 & 809181 & 4.2 & 4.6992 & TRN \\
\hline CHEMBL1971289 & 809181 & 4.2 & 4.2352 & TRN \\
\hline CHEMBL1988437 & 809181 & 4.2 & 4.6633 & TST \\
\hline CHEMBL1998121 & 809181 & 4.9 & 5.0676 & TRN \\
\hline CHEMBL1233887 & 809181 & 5.3 & 4.5391 & TRN \\
\hline CHEMBL 2003689 & 809181 & 4.2 & 4.1849 & TRN \\
\hline CHEMBL1979357 & 809181 & 4.9 & 4.9576 & TRN \\
\hline CHEMBL1996649 & 809181 & 6.2 & 5.9583 & TRN \\
\hline CHEMBL1996817 & 809181 & 4.9 & 4.9053 & TRN \\
\hline
\end{tabular}

TRN 


\begin{tabular}{|c|c|c|c|c|}
\hline \multicolumn{5}{|c|}{ Supplemental Table S2.txt } \\
\hline CHEMBL1986756 & 809181 & 4.2 & 4.255 & TRN \\
\hline CHEMBL468280 & 809181 & 4.9 & 4.7447 & TST \\
\hline CHEMBL1990884 & 809181 & 4.9 & 5.6764 & TRN \\
\hline CHEMBL 3109278 & 809181 & 4.4 & 4.8205 & TRN \\
\hline CHEMBL 256835 & 809181 & 4.9 & 5.0446 & TRN \\
\hline CHEMBL1974998 & 809181 & 4.2 & 4.0475 & TRN \\
\hline CHEMBL1980142 & 809181 & 4.9 & 4.8333 & TRN \\
\hline CHEMBL41783 & 809181 & 4.9 & 4.8364 & TRN \\
\hline CHEMBL 2004438 & 809181 & 4.2 & 4.345 & TRN \\
\hline CHEMBL191003 & 809181 & 4.2 & 4.8243 & TRN \\
\hline CHEMBL271381 & 809181 & 6.2 & 5.6467 & TRN \\
\hline CHEMBL 2006785 & 809181 & 4.9 & 4.916 & TRN \\
\hline CHEMBL1982466 & 809181 & 4.9 & 6.8857 & TRN \\
\hline CHEMBL1973359 & 809181 & 6.4 & 5.6204 & TST \\
\hline CHEMBL1995740 & 809181 & 4.9 & 4.878 & TRN \\
\hline CHEMBL1979690 & 809181 & 6.4 & 6.3307 & TRN \\
\hline CHEMBL 234085 & 809181 & 4.2 & 4.4821 & TRN \\
\hline CHEMBL1995832 & 809181 & 4.9 & 4.9815 & TRN \\
\hline CHEMBL1969042 & 809181 & 4.9 & 4.6335 & TRN \\
\hline CHEMBL1999931 & 809181 & 4.9 & 4.8133 & TRN \\
\hline CHEMBL1976376 & 809181 & 7.1 & 6.0042 & TRN \\
\hline CHEMBL1983575 & 809181 & 5.5 & 4.8872 & TRN \\
\hline CHEMBL1968868 & 809181 & 4.2 & 4.4629 & TRN \\
\hline CHEMBL 2007064 & 809181 & 6.1 & 5.0558 & TRN \\
\hline CHEMBL1981047 & 809181 & 6.7 & 6.4238 & TRN \\
\hline CHEMBL229968 & 809181 & 4.9 & 4.7003 & TRN \\
\hline CHEMBL1976196 & 809181 & 4.2 & 4.4856 & TST \\
\hline CHEMBL 2002432 & 809181 & 4.2 & 5.1234 & TRN \\
\hline CHEMBL1976240 & 809181 & 4.9 & 4.9355 & TRN \\
\hline CHEMBL1997197 & 809181 & 4.2 & 4.3812 & TRN \\
\hline CHEMBL1979093 & 809181 & 4.9 & 5.3334 & TRN \\
\hline CHEMBL1968151 & 809181 & 4.9 & 4.9078 & TST \\
\hline CHEMBL1987009 & 809181 & 4.9 & 4.4116 & TRN \\
\hline CHEMBL379218 & 809181 & 4.9 & 4.6283 & TST \\
\hline CHEMBL 2003817 & 809181 & 4.9 & 4.7724 & TST \\
\hline CHEMBL1994830 & 809181 & 4.9 & 4.7549 & TST \\
\hline CHEMBL 226403 & 809181 & 4.9 & 4.8421 & TST \\
\hline CHEMBL1994938 & 809181 & 8.0 & 7.0336 & TST \\
\hline CHEMBL1995765 & 809181 & 4.5 & 4.5368 & TST \\
\hline CHEMBL1966279 & 809181 & 4.9 & 4.8782 & TST \\
\hline CHEMBL1984760 & 809181 & 4.2 & 4.0953 & TST \\
\hline CHEMBL1997846 & 809181 & 4.4 & 4.0701 & TST \\
\hline CHEMBL2004419 & 809181 & 4.9 & 5.0559 & TST \\
\hline CHEMBL360847 & 809181 & 4.2 & 4.2842 & TST \\
\hline CHEMBL 2007073 & 809181 & 4.2 & 4.1256 & TST \\
\hline CHEMBL1995811 & 809181 & 4.2 & 4.4452 & TST \\
\hline CHEMBL1994074 & 809181 & 4.9 & 4.4347 & TST \\
\hline CHEMBL1992937 & 809181 & 4.2 & 4.1254 & TST \\
\hline
\end{tabular}




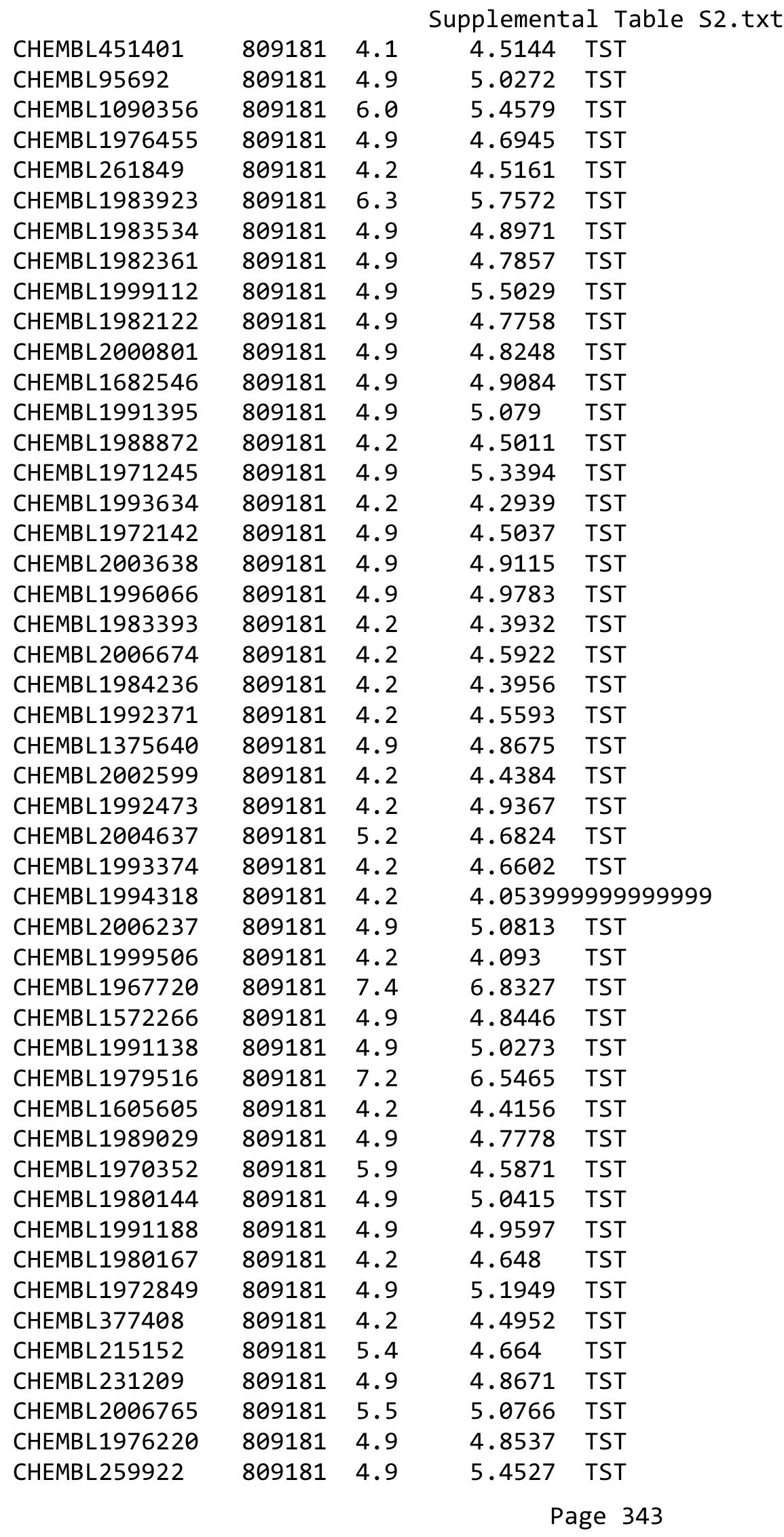




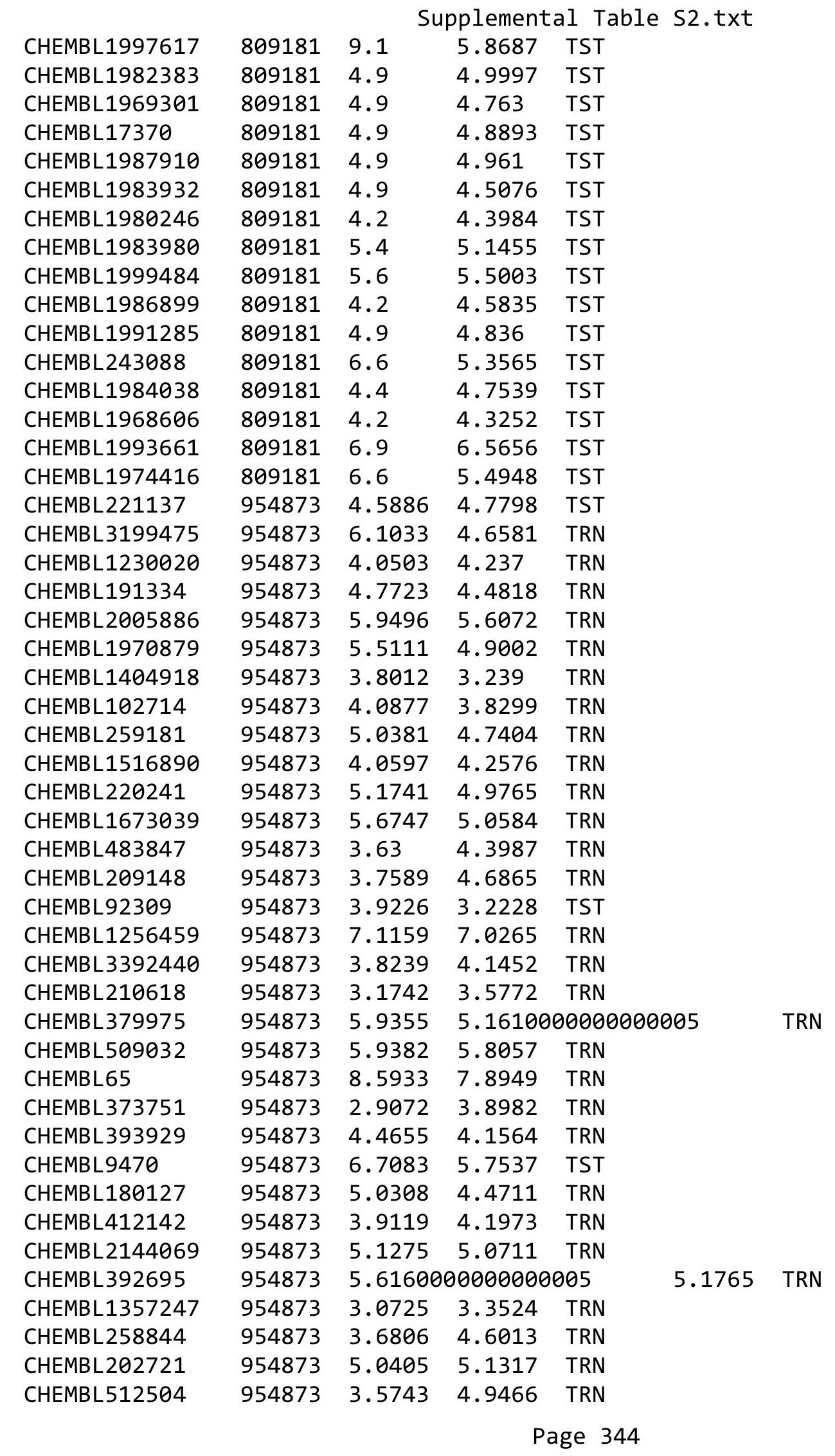


Supplemental Table S2.txt

\begin{tabular}{|c|c|c|c|c|c|}
\hline CHEMBL1788116 & 954873 & 4.671 & 4.5539 & TRN & \\
\hline CHEMBL515416 & 954873 & 4.074 & 4.654 & TRN & \\
\hline CHEMBL379300 & 954873 & 4.9605 & 6.3415 & TRN & \\
\hline CHEMBL577784 & 954873 & 4.7786 & 5.3691 & TRN & \\
\hline CHEMBL192566 & 954873 & 6.5215 & 7.7903 & TST & \\
\hline CHEMBL135561 & 954873 & 4.1364 & 4.575 & TRN & \\
\hline CHEMBL1242367 & 954873 & 5.1615 & 4.4995 & TRN & \\
\hline CHEMBL1909414 & 954873 & 5.5338 & 4.2334 & TRN & \\
\hline CHEMBL449158 & 954873 & 5.7666 & 6.6918 & TST & \\
\hline CHEMBL483849 & 954873 & 3.3622 & 2.6321 & TRN & \\
\hline CHEMBL 240954 & 954873 & 3.8359 & 3.9833 & TST & \\
\hline CHEMBL573107 & 954873 & 4.6568 & 5.2247 & TRN & \\
\hline CHEMBL300389 & 954873 & 7.1802 & 6.7659 & TRN & \\
\hline CHEMBL1643959 & 954873 & 3.3877 & 4.0416 & TRN & \\
\hline CHEMBL585951 & 954873 & 6.1524 & 6.1748 & TRN & \\
\hline CHEMBL3349342 & 954873 & 4.7616 & 5.1389 & TRN & \\
\hline CHEMBL558642 & 954873 & 4.2005 & 4.4069 & TRN & \\
\hline CHEMBL472940 & 954873 & 4.5891 & 3.9294 & TRN & \\
\hline CHEMBL188678 & 954873 & 4.3455 & \multicolumn{2}{|c|}{4.6819999999999995} & TST \\
\hline CHEMBL2363137 & 954873 & 4.9058 & 4.8208 & TST & \\
\hline CHEMBL 222102 & 954873 & 4.5412 & 4.1171 & TST & \\
\hline CHEMBL514499 & 954873 & 7.0928 & 6.7503 & TST & \\
\hline CHEMBL1590308 & 954873 & 3.4204 & 3.7285 & TST & \\
\hline CHEMBL1190711 & 954873 & 4.8654 & 5.1478 & TST & \\
\hline CHEMBL189584 & 954873 & 5.1259 & 4.7621 & TST & \\
\hline CHEMBL3186408 & 954873 & 4.8983 & 4.0683 & TST & \\
\hline CHEMBL 213100 & 954873 & 4.1587 & 5.176 & TST & \\
\hline CHEMBL1370704 & 688481 & 4.5 & \multicolumn{2}{|c|}{4.4910000000000005} & TRN \\
\hline CHEMBL1499859 & 688481 & 5.5 & 5.4988 & TRN & \\
\hline CHEMBL1306714 & 688481 & 5.15 & 5.1894 & TRN & \\
\hline CHEMBL 2006072 & 688481 & 4.75 & 4.7613 & TRN & \\
\hline CHEMBL1461802 & 688481 & 4.85 & 4.8483 & TRN & \\
\hline CHEMBL1502753 & 688481 & 5.75 & 5.7539 & TRN & \\
\hline CHEMBL1503187 & 688481 & 5.15 & 5.1396 & TRN & \\
\hline CHEMBL581225 & 688481 & 4.95 & 4.9472 & TRN & \\
\hline CHEMBL1588160 & 688481 & 5.0 & 4.9946 & TRN & \\
\hline CHEMBL1504634 & 688481 & 5.65 & 5.6398 & TRN & \\
\hline CHEMBL1417556 & 688481 & 4.9 & 6.3952 & TST & \\
\hline CHEMBL3207913 & 688481 & 5.15 & 5.143 & TRN & \\
\hline CHEMBL1357674 & 688481 & 4.9 & 4.5029 & TST & \\
\hline CHEMBL1346893 & 688481 & 4.8 & 4.8088 & TRN & \\
\hline CHEMBL1364389 & 688481 & 4.85 & 4.8541 & TRN & \\
\hline CHEMBL3208316 & 688481 & 5.1 & 5.0944 & TRN & \\
\hline CHEMBL1343943 & 688481 & 4.65 & 4.6524 & TRN & \\
\hline CHEMBL1358659 & 688481 & 4.35 & 5.6631 & TST & \\
\hline CHEMBL1480992 & 688481 & 4.85 & 4.8545 & TRN & \\
\hline CHEMBL1302913 & 688481 & 5.05 & 4.8638 & TST & \\
\hline CHEMBL1493377 & 688481 & 4.9 & 4.8833 & TRN & \\
\hline
\end{tabular}




\begin{tabular}{|c|c|c|c|c|c|}
\hline & & \multicolumn{4}{|c|}{ Supplemental Table S2.txt } \\
\hline CHEMBL1336264 & 688481 & 5.4 & 5.4119 & TRN & \\
\hline CHEMBL1303594 & 688481 & 4.85 & 4.8535 & TRN & \\
\hline CHEMBL1600326 & 688481 & 5.6 & 5.5984 & TRN & \\
\hline CHEMBL1333544 & 688481 & 4.85 & 4.8483 & TRN & \\
\hline CHEMBL3212101 & 688481 & 4.85 & 4.8426 & TRN & \\
\hline CHEMBL1477127 & 688481 & 5.8 & 5.8065 & TRN & \\
\hline CHEMBL1565133 & 688481 & 4.55 & 5.7633 & TST & \\
\hline CHEMBL1501987 & 688481 & 5.05 & 5.0483 & TRN & \\
\hline CHEMBL1409483 & 688481 & 5.2 & 5.19799 & 99999999995 & TRN \\
\hline CHEMBL3207671 & 688481 & 4.95 & 4.9571 & TRN & \\
\hline CHEMBL1988457 & 688481 & 4.85 & 4.8472 & TRN & \\
\hline CHEMBL1524928 & 688481 & 4.6 & 4.598 & TRN & \\
\hline CHEMBL1424025 & 688481 & 4.6 & 4.6029 & TRN & \\
\hline CHEMBL269733 & 688481 & 5.2 & 5.7915 & TST & \\
\hline CHEMBL1377408 & 688481 & 9.3979 & 9.4082 & TRN & \\
\hline CHEMBL1419164 & 688481 & 4.95 & 4.9411 & TRN & \\
\hline CHEMBL1346173 & 688481 & 5.05 & 5.0372 & TRN & \\
\hline CHEMBL1494852 & 688481 & 5.45 & 5.3975 & TRN & \\
\hline CHEMBL1472131 & 688481 & 4.85 & 4.8525 & TRN & \\
\hline CHEMBL1491900 & 688481 & 5.0 & 5.0143 & TRN & \\
\hline CHEMBL548062 & 688481 & 5.3 & 5.2793 & TRN & \\
\hline CHEMBL3193541 & 688481 & 4.85 & 4.856 & TRN & \\
\hline CHEMBL1971695 & 688481 & 4.55 & 4.5463 & TRN & \\
\hline CHEMBL1510394 & 688481 & 5.4 & 5.4121 & TRN & \\
\hline CHEMBL1421488 & 688481 & 4.95 & 4.9427 & TRN & \\
\hline CHEMBL1611372 & 688481 & 5.35 & 5.3532 & TRN & \\
\hline CHEMBL1367106 & 688481 & 4.85 & 4.8485 & TRN & \\
\hline CHEMBL1422235 & 688481 & 5.15 & 5.1413 & TRN & \\
\hline CHEMBL1330030 & 688481 & 4.9 & 4.8999 & TRN & \\
\hline CHEMBL3213974 & 688481 & 9.3979 & 9.3956 & TRN & \\
\hline CHEMBL1466180 & 688481 & 4.7 & 4.6945 & TRN & \\
\hline CHEMBL1547938 & 688481 & 5.0 & 5.0018 & TRN & \\
\hline CHEMBL1352113 & 688481 & 4.95 & 4.9169 & TRN & \\
\hline CHEMBL1450086 & 688481 & 5.05 & 4.6504 & TST & \\
\hline CHEMBL1498280 & 688481 & 4.8 & 4.8003 & TRN & \\
\hline CHEMBL1324890 & 688481 & 5.1 & 5.0988 & TRN & \\
\hline CHEMBL1470827 & 688481 & 4.8 & 4.8062 & TRN & \\
\hline CHEMBL1392987 & 688481 & 5.1 & 5.1062 & TRN & \\
\hline CHEMBL1375635 & 688481 & 5.45 & 5.4456 & TRN & \\
\hline CHEMBL1517883 & 688481 & 4.85 & 4.8573 & TRN & \\
\hline CHEMBL1497017 & 688481 & 5.35 & 5.3378 & TRN & \\
\hline CHEMBL1504286 & 688481 & 4.85 & 4.8509 & TRN & \\
\hline CHEMBL1444730 & 688481 & 4.95 & 4.9614 & TRN & \\
\hline CHEMBL1437992 & 688481 & 5.65 & 5.6488 & TRN & \\
\hline CHEMBL1301842 & 688481 & 4.9 & 5.8149 & TST & \\
\hline CHEMBL319620 & 688481 & 5.7 & 4.2156 & TST & \\
\hline CHEMBL1485307 & 688481 & 4.9 & 4.913 & TRN & \\
\hline CHEMBL1359410 & 688481 & 6.25 & 6.2452 & TRN & \\
\hline
\end{tabular}




\begin{tabular}{|c|c|c|c|c|}
\hline \multicolumn{5}{|c|}{ Supplemental Table S2.txt } \\
\hline CHEMBL1332112 & 688481 & 3.85 & 3.8583 & TRN \\
\hline CHEMBL1449027 & 688481 & 4.9 & 4.9042 & TRN \\
\hline CHEMBL1549804 & 688481 & 4.9 & 4.9459 & TRN \\
\hline CHEMBL1465029 & 688481 & 4.8 & 4.8035 & TRN \\
\hline CHEMBL1509082 & 688481 & 4.5 & 4.4974 & TRN \\
\hline CHEMBL3195374 & 688481 & 5.25 & 5.2511 & TRN \\
\hline CHEMBL1324634 & 688481 & 4.8 & 4.8078 & TRN \\
\hline CHEMBL2374259 & 688481 & 5.1 & 4.9875 & TST \\
\hline CHEMBL1559351 & 688481 & 5.6 & 4.658 & TST \\
\hline CHEMBL1500528 & 688481 & 4.85 & 4.9205 & TST \\
\hline CHEMBL1325656 & 688481 & 5.0 & 4.2993 & TST \\
\hline CHEMBL1300682 & 688481 & 4.95 & 5.7055 & TST \\
\hline CHEMBL1567944 & 688481 & 4.75 & 5.5244 & TST \\
\hline CHEMBL1514486 & 688481 & 5.3 & 4.9993 & TST \\
\hline CHEMBL1563641 & 688481 & 4.8 & 4.8119 & TST \\
\hline CHEMBL1460312 & 688481 & 4.4 & 5.1499 & TST \\
\hline CHEMBL1390971 & 688481 & 4.9 & 4.4325 & TST \\
\hline CHEMBL1417798 & 688481 & 5.55 & 4.925 & TST \\
\hline CHEMBL1361245 & 688481 & 4.8 & 5.055 & TST \\
\hline CHEMBL1304739 & 688481 & 4.8 & 5.1507 & TST \\
\hline CHEMBL1438881 & 688481 & 5.35 & 4.3809 & TST \\
\hline CHEMBL147232 & 50848 & 7.4437 & 7.3181 & TRN \\
\hline CHEMBL148865 & 50848 & 6.8539 & 6.8614 & TRN \\
\hline CHEMBL149932 & 50848 & 6.7447 & 6.8354 & TRN \\
\hline CHEMBL359158 & 50848 & 7.4815 & 7.3708 & TRN \\
\hline CHEMBL146702 & 50848 & 5.3979 & 5.3038 & TRN \\
\hline CHEMBL28377 & 50848 & 6.5686 & 6.3526 & TRN \\
\hline CHEMBL148995 & 50848 & 7.8239 & 7.9256 & TRN \\
\hline CHEMBL149087 & 50848 & 7.3188 & 7.4065 & TRN \\
\hline CHEMBL151774 & 50848 & 6.6198 & 6.2063 & TRN \\
\hline CHEMBL421957 & 50848 & 5.9586 & 5.8295 & TRN \\
\hline CHEMBL148942 & 50848 & 5.2518 & 5.2981 & TRN \\
\hline CHEMBL146812 & 50848 & 5.8861 & 6.8918 & TST \\
\hline CHEMBL356148 & 50848 & 4.6021 & 4.5849 & TRN \\
\hline CHEMBL148669 & 50848 & 7.7696 & 7.9138 & TRN \\
\hline CHEMBL147018 & 50848 & 6.8539 & 6.966 & TST \\
\hline CHEMBL434700 & 50848 & 7.0655 & 7.853 & TST \\
\hline CHEMBL147184 & 50848 & 7.3768 & 7.2608 & TRN \\
\hline CHEMBL355984 & 50848 & 6.3098 & 5.937 & TRN \\
\hline CHEMBL148992 & 50848 & 7.0706 & 7.2719 & TRN \\
\hline CHEMBL147243 & 50848 & 4.4559 & 4.967 & TRN \\
\hline CHEMBL356331 & 50848 & 4.4318 & 4.659 & TRN \\
\hline CHEMBL435633 & 50848 & 6.9208 & 7.1229 & TRN \\
\hline CHEMBL149931 & 50848 & 6.585 & 6.5288 & TRN \\
\hline CHEMBL148994 & 50848 & 6.3188 & 5.6178 & TST \\
\hline CHEMBL356700 & 50848 & 7.0177 & 8.0479 & TST \\
\hline CHEMBL151546 & 50848 & 7.8861 & 7.9587 & TRN \\
\hline CHEMBL342276 & 50848 & 6.6198 & 7.1289 & TST \\
\hline
\end{tabular}




\begin{tabular}{|c|c|c|c|c|c|}
\hline \multirow[b]{2}{*}{ CHEMBL151161 } & \multirow{2}{*}{50848} & \multicolumn{4}{|c|}{ ICILA } \\
\hline & & 6.7959 & 6.6198 & TRN & \\
\hline CHEMBL359295 & 50848 & 4.4559 & 4.4176 & TRN & \\
\hline CHEMBL150859 & 50848 & 7.2147 & 7.3897 & TST & \\
\hline CHEMBL149834 & 50848 & 7.8539 & 7.6973 & TRN & \\
\hline CHEMBL148804 & 50848 & 6.8861 & 7.0935 & TST & \\
\hline CHEMBL359200 & 50848 & 7.6778 & 7.1785 & TST & \\
\hline CHEMBL150272 & 50848 & 5.8239 & 5.4492 & TRN & \\
\hline CHEMBL356392 & 50848 & 7.2596 & 7.3368 & TST & \\
\hline CHEMBL149675 & 50848 & 4.585 & 6.2573 & TST & \\
\hline CHEMBL346831 & 50848 & 7.1192 & 7.1571 & TRN & \\
\hline CHEMBL359180 & 50848 & 6.5528 & 6.6407 & TRN & \\
\hline CHEMBL356728 & 50848 & 7.585 & 7.8492 & TST & \\
\hline CHEMBL150867 & 50848 & 8.0458 & 7.8225 & TRN & \\
\hline CHEMBL148977 & 50848 & 7.0757 & 6.8799 & TRN & \\
\hline CHEMBL149450 & 50848 & 7.585 & 7.2474 & TST & \\
\hline CHEMBL148699 & 50848 & 6.5376 & 6.4557 & TRN & \\
\hline CHEMBL148723 & 50848 & 4.7696 & 6.5587 & TST & \\
\hline CHEMBL347981 & 50848 & 6.4949 & 6.6943 & TRN & \\
\hline CHEMBL149168 & 50848 & 6.0458 & 6.2618 & TRN & \\
\hline CHEMBL148638 & 50848 & 7.9586 & 8.1349 & TRN & \\
\hline CHEMBL149015 & 50848 & 7.4318 & 7.2947 & TRN & \\
\hline CHEMBL357260 & 50848 & 6.0757 & 5.8908 & TRN & \\
\hline CHEMBL147111 & 50848 & 6.2757 & $6.08200 t$ & 0000000001 & TRN \\
\hline CHEMBL342275 & 50848 & 7.4437 & 7.4428 & TRN & \\
\hline CHEMBL 358525 & 50848 & 7.585 & 7.8132 & TRN & \\
\hline CHEMBL149096 & 50848 & 7.8861 & 7.7692 & TST & \\
\hline CHEMBL147122 & 50848 & 6.4318 & 6.21299 & 9999999999 & TRN \\
\hline CHEMBL149261 & 50848 & 6.0088 & 6.1614 & TRN & \\
\hline CHEMBL358922 & 50848 & 7.5376 & 7.6114 & TRN & \\
\hline CHEMBL436466 & 50848 & 6.1135 & 6.3236 & TRN & \\
\hline CHEMBL151991 & 50848 & 4.9586 & 5.5171 & TRN & \\
\hline CHEMBL13673 & 54735 & 10.18 & 10.1977 & TRN & \\
\hline CHEMBL31713 & 54735 & 10.54 & 10.4212 & TRN & \\
\hline CHEMBL31487 & 54735 & 6.89 & 6.7005 & TST & \\
\hline CHEMBL6742 & 54735 & 4.51 & 4.6839 & TRN & \\
\hline CHEMBL14201 & 54735 & 8.59 & 9.1507 & TRN & \\
\hline CHEMBL 30938 & 54735 & 9.31 & 6.9294 & TST & \\
\hline CHEMBL416177 & 54735 & 6.48 & 6.50799 & 9999999999 & TRN \\
\hline CHEMBL268414 & 54735 & 5.58 & 4.9796 & TRN & \\
\hline CHEMBL19772 & 54735 & 6.23 & 6.6611 & TRN & \\
\hline CHEMBL19293 & 54735 & 6.82 & 6.8046 & TRN & \\
\hline CHEMBL 20911 & 54735 & 3.48 & 5.5771 & TST & \\
\hline CHEMBL6948 & 54735 & 5.69 & 6.1071 & TST & \\
\hline CHEMBL19383 & 54735 & 6.78 & 6.3686 & TRN & \\
\hline CHEMBL 31402 & 54735 & 7.22 & 7.5448 & TRN & \\
\hline CHEMBL418347 & 54735 & 10.46 & 10.0134 & TRN & \\
\hline CHEMBL418769 & 54735 & 7.69 & 7.4388 & TRN & \\
\hline CHEMBL30937 & 54735 & 5.6 & 6.023 & TRN & \\
\hline & & & & ge 348 & \\
\hline
\end{tabular}




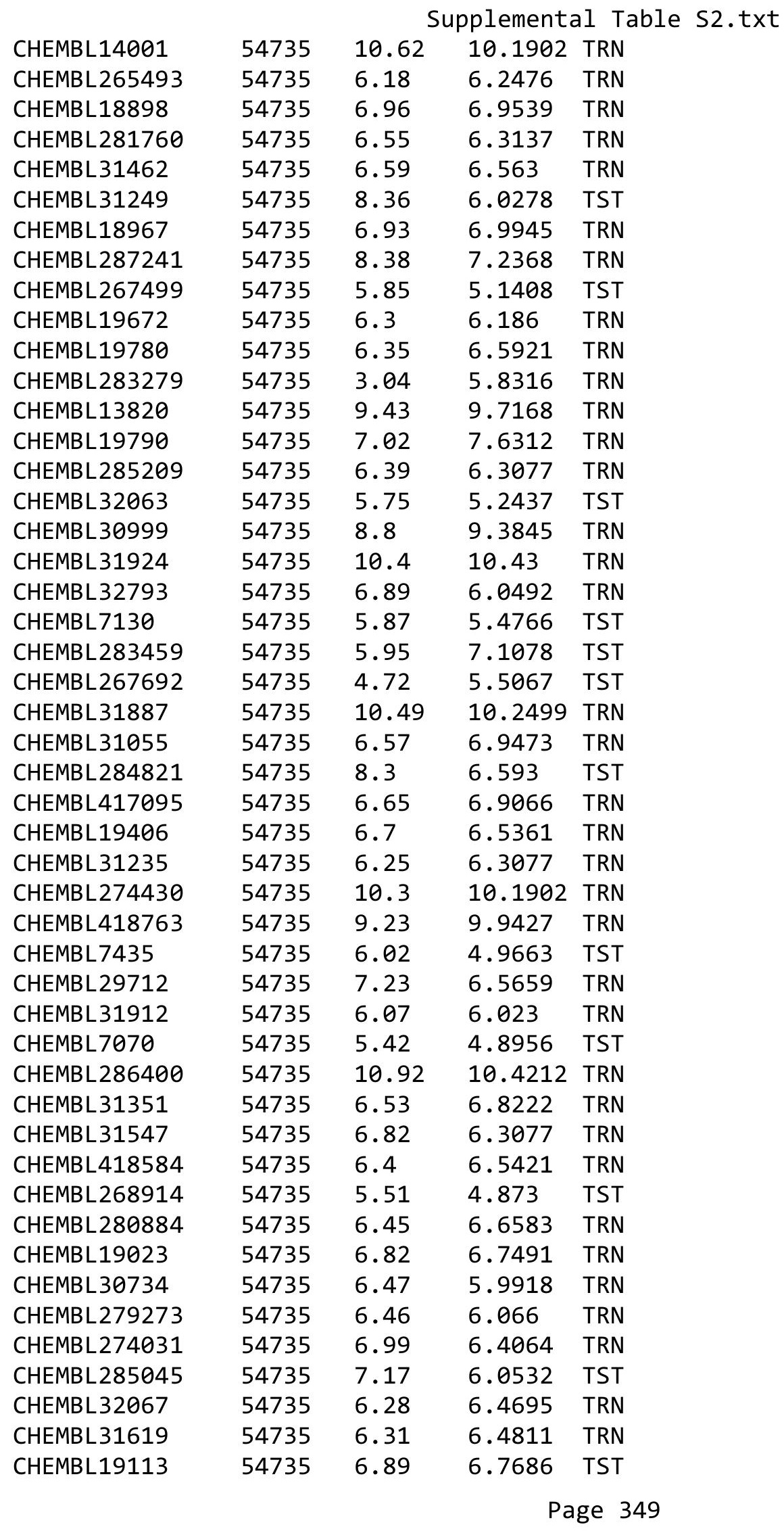




\begin{tabular}{|c|c|c|c|c|c|}
\hline \multicolumn{6}{|c|}{ Supplemental Table S2.txt } \\
\hline CHEMBL31946 & 54735 & 6.82 & 6.2609 & TRN & \\
\hline CHEMBL 7357 & 54735 & 5.31 & 5.3074 & TST & \\
\hline CHEMBL175066 & 64007 & 4.5229 & 4.0168 & TRN & \\
\hline CHEMBL177195 & 64007 & 3.0 & 3.8224 & TRN & \\
\hline CHEMBL174818 & 64007 & 3.0458 & 3.7889 & TRN & \\
\hline CHEMBL366391 & 64007 & 3.0 & 3.9797 & TRN & \\
\hline CHEMBL441112 & 64007 & 3.0 & 3.7622 & TRN & \\
\hline CHEMBL367551 & 64007 & 4.4559 & 3.8862 & TRN & \\
\hline CHEMBL369874 & 64007 & 3.0 & 3.9449 & TRN & \\
\hline CHEMBL366544 & 64007 & 4.8861 & 4.0259 & TRN & \\
\hline CHEMBL368360 & 64007 & 4.1805 & 3.909 & TST & \\
\hline CHEMBL179138 & 64007 & 4.3768 & 3.9437 & TRN & \\
\hline CHEMBL366387 & 64007 & 3.0 & 3.1522 & TST & \\
\hline CHEMBL368255 & 64007 & 3.0 & 3.8668 & TRN & \\
\hline CHEMBL415762 & 64007 & 3.0 & 2.9023 & TRN & \\
\hline CHEMBL175924 & 64007 & 3.0 & 2.8956 & TRN & \\
\hline CHEMBL175277 & 64007 & 4.7212 & 3.9552 & TRN & \\
\hline CHEMBL426589 & 64007 & 3.0 & 3.0556 & TRN & \\
\hline CHEMBL368847 & 64007 & 4.1249 & 3.7622 & TRN & \\
\hline CHEMBL174658 & 64007 & 3.0 & 3.6395 & TRN & \\
\hline CHEMBL177602 & 64007 & 3.0 & 2.9187 & TRN & \\
\hline CHEMBL445076 & 64007 & 3.0 & 3.9463 & TRN & \\
\hline CHEMBL177502 & 64007 & 3.0 & 2.99399 & 99999999998 & TST \\
\hline CHEMBL368461 & 64007 & 5.6198 & 4.1519 & TRN & \\
\hline CHEMBL176152 & 64007 & 3.0 & 3.0422 & TRN & \\
\hline CHEMBL177023 & 64007 & 3.0 & 3.7797 & TRN & \\
\hline CHEMBL368853 & 64007 & 4.2596 & 4.0863 & TRN & \\
\hline CHEMBL173833 & 64007 & 3.0 & 3.5516 & TRN & \\
\hline CHEMBL368286 & 64007 & 4.6576 & 4.0623 & TRN & \\
\hline CHEMBL174448 & 64007 & 4.4685 & 3.9437 & TRN & \\
\hline CHEMBL177261 & 64007 & 4.585 & 3.9589 & TRN & \\
\hline CHEMBL174635 & 64007 & 3.0 & 3.725 & TRN & \\
\hline CHEMBL176513 & 64007 & 4.0044 & 3.81100 & 00000000004 & TRN \\
\hline CHEMBL172178 & 64007 & 4.0177 & 3.1397 & TST & \\
\hline CHEMBL177431 & 64007 & 4.9208 & 3.9698 & TRN & \\
\hline CHEMBL176093 & 64007 & 3.0 & 2.8941 & TRN & \\
\hline CHEMBL367313 & 64007 & 3.0 & 2.9201 & TRN & \\
\hline CHEMBL369202 & 64007 & 4.1739 & 3.989 & TRN & \\
\hline CHEMBL176430 & 64007 & 3.0 & 3.2875 & TST & \\
\hline CHEMBL176913 & 64007 & 3.0 & 3.8381 & TRN & \\
\hline CHEMBL368788 & 64007 & 3.0 & 3.2933 & TST & \\
\hline CHEMBL174171 & 64007 & 4.0969 & 4.0041 & TRN & \\
\hline CHEMBL369386 & 64007 & 4.1805 & 3.9812 & TRN & \\
\hline CHEMBL428298 & 64007 & 4.3665 & 2.9629 & TRN & \\
\hline CHEMBL435901 & 64007 & 4.3188 & 3.875 & TRN & \\
\hline CHEMBL435156 & 64007 & 3.0 & 2.9497 & TST & \\
\hline CHEMBL176794 & 64007 & 3.0 & 3.2188 & TRN & \\
\hline CHEMBL176514 & 64007 & 4.4685 & 3.9544 & TST & \\
\hline
\end{tabular}




\begin{tabular}{|c|c|c|c|c|c|}
\hline \multicolumn{6}{|c|}{ Supplemental Table S2.txt } \\
\hline CHEMBL173826 & 64007 & 3.0 & 3.9072 & TRN & \\
\hline CHEMBL367208 & 64007 & 4.4318 & 4.1502 & TST & \\
\hline CHEMBL368641 & 64007 & 4.2518 & 3.8188 & TST & \\
\hline CHEMBL174686 & 64007 & 4.2596 & 3.7276 & TST & \\
\hline CHEMBL176565 & 64007 & 4.1871 & 2.9268 & TST & \\
\hline CHEMBL171855 & 64007 & 3.0 & 3.0687 & TST & \\
\hline CHEMBL521938 & 688502 & 3.2218 & 3.1997 & TRN & \\
\hline CHEMBL490783 & 688502 & 3.301 & 3.1109 & TRN & \\
\hline CHEMBL519955 & 688502 & 3.301 & 3.5552 & TRN & \\
\hline CHEMBL494068 & 688502 & 4.0 & 4.0412 & TRN & \\
\hline CHEMBL209511 & 688502 & 3.2218 & 3.3592 & TRN & \\
\hline CHEMBL491499 & 688502 & 3.5229 & 3.7597 & TST & \\
\hline CHEMBL1515444 & 688502 & 3.2218 & 3.0705 & TRN & \\
\hline CHEMBL578512 & 688502 & 6.727 & 3.8508 & TST & \\
\hline CHEMBL489372 & 688502 & 3.2218 & 2.958 & TRN & \\
\hline CHEMBL490602 & 688502 & 3.2218 & 2.99899 & 99999999997 & TRN \\
\hline CHEMBL489772 & 688502 & 3.2218 & 3.3756 & TRN & \\
\hline CHEMBL1583199 & 688502 & 3.5229 & 3.8668 & TST & \\
\hline CHEMBL1551669 & 688502 & 3.2218 & 3.1222 & TRN & \\
\hline CHEMBL134009 & 688502 & 3.301 & 3.7678 & TRN & \\
\hline CHEMBL482264 & 688502 & 4.0 & 4.0791 & TRN & \\
\hline CHEMBL1396145 & 688502 & 3.301 & 4.0745 & TRN & \\
\hline CHEMBL489566 & 688502 & 3.2218 & 3.2955 & TRN & \\
\hline CHEMBL555689 & 688502 & 6.727 & 3.7169 & TST & \\
\hline CHEMBL1404609 & 688502 & 3.2218 & 3.3834 & TRN & \\
\hline CHEMBL482131 & 688502 & 4.0 & 3.5584 & TRN & \\
\hline CHEMBL1412717 & 688502 & 3.2218 & 3.2567 & TRN & \\
\hline CHEMBL1474345 & 688502 & 3.301 & 3.5205 & TRN & \\
\hline CHEMBL489970 & 688502 & 3.2218 & 3.2947 & TRN & \\
\hline CHEMBL482117 & 688502 & 3.301 & 3.7397 & TRN & \\
\hline CHEMBL478891 & 688502 & 3.301 & 3.1246 & TRN & \\
\hline CHEMBL1317679 & 688502 & 4.0 & 3.9611 & TRN & \\
\hline CHEMBL1759 & 688502 & 3.301 & 4.0521 & TRN & \\
\hline CHEMBL1396038 & 688502 & 3.2218 & 3.1655 & TRN & \\
\hline CHEMBL490596 & 688502 & 3.2218 & 2.9197 & TRN & \\
\hline CHEMBL210638 & 688502 & 4.2927 & 3.6057 & TRN & \\
\hline CHEMBL521966 & 688502 & 3.2218 & 3.1631 & TRN & \\
\hline CHEMBL489971 & 688502 & 3.2218 & 3.2287 & TRN & \\
\hline CHEMBL489767 & 688502 & 3.301 & 3.2526 & TRN & \\
\hline CHEMBL1396244 & 688502 & 3.301 & 3.5922 & TRN & \\
\hline CHEMBL482130 & 688502 & 3.301 & 3.6522 & TRN & \\
\hline CHEMBL1627149 & 688502 & 3.2218 & 3.2357 & TRN & \\
\hline CHEMBL1436129 & 688502 & 4.0 & 3.8413 & TRN & \\
\hline CHEMBL480967 & 688502 & 4.0 & 3.815 & TRN & \\
\hline CHEMBL493021 & 688502 & 4.0 & 4.189 & TRN & \\
\hline CHEMBL1489106 & 688502 & 3.301 & 3.8122 & TRN & \\
\hline CHEMBL495285 & 688502 & 4.0 & 4.0793 & TRN & \\
\hline CHEMBL1356549 & 688502 & 4.2811 & 3.5791 & TRN & \\
\hline
\end{tabular}




\begin{tabular}{|c|c|c|c|c|c|}
\hline \multicolumn{6}{|c|}{ Supplemental Table S2.txt } \\
\hline CHEMBL1306960 & 688502 & 5.5025 & 3.6505 & TST & \\
\hline CHEMBL1412538 & 688502 & 3.5229 & 3.6146 & TRN & \\
\hline CHEMBL1515699 & 688502 & 3.2218 & 3.2998 & TRN & \\
\hline CHEMBL1436777 & 688502 & 4.0 & 4.2922 & TRN & \\
\hline CHEMBL1502839 & 688502 & 3.5229 & 3.6062 & TST & \\
\hline CHEMBL1357064 & 688502 & 3.301 & 3.7101 & TRN & \\
\hline CHEMBL494825 & 688502 & 4.0 & 4.1209 & TRN & \\
\hline CHEMBL1473002 & 688502 & 3.2218 & 3.4961 & TRN & \\
\hline CHEMBL1590250 & 688502 & 7.2041 & 4.3969 & TRN & \\
\hline CHEMBL480978 & 688502 & 3.301 & 3.758 & TRN & \\
\hline CHEMBL480976 & 688502 & 3.301 & 3.7642 & TRN & \\
\hline CHEMBL1526851 & 688502 & 3.5229 & 3.9441 & TST & \\
\hline CHEMBL1559511 & 688502 & 3.2218 & 3.1593 & TRN & \\
\hline CHEMBL522110 & 688502 & 3.2218 & 2.9519 & TRN & \\
\hline CHEMBL1488313 & 688502 & 4.7932 & 3.898 & TRN & \\
\hline CHEMBL1495074 & 688502 & 3.301 & 3.9064 & TRN & \\
\hline CHEMBL52 & 688502 & 3.5229 & 3.8073 & TST & \\
\hline CHEMBL1474167 & 688502 & 3.301 & 3.5305 & TRN & \\
\hline CHEMBL1379677 & 688502 & 3.5229 & 3.5163 & TST & \\
\hline CHEMBL1313900 & 688502 & 3.5229 & 3.667 & TST & \\
\hline CHEMBL476574 & 688502 & 3.2218 & 3.26899 & 99999999997 & TRN \\
\hline CHEMBL1515318 & 688502 & 4.4705 & 3.9494 & TRN & \\
\hline CHEMBL 242108 & 688502 & 4.0 & 4.19300 & 00000000005 & TRN \\
\hline CHEMBL1435236 & 688502 & 3.301 & 3.5612 & TST & \\
\hline CHEMBL1627148 & 688502 & 3.2218 & 3.2989 & TST & \\
\hline CHEMBL1627152 & 688502 & 3.2218 & 3.383 & TST & \\
\hline CHEMBL1488035 & 688502 & 5.564 & 3.6823 & TST & \\
\hline CHEMBL1603087 & 688502 & 3.301 & 3.8265 & TST & \\
\hline CHEMBL480977 & 688502 & 3.301 & 3.83399 & 99999999996 & TST \\
\hline CHEMBL1473197 & 688502 & 3.2218 & 3.9501 & TST & \\
\hline CHEMBL1534307 & 688502 & 4.3165 & 3.2483 & TST & \\
\hline CHEMBL491808 & 688502 & 3.2218 & 3.2201 & TST & \\
\hline CHEMBL 3695251 & 1640307 & 5.8861 & 5.74799 & 9999999999 & TRN \\
\hline CHEMBL3698904 & 1640307 & 6.4023 & 5.9704 & TRN & \\
\hline CHEMBL3698774 & 1640307 & 5.7172 & 5.8785 & TRN & \\
\hline CHEMBL3698825 & 1640307 & 6.3904 & 6.0332 & TRN & \\
\hline CHEMBL3698834 & 1640307 & 5.6876 & 5.7081 & TRN & \\
\hline CHEMBL 3647960 & 1640307 & 5.7959 & 5.9704 & TRN & \\
\hline CHEMBL3695260 & 1640307 & 5.5176 & 6.01 & TRN & \\
\hline CHEMBL3695276 & 1640307 & 5.7291 & 5.37200 & 0000000001 & TRN \\
\hline CHEMBL 3695240 & 1640307 & 6.4078 & 6.0625 & TRN & \\
\hline CHEMBL3698877 & 1640307 & 6.3188 & 6.3572 & TRN & \\
\hline CHEMBL 3698751 & 1640307 & 5.2962 & 5.4287 & TRN & \\
\hline CHEMBL3698841 & 1640307 & 5.8297 & 5.9411 & TRN & \\
\hline CHEMBL3695279 & 1640307 & 5.3995 & 5.5499 & TRN & \\
\hline CHEMBL 3695266 & 1640307 & 5.7224 & 5.724 & TRN & \\
\hline CHEMBL3698845 & 1640307 & 5.5007 & 5.6476 & TRN & \\
\hline CHEMBL3647961 & 1640307 & 5.73 & 5.4404 & TST & \\
\hline
\end{tabular}


Supplemental Table S2.txt

\begin{tabular}{|c|c|c|c|c|}
\hline CHEMBL 3889570 & 1640307 & 4.7891 & 4.5598 & TRN \\
\hline CHEMBL 3698772 & 1640307 & 5.5549 & 5.6749 & TRN \\
\hline CHEMBL 3695235 & 1640307 & 6.6778 & 6.3978 & TST \\
\hline CHEMBL 3698864 & 1640307 & 5.284 & 5.3823 & TRN \\
\hline CHEMBL 3698876 & 1640307 & 4.9229 & 5.3848 & TST \\
\hline CHEMBL3698764 & 1640307 & 6.6055 & 6.211 & TST \\
\hline CHEMBL 3698858 & 1640307 & 6.7077 & 6.2858 & TRN \\
\hline CHEMBL 3698752 & 1640307 & 5.8665 & 5.3834 & TRN \\
\hline CHEMBL3695238 & 1640307 & 5.5686 & 6.2769 & TST \\
\hline CHEMBL 3698895 & 1640307 & 4.7718 & 5.4816 & TRN \\
\hline CHEMBL 3695272 & 1640307 & 5.8383 & 5.8452 & TRN \\
\hline CHEMBL3698861 & 1640307 & 5.9431 & 6.1322 & TRN \\
\hline CHEMBL 3698868 & 1640307 & 5.7959 & 5.8782 & TRN \\
\hline CHEMBL3698862 & 1640307 & 5.5969 & 5.5107 & TRN \\
\hline CHEMBL 3698816 & 1640307 & 6.3536 & 6.8856 & TRN \\
\hline CHEMBL3698902 & 1640307 & 6.1494 & 5.9704 & TRN \\
\hline CHEMBL210665 & 1640307 & 4.8706 & 5.4402 & TST \\
\hline CHEMBL 3698817 & 1640307 & 6.3125 & 6.6397 & TRN \\
\hline CHEMBL3695249 & 1640307 & 5.9654 & 5.2099 & TRN \\
\hline CHEMBL 3698856 & 1640307 & 5.3884 & 5.8137 & TST \\
\hline CHEMBL 3695253 & 1640307 & 6.1409 & 5.4528 & TRN \\
\hline CHEMBL3695229 & 1640307 & 5.6003 & 5.6603 & TRN \\
\hline CHEMBL 3698851 & 1640307 & 6.0 & 5.8185 & TRN \\
\hline CHEMBL 3898898 & 1640307 & 6.3747 & 5.5148 & TST \\
\hline CHEMBL 3695281 & 1640307 & 5.6256 & 5.1342 & TRN \\
\hline CHEMBL 3698794 & 1640307 & 6.58 & 6.3134 & TRN \\
\hline CHEMBL 3698889 & 1640307 & 5.5751 & 5.3909 & TST \\
\hline CHEMBL 3695254 & 1640307 & 6.191 & 6.0868 & TST \\
\hline CHEMBL3698786 & 1640307 & 6.1512 & 5.9279 & TRN \\
\hline CHEMBL 3698873 & 1640307 & 5.3279 & 5.8458 & TRN \\
\hline CHEMBL 3698776 & 1640307 & 5.7791 & 5.7453 & TST \\
\hline CHEMBL 3698869 & 1640307 & 5.6478 & 5.7767 & TRN \\
\hline CHEMBL3698836 & 1640307 & 5.3625 & 6.0911 & TRN \\
\hline CHEMBL3698801 & 1640307 & 5.7293 & 5.2795 & TST \\
\hline CHEMBL 3698890 & 1640307 & 4.8447 & 4.7045 & TRN \\
\hline CHEMBL3698899 & 1640307 & 5.6861 & 5.8018 & TRN \\
\hline CHEMBL 3698763 & 1640307 & 6.0 & 5.7652 & TRN \\
\hline CHEMBL3698765 & 1640307 & 6.1688 & 5.9704 & TRN \\
\hline CHEMBL 3698844 & 1640307 & 5.4844 & 5.5957 & TRN \\
\hline CHEMBL 3698837 & 1640307 & 5.9412 & 5.7614 & TRN \\
\hline CHEMBL 3939135 & 1640307 & 6.1469 & 5.4657 & TRN \\
\hline CHEMBL 3695244 & 1640307 & 6.3354 & 6.2075 & TRN \\
\hline CHEMBL 3698842 & 1640307 & 5.8153 & 5.6198 & TRN \\
\hline CHEMBL 3695234 & 1640307 & 5.4776 & 5.2839 & TST \\
\hline CHEMBL 3944932 & 1640307 & 5.8173 & 5.7263 & TRN \\
\hline CHEMBL 3695228 & 1640307 & 4.8919 & 5.3408 & TRN \\
\hline CHEMBL 3909917 & 1640307 & 4.9923 & 4.9469 & TST \\
\hline CHEMBL3930169 & 1640307 & 4.4293 & 5.432 & TRN \\
\hline
\end{tabular}


Supplemental Table S2.txt

\begin{tabular}{|c|c|c|c|c|c|}
\hline CHEMBL3698819 & 1640307 & 6.1778 & 6.0145 & TRN & \\
\hline CHEMBL3698872 & 1640307 & 5.5349 & 5.3187 & TRN & \\
\hline CHEMBL3698795 & 1640307 & 6.3449 & 6.6418 & TRN & \\
\hline CHEMBL 3698848 & 1640307 & 5.6824 & 5.7381 & TRN & \\
\hline CHEMBL 3698793 & 1640307 & 6.3979 & 6.7129 & TRN & \\
\hline CHEMBL 3698865 & 1640307 & 4.9626 & 5.2977 & TRN & \\
\hline CHEMBL3695262 & 1640307 & 6.2013 & 5.71700 & 00000000005 & TRN \\
\hline CHEMBL 3698790 & 1640307 & 7.2204 & 6.1665 & TRN & \\
\hline CHEMBL 3698854 & 1640307 & 6.0521 & 6.0715 & TRN & \\
\hline CHEMBL 3698884 & 1640307 & 6.3382 & 6.1569 & TRN & \\
\hline CHEMBL 3698769 & 1640307 & 5.7637 & 5.7886 & TRN & \\
\hline CHEMBL 3698843 & 1640307 & 5.6214 & 5.7242 & TRN & \\
\hline CHEMBL 3698823 & 1640307 & 5.2604 & 4.8974 & TST & \\
\hline CHEMBL3698809 & 1640307 & 5.4115 & 5.6677 & TRN & \\
\hline CHEMBL 3698850 & 1640307 & 5.2773 & 5.496 & TRN & \\
\hline CHEMBL3698814 & 1640307 & 5.4827 & 6.0332 & TRN & \\
\hline CHEMBL 3695257 & 1640307 & 5.6358 & 5.6254 & TRN & \\
\hline CHEMBL 3698866 & 1640307 & 5.0506 & 5.4887 & TRN & \\
\hline CHEMBL 3698768 & 1640307 & 5.9069 & 5.7505 & TRN & \\
\hline CHEMBL 3647963 & 1640307 & 5.8428 & 5.9704 & TRN & \\
\hline CHEMBL3698770 & 1640307 & 5.5643 & 5.6825 & TRN & \\
\hline CHEMBL3698791 & 1640307 & 6.1057 & 6.4984 & TRN & \\
\hline CHEMBL 3698785 & 1640307 & 5.9147 & 5.9571 & TRN & \\
\hline CHEMBL3695277 & 1640307 & 6.0921 & 5.5351 & TRN & \\
\hline CHEMBL 3698907 & 1640307 & 6.5127 & 6.6534 & TRN & \\
\hline CHEMBL3639941 & 1640307 & 5.4949 & 5.2594 & TRN & \\
\hline CHEMBL 3698874 & 1640307 & 5.5518 & 5.4185 & TRN & \\
\hline CHEMBL 3695220 & 1640307 & 6.1135 & 5.6787 & TRN & \\
\hline CHEMBL3695261 & 1640307 & 5.4043 & 5.4211 & TRN & \\
\hline CHEMBL 3698821 & 1640307 & 6.1618 & 5.9532 & TRN & \\
\hline CHEMBL 3698863 & 1640307 & 5.4067 & 5.4401 & TRN & \\
\hline CHEMBL3695219 & 1640307 & 5.7773 & 5.7873 & TRN & \\
\hline CHEMBL3698852 & 1640307 & 5.6002 & 6.0172 & TRN & \\
\hline CHEMBL3695236 & 1640307 & 6.129 & 6.1886 & TRN & \\
\hline CHEMBL3695265 & 1640307 & 5.4225 & 5.5833 & TRN & \\
\hline CHEMBL3698781 & 1640307 & 5.2541 & 5.4392 & TRN & \\
\hline CHEMBL3698853 & 1640307 & 5.1292 & 5.3653 & TRN & \\
\hline CHEMBL 3698867 & 1640307 & 3.699 & \multicolumn{2}{|c|}{5.1160000000000005} & TRN \\
\hline CHEMBL3698896 & 1640307 & 5.8401 & 5.8091 & TST & \\
\hline CHEMBL3698879 & 1640307 & 5.2757 & 5.3907 & TRN & \\
\hline CHEMBL3695268 & 1640307 & 5.1936 & 5.2312 & TRN & \\
\hline CHEMBL3695252 & 1640307 & 6.4237 & 6.1085 & TRN & \\
\hline CHEMBL3695224 & 1640307 & 5.9311 & 5.4929 & TRN & \\
\hline CHEMBL3698796 & 1640307 & 5.7467 & 6.0082 & TRN & \\
\hline CHEMBL3698903 & 1640307 & 5.9876 & 5.7769 & TRN & \\
\hline CHEMBL3698900 & 1640307 & 6.1555 & 5.8018 & TRN & \\
\hline CHEMBL3695270 & 1640307 & 6.2027 & 6.025 & TST & \\
\hline CHEMBL3698778 & 1640307 & 6.0 & 5.8874 & TRN & \\
\hline
\end{tabular}


Supplemental Table S2.txt

\begin{tabular}{|c|c|c|c|c|c|c|}
\hline CHEMBL 3698894 & 1640307 & 4.2381 & 4.5493 & TRN & & \\
\hline CHEMBL 3695267 & 1640307 & 5.8274 & 5.9761 & TRN & & \\
\hline CHEMBL 3695217 & 1640307 & 6.0 & 5.9307 & TRN & & \\
\hline CHEMBL 3985983 & 1640307 & 5.2803 & 5.4581 & TRN & & \\
\hline CHEMBL 3698878 & 1640307 & 6.1681 & 5.8018 & TRN & & \\
\hline CHEMBL3695255 & 1640307 & 5.7011 & 5.5515 & TRN & & \\
\hline CHEMBL 3698839 & 1640307 & 5.7867 & 5.8577 & TRN & & \\
\hline CHEMBL 3695286 & 1640307 & 5.4489 & 5.5572 & TRN & & \\
\hline CHEMBL 3695243 & 1640307 & 6.3116 & 5.7725 & TST & & \\
\hline CHEMBL 3695278 & 1640307 & 6.2899 & 5.9191 & TRN & & \\
\hline CHEMBL 3698846 & 1640307 & 5.9212 & 5.9233 & TRN & & \\
\hline CHEMBL 3698759 & 1640307 & 5.0323 & 4.8313 & TST & & \\
\hline CHEMBL 3695259 & 1640307 & 5.46899 & 999999999 & 99 & 5.6469 & TRN \\
\hline CHEMBL 3698826 & 1640307 & 4.8424 & 5.4225 & TRN & & \\
\hline CHEMBL 3698820 & 1640307 & 6.4012 & 6.1033 & TRN & & \\
\hline CHEMBL 3695283 & 1640307 & 5.8713 & 5.3181 & TRN & & \\
\hline CHEMBL 3695284 & 1640307 & 6.1979 & 5.8013 & TRN & & \\
\hline CHEMBL 3698838 & 1640307 & 5.96899 & 999999999 & 99 & 5.7024 & TRN \\
\hline CHEMBL 3698901 & 1640307 & 5.4648 & 5.74 & TRN & & \\
\hline CHEMBL 3698788 & 1640307 & 5.8362 & 5.9089 & TRN & & \\
\hline CHEMBL 3698882 & 1640307 & 4.3371 & 4.9998 & TRN & & \\
\hline CHEMBL 3698847 & 1640307 & 5.2795 & 5.445 & TRN & & \\
\hline CHEMBL 3698906 & 1640307 & 6.4342 & 6.4673 & TRN & & \\
\hline CHEMBL 3698799 & 1640307 & 5.7144 & 6.002000 & 0000000001 & & TI \\
\hline CHEMBL 3698789 & 1640307 & 5.8617 & 5.9176 & TRN & & \\
\hline CHEMBL 3695245 & 1640307 & 6.0 & 5.519 & TST & & \\
\hline CHEMBL 3698840 & 1640307 & 5.8548 & 5.7177 & TRN & & \\
\hline CHEMBL 3698857 & 1640307 & 5.1702 & 5.8958 & TST & & \\
\hline CHEMBL 3698771 & 1640307 & 6.06 & 6.0597 & TST & & \\
\hline CHEMBL 3698849 & 1640307 & 4.5747 & 5.0352 & TRN & & \\
\hline CHEMBL 3698760 & 1640307 & 5.4387 & 5.4783 & TRN & & \\
\hline CHEMBL 3695218 & 1640307 & 6.0867 & 6.1771 & TRN & & \\
\hline CHEMBL 3984664 & 1640307 & 6.5346 & 6.7013 & TST & & \\
\hline CHEMBL 3695263 & 1640307 & 5.61299 & 999999999 & 995 & 5.4762 & TRN \\
\hline CHEMBL 3698828 & 1640307 & 5.7547 & 5.8825 & TRN & & \\
\hline CHEMBL 3695269 & 1640307 & 5.4761 & 5.3495 & TRN & & \\
\hline CHEMBL 3698827 & 1640307 & 6.1739 & 6.0053 & TST & & \\
\hline CHEMBL 3698787 & 1640307 & 5.3546 & 5.4534 & TRN & & \\
\hline CHEMBL 3698773 & 1640307 & 5.6688 & 5.7014 & TRN & & \\
\hline CHEMBL 3698753 & 1640307 & 6.2807 & 5.789 & TRN & & \\
\hline CHEMBL 3698755 & 1640307 & 5.1767 & 5.5203 & TRN & & \\
\hline CHEMBL 3695242 & 1640307 & 6.7258 & 5.7769 & TRN & & \\
\hline CHEMBL 3900892 & 1640307 & 6.0 & 5.7957 & TRN & & \\
\hline CHEMBL 3695237 & 1640307 & 6.0 & 5.9475 & TRN & & \\
\hline CHEMBL 3695221 & 1640307 & 6.2291 & 6.3891 & TST & & \\
\hline CHEMBL 3698813 & 1640307 & 3.699 & 4.9495 & TST & & \\
\hline CHEMBL 3695256 & 1640307 & 5.2147 & 5.4218 & TST & & \\
\hline CHEMBL 3698762 & 1640307 & 5.482 & 5.4567 & TST & & \\
\hline
\end{tabular}


Supplemental Table S2.txt

\begin{tabular}{|c|c|c|c|c|c|}
\hline CHEMBL3698798 & 1640307 & 5.9355 & 5.8228 & TST & \\
\hline CHEMBL3698756 & 1640307 & 5.3554 & 5.6867 & TST & \\
\hline CHEMBL3698870 & 1640307 & 5.8327 & 5.4854 & TST & \\
\hline CHEMBL3647959 & 1640307 & 6.0 & 5.3879 & TST & \\
\hline CHEMBL3695280 & 1640307 & 5.8496 & 5.3957 & TST & \\
\hline CHEMBL3695273 & 1640307 & 6.0 & 6.018 & TST & \\
\hline CHEMBL3698792 & 1640307 & 6.1135 & 6.2624 & TST & \\
\hline CHEMBL3695216 & 1640307 & 5.4124 & 5.8705 & TST & \\
\hline CHEMBL3698898 & 1640307 & 3.699 & 4.9441 & TST & \\
\hline CHEMBL3698835 & 1640307 & 4.768 & 5.217000 & 30000000005 & TST \\
\hline CHEMBL 3698897 & 1640307 & 5.0493 & 5.7053 & TST & \\
\hline CHEMBL3695222 & 1640307 & 4.9172 & 5.6432 & TST & \\
\hline CHEMBL 3698818 & 1640307 & 6.7959 & 6.5985 & TST & \\
\hline CHEMBL3698804 & 1640307 & 5.5528 & 4.8837 & TST & \\
\hline CHEMBL 3698775 & 1640307 & 5.7181 & 6.0675 & TST & \\
\hline CHEMBL 3698754 & 1640307 & 6.0 & 5.6622 & TST & \\
\hline CHEMBL3647958 & 1640307 & 6.0 & 5.4697 & TST & \\
\hline CHEMBL 3770060 & 1556440 & 8.3188 & 7.3519 & TRN & \\
\hline CHEMBL3771357 & 1556440 & 6.9208 & 7.8468 & TRN & \\
\hline CHEMBL 3770804 & 1556440 & 8.2366 & 7.9652 & TRN & \\
\hline CHEMBL3770585 & 1556440 & 9.3098 & 9.7338 & TRN & \\
\hline CHEMBL3770009 & 1556440 & 6.4089 & 7.4005 & TRN & \\
\hline CHEMBL3771172 & 1556440 & 6.6198 & 7.7851 & TST & \\
\hline CHEMBL3771251 & 1556440 & 5.301 & 8.2757 & TST & \\
\hline CHEMBL 3770947 & 1556440 & 7.5086 & 8.399 & TRN & \\
\hline CHEMBL3770523 & 1556440 & 7.3565 & 6.7569 & TRN & \\
\hline CHEMBL3771211 & 1556440 & 8.0969 & 7.5685 & TST & \\
\hline CHEMBL3771085 & 1556440 & 6.2676 & 7.7537 & TST & \\
\hline CHEMBL3769662 & 1556440 & 8.4815 & 7.7166 & TRN & \\
\hline CHEMBL 3770721 & 1556440 & 6.1739 & 8.7143 & TST & \\
\hline CHEMBL3771255 & 1556440 & 8.6383 & 8.0096 & TRN & \\
\hline CHEMBL3771181 & 1556440 & 5.9586 & 8.1706 & TST & \\
\hline CHEMBL3771241 & 1556440 & 6.1135 & 8.4423 & TST & \\
\hline CHEMBL3770557 & 1556440 & 5.8539 & 8.1942 & TST & \\
\hline CHEMBL3769754 & 1556440 & 8.283999 & 999999999 & 8.2804 & TRN \\
\hline CHEMBL3769875 & 1556440 & 7.6198 & 7.9391 & TRN & \\
\hline CHEMBL 3771202 & 1556440 & 6.6021 & 6.4196 & TRN & \\
\hline CHEMBL3769484 & 1556440 & 8.6576 & 8.2721 & TRN & \\
\hline CHEMBL3769461 & 1556440 & 9.0555 & 8.2916 & TRN & \\
\hline CHEMBL3769932 & 1556440 & 10.1367 & 9.5824 & TRN & \\
\hline CHEMBL3770453 & 1556440 & 7.8239 & 7.7669 & TRN & \\
\hline CHEMBL3770158 & 1556440 & 7.6021 & 7.3874 & TRN & \\
\hline CHEMBL3770977 & 1556440 & 8.1805 & 8.8155 & TRN & \\
\hline CHEMBL3769961 & 1556440 & 10.2076 & 9.5949 & TRN & \\
\hline CHEMBL3769655 & 1556440 & 8.8539 & 9.1812 & TRN & \\
\hline CHEMBL3769843 & 1556440 & 7.5376 & 6.9571 & TRN & \\
\hline CHEMBL 3770529 & 1556440 & 7.8539 & 7.5949 & TRN & \\
\hline CHEMBL3769419 & 1556440 & 8.5229 & 8.4021 & TRN & \\
\hline
\end{tabular}


Supplemental Table S2.txt

\begin{tabular}{|c|c|c|c|c|}
\hline HEMBL3770467 & 556440 & 8.7959 & 8.6521 & TR \\
\hline HEMBL3770107 & 556440 & 8.7212 & 9.0284 & \\
\hline HEMBL3770114 & 40 & 5.5528 & 1026 & \\
\hline HEMBL3770427 & 56440 & 9.3872 & & \\
\hline HEMBL3770311 & 556440 & 7.5229 & 5416 & \\
\hline HEMBL3771311 & 556440 & 8.5686 & 8.4918 & \\
\hline HEMBL3769495 & 556440 & 7.5086 & 8.01 & \\
\hline HEMBL3770286 & 556440 & & & \\
\hline HEMBL3771078 & 556440 & 8.6383 & 8.8481 & \\
\hline HEMBL3770470 & 556440 & 9.0706 & 8.601 & \\
\hline HEMBL 3770350 & 556440 & 7.3768 & 8.0269 & \\
\hline HEMBL37 & 556440 & 7.1871 & 946 & \\
\hline HEMBL37 & 10 & 10.1308 & & \\
\hline HEMBL3769614 & 556440 & 8.8861 & 7.9689 & \\
\hline HEMBL37 & 5564 & 7.5528 & 7. & \\
\hline AEMBL3769474 & 556440 & 8.5528 & 8.1007 & \\
\hline HEMBL3 & 556 & 218 & 7.808 & \\
\hline HEMBL3 & $\theta$ & 007 & 46 & \\
\hline HEMBL37 & 10 & 8.3098 & 8.0049 & \\
\hline HEMBL37 & 556 & 7. & 8 . & ST \\
\hline HEMBL3 & 10 & 7. & 7. & RN \\
\hline HEMBL: & $\theta$ & 59 & 19 & RN \\
\hline HEMBL3 & 10 & 08 & 7. & $\mathrm{RN}$ \\
\hline HEMBL3770641 & 556440 & 376 & 7.7977 & $2 N$ \\
\hline HEMBL3C & 6 & 5 . & 5 . & TRN \\
\hline HEMBL6 & 6 & 38 & 46 & $\Gamma \mathrm{RN}$ \\
\hline HEMBL & 16 & 8 & 26 & RN \\
\hline HEMBL6 & 16 & 2. & 88 & ST \\
\hline HEMBL36 & 16 & 3 & & $\Gamma \mathrm{RN}$ \\
\hline HEMBL7: & 24 & 6 . & 75 & TST \\
\hline HEMBL 6 & 6 & 2 & 87 & TRN \\
\hline HEMBL2 & 6 & & 61 & RN \\
\hline HEMBL 3 & 6 & 4 & 73 & ST \\
\hline HEMBL61624 & 24216 & 3.3585 & 3.4265 & TRN \\
\hline HEMBL63718 & 24216 & 3.0 & 3.1082 & TRN \\
\hline HEMBL6: & 24 & 5 & 5.5819 & $\mathrm{RN}$ \\
\hline CHEMBL3 & 6 & 3 . & 63 & RN \\
\hline HEMBL2 & 16 & & 2.8617 & $\Gamma \mathrm{RN}$ \\
\hline HEMBL304699 & 24216 & 5.284 & 5.0221 & TRN \\
\hline HEMBL6 & 242 & 6.7959 & 6.0352 & TST \\
\hline CHEMBL6 & 224216 & 6.6383 & 7.3597 & TST \\
\hline CHEMBL $2 S$ & 224216 & 5.1308 & 5.1535 & RN \\
\hline CHEMBL62388 & 24216 & 4.7471 & 4.9127 & TRN \\
\hline HEMBL304905 & 24216 & 5.9586 & 5.9856 & $\Gamma R$ \\
\hline LHEMBL6 & 1 & & 5.0827 & \\
\hline CHEMBL 30264 & 224216 & 6.6021 & 6.6955 & \\
\hline CHEMBL60732 & 24216 & 6.699 & 6.1594 & \\
\hline CHEMBL65229 & 224216 & 4.6655 & 4.7494 & 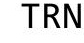 \\
\hline
\end{tabular}




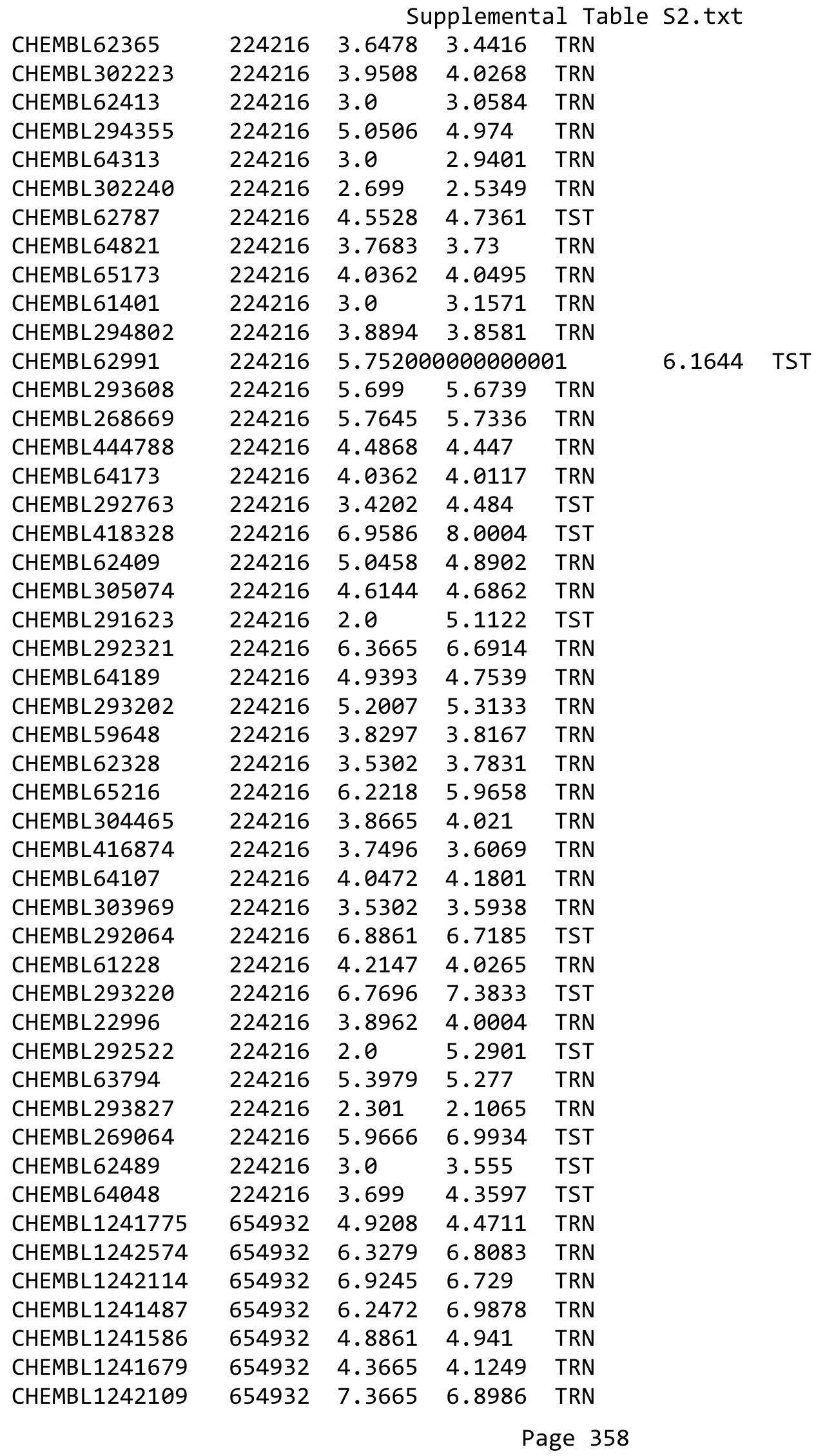




\begin{tabular}{|c|c|c|c|c|}
\hline \multicolumn{5}{|c|}{ Supplemental Table S2.txt } \\
\hline CHEMBL1241771 & 654932 & 4.0 & 4.2718 & TRN \\
\hline CHEMBL1242379 & 654932 & 4.0 & 4.5781 & TRN \\
\hline CHEMBL1241860 & 654932 & 5.9208 & 4.9827 & TRN \\
\hline CHEMBL1241439 & 654932 & 5.9914 & 4.8799 & TST \\
\hline CHEMBL1241862 & 654932 & 4.0 & 4.4646 & TRN \\
\hline CHEMBL1242110 & 654932 & 5.7799 & 6.1417 & TRN \\
\hline CHEMBL1242475 & 654932 & 6.3862 & 6.6632 & TRN \\
\hline CHEMBL1240554 & 654932 & 5.684 & 5.3771 & TRN \\
\hline CHEMBL1240545 & 654932 & 4.9586 & 4.5186 & TRN \\
\hline CHEMBL1241684 & 654932 & 5.7852 & 4.673 & TST \\
\hline CHEMBL1241769 & 654932 & 5.5058 & 5.3699 & TRN \\
\hline CHEMBL1242754 & 654932 & 5.2518 & 5.6301 & TRN \\
\hline CHEMBL1241677 & 654932 & 6.7595 & 6.3554 & TRN \\
\hline CHEMBL1241299 & 654932 & 5.5229 & 6.2158 & TRN \\
\hline CHEMBL1240553 & 654932 & 5.7721 & 5.6299 & TRN \\
\hline CHEMBL1242376 & 654932 & 7.2596 & 7.3977 & TRN \\
\hline CHEMBL1241776 & 654932 & 5.0915 & 5.7132 & TRN \\
\hline CHEMBL1241300 & 654932 & 5.9747 & 5.2624 & TST \\
\hline CHEMBL1242385 & 654932 & 6.7645 & 6.481 & TRN \\
\hline CHEMBL1242476 & 654932 & 5.2007 & 6.1432 & TRN \\
\hline CHEMBL1233882 & 654932 & 6.5086 & 6.0837 & TRN \\
\hline CHEMBL1242285 & 654932 & 7.3565 & 6.8549 & TRN \\
\hline CHEMBL1241945 & 654932 & 5.8153 & 6.7789 & TRN \\
\hline CHEMBL1242295 & 654932 & 8.0458 & 7.4138 & TRN \\
\hline CHEMBL1242660 & 654932 & 4.0 & 4.9614 & TRN \\
\hline CHEMBL1241946 & 654932 & 4.0 & 4.5816 & TRN \\
\hline CHEMBL1241390 & 654932 & 4.0 & 3.9319 & TRN \\
\hline CHEMBL1241683 & 654932 & 6.0177 & 5.3799 & TRN \\
\hline CHEMBL1241676 & 654932 & 8.3665 & 7.8681 & TRN \\
\hline CHEMBL1241773 & 654932 & 4.0 & 4.3132 & TRN \\
\hline CHEMBL1242201 & 654932 & 6.5867 & 7.0789 & TRN \\
\hline CHEMBL1242290 & 654932 & 4.0 & 4.9176 & TRN \\
\hline CHEMBL1242656 & 654932 & 7.1135 & 7.2199 & TRN \\
\hline CHEMBL1241682 & 654932 & 5.9586 & 5.1835 & TRN \\
\hline CHEMBL1241863 & 654932 & 4.0 & 4.5441 & TRN \\
\hline CHEMBL1242469 & 654932 & 5.6716 & 5.4797 & TST \\
\hline CHEMBL1241681 & 654932 & 5.3565 & 5.9625 & TRN \\
\hline CHEMBL1242750 & 654932 & 6.7496 & 6.6558 & TRN \\
\hline CHEMBL1241241 & 654932 & 5.8386 & 6.0602 & TRN \\
\hline CHEMBL1241485 & 654932 & 5.585 & 5.3783 & TRN \\
\hline CHEMBL1242208 & 654932 & 4.7212 & 4.7591 & TRN \\
\hline CHEMBL1242289 & 654932 & 6.9626 & 6.4111 & TRN \\
\hline CHEMBL1242026 & 654932 & 8.0 & 7.2783 & TRN \\
\hline CHEMBL1242203 & 654932 & 5.9393 & 5.4377 & TRN \\
\hline CHEMBL1241482 & 654932 & 4.0 & 4.7483 & TST \\
\hline CHEMBL1241491 & 654932 & 5.9136 & 6.0372 & TRN \\
\hline CHEMBL1242665 & 654932 & 4.0 & 4.132 & TST \\
\hline CHEMBL1242378 & 654932 & 6.0 & 5.9853 & TRN \\
\hline
\end{tabular}




\begin{tabular}{|c|c|c|c|c|c|}
\hline \multicolumn{6}{|c|}{ Supplemental Table S2.txt } \\
\hline CHEMBL1242844 & 654932 & 4.9281 & 4.6411 & TRN & \\
\hline CHEMBL1242286 & 654932 & 5.6946 & 5.581 & TRN & \\
\hline CHEMBL1242025 & 654932 & 4.0 & 4.3851 & TST & \\
\hline CHEMBL1242209 & 654932 & 4.0 & 5.039 & TRN & \\
\hline CHEMBL1242030 & 654932 & 5.2299 & 4.4434 & TRN & \\
\hline CHEMBL1241391 & 654932 & 4.0 & 3.7596 & TRN & \\
\hline CHEMBL1242381 & 654932 & 6.0 & 5.2161 & TST & \\
\hline CHEMBL1242569 & 654932 & 4.0 & 4.1794 & TRN & \\
\hline CHEMBL1242202 & 654932 & 7.2596 & 7.1489 & TRN & \\
\hline CHEMBL1241578 & 654932 & 7.2596 & 7.2434 & TRN & \\
\hline CHEMBL1242119 & 654932 & 4.8539 & 5.1493 & TRN & \\
\hline CHEMBL1242200 & 654932 & 5.9914 & 5.2733 & TRN & \\
\hline CHEMBL1230790 & 654932 & 6.6716 & 6.4259 & TRN & \\
\hline CHEMBL1242752 & 654932 & 4.0 & 4.6089 & TRN & \\
\hline CHEMBL1242566 & 654932 & 6.2865 & 6.5225 & TRN & \\
\hline CHEMBL1242567 & 654932 & 5.9393 & 5.8966 & TRN & \\
\hline CHEMBL1242659 & 654932 & 4.0 & 4.9906 & TRN & \\
\hline CHEMBL1242568 & 654932 & 6.9747 & 7.1023 & TRN & \\
\hline CHEMBL1241270 & 654932 & 6.6253 & 5.7359 & TST & \\
\hline CHEMBL1242027 & 654932 & 5.5058 & 5.0948 & TRN & \\
\hline CHEMBL1241587 & 654932 & 4.0 & 4.8696 & TST & \\
\hline CHEMBL1242756 & 654932 & 4.9208 & 4.9219 & TRN & \\
\hline CHEMBL1242666 & 654932 & 5.6576 & 5.6947 & TRN & \\
\hline CHEMBL1242199 & 654932 & 7.3188 & 7.0239 & TRN & \\
\hline CHEMBL1241481 & 654932 & 5.6517 & 6.1874 & TRN & \\
\hline CHEMBL1241675 & 654932 & 3.301 & 4.9483 & TST & \\
\hline CHEMBL1242031 & 654932 & 5.3372 & 4.6926 & TRN & \\
\hline CHEMBL1241943 & 654932 & 5.8928 & 5.5064 & TRN & \\
\hline CHEMBL1241680 & 654932 & 5.3665 & 4.2287 & TRN & \\
\hline CHEMBL1242288 & 654932 & 6.0595 & 5.4477 & TRN & \\
\hline CHEMBL1242852 & 654932 & 6.8153 & 6.374 & TRN & \\
\hline CHEMBL1242118 & 654932 & 4.0 & 4.6239 & TRN & \\
\hline CHEMBL1242472 & 654932 & 4.8729 & 4.71399 & 99999999995 & TRN \\
\hline CHEMBL1242848 & 654932 & 5.6655 & 6.2533 & TRN & \\
\hline CHEMBL1241770 & 654932 & 6.3615 & 5.8113 & TRN & \\
\hline CHEMBL1242755 & 654932 & 5.7959 & 6.1385 & TRN & \\
\hline CHEMBL1242113 & 654932 & 6.5544 & 6.0369 & TRN & \\
\hline CHEMBL1242287 & 654932 & 7.3979 & 7.4043 & TRN & \\
\hline CHEMBL1241858 & 654932 & 5.1451 & 5.1109 & TRN & \\
\hline CHEMBL1242115 & 654932 & 5.7747 & 5.2288 & TST & \\
\hline CHEMBL1242657 & 654932 & 6.0 & 5.9524 & TRN & \\
\hline CHEMBL1241767 & 654932 & 3.301 & 4.3084 & TST & \\
\hline CHEMBL1241944 & 654932 & 5.8539 & 5.9753 & TRN & \\
\hline CHEMBL1242753 & 654932 & 4.8996 & 4.0272 & TRN & \\
\hline CHEMBL1241948 & 654932 & 4.0 & 4.3666 & TRN & \\
\hline CHEMBL1242845 & 654932 & 4.0 & 5.284 & TST & \\
\hline CHEMBL1241582 & 654932 & 4.0 & 4.835 & TRN & \\
\hline CHEMBL1241486 & 654932 & 6.7122 & 5.1551 & TRN & \\
\hline
\end{tabular}


Supplemental Table S2.txt

\begin{tabular}{|c|c|c|c|c|c|}
\hline CHEMBL1241588 & 654932 & 4.6778 & 5.0506 & TST & \\
\hline CHEMBL1242028 & 654932 & 5.0915 & 6.1715 & TRN & \\
\hline CHEMBL1241583 & 654932 & 5.3188 & 4.3103 & TRN & \\
\hline CHEMBL1242032 & 654932 & 4.0052 & 4.4007 & TRN & \\
\hline CHEMBL1242024 & 654932 & 6.6716 & 6.6841 & TRN & \\
\hline CHEMBL1242757 & 654932 & 5.1612 & 5.6358 & TST & \\
\hline CHEMBL1242664 & 654932 & 6.8729 & 7.3033 & TRN & \\
\hline CHEMBL1233881 & 654932 & 5.1549 & 5.7731 & TRN & \\
\hline CHEMBL1242029 & 654932 & 4.0 & 5.0382 & TRN & \\
\hline CHEMBL1242117 & 654932 & 4.0 & 3.799 & TRN & \\
\hline CHEMBL1242386 & 654932 & 6.5302 & 6.3631 & TRN & \\
\hline CHEMBL1241772 & 654932 & 4.0 & 4.0581 & TRN & \\
\hline CHEMBL1241483 & 654932 & 4.0 & 5.1863 & TRN & \\
\hline CHEMBL1081312 & 654932 & 7.9208 & 8.0986 & TRN & \\
\hline CHEMBL1241861 & 654932 & 5.8539 & 4.8648 & TRN & \\
\hline CHEMBL1242384 & 654932 & 6.1457 & 5.9528 & TRN & \\
\hline CHEMBL1241484 & 654932 & 7.699 & 7.2315 & TRN & \\
\hline CHEMBL1242853 & 654932 & 6.0757 & 6.3591 & TRN & \\
\hline CHEMBL1242034 & 654932 & 5.1549 & 4.5782 & TRN & \\
\hline CHEMBL1241949 & 654932 & 5.2924 & 5.286006 & 00000000005 & TRN \\
\hline CHEMBL1241492 & 654932 & 4.0 & 4.5096 & TRN & \\
\hline CHEMBL1242198 & 654932 & 7.0315 & 6.5826 & TRN & \\
\hline CHEMBL1241271 & 654932 & \multicolumn{2}{|c|}{6.821000000000001} & 6.1291 & TRN \\
\hline CHEMBL1242294 & 654932 & 7.1192 & 7.0848 & TRN & \\
\hline CHEMBL1241864 & 654932 & 4.0 & 4.6536 & TRN & \\
\hline CHEMBL1234815 & 654932 & 5.9586 & 5.1323 & TRN & \\
\hline CHEMBL1242111 & 654932 & 6.0453 & 6.4448 & TST & \\
\hline CHEMBL1242293 & 654932 & 7.7212 & 7.4211 & TRN & \\
\hline CHEMBL1241490 & 654932 & 5.5376 & 5.5468 & TRN & \\
\hline CHEMBL1242377 & 654932 & 7.1675 & 6.9452 & TRN & \\
\hline CHEMBL1241950 & 654932 & 4.301 & 5.0352 & TRN & \\
\hline CHEMBL1242748 & 654932 & 6.0 & 5.922006 & 0000000001 & TST \\
\hline CHEMBL1240565 & 654932 & 6.0269 & 6.4687 & TST & \\
\hline CHEMBL1242112 & 654932 & 4.0 & 6.0918 & TST & \\
\hline CHEMBL1241774 & 654932 & 4.8861 & 4.9457 & TST & \\
\hline CHEMBL1242471 & 654932 & 4.0 & 3.7057 & TST & \\
\hline CHEMBL1241947 & 654932 & 5.9788 & 5.0022 & TST & \\
\hline CHEMBL1242758 & 654932 & \multicolumn{2}{|c|}{5.3839999999999995} & 6.1346 & TST \\
\hline CHEMBL1242470 & 654932 & 5.5376 & 5.5752 & TST & \\
\hline CHEMBL1242662 & 654932 & 8.0 & 7.1374 & TST & \\
\hline CHEMBL1241859 & 654932 & 5.4225 & 5.1921 & TST & \\
\hline CHEMBL1242033 & 654932 & 4.0 & 4.7648 & TST & \\
\hline CHEMBL1241581 & 654932 & 6.1238 & 6.5089 & TST & \\
\hline CHEMBL1242847 & 654932 & 5.3605 & 5.0294 & TST & \\
\hline CHEMBL1242572 & 654932 & 6.4815 & 6.659 & TST & \\
\hline CHEMBL1240566 & 654932 & 4.9586 & 5.8748 & TST & \\
\hline CHEMBL1242477 & 654932 & 6.3768 & 6.2521 & TST & \\
\hline CHEMBL1241674 & 654932 & 5.8239 & 6.228 & TST & \\
\hline
\end{tabular}


Supplemental Table S2.txt

\begin{tabular}{|c|c|c|c|c|}
\hline CHEMBL1241580 & 654932 & 7.2076 & 7.2432 & TST \\
\hline CHEMBL1242751 & 654932 & 5.2765 & 4.5516 & TST \\
\hline CHEMBL1242207 & 654932 & 4.3098 & 4.5285 & TST \\
\hline CHEMBL1242573 & 654932 & 6.6676 & 5.8547 & TST \\
\hline CHEMBL1242663 & 654932 & 4.0 & 5.0952 & TST \\
\hline CHEMBL1242661 & 654932 & 6.2596 & 4.7421 & TST \\
\hline CHEMBL449158 & 954987 & 7.2291 & 6.5914 & TST \\
\hline CHEMBL 379300 & 954987 & 6.2149 & 6.2271 & TRN \\
\hline CHEMBL412142 & 954987 & 3.6945 & 3.6716 & TRN \\
\hline CHEMBL515416 & 954987 & 3.6269 & 3.6309 & TRN \\
\hline CHEMBL222102 & 954987 & 5.3387 & 5.3149 & TRN \\
\hline CHEMBL1404918 & 954987 & 3.0101 & 3.0127 & TRN \\
\hline CHEMBL1643959 & 954987 & 3.0439 & 3.0491 & TRN \\
\hline CHEMBL1190711 & 954987 & 4.7476 & 4.7494 & TRN \\
\hline CHEMBL1788116 & 954987 & 3.4508 & 3.4505 & TRN \\
\hline CHEMBL 9470 & 954987 & 5.9174 & 5.2552 & TST \\
\hline CHEMBL1256459 & 954987 & 7.6641 & 7.661000 & 00000000005 \\
\hline CHEMBL191334 & 954987 & 4.4608 & 4.4679 & TRN \\
\hline CHEMBL373751 & 954987 & 2.9569 & 2.9518 & TRN \\
\hline CHEMBL483847 & 954987 & 6.7888 & 6.785 & TRN \\
\hline CHEMBL3199475 & 954987 & 4.3069 & 4.3121 & TRN \\
\hline CHEMBL393929 & 954987 & 3.9543 & 3.9566 & TRN \\
\hline CHEMBL259181 & 954987 & 4.689 & 4.6899 & TRN \\
\hline CHEMBL1673039 & 954987 & 4.9839 & 5.0002 & TRN \\
\hline CHEMBL192566 & 954987 & 7.7113 & 7.5878 & TST \\
\hline CHEMBL1970879 & 954987 & 6.834 & 6.8516 & TRN \\
\hline CHEMBL585951 & 954987 & 5.5306 & 5.5258 & TRN \\
\hline CHEMBL483849 & 954987 & 3.3614 & 3.3641 & TRN \\
\hline CHEMBL220241 & 954987 & 4.8641 & 4.8556 & TRN \\
\hline CHEMBL1590308 & 954987 & 4.4878 & 3.398 & TST \\
\hline CHEMBL92309 & 954987 & 2.6765 & 3.2544 & TST \\
\hline CHEMBL1230020 & 954987 & 4.8241 & 4.8238 & TRN \\
\hline CHEMBL258844 & 954987 & 4.1821 & 4.1786 & TRN \\
\hline CHEMBL213100 & 954987 & 11.423 & 11.4176 & TRN \\
\hline CHEMBL1516890 & 954987 & 3.8378 & 3.8196 & TRN \\
\hline CHEMBL3349342 & 954987 & 6.4976 & 6.4928 & TRN \\
\hline CHEMBL379975 & 954987 & 5.0569 & 5.0428 & TRN \\
\hline CHEMBL 2005886 & 954987 & 5.1778 & 5.1795 & TRN \\
\hline CHEMBL509032 & 954987 & 5.553 & 5.5472 & TRN \\
\hline CHEMBL1909414 & 954987 & 4.3581 & 4.3637 & TRN \\
\hline CHEMBL577784 & 954987 & 5.7523 & 5.7474 & TRN \\
\hline CHEMBL 2144069 & 954987 & 6.7157 & 6.7025 & TRN \\
\hline CHEMBL240954 & 954987 & 4.1553 & 4.4828 & TST \\
\hline CHEMBL202721 & 954987 & 5.7557 & 5.7565 & TRN \\
\hline CHEMBL472940 & 954987 & 3.6569 & \multicolumn{2}{|c|}{3.6639999999999997} \\
\hline CHEMBL209148 & 954987 & 4.76 & 4.7656 & TRN \\
\hline CHEMBL135561 & 954987 & 3.9122 & 3.9023 & TRN \\
\hline CHEMBL512504 & 954987 & 6.5112 & 6.5147 & TRN \\
\hline
\end{tabular}




\begin{tabular}{|c|c|c|c|c|c|}
\hline \multicolumn{6}{|c|}{ Supplemental Table S2.txt } \\
\hline CHEMBL189584 & 954987 & 5.3436 & 5.3448 & TRN & \\
\hline CHEMBL102714 & 954987 & 4.35 & 4.3747 & TRN & \\
\hline CHEMBL210618 & 954987 & 4.2046 & 4.2085 & TRN & \\
\hline CHEMBL1357247 & 954987 & 3.4267 & 3.4361 & TRN & \\
\hline CHEMBL65 & 954987 & 8.1537 & 8.1664 & TRN & \\
\hline CHEMBL221137 & 954987 & 4.7324 & 4.266999 & 99999999995 & TST \\
\hline CHEMBL3186408 & 954987 & 3.576 & 3.8746 & TST & \\
\hline CHEMBL573107 & 954987 & 5.9477 & 5.9611 & TRN & \\
\hline CHEMBL 3392440 & 954987 & 3.2666 & 3.2608 & TRN & \\
\hline CHEMBL300389 & 954987 & 6.6922 & 6.683 & TRN & \\
\hline CHEMBL558642 & 954987 & 4.9903 & 4.0182 & TST & \\
\hline CHEMBL1242367 & 954987 & 4.7419 & 4.1452 & TST & \\
\hline CHEMBL188678 & 954987 & 6.0051 & 5.4843 & TST & \\
\hline CHEMBL514499 & 954987 & 7.3988 & 7.5271 & TST & \\
\hline CHEMBL180127 & 954987 & 4.8028 & 4.5649 & TST & \\
\hline CHEMBL 2363137 & 954987 & 5.2157 & 4.7188 & TST & \\
\hline CHEMBL392695 & 954987 & 5.5005 & 5.3651 & TST & \\
\hline CHEMBL 3884941 & 1633656 & 3.0 & 3.7469 & TRN & \\
\hline CHEMBL3885499 & 1633656 & 3.0 & 4.9481 & TRN & \\
\hline CHEMBL3884270 & 1633656 & 3.0 & 4.6668 & TRN & \\
\hline CHEMBL 3883447 & 1633656 & 7.2924 & 6.9287 & TRN & \\
\hline CHEMBL3883579 & 1633656 & 6.2958 & 5.1969 & TST & \\
\hline CHEMBL 3885151 & 1633656 & 4.9889 & 5.5258 & TRN & \\
\hline CHEMBL 3885331 & 1633656 & 7.2218 & 6.9979 & TRN & \\
\hline CHEMBL3883812 & 1633656 & 7.5086 & 7.2544 & TRN & \\
\hline CHEMBL3884517 & 1633656 & 3.0 & 5.5444 & TST & \\
\hline CHEMBL 3884134 & 1633656 & 6.0521 & 6.3124 & TRN & \\
\hline CHEMBL 3884580 & 1633656 & 5.1904 & 6.2021 & TRN & \\
\hline CHEMBL 3883572 & 1633656 & 6.8182 & 6.9867 & TRN & \\
\hline CHEMBL3884077 & 1633656 & 6.1141 & 4.7587 & TRN & \\
\hline CHEMBL3885035 & 1633656 & 3.0 & 4.4963 & TST & \\
\hline CHEMBL3884038 & 1633656 & 6.4318 & 6.4766 & TRN & \\
\hline CHEMBL3884995 & 1633656 & 6.6345 & 6.3654 & TRN & \\
\hline CHEMBL3883521 & 1633656 & 3.0 & 3.2774 & TRN & \\
\hline CHEMBL3884173 & 1633656 & 6.1379 & 6.4073 & TRN & \\
\hline CHEMBL 3885195 & 1633656 & 5.6778 & 4.1926 & TRN & \\
\hline CHEMBL3883597 & 1633656 & 7.6576 & 5.0994 & TST & \\
\hline CHEMBL3883502 & 1633656 & 3.0 & 3.9507 & TRN & \\
\hline CHEMBL 3884740 & 1633656 & 3.0 & 4.9665 & TRN & \\
\hline CHEMBL3883998 & 1633656 & 5.3215 & 4.6917 & TRN & \\
\hline CHEMBL3883658 & 1633656 & 5.6696 & 5.5045 & TRN & \\
\hline CHEMBL3883471 & 1633656 & 6.4828 & 6.9967 & TRN & \\
\hline CHEMBL3884172 & 1633656 & 5.5867 & 5.2055 & TRN & \\
\hline CHEMBL3884966 & 1633656 & 6.757000 & 300000000 & 6.1103 & TST \\
\hline CHEMBL3885275 & 1633656 & 6.5654 & 6.338999 & 99999999995 & TRN \\
\hline CHEMBL3883947 & 1633656 & 5.5045 & 5.4499 & TRN & \\
\hline CHEMBL3883401 & 1633656 & 5.3747 & 5.2692 & TRN & \\
\hline CHEMBL 3884888 & 1633656 & 5.3288 & 5.1358 & TRN & \\
\hline
\end{tabular}


Supplemental Table S2.txt

\begin{tabular}{|c|c|c|c|c|c|c|}
\hline CHEMBL3884986 & 1633656 & 5.6345 & 6.2448 & TRN & & \\
\hline CHEMBL3883456 & 1633656 & 6.5528 & 6.7494 & TRN & & \\
\hline CHEMBL3883805 & 1633656 & 5.3458 & 3.9068 & TRN & & \\
\hline CHEMBL3884809 & 1633656 & 7.3098 & 6.4981 & TRN & & \\
\hline CHEMBL3885468 & 1633656 & 6.4559 & 6.3077 & TRN & & \\
\hline CHEMBL3885415 & 1633656 & 5.4012 & 4.9262 & TRN & & \\
\hline CHEMBL3885187 & 1633656 & 3.0 & 5.916 & TST & & \\
\hline CHEMBL3885357 & 1633656 & 3.0 & 4.1983 & TRN & & \\
\hline CHEMBL3884862 & 1633656 & 3.0 & 5.9492 & TST & & \\
\hline CHEMBL3884056 & 1633656 & 5.5129 & 5.7884 & TRN & & \\
\hline CHEMBL 3884048 & 1633656 & 5.6038 & 5.0219 & TRN & & \\
\hline CHEMBL3883972 & 1633656 & 7.6021 & 6.7457 & TRN & & \\
\hline CHEMBL3884292 & 1633656 & 5.7773 & 5.3563 & TST & & \\
\hline CHEMBL3883549 & 1633656 & 3.0 & 6.0186 & TST & & \\
\hline CHEMBL3884795 & 1633656 & 6.2581 & 5.5156 & TRN & & \\
\hline CHEMBL3884099 & 1633656 & 5.5513 & 5.2654 & TRN & & \\
\hline CHEMBL3883377 & 1633656 & 6.8447 & 6.3709 & TRN & & \\
\hline CHEMBL3885229 & 1633656 & 5.8069 & 5.5602 & TRN & & \\
\hline CHEMBL3883555 & 1633656 & 6.3851 & 6.5197 & TRN & & \\
\hline CHEMBL3885034 & 1633656 & 3.0 & 5.7979 & TST & & \\
\hline CHEMBL3883420 & 1633656 & 3.0 & 5.8123 & TST & & \\
\hline CHEMBL3885068 & 1633656 & 5.1739 & 3.8075 & TST & & \\
\hline CHEMBL3885401 & 1633656 & \multicolumn{3}{|c|}{5.4510000000000005} & 5.6673 & TRN \\
\hline CHEMBL3883399 & 1633656 & 3.0 & 5.4679 & TST & & \\
\hline CHEMBL3883991 & 1633656 & 5.3958 & 4.6271 & TST & & \\
\hline CHEMBL3884011 & 1633656 & 6.4486 & 4.4475 & TRN & & \\
\hline CHEMBL3885074 & 1633656 & 5.9706 & 6.5093 & TRN & & \\
\hline CHEMBL3883646 & 1633656 & 4.6737 & 5.0356 & TST & & \\
\hline CHEMBL3883621 & 1633656 & 6.1494 & 6.3863 & TRN & & \\
\hline CHEMBL1256364 & 688563 & 4.783 & 4.7797 & TRN & & \\
\hline CHEMBL48449 & 688563 & 4.833 & 4.8363 & TRN & & \\
\hline CHEMBL250711 & 688563 & 4.883 & 4.888 & TRN & & \\
\hline CHEMBL559612 & 688563 & 4.783 & 4.784 & TRN & & \\
\hline CHEMBL319244 & 688563 & 5.033 & 5.0363 & TRN & & \\
\hline CHEMBL269733 & 688563 & 4.633 & 4.6316 & TRN & & \\
\hline CHEMBL 2374027 & 688563 & 4.583 & 4.5808 & TRN & & \\
\hline CHEMBL567175 & 688563 & 4.833 & 4.8372 & TRN & & \\
\hline CHEMBL1357488 & 688563 & 5.733 & 4.7519 & TST & & \\
\hline CHEMBL492008 & 688563 & 4.583 & 4.5873 & TRN & & \\
\hline CHEMBL1256911 & 688563 & 4.583 & 4.5855 & TRN & & \\
\hline CHEMBL296586 & 688563 & 4.583 & 4.5834 & TRN & & \\
\hline CHEMBL1316314 & 688563 & 4.683 & 4.6844 & TRN & & \\
\hline CHEMBL1256749 & 688563 & \multicolumn{3}{|c|}{4.7330000000000005} & 4.7321 & TRN \\
\hline CHEMBL1513654 & 688563 & 4.583 & 4.5839 & TRN & & \\
\hline CHEMBL596674 & 688563 & 4.583 & 4.5849 & TRN & & \\
\hline CHEMBL275516 & 688563 & 4.883 & 4.8802 & TRN & & \\
\hline CHEMBL1241268 & 688563 & 4.683 & 4.6856 & TRN & & \\
\hline CHEMBL1525723 & 688563 & 5.28299 & 99999999 & 995 & 5.2845 & TRN \\
\hline
\end{tabular}




\begin{tabular}{|c|c|c|c|c|c|c|}
\hline & & \multicolumn{5}{|c|}{ Supplemental Table S2.txt } \\
\hline CHEMBL568150 & 688563 & 4.583 & 4.5791 & TRN & & \\
\hline CHEMBL1256360 & 688563 & 4.583 & 4.5853 & TRN & & \\
\hline CHEMBL2374058 & 688563 & 4.633 & 4.6329 & TRN & & \\
\hline CHEMBL15192 & 688563 & 4.583 & 4.5826 & TRN & & \\
\hline CHEMBL596380 & 688563 & \multicolumn{3}{|c|}{5.5329999999999995} & 5.5289 & TRN \\
\hline CHEMBL 188 & 688563 & 4.833 & 4.8345 & TRN & & \\
\hline CHEMBL8747 & 688563 & 4.583 & 4.583 & TRN & & \\
\hline CHEMBL3186408 & 688563 & 5.033 & 5.0336 & TRN & & \\
\hline CHEMBL60718 & 688563 & \multicolumn{3}{|c|}{4.7330000000000005} & 4.7242 & TRN \\
\hline CHEMBL402468 & 688563 & 4.583 & 4.5931 & TRN & & \\
\hline CHEMBL520992 & 688563 & \multicolumn{3}{|c|}{4.7330000000000005} & 4.7308 & TRN \\
\hline CHEMBL1516388 & 688563 & 4.833 & 4.6946 & TST & & \\
\hline CHEMBL1256656 & 688563 & 4.783 & 4.7825 & TRN & & \\
\hline CHEMBL1256686 & 688563 & 4.833 & 4.8362 & TRN & & \\
\hline CHEMBL295212 & 688563 & 4.633 & 4.6303 & TRN & & \\
\hline CHEMBL569864 & 688563 & 4.583 & 4.5779 & TRN & & \\
\hline CHEMBL 280998 & 688563 & 4.633 & 4.619 & TRN & & \\
\hline CHEMBL98350 & 688563 & 5.433 & 5.4357 & TRN & & \\
\hline CHEMBL536950 & 688563 & 4.583 & 4.5864 & TRN & & \\
\hline CHEMBL1255659 & 688563 & 4.583 & 4.6891 & TST & & \\
\hline CHEMBL399491 & 688563 & 5.183 & 4.9083 & TST & & \\
\hline CHEMBL455983 & 688563 & 4.883 & 4.883 & TRN & & \\
\hline CHEMBL1355963 & 688563 & 4.583 & 4.5843 & TRN & & \\
\hline CHEMBL2374259 & 688563 & 4.633 & 4.6272 & TRN & & \\
\hline CHEMBL258893 & 688563 & \multicolumn{3}{|c|}{5.5329999999999995} & 5.5336 & TRN \\
\hline CHEMBL19612 & 688563 & 4.633 & 4.8731 & TST & & \\
\hline CHEMBL51085 & 688563 & 4.833 & 4.8373 & TRN & & \\
\hline CHEMBL1554098 & 688563 & 7.684 & 7.683 & TRN & & \\
\hline CHEMBL365739 & 688563 & 4.783 & 4.7839 & TRN & & \\
\hline CHEMBL1512503 & 688563 & 4.583 & 4.5818 & TRN & & \\
\hline CHEMBL1257041 & 688563 & 4.833 & 4.8362 & TRN & & \\
\hline CHEMBL605003 & 688563 & 5.183 & 5.1883 & TRN & & \\
\hline CHEMBL 303958 & 688563 & 4.833 & 4.7907 & TST & & \\
\hline CHEMBL1528565 & 688563 & 4.583 & 4.5801 & TRN & & \\
\hline CHEMBL224864 & 688563 & 5.483 & 5.4783 & TRN & & \\
\hline CHEMBL355496 & 688563 & \multicolumn{3}{|c|}{4.7330000000000005} & 4.7258 & TRN \\
\hline CHEMBL1559663 & 688563 & \multicolumn{3}{|c|}{5.5329999999999995} & 5.5331 & TRN \\
\hline CHEMBL1516111 & 688563 & 4.783 & 4.7843 & TRN & & \\
\hline CHEMBL 303579 & 688563 & 4.583 & 4.5852 & TRN & & \\
\hline CHEMBL123 & 688563 & 4.583 & 4.9932 & TST & & \\
\hline CHEMBL 9843 & 688563 & \multicolumn{3}{|c|}{4.7330000000000005} & 4.7929 & TST \\
\hline CHEMBL192566 & 688563 & 4.583 & 5.0623 & TST & & \\
\hline CHEMBL 275035 & 688563 & 4.583 & \multicolumn{3}{|c|}{4.781000000000001} & TST \\
\hline CHEMBL 24983 & 688563 & 4.783 & 4.8343 & TST & & \\
\hline CHEMBL1208858 & 688563 & 4.633 & 4.6413 & TST & & \\
\hline CHEMBL288096 & 688563 & 4.833 & 4.816 & TST & & \\
\hline CHEMBL1337170 & 688563 & 5.683 & 4.7966 & TST & & \\
\hline CHEMBL 21260 & 688563 & 7.6326 & 5.8043 & TST & & \\
\hline
\end{tabular}




\begin{tabular}{|c|c|c|c|c|c|c|}
\hline \multicolumn{7}{|c|}{ Supplemental Table S2.txt } \\
\hline CHEMBL16687 & 688563 & 4.833 & 5.0281 & TST & & \\
\hline CHEMBL 29726 & 688563 & 6.58299 & 99999999 & & 4.8489 & TST \\
\hline CHEMBL1256876 & 688563 & 4.73300 & 00000000 & 005 & 4.5627 & TST \\
\hline CHEMBL 3220958 & 1330007 & 4.0 & 4.0194 & TRN & & \\
\hline CHEMBL 3221206 & 1330007 & 4.0 & 4.0966 & TRN & & \\
\hline CHEMBL 3221186 & 1330007 & 4.0 & 4.0878 & TRN & & \\
\hline CHEMBL 3221203 & 1330007 & 5.3206 & 5.2863 & TRN & & \\
\hline CHEMBL 3221208 & 1330007 & 4.0 & 3.9501 & TRN & & \\
\hline CHEMBL 3221181 & 1330007 & 4.0 & 4.0395 & TRN & & \\
\hline CHEMBL3221197 & 1330007 & 5.6716 & 5.6316 & TRN & & \\
\hline CHEMBL 3220959 & 1330007 & 4.0 & 3.9892 & TRN & & \\
\hline CHEMBL 3221195 & 1330007 & 4.0 & 4.0727 & TRN & & \\
\hline CHEMBL3221189 & 1330007 & 4.0 & 4.2272 & TRN & & \\
\hline CHEMBL 3221211 & 1330007 & 4.0 & 4.0062 & TRN & & \\
\hline CHEMBL3221185 & 1330007 & 4.0 & 4.0217 & TRN & & \\
\hline CHEMBL 3220944 & 1330007 & 4.0 & 4.8942 & TST & & \\
\hline CHEMBL3220943 & 1330007 & 4.0 & 3.9464 & TRN & & \\
\hline CHEMBL161343 & 1330007 & 4.0 & 3.95899 & 99999 & 96 & \\
\hline CHEMBL 3220948 & 1330007 & 4.0 & 4.1274 & TST & & \\
\hline CHEMBL 3220957 & 1330007 & 4.0 & 3.8629 & TRN & & \\
\hline CHEMBL 3221182 & 1330007 & 4.0 & 3.987 & TRN & & \\
\hline CHEMBL3220955 & 1330007 & 4.0 & 3.995 & TRN & & \\
\hline CHEMBL 3221193 & 1330007 & 4.0 & 4.0121 & TRN & & \\
\hline CHEMBL 3221180 & 1330007 & 4.0 & 3.9786 & TRN & & \\
\hline CHEMBL 3221192 & 1330007 & 4.0 & 3.9985 & TRN & & \\
\hline CHEMBL 3221184 & 1330007 & 4.0 & 3.9796 & TRN & & \\
\hline CHEMBL 3220953 & 1330007 & 4.0 & 4.0834 & TRN & & \\
\hline CHEMBL 3221200 & 1330007 & 5.6402 & 5.3489 & TRN & & \\
\hline CHEMBL 3221196 & 1330007 & 5.7959 & 5.6456 & TRN & & \\
\hline CHEMBL 3221204 & 1330007 & 4.0 & 4.0777 & TST & & \\
\hline CHEMBL3221199 & 1330007 & 5.6655 & 5.7093 & TRN & & \\
\hline CHEMBL 3221187 & 1330007 & 4.0 & 4.0793 & TRN & & \\
\hline CHEMBL 3221183 & 1330007 & 4.0 & 4.0545 & TRN & & \\
\hline CHEMBL 3221188 & 1330007 & 4.0 & 4.3493 & TRN & & \\
\hline CHEMBL 3221202 & 1330007 & 6.0706 & 6.0735 & TRN & & \\
\hline CHEMBL 3221207 & 1330007 & 4.0 & 4.0 & TRN & & \\
\hline CHEMBL3220952 & 1330007 & 5.8729 & 5.2426 & TST & & \\
\hline CHEMBL 3220945 & 1330007 & 4.0 & 4.35800 & 20000 & 005 & 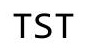 \\
\hline CHEMBL 3220947 & 1330007 & 4.6757 & 4.3072 & TST & & \\
\hline CHEMBL 3221190 & 1330007 & 5.6799 & 4.8857 & TRN & & \\
\hline CHEMBL 3220954 & 1330007 & 4.0 & 4.0166 & TRN & & \\
\hline CHEMBL3220950 & 1330007 & 4.0 & 3.7737 & TST & & \\
\hline CHEMBL 3221201 & 1330007 & 5.4976 & 6.3329 & TRN & & \\
\hline CHEMBL 3220946 & 1330007 & 4.0 & 4.3171 & TST & & \\
\hline CHEMBL3221209 & 1330007 & 4.0 & 3.8673 & TRN & & \\
\hline CHEMBL 3221205 & 1330007 & 4.0 & 4.0455 & TRN & & \\
\hline CHEMBL3217791 & 1330007 & 4.0 & 4.0396 & TRN & & \\
\hline CHEMBL 3220949 & 1330007 & 4.0 & 3.8197 & TST & & \\
\hline
\end{tabular}




\begin{tabular}{|c|c|c|c|c|c|}
\hline \multicolumn{6}{|c|}{ Supplemental Table S2.txt } \\
\hline CHEMBL3220951 & 1330007 & 4.0 & 5.3263 & TST & \\
\hline CHEMBL 3221210 & 1330007 & 4.0 & 4.0131 & TRN & \\
\hline CHEMBL3221198 & 1330007 & 6.6021 & 6.2253 & TRN & \\
\hline CHEMBL3220956 & 1330007 & 4.0 & 3.9859 & TRN & \\
\hline CHEMBL3221194 & 1330007 & 4.0 & 3.6912 & TST & \\
\hline CHEMBL3221191 & 1330007 & 4.0 & 3.8519 & TST & \\
\hline CHEMBL202896 & 340343 & 5.0074 & 5.0673 & TRN & \\
\hline CHEMBL206227 & 340343 & 6.3116 & 6.0579 & TRN & \\
\hline CHEMBL206546 & 340343 & 5.8013 & 6.0708 & TRN & \\
\hline CHEMBL378798 & 340343 & 5.3363 & 5.7259 & TST & \\
\hline CHEMBL 206582 & 340343 & 5.9872 & 5.9381 & TST & \\
\hline CHEMBL202781 & 340343 & 5.1643 & 4.9155 & TRN & \\
\hline CHEMBL 205988 & 340343 & 4.0 & 4.2028 & TRN & \\
\hline CHEMBL 203123 & 340343 & 6.8041 & 5.9355 & TST & \\
\hline CHEMBL204922 & 340343 & 6.7986 & 6.15799 & 99999999995 & TRN \\
\hline CHEMBL426854 & 340343 & 5.2628 & 4.9267 & TRN & \\
\hline CHEMBL204222 & 340343 & 5.0 & 5.3507 & TRN & \\
\hline CHEMBL206547 & 340343 & 6.9957 & 6.6002 & TST & \\
\hline CHEMBL381622 & 340343 & 4.0 & 4.5385 & TRN & \\
\hline CHEMBL 205009 & 340343 & 4.0 & 4.2851 & TRN & \\
\hline CHEMBL206406 & 340343 & 6.224 & 5.7088 & TRN & \\
\hline CHEMBL206218 & 340343 & 4.0 & 5.2626 & TRN & \\
\hline CHEMBL 204272 & 340343 & 4.9355 & 5.7134 & TRN & \\
\hline CHEMBL 202673 & 340343 & 6.2034 & 6.1744 & TST & \\
\hline CHEMBL 383753 & 340343 & 5.3708 & 5.0631 & TRN & \\
\hline CHEMBL414859 & 340343 & 6.2343 & 5.5739 & TRN & \\
\hline CHEMBL381337 & 340343 & 6.475 & 6.1458 & TST & \\
\hline CHEMBL 204768 & 340343 & 5.5984 & 6.1718 & TRN & \\
\hline CHEMBL206441 & 340343 & 5.3809 & 5.2693 & TRN & \\
\hline CHEMBL204959 & 340343 & 4.0 & 4.7702 & TRN & \\
\hline CHEMBL 380720 & 340343 & 6.2328 & 5.8789 & TRN & \\
\hline CHEMBL380452 & 340343 & 5.5186 & 4.4718 & TRN & \\
\hline CHEMBL 380362 & 340343 & 5.9172 & 6.0853 & TST & \\
\hline CHEMBL204118 & 340343 & 5.9626 & 5.3215 & TRN & \\
\hline CHEMBL 380717 & 340343 & 6.1451 & 6.3739 & TRN & \\
\hline CHEMBL 203348 & 340343 & 6.224 & 6.0791 & TRN & \\
\hline CHEMBL204819 & 340343 & 5.8928 & 5.6195 & TRN & \\
\hline CHEMBL 206440 & 340343 & 5.3382 & 4.6891 & TRN & \\
\hline CHEMBL204024 & 340343 & 6.2027 & 5.9891 & TST & \\
\hline CHEMBL 206600 & 340343 & 6.1844 & 5.4373 & TRN & \\
\hline CHEMBL 203072 & 340343 & 6.8894 & 6.6816 & TST & \\
\hline CHEMBL 204025 & 340343 & 6.3298 & 5.5655 & TST & \\
\hline CHEMBL204902 & 340343 & 6.3152 & 6.3959 & TRN & \\
\hline CHEMBL204119 & 340343 & 5.4306 & 5.6206 & TRN & \\
\hline CHEMBL204056 & 340343 & 5.5058 & 5.544 & TRN & \\
\hline CHEMBL381697 & 340343 & 6.6478 & 6.0694 & TRN & \\
\hline CHEMBL 206727 & 340343 & 6.6421 & 6.4634 & TRN & \\
\hline CHEMBL 380844 & 340343 & 4.8447 & 5.3751 & TRN & \\
\hline
\end{tabular}




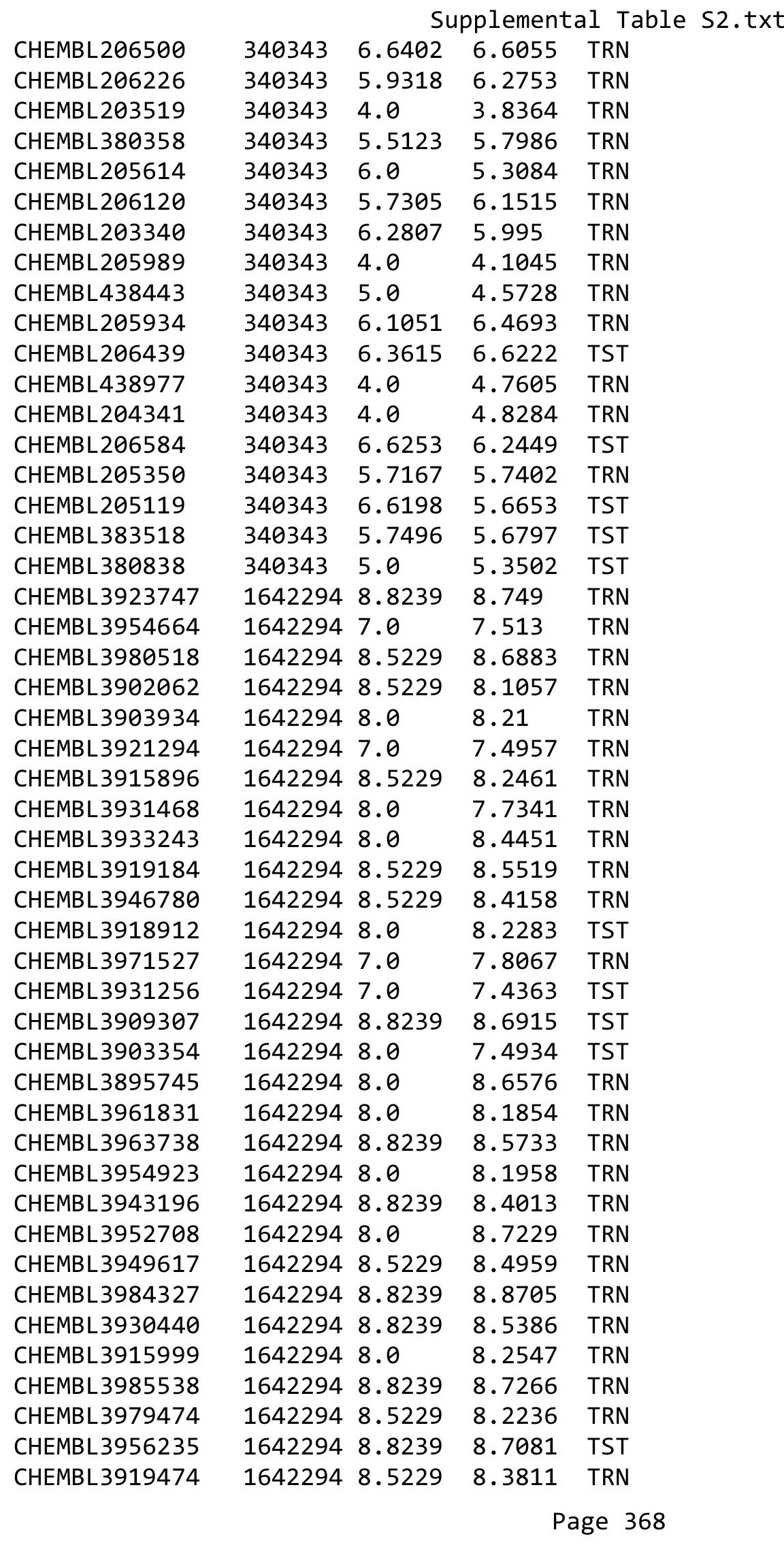


Supplemental Table S2.txt

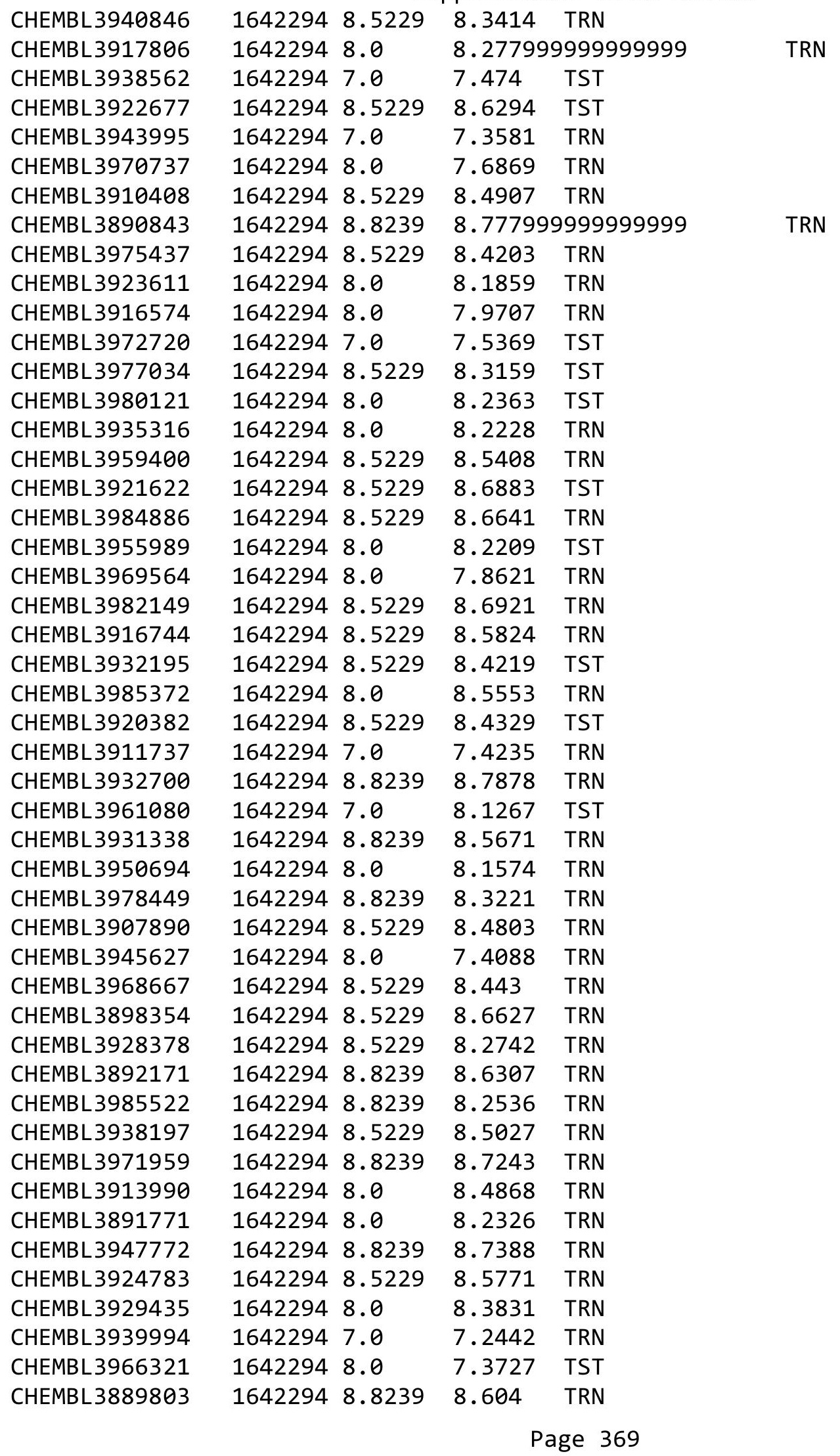


Supplemental Table S2.txt

\begin{tabular}{|c|c|c|c|c|c|}
\hline CHEMBL3943587 & 1642294 & 8.8239 & 8.5039 & TRN & \\
\hline CHEMBL3975272 & 1642294 & 8.8239 & 8.6695 & TRN & \\
\hline CHEMBL3912853 & 1642294 & 8.0 & 7.9691 & TRN & \\
\hline CHEMBL3929670 & 1642294 & 8.0 & 8.4835 & TRN & \\
\hline CHEMBL3971833 & 1642294 & 8.5229 & 8.4598 & TRN & \\
\hline CHEMBL3916897 & 1642294 & 8.8239 & 8.2755 & TRN & \\
\hline CHEMBL3922477 & 1642294 & 7.0 & 7.6091 & TST & \\
\hline CHEMBL3941055 & 1642294 & 7.0 & 7.513 & TRN & \\
\hline CHEMBL3931115 & 1642294 & 8.5229 & 8.3532 & TST & \\
\hline CHEMBL3919044 & 1642294 & 8.0 & 8.3191 & TRN & \\
\hline CHEMBL3896086 & 1642294 & 8.0 & 7.9861 & TRN & \\
\hline CHEMBL3936211 & 1642294 & 7.0 & 7.5816 & TST & \\
\hline CHEMBL3984323 & 1642294 & 8.0 & 8.0292 & TRN & \\
\hline CHEMBL3909236 & 1642294 & 8.0 & 8.1669 & TRN & \\
\hline CHEMBL3940936 & 1642294 & 8.0 & 8.1789 & TRN & \\
\hline CHEMBL3925343 & 1642294 & 8.0 & 8.1208 & TRN & \\
\hline CHEMBL3915872 & 1642294 & 8.8239 & 8.5448 & TRN & \\
\hline CHEMBL3892095 & 1642294 & 8.0 & 8.0677 & TRN & \\
\hline CHEMBL3956706 & 1642294 & 8.5229 & 8.3144 & TRN & \\
\hline CHEMBL3980158 & 1642294 & 8.8239 & 8.8235 & TRN & \\
\hline CHEMBL3952082 & 1642294 & 8.5229 & 8.4585 & TRN & \\
\hline CHEMBL3896740 & 1642294 & 8.5229 & 8.1919 & TRN & \\
\hline CHEMBL3895616 & 1642294 & 8.0 & 7.7871 & TRN & \\
\hline CHEMBL3891126 & 1642294 & 8.5229 & 8.6842 & TRN & \\
\hline CHEMBL3900993 & 1642294 & 8.0 & 7.6368 & TRN & \\
\hline CHEMBL3919338 & 1642294 & 8.5229 & 8.7956 & TRN & \\
\hline CHEMBL3896079 & 1642294 & 8.0 & 7.5364 & TRN & \\
\hline CHEMBL3895278 & 1642294 & 8.5229 & 8.3152 & TRN & \\
\hline CHEMBL3908778 & 1642294 & 8.0 & 7.5483 & TRN & \\
\hline CHEMBL3927043 & 1642294 & 8.5229 & 8.5571 & TST & \\
\hline CHEMBL3906502 & 1642294 & 8.0 & 8.277006 & 0000000001 & TRN \\
\hline CHEMBL3904581 & 1642294 & 8.0 & 7.8645 & TST & \\
\hline CHEMBL3977169 & 1642294 & 8.0 & 8.5628 & TRN & \\
\hline CHEMBL3926764 & 1642294 & 8.5229 & 8.4202 & TRN & \\
\hline CHEMBL3984412 & 1642294 & 8.0 & 8.1013 & TRN & \\
\hline CHEMBL3894306 & 1642294 & 8.5229 & 8.6618 & TRN & \\
\hline CHEMBL3904385 & 1642294 & 8.8239 & 8.603 & TRN & \\
\hline CHEMBL3944797 & 1642294 & 8.5229 & 8.5729 & TRN & \\
\hline CHEMBL3943539 & 1642294 & 7.0 & 7.3296 & TRN & \\
\hline CHEMBL3968958 & 1642294 & 8.5229 & 8.34 & TRN & \\
\hline CHEMBL3950524 & 1642294 & 8.0 & 8.5838 & TRN & \\
\hline CHEMBL3910276 & 1642294 & 8.8239 & 8.697006 & 2000000001 & TRN \\
\hline CHEMBL3953508 & 1642294 & 8.0 & 7.8143 & TRN & \\
\hline CHEMBL3918874 & 1642294 & 8.5229 & 8.4395 & TRN & \\
\hline CHEMBL3914507 & 1642294 & 8.0 & 7.5256 & TST & \\
\hline CHEMBL3928858 & 1642294 & 8.5229 & 8.4795 & TRN & \\
\hline CHEMBL3974819 & 1642294 & 8.0 & 8.1494 & TRN & \\
\hline CHEMBL3921247 & 1642294 & 8.0 & 7.5213 & TRN & \\
\hline
\end{tabular}




\begin{tabular}{|c|c|c|c|c|}
\hline \multicolumn{5}{|c|}{ Supplemental Table S2.txt } \\
\hline CHEMBL3973089 & 1642294 & 7.0 & 7.4285 & TRN \\
\hline CHEMBL 3934438 & 1642294 & 8.5229 & 8.3184 & TRN \\
\hline CHEMBL 3927596 & 1642294 & 8.0 & 7.9866 & TRN \\
\hline CHEMBL 3985241 & 1642294 & 8.5229 & 8.4703 & TRN \\
\hline CHEMBL 3955566 & 1642294 & 8.8239 & 8.6422 & TRN \\
\hline CHEMBL3985702 & 1642294 & 8.0 & 7.4626 & TST \\
\hline CHEMBL3947539 & 1642294 & 8.5229 & 8.2538 & TRN \\
\hline CHEMBL 3985954 & 1642294 & 8.0 & 7.5209 & TRN \\
\hline CHEMBL 3904420 & 1642294 & 8.8239 & 8.6362 & TRN \\
\hline CHEMBL3934205 & 1642294 & 8.8239 & 8.4354 & TRN \\
\hline CHEMBL 3943824 & 1642294 & 8.5229 & 8.3468 & TRN \\
\hline CHEMBL 3892819 & 1642294 & 8.0 & 8.4083 & TRN \\
\hline CHEMBL3960782 & 1642294 & 8.0 & 8.2033 & TRN \\
\hline CHEMBL 3901065 & 1642294 & 8.8239 & 8.5005 & TRN \\
\hline CHEMBL3962112 & 1642294 & 8.5229 & 8.4999 & TRN \\
\hline CHEMBL3927876 & 1642294 & 8.0 & 7.5095 & TST \\
\hline CHEMBL 3928470 & 1642294 & 8.5229 & 8.2588 & TRN \\
\hline CHEMBL3979910 & 1642294 & 8.8239 & 8.5946 & TRN \\
\hline CHEMBL 3957288 & 1642294 & 8.5229 & 8.189 & TST \\
\hline CHEMBL3904619 & 1642294 & 8.0 & 8.6328 & TST \\
\hline CHEMBL3946601 & 1642294 & 8.8239 & 8.1921 & TST \\
\hline CHEMBL 3904190 & 1642294 & 8.8239 & 8.8019 & TST \\
\hline CHEMBL3950198 & 1642294 & 7.0 & 7.5374 & TST \\
\hline CHEMBL3984119 & 1642294 & 8.5229 & 8.1892 & TST \\
\hline CHEMBL3967101 & 1642294 & 8.0 & 7.7924 & TST \\
\hline CHEMBL3889505 & 1642294 & 8.0 & 7.8338 & TST \\
\hline CHEMBL 3942227 & 1642294 & 8.5229 & 8.3115 & TST \\
\hline CHEMBL3901208 & 1642294 & 7.0 & 8.4077 & TST \\
\hline CHEMBL 3943961 & 1642294 & 8.0 & 8.443 & TST \\
\hline CHEMBL3935860 & 1642294 & 8.5229 & 8.6925 & TST \\
\hline CHEMBL3904988 & 1642294 & 8.5229 & 8.3565 & TST \\
\hline CHEMBL3976096 & 1642294 & 8.8239 & 8.477 & TST \\
\hline CHEMBL3941194 & 1642294 & 8.8239 & 8.7425 & TST \\
\hline CHEMBL3941967 & 1642294 & 8.0 & 8.3446 & TST \\
\hline CHEMBL3968490 & 1642294 & 8.0 & 7.5469 & TST \\
\hline CHEMBL70971 & 688769 & 4.9 & 4.5964 & TRN \\
\hline CHEMBL1522486 & 688769 & 4.8 & 4.5851 & TRN \\
\hline CHEMBL295652 & 688769 & 6.8 & 4.3708 & TRN \\
\hline CHEMBL1576086 & 688769 & 4.4 & 4.4123 & TRN \\
\hline CHEMBL1600998 & 688769 & 5.1 & 5.3574 & TRN \\
\hline CHEMBL418068 & 688769 & 4.3 & 4.5158 & TRN \\
\hline CHEMBL1485974 & 688769 & 4.5 & 4.3838 & TRN \\
\hline CHEMBL1562104 & 688769 & 5.1 & 5.3222 & TRN \\
\hline CHEMBL224282 & 688769 & 4.3 & 4.2733 & TRN \\
\hline CHEMBL1430204 & 688769 & 4.3 & 4.4345 & TRN \\
\hline CHEMBL462576 & 688769 & 4.3 & 4.4709 & TRN \\
\hline CHEMBL1559341 & 688769 & 4.5 & 4.4431 & TRN \\
\hline CHEMBL1449018 & 688769 & 4.4 & 4.5901 & TRN \\
\hline
\end{tabular}




\begin{tabular}{|c|c|c|c|c|}
\hline \multicolumn{5}{|c|}{ Supplemental Table S2.txt } \\
\hline CHEMBL1418603 & 688769 & 4.4 & 4.2409 & TRN \\
\hline CHEMBL1499545 & 688769 & 5.4 & 5.2349 & TRN \\
\hline CHEMBL8739 & 688769 & 4.3 & 4.2616 & TRN \\
\hline CHEMBL1407826 & 688769 & 4.4 & 4.6875 & TST \\
\hline CHEMBL1527567 & 688769 & 4.3 & 4.3116 & TRN \\
\hline CHEMBL1489064 & 688769 & 4.3 & 4.2697 & TRN \\
\hline CHEMBL1549844 & 688769 & 4.4 & 4.6116 & TST \\
\hline CHEMBL1200471 & 688769 & 6.5 & 6.4617 & TRN \\
\hline CHEMBL1439332 & 688769 & 4.4 & 4.8396 & TRN \\
\hline CHEMBL1609459 & 688769 & 5.1 & 5.0933 & TRN \\
\hline CHEMBL1369243 & 688769 & 4.1 & 4.3813 & TRN \\
\hline CHEMBL443949 & 688769 & 4.4 & 4.4411 & TRN \\
\hline CHEMBL1530684 & 688769 & 4.3 & 4.4056 & TRN \\
\hline CHEMBL1142 & 688769 & 4.4 & 4.3766 & TRN \\
\hline CHEMBL1338613 & 688769 & 4.4 & 4.3664 & TST \\
\hline CHEMBL1364985 & 688769 & 4.2 & 4.5511 & TRN \\
\hline CHEMBL1495381 & 688769 & 5.9 & 5.0379 & TST \\
\hline CHEMBL538146 & 688769 & 4.3 & 4.751 & TRN \\
\hline CHEMBL509531 & 688769 & 4.7 & 4.8376 & TST \\
\hline CHEMBL1308088 & 688769 & 4.9 & 4.8275 & TRN \\
\hline CHEMBL1519327 & 688769 & 6.5 & 6.1956 & TRN \\
\hline CHEMBL58835 & 688769 & 4.4 & 4.4481 & TRN \\
\hline CHEMBL192627 & 688769 & 4.4 & 4.5949 & TRN \\
\hline CHEMBL1452158 & 688769 & 4.4 & 4.3192 & TRN \\
\hline CHEMBL1580759 & 688769 & 4.4 & 4.4757 & TRN \\
\hline CHEMBL1330518 & 688769 & 4.3 & 4.3359 & TRN \\
\hline CHEMBL1304981 & 688769 & 4.3 & 4.2533 & TST \\
\hline CHEMBL1526721 & 688769 & 5.5 & 5.0286 & TRN \\
\hline CHEMBL230156 & 688769 & 4.3 & 4.275 & TRN \\
\hline CHEMBL140 & 688769 & 4.6 & 4.3742 & TRN \\
\hline CHEMBL1309179 & 688769 & 4.9 & 4.7759 & TRN \\
\hline CHEMBL1486465 & 688769 & 4.4 & 4.5732 & TRN \\
\hline CHEMBL1408847 & 688769 & 5.2 & 5.2347 & TRN \\
\hline CHEMBL70582 & 688769 & 4.4 & 4.5365 & TRN \\
\hline CHEMBL1409985 & 688769 & 5.4 & 5.2159 & TRN \\
\hline CHEMBL1602699 & 688769 & 5.3 & 5.2322 & TRN \\
\hline CHEMBL1303139 & 688769 & 5.1 & 5.12 & TRN \\
\hline CHEMBL1492884 & 688769 & 4.4 & 4.3915 & TRN \\
\hline CHEMBL175193 & 688769 & 4.1 & 4.2354 & TRN \\
\hline CHEMBL 28 & 688769 & 4.1 & 4.3468 & TRN \\
\hline CHEMBL1471289 & 688769 & 4.4 & 4.4653 & TRN \\
\hline CHEMBL8320 & 688769 & 4.3 & 4.3954 & TRN \\
\hline CHEMBL486193 & 688769 & 4.3 & 4.7417 & TST \\
\hline CHEMBL3391990 & 688769 & 4.4 & 4.4721 & TST \\
\hline CHEMBL935 & 688769 & 4.4 & 4.3728 & TRN \\
\hline CHEMBL1414154 & 688769 & 4.3 & 4.205 & TRN \\
\hline CHEMBL1517425 & 688769 & 4.3 & 4.1904 & TRN \\
\hline CHEMBL1569226 & 688769 & 5.1 & 5.187 & TRN \\
\hline
\end{tabular}




\begin{tabular}{|c|c|c|c|c|c|c|}
\hline \multicolumn{7}{|c|}{ Supplemental Table S2.txt } \\
\hline CHEMBL1319452 & 688769 & 4.4 & 4.5138 & TRN & & \\
\hline CHEMBL1558796 & 688769 & 4.4 & 4.5561 & TRN & & \\
\hline CHEMBL1393325 & 688769 & 4.4 & 4.3776 & TRN & & \\
\hline CHEMBL1496957 & 688769 & 4.5 & 4.6732 & TRN & & \\
\hline CHEMBL1462419 & 688769 & 4.3 & 4.4458 & TST & & \\
\hline CHEMBL105712 & 688769 & 4.9 & 4.9713 & TRN & & \\
\hline CHEMBL1451833 & 688769 & 4.4 & 4.4553 & TST & & \\
\hline CHEMBL220845 & 688769 & 4.3 & 4.2934 & TRN & & \\
\hline CHEMBL167423 & 688769 & 4.1 & 4.303 & TRN & & \\
\hline CHEMBL440287 & 688769 & 4.3 & 4.5028 & TRN & & \\
\hline CHEMBL144530 & 688769 & 4.4 & 4.331 & TRN & & \\
\hline CHEMBL289277 & 688769 & 4.3 & 4.4081 & TRN & & \\
\hline CHEMBL1492729 & 688769 & 4.6 & 4.6732 & TRN & & \\
\hline CHEMBL1366408 & 688769 & 4.4 & 4.5761 & TRN & & \\
\hline CHEMBL334255 & 688769 & 4.8 & 4.9233 & TRN & & \\
\hline CHEMBL36296 & 688769 & 4.3 & 4.2716 & TRN & & \\
\hline CHEMBL1492104 & 688769 & 4.4 & 4.7748 & TST & & \\
\hline CHEMBL1448387 & 688769 & 4.4 & 4.5665 & TRN & & \\
\hline CHEMBL195953 & 688769 & 4.3 & 4.2482 & TRN & & \\
\hline CHEMBL1526319 & 688769 & 4.5 & 4.3878 & TRN & & \\
\hline CHEMBL 242080 & 688769 & 4.3 & 4.5122 & TRN & & \\
\hline CHEMBL1485360 & 688769 & 4.9 & 4.5746 & TST & & \\
\hline CHEMBL1331245 & 688769 & 4.3 & 4.2581 & TRN & & \\
\hline CHEMBL1569493 & 688769 & 5.9 & 5.7944 & TRN & & \\
\hline CHEMBL1450607 & 688769 & 4.6 & 4.5876 & TRN & & \\
\hline CHEMBL1535689 & 688769 & 4.5 & 4.3421 & TRN & & \\
\hline CHEMBL44072 & 688769 & 4.4 & 4.3697 & TST & & \\
\hline CHEMBL1566504 & 688769 & 4.5 & 4.3566 & TST & & \\
\hline CHEMBL1518369 & 688769 & 4.4 & 4.4304 & TST & & \\
\hline CHEMBL1565705 & 688769 & 4.3 & 4.3491 & TST & & \\
\hline CHEMBL162598 & 688769 & 4.3 & 4.3445 & TST & & \\
\hline CHEMBL402063 & 688769 & 6.0 & 5.2624 & TST & & \\
\hline CHEMBL1447588 & 688769 & 5.5 & 4.982 & TST & & \\
\hline CHEMBL1524617 & 688769 & 5.1 & 5.0793 & TST & & \\
\hline CHEMBL1612246 & 688769 & 4.5 & 4.4994 & TST & & \\
\hline CHEMBL1484480 & 688769 & 4.1 & 4.1743 & TST & & \\
\hline CHEMBL57394 & 688769 & 4.4 & 4.4854 & TST & & \\
\hline CHEMBL454173 & 688769 & 4.3 & 4.7763 & TST & & \\
\hline CHEMBL1545634 & 688769 & 6.5 & 6.3653 & TST & & \\
\hline CHEMBL3199041 & 737258 & 5.0947 & 5.0174 & TRN & & \\
\hline CHEMBL1255778 & 737258 & 4.9393 & 4.3863 & TST & & \\
\hline CHEMBL1719094 & 737258 & 4.9031 & 4.9634 & TRN & & \\
\hline CHEMBL1399492 & 737258 & 4.8153 & 4.7521 & TRN & & \\
\hline CHEMBL1469921 & 737258 & 4.6737 & 4.6949 & TRN & & \\
\hline CHEMBL1459664 & 737258 & 4.05399 & 999999999 & 99 & 4.1388 & TRN \\
\hline CHEMBL1426383 & 737258 & 4.2104 & 4.477 & TRN & & \\
\hline CHEMBL1724929 & 737258 & 3.0 & 4.612 & TRN & & \\
\hline CHEMBL1381922 & 737258 & 5.0367 & 4.9618 & TRN & & \\
\hline
\end{tabular}




\begin{tabular}{|c|c|c|c|c|c|c|}
\hline & & \multicolumn{5}{|c|}{ Supplemental Table S2.txt } \\
\hline CHEMBL1458290 & 737258 & 4.2749 & 4.367 & TRN & & \\
\hline CHEMBL1442460 & 737258 & 5.011 & 4.4629 & TST & & \\
\hline CHEMBL1510785 & 737258 & 4.0757 & 3.9672 & TRN & & \\
\hline CHEMBL1387581 & 737258 & 4.5969 & 4.886 & TRN & & \\
\hline CHEMBL1528487 & 737258 & 4.7282 & 4.5886 & TRN & & \\
\hline CHEMBL1732408 & 737258 & 4.7033 & 4.7478 & TRN & & \\
\hline CHEMBL1326265 & 737258 & 4.7696 & 4.7432 & TRN & & \\
\hline CHEMBL1449875 & 737258 & 4.8794 & 4.2409 & TST & & \\
\hline CHEMBL3199286 & 737258 & 4.1325 & 4.7278 & TRN & & \\
\hline CHEMBL1381655 & 737258 & 5.0079 & 4.7956 & TRN & & \\
\hline CHEMBL1320007 & 737258 & 4.8327 & 4.7907 & TRN & & \\
\hline CHEMBL1443436 & 737258 & 4.7282 & 4.828 & TRN & & \\
\hline CHEMBL1328229 & 737258 & 4.2218 & 4.2505 & TRN & & \\
\hline CHEMBL1536250 & 737258 & 4.27 & 4.0652 & TRN & & \\
\hline CHEMBL1386267 & 737258 & 4.5467 & 4.8057 & TST & & \\
\hline CHEMBL1730620 & 737258 & 4.7773 & 4.9289 & TRN & & \\
\hline CHEMBL1410588 & 737258 & 4.3862 & 4.4327 & TRN & & \\
\hline CHEMBL3193098 & 737258 & 4.4535 & 4.37 & TRN & & \\
\hline CHEMBL1338507 & 737258 & 4.5935 & 4.6437 & TRN & & \\
\hline CHEMBL3189698 & 737258 & 4.71899 & 99999999 & 99 & 4.7362 & TRN \\
\hline CHEMBL1548196 & 737258 & 4.8665 & 4.8936 & TRN & & \\
\hline CHEMBL1411435 & 737258 & 4.8665 & 4.9096 & TRN & & \\
\hline CHEMBL1499914 & 737258 & 4.8962 & 4.8264 & TRN & & \\
\hline CHEMBL1505198 & 737258 & 6.1439 & 5.9234 & TRN & & \\
\hline CHEMBL1987472 & 737258 & 4.9508 & 4.8396 & TRN & & \\
\hline CHEMBL 2094652 & 737258 & 4.1221 & 4.8933 & TRN & & \\
\hline CHEMBL1969992 & 737258 & 4.9586 & 4.5864 & TRN & & \\
\hline CHEMBL1366575 & 737258 & 4.684 & 4.5986 & TRN & & \\
\hline CHEMBL1527436 & 737258 & 4.7282 & 4.7739 & TRN & & \\
\hline CHEMBL3198618 & 737258 & 4.9626 & 4.8945 & TRN & & \\
\hline CHEMBL195258 & 737258 & 4.9208 & 4.9858 & TRN & & \\
\hline CHEMBL1506682 & 737258 & 3.0 & 4.3685 & TST & & \\
\hline CHEMBL1721503 & 737258 & 4.1612 & 3.9505 & TRN & & \\
\hline CHEMBL1352305 & 737258 & 4.6364 & 4.5763 & TRN & & \\
\hline CHEMBL1425242 & 737258 & 4.8416 & 4.7841 & TST & & \\
\hline CHEMBL1510541 & 737258 & 4.8447 & 4.80399 & 9999999999 & & IRIN \\
\hline CHEMBL3211705 & 737258 & 4.1549 & 4.1269 & TRN & & \\
\hline CHEMBL1405239 & 737258 & 4.71899 & 99999999 & 99 & 4.7137 & TRN \\
\hline CHEMBL1357672 & 737258 & 4.8182 & 4.6954 & TRN & & \\
\hline CHEMBL3190268 & 737258 & 5.2418 & 4.4842 & TRN & & \\
\hline CHEMBL1583835 & 737258 & 4.71 & 4.773 & TRN & & \\
\hline CHEMBL1544375 & 737258 & 4.8153 & 4.7579 & TRN & & \\
\hline CHEMBL1323179 & 737258 & 4.8697 & 4.9451 & TRN & & \\
\hline CHEMBL1556273 & 737258 & 4.0825 & 4.3612 & TRN & & \\
\hline CHEMBL1463851 & 737258 & 4.8153 & 4.878 & TRN & & \\
\hline CHEMBL1370019 & 737258 & 4.2518 & 4.1954 & TRN & & \\
\hline CHEMBL1476029 & 737258 & 6.1785 & 5.1645 & TST & & \\
\hline CHEMBL1461502 & 737258 & 4.2062 & 4.2903 & TRN & & \\
\hline
\end{tabular}


Supplemental Table S2.txt

\begin{tabular}{|c|c|c|c|c|c|c|}
\hline CHEMBL3199008 & 737258 & 5.1068 & 4.9072 & TRN & & \\
\hline CHEMBL1718303 & 737258 & 4.7932 & 4.6678 & TST & & \\
\hline CHEMBL3144972 & 737258 & 4.5114 & 4.4776 & TRN & & \\
\hline CHEMBL1728960 & 737258 & 4.9031 & 4.7058 & TST & & \\
\hline CHEMBL1699830 & 737258 & 4.1238 & 3.9 & TRN & & \\
\hline CHEMBL1319190 & 737258 & 4.7773 & 4.5428 & TRN & & \\
\hline CHEMBL3207619 & 737258 & 4.6345 & 4.7662 & TRN & & \\
\hline CHEMBL3191453 & 737258 & 4.7852 & 4.8449 & TRN & & \\
\hline CHEMBL1585596 & 737258 & 4.618 & 4.6307 & TRN & & \\
\hline CHEMBL1393616 & 737258 & 4.4449 & 4.6456 & TRN & & \\
\hline CHEMBL3213353 & 737258 & 4.8794 & 4.7782 & TRN & & \\
\hline CHEMBL1587847 & 737258 & 4.1451 & 3.9495 & TRN & & \\
\hline CHEMBL1370217 & 737258 & 4.2161 & 4.4105 & TRN & & \\
\hline CHEMBL1398243 & 737258 & 4.1925 & 4.0977 & TRN & & \\
\hline CHEMBL3199528 & 737258 & 4.1752 & 4.5181 & TRN & & \\
\hline CHEMBL1507315 & 737258 & 4.0894 & 3.9604 & TRN & & \\
\hline CHEMBL70501 & 737258 & 3.0 & 4.5691 & TST & & \\
\hline CHEMBL1610857 & 737258 & 4.6021 & 4.6239 & TST & & \\
\hline CHEMBL1594374 & 737258 & 4.8386 & 4.7099 & TST & & \\
\hline CHEMBL1474042 & 737258 & 4.8097 & 4.8162 & TRN & & \\
\hline CHEMBL3199267 & 737258 & 4.8729 & 4.8019 & TRN & & \\
\hline CHEMBL1506262 & 737258 & 4.857 & 4.8239 & TRN & & \\
\hline CHEMBL1590634 & 737258 & 4.7496 & 4.6866 & TRN & & \\
\hline CHEMBL1300370 & 737258 & 6.2596 & 5.9045 & TRN & & \\
\hline CHEMBL1702573 & 737258 & 4.7305 & 4.7319 & TRN & & \\
\hline CHEMBL1375639 & 737258 & \multicolumn{3}{|c|}{5.718999999999999} & 4.9784 & TRN \\
\hline CHEMBL1348355 & 737258 & 4.9788 & 5.0387 & TRN & & \\
\hline CHEMBL1393486 & 737258 & 4.6904 & 4.5089 & TRN & & \\
\hline CHEMBL1584967 & 737258 & 4.1073 & 4.0765 & TRN & & \\
\hline CHEMBL1701354 & 737258 & 4.9788 & 4.9367 & TST & & \\
\hline CHEMBL1701850 & 737258 & 4.1029 & 3.9871 & TST & & \\
\hline CHEMBL1707286 & 737258 & 4.3737 & 5.0999 & TST & & \\
\hline CHEMBL1406348 & 737258 & 4.7852 & 4.8489 & TST & & \\
\hline CHEMBL1721433 & 737258 & 4.857 & 4.8409 & TST & & \\
\hline CHEMBL1355012 & 737258 & 4.8069 & 4.85 & TST & & \\
\hline CHEMBL1578931 & 737258 & 4.8697 & 4.7836 & TST & & \\
\hline CHEMBL3145067 & 737258 & 4.8182 & 4.675 & TST & & \\
\hline CHEMBL1323450 & 737258 & 4.8633 & 4.9036 & TST & & \\
\hline CHEMBL3195463 & 737258 & 4.2269 & 4.6684 & TST & & \\
\hline CHEMBL89445 & 737258 & 4.567 & 4.6295 & TST & & \\
\hline CHEMBL1371245 & 737258 & 4.9101 & 4.846 & TST & & \\
\hline CHEMBL1357122 & 737258 & 4.8327 & 4.8197 & TST & & \\
\hline CHEMBL1241165 & 659976 & 4.42 & 4.4629 & TRN & & \\
\hline CHEMBL1241164 & 659976 & 4.44 & 4.4785 & TRN & & \\
\hline CHEMBL1241262 & 659976 & 4.41 & 4.7628 & TST & & \\
\hline CHEMBL1241261 & 659976 & 4.96 & 4.9677 & TRN & & \\
\hline CHEMBL1241260 & 659976 & 4.64 & 4.6739 & TRN & & \\
\hline CHEMBL1241123 & 659976 & 4.36 & 4.3109 & TRN & & \\
\hline
\end{tabular}




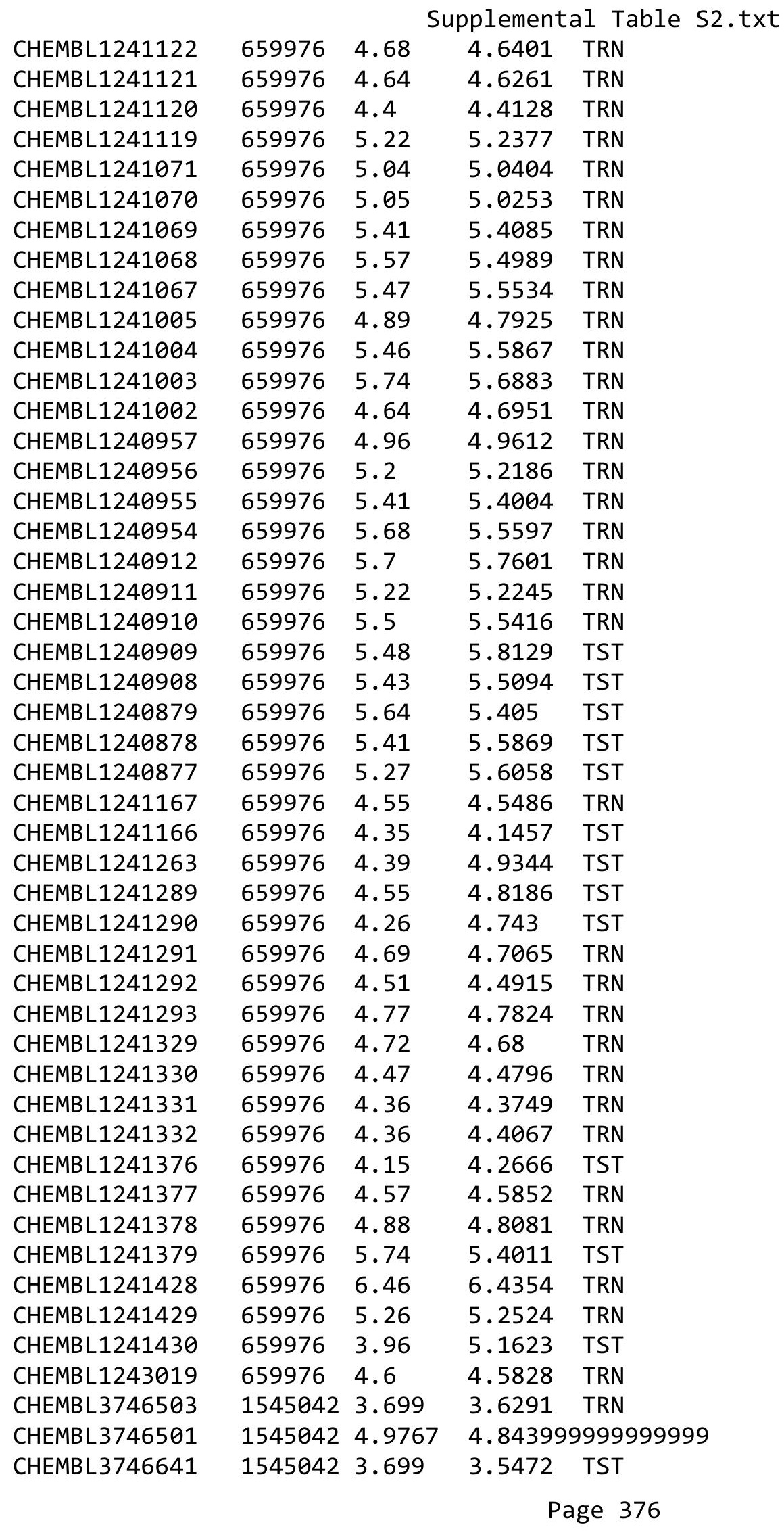

TRN 
Supplemental Table S2.txt

\begin{tabular}{|c|c|c|c|c|c|}
\hline CHEMBL 3747725 & 1545042 & 5.5654 & 5.7601 & TRN & \\
\hline CHEMBL3747035 & 1545042 & 5.3116 & 5.5111 & TRN & \\
\hline CHEMBL3747374 & 1545042 & 3.699 & 3.8147 & TST & \\
\hline CHEMBL3745908 & 1545042 & 5.7352 & 5.5522 & TRN & \\
\hline CHEMBL3746023 & 1545042 & 3.699 & 3.5881 & TST & \\
\hline CHEMBL3747163 & 1545042 & 3.699 & 3.4038 & TST & \\
\hline CHEMBL3746096 & 1545042 & 5.6289 & 5.7067 & TRN & \\
\hline CHEMBL3747671 & 1545042 & 3.699 & 3.6792 & TRN & \\
\hline CHEMBL3747598 & 1545042 & 5.6021 & 5.6801 & TRN & \\
\hline CHEMBL3746560 & 1545042 & 3.699 & 3.7382 & TRN & \\
\hline CHEMBL3747101 & 1545042 & 5.6517 & 5.5857 & TRN & \\
\hline CHEMBL 3745820 & 1545042 & 5.1555 & 5.2367 & TRN & \\
\hline CHEMBL3747564 & 1545042 & 5.0888 & 5.0591 & TRN & \\
\hline CHEMBL3745972 & 1545042 & 3.699 & 3.5072 & TST & \\
\hline CHEMBL3746628 & 1545042 & 5.4123 & 5.6627 & TRN & \\
\hline CHEMBL3747232 & 1545042 & 5.5114 & 5.5836 & TRN & \\
\hline CHEMBL3746767 & 1545042 & 3.699 & 4.0286 & TRN & \\
\hline CHEMBL 3746194 & 1545042 & 3.699 & 3.5083 & TST & \\
\hline CHEMBL3746790 & 1545042 & 3.699 & $3.72300 t$ & 00000000003 & TRN \\
\hline CHEMBL3747176 & 1545042 & 4.9654 & 4.8331 & TRN & \\
\hline CHEMBL3747627 & 1545042 & 5.0237 & 4.9228 & TRN & \\
\hline CHEMBL3746005 & 1545042 & 3.699 & 3.7212 & TRN & \\
\hline CHEMBL 3746360 & 1545042 & 3.699 & 3.4494 & TST & \\
\hline CHEMBL3747200 & 1545042 & 3.699 & 3.7429 & TRN & \\
\hline CHEMBL 3746744 & 1545042 & 5.1062 & 5.1351 & TRN & \\
\hline CHEMBL3746811 & 1545042 & 5.2899 & 5.3883 & TRN & \\
\hline CHEMBL3745971 & 1545042 & 3.699 & 3.6824 & TRN & \\
\hline CHEMBL 3746698 & 1545042 & 5.2464 & 5.0299 & TRN & \\
\hline CHEMBL3746688 & 1545042 & 5.0888 & 5.0133 & TRN & \\
\hline CHEMBL3746403 & 1545042 & 5.2933 & 5.2705 & TRN & \\
\hline CHEMBL3746500 & 1545042 & 3.699 & 3.4048 & TST & \\
\hline CHEMBL3746937 & 1545042 & 5.7305 & 5.7045 & TRN & \\
\hline CHEMBL 3747127 & 1545042 & 3.699 & 3.3585 & TST & \\
\hline CHEMBL3746216 & 1545042 & 4.9578 & 4.8511 & TRN & \\
\hline CHEMBL3747658 & 1545042 & 3.699 & 3.595 & TST & \\
\hline CHEMBL3747731 & 1545042 & 3.699 & 3.4732 & TST & \\
\hline CHEMBL3746684 & 1545042 & 5.7496 & 5.6381 & TRN & \\
\hline CHEMBL 3747384 & 1545042 & 3.699 & 3.8154 & TST & \\
\hline CHEMBL3746319 & 1545042 & 5.0883 & 4.9707 & TRN & \\
\hline CHEMBL3746987 & 1545042 & 3.699 & 3.7054 & TRN & \\
\hline CHEMBL3746668 & 1545042 & 5.1972 & 5.1584 & TRN & \\
\hline CHEMBL3746704 & 1545042 & 5.0482 & 4.9655 & TRN & \\
\hline CHEMBL3746132 & 1545042 & 5.1391 & 5.1917 & TRN & \\
\hline CHEMBL 3747745 & 1545042 & 3.699 & 3.5816 & TST & \\
\hline CHEMBL 3747242 & 1545042 & 3.699 & 3.8763 & TRN & \\
\hline CHEMBL3745869 & 1545042 & 5.0246 & 4.9533 & TRN & \\
\hline CHEMBL3746020 & 1545042 & 3.699 & 3.7671 & TRN & \\
\hline CHEMBL3747409 & 1545042 & 5.1637 & 5.3057 & TRN & \\
\hline
\end{tabular}


Supplemental Table S2.txt

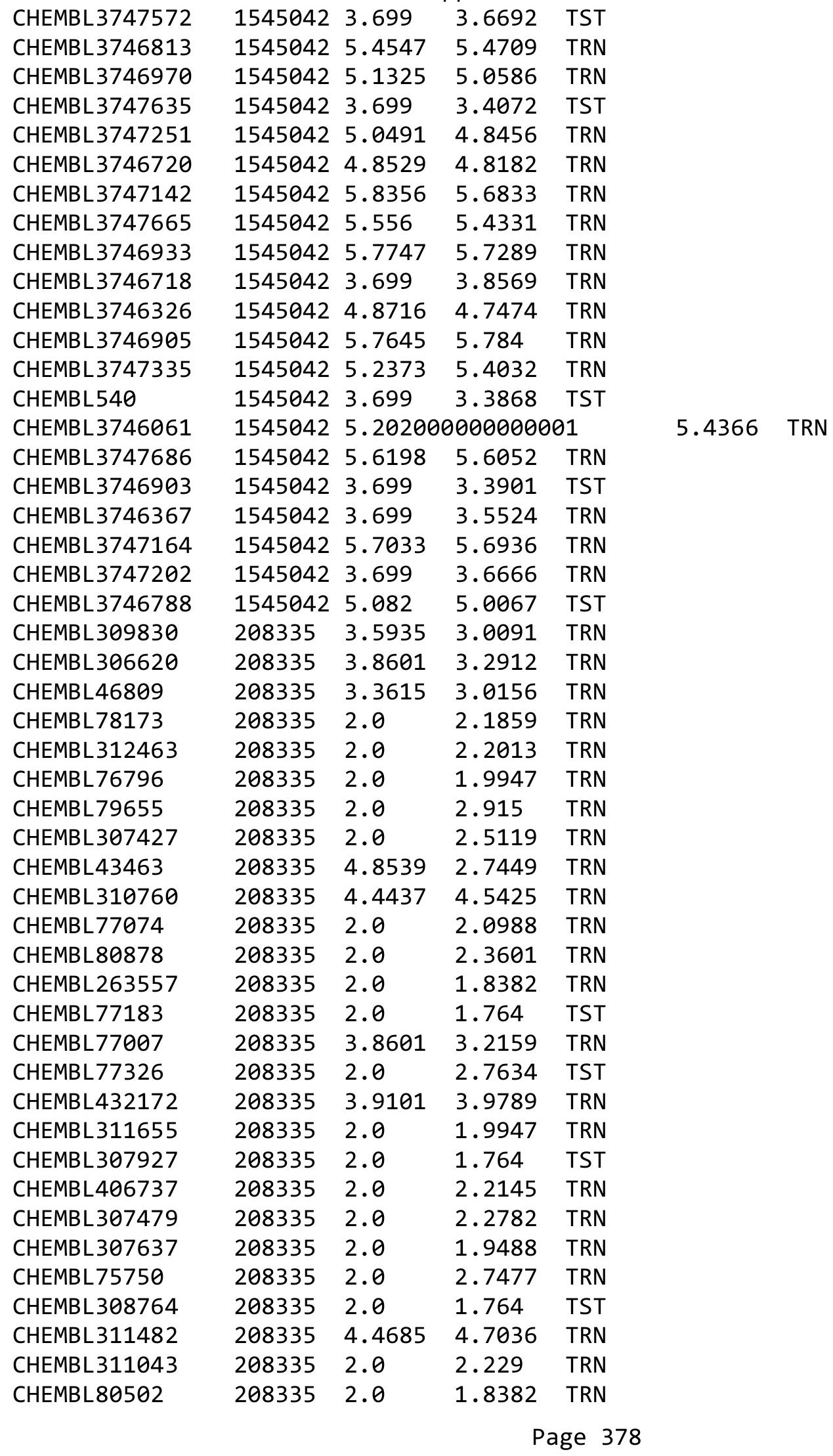




\begin{tabular}{|c|c|c|c|c|c|}
\hline \multicolumn{6}{|c|}{ Supplemental Table S2.txt } \\
\hline CHEMBL308632 & 208335 & 2.0 & 2.7222 & TRN & \\
\hline CHEMBL80930 & 208335 & 2.0 & 1.8872 & TRN & \\
\hline CHEMBL77043 & 208335 & 3.9508 & 3.2667 & TST & \\
\hline CHEMBL298256 & 208335 & 4.2218 & 4.3161 & TRN & \\
\hline CHEMBL75624 & 208335 & 2.0 & 2.1347 & TST & \\
\hline CHEMBL75972 & 208335 & 2.0 & 1.9947 & TRN & \\
\hline CHEMBL 76883 & 208335 & 2.0 & 1.9947 & TRN & \\
\hline CHEMBL77949 & 208335 & 3.8356 & 2.9157 & TST & \\
\hline CHEMBL431969 & 208335 & 2.0 & 2.1455 & TRN & \\
\hline CHEMBL309395 & 208335 & 2.0 & 2.6851 & TST & \\
\hline CHEMBL76967 & 208335 & 2.0 & 1.91400 & 00000000001 & TRN \\
\hline CHEMBL77998 & 208335 & 2.0 & 2.0239 & TRN & \\
\hline CHEMBL 78283 & 208335 & 3.4401 & 3.529 & TRN & \\
\hline CHEMBL75635 & 208335 & 3.8861 & 3.0793 & TST & \\
\hline CHEMBL263244 & 208335 & 2.0 & 2.2077 & TRN & \\
\hline CHEMBL306622 & 208335 & 3.27 & 2.8515 & TRN & \\
\hline CHEMBL77361 & 208335 & 3.5702 & 2.5697 & TRN & \\
\hline CHEMBL 76070 & 208335 & 2.0 & 2.1 & TST & \\
\hline CHEMBL307597 & 208335 & 2.0 & 2.383 & TRN & \\
\hline CHEMBL312023 & 208335 & 2.0 & 2.5117 & TST & \\
\hline CHEMBL306258 & 208335 & 3.1302 & 2.2856 & TRN & \\
\hline CHEMBL75679 & 208335 & 2.0 & 2.3374 & TRN & \\
\hline CHEMBL 307374 & 208335 & 2.0 & 2.2781 & TST & \\
\hline CHEMBL 308630 & 208335 & 2.0 & 1.9304 & TRN & \\
\hline CHEMBL310412 & 208335 & 2.0 & 2.2263 & TRN & \\
\hline CHEMBL308074 & 208335 & 2.0 & 2.6839 & TRN & \\
\hline CHEMBL448786 & 208335 & 4.5376 & 4.6601 & TRN & \\
\hline CHEMBL263454 & 208335 & 2.0 & 2.2777 & TST & \\
\hline CHEMBL42900 & 208335 & 2.0 & 1.8872 & TST & \\
\hline CHEMBL 76424 & 208335 & 3.6716 & 3.1121 & TST & \\
\hline CHEMBL21013 & 48641 & 7.0915 & 7.1457 & TRN & \\
\hline CHEMBL 277184 & 48641 & 6.1675 & 6.1473 & TRN & \\
\hline CHEMBL283585 & 48641 & 7.3372 & 7.4012 & TRN & \\
\hline CHEMBL20639 & 48641 & 7.8861 & 7.4603 & TST & \\
\hline CHEMBL20629 & 48641 & 7.1805 & 7.3143 & TRN & \\
\hline CHEMBL21064 & 48641 & 6.7799 & 6.7901 & TRN & \\
\hline CHEMBL21197 & 48641 & 7.1249 & 7.1645 & TRN & \\
\hline CHEMBL20660 & 48641 & 8.5229 & 8.5999 & TRN & \\
\hline CHEMBL 280725 & 48641 & 7.3979 & 8.3986 & TST & \\
\hline CHEMBL21820 & 48641 & 7.5686 & 7.7236 & TRN & \\
\hline CHEMBL20413 & 48641 & 6.8861 & 6.8511 & TRN & \\
\hline CHEMBL20961 & 48641 & 7.3872 & 7.5206 & TRN & \\
\hline CHEMBL416180 & 48641 & 5.6778 & 8.0747 & TST & \\
\hline CHEMBL21154 & 48641 & 6.9508 & 8.19 & TST & \\
\hline CHEMBL21027 & 48641 & 8.5229 & 8.4862 & TRN & \\
\hline CHEMBL280947 & 48641 & 8.0969 & 7.8745 & TST & \\
\hline CHEMBL20603 & 48641 & 8.0969 & 7.978 & TST & \\
\hline CHEMBL20794 & 48641 & 7.3279 & 7.1246 & TRN & \\
\hline
\end{tabular}




\begin{tabular}{|c|c|c|c|c|c|}
\hline \multirow[b]{2}{*}{ CHEMBL279091 } & & \multicolumn{4}{|c|}{ Supplemental Table S2.txt } \\
\hline & 48641 & 8.301 & 8.23200 & 0000000001 & TRN \\
\hline CHEMBL278311 & 48641 & 7.1549 & 7.2127 & TRN & \\
\hline CHEMBL281175 & 48641 & 8.699 & 8.5839 & TRN & \\
\hline CHEMBL277949 & 48641 & 8.699 & 8.7271 & TRN & \\
\hline CHEMBL20815 & 48641 & 7.0362 & 8.3045 & TST & \\
\hline CHEMBL21092 & 48641 & 6.4202 & 6.3606 & TRN & \\
\hline CHEMBL278842 & 48641 & 7.4437 & 7.4394 & TRN & \\
\hline CHEMBL281581 & 48641 & 7.2366 & 7.2135 & TRN & \\
\hline CHEMBL282010 & 48641 & 7.4089 & 7.2941 & TRN & \\
\hline CHEMBL20536 & 48641 & 8.2218 & 8.3653 & TRN & \\
\hline CHEMBL20476 & 48641 & 7.0269 & 7.7577 & TST & \\
\hline CHEMBL20281 & 48641 & 7.4089 & 7.5339 & TRN & \\
\hline CHEMBL277028 & 48641 & 7.4437 & 7.3901 & TRN & \\
\hline CHEMBL277679 & 48641 & 8.301 & 8.2188 & TRN & \\
\hline CHEMBL21312 & 48641 & 7.8861 & 7.6272 & TST & \\
\hline CHEMBL280696 & 48641 & 8.3979 & 8.1974 & TRN & \\
\hline CHEMBL279212 & 48641 & 9.0 & 9.0202 & TRN & \\
\hline CHEMBL22115 & 48641 & 7.8539 & 7.7066 & TRN & \\
\hline CHEMBL282459 & 48641 & 7.8239 & 8.1442 & TST & \\
\hline CHEMBL20708 & 48641 & 6.8827 & 6.8467 & TRN & \\
\hline CHEMBL279519 & 48641 & 7.9586 & 8.0984 & TRN & \\
\hline CHEMBL20604 & 48641 & 8.0458 & 8.0146 & TRN & \\
\hline CHEMBL 20475 & 48641 & 6.6676 & 7.9691 & TST & \\
\hline CHEMBL278128 & 48641 & 7.5376 & 7.8516 & TRN & \\
\hline CHEMBL20766 & 48641 & 8.1549 & 8.1839 & TRN & \\
\hline CHEMBL 20934 & 48641 & 8.699 & 8.5873 & TRN & \\
\hline CHEMBL20258 & 48641 & 6.9666 & 8.3526 & TST & \\
\hline CHEMBL 20714 & 48641 & 9.0 & 9.0068 & TRN & \\
\hline CHEMBL 21125 & 48641 & 8.699 & 8.6957 & TRN & \\
\hline CHEMBL279287 & 48641 & 8.3979 & 8.0198 & TST & \\
\hline CHEMBL19990 & 48641 & 7.6383 & 7.6791 & TRN & \\
\hline CHEMBL20821 & 48641 & 7.0555 & 7.0247 & TRN & \\
\hline CHEMBL21039 & 48641 & 7.585 & 7.5775 & TRN & \\
\hline CHEMBL 20299 & 48641 & 8.1549 & 8.1481 & TRN & \\
\hline CHEMBL 20561 & 48641 & 8.0969 & 7.3398 & TST & \\
\hline CHEMBL416733 & 48641 & 7.6576 & 7.7166 & TRN & \\
\hline CHEMBL21065 & 48641 & 8.2218 & 8.1266 & TRN & \\
\hline CHEMBL20832 & 48641 & 8.301 & 8.1574 & TRN & \\
\hline CHEMBL 3356057 & 1445188 & 6.3778 & 6.6066 & TRN & \\
\hline CHEMBL 3092465 & 1445188 & 8.5229 & 7.9362 & TRN & \\
\hline CHEMBL 3092460 & 1445188 & 8.5229 & 8.0916 & TRN & \\
\hline CHEMBL 3356045 & 1445188 & 6.3904 & 6.5044 & TRN & \\
\hline CHEMBL3356049 & 1445188 & 8.699 & 8.8079 & TRN & \\
\hline CHEMBL 3356014 & 1445188 & 5.7447 & 8.333 & TST & \\
\hline CHEMBL 3356044 & 1445188 & 8.699 & 8.6359 & TRN & \\
\hline CHEMBL 3356013 & 1445188 & 5.6459 & 7.9379 & TST & \\
\hline CHEMBL 3092467 & 1445188 & 8.699 & 8.5776 & TRN & \\
\hline CHEMBL 3356034 & 1445188 & 10.0 & 10.3778 & TRN & \\
\hline
\end{tabular}




\begin{tabular}{|c|c|c|c|c|c|}
\hline \multicolumn{6}{|c|}{ Supplemental Table s2.txt } \\
\hline CHEMBL3356051 & 1445188 & 8.0 & 8.0412 & TRN & \\
\hline CHEMBL3356054 & 1445188 & 8.5229 & 8.2158 & TRN & \\
\hline CHEMBL3356050 & 1445188 & 8.699 & 9.0063 & TRN & \\
\hline CHEMBL3356019 & 1445188 & 7.8539 & 8.3874 & TST & \\
\hline CHEMBL3356025 & 1445188 & 10.0 & 10.293 & TRN & \\
\hline CHEMBL3356058 & 1445188 & 7.8861 & 8.0443 & TRN & \\
\hline CHEMBL3356032 & 1445188 & 10.0 & 9.7288 & TRN & \\
\hline CHEMBL3356042 & 1445188 & 7.6778 & 7.8696 & TRN & \\
\hline CHEMBL3356023 & 1445188 & 10.0 & 9.6394 & TRN & \\
\hline CHEMBL3356029 & 1445188 & 9.0 & 9.0934 & TRN & \\
\hline CHEMBL3356056 & 1445188 & 6.3045 & 6.422999 & 9999999999 & TRN \\
\hline CHEMBL3356037 & 1445188 & 10.0 & 10.5501 & TRN & \\
\hline CHEMBL3092466 & 1445188 & 8.699 & 8.5765 & TRN & \\
\hline CHEMBL3356015 & 1445188 & 6.5017 & 6.8743 & TRN & \\
\hline CHEMBL3356047 & 1445188 & 7.8239 & 7.9749 & TRN & \\
\hline CHEMBL 3092468 & 1445188 & 9.0 & 8.6443 & TRN & \\
\hline CHEMBL3356036 & 1445188 & 9.301 & 9.738 & TRN & \\
\hline CHEMBL3092464 & 1445188 & 8.3979 & 8.4802 & TRN & \\
\hline CHEMBL3356053 & 1445188 & 8.699 & 8.4426 & TRN & \\
\hline CHEMBL3356030 & 1445188 & 10.0 & 9.2623 & TRN & \\
\hline CHEMBL3356041 & 1445188 & 7.8539 & 7.9553 & TRN & \\
\hline CHEMBL3356018 & 1445188 & 8.5229 & 8.7479 & TRN & \\
\hline CHEMBL3356016 & 1445188 & 7.5528 & 7.2579 & TRN & \\
\hline CHEMBL 3356024 & 1445188 & 8.699 & 9.6721 & TST & \\
\hline CHEMBL 3092461 & 1445188 & 8.301 & 8.542 & TRN & \\
\hline CHEMBL3356033 & 1445188 & 10.0 & 9.8663 & TST & \\
\hline CHEMBL3356052 & 1445188 & 8.5229 & 8.4007 & TRN & \\
\hline CHEMBL3356055 & 1445188 & 6.3575 & 6.5842 & TRN & \\
\hline CHEMBL3356027 & 1445188 & 7.3372 & 8.7527 & TST & \\
\hline CHEMBL3356059 & 1445188 & 8.699 & 8.6604 & TRN & \\
\hline CHEMBL3356038 & 1445188 & 7.7959 & 7.6001 & TRN & \\
\hline CHEMBL3356021 & 1445188 & 10.0 & 9.607999 & 9999999999 & TST \\
\hline CHEMBL3356060 & 1445188 & 8.5229 & 8.1534 & TRN & \\
\hline CHEMBL3356017 & 1445188 & 4.8794 & 8.7089 & TST & \\
\hline CHEMBL3356012 & 1445188 & 5.1463 & 7.7628 & TST & \\
\hline CHEMBL3356039 & 1445188 & 8.3979 & 7.9232 & TRN & \\
\hline CHEMBL3356028 & 1445188 & 9.699 & 10.0247 & TST & \\
\hline CHEMBL3356035 & 1445188 & 9.301 & 10.4152 & TST & \\
\hline CHEMBL 3092462 & 1445188 & 8.699 & 8.5204 & TRN & \\
\hline CHEMBL3356031 & 1445188 & 8.0458 & 9.0922 & TST & \\
\hline CHEMBL3356048 & 1445188 & 8.699 & 8.4746 & TRN & \\
\hline CHEMBL3356061 & 1445188 & 7.5376 & 7.8268 & TRN & \\
\hline CHEMBL3356026 & 1445188 & 8.2218 & 9.5127 & TST & \\
\hline CHEMBL3356022 & 1445188 & 6.9066 & 8.2453 & TST & \\
\hline CHEMBL 3092463 & 1445188 & 8.699 & 8.591000 & 0000000001 & TRN \\
\hline CHEMBL3356040 & 1445188 & 6.7077 & 7.4605 & TRN & \\
\hline CHEMBL3356046 & 1445188 & 7.6576 & 7.8157 & TRN & \\
\hline CHEMBL3356020 & 1445188 & 7.7212 & 8.4011 & TST & \\
\hline
\end{tabular}


Supplemental Table S2.txt

\begin{tabular}{|c|c|c|c|c|c|}
\hline CHEMBL583691 & 588709 & 7.6778 & 7.7186 & TRN & \\
\hline CHEMBL573045 & 588709 & 7.5376 & 7.9927 & TST & \\
\hline CHEMBL584563 & 588709 & 8.1549 & 8.0227 & TRN & \\
\hline CHEMBL575263 & 588709 & 8.699 & 8.4121 & TRN & \\
\hline CHEMBL573044 & 588709 & 6.9626 & 6.8723 & TRN & \\
\hline CHEMBL573463 & 588709 & 9.0458 & 8.2884 & TST & \\
\hline CHEMBL572556 & 588709 & 7.0809 & 7.5793 & TRN & \\
\hline CHEMBL573477 & 588709 & 4.8465 & 4.9437 & TRN & \\
\hline CHEMBL576734 & 588709 & 7.6383 & 7.6722 & TST & \\
\hline CHEMBL573012 & 588709 & 8.5229 & 8.4111 & TST & \\
\hline CHEMBL584161 & 588709 & 7.2218 & 7.1191 & TRN & \\
\hline CHEMBL573923 & 588709 & 7.3565 & 7.306 & TRN & \\
\hline CHEMBL573476 & 588709 & 6.8327 & 6.0319 & TRN & \\
\hline CHEMBL573929 & 588709 & 7.3872 & 6.7172 & TST & \\
\hline CHEMBL575255 & 588709 & 7.8861 & 8.0994 & TRN & \\
\hline CHEMBL584564 & 588709 & 4.8465 & 7.1332 & TST & \\
\hline CHEMBL575460 & 588709 & 4.8465 & 4.93199 & 99999999995 & TRN \\
\hline CHEMBL572783 & 588709 & 8.5229 & 8.186 & TRN & \\
\hline CHEMBL575461 & 588709 & 8.5229 & 7.9936 & TRN & \\
\hline CHEMBL575470 & 588709 & 7.7959 & 8.1466 & TRN & \\
\hline CHEMBL573011 & 588709 & 6.0273 & 6.2885 & TRN & \\
\hline CHEMBL572550 & 588709 & 7.9208 & 7.8713 & TRN & \\
\hline CHEMBL573696 & 588709 & 4.8465 & 4.6276 & TRN & \\
\hline CHEMBL583947 & 588709 & 7.3979 & 7.1148 & TRN & \\
\hline CHEMBL573956 & 588709 & 4.8465 & 5.4889 & TRN & \\
\hline CHEMBL583913 & 588709 & 8.3979 & 8.6329 & TRN & \\
\hline CHEMBL573705 & 588709 & 7.8861 & 8.0108 & TRN & \\
\hline CHEMBL573036 & 588709 & 7.1805 & 7.8052 & TRN & \\
\hline CHEMBL576387 & 588709 & 8.699 & 8.5515 & TRN & \\
\hline CHEMBL572743 & 588709 & 6.399 & 6.9338 & TRN & \\
\hline CHEMBL585182 & 588709 & 8.5229 & 8.5813 & TRN & \\
\hline CHEMBL575469 & 588709 & 4.8465 & 4.3383 & TRN & \\
\hline CHEMBL576388 & 588709 & 8.2218 & 8.2154 & TRN & \\
\hline CHEMBL575264 & 588709 & 6.8182 & 7.1082 & TRN & \\
\hline CHEMBL575675 & 588709 & 7.6576 & 7.607 & TRN & \\
\hline CHEMBL573697 & 588709 & 6.1481 & 5.8567 & TRN & \\
\hline CHEMBL573659 & 588709 & 6.8268 & 6.7832 & TST & \\
\hline CHEMBL573478 & 588709 & 6.3872 & 6.8918 & TRN & \\
\hline CHEMBL575471 & 588709 & 4.8477 & 6.6961 & TRN & \\
\hline CHEMBL583690 & 588709 & 4.8465 & 5.1815 & TRN & \\
\hline CHEMBL573475 & 588709 & 6.6861 & 7.2403 & TST & \\
\hline CHEMBL572745 & 588709 & 7.2007 & 7.0645 & TRN & \\
\hline CHEMBL573957 & 588709 & 8.301 & 7.8227 & TST & \\
\hline CHEMBL572809 & 588709 & 6.8153 & 6.1423 & TRN & \\
\hline CHEMBL574168 & 588709 & 7.5229 & 7.6984 & TRN & \\
\hline CHEMBL575254 & 588709 & 7.5376 & 7.4264 & TRN & \\
\hline CHEMBL572514 & 588709 & 8.301 & 8.3844 & TRN & \\
\hline CHEMBL573046 & 588709 & 6.9208 & 7.7374 & TST & \\
\hline
\end{tabular}




\begin{tabular}{|c|c|c|c|c|c|}
\hline \multirow[b]{2}{*}{ CHEMBL583385 } & \\
\hline & 588709 & 7.3468 & 6.9381 & TRN & \\
\hline CHEMBL582966 & 588709 & 5.9431 & 5.9592 & TST & \\
\hline CHEMBL574169 & 588709 & 8.699 & 8.3135 & TRN & \\
\hline CHEMBL583581 & 588709 & 7.4437 & 7.3063 & TRN & \\
\hline CHEMBL572810 & 588709 & 7.0044 & 7.3427 & TRN & \\
\hline CHEMBL572815 & 588709 & 7.4949 & 6.9541 & TRN & \\
\hline CHEMBL572781 & 588709 & 8.0 & 7.2813 & TST & \\
\hline CHEMBL582844 & 588709 & 7.8861 & 7.23 & TRN & \\
\hline CHEMBL583187 & 588709 & 8.699 & 8.4916 & TST & \\
\hline CHEMBL575463 & 588709 & 8.699 & 8.2156 & TRN & \\
\hline CHEMBL573038 & 588709 & 6.6234 & 6.8238 & TRN & \\
\hline CHEMBL583099 & 588709 & 6.9136 & 7.2611 & TRN & \\
\hline CHEMBL573702 & 588709 & 7.6778 & 7.9379 & TRN & \\
\hline CHEMBL573462 & 588709 & 6.8601 & 7.0136 & TST & \\
\hline CHEMBL572784 & 588709 & 8.2218 & 8.0591 & TRN & \\
\hline CHEMBL583144 & 588709 & 6.7846 & 6.7099 & TST & \\
\hline CHEMBL583273 & 588709 & 8.0969 & 7.2417 & TRN & \\
\hline CHEMBL584159 & 588709 & 5.9031 & 6.86299 & 99999999995 & TST \\
\hline CHEMBL573037 & 588709 & 6.6757 & 6.9607 & TRN & \\
\hline CHEMBL573470 & 588709 & 7.4685 & 7.9251 & TST & \\
\hline CHEMBL3984168 & 1639949 & 8.301 & 7.5458 & TST & \\
\hline CHEMBL3896927 & 1639949 & 8.301 & 7.7837 & TRN & \\
\hline CHEMBL 3897525 & 1639949 & 8.301 & 8.6649 & TRN & \\
\hline CHEMBL3932218 & 1639949 & 7.301 & 7.7911 & TRN & \\
\hline CHEMBL3976826 & 1639949 & 6.0 & 6.6217 & TST & \\
\hline CHEMBL3937598 & 1639949 & 7.301 & 7.5496 & TRN & \\
\hline CHEMBL3896067 & 1639949 & 7.301 & 7.1877 & TRN & \\
\hline CHEMBL3912646 & 1639949 & 7.301 & 7.9014 & TRN & \\
\hline CHEMBL 3952048 & 1639949 & 7.301 & 7.481 & TRN & \\
\hline CHEMBL3919145 & 1639949 & 7.301 & 7.4546 & TRN & \\
\hline CHEMBL3916297 & 1639949 & 7.301 & 6.927006 & 00000000005 & TRN \\
\hline CHEMBL 3944702 & 1639949 & 7.301 & 7.4483 & TRN & \\
\hline CHEMBL3935851 & 1639949 & 7.301 & 7.8158 & TST & \\
\hline CHEMBL 3892030 & 1639949 & 8.301 & 7.9984 & TRN & \\
\hline CHEMBL 3977221 & 1639949 & 8.301 & 7.6456 & TRN & \\
\hline CHEMBL3974328 & 1639949 & 7.301 & 7.0136 & TRN & \\
\hline CHEMBL3944857 & 1639949 & 8.301 & 7.9495 & TRN & \\
\hline CHEMBL3907879 & 1639949 & 7.301 & 7.5184 & TRN & \\
\hline CHEMBL 3890263 & 1639949 & 8.301 & 7.5951 & TRN & \\
\hline CHEMBL3907215 & 1639949 & 7.301 & 7.7167 & TRN & \\
\hline CHEMBL 3922278 & 1639949 & 8.301 & 7.942 & TRN & \\
\hline CHEMBL3959160 & 1639949 & 6.0 & 6.6084 & TST & \\
\hline CHEMBL3932115 & 1639949 & 6.0 & 7.0838 & TRN & \\
\hline CHEMBL3972712 & 1639949 & 8.301 & 8.2774 & TRN & \\
\hline CHEMBL 3936440 & 1639949 & 7.301 & 7.1269 & TST & \\
\hline CHEMBL3928696 & 1639949 & 8.301 & 7.69 & TRN & \\
\hline CHEMBL3959254 & 1639949 & 8.301 & 7.9198 & TST & \\
\hline CHEMBL 3943570 & 1639949 & 8.301 & 8.03 & TRN & \\
\hline & & & & ge 383 & \\
\hline
\end{tabular}


Supplemental Table S2.txt

\begin{tabular}{|c|c|c|c|c|c|}
\hline CHEMBL3939671 & 1639949 & 8.301 & 8.3253 & TRN & \\
\hline CHEMBL3895129 & 1639949 & 8.301 & 7.9983 & TRN & \\
\hline CHEMBL3936151 & 1639949 & 8.301 & 7.9408 & TRN & \\
\hline CHEMBL3963821 & 1639949 & 8.301 & 7.7381 & TRN & \\
\hline CHEMBL3930429 & 1639949 & 7.301 & 7.4306 & TRN & \\
\hline CHEMBL3905012 & 1639949 & 7.301 & 7.5534 & TRN & \\
\hline CHEMBL3979317 & 1639949 & 7.301 & 7.1792 & TRN & \\
\hline CHEMBL3925935 & 1639949 & 8.301 & 8.1572 & TRN & \\
\hline CHEMBL3899485 & 1639949 & 7.301 & 7.0426 & TRN & \\
\hline CHEMBL3900567 & 1639949 & 6.0 & 6.2662 & TRN & \\
\hline CHEMBL3914671 & 1639949 & 7.301 & 7.6351 & TRN & \\
\hline CHEMBL3970332 & 1639949 & 6.0 & 6.8936 & TRN & \\
\hline CHEMBL3955873 & 1639949 & 6.0 & 6.7431 & TST & \\
\hline CHEMBL 3943734 & 1639949 & 7.301 & 6.9527 & TRN & \\
\hline CHEMBL3983245 & 1639949 & 8.301 & 7.8379 & TRN & \\
\hline CHEMBL3964536 & 1639949 & 8.301 & 8.4734 & TRN & \\
\hline CHEMBL3928180 & 1639949 & 8.301 & 7.9918 & TRN & \\
\hline CHEMBL3979687 & 1639949 & 6.0 & 6.6759 & TRN & \\
\hline CHEMBL3930406 & 1639949 & 7.301 & 7.3368 & TRN & \\
\hline CHEMBL3968519 & 1639949 & 8.301 & 8.2648 & TST & \\
\hline CHEMBL3923645 & 1639949 & 7.301 & 7.0925 & TRN & \\
\hline CHEMBL3986102 & 1639949 & 8.301 & 8.3851 & TRN & \\
\hline CHEMBL3965096 & 1639949 & 7.301 & 8.2341 & TRN & \\
\hline CHEMBL3937857 & 1639949 & 6.0 & 6.7803 & TST & \\
\hline CHEMBL 3924380 & 1639949 & 7.301 & 7.0199 & TRN & \\
\hline CHEMBL3891130 & 1639949 & 7.301 & 7.6414 & TST & \\
\hline CHEMBL3949434 & 1639949 & 8.301 & 7.8653 & TST & \\
\hline CHEMBL3913860 & 1639949 & 7.301 & 7.5569 & TRN & \\
\hline CHEMBL3916706 & 1639949 & 8.301 & 7.5824 & TST & \\
\hline CHEMBL3979728 & 1639949 & 8.301 & 7.737 & TRN & \\
\hline CHEMBL3931724 & 1639949 & 7.301 & 7.5362 & TRN & \\
\hline CHEMBL3919051 & 1639949 & 8.301 & 7.7048 & TRN & \\
\hline CHEMBL3940839 & 1639949 & 8.301 & 8.4199 & TRN & \\
\hline CHEMBL 3904460 & 1639949 & 8.301 & 8.3515 & TRN & \\
\hline CHEMBL3914180 & 1639949 & 8.301 & 8.1914 & TRN & \\
\hline CHEMBL3931393 & 1639949 & 7.301 & 7.6665 & TRN & \\
\hline CHEMBL3926466 & 1639949 & 8.301 & 7.8248 & TRN & \\
\hline CHEMBL3962335 & 1639949 & 8.301 & 7.6562 & TST & \\
\hline CHEMBL3914189 & 1639949 & 7.301 & 8.0969 & TST & \\
\hline CHEMBL3913719 & 1639949 & 8.301 & 7.9566 & TRN & \\
\hline CHEMBL3933130 & 1639949 & 7.301 & 7.9152 & TST & \\
\hline CHEMBL3923449 & 1639949 & 8.301 & 8.05299 & 9999999999 & TRN \\
\hline CHEMBL3960730 & 1639949 & 8.301 & 6.9908 & TST & \\
\hline CHEMBL3895424 & 1639949 & 7.301 & 7.1122 & TRN & \\
\hline CHEMBL3962355 & 1639949 & 7.301 & 7.9113 & TRN & \\
\hline CHEMBL3958721 & 1639949 & 6.0 & 6.5996 & TRN & \\
\hline CHEMBL3977320 & 1639949 & 8.301 & 7.857 & TST & \\
\hline CHEMBL3971864 & 1639949 & 6.0 & 6.7288 & TRN & \\
\hline
\end{tabular}


Supplemental Table S2.txt

\begin{tabular}{|c|c|c|c|c|}
\hline HEMBL3968030 & 539949 & 年 & 7.6099 & TRN \\
\hline HEMBL3893058 & 639949 & 6.0 & 6.8307 & TST \\
\hline 31193 & 539949 & 7.301 & & $\mathrm{RN}$ \\
\hline IEMBL 3904481 & 539949 & 8.301 & 768 & RN \\
\hline AEMBL3959857 & 539949 & 7.301 & 9253 & $\mathrm{~T}$ \\
\hline AEMBL3933123 & 639949 & 7.301 & .6161 & ST \\
\hline AEMBL 3923013 & 639949 & 8.301 & 8382 & RN \\
\hline IEMBL39 & 539949 & 8.301 & 8533 & RN \\
\hline AEMBL 3890300 & 639949 & 6.0 & 6.6913 & ST \\
\hline AEMBL3953937 & 639949 & 7.301 & 7.647 & N \\
\hline AEMBL3909572 & 639949 & 7.301 & 1068 & \\
\hline AEMBL3893416 & 639949 & 7.301 & 5086 & RN \\
\hline IEMBL3937092 & 539949 & 7.301 & 221 & RN \\
\hline AEMBL 3955447 & 639949 & 7.301 & .782 & \\
\hline IEMBL3983450 & 639949 & 6.0 & .9008 & $\mathrm{RN}$ \\
\hline AEMBL 3938869 & 639949 & 7.301 & 9586 & RN \\
\hline AEMBL3906715 & 639949 & .301 & .7342 & RN \\
\hline AEMBL 3942671 & 639949 & 7.301 & .3662 & RN \\
\hline AEMBL3939199 & 639949 & 7.301 & .6743 & ST \\
\hline IEMBL 3921482 & 639949 & 8.301 & 611 & TRN \\
\hline AEMBL 3958507 & 1639949 & 7.301 & 9332 & ST \\
\hline AEMBL3959038 & 639949 & 7.301 & 484 & RN \\
\hline AEMBL 3937048 & 639949 & 7.301 & 813 & ST \\
\hline AEMBL3S & 639949 & 7.301 & .6096 & $\mathrm{RN}$ \\
\hline IEMBL3984213 & 639949 & 301 & 624 & TST \\
\hline AEMBL 3893128 & 1639949 & 6 & 415 & TST \\
\hline IEMBL3958678 & 1639949 & 7.301 & 2771 & RN \\
\hline IEMBL3898627 & 6390 & 8.301 & 548 & ST \\
\hline IEMBL3951527 & 1639949 & 8.301 & 104 & TRN \\
\hline IEMBL 3957171 & 539949 & 301 & 15 & TST \\
\hline AEMBL 3951099 & 1639949 & & 661 & TST \\
\hline IEMBL3929002 & 1639949 & & 431 & ГST \\
\hline 860 & 49 & 7.301 & 514 & TRN \\
\hline EMBL3896044 & 1639949 & & 427 & TST \\
\hline AEMBL 3981613 & 639949 & 7.301 & 994 & TRN \\
\hline AEMBL3954731 & 1639949 & 7.301 & & RN \\
\hline IEMBL3947769 & 1639949 & 7.301 & 283 & TRN \\
\hline AEMBL39 & 1639949 & 7.301 & 091 & TRN \\
\hline HEMBL3898138 & 1639949 & 7.301 & 7.7544 & TRN \\
\hline AEMBL3906936 & 639949 & 8.301 & 2075 & TRN \\
\hline CHEMBL3959195 & 1639949 & 8.301 & 3555 & TST \\
\hline CHEMBL3955359 & 1639949 & 7.301 & .9839 & TST \\
\hline CHEMBL3935265 & 1639949 & 8.301 & 8.2811 & TRN \\
\hline IEMBL3924998 & 1639949 & 8.301 & .1457 & TRN \\
\hline EMBL394 & 639949 & 8.301 & . 7599 & RN \\
\hline CHEMBL 3951755 & 1639949 & 7.301 & 7.4209 & RN \\
\hline CHEMBL 3952493 & 1639949 & 6.0 & 6.7474 & ST \\
\hline CHEMBL3956056 & 1639949 & 7.301 & 7.6077 & $5 \mathrm{~T}$ \\
\hline
\end{tabular}

Page 385 
Supplemental Table S2.txt

\begin{tabular}{|c|c|c|c|c|c|}
\hline CHEMBL3955486 & 1639949 & 7.301 & 6.8899 & TRN & \\
\hline CHEMBL3985896 & 1639949 & 7.301 & 7.4123 & TRN & \\
\hline CHEMBL3968956 & 1639949 & 8.301 & 8.0172 & TRN & \\
\hline CHEMBL 3894418 & 1639949 & 7.301 & 7.0043 & TRN & \\
\hline CHEMBL3929188 & 1639949 & 7.301 & 7.5509 & TRN & \\
\hline CHEMBL3981432 & 1639949 & 8.301 & 8.0956 & TRN & \\
\hline CHEMBL3952465 & 1639949 & 7.301 & 7.4748 & TRN & \\
\hline CHEMBL3934095 & 1639949 & 7.301 & 7.5403 & TRN & \\
\hline CHEMBL3921689 & 1639949 & 7.301 & 7.0069 & TRN & \\
\hline CHEMBL3968233 & 1639949 & 8.301 & 7.6316 & TRN & \\
\hline CHEMBL3943632 & 1639949 & 6.0 & 6.5996 & TST & \\
\hline CHEMBL3948661 & 1639949 & 6.0 & 6.0989 & TST & \\
\hline CHEMBL3985840 & 1639949 & 6.0 & 6.4175 & TST & \\
\hline CHEMBL3909626 & 1639949 & 8.301 & 7.0863 & TST & \\
\hline CHEMBL3971051 & 1639949 & 7.301 & 6.9313 & TRN & \\
\hline CHEMBL3895890 & 1639949 & 7.301 & 7.6956 & TRN & \\
\hline CHEMBL3952188 & 1639949 & 8.301 & 7.88299 & 9999999999 & TRN \\
\hline CHEMBL3906789 & 1639949 & 8.301 & 7.43 & TST & \\
\hline CHEMBL3928212 & 1639949 & 8.301 & 7.0785 & TST & \\
\hline CHEMBL3893846 & 1639949 & 8.301 & 7.949 & TRN & \\
\hline CHEMBL3964556 & 1639949 & 7.301 & 7.1825 & TRN & \\
\hline CHEMBL3931427 & 1639949 & 7.301 & 7.6277 & TRN & \\
\hline CHEMBL3932578 & 1639949 & 8.301 & 8.2126 & TRN & \\
\hline CHEMBL 3978177 & 1639949 & 8.301 & 8.1191 & TRN & \\
\hline CHEMBL3985163 & 1639949 & 8.301 & 7.7913 & TST & \\
\hline CHEMBL3944780 & 1639949 & 7.301 & 7.4154 & TRN & \\
\hline CHEMBL 3899440 & 1639949 & 7.301 & 7.8566 & TRN & \\
\hline CHEMBL3977503 & 1639949 & 8.301 & 7.6145 & TRN & \\
\hline CHEMBL3945177 & 1639949 & 8.301 & 8.07 & TRN & \\
\hline CHEMBL3914599 & 1639949 & 8.301 & \multicolumn{2}{|c|}{8.152000000000001} & TRN \\
\hline CHEMBL3916953 & 1639949 & 6.0 & 6.4813 & TRN & \\
\hline CHEMBL 3924098 & 1639949 & 7.301 & 7.4914 & TRN & \\
\hline CHEMBL3939133 & 1639949 & 7.301 & 7.2778 & TRN & \\
\hline CHEMBL 3973688 & 1639949 & 7.301 & 7.2475 & TRN & \\
\hline CHEMBL3898808 & 1639949 & 8.301 & 8.4649 & TRN & \\
\hline CHEMBL3986082 & 1639949 & 6.0 & 6.9981 & TRN & \\
\hline CHEMBL3904192 & 1639949 & 7.301 & 7.4893 & TRN & \\
\hline CHEMBL3895123 & 1639949 & 7.301 & 7.3539 & TRN & \\
\hline CHEMBL3959559 & 1639949 & 8.301 & \multicolumn{2}{|c|}{7.7989999999999995} & TST \\
\hline CHEMBL3946469 & 1639949 & 7.301 & 7.7657 & TRN & \\
\hline CHEMBL3955824 & 1639949 & 7.301 & 8.0771 & TRN & \\
\hline CHEMBL3973632 & 1639949 & 8.301 & 8.632 & TRN & \\
\hline CHEMBL3959495 & 1639949 & 7.301 & 7.5929 & TRN & \\
\hline CHEMBL3895458 & 1639949 & 6.0 & 6.3832 & TST & \\
\hline CHEMBL3912287 & 1639949 & 7.301 & 7.3719 & TRN & \\
\hline CHEMBL3933848 & 1639949 & 6.0 & 6.5927 & TST & \\
\hline CHEMBL3961472 & 1639949 & 8.301 & 7.9214 & TRN & \\
\hline CHEMBL 3898088 & 1639949 & 7.301 & 7.5956 & TRN & \\
\hline
\end{tabular}


Supplemental Table S2.txt

\begin{tabular}{|c|c|c|c|c|}
\hline 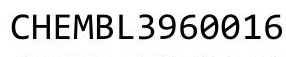 & 1639949 & 8.301 & 7.8459 & 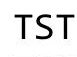 \\
\hline HEMBL3972940 & 1639949 & 7.301 & 7.1465 & TRN \\
\hline HEMBL3942161 & 639949 & 8.301 & .3806 & \\
\hline HEMBL 3955083 & 639949 & 7.301 & 405 & \\
\hline HEMBL3958898 & 639949 & 8.301 & 7845 & \\
\hline HEMBL3932698 & 639949 & 7.301 & 1792 & r \\
\hline HEMBL3960132 & 639949 & 8.301 & 7.7436 & \\
\hline HEMBL3976226 & 639949 & 8.301 & 7.7512 & \\
\hline HEMBL3949155 & 639949 & 7.301 & 7. 3999 & \\
\hline HEMBL3928601 & 639949 & 7.301 & .8077 & \\
\hline HEMBL3947408 & 1639949 & 7.301 & 7.7146 & \\
\hline HEMBL3962203 & 639949 & 7.301 & 7.6042 & \\
\hline HEMBL3900296 & 163 & 7.301 & 7169 & \\
\hline HEMBL 395 & 163 & 7.301 & .3707 & \\
\hline HEMBL 394 & 163 & 7.301 & .4338 & \\
\hline HEMBL3916225 & 1639949 & 8.301 & 7.6989 & \\
\hline HEMBL3901787 & 639949 & 7.301 & 957 & \\
\hline HEMBL3965938 & 163 & 7.301 & 4652 & \\
\hline HEMBL 3985254 & 163 & 8.301 & 8877 & \\
\hline HEMBL3986404 & 163 & 8.301 & 2244 & \\
\hline HEMBL3911207 & 1639949 & 7.301 & 6733 & \\
\hline HEMBL3916759 & 49 & 7.301 & & N \\
\hline HEMBL3893032 & 163 & 7.301 & 33 & Iv \\
\hline HEMBL3S & 163 & 7.301 & 734 & \\
\hline HEMBL3 & 163 & 8.301 & 322 & RN \\
\hline HEMBL3965625 & 1639949 & 7.301 & $\partial 271$ & $\mathrm{~T}$ \\
\hline HEMBL3913993 & 63 & 7.301 & 16 & $2 \mathrm{~N}$ \\
\hline HEMBL3962487 & 163 & 8.301 & 2773 & RN \\
\hline HEMBL3 & 16 & 7.301 & 073 & RN \\
\hline HEMBL3891059 & 163 & 7.301 & 7.681 & RN \\
\hline HEMBL 3968322 & 1639949 & 7.301 & & ST \\
\hline HEMBL3921861 & 1639 & 7.301 & 1063 & TRN \\
\hline HEMBL3919501 & 49 & 7.301 & 328 & RN \\
\hline HEMBL3 & 16 & 6. & 104 & ST \\
\hline HEMBL3 & 16 & 7.301 & 5165 & $\mathrm{RN}$ \\
\hline HEMBL3946590 & 1639949 & 7.301 & 2559 & RN \\
\hline HEMBL3918306 & 1639949 & 7.301 & 1034 & RN \\
\hline HEMBL3 & 16 & 01 & & RN \\
\hline HEMBL3 & 16 & 7.301 & 17 & ST \\
\hline CHEMBL 3963620 & 1639949 & 6.0 & 1671 & $\Gamma R N$ \\
\hline HEMBL3969472 & 1639949 & 8.301 & 9193 & RN \\
\hline CHEMBL3949560 & 1639949 & 8.301 & 8271 & RN \\
\hline CHEMBL3 & 16 & & & RN \\
\hline CHEMBL3895848 & 1639949 & 6.0 & 5.5332 & IST \\
\hline CHEMBL3968522 & 1639949 & 8.301 & 8.2635 & RN \\
\hline CHEMBL 3944791 & 1639949 & 301 & .0945 & RN \\
\hline CHEMBL 39187 & 163 & 8.301 & & \\
\hline CHEMBL396777 & 639949 & 7.301 & 7.4862 & \\
\hline
\end{tabular}

Page 387 
Supplemental Table S2.txt

\begin{tabular}{|c|c|c|c|c|c|}
\hline CHEMBL3925803 & 1639949 & 8.301 & 7.8876 & TRN & \\
\hline CHEMBL3952023 & 1639949 & 8.301 & 7.7015 & TST & \\
\hline CHEMBL3944502 & 1639949 & 6.0 & 6.7661 & TST & \\
\hline CHEMBL3953606 & 1639949 & 7.301 & 7.4264 & TRN & \\
\hline CHEMBL3976788 & 1639949 & 7.301 & 7.0692 & TRN & \\
\hline CHEMBL3937297 & 1639949 & 8.301 & 8.3041 & TRN & \\
\hline CHEMBL3939874 & 1639949 & 7.301 & 7.7711 & TST & \\
\hline CHEMBL3934134 & 1639949 & 8.301 & 7.3389 & TST & \\
\hline CHEMBL3955495 & 1639949 & 8.301 & 8.0427 & TRN & \\
\hline CHEMBL3905501 & 1639949 & 8.301 & 7.6536 & TRN & \\
\hline CHEMBL3975704 & 1639949 & 8.301 & 7.8304 & TRN & \\
\hline CHEMBL3965160 & 1639949 & 7.301 & 7.4686 & TST & \\
\hline CHEMBL3926038 & 1639949 & 8.301 & 7.9743 & TRN & \\
\hline CHEMBL3927849 & 1639949 & 7.301 & 7.0438 & TRN & \\
\hline CHEMBL3945353 & 1639949 & 7.301 & 7.5391 & TST & \\
\hline CHEMBL3941200 & 1639949 & 7.301 & 7.15 & TRN & \\
\hline CHEMBL3959774 & 1639949 & 8.301 & 8.3952 & TRN & \\
\hline CHEMBL3917442 & 1639949 & 8.301 & 8.7088 & TRN & \\
\hline CHEMBL3914394 & 1639949 & 7.301 & 7.5791 & TRN & \\
\hline CHEMBL3938621 & 1639949 & 8.301 & 7.46200 & 0000000001 & TST \\
\hline CHEMBL3983938 & 1639949 & 8.301 & 8.2443 & TRN & \\
\hline CHEMBL3920114 & 1639949 & 8.301 & 7.8694 & TRN & \\
\hline CHEMBL3947643 & 1639949 & 7.301 & 7.0721 & TRN & \\
\hline CHEMBL3933359 & 1639949 & 7.301 & 7.0976 & TRN & \\
\hline CHEMBL3968192 & 1639949 & 7.301 & 7.767 & TRN & \\
\hline CHEMBL3942082 & 1639949 & 8.301 & 7.7751 & TRN & \\
\hline CHEMBL3923692 & 1639949 & 8.301 & 7.7557 & TRN & \\
\hline CHEMBL3959638 & 1639949 & 8.301 & 8.6535 & TRN & \\
\hline CHEMBL3972190 & 1639949 & 8.301 & 7.4853 & TRN & \\
\hline CHEMBL3983466 & 1639949 & 8.301 & 7.7616 & TST & \\
\hline CHEMBL3966429 & 1639949 & 8.301 & 7.9319 & TRN & \\
\hline CHEMBL3961005 & 1639949 & 7.301 & 7.271 & TRN & \\
\hline CHEMBL3896699 & 1639949 & 8.301 & 8.0705 & TRN & \\
\hline CHEMBL3900295 & 1639949 & 7.301 & 7.3847 & TRN & \\
\hline CHEMBL3946018 & 1639949 & 6.0 & 6.3192 & TST & \\
\hline CHEMBL3939717 & 1639949 & 7.301 & 6.96399 & 99999999995 & TRN \\
\hline CHEMBL3897215 & 1639949 & 7.301 & 7.1122 & TRN & \\
\hline CHEMBL3941947 & 1639949 & 7.301 & 7.5687 & TRN & \\
\hline CHEMBL3983201 & 1639949 & 6.0 & 5.8004 & TRN & \\
\hline CHEMBL3919493 & 1639949 & 7.301 & 7.9296 & TRN & \\
\hline CHEMBL3951403 & 1639949 & 7.301 & 7.4817 & TRN & \\
\hline CHEMBL3907230 & 1639949 & 7.301 & 6.9829 & TRN & \\
\hline CHEMBL3982666 & 1639949 & 7.301 & 7.5184 & TRN & \\
\hline CHEMBL3909744 & 1639949 & 8.301 & 7.8687 & TRN & \\
\hline CHEMBL3910102 & 1639949 & 7.301 & 7.375 & TRN & \\
\hline CHEMBL3923153 & 1639949 & 8.301 & 8.2812 & TRN & \\
\hline CHEMBL3944984 & 1639949 & 7.301 & 7.2919 & TST & \\
\hline CHEMBL3924779 & 1639949 & 8.301 & 8.3595 & TRN & \\
\hline
\end{tabular}




\begin{tabular}{|c|c|c|c|c|c|}
\hline \\
\hline CHEMBL 3914264 & 1639949 & 6.0 & 7.4597 & TST & \\
\hline CHEMBL3968843 & 1639949 & 7.301 & 7.4938 & TRN & \\
\hline CHEMBL3941402 & 1639949 & 8.301 & 8.3102 & TRN & \\
\hline CHEMBL3893575 & 1639949 & 7.301 & 7.6868 & TRN & \\
\hline CHEMBL3971560 & 1639949 & 7.301 & 7.3701 & TST & \\
\hline CHEMBL 3924442 & 1639949 & 6.0 & 6.8661 & TST & \\
\hline CHEMBL3985116 & 1639949 & 6.0 & 7.1245 & TST & \\
\hline CHEMBL3951258 & 1639949 & 8.301 & 8.1308 & TRN & \\
\hline CHEMBL3917294 & 1639949 & 8.301 & 7.9549 & TRN & \\
\hline CHEMBL3958466 & 1639949 & 8.301 & 7.9034 & TRN & \\
\hline CHEMBL3933398 & 1639949 & 7.301 & 6.9574 & TRN & \\
\hline CHEMBL3966040 & 1639949 & 7.301 & 7.4285 & TRN & \\
\hline CHEMBL3893845 & 1639949 & 7.301 & 7.6248 & TRN & \\
\hline CHEMBL3900858 & 1639949 & 6.0 & 6.5463 & TST & \\
\hline CHEMBL3904510 & 1639949 & 7.301 & 6.3006 & TST & \\
\hline CHEMBL3899410 & 1639949 & 8.301 & 7.8782 & TRN & \\
\hline CHEMBL3893176 & 1639949 & 7.301 & 7.8167 & TRN & \\
\hline CHEMBL 3942387 & 1639949 & 7.301 & 7.5845 & TRN & \\
\hline CHEMBL3913496 & 1639949 & 8.301 & 8.1416 & TST & \\
\hline CHEMBL3983179 & 1639949 & 7.301 & 7.5776 & TRN & \\
\hline CHEMBL3961982 & 1639949 & 6.0 & 6.8359 & TST & \\
\hline CHEMBL3961417 & 1639949 & 7.301 & 7.0314 & TRN & \\
\hline CHEMBL3896122 & 1639949 & 8.301 & 8.2375 & TRN & \\
\hline CHEMBL3922630 & 1639949 & 6.0 & 6.5877 & TST & \\
\hline CHEMBL3986135 & 1639949 & 8.301 & 7.7525 & TST & \\
\hline CHEMBL3892117 & 1639949 & 7.301 & 7.4126 & TRN & \\
\hline CHEMBL3964605 & 1639949 & 7.301 & 7.3274 & TST & \\
\hline CHEMBL3949400 & 1639949 & 7.301 & 7.6742 & TRN & \\
\hline CHEMBL 3928439 & 1639949 & 7.301 & 7.6291 & TRN & \\
\hline CHEMBL3934158 & 1639949 & 7.301 & 7.1274 & TRN & \\
\hline CHEMBL 3924455 & 1639949 & 7.301 & 7.3543 & TRN & \\
\hline CHEMBL3986301 & 1639949 & 8.301 & 7.9639 & TRN & \\
\hline CHEMBL3920036 & 1639949 & 7.301 & 7.67899 & 9999999999 & TRN \\
\hline CHEMBL3921390 & 1639949 & 8.301 & 7.7397 & TRN & \\
\hline CHEMBL3971050 & 1639949 & 8.301 & 8.5995 & TRN & \\
\hline CHEMBL3918670 & 1639949 & 7.301 & 7.7983 & TRN & \\
\hline CHEMBL3903022 & 1639949 & 7.301 & 7.1022 & TST & \\
\hline CHEMBL3939828 & 1639949 & 7.301 & 7.3815 & TST & \\
\hline CHEMBL3979195 & 1639949 & 7.301 & 7.71700 & 00000000005 & TRN \\
\hline CHEMBL3952693 & 1639949 & 8.301 & 7.4572 & TST & \\
\hline CHEMBL3897256 & 1639949 & 8.301 & 8.1285 & TRN & \\
\hline CHEMBL3909603 & 1639949 & 7.301 & 7.7745 & TST & \\
\hline CHEMBL3929942 & 1639949 & 7.301 & 7.4432 & TRN & \\
\hline CHEMBL 3952315 & 1639949 & 7.301 & 7.8062 & TRN & \\
\hline CHEMBL3910064 & 1639949 & 7.301 & 7.3049 & TRN & \\
\hline CHEMBL3929966 & 1639949 & 7.301 & 7.5661 & TRN & \\
\hline CHEMBL3933897 & 1639949 & 7.301 & 7.9614 & TRN & \\
\hline CHEMBL3986123 & 1639949 & 7.301 & 7.5194 & TRN & \\
\hline
\end{tabular}


Supplemental Table S2.txt

\begin{tabular}{|c|c|c|c|c|}
\hline 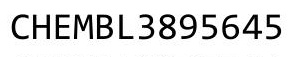 & 639949 & 7.301 & 7.5585 & \\
\hline HEMBL3907764 & 639949 & 7.301 & 7.4949 & TRN \\
\hline HEMBL3958778 & 639949 & 7.301 & 1097 & \\
\hline HEMBL 3916828 & & 7.301 & 3979 & \\
\hline HEMBL3935392 & 639949 & 8.301 & 3487 & \\
\hline HEMBL 308532 & 22089 & 8.4559 & 2454 & \\
\hline HEMBL 305932 & 22089 & 7.3768 & 7.9537 & \\
\hline HEMBL412425 & 22089 & 9.9208 & 9.6347 & \\
\hline HEMBL 312531 & 22089 & 9.6383 & 9.5279 & \\
\hline HEMBL 2282764 & 22089 & 9.301 & 9.5757 & \\
\hline HEMBL2282762 & 922089 & 8.7447 & 8.3872 & \\
\hline HEMBL432729 & 22089 & 8.7212 & 8.6795 & \\
\hline HEMBL2282763 & 22089 & 9.699 & 9.4564 & \\
\hline HEMBL7€ & 22089 & 3098 & 8.4635 & \\
\hline HEMBL 2 & 89 & 979 & 176 & \\
\hline HEMBL 312143 & 22089 & 8.7696 & 8.7895 & \\
\hline HEMBL 307181 & 22089 & 8.6778 & 8.7065 & \\
\hline HEMBL7\& & 22089 & 8.8539 & 8.9646 & \\
\hline HEMBL 8 & 22089 & 8.3768 & 9954 & \\
\hline HEMBL3 & 39 & 861 & 9703 & \\
\hline HEMBL 76892 & 22089 & 8.6383 & 8.4311 & \\
\hline HEMBL 228278 & $22 \ell$ & 437 & 25 & $R / N$ \\
\hline HEMBL75 & 22089 & 8.0655 & 8.4343 & RIV \\
\hline HEM & 39 & 8.8239 & 269 & \\
\hline HEMBL2 & 39 & 10.0458 & 258 & \\
\hline HEMBL 77129 & 22089 & 9.301 & 8.7201 & RN \\
\hline HEMBL 2282 & $22 \epsilon$ & 9.5229 & 6476 & $2 \mathrm{~N}$ \\
\hline HEMBL 768 & 226 & 8.2218 & 3612 & RN \\
\hline HEMBL 7 & 39 & 68 & 532 & ST \\
\hline HEMBL3 & 39 & 979 & 9.6477 & RN \\
\hline HEMBL 307 & 226 & 198 & 5389 & RN \\
\hline HEMBL 306554 & 22089 & 99 & 5197 & ГRN \\
\hline HEMBL36 & 9 & 739 & 077 & RN \\
\hline HEMBL 2 & 39 & 28 & 241 & RN \\
\hline HEMBL 2 & 39 & 861 & 304 & RN \\
\hline HEMBL 76192 & 22089 & 9.0555 & 8708 & IRN \\
\hline HEMBL3706585 & 22089 & 8.0915 & 8.3017 & RN \\
\hline HEMBL 2 & 9 & & 3364 & RN \\
\hline HFMRI 2 & 39 & 8 & 3876 & $\mathrm{RN}$ \\
\hline HEMBL3085538 & 922089 & 10.3979 & 9.9784 & $\mathrm{RN}$ \\
\hline HEMBL 77124 & 22089 & 9.301 & 9.2951 & ST \\
\hline HEMBL 306722 & 22089 & 959 & 7279 & RN \\
\hline CHEMBL2 & & & 655 & \\
\hline CHEMBL 309261 & 22089 & 8.2441 & 8.0927 & ST \\
\hline HEMBL 76671 & 22089 & 7.3979 & 8.0481 & ST \\
\hline HEMBL 308258 & 922089 & 10.0458 & 9.7921 & RN \\
\hline CHEMBL 7 & & 9 . & 9.3776 & RN \\
\hline CHEMBL77 & & 10 & & \\
\hline
\end{tabular}

Page 390 


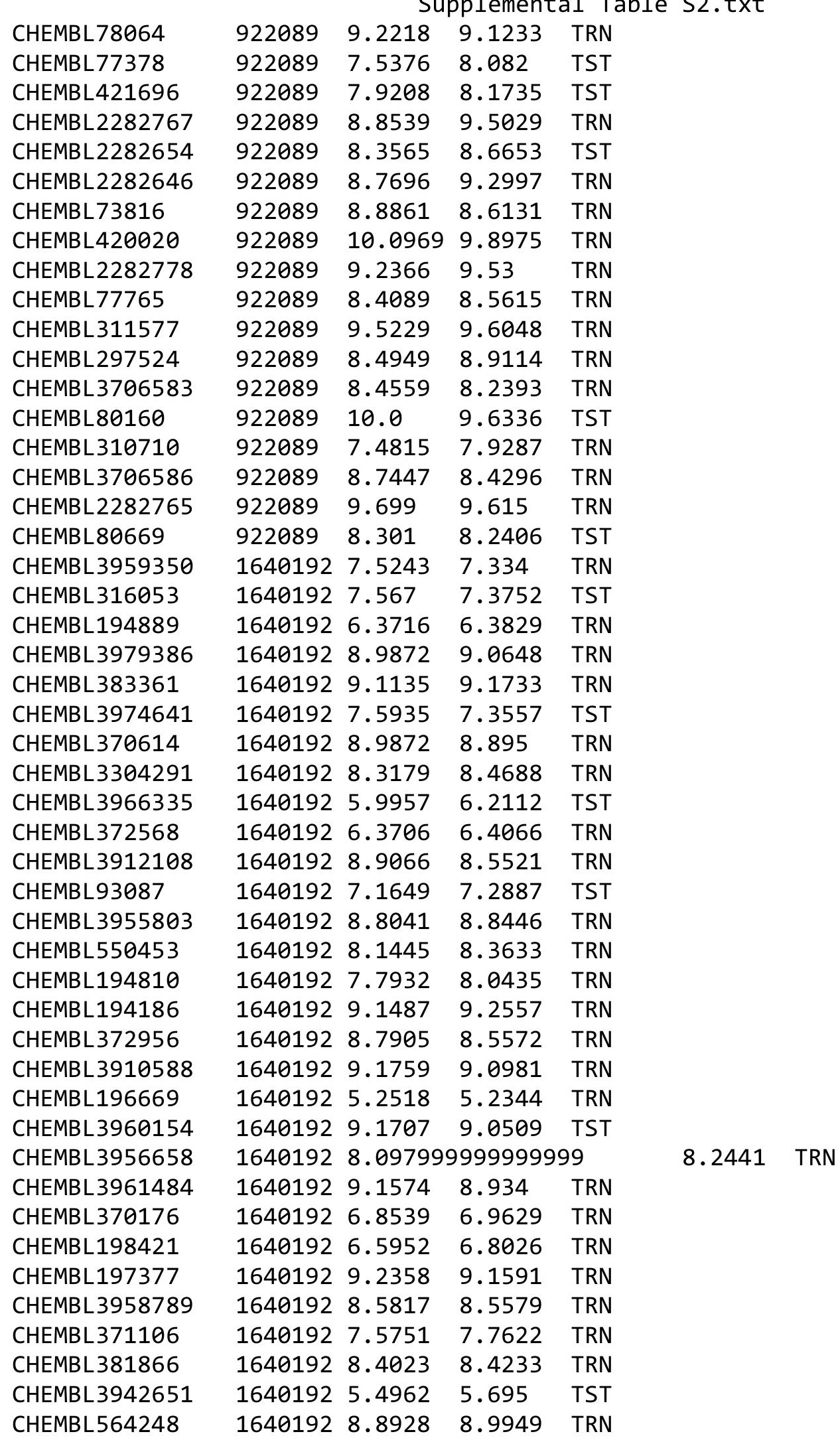


Supplemental Table S2.txt

\begin{tabular}{|c|c|c|c|c|}
\hline . & 540192 & & & \\
\hline HEMBL198654 & 640192 & 8.2321 & & \\
\hline & & & & \\
\hline IEMBL 392 & 0192 & 5271 & & \\
\hline AEMBL3305961 & 640192 & 33 & 8886 & \\
\hline HEMBL196162 & 640192 & 8.5436 & 7964 & \\
\hline 423 & 92 & 402 & & \\
\hline IEMBL190142 & & & & \\
\hline AEMBL3972799 & 640192 & 9.1624 & 9.068 & \\
\hline HEMBL3986101 & 640192 & 9.0301 & 0462 & \\
\hline AEMBL 557915 & 92 & 8.7328 & 8.7961 & \\
\hline IEMBL19 & 92 & 405 & 0786 & \\
\hline IEMBL19 & & & & \\
\hline HEMBL 3904655 & 640192 & 8.6635 & 8.7021 & \\
\hline AEMBL364284 & 92 & 96 & .7294 & \\
\hline AEMBL3907419 & 64 & 8. & 8.561 & \\
\hline AEMBL: & 2 & & 961 & \\
\hline HEMBL: & & & 066 & \\
\hline HEMBL39 & 92 & 45 & 7.8569 & \\
\hline HEMBL436 & 92 & & & \\
\hline HEIMBL4C & 64 & 8 & 7577 & 1SI \\
\hline HEMBL3S & $\angle$ & & 285 & ודים \\
\hline HEMBL1S & & & 46 & \\
\hline HEMBL 12 & & 93 & 7.2002 & \\
\hline JEMBL14 & & & & TRN \\
\hline HEMBL1 & 45 & & 077 & RN \\
\hline HEMBL3 & 7 & & & 然 \\
\hline HFMBI 12 & 17 & 4. & 5712 & ST \\
\hline HEMBL13. & & 5.2306 & 1402 & IS \\
\hline HEMBL1516418 & & & 245 & $\Gamma \mathrm{RN}$ \\
\hline HEMBL13 & 17 & & 568 & RN \\
\hline HEMBL: & .7 & & 19 & RN \\
\hline 2 & & 52 & 529 & $\mathrm{R}$ \\
\hline HEMBL141 & & & 8691 & is \\
\hline HEMBL1709877 & & 4. & 3.7078 & TRN \\
\hline HEMBL3 & & 947 & 411 & RN \\
\hline HEMRI 1 & 7 & 3. & 34 & $\Gamma \mathrm{RN}$ \\
\hline HEMBL2C & & 4. & 3897 & 「RN \\
\hline HEMBL1580420 & 495417 & 5.0768 & 4.9515 & TST \\
\hline HEMBL137 & & & 5805 & TRN \\
\hline HEMBL 35 & 49 & 3. & 3511 & \\
\hline CHEMBL14 & 7 & 5.3716 & 4.8908 & ГST \\
\hline HEMBL1270082 & & 5.1051 & 5.4673 & TRN \\
\hline HEMBL 3560971 & 495 & 5.9586 & 1433 & TR \\
\hline MBL35 & 10 & 5.5376 & & RN \\
\hline HEMBL13 & & .8996 & .6973 & \\
\hline CHEMBL1502487 & 4954 & 6.1791 & .2216 & \\
\hline LHEMBL3561941 & 1495417 & 3.301 & 4.0581 & ГRN \\
\hline
\end{tabular}

Page 392 


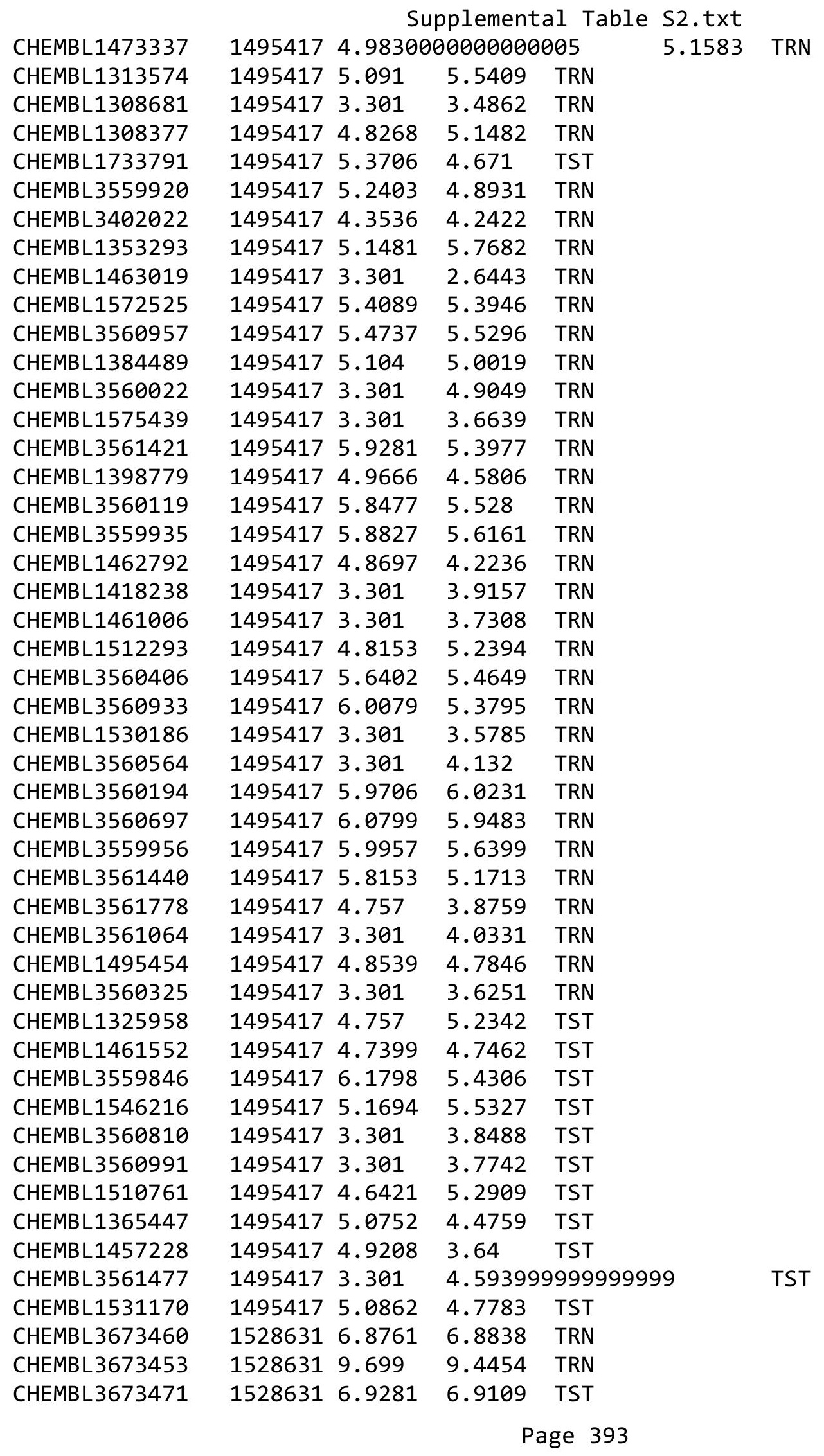


Supplemental Table S2.txt

\begin{tabular}{|c|c|c|c|c|c|}
\hline CHEMBL 3678288 & 1528631 & 7.0969 & 7.0805 & TRN & \\
\hline CHEMBL 3673461 & 1528631 & 7.8861 & 7.8657 & TRN & \\
\hline CHEMBL 3673476 & 1528631 & 9.5229 & 9.3693 & TRN & \\
\hline CHEMBL 3673446 & 1528631 & 6.5901 & 6.4251 & TRN & \\
\hline CHEMBL 3673441 & 1528631 & 6.5986 & 6.7968 & TST & \\
\hline CHEMBL 3678302 & 1528631 & 8.3979 & 8.5792 & TST & \\
\hline CHEMBL 3673463 & 1528631 & 9.2218 & 9.3313 & TRN & \\
\hline CHEMBL 3673443 & 1528631 & 7.0655 & 6.9437 & TRN & \\
\hline CHEMBL 3678290 & 1528631 & 7.2924 & 7.2438 & TRN & \\
\hline CHEMBL 3673478 & 1528631 & 9.5229 & 9.3536 & TRN & \\
\hline CHEMBL 3678285 & 1528631 & 9.699 & 9.9131 & TRN & \\
\hline CHEMBL 3673445 & 1528631 & 5.4609 & 5.4862 & TRN & \\
\hline CHEMBL 3678295 & 1528631 & 7.8539 & 7.7039 & TRN & \\
\hline CHEMBL 3673485 & 1528631 & 7.8861 & 8.0326 & TRN & \\
\hline CHEMBL 3673442 & 1528631 & 8.301 & 8.2964 & TRN & \\
\hline CHEMBL 3673457 & 1528631 & 7.284 & 7.2247 & TRN & \\
\hline CHEMBL 3673467 & 1528631 & 7.3665 & 7.5 & TST & \\
\hline CHEMBL 3678284 & 1528631 & 9.2218 & 9.408 & TRN & \\
\hline CHEMBL 3673482 & 1528631 & 8.3979 & 8.1581 & TRN & \\
\hline CHEMBL 3673481 & 1528631 & 8.3979 & 8.5106 & TRN & \\
\hline CHEMBL 3673484 & 1528631 & 7.7959 & 7.954 & TRN & \\
\hline CHEMBL 3673464 & 1528631 & 7.6198 & 7.4659 & TRN & \\
\hline CHEMBL 3678303 & 1528631 & 7.8861 & 7.8057 & TST & \\
\hline CHEMBL 3673448 & 1528631 & 6.9208 & 6.9725 & TRN & \\
\hline CHEMBL 3673451 & 1528631 & 5.3595 & 5.4192 & TRN & \\
\hline CHEMBL3673456 & 1528631 & 7.5086 & 7.7506 & TRN & \\
\hline CHEMBL3678289 & 1528631 & 8.5229 & 8.5109 & TRN & \\
\hline CHEMBL 3678293 & 1528631 & 7.4318 & 7.2597 & TST & \\
\hline CHEMBL 3673462 & 1528631 & 9.0458 & 9.1147 & TRN & \\
\hline CHEMBL 3678299 & 1528631 & 9.0 & 8.7786 & TRN & \\
\hline CHEMBL 3678304 & 1528631 & 6.6596 & 6.8917 & TST & \\
\hline CHEMBL 3673459 & 1528631 & 7.6778 & 7.7371 & TRN & \\
\hline CHEMBL 3673438 & 1528631 & 8.3979 & 8.4654 & TRN & \\
\hline CHEMBL3673469 & 1528631 & 6.5157 & 6.4009 & TRN & \\
\hline CHEMBL 3673452 & 1528631 & 10.0 & 10.0305 & TRN & \\
\hline CHEMBL3673465 & 1528631 & 6.4989 & 6.537000 & 000000001 & TRN \\
\hline CHEMBL 3673439 & 1528631 & 9.0 & 9.0191 & TRN & \\
\hline CHEMBL 3673436 & 1528631 & 9.301 & 9.2075 & TRN & \\
\hline CHEMBL 3673455 & 1528631 & 7.2441 & 7.1073 & TRN & \\
\hline CHEMBL 3678301 & 1528631 & 9.0 & 8.8796 & TRN & \\
\hline CHEMBL 3673447 & 1528631 & 6.2411 & 6.1983 & TRN & \\
\hline CHEMBL 3678296 & 1528631 & 6.8962 & 6.9815 & TRN & \\
\hline CHEMBL 3673473 & 1528631 & 6.8239 & 6.9254 & TST & \\
\hline CHEMBL 3678305 & 1528631 & 7.2147 & 7.0484 & TST & \\
\hline CHEMBL 3678300 & 1528631 & 9.2218 & 9.2904 & TRN & \\
\hline CHEMBL 3673450 & 1528631 & 6.3536 & 6.4282 & TRN & \\
\hline CHEMBL 3673437 & 1528631 & 7.6383 & 7.7245 & TRN & \\
\hline CHEMBL 3673458 & 1528631 & 6.4572 & 6.5506 & TRN & \\
\hline
\end{tabular}


Supplemental Table S2.txt

\begin{tabular}{|c|c|c|c|c|}
\hline CHEMBL 3673477 & 1528631 & 9.699 & 9.7049 & TRN \\
\hline CHEMBL 3678286 & 1528631 & 9.5229 & 9.4872 & TRN \\
\hline CHEMBL 3673444 & 1528631 & 6.3575 & 6.4316 & TRN \\
\hline CHEMBL 3673474 & 1528631 & 6.4295 & 6.2637 & TST \\
\hline CHEMBL 3673449 & 1528631 & 6.1959 & 6.1279 & TST \\
\hline CHEMBL 3678294 & 1528631 & 6.3696 & 6.385 & TRN \\
\hline CHEMBL 3673480 & 1528631 & 9.699 & 9.7928 & TRN \\
\hline CHEMBL 3673489 & 1528631 & 9.2218 & 9.1605 & TRN \\
\hline CHEMBL 3678306 & 1528631 & 7.1675 & 7.0176 & TST \\
\hline CHEMBL 3639723 & 1528631 & 6.5017 & \multicolumn{2}{|c|}{6.41100000000} \\
\hline CHEMBL 3678291 & 1528631 & 7.3872 & 7.7053 & TST \\
\hline CHEMBL 3673472 & 1528631 & 6.0511 & 6.0679 & TST \\
\hline CHEMBL 3678283 & 1528631 & 9.699 & 9.6744 & TRN \\
\hline CHEMBL 3673475 & 1528631 & 7.585 & 7.6727 & TRN \\
\hline CHEMBL 3673440 & 1528631 & 8.2218 & 8.4554 & TRN \\
\hline CHEMBL 3678287 & 1528631 & 9.699 & 9.6539 & TRN \\
\hline CHEMBL3673487 & 1528631 & 8.699 & 8.6168 & TRN \\
\hline CHEMBL 3673479 & 1528631 & 9.699 & 9.7478 & TRN \\
\hline CHEMBL 3678292 & 1528631 & 9.0 & 8.4736 & TST \\
\hline CHEMBL 3673486 & 1528631 & 9.1549 & 8.9651 & TRN \\
\hline CHEMBL 3673483 & 1528631 & 8.699 & 8.73 & TRN \\
\hline CHEMBL 3673468 & 1528631 & 7.7447 & 7.6758 & TST \\
\hline CHEMBL 3673470 & 1528631 & 5.3686 & 5.5367 & TST \\
\hline CHEMBL3673466 & 1528631 & 7.2441 & 7.3494 & TST \\
\hline CHEMBL 3673488 & 1528631 & 8.699 & 8.8401 & TRN \\
\hline CHEMBL128216 & 211079 & 5.5229 & 5.3041 & TRN \\
\hline CHEMBL128388 & 211079 & 5.3279 & 5.3546 & TRN \\
\hline CHEMBL339155 & 211079 & 6.1487 & 5.5734 & TRN \\
\hline CHEMBL131499 & 211079 & 4.0 & 4.7809 & TRN \\
\hline CHEMBL131235 & 211079 & 5.284 & 5.2532 & TST \\
\hline CHEMBL421090 & 211079 & 4.5229 & 4.8605 & TRN \\
\hline CHEMBL338499 & 211079 & 5.6383 & 5.6527 & TRN \\
\hline CHEMBL129983 & 211079 & 5.9586 & 5.8822 & TRN \\
\hline CHEMBL436189 & 211079 & 6.5086 & 5.9487 & TRN \\
\hline CHEMBL128680 & 211079 & 5.0 & 5.15 & TRN \\
\hline CHEMBL340016 & 211079 & 4.7959 & 5.0197 & TRN \\
\hline CHEMBL339929 & 211079 & 5.5229 & 5.9155 & TRN \\
\hline CHEMBL128712 & 211079 & 6.1487 & 6.0153 & TRN \\
\hline CHEMBL336857 & 211079 & 5.0 & 4.5044 & TRN \\
\hline CHEMBL128422 & 211079 & 5.2366 & 5.1257 & TRN \\
\hline CHEMBL340915 & 211079 & 5.4437 & 5.5544 & TRN \\
\hline CHEMBL128163 & 211079 & 5.5229 & 5.7249 & TRN \\
\hline CHEMBL338576 & 211079 & 6.1549 & 6.0759 & TRN \\
\hline CHEMBL128417 & 211079 & 5.5229 & 5.6552 & TRN \\
\hline CHEMBL341339 & 211079 & 4.1079 & 5.0502 & TRN \\
\hline CHEMBL131477 & 211079 & 6.3565 & 6.4954 & TRN \\
\hline CHEMBL335876 & 211079 & 4.5229 & 5.2256 & TRN \\
\hline CHEMBL337221 & 211079 & 5.7959 & 5.6103 & TRN \\
\hline
\end{tabular}

Page 395 


\begin{tabular}{|c|c|c|c|c|c|}
\hline \multirow[b]{2}{*}{ CHEMBL130905 } & \multicolumn{5}{|c|}{ Supplemental Table S2.txt } \\
\hline & 211079 & 6.3098 & 6.1401 & TRN & \\
\hline CHEMBL128328 & 211079 & 6.0 & 5.2844 & TRN & \\
\hline CHEMBL128194 & 211079 & 5.6576 & 5.6499 & TST & \\
\hline CHEMBL419973 & 211079 & 5.7696 & 5.5248 & TRN & \\
\hline CHEMBL 337853 & 211079 & 6.1675 & 5.8198 & TRN & \\
\hline CHEMBL434993 & 211079 & 4.5229 & 4.8483 & TRN & \\
\hline CHEMBL405016 & 211079 & 6.1135 & 5.7555 & TRN & \\
\hline CHEMBL130803 & 211079 & 4.5229 & 4.6773 & TRN & \\
\hline CHEMBL338548 & 211079 & 5.7212 & 5.7992 & TRN & \\
\hline CHEMBL335634 & 211079 & 5.4089 & 5.1522 & TRN & \\
\hline CHEMBL435409 & 211079 & 5.3979 & 5.5668 & TRN & \\
\hline CHEMBL338711 & 211079 & 5.9208 & 6.28600 & 00000000005 & TRN \\
\hline CHEMBL 337842 & 211079 & 5.4949 & 5.1488 & TST & \\
\hline CHEMBL128652 & 211079 & 5.5229 & 6.0102 & TRN & \\
\hline CHEMBL340639 & 211079 & 5.3979 & 5.5132 & TRN & \\
\hline CHEMBL128726 & 211079 & 5.8239 & 6.0216 & TRN & \\
\hline CHEMBL338177 & 211079 & 6.0223 & 5.6757 & TRN & \\
\hline CHEMBL128228 & 211079 & 5.5686 & 5.3262 & TRN & \\
\hline CHEMBL131538 & 211079 & 5.4089 & 5.3799 & TST & \\
\hline CHEMBL339464 & 211079 & 4.5229 & 4.8801 & TRN & \\
\hline CHEMBL339783 & 211079 & 4.0 & 4.5302 & TRN & \\
\hline CHEMBL 265073 & 211079 & 5.6576 & 5.6389 & TST & \\
\hline CHEMBL341338 & 211079 & 5.5376 & 5.1913 & TRN & \\
\hline CHEMBL339357 & 211079 & 5.5229 & 5.2055 & TST & \\
\hline CHEMBL 130476 & 211079 & 5.5229 & 6.1573 & TRN & \\
\hline CHEMBL340772 & 211079 & 5.0 & 4.6256 & TRN & \\
\hline CHEMBL340388 & 211079 & 6.301 & 5.9395 & TST & \\
\hline CHEMBL340334 & 211079 & 4.5229 & 4.9136 & TRN & \\
\hline CHEMBL131269 & 211079 & 5.0 & 5.2589 & TRN & \\
\hline CHEMBL128489 & 211079 & 5.9208 & 6.1614 & TST & \\
\hline CHEMBL338635 & 211079 & 5.4559 & 5.6293 & TST & \\
\hline CHEMBL339433 & 211079 & 5.5686 & 5.5701 & TRN & \\
\hline CHEMBL276906 & 211079 & 5.3372 & 5.2736 & TRN & \\
\hline CHEMBL 2112663 & 211079 & 5.9586 & 5.966 & TST & \\
\hline CHEMBL132389 & 211079 & 6.3665 & 6.17200 & 3000000001 & TRN \\
\hline CHEMBL132391 & 211079 & 6.1938 & 5.8761 & TRN & \\
\hline CHEMBL338118 & 211079 & 6.3279 & 5.9505 & TRN & \\
\hline CHEMBL130993 & 211079 & 6.0 & 5.7826 & TRN & \\
\hline CHEMBL336992 & 211079 & 5.0915 & 5.1825 & TRN & \\
\hline CHEMBL 2111851 & 211079 & 6.0 & 5.88299 & 9999999999 & TRN \\
\hline CHEMBL132064 & 211079 & 4.5229 & 5.0638 & TST & \\
\hline CHEMBL338951 & 211079 & 5.6778 & 5.8162 & TRN & \\
\hline CHEMBL128383 & 211079 & 6.301 & 5.9051 & TST & \\
\hline CHEMBL337889 & 211079 & 7.1739 & 6.5532 & TRN & \\
\hline CHEMBL129971 & 211079 & 5.5229 & 5.1615 & TRN & \\
\hline CHEMBL334332 & 211079 & 4.5229 & 5.1156 & TRN & \\
\hline CHEMBL422612 & 211079 & 5.5229 & 5.2864 & TRN & \\
\hline CHEMBL131388 & 211079 & 5.4318 & 5.8139 & TRN & \\
\hline & & & & 396 & \\
\hline
\end{tabular}




\begin{tabular}{|c|c|c|c|c|c|}
\hline \multicolumn{6}{|c|}{ Supplemental Table S2.txt } \\
\hline CHEMBL341311 & 211079 & 5.8239 & 5.5055 & TRN & \\
\hline CHEMBL337888 & 211079 & 5.5229 & 5.6893 & TRN & \\
\hline CHEMBL129234 & 211079 & 5.0 & 5.0901 & TST & \\
\hline CHEMBL130887 & 211079 & 5.9586 & 5.9673 & TRN & \\
\hline CHEMBL336082 & 211079 & 5.6383 & 6.393 & TRN & \\
\hline CHEMBL132211 & 211079 & 5.5229 & 5.5908 & TRN & \\
\hline CHEMBL433662 & 211079 & 6.7959 & 6.1099 & TST & \\
\hline CHEMBL339498 & 211079 & 6.3565 & 6.221 & TRN & \\
\hline CHEMBL340964 & 211079 & 5.7212 & 5.6793 & TRN & \\
\hline CHEMBL131101 & 211079 & 4.0 & 5.1748 & TST & \\
\hline CHEMBL335886 & 211079 & 5.5229 & 5.5704 & TRN & \\
\hline CHEMBL131239 & 211079 & 5.8239 & 5.4792 & TRN & \\
\hline CHEMBL128327 & 211079 & 4.5229 & 5.2131 & TST & \\
\hline CHEMBL435613 & 211079 & 5.0 & \multicolumn{2}{|c|}{5.212000000000001} & TRN \\
\hline CHEMBL421248 & 211079 & 5.3279 & 5.2693 & TRN & \\
\hline CHEMBL449399 & 211079 & 5.699 & 5.8218 & TST & \\
\hline CHEMBL338921 & 211079 & 5.7212 & 6.305 & TRN & \\
\hline CHEMBL130891 & 211079 & 6.9586 & 6.3947 & TST & \\
\hline CHEMBL341289 & 211079 & 6.0 & 6.5032 & TST & \\
\hline CHEMBL339124 & 211079 & 5.8539 & 5.4154 & TRN & \\
\hline CHEMBL339151 & 211079 & 5.0 & 5.6345 & TRN & \\
\hline CHEMBL336195 & 211079 & 5.7696 & 5.6362 & TST & \\
\hline CHEMBL339524 & 211079 & 6.9208 & 6.5359 & TST & \\
\hline CHEMBL128423 & 211079 & 6.0809 & 5.8174 & TRN & \\
\hline CHEMBL336742 & 211079 & 4.5229 & 5.1351 & TRN & \\
\hline CHEMBL341049 & 211079 & 6.4318 & 6.267 & TST & \\
\hline CHEMBL128219 & 211079 & 6.3098 & 6.1228 & TRN & \\
\hline CHEMBL338503 & 211079 & 5.6778 & 5.4524 & TST & \\
\hline CHEMBL337212 & 211079 & 6.0 & 4.9269 & TRN & \\
\hline CHEMBL340150 & 211079 & 4.5229 & 5.0842 & TRN & \\
\hline CHEMBL128749 & 211079 & 6.2757 & 5.8383 & TRN & \\
\hline CHEMBL340362 & 211079 & 5.3979 & 5.4457 & TRN & \\
\hline CHEMBL130768 & 211079 & 5.5229 & 5.1726 & TST & \\
\hline CHEMBL132210 & 211079 & 6.0 & 5.9097 & TRN & \\
\hline CHEMBL128258 & 211079 & 6.3872 & 6.1036 & TST & \\
\hline CHEMBL131564 & 211079 & 5.5229 & 5.2359 & TRN & \\
\hline CHEMBL337615 & 211079 & 5.0 & \multicolumn{2}{|c|}{5.4639999999999995} & TRN \\
\hline CHEMBL339768 & 211079 & 6.301 & 5.9182 & TST & \\
\hline CHEMBL276079 & 211079 & 5.0 & 4.6556 & TRN & \\
\hline CHEMBL338984 & 211079 & 6.2757 & 5.9656 & TST & \\
\hline CHEMBL435019 & 211079 & 6.041 & 5.8245 & TST & \\
\hline CHEMBL435398 & 211079 & 5.0 & \multicolumn{2}{|c|}{4.8839999999999995} & TRN \\
\hline CHEMBL130848 & 211079 & 5.5229 & 6.1081 & TRN & \\
\hline CHEMBL131581 & 211079 & 5.3979 & 5.3991 & TRN & \\
\hline CHEMBL336362 & 211079 & 4.0 & 4.0818 & TRN & \\
\hline CHEMBL337667 & 211079 & 5.9208 & 5.8669 & TRN & \\
\hline CHEMBL338383 & 211079 & 5.9586 & \multicolumn{2}{|c|}{5.962000000000001} & TST \\
\hline \multirow[t]{2}{*}{ CHEMBL340676 } & 211079 & 5.8861 & \multicolumn{2}{|c|}{5.736000000000001} & TRN \\
\hline & & & & e 397 & \\
\hline
\end{tabular}




\begin{tabular}{|c|c|c|c|c|}
\hline \multicolumn{5}{|c|}{ Supplemental Table S2.txt } \\
\hline CHEMBL338636 & 211079 & 5.0 & 5.4518 & TRN \\
\hline CHEMBL435009 & 211079 & 5.5686 & 5.2147 & TRN \\
\hline CHEMBL339096 & 211079 & 5.0362 & 5.4728 & TST \\
\hline CHEMBL132157 & 211079 & 5.4318 & 5.7813 & TST \\
\hline CHEMBL335182 & 211079 & 6.3188 & 5.8873 & TRN \\
\hline CHEMBL127445 & 211079 & 6.5376 & 6.1664 & TRN \\
\hline CHEMBL423156 & 211079 & 4.5229 & 5.0242 & TRN \\
\hline CHEMBL338490 & 211079 & 5.0 & 4.3673 & TRN \\
\hline CHEMBL339132 & 211079 & 6.0177 & 5.8327 & TST \\
\hline CHEMBL132496 & 211079 & 5.3468 & 5.2889 & TRN \\
\hline CHEMBL128398 & 211079 & 4.7959 & 5.1574 & TRN \\
\hline CHEMBL335944 & 211079 & 6.2757 & 5.7439 & TRN \\
\hline CHEMBL420144 & 211079 & 4.0 & 5.2722 & TST \\
\hline CHEMBL339366 & 211079 & 4.5229 & 5.2088 & TRN \\
\hline CHEMBL132165 & 211079 & 5.7696 & 5.3078 & TRN \\
\hline CHEMBL131551 & 211079 & 6.0506 & 5.9035 & TRN \\
\hline CHEMBL131168 & 211079 & 5.5229 & 4.9967 & TRN \\
\hline CHEMBL341507 & 211079 & 5.5376 & 5.2756 & TRN \\
\hline CHEMBL334610 & 211079 & 5.5229 & 6.1025 & TRN \\
\hline CHEMBL422080 & 211079 & 5.5229 & 5.2803 & TRN \\
\hline CHEMBL339756 & 211079 & 6.4949 & 5.9733 & TST \\
\hline CHEMBL130770 & 211079 & 5.0 & 4.8688 & TRN \\
\hline CHEMBL334953 & 211079 & 6.0 & 5.1021 & TST \\
\hline CHEMBL341470 & 211079 & 5.0 & 5.0262 & TST \\
\hline CHEMBL1089206 & 627703 & 5.5272 & 6.7159 & TRN \\
\hline CHEMBL1091187 & 627703 & 6.6655 & 6.7753 & TRN \\
\hline CHEMBL1092006 & 627703 & 6.4365 & 7.034 & TRN \\
\hline CHEMBL1091996 & 627703 & 6.7399 & 7.1091 & TRN \\
\hline CHEMBL1089872 & 627703 & 7.0655 & 7.1289 & TRN \\
\hline CHEMBL1092888 & 627703 & 6.9957 & 7.2734 & TRN \\
\hline CHEMBL1089139 & 627703 & 5.7905 & 5.9303 & TRN \\
\hline CHEMBL1093186 & 627703 & 6.5186 & 7.2259 & TRN \\
\hline CHEMBL1088921 & 627703 & 7.585 & 7.1123 & TRN \\
\hline CHEMBL1092308 & 627703 & 7.3768 & 6.8177 & TRN \\
\hline CHEMBL1092296 & 627703 & 6.6576 & 6.8333 & TRN \\
\hline CHEMBL1092380 & 627703 & 6.9914 & 6.8656 & TRN \\
\hline CHEMBL1088894 & 627703 & 7.7447 & 7.7646 & TRN \\
\hline CHEMBL1089096 & 627703 & 6.0747 & 6.6842 & TST \\
\hline CHEMBL1093165 & 627703 & 6.8125 & 6.9931 & TRN \\
\hline CHEMBL1091590 & 627703 & 7.4437 & 6.9434 & TRN \\
\hline CHEMBL1090122 & 627703 & 6.0706 & 5.9664 & TRN \\
\hline CHEMBL1089877 & 627703 & 7.8861 & 7.8411 & TRN \\
\hline CHEMBL1089883 & 627703 & 7.6091 & 7.7596 & TRN \\
\hline CHEMBL1089547 & 627703 & 7.7696 & 7.7705 & TRN \\
\hline CHEMBL1093166 & 627703 & 6.6038 & 6.9487 & TRN \\
\hline CHEMBL1090474 & 627703 & 6.2503 & 5.9176 & TRN \\
\hline CHEMBL1092584 & 627703 & 6.4881 & 6.3241 & TST \\
\hline CHEMBL1091186 & 627703 & 7.4559 & 6.9131 & TRN \\
\hline
\end{tabular}




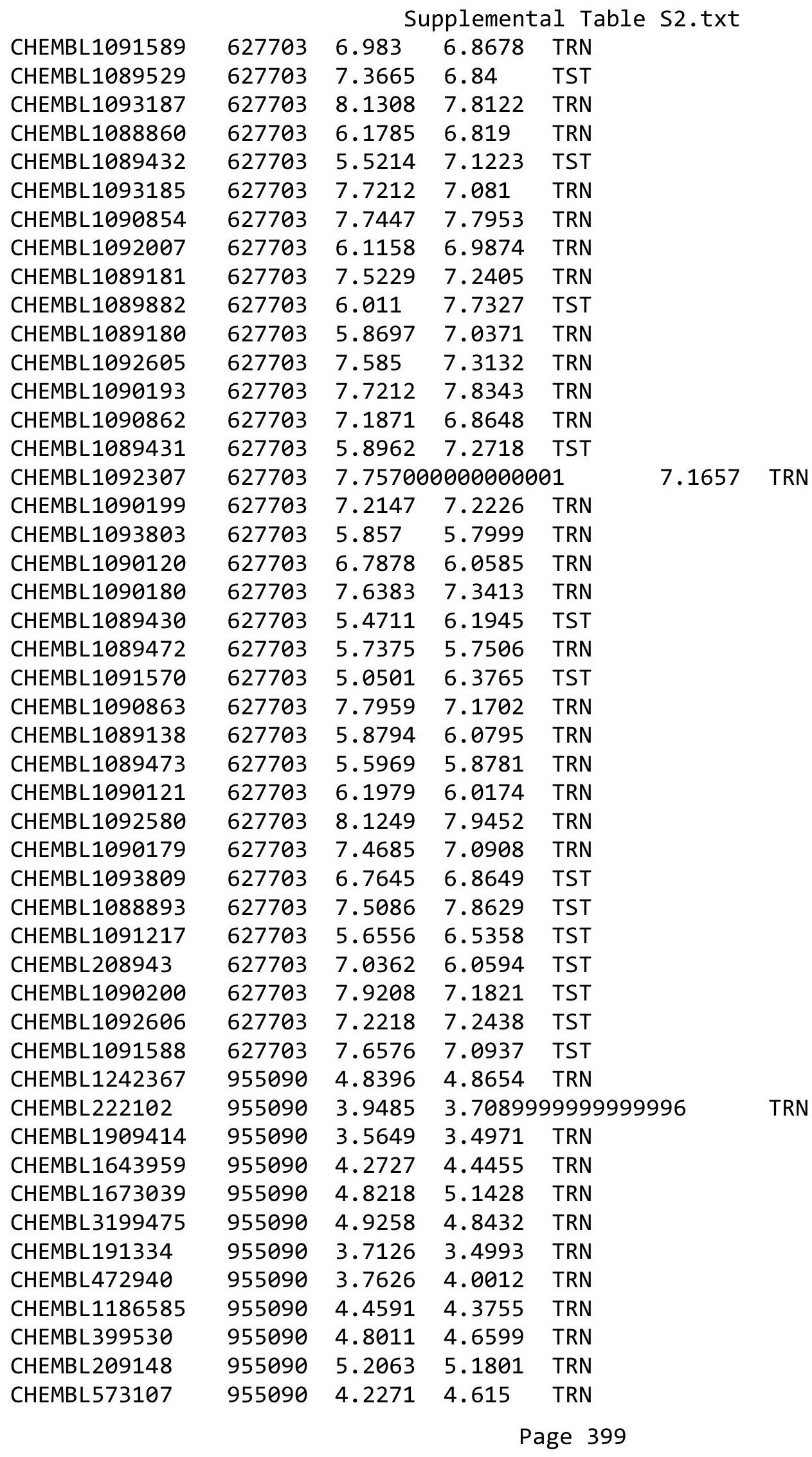




\begin{tabular}{|c|c|c|c|c|c|}
\hline & & & & & \\
\hline CHEMBL180127 & 955090 & 4.7607 & 4.8225 & TRN & \\
\hline CHEMBL258844 & 955090 & 4.8029 & 5.1171 & TRN & \\
\hline CHEMBL1357247 & 955090 & 4.2087 & 3.745 & TRN & \\
\hline CHEMBL1970879 & 955090 & 4.7134 & 4.9591 & TRN & \\
\hline CHEMBL585951 & 955090 & 6.0579 & 6.5133 & TRN & \\
\hline CHEMBL1190711 & 955090 & 5.4571 & 5.4648 & TRN & \\
\hline CHEMBL393929 & 955090 & 3.5234 & 3.7545 & TRN & \\
\hline CHEMBL189584 & 955090 & 5.1926 & 4.6579 & TRN & \\
\hline CHEMBL 2134202 & 955090 & 4.3314 & 4.5034 & TRN & \\
\hline CHEMBL1230020 & 955090 & 3.4094 & 3.5682 & TRN & \\
\hline CHEMBL92309 & 955090 & 3.5623 & 3.4147 & TST & \\
\hline CHEMBL509032 & 955090 & 6.2582 & 6.2847 & TRN & \\
\hline CHEMBL2137530 & 955090 & 4.0999 & 4.6694 & TRN & \\
\hline CHEMBL135561 & 955090 & 5.7401 & 4.9671 & TRN & \\
\hline CHEMBL 373751 & 955090 & 3.5058 & 4.1086 & TRN & \\
\hline CHEMBL221137 & 955090 & 4.9962 & 5.2236 & TST & \\
\hline CHEMBL483849 & 955090 & 2.3889 & 2.4053 & TST & \\
\hline CHEMBL192566 & 955090 & 8.2611 & 8.6834 & TST & \\
\hline CHEMBL379975 & 955090 & 4.503 & 4.5179 & TRN & \\
\hline CHEMBL 300389 & 955090 & 7.6045 & 7.5069 & TRN & \\
\hline CHEMBL65 & 955090 & 7.1798 & 6.8026 & TRN & \\
\hline CHEMBL449158 & 955090 & 7.1594 & 6.9911 & TST & \\
\hline CHEMBL217354 & 955090 & 5.8889 & 5.9012 & TRN & \\
\hline CHEMBL102714 & 955090 & 3.2369 & 3.2574 & TRN & \\
\hline CHEMBL3186408 & 955090 & 5.1167 & 3.9624 & TST & \\
\hline CHEMBL220241 & 955090 & 5.3062 & 4.991006 & 00000000005 & TRN \\
\hline CHEMBL 213100 & 955090 & 5.3119 & 4.8762 & TRN & \\
\hline CHEMBL240954 & 955090 & 3.6093 & 3.8334 & TST & \\
\hline CHEMBL577784 & 955090 & 4.4264 & 4.7515 & TRN & \\
\hline CHEMBL 9470 & 955090 & 5.5494 & 6.1105 & TST & \\
\hline CHEMBL1404918 & 955090 & 3.2655 & 3.0988 & TRN & \\
\hline CHEMBL379300 & 955090 & 6.9462 & 7.1372 & TRN & \\
\hline CHEMBL2363137 & 955090 & 5.5335 & 5.3185 & TRN & \\
\hline CHEMBL412142 & 955090 & 3.6549 & 4.0848 & TRN & \\
\hline CHEMBL483847 & 955090 & 4.6515 & 4.5922 & TRN & \\
\hline CHEMBL512504 & 955090 & 4.4769 & 4.5823 & TRN & \\
\hline CHEMBL514499 & 955090 & 7.9234 & 7.8302 & TRN & \\
\hline CHEMBL255342 & 955090 & 3.8371 & 3.6336 & TRN & \\
\hline CHEMBL515416 & 955090 & 4.8732 & 4.9353 & TRN & \\
\hline CHEMBL2005886 & 955090 & 6.2571 & 6.4415 & TRN & \\
\hline CHEMBL 2144069 & 955090 & 4.8241 & 4.5923 & TRN & \\
\hline CHEMBL1788116 & 955090 & 5.9548 & 5.4141 & TRN & \\
\hline CHEMBL1516890 & 955090 & 4.3157 & 4.1009 & TRN & \\
\hline CHEMBL3392440 & 955090 & 3.8913 & 4.1302 & TRN & \\
\hline CHEMBL259181 & 955090 & 4.3123 & 5.0658 & TST & \\
\hline CHEMBL210618 & 955090 & 4.6084 & 3.3888 & TST & \\
\hline CHEMBL1590308 & 955090 & 3.8678 & 3.5952 & TST & \\
\hline CHEMBL558642 & 955090 & 4.4548 & 4.9963 & TST & \\
\hline
\end{tabular}




\begin{tabular}{|c|c|c|c|c|c|}
\hline \multirow[b]{2}{*}{ CHEMBL3349342 } & \multicolumn{5}{|c|}{ Supplemental Table S2.txt } \\
\hline & 955090 & 4.6355 & 4.7759 & TST & \\
\hline CHEMBL392695 & 955090 & 6.0324 & 5.86299 & 99999999995 & TST \\
\hline CHEMBL202721 & 955090 & 4.6618 & 4.5218 & TST & \\
\hline CHEMBL188678 & 955090 & 5.2761 & 4.129 & TST & \\
\hline CHEMBL1256459 & 955090 & 7.7836 & 7.9616 & TST & \\
\hline CHEMBL368751 & 157907 & 7.8239 & 7.7184 & TRN & \\
\hline CHEMBL369207 & 157907 & 7.5229 & 7.6041 & TRN & \\
\hline CHEMBL367781 & 157907 & 7.7959 & 6.9567 & TST & \\
\hline CHEMBL 2110252 & 157907 & 6.0 & 7.0016 & TRN & \\
\hline CHEMBL170418 & 157907 & 6.0 & 6.0579 & TRN & \\
\hline CHEMBL170711 & 157907 & 6.7447 & 6.4703 & TRN & \\
\hline CHEMBL171570 & 157907 & 7.1427 & 7.107 & TST & \\
\hline CHEMBL170232 & 157907 & 8.0458 & 7.7515 & TRN & \\
\hline CHEMBL170300 & 157907 & 7.6778 & 7.7367 & TRN & \\
\hline CHEMBL172341 & 157907 & 6.7696 & 6.4432 & TRN & \\
\hline CHEMBL173029 & 157907 & 6.3565 & 7.1966 & TRN & \\
\hline CHEMBL354336 & 157907 & 7.9586 & 7.7782 & TRN & \\
\hline CHEMBL171408 & 157907 & 6.699 & 6.11299 & 99999999995 & TRN \\
\hline CHEMBL174476 & 157907 & 6.7212 & 7.2383 & TRN & \\
\hline CHEMBL352998 & 157907 & 6.6383 & 6.653 & TRN & \\
\hline CHEMBL171128 & 157907 & 7.301 & 7.5923 & TRN & \\
\hline CHEMBL170511 & 157907 & 7.3872 & 7.2374 & TRN & \\
\hline CHEMBL354620 & 157907 & 7.5376 & 7.8529 & TRN & \\
\hline CHEMBL265475 & 157907 & 8.301 & 7.9866 & TRN & \\
\hline CHEMBL171924 & 157907 & 6.6576 & 6.86 & TST & \\
\hline CHEMBL172858 & 157907 & 7.5686 & 7.4996 & TRN & \\
\hline CHEMBL442978 & 157907 & 7.8539 & 7.8255 & TRN & \\
\hline CHEMBL170031 & 157907 & 7.8861 & 7.5573 & TST & \\
\hline CHEMBL354314 & 157907 & 7.5376 & 7.7287 & TRN & \\
\hline CHEMBL173611 & 157907 & 8.2218 & 7.3099 & TRN & \\
\hline CHEMBL173238 & 157907 & 7.3188 & 7.4267 & TRN & \\
\hline CHEMBL2110250 & 157907 & 6.0 & 6.0982 & TRN & \\
\hline CHEMBL172926 & 157907 & 6.4815 & 5.9461 & TST & \\
\hline CHEMBL172044 & 157907 & 6.8239 & 6.0766 & TST & \\
\hline CHEMBL354415 & 157907 & 7.9208 & 6.46700 & 00000000005 & TST \\
\hline CHEMBL170523 & 157907 & 7.1079 & 7.1343 & TRN & \\
\hline CHEMBL173924 & 157907 & 6.0 & 6.541 & TRN & \\
\hline CHEMBL171863 & 157907 & 7.284 & 7.1333 & TRN & \\
\hline CHEMBL367099 & 157907 & 6.7696 & 6.5454 & TST & \\
\hline CHEMBL174412 & 157907 & 7.3468 & 7.1059 & TRN & \\
\hline CHEMBL171238 & 157907 & 7.699 & 7.5937 & TRN & \\
\hline CHEMBL354973 & 157907 & 6.0 & 6.0132 & TST & \\
\hline CHEMBL355495 & 157907 & 6.7959 & 7.2531 & TRN & \\
\hline CHEMBL367431 & 157907 & 6.6198 & 6.5354 & TST & \\
\hline CHEMBL366719 & 157907 & 7.585 & 7.2715 & TRN & \\
\hline CHEMBL173752 & 157907 & 6.284 & 6.1387 & TST & \\
\hline CHEMBL352870 & 157907 & 7.7696 & 7.3132 & TRN & \\
\hline CHEMBL354312 & 157907 & 7.9208 & 7.6714 & TRN & \\
\hline
\end{tabular}




\begin{tabular}{|c|c|c|c|c|}
\hline \multicolumn{5}{|c|}{ Supplemental Table S2.txt } \\
\hline CHEMBL 2110251 & 157907 & 6.0 & 6.2824 & TST \\
\hline CHEMBL355706 & 157907 & 6.7696 & 7.1385 & TRN \\
\hline CHEMBL171336 & 157907 & 6.7696 & 7.004 & TRN \\
\hline CHEMBL174239 & 157907 & 7.7959 & 7.6634 & TRN \\
\hline CHEMBL367098 & 157907 & 7.2924 & 6.8608 & TRN \\
\hline CHEMBL171091 & 157907 & 9.301 & 7.0497 & TST \\
\hline CHEMBL367175 & 157907 & 7.6383 & 7.8078 & TRN \\
\hline CHEMBL174322 & 157907 & 6.4559 & 7.1111 & TST \\
\hline CHEMBL426401 & 157907 & 6.2596 & 6.5513 & TRN \\
\hline CHEMBL173983 & 157907 & 6.5229 & 6.7529 & TRN \\
\hline CHEMBL170925 & 157907 & 6.4815 & 6.6452 & TST \\
\hline CHEMBL173903 & 157907 & 7.0969 & 6.5335 & TRN \\
\hline CHEMBL174403 & 157907 & 6.8239 & 7.0388 & TRN \\
\hline CHEMBL367911 & 157907 & 8.0969 & 7.8719 & TRN \\
\hline CHEMBL1091651 & 623654 & 4.4949 & 3.968 & TRN \\
\hline CHEMBL1091258 & 623654 & 4.9208 & 3.9907 & TRN \\
\hline CHEMBL1093553 & 623654 & 4.9586 & 3.7531 & TRN \\
\hline CHEMBL1093920 & 623654 & 5.3979 & 3.8031 & TRN \\
\hline CHEMBL1094255 & 623654 & 3.0 & 3.6611 & TRN \\
\hline CHEMBL1092703 & 623654 & 4.9586 & 3.8888 & TRN \\
\hline CHEMBL1095561 & 623654 & 3.0 & 4.1884 & TRN \\
\hline CHEMBL1092967 & 623654 & 3.0 & 3.5827 & TST \\
\hline CHEMBL1092984 & 623654 & 3.0 & 3.6473 & TST \\
\hline CHEMBL1091652 & 623654 & 5.5229 & 3.833 & TRN \\
\hline CHEMBL1090678 & 623654 & 4.5686 & 4.0166 & TRN \\
\hline CHEMBL1092947 & 623654 & 3.3468 & 3.9192 & TRN \\
\hline CHEMBL1093263 & 623654 & 5.0458 & 4.9145 & TRN \\
\hline CHEMBL1092978 & 623654 & 5.0458 & 4.2249 & TRN \\
\hline CHEMBL1093492 & 623654 & 3.0 & 3.783 & TRN \\
\hline CHEMBL1089235 & 623654 & 4.3979 & 3.6287 & TRN \\
\hline CHEMBL1091953 & 623654 & 3.0 & 3.9886 & TRN \\
\hline CHEMBL1092702 & 623654 & 5.1549 & 4.9256 & TRN \\
\hline CHEMBL1092938 & 623654 & 3.0 & 3.9823 & TRN \\
\hline CHEMBL1093513 & 623654 & 3.0 & 4.0792 & TRN \\
\hline CHEMBL1089907 & 623654 & 3.0 & 3.5765 & TRN \\
\hline CHEMBL1093220 & 623654 & 3.0 & 3.7857 & TST \\
\hline CHEMBL1091257 & 623654 & 5.2218 & 5.3045 & TRN \\
\hline CHEMBL1092937 & 623654 & 4.5229 & 3.7341 & TST \\
\hline CHEMBL1093907 & 623654 & 3.0 & 4.7605 & TRN \\
\hline CHEMBL1093919 & 623654 & 5.1549 & 4.4059 & TRN \\
\hline CHEMBL1093827 & 623654 & 4.6198 & 4.0628 & TRN \\
\hline CHEMBL159895 & 623654 & 3.0 & 3.5728 & TST \\
\hline CHEMBL1092673 & 623654 & 5.0 & 4.1153 & TRN \\
\hline CHEMBL1093875 & 623654 & 5.5229 & 6.0932 & TRN \\
\hline CHEMBL209918 & 623654 & 3.0 & 3.6037 & TRN \\
\hline CHEMBL1092985 & 623654 & 3.0 & 3.6145 & TST \\
\hline CHEMBL1093853 & 623654 & 3.0 & 3.6887 & TRN \\
\hline CHEMBL1093876 & 623654 & 3.0 & 3.9302 & TRN \\
\hline
\end{tabular}




\begin{tabular}{|c|c|c|c|c|c|}
\hline \multicolumn{6}{|c|}{ Supplemental Table S2.txt } \\
\hline CHEMBL1092746 & 623654 & 3.7447 & 4.3399 & TRN & \\
\hline CHEMBL111951 & 623654 & 4.7212 & 3.7847 & TST & \\
\hline CHEMBL1088991 & 623654 & 3.0 & 3.6364 & TST & \\
\hline CHEMBL1092979 & 623654 & 4.8861 & 4.118 & TRN & \\
\hline CHEMBL1093508 & 623654 & 5.5229 & 5.0461 & TRN & \\
\hline CHEMBL1091736 & 623654 & 5.301 & 5.0768 & TRN & \\
\hline CHEMBL1089893 & 623654 & 4.3468 & 3.6842 & TRN & \\
\hline CHEMBL1092614 & 623654 & 4.7696 & 3.9184 & TRN & \\
\hline CHEMBL1090936 & 623654 & 4.9586 & 4.1917 & TRN & \\
\hline CHEMBL1092936 & 623654 & 3.0 & 3.5757 & TST & \\
\hline CHEMBL1090566 & 623654 & 3.0 & 3.5916 & TRN & \\
\hline CHEMBL1090692 & 623654 & 3.0 & 3.7922 & TRN & \\
\hline CHEMBL1093507 & 623654 & 3.0 & 3.7002 & TRN & \\
\hline CHEMBL1092701 & 623654 & 5.0458 & 4.5111 & TRN & \\
\hline CHEMBL1090567 & 623654 & 3.0 & 3.69100 & 00000000003 & TRN \\
\hline CHEMBL1093233 & 623654 & 3.6198 & 4.3332 & TRN & \\
\hline CHEMBL98778 & 623654 & 4.5686 & 5.0707 & TST & \\
\hline CHEMBL1091037 & 623654 & 5.6021 & 5.4084 & TRN & \\
\hline CHEMBL1093520 & 623654 & 3.0 & 3.6289 & TRN & \\
\hline CHEMBL418899 & 623654 & 4.699 & 3.9061 & TST & \\
\hline CHEMBL1093512 & 623654 & 5.8239 & 5.0003 & TRN & \\
\hline CHEMBL564201 & 623654 & 3.699 & 4.2866 & TST & \\
\hline CHEMBL1090903 & 623654 & 4.4949 & 4.0012 & TRN & \\
\hline CHEMBL1093874 & 623654 & 4.7212 & 5.1257 & TRN & \\
\hline CHEMBL1089234 & 623654 & 4.8539 & 5.3233 & TRN & \\
\hline CHEMBL1093511 & 623654 & 3.0 & 3.8447 & TRN & \\
\hline CHEMBL1093493 & 623654 & 5.0458 & 4.0022 & TRN & \\
\hline CHEMBL1093988 & 623654 & 4.7696 & 4.8309 & TRN & \\
\hline CHEMBL1093873 & 623654 & 4.6576 & 4.0732 & TRN & \\
\hline CHEMBL1092935 & 623654 & 3.1249 & 3.977 & TRN & \\
\hline CHEMBL341112 & 623654 & 4.0605 & 3.9376 & TRN & \\
\hline CHEMBL1090902 & 623654 & 4.8861 & 4.6809 & TRN & \\
\hline CHEMBL1091653 & 623654 & 4.7959 & 4.8673 & TRN & \\
\hline CHEMBL1090901 & 623654 & 3.0 & 3.5784 & TRN & \\
\hline CHEMBL1092966 & 623654 & 3.6021 & 4.2723 & TST & \\
\hline CHEMBL1093826 & 623654 & 5.3979 & 3.8185 & TST & \\
\hline CHEMBL1092613 & 623654 & 4.9586 & 4.5581 & TST & \\
\hline CHEMBL1095562 & 623654 & 4.6778 & 5.0824 & TST & \\
\hline CHEMBL1092674 & 623654 & 3.0969 & 3.7147 & TST & \\
\hline CHEMBL1092095 & 623654 & 3.699 & 4.3218 & TST & \\
\hline CHEMBL1094254 & 623654 & 3.0 & 3.9379 & TST & \\
\hline CHEMBL49403 & 100508 & 6.2518 & 5.75299 & 9999999999 & TST \\
\hline CHEMBL50299 & 100508 & 6.7696 & 6.5774 & TRN & \\
\hline CHEMBL 297515 & 100508 & 5.6778 & 5.6038 & TRN & \\
\hline CHEMBL52005 & 100508 & 7.0 & 6.9389 & TRN & \\
\hline CHEMBL299013 & 100508 & 6.9208 & 6.6576 & TRN & \\
\hline CHEMBL301387 & 100508 & 7.5229 & 7.646 & TRN & \\
\hline CHEMBL50220 & 100508 & 5.3372 & 5.3056 & TRN & \\
\hline
\end{tabular}




\begin{tabular}{|c|c|c|c|c|c|}
\hline & & & нетіетісы & & \\
\hline CHEMBL49066 & 100508 & 6.8861 & 6.9038 & TRN & \\
\hline CHEMBL50375 & 100508 & 5.1612 & 6.4172 & TST & \\
\hline CHEMBL48748 & 100508 & 6.7447 & 6.315 & TST & \\
\hline CHEMBL298926 & 100508 & 5.2518 & 5.2063 & TRN & \\
\hline CHEMBL48569 & 100508 & 6.0223 & 6.0258 & TRN & \\
\hline CHEMBL49668 & 100508 & 6.9208 & 7.2063 & TRN & \\
\hline CHEMBL49161 & 100508 & 6.8861 & 7.121 & TRN & \\
\hline CHEMBL299993 & 100508 & 6.301 & 6.0836 & TST & \\
\hline CHEMBL51341 & 100508 & 6.6021 & 6.4879 & TRN & \\
\hline CHEMBL297924 & 100508 & 5.7696 & 5.9168 & TRN & \\
\hline CHEMBL301081 & 100508 & 6.9586 & 6.9947 & TRN & \\
\hline CHEMBL48288 & 100508 & 5.3565 & 5.6112 & TRN & \\
\hline CHEMBL301581 & 100508 & 6.5376 & 6.5649 & TRN & \\
\hline CHEMBL51878 & 100508 & 5.585 & 5.54299 & 9999999999 & TRN \\
\hline CHEMBL51383 & 100508 & 6.7696 & 6.7709 & TRN & \\
\hline CHEMBL48926 & 100508 & 7.5229 & 7.5263 & TRN & \\
\hline CHEMBL301099 & 100508 & 6.699 & 6.9234 & TRN & \\
\hline CHEMBL50420 & 100508 & 4.1549 & 5.9601 & TST & \\
\hline CHEMBL417536 & 100508 & 6.1308 & 6.1759 & TST & \\
\hline CHEMBL49452 & 100508 & 6.0 & 6.2375 & TST & \\
\hline CHEMBL51525 & 100508 & 5.9586 & 5.9509 & TRN & \\
\hline CHEMBL48357 & 100508 & 4.8539 & 4.9844 & TRN & \\
\hline CHEMBL48792 & 100508 & 3.8697 & 6.3273 & TST & \\
\hline CHEMBL46442 & 100508 & 6.3279 & 6.9597 & TST & \\
\hline CHEMBL50240 & 100508 & 5.6778 & 5.4987 & TRN & \\
\hline CHEMBL49821 & 100508 & 7.301 & 7.3605 & TRN & \\
\hline CHEMBL48752 & 100508 & 3.5528 & 5.3641 & TST & \\
\hline CHEMBL299201 & 100508 & 6.8239 & 6.4224 & TST & \\
\hline CHEMBL 301101 & 100508 & 7.2218 & 7.1969 & TRN & \\
\hline CHEMBL48312 & 100508 & 7.1549 & 7.1729 & TRN & \\
\hline CHEMBL48774 & 100508 & 6.9208 & 7.1009 & TRN & \\
\hline CHEMBL283830 & 100508 & 7.5229 & 7.46299 & 9999999999 & TRN \\
\hline CHEMBL51846 & 100508 & 6.7696 & 6.5129 & TRN & \\
\hline CHEMBL51894 & 100508 & 6.2757 & 6.1912 & TST & \\
\hline CHEMBL299959 & 100508 & 7.3979 & 7.011 & TRN & \\
\hline CHEMBL51721 & 100508 & 6.9586 & 6.9047 & TRN & \\
\hline CHEMBL300881 & 100508 & 7.5229 & 7.5478 & TRN & \\
\hline CHEMBL50918 & 100508 & 6.4318 & 6.4123 & TRN & \\
\hline CHEMBL46436 & 100508 & 3.7447 & 6.7021 & TST & \\
\hline CHEMBL50896 & 100508 & 6.5229 & 6.6041 & TRN & \\
\hline CHEMBL302487 & 100508 & 6.9208 & 6.7346 & TST & \\
\hline CHEMBL298184 & 100508 & 6.699 & 6.2656 & TRN & \\
\hline CHEMBL50963 & 100508 & 5.3372 & 5.4046 & TRN & \\
\hline CHEMBL48535 & 100508 & 6.1675 & 6.0231 & TRN & \\
\hline CHEMBL48702 & 100508 & 6.699 & 6.1654 & TST & \\
\hline CHEMBL51194 & 100508 & 7.1549 & 7.2592 & TRN & \\
\hline CHEMBL51178 & 100508 & 6.5376 & 6.4449 & TST & \\
\hline CHEMBL297874 & 100508 & 6.5229 & 6.221 & TRN & \\
\hline
\end{tabular}




\begin{tabular}{|c|c|c|c|c|c|}
\hline \multicolumn{6}{|c|}{ Supplemental Table s2.txt } \\
\hline CHEMBL51020 & 100508 & 5.301 & 5.4392 & TRN & \\
\hline CHEMBL51845 & 100508 & 6.699 & 6.6767 & TRN & \\
\hline CHEMBL46047 & 100508 & 6.1079 & 6.1018 & TRN & \\
\hline CHEMBL298182 & 100508 & 5.0 & 5.4592 & TRN & \\
\hline CHEMBL299422 & 100508 & 4.8861 & 4.7885 & TRN & \\
\hline CHEMBL48457 & 100508 & 5.699 & 5.8943 & TRN & \\
\hline CHEMBL3979708 & 1641365 & 4.0 & 3.495 & TST & \\
\hline CHEMBL3925686 & 1641365 & 5.8138 & 4.7197 & TRN & \\
\hline CHEMBL3952922 & 1641365 & 4.0 & 3.9272 & TST & \\
\hline CHEMBL3974530 & 1641365 & 4.0 & 4.1364 & TST & \\
\hline CHEMBL3892333 & 1641365 & 6.2889 & 5.1755 & TRN & \\
\hline CHEMBL3941719 & 1641365 & 4.0 & 4.6624 & TRN & \\
\hline CHEMBL3952168 & 1641365 & 4.0 & 3.1803 & TST & \\
\hline CHEMBL 3984650 & 1641365 & 5.8344 & 4.5865 & TRN & \\
\hline CHEMBL3923528 & 1641365 & 4.0 & 4.3363 & TRN & \\
\hline CHEMBL 3901244 & 1641365 & 4.0 & 5.6663 & TRN & \\
\hline CHEMBL3903077 & 1641365 & 4.0 & 4.5848 & TRN & \\
\hline CHEMBL3955301 & 1641365 & 5.8687 & 4.3552 & TRN & \\
\hline CHEMBL3958904 & 1641365 & 4.0 & 3.3957 & TRN & \\
\hline CHEMBL3960112 & 1641365 & 4.0 & 3.9933 & TRN & \\
\hline CHEMBL3963383 & 1641365 & 4.0 & 4.0466 & TST & \\
\hline CHEMBL3980142 & 1641365 & 4.0 & 4.6093 & TRN & \\
\hline CHEMBL 3916188 & 1641365 & 4.0 & 4.0523 & TST & \\
\hline CHEMBL 3984588 & 1641365 & 6.505 & 5.8026 & TRN & \\
\hline CHEMBL3914787 & 1641365 & 5.6069 & 3.9973 & TRN & \\
\hline CHEMBL3961624 & 1641365 & 4.0 & 3.9526 & TST & \\
\hline CHEMBL3893664 & 1641365 & 4.0 & 3.6052 & TST & \\
\hline CHEMBL3942960 & 1641365 & 7.2291 & 6.5945 & TRN & \\
\hline CHEMBL3952505 & 1641365 & 5.9565 & 4.3939 & TRN & \\
\hline CHEMBL3973724 & 1641365 & 4.0 & 3.7906 & TRN & \\
\hline CHEMBL3916117 & 1641365 & 4.0 & 3.6184 & TST & \\
\hline CHEMBL3960368 & 1641365 & 4.0 & 4.5803 & TRN & \\
\hline CHEMBL 3977882 & 1641365 & 4.0 & 4.1142 & TRN & \\
\hline CHEMBL 3907797 & 1641365 & 4.0 & 4.9928 & TRN & \\
\hline CHEMBL3947166 & 1641365 & 4.0 & 4.7998 & TRN & \\
\hline CHEMBL3891493 & 1641365 & 4.0 & 4.9643 & TRN & \\
\hline CHEMBL3986365 & 1641365 & 6.4472 & 5.57600 & 00000000005 & TST \\
\hline CHEMBL3984855 & 1641365 & 4.0 & 4.2361 & TRN & \\
\hline CHEMBL 3935500 & 1641365 & 5.8365 & 4.5869 & TRN & \\
\hline CHEMBL3899121 & 1641365 & 4.0 & 5.0042 & TRN & \\
\hline CHEMBL3902630 & 1641365 & 4.0 & 3.5445 & TST & \\
\hline CHEMBL3896458 & 1641365 & 6.4206 & 4.7542 & TRN & \\
\hline CHEMBL3946858 & 1641365 & 4.0 & 4.625 & TRN & \\
\hline CHEMBL3927971 & 1641365 & 4.0 & 4.1674 & TRN & \\
\hline CHEMBL3949921 & 1641365 & 4.0 & 4.5949 & TRN & \\
\hline CHEMBL3932478 & 1641365 & 4.0 & 4.1654 & TRN & \\
\hline CHEMBL3956121 & 1641365 & 4.0 & 4.734 & TST & \\
\hline CHEMBL3976098 & 1641365 & 4.0 & 4.2936 & TRN & \\
\hline
\end{tabular}




$$
\text { Supplemental Table S2.txt }
$$

\begin{tabular}{|c|c|c|c|c|c|}
\hline CHEMBL 3929723 & 1641365 & 6.2853 & 5.3498 & TRN & \\
\hline CHEMBL 3931215 & 1641365 & 4.0 & 4.2629 & TST & \\
\hline CHEMBL 3929481 & 1641365 & 5.8566 & 5.3538 & TRN & \\
\hline CHEMBL 3947093 & 1641365 & 4.0 & 3.3413 & TRN & \\
\hline CHEMBL 3984352 & 1641365 & 4.0 & 4.4204 & TRN & \\
\hline CHEMBL 3896284 & 1641365 & 4.0 & 4.298 & TRN & \\
\hline CHEMBL 3941072 & 1641365 & 4.0 & 3.9628 & TRN & \\
\hline CHEMBL 3936370 & 1641365 & 6.1312 & 4.7765 & TST & \\
\hline CHEMBL 3944695 & 1641365 & 4.0 & 4.2132 & TRN & \\
\hline CHEMBL 3915763 & 1641365 & 4.0 & 4.7047 & TRN & \\
\hline CHEMBL 3914627 & 1641365 & 7.1487 & 6.1829 & TRN & \\
\hline CHEMBL 3893874 & 1641365 & 7.0367 & 5.691 & TRN & \\
\hline CHEMBL 3919055 & 1641365 & 4.0 & 4.5656 & TRN & \\
\hline CHEMBL 3965581 & 1641365 & 4.0 & 4.1049 & TRN & \\
\hline CHEMBL 3986747 & 1641365 & 4.0 & 3.6093 & TRN & \\
\hline CHEMBL 3956670 & 1641365 & 4.0 & 3.8023 & TRN & \\
\hline CHEMBL 3916667 & 1641365 & 4.0 & 4.4273 & TRN & \\
\hline CHEMBL 3982760 & 1641365 & 4.0 & 4.2123 & TRN & \\
\hline CHEMBL 3931943 & 1641365 & 7.0915 & 6.0685 & TST & \\
\hline CHEMBL 3941936 & 1641365 & 4.0 & 3.6225 & TRN & \\
\hline CHEMBL 3899538 & 1641365 & 5.8578 & 4.826000 & 30000000005 & TRN \\
\hline CHEMBL 3898091 & 1641365 & 4.0 & 3.9554 & TRN & \\
\hline CHEMBL 3900714 & 1641365 & 4.0 & 4.702 & TRN & \\
\hline CHEMBL 3978368 & 1641365 & 4.0 & 3.7893 & TST & \\
\hline CHEMBL 3956773 & 1641365 & 4.0 & 5.2809 & TRN & \\
\hline CHEMBL 3971867 & 1641365 & 4.0 & 3.2463 & TRN & \\
\hline CHEMBL 3938202 & 1641365 & 4.0 & 4.7487 & TRN & \\
\hline CHEMBL 3959496 & 1641365 & 4.0 & 4.0606 & TRN & \\
\hline CHEMBL 3975296 & 1641365 & 4.0 & 3.9595 & TST & \\
\hline CHEMBL 3956138 & 1641365 & 4.0 & 4.7374 & TRN & \\
\hline CHEMBL 3908766 & 1641365 & 5.7885 & 5.2775 & TST & \\
\hline CHEMBL 3944247 & 1641365 & 4.0 & 4.5775 & TRN & \\
\hline CHEMBL 3903537 & 1641365 & 4.0 & 4.7127 & TRN & \\
\hline CHEMBL 3961652 & 1641365 & 6.937 & 5.2998 & TST & \\
\hline CHEMBL 3913328 & 1641365 & 4.0 & 4.5407 & TST & \\
\hline CHEMBL 3915066 & 1641365 & 4.0 & 3.8841 & TST & \\
\hline CHEMBL 3933881 & 1641365 & 4.0 & 4.5184 & TRN & \\
\hline CHEMBL 3940084 & 1641365 & 5.94600 & 000000000 & 5.0683 & TRN \\
\hline CHEMBL 3927421 & 1641365 & 4.0 & 3.7665 & TRN & \\
\hline CHEMBL 3929434 & 1641365 & 6.0962 & 5.3624 & TRN & \\
\hline CHEMBL 3930575 & 1641365 & 5.8274 & 5.6936 & TRN & \\
\hline CHEMBL 3929186 & 1641365 & 4.0 & 5.2374 & TRN & \\
\hline CHEMBL 3920986 & 1641365 & 4.0 & 3.9825 & TRN & \\
\hline CHEMBL 3946687 & 1641365 & 4.0 & 4.6915 & TRN & \\
\hline CHEMBL 3913393 & 1641365 & 4.0 & 3.9588 & TST & \\
\hline CHEMBL 3939093 & 1641365 & 4.0 & 3.7162 & TST & \\
\hline CHEMBL 3943206 & 1641365 & 6.1838 & 5.3511 & TRN & \\
\hline CHEMBL 3913820 & 1641365 & 4.0 & 5.3331 & TRN & \\
\hline
\end{tabular}


Supplemental Table S2.txt

\begin{tabular}{|c|c|c|c|c|c|}
\hline CHEMBL 3983067 & 1641365 & 4.0 & 4.3255 & TRN & \\
\hline CHEMBL 3939474 & 1641365 & 4.0 & 4.7816 & TRN & \\
\hline CHEMBL3960914 & 1641365 & 4.0 & 4.4431 & TRN & \\
\hline CHEMBL 3918435 & 1641365 & 4.0 & 4.2549 & TRN & \\
\hline CHEMBL3960865 & 1641365 & 4.0 & 4.4301 & TRN & \\
\hline CHEMBL 3987034 & 1641365 & 4.0 & 4.3768 & TRN & \\
\hline CHEMBL3925709 & 1641365 & 4.0 & 4.5572 & TRN & \\
\hline CHEMBL3977484 & 1641365 & 6.2195 & 4.7975 & TRN & \\
\hline CHEMBL3939019 & 1641365 & 4.0 & 4.3618 & TST & \\
\hline CHEMBL3945889 & 1641365 & 4.0 & 4.4655 & TRN & \\
\hline CHEMBL3971343 & 1641365 & 4.0 & 4.5069 & TRN & \\
\hline CHEMBL3938227 & 1641365 & 4.0 & 4.3536 & TRN & \\
\hline CHEMBL 3933825 & 1641365 & 4.0 & 4.3457 & TRN & \\
\hline CHEMBL3901105 & 1641365 & 6.1687 & 5.4531 & TRN & \\
\hline CHEMBL 3889901 & 1641365 & 4.0 & 2.87399 & 99999999997 & TST \\
\hline CHEMBL3974280 & 1641365 & 4.0 & 4.3793 & TRN & \\
\hline CHEMBL3960308 & 1641365 & 4.0 & 4.6069 & TRN & \\
\hline CHEMBL3911409 & 1641365 & 4.0 & 4.5181 & TRN & \\
\hline CHEMBL3914978 & 1641365 & 7.8665 & 5.9491 & TRN & \\
\hline CHEMBL3961429 & 1641365 & 4.0 & 4.465 & TRN & \\
\hline CHEMBL3963634 & 1641365 & 4.0 & 4.43199 & 99999999995 & TRN \\
\hline CHEMBL 3892074 & 1641365 & 4.0 & 4.2019 & TRN & \\
\hline CHEMBL3925671 & 1641365 & 4.0 & 4.1763 & TRN & \\
\hline CHEMBL 3968642 & 1641365 & 5.7919 & 4.8958 & TRN & \\
\hline CHEMBL 3582018 & 1641365 & 4.0 & 4.7916 & TRN & \\
\hline CHEMBL3932203 & 1641365 & 4.0 & 3.3802 & TST & \\
\hline CHEMBL3944091 & 1641365 & 6.4257 & 5.3846 & TRN & \\
\hline CHEMBL3917911 & 1641365 & 4.0 & 4.8224 & TRN & \\
\hline CHEMBL3908071 & 1641365 & 4.0 & 4.9757 & TRN & \\
\hline CHEMBL3914196 & 1641365 & 4.0 & 4.9838 & TRN & \\
\hline CHEMBL3947963 & 1641365 & 4.0 & 4.1423 & TRN & \\
\hline CHEMBL3953313 & 1641365 & 4.0 & 4.2996 & TST & \\
\hline CHEMBL 3899374 & 1641365 & 4.0 & 3.2468 & TRN & \\
\hline CHEMBL3964199 & 1641365 & 4.0 & 4.3031 & TRN & \\
\hline CHEMBL3962321 & 1641365 & 4.0 & 4.1654 & TST & \\
\hline CHEMBL3978666 & 1641365 & 4.0 & 3.9624 & TRN & \\
\hline CHEMBL3921275 & 1641365 & 4.0 & 4.1355 & TRN & \\
\hline CHEMBL3959029 & 1641365 & 4.0 & 5.3276 & TRN & \\
\hline CHEMBL 3925228 & 1641365 & 4.0 & 4.0899 & TRN & \\
\hline CHEMBL3941691 & 1641365 & 6.4424 & 5.2242 & TST & \\
\hline CHEMBL3965929 & 1641365 & 4.0 & 4.2404 & TST & \\
\hline CHEMBL3924062 & 1641365 & 5.6659 & 4.7002 & TRN & \\
\hline CHEMBL3963672 & 1641365 & 4.0 & 3.9833 & TRN & \\
\hline CHEMBL3946389 & 1641365 & 5.9044 & 4.8469 & TRN & \\
\hline CHEMBL3939355 & 1641365 & 4.0 & 5.2474 & TRN & \\
\hline CHEMBL 3979647 & 1641365 & 4.0 & 4.3805 & TRN & \\
\hline CHEMBL3936836 & 1641365 & 7.0429 & 5.385 & TRN & \\
\hline CHEMBL3900719 & 1641365 & 6.2512 & 5.0694 & TRN & \\
\hline
\end{tabular}


Supplemental Table S2.txt

\begin{tabular}{|c|c|c|c|c|}
\hline CHEMBL3901519 & 1641365 & 4.0 & 4.2527 & TRN \\
\hline CHEMBL3955150 & 1641365 & 5.8868 & 5.0575 & TRN \\
\hline CHEMBL3983354 & 1641365 & 4.0 & 5.2017 & TRN \\
\hline CHEMBL3929609 & 1641365 & 4.0 & 4.0083 & TRN \\
\hline CHEMBL 3894382 & 1641365 & 4.0 & 4.6676 & TRN \\
\hline CHEMBL3922433 & 1641365 & 4.0 & 3.2149 & TST \\
\hline CHEMBL3968304 & 1641365 & 4.0 & 3.8962 & TRN \\
\hline CHEMBL3904932 & 1641365 & 4.0 & 4.0358 & TRN \\
\hline CHEMBL 3893213 & 1641365 & 5.9727 & 4.3174 & TRN \\
\hline CHEMBL3935837 & 1641365 & 6.4725 & 4.662 & TST \\
\hline CHEMBL3947998 & 1641365 & 4.0 & 4.3462 & TRN \\
\hline CHEMBL3955761 & 1641365 & 4.0 & 4.2913 & TST \\
\hline CHEMBL3984767 & 1641365 & 6.1324 & 5.5265 & TST \\
\hline CHEMBL3936189 & 1641365 & 4.0 & 4.5837 & TRN \\
\hline CHEMBL3928520 & 1641365 & 4.0 & 3.9939 & TRN \\
\hline CHEMBL3947911 & 1641365 & 4.0 & 5.235 & TRN \\
\hline CHEMBL 3924484 & 1641365 & 4.0 & 4.9221 & TRN \\
\hline CHEMBL 3984121 & 1641365 & 5.9203 & 5.2822 & TRN \\
\hline CHEMBL3922999 & 1641365 & 4.0 & 4.7855 & TST \\
\hline CHEMBL3899636 & 1641365 & 4.0 & 5.025 & TRN \\
\hline CHEMBL 3894398 & 1641365 & 4.0 & 3.8526 & TRN \\
\hline CHEMBL3973630 & 1641365 & 4.0 & 4.9379 & TRN \\
\hline CHEMBL3919875 & 1641365 & 4.0 & 4.712 & TST \\
\hline CHEMBL3911193 & 1641365 & 4.0 & 3.9466 & TRN \\
\hline CHEMBL 3976333 & 1641365 & 4.0 & 4.2721 & TRN \\
\hline CHEMBL 3965420 & 1641365 & 6.4542 & 5.1592 & TRN \\
\hline CHEMBL 3898565 & 1641365 & 4.0 & 4.5146 & TRN \\
\hline CHEMBL3917914 & 1641365 & 4.0 & 4.6277 & TRN \\
\hline CHEMBL3955330 & 1641365 & 4.0 & 5.4023 & TST \\
\hline CHEMBL3959114 & 1641365 & 4.0 & 4.2145 & TRN \\
\hline CHEMBL3938109 & 1641365 & 4.0 & 4.6687 & TRN \\
\hline CHEMBL3970254 & 1641365 & 4.0 & 4.9546 & TRN \\
\hline CHEMBL3978241 & 1641365 & 4.0 & 4.2051 & TST \\
\hline CHEMBL 3908081 & 1641365 & 4.0 & 4.1341 & TRN \\
\hline CHEMBL3938149 & 1641365 & 4.0 & 4.534 & TRN \\
\hline CHEMBL3934807 & 1641365 & 4.0 & 4.5282 & TRN \\
\hline CHEMBL3897938 & 1641365 & 4.0 & 3.8761 & TRN \\
\hline CHEMBL3909495 & 1641365 & 4.0 & 4.1832 & TRN \\
\hline CHEMBL3901410 & 1641365 & 4.0 & 4.9024 & TRN \\
\hline CHEMBL 3894124 & 1641365 & 4.0 & 4.0644 & TRN \\
\hline CHEMBL 3907426 & 1641365 & 4.0 & 4.1892 & TRN \\
\hline CHEMBL 3982424 & 1641365 & 6.6371 & 5.4191 & TRN \\
\hline CHEMBL3966833 & 1641365 & 4.0 & 5.1644 & TRN \\
\hline CHEMBL3910298 & 1641365 & 4.0 & 4.2934 & TST \\
\hline CHEMBL3973300 & 1641365 & 6.1528 & 4.6808 & TRN \\
\hline CHEMBL3984059 & 1641365 & 4.0 & 3.3561 & TST \\
\hline CHEMBL3934189 & 1641365 & 4.0 & 3.7579 & TST \\
\hline CHEMBL3906134 & 1641365 & 4.0 & 4.9494 & TRN \\
\hline
\end{tabular}


Supplemental Table S2.txt

\begin{tabular}{|c|c|c|c|c|}
\hline CHEMBL 3924535 & 1641365 & 5.6692 & 4.8116 & TRN \\
\hline CHEMBL3930967 & 1641365 & 4.0 & 4.106 & TST \\
\hline CHEMBL3972369 & 1641365 & 6.3233 & 4.814 & TRN \\
\hline CHEMBL3952751 & 1641365 & 4.0 & 4.1907 & TRN \\
\hline CHEMBL3938529 & 1641365 & 4.0 & 4.9222 & TRN \\
\hline CHEMBL3911416 & 1641365 & 4.0 & 4.7454 & TST \\
\hline CHEMBL3923402 & 1641365 & 4.0 & 4.2485 & TST \\
\hline CHEMBL3920641 & 1641365 & 4.0 & 3.8861 & TRN \\
\hline CHEMBL3895945 & 1641365 & 4.0 & 4.2235 & TRN \\
\hline CHEMBL3970171 & 1641365 & 4.0 & 3.9989 & TST \\
\hline CHEMBL 3892366 & 1641365 & 4.0 & 4.1955 & TRN \\
\hline CHEMBL3971011 & 1641365 & 8.2366 & 3.9833 & TRN \\
\hline CHEMBL 3909476 & 1641365 & 4.0 & 4.5056 & TRN \\
\hline CHEMBL3928429 & 1641365 & 4.0 & 4.7899 & TST \\
\hline CHEMBL3910961 & 1641365 & 4.0 & 4.1634 & TST \\
\hline CHEMBL3917096 & 1641365 & 6.2205 & 5.4498 & TRN \\
\hline CHEMBL3898967 & 1641365 & 4.0 & 3.6503 & TST \\
\hline CHEMBL 3900151 & 1641365 & 4.0 & 3.9243 & TRN \\
\hline CHEMBL 3960251 & 1641365 & 4.0 & 4.9288 & TRN \\
\hline CHEMBL3954663 & 1641365 & 4.0 & 3.8951 & TRN \\
\hline CHEMBL3965308 & 1641365 & 4.0 & 3.9992 & TST \\
\hline CHEMBL3962065 & 1641365 & 6.6863 & 5.961 & TRN \\
\hline CHEMBL 3950265 & 1641365 & 6.9115 & 6.5137 & TRN \\
\hline CHEMBL3934815 & 1641365 & 5.7291 & 5.6396 & TST \\
\hline CHEMBL3937415 & 1641365 & 4.0 & 4.0734 & TRN \\
\hline CHEMBL3972519 & 1641365 & 4.0 & 4.8357 & TRN \\
\hline CHEMBL3950068 & 1641365 & 4.0 & 4.9662 & TRN \\
\hline CHEMBL 3972732 & 1641365 & 4.0 & 4.0065 & TRN \\
\hline CHEMBL3947805 & 1641365 & 4.0 & 3.5227 & TST \\
\hline CHEMBL3956544 & 1641365 & 5.6395 & 4.3522 & TRN \\
\hline CHEMBL3934604 & 1641365 & 4.0 & 4.3418 & TRN \\
\hline CHEMBL3948440 & 1641365 & 4.0 & 3.8109 & TST \\
\hline CHEMBL 3976410 & 1641365 & 6.1888 & 4.8961 & TRN \\
\hline CHEMBL3897189 & 1641365 & 4.0 & 3.3948 & TST \\
\hline CHEMBL3902797 & 1641365 & 5.8089 & 4.9254 & TRN \\
\hline CHEMBL3960990 & 1641365 & 5.0 & 4.2953 & TRN \\
\hline CHEMBL3960116 & 1641365 & 4.0 & 4.9558 & TRN \\
\hline CHEMBL 3921328 & 1641365 & 4.0 & 3.9126 & TRN \\
\hline CHEMBL 3967292 & 1641365 & 4.0 & 4.6816 & TRN \\
\hline CHEMBL3981657 & 1641365 & 4.0 & 4.3186 & TRN \\
\hline CHEMBL3985966 & 1641365 & 4.0 & 5.5276 & TRN \\
\hline CHEMBL3963482 & 1641365 & 4.0 & 4.6238 & TRN \\
\hline CHEMBL 3917885 & 1641365 & 4.0 & 4.7628 & TRN \\
\hline CHEMBL3913332 & 1641365 & 4.0 & 2.9579 & TRN \\
\hline CHEMBL3939198 & 1641365 & 4.0 & 4.0787 & TRN \\
\hline CHEMBL 3940634 & 1641365 & 4.0 & 4.0182 & TST \\
\hline CHEMBL3930443 & 1641365 & 4.0 & 3.4894 & TRN \\
\hline CHEMBL 3911429 & 1641365 & 4.0 & 4.6558 & TRN \\
\hline
\end{tabular}


Supplemental Table S2.txt

\begin{tabular}{|c|c|c|c|c|}
\hline HEMBL3947055 & 1641365 & 4.0 & 4.8959 & TRN \\
\hline HEMBL3935297 & 641365 & 4.0 & 3.7661 & \\
\hline HEMBL3964164 & 641365 & 4.0 & 3302 & \\
\hline HEMBL3927203 & 641365 & 4.0 & 2781 & RN \\
\hline HEMBL3895950 & 641365 & 6.2111 & .8777 & N \\
\hline HEMBL3981738 & 641365 & 5.8658 & 4.2334 & \\
\hline HEMBL3950558 & 641365 & 4.0 & 4.0711 & \\
\hline HEMBL3939624 & 641365 & 4.0 & .625 & \\
\hline HEMBL3975790 & 1641365 & 4.0 & 4.166 & RN \\
\hline HEMBL3961453 & 1641365 & 7.1255 & 5.4724 & $R N$ \\
\hline HEMBL3984375 & 641365 & 4.0 & 4.2191 & \\
\hline HEMBL3986428 & 365 & 4.0 & .3681 & RN \\
\hline HEMBL3977861 & 365 & 4.0 & & RN \\
\hline HEMBL3958669 & 164 & 4.0 & 4.387 & \\
\hline HEMBL3955963 & 65 & 4.0 & 4.2331 & $\Gamma \mathrm{RN}$ \\
\hline HEMBL3950329 & 64 & 4.0 & 3.9843 & $\mathrm{RN}$ \\
\hline HEMBL3977674 & 64 & 4.0 & .1425 & ובנ \\
\hline HEMBL3963221 & 6 & 7.0391 & 5.5234 & RN \\
\hline HEMBL3925192 & 16 & 4.0 & 5.1452 & $\mathrm{RN}$ \\
\hline HEMBL3959751 & 65 & 4.0 & 78 & ST \\
\hline HEMBL3922561 & 65 & 4.0 & 1.3005 & TRN \\
\hline HEMBL3904854 & 55 & 4.0 & 15 & 31 \\
\hline HEMBL3936958 & 62 & 4.0 & 4.3112 & ST \\
\hline HEMBL3935181 & 65 & 4.0 & 5.0108 & $\Gamma \mathrm{RN}$ \\
\hline HEMBL3947695 & 64 & 4.0 & 76 & TST \\
\hline HEMBL3933106 & 62 & 4.0 & 2991 & TRN \\
\hline HEMBL3942708 & 62 & 4.0 & 5498 & RN \\
\hline HEMBL3938098 & 55 & 5.79 & 4.8276 & TRN \\
\hline HEMBL3950352 & 16 & 4.0 & 5.1059 & TST \\
\hline HEMBL3928599 & 164 & 4.0 & 7 & IRN \\
\hline HEMBL3894212 & 16 & 6.63 & 4749 & IRN \\
\hline HEMBL3905855 & $16<$ & 4.0 & 9053 & RN \\
\hline CHEMBL3969983 & 65 & 4.0 & 3472 & TRN \\
\hline CHEMBL3899730 & 164 & 4.0 & 4.5156 & TST \\
\hline HEMBL3928538 & 164 & 4.0 & 3.8278 & TST \\
\hline HEMBL3968015 & 16 & 6.02 & 2156 & $\Gamma \mathrm{RN}$ \\
\hline CHEMBL3892993 & 16 & 4.0 & .73 & RN \\
\hline CHEMBL3914029 & 16 & 4.0 & 4.4154 & TRN \\
\hline CHEMBL3951612 & 365 & 4.0 & 4.3084 & TST \\
\hline HEMBL3921874 & 16 & 4.0 & 4.7187 & TRN \\
\hline CHEMBL3899049 & 164 & 5.77 & 5.3975 & TST \\
\hline CHEMBL3956348 & 164 & 4.0 & 4.2051 & TST \\
\hline CHEMBL3932067 & 164 & 4.0 & 3.9078 & TST \\
\hline CHEMBL3930486 & 1641365 & 4.0 & 4.8284 & TRN \\
\hline CHEMBL3978578 & 6 & 4.0 & 4.0693 & TRN \\
\hline CHEMBL 3899976 & 164 & 4.0 & 5.4895 & $1 \mathrm{~K}$ \\
\hline CHEMBL3912526 & 164 & 4.0 & 5.2237 & $\mathrm{RN}$ \\
\hline CHEMBL3914543 & 1641365 & 4.0 & 4.1585 & TRN \\
\hline
\end{tabular}

Page 410 


\begin{tabular}{|c|c|c|c|c|c|}
\hline \multicolumn{6}{|c|}{ 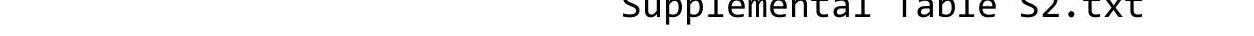 } \\
\hline CHEMBL3984883 & 1641365 & 4.0 & 3.8873 & TRN & \\
\hline CHEMBL3959976 & 1641365 & 4.0 & 4.3507 & TRN & \\
\hline CHEMBL3955957 & 1641365 & 4.0 & 4.0213 & TST & \\
\hline CHEMBL3933871 & 1641365 & 5.88 & 4.5738 & TRN & \\
\hline CHEMBL3939087 & 1641365 & 6.1529 & 4.9899 & TRN & \\
\hline CHEMBL3944149 & 1641365 & 6.4598 & 5.2617 & TRN & \\
\hline CHEMBL3901846 & 1641365 & 5.8398 & 4.8607 & TRN & \\
\hline CHEMBL3970448 & 1641365 & 4.0 & 4.5208 & TRN & \\
\hline CHEMBL3946782 & 1641365 & 6.1713 & 4.6256 & TRN & \\
\hline CHEMBL3910448 & 1641365 & 4.0 & 4.5616 & TRN & \\
\hline CHEMBL3959709 & 1641365 & 4.0 & 3.6101 & TRN & \\
\hline CHEMBL3938697 & 1641365 & 7.041 & 6.4993 & TRN & \\
\hline CHEMBL3952139 & 1641365 & 4.0 & 4.2551 & TRN & \\
\hline CHEMBL3901485 & 1641365 & 4.0 & 4.3073 & TRN & \\
\hline CHEMBL3964253 & 1641365 & 4.0 & 3.7077 & TST & \\
\hline CHEMBL3947228 & 1641365 & 4.0 & 4.1328 & TRN & \\
\hline CHEMBL3964412 & 1641365 & 4.0 & 4.5115 & TST & \\
\hline CHEMBL 3974437 & 1641365 & 6.99100 & 20000000 & 5.6941 & TRN \\
\hline CHEMBL3926371 & 1641365 & 4.0 & 3.5722 & TST & \\
\hline CHEMBL 3932727 & 1641365 & 4.0 & 3.2692 & TRN & \\
\hline CHEMBL3924992 & 1641365 & 4.0 & 3.20300 & 00000000003 & TRN \\
\hline CHEMBL 3943786 & 1641365 & 4.0 & 4.6614 & TRN & \\
\hline CHEMBL 3897188 & 1641365 & 4.0 & 4.2007 & TRN & \\
\hline CHEMBL3954460 & 1641365 & 4.0 & 4.8425 & TRN & \\
\hline CHEMBL3935858 & 1641365 & 4.0 & 4.5566 & TRN & \\
\hline CHEMBL3949863 & 1641365 & 4.0 & 4.395 & TST & \\
\hline CHEMBL3960754 & 1641365 & 4.0 & 4.2797 & TRN & \\
\hline CHEMBL 3924273 & 1641365 & 4.0 & 3.551 & TRN & \\
\hline CHEMBL3959215 & 1641365 & 4.0 & 3.7278 & TRN & \\
\hline CHEMBL3955026 & 1641365 & 4.0 & 3.492 & TST & \\
\hline CHEMBL3918340 & 1641365 & 4.0 & 4.90300 & 00000000005 & TRN \\
\hline CHEMBL3969784 & 1641365 & 4.0 & 4.0003 & TRN & \\
\hline CHEMBL3942088 & 1641365 & 4.0 & 4.2599 & TRN & \\
\hline CHEMBL3929309 & 1641365 & 6.8351 & 5.7505 & TRN & \\
\hline CHEMBL3906625 & 1641365 & 7.0531 & 4.8051 & TST & \\
\hline CHEMBL3949123 & 1641365 & 4.0 & 4.2634 & TRN & \\
\hline CHEMBL 3963437 & 1641365 & 4.0 & 4.4375 & TRN & \\
\hline CHEMBL3925731 & 1641365 & 4.0 & 4.5264 & TST & \\
\hline CHEMBL3949579 & 1641365 & 4.0 & 4.1533 & TRN & \\
\hline CHEMBL 3966497 & 1641365 & 4.0 & 4.4976 & TST & \\
\hline CHEMBL3945771 & 1641365 & 4.0 & 4.9216 & TRN & \\
\hline CHEMBL 3944617 & 1641365 & 4.0 & 3.9304 & TST & \\
\hline CHEMBL3929175 & 1641365 & 5.8261 & 4.4409 & TRN & \\
\hline CHEMBL3952323 & 1641365 & 4.0 & 4.007 & TRN & \\
\hline CHEMBL 3949521 & 1641365 & 4.0 & 4.1983 & TRN & \\
\hline CHEMBL 3937354 & 1641365 & 4.0 & 3.8139 & TST & \\
\hline CHEMBL 3890945 & 1641365 & 4.0 & 3.9301 & TST & \\
\hline CHEMBL3901179 & 1641365 & 4.0 & 3.6694 & TST & \\
\hline
\end{tabular}




\begin{tabular}{|c|c|c|c|c|c|}
\hline \\
\hline CHEMBL3915046 & 1641365 & 4.0 & 3.5179 & TST & \\
\hline CHEMBL3984450 & 1641365 & 4.0 & 4.7028 & TRN & \\
\hline CHEMBL3906302 & 1641365 & 4.0 & 4.2078 & TRN & \\
\hline CHEMBL 3963244 & 1641365 & 6.8904 & 5.7184 & TRN & \\
\hline CHEMBL3911366 & 1641365 & 4.0 & 4.0486 & TST & \\
\hline CHEMBL 3895301 & 1641365 & 4.0 & 4.3331 & TRN & \\
\hline CHEMBL 3922344 & 1641365 & 4.0 & 4.4544 & TST & \\
\hline CHEMBL3918821 & 1641365 & 5.6344 & 4.1347 & TRN & \\
\hline CHEMBL3980706 & 1641365 & 4.0 & 3.9176 & TRN & \\
\hline CHEMBL3977983 & 1641365 & 4.0 & 4.2069 & TRN & \\
\hline CHEMBL3933346 & 1641365 & 6.8219 & 5.38399 & 99999999995 & TRN \\
\hline CHEMBL 3968971 & 1641365 & 4.0 & 4.3177 & TRN & \\
\hline CHEMBL3955332 & 1641365 & 4.0 & 3.6547 & TST & \\
\hline CHEMBL3923668 & 1641365 & 5.8272 & 4.4146 & TRN & \\
\hline CHEMBL 3894289 & 1641365 & 4.0 & 3.9731 & TST & \\
\hline CHEMBL 3986467 & 1641365 & 5.8413 & 4.2245 & TRN & \\
\hline CHEMBL 3937429 & 1641365 & 4.0 & 4.1679 & TRN & \\
\hline CHEMBL3952426 & 1641365 & 4.0 & 4.813 & TRN & \\
\hline CHEMBL 3898112 & 1641365 & 4.0 & 4.0562 & TRN & \\
\hline CHEMBL 3944614 & 1640614 & 7.6021 & 7.4196 & TRN & \\
\hline CHEMBL 3907364 & 1640614 & 6.5086 & 6.6216 & TRN & \\
\hline CHEMBL 3967667 & 1640614 & 6.684 & 6.9651 & TRN & \\
\hline CHEMBL 3978828 & 1640614 & 7.2366 & 7.0827 & TRN & \\
\hline CHEMBL3969035 & 1640614 & 7.6576 & 6.7584 & TST & \\
\hline CHEMBL 3942010 & 1640614 & 7.4089 & 7.6591 & TRN & \\
\hline CHEMBL3899133 & 1640614 & 7.7447 & 7.5424 & TRN & \\
\hline CHEMBL 3952040 & 1640614 & 7.0269 & 6.933 & TRN & \\
\hline CHEMBL3911191 & 1640614 & 6.8539 & 7.2491 & TRN & \\
\hline CHEMBL 3896682 & 1640614 & 6.0 & 7.3729 & TST & \\
\hline CHEMBL 3987121 & 1640614 & 6.6198 & 6.2302 & TRN & \\
\hline CHEMBL 3920334 & 1640614 & 7.4559 & 7.3771 & TRN & \\
\hline CHEMBL 3950052 & 1640614 & 6.0013 & 6.1819 & TRN & \\
\hline CHEMBL3965933 & 1640614 & 6.3468 & 6.3023 & TST & \\
\hline CHEMBL3926014 & 1640614 & 7.2441 & 6.9406 & TRN & \\
\hline CHEMBL 3930702 & 1640614 & 7.6576 & 7.7666 & TRN & \\
\hline CHEMBL3896959 & 1640614 & 7.7212 & 7.476 & TRN & \\
\hline CHEMBL 3958727 & 1640614 & 6.3224 & 6.4238 & TRN & \\
\hline CHEMBL 3986569 & 1640614 & 6.1911 & 6.0911 & TRN & \\
\hline CHEMBL 3898767 & 1640614 & 7.1871 & 6.9718 & TRN & \\
\hline CHEMBL 3944270 & 1640614 & 7.3372 & 7.3758 & TRN & \\
\hline CHEMBL 3929344 & 1640614 & 6.0985 & 6.1432 & TRN & \\
\hline CHEMBL 3914015 & 1640614 & 7.5376 & 7.5845 & TRN & \\
\hline CHEMBL3949766 & 1640614 & 6.0605 & 6.175 & TRN & \\
\hline CHEMBL 3978231 & 1640614 & 6.3516 & 6.6683 & TRN & \\
\hline CHEMBL 3956436 & 1640614 & 6.1415 & 6.4073 & TRN & \\
\hline CHEMBL 3975164 & 1640614 & 7.5376 & 7.6591 & TRN & \\
\hline CHEMBL 3967022 & 1640614 & 7.4202 & 7.1569 & TRN & \\
\hline CHEMBL 3934220 & 1640614 & 6.8153 & 6.8339 & TRN & \\
\hline
\end{tabular}


Supplemental Table S2.txt

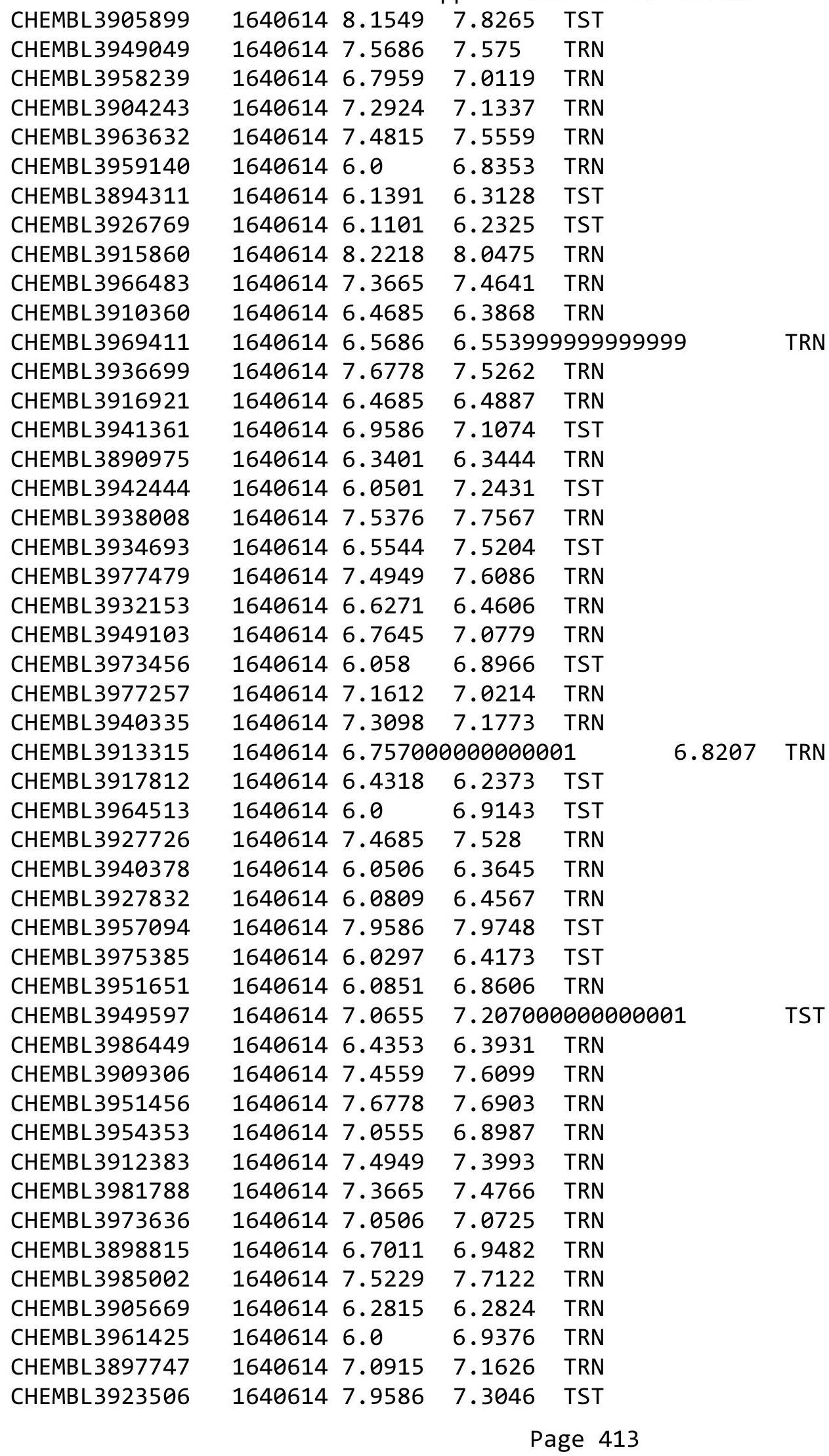


Supplemental Table s2.txt

\begin{tabular}{|c|c|c|c|c|}
\hline CHEMBL 3985601 & 1640614 & 7.1675 & 7.3702 & TST \\
\hline CHEMBL 3894144 & 1640614 & 6.5214 & 6.6093 & TRN \\
\hline CHEMBL3943950 & 1640614 & 6.2396 & 6.2448 & TST \\
\hline CHEMBL 3986621 & 1640614 & 7.2676 & 7.0773 & TST \\
\hline CHEMBL 3985911 & 1640614 & 7.2076 & 7.3608 & TRN \\
\hline CHEMBL 3930194 & 1640614 & 6.1593 & 6.1157 & TRN \\
\hline CHEMBL3913231 & 1640614 & 6.1186 & 6.1646 & TRN \\
\hline CHEMBL3981397 & 1640614 & 6.5391 & 6.6059 & TRN \\
\hline CHEMBL 3973412 & 1640614 & 6.61799 & 99999999 & 6.8037 \\
\hline CHEMBL3903093 & 1640614 & 7.0315 & 7.0552 & TRN \\
\hline CHEMBL3951836 & 1640614 & 6.1688 & 6.1991 & TRN \\
\hline CHEMBL 3951318 & 1640614 & 6.4935 & 6.8253 & TRN \\
\hline CHEMBL 3954414 & 1640614 & 6.5544 & 6.3715 & TRN \\
\hline CHEMBL3971938 & 1640614 & 7.9208 & 7.5927 & TRN \\
\hline CHEMBL3956915 & 1640614 & 7.2441 & 6.9173 & TRN \\
\hline CHEMBL 3943280 & 1640614 & 6.284 & 6.2486 & TRN \\
\hline CHEMBL3968960 & 1640614 & 6.2062 & 7.0784 & TST \\
\hline CHEMBL3963082 & 1640614 & 7.0969 & 6.8983 & TRN \\
\hline CHEMBL 3910747 & 1640614 & 7.8861 & 7.8476 & TST \\
\hline CHEMBL 3921814 & 1640614 & 6.9136 & 7.0106 & TRN \\
\hline CHEMBL3933616 & 1640614 & 6.5272 & 6.4536 & TST \\
\hline CHEMBL3958101 & 1640614 & 7.8539 & 7.5867 & TRN \\
\hline CHEMBL3955953 & 1640614 & 6.7696 & 6.601 & TRN \\
\hline CHEMBL3949161 & 1640614 & 6.9136 & 6.6085 & TRN \\
\hline CHEMBL3971206 & 1640614 & 6.8928 & 7.0255 & TRN \\
\hline CHEMBL3941690 & 1640614 & 6.0 & 7.8502 & TST \\
\hline CHEMBL3952886 & 1640614 & 7.7447 & 7.6924 & TRN \\
\hline CHEMBL 3984426 & 1640614 & 6.7799 & 7.3094 & TST \\
\hline CHEMBL3911399 & 1640614 & 6.5834 & 6.2866 & TRN \\
\hline CHEMBL 3891723 & 1640614 & 7.2291 & 6.9527 & TRN \\
\hline CHEMBL3974993 & 1640614 & 7.6198 & 7.6698 & TRN \\
\hline CHEMBL 3963320 & 1640614 & 8.0969 & 7.7878 & TST \\
\hline CHEMBL3968122 & 1640614 & 7.6198 & 7.5526 & TRN \\
\hline CHEMBL3946398 & 1640614 & 7.4685 & 7.55 & TRN \\
\hline CHEMBL3903196 & 1640614 & 6.5114 & 7.1082 & TST \\
\hline CHEMBL3909403 & 1640614 & 8.301 & 7.6852 & TRN \\
\hline CHEMBL 3927258 & 1640614 & 7.4559 & 7.5949 & TRN \\
\hline CHEMBL 3942258 & 1640614 & 7.4559 & 7.7564 & TST \\
\hline CHEMBL3912836 & 1640614 & 8.0969 & 7.8906 & TST \\
\hline CHEMBL3931673 & 1640614 & 7.1675 & 6.8754 & TRN \\
\hline CHEMBL3949639 & 1640614 & 7.6021 & 7.479 & TRN \\
\hline CHEMBL 3972328 & 1640614 & 6.7932 & 6.75899 & 99999999995 \\
\hline CHEMBL3901476 & 1640614 & 6.1209 & 7.0004 & TST \\
\hline CHEMBL 3937808 & 1640614 & 6.3915 & 6.805 & TRN \\
\hline CHEMBL3939470 & 1640614 & 6.4342 & 6.265 & TRN \\
\hline CHEMBL 3935229 & 1640614 & 7.1805 & 7.2785 & TST \\
\hline CHEMBL 3956993 & 1640614 & 7.4089 & 6.7399 & TRN \\
\hline CHEMBL 3957941 & 1640614 & 7.2757 & 7.0015 & TRN \\
\hline
\end{tabular}


Supplemental Table S2.txt

\begin{tabular}{|c|c|c|c|c|}
\hline W & 3614 & .8894 & & \\
\hline & 640614 & 7.1739 & 6.5878 & \\
\hline 50 & 614 & 212 & & \\
\hline AEMBL3961068 & $\partial 614$ & 4935 & & \\
\hline AEMBL3975071 & 614 & 949 & 5027 & \\
\hline HEMBL3983080 & 640614 & 2223 & 947 & \\
\hline 899 & & 212 & & \\
\hline 166 & 614 & 969 & & \\
\hline AEMBL3932722 & 3614 & 9208 & 95 & \\
\hline AEMBL3966611 & 640614 & 2044 & 0304 & \\
\hline HEMBL3975104 & 614 & 2924 & . 1771 & \\
\hline IEMBL3S & 14 & 696 & 85 & \\
\hline IEMBL3 & & & & \\
\hline HEMBL38 & 614 & 208 & 7.6062 & \\
\hline AEMBL3S & 514 & 447 & & \\
\hline AEMBL39 & 14 & 97 & 86 & \\
\hline AEMBL3S & 14 & & 534 & \\
\hline AEMBL3S & & & 246 & \\
\hline AEMBL38 & 640614 & 799 & 7.12 & \\
\hline AEMBL17 & 21 & 72 & & \\
\hline 105 & 1 & 91 & & \\
\hline AEMBL2 & 1 & & 86 & 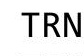 \\
\hline AEMBL2: & 21 & & & \\
\hline 194 & & & & \\
\hline IEMBL23 & & & & \\
\hline AEMBL23 & 1 & & & RN \\
\hline AEMBL2: & 1 & & & RN \\
\hline AFMBI 2 & 21 & & 48 & \\
\hline HEMBL131 & & & & r \\
\hline HEMBL2314178 & & & & s \\
\hline HEMBL2Z & 1 & & 12 & RIV \\
\hline HEMBL2: & $\perp$ & & & KIN \\
\hline AEMBL2 & & & 33 & RN \\
\hline AEMBL2314191 & & & 346 & RIV \\
\hline HEMBL2314502 & 21 & & 2048 & ГRN \\
\hline HEMBL23 & & & 197 & \\
\hline HFMRI & & & & RIV \\
\hline HEMBL2: & & & & RN \\
\hline HEMBL2314209 & 21 & & 7.1748 & $\Gamma \mathrm{RN}$ \\
\hline EMBL2 & & & & RN \\
\hline HEMBL23 & & & 444 & \\
\hline HEMBL 23 & & & & RN \\
\hline HEMBL2314512 & & 218 & 5.2617 & IST \\
\hline AEMBL2314504 & 21 & 85 & 5775 & TRN \\
\hline L2 & & & & \\
\hline HEMBL23 & & & .6226 & \\
\hline HEMBL 231 & & .2076 & 4.1738 & \\
\hline HEMBL2314517 & 934321 & 5.0223 & 4.8653 & RN \\
\hline
\end{tabular}


Supplemental Table S2.txt

\begin{tabular}{|c|c|c|c|c|c|}
\hline CHEMBL 2314205 & 934321 & 6.0915 & 6.1493 & TRN & \\
\hline CHEMBL2314192 & 934321 & 5.9586 & 5.9795 & TRN & \\
\hline CHEMBL 2314172 & 934321 & 6.5376 & 6.558 & TRN & \\
\hline CHEMBL 2314176 & 934321 & 6.6021 & \multicolumn{2}{|c|}{6.702999999999999} & TRN \\
\hline CHEMBL 2314187 & 934321 & 5.7696 & 5.8101 & TRN & \\
\hline CHEMBL278390 & 934321 & 2.0 & 4.6377 & TST & \\
\hline CHEMBL 2314515 & 934321 & 5.0177 & 4.9795 & TRN & \\
\hline CHEMBL 2314186 & 934321 & 5.7212 & 5.7961 & TRN & \\
\hline CHEMBL 2314510 & 934321 & 4.0915 & 4.8988 & TST & \\
\hline CHEMBL36834 & 934321 & 3.7959 & 5.1607 & TST & \\
\hline CHEMBL 2314509 & 934321 & 4.0458 & 3.5601 & TST & \\
\hline CHEMBL 2314204 & 934321 & 4.8539 & 4.7895 & TRN & \\
\hline CHEMBL 2314522 & 934321 & 5.0555 & 5.1396 & TRN & \\
\hline CHEMBL 2314201 & 934321 & 6.5229 & 6.5436 & TRN & \\
\hline CHEMBL 2314189 & 934321 & 5.0088 & 4.9391 & TRN & \\
\hline CHEMBL 2314175 & 934321 & 5.7959 & 5.7275 & TRN & \\
\hline CHEMBL 2314173 & 934321 & 6.4949 & \multicolumn{2}{|c|}{6.3420000000000005} & TRN \\
\hline CHEMBL 2314184 & 934321 & 6.3279 & 6.3276 & TRN & \\
\hline CHEMBL 2314202 & 934321 & 5.5376 & 5.4918 & TRN & \\
\hline CHEMBL 2314179 & 934321 & 6.1427 & 6.0825 & TRN & \\
\hline CHEMBL 2314505 & 934321 & 4.284 & 4.3405 & TRN & \\
\hline CHEMBL 2314195 & 934321 & 5.1192 & 5.1092 & TRN & \\
\hline CHEMBL 2314177 & 934321 & 6.9208 & 6.8185 & TRN & \\
\hline CHEMBL1612421 & 934321 & 4.6576 & 4.6357 & TRN & \\
\hline CHEMBL 2314200 & 934321 & 6.3188 & 6.3754 & TRN & \\
\hline CHEMBL84095 & 934321 & 2.0 & 3.3684 & TST & \\
\hline CHEMBL 2314206 & 934321 & 6.7959 & 6.6483 & TRN & \\
\hline CHEMBL 2314523 & 934321 & 4.3979 & 4.3917 & TRN & \\
\hline CHEMBL 2314207 & 934321 & 6.1549 & 6.2591 & TRN & \\
\hline CHEMBL 2314520 & 934321 & 4.4559 & 5.2219 & TST & \\
\hline CHEMBL 2314196 & 934321 & 5.284 & 5.7021 & TST & \\
\hline CHEMBL 2314506 & 934321 & 4.6383 & 4.55399 & 7999999999 & TST \\
\hline CHEMBL 2314513 & 934321 & 4.0655 & 2.5745 & TST & \\
\hline CHEMBL 2314518 & 934321 & 4.8356 & 4.711 & TST & \\
\hline CHEMBL 2314503 & 934321 & 6.7447 & 6.4444 & TST & \\
\hline CHEMBL2314516 & 934321 & 6.4318 & 6.29700 & 0000000001 & TST \\
\hline CHEMBL 2314199 & 934321 & 5.1249 & 5.28100 & 0000000001 & TST \\
\hline CHEMBL 2314521 & 934321 & 4.8239 & 6.3384 & TST & \\
\hline CHEMBL 2314507 & 934321 & 3.9914 & 4.3427 & TST & \\
\hline CHEMBL 2314188 & 934321 & 4.7959 & 5.2325 & TST & \\
\hline CHEMBL3349113 & 204598 & 8.5528 & 8.2769 & TST & \\
\hline CHEMBL3349169 & 204598 & 6.301 & 6.0915 & TRN & \\
\hline CHEMBL3085570 & 204598 & 8.1024 & 8.192 & TRN & \\
\hline CHEMBL3349090 & 204598 & 7.0315 & 7.1982 & TRN & \\
\hline CHEMBL3349510 & 204598 & 7.4437 & 7.5621 & TST & \\
\hline CHEMBL3349145 & 204598 & 7.5686 & 7.3716 & TRN & \\
\hline CHEMBL 3349160 & 204598 & 7.8861 & 7.7738 & TRN & \\
\hline CHEMBL3349290 & 204598 & 7.0315 & 7.1276 & TST & \\
\hline
\end{tabular}




\begin{tabular}{|c|c|c|c|c|c|}
\hline \multicolumn{6}{|c|}{ Supplemental Table S2.txt } \\
\hline CHEMBL3349098 & 204598 & 7.0 & 6.8509 & TRN & \\
\hline CHEMBL3349135 & 204598 & 6.3665 & 6.3119 & TST & \\
\hline CHEMBL3349170 & 204598 & 9.2518 & 8.832 & TRN & \\
\hline CHEMBL 2298401 & 204598 & 7.0655 & 6.6628 & TRN & \\
\hline CHEMBL1790294 & 204598 & 8.7696 & 8.5045 & TRN & \\
\hline CHEMBL 2298402 & 204598 & 7.699 & 7.812 & TRN & \\
\hline CHEMBL3349112 & 204598 & 7.4202 & 7.4359 & TRN & \\
\hline CHEMBL3349512 & 204598 & 6.6576 & 7.6517 & TST & \\
\hline CHEMBL3349099 & 204598 & 6.3979 & 6.3644 & TRN & \\
\hline CHEMBL3349151 & 204598 & 7.301 & 7.65799 & 99999999995 & TRN \\
\hline CHEMBL3349104 & 204598 & 7.7696 & 7.6357 & TRN & \\
\hline CHEMBL3349166 & 204598 & 6.301 & 6.1826 & TRN & \\
\hline CHEMBL3085568 & 204598 & 7.4318 & 7.61100 & 0000000001 & TRN \\
\hline CHEMBL3349087 & 204598 & 6.3665 & 5.8996 & TST & \\
\hline CHEMBL1790284 & 204598 & 8.1192 & 8.3634 & TST & \\
\hline CHEMBL1790288 & 204598 & 7.8861 & 8.4085 & TRN & \\
\hline CHEMBL3349167 & 204598 & 8.3372 & 8.0596 & TRN & \\
\hline CHEMBL3349292 & 204598 & 6.0 & 6.1087 & TRN & \\
\hline CHEMBL3349288 & 204598 & 8.6021 & 8.6384 & TRN & \\
\hline CHEMBL572724 & 204598 & 6.5376 & 6.3016 & TRN & \\
\hline CHEMBL3349088 & 204598 & 7.699 & 8.7649 & TRN & \\
\hline CHEMBL3349121 & 204598 & 6.3372 & 6.7731 & TRN & \\
\hline CHEMBL3349114 & 204598 & 7.3979 & 7.5904 & TST & \\
\hline CHEMBL3349141 & 204598 & 8.1192 & 8.167 & TRN & \\
\hline CHEMBL3349138 & 204598 & 7.4815 & 7.8086 & TRN & \\
\hline CHEMBL3349152 & 204598 & 5.0 & 4.9377 & TRN & \\
\hline CHEMBL 2298601 & 204598 & 7.9586 & 7.3124 & TRN & \\
\hline CHEMBL3349158 & 204598 & 7.1024 & 6.9822 & TRN & \\
\hline CHEMBL3349118 & 204598 & 9.8861 & 8.9942 & TRN & \\
\hline CHEMBL3349073 & 204598 & 7.6576 & 7.9493 & TRN & \\
\hline CHEMBL3349116 & 204598 & 8.1192 & 7.9154 & TRN & \\
\hline CHEMBL3349076 & 204598 & 5.0 & 5.1855 & TRN & \\
\hline CHEMBL575767 & 204598 & 6.8539 & 7.0054 & TST & \\
\hline CHEMBL3349289 & 204598 & 5.9318 & 6.8753 & TST & \\
\hline CHEMBL 2295868 & 204598 & 7.699 & 7.3946 & TRN & \\
\hline CHEMBL1790279 & 204598 & 8.4202 & 8.557 & TRN & \\
\hline CHEMBL3349147 & 204598 & 8.3372 & 7.1797 & TST & \\
\hline CHEMBL3349293 & 204598 & 7.4318 & 7.0123 & TST & \\
\hline CHEMBL3349168 & 204598 & 8.2007 & 8.9451 & TRN & \\
\hline CHEMBL3349150 & 204598 & 6.9208 & 7.3384 & TRN & \\
\hline CHEMBL3349105 & 204598 & 9.6778 & 8.7649 & TRN & \\
\hline CHEMBL3349128 & 204598 & 7.6021 & 7.7429 & TRN & \\
\hline CHEMBL1790287 & 204598 & 8.4685 & 8.5983 & TRN & \\
\hline CHEMBL590709 & 204598 & 6.8539 & 7.0172 & TRN & \\
\hline CHEMBL3349093 & 204598 & 6.4685 & 6.7066 & TRN & \\
\hline CHEMBL573180 & 204598 & 7.0655 & 7.4476 & TST & \\
\hline CHEMBL3349075 & 204598 & 8.9208 & 8.686 & TRN & \\
\hline CHEMBL3349083 & 204598 & 7.8861 & 8.0582 & TST & \\
\hline
\end{tabular}


Supplemental Table S2.txt

\begin{tabular}{|c|c|c|c|c|c|}
\hline CHEMBL 2298410 & 204598 & 8.1675 & 8.2165 & TRN & \\
\hline CHEMBL3349159 & 204598 & 6.3665 & 6.436 & TRN & \\
\hline CHEMBL3349144 & 204598 & 8.7212 & 8.5282 & TRN & \\
\hline CHEMBL1790293 & 204598 & 8.4437 & 8.5364 & TRN & \\
\hline CHEMBL3349111 & 204598 & 7.9208 & 7.6367 & TST & \\
\hline CHEMBL3349139 & 204598 & 7.9586 & 7.8644 & TST & \\
\hline CHEMBL372236 & 305847 & 5.5751 & 5.4581 & TRN & \\
\hline CHEMBL188242 & 305847 & 6.0177 & 5.9794 & TRN & \\
\hline CHEMBL361091 & 305847 & 6.0969 & 6.2252 & TRN & \\
\hline CHEMBL360829 & 305847 & 6.2518 & 6.0191 & TRN & \\
\hline CHEMBL188447 & 305847 & 6.3665 & 6.2565 & TRN & \\
\hline CHEMBL372900 & 305847 & 5.4078 & 5.1774 & TRN & \\
\hline CHEMBL363184 & 305847 & 5.9101 & 5.5893 & TRN & \\
\hline CHEMBL191397 & 305847 & 5.9355 & 5.7842 & TRN & \\
\hline CHEMBL188290 & 305847 & 6.3979 & 5.6997 & TRN & \\
\hline CHEMBL188755 & 305847 & 6.4949 & 6.062 & TRN & \\
\hline CHEMBL442038 & 305847 & 4.0 & 5.1456 & TST & \\
\hline CHEMBL433960 & 305847 & 4.0 & 3.8635 & TRN & \\
\hline CHEMBL188599 & 305847 & 4.0 & 5.1138 & TST & \\
\hline CHEMBL188756 & 305847 & 5.7545 & 6.3578 & TRN & \\
\hline CHEMBL188435 & 305847 & 5.3788 & 5.4972 & TRN & \\
\hline CHEMBL191417 & 305847 & 5.9914 & 5.9441 & TRN & \\
\hline CHEMBL185656 & 305847 & 5.8182 & 5.9491 & TRN & \\
\hline CHEMBL190983 & 305847 & 6.7212 & 6.8167 & TRN & \\
\hline CHEMBL373309 & 305847 & 4.0 & 5.021 & TST & \\
\hline CHEMBL189767 & 305847 & 6.3188 & 6.2492 & TRN & \\
\hline CHEMBL189469 & 305847 & 6.0458 & 5.625 & TST & \\
\hline CHEMBL433788 & 305847 & 4.0 & 5.71 & TST & \\
\hline CHEMBL 360830 & 305847 & 5.9208 & 6.1012 & TRN & \\
\hline CHEMBL 364856 & 305847 & 4.0 & 4.5094 & TRN & \\
\hline CHEMBL363382 & 305847 & 5.8539 & 5.4047 & TRN & \\
\hline CHEMBL188221 & 305847 & 5.4895 & 5.8064 & TRN & \\
\hline CHEMBL190782 & 305847 & 5.301 & 5.7827 & TRN & \\
\hline CHEMBL191582 & 305847 & 5.7825 & 5.7525 & TRN & \\
\hline CHEMBL191305 & 305847 & 5.6216 & 5.7123 & TST & \\
\hline CHEMBL363395 & 305847 & 5.6144 & 6.2248 & TRN & \\
\hline CHEMBL187596 & 305847 & 5.6615 & 5.5929 & TST & \\
\hline CHEMBL187597 & 305847 & 6.2291 & 5.6483 & TRN & \\
\hline CHEMBL365500 & 305847 & 5.5258 & 5.5008 & TRN & \\
\hline CHEMBL363573 & 305847 & 5.556 & 5.91200 & 0000000001 & TRN \\
\hline CHEMBL360217 & 305847 & 6.6576 & 6.8291 & TRN & \\
\hline CHEMBL365024 & 305847 & 5.8153 & 5.3525 & TST & \\
\hline CHEMBL187381 & 305847 & 4.0 & 4.1025 & TRN & \\
\hline CHEMBL363572 & 305847 & 4.0 & 4.1738 & TRN & \\
\hline CHEMBL 364812 & 305847 & 6.5229 & 6.362 & TRN & \\
\hline CHEMBL188708 & 305847 & 5.9626 & 6.0717 & TRN & \\
\hline CHEMBL447479 & 305847 & 4.0 & 5.0317 & TRN & \\
\hline CHEMBL191447 & 305847 & 4.0 & 4.5366 & TRN & \\
\hline
\end{tabular}




\begin{tabular}{|c|c|c|c|c|c|}
\hline \multicolumn{6}{|c|}{ Supplemental Table S2.txt } \\
\hline CHEMBL187665 & 305847 & 5.7375 & 5.3074 & TST & \\
\hline CHEMBL188676 & 305847 & 6.3565 & 6.1047 & TRN & \\
\hline CHEMBL363257 & 305847 & 5.8239 & 5.8127 & TRN & \\
\hline CHEMBL187826 & 305847 & 5.9469 & 6.524 & TRN & \\
\hline CHEMBL190590 & 305847 & 5.8996 & 5.9561 & TRN & \\
\hline CHEMBL364872 & 305847 & 7.0 & 6.3166 & TRN & \\
\hline CHEMBL189510 & 305847 & 5.7773 & 5.3772 & TRN & \\
\hline CHEMBL188874 & 305847 & 5.7077 & 5.999 & TRN & \\
\hline CHEMBL188252 & 305847 & 6.3768 & 5.8777 & TRN & \\
\hline CHEMBL188446 & 305847 & 6.0915 & 5.8503 & TRN & \\
\hline CHEMBL364655 & 305847 & 5.8633 & 4.9936 & TRN & \\
\hline CHEMBL361081 & 305847 & 6.4318 & 6.6381 & TRN & \\
\hline CHEMBL190168 & 305847 & 5.4976 & 5.683 & TST & \\
\hline CHEMBL188202 & 305847 & 6.0555 & 5.0128 & TST & \\
\hline CHEMBL188727 & 305847 & 5.7399 & 5.8194 & TST & \\
\hline CHEMBL189184 & 305847 & 5.8962 & 5.7181 & TST & \\
\hline CHEMBL365651 & 305847 & 6.0506 & 6.07100 & 0000000001 & TST \\
\hline CHEMBL366084 & 305847 & 4.0 & 4.9801 & TST & \\
\hline CHEMBL573607 & 587658 & 3.5086 & 3.4951 & TRN & \\
\hline CHEMBL573542 & 587658 & 3.0 & 3.0203 & TRN & \\
\hline CHEMBL573611 & 587658 & 3.0 & 2.9966 & TRN & \\
\hline CHEMBL573541 & 587658 & 3.0 & 2.9924 & TRN & \\
\hline CHEMBL573608 & 587658 & 4.0458 & 3.5407 & TST & \\
\hline CHEMBL573864 & 587658 & 3.0 & 2.9816 & TRN & \\
\hline CHEMBL573370 & 587658 & 4.5229 & 3.3519 & TST & \\
\hline CHEMBL577182 & 587658 & 3.0 & 3.2455 & TRN & \\
\hline CHEMBL573371 & 587658 & 3.0 & 3.0387 & TRN & \\
\hline CHEMBL574096 & 587658 & 3.301 & 3.0816 & TRN & \\
\hline CHEMBL573752 & 587658 & 3.0 & 3.0761 & TST & \\
\hline CHEMBL574322 & 587658 & 3.0 & 3.378 & TST & \\
\hline CHEMBL575208 & 587658 & 3.4202 & 3.4139 & TST & \\
\hline CHEMBL573625 & 587658 & 3.0 & 3.1925 & TRN & \\
\hline CHEMBL573539 & 587658 & 3.0 & 3.0478 & TRN & \\
\hline CHEMBL575210 & 587658 & 3.0 & 3.1706 & TRN & \\
\hline CHEMBL573372 & 587658 & 3.0 & 3.1278 & TRN & \\
\hline CHEMBL584804 & 587658 & 3.0 & 2.9295 & TRN & \\
\hline CHEMBL575433 & 587658 & 3.0 & 3.3624 & TRN & \\
\hline CHEMBL573619 & 587658 & 3.0 & 3.0106 & TRN & \\
\hline CHEMBL574549 & 587658 & 3.8539 & 3.5017 & TST & \\
\hline CHEMBL575426 & 587658 & 3.0 & 2.8874 & TRN & \\
\hline CHEMBL573626 & 587658 & 3.0 & 3.1882 & TRN & \\
\hline CHEMBL572449 & 587658 & 3.0 & 3.0633 & TRN & \\
\hline CHEMBL575861 & 587658 & 3.3279 & 3.7331 & TST & \\
\hline CHEMBL575656 & 587658 & 3.0 & 3.07899 & 99999999997 & TST \\
\hline CHEMBL575862 & 587658 & 3.4202 & 3.2695 & TRN & \\
\hline CHEMBL583739 & 587658 & 3.0 & 2.9159 & TRN & \\
\hline CHEMBL575209 & 587658 & 3.6021 & 3.5596 & TRN & \\
\hline CHEMBL573369 & 587658 & 3.1549 & 3.003 & TRN & \\
\hline
\end{tabular}




\begin{tabular}{|c|c|c|c|c|c|c|}
\hline \multicolumn{7}{|c|}{ Supplemental Table S2.txt } \\
\hline CHEMBL583763 & 587658 & 3.0 & 3.0951 & TRN & & \\
\hline CHEMBL573628 & 587658 & 3.0 & 2.9267 & TRN & & \\
\hline CHEMBL572646 & 587658 & 4.0969 & 3.4278 & TRN & & \\
\hline CHEMBL573352 & 587658 & 3.0 & 3.1943 & TST & & \\
\hline CHEMBL573606 & 587658 & 3.2676 & 3.4417 & TRN & & \\
\hline CHEMBL575651 & 587658 & 3.284 & 3.9651 & TRN & & \\
\hline CHEMBL418899 & 587658 & 5.6198 & 3.8192 & TST & & \\
\hline CHEMBL574095 & 587658 & 3.301 & 3.355 & TRN & & \\
\hline CHEMBL585009 & 587658 & 3.0706 & 3.2969 & TRN & & \\
\hline CHEMBL583379 & 587658 & 3.4437 & 3.4951 & TRN & & \\
\hline CHEMBL583512 & 587658 & 3.3098 & 3.3558 & TRN & & \\
\hline CHEMBL564201 & 587658 & 3.0 & 3.6454 & TST & & \\
\hline CHEMBL573850 & 587658 & 3.3768 & 3.2451 & TRN & & \\
\hline CHEMBL575655 & 587658 & 3.0 & 2.9675 & TRN & & \\
\hline CHEMBL573609 & 587658 & 4.9208 & 4.1071 & TRN & & \\
\hline CHEMBL584359 & 587658 & 3.0 & 3.1678 & TRN & & \\
\hline CHEMBL573627 & 587658 & 4.4815 & 3.4795 & TRN & & \\
\hline CHEMBL573540 & 587658 & 3.0 & 2.9442 & TRN & & \\
\hline CHEMBL573618 & 587658 & 3.0 & 3.0534 & TRN & & \\
\hline CHEMBL575652 & 587658 & 3.0 & 3.1697 & TRN & & \\
\hline CHEMBL574100 & 587658 & 3.0 & 2.9222 & TRN & & \\
\hline CHEMBL575657 & 587658 & 3.3979 & 3.6214 & TRN & & \\
\hline CHEMBL574101 & 587658 & 3.0 & 2.9775 & TRN & & \\
\hline CHEMBL575432 & 587658 & 3.0 & 2.9688 & TRN & & \\
\hline CHEMBL575650 & 587658 & 3.4815 & 3.887 & TRN & & \\
\hline CHEMBL572677 & 587658 & 3.0458 & 3.0143 & TRN & & \\
\hline CHEMBL583948 & 587658 & 3.0 & 3.0821 & TST & & \\
\hline CHEMBL573132 & 587658 & 3.2676 & 3.8711 & TST & & \\
\hline CHEMBL573842 & 587658 & 3.699 & 4.053 & TST & & \\
\hline CHEMBL573624 & 587658 & 3.0 & 2.898 & TST & & \\
\hline CHEMBL573852 & 587658 & 3.0 & 3.4405 & TST & & \\
\hline CHEMBL 3898837 & 1642190 & 5.4535 & 5.4064 & TRN & & \\
\hline CHEMBL 3891075 & 1642190 & 8.1739 & 8.07 & TRN & & \\
\hline CHEMBL 3970292 & 1642190 & 6.0181 & 6.2401 & TST & & \\
\hline CHEMBL 3985789 & 1642190 & 8.7959 & 8.9706 & TRN & & \\
\hline CHEMBL3940987 & 1642190 & 7.5031 & 7.504 & TRN & & \\
\hline CHEMBL3935385 & 1642190 & 5.7097 & 6.812 & TST & & \\
\hline CHEMBL 3984093 & 1642190 & 6.5865 & 6.6261 & TRN & & \\
\hline CHEMBL 3959554 & 1642190 & 7.3605 & 7.3615 & TRN & & \\
\hline CHEMBL 3961870 & 1642190 & 6.9788 & 6.9315 & TRN & & \\
\hline CHEMBL 3894568 & 1642190 & 7.4492 & 7.3888 & TRN & & \\
\hline CHEMBL 3982458 & 1642190 & 6.5682 & 6.5895 & TRN & & \\
\hline CHEMBL3914118 & 1642190 & $6.7520 e$ & 000000000 & $\partial 1$ & 6.7166 & TRN \\
\hline CHEMBL 3984274 & 1642190 & 6.3675 & 6.6866 & TST & & \\
\hline CHEMBL 3947414 & 1642190 & 7.5361 & 7.4076 & TRN & & \\
\hline CHEMBL3909833 & 1642190 & 6.5364 & 6.4761 & TRN & & \\
\hline CHEMBL3913054 & 1642190 & 7.9031 & 7.8949 & TRN & & \\
\hline CHEMBL3921775 & 1642190 & 5.8239 & 5.4883 & TST & & \\
\hline
\end{tabular}


Supplemental Table S2.txt

\begin{tabular}{|c|c|c|c|c|}
\hline Th & 190 & .3279 & & \\
\hline & 642190 & 5.7804 & & \\
\hline & & 3778 & & \\
\hline AEMBL39 & 190 & & & \\
\hline AEMBL3937345 & 190 & 388 & & \\
\hline HEMBL3949670 & 190 & 8.4815 & 4802 & \\
\hline & 90 & & 879 & \\
\hline IFMPI 30 & & & & \\
\hline AEMBL3963849 & & 959 & 5607 & \\
\hline HEMBL3918042 & 90 & 5.9397 & 2703 & \\
\hline AEMBL3934761 & 90 & 18 & 332 & \\
\hline IEMBL39 & 90 & 45 & 352 & \\
\hline AEMBL3S & & & & \\
\hline HEMBL39 & 90 & & 668 & \\
\hline AEMBL395 & 90 & & & \\
\hline AEMBL389 & 90 & 25 & 208 & \\
\hline HEMBL39 & 90 & & 389 & \\
\hline HEMBL39 & & & & \\
\hline HEMBL 394 & & 962 & 7861 & \\
\hline AEMBL39 & & & & \\
\hline HEIMBLSS & $\theta 0$ & & 62 & 1 \\
\hline AEMBL3S & & & 87 & 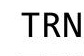 \\
\hline HEMBL3S & & & 47 & \\
\hline HFMRI 39 & & & 354 & \\
\hline HEMBL 396 & & & & 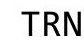 \\
\hline AEMBL3S & 90 & & 13 & RN \\
\hline HEMBL3 & & & & Niv \\
\hline HFMBI $3 c$ & & & 09 & \\
\hline HEMBL3 & & & 2523 & " \\
\hline HEMBL 390 & & & & r \\
\hline HEMBL39 & $\theta 0$ & & 869 & RN \\
\hline HEMBL3 & & & 57 & RN \\
\hline JEMPI & & & 311 & RN \\
\hline HEMBL393 & 90 & & & IS \\
\hline HEMBL3902345 & $\theta 0$ & & 5558 & TST \\
\hline HEMBL39 & & & & RN \\
\hline HFMRI 3 & & & 972 & RIV \\
\hline HEMBL3S & & & 376 & ST \\
\hline HEMBL3973353 & 90 & & 5868 & $\Gamma \mathrm{RN}$ \\
\hline AEMBL392 & & & 547 & RN \\
\hline HEMBL39 & 90 & & 181 & \\
\hline CHEMBL396 & & & & RIN \\
\hline HEMBL396 & 90 & & 6.6784 & RN \\
\hline HEMBL396 & 90 & 6.2055 & 3129 & TRN \\
\hline $1:=8+$ & & & 716 & $\mathrm{~N}$ \\
\hline HEMBL 39 & & & 3806 & \\
\hline CHEMBL 390 & & & 6.7815 & \\
\hline HEMBL389242€ & $164219 €$ & 7.8729 & 7.8914 & ГRN \\
\hline
\end{tabular}


Supplemental Table S2.txt

\begin{tabular}{|c|c|c|c|c|c|c|}
\hline CHEMBL3913815 & 1642190 & 7.1726 & 7.1686 & TRN & & \\
\hline CHEMBL3908329 & 1642190 & 8.4089 & 8.3862 & TRN & & \\
\hline CHEMBL3901897 & 1642190 & 6.6345 & 6.712999 & 99999999 & & TRN \\
\hline CHEMBL3929836 & 1642190 & 6.6925 & 6.8563 & TRN & & \\
\hline CHEMBL3920318 & 1642190 & 7.2495 & 7.2992 & TRN & & \\
\hline CHEMBL3930408 & 1642190 & 5.6772 & 5.6951 & TRN & & \\
\hline CHEMBL3928041 & 1642190 & 8.2596 & 8.0906 & TRN & & \\
\hline CHEMBL3934800 & 1642190 & 6.9508 & 6.9143 & TRN & & \\
\hline CHEMBL3972435 & 1642190 & 5.2506 & 4.5345 & TST & & \\
\hline CHEMBL3977411 & 1642190 & 6.7352 & 4.8631 & TST & & \\
\hline CHEMBL3928819 & 1642190 & 7.066 & 7.0727 & TST & & \\
\hline CHEMBL3937535 & 1642190 & 7.0915 & 7.466 & TST & & \\
\hline CHEMBL3925066 & 1642190 & 6.4908 & 6.2918 & TRN & & \\
\hline CHEMBL3961454 & 1642190 & 7.5952 & 7.6572 & TRN & & \\
\hline CHEMBL3985645 & 1642190 & 7.7051 & 7.7793 & TRN & & \\
\hline CHEMBL3907858 & 1642190 & 6.9706 & 6.9363 & TRN & & \\
\hline CHEMBL3973797 & 1642190 & 8.7696 & 8.6729 & TRN & & \\
\hline CHEMBL3910228 & 1642190 & 9.0605 & 9.0218 & TRN & & \\
\hline CHEMBL3947812 & 1642190 & 6.2799 & 6.1483 & TRN & & \\
\hline CHEMBL3933481 & 1642190 & 6.0985 & 6.0449 & TST & & \\
\hline CHEMBL3943544 & 1642190 & $6.2470 e$ & 000000000 & 01 & 6.2836 & TRN \\
\hline CHEMBL3939748 & 1642190 & 5.9024 & 5.8662 & TRN & & \\
\hline CHEMBL3914820 & 1642190 & 6.7905 & 6.7719 & TRN & & \\
\hline CHEMBL3936335 & 1642190 & 5.5555 & 5.5605 & TRN & & \\
\hline CHEMBL3913634 & 1642190 & 8.9208 & 8.8742 & TRN & & \\
\hline CHEMBL3954775 & 1642190 & 7.0651 & 7.141 & TRN & & \\
\hline CHEMBL3893733 & 1642190 & 6.7226 & 6.7387 & TRN & & \\
\hline CHEMBL3942915 & 1642190 & 9.301 & 9.2513 & TRN & & \\
\hline CHEMBL3917414 & 1642190 & 6.8894 & 6.8483 & TRN & & \\
\hline CHEMBL3978589 & 1642190 & 6.6498 & 6.7034 & TRN & & \\
\hline CHEMBL3898798 & 1642190 & 6.8794 & 6.8343 & TRN & & \\
\hline CHEMBL3915583 & 1642190 & 7.6289 & 7.6235 & TRN & & \\
\hline CHEMBL3935772 & 1642190 & 7.7282 & 7.7371 & TRN & & \\
\hline CHEMBL3901303 & 1642190 & 8.0 & 6.8042 & TST & & \\
\hline CHEMBL3898839 & 1642190 & 6.0533 & 5.5449 & TST & & \\
\hline CHEMBL3892917 & 1642190 & 8.1612 & 8.0198 & TRN & & \\
\hline CHEMBL3977064 & 1642190 & 7.454 & 7.5569 & TRN & & \\
\hline CHEMBL3944761 & 1642190 & 7.2441 & 7.4189 & TRN & & \\
\hline CHEMBL3918648 & 1642190 & 8.7696 & 8.7231 & TRN & & \\
\hline CHEMBL3945243 & 1642190 & 6.4711 & 6.5493 & TRN & & \\
\hline CHEMBL 3914234 & 1642190 & $7.7520 e$ & 200000000 & $\partial 1$ & 7.7575 & TRN \\
\hline CHEMBL3983929 & 1642190 & 7.7167 & 8.0003 & TST & & \\
\hline CHEMBL3926283 & 1642190 & 5.4157 & 5.5723 & TST & & \\
\hline CHEMBL3895439 & 1642190 & 8.0 & 8.0029 & TRN & & \\
\hline CHEMBL3969218 & 1642190 & 7.5249 & 7.4697 & TRN & & \\
\hline CHEMBL3911285 & 1642190 & 6.7062 & 6.7139 & TRN & & \\
\hline CHEMBL3962552 & 1642190 & 6.7905 & 6.8136 & TRN & & \\
\hline CHEMBL3975471 & 1642190 & 6.061 & 7.7551 & TST & & \\
\hline
\end{tabular}


Supplemental Table S2.txt

\begin{tabular}{|c|c|c|c|c|}
\hline 60 & 190 & 5.0393 & & \\
\hline & 642190 & 7.5186 & 7.3877 & \\
\hline & 2190 & 52 & & \\
\hline IEMBL & 90 & 857 & & \\
\hline IEMBL 3984963 & 642190 & 547 & 015 & \\
\hline AEMBL: & 90 & 6.9367 & 71 & \\
\hline 54 & 49 & 586 & & \\
\hline IEMB & & 512 & & \\
\hline AEMBL3650948 & 449 & 6.0 & 613 & \\
\hline AEMBL3650921 & 49 & 024 & 877 & \\
\hline 0930 & & 575 & & \\
\hline 97 & 19 & 586 & & \\
\hline IEME & & 305 & & \\
\hline 50857 & 49 & 6.6383 & & \\
\hline 54266 & 49 & 6.8539 & & \\
\hline 1 & & 7.829 & & \\
\hline 6 & & 596 & & \\
\hline 8 & & 437 & & \\
\hline 50958 & & 6.0 & & \\
\hline 54 & & & & \\
\hline$\theta$ & & & & \\
\hline כ & & & & \\
\hline 4 & & 29 & & \\
\hline 50878 & & & & \\
\hline 0867 & & & & \\
\hline 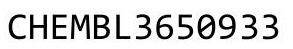 & & & & \\
\hline & & & & \\
\hline & & 61 & & \\
\hline & & & & \\
\hline 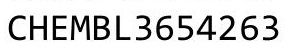 & & 6. & & \\
\hline & & & & \\
\hline & & & & \\
\hline & & 6. & & \\
\hline & & & & \\
\hline 54292 & & & & \\
\hline & & & & \\
\hline & & 7. & & \\
\hline & & 7.4 & & \\
\hline 50950 & & 7.1675 & & \\
\hline & & 6. & & \\
\hline & & 7. & & \\
\hline CHEMB & & 6.284 & & \\
\hline CHEMBL & & 6.0 & & \\
\hline 50957 & 49 & 3.4318 & 74 & \\
\hline 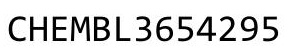 & & 7.0132 & & \\
\hline $\mathrm{CH}$ & & 6.6576 & & \\
\hline & & 7.3665 & 7.2999 & \\
\hline CHEMBL 3650887 & 1528449 & 5.8239 & 6.7626 & \\
\hline
\end{tabular}

Page 423 
Supplemental Table S2.txt

\begin{tabular}{|c|c|c|c|c|}
\hline CHEMBL3961497 & 1528449 & 6.0 & 6.0987 & TRN \\
\hline CHEMBL3654265 & 1528449 & 6.7959 & 6.7576 & TRN \\
\hline CHEMBL3650886 & 1528449 & 6.9586 & 6.9203 & TRN \\
\hline CHEMBL 3650890 & 1528449 & 7.2076 & 7.2515 & TRN \\
\hline CHEMBL 3654271 & 1528449 & 6.4949 & 6.4091 & TRN \\
\hline CHEMBL3650915 & 1528449 & 6.9208 & 6.9042 & TRN \\
\hline CHEMBL 3650927 & 1528449 & 7.1079 & 7.2002 & TRN \\
\hline CHEMBL3650959 & 1528449 & 7.5686 & 7.5203 & TRN \\
\hline CHEMBL3926752 & 1528449 & 6.9586 & 6.9974 & TRN \\
\hline CHEMBL3650931 & 1528449 & 7.041 & 7.0416 & TRN \\
\hline CHEMBL3650966 & 1528449 & 6.0 & \multicolumn{2}{|c|}{6.077000000000001} \\
\hline CHEMBL3650924 & 1528449 & 6.9208 & 6.7434 & TRN \\
\hline CHEMBL3650962 & 1528449 & 7.4089 & 7.4133 & TRN \\
\hline CHEMBL3650929 & 1528449 & 6.9586 & 7.0581 & TRN \\
\hline CHEMBL 3650938 & 1528449 & 6.0 & 6.716 & TRN \\
\hline CHEMBL3650905 & 1528449 & 6.0 & 6.0245 & TRN \\
\hline CHEMBL3650885 & 1528449 & 6.1549 & 5.6569 & TST \\
\hline CHEMBL3650935 & 1528449 & 7.301 & 7.2326 & TRN \\
\hline CHEMBL 3650904 & 1528449 & 6.585 & 6.5955 & TST \\
\hline CHEMBL3650971 & 1528449 & 5.9586 & 4.8278 & TST \\
\hline CHEMBL 3654319 & 1528449 & 6.7212 & 6.7949 & TST \\
\hline CHEMBL3654264 & 1528449 & 7.1024 & 6.9304 & TRN \\
\hline CHEMBL 3654301 & 1528449 & 6.0 & 5.7851 & TRN \\
\hline CHEMBL 3650907 & 1528449 & 6.3872 & 6.5474 & TRN \\
\hline CHEMBL 3654276 & 1528449 & 6.8539 & 6.8286 & TRN \\
\hline CHEMBL 3650953 & 1528449 & 6.8539 & 6.856 & TRN \\
\hline CHEMBL 3654305 & 1528449 & 7.3372 & 7.1963 & TRN \\
\hline CHEMBL 3650893 & 1528449 & 7.0 & \multicolumn{2}{|c|}{6.922999999999999} \\
\hline CHEMBL 3654306 & 1528449 & 7.0862 & 6.9184 & TRN \\
\hline CHEMBL3650939 & 1528449 & 7.5686 & 7.3836 & TRN \\
\hline CHEMBL 3650928 & 1528449 & 7.4559 & 7.4145 & TRN \\
\hline CHEMBL 3654281 & 1528449 & 7.1079 & 7.0888 & TRN \\
\hline CHEMBL3650955 & 1528449 & 7.9208 & 8.0771 & TST \\
\hline CHEMBL 3654297 & 1528449 & 7.284 & 7.155 & TRN \\
\hline CHEMBL 3654272 & 1528449 & 6.7696 & 6.7225 & TRN \\
\hline CHEMBL 3654275 & 1528449 & 6.8239 & 6.7932 & TRN \\
\hline CHEMBL 3654318 & 1528449 & 8.9586 & 7.8226 & TST \\
\hline CHEMBL 3650862 & 1528449 & 6.7696 & 6.5894 & TST \\
\hline CHEMBL 3654286 & 1528449 & 7.1135 & 6.8283 & TRN \\
\hline CHEMBL3654285 & 1528449 & 7.3098 & 7.3715 & TRN \\
\hline CHEMBL 3654280 & 1528449 & 6.8861 & 6.81 & TRN \\
\hline CHEMBL3650895 & 1528449 & 6.6778 & 6.7477 & TRN \\
\hline CHEMBL 3654273 & 1528449 & 6.7212 & 6.8387 & TRN \\
\hline CHEMBL3650892 & 1528449 & 7.0177 & 6.8966 & TST \\
\hline CHEMBL3650916 & 1528449 & 7.6198 & 7.4879 & TST \\
\hline CHEMBL 3654279 & 1528449 & 6.5686 & 6.6815 & TRN \\
\hline CHEMBL3650903 & 1528449 & 6.8861 & 6.9138 & TRN \\
\hline CHEMBL 3650975 & 1528449 & 7.3768 & 7.3529 & TRN \\
\hline
\end{tabular}


Supplemental Table S2.txt

\begin{tabular}{|c|c|c|c|c|c|}
\hline CHEMBL3650954 & 1528449 & 7.7696 & 7.8467 & TRN & \\
\hline CHEMBL3650972 & 1528449 & 6.0 & 5.9916 & TRN & \\
\hline CHEMBL3650969 & 1528449 & 6.0 & 6.1723 & TRN & \\
\hline CHEMBL 3650855 & 1528449 & 6.7696 & 6.5394 & TST & \\
\hline CHEMBL3654325 & 1528449 & 7.3979 & 7.4115 & TRN & \\
\hline CHEMBL3650926 & 1528449 & 7.2007 & 7.2431 & TRN & \\
\hline CHEMBL3654316 & 1528449 & 7.2596 & 7.3088 & TRN & \\
\hline CHEMBL3654294 & 1528449 & 6.8539 & 7.1137 & TRN & \\
\hline CHEMBL3937587 & 1528449 & 6.0 & 5.8482 & TRN & \\
\hline CHEMBL3654269 & 1528449 & 6.5376 & 6.552006 & 00000000005 & TRN \\
\hline CHEMBL3654303 & 1528449 & 7.0809 & 7.0725 & TRN & \\
\hline CHEMBL3650925 & 1528449 & 6.8861 & 6.8579 & TRN & \\
\hline CHEMBL3654326 & 1528449 & 7.5229 & 7.4398 & TRN & \\
\hline CHEMBL3650934 & 1528449 & 7.4089 & 7.3951 & TRN & \\
\hline CHEMBL 3650942 & 1528449 & 6.1079 & 6.1118 & TRN & \\
\hline CHEMBL3650936 & 1528449 & 7.3279 & 7.2625 & TRN & \\
\hline CHEMBL3650932 & 1528449 & 7.5528 & 7.5074 & TRN & \\
\hline CHEMBL3654277 & 1528449 & 6.8239 & 6.8119 & TRN & \\
\hline CHEMBL3654307 & 1528449 & 7.5376 & 7.5554 & TRN & \\
\hline CHEMBL3650879 & 1528449 & 6.0 & 6.0677 & TST & \\
\hline CHEMBL 3654278 & 1528449 & 6.8861 & 6.9968 & TRN & \\
\hline CHEMBL3654267 & 1528449 & 6.9586 & 7.0466 & TRN & \\
\hline CHEMBL3650906 & 1528449 & 6.9208 & 6.67700 & 00000000005 & TRN \\
\hline CHEMBL3654317 & 1528449 & 7.3468 & 7.3885 & TRN & \\
\hline CHEMBL3650881 & 1528449 & 6.0 & 5.9804 & TRN & \\
\hline CHEMBL3650896 & 1528449 & 7.0706 & 7.1176 & TRN & \\
\hline CHEMBL3650909 & 1528449 & 6.8539 & 6.885 & TRN & \\
\hline CHEMBL 3654287 & 1528449 & 7.0862 & 7.1235 & TRN & \\
\hline CHEMBL3654282 & 1528449 & 6.8539 & 6.8072 & TRN & \\
\hline CHEMBL3654289 & 1528449 & 7.5229 & 7.2871 & TST & \\
\hline CHEMBL3654268 & 1528449 & 7.0969 & 7.0006 & TRN & \\
\hline CHEMBL3650922 & 1528449 & 6.6778 & 6.7186 & TRN & \\
\hline CHEMBL3650947 & 1528449 & 7.2291 & 7.3716 & TST & \\
\hline CHEMBL3650918 & 1528449 & 7.5686 & 7.5367 & TRN & \\
\hline CHEMBL3654296 & 1528449 & 7.2366 & 7.4076 & TST & \\
\hline CHEMBL3650914 & 1528449 & 6.699 & 6.7841 & TST & \\
\hline CHEMBL3650894 & 1528449 & 6.9208 & 6.9782 & TST & \\
\hline CHEMBL3650889 & 1528449 & 6.0 & 5.8722 & TST & \\
\hline CHEMBL3654302 & 1528449 & 7.0223 & 7.1083 & TST & \\
\hline CHEMBL3654288 & 1528449 & 7.3372 & 6.9077 & TST & \\
\hline CHEMBL3650961 & 1528449 & 7.4949 & 7.4262 & TST & \\
\hline CHEMBL3650856 & 1528449 & 6.3979 & 6.2982 & TST & \\
\hline CHEMBL3650974 & 1528449 & 6.0 & 6.4376 & TST & \\
\hline CHEMBL3654300 & 1528449 & 7.7959 & 7.7731 & TST & \\
\hline CHEMBL3654284 & 1528449 & 7.0605 & 7.1912 & TST & \\
\hline CHEMBL187898 & 302952 & 3.9586 & 3.4444 & TRN & \\
\hline CHEMBL361278 & 302952 & 4.0 & 3.58 & TRN & \\
\hline CHEMBL93178 & 302952 & 3.4685 & 3.0766 & TRN & \\
\hline
\end{tabular}




\begin{tabular}{|c|c|c|c|c|c|}
\hline \multirow[b]{2}{*}{ CHEMBL 365790} & \multicolumn{5}{|c|}{ Supplemental Table S2 } \\
\hline & 302952 & 2.8861 & 3.3603 & TRN & \multirow[b]{2}{*}{ TRN } \\
\hline CHEMBL371579 & 302952 & 3.699 & \multicolumn{2}{|c|}{ 3.6189999999999998 } & \\
\hline CHEMBL66839 & 302952 & 3.0655 & 3.0602 & TRN & \\
\hline CHEMBL190361 & 302952 & 3.2924 & 3.4119 & TRN & \\
\hline CHEMBL316103 & 302952 & 4.0458 & 3.4686 & TRN & \\
\hline CHEMBL429950 & 302952 & 6.0 & \multicolumn{2}{|c|}{4.468999999999999} & TRN \\
\hline CHEMBL190704 & 302952 & 2.0088 & 3.1043 & TST & \\
\hline CHEMBL189210 & 302952 & 3.7447 & 4.0559 & TRN & \\
\hline CHEMBL191472 & 302952 & 4.0 & 4.1899 & TRN & \\
\hline CHEMBL90069 & 302952 & 4.0 & 4.1329 & TRN & \\
\hline CHEMBL190254 & 302952 & 1.8539 & 2.3991 & TRN & \\
\hline CHEMBL190179 & 302952 & 3.8539 & 4.5101 & TRN & \\
\hline CHEMBL192867 & 302952 & 3.8539 & 4.2747 & TRN & \\
\hline CHEMBL190272 & 302952 & 6.0 & 5.4323 & TRN & \\
\hline CHEMBL191212 & 302952 & 2.1938 & 2.1012 & TRN & \\
\hline CHEMBL364278 & 302952 & 2.1024 & 2.8375 & TRN & \\
\hline CHEMBL427343 & 302952 & 3.7696 & 3.4442 & TRN & \\
\hline CHEMBL 292467 & 302952 & 3.0 & 3.1755 & TST & \\
\hline CHEMBL190668 & 302952 & 2.8539 & 3.273 & TRN & \\
\hline CHEMBL190994 & 302952 & 3.5528 & 3.8786 & TRN & \\
\hline CHEMBL8486 & 302952 & 4.301 & 5.0963 & TRN & \\
\hline CHEMBL190897 & 302952 & 3.9586 & 3.6974 & TRN & \\
\hline CHEMBL 91090 & 302952 & 3.9208 & 3.7981 & TRN & \\
\hline CHEMBL190126 & 302952 & 2.5376 & 4.4406 & TST & \\
\hline CHEMBL190085 & 302952 & 2.8239 & 3.7033 & TST & \\
\hline CHEMBL363832 & 302952 & 2.9586 & 2.8058 & TRN & \\
\hline CHEMBL2371842 & 302952 & 3.0132 & 3.4762 & TRN & \\
\hline CHEMBL190327 & 302952 & 4.0458 & 3.7978 & TST & \\
\hline CHEMBL188696 & 302952 & 3.4815 & 2.627 & TRN & \\
\hline CHEMBL17171 & 302952 & 3.3872 & 4.1583 & TRN & \\
\hline CHEMBL426809 & 302952 & 2.699 & 2.2419 & TST & \\
\hline CHEMBL188695 & 302952 & 3.5229 & 3.2969 & TRN & \\
\hline CHEMBL191422 & 302952 & 3.4559 & 2.7237 & TRN & \\
\hline CHEMBL434535 & 302952 & 3.7696 & 3.4992 & TRN & \\
\hline CHEMBL 371194 & 302952 & 2.9208 & 2.8687 & TRN & \\
\hline CHEMBL189273 & 302952 & 4.0458 & 3.8715 & TRN & \\
\hline CHEMBL 2371837 & 302952 & 1.7212 & 3.8841 & TRN & \\
\hline CHEMBL188866 & 302952 & 3.7959 & 3.4163 & TRN & \\
\hline CHEMBL191532 & 302952 & 2.2676 & 3.2969 & TRN & \\
\hline CHEMBL2371839 & 302952 & 3.6021 & 2.7843 & TRN & \\
\hline CHEMBL187443 & 302952 & 1.8539 & 2.6132 & TRN & \\
\hline CHEMBL 80548 & 302952 & 3.5229 & 3.5403 & TRN & \\
\hline CHEMBL190869 & 302952 & 5.0 & 4.7867 & TRN & \\
\hline CHEMBL2371834 & 302952 & 4.699 & 4.4015 & TRN & \\
\hline CHEMBL190728 & 302952 & 4.0458 & 3.5023 & TRN & \\
\hline CHEMBL190414 & 302952 & 6.0 & 4.4735 & TRN & \\
\hline CHEMBL55868 & 302952 & 3.9586 & 4.8004 & TRN & \\
\hline CHEMBL447844 & 302952 & 3.8539 & 4.1795 & TRN & \\
\hline & & & & ge 426 & \\
\hline
\end{tabular}




\begin{tabular}{|c|c|c|c|c|c|}
\hline & & \multicolumn{4}{|c|}{ Supplemental Table S2.txt } \\
\hline CHEMBL363341 & 302952 & 3.699 & 3.9544 & TRN & \\
\hline CHEMBL188159 & 302952 & 3.9586 & 4.3097 & TRN & \\
\hline CHEMBL191493 & 302952 & 4.0458 & 4.0245 & TRN & \\
\hline CHEMBL186269 & 302952 & 6.0 & 4.6484 & TRN & \\
\hline CHEMBL188505 & 302952 & 3.8239 & 3.9285 & TRN & \\
\hline CHEMBL1161744 & 302952 & 1.8239 & 3.1908 & TST & \\
\hline CHEMBL190027 & 302952 & 1.699 & 3.4301 & TST & \\
\hline CHEMBL188747 & 302952 & 3.699 & 3.609 & TRN & \\
\hline CHEMBL 2371146 & 302952 & 4.2218 & 4.0982 & TRN & \\
\hline CHEMBL17503 & 302952 & 3.4948 & 4.0042 & TRN & \\
\hline CHEMBL1672 & 302952 & 0.5229 & 2.13 & TST & \\
\hline CHEMBL94250 & 302952 & 2.1367 & 4.0348 & TST & \\
\hline CHEMBL90074 & 302952 & 3.6021 & 4.2852 & TST & \\
\hline CHEMBL190549 & 302952 & 2.6021 & 2.7204 & TST & \\
\hline CHEMBL189887 & 302952 & 3.8539 & 4.4513 & TST & \\
\hline CHEMBL 297722 & 302952 & 6.0 & 3.6877 & TST & \\
\hline CHEMBL190809 & 302952 & 2.5086 & 3.6242 & TST & \\
\hline CHEMBL190343 & 302952 & 1.7959 & 2.4344 & TST & \\
\hline CHEMBL364928 & 302952 & 3.6198 & 2.7238 & TST & \\
\hline CHEMBL190933 & 302952 & 3.8539 & 4.8114 & TST & \\
\hline CHEMBL195205 & 304902 & 3.0 & 2.9666 & TRN & \\
\hline CHEMBL191858 & 304902 & 3.0 & 3.00600 & 00000000002 & TRN \\
\hline CHEMBL192365 & 304902 & 4.1739 & 4.2956 & TRN & \\
\hline CHEMBL190454 & 304902 & 3.0 & 3.0711 & TRN & \\
\hline CHEMBL195378 & 304902 & 4.284 & 4.4116 & TRN & \\
\hline CHEMBL 363584 & 304902 & 3.0 & 3.0815 & TRN & \\
\hline CHEMBL195270 & 304902 & 3.0 & 3.0916 & TRN & \\
\hline CHEMBL552788 & 304902 & 3.0 & 3.5929 & TST & \\
\hline CHEMBL193887 & 304902 & 3.0 & 2.7622 & TRN & \\
\hline CHEMBL191652 & 304902 & 3.0 & 3.0311 & TRN & \\
\hline CHEMBL 22310 & 304902 & 5.5654 & 3.9498 & TST & \\
\hline CHEMBL192980 & 304902 & 3.0 & 3.0778 & TRN & \\
\hline CHEMBL194489 & 304902 & 3.0 & 2.9597 & TRN & \\
\hline CHEMBL191769 & 304902 & 3.0 & 3.0259 & TRN & \\
\hline CHEMBL192449 & 304902 & 3.0 & 3.1807 & TRN & \\
\hline CHEMBL191354 & 304902 & 3.0 & 2.8844 & TRN & \\
\hline CHEMBL365780 & 304902 & 4.3468 & 3.9053 & TRN & \\
\hline CHEMBL192421 & 304902 & 4.4318 & 4.4518 & TRN & \\
\hline CHEMBL365996 & 304902 & 3.0 & 3.0781 & TRN & \\
\hline CHEMBL191812 & 304902 & 4.1024 & 4.1477 & TRN & \\
\hline CHEMBL370079 & 304902 & 3.0 & 2.9674 & TRN & \\
\hline CHEMBL366031 & 304902 & 3.0 & 3.1723 & TRN & \\
\hline CHEMBL190979 & 304902 & 3.0 & 2.9064 & TRN & \\
\hline CHEMBL192781 & 304902 & 3.0 & 3.0258 & TRN & \\
\hline CHEMBL 372472 & 304902 & 3.0 & 3.0725 & TRN & \\
\hline CHEMBL 370033 & 304902 & 3.0 & 3.0646 & TRN & \\
\hline CHEMBL189881 & 304902 & 4.0655 & 4.1074 & TRN & \\
\hline CHEMBL 370240 & 304902 & 3.0 & 3.0194 & TRN & \\
\hline
\end{tabular}




\begin{tabular}{|c|c|c|c|c|c|}
\hline \\
\hline CHEMBL369888 & 304902 & 3.0 & 2.911 & TRN & \\
\hline CHEMBL263326 & 304902 & 3.0 & 3.3112 & TRN & \\
\hline CHEMBL370072 & 304902 & 3.0 & 2.9673 & TRN & \\
\hline CHEMBL365953 & 304902 & 3.0 & 3.0138 & TRN & \\
\hline CHEMBL195905 & 304902 & 4.2518 & 4.1899 & TRN & \\
\hline CHEMBL362976 & 304902 & 3.0 & 3.1183 & TRN & \\
\hline CHEMBL192396 & 304902 & 3.0 & 2.8675 & TST & \\
\hline CHEMBL362973 & 304902 & 3.0 & 2.7245 & TRN & \\
\hline CHEMBL191906 & 304902 & 3.0 & 2.864 & TRN & \\
\hline CHEMBL365575 & 304902 & 4.0223 & 3.95399 & 99999999997 & TRN \\
\hline CHEMBL195443 & 304902 & 3.0 & 3.0846 & TRN & \\
\hline CHEMBL195667 & 304902 & 3.0 & 3.2153 & TST & \\
\hline CHEMBL364057 & 304902 & 4.2441 & 4.2476 & TRN & \\
\hline CHEMBL278729 & 304902 & 3.0 & 2.985 & TRN & \\
\hline CHEMBL192117 & 304902 & 4.2291 & 3.9259 & TRN & \\
\hline CHEMBL371846 & 304902 & 3.0 & 3.009 & TRN & \\
\hline CHEMBL191823 & 304902 & 3.0 & 3.0473 & TRN & \\
\hline CHEMBL363175 & 304902 & 3.0 & 2.9788 & TRN & \\
\hline CHEMBL192983 & 304902 & 3.0 & 2.8328 & TST & \\
\hline CHEMBL195755 & 304902 & 3.0 & 3.0458 & TRN & \\
\hline CHEMBL366173 & 304902 & 4.1079 & 4.0381 & TRN & \\
\hline CHEMBL191933 & 304902 & 3.0 & 3.0791 & TRN & \\
\hline CHEMBL370734 & 304902 & 3.0 & 2.9474 & TST & \\
\hline CHEMBL195173 & 304902 & 4.3188 & 4.2693 & TST & \\
\hline CHEMBL195862 & 304902 & 3.0 & 2.7621 & TST & \\
\hline CHEMBL364093 & 304902 & 4.4685 & 3.7828 & TST & \\
\hline CHEMBL194437 & 304902 & 3.0 & 2.9319 & TST & \\
\hline CHEMBL425375 & 304902 & 3.0 & 3.3049 & TST & \\
\hline CHEMBL362930 & 304902 & 3.0 & 3.4511 & TST & \\
\hline CHEMBL195739 & 304902 & 3.0 & 4.0282 & TST & \\
\hline CHEMBL192425 & 304902 & 3.0 & 3.3249 & TST & \\
\hline CHEMBL191514 & 304902 & 3.0 & 3.39899 & 99999999996 & TST \\
\hline CHEMBL257678 & 899993 & 7.6498 & 7.6651 & TRN & \\
\hline CHEMBL 259678 & 899993 & 6.5224 & 6.5463 & TRN & \\
\hline CHEMBL270294 & 899993 & 8.3872 & 8.3408 & TST & \\
\hline CHEMBL403827 & 899993 & 6.6751 & 6.6854 & TRN & \\
\hline CHEMBL257295 & 899993 & 6.6225 & 6.6397 & TST & \\
\hline CHEMBL272862 & 899993 & 7.7447 & 7.7958 & TRN & \\
\hline CHEMBL272433 & 899993 & 8.9208 & 8.8825 & TRN & \\
\hline CHEMBL404362 & 899993 & 6.98799 & 79999999ऽ & 6.9595 & TRN \\
\hline CHEMBL272627 & 899993 & 7.3325 & 7.3113 & TRN & \\
\hline CHEMBL271932 & 899993 & 8.2924 & 8.288 & TRN & \\
\hline CHEMBL408897 & 899993 & 6.095 & 5.7043 & TST & \\
\hline CHEMBL405564 & 899993 & 8.0362 & 8.0566 & TRN & \\
\hline CHEMBL257103 & 899993 & 6.3225 & 6.4163 & TST & \\
\hline CHEMBL272678 & 899993 & 7.4179 & 7.3709 & TRN & \\
\hline CHEMBL406527 & 899993 & 7.4248 & 7.4067 & TRN & \\
\hline CHEMBL271551 & 899993 & 6.8539 & 6.7117 & TRN & \\
\hline
\end{tabular}


Supplemental Table S2.txt

\begin{tabular}{|c|c|c|c|c|c|}
\hline CHEMBL 257491 & 899993 & 6.1375 & 5.4434 & TST & \\
\hline CHEMBL 272605 & 899993 & 5.2426 & 5.2281 & TRN & \\
\hline CHEMBL403720 & 899993 & 6.3425 & 6.2416 & TST & \\
\hline CHEMBL 257108 & 899993 & 7.4353 & 7.4323 & TRN & \\
\hline CHEMBL 271348 & 899993 & 8.1249 & 8.1045 & TRN & \\
\hline CHEMBL414005 & 899993 & 6.565 & 6.6015 & TRN & \\
\hline CHEMBL408216 & 899993 & 6.8401 & 6.8896 & TRN & \\
\hline CHEMBL408215 & 899993 & 7.2848 & 7.2986 & TRN & \\
\hline CHEMBL403099 & 899993 & 6.2775 & 6.2543 & TRN & \\
\hline CHEMBL 270078 & 899993 & 8.9208 & 8.9175 & TRN & \\
\hline CHEMBL403957 & 899993 & 8.2676 & 8.2552 & TRN & \\
\hline CHEMBL 271338 & 899993 & 8.6778 & 8.6799 & TRN & \\
\hline CHEMBL 272239 & 899993 & 7.0424 & 6.9682 & TRN & \\
\hline CHEMBL 271763 & 899993 & 6.5251 & 6.52 & TRN & \\
\hline CHEMBL 271103 & 899993 & 7.0273 & 6.9963 & TRN & \\
\hline CHEMBL 271104 & 899993 & 8.0088 & 7.9942 & TRN & \\
\hline CHEMBL 272587 & 899993 & 5.7144 & 5.6988 & TRN & \\
\hline CHEMBL257299 & 899993 & 7.3526 & 7.3102 & TRN & \\
\hline CHEMBL 2234866 & 899993 & 5.4001 & 5.1115 & TST & \\
\hline CHEMBL 271173 & 899993 & 9.5229 & 9.4893 & TRN & \\
\hline CHEMBL 272208 & 899993 & 6.5626 & 6.6357 & TRN & \\
\hline CHEMBL270730 & 899993 & 7.5406 & 7.1263 & TST & \\
\hline CHEMBL 270510 & 899993 & 7.3152 & 7.3272 & TRN & \\
\hline CHEMBL 270293 & 899993 & 9.3979 & 9.3905 & TRN & \\
\hline CHEMBL 2234865 & 899993 & 5.9172 & 5.9441 & TRN & \\
\hline CHEMBL 269832 & 899993 & 7.3072 & 7.3021 & TRN & \\
\hline CHEMBL 271614 & 899993 & 7.9872 & 7.9791 & TRN & \\
\hline CHEMBL 271549 & 899993 & 8.6198 & 8.634 & TRN & \\
\hline CHEMBL270305 & 899993 & 7.9626 & 8.0043 & TRN & \\
\hline CHEMBL 269818 & 899993 & 7.9318 & 7.9724 & TRN & \\
\hline CHEMBL271339 & 899993 & 7.1487 & 7.2171 & TRN & \\
\hline CHEMBL409468 & 899993 & 5.5544 & 5.7229 & TRN & \\
\hline CHEMBL 270111 & 899993 & 5.8297 & 5.247000 & 0000000001 & TST \\
\hline CHEMBL 259468 & 899993 & 8.2147 & 8.259 & TRN & \\
\hline CHEMBL 257483 & 899993 & 6.1025 & 6.06 & TST & \\
\hline CHEMBL408788 & 899993 & 7.61799 & 999999999 & 7.643 & TRN \\
\hline CHEMBL405841 & 899993 & 7.1124 & 7.0881 & TRN & \\
\hline CHEMBL 273118 & 899993 & 6.5325 & 6.5888 & TRN & \\
\hline CHEMBL 272393 & 899993 & 7.1002 & 7.1247 & TRN & \\
\hline CHEMBL 2234864 & 899993 & 7.4828 & 6.4208 & TST & \\
\hline CHEMBL 256847 & 899993 & 7.1624 & 7.1715 & TRN & \\
\hline CHEMBL 259469 & 899993 & 5.7167 & 5.7325 & TRN & \\
\hline CHEMBL410524 & 899993 & 5.4776 & 5.3326 & TRN & \\
\hline CHEMBL405123 & 899993 & 7.0778 & 7.0737 & TRN & \\
\hline CHEMBL 270723 & 899993 & 6.2775 & 6.5398 & TST & \\
\hline CHEMBL405071 & 899993 & 7.5072 & 7.5068 & TRN & \\
\hline CHEMBL 271312 & 899993 & 6.2825 & 6.0982 & TST & \\
\hline CHEMBL442706 & 899993 & 6.8526 & 6.7965 & TRN & \\
\hline
\end{tabular}




\begin{tabular}{|c|c|c|c|c|c|}
\hline & & & 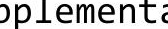 & & \\
\hline CHEMBL257677 & 899993 & 7.4724 & 7.1471 & TST & \\
\hline CHEMBL 271337 & 899993 & 6.8024 & 7.9011 & TST & \\
\hline CHEMBL 255378 & 899993 & 7.5969 & 7.3849 & TST & \\
\hline CHEMBL 257300 & 899993 & 6.1972 & 6.1572 & TST & \\
\hline CHEMBL270517 & 899993 & 6.9176 & 6.9477 & TST & \\
\hline CHEMBL 3672017 & 1528097 & 6.4711 & 6.5175 & TRN & \\
\hline CHEMBL3672058 & 1528097 & 7.4949 & 7.444 & TRN & \\
\hline CHEMBL 3672075 & 1528097 & 7.7447 & 7.6724 & TST & \\
\hline CHEMBL 3672056 & 1528097 & 6.4498 & 6.46299 & 9999999999 & TRN \\
\hline CHEMBL 3672044 & 1528097 & 7.6576 & 7.6107 & TRN & \\
\hline CHEMBL 3672069 & 1528097 & 7.5229 & 7.6119 & TRN & \\
\hline CHEMBL 3672094 & 1528097 & 7.2596 & 7.2023 & TST & \\
\hline CHEMBL3672016 & 1528097 & 7.3768 & 7.39 & TRN & \\
\hline CHEMBL 3672048 & 1528097 & 7.9586 & 7.8302 & TRN & \\
\hline CHEMBL 3672074 & 1528097 & 8.0969 & 7.7201 & TST & \\
\hline CHEMBL3639709 & 1528097 & 8.1549 & 8.1554 & TRN & \\
\hline CHEMBL3672072 & 1528097 & 7.9586 & 7.8991 & TRN & \\
\hline CHEMBL 3672037 & 1528097 & 7.1135 & 6.8694 & TST & \\
\hline CHEMBL3672036 & 1528097 & 7.5376 & 7.436 & TRN & \\
\hline CHEMBL 3672068 & 1528097 & 8.2218 & 8.2332 & TRN & \\
\hline CHEMBL 3672043 & 1528097 & 7.2007 & 7.3374 & TRN & \\
\hline CHEMBL3672021 & 1528097 & 5.8386 & 5.8566 & TRN & \\
\hline CHEMBL 3672078 & 1528097 & 7.4815 & 7.5234 & TRN & \\
\hline CHEMBL3672059 & 1528097 & 7.2518 & 7.3874 & TRN & \\
\hline CHEMBL 3672042 & 1528097 & 8.301 & 7.7863 & TST & \\
\hline CHEMBL 3672020 & 1528097 & 6.2798 & 6.2726 & TRN & \\
\hline CHEMBL3672014 & 1528097 & 6.9508 & 6.9919 & TRN & \\
\hline CHEMBL 3672050 & 1528097 & 8.1549 & 7.79299 & 9999999999 & TST \\
\hline CHEMBL3672038 & 1528097 & 7.8861 & 7.9356 & TRN & \\
\hline CHEMBL 3667041 & 1528097 & 8.301 & 8.0697 & TST & \\
\hline CHEMBL3672055 & 1528097 & 7.2076 & 7.3653 & TRN & \\
\hline CHEMBL 3672047 & 1528097 & 7.4949 & 7.4893 & TRN & \\
\hline CHEMBL 3672087 & 1528097 & 7.585 & 7.4414 & TRN & \\
\hline CHEMBL 3672080 & 1528097 & 7.5376 & 7.5082 & TRN & \\
\hline CHEMBL3672089 & 1528097 & 7.2676 & 7.3045 & TRN & \\
\hline CHEMBL3672093 & 1528097 & 7.2218 & 7.2229 & TRN & \\
\hline CHEMBL 3672029 & 1528097 & 7.8539 & 7.5527 & TST & \\
\hline CHEMBL 3672028 & 1528097 & 7.9208 & 7.7019 & TST & \\
\hline CHEMBL 3672030 & 1528097 & 7.0757 & 7.0974 & TRN & \\
\hline CHEMBL 3672027 & 1528097 & 8.3979 & 8.3697 & TRN & \\
\hline CHEMBL 3667045 & 1528097 & 6.8041 & 6.7769 & TRN & \\
\hline CHEMBL 3672073 & 1528097 & 7.8539 & 7.6905 & TST & \\
\hline CHEMBL 3672083 & 1528097 & 8.301 & 8.3762 & TRN & \\
\hline CHEMBL3672045 & 1528097 & 8.1549 & 8.0673 & TRN & \\
\hline CHEMBL 3672026 & 1528097 & 8.1549 & 8.1556 & TRN & \\
\hline CHEMBL3672039 & 1528097 & 7.5376 & 7.49100 & 00000000005 & TRN \\
\hline CHEMBL 3672011 & 1528097 & 7.0809 & 7.1847 & TRN & \\
\hline CHEMBL 3672063 & 1528097 & 7.9586 & 7.9201 & TRN & \\
\hline
\end{tabular}


Supplemental Table S2.txt

\begin{tabular}{|c|c|c|c|c|}
\hline CHEMBL3672060 & 1528097 & 8.0458 & 8.0515 & TRN \\
\hline CHEMBL3672052 & 1528097 & 7.8861 & 7.7619 & TRN \\
\hline CHEMBL3672067 & 1528097 & 8.0 & 7.9575 & TRN \\
\hline CHEMBL3672079 & 1528097 & 7.6021 & 7.5549 & TRN \\
\hline CHEMBL3672092 & 1528097 & 7.1427 & 7.0835 & TRN \\
\hline CHEMBL3667042 & 1528097 & 7.6383 & 7.3482 & TST \\
\hline CHEMBL3672010 & 1528097 & 7.2518 & 7.1996 & TRN \\
\hline CHEMBL3672090 & 1528097 & 7.9208 & 8.0123 & TRN \\
\hline CHEMBL3672046 & 1528097 & 8.0 & 8.0852 & TRN \\
\hline CHEMBL3667044 & 1528097 & 8.2218 & 7.9571 & TST \\
\hline CHEMBL3672022 & 1528097 & 6.5406 & 6.3484 & TST \\
\hline CHEMBL3672015 & 1528097 & 5.5229 & 5.6108 & TRN \\
\hline CHEMBL3672091 & 1528097 & 8.0 & 8.0604 & TRN \\
\hline CHEMBL3672070 & 1528097 & 7.3768 & 7.4338 & TRN \\
\hline CHEMBL3672062 & 1528097 & 6.7305 & 6.8166 & TRN \\
\hline CHEMBL3672082 & 1528097 & 7.8539 & 7.8743 & TRN \\
\hline CHEMBL3672065 & 1528097 & 8.5229 & 8.5337 & TRN \\
\hline CHEMBL3672051 & 1528097 & 8.301 & 7.7276 & TST \\
\hline CHEMBL3672033 & 1528097 & 8.1549 & 7.5323 & TST \\
\hline CHEMBL 3672024 & 1528097 & 7.3565 & 7.3032 & TRN \\
\hline CHEMBL3672013 & 1528097 & 7.4089 & 7.3429 & TRN \\
\hline CHEMBL3672088 & 1528097 & 8.301 & 8.3184 & TRN \\
\hline CHEMBL3672019 & 1528097 & 7.6021 & 7.3382 & TST \\
\hline CHEMBL3672071 & 1528097 & 7.7959 & 7.8692 & TRN \\
\hline CHEMBL3672034 & 1528097 & 7.585 & 7.6843 & TRN \\
\hline CHEMBL 3672025 & 1528097 & 5.3595 & 6.0758 & TST \\
\hline CHEMBL 3672084 & 1528097 & 8.301 & 8.1934 & TRN \\
\hline CHEMBL3672035 & 1528097 & 6.4377 & 6.8164 & TST \\
\hline CHEMBL3672032 & 1528097 & 7.1549 & 7.0938 & TRN \\
\hline CHEMBL3672053 & 1528097 & 7.5528 & 7.6963 & TRN \\
\hline CHEMBL 3672023 & 1528097 & 6.5017 & 6.3368 & TRN \\
\hline CHEMBL 3672040 & 1528097 & 6.6073 & 6.8269 & TST \\
\hline CHEMBL3672031 & 1528097 & 5.1739 & 5.9301 & TST \\
\hline CHEMBL3672066 & 1528097 & 8.2218 & 8.1893 & TRN \\
\hline CHEMBL3672057 & 1528097 & 7.3872 & 7.3736 & TRN \\
\hline CHEMBL3672041 & 1528097 & 8.0 & 7.9823 & TRN \\
\hline CHEMBL3672076 & 1528097 & 8.0 & 7.7316 & TST \\
\hline CHEMBL3672064 & 1528097 & 7.6021 & 7.6455 & TRN \\
\hline CHEMBL 3667043 & 1528097 & 8.301 & 8.0947 & TST \\
\hline CHEMBL3672061 & 1528097 & 8.0969 & 7.9004 & TRN \\
\hline CHEMBL3672018 & 1528097 & 7.3768 & 7.8404 & TST \\
\hline CHEMBL3672086 & 1528097 & 7.1135 & 7.0717 & TRN \\
\hline CHEMBL3672081 & 1528097 & 7.6198 & 7.4969 & TRN \\
\hline CHEMBL 3672077 & 1528097 & 7.5229 & \multicolumn{2}{|c|}{7.6339999999999995} \\
\hline CHEMBL3672054 & 1528097 & 7.6576 & 7.5093 & TRN \\
\hline CHEMBL3672085 & 1528097 & 8.1549 & 8.3209 & TRN \\
\hline CHEMBL313159 & 177567 & 3.301 & 3.8988 & TRN \\
\hline CHEMBL91279 & 177567 & 5.2132 & 5.2429 & TRN \\
\hline
\end{tabular}




\begin{tabular}{|c|c|c|c|c|c|}
\hline \multirow{3}{*}{ CHEMBL 327207} & & \multicolumn{4}{|c|}{ Supplemental Table S2.txt } \\
\hline & 177567 & 5.8239 & 5.48600 & 0000000001 & TRN \\
\hline & 177567 & 5.2457 & 6.2813 & TRN & \\
\hline CHEMBL88467 & 177567 & 5.1549 & 4.7396 & TRN & \\
\hline CHEMBL90061 & 177567 & 5.3363 & 5.7852 & TRN & \\
\hline CHEMBL330294 & 177567 & 6.301 & 5.7916 & TRN & \\
\hline CHEMBL327821 & 177567 & 6.3979 & 6.1363 & TRN & \\
\hline CHEMBL92848 & 177567 & 6.5229 & 6.723 & TRN & \\
\hline CHEMBL314966 & 177567 & 4.7959 & 5.9007 & TST & \\
\hline CHEMBL 91303 & 177567 & 6.0 & 5.6586 & TRN & \\
\hline CHEMBL93177 & 177567 & 5.6383 & 5.6681 & TRN & \\
\hline CHEMBL90516 & 177567 & 6.0132 & 6.0391 & TRN & \\
\hline CHEMBL88765 & 177567 & 3.301 & 4.7559 & TRN & \\
\hline CHEMBL 313390 & 177567 & 5.6021 & 5.9242 & TST & \\
\hline CHEMBL1199648 & 177567 & 5.0269 & 5.2557 & TRN & \\
\hline CHEMBL314733 & 177567 & 5.699 & 5.5818 & TRN & \\
\hline CHEMBL329442 & 177567 & 5.5229 & 5.6038 & TRN & \\
\hline CHEMBL94069 & 177567 & 6.0 & 5.3759 & TRN & \\
\hline CHEMBL91305 & 177567 & 5.699 & 5.1207 & TST & \\
\hline CHEMBL430839 & 177567 & 6.5229 & 5.7509 & TRN & \\
\hline CHEMBL328066 & 177567 & 5.699 & 5.9026 & TRN & \\
\hline CHEMBL 327458 & 177567 & 5.9586 & 5.3823 & TRN & \\
\hline CHEMBL329787 & 177567 & 5.5686 & 5.8383 & TRN & \\
\hline CHEMBL90185 & 177567 & 6.1871 & 6.5786 & TRN & \\
\hline CHEMBL92029 & 177567 & 5.3125 & 5.5077 & TRN & \\
\hline CHEMBL327211 & 177567 & 5.4559 & 5.6937 & TRN & \\
\hline CHEMBL91307 & 177567 & 6.301 & 5.2855 & TST & \\
\hline CHEMBL1199647 & 177567 & 5.2291 & 5.119 & TRN & \\
\hline CHEMBL92494 & 177567 & 4.699 & 5.1477 & TRN & \\
\hline CHEMBL91423 & 177567 & 6.4559 & 5.2348 & TST & \\
\hline CHEMBL316101 & 177567 & 3.301 & 4.2324 & TRN & \\
\hline CHEMBL315954 & 177567 & 5.8239 & 5.3876 & TRN & \\
\hline CHEMBL 91825 & 177567 & 5.5376 & 5.482 & TRN & \\
\hline CHEMBL90750 & 177567 & 3.301 & 4.3774 & TRN & \\
\hline CHEMBL 92355 & 177567 & 5.1367 & 5.395 & TRN & \\
\hline CHEMBL91236 & 177567 & 5.0458 & 4.6902 & TST & \\
\hline CHEMBL1199895 & 177567 & 4.5229 & 4.8775 & TRN & \\
\hline CHEMBL90293 & 177567 & 5.699 & 5.1686 & TRN & \\
\hline CHEMBL93053 & 177567 & 4.8239 & 4.8402 & TRN & \\
\hline CHEMBL 330110 & 177567 & 6.0969 & 5.4949 & TRN & \\
\hline CHEMBL313158 & 177567 & 6.1249 & 6.4356 & TRN & \\
\hline CHEMBL316450 & 177567 & 5.4559 & 5.0571 & TRN & \\
\hline CHEMBL91281 & 177567 & 6.1871 & 4.6039 & TRN & \\
\hline CHEMBL90589 & 177567 & 5.6021 & 5.9736 & TRN & \\
\hline CHEMBL414216 & 177567 & 5.5884 & 5.9003 & TRN & \\
\hline CHEMBL90914 & 177567 & 6.3468 & 5.6047 & TRN & \\
\hline CHEMBL330534 & 177567 & 5.6198 & 5.4437 & TST & \\
\hline CHEMBL 91442 & 177567 & 5.6021 & 5.8046 & TRN & \\
\hline CHEMBL316102 & 177567 & 5.699 & 5.9155 & TRN & \\
\hline
\end{tabular}




\begin{tabular}{|c|c|c|c|c|c|}
\hline & & & pplement & al Table S & \\
\hline CHEMBL327464 & 177567 & 5.6021 & 5.7712 & TRN & \\
\hline CHEMBL 88358 & 177567 & 5.6778 & 5.36799 & 9999999999 & TRN \\
\hline CHEMBL91406 & 177567 & 6.1549 & 5.9244 & TRN & \\
\hline CHEMBL316289 & 177567 & 6.1805 & 6.1361 & TRN & \\
\hline CHEMBL327683 & 177567 & 5.4559 & 5.3349 & TRN & \\
\hline CHEMBL88517 & 177567 & 5.8239 & 5.9192 & TRN & \\
\hline CHEMBL88540 & 177567 & 6.2596 & 5.8917 & TRN & \\
\hline CHEMBL328505 & 177567 & 5.1367 & 4.4306 & TRN & \\
\hline CHEMBL88795 & 177567 & 5.699 & 4.6244 & TST & \\
\hline CHEMBL90648 & 177567 & 5.0458 & 5.2202 & TST & \\
\hline CHEMBL 88786 & 177567 & 5.699 & 5.7629 & TST & \\
\hline CHEMBL92317 & 177567 & 5.4841 & 5.18 & TST & \\
\hline CHEMBL314096 & 177567 & 6.0 & 5.9718 & TST & \\
\hline CHEMBL314932 & 177567 & 4.301 & 5.8569 & TST & \\
\hline CHEMBL328988 & 177567 & 5.1549 & 5.291 & TST & \\
\hline CHEMBL88719 & 177567 & 6.0706 & 5.7119 & TST & \\
\hline CHEMBL91032 & 177567 & 6.2596 & 5.1139 & TST & \\
\hline CHEMBL90268 & 177567 & 5.5686 & 4.763 & TST & \\
\hline CHEMBL315868 & 177567 & 6.0 & 5.6455 & TST & \\
\hline CHEMBL3431207 & 1479006 & 6.0 & 5.7402 & TRN & \\
\hline CHEMBL3431208 & 1479006 & 4.6 & 4.8165 & TRN & \\
\hline CHEMBL3431209 & 1479006 & 6.1 & 6.2441 & TRN & \\
\hline CHEMBL 3431210 & 1479006 & 3.3 & 4.0011 & TRN & \\
\hline CHEMBL3431211 & 1479006 & 4.4 & 4.9576 & TRN & \\
\hline CHEMBL3431212 & 1479006 & 5.8 & 5.1251 & TRN & \\
\hline CHEMBL3431213 & 1479006 & 4.4 & 4.0293 & TRN & \\
\hline CHEMBL3431214 & 1479006 & 3.3 & 3.7778 & TRN & \\
\hline CHEMBL 3431215 & 1479006 & 5.6 & 5.7791 & TRN & \\
\hline CHEMBL3431216 & 1479006 & 5.5 & 5.3393 & TRN & \\
\hline CHEMBL3431217 & 1479006 & 4.6 & 5.5165 & TRN & \\
\hline CHEMBL3431218 & 1479006 & 3.3 & 4.394 & TRN & \\
\hline CHEMBL3431219 & 1479006 & 3.3 & 3.8035 & TRN & \\
\hline CHEMBL 3431220 & 1479006 & 5.5 & 5.3113 & TRN & \\
\hline CHEMBL3431221 & 1479006 & 5.6 & 5.6902 & TRN & \\
\hline CHEMBL3431222 & 1479006 & 3.3 & 4.1843 & TRN & \\
\hline CHEMBL3431223 & 1479006 & 3.3 & 3.9037 & TST & \\
\hline CHEMBL 3431224 & 1479006 & 5.3 & 3.7452 & TRN & \\
\hline CHEMBL 3431225 & 1479006 & 5.6 & 5.6509 & TRN & \\
\hline CHEMBL3431226 & 1479006 & 5.4 & 5.3143 & TRN & \\
\hline CHEMBL 3431227 & 1479006 & 5.1 & 5.2174 & TRN & \\
\hline CHEMBL3431228 & 1479006 & 3.3 & 4.3945 & TRN & \\
\hline CHEMBL3431229 & 1479006 & 6.6 & 6.0014 & TRN & \\
\hline CHEMBL3431230 & 1479006 & 6.7 & 5.9903 & TRN & \\
\hline CHEMBL 2441267 & 1479006 & 6.1 & 6.6921 & TRN & \\
\hline CHEMBL3430916 & 1479006 & 3.3 & 3.9142 & TRN & \\
\hline CHEMBL3431231 & 1479006 & 5.3 & 5.6324 & TRN & \\
\hline CHEMBL3431232 & 1479006 & 5.7 & 4.532 & TRN & \\
\hline CHEMBL3431233 & 1479006 & 5.1 & 5.7693 & TRN & \\
\hline
\end{tabular}




\begin{tabular}{|c|c|c|c|c|}
\hline & & & ent & al Ta \\
\hline CHEMBL3431234 & 1479006 & 5.3 & 5.4803 & TRN \\
\hline CHEMBL3431235 & 1479006 & 3.3 & 4.7954 & TST \\
\hline CHEMBL3431236 & 1479006 & 4.3 & 4.2077 & TST \\
\hline CHEMBL 3431237 & 1479006 & 4.4 & 4.8891 & TRN \\
\hline CHEMBL3431238 & 1479006 & 5.6 & 4.3804 & TRN \\
\hline CHEMBL3431239 & 1479006 & 3.3 & 3.7407 & TRN \\
\hline CHEMBL3431240 & 1479006 & 5.4 & 4.0426 & TST \\
\hline CHEMBL 3431241 & 1479006 & 3.3 & 5.4977 & TRN \\
\hline CHEMBL 3431242 & 1479006 & 3.3 & 3.9375 & TRN \\
\hline CHEMBL3431243 & 1479006 & 3.3 & 3.86 & TST \\
\hline CHEMBL 3431244 & 1479006 & 4.4 & 3.9911 & TRN \\
\hline CHEMBL3431245 & 1479006 & 4.5 & 5.1741 & TRN \\
\hline CHEMBL3431246 & 1479006 & 4.7 & 5.3082 & TRN \\
\hline CHEMBL 3431247 & 1479006 & 5.3 & 5.6707 & TRN \\
\hline CHEMBL 3431248 & 1479006 & 3.3 & 4.1659 & TRN \\
\hline CHEMBL 3431249 & 1479006 & 4.9 & 4.2873 & TRN \\
\hline CHEMBL3431250 & 1479006 & 3.3 & 3.7455 & TRN \\
\hline CHEMBL3431251 & 1479006 & 3.3 & 3.8677 & TRN \\
\hline CHEMBL3431252 & 1479006 & 3.3 & 3.8204 & TRN \\
\hline CHEMBL3431253 & 1479006 & 3.3 & 4.6048 & TST \\
\hline CHEMBL 3431254 & 1479006 & 4.8 & 5.0906 & TRN \\
\hline CHEMBL 3431255 & 1479006 & 4.9 & 4.5414 & TST \\
\hline CHEMBL3431256 & 1479006 & 6.1 & 5.5818 & TST \\
\hline CHEMBL3431257 & 1479006 & 5.5 & 3.9307 & TRN \\
\hline CHEMBL3431258 & 1479006 & 6.5 & 5.0223 & TRN \\
\hline CHEMBL 3431259 & 1479006 & 3.3 & 3.804 & TRN \\
\hline CHEMBL3431260 & 1479006 & 4.8 & 4.5647 & TRN \\
\hline CHEMBL3431261 & 1479006 & 4.9 & 4.6866 & TRN \\
\hline CHEMBL2356920 & 1479006 & 3.3 & 4.8326 & TRN \\
\hline CHEMBL3431262 & 1479006 & 3.3 & 3.7833 & TRN \\
\hline CHEMBL 3431263 & 1479006 & 4.9 & 4.1236 & TRN \\
\hline CHEMBL3431264 & 1479006 & 3.3 & 3.9926 & TRN \\
\hline CHEMBL 3431265 & 1479006 & 3.3 & 3.8926 & TST \\
\hline CHEMBL3431266 & 1479006 & 4.5 & 4.5602 & TRN \\
\hline CHEMBL 3431267 & 1479006 & 5.2 & 5.2214 & TRN \\
\hline CHEMBL3431268 & 1479006 & 5.4 & 5.1492 & TST \\
\hline CHEMBL3431269 & 1479006 & 5.5 & 5.4179 & TRN \\
\hline CHEMBL 3431270 & 1479006 & 5.5 & 4.7256 & TST \\
\hline CHEMBL 3431271 & 1479006 & 3.3 & 3.7689 & TRN \\
\hline CHEMBL 3431272 & 1479006 & 3.3 & 3.7066 & TRN \\
\hline CHEMBL3431273 & 1479006 & 5.2 & 5.4961 & TRN \\
\hline CHEMBL 3431274 & 1479006 & 5.5 & 5.4529 & TRN \\
\hline CHEMBL3431275 & 1479006 & 3.3 & 4.6592 & TRN \\
\hline CHEMBL3431276 & 1479006 & 5.2 & 5.0252 & TST \\
\hline CHEMBL 3431277 & 1479006 & 5.3 & 5.4171 & TRN \\
\hline CHEMBL3431278 & 1479006 & 3.3 & 3.8636 & TRN \\
\hline CHEMBL3431279 & 1479006 & 4.3 & 3.9485 & TST \\
\hline CHEMBL 3431280 & 1479006 & 4.7 & 4.4958 & TST \\
\hline
\end{tabular}




\begin{tabular}{|c|c|c|c|c|}
\hline \multicolumn{5}{|c|}{ pplemental T } \\
\hline CHEMBL3431281 & 1479006 & 4.7 & 4.9501 & TST \\
\hline CHEMBL3431282 & 1479006 & 3.3 & 3.9253 & TST \\
\hline CHEMBL3431283 & 1479006 & 3.3 & 3.9422 & TST \\
\hline CHEMBL3431284 & 1479006 & 4.9 & 5.0191 & TRN \\
\hline CHEMBL3431285 & 1479006 & 6.1 & 5.555 & TRN \\
\hline CHEMBL3431286 & 1479006 & 3.3 & 4.0437 & TST \\
\hline CHEMBL3431287 & 1479006 & 3.3 & 4.4003 & TST \\
\hline CHEMBL3431288 & 1479006 & 4.4 & 4.7797 & TRN \\
\hline CHEMBL3431289 & 1479006 & 3.3 & 3.9401 & TST \\
\hline CHEMBL3431290 & 1479006 & 5.5 & 4.6128 & TRN \\
\hline CHEMBL3431291 & 1479006 & 3.3 & 3.9225 & TRN \\
\hline CHEMBL3431292 & 1479006 & 3.3 & 4.3283 & TRN \\
\hline CHEMBL3431293 & 1479006 & 3.3 & 3.8248 & TRN \\
\hline CHEMBL3431294 & 1479006 & 3.3 & 3.713 & TRN \\
\hline CHEMBL3431295 & 1479006 & 7.1 & 5.2611 & TRN \\
\hline CHEMBL3431297 & 1479006 & 7.4 & 5.1776 & TRN \\
\hline CHEMBL3431298 & 1479006 & 7.5 & 5.3121 & TRN \\
\hline CHEMBL3431299 & 1479006 & 5.2 & 5.2561 & TRN \\
\hline CHEMBL3431300 & 1479006 & 4.8 & 3.905 & TRN \\
\hline CHEMBL3431301 & 1479006 & 3.3 & 3.8223 & TST \\
\hline CHEMBL3431302 & 1479006 & 4.4 & 4.0617 & TRN \\
\hline CHEMBL3431303 & 1479006 & 5.7 & 4.484 & TRN \\
\hline CHEMBL3431304 & 1479006 & 4.8 & 5.1777 & TRN \\
\hline CHEMBL3431305 & 1479006 & 3.3 & 3.7724 & TRN \\
\hline CHEMBL3431306 & 1479006 & 5.4 & 5.1522 & TRN \\
\hline CHEMBL3431307 & 1479006 & 5.6 & 4.8333 & TRN \\
\hline CHEMBL3431308 & 1479006 & 5.1 & 5.136 & TRN \\
\hline CHEMBL3431309 & 1479006 & 4.6 & 5.4691 & TRN \\
\hline CHEMBL3431310 & 1479006 & 3.3 & 4.7613 & TRN \\
\hline CHEMBL3431311 & 1479006 & 6.0 & 6.0493 & TRN \\
\hline CHEMBL3431312 & 1479006 & 5.7 & 5.8481 & TRN \\
\hline CHEMBL3431313 & 1479006 & 5.8 & 5.9749 & TRN \\
\hline CHEMBL3431314 & 1479006 & 5.8 & 6.1004 & TRN \\
\hline CHEMBL3431315 & 1479006 & 5.7 & 5.3961 & TRN \\
\hline CHEMBL3431316 & 1479006 & 4.7 & 3.9447 & TST \\
\hline CHEMBL3431317 & 1479006 & 4.9 & 5.0739 & TRN \\
\hline CHEMBL3431318 & 1479006 & 5.1 & 4.6271 & TST \\
\hline CHEMBL3431319 & 1479006 & 3.3 & 4.7668 & TRN \\
\hline CHEMBL3431320 & 1479006 & 3.3 & 3.9391 & TST \\
\hline CHEMBL3431321 & 1479006 & 4.9 & 3.8644 & TRN \\
\hline CHEMBL3431322 & 1479006 & 4.5 & 3.8447 & TRN \\
\hline CHEMBL3431323 & 1479006 & 5.0 & 4.2215 & TRN \\
\hline CHEMBL3431324 & 1479006 & 5.3 & 3.9446 & TST \\
\hline CHEMBL3431325 & 1479006 & 4.6 & 4.3955 & TRN \\
\hline CHEMBL3431326 & 1479006 & 6.4 & 3.8511 & TRN \\
\hline CHEMBL3431327 & 1479006 & 4.9 & 5.5108 & TST \\
\hline CHEMBL3431328 & 1479006 & 4.9 & 4.2897 & TST \\
\hline CHEMBL3431329 & 1479006 & 5.0 & 5.3448 & TST \\
\hline
\end{tabular}




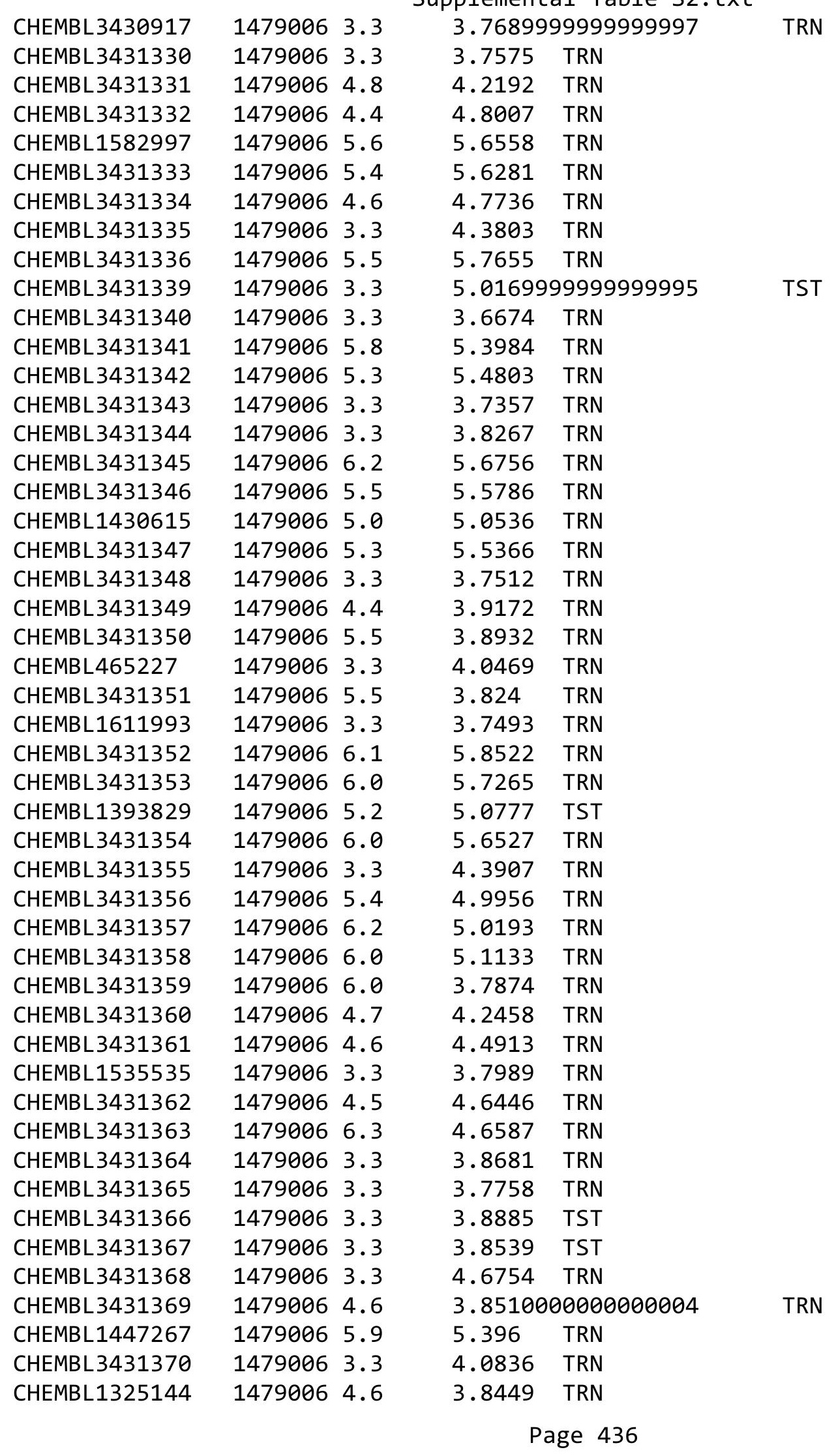




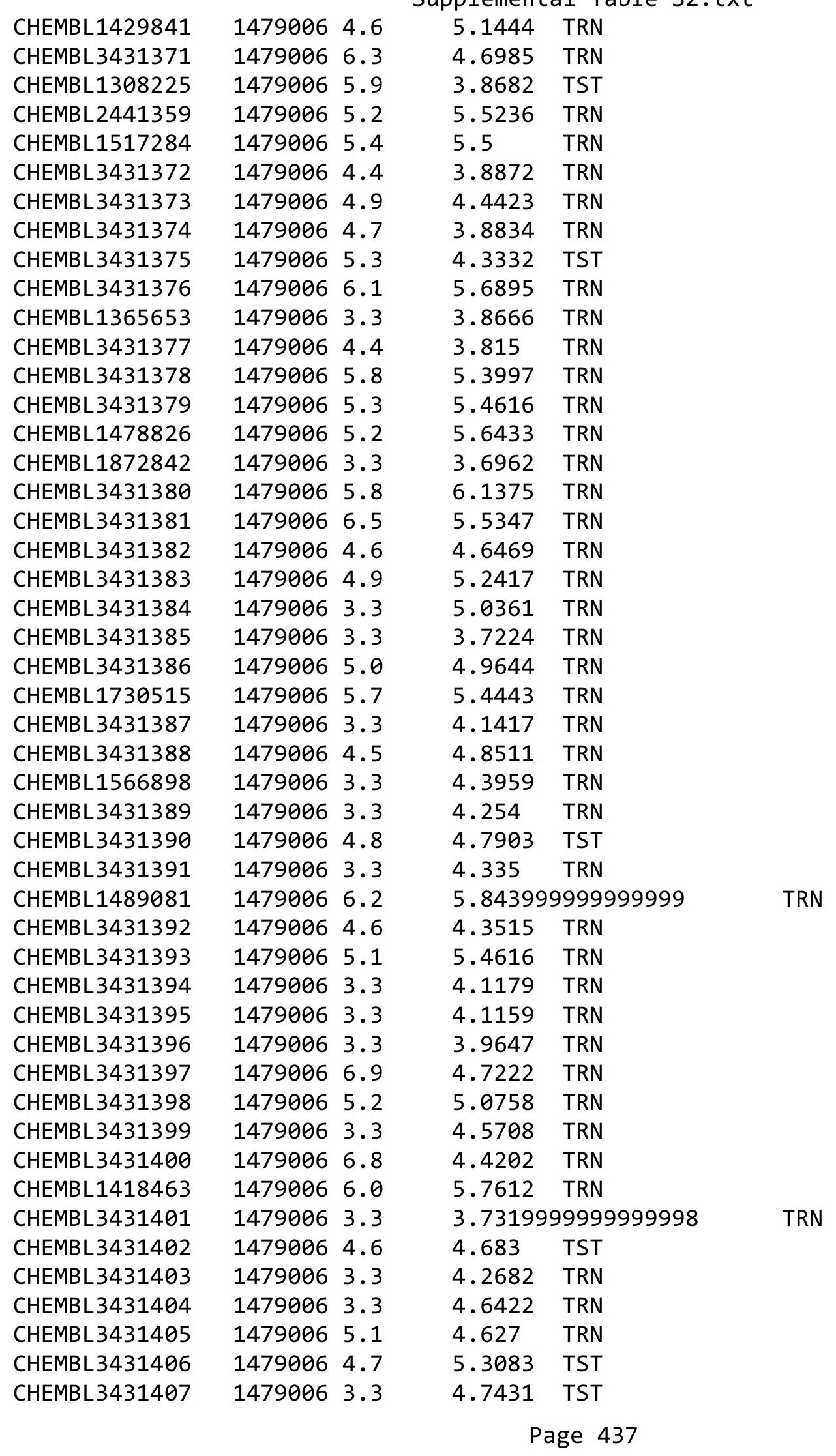




\begin{tabular}{|c|c|c|c|c|c|}
\hline \multicolumn{6}{|c|}{ Supplemental Table S2.txt } \\
\hline CHEMBL3431408 & 1479006 & 5.1 & 4.3687 & TRN & \\
\hline CHEMBL3431409 & 1479006 & 4.4 & 5.567 & TRN & \\
\hline CHEMBL3431410 & 1479006 & 3.3 & 3.8946 & TST & \\
\hline CHEMBL3431411 & 1479006 & 3.3 & 3.9232 & TRN & \\
\hline CHEMBL3431412 & 1479006 & 5.7 & 4.7 & TST & \\
\hline CHEMBL3431413 & 1479006 & 5.7 & 5.3293 & TST & \\
\hline CHEMBL3431414 & 1479006 & 5.1 & 4.8516 & TRN & \\
\hline CHEMBL3431415 & 1479006 & 5.1 & 4.6348 & TRN & \\
\hline CHEMBL3431416 & 1479006 & 4.9 & 4.832 & TST & \\
\hline CHEMBL291721 & 1479006 & 3.3 & 4.7059 & TST & \\
\hline CHEMBL 3431417 & 1479006 & 4.9 & 4.4457 & TRN & \\
\hline CHEMBL3431418 & 1479006 & 3.3 & 3.8044 & TST & \\
\hline CHEMBL487186 & 1479006 & 5.5 & 3.8034 & TST & \\
\hline CHEMBL3431419 & 1479006 & 3.3 & 3.9088 & TRN & \\
\hline CHEMBL 3431420 & 1479006 & 3.3 & 3.7426 & TRN & \\
\hline CHEMBL3431421 & 1479006 & 3.3 & 4.4558 & TRN & \\
\hline CHEMBL3431422 & 1479006 & 5.1 & 5.01699 & 99999999995 & TRN \\
\hline CHEMBL3431423 & 1479006 & 3.3 & 3.8033 & TRN & \\
\hline CHEMBL3431424 & 1479006 & 3.3 & 4.7103 & TRN & \\
\hline CHEMBL3431425 & 1479006 & 5.4 & 5.6198 & TRN & \\
\hline CHEMBL3431426 & 1479006 & 4.4 & 4.5297 & TRN & \\
\hline CHEMBL3431427 & 1479006 & 4.4 & 4.2329 & TRN & \\
\hline CHEMBL3431428 & 1479006 & 3.3 & 4.235 & TST & \\
\hline CHEMBL1725748 & 1479006 & 3.3 & 4.0721 & TRN & \\
\hline CHEMBL3430918 & 1479006 & 3.3 & 4.6388 & TST & \\
\hline CHEMBL522630 & 1479006 & 6.9 & 5.7112 & TRN & \\
\hline CHEMBL3431429 & 1479006 & 5.4 & 5.5887 & TRN & \\
\hline CHEMBL523468 & 1479006 & 6.5 & 5.5264 & TRN & \\
\hline CHEMBL523303 & 1479006 & 6.6 & 5.6839 & TRN & \\
\hline CHEMBL3431430 & 1479006 & 3.3 & 4.3616 & TST & \\
\hline CHEMBL128672 & 1479006 & 3.3 & 4.3666 & TRN & \\
\hline CHEMBL491149 & 1479006 & 6.5 & 5.4295 & TRN & \\
\hline CHEMBL 3431431 & 1479006 & 6.1 & 5.8235 & TRN & \\
\hline CHEMBL3431432 & 1479006 & 6.1 & 5.7991 & TRN & \\
\hline CHEMBL3431433 & 1479006 & 6.7 & 6.7119 & TRN & \\
\hline CHEMBL3431434 & 1479006 & 3.3 & 4.7541 & TST & \\
\hline CHEMBL3431435 & 1479006 & 7.2 & 6.7176 & TRN & \\
\hline CHEMBL 3431436 & 1479006 & 4.7 & 5.2858 & TRN & \\
\hline CHEMBL3431437 & 1479006 & 3.3 & 4.023 & TRN & \\
\hline CHEMBL3431438 & 1479006 & 4.8 & 5.0922 & TST & \\
\hline CHEMBL3431439 & 1479006 & 3.3 & 4.0094 & TST & \\
\hline CHEMBL 3431440 & 1479006 & 3.3 & 4.5887 & TST & \\
\hline CHEMBL3431441 & 1479006 & 3.3 & 3.8367 & TRN & \\
\hline CHEMBL3431442 & 1479006 & 3.3 & 4.5181 & TST & \\
\hline CHEMBL3431443 & 1479006 & 5.0 & 4.8195 & TRN & \\
\hline CHEMBL3431444 & 1479006 & 5.2 & 5.2681 & TST & \\
\hline CHEMBL 3431445 & 1479006 & 3.3 & 4.31800 & 00000000005 & TRN \\
\hline CHEMBL549020 & 1479006 & 5.3 & 4.8066 & TRN & \\
\hline
\end{tabular}




\begin{tabular}{|c|c|c|c|c|c|}
\hline \\
\hline CHEMBL526199 & 1479006 & 6.1 & 4.8851 & TRN & \\
\hline CHEMBL3430919 & 1479006 & 5.6 & 5.6696 & TRN & \\
\hline CHEMBL528583 & 1479006 & 5.6 & 4.9516 & TRN & \\
\hline CHEMBL530358 & 1479006 & 5.1 & 4.9356 & TRN & \\
\hline CHEMBL530275 & 1479006 & 6.1 & 5.4665 & TRN & \\
\hline CHEMBL534517 & 1479006 & 5.8 & 5.5581 & TRN & \\
\hline CHEMBL3430920 & 1479006 & 5.0 & 5.8591 & TRN & \\
\hline CHEMBL3430921 & 1479006 & 4.5 & 4.7287 & TST & \\
\hline CHEMBL3430922 & 1479006 & 3.3 & 4.566 & TST & \\
\hline CHEMBL2098124 & 1479006 & 6.9 & 5.0381 & TRN & \\
\hline CHEMBL2098408 & 1479006 & 5.9 & 5.40600 & 0000000001 & TRN \\
\hline CHEMBL1578482 & 1479006 & 5.8 & 5.4218 & TRN & \\
\hline CHEMBL2098276 & 1479006 & 5.1 & 5.4979 & TRN & \\
\hline CHEMBL3430923 & 1479006 & 3.3 & 3.8232 & TST & \\
\hline CHEMBL3430924 & 1479006 & 5.8 & 5.4859 & TRN & \\
\hline CHEMBL3430925 & 1479006 & 4.8 & 4.0309 & TST & \\
\hline CHEMBL3430926 & 1479006 & 5.2 & 3.7993 & TST & \\
\hline CHEMBL2165401 & 1479006 & 5.6 & 4.7115 & TST & \\
\hline CHEMBL3430927 & 1479006 & 5.6 & 5.7213 & TRN & \\
\hline CHEMBL3430928 & 1479006 & 5.6 & 5.7437 & TRN & \\
\hline CHEMBL3430929 & 1479006 & 5.1 & 5.4111 & TRN & \\
\hline CHEMBL3430930 & 1479006 & 3.3 & 3.8169 & TRN & \\
\hline CHEMBL305686 & 1479006 & 3.3 & 3.9602 & TST & \\
\hline CHEMBL3430931 & 1479006 & 3.3 & 4.4689 & TST & \\
\hline CHEMBL3430932 & 1479006 & 4.6 & 3.7545 & TST & \\
\hline CHEMBL1232777 & 1479006 & 6.4 & 5.4727 & TST & \\
\hline CHEMBL3430933 & 1479006 & 4.4 & 4.4357 & TRN & \\
\hline CHEMBL3430913 & 1479006 & 3.2 & 3.9028 & TRN & \\
\hline CHEMBL3430934 & 1479006 & 5.1 & 5.105 & TRN & \\
\hline CHEMBL3430935 & 1479006 & 5.9 & 4.6287 & TST & \\
\hline CHEMBL3430936 & 1479006 & 3.3 & 3.7637 & TRN & \\
\hline CHEMBL3430937 & 1479006 & 4.4 & 4.5396 & TRN & \\
\hline CHEMBL3430938 & 1479006 & 5.0 & 5.1335 & TRN & \\
\hline CHEMBL3430939 & 1479006 & 4.9 & 5.1834 & TRN & \\
\hline CHEMBL3430940 & 1479006 & 5.1 & 5.1852 & TRN & \\
\hline CHEMBL3430941 & 1479006 & 4.9 & 5.1572 & TRN & \\
\hline CHEMBL3430942 & 1479006 & 4.9 & 5.12700 & 2000000001 & TRN \\
\hline CHEMBL 3430943 & 1479006 & 5.1 & 5.1542 & TRN & \\
\hline CHEMBL3430944 & 1479006 & 5.1 & 5.1152 & TRN & \\
\hline CHEMBL3430945 & 1479006 & 5.3 & 4.8114 & TRN & \\
\hline CHEMBL3430946 & 1479006 & 4.8 & 5.2916 & TRN & \\
\hline CHEMBL3430947 & 1479006 & 6.2 & 5.2211 & TRN & \\
\hline CHEMBL3430948 & 1479006 & 3.3 & 4.3706 & TRN & \\
\hline CHEMBL3430949 & 1479006 & 6.0 & 6.0793 & TRN & \\
\hline CHEMBL1388922 & 1479006 & 5.5 & 5.2708 & TRN & \\
\hline CHEMBL3430950 & 1479006 & 3.3 & 3.6759 & TRN & \\
\hline CHEMBL3430951 & 1479006 & 4.5 & 5.0472 & TST & \\
\hline CHEMBL1321334 & 1479006 & 3.3 & 3.9434 & TRN & \\
\hline
\end{tabular}




\begin{tabular}{|c|c|c|c|c|c|}
\hline CHEMBL3430952 & 1479006 & 3.3 & 5.7758 & TRN & \\
\hline CHEMBL3430953 & 1479006 & 3.3 & 3.8409 & TRN & \\
\hline CHEMBL3430954 & 1479006 & 5.5 & 4.3512 & TRN & \\
\hline CHEMBL3430955 & 1479006 & 3.3 & 4.8197 & TST & \\
\hline CHEMBL3430956 & 1479006 & 5.6 & 5.15799 & 99999999995 & TRN \\
\hline CHEMBL3430957 & 1479006 & 4.5 & 4.6509 & TRN & \\
\hline CHEMBL3430958 & 1479006 & 5.3 & 4.7445 & TRN & \\
\hline CHEMBL3430959 & 1479006 & 5.3 & 5.8544 & TRN & \\
\hline CHEMBL3430960 & 1479006 & 5.3 & 3.8009 & TRN & \\
\hline CHEMBL3430961 & 1479006 & 5.5 & 5.4418 & TRN & \\
\hline CHEMBL3430962 & 1479006 & 4.6 & 4.0604 & TRN & \\
\hline CHEMBL3430963 & 1479006 & 5.3 & 5.1106 & TRN & \\
\hline CHEMBL3430964 & 1479006 & 5.1 & 5.1099 & TRN & \\
\hline CHEMBL3430965 & 1479006 & 5.6 & 5.4315 & TRN & \\
\hline CHEMBL3430966 & 1479006 & 4.6 & 4.5727 & TRN & \\
\hline CHEMBL3430967 & 1479006 & 3.3 & 4.7615 & TRN & \\
\hline CHEMBL3430968 & 1479006 & 5.7 & 5.8646 & TRN & \\
\hline CHEMBL3430969 & 1479006 & 5.9 & 5.3896 & TRN & \\
\hline CHEMBL3430970 & 1479006 & 3.3 & 5.2756 & TRN & \\
\hline CHEMBL1482137 & 1479006 & 3.3 & 4.0856 & TRN & \\
\hline CHEMBL3430971 & 1479006 & 3.3 & 3.766 & TRN & \\
\hline CHEMBL3430972 & 1479006 & 4.4 & 3.8067 & TRN & \\
\hline CHEMBL3430973 & 1479006 & 5.5 & 4.7882 & TRN & \\
\hline CHEMBL3430974 & 1479006 & 5.4 & 4.792 & TRN & \\
\hline CHEMBL3430975 & 1479006 & 3.3 & 3.6983 & TRN & \\
\hline CHEMBL3430976 & 1479006 & 3.3 & 3.6806 & TRN & \\
\hline CHEMBL3430977 & 1479006 & 3.3 & 3.8334 & TST & \\
\hline CHEMBL164422 & 1479006 & 5.8 & 5.9855 & TRN & \\
\hline CHEMBL3430978 & 1479006 & 4.4 & 3.8392 & TRN & \\
\hline CHEMBL3430979 & 1479006 & 3.3 & 3.9141 & TRN & \\
\hline CHEMBL3430980 & 1479006 & 6.1 & 5.0728 & TRN & \\
\hline CHEMBL1487481 & 1479006 & 5.3 & 4.1026 & TRN & \\
\hline CHEMBL1487467 & 1479006 & 3.3 & 3.6879 & TRN & \\
\hline CHEMBL3430981 & 1479006 & 4.9 & 5.1575 & TRN & \\
\hline CHEMBL3430982 & 1479006 & 5.4 & 5.2597 & TRN & \\
\hline CHEMBL3430983 & 1479006 & 5.9 & 4.9897 & TRN & \\
\hline CHEMBL592827 & 1479006 & 5.4 & 4.3795 & TRN & \\
\hline CHEMBL 3430984 & 1479006 & 3.3 & 3.9519 & TRN & \\
\hline CHEMBL3430985 & 1479006 & 4.5 & 5.1505 & TRN & \\
\hline CHEMBL 1466712 & 1479006 & 5.5 & 5.4821 & TRN & \\
\hline CHEMBL3430986 & 1479006 & 3.3 & 3.9136 & TRN & \\
\hline CHEMBL 3430987 & 1479006 & 5.1 & 5.0119 & TST & \\
\hline CHEMBL3430988 & 1479006 & 6.4 & 4.5033 & TRN & \\
\hline CHEMBL3430989 & 1479006 & 3.3 & \multicolumn{2}{|c|}{3.7760000000000002} & TRN \\
\hline CHEMBL 3430990 & 1479006 & 3.3 & 3.8686 & TRN & \\
\hline CHEMBL 3430991 & 1479006 & 3.3 & 4.1084 & TRN & \\
\hline CHEMBL 3430992 & 1479006 & 3.3 & 4.2287 & TRN & \\
\hline CHEMBL3430993 & 1479006 & 3.3 & 3.733 & TRN & \\
\hline
\end{tabular}




\begin{tabular}{|c|c|c|c|c|}
\hline & & & ent & al Ta \\
\hline CHEMBL3430994 & 1479006 & 3.3 & 3.7768 & TRN \\
\hline CHEMBL3430995 & 1479006 & 4.6 & 4.577 & TST \\
\hline CHEMBL3430996 & 1479006 & 3.3 & 3.7001 & TRN \\
\hline CHEMBL3430997 & 1479006 & 3.3 & 3.7426 & TRN \\
\hline CHEMBL3430998 & 1479006 & 4.7 & 3.9375 & TRN \\
\hline CHEMBL3430999 & 1479006 & 4.3 & 4.5715 & TRN \\
\hline CHEMBL3431000 & 1479006 & 4.7 & 4.494 & TRN \\
\hline CHEMBL3431001 & 1479006 & 5.2 & 4.2518 & TRN \\
\hline CHEMBL3431002 & 1479006 & 3.3 & 4.5427 & TST \\
\hline CHEMBL3431003 & 1479006 & 6.3 & 5.6543 & TRN \\
\hline CHEMBL 3431004 & 1479006 & 6.4 & 5.7588 & TRN \\
\hline CHEMBL3431005 & 1479006 & 5.1 & 5.147 & TRN \\
\hline CHEMBL3431006 & 1479006 & 5.5 & 5.519 & TRN \\
\hline CHEMBL3431007 & 1479006 & 4.8 & 4.2904 & TRN \\
\hline CHEMBL3431008 & 1479006 & 5.4 & 5.4369 & TST \\
\hline CHEMBL3431009 & 1479006 & 5.1 & 5.5517 & TRN \\
\hline CHEMBL2355685 & 1479006 & 5.5 & 5.2204 & TST \\
\hline CHEMBL3431010 & 1479006 & 5.2 & 5.2932 & TRN \\
\hline CHEMBL3431011 & 1479006 & 6.4 & 3.9944 & TRN \\
\hline CHEMBL3431012 & 1479006 & 3.3 & 3.7505 & TST \\
\hline CHEMBL1731664 & 1479006 & 6.1 & 4.9162 & TRN \\
\hline CHEMBL3431013 & 1479006 & 5.2 & 4.9661 & TRN \\
\hline CHEMBL3431014 & 1479006 & 3.3 & 4.8401 & TRN \\
\hline CHEMBL3431015 & 1479006 & 4.6 & 4.4448 & TRN \\
\hline CHEMBL3431016 & 1479006 & 3.3 & 4.2592 & TRN \\
\hline CHEMBL3431017 & 1479006 & 4.9 & 3.8994 & TRN \\
\hline CHEMBL3431018 & 1479006 & 5.7 & 5.6928 & TRN \\
\hline CHEMBL3431019 & 1479006 & 5.2 & 5.5896 & TRN \\
\hline CHEMBL3431020 & 1479006 & 4.4 & 3.8791 & TRN \\
\hline CHEMBL3431021 & 1479006 & 3.3 & 3.9393 & TRN \\
\hline CHEMBL 3431022 & 1479006 & 5.7 & 5.6241 & TRN \\
\hline CHEMBL3431023 & 1479006 & 3.3 & 4.8143 & TST \\
\hline CHEMBL 3431024 & 1479006 & 3.3 & 3.6999 & TRN \\
\hline CHEMBL 3431025 & 1479006 & 6.9 & 3.8617 & TRN \\
\hline CHEMBL 3431026 & 1479006 & 5.2 & 5.1723 & TST \\
\hline CHEMBL3431027 & 1479006 & 3.3 & 4.2274 & TRN \\
\hline CHEMBL3431028 & 1479006 & 4.7 & 3.7035 & TRN \\
\hline CHEMBL3431029 & 1479006 & 4.5 & 4.1633 & TRN \\
\hline CHEMBL3431030 & 1479006 & 4.4 & 5.1307 & TRN \\
\hline CHEMBL3431031 & 1479006 & 4.6 & 4.8395 & TRN \\
\hline CHEMBL3431032 & 1479006 & 6.0 & 4.9838 & TRN \\
\hline CHEMBL1527364 & 1479006 & 3.3 & 3.9027 & TRN \\
\hline CHEMBL3430914 & 1479006 & 5.6 & 5.0837 & TRN \\
\hline CHEMBL3431033 & 1479006 & 6.3 & 5.9276 & TRN \\
\hline CHEMBL 3431034 & 1479006 & 6.1 & 5.102 & TRN \\
\hline CHEMBL3431035 & 1479006 & 5.9 & 4.3723 & TRN \\
\hline CHEMBL3431036 & 1479006 & 4.7 & 3.9305 & TRN \\
\hline CHEMBL3431037 & 1479006 & 5.5 & 5.4976 & TRN \\
\hline
\end{tabular}




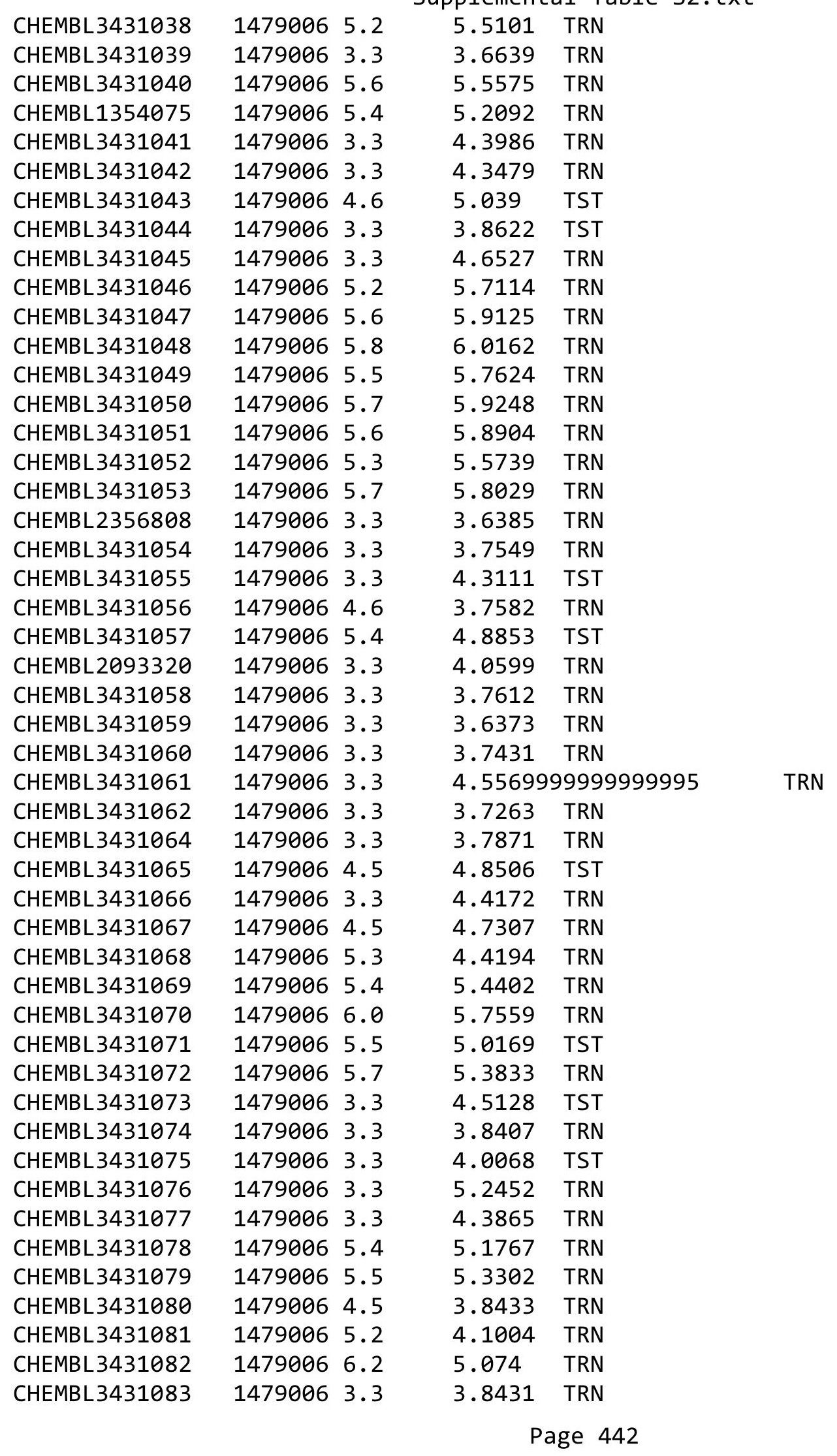




\begin{tabular}{|c|c|c|c|c|c|}
\hline CHEMBL 3431084 & 1479006 & 5.9 & 3.7575 & TST & \\
\hline CHEMBL1585368 & 1479006 & 6.0 & \multicolumn{2}{|c|}{4.946000000000001} & TRN \\
\hline CHEMBL3431085 & 1479006 & 5.2 & 3.7574 & TRN & \\
\hline CHEMBL3431086 & 1479006 & 4.5 & 4.7582 & TRN & \\
\hline CHEMBL3431087 & 1479006 & 5.0 & 5.1278 & TRN & \\
\hline CHEMBL3431088 & 1479006 & 4.6 & 3.9212 & TRN & \\
\hline CHEMBL3431089 & 1479006 & 5.3 & 4.8327 & TRN & \\
\hline CHEMBL3431090 & 1479006 & 4.9 & 4.5787 & TRN & \\
\hline CHEMBL3431091 & 1479006 & 5.1 & 5.2225 & TRN & \\
\hline CHEMBL3431092 & 1479006 & 5.4 & 5.2707 & TRN & \\
\hline CHEMBL3431093 & 1479006 & 5.2 & 5.4109 & TRN & \\
\hline CHEMBL 3431094 & 1479006 & 3.3 & 3.8693 & TRN & \\
\hline CHEMBL3431095 & 1479006 & 5.5 & 5.0676 & TRN & \\
\hline CHEMBL3431096 & 1479006 & 3.3 & 3.8578 & TRN & \\
\hline CHEMBL3431097 & 1479006 & 5.7 & 5.2686 & TRN & \\
\hline CHEMBL3431098 & 1479006 & 5.6 & 5.3397 & TRN & \\
\hline CHEMBL3431099 & 1479006 & 3.3 & 4.67 & TST & \\
\hline CHEMBL3431100 & 1479006 & 5.7 & 5.2428 & TRN & \\
\hline CHEMBL3431101 & 1479006 & 5.0 & 4.9882 & TST & \\
\hline CHEMBL3431102 & 1479006 & 3.3 & 4.3043 & TST & \\
\hline CHEMBL3431103 & 1479006 & 5.2 & 5.596 & TST & \\
\hline CHEMBL3431104 & 1479006 & 5.3 & 3.8093 & TRN & \\
\hline CHEMBL3431105 & 1479006 & 6.3 & 3.9511 & TRN & \\
\hline CHEMBL3431106 & 1479006 & 6.4 & 5.006 & TST & \\
\hline CHEMBL3431107 & 1479006 & 4.4 & 4.3744 & TRN & \\
\hline CHEMBL3431108 & 1479006 & 5.3 & 4.4062 & TRN & \\
\hline CHEMBL3431109 & 1479006 & 5.0 & 4.9314 & TRN & \\
\hline CHEMBL3431110 & 1479006 & 5.0 & 4.9512 & TRN & \\
\hline CHEMBL3431111 & 1479006 & 4.4 & 5.1127 & TRN & \\
\hline CHEMBL3431112 & 1479006 & 5.4 & 5.7165 & TRN & \\
\hline CHEMBL3431113 & 1479006 & 5.6 & 5.7614 & TRN & \\
\hline CHEMBL 3431114 & 1479006 & 3.3 & 4.7702 & TRN & \\
\hline CHEMBL3431115 & 1479006 & 3.3 & 3.7952 & TRN & \\
\hline CHEMBL3431116 & 1479006 & 3.3 & 3.81 & TRN & \\
\hline CHEMBL3431117 & 1479006 & 5.3 & 5.1208 & TRN & \\
\hline CHEMBL3431118 & 1479006 & 5.0 & 4.4482 & TRN & \\
\hline CHEMBL3431119 & 1479006 & 5.2 & 5.8075 & TRN & \\
\hline CHEMBL3431120 & 1479006 & 3.3 & 3.8882 & TRN & \\
\hline CHEMBL3431121 & 1479006 & 5.0 & 4.0385 & TST & \\
\hline CHEMBL3431122 & 1479006 & 5.4 & 4.4155 & TRN & \\
\hline CHEMBL3431123 & 1479006 & 3.3 & 4.7877 & TRN & \\
\hline CHEMBL3431124 & 1479006 & 5.3 & 4.0823 & TRN & \\
\hline CHEMBL3431125 & 1479006 & 4.3 & 3.8455 & TST & \\
\hline CHEMBL3431126 & 1479006 & 3.3 & 3.8480 & 00000000003 & TRN \\
\hline CHEMBL 3431127 & 1479006 & 7.4 & 6.2539 & TST & \\
\hline CHEMBL 3431128 & 1479006 & 5.6 & 5.6873 & TST & \\
\hline CHEMBL3431129 & 1479006 & 6.1 & 5.8818 & TST & \\
\hline CHEMBL3431130 & 1479006 & 5.4 & 5.2344 & TST & \\
\hline
\end{tabular}




\begin{tabular}{|c|c|c|c|c|}
\hline & & & pplement & al $\mathrm{Ta}$ \\
\hline CHEMBL3431131 & 1479006 & 5.0 & 5.0729 & TRN \\
\hline CHEMBL3430915 & 1479006 & 5.6 & 3.7191 & TRN \\
\hline CHEMBL3431132 & 1479006 & 4.8 & 4.6154 & TRN \\
\hline CHEMBL3431133 & 1479006 & 4.5 & 4.6683 & TRN \\
\hline CHEMBL3431134 & 1479006 & 4.6 & 5.1141 & TRN \\
\hline CHEMBL3431135 & 1479006 & 3.3 & 3.6887 & TRN \\
\hline CHEMBL3431136 & 1479006 & 5.4 & 5.6671 & TRN \\
\hline CHEMBL3431137 & 1479006 & 5.2 & 5.1551 & TRN \\
\hline CHEMBL3431138 & 1479006 & 5.7 & 3.8018 & TST \\
\hline CHEMBL3431139 & 1479006 & 6.4 & 4.9432 & TST \\
\hline CHEMBL 3431140 & 1479006 & 3.3 & 4.2412 & TST \\
\hline CHEMBL 3431141 & 1479006 & 5.3 & 4.8428 & TRN \\
\hline CHEMBL3431142 & 1479006 & 3.3 & 4.0481 & TST \\
\hline CHEMBL3431143 & 1479006 & 5.7 & 5.706 & TRN \\
\hline CHEMBL3431144 & 1479006 & 4.4 & 3.9968 & TRN \\
\hline CHEMBL3431145 & 1479006 & 4.7 & 5.1188 & TRN \\
\hline CHEMBL3431146 & 1479006 & 5.9 & 5.0376 & TRN \\
\hline CHEMBL3431147 & 1479006 & 4.8 & 4.7585 & TST \\
\hline CHEMBL3431148 & 1479006 & 3.3 & 3.8787 & TRN \\
\hline CHEMBL3431149 & 1479006 & 5.4 & 5.2303 & TRN \\
\hline CHEMBL3431150 & 1479006 & 4.5 & 3.9707 & TRN \\
\hline CHEMBL3431151 & 1479006 & 5.7 & 4.5918 & TRN \\
\hline CHEMBL3431152 & 1479006 & 3.3 & 4.1633 & TRN \\
\hline CHEMBL3431153 & 1479006 & 3.3 & 3.8082 & TRN \\
\hline CHEMBL3431154 & 1479006 & 4.7 & 5.1052 & TST \\
\hline CHEMBL3431155 & 1479006 & 6.0 & 4.7021 & TRN \\
\hline CHEMBL3431156 & 1479006 & 4.8 & 3.8448 & TRN \\
\hline CHEMBL3431157 & 1479006 & 3.3 & 4.1389 & TST \\
\hline CHEMBL3431158 & 1479006 & 5.2 & 5.6276 & TST \\
\hline CHEMBL3431159 & 1479006 & 4.4 & 4.0009 & TST \\
\hline CHEMBL1593679 & 1479006 & 5.9 & 3.8151 & TRN \\
\hline CHEMBL3431160 & 1479006 & 4.6 & 4.699 & TRN \\
\hline CHEMBL3431161 & 1479006 & 4.7 & 4.6848 & TST \\
\hline CHEMBL3431162 & 1479006 & 3.3 & 4.3174 & TST \\
\hline CHEMBL3431163 & 1479006 & 3.3 & 4.6155 & TRN \\
\hline CHEMBL3431164 & 1479006 & 4.8 & 3.7678 & TRN \\
\hline CHEMBL3431165 & 1479006 & 3.3 & 3.8597 & TST \\
\hline CHEMBL1458931 & 1479006 & 4.7 & 3.8861 & TRN \\
\hline CHEMBL3431166 & 1479006 & 3.3 & 3.7455 & TRN \\
\hline CHEMBL3431167 & 1479006 & 3.3 & 3.8256 & TRN \\
\hline CHEMBL3431168 & 1479006 & 5.9 & 5.709 & TST \\
\hline CHEMBL3431169 & 1479006 & 5.2 & 5.1621 & TST \\
\hline CHEMBL3431170 & 1479006 & 6.2 & 6.3079 & TST \\
\hline CHEMBL3431171 & 1479006 & 3.3 & 3.9011 & TST \\
\hline CHEMBL3431172 & 1479006 & 6.1 & 5.7216 & TST \\
\hline CHEMBL3431173 & 1479006 & 5.1 & 5.3151 & TST \\
\hline CHEMBL3431174 & 1479006 & 5.4 & 5.2611 & TST \\
\hline CHEMBL3431175 & 1479006 & 3.3 & 3.9238 & TST \\
\hline
\end{tabular}




\begin{tabular}{|c|c|c|c|c|c|}
\hline \\
\hline CHEMBL3431176 & 1479006 & 5.6 & 5.737 & TST & \\
\hline CHEMBL3431177 & 1479006 & 5.7 & 5.5299 & TST & \\
\hline CHEMBL3431178 & 1479006 & 5.8 & 5.4348 & TST & \\
\hline CHEMBL3431179 & 1479006 & 5.6 & 5.1159 & TST & \\
\hline CHEMBL3431180 & 1479006 & 5.3 & 5.6309 & TST & \\
\hline CHEMBL3431181 & 1479006 & 5.5 & 5.5242 & TST & \\
\hline CHEMBL3431182 & 1479006 & 5.5 & 4.9944 & TST & \\
\hline CHEMBL3431183 & 1479006 & 4.3 & 4.5087 & TST & \\
\hline CHEMBL3431184 & 1479006 & 4.4 & 4.9443 & TST & \\
\hline CHEMBL3431185 & 1479006 & 5.5 & 5.6116 & TST & \\
\hline CHEMBL3431186 & 1479006 & 5.4 & 5.8921 & TST & \\
\hline CHEMBL3431187 & 1479006 & 6.4 & 5.9092 & TST & \\
\hline CHEMBL3431188 & 1479006 & 6.5 & 6.0806 & TST & \\
\hline CHEMBL3431189 & 1479006 & 3.3 & 4.7267 & TST & \\
\hline CHEMBL3431190 & 1479006 & 4.6 & 4.9391 & TST & \\
\hline CHEMBL3431191 & 1479006 & 4.4 & 4.6279 & TST & \\
\hline CHEMBL3431192 & 1479006 & 6.1 & 6.3373 & TST & \\
\hline CHEMBL3431193 & 1479006 & 6.2 & 6.3893 & TST & \\
\hline CHEMBL3431194 & 1479006 & 7.0 & 5.7371 & TST & \\
\hline CHEMBL3431195 & 1479006 & 5.8 & 5.9043 & TST & \\
\hline CHEMBL3431196 & 1479006 & 5.9 & 5.6073 & TST & \\
\hline CHEMBL3431197 & 1479006 & 5.5 & 5.8472 & TST & \\
\hline CHEMBL3431198 & 1479006 & 5.5 & 5.919 & TST & \\
\hline CHEMBL3431199 & 1479006 & 4.8 & 4.6738 & TST & \\
\hline CHEMBL3431200 & 1479006 & 3.3 & 3.9518 & TST & \\
\hline CHEMBL3431201 & 1479006 & 3.3 & 4.6102 & TST & \\
\hline CHEMBL3431202 & 1479006 & 3.3 & 4.0254 & TST & \\
\hline CHEMBL3431203 & 1479006 & 5.9 & 5.8825 & TST & \\
\hline CHEMBL3431204 & 1479006 & 5.2 & 4.909 & TST & \\
\hline CHEMBL3431205 & 1479006 & 3.3 & 4.2593 & TST & \\
\hline CHEMBL3431206 & 1479006 & 5.5 & 6.5665 & TST & \\
\hline CHEMBL110331 & 157693 & 6.38 & 6.2891 & TRN & \\
\hline CHEMBL323954 & 157693 & 5.96 & 6.0147 & TRN & \\
\hline CHEMBL421417 & 157693 & 6.33 & 6.3098 & TRN & \\
\hline CHEMBL110660 & 157693 & 6.39 & 6.2297 & TST & \\
\hline CHEMBL274893 & 157693 & 7.59 & 7.365 & TRN & \\
\hline CHEMBL109486 & 157693 & 5.18 & 6.2695 & TST & \\
\hline CHEMBL54649 & 157693 & 7.68 & 7.641 & TRN & \\
\hline CHEMBL52872 & 157693 & 8.22 & 8.56200 & 0000000001 & TRN \\
\hline CHEMBL29136 & 157693 & 6.47 & 7.711 & TST & \\
\hline CHEMBL 29472 & 157693 & 7.92 & 6.9361 & TST & \\
\hline CHEMBL88649 & 157693 & 6.89 & 7.053 & TRN & \\
\hline CHEMBL 297008 & 157693 & 7.22 & 7.0071 & TST & \\
\hline CHEMBL44283 & 157693 & 7.3 & 7.5535 & TST & \\
\hline CHEMBL44977 & 157693 & 6.48 & 6.3295 & TRN & \\
\hline CHEMBL43089 & 157693 & 6.34 & 6.3906 & TRN & \\
\hline CHEMBL43553 & 157693 & 6.85 & 6.8487 & TRN & \\
\hline CHEMBL322136 & 157693 & 5.74 & 5.7141 & TRN & \\
\hline
\end{tabular}




\begin{tabular}{|c|c|c|c|c|c|}
\hline \multicolumn{6}{|c|}{ Supplemental Table S2.txt } \\
\hline CHEMBL327078 & 157693 & 6.14 & 6.3451 & TRN & \\
\hline CHEMBL54945 & 157693 & 6.62 & 7.0046 & TRN & \\
\hline CHEMBL110612 & 157693 & 6.77 & 6.6801 & TST & \\
\hline CHEMBL29839 & 157693 & 8.1 & 8.1215 & TRN & \\
\hline CHEMBL28881 & 157693 & 8.33 & 7.9081 & TRN & \\
\hline CHEMBL29133 & 157693 & 7.66 & 7.7175 & TST & \\
\hline CHEMBL 274990 & 157693 & 7.0 & 7.0076 & TRN & \\
\hline CHEMBL111562 & 157693 & 8.7 & 8.12 & TST & \\
\hline CHEMBL43002 & 157693 & 7.22 & 7.1566 & TST & \\
\hline CHEMBL298208 & 157693 & 6.6 & 7.2404 & TST & \\
\hline CHEMBL42561 & 157693 & 6.8 & 6.7088 & TRN & \\
\hline CHEMBL415895 & 157693 & 6.64 & 6.6766 & TRN & \\
\hline CHEMBL320790 & 157693 & 6.33 & 5.8261 & TST & \\
\hline CHEMBL320784 & 157693 & 8.15 & 8.2801 & TRN & \\
\hline CHEMBL322949 & 157693 & 7.52 & 7.575 & TRN & \\
\hline CHEMBL28528 & 157693 & 7.12 & 7.2756 & TST & \\
\hline CHEMBL29403 & 157693 & 7.28 & 7.2044 & TRN & \\
\hline CHEMBL314225 & 157693 & 8.52 & 8.5695 & TRN & \\
\hline CHEMBL46712 & 157693 & 7.22 & 6.92299 & 9999999999 & TRN \\
\hline CHEMBL42094 & 157693 & 6.68 & 6.5528 & TRN & \\
\hline CHEMBL42398 & 157693 & 7.52 & 7.41700 & 0000000001 & TRN \\
\hline CHEMBL43331 & 157693 & 6.14 & 6.2066 & TRN & \\
\hline CHEMBL54370 & 157693 & 8.4 & 8.5632 & TRN & \\
\hline CHEMBL29717 & 157693 & 7.82 & 8.0563 & TRN & \\
\hline CHEMBL281978 & 157693 & 7.25 & 7.0108 & TRN & \\
\hline CHEMBL282301 & 157693 & 7.31 & 7.7144 & TST & \\
\hline CHEMBL285335 & 157693 & 6.7 & 6.7301 & TRN & \\
\hline CHEMBL 29500 & 157693 & 7.51 & 7.5091 & TRN & \\
\hline CHEMBL88550 & 157693 & 8.0 & 8.0267 & TRN & \\
\hline CHEMBL110846 & 157693 & 6.77 & 6.66200 & 3000000001 & TRN \\
\hline CHEMBL42225 & 157693 & 6.92 & 6.6999 & TRN & \\
\hline CHEMBL42996 & 157693 & 6.15 & 6.3958 & TRN & \\
\hline CHEMBL296515 & 157693 & 5.24 & 5.9894 & TRN & \\
\hline CHEMBL296984 & 157693 & 7.4 & 7.2785 & TRN & \\
\hline CHEMBL42709 & 157693 & 7.4 & 7.6616 & TRN & \\
\hline CHEMBL326639 & 157693 & 6.03 & 5.6647 & TRN & \\
\hline CHEMBL 109030 & 157693 & 6.06 & 6.03799 & 9999999999 & TRN \\
\hline CHEMBL 29445 & 157693 & 6.89 & 7.1946 & TRN & \\
\hline CHEMBL29842 & 157693 & 7.1 & 6.5092 & TST & \\
\hline CHEMBL29469 & 157693 & 6.64 & 6.6787 & TRN & \\
\hline CHEMBL44101 & 157693 & 5.41 & 5.9397 & TST & \\
\hline CHEMBL42175 & 157693 & 7.22 & 7.2485 & TRN & \\
\hline CHEMBL44468 & 157693 & 6.46 & 6.3783 & TRN & \\
\hline CHEMBL43645 & 157693 & 6.4 & 6.5817 & TRN & \\
\hline CHEMBL44926 & 157693 & 7.0 & 7.101 & TRN & \\
\hline CHEMBL42223 & 157693 & 6.6 & 6.7282 & TRN & \\
\hline CHEMBL43493 & 157693 & 6.48 & 6.7059 & TRN & \\
\hline CHEMBL110574 & 157693 & 5.02 & 4.8505 & TRN & \\
\hline
\end{tabular}




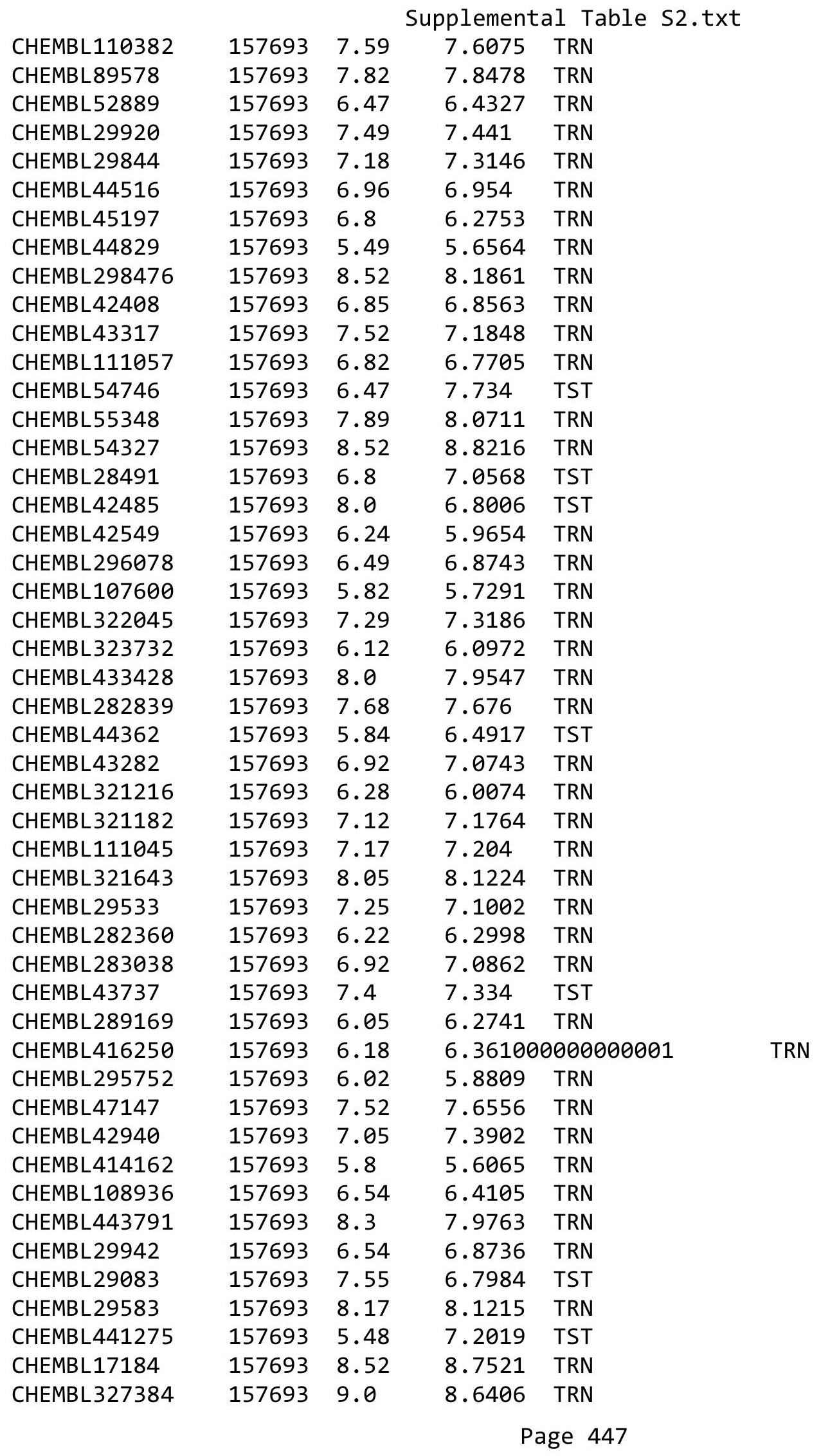




\begin{tabular}{|c|c|c|c|c|}
\hline \multicolumn{5}{|c|}{ Supplemental Table S2.txt } \\
\hline CHEMBL88717 & 157693 & 9.0 & 9.0969 & TRN \\
\hline CHEMBL89263 & 157693 & 6.87 & 6.6134 & TRN \\
\hline CHEMBL312822 & 157693 & 8.82 & 8.6359 & TRN \\
\hline CHEMBL416989 & 157693 & 6.46 & 6.4761 & TRN \\
\hline CHEMBL42180 & 157693 & 6.96 & 6.7673 & TRN \\
\hline CHEMBL109143 & 157693 & 6.28 & 6.4383 & TRN \\
\hline CHEMBL265562 & 157693 & 8.15 & 8.0576 & TRN \\
\hline CHEMBL52019 & 157693 & 7.72 & 7.5488 & TRN \\
\hline CHEMBL54326 & 157693 & 8.3 & 8.4395 & TRN \\
\hline CHEMBL284914 & 157693 & 5.32 & 5.6734 & TRN \\
\hline CHEMBL111518 & 157693 & 7.62 & 7.5268 & TRN \\
\hline CHEMBL42119 & 157693 & 6.77 & 6.6709 & TRN \\
\hline CHEMBL 325790 & 157693 & 5.74 & 5.5924 & TRN \\
\hline CHEMBL 321881 & 157693 & 5.89 & 5.8387 & TRN \\
\hline CHEMBL110446 & 157693 & 6.2 & 6.3835 & TRN \\
\hline CHEMBL418574 & 157693 & 7.24 & 7.2173 & TRN \\
\hline CHEMBL43366 & 157693 & 6.12 & 6.7312 & TST \\
\hline CHEMBL45139 & 157693 & 6.1 & 6.0174 & TRN \\
\hline CHEMBL43149 & 157693 & 6.89 & 6.8689 & TRN \\
\hline CHEMBL43090 & 157693 & 5.81 & 5.8114 & TRN \\
\hline CHEMBL55072 & 157693 & 7.89 & 8.0713 & TRN \\
\hline CHEMBL286953 & 157693 & 7.57 & 7.4833 & TRN \\
\hline CHEMBL 287447 & 157693 & 6.47 & 6.9901 & TST \\
\hline CHEMBL92102 & 157693 & 8.82 & 8.6925 & TRN \\
\hline CHEMBL294715 & 157693 & 7.21 & 7.251 & TRN \\
\hline CHEMBL42085 & 157693 & 7.1 & 5.8117 & TST \\
\hline CHEMBL 297820 & 157693 & 5.54 & 5.9001 & TST \\
\hline CHEMBL 294971 & 157693 & 6.33 & 5.5408 & TST \\
\hline CHEMBL45090 & 157693 & 6.77 & 6.7259 & TRN \\
\hline CHEMBL 296571 & 157693 & 7.52 & 7.6065 & TRN \\
\hline CHEMBL106151 & 157693 & 5.92 & 5.8481 & TRN \\
\hline CHEMBL52760 & 157693 & 8.0 & 7.8987 & TRN \\
\hline CHEMBL 29257 & 157693 & 8.0 & 8.2143 & TRN \\
\hline CHEMBL88286 & 157693 & 8.15 & 8.3224 & TRN \\
\hline CHEMBL44924 & 157693 & 5.23 & 5.0262 & TRN \\
\hline CHEMBL109578 & 157693 & 5.49 & 5.9966 & TST \\
\hline CHEMBL283177 & 157693 & 7.59 & 7.1257 & TST \\
\hline CHEMBL86363 & 157693 & 8.89 & 8.7065 & TRN \\
\hline CHEMBL313313 & 157693 & 8.7 & 8.7697 & TRN \\
\hline CHEMBL315520 & 157693 & 8.22 & 8.2286 & TRN \\
\hline CHEMBL111095 & 157693 & 8.05 & 7.8903 & TRN \\
\hline CHEMBL44313 & 157693 & 5.99 & 6.8427 & TST \\
\hline CHEMBL45383 & 157693 & 5.08 & 5.0924 & TRN \\
\hline CHEMBL111427 & 157693 & 7.8 & 7.6989 & TRN \\
\hline CHEMBL52402 & 157693 & 8.22 & 7.6544 & TRN \\
\hline CHEMBL442164 & 157693 & 7.85 & 7.648 & TRN \\
\hline CHEMBL296384 & 157693 & 8.4 & 8.2138 & TRN \\
\hline CHEMBL282093 & 157693 & 8.0 & 8.08 & TRN \\
\hline
\end{tabular}




\begin{tabular}{|c|c|c|c|c|c|}
\hline \multicolumn{6}{|c|}{ Supplemental Table s2.txt } \\
\hline CHEMBL432945 & 157693 & 9.0 & 8.788 & TRN & \\
\hline CHEMBL88549 & 157693 & 8.6 & 7.9376 & TST & \\
\hline CHEMBL91258 & 157693 & 7.48 & 7.5658 & TRN & \\
\hline CHEMBL46584 & 157693 & 8.15 & 7.9511 & TRN & \\
\hline CHEMBL42884 & 157693 & 6.96 & 6.8952 & TRN & \\
\hline CHEMBL46636 & 157693 & 6.21 & 6.3345 & TRN & \\
\hline CHEMBL325755 & 157693 & 5.77 & 5.9651 & TRN & \\
\hline CHEMBL108201 & 157693 & 8.3 & 7.5854 & TST & \\
\hline CHEMBL287646 & 157693 & 7.68 & 7.3784 & TRN & \\
\hline CHEMBL424063 & 157693 & 8.7 & 7.931 & TST & \\
\hline CHEMBL43511 & 157693 & 7.85 & 7.2159 & TST & \\
\hline CHEMBL43265 & 157693 & 6.39 & 6.324 & TRN & \\
\hline CHEMBL289484 & 157693 & 5.24 & 4.5949 & TST & \\
\hline CHEMBL321016 & 157693 & 5.8 & 5.7528 & TRN & \\
\hline CHEMBL52888 & 157693 & 7.19 & 6.8896 & TRN & \\
\hline CHEMBL29439 & 157693 & 7.8 & 7.6897 & TRN & \\
\hline CHEMBL43957 & 157693 & 6.29 & 6.49700 & 0000000001 & TST \\
\hline CHEMBL320961 & 157693 & 5.54 & 5.4902 & TRN & \\
\hline CHEMBL110876 & 157693 & 5.96 & 5.9106 & TRN & \\
\hline CHEMBL320926 & 157693 & 6.37 & 6.4539 & TRN & \\
\hline CHEMBL324863 & 157693 & 6.85 & 7.2284 & TRN & \\
\hline CHEMBL405623 & 157693 & 7.68 & 7.3163 & TST & \\
\hline CHEMBL111787 & 157693 & 7.74 & 7.8127 & TRN & \\
\hline CHEMBL291912 & 157693 & 6.59 & 6.6358 & TRN & \\
\hline CHEMBL282085 & 157693 & 7.82 & 7.7856 & TRN & \\
\hline CHEMBL88532 & 157693 & 8.7 & 8.4413 & TRN & \\
\hline CHEMBL 289813 & 157693 & 5.49 & 6.7133 & TST & \\
\hline CHEMBL296662 & 157693 & 7.52 & 7.5713 & TRN & \\
\hline CHEMBL298296 & 157693 & 6.62 & 6.655 & TRN & \\
\hline CHEMBL320330 & 157693 & 6.02 & 5.9748 & TRN & \\
\hline CHEMBL108452 & 157693 & 6.36 & 6.5582 & TRN & \\
\hline CHEMBL110145 & 157693 & 5.55 & 5.5441 & TRN & \\
\hline CHEMBL299806 & 157693 & 8.1 & 7.974 & TRN & \\
\hline CHEMBL 27975 & 157693 & 7.51 & 8.3627 & TST & \\
\hline CHEMBL30091 & 157693 & 7.08 & 6.1903 & TST & \\
\hline CHEMBL44290 & 157693 & 5.79 & 6.5968 & TST & \\
\hline CHEMBL42595 & 157693 & 6.92 & 7.0328 & TRN & \\
\hline CHEMBL298313 & 157693 & 7.7 & 7.607 & TRN & \\
\hline CHEMBL43933 & 157693 & 6.49 & 6.6384 & TRN & \\
\hline CHEMBL326024 & 157693 & 5.38 & 5.7809 & TST & \\
\hline CHEMBL111657 & 157693 & 7.29 & 7.3971 & TRN & \\
\hline CHEMBL55188 & 157693 & 6.85 & 7.1322 & TRN & \\
\hline CHEMBL89089 & 157693 & 8.3 & 8.3848 & TRN & \\
\hline CHEMBL313387 & 157693 & 9.0 & 9.2227 & TRN & \\
\hline CHEMBL111590 & 157693 & 8.52 & 8.4915 & TRN & \\
\hline CHEMBL40245 & 157693 & 7.7 & 8.033 & TST & \\
\hline CHEMBL42674 & 157693 & 8.0 & 8.0554 & TRN & \\
\hline CHEMBL289561 & 157693 & 7.7 & 7.5147 & TRN & \\
\hline
\end{tabular}




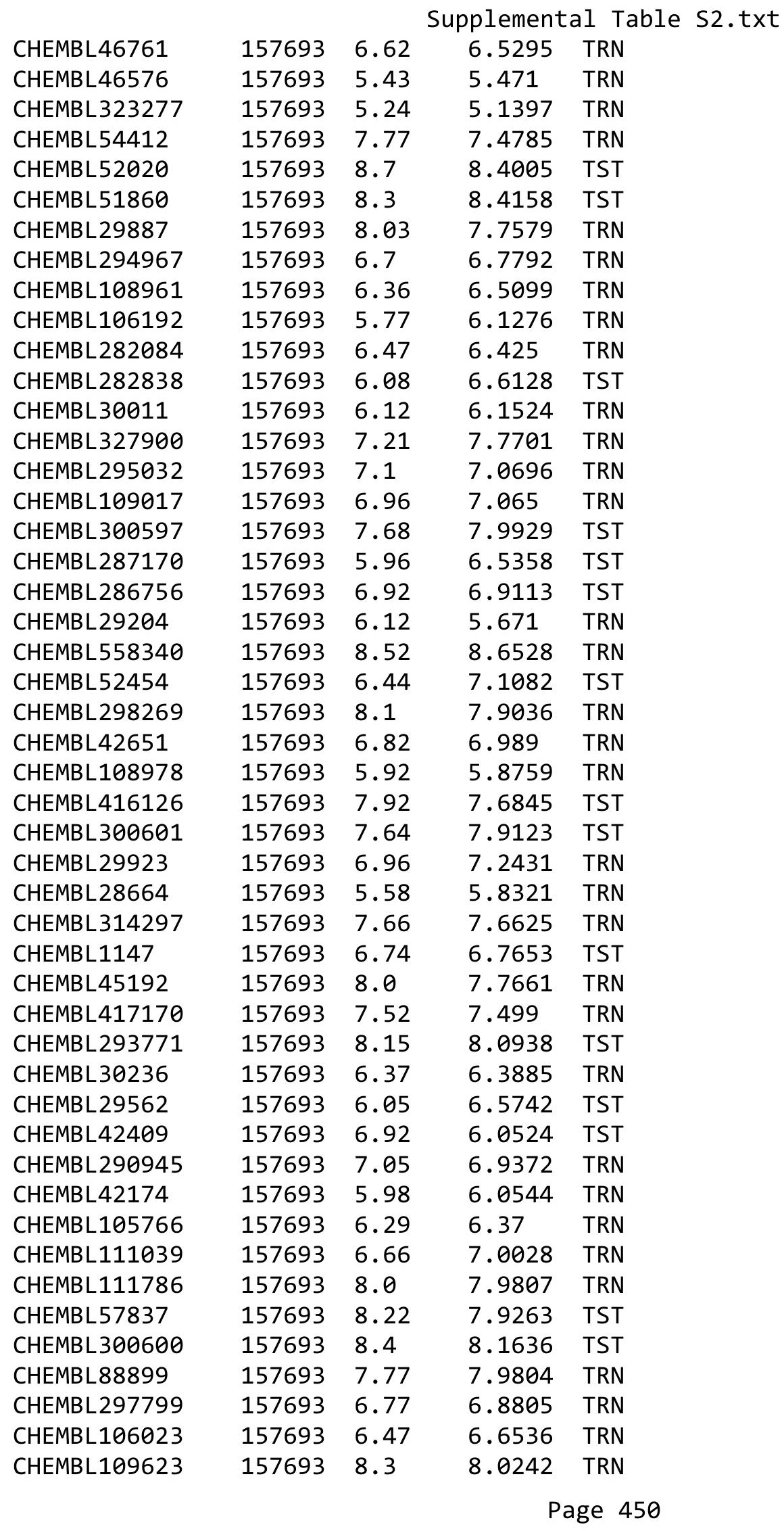




\begin{tabular}{|c|c|c|c|c|c|}
\hline \multicolumn{6}{|c|}{ Supplemental Table S2.txt } \\
\hline CHEMBL111356 & 157693 & 8.7 & 8.7349 & TRN & \\
\hline CHEMBL417748 & 157693 & 7.89 & 8.2332 & TST & \\
\hline CHEMBL52820 & 157693 & 8.7 & 8.2416 & TST & \\
\hline CHEMBL55395 & 157693 & 7.49 & 8.2481 & TST & \\
\hline CHEMBL283388 & 157693 & 6.19 & 6.1277 & TRN & \\
\hline CHEMBL281975 & 157693 & 7.89 & 7.9613 & TRN & \\
\hline CHEMBL283086 & 157693 & 7.55 & 7.8186 & TST & \\
\hline CHEMBL315585 & 157693 & 8.7 & 8.5627 & TRN & \\
\hline CHEMBL92107 & 157693 & 8.48 & 8.2782 & TRN & \\
\hline CHEMBL90447 & 157693 & 8.4 & 7.9614 & TRN & \\
\hline CHEMBL297108 & 157693 & 7.4 & 7.4737 & TRN & \\
\hline CHEMBL296673 & 157693 & 7.52 & 7.3836 & TRN & \\
\hline CHEMBL418448 & 157693 & 7.89 & 8.0099 & TST & \\
\hline CHEMBL55805 & 157693 & 8.52 & 8.4896 & TST & \\
\hline CHEMBL28599 & 157693 & 7.16 & 6.9396 & TRN & \\
\hline CHEMBL89625 & 157693 & 7.57 & 7.5463 & TST & \\
\hline CHEMBL43616 & 157693 & 7.1 & 7.3163 & TRN & \\
\hline CHEMBL321156 & 157693 & 7.15 & 6.9717 & TRN & \\
\hline CHEMBL442166 & 157693 & 7.48 & 7.3605 & TST & \\
\hline CHEMBL29456 & 157693 & 6.46 & 6.9208 & TRN & \\
\hline CHEMBL320998 & 157693 & 6.28 & 7.2772 & TST & \\
\hline CHEMBL46623 & 157693 & 8.0 & 7.7758 & TRN & \\
\hline CHEMBL321407 & 157693 & 5.74 & 5.7589 & TRN & \\
\hline CHEMBL111314 & 157693 & 6.92 & 7.191 & TRN & \\
\hline CHEMBL111321 & 157693 & 8.7 & 8.5891 & TRN & \\
\hline CHEMBL110418 & 157693 & 7.08 & 7.1965 & TST & \\
\hline CHEMBL280636 & 157693 & 8.28 & 7.5816 & TST & \\
\hline CHEMBL280601 & 157693 & 6.54 & 6.33700 & 0000000001 & TST \\
\hline CHEMBL88493 & 157693 & 8.4 & 8.7345 & TRN & \\
\hline CHEMBL89429 & 157693 & 7.59 & 7.6254 & TST & \\
\hline CHEMBL44038 & 157693 & 6.85 & 6.0474 & TST & \\
\hline CHEMBL432112 & 157693 & 7.0 & 6.7882 & TRN & \\
\hline CHEMBL264300 & 157693 & 6.24 & 6.3989 & TRN & \\
\hline CHEMBL46667 & 157693 & 6.04 & 6.2046 & TRN & \\
\hline CHEMBL43672 & 157693 & 7.52 & 7.605 & TRN & \\
\hline CHEMBL108975 & 157693 & 7.28 & 7.0563 & TRN & \\
\hline CHEMBL111597 & 157693 & 8.0 & 7.9208 & TRN & \\
\hline CHEMBL321160 & 157693 & 7.77 & 7.50799 & 9999999999 & TRN \\
\hline CHEMBL54039 & 157693 & 7.72 & 7.3523 & TST & \\
\hline CHEMBL 30084 & 157693 & 7.57 & 7.4605 & TRN & \\
\hline CHEMBL29397 & 157693 & 6.46 & 7.0102 & TST & \\
\hline CHEMBL92154 & 157693 & 8.12 & 8.1897 & TRN & \\
\hline CHEMBL45200 & 28334 & 6.2218 & 6.4901 & TST & \\
\hline CHEMBL295878 & 28334 & 6.7959 & 6.9968 & TRN & \\
\hline CHEMBL42873 & 28334 & 6.1739 & 6.4811 & TRN & \\
\hline CHEMBL43537 & 28334 & 7.1549 & 6.0784 & TRN & \\
\hline CHEMBL296412 & 28334 & 7.1367 & 6.9384 & TRN & \\
\hline CHEMBL297185 & 28334 & 6.6383 & 6.9416 & TRN & \\
\hline
\end{tabular}




\begin{tabular}{|c|c|c|c|c|c|}
\hline \multicolumn{6}{|c|}{ Supplemental Table S2.txt } \\
\hline CHEMBL45146 & 28334 & 5.0 & 5.1849 & TRN & \\
\hline CHEMBL44755 & 28334 & 6.6778 & \multicolumn{2}{|c|}{6.672999999999999} & TRN \\
\hline CHEMBL42165 & 28334 & 6.7696 & 6.5217 & TRN & \\
\hline CHEMBL44318 & 28334 & 6.7696 & 6.9456 & TRN & \\
\hline CHEMBL44848 & 28334 & 6.699 & 6.8925 & TRN & \\
\hline CHEMBL43989 & 28334 & 7.1612 & 7.2307 & TRN & \\
\hline CHEMBL47084 & 28334 & 6.6021 & 6.6332 & TRN & \\
\hline CHEMBL290630 & 28334 & 7.0458 & 6.6861 & TRN & \\
\hline CHEMBL46450 & 28334 & 6.8861 & 6.9381 & TRN & \\
\hline CHEMBL295033 & 28334 & 7.3098 & 7.1047 & TRN & \\
\hline CHEMBL297553 & 28334 & 6.6383 & 7.1148 & TRN & \\
\hline CHEMBL297054 & 28334 & 6.3468 & 5.813 & TRN & \\
\hline CHEMBL42760 & 28334 & 6.8239 & 6.8314 & TRN & \\
\hline CHEMBL44956 & 28334 & 6.2676 & 6.8045 & TRN & \\
\hline CHEMBL296094 & 28334 & 7.3665 & 7.0861 & TRN & \\
\hline CHEMBL295184 & 28334 & 6.8539 & 6.3795 & TRN & \\
\hline CHEMBL43603 & 28334 & 6.6576 & 6.8223 & TRN & \\
\hline CHEMBL297351 & 28334 & 6.2441 & 6.3577 & TRN & \\
\hline CHEMBL46418 & 28334 & 6.0555 & 6.0939 & TRN & \\
\hline CHEMBL42498 & 28334 & 5.0 & 5.4086 & TRN & \\
\hline CHEMBL47030 & 28334 & 7.1135 & 6.8753 & TRN & \\
\hline CHEMBL297454 & 28334 & 6.8539 & 6.9455 & TRN & \\
\hline CHEMBL42821 & 28334 & 6.585 & 6.438 & TST & \\
\hline CHEMBL 290000 & 28334 & 7.0 & 5.7618 & TST & \\
\hline CHEMBL296852 & 28334 & 6.3372 & 6.5789 & TRN & \\
\hline CHEMBL44863 & 28334 & 7.0757 & 6.9074 & TRN & \\
\hline CHEMBL43592 & 28334 & 6.8861 & 5.8619 & TST & \\
\hline CHEMBL47235 & 28334 & 5.0 & 6.199 & TST & \\
\hline CHEMBL46769 & 28334 & 6.7447 & \multicolumn{2}{|c|}{6.662999999999999} & TRN \\
\hline CHEMBL296463 & 28334 & 7.301 & 6.9937 & TRN & \\
\hline CHEMBL297770 & 28334 & 7.1367 & 6.9529 & TRN & \\
\hline CHEMBL295466 & 28334 & 6.7212 & 6.7776 & TRN & \\
\hline CHEMBL43107 & 28334 & 6.6383 & 6.7191 & TRN & \\
\hline CHEMBL441429 & 28334 & 7.1487 & 7.1043 & TRN & \\
\hline CHEMBL46861 & 28334 & 6.7959 & 5.4354 & TST & \\
\hline CHEMBL47095 & 28334 & 7.0555 & 6.9707 & TRN & \\
\hline CHEMBL45033 & 28334 & 6.6778 & 6.4759 & TST & \\
\hline CHEMBL277986 & 28334 & 6.7447 & \multicolumn{2}{|c|}{6.257000000000001} & TST \\
\hline CHEMBL288332 & 28334 & 6.6778 & 6.7785 & TRN & \\
\hline CHEMBL297374 & 28334 & 5.0 & 5.8786 & TST & \\
\hline CHEMBL45148 & 28334 & 5.0 & 5.0044 & TRN & \\
\hline CHEMBL46430 & 28334 & 7.3565 & 7.0528 & TRN & \\
\hline CHEMBL46641 & 28334 & 6.5376 & 6.4296 & TST & \\
\hline CHEMBL46756 & 28334 & 7.0 & 7.1149 & TRN & \\
\hline CHEMBL42552 & 28334 & 6.5229 & \multicolumn{2}{|c|}{6.6770000000000005} & TRN \\
\hline CHEMBL44702 & 28334 & 6.2924 & 5.7594 & TST & \\
\hline CHEMBL295616 & 28334 & 6.8239 & 6.971 & TRN & \\
\hline CHEMBL42296 & 28334 & 6.5528 & 6.8123 & TRN & \\
\hline
\end{tabular}




\begin{tabular}{|c|c|c|c|c|c|}
\hline & & \multicolumn{4}{|c|}{ Supplemental Table S2.txt } \\
\hline CHEMBL298236 & 28334 & 7.2596 & 7.1598 & TRN & \\
\hline CHEMBL417177 & 28334 & 6.3372 & 6.3623 & TRN & \\
\hline CHEMBL42477 & 28334 & 6.7447 & 6.735 & TRN & \\
\hline CHEMBL417896 & 28334 & 6.8539 & 6.4013 & TRN & \\
\hline CHEMBL296714 & 28334 & 6.9208 & 6.8424 & TST & \\
\hline CHEMBL44960 & 28334 & 5.0 & 5.6811 & TST & \\
\hline CHEMBL47093 & 28334 & 6.6576 & 6.4041 & TST & \\
\hline CHEMBL295867 & 28334 & 7.0969 & 6.6691 & TRN & \\
\hline CHEMBL 295846 & 28334 & 6.3872 & 6.0584 & TRN & \\
\hline CHEMBL43422 & 28334 & 7.3188 & 6.7212 & TST & \\
\hline CHEMBL43908 & 28334 & 7.0132 & 6.3415 & TST & \\
\hline CHEMBL297580 & 28334 & 5.0 & 6.0189 & TST & \\
\hline CHEMBL46503 & 28334 & 5.8861 & 5.9644 & TRN & \\
\hline CHEMBL42128 & 28334 & 5.0 & 5.1577 & TRN & \\
\hline CHEMBL295171 & 28334 & 6.8539 & 7.13399 & 99999999995 & TRN \\
\hline CHEMBL45319 & 28334 & 6.3188 & 6.4529 & TRN & \\
\hline CHEMBL42384 & 28334 & 5.0 & 5.5868 & TRN & \\
\hline CHEMBL294932 & 28334 & 6.6383 & 6.5179 & TST & \\
\hline CHEMBL44336 & 28334 & 6.4949 & 6.4269 & TST & \\
\hline CHEMBL43675 & 28334 & 6.7959 & 6.6768 & TRN & \\
\hline CHEMBL295824 & 28334 & 6.4685 & 6.9214 & TRN & \\
\hline CHEMBL221137 & 954644 & 5.2324 & 5.0836 & TST & \\
\hline CHEMBL102714 & 954644 & 3.4209 & 3.8948 & TRN & \\
\hline CHEMBL1186585 & 954644 & 4.3271 & 3.8628 & TRN & \\
\hline CHEMBL 217354 & 954644 & 6.1574 & 6.4715 & TRN & \\
\hline CHEMBL3349342 & 954644 & 7.1867 & 7.4636 & TRN & \\
\hline CHEMBL3392440 & 954644 & 4.6527 & 4.3441 & TRN & \\
\hline CHEMBL1970879 & 954644 & 4.3882 & 4.9035 & TRN & \\
\hline CHEMBL92309 & 954644 & 3.8923 & 3.0932 & TST & \\
\hline CHEMBL1242367 & 954644 & 4.8544 & 4.7172 & TRN & \\
\hline CHEMBL 2134202 & 954644 & 3.7575 & 4.2097 & TRN & \\
\hline CHEMBL1190711 & 954644 & 4.7034 & 4.9489 & TRN & \\
\hline CHEMBL 220241 & 954644 & 4.6688 & 4.6327 & TRN & \\
\hline CHEMBL 222102 & 954644 & 3.8715 & 3.6571 & TRN & \\
\hline CHEMBL202721 & 954644 & 4.2591 & 4.2369 & TRN & \\
\hline CHEMBL483849 & 954644 & 2.7247 & 2.0559 & TST & \\
\hline CHEMBL258844 & 954644 & 4.9093 & 4.6734 & TRN & \\
\hline CHEMBL 2144069 & 954644 & 9.9961 & 9.6995 & TRN & \\
\hline CHEMBL65 & 954644 & 7.0672 & 6.6621 & TRN & \\
\hline CHEMBL209148 & 954644 & 4.8933 & 5.0887 & TRN & \\
\hline CHEMBL1673039 & 954644 & 5.0607 & 4.9502 & TRN & \\
\hline CHEMBL191334 & 954644 & 3.807 & 4.2891 & TRN & \\
\hline CHEMBL585951 & 954644 & 7.1044 & 6.5748 & TRN & \\
\hline CHEMBL 399530 & 954644 & 5.0037 & 4.4398 & TRN & \\
\hline CHEMBL259181 & 954644 & 5.2208 & 5.5015 & TRN & \\
\hline CHEMBL392695 & 954644 & 5.8344 & 5.6017 & TRN & \\
\hline CHEMBL1516890 & 954644 & 6.0629 & 4.5122 & TRN & \\
\hline CHEMBL373751 & 954644 & 3.2425 & 3.8862 & TRN & \\
\hline
\end{tabular}


Supplemental Table S2.txt

\begin{tabular}{|c|c|c|c|c|c|c|}
\hline CHEMBL1643959 & 954644 & 3.9543 & 3.7232 & TRN & & \\
\hline CHEMBL1357247 & 954644 & 3.3139 & 3.48100 & 0000000000 & & TRN \\
\hline CHEMBL509032 & 954644 & 5.0366 & 5.0925 & TRN & & \\
\hline CHEMBL 2137530 & 954644 & 4.7173 & 4.6328 & TRN & & \\
\hline CHEMBL135561 & 954644 & 5.1917 & 5.1729 & TRN & & \\
\hline CHEMBL3186408 & 954644 & 4.0445 & 3.9681 & TST & & \\
\hline CHEMBL9470 & 954644 & 6.0377 & 5.8655 & TST & & \\
\hline CHEMBL1590308 & 954644 & 3.3066 & 3.4443 & TST & & \\
\hline CHEMBL1788116 & 954644 & 5.0568 & 4.9184 & TRN & & \\
\hline CHEMBL 255342 & 954644 & \multicolumn{3}{|c|}{3.8789999999999996} & 3.6327 & TRN \\
\hline CHEMBL379300 & 954644 & 6.0415 & 6.6437 & TRN & & \\
\hline CHEMBL 2363137 & 954644 & 5.4312 & 6.0511 & TRN & & \\
\hline CHEMBL515416 & 954644 & 5.3599 & 4.7307 & TRN & & \\
\hline CHEMBL 2005886 & 954644 & 5.7023 & 5.8987 & TRN & & \\
\hline CHEMBL192566 & 954644 & 8.3288 & 8.7391 & TST & & \\
\hline CHEMBL1909414 & 954644 & 5.9397 & 5.8338 & TRN & & \\
\hline CHEMBL449158 & 954644 & 7.6676 & 7.3596 & TST & & \\
\hline CHEMBL577784 & 954644 & 4.1481 & 4.1727 & TRN & & \\
\hline CHEMBL514499 & 954644 & 7.4777 & 7.33799 & 9999999999 & & TRN \\
\hline CHEMBL189584 & 954644 & 3.708 & 3.9456 & TRN & & \\
\hline CHEMBL412142 & 954644 & 4.228 & 4.6058 & TRN & & \\
\hline CHEMBL379975 & 954644 & 4.1296 & 4.2812 & TRN & & \\
\hline CHEMBL558642 & 954644 & 4.5903 & 4.5951 & TRN & & \\
\hline CHEMBL 210618 & 954644 & 3.6176 & 3.3788 & TRN & & \\
\hline CHEMBL1230020 & 954644 & 6.4148 & 6.2086 & TRN & & \\
\hline CHEMBL300389 & 954644 & 6.7813 & 6.644 & TRN & & \\
\hline CHEMBL483847 & 954644 & 4.2018 & 4.975 & TRN & & \\
\hline CHEMBL213100 & 954644 & 5.3741 & 5.5513 & TRN & & \\
\hline CHEMBL1256459 & 954644 & 7.8239 & 7.8397 & TRN & & \\
\hline CHEMBL 240954 & 954644 & 3.2589 & 3.4493 & TST & & \\
\hline CHEMBL180127 & 954644 & 3.9777 & 4.5027 & TST & & \\
\hline CHEMBL472940 & 954644 & 3.8397 & 3.2119 & TST & & \\
\hline CHEMBL1404918 & 954644 & 3.6795 & 3.3904 & TST & & \\
\hline CHEMBL393929 & 954644 & 3.3889 & 3.7212 & TST & & \\
\hline CHEMBL188678 & 954644 & 5.1111 & 4.2969 & TST & & \\
\hline CHEMBL3199475 & 954644 & 5.7469 & 4.5826 & TST & & \\
\hline CHEMBL512504 & 954644 & 4.284 & 4.6128 & TST & & \\
\hline CHEMBL573107 & 954644 & 5.5738 & 4.6038 & TST & & \\
\hline CHEMBL3702423 & 1528145 & 8.0458 & 7.8341 & TRN & & \\
\hline CHEMBL3702444 & 1528145 & 7.3372 & 7.6347 & TRN & & \\
\hline CHEMBL3702385 & 1528145 & 7.3872 & 7.0464 & TST & & \\
\hline CHEMBL3702463 & 1528145 & 6.6576 & 7.2273 & TRN & & \\
\hline CHEMBL3702417 & 1528145 & 7.699 & 6.9488 & TRN & & \\
\hline CHEMBL 3644390 & 1528145 & 6.3054 & 6.8388 & TRN & & \\
\hline CHEMBL 3644374 & 1528145 & 6.7399 & 7.1749 & TST & & \\
\hline CHEMBL3702450 & 1528145 & 8.0458 & 8.7514 & TRN & & \\
\hline CHEMBL 3644378 & 1528145 & 6.0783 & 7.4032 & TST & & \\
\hline CHEMBL 3644413 & 1528145 & 7.1024 & 7.0421 & TRN & & \\
\hline
\end{tabular}


Supplemental Table S2.txt

\begin{tabular}{|c|c|c|c|c|c|}
\hline CHEMBL3702358 & 1528145 & 6.0 & 6.9975 & TRN & \\
\hline CHEMBL 3644380 & 1528145 & 7.6383 & 7.8106 & TRN & \\
\hline CHEMBL 3644416 & 1528145 & 6.0 & \multicolumn{2}{|c|}{5.962000000000001} & TRN \\
\hline CHEMBL 3644423 & 1528145 & 7.7447 & 7.3951 & TRN & \\
\hline CHEMBL 3644382 & 1528145 & 6.5686 & 7.0852 & TRN & \\
\hline CHEMBL 3702416 & 1528145 & 5.7696 & 6.5658 & TST & \\
\hline CHEMBL3702379 & 1528145 & 6.3595 & 5.954 & TRN & \\
\hline CHEMBL 3702402 & 1528145 & 7.1805 & 7.3879 & TRN & \\
\hline CHEMBL 3702357 & 1528145 & 7.0458 & 7.7344 & TST & \\
\hline CHEMBL 3702445 & 1528145 & 6.4685 & 6.9731 & TRN & \\
\hline CHEMBL 3702386 & 1528145 & 7.8539 & 7.2884 & TST & \\
\hline CHEMBL3702439 & 1528145 & 6.567 & 6.9881 & TRN & \\
\hline CHEMBL 3702454 & 1528145 & 7.4318 & \multicolumn{2}{|c|}{7.3260000000000005} & TRN \\
\hline CHEMBL3702377 & 1528145 & 7.1805 & 6.2298 & TST & \\
\hline CHEMBL 3644418 & 1528145 & 7.699 & 7.5858 & TRN & \\
\hline CHEMBL3644424 & 1528145 & 8.0 & 7.1419 & TRN & \\
\hline CHEMBL3702419 & 1528145 & 7.5686 & 7.2449 & TRN & \\
\hline CHEMBL 3702381 & 1528145 & 7.0458 & 7.6112 & TST & \\
\hline CHEMBL 3644414 & 1528145 & 7.0315 & 7.1581 & TRN & \\
\hline CHEMBL 3702373 & 1528145 & 5.9208 & 6.4518 & TRN & \\
\hline CHEMBL3702453 & 1528145 & 5.5686 & 6.9508 & TRN & \\
\hline CHEMBL3702380 & 1528145 & 7.0969 & 6.8131 & TST & \\
\hline CHEMBL 3644430 & 1528145 & 7.3372 & 7.5582 & TRN & \\
\hline CHEMBL3639432 & 1528145 & 8.699 & 8.1799 & TRN & \\
\hline CHEMBL 3644402 & 1528145 & 7.2518 & 7.3307 & TRN & \\
\hline CHEMBL3702372 & 1528145 & 5.3468 & 7.4248 & TST & \\
\hline CHEMBL3702395 & 1528145 & 5.7959 & 6.2445 & TRN & \\
\hline CHEMBL3702424 & 1528145 & 7.4685 & 7.3681 & TRN & \\
\hline CHEMBL3702363 & 1528145 & 6.2218 & 5.5462 & TRN & \\
\hline CHEMBL 3702447 & 1528145 & 7.1612 & 7.6466 & TRN & \\
\hline CHEMBL3644405 & 1528145 & 8.1549 & 8.0193 & TRN & \\
\hline CHEMBL 3644383 & 1528145 & 6.4841 & 6.8195 & TST & \\
\hline CHEMBL3702397 & 1528145 & 6.5686 & 6.7062 & TRN & \\
\hline CHEMBL3644365 & 1528145 & 8.699 & 8.2564 & TRN & \\
\hline CHEMBL 3644367 & 1528145 & 6.8665 & 7.1339 & TRN & \\
\hline CHEMBL3644388 & 1528145 & 6.2882 & 7.1956 & TST & \\
\hline CHEMBL 3644362 & 1528145 & 8.699 & 7.9701 & TRN & \\
\hline CHEMBL 3702390 & 1528145 & 6.2147 & 6.6803 & TST & \\
\hline CHEMBL3644394 & 1528145 & 8.1549 & 7.6872 & TRN & \\
\hline CHEMBL3644411 & 1528145 & 7.7212 & 7.1425 & TRN & \\
\hline CHEMBL3644370 & 1528145 & 7.7959 & 7.2993 & TST & \\
\hline CHEMBL 3702443 & 1528145 & 7.7696 & 7.5153 & TRN & \\
\hline CHEMBL3702434 & 1528145 & 7.9208 & 7.388 & TRN & \\
\hline CHEMBL3702411 & 1528145 & 6.2716 & 6.1765 & TRN & \\
\hline CHEMBL3702361 & 1528145 & 7.1249 & 7.6898 & TRN & \\
\hline CHEMBL3925150 & 1528145 & 8.1549 & 8.0823 & TRN & \\
\hline CHEMBL 3702396 & 1528145 & 6.1549 & 6.0277 & TRN & \\
\hline CHEMBL3702403 & 1528145 & 8.1549 & 7.5378 & TRN & \\
\hline
\end{tabular}


Supplemental Table S2.txt

\begin{tabular}{|c|c|c|c|c|}
\hline HEMBL 3702406 & 528145 & 7.8539 & 7.4115 & \\
\hline HEMBL3644371 & 528145 & 7.7447 & 7.1222 & \\
\hline 381 & 28145 & 6.9393 & 6723 & \\
\hline HEMBL3702399 & 28145 & 5.8861 & 8818 & \\
\hline HEMBL3702394 & 528145 & 6.1643 & .1868 & \\
\hline HEMBL 3644431 & 528145 & 6.6676 & 7.2257 & \\
\hline HEMBL36 & 528145 & 8.0969 & 7.9832 & \\
\hline HEMBL3 & & 5.6576 & 5.5268 & \\
\hline HEMBL3 & 52 & 5.2596 & 6.4868 & \\
\hline HEMBL3644415 & 528145 & 7.585 & 7.7684 & \\
\hline HEMBL 36 & 528145 & 6.9208 & 7.6083 & \\
\hline HEMBL3 & 528 & 5.4559 & .6073 & \\
\hline HEMBL3 & 45 & & .4974 & \\
\hline HEMBL36 & 528145 & 7.1487 & 6.6256 & \\
\hline HEMBL37 & 528 & 5.284 & .6866 & \\
\hline HEMBL3 & 528 & 6.7696 & 6.0347 & \\
\hline HEMBL3 & $\partial<$ & 7.3372 & 5.9957 & \\
\hline HEMBL3 & 5 & 9.0 & 8.1684 & \\
\hline HEMBL3 & 45 & 7.4202 & 7.5457 & \\
\hline HEMBL3 & 57. & 5 . & 5.6655 & \\
\hline HEMBL3 & 52 & 47 & 7.2819 & \\
\hline AEMBL3 & 52 & 89 & .9707 & \\
\hline HEMBL & 15 & 14 & 7.1048 & \\
\hline HEMBL3 & 45 & 7.7696 & 7.5381 & \\
\hline HEMBL36 & & & 6.6 & \\
\hline HEMBL3 & 52 & 7. & 7.0958 & \\
\hline HEMBL3 & 5 & 6. & 149 & \\
\hline HEMBL 3 & 5 & 01 & 7.3594 & \\
\hline HEMBL3 & & 8.2218 & 7.7728 & \\
\hline HEMBL37 & 52 & 8.0 & 7.0818 & \\
\hline HEMBL3 & -1 & 882 & 7.0818 & \\
\hline HEMBL & 5 & 51 & 6.9183 & \\
\hline HEMBL3 & 5 & 27 & 6.9268 & \\
\hline HEMBL37 & 52 & 7.9586 & 7.6796 & \\
\hline HEMBL3702370 & 528 & 5.6576 & 5.33 & \\
\hline HEMBL3 & 2 & 7.8539 & 7.6787 & \\
\hline HEMBL & כ & 8. & 8.375 & \\
\hline HEMBL3 & & & 5.9439 & \\
\hline HEMBL $37 €$ & 528 & 6.4597 & 7.1952 & \\
\hline HEMBL3 & $52 \varepsilon$ & 255 & 7.0296 & \\
\hline HEMBL3 & 52 & 6.7447 & 7.0451 & \\
\hline CHEMBL3 & 1520 & & 7.2199 & \\
\hline CHEMBL37 & 45 & 6.1457 & 6.7427 & \\
\hline CHEMBL37 & 528 & 5.3872 & 5.4519 & \\
\hline MBL3 & 57 & 7.05 & 7.239 & \\
\hline HEMBL3 & & 7.2757 & 8.0347 & \\
\hline CHEMBL3702384 & 15281 & 7.8861 & 7.5049 & \\
\hline CHEMBL3644421 & 1528145 & 8.699 & 8.3284 & \\
\hline
\end{tabular}


Supplemental Table S2.txt

\begin{tabular}{|c|c|c|c|c|c|}
\hline CHEMBL3702367 & 1528145 & 7.0862 & 6.755 & TRN & \\
\hline CHEMBL3702366 & 1528145 & 7.3372 & 6.8594 & TRN & \\
\hline CHEMBL3644406 & 1528145 & 9.0 & 8.5417 & TRN & \\
\hline CHEMBL3702465 & 1528145 & 7.7959 & 8.5324 & TRN & \\
\hline CHEMBL3702360 & 1528145 & 7.3565 & 7.1036 & TST & \\
\hline CHEMBL3702455 & 1528145 & 7.8539 & 7.7737 & TRN & \\
\hline CHEMBL3702451 & 1528145 & 10.0 & 8.6248 & TRN & \\
\hline CHEMBL3702364 & 1528145 & 6.4622 & 6.9748 & TRN & \\
\hline CHEMBL 3702374 & 1528145 & 5.4089 & 6.5709 & TRN & \\
\hline CHEMBL3702389 & 1528145 & 7.301 & 7.5115 & TST & \\
\hline CHEMBL3644429 & 1528145 & 8.699 & 8.0135 & TRN & \\
\hline CHEMBL3702382 & 1528145 & 6.8239 & 6.5052 & TST & \\
\hline CHEMBL3702425 & 1528145 & 7.4949 & 7.4443 & TRN & \\
\hline CHEMBL 3644389 & 1528145 & 5.7959 & 6.9812 & TST & \\
\hline CHEMBL 3702461 & 1528145 & 6.8962 & 6.9586 & TRN & \\
\hline CHEMBL 3702437 & 1528145 & 8.301 & 7.3482 & TST & \\
\hline CHEMBL3702432 & 1528145 & 7.5528 & 7.33700 & 0000000001 & TRN \\
\hline CHEMBL3644375 & 1528145 & 7.1675 & 7.1664 & TRN & \\
\hline CHEMBL3702438 & 1528145 & 7.699 & 6.9909 & TRN & \\
\hline CHEMBL 3644376 & 1528145 & 6.7747 & 7.2071 & TRN & \\
\hline CHEMBL3702442 & 1528145 & 7.0 & 7.5649 & TRN & \\
\hline CHEMBL3702448 & 1528145 & 7.5528 & 6.8663 & TST & \\
\hline CHEMBL3702383 & 1528145 & 6.0 & 6.3598 & TST & \\
\hline CHEMBL3644409 & 1528145 & 6.7033 & 6.7797 & TRN & \\
\hline CHEMBL3702392 & 1528145 & 7.4949 & 5.8995 & TST & \\
\hline CHEMBL 3702375 & 1528145 & 7.1487 & 6.8198 & TST & \\
\hline CHEMBL3702362 & 1528145 & 7.6198 & 6.5144 & TST & \\
\hline CHEMBL3702426 & 1528145 & 6.2676 & 6.6839 & TRN & \\
\hline CHEMBL3644433 & 1528145 & 6.5638 & 6.7933 & TRN & \\
\hline CHEMBL 3702418 & 1528145 & 7.3098 & 6.8458 & TRN & \\
\hline CHEMBL3644368 & 1528145 & 6.8153 & 6.961 & TRN & \\
\hline CHEMBL3702446 & 1528145 & 7.2518 & 7.4813 & TRN & \\
\hline CHEMBL3644398 & 1528145 & 7.9208 & 7.9603 & TRN & \\
\hline CHEMBL 3702457 & 1528145 & 7.1135 & 6.862 & TRN & \\
\hline CHEMBL 3644377 & 1528145 & 5.9626 & 6.8866 & TRN & \\
\hline CHEMBL3644420 & 1528145 & 6.0 & 8.3517 & TRN & \\
\hline CHEMBL3702409 & 1528145 & 6.4622 & 6.2134 & TST & \\
\hline CHEMBL3702433 & 1528145 & 7.4089 & 7.4473 & TRN & \\
\hline CHEMBL3640012 & 1528145 & 7.4559 & 5.9784 & TST & \\
\hline CHEMBL 3644427 & 1528145 & 6.7447 & 6.6271 & TRN & \\
\hline CHEMBL 3644372 & 1528145 & 8.1549 & \multicolumn{2}{|c|}{7.6770000000000005} & TRN \\
\hline CHEMBL3702401 & 1528145 & 7.4559 & 6.5872 & TST & \\
\hline CHEMBL3702422 & 1528145 & 7.6576 & 7.7896 & TRN & \\
\hline CHEMBL3644369 & 1528145 & 7.585 & 7.0068 & TRN & \\
\hline CHEMBL3702456 & 1528145 & 7.0809 & 7.0257 & TRN & \\
\hline CHEMBL 3702413 & 1528145 & 6.6778 & 6.8891 & TRN & \\
\hline CHEMBL 3644404 & 1528145 & 8.301 & 7.7708 & TRN & \\
\hline CHEMBL 3702387 & 1528145 & 5.4202 & 6.7498 & TST & \\
\hline
\end{tabular}


Supplemental Table S2.txt

\begin{tabular}{|c|c|c|c|c|c|}
\hline CHEMBL3702441 & 1528145 & 7.4685 & 7.3802 & TRN & \\
\hline CHEMBL3702405 & 1528145 & 5.3098 & 6.7154 & TST & \\
\hline CHEMBL3644391 & 1528145 & 6.3872 & 6.5605 & TRN & \\
\hline CHEMBL3702462 & 1528145 & 6.9914 & 7.1513 & TRN & \\
\hline CHEMBL3644379 & 1528145 & 7.041 & 7.0575 & TRN & \\
\hline CHEMBL3702440 & 1528145 & 7.5086 & 7.2472 & TRN & \\
\hline CHEMBL3702376 & 1528145 & 7.6576 & 6.1741 & TST & \\
\hline CHEMBL 3644403 & 1528145 & 6.9666 & 7.6949 & TRN & \\
\hline CHEMBL3702435 & 1528145 & 6.8297 & 7.2545 & TRN & \\
\hline CHEMBL3644407 & 1528145 & 7.5686 & 7.7552 & TRN & \\
\hline CHEMBL3702398 & 1528145 & 7.4559 & 6.4972 & TST & \\
\hline CHEMBL3644392 & 1528145 & 7.4559 & 7.7289 & TRN & \\
\hline CHEMBL3702420 & 1528145 & 6.5607 & 6.6345 & TST & \\
\hline CHEMBL3644401 & 1528145 & 7.9586 & 8.0729 & TRN & \\
\hline CHEMBL 3644373 & 1528145 & 6.9136 & 6.5479 & TRN & \\
\hline CHEMBL3702393 & 1528145 & 7.4949 & 6.6879 & TST & \\
\hline CHEMBL3702428 & 1528145 & 6.8386 & 6.6482 & TRN & \\
\hline CHEMBL 3702429 & 1528145 & 7.4437 & 7.0153 & TRN & \\
\hline CHEMBL3702436 & 1528145 & 6.8827 & 7.3386 & TRN & \\
\hline CHEMBL 3644428 & 1528145 & 8.2218 & 8.1612 & TRN & \\
\hline CHEMBL3644422 & 1528145 & 7.7212 & 7.6281 & TRN & \\
\hline CHEMBL1989474 & 809271 & 4.0 & 3.6833 & TRN & \\
\hline CHEMBL1090360 & 809271 & 6.5 & 6.40799 & 79999999995 & TRN \\
\hline CHEMBL210887 & 809271 & 4.0 & 4.3601 & TRN & \\
\hline CHEMBL1988805 & 809271 & 4.5 & 4.636 & TST & \\
\hline CHEMBL458997 & 809271 & 5.6 & 5.3024 & TRN & \\
\hline CHEMBL1971021 & 809271 & 4.0 & 3.9219 & TRN & \\
\hline CHEMBL227271 & 809271 & 4.0 & 4.0831 & TRN & \\
\hline CHEMBL583144 & 809271 & 4.0 & 3.8686 & TRN & \\
\hline CHEMBL1974310 & 809271 & 4.0 & 4.0157 & TRN & \\
\hline CHEMBL1969942 & 809271 & 4.5 & 4.4471 & TRN & \\
\hline CHEMBL1978567 & 809271 & 4.5 & 4.495 & TRN & \\
\hline CHEMBL1982660 & 809271 & 4.0 & 4.2277 & TRN & \\
\hline CHEMBL1994693 & 809271 & 5.3 & 5.0981 & TRN & \\
\hline CHEMBL1982957 & 809271 & 6.0 & 5.5316 & TRN & \\
\hline CHEMBL1725279 & 809271 & 5.2 & 5.2566 & TST & \\
\hline CHEMBL 86755 & 809271 & 4.5 & 4.2392 & TRN & \\
\hline CHEMBL1975138 & 809271 & 6.2 & 4.2442 & TST & \\
\hline CHEMBL424872 & 809271 & 4.0 & 4.0868 & TRN & \\
\hline CHEMBL 2006836 & 809271 & 4.1 & 4.8025 & TST & \\
\hline CHEMBL1971947 & 809271 & 5.7 & 5.8818 & TRN & \\
\hline CHEMBL412142 & 809271 & 4.0 & 3.7398 & TST & \\
\hline CHEMBL1980704 & 809271 & 4.0 & 4.183 & TST & \\
\hline CHEMBL 2003271 & 809271 & 4.0 & 4.2221 & TRN & \\
\hline CHEMBL1966808 & 809271 & 4.0 & 4.0242 & TST & \\
\hline CHEMBL 2004447 & 809271 & 4.0 & 4.1693 & TRN & \\
\hline CHEMBL1983111 & 809271 & 6.1 & 6.1191 & TST & \\
\hline CHEMBL1973860 & 809271 & 4.0 & 4.0167 & TRN & \\
\hline
\end{tabular}




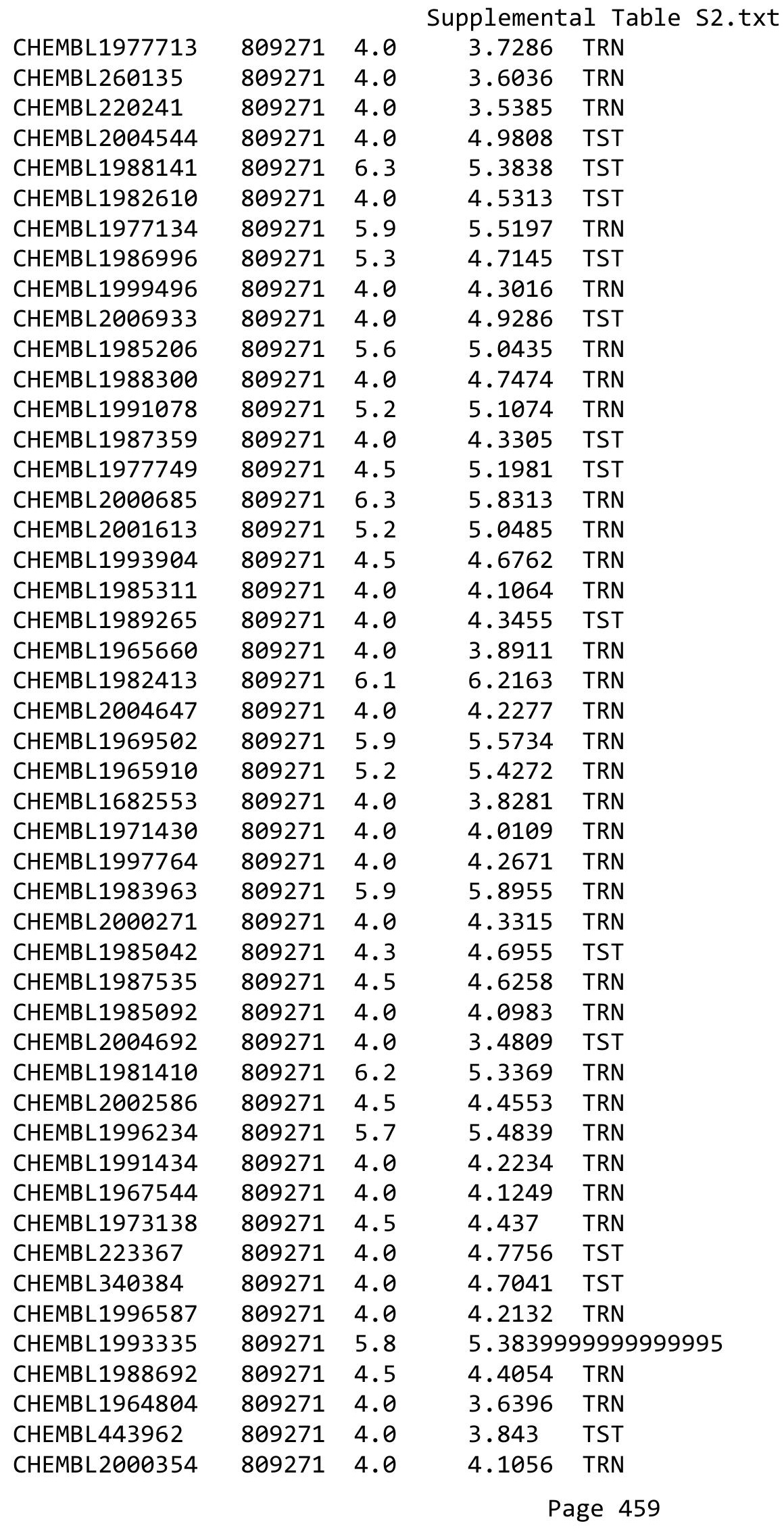

TRN 


\begin{tabular}{|c|c|c|c|c|c|}
\hline \multicolumn{6}{|c|}{ Supplemental Table S2.txt } \\
\hline CHEMBL1965507 & 809271 & 4.2 & 4.2464 & TRN & \\
\hline CHEMBL 274064 & 809271 & 4.0 & 4.0721 & TRN & \\
\hline CHEMBL1998680 & 809271 & 4.5 & 4.4247 & TRN & \\
\hline CHEMBL1967564 & 809271 & 4.0 & 3.7243 & TRN & \\
\hline CHEMBL592030 & 809271 & 4.0 & 4.6059 & TST & \\
\hline CHEMBL 2000071 & 809271 & 4.0 & 3.877 & TRN & \\
\hline CHEMBL1979176 & 809271 & 4.0 & 4.20100 & 00000000005 & TRN \\
\hline CHEMBL1970317 & 809271 & 7.2 & 7.305 & TRN & \\
\hline CHEMBL 2000408 & 809271 & 4.0 & 4.2575 & TRN & \\
\hline CHEMBL248757 & 809271 & 4.0 & 4.401 & TST & \\
\hline CHEMBL1978014 & 809271 & 4.0 & 4.0822 & TRN & \\
\hline CHEMBL1997007 & 809271 & 4.5 & 4.2997 & TRN & \\
\hline CHEMBL1994538 & 809271 & 4.0 & 3.9137 & TRN & \\
\hline CHEMBL1983195 & 809271 & 5.1 & 4.4132 & TST & \\
\hline CHEMBL1975490 & 809271 & 5.5 & 4.8965 & TRN & \\
\hline CHEMBL1964444 & 809271 & 4.0 & 4.2063 & TRN & \\
\hline CHEMBL1989957 & 809271 & 4.0 & 4.0193 & TRN & \\
\hline CHEMBL 2002690 & 809271 & 4.5 & 4.0135 & TRN & \\
\hline CHEMBL2006567 & 809271 & 4.0 & 4.2317 & TRN & \\
\hline CHEMBL1986139 & 809271 & 4.0 & 3.8232 & TRN & \\
\hline CHEMBL383527 & 809271 & 4.0 & 4.5469 & TRN & \\
\hline CHEMBL1980540 & 809271 & 4.0 & 3.9913 & TRN & \\
\hline CHEMBL 278041 & 809271 & 4.5 & 4.1639 & TRN & \\
\hline CHEMBL1979883 & 809271 & 6.4 & 6.1011 & TRN & \\
\hline CHEMBL1984162 & 809271 & 6.8 & 6.5495 & TRN & \\
\hline CHEMBL491758 & 809271 & 4.0 & 4.2647 & TRN & \\
\hline CHEMBL1986590 & 809271 & 4.5 & 4.2804 & TRN & \\
\hline CHEMBL549730 & 809271 & 4.0 & 4.4433 & TRN & \\
\hline CHEMBL1682360 & 809271 & 4.0 & 4.0093 & TRN & \\
\hline CHEMBL1970189 & 809271 & 4.0 & 3.9916 & TRN & \\
\hline CHEMBL1996791 & 809271 & 4.0 & 4.1952 & TRN & \\
\hline CHEMBL371206 & 809271 & 6.4 & 5.9952 & TRN & \\
\hline CHEMBL1974664 & 809271 & 4.0 & 4.3972 & TRN & \\
\hline CHEMBL406845 & 809271 & 4.5 & 4.8788 & TRN & \\
\hline CHEMBL1970104 & 809271 & 5.3 & 5.2813 & TRN & \\
\hline CHEMBL1974288 & 809271 & 4.0 & 3.9231 & TRN & \\
\hline CHEMBL1984296 & 809271 & 5.9 & 6.0412 & TST & \\
\hline CHEMBL196363 & 809271 & 6.2 & 6.1031 & TRN & \\
\hline CHEMBL1190711 & 809271 & 4.0 & 4.155 & TRN & \\
\hline CHEMBL1964718 & 809271 & 4.7 & 4.4274 & TST & \\
\hline CHEMBL1968705 & 809271 & 4.0 & 4.1885 & TRN & \\
\hline CHEMBL1964441 & 809271 & 7.0 & 6.7016 & TRN & \\
\hline CHEMBL546797 & 809271 & 4.5 & 4.473 & TRN & \\
\hline CHEMBL404367 & 809271 & 5.5 & 4.9578 & TRN & \\
\hline CHEMBL1966343 & 809271 & 4.0 & 3.7024 & TRN & \\
\hline CHEMBL1967887 & 809271 & 4.0 & 3.8137 & TRN & \\
\hline CHEMBL 2007266 & 809271 & 4.5 & 4.4323 & TRN & \\
\hline CHEMBL 2000568 & 809271 & 4.2 & 3.8984 & TRN & \\
\hline
\end{tabular}




\begin{tabular}{|c|c|c|c|c|}
\hline & & & ipplemen & al $\mathrm{Ta}$ \\
\hline CHEMBL1994308 & 809271 & 4.5 & 4.3723 & TRN \\
\hline CHEMBL 2000335 & 809271 & 6.3 & 6.3387 & TRN \\
\hline CHEMBL1977604 & 809271 & 4.0 & 4.4236 & TST \\
\hline CHEMBL1988717 & 809271 & 5.3 & 5.2191 & TRN \\
\hline CHEMBL1974328 & 809271 & 4.5 & 4.2531 & TRN \\
\hline CHEMBL509032 & 809271 & 6.1 & 6.0353 & TRN \\
\hline CHEMBL1973808 & 809271 & 4.0 & 3.8959 & TRN \\
\hline CHEMBL2000429 & 809271 & 4.0 & 3.9493 & TRN \\
\hline CHEMBL1972576 & 809271 & 5.4 & 4.6283 & TRN \\
\hline CHEMBL1992555 & 809271 & 4.0 & 4.2816 & TRN \\
\hline CHEMBL1992342 & 809271 & 4.0 & 3.6275 & TRN \\
\hline CHEMBL1988173 & 809271 & 5.5 & 4.7674 & TST \\
\hline CHEMBL1973013 & 809271 & 4.5 & 4.5713 & TRN \\
\hline CHEMBL535331 & 809271 & 4.0 & 3.6554 & TRN \\
\hline CHEMBL1989805 & 809271 & 4.0 & 4.6265 & TST \\
\hline CHEMBL1982980 & 809271 & 4.0 & 4.6801 & TST \\
\hline CHEMBL1965423 & 809271 & 4.0 & 4.1024 & TRN \\
\hline CHEMBL1983025 & 809271 & 6.2 & 6.1457 & TRN \\
\hline CHEMBL 205415 & 809271 & 4.2 & 4.3012 & TRN \\
\hline CHEMBL1977135 & 809271 & 4.0 & 3.8457 & TRN \\
\hline CHEMBL 2001920 & 809271 & 4.0 & 4.3376 & TRN \\
\hline CHEMBL 2002322 & 809271 & 4.0 & 3.7781 & TRN \\
\hline CHEMBL1997119 & 809271 & 4.2 & 4.1513 & TST \\
\hline CHEMBL1977138 & 809271 & 4.5 & 4.8913 & TST \\
\hline CHEMBL 2002323 & 809271 & 4.0 & 3.9069 & TRN \\
\hline CHEMBL1241473 & 809271 & 7.7 & 7.2608 & TRN \\
\hline CHEMBL1978448 & 809271 & 4.8 & 5.2248 & TST \\
\hline CHEMBL 2004513 & 809271 & 4.0 & 3.8761 & TRN \\
\hline CHEMBL1972258 & 809271 & 4.0 & 3.9684 & TRN \\
\hline CHEMBL1980329 & 809271 & 4.5 & 4.5634 & TRN \\
\hline CHEMBL 2001257 & 809271 & 5.9 & 5.5334 & TRN \\
\hline CHEMBL1992042 & 809271 & 5.8 & 5.7105 & TRN \\
\hline CHEMBL 2005548 & 809271 & 4.0 & 4.1419 & TRN \\
\hline CHEMBL1987793 & 809271 & 5.2 & 4.6734 & TST \\
\hline CHEMBL1992536 & 809271 & 4.0 & 3.9237 & TRN \\
\hline CHEMBL21156 & 809271 & 4.5 & 4.6677 & TST \\
\hline CHEMBL1992740 & 809271 & 4.0 & 4.2554 & TRN \\
\hline CHEMBL1994724 & 809271 & 4.5 & 4.6011 & TRN \\
\hline CHEMBL1989267 & 809271 & 6.5 & 6.7847 & TRN \\
\hline CHEMBL2002373 & 809271 & 4.0 & 3.8463 & TRN \\
\hline CHEMBL439340 & 809271 & 4.0 & 4.085 & TRN \\
\hline CHEMBL1974574 & 809271 & 5.7 & 4.4376 & TST \\
\hline CHEMBL 2006188 & 809271 & 4.0 & 3.7832 & TRN \\
\hline CHEMBL1967531 & 809271 & 6.2 & 6.1424 & TRN \\
\hline CHEMBL1970913 & 809271 & 4.0 & 3.8883 & TRN \\
\hline CHEMBL1973893 & 809271 & 4.0 & 3.7922 & TRN \\
\hline CHEMBL1995736 & 809271 & 4.0 & 4.3232 & TRN \\
\hline CHEMBL1997534 & 809271 & 4.0 & 3.9339 & TRN \\
\hline
\end{tabular}




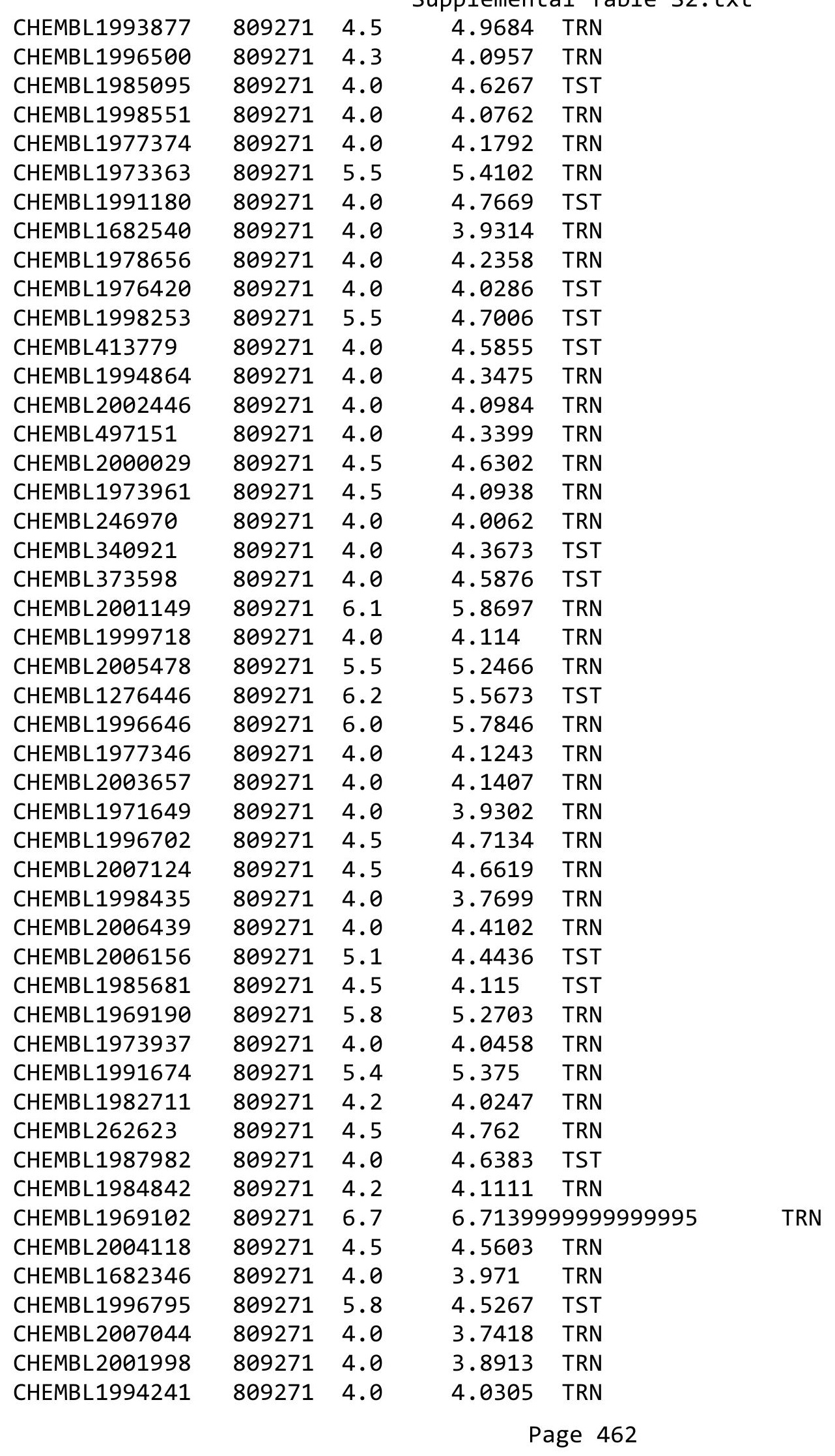




\begin{tabular}{|c|c|c|c|c|}
\hline \multicolumn{5}{|c|}{ Supplemental Table S2.txt } \\
\hline CHEMBL223460 & 809271 & 4.0 & 4.2593 & TST \\
\hline CHEMBL1998829 & 809271 & 4.0 & 4.1314 & TRN \\
\hline CHEMBL50894 & 809271 & 4.2 & 4.0582 & TRN \\
\hline CHEMBL1988838 & 809271 & 5.2 & 5.485 & TRN \\
\hline CHEMBL1981725 & 809271 & 7.4 & 6.8322 & TRN \\
\hline CHEMBL375284 & 809271 & 4.0 & 4.0149 & TRN \\
\hline CHEMBL1991818 & 809271 & 5.7 & 4.4885 & TST \\
\hline CHEMBL1081312 & 809271 & 4.5 & 4.5852 & TRN \\
\hline CHEMBL1965170 & 809271 & 6.0 & 5.849 & TRN \\
\hline CHEMBL1982866 & 809271 & 4.0 & 3.8231 & TRN \\
\hline CHEMBL2005792 & 809271 & 4.2 & 4.1874 & TRN \\
\hline CHEMBL1968926 & 809271 & 4.0 & 4.0123 & TRN \\
\hline CHEMBL1984206 & 809271 & 4.0 & 3.8355 & TRN \\
\hline CHEMBL462120 & 809271 & 4.0 & 4.6032 & TST \\
\hline CHEMBL1991577 & 809271 & 4.0 & 4.0961 & TRN \\
\hline CHEMBL1991867 & 809271 & 4.7 & 3.3481 & TST \\
\hline CHEMBL1965570 & 809271 & 6.1 & 6.0846 & TRN \\
\hline CHEMBL2007592 & 809271 & 4.0 & 4.2318 & TST \\
\hline CHEMBL1972355 & 809271 & 6.5 & 6.3923 & TRN \\
\hline CHEMBL1997892 & 809271 & 4.5 & 4.6374 & TRN \\
\hline CHEMBL1997193 & 809271 & 4.5 & 5.077 & TST \\
\hline CHEMBL210963 & 809271 & 4.0 & 4.0834 & TRN \\
\hline CHEMBL1964902 & 809271 & 4.5 & 4.3319 & TRN \\
\hline CHEMBL1082440 & 809271 & 4.0 & 4.3691 & TST \\
\hline CHEMBL1614705 & 809271 & 4.0 & 4.0032 & TRN \\
\hline CHEMBL1972362 & 809271 & 4.0 & 4.2622 & TRN \\
\hline CHEMBL1984633 & 809271 & 4.0 & 4.2859 & TRN \\
\hline CHEMBL1965845 & 809271 & 4.0 & 4.6777 & TRN \\
\hline CHEMBL2007372 & 809271 & 4.0 & 3.758 & TRN \\
\hline CHEMBL1983715 & 809271 & 6.5 & 6.3968 & TRN \\
\hline CHEMBL1982167 & 809271 & 5.3 & 4.364 & TRN \\
\hline CHEMBL 2006715 & 809271 & 6.6 & 6.4578 & TRN \\
\hline CHEMBL1986597 & 809271 & 4.0 & 4.525 & TRN \\
\hline CHEMBL1971017 & 809271 & 4.0 & 4.3796 & TRN \\
\hline CHEMBL1990482 & 809271 & 4.0 & 4.0964 & TRN \\
\hline CHEMBL1990904 & 809271 & 4.0 & 3.7534 & TRN \\
\hline CHEMBL 2000104 & 809271 & 4.0 & 4.2616 & TRN \\
\hline CHEMBL1975121 & 809271 & 4.0 & 4.055 & TRN \\
\hline CHEMBL2005475 & 809271 & 4.0 & 3.8295 & TRN \\
\hline CHEMBL402846 & 809271 & 4.1 & 4.948 & TRN \\
\hline CHEMBL1997349 & 809271 & 5.7 & 4.6792 & TST \\
\hline CHEMBL183844 & 809271 & 4.0 & 3.6853 & TRN \\
\hline CHEMBL220057 & 809271 & 4.0 & 4.0748 & TRN \\
\hline CHEMBL1682545 & 809271 & 4.0 & 4.376 & TRN \\
\hline CHEMBL 383541 & 809271 & 4.0 & 4.1638 & TRN \\
\hline CHEMBL2001224 & 809271 & 4.0 & 4.0702 & TRN \\
\hline CHEMBL10 & 809271 & 4.2 & 4.2268 & TRN \\
\hline CHEMBL1976732 & 809271 & 4.0 & 4.14199 & 99999999995 \\
\hline
\end{tabular}




\begin{tabular}{|c|c|c|c|c|}
\hline \multicolumn{5}{|c|}{ Supplemental Table S2.txt } \\
\hline CHEMBL1969506 & 809271 & 4.0 & 4.1624 & TRN \\
\hline CHEMBL1964937 & 809271 & 5.1 & 4.467 & TRN \\
\hline CHEMBL1980763 & 809271 & 4.5 & 4.5066 & TRN \\
\hline CHEMBL1980163 & 809271 & 4.0 & 3.3291 & TRN \\
\hline CHEMBL590109 & 809271 & 4.0 & 4.5669 & TST \\
\hline CHEMBL1970879 & 809271 & 6.7 & 6.3963 & TRN \\
\hline CHEMBL1989856 & 809271 & 4.0 & 4.5409 & TST \\
\hline CHEMBL 2005899 & 809271 & 4.0 & 4.1697 & TRN \\
\hline CHEMBL1682552 & 809271 & 4.0 & 3.9231 & TRN \\
\hline CHEMBL259850 & 809271 & 4.0 & 3.7312 & TRN \\
\hline CHEMBL1972568 & 809271 & 4.0 & 3.8691 & TRN \\
\hline CHEMBL 2007479 & 809271 & 4.5 & 4.564 & TRN \\
\hline CHEMBL1996155 & 809271 & 4.0 & 4.001 & TRN \\
\hline CHEMBL229799 & 809271 & 4.0 & 4.0027 & TRN \\
\hline CHEMBL105739 & 809271 & 4.0 & 4.4201 & TRN \\
\hline CHEMBL1682359 & 809271 & 4.0 & 4.0759 & TRN \\
\hline CHEMBL1972220 & 809271 & 6.9 & 6.1317 & TRN \\
\hline CHEMBL379300 & 809271 & 4.0 & 3.9916 & TRN \\
\hline CHEMBL203673 & 809271 & 4.0 & 3.9509 & TRN \\
\hline CHEMBL1969523 & 809271 & 6.5 & 6.1199 & TRN \\
\hline CHEMBL1988995 & 809271 & 4.0 & 4.0917 & TRN \\
\hline CHEMBL207995 & 809271 & 4.0 & 4.2912 & TRN \\
\hline CHEMBL2001923 & 809271 & 4.0 & 4.1892 & TRN \\
\hline CHEMBL1986781 & 809271 & 4.0 & 4.0232 & TRN \\
\hline CHEMBL526133 & 809271 & 4.0 & 4.4711 & TRN \\
\hline CHEMBL1989043 & 809271 & 4.5 & 4.5169 & TRN \\
\hline CHEMBL1979057 & 809271 & 4.0 & 4.1563 & TRN \\
\hline CHEMBL1981045 & 809271 & 4.0 & 4.0232 & TRN \\
\hline CHEMBL387971 & 809271 & 4.0 & 4.2099 & TRN \\
\hline CHEMBL1975418 & 809271 & 4.0 & 4.3428 & TRN \\
\hline CHEMBL1992796 & 809271 & 4.0 & 4.7785 & TST \\
\hline CHEMBL1164180 & 809271 & 4.5 & 4.9702 & TST \\
\hline CHEMBL223257 & 809271 & 4.0 & 4.5772 & TST \\
\hline CHEMBL1999428 & 809271 & 4.0 & 3.9419 & TRN \\
\hline CHEMBL1967560 & 809271 & 4.0 & 4.477 & TRN \\
\hline CHEMBL1997611 & 809271 & 5.7 & 5.5369 & TST \\
\hline CHEMBL1516890 & 809271 & 5.3 & 4.8214 & TRN \\
\hline CHEMBL211378 & 809271 & 5.1 & 5.284 & TRN \\
\hline CHEMBL1982465 & 809271 & 6.4 & 6.7026 & TRN \\
\hline CHEMBL 2001751 & 809271 & 5.7 & 5.6426 & TRN \\
\hline CHEMBL2003420 & 809271 & 4.0 & 3.9423 & TRN \\
\hline CHEMBL1984586 & 809271 & 5.8 & 5.7319 & TRN \\
\hline CHEMBL1999774 & 809271 & 4.0 & 3.8273 & TRN \\
\hline CHEMBL1972659 & 809271 & 4.0 & 4.2851 & TST \\
\hline CHEMBL1973395 & 809271 & 4.0 & 4.4153 & TRN \\
\hline CHEMBL272453 & 809271 & 4.0 & 4.2665 & TRN \\
\hline CHEMBL1970217 & 809271 & 4.0 & 3.9179 & TRN \\
\hline CHEMBL1971801 & 809271 & 4.0 & 3.80899 & 99999999997 \\
\hline
\end{tabular}




\begin{tabular}{|c|c|c|c|c|c|}
\hline \\
\hline CHEMBL1968850 & 809271 & 4.0 & 3.9754 & TRN & \\
\hline CHEMBL2005528 & 809271 & 4.0 & 4.1571 & TST & \\
\hline CHEMBL1984686 & 809271 & 4.5 & 4.4444 & TRN & \\
\hline CHEMBL185569 & 809271 & 4.0 & 4.0 & TRN & \\
\hline CHEMBL1969843 & 809271 & 4.0 & 4.1374 & TRN & \\
\hline CHEMBL 2007002 & 809271 & 4.0 & 4.0355 & TRN & \\
\hline CHEMBL1990288 & 809271 & 4.0 & 4.1833 & TRN & \\
\hline CHEMBL1987007 & 809271 & 4.0 & 3.7466 & TRN & \\
\hline CHEMBL1973793 & 809271 & 4.5 & 4.2221 & TST & \\
\hline CHEMBL1969588 & 809271 & 4.0 & 4.0801 & TRN & \\
\hline CHEMBL1984711 & 809271 & 5.1 & 5.3703 & TRN & \\
\hline CHEMBL1990212 & 809271 & 4.0 & 4.0134 & TRN & \\
\hline CHEMBL484390 & 809271 & 4.0 & 3.8022 & TRN & \\
\hline CHEMBL1979252 & 809271 & 4.0 & 4.3907 & TRN & \\
\hline CHEMBL2007559 & 809271 & 4.5 & 4.4279 & TRN & \\
\hline CHEMBL1992581 & 809271 & 4.5 & 4.6961 & TRN & \\
\hline CHEMBL1682341 & 809271 & 4.0 & 3.84800 & 00000000003 & TRN \\
\hline CHEMBL 2004290 & 809271 & 5.9 & 5.8745 & TRN & \\
\hline CHEMBL1986499 & 809271 & 4.0 & 3.9225 & TRN & \\
\hline CHEMBL1972937 & 809271 & 4.0 & 4.1867 & TRN & \\
\hline CHEMBL1972250 & 809271 & 4.0 & 4.0509 & TRN & \\
\hline CHEMBL 2000393 & 809271 & 4.0 & 4.7437 & TST & \\
\hline CHEMBL2004072 & 809271 & 4.0 & 3.4286 & TRN & \\
\hline CHEMBL 2004311 & 809271 & 4.0 & 4.0176 & TRN & \\
\hline CHEMBL1992634 & 809271 & 4.0 & 4.2919 & TRN & \\
\hline CHEMBL1242373 & 809271 & 4.0 & 4.772 & TRN & \\
\hline CHEMBL 2000433 & 809271 & 4.0 & 4.4201 & TST & \\
\hline CHEMBL56543 & 809271 & 4.0 & 4.0645 & TRN & \\
\hline CHEMBL316264 & 809271 & 4.0 & 4.0617 & TRN & \\
\hline CHEMBL1988075 & 809271 & 6.7 & 6.2131 & TRN & \\
\hline CHEMBL1996576 & 809271 & 4.5 & 4.93 & TST & \\
\hline CHEMBL1991678 & 809271 & 4.4 & 4.177 & TRN & \\
\hline CHEMBL2001239 & 809271 & 4.0 & 5.2433 & TST & \\
\hline CHEMBL1988594 & 809271 & 4.0 & 4.2571 & TRN & \\
\hline CHEMBL 2001288 & 809271 & 4.0 & 4.2762 & TRN & \\
\hline CHEMBL260092 & 809271 & 6.0 & 6.0725 & TRN & \\
\hline CHEMBL1999811 & 809271 & 4.0 & 4.2242 & TRN & \\
\hline CHEMBL1965495 & 809271 & 4.0 & 4.66100 & 00000000005 & TRN \\
\hline CHEMBL1985074 & 809271 & 4.0 & 4.046 & TST & \\
\hline CHEMBL 2000481 & 809271 & 5.4 & 4.6836 & TRN & \\
\hline CHEMBL1982874 & 809271 & 4.0 & 4.26699 & 99999999995 & TRN \\
\hline CHEMBL1991725 & 809271 & 4.0 & 4.4584 & TRN & \\
\hline CHEMBL1992242 & 809271 & 4.0 & 3.5192 & TRN & \\
\hline CHEMBL 2007296 & 809271 & 4.0 & 3.9088 & TRN & \\
\hline CHEMBL 208637 & 809271 & 4.0 & 3.9716 & TRN & \\
\hline CHEMBL396523 & 809271 & 5.6 & 5.6326 & TRN & \\
\hline CHEMBL1978371 & 809271 & 6.6 & 5.8887 & TST & \\
\hline CHEMBL1970203 & 809271 & 4.0 & 4.1995 & TRN & \\
\hline
\end{tabular}




\begin{tabular}{|c|c|c|c|c|c|}
\hline \multicolumn{6}{|c|}{ Supplemental Table S2.txt } \\
\hline CHEMBL1986530 & 809271 & 4.0 & 4.3376 & TST & \\
\hline CHEMBL1965351 & 809271 & 4.0 & 4.0121 & TRN & \\
\hline CHEMBL1999321 & 809271 & 4.0 & 3.9567 & TRN & \\
\hline CHEMBL1968590 & 809271 & 5.5 & 5.7564 & TRN & \\
\hline CHEMBL1999749 & 809271 & 4.0 & 4.0644 & TRN & \\
\hline CHEMBL 2005375 & 809271 & 4.0 & 4.8578 & TRN & \\
\hline CHEMBL1984191 & 809271 & 4.0 & 3.8471 & TRN & \\
\hline CHEMBL1983006 & 809271 & 4.0 & 3.9222 & TRN & \\
\hline CHEMBL1972183 & 809271 & 4.0 & 3.7574 & TRN & \\
\hline CHEMBL1971029 & 809271 & 4.0 & 4.9679 & TRN & \\
\hline CHEMBL394790 & 809271 & 5.4 & 5.2905 & TRN & \\
\hline CHEMBL226471 & 809271 & 4.0 & 4.4845 & TRN & \\
\hline CHEMBL1974702 & 809271 & 4.0 & 3.9208 & TRN & \\
\hline CHEMBL1996111 & 809271 & 4.0 & 3.9686 & TRN & \\
\hline CHEMBL1965589 & 809271 & 4.0 & 4.2397 & TRN & \\
\hline CHEMBL1998193 & 809271 & 4.0 & 4.1965 & TRN & \\
\hline CHEMBL474432 & 809271 & 6.2 & 5.1463 & TST & \\
\hline CHEMBL1973016 & 809271 & 4.5 & 4.9316 & TRN & \\
\hline CHEMBL1965387 & 809271 & 4.5 & 4.4822 & TRN & \\
\hline CHEMBL1988153 & 809271 & 4.0 & 3.8354 & TRN & \\
\hline CHEMBL550418 & 809271 & 4.5 & 4.7342 & TRN & \\
\hline CHEMBL1972584 & 809271 & 6.1 & 6.2588 & TRN & \\
\hline CHEMBL1971289 & 809271 & 4.5 & 4.7795 & TRN & \\
\hline CHEMBL1999556 & 809271 & 4.0 & 4.4386 & TRN & \\
\hline CHEMBL1988437 & 809271 & 4.2 & 5.1598 & TST & \\
\hline CHEMBL1968245 & 809271 & 4.0 & 4.1921 & TRN & \\
\hline CHEMBL1979577 & 809271 & 6.3 & 6.3178 & TRN & \\
\hline CHEMBL1998121 & 809271 & 5.3 & 5.081 & TRN & \\
\hline CHEMBL1991800 & 809271 & 4.0 & 3.9896 & TRN & \\
\hline CHEMBL 52387 & 809271 & 4.0 & 3.62100 & 00000000004 & TST \\
\hline CHEMBL1985566 & 809271 & 4.0 & 4.0297 & TRN & \\
\hline CHEMBL 2003689 & 809271 & 4.5 & 4.44300 & 00000000005 & TRN \\
\hline CHEMBL379835 & 809271 & 4.0 & 4.1108 & TST & \\
\hline CHEMBL1979357 & 809271 & 4.0 & 4.0819 & TRN & \\
\hline CHEMBL1980802 & 809271 & 4.0 & 4.917 & TST & \\
\hline CHEMBL1996817 & 809271 & 4.0 & 4.0298 & TRN & \\
\hline CHEMBL1979554 & 809271 & 4.0 & 4.1043 & TRN & \\
\hline CHEMBL3197315 & 809271 & 4.0 & 3.1678 & TST & \\
\hline CHEMBL 2004355 & 809271 & 4.0 & 4.0333 & TRN & \\
\hline CHEMBL468280 & 809271 & 4.0 & 4.0754 & TST & \\
\hline CHEMBL1990884 & 809271 & 4.0 & 4.329 & TRN & \\
\hline CHEMBL3109278 & 809271 & 4.6 & 4.4306 & TRN & \\
\hline CHEMBL256835 & 809271 & 4.0 & 3.715 & TRN & \\
\hline CHEMBL1970006 & 809271 & 4.0 & 4.2882 & TST & \\
\hline CHEMBL1980142 & 809271 & 4.0 & 3.9848 & TRN & \\
\hline CHEMBL41783 & 809271 & 4.0 & 4.3017 & TRN & \\
\hline CHEMBL 2004438 & 809271 & 4.2 & 4.3052 & TRN & \\
\hline CHEMBL2006276 & 809271 & 4.0 & 3.7293 & TRN & \\
\hline
\end{tabular}




\begin{tabular}{|c|c|c|c|c|c|}
\hline & & \multicolumn{4}{|c|}{ Supplemental Table S2.txt } \\
\hline CHEMBL191003 & 809271 & 4.5 & 5.1753 & TRN & \\
\hline CHEMBL271381 & 809271 & 4.1 & 4.7138 & TRN & \\
\hline CHEMBL 2006785 & 809271 & 4.0 & 3.9803 & TRN & \\
\hline CHEMBL1982466 & 809271 & 7.1 & 6.8236 & TRN & \\
\hline CHEMBL1973359 & 809271 & 7.2 & 6.2041 & TST & \\
\hline CHEMBL1995740 & 809271 & 4.0 & 3.9926 & TRN & \\
\hline CHEMBL1996390 & 809271 & 4.0 & 3.7512 & TRN & \\
\hline CHEMBL1986943 & 809271 & 5.2 & 5.0192 & TRN & \\
\hline CHEMBL1979690 & 809271 & 5.6 & 5.5903 & TRN & \\
\hline CHEMBL234085 & 809271 & 4.4 & 4.2985 & TRN & \\
\hline CHEMBL1995832 & 809271 & 4.0 & 4.4841 & TRN & \\
\hline CHEMBL1998414 & 809271 & 4.0 & 3.7802 & TRN & \\
\hline CHEMBL1969042 & 809271 & 4.0 & 3.9842 & TRN & \\
\hline CHEMBL2000345 & 809271 & 4.0 & 4.4021 & TRN & \\
\hline CHEMBL1999931 & 809271 & 5.1 & 4.76699 & 99999999995 & TRN \\
\hline CHEMBL1976376 & 809271 & 4.5 & 4.6372 & TRN & \\
\hline CHEMBL1991640 & 809271 & 5.7 & 4.2557 & TST & \\
\hline CHEMBL1983575 & 809271 & 5.8 & 5.5996 & TRN & \\
\hline CHEMBL1375418 & 809271 & 4.0 & 4.0752 & TRN & \\
\hline CHEMBL 302449 & 809271 & 4.0 & 5.3525 & TST & \\
\hline CHEMBL 2007064 & 809271 & 5.3 & 5.1099 & TRN & \\
\hline CHEMBL1981047 & 809271 & 4.2 & 4.287 & TRN & \\
\hline CHEMBL229968 & 809271 & 4.0 & 3.6413 & TRN & \\
\hline CHEMBL1976196 & 809271 & 6.9 & 4.8404 & TST & \\
\hline CHEMBL1976240 & 809271 & 4.0 & 3.9418 & TRN & \\
\hline CHEMBL1997197 & 809271 & 4.5 & 4.9407 & TST & \\
\hline CHEMBL1983630 & 809271 & 4.4 & 4.5662 & TRN & \\
\hline CHEMBL1979093 & 809271 & 5.3 & 4.9852 & TRN & \\
\hline CHEMBL1968151 & 809271 & 4.0 & 4.2629 & TST & \\
\hline CHEMBL1381197 & 809271 & 4.0 & 3.9504 & TRN & \\
\hline CHEMBL1987009 & 809271 & 4.0 & 4.4688 & TRN & \\
\hline CHEMBL379218 & 809271 & 4.0 & 3.9 & TRN & \\
\hline CHEMBL 2003817 & 809271 & 4.0 & 4.2932 & TRN & \\
\hline CHEMBL336961 & 809271 & 4.0 & 3.6563 & TRN & \\
\hline CHEMBL1994830 & 809271 & 4.0 & 3.9258 & TRN & \\
\hline CHEMBL1987054 & 809271 & 6.5 & 6.3468 & TRN & \\
\hline CHEMBL1970083 & 809271 & 6.1 & 6.3927 & TRN & \\
\hline CHEMBL 226403 & 809271 & 4.0 & 4.2441 & TRN & \\
\hline CHEMBL2005631 & 809271 & 6.4 & 7.0682 & TRN & \\
\hline CHEMBL1994938 & 809271 & 5.4 & 5.0891 & TRN & \\
\hline CHEMBL1825138 & 809271 & 4.0 & 4.4439 & TST & \\
\hline CHEMBL1977223 & 809271 & 4.0 & 3.772 & TRN & \\
\hline CHEMBL1995765 & 809271 & 5.5 & 4.6236 & TST & \\
\hline CHEMBL1966279 & 809271 & 4.0 & 4.8166 & TRN & \\
\hline CHEMBL1236126 & 809271 & 4.0 & 3.9187 & TRN & \\
\hline CHEMBL1984760 & 809271 & 4.5 & 4.4738 & TRN & \\
\hline CHEMBL1997846 & 809271 & 5.2 & 5.0868 & TRN & \\
\hline CHEMBL2004419 & 809271 & 4.0 & 3.7107 & TRN & \\
\hline
\end{tabular}




\begin{tabular}{|c|c|c|c|c|c|}
\hline & & & & & \\
\hline CHEMBL1991728 & 809271 & 5.5 & 5.6804 & TRN & \\
\hline CHEMBL 360847 & 809271 & 4.5 & 4.9027 & TST & \\
\hline CHEMBL1995811 & 809271 & 4.5 & 4.3414 & TRN & \\
\hline CHEMBL1975787 & 809271 & 4.0 & 4.2234 & TRN & \\
\hline CHEMBL 2002407 & 809271 & 4.0 & 3.4505 & TRN & \\
\hline CHEMBL1972489 & 809271 & 4.0 & 3.9129 & TRN & \\
\hline CHEMBL1994074 & 809271 & 4.0 & 3.9874 & TRN & \\
\hline CHEMBL1992937 & 809271 & 4.3 & 4.8537 & TST & \\
\hline CHEMBL536151 & 809271 & 4.0 & 4.5117 & TST & \\
\hline CHEMBL1972119 & 809271 & 4.0 & 4.075 & TRN & \\
\hline CHEMBL1986328 & 809271 & 4.0 & 4.4112 & TST & \\
\hline CHEMBL95692 & 809271 & 4.0 & 3.8275 & TRN & \\
\hline CHEMBL1090356 & 809271 & 6.4 & 6.3441 & TRN & \\
\hline CHEMBL1976455 & 809271 & 4.0 & 4.0997 & TRN & \\
\hline CHEMBL1983923 & 809271 & 4.2 & 4.5569 & TRN & \\
\hline CHEMBL1983534 & 809271 & 4.0 & 4.0976 & TRN & \\
\hline CHEMBL1982361 & 809271 & 4.0 & 4.1696 & TRN & \\
\hline CHEMBL1999112 & 809271 & 4.0 & 4.67399 & 99999999995 & TST \\
\hline CHEMBL1982122 & 809271 & 4.0 & 4.1222 & TRN & \\
\hline CHEMBL 2000801 & 809271 & 4.0 & 3.8121 & TRN & \\
\hline CHEMBL1682546 & 809271 & 4.0 & 4.0002 & TRN & \\
\hline CHEMBL1991395 & 809271 & 4.0 & 3.7967 & TRN & \\
\hline CHEMBL1971245 & 809271 & 4.0 & 4.6278 & TRN & \\
\hline CHEMBL1987648 & 809271 & 4.0 & 3.94100 & 00000000003 & TRN \\
\hline CHEMBL1996780 & 809271 & 4.0 & 3.9069 & TST & \\
\hline CHEMBL1972142 & 809271 & 4.0 & 3.7145 & TRN & \\
\hline CHEMBL1966514 & 809271 & 5.8 & 6.6263 & TRN & \\
\hline CHEMBL 2003638 & 809271 & 4.0 & 4.5017 & TRN & \\
\hline CHEMBL296586 & 809271 & 4.0 & 4.2875 & TRN & \\
\hline CHEMBL1996066 & 809271 & 4.0 & 4.8756 & TST & \\
\hline CHEMBL1983393 & 809271 & 4.5 & 4.2782 & TRN & \\
\hline CHEMBL516429 & 809271 & 4.0 & 4.5141 & TRN & \\
\hline CHEMBL1993722 & 809271 & 4.0 & 4.0343 & TRN & \\
\hline CHEMBL1970806 & 809271 & 4.0 & 3.7877 & TST & \\
\hline CHEMBL 2006674 & 809271 & 4.5 & 4.4651 & TST & \\
\hline CHEMBL1984236 & 809271 & 4.5 & 4.0922 & TST & \\
\hline CHEMBL1992371 & 809271 & 4.5 & 4.4641 & TRN & \\
\hline CHEMBL202635 & 809271 & 4.0 & 4.1774 & TRN & \\
\hline CHEMBL1375640 & 809271 & 5.1 & 4.5398 & TST & \\
\hline CHEMBL1979970 & 809271 & 4.0 & 4.2025 & TRN & \\
\hline CHEMBL 249282 & 809271 & 4.0 & 3.7389 & TRN & \\
\hline CHEMBL1993374 & 809271 & 4.5 & 4.6895 & TRN & \\
\hline CHEMBL1969264 & 809271 & 4.0 & 4.132 & TRN & \\
\hline CHEMBL1973711 & 809271 & 5.3 & 5.1102 & TRN & \\
\hline CHEMBL2006237 & 809271 & 4.0 & 3.8208 & TRN & \\
\hline CHEMBL1967720 & 809271 & 7.0 & 6.9117 & TRN & \\
\hline CHEMBL1572266 & 809271 & 4.0 & 4.3933 & TST & \\
\hline CHEMBL1991138 & 809271 & 4.0 & 4.4517 & TRN & \\
\hline & & & & 468 & \\
\hline
\end{tabular}




\begin{tabular}{|c|c|c|c|c|}
\hline \multicolumn{5}{|c|}{ Supplemental Table S2.txt } \\
\hline CHEMBL1969755 & 809271 & 4.0 & 3.8283 & TRN \\
\hline CHEMBL1979516 & 809271 & 6.8 & 6.3793 & TRN \\
\hline CHEMBL1972820 & 809271 & 4.0 & 4.2158 & TST \\
\hline CHEMBL1605605 & 809271 & 4.5 & 4.6749 & TRN \\
\hline CHEMBL1996208 & 809271 & 4.0 & 3.8746 & TRN \\
\hline CHEMBL1989029 & 809271 & 4.0 & 4.166 & TRN \\
\hline CHEMBL392642 & 809271 & 4.0 & 4.1322 & TRN \\
\hline CHEMBL514499 & 809271 & 6.3 & 4.7077 & TST \\
\hline CHEMBL1970352 & 809271 & 5.9 & 5.2251 & TST \\
\hline CHEMBL1965631 & 809271 & 4.0 & 3.7465 & TRN \\
\hline CHEMBL1980144 & 809271 & 4.0 & 4.1603 & TRN \\
\hline CHEMBL1991188 & 809271 & 4.0 & 3.9674 & TRN \\
\hline CHEMBL1980167 & 809271 & 4.5 & 4.7467 & TST \\
\hline CHEMBL1972849 & 809271 & 4.0 & 4.12 & TRN \\
\hline CHEMBL 377408 & 809271 & 4.0 & 4.2655 & TRN \\
\hline CHEMBL215152 & 809271 & 4.2 & 4.4551 & TRN \\
\hline CHEMBL231209 & 809271 & 5.4 & 5.3258 & TRN \\
\hline CHEMBL1975357 & 809271 & 4.0 & 4.3474 & TST \\
\hline CHEMBL1976220 & 809271 & 5.3 & 5.19 & TRN \\
\hline CHEMBL 259922 & 809271 & 4.0 & 4.5104 & TST \\
\hline CHEMBL1997617 & 809271 & 5.8 & 5.5919 & TRN \\
\hline CHEMBL1969301 & 809271 & 4.0 & 3.7991 & TRN \\
\hline CHEMBL1982383 & 809271 & 4.0 & 3.6038 & TRN \\
\hline CHEMBL17370 & 809271 & 4.0 & 4.1026 & TRN \\
\hline CHEMBL1980246 & 809271 & 4.5 & 4.7953 & TST \\
\hline CHEMBL1987910 & 809271 & 4.0 & 4.3943 & TRN \\
\hline CHEMBL1983932 & 809271 & 4.0 & 4.0088 & TRN \\
\hline CHEMBL1983980 & 809271 & 5.9 & 6.1497 & TRN \\
\hline CHEMBL1999484 & 809271 & 6.6 & 6.7237 & TRN \\
\hline CHEMBL1966069 & 809271 & 4.0 & 4.0514 & TRN \\
\hline CHEMBL1986899 & 809271 & 4.5 & 4.8547 & TRN \\
\hline CHEMBL1991285 & 809271 & 4.0 & 3.9956 & TRN \\
\hline CHEMBL1997822 & 809271 & 7.4 & 6.6903 & TRN \\
\hline CHEMBL 243088 & 809271 & 5.6 & 5.6577 & TRN \\
\hline CHEMBL1984038 & 809271 & 4.2 & 3.9099 & TRN \\
\hline CHEMBL1993661 & 809271 & 6.9 & 7.0442 & TRN \\
\hline CHEMBL1974416 & 809271 & 5.2 & 4.6681 & TRN \\
\hline CHEMBL 2004615 & 809271 & 4.0 & 4.0631 & TST \\
\hline CHEMBL1984039 & 809271 & 4.0 & 4.4365 & TST \\
\hline CHEMBL1997872 & 809271 & 4.0 & 3.7188 & TRN \\
\hline CHEMBL1964290 & 809271 & 4.0 & 4.0761 & TRN \\
\hline CHEMBL 2003768 & 809271 & 4.0 & 3.9188 & TRN \\
\hline CHEMBL213505 & 809271 & 6.0 & 6.0953 & TRN \\
\hline CHEMBL202721 & 809271 & 4.5 & 4.5987 & TRN \\
\hline CHEMBL1982880 & 809271 & 4.0 & 4.0702 & TRN \\
\hline CHEMBL1987034 & 809271 & 6.7 & 5.8539 & TRN \\
\hline CHEMBL1993941 & 809271 & 6.9 & 6.6385 & TRN \\
\hline CHEMBL377383 & 809271 & 4.0 & 3.833 & TRN \\
\hline
\end{tabular}




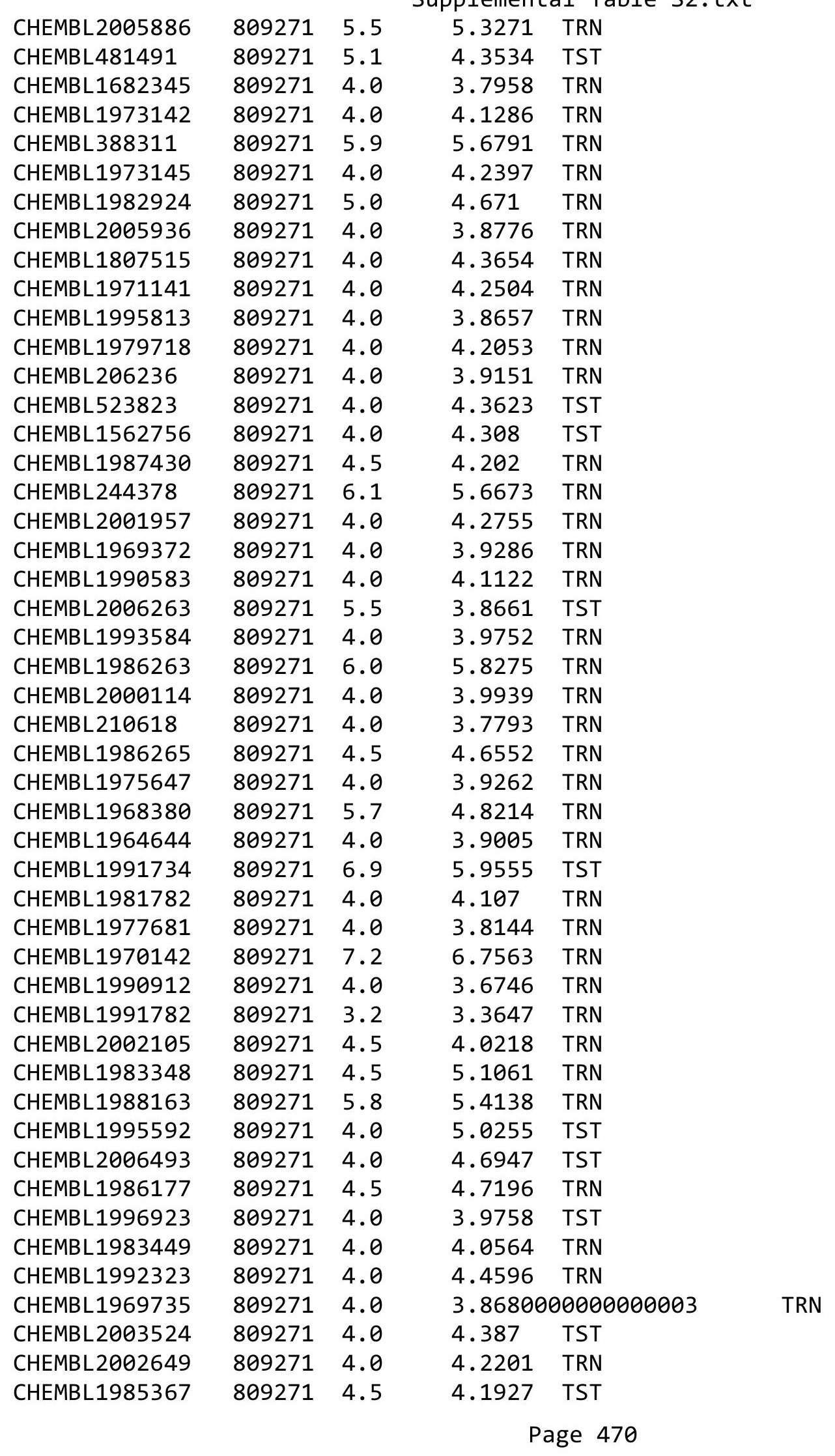




\begin{tabular}{|c|c|c|c|c|c|}
\hline \multicolumn{6}{|c|}{ Supplemental Table S2.txt } \\
\hline CHEMBL437747 & 809271 & 4.0 & 4.3732 & TRN & \\
\hline CHEMBL1995172 & 809271 & 4.1 & 3.8404 & TST & \\
\hline CHEMBL 2001584 & 809271 & 4.5 & 4.5479 & TRN & \\
\hline CHEMBL507936 & 809271 & 4.0 & 3.7694 & TRN & \\
\hline CHEMBL104264 & 809271 & 4.0 & 4.5974 & TST & \\
\hline CHEMBL1994321 & 809271 & 6.5 & 6.6354 & TRN & \\
\hline CHEMBL1978562 & 809271 & 4.5 & 5.085 & TRN & \\
\hline CHEMBL1997129 & 809271 & 6.2 & 6.0393 & TRN & \\
\hline CHEMBL1984788 & 809271 & 4.0 & 4.329 & TRN & \\
\hline CHEMBL451964 & 809271 & 4.0 & 4.1073 & TRN & \\
\hline CHEMBL1974875 & 809271 & 5.0 & 4.1284 & TST & \\
\hline CHEMBL1996604 & 809271 & 4.0 & 4.0264 & TRN & \\
\hline CHEMBL1964307 & 809271 & 4.0 & 4.0288 & TRN & \\
\hline CHEMBL1989471 & 809271 & 4.5 & 4.8719 & TST & \\
\hline CHEMBL 2000508 & 809271 & 4.0 & 3.7179 & TRN & \\
\hline CHEMBL1971694 & 809271 & 4.0 & 3.9401 & TST & \\
\hline CHEMBL 2001547 & 809271 & 4.0 & 3.7507 & TRN & \\
\hline CHEMBL210928 & 809271 & 4.0 & 3.9748 & TRN & \\
\hline CHEMBL1978195 & 809271 & 4.5 & 4.3937 & TRN & \\
\hline CHEMBL1994361 & 809271 & 4.0 & 4.1694 & TRN & \\
\hline CHEMBL1986603 & 809271 & 4.0 & 4.3789 & TST & \\
\hline CHEMBL1972840 & 809271 & 4.0 & 4.2766 & TRN & \\
\hline CHEMBL1977148 & 809271 & 4.0 & 5.3918 & TRN & \\
\hline CHEMBL1968025 & 809271 & 5.5 & 4.6889 & TST & \\
\hline CHEMBL 2003286 & 809271 & 4.0 & 4.0481 & TRN & \\
\hline CHEMBL1992306 & 809271 & 4.0 & 4.1773 & TRN & \\
\hline CHEMBL 2002165 & 809271 & 7.2 & 7.1274 & TRN & \\
\hline CHEMBL 2001668 & 809271 & 4.0 & 4.3082 & TST & \\
\hline CHEMBL1979318 & 809271 & 4.0 & 4.0603 & TRN & \\
\hline CHEMBL 206382 & 809271 & 4.0 & 3.9259 & TRN & \\
\hline CHEMBL1998585 & 809271 & 5.9 & 6.3267 & TRN & \\
\hline CHEMBL127898 & 809271 & 4.0 & 4.7281 & TST & \\
\hline CHEMBL519697 & 809271 & 4.0 & 4.0077 & TRN & \\
\hline CHEMBL 2004934 & 809271 & 4.0 & 3.9713 & TRN & \\
\hline CHEMBL1996345 & 809271 & 4.5 & 4.4464 & TST & \\
\hline CHEMBL1975128 & 809271 & 5.1 & 4.6211 & TRN & \\
\hline CHEMBL 2004025 & 809271 & 4.5 & 5.3988 & TST & \\
\hline CHEMBL1996048 & 809271 & 4.5 & 5.0422 & TST & \\
\hline CHEMBL1970369 & 809271 & 4.0 & 3.89300 & 00000000002 & TRN \\
\hline CHEMBL461876 & 809271 & 4.5 & 4.484 & TRN & \\
\hline CHEMBL1965033 & 809271 & 4.5 & 4.4171 & TRN & \\
\hline CHEMBL 2001485 & 809271 & 6.7 & 6.3937 & TRN & \\
\hline CHEMBL504950 & 809271 & 4.0 & 4.6006 & TRN & \\
\hline CHEMBL1997335 & 809271 & 6.7 & 6.0859 & TRN & \\
\hline CHEMBL1966425 & 809271 & 5.2 & 4.8996 & TRN & \\
\hline CHEMBL1984363 & 809271 & 4.0 & 3.9801 & TRN & \\
\hline CHEMBL1978099 & 809271 & 4.0 & 4.1493 & TRN & \\
\hline CHEMBL1977041 & 809271 & 6.6 & 6.3287 & TRN & \\
\hline
\end{tabular}




\begin{tabular}{|c|c|c|c|c|c|}
\hline \\
\hline CHEMBL1968070 & 809271 & 4.0 & 4.4738 & TRN & \\
\hline CHEMBL1988608 & 809271 & 5.1 & 4.3973 & TRN & \\
\hline CHEMBL184847 & 809271 & 4.0 & 3.9609 & TRN & \\
\hline CHEMBL1994808 & 809271 & 4.4 & 4.2128 & TRN & \\
\hline CHEMBL1984367 & 809271 & 4.0 & 3.81600 & 20000000003 & TRN \\
\hline CHEMBL178737 & 809271 & 4.0 & 4.2102 & TST & \\
\hline CHEMBL 226898 & 809271 & 4.0 & 4.5215 & TRN & \\
\hline CHEMBL1982563 & 809271 & 4.0 & 3.8852 & TRN & \\
\hline CHEMBL539474 & 809271 & 6.3 & 5.0732 & TST & \\
\hline CHEMBL575824 & 809271 & 4.0 & 4.1685 & TRN & \\
\hline CHEMBL1988387 & 809271 & 6.5 & 6.4592 & TRN & \\
\hline CHEMBL1973868 & 809271 & 4.5 & 4.4037 & TRN & \\
\hline CHEMBL1972462 & 809271 & 4.5 & 4.6277 & TRN & \\
\hline CHEMBL1997759 & 809271 & 4.0 & 4.4906 & TRN & \\
\hline CHEMBL1974803 & 809271 & 4.0 & 4.5933 & TST & \\
\hline CHEMBL1970074 & 809271 & 4.0 & 4.3295 & TRN & \\
\hline CHEMBL1984500 & 809271 & 3.2 & 3.47399 & 99999999998 & TRN \\
\hline CHEMBL1986970 & 809271 & 4.0 & 3.8211 & TRN & \\
\hline CHEMBL 2005112 & 809271 & 4.0 & 4.4201 & TST & \\
\hline CHEMBL1958401 & 809271 & 4.0 & 3.9027 & TRN & \\
\hline CHEMBL1984044 & 809271 & 4.0 & 4.0978 & TRN & \\
\hline CHEMBL2003456 & 809271 & 4.0 & 4.2026 & TRN & \\
\hline CHEMBL1966816 & 809271 & 4.0 & 4.1635 & TRN & \\
\hline CHEMBL2002992 & 809271 & 4.0 & 3.9505 & TRN & \\
\hline CHEMBL560813 & 809271 & 4.0 & 3.9458 & TRN & \\
\hline CHEMBL 207253 & 809271 & 4.0 & 3.9538 & TST & \\
\hline CHEMBL1890036 & 809271 & 4.0 & 4.1612 & TST & \\
\hline CHEMBL1982700 & 809271 & 4.5 & 4.6984 & TST & \\
\hline CHEMBL1968791 & 809271 & 5.5 & 5.2402 & TRN & \\
\hline CHEMBL326282 & 809271 & 4.0 & 4.2892 & TST & \\
\hline CHEMBL2002682 & 809271 & 4.0 & 4.6459 & TST & \\
\hline CHEMBL1977634 & 809271 & 4.5 & 4.4039 & TRN & \\
\hline CHEMBL1992732 & 809271 & 4.0 & 3.3529 & TST & \\
\hline CHEMBL1971186 & 809271 & 4.0 & 3.9929 & TRN & \\
\hline CHEMBL 2003482 & 809271 & 4.0 & 3.9549 & TRN & \\
\hline CHEMBL1969156 & 809271 & 4.1 & 3.6498 & TST & \\
\hline CHEMBL1973211 & 809271 & 6.4 & 6.3313 & TRN & \\
\hline CHEMBL1984700 & 809271 & 4.0 & 3.94199 & 99999999997 & TRN \\
\hline CHEMBL2007151 & 809271 & 5.2 & 5.5686 & TRN & \\
\hline CHEMBL1972125 & 809271 & 4.0 & 4.115 & TRN & \\
\hline CHEMBL1461728 & 809271 & 4.0 & 3.9785 & TRN & \\
\hline CHEMBL1999120 & 809271 & 4.2 & 4.5992 & TST & \\
\hline CHEMBL1976134 & 809271 & 4.0 & 3.8536 & TRN & \\
\hline CHEMBL1965131 & 809271 & 4.0 & 4.2508 & TRN & \\
\hline CHEMBL1995448 & 809271 & 4.0 & 4.0659 & TRN & \\
\hline CHEMBL1972158 & 809271 & 4.0 & 4.0286 & TRN & \\
\hline CHEMBL1981215 & 809271 & 4.5 & 4.4043 & TRN & \\
\hline CHEMBL1974457 & 809271 & 4.0 & 3.6752 & TRN & \\
\hline
\end{tabular}




\begin{tabular}{|c|c|c|c|c|c|}
\hline \multirow[b]{2}{*}{ CHEMBL 2006580} & \multirow[b]{2}{*}{809271} & \\
\hline & & 4.0 & 3.5207 & TRN & \\
\hline CHEMBL 2006581 & 809271 & 4.0 & 3.8165 & TRN & \\
\hline CHEMBL2006481 & 809271 & 4.0 & 3.8076 & TRN & \\
\hline CHEMBL1979855 & 809271 & 4.0 & 4.3301 & TRN & \\
\hline CHEMBL1970340 & 809271 & 4.0 & 3.8751 & TRN & \\
\hline CHEMBL1967992 & 809271 & 4.5 & 4.231 & TRN & \\
\hline CHEMBL 2005186 & 809271 & 4.0 & 4.2254 & TRN & \\
\hline CHEMBL1995927 & 809271 & 4.0 & 3.76 & TRN & \\
\hline CHEMBL1975534 & 809271 & 4.0 & 4.4085 & TRN & \\
\hline CHEMBL1993424 & 809271 & 4.0 & 4.6754 & TRN & \\
\hline CHEMBL1966703 & 809271 & 4.0 & 3.73199 & 99999999998 & TRN \\
\hline CHEMBL1969561 & 809271 & 4.0 & 3.7914 & TRN & \\
\hline CHEMBL1983640 & 809271 & 7.0 & 6.1528 & TRN & \\
\hline CHEMBL1997023 & 809271 & 4.0 & 3.682 & TST & \\
\hline CHEMBL1964687 & 809271 & 4.1 & 4.0581 & TRN & \\
\hline CHEMBL1994581 & 809271 & 5.3 & 4.4419 & TST & \\
\hline CHEMBL1971943 & 809271 & 4.0 & 4.2155 & TRN & \\
\hline CHEMBL1999918 & 809271 & 5.3 & 4.6182 & TRN & \\
\hline CHEMBL1974254 & 809271 & 5.4 & 5.6553 & TRN & \\
\hline CHEMBL1988537 & 809271 & 4.0 & 3.6363 & TST & \\
\hline CHEMBL1969049 & 809271 & 4.0 & 3.8829 & TRN & \\
\hline CHEMBL 2005828 & 809271 & 5.9 & 5.7589 & TRN & \\
\hline CHEMBL 2002240 & 809271 & 4.0 & 4.0581 & TRN & \\
\hline CHEMBL1991143 & 809271 & 4.0 & 4.5255 & TST & \\
\hline CHEMBL1998611 & 809271 & 4.0 & 3.826 & TRN & \\
\hline CHEMBL485556 & 809271 & 4.0 & 4.2347 & TRN & \\
\hline CHEMBL1975900 & 809271 & 4.0 & 4.3172 & TRN & \\
\hline CHEMBL255822 & 809271 & 4.0 & 4.2161 & TRN & \\
\hline CHEMBL1972221 & 809271 & 4.0 & 3.5733 & TRN & \\
\hline CHEMBL2006778 & 809271 & 7.9 & 6.8411 & TRN & \\
\hline CHEMBL378627 & 809271 & 4.0 & 4.1273 & TRN & \\
\hline CHEMBL1996979 & 809271 & 4.2 & 4.618 & TRN & \\
\hline CHEMBL1997025 & 809271 & 4.0 & 4.287 & TRN & \\
\hline CHEMBL1968406 & 809271 & 4.0 & 4.8186 & TRN & \\
\hline CHEMBL1982476 & 809271 & 6.7 & 6.9683 & TRN & \\
\hline CHEMBL1984274 & 809271 & 4.0 & 4.1258 & TST & \\
\hline CHEMBL1998545 & 809271 & 4.0 & 3.64899 & 99999999996 & TRN \\
\hline CHEMBL1986869 & 809271 & 4.0 & 4.1973 & TRN & \\
\hline CHEMBL2004033 & 809271 & 5.5 & 4.4005 & TST & \\
\hline CHEMBL1975923 & 809271 & 4.8 & 5.4522 & TST & \\
\hline CHEMBL2005449 & 809271 & 4.5 & 4.1114 & TRN & \\
\hline CHEMBL1987998 & 809271 & 4.5 & 4.2785 & TRN & \\
\hline CHEMBL2006010 & 809271 & 4.0 & 4.0522 & TRN & \\
\hline CHEMBL1682558 & 809271 & 4.0 & 3.6869 & TRN & \\
\hline CHEMBL1990496 & 809271 & 4.1 & 4.2604 & TRN & \\
\hline CHEMBL242865 & 809271 & 4.5 & 4.8473 & TRN & \\
\hline CHEMBL1997623 & 809271 & 4.0 & 4.3218 & TRN & \\
\hline CHEMBL2002479 & 809271 & 5.3 & 5.2716 & TRN & \\
\hline & & & & 473 & \\
\hline
\end{tabular}




\begin{tabular}{|c|c|c|c|c|}
\hline & & & pplement & $\mathrm{a} \perp \mathrm{Ta}$ \\
\hline CHEMBL1993166 & 809271 & 5.3 & 5.2112 & TRN \\
\hline CHEMBL1967094 & 809271 & 4.0 & 4.2011 & TRN \\
\hline CHEMBL1966035 & 809271 & 4.0 & 4.1272 & TRN \\
\hline CHEMBL2003341 & 809271 & 4.0 & 4.0003 & TRN \\
\hline CHEMBL1992645 & 809271 & 4.0 & 4.7323 & TST \\
\hline CHEMBL1982992 & 809271 & 4.0 & 4.1677 & TRN \\
\hline CHEMBL1974363 & 809271 & 4.0 & 4.3316 & TRN \\
\hline CHEMBL1998110 & 809271 & 4.5 & 4.495 & TRN \\
\hline CHEMBL1999590 & 809271 & 4.0 & 4.3917 & TST \\
\hline CHEMBL1981079 & 809271 & 4.0 & 3.9085 & TRN \\
\hline CHEMBL1978166 & 809271 & 6.4 & 6.7516 & TRN \\
\hline CHEMBL1982993 & 809271 & 5.5 & 5.3472 & TRN \\
\hline CHEMBL1972276 & 809271 & 4.0 & 3.7525 & TRN \\
\hline CHEMBL1980489 & 809271 & 4.0 & 4.1343 & TRN \\
\hline CHEMBL 2000832 & 809271 & 5.6 & 4.5972 & TRN \\
\hline CHEMBL1967116 & 809271 & 7.2 & 7.3282 & TRN \\
\hline CHEMBL1977814 & 809271 & 4.2 & 4.1688 & TST \\
\hline CHEMBL513846 & 809271 & 4.0 & 3.7985 & TRN \\
\hline CHEMBL1970709 & 809271 & 4.0 & 4.1295 & TRN \\
\hline CHEMBL1974617 & 809271 & 4.4 & 4.2937 & TRN \\
\hline CHEMBL1992125 & 809271 & 6.0 & 6.0851 & TRN \\
\hline CHEMBL1998112 & 809271 & 4.0 & 4.4594 & TRN \\
\hline CHEMBL1969126 & 809271 & 4.0 & 3.9656 & TRN \\
\hline CHEMBL1980896 & 809271 & 5.7 & 5.7229 & TRN \\
\hline CHEMBL1975208 & 809271 & 4.0 & 4.3233 & TRN \\
\hline CHEMBL1991429 & 809271 & 6.3 & 6.5074 & TRN \\
\hline CHEMBL1964777 & 809271 & 4.0 & 3.9235 & TRN \\
\hline CHEMBL1971149 & 809271 & 4.0 & 4.0596 & TRN \\
\hline CHEMBL1999714 & 809271 & 4.0 & 3.7335 & TRN \\
\hline CHEMBL1987533 & 809271 & 4.0 & 4.2056 & TRN \\
\hline CHEMBL1994040 & 809271 & 4.0 & 3.8586 & TRN \\
\hline CHEMBL388978 & 809271 & 5.6 & 7.7671 & TST \\
\hline CHEMBL579246 & 809271 & 4.0 & 3.8321 & TRN \\
\hline CHEMBL398951 & 809271 & 4.0 & 4.1364 & TRN \\
\hline CHEMBL1982506 & 809271 & 4.0 & 4.2906 & TST \\
\hline CHEMBL 2004716 & 809271 & 6.9 & 6.8113 & TRN \\
\hline CHEMBL1968127 & 809271 & 4.0 & 3.9431 & TRN \\
\hline CHEMBL1975233 & 809271 & 4.0 & 3.9609 & TRN \\
\hline CHEMBL1985406 & 809271 & 4.0 & 3.8713 & TRN \\
\hline CHEMBL207400 & 809271 & 4.0 & 4.1866 & TST \\
\hline CHEMBL 2000894 & 809271 & 4.0 & 4.1462 & TST \\
\hline CHEMBL1421720 & 809271 & 6.0 & 6.0392 & TRN \\
\hline CHEMBL1968130 & 809271 & 5.6 & 4.4472 & TST \\
\hline CHEMBL 2002553 & 809271 & 4.0 & 4.0489 & TRN \\
\hline CHEMBL1982135 & 809271 & 5.2 & 4.6212 & TRN \\
\hline CHEMBL1976090 & 809271 & 5.1 & 4.4622 & TRN \\
\hline CHEMBL1993243 & 809271 & 6.0 & 6.0349 & TRN \\
\hline CHEMBL 2004771 & 809271 & 4.0 & 3.9285 & TRN \\
\hline
\end{tabular}




\begin{tabular}{|c|c|c|c|c|}
\hline & & & upplement & al Ta \\
\hline CHEMBL1992922 & 809271 & 4.0 & 4.1045 & TRN \\
\hline CHEMBL 399021 & 809271 & 5.7 & 4.9295 & TRN \\
\hline CHEMBL1997597 & 809271 & 4.0 & 3.742 & TRN \\
\hline CHEMBL1969537 & 809271 & 4.0 & 4.1178 & TST \\
\hline CHEMBL1976093 & 809271 & 4.0 & 3.7148 & TST \\
\hline CHEMBL 210032 & 809271 & 4.0 & 3.995 & TST \\
\hline CHEMBL1996543 & 809271 & 4.0 & 3.9582 & TST \\
\hline CHEMBL1975256 & 809271 & 4.0 & 3.6023 & TST \\
\hline CHEMBL508928 & 809271 & 6.3 & 5.1956 & TST \\
\hline CHEMBL1991356 & 809271 & 4.0 & 4.2701 & TST \\
\hline CHEMBL1983309 & 809271 & 4.0 & 4.3091 & TST \\
\hline CHEMBL2004892 & 809271 & 4.0 & 3.5917 & TST \\
\hline CHEMBL1999126 & 809271 & 4.0 & 4.5916 & TST \\
\hline CHEMBL1997503 & 809271 & 4.0 & 3.9248 & TST \\
\hline CHEMBL116070 & 809271 & 4.0 & 4.0061 & TST \\
\hline CHEMBL1990821 & 809271 & 4.0 & 4.7835 & TST \\
\hline CHEMBL1970314 & 809271 & 4.0 & 3.3363 & TST \\
\hline CHEMBL 2004871 & 809271 & 4.0 & 3.6504 & TST \\
\hline CHEMBL 2004872 & 809271 & 4.0 & 4.2119 & TST \\
\hline CHEMBL1727312 & 809271 & 4.0 & 3.3301 & TST \\
\hline CHEMBL1990223 & 809271 & 4.5 & 4.3517 & TST \\
\hline CHEMBL1969879 & 809271 & 4.0 & 3.9962 & TST \\
\hline CHEMBL1964382 & 809271 & 4.5 & 4.9395 & TST \\
\hline CHEMBL101311 & 809271 & 4.5 & 4.601 & TST \\
\hline CHEMBL1981720 & 809271 & 4.0 & 3.6844 & TST \\
\hline CHEMBL419932 & 809271 & 4.0 & 4.2283 & TST \\
\hline CHEMBL 262433 & 809271 & 6.0 & 5.5975 & TST \\
\hline CHEMBL 306380 & 809271 & 4.0 & 5.1814 & TST \\
\hline CHEMBL1966722 & 809271 & 6.2 & 4.5524 & TST \\
\hline CHEMBL1988581 & 809271 & 7.5 & 6.5285 & TST \\
\hline CHEMBL 2005699 & 809271 & 4.5 & 4.3003 & TST \\
\hline CHEMBL1975500 & 809271 & 4.0 & 4.4703 & TST \\
\hline CHEMBL1976328 & 809271 & 4.0 & 4.2549 & TST \\
\hline CHEMBL 394619 & 809271 & 5.3 & 5.4652 & TST \\
\hline CHEMBL1964399 & 809271 & 6.2 & 6.0678 & TST \\
\hline CHEMBL1996831 & 809271 & 4.0 & 4.3909 & TST \\
\hline CHEMBL411903 & 809271 & 5.9 & 5.6656 & TST \\
\hline CHEMBL1978167 & 809271 & 4.5 & 5.2702 & TST \\
\hline CHEMBL1965988 & 809271 & 6.0 & 6.4072 & TST \\
\hline CHEMBL418203 & 809271 & 4.2 & 3.6561 & TST \\
\hline CHEMBL1989646 & 809271 & 4.0 & 4.1108 & TST \\
\hline CHEMBL1682357 & 809271 & 4.0 & 3.9902 & TST \\
\hline CHEMBL225519 & 809271 & 4.2 & 4.3648 & TST \\
\hline CHEMBL 209534 & 809271 & 4.0 & 3.8034 & TST \\
\hline CHEMBL1978200 & 809271 & 4.0 & 4.1394 & TST \\
\hline CHEMBL 2006631 & 809271 & 4.0 & 3.9156 & TST \\
\hline CHEMBL1970522 & 809271 & 4.0 & 3.988 & TST \\
\hline CHEMBL1990415 & 809271 & 4.0 & 3.5386 & TST \\
\hline
\end{tabular}




\begin{tabular}{|c|c|c|c|c|c|}
\hline \multicolumn{6}{|c|}{ Supplemental Table S2.txt } \\
\hline CHEMBL1966087 & 809271 & 4.0 & 3.9227 & TST & \\
\hline CHEMBL1964692 & 809271 & 6.0 & 5.5492 & TST & \\
\hline CHEMBL1996931 & 809271 & 4.0 & 3.7731 & TST & \\
\hline CHEMBL1964413 & 809271 & 4.0 & 4.1168 & TST & \\
\hline CHEMBL1973483 & 809271 & 4.0 & 4.4236 & TST & \\
\hline CHEMBL1984432 & 809271 & 4.0 & 4.0768 & TST & \\
\hline CHEMBL1970735 & 809271 & 4.0 & 3.9627 & TST & \\
\hline CHEMBL 219722 & 809271 & 4.0 & 3.9411 & TST & \\
\hline CHEMBL1997340 & 809271 & 4.0 & 3.9407 & TST & \\
\hline CHEMBL2004365 & 809271 & 4.0 & 3.8803 & TST & \\
\hline CHEMBL1522508 & 809271 & 4.0 & 3.8909 & TST & \\
\hline CHEMBL1086694 & 631548 & 7.7959 & 7.5462 & TRN & \\
\hline CHEMBL1087723 & 631548 & 9.0 & 8.8723 & TRN & \\
\hline CHEMBL1088373 & 631548 & 6.699 & 7.0235 & TRN & \\
\hline CHEMBL1088699 & 631548 & 7.7212 & 7.4035 & TRN & \\
\hline CHEMBL1087722 & 631548 & 7.0 & 6.9926 & TRN & \\
\hline CHEMBL1095472 & 631548 & 7.7447 & 7.4641 & TST & \\
\hline CHEMBL1088545 & 631548 & 8.1549 & 8.1521 & TRN & \\
\hline CHEMBL1087862 & 631548 & 6.6289 & 7.4376 & TRN & \\
\hline CHEMBL1086820 & 631548 & 9.0 & 8.4518 & TRN & \\
\hline CHEMBL1096115 & 631548 & 7.7959 & 7.9708 & TRN & \\
\hline CHEMBL1087468 & 631548 & 8.0969 & 8.4093 & TRN & \\
\hline CHEMBL1087491 & 631548 & 8.3979 & 8.5736 & TRN & \\
\hline CHEMBL1088547 & 631548 & 8.3979 & 8.4639 & TRN & \\
\hline CHEMBL1097179 & 631548 & 7.9208 & 7.6576 & TRN & \\
\hline CHEMBL1088563 & 631548 & 7.9586 & 7.6033 & TRN & \\
\hline CHEMBL1088689 & 631548 & 7.5686 & 7.24799 & 9999999999 & TST \\
\hline CHEMBL1088084 & 631548 & 7.2676 & 7.0329 & TRN & \\
\hline CHEMBL1088688 & 631548 & 6.8861 & 6.7506 & TRN & \\
\hline CHEMBL1087983 & 631548 & 6.0969 & 6.4224 & TRN & \\
\hline CHEMBL478146 & 631548 & 7.4437 & 7.068 & TST & \\
\hline CHEMBL1088366 & 631548 & 9.0 & 8.5564 & TST & \\
\hline CHEMBL1086821 & 631548 & 8.699 & 8.7322 & TRN & \\
\hline CHEMBL1098468 & 631548 & 7.2076 & 7.3867 & TRN & \\
\hline CHEMBL1087346 & 631548 & 7.7447 & 8.3043 & TRN & \\
\hline CHEMBL1088227 & 631548 & 9.0 & 9.087 & TRN & \\
\hline CHEMBL1087864 & 631548 & 6.7696 & 6.7932 & TRN & \\
\hline CHEMBL1098469 & 631548 & 5.5528 & 6.03100 & 0000000001 & TRN \\
\hline CHEMBL1086982 & 631548 & 7.7212 & 7.5447 & TRN & \\
\hline CHEMBL1088228 & 631548 & 8.5229 & 8.4956 & TST & \\
\hline CHEMBL1097524 & 631548 & 6.5528 & 6.8064 & TRN & \\
\hline CHEMBL1088698 & 631548 & 7.3188 & 7.5133 & TRN & \\
\hline CHEMBL1088083 & 631548 & 9.0 & 8.7477 & TST & \\
\hline CHEMBL1095471 & 631548 & 7.6576 & 7.9793 & TRN & \\
\hline CHEMBL1097522 & 631548 & 7.8239 & 7.9749 & TRN & \\
\hline CHEMBL1087863 & 631548 & 6.6003 & 6.2675 & TRN & \\
\hline CHEMBL1087344 & 631548 & 6.1192 & 6.3554 & TRN & \\
\hline CHEMBL1088565 & 631548 & 7.9208 & 7.431 & TST & \\
\hline
\end{tabular}


Supplemental Table S2.txt

\begin{tabular}{|c|c|c|c|c|c|}
\hline CHEMBL1096452 & 631548 & 7.3279 & 7.1291 & TRN & \\
\hline CHEMBL1088420 & 631548 & 8.699 & 8.4572 & TRN & \\
\hline CHEMBL1088682 & 631548 & 7.8539 & 8.0184 & TRN & \\
\hline CHEMBL1087854 & 631548 & 7.0969 & 7.4198 & TST & \\
\hline CHEMBL1087450 & 631548 & 8.0969 & 7.6505 & TST & \\
\hline CHEMBL1087492 & 631548 & 8.5229 & 8.5476 & TRN & \\
\hline CHEMBL1087977 & 631548 & 7.699 & 7.6025 & TST & \\
\hline CHEMBL1087490 & 631548 & 8.301 & 8.4445 & TRN & \\
\hline CHEMBL1088546 & 631548 & 8.699 & 8.3481 & TRN & \\
\hline CHEMBL1087853 & 631548 & 7.7212 & 7.728 & TST & \\
\hline CHEMBL1099390 & 631548 & 9.0 & 8.8183 & TRN & \\
\hline CHEMBL1088700 & 631548 & 8.5229 & 8.1152 & TRN & \\
\hline CHEMBL1086851 & 631548 & 8.3979 & 8.1677 & TRN & \\
\hline CHEMBL1097684 & 631548 & 6.7959 & 6.3819 & TRN & \\
\hline CHEMBL1088118 & 631548 & 6.6383 & 6.5482 & TST & \\
\hline CHEMBL1099360 & 631548 & 7.2676 & 7.7388 & TST & \\
\hline CHEMBL1086693 & 631548 & 6.8539 & 6.9937 & TRN & \\
\hline CHEMBL1088350 & 631548 & 8.301 & 8.6809 & TST & \\
\hline CHEMBL1096113 & 631548 & 8.0458 & 8.0719 & TRN & \\
\hline CHEMBL1087345 & 631548 & 7.4202 & 7.2853 & TRN & \\
\hline CHEMBL1087062 & 631548 & 6.4949 & 6.4655 & TRN & \\
\hline CHEMBL1096767 & 631548 & 7.3098 & 7.0459 & TRN & \\
\hline CHEMBL1088687 & 631548 & 6.9208 & 7.2811 & TST & \\
\hline CHEMBL1088351 & 631548 & 8.5229 & 9.0109 & TRN & \\
\hline CHEMBL1087991 & 631548 & 7.7447 & 7.36799 & 9999999999 & TRN \\
\hline CHEMBL1095470 & 631548 & 6.8861 & 6.9585 & TRN & \\
\hline CHEMBL1087716 & 631548 & 6.3098 & 7.1263 & TST & \\
\hline CHEMBL1096114 & 631548 & 6.9586 & 7.0448 & TST & \\
\hline CHEMBL1088564 & 631548 & 8.699 & 8.5991 & TRN & \\
\hline CHEMBL1097523 & 631548 & 7.1675 & 7.0843 & TRN & \\
\hline CHEMBL 2035948 & 822045 & 4.5965 & 4.3342 & TRN & \\
\hline CHEMBL 2036348 & 822045 & 4.9658 & 5.0893 & TRN & \\
\hline CHEMBL387599 & 822045 & 5.015 & 5.2604 & TRN & \\
\hline CHEMBL477256 & 822045 & 4.9821 & 5.0123 & TRN & \\
\hline CHEMBL2036347 & 822045 & 4.555 & 4.3399 & TRN & \\
\hline CHEMBL475523 & 822045 & 4.9122 & 5.078 & TRN & \\
\hline CHEMBL493001 & 822045 & 5.6517 & 5.5828 & TRN & \\
\hline CHEMBL496321 & 822045 & 4.8514 & 4.966 & TST & \\
\hline CHEMBL129073 & 822045 & 4.8742 & 4.9104 & TRN & \\
\hline CHEMBL17212 & 822045 & 5.8861 & 5.5094 & TST & \\
\hline CHEMBL485636 & 822045 & 4.8636 & 4.8456 & TRN & \\
\hline CHEMBL 2036332 & 822045 & 5.7645 & 5.9656 & TRN & \\
\hline CHEMBL598461 & 822045 & 5.0353 & 5.3312 & TST & \\
\hline CHEMBL512585 & 822045 & 5.4283 & 5.5177 & TRN & \\
\hline CHEMBL2036328 & 822045 & 5.6861 & 5.7393 & TRN & \\
\hline CHEMBL 2036333 & 822045 & 5.5735 & 5.7471 & TST & \\
\hline CHEMBL 2036346 & 822045 & 4.76 & 4.7926 & TRN & \\
\hline CHEMBL482409 & 822045 & 4.8791 & 4.5597 & TRN & \\
\hline
\end{tabular}




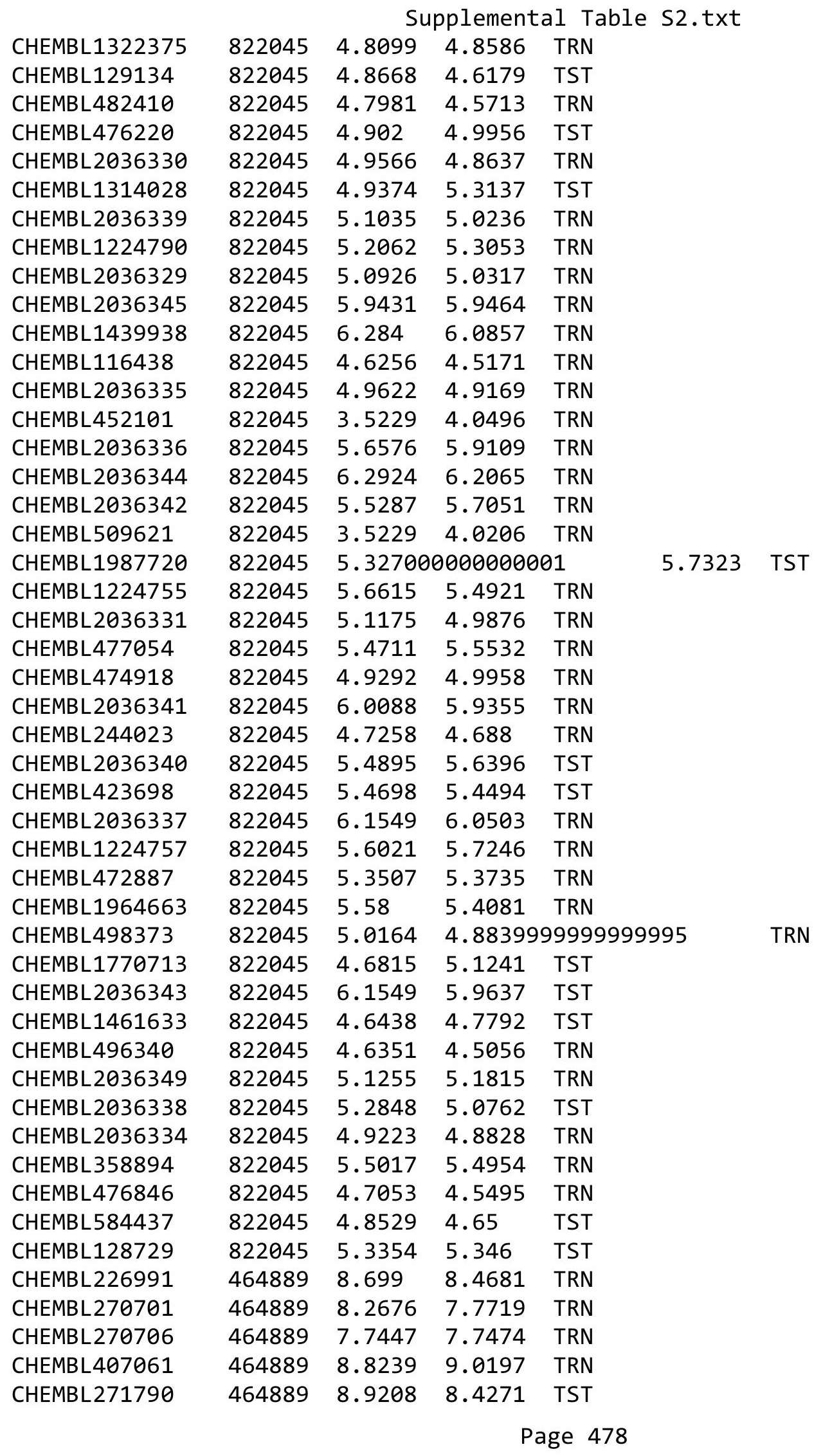




\begin{tabular}{|c|c|c|c|c|c|}
\hline \multicolumn{6}{|c|}{ Supplemental Table S2.txt } \\
\hline CHEMBL405880 & 464889 & 9.2518 & 8.8779 & TRN & \\
\hline CHEMBL407546 & 464889 & 8.3979 & 8.4444 & TRN & \\
\hline CHEMBL270916 & 464889 & 8.301 & 7.7665 & TRN & \\
\hline CHEMBL226990 & 464889 & 8.4685 & 8.4566 & TRN & \\
\hline CHEMBL412118 & 464889 & 8.0458 & 7.7407 & TRN & \\
\hline CHEMBL271788 & 464889 & 7.2676 & 8.0944 & TRN & \\
\hline CHEMBL220770 & 464889 & 9.3979 & 8.0123 & TST & \\
\hline CHEMBL279796 & 464889 & 8.5229 & 8.2761 & TRN & \\
\hline CHEMBL412111 & 464889 & 7.4815 & 7.4559 & TRN & \\
\hline CHEMBL408029 & 464889 & 8.0969 & 8.1831 & TRN & \\
\hline CHEMBL427424 & 464889 & 8.8861 & 8.8456 & TRN & \\
\hline CHEMBL272111 & 464889 & 9.699 & 9.5296 & TRN & \\
\hline CHEMBL269857 & 464889 & 8.4559 & 8.6145 & TRN & \\
\hline CHEMBL271325 & 464889 & 6.8239 & 6.8277 & TRN & \\
\hline CHEMBL272463 & 464889 & 8.8861 & 8.5085 & TRN & \\
\hline CHEMBL260535 & 464889 & 8.2147 & 7.773 & TRN & \\
\hline CHEMBL271209 & 464889 & 7.5086 & 7.4226 & TRN & \\
\hline CHEMBL271789 & 464889 & 7.1871 & 7.2918 & TRN & \\
\hline CHEMBL272228 & 464889 & 7.3872 & 7.3874 & TRN & \\
\hline CHEMBL270267 & 464889 & 4.5229 & 4.8565 & TRN & \\
\hline CHEMBL270108 & 464889 & 8.1805 & 8.0796 & TRN & \\
\hline CHEMBL411042 & 464889 & 7.8861 & 8.3142 & TRN & \\
\hline CHEMBL412117 & 464889 & 7.4949 & 6.7898 & TST & \\
\hline CHEMBL272257 & 464889 & 4.699 & 4.2965 & TRN & \\
\hline CHEMBL272038 & 464889 & 9.0969 & 8.9418 & TRN & \\
\hline CHEMBL405604 & 464889 & 9.0969 & 8.9823 & TRN & \\
\hline CHEMBL220729 & 464889 & 7.5229 & 6.1914 & TST & \\
\hline CHEMBL271389 & 464889 & 7.6576 & 7.8503 & TRN & \\
\hline CHEMBL272428 & 464889 & 8.3468 & 8.5127 & TRN & \\
\hline CHEMBL260745 & 464889 & 7.3565 & 7.6041 & TRN & \\
\hline CHEMBL271530 & 464889 & 8.6383 & 8.5599 & TRN & \\
\hline CHEMBL410301 & 464889 & 5.9208 & 6.7904 & TRN & \\
\hline CHEMBL415102 & 464889 & 8.0 & 7.9076 & TRN & \\
\hline CHEMBL407714 & 464889 & 7.8539 & 7.9377 & TRN & \\
\hline CHEMBL270720 & 464889 & 8.699 & 8.7737 & TRN & \\
\hline CHEMBL271383 & 464889 & 7.6021 & 7.1837 & TST & \\
\hline CHEMBL270487 & 464889 & 8.9208 & 8.7816 & TRN & \\
\hline CHEMBL271791 & 464889 & 5.1549 & 5.2812 & TRN & \\
\hline CHEMBL271792 & 464889 & 8.699 & 8.5369 & TRN & \\
\hline CHEMBL411071 & 464889 & 8.5376 & 8.7895 & TRN & \\
\hline CHEMBL272829 & 464889 & 8.3979 & 8.3843 & TRN & \\
\hline CHEMBL272462 & 464889 & 8.9208 & 8.6402 & TRN & \\
\hline CHEMBL260747 & 464889 & 7.6576 & 7.71899 & 9999999999 & TRN \\
\hline CHEMBL260746 & 464889 & 8.6576 & 8.5927 & TRN & \\
\hline CHEMBL271380 & 464889 & 8.0 & 7.9571 & TRN & \\
\hline CHEMBL272831 & 464889 & 8.5229 & 8.5851 & TST & \\
\hline CHEMBL271390 & 464889 & 8.7959 & 8.92799 & 9999999999 & TRN \\
\hline CHEMBL405823 & 464889 & 8.4437 & 8.4202 & TRN & \\
\hline
\end{tabular}




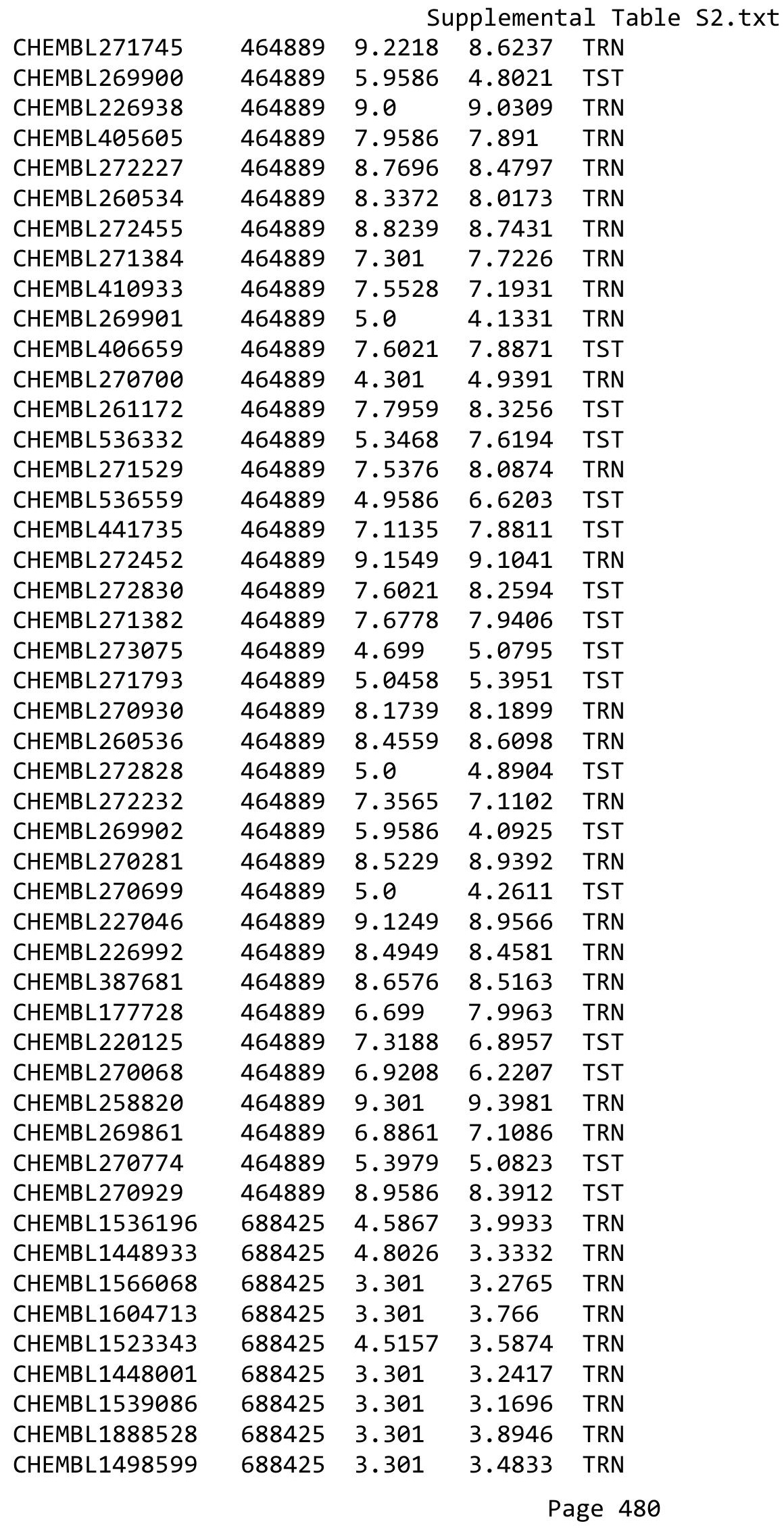




\begin{tabular}{|c|c|c|c|c|c|}
\hline \multirow[b]{2}{*}{ CHEMBL1305911 } & \multicolumn{5}{|c|}{ Supplemental Table S2.txt } \\
\hline & 688425 & 4.4178 & 3.7613 & TRN & \\
\hline CHEMBL1712384 & 688425 & 3.301 & 4.2519 & TRN & \\
\hline CHEMBL1570062 & 688425 & 3.301 & 3.9279 & TRN & \\
\hline CHEMBL1400512 & 688425 & 3.301 & 4.1268 & TRN & \\
\hline CHEMBL 3207983 & 688425 & 3.301 & 3.4638 & TRN & \\
\hline CHEMBL1429429 & 688425 & 3.301 & 3.6669 & TRN & \\
\hline CHEMBL1569711 & 688425 & 5.0137 & 4.4224 & TRN & \\
\hline CHEMBL1598807 & 688425 & 3.301 & 3.4794 & TRN & \\
\hline CHEMBL1418174 & 688425 & 3.301 & 3.6551 & TRN & \\
\hline CHEMBL1576587 & 688425 & 3.301 & 3.5755 & TRN & \\
\hline CHEMBL560919 & 688425 & 4.5287 & 4.2224 & TRN & \\
\hline CHEMBL3195409 & 688425 & 4.7918 & 3.8626 & TRN & \\
\hline CHEMBL527586 & 688425 & 4.9402 & 3.6938 & TRN & \\
\hline CHEMBL1598842 & 688425 & 3.301 & 3.7911 & TRN & \\
\hline CHEMBL3199050 & 688425 & 5.5674 & 4.4295 & TRN & \\
\hline CHEMBL1542862 & 688425 & 3.301 & 4.137 & TRN & \\
\hline CHEMBL1427991 & 688425 & 3.301 & 4.1343 & TST & \\
\hline CHEMBL1424046 & 688425 & 3.301 & 3.5257 & TST & \\
\hline CHEMBL1432873 & 688425 & 3.301 & 3.708 & TST & \\
\hline CHEMBL1352170 & 688425 & 3.301 & 4.1325 & TRN & \\
\hline CHEMBL1318817 & 688425 & 5.2051 & 3.9343 & TRN & \\
\hline CHEMBL1470492 & 688425 & 4.6982 & 3.7724 & TRN & \\
\hline CHEMBL3198910 & 688425 & 3.301 & 4.2057 & TRN & \\
\hline CHEMBL1335945 & 688425 & 5.8468 & 4.1865 & TRN & \\
\hline CHEMBL1309385 & 688425 & 3.301 & 2.9825 & TRN & \\
\hline CHEMBL1352532 & 688425 & 3.301 & 3.8367 & TRN & \\
\hline CHEMBL1708334 & 688425 & 3.301 & 4.205 & TRN & \\
\hline CHEMBL1478652 & 688425 & 4.927 & 4.0665 & TST & \\
\hline CHEMBL1605248 & 688425 & 3.301 & 3.6298 & TRN & \\
\hline CHEMBL1589385 & 688425 & 3.301 & 3.8788 & TST & \\
\hline CHEMBL1478825 & 688425 & 3.301 & 3.3374 & TRN & \\
\hline CHEMBL1479889 & 688425 & 3.301 & 3.2928 & TRN & \\
\hline CHEMBL1426008 & 688425 & 3.301 & 3.4957 & TRN & \\
\hline CHEMBL1499248 & 688425 & 3.301 & 3.4514 & TST & \\
\hline CHEMBL3191022 & 688425 & 5.0723 & 3.6448 & TRN & \\
\hline CHEMBL602969 & 688425 & 4.8622 & 4.1852 & TRN & \\
\hline CHEMBL1603187 & 688425 & 3.301 & 3.4436 & TRN & \\
\hline CHEMBL1487717 & 688425 & 3.301 & 3.3078 & TRN & \\
\hline CHEMBL3195599 & 688425 & 4.4212 & 4.0321 & TRN & \\
\hline CHEMBL1527982 & 688425 & 3.301 & 3.4186 & TRN & \\
\hline CHEMBL1327816 & 688425 & 5.0459 & 4.328 & TRN & \\
\hline CHEMBL1538023 & 688425 & 3.301 & 3.8854 & TST & \\
\hline CHEMBL1437928 & 688425 & 4.5793 & 3.5896 & TST & \\
\hline CHEMBL1978279 & 688425 & 7.4078 & 4.1257 & TRN & \\
\hline CHEMBL1381074 & 688425 & 3.301 & 3.86800 & 00000000003 & TRN \\
\hline CHEMBL1372470 & 688425 & 3.301 & 3.2965 & TRN & \\
\hline CHEMBL1587842 & 688425 & 4.5007 & 4.1677 & TRN & \\
\hline CHEMBL3189151 & 688425 & 4.5394 & 3.6003 & TRN & \\
\hline
\end{tabular}




\begin{tabular}{|c|c|c|c|c|c|}
\hline & & \multicolumn{4}{|c|}{ Supplemental Table S2.txt } \\
\hline CHEMBL1321528 & 688425 & 3.301 & 3.5176 & TRN & \\
\hline CHEMBL1501913 & 688425 & 4.8788 & 4.1568 & TRN & \\
\hline CHEMBL1470275 & 688425 & 3.301 & 3.8894 & TRN & \\
\hline CHEMBL1348144 & 688425 & 3.301 & 4.2324 & TRN & \\
\hline CHEMBL1308037 & 688425 & 3.301 & 3.4396 & TRN & \\
\hline CHEMBL1306267 & 688425 & 4.716 & 3.85399 & 99999999996 & TRN \\
\hline CHEMBL1544763 & 688425 & 3.301 & 3.5775 & TST & \\
\hline CHEMBL1453636 & 688425 & 5.1832 & 3.761 & TRN & \\
\hline CHEMBL1306885 & 688425 & 3.301 & 3.7389 & TRN & \\
\hline CHEMBL1556634 & 688425 & 5.1979 & 4.1133 & TRN & \\
\hline CHEMBL1322563 & 688425 & 3.301 & 3.3895 & TRN & \\
\hline CHEMBL1995112 & 688425 & 5.3486 & 3.9853 & TRN & \\
\hline CHEMBL1345952 & 688425 & 3.301 & 3.9231 & TST & \\
\hline CHEMBL1486131 & 688425 & 3.301 & 4.0667 & TST & \\
\hline CHEMBL1482724 & 688425 & 3.301 & 3.8061 & TRN & \\
\hline CHEMBL1597427 & 688425 & 5.0501 & 3.2493 & TRN & \\
\hline CHEMBL1508761 & 688425 & 3.301 & 3.9366 & TST & \\
\hline CHEMBL1984001 & 688425 & 4.9502 & 4.3417 & TRN & \\
\hline CHEMBL3199447 & 688425 & 3.301 & 3.8855 & TRN & \\
\hline CHEMBL3213857 & 688425 & 3.301 & 3.7633 & TRN & \\
\hline CHEMBL1408056 & 688425 & 3.301 & 4.0715 & TRN & \\
\hline CHEMBL1309254 & 688425 & 3.301 & 3.7544 & TRN & \\
\hline CHEMBL1495170 & 688425 & 3.301 & 3.5549 & TRN & \\
\hline CHEMBL534743 & 688425 & 3.301 & 3.3289 & TRN & \\
\hline CHEMBL1571034 & 688425 & 3.301 & 3.7695 & TRN & \\
\hline CHEMBL1602775 & 688425 & 3.301 & 3.4633 & TST & \\
\hline CHEMBL1422034 & 688425 & 3.301 & 3.4822 & TRN & \\
\hline CHEMBL1507036 & 688425 & 3.301 & 3.5375 & TRN & \\
\hline CHEMBL3193400 & 688425 & 4.6266 & 3.7833 & TRN & \\
\hline CHEMBL1535503 & 688425 & 3.301 & 3.4727 & TRN & \\
\hline CHEMBL1387155 & 688425 & 3.301 & 4.0014 & TRN & \\
\hline CHEMBL 2006628 & 688425 & 3.301 & 3.43399 & 99999999997 & TRN \\
\hline CHEMBL1417815 & 688425 & 3.301 & 3.35 & TRN & \\
\hline CHEMBL1566565 & 688425 & 3.301 & 3.5343 & TRN & \\
\hline CHEMBL1451327 & 688425 & 3.301 & 3.6676 & TST & \\
\hline CHEMBL1391552 & 688425 & 4.3714 & 4.3076 & TRN & \\
\hline CHEMBL3209299 & 688425 & 3.301 & 4.0345 & TRN & \\
\hline CHEMBL1417099 & 688425 & 3.301 & 4.1434 & TST & \\
\hline CHEMBL3193771 & 688425 & 4.5965 & 4.0916 & TRN & \\
\hline CHEMBL1486827 & 688425 & 5.3286 & 4.2506 & TRN & \\
\hline CHEMBL1610056 & 688425 & 3.301 & 3.2669 & TRN & \\
\hline CHEMBL1398964 & 688425 & 3.301 & 3.7048 & TST & \\
\hline CHEMBL3199336 & 688425 & 3.301 & 3.7728 & TRN & \\
\hline CHEMBL601757 & 688425 & 5.2155 & 3.9978 & TST & \\
\hline CHEMBL1338975 & 688425 & 3.301 & 3.9477 & TRN & \\
\hline CHEMBL1392313 & 688425 & 3.301 & 3.2627 & TRN & \\
\hline CHEMBL1443946 & 688425 & 3.301 & 4.0479 & TRN & \\
\hline CHEMBL1461082 & 688425 & 3.301 & 3.8226 & TRN & \\
\hline
\end{tabular}




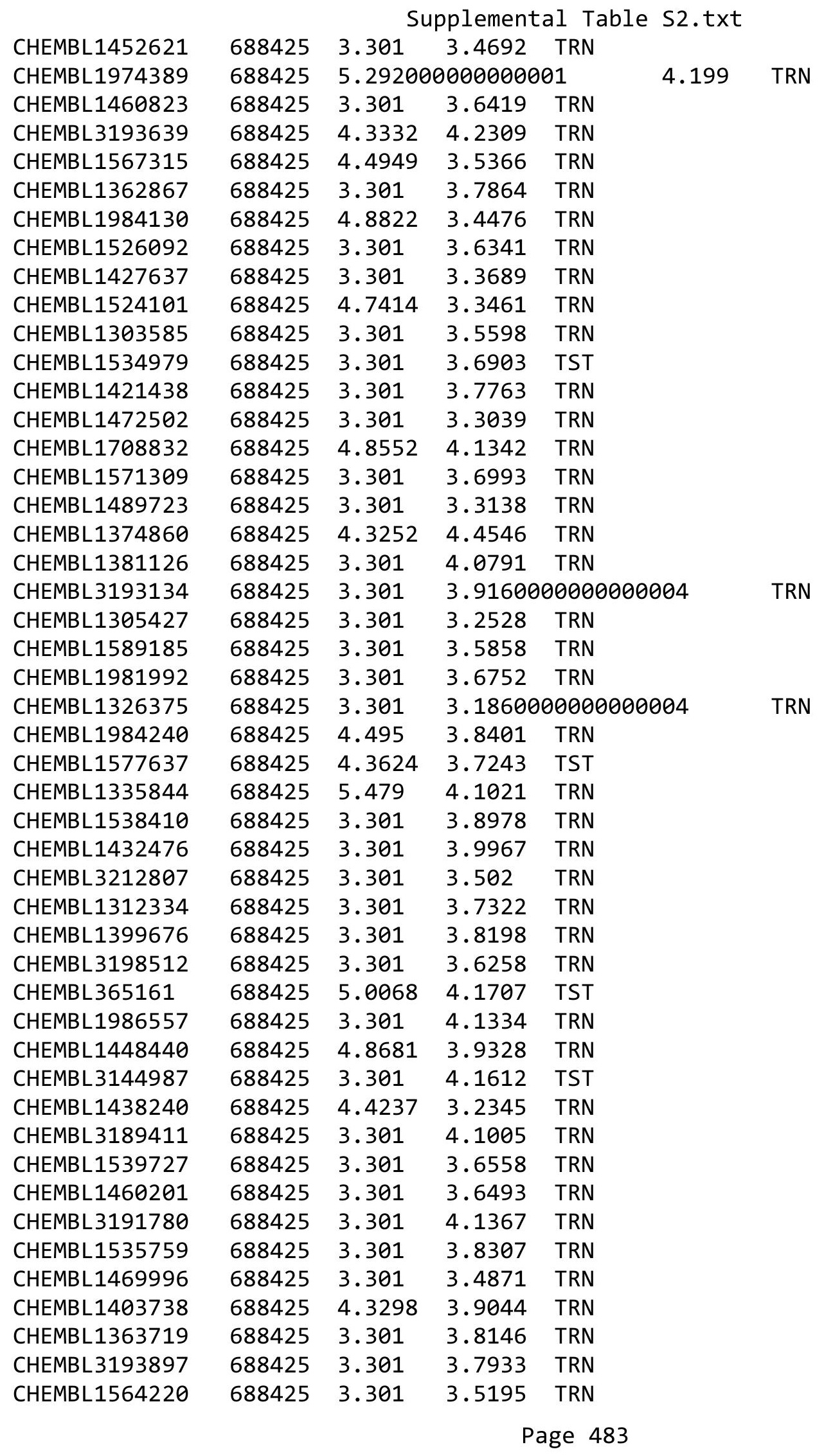




\begin{tabular}{|c|c|c|c|c|}
\hline & & & oplement & al $\mathrm{Tc}$ \\
\hline CHEMBL1566853 & 688425 & 3.301 & 3.3734 & TRN \\
\hline CHEMBL1376590 & 688425 & 3.301 & 3.6165 & TRN \\
\hline CHEMBL1546522 & 688425 & 4.7675 & 3.8422 & TST \\
\hline CHEMBL1256360 & 688425 & 3.301 & 3.8134 & TRN \\
\hline CHEMBL3210264 & 688425 & 3.301 & 3.6308 & TRN \\
\hline CHEMBL2007180 & 688425 & 4.5891 & 4.3142 & TRN \\
\hline CHEMBL3192605 & 688425 & 3.301 & 3.9887 & TRN \\
\hline CHEMBL3195721 & 688425 & 3.301 & 3.7007 & TST \\
\hline CHEMBL1505060 & 688425 & 4.973 & 3.7852 & TRN \\
\hline CHEMBL1461753 & 688425 & 3.301 & 3.4983 & TRN \\
\hline CHEMBL3212969 & 688425 & 3.301 & 3.885 & TRN \\
\hline CHEMBL 3192400 & 688425 & 5.2709 & 3.8844 & TRN \\
\hline CHEMBL1400481 & 688425 & 5.1259 & 4.0663 & TRN \\
\hline CHEMBL1340417 & 688425 & 4.4026 & 4.0117 & TRN \\
\hline CHEMBL 3197141 & 688425 & 3.301 & 4.066 & TRN \\
\hline CHEMBL1329824 & 688425 & 3.301 & 3.3331 & TRN \\
\hline CHEMBL1531364 & 688425 & 3.301 & 3.5923 & TRN \\
\hline CHEMBL1560740 & 688425 & 3.301 & 3.1905 & TRN \\
\hline CHEMBL1572585 & 688425 & 3.301 & 3.2487 & TRN \\
\hline CHEMBL1460155 & 688425 & 3.301 & 3.7898 & TRN \\
\hline CHEMBL1340713 & 688425 & 3.301 & 3.699 & TST \\
\hline CHEMBL1464193 & 688425 & 3.301 & 3.3722 & TRN \\
\hline CHEMBL1409308 & 688425 & 3.301 & 3.9664 & TRN \\
\hline CHEMBL1549128 & 688425 & 3.301 & 3.8111 & TST \\
\hline CHEMBL3193011 & 688425 & 3.301 & 3.4729 & TRN \\
\hline CHEMBL1482010 & 688425 & 3.301 & 3.3316 & TRN \\
\hline CHEMBL1364630 & 688425 & 3.301 & 3.5606 & TRN \\
\hline CHEMBL1567571 & 688425 & 5.5039 & 4.242 & TRN \\
\hline CHEMBL1991736 & 688425 & 3.301 & 4.0631 & TRN \\
\hline CHEMBL1404245 & 688425 & 3.301 & 3.6201 & TRN \\
\hline CHEMBL1372853 & 688425 & 3.301 & 3.4113 & TRN \\
\hline CHEMBL1463829 & 688425 & 3.301 & 3.3561 & TRN \\
\hline CHEMBL1502929 & 688425 & 3.301 & 3.5808 & TRN \\
\hline CHEMBL1494100 & 688425 & 3.301 & 3.5071 & TRN \\
\hline CHEMBL1318943 & 688425 & 4.3166 & 3.8433 & TRN \\
\hline CHEMBL233347 & 688425 & 4.4034 & 3.6496 & TRN \\
\hline CHEMBL608699 & 688425 & 4.7499 & 4.1786 & TRN \\
\hline CHEMBL1336673 & 688425 & 3.301 & 3.6635 & TRN \\
\hline CHEMBL1596931 & 688425 & 5.0136 & 3.6617 & TRN \\
\hline CHEMBL1376784 & 688425 & 3.301 & 3.9768 & TRN \\
\hline CHEMBL1606583 & 688425 & 3.301 & 3.9239 & TRN \\
\hline CHEMBL1598538 & 688425 & 3.301 & 3.574 & TRN \\
\hline CHEMBL3191602 & 688425 & 3.301 & 3.7789 & TRN \\
\hline CHEMBL1326955 & 688425 & 3.301 & 3.7219 & TRN \\
\hline CHEMBL1587145 & 688425 & 3.301 & 3.7027 & TRN \\
\hline CHEMBL1373741 & 688425 & 3.301 & 3.1257 & TRN \\
\hline CHEMBL1304584 & 688425 & 4.4814 & 3.6755 & TRN \\
\hline CHEMBL1378966 & 688425 & 3.301 & 3.9116 & TRN \\
\hline
\end{tabular}




\begin{tabular}{|c|c|c|c|c|c|}
\hline & & \multicolumn{4}{|c|}{ Supplemental Table S2.txt } \\
\hline CHEMBL1413305 & 688425 & 3.301 & 4.0004 & TRN & \\
\hline CHEMBL1984894 & 688425 & 3.301 & 3.867 & TRN & \\
\hline CHEMBL1348194 & 688425 & 4.6106 & 3.7655 & TST & \\
\hline CHEMBL3193349 & 688425 & 3.301 & 4.1357 & TRN & \\
\hline CHEMBL1313485 & 688425 & 4.7113 & 3.9164 & TRN & \\
\hline CHEMBL1506757 & 688425 & 3.301 & 3.45600 & 00000000004 & TRN \\
\hline CHEMBL1385611 & 688425 & 3.301 & 3.7762 & TRN & \\
\hline CHEMBL1335505 & 688425 & 3.301 & 3.3474 & TRN & \\
\hline CHEMBL1569541 & 688425 & 3.301 & 4.1059 & TST & \\
\hline CHEMBL1309256 & 688425 & 3.301 & 3.9186 & TST & \\
\hline CHEMBL1568805 & 688425 & 3.301 & 4.0813 & TRN & \\
\hline CHEMBL3189217 & 688425 & 5.2193 & 4.3515 & TRN & \\
\hline CHEMBL 244743 & 688425 & 3.301 & 4.0687 & TRN & \\
\hline CHEMBL1498370 & 688425 & 3.301 & 3.84800 & 00000000003 & TRN \\
\hline CHEMBL1494497 & 688425 & 3.301 & 3.4513 & TST & \\
\hline CHEMBL1578230 & 688425 & 3.301 & 3.7288 & TRN & \\
\hline CHEMBL1557987 & 688425 & 3.301 & 3.1005 & TRN & \\
\hline CHEMBL1380131 & 688425 & 3.301 & 3.3621 & TRN & \\
\hline CHEMBL1543965 & 688425 & 3.301 & 3.8864 & TST & \\
\hline CHEMBL1444986 & 688425 & 3.301 & 3.2807 & TRN & \\
\hline CHEMBL1499778 & 688425 & 3.301 & 3.9909 & TRN & \\
\hline CHEMBL591126 & 688425 & 4.8229 & 3.7762 & TRN & \\
\hline CHEMBL1441066 & 688425 & 3.301 & 3.5364 & TRN & \\
\hline CHEMBL1563766 & 688425 & 4.9291 & 3.6656 & TRN & \\
\hline CHEMBL1400414 & 688425 & 3.301 & 3.1647 & TRN & \\
\hline CHEMBL3190263 & 688425 & 3.301 & 3.6568 & TRN & \\
\hline CHEMBL3196993 & 688425 & 5.0486 & 3.6941 & TRN & \\
\hline CHEMBL1970371 & 688425 & 3.301 & 4.1465 & TRN & \\
\hline CHEMBL1991599 & 688425 & 4.9856 & 4.0959 & TRN & \\
\hline CHEMBL1427539 & 688425 & 3.301 & 3.5208 & TRN & \\
\hline CHEMBL1350308 & 688425 & 5.0642 & 3.8259 & TST & \\
\hline CHEMBL 3189845 & 688425 & 3.301 & 3.6732 & TRN & \\
\hline CHEMBL1973669 & 688425 & 3.301 & 3.6563 & TRN & \\
\hline CHEMBL1311100 & 688425 & 3.301 & 3.6787 & TRN & \\
\hline CHEMBL1331562 & 688425 & 5.2675 & 3.7909 & TRN & \\
\hline CHEMBL1332626 & 688425 & 3.301 & 3.7005 & TRN & \\
\hline CHEMBL1417290 & 688425 & 4.8978 & 3.7384 & TRN & \\
\hline CHEMBL1416036 & 688425 & 3.301 & 3.3324 & TRN & \\
\hline CHEMBL1497287 & 688425 & 4.5478 & 4.0308 & TRN & \\
\hline CHEMBL1457747 & 688425 & 3.301 & 3.5291 & TRN & \\
\hline CHEMBL1385343 & 688425 & 5.309 & 4.1415 & TST & \\
\hline CHEMBL1411897 & 688425 & 4.5971 & 3.9433 & TST & \\
\hline CHEMBL1872457 & 688425 & 3.301 & 3.6217 & TRN & \\
\hline CHEMBL1528135 & 688425 & 3.301 & 3.5046 & TRN & \\
\hline CHEMBL1412013 & 688425 & 3.301 & 4.1029 & TRN & \\
\hline CHEMBL1427219 & 688425 & 3.301 & 3.2571 & TRN & \\
\hline CHEMBL1347697 & 688425 & 3.301 & 3.7823 & TRN & \\
\hline CHEMBL1398645 & 688425 & 3.301 & 3.9118 & TST & \\
\hline
\end{tabular}




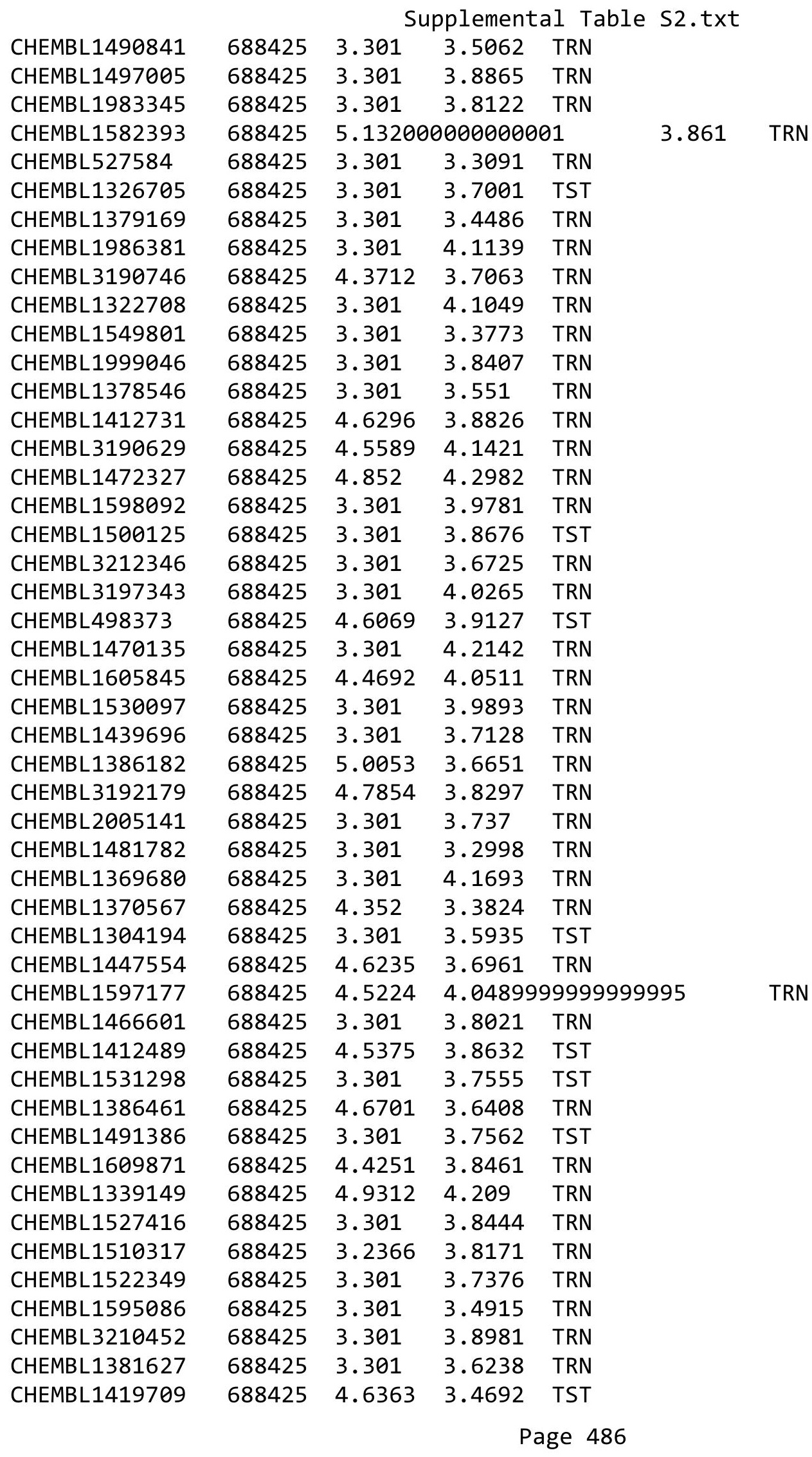




\begin{tabular}{|c|c|c|c|c|c|c|}
\hline & & \multicolumn{5}{|c|}{ Supplemental Table S2.txt } \\
\hline CHEMBL1968355 & 688425 & 4.5399 & 4.0203 & TRN & & \\
\hline CHEMBL1471010 & 688425 & 3.301 & 3.5237 & TRN & & \\
\hline CHEMBL3192675 & 688425 & 3.301 & 4.3841 & TRN & & \\
\hline CHEMBL1324142 & 688425 & 3.301 & 3.6722 & TRN & & \\
\hline CHEMBL1324566 & 688425 & 3.301 & 4.0833 & TRN & & \\
\hline CHEMBL1390840 & 688425 & \multicolumn{3}{|c|}{5.9110000000000005} & 4.1514 & TRN \\
\hline CHEMBL1424358 & 688425 & 3.301 & 3.4586 & TRN & & \\
\hline CHEMBL1521297 & 688425 & 3.301 & 4.1751 & TRN & & \\
\hline CHEMBL1422188 & 688425 & 3.301 & 3.2532 & TRN & & \\
\hline CHEMBL1403339 & 688425 & 3.301 & 3.4664 & TRN & & \\
\hline CHEMBL1564403 & 688425 & 3.301 & 3.6899 & TRN & & \\
\hline CHEMBL 3191525 & 688425 & 4.8872 & 3.8311 & TRN & & \\
\hline CHEMBL1586256 & 688425 & 3.301 & 3.6476 & TRN & & \\
\hline CHEMBL1377923 & 688425 & 3.301 & 3.72 & TRN & & \\
\hline CHEMBL1442714 & 688425 & 3.301 & 3.8831 & TRN & & \\
\hline CHEMBL1542574 & 688425 & 3.301 & 3.4762 & TRN & & \\
\hline CHEMBL604321 & 688425 & 3.301 & 3.705 & TRN & & \\
\hline CHEMBL1392651 & 688425 & 5.6776 & 4.2551 & TRN & & \\
\hline CHEMBL1416798 & 688425 & 3.301 & 3.5523 & TRN & & \\
\hline CHEMBL1556680 & 688425 & 3.301 & 3.6829 & TRN & & \\
\hline CHEMBL1327549 & 688425 & 3.301 & 3.8986 & TST & & \\
\hline CHEMBL1712181 & 688425 & 3.301 & 3.8349 & TST & & \\
\hline CHEMBL1378294 & 688425 & 3.301 & 4.0504 & TRN & & \\
\hline CHEMBL522983 & 688425 & 4.5091 & 3.8713 & TST & & \\
\hline CHEMBL1481390 & 688425 & 3.301 & 3.8381 & TRN & & \\
\hline CHEMBL3195211 & 688425 & 3.301 & 4.1616 & TRN & & \\
\hline CHEMBL1565964 & 688425 & 3.301 & 3.8493 & TST & & \\
\hline CHEMBL1559622 & 688425 & 4.9392 & 3.9877 & TRN & & \\
\hline CHEMBL 2006418 & 688425 & 3.301 & 3.6884 & TRN & & \\
\hline CHEMBL1382262 & 688425 & 3.301 & 3.5873 & TRN & & \\
\hline CHEMBL1510959 & 688425 & 3.301 & 3.1502 & TRN & & \\
\hline CHEMBL 3191285 & 688425 & 3.301 & 3.4822 & TST & & \\
\hline CHEMBL1443791 & 688425 & 3.301 & 3.7439 & TRN & & \\
\hline CHEMBL1453230 & 688425 & 3.301 & 3.3206 & TRN & & \\
\hline CHEMBL3212159 & 688425 & 3.301 & 3.3157 & TRN & & \\
\hline CHEMBL1489861 & 688425 & 3.301 & 3.3011 & TRN & & \\
\hline CHEMBL1609927 & 688425 & 3.301 & 3.4142 & TRN & & \\
\hline CHEMBL 3208842 & 688425 & 3.301 & 3.9856 & TRN & & \\
\hline CHEMBL 3198784 & 688425 & 3.301 & 4.0294 & TRN & & \\
\hline CHEMBL 3199870 & 688425 & 4.8062 & 3.8452 & TRN & & \\
\hline CHEMBL1530090 & 688425 & 3.301 & 3.4016 & TRN & & \\
\hline CHEMBL1423690 & 688425 & 3.301 & 3.9514 & TRN & & \\
\hline CHEMBL1341842 & 688425 & 4.5893 & 3.8609 & TRN & & \\
\hline CHEMBL1504661 & 688425 & 4.5607 & 3.7647 & TRN & & \\
\hline CHEMBL1490628 & 688425 & 3.301 & 3.9624 & TRN & & \\
\hline CHEMBL1301204 & 688425 & 3.301 & 3.3059 & TST & & \\
\hline CHEMBL1311175 & 688425 & 3.301 & 3.9051 & TRN & & \\
\hline CHEMBL3198618 & 688425 & 3.301 & 3.6232 & TRN & & \\
\hline
\end{tabular}




\begin{tabular}{|c|c|c|c|c|c|}
\hline & & \multicolumn{4}{|c|}{ Supplemental Table s2.txt } \\
\hline CHEMBL1500690 & 688425 & 3.301 & 4.0779 & TST & \\
\hline CHEMBL 3192276 & 688425 & 3.301 & 3.6925 & TRN & \\
\hline CHEMBL1965471 & 688425 & 3.301 & 3.6384 & TRN & \\
\hline CHEMBL1310318 & 688425 & 5.0481 & 4.1364 & TRN & \\
\hline CHEMBL1306714 & 688425 & 3.301 & 3.3497 & TRN & \\
\hline CHEMBL1993627 & 688425 & 6.0816 & 4.3336 & TRN & \\
\hline CHEMBL1423122 & 688425 & 3.301 & 3.2359 & TRN & \\
\hline CHEMBL 3193835 & 688425 & 3.301 & 4.1578 & TRN & \\
\hline CHEMBL1585645 & 688425 & 3.301 & 3.0404 & TRN & \\
\hline CHEMBL1418971 & 688425 & 3.301 & 3.9423 & TRN & \\
\hline CHEMBL1530670 & 688425 & 4.9077 & 3.8729 & TRN & \\
\hline CHEMBL1459905 & 688425 & 3.301 & 3.6743 & TRN & \\
\hline CHEMBL1321972 & 688425 & 3.301 & 3.7618 & TRN & \\
\hline CHEMBL1506510 & 688425 & \multicolumn{3}{|c|}{4.5089999999999995} & TRN \\
\hline CHEMBL1507982 & 688425 & 3.301 & 4.0977 & TST & \\
\hline CHEMBL1598356 & 688425 & 3.301 & 3.9548 & TRN & \\
\hline CHEMBL1557307 & 688425 & 3.301 & 3.8722 & TRN & \\
\hline CHEMBL1432973 & 688425 & 3.301 & 3.5032 & TRN & \\
\hline CHEMBL 3190407 & 688425 & 4.4132 & 4.3062 & TRN & \\
\hline CHEMBL1413777 & 688425 & 3.301 & 3.5459 & TRN & \\
\hline CHEMBL1587556 & 688425 & 4.4514 & 3.764 & TRN & \\
\hline CHEMBL1588331 & 688425 & 3.301 & 3.5434 & TRN & \\
\hline CHEMBL1495812 & 688425 & 3.301 & 3.6928 & TST & \\
\hline CHEMBL1587382 & 688425 & 3.301 & 3.4788 & TRN & \\
\hline CHEMBL1997951 & 688425 & 3.301 & 3.72399 & 99999999998 & TRN \\
\hline CHEMBL1332857 & 688425 & 3.301 & 3.3343 & TRN & \\
\hline CHEMBL339561 & 688425 & 3.301 & 4.1376 & TRN & \\
\hline CHEMBL1456343 & 688425 & 3.301 & 3.2254 & TRN & \\
\hline CHEMBL1369932 & 688425 & 3.301 & 3.81399 & 99999999996 & TST \\
\hline CHEMBL1465693 & 688425 & 5.147 & 4.0119 & TRN & \\
\hline CHEMBL1370499 & 688425 & 3.301 & 3.1167 & TRN & \\
\hline CHEMBL1322742 & 688425 & 3.301 & 3.5069 & TRN & \\
\hline CHEMBL1609735 & 688425 & 3.301 & 3.1839 & TRN & \\
\hline CHEMBL1406225 & 688425 & 3.301 & 3.6722 & TST & \\
\hline CHEMBL1299989 & 688425 & 4.3347 & 3.7097 & TRN & \\
\hline CHEMBL1373107 & 688425 & 3.301 & 3.4149 & TRN & \\
\hline CHEMBL1410147 & 688425 & 5.8243 & 4.0824 & TRN & \\
\hline CHEMBL1567974 & 688425 & 3.301 & 3.5644 & TRN & \\
\hline CHEMBL1540618 & 688425 & 3.301 & 3.45399 & 99999999997 & TRN \\
\hline CHEMBL1469227 & 688425 & 3.301 & 3.2923 & TRN & \\
\hline CHEMBL1542284 & 688425 & 3.301 & 3.3025 & TRN & \\
\hline CHEMBL1400130 & 688425 & 3.301 & 3.7603 & TST & \\
\hline CHEMBL3190766 & 688425 & 3.301 & 3.8104 & TST & \\
\hline CHEMBL1610701 & 688425 & 3.301 & 3.3082 & TRN & \\
\hline CHEMBL1483809 & 688425 & 3.301 & 3.8752 & TRN & \\
\hline CHEMBL1463647 & 688425 & 3.301 & 3.7673 & TST & \\
\hline CHEMBL 75412 & 688425 & 4.6649 & 3.9931 & TRN & \\
\hline CHEMBL1607035 & 688425 & 4.3598 & 3.375 & TST & \\
\hline
\end{tabular}




\begin{tabular}{|c|c|c|c|c|}
\hline & & & oplement & al $\mathrm{T}$ \\
\hline CHEMBL1510953 & 688425 & 4.3664 & 3.6365 & TRN \\
\hline CHEMBL1343144 & 688425 & 3.301 & 3.2479 & TRN \\
\hline CHEMBL1555771 & 688425 & 3.301 & 3.9069 & TRN \\
\hline CHEMBL1453954 & 688425 & 3.301 & 3.6145 & TST \\
\hline CHEMBL1517746 & 688425 & 3.301 & 3.2885 & TRN \\
\hline CHEMBL1970780 & 688425 & 3.301 & 3.6046 & TRN \\
\hline CHEMBL1479204 & 688425 & 4.8416 & 4.4018 & TRN \\
\hline CHEMBL3190162 & 688425 & 4.633 & 4.0782 & TST \\
\hline CHEMBL1341913 & 688425 & 3.301 & 3.6251 & TST \\
\hline CHEMBL1376622 & 688425 & 3.301 & 3.5117 & TST \\
\hline CHEMBL1547498 & 688425 & 4.4669 & 3.4409 & TST \\
\hline CHEMBL1493396 & 688425 & 3.301 & 4.0738 & TST \\
\hline CHEMBL3212393 & 688425 & 3.301 & 3.9111 & TST \\
\hline CHEMBL1463482 & 688425 & 3.301 & 3.6931 & TST \\
\hline CHEMBL1422691 & 688425 & 4.6998 & 3.7839 & TST \\
\hline CHEMBL1504524 & 688425 & 3.301 & 3.5191 & TST \\
\hline CHEMBL1543548 & 688425 & 3.301 & 3.5512 & TST \\
\hline CHEMBL1346909 & 688425 & 3.301 & 3.8283 & TST \\
\hline CHEMBL99408 & 688425 & 3.301 & 3.8973 & TST \\
\hline CHEMBL51085 & 688425 & 7.4078 & 4.4181 & TST \\
\hline CHEMBL1965172 & 688425 & 3.301 & 3.7534 & TST \\
\hline CHEMBL1451772 & 688425 & 3.301 & 4.1017 & TST \\
\hline CHEMBL1492541 & 688425 & 3.301 & 3.7382 & TST \\
\hline CHEMBL3196407 & 688425 & 4.8306 & 4.034 & TST \\
\hline CHEMBL1890161 & 688425 & 3.301 & 3.545 & TST \\
\hline CHEMBL1341906 & 688425 & 5.189 & 3.7231 & TST \\
\hline CHEMBL3195177 & 688425 & 4.9218 & 3.9889 & TST \\
\hline CHEMBL1311955 & 688425 & 3.301 & 3.5463 & TST \\
\hline CHEMBL1536780 & 688425 & 3.301 & 3.8093 & TST \\
\hline CHEMBL1336959 & 688425 & 4.6566 & 4.3268 & TST \\
\hline CHEMBL3191474 & 688425 & 3.301 & 3.8637 & TST \\
\hline CHEMBL1313583 & 688425 & 3.301 & 3.9285 & TST \\
\hline CHEMBL1348071 & 688425 & 3.301 & 3.5343 & TST \\
\hline CHEMBL3196910 & 688425 & 3.301 & 3.8183 & TST \\
\hline CHEMBL3190974 & 688425 & 3.301 & 3.7469 & TST \\
\hline CHEMBL1979957 & 688425 & 4.623 & 4.008 & TST \\
\hline CHEMBL1600114 & 688425 & 5.1618 & 4.0941 & TST \\
\hline CHEMBL1325945 & 688425 & 4.8798 & 3.8193 & TST \\
\hline CHEMBL1584408 & 688425 & 3.301 & 3.7577 & TST \\
\hline CHEMBL1310221 & 688425 & 3.301 & 3.8781 & TST \\
\hline CHEMBL1596115 & 688425 & 3.301 & 3.6606 & TST \\
\hline CHEMBL1545603 & 688425 & 5.3148 & 4.2485 & TST \\
\hline CHEMBL3191412 & 688425 & 3.301 & 3.8458 & TST \\
\hline CHEMBL1610965 & 688425 & 3.301 & 3.7745 & TST \\
\hline CHEMBL1612425 & 688425 & 3.301 & 3.7708 & TST \\
\hline CHEMBL3195904 & 688425 & 3.301 & 3.4012 & TST \\
\hline CHEMBL1985826 & 688425 & 3.301 & 3.7088 & TST \\
\hline CHEMBL1383025 & 688425 & 4.6407 & 3.9566 & TST \\
\hline
\end{tabular}




\begin{tabular}{|c|c|c|c|c|c|}
\hline \multirow[b]{2}{*}{ CHEMBL 3196377} & \multicolumn{5}{|c|}{ Supplemental Table s2.txt } \\
\hline & 688425 & 3.301 & 3.7657 & TST & \\
\hline CHEMBL3193550 & 688425 & 3.301 & 3.5899 & TST & \\
\hline CHEMBL1471698 & 688425 & 3.301 & 3.9831 & TST & \\
\hline CHEMBL1588123 & 688425 & 3.301 & 3.9986 & TST & \\
\hline CHEMBL1337183 & 688425 & 3.301 & 3.64300 & 00000000002 & TST \\
\hline CHEMBL216973 & 688425 & 3.301 & 3.8986 & TST & \\
\hline CHEMBL1300410 & 688425 & 5.1297 & 4.2341 & TST & \\
\hline CHEMBL1416262 & 688425 & 4.4823 & 3.958 & TST & \\
\hline CHEMBL1966224 & 688425 & 4.9179 & 4.4747 & TST & \\
\hline CHEMBL1421559 & 688425 & 3.301 & 4.14 & TST & \\
\hline CHEMBL1577887 & 688425 & 3.301 & 3.8393 & TST & \\
\hline CHEMBL1455957 & 688425 & 3.301 & 3.8008 & TST & \\
\hline CHEMBL1340299 & 688425 & 3.301 & 4.1643 & TST & \\
\hline CHEMBL1986259 & 688425 & 5.4282 & 4.484 & TST & \\
\hline CHEMBL1557646 & 688425 & 3.301 & 3.2408 & TST & \\
\hline CHEMBL1408319 & 688425 & 3.301 & 3.5153 & TST & \\
\hline CHEMBL3908550 & 1637339 & 6.301 & 6.8064 & TST & \\
\hline CHEMBL3891565 & 1637339 & 7.301 & 7.3133 & TRN & \\
\hline CHEMBL3943130 & 1637339 & 7.301 & 7.3074 & TRN & \\
\hline CHEMBL3935991 & 1637339 & 7.301 & 7.0323 & TRN & \\
\hline CHEMBL3962729 & 1637339 & 6.301 & 7.3462 & TRN & \\
\hline CHEMBL3922352 & 1637339 & 7.301 & 7.6727 & TRN & \\
\hline CHEMBL3936787 & 1637339 & 7.301 & 7.206 & TRN & \\
\hline CHEMBL3979516 & 1637339 & 7.301 & 6.6796 & TRN & \\
\hline CHEMBL3986740 & 1637339 & 4.0 & 6.3614 & TST & \\
\hline CHEMBL3910873 & 1637339 & 7.301 & 6.8155 & TRN & \\
\hline CHEMBL3952133 & 1637339 & 7.301 & 7.5154 & TRN & \\
\hline CHEMBL3914502 & 1637339 & 7.301 & 7.3566 & TRN & \\
\hline CHEMBL3905098 & 1637339 & 7.301 & 6.8925 & TRN & \\
\hline CHEMBL3928728 & 1637339 & 6.301 & 5.8985 & TRN & \\
\hline CHEMBL3930646 & 1637339 & 6.301 & 6.3191 & TRN & \\
\hline CHEMBL3939424 & 1637339 & 6.301 & 5.6524 & TST & \\
\hline CHEMBL3908815 & 1637339 & 7.301 & 7.6161 & TRN & \\
\hline CHEMBL3948319 & 1637339 & 7.301 & 7.2109 & TRN & \\
\hline CHEMBL3939025 & 1637339 & 7.301 & 7.5615 & TRN & \\
\hline CHEMBL3968353 & 1637339 & 7.301 & 7.4375 & TRN & \\
\hline CHEMBL3975762 & 1637339 & 7.301 & 7.3454 & TRN & \\
\hline CHEMBL3957136 & 1637339 & 6.301 & 6.2833 & TRN & \\
\hline CHEMBL3936658 & 1637339 & 7.301 & 7.1994 & TRN & \\
\hline CHEMBL3893292 & 1637339 & 7.301 & 7.129 & TRN & \\
\hline CHEMBL3890524 & 1637339 & 6.301 & 7.0555 & TRN & \\
\hline CHEMBL3959087 & 1637339 & 7.301 & 7.0879 & TRN & \\
\hline CHEMBL3982239 & 1637339 & 7.301 & 6.8634 & TRN & \\
\hline CHEMBL3924083 & 1637339 & 7.301 & 6.9746 & TRN & \\
\hline CHEMBL3948689 & 1637339 & 7.301 & 6.8573 & TRN & \\
\hline CHEMBL3898178 & 1637339 & 7.301 & 7.4346 & TRN & \\
\hline CHEMBL3893649 & 1637339 & 4.0 & 6.2387 & TST & \\
\hline CHEMBL3977291 & 1637339 & 6.301 & 6.0144 & TST & \\
\hline
\end{tabular}


Supplemental Table S2.txt

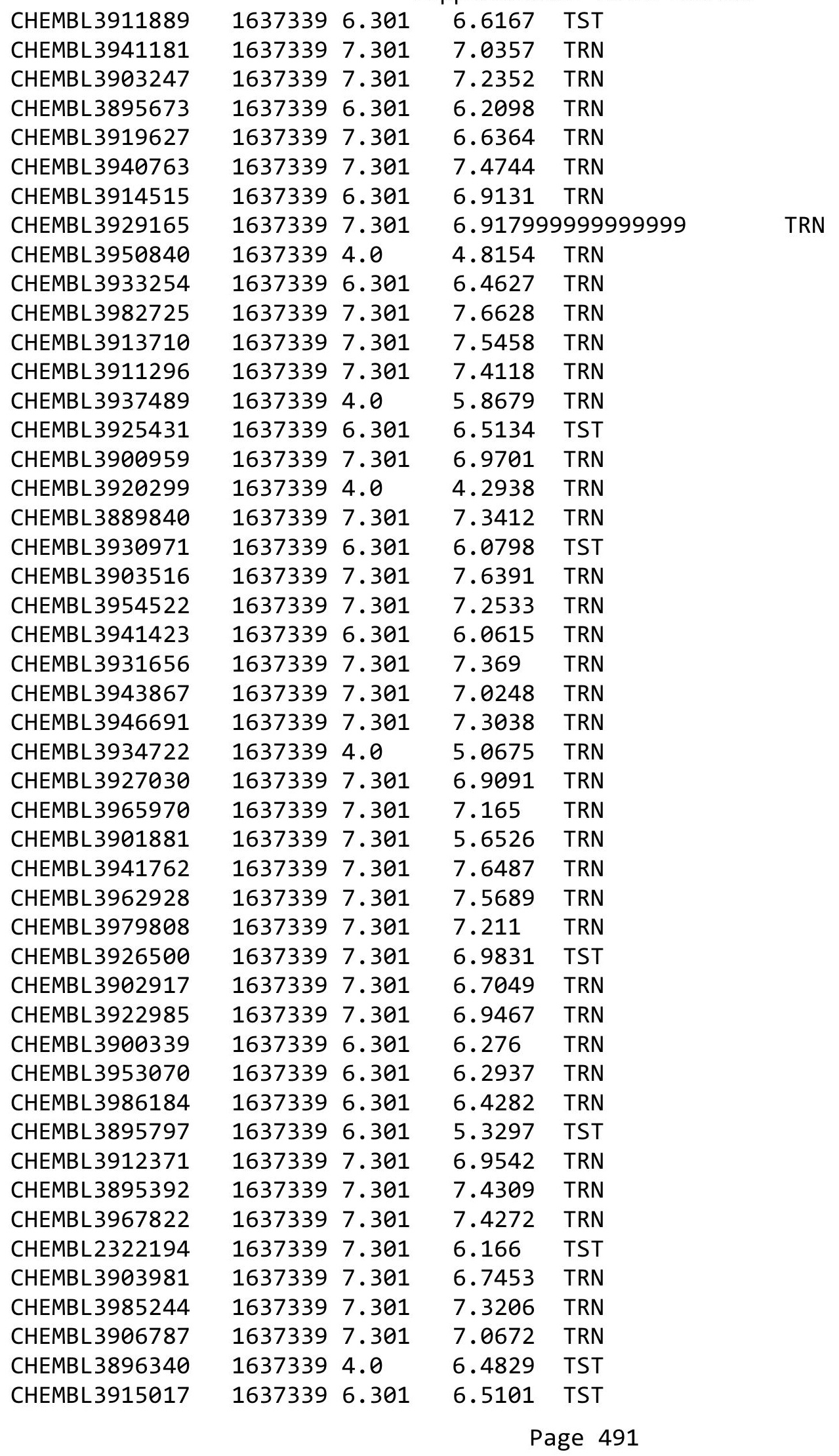


Supplemental Table S2.txt

\begin{tabular}{|c|c|c|c|c|}
\hline 317 & 339 & & & \\
\hline HEMBL3901573 & 637339 & 4.0 & 6162 & \\
\hline & 7339 & 7.301 & & \\
\hline EMBL3 & 37339 & 7.301 & & ET \\
\hline IEMBL3946859 & 537339 & 7.301 & 5416 & \\
\hline AEMBL 3892942 & 537339 & 7.301 & 1372 & \\
\hline AEMBL 3937115 & 637339 & 7.301 & 454 & \\
\hline 9622 & 537339 & 7.301 & 5871 & \\
\hline IEMBL39 & 339 & 7.301 & .4351 & ST \\
\hline AEMBL3954801 & 637339 & 7.301 & .9093 & \\
\hline AEMBL3921364 & 637339 & 7.301 & 002 & \\
\hline AEMBL395 & 339 & 7.301 & 5573 & \\
\hline IEMBL3C & & 301 & 46 & \\
\hline IEMBL39 & 339 & 6.301 & .4094 & \\
\hline IEMBL3952148 & 339 & 301 & 1315 & \\
\hline AEMBL 3946106 & 39 & & 3556 & \\
\hline AEMBL39 & 39 & 6.301 & 803 & \\
\hline AEMBL 3919596 & 39 & & & \\
\hline AEMBL39 & 39 & 301 & & \\
\hline AEMBL 3965927 & 39 & 301 & & \\
\hline AEMBL 3917576 & 39 & 7.301 & .5242 & MT \\
\hline IEMBL39: & 39 & 7.301 & 61 & \\
\hline AEMBL39 & 39 & 7.301 & & \\
\hline 094 & 39 & 301 & & 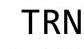 \\
\hline IEMBL3950952 & 39 & 301 & 17 & RN \\
\hline IEMBL 395 & 9 & 301 & 37 & $\mathrm{RI}$ \\
\hline IEMBL39 & 63 & 301 & 06 & RI \\
\hline 440 & & 301 & & ו \\
\hline IEMBL3S & 39 & 7.301 & & $-T$ \\
\hline AEMBL 3898809 & 39 & & & RI \\
\hline IEMBL39 & 39 & 7.301 & 82 & $\mathrm{~S}$ \\
\hline IEMBI 39 & 9 & 301 & 34 & m \\
\hline 209 & 9 & & & RN \\
\hline IEMBL3925823 & 6. & 7.301 & & RN \\
\hline IEMBL3984306 & 63 & 7.301 & 95 & ST \\
\hline IEMBL39 & 39 & 7.301 & & RI \\
\hline 456 & 9 & 01 & & Nin \\
\hline IEMBL39 & & 01 & & ST \\
\hline HEMBL3973322 & 39 & 7.301 & .1736 & RN \\
\hline EMBL13 & 882 & 2.823 & & $S$ \\
\hline IEMBL1322395 & 35 & .4002 & 969 & $\mathrm{RI}$ \\
\hline CHEMBL3209306 & & 4.7457 & 4.2921 & RN \\
\hline HEMBL1521960 & 88235 & 5.0259 & .5769 & $\mathrm{RN}$ \\
\hline IEMBL1606504 & 88235 & 4.3333 & 2411 & RI \\
\hline EMBL14 & 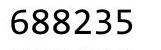 & 4.1006 & & RI \\
\hline CHEMBL 3197628 & 88 & 9449 & .1088 & 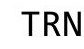 \\
\hline CHEMBL1495173 & 88235 & 3.8828 & 3.9888 & RI \\
\hline CHEMBL1365456 & 688235 & 4.4519 & 4.247 & TR \\
\hline
\end{tabular}

Page 492 


\begin{tabular}{|c|c|c|c|c|c|c|}
\hline & & \multicolumn{5}{|c|}{ Supplemental Table S2.txt } \\
\hline CHEMBL1327202 & 688235 & 4.8965 & 5.0808 & TRN & & \\
\hline CHEMBL1572266 & 688235 & 5.8729 & 6.1472 & TRN & & \\
\hline CHEMBL1330113 & 688235 & 6.0 & 5.4013 & TST & & \\
\hline CHEMBL334707 & 688235 & 5.7905 & 5.6845 & TRN & & \\
\hline CHEMBL586135 & 688235 & 4.8827 & 4.8168 & TRN & & \\
\hline CHEMBL1971410 & 688235 & 4.052 & 3.9557 & TRN & & \\
\hline CHEMBL1337416 & 688235 & 4.6304 & 4.6786 & TRN & & \\
\hline CHEMBL1520465 & 688235 & 4.3945 & 4.1732 & TRN & & \\
\hline CHEMBL1327470 & 688235 & 4.6975 & 4.5416 & TRN & & \\
\hline CHEMBL1418974 & 688235 & 4.0107 & 4.0592 & TRN & & \\
\hline CHEMBL1304363 & 688235 & 4.5438 & 4.44 & TRN & & \\
\hline CHEMBL1438881 & 688235 & 4.7181 & 4.7298 & TRN & & \\
\hline CHEMBL1588513 & 688235 & 3.9811 & 4.3981 & TRN & & \\
\hline CHEMBL1312320 & 688235 & 4.2824 & 4.0486 & TRN & & \\
\hline CHEMBL348267 & 688235 & 3.9641 & 4.2502 & TRN & & \\
\hline CHEMBL1968732 & 688235 & 4.4869 & 4.1843 & TST & & \\
\hline CHEMBL1501653 & 688235 & 4.3171 & 4.2305 & TRN & & \\
\hline CHEMBL1563323 & 688235 & 3.8651 & 3.8877 & TRN & & \\
\hline CHEMBL 1407234 & 688235 & \multicolumn{3}{|c|}{4.2139999999999995} & 4.4067 & TST \\
\hline CHEMBL1557213 & 688235 & 4.0945 & 4.1828 & TST & & \\
\hline CHEMBL1309890 & 688235 & 4.4744 & 4.6566 & TRN & & \\
\hline CHEMBL1305997 & 688235 & 4.248 & 4.2567 & TRN & & \\
\hline CHEMBL1329197 & 688235 & 4.0936 & 4.2342 & TRN & & \\
\hline CHEMBL1998606 & 688235 & 3.8991 & 4.1493 & TRN & & \\
\hline CHEMBL3194133 & 688235 & 4.0937 & 3.5612 & TRN & & \\
\hline CHEMBL1448592 & 688235 & 4.7889 & 4.7474 & TRN & & \\
\hline CHEMBL1456244 & 688235 & 2.8239 & 3.8029 & TST & & \\
\hline CHEMBL1483235 & 688235 & 4.7051 & 4.6823 & TRN & & \\
\hline CHEMBL1304402 & 688235 & 4.3579 & 4.3986 & TRN & & \\
\hline CHEMBL1559564 & 688235 & 4.3302 & 4.27 & TRN & & \\
\hline CHEMBL1577983 & 688235 & 3.9233 & 3.6658 & TRN & & \\
\hline CHEMBL1565059 & 688235 & 4.1871 & 4.1732 & TRN & & \\
\hline CHEMBL1870697 & 688235 & 3.9819 & 3.6839 & TRN & & \\
\hline CHEMBL199387 & 688235 & 4.6169 & 4.5364 & TRN & & \\
\hline CHEMBL1419557 & 688235 & 4.4169 & 4.3603 & TRN & & \\
\hline CHEMBL1500500 & 688235 & 4.3094 & 4.2843 & TRN & & \\
\hline CHEMBL1398224 & 688235 & 4.3718 & 4.4695 & TST & & \\
\hline CHEMBL1584133 & 688235 & 4.0054 & 4.2189 & TRN & & \\
\hline CHEMBL1430611 & 688235 & 6.1938 & 5.5245 & TRN & & \\
\hline CHEMBL1505902 & 688235 & 3.9747 & 4.1973 & TST & & \\
\hline CHEMBL1454183 & 688235 & 3.9562 & 3.4288 & TST & & \\
\hline CHEMBL67311 & 688235 & 3.8431 & 4.4092 & TST & & \\
\hline CHEMBL1505275 & 688235 & 4.8145 & 4.8445 & TRN & & \\
\hline CHEMBL3193102 & 688235 & 2.8239 & 4.1026 & TRN & & \\
\hline CHEMBL1350237 & 688235 & 3.9201 & 4.276 & TST & & \\
\hline CHEMBL1548109 & 688235 & 4.4109 & 4.2614 & TRN & & \\
\hline CHEMBL547285 & 688235 & 3.9984 & 4.3755 & TRN & & \\
\hline CHEMBL1610049 & 688235 & 2.8239 & 3.7918 & TST & & \\
\hline
\end{tabular}


Supplemental Table S2.txt

\begin{tabular}{|c|c|c|c|c|}
\hline & & & & \\
\hline AEMBL 15 & 8235 & & 5836 & \\
\hline IEMBL1308687 & 3235 & 172 & 5834 & \\
\hline HEMBL117 & 235 & 836 & 5071 & \\
\hline 730 & 235 & & 475 & \\
\hline IEMBL 160 & 235 & & 759 & \\
\hline AEMBL1421048 & 88235 & 63 & 2121 & \\
\hline AEMBL1491847 & 88235 & 34 & 4529 & \\
\hline AEMBL1558725 & 235 & & 882 & \\
\hline IEMBL161 & 235 & & & \\
\hline AEMBL1464731 & & & 761 & \\
\hline AEMBL1362935 & 688235 & & 079 & \\
\hline AEMBL572203 & 235 & & 725 & \\
\hline IEMBL156 & & & 342 & \\
\hline IEMBL152 & & & 248 & \\
\hline HEMBL 141 & & & 082 & \\
\hline AEMBL1576581 & 235 & & 346 & RN \\
\hline AEMBL1424729 & 235 & & 63 & S \\
\hline IEMBL19ع & & & 932 & \\
\hline HEMBL138 & & & 928 & \\
\hline AEMBL 137 & & & 663 & \\
\hline AEMBL13: & 35 & & 3661 & \\
\hline HEMBL199 & & & & \\
\hline IEMBL14 & & & 235 & \\
\hline IEMBL13 & & & 81 & $\mathrm{RN}$ \\
\hline AFMBI 15 & 35 & & 291 & Th \\
\hline JEMBL147 & & & 299 & ST \\
\hline AEMBL13] & & & & ST \\
\hline HEMBL147 & & & 21 & RI \\
\hline HEMBL15 & 35 & & 941 & . \\
\hline 0 & & & 451 & - \\
\hline AEMBL3193964 & & & & ST \\
\hline AEMBL1403380 & & & & RI \\
\hline HEMBL142 & & & 795 & RI \\
\hline AFMBI 15 & & & & $\cdots$ \\
\hline 4 & & & & ST \\
\hline AEMBL1541657 & & & 662 & ГST \\
\hline AEMBL1555739 & & & & $\mathrm{R}$ \\
\hline IEMBL146 & & & & RI \\
\hline 1 & & & 07 & \\
\hline HEMBL $15^{\circ}$ & & & 56 & ST \\
\hline HEMBL1610525 & 235 & & 2301 & $\mathrm{R}$ \\
\hline IEMBL1532668 & & & 789 & TR \\
\hline 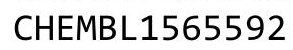 & & & & TS \\
\hline HEMBL147 & & & & \\
\hline CHEMBL3191713 & & & 114 & RN \\
\hline AEMBL601547 & 8235 & 4.0579 & 3.8915 & $\mathrm{TR}$ \\
\hline HFMBI 319533 & 688235 & 4.0259 & 3.7119 & \\
\hline
\end{tabular}

Page 494 


\begin{tabular}{|c|c|c|c|c|c|}
\hline & & \multicolumn{4}{|c|}{ Supplemental Table S2.txt } \\
\hline CHEMBL1399035 & 688235 & 2.8239 & 3.8932 & TRN & \\
\hline CHEMBL1466123 & 688235 & 4.4391 & 4.2999 & TRN & \\
\hline CHEMBL1450615 & 688235 & 4.1829 & 4.0398 & TRN & \\
\hline CHEMBL1981840 & 688235 & 3.8607 & 4.1263 & TRN & \\
\hline CHEMBL3144874 & 688235 & 4.1034 & 3.991 & TRN & \\
\hline CHEMBL1485442 & 688235 & 4.2022 & 4.4024 & TRN & \\
\hline CHEMBL1511879 & 688235 & 2.8239 & 3.842 & TRN & \\
\hline CHEMBL3196403 & 688235 & 2.8239 & 3.7182 & TRN & \\
\hline CHEMBL1958251 & 688235 & 4.6868 & 4.6242 & TRN & \\
\hline CHEMBL570345 & 688235 & 4.4076 & 4.3357 & TRN & \\
\hline CHEMBL1479316 & 688235 & 4.2124 & 4.398 & TRN & \\
\hline CHEMBL1594055 & 688235 & 5.8928 & 6.1367 & TST & \\
\hline CHEMBL1549646 & 688235 & 4.1882 & 3.595 & TST & \\
\hline CHEMBL1568848 & 688235 & 4.4966 & 4.5416 & TRN & \\
\hline CHEMBL3212972 & 688235 & 3.8263 & 4.1281 & TST & \\
\hline CHEMBL1583127 & 688235 & 4.3816 & 3.9925 & TRN & \\
\hline CHEMBL1990959 & 688235 & 2.8239 & 3.7266 & TRN & \\
\hline CHEMBL1342436 & 688235 & 3.8941 & 4.4587 & TST & \\
\hline CHEMBL1534053 & 688235 & 4.4099 & 4.4031 & TRN & \\
\hline CHEMBL1562066 & 688235 & 4.1158 & 3.7996 & TRN & \\
\hline CHEMBL1348582 & 688235 & 4.512 & 4.5879 & TRN & \\
\hline CHEMBL3198095 & 688235 & 2.8239 & 3.628 & TRN & \\
\hline CHEMBL1370927 & 688235 & 2.8239 & 3.9836 & TRN & \\
\hline CHEMBL1993199 & 688235 & 4.0034 & 4.0289 & TRN & \\
\hline CHEMBL139935 & 688235 & 5.0434 & 5.2934 & TRN & \\
\hline CHEMBL1422161 & 688235 & 4.1595 & 4.1303 & TRN & \\
\hline CHEMBL1524986 & 688235 & 4.3215 & 4.3125 & TRN & \\
\hline CHEMBL1310632 & 688235 & 4.5312 & 4.4269 & TRN & \\
\hline CHEMBL428064 & 688235 & 5.5638 & 5.12299 & 9999999999 & TRN \\
\hline CHEMBL51931 & 688235 & 4.9702 & 4.4133 & TRN & \\
\hline CHEMBL3190974 & 688235 & 4.515 & 4.34399 & 9999999999 & TRN \\
\hline CHEMBL3197599 & 688235 & 3.9313 & 3.5504 & TRN & \\
\hline CHEMBL1470712 & 688235 & 3.9085 & 3.9836 & TRN & \\
\hline CHEMBL602377 & 688235 & 4.5502 & 4.1867 & TRN & \\
\hline CHEMBL1482740 & 688235 & 4.1233 & 4.3246 & TRN & \\
\hline CHEMBL1483252 & 688235 & 4.4752 & 4.6695 & TRN & \\
\hline CHEMBL89445 & 688235 & 4.6733 & 4.484 & TRN & \\
\hline CHEMBL1526539 & 688235 & 4.21399 & 99999999 & 4.4843 & TRN \\
\hline CHEMBL935 & 688235 & 3.9237 & 4.2097 & TRN & \\
\hline CHEMBL1520777 & 688235 & 4.1994 & 4.2738 & TRN & \\
\hline CHEMBL1598785 & 688235 & 4.3976 & 4.2648 & TRN & \\
\hline CHEMBL3192400 & 688235 & 4.0063 & 3.8613 & TRN & \\
\hline CHEMBL1573630 & 688235 & 4.0367 & 3.9695 & TRN & \\
\hline CHEMBL1550897 & 688235 & 4.4407 & 4.2081 & TRN & \\
\hline CHEMBL68997 & 688235 & 4.6668 & 4.3373 & TRN & \\
\hline CHEMBL1388892 & 688235 & 3.8333 & 3.8545 & TRN & \\
\hline CHEMBL1402267 & 688235 & 2.8239 & 3.883 & TRN & \\
\hline CHEMBL1577165 & 688235 & 2.8239 & 3.7228 & TRN & \\
\hline
\end{tabular}




\begin{tabular}{|c|c|c|c|c|c|}
\hline & & \multicolumn{4}{|c|}{ Supplemental Table S2.txt } \\
\hline CHEMBL1325908 & 688235 & 4.1538 & 3.7543 & TRN & \\
\hline CHEMBL3192690 & 688235 & 3.8414 & 3.9012 & TRN & \\
\hline CHEMBL1419945 & 688235 & 4.3786 & 4.294 & TRN & \\
\hline CHEMBL1546767 & 688235 & 4.5887 & 4.6723 & TRN & \\
\hline CHEMBL1542886 & 688235 & 4.3897 & 3.9869 & TRN & \\
\hline CHEMBL3194704 & 688235 & 4.4574 & 4.4355 & TRN & \\
\hline CHEMBL32793 & 688235 & 4.4184 & 4.2901 & TRN & \\
\hline CHEMBL1528900 & 688235 & 4.4684 & 4.2566 & TRN & \\
\hline CHEMBL283849 & 688235 & 6.0315 & 5.7173 & TRN & \\
\hline CHEMBL142816 & 688235 & 4.3967 & 4.4439 & TST & \\
\hline CHEMBL1533590 & 688235 & 3.9309 & 4.1033 & TRN & \\
\hline CHEMBL1566118 & 688235 & 3.8786 & 3.7225 & TRN & \\
\hline CHEMBL3197141 & 688235 & 4.6417 & 4.0132 & TRN & \\
\hline CHEMBL1325192 & 688235 & 4.3932 & 4.1224 & TRN & \\
\hline CHEMBL1994463 & 688235 & 4.734 & 4.4581 & TST & \\
\hline CHEMBL3196837 & 688235 & 4.6819 & 4.4661 & TRN & \\
\hline CHEMBL1393256 & 688235 & 4.4646 & 3.8163 & TST & \\
\hline CHEMBL1990174 & 688235 & 4.7706 & 4.4149 & TRN & \\
\hline CHEMBL1346468 & 688235 & 4.5998 & 4.3953 & TRN & \\
\hline CHEMBL1579686 & 688235 & 5.1007 & 4.54899 & 99999999995 & TRN \\
\hline CHEMBL1321398 & 688235 & 4.5707 & 4.3809 & TRN & \\
\hline CHEMBL590186 & 688235 & 4.4171 & 3.9818 & TRN & \\
\hline CHEMBL1487639 & 688235 & 5.0904 & 4.8664 & TRN & \\
\hline CHEMBL1378952 & 688235 & 4.4743 & 4.7239 & TRN & \\
\hline CHEMBL589715 & 688235 & 3.9891 & 4.1116 & TRN & \\
\hline CHEMBL1971144 & 688235 & 4.5913 & 4.4924 & TRN & \\
\hline CHEMBL1576087 & 688235 & 4.266 & 4.0392 & TRN & \\
\hline CHEMBL1481601 & 688235 & 4.1862 & 4.2604 & TST & \\
\hline CHEMBL1541468 & 688235 & 4.4261 & 4.1163 & TST & \\
\hline CHEMBL1556805 & 688235 & 4.1372 & 4.2446 & TRN & \\
\hline CHEMBL1540231 & 688235 & 4.2429 & 4.4361 & TST & \\
\hline CHEMBL592124 & 688235 & 4.1141 & 4.0441 & TST & \\
\hline CHEMBL1968085 & 688235 & 4.7371 & 4.4192 & TRN & \\
\hline CHEMBL461579 & 688235 & 4.7126 & 4.7468 & TRN & \\
\hline CHEMBL1482500 & 688235 & 4.1571 & 4.2207 & TRN & \\
\hline CHEMBL 2369277 & 688235 & 4.4476 & 4.2989 & TRN & \\
\hline CHEMBL1480887 & 688235 & 3.8424 & 3.9478 & TRN & \\
\hline CHEMBL1585390 & 688235 & 4.4232 & 4.2365 & TRN & \\
\hline CHEMBL1595936 & 688235 & 2.8239 & 4.04899 & 99999999995 & TRN \\
\hline CHEMBL533226 & 688235 & 4.106 & 3.6143 & TRN & \\
\hline CHEMBL580918 & 688235 & 4.1494 & 4.6257 & TRN & \\
\hline CHEMBL1323853 & 688235 & 4.1188 & 4.135 & TRN & \\
\hline CHEMBL1306079 & 688235 & 3.873 & 4.2827 & TRN & \\
\hline CHEMBL1373096 & 688235 & 3.9989 & 4.1563 & TRN & \\
\hline CHEMBL81782 & 688235 & 4.4824 & 4.4504 & TRN & \\
\hline CHEMBL532641 & 688235 & 4.0009 & 3.6623 & TRN & \\
\hline CHEMBL3191503 & 688235 & 3.1249 & 3.6431 & TRN & \\
\hline CHEMBL1518625 & 688235 & 4.4099 & 4.3115 & TRN & \\
\hline
\end{tabular}




\begin{tabular}{|c|c|c|c|c|}
\hline \multicolumn{5}{|c|}{ Supplemental Table s2.txt } \\
\hline CHEMBL1607938 & 688235 & 2.8239 & 4.101 & TRN \\
\hline CHEMBL1456240 & 688235 & 3.9405 & 4.2093 & TRN \\
\hline CHEMBL1490728 & 688235 & 4.1215 & 4.2295 & TRN \\
\hline CHEMBL1522486 & 688235 & 4.6103 & 4.8402 & TRN \\
\hline CHEMBL582980 & 688235 & 4.2865 & 4.1603 & TRN \\
\hline CHEMBL1405776 & 688235 & 4.1116 & 3.9827 & TST \\
\hline CHEMBL1323744 & 688235 & 4.6517 & 4.2786 & TRN \\
\hline CHEMBL1340176 & 688235 & 2.8239 & 3.8174 & TST \\
\hline CHEMBL1425521 & 688235 & 4.1222 & 4.3643 & TRN \\
\hline CHEMBL1589425 & 688235 & 4.7238 & 4.6941 & TRN \\
\hline CHEMBL1594766 & 688235 & 4.0661 & 3.8831 & TRN \\
\hline CHEMBL1334164 & 688235 & 2.8239 & 3.9676 & TRN \\
\hline CHEMBL584269 & 688235 & 4.5493 & 4.3492 & TRN \\
\hline CHEMBL1198307 & 688235 & 4.1119 & 4.0734 & TRN \\
\hline CHEMBL1469579 & 688235 & 4.6028 & 4.2726 & TRN \\
\hline CHEMBL1577829 & 688235 & 4.0923 & 4.0434 & TRN \\
\hline CHEMBL1549308 & 688235 & 4.4124 & 4.1254 & TRN \\
\hline CHEMBL1331185 & 688235 & 4.0612 & 3.9955 & TRN \\
\hline CHEMBL1505338 & 688235 & 3.9724 & 3.7144 & TRN \\
\hline CHEMBL1522007 & 688235 & 5.0114 & 4.5402 & TRN \\
\hline CHEMBL1541834 & 688235 & 4.7602 & 4.9029 & TRN \\
\hline CHEMBL1983530 & 688235 & 4.2077 & 4.1471 & TRN \\
\hline CHEMBL1485793 & 688235 & 4.1543 & 4.2122 & TRN \\
\hline CHEMBL1330558 & 688235 & 4.776 & 4.8702 & TRN \\
\hline CHEMBL1309207 & 688235 & 2.8239 & 3.9766 & TRN \\
\hline CHEMBL591834 & 688235 & 4.4476 & 4.3122 & TRN \\
\hline CHEMBL1342852 & 688235 & 4.8456 & 4.6659 & TRN \\
\hline CHEMBL1200567 & 688235 & 5.5421 & 5.64 & TST \\
\hline CHEMBL2006909 & 688235 & 4.1525 & 3.4316 & TRN \\
\hline CHEMBL1387835 & 688235 & 4.0439 & 4.6052 & TRN \\
\hline CHEMBL1502014 & 688235 & 4.0854 & 3.9462 & TST \\
\hline CHEMBL1492696 & 688235 & 3.9634 & 3.8349 & TRN \\
\hline CHEMBL 3145303 & 688235 & 4.7199 & 4.2024 & TRN \\
\hline CHEMBL3197372 & 688235 & 4.0493 & 3.3406 & TRN \\
\hline CHEMBL1570835 & 688235 & 3.915 & 3.966 & TRN \\
\hline CHEMBL1309806 & 688235 & 4.0469 & 3.9977 & TRN \\
\hline CHEMBL1432707 & 688235 & 3.9299 & 4.145 & TRN \\
\hline CHEMBL1310009 & 688235 & 4.1504 & 4.1484 & TST \\
\hline CHEMBL3190369 & 688235 & 4.6544 & 4.7104 & TST \\
\hline CHEMBL1467720 & 688235 & 4.1515 & 4.2096 & TRN \\
\hline CHEMBL123 & 688235 & 4.7086 & 4.5448 & TST \\
\hline CHEMBL1448849 & 688235 & 4.0921 & 3.7859 & TRN \\
\hline CHEMBL1593697 & 688235 & 6.0 & 5.91 & TST \\
\hline CHEMBL1589298 & 688235 & 4.3704 & 4.0953 & TRN \\
\hline CHEMBL1507898 & 688235 & 4.3915 & 4.2287 & TRN \\
\hline CHEMBL1594717 & 688235 & 3.9755 & 4.3082 & TRN \\
\hline CHEMBL 2004417 & 688235 & 4.7404 & 4.6789 & TRN \\
\hline CHEMBL1459734 & 688235 & 3.9227 & 3.7602 & TST \\
\hline
\end{tabular}




\begin{tabular}{|c|c|c|c|c|c|}
\hline & & \multicolumn{4}{|c|}{ Supplemental Table S2.txt } \\
\hline CHEMBL1413726 & 688235 & 4.1421 & 4.0966 & TRN & \\
\hline CHEMBL1326083 & 688235 & 4.7036 & 4.7528 & TRN & \\
\hline CHEMBL69612 & 688235 & 4.6631 & 4.4147 & TRN & \\
\hline CHEMBL1391048 & 688235 & 4.271 & 4.1927 & TST & \\
\hline CHEMBL3196606 & 688235 & 2.8239 & 3.8882 & TRN & \\
\hline CHEMBL1588476 & 688235 & 4.2869 & 3.9568 & TRN & \\
\hline CHEMBL3191273 & 688235 & 4.7144 & 4.3921 & TRN & \\
\hline CHEMBL587892 & 688235 & 4.2827 & 4.1144 & TRN & \\
\hline CHEMBL1303446 & 688235 & 2.8239 & 3.8772 & TRN & \\
\hline CHEMBL1416618 & 688235 & 4.2427 & 4.0116 & TRN & \\
\hline CHEMBL581880 & 688235 & 4.3147 & 4.4172 & TRN & \\
\hline CHEMBL1485275 & 688235 & 6.0 & 6.0011 & TST & \\
\hline CHEMBL 2018847 & 688235 & 3.972 & 4.1454 & TRN & \\
\hline CHEMBL1487183 & 688235 & 5.2588 & 4.9241 & TST & \\
\hline CHEMBL1604947 & 688235 & 4.3298 & 4.243 & TRN & \\
\hline CHEMBL1563943 & 688235 & 3.8245 & 3.9272 & TRN & \\
\hline CHEMBL417727 & 688235 & 4.9582 & 4.5342 & TRN & \\
\hline CHEMBL1457463 & 688235 & 3.9334 & 3.9222 & TRN & \\
\hline CHEMBL1964793 & 688235 & 4.6792 & 4.397 & TRN & \\
\hline CHEMBL578294 & 688235 & 3.9566 & 3.7587 & TRN & \\
\hline CHEMBL3192181 & 688235 & 4.4729 & 4.2553 & TRN & \\
\hline CHEMBL1348018 & 688235 & 3.9277 & 3.5858 & TRN & \\
\hline CHEMBL1332756 & 688235 & 4.327 & 4.2026 & TRN & \\
\hline CHEMBL523200 & 688235 & 3.9879 & 4.3138 & TRN & \\
\hline CHEMBL1333537 & 688235 & 5.1864 & 4.6713 & TRN & \\
\hline CHEMBL19954 & 688235 & 4.6885 & 4.6551 & TST & \\
\hline CHEMBL1462938 & 688235 & 5.091 & 4.7399 & TRN & \\
\hline CHEMBL1470669 & 688235 & 4.3707 & 3.8088 & TRN & \\
\hline CHEMBL 3192557 & 688235 & 4.263 & 4.1868 & TRN & \\
\hline CHEMBL414400 & 688235 & 4.9948 & 5.2778 & TRN & \\
\hline CHEMBL146525 & 688235 & 4.573 & 4.202 & TRN & \\
\hline CHEMBL1426059 & 688235 & 4.127 & 3.8995 & TST & \\
\hline CHEMBL 2359911 & 688235 & 4.7156 & 4.2245 & TRN & \\
\hline CHEMBL1601781 & 688235 & 4.2748 & 4.3574 & TRN & \\
\hline CHEMBL590408 & 688235 & 3.9008 & 3.8932 & TRN & \\
\hline CHEMBL1588223 & 688235 & 4.4665 & 4.3915 & TRN & \\
\hline CHEMBL1410758 & 688235 & 4.2868 & 4.3038 & TRN & \\
\hline CHEMBL1093246 & 688235 & 3.9265 & 4.05399 & 9999999999 & TST \\
\hline CHEMBL1256737 & 688235 & 4.0596 & 4.209 & TST & \\
\hline CHEMBL66953 & 688235 & 4.6586 & 4.6775 & TRN & \\
\hline CHEMBL 2369280 & 688235 & 2.8239 & 3.9436 & TST & \\
\hline CHEMBL1608375 & 688235 & 4.3591 & 3.8212 & TST & \\
\hline CHEMBL1329974 & 688235 & 4.0785 & 4.1328 & TRN & \\
\hline CHEMBL1519239 & 688235 & 4.537 & 4.544 & TRN & \\
\hline CHEMBL1326371 & 688235 & 4.1374 & 4.9023 & TRN & \\
\hline CHEMBL1339328 & 688235 & 3.8942 & 3.6862 & TST & \\
\hline CHEMBL3191504 & 688235 & 4.0558 & 4.0132 & TRN & \\
\hline CHEMBL1378260 & 688235 & 4.4114 & 4.4025 & TRN & \\
\hline
\end{tabular}




\begin{tabular}{|c|c|c|c|c|c|}
\hline \multicolumn{6}{|c|}{ Supplemental Table S2.txt } \\
\hline CHEMBL1545565 & 688235 & 2.8239 & 3.5299 & TRN & \\
\hline CHEMBL290077 & 688235 & 4.4847 & 4.5641 & TST & \\
\hline CHEMBL1980844 & 688235 & 4.5184 & 4.5276 & TST & \\
\hline CHEMBL1461972 & 688235 & 4.4305 & 3.7985 & TRN & \\
\hline CHEMBL1431928 & 688235 & 3.8998 & 4.075 & TRN & \\
\hline CHEMBL1588107 & 688235 & 4.4557 & 4.1436 & TRN & \\
\hline CHEMBL 2373661 & 688235 & 4.8477 & 4.8839 & TST & \\
\hline CHEMBL1563898 & 688235 & 4.5452 & 3.8218 & TRN & \\
\hline CHEMBL1596681 & 688235 & 4.4295 & 4.6495 & TRN & \\
\hline CHEMBL600778 & 688235 & 4.3118 & 4.4888 & TRN & \\
\hline CHEMBL3189743 & 688235 & 4.0688 & 3.9395 & TRN & \\
\hline CHEMBL1609529 & 688235 & 4.3263 & 4.2674 & TRN & \\
\hline CHEMBL1467637 & 688235 & 2.8239 & 3.8247 & TST & \\
\hline CHEMBL1351542 & 688235 & 4.6776 & 4.8249 & TRN & \\
\hline CHEMBL1974450 & 688235 & 4.2479 & 3.8625 & TRN & \\
\hline CHEMBL582444 & 688235 & 4.1234 & 4.2835 & TST & \\
\hline CHEMBL1489944 & 688235 & 3.86 & 3.9022 & TRN & \\
\hline CHEMBL1361821 & 688235 & 2.8239 & 3.8865 & TRN & \\
\hline CHEMBL1496705 & 688235 & 4.7033 & 4.6312 & TRN & \\
\hline CHEMBL1467705 & 688235 & 2.8239 & 3.8617 & TRN & \\
\hline CHEMBL1375045 & 688235 & 4.5947 & 4.7659 & TRN & \\
\hline CHEMBL3189342 & 688235 & 5.0443 & 4.7215 & TRN & \\
\hline CHEMBL1427476 & 688235 & 3.887 & 3.9196 & TRN & \\
\hline CHEMBL3208179 & 688235 & 4.2804 & 4.1062 & TRN & \\
\hline CHEMBL1448161 & 688235 & 3.9623 & 3.72300 & 00000000003 & TRN \\
\hline CHEMBL1318861 & 688235 & 5.6421 & 5.6052 & TST & \\
\hline CHEMBL1497597 & 688235 & 4.5859 & 4.3684 & TRN & \\
\hline CHEMBL1437516 & 688235 & 4.1721 & 4.5836 & TRN & \\
\hline CHEMBL1977877 & 688235 & 4.5931 & 4.3962 & TRN & \\
\hline CHEMBL1584502 & 688235 & 2.8239 & 3.78899 & 99999999997 & TRN \\
\hline CHEMBL1404984 & 688235 & 3.9985 & 3.952 & TRN & \\
\hline CHEMBL3198912 & 688235 & 4.021 & 4.0023 & TRN & \\
\hline CHEMBL1429849 & 688235 & 3.838 & 3.5986 & TRN & \\
\hline CHEMBL3189791 & 688235 & 4.2538 & 4.2117 & TRN & \\
\hline CHEMBL1604283 & 688235 & 6.0 & 5.8608 & TST & \\
\hline CHEMBL3195409 & 688235 & 4.5449 & 4.2091 & TRN & \\
\hline CHEMBL 1441196 & 688235 & 4.6594 & 4.6392 & TRN & \\
\hline CHEMBL193872 & 688235 & 4.8901 & 4.538 & TRN & \\
\hline CHEMBL1329235 & 688235 & 4.0944 & 3.9754 & TRN & \\
\hline CHEMBL1353170 & 688235 & 4.5592 & 4.1686 & TRN & \\
\hline CHEMBL3189712 & 688235 & 4.1406 & 3.9252 & TRN & \\
\hline CHEMBL1572134 & 688235 & 4.3722 & 4.0128 & TRN & \\
\hline CHEMBL1983839 & 688235 & 4.5955 & 4.1166 & TRN & \\
\hline CHEMBL3191293 & 688235 & 4.4686 & 4.5056 & TRN & \\
\hline CHEMBL1242180 & 688235 & 4.7038 & 4.564 & TRN & \\
\hline CHEMBL1403593 & 688235 & 2.8239 & 4.0803 & TRN & \\
\hline CHEMBL586602 & 688235 & 4.5046 & 4.6257 & TRN & \\
\hline CHEMBL1415894 & 688235 & 2.8239 & 3.8768 & TRN & \\
\hline
\end{tabular}


Supplemental Table S2.txt

\begin{tabular}{|c|c|c|c|c|}
\hline & & 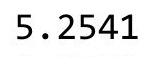 & & \\
\hline HEMBL1463614 & 88235 & 0756 & 4.1927 & \\
\hline HEMBL1489407 & 35 & 1057 & 3161 & \\
\hline 647 & & 248 & 78 & \\
\hline HEMBL1928491 & & & 2057 & \\
\hline AEMBL1388845 & 88235 & 1602 & 2882 & \\
\hline HEMBL1527341 & 88235 & 4.6692 & .3816 & \\
\hline HEMBL1568414 & 35 & 957 & 4434 & \\
\hline AEMBL19 & & 816 & .8127 & \\
\hline IEMBL13 & & & .5122 & \\
\hline HEMBL1463272 & 88235 & 931 & .7003 & \\
\hline HEMBL 2000750 & 88235 & 264 & .1542 & \\
\hline HEMBL3195484 & 5 & & 7211 & \\
\hline HEMBL14 & & & 2034 & \\
\hline HEMBL13 & & & 5378 & \\
\hline HEMBL1530097 & 88235 & 528 & 4.0022 & \\
\hline HEMBL3196813 & & 71 & 3.7002 & \\
\hline HEMBL73 & & 3 & 3.8569 & \\
\hline L13 & & & 319 & \\
\hline AEMBL13 & & & 17 & \\
\hline HEMBL1422849 & & & 5231 & \\
\hline HEMBL1528425 & & & & \\
\hline HEMBL14 & 35 & 23 & 2654 & RIV \\
\hline L15 & & & 1839 & \\
\hline 07 & & & 302 & \\
\hline L13 & & & 8219 & \\
\hline IEMBL15e & & & & r \\
\hline HEMBL14 & & & & RN \\
\hline L1S & & & 621 & RN \\
\hline AEMBL15 & & $\partial 8$ & 3.9534 & ST \\
\hline JEMBL14 & & & 7774 & 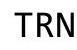 \\
\hline HEMBL 580340 & & & 3026 & $\mathrm{RN}$ \\
\hline HEMBL15 & & & 03 & RN \\
\hline IIN & & & 16 & RN \\
\hline 7 & & & 032 & $\mathrm{RN}$ \\
\hline AEMBL1301480 & & & 337 & TRN \\
\hline AEMBL1509380 & & & 462 & RN \\
\hline & & & & RIN \\
\hline ריסובות & & & 22 & RIN \\
\hline HEMBL13 & & & 248 & $\mathrm{RN}$ \\
\hline AEMBL1463234 & 88235 & 089 & 2212 & ST \\
\hline HEMBL12. & & 996 & & ST \\
\hline 153 & & & & \\
\hline HEMBL19 & & & 2441 & \\
\hline HEMBL15 & & & 4.3896 & $\mathrm{RN}$ \\
\hline IEMBL15 & 35 & 4. & 482 & \\
\hline 15 & & & & \\
\hline CHEM & & 4.0689 & & \\
\hline
\end{tabular}

Page 500 


\begin{tabular}{|c|c|c|c|c|c|}
\hline & & \multicolumn{4}{|c|}{ Supplemental Table S2.txt } \\
\hline CHEMBL1600855 & 688235 & 4.5154 & 4.659 & TRN & \\
\hline CHEMBL1455650 & 688235 & 4.6494 & 4.3868 & TRN & \\
\hline CHEMBL1499792 & 688235 & 4.5424 & 4.6977 & TRN & \\
\hline CHEMBL1380497 & 688235 & 3.1249 & 3.7622 & TRN & \\
\hline CHEMBL520667 & 688235 & 4.1164 & 4.0734 & TRN & \\
\hline CHEMBL1492585 & 688235 & 4.4279 & 4.3811 & TRN & \\
\hline CHEMBL601757 & 688235 & 5.9626 & 5.7837 & TST & \\
\hline CHEMBL3198111 & 688235 & 4.3129 & 4.0244 & TRN & \\
\hline CHEMBL1974180 & 688235 & 3.906 & 3.4754 & TRN & \\
\hline CHEMBL1514790 & 688235 & 4.4905 & 4.4558 & TRN & \\
\hline CHEMBL1425316 & 688235 & 4.0674 & 4.6647 & TRN & \\
\hline CHEMBL1587753 & 688235 & 4.8038 & 5.231 & TRN & \\
\hline CHEMBL251670 & 688235 & 6.1079 & 5.7698 & TRN & \\
\hline CHEMBL429095 & 688235 & 4.1674 & 4.04899 & 99999999995 & TRN \\
\hline CHEMBL1502937 & 688235 & 4.0455 & 4.053 & TRN & \\
\hline CHEMBL1388038 & 688235 & 4.0798 & 3.9708 & TRN & \\
\hline CHEMBL573543 & 688235 & 4.4381 & 4.6488 & TRN & \\
\hline CHEMBL1416329 & 688235 & 4.0361 & 3.9608 & TRN & \\
\hline CHEMBL1386820 & 688235 & 4.2091 & 4.1852 & TRN & \\
\hline CHEMBL1454171 & 688235 & 4.0842 & 3.9698 & TRN & \\
\hline CHEMBL3199549 & 688235 & 2.8239 & 4.0556 & TRN & \\
\hline CHEMBL1300831 & 688235 & 4.2822 & 4.1136 & TST & \\
\hline CHEMBL1427448 & 688235 & 3.8604 & 4.0091 & TST & \\
\hline CHEMBL1427508 & 688235 & 3.8487 & 3.6083 & TRN & \\
\hline CHEMBL1454614 & 688235 & 4.2559 & 4.0801 & TRN & \\
\hline CHEMBL1385808 & 688235 & 6.0 & 5.8276 & TST & \\
\hline CHEMBL1604894 & 688235 & 2.8239 & 3.8724 & TRN & \\
\hline CHEMBL1597655 & 688235 & 4.7338 & 4.4239 & TRN & \\
\hline CHEMBL1486366 & 688235 & 4.3398 & 4.2741 & TRN & \\
\hline CHEMBL3189460 & 688235 & 4.4557 & 4.3145 & TRN & \\
\hline CHEMBL3213876 & 688235 & 4.3101 & 4.0497 & TST & \\
\hline CHEMBL1567315 & 688235 & 4.3784 & 4.1981 & TST & \\
\hline CHEMBL1503359 & 688235 & 5.1759 & 4.5827 & TST & \\
\hline CHEMBL1550957 & 688235 & 2.8239 & 3.9758 & TST & \\
\hline CHEMBL601768 & 688235 & 3.9679 & 4.5187 & TST & \\
\hline CHEMBL1500265 & 688235 & 3.9775 & 3.9633 & TST & \\
\hline CHEMBL1560982 & 688235 & 4.1237 & 3.9474 & TST & \\
\hline CHEMBL1336722 & 688235 & 2.8239 & 4.2572 & TST & \\
\hline CHEMBL1319643 & 688235 & 3.9115 & 3.6641 & TST & \\
\hline CHEMBL1360037 & 688235 & 4.4559 & 4.1946 & TST & \\
\hline CHEMBL3191443 & 688235 & 4.5237 & 4.0396 & TST & \\
\hline CHEMBL1309484 & 688235 & 4.4694 & 4.5044 & TST & \\
\hline CHEMBL1423463 & 688235 & 4.4568 & 4.3521 & TST & \\
\hline CHEMBL3193515 & 688235 & 4.7747 & 4.4092 & TST & \\
\hline CHEMBL1459764 & 688235 & 4.4154 & 4.4117 & TST & \\
\hline CHEMBL1613425 & 688235 & 2.8239 & 3.4201 & TST & \\
\hline CHEMBL3199539 & 688235 & 4.1482 & 4.0229 & TST & \\
\hline CHEMBL1460004 & 688235 & 4.4019 & 4.2507 & TST & \\
\hline
\end{tabular}




\begin{tabular}{|c|c|c|c|c|}
\hline & & & oplement & al $\mathrm{Ta}$ \\
\hline CHEMBL1384935 & 688235 & 2.8239 & 4.0109 & TST \\
\hline CHEMBL1511437 & 688235 & 2.8239 & 4.0777 & TST \\
\hline CHEMBL309016 & 688235 & 4.4868 & 4.1226 & TST \\
\hline CHEMBL1409001 & 688235 & 2.8239 & 4.4217 & TST \\
\hline CHEMBL3197991 & 688235 & 4.0536 & 4.2506 & TST \\
\hline CHEMBL3190468 & 688235 & 3.9635 & 4.1664 & TST \\
\hline CHEMBL1980226 & 688235 & 4.4298 & 4.1959 & TST \\
\hline CHEMBL3197896 & 688235 & 4.169 & 3.9154 & TST \\
\hline CHEMBL1460315 & 688235 & 3.8802 & 4.1851 & TST \\
\hline CHEMBL1608143 & 688235 & 4.3401 & 4.2427 & TST \\
\hline CHEMBL1415720 & 688235 & 4.4233 & 4.3558 & TST \\
\hline CHEMBL1986183 & 688235 & 4.1077 & 3.7455 & TST \\
\hline CHEMBL1414291 & 688235 & 3.8445 & 3.748 & TST \\
\hline CHEMBL1352234 & 688235 & 4.3382 & 4.1747 & TST \\
\hline CHEMBL351660 & 688235 & 6.1308 & 5.4284 & TST \\
\hline CHEMBL1388152 & 688235 & 4.3945 & 4.1986 & TST \\
\hline CHEMBL1411646 & 688235 & 4.0814 & 4.2642 & TST \\
\hline CHEMBL1564591 & 688235 & 4.0796 & 4.197 & TST \\
\hline CHEMBL530609 & 688235 & 4.0644 & 3.9815 & TST \\
\hline CHEMBL140425 & 688235 & 5.301 & 5.3513 & TST \\
\hline CHEMBL1513972 & 688235 & 4.5817 & 4.408 & TST \\
\hline CHEMBL1404086 & 688235 & 4.4102 & 4.2614 & TST \\
\hline CHEMBL1521705 & 688235 & 4.9194 & 4.7405 & TST \\
\hline CHEMBL1366942 & 688235 & 4.7256 & 4.5632 & TST \\
\hline CHEMBL1385206 & 688235 & 5.0921 & 4.9611 & TST \\
\hline CHEMBL 3192021 & 688235 & 4.2398 & 3.8011 & TST \\
\hline CHEMBL1766766 & 743338 & 6.8861 & 6.8848 & TRN \\
\hline CHEMBL1766784 & 743338 & 6.9586 & 6.9583 & TRN \\
\hline CHEMBL1766767 & 743338 & 5.8861 & 5.8834 & TRN \\
\hline CHEMBL104468 & 743338 & 3.0 & 5.0756 & TST \\
\hline CHEMBL479488 & 743338 & 5.1427 & 4.2851 & TST \\
\hline CHEMBL1766803 & 743338 & 7.6576 & 6.5861 & TST \\
\hline CHEMBL1766775 & 743338 & 5.6576 & 5.6563 & TRN \\
\hline CHEMBL1766761 & 743338 & 5.284 & 5.2846 & TRN \\
\hline CHEMBL 222102 & 743338 & 3.0 & 5.244 & TST \\
\hline CHEMBL1766791 & 743338 & 7.2518 & 7.2504 & TRN \\
\hline CHEMBL1766782 & 743338 & 5.6198 & 5.6163 & TRN \\
\hline CHEMBL1766796 & 743338 & 8.2218 & 8.2215 & TRN \\
\hline CHEMBL1766794 & 743338 & 7.8539 & 7.8554 & TRN \\
\hline CHEMBL1766802 & 743338 & 7.4437 & 6.4049 & TST \\
\hline CHEMBL1766760 & 743338 & 5.1487 & 5.1464 & TRN \\
\hline CHEMBL1766773 & 743338 & 6.4685 & 6.4721 & TRN \\
\hline CHEMBL1766781 & 743338 & 5.8239 & 5.8221 & TRN \\
\hline CHEMBL1766790 & 743338 & 7.3188 & 7.3176 & TRN \\
\hline CHEMBL1766800 & 743338 & 5.4486 & 5.4482 & TRN \\
\hline CHEMBL1766788 & 743338 & 7.2676 & 7.2725 & TRN \\
\hline CHEMBL1766765 & 743338 & 7.6198 & 7.6196 & TRN \\
\hline CHEMBL1766804 & 743338 & 7.6383 & 6.4527 & TST \\
\hline
\end{tabular}




\begin{tabular}{|c|c|c|c|c|}
\hline \multicolumn{5}{|c|}{ Supplemental Table s2.txt } \\
\hline CHEMBL1766787 & 743338 & 7.2676 & 7.2685 & TRN \\
\hline CHEMBL1766785 & 743338 & 6.7447 & 6.7477 & TRN \\
\hline CHEMBL1766776 & 743338 & 5.7959 & 5.7982 & TRN \\
\hline CHEMBL1766799 & 743338 & 8.0 & 8.0002 & TRN \\
\hline CHEMBL1766780 & 743338 & 6.4949 & 6.495 & TRN \\
\hline CHEMBL1766789 & 743338 & 7.585 & 7.5863 & TRN \\
\hline CHEMBL1766774 & 743338 & 6.2676 & 6.2653 & TRN \\
\hline CHEMBL1766759 & 743338 & 6.2076 & 6.2043 & TRN \\
\hline CHEMBL1766795 & 743338 & 8.0 & 8.0015 & TRN \\
\hline CHEMBL1766793 & 743338 & 8.0969 & 8.0956 & TRN \\
\hline CHEMBL1766786 & 743338 & 7.0 & 6.9918 & TRN \\
\hline CHEMBL1766771 & 743338 & 5.8539 & 5.855 & TRN \\
\hline CHEMBL1766798 & 743338 & 8.0969 & 8.0944 & TRN \\
\hline CHEMBL1766772 & 743338 & 6.3979 & 6.3954 & TRN \\
\hline CHEMBL1766762 & 743338 & 5.5229 & 5.8921 & TST \\
\hline CHEMBL1766783 & 743338 & 5.7696 & 5.775 & TRN \\
\hline CHEMBL1766777 & 743338 & 6.2518 & 6.2532 & TRN \\
\hline CHEMBL1766768 & 743338 & 5.6198 & 5.6214 & TRN \\
\hline CHEMBL1766764 & 743338 & 6.1938 & 6.1939 & TRN \\
\hline CHEMBL1766778 & 743338 & 6.7447 & 6.7465 & TRN \\
\hline CHEMBL1765107 & 743338 & 6.7447 & 6.7473 & TRN \\
\hline CHEMBL1766763 & 743338 & 5.6778 & 5.6806 & TRN \\
\hline CHEMBL1766770 & 743338 & 6.1549 & 6.091 & TST \\
\hline CHEMBL1766801 & 743338 & 7.5229 & 6.7413 & TST \\
\hline CHEMBL1766792 & 743338 & 7.9208 & 7.5867 & TST \\
\hline CHEMBL1766779 & 743338 & 7.585 & 6.9944 & TST \\
\hline CHEMBL1766797 & 743338 & 7.9208 & 8.3073 & TST \\
\hline CHEMBL1766769 & 743338 & 6.1308 & 5.4529 & TST \\
\hline CHEMBL 216145 & 421230 & 7.4202 & 8.6211 & TST \\
\hline CHEMBL216565 & 421230 & 8.6778 & 8.9968 & TRN \\
\hline CHEMBL217614 & 421230 & 8.1805 & 7.5389 & TRN \\
\hline CHEMBL425979 & 421230 & 5.9586 & 6.8666 & TRN \\
\hline CHEMBL216184 & 421230 & 7.3979 & 7.5752 & TRN \\
\hline CHEMBL385941 & 421230 & 9.0969 & 8.734 & TRN \\
\hline CHEMBL385398 & 421230 & 8.0458 & 7.9738 & TRN \\
\hline CHEMBL87370 & 421230 & 8.0969 & 8.8724 & TRN \\
\hline CHEMBL217575 & 421230 & 7.3665 & 6.896 & TRN \\
\hline CHEMBL217560 & 421230 & 5.5686 & 8.4051 & TST \\
\hline CHEMBL385389 & 421230 & 7.699 & 7.9054 & TRN \\
\hline CHEMBL217462 & 421230 & 8.3979 & 8.1894 & TRN \\
\hline CHEMBL 216580 & 421230 & 8.8539 & 8.741 & TRN \\
\hline CHEMBL213873 & 421230 & 4.3979 & 5.8156 & TRN \\
\hline CHEMBL 214450 & 421230 & 6.7212 & 7.9903 & TRN \\
\hline CHEMBL216324 & 421230 & 8.9208 & 9.058 & TRN \\
\hline CHEMBL386320 & 421230 & 8.9208 & 8.3555 & TRN \\
\hline CHEMBL 215955 & 421230 & 5.0809 & 6.7886 & TST \\
\hline CHEMBL215965 & 421230 & 7.6576 & 8.2108 & TRN \\
\hline CHEMBL 215586 & 421230 & 5.9586 & 7.2631 & TRN \\
\hline
\end{tabular}




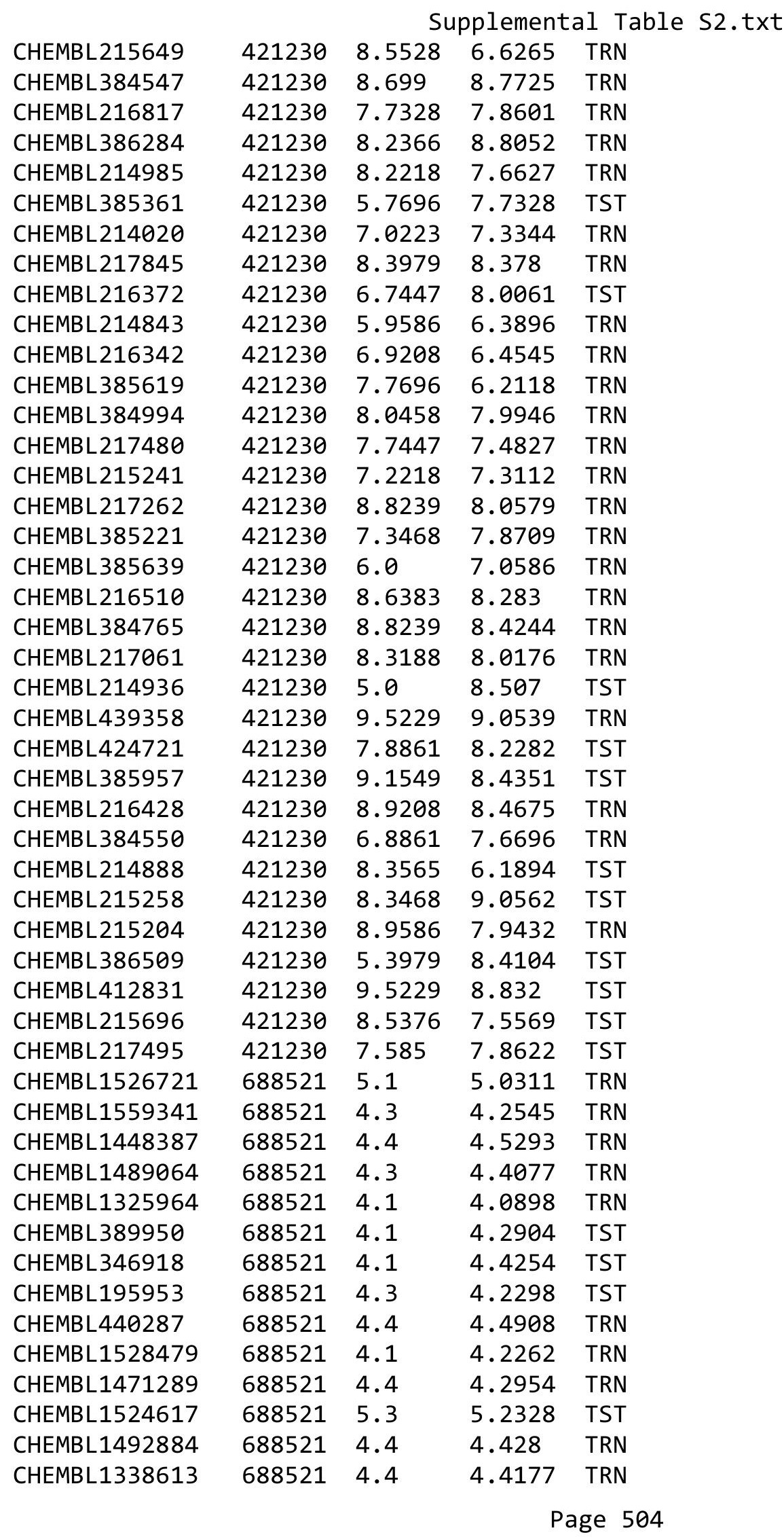




\begin{tabular}{|c|c|c|c|c|c|}
\hline \multicolumn{6}{|c|}{ Supplemental Table S2.txt } \\
\hline CHEMBL230156 & 688521 & 4.3 & 4.2239 & TRN & \\
\hline CHEMBL1484480 & 688521 & 4.4 & 4.1593 & TRN & \\
\hline CHEMBL935 & 688521 & 4.5 & 4.4512 & TRN & \\
\hline CHEMBL1549844 & 688521 & 4.9 & 4.5378 & TST & \\
\hline CHEMBL1370662 & 688521 & 4.4 & 4.3145 & TRN & \\
\hline CHEMBL1530684 & 688521 & 4.4 & 4.4266 & TRN & \\
\hline CHEMBL70582 & 688521 & 4.5 & 4.4564 & TRN & \\
\hline CHEMBL1304981 & 688521 & 4.1 & 4.0154 & TRN & \\
\hline CHEMBL1585396 & 688521 & 4.3 & 4.3886 & TST & \\
\hline CHEMBL2373279 & 688521 & 4.3 & 4.414 & TST & \\
\hline CHEMBL1612246 & 688521 & 4.4 & 4.5948 & TRN & \\
\hline CHEMBL1569226 & 688521 & 5.3 & 5.3927 & TRN & \\
\hline CHEMBL1558796 & 688521 & 4.4 & 4.495 & TRN & \\
\hline CHEMBL192627 & 688521 & 4.9 & 4.7516 & TST & \\
\hline CHEMBL1462419 & 688521 & 4.2 & 4.4482 & TST & \\
\hline CHEMBL1200471 & 688521 & 6.4 & 6.5031 & TRN & \\
\hline CHEMBL1576086 & 688521 & 4.5 & 4.3709 & TRN & \\
\hline CHEMBL1499545 & 688521 & 5.3 & 5.3135 & TRN & \\
\hline CHEMBL402063 & 688521 & 6.0 & 5.5795 & TST & \\
\hline CHEMBL1609459 & 688521 & 5.4 & 5.294 & TRN & \\
\hline CHEMBL1407826 & 688521 & 4.4 & 4.7323 & TST & \\
\hline CHEMBL285235 & 688521 & 4.1 & 4.1557 & TRN & \\
\hline CHEMBL538146 & 688521 & 4.1 & 4.1453 & TRN & \\
\hline CHEMBL220845 & 688521 & 4.3 & 4.4878 & TRN & \\
\hline CHEMBL172064 & 688521 & 4.3 & 4.3321 & TRN & \\
\hline CHEMBL454173 & 688521 & 4.3 & 4.3831 & TRN & \\
\hline CHEMBL1344952 & 688521 & 4.1 & 4.199 & TRN & \\
\hline CHEMBL28 & 688521 & 4.3 & 4.2382 & TRN & \\
\hline CHEMBL1319452 & 688521 & 4.3 & 4.3811 & TRN & \\
\hline CHEMBL1409985 & 688521 & 5.3 & 5.2063 & TRN & \\
\hline CHEMBL44072 & 688521 & 4.5 & 4.2303 & TST & \\
\hline CHEMBL1236200 & 688521 & 4.1 & 4.3317 & TRN & \\
\hline CHEMBL144530 & 688521 & 4.5 & 4.3887 & TRN & \\
\hline CHEMBL1526319 & 688521 & 4.5 & 4.5823 & TRN & \\
\hline CHEMBL1452158 & 688521 & 4.4 & 4.3134 & TRN & \\
\hline CHEMBL280998 & 688521 & 4.8 & 4.5795 & TRN & \\
\hline CHEMBL540851 & 688521 & 4.3 & 4.3524 & TST & \\
\hline CHEMBL334255 & 688521 & 4.8 & 4.9224 & TRN & \\
\hline CHEMBL224282 & 688521 & 4.3 & 4.1449 & TRN & \\
\hline CHEMBL1565705 & 688521 & 4.1 & 4.0704 & TRN & \\
\hline CHEMBL1510786 & 688521 & 4.0 & 3.9717 & TRN & \\
\hline CHEMBL1485974 & 688521 & 4.6 & 4.5957 & TRN & \\
\hline CHEMBL1600998 & 688521 & 5.3 & 5.2223 & TRN & \\
\hline CHEMBL1303139 & 688521 & 5.4 & 5.3648 & TRN & \\
\hline CHEMBL1450607 & 688521 & 4.6 & 4.7871 & TST & \\
\hline CHEMBL1579130 & 688521 & 6.0 & 5.92299 & 9999999999 & TRN \\
\hline CHEMBL1419151 & 688521 & 4.3 & 4.323 & TRN & \\
\hline CHEMBL1545634 & 688521 & 6.5 & 6.4889 & TRN & \\
\hline
\end{tabular}




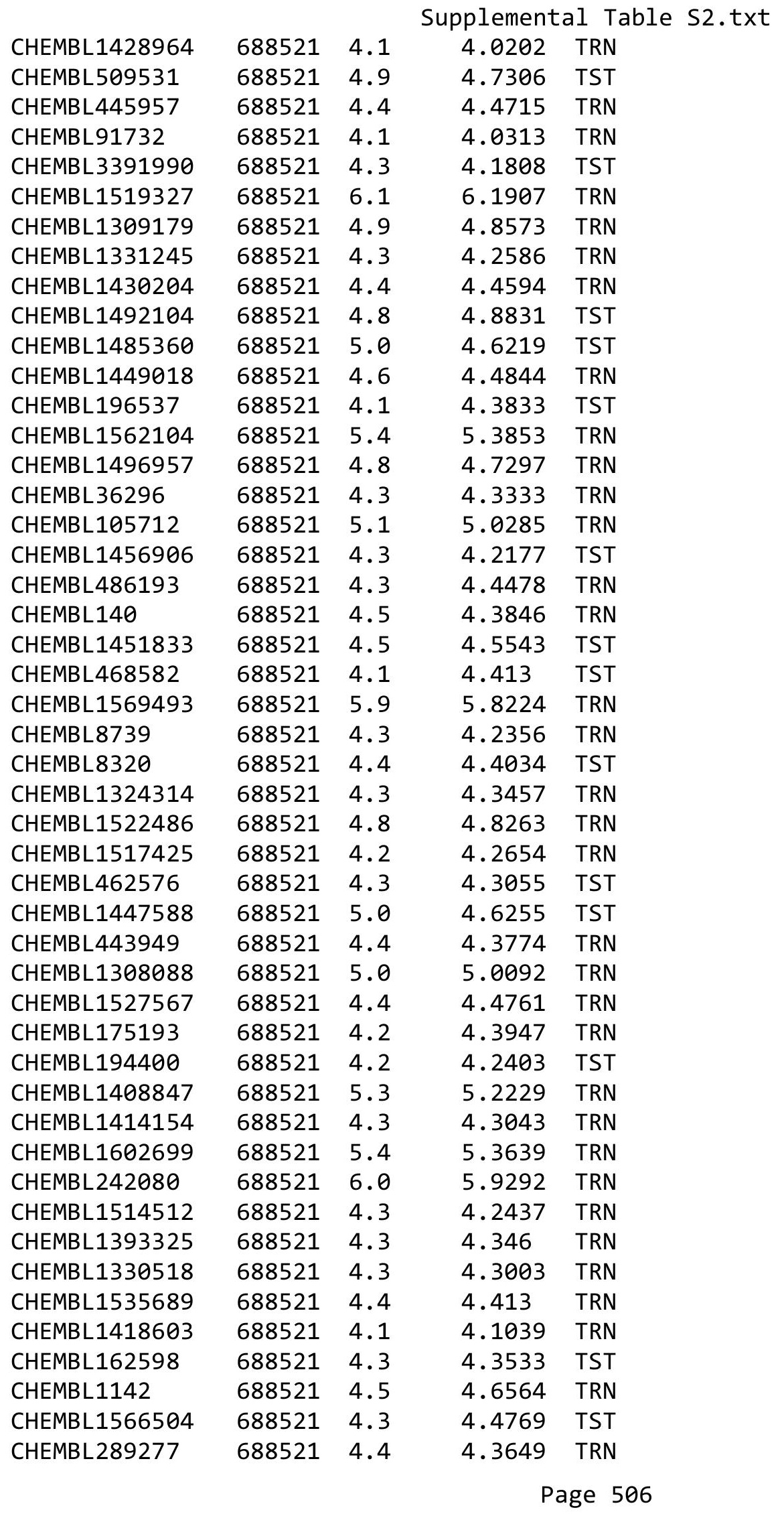




\begin{tabular}{|c|c|c|c|c|}
\hline \multicolumn{5}{|c|}{ Supplemental Table S2.txt } \\
\hline CHEMBL1489568 & 688521 & 4.3 & 4.2829 & TRN \\
\hline CHEMBL197592 & 654561 & 5.92 & 5.9197 & TRN \\
\hline CHEMBL438797 & 654561 & 5.89 & 5.8913 & TRN \\
\hline CHEMBL 371329 & 654561 & 6.96 & 6.9404 & TRN \\
\hline CHEMBL198267 & 654561 & 6.05 & 6.0529 & TRN \\
\hline CHEMBL445394 & 654561 & 6.04 & 6.0453 & TRN \\
\hline CHEMBL371889 & 654561 & 6.44 & 6.4459 & TRN \\
\hline CHEMBL 365784 & 654561 & 5.8 & 5.7986 & TRN \\
\hline CHEMBL194270 & 654561 & 6.0 & 5.9865 & TRN \\
\hline CHEMBL196747 & 654561 & 6.4 & 6.4055 & TRN \\
\hline CHEMBL196499 & 654561 & 6.07 & 6.0786 & TRN \\
\hline CHEMBL194321 & 654561 & 6.05 & 6.0585 & TRN \\
\hline CHEMBL382517 & 654561 & 6.68 & 6.6937 & TRN \\
\hline CHEMBL 372174 & 654561 & 5.92 & 5.9245 & TRN \\
\hline CHEMBL195955 & 654561 & 6.89 & 6.8858 & TRN \\
\hline CHEMBL194236 & 654561 & 5.96 & 5.9563 & TRN \\
\hline CHEMBL370325 & 654561 & 7.0 & 6.9961 & TRN \\
\hline CHEMBL1242107 & 654561 & 6.29 & 6.2833 & TRN \\
\hline CHEMBL371206 & 654561 & 6.77 & 6.7659 & TRN \\
\hline CHEMBL381034 & 654561 & 6.44 & 6.4316 & TRN \\
\hline CHEMBL381207 & 654561 & 7.77 & 7.7696 & TRN \\
\hline CHEMBL197635 & 654561 & 6.92 & 6.9256 & TRN \\
\hline CHEMBL198601 & 654561 & 6.33 & 6.319 & TRN \\
\hline CHEMBL 382112 & 654561 & 6.85 & 6.8518 & TRN \\
\hline CHEMBL194842 & 654561 & 6.37 & 6.3744 & TRN \\
\hline CHEMBL 372388 & 654561 & 6.2 & 6.194 & TRN \\
\hline CHEMBL366241 & 654561 & 6.47 & 6.4704 & TRN \\
\hline CHEMBL196363 & 654561 & 6.14 & 7.0477 & TST \\
\hline CHEMBL 371225 & 654561 & 6.54 & 6.5452 & TRN \\
\hline CHEMBL371890 & 654561 & 6.24 & 6.2388 & TRN \\
\hline CHEMBL 372755 & 654561 & 6.06 & 6.0497 & TRN \\
\hline CHEMBL371379 & 654561 & 6.6 & 6.5945 & TRN \\
\hline CHEMBL369908 & 654561 & 6.57 & 6.5773 & TRN \\
\hline CHEMBL197353 & 654561 & 6.59 & 6.6101 & TRN \\
\hline CHEMBL198155 & 654561 & 6.66 & 6.664 & TRN \\
\hline CHEMBL198297 & 654561 & 6.96 & 6.9521 & TRN \\
\hline CHEMBL196636 & 654561 & 6.72 & 6.726 & TRN \\
\hline CHEMBL196021 & 654561 & 6.0 & 5.9949 & TRN \\
\hline CHEMBL194057 & 654561 & 6.22 & 6.2221 & TRN \\
\hline CHEMBL363389 & 654561 & 6.27 & 6.3503 & TST \\
\hline CHEMBL194150 & 654561 & 6.52 & 6.3726 & TST \\
\hline CHEMBL196841 & 654561 & 6.72 & 6.3001 & TST \\
\hline CHEMBL194149 & 654561 & 7.55 & 5.7123 & TST \\
\hline CHEMBL194911 & 654561 & 8.7 & 7.4539 & TST \\
\hline CHEMBL195567 & 654561 & 7.23 & 5.7745 & TST \\
\hline CHEMBL193752 & 654561 & 6.56 & 5.8018 & TST \\
\hline CHEMBL362915 & 654561 & 5.75 & 6.3576 & TST \\
\hline CHEMBL 383603 & 654561 & 5.83 & 6.2555 & TST \\
\hline
\end{tabular}




\begin{tabular}{|c|c|c|c|c|c|c|}
\hline \multicolumn{7}{|c|}{ Supplemental Table S2.txt } \\
\hline CHEMBL372845 & 654561 & 6.3 & 6.0316 & TST & & \\
\hline CHEMBL365773 & 654561 & 6.07 & 6.5173 & TST & & \\
\hline CHEMBL372617 & 654561 & 7.66 & 5.7291 & TST & & \\
\hline CHEMBL81239 & 164620 & 8.5686 & 7.5789 & TST & & \\
\hline CHEMBL81970 & 164620 & 8.5686 & 9.2562 & TRN & & \\
\hline CHEMBL312154 & 164620 & 8.4089 & 8.5378 & TRN & & \\
\hline CHEMBL309229 & 164620 & 5.0 & 6.5161 & TRN & & \\
\hline CHEMBL311880 & 164620 & 9.0969 & 8.7321 & TRN & & \\
\hline CHEMBL 81112 & 164620 & 8.5376 & 8.2601 & TRN & & \\
\hline CHEMBL 78653 & 164620 & 8.8861 & 8.9542 & TRN & & \\
\hline CHEMBL310835 & 164620 & 6.4578 & 7.2724 & TRN & & \\
\hline CHEMBL312682 & 164620 & 8.9208 & 8.3009 & TST & & \\
\hline CHEMBL312390 & 164620 & 5.0 & 7.5256 & TST & & \\
\hline CHEMBL309558 & 164620 & 8.7959 & 8.2185 & TRN & & \\
\hline CHEMBL 311327 & 164620 & 8.6383 & 8.5628 & TRN & & \\
\hline CHEMBL310532 & 164620 & 8.8539 & 7.7975 & TST & & \\
\hline CHEMBL311180 & 164620 & 9.0 & 9.3068 & TRN & & \\
\hline CHEMBL311415 & 164620 & 7.9547 & 7.9854 & TRN & & \\
\hline CHEMBL 81072 & 164620 & 8.1549 & 7.9898 & TRN & & \\
\hline CHEMBL 79022 & 164620 & 7.9393 & 7.3118 & TRN & & \\
\hline CHEMBL312778 & 164620 & $7.7620 e$ & 00000000 & 205 & 7.8931 & TRN \\
\hline CHEMBL81433 & 164620 & 8.5086 & 9.352 & TRN & & \\
\hline CHEMBL311066 & 164620 & 8.6778 & 8.2804 & TRN & & \\
\hline CHEMBL78769 & 164620 & 7.9788 & 8.5902 & TST & & \\
\hline CHEMBL310550 & 164620 & 8.8539 & 8.5889 & TST & & \\
\hline CHEMBL 78015 & 164620 & 8.4318 & 8.5876 & TRN & & \\
\hline CHEMBL 309535 & 164620 & 8.585 & 8.3077 & TRN & & \\
\hline CHEMBL 82075 & 164620 & 8.4559 & 7.5842 & TRN & & \\
\hline CHEMBL 81272 & 164620 & 9.0 & 8.5202 & TST & & \\
\hline CHEMBL 79051 & 164620 & 5.0 & 7.6111 & TST & & \\
\hline CHEMBL79135 & 164620 & 8.7212 & 8.8817 & TRN & & \\
\hline CHEMBL442181 & 164620 & 8.1675 & 7.5904 & TRN & & \\
\hline CHEMBL 309722 & 164620 & 7.5935 & 7.6095 & TRN & & \\
\hline CHEMBL 78197 & 164620 & 7.6402 & 7.4059 & TRN & & \\
\hline CHEMBL 79196 & 164620 & 8.1549 & 8.1555 & TRN & & \\
\hline CHEMBL 81724 & 164620 & 8.7447 & 8.0108 & TRN & & \\
\hline CHEMBL79226 & 164620 & 8.585 & 7.8852 & TST & & \\
\hline CHEMBL81906 & 164620 & 6.9706 & 7.8587 & TST & & \\
\hline CHEMBL311057 & 164620 & 8.3979 & 8.6955 & TRN & & \\
\hline CHEMBL310075 & 164620 & 8.6778 & 9.6408 & TRN & & \\
\hline CHEMBL 82133 & 164620 & 8.5086 & 8.1996 & TRN & & \\
\hline CHEMBL 82311 & 164620 & 9.1549 & 7.1277 & TST & & \\
\hline CHEMBL78886 & 164620 & 7.4001 & 7.5163 & TRN & & \\
\hline CHEMBL 310758 & 164620 & 9.5229 & 8.623 & TRN & & \\
\hline CHEMBL78360 & 164620 & 9.0969 & 8.8806 & TST & & \\
\hline CHEMBL310549 & 164620 & 8.6021 & 7.8912 & TRN & & \\
\hline CHEMBL311755 & 164620 & 7.5406 & 7.7503 & TRN & & \\
\hline CHEMBL78931 & 164620 & 8.8539 & 8.3026 & TRN & & \\
\hline
\end{tabular}




\begin{tabular}{|c|c|c|c|c|c|c|}
\hline & & \multicolumn{5}{|c|}{ Supplemental Table s2.txt } \\
\hline CHEMBL81499 & 164620 & 8.7447 & 9.2456 & TRN & & \\
\hline CHEMBL311676 & 164620 & 9.5229 & 8.9423 & TRN & & \\
\hline CHEMBL78954 & 164620 & 8.3979 & 8.4117 & TRN & & \\
\hline CHEMBL420214 & 164620 & 8.585 & 8.0864 & TRN & & \\
\hline CHEMBL82718 & 164620 & 8.3468 & 7.8092 & TRN & & \\
\hline CHEMBL433332 & 164620 & 8.1675 & 8.5489 & TRN & & \\
\hline CHEMBL78606 & 164620 & 5.0 & 7.135 & TRN & & \\
\hline CHEMBL311766 & 164620 & 8.0 & 7.6522 & TRN & & \\
\hline CHEMBL81496 & 164620 & 8.8239 & 7.3283 & TST & & \\
\hline CHEMBL310530 & 164620 & 9.301 & 8.0578 & TST & & \\
\hline CHEMBL81212 & 164620 & 8.1487 & 8.2863 & TRN & & \\
\hline CHEMBL3979827 & 1641912 & 8.5258 & 8.163 & TRN & & \\
\hline CHEMBL3909197 & 1641912 & 6.0 & 8.6016 & TRN & & \\
\hline CHEMBL3912203 & 1641912 & 8.9996 & 8.6668 & TRN & & \\
\hline CHEMBL3895549 & 1641912 & 9.1308 & 8.7966 & TRN & & \\
\hline CHEMBL3907629 & 1641912 & 9.7878 & 9.0634 & TST & & \\
\hline CHEMBL 3943855 & 1641912 & 9.3045 & 9.1681 & TST & & \\
\hline CHEMBL3983558 & 1641912 & 9.5072 & 9.2033 & TRN & & \\
\hline CHEMBL3976189 & 1641912 & 9.5003 & 8.8996 & TRN & & \\
\hline CHEMBL3945756 & 1641912 & 6.0 & 8.9858 & TRN & & \\
\hline CHEMBL3936711 & 1641912 & 8.7959 & 8.6901 & TRN & & \\
\hline CHEMBL 3955553 & 1641912 & 9.7258 & 9.2262 & TST & & \\
\hline CHEMBL3979783 & 1641912 & 8.0898 & 8.7611 & TRN & & \\
\hline CHEMBL3925643 & 1641912 & 8.8213 & 8.2418 & TRN & & \\
\hline CHEMBL3961529 & 1641912 & 6.0 & 8.7822 & TRN & & \\
\hline CHEMBL3903662 & 1641912 & 9.85700 & 000000006 & 01 & 9.3184 & TRN \\
\hline CHEMBL3901889 & 1641912 & 7.0573 & 8.7693 & TRN & & \\
\hline CHEMBL3968623 & 1641912 & 8.1646 & 8.6502 & TST & & \\
\hline CHEMBL3980916 & 1641912 & 8.432 & 8.8141 & TST & & \\
\hline CHEMBL3985044 & 1641912 & 9.5258 & 9.2213 & TRN & & \\
\hline CHEMBL3959690 & 1641912 & 7.8465 & 8.8372 & TRN & & \\
\hline CHEMBL3904160 & 1641912 & 9.7721 & 9.3858 & TST & & \\
\hline CHEMBL3931214 & 1641912 & 9.3526 & 9.17 & TRN & & \\
\hline CHEMBL3928665 & 1641912 & 9.4547 & 9.0886 & TRN & & \\
\hline CHEMBL3892710 & 1641912 & 9.1085 & 8.2432 & TRN & & \\
\hline CHEMBL 3925187 & 1641912 & 6.0 & 8.2716 & TRN & & \\
\hline CHEMBL3921717 & 1641912 & 6.0 & 7.3164 & TRN & & \\
\hline CHEMBL3973720 & 1641912 & 8.776 & 7.6452 & TST & & \\
\hline CHEMBL3901714 & 1641912 & 8.7706 & 8.8731 & TST & & \\
\hline CHEMBL3932259 & 1641912 & 9.5513 & 8.6563 & TST & & \\
\hline CHEMBL3895665 & 1641912 & 9.9031 & 9.0861 & TRN & & \\
\hline CHEMBL3926268 & 1641912 & 6.0 & 8.6505 & TRN & & \\
\hline CHEMBL3896773 & 1641912 & 8.5896 & 9.3341 & TST & & \\
\hline CHEMBL3922357 & 1641912 & 9.8827 & 8.1745 & TRN & & \\
\hline CHEMBL3902132 & 1641912 & 9.9393 & 9.1818 & TRN & & \\
\hline CHEMBL3961756 & 1641912 & 9.5436 & 8.9292 & TST & & \\
\hline CHEMBL3900233 & 1641912 & 8.969 & 9.22299 & 9999999999 & & TST \\
\hline CHEMBL3912023 & 1641912 & 8.7242 & 8.7551 & TRN & & \\
\hline
\end{tabular}


Supplemental Table S2.txt

\begin{tabular}{|c|c|c|c|c|c|c|}
\hline CHEMBL3961711 & 1641912 & 8.4921 & 8.316 & TRN & & \\
\hline CHEMBL3978059 & 1641912 & 9.4763 & 8.1884 & TST & & \\
\hline CHEMBL3964289 & 1641912 & 9.9172 & 9.2092 & TST & & \\
\hline CHEMBL3984231 & 1641912 & 8.7102 & 9.1462 & TRN & & \\
\hline CHEMBL 3965576 & 1641912 & 9.317 & 8.0683 & TST & & \\
\hline CHEMBL 3973707 & 1641912 & 9.5952 & 9.3426 & TRN & & \\
\hline CHEMBL3971176 & 1641912 & 9.5003 & 9.0934 & TRN & & \\
\hline CHEMBL3903599 & 1641912 & 9.6308 & 9.1716 & TRN & & \\
\hline CHEMBL 3935668 & 1641912 & 9.98299 & 79999999 & 99 & 9.1702 & TRN \\
\hline CHEMBL 3975972 & 1641912 & 9.7645 & 8.9559 & TST & & \\
\hline CHEMBL 3954470 & 1641912 & 9.5114 & 9.1566 & TRN & & \\
\hline CHEMBL3956352 & 1641912 & 9.9136 & 8.9958 & TST & & \\
\hline CHEMBL3909112 & 1641912 & 9.6091 & 8.0005 & TRN & & \\
\hline CHEMBL3961386 & 1641912 & 9.3696 & 7.971 & TRN & & \\
\hline CHEMBL 3978167 & 1641912 & 6.0 & 9.1039 & TRN & & \\
\hline CHEMBL 3902934 & 1641912 & 9.4248 & 8.8875 & TRN & & \\
\hline CHEMBL3912687 & 1641912 & 8.1453 & 8.7568 & TRN & & \\
\hline CHEMBL 3946024 & 1641912 & 9.1605 & 8.8863 & TRN & & \\
\hline CHEMBL 3983005 & 1641912 & 9.3363 & 9.1111 & TRN & & \\
\hline CHEMBL 3910791 & 1641912 & 9.5302 & 8.1042 & TRN & & \\
\hline CHEMBL 3914272 & 1641912 & 6.0437 & 8.2472 & TRN & & \\
\hline CHEMBL3906793 & 1641912 & 8.2519 & 9.34 & TST & & \\
\hline CHEMBL3901604 & 1641912 & 9.8239 & 9.2903 & TRN & & \\
\hline CHEMBL 3922965 & 1641912 & 9.8539 & 8.5957 & TST & & \\
\hline CHEMBL 3898237 & 1641912 & 9.3098 & 9.2169 & TRN & & \\
\hline CHEMBL3969509 & 1641912 & 9.6925 & 9.3019 & TRN & & \\
\hline CHEMBL3949888 & 1641912 & 9.7328 & 8.2391 & TRN & & \\
\hline CHEMBL3899074 & 1641912 & 9.7932 & 8.9928 & TRN & & \\
\hline CHEMBL3975933 & 1641912 & 9.9747 & 9.3308 & TRN & & \\
\hline CHEMBL3919420 & 1641912 & 9.1891 & 7.6629 & TST & & \\
\hline CHEMBL3932419 & 1641912 & 9.3391 & 9.2689 & TRN & & \\
\hline CHEMBL 3974082 & 1641912 & 9.3143 & 9.2303 & TST & & \\
\hline CHEMBL3953073 & 1641912 & 9.8928 & 8.875 & TRN & & \\
\hline CHEMBL3949589 & 1641912 & 9.7122 & 9.0367 & TRN & & \\
\hline CHEMBL3937960 & 1641912 & 7.5207 & 8.2464 & TRN & & \\
\hline CHEMBL 3900501 & 1641912 & 9.5735 & 8.8906 & TRN & & \\
\hline CHEMBL 3962395 & 1641912 & 6.0 & 9.0746 & TRN & & \\
\hline CHEMBL 3942945 & 1641912 & 9.1972 & 9.1561 & TRN & & \\
\hline CHEMBL 3962752 & 1641912 & 9.2277 & 8.7435 & TRN & & \\
\hline CHEMBL 3892910 & 1641912 & 9.3969 & 8.2987 & TRN & & \\
\hline CHEMBL 3967624 & 1641912 & 8.8586 & 8.4782 & TRN & & \\
\hline CHEMBL 3953300 & 1641912 & 9.4908 & 9.0339 & TST & & \\
\hline CHEMBL3955169 & 1641912 & 9.7033 & 9.4241 & TST & & \\
\hline CHEMBL 3980581 & 1641912 & 7.8652 & 7.2276 & TRN & & \\
\hline CHEMBL 3894270 & 1641912 & 6.0 & 8.2995 & TRN & & \\
\hline CHEMBL 3895513 & 1641912 & 8.7783 & 7.354 & TRN & & \\
\hline CHEMBL 3983285 & 1641912 & 9.1096 & 8.7198 & TRN & & \\
\hline CHEMBL 3954710 & 1641912 & 9.4318 & 8.9795 & TRN & & \\
\hline
\end{tabular}

Page 510 
Supplemental Table S2.txt

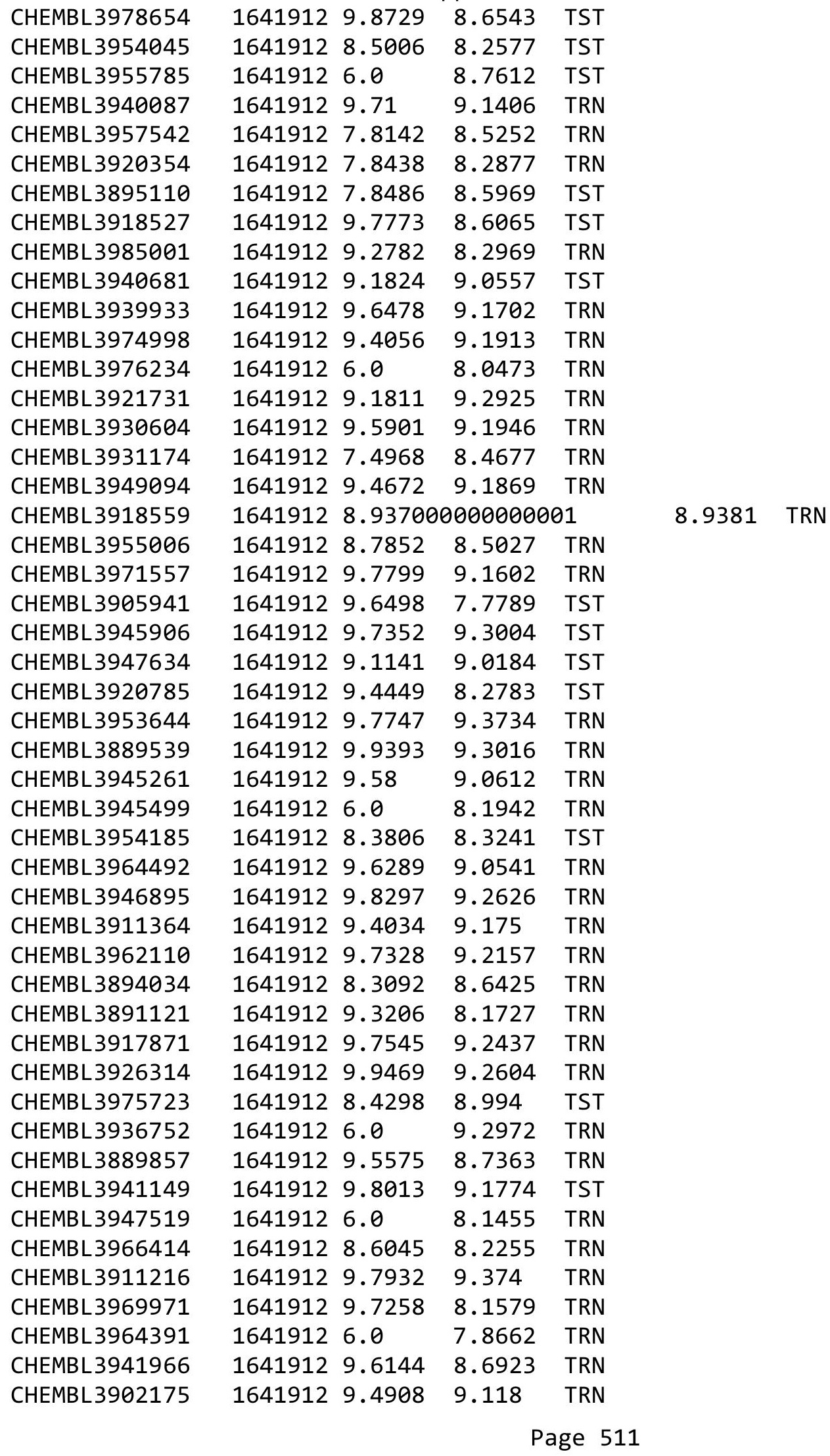


Supplemental Table S2.txt

\begin{tabular}{|c|c|c|c|c|c|}
\hline CHEMBL3927773 & 1641912 & 8.9024 & 8.1234 & TRN & \\
\hline CHEMBL3896230 & 1641912 & 9.5186 & 8.2226 & TRN & \\
\hline CHEMBL3925236 & 1641912 & 6.0 & 9.0888 & TRN & \\
\hline CHEMBL3919093 & 1641912 & 9.8182 & 9.2706 & TRN & \\
\hline CHEMBL3930918 & 1641912 & 9.5143 & 9.2077 & TRN & \\
\hline CHEMBL3948248 & 1641912 & 9.8794 & 9.2689 & TST & \\
\hline CHEMBL3916320 & 1641912 & 9.8633 & 9.1831 & TRN & \\
\hline CHEMBL3918896 & 1641912 & 9.6655 & 9.2423 & TRN & \\
\hline CHEMBL3927561 & 1641912 & 9.2933 & 9.1969 & TRN & \\
\hline CHEMBL3917376 & 1641912 & 9.71 & 8.9984 & TRN & \\
\hline CHEMBL3954342 & 1641912 & 9.8633 & 9.3735 & TRN & \\
\hline CHEMBL3958779 & 1641912 & 9.4855 & 8.059 & TRN & \\
\hline CHEMBL3945611 & 1641912 & 8.7345 & 8.8614 & TRN & \\
\hline CHEMBL 3944419 & 1641912 & 8.9638 & 8.7021 & TRN & \\
\hline CHEMBL 3940794 & 1641912 & 9.9586 & 9.2783 & TST & \\
\hline CHEMBL3962088 & 1641912 & 9.5421 & 9.207 & TRN & \\
\hline CHEMBL3975023 & 1641912 & 9.4935 & 8.1144 & TRN & \\
\hline CHEMBL3909065 & 1641912 & 9.4225 & 9.0057 & TRN & \\
\hline CHEMBL3902368 & 1641912 & 9.2 & 8.3062 & TRN & \\
\hline CHEMBL3966525 & 1641912 & 9.5751 & 8.9786 & TRN & \\
\hline CHEMBL3923310 & 1641912 & 6.0 & 9.0729 & TRN & \\
\hline CHEMBL3962264 & 1641912 & 9.5302 & 9.1273 & TRN & \\
\hline CHEMBL3918620 & 1641912 & 9.065 & 9.253 & TST & \\
\hline CHEMBL3904935 & 1641912 & 9.0605 & 8.829 & TST & \\
\hline CHEMBL 3895323 & 1641912 & 6.0 & 8.4065 & TRN & \\
\hline CHEMBL3908421 & 1641912 & 9.9747 & 9.1984 & TRN & \\
\hline CHEMBL3906442 & 1641912 & 8.5699 & 8.5726 & TRN & \\
\hline CHEMBL3953706 & 1641912 & 9.3737 & 8.7565 & TRN & \\
\hline CHEMBL3935262 & 1641912 & 9.7852 & 8.9614 & TRN & \\
\hline CHEMBL 3974644 & 1641912 & 9.289 & 9.1211 & TST & \\
\hline CHEMBL3949558 & 1641912 & 8.7726 & 8.5533 & TRN & \\
\hline CHEMBL3935157 & 1641912 & 6.0 & 8.1314 & TRN & \\
\hline CHEMBL3981229 & 1641912 & 8.5907 & 8.7962 & TST & \\
\hline CHEMBL3939598 & 1641912 & 9.6021 & 9.2571 & TRN & \\
\hline CHEMBL3929622 & 1641912 & 9.1302 & 8.6929 & TRN & \\
\hline CHEMBL3969153 & 1641912 & 9.6968 & 9.246 & TRN & \\
\hline CHEMBL3900015 & 1641912 & 8.8413 & 8.964 & TRN & \\
\hline CHEMBL3913136 & 1641912 & 8.4088 & 9.0633 & TST & \\
\hline CHEMBL3893708 & 1641912 & 8.1026 & 7.207999 & э999999999 & TRN \\
\hline CHEMBL3959598 & 1641912 & 6.0 & 9.0835 & TRN & \\
\hline CHEMBL3918131 & 1641912 & 9.4486 & 9.5252 & TRN & \\
\hline CHEMBL3906706 & 1641912 & 7.8668 & 8.3973 & TST & \\
\hline CHEMBL3986913 & 1641912 & 6.0 & 8.3128 & TRN & \\
\hline CHEMBL3902919 & 1641912 & 8.7852 & 8.3071 & TST & \\
\hline CHEMBL3890144 & 1641912 & 8.6214 & 8.9524 & TRN & \\
\hline CHEMBL3902052 & 1641912 & 9.7773 & 8.2286 & TRN & \\
\hline CHEMBL3919729 & 1641912 & 8.2473 & 8.1714 & TRN & \\
\hline CHEMBL3978626 & 1641912 & 9.2565 & 8.927 & TRN & \\
\hline
\end{tabular}


Supplemental Table S2.txt

\begin{tabular}{|c|c|c|c|c|}
\hline CHEMBL3961681 & 1641912 & 9.7282 & 8.8459 & TRN \\
\hline CHEMBL3916949 & 1641912 & 8.2941 & 8.6119 & TST \\
\hline CHEMBL3891351 & 1641912 & 8.4607 & 7.5242 & TST \\
\hline CHEMBL3914415 & 1641912 & 9.7122 & 8.3042 & TRN \\
\hline CHEMBL3416924 & 1473382 & 7.6021 & 7.6143 & TST \\
\hline CHEMBL3416927 & 1473382 & 8.301 & 8.4683 & TRN \\
\hline CHEMBL3416916 & 1473382 & 6.3872 & 6.1185 & TRN \\
\hline CHEMBL3416939 & 1473382 & 7.5528 & 7.5728 & TRN \\
\hline CHEMBL3416910 & 1473382 & 6.3279 & 6.3186 & TRN \\
\hline CHEMBL3416908 & 1473382 & 6.585 & 7.0898 & TRN \\
\hline CHEMBL3416906 & 1473382 & 6.3279 & 6.5008 & TRN \\
\hline CHEMBL3417035 & 1473382 & 8.0969 & 8.0073 & TRN \\
\hline CHEMBL3416917 & 1473382 & 8.0458 & 7.5704 & TRN \\
\hline CHEMBL3416931 & 1473382 & 8.0969 & 7.9445 & TRN \\
\hline CHEMBL3318132 & 1473382 & 8.5229 & 7.20799 & 9999999999 \\
\hline CHEMBL3416937 & 1473382 & 8.3979 & 8.3619 & TRN \\
\hline CHEMBL3416946 & 1473382 & 8.3979 & 8.3571 & TRN \\
\hline CHEMBL3416943 & 1473382 & 8.3979 & 8.3571 & TRN \\
\hline CHEMBL3416933 & 1473382 & 8.3979 & 8.2204 & TRN \\
\hline CHEMBL3416895 & 1473382 & 6.0269 & 6.3186 & TRN \\
\hline CHEMBL3416935 & 1473382 & 7.2007 & 7.6919 & TRN \\
\hline CHEMBL3416945 & 1473382 & 7.4685 & 7.8309 & TRN \\
\hline CHEMBL3416919 & 1473382 & 7.4089 & 7.5172 & TRN \\
\hline CHEMBL3416914 & 1473382 & 6.7696 & 6.7524 & TRN \\
\hline CHEMBL3416912 & 1473382 & 4.301 & 6.1497 & TST \\
\hline CHEMBL3416911 & 1473382 & 4.301 & 5.5704 & TST \\
\hline CHEMBL3416936 & 1473382 & 7.6383 & 7.6919 & TRN \\
\hline CHEMBL 3416886 & 1473382 & 8.0 & 8.0073 & TRN \\
\hline CHEMBL3416894 & 1473382 & 6.3665 & 7.0789 & TRN \\
\hline CHEMBL 3416922 & 1473382 & 8.0458 & 7.9465 & TRN \\
\hline CHEMBL3416896 & 1473382 & 6.6778 & 6.8965 & TRN \\
\hline CHEMBL 3417041 & 1473382 & 8.7959 & 8.291 & TRN \\
\hline CHEMBL3416899 & 1473382 & 6.7212 & 6.3186 & TRN \\
\hline CHEMBL3416932 & 1473382 & 7.6198 & 7.6919 & TRN \\
\hline CHEMBL3416920 & 1473382 & 7.7212 & 7.8832 & TRN \\
\hline CHEMBL3416925 & 1473382 & 7.6198 & 7.6642 & TRN \\
\hline CHEMBL3416893 & 1473382 & 6.2007 & 6.6959 & TRN \\
\hline CHEMBL 3416944 & 1473382 & 8.301 & 8.3571 & TRN \\
\hline CHEMBL3416902 & 1473382 & 7.0458 & 7.2552 & TRN \\
\hline CHEMBL3417038 & 1473382 & 8.3979 & 8.291 & TRN \\
\hline CHEMBL3416889 & 1473382 & 6.4318 & 6.2378 & TRN \\
\hline CHEMBL3416890 & 1473382 & 7.0 & 7.0894 & TRN \\
\hline CHEMBL3416934 & 1473382 & 7.7212 & 7.6919 & TRN \\
\hline CHEMBL3417039 & 1473382 & 7.9586 & 7.7689 & TRN \\
\hline CHEMBL3416923 & 1473382 & 8.301 & 7.8832 & TRN \\
\hline CHEMBL3416904 & 1473382 & 6.7212 & 6.3186 & TRN \\
\hline CHEMBL3416929 & 1473382 & 6.6271 & 7.053 & TRN \\
\hline CHEMBL3416907 & 1473382 & 6.4815 & 6.3186 & TRN \\
\hline
\end{tabular}


Supplemental Table S2.txt

\begin{tabular}{|c|c|c|c|c|}
\hline & & & & \\
\hline СНСMPI 2117927 & 473382 & 7.2676 & & \\
\hline IEMBL & 382 & & & \\
\hline IEMBL3 & 3382 & & 038 & \\
\hline AEMBL3416938 & 173382 & 8.0 & 866 & \\
\hline AEMBL & 382 & 24 & & \\
\hline & 382 & & & \\
\hline IEMBL: & 3382 & 6.3665 & 796 & \\
\hline AEMBL34 & 3382 & 7.8861 & 689 & \\
\hline HEMBL3 & 382 & 8.3979 & 558 & \\
\hline IEMBL & 382 & 6.1612 & 186 & \\
\hline ᄃMPI & 382 & 8.5229 & & \\
\hline IEMBL & 382 & 6.301 & 186 & \\
\hline AEMBL 3 & 382 & 5.9208 & 185 & \\
\hline IEMBL & 382 & 6.7696 & 772 & \\
\hline 3 & 382 & 969 & 82 & \\
\hline & 382 & & & \\
\hline IFMB & 382 & 7.0655 & 928 & \\
\hline 21 & & & 832 & \\
\hline 9 & 382 & 32 & 28 & \\
\hline & 82 & 69 & 28 & \\
\hline & 82 & & 04 & \\
\hline 01 & 382 & 861 & 257 & \\
\hline & & & 227 & \\
\hline 2 & 82 & 586 & 04 & \\
\hline & 82 & 383 & 86 & \\
\hline & & & & \\
\hline & & 243 & 55 & \\
\hline & & & & \\
\hline 8 & & 3. & 65 & \\
\hline & & 3 . & 55 & \\
\hline & & & & \\
\hline & & & & \\
\hline & & & & \\
\hline 3 & & 346 & 96 & \\
\hline & & 706 & & \\
\hline & & & & \\
\hline & & & & \\
\hline & & 5 . & 119 & \\
\hline & & 213 & 335 & \\
\hline & & & 212 & \\
\hline & & & & \\
\hline MBL & & 243 & 935 & \\
\hline 6 & & 243 & 564 & \\
\hline & & & & \\
\hline - & & 5.2832 & 4.6456 & \\
\hline CHEMBL1 & & 3.5243 & 3.4595 & \\
\hline CHEMBL581449 & 688381 & 4.8327 & 4.2462 & \\
\hline
\end{tabular}

Page 514 
Supplemental Table S2.txt

\begin{tabular}{|c|c|c|c|c|}
\hline CHEMBL1421574 & 688381 & 3.5243 & 3.4213 & TRN \\
\hline CHEMBL1460624 & 688381 & 3.5243 & 4.5315 & TRN \\
\hline CHEMBL1504286 & 688381 & 3.5243 & 3.5352 & TRN \\
\hline CHEMBL1602153 & 688381 & 3.5243 & 3.7854 & TRN \\
\hline CHEMBL1430184 & 688381 & 4.0013 & 4.3859 & TRN \\
\hline CHEMBL1382411 & 688381 & 3.5243 & 3.2363 & TRN \\
\hline CHEMBL1351173 & 688381 & 3.5243 & 4.4352 & TRN \\
\hline CHEMBL1603040 & 688381 & 3.5243 & 4.0049 & TST \\
\hline CHEMBL1359986 & 688381 & 3.5243 & 3.37 & TRN \\
\hline CHEMBL1458848 & 688381 & 3.5243 & 3.3515 & TRN \\
\hline CHEMBL1506427 & 688381 & 3.5243 & 3.9723 & TRN \\
\hline CHEMBL1414923 & 688381 & 5.9872 & 5.2225 & TRN \\
\hline CHEMBL601135 & 688381 & 4.4789 & 4.3395 & TRN \\
\hline CHEMBL1383045 & 688381 & 3.5243 & 3.8166 & TRN \\
\hline CHEMBL1408066 & 688381 & 3.5243 & 3.4729 & TRN \\
\hline CHEMBL1351659 & 688381 & 3.5243 & 3.8476 & TRN \\
\hline CHEMBL1528702 & 688381 & 3.5243 & 3.7103 & TRN \\
\hline CHEMBL1507439 & 688381 & 3.5243 & 3.9111 & TST \\
\hline CHEMBL1377321 & 688381 & 3.5243 & 3.2766 & TRN \\
\hline CHEMBL1319502 & 688381 & 3.5243 & 3.5062 & TRN \\
\hline CHEMBL1465815 & 688381 & 3.5243 & 3.2653 & TRN \\
\hline CHEMBL1400385 & 688381 & 3.5243 & 3.4055 & TRN \\
\hline CHEMBL1976525 & 688381 & 3.5243 & 4.7098 & TRN \\
\hline CHEMBL1428566 & 688381 & 3.5243 & 3.984 & TST \\
\hline CHEMBL1543131 & 688381 & 5.4012 & 5.0712 & TRN \\
\hline CHEMBL1494852 & 688381 & 5.2055 & 4.8137 & TRN \\
\hline CHEMBL1560584 & 688381 & 3.5243 & 3.5449 & TRN \\
\hline CHEMBL1603731 & 688381 & 3.5243 & 3.4772 & TRN \\
\hline CHEMBL1585420 & 688381 & 3.5243 & 3.8909 & TRN \\
\hline CHEMBL1402083 & 688381 & 5.266 & 4.6208 & TST \\
\hline CHEMBL1365061 & 688381 & 3.5243 & 4.0497 & TST \\
\hline CHEMBL1393535 & 688381 & 3.5243 & 3.3608 & TRN \\
\hline CHEMBL1598968 & 688381 & 3.5243 & 3.4849 & TRN \\
\hline CHEMBL1596184 & 688381 & 4.0013 & 4.1823 & TRN \\
\hline CHEMBL1412812 & 688381 & 3.5243 & 3.2669 & TRN \\
\hline CHEMBL1329925 & 688381 & 4.6144 & 3.5918 & TRN \\
\hline CHEMBL1971695 & 688381 & 5.2299 & 4.8546 & TRN \\
\hline CHEMBL1389483 & 688381 & 3.5243 & 3.3903 & TRN \\
\hline CHEMBL455399 & 688381 & 4.9547 & 4.9813 & TRN \\
\hline CHEMBL1446321 & 688381 & 3.5243 & 4.2041 & TRN \\
\hline CHEMBL1470369 & 688381 & 3.5243 & 4.0629 & TST \\
\hline CHEMBL1574121 & 688381 & 5.3468 & 4.6929 & TRN \\
\hline CHEMBL1985429 & 688381 & 3.5243 & 3.6708 & TST \\
\hline CHEMBL1968278 & 688381 & 3.5243 & 3.6127 & TST \\
\hline CHEMBL1419072 & 688381 & 3.5243 & 3.6331 & TST \\
\hline CHEMBL1484458 & 688381 & 3.5243 & 3.4666 & TST \\
\hline CHEMBL1595978 & 688381 & 3.5243 & 3.6727 & TST \\
\hline CHEMBL1569585 & 688381 & 5.9508 & 4.42 & TST \\
\hline
\end{tabular}




\begin{tabular}{|c|c|c|c|c|c|}
\hline \multirow[b]{2}{*}{ CHEMBL1360021 } & & \multicolumn{4}{|c|}{ Supplemental Table s2.txt } \\
\hline & 688381 & 3.5243 & 3.31399 & 99999999996 & TST \\
\hline CHEMBL1527735 & 688381 & 5.5591 & 4.7372 & TST & \\
\hline CHEMBL1352344 & 688381 & 5.7212 & 4.9525 & TST & \\
\hline CHEMBL1588763 & 688381 & 3.5243 & 3.1582 & TST & \\
\hline CHEMBL 3039775 & 688381 & 4.8477 & 4.2978 & TST & \\
\hline CHEMBL487521 & 556877 & 3.301 & 3.3278 & TRN & \\
\hline CHEMBL487730 & 556877 & 3.301 & 3.1817 & TRN & \\
\hline CHEMBL486497 & 556877 & 3.301 & 3.3017 & TRN & \\
\hline CHEMBL409861 & 556877 & 3.301 & 3.3235 & TRN & \\
\hline CHEMBL530335 & 556877 & 3.301 & 3.3838 & TRN & \\
\hline CHEMBL486301 & 556877 & 3.301 & 3.4252 & TRN & \\
\hline CHEMBL486711 & 556877 & 3.301 & 3.2394 & TRN & \\
\hline CHEMBL407095 & 556877 & 3.301 & 3.5425 & TRN & \\
\hline CHEMBL487526 & 556877 & 4.3279 & 4.1569 & TST & \\
\hline CHEMBL477077 & 556877 & 3.301 & 3.4243 & TRN & \\
\hline CHEMBL484288 & 556877 & 3.301 & 3.1862 & TRN & \\
\hline CHEMBL520458 & 556877 & 3.301 & 3.2225 & TRN & \\
\hline CHEMBL477073 & 556877 & 3.301 & 3.3696 & TRN & \\
\hline CHEMBL486091 & 556877 & 3.301 & 3.281 & TRN & \\
\hline CHEMBL487326 & 556877 & 3.301 & 3.2107 & TRN & \\
\hline CHEMBL486285 & 556877 & 4.3279 & 3.9754 & TRN & \\
\hline CHEMBL488955 & 556877 & 3.301 & 3.1966 & TRN & \\
\hline CHEMBL488349 & 556877 & 3.301 & 3.3918 & TRN & \\
\hline CHEMBL489655 & 556877 & 3.301 & 3.3103 & TRN & \\
\hline CHEMBL521459 & 556877 & 3.301 & 3.3502 & TRN & \\
\hline CHEMBL487737 & 556877 & 3.301 & 3.116 & TST & \\
\hline CHEMBL482919 & 556877 & 3.301 & 3.1599 & TRN & \\
\hline CHEMBL482918 & 556877 & 3.301 & 3.3409 & TRN & \\
\hline CHEMBL488549 & 556877 & 3.301 & 3.2952 & TRN & \\
\hline CHEMBL482678 & 556877 & 3.5528 & 3.83399 & 99999999996 & TRN \\
\hline CHEMBL488562 & 556877 & 3.301 & 3.2791 & TRN & \\
\hline CHEMBL483081 & 556877 & 3.301 & 3.2803 & TRN & \\
\hline CHEMBL520864 & 556877 & 3.301 & 3.3167 & TRN & \\
\hline CHEMBL488342 & 556877 & 3.301 & 3.2017 & TST & \\
\hline CHEMBL485892 & 556877 & 3.301 & 3.1829 & TRN & \\
\hline CHEMBL483530 & 556877 & 3.301 & 3.2264 & TRN & \\
\hline CHEMBL486284 & 556877 & 4.7077 & 4.3572 & TRN & \\
\hline CHEMBL485878 & 556877 & 3.301 & 3.4371 & TRN & \\
\hline CHEMBL482883 & 556877 & 4.6778 & 4.7008 & TRN & \\
\hline CHEMBL488548 & 556877 & 5.0915 & 5.1748 & TRN & \\
\hline CHEMBL515949 & 556877 & 3.301 & 3.2797 & TRN & \\
\hline CHEMBL486286 & 556877 & 3.301 & 3.4368 & TRN & \\
\hline CHEMBL486487 & 556877 & 4.4001 & 4.3747 & TST & \\
\hline CHEMBL487328 & 556877 & 3.301 & 3.3008 & TRN & \\
\hline CHEMBL486712 & 556877 & 3.301 & 3.3834 & TRN & \\
\hline CHEMBL487531 & 556877 & 5.1135 & 5.1201 & TRN & \\
\hline CHEMBL485877 & 556877 & 3.301 & 3.3456 & TRN & \\
\hline CHEMBL 260864 & 556877 & 3.301 & 3.3093 & TRN & \\
\hline
\end{tabular}




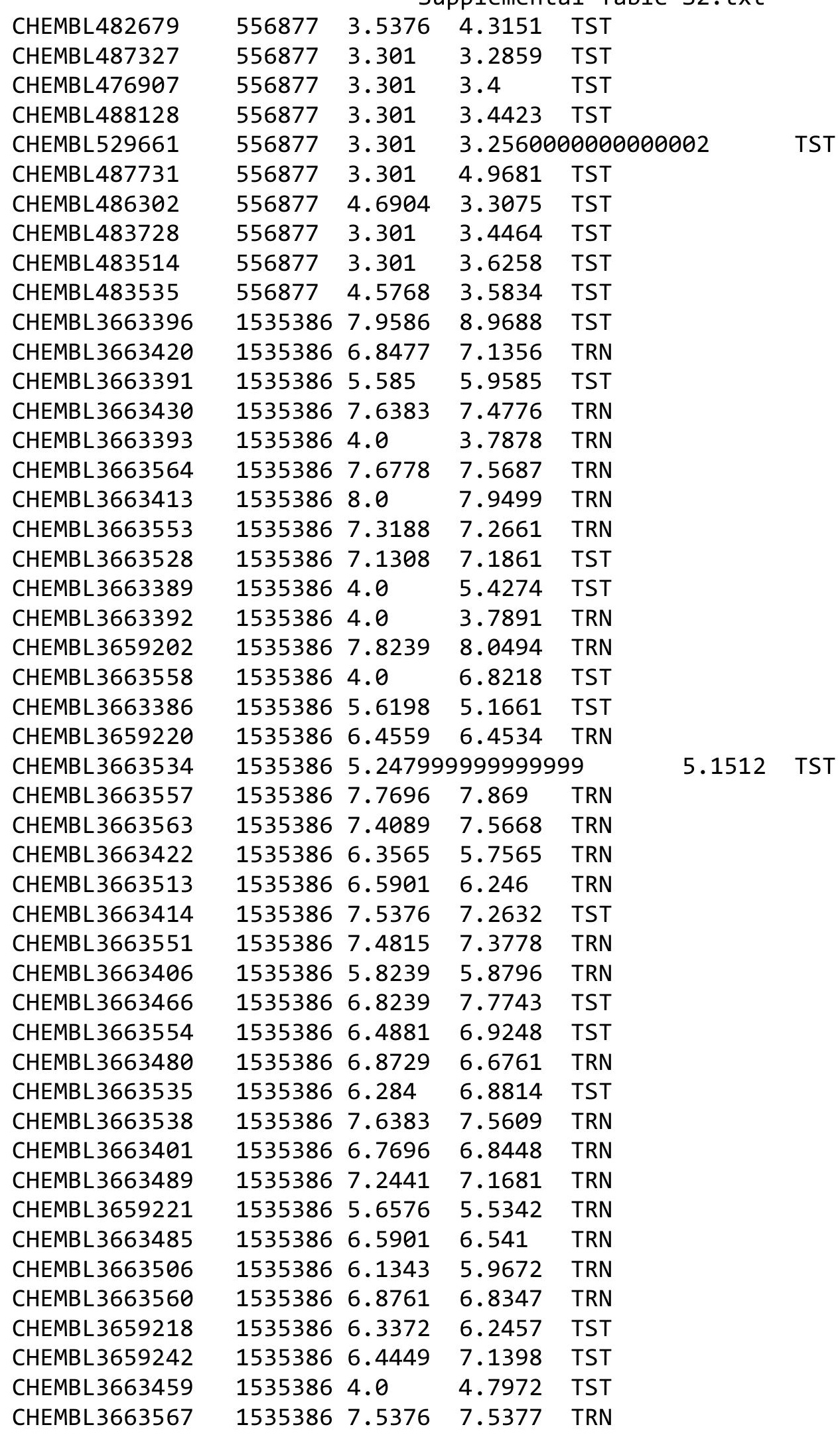


Supplemental Table S2.txt

\begin{tabular}{|c|c|c|c|c|}
\hline - & & & & \\
\hline HEMBL3663575 & & 7.6778 & 7.6251 & \\
\hline & & 21 & & \\
\hline 3472 & 386 & 83 & & \\
\hline AEMBL3663419 & 535386 & 7.2441 & 3466 & \\
\hline AEMBL3663572 & 535386 & 7.8239 & 8767 & \\
\hline HEMBL & & 7.7447 & .4874 & \\
\hline IEM & & 7.3979 & 3729 & \\
\hline IEMBL3 & 386 & 4.0 & .157 & \\
\hline HEMBL3659230 & 535386 & 7.1308 & 0641 & \\
\hline HEMBL3663505 & 535386 & 6.9586 & 1256 & \\
\hline AEMBL3 & 386 & 3188 & 3759 & \\
\hline AEMBL. & & & & \\
\hline HEMBL. & 86 & 6 & 2692 & \\
\hline AEMBL3 & 386 & 079 & 2039 & \\
\hline AEMBL3659241 & 36 & 6.556 & 5513 & \\
\hline HEMBL3 & 36 & 747 & 3069 & \\
\hline HEMBL3 & & 192 & & \\
\hline HEMBL & & 261 & 988 & \\
\hline HEMBL366 & & 79 & & RN \\
\hline AEMBL3663529 & 36 & 8 & 112 & RN \\
\hline HEMBL3 & 36 & 4 & 401 & \\
\hline HEMBL3 & & & & \\
\hline 475 & & & & $2 \mathrm{~N}$ \\
\hline AEMBL36 & 86 & 6 & 62 & RIN \\
\hline MBL & 86 & 9 & 993 & TRN \\
\hline AEMBL 3 & 0 & 49 & 166 & - \\
\hline HFM & & 58 & & RN \\
\hline AEMBL3 & & & & RN \\
\hline HEMBL36634 & 86 & 17 & 703 & ST \\
\hline AEMBL 36634 & 36 & 39 & 7821 & RN \\
\hline AFMBI 3 & & 1 & 596 & RN \\
\hline 1 & & & & RN \\
\hline HEMBL3663548 & & 539 & 412 & RN \\
\hline AEMBL3659227 & 53 & 85 & 5227 & RN \\
\hline HEMBL3663502 & 3 & 85 & 5426 & RN \\
\hline ב נIMP & & & 969 & RN \\
\hline & & & 891 & RN \\
\hline HEMBL3663566 & 5353 & 7.8539 & 0662 & TRN \\
\hline AEMBL36634e & 3 & 23 & 987 & RN \\
\hline HEMBL3659238 & 535 & 555 & 346 & RN \\
\hline HEMBL3663512 & & & 7197 & RN \\
\hline HEMBL3663547 & 535386 & 7.3565 & 4121 & $\mathrm{RN}$ \\
\hline HEMBL3659176 & 535386 & 7.6021 & 6142 & RN \\
\hline IEMBL36635 & & & & \\
\hline HEMBL 3663490 & 1535 & 7.2291 & 7.0578 & \\
\hline HEMBL3 & 535 & & .697 & \\
\hline CHEMBL3663399 & 1535386 & 7.699 & 8.0977 & ГST \\
\hline
\end{tabular}

Page 518 
Supplemental Table S2.txt

\begin{tabular}{|c|c|c|c|c|c|}
\hline CHEMBL 3663411 & 1535386 & 6.5229 & 6.9643 & TRN & \\
\hline CHEMBL 3663550 & 1535386 & 8.301 & 8.405 & TRN & \\
\hline CHEMBL 3659225 & 1535386 & 6.0 & 5.9118 & TRN & \\
\hline CHEMBL 3663473 & 1535386 & 5.6021 & 5.4977 & TRN & \\
\hline CHEMBL 3659217 & 1535386 & 7.0915 & 7.2348 & TRN & \\
\hline CHEMBL 3663460 & 1535386 & 7.0269 & 7.3789 & TST & \\
\hline CHEMBL 3663385 & 1535386 & 6.3788 & 6.9659 & TST & \\
\hline CHEMBL 3663526 & 1535386 & 7.5086 & 7.43 & TRN & \\
\hline CHEMBL 3663533 & 1535386 & 7.2441 & 7.0229 & TRN & \\
\hline CHEMBL 3663417 & 1535386 & 5.4685 & 5.4582 & TRN & \\
\hline CHEMBL 3663418 & 1535386 & 7.699 & 7.4226 & TRN & \\
\hline CHEMBL 3663576 & 1535386 & 8.0458 & 8.0105 & TRN & \\
\hline CHEMBL 3663520 & 1535386 & 4.0 & 4.7698 & TRN & \\
\hline CHEMBL 3663487 & 1535386 & 5.5376 & 5.3181 & TRN & \\
\hline CHEMBL 3663537 & 1535386 & 6.8097 & 6.7258 & TRN & \\
\hline CHEMBL 3663429 & 1535386 & 7.3279 & 7.084 & TRN & \\
\hline CHEMBL3663530 & 1535386 & 7.5376 & 7.59200 & 30000000005 & TRN \\
\hline CHEMBL 3663394 & 1535386 & 5.3768 & 5.50899 & 99999999995 & TRN \\
\hline CHEMBL 3663387 & 1535386 & 5.9586 & 4.4498 & TST & \\
\hline CHEMBL 3663514 & 1535386 & 7.4202 & 7.0262 & TRN & \\
\hline CHEMBL 3663515 & 1535386 & 6.7645 & 6.8085 & TRN & \\
\hline CHEMBL 3663461 & 1535386 & 5.5331 & 6.5224 & TST & \\
\hline CHEMBL 3663519 & 1535386 & 6.2757 & 6.6304 & TRN & \\
\hline CHEMBL 3663549 & 1535386 & 7.699 & 7.9425 & TRN & \\
\hline CHEMBL 3663571 & 1535386 & 7.6778 & 7.9018 & TRN & \\
\hline CHEMBL 3663488 & 1535386 & 6.3468 & 6.2699 & TRN & \\
\hline CHEMBL 3663403 & 1535386 & 7.1549 & 7.0764 & TRN & \\
\hline CHEMBL 3663503 & 1535386 & 5.9586 & 5.9456 & TRN & \\
\hline CHEMBL 3663542 & 1535386 & 7.3768 & 7.4731 & TRN & \\
\hline CHEMBL 3659222 & 1535386 & 5.4559 & 5.8241 & TRN & \\
\hline CHEMBL 3663479 & 1535386 & 5.8239 & 6.2493 & TRN & \\
\hline CHEMBL 3663409 & 1535386 & 5.7696 & 5.6105 & TRN & \\
\hline CHEMBL 3663402 & 1535386 & 6.6073 & 6.6014 & TRN & \\
\hline CHEMBL 3659204 & 1535386 & 7.1612 & 7.1621 & TRN & \\
\hline CHEMBL 3663458 & 1535386 & 5.8041 & 6.2294 & TST & \\
\hline CHEMBL 3663388 & 1535386 & 6.0381 & 6.3277 & TST & \\
\hline CHEMBL 3663483 & 1535386 & 6.1158 & 6.4214 & TRN & \\
\hline CHEMBL 3659224 & 1535386 & 4.0 & 4.0636 & TRN & \\
\hline CHEMBL 3663545 & 1535386 & 4.0 & 3.8012 & TRN & \\
\hline CHEMBL 3659240 & 1535386 & 6.8633 & 6.2908 & TST & \\
\hline CHEMBL 3663395 & 1535386 & 7.3279 & \multicolumn{2}{|c|}{7.462000000000001} & TST \\
\hline CHEMBL 3663577 & 1535386 & 8.301 & 8.4535 & TRN & \\
\hline CHEMBL 3663383 & 1535386 & 4.0 & 5.245 & TST & \\
\hline CHEMBL 3659236 & 1535386 & 7.5686 & 7.3287 & TRN & \\
\hline CHEMBL 3663525 & 1535386 & 6.8729 & 6.6996 & TRN & \\
\hline CHEMBL 3663495 & 1535386 & 5.4318 & 4.5479 & TST & \\
\hline CHEMBL 3663463 & 1535386 & 5.0605 & 6.4862 & TST & \\
\hline CHEMBL 3663408 & 1535386 & 6.1871 & 6.3051 & TRN & \\
\hline
\end{tabular}

Page 519 
Supplemental Table S2.txt

\begin{tabular}{|c|c|c|c|c|c|}
\hline CHEMBL 3663540 & 1535386 & 7.0757 & 7.1656 & TRN & \\
\hline CHEMBL3663569 & 1535386 & 7.0269 & 7.0906 & TRN & \\
\hline CHEMBL 3663384 & 1535386 & 6.9872 & 7.3008 & TST & \\
\hline CHEMBL 3663532 & 1535386 & 6.8153 & 6.0285 & TRN & \\
\hline CHEMBL3663484 & 1535386 & 6.2299 & 6.7782 & TRN & \\
\hline CHEMBL 3663507 & 1535386 & 5.5528 & 5.644 & TRN & \\
\hline CHEMBL 3663494 & 1535386 & 5.9586 & 5.5831 & TRN & \\
\hline CHEMBL 3663574 & 1535386 & 7.6383 & 7.3602 & TRN & \\
\hline CHEMBL 3663556 & 1535386 & 7.6778 & 7.5497 & TRN & \\
\hline CHEMBL3659215 & 1535386 & 6.3372 & 6.5877 & TRN & \\
\hline CHEMBL 3659233 & 1535386 & 5.8416 & 6.0999 & TRN & \\
\hline CHEMBL 3663415 & 1535386 & 7.2676 & 6.8817 & TRN & \\
\hline CHEMBL3659180 & 1535386 & 6.0 & 6.0881 & TRN & \\
\hline CHEMBL 3663464 & 1535386 & 6.3206 & 7.1611 & TST & \\
\hline CHEMBL3663426 & 1535386 & 6.9281 & 6.8571 & TRN & \\
\hline CHEMBL 3663478 & 1535386 & 6.7235 & 6.1802 & TRN & \\
\hline CHEMBL3663410 & 1535386 & 5.9586 & 5.672000 & 0000000001 & TRN \\
\hline CHEMBL3663390 & 1535386 & 6.0 & 7.6079 & TST & \\
\hline CHEMBL 3663552 & 1535386 & 6.3468 & 6.3563 & TRN & \\
\hline CHEMBL3663543 & 1535386 & 4.0 & 4.9926 & TST & \\
\hline CHEMBL3663421 & 1535386 & 7.2076 & 7.0768 & TRN & \\
\hline CHEMBL3663397 & 1535386 & 5.5229 & 5.5548 & TRN & \\
\hline CHEMBL3659239 & 1535386 & 5.9208 & 6.138999 & э999999999 & TST \\
\hline CHEMBL 3663565 & 1535386 & 6.3134 & 5.8056 & TST & \\
\hline CHEMBL 3659223 & 1535386 & 6.9245 & 7.0064 & TRN & \\
\hline CHEMBL 3659226 & 1535386 & 7.0555 & 6.9543 & TRN & \\
\hline CHEMBL 3663541 & 1535386 & 7.0706 & 6.9408 & TRN & \\
\hline CHEMBL3663524 & 1535386 & 6.3979 & 7.1055 & TST & \\
\hline CHEMBL 3663508 & 1535386 & 6.301 & 6.4483 & TRN & \\
\hline CHEMBL3659235 & 1535386 & 7.3188 & 7.4685 & TRN & \\
\hline CHEMBL 3663527 & 1535386 & 7.4685 & 7.5375 & TRN & \\
\hline CHEMBL3663423 & 1535386 & 6.301 & 6.4383 & TRN & \\
\hline CHEMBL3663510 & 1535386 & 7.0044 & 6.5294 & TST & \\
\hline CHEMBL3663523 & 1535386 & 7.6576 & 7.728 & TRN & \\
\hline CHEMBL3659234 & 1535386 & 6.7055 & 6.8786 & TRN & \\
\hline CHEMBL3659216 & 1535386 & 5.4089 & 5.7202 & TST & \\
\hline CHEMBL3663405 & 1535386 & 4.0 & 4.6105 & TST & \\
\hline CHEMBL3663481 & 1535386 & 7.0915 & 6.7641 & TRN & \\
\hline CHEMBL 3663544 & 1535386 & 7.8539 & 7.936 & TRN & \\
\hline CHEMBL3659232 & 1535386 & 7.7447 & 7.2914 & TST & \\
\hline CHEMBL3659229 & 1535386 & 5.5528 & 4.8399 & TST & \\
\hline CHEMBL3663465 & 1535386 & 5.0706 & 6.2453 & TST & \\
\hline CHEMBL3663562 & 1535386 & 7.0605 & 6.8645 & TRN & \\
\hline CHEMBL3663482 & 1535386 & 6.5302 & 6.4996 & TRN & \\
\hline CHEMBL3663427 & 1535386 & 6.3979 & 6.8096 & TST & \\
\hline CHEMBL 3663404 & 1535386 & 7.4559 & 7.1363 & TST & \\
\hline CHEMBL3663559 & 1535386 & 4.0 & 4.0906 & TRN & \\
\hline CHEMBL449158 & 954896 & 7.815 & 7.1893 & TST & \\
\hline
\end{tabular}




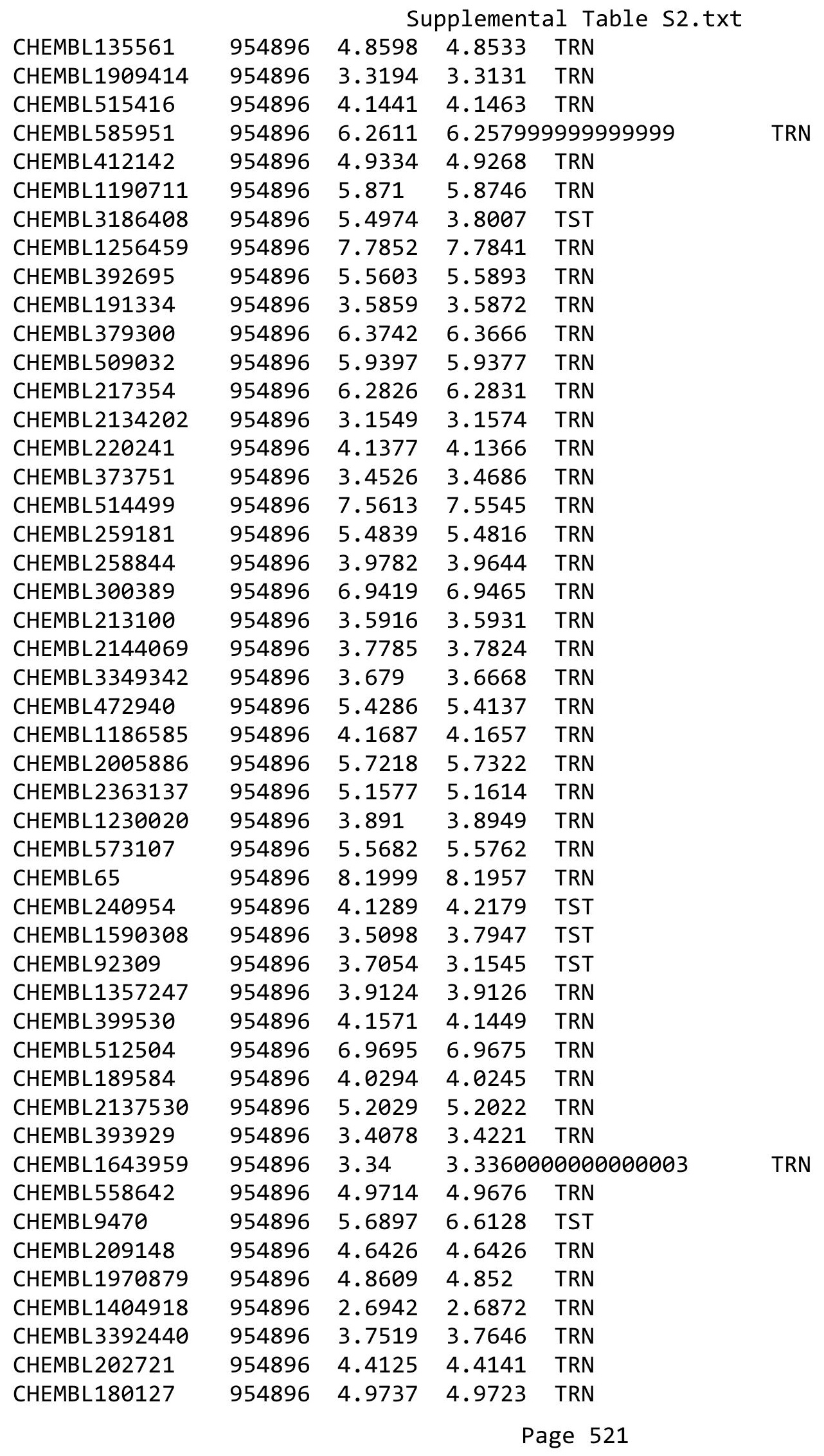




\begin{tabular}{|c|c|c|c|c|}
\hline \multicolumn{5}{|c|}{ Supplemental Table S2.txt } \\
\hline CHEMBL379975 & 954896 & 5.9153 & 5.9304 & TRN \\
\hline CHEMBL221137 & 954896 & 4.9502 & 5.0955 & TST \\
\hline CHEMBL102714 & 954896 & 3.1974 & 3.1984 & TRN \\
\hline CHEMBL577784 & 954896 & 4.1087 & 4.1113 & TRN \\
\hline CHEMBL255342 & 954896 & 3.3258 & 3.3116 & TRN \\
\hline CHEMBL 222102 & 954896 & 3.5074 & 3.5192 & TRN \\
\hline CHEMBL192566 & 954896 & 7.3349 & 8.6038 & TST \\
\hline CHEMBL1788116 & 954896 & 5.1497 & 4.7572 & TST \\
\hline CHEMBL 210618 & 954896 & 3.4307 & 3.3691 & TST \\
\hline CHEMBL1516890 & 954896 & 3.9621 & 3.64 & TST \\
\hline CHEMBL483847 & 954896 & 3.4895 & 3.8953 & TST \\
\hline CHEMBL1673039 & 954896 & 5.2255 & 4.5723 & TST \\
\hline CHEMBL1242367 & 954896 & 4.3607 & 4.578 & TST \\
\hline CHEMBL483849 & 954896 & 3.0949 & 2.3556 & TST \\
\hline CHEMBL3199475 & 954896 & 5.4362 & 4.8574 & TST \\
\hline CHEMBL188678 & 954896 & 3.7655 & 4.1848 & TST \\
\hline CHEMBL3287016 & 1641011 & 5.5036 & 5.4436 & TRN \\
\hline CHEMBL3891112 & 1641011 & 6.5969 & 6.9556 & TST \\
\hline CHEMBL3977346 & 1641011 & 7.5229 & 7.0041 & TST \\
\hline CHEMBL3929797 & 1641011 & 5.9289 & 6.846 & TST \\
\hline CHEMBL 3919448 & 1641011 & 7.1249 & 7.1128 & TST \\
\hline CHEMBL 3287252 & 1641011 & 6.5918 & 6.7806 & TRN \\
\hline CHEMBL3287254 & 1641011 & 6.7258 & 6.8407 & TRN \\
\hline CHEMBL3287257 & 1641011 & 6.4237 & 6.6028 & TRN \\
\hline CHEMBL 3906734 & 1641011 & 7.284 & 7.143 & TRN \\
\hline CHEMBL 3287250 & 1641011 & 6.9914 & 6.6499 & TRN \\
\hline CHEMBL3287010 & 1641011 & 6.9747 & 6.5703 & TST \\
\hline CHEMBL 3287253 & 1641011 & 6.4461 & 6.4248 & TRN \\
\hline CHEMBL 3897044 & 1641011 & 7.1249 & 7.0259 & TRN \\
\hline CHEMBL3287017 & 1641011 & 5.7857 & 5.6858 & TRN \\
\hline CHEMBL 3925574 & 1641011 & 6.1379 & 6.148 & TRN \\
\hline CHEMBL3937977 & 1641011 & 4.8647 & 5.5397 & TRN \\
\hline CHEMBL 3287023 & 1641011 & 6.9706 & 6.5045 & TRN \\
\hline CHEMBL3287251 & 1641011 & 6.1605 & 6.1865 & TRN \\
\hline CHEMBL3287022 & 1641011 & 6.2111 & 6.3958 & TRN \\
\hline CHEMBL3963714 & 1641011 & 6.7258 & 6.9675 & TST \\
\hline CHEMBL3968861 & 1641011 & 6.9747 & 7.2861 & TRN \\
\hline CHEMBL 3934705 & 1641011 & 5.4182 & 5.6495 & TRN \\
\hline CHEMBL3953198 & 1641011 & 6.4157 & 6.3166 & TRN \\
\hline CHEMBL3915628 & 1641011 & 6.4389 & 6.8544 & TST \\
\hline CHEMBL 3961271 & 1641011 & 7.7959 & 7.8369 & TRN \\
\hline CHEMBL3287019 & 1641011 & 5.654 & 5.8058 & TRN \\
\hline CHEMBL3930328 & 1641011 & 7.9586 & 7.4837 & TRN \\
\hline CHEMBL3287261 & 1641011 & 6.6968 & 6.7647 & TRN \\
\hline CHEMBL3287266 & 1641011 & 6.9747 & 7.1367 & TRN \\
\hline CHEMBL 3287260 & 1641011 & 6.3439 & 6.1189 & TRN \\
\hline CHEMBL3948298 & 1641011 & 7.2218 & 7.3358 & TRN \\
\hline CHEMBL 3287007 & 1641011 & 5.5481 & 6.0593 & TST \\
\hline
\end{tabular}


Supplemental Table S2.txt

\begin{tabular}{|c|c|c|c|c|}
\hline CHEMBL 3287021 & 1641011 & 6.7144 & 6.2631 & TRN \\
\hline CHEMBL3902539 & 1641011 & 7.2007 & 7.2341 & TRN \\
\hline CHEMBL3919167 & 1641011 & 6.2725 & 6.2669 & TRN \\
\hline CHEMBL 3287008 & 1641011 & 7.2366 & 6.5992 & TST \\
\hline CHEMBL 3968415 & 1641011 & 6.4855 & 6.4067 & TRN \\
\hline CHEMBL 3939518 & 1641011 & 7.1938 & 7.4141 & TRN \\
\hline CHEMBL3287265 & 1641011 & 5.657 & 5.7224 & TRN \\
\hline CHEMBL3911545 & 1641011 & 8.0 & 7.4141 & TRN \\
\hline CHEMBL3287269 & 1641011 & 6.5591 & 6.2915 & TRN \\
\hline CHEMBL 3961083 & 1641011 & 6.6038 & 7.2473 & TRN \\
\hline CHEMBL 3287255 & 1641011 & 6.5817 & 6.5852 & TRN \\
\hline CHEMBL 3287263 & 1641011 & 6.8013 & 6.786000 & 00000000005 \\
\hline CHEMBL3971832 & 1641011 & 5.6855 & 5.7266 & TRN \\
\hline CHEMBL3287258 & 1641011 & 6.5031 & 6.569 & TRN \\
\hline CHEMBL 3968356 & 1641011 & 6.7595 & 6.846 & TST \\
\hline CHEMBL 3903212 & 1641011 & 7.4318 & 7.4141 & TRN \\
\hline CHEMBL3287009 & 1641011 & 5.4488 & 6.0838 & TST \\
\hline CHEMBL3925099 & 1641011 & 7.0132 & 7.0894 & TRN \\
\hline CHEMBL3956299 & 1641011 & 5.4186 & 5.1757 & TRN \\
\hline CHEMBL 3947397 & 1641011 & 6.4535 & 6.3821 & TRN \\
\hline CHEMBL3918869 & 1641011 & 5.3658 & 5.3842 & TRN \\
\hline CHEMBL3984885 & 1641011 & 6.5017 & 6.0563 & TRN \\
\hline CHEMBL3939120 & 1641011 & 7.0655 & 7.2473 & TRN \\
\hline CHEMBL3287256 & 1641011 & 6.4881 & 6.2818 & TRN \\
\hline CHEMBL3976623 & 1641011 & 6.7932 & 6.7308 & TRN \\
\hline CHEMBL3933626 & 1641011 & 7.1367 & 7.2473 & TRN \\
\hline CHEMBL 3287268 & 1641011 & 6.8477 & 7.4117 & TST \\
\hline CHEMBL3943359 & 1641011 & 6.6498 & 6.6052 & TRN \\
\hline CHEMBL3935445 & 1641011 & 6.16299 & 999999999 & 5.9635 \\
\hline CHEMBL 3942298 & 1641011 & 6.0482 & 6.6033 & TST \\
\hline CHEMBL3287020 & 1641011 & 5.8022 & 5.8978 & TST \\
\hline CHEMBL 3891163 & 1641011 & 6.3872 & 6.3355 & TST \\
\hline CHEMBL3952593 & 1641011 & 5.5357 & 5.8785 & TRN \\
\hline CHEMBL3959685 & 1641011 & 5.6488 & 5.8653 & TRN \\
\hline CHEMBL 3960364 & 1641011 & 6.7545 & 6.7308 & TRN \\
\hline CHEMBL3287262 & 1641011 & 7.1024 & 6.6056 & TST \\
\hline CHEMBL 3923995 & 1641011 & 6.5817 & 6.5468 & TRN \\
\hline CHEMBL3933987 & 1641011 & 6.8861 & 7.0287 & TRN \\
\hline CHEMBL 3287259 & 1641011 & 6.2314 & 6.0617 & TST \\
\hline CHEMBL 3947538 & 1641011 & 6.3054 & 6.2669 & TRN \\
\hline CHEMBL380175 & 370934 & 7.4815 & 7.4671 & TRN \\
\hline CHEMBL211602 & 370934 & 7.3979 & 5.4934 & TRN \\
\hline CHEMBL 378520 & 370934 & 5.2376 & 6.2082 & TRN \\
\hline CHEMBL 377018 & 370934 & 5.5302 & 5.5469 & TRN \\
\hline CHEMBL 209086 & 370934 & 7.6198 & 7.2101 & TRN \\
\hline CHEMBL 380003 & 370934 & 7.0969 & 5.6208 & TRN \\
\hline CHEMBL 208715 & 370934 & 5.6253 & 5.5486 & TRN \\
\hline CHEMBL209585 & 370934 & 6.2993 & 6.4592 & TRN \\
\hline
\end{tabular}




\begin{tabular}{|c|c|c|c|c|c|c|}
\hline \multicolumn{7}{|c|}{ Supplemental Table S2.txt } \\
\hline CHEMBL210286 & 370934 & 4.0 & 5.0757 & TRN & & \\
\hline CHEMBL430893 & 370934 & 4.0 & 5.319 & TST & & \\
\hline CHEMBL212307 & 370934 & 4.0 & 5.2972 & TST & & \\
\hline CHEMBL210816 & 370934 & 4.0 & 5.9655 & TRN & & \\
\hline CHEMBL376991 & 370934 & 4.0 & 5.2297 & TRN & & \\
\hline CHEMBL210476 & 370934 & 5.4868 & 5.4424 & TRN & & \\
\hline CHEMBL211064 & 370934 & 7.3188 & 7.2328 & TRN & & \\
\hline CHEMBL209151 & 370934 & 7.3372 & 7.3893 & TRN & & \\
\hline CHEMBL378318 & 370934 & 6.9586 & 5.41700 & 000000000 & & TRN \\
\hline CHEMBL212565 & 370934 & 5.7305 & 5.3932 & TRN & & \\
\hline CHEMBL425958 & 370934 & 6.9914 & 7.3607 & TRN & & \\
\hline CHEMBL380099 & 370934 & 7.699 & 7.5278 & TRN & & \\
\hline CHEMBL378480 & 370934 & 4.0 & 5.0321 & TRN & & \\
\hline CHEMBL210253 & 370934 & 6.284 & 5.5645 & TRN & & \\
\hline CHEMBL209150 & 370934 & 5.7496 & 5.5255 & TRN & & \\
\hline CHEMBL211054 & 370934 & 5.9897 & 6.3436 & TST & & \\
\hline CHEMBL382119 & 370934 & 4.0 & 5.7457 & TST & & \\
\hline CHEMBL211856 & 370934 & 4.0 & 5.3511 & TRN & & \\
\hline CHEMBL 379371 & 370934 & 7.1487 & 7.4137 & TRN & & \\
\hline CHEMBL379801 & 370934 & 4.0 & 5.181 & TRN & & \\
\hline CHEMBL425778 & 370934 & 5.58 & 5.2923 & TST & & \\
\hline CHEMBL379813 & 370934 & 6.9031 & 5.5372 & TRN & & \\
\hline CHEMBL210721 & 370934 & 6.7077 & 5.4753 & TRN & & \\
\hline CHEMBL437880 & 370934 & 6.5918 & 7.3089 & TRN & & \\
\hline CHEMBL378779 & 370934 & 6.1805 & 5.38299 & 999999999 & & TRN \\
\hline CHEMBL377244 & 370934 & 4.0 & 5.6891 & TST & & \\
\hline CHEMBL426135 & 370934 & 4.0 & 5.5578 & TRN & & \\
\hline CHEMBL377525 & 370934 & 6.3778 & 5.6231 & TRN & & \\
\hline CHEMBL210542 & 370934 & 7.6021 & 7.3802 & TRN & & \\
\hline CHEMBL210463 & 370934 & 6.9066 & 6.37799 & 999999999 & & TRN \\
\hline CHEMBL208495 & 370934 & 7.3665 & 7.3522 & TRN & & \\
\hline CHEMBL210049 & 370934 & 7.6021 & 7.5511 & TRN & & \\
\hline CHEMBL210859 & 370934 & 5.4413 & 5.3035 & TRN & & \\
\hline CHEMBL377031 & 370934 & 6.7447 & 5.8233 & TRN & & \\
\hline CHEMBL379754 & 370934 & 4.0 & 5.1662 & TRN & & \\
\hline CHEMBL377534 & 370934 & 6.2993 & 6.3194 & TRN & & \\
\hline CHEMBL211137 & 370934 & 7.1938 & 7.325 & TRN & & \\
\hline CHEMBL377446 & 370934 & 4.0 & 5.2363 & TST & & \\
\hline CHEMBL 378305 & 370934 & 5.6421 & 5.1963 & TRN & & \\
\hline CHEMBL209309 & 370934 & 7.3768 & 7.4298 & TRN & & \\
\hline CHEMBL212211 & 370934 & $5.3270 e$ & 00000000 & 01 & 5.556 & 15 \\
\hline CHEMBL209538 & 370934 & 5.7071 & 6.3988 & TST & & \\
\hline CHEMBL209154 & 370934 & 7.3768 & 7.3101 & TRN & & \\
\hline CHEMBL378149 & 370934 & 4.0 & 5.6667 & TST & & \\
\hline CHEMBL209673 & 370934 & 6.983 & 7.4355 & TST & & \\
\hline CHEMBL212274 & 370934 & 7.3372 & 7.5033 & TST & & \\
\hline CHEMBL211269 & 370934 & 5.1574 & 6.3248 & TST & & \\
\hline CHEMBL377571 & 370934 & 6.0969 & 7.4094 & TST & & \\
\hline
\end{tabular}




\begin{tabular}{|c|c|c|c|c|c|c|}
\hline & & \multicolumn{5}{|c|}{ Supplemental Table S2.txt } \\
\hline CHEMBL438799 & 370934 & 7.2757 & 7.5103 & TST & & \\
\hline CHEMBL209482 & 370934 & 5.1023 & 6.2101 & TST & & \\
\hline CHEMBL98386 & 737216 & 4.4486 & 4.1431 & TRN & & \\
\hline CHEMBL1334768 & 737216 & 3.0 & 3.8346 & TRN & & \\
\hline CHEMBL1732623 & 737216 & 5.3747 & 5.2088 & TRN & & \\
\hline CHEMBL1448063 & 737216 & 3.0 & 2.7601 & TST & & \\
\hline CHEMBL1711919 & 737216 & 4.8447 & 4.2377 & TRN & & \\
\hline CHEMBL1727194 & 737216 & 4.0168 & 3.9471 & TRN & & \\
\hline CHEMBL1354431 & 737216 & 4.2798 & 4.7368 & TRN & & \\
\hline CHEMBL1520143 & 737216 & 4.7423 & 4.3818 & TRN & & \\
\hline CHEMBL1720939 & 737216 & 3.0 & 3.9835 & TRN & & \\
\hline CHEMBL1718784 & 737216 & 3.0 & 2.2012 & TRN & & \\
\hline CHEMBL1553163 & 737216 & 4.061 & 4.7223 & TRN & & \\
\hline CHEMBL1556634 & 737216 & 3.0 & 3.4403 & TRN & & \\
\hline CHEMBL1471698 & 737216 & 3.0 & 3.4234 & TST & & \\
\hline CHEMBL1708860 & 737216 & 3.0 & 3.1929 & TRN & & \\
\hline CHEMBL1447470 & 737216 & 3.0 & 3.2189 & TST & & \\
\hline CHEMBL1711505 & 737216 & 4.0526 & 3.1106 & TRN & & \\
\hline CHEMBL1700881 & 737216 & 3.0 & 3.032 & TRN & & \\
\hline CHEMBL 74497 & 737216 & 3.0 & 3.0317 & TRN & & \\
\hline CHEMBL1732571 & 737216 & 3.0 & 2.8824 & TRN & & \\
\hline CHEMBL1391552 & 737216 & 3.0 & 3.8502 & TRN & & \\
\hline CHEMBL1499314 & 737216 & 3.0 & 2.7897 & TST & & \\
\hline CHEMBL1397665 & 737216 & 3.0 & 3.5867 & TRN & & \\
\hline CHEMBL1575600 & 737216 & 3.0 & 2.7427 & TST & & \\
\hline CHEMBL1725175 & 737216 & 3.0 & 3.0334 & TRN & & \\
\hline CHEMBL1328836 & 737216 & 3.0 & 2.8733 & TST & & \\
\hline CHEMBL608699 & 737216 & 4.1811 & 3.8385 & TRN & & \\
\hline CHEMBL1719803 & 737216 & 3.0 & 3.3628 & TRN & & \\
\hline CHEMBL1730721 & 737216 & 3.0 & 2.5841 & TRN & & \\
\hline CHEMBL1721020 & 737216 & 3.0 & 2.9455 & TRN & & \\
\hline CHEMBL77534 & 737216 & 3.0 & 3.1126 & TRN & & \\
\hline CHEMBL1602859 & 737216 & 3.0 & 2.8436 & TST & & \\
\hline CHEMBL1410147 & 737216 & 3.0 & 4.1343 & TST & & \\
\hline CHEMBL1406130 & 737216 & 4.05399 & 999999999 & 99 & 4.7059 & TRN \\
\hline CHEMBL1734684 & 737216 & 3.0 & 3.1318 & TRN & & \\
\hline CHEMBL1569077 & 737216 & 3.0 & 3.4076 & TRN & & \\
\hline CHEMBL1571309 & 737216 & 3.0 & 3.1435 & TST & & \\
\hline CHEMBL1352830 & 737216 & 3.0 & 3.8857 & TST & & \\
\hline CHEMBL1734202 & 737216 & 3.0 & 2.8312 & TRN & & \\
\hline CHEMBL1411210 & 737216 & 3.0 & 3.0619 & TST & & \\
\hline CHEMBL1698318 & 737216 & 3.0 & 2.6871 & TRN & & \\
\hline CHEMBL1720245 & 737216 & 3.0 & 3.2489 & TRN & & \\
\hline CHEMBL3197242 & 737216 & 3.0 & 3.1863 & TRN & & \\
\hline CHEMBL1728993 & 737216 & 3.0 & 2.9995 & TRN & & \\
\hline CHEMBL1374283 & 737216 & 3.0 & 3.465 & TST & & \\
\hline CHEMBL1704102 & 737216 & 5.3188 & 3.6594 & TRN & & \\
\hline CHEMBL1701478 & 737216 & 4.7375 & 3.9209 & TRN & & \\
\hline
\end{tabular}




\begin{tabular}{|c|c|c|c|c|c|}
\hline \multicolumn{6}{|c|}{ Supplemental Table S2.txt } \\
\hline CHEMBL1734915 & 737216 & 3.0 & 3.9505 & TRN & \\
\hline CHEMBL45152 & 737216 & 4.433 & 4.0208 & TRN & \\
\hline CHEMBL1708334 & 737216 & 3.0 & 3.2041 & TRN & \\
\hline CHEMBL1527869 & 737216 & 3.0 & 3.2855 & TST & \\
\hline CHEMBL3196067 & 737216 & 3.0 & 3.4245 & TST & \\
\hline CHEMBL1589626 & 737216 & 3.0 & 2.8296 & TST & \\
\hline CHEMBL1733695 & 737216 & 3.0 & 3.1024 & TRN & \\
\hline CHEMBL1570441 & 737216 & 4.1169 & 4.3232 & TRN & \\
\hline CHEMBL1712661 & 737216 & 3.0 & 4.2848 & TRN & \\
\hline CHEMBL1567359 & 737216 & 3.0 & 3.0223 & TST & \\
\hline CHEMBL51085 & 737216 & 6.1726 & 4.3674 & TRN & \\
\hline CHEMBL1712495 & 737216 & 3.0 & 4.0415 & TRN & \\
\hline CHEMBL1700715 & 737216 & 4.6517 & 4.3038 & TRN & \\
\hline CHEMBL1702821 & 737216 & 4.055 & 4.0051 & TRN & \\
\hline CHEMBL1411202 & 737216 & 4.7496 & 4.7725 & TRN & \\
\hline CHEMBL1329850 & 737216 & 3.0 & 3.5704 & TST & \\
\hline CHEMBL1306415 & 737216 & 3.0 & 2.9162 & TST & \\
\hline CHEMBL1698074 & 737216 & 3.0 & 3.1303 & TRN & \\
\hline CHEMBL1443661 & 737216 & 3.0 & 3.26899 & 99999999997 & TRN \\
\hline CHEMBL1325823 & 737216 & 3.0 & 3.0116 & TST & \\
\hline CHEMBL1732009 & 737216 & 3.0 & 2.8339 & TRN & \\
\hline CHEMBL1558672 & 737216 & 3.0 & 3.002 & TST & \\
\hline CHEMBL1314602 & 737216 & 5.0405 & 4.8053 & TRN & \\
\hline CHEMBL1734992 & 737216 & 4.0205 & 3.1802 & TRN & \\
\hline CHEMBL1708335 & 737216 & 4.0696 & 4.0964 & TRN & \\
\hline CHEMBL1601716 & 737216 & 4.5045 & 4.7025 & TRN & \\
\hline CHEMBL1709252 & 737216 & 3.0 & 2.8708 & TRN & \\
\hline CHEMBL1735003 & 737216 & 3.0 & 3.0002 & TRN & \\
\hline CHEMBL1609086 & 737216 & 3.0 & 3.0532 & TRN & \\
\hline CHEMBL1708710 & 737216 & 3.0 & 3.8268 & TRN & \\
\hline CHEMBL1482621 & 737216 & 3.0 & 2.7809 & TST & \\
\hline CHEMBL1715058 & 737216 & 3.0 & 4.0293 & TRN & \\
\hline CHEMBL1712193 & 737216 & 4.2418 & 3.2393 & TRN & \\
\hline CHEMBL1732887 & 737216 & 3.0 & 3.2427 & TRN & \\
\hline CHEMBL1371792 & 737216 & 5.0057 & 4.312 & TRN & \\
\hline CHEMBL1558816 & 737216 & 3.0 & 2.8633 & TST & \\
\hline CHEMBL1724133 & 737216 & 3.0 & 2.9338 & TRN & \\
\hline CHEMBL1713178 & 737216 & 3.0 & 3.7613 & TRN & \\
\hline CHEMBL1725977 & 737216 & 5.025 & 4.7136 & TRN & \\
\hline CHEMBL1728270 & 737216 & 3.0 & 2.7945 & TRN & \\
\hline CHEMBL75913 & 737216 & 3.0 & 3.4293 & TRN & \\
\hline CHEMBL1530439 & 737216 & 3.0 & 3.1401 & TRN & \\
\hline CHEMBL1725043 & 737216 & 3.0 & 2.6758 & TRN & \\
\hline CHEMBL1711106 & 737216 & 3.0 & 2.8889 & TRN & \\
\hline CHEMBL1704299 & 737216 & 3.0 & 2.9065 & TRN & \\
\hline CHEMBL1703311 & 737216 & 4.2336 & 4.1708 & TRN & \\
\hline CHEMBL1728593 & 737216 & 3.0 & 3.2276 & TRN & \\
\hline CHEMBL1724427 & 737216 & 5.6819 & 4.7791 & TRN & \\
\hline
\end{tabular}


Supplemental Table S2.txt

\begin{tabular}{|c|c|c|c|c|}
\hline CHEMBL1708115 & 737216 & 4.2573 & 3.8079 & TRN \\
\hline CHEMBL1605787 & 737216 & 3.0 & 3.4379 & TST \\
\hline CHEMBL1706897 & 737216 & 3.0 & 4.1292 & TRN \\
\hline CHEMBL568739 & 737216 & 3.0 & 3.0325 & TST \\
\hline CHEMBL1730714 & 737216 & 3.0 & 2.2976 & TRN \\
\hline CHEMBL1562260 & 737216 & 3.0 & 2.9211 & TST \\
\hline CHEMBL1412731 & 737216 & 3.0 & 3.415 & TRN \\
\hline CHEMBL1718499 & 737216 & 3.0 & 3.1605 & TRN \\
\hline CHEMBL1702227 & 737216 & 3.0 & 3.2868 & TRN \\
\hline CHEMBL1338317 & 737216 & 4.5258 & 4.1737 & TRN \\
\hline CHEMBL1720777 & 737216 & 3.0 & 3.9361 & TRN \\
\hline CHEMBL1404277 & 737216 & 3.0 & 3.4387 & TRN \\
\hline CHEMBL1524838 & 737216 & 3.0 & 2.6285 & TST \\
\hline CHEMBL1605045 & 737216 & 3.0 & 2.82800 & 30000000003 \\
\hline CHEMBL1400196 & 737216 & 3.0 & 2.8523 & TST \\
\hline CHEMBL1423690 & 737216 & 4.8356 & 4.2555 & TRN \\
\hline CHEMBL1732801 & 737216 & 3.0 & 2.8929 & TST \\
\hline CHEMBL1704576 & 737216 & 3.1818 & 3.3126 & TRN \\
\hline CHEMBL1709285 & 737216 & 3.0 & 3.0386 & TRN \\
\hline CHEMBL1318817 & 737216 & 4.0119 & 3.5673 & TRN \\
\hline CHEMBL1422255 & 737216 & 3.0 & 3.2082 & TST \\
\hline CHEMBL1698123 & 737216 & 4.2248 & 4.1927 & TRN \\
\hline CHEMBL1715772 & 737216 & 3.0 & 3.5958 & TRN \\
\hline CHEMBL1726776 & 737216 & 5.0429 & 4.3537 & TRN \\
\hline CHEMBL1333250 & 737216 & 5.2882 & 4.9874 & TRN \\
\hline CHEMBL1603385 & 737216 & 3.0 & 2.4731 & TST \\
\hline CHEMBL1731467 & 737216 & 4.0159 & 3.5568 & TRN \\
\hline CHEMBL1736848 & 737216 & 3.0 & 3.0228 & TRN \\
\hline CHEMBL1733176 & 737216 & 3.0 & 3.0759 & TRN \\
\hline CHEMBL1369613 & 737216 & 4.8125 & 4.7758 & TRN \\
\hline CHEMBL1707406 & 737216 & 3.0 & 3.1321 & TRN \\
\hline CHEMBL1733472 & 737216 & 5.4724 & 3.7162 & TRN \\
\hline CHEMBL1712384 & 737216 & 3.0 & 3.1634 & TRN \\
\hline CHEMBL1727796 & 737216 & 3.0 & 3.2149 & TRN \\
\hline CHEMBL1496326 & 737216 & 3.0 & 3.2641 & TST \\
\hline CHEMBL1731974 & 737216 & 3.0 & 3.2486 & TRN \\
\hline CHEMBL1737005 & 737216 & 3.0 & 3.545 & TRN \\
\hline CHEMBL1699167 & 737216 & 4.1175 & 3.0402 & TRN \\
\hline CHEMBL1712016 & 737216 & 3.0 & 3.58 & TRN \\
\hline CHEMBL1321356 & 737216 & 3.0 & 2.9777 & TST \\
\hline CHEMBL1709105 & 737216 & 4.5702 & 4.0864 & TRN \\
\hline CHEMBL1325232 & 737216 & 3.0 & 3.3033 & TST \\
\hline CHEMBL1705022 & 737216 & 3.0 & 3.3623 & TRN \\
\hline CHEMBL1710748 & 737216 & 3.0 & 2.9723 & TRN \\
\hline CHEMBL1608601 & 737216 & 3.0 & 3.4381 & TST \\
\hline CHEMBL1712029 & 737216 & 3.0 & 3.3195 & TRN \\
\hline CHEMBL1722737 & 737216 & 3.0 & \multicolumn{2}{|c|}{3.2760000000000002} \\
\hline CHEMBL1699421 & 737216 & 3.0 & 2.9172 & TRN \\
\hline
\end{tabular}




\begin{tabular}{|c|c|c|c|c|}
\hline \multicolumn{5}{|c|}{ Supplemental Table } \\
\hline CHEMBL1714207 & 737216 & 3.0 & 3.3363 & TRN \\
\hline CHEMBL1707546 & 737216 & 3.0 & 3.5441 & TRN \\
\hline CHEMBL1573550 & 737216 & 3.0 & 2.7317 & TST \\
\hline CHEMBL1392315 & 737216 & 3.0 & 3.1129 & TRN \\
\hline CHEMBL1714438 & 737216 & 3.0 & 3.8656 & TRN \\
\hline CHEMBL1322803 & 737216 & 3.0 & 3.1634 & TST \\
\hline CHEMBL1731106 & 737216 & 3.0 & 2.8872 & TRN \\
\hline CHEMBL 3192684 & 737216 & 3.0 & 3.8603 & TST \\
\hline CHEMBL1712882 & 737216 & 3.0 & 3.5361 & TRN \\
\hline CHEMBL297304 & 737216 & 3.0 & 3.1487 & TST \\
\hline CHEMBL1703790 & 737216 & 3.0 & 2.6227 & TRN \\
\hline CHEMBL1711440 & 737216 & 5.0585 & 3.7944 & TRN \\
\hline CHEMBL1606007 & 737216 & 4.9666 & 4.7484 & TRN \\
\hline CHEMBL1701021 & 737216 & 3.0 & 3.4572 & TRN \\
\hline CHEMBL1734048 & 737216 & 3.0 & 2.6453 & TRN \\
\hline CHEMBL1714665 & 737216 & 5.6091 & 5.2864 & TRN \\
\hline CHEMBL1725457 & 737216 & 5.8996 & 4.7086 & TRN \\
\hline CHEMBL1730307 & 737216 & 3.0 & 3.1795 & TRN \\
\hline CHEMBL1550861 & 737216 & 3.0 & 2.9089 & TST \\
\hline CHEMBL1714415 & 737216 & 3.0 & 3.4903 & TRN \\
\hline CHEMBL1728676 & 737216 & 3.0 & 3.4844 & TRN \\
\hline CHEMBL1721184 & 737216 & 3.0 & 3.07 & TRN \\
\hline CHEMBL1449845 & 737216 & 4.7471 & 4.2807 & TRN \\
\hline CHEMBL1731796 & 737216 & 3.0 & 3.5677 & TRN \\
\hline CHEMBL1706310 & 737216 & 3.0 & 3.0094 & TRN \\
\hline CHEMBL1725446 & 737216 & 3.0 & 2.8905 & TST \\
\hline CHEMBL1714976 & 737216 & 3.0 & 3.0902 & TRN \\
\hline CHEMBL1334528 & 737216 & 3.0 & 3.1457 & TST \\
\hline CHEMBL1347373 & 737216 & 3.0 & 4.1871 & TST \\
\hline CHEMBL1720377 & 737216 & 4.0835 & 3.5946 & TRN \\
\hline CHEMBL 3671060 & 1528435 & 6.0 & 9.0769 & TST \\
\hline CHEMBL3671039 & 1528435 & 9.0969 & 8.6313 & TRN \\
\hline CHEMBL 3671046 & 1528435 & 8.7447 & 9.4553 & TRN \\
\hline CHEMBL3671016 & 1528435 & 7.8327 & 8.4235 & TRN \\
\hline CHEMBL 3671057 & 1528435 & 8.8861 & 8.5932 & TRN \\
\hline CHEMBL3671066 & 1528435 & 8.9208 & 8.459 & TRN \\
\hline CHEMBL3671074 & 1528435 & 9.0969 & 9.1229 & TRN \\
\hline CHEMBL3671076 & 1528435 & 9.0969 & 9.4987 & TRN \\
\hline CHEMBL3671071 & 1528435 & 8.7696 & 9.105 & TRN \\
\hline CHEMBL 3671078 & 1528435 & 10.0 & 9.6263 & TRN \\
\hline CHEMBL 3671024 & 1528435 & 8.7959 & 9.1211 & TST \\
\hline CHEMBL3671089 & 1528435 & 8.5376 & 8.4073 & TRN \\
\hline CHEMBL3671038 & 1528435 & 7.9747 & 8.4632 & TRN \\
\hline CHEMBL 3671090 & 1528435 & 9.3979 & 9.1137 & TRN \\
\hline CHEMBL 3671075 & 1528435 & 9.1549 & 9.6059 & TRN \\
\hline CHEMBL3671042 & 1528435 & 9.0 & 9.5109 & TRN \\
\hline CHEMBL3671025 & 1528435 & 8.3979 & 8.3736 & TRN \\
\hline CHEMBL3671081 & 1528435 & 7.8508 & 8.9233 & TST \\
\hline
\end{tabular}


Supplemental Table S2.txt

\begin{tabular}{|c|c|c|c|c|}
\hline CHEMBL 3671036 & 1528435 & 8.4815 & 8.5022 & TRN \\
\hline CHEMBL3671045 & 1528435 & 9.0969 & 9.1911 & TRN \\
\hline CHEMBL3671055 & 1528435 & 8.1739 & 8.554 & TRN \\
\hline CHEMBL 3671073 & 1528435 & 8.9208 & 8.5142 & TRN \\
\hline CHEMBL 3671048 & 1528435 & 8.6021 & 9.0234 & TRN \\
\hline CHEMBL3671028 & 1528435 & 8.6383 & 8.6971 & TRN \\
\hline CHEMBL 3671032 & 1528435 & 9.0 & 9.2708 & TRN \\
\hline CHEMBL3671069 & 1528435 & 9.0458 & 9.1159 & TRN \\
\hline CHEMBL3671068 & 1528435 & 8.7959 & 8.9329 & TRN \\
\hline CHEMBL 3671043 & 1528435 & 9.0969 & 8.7457 & TRN \\
\hline CHEMBL 3671029 & 1528435 & 8.7959 & 8.7545 & TRN \\
\hline CHEMBL3671052 & 1528435 & 8.8861 & 8.9116 & TRN \\
\hline CHEMBL3671034 & 1528435 & 9.0 & 8.7537 & TRN \\
\hline CHEMBL3671064 & 1528435 & 6.0 & 7.7221 & TRN \\
\hline CHEMBL 3671035 & 1528435 & 8.7212 & 8.824 & TRN \\
\hline CHEMBL 3671061 & 1528435 & 9.0458 & 9.59799 & 9999999999 \\
\hline CHEMBL3671053 & 1528435 & 9.0 & 8.6267 & TRN \\
\hline CHEMBL 3671031 & 1528435 & 8.699 & 8.6624 & TST \\
\hline CHEMBL 3671037 & 1528435 & 8.6778 & 8.7474 & TRN \\
\hline CHEMBL 3671070 & 1528435 & 8.9586 & 9.2271 & TRN \\
\hline CHEMBL3671059 & 1528435 & 6.0 & 8.9304 & TST \\
\hline CHEMBL3671083 & 1528435 & 8.2441 & 8.4705 & TRN \\
\hline CHEMBL3671080 & 1528435 & 8.9208 & 9.1771 & TST \\
\hline CHEMBL 3671065 & 1528435 & 10.0 & 8.8801 & TST \\
\hline CHEMBL 3671027 & 1528435 & 8.8239 & 8.5333 & TRN \\
\hline CHEMBL 3671049 & 1528435 & 9.0969 & 8.8033 & TRN \\
\hline CHEMBL3671030 & 1528435 & 8.7212 & 8.5063 & TRN \\
\hline CHEMBL3671086 & 1528435 & 7.6108 & 9.0075 & TST \\
\hline CHEMBL3671054 & 1528435 & 9.0969 & 8.6544 & TRN \\
\hline CHEMBL3671077 & 1528435 & 10.0 & 9.5551 & TRN \\
\hline CHEMBL3671041 & 1528435 & 9.0458 & 9.2535 & TRN \\
\hline CHEMBL3671072 & 1528435 & 9.699 & 9.132 & TRN \\
\hline CHEMBL3671091 & 1528435 & 9.0458 & 9.3867 & TST \\
\hline CHEMBL3671022 & 1528435 & 8.8239 & 8.248 & TRN \\
\hline CHEMBL3671047 & 1528435 & 8.4318 & 8.7162 & TRN \\
\hline CHEMBL3671056 & 1528435 & 8.9208 & 8.9641 & TST \\
\hline CHEMBL 3671088 & 1528435 & 8.5229 & 9.037 & TST \\
\hline CHEMBL 3671023 & 1528435 & 9.3979 & 9.0126 & TRN \\
\hline CHEMBL3671050 & 1528435 & 9.0969 & 9.3556 & TRN \\
\hline CHEMBL3671026 & 1528435 & 8.3279 & 9.0117 & TST \\
\hline CHEMBL 3671084 & 1528435 & 9.0969 & 9.1097 & TRN \\
\hline CHEMBL3671063 & 1528435 & 9.301 & 8.5736 & TRN \\
\hline CHEMBL3671044 & 1528435 & 9.2218 & 9.0236 & TRN \\
\hline CHEMBL3671067 & 1528435 & 8.6778 & 8.5302 & TRN \\
\hline CHEMBL3671051 & 1528435 & 9.3979 & 9.5064 & TST \\
\hline CHEMBL 3671085 & 1528435 & 9.2218 & 8.8909 & TRN \\
\hline CHEMBL 3671020 & 1528435 & 6.0 & 8.9398 & TST \\
\hline CHEMBL3671058 & 1528435 & 8.7959 & 8.9952 & TST \\
\hline
\end{tabular}


Supplemental Table S2.txt

\begin{tabular}{|c|c|c|c|c|c|}
\hline CHEMBL3671062 & 1528435 & 9.0458 & 8.9701 & TRN & \\
\hline CHEMBL3671019 & 1528435 & 6.0 & 9.0745 & TST & \\
\hline CHEMBL3671082 & 1528435 & 8.5528 & 8.6756 & TST & \\
\hline CHEMBL 270490 & 1639970 & 4.0 & 3.9274 & TRN & \\
\hline CHEMBL3648066 & 1639970 & 7.8827 & 7.7237 & TST & \\
\hline CHEMBL 218042 & 1639970 & 5.8182 & 5.8439 & TRN & \\
\hline CHEMBL 3648018 & 1639970 & 4.0 & 3.9628 & TRN & \\
\hline CHEMBL3651226 & 1639970 & 5.0969 & 5.1216 & TRN & \\
\hline CHEMBL3651293 & 1639970 & 7.0443 & 7.3273 & TST & \\
\hline CHEMBL3651282 & 1639970 & 6.9101 & 6.8192 & TRN & \\
\hline CHEMBL221975 & 1639970 & 6.8861 & 6.5885 & TST & \\
\hline CHEMBL3651201 & 1639970 & 5.0 & 5.0035 & TRN & \\
\hline CHEMBL395984 & 1639970 & 7.9101 & 7.7643 & TRN & \\
\hline CHEMBL231338 & 1639970 & 7.1772 & 7.2629 & TRN & \\
\hline CHEMBL3648031 & 1639970 & 7.5686 & 7.6436 & TRN & \\
\hline CHEMBL 3648060 & 1639970 & 7.8356 & 7.7214 & TST & \\
\hline CHEMBL3651240 & 1639970 & 7.8633 & 7.9398 & TRN & \\
\hline CHEMBL3651266 & 1639970 & 7.9914 & 7.9301 & TRN & \\
\hline CHEMBL221582 & 1639970 & 7.4437 & 7.3436 & TRN & \\
\hline CHEMBL3651209 & 1639970 & 7.2168 & 7.186 & TRN & \\
\hline CHEMBL3648017 & 1639970 & 4.0 & 3.7644 & TRN & \\
\hline CHEMBL230830 & 1639970 & 7.9747 & 8.0458 & TRN & \\
\hline CHEMBL3651281 & 1639970 & 6.8069 & 6.8322 & TRN & \\
\hline CHEMBL3651203 & 1639970 & 5.0 & 5.3104 & TRN & \\
\hline CHEMBL231220 & 1639970 & 7.8996 & 7.883999 & 99999999995 & TRN \\
\hline CHEMBL3651225 & 1639970 & 7.9136 & 8.1516 & TST & \\
\hline CHEMBL3651258 & 1639970 & 8.585 & 8.363 & TST & \\
\hline CHEMBL 271990 & 1639970 & 7.2741 & 7.1036 & TRN & \\
\hline CHEMBL3648036 & 1639970 & 7.4101 & 7.447 & TRN & \\
\hline CHEMBL3648063 & 1639970 & 7.5986 & 7.6421 & TRN & \\
\hline CHEMBL3648059 & 1639970 & 7.382999 & 999999999 & 7.6202 & TST \\
\hline CHEMBL 3651247 & 1639970 & 7.3325 & 7.5808 & TST & \\
\hline CHEMBL3648012 & 1639970 & 4.0 & 4.3838 & TRN & \\
\hline CHEMBL3651200 & 1639970 & 7.4949 & 7.7071 & TST & \\
\hline CHEMBL3651224 & 1639970 & 5.3458 & 6.0397 & TST & \\
\hline CHEMBL3651195 & 1639970 & 7.9245 & 7.945 & TRN & \\
\hline CHEMBL230614 & 1639970 & 7.6778 & 7.7071 & TRN & \\
\hline CHEMBL230686 & 1639970 & 8.0269 & 7.9395 & TRN & \\
\hline CHEMBL251015 & 1639970 & 6.4698 & 6.6529 & TST & \\
\hline CHEMBL230509 & 1639970 & 7.1415 & 7.1146 & TRN & \\
\hline CHEMBL3651286 & 1639970 & 9.0 & 9.0605 & TRN & \\
\hline CHEMBL230899 & 1639970 & 5.7447 & 5.6637 & TRN & \\
\hline CHEMBL3651295 & 1639970 & 8.4437 & 8.5308 & TRN & \\
\hline CHEMBL3651244 & 1639970 & 5.0969 & 5.0626 & TRN & \\
\hline CHEMBL3651285 & 1639970 & 8.9586 & 8.9691 & TRN & \\
\hline CHEMBL 3651252 & 1639970 & 5.0 & 4.934 & TST & \\
\hline CHEMBL3648069 & 1639970 & 6.5436 & 6.7204 & TST & \\
\hline CHEMBL3651249 & 1639970 & 8.1675 & 8.2413 & TST & \\
\hline
\end{tabular}


Supplemental Table S2.txt

\begin{tabular}{|c|c|c|c|c|c|c|}
\hline CHEMBL230685 & 1639970 & 6.4672 & 6.5768 & TRN & & \\
\hline CHEMBL 3648045 & 1639970 & 7.5986 & 7.6013 & TRN & & \\
\hline CHEMBL3651294 & 1639970 & 6.8761 & 7.0481 & TRN & & \\
\hline CHEMBL3651236 & 1639970 & 7.6655 & 7.826000 & 0000000000 & 05 & TST \\
\hline CHEMBL 3648010 & 1639970 & 7.1169 & 7.0352 & TST & & \\
\hline CHEMBL3648044 & 1639970 & 7.6345 & 7.687 & TRN & & \\
\hline CHEMBL230816 & 1639970 & 7.9788 & 7.8604 & TRN & & \\
\hline CHEMBL3651221 & 1639970 & 7.466 & 7.4622 & TRN & & \\
\hline CHEMBL3648062 & 1639970 & 7.8153 & 7.7953 & TRN & & \\
\hline CHEMBL3648024 & 1639970 & 4.0 & 3.9071 & TRN & & \\
\hline CHEMBL376860 & 1639970 & 4.0 & 3.9292 & TRN & & \\
\hline CHEMBL3651292 & 1639970 & 8.9208 & 8.9526 & TRN & & \\
\hline CHEMBL3651257 & 1639970 & 8.3768 & 8.6242 & TRN & & \\
\hline CHEMBL3648064 & 1639970 & 7.7375 & 7.7194 & TST & & \\
\hline CHEMBL 3648058 & 1639970 & \multicolumn{3}{|c|}{7.757000000000001} & 7.9314 & TST \\
\hline CHEMBL3962103 & 1639970 & 7.1192 & 7.3945 & TST & & \\
\hline CHEMBL436516 & 1639970 & 6.4921 & 6.5766 & TRN & & \\
\hline CHEMBL3648038 & 1639970 & 4.9318 & 5.275 & TST & & \\
\hline CHEMBL3651198 & 1639970 & 7.9136 & 7.9524 & TRN & & \\
\hline CHEMBL3651242 & 1639970 & 7.5654 & 7.4801 & TRN & & \\
\hline CHEMBL3651207 & 1639970 & 5.301 & 5.2809 & TRN & & \\
\hline CHEMBL 3648042 & 1639970 & 4.1249 & 4.062 & TRN & & \\
\hline CHEMBL230898 & 1639970 & 6.684 & 6.5395 & TRN & & \\
\hline CHEMBL231219 & 1639970 & 7.8539 & 7.8426 & TRN & & \\
\hline CHEMBL3648008 & 1639970 & 5.0458 & 5.5789 & TST & & \\
\hline CHEMBL397998 & 1639970 & 4.0 & 4.1782 & TRN & & \\
\hline CHEMBL3651222 & 1639970 & 6.9547 & 6.8017 & TRN & & \\
\hline CHEMBL231627 & 1639970 & 6.2 & 6.1037 & TRN & & \\
\hline CHEMBL440963 & 1639970 & 8.5086 & 8.4403 & TRN & & \\
\hline CHEMBL3651288 & 1639970 & 9.02 & 9.0815 & TRN & & \\
\hline CHEMBL3651262 & 1639970 & 8.9208 & 8.9011 & TRN & & \\
\hline CHEMBL3648034 & 1639970 & 6.4672 & 6.442 & TRN & & \\
\hline CHEMBL400303 & 1639970 & 8.8239 & 8.8333 & TRN & & \\
\hline CHEMBL3648052 & 1639970 & 5.8239 & 6.0072 & TST & & \\
\hline CHEMBL250821 & 1639970 & 9.1549 & 9.2295 & TRN & & \\
\hline CHEMBL3651272 & 1639970 & 6.4377 & 6.4045 & TRN & & \\
\hline CHEMBL3648007 & 1639970 & 4.0 & 4.3175 & TRN & & \\
\hline CHEMBL3648070 & 1639970 & 4.0 & 3.8897 & TRN & & \\
\hline CHEMBL3651280 & 1639970 & 8.28399 & 999999999 & & 8.1846 & TRN \\
\hline CHEMBL3639501 & 1639970 & 9.266 & 9.3139 & TRN & & \\
\hline CHEMBL217961 & 1639970 & 6.8729 & 6.8619 & TRN & & \\
\hline CHEMBL3648037 & 1639970 & 7.4461 & 7.542000 & 0000000001 & & TRN \\
\hline CHEMBL446951 & 1639970 & 6.8633 & 6.7649 & TRN & & \\
\hline CHEMBL390479 & 1639970 & 7.6904 & 7.6403 & TRN & & \\
\hline CHEMBL3651245 & 1639970 & 5.8386 & 5.9528 & TST & & \\
\hline CHEMBL250625 & 1639970 & 8.28399 & 999999999 & & 8.3763 & TRN \\
\hline CHEMBL 3648033 & 1639970 & 5.8239 & 5.796 & TRN & & \\
\hline CHEMBL3648013 & 1639970 & 4.0 & 3.9713 & TRN & & \\
\hline
\end{tabular}


Supplemental Table S2.txt

\begin{tabular}{|c|c|c|c|c|}
\hline CHEMBL394765 & 1639970 & 6.1035 & 6.0769 & TRN \\
\hline CHEMBL394518 & 1639970 & 6.6819 & 6.6473 & TRN \\
\hline CHEMBL3648056 & 1639970 & 6.9281 & 6.91299 & 7999999999 \\
\hline CHEMBL 3651275 & 1639970 & 7.1096 & 7.0414 & TRN \\
\hline CHEMBL3648041 & 1639970 & 6.2147 & 6.1405 & TRN \\
\hline CHEMBL398279 & 1639970 & 8.3872 & 8.3406 & TRN \\
\hline CHEMBL3648014 & 1639970 & 4.0 & 3.9761 & TST \\
\hline CHEMBL230999 & 1639970 & 7.8239 & 7.7134 & TRN \\
\hline CHEMBL3651218 & 1639970 & 6.3575 & 6.3917 & TRN \\
\hline CHEMBL218549 & 1639970 & 8.1938 & 8.2156 & TRN \\
\hline CHEMBL374248 & 1639970 & 6.5317 & 6.1347 & TRN \\
\hline CHEMBL249821 & 1639970 & 8.4437 & 8.5714 & TRN \\
\hline CHEMBL3648015 & 1639970 & 4.0 & 4.2903 & TST \\
\hline CHEMBL441545 & 1639970 & 4.0 & 3.9259 & TRN \\
\hline CHEMBL3651241 & 1639970 & 8.0706 & 8.1408 & TRN \\
\hline CHEMBL3651260 & 1639970 & 8.7447 & 8.5738 & TST \\
\hline CHEMBL399268 & 1639970 & 8.301 & 8.3163 & TRN \\
\hline CHEMBL3651208 & 1639970 & 7.0372 & 7.0067 & TRN \\
\hline CHEMBL 3648030 & 1639970 & 7.3768 & 7.4301 & TRN \\
\hline CHEMBL3651269 & 1639970 & 6.5513 & 6.5218 & TRN \\
\hline CHEMBL3651274 & 1639970 & 7.6655 & 7.5682 & TRN \\
\hline CHEMBL3651279 & 1639970 & 8.8239 & 8.4363 & TST \\
\hline CHEMBL3949485 & 1639970 & 7.4248 & 7.4116 & TST \\
\hline CHEMBL230793 & 1639970 & 5.9208 & 5.9509 & TRN \\
\hline CHEMBL231524 & 1639970 & 7.2924 & 7.2376 & TRN \\
\hline CHEMBL218656 & 1639970 & 8.0146 & 8.0061 & TRN \\
\hline CHEMBL230815 & 1639970 & 5.5376 & 5.5364 & TRN \\
\hline CHEMBL397691 & 1639970 & 7.6904 & 7.6498 & TRN \\
\hline CHEMBL 3651254 & 1639970 & 5.7515 & 5.6307 & TST \\
\hline CHEMBL3651216 & 1639970 & 6.8477 & 6.8616 & TRN \\
\hline CHEMBL3651248 & 1639970 & 4.0 & 3.9573 & TRN \\
\hline CHEMBL231237 & 1639970 & 7.9914 & 8.082 & TRN \\
\hline CHEMBL 3651270 & 1639970 & 6.4168 & 6.4041 & TST \\
\hline CHEMBL 3651237 & 1639970 & 6.9266 & 7.0455 & TST \\
\hline CHEMBL230272 & 1639970 & 7.9101 & 7.8999 & TRN \\
\hline CHEMBL3651256 & 1639970 & 5.0 & 4.872 & TRN \\
\hline CHEMBL3651271 & 1639970 & 7.1624 & 7.2179 & TST \\
\hline CHEMBL218742 & 1639970 & 6.7496 & 6.5953 & TRN \\
\hline CHEMBL 3651205 & 1639970 & 7.3536 & 7.4768 & TRN \\
\hline CHEMBL 3651204 & 1639970 & 7.3261 & 7.0532 & TRN \\
\hline CHEMBL436137 & 1639970 & 8.1675 & 8.2037 & TRN \\
\hline CHEMBL249820 & 1639970 & 7.153 & 7.0068 & TRN \\
\hline CHEMBL3651287 & 1639970 & 8.6198 & 8.4693 & TRN \\
\hline CHEMBL220798 & 1639970 & 6.8539 & 6.6586 & TRN \\
\hline CHEMBL 3651223 & 1639970 & 6.0555 & 6.0628 & TRN \\
\hline CHEMBL221739 & 1639970 & 4.0 & 5.5509 & TST \\
\hline CHEMBL250423 & 1639970 & 8.1805 & 8.1702 & TRN \\
\hline CHEMBL3648006 & 1639970 & 4.0 & 3.991 & TRN \\
\hline
\end{tabular}


Supplemental Table S2.txt

\begin{tabular}{|c|c|c|c|c|}
\hline CHEMBL231218 & 1639970 & 8.041 & 8.0327 & TRN \\
\hline CHEMBL3648065 & 1639970 & 7.5622 & 7.447 & TST \\
\hline CHEMBL 250019 & 1639970 & 8.5229 & 8.5281 & TRN \\
\hline CHEMBL 3651278 & 1639970 & 8.3665 & 8.4918 & TRN \\
\hline CHEMBL 3648068 & 1639970 & 7.7375 & 7.7931 & TST \\
\hline CHEMBL3651263 & 1639970 & 5.4004 & 5.4867 & TRN \\
\hline CHEMBL3651202 & 1639970 & 6.2518 & \multicolumn{2}{|c|}{6.1610000000000005} \\
\hline CHEMBL 3651229 & 1639970 & $5.76200 e$ & 000000000 & 5.6737 \\
\hline CHEMBL3648046 & 1639970 & 7.5406 & 7.524 & TRN \\
\hline CHEMBL3651233 & 1639970 & 4.0 & 5.0248 & TST \\
\hline CHEMBL 3651234 & 1639970 & 6.9208 & 7.2709 & TST \\
\hline CHEMBL3651265 & 1639970 & 7.644 & 7.5803 & TRN \\
\hline CHEMBL400402 & 1639970 & 8.7959 & 8.7511 & TRN \\
\hline CHEMBL3651211 & 1639970 & 6.5654 & 6.6256 & TRN \\
\hline CHEMBL3648032 & 1639970 & 7.4828 & 7.5245 & TRN \\
\hline CHEMBL 250218 & 1639970 & 8.3188 & 8.4252 & TRN \\
\hline CHEMBL3651246 & 1639970 & 8.7959 & 8.7442 & TRN \\
\hline CHEMBL221431 & 1639970 & 6.9666 & 6.9527 & TRN \\
\hline CHEMBL3648011 & 1639970 & 4.0 & 4.032 & TRN \\
\hline CHEMBL 399246 & 1639970 & 8.5376 & 8.5449 & TRN \\
\hline CHEMBL3648021 & 1639970 & 4.0 & 4.1623 & TRN \\
\hline CHEMBL230918 & 1639970 & 6.5017 & 6.502000 & 000000001 \\
\hline CHEMBL3648049 & 1639970 & 6.0 & 6.1115 & TST \\
\hline CHEMBL3651264 & 1639970 & 7.2182 & 7.2318 & TRN \\
\hline CHEMBL 3651239 & 1639970 & 7.2774 & 7.3007 & TRN \\
\hline CHEMBL3651253 & 1639970 & 8.3768 & 8.1638 & TST \\
\hline CHEMBL3651235 & 1639970 & 7.5719 & 7.6141 & TST \\
\hline CHEMBL3651250 & 1639970 & 8.7447 & 8.5679 & TRN \\
\hline CHEMBL218738 & 1639970 & 4.0 & 4.1106 & TST \\
\hline CHEMBL 3648023 & 1639970 & 4.0 & 4.0754 & TRN \\
\hline CHEMBL3651194 & 1639970 & 7.5935 & 7.6004 & TRN \\
\hline CHEMBL 3648009 & 1639970 & 7.1427 & 7.0174 & TST \\
\hline CHEMBL3648019 & 1639970 & 4.0 & 3.7362 & TRN \\
\hline CHEMBL3651276 & 1639970 & 8.4685 & 8.3464 & TRN \\
\hline CHEMBL3648061 & 1639970 & 7.8356 & 7.8644 & TST \\
\hline CHEMBL3639468 & 1639970 & 4.0 & 4.1363 & TRN \\
\hline CHEMBL3651268 & 1639970 & 7.3546 & 7.4035 & TRN \\
\hline CHEMBL218109 & 1639970 & 4.0 & 4.2655 & TRN \\
\hline CHEMBL 218049 & 1639970 & 7.317 & 7.237 & TRN \\
\hline CHEMBL3651259 & 1639970 & 7.9872 & 7.7835 & TST \\
\hline CHEMBL3651199 & 1639970 & 7.4584 & 7.4403 & TRN \\
\hline CHEMBL3651210 & 1639970 & 8.4685 & 8.4251 & TRN \\
\hline CHEMBL 3648020 & 1639970 & 4.0 & 4.1594 & TRN \\
\hline CHEMBL3648022 & 1639970 & 4.0 & 4.0517 & TRN \\
\hline CHEMBL 231251 & 1639970 & 8.1675 & 8.1055 & TRN \\
\hline CHEMBL 250214 & 1639970 & 8.4437 & 8.5311 & TRN \\
\hline CHEMBL 3648048 & 1639970 & 7.7932 & 7.9802 & TST \\
\hline CHEMBL 272233 & 1639970 & 5.0 & 5.1179 & TRN \\
\hline
\end{tabular}


Supplemental Table S2.txt

\begin{tabular}{|c|c|c|c|c|c|}
\hline CHEMBL 3648016 & 1639970 & 4.0 & 4.3055 & TRN & \\
\hline CHEMBL3651197 & 1639970 & 7.0526 & 7.1127 & TRN & \\
\hline CHEMBL3651215 & 1639970 & 4.0 & 4.8228 & TST & \\
\hline CHEMBL 220480 & 1639970 & 6.0191 & 6.1836 & TRN & \\
\hline CHEMBL 3651261 & 1639970 & 6.3635 & 6.4545 & TRN & \\
\hline CHEMBL218102 & 1639970 & 7.9914 & 7.9482 & TRN & \\
\hline CHEMBL403990 & 1639970 & 6.5735 & 6.5785 & TRN & \\
\hline CHEMBL230829 & 1639970 & 8.0132 & 8.0558 & TRN & \\
\hline CHEMBL 3651219 & 1639970 & 8.1871 & 8.0518 & TST & \\
\hline CHEMBL3651196 & 1639970 & 7.5406 & 7.5438 & TRN & \\
\hline CHEMBL 3651206 & 1639970 & 8.1024 & 8.0786 & TRN & \\
\hline CHEMBL 268825 & 1639970 & 7.4584 & 7.2349 & TRN & \\
\hline CHEMBL 3651291 & 1639970 & 8.4202 & 8.4301 & TRN & \\
\hline CHEMBL218842 & 1639970 & 4.0 & 3.9363 & TRN & \\
\hline CHEMBL 3651283 & 1639970 & 8.4318 & 8.5416 & TRN & \\
\hline CHEMBL 3651220 & 1639970 & 7.5243 & 7.5343 & TRN & \\
\hline CHEMBL230615 & 1639970 & 7.4034 & 7.5508 & TRN & \\
\hline CHEMBL 3651277 & 1639970 & 8.3665 & 8.4426 & TST & \\
\hline CHEMBL 3651227 & 1639970 & 8.0 & 7.927006 & 30000000005 & TD \\
\hline CHEMBL 3651273 & 1639970 & 7.1979 & 7.2153 & TRN & \\
\hline CHEMBL 3648057 & 1639970 & 6.6345 & 6.6767 & TRN & \\
\hline CHEMBL 3648025 & 1639970 & 4.0 & 3.9612 & TRN & \\
\hline CHEMBL3651212 & 1639970 & 8.1805 & 8.2568 & TRN & \\
\hline CHEMBL 3648028 & 1639970 & 6.7235 & 6.2987 & TRN & \\
\hline CHEMBL 220912 & 1639970 & 6.6126 & 6.6744 & TRN & \\
\hline CHEMBL250623 & 1639970 & 8.1805 & 8.0094 & TRN & \\
\hline CHEMBL397692 & 1639970 & 7.8996 & 7.9478 & TRN & \\
\hline CHEMBL3651217 & 1639970 & \multicolumn{3}{|c|}{7.752000000000001} & $1 \mathrm{NT}$ \\
\hline CHEMBL 3651251 & 1639970 & 5.0 & 4.3902 & TST & \\
\hline CHEMBL231316 & 1639970 & 7.5986 & 7.6694 & TRN & \\
\hline CHEMBL 3651255 & 1639970 & 8.4815 & 8.526 & TST & \\
\hline CHEMBL250021 & 1639970 & 8.4949 & 8.4286 & TRN & \\
\hline CHEMBL3648039 & 1639970 & 8.0506 & 7.9042 & TRN & \\
\hline CHEMBL230792 & 1639970 & 6.2967 & 6.1097 & TRN & \\
\hline CHEMBL 3648047 & 1639970 & 7.0173 & 7.4941 & TST & \\
\hline CHEMBL3651238 & 1639970 & 7.9508 & 7.8696 & TST & \\
\hline CHEMBL 3651230 & 1639970 & 6.9318 & 7.0421 & TRN & \\
\hline CHEMBL374868 & 1639970 & 4.0 & 3.9581 & TRN & \\
\hline CHEMBL 3648054 & 1639970 & 7.5784 & 7.7492 & TRN & \\
\hline CHEMBL 218281 & 1639970 & 6.8928 & 7.02 & TRN & \\
\hline CHEMBL 3648027 & 1639970 & 4.0 & 3.9396 & TRN & \\
\hline CHEMBL 3648029 & 1639970 & 6.8633 & 7.0544 & TRN & \\
\hline CHEMBL231525 & 1639970 & 6.5498 & 6.6127 & TRN & \\
\hline CHEMBL 3651231 & 1639970 & 8.2441 & 8.3435 & TST & \\
\hline CHEMBL 3941384 & 1639970 & 5.2366 & 5.5088 & TST & \\
\hline CHEMBL 3648053 & 1639970 & 7.6778 & 7.6983 & TRN & \\
\hline CHEMBL 3648043 & 1639970 & 7.5622 & 7.6355 & TRN & \\
\hline CHEMBL 3651267 & 1639970 & 5.6544 & 5.6103 & TRN & \\
\hline
\end{tabular}

Page 534 
Supplemental Table S2.txt

\begin{tabular}{|c|c|c|c|c|c|}
\hline CHEMBL 3648035 & 1639970 & 7.1249 & 7.0339 & TRN & \\
\hline CHEMBL 3651284 & 1639970 & 8.7959 & 8.8151 & TRN & \\
\hline CHEMBL 3651290 & 1639970 & 8.6778 & 8.7024 & TRN & \\
\hline CHEMBL 218160 & 1639970 & 4.0 & 4.1883 & TST & \\
\hline CHEMBL3651232 & 1639970 & 6.8633 & 7.3433 & TST & \\
\hline CHEMBL3651243 & 1639970 & 7.5834 & 7.7023 & TRN & \\
\hline CHEMBL 3651228 & 1639970 & 8.3188 & 8.2897 & TST & \\
\hline CHEMBL249819 & 1639970 & 8.5229 & 8.5067 & TRN & \\
\hline CHEMBL 218598 & 1639970 & 5.7447 & 5.8698 & TST & \\
\hline CHEMBL3648055 & 1639970 & 7.0269 & 7.0607 & TST & \\
\hline CHEMBL 3648040 & 1639970 & 6.2581 & 6.4273 & TRN & \\
\hline CHEMBL 3648026 & 1639970 & 4.0 & 3.6844 & TST & \\
\hline CHEMBL 3648050 & 1639970 & 8.3372 & 8.2987 & TST & \\
\hline CHEMBL 218551 & 1639970 & 4.0 & 4.2934 & TST & \\
\hline CHEMBL 3651289 & 1639970 & 7.1013 & 7.1764 & TRN & \\
\hline CHEMBL3648067 & 1639970 & 7.5346 & 7.6105 & TRN & \\
\hline CHEMBL3648051 & 1639970 & 7.7545 & 7.7824 & TST & \\
\hline CHEMBL 230271 & 1639970 & 6.9172 & 7.0296 & TRN & \\
\hline CHEMBL218597 & 1639970 & 6.8447 & 6.6656 & TST & \\
\hline CHEMBL 399530 & 954948 & 5.1561 & 4.8552 & TRN & \\
\hline CHEMBL1357247 & 954948 & 3.8377 & 3.614 & TRN & \\
\hline CHEMBL 2134202 & 954948 & 3.082 & 3.4678 & TRN & \\
\hline CHEMBL92309 & 954948 & 3.2047 & 3.1871 & TST & \\
\hline CHEMBL220241 & 954948 & 4.5317 & 4.3254 & TRN & \\
\hline CHEMBL202721 & 954948 & 4.9513 & 4.8316 & TRN & \\
\hline CHEMBL1186585 & 954948 & 4.1527 & 3.81399 & 99999999996 & TRN \\
\hline CHEMBL3349342 & 954948 & 5.1388 & 5.1844 & TRN & \\
\hline CHEMBL393929 & 954948 & 3.6466 & 3.7827 & TRN & \\
\hline CHEMBL585951 & 954948 & 6.3459 & 6.3117 & TRN & \\
\hline CHEMBL 3392440 & 954948 & 3.985 & 3.9021 & TRN & \\
\hline CHEMBL449158 & 954948 & 6.7422 & 6.7086 & TST & \\
\hline CHEMBL1643959 & 954948 & 3.5131 & 3.3692 & TRN & \\
\hline CHEMBL3199475 & 954948 & 5.347 & 5.0653 & TRN & \\
\hline CHEMBL509032 & 954948 & 5.8726 & 5.5809 & TRN & \\
\hline CHEMBL472940 & 954948 & 2.86 & 3.7769 & TRN & \\
\hline CHEMBL483849 & 954948 & 2.9365 & 2.2514 & TST & \\
\hline CHEMBL 2137530 & 954948 & 4.6378 & 4.9487 & TRN & \\
\hline CHEMBL221137 & 954948 & 4.8262 & 4.9145 & TST & \\
\hline CHEMBL2363137 & 954948 & 5.0686 & 5.1495 & TRN & \\
\hline CHEMBL 213100 & 954948 & 4.8807 & 4.7316 & TRN & \\
\hline CHEMBL188678 & 954948 & 5.5692 & 5.0569 & TRN & \\
\hline CHEMBL 9470 & 954948 & 5.8803 & 6.0241 & TST & \\
\hline CHEMBL514499 & 954948 & 7.6472 & 7.4907 & TRN & \\
\hline CHEMBL65 & 954948 & 7.1556 & 7.5754 & TRN & \\
\hline CHEMBL 379300 & 954948 & 6.6924 & 6.8995 & TRN & \\
\hline CHEMBL1970879 & 954948 & 5.5974 & 5.146 & TRN & \\
\hline CHEMBL412142 & 954948 & 4.1334 & 3.9441 & TRN & \\
\hline CHEMBL558642 & 954948 & 4.4814 & 4.5156 & TRN & \\
\hline
\end{tabular}




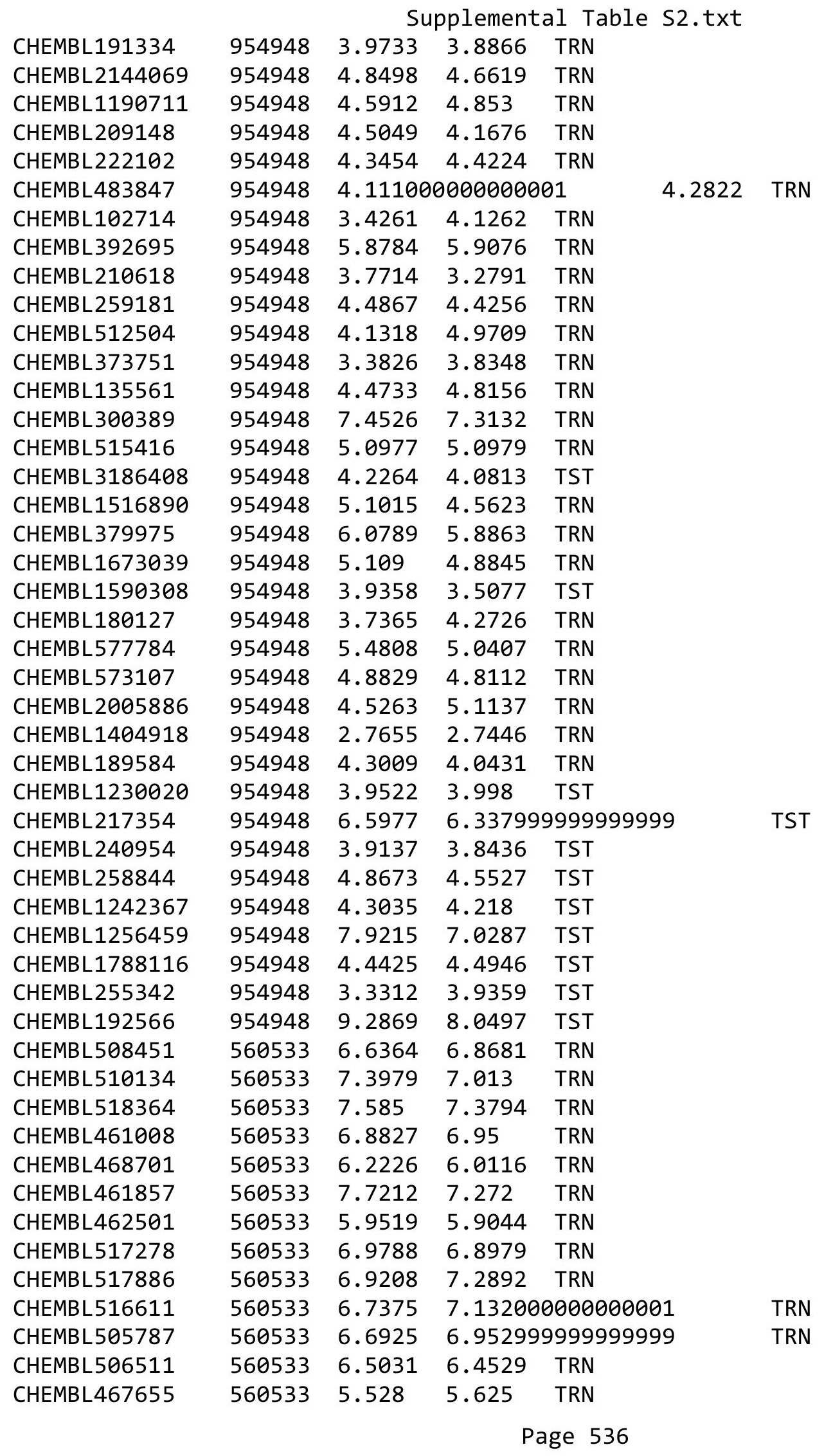




\begin{tabular}{|c|c|c|c|c|c|}
\hline & & & & & \\
\hline CHEMBL517418 & 560533 & 6.3979 & 6.5745 & TRN & \\
\hline CHEMBL467245 & 560533 & 7.0088 & 7.0788 & TRN & \\
\hline CHEMBL442670 & 560533 & 6.5361 & 6.5409 & TRN & \\
\hline CHEMBL517277 & 560533 & 5.9333 & 5.6469 & TRN & \\
\hline CHEMBL461650 & 560533 & 7.1135 & 6.7877 & TRN & \\
\hline CHEMBL461649 & 560533 & 7.0 & 7.0296 & TRN & \\
\hline CHEMBL467244 & 560533 & 6.9586 & 7.0807 & TRN & \\
\hline CHEMBL512812 & 560533 & 6.7212 & 6.6518 & TRN & \\
\hline CHEMBL517429 & 560533 & 6.9788 & 6.7814 & TRN & \\
\hline CHEMBL460799 & 560533 & 6.9318 & 6.9656 & TRN & \\
\hline CHEMBL516800 & 560533 & 6.7212 & 6.8935 & TRN & \\
\hline CHEMBL506101 & 560533 & 7.1079 & 6.9174 & TRN & \\
\hline CHEMBL460596 & 560533 & 6.1349 & 6.5176 & TRN & \\
\hline CHEMBL511413 & 560533 & 5.5967 & 5.5997 & TRN & \\
\hline CHEMBL508558 & 560533 & 6.2573 & 6.3538 & TRN & \\
\hline CHEMBL516483 & 560533 & 7.2007 & 6.95799 & 9999999999 & TRN \\
\hline CHEMBL260557 & 560533 & 6.1891 & 5.6261 & TST & \\
\hline CHEMBL449596 & 560533 & 6.0311 & 6.2258 & TRN & \\
\hline CHEMBL404447 & 560533 & 5.3053 & 5.3889 & TST & \\
\hline CHEMBL449469 & 560533 & 7.0655 & 6.8058 & TRN & \\
\hline CHEMBL461007 & 560533 & 6.1319 & 6.147 & TRN & \\
\hline CHEMBL461656 & 560533 & 5.3827 & 5.2248 & TRN & \\
\hline CHEMBL516770 & 560533 & 6.6038 & 6.8479 & TRN & \\
\hline CHEMBL467867 & 560533 & 6.0487 & 6.0802 & TRN & \\
\hline CHEMBL459322 & 560533 & 7.301 & 7.4048 & TRN & \\
\hline CHEMBL461858 & 560533 & 5.7786 & 5.9384 & TST & \\
\hline CHEMBL460976 & 560533 & 5.309 & 5.7362 & TRN & \\
\hline CHEMBL459312 & 560533 & 5.4408 & 5.5918 & TST & \\
\hline CHEMBL513661 & 560533 & 6.9281 & 7.1078 & TRN & \\
\hline CHEMBL467035 & 560533 & 6.6383 & 6.7668 & TST & \\
\hline CHEMBL467246 & 560533 & 7.3768 & 6.9973 & TRN & \\
\hline CHEMBL518178 & 560533 & 6.1549 & 6.0908 & TRN & \\
\hline CHEMBL460975 & 560533 & 6.7212 & 6.7668 & TRN & \\
\hline CHEMBL406499 & 560533 & 5.5583 & 5.4238 & TST & \\
\hline CHEMBL517417 & 560533 & 6.8794 & 6.7298 & TRN & \\
\hline CHEMBL462488 & 560533 & 7.1192 & 6.7411 & TST & \\
\hline CHEMBL518497 & 560533 & 7.1135 & 7.5068 & TST & \\
\hline CHEMBL468256 & 560533 & 7.5686 & 6.9298 & TST & \\
\hline CHEMBL461651 & 560533 & 7.3468 & 7.2134 & TST & \\
\hline CHEMBL511405 & 560533 & 6.8125 & 6.2024 & TST & \\
\hline CHEMBL507426 & 560533 & 7.0809 & 6.5555 & TST & \\
\hline CHEMBL443665 & 560533 & 6.4962 & 7.1669 & TST & \\
\hline CHEMBL505977 & 560533 & 6.1141 & 6.2256 & TST & \\
\hline CHEMBL460805 & 560533 & 5.9458 & 6.4136 & TST & \\
\hline CHEMBL3746130 & 1545532 & 5.857 & 4.9941 & TRN & \\
\hline CHEMBL3746465 & 1545532 & 7.4318 & 7.7099 & TRN & \\
\hline CHEMBL3747296 & 1545532 & 7.585 & 7.316 & TRN & \\
\hline CHEMBL 3747341 & 1545532 & 7.6576 & 6.8935 & TRN & \\
\hline
\end{tabular}


Supplemental Table S2.txt

\begin{tabular}{|c|c|c|c|c|}
\hline CHEMBL 3747151 & 1545532 & 3.301 & 6.0876 & TST \\
\hline CHEMBL3747395 & 1545532 & 6.2007 & 7.2541 & TRN \\
\hline CHEMBL3746693 & 1545532 & 3.301 & 7.4788 & TST \\
\hline CHEMBL3746817 & 1545532 & 5.2924 & 6.5033 & TST \\
\hline CHEMBL 3747768 & 1545532 & 6.0605 & 5.1786 & TRN \\
\hline CHEMBL3746290 & 1545532 & 5.7212 & 6.5832 & TRN \\
\hline CHEMBL3747246 & 1545532 & 6.699 & 6.3372 & TRN \\
\hline CHEMBL3746161 & 1545532 & 5.0223 & 5.3334 & TST \\
\hline CHEMBL3746829 & 1545532 & 5.6345 & 5.5064 & TST \\
\hline CHEMBL3747293 & 1545532 & 6.6198 & 7.1982 & TRN \\
\hline CHEMBL 3745944 & 1545532 & 4.6655 & 4.8235 & TRN \\
\hline CHEMBL3746520 & 1545532 & 7.8539 & 7.5049 & TRN \\
\hline CHEMBL 2434990 & 1545532 & 8.0706 & 7.6288 & TRN \\
\hline CHEMBL 3747218 & 1545532 & 6.6198 & 7.0915 & TRN \\
\hline CHEMBL3746368 & 1545532 & 3.301 & 5.2971 & TST \\
\hline CHEMBL 3747701 & 1545532 & 6.6778 & 5.7488 & TRN \\
\hline CHEMBL3746222 & 1545532 & 6.8861 & 7.6186 & TRN \\
\hline CHEMBL3747093 & 1545532 & 3.301 & 6.33 & TST \\
\hline CHEMBL3747314 & 1545532 & 6.9208 & 6.5507 & TRN \\
\hline CHEMBL3747711 & 1545532 & 5.1938 & 5.8855 & TRN \\
\hline CHEMBL 3746078 & 1545532 & 7.041 & 6.6253 & TRN \\
\hline CHEMBL3746013 & 1545532 & 7.7447 & 8.1497 & TRN \\
\hline CHEMBL3746576 & 1545532 & 6.4202 & 5.777 & TRN \\
\hline CHEMBL3746116 & 1545532 & 6.2291 & 6.5956 & TRN \\
\hline CHEMBL3747092 & 1545532 & 4.5406 & 4.9941 & TRN \\
\hline CHEMBL3747730 & 1545532 & 7.1805 & 7.8641 & TRN \\
\hline CHEMBL3746676 & 1545532 & 5.6576 & 6.0474 & TRN \\
\hline CHEMBL 3745867 & 1545532 & 3.301 & 4.6769 & TRN \\
\hline CHEMBL 3746880 & 1545532 & 6.1308 & 6.067 & TRN \\
\hline CHEMBL3747624 & 1545532 & 5.0088 & 4.823 & TRN \\
\hline CHEMBL3747213 & 1545532 & 6.8861 & 6.5789 & TRN \\
\hline CHEMBL 3747642 & 1545532 & 6.8239 & 7.2981 & TRN \\
\hline CHEMBL 3745834 & 1545532 & 4.7328 & 4.8543 & TRN \\
\hline CHEMBL3746210 & 1545532 & 3.301 & 6.237 & TST \\
\hline CHEMBL3747703 & 1545532 & 8.6383 & 7.555 & TRN \\
\hline CHEMBL3747675 & 1545532 & 7.0177 & 6.7238 & TRN \\
\hline CHEMBL3746622 & 1545532 & 3.301 & 6.305 & TST \\
\hline CHEMBL3747640 & 1545532 & 6.9586 & 7.6363 & TRN \\
\hline CHEMBL197946 & 1545532 & 6.2291 & 5.1619 & TST \\
\hline CHEMBL3745792 & 1545532 & 5.7077 & 5.8704 & TRN \\
\hline CHEMBL3747383 & 1545532 & 7.1135 & 6.4819 & TRN \\
\hline CHEMBL3746400 & 1545532 & 3.301 & 5.15600 & 0000000001 \\
\hline CHEMBL3747184 & 1545532 & 8.0 & 7.5748 & TRN \\
\hline CHEMBL3746404 & 1545532 & 7.0132 & 6.2171 & TRN \\
\hline CHEMBL3747394 & 1545532 & 8.0 & 6.813 & TRN \\
\hline CHEMBL3747284 & 1545532 & 5.9872 & 6.0252 & TRN \\
\hline CHEMBL3746415 & 1545532 & 6.6778 & 5.6269 & TRN \\
\hline CHEMBL3746653 & 1545532 & 5.4034 & 5.8874 & TRN \\
\hline
\end{tabular}


Supplemental Table S2.txt

\begin{tabular}{|c|c|c|c|c|}
\hline CHEMBL 3747559 & 1545532 & 3.301 & 6.528 & TST \\
\hline CHEMBL 3746619 & 1545532 & 4.341 & 5.053 & TST \\
\hline CHEMBL 3746263 & 1545532 & 3.301 & 7.2873 & TST \\
\hline CHEMBL 3745811 & 1545532 & 3.301 & 6.2887 & TST \\
\hline CHEMBL 2171067 & 865016 & 6.585 & 7.1275 & TRN \\
\hline CHEMBL 2170901 & 865016 & 8.0 & 6.6036 & TST \\
\hline CHEMBL 2170883 & 865016 & 7.0458 & 6.3134 & TRN \\
\hline CHEMBL 2170864 & 865016 & 3.8239 & 5.2991 & TST \\
\hline CHEMBL 2171074 & 865016 & 3.8239 & 5.3007 & TRN \\
\hline CHEMBL 2170865 & 865016 & 6.0862 & 6.2337 & TRN \\
\hline CHEMBL 2170903 & 865016 & 3.8239 & 4.4604 & TRN \\
\hline CHEMBL 2170891 & 865016 & 7.699 & 7.1709 & TRN \\
\hline CHEMBL1093371 & 865016 & 6.6576 & 6.4154 & TRN \\
\hline CHEMBL 2171056 & 865016 & 7.0 & 5.6317 & TST \\
\hline CHEMBL 2171051 & 865016 & 5.8239 & 5.6058 & TRN \\
\hline CHEMBL 2170885 & 865016 & 6.8861 & 6.1426 & TRN \\
\hline CHEMBL 2171076 & 865016 & 5.4685 & 4.5737 & TRN \\
\hline CHEMBL 2170869 & 865016 & 3.8239 & 4.7284 & TST \\
\hline CHEMBL 2170862 & 865016 & 6.1938 & 5.7931 & TST \\
\hline CHEMBL 2170892 & 865016 & 7.0969 & 6.6703 & TRN \\
\hline CHEMBL 2170873 & 865016 & 7.301 & 6.0434 & TRN \\
\hline CHEMBL 2170868 & 865016 & 5.1367 & 4.9833 & TST \\
\hline CHEMBL 2171065 & 865016 & 3.8239 & 4.8959 & TRN \\
\hline CHEMBL1093727 & 865016 & 6.2596 & 6.0211 & TRN \\
\hline CHEMBL 2171075 & 865016 & 3.8239 & 4.2823 & TST \\
\hline CHEMBL 2171060 & 865016 & 6.8861 & 6.8164 & TRN \\
\hline CHEMBL 2170880 & 865016 & 7.5229 & 6.6371 & TST \\
\hline CHEMBL 2171082 & 865016 & 7.5229 & 8.0925 & TRN \\
\hline CHEMBL 2171078 & 865016 & 7.1549 & 7.7936 & TRN \\
\hline CHEMBL 2170895 & 865016 & 6.9208 & 6.6032 & TRN \\
\hline CHEMBL 2171083 & 865016 & 7.3979 & 7.8036 & TRN \\
\hline CHEMBL 2170875 & 865016 & 7.699 & 6.6211 & TRN \\
\hline CHEMBL 2170893 & 865016 & 3.8239 & 4.5025 & TRN \\
\hline CHEMBL582392 & 865016 & 6.5229 & 5.7838 & TST \\
\hline CHEMBL 2170878 & 865016 & 6.7696 & 6.2752 & TRN \\
\hline CHEMBL 2170874 & 865016 & 7.5229 & 5.9619 & TST \\
\hline CHEMBL 2170896 & 865016 & 6.7447 & 6.3592 & TRN \\
\hline CHEMBL 2170894 & 865016 & 3.8239 & 4.4596 & TST \\
\hline CHEMBL 2171085 & 865016 & 7.5229 & 7.7383 & TRN \\
\hline CHEMBL 2171055 & 865016 & 3.8239 & 4.5987 & TRN \\
\hline CHEMBL 2171052 & 865016 & 3.8239 & 4.4971 & TST \\
\hline CHEMBL1093726 & 865016 & 6.7447 & 7.1746 & TRN \\
\hline CHEMBL 2170886 & 865016 & 6.0223 & 5.8836 & TRN \\
\hline CHEMBL 2171070 & 865016 & 7.0915 & 7.8455 & TRN \\
\hline CHEMBL 2170898 & 865016 & 6.5528 & 5.7897 & TRN \\
\hline CHEMBL1093370 & 865016 & 6.5229 & 6.9539 & TRN \\
\hline CHEMBL 2170888 & 865016 & 6.9208 & 6.3192 & TRN \\
\hline CHEMBL 2170863 & 865016 & 5.2007 & 4.874 & TST \\
\hline
\end{tabular}




\begin{tabular}{|c|c|c|c|c|c|}
\hline & & \multicolumn{4}{|c|}{ Supplemental Table S2.txt } \\
\hline CHEMBL1093728 & 865016 & 6.0605 & 6.2208 & TRN & \\
\hline CHEMBL 2170887 & 865016 & 7.0969 & 6.3483 & TRN & \\
\hline CHEMBL 2171054 & 865016 & 3.8239 & 4.7505 & TRN & \\
\hline CHEMBL 2171059 & 865016 & 6.9586 & 6.1253 & TRN & \\
\hline CHEMBL 2170902 & 865016 & 6.4437 & 5.6633 & TST & \\
\hline CHEMBL 2171057 & 865016 & 6.6383 & 6.2524 & TRN & \\
\hline CHEMBL 2170890 & 865016 & 6.699 & 6.7009 & TRN & \\
\hline CHEMBL 2170884 & 865016 & 8.0 & 6.7473 & TRN & \\
\hline CHEMBL 2171072 & 865016 & 3.8239 & 4.346 & TST & \\
\hline CHEMBL 2171066 & 865016 & 3.8239 & 4.9289 & TRN & \\
\hline CHEMBL 2170872 & 865016 & 6.3768 & 6.1609 & TRN & \\
\hline CHEMBL 2170897 & 865016 & 6.4202 & 7.0042 & TRN & \\
\hline CHEMBL 2171062 & 865016 & 4.6778 & 4.9751 & TRN & \\
\hline CHEMBL 2170879 & 865016 & 6.7447 & 6.3051 & TRN & \\
\hline CHEMBL1092774 & 865016 & 6.8861 & 6.9976 & TRN & \\
\hline CHEMBL 2170867 & 865016 & 6.284 & 6.0414 & TRN & \\
\hline CHEMBL 2170904 & 865016 & 6.4202 & 5.9997 & TRN & \\
\hline CHEMBL 2170859 & 865016 & 6.5376 & 5.8831 & TST & \\
\hline CHEMBL 2171061 & 865016 & 5.8386 & 5.7053 & TRN & \\
\hline CHEMBL 2170905 & 865016 & 3.8239 & 4.7076 & TRN & \\
\hline CHEMBL 2171063 & 865016 & 6.0223 & 6.1673 & TRN & \\
\hline CHEMBL 2170881 & 865016 & 6.6778 & 5.8803 & TST & \\
\hline CHEMBL 2171069 & 865016 & 5.1805 & 4.805 & TST & \\
\hline CHEMBL 2170877 & 865016 & 8.0 & 6.6532 & TRN & \\
\hline CHEMBL2170899 & 865016 & 7.3979 & 6.1221 & TST & \\
\hline CHEMBL 2170860 & 865016 & 6.2757 & 6.2103 & TRN & \\
\hline CHEMBL 2171081 & 865016 & 6.7959 & 7.0523 & TRN & \\
\hline CHEMBL 2171071 & 865016 & 5.6576 & 7.0523 & TRN & \\
\hline CHEMBL 2171084 & 865016 & 7.0969 & 7.8946 & TRN & \\
\hline CHEMBL 2171073 & 865016 & 5.8861 & 6.1253 & TRN & \\
\hline CHEMBL 2170876 & 865016 & 7.2218 & 6.1892 & TRN & \\
\hline CHEMBL1090974 & 865016 & 6.0862 & 5.7475 & TRN & \\
\hline CHEMBL 2170889 & 865016 & 7.3979 & 6.6039 & TST & \\
\hline CHEMBL 2171064 & 865016 & 4.8539 & 4.8465 & TRN & \\
\hline CHEMBL 2171080 & 865016 & 7.699 & 8.1625 & TRN & \\
\hline CHEMBL 2171058 & 865016 & 6.2676 & 5.6367 & TRN & \\
\hline CHEMBL 2170866 & 865016 & 6.7959 & 6.2915 & TRN & \\
\hline CHEMBL 2171077 & 865016 & 6.6576 & 7.4464 & TRN & \\
\hline CHEMBL 2170900 & 865016 & 7.2218 & 6.1783 & TST & \\
\hline CHEMBL 2170882 & 865016 & 8.0 & 7.1918 & TRN & \\
\hline CHEMBL 2171053 & 865016 & 3.8239 & 4.7724 & TRN & \\
\hline CHEMBL 2170871 & 865016 & 7.0 & 6.4366 & TRN & \\
\hline CHEMBL 2171079 & 865016 & 7.1549 & 7.9888 & TRN & \\
\hline CHEMBL 2171068 & 865016 & 6.8861 & 7.5235 & TRN & \\
\hline CHEMBL 2170861 & 865016 & 6.4559 & 6.20799 & 9999999999 & TRN \\
\hline CHEMBL 2170858 & 865016 & 3.8239 & 4.8746 & TST & \\
\hline CHEMBL 2170870 & 865016 & 3.8239 & 4.3867 & TST & \\
\hline CHEMBL611393 & 304036 & 7.18 & 7.5191 & TRN & \\
\hline
\end{tabular}




\begin{tabular}{|c|c|c|c|c|c|}
\hline & & \multicolumn{4}{|c|}{ Supplemental Table S2.txt } \\
\hline CHEMBL607067 & 304036 & 5.97 & 6.4468 & TST & \\
\hline CHEMBL607118 & 304036 & 5.99 & 7.0327 & TST & \\
\hline CHEMBL179679 & 304036 & 5.55 & 6.3991 & TST & \\
\hline CHEMBL359917 & 304036 & 5.87 & 6.2734 & TST & \\
\hline CHEMBL178829 & 304036 & 4.88 & 6.3944 & TST & \\
\hline CHEMBL606740 & 304036 & 6.15 & 5.9671 & TRN & \\
\hline CHEMBL606673 & 304036 & 5.89 & 5.7553 & TRN & \\
\hline CHEMBL607484 & 304036 & 5.55 & 5.4658 & TRN & \\
\hline CHEMBL606738 & 304036 & 5.34 & 5.4658 & TRN & \\
\hline CHEMBL606608 & 304036 & 5.34 & 5.4658 & TRN & \\
\hline CHEMBL606676 & 304036 & 5.59 & 5.9726 & TRN & \\
\hline CHEMBL606607 & 304036 & 5.89 & 5.9237 & TRN & \\
\hline CHEMBL606798 & 304036 & 5.92 & 5.8396 & TRN & \\
\hline CHEMBL606675 & 304036 & 5.1 & 5.3548 & TRN & \\
\hline CHEMBL606606 & 304036 & 5.55 & 5.4521 & TRN & \\
\hline CHEMBL610618 & 304036 & 5.82 & 5.8304 & TRN & \\
\hline CHEMBL610617 & 304036 & 5.84 & 6.1438 & TRN & \\
\hline CHEMBL611397 & 304036 & 6.44 & \multicolumn{2}{|c|}{6.162000000000001} & TRN \\
\hline CHEMBL610878 & 304036 & 6.78 & 6.5296 & TRN & \\
\hline CHEMBL611399 & 304036 & 6.53 & 6.9781 & TRN & \\
\hline CHEMBL611132 & 304036 & 7.09 & 6.8458 & TRN & \\
\hline CHEMBL611133 & 304036 & 5.89 & 6.1532 & TRN & \\
\hline CHEMBL611396 & 304036 & 6.63 & 6.5528 & TRN & \\
\hline CHEMBL610616 & 304036 & 6.17 & 6.3327 & TRN & \\
\hline CHEMBL611131 & 304036 & 6.91 & 6.7511 & TRN & \\
\hline CHEMBL611398 & 304036 & 7.47 & 7.3489 & TRN & \\
\hline CHEMBL610620 & 304036 & 6.8 & 6.9474 & TRN & \\
\hline CHEMBL610880 & 304036 & 7.12 & 7.2867 & TRN & \\
\hline CHEMBL606741 & 304036 & 6.15 & 6.6436 & TST & \\
\hline CHEMBL606795 & 304036 & 6.62 & 7.1676 & TST & \\
\hline CHEMBL606674 & 304036 & 5.96 & 6.8238 & TST & \\
\hline CHEMBL363631 & 304036 & 5.55 & 6.8389 & TST & \\
\hline CHEMBL193877 & 304036 & 6.1 & 6.5765 & TST & \\
\hline CHEMBL 370897 & 304036 & 5.73 & 6.9617 & TST & \\
\hline CHEMBL195784 & 304036 & 8.82 & 8.4834 & TRN & \\
\hline CHEMBL370544 & 304036 & 7.96 & 7.9231 & TRN & \\
\hline CHEMBL192443 & 304036 & 7.87 & 8.0047 & TRN & \\
\hline CHEMBL195684 & 304036 & 7.29 & 7.5803 & TRN & \\
\hline CHEMBL194021 & 304036 & 6.72 & 6.8324 & TRN & \\
\hline CHEMBL364055 & 304036 & 6.81 & 6.1502 & TRN & \\
\hline CHEMBL 2112568 & 304036 & 6.19 & 6.1062 & TRN & \\
\hline CHEMBL 2112573 & 304036 & 6.51 & \multicolumn{2}{|c|}{6.617000000000001} & TRN \\
\hline CHEMBL195770 & 304036 & 8.38 & 8.5593 & TRN & \\
\hline CHEMBL363601 & 304036 & 8.22 & 8.0924 & TRN & \\
\hline CHEMBL363348 & 304036 & 7.66 & 7.8311 & TRN & \\
\hline CHEMBL 2112570 & 304036 & 6.46 & 6.6916 & TRN & \\
\hline CHEMBL371565 & 304036 & 6.6 & 6.3921 & TRN & \\
\hline CHEMBL 2112578 & 304036 & 6.63 & 6.2945 & TRN & \\
\hline
\end{tabular}




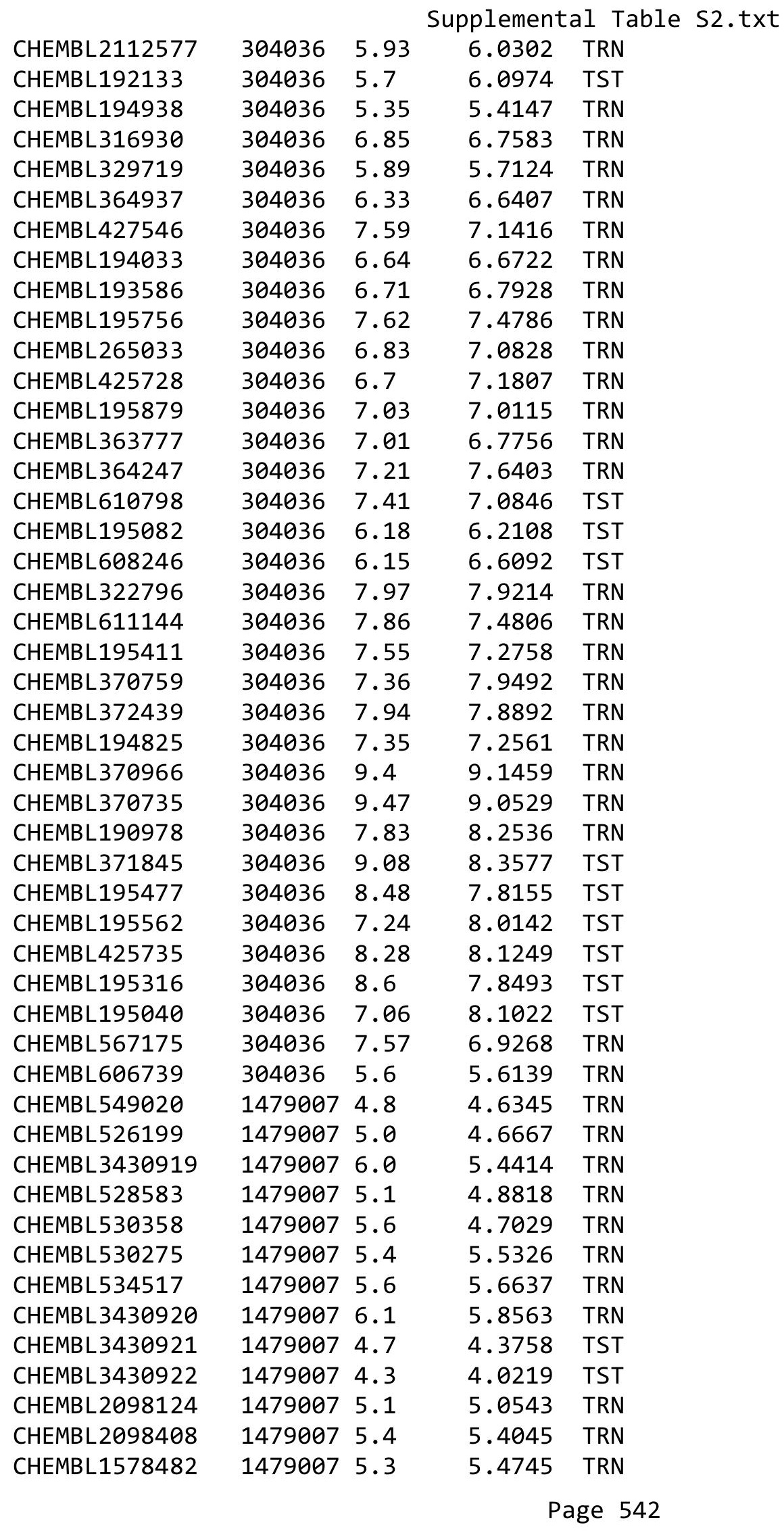




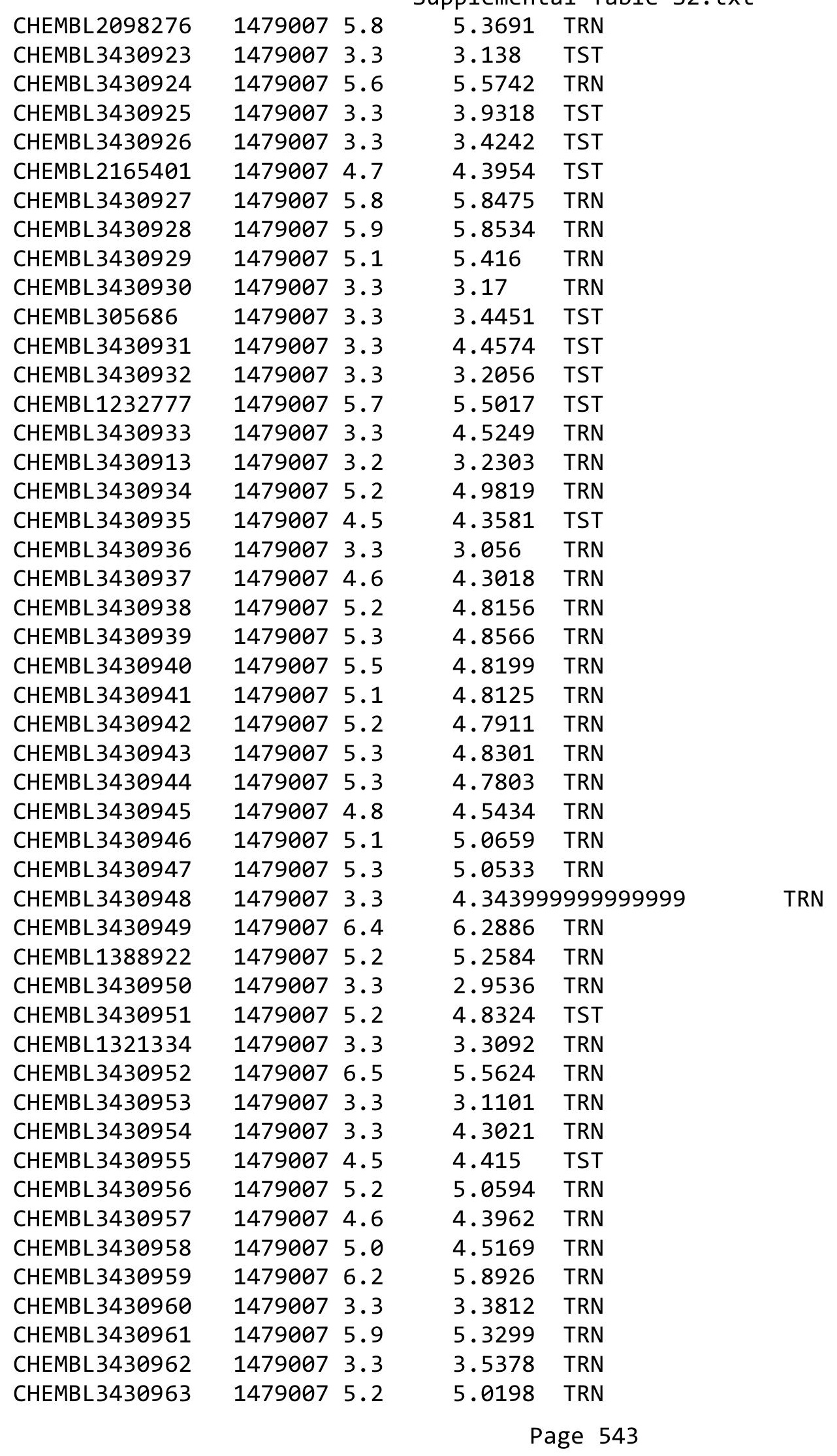




\begin{tabular}{|c|c|c|c|c|c|}
\hline \\
\hline CHEMBL3430964 & 1479007 & 5.1 & 5.0662 & TRN & \\
\hline CHEMBL3430965 & 1479007 & 5.7 & 5.3406 & TRN & \\
\hline CHEMBL3430966 & 1479007 & 4.4 & 4.3453 & TRN & \\
\hline CHEMBL3430967 & 1479007 & 4.8 & 4.4662 & TRN & \\
\hline CHEMBL3430968 & 1479007 & 6.3 & 5.9787 & TRN & \\
\hline CHEMBL3430969 & 1479007 & 5.2 & 5.4609 & TRN & \\
\hline CHEMBL3430970 & 1479007 & 5.3 & 4.9864 & TRN & \\
\hline CHEMBL1482137 & 1479007 & 3.3 & 3.752 & TRN & \\
\hline CHEMBL3430971 & 1479007 & 3.3 & 3.0672 & TRN & \\
\hline CHEMBL3430972 & 1479007 & 3.3 & 3.2312 & TRN & \\
\hline CHEMBL3430973 & 1479007 & 4.9 & 4.559 & TRN & \\
\hline CHEMBL 3430974 & 1479007 & 4.9 & 4.4383 & TRN & \\
\hline CHEMBL3430975 & 1479007 & 3.3 & 2.9429 & TRN & \\
\hline CHEMBL3430976 & 1479007 & 3.3 & 2.9148 & TRN & \\
\hline CHEMBL3430977 & 1479007 & 3.3 & 3.1651 & TST & \\
\hline CHEMBL164422 & 1479007 & 6.4 & 6.1664 & TRN & \\
\hline CHEMBL3430978 & 1479007 & 3.3 & 3.2605 & TRN & \\
\hline CHEMBL3430979 & 1479007 & 3.3 & 3.2865 & TRN & \\
\hline CHEMBL3430980 & 1479007 & 5.2 & 5.072 & TRN & \\
\hline CHEMBL1487481 & 1479007 & 3.3 & 3.6676 & TRN & \\
\hline CHEMBL1487467 & 1479007 & 3.3 & 3.0780 & 00000000003 & TRN \\
\hline CHEMBL3430981 & 1479007 & 5.3 & 4.8546 & TRN & \\
\hline CHEMBL3430982 & 1479007 & 5.4 & 5.0035 & TRN & \\
\hline CHEMBL3430983 & 1479007 & 5.1 & 4.6632 & TRN & \\
\hline CHEMBL592827 & 1479007 & 3.3 & 4.5097 & TRN & \\
\hline CHEMBL 3430984 & 1479007 & 3.3 & 3.3001 & TRN & \\
\hline CHEMBL3430985 & 1479007 & 5.4 & 4.9076 & TRN & \\
\hline CHEMBL1466712 & 1479007 & 5.6 & 5.4675 & TRN & \\
\hline CHEMBL3430986 & 1479007 & 3.3 & 3.3272 & TRN & \\
\hline CHEMBL3430987 & 1479007 & 5.2 & 4.7429 & TST & \\
\hline CHEMBL 3430988 & 1479007 & 3.3 & 4.6655 & TRN & \\
\hline CHEMBL3430989 & 1479007 & 3.3 & 3.065 & TRN & \\
\hline CHEMBL3430990 & 1479007 & 3.3 & 3.1999 & TRN & \\
\hline CHEMBL3430991 & 1479007 & 3.3 & 3.7705 & TRN & \\
\hline CHEMBL3430992 & 1479007 & 3.3 & 4.0077 & TRN & \\
\hline CHEMBL3430993 & 1479007 & 3.3 & 2.9936 & TRN & \\
\hline CHEMBL3430994 & 1479007 & 3.3 & 3.0806 & TRN & \\
\hline CHEMBL3430995 & 1479007 & 4.5 & 4.1571 & TST & \\
\hline CHEMBL3430996 & 1479007 & 3.3 & 2.9257 & TRN & \\
\hline CHEMBL3430997 & 1479007 & 3.3 & 3.0256 & TRN & \\
\hline CHEMBL3430998 & 1479007 & 3.3 & 3.4268 & TRN & \\
\hline CHEMBL3430999 & 1479007 & 4.5 & 4.3196 & TRN & \\
\hline CHEMBL3431000 & 1479007 & 4.3 & 4.06 & TRN & \\
\hline CHEMBL3431001 & 1479007 & 3.3 & 4.2128 & TRN & \\
\hline CHEMBL3431002 & 1479007 & 4.7 & 4.0909 & TST & \\
\hline CHEMBL 3431003 & 1479007 & 6.1 & 5.5656 & TRN & \\
\hline CHEMBL 3431004 & 1479007 & 6.0 & 5.8610 & 3000000001 & TRN \\
\hline CHEMBL3431005 & 1479007 & 5.2 & 5.0107 & TRN & \\
\hline
\end{tabular}




\begin{tabular}{|c|c|c|c|c|}
\hline & & & & $a \perp 1 a$ \\
\hline CHEMBL3431006 & 1479007 & 5.6 & 5.5146 & TRN \\
\hline CHEMBL3431007 & 1479007 & 3.3 & 4.1879 & TRN \\
\hline CHEMBL3431008 & 1479007 & 5.7 & 5.2932 & TST \\
\hline CHEMBL3431009 & 1479007 & 5.8 & 5.5055 & TRN \\
\hline CHEMBL2355685 & 1479007 & 5.3 & 5.2599 & TST \\
\hline CHEMBL3431010 & 1479007 & 5.3 & 5.3727 & TRN \\
\hline CHEMBL3431011 & 1479007 & 3.3 & 3.7698 & TRN \\
\hline CHEMBL3431012 & 1479007 & 3.3 & 3.0393 & TST \\
\hline CHEMBL1731664 & 1479007 & 5.1 & 4.7023 & TRN \\
\hline CHEMBL3431013 & 1479007 & 5.5 & 4.7475 & TRN \\
\hline CHEMBL3431014 & 1479007 & 4.8 & 4.6165 & TRN \\
\hline CHEMBL3431015 & 1479007 & 4.4 & 4.0153 & TRN \\
\hline CHEMBL3431016 & 1479007 & 3.3 & 4.0991 & TRN \\
\hline CHEMBL3431017 & 1479007 & 3.3 & 3.3634 & TRN \\
\hline CHEMBL3431018 & 1479007 & 6.3 & 5.6995 & TRN \\
\hline CHEMBL3431019 & 1479007 & 6.0 & 5.7052 & TRN \\
\hline CHEMBL3431020 & 1479007 & 3.3 & 3.3362 & TRN \\
\hline CHEMBL3431021 & 1479007 & 3.3 & 3.3057 & TRN \\
\hline CHEMBL3431022 & 1479007 & 6.6 & 5.277 & TRN \\
\hline CHEMBL3431023 & 1479007 & 5.0 & 4.4412 & TST \\
\hline CHEMBL3431024 & 1479007 & 3.3 & 3.0003 & TRN \\
\hline CHEMBL3431025 & 1479007 & 3.3 & 3.5157 & TRN \\
\hline CHEMBL3431026 & 1479007 & 5.1 & 5.2126 & TST \\
\hline CHEMBL3431027 & 1479007 & 3.3 & 4.0623 & TRN \\
\hline CHEMBL3431028 & 1479007 & 3.3 & 3.0993 & TRN \\
\hline CHEMBL 3431029 & 1479007 & 3.3 & 3.9874 & TRN \\
\hline CHEMBL3431030 & 1479007 & 4.8 & 5.0064 & TRN \\
\hline CHEMBL3431031 & 1479007 & 4.6 & 4.5396 & TRN \\
\hline CHEMBL3431032 & 1479007 & 5.0 & 4.7411 & TRN \\
\hline CHEMBL1527364 & 1479007 & 3.3 & 3.4215 & TRN \\
\hline CHEMBL3430914 & 1479007 & 5.1 & 4.9811 & TRN \\
\hline CHEMBL3431033 & 1479007 & 6.1 & 6.0672 & TRN \\
\hline CHEMBL 3431034 & 1479007 & 5.2 & 4.9838 & TRN \\
\hline CHEMBL3431035 & 1479007 & 3.3 & 4.3605 & TRN \\
\hline CHEMBL3431036 & 1479007 & 3.3 & 3.3952 & TRN \\
\hline CHEMBL3431037 & 1479007 & 5.7 & 5.2636 & TRN \\
\hline CHEMBL3431038 & 1479007 & 5.5 & 5.3452 & TRN \\
\hline CHEMBL3431039 & 1479007 & 3.3 & 2.9484 & TRN \\
\hline CHEMBL3431040 & 1479007 & 5.8 & 5.7713 & TRN \\
\hline CHEMBL1354075 & 1479007 & 5.0 & 5.1833 & TRN \\
\hline CHEMBL3431041 & 1479007 & 4.5 & 3.7608 & TRN \\
\hline CHEMBL3431042 & 1479007 & 3.3 & 4.1323 & TRN \\
\hline CHEMBL3431043 & 1479007 & 5.5 & 4.6604 & TST \\
\hline CHEMBL3431044 & 1479007 & 3.3 & 3.1775 & TST \\
\hline CHEMBL3431045 & 1479007 & 4.7 & 4.282 & TRN \\
\hline CHEMBL3431046 & 1479007 & 5.7 & 5.8081 & TRN \\
\hline CHEMBL3431047 & 1479007 & 6.1 & 6.0821 & TRN \\
\hline CHEMBL 3431048 & 1479007 & 6.3 & 6.1805 & TRN \\
\hline
\end{tabular}




\begin{tabular}{|c|c|c|c|c|c|}
\hline CHEMBL3431049 & 1479007 & 5.9 & 5.8255 & TRN & \\
\hline CHEMBL3431050 & 1479007 & 6.1 & 6.0836 & TRN & \\
\hline CHEMBL3431051 & 1479007 & 6.0 & 5.9918 & TRN & \\
\hline CHEMBL3431052 & 1479007 & 5.5 & 5.5327 & TRN & \\
\hline CHEMBL3431053 & 1479007 & 6.1 & 5.83899 & 99999999995 & TRN \\
\hline CHEMBL2356808 & 1479007 & 3.3 & 2.9241 & TRN & \\
\hline CHEMBL 3431054 & 1479007 & 3.3 & 3.0526 & TRN & \\
\hline CHEMBL3431055 & 1479007 & 3.3 & 4.0614 & TST & \\
\hline CHEMBL3431056 & 1479007 & 3.3 & 3.2252 & TRN & \\
\hline CHEMBL3431057 & 1479007 & 5.3 & 4.5306 & TST & \\
\hline CHEMBL2093320 & 1479007 & 3.3 & 3.5808 & TRN & \\
\hline CHEMBL3431058 & 1479007 & 3.3 & 3.0288 & TRN & \\
\hline CHEMBL3431059 & 1479007 & 3.3 & 2.8264 & TRN & \\
\hline CHEMBL3431060 & 1479007 & 3.3 & 2.964 & TRN & \\
\hline CHEMBL3431061 & 1479007 & 5.1 & 3.8652 & TRN & \\
\hline CHEMBL3431062 & 1479007 & 3.3 & 2.9251 & TRN & \\
\hline CHEMBL3431063 & 1479007 & 3.3 & 2.8779 & TRN & \\
\hline CHEMBL3431064 & 1479007 & 3.3 & 3.0938 & TRN & \\
\hline CHEMBL3431065 & 1479007 & 4.5 & 4.6642 & TST & \\
\hline CHEMBL3431066 & 1479007 & 4.5 & 3.883 & TRN & \\
\hline CHEMBL3431067 & 1479007 & 4.6 & 4.4903 & TRN & \\
\hline CHEMBL3431068 & 1479007 & 3.3 & 4.53100 & 0000000001 & TRN \\
\hline CHEMBL3431069 & 1479007 & 5.6 & 5.3505 & TRN & \\
\hline CHEMBL3431070 & 1479007 & 5.7 & 5.8078 & TRN & \\
\hline CHEMBL3431071 & 1479007 & 5.3 & 4.8054 & TST & \\
\hline CHEMBL3431072 & 1479007 & 5.9 & 5.301 & TRN & \\
\hline CHEMBL3431073 & 1479007 & 4.7 & 3.8969 & TST & \\
\hline CHEMBL 3431074 & 1479007 & 3.3 & 3.1528 & TRN & \\
\hline CHEMBL3431075 & 1479007 & 3.3 & 3.4016 & TST & \\
\hline CHEMBL3431076 & 1479007 & 5.9 & 5.0881 & TRN & \\
\hline CHEMBL3431077 & 1479007 & 3.3 & 4.3003 & TRN & \\
\hline CHEMBL 3431078 & 1479007 & 5.3 & 4.9447 & TRN & \\
\hline CHEMBL3431079 & 1479007 & 5.3 & 5.2592 & TRN & \\
\hline CHEMBL3431080 & 1479007 & 3.3 & 3.3569 & TRN & \\
\hline CHEMBL3431081 & 1479007 & 3.3 & 3.6392 & TRN & \\
\hline CHEMBL3431082 & 1479007 & 5.0 & 5.025 & TRN & \\
\hline CHEMBL3431083 & 1479007 & 3.3 & 3.1929 & TRN & \\
\hline CHEMBL3431084 & 1479007 & 3.3 & 3.3329 & TST & \\
\hline CHEMBL1585368 & 1479007 & 5.3 & 4.6861 & TRN & \\
\hline CHEMBL3431085 & 1479007 & 3.3 & 3.2178 & TRN & \\
\hline CHEMBL3431086 & 1479007 & 4.6 & 4.5177 & TRN & \\
\hline CHEMBL 3431087 & 1479007 & 5.4 & 4.933 & TRN & \\
\hline CHEMBL3431088 & 1479007 & 3.3 & 3.3405 & TRN & \\
\hline CHEMBL3431089 & 1479007 & 4.4 & 4.9452 & TRN & \\
\hline CHEMBL3431090 & 1479007 & 4.4 & 4.3182 & TRN & \\
\hline CHEMBL 3431091 & 1479007 & 5.2 & 5.1253 & TRN & \\
\hline CHEMBL 3431092 & 1479007 & 5.7 & 5.0525 & TRN & \\
\hline CHEMBL3431093 & 1479007 & 5.9 & 5.1999 & TRN & \\
\hline
\end{tabular}




\begin{tabular}{|c|c|c|c|c|c|}
\hline CHEMBL3431094 & 1479007 & 3.3 & 3.1809 & TRN & \\
\hline CHEMBL3431095 & 1479007 & 5.2 & 5.0542 & TRN & \\
\hline CHEMBL3431096 & 1479007 & 3.3 & 3.2842 & TRN & \\
\hline CHEMBL3431097 & 1479007 & 5.0 & 5.3026 & TRN & \\
\hline CHEMBL3431098 & 1479007 & 5.7 & 5.154 & TRN & \\
\hline CHEMBL3431099 & 1479007 & 4.7 & 4.3146 & TST & \\
\hline CHEMBL3431100 & 1479007 & 5.1 & 5.0895 & TRN & \\
\hline CHEMBL3431101 & 1479007 & 5.2 & 4.7729 & TST & \\
\hline CHEMBL3431102 & 1479007 & 3.3 & 4.1253 & TST & \\
\hline CHEMBL3431103 & 1479007 & 6.4 & 5.4645 & TST & \\
\hline CHEMBL3431104 & 1479007 & 3.3 & 3.3511 & TRN & \\
\hline CHEMBL3431105 & 1479007 & 3.3 & \multicolumn{2}{|c|}{3.5610000000000004} & TRN \\
\hline CHEMBL3431106 & 1479007 & 5.4 & 4.8134 & TST & \\
\hline CHEMBL3431107 & 1479007 & 3.3 & 4.2787 & TRN & \\
\hline CHEMBL3431108 & 1479007 & 3.3 & 4.4592 & TRN & \\
\hline CHEMBL3431109 & 1479007 & 5.0 & 4.7242 & TRN & \\
\hline CHEMBL3431110 & 1479007 & 5.0 & 4.6057 & TRN & \\
\hline CHEMBL3431111 & 1479007 & 5.3 & 4.7989 & TRN & \\
\hline CHEMBL3431112 & 1479007 & 5.8 & 5.7892 & TRN & \\
\hline CHEMBL3431113 & 1479007 & 5.9 & 5.9115 & TRN & \\
\hline CHEMBL3431114 & 1479007 & 3.3 & 4.9682 & TRN & \\
\hline CHEMBL3431115 & 1479007 & 3.3 & 3.3269 & TRN & \\
\hline CHEMBL3431116 & 1479007 & 3.3 & 3.0344 & TRN & \\
\hline CHEMBL3431117 & 1479007 & 5.3 & \multicolumn{2}{|c|}{5.132999999999999} & TRN \\
\hline CHEMBL3431118 & 1479007 & 4.7 & 4.0403 & TRN & \\
\hline CHEMBL3431119 & 1479007 & 6.3 & 5.6665 & TRN & \\
\hline CHEMBL3431120 & 1479007 & 3.3 & 3.3404 & TRN & \\
\hline CHEMBL 3431121 & 1479007 & 3.3 & 3.8303 & TST & \\
\hline CHEMBL3431122 & 1479007 & 3.3 & 4.5047 & TRN & \\
\hline CHEMBL3431123 & 1479007 & 4.5 & 4.4482 & TRN & \\
\hline CHEMBL3431124 & 1479007 & 3.3 & 3.6679 & TRN & \\
\hline CHEMBL 3431125 & 1479007 & 3.3 & 3.2205 & TST & \\
\hline CHEMBL3431126 & 1479007 & 3.3 & 3.2212 & TRN & \\
\hline CHEMBL3431127 & 1479007 & 7.0 & 6.4689 & TST & \\
\hline CHEMBL3431128 & 1479007 & 5.7 & 5.766 & TST & \\
\hline CHEMBL3431129 & 1479007 & 6.1 & 6.091 & TST & \\
\hline CHEMBL3431130 & 1479007 & 4.8 & 5.1319 & TST & \\
\hline CHEMBL 3431131 & 1479007 & 5.2 & 4.9076 & TRN & \\
\hline CHEMBL3430915 & 1479007 & 3.3 & 3.1871 & TRN & \\
\hline CHEMBL3431132 & 1479007 & 4.7 & 4.285 & TRN & \\
\hline CHEMBL3431133 & 1479007 & 4.3 & 4.4291 & TRN & \\
\hline CHEMBL 3431134 & 1479007 & 5.1 & 5.1206 & TRN & \\
\hline CHEMBL3431135 & 1479007 & 3.3 & 2.987 & TRN & \\
\hline CHEMBL3431136 & 1479007 & 6.0 & 5.5731 & TRN & \\
\hline CHEMBL3431137 & 1479007 & 5.3 & 4.923 & TRN & \\
\hline CHEMBL 3431138 & 1479007 & 3.3 & 3.2402 & TST & \\
\hline CHEMBL3431139 & 1479007 & 4.9 & 4.8798 & TST & \\
\hline CHEMBL3431140 & 1479007 & 3.3 & 4.027 & TST & \\
\hline
\end{tabular}




\begin{tabular}{|c|c|c|c|c|}
\hline & & & & al \\
\hline CHEMBL3431141 & 1479007 & 5.0 & 4.5793 & TRN \\
\hline CHEMBL3431142 & 1479007 & 3.3 & 3.4465 & TST \\
\hline CHEMBL3431143 & 1479007 & 5.9 & 5.8465 & TRN \\
\hline CHEMBL 3431144 & 1479007 & 3.3 & 3.4685 & TRN \\
\hline CHEMBL3431145 & 1479007 & 4.9 & 4.9591 & TRN \\
\hline CHEMBL3431146 & 1479007 & 5.4 & 4.8376 & TRN \\
\hline CHEMBL3431147 & 1479007 & 4.8 & 4.5067 & TST \\
\hline CHEMBL3431148 & 1479007 & 3.3 & 3.2605 & TRN \\
\hline CHEMBL3431149 & 1479007 & 5.5 & 5.221 & TRN \\
\hline CHEMBL3431150 & 1479007 & 3.3 & 3.4189 & TRN \\
\hline CHEMBL3431151 & 1479007 & 3.3 & 5.0113 & TRN \\
\hline CHEMBL3431152 & 1479007 & 3.3 & 3.9173 & TRN \\
\hline CHEMBL3431153 & 1479007 & 3.3 & 3.2076 & TRN \\
\hline CHEMBL3431154 & 1479007 & 5.3 & 4.9619 & TST \\
\hline CHEMBL3431155 & 1479007 & 3.3 & 5.1615 & TRN \\
\hline CHEMBL3431156 & 1479007 & 3.3 & 3.3098 & TRN \\
\hline CHEMBL3431157 & 1479007 & 3.3 & 3.468 & TST \\
\hline CHEMBL3431158 & 1479007 & 6.5 & 5.3906 & TST \\
\hline CHEMBL3431159 & 1479007 & 3.3 & 3.4462 & TST \\
\hline CHEMBL1593679 & 1479007 & 3.3 & 3.4893 & TRN \\
\hline CHEMBL3431160 & 1479007 & 4.8 & 4.3969 & TRN \\
\hline CHEMBL3431161 & 1479007 & 4.6 & 4.3102 & TST \\
\hline CHEMBL3431162 & 1479007 & 3.3 & 3.9961 & TST \\
\hline CHEMBL3431163 & 1479007 & 4.3 & 4.3863 & TRN \\
\hline CHEMBL3431164 & 1479007 & 3.3 & 3.2251 & TRN \\
\hline CHEMBL3431165 & 1479007 & 3.3 & 3.2091 & TST \\
\hline CHEMBL1458931 & 1479007 & 3.3 & 3.3568 & TRN \\
\hline CHEMBL3431166 & 1479007 & 3.3 & 3.0451 & TRN \\
\hline CHEMBL3431167 & 1479007 & 3.3 & 3.2235 & TRN \\
\hline CHEMBL3431168 & 1479007 & 5.9 & 6.0728 & TRN \\
\hline CHEMBL3431169 & 1479007 & 5.1 & 4.9204 & TRN \\
\hline CHEMBL3431170 & 1479007 & 6.7 & 6.8321 & TRN \\
\hline CHEMBL3431171 & 1479007 & 3.3 & 3.2805 & TRN \\
\hline CHEMBL3431172 & 1479007 & 5.7 & 5.9437 & TRN \\
\hline CHEMBL3431173 & 1479007 & 5.6 & 5.1453 & TRN \\
\hline CHEMBL3431174 & 1479007 & 5.5 & 5.01399 & 9999999999 \\
\hline CHEMBL3431175 & 1479007 & 3.3 & 3.2856 & TST \\
\hline CHEMBL3431176 & 1479007 & 6.5 & 5.6955 & TRN \\
\hline CHEMBL3431177 & 1479007 & 5.4 & 5.6227 & TRN \\
\hline CHEMBL3431178 & 1479007 & 5.3 & 5.393 & TRN \\
\hline CHEMBL3431179 & 1479007 & 5.3 & 4.868 & TRN \\
\hline CHEMBL3431180 & 1479007 & 6.1 & 5.6127 & TRN \\
\hline CHEMBL3431181 & 1479007 & 5.3 & 5.8241 & TRN \\
\hline CHEMBL3431182 & 1479007 & 5.2 & 4.6879 & TRN \\
\hline CHEMBL3431183 & 1479007 & 3.3 & 4.4251 & TRN \\
\hline CHEMBL 3431184 & 1479007 & 5.0 & 4.6596 & TRN \\
\hline CHEMBL3431185 & 1479007 & 5.6 & 5.8462 & TRN \\
\hline CHEMBL3431186 & 1479007 & 5.7 & 6.1815 & TRN \\
\hline
\end{tabular}




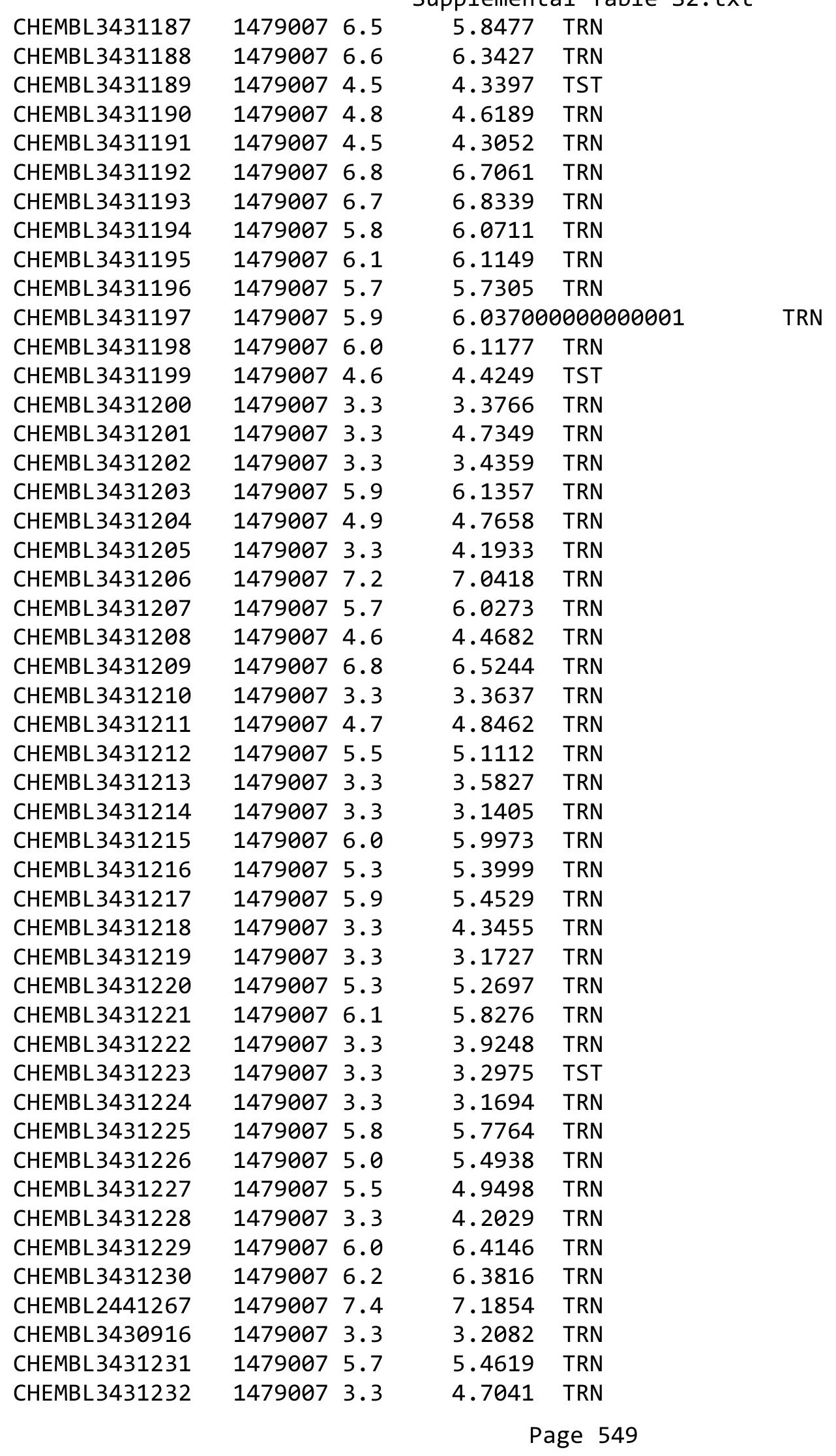




\begin{tabular}{|c|c|c|c|c|}
\hline & & & & \\
\hline CHEMBL3431233 & 1479007 & 6.0 & 5.7899 & TRN \\
\hline CHEMBL3431234 & 1479007 & 5.5 & 5.3806 & TRN \\
\hline CHEMBL3431235 & 1479007 & 4.7 & 4.4522 & TST \\
\hline CHEMBL 3431236 & 1479007 & 3.3 & 4.0937 & TST \\
\hline CHEMBL3431237 & 1479007 & 5.0 & 4.5016 & TRN \\
\hline CHEMBL3431238 & 1479007 & 3.3 & 4.345 & TRN \\
\hline CHEMBL3431239 & 1479007 & 3.3 & 3.0353 & TRN \\
\hline CHEMBL3431240 & 1479007 & 3.3 & 3.5013 & TST \\
\hline CHEMBL 3431241 & 1479007 & 3.3 & 6.2128 & TRN \\
\hline CHEMBL3431242 & 1479007 & 3.3 & 3.3678 & TRN \\
\hline CHEMBL3431243 & 1479007 & 3.3 & 3.2674 & TST \\
\hline CHEMBL3431244 & 1479007 & 3.3 & 3.5104 & TRN \\
\hline CHEMBL 3431245 & 1479007 & 5.3 & 4.9077 & TRN \\
\hline CHEMBL3431246 & 1479007 & 5.6 & 5.1317 & TRN \\
\hline CHEMBL3431247 & 1479007 & 6.2 & 5.5579 & TRN \\
\hline CHEMBL3431248 & 1479007 & 3.3 & 3.9231 & TRN \\
\hline CHEMBL3431249 & 1479007 & 3.3 & 4.3145 & TRN \\
\hline CHEMBL 3431250 & 1479007 & 3.3 & 3.0548 & TRN \\
\hline CHEMBL3431251 & 1479007 & 3.3 & 3.1489 & TRN \\
\hline CHEMBL3431252 & 1479007 & 3.3 & 3.1471 & TRN \\
\hline CHEMBL3431253 & 1479007 & 4.4 & 4.2134 & TST \\
\hline CHEMBL 3431254 & 1479007 & 5.1 & 4.7985 & TRN \\
\hline CHEMBL3431255 & 1479007 & 4.5 & 4.2196 & TST \\
\hline CHEMBL3431256 & 1479007 & 6.0 & 5.5396 & TST \\
\hline CHEMBL 3431257 & 1479007 & 3.3 & 3.5468 & TRN \\
\hline CHEMBL3431258 & 1479007 & 5.3 & 4.923 & TRN \\
\hline CHEMBL3431259 & 1479007 & 3.3 & 3.1633 & TRN \\
\hline CHEMBL3431260 & 1479007 & 3.3 & 4.8712 & TRN \\
\hline CHEMBL3431261 & 1479007 & 4.7 & 4.4979 & TRN \\
\hline CHEMBL 2356920 & 1479007 & 4.6 & 4.3969 & TRN \\
\hline CHEMBL3431262 & 1479007 & 3.3 & 3.0768 & TRN \\
\hline CHEMBL3431263 & 1479007 & 3.3 & 3.9884 & TRN \\
\hline CHEMBL3431264 & 1479007 & 3.3 & 3.4651 & TRN \\
\hline CHEMBL3431265 & 1479007 & 3.3 & 3.298 & TST \\
\hline CHEMBL3431266 & 1479007 & 3.3 & 4.8012 & TRN \\
\hline CHEMBL3431267 & 1479007 & 5.1 & 5.0459 & TRN \\
\hline CHEMBL3431268 & 1479007 & 5.4 & 5.0227 & TST \\
\hline CHEMBL3431269 & 1479007 & 5.5 & 5.4513 & TRN \\
\hline CHEMBL 3431270 & 1479007 & 4.5 & 4.6389 & TST \\
\hline CHEMBL 3431271 & 1479007 & 3.3 & 3.0068 & TRN \\
\hline CHEMBL3431272 & 1479007 & 3.3 & 2.9893 & TRN \\
\hline CHEMBL3431273 & 1479007 & 5.8 & 5.4414 & TRN \\
\hline CHEMBL3431274 & 1479007 & 5.7 & 5.4008 & TRN \\
\hline CHEMBL3431275 & 1479007 & 4.5 & 4.2382 & TRN \\
\hline CHEMBL3431276 & 1479007 & 5.0 & 4.857 & TST \\
\hline CHEMBL3431277 & 1479007 & 5.7 & 5.407 & TRN \\
\hline CHEMBL 3431278 & 1479007 & 3.3 & 3.3162 & TRN \\
\hline CHEMBL3431279 & 1479007 & 3.3 & 3.4241 & TST \\
\hline
\end{tabular}




\begin{tabular}{|c|c|c|c|c|c|}
\hline \multirow{3}{*}{ CHEMBL 3431280} & \multirow{2}{*}{1479007} & \\
\hline & & 4.4 & 4.2005 & \multicolumn{2}{|l|}{ TST } \\
\hline & 1479007 & 5.1 & 4.7372 & \multicolumn{2}{|l|}{ TST } \\
\hline CHEMBL3431282 & 1479007 & 3.3 & 3.2645 & \multicolumn{2}{|l|}{ TST } \\
\hline CHEMBL3431283 & 1479007 & 3.3 & 3.3973 & \multicolumn{2}{|l|}{ TST } \\
\hline CHEMBL3431284 & 1479007 & 4.9 & 4.8386 & \multicolumn{2}{|l|}{ TRN } \\
\hline CHEMBL3431285 & 1479007 & 6.4 & 5.5529 & \multicolumn{2}{|l|}{ TRN } \\
\hline CHEMBL3431286 & 1479007 & 3.3 & 3.4415 & \multicolumn{2}{|l|}{ TST } \\
\hline CHEMBL3431287 & 1479007 & 3.3 & 4.3459 & \multicolumn{2}{|l|}{ TST } \\
\hline CHEMBL3431288 & 1479007 & 3.3 & 5.0621 & \multicolumn{2}{|l|}{ TRN } \\
\hline CHEMBL3431289 & 1479007 & 3.3 & 3.2992 & \multicolumn{2}{|l|}{ TST } \\
\hline CHEMBL3431290 & 1479007 & 3.3 & 4.815 & \multicolumn{2}{|l|}{ TRN } \\
\hline CHEMBL3431291 & 1479007 & 3.3 & 3.3757 & \multicolumn{2}{|l|}{ TRN } \\
\hline CHEMBL3431292 & 1479007 & 3.3 & 4.1899 & \multicolumn{2}{|l|}{ TRN } \\
\hline CHEMBL3431293 & 1479007 & 3.3 & 3.2244 & \multicolumn{2}{|l|}{ TRN } \\
\hline CHEMBL3431294 & 1479007 & 3.3 & 3.0458 & \multicolumn{2}{|l|}{ TRN } \\
\hline CHEMBL3431295 & 1479007 & 5.3 & 5.4251 & \multicolumn{2}{|l|}{ TRN } \\
\hline CHEMBL3431296 & 1479007 & 5.1 & 5.2497 & \multicolumn{2}{|l|}{ TRN } \\
\hline CHEMBL3431297 & 1479007 & 5.3 & 5.3521 & \multicolumn{2}{|l|}{ TRN } \\
\hline CHEMBL3431298 & 1479007 & 5.5 & 5.4659 & TRN & \\
\hline CHEMBL3431299 & 1479007 & 5.4 & 5.074 & TRN & \\
\hline CHEMBL 3431300 & 1479007 & 3.3 & 3.4748 & TRN & \\
\hline CHEMBL3431301 & 1479007 & 3.3 & 3.2368 & TST & \\
\hline CHEMBL3431302 & 1479007 & 3.3 & 3.6508 & TRN & \\
\hline CHEMBL3431303 & 1479007 & 3.3 & 4.7496 & TRN & \\
\hline CHEMBL3431304 & 1479007 & 5.4 & 4.8975 & TRN & \\
\hline CHEMBL3431305 & 1479007 & 3.3 & 3.0741 & TRN & \\
\hline CHEMBL3431306 & 1479007 & 5.2 & 4.8282 & TRN & \\
\hline CHEMBL3431307 & 1479007 & 3.3 & 5.37299 & 9999999999 & TRN \\
\hline CHEMBL3431308 & 1479007 & 5.2 & 4.8029 & TRN & \\
\hline CHEMBL3431309 & 1479007 & 5.6 & 5.4871 & TRN & \\
\hline CHEMBL3431310 & 1479007 & 4.8 & 4.3036 & TRN & \\
\hline CHEMBL3431311 & 1479007 & 6.3 & 6.2339 & TRN & \\
\hline CHEMBL3431312 & 1479007 & 6.1 & 5.9358 & TRN & \\
\hline CHEMBL3431313 & 1479007 & 6.2 & 6.1728 & TRN & \\
\hline CHEMBL3431314 & 1479007 & 6.2 & 6.4415 & TRN & \\
\hline CHEMBL3431315 & 1479007 & 5.5 & 5.33700 & 3000000001 & TRN \\
\hline CHEMBL3431316 & 1479007 & 3.3 & 3.3554 & TST & \\
\hline CHEMBL3431317 & 1479007 & 5.1 & 4.7075 & TRN & \\
\hline CHEMBL3431318 & 1479007 & 3.3 & 4.9755 & TST & \\
\hline CHEMBL3431319 & 1479007 & 5.1 & 4.34 & TRN & \\
\hline CHEMBL3431320 & 1479007 & 3.3 & 3.3922 & TST & \\
\hline CHEMBL3431321 & 1479007 & 3.3 & 3.2583 & TRN & \\
\hline CHEMBL3431322 & 1479007 & 3.3 & 3.3133 & TRN & \\
\hline CHEMBL3431323 & 1479007 & 3.3 & 4.0646 & TRN & \\
\hline CHEMBL3431324 & 1479007 & 3.3 & 3.4755 & TST & \\
\hline CHEMBL3431325 & 1479007 & 4.4 & 4.0508 & TRN & \\
\hline CHEMBL3431326 & 1479007 & 3.3 & 3.4885 & TRN & \\
\hline CHEMBL3431327 & 1479007 & 5.8 & 5.34200 & 00000000005 & TST \\
\hline & & & & 551 & \\
\hline
\end{tabular}




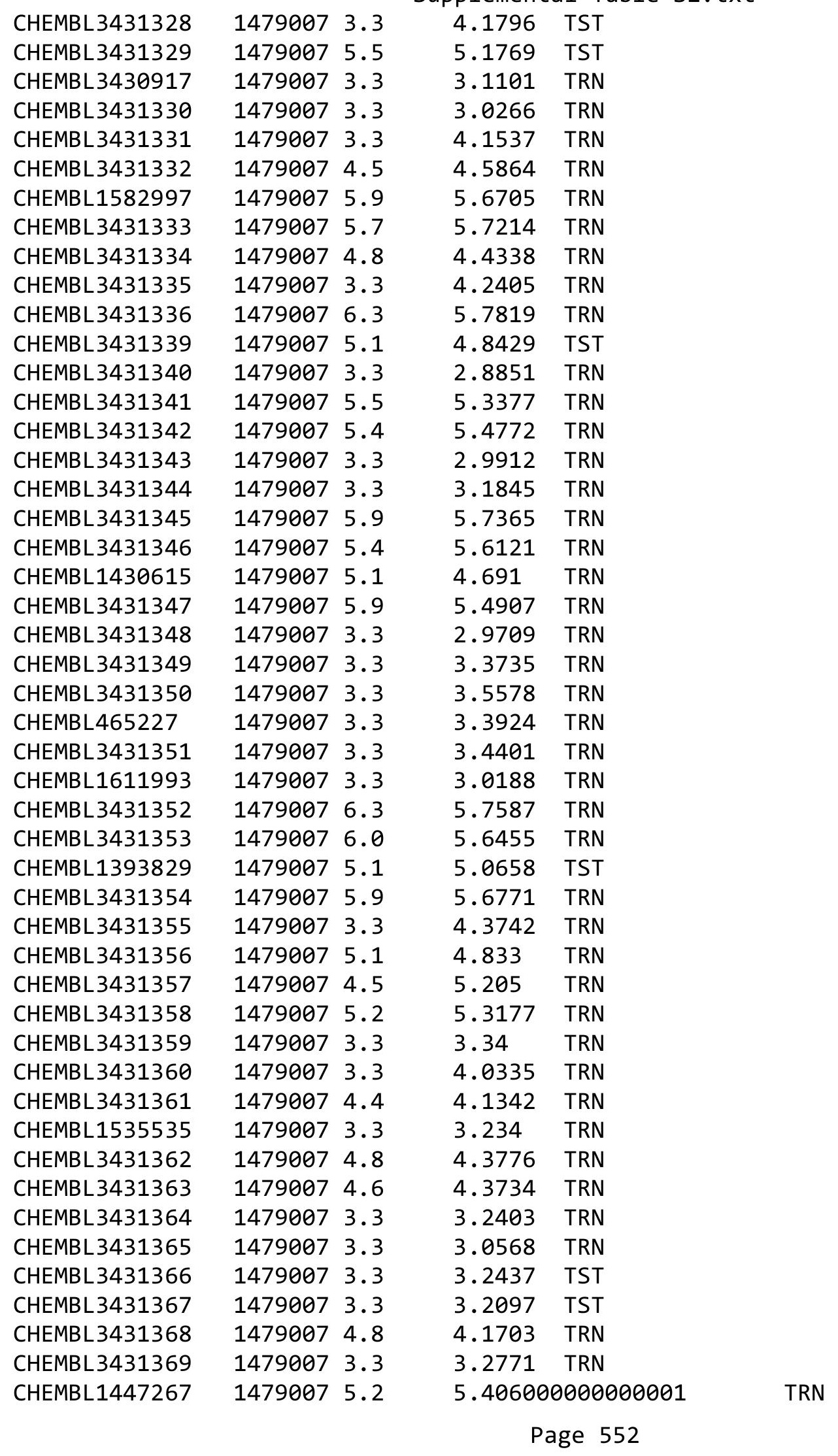




\begin{tabular}{|c|c|c|c|c|c|}
\hline & & & & & \\
\hline CHEMBL3431370 & 1479007 & 3.3 & 3.4792 & TRN & \\
\hline CHEMBL1325144 & 1479007 & 3.3 & 3.3955 & TRN & \\
\hline CHEMBL1429841 & 1479007 & 5.1 & 4.9422 & TRN & \\
\hline CHEMBL3431371 & 1479007 & 3.3 & 5.225 & TRN & \\
\hline CHEMBL1308225 & 1479007 & 3.3 & 3.4062 & TST & \\
\hline CHEMBL2441359 & 1479007 & 5.6 & 5.5078 & TRN & \\
\hline CHEMBL1517284 & 1479007 & 5.5 & 5.5615 & TRN & \\
\hline CHEMBL3431372 & 1479007 & 3.3 & 3.3519 & TRN & \\
\hline CHEMBL3431373 & 1479007 & 3.3 & 4.3523 & TRN & \\
\hline CHEMBL3431374 & 1479007 & 3.3 & 3.3859 & TRN & \\
\hline CHEMBL3431375 & 1479007 & 3.3 & 4.2823 & TST & \\
\hline CHEMBL3431376 & 1479007 & 6.0 & 5.7328 & TRN & \\
\hline CHEMBL1365653 & 1479007 & 3.3 & 3.1819 & TRN & \\
\hline CHEMBL3431377 & 1479007 & 3.3 & 3.2613 & TRN & \\
\hline CHEMBL3431378 & 1479007 & 5.6 & 5.3056 & TRN & \\
\hline CHEMBL3431379 & 1479007 & 5.5 & 5.2928 & TRN & \\
\hline CHEMBL1478826 & 1479007 & 5.8 & 5.6997 & TRN & \\
\hline CHEMBL1872842 & 1479007 & 3.3 & 3.0161 & TRN & \\
\hline CHEMBL3431380 & 1479007 & 6.6 & 6.3577 & TRN & \\
\hline CHEMBL3431381 & 1479007 & 5.8 & 5.4194 & TRN & \\
\hline CHEMBL3431382 & 1479007 & 4.5 & 4.4123 & TRN & \\
\hline CHEMBL3431383 & 1479007 & 5.0 & 5.0401 & TRN & \\
\hline CHEMBL 3431384 & 1479007 & 5.2 & 4.5728 & TRN & \\
\hline CHEMBL3431385 & 1479007 & 3.3 & 3.0022 & TRN & \\
\hline CHEMBL3431386 & 1479007 & 5.1 & 4.7468 & TRN & \\
\hline CHEMBL1730515 & 1479007 & 5.5 & 5.4437 & TRN & \\
\hline CHEMBL3431387 & 1479007 & 3.3 & 3.568 & TRN & \\
\hline CHEMBL3431388 & 1479007 & 4.6 & 4.609 & TRN & \\
\hline CHEMBL1566898 & 1479007 & 4.4 & 3.9616 & TRN & \\
\hline CHEMBL3431389 & 1479007 & 3.3 & 4.0007 & TRN & \\
\hline CHEMBL3431390 & 1479007 & 4.7 & 4.6728 & TST & \\
\hline CHEMBL3431391 & 1479007 & 3.3 & 4.1419 & TRN & \\
\hline CHEMBL1489081 & 1479007 & 5.9 & 6.0233 & TRN & \\
\hline CHEMBL3431392 & 1479007 & 3.3 & 4.3116 & TRN & \\
\hline CHEMBL3431393 & 1479007 & 5.7 & 5.3507 & TRN & \\
\hline CHEMBL3431394 & 1479007 & 3.3 & 3.9634 & TRN & \\
\hline CHEMBL3431395 & 1479007 & 3.3 & 3.45600 & 00000000004 & TRN \\
\hline CHEMBL3431396 & 1479007 & 3.3 & 3.3061 & TRN & \\
\hline CHEMBL3431397 & 1479007 & 4.6 & 4.7453 & TRN & \\
\hline CHEMBL3431398 & 1479007 & 5.3 & 4.8737 & TRN & \\
\hline CHEMBL3431399 & 1479007 & 3.3 & 4.5764 & TRN & \\
\hline CHEMBL3431400 & 1479007 & 3.3 & 4.7114 & TST & \\
\hline CHEMBL1418463 & 1479007 & 6.0 & 5.7244 & TST & \\
\hline CHEMBL3431401 & 1479007 & 3.3 & 3.03899 & 99999999997 & TST \\
\hline CHEMBL3431402 & 1479007 & 4.4 & 4.5569 & TST & \\
\hline CHEMBL3431403 & 1479007 & 3.3 & 4.0565 & TST & \\
\hline CHEMBL 3431404 & 1479007 & 4.3 & 4.2941 & TST & \\
\hline CHEMBL3431405 & 1479007 & 3.3 & 4.6997 & TST & \\
\hline & & & & e 553 & \\
\hline
\end{tabular}




\begin{tabular}{|c|c|c|c|c|c|}
\hline & & & & & \\
\hline CHEMBL3431406 & 1479007 & 5.6 & 5.274 & TST & \\
\hline CHEMBL3431407 & 1479007 & 4.7 & 4.4404 & TST & \\
\hline CHEMBL3431408 & 1479007 & 3.3 & 4.4262 & TST & \\
\hline CHEMBL3431409 & 1479007 & 5.9 & 5.5155 & TST & \\
\hline CHEMBL3431410 & 1479007 & 3.3 & 3.2628 & TST & \\
\hline CHEMBL3431411 & 1479007 & 3.3 & 3.3227 & TST & \\
\hline CHEMBL3431412 & 1479007 & 4.4 & 4.522 & TST & \\
\hline CHEMBL3431413 & 1479007 & 5.3 & 5.2388 & TST & \\
\hline CHEMBL3431414 & 1479007 & 5.0 & 4.6059 & TST & \\
\hline CHEMBL3431415 & 1479007 & 4.7 & 4.3316 & TST & \\
\hline CHEMBL3431416 & 1479007 & 4.6 & 4.508 & TST & \\
\hline CHEMBL291721 & 1479007 & 4.5 & 4.2022 & TST & \\
\hline CHEMBL3431417 & 1479007 & 3.3 & 4.4025 & TST & \\
\hline CHEMBL3431418 & 1479007 & 3.3 & 3.1706 & TST & \\
\hline CHEMBL487186 & 1479007 & 3.3 & 3.3179 & TST & \\
\hline CHEMBL3431419 & 1479007 & 3.3 & 3.3285 & TST & \\
\hline CHEMBL3431420 & 1479007 & 3.3 & 3.03899 & 99999999997 & TST \\
\hline CHEMBL3431421 & 1479007 & 5.2 & 3.5017 & TST & \\
\hline CHEMBL3431422 & 1479007 & 5.7 & 4.6628 & TST & \\
\hline CHEMBL3431423 & 1479007 & 3.3 & 3.1261 & TST & \\
\hline CHEMBL3431424 & 1479007 & 3.3 & 5.0125 & TST & \\
\hline CHEMBL3431425 & 1479007 & 5.7 & 5.624 & TST & \\
\hline CHEMBL3431426 & 1479007 & 4.5 & 4.1182 & TST & \\
\hline CHEMBL3431427 & 1479007 & 3.3 & 4.1325 & TST & \\
\hline CHEMBL3431428 & 1479007 & 3.3 & 3.9948 & TST & \\
\hline CHEMBL1725748 & 1479007 & 3.3 & 3.4609 & TST & \\
\hline CHEMBL3430918 & 1479007 & 4.5 & 4.1448 & TST & \\
\hline CHEMBL522630 & 1479007 & 6.0 & 5.7504 & TST & \\
\hline CHEMBL3431429 & 1479007 & 6.0 & 5.5385 & TST & \\
\hline CHEMBL523468 & 1479007 & 5.5 & 5.5243 & TST & \\
\hline CHEMBL523303 & 1479007 & 5.9 & 5.7507 & TST & \\
\hline CHEMBL3431430 & 1479007 & 3.3 & 4.2662 & TST & \\
\hline CHEMBL128672 & 1479007 & 3.3 & 4.2498 & TST & \\
\hline CHEMBL491149 & 1479007 & 5.4 & 5.4405 & TST & \\
\hline CHEMBL 3431431 & 1479007 & 5.7 & 6.1455 & TST & \\
\hline CHEMBL3431432 & 1479007 & 5.7 & 6.0132 & TST & \\
\hline CHEMBL3431433 & 1479007 & 7.6 & 7.1676 & TST & \\
\hline CHEMBL3431434 & 1479007 & 4.7 & 4.2628 & TST & \\
\hline CHEMBL3431435 & 1479007 & 7.8 & 7.3861 & TST & \\
\hline CHEMBL3431436 & 1479007 & 5.0 & 5.255 & TST & \\
\hline CHEMBL3431437 & 1479007 & 3.3 & 3.3567 & TST & \\
\hline CHEMBL3431438 & 1479007 & 5.3 & 4.9142 & TST & \\
\hline CHEMBL3431439 & 1479007 & 3.3 & 3.3566 & TST & \\
\hline CHEMBL 3431440 & 1479007 & 4.6 & 4.1567 & TST & \\
\hline CHEMBL 3431441 & 1479007 & 3.3 & 3.2508 & TST & \\
\hline CHEMBL 3431442 & 1479007 & 4.4 & 4.0314 & TST & \\
\hline CHEMBL 3431443 & 1479007 & 4.7 & 4.6678 & TST & \\
\hline CHEMBL3431444 & 1479007 & 5.7 & 5.1078 & TST & \\
\hline
\end{tabular}




\begin{tabular}{|c|c|c|c|c|c|}
\hline \\
\hline CHEMBL 3431445 & 1479007 & 3.3 & 4.0827 & TST & \\
\hline CHEMBL483530 & 556875 & 6.8861 & 6.4781 & TRN & \\
\hline CHEMBL488548 & 556875 & 5.4559 & 5.0708 & TRN & \\
\hline CHEMBL484288 & 556875 & 5.699 & 5.822999 & 99999999995 & TRN \\
\hline CHEMBL482919 & 556875 & 4.556 & 5.4183 & TRN & \\
\hline CHEMBL486711 & 556875 & 6.8861 & 6.881 & TRN & \\
\hline CHEMBL 260864 & 556875 & 7.4318 & 7.027 & TRN & \\
\hline CHEMBL487731 & 556875 & 4.9586 & 4.973 & TRN & \\
\hline CHEMBL407095 & 556875 & 5.9586 & 6.0629 & TRN & \\
\hline CHEMBL488342 & 556875 & 4.9586 & 4.4103 & TST & \\
\hline CHEMBL489655 & 556875 & 3.301 & 3.3006 & TRN & \\
\hline CHEMBL485878 & 556875 & 4.4597 & 5.7688 & TRN & \\
\hline CHEMBL487526 & 556875 & 4.3872 & 6.1819 & TST & \\
\hline CHEMBL476907 & 556875 & 5.5686 & 5.9837 & TRN & \\
\hline CHEMBL487737 & 556875 & 5.6383 & 4.5253 & TST & \\
\hline CHEMBL483514 & 556875 & 4.7122 & 5.1173 & TRN & \\
\hline CHEMBL520458 & 556875 & 7.5686 & 7.414 & TRN & \\
\hline CHEMBL486301 & 556875 & 5.6021 & 5.032 & TRN & \\
\hline CHEMBL486712 & 556875 & 6.5086 & 6.4444 & TRN & \\
\hline CHEMBL487532 & 556875 & 4.8447 & 4.6538 & TRN & \\
\hline CHEMBL486497 & 556875 & 6.9586 & 6.99 & TRN & \\
\hline CHEMBL487326 & 556875 & 6.4089 & 5.5482 & TRN & \\
\hline CHEMBL485892 & 556875 & 5.7905 & 5.8558 & TRN & \\
\hline CHEMBL521459 & 556875 & 5.9031 & 6.2835 & TRN & \\
\hline CHEMBL487531 & 556875 & 6.8861 & 6.5597 & TRN & \\
\hline CHEMBL488128 & 556875 & 6.4949 & 6.0763 & TST & \\
\hline CHEMBL482678 & 556875 & 5.3872 & 5.2265 & TRN & \\
\hline CHEMBL488549 & 556875 & 6.0 & 5.9418 & TRN & \\
\hline CHEMBL485877 & 556875 & 6.0362 & 5.5433 & TRN & \\
\hline CHEMBL515949 & 556875 & 6.8861 & 6.7177 & TRN & \\
\hline CHEMBL530335 & 556875 & 6.0862 & 6.1083 & TRN & \\
\hline CHEMBL487327 & 556875 & 6.4815 & 6.579 & TRN & \\
\hline CHEMBL520864 & 556875 & 4.82100 & 000000000 & 4.3785 & TRN \\
\hline CHEMBL529661 & 556875 & 6.8539 & 7.018 & TRN & \\
\hline CHEMBL486091 & 556875 & 7.0 & 6.8851 & TRN & \\
\hline CHEMBL483081 & 556875 & 6.6021 & 6.7606 & TRN & \\
\hline CHEMBL488562 & 556875 & 7.0969 & 7.0823 & TRN & \\
\hline CHEMBL486284 & 556875 & 5.4815 & 5.2141 & TRN & \\
\hline CHEMBL488955 & 556875 & 6.3188 & 5.9627 & TRN & \\
\hline CHEMBL486487 & 556875 & 4.6737 & 6.1432 & TST & \\
\hline CHEMBL486286 & 556875 & 5.8539 & 5.9941 & TRN & \\
\hline CHEMBL487730 & 556875 & 6.8539 & 6.9197 & TRN & \\
\hline CHEMBL482918 & 556875 & 7.3872 & 7.5761 & TRN & \\
\hline CHEMBL488349 & 556875 & 7.301 & 7.3938 & TRN & \\
\hline CHEMBL482679 & 556875 & 3.5376 & 4.3502 & TRN & \\
\hline CHEMBL483535 & 556875 & 4.8013 & 4.7933 & TRN & \\
\hline CHEMBL409861 & 556875 & 5.7447 & 4.7672 & TST & \\
\hline CHEMBL482883 & 556875 & 5.0 & 4.7633 & TST & \\
\hline
\end{tabular}


Supplemental Table S2.txt

\begin{tabular}{|c|c|c|c|c|}
\hline CHEMBL486302 & 556875 & 6.5229 & 6.0705 & TST \\
\hline CHEMBL477077 & 556875 & 5.5229 & 6.1307 & TST \\
\hline CHEMBL487328 & 556875 & 6.6576 & 7.103 & TST \\
\hline CHEMBL487521 & 556875 & 6.4949 & 5.4354 & TST \\
\hline CHEMBL477073 & 556875 & 5.5528 & 6.0958 & TST \\
\hline CHEMBL486285 & 556875 & 4.9172 & 5.9628 & TST \\
\hline CHEMBL483728 & 556875 & 6.0 & 6.0251 & TST \\
\hline CHEMBL 3640048 & 1527765 & 5.6778 & 5.854 & TST \\
\hline CHEMBL 3679445 & 1527765 & 7.2924 & 7.2534 & TRN \\
\hline CHEMBL3640062 & 1527765 & 5.9586 & 5.7866 & TST \\
\hline CHEMBL3679503 & 1527765 & 7.0915 & 7.1327 & TRN \\
\hline CHEMBL3679555 & 1527765 & 7.9208 & 7.897 & TRN \\
\hline CHEMBL3679513 & 1527765 & 7.4437 & 7.4935 & TRN \\
\hline CHEMBL 3679546 & 1527765 & 7.5086 & 7.575 & TRN \\
\hline CHEMBL3640046 & 1527765 & 5.7696 & 5.2527 & TST \\
\hline CHEMBL3679502 & 1527765 & 7.1487 & 7.1518 & TRN \\
\hline CHEMBL3679541 & 1527765 & 7.8239 & 7.8104 & TRN \\
\hline CHEMBL3679553 & 1527765 & 8.1549 & 7.7584 & TRN \\
\hline CHEMBL 3679516 & 1527765 & 7.1612 & 7.1661 & TRN \\
\hline CHEMBL3640055 & 1527765 & 5.6778 & 5.9037 & TRN \\
\hline CHEMBL3679594 & 1527765 & 6.0706 & 5.5295 & TST \\
\hline CHEMBL3679579 & 1527765 & 7.585 & 7.5178 & TRN \\
\hline CHEMBL3679598 & 1527765 & 6.9208 & 5.6814 & TST \\
\hline CHEMBL 3679543 & 1527765 & 7.7696 & 8.0107 & TRN \\
\hline CHEMBL3679434 & 1527765 & 7.4437 & 7.0255 & TRN \\
\hline CHEMBL3679565 & 1527765 & 7.0 & 6.9725 & TRN \\
\hline CHEMBL3679486 & 1527765 & 7.7212 & 7.6739 & TRN \\
\hline CHEMBL 3640058 & 1527765 & 6.0706 & 5.6756 & TST \\
\hline CHEMBL 3679472 & 1527765 & 6.4202 & 6.8767 & TRN \\
\hline CHEMBL3679477 & 1527765 & 7.0969 & 6.8376 & TRN \\
\hline CHEMBL3679530 & 1527765 & 8.301 & 7.9444 & TRN \\
\hline CHEMBL 3679540 & 1527765 & 7.8239 & 7.8426 & TRN \\
\hline CHEMBL3679452 & 1527765 & 7.4202 & 7.5677 & TRN \\
\hline CHEMBL 3679575 & 1527765 & 7.5229 & 7.83299 & 9999999999 \\
\hline CHEMBL 3679437 & 1527765 & 6.8539 & 6.8448 & TRN \\
\hline CHEMBL3679428 & 1527765 & 7.6021 & 7.7078 & TRN \\
\hline CHEMBL3679585 & 1527765 & 7.1367 & 7.4216 & TRN \\
\hline CHEMBL3679488 & 1527765 & 7.6778 & 7.4953 & TRN \\
\hline CHEMBL3679536 & 1527765 & 8.0 & 7.6314 & TRN \\
\hline CHEMBL3679496 & 1527765 & 7.4685 & 7.4101 & TRN \\
\hline CHEMBL3679523 & 1527765 & 6.9208 & 6.9561 & TST \\
\hline CHEMBL3679501 & 1527765 & 7.1871 & 7.6148 & TRN \\
\hline CHEMBL3679542 & 1527765 & 7.7959 & 8.0427 & TRN \\
\hline CHEMBL 3640068 & 1527765 & 5.9586 & 5.9903 & TRN \\
\hline CHEMBL 3679447 & 1527765 & 7.0862 & 7.3275 & TRN \\
\hline CHEMBL3679463 & 1527765 & 7.0 & 7.0971 & TRN \\
\hline CHEMBL3679550 & 1527765 & 6.1938 & 6.9275 & TST \\
\hline CHEMBL3679470 & 1527765 & 6.5229 & 6.8028 & TRN \\
\hline
\end{tabular}


Supplemental Table S2.txt

\begin{tabular}{|c|c|c|c|c|c|}
\hline CHEMBL3679464 & 1527765 & 6.9586 & 7.2254 & TRN & \\
\hline CHEMBL3679561 & 1527765 & 7.7696 & 7.8357 & TRN & \\
\hline CHEMBL3640050 & 1527765 & 7.2218 & 6.5675 & TRN & \\
\hline CHEMBL3679524 & 1527765 & 6.8239 & 6.8996 & TRN & \\
\hline CHEMBL3640051 & 1527765 & 6.7447 & 6.3184 & TRN & \\
\hline CHEMBL3679590 & 1527765 & 7.6383 & 5.8802 & TST & \\
\hline CHEMBL3679438 & 1527765 & 6.8239 & 6.9184 & TRN & \\
\hline CHEMBL3679595 & 1527765 & 5.9208 & 6.0227 & TST & \\
\hline CHEMBL3679545 & 1527765 & 7.5376 & 7.6018 & TRN & \\
\hline CHEMBL3679588 & 1527765 & 8.3979 & 8.1161 & TRN & \\
\hline CHEMBL3679435 & 1527765 & 7.1938 & 6.8762 & TRN & \\
\hline CHEMBL3679520 & 1527765 & 6.2218 & 7.109 & TST & \\
\hline CHEMBL3679448 & 1527765 & 7.041 & 7.0891 & TRN & \\
\hline CHEMBL3679522 & 1527765 & 7.3979 & 7.1204 & TST & \\
\hline CHEMBL3640057 & 1527765 & 5.7959 & 6.0713 & TRN & \\
\hline CHEMBL3679458 & 1527765 & 7.1427 & 7.3879 & TRN & \\
\hline CHEMBL3679479 & 1527765 & 5.7696 & 5.6564 & TRN & \\
\hline CHEMBL3679465 & 1527765 & 6.9586 & 6.8654 & TST & \\
\hline CHEMBL3679593 & 1527765 & 6.1549 & 5.8598 & TST & \\
\hline CHEMBL3679529 & 1527765 & 8.3979 & 8.0923 & TRN & \\
\hline CHEMBL3679526 & 1527765 & 7.0 & 7.0156 & TRN & \\
\hline CHEMBL3679468 & 1527765 & 6.7447 & 6.9425 & TRN & \\
\hline CHEMBL3679511 & 1527765 & 7.6778 & 7.598 & TRN & \\
\hline CHEMBL 3679500 & 1527765 & 7.2518 & 7.0831 & TRN & \\
\hline CHEMBL3679569 & 1527765 & 7.9208 & 7.8878 & TRN & \\
\hline CHEMBL3679564 & 1527765 & 7.1871 & 6.5215 & TRN & \\
\hline CHEMBL3679534 & 1527765 & 8.0969 & 8.106 & TRN & \\
\hline CHEMBL3640053 & 1527765 & 6.2366 & 6.3431 & TRN & \\
\hline CHEMBL 3679528 & 1527765 & 8.3979 & 7.9974 & TRN & \\
\hline CHEMBL3679453 & 1527765 & 7.3872 & 7.25200 & 3000000001 & TRN \\
\hline CHEMBL3640066 & 1527765 & 7.2218 & 6.5489 & TST & \\
\hline CHEMBL3679583 & 1527765 & 7.2676 & 7.3383 & TRN & \\
\hline CHEMBL3640064 & 1527765 & 5.5686 & 6.9498 & TST & \\
\hline CHEMBL 3679571 & 1527765 & 7.7447 & 8.0887 & TRN & \\
\hline CHEMBL3679537 & 1527765 & 7.9586 & 8.0347 & TRN & \\
\hline CHEMBL3679485 & 1527765 & 7.7212 & 7.4953 & TRN & \\
\hline CHEMBL3679596 & 1527765 & 5.5686 & 5.9496 & TST & \\
\hline CHEMBL3679517 & 1527765 & 6.6576 & 6.9832 & TRN & \\
\hline CHEMBL 3679430 & 1527765 & 7.5376 & 7.6025 & TRN & \\
\hline CHEMBL 3679441 & 1527765 & 6.3372 & 6.4973 & TRN & \\
\hline CHEMBL3679498 & 1527765 & 7.3098 & 7.4611 & TRN & \\
\hline CHEMBL3679549 & 1527765 & 6.6576 & 6.9542 & TST & \\
\hline CHEMBL3679454 & 1527765 & 7.3565 & 7.2871 & TRN & \\
\hline CHEMBL 3640069 & 1527765 & 6.0362 & 6.4521 & TRN & \\
\hline CHEMBL3679460 & 1527765 & 7.0757 & 7.2697 & TRN & \\
\hline CHEMBL3679493 & 1527765 & 7.5376 & 7.2476 & TRN & \\
\hline CHEMBL3679487 & 1527765 & 7.699 & 7.4674 & TRN & \\
\hline CHEMBL3640054 & 1527765 & 5.9586 & 6.0487 & TST & \\
\hline
\end{tabular}


Supplemental Table S2.txt

\begin{tabular}{|c|c|c|c|c|c|}
\hline CHEMBL3679459 & 1527765 & 7.1192 & 6.9925 & TRN & \\
\hline CHEMBL3640060 & 1527765 & 6.2007 & 5.3868 & TST & \\
\hline CHEMBL3679426 & 1527765 & 7.5376 & 7.4547 & TRN & \\
\hline CHEMBL3679439 & 1527765 & 6.7447 & 6.7313 & TRN & \\
\hline CHEMBL3679483 & 1527765 & 7.7696 & 7.6428 & TRN & \\
\hline CHEMBL3679481 & 1527765 & 6.3665 & 6.8511 & TRN & \\
\hline CHEMBL3679568 & 1527765 & 6.1739 & 5.8804 & TRN & \\
\hline CHEMBL3679506 & 1527765 & 6.9586 & 7.1685 & TRN & \\
\hline CHEMBL3679422 & 1527765 & 8.1549 & 8.0489 & TRN & \\
\hline CHEMBL3679556 & 1527765 & 7.9208 & 7.9758 & TRN & \\
\hline CHEMBL 3640044 & 1527765 & 5.9208 & 5.7801 & TST & \\
\hline CHEMBL3640052 & 1527765 & 6.7212 & 6.6869 & TST & \\
\hline CHEMBL3679531 & 1527765 & 8.2218 & 8.089 & TRN & \\
\hline CHEMBL 3679551 & 1527765 & 7.8239 & 7.8363 & TRN & \\
\hline CHEMBL3679567 & 1527765 & 6.3665 & 6.2767 & TRN & \\
\hline CHEMBL3679589 & 1527765 & 8.0 & 7.7885 & TRN & \\
\hline CHEMBL3640061 & 1527765 & 6.1871 & 6.0676 & TST & \\
\hline CHEMBL3679421 & 1527765 & 9.0 & 8.3146 & TRN & \\
\hline CHEMBL 3679521 & 1527765 & 6.1308 & 6.86 & TST & \\
\hline CHEMBL3679427 & 1527765 & 7.8539 & 8.0123 & TRN & \\
\hline CHEMBL3679451 & 1527765 & 7.5086 & 7.4691 & TRN & \\
\hline CHEMBL3679515 & 1527765 & 7.2596 & 7.3672 & TRN & \\
\hline CHEMBL3679577 & 1527765 & 7.1024 & 7.9953 & TST & \\
\hline CHEMBL 3679510 & 1527765 & 7.7959 & 7.6087 & TRN & \\
\hline CHEMBL3679461 & 1527765 & 7.0555 & 7.0862 & TRN & \\
\hline CHEMBL3679455 & 1527765 & 7.2676 & 7.3642 & TRN & \\
\hline CHEMBL3679467 & 1527765 & 6.7696 & 7.2975 & TST & \\
\hline CHEMBL 3679446 & 1527765 & 7.0088 & 7.1578 & TRN & \\
\hline CHEMBL 3640059 & 1527765 & 6.2596 & 5.6226 & TST & \\
\hline CHEMBL3679504 & 1527765 & 7.0 & 7.3797 & TRN & \\
\hline CHEMBL3679478 & 1527765 & 6.2007 & 6.50799 & 9999999999 & TRN \\
\hline CHEMBL3679552 & 1527765 & 8.2218 & 7.9023 & TRN & \\
\hline CHEMBL3679538 & 1527765 & 7.8861 & 7.8763 & TRN & \\
\hline CHEMBL3679436 & 1527765 & 7.1805 & 7.2065 & TRN & \\
\hline CHEMBL 3679480 & 1527765 & 5.7212 & 5.7548 & TRN & \\
\hline CHEMBL3679508 & 1527765 & 6.6198 & 7.104 & TST & \\
\hline CHEMBL3679494 & 1527765 & 7.5229 & 7.6188 & TRN & \\
\hline CHEMBL3679509 & 1527765 & 6.8861 & 7.2087 & TRN & \\
\hline CHEMBL 3679484 & 1527765 & 7.7447 & 7.586 & TRN & \\
\hline CHEMBL 3679476 & 1527765 & 6.7212 & 7.1485 & TRN & \\
\hline CHEMBL3679558 & 1527765 & 7.8861 & 8.0266 & TRN & \\
\hline CHEMBL3679497 & 1527765 & 7.3279 & 7.3094 & TRN & \\
\hline CHEMBL3679562 & 1527765 & 7.4089 & 7.3477 & TRN & \\
\hline CHEMBL3679559 & 1527765 & 7.8539 & 7.9348 & TRN & \\
\hline CHEMBL3679576 & 1527765 & 7.4202 & 7.4198 & TST & \\
\hline CHEMBL3679450 & 1527765 & 7.7447 & 7.0299 & TRN & \\
\hline CHEMBL3679482 & 1527765 & 7.9586 & 7.4988 & TST & \\
\hline CHEMBL3679429 & 1527765 & 8.3979 & 8.2584 & TRN & \\
\hline
\end{tabular}


Supplemental Table S2.txt

\begin{tabular}{|c|c|c|c|c|}
\hline HEMB & 527765 & 7.2596 & & \\
\hline & 527765 & 7.0458 & 7.0342 & \\
\hline HEMRI & 27765 & & 227 & \\
\hline AEMBL & 27765 & 36 & 3 & \\
\hline AEMBL3679544 & 527765 & 5576 & 4955 & \\
\hline HEMBL3679554 & 527765 & 8.0969 & .8415 & \\
\hline 570 & כל & 089 & 5072 & \\
\hline AEMBL. & & & 1951 & \\
\hline HEMBL3640056 & 527765 & 5.6576 & .0012 & \\
\hline HEMBL3679443 & 765 & 6.1079 & 6385 & \\
\hline HEMBL3679533 & נד & 49 & 2637 & \\
\hline IEMBL & כל & 362 & 0621 & \\
\hline HEMBL; & & & 2657 & \\
\hline HEMBL3679591 & 765 & 7.1024 & 9466 & \\
\hline AEMBL3679495 & & 7.5086 & & \\
\hline HEMBL & כ2 & 6. & 5071 & \\
\hline HEMBL & 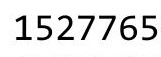 & & 789 & \\
\hline HEMBL; & 65 & & 264 & \\
\hline 79424 & 65 & & 7685 & \\
\hline HEMBL3679423 & & & & I RIV \\
\hline HEMBL & $b$ & & 58 & RN \\
\hline HEM & & & 73 & וד \\
\hline HEMBL & 55 & 84 & 83 & \\
\hline HEMBL & & 7 & & \\
\hline AEMBL3 & & 7. & 274 & RN \\
\hline HEMBL; & & 15 & 16 & RI \\
\hline HFM & & & 93 & KIN \\
\hline 99 & & 7. & 77 & \\
\hline HEMBL & & & & IRN \\
\hline HEMBL3679457 & 52 & 7. & 8877 & RN \\
\hline HEMBL & & & 387 & RN \\
\hline HFM & 5 & & & RN \\
\hline וסMFנI & & & & RN \\
\hline HEMBL3 & & & & ГRN \\
\hline HEMBL3679581 & 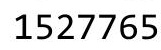 & 89 & 13 & RN \\
\hline AFMRI & & & 89 & TRN \\
\hline 9 & & & & ГRN \\
\hline HEMBL3 & & & & TRN \\
\hline HEMBL3 & & & .04 & TST \\
\hline Th & & & 107 & $\mathrm{RN}$ \\
\hline HEMBL3 & & & & Niv \\
\hline HEMBL3 & & & 935 & ST \\
\hline HEMBL3679586 & -1 & 6.7447 & 9811 & $T R$ \\
\hline HEMBL3 & 152 & 7. & 297 & TR \\
\hline 年 & & & & $\mathrm{T}$ \\
\hline HEMBL3679574 & & & 7.7296 & \\
\hline CHEMBL3679471 & 152 & 6.4815 & 6.8223 & IST \\
\hline CHEMBL3640063 & 1527765 & 5.7447 & 6.4507 & 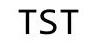 \\
\hline
\end{tabular}

Page 559 
Supplemental Table S2.txt

\begin{tabular}{|c|c|c|c|c|}
\hline HEMBL3 & 527765 & 8.1549 & 8.1476 & TRN \\
\hline HEMBL3679535 & 527765 & 8.0969 & 8.1315 & \\
\hline HEMBL3 & 527765 & 7.3279 & 5242 & \\
\hline HEMBL3679560 & 527765 & 7.8239 & 8456 & \\
\hline HEMBL3679444 & 527765 & 6.8539 & 7.0761 & \\
\hline HEMBL3679466 & 527765 & 6.8539 & 6.9633 & \\
\hline HEMBL3679573 & 527765 & 7.585 & 8.0402 & \\
\hline HEMBL3679432 & 527765 & 8.1549 & 7.7962 & \\
\hline AEMBL3640065 & .527765 & 6.9586 & 6.735 & \\
\hline HEMBL3679431 & 527765 & 7.3279 & 7.5216 & \\
\hline HEMBL3679425 & 527765 & 7.6021 & 7.9969 & \\
\hline HEMBL3679592 & 527765 & 6.0 & 5.2044 & \\
\hline HEMBL36 & 65 & 6.0 & .1129 & ST \\
\hline HEMBL3€ & 1527 & 6.2518 & 5.7787 & RN \\
\hline HEMBL3679489 & 527 & 7.6198 & 7.5011 & RN \\
\hline HEMBL3679462 & 527 & 7.0506 & 7.3375 & I \\
\hline HEMBL3679563 & 527 & 7.3188 & 7.6929 & RN \\
\hline HEMBL 36 & 52 & 7.301 & 7.3708 & RN \\
\hline HEMBL36 & 52 & 7.1871 & 7.5195 & RN \\
\hline HEMBL3679442 & 65 & 6.4815 & 6.9565 & RN \\
\hline HEMBL149168 & 11 & 6.1675 & 9339 & RN \\
\hline HEMBL1C & 11 & 4.7212 & 028 & $\mathrm{RN}$ \\
\hline HEMBL14 & 2 & 5.2366 & 274 & RN \\
\hline HEMBL15 & 11 & 6.3098 & 6.0021 & RN \\
\hline HEMBL150867 & 1172 & 7.1739 & 7 & RN \\
\hline HEMBL 28377 & 117 & 468 & 51 & RN \\
\hline HEMBL 35 & 11 & 4.6021 & 105 & RN \\
\hline HEMBL43 & & 4.7959 & 48 & RN \\
\hline HEMBL151546 & 2 & 7.2441 & & RN \\
\hline HEMBL434700 & 11 & 6.0757 & 04 & ST \\
\hline HEMBL 358922 & 117 & 7.2596 & 1321 & RN \\
\hline HEMBL14 & 2 & 4.585 & 89 & ST \\
\hline HEMBL14 & 2 & 441 & & RN \\
\hline HEMBL147243 & 1172 & 4.4559 & 53 & RN \\
\hline HEMBL148638 & 11 & 6.8239 & 6.5334 & RN \\
\hline HEMBL14 & 1 & 044 & 579 & RN \\
\hline HEMBL1 14 & in & 59 & 79 & ST \\
\hline HEMBL148865 & 1172 & 5.8539 & 5.7095 & TRN \\
\hline LHEMBL149261 & 1172 & 4.4559 & 4.5539 & TRN \\
\hline HEMBL346831 & 11 & 5.8861 & 5.9756 & 「RN \\
\hline CHEMBL347981 & 51172 & 6.5086 & 6.5706 & $\mathrm{RN}$ \\
\hline CHEMBL421957 & & 4.4949 & 4.3407 & RN \\
\hline CHEMBL147018 & 1172 & 5.0915 & 5.3246 & TST \\
\hline CHEMBL359180 & 1172 & 6.1938 & 5.9725 & TRN \\
\hline CHEMBL342275 & 1172 & 6.9586 & 7.0182 & RN \\
\hline CHEMBL149932 & 51172 & 5.3468 & 5.4889 & 8 \\
\hline CHEMBL147184 & 51172 & 6.7212 & 6.7264 & RN \\
\hline CHEMBL148669 & 51172 & 6.4559 & 6.1136 & $\mathrm{R}$ \\
\hline
\end{tabular}

Page 560 


\begin{tabular}{|c|c|c|c|c|}
\hline & & & oplement & al $\mathrm{T}$ \\
\hline CHEMBL149834 & 51172 & 7.8861 & 7.879 & TRN \\
\hline CHEMBL148699 & 51172 & 4.699 & 5.3131 & TRN \\
\hline CHEMBL435633 & 51172 & 6.4685 & 6.3761 & TRN \\
\hline CHEMBL149931 & 51172 & 4.5086 & 5.0387 & TRN \\
\hline CHEMBL355984 & 51172 & 5.7212 & 5.7258 & TRN \\
\hline CHEMBL146812 & 51172 & 4.585 & 5.5667 & TST \\
\hline CHEMBL359295 & 51172 & 4.4559 & 4.0547 & TRN \\
\hline CHEMBL148994 & 51172 & 4.4318 & 4.738 & TST \\
\hline CHEMBL150272 & 51172 & 4.4089 & 4.4956 & TRN \\
\hline CHEMBL356331 & 51172 & 4.4318 & 4.4046 & TRN \\
\hline CHEMBL358525 & 51172 & 7.7447 & 7.8701 & TRN \\
\hline CHEMBL151774 & 51172 & 6.0757 & 5.6947 & TRN \\
\hline CHEMBL356392 & 51172 & 6.3665 & 6.5988 & TST \\
\hline CHEMBL148995 & 51172 & 8.1549 & 8.2039 & TRN \\
\hline CHEMBL149096 & 51172 & 7.2757 & 6.3924 & TST \\
\hline CHEMBL147111 & 51172 & 5.6383 & 5.9669 & TRN \\
\hline CHEMBL148942 & 51172 & 4.5528 & 5.2907 & TRN \\
\hline CHEMBL148804 & 51172 & 6.5229 & 6.0558 & TST \\
\hline CHEMBL342276 & 51172 & 5.8861 & 6.5237 & TST \\
\hline CHEMBL356728 & 51172 & 6.8861 & 6.54 & TST \\
\hline CHEMBL149015 & 51172 & 6.9208 & 6.8295 & TRN \\
\hline CHEMBL148992 & 51172 & 6.9586 & 6.9686 & TRN \\
\hline CHEMBL150859 & 51172 & 4.8239 & 6.3241 & TST \\
\hline CHEMBL356700 & 51172 & 6.4437 & 6.7858 & TST \\
\hline CHEMBL147122 & 51172 & 6.0655 & 6.2124 & TRN \\
\hline CHEMBL359158 & 51172 & 7.301 & 7.3343 & TRN \\
\hline CHEMBL151991 & 51172 & 4.3768 & 4.4429 & TRN \\
\hline CHEMBL359200 & 51172 & 4.8861 & 5.3954 & TST \\
\hline CHEMBL149087 & 51172 & 6.4685 & 6.2188 & TST \\
\hline CHEMBL357260 & 51172 & 4.4318 & 4.1388 & TRN \\
\hline CHEMBL405600 & 105390 & 7.4437 & 7.5755 & TRN \\
\hline CHEMBL 293774 & 105390 & 7.5086 & 7.6309 & TRN \\
\hline CHEMBL55521 & 105390 & 9.1549 & 8.7997 & TRN \\
\hline CHEMBL56951 & 105390 & 7.6778 & 7.7827 & TRN \\
\hline CHEMBL52532 & 105390 & 7.5376 & 7.6191 & TRN \\
\hline CHEMBL54436 & 105390 & 8.5528 & 8.4555 & TRN \\
\hline CHEMBL55907 & 105390 & 7.6021 & 7.7381 & TRN \\
\hline CHEMBL55236 & 105390 & 7.3565 & 7.3712 & TRN \\
\hline CHEMBL 280017 & 105390 & 7.8539 & 7.9675 & TRN \\
\hline CHEMBL54054 & 105390 & 9.0969 & 8.7349 & TRN \\
\hline CHEMBL53051 & 105390 & 7.8539 & 7.8326 & TST \\
\hline CHEMBL 301177 & 105390 & 7.7447 & 7.5125 & TRN \\
\hline CHEMBL417200 & 105390 & 8.0458 & 7.8563 & TST \\
\hline CHEMBL55107 & 105390 & 7.3665 & 7.4633 & TRN \\
\hline CHEMBL54406 & 105390 & 7.6778 & 7.5289 & TRN \\
\hline CHEMBL 292657 & 105390 & 7.2757 & 7.2403 & TRN \\
\hline CHEMBL 293503 & 105390 & 9.2218 & 9.0116 & TRN \\
\hline CHEMBL417757 & 105390 & 7.6383 & 7.6043 & TRN \\
\hline
\end{tabular}




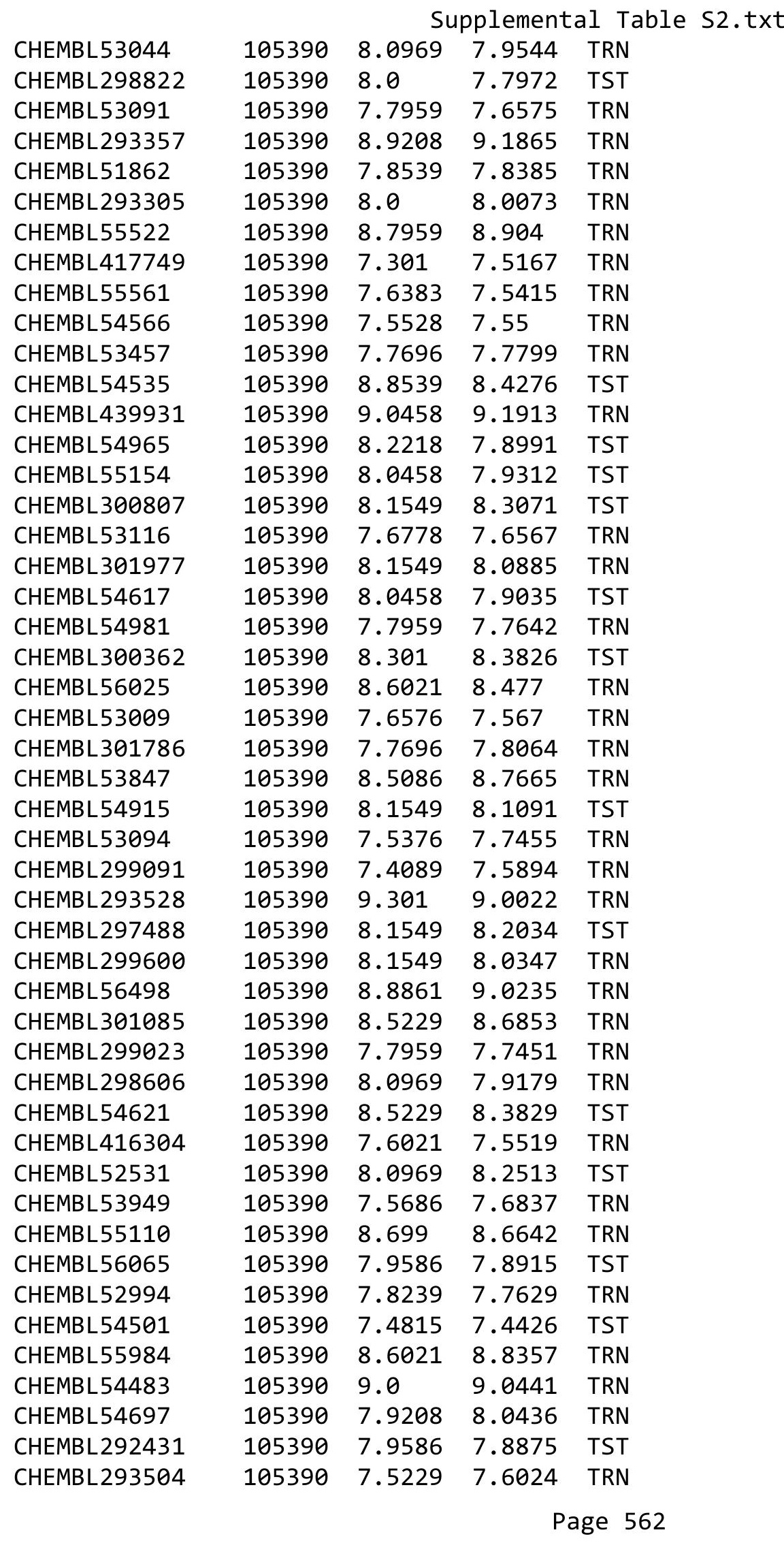




\begin{tabular}{|c|c|c|c|c|c|}
\hline \multirow[b]{2}{*}{ CHEMBL55744 } & \\
\hline & 105390 & 7.8539 & 7.7224 & TRN & \\
\hline CHEMBL54904 & 105390 & 8.8861 & 8.8154 & TST & \\
\hline CHEMBL1688021 & 729456 & 3.8239 & 4.4158 & TRN & \\
\hline CHEMBL1688024 & 729456 & 3.8239 & 3.4433 & TRN & \\
\hline CHEMBL1254871 & 729456 & 5.3143 & \multicolumn{2}{|c|}{5.382999999999999} & TRN \\
\hline CHEMBL524969 & 729456 & 5.1561 & \multicolumn{2}{|c|}{5.242000000000001} & TRN \\
\hline CHEMBL1688004 & 729456 & 3.8239 & 3.8939 & TRN & \\
\hline CHEMBL1688002 & 729456 & 3.8239 & 4.382 & TRN & \\
\hline CHEMBL1688022 & 729456 & 5.2612 & 4.5065 & TRN & \\
\hline CHEMBL1688010 & 729456 & 5.3635 & 4.7648 & TRN & \\
\hline CHEMBL1688023 & 729456 & 3.8239 & 4.2715 & TRN & \\
\hline CHEMBL1688016 & 729456 & 5.0565 & 4.8656 & TRN & \\
\hline CHEMBL1687989 & 729456 & 5.2097 & 5.2157 & TRN & \\
\hline CHEMBL1688025 & 729456 & 3.8239 & 3.7475 & TRN & \\
\hline CHEMBL1688018 & 729456 & 5.0878 & \multicolumn{2}{|c|}{4.4639999999999995} & TRN \\
\hline CHEMBL1687984 & 729456 & 5.1733 & 5.1782 & TRN & \\
\hline CHEMBL1688027 & 729456 & 3.8239 & 4.7989 & TST & \\
\hline CHEMBL1687991 & 729456 & 6.1612 & 5.334 & TRN & \\
\hline CHEMBL1688026 & 729456 & 5.2076 & 5.2365 & TRN & \\
\hline CHEMBL1688007 & 729456 & 5.301 & 4.9112 & TRN & \\
\hline CHEMBL1688013 & 729456 & 3.8239 & 4.164 & TRN & \\
\hline CHEMBL1688017 & 729456 & 5.1694 & 5.0016 & TRN & \\
\hline CHEMBL1688031 & 729456 & 5.7696 & 5.2701 & TST & \\
\hline CHEMBL1254783 & 729456 & 5.1649 & 5.5612 & TRN & \\
\hline CHEMBL1688029 & 729456 & 7.1024 & 5.3709 & TST & \\
\hline CHEMBL1688020 & 729456 & 3.8239 & 3.677 & TRN & \\
\hline CHEMBL1688001 & 729456 & 3.8239 & 3.5553 & TRN & \\
\hline CHEMBL1687996 & 729456 & 5.4365 & 5.5738 & TRN & \\
\hline CHEMBL1688005 & 729456 & 5.1612 & 5.4913 & TRN & \\
\hline CHEMBL1687987 & 729456 & 5.6882 & 5.8712 & TRN & \\
\hline CHEMBL1688028 & 729456 & 5.2204 & 5.3026 & TST & \\
\hline CHEMBL1688003 & 729456 & 5.5834 & 4.8763 & TRN & \\
\hline CHEMBL1687993 & 729456 & 5.3261 & 5.1764 & TRN & \\
\hline CHEMBL1687990 & 729456 & 5.5591 & 4.836 & TRN & \\
\hline CHEMBL1687983 & 729456 & 5.8041 & 5.735 & TRN & \\
\hline CHEMBL1688030 & 729456 & 4.9957 & 5.1662 & TST & \\
\hline CHEMBL1687986 & 729456 & 3.8239 & 5.0154 & TRN & \\
\hline CHEMBL1688015 & 729456 & 3.8239 & 4.5327 & TRN & \\
\hline CHEMBL1688006 & 729456 & 5.1524 & 5.3323 & TRN & \\
\hline CHEMBL1687997 & 729456 & 5.7235 & 5.0138 & TRN & \\
\hline CHEMBL1688009 & 729456 & 5.1361 & 4.9265 & TRN & \\
\hline CHEMBL 1254870 & 729456 & 5.1675 & 5.5686 & TRN & \\
\hline CHEMBL1687999 & 729456 & 4.9978 & 5.1131 & TRN & \\
\hline CHEMBL1688012 & 729456 & 5.1811 & 4.6044 & TST & \\
\hline CHEMBL1687992 & 729456 & 3.8239 & 4.7545 & TRN & \\
\hline CHEMBL547264 & 729456 & 5.3242 & 5.3672 & TRN & \\
\hline CHEMBL1687988 & 729456 & 5.3726 & 5.4665 & TRN & \\
\hline CHEMBL587639 & 729456 & 5.4763 & 5.119 & TRN & \\
\hline & & & & ge 563 & \\
\hline
\end{tabular}




\begin{tabular}{|c|c|c|c|c|c|}
\hline & & \multicolumn{4}{|c|}{ Supplemental Table S2.txt } \\
\hline CHEMBL1688014 & 729456 & 3.8239 & 4.2295 & TRN & \\
\hline CHEMBL1687945 & 729456 & 3.8239 & 4.1181 & TRN & \\
\hline CHEMBL1687985 & 729456 & 5.1612 & 5.25 & TRN & \\
\hline CHEMBL524922 & 729456 & 6.9586 & 6.6082 & TRN & \\
\hline CHEMBL1688008 & 729456 & 5.5607 & 5.0817 & TST & \\
\hline CHEMBL1688000 & 729456 & 5.5229 & 4.5002 & TST & \\
\hline CHEMBL1687994 & 729456 & 5.3054 & 4.7169 & TST & \\
\hline CHEMBL1687998 & 729456 & 5.3354 & 5.4788 & TST & \\
\hline CHEMBL1688011 & 729456 & 5.1079 & 6.3565 & TST & \\
\hline CHEMBL548963 & 729456 & 5.5058 & 5.8428 & TST & \\
\hline CHEMBL1688019 & 729456 & 5.2104 & 4.9839 & TST & \\
\hline CHEMBL1687995 & 729456 & 5.7852 & 4.9126 & TST & \\
\hline CHEMBL439259 & 729456 & 6.4089 & 5.9535 & TST & \\
\hline CHEMBL 278075 & 28797 & 3.301 & 2.9998 & TRN & \\
\hline CHEMBL22223 & 28797 & 5.5686 & 5.6539 & TRN & \\
\hline CHEMBL422930 & 28797 & 5.301 & 5.1624 & TRN & \\
\hline CHEMBL 21976 & 28797 & 4.7959 & 4.9172 & TRN & \\
\hline CHEMBL24992 & 28797 & 4.6778 & 4.7052 & TST & \\
\hline CHEMBL25111 & 28797 & 4.9208 & 4.9454 & TRN & \\
\hline CHEMBL 279920 & 28797 & 4.0862 & 4.3196 & TRN & \\
\hline CHEMBL 279727 & 28797 & 5.7696 & 5.7501 & TRN & \\
\hline CHEMBL 282440 & 28797 & 3.301 & 3.378 & TRN & \\
\hline CHEMBL21947 & 28797 & 3.6021 & 3.7271 & TRN & \\
\hline CHEMBL277001 & 28797 & 7.0 & 7.142 & TRN & \\
\hline CHEMBL21561 & 28797 & 3.301 & 3.2391 & TRN & \\
\hline CHEMBL 278132 & 28797 & 5.7212 & 5.6501 & TRN & \\
\hline CHEMBL22774 & 28797 & 6.1427 & 5.7445 & TRN & \\
\hline CHEMBL22470 & 28797 & 5.0555 & 4.8565 & TRN & \\
\hline CHEMBL21687 & 28797 & 4.7122 & 5.1724 & TST & \\
\hline CHEMBL283531 & 28797 & 4.5229 & 4.7103 & TRN & \\
\hline CHEMBL 278761 & 28797 & 3.301 & 3.30899 & 99999999997 & TRN \\
\hline CHEMBL22739 & 28797 & 5.7212 & 5.7445 & TRN & \\
\hline CHEMBL21350 & 28797 & 4.3188 & 4.3514 & TRN & \\
\hline CHEMBL22406 & 28797 & 4.7959 & 4.9668 & TST & \\
\hline CHEMBL21870 & 28797 & 4.2366 & 3.9916 & TRN & \\
\hline CHEMBL21355 & 28797 & 3.301 & 3.2471 & TRN & \\
\hline CHEMBL22525 & 28797 & 4.284 & 3.5341 & TST & \\
\hline CHEMBL22725 & 28797 & 4.5229 & 4.3302 & TRN & \\
\hline CHEMBL22093 & 28797 & 3.301 & 3.3213 & TRN & \\
\hline CHEMBL24996 & 28797 & 3.301 & 3.4811 & TRN & \\
\hline CHEMBL 279950 & 28797 & 3.0 & 2.8695 & TRN & \\
\hline CHEMBL22950 & 28797 & 3.301 & 3.3981 & TRN & \\
\hline CHEMBL21751 & 28797 & 4.8697 & 4.8977 & TRN & \\
\hline CHEMBL415036 & 28797 & 4.3979 & 4.7752 & TRN & \\
\hline CHEMBL422929 & 28797 & 4.6383 & 4.6893 & TRN & \\
\hline CHEMBL21279 & 28797 & 5.4089 & 5.2292 & TRN & \\
\hline CHEMBL 278131 & 28797 & 6.2924 & 5.7445 & TRN & \\
\hline CHEMBL 280687 & 28797 & 4.5376 & 4.55399 & 9999999999 & TRN \\
\hline & & & & 564 & \\
\hline
\end{tabular}




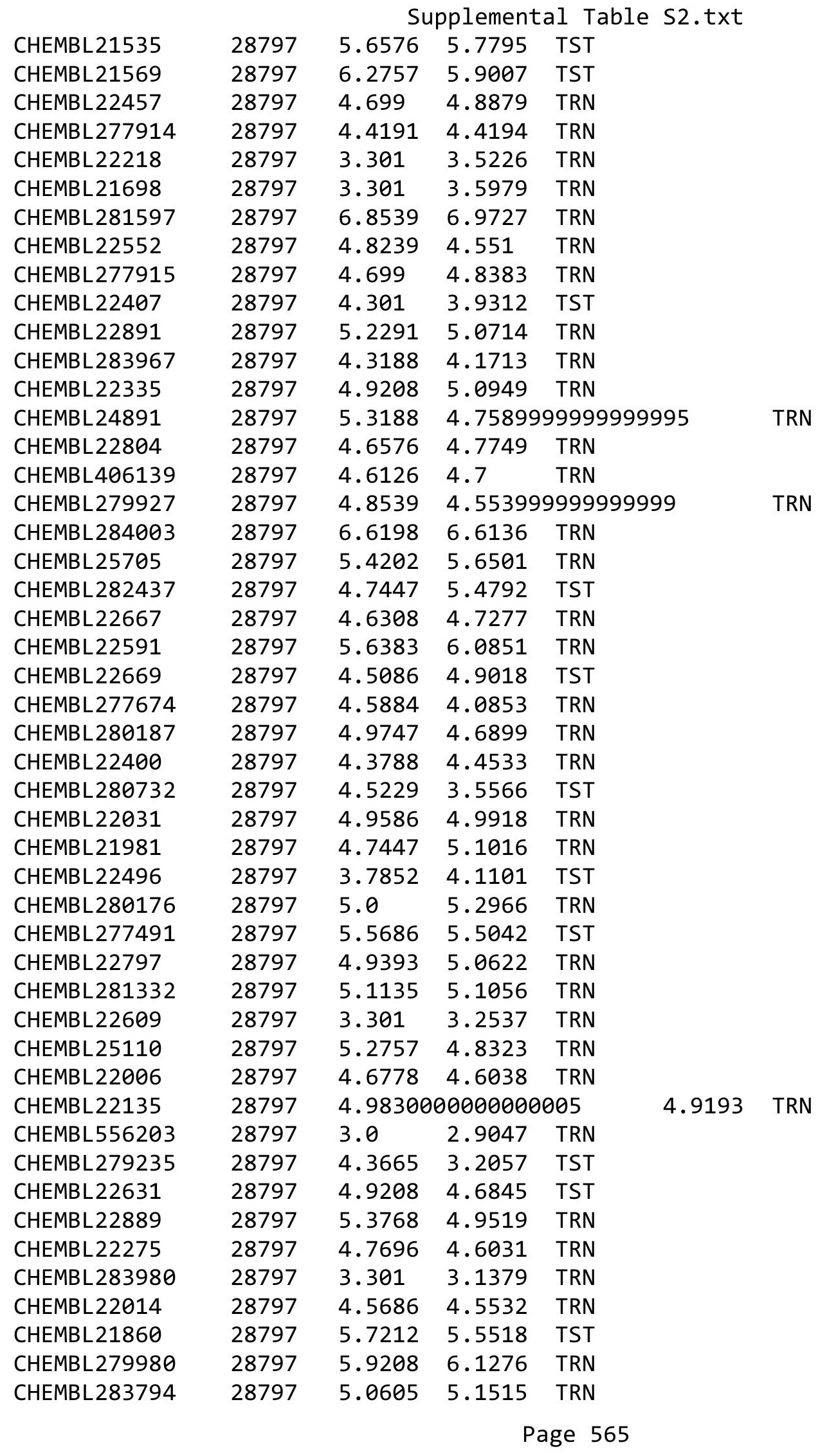




\begin{tabular}{|c|c|c|c|c|c|}
\hline \multicolumn{6}{|c|}{ Supplemental Table S2.txt } \\
\hline CHEMBL22953 & 28797 & 3.6021 & 4.1353 & TRN & \\
\hline CHEMBL282671 & 28797 & 4.1805 & 4.2043 & TRN & \\
\hline CHEMBL22673 & 28797 & 6.4437 & 5.9328 & TST & \\
\hline CHEMBL 24943 & 28797 & 4.8861 & 4.8357 & TRN & \\
\hline CHEMBL282247 & 28797 & 4.0 & 4.5532 & TRN & \\
\hline CHEMBL281188 & 28797 & 5.4949 & 6.6406 & TST & \\
\hline CHEMBL22297 & 28797 & 4.3768 & 4.2197 & TRN & \\
\hline CHEMBL429222 & 28797 & 4.6615 & 4.6528 & TRN & \\
\hline CHEMBL 21586 & 28797 & 5.6021 & 5.675 & TRN & \\
\hline CHEMBL424218 & 28797 & 4.8861 & 4.7752 & TRN & \\
\hline CHEMBL25499 & 28797 & 4.8861 & 4.8595 & TRN & \\
\hline CHEMBL21539 & 28797 & 4.5086 & 4.6557 & TRN & \\
\hline CHEMBL278161 & 28797 & 4.0223 & 5.3427 & TST & \\
\hline CHEMBL 22695 & 28797 & 4.0458 & 3.7761 & TRN & \\
\hline CHEMBL22952 & 28797 & 5.0915 & 5.2453 & TRN & \\
\hline CHEMBL21437 & 28797 & 4.4202 & 4.3815 & TRN & \\
\hline CHEMBL24887 & 28797 & 6.4815 & 5.6501 & TRN & \\
\hline CHEMBL21797 & 28797 & 4.2757 & 3.7221 & TRN & \\
\hline CHEMBL423290 & 28797 & 4.6576 & 4.5226 & TRN & \\
\hline CHEMBL21583 & 28797 & 5.3872 & 5.4563 & TRN & \\
\hline CHEMBL22296 & 28797 & 3.301 & 3.5494 & TRN & \\
\hline CHEMBL22842 & 28797 & 4.4815 & 4.4655 & TRN & \\
\hline CHEMBL22733 & 28797 & 5.9586 & 6.015 & TRN & \\
\hline CHEMBL278147 & 28797 & 4.3098 & 4.1633 & TRN & \\
\hline CHEMBL22112 & 28797 & 4.2366 & 4.9519 & TRN & \\
\hline CHEMBL21415 & 28797 & 5.6778 & 5.5751 & TRN & \\
\hline CHEMBL22476 & 28797 & 6.6383 & 5.9372 & TST & \\
\hline CHEMBL25216 & 28797 & 3.301 & 3.3213 & TRN & \\
\hline CHEMBL281600 & 28797 & 4.6383 & 4.6796 & TRN & \\
\hline CHEMBL22494 & 28797 & 4.9586 & 4.9249 & TRN & \\
\hline CHEMBL283532 & 28797 & 4.7959 & 4.5166 & TRN & \\
\hline CHEMBL22839 & 28797 & 4.9208 & 4.4952 & TRN & \\
\hline CHEMBL282938 & 28797 & 4.585 & 4.8488 & TRN & \\
\hline CHEMBL22634 & 28797 & 4.301 & 4.6666 & TRN & \\
\hline CHEMBL 22422 & 28797 & 3.301 & 3.7455 & TRN & \\
\hline CHEMBL22645 & 28797 & 4.4559 & 4.5166 & TRN & \\
\hline CHEMBL 22750 & 28797 & 5.4949 & 5.8427 & TST & \\
\hline CHEMBL 22424 & 28797 & 4.0132 & 3.9855 & TRN & \\
\hline CHEMBL 278808 & 28797 & 5.6576 & 5.7576 & TRN & \\
\hline CHEMBL21588 & 28797 & 3.0 & 3.54600 & 00000000003 & TRN \\
\hline CHEMBL282718 & 28797 & 4.2596 & 4.3131 & TRN & \\
\hline CHEMBL21416 & 28797 & 3.6021 & 3.6409 & TRN & \\
\hline CHEMBL22415 & 28797 & 6.3768 & 6.0243 & TRN & \\
\hline CHEMBL21637 & 28797 & 4.6021 & 5.3412 & TST & \\
\hline CHEMBL22836 & 28797 & 4.8861 & 4.6897 & TRN & \\
\hline CHEMBL279009 & 28797 & 5.7212 & 5.3199 & TRN & \\
\hline CHEMBL22185 & 28797 & 5.0605 & 3.9908 & TST & \\
\hline CHEMBL280349 & 28797 & 6.3979 & 6.0865 & TRN & \\
\hline
\end{tabular}




\begin{tabular}{|c|c|c|c|c|c|}
\hline \multirow[b]{2}{*}{ CHEMBL22153 } & \multicolumn{5}{|c|}{ Supplemental Table s2.txt } \\
\hline & 28797 & 4.9872 & 4.7752 & TRN & \\
\hline CHEMBL 21803 & 28797 & 4.7747 & 4.73600 & 0000000001 & TRN \\
\hline CHEMBL280686 & 28797 & 4.284 & 5.3427 & TST & \\
\hline CHEMBL 277641 & 28797 & 4.7212 & 4.6326 & TRN & \\
\hline CHEMBL544924 & 28797 & 4.5086 & 4.4909 & TST & \\
\hline CHEMBL 279513 & 28797 & 4.4202 & 4.5502 & TRN & \\
\hline CHEMBL 278594 & 28797 & 4.301 & 5.3977 & TST & \\
\hline CHEMBL22948 & 28797 & 3.301 & 3.5271 & TRN & \\
\hline CHEMBL 280147 & 28797 & 3.0 & 3.2767 & TRN & \\
\hline CHEMBL 279928 & 28797 & 5.3372 & 4.9925 & TST & \\
\hline CHEMBL 277766 & 28797 & 4.1612 & 5.7445 & TRN & \\
\hline CHEMBL 22722 & 28797 & 4.0506 & 5.5042 & TST & \\
\hline CHEMBL21863 & 28797 & 4.8239 & 4.7977 & TRN & \\
\hline CHEMBL 25655 & 28797 & 6.3768 & 6.1461 & TRN & \\
\hline CHEMBL22058 & 28797 & 3.0 & 2.8965 & TRN & \\
\hline CHEMBL281598 & 28797 & 4.8539 & 4.5532 & TRN & \\
\hline CHEMBL 23043 & 28797 & 4.9431 & 5.0175 & TRN & \\
\hline CHEMBL22519 & 28797 & 5.2924 & 5.11600 & 00000000005 & TST \\
\hline CHEMBL281391 & 28797 & 6.4437 & 6.1847 & TRN & \\
\hline CHEMBL424585 & 28797 & 3.301 & 3.3792 & TRN & \\
\hline CHEMBL22409 & 28797 & 4.585 & 4.2902 & TST & \\
\hline CHEMBL21972 & 28797 & 3.301 & 3.6745 & TST & \\
\hline CHEMBL21794 & 28797 & 4.8239 & 5.5758 & TST & \\
\hline CHEMBL 22985 & 28797 & 5.1675 & 4.5532 & TST & \\
\hline CHEMBL21579 & 28797 & 3.301 & 3.707 & TST & \\
\hline CHEMBL22279 & 28797 & 5.0269 & 4.1847 & TST & \\
\hline CHEMBL422040 & 28797 & 5.3665 & 5.5042 & TST & \\
\hline CHEMBL 22607 & 28797 & 4.1871 & 4.4447 & TST & \\
\hline CHEMBL 22896 & 28797 & 5.7696 & 5.4995 & TST & \\
\hline CHEMBL 22217 & 28797 & 4.3098 & 4.3059 & TST & \\
\hline CHEMBL 282051 & 28797 & 4.6778 & 5.165 & TST & \\
\hline CHEMBL429228 & 28797 & 5.8861 & 5.1976 & TST & \\
\hline CHEMBL416183 & 28797 & 4.6576 & 4.8537 & TST & \\
\hline CHEMBL22834 & 28797 & 6.3768 & 6.2355 & TST & \\
\hline CHEMBL3932273 & 1640500 & 7.4949 & 7.644 & TRN & \\
\hline CHEMBL3904381 & 1640500 & 7.9208 & 7.7548 & TRN & \\
\hline CHEMBL3946609 & 1640500 & 7.4089 & 7.5961 & TRN & \\
\hline CHEMBL3894665 & 1640500 & 6.7595 & 6.6607 & TRN & \\
\hline CHEMBL3902420 & 1640500 & 6.9508 & 6.70799 & 9999999999 & TRN \\
\hline CHEMBL3915060 & 1640500 & 7.1805 & 5.7725 & TST & \\
\hline CHEMBL3970027 & 1640500 & 6.7447 & 6.9552 & TST & \\
\hline CHEMBL3915648 & 1640500 & 7.5686 & 7.6175 & TRN & \\
\hline CHEMBL3912425 & 1640500 & 7.0915 & 7.2368 & TRN & \\
\hline CHEMBL3952028 & 1640500 & 5.9698 & 5.941 & TRN & \\
\hline CHEMBL3983518 & 1640500 & 7.3872 & 7.2482 & TST & \\
\hline CHEMBL 3897204 & 1640500 & 7.3979 & 8.4928 & TST & \\
\hline CHEMBL3977285 & 1640500 & 7.0862 & 6.9378 & TST & \\
\hline CHEMBL3975008 & 1640500 & 7.6198 & 7.6292 & TRN & \\
\hline
\end{tabular}


Supplemental Table S2.txt

\begin{tabular}{|c|c|c|c|c|}
\hline - & & & & \\
\hline HEMBL3970745 & 640500 & 7.2441 & 7.3559 & \\
\hline & & & & \\
\hline 19788 & 500 & & & \\
\hline IEMBL3932385 & 540500 & 7.6576 & 3241 & \\
\hline AEMBL3928536 & 640500 & 6.0 & .0541 & \\
\hline HEMBL395 & 500 & & .2689 & \\
\hline 85 & 500 & & 121 & \\
\hline IEMBL3 & 500 & & .7534 & \\
\hline AEMBL3913302 & 500 & 6 . & 8133 & \\
\hline HEMBL3944386 & 540500 & 6.7122 & 645 & \\
\hline IEMBL39 & 500 & $\partial 8$ & 364 & \\
\hline IEM & & & & \\
\hline HEMBL & 50 & & .9751 & \\
\hline AEMBL3S & 500 & & 5068 & \\
\hline AEMBL39 & 00 & 75 & 17 & \\
\hline HEMBL3 & 50 & & 025 & \\
\hline HEMBL3 & & & & \\
\hline HEMBL3S & 00 & & 7.0091 & \\
\hline AEMBL3S & 00 & & 915 & \\
\hline HEMBL3963b51 & 00 & 7. & 7.0029 & 31 \\
\hline HEMBL3 & $\partial \theta$ & 8 & 749 & ST \\
\hline HEM & & & & \\
\hline 07 & & & 4171 & \\
\hline AEMBL3 & 00 & & & $\mid$ \\
\hline HEM & $\partial \theta$ & & 68 & $2 \mathrm{~N}$ \\
\hline HEM & 0 & & 012 & RN \\
\hline 0 & & & 762 & \\
\hline 575 & 500 & & 7.8236 & | \\
\hline AEMBL3S & 30 & & 213 & IRN \\
\hline HEMBL3E & $\partial 0$ & & 475 & RN \\
\hline 3 & 30 & & 24 & NIV \\
\hline 97 & & & 67 & TRN \\
\hline HEMBL3S & & & 61 & $\pi$ \\
\hline HEMBL3955062 & $\partial 0$ & & 28 & 「RN \\
\hline AEMBL3 & $\theta 0$ & & 548 & RN \\
\hline 1 & & & & ST \\
\hline & & & 351 & TRN \\
\hline HEMBL3943892 & 500 & & 5.8475 & TRN \\
\hline AEMBL3 & 00 & & 7.9544 & IST \\
\hline HEMBL3 3 & $\theta 0$ & 36 & 693 & RN \\
\hline HEMBL $3 \subseteq$ & & 6 & & $\Gamma \mathrm{RN}$ \\
\hline HEMBL39 & 500 & & 7.0552 & ГRN \\
\hline HEMBL3963623 & 640500 & 7. & 7.5754 & $\Gamma R$ \\
\hline L3 & & & 537 & TRN \\
\hline HEMBL 3899980 & 1640500 & & 7.5096 & \\
\hline CHEMBL 3979076 & 1640500 & & 7.3857 & \\
\hline HEMBL3982586 & 1640500 & 7.7212 & 7.8217 & $\mathrm{RN}$ \\
\hline
\end{tabular}

Page 568 
Supplemental Table S2.txt

\begin{tabular}{|c|c|c|c|c|c|}
\hline CHEMBL3936252 & 1640500 & 6.9318 & 6.9952 & TRN & \\
\hline CHEMBL3904948 & 1640500 & 7.699 & 7.1895 & TST & \\
\hline CHEMBL3985385 & 1640500 & 7.3565 & 7.3878 & TRN & \\
\hline CHEMBL3906075 & 1640500 & 6.983 & 7.1471 & TRN & \\
\hline CHEMBL3969319 & 1640500 & 7.0605 & 7.1189 & TRN & \\
\hline CHEMBL3929323 & 1640500 & 7.5086 & 6.7406 & TST & \\
\hline CHEMBL3959841 & 1640500 & 6.8508 & 6.8895 & TRN & \\
\hline CHEMBL3958091 & 1640500 & 6.4584 & 5.7201 & TST & \\
\hline CHEMBL3953184 & 1640500 & 7.585 & \multicolumn{2}{|c|}{7.7139999999999995} & TRN \\
\hline CHEMBL 3892574 & 1640500 & 7.3768 & 7.8789 & TST & \\
\hline CHEMBL3911954 & 1640500 & 7.5376 & 7.2414 & TRN & \\
\hline CHEMBL3896558 & 1640500 & 5.4996 & 5.7564 & TRN & \\
\hline CHEMBL3892946 & 1640500 & 6.4377 & \multicolumn{2}{|c|}{6.7139999999999995} & TRN \\
\hline CHEMBL3898326 & 1640500 & 7.0757 & 8.0418 & TST & \\
\hline CHEMBL 3898334 & 1640500 & 7.9586 & 6.6382 & TST & \\
\hline CHEMBL 3899047 & 1640500 & 6.8794 & 7.1128 & TRN & \\
\hline CHEMBL3967784 & 1640500 & 7.1192 & 7.2885 & TRN & \\
\hline CHEMBL 3893570 & 1640500 & 6.7825 & 6.7646 & TST & \\
\hline CHEMBL3892705 & 1640500 & 7.7447 & 7.1216 & TST & \\
\hline CHEMBL 3907841 & 1640500 & 6.0 & 7.0613 & TRN & \\
\hline CHEMBL3954867 & 1640500 & 6.4123 & 6.4692 & TRN & \\
\hline CHEMBL3943611 & 1640500 & 8.2218 & 7.9882 & TST & \\
\hline CHEMBL3945169 & 1640500 & 7.4089 & 7.3183 & TST & \\
\hline CHEMBL3937989 & 1640500 & 7.8861 & 7.9057 & TRN & \\
\hline CHEMBL3907351 & 1640500 & 6.2328 & 6.2915 & TRN & \\
\hline CHEMBL3967736 & 1640500 & 7.4815 & 7.2403 & TRN & \\
\hline CHEMBL3975060 & 1640500 & 6.0 & 5.8907 & TST & \\
\hline CHEMBL3901218 & 1640500 & 7.7959 & 7.6367 & TRN & \\
\hline CHEMBL 3890547 & 1640500 & 7.4318 & 7.4543 & TRN & \\
\hline CHEMBL 3945623 & 1640500 & 7.5376 & 7.4722 & TRN & \\
\hline CHEMBL3933002 & 1640500 & 7.3188 & 8.0214 & TST & \\
\hline CHEMBL3970627 & 1640500 & 7.6021 & 7.3511 & TRN & \\
\hline CHEMBL3936062 & 1640500 & 7.1427 & 6.9573 & TRN & \\
\hline CHEMBL3970833 & 1640500 & 7.699 & 7.6364 & TST & \\
\hline CHEMBL3949231 & 1640500 & 6.4168 & 6.5786 & TRN & \\
\hline CHEMBL3903818 & 1640500 & 7.4685 & 7.1809 & TRN & \\
\hline CHEMBL3968766 & 1640500 & 5.459 & 5.6514 & TRN & \\
\hline CHEMBL3951327 & 1640500 & 7.3979 & 7.1459 & TRN & \\
\hline CHEMBL3899666 & 1640500 & 7.585 & 7.3243 & TRN & \\
\hline CHEMBL3982081 & 1640500 & 7.1675 & 6.94 & TRN & \\
\hline CHEMBL3984896 & 1640500 & 6.9136 & 7.12799 & 9999999999 & TRN \\
\hline CHEMBL 3958472 & 1640500 & 6.5243 & 6.6259 & TRN & \\
\hline CHEMBL3905118 & 1640500 & 7.3872 & 7.0123 & TRN & \\
\hline CHEMBL3934130 & 1640500 & 7.6778 & 7.4012 & TST & \\
\hline CHEMBL3969907 & 1640500 & 7.1427 & 7.0711 & TRN & \\
\hline CHEMBL3896468 & 1640500 & 5.6737 & 5.6742 & TRN & \\
\hline CHEMBL 3957262 & 1640500 & 7.3188 & 7.3515 & TRN & \\
\hline CHEMBL3909036 & 1640500 & 7.1938 & 6.7347 & TRN & \\
\hline
\end{tabular}


Supplemental Table S2.txt

\begin{tabular}{|c|c|c|c|c|c|}
\hline CHEMBL3932628 & 1640500 & 7.4559 & 7.2113 & TST & \\
\hline CHEMBL 3899745 & 1640500 & 7.2007 & 6.9914 & TRN & \\
\hline CHEMBL3975621 & 1640500 & 7.1427 & 7.3288 & TRN & \\
\hline CHEMBL3941317 & 1640500 & 7.1871 & 6.9766 & TRN & \\
\hline CHEMBL 3928694 & 1640500 & 7.5528 & 6.9516 & TST & \\
\hline CHEMBL3906633 & 1640500 & 7.2007 & \multicolumn{2}{|c|}{7.1579999999999995} & TRN \\
\hline CHEMBL3902096 & 1640500 & 7.3468 & 7.0834 & TRN & \\
\hline CHEMBL3960655 & 1640500 & 6.0132 & 7.1921 & TST & \\
\hline CHEMBL 3903485 & 1640500 & 7.2924 & 8.1869 & TST & \\
\hline CHEMBL 3984640 & 1640500 & 7.4089 & 6.9472 & TRN & \\
\hline CHEMBL 3984825 & 1640500 & 6.4584 & 6.5941 & TRN & \\
\hline CHEMBL 3970894 & 1640500 & 6.8386 & 7.0388 & TRN & \\
\hline CHEMBL 3963046 & 1640500 & 7.5686 & 7.7137 & TRN & \\
\hline CHEMBL3916088 & 1640500 & 6.0 & \multicolumn{2}{|c|}{6.867000000000001} & TRN \\
\hline CHEMBL 3982990 & 1640500 & 7.2076 & 7.1663 & TRN & \\
\hline CHEMBL3970512 & 1640500 & 6.8477 & 6.681 & TRN & \\
\hline CHEMBL3892916 & 1640500 & 7.2366 & 6.5934 & TST & \\
\hline CHEMBL3914977 & 1640500 & 7.1427 & 7.0402 & TRN & \\
\hline CHEMBL3978660 & 1640500 & 6.7077 & 7.091 & TRN & \\
\hline CHEMBL 3899327 & 1640500 & 7.2757 & 7.1265 & TRN & \\
\hline CHEMBL3927688 & 1640500 & 6.0969 & 6.1284 & TRN & \\
\hline CHEMBL 3977525 & 1640500 & 6.8928 & 5.5192 & TST & \\
\hline CHEMBL3946655 & 1640500 & 6.8861 & 7.0113 & TRN & \\
\hline CHEMBL3969786 & 1640500 & 7.585 & 7.7631 & TRN & \\
\hline CHEMBL 3955193 & 1640500 & 7.0706 & 6.7734 & TRN & \\
\hline CHEMBL3978752 & 1640500 & 7.6383 & 7.3167 & TRN & \\
\hline CHEMBL 3976928 & 1640500 & 7.1024 & 7.0416 & TRN & \\
\hline CHEMBL3910206 & 1640500 & 7.1739 & 7.0547 & TRN & \\
\hline CHEMBL3890695 & 1640500 & 5.1376 & 5.4131 & TST & \\
\hline CHEMBL 3909894 & 1640500 & 7.0757 & 7.1248 & TRN & \\
\hline CHEMBL3909760 & 1640500 & 7.2518 & 7.2928 & TRN & \\
\hline CHEMBL3919139 & 1640500 & 5.1973 & 5.1993 & TRN & \\
\hline CHEMBL3966219 & 1640500 & 7.4685 & 7.5568 & TRN & \\
\hline CHEMBL3939461 & 1640500 & 7.3979 & 7.6236 & TRN & \\
\hline CHEMBL3984147 & 1640500 & 5.9136 & 5.8676 & TRN & \\
\hline CHEMBL3919993 & 1640500 & 5.8256 & 5.9924 & TRN & \\
\hline CHEMBL 3891738 & 1640500 & 7.2518 & 7.0921 & TRN & \\
\hline CHEMBL 3972628 & 1640500 & 7.4202 & 7.7066 & TRN & \\
\hline CHEMBL 3956322 & 1640500 & 6.6536 & 6.41 & TRN & \\
\hline CHEMBL3976288 & 1640500 & 7.4437 & 7.4601 & TRN & \\
\hline CHEMBL3983141 & 1640500 & 5.5771 & 5.1301 & TST & \\
\hline CHEMBL 3908330 & 1640500 & 7.6576 & 7.6272 & TRN & \\
\hline CHEMBL3941599 & 1640500 & 7.1675 & 7.025 & TRN & \\
\hline CHEMBL3920179 & 1640500 & 7.3665 & 7.5543 & TRN & \\
\hline CHEMBL3924065 & 1640500 & 7.1739 & 7.1929 & TST & \\
\hline CHEMBL3936477 & 1640500 & 7.6383 & 7.709 & TRN & \\
\hline CHEMBL 3974718 & 1640500 & 6.3054 & 6.1626 & TRN & \\
\hline CHEMBL 3905018 & 1640500 & 7.2366 & 7.6597 & TST & \\
\hline
\end{tabular}


Supplemental Table S2.txt

\begin{tabular}{|c|c|c|c|c|c|}
\hline CHEMBL3976753 & 1640500 & 6.9101 & 6.4138 & TST & \\
\hline CHEMBL3922289 & 1640500 & 6.3546 & 6.4448 & TRN & \\
\hline CHEMBL 3892525 & 1640500 & 7.2366 & 7.1436 & TRN & \\
\hline CHEMBL3929469 & 1640500 & 7.6021 & 7.2971 & TRN & \\
\hline CHEMBL3944530 & 1640500 & 5.6043 & 6.1365 & TRN & \\
\hline CHEMBL3961744 & 1640500 & 6.8097 & 6.6615 & TST & \\
\hline CHEMBL3929564 & 1640500 & 6.9031 & 7.0495 & TRN & \\
\hline CHEMBL3918592 & 1640500 & 7.0605 & 7.1269 & TRN & \\
\hline CHEMBL3951769 & 1640500 & 7.2366 & 6.9018 & TST & \\
\hline CHEMBL3963825 & 1640500 & 7.1938 & 7.359 & TRN & \\
\hline CHEMBL3965674 & 1640500 & 7.3188 & 7.4676 & TRN & \\
\hline CHEMBL3911420 & 1640500 & 6.1688 & 6.9919 & TST & \\
\hline CHEMBL3900200 & 1640500 & 7.6198 & 8.4545 & TST & \\
\hline CHEMBL 3894827 & 1640500 & 7.2147 & 7.3528 & TRN & \\
\hline CHEMBL3981628 & 1640500 & 7.7212 & 7.6383 & TST & \\
\hline CHEMBL3899512 & 1640500 & 7.6198 & 7.607 & TRN & \\
\hline CHEMBL3950980 & 1640500 & 7.8239 & 7.7937 & TRN & \\
\hline CHEMBL3941267 & 1640500 & 7.7447 & 7.8192 & TST & \\
\hline CHEMBL3946500 & 1640500 & 6.8327 & \multicolumn{2}{|c|}{6.9510000000000005} & TRN \\
\hline CHEMBL3929170 & 1640500 & 7.5686 & 7.8174 & TRN & \\
\hline CHEMBL3894647 & 1640500 & 7.2218 & 6.1481 & TST & \\
\hline CHEMBL3942601 & 1640500 & 6.3468 & 6.438 & TRN & \\
\hline CHEMBL 3895113 & 1640500 & 6.1421 & 6.2956 & TRN & \\
\hline CHEMBL3912834 & 1640500 & 6.6003 & 6.6478 & TRN & \\
\hline CHEMBL 3906651 & 1640500 & 6.3261 & 6.3301 & TRN & \\
\hline CHEMBL3976146 & 1640500 & 7.1675 & 7.1793 & TRN & \\
\hline CHEMBL3914913 & 1640500 & 6.9469 & 6.7825 & TRN & \\
\hline CHEMBL 3918830 & 1640500 & 6.9508 & 7.0831 & TST & \\
\hline CHEMBL3953002 & 1640500 & 7.1938 & 7.1536 & TRN & \\
\hline CHEMBL 3971848 & 1640500 & 7.4559 & 7.6416 & TRN & \\
\hline CHEMBL3920568 & 1640500 & 6.8327 & 7.0289 & TRN & \\
\hline CHEMBL3952325 & 1640500 & 7.4949 & 7.6632 & TRN & \\
\hline CHEMBL 3960354 & 1640500 & 6.7399 & 6.8636 & TRN & \\
\hline CHEMBL3981392 & 1640500 & 6.6108 & 6.7691 & TRN & \\
\hline CHEMBL3961960 & 1640500 & 7.4437 & 7.1403 & TRN & \\
\hline CHEMBL3915652 & 1640500 & 7.7696 & 7.7626 & TRN & \\
\hline CHEMBL3940347 & 1640500 & 7.1675 & 7.449 & TRN & \\
\hline CHEMBL 3922301 & 1640500 & 7.699 & 7.7287 & TST & \\
\hline CHEMBL3944480 & 1640500 & 7.9208 & 7.437 & TRN & \\
\hline CHEMBL3959624 & 1640500 & 7.2007 & 7.1151 & TRN & \\
\hline CHEMBL3913268 & 1640500 & 5.3931 & 5.4415 & TST & \\
\hline CHEMBL3930831 & 1640500 & 7.2147 & 7.2621 & TRN & \\
\hline CHEMBL 3924494 & 1640500 & 7.6778 & \multicolumn{2}{|c|}{ 7.4879999999999995 } & TST \\
\hline CHEMBL3948113 & 1640500 & 7.4685 & 7.6866 & TRN & \\
\hline CHEMBL3891810 & 1640500 & 7.6198 & 7.6456 & TRN & \\
\hline CHEMBL3943617 & 1640500 & 5.8928 & 5.9724 & TRN & \\
\hline CHEMBL3919008 & 1640500 & 6.4547 & 6.516 & TRN & \\
\hline CHEMBL3961518 & 1640500 & 7.2291 & 7.0445 & TRN & \\
\hline
\end{tabular}


Supplemental Table S2.txt

\begin{tabular}{|c|c|c|c|c|}
\hline CHEMBL3906150 & 1640500 & 6.9066 & 7.1304 & TRN \\
\hline CHEMBL3943113 & 1640500 & 7.5086 & 7.6465 & TRN \\
\hline CHEMBL3952837 & 1640500 & 7.4202 & 7.5255 & TRN \\
\hline CHEMBL3975159 & 1640500 & 5.1096 & 4.8574 & TRN \\
\hline CHEMBL3896907 & 1640500 & 7.0506 & 7.0242 & TRN \\
\hline CHEMBL3955316 & 1640500 & 7.3279 & 7.1493 & TRN \\
\hline CHEMBL 3890540 & 1640500 & 7.4685 & 7.5361 & TRN \\
\hline CHEMBL 3921660 & 1640500 & 5.5262 & \multicolumn{2}{|c|}{5.577999999999999} \\
\hline CHEMBL 3983105 & 1640500 & 6.0329 & 5.0461 & TST \\
\hline CHEMBL3967162 & 1640500 & 7.1871 & 7.209 & TRN \\
\hline CHEMBL 3947476 & 1640500 & 7.8861 & 7.8716 & TRN \\
\hline CHEMBL3956206 & 1640500 & 6.9788 & 6.3984 & TST \\
\hline CHEMBL3983827 & 1640500 & 7.2596 & 7.1118 & TRN \\
\hline CHEMBL 3908213 & 1640500 & 7.2076 & 7.1 & TRN \\
\hline CHEMBL3923382 & 1640500 & 7.6198 & 7.6943 & TRN \\
\hline CHEMBL 3942682 & 1640500 & 7.7959 & 7.5066 & TRN \\
\hline CHEMBL3957873 & 1640500 & 7.7959 & 7.5606 & TRN \\
\hline CHEMBL 3897742 & 1640500 & 6.7447 & 6.7261 & TRN \\
\hline CHEMBL3915101 & 1640500 & 7.6576 & 7.6592 & TRN \\
\hline CHEMBL3913253 & 1640500 & 7.6198 & 7.7356 & TRN \\
\hline CHEMBL3935750 & 1640500 & 5.6112 & 5.8004 & TRN \\
\hline CHEMBL3965936 & 1640500 & 6.9508 & 6.8273 & TST \\
\hline CHEMBL3958463 & 1640500 & 7.9586 & 7.6919 & TST \\
\hline CHEMBL3950899 & 1640500 & 7.3979 & 7.5595 & TST \\
\hline CHEMBL 3902079 & 1640500 & 7.7696 & 7.9388 & TST \\
\hline CHEMBL 3986092 & 1640500 & 7.3468 & 6.3349 & TST \\
\hline CHEMBL3928171 & 1640500 & 6.4237 & 7.1734 & TST \\
\hline CHEMBL3958894 & 1640500 & 7.2291 & 7.0978 & TRN \\
\hline CHEMBL 3912820 & 1640500 & 7.6576 & 7.4285 & TRN \\
\hline CHEMBL 3980955 & 1640500 & 7.1612 & 8.0412 & TST \\
\hline CHEMBL 3897756 & 1640500 & 7.4318 & 7.3706 & TRN \\
\hline CHEMBL3898823 & 1640500 & 7.0655 & 7.1904 & TST \\
\hline CHEMBL 3958314 & 1640500 & 6.5591 & 6.3863 & TRN \\
\hline CHEMBL 3941033 & 1640500 & 7.699 & 7.5029 & TRN \\
\hline CHEMBL3945702 & 1640500 & 7.4949 & 7.4192 & TRN \\
\hline CHEMBL3986566 & 1640500 & 7.8861 & 7.775 & TRN \\
\hline CHEMBL3909708 & 1640500 & 7.1805 & 7.1333 & TST \\
\hline CHEMBL3984997 & 1640500 & 7.5686 & 7.741000 & 30000000005 \\
\hline CHEMBL 3890939 & 1640500 & 6.0 & 7.0018 & TRN \\
\hline CHEMBL3954545 & 1640500 & 7.3872 & 7.2433 & TRN \\
\hline CHEMBL3974594 & 1640500 & 7.284 & 7.2145 & TRN \\
\hline CHEMBL 3985232 & 1640500 & 7.585 & 7.3637 & TRN \\
\hline CHEMBL3912230 & 1640500 & 7.1427 & 6.8912 & TRN \\
\hline CHEMBL 3976821 & 1640500 & 7.585 & 7.845 & TRN \\
\hline CHEMBL3899895 & 1642272 & 8.699 & 8.6648 & TRN \\
\hline CHEMBL3962392 & 1642272 & 8.699 & 8.7013 & TRN \\
\hline CHEMBL3971936 & 1642272 & 8.699 & 8.6561 & TRN \\
\hline CHEMBL3924601 & 1642272 & 7.301 & 7.1866 & TRN \\
\hline
\end{tabular}


Supplemental Table S2.txt

\begin{tabular}{|c|c|c|c|c|c|}
\hline CHEMBL3918815 & 1642272 & 8.699 & 8.6679 & TRN & \\
\hline CHEMBL3967319 & 1642272 & 8.699 & 8.5975 & TRN & \\
\hline CHEMBL3982124 & 1642272 & 8.699 & 8.2478 & TRN & \\
\hline CHEMBL3932350 & 1642272 & 8.699 & 8.7872 & TRN & \\
\hline CHEMBL3959184 & 1642272 & 7.301 & 7.3483 & TST & \\
\hline CHEMBL3942329 & 1642272 & 7.301 & 7.3078 & TRN & \\
\hline CHEMBL3942382 & 1642272 & 8.301 & 7.7538 & TRN & \\
\hline CHEMBL3908380 & 1642272 & 8.699 & 8.4786 & TRN & \\
\hline CHEMBL3904434 & 1642272 & 8.699 & 8.8745 & TRN & \\
\hline CHEMBL3974350 & 1642272 & 8.699 & 8.7423 & TRN & \\
\hline CHEMBL3979231 & 1642272 & 7.699 & 7.7973 & TRN & \\
\hline CHEMBL3970653 & 1642272 & 8.699 & 8.7934 & TRN & \\
\hline CHEMBL3901039 & 1642272 & 5.0 & 5.5212 & TRN & \\
\hline CHEMBL3968717 & 1642272 & 7.0 & 6.6066 & TRN & \\
\hline CHEMBL3892670 & 1642272 & 8.699 & 8.4777 & TRN & \\
\hline CHEMBL3986981 & 1642272 & 8.699 & \multicolumn{2}{|c|}{8.806000000000001} & TRN \\
\hline CHEMBL3889853 & 1642272 & 8.699 & 8.6481 & TRN & \\
\hline CHEMBL3932524 & 1642272 & 8.0 & 7.6631 & TRN & \\
\hline CHEMBL3906581 & 1642272 & 7.301 & 7.5913 & TRN & \\
\hline CHEMBL3933520 & 1642272 & 8.699 & 8.6844 & TRN & \\
\hline CHEMBL3950186 & 1642272 & 8.699 & 8.0838 & TST & \\
\hline CHEMBL3892608 & 1642272 & 7.0 & 6.0564 & TST & \\
\hline CHEMBL3901621 & 1642272 & 8.699 & 8.6496 & TRN & \\
\hline CHEMBL3892176 & 1642272 & 8.0 & 8.1755 & TRN & \\
\hline CHEMBL3972759 & 1642272 & 5.0 & \multicolumn{2}{|c|}{5.247999999999999} & TRN \\
\hline CHEMBL3934545 & 1642272 & 8.301 & 8.3321 & TRN & \\
\hline CHEMBL3896626 & 1642272 & 8.699 & 9.0411 & TRN & \\
\hline CHEMBL3975901 & 1642272 & 8.699 & \multicolumn{2}{|c|}{8.658999999999999} & TRN \\
\hline CHEMBL3971896 & 1642272 & 8.699 & 8.8881 & TRN & \\
\hline CHEMBL3941707 & 1642272 & 8.699 & 8.655 & TRN & \\
\hline CHEMBL3965442 & 1642272 & 8.699 & 8.6815 & TRN & \\
\hline CHEMBL3904353 & 1642272 & 5.0 & 6.8085 & TST & \\
\hline CHEMBL3967692 & 1642272 & 7.699 & 7.9057 & TRN & \\
\hline CHEMBL3928184 & 1642272 & 5.0 & 7.1521 & TST & \\
\hline CHEMBL3957673 & 1642272 & 8.699 & 8.1593 & TST & \\
\hline CHEMBL3935969 & 1642272 & 8.301 & 8.113 & TRN & \\
\hline CHEMBL3985139 & 1642272 & 8.699 & 8.5565 & TRN & \\
\hline CHEMBL3944283 & 1642272 & 8.0 & 7.649 & TRN & \\
\hline CHEMBL3952455 & 1642272 & 8.301 & 8.1909 & TST & \\
\hline CHEMBL3917972 & 1642272 & 7.699 & 7.8006 & TRN & \\
\hline CHEMBL3910134 & 1642272 & 8.301 & 8.2966 & TRN & \\
\hline CHEMBL3941437 & 1642272 & 8.699 & 8.1405 & TST & \\
\hline CHEMBL3915096 & 1642272 & 8.301 & 8.7267 & TRN & \\
\hline CHEMBL3923580 & 1642272 & 8.699 & 8.6971 & TRN & \\
\hline CHEMBL3980132 & 1642272 & 8.301 & 8.3907 & TRN & \\
\hline CHEMBL3890853 & 1642272 & 8.699 & 8.7231 & TRN & \\
\hline CHEMBL3981963 & 1642272 & 7.699 & 7.7192 & TRN & \\
\hline CHEMBL3971472 & 1642272 & 8.301 & 8.1981 & TRN & \\
\hline
\end{tabular}


Supplemental Table S2.txt

\begin{tabular}{|c|c|c|c|c|}
\hline (2) & 642272 & & 5271 & TR \\
\hline HEMBL3940192 & 642272 & 8.699 & 8.6174 & \\
\hline 9300 & 2272 & & 852 & \\
\hline HEMBL 3974734 & 542272 & 5.0 & 93 & \\
\hline AEMBL3948742 & 642272 & 7.0 & 0691 & \\
\hline AEMBL3914954 & 642272 & 7.699 & .4858 & \\
\hline HEMBL3958881 & 642272 & 7.699 & .0638 & \\
\hline AEMBL3911069 & 272 & 599 & 635 & \\
\hline AEMBL3967584 & 272 & 7.301 & .2934 & \\
\hline HEMBL3906683 & 642272 & 8.0 & .1963 & \\
\hline HEMBL3901273 & 642272 & 8.0 & .9111 & \\
\hline HEMBL3928192 & 272 & 7.0 & .0806 & \\
\hline HEMBL3893960 & & & .0837 & RN \\
\hline HEMBL3919894 & 272 & 599 & .6623 & \\
\hline HEMBL3918922 & 272 & 8.699 & .734 & RN \\
\hline AEMBL3889594 & 272 & 8.301 & .3314 & KIV \\
\hline HEMBL3908536 & 72 & 599 & 7291 & \\
\hline HEMBL3957442 & 72 & 99 & 4657 & RN \\
\hline HEMBL3946639 & 72 & 8.699 & 8.33 & \\
\hline HEMBL3954762 & 72 & 99 & 5607 & RN \\
\hline HEMBL3937080 & 72 & 8.5229 & 8.4238 & KIV \\
\hline HEMBL3894129 & 72 & 01 & 759 & 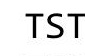 \\
\hline HEMBL 391 & & 7.301 & 28 & RN \\
\hline HEMBL3896574 & 72 & 8.301 & 8.2165 & RN \\
\hline AEMBL3935002 & 72 & 01 & 3571 & RN \\
\hline HEMBL3942122 & 72 & 599 & 3698 & IST \\
\hline HEMBL3975819 & 72 & 5. & 4289 & RN \\
\hline HEMBL39 & 72 & 8 . & 143 & RN \\
\hline HEMBL3933674 & 72 & 8 . & 8.4288 & ST \\
\hline HEMBL3932107 & 72 & 8 . & 892 & IST \\
\hline AEMBL3912145 & 72 & 8. & .8628 & RN \\
\hline HEMBI 39 & 72 & 99 & 5296 & ST \\
\hline 56 & 72 & 7.699 & 7.8033 & TST \\
\hline HEMBL3929098 & 72 & 8.0 & 8.0531 & TRN \\
\hline HEMBL3920980 & 72 & 8.301 & 5608 & TRN \\
\hline HEMBL3943268 & 72 & 8 . & 3164 & RN \\
\hline HFMRI 3 & 72 & 8. & 489 & ST \\
\hline HEMBL3920974 & 272 & 7.5229 & 8.0851 & TRN \\
\hline HEMBL3984491 & 272 & 8.699 & 8.6232 & TRN \\
\hline HEMBL3939030 & 72 & 8.699 & 3.8103 & 「RN \\
\hline HEMBL3926549 & 72 & 7.301 & 5.7963 & $\mathrm{RN}$ \\
\hline CHEMBL 3936573 & & 7.699 & 8.0305 & RN \\
\hline HEMBL3975280 & 272 & 8.699 & 8.7462 & TRN \\
\hline HEMBL3980333 & 272 & 7.0 & .9374 & TRN \\
\hline IEMBL3979330 & 72 & 8.699 & 8.7559 & TRN \\
\hline CHEMBL3975221 & 1642272 & 8.0 & 7.897 & \\
\hline CHEMBL 39 & 272 & 8.699 & 8.7547 & RN \\
\hline CHEMBL3966943 & 1642272 & 8.699 & 8.6793 & IST \\
\hline
\end{tabular}

Page 574 
Supplemental Table S2.txt

\begin{tabular}{|c|c|c|c|c|}
\hline AEMB & 642272 & 5.0 & 5.9759 & TS \\
\hline HEMBL3913439 & 642272 & 8.699 & 8.7093 & \\
\hline HFMBL 3963 & 642272 & 599 & & \\
\hline HEMBL3908546 & 642272 & 8.699 & 4849 & $3 N$ \\
\hline HEMBL3913196 & 642272 & 7.301 & 7879 & \\
\hline HEMBL3954373 & 642272 & 8.301 & .4543 & \\
\hline HEMBL3914879 & 642272 & 8.699 & 788 & \\
\hline AEMBL3896031 & 272 & 8.699 & 877 & \\
\hline HEMBL3942677 & 272 & 8.699 & 1096 & \\
\hline HEMBL3956331 & 642272 & 8.699 & .6715 & \\
\hline HEMBL3897679 & 642272 & 7.0 & . 7751 & \\
\hline HEMBL3902048 & 272 & 7.0 & 16 & \\
\hline HEMBL 3899 & 272 & 5.0 & & \\
\hline HEMBL3948905 & 272 & 8.301 & 3.19 & \\
\hline HEMBL3912539 & 272 & 8 . & & \\
\hline HEMBL3966923 & 72 & 7.699 & 89 & \\
\hline HEMBL39439 & 72 & 8.301 & 42 & \\
\hline HEMBL3898 & 72 & 7.699 & & \\
\hline HEMBL3899477 & 272 & 8.699 & 8.7283 & \\
\hline HEMBL3968458 & 72 & 7. & 86 & 3 \\
\hline HEMBL393 & 72 & 8.699 & 4413 & \\
\hline HEMBL396 & 72 & 8 . & 42 & \\
\hline HEMBL395 & 72 & 8.699 & & RN \\
\hline HEMBL3923581 & 272 & 8.699 & 3969 & $\mathrm{RN}$ \\
\hline HEMBL3915673 & 72 & & & $R N$ \\
\hline HEMBL3927886 & 164 & 8.699 & & I \\
\hline HEMBL393 & 72 & 8 . & & RN \\
\hline HEMBL3899645 & 72 & 7.699 & & RN \\
\hline HEMBL3972273 & 72 & 7.699 & & ST \\
\hline HEMBL3982199 & 72 & 8.301 & 69 & TRN \\
\hline HEMBL 38955 & 64 & 8.699 & 337 & RN \\
\hline HEMBL 39 & 72 & 8.699 & 18 & RN \\
\hline HEMBL392 & 72 & 8. & 3276 & ST \\
\hline HEMBL3961668 & 272 & 8.301 & 4271 & $\Gamma \mathrm{RN}$ \\
\hline HEMBL3899566 & 272 & 8.699 & 3.5838 & $\Gamma \mathrm{RN}$ \\
\hline HEMBL3897579 & 72 & 7.699 & 289 & $\Gamma \mathrm{RN}$ \\
\hline CHEMBL 39 & 16 & 8 . & & ST \\
\hline HEMBL391 & 164 & 7.699 & 8265 & TST \\
\hline HEMBL3937170 & 272 & 7.0 & 9461 & TST \\
\hline HEMBL3946 & 72 & 8.699 & 5135 & TST \\
\hline CHEMBL3975406 & 164 & 7. & 6.9065 & TST \\
\hline CHEMBL3928389 & 1642272 & 8.699 & 8.7747 & $\Gamma \mathrm{RN}$ \\
\hline CHEMBL3906918 & 1642272 & 8.699 & 8.7177 & TRN \\
\hline CHEMBL3957554 & 1642272 & 8.699 & 4305 & RN \\
\hline CHEMBL 389 & 72 & 8.699 & 8.7861 & \\
\hline CHEMBL3982805 & 1642272 & 8.699 & & \\
\hline CHEMBL 3898470 & 1642272 & 8.699 & 8.6917 & \\
\hline CHEMBL3907045 & 1642272 & 8.699 & 7.7903 & 「RN \\
\hline
\end{tabular}

Page 575 
Supplemental Table S2.txt

\begin{tabular}{|c|c|c|c|c|c|}
\hline CHEMBL3933115 & 1642272 & 8.699 & 8.7266 & TRN & \\
\hline CHEMBL3965861 & 1642272 & 8.301 & 8.1978 & TRN & \\
\hline CHEMBL3949502 & 1642272 & 8.0 & 7.972 & TST & \\
\hline CHEMBL3948194 & 1642272 & 8.301 & 8.4482 & TST & \\
\hline CHEMBL3954119 & 1642272 & 8.0 & 7.8581 & TRN & \\
\hline CHEMBL3971195 & 1642272 & 8.0 & 7.3737 & TST & \\
\hline CHEMBL3921504 & 1642272 & 8.301 & 8.1051 & TRN & \\
\hline CHEMBL3955195 & 1642272 & 8.699 & 8.6618 & TRN & \\
\hline CHEMBL24289 & 30305 & 5.0227 & 5.0439 & TRN & \\
\hline CHEMBL273953 & 30305 & 5.2573 & 5.2591 & TRN & \\
\hline CHEMBL27041 & 30305 & 7.3979 & 7.4212 & TRN & \\
\hline CHEMBL350469 & 30305 & 7.3325 & 7.309 & TRN & \\
\hline CHEMBL 8488 & 30305 & 5.8761 & 5.8608 & TRN & \\
\hline CHEMBL304356 & 30305 & 4.8125 & 4.8514 & TRN & \\
\hline CHEMBL67323 & 30305 & 5.2503 & 5.254 & TRN & \\
\hline CHEMBL290643 & 30305 & 5.1851 & 5.1598 & TRN & \\
\hline CHEMBL66881 & 30305 & 5.7645 & 5.7761 & TRN & \\
\hline CHEMBL11146 & 30305 & 4.9547 & 4.9542 & TRN & \\
\hline CHEMBL286785 & 30305 & 5.8761 & 5.8375 & TRN & \\
\hline CHEMBL27047 & 30305 & 7.2168 & 7.2237 & TRN & \\
\hline CHEMBL157836 & 30305 & 7.0991 & 7.0899 & TRN & \\
\hline CHEMBL183 & 30305 & 7.1952 & 8.1442 & TST & \\
\hline CHEMBL304455 & 30305 & 6.2916 & 6.2609 & TRN & \\
\hline CHEMBL67313 & 30305 & 5.6326 & 5.6285 & TRN & \\
\hline CHEMBL11332 & 30305 & 6.5391 & 6.5501 & TRN & \\
\hline CHEMBL 37243 & 30305 & 7.4685 & 7.6768 & TST & \\
\hline CHEMBL26406 & 30305 & 5.4698 & 5.2584 & TST & \\
\hline CHEMBL67415 & 30305 & 6.2581 & 6.2817 & TRN & \\
\hline CHEMBL66011 & 30305 & 4.6289 & 4.6397 & TRN & \\
\hline CHEMBL24759 & 30305 & 4.7122 & 4.7128 & TRN & \\
\hline CHEMBL 20402 & 30305 & 5.0048 & 5.0147 & TRN & \\
\hline CHEMBL416884 & 30305 & 5.1586 & 5.157 & TRN & \\
\hline CHEMBL304319 & 30305 & 4.8539 & 4.8531 & TRN & \\
\hline CHEMBL68278 & 30305 & 6.3757 & 6.3417 & TRN & \\
\hline CHEMBL11348 & 30305 & 7.2076 & 7.1575 & TRN & \\
\hline CHEMBL308660 & 30305 & 6.5086 & 6.5066 & TRN & \\
\hline CHEMBL156178 & 30305 & 6.7258 & 6.7326 & TRN & \\
\hline CHEMBL302344 & 30305 & 6.0155 & 6.8086 & TST & \\
\hline CHEMBL67110 & 30305 & 6.5072 & 5.6729 & TST & \\
\hline CHEMBL416013 & 30305 & 5.75200 & 000000000 & $\partial 1$ & 5.8035 \\
\hline CHEMBL67060 & 30305 & 4.8239 & 4.8102 & TRN & \\
\hline CHEMBL307105 & 30305 & 6.1605 & 6.6438 & TST & \\
\hline CHEMBL67109 & 30305 & 4.6289 & 4.618 & TRN & \\
\hline CHEMBL68660 & 30305 & 5.1203 & 5.8869 & TST & \\
\hline CHEMBL39986 & 30305 & 6.4437 & 6.8297 & TST & \\
\hline CHEMBL308464 & 30305 & 5.06 & 5.0438 & TRN & \\
\hline CHEMBL67949 & 30305 & 6.3893 & 6.1823 & TST & \\
\hline CHEMBL157655 & 30305 & 5.9547 & 6.4464 & TST & \\
\hline
\end{tabular}




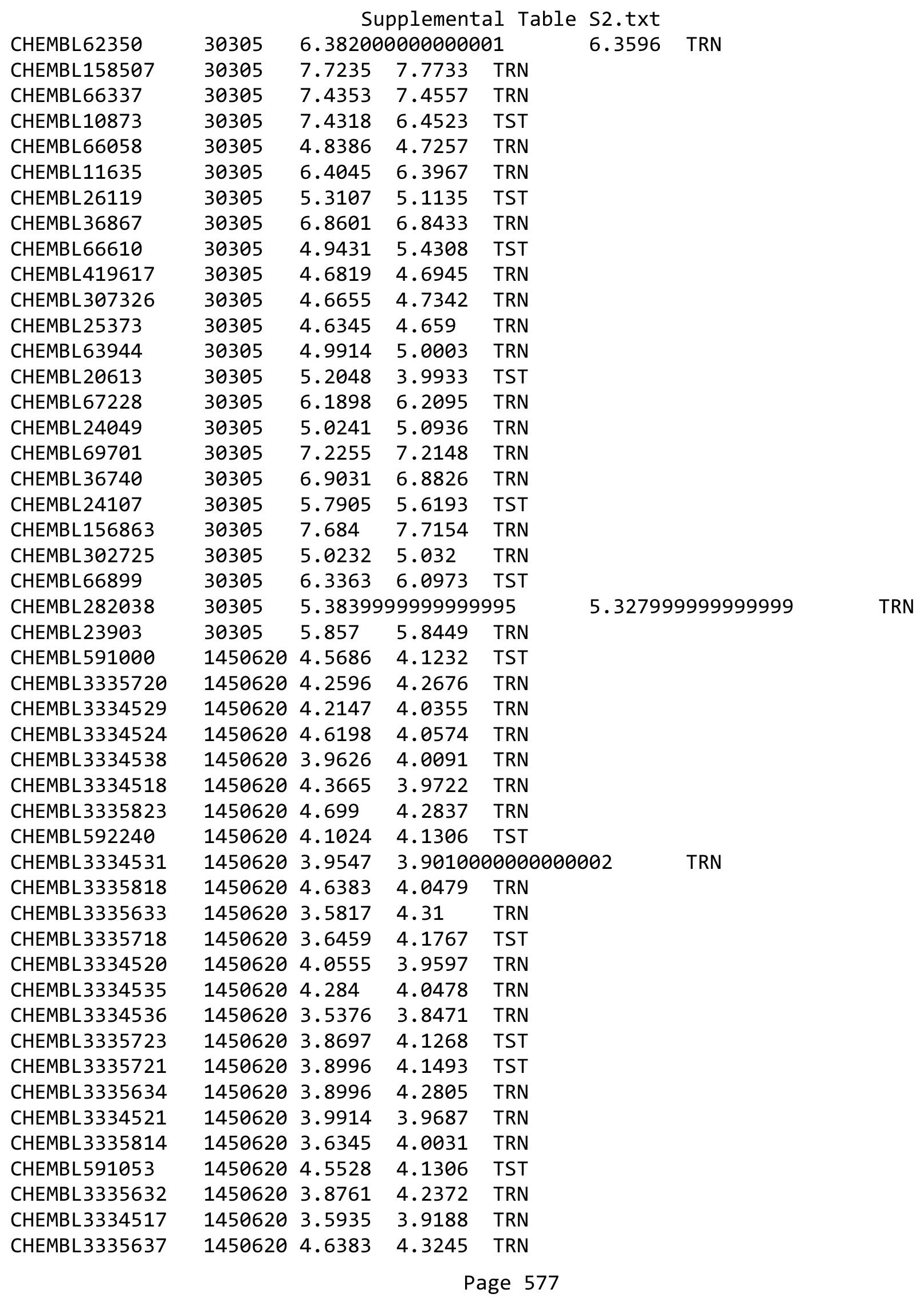


Supplemental Table S2.txt

\begin{tabular}{|c|c|c|c|c|c|c|}
\hline CHEMBL 3334516 & 1450620 & 3.7352 & 3.9872 & TRN & & \\
\hline CHEMBL3335727 & 1450620 & 4.284 & 4.1487 & TST & & \\
\hline CHEMBL589165 & 1450620 & 3.9547 & 4.1306 & TST & & \\
\hline CHEMBL3335728 & 1450620 & 4.1308 & 4.2633 & TRN & & \\
\hline CHEMBL3334519 & 1450620 & 4.2366 & 4.0182 & TRN & & \\
\hline CHEMBL3335716 & 1450620 & 3.6073 & 4.1828 & TST & & \\
\hline CHEMBL3335816 & 1450620 & 4.3279 & 4.1036 & TRN & & \\
\hline CHEMBL3335635 & 1450620 & 4.0132 & 4.2681 & TRN & & \\
\hline CHEMBL3335812 & 1450620 & 4.2518 & 4.2749 & TRN & & \\
\hline CHEMBL3335820 & 1450620 & 4.6383 & 4.1149 & TRN & & \\
\hline CHEMBL3335822 & 1450620 & 4.8239 & 4.1929 & TRN & & \\
\hline CHEMBL3334539 & 1450620 & 2.4948 & 3.9828 & TRN & & \\
\hline CHEMBL 3334522 & 1450620 & 3.5935 & 3.9188 & TRN & & \\
\hline CHEMBL3334525 & 1450620 & 3.9547 & 3.8978 & TRN & & \\
\hline CHEMBL3335817 & 1450620 & 4.4437 & 4.0799 & TRN & & \\
\hline CHEMBL3334527 & 1450620 & 3.5686 & 3.8854 & TRN & & \\
\hline CHEMBL3334526 & 1450620 & 4.1192 & 3.9928 & TRN & & \\
\hline CHEMBL 3335813 & 1450620 & 5.0969 & 4.2466 & TRN & & \\
\hline CHEMBL3334523 & 1450620 & 4.3665 & 3.9188 & TRN & & \\
\hline CHEMBL 3334532 & 1450620 & 4.0862 & 4.0184 & TRN & & \\
\hline CHEMBL3334528 & 1450620 & 4.4318 & 4.0775 & TRN & & \\
\hline CHEMBL3335808 & 1450620 & 4.2757 & 4.2773 & TRN & & \\
\hline CHEMBL3335717 & 1450620 & 4.4437 & 4.23 & TST & & \\
\hline CHEMBL3335639 & 1450620 & 4.0506 & 4.3915 & TRN & & \\
\hline CHEMBL3334533 & 1450620 & 3.9281 & 3.9117 & TRN & & \\
\hline CHEMBL3334537 & 1450620 & 4.4202 & 3.9471 & TRN & & \\
\hline CHEMBL3335638 & 1450620 & 3.9586 & 4.4715 & TRN & & \\
\hline CHEMBL3335821 & 1450620 & 4.7212 & 4.2595 & TRN & & \\
\hline CHEMBL 3335640 & 1450620 & 4.5086 & 4.4941 & TRN & & \\
\hline CHEMBL3335724 & 1450620 & 4.1938 & 4.3234 & TRN & & \\
\hline CHEMBL3335819 & 1450620 & 3.68399 & 79999999 & 997 & 4.0212 & $\mathrm{TH}$ \\
\hline CHEMBL3334534 & 1450620 & 4.4437 & 4.0406 & TRN & & \\
\hline CHEMBL3334515 & 1450620 & 4.2757 & 3.9979 & TRN & & \\
\hline CHEMBL 3335725 & 1450620 & 3.9431 & 4.2838 & TRN & & \\
\hline CHEMBL3334514 & 1450620 & 3.9788 & 3.9115 & TRN & & \\
\hline CHEMBL3335636 & 1450620 & 3.71 & 4.2258 & TRN & & \\
\hline CHEMBL3335815 & 1450620 & 4.0044 & 4.0408 & TRN & & \\
\hline CHEMBL3335809 & 1450620 & 3.7799 & 4.2897 & TST & & \\
\hline CHEMBL3335726 & 1450620 & 5.5376 & 4.3357 & TRN & & \\
\hline CHEMBL3335642 & 1450620 & 4.6198 & 4.2023 & TST & & \\
\hline CHEMBL3335719 & 1450620 & 3.6615 & 4.1735 & TST & & \\
\hline CHEMBL3335810 & 1450620 & 2.4948 & 4.0904 & TST & & \\
\hline CHEMBL3335631 & 1450620 & 3.6778 & 4.2151 & TRN & & \\
\hline CHEMBL 3334530 & 1450620 & 2.4948 & 4.0656 & TRN & & \\
\hline CHEMBL3335811 & 1450620 & 5.4089 & 4.2012 & TST & & \\
\hline CHEMBL 3335807 & 1450620 & 4.699 & 4.1598 & TST & & \\
\hline CHEMBL3335722 & 1450620 & 2.4948 & 4.1977 & TST & & \\
\hline CHEMBL3335641 & 1450620 & 6.0458 & 4.2077 & TST & & \\
\hline
\end{tabular}

Page 578 


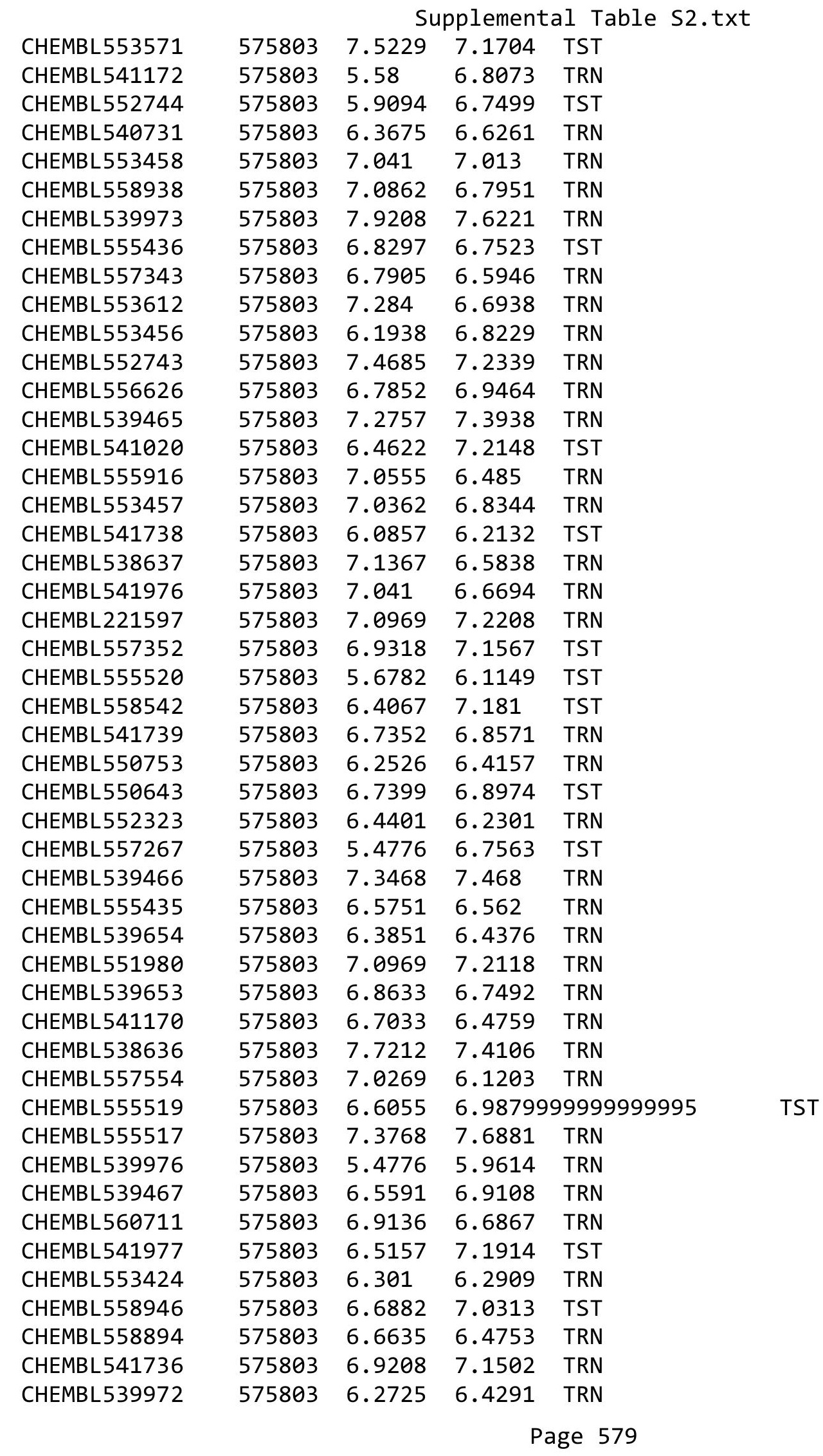




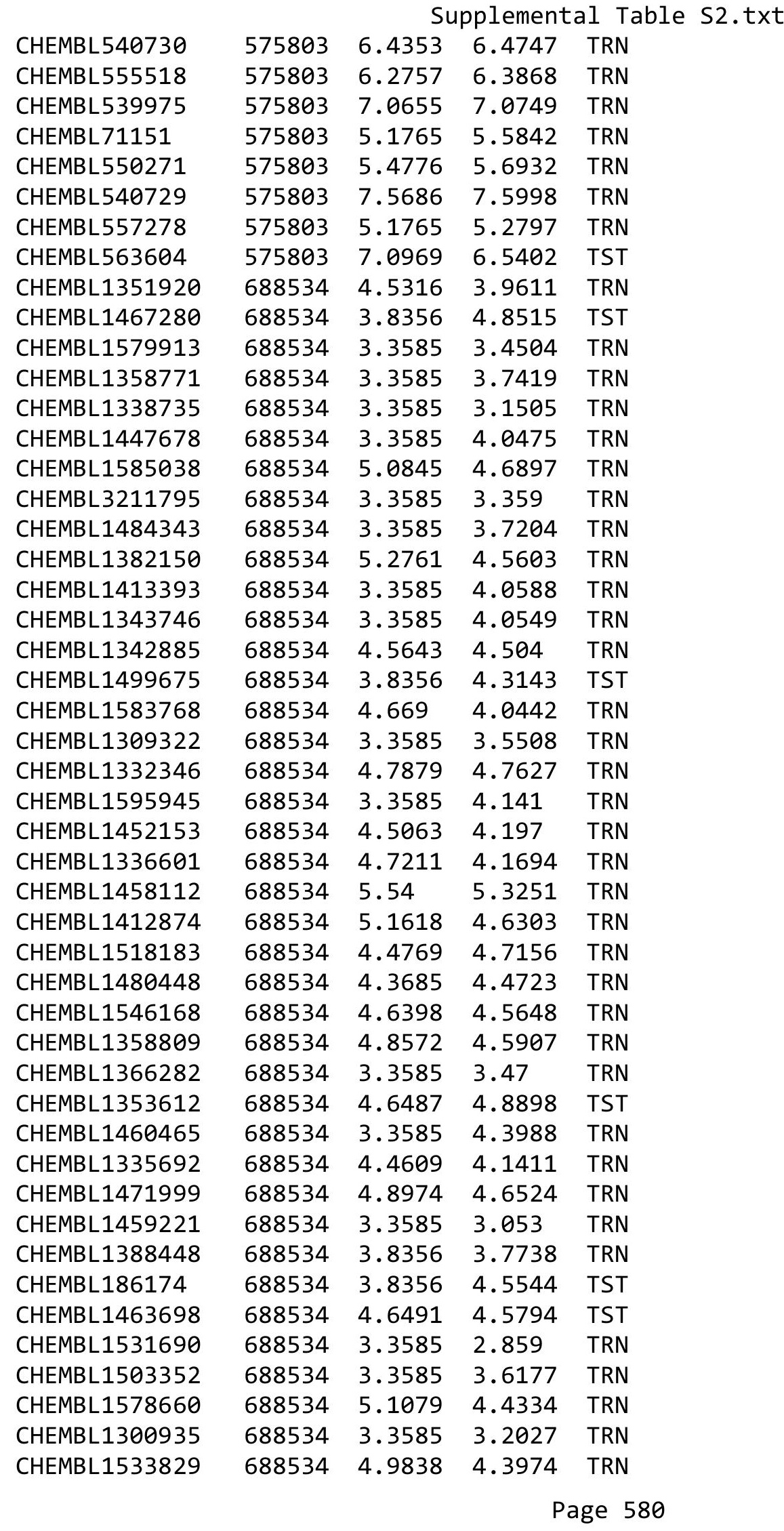




\begin{tabular}{|c|c|c|c|c|}
\hline \multicolumn{5}{|c|}{ Supplemental Table s2.txt } \\
\hline CHEMBL1380202 & 688534 & 3.3585 & 3.4247 & TRN \\
\hline CHEMBL1319565 & 688534 & 4.9888 & 4.086 & TST \\
\hline CHEMBL1306232 & 688534 & 3.3585 & 3.7886 & TRN \\
\hline CHEMBL1517453 & 688534 & 3.3585 & 3.1432 & TRN \\
\hline CHEMBL1572885 & 688534 & 3.3585 & 3.668 & TRN \\
\hline CHEMBL1540447 & 688534 & 3.3585 & 4.2023 & TRN \\
\hline CHEMBL1482022 & 688534 & 4.5402 & 4.0653 & TRN \\
\hline CHEMBL1359489 & 688534 & 3.8356 & 4.1442 & TRN \\
\hline CHEMBL1609915 & 688534 & 4.6217 & 4.5803 & TRN \\
\hline CHEMBL1586617 & 688534 & 4.5916 & 4.8206 & TRN \\
\hline CHEMBL1300997 & 688534 & 3.3585 & 3.765 & TRN \\
\hline CHEMBL1568072 & 688534 & 5.1054 & 4.9232 & TRN \\
\hline CHEMBL1500235 & 688534 & 3.3585 & 3.2907 & TRN \\
\hline CHEMBL1335094 & 688534 & 3.3585 & 4.4899 & TST \\
\hline CHEMBL1416734 & 688534 & 4.4914 & 4.5213 & TRN \\
\hline CHEMBL1370401 & 688534 & 4.9017 & 4.1787 & TST \\
\hline CHEMBL1325848 & 688534 & 3.3585 & 3.3918 & TST \\
\hline CHEMBL1589399 & 688534 & 3.3585 & 4.4385 & TRN \\
\hline CHEMBL1582511 & 688534 & 3.3585 & 4.1026 & TRN \\
\hline CHEMBL1402796 & 688534 & 3.3585 & 3.4988 & TRN \\
\hline CHEMBL1426998 & 688534 & 3.3585 & 3.0488 & TRN \\
\hline CHEMBL1506732 & 688534 & 3.3585 & 3.4448 & TRN \\
\hline CHEMBL1335256 & 688534 & 3.8356 & 3.7626 & TRN \\
\hline CHEMBL1418691 & 688534 & 4.6284 & 4.7827 & TRN \\
\hline CHEMBL1579263 & 688534 & 3.3585 & 3.2671 & TRN \\
\hline CHEMBL1538214 & 688534 & 3.3585 & 3.339 & TRN \\
\hline CHEMBL1412407 & 688534 & 3.3585 & 3.321 & TRN \\
\hline CHEMBL1386141 & 688534 & 3.3585 & 4.0654 & TRN \\
\hline CHEMBL1536967 & 688534 & 4.6682 & 4.6359 & TRN \\
\hline CHEMBL1543278 & 688534 & 4.4411 & 4.9161 & TRN \\
\hline CHEMBL1359426 & 688534 & 5.232 & 4.678 & TRN \\
\hline CHEMBL1587146 & 688534 & 3.3585 & 3.529 & TRN \\
\hline CHEMBL1569862 & 688534 & 4.4614 & 4.3275 & TRN \\
\hline CHEMBL1464847 & 688534 & 4.9737 & 4.8754 & TRN \\
\hline CHEMBL1588709 & 688534 & 3.3585 & 3.4752 & TRN \\
\hline CHEMBL1456577 & 688534 & 5.2704 & 4.096 & TRN \\
\hline CHEMBL1339046 & 688534 & 4.6224 & 4.3159 & TRN \\
\hline CHEMBL1319175 & 688534 & 3.3585 & 3.9013 & TRN \\
\hline CHEMBL1584538 & 688534 & 5.5322 & 4.5776 & TRN \\
\hline CHEMBL1401638 & 688534 & 3.3585 & 4.4607 & TRN \\
\hline CHEMBL1468887 & 688534 & 3.3585 & 3.1373 & TRN \\
\hline CHEMBL3209782 & 688534 & 4.5526 & 3.764 & TRN \\
\hline CHEMBL1576145 & 688534 & 4.658 & 4.4452 & TRN \\
\hline CHEMBL1585808 & 688534 & 3.3585 & 3.6024 & TRN \\
\hline CHEMBL1498512 & 688534 & 3.3585 & 4.4807 & TST \\
\hline CHEMBL1582334 & 688534 & 4.9624 & 4.479 & TST \\
\hline CHEMBL1364722 & 688534 & 3.3585 & 4.0659 & TRN \\
\hline CHEMBL1501491 & 688534 & 3.3585 & 3.6497 & TST \\
\hline
\end{tabular}




\begin{tabular}{|c|c|c|c|c|c|}
\hline \multicolumn{6}{|c|}{ Supplemental Table s2.txt } \\
\hline CHEMBL1371138 & 688534 & 3.3585 & 3.5533 & TRN & \\
\hline CHEMBL1350024 & 688534 & 5.1902 & 4.7733 & TRN & \\
\hline CHEMBL1977747 & 688534 & 3.8356 & 4.6085 & TST & \\
\hline CHEMBL1312413 & 688534 & 5.2536 & 4.5421 & TST & \\
\hline CHEMBL1609697 & 688534 & 3.3585 & 2.9384 & TRN & \\
\hline CHEMBL1335685 & 688534 & 4.973 & 4.4018 & TRN & \\
\hline CHEMBL1371990 & 688534 & 3.3585 & 2.9974 & TRN & \\
\hline CHEMBL1404493 & 688534 & 5.0364 & 4.4186 & TST & \\
\hline CHEMBL1446321 & 688534 & 5.3792 & 4.9312 & TRN & \\
\hline CHEMBL1565197 & 688534 & 3.3585 & 3.3224 & TRN & \\
\hline CHEMBL1344766 & 688534 & 4.5486 & 4.6442 & TST & \\
\hline CHEMBL1562905 & 688534 & 3.3585 & 3.0481 & TRN & \\
\hline CHEMBL1549996 & 688534 & 4.7729 & 4.8883 & TST & \\
\hline CHEMBL1421312 & 688534 & 3.3585 & 3.8999 & TRN & \\
\hline CHEMBL1538063 & 688534 & 4.8481 & 4.2774 & TRN & \\
\hline CHEMBL1311692 & 688534 & 5.1537 & 4.2826 & TRN & \\
\hline CHEMBL1507724 & 688534 & 4.8721 & 4.0908 & TRN & \\
\hline CHEMBL1509579 & 688534 & 3.3585 & 3.8551 & TRN & \\
\hline CHEMBL1337101 & 688534 & 3.8356 & 3.8285 & TRN & \\
\hline CHEMBL1454002 & 688534 & 3.3585 & 3.7267 & TRN & \\
\hline CHEMBL1539046 & 688534 & 3.3585 & 4.6827 & TRN & \\
\hline CHEMBL1335373 & 688534 & 3.3585 & 3.6185 & TRN & \\
\hline CHEMBL1344848 & 688534 & 3.3585 & 3.8047 & TRN & \\
\hline CHEMBL1383506 & 688534 & 3.3585 & 3.6022 & TST & \\
\hline CHEMBL1589201 & 688534 & 4.3127 & 4.5417 & TST & \\
\hline CHEMBL1452812 & 688534 & 4.7136 & 3.9218 & TST & \\
\hline CHEMBL1387472 & 688534 & 3.3585 & 4.5533 & TST & \\
\hline CHEMBL1537947 & 688534 & 5.1769 & 4.4508 & TST & \\
\hline CHEMBL1493564 & 688534 & 3.8356 & 4.1691 & TST & \\
\hline CHEMBL1461182 & 688534 & 5.0237 & 4.4236 & TST & \\
\hline CHEMBL1339438 & 688534 & 4.7052 & 5.2518 & TST & \\
\hline CHEMBL1610617 & 688534 & 3.3585 & 3.5051 & TST & \\
\hline CHEMBL 3193144 & 688534 & 3.3585 & 3.8061 & TST & \\
\hline CHEMBL1388042 & 688534 & 3.3585 & 3.3159 & TST & \\
\hline CHEMBL1314041 & 688534 & 3.8356 & 3.8886 & TST & \\
\hline CHEMBL1595687 & 688534 & 4.3127 & 4.414 & TST & \\
\hline CHEMBL1436519 & 688534 & 5.1044 & 4.6288 & TST & \\
\hline CHEMBL1573548 & 688534 & 4.4524 & 3.9233 & TST & \\
\hline CHEMBL1454235 & 688354 & 3.3979 & 3.861 & TST & \\
\hline CHEMBL1529705 & 688354 & 4.5929 & 3.35399 & 99999999996 & \\
\hline CHEMBL1540185 & 688354 & 3.3979 & 3.9701 & TRN & \\
\hline CHEMBL1346478 & 688354 & 3.3979 & 4.2984 & TRN & \\
\hline CHEMBL1465101 & 688354 & 3.3979 & 3.4815 & TRN & \\
\hline CHEMBL1545561 & 688354 & 4.6131 & 4.1693 & TRN & \\
\hline CHEMBL1434292 & 688354 & 4.6135 & 4.0869 & TRN & \\
\hline CHEMBL1423567 & 688354 & 5.2314 & 4.8287 & TRN & \\
\hline CHEMBL1578482 & 688354 & 4.8876 & 5.0855 & TRN & \\
\hline CHEMBL1333730 & 688354 & 5.1097 & 4.2966 & TRN & \\
\hline
\end{tabular}


Supplemental Table S2.txt

\begin{tabular}{|c|c|c|c|c|}
\hline r & & & & \\
\hline HEMPI 110926 & & .9893 & 4.6351 & \\
\hline 100 & & & & \\
\hline JEMBL 32 & & & 85 & \\
\hline AEMBL3213140 & 354 & & & \\
\hline HEMBL1608078 & 38354 & 352 & 0213 & \\
\hline HEMBL13 & 3354 & & 053 & \\
\hline IFMBI 14 & & & & \\
\hline AEMBL1530670 & 354 & & 5744 & \\
\hline HEMBL16 & 354 & 789 & 3585 & \\
\hline HEMBL145 & 354 & 4.98 & 615 & \\
\hline IEMBL15 & & 979 & 393 & \\
\hline AEMBL1: & & & & \\
\hline HEMBL 32 & 54 & 79 & 4291 & \\
\hline IEMBL 31 & & 82 & 3678 & \\
\hline AEMBL15 & 4 & 18 & 3346 & \\
\hline AEMBL13 & & & 269 & \\
\hline HEMBL31 & & & 375 & \\
\hline AEMBL15 & & 88 & 3313 & \\
\hline IEMBL13 & & & & \\
\hline AEMBLIS & & & 998 & NIN \\
\hline AEMBL13 & & & 539 & 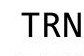 \\
\hline HEMBL15 & & & 127 & \\
\hline AEMBL13 & & & 3682 & \\
\hline AEMBL32 & & & & 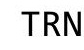 \\
\hline HEMBL1: & & & 028 & $\cdots$ \\
\hline HEMBL1 & & & 229 & RN \\
\hline AFMB 17 & 54 & & 272 & \\
\hline HEMBL15 & & & .755 & I KIV \\
\hline HEMBL197 & & & 067 & 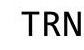 \\
\hline HEMBL31 & & & 626 & RN \\
\hline HEMBL1 & & & 731 & RN \\
\hline HEMBL: & & 94 & 723 & $\mathrm{RN}$ \\
\hline HEMBL 27 & & & 404 & is \\
\hline HEMBL1586425 & & & 397 & TRN \\
\hline HEMBL15 & 4 & & 258 & RN \\
\hline HᄃMPI 1 & & 79 & & RN \\
\hline JEMBL14 & & & 062 & TRN \\
\hline HEMBL13 & 88354 & & 5594 & TRN \\
\hline AEMBL1S & 4 & & 324 & $\Gamma \mathrm{RN}$ \\
\hline HEMBL1 14 & 54 & & 508 & \\
\hline CHEMBL14 & & & 884 & I NIV \\
\hline HEMBL13 & & & 5886 & $\Gamma \mathrm{RN}$ \\
\hline AEMBL14 & 38354 & 979 & 0992 & TRN \\
\hline HEMBL15 & & & 408 & 3 \\
\hline HEMBL13 & & & 6691 & \\
\hline HEMBL15 & & & .4658 & \\
\hline HEMBL1428121 & 688354 & 5.434 & 4.9041 & \\
\hline
\end{tabular}

Page 583 
Supplemental Table S2.txt

\begin{tabular}{|c|c|c|c|c|c|}
\hline CHEMBL1599499 & 688354 & 5.1102 & 4.2276 & TRN & \\
\hline CHEMBL1448161 & 688354 & 4.7798 & 4.444 & TRN & \\
\hline CHEMBL1583998 & 688354 & 4.399 & 4.0142 & TRN & \\
\hline CHEMBL1589540 & 688354 & 5.1264 & 5.0975 & TRN & \\
\hline CHEMBL1469448 & 688354 & 4.5538 & 4.1766 & TRN & \\
\hline CHEMBL338474 & 688354 & 4.7296 & 4.4295 & TST & \\
\hline CHEMBL1374155 & 688354 & 3.3979 & 4.0809 & TRN & \\
\hline CHEMBL1312523 & 688354 & 3.3979 & 4.0855 & TRN & \\
\hline CHEMBL1487991 & 688354 & 4.435 & 4.1492 & TRN & \\
\hline CHEMBL3190347 & 688354 & 4.4439 & 4.6124 & TRN & \\
\hline CHEMBL1303334 & 688354 & 5.0065 & 5.1497 & TRN & \\
\hline CHEMBL1335315 & 688354 & 3.3979 & 3.9957 & TST & \\
\hline CHEMBL1540808 & 688354 & 4.8081 & 4.173 & TRN & \\
\hline CHEMBL3197135 & 688354 & 4.5691 & 4.1073 & TRN & \\
\hline CHEMBL1309127 & 688354 & 5.2701 & 4.825 & TRN & \\
\hline CHEMBL1336386 & 688354 & 3.3979 & 3.9464 & TRN & \\
\hline CHEMBL3192625 & 688354 & 4.8763 & 4.36 & TST & \\
\hline CHEMBL1520643 & 688354 & 4.5799 & 4.1679 & TRN & \\
\hline CHEMBL3189814 & 688354 & 3.3979 & 4.0339 & TRN & \\
\hline CHEMBL1341609 & 688354 & 3.3979 & 3.5568 & TRN & \\
\hline CHEMBL1603871 & 688354 & 5.2947 & 4.536000 & 30000000005 & TRN \\
\hline CHEMBL1972216 & 688354 & 4.9928 & 5.2022 & TRN & \\
\hline CHEMBL571380 & 688354 & 3.3979 & 4.3993 & TRN & \\
\hline CHEMBL1549587 & 688354 & 4.5986 & 4.3608 & TRN & \\
\hline CHEMBL1404578 & 688354 & 5.2315 & 4.8528 & TRN & \\
\hline CHEMBL1374750 & 688354 & 3.3979 & 3.775 & TRN & \\
\hline CHEMBL1604367 & 688354 & 4.87 & 5.1085 & TRN & \\
\hline CHEMBL1592294 & 688354 & 3.3979 & 4.6497 & TRN & \\
\hline CHEMBL1301939 & 688354 & 4.4044 & 3.9622 & TRN & \\
\hline CHEMBL1514866 & 688354 & 4.6989 & 4.494 & TRN & \\
\hline CHEMBL1361034 & 688354 & 4.8852 & 4.735 & TRN & \\
\hline CHEMBL1598569 & 688354 & 4.4912 & 5.0896 & TRN & \\
\hline CHEMBL1416497 & 688354 & 4.8824 & 4.1596 & TRN & \\
\hline CHEMBL1457787 & 688354 & 3.3979 & 4.2802 & TRN & \\
\hline CHEMBL3199403 & 688354 & 4.968 & 4.6069 & TRN & \\
\hline CHEMBL3196324 & 688354 & 5.4579 & 5.6702 & TRN & \\
\hline CHEMBL1491932 & 688354 & 4.7808 & 5.0269 & TRN & \\
\hline CHEMBL1342053 & 688354 & 5.6535 & 5.4672 & TRN & \\
\hline CHEMBL1390716 & 688354 & 4.8285 & 4.3664 & TST & \\
\hline CHEMBL1988579 & 688354 & 3.3979 & 3.3685 & TRN & \\
\hline CHEMBL1303426 & 688354 & 5.6326 & 5.4838 & TRN & \\
\hline CHEMBL 2094484 & 688354 & 5.34399 & 999999999 & 5.5052 & TRN \\
\hline CHEMBL1537991 & 688354 & 4.8667 & 4.4954 & TRN & \\
\hline CHEMBL1485503 & 688354 & 3.3979 & 3.7386 & TST & \\
\hline CHEMBL1309573 & 688354 & 5.4019 & 4.9143 & TRN & \\
\hline CHEMBL1549272 & 688354 & 4.8206 & 4.1597 & TRN & \\
\hline CHEMBL1402558 & 688354 & 4.8103 & 4.5038 & TRN & \\
\hline CHEMBL1312377 & 688354 & 5.0593 & 4.1429 & TRN & \\
\hline
\end{tabular}




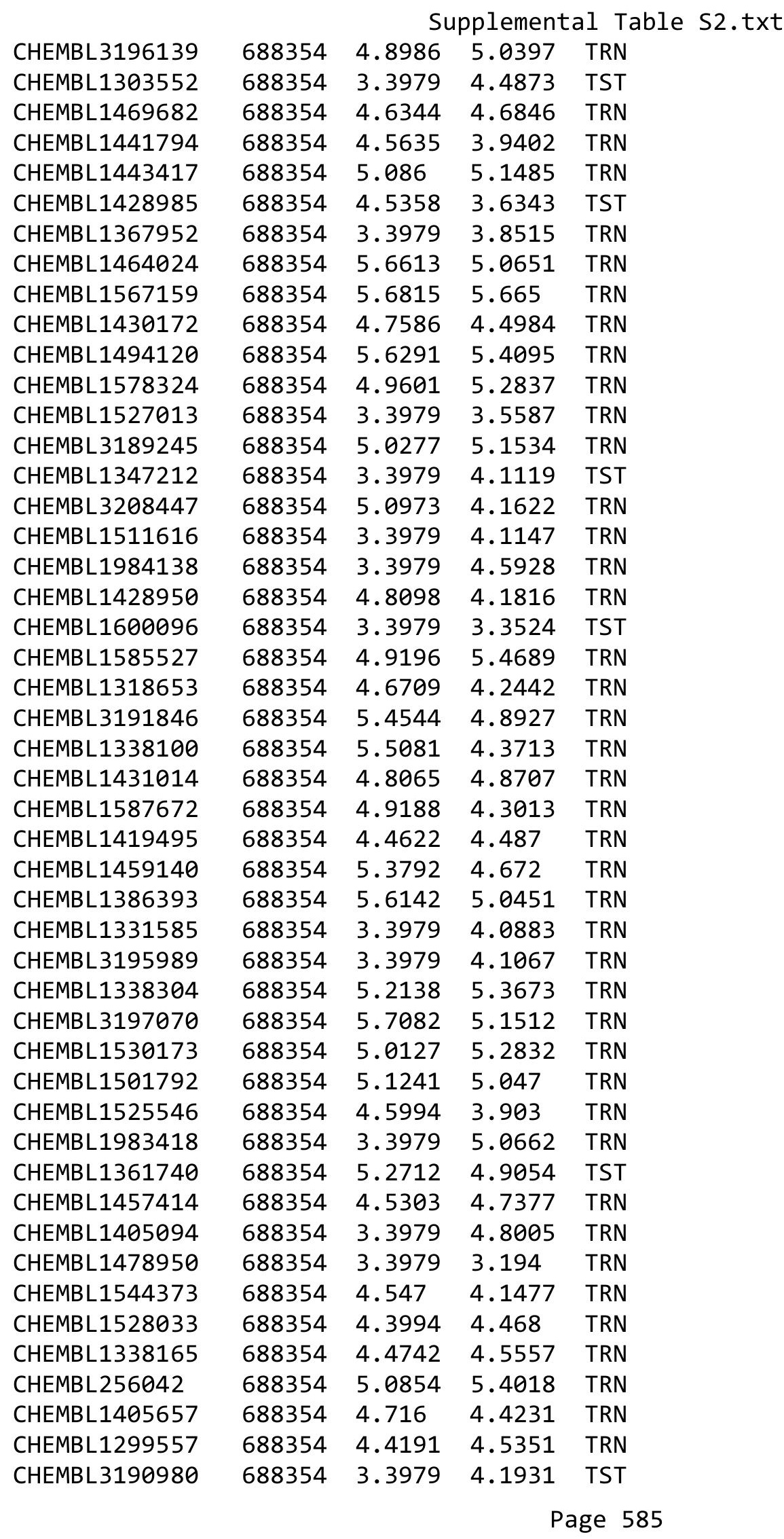


Supplemental Table S2.txt

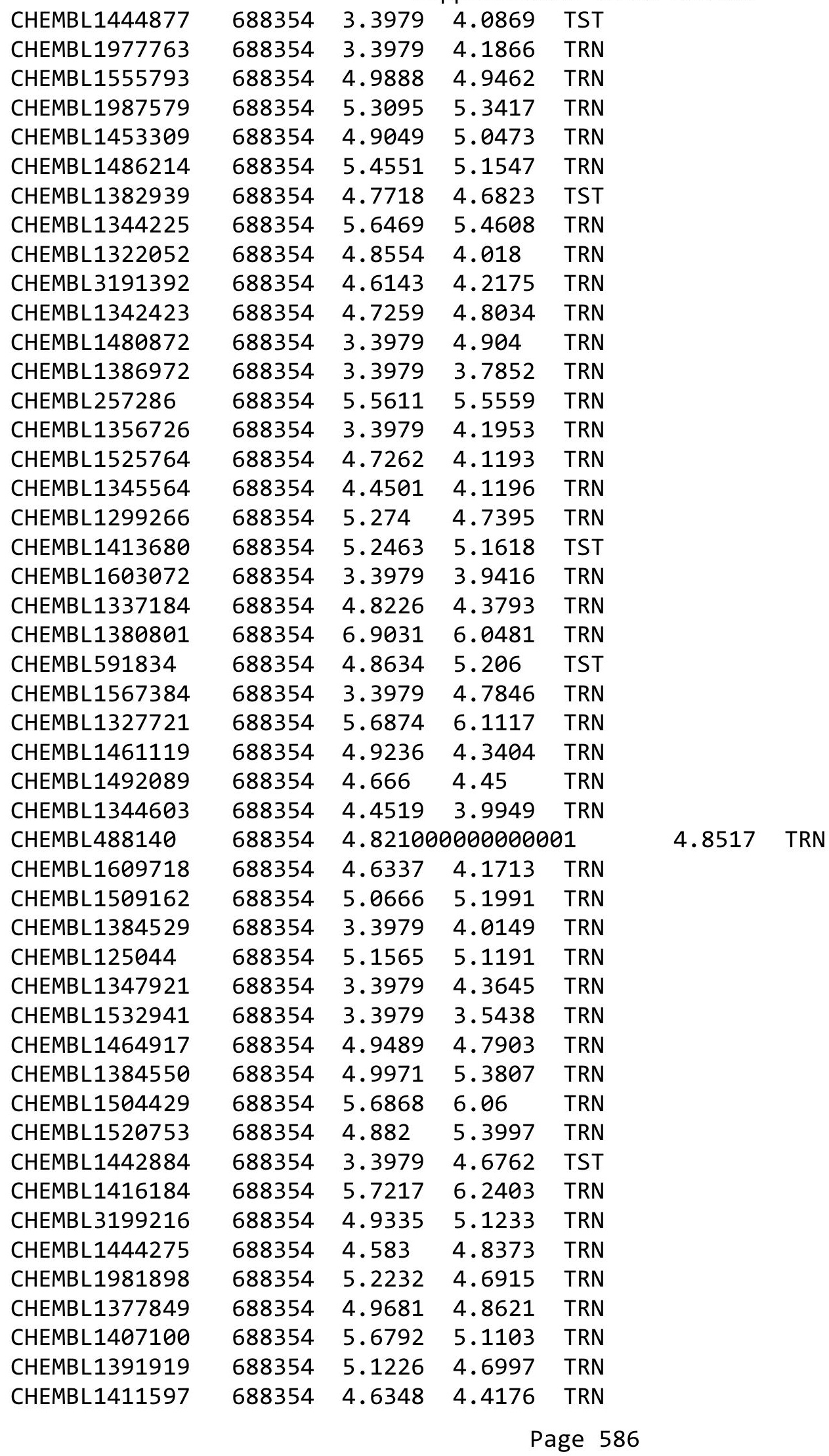


Supplemental Table S2.txt

\begin{tabular}{|c|c|c|c|c|}
\hline 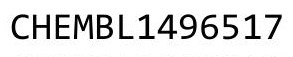 & & & & \\
\hline HEMBL1566610 & 88354 & 218 & 4743 & 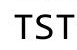 \\
\hline HEMBL1324082 & 54 & 979 & 4957 & \\
\hline 8797 & & & & \\
\hline AEMBL1401122 & & & & \\
\hline AEMBL1522007 & 88354 & .9031 & 2383 & \\
\hline HEMBL1406262 & 88354 & 3979 & .3629 & \\
\hline HEMBL1505508 & & 79 & & \\
\hline AEMBL3190971 & & 979 & 5907 & \\
\hline AEMBL1474191 & & & & \\
\hline HEMBL1485784 & 88354 & 139 & .7402 & \\
\hline HEMBL1445650 & 54 & .4109 & 5.2039 & \\
\hline HEMBL1495849 & 4 & 7744 & 4.8053 & \\
\hline HEMBL1577988 & & 857 & & \\
\hline HEMBL1597454 & & & & \\
\hline HEMBL1334719 & 54 & 3979 & 2337 & \\
\hline AEMBL1427431 & & & & \\
\hline HEMBL319 & & 979 & 83 & \\
\hline 385 & & 44 & & \\
\hline AEMBL13 & & 31 & & \\
\hline HEMBL586135 & & 513 & 3782 & \\
\hline AEMBL1613515 & & & & \\
\hline HEMBL1572001 & & 12 & & \\
\hline 553 & & 44 & & \\
\hline 205 & & 79 & & \\
\hline L3193181 & & & & 1 \\
\hline AEMBL1546607 & & 8 & & IV \\
\hline HEMBL3195226 & & & & $\mathrm{R} N$ \\
\hline HEN & & & & RN \\
\hline 049 & & 94 & 08 & RN \\
\hline AEMBL528694 & & & & RN \\
\hline HEMBL 2005961 & & 11 & & RN \\
\hline AEMBL13: & & & & RN \\
\hline 78 & & 79 & & RN \\
\hline 45 & & 45 & 85 & $\mathrm{RN}$ \\
\hline AEMBL1498886 & & 771 & 3735 & IRN \\
\hline AEMBL1512236 & & & 34 & $2 \mathrm{~N}$ \\
\hline & & & & RN \\
\hline 2 & & & & RI \\
\hline HEMBL14 & & & 548 & $\mathrm{RN}$ \\
\hline AEMBL1378818 & & 979 & 4.8944 & $\mathrm{RN}$ \\
\hline HEMBL1348954 & & 15 & 7272 & ST \\
\hline 021 & & & & \\
\hline HEMBL14 & & & .2715 & \\
\hline HEMBL1898721 & & 979 & 8279 & $\mathrm{RN}$ \\
\hline IEMBL40091 & & 699 & 2435 & \\
\hline HEMBL320778 & & 979 & & \\
\hline CHEN & 688 & & 5.202 & \\
\hline
\end{tabular}


Supplemental Table S2.txt

\begin{tabular}{|c|c|c|c|c|}
\hline 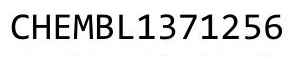 & & 3979 & 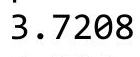 & \\
\hline HEMBL1968402 & 88354 & 3979 & 204 & \\
\hline HEMBL1421770 & 54 & 031 & $\partial 163$ & \\
\hline 221 & & & 5839 & \\
\hline AEMBL1316828 & & & 337 & \\
\hline AEMBL1360149 & 88354 & 439 & 4439 & \\
\hline HEMBL1377737 & 88354 & .5348 & .4151 & \\
\hline HEMBL1605686 & & 79 & 4072 & \\
\hline HEMBL137 & & .2827 & 9007 & \\
\hline AEMBL1514691 & & 281 & 4.1939 & \\
\hline HEMBL 364893 & 88354 & 4538 & 4.7094 & \\
\hline HEMBL1467556 & 54 & .4509 & 4.6717 & \\
\hline HEMBL1550 & 4 & 4818 & 6137 & \\
\hline HEMBL14 & & 241 & 45 & \\
\hline HEMBL13 & & 16 & & \\
\hline HEMBL1505604 & 54 & $\partial 243$ & 7628 & \\
\hline AEMBL1346661 & & & & \\
\hline HEMBL138 & 4 & 979 & 1136 & \\
\hline L14 & & & 299 & \\
\hline AEMBL13 & & & 864 & \\
\hline HEMBL1367827 & & 51 & $\partial 675$ & \\
\hline AEMBL1543154 & & & & \\
\hline HEMBL160 & 4 & 56 & 104 & \\
\hline L15 & & & 31 & \\
\hline 46 & & & & \\
\hline L146 & & & 7874 & \\
\hline HEMBL144 & & & & RN \\
\hline HEMBL 14 & & & 889 & \\
\hline HEMBL15 & & & 28 & RN \\
\hline AFMB 15 & & 41 & 163 & RN \\
\hline AEMBL1592181 & & & 69 & RN \\
\hline HEMBL1321754 & & & 63 & RN \\
\hline AEMBL13 & & & 78 & RN \\
\hline$A E N$ & & & 01 & RN \\
\hline L14 & & $\partial 1$ & 485 & $\mathrm{RN}$ \\
\hline AEMBL1534477 & & & & $2 \mathrm{~N}$ \\
\hline HEMBL1498428 & & & & $2 \mathrm{~N}$ \\
\hline 4 & & & & RN \\
\hline 12 & & & 286 & RIV \\
\hline HEMBL152 & & & 5353 & ST \\
\hline AEMBL3210489 & & 3979 & 1441 & $\mathrm{RN}$ \\
\hline HEMBL1601762 & & 979 & 05 & \\
\hline & & & & \\
\hline HEMBL3197126 & & & 5264 & RN \\
\hline HEMBL1488802 & & & 3041 & $\mathrm{RN}$ \\
\hline AEMBL1589900 & & & 7179 & \\
\hline HEMBL1543 & & & & \\
\hline 171902 & & & & \\
\hline
\end{tabular}

Page 588 
Supplemental Table S2.txt

\begin{tabular}{|c|c|c|c|c|}
\hline כ & & & & \\
\hline HEMBL1394750 & & .3979 & 3.3245 & \\
\hline 58 & & & & \\
\hline AEMBL1 & & 79 & & \\
\hline AEMBL1380035 & 354 & 765 & & \\
\hline HEMBL1504620 & 38354 & 3979 & 5689 & \\
\hline רס1 1 & 54 & & & \\
\hline AEMBL133 & & & & \\
\hline AEMBL3192432 & & & 2822 & \\
\hline HEMBL1421427 & 354 & 14 & 286 & \\
\hline HEMBL1975257 & 354 & & & \\
\hline IEMBL134 & & & & \\
\hline IEMBL1 & & & & \\
\hline JEMBL157 & 354 & & 93 & \\
\hline HEMBL156 & & & & \\
\hline IEMBL421 & 54 & & 47 & \\
\hline HEMBL136 & & & 42 & \\
\hline HEMBL137 & & & & \\
\hline HEMBL138 & 54 & & & \\
\hline HEMBL 321 & & & & \\
\hline HEMBLI & 4 & & & \\
\hline HEMBL1 & & & & \\
\hline HEMBL1 & & & & \\
\hline HEMBL1481281 & & & & \\
\hline IEMBL14€ & & & & $\cdots$ \\
\hline HEMBL1 & & & & \\
\hline HEMBL1 & & & 77 & \\
\hline HFMBI 1 & 4 & & & RN \\
\hline HEMBL1 & & & & TRIV \\
\hline HEMBL504977 & & & & ISI \\
\hline HEMBL1587 & 4 & & & ST \\
\hline HEMBL1 & & & & Riv \\
\hline HEMBL1 & & & 57 & ST \\
\hline HEMBL1370701 & & & & $\mathrm{S}$ \\
\hline HEMBL1416089 & 54 & & & TST \\
\hline HEMBL1 & 4 & & & TST \\
\hline HFMRI - & & & & ST \\
\hline & & & & TST \\
\hline HEMBL1547736 & 88354 & & & TST \\
\hline IEMBL1 & 88354 & & 599 & TST \\
\hline HEMBL1588194 & 88354 & & & \\
\hline CHEMBL2131333 & & & & ST \\
\hline HEMBL1566084 & 38354 & & 3005 & TST \\
\hline AEMBL1528883 & 38354 & & 3827 & rS \\
\hline EMBL1 & & & & TS \\
\hline CHEMBL3190198 & & & & \\
\hline CHEMBL3213220 & & & .5804 & \\
\hline THEMBL1456428 & 688354 & 4.4053 & 4.3432 & (1) \\
\hline
\end{tabular}

Page 589 
Supplemental Table S2.txt

\begin{tabular}{|c|c|c|c|c|c|}
\hline CHEMBL 3194040 & 688354 & 5.0602 & 5.1926 & TST & \\
\hline CHEMBL1966283 & 688354 & 4.5623 & 3.1579 & TST & \\
\hline CHEMBL1605977 & 688354 & 4.6326 & 4.7549 & TST & \\
\hline CHEMBL1407961 & 688354 & 5.2294 & 5.0374 & TST & \\
\hline CHEMBL1487635 & 688354 & 5.435 & 5.7029 & TST & \\
\hline CHEMBL1477291 & 688354 & 4.7713 & 4.7497 & TST & \\
\hline CHEMBL1964873 & 688354 & 5.1848 & 5.0502 & TST & \\
\hline CHEMBL1438779 & 688354 & \multicolumn{2}{|c|}{4.946000000000001} & 4.6009 & TST \\
\hline CHEMBL1324011 & 688354 & 5.0069 & 5.062 & TST & \\
\hline CHEMBL1348215 & 688354 & 4.5269 & 4.0792 & TST & \\
\hline CHEMBL1613520 & 688354 & 4.5534 & 4.3946 & TST & \\
\hline CHEMBL1369513 & 688354 & 3.3979 & 3.639 & TST & \\
\hline CHEMBL1518619 & 688354 & 4.6397 & 4.5144 & TST & \\
\hline CHEMBL1504077 & 688354 & 4.9277 & 4.6923 & TST & \\
\hline CHEMBL1375248 & 688354 & 4.8875 & 5.2108 & TST & \\
\hline CHEMBL1318350 & 688354 & 3.3979 & 4.7439 & TST & \\
\hline CHEMBL1368499 & 688354 & 4.4721 & 3.6718 & TST & \\
\hline CHEMBL1373553 & 688354 & 3.3979 & 4.1939 & TST & \\
\hline CHEMBL1561907 & 688354 & 4.748 & 4.4088 & TST & \\
\hline CHEMBL1358014 & 688354 & 3.3979 & 4.7166 & TST & \\
\hline CHEMBL1522230 & 688354 & 4.5639 & 4.5446 & TST & \\
\hline CHEMBL1597563 & 688354 & 4.8617 & 5.0715 & TST & \\
\hline CHEMBL1387520 & 688354 & 4.5057 & 4.2874 & TST & \\
\hline CHEMBL1375373 & 688354 & 4.4528 & 4.721999 & 99999999995 & TST \\
\hline CHEMBL1311252 & 688354 & 3.3979 & 4.3762 & TST & \\
\hline CHEMBL 3145368 & 688354 & 3.3979 & 3.9386 & TST & \\
\hline CHEMBL1327815 & 688354 & 4.6211 & 4.5601 & TST & \\
\hline CHEMBL3191999 & 688354 & 5.1029 & 5.0696 & TST & \\
\hline CHEMBL1602056 & 688354 & 4.4044 & 3.9202 & TST & \\
\hline CHEMBL1550499 & 688354 & 3.3979 & 4.5725 & TST & \\
\hline CHEMBL 261693 & 688354 & 5.5387 & 5.3196 & TST & \\
\hline CHEMBL1321817 & 688354 & 3.3979 & 3.5788 & TST & \\
\hline CHEMBL1567702 & 688354 & 5.4048 & 4.2295 & TST & \\
\hline CHEMBL1327546 & 688354 & 4.5964 & 4.5407 & TST & \\
\hline CHEMBL1523699 & 688354 & 4.9076 & 5.1219 & TST & \\
\hline CHEMBL1256656 & 688701 & 5.233 & 5.2155 & TRN & \\
\hline CHEMBL319244 & 688701 & 6.183 & 5.3671 & TRN & \\
\hline CHEMBL 243954 & 688701 & 4.633 & 4.4903 & TRN & \\
\hline CHEMBL568150 & 688701 & 4.833 & 5.604 & TRN & \\
\hline CHEMBL1522486 & 688701 & 7.3325 & 6.0472 & TRN & \\
\hline CHEMBL1613220 & 688701 & 4.883 & 5.0798 & TRN & \\
\hline CHEMBL1256698 & 688701 & 4.633 & 4.5554 & TRN & \\
\hline CHEMBL1407012 & 688701 & 4.583 & 4.6546 & TRN & \\
\hline CHEMBL1355762 & 688701 & 4.883 & 5.5413 & TRN & \\
\hline CHEMBL544115 & 688701 & 4.633 & 4.5745 & TRN & \\
\hline CHEMBL 2373602 & 688701 & 4.633 & 4.6051 & TRN & \\
\hline CHEMBL542493 & 688701 & 5.13299 & 999999999 & 4.8384 & $\mathrm{NI}$ \\
\hline CHEMBL1256914 & 688701 & 6.9329 & 5.5419 & TRN & \\
\hline
\end{tabular}




\begin{tabular}{|c|c|c|c|c|c|c|}
\hline \multirow[b]{2}{*}{ CHEMBL1528565 } & & \multicolumn{5}{|c|}{ Supplemental Table S2.txt } \\
\hline & 688701 & 5.233 & 5.1435 & TRN & & \\
\hline CHEMBL425294 & 688701 & \multicolumn{3}{|c|}{5.332999999999999} & 5.2202 & TRN \\
\hline CHEMBL293749 & 688701 & \multicolumn{3}{|c|}{4.7330000000000005} & 4.7935 & TRN \\
\hline CHEMBL 379787 & 688701 & 4.633 & 4.4334 & TRN & & \\
\hline CHEMBL429095 & 688701 & 5.433 & 5.4716 & TRN & & \\
\hline CHEMBL1324022 & 688701 & 4.583 & 4.8877 & TRN & & \\
\hline CHEMBL448741 & 688701 & 4.633 & 5.3347 & TRN & & \\
\hline CHEMBL164 & 688701 & 4.783 & 5.4579 & TST & & \\
\hline CHEMBL1595524 & 688701 & 4.883 & 5.4505 & TRN & & \\
\hline CHEMBL192566 & 688701 & 8.4318 & 7.961 & TRN & & \\
\hline CHEMBL1590980 & 688701 & 5.983 & 6.0845 & TRN & & \\
\hline CHEMBL1320902 & 688701 & 5.083 & 5.1492 & TRN & & \\
\hline CHEMBL48449 & 688701 & \multicolumn{3}{|c|}{5.332999999999999} & 5.5362 & TST \\
\hline CHEMBL53898 & 688701 & \multicolumn{3}{|c|}{4.7330000000000005} & 4.8009 & TRN \\
\hline CHEMBL1440857 & 688701 & \multicolumn{3}{|c|}{6.632999999999999} & 6.8614 & TRN \\
\hline CHEMBL1255867 & 688701 & 4.783 & 4.7329 & TRN & & \\
\hline CHEMBL165 & 688701 & 5.433 & 5.5929 & TRN & & \\
\hline CHEMBL303579 & 688701 & \multicolumn{3}{|c|}{5.2829999999999995} & 4.8736 & TRN \\
\hline CHEMBL98350 & 688701 & \multicolumn{3}{|c|}{6.382999999999999} & 5.3594 & TRN \\
\hline CHEMBL1554717 & 688701 & 4.933 & 4.9995 & TRN & & \\
\hline CHEMBL 78150 & 688701 & \multicolumn{3}{|c|}{5.632999999999999} & 5.4353 & TRN \\
\hline CHEMBL1600780 & 688701 & 4.883 & 5.6082 & TRN & & \\
\hline CHEMBL1256749 & 688701 & \multicolumn{3}{|c|}{4.7330000000000005} & 5.1429 & TRN \\
\hline CHEMBL1256686 & 688701 & \multicolumn{3}{|c|}{5.832999999999999} & 4.9719 & TST \\
\hline CHEMBL540848 & 688701 & 4.633 & 4.7532 & TRN & & \\
\hline CHEMBL539947 & 688701 & 4.583 & 5.2563 & TRN & & \\
\hline CHEMBL365739 & 688701 & 7.2328 & 6.1261 & TRN & & \\
\hline CHEMBL8197 & 688701 & \multicolumn{3}{|c|}{5.7829999999999995} & 5.0348 & TRN \\
\hline CHEMBL21260 & 688701 & 7.8327 & 7.001 & TRN & & \\
\hline CHEMBL 225284 & 688701 & 4.833 & 4.4479 & TRN & & \\
\hline CHEMBL 303958 & 688701 & 4.583 & 5.0326 & TST & & \\
\hline CHEMBL1516388 & 688701 & 4.833 & 5.4061 & TST & & \\
\hline CHEMBL1257041 & 688701 & 4.833 & 4.9382 & TRN & & \\
\hline CHEMBL 845 & 688701 & \multicolumn{3}{|c|}{4.7330000000000005} & 5.1737 & TRN \\
\hline CHEMBL1357488 & 688701 & \multicolumn{3}{|c|}{5.632999999999999} & 5.4613 & TST \\
\hline CHEMBL1255659 & 688701 & \multicolumn{3}{|c|}{5.2829999999999995} & 5.6425 & TST \\
\hline CHEMBL602375 & 688701 & \multicolumn{3}{|c|}{5.332999999999999} & 5.3235 & TST \\
\hline CHEMBL1256659 & 688701 & 4.633 & 4.5543 & TRN & & \\
\hline CHEMBL 2374058 & 688701 & 4.633 & 5.9118 & TRN & & \\
\hline CHEMBL1525723 & 688701 & 4.833 & 4.9186 & TRN & & \\
\hline CHEMBL 1256647 & 688701 & 4.633 & 4.4272 & TRN & & \\
\hline CHEMBL1553428 & 688701 & 4.833 & 4.6302 & TRN & & \\
\hline CHEMBL14563 & 688701 & 4.633 & 4.9266 & TRN & & \\
\hline CHEMBL 250711 & 688701 & \multicolumn{3}{|c|}{5.2829999999999995} & 5.1837 & TRN \\
\hline CHEMBL1408519 & 688701 & 4.833 & 4.5607 & TRN & & \\
\hline CHEMBL399491 & 688701 & \multicolumn{3}{|c|}{5.5329999999999995} & 4.8773 & TST \\
\hline CHEMBL179288 & 688701 & 5.233 & 4.8444 & TRN & & \\
\hline CHEMBL275035 & 688701 & 4.633 & 4.9508 & TRN & & \\
\hline
\end{tabular}




\begin{tabular}{|c|c|c|c|c|c|c|}
\hline \multirow[b]{2}{*}{ CHEMBL1493117 } & \multicolumn{6}{|c|}{ Supplemental Table S2.txt } \\
\hline & 688701 & 4.583 & 5.1975 & TRN & & \\
\hline CHEMBL1208858 & 688701 & 4.783 & 5.3028 & TST & & \\
\hline CHEMBL596380 & 688701 & 5.683 & 6.0449 & TRN & & \\
\hline CHEMBL1516111 & 688701 & 4.683 & 5.0989 & TRN & & \\
\hline CHEMBL1337170 & 688701 & 5.733 & 5.7891 & TST & & \\
\hline CHEMBL1316314 & 688701 & 4.583 & 5.0065 & TRN & & \\
\hline CHEMBL328710 & 688701 & 8.0809 & 6.6157 & TRN & & \\
\hline CHEMBL567175 & 688701 & 4.833 & 4.6244 & TRN & & \\
\hline CHEMBL569864 & 688701 & \multicolumn{3}{|c|}{5.582999999999999} & 4.8788 & TRN \\
\hline CHEMBL1559663 & 688701 & \multicolumn{3}{|c|}{6.132999999999999} & 5.7812 & TST \\
\hline CHEMBL24983 & 688701 & \multicolumn{3}{|c|}{4.7330000000000005} & 5.5513 & TRN \\
\hline CHEMBL596674 & 688701 & 4.883 & 5.0492 & TRN & & \\
\hline CHEMBL1534566 & 688701 & 4.633 & 4.6365 & TRN & & \\
\hline CHEMBL65 & 688701 & 6.983 & 7.3082 & TRN & & \\
\hline CHEMBL1512503 & 688701 & 4.833 & \multicolumn{3}{|c|}{5.4910000000000005} & TRN \\
\hline CHEMBL1256876 & 688701 & 4.633 & 5.0073 & TRN & & \\
\hline CHEMBL1355963 & 688701 & 8.4815 & 5.9078 & TST & & \\
\hline CHEMBL1628215 & 688701 & 5.433 & 5.4373 & TRN & & \\
\hline CHEMBL34704 & 688701 & 4.883 & 5.1361 & TRN & & \\
\hline CHEMBL17331 & 688701 & 8.0809 & 5.5841 & TST & & \\
\hline CHEMBL 2374027 & 688701 & 4.583 & 4.8844 & TRN & & \\
\hline CHEMBL1513654 & 688701 & 5.183 & 4.4836 & TRN & & \\
\hline CHEMBL60718 & 688701 & 4.683 & 4.5763 & TRN & & \\
\hline CHEMBL1554098 & 688701 & 5.433 & 5.9196 & TRN & & \\
\hline CHEMBL1256911 & 688701 & \multicolumn{3}{|c|}{5.5329999999999995} & 4.9589 & TRN \\
\hline CHEMBL29027 & 688701 & \multicolumn{3}{|c|}{5.5329999999999995} & 5.2493 & TRN \\
\hline CHEMBL26320 & 688701 & 4.833 & 4.5096 & TRN & & \\
\hline CHEMBL1322702 & 688701 & 4.583 & 4.7196 & TRN & & \\
\hline CHEMBL402468 & 688701 & 4.583 & 5.8842 & TRN & & \\
\hline CHEMBL188 & 688701 & \multicolumn{3}{|c|}{4.7330000000000005} & 4.8002 & TRN \\
\hline CHEMBL1972346 & 688701 & 4.633 & 5.4896 & TRN & & \\
\hline CHEMBL445102 & 688701 & \multicolumn{3}{|c|}{5.632999999999999} & 4.7787 & TRN \\
\hline CHEMBL1529009 & 688701 & 4.633 & 4.7568 & TRN & & \\
\hline CHEMBL153036 & 688701 & 4.583 & 5.4401 & TST & & \\
\hline CHEMBL58033 & 688701 & 4.833 & 4.4926 & TST & & \\
\hline CHEMBL25236 & 688701 & 4.783 & 4.8018 & TST & & \\
\hline CHEMBL 376505 & 688701 & 5.733 & 5.8658 & TST & & \\
\hline CHEMBL429023 & 688701 & 7.3325 & 6.6063 & TST & & \\
\hline CHEMBL288096 & 688701 & 4.633 & 4.7897 & TST & & \\
\hline CHEMBL601364 & 688701 & 7.2832 & 5.6147 & TST & & \\
\hline CHEMBL288174 & 688701 & \multicolumn{3}{|c|}{4.7330000000000005} & 5.1805 & TST \\
\hline CHEMBL1256661 & 688701 & 4.783 & 5.0818 & TST & & \\
\hline CHEMBL280998 & 688701 & \multicolumn{3}{|c|}{6.0329999999999995} & 5.3233 & TST \\
\hline CHEMBL355496 & 688701 & \multicolumn{3}{|c|}{5.632999999999999} & 5.7855 & TST \\
\hline CHEMBL16687 & 688701 & \multicolumn{3}{|c|}{4.7330000000000005} & 5.3405 & TST \\
\hline CHEMBL 275516 & 688701 & 5.433 & 4.9753 & TST & & \\
\hline CHEMBL3661305 & 1534980 & 5.178 & 6.0789 & TRN & & \\
\hline CHEMBL3661288 & 1534980 & 6.0125 & 5.9875 & TRN & & \\
\hline
\end{tabular}


Supplemental Table S2.txt

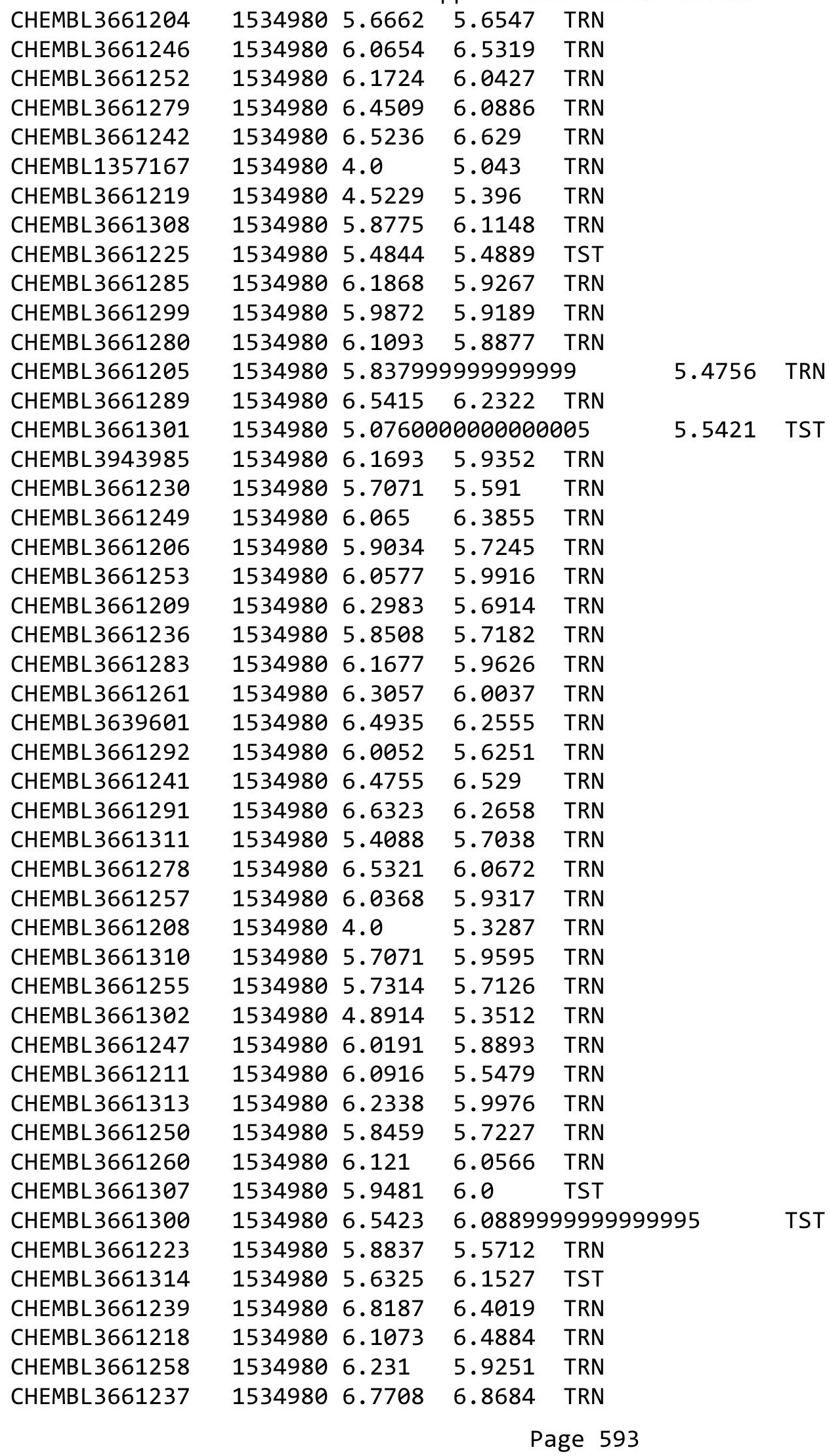


Supplemental Table S2.txt

\begin{tabular}{|c|c|c|c|c|c|}
\hline CHEMBL3665862 & 1534980 & 6.8768 & 6.6093 & TRN & \\
\hline CHEMBL3665857 & 1534980 & 6.5213 & 6.5008 & TRN & \\
\hline CHEMBL3661293 & 1534980 & 5.841 & 5.6828 & TRN & \\
\hline CHEMBL 3661217 & 1534980 & 5.9739 & 5.9785 & TRN & \\
\hline CHEMBL3665858 & 1534980 & 6.7943 & 6.551 & TRN & \\
\hline CHEMBL 3661216 & 1534980 & 6.0521 & 5.6924 & TRN & \\
\hline CHEMBL 3661271 & 1534980 & 5.8908 & 5.7681 & TRN & \\
\hline CHEMBL 3661281 & 1534980 & 5.6708 & 5.8083 & TRN & \\
\hline CHEMBL 3661231 & 1534980 & 6.1025 & 6.547999 & 9999999999 & TRN \\
\hline CHEMBL3661306 & 1534980 & 5.3545 & 5.7312 & TRN & \\
\hline CHEMBL 3661254 & 1534980 & 5.5962 & 5.5186 & TRN & \\
\hline CHEMBL 3661294 & 1534980 & 6.558 & 6.1901 & TRN & \\
\hline CHEMBL3661228 & 1534980 & 6.1642 & 5.7334 & TRN & \\
\hline CHEMBL 3661265 & 1534980 & 6.0611 & 5.966 & TRN & \\
\hline CHEMBL3661233 & 1534980 & 5.8847 & 5.6399 & TRN & \\
\hline CHEMBL 3661284 & 1534980 & 6.2832 & 6.0825 & TRN & \\
\hline CHEMBL3661220 & 1534980 & 6.2367 & 5.6707 & TRN & \\
\hline CHEMBL3665865 & 1534980 & 5.4544 & 6.4601 & TST & \\
\hline CHEMBL 3661295 & 1534980 & 6.1231 & 6.0138 & TRN & \\
\hline CHEMBL3661282 & 1534980 & 5.4959 & 6.1071 & TRN & \\
\hline CHEMBL 3661304 & 1534980 & 5.3754 & 5.7513 & TRN & \\
\hline CHEMBL 3661245 & 1534980 & 5.6202 & 6.2391 & TRN & \\
\hline CHEMBL 3661298 & 1534980 & 6.388 & 6.0615 & TRN & \\
\hline CHEMBL 3661276 & 1534980 & 6.8668 & 6.8745 & TST & \\
\hline CHEMBL 3661207 & 1534980 & 5.7199 & 5.67 & TRN & \\
\hline CHEMBL 3661266 & 1534980 & 5.3893 & 5.5593 & TRN & \\
\hline CHEMBL 3661243 & 1534980 & 5.9112 & 6.3927 & TRN & \\
\hline CHEMBL 3661235 & 1534980 & 5.5894 & 5.5949 & TRN & \\
\hline CHEMBL 3661248 & 1534980 & 6.0292 & 5.7831 & TRN & \\
\hline CHEMBL 3661227 & 1534980 & 6.6101 & 6.6771 & TRN & \\
\hline CHEMBL 3661238 & 1534980 & \multicolumn{3}{|c|}{6.537000000000001} & $10 \mathrm{~N}$ \\
\hline CHEMBL 3661303 & 1534980 & 5.9751 & 5.9015 & TRN & \\
\hline CHEMBL 3661262 & 1534980 & 6.224 & 5.8802 & TRN & \\
\hline CHEMBL 3665863 & 1534980 & 6.7047 & 7.1932 & TRN & \\
\hline CHEMBL 3661240 & 1534980 & 6.5465 & 6.5742 & TRN & \\
\hline CHEMBL3661277 & 1534980 & 7.0173 & 6.8818 & TST & \\
\hline CHEMBL3661269 & 1534980 & 5.8069 & 5.7957 & TST & \\
\hline CHEMBL 3661251 & 1534980 & 6.1244 & 6.1936 & TST & \\
\hline CHEMBL 3661267 & 1534980 & 6.1495 & 5.9899 & TST & \\
\hline CHEMBL3661202 & 1534980 & 5.0243 & 5.0818 & TRN & \\
\hline CHEMBL3661226 & 1534980 & 4.0 & 5.9748 & TRN & \\
\hline CHEMBL3661201 & 1534980 & 5.6676 & 5.4523 & TRN & \\
\hline CHEMBL3661286 & 1534980 & \multicolumn{2}{|c|}{6.537000000000001} & 6.31 & TST \\
\hline CHEMBL 3661312 & 1534980 & 5.5304 & 5.5931 & TST & \\
\hline CHEMBL3661290 & 1534980 & 6.1339 & 5.9851 & TST & \\
\hline CHEMBL 3661212 & 1534980 & 5.8582 & 5.649 & TRN & \\
\hline CHEMBL 3661273 & 1534980 & 6.2334 & 6.126 & TST & \\
\hline CHEMBL 3661272 & 1534980 & 6.2454 & 6.0664 & TST & \\
\hline
\end{tabular}


Supplemental Table S2.txt

\begin{tabular}{|c|c|c|c|c|c|}
\hline CHEMBL 3661268 & 1534980 & 5.7932 & 5.7559 & TST & \\
\hline CHEMBL 3661210 & 1534980 & 6.0545 & 5.7212 & TRN & \\
\hline CHEMBL 3661222 & 1534980 & 5.1553 & 5.6752 & TRN & \\
\hline CHEMBL 3661263 & 1534980 & 6.0739 & 5.7835 & TST & \\
\hline CHEMBL3661309 & 1534980 & 5.6258 & 5.9689 & TST & \\
\hline CHEMBL 3665859 & 1534980 & 7.4401 & 7.2751 & TRN & \\
\hline CHEMBL3661221 & 1534980 & 6.013 & 5.8635 & TRN & \\
\hline CHEMBL 3661264 & 1534980 & 6.2005 & 5.8867 & TST & \\
\hline CHEMBL 3661274 & 1534980 & 6.4712 & 6.2501 & TST & \\
\hline CHEMBL3665861 & 1534980 & 6.8336 & 7.1241 & TST & \\
\hline CHEMBL 3661224 & 1534980 & 5.8539 & 5.5916 & TST & \\
\hline CHEMBL3661315 & 1534980 & 6.1409 & 6.1141 & TST & \\
\hline CHEMBL 3661259 & 1534980 & 5.8948 & 5.6675 & TST & \\
\hline CHEMBL3665864 & 1534980 & 6.5918 & 7.3344 & TST & \\
\hline CHEMBL 3661203 & 1534980 & 6.5935 & 6.6027 & TRN & \\
\hline CHEMBL3661316 & 1534980 & 6.2288 & 6.4824 & TRN & \\
\hline CHEMBL3661287 & 1534980 & 6.2081 & 6.0743 & TST & \\
\hline CHEMBL 3661270 & 1534980 & 5.8514 & 5.754 & TST & \\
\hline CHEMBL3661229 & 1534980 & 6.0781 & 5.7269 & TRN & \\
\hline CHEMBL 3661213 & 1534980 & 5.5095 & 5.6888 & TRN & \\
\hline CHEMBL 3661232 & 1534980 & 6.3932 & 6.0899 & TST & \\
\hline CHEMBL3661275 & 1534980 & 5.4074 & 5.84 & TST & \\
\hline CHEMBL 3661234 & 1534980 & 6.301 & 6.0312 & TRN & \\
\hline CHEMBL3661296 & 1534980 & 6.3571 & 6.0036 & TST & \\
\hline CHEMBL 3661215 & 1534980 & 5.8077 & 5.5899 & TRN & \\
\hline CHEMBL 3665860 & 1534980 & 7.1599 & 6.9635 & TRN & \\
\hline CHEMBL3661256 & 1534980 & 5.9133 & 5.7615 & TST & \\
\hline CHEMBL 3953653 & 1640861 & \multicolumn{2}{|c|}{6.752000000000001} & 6.5794 & TRN \\
\hline CHEMBL 3920296 & 1640861 & 6.8069 & 6.3898 & TRN & \\
\hline CHEMBL 3905575 & 1640861 & 6.5361 & 6.3481 & TRN & \\
\hline CHEMBL 3890555 & 1640861 & 6.0 & 5.6134 & TRN & \\
\hline CHEMBL3913469 & 1640861 & 6.3696 & 6.7317 & TRN & \\
\hline CHEMBL 3965854 & 1640861 & 5.8975 & \multicolumn{2}{|c|}{6.382000000000001} & TRN \\
\hline CHEMBL3981781 & 1640861 & 6.1818 & 6.5148 & TRN & \\
\hline CHEMBL 3960663 & 1640861 & 5.6203 & 5.9564 & TRN & \\
\hline CHEMBL3986739 & 1640861 & 6.3664 & 6.584 & TRN & \\
\hline CHEMBL3982355 & 1640861 & 6.0 & 5.6114 & TRN & \\
\hline CHEMBL3907799 & 1640861 & 6.0 & 6.3905 & TRN & \\
\hline CHEMBL 3623828 & 1640861 & 6.0 & 5.8191 & TRN & \\
\hline CHEMBL 3927868 & 1640861 & 4.6345 & 5.6304 & TST & \\
\hline CHEMBL 3623826 & 1640861 & \multicolumn{3}{|c|}{6.082999999999999} & TRN \\
\hline CHEMBL 3922462 & 1640861 & 6.5591 & 6.3832 & TRN & \\
\hline CHEMBL3890743 & 1640861 & 6.1308 & 6.7654 & TRN & \\
\hline CHEMBL3891800 & 1640861 & 5.1063 & 5.4108 & TRN & \\
\hline CHEMBL 3623824 & 1640861 & 6.0 & 5.9677 & TRN & \\
\hline CHEMBL3968236 & 1640861 & 6.0 & 5.5708 & TRN & \\
\hline CHEMBL 3903405 & 1640861 & 5.4122 & 5.7309 & TST & \\
\hline CHEMBL3896210 & 1640861 & 6.4097 & 5.8628 & TST & \\
\hline
\end{tabular}




\begin{tabular}{|c|c|c|c|c|c|c|}
\hline \multicolumn{7}{|c|}{ Supplemental Table S2.txt } \\
\hline CHEMBL3951086 & 1640861 & 6.0 & 6.8792 & TST & & \\
\hline CHEMBL3930177 & 1640861 & 6.0 & 6.5333 & TRN & & \\
\hline CHEMBL3948899 & 1640861 & 5.6329 & 5.9927 & TST & & \\
\hline CHEMBL3927826 & 1640861 & 6.0 & 6.9616 & TST & & \\
\hline CHEMBL3975309 & 1640861 & 7.9208 & 7.6635 & TRN & & \\
\hline CHEMBL3974910 & 1640861 & 6.0 & 5.54200 & 0000000001 & & TST \\
\hline CHEMBL3980039 & 1640861 & 6.0 & 6.1645 & TST & & \\
\hline CHEMBL3623822 & 1640861 & 6.76200 & 00000000 & 005 & 6.8255 & TRN \\
\hline CHEMBL3897910 & 1640861 & 7.3897 & 6.5351 & TST & & \\
\hline CHEMBL3968860 & 1640861 & 6.3188 & 6.4261 & TRN & & \\
\hline CHEMBL3899870 & 1640861 & 5.4506 & 5.6742 & TRN & & \\
\hline CHEMBL3623823 & 1640861 & 6.3747 & 6.166 & TRN & & \\
\hline CHEMBL3981089 & 1640861 & 6.4393 & 6.1523 & TRN & & \\
\hline CHEMBL3982219 & 1640861 & 6.20200 & 00000000 & 01 & 6.5661 & TST \\
\hline CHEMBL3893382 & 1640861 & 6.0 & 5.8484 & TRN & & \\
\hline CHEMBL3913652 & 1640861 & 5.9246 & 6.3856 & TST & & \\
\hline CHEMBL3942767 & 1640861 & 6.0 & 5.6728 & TRN & & \\
\hline CHEMBL3981240 & 1640861 & 8.6383 & 6.8044 & TST & & \\
\hline CHEMBL3981819 & 1640861 & 6.0 & 5.7973 & TRN & & \\
\hline CHEMBL3976971 & 1640861 & 7.5229 & 7.2599 & TRN & & \\
\hline CHEMBL3623825 & 1640861 & 5.3781 & 5.4814 & TRN & & \\
\hline CHEMBL3906279 & 1640861 & 8.0969 & 7.7792 & TRN & & \\
\hline CHEMBL3911227 & 1640861 & 6.0 & 6.3101 & TRN & & \\
\hline CHEMBL 3893227 & 1640861 & 6.0 & 6.1841 & TRN & & \\
\hline CHEMBL 3967443 & 1640861 & 6.3561 & 6.2907 & TRN & & \\
\hline CHEMBL3900969 & 1640861 & 7.1487 & 6.687 & TRN & & \\
\hline CHEMBL3956360 & 1640861 & 8.301 & 6.3609 & TST & & \\
\hline CHEMBL3928758 & 1640861 & 6.0 & 6.09399 & 9999999999 & & TST \\
\hline CHEMBL3898775 & 1640861 & 6.0 & 5.8176 & TRN & & \\
\hline CHEMBL 3890878 & 1640861 & 5.6492 & 5.67899 & 9999999999 & & TRN \\
\hline CHEMBL3915255 & 1640861 & 7.5086 & 7.2528 & TRN & & \\
\hline CHEMBL3983286 & 1640861 & 5.7503 & 5.6154 & TRN & & \\
\hline CHEMBL3897663 & 1640861 & 5.961 & 6.0958 & TRN & & \\
\hline CHEMBL 3623827 & 1640861 & 5.9401 & 5.9492 & TRN & & \\
\hline CHEMBL3936861 & 1640861 & 5.9119 & 5.9528 & TRN & & \\
\hline CHEMBL3892643 & 1640861 & 5.8605 & 6.03 & TRN & & \\
\hline CHEMBL3623829 & 1640861 & 6.0 & 5.8518 & TRN & & \\
\hline CHEMBL3973147 & 1640861 & 5.6629 & 6.0075 & TRN & & \\
\hline CHEMBL3926525 & 1640861 & 6.0 & 6.2959 & TRN & & \\
\hline CHEMBL3979100 & 1640861 & 5.7207 & 5.849 & TRN & & \\
\hline CHEMBL3974342 & 1640861 & 5.7073 & 5.8432 & TST & & \\
\hline CHEMBL3956843 & 1640861 & 7.1403 & 6.5205 & TST & & \\
\hline CHEMBL3641566 & 1528302 & 7.4413 & 7.659 & TRN & & \\
\hline CHEMBL 3643763 & 1528302 & 7.0878 & 6.9864 & TRN & & \\
\hline CHEMBL 3643751 & 1528302 & 6.0261 & 7.7488 & TST & & \\
\hline CHEMBL 3641660 & 1528302 & 7.5784 & 7.5863 & TRN & & \\
\hline CHEMBL 3641620 & 1528302 & 8.3279 & 8.6351 & TRN & & \\
\hline CHEMBL3641663 & 1528302 & 7.5058 & 7.2463 & TRN & & \\
\hline
\end{tabular}


Supplemental Table S2.txt

\begin{tabular}{|c|c|c|c|c|c|}
\hline CHEMBL 3641675 & 1528302 & 7.5498 & 7.3494 & TRN & \\
\hline CHEMBL3641597 & 1528302 & 7.4559 & 7.4311 & TRN & \\
\hline CHEMBL 3641681 & 1528302 & 7.3298 & 7.2449 & TRN & \\
\hline CHEMBL 3643812 & 1528302 & 7.7235 & 7.966 & TRN & \\
\hline CHEMBL3643733 & 1528302 & 7.5986 & 7.769 & TRN & \\
\hline CHEMBL 3641659 & 1528302 & 7.475 & 7.5197 & TRN & \\
\hline CHEMBL 3641571 & 1528302 & 6.4001 & 6.4838 & TRN & \\
\hline CHEMBL 3641520 & 1528302 & 6.0 & 5.8366 & TRN & \\
\hline CHEMBL 3641595 & 1528302 & 7.7645 & 8.0163 & TRN & \\
\hline CHEMBL3643731 & 1528302 & 8.0 & 7.9908 & TRN & \\
\hline CHEMBL 3643816 & 1528302 & 7.75200 & 000000000 & 7.4012 & TST \\
\hline CHEMBL 3643824 & 1528302 & 8.1427 & \multicolumn{2}{|c|}{7.837999999999999} & TRN \\
\hline CHEMBL 3643771 & 1528302 & 7.5229 & 7.5614 & TRN & \\
\hline CHEMBL 3643735 & 1528302 & 7.2958 & 7.5319 & TRN & \\
\hline CHEMBL 3643807 & 1528302 & 8.3468 & \multicolumn{2}{|c|}{8.158999999999999} & TRN \\
\hline CHEMBL 3641630 & 1528302 & 7.7212 & 7.4917 & TRN & \\
\hline CHEMBL3641534 & 1528302 & 8.1024 & 7.8379 & TRN & \\
\hline CHEMBL 3641564 & 1528302 & 7.2848 & 7.349 & TRN & \\
\hline CHEMBL 3641539 & 1528302 & 7.5214 & 7.3684 & TRN & \\
\hline CHEMBL3641679 & 1528302 & 7.2815 & 7.5239 & TRN & \\
\hline CHEMBL 3641658 & 1528302 & 7.3468 & 7.3438 & TRN & \\
\hline CHEMBL3641629 & 1528302 & 6.7493 & 6.9281 & TRN & \\
\hline CHEMBL 3641538 & 1528302 & 7.5482 & 7.7008 & TRN & \\
\hline CHEMBL 3641614 & 1528302 & 7.6162 & 7.6837 & TRN & \\
\hline CHEMBL 3641507 & 1528302 & 8.1805 & 7.7961 & TRN & \\
\hline CHEMBL 3643753 & 1528302 & 6.9412 & 7.8378 & TST & \\
\hline CHEMBL 3641531 & 1528302 & 7.7122 & 8.1721 & TST & \\
\hline CHEMBL 3641617 & 1528302 & 7.7258 & 7.5287 & TRN & \\
\hline CHEMBL 3641640 & 1528302 & 7.3716 & 7.4402 & TRN & \\
\hline CHEMBL3641559 & 1528302 & 7.0894 & 7.6391 & TRN & \\
\hline CHEMBL 3641585 & 1528302 & 6.965 & 6.9666 & TRN & \\
\hline CHEMBL3643820 & 1528302 & 8.6198 & 7.8487 & TST & \\
\hline CHEMBL 3643808 & 1528302 & 8.2441 & 7.994 & TRN & \\
\hline CHEMBL 3641537 & 1528302 & 6.6653 & 6.8204 & TRN & \\
\hline CHEMBL 3643743 & 1528302 & 7.4377 & 7.7145 & TRN & \\
\hline CHEMBL 3643732 & 1528302 & 7.8356 & 7.8046 & TRN & \\
\hline CHEMBL3641666 & 1528302 & 7.6799 & 7.4566 & TRN & \\
\hline CHEMBL3643752 & 1528302 & 6.8444 & 6.8256 & TRN & \\
\hline CHEMBL 3643813 & 1528302 & 6.8002 & 7.8372 & TST & \\
\hline CHEMBL3641524 & 1528302 & 7.7328 & 7.4781 & TST & \\
\hline CHEMBL3641650 & 1528302 & 7.1118 & 7.1586 & TRN & \\
\hline CHEMBL 3643798 & 1528302 & 7.8097 & 8.1112 & TST & \\
\hline CHEMBL3643788 & 1528302 & 7.4908 & 7.2863 & TRN & \\
\hline CHEMBL 3641608 & 1528302 & 7.2118 & 7.3044 & TRN & \\
\hline CHEMBL3643818 & 1528302 & 7.9872 & 7.7549 & TST & \\
\hline CHEMBL 3643728 & 1528302 & 7.4353 & 7.3185 & TST & \\
\hline CHEMBL 3643781 & 1528302 & 8.3279 & 8.5463 & TRN & \\
\hline CHEMBL 3641556 & 1528302 & 6.6185 & 7.5032 & TST & \\
\hline
\end{tabular}


Supplemental Table S2.txt

\begin{tabular}{|c|c|c|c|c|c|}
\hline CHEMBL3641573 & 1528302 & 6.6426 & 6.7698 & TRN & \\
\hline CHEMBL3641586 & 1528302 & 7.8729 & 7.6845 & TRN & \\
\hline CHEMBL3641687 & 1528302 & 7.5901 & 7.604 & TRN & \\
\hline CHEMBL3643727 & 1528302 & 7.0348 & 7.9168 & TST & \\
\hline CHEMBL3643801 & 1528302 & 7.7721 & 7.9005 & TST & \\
\hline CHEMBL3641622 & 1528302 & 7.4425 & 7.5949 & TRN & \\
\hline CHEMBL3641685 & 1528302 & 7.1979 & 6.9466 & TRN & \\
\hline CHEMBL3641604 & 1528302 & 7.6126 & 7.7167 & TRN & \\
\hline CHEMBL3641607 & 1528302 & 8.5086 & 8.0996 & TRN & \\
\hline CHEMBL3641519 & 1528302 & 7.5157 & 7.4161 & TST & \\
\hline CHEMBL 3643748 & 1528302 & 6.8623 & 8.1341 & TST & \\
\hline CHEMBL3641517 & 1528302 & 7.61799 & 999999999 & 7.6342 & TRN \\
\hline CHEMBL3641674 & 1528302 & 7.4283 & 7.4772 & TRN & \\
\hline CHEMBL 3643757 & 1528302 & 7.4802 & 7.6651 & TRN & \\
\hline CHEMBL3641599 & 1528302 & 7.2916 & 7.3956 & TRN & \\
\hline CHEMBL3641560 & 1528302 & 7.3872 & 7.7358 & TRN & \\
\hline CHEMBL3641511 & 1528302 & 6.0 & 6.9884 & TRN & \\
\hline CHEMBL3641633 & 1528302 & 7.6536 & 7.5605 & TRN & \\
\hline CHEMBL3641546 & 1528302 & 7.3768 & 8.1269 & TST & \\
\hline CHEMBL3641601 & 1528302 & 7.301 & 7.3685 & TRN & \\
\hline CHEMBL3639404 & 1528302 & 8.4202 & 8.1076 & TRN & \\
\hline CHEMBL3641552 & 1528302 & 8.6198 & 8.1795 & TRN & \\
\hline CHEMBL3641557 & 1528302 & 7.2907 & 7.6883 & TRN & \\
\hline CHEMBL 3643765 & 1528302 & 6.7612 & 6.8314 & TRN & \\
\hline CHEMBL 3643742 & 1528302 & 7.2418 & 7.485 & TRN & \\
\hline CHEMBL3641631 & 1528302 & 7.5017 & 7.7654 & TRN & \\
\hline CHEMBL3643793 & 1528302 & 7.7747 & 7.7994 & TRN & \\
\hline CHEMBL3641665 & 1528302 & 7.4401 & 7.6323 & TRN & \\
\hline CHEMBL3641680 & 1528302 & 7.7055 & 8.2267 & TRN & \\
\hline CHEMBL 3641563 & 1528302 & 7.8125 & 7.2613 & TST & \\
\hline CHEMBL3643761 & 1528302 & 7.3958 & 7.1168 & TRN & \\
\hline CHEMBL3643804 & 1528302 & 7.7595 & 7.912000 & 0000000001 & $T$. \\
\hline CHEMBL3641547 & 1528302 & 8.4949 & 8.4789 & TRN & \\
\hline CHEMBL 3643779 & 1528302 & 8.2147 & 8.3798 & TRN & \\
\hline CHEMBL3643789 & 1528302 & 7.7447 & 7.4373 & TRN & \\
\hline CHEMBL3641550 & 1528302 & 7.8861 & 7.6513 & TRN & \\
\hline CHEMBL3643799 & 1528302 & 7.4841 & 7.6581 & TST & \\
\hline CHEMBL3643806 & 1528302 & 7.8962 & 7.7884 & TRN & \\
\hline CHEMBL 3641647 & 1528302 & 7.7399 & 7.6773 & TRN & \\
\hline CHEMBL3639426 & 1528302 & 6.5373 & 7.4586 & TST & \\
\hline CHEMBL3643770 & 1528302 & 6.58799 & 999999999 & 7.9056 & נו \\
\hline CHEMBL3641623 & 1528302 & 8.2366 & 8.1989 & TRN & \\
\hline CHEMBL3643767 & 1528302 & 7.2007 & 7.4806 & TST & \\
\hline CHEMBL3641606 & 1528302 & 7.8013 & 8.0163 & TRN & \\
\hline CHEMBL3643811 & 1528302 & 7.6498 & 8.0597 & TRN & \\
\hline CHEMBL3641551 & 1528302 & 7.3316 & 7.6658 & TRN & \\
\hline CHEMBL 3641682 & 1528302 & 7.6216 & 7.4388 & TRN & \\
\hline CHEMBL3641589 & 1528302 & 8.0809 & 7.6737 & TRN & \\
\hline
\end{tabular}


Supplemental Table S2.txt

\begin{tabular}{|c|c|c|c|c|c|c|}
\hline CHEMBL 3643745 & 1528302 & 8.8239 & 8.5454 & TRN & & \\
\hline CHEMBL 3641565 & 1528302 & 8.2366 & 8.1485 & TST & & \\
\hline CHEMBL 3641558 & 1528302 & 7.6021 & 7.814 & TRN & & \\
\hline CHEMBL 3643791 & 1528302 & 7.9626 & 7.443 & TRN & & \\
\hline CHEMBL3641651 & 1528302 & 7.4855 & 7.296 & TRN & & \\
\hline CHEMBL 3641638 & 1528302 & 7.6421 & 7.3486 & TRN & & \\
\hline CHEMBL 3641505 & 1528302 & 7.8182 & 7.8966 & TRN & & \\
\hline CHEMBL 3641612 & 1528302 & 7.4935 & 7.3994 & TRN & & \\
\hline CHEMBL 3641667 & 1528302 & 7.4498 & 7.4204 & TRN & & \\
\hline CHEMBL3641625 & 1528302 & 7.3152 & 7.3198 & TRN & & \\
\hline CHEMBL 3641523 & 1528302 & 6.9531 & 7.4795 & TST & & \\
\hline CHEMBL 3641654 & 1528302 & 7.5376 & 7.4019 & TRN & & \\
\hline CHEMBL 3641548 & 1528302 & 8.0269 & 8.085 & TRN & & \\
\hline CHEMBL 3641641 & 1528302 & 7.5918 & 7.3204 & TRN & & \\
\hline CHEMBL3641628 & 1528302 & 7.34200 & $00000000 t$ & 305 & 7.5024 & TRN \\
\hline CHEMBL 3641637 & 1528302 & 7.9101 & 8.0409 & TRN & & \\
\hline CHEMBL3643744 & 1528302 & 8.4202 & 8.3708 & TRN & & \\
\hline CHEMBL 3641554 & 1528302 & 7.8097 & 7.5626 & TST & & \\
\hline CHEMBL 3641642 & 1528302 & 8.3872 & 8.5102 & TRN & & \\
\hline CHEMBL3641574 & 1528302 & 7.9547 & 8.3382 & TRN & & \\
\hline CHEMBL3643760 & 1528302 & 7.3936 & 7.3906 & TRN & & \\
\hline CHEMBL 3643777 & 1528302 & 8.0605 & 8.3036 & TRN & & \\
\hline CHEMBL 3643764 & 1528302 & 6.5296 & 6.4649 & TRN & & \\
\hline CHEMBL 3643785 & 1528302 & 7.3478 & 7.6758 & TRN & & \\
\hline CHEMBL 3641509 & 1528302 & 7.6421 & 7.7895 & TRN & & \\
\hline CHEMBL 3643754 & 1528302 & 7.0223 & 8.0591 & TST & & \\
\hline CHEMBL3641526 & 1528302 & 8.0969 & 7.785 & TST & & \\
\hline CHEMBL 3643805 & 1528302 & 7.466 & 7.6411 & TRN & & \\
\hline CHEMBL3641527 & 1528302 & 7.3019 & 7.3412 & TRN & & \\
\hline CHEMBL 3641545 & 1528302 & 8.0555 & 7.8251 & TRN & & \\
\hline CHEMBL 3641669 & 1528302 & 7.3242 & 7.6097 & TRN & & \\
\hline CHEMBL 3641503 & 1528302 & 7.8633 & 7.9868 & TST & & \\
\hline CHEMBL 3643738 & 1528302 & 7.9957 & 8.1039 & TRN & & \\
\hline CHEMBL 3643822 & 1528302 & 7.4908 & 7.4287 & TRN & & \\
\hline CHEMBL 3641678 & 1528302 & 7.4698 & 7.7791 & TRN & & \\
\hline CHEMBL 3643758 & 1528302 & 6.8557 & 6.9906 & TRN & & \\
\hline CHEMBL3641673 & 1528302 & 7.2373 & 7.3292 & TRN & & \\
\hline CHEMBL 3641583 & 1528302 & 7.3251 & 7.528 & TRN & & \\
\hline CHEMBL 3643810 & 1528302 & 7.7305 & 7.7483 & TRN & & \\
\hline CHEMBL 3641618 & 1528302 & 7.1113 & 6.9934 & TRN & & \\
\hline CHEMBL3643762 & 1528302 & 7.3872 & 7.527 & TRN & & \\
\hline CHEMBL 3643815 & 1528302 & 7.3625 & 7.4669 & TRN & & \\
\hline CHEMBL 3641590 & 1528302 & 7.8268 & 7.6751 & TRN & & \\
\hline CHEMBL3641516 & 1528302 & 8.0 & 7.8601 & TRN & & \\
\hline CHEMBL 3641672 & 1528302 & 7.5482 & 7.345 & TRN & & \\
\hline CHEMBL 3641562 & 1528302 & 7.3478 & 7.3031 & TRN & & \\
\hline CHEMBL3641661 & 1528302 & 7.3279 & 7.3968 & TRN & & \\
\hline CHEMBL3643780 & 1528302 & 7.7747 & 7.8923 & TRN & & \\
\hline
\end{tabular}

Page 599 
Supplemental Table S2.txt

\begin{tabular}{|c|c|c|c|c|c|}
\hline CHEMBL3641653 & 1528302 & 7.5214 & 7.6572 & TRN & \\
\hline CHEMBL3643784 & 1528302 & 7.71 & 7.9145 & TRN & \\
\hline CHEMBL3641664 & 1528302 & 7.4828 & 7.2152 & TRN & \\
\hline CHEMBL3643768 & 1528302 & 6.0353 & 7.1039 & TST & \\
\hline CHEMBL3641587 & 1528302 & 8.1024 & 7.8638 & TRN & \\
\hline CHEMBL3643755 & 1528302 & 6.2884 & 6.6104 & TRN & \\
\hline CHEMBL3641600 & 1528302 & 7.8928 & 8.0578 & TRN & \\
\hline CHEMBL3641575 & 1528302 & 6.3477 & 6.6427 & TRN & \\
\hline CHEMBL3643756 & 1528302 & 7.209 & 7.4384 & TRN & \\
\hline CHEMBL3643797 & 1528302 & 7.4547 & 7.8027 & TST & \\
\hline CHEMBL3641603 & 1528302 & 6.8204 & 7.0043 & TRN & \\
\hline CHEMBL3641541 & 1528302 & 7.9281 & 8.0369 & TRN & \\
\hline CHEMBL3895662 & 1528302 & 7.3478 & 7.4224 & TST & \\
\hline CHEMBL 3641580 & 1528302 & 6.433 & 6.5786 & TRN & \\
\hline CHEMBL3641648 & 1528302 & 7.3635 & 7.5694 & TRN & \\
\hline CHEMBL3641602 & 1528302 & 8.1739 & 8.2552 & TRN & \\
\hline CHEMBL3641616 & 1528302 & 7.5186 & 7.5733 & TRN & \\
\hline CHEMBL3641561 & 1528302 & 7.6716 & 7.6359 & TRN & \\
\hline CHEMBL3641555 & 1528302 & 5.7618 & 7.534 & TST & \\
\hline CHEMBL3641626 & 1528302 & 7.5436 & 7.4195 & TRN & \\
\hline CHEMBL3643823 & 1528302 & 7.4634 & 7.816 & TRN & \\
\hline CHEMBL3643786 & 1528302 & 7.7799 & 7.50899 & 99999999995 & TRN \\
\hline CHEMBL3641510 & 1528302 & 7.2168 & 7.0985 & TRN & \\
\hline CHEMBL 3643776 & 1528302 & 7.0097 & 7.1273 & TRN & \\
\hline CHEMBL3641515 & 1528302 & 8.0655 & 7.9907 & TRN & \\
\hline CHEMBL3643746 & 1528302 & 7.8794 & 7.7061 & TRN & \\
\hline CHEMBL3641668 & 1528302 & 6.7131 & 6.9724 & TRN & \\
\hline CHEMBL3641639 & 1528302 & 7.7645 & 7.5969 & TRN & \\
\hline CHEMBL3643795 & 1528302 & 8.8539 & 8.5392 & TRN & \\
\hline CHEMBL3643787 & 1528302 & 7.9355 & 7.6863 & TRN & \\
\hline CHEMBL3641627 & 1528302 & 7.5391 & 7.8899 & TRN & \\
\hline CHEMBL3641611 & 1528302 & 7.8069 & 7.9076 & TRN & \\
\hline CHEMBL3641676 & 1528302 & 7.3675 & 7.4452 & TRN & \\
\hline CHEMBL 3641684 & 1528302 & 7.5513 & 7.8164 & TRN & \\
\hline CHEMBL3641544 & 1528302 & 7.82100 & 0000000 & 7.8053 & TRN \\
\hline CHEMBL3643821 & 1528302 & 8.3468 & 8.2846 & TRN & \\
\hline CHEMBL3641605 & 1528302 & 7.7399 & 7.5938 & TRN & \\
\hline CHEMBL3641686 & 1528302 & 7.7645 & 7.6014 & TRN & \\
\hline CHEMBL3641645 & 1528302 & 7.8601 & 7.9896 & TRN & \\
\hline CHEMBL3641621 & 1528302 & 7.7282 & 7.6067 & TRN & \\
\hline CHEMBL3641536 & 1528302 & 6.9559 & 6.8814 & TRN & \\
\hline CHEMBL3643782 & 1528302 & 9.0 & 8.4941 & TRN & \\
\hline CHEMBL3643803 & 1528302 & 8.2147 & 7.7874 & TRN & \\
\hline CHEMBL3641594 & 1528302 & 7.2233 & 6.8402 & TRN & \\
\hline CHEMBL3641619 & 1528302 & 7.6021 & 7.08899 & 99999999995 & TRN \\
\hline CHEMBL3641677 & 1528302 & 7.9101 & 7.9147 & TRN & \\
\hline CHEMBL3641655 & 1528302 & 7.8928 & 8.1349 & TRN & \\
\hline CHEMBL3641506 & 1528302 & 7.6757 & 7.7726 & TST & \\
\hline
\end{tabular}


Supplemental Table S2.txt

\begin{tabular}{|c|c|c|c|c|c|}
\hline CHEMBL3643790 & 1528302 & 7.5376 & 7.5493 & TRN & \\
\hline CHEMBL3643741 & 1528302 & 7.6402 & 7.3211 & TRN & \\
\hline CHEMBL3641610 & 1528302 & 7.3242 & 7.6256 & TRN & \\
\hline CHEMBL3641528 & 1528302 & 8.0044 & 7.4286 & TST & \\
\hline CHEMBL3643749 & 1528302 & 6.9527 & 7.7578 & TST & \\
\hline CHEMBL3641518 & 1528302 & 8.9208 & 8.4902 & TRN & \\
\hline CHEMBL3641549 & 1528302 & 7.6253 & 7.5473 & TRN & \\
\hline CHEMBL3641652 & 1528302 & 7.3958 & 6.984 & TST & \\
\hline CHEMBL3641522 & 1528302 & 7.6861 & 7.6375 & TST & \\
\hline CHEMBL3641670 & 1528302 & 7.0711 & 7.2212 & TRN & \\
\hline CHEMBL3643725 & 1528302 & 7.4271 & 7.1103 & TRN & \\
\hline CHEMBL3641591 & 1528302 & 6.0 & 5.8745 & TRN & \\
\hline CHEMBL3641584 & 1528302 & 8.0757 & 7.8806 & TRN & \\
\hline CHEMBL3643750 & 1528302 & 6.4154 & 7.6679 & TST & \\
\hline CHEMBL3641504 & 1528302 & 7.699 & 7.3821 & TST & \\
\hline CHEMBL3641529 & 1528302 & 8.9208 & 8.3437 & TRN & \\
\hline CHEMBL3643792 & 1528302 & 7.4962 & 7.707000 & 0000000001 & $T R$ \\
\hline CHEMBL3641572 & 1528302 & 6.2208 & 6.6966 & TRN & \\
\hline CHEMBL3641643 & 1528302 & 7.7747 & 7.6073 & TRN & \\
\hline CHEMBL3643740 & 1528302 & 8.3665 & 8.2379 & TRN & \\
\hline CHEMBL3641646 & 1528302 & 7.068 & 7.7613 & TRN & \\
\hline CHEMBL3643736 & 1528302 & 6.9991 & 7.3237 & TRN & \\
\hline CHEMBL3641632 & 1528302 & 7.767 & 7.7854 & TRN & \\
\hline CHEMBL3643809 & 1528302 & 8.2291 & 7.6995 & TRN & \\
\hline CHEMBL3641624 & 1528302 & 7.3261 & 7.4537 & TRN & \\
\hline CHEMBL3641581 & 1528302 & 6.9382 & 6.9603 & TRN & \\
\hline CHEMBL3641662 & 1528302 & 7.7375 & 8.1066 & TRN & \\
\hline CHEMBL3643729 & 1528302 & 7.7696 & 8.1181 & TST & \\
\hline CHEMBL3643814 & 1528302 & 8.7447 & 8.3943 & TRN & \\
\hline CHEMBL3641613 & 1528302 & 7.3872 & 7.4662 & TRN & \\
\hline CHEMBL3643769 & 1528302 & 7.2676 & 8.187000 & 0000000001 & ובנו \\
\hline CHEMBL3641596 & 1528302 & 7.2204 & 6.9928 & TRN & \\
\hline CHEMBL3641576 & 1528302 & 7.6882 & 7.4174 & TRN & \\
\hline CHEMBL3641649 & 1528302 & 7.3872 & 7.169 & TRN & \\
\hline CHEMBL3641683 & 1528302 & 7.5513 & 7.4529 & TRN & \\
\hline CHEMBL3643817 & 1528302 & 8.5686 & 8.2285 & TRN & \\
\hline CHEMBL3643759 & 1528302 & 8.4318 & 8.1034 & TRN & \\
\hline CHEMBL3643730 & 1528302 & 7.5186 & 7.5291 & TRN & \\
\hline CHEMBL3641542 & 1528302 & 7.9355 & 7.6289 & TRN & \\
\hline CHEMBL3641636 & 1528302 & 7.6162 & 7.5605 & TRN & \\
\hline CHEMBL3641533 & 1528302 & 8.28399 & 799999999 & 7.6795 & $1 \mathrm{KT}$ \\
\hline CHEMBL3643774 & 1528302 & 7.7212 & 7.5949 & TRN & \\
\hline CHEMBL3641568 & 1528302 & 6.8016 & 6.6851 & TRN & \\
\hline CHEMBL3641502 & 1528302 & 6.6066 & 7.848 & TST & \\
\hline CHEMBL3641569 & 1528302 & 7.251 & 6.941 & TRN & \\
\hline CHEMBL3643819 & 1528302 & 8.9208 & 8.3245 & TST & \\
\hline CHEMBL 3641567 & 1528302 & 7.5186 & 7.6803 & TRN & \\
\hline CHEMBL3643766 & 1528302 & 6.7385 & 7.6449 & TST & \\
\hline
\end{tabular}


Supplemental Table S2.txt

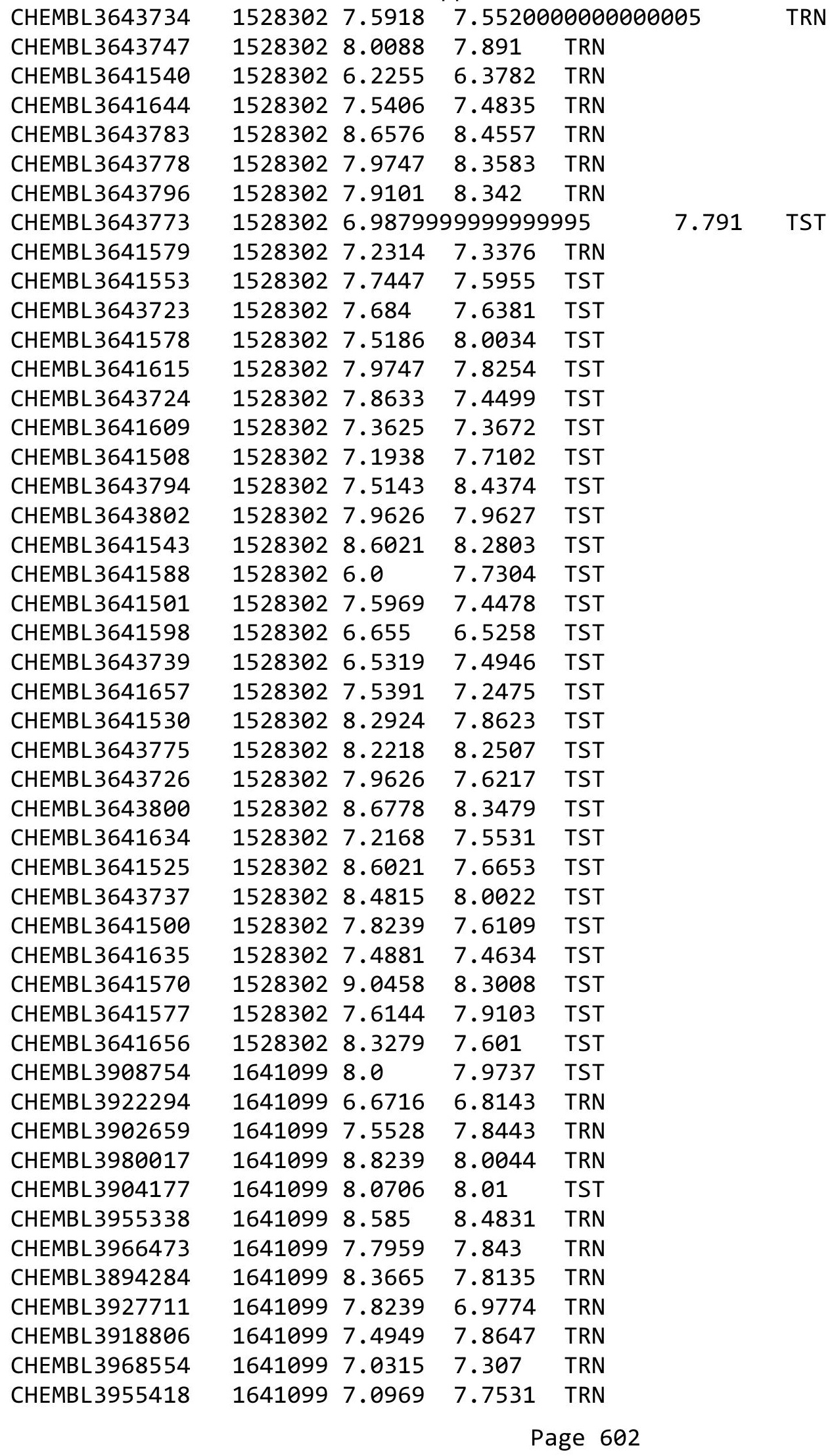


Supplemental Table S2.txt

\begin{tabular}{|c|c|c|c|c|}
\hline & & & & \\
\hline CHEMBL 3946736 & 1641099 & 9.0 & 8.5924 & \\
\hline HEMBL3936697 & 41099 & 8.4 & 42 & \\
\hline & 099 & & & \\
\hline IEMBL 3934047 & 641099 & 86 & 357 & \\
\hline AEMBL 3922238 & 641099 & 7.9586 & 346 & \\
\hline HEMBL3965261 & 641099 & 7.6576 & 8865 & \\
\hline AEMBL39 & 641099 & 36 & & \\
\hline IEMBL3 & 099 & 7.2291 & 5701 & \\
\hline IEMBL3 & 099 & & & \\
\hline AEMBL3963847 & 641099 & 8.2757 & 9919 & \\
\hline HEMBL3931225 & 641099 & 7.4089 & 04 & \\
\hline HEMBL3S & 641099 & 79 & & \\
\hline AEMBL & 099 & 49 & & \\
\hline AEMBL & 099 & & & \\
\hline AEMBL 3921072 & 641099 & 6737 & & \\
\hline AEMBL39 & 641099 & & & \\
\hline HEMBL & 699 & 76 & & \\
\hline AEMBL: & 099 & 1 & & \\
\hline HEMBL; & 099 & & & \\
\hline HEMBL; & 1641099 & 8. & & \\
\hline AEMBL39 & 099 & & & \\
\hline HEMBL & 164 & & & \\
\hline AEMBL & 099 & & & \\
\hline HEMB & 099 & & & \\
\hline 193 & 099 & 8.0 & & \\
\hline AEMBL39 & 099 & 88 & & \\
\hline HEMBL3S & 1099 & & & \\
\hline IEMB & 162 & & & \\
\hline 79 & 099 & 39 & 08 & \\
\hline IEMBL: & 099 & & & \\
\hline AEMBL39 & 1641099 & 5 & & RN \\
\hline AEMBL. & 16 & & & \\
\hline IEME & 16 & 1 & & \\
\hline 44 & 16 & & & RN \\
\hline AEMBL3S & 1641099 & & & \\
\hline AEMBL38 & 1641099 & & & \\
\hline 55 & & & & $\mathrm{RN}$ \\
\hline 26 & 9 & 1 & 21 & \\
\hline 75 & 16 & & & RI \\
\hline AEMBL3936107 & 1641099 & 79 & & \\
\hline AEMBL & 095 & & & \\
\hline CHEMB & & & & \\
\hline HEMBL; & 099 & & 5529 & \\
\hline HEMBL & 641099 & & 8.2377 & RN \\
\hline AEMBL39 & 641099 & 7.3979 & 155 & \\
\hline CHEMBL 3 & & 22 & & \\
\hline CHEMBL396701 & 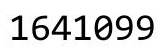 & & & \\
\hline
\end{tabular}

Page 603 
Supplemental Table S2.txt

\begin{tabular}{|c|c|c|c|c|c|}
\hline CHEMBL 3973423 & 1641099 & 5.871 & 6.8191 & TRN & \\
\hline CHEMBL3960631 & 1641099 & 8.1367 & 7.2629 & TRN & \\
\hline CHEMBL3941176 & 1641099 & 8.0 & 8.4975 & TST & \\
\hline CHEMBL3966791 & 1641099 & 6.983 & 6.59 & TRN & \\
\hline CHEMBL 3889657 & 1641099 & 7.7447 & 7.2896 & TST & \\
\hline CHEMBL 3951042 & 1641099 & 8.3279 & 8.41 & TRN & \\
\hline CHEMBL 3924335 & 1641099 & 7.9208 & 7.428999 & 9999999999 & TRN \\
\hline CHEMBL3923663 & 1641099 & 7.9586 & 6.7519 & TRN & \\
\hline CHEMBL3908776 & 1641099 & 6.71899 & 999999999 & 7.2103 & TRN \\
\hline CHEMBL 3974021 & 1641099 & 6.0 & 7.2559 & TRN & \\
\hline CHEMBL 3897267 & 1641099 & 7.3279 & 7.0675 & TRN & \\
\hline CHEMBL 3923314 & 1641099 & 7.2757 & 7.5481 & TRN & \\
\hline CHEMBL 3971934 & 1641099 & 6.5528 & 7.5451 & TST & \\
\hline CHEMBL3940408 & 1641099 & 8.0706 & 8.5472 & TRN & \\
\hline CHEMBL 3946632 & 1641099 & 7.7447 & 7.7613 & TRN & \\
\hline CHEMBL 3951376 & 1641099 & 7.9586 & 7.7772 & TRN & \\
\hline CHEMBL 3980388 & 1641099 & 8.2441 & 7.6105 & TRN & \\
\hline CHEMBL 3968063 & 1641099 & 6.8041 & \multicolumn{2}{|c|}{7.412000000000001} & TST \\
\hline CHEMBL3962460 & 1641099 & 6.34200 & 000000000 & 6.8808 & TRN \\
\hline CHEMBL 3934040 & 1641099 & 8.4202 & 8.6482 & TST & \\
\hline CHEMBL3971701 & 1641099 & 8.5686 & 8.1898 & TST & \\
\hline CHEMBL3934939 & 1641099 & 7.5528 & 7.6253 & TST & \\
\hline CHEMBL 3909274 & 1641099 & 8.1549 & 7.3118 & TST & \\
\hline CHEMBL 3950358 & 1641099 & 6.3298 & 6.2769 & TRN & \\
\hline CHEMBL 3904439 & 1641099 & 6.0 & 7.9149 & TRN & \\
\hline CHEMBL3921215 & 1641099 & 7.3979 & 7.807 & TRN & \\
\hline CHEMBL3920835 & 1641099 & 7.0706 & 6.9838 & TRN & \\
\hline CHEMBL3946095 & 1641099 & 7.8861 & 8.0222 & TST & \\
\hline CHEMBL3937201 & 1641099 & 8.3468 & 7.7942 & TST & \\
\hline CHEMBL 3966436 & 1641099 & 6.9469 & 7.0348 & TST & \\
\hline CHEMBL 3890030 & 1641099 & 6.51 & 6.8641 & TST & \\
\hline CHEMBL 3935049 & 1641099 & 6.1391 & 6.5362 & TRN & \\
\hline CHEMBL3686333 & 1536298 & 8.6198 & 8.6351 & TRN & \\
\hline CHEMBL3686303 & 1536298 & 8.7696 & 8.7029 & TST & \\
\hline CHEMBL 3686289 & 1536298 & 7.8239 & 7.7473 & TRN & \\
\hline CHEMBL 3686341 & 1536298 & 9.0458 & 7.7203 & TST & \\
\hline CHEMBL 3686325 & 1536298 & 8.1805 & 8.086 & TRN & \\
\hline CHEMBL 3686311 & 1536298 & 9.0458 & 8.9874 & TRN & \\
\hline CHEMBL 3686300 & 1536298 & 8.5376 & 8.5346 & TRN & \\
\hline CHEMBL 3686323 & 1536298 & 9.5229 & 9.5187 & TRN & \\
\hline CHEMBL3686310 & 1536298 & 8.5229 & 8.5777 & TRN & \\
\hline CHEMBL 3686324 & 1536298 & 9.301 & 9.3232 & TRN & \\
\hline CHEMBL 3686332 & 1536298 & 8.9208 & 8.8898 & TRN & \\
\hline CHEMBL3686292 & 1536298 & 6.0 & 6.0176 & TRN & \\
\hline CHEMBL3686284 & 1536298 & 6.0 & 6.3611 & TRN & \\
\hline CHEMBL 3686339 & 1536298 & 9.301 & 9.3341 & TRN & \\
\hline CHEMBL 3686326 & 1536298 & 8.6021 & 8.6306 & TRN & \\
\hline CHEMBL 3686342 & 1536298 & 6.0 & 5.8267 & TRN & \\
\hline
\end{tabular}


Supplemental Table S2.txt

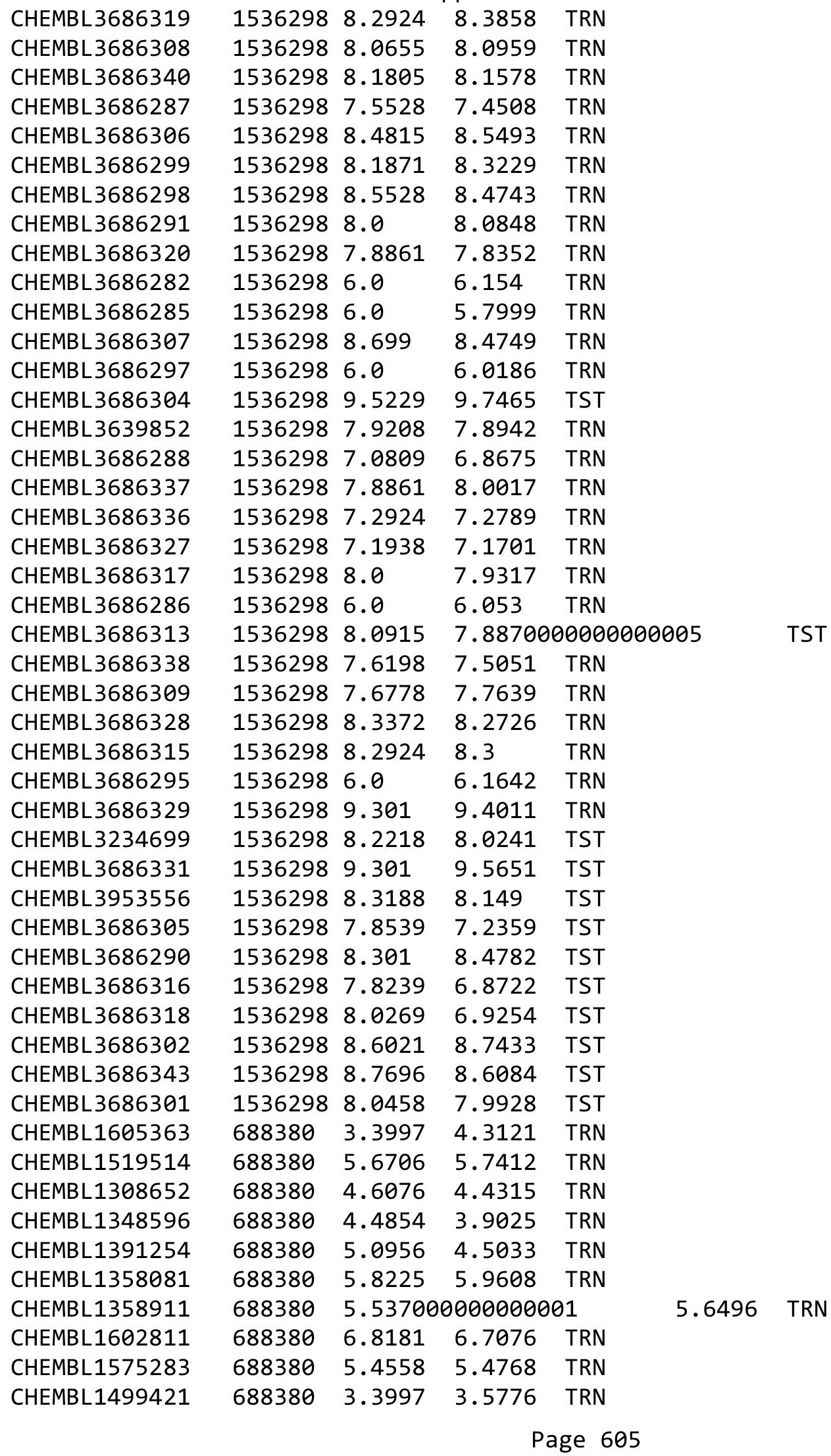




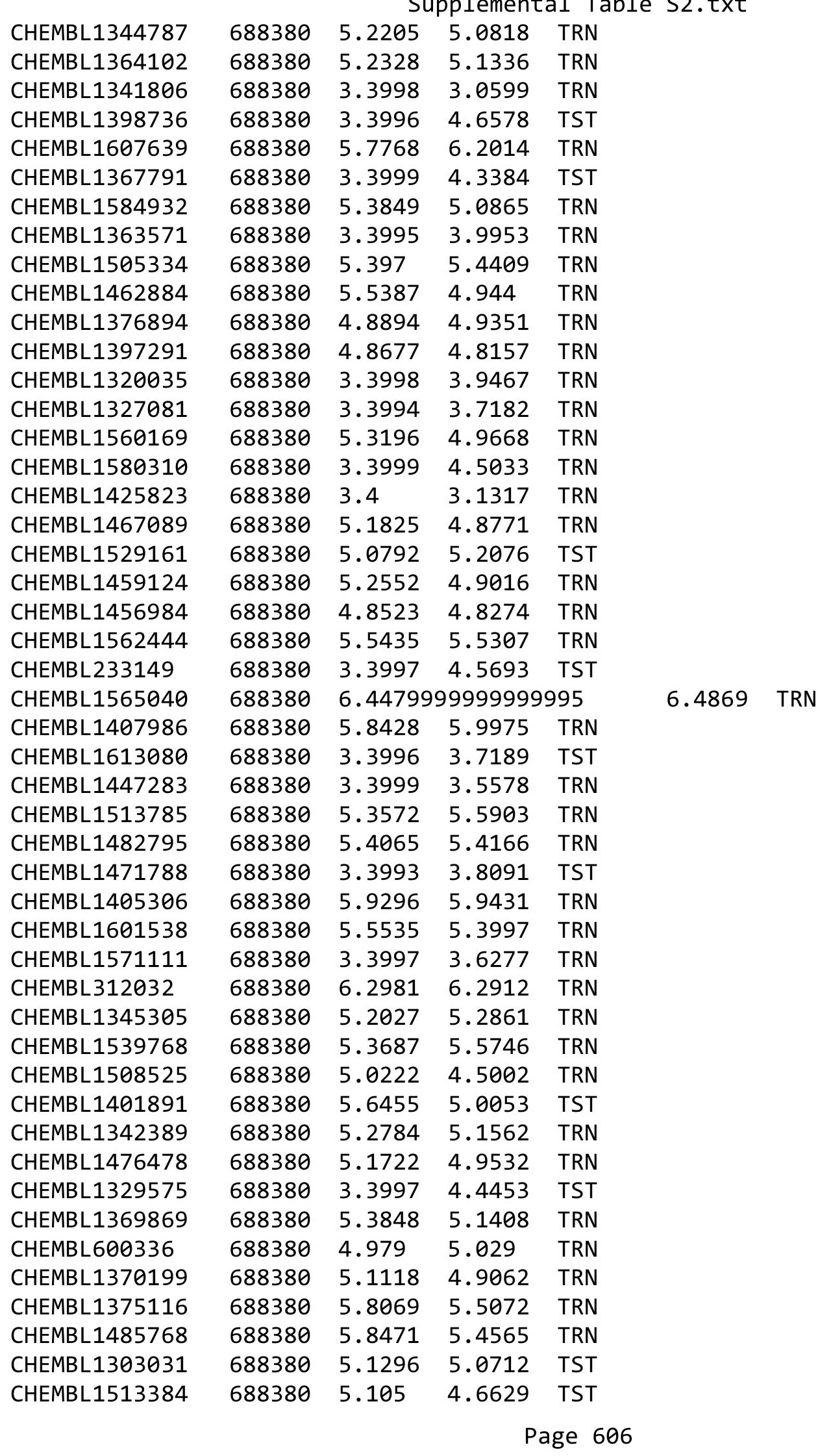




\begin{tabular}{|c|c|c|c|c|c|}
\hline \multirow{2}{*}{ CHEMBL1354460 } & \multirow[b]{2}{*}{688380} & \\
\hline & & 5.4528 & \multicolumn{2}{|c|}{5.367000000000001} & TRN \\
\hline CHEMBL1531523 & 688380 & 5.2563 & 5.4245 & TRN & \\
\hline CHEMBL1406915 & 688380 & 5.3072 & 5.0958 & TRN & \\
\hline CHEMBL1337717 & 688380 & 3.3996 & 3.9312 & TRN & \\
\hline CHEMBL1539438 & 688380 & 5.5306 & 5.6648 & TRN & \\
\hline CHEMBL1341089 & 688380 & 5.0995 & 4.9919 & TRN & \\
\hline CHEMBL1314687 & 688380 & 4.953 & 5.1594 & TRN & \\
\hline CHEMBL1359865 & 688380 & 5.0017 & 4.9571 & TRN & \\
\hline CHEMBL1344739 & 688380 & 5.4211 & 5.4397 & TRN & \\
\hline CHEMBL1579942 & 688380 & 4.9292 & 4.965 & TRN & \\
\hline CHEMBL1304667 & 688380 & 5.1802 & 5.612 & TRN & \\
\hline CHEMBL1541024 & 688380 & 5.2281 & 5.2189 & TRN & \\
\hline CHEMBL1542847 & 688380 & 5.3986 & 5.1404 & TRN & \\
\hline CHEMBL1410870 & 688380 & 5.7637 & 5.5797 & TRN & \\
\hline CHEMBL1431253 & 688380 & 5.0661 & 5.3168 & TRN & \\
\hline CHEMBL1488651 & 688380 & 5.5759 & 5.5916 & TRN & \\
\hline CHEMBL1482670 & 688380 & 6.1327 & 5.7396 & TRN & \\
\hline CHEMBL1461732 & 688380 & 3.3996 & 3.6258 & TRN & \\
\hline CHEMBL1539954 & 688380 & 5.1261 & 5.4184 & TRN & \\
\hline CHEMBL1576907 & 688380 & 4.3538 & 4.5982 & TRN & \\
\hline CHEMBL1497617 & 688380 & 5.3821 & 4.44600 & 0000000001 & TRN \\
\hline CHEMBL1462503 & 688380 & 5.1166 & 5.0883 & TRN & \\
\hline CHEMBL1582191 & 688380 & 5.0565 & 5.2568 & TRN & \\
\hline CHEMBL1589959 & 688380 & 5.0207 & 5.279 & TRN & \\
\hline CHEMBL1468336 & 688380 & 3.3997 & 3.5154 & TRN & \\
\hline CHEMBL1543662 & 688380 & 5.1846 & 5.0048 & TRN & \\
\hline CHEMBL1523808 & 688380 & 5.3281 & 5.232 & TRN & \\
\hline CHEMBL1610464 & 688380 & 3.4 & 3.5156 & TRN & \\
\hline CHEMBL1456706 & 688380 & 5.1439 & 5.1262 & TRN & \\
\hline CHEMBL1453623 & 688380 & 5.7508 & 5.6361 & TRN & \\
\hline CHEMBL1464502 & 688380 & 5.6985 & 5.9527 & TRN & \\
\hline CHEMBL1368667 & 688380 & 5.8351 & 5.7713 & TRN & \\
\hline CHEMBL1357156 & 688380 & 5.0591 & 4.4535 & TRN & \\
\hline CHEMBL1318849 & 688380 & 4.9706 & 5.3218 & TST & \\
\hline CHEMBL1462838 & 688380 & 5.2353 & 5.0237 & TRN & \\
\hline CHEMBL1380313 & 688380 & 5.3102 & 5.559 & TRN & \\
\hline CHEMBL1300912 & 688380 & 4.7437 & 5.0565 & TRN & \\
\hline CHEMBL1392806 & 688380 & 5.66 & 5.9238 & TRN & \\
\hline CHEMBL1544051 & 688380 & 3.3997 & 5.4345 & TST & \\
\hline CHEMBL1304585 & 688380 & 5.6651 & 5.2736 & TST & \\
\hline CHEMBL1457096 & 688380 & 4.5635 & 3.7622 & TST & \\
\hline CHEMBL1601194 & 688380 & 6.1013 & 5.3512 & TST & \\
\hline CHEMBL1302552 & 688380 & 6.0264 & 5.5459 & TST & \\
\hline CHEMBL1402172 & 688380 & 4.7739 & 4.6604 & TST & \\
\hline CHEMBL1366522 & 688380 & 5.0463 & 4.6234 & TST & \\
\hline CHEMBL1367087 & 688380 & 5.3787 & 4.9648 & TST & \\
\hline CHEMBL1417231 & 688380 & 5.9101 & 6.2805 & TST & \\
\hline CHEMBL1464805 & 688380 & 5.2959 & 5.6602 & TST & \\
\hline
\end{tabular}




\begin{tabular}{|c|c|c|c|c|c|}
\hline \multicolumn{6}{|c|}{ Supplemental Table S2.txt } \\
\hline CHEMBL1431688 & 688380 & 4.9619 & 5.1042 & TST & \\
\hline CHEMBL1385747 & 688380 & 5.6847 & 4.1252 & TST & \\
\hline CHEMBL1431953 & 688380 & 4.8378 & 4.7594 & TST & \\
\hline CHEMBL1534931 & 688380 & 3.3997 & 3.6102 & TST & \\
\hline CHEMBL1339297 & 688380 & 3.3997 & 5.1706 & TST & \\
\hline CHEMBL1471296 & 688380 & 5.7452 & 5.3995 & TST & \\
\hline CHEMBL1442635 & 688380 & 5.4314 & 5.2666 & TST & \\
\hline CHEMBL1494994 & 688380 & 3.3999 & 4.6107 & TST & \\
\hline CHEMBL 3931657 & 1641860 & 9.0 & 8.8079 & TRN & \\
\hline CHEMBL3917179 & 1641860 & 6.3468 & 7.7622 & TRN & \\
\hline CHEMBL 3945875 & 1641860 & 8.2218 & 8.4033 & TRN & \\
\hline CHEMBL 3986640 & 1641860 & 8.699 & 8.1269 & TST & \\
\hline CHEMBL3954709 & 1641860 & 9.5229 & 8.8781 & TRN & \\
\hline CHEMBL 3952484 & 1641860 & 6.7447 & 5.959 & TRN & \\
\hline CHEMBL3911773 & 1641860 & 9.0458 & 7.9898 & TRN & \\
\hline CHEMBL 3952042 & 1641860 & 4.301 & 8.6432 & TRN & \\
\hline CHEMBL 3644495 & 1641860 & 5.6021 & 5.8117 & TRN & \\
\hline CHEMBL 3644504 & 1641860 & 7.5376 & 8.4866 & TRN & \\
\hline CHEMBL 3932863 & 1641860 & 9.3979 & 8.5377 & TRN & \\
\hline CHEMBL 3982748 & 1641860 & 7.1308 & 7.3837 & TRN & \\
\hline CHEMBL 3969462 & 1641860 & 6.4089 & 6.4708 & TST & \\
\hline CHEMBL3928313 & 1641860 & 4.699 & 6.4981 & TST & \\
\hline CHEMBL3925334 & 1641860 & 6.7878 & 7.017 & TRN & \\
\hline CHEMBL 3976439 & 1641860 & 8.699 & 8.6801 & TRN & \\
\hline CHEMBL3948031 & 1641860 & 8.3979 & 8.1251 & TRN & \\
\hline CHEMBL 3947142 & 1641860 & 8.301 & 8.3657 & TRN & \\
\hline CHEMBL 3962756 & 1641860 & 7.699 & 7.4726 & TRN & \\
\hline CHEMBL3986436 & 1641860 & 8.3979 & 8.4534 & TRN & \\
\hline CHEMBL3971431 & 1641860 & 9.2218 & 8.6234 & TRN & \\
\hline CHEMBL3892871 & 1641860 & 6.1675 & 6.2337 & TST & \\
\hline CHEMBL 3938524 & 1641860 & 9.0 & 8.6927 & TRN & \\
\hline CHEMBL 3938364 & 1641860 & 9.3979 & 8.9254 & TRN & \\
\hline CHEMBL 3932267 & 1641860 & 8.2218 & 7.2474 & TRN & \\
\hline CHEMBL3916613 & 1641860 & 5.4559 & 6.5084 & TST & \\
\hline CHEMBL3977963 & 1641860 & 4.8477 & 7.3093 & TST & \\
\hline CHEMBL3944621 & 1641860 & 6.699 & 6.227 & TRN & \\
\hline CHEMBL3984643 & 1641860 & 6.301 & 5.367006 & 0000000001 & TRN \\
\hline CHEMBL 3958223 & 1641860 & 6.0 & 6.3009 & TRN & \\
\hline CHEMBL3894945 & 1641860 & 6.5686 & 6.5103 & TRN & \\
\hline CHEMBL3962096 & 1641860 & 9.0 & 8.3247 & TRN & \\
\hline CHEMBL 3936729 & 1641860 & 6.0458 & 6.4744 & TST & \\
\hline CHEMBL3953457 & 1641860 & 6.5528 & 7.1137 & TRN & \\
\hline CHEMBL3978166 & 1641860 & 6.0362 & 6.0073 & TST & \\
\hline CHEMBL3966151 & 1641860 & 9.0 & 8.9121 & TRN & \\
\hline CHEMBL3913808 & 1641860 & 5.8861 & 6.8594 & TRN & \\
\hline CHEMBL 3921402 & 1641860 & 8.699 & 8.5698 & TRN & \\
\hline CHEMBL3938310 & 1641860 & 6.3468 & 6.5358 & TRN & \\
\hline CHEMBL 3972551 & 1641860 & 9.0 & 7.705 & TST & \\
\hline
\end{tabular}


Supplemental Table S2.txt

\begin{tabular}{|c|c|c|c|c|}
\hline 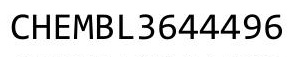 & & & & \\
\hline HEMBL3644499 & 541860 & 8.2218 & 3398 & \\
\hline HEMBL3977927 & 860 & 5.8539 & 2665 & \\
\hline 398279 & & & & \\
\hline EMBL3973186 & 60 & 37 & 196 & $\mathrm{RN}$ \\
\hline HEMBL3644497 & 641860 & 4.699 & 506 & \\
\hline HEMBL3644498 & 641860 & 7.5229 & .1826 & \\
\hline HEMBL 394 & & 3872 & & \\
\hline IEMBL396 & 360 & .0 & .6673 & \\
\hline HEMBL 395 & 360 & 9.3979 & .933 & \\
\hline HEMBL3913144 & 360 & 9458 & 1242 & \\
\hline HEMBL3958848 & 360 & 9.0 & 7.6844 & \\
\hline HEMBL3958464 & 60 & 98 & 7.4818 & \\
\hline HEMBL 398 & 50 & 69 & .8495 & \\
\hline AEMBL36 & 60 & 198 & .4424 & \\
\hline HEMBL 396 & 60 & 101 & .1341 & \\
\hline HEMBL364 & 60 & 8.699 & & \\
\hline HEMBL 217 & 6 & 25 & 42 & \\
\hline HEMBL 21 & & & & \\
\hline HEMBL 21 & & 44 & & \\
\hline HEMBL 217 & 5 & 212 & & \\
\hline HEMBL 217 & & 6 & & \\
\hline HEMBL 217 & כ & 06 & & \\
\hline HEMBL 21 & & 39 & & RN \\
\hline HEMBL217 & & 72 & 33 & $\mathrm{RN}$ \\
\hline HEMBL 217 & & 47 & & RN \\
\hline AEMBL 217 & 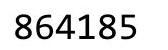 & 862 & & IRN \\
\hline HEMBL 217 & & 95 & & \\
\hline HEMBL217 & 5 & & & RN \\
\hline HEMBL 217 & & & 326 & RN \\
\hline HEMBL 217 & & & & IRN \\
\hline HEMBL 2172 & 3 & 576 & 357 & TRN \\
\hline HEMBL21 & & & & RN \\
\hline 4 & & 46 & 38 & RN \\
\hline HEMBL 217 & & 7. & 7.7485 & RN \\
\hline HEMBL2172137 & & 6.7375 & 6.7744 & IRN \\
\hline HEMBL 217 & כ & 7. & 7. & RN \\
\hline HLTIDLCL & & 68 & & RN \\
\hline 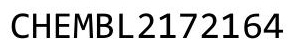 & & & & RN \\
\hline HEMBL 2172148 & & 086 & 8.5627 & $\mathrm{RN}$ \\
\hline HEMBL 217 & & 969 & 267 & IRN \\
\hline HEMBL 217 & & & 991 & RN \\
\hline HEMBL217 & & & & \\
\hline CHEMBL 217 & & & 7.2191 & RN \\
\hline HEMBL2172283 & & 4.301 & .5954 & ST \\
\hline HEMBL 217 & 5 & 2708 & .5349 & RN \\
\hline L217 & & & & \\
\hline & & & & \\
\hline
\end{tabular}

Page 609 
Supplemental Table S2.txt

\begin{tabular}{|c|c|c|c|c|c|}
\hline CHEMBL 2172267 & 864185 & 7.1805 & 7.3943 & TRN & \\
\hline CHEMBL 2172140 & 864185 & 8.1135 & 8.4613 & TRN & \\
\hline CHEMBL 2172279 & 864185 & 6.6162 & 6.1914 & TST & \\
\hline CHEMBL 2172145 & 864185 & 6.8861 & 6.9999 & TRN & \\
\hline CHEMBL 2172144 & 864185 & 7.3979 & 6.9784 & TRN & \\
\hline CHEMBL 2172162 & 864185 & 7.2518 & 7.2529 & TRN & \\
\hline CHEMBL 2172282 & 864185 & 5.5654 & 5.8613 & TST & \\
\hline CHEMBL 2172158 & 864185 & 6.6234 & 6.6093 & TRN & \\
\hline CHEMBL 2172284 & 864185 & 6.3382 & 6.3731 & TST & \\
\hline CHEMBL 2172272 & 864185 & 8.1367 & 7.6563 & TRN & \\
\hline CHEMBL 2172166 & 864185 & \multicolumn{3}{|c|}{6.7620000000000005} & TST \\
\hline CHEMBL 2172152 & 864185 & 6.0 & 6.3536 & TRN & \\
\hline CHEMBL 2172280 & 864185 & 6.6038 & 6.276 & TST & \\
\hline CHEMBL 2172273 & 864185 & 7.699 & 7.773 & TRN & \\
\hline CHEMBL 3145352 & 864185 & 4.301 & 5.6362 & TST & \\
\hline CHEMBL 2172135 & 864185 & 6.7645 & 7.0224 & TRN & \\
\hline CHEMBL2172161 & 864185 & 7.2518 & 7.1532 & TRN & \\
\hline CHEMBL 2172133 & 864185 & 8.1871 & 8.5867 & TRN & \\
\hline CHEMBL 2172132 & 864185 & 7.6383 & 7.20100 & 00000000005 & t \\
\hline CHEMBL 2172268 & 864185 & 7.2518 & 7.3473 & TRN & \\
\hline CHEMBL 2172275 & 864185 & 7.0655 & 6.3353 & TST & \\
\hline CHEMBL 2172143 & 864185 & 7.5229 & 7.1893 & TRN & \\
\hline CHEMBL 2172146 & 864185 & 8.2441 & 7.8516 & TST & \\
\hline CHEMBL 2172264 & 864185 & 6.5482 & 6.579 & TST & \\
\hline CHEMBL 2172136 & 864185 & 6.684 & 6.3741 & TST & \\
\hline CHEMBL611393 & 304044 & 7.44 & 7.1747 & TST & \\
\hline CHEMBL607067 & 304044 & 6.07 & 6.5538 & TST & \\
\hline CHEMBL607118 & 304044 & 6.92 & 7.145 & TST & \\
\hline CHEMBL359917 & 304044 & 5.44 & 6.273 & TST & \\
\hline CHEMBL178829 & 304044 & 5.1 & 6.1795 & TST & \\
\hline CHEMBL606740 & 304044 & 6.42 & 6.1068 & TRN & \\
\hline CHEMBL606673 & 304044 & 6.05 & 5.8385 & TRN & \\
\hline CHEMBL607484 & 304044 & 5.7 & 5.4848 & TRN & \\
\hline CHEMBL606738 & 304044 & 5.51 & 5.4848 & TRN & \\
\hline CHEMBL607485 & 304044 & 5.21 & 5.8808 & TRN & \\
\hline CHEMBL606676 & 304044 & 6.19 & 6.1022 & TRN & \\
\hline CHEMBL606607 & 304044 & 6.17 & 6.149 & TRN & \\
\hline CHEMBL606798 & 304044 & 6.02 & 5.8054 & TRN & \\
\hline CHEMBL606675 & 304044 & 5.42 & 5.6996 & TRN & \\
\hline CHEMBL606606 & 304044 & 5.49 & 5.51200 & 00000000005 & ти \\
\hline CHEMBL610618 & 304044 & 5.53 & 5.8869 & TRN & \\
\hline CHEMBL610617 & 304044 & 5.88 & 6.325 & TRN & \\
\hline CHEMBL611397 & 304044 & 6.27 & 5.9287 & TRN & \\
\hline CHEMBL610878 & 304044 & 6.45 & 6.4414 & TRN & \\
\hline CHEMBL611399 & 304044 & 7.12 & 7.035 & TRN & \\
\hline CHEMBL611132 & 304044 & 7.09 & 6.7401 & TRN & \\
\hline CHEMBL611133 & 304044 & 6.2 & 6.0237 & TRN & \\
\hline CHEMBL611396 & 304044 & 6.63 & 6.6094 & TRN & \\
\hline
\end{tabular}




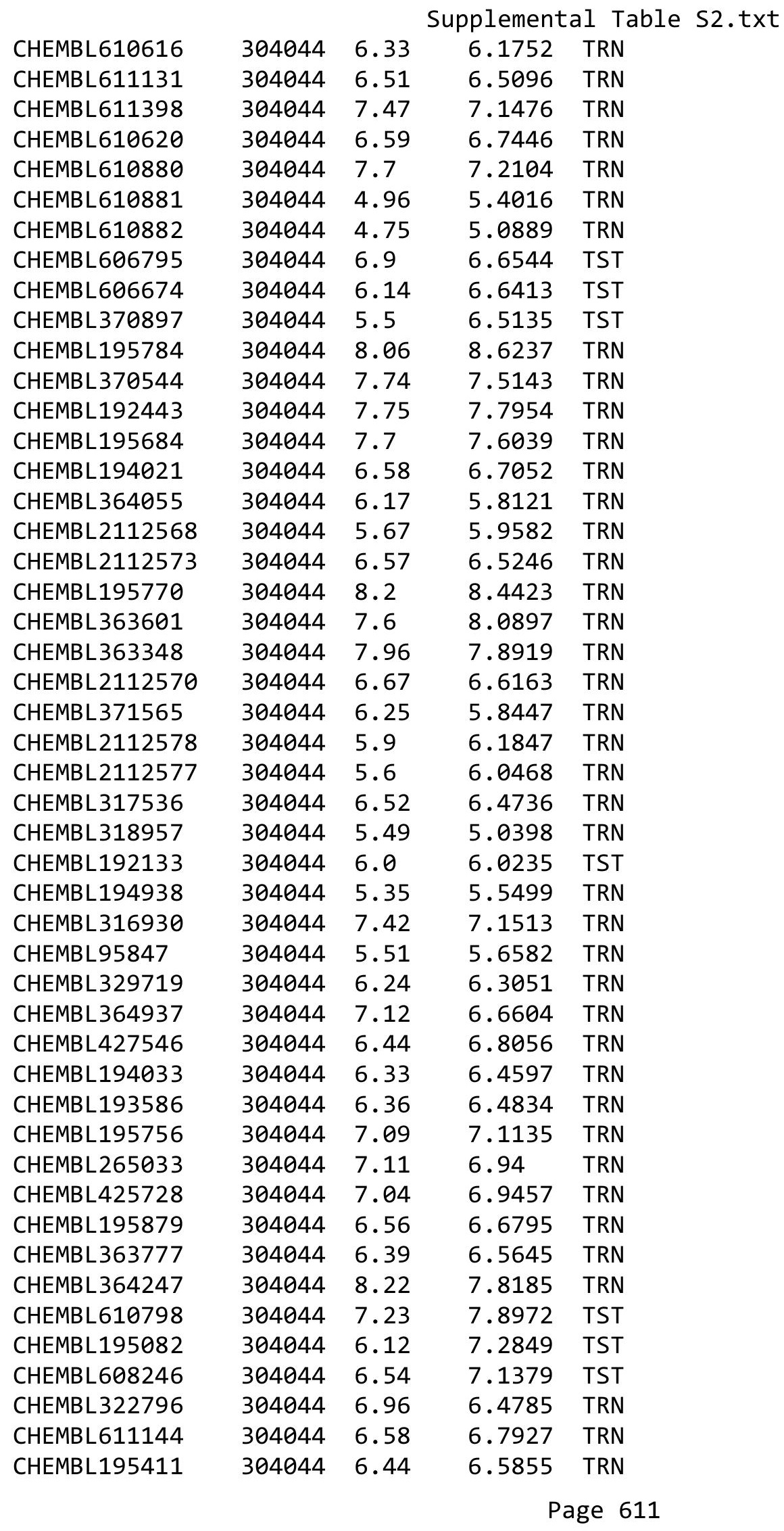




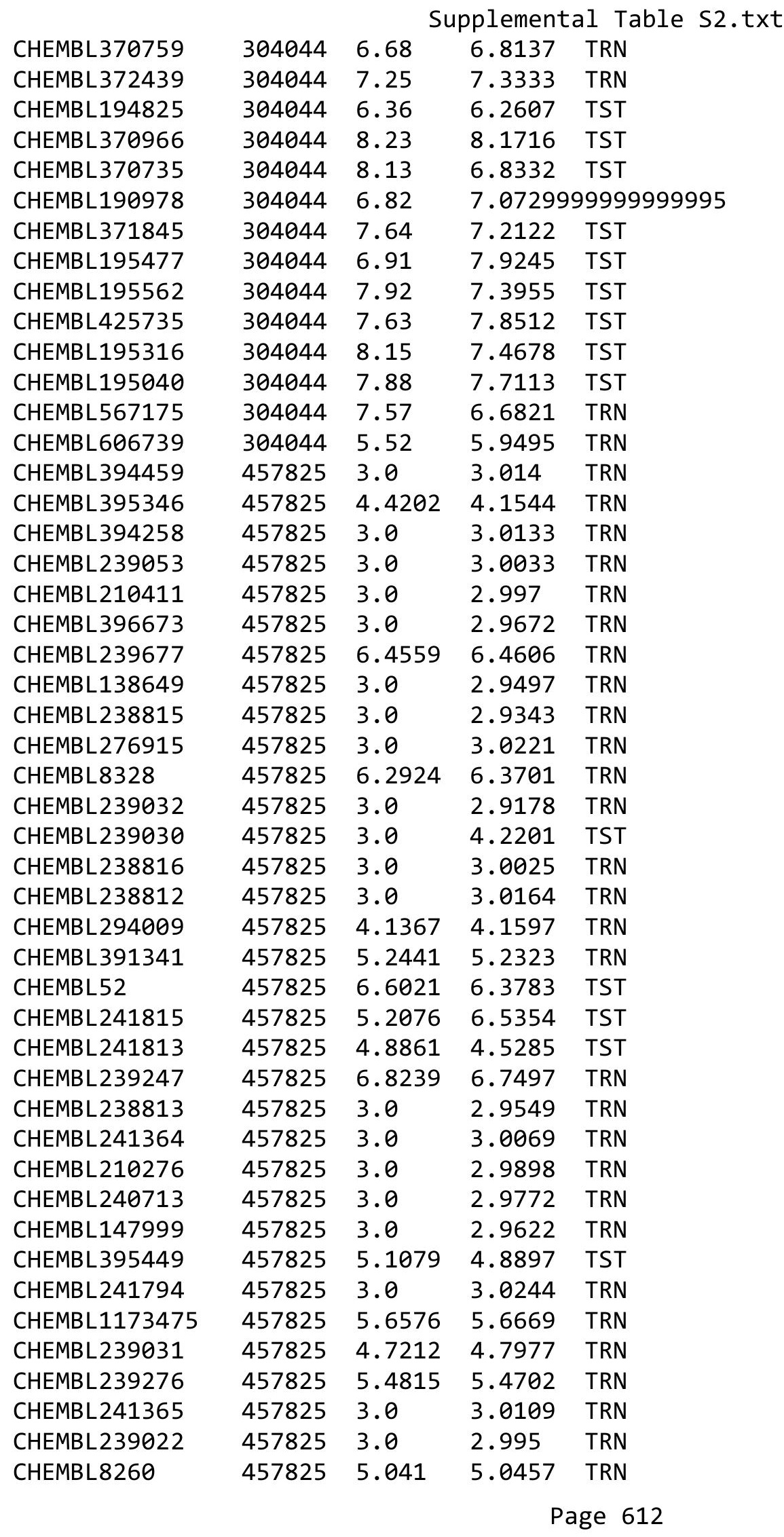




\begin{tabular}{|c|c|c|c|c|}
\hline \multicolumn{5}{|c|}{ Supplemental Table S2.txt } \\
\hline CHEMBL 239023 & 457825 & 3.0 & 3.0266 & TRN \\
\hline CHEMBL241363 & 457825 & 3.0 & 2.7999 & TRN \\
\hline CHEMBL391342 & 457825 & 5.4318 & 5.4368 & TRN \\
\hline CHEMBL395115 & 457825 & 3.0 & 3.0869 & TRN \\
\hline CHEMBL 239893 & 457825 & 6.6778 & 6.8805 & TST \\
\hline CHEMBL239156 & 457825 & 4.3098 & 3.1109 & TST \\
\hline CHEMBL241814 & 457825 & 5.0458 & 6.4098 & TST \\
\hline CHEMBL1728023 & 457825 & 5.8539 & 5.8408 & TRN \\
\hline CHEMBL 238821 & 457825 & 3.0 & 5.3456 & TST \\
\hline CHEMBL238843 & 457825 & 4.9586 & 4.9392 & TST \\
\hline CHEMBL 239033 & 457825 & 6.6778 & 4.7624 & TST \\
\hline CHEMBL238814 & 457825 & 3.0 & 3.0251 & TRN \\
\hline CHEMBL 240505 & 457825 & 3.0 & 3.2507 & TRN \\
\hline CHEMBL 238844 & 457825 & 5.0809 & 5.6405 & TST \\
\hline CHEMBL241366 & 457825 & 3.0 & 3.2246 & TRN \\
\hline CHEMBL394257 & 457825 & 4.7447 & 4.7472 & TRN \\
\hline CHEMBL 239028 & 457825 & 3.0 & 4.7192 & TST \\
\hline CHEMBL168793 & 105142 & 5.5686 & 5.5808 & TRN \\
\hline CHEMBL172291 & 105142 & 6.3188 & 6.4725 & TRN \\
\hline CHEMBL172616 & 105142 & 7.301 & 7.1405 & TRN \\
\hline CHEMBL169341 & 105142 & 5.2441 & 5.1903 & TRN \\
\hline CHEMBL354202 & 105142 & 6.301 & 6.1918 & TRN \\
\hline CHEMBL169242 & 105142 & 5.9208 & 5.7038 & TRN \\
\hline CHEMBL172210 & 105142 & 4.8539 & 5.6594 & TST \\
\hline CHEMBL170990 & 105142 & 5.6778 & 5.8894 & TRN \\
\hline CHEMBL172623 & 105142 & 6.5086 & 7.3386 & TST \\
\hline CHEMBL167833 & 105142 & 6.6021 & 5.6354 & TST \\
\hline CHEMBL354434 & 105142 & 5.2147 & 5.6447 & TRN \\
\hline CHEMBL169959 & 105142 & 6.5376 & 6.2778 & TRN \\
\hline CHEMBL167716 & 105142 & 5.4949 & 5.4802 & TRN \\
\hline CHEMBL170733 & 105142 & 6.8861 & 7.1021 & TRN \\
\hline CHEMBL354657 & 105142 & 5.6198 & 5.3653 & TRN \\
\hline CHEMBL172388 & 105142 & 5.8539 & 5.7538 & TRN \\
\hline CHEMBL171661 & 105142 & 6.0458 & 5.7038 & TRN \\
\hline CHEMBL168390 & 105142 & 6.3768 & 5.4095 & TST \\
\hline CHEMBL352761 & 105142 & 5.3872 & 5.5335 & TRN \\
\hline CHEMBL169958 & 105142 & 6.5686 & 6.7539 & TRN \\
\hline CHEMBL169461 & 105142 & 6.5086 & 6.4219 & TRN \\
\hline CHEMBL170667 & 105142 & 6.6778 & 6.7611 & TRN \\
\hline CHEMBL426575 & 105142 & 5.7696 & 6.0355 & TRN \\
\hline CHEMBL169810 & 105142 & 5.585 & 5.6784 & TRN \\
\hline CHEMBL172519 & 105142 & 5.7959 & 5.5335 & TRN \\
\hline CHEMBL171478 & 105142 & 6.0969 & 6.1035 & TRN \\
\hline CHEMBL 352793 & 105142 & 4.7959 & 4.4921 & TST \\
\hline CHEMBL166381 & 105142 & 6.699 & 6.9041 & TRN \\
\hline CHEMBL167482 & 105142 & 7.301 & 7.5797 & TST \\
\hline CHEMBL171313 & 105142 & 6.6021 & 6.7547 & TRN \\
\hline CHEMBL171142 & 105142 & 7.301 & 6.8979 & TST \\
\hline
\end{tabular}




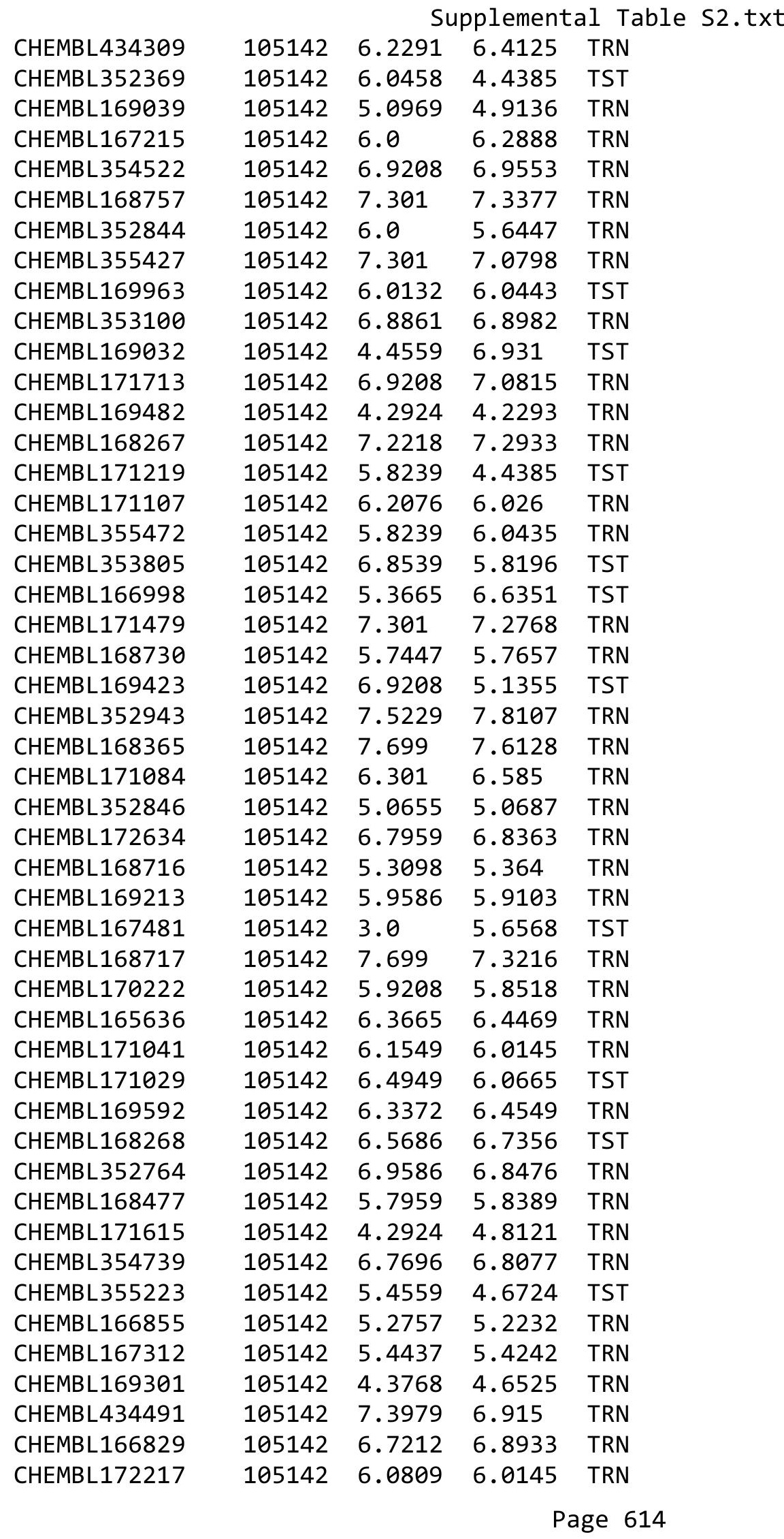




\begin{tabular}{|c|c|c|c|c|c|}
\hline \multirow[b]{2}{*}{ CHEMBL353170 } & \multicolumn{5}{|c|}{ Supplemental Table S2.txt } \\
\hline & 105142 & 6.2518 & 5.8105 & TRN & \\
\hline CHEMBL171731 & 105142 & 7.5229 & 7.7989 & TST & \\
\hline CHEMBL440746 & 105142 & 6.3372 & 7.6748 & TST & \\
\hline CHEMBL171591 & 105142 & 5.8861 & 6.1502 & TRN & \\
\hline CHEMBL169319 & 105142 & 6.5376 & 6.6016 & TRN & \\
\hline CHEMBL352306 & 105142 & 4.9031 & 4.9705 & TRN & \\
\hline CHEMBL170386 & 105142 & 5.7959 & 5.902 & TRN & \\
\hline CHEMBL353506 & 105142 & 6.6198 & 6.2575 & TRN & \\
\hline CHEMBL166955 & 105142 & 7.301 & 7.7479 & TST & \\
\hline CHEMBL168849 & 105142 & 6.0706 & 4.9699 & TST & \\
\hline CHEMBL169964 & 105142 & 5.8861 & 5.4802 & TST & \\
\hline CHEMBL169681 & 105142 & 6.8539 & 6.4693 & TRN & \\
\hline CHEMBL422743 & 105142 & 5.9586 & 5.6855 & TRN & \\
\hline CHEMBL169405 & 105142 & 4.1308 & 4.2694 & TRN & \\
\hline CHEMBL355112 & 105142 & 4.8539 & 6.7017 & TST & \\
\hline CHEMBL172153 & 105142 & 7.1549 & 6.9778 & TRN & \\
\hline CHEMBL170271 & 105142 & 6.7212 & 6.9559 & TRN & \\
\hline CHEMBL1862902 & 830583 & 3.0 & 3.1981 & TRN & \\
\hline CHEMBL1863082 & 830583 & 4.2668 & 3.9378 & TRN & \\
\hline CHEMBL1863502 & 830583 & 4.1805 & 3.7607 & TRN & \\
\hline CHEMBL1862999 & 830583 & 4.2441 & 4.1101 & TRN & \\
\hline CHEMBL1863197 & 830583 & 4.0675 & 4.0256 & TRN & \\
\hline CHEMBL 2058278 & 830583 & 4.2518 & 3.3251 & TRN & \\
\hline CHEMBL1863282 & 830583 & 4.2457 & 3.8134 & TST & \\
\hline CHEMBL1863321 & 830583 & 4.2034 & 4.2075 & TRN & \\
\hline CHEMBL1863443 & 830583 & 3.0 & 3.3821 & TST & \\
\hline CHEMBL1862893 & 830583 & 3.0 & 3.0681 & TRN & \\
\hline CHEMBL1863004 & 830583 & 4.3224 & 4.2956 & TRN & \\
\hline CHEMBL1862871 & 830583 & 3.0 & 3.2168 & TRN & \\
\hline CHEMBL1863383 & 830583 & 3.0 & 3.5749 & TRN & \\
\hline CHEMBL1863223 & 830583 & 4.1192 & 3.8034 & TST & \\
\hline CHEMBL1863258 & 830583 & 3.0 & 3.4421 & TRN & \\
\hline CHEMBL1862982 & 830583 & 4.2495 & 4.1751 & TRN & \\
\hline CHEMBL1863183 & 830583 & 3.0 & 3.4279 & TRN & \\
\hline CHEMBL1863172 & 830583 & 4.2055 & 3.8121 & TST & \\
\hline CHEMBL1862839 & 830583 & 3.0 & 3.2059 & TST & \\
\hline CHEMBL1863379 & 830583 & 4.1163 & 4.6432 & TRN & \\
\hline CHEMBL1863224 & 830583 & 3.0 & 3.2232 & TRN & \\
\hline CHEMBL1862842 & 830583 & 4.2314 & 4.00899 & 99999999995 & TST \\
\hline CHEMBL1863325 & 830583 & 4.251 & 3.9917 & TRN & \\
\hline CHEMBL1862958 & 830583 & 3.0 & 3.3163 & TRN & \\
\hline CHEMBL1863450 & 830583 & 4.2269 & 3.88100 & 00000000002 & TRN \\
\hline CHEMBL1863007 & 830583 & 4.0482 & 3.8201 & TRN & \\
\hline CHEMBL1863484 & 830583 & 3.0 & 3.0394 & TRN & \\
\hline CHEMBL1862838 & 830583 & 4.2262 & 3.77100 & 00000000004 & TRN \\
\hline CHEMBL1863074 & 830583 & 4.2314 & 4.1497 & TRN & \\
\hline CHEMBL1863284 & 830583 & 4.1694 & 3.3573 & TRN & \\
\hline CHEMBL1863489 & 830583 & 4.1713 & 4.8168 & TRN & \\
\hline
\end{tabular}




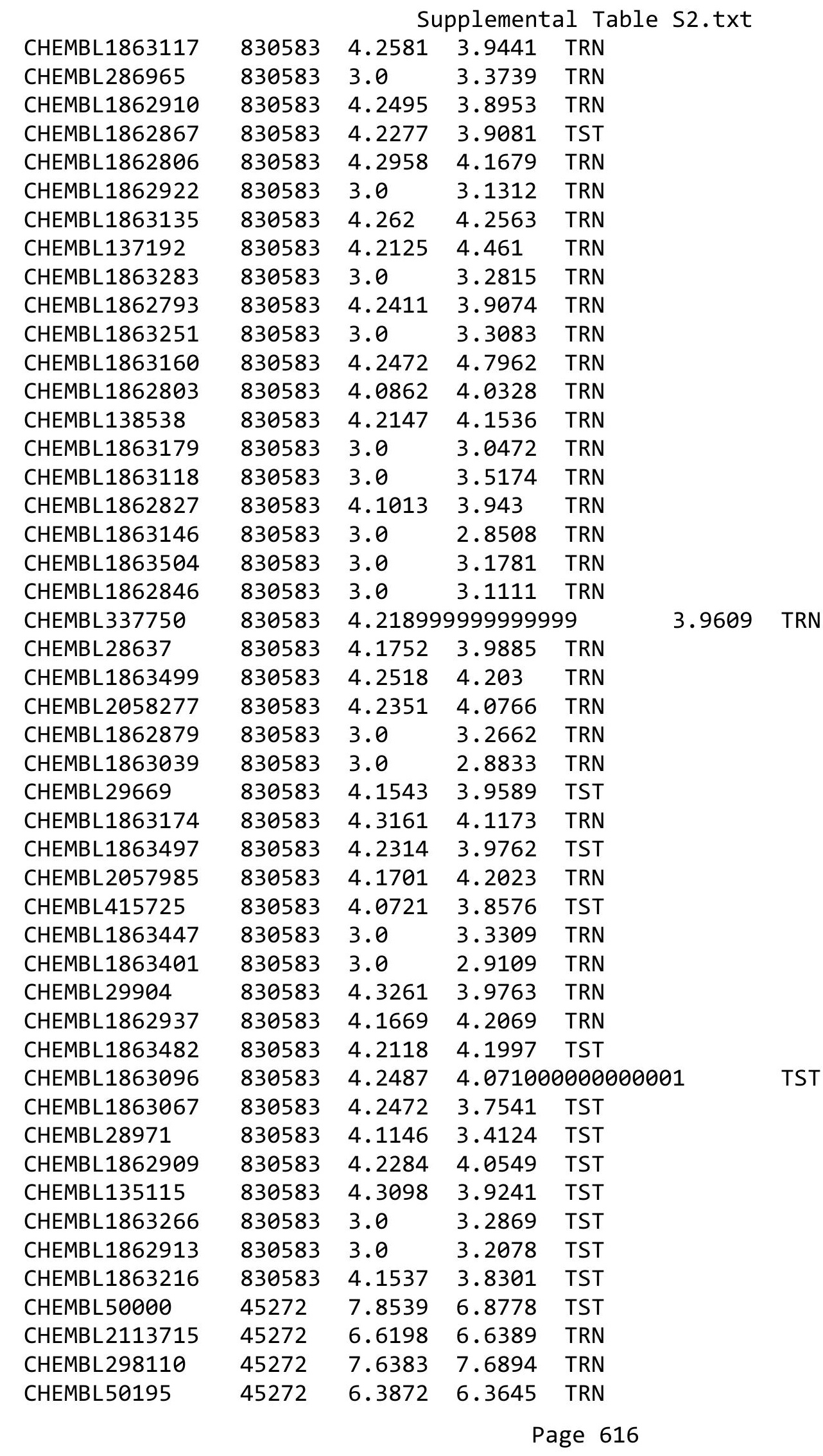




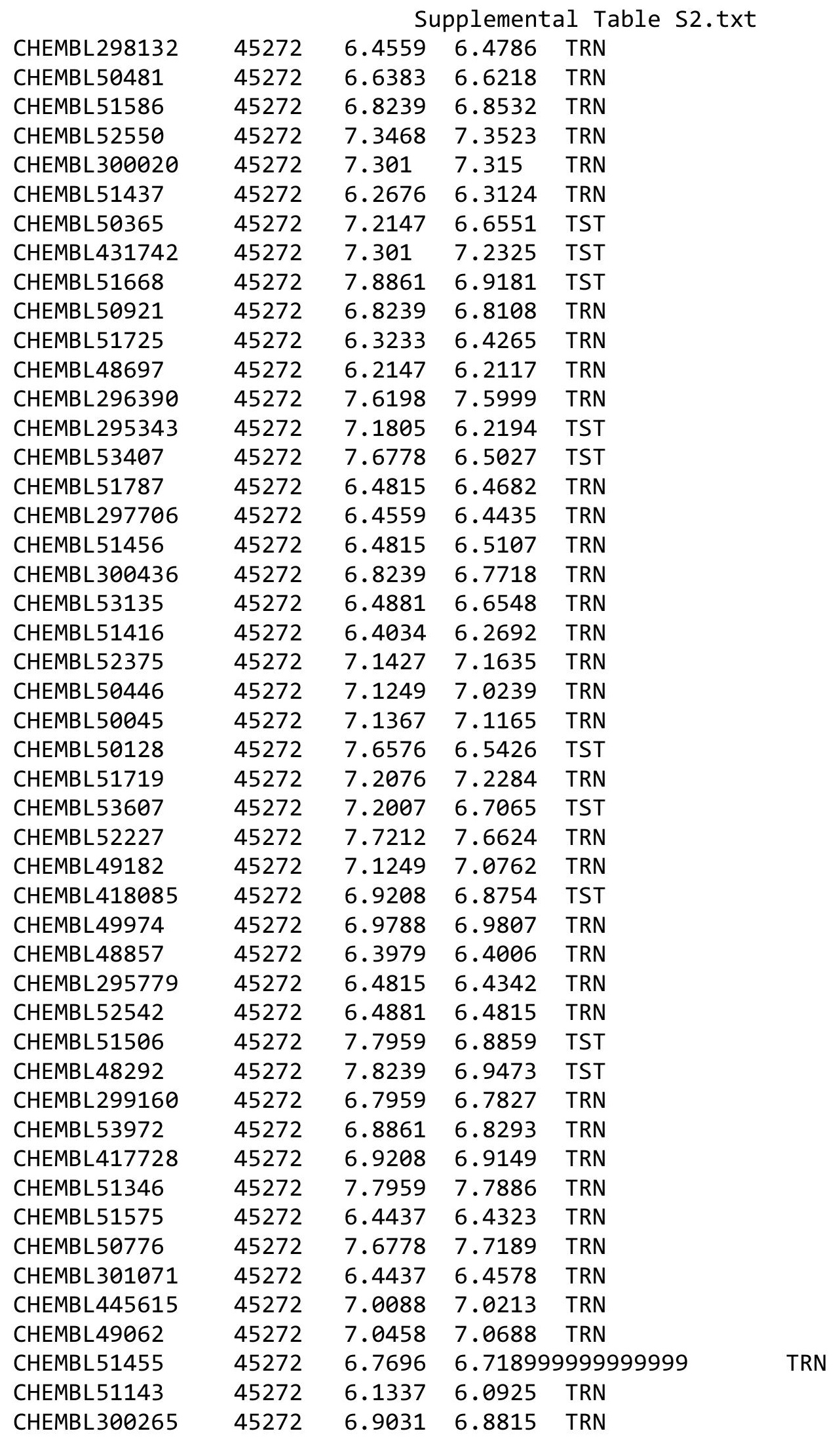

Page 617 


\begin{tabular}{|c|c|c|c|c|c|c|}
\hline & & \multicolumn{5}{|c|}{ Supplemental Table s2.txt } \\
\hline CHEMBL51213 & 45272 & 6.1871 & 6.2325 & TRN & & \\
\hline CHEMBL51200 & 45272 & 6.8097 & 6.8364 & TRN & & \\
\hline CHEMBL297892 & 45272 & 6.2218 & 6.2616 & TRN & & \\
\hline CHEMBL 298755 & 45272 & 7.0969 & 7.0986 & TRN & & \\
\hline CHEMBL50897 & 45272 & 6.7959 & 6.8375 & TRN & & \\
\hline CHEMBL 299744 & 45272 & 6.4685 & 6.4726 & TST & & \\
\hline CHEMBL 2113714 & 45272 & 7.0655 & 6.9194 & TST & & \\
\hline CHEMBL50881 & 45272 & 6.4498 & 6.3664 & TST & & \\
\hline CHEMBL51517 & 45272 & 6.1427 & 6.1965 & TST & & \\
\hline CHEMBL54235 & 45272 & 7.6021 & 6.3989 & TST & & \\
\hline CHEMBL116958 & 213809 & 5.0 & 5.3074 & TRN & & \\
\hline CHEMBL421231 & 213809 & 5.0 & 5.6945 & TRN & & \\
\hline CHEMBL118022 & 213809 & \multicolumn{3}{|c|}{6.718999999999999} & 6.4748 & TRN \\
\hline CHEMBL116454 & 213809 & 5.0 & 4.6472 & TST & & \\
\hline CHEMBL115966 & 213809 & 5.0 & 5.9434 & TRN & & \\
\hline CHEMBL119901 & 213809 & 5.0 & 6.3259 & TST & & \\
\hline CHEMBL119522 & 213809 & 5.0 & 5.66799 & 9999999999 & & TRN \\
\hline CHEMBL118358 & 213809 & 5.0 & 5.3104 & TRN & & \\
\hline CHEMBL115462 & 213809 & 6.0315 & 6.0781 & TRN & & \\
\hline CHEMBL326771 & 213809 & 6.6198 & 6.0598 & TRN & & \\
\hline CHEMBL331055 & 213809 & 5.7447 & 5.8717 & TRN & & \\
\hline CHEMBL119599 & 213809 & 6.4815 & 6.4773 & TRN & & \\
\hline CHEMBL326271 & 213809 & 5.0 & 6.1603 & TRN & & \\
\hline CHEMBL118886 & 213809 & 5.0 & 5.6709 & TRN & & \\
\hline CHEMBL118074 & 213809 & 5.0 & 5.5261 & TRN & & \\
\hline CHEMBL326120 & 213809 & 7.7696 & 7.0268 & TRN & & \\
\hline CHEMBL331662 & 213809 & 5.0 & 6.3179 & TRN & & \\
\hline CHEMBL115971 & 213809 & 7.041 & 6.0978 & TRN & & \\
\hline CHEMBL116363 & 213809 & 5.0 & 5.5761 & TRN & & \\
\hline CHEMBL117279 & 213809 & 6.9208 & 6.0162 & TRN & & \\
\hline CHEMBL419046 & 213809 & 5.8539 & 6.0436 & TST & & \\
\hline CHEMBL119091 & 213809 & 5.0 & 5.5555 & TRN & & \\
\hline CHEMBL117671 & 213809 & 5.0 & 5.7243 & TST & & \\
\hline CHEMBL325651 & 213809 & 5.0 & 5.546 & TST & & \\
\hline CHEMBL115432 & 213809 & 5.0 & 4.5525 & TRN & & \\
\hline CHEMBL324158 & 213809 & 6.0 & 5.8069 & TRN & & \\
\hline CHEMBL434222 & 213809 & 5.0 & 5.9322 & TRN & & \\
\hline CHEMBL115534 & 213809 & 5.0 & 5.2593 & TRN & & \\
\hline CHEMBL117894 & 213809 & 8.2218 & 6.2987 & TRN & & \\
\hline CHEMBL118089 & 213809 & 7.1308 & 6.3342 & TRN & & \\
\hline CHEMBL116089 & 213809 & 6.0 & 5.391 & TRN & & \\
\hline CHEMBL325033 & 213809 & 5.0 & 5.24 & TST & & \\
\hline CHEMBL119733 & 213809 & 7.2218 & 6.9502 & TRN & & \\
\hline CHEMBL119815 & 213809 & 5.0 & 6.6546 & TRN & & \\
\hline CHEMBL117452 & 213809 & 5.0 & 5.5795 & TST & & \\
\hline CHEMBL119348 & 213809 & 5.0 & 5.1938 & TST & & \\
\hline CHEMBL117668 & 213809 & 5.0 & 6.0809 & TRN & & \\
\hline CHEMBL117367 & 213809 & 5.0 & 5.9755 & TST & & \\
\hline
\end{tabular}




\begin{tabular}{|c|c|c|c|c|c|}
\hline & & \multicolumn{4}{|c|}{ Supplemental Table S2.txt } \\
\hline CHEMBL115742 & 213809 & 5.8153 & 6.0446 & TRN & \\
\hline CHEMBL115637 & 213809 & 7.1024 & 5.8811 & TRN & \\
\hline CHEMBL119705 & 213809 & 6.6198 & 6.505 & TRN & \\
\hline CHEMBL116307 & 213809 & 5.0 & 5.2611 & TRN & \\
\hline CHEMBL115431 & 213809 & 6.7696 & 5.1302 & TRN & \\
\hline CHEMBL117198 & 213809 & 7.0706 & 6.5615 & TRN & \\
\hline CHEMBL119532 & 213809 & 5.0 & 5.9912 & TRN & \\
\hline CHEMBL116152 & 213809 & 7.0 & 6.4364 & TRN & \\
\hline CHEMBL324824 & 213809 & 6.3279 & 4.8082 & TRN & \\
\hline CHEMBL118300 & 213809 & 6.4318 & 5.33799 & 9999999999 & TRN \\
\hline CHEMBL119183 & 213809 & 7.6383 & 6.1246 & TRN & \\
\hline CHEMBL117453 & 213809 & 4.9586 & 5.5775 & TRN & \\
\hline CHEMBL118114 & 213809 & 5.0 & 5.7613 & TST & \\
\hline CHEMBL325286 & 213809 & 6.1079 & 6.4662 & TST & \\
\hline CHEMBL117565 & 213809 & 5.0 & 5.6619 & TST & \\
\hline CHEMBL324133 & 213809 & 6.8861 & 5.8006 & TRN & \\
\hline CHEMBL115815 & 213809 & 5.0 & 4.6092 & TRN & \\
\hline CHEMBL117571 & 213809 & 4.3979 & 5.2691 & TRN & \\
\hline CHEMBL 325618 & 213809 & 5.0 & 5.8238 & TRN & \\
\hline CHEMBL331584 & 213809 & 5.0 & 6.0162 & TRN & \\
\hline CHEMBL118113 & 213809 & 5.0 & 5.8815 & TST & \\
\hline CHEMBL 323832 & 213809 & 5.0 & 5.1482 & TRN & \\
\hline CHEMBL325893 & 213809 & 6.0706 & 6.5536 & TRN & \\
\hline CHEMBL119732 & 213809 & 6.8539 & 6.1041 & TRN & \\
\hline CHEMBL119039 & 213809 & 8.301 & 6.6054 & TRN & \\
\hline CHEMBL268567 & 213809 & 4.3979 & 5.6999 & TST & \\
\hline CHEMBL118299 & 213809 & 5.0 & 5.0637 & TRN & \\
\hline CHEMBL118034 & 213809 & 5.0 & 6.1533 & TRN & \\
\hline CHEMBL115981 & 213809 & 5.0 & 4.9972 & TRN & \\
\hline CHEMBL6320 & 213809 & 4.3979 & 5.0698 & TST & \\
\hline CHEMBL326712 & 213809 & 5.0 & 7.9496 & TST & \\
\hline CHEMBL119711 & 213809 & 5.0 & 5.5528 & TST & \\
\hline CHEMBL325184 & 213809 & 7.7212 & 6.5799 & TRN & \\
\hline CHEMBL331248 & 213809 & 5.0 & 5.5766 & TRN & \\
\hline CHEMBL119886 & 213809 & 5.0 & 6.3567 & TRN & \\
\hline CHEMBL117936 & 213809 & 7.1938 & 7.0323 & TRN & \\
\hline CHEMBL118518 & 213809 & 5.4089 & 5.9869 & TRN & \\
\hline CHEMBL119523 & 213809 & 6.0555 & 5.597 & TRN & \\
\hline CHEMBL117093 & 213809 & 5.0 & 6.8023 & TST & \\
\hline CHEMBL326360 & 213809 & 5.0 & 5.5477 & TST & \\
\hline CHEMBL 267678 & 213809 & 5.0 & 5.3541 & TST & \\
\hline CHEMBL115960 & 213809 & 6.3768 & 6.5071 & TRN & \\
\hline CHEMBL119501 & 213809 & 5.0 & 4.9109 & TRN & \\
\hline CHEMBL117746 & 213809 & 5.0 & 6.0809 & TRN & \\
\hline CHEMBL117292 & 213809 & 5.0 & 5.5931 & TST & \\
\hline CHEMBL6370 & 213809 & 4.3979 & 5.3699 & TST & \\
\hline CHEMBL116070 & 213809 & 7.3188 & 6.6955 & TRN & \\
\hline CHEMBL1383849 & 809378 & 5.1986 & 5.1323 & TRN & \\
\hline
\end{tabular}




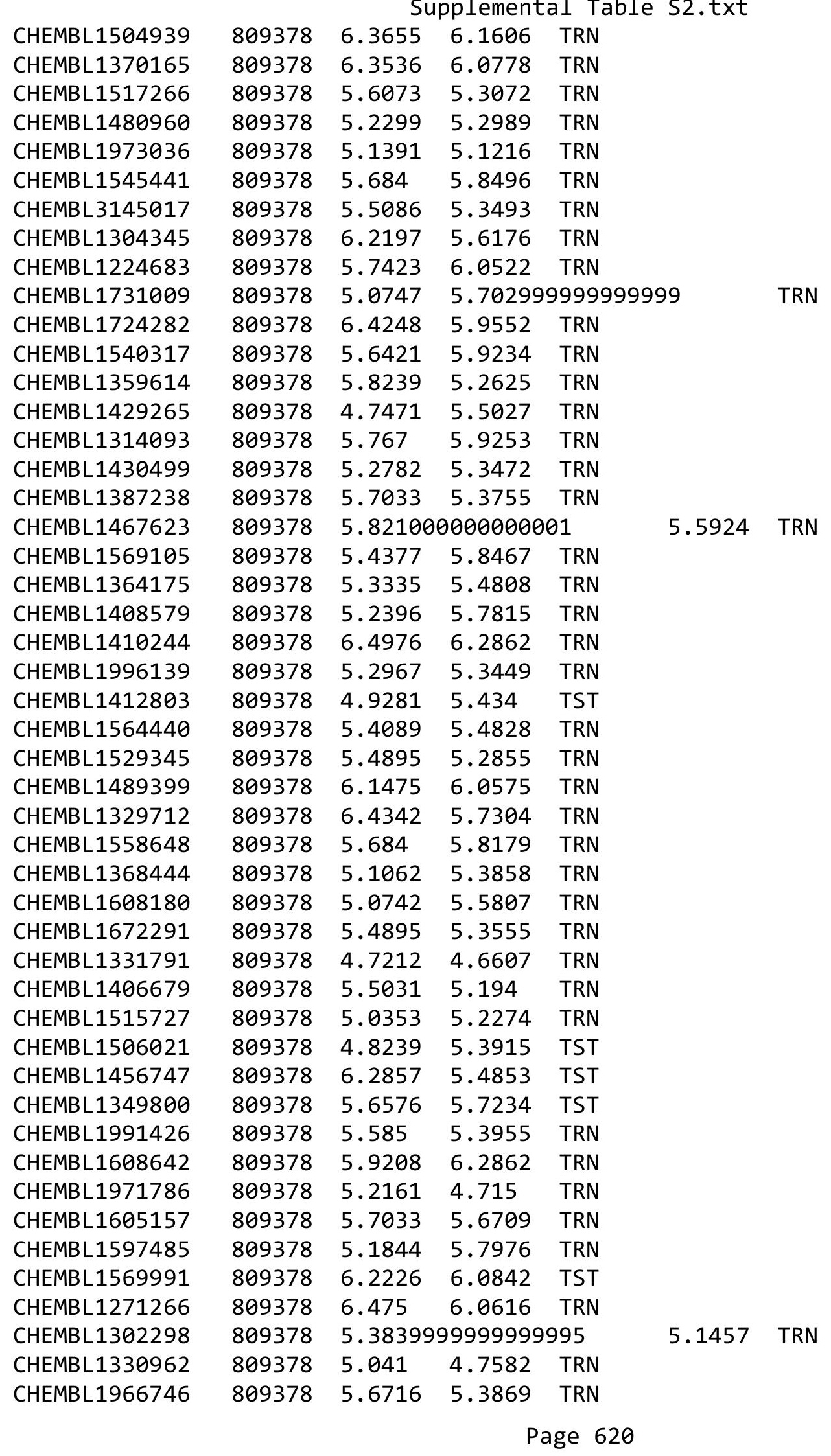




\begin{tabular}{|c|c|c|c|c|c|c|}
\hline & & \multicolumn{5}{|c|}{ Supplemental Table s2.txt } \\
\hline CHEMBL1985932 & 809378 & 5.3546 & 5.2734 & TRN & & \\
\hline CHEMBL1540065 & 809378 & 5.4989 & 6.0217 & TRN & & \\
\hline CHEMBL1518926 & 809378 & 5.6696 & 5.3703 & TRN & & \\
\hline CHEMBL1405311 & 809378 & 5.6576 & 5.4183 & TRN & & \\
\hline CHEMBL1331149 & 809378 & 5.9586 & 6.21899 & 9999999999 & & TRN \\
\hline CHEMBL1381758 & 809378 & 5.6234 & 5.691 & TST & & \\
\hline CHEMBL1360394 & 809378 & 4.82100 & 0000000 & $\partial 1$ & 5.3453 & TRN \\
\hline CHEMBL1996666 & 809378 & 5.2684 & 5.6494 & TRN & & \\
\hline CHEMBL1993173 & 809378 & 5.8633 & 5.4355 & TRN & & \\
\hline CHEMBL1964442 & 809378 & 6.0214 & 5.6041 & TRN & & \\
\hline CHEMBL1334491 & 809378 & 5.5045 & 5.8603 & TRN & & \\
\hline CHEMBL220259 & 809378 & 5.983 & 5.5227 & TRN & & \\
\hline CHEMBL1550032 & 809378 & 5.8097 & 5.5969 & TRN & & \\
\hline CHEMBL1971015 & 809378 & 5.6576 & 5.4067 & TRN & & \\
\hline CHEMBL1721094 & 809378 & 5.9469 & 5.4513 & TRN & & \\
\hline CHEMBL1537922 & 809378 & 5.699 & 5.9332 & TRN & & \\
\hline CHEMBL1445488 & 809378 & 5.9666 & 5.9779 & TST & & \\
\hline CHEMBL1566674 & 809378 & 5.1129 & 5.4899 & TRN & & \\
\hline CHEMBL1735536 & 809378 & 5.2013 & 5.6667 & TST & & \\
\hline CHEMBL1487426 & 809378 & 3.0969 & 3.7043 & TRN & & \\
\hline CHEMBL1405203 & 809378 & 5.7258 & 6.0046 & TRN & & \\
\hline CHEMBL1991021 & 809378 & 5.7825 & 5.574 & TRN & & \\
\hline CHEMBL1460464 & 809378 & 3.0969 & 4.5061 & TST & & \\
\hline CHEMBL1364192 & 809378 & 5.4001 & 5.3232 & TRN & & \\
\hline CHEMBL1509369 & 809378 & 5.3546 & 5.1786 & TRN & & \\
\hline CHEMBL1308781 & 809378 & 4.2299 & 4.5049 & TRN & & \\
\hline CHEMBL1350887 & 809378 & 6.3883 & 5.8634 & TRN & & \\
\hline CHEMBL1301519 & 809378 & 4.9281 & 5.6461 & TRN & & \\
\hline CHEMBL1982044 & 809378 & 5.7144 & 5.4727 & TRN & & \\
\hline CHEMBL1585855 & 809378 & 4.9469 & 5.4013 & TRN & & \\
\hline CHEMBL1484595 & 809378 & 5.7077 & 5.3808 & TST & & \\
\hline CHEMBL1489711 & 809378 & 5.9393 & 5.1652 & TRN & & \\
\hline CHEMBL1453902 & 809378 & 6.1135 & 5.7077 & TRN & & \\
\hline CHEMBL1463248 & 809378 & 6.1772 & 6.4822 & TRN & & \\
\hline CHEMBL1412602 & 809378 & 5.0052 & 5.4812 & TST & & \\
\hline CHEMBL1580036 & 809378 & 6.1101 & 5.7446 & TRN & & \\
\hline CHEMBL1470628 & 809378 & 5.4724 & 5.6902 & TRN & & \\
\hline CHEMBL1485717 & 809378 & 6.0742 & 6.0933 & TRN & & \\
\hline CHEMBL1407021 & 809378 & 5.1662 & 4.9057 & TRN & & \\
\hline CHEMBL1586977 & 809378 & 4.8386 & 4.8192 & TRN & & \\
\hline CHEMBL1991440 & 809378 & 5.9031 & 5.2874 & TRN & & \\
\hline CHEMBL1461216 & 809378 & 6.341 & 5.9495 & TRN & & \\
\hline CHEMBL1529185 & 809378 & 5.3197 & 5.7031 & TRN & & \\
\hline CHEMBL1466912 & 809378 & 5.2495 & 5.34399 & 9999999999 & & TRN \\
\hline CHEMBL1310336 & 809378 & 5.5302 & 5.4235 & TRN & & \\
\hline CHEMBL1407203 & 809378 & 5.26200 & 000000006 & 205 & 5.8035 & TRN \\
\hline CHEMBL1511981 & 809378 & 5.9547 & 5.6204 & TRN & & \\
\hline CHEMBL1893914 & 809378 & 5.6216 & 5.4073 & TRN & & \\
\hline
\end{tabular}




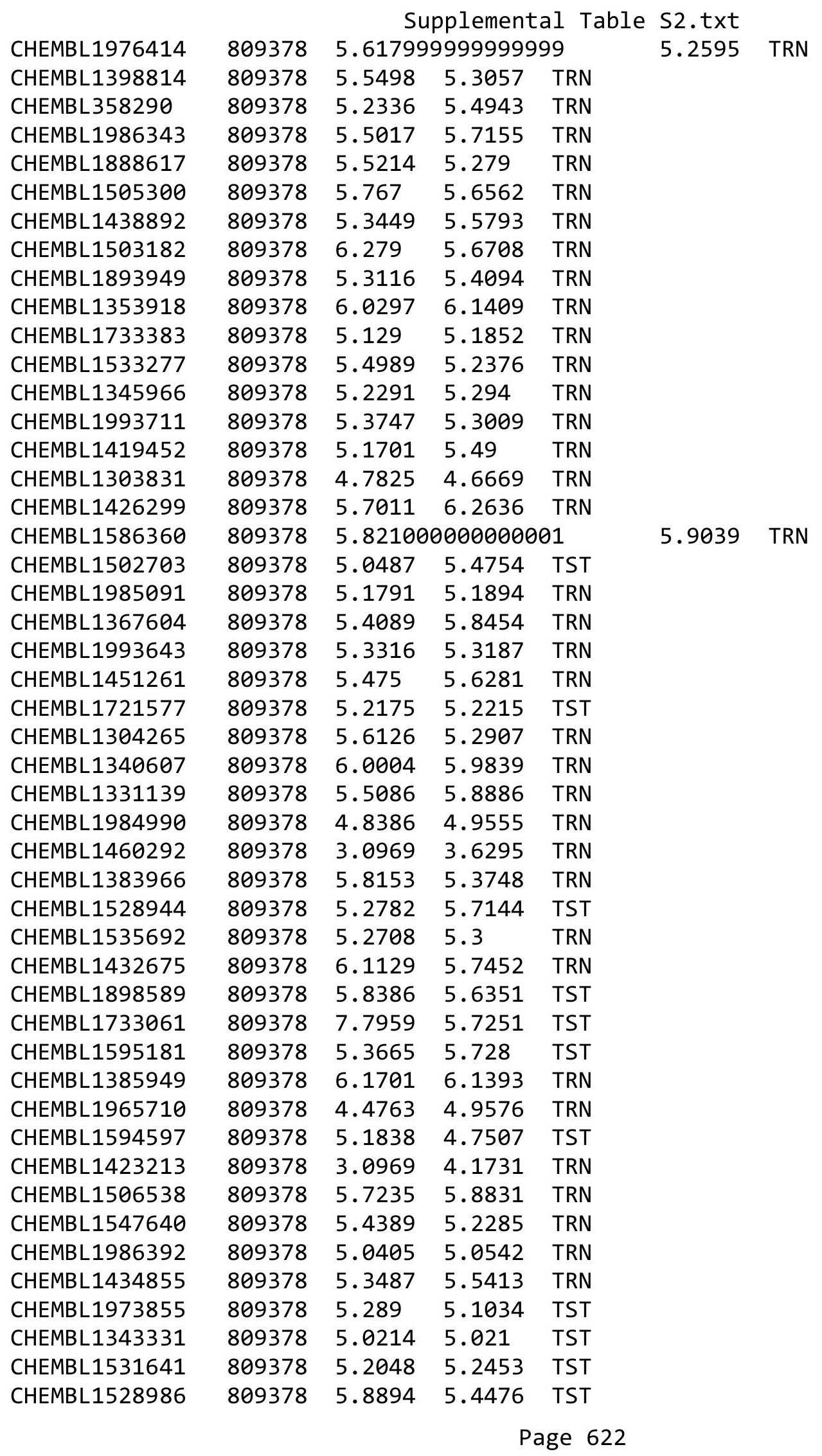




\begin{tabular}{|c|c|c|c|c|c|c|}
\hline & & \multicolumn{5}{|c|}{ Supplemental Table S2.txt } \\
\hline CHEMBL1500616 & 809378 & 5.4622 & 5.5646 & TST & & \\
\hline CHEMBL1875123 & 809378 & 5.3809 & 5.2948 & TST & & \\
\hline CHEMBL1477633 & 809378 & 5.0964 & 5.5197 & TST & & \\
\hline CHEMBL1433062 & 809378 & 6.3288 & 5.8704 & TST & & \\
\hline CHEMBL1421470 & 809378 & 6.0501 & 6.2066 & TST & & \\
\hline CHEMBL1314584 & 809378 & 5.7055 & 5.8796 & TST & & \\
\hline CHEMBL1344075 & 809378 & 5.4881 & 5.9879 & TST & & \\
\hline CHEMBL1417141 & 809378 & 5.6055 & 5.3347 & TST & & \\
\hline CHEMBL1523808 & 809378 & 5.3665 & 5.1334 & TST & & \\
\hline CHEMBL1487101 & 809378 & 5.4763 & 5.9045 & TST & & \\
\hline CHEMBL1971404 & 809378 & 5.466 & 5.6701 & TST & & \\
\hline CHEMBL1888077 & 809378 & \multicolumn{3}{|c|}{5.2620000000000005} & 5.8054 & TST \\
\hline CHEMBL1478082 & 809378 & 5.9469 & 5.8221 & TST & & \\
\hline CHEMBL1714422 & 809378 & 6.0301 & 5.4555 & TST & & \\
\hline CHEMBL1381413 & 809378 & 6.1319 & 6.0612 & TST & & \\
\hline CHEMBL1421970 & 809378 & 5.7423 & 6.1858 & TST & & \\
\hline CHEMBL1584150 & 809378 & 5.4881 & 5.5465 & TST & & \\
\hline CHEMBL1725497 & 809378 & 5.4056 & 5.3291 & TST & & \\
\hline CHEMBL1982391 & 809378 & 5.6676 & 5.3674 & TST & & \\
\hline CHEMBL1976599 & 809378 & 5.6968 & 5.4138 & TST & & \\
\hline CHEMBL120750 & 36933 & 7.699 & 7.2995 & TRN & & \\
\hline CHEMBL121847 & 36933 & 8.4437 & 8.9355 & TST & & \\
\hline CHEMBL121125 & 36933 & 7.7447 & 7.4237 & TST & & \\
\hline CHEMBL329466 & 36933 & 7.0915 & 7.6473 & TRN & & \\
\hline CHEMBL327837 & 36933 & 8.1739 & 7.3145 & TRN & & \\
\hline CHEMBL334145 & 36933 & 9.3768 & 9.0869 & TRN & & \\
\hline CHEMBL120762 & 36933 & 7.6576 & 7.6517 & TRN & & \\
\hline CHEMBL328598 & 36933 & 7.4318 & 7.3616 & TRN & & \\
\hline CHEMBL93886 & 36933 & 9.1938 & 9.1846 & TRN & & \\
\hline CHEMBL327862 & 36933 & 7.6778 & 7.5718 & TRN & & \\
\hline CHEMBL332897 & 36933 & 9.2596 & 9.115 & TST & & \\
\hline CHEMBL120549 & 36933 & 7.1192 & 7.4926 & TRN & & \\
\hline CHEMBL443269 & 36933 & 8.9586 & 8.971 & TST & & \\
\hline CHEMBL 93547 & 36933 & 8.7696 & 9.1555 & TRN & & \\
\hline CHEMBL120716 & 36933 & 6.8861 & 7.3716 & TST & & \\
\hline CHEMBL281386 & 36933 & \multicolumn{3}{|c|}{9.283999999999999} & 9.1708 & $1 \mathrm{~K}$ \\
\hline CHEMBL121404 & 36933 & 6.0 & 7.681 & TRN & & \\
\hline CHEMBL333978 & 36933 & 8.7959 & 9.1261 & TRN & & \\
\hline CHEMBL 331063 & 36933 & 7.2518 & 7.5435 & TRN & & \\
\hline CHEMBL120199 & 36933 & 9.6198 & 9.1994 & TRN & & \\
\hline CHEMBL120457 & 36933 & 9.1739 & 9.1816 & TRN & & \\
\hline CHEMBL315878 & 36933 & 8.4949 & 8.9549 & TRN & & \\
\hline CHEMBL118431 & 36933 & 7.5229 & 7.5233 & TST & & \\
\hline CHEMBL93735 & 36933 & 7.8861 & 7.425 & TRN & & \\
\hline CHEMBL330571 & 36933 & 8.6383 & 8.9791 & TRN & & \\
\hline CHEMBL334083 & 36933 & 7.3872 & 7.6433 & TST & & \\
\hline CHEMBL331886 & 36933 & 7.1192 & 7.2787 & TRN & & \\
\hline CHEMBL92821 & 36933 & 7.8861 & 7.443 & TRN & & \\
\hline
\end{tabular}




\begin{tabular}{|c|c|c|c|c|c|}
\hline & & \multicolumn{4}{|c|}{ Supplemental Table S2.txt } \\
\hline CHEMBL 338740 & 36933 & 9.1612 & 9.0653 & TRN & \\
\hline CHEMBL419321 & 36933 & 7.0458 & 7.45200 & 0000000001 & TRN \\
\hline CHEMBL120605 & 36933 & 6.7959 & 7.3367 & TST & \\
\hline CHEMBL406791 & 36933 & 7.6383 & 7.7143 & TRN & \\
\hline CHEMBL90774 & 36933 & 9.301 & 9.0675 & TRN & \\
\hline CHEMBL92654 & 36933 & 9.6198 & 9.2257 & TRN & \\
\hline CHEMBL92472 & 36933 & 9.2218 & 9.0041 & TRN & \\
\hline CHEMBL431887 & 36933 & 8.5686 & 9.1494 & TST & \\
\hline CHEMBL433646 & 36933 & 9.699 & 9.1259 & TST & \\
\hline CHEMBL120290 & 36933 & 8.0969 & 7.4234 & TRN & \\
\hline CHEMBL327982 & 36933 & 8.5376 & 9.1216 & TRN & \\
\hline CHEMBL93226 & 36933 & 9.4559 & 9.1407 & TRN & \\
\hline CHEMBL907 & 36933 & 8.5528 & 9.0514 & TST & \\
\hline CHEMBL331475 & 36933 & 8.4318 & 9.1016 & TRN & \\
\hline CHEMBL91287 & 36933 & 7.0 & 7.3402 & TRN & \\
\hline CHEMBL121416 & 36933 & 8.6021 & 8.7522 & TRN & \\
\hline CHEMBL329616 & 36933 & 9.7447 & 9.1057 & TRN & \\
\hline CHEMBL94002 & 36933 & 9.1135 & 9.1188 & TRN & \\
\hline CHEMBL329541 & 36933 & 6.9788 & 7.2658 & TRN & \\
\hline CHEMBL331078 & 36933 & 7.699 & 7.3912 & TRN & \\
\hline CHEMBL 94221 & 36933 & 8.8861 & 9.0332 & TRN & \\
\hline CHEMBL334192 & 36933 & 8.6778 & 9.0866 & TST & \\
\hline CHEMBL 327718 & 36933 & 8.0223 & 7.5041 & TRN & \\
\hline CHEMBL93289 & 36933 & 7.2596 & 7.2897 & TRN & \\
\hline CHEMBL123767 & 36933 & 8.7696 & 9.0891 & TST & \\
\hline CHEMBL283975 & 36933 & 8.699 & 8.9818 & TST & \\
\hline CHEMBL90011 & 36933 & 9.3372 & 8.9546 & TRN & \\
\hline CHEMBL 333800 & 36933 & 9.0969 & 8.7702 & TRN & \\
\hline CHEMBL 2098408 & 1561970 & 4.9626 & 4.9491 & TRN & \\
\hline CHEMBL3775545 & 1561970 & 7.4089 & 7.4132 & TRN & \\
\hline CHEMBL3774672 & 1561970 & 5.0555 & 5.0567 & TRN & \\
\hline CHEMBL3774710 & 1561970 & 6.1249 & 6.1484 & TRN & \\
\hline CHEMBL3775637 & 1561970 & 4.7696 & 4.7679 & TRN & \\
\hline CHEMBL3774747 & 1561970 & 6.4089 & 6.4045 & TRN & \\
\hline CHEMBL3775956 & 1561970 & 6.684 & 6.6807 & TRN & \\
\hline CHEMBL3775454 & 1561970 & 5.6383 & 5.6424 & TRN & \\
\hline CHEMBL3775121 & 1561970 & 7.4437 & 7.4393 & TRN & \\
\hline CHEMBL3774798 & 1561970 & 5.301 & 6.4231 & TST & \\
\hline CHEMBL3775899 & 1561970 & 7.301 & 7.24299 & 9999999999 & TRN \\
\hline CHEMBL3775145 & 1561970 & 6.7825 & 6.7911 & TRN & \\
\hline CHEMBL 3775802 & 1561970 & 5.5528 & 5.3269 & TST & \\
\hline CHEMBL3775465 & 1561970 & 6.8268 & 6.8377 & TRN & \\
\hline CHEMBL 2098433 & 1561970 & 5.1938 & 5.2043 & TRN & \\
\hline CHEMBL3774456 & 1561970 & 7.3872 & 7.3855 & TRN & \\
\hline CHEMBL3775362 & 1561970 & 6.7696 & 6.0209 & TST & \\
\hline CHEMBL3775953 & 1561970 & 7.2147 & 7.1524 & TRN & \\
\hline CHEMBL 3774437 & 1561970 & 5.6383 & 5.6371 & TRN & \\
\hline CHEMBL3774418 & 1561970 & 3.0 & 4.5097 & TST & \\
\hline
\end{tabular}


Supplemental Table S2.txt

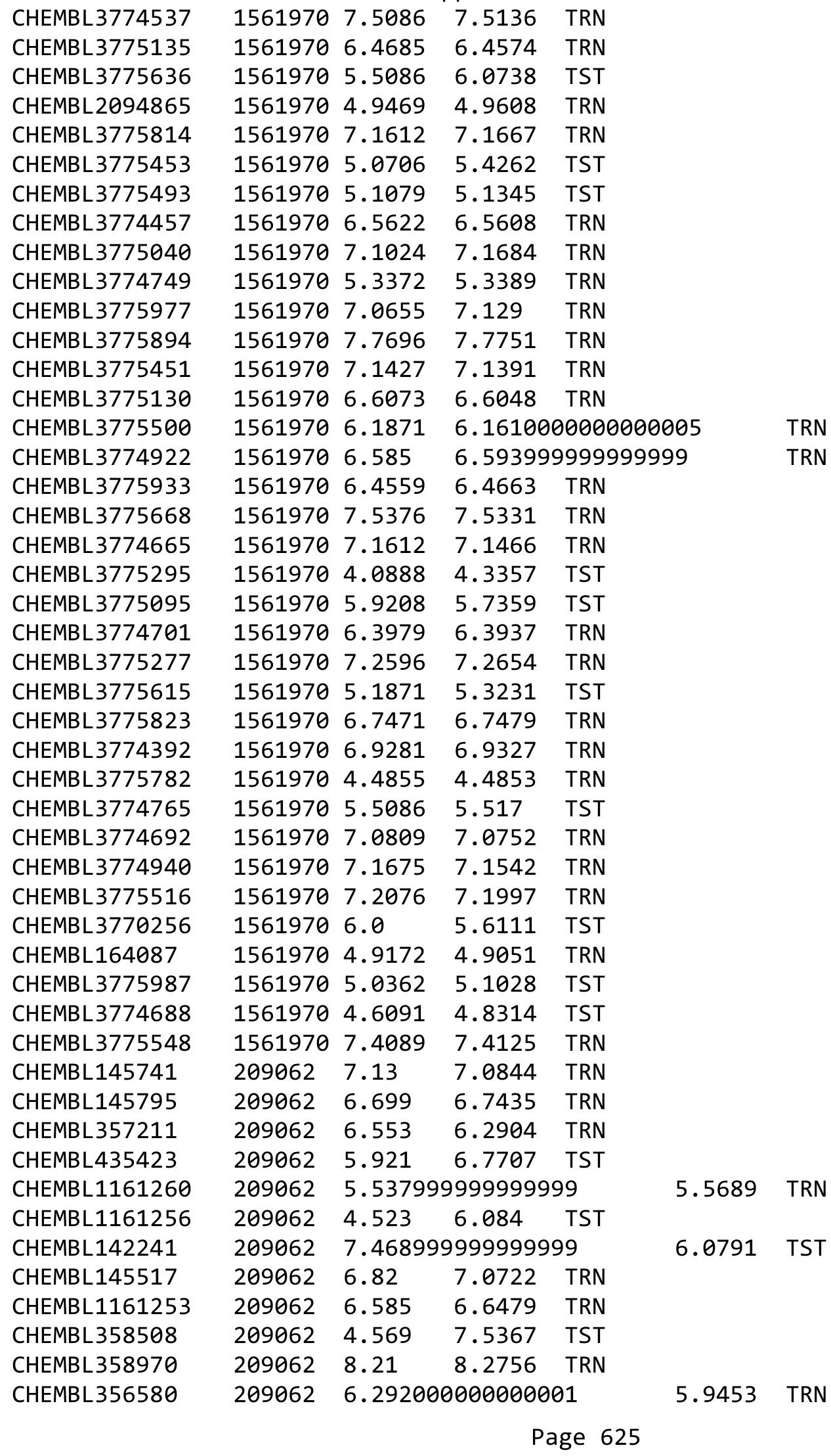




\begin{tabular}{|c|c|c|c|c|c|c|c|}
\hline \multicolumn{7}{|c|}{ pplemental T } & \\
\hline CHEMBL358999 & 209062 & 4.886 & 7.7497 & TST & & & \\
\hline CHEMBL358110 & 209062 & 8.37 & 8.2935 & TRN & & & \\
\hline CHEMBL356711 & 209062 & 6.921 & 6.624 & TST & & & \\
\hline CHEMBL144847 & 209062 & 4.77 & 4.9726 & TST & & & \\
\hline CHEMBL344552 & 209062 & 8.301 & 8.3549 & TRN & & & \\
\hline CHEMBL145504 & 209062 & 7.19 & 7.3656 & TRN & & & \\
\hline CHEMBL145250 & 209062 & 5.638 & 5.7431 & TRN & & & \\
\hline CHEMBL1161263 & 209062 & 4.456 & 5.2582 & TST & & & \\
\hline CHEMBL323101 & 209062 & 8.481 & 8.3395 & TRN & & & \\
\hline CHEMBL145108 & 209062 & 7.432 & 7.4346 & TRN & & & \\
\hline CHEMBL358491 & 209062 & 6.456 & 6.5114 & TRN & & & \\
\hline CHEMBL1161245 & 209062 & 6.244 & 6.1633 & TRN & & & \\
\hline CHEMBL358961 & 209062 & 6.046 & 6.0828 & TRN & & & \\
\hline CHEMBL359422 & 209062 & 5.2079 & 99999999 & 99 & 5.7199 & TST & \\
\hline CHEMBL609410 & 209062 & 4.82 & 4.8671 & TRN & & & \\
\hline CHEMBL145630 & 209062 & 7.678 & 7.3656 & TRN & & & \\
\hline CHEMBL143067 & 209062 & 7.051 & 7.2441 & TRN & & & \\
\hline CHEMBL342542 & 209062 & 6.82 & 6.7531 & TRN & & & \\
\hline CHEMBL356348 & 209062 & 7.585 & 7.6998 & TRN & & & \\
\hline CHEMBL143594 & 209062 & 7.721 & 7.7898 & TRN & & & \\
\hline CHEMBL435621 & 209062 & 7.585 & 7.5649 & TRN & & & \\
\hline CHEMBL358366 & 209062 & 7.432 & 7.4519 & TRN & & & \\
\hline CHEMBL357635 & 209062 & 5.5089 & 99999999 & 995 & 5.585 & TRN & \\
\hline CHEMBL344104 & 209062 & 6.638 & 6.746 & TRN & & & \\
\hline CHEMBL358526 & 209062 & 7.229 & 7.2191 & TRN & & & \\
\hline CHEMBL145211 & 209062 & 7.284 & 7.365 & TRN & & & \\
\hline CHEMBL344790 & 209062 & 6.96 & 6.5815 & TST & & & \\
\hline CHEMBL 356792 & 209062 & 6.284 & 6.2833 & TRN & & & \\
\hline CHEMBL344283 & 209062 & 7.237 & 7.2213 & TRN & & & \\
\hline CHEMBL342764 & 209062 & 6.4689 & 99999999 & & 6.3654 & TRN & \\
\hline CHEMBL143205 & 209062 & 6.796 & 6.595 & TRN & & & \\
\hline CHEMBL356071 & 209062 & 6.2 & 6.053 & TRN & & & \\
\hline CHEMBL145223 & 209062 & 5.745 & 5.8139 & TRN & & & \\
\hline CHEMBL342722 & 209062 & 7.886 & 6.8651 & TST & & & \\
\hline CHEMBL423555 & 209062 & 7.16 & 7.084 & TRN & & & \\
\hline CHEMBL318352 & 209062 & 8.06 & 8.1133 & TRN & & & \\
\hline CHEMBL142924 & 209062 & 6.553 & 7.2315 & TST & & & \\
\hline CHEMBL145132 & 209062 & 6.18 & 6.244 & TRN & & & \\
\hline CHEMBL145343 & 209062 & 5.5089 & 99999999 & 995 & 4.4742 & TST & \\
\hline CHEMBL142747 & 209062 & 6.495 & 6.5264 & TRN & & & \\
\hline CHEMBL439810 & 209062 & 5.244 & 5.8008 & TST & & & \\
\hline CHEMBL1161255 & 209062 & $5.137 e$ & 00000000 & 305 & 5.1148 & TRN & \\
\hline CHEMBL359184 & 209062 & 4.36 & 4.6615 & TST & & & \\
\hline CHEMBL141782 & 209062 & 8.13 & 6.0206 & TST & & & \\
\hline CHEMBL145148 & 209062 & $7.377 e$ & 00000000 & & 6.9520 & 0000000001 & TST \\
\hline CHEMBL343254 & 209062 & 6.638 & 6.4844 & TRN & & & \\
\hline CHEMBL343892 & 209062 & 7.77 & 7.7436 & TRN & & & \\
\hline CHEMBL145655 & 209062 & 6.745 & 6.7553 & TRN & & & \\
\hline
\end{tabular}




\begin{tabular}{|c|c|c|c|c|c|c|c|}
\hline \multicolumn{8}{|c|}{ Supplemental Table S2.txt } \\
\hline CHEMBL358081 & 209062 & 7.796 & 7.5741 & TRN & & & \\
\hline CHEMBL1161247 & 209062 & 7.745 & 7.767 & TRN & & & \\
\hline CHEMBL145173 & 209062 & 5.678 & 5.6656 & TRN & & & \\
\hline CHEMBL142312 & 209062 & 6.585 & 7.0083 & TRN & & & \\
\hline CHEMBL320512 & 209062 & 7.444 & 7.4726 & TRN & & & \\
\hline CHEMBL144993 & 209062 & 6.523 & 6.5844 & TRN & & & \\
\hline CHEMBL143501 & 209062 & 4.745 & 4.9614 & TST & & & \\
\hline CHEMBL1161248 & 209062 & 6.921 & 5.4432 & TST & & & \\
\hline CHEMBL358077 & 209062 & 6.678 & 6.7246 & TRN & & & \\
\hline CHEMBL356295 & 209062 & 6.77 & 6.7236 & TRN & & & \\
\hline CHEMBL142417 & 209062 & 7.585 & 7.4956 & TRN & & & \\
\hline CHEMBL1161244 & 209062 & 6.301 & 6.3666 & TRN & & & \\
\hline CHEMBL145206 & 209062 & 7.523 & 7.3656 & TRN & & & \\
\hline CHEMBL357210 & 209062 & 7.85 & 7.0227 & TST & & & \\
\hline CHEMBL356094 & 209062 & 6.284 & 6.2504 & TRN & & & \\
\hline CHEMBL143910 & 209062 & 5.42 & 4.7439 & TST & & & \\
\hline CHEMBL145664 & 209062 & 8.38 & 8.328 & TRN & & & \\
\hline CHEMBL423195 & 209062 & 7.495 & 7.2777 & TRN & & & \\
\hline CHEMBL142447 & 209062 & 7.37700 & 00000000 & & $7.4060 e$ & 0000000001 & TRN \\
\hline CHEMBL1161250 & 209062 & 5.96 & 5.7855 & TRN & & & \\
\hline CHEMBL341636 & 209062 & 6.149 & 6.5057 & TRN & & & \\
\hline CHEMBL104815 & 209062 & 7.638 & 7.5527 & TRN & & & \\
\hline CHEMBL357660 & 209062 & 7.018 & 6.9075 & TRN & & & \\
\hline CHEMBL429002 & 209062 & 6.37700 & 00000000 & & 6.4169 & TRN & \\
\hline CHEMBL348255 & 209062 & 6.553 & 6.8267 & TRN & & & \\
\hline CHEMBL146492 & 209062 & 6.46899 & 99999999 & 99 & 6.6176 & TRN & \\
\hline CHEMBL444601 & 209062 & 6.921 & 6.1051 & TST & & & \\
\hline CHEMBL358085 & 209062 & 6.16100 & 00000000 & 205 & 6.1536 & TRN & \\
\hline CHEMBL225705 & 435462 & 5.0 & 5.6549 & TRN & & & \\
\hline CHEMBL225728 & 435462 & 5.0 & 6.1711 & TRN & & & \\
\hline CHEMBL226504 & 435462 & 5.0 & 6.3313 & TST & & & \\
\hline CHEMBL226451 & 435462 & 5.0 & 4.6937 & TRN & & & \\
\hline CHEMBL 225695 & 435462 & 6.2218 & 6.5963 & TRN & & & \\
\hline CHEMBL225678 & 435462 & 6.6676 & 6.4813 & TRN & & & \\
\hline CHEMBL225670 & 435462 & 7.0809 & 6.6279 & TRN & & & \\
\hline CHEMBL226486 & 435462 & 7.0 & 7.3044 & TRN & & & \\
\hline CHEMBL225886 & 435462 & 6.9586 & 6.5596 & TRN & & & \\
\hline CHEMBL 387630 & 435462 & 6.0132 & 6.5311 & TST & & & \\
\hline CHEMBL225706 & 435462 & 6.0 & 5.8265 & TRN & & & \\
\hline CHEMBL387486 & 435462 & 6.6383 & 5.8375 & TRN & & & \\
\hline CHEMBL449402 & 435462 & 6.9101 & 7.245 & TRN & & & \\
\hline CHEMBL388192 & 435462 & 6.1367 & 6.4461 & TRN & & & \\
\hline CHEMBL 225707 & 435462 & 5.0 & 5.0183 & TRN & & & \\
\hline CHEMBL225671 & 435462 & 7.2366 & 6.8803 & TRN & & & \\
\hline CHEMBL225679 & 435462 & 7.0555 & 6.7501 & TRN & & & \\
\hline CHEMBL 376844 & 435462 & 6.7932 & 6.9232 & TRN & & & \\
\hline CHEMBL225694 & 435462 & 6.1549 & 5.5319 & TRN & & & \\
\hline CHEMBL387629 & 435462 & 5.0 & 5.8533 & TST & & & \\
\hline
\end{tabular}




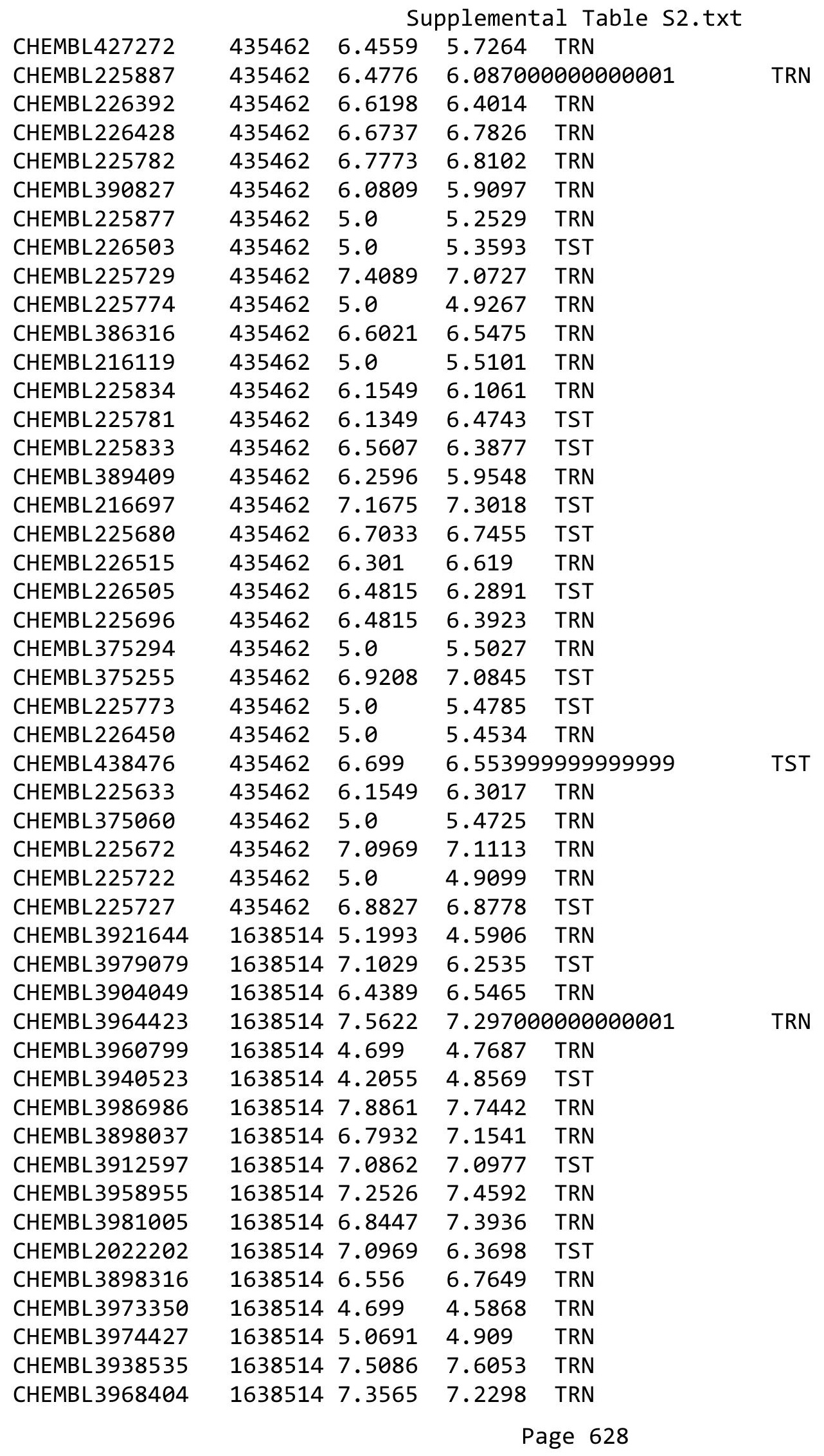


Supplemental Table S2.txt

\begin{tabular}{|c|c|c|c|c|}
\hline CHEMBL3971903 & 1638514 & 6.3072 & 6.3661 & TRN \\
\hline CHEMBL3978936 & 1638514 & 7.0545 & 7.124 & TRN \\
\hline CHEMBL3958119 & 1638514 & 8.5287 & 7.8397 & TRN \\
\hline CHEMBL3911250 & 1638514 & 5.0867 & 4.968 & TRN \\
\hline CHEMBL 3951997 & 1638514 & 7.2628 & 7.0764 & TRN \\
\hline CHEMBL3900928 & 1638514 & 7.3979 & 7.5664 & TRN \\
\hline CHEMBL3926091 & 1638514 & 4.699 & 4.6245 & TRN \\
\hline CHEMBL3939468 & 1638514 & 5.767 & 5.8803 & TRN \\
\hline CHEMBL3932765 & 1638514 & 6.4179 & 7.2281 & TST \\
\hline CHEMBL 2024532 & 1638514 & 6.2941 & 6.084 & TRN \\
\hline CHEMBL 2024531 & 1638514 & 7.0655 & 6.5118 & TRN \\
\hline CHEMBL3981372 & 1638514 & 7.1007 & 7.1119 & TRN \\
\hline CHEMBL3949601 & 1638514 & 6.4572 & 6.7408 & TRN \\
\hline CHEMBL 2022201 & 1638514 & 7.2676 & 7.2432 & TRN \\
\hline CHEMBL3923320 & 1638514 & 5.1261 & 5.185 & TRN \\
\hline CHEMBL3960568 & 1638514 & 5.2815 & 5.3641 & TRN \\
\hline CHEMBL 2022199 & 1638514 & 3.699 & 4.4982 & TRN \\
\hline CHEMBL3889708 & 1638514 & 6.9788 & 6.3818 & TST \\
\hline CHEMBL3938868 & 1638514 & 7.3134 & 7.4697 & TRN \\
\hline CHEMBL 3981998 & 1638514 & 4.699 & 4.8041 & TST \\
\hline CHEMBL2024104 & 1638514 & 6.1824 & 6.0915 & TRN \\
\hline CHEMBL 2024102 & 1638514 & 6.0 & 6.5842 & TRN \\
\hline CHEMBL3934969 & 1638514 & 7.6038 & 7.3307 & TRN \\
\hline CHEMBL3955768 & 1638514 & 7.2557 & 7.1075 & TRN \\
\hline CHEMBL3935035 & 1638514 & 4.2055 & 4.1578 & TRN \\
\hline CHEMBL 2024545 & 1638514 & 7.3768 & 7.66299 & 9999999999 \\
\hline CHEMBL 2024534 & 1638514 & 5.3536 & 5.2051 & TRN \\
\hline CHEMBL3951468 & 1638514 & 6.3316 & 6.3541 & TRN \\
\hline CHEMBL3937493 & 1638514 & 7.0013 & 6.9767 & TRN \\
\hline CHEMBL 3981754 & 1638514 & 5.2708 & 5.2978 & TRN \\
\hline CHEMBL3957140 & 1638514 & 6.3372 & 6.0957 & TRN \\
\hline CHEMBL3972365 & 1638514 & 4.699 & 4.8034 & TRN \\
\hline CHEMBL3974836 & 1638514 & 7.2676 & 7.3188 & TRN \\
\hline CHEMBL3978676 & 1638514 & 4.699 & 4.7509 & TRN \\
\hline CHEMBL3973061 & 1638514 & 7.0177 & 6.7805 & TRN \\
\hline CHEMBL3899228 & 1638514 & 6.6615 & 6.5635 & TRN \\
\hline CHEMBL3939002 & 1638514 & 7.5528 & 7.3774 & TRN \\
\hline CHEMBL3941723 & 1638514 & 7.2668 & 6.7125 & TRN \\
\hline CHEMBL3936546 & 1638514 & 6.0343 & 6.0237 & TST \\
\hline CHEMBL3973758 & 1638514 & 4.699 & 4.7967 & TRN \\
\hline CHEMBL2024103 & 1638514 & 6.0 & 6.7797 & TRN \\
\hline CHEMBL2024536 & 1638514 & 7.3768 & 7.1997 & TRN \\
\hline CHEMBL3957071 & 1638514 & 6.9666 & 7.2209 & TRN \\
\hline CHEMBL3904459 & 1638514 & 7.064 & 7.2145 & TRN \\
\hline CHEMBL 3895398 & 1638514 & 7.3468 & 7.4373 & TRN \\
\hline CHEMBL3917585 & 1638514 & 5.2147 & 4.7062 & TRN \\
\hline CHEMBL 3982855 & 1638514 & 7.7878 & 7.678 & TRN \\
\hline CHEMBL3893592 & 1638514 & 7.5768 & 7.5947 & TRN \\
\hline
\end{tabular}


Supplemental Table S2.txt

\begin{tabular}{|c|c|c|c|c|}
\hline CHEMBL3965851 & 1638514 & 7.2668 & 7.2425 & TRN \\
\hline CHEMBL3944415 & 1638514 & 6.5302 & 6.4169 & TRN \\
\hline CHEMBL3962207 & 1638514 & 7.1013 & 7.1171 & TRN \\
\hline CHEMBL3896289 & 1638514 & 6.5918 & 6.9116 & TST \\
\hline CHEMBL3951084 & 1638514 & 7.6021 & 7.5473 & TRN \\
\hline CHEMBL 3980427 & 1638514 & 7.27 & 7.3518 & TRN \\
\hline CHEMBL3972390 & 1638514 & 7.5157 & 6.7566 & TST \\
\hline CHEMBL3918679 & 1638514 & 6.0232 & 5.9743 & TRN \\
\hline CHEMBL3969791 & 1638514 & 7.5243 & 7.5692 & TRN \\
\hline CHEMBL3914363 & 1638514 & 6.9957 & 6.9961 & TRN \\
\hline CHEMBL3926099 & 1638514 & 7.9431 & 7.9921 & TRN \\
\hline CHEMBL3985115 & 1638514 & 7.27 & 7.4303 & TRN \\
\hline CHEMBL3974864 & 1638514 & 6.8794 & 7.0296 & TRN \\
\hline CHEMBL 2024535 & 1638514 & 6.6946 & 6.6529 & TRN \\
\hline CHEMBL3890425 & 1638514 & $6.7620 e$ & 00000000 & 6.7946 \\
\hline CHEMBL3965941 & 1638514 & 7.699 & 6.5043 & TST \\
\hline CHEMBL3932278 & 1638514 & 7.1487 & 6.7417 & TRN \\
\hline CHEMBL3914480 & 1638514 & 4.699 & 4.7697 & TRN \\
\hline CHEMBL3930439 & 1638514 & 6.5935 & 6.2096 & TST \\
\hline CHEMBL1096381 & 1638514 & 8.4134 & 8.23200 & 0000000001 \\
\hline CHEMBL 2024533 & 1638514 & 7.0132 & 6.9558 & TRN \\
\hline CHEMBL3947686 & 1638514 & 7.3665 & 7.1772 & TRN \\
\hline CHEMBL3984277 & 1638514 & 7.3565 & 7.2184 & TRN \\
\hline CHEMBL 3948453 & 1638514 & 7.5436 & 7.6236 & TRN \\
\hline CHEMBL3901995 & 1638514 & 7.1549 & 6.9732 & TRN \\
\hline CHEMBL 3950962 & 1638514 & 7.4763 & 7.6796 & TRN \\
\hline CHEMBL 3974467 & 1638514 & 7.6216 & 7.4496 & TRN \\
\hline CHEMBL 3940247 & 1638514 & 7.7212 & 7.5541 & TRN \\
\hline CHEMBL 3979338 & 1638514 & 5.1599 & 5.7003 & TST \\
\hline CHEMBL3902085 & 1638514 & 7.3706 & 6.1459 & TST \\
\hline CHEMBL 3978990 & 1638514 & 6.6038 & 6.7746 & TRN \\
\hline CHEMBL3965361 & 1638514 & 5.3665 & 5.6927 & TRN \\
\hline CHEMBL 3920286 & 1638514 & 6.3645 & 6.405 & TRN \\
\hline CHEMBL 3950366 & 1638514 & 7.4202 & 7.5413 & TRN \\
\hline CHEMBL3970118 & 1638514 & 6.6055 & 6.3601 & TST \\
\hline CHEMBL319291 & 1638514 & 6.4045 & 6.2195 & TST \\
\hline CHEMBL 3903637 & 1638514 & 3.699 & 3.8841 & TRN \\
\hline CHEMBL3969372 & 1638514 & 7.3565 & 7.1189 & TRN \\
\hline CHEMBL 3948564 & 1638514 & 3.699 & 3.8224 & TRN \\
\hline CHEMBL3979329 & 1638514 & 4.2055 & 6.5461 & TST \\
\hline CHEMBL3983933 & 1638514 & 7.5086 & 7.8754 & TRN \\
\hline CHEMBL 3985023 & 1638514 & 5.7773 & 5.8593 & TRN \\
\hline CHEMBL3942870 & 1638514 & 7.2924 & 7.2588 & TRN \\
\hline CHEMBL 3970647 & 1638514 & 7.7959 & 7.9224 & TRN \\
\hline CHEMBL3945967 & 1638514 & 6.9788 & 6.9425 & TRN \\
\hline CHEMBL3902715 & 1638514 & 6.9066 & 6.8867 & TRN \\
\hline CHEMBL 3953698 & 1638514 & 5.6289 & 5.55 & TRN \\
\hline CHEMBL 2024546 & 1638514 & 7.699 & 7.6219 & TRN \\
\hline
\end{tabular}


Supplemental Table S2.txt

\begin{tabular}{|c|c|c|c|c|}
\hline CHEMBL3966128 & 1638514 & 4.699 & 6.1899 & TST \\
\hline CHEMBL3984744 & 1638514 & 6.0 & 5.9735 & TRN \\
\hline CHEMBL3975789 & 1638514 & 7.6216 & 7.3291 & TST \\
\hline CHEMBL3972149 & 1638514 & 5.6162 & 6.7041 & TST \\
\hline CHEMBL 3937812 & 1638514 & 7.2676 & 7.277 & TRN \\
\hline CHEMBL3909915 & 1638514 & 5.3915 & 5.7172 & TRN \\
\hline CHEMBL3953817 & 1638514 & 4.699 & 6.3156 & TST \\
\hline CHEMBL 3945234 & 1638514 & 6.399 & 6.2291 & TRN \\
\hline CHEMBL3929997 & 1638514 & 6.9031 & 6.9538 & TRN \\
\hline CHEMBL 3890410 & 1638514 & 7.0227 & 7.0259 & TRN \\
\hline CHEMBL 3912573 & 1638514 & 6.2865 & 6.1084 & TRN \\
\hline CHEMBL 3979063 & 1638514 & 5.7258 & 6.4139 & TST \\
\hline CHEMBL 3925831 & 1638514 & 7.8268 & 7.8285 & TRN \\
\hline CHEMBL 3969680 & 1638514 & 7.5969 & 6.7334 & TST \\
\hline CHEMBL 3898058 & 1638514 & 7.3768 & 7.3045 & TST \\
\hline CHEMBL3918019 & 1638514 & 7.0969 & 5.9854 & TST \\
\hline CHEMBL3976214 & 1638514 & 7.4449 & 7.6615 & TST \\
\hline CHEMBL 3953294 & 1638514 & 8.0862 & 7.9879 & TST \\
\hline CHEMBL3928753 & 1638514 & 7.9586 & 6.0101 & TST \\
\hline CHEMBL 3955485 & 1638514 & 7.5129 & 8.1583 & TST \\
\hline CHEMBL3913685 & 1638514 & 7.6778 & 7.5427 & TST \\
\hline CHEMBL3917265 & 1638514 & 6.7825 & 6.54700 & 0000000001 \\
\hline CHEMBL 3937147 & 1638514 & 6.1785 & 6.4482 & TST \\
\hline CHEMBL 3952194 & 1638514 & 7.3316 & 7.1837 & TST \\
\hline CHEMBL 3943166 & 1638514 & 6.3936 & 6.8564 & TST \\
\hline CHEMBL3890711 & 1638514 & 7.6198 & 6.2506 & TST \\
\hline CHEMBL43929 & 2526 & 7.0 & 6.763 & TRN \\
\hline CHEMBL 289436 & 2526 & 5.5 & 5.7995 & TRN \\
\hline CHEMBL42257 & 2526 & 5.4 & 5.5696 & TRN \\
\hline CHEMBL 296189 & 2526 & 6.8 & 6.5419 & TRN \\
\hline CHEMBL43496 & 2526 & 5.5 & 6.0528 & TRN \\
\hline CHEMBL 295228 & 2526 & 5.4 & 6.55399 & 9999999999 \\
\hline CHEMBL 265991 & 2526 & 5.6 & 5.8851 & TRN \\
\hline CHEMBL 297784 & 2526 & 5.7 & 5.9574 & TST \\
\hline CHEMBL 296090 & 2526 & 7.2 & 7.1073 & TRN \\
\hline CHEMBL43808 & 2526 & 6.4 & 6.1007 & TRN \\
\hline CHEMBL417713 & 2526 & 7.2 & 5.82700 & 0000000001 \\
\hline CHEMBL 297445 & 2526 & 6.2 & 6.3528 & TRN \\
\hline CHEMBL 295020 & 2526 & 5.6 & 6.0591 & TRN \\
\hline CHEMBL 296236 & 2526 & 5.3 & 5.0079 & TRN \\
\hline CHEMBL38027 & 2526 & 5.4 & 5.5139 & TRN \\
\hline CHEMBL 288108 & 2526 & 6.3 & 6.4275 & TRN \\
\hline CHEMBL 289063 & 2526 & 6.2 & 6.1067 & TST \\
\hline CHEMBL40579 & 2526 & 5.4 & 5.3554 & TRN \\
\hline CHEMBL 38407 & 2526 & 5.4 & 6.0738 & TST \\
\hline CHEMBL 290666 & 2526 & 5.4 & 5.5775 & TRN \\
\hline CHEMBL 297043 & 2526 & 6.6 & 6.4554 & TRN \\
\hline CHEMBL41792 & 2526 & 6.2 & 5.8894 & TRN \\
\hline
\end{tabular}




\begin{tabular}{|c|c|c|c|c|c|}
\hline \multicolumn{6}{|c|}{ Supplemental Table s2.txt } \\
\hline CHEMBL14352 & 2526 & 6.0 & 5.7724 & TRN & \\
\hline CHEMBL41510 & 2526 & 5.8 & 5.5123 & TRN & \\
\hline CHEMBL42681 & 2526 & 7.5 & 6.2512 & TST & \\
\hline CHEMBL296687 & 2526 & 5.9 & 5.9049 & TRN & \\
\hline CHEMBL44206 & 2526 & 5.4 & 5.3795 & TRN & \\
\hline CHEMBL41940 & 2526 & 6.3 & 6.1307 & TRN & \\
\hline CHEMBL416806 & 2526 & 5.8 & 5.895 & TRN & \\
\hline CHEMBL44015 & 2526 & 5.6 & 5.7993 & TRN & \\
\hline CHEMBL42806 & 2526 & 5.9 & 6.0798 & TRN & \\
\hline CHEMBL41153 & 2526 & 5.3 & 5.8648 & TRN & \\
\hline CHEMBL42276 & 2526 & 5.6 & 6.2731 & TST & \\
\hline CHEMBL42273 & 2526 & 6.2 & 6.1825 & TRN & \\
\hline CHEMBL44095 & 2526 & 6.4 & 6.69799 & 99999999995 & TRN \\
\hline CHEMBL42024 & 2526 & 6.8 & 6.8264 & TRN & \\
\hline CHEMBL40698 & 2526 & 5.7 & 5.581 & TRN & \\
\hline CHEMBL 276140 & 2526 & 6.4 & 6.0539 & TRN & \\
\hline CHEMBL40946 & 2526 & 6.2 & 6.1549 & TRN & \\
\hline CHEMBL443518 & 2526 & 6.2 & 6.0119 & TRN & \\
\hline CHEMBL42463 & 2526 & 6.9 & 6.6594 & TST & \\
\hline CHEMBL44552 & 2526 & 6.2 & 5.9795 & TST & \\
\hline CHEMBL431729 & 2526 & 5.3 & 5.5697 & TST & \\
\hline CHEMBL43916 & 2526 & 7.2 & 7.0706 & TRN & \\
\hline CHEMBL42758 & 2526 & 5.6 & 5.7088 & TRN & \\
\hline CHEMBL43633 & 2526 & 5.7 & 5.8899 & TRN & \\
\hline CHEMBL 288129 & 2526 & 6.3 & 6.1913 & TRN & \\
\hline CHEMBL 290395 & 2526 & 5.6 & 5.635 & TRN & \\
\hline CHEMBL38911 & 2526 & 6.1 & 5.9903 & TRN & \\
\hline CHEMBL40342 & 2526 & 6.2 & 5.7264 & TRN & \\
\hline CHEMBL41347 & 2526 & 5.3 & 6.1213 & TST & \\
\hline CHEMBL 296791 & 2526 & 5.5 & 5.3818 & TRN & \\
\hline CHEMBL40699 & 2526 & 5.3 & 6.0596 & TST & \\
\hline CHEMBL40341 & 2526 & 5.2 & 5.935 & TST & \\
\hline CHEMBL41389 & 2526 & 5.8 & 5.7233 & TST & \\
\hline CHEMBL1406051 & 737422 & 4.7144 & 4.602 & TRN & \\
\hline CHEMBL1541034 & 737422 & 5.1649 & 5.0295 & TRN & \\
\hline CHEMBL1322943 & 737422 & 4.9031 & 4.8048 & TRN & \\
\hline CHEMBL1200847 & 737422 & 5.1911 & 4.9504 & TST & \\
\hline CHEMBL1574219 & 737422 & 5.1765 & 5.4267 & TRN & \\
\hline CHEMBL1379467 & 737422 & 4.6615 & 4.8144 & TST & \\
\hline CHEMBL1503238 & 737422 & 4.5376 & 5.2627 & TST & \\
\hline CHEMBL1565806 & 737422 & 3.0 & 3.5012 & TRN & \\
\hline CHEMBL1342598 & 737422 & 4.7375 & 5.0634 & TRN & \\
\hline CHEMBL1978997 & 737422 & 4.71 & 4.9368 & TRN & \\
\hline CHEMBL1487135 & 737422 & 4.9281 & 4.8144 & TRN & \\
\hline CHEMBL1522953 & 737422 & 4.9101 & 4.8547 & TRN & \\
\hline CHEMBL1583997 & 737422 & 5.0264 & 4.9793 & TRN & \\
\hline CHEMBL1463480 & 737422 & 4.4828 & 4.9729 & TRN & \\
\hline CHEMBL1572280 & 737422 & 5.2255 & 5.37 & TST & \\
\hline & & & & 632 & \\
\hline
\end{tabular}


Supplemental Table S2.txt

\begin{tabular}{|c|c|c|c|c|c|}
\hline CHEMBL1303810 & 737422 & 5.684 & 5.6662 & TRN & \\
\hline CHEMBL1988138 & 737422 & 4.9626 & 5.2438 & TRN & \\
\hline CHEMBL1367432 & 737422 & 4.9172 & 5.1165 & TRN & \\
\hline CHEMBL1300391 & 737422 & 4.7878 & 4.8387 & TRN & \\
\hline CHEMBL1304750 & 737422 & 5.06 & 4.751 & TST & \\
\hline CHEMBL1478401 & 737422 & 4.7352 & 4.8643 & TRN & \\
\hline CHEMBL1392140 & 737422 & 5.0521 & 4.8063 & TRN & \\
\hline CHEMBL1421736 & 737422 & 6.4202 & 5.4835 & TRN & \\
\hline CHEMBL1494336 & 737422 & 4.6234 & 4.5483 & TRN & \\
\hline CHEMBL1389702 & 737422 & 4.7696 & 4.9184 & TRN & \\
\hline CHEMBL1560290 & 737422 & 4.4789 & 4.6093 & TRN & \\
\hline CHEMBL1302758 & 737422 & 5.0146 & 4.7526 & TST & \\
\hline CHEMBL211969 & 737422 & 5.6819 & 5.4267 & TRN & \\
\hline CHEMBL1304513 & 737422 & 5.4134 & 5.2439 & TRN & \\
\hline CHEMBL1995364 & 737422 & 4.6038 & 4.5522 & TRN & \\
\hline CHEMBL1510030 & 737422 & 5.1255 & 4.9939 & TRN & \\
\hline CHEMBL1387069 & 737422 & 4.8601 & 4.9088 & TRN & \\
\hline CHEMBL1369392 & 737422 & 5.4763 & 6.3244 & TRN & \\
\hline CHEMBL1410897 & 737422 & 5.0742 & 5.1776 & TRN & \\
\hline CHEMBL1313174 & 737422 & 5.059 & 4.8394 & TRN & \\
\hline CHEMBL1553717 & 737422 & 4.8697 & 4.8002 & TRN & \\
\hline CHEMBL1470485 & 737422 & 5.7375 & 5.3538 & TST & \\
\hline CHEMBL1549738 & 737422 & 5.3526 & 5.37299 & 9999999999 & TRN \\
\hline CHEMBL1401698 & 737422 & 4.9318 & 5.1617 & TRN & \\
\hline CHEMBL1495590 & 737422 & 4.8097 & 4.9421 & TRN & \\
\hline CHEMBL1505636 & 737422 & 5.857 & 5.5784 & TRN & \\
\hline CHEMBL1364072 & 737422 & 4.9586 & 5.1732 & TST & \\
\hline CHEMBL1318817 & 737422 & 5.4237 & 5.6899 & TRN & \\
\hline CHEMBL 3192555 & 737422 & 4.9245 & 5.2877 & TRN & \\
\hline CHEMBL546576 & 737422 & 4.5467 & 4.8059 & TRN & \\
\hline CHEMBL1995800 & 737422 & 5.8827 & 5.675 & TRN & \\
\hline CHEMBL1372598 & 737422 & 4.9666 & 4.7942 & TRN & \\
\hline CHEMBL1554169 & 737422 & 5.2933 & 5.2986 & TRN & \\
\hline CHEMBL1359792 & 737422 & 4.8125 & 5.0902 & TRN & \\
\hline CHEMBL1547145 & 737422 & 4.5214 & 4.8187 & TRN & \\
\hline CHEMBL1399896 & 737422 & 5.2636 & 5.1407 & TRN & \\
\hline CHEMBL1419625 & 737422 & 4.9031 & 4.7257 & TRN & \\
\hline CHEMBL1390546 & 737422 & 4.7595 & 4.7546 & TRN & \\
\hline CHEMBL1515506 & 737422 & 5.8239 & 5.8294 & TRN & \\
\hline CHEMBL1331798 & 737422 & 4.8416 & 4.7942 & TRN & \\
\hline CHEMBL3192609 & 737422 & 5.1325 & 5.2632 & TST & \\
\hline CHEMBL1549334 & 737422 & 4.4776 & 4.598 & TRN & \\
\hline CHEMBL1409835 & 737422 & 5.2557 & 5.0179 & TST & \\
\hline CHEMBL1986259 & 737422 & 7.699 & 7.4404 & TRN & \\
\hline CHEMBL1561609 & 737422 & 5.8097 & 5.4644 & TRN & \\
\hline CHEMBL1549975 & 737422 & 4.8327 & 4.8236 & TRN & \\
\hline CHEMBL1345116 & 737422 & 4.4597 & 4.4927 & TRN & \\
\hline CHEMBL1453108 & 737422 & 4.9281 & 5.1161 & TRN & \\
\hline
\end{tabular}




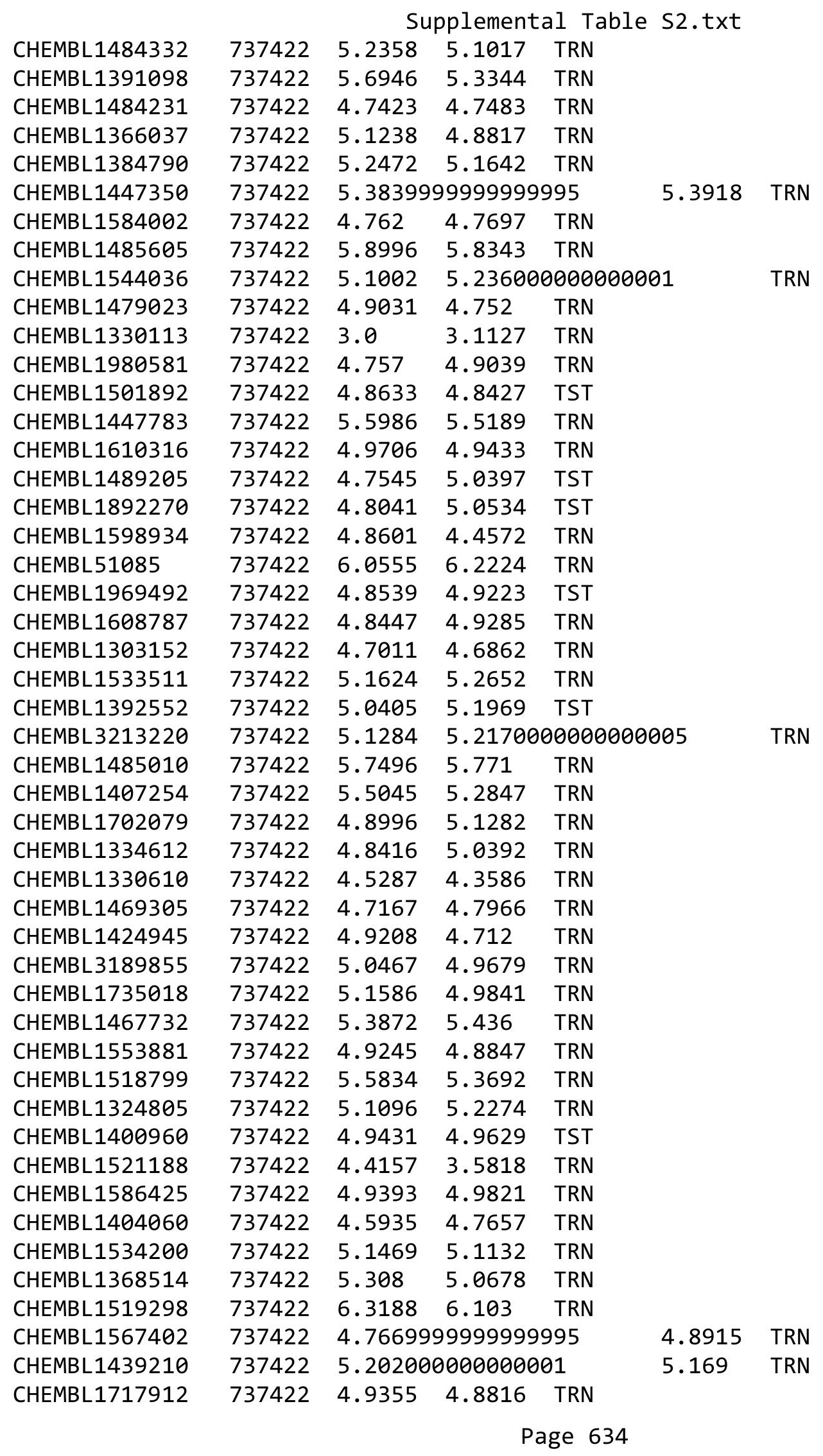




\begin{tabular}{|c|c|c|c|c|c|}
\hline & & \multicolumn{4}{|c|}{ Supplemental Table S2.txt } \\
\hline CHEMBL1561256 & 737422 & 4.2581 & 4.7739 & TRN & \\
\hline CHEMBL1371138 & 737422 & 5.0511 & 5.2288 & TRN & \\
\hline CHEMBL3198175 & 737422 & 5.3665 & 5.1069 & TRN & \\
\hline CHEMBL1450616 & 737422 & 5.5346 & 5.6606 & TRN & \\
\hline CHEMBL1549175 & 737422 & 5.6421 & 5.2188 & TST & \\
\hline CHEMBL1527341 & 737422 & 4.9208 & 4.9246 & TRN & \\
\hline CHEMBL1581799 & 737422 & 4.2083 & 4.4292 & TRN & \\
\hline CHEMBL1984894 & 737422 & 5.6536 & 5.5248 & TRN & \\
\hline CHEMBL1408586 & 737422 & 4.8894 & 4.8322 & TRN & \\
\hline CHEMBL1546440 & 737422 & 4.644 & 4.8851 & TRN & \\
\hline CHEMBL1503205 & 737422 & 4.8539 & 4.9559 & TRN & \\
\hline CHEMBL1466519 & 737422 & 5.1302 & 5.0671 & TRN & \\
\hline CHEMBL1353110 & 737422 & 5.8601 & 5.5572 & TRN & \\
\hline CHEMBL1372447 & 737422 & 5.1331 & 5.1677 & TRN & \\
\hline CHEMBL3199050 & 737422 & 6.5686 & 6.8761 & TST & \\
\hline CHEMBL1554002 & 737422 & 4.7399 & 4.8204 & TST & \\
\hline CHEMBL1376212 & 737422 & 4.7235 & 5.1277 & TST & \\
\hline CHEMBL1315414 & 737422 & 5.0996 & 4.9659 & TST & \\
\hline CHEMBL1363382 & 737422 & 5.4776 & 5.2223 & TST & \\
\hline CHEMBL1533040 & 737422 & 5.5031 & 3.5422 & TST & \\
\hline CHEMBL1376392 & 737422 & 5.6308 & 5.2631 & TST & \\
\hline CHEMBL1964878 & 737422 & 5.0061 & 5.1888 & TST & \\
\hline CHEMBL1303703 & 737422 & 5.1463 & 4.8793 & TST & \\
\hline CHEMBL1542058 & 737422 & 4.7986 & 5.1253 & TST & \\
\hline CHEMBL1562493 & 737422 & 5.1296 & 5.1648 & TST & \\
\hline CHEMBL1335988 & 737422 & 5.2472 & 5.1785 & TST & \\
\hline CHEMBL1459930 & 737422 & 5.5214 & 5.2576 & TST & \\
\hline CHEMBL1463422 & 737422 & 5.5751 & 5.2609 & TST & \\
\hline CHEMBL1559558 & 737422 & 4.7595 & 4.80399 & 9999999999 & TST \\
\hline CHEMBL1315006 & 737422 & 5.0287 & 4.9646 & TST & \\
\hline CHEMBL1304814 & 737422 & 4.9508 & 5.0812 & TST & \\
\hline CHEMBL1505875 & 737422 & 5.1524 & 4.7428 & TST & \\
\hline CHEMBL1384531 & 737422 & 4.3778 & 4.6609 & TST & \\
\hline CHEMBL1471900 & 737422 & 5.6091 & 5.4745 & TST & \\
\hline CHEMBL3731117 & 1537627 & 8.0867 & 8.4624 & TRN & \\
\hline CHEMBL3728016 & 1537627 & 5.7932 & 6.3399 & TRN & \\
\hline CHEMBL3731616 & 1537627 & 6.0 & 5.90600 & 0000000001 & TRN \\
\hline CHEMBL3729237 & 1537627 & 6.0 & 6.5263 & TST & \\
\hline CHEMBL3730793 & 1537627 & 8.383 & 8.4365 & TRN & \\
\hline CHEMBL3728640 & 1537627 & 8.1945 & 7.518 & TRN & \\
\hline CHEMBL3730345 & 1537627 & 6.7696 & 6.7827 & TST & \\
\hline CHEMBL3727767 & 1537627 & 7.7696 & 7.9402 & TRN & \\
\hline CHEMBL3731156 & 1537627 & 6.0 & 6.3742 & TRN & \\
\hline CHEMBL3727959 & 1537627 & 7.3979 & 6.7073 & TRN & \\
\hline CHEMBL3729524 & 1537627 & 7.7423 & 8.0606 & TRN & \\
\hline CHEMBL3729769 & 1537627 & 7.2218 & 5.8259 & TST & \\
\hline CHEMBL3729569 & 1537627 & 7.699 & 7.1246 & TRN & \\
\hline CHEMBL3727796 & 1537627 & 6.0 & 7.5425 & TRN & \\
\hline
\end{tabular}


Supplemental Table S2.txt

\begin{tabular}{|c|c|c|c|c|c|}
\hline CHEMBL3729772 & 1537627 & 8.2069 & 7.3411 & TRN & \\
\hline CHEMBL3729163 & 1537627 & 8.2328 & 8.5369 & TRN & \\
\hline CHEMBL 3728710 & 1537627 & 5.1918 & 7.0069 & TST & \\
\hline CHEMBL 3731320 & 1537627 & 7.1549 & 6.8611 & TRN & \\
\hline CHEMBL 3731804 & 1537627 & 8.0991 & 6.6487 & TST & \\
\hline CHEMBL3731512 & 1537627 & 6.699 & 6.8585 & TRN & \\
\hline CHEMBL3732323 & 1537627 & 8.4067 & 7.4221 & TRN & \\
\hline CHEMBL 3730252 & 1537627 & 8.2358 & 8.1846 & TRN & \\
\hline CHEMBL 3730817 & 1537627 & 8.0334 & 6.9884 & TRN & \\
\hline CHEMBL 3733088 & 1537627 & 6.0 & 6.0621 & TRN & \\
\hline CHEMBL 3733255 & 1537627 & 6.0 & 6.0121 & TRN & \\
\hline CHEMBL3730967 & 1537627 & 8.3904 & 8.3754 & TRN & \\
\hline CHEMBL 3732465 & 1537627 & 6.0 & 6.0771 & TRN & \\
\hline CHEMBL 3732387 & 1537627 & 7.9957 & 7.4283 & TRN & \\
\hline CHEMBL 3732859 & 1537627 & 6.8539 & \multicolumn{2}{|c|}{6.3839999999999995} & TRN \\
\hline CHEMBL 3727745 & 1537627 & 6.1871 & 6.9708 & TRN & \\
\hline CHEMBL3732209 & 1537627 & 6.0 & 6.5529 & TRN & \\
\hline CHEMBL 3727844 & 1537627 & 7.7721 & 7.8553 & TRN & \\
\hline CHEMBL 3732320 & 1537627 & 7.983 & 7.2134 & TRN & \\
\hline CHEMBL 3728416 & 1537627 & 5.7932 & 6.9586 & TRN & \\
\hline CHEMBL 3729252 & 1537627 & 7.7878 & 7.3772 & TST & \\
\hline CHEMBL3730195 & 1537627 & 8.1146 & 7.6951 & TRN & \\
\hline CHEMBL3730695 & 1537627 & 8.5817 & 7.6509 & TRN & \\
\hline CHEMBL 3732640 & 1537627 & 8.0283 & 8.3628 & TRN & \\
\hline CHEMBL 3732287 & 1537627 & 7.4789 & 7.1174 & TRN & \\
\hline CHEMBL3731907 & 1537627 & 7.0969 & 6.7011 & TRN & \\
\hline CHEMBL 3729227 & 1537627 & 7.7212 & 7.8133 & TST & \\
\hline CHEMBL3732674 & 1537627 & 7.7986 & 7.629 & TRN & \\
\hline CHEMBL 3730382 & 1537627 & 7.1772 & 6.9928 & TRN & \\
\hline CHEMBL 3732234 & 1537627 & 7.699 & 7.5327 & TRN & \\
\hline CHEMBL3732153 & 1537627 & 6.6576 & 6.8699 & TRN & \\
\hline CHEMBL3728371 & 1537627 & 6.0 & 7.0586 & TRN & \\
\hline CHEMBL3729535 & 1537627 & 6.0 & 6.0647 & TRN & \\
\hline CHEMBL 3730307 & 1537627 & 6.4935 & 7.4659 & TRN & \\
\hline CHEMBL 3728386 & 1537627 & 6.0 & 6.6709 & TRN & \\
\hline CHEMBL3727946 & 1537627 & 8.0862 & 8.3434 & TRN & \\
\hline CHEMBL 3729804 & 1537627 & 6.0 & 7.4731 & TST & \\
\hline CHEMBL3732417 & 1537627 & 8.1331 & 7.593 & TRN & \\
\hline CHEMBL 3732140 & 1537627 & 6.0 & 6.598 & TRN & \\
\hline CHEMBL3732904 & 1537627 & 6.3872 & 6.8449 & TST & \\
\hline CHEMBL 3728984 & 1537627 & 7.2218 & 6.9321 & TRN & \\
\hline CHEMBL 3728287 & 1537627 & 8.7144 & 7.9544 & TRN & \\
\hline CHEMBL 3728674 & 1537627 & 7.5229 & 7.9206 & TRN & \\
\hline CHEMBL 3728848 & 1537627 & 7.6576 & 7.1487 & TRN & \\
\hline CHEMBL 3728219 & 1537627 & 8.699 & 8.612 & TRN & \\
\hline CHEMBL 3727733 & 1537627 & 5.7932 & 6.5642 & TST & \\
\hline CHEMBL 3732793 & 1537627 & 6.0 & 5.8599 & TRN & \\
\hline CHEMBL3733359 & 1537627 & 6.4935 & 6.2997 & TRN & \\
\hline
\end{tabular}

Page 636 
Supplemental Table S2.txt

\begin{tabular}{|c|c|c|c|c|c|}
\hline CHEMBL3731967 & 1537627 & 8.3019 & 7.8788 & TRN & \\
\hline CHEMBL3729721 & 1537627 & 7.7423 & 6.8787 & TRN & \\
\hline CHEMBL3730391 & 1537627 & 8.1805 & 7.3702 & TRN & \\
\hline CHEMBL3729735 & 1537627 & 8.1427 & 7.3009 & TRN & \\
\hline CHEMBL 3730871 & 1537627 & 7.7721 & 6.9305 & TRN & \\
\hline CHEMBL3733212 & 1537627 & 6.0 & 7.0467 & TRN & \\
\hline CHEMBL3733341 & 1537627 & 8.4377 & 7.3898 & TRN & \\
\hline CHEMBL3733194 & 1537627 & 7.0969 & 7.298999 & 99999999995 & TRN \\
\hline CHEMBL3729443 & 1537627 & 7.8861 & 7.1136 & TRN & \\
\hline CHEMBL3727565 & 1537627 & 8.3028 & 7.528 & TRN & \\
\hline CHEMBL3731955 & 1537627 & 8.0 & 8.2298 & TRN & \\
\hline CHEMBL3730273 & 1537627 & 9.0 & 8.4047 & TRN & \\
\hline CHEMBL3730342 & 1537627 & 6.2757 & 7.7579 & TST & \\
\hline CHEMBL3732758 & 1537627 & 7.9469 & 7.5963 & TRN & \\
\hline CHEMBL3731763 & 1537627 & 6.0 & 6.7312 & TRN & \\
\hline CHEMBL3729672 & 1537627 & 8.0 & 7.5439 & TST & \\
\hline CHEMBL3729832 & 1537627 & 8.4023 & 8.7942 & TRN & \\
\hline CHEMBL3732123 & 1537627 & 6.0 & 7.276 & TRN & \\
\hline CHEMBL3729913 & 1537627 & 8.068 & 7.4884 & TRN & \\
\hline CHEMBL3731322 & 1537627 & 6.0 & 6.8335 & TRN & \\
\hline CHEMBL3730912 & 1537627 & 9.0 & 8.0513 & TRN & \\
\hline CHEMBL3731097 & 1537627 & 5.1918 & 6.9835 & TST & \\
\hline CHEMBL3727829 & 1537627 & 8.2411 & 7.4306 & TRN & \\
\hline CHEMBL3730876 & 1537627 & 6.8861 & 7.176 & TRN & \\
\hline CHEMBL3729944 & 1537627 & 6.9586 & 7.2147 & TST & \\
\hline CHEMBL3731284 & 1537627 & 9.0 & 8.6911 & TRN & \\
\hline CHEMBL3730930 & 1537627 & 6.9208 & 6.8087 & TRN & \\
\hline CHEMBL3732962 & 1537627 & 6.0 & 7.1635 & TRN & \\
\hline CHEMBL3730993 & 1537627 & 7.4134 & 7.7485 & TRN & \\
\hline CHEMBL3728944 & 1537627 & 7.3862 & 8.0713 & TRN & \\
\hline CHEMBL3730808 & 1537627 & 6.0 & 7.2258 & TRN & \\
\hline CHEMBL3733034 & 1537627 & 7.8861 & 7.1986 & TRN & \\
\hline CHEMBL3732343 & 1537627 & 6.0 & 6.6135 & TST & \\
\hline CHEMBL3732627 & 1537627 & 7.9431 & 8.3912 & TRN & \\
\hline CHEMBL3730780 & 1537627 & 7.0 & 7.057 & TST & \\
\hline CHEMBL3732864 & 1537627 & 8.4895 & 8.6203 & TRN & \\
\hline CHEMBL3729553 & 1537627 & 6.0 & 6.7911 & TRN & \\
\hline CHEMBL 3727470 & 1537627 & 6.0 & 6.9361 & TRN & \\
\hline CHEMBL3732808 & 1537627 & 8.0 & 8.2252 & TRN & \\
\hline CHEMBL3730513 & 1537627 & 8.2076 & \multicolumn{2}{|c|}{7.422999999999999} & TRN \\
\hline CHEMBL3727502 & 1537627 & 6.699 & 7.3734 & TRN & \\
\hline CHEMBL 3733221 & 1537627 & 7.5528 & 7.7005 & TRN & \\
\hline CHEMBL3731880 & 1537627 & 7.4067 & 8.2304 & TRN & \\
\hline CHEMBL3731609 & 1537627 & 8.9431 & 7.0784 & TRN & \\
\hline CHEMBL3730148 & 1537627 & 5.8665 & 6.0148 & TST & \\
\hline CHEMBL3730823 & 1537627 & 9.2924 & 8.8111 & TRN & \\
\hline CHEMBL 3732033 & 1537627 & 7.4921 & 8.8635 & TST & \\
\hline CHEMBL 3731498 & 1537627 & 8.7545 & 8.859 & TST & \\
\hline
\end{tabular}




\begin{tabular}{|c|c|c|c|c|c|}
\hline \multicolumn{6}{|c|}{ Supplemental Table S2.txt } \\
\hline CHEMBL 3732400 & 1537627 & 6.0 & 6.3682 & TRN & \\
\hline CHEMBL3727603 & 1537627 & 6.0 & 7.819 & TRN & \\
\hline CHEMBL3728459 & 1537627 & 8.0737 & 8.2567 & TRN & \\
\hline CHEMBL3729402 & 1537627 & 7.0655 & 6.5341 & TRN & \\
\hline CHEMBL3730890 & 1537627 & 7.2924 & 6.8204 & TRN & \\
\hline CHEMBL3733275 & 1537627 & 9.1135 & 8.8209 & TRN & \\
\hline CHEMBL3732262 & 1537627 & 7.1662 & 6.6281 & TRN & \\
\hline CHEMBL 3730700 & 1537627 & 6.5376 & 7.1662 & TRN & \\
\hline CHEMBL3732927 & 1537627 & 7.6126 & 8.139 & TRN & \\
\hline CHEMBL3732823 & 1537627 & 6.52 & 6.8579 & TST & \\
\hline CHEMBL3729883 & 1537627 & 6.0 & 7.0352 & TRN & \\
\hline CHEMBL3731771 & 1537627 & 8.0088 & 7.8498 & TRN & \\
\hline CHEMBL3728789 & 1537627 & 8.0804 & 8.1078 & TRN & \\
\hline CHEMBL3732804 & 1537627 & 7.5229 & 6.9537 & TRN & \\
\hline CHEMBL3728681 & 1537627 & 8.0155 & 7.9109 & TRN & \\
\hline CHEMBL3731528 & 1537627 & 7.5229 & 7.4954 & TRN & \\
\hline CHEMBL3731993 & 1537627 & 6.7959 & 7.0683 & TST & \\
\hline CHEMBL3730758 & 1537627 & 7.0061 & 7.8178 & TST & \\
\hline CHEMBL3730483 & 1537627 & 8.0177 & 7.5437 & TRN & \\
\hline CHEMBL3730210 & 1537627 & 7.1549 & 7.2723 & TRN & \\
\hline CHEMBL3728336 & 1537627 & 6.4949 & 7.0043 & TRN & \\
\hline CHEMBL3730929 & 1537627 & 7.8386 & 7.6409 & TRN & \\
\hline CHEMBL3728116 & 1537627 & 6.0 & 6.0804 & TRN & \\
\hline CHEMBL3732771 & 1537627 & 7.4365 & 6.3619 & TRN & \\
\hline CHEMBL3727890 & 1537627 & 6.0 & 6.90600 & 0000000001 & TRN \\
\hline CHEMBL3731460 & 1537627 & 5.7932 & 5.5261 & TRN & \\
\hline CHEMBL3732447 & 1537627 & 6.0 & 6.5603 & TRN & \\
\hline CHEMBL 3728651 & 1537627 & 6.0 & 6.2402 & TRN & \\
\hline CHEMBL3732769 & 1537627 & 7.699 & 7.4978 & TRN & \\
\hline CHEMBL3729613 & 1537627 & 9.5086 & 6.437 & TST & \\
\hline CHEMBL3732498 & 1537627 & 7.4365 & 7.4574 & TRN & \\
\hline CHEMBL3727898 & 1537627 & 7.3883 & 8.145 & TRN & \\
\hline CHEMBL 3727680 & 1537627 & 6.3872 & 6.5324 & TRN & \\
\hline CHEMBL3731011 & 1537627 & 8.5229 & 8.0785 & TRN & \\
\hline CHEMBL3732460 & 1537627 & 5.7696 & 7.1903 & TST & \\
\hline CHEMBL3733208 & 1537627 & 6.0 & 7.5917 & TST & \\
\hline CHEMBL3731483 & 1537627 & 5.7932 & 6.058 & TRN & \\
\hline CHEMBL3729976 & 1537627 & 7.7905 & 7.3713 & TRN & \\
\hline CHEMBL3729051 & 1537627 & 7.8539 & 8.0334 & TST & \\
\hline CHEMBL3728626 & 1537627 & 6.0 & 6.9063 & TRN & \\
\hline CHEMBL3730276 & 1537627 & 8.3344 & 6.9888 & TST & \\
\hline CHEMBL3732147 & 1537627 & 7.6289 & 7.4197 & TST & \\
\hline CHEMBL 2017971 & 1537627 & 6.1487 & 6.4435 & TST & \\
\hline CHEMBL 3727776 & 1537627 & 7.5935 & 7.3798 & TRN & \\
\hline CHEMBL 3732543 & 1537627 & 6.0 & 5.8487 & TRN & \\
\hline CHEMBL3729374 & 1537627 & 6.8539 & 7.3335 & TRN & \\
\hline CHEMBL3732496 & 1537627 & 6.0 & 6.6086 & TRN & \\
\hline CHEMBL3730248 & 1537627 & 6.0 & 6.2976 & TRN & \\
\hline
\end{tabular}


Supplemental Table S2.txt

\begin{tabular}{|c|c|c|c|c|}
\hline CHEMBL3730475 & 1537627 & 6.0 & 7.2512 & TRN \\
\hline CHEMBL 3732744 & 1537627 & 8.3979 & 8.7572 & TRN \\
\hline CHEMBL3729960 & 1537627 & 8.3497 & 7.3174 & TRN \\
\hline CHEMBL 3731453 & 1537627 & 8.5735 & 7.5695 & TST \\
\hline CHEMBL 3732188 & 1537627 & 7.7825 & 7.481 & TRN \\
\hline CHEMBL 3729060 & 1537627 & 8.0531 & 7.4203 & TRN \\
\hline CHEMBL3730558 & 1537627 & 6.0 & 7.3075 & TST \\
\hline CHEMBL3729391 & 1537627 & 7.3726 & 7.0028 & TRN \\
\hline CHEMBL 3730820 & 1537627 & 6.6576 & 5.7585 & TRN \\
\hline CHEMBL3730191 & 1537627 & 6.0 & \multicolumn{2}{|c|}{7.872999999999999} \\
\hline CHEMBL 3727638 & 1537627 & 7.699 & 7.4437 & TRN \\
\hline CHEMBL3731162 & 1537627 & 6.3098 & 8.0022 & TST \\
\hline CHEMBL3732998 & 1537627 & 6.0 & 6.8534 & TRN \\
\hline CHEMBL 3730377 & 1537627 & 7.7447 & 6.7013 & TRN \\
\hline CHEMBL3728271 & 1537627 & 6.7328 & 6.772 & TRN \\
\hline CHEMBL3727519 & 1537627 & 6.0 & 6.4336 & TRN \\
\hline CHEMBL3728939 & 1537627 & 7.7696 & 7.801 & TRN \\
\hline CHEMBL3731318 & 1537627 & 6.7447 & 7.0823 & TRN \\
\hline CHEMBL 3733120 & 1537627 & 6.9352 & 7.6887 & TRN \\
\hline CHEMBL3732912 & 1537627 & 9.0 & 9.3901 & TRN \\
\hline CHEMBL3729324 & 1537627 & 6.0 & 7.3092 & TST \\
\hline CHEMBL3731594 & 1537627 & 7.8539 & 7.7045 & TRN \\
\hline CHEMBL3729285 & 1537627 & 7.6904 & 7.5114 & TRN \\
\hline CHEMBL3729601 & 1537627 & 6.9747 & 6.8028 & TST \\
\hline CHEMBL3732918 & 1537627 & 8.0214 & 7.5115 & TRN \\
\hline CHEMBL3727916 & 1537627 & 7.4962 & 7.3457 & TRN \\
\hline CHEMBL3727525 & 1537627 & 6.0 & 6.1862 & TRN \\
\hline CHEMBL3730744 & 1537627 & 7.5591 & 7.2569 & TST \\
\hline CHEMBL3732975 & 1537627 & 6.0 & 7.1809 & TST \\
\hline CHEMBL3732057 & 1537627 & 5.7932 & 5.7898 & TRN \\
\hline CHEMBL3730790 & 1537627 & 8.5086 & 7.3939 & TRN \\
\hline CHEMBL 3728348 & 1537627 & 6.1612 & 6.3753 & TST \\
\hline CHEMBL3731591 & 1537627 & 7.2321 & 6.6837 & TRN \\
\hline CHEMBL3729179 & 1537627 & 6.9957 & 7.3015 & TRN \\
\hline CHEMBL3732199 & 1537627 & 6.7929 & 7.1492 & TRN \\
\hline CHEMBL3730768 & 1537627 & 6.3686 & 6.8891 & TST \\
\hline CHEMBL 3732448 & 1537627 & 7.4989 & 7.43 & TRN \\
\hline CHEMBL3728814 & 1537627 & 6.0 & 7.2362 & TRN \\
\hline CHEMBL3729567 & 1537627 & 8.1549 & 7.8207 & TRN \\
\hline CHEMBL3733108 & 1537627 & 8.3439 & 7.6232 & TRN \\
\hline CHEMBL3729148 & 1537627 & 9.0 & 8.684 & TRN \\
\hline CHEMBL3727513 & 1537627 & 6.0 & 6.2911 & TST \\
\hline CHEMBL3731841 & 1537627 & 7.9208 & 7.987 & TRN \\
\hline CHEMBL3730375 & 1537627 & 6.0 & 6.2244 & TST \\
\hline CHEMBL3727535 & 1537627 & 8.3028 & 7.8234 & TRN \\
\hline CHEMBL3732135 & 1537627 & 6.0 & 7.2417 & TRN \\
\hline CHEMBL3729714 & 1537627 & 6.3665 & 6.636 & TRN \\
\hline CHEMBL3729651 & 1537627 & 7.9318 & 7.6871 & TRN \\
\hline
\end{tabular}


Supplemental Table S2.txt

\begin{tabular}{|c|c|c|c|c|c|}
\hline CHEMBL 3729634 & 1537627 & 6.7852 & 6.3999 & TRN & \\
\hline CHEMBL 3733135 & 1537627 & 7.8601 & 6.8877 & TRN & \\
\hline CHEMBL 3729547 & 1537627 & 8.1643 & 7.5834 & TST & \\
\hline CHEMBL 3729398 & 1537627 & 6.6778 & 6.6105 & TRN & \\
\hline CHEMBL3729884 & 1537627 & 6.6576 & 6.7815 & TRN & \\
\hline CHEMBL 3729997 & 1537627 & 6.0915 & 7.1996 & TST & \\
\hline CHEMBL 3730048 & 1537627 & 7.0872 & 6.2696 & TRN & \\
\hline CHEMBL 3727772 & 1537627 & 7.5513 & 7.7128 & TRN & \\
\hline CHEMBL 3730623 & 1537627 & 7.3233 & 7.9093 & TRN & \\
\hline CHEMBL 3729505 & 1537627 & 7.7212 & 7.7424 & TRN & \\
\hline CHEMBL 3729863 & 1537627 & 7.8447 & 8.1962 & TRN & \\
\hline CHEMBL 3729719 & 1537627 & 8.0 & 6.9122 & TRN & \\
\hline CHEMBL 3728098 & 1537627 & 8.5467 & 7.5847 & TRN & \\
\hline CHEMBL 3727553 & 1537627 & 8.0635 & 8.0003 & TRN & \\
\hline CHEMBL3732966 & 1537627 & 6.0 & 8.0752 & TST & \\
\hline CHEMBL 3732292 & 1537627 & 7.0061 & 7.0898 & TRN & \\
\hline CHEMBL 3733093 & 1537627 & 6.5528 & 8.0941 & TST & \\
\hline CHEMBL 3730621 & 1537627 & 8.1805 & 8.0968 & TRN & \\
\hline CHEMBL 3729696 & 1537627 & 8.9208 & 8.168 & TRN & \\
\hline CHEMBL3728623 & 1537627 & 8.3002 & 8.0505 & TRN & \\
\hline CHEMBL3731181 & 1537627 & 7.1549 & 6.8657 & TRN & \\
\hline CHEMBL 3728711 & 1537627 & 6.0 & 5.9544 & TRN & \\
\hline CHEMBL 3727990 & 1537627 & 8.0921 & 8.3596 & TRN & \\
\hline CHEMBL 3729369 & 1537627 & 8.699 & 8.5039 & TRN & \\
\hline CHEMBL 3731906 & 1537627 & 5.9706 & 6.4706 & TRN & \\
\hline CHEMBL 3729565 & 1537627 & 6.6778 & 7.2381 & TST & \\
\hline CHEMBL 3730980 & 1537627 & 5.7932 & 5.8526 & TRN & \\
\hline CHEMBL 3727659 & 1537627 & 8.0969 & 7.8274 & TRN & \\
\hline CHEMBL 3733079 & 1537627 & 6.8069 & 6.2452 & TST & \\
\hline CHEMBL 3733309 & 1537627 & 7.5258 & 7.6875 & TRN & \\
\hline CHEMBL 3728612 & 1537627 & 7.2518 & 7.7052 & TRN & \\
\hline CHEMBL 3730670 & 1537627 & 7.61799 & 999999999 & 99 & 7.7933 \\
\hline CHEMBL 3729085 & 1537627 & 6.0 & 6.2325 & TRN & \\
\hline CHEMBL 3728015 & 1537627 & 6.0 & 5.7431 & TST & \\
\hline CHEMBL 3729575 & 1537627 & 6.5686 & 6.6442 & TRN & \\
\hline CHEMBL 3728594 & 1537627 & 6.0 & 6.206 & TRN & \\
\hline CHEMBL 3730851 & 1537627 & 6.0 & 6.7485 & TRN & \\
\hline CHEMBL 3733234 & 1537627 & 7.7747 & 7.9826 & TRN & \\
\hline CHEMBL 3733164 & 1537627 & 6.0 & 7.0157 & TST & \\
\hline CHEMBL 3727681 & 1537627 & 8.2343 & 7.2784 & TRN & \\
\hline CHEMBL 3727942 & 1537627 & 8.5243 & 7.2849 & TRN & \\
\hline CHEMBL 3731025 & 1537627 & 6.0 & 6.5515 & TRN & \\
\hline CHEMBL 3732335 & 1537627 & 7.4168 & 7.8026 & TRN & \\
\hline CHEMBL 3732538 & 1537627 & 7.3089 & 7.8232 & TRN & \\
\hline CHEMBL 3732685 & 1537627 & 8.6289 & 7.1431 & TRN & \\
\hline CHEMBL 3731962 & 1537627 & 7.1824 & 7.8169 & TST & \\
\hline CHEMBL 3731242 & 1537627 & 6.0 & 6.7058 & TRN & \\
\hline CHEMBL 3729510 & 1537627 & 7.1278 & 6.5608 & TRN & \\
\hline
\end{tabular}


Supplemental Table S2.txt

\begin{tabular}{|c|c|c|c|c|c|}
\hline CHEMBL3727765 & 1537627 & 7.2132 & 7.2037 & TRN & \\
\hline CHEMBL3728082 & 1537627 & 6.3188 & 6.8881 & TST & \\
\hline CHEMBL3729093 & 1537627 & 6.0 & 5.8381 & TRN & \\
\hline CHEMBL3727679 & 1537627 & 7.2111 & 7.0364 & TRN & \\
\hline CHEMBL3731707 & 1537627 & 7.8297 & 7.6481 & TRN & \\
\hline CHEMBL3733205 & 1537627 & 6.0 & 6.8397 & TRN & \\
\hline CHEMBL 3727721 & 1537627 & 8.2426 & 8.7411 & TRN & \\
\hline CHEMBL3728489 & 1537627 & 7.6144 & 7.0468 & TST & \\
\hline CHEMBL3732383 & 1537627 & 8.4763 & 8.1883 & TRN & \\
\hline CHEMBL3727991 & 1537627 & 8.699 & 7.8223 & TRN & \\
\hline CHEMBL 3729945 & 1537627 & 6.0 & 6.7011 & TRN & \\
\hline CHEMBL3729194 & 1537627 & 7.1726 & 7.2366 & TST & \\
\hline CHEMBL3733157 & 1537627 & 7.6021 & 7.6465 & TST & \\
\hline CHEMBL3729700 & 1537627 & 6.7696 & 6.7415 & TRN & \\
\hline CHEMBL3732560 & 1537627 & 8.0 & 6.96 & TRN & \\
\hline CHEMBL3728114 & 1537627 & 7.5317 & 7.9563 & TRN & \\
\hline CHEMBL3732071 & 1537627 & 7.1549 & 8.2349 & TRN & \\
\hline CHEMBL3729103 & 1537627 & 8.0458 & 7.5935 & TRN & \\
\hline CHEMBL3728429 & 1537627 & 7.3665 & 7.0951 & TRN & \\
\hline CHEMBL3730738 & 1537627 & 6.0 & 6.3156 & TST & \\
\hline CHEMBL3729191 & 1537627 & 8.0 & 7.9716 & TRN & \\
\hline CHEMBL3732755 & 1537627 & 7.064 & 7.1088 & TRN & \\
\hline CHEMBL3731991 & 1537627 & 7.301 & 7.7889 & TRN & \\
\hline CHEMBL3728354 & 1537627 & 6.0 & 6.4919 & TST & \\
\hline CHEMBL3732599 & 1537627 & 7.4202 & 7.1496 & TRN & \\
\hline CHEMBL3732271 & 1537627 & 8.0 & 8.0098 & TRN & \\
\hline CHEMBL3731405 & 1537627 & 8.6383 & 8.39 & TRN & \\
\hline CHEMBL3731670 & 1537627 & 6.0809 & 6.8627 & TRN & \\
\hline CHEMBL3731724 & 1537627 & 7.8861 & 7.6794 & TRN & \\
\hline CHEMBL3731631 & 1537627 & 6.0 & 5.8863 & TRN & \\
\hline CHEMBL3730911 & 1537627 & 7.3979 & 8.1805 & TST & \\
\hline CHEMBL3728181 & 1537627 & 7.1007 & 6.672006 & 2000000001 & TRN \\
\hline CHEMBL3732528 & 1537627 & 6.0 & 7.1393 & TST & \\
\hline CHEMBL3731062 & 1537627 & 8.1979 & 7.7267 & TRN & \\
\hline CHEMBL3730836 & 1537627 & 8.0 & 8.0543 & TRN & \\
\hline CHEMBL3727397 & 1537627 & 9.0 & 9.3041 & TRN & \\
\hline CHEMBL3729157 & 1537627 & 7.1549 & 5.9964 & TST & \\
\hline CHEMBL3729007 & 1537627 & 6.0 & 6.6889 & TRN & \\
\hline CHEMBL3728997 & 1537627 & 8.4763 & 8.4619 & TRN & \\
\hline CHEMBL3732600 & 1537627 & 8.0 & 7.7948 & TST & \\
\hline CHEMBL3730236 & 1537627 & 6.0 & 7.2503 & TRN & \\
\hline CHEMBL3730117 & 1537627 & 6.9136 & 7.1713 & TRN & \\
\hline CHEMBL3728441 & 1537627 & 6.0 & 6.428 & TRN & \\
\hline CHEMBL3732855 & 1537627 & 6.0088 & 6.4461 & TRN & \\
\hline CHEMBL3730533 & 1537627 & 8.0931 & 7.5796 & TRN & \\
\hline CHEMBL3731139 & 1537627 & 6.0 & 6.717006 & 00000000005 & TRN \\
\hline CHEMBL3732434 & 1537627 & 8.2557 & 8.0643 & TRN & \\
\hline CHEMBL3731159 & 1537627 & 7.699 & 7.0284 & TRN & \\
\hline
\end{tabular}




\begin{tabular}{|c|c|c|c|c|c|c|}
\hline \multicolumn{7}{|c|}{ Supplemental Table s2.txt } \\
\hline CHEMBL 3728682 & 1537627 & 6.0 & 6.1561 & TRN & & \\
\hline CHEMBL 3732256 & 1537627 & 6.0 & 6.4963 & TST & & \\
\hline CHEMBL3727797 & 1537627 & 8.5229 & 7.8556 & TRN & & \\
\hline CHEMBL 3727660 & 1537627 & 6.0 & 6.315 & TST & & \\
\hline CHEMBL3733171 & 1537627 & 7.4685 & 8.26100 & 0000000001 & & TST \\
\hline CHEMBL3728407 & 1537627 & 5.76200 & 0000000 & 205 & 7.0981 & TST \\
\hline CHEMBL 3728310 & 1537627 & 7.9431 & 7.2572 & TRN & & \\
\hline CHEMBL3729121 & 1537627 & 8.0883 & 7.7874 & TRN & & \\
\hline CHEMBL3730992 & 1537627 & 7.4881 & 7.1554 & TRN & & \\
\hline CHEMBL3730465 & 1537627 & 7.8182 & 7.5281 & TRN & & \\
\hline CHEMBL 3732707 & 1537627 & 6.0 & 6.7555 & TRN & & \\
\hline CHEMBL 3728972 & 1537627 & 7.1612 & 7.2358 & TRN & & \\
\hline CHEMBL3731490 & 1537627 & 7.2684 & 7.7156 & TRN & & \\
\hline CHEMBL 3733122 & 1537627 & 7.5513 & 7.2683 & TST & & \\
\hline CHEMBL3728074 & 1537627 & 7.3354 & 7.1518 & TST & & \\
\hline CHEMBL3732684 & 1537627 & 8.9031 & 8.6139 & TRN & & \\
\hline CHEMBL3733147 & 1537627 & 7.585 & 7.9126 & TRN & & \\
\hline CHEMBL3729112 & 1537627 & 7.7773 & 7.8611 & TRN & & \\
\hline CHEMBL3729476 & 1537627 & 7.301 & 7.1884 & TRN & & \\
\hline CHEMBL3728240 & 1537627 & 8.0 & 8.314 & TRN & & \\
\hline CHEMBL3728986 & 1537627 & 6.0 & 6.3997 & TRN & & \\
\hline CHEMBL 3729274 & 1537627 & 6.9586 & 7.1167 & TRN & & \\
\hline CHEMBL3731916 & 1537627 & 8.6861 & 7.8531 & TRN & & \\
\hline CHEMBL3731339 & 1537627 & 7.699 & 8.0492 & TRN & & \\
\hline CHEMBL3730592 & 1537627 & 6.4949 & 6.0738 & TRN & & \\
\hline CHEMBL3729658 & 1537627 & 6.8861 & 6.8677 & TRN & & \\
\hline CHEMBL3730491 & 1537627 & 5.7932 & 5.6125 & TRN & & \\
\hline CHEMBL3731464 & 1537627 & 7.7696 & 7.1921 & TRN & & \\
\hline CHEMBL3728673 & 1537627 & 6.0 & 6.6036 & TRN & & \\
\hline CHEMBL3731696 & 1537627 & 6.0 & 6.1601 & TRN & & \\
\hline CHEMBL3728902 & 1537627 & 9.2411 & 7.88299 & 9999999999 & & ודו \\
\hline CHEMBL3731838 & 1537627 & 8.0343 & 8.8152 & TRN & & \\
\hline CHEMBL 3732280 & 1537627 & 7.0458 & 7.2879 & TST & & \\
\hline CHEMBL 3729350 & 1537627 & 6.1675 & 6.8751 & TRN & & \\
\hline CHEMBL3732217 & 1537627 & 6.0 & 6.5607 & TRN & & \\
\hline CHEMBL3731417 & 1537627 & 5.9626 & 6.6145 & TRN & & \\
\hline CHEMBL3730626 & 1537627 & 7.301 & 6.9816 & TRN & & \\
\hline CHEMBL3728061 & 1537627 & 6.0 & 6.0223 & TRN & & \\
\hline CHEMBL3729351 & 1537627 & 8.0969 & 7.5884 & TRN & & \\
\hline CHEMBL3727644 & 1537627 & 7.9172 & 7.8195 & TST & & \\
\hline CHEMBL3728693 & 1537627 & 7.9872 & 7.6614 & TRN & & \\
\hline CHEMBL3728729 & 1537627 & 8.2034 & 7.2874 & TRN & & \\
\hline CHEMBL3732012 & 1537627 & 6.0 & 7.5277 & TRN & & \\
\hline CHEMBL3728366 & 1537627 & 8.2277 & 7.4471 & TRN & & \\
\hline CHEMBL3727987 & 1537627 & 6.8827 & 6.8652 & TRN & & \\
\hline CHEMBL3733015 & 1537627 & 7.699 & 7.4286 & TRN & & \\
\hline CHEMBL3732422 & 1537627 & 5.75700 & 000000006 & & 5.8258 & RI \\
\hline CHEMBL3732231 & 1537627 & 6.0 & 6.6791 & TRN & & \\
\hline
\end{tabular}


Supplemental Table S2.txt

\begin{tabular}{|c|c|c|c|c|c|}
\hline CHEMBL3733144 & 1537627 & 7.3665 & 7.4825 & TRN & \\
\hline CHEMBL3732680 & 1537627 & 6.1308 & 6.6467 & TST & \\
\hline CHEMBL3728669 & 1537627 & 6.0 & 6.6103 & TRN & \\
\hline CHEMBL3733035 & 1537627 & 7.684 & 7.2023 & TRN & \\
\hline CHEMBL3732088 & 1537627 & 8.4949 & 7.5981 & TRN & \\
\hline CHEMBL3730862 & 1537627 & \multicolumn{2}{|c|}{ 7.218999999999999 } & 7.1433 & TRN \\
\hline CHEMBL3727625 & 1537627 & 8.0 & 8.2081 & TST & \\
\hline CHEMBL3730735 & 1537627 & 7.5171 & 8.2351 & TRN & \\
\hline CHEMBL3729710 & 1537627 & 6.8447 & 6.7735 & TRN & \\
\hline CHEMBL3727666 & 1537627 & 6.7959 & 6.3479 & TRN & \\
\hline CHEMBL3731797 & 1537627 & 6.9586 & 7.2724 & TRN & \\
\hline CHEMBL3733343 & 1537627 & 7.857 & 8.0729 & TRN & \\
\hline CHEMBL3729943 & 1537627 & 6.0 & \multicolumn{2}{|c|}{6.577000000000001} & TRN \\
\hline CHEMBL3728083 & 1537627 & 6.6576 & 6.3512 & TRN & \\
\hline CHEMBL3731505 & 1537627 & 7.4895 & 7.0955 & TRN & \\
\hline CHEMBL3729749 & 1537627 & 6.8633 & \multicolumn{2}{|c|}{6.877999999999999} & TST \\
\hline CHEMBL3728816 & 1537627 & 6.7696 & 8.1368 & TST & \\
\hline CHEMBL3728313 & 1537627 & 7.7447 & 7.1785 & TST & \\
\hline CHEMBL3727421 & 1537627 & 6.6778 & 6.6433 & TST & \\
\hline CHEMBL 3730040 & 1537627 & 8.4237 & 6.6411 & TST & \\
\hline CHEMBL3727508 & 1537627 & 8.3391 & 8.0954 & TST & \\
\hline CHEMBL3729456 & 1537627 & 6.0 & 6.1748 & TST & \\
\hline CHEMBL3732917 & 1537627 & 7.6198 & 7.2755 & TST & \\
\hline CHEMBL3729826 & 1537627 & 7.6198 & 8.3003 & TST & \\
\hline CHEMBL 3728686 & 1537627 & 6.5686 & 7.0729 & TST & \\
\hline CHEMBL3732360 & 1537627 & 6.0 & 7.0841 & TST & \\
\hline CHEMBL3731104 & 1537627 & 8.2924 & 7.303 & TST & \\
\hline CHEMBL3728787 & 1537627 & 6.8861 & 6.7333 & TST & \\
\hline CHEMBL3729389 & 1537627 & 6.0 & 6.6588 & TST & \\
\hline CHEMBL3730516 & 1537627 & 6.0 & 6.5649 & TST & \\
\hline CHEMBL3732702 & 1537627 & 8.3737 & 7.9344 & TST & \\
\hline CHEMBL3732948 & 1537627 & 6.0 & 6.474 & TST & \\
\hline CHEMBL3730552 & 1537627 & 6.6737 & 7.285 & TST & \\
\hline CHEMBL3728490 & 1537627 & 6.0 & 7.3844 & TST & \\
\hline CHEMBL3732260 & 1537627 & 7.9245 & 7.3092 & TST & \\
\hline CHEMBL3727449 & 1537627 & 9.0 & 7.685 & TST & \\
\hline CHEMBL3728872 & 1537627 & 7.7077 & 7.0871 & TST & \\
\hline CHEMBL3731122 & 1537627 & 6.0 & 6.7763 & TST & \\
\hline CHEMBL3728224 & 1537627 & 6.9586 & 6.2156 & TST & \\
\hline CHEMBL3730397 & 1537627 & 7.0 & 7.2705 & TST & \\
\hline CHEMBL3727692 & 1537627 & 8.5229 & 8.4152 & TST & \\
\hline CHEMBL 3728845 & 1537627 & 6.2676 & 6.3442 & TST & \\
\hline CHEMBL1387008 & 752567 & 6.8962 & 5.66 & TRN & \\
\hline CHEMBL1562172 & 752567 & 5.4499 & 5.3382 & TRN & \\
\hline CHEMBL1330751 & 752567 & 4.7788 & 5.3621 & TRN & \\
\hline CHEMBL1360519 & 752567 & 6.4976 & 5.5429 & TRN & \\
\hline CHEMBL 1342646 & 752567 & 4.8725 & 5.2528 & TRN & \\
\hline CHEMBL1305588 & 752567 & 5.1357 & 5.4011 & TRN & \\
\hline
\end{tabular}




\begin{tabular}{|c|c|c|c|c|c|c|}
\hline & & \multicolumn{5}{|c|}{ Supplemental Table s2.txt } \\
\hline CHEMBL1421232 & 752567 & 4.9411 & 5.3725 & TRN & & \\
\hline CHEMBL1464548 & 752567 & 6.0862 & 5.8702 & TRN & & \\
\hline CHEMBL1575447 & 752567 & 5.9706 & 5.4216 & TRN & & \\
\hline CHEMBL1483238 & 752567 & 6.2125 & 5.7986 & TRN & & \\
\hline CHEMBL1482760 & 752567 & 4.9 & 5.2951 & TST & & \\
\hline CHEMBL95770 & 752567 & 4.6781 & 5.8129 & TRN & & \\
\hline CHEMBL1542151 & 752567 & 5.5918 & 5.6735 & TRN & & \\
\hline CHEMBL279821 & 752567 & 2.9208 & 5.64 & TRN & & \\
\hline CHEMBL3210696 & 752567 & 5.2281 & 5.5184 & TRN & & \\
\hline CHEMBL1457077 & 752567 & 5.0916 & 5.2424 & TRN & & \\
\hline CHEMBL566701 & 752567 & \multicolumn{3}{|c|}{6.617999999999999} & 5.4316 & TRN \\
\hline CHEMBL1718252 & 752567 & 4.9103 & 5.2375 & TRN & & \\
\hline CHEMBL3212330 & 752567 & 5.8136 & 5.9726 & TRN & & \\
\hline CHEMBL87706 & 752567 & \multicolumn{3}{|c|}{6.382999999999999} & 6.0955 & TRN \\
\hline CHEMBL1451253 & 752567 & 6.1169 & 5.5759 & TRN & & \\
\hline CHEMBL 83103 & 752567 & 2.9208 & 5.3933 & TRN & & \\
\hline CHEMBL3191222 & 752567 & 5.1021 & 5.6197 & TRN & & \\
\hline CHEMBL1523795 & 752567 & 5.49 & 5.5249 & TRN & & \\
\hline CHEMBL1423452 & 752567 & 5.1524 & 5.6375 & TST & & \\
\hline CHEMBL1495539 & 752567 & 5.7768 & 5.342006 & 0000000000 & 05 & TRN \\
\hline CHEMBL1399528 & 752567 & 5.0185 & 5.487 & TRN & & \\
\hline CHEMBL1732657 & 752567 & 5.5577 & 5.4648 & TRN & & \\
\hline CHEMBL1605666 & 752567 & 5.0757 & 5.4936 & TRN & & \\
\hline CHEMBL1595610 & 752567 & 5.3361 & 5.3911 & TRN & & \\
\hline CHEMBL1575202 & 752567 & 5.3792 & 5.2945 & TRN & & \\
\hline CHEMBL1308936 & 752567 & 5.4136 & 5.3234 & TRN & & \\
\hline CHEMBL1326968 & 752567 & 5.4074 & 5.4085 & TRN & & \\
\hline CHEMBL1359516 & 752567 & 4.8661 & 5.5896 & TST & & \\
\hline CHEMBL1452227 & 752567 & 4.2041 & 5.4041 & TRN & & \\
\hline CHEMBL1444811 & 752567 & 5.0191 & 5.436 & TST & & \\
\hline CHEMBL3195224 & 752567 & 5.4901 & 5.7125 & TRN & & \\
\hline CHEMBL1390286 & 752567 & 5.0369 & 5.1513 & TST & & \\
\hline CHEMBL1303049 & 752567 & 5.1292 & 5.2189 & TRN & & \\
\hline CHEMBL1419228 & 752567 & 6.0 & 5.8061 & TRN & & \\
\hline CHEMBL233149 & 752567 & 5.7053 & 5.7583 & TRN & & \\
\hline CHEMBL1729815 & 752567 & 5.0488 & 5.9096 & TRN & & \\
\hline CHEMBL1547095 & 752567 & 6.1325 & 5.6835 & TRN & & \\
\hline CHEMBL1540957 & 752567 & 4.8716 & 5.157 & TRN & & \\
\hline CHEMBL1569442 & 752567 & 5.5005 & 5.4623 & TRN & & \\
\hline CHEMBL1970896 & 752567 & 5.7042 & 5.5652 & TRN & & \\
\hline CHEMBL1163377 & 752567 & 5.98799 & 99999999 & 995 & 5.3703 & TRN \\
\hline CHEMBL1379552 & 752567 & 6.2233 & 5.8251 & TRN & & \\
\hline CHEMBL1419196 & 752567 & 5.1319 & 5.2866 & TRN & & \\
\hline CHEMBL1462918 & 752567 & 5.3868 & 5.7809 & TRN & & \\
\hline CHEMBL1440675 & 752567 & 5.9401 & 5.6787 & TRN & & \\
\hline CHEMBL1430621 & 752567 & 5.0349 & 5.1229 & TST & & \\
\hline CHEMBL36654 & 752567 & 5.5953 & 5.364 & TST & & \\
\hline CHEMBL1881161 & 752567 & 6.58 & 5.7004 & TRN & & \\
\hline
\end{tabular}


Supplemental Table S2.txt

\begin{tabular}{|c|c|c|c|c|c|}
\hline CHEMBL1389547 & 752567 & 5.3772 & 5.4079 & TRN & \\
\hline CHEMBL1719643 & 752567 & 4.3084 & 5.3173 & TST & \\
\hline CHEMBL1303325 & 752567 & 5.4656 & 5.5074 & TRN & \\
\hline CHEMBL 3193773 & 752567 & 5.8986 & 5.5492 & TRN & \\
\hline CHEMBL139250 & 752567 & 4.9755 & 5.7746 & TRN & \\
\hline CHEMBL1306229 & 752567 & 4.8393 & 5.3197 & TST & \\
\hline CHEMBL1965713 & 752567 & 5.9813 & 5.4377 & TST & \\
\hline CHEMBL1377608 & 752567 & 6.1367 & 5.3148 & TRN & \\
\hline CHEMBL 3193172 & 752567 & 6.5817 & 5.8997 & TRN & \\
\hline CHEMBL599924 & 752567 & 6.5513 & 5.4318 & TST & \\
\hline CHEMBL 380071 & 752567 & 5.6173 & 5.4008 & TRN & \\
\hline CHEMBL1335615 & 752567 & 5.4444 & 5.556 & TRN & \\
\hline CHEMBL478791 & 752567 & 5.0825 & 5.6746 & TRN & \\
\hline CHEMBL1468472 & 752567 & 5.3126 & 5.6298 & TST & \\
\hline CHEMBL365356 & 752567 & 4.876 & 5.3364 & TRN & \\
\hline CHEMBL1537734 & 752567 & 5.5036 & 5.3551 & TRN & \\
\hline CHEMBL1492211 & 752567 & 5.2055 & 5.801 & TRN & \\
\hline CHEMBL1593484 & 752567 & 4.8923 & 4.9661 & TST & \\
\hline CHEMBL1365439 & 752567 & 5.1562 & 5.3704 & TRN & \\
\hline CHEMBL1994036 & 752567 & 5.195 & 5.4334 & TRN & \\
\hline CHEMBL1339888 & 752567 & 5.1248 & 5.4903 & TRN & \\
\hline CHEMBL1474143 & 752567 & 5.9547 & 5.6482 & TST & \\
\hline CHEMBL1713143 & 752567 & 5.9027 & 5.2918 & TRN & \\
\hline CHEMBL1432342 & 752567 & 5.0248 & 5.3397 & TRN & \\
\hline CHEMBL1447704 & 752567 & 5.4268 & 5.7181 & TST & \\
\hline CHEMBL510929 & 752567 & 4.1106 & 5.3376 & TRN & \\
\hline CHEMBL1545032 & 752567 & 5.0678 & 5.1422 & TRN & \\
\hline CHEMBL1486775 & 752567 & 5.4793 & 5.7912 & TRN & \\
\hline CHEMBL3189516 & 752567 & 6.8297 & 5.3976 & TRN & \\
\hline CHEMBL1998184 & 752567 & 5.5358 & 5.5467 & TRN & \\
\hline CHEMBL1484278 & 752567 & 4.9746 & 5.6947 & TRN & \\
\hline CHEMBL 241608 & 752567 & 4.7922 & 5.8502 & TRN & \\
\hline CHEMBL1558295 & 752567 & 5.3223 & 5.561 & TRN & \\
\hline CHEMBL1355064 & 752567 & 5.1946 & 5.5222 & TRN & \\
\hline CHEMBL1526249 & 752567 & 5.4099 & 5.46 & TRN & \\
\hline CHEMBL1542140 & 752567 & 5.33 & 5.4325 & TRN & \\
\hline CHEMBL1492963 & 752567 & 6.3507 & 5.3613 & TRN & \\
\hline CHEMBL1721752 & 752567 & 5.5983 & 5.7787 & TRN & \\
\hline CHEMBL1326282 & 752567 & 4.9465 & 5.306 & TRN & \\
\hline CHEMBL1321572 & 752567 & 5.5677 & 5.7971 & TRN & \\
\hline CHEMBL1494549 & 752567 & 5.3108 & 5.3244 & TRN & \\
\hline CHEMBL1560197 & 752567 & 5.4486 & 5.212999 & 9999999999 & TRN \\
\hline CHEMBL1350041 & 752567 & 5.7873 & 5.5283 & TRN & \\
\hline CHEMBL1489794 & 752567 & 5.1096 & 5.4293 & TRN & \\
\hline CHEMBL1533766 & 752567 & 4.8858 & 5.2012 & TRN & \\
\hline CHEMBL1972346 & 752567 & 5.122999 & 999999999 & 5.9673 & TRN \\
\hline CHEMBL1528007 & 752567 & 5.234 & 5.3764 & TRN & \\
\hline CHEMBL159327 & 752567 & 4.7185 & 5.5511 & TRN & \\
\hline
\end{tabular}




\begin{tabular}{|c|c|c|c|c|c|}
\hline \multirow[b]{2}{*}{ CHEMBL150 } & \multicolumn{5}{|c|}{ Supplemental Table S2.txt } \\
\hline & 752567 & 5.9 & 5.982 & TRN & \\
\hline CHEMBL1383050 & 752567 & 5.1734 & 5.58299 & 9999999999 & TRN \\
\hline CHEMBL1880186 & 752567 & 5.5493 & 5.602 & TRN & \\
\hline CHEMBL1327713 & 752567 & 6.0 & 5.5985 & TST & \\
\hline CHEMBL165064 & 752567 & 5.3695 & 5.9552 & TRN & \\
\hline CHEMBL1494965 & 752567 & 6.0195 & 5.4608 & TRN & \\
\hline CHEMBL486817 & 752567 & 6.5258 & 5.61700 & 0000000001 & TST \\
\hline CHEMBL1487178 & 752567 & 4.8741 & 5.3497 & TST & \\
\hline CHEMBL1473205 & 752567 & 5.5039 & 5.6641 & TRN & \\
\hline CHEMBL1485928 & 752567 & 5.0469 & 5.5203 & TRN & \\
\hline CHEMBL1301925 & 752567 & 5.6428 & 5.7636 & TST & \\
\hline CHEMBL1335637 & 752567 & 5.0073 & 5.2465 & TST & \\
\hline CHEMBL1304316 & 752567 & 5.1 & 5.2513 & TRN & \\
\hline CHEMBL1420023 & 752567 & 5.3068 & 5.2829 & TRN & \\
\hline CHEMBL1540032 & 752567 & 4.9644 & 5.6384 & TST & \\
\hline CHEMBL1379535 & 752567 & 5.8847 & 5.5268 & TRN & \\
\hline CHEMBL1368493 & 752567 & 6.1255 & 5.3541 & TRN & \\
\hline CHEMBL1465247 & 752567 & 5.5837 & 5.4368 & TRN & \\
\hline CHEMBL1440829 & 752567 & 6.9872 & 5.3847 & TRN & \\
\hline CHEMBL21677 & 752567 & 5.7402 & 5.5837 & TRN & \\
\hline CHEMBL1411489 & 752567 & 4.8676 & 5.3865 & TRN & \\
\hline CHEMBL1370417 & 752567 & 5.965 & 5.5577 & TRN & \\
\hline CHEMBL1571845 & 752567 & 5.4789 & 5.4072 & TST & \\
\hline CHEMBL1607471 & 752567 & 6.0857 & 5.6729 & TRN & \\
\hline CHEMBL492267 & 752567 & 6.3625 & 5.5801 & TRN & \\
\hline CHEMBL172350 & 752567 & 4.8952 & 5.7971 & TRN & \\
\hline CHEMBL3195918 & 752567 & 5.2341 & 5.4955 & TRN & \\
\hline CHEMBL1716354 & 752567 & 5.5053 & 5.7313 & TRN & \\
\hline CHEMBL 250450 & 752567 & 5.1122 & 5.7643 & TRN & \\
\hline CHEMBL 365342 & 752567 & 4.9218 & 5.5201 & TRN & \\
\hline CHEMBL1899055 & 752567 & 6.0701 & 5.5226 & TRN & \\
\hline CHEMBL1884217 & 752567 & 4.8911 & 5.4153 & TST & \\
\hline CHEMBL1459203 & 752567 & 5.0086 & 5.3229 & TRN & \\
\hline CHEMBL1471978 & 752567 & 6.4168 & 5.9067 & TRN & \\
\hline CHEMBL1491724 & 752567 & 5.4856 & 5.4355 & TRN & \\
\hline CHEMBL1870918 & 752567 & 5.3715 & 5.4689 & TRN & \\
\hline CHEMBL1301723 & 752567 & 5.2625 & 5.4685 & TRN & \\
\hline CHEMBL565759 & 752567 & 5.3764 & 5.6513 & TRN & \\
\hline CHEMBL1429141 & 752567 & 4.9253 & 5.3213 & TRN & \\
\hline CHEMBL1876533 & 752567 & 5.8545 & 5.7301 & TST & \\
\hline CHEMBL1300394 & 752567 & 5.2756 & 5.3191 & TRN & \\
\hline CHEMBL1406121 & 752567 & 5.6349 & 5.5045 & TRN & \\
\hline CHEMBL1576388 & 752567 & 5.1033 & 5.4161 & TRN & \\
\hline CHEMBL1323041 & 752567 & 4.9228 & 5.4629 & TRN & \\
\hline CHEMBL1565112 & 752567 & 5.0808 & 5.6584 & TRN & \\
\hline CHEMBL1438559 & 752567 & 4.1991 & 5.42399 & 99999999995 & TRN \\
\hline CHEMBL1609472 & 752567 & 5.8652 & 5.5451 & TRN & \\
\hline CHEMBL1389125 & 752567 & 6.0531 & 5.7289 & TRN & \\
\hline
\end{tabular}




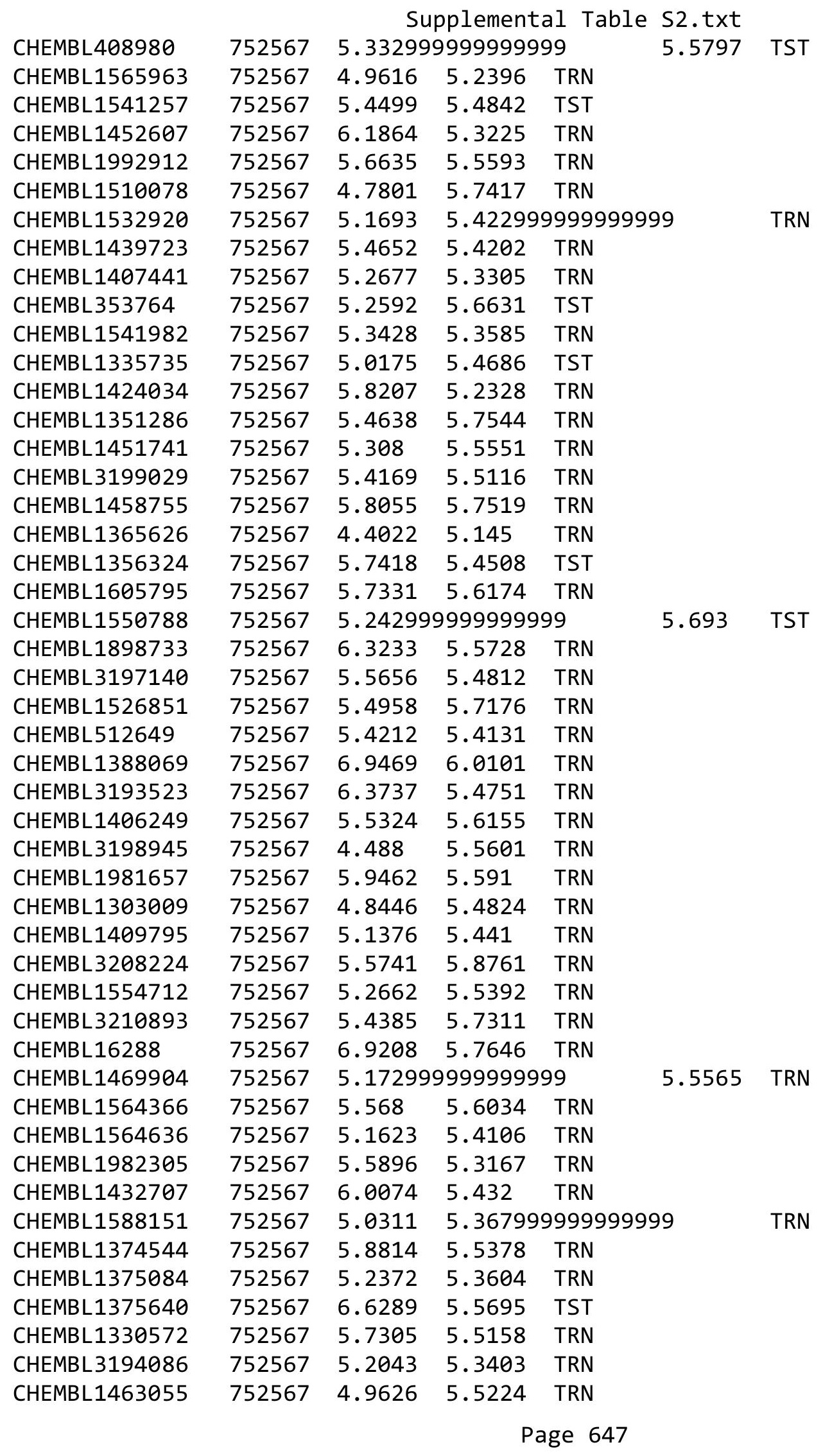




\begin{tabular}{|c|c|c|c|c|c|}
\hline & & & & & \\
\hline CHEMBL3190248 & 752567 & 5.8941 & 5.5742 & TST & \\
\hline CHEMBL1523240 & 752567 & 4.7972 & 5.47 & TRN & \\
\hline CHEMBL1549362 & 752567 & 5.3526 & 5.3728 & TRN & \\
\hline CHEMBL1611561 & 752567 & 5.178 & 5.2132 & TRN & \\
\hline CHEMBL1364176 & 752567 & 5.2563 & 5.7848 & TRN & \\
\hline CHEMBL1310492 & 752567 & 5.501 & 5.2465 & TRN & \\
\hline CHEMBL496153 & 752567 & 5.1881 & 5.3537 & TRN & \\
\hline CHEMBL1539924 & 752567 & 6.3615 & 5.8337 & TRN & \\
\hline CHEMBL1980697 & 752567 & 4.9904 & 5.462006 & 0000000001 & TRN \\
\hline CHEMBL1564500 & 752567 & 6.2823 & 5.557 & TRN & \\
\hline CHEMBL1517129 & 752567 & 5.2308 & 5.5873 & TRN & \\
\hline CHEMBL1503766 & 752567 & 5.2346 & 5.3999 & TRN & \\
\hline CHEMBL1334203 & 752567 & 4.9261 & 5.3624 & TRN & \\
\hline CHEMBL1928483 & 752567 & 5.2818 & 5.693 & TRN & \\
\hline CHEMBL1305254 & 752567 & 5.6243 & 5.4877 & TST & \\
\hline CHEMBL1400538 & 752567 & 5.0735 & 5.422006 & 3000000001 & TRN \\
\hline CHEMBL1431585 & 752567 & 5.8681 & 5.4634 & TRN & \\
\hline CHEMBL1486585 & 752567 & 5.3342 & 5.4919 & TRN & \\
\hline CHEMBL232714 & 752567 & 5.2058 & 5.5866 & TRN & \\
\hline CHEMBL1392536 & 752567 & 5.8422 & 5.292006 & 2000000001 & TRN \\
\hline CHEMBL19954 & 752567 & 5.5442 & 5.6669 & TRN & \\
\hline CHEMBL1454685 & 752567 & 5.3193 & 5.5083 & TST & \\
\hline CHEMBL1578574 & 752567 & 5.2646 & 5.4711 & TST & \\
\hline CHEMBL1570470 & 752567 & 4.9581 & 5.4103 & TRN & \\
\hline CHEMBL1307419 & 752567 & 5.1017 & 5.3975 & TRN & \\
\hline CHEMBL1718690 & 752567 & 5.0498 & 5.2516 & TRN & \\
\hline CHEMBL1334239 & 752567 & 5.1498 & 5.2816 & TRN & \\
\hline CHEMBL1482277 & 752567 & 5.016999 & 79999999ऽ & 5.5854 & TRN \\
\hline CHEMBL1318100 & 752567 & 5.9944 & 5.1314 & TRN & \\
\hline CHEMBL1999630 & 752567 & 5.3861 & 5.2811 & TRN & \\
\hline CHEMBL1716479 & 752567 & 5.1563 & 6.0129 & TRN & \\
\hline CHEMBL3197208 & 752567 & 4.5505 & 5.6271 & TST & \\
\hline CHEMBL1718371 & 752567 & 5.9574 & 5.3503 & TRN & \\
\hline CHEMBL1494656 & 752567 & 5.1183 & 5.63399 & 99999999995 & TRN \\
\hline CHEMBL118266 & 752567 & 6.1701 & 5.3683 & TRN & \\
\hline CHEMBL1325292 & 752567 & 5.1639 & 5.4296 & TRN & \\
\hline CHEMBL1728023 & 752567 & 6.6055 & 5.8999 & TRN & \\
\hline CHEMBL1476552 & 752567 & 4.5819 & 5.271 & TRN & \\
\hline CHEMBL1324819 & 752567 & 5.7366 & 5.5037 & TRN & \\
\hline CHEMBL1511561 & 752567 & 5.0782 & 5.078 & TRN & \\
\hline CHEMBL129208 & 752567 & 5.5248 & 5.6585 & TRN & \\
\hline CHEMBL1529353 & 752567 & 5.9547 & 5.421 & TRN & \\
\hline CHEMBL1519313 & 752567 & 5.4985 & 5.4448 & TST & \\
\hline CHEMBL 78223 & 752567 & 5.959 & 5.2956 & TRN & \\
\hline CHEMBL1597695 & 752567 & 5.5484 & 5.4689 & TST & \\
\hline CHEMBL1348873 & 752567 & 4.9542 & 5.5641 & TRN & \\
\hline CHEMBL1536369 & 752567 & 5.9851 & 5.5149 & TRN & \\
\hline CHEMBL2007318 & 752567 & 6.317 & 5.815 & TRN & \\
\hline
\end{tabular}


Supplemental Table S2.txt

\begin{tabular}{|c|c|c|c|c|}
\hline CHEMBL1362201 & 752567 & 5.1594 & 5.4807 & TST \\
\hline CHEMBL1461862 & 752567 & 4.9727 & 5.2066 & TRN \\
\hline CHEMBL1732789 & 752567 & 5.9991 & 5.8083 & TRN \\
\hline CHEMBL1584224 & 752567 & 4.8534 & 5.4765 & TRN \\
\hline CHEMBL1594514 & 752567 & 7.4089 & 5.8765 & TRN \\
\hline CHEMBL1553844 & 752567 & 5.3382 & 5.5437 & TRN \\
\hline CHEMBL1328193 & 752567 & 5.1097 & 5.2531 & TST \\
\hline CHEMBL1427273 & 752567 & 5.9821 & 5.4827 & TRN \\
\hline CHEMBL1442585 & 752567 & 5.0581 & 5.4601 & TRN \\
\hline CHEMBL421486 & 752567 & 5.0741 & 5.7361 & TRN \\
\hline CHEMBL1317166 & 752567 & 4.8969 & 5.7067 & TRN \\
\hline CHEMBL1870066 & 752567 & 5.2171 & 5.6588 & TRN \\
\hline CHEMBL1402845 & 752567 & 5.1844 & 5.7046 & TRN \\
\hline CHEMBL1481058 & 752567 & 4.9611 & 5.4294 & TRN \\
\hline CHEMBL463783 & 752567 & 5.1137 & 5.4456 & TRN \\
\hline CHEMBL1301063 & 752567 & 6.1013 & 5.3282 & TRN \\
\hline CHEMBL1420552 & 752567 & 5.1503 & 5.2379 & TRN \\
\hline CHEMBL1427981 & 752567 & 5.4355 & 5.3237 & TRN \\
\hline CHEMBL1500375 & 752567 & 5.3273 & 5.5751 & TRN \\
\hline CHEMBL1964393 & 752567 & 6.0315 & 5.7015 & TRN \\
\hline CHEMBL1463711 & 752567 & 4.8106 & 5.3138 & TRN \\
\hline CHEMBL1329525 & 752567 & 5.9176 & 5.535 & TRN \\
\hline CHEMBL530698 & 752567 & 4.9763 & 5.4042 & TRN \\
\hline CHEMBL196814 & 752567 & 4.9803 & 5.5285 & TST \\
\hline CHEMBL1327870 & 752567 & 5.0938 & 5.6432 & TRN \\
\hline CHEMBL 3193527 & 752567 & 5.0202 & 5.8736 & TRN \\
\hline CHEMBL1724009 & 752567 & 5.2284 & 5.3962 & TRN \\
\hline CHEMBL1550338 & 752567 & 5.24799 & 99999999 & 5.6777 \\
\hline CHEMBL1985333 & 752567 & 5.0122 & 5.5784 & TRN \\
\hline CHEMBL1588057 & 752567 & 5.5786 & 5.3884 & TRN \\
\hline CHEMBL1328581 & 752567 & 5.6988 & 5.4066 & TST \\
\hline CHEMBL1447403 & 752567 & 5.6262 & 5.8383 & TRN \\
\hline CHEMBL1563857 & 752567 & 6.1675 & 5.6442 & TRN \\
\hline CHEMBL395808 & 752567 & 5.0261 & 5.6941 & TRN \\
\hline CHEMBL1367920 & 752567 & 5.0048 & 5.2381 & TRN \\
\hline CHEMBL1731237 & 752567 & 5.6209 & 5.4348 & TRN \\
\hline CHEMBL1451725 & 752567 & 5.0677 & 5.8385 & TST \\
\hline CHEMBL1462031 & 752567 & 5.1227 & 5.3276 & TRN \\
\hline CHEMBL1564348 & 752567 & 5.4362 & 5.837000 & 0000000001 \\
\hline CHEMBL1410306 & 752567 & 5.3995 & 5.3331 & TRN \\
\hline CHEMBL1422378 & 752567 & 5.6895 & 5.3603 & TST \\
\hline CHEMBL1500607 & 752567 & 5.2601 & 5.6619 & TRN \\
\hline CHEMBL1354146 & 752567 & 5.901 & 5.5958 & TRN \\
\hline CHEMBL303958 & 752567 & 4.9733 & 5.5898 & TST \\
\hline CHEMBL1364276 & 752567 & 5.6338 & 5.1785 & TST \\
\hline CHEMBL1440473 & 752567 & 6.0334 & 5.7389 & TRN \\
\hline CHEMBL1612740 & 752567 & 5.2283 & 5.6985 & TST \\
\hline CHEMBL1501544 & 752567 & 5.5516 & 5.7594 & TRN \\
\hline
\end{tabular}


Supplemental Table S2.txt

\begin{tabular}{|c|c|c|c|c|}
\hline CHEMBL1587933 & 752567 & 5.7635 & 5.4872 & TRN \\
\hline CHEMBL1483060 & 752567 & 4.7227 & 5.3337 & TRN \\
\hline CHEMBL1489335 & 752567 & 6.7235 & 5.6769 & TRN \\
\hline CHEMBL3195751 & 752567 & 4.9735 & 5.5843 & TRN \\
\hline CHEMBL1481419 & 752567 & 5.7724 & 5.4442 & TRN \\
\hline CHEMBL1493955 & 752567 & 5.1803 & 5.6181 & TRN \\
\hline CHEMBL1578178 & 752567 & 5.4337 & 5.61799 & 999999999 \\
\hline CHEMBL1323370 & 752567 & 4.7924 & 5.3762 & TST \\
\hline CHEMBL1519408 & 752567 & 6.1543 & 5.5703 & TRN \\
\hline CHEMBL3190339 & 752567 & 5.4464 & 5.6535 & TST \\
\hline CHEMBL1492565 & 752567 & 5.6592 & 5.3168 & TRN \\
\hline CHEMBL1996902 & 752567 & 6.0809 & 5.5042 & TRN \\
\hline CHEMBL1405247 & 752567 & 5.5581 & 5.7908 & TRN \\
\hline CHEMBL3199462 & 752567 & 7.1308 & 5.8334 & TRN \\
\hline CHEMBL344241 & 752567 & 5.1651 & 5.6395 & TRN \\
\hline CHEMBL1341362 & 752567 & 5.7075 & 5.2382 & TRN \\
\hline CHEMBL1548132 & 752567 & 4.6828 & 5.3224 & TRN \\
\hline CHEMBL1574325 & 752567 & 5.5088 & 5.2483 & TRN \\
\hline CHEMBL1596464 & 752567 & 5.2278 & 5.5447 & TRN \\
\hline CHEMBL1590676 & 752567 & 4.7436 & 5.7755 & TRN \\
\hline CHEMBL1403668 & 752567 & 6.0747 & 5.4045 & TRN \\
\hline CHEMBL1540329 & 752567 & 4.9354 & 5.1817 & TRN \\
\hline CHEMBL1506264 & 752567 & 5.1197 & 5.5938 & TRN \\
\hline CHEMBL1541023 & 752567 & 5.5769 & 5.5113 & TST \\
\hline CHEMBL1538639 & 752567 & 5.245 & 5.3334 & TST \\
\hline CHEMBL1538954 & 752567 & 5.4772 & 5.5661 & TRN \\
\hline CHEMBL1475498 & 752567 & 4.9158 & 5.6918 & TST \\
\hline CHEMBL1360562 & 752567 & 5.5438 & 5.4718 & TRN \\
\hline CHEMBL 77064 & 752567 & 5.7328 & 5.3007 & TRN \\
\hline CHEMBL3198769 & 752567 & 5.2552 & 5.4607 & TRN \\
\hline CHEMBL1395713 & 752567 & 5.6718 & 5.4624 & TRN \\
\hline CHEMBL1581596 & 752567 & 5.0202 & 5.9688 & TRN \\
\hline CHEMBL1577128 & 752567 & 5.3583 & 5.5451 & TST \\
\hline CHEMBL1968089 & 752567 & 5.2119 & 5.5618 & TRN \\
\hline CHEMBL1711509 & 752567 & 5.3353 & 5.8203 & TRN \\
\hline CHEMBL1982888 & 752567 & 5.6981 & 5.4885 & TRN \\
\hline CHEMBL3190155 & 752567 & 6.7144 & 5.2879 & TRN \\
\hline CHEMBL1549926 & 752567 & 5.2546 & 5.3472 & TRN \\
\hline CHEMBL1307163 & 752567 & 5.9104 & 5.481 & TRN \\
\hline CHEMBL1381974 & 752567 & 5.8665 & 5.497006 & 000000001 \\
\hline CHEMBL1318777 & 752567 & 5.7073 & 5.3432 & TST \\
\hline CHEMBL1301059 & 752567 & 5.0803 & 5.8042 & TRN \\
\hline CHEMBL 388342 & 752567 & 6.0 & 5.5601 & TST \\
\hline CHEMBL1432926 & 752567 & 5.2484 & 5.5912 & TRN \\
\hline CHEMBL1467876 & 752567 & 5.5445 & 5.3401 & TRN \\
\hline CHEMBL1455989 & 752567 & 5.5217 & 5.4429 & TRN \\
\hline CHEMBL1490620 & 752567 & 5.0628 & 5.1474 & TRN \\
\hline CHEMBL1376791 & 752567 & 6.0 & 5.4236 & TST \\
\hline
\end{tabular}


Supplemental Table S2.txt

\begin{tabular}{|c|c|c|c|c|}
\hline CHEMBL1702624 & 752567 & 6.5186 & 5.4476 & TRN \\
\hline CHEMBL1571328 & 752567 & 6.1226 & 5.8827 & TRN \\
\hline CHEMBL1492396 & 752567 & 5.7698 & 5.8373 & TRN \\
\hline CHEMBL1315999 & 752567 & 4.8239 & 5.0957 & TRN \\
\hline CHEMBL1517417 & 752567 & 5.1338 & 5.4131 & TRN \\
\hline CHEMBL1477804 & 752567 & 5.2697 & 5.5175 & TST \\
\hline CHEMBL3197032 & 752567 & 5.9566 & 5.427000 & 0000000005 \\
\hline CHEMBL1557364 & 752567 & 4.9784 & 5.5292 & TRN \\
\hline CHEMBL3192898 & 752567 & 5.1479 & 5.4745 & TRN \\
\hline CHEMBL358692 & 752567 & 6.2668 & 5.7638 & TRN \\
\hline CHEMBL1543965 & 752567 & 5.397 & 5.5911 & TRN \\
\hline CHEMBL1540954 & 752567 & 5.1504 & 5.8174 & TRN \\
\hline CHEMBL1486470 & 752567 & 5.5207 & 5.7302 & TRN \\
\hline CHEMBL1386605 & 752567 & 5.2742 & 5.3492 & TRN \\
\hline CHEMBL1337353 & 752567 & 7.699 & 5.5832 & TRN \\
\hline CHEMBL1575997 & 752567 & 5.1665 & 5.6941 & TRN \\
\hline CHEMBL1480487 & 752567 & 5.6968 & 5.4328 & TRN \\
\hline CHEMBL1509620 & 752567 & 5.5184 & 5.184 & TST \\
\hline CHEMBL1372334 & 752567 & 5.5354 & 5.6411 & TRN \\
\hline CHEMBL269881 & 752567 & 5.2066 & 5.5758 & TST \\
\hline CHEMBL1491939 & 752567 & 6.0585 & 5.5147 & TRN \\
\hline CHEMBL1579512 & 752567 & 6.4584 & 5.7032 & TRN \\
\hline CHEMBL1702849 & 752567 & 5.3127 & 5.5626 & TRN \\
\hline CHEMBL 2000517 & 752567 & 6.053999 & 99999999 & 5.6594 \\
\hline CHEMBL1623028 & 752567 & 5.3254 & 5.4843 & TRN \\
\hline CHEMBL1610701 & 752567 & 5.1059 & 5.4222 & TRN \\
\hline CHEMBL1467422 & 752567 & 5.9226 & 5.7293 & TRN \\
\hline CHEMBL1414874 & 752567 & 4.1753 & 5.1298 & TST \\
\hline CHEMBL1341388 & 752567 & 6.2328 & 5.836 & TRN \\
\hline CHEMBL1396239 & 752567 & 5.4037 & 5.2849 & TRN \\
\hline CHEMBL3211762 & 752567 & 6.1349 & 5.9209 & TRN \\
\hline CHEMBL1605993 & 752567 & 4.9453 & 5.4093 & TRN \\
\hline CHEMBL322970 & 752567 & 5.5078 & 5.7269 & TRN \\
\hline CHEMBL1562355 & 752567 & 5.0394 & 5.1077 & TRN \\
\hline CHEMBL1431692 & 752567 & 5.2567 & 5.2194 & TRN \\
\hline CHEMBL512578 & 752567 & 5.2114 & 5.835 & TRN \\
\hline CHEMBL1510317 & 752567 & 5.5236 & 5.5027 & TST \\
\hline CHEMBL1410991 & 752567 & 6.3363 & 5.5051 & TRN \\
\hline CHEMBL1302066 & 752567 & 5.7387 & 5.9315 & TRN \\
\hline CHEMBL567331 & 752567 & 7.301 & 5.5867 & TRN \\
\hline CHEMBL1896205 & 752567 & 5.4306 & 5.3334 & TRN \\
\hline CHEMBL1467824 & 752567 & 2.9208 & 5.3812 & TRN \\
\hline CHEMBL1905002 & 752567 & 6.3726 & 5.7402 & TRN \\
\hline CHEMBL3190926 & 752567 & 5.4464 & 5.4518 & TST \\
\hline CHEMBL1376924 & 752567 & 5.5974 & 5.9549 & TRN \\
\hline CHEMBL580183 & 752567 & 5.9718 & 5.5434 & TRN \\
\hline CHEMBL1716217 & 752567 & 5.4998 & 5.4523 & TRN \\
\hline CHEMBL1532515 & 752567 & 4.4833 & 5.2785 & TRN \\
\hline
\end{tabular}




\begin{tabular}{|c|c|c|c|c|c|c|}
\hline & & \multicolumn{5}{|c|}{ Supplemental Table S2.txt } \\
\hline CHEMBL1870203 & 752567 & 5.0421 & 5.4867 & TST & & \\
\hline CHEMBL395263 & 752567 & 6.6144 & 5.7353 & TRN & & \\
\hline CHEMBL1444643 & 752567 & 6.091 & 5.3084 & TRN & & \\
\hline CHEMBL1325945 & 752567 & 6.6038 & 5.4657 & TST & & \\
\hline CHEMBL3193930 & 752567 & 5.6146 & 5.4336 & TST & & \\
\hline CHEMBL566722 & 752567 & 6.9626 & 5.5291 & TRN & & \\
\hline CHEMBL 3190808 & 752567 & 5.4961 & 5.7671 & TRN & & \\
\hline CHEMBL1589101 & 752567 & 5.0224 & 5.642 & TRN & & \\
\hline CHEMBL1450770 & 752567 & 7.0555 & 5.6923 & TRN & & \\
\hline CHEMBL1578557 & 752567 & 4.7002 & 5.3489 & TRN & & \\
\hline CHEMBL1309254 & 752567 & 6.6162 & 5.6807 & TRN & & \\
\hline CHEMBL1379970 & 752567 & 4.8667 & 5.4935 & TST & & \\
\hline CHEMBL1336403 & 752567 & 5.1532 & 5.7909 & TRN & & \\
\hline CHEMBL1535706 & 752567 & 5.0055 & 5.3105 & TRN & & \\
\hline CHEMBL1333106 & 752567 & 5.6026 & 5.397 & TRN & & \\
\hline CHEMBL1542508 & 752567 & 5.608 & 5.687 & TRN & & \\
\hline CHEMBL1485263 & 752567 & 5.4275 & 5.5492 & TRN & & \\
\hline CHEMBL1438256 & 752567 & 5.2145 & 5.295 & TRN & & \\
\hline CHEMBL1322755 & 752567 & 5.8324 & 5.7875 & TRN & & \\
\hline CHEMBL1548109 & 752567 & 5.9462 & 5.6025 & TRN & & \\
\hline CHEMBL1584610 & 752567 & 5.2299 & 5.3869 & TRN & & \\
\hline CHEMBL1733848 & 752567 & 6.1986 & 5.8115 & TRN & & \\
\hline CHEMBL1448670 & 752567 & 6.4034 & 5.7798 & TRN & & \\
\hline CHEMBL1588286 & 752567 & 5.1241 & 5.7272 & TRN & & \\
\hline CHEMBL1441660 & 752567 & 5.3827 & 5.4593 & TRN & & \\
\hline CHEMBL1526509 & 752567 & 5.3528 & 5.5104 & TRN & & \\
\hline CHEMBL1491011 & 752567 & 4.8675 & 5.8447 & TST & & \\
\hline CHEMBL1583292 & 752567 & 5.1315 & 5.614 & TRN & & \\
\hline CHEMBL1607932 & 752567 & 5.1074 & 5.6989 & TRN & & \\
\hline CHEMBL1884942 & 752567 & 6.1141 & 5.7493 & TRN & & \\
\hline CHEMBL3208377 & 752567 & 5.004 & 5.4203 & TRN & & \\
\hline CHEMBL1497631 & 752567 & 6.3546 & 5.3662 & TRN & & \\
\hline CHEMBL1548248 & 752567 & 6.3233 & 5.5711 & TRN & & \\
\hline CHEMBL1496592 & 752567 & 5.0338 & 5.6025 & TRN & & \\
\hline CHEMBL1341140 & 752567 & 5.285 & 5.1893 & TRN & & \\
\hline CHEMBL1425709 & 752567 & 5.8386 & 5.4136 & TRN & & \\
\hline CHEMBL1474649 & 752567 & 5.01 & 5.4311 & TRN & & \\
\hline CHEMBL1714919 & 752567 & 5.2099 & 5.6029 & TRN & & \\
\hline CHEMBL1556418 & 752567 & 4.8612 & 5.3929 & TRN & & \\
\hline CHEMBL463563 & 752567 & 6.0496 & 5.7957 & TRN & & \\
\hline CHEMBL1412354 & 752567 & 5.2372 & 5.6753 & TST & & \\
\hline CHEMBL1728280 & 752567 & 5.5976 & 5.6907 & TST & & \\
\hline CHEMBL1400208 & 752567 & 5.244 & 5.4421 & TRN & & \\
\hline CHEMBL1444580 & 752567 & 5.4085 & 5.3063 & TRN & & \\
\hline CHEMBL1517599 & 752567 & 5.2261 & 5.3695 & TST & & \\
\hline CHEMBL1389315 & 752567 & 4.5736 & 5.2687 & TST & & \\
\hline CHEMBL1523263 & 752567 & 4.84399 & 999999999 & 99 & 5.7711 & TST \\
\hline CHEMBL1461566 & 752567 & 5.325 & 5.5719 & TRN & & \\
\hline
\end{tabular}




\begin{tabular}{|c|c|c|c|c|c|c|}
\hline \multirow[b]{2}{*}{ CHEMBL1447615 } & & \multicolumn{5}{|c|}{ Supplemental Table S2.txt } \\
\hline & 752567 & 5.0209 & 5.3584 & TST & & \\
\hline CHEMBL239103 & 752567 & 5.71200 & 00000000 & & 5.6295 & TRN \\
\hline CHEMBL1301300 & 752567 & 5.919 & 5.5056 & TRN & & \\
\hline CHEMBL1360580 & 752567 & 5.6101 & 5.3945 & TRN & & \\
\hline CHEMBL1508826 & 752567 & 5.2592 & 5.3312 & TRN & & \\
\hline CHEMBL1332860 & 752567 & 6.9547 & 5.9299 & TRN & & \\
\hline CHEMBL1698715 & 752567 & 5.5005 & 5.7076 & TST & & \\
\hline CHEMBL1482352 & 752567 & 4.7261 & 5.4249 & TRN & & \\
\hline CHEMBL1411764 & 752567 & 5.1649 & 5.4218 & TRN & & \\
\hline CHEMBL1440984 & 752567 & 5.3258 & 5.6515 & TRN & & \\
\hline CHEMBL1328408 & 752567 & 5.3825 & 5.4111 & TRN & & \\
\hline CHEMBL1450623 & 752567 & 2.9208 & 5.4457 & TRN & & \\
\hline CHEMBL1305514 & 752567 & 5.3777 & 5.3978 & TST & & \\
\hline CHEMBL1365550 & 752567 & 6.15799 & 99999999 & 995 & 5.5164 & TRN \\
\hline CHEMBL1589352 & 752567 & 4.9374 & 5.4679 & TRN & & \\
\hline CHEMBL1551934 & 752567 & 5.5427 & 5.8796 & TRN & & \\
\hline CHEMBL1443750 & 752567 & 5.3258 & 5.4615 & TST & & \\
\hline CHEMBL1704558 & 752567 & 6.8447 & 5.7493 & TRN & & \\
\hline CHEMBL1570616 & 752567 & 5.4346 & 5.5786 & TRN & & \\
\hline CHEMBL1434087 & 752567 & 5.4487 & 5.5647 & TRN & & \\
\hline CHEMBL1405550 & 752567 & 4.954 & 5.3424 & TRN & & \\
\hline CHEMBL446827 & 752567 & 6.1931 & 6.0059 & TRN & & \\
\hline CHEMBL1605235 & 752567 & 5.71200 & 00000000 & & 5.6912 & TRN \\
\hline CHEMBL1364071 & 752567 & 5.71 & 5.3153 & TRN & & \\
\hline CHEMBL1549497 & 752567 & 5.6048 & 5.37 & TRN & & \\
\hline CHEMBL416556 & 752567 & 5.0953 & 5.6015 & TRN & & \\
\hline CHEMBL1350938 & 752567 & 6.1993 & 5.3984 & TRN & & \\
\hline CHEMBL3198919 & 752567 & 6.5317 & 5.5345 & TRN & & \\
\hline CHEMBL1446788 & 752567 & 6.3261 & 5.3857 & TRN & & \\
\hline CHEMBL1533533 & 752567 & 5.7997 & 5.6442 & TST & & \\
\hline CHEMBL1503033 & 752567 & 5.3349 & 5.8627 & TRN & & \\
\hline CHEMBL1510727 & 752567 & 6.3706 & 5.5629 & TST & & \\
\hline CHEMBL1369699 & 752567 & 5.9119 & 6.057 & TRN & & \\
\hline CHEMBL1301928 & 752567 & 4.8076 & 5.3397 & TRN & & \\
\hline CHEMBL1542591 & 752567 & 6.6655 & 5.7058 & TRN & & \\
\hline CHEMBL224521 & 752567 & 6.983 & 6.0121 & TRN & & \\
\hline CHEMBL1529610 & 752567 & 5.4078 & 5.3359 & TRN & & \\
\hline CHEMBL1443336 & 752567 & 5.4934 & 5.4902 & TRN & & \\
\hline CHEMBL1578108 & 752567 & 5.4876 & 5.2639 & TRN & & \\
\hline CHEMBL3199812 & 752567 & 5.3325 & 5.8319 & TRN & & \\
\hline CHEMBL3189445 & 752567 & 6.2328 & 5.9326 & TRN & & \\
\hline CHEMBL1522508 & 752567 & 5.3093 & 5.4568 & TRN & & \\
\hline CHEMBL1415432 & 752567 & 5.6949 & 5.6502 & TST & & \\
\hline CHEMBL1383750 & 752567 & 4.49 & 5.2446 & TRN & & \\
\hline CHEMBL1391235 & 752567 & 5.5346 & 5.6661 & TST & & \\
\hline CHEMBL1608230 & 752567 & 5.9208 & 5.4849 & TRN & & \\
\hline CHEMBL 258853 & 752567 & 6.3072 & 5.2528 & TRN & & \\
\hline CHEMBL1705959 & 752567 & 5.0717 & 5.3436 & TRN & & \\
\hline
\end{tabular}


Supplemental Table S2.txt

\begin{tabular}{|c|c|c|c|c|}
\hline CHEMBL1706982 & 752567 & 5.5737 & 5.4886 & TRN \\
\hline CHEMBL1495967 & 752567 & 5.9059 & 5.5025 & TST \\
\hline CHEMBL1559383 & 752567 & 5.0417 & 5.4034 & TRN \\
\hline CHEMBL1445377 & 752567 & 4.8164 & 5.1784 & TRN \\
\hline CHEMBL1558036 & 752567 & 6.2612 & 5.4299 & TRN \\
\hline CHEMBL1524686 & 752567 & 5.9539 & 5.7108 & TRN \\
\hline CHEMBL1439919 & 752567 & 5.0598 & 5.0169 & TST \\
\hline CHEMBL1437938 & 752567 & 4.9942 & 5.5518 & TRN \\
\hline CHEMBL1343789 & 752567 & 5.1023 & 5.3087 & TRN \\
\hline CHEMBL1403656 & 752567 & 5.1984 & 5.2529 & TRN \\
\hline CHEMBL1727903 & 752567 & 5.245 & 5.705 & TST \\
\hline CHEMBL1734687 & 752567 & 5.5794 & 5.4047 & TRN \\
\hline CHEMBL1300894 & 752567 & 5.4327 & 5.40799 & э9999999995 \\
\hline CHEMBL1514790 & 752567 & 4.1026 & 5.20799 & 7999999999 \\
\hline CHEMBL 306783 & 752567 & 4.8377 & 5.2724 & TRN \\
\hline CHEMBL1457723 & 752567 & 5.1519 & 5.8136 & TRN \\
\hline CHEMBL1450671 & 752567 & 6.1662 & 5.648 & TRN \\
\hline CHEMBL3196117 & 752567 & 6.5986 & 5.5211 & TST \\
\hline CHEMBL1460938 & 752567 & 6.4353 & 5.4975 & TRN \\
\hline CHEMBL1538844 & 752567 & 5.9566 & 5.51 & TRN \\
\hline CHEMBL482604 & 752567 & 4.4418 & 5.5458 & TRN \\
\hline CHEMBL1360045 & 752567 & 4.9841 & 5.2888 & TRN \\
\hline CHEMBL550174 & 752567 & 5.3939 & 5.4249 & TRN \\
\hline CHEMBL1526391 & 752567 & 5.276 & 5.6764 & TRN \\
\hline CHEMBL1605789 & 752567 & 6.0778 & 5.4679 & TRN \\
\hline CHEMBL171699 & 752567 & 6.8013 & 5.6803 & TRN \\
\hline CHEMBL478754 & 752567 & 5.6805 & 5.5227 & TST \\
\hline CHEMBL1340808 & 752567 & 5.1203 & 5.4562 & TRN \\
\hline CHEMBL1496823 & 752567 & 5.3592 & 5.2019 & TRN \\
\hline CHEMBL3196222 & 752567 & 5.4131 & 5.6111 & TRN \\
\hline CHEMBL1395367 & 752567 & 5.2591 & 5.3216 & TRN \\
\hline CHEMBL66953 & 752567 & 5.7918 & 5.7668 & TRN \\
\hline CHEMBL1594299 & 752567 & 4.895 & 5.4458 & TST \\
\hline CHEMBL1866570 & 752567 & 4.5267 & 5.1982 & TST \\
\hline CHEMBL1516880 & 752567 & 5.3624 & 5.6121 & TRN \\
\hline CHEMBL1496209 & 752567 & 5.1178 & 5.3432 & TRN \\
\hline CHEMBL3213511 & 752567 & 5.433 & 5.7391 & TRN \\
\hline CHEMBL1478489 & 752567 & 5.2245 & 5.4126 & TRN \\
\hline CHEMBL1596228 & 752567 & 5.6394 & 5.4293 & TST \\
\hline CHEMBL1458043 & 752567 & 5.3631 & 5.7958 & TRN \\
\hline CHEMBL1558577 & 752567 & 7.2291 & 5.7717 & TRN \\
\hline CHEMBL1567800 & 752567 & 5.1211 & 5.4979 & TST \\
\hline CHEMBL144719 & 752567 & 5.0998 & 5.4076 & TRN \\
\hline CHEMBL545751 & 752567 & 4.8684 & 5.1238 & TRN \\
\hline CHEMBL490355 & 752567 & 5.6345 & \multicolumn{2}{|c|}{5.997000000000001} \\
\hline CHEMBL1560355 & 752567 & 5.734 & 5.3883 & TRN \\
\hline CHEMBL1545765 & 752567 & 5.3169 & 5.2342 & TRN \\
\hline CHEMBL1323790 & 752567 & 6.0259 & 5.2903 & TRN \\
\hline
\end{tabular}


Supplemental Table S2.txt

\begin{tabular}{|c|c|c|c|c|c|}
\hline CHEMBL1528581 & 752567 & 4.9959 & 5.6353 & TRN & \\
\hline CHEMBL1304721 & 752567 & 6.7144 & 5.8569 & TRN & \\
\hline CHEMBL1741794 & 752567 & 5.2867 & 5.26399 & 999999999 & (1) \\
\hline CHEMBL1313936 & 752567 & 6.0061 & 5.6491 & TRN & \\
\hline CHEMBL 8260 & 752567 & 4.8378 & 5.6333 & TRN & \\
\hline CHEMBL1347033 & 752567 & 5.5923 & 5.6846 & TRN & \\
\hline CHEMBL1441323 & 752567 & 6.1226 & 5.4128 & TST & \\
\hline CHEMBL1399893 & 752567 & 5.0506 & 5.2944 & TRN & \\
\hline CHEMBL1610585 & 752567 & 5.3331 & 5.3804 & TST & \\
\hline CHEMBL1300063 & 752567 & 6.5901 & 5.2011 & TRN & \\
\hline CHEMBL1329427 & 752567 & 5.1049 & 5.3981 & TRN & \\
\hline CHEMBL1489830 & 752567 & 5.1688 & 5.16100 & 0000000005 & \\
\hline CHEMBL1329661 & 752567 & 6.3665 & 5.3333 & TRN & \\
\hline CHEMBL3965817 & 752567 & 5.4888 & 5.9478 & TRN & \\
\hline CHEMBL1566342 & 752567 & 5.5635 & 5.6927 & TRN & \\
\hline CHEMBL1732383 & 752567 & 6.7077 & 5.6949 & TRN & \\
\hline CHEMBL1528327 & 752567 & 4.7306 & 6.0164 & TRN & \\
\hline CHEMBL1429067 & 752567 & 5.3188 & 5.6652 & TRN & \\
\hline CHEMBL1325366 & 752567 & 4.9428 & 5.7019 & TRN & \\
\hline CHEMBL1351329 & 752567 & 5.1096 & 5.6845 & TRN & \\
\hline CHEMBL1320104 & 752567 & 5.4983 & 5.1906 & TST & \\
\hline CHEMBL6665 & 752567 & 4.94600 & 00000000 & 5.8347 & \\
\hline CHEMBL1568183 & 752567 & 5.0902 & 5.3383 & TRN & \\
\hline CHEMBL1610597 & 752567 & 5.5591 & 5.4477 & TRN & \\
\hline CHEMBL1549257 & 752567 & 4.8999 & 5.5309 & TST & \\
\hline CHEMBL1542509 & 752567 & 5.4742 & 5.3071 & TRN & \\
\hline CHEMBL1349236 & 752567 & 6.5031 & 5.7049 & TRN & \\
\hline CHEMBL1717028 & 752567 & 5.5006 & 5.3488 & TRN & \\
\hline CHEMBL1240787 & 752567 & 5.1254 & 5.4163 & TRN & \\
\hline CHEMBL1346456 & 752567 & 6.3915 & 5.8928 & TRN & \\
\hline CHEMBL1312163 & 752567 & 5.1133 & 5.3097 & TRN & \\
\hline CHEMBL1435857 & 752567 & 5.1567 & 5.4388 & TRN & \\
\hline CHEMBL1447816 & 752567 & 6.4737 & 5.3909 & TRN & \\
\hline CHEMBL1574284 & 752567 & 5.5702 & 5.501 & TRN & \\
\hline CHEMBL1334123 & 752567 & 5.1324 & 5.4275 & TRN & \\
\hline CHEMBL1371912 & 752567 & 5.4277 & 5.4419 & TRN & \\
\hline CHEMBL3214280 & 752567 & 7.1487 & 5.6042 & TRN & \\
\hline CHEMBL3194406 & 752567 & 5.4173 & 5.6875 & TRN & \\
\hline CHEMBL1302093 & 752567 & 6.1481 & 5.2246 & TRN & \\
\hline CHEMBL1370140 & 752567 & 4.9903 & 5.4909 & TRN & \\
\hline CHEMBL1436898 & 752567 & 4.7376 & 5.7164 & TRN & \\
\hline CHEMBL1303189 & 752567 & 6.3904 & 5.5397 & TRN & \\
\hline CHEMBL303846 & 752567 & 5.063 & 5.6532 & TST & \\
\hline CHEMBL1705676 & 752567 & 5.045 & 5.769 & TRN & \\
\hline CHEMBL1588187 & 752567 & \multicolumn{2}{|c|}{5.0169999999999995} & 5.3309 & \\
\hline CHEMBL3197772 & 752567 & 5.1381 & 5.6192 & TST & \\
\hline CHEMBL1532959 & 752567 & 6.0645 & 5.6532 & TRN & \\
\hline CHEMBL1572429 & 752567 & 4.9795 & 5.2364 & TRN & \\
\hline
\end{tabular}


Supplemental Table S2.txt

\begin{tabular}{|c|c|c|c|c|c|}
\hline CHEMBL3191976 & 752567 & 4.9292 & 5.6183 & TRN & \\
\hline CHEMBL1439045 & 752567 & 5.6474 & 5.4435 & TRN & \\
\hline CHEMBL1577953 & 752567 & 5.1986 & 5.8127 & TRN & \\
\hline CHEMBL601757 & 752567 & 6.6676 & 5.6108 & TST & \\
\hline CHEMBL1510822 & 752567 & 5.8377 & 5.6009 & TRN & \\
\hline CHEMBL1392934 & 752567 & 5.1221 & 5.4961 & TST & \\
\hline CHEMBL1379338 & 752567 & 4.9538 & 5.3997 & TRN & \\
\hline CHEMBL1369623 & 752567 & 5.1718 & 5.5452 & TRN & \\
\hline CHEMBL1312974 & 752567 & 6.7011 & 5.6213 & TST & \\
\hline CHEMBL213017 & 752567 & 5.1679 & 5.4183 & TRN & \\
\hline CHEMBL417727 & 752567 & \multicolumn{3}{|c|}{6.2620000000000005} & 5.707000000000001 \\
\hline CHEMBL1468329 & 752567 & 6.2388 & 5.5645 & TRN & \\
\hline CHEMBL1495027 & 752567 & 4.9659 & 5.4085 & TRN & \\
\hline CHEMBL1604911 & 752567 & 5.1874 & 5.6046 & TRN & \\
\hline CHEMBL1351986 & 752567 & 5.1314 & 5.4245 & TRN & \\
\hline CHEMBL1726145 & 752567 & 5.8136 & 5.3973 & TRN & \\
\hline CHEMBL1547667 & 752567 & 5.1792 & 5.4562 & TRN & \\
\hline CHEMBL300389 & 752567 & 7.8861 & 5.1416 & TRN & \\
\hline CHEMBL3197091 & 752567 & 5.7452 & 5.3143 & TRN & \\
\hline CHEMBL609970 & 752567 & 5.0508 & 5.403 & TRN & \\
\hline CHEMBL566474 & 752567 & 7.4202 & 5.9826 & TRN & \\
\hline CHEMBL1303641 & 752567 & 5.8027 & 5.3743 & TRN & \\
\hline CHEMBL1303551 & 752567 & 5.1238 & 5.2922 & TRN & \\
\hline CHEMBL1320145 & 752567 & 5.0446 & 5.6495 & TST & \\
\hline CHEMBL3199751 & 752567 & 4.5606 & 5.6023 & TRN & \\
\hline CHEMBL1606808 & 752567 & 5.5261 & 5.1407 & TRN & \\
\hline CHEMBL1390258 & 752567 & 6.1232 & 5.4479 & TST & \\
\hline CHEMBL1564983 & 752567 & 6.71 & 5.8852 & TRN & \\
\hline CHEMBL275224 & 752567 & 5.0582 & 5.4321 & TRN & \\
\hline CHEMBL1409277 & 752567 & 6.5114 & 5.8671 & TRN & \\
\hline CHEMBL1867939 & 752567 & 5.1166 & 5.4488 & TRN & \\
\hline CHEMBL1339071 & 752567 & 4.4515 & 5.2338 & TRN & \\
\hline CHEMBL1320535 & 752567 & 5.1399 & 5.8628 & TRN & \\
\hline CHEMBL1580010 & 752567 & 6.5638 & 5.5472 & TRN & \\
\hline CHEMBL3194198 & 752567 & 6.0991 & 5.5552 & TRN & \\
\hline CHEMBL1574454 & 752567 & 5.9115 & 5.4627 & TRN & \\
\hline CHEMBL1303255 & 752567 & 5.3413 & 5.6238 & TST & \\
\hline CHEMBL3193709 & 752567 & 5.5653 & 5.3304 & TRN & \\
\hline CHEMBL1469441 & 752567 & 4.637 & 5.3836 & TRN & \\
\hline CHEMBL1607577 & 752567 & 4.9527 & 5.5764 & TST & \\
\hline CHEMBL1975754 & 752567 & 5.9825 & 5.7821 & TRN & \\
\hline CHEMBL1386916 & 752567 & 6.5575 & 5.4149 & TRN & \\
\hline CHEMBL1530844 & 752567 & 6.5114 & 5.7844 & TRN & \\
\hline CHEMBL1537627 & 752567 & 5.3094 & 5.2987 & TRN & \\
\hline CHEMBL441986 & 752567 & 5.2466 & 5.3557 & TRN & \\
\hline CHEMBL1450635 & 752567 & 6.5272 & 5.7402 & TRN & \\
\hline CHEMBL1597286 & 752567 & 4.769 & 5.5143 & TRN & \\
\hline CHEMBL3191761 & 752567 & 5.0562 & 5.336 & TRN & \\
\hline
\end{tabular}




\begin{tabular}{|c|c|c|c|c|c|}
\hline \multirow[b]{2}{*}{ CHEMBL1299186 } & \multicolumn{5}{|c|}{ Supplemental Table S2.txt } \\
\hline & 752567 & 5.6501 & 5.6363 & TRN & \\
\hline CHEMBL1450047 & 752567 & 5.267 & 5.5138 & TRN & \\
\hline CHEMBL561114 & 752567 & 6.091 & 5.4105 & TRN & \\
\hline CHEMBL1302238 & 752567 & 6.7773 & 6.0545 & TRN & \\
\hline CHEMBL1322078 & 752567 & 5.0596 & 5.475 & TRN & \\
\hline CHEMBL1341124 & 752567 & 5.3144 & 5.4189 & TRN & \\
\hline CHEMBL1585860 & 752567 & 6.9469 & 5.428 & TRN & \\
\hline CHEMBL1386805 & 752567 & 5.3298 & 5.482 & TRN & \\
\hline CHEMBL1480880 & 752567 & 5.6383 & 5.6197 & TRN & \\
\hline CHEMBL1572115 & 752567 & 6.0 & 5.8092 & TRN & \\
\hline CHEMBL1383996 & 752567 & 5.3704 & 5.1775 & TRN & \\
\hline CHEMBL1387587 & 752567 & 5.9154 & 5.7797 & TRN & \\
\hline CHEMBL1405081 & 752567 & 5.5217 & 5.6714 & TRN & \\
\hline CHEMBL1606232 & 752567 & 4.8081 & 5.5434 & TRN & \\
\hline CHEMBL1537130 & 752567 & 5.6258 & 5.2279 & TRN & \\
\hline CHEMBL1385662 & 752567 & 5.3273 & 5.7711 & TRN & \\
\hline CHEMBL1347598 & 752567 & 6.057 & 5.3931 & TST & \\
\hline CHEMBL1997990 & 752567 & 5.7886 & 5.8553 & TRN & \\
\hline CHEMBL1487236 & 752567 & 5.1216 & 5.2365 & TRN & \\
\hline CHEMBL3192248 & 752567 & 5.1851 & 5.5813 & TRN & \\
\hline CHEMBL1729475 & 752567 & 6.0899 & 5.3679 & TRN & \\
\hline CHEMBL1556197 & 752567 & 4.5246 & 5.3576 & TRN & \\
\hline CHEMBL1429471 & 752567 & 5.534 & 5.3776 & TST & \\
\hline CHEMBL1604242 & 752567 & 2.9208 & 5.3341 & TRN & \\
\hline CHEMBL1418344 & 752567 & 4.9482 & 5.4983 & TRN & \\
\hline CHEMBL1319083 & 752567 & 6.2495 & 5.4928 & TRN & \\
\hline CHEMBL1190214 & 752567 & 5.8827 & 5.5394 & TRN & \\
\hline CHEMBL1326359 & 752567 & 4.9923 & 5.6139 & TRN & \\
\hline CHEMBL1611774 & 752567 & 5.2228 & 5.6432 & TST & \\
\hline CHEMBL1455993 & 752567 & 6.0052 & 5.5713 & TRN & \\
\hline CHEMBL1454614 & 752567 & 5.2888 & 5.3659 & TRN & \\
\hline CHEMBL1487749 & 752567 & 7.1308 & 5.5602 & TRN & \\
\hline CHEMBL1348094 & 752567 & 6.5243 & 5.3885 & TRN & \\
\hline CHEMBL1730926 & 752567 & 5.2729 & 5.2177 & TRN & \\
\hline CHEMBL1373964 & 752567 & 5.5302 & 5.2869 & TRN & \\
\hline CHEMBL1423729 & 752567 & 4.931999 & 99999999 & 995 & 5.5111 \\
\hline CHEMBL1504461 & 752567 & 5.7791 & 5.7986 & TRN & \\
\hline CHEMBL1301010 & 752567 & 4.7846 & 5.5883 & TST & \\
\hline CHEMBL 244857 & 752567 & 4.8419 & 5.4424 & TRN & \\
\hline CHEMBL1609956 & 752567 & 4.9931 & 5.6467 & TST & \\
\hline CHEMBL1732782 & 752567 & 6.1662 & 5.7002 & TRN & \\
\hline CHEMBL1718931 & 752567 & 5.4275 & 5.4198 & TST & \\
\hline CHEMBL1331857 & 752567 & 4.9135 & 5.6114 & TRN & \\
\hline CHEMBL1382399 & 752567 & 4.6089 & 5.669 & TST & \\
\hline CHEMBL3199139 & 752567 & 6.7122 & 5.9475 & TRN & \\
\hline CHEMBL540851 & 752567 & 5.0377 & 5.6749 & TST & \\
\hline CHEMBL1482957 & 752567 & 6.0 & 5.9603 & TRN & \\
\hline CHEMBL1583874 & 752567 & 5.0304 & 5.5085 & TST & \\
\hline
\end{tabular}




\begin{tabular}{|c|c|c|c|c|c|}
\hline \multicolumn{6}{|c|}{ Supplemental Table S2.txt } \\
\hline CHEMBL1443881 & 752567 & 5.4001 & 5.5707 & TST & \\
\hline CHEMBL 2002776 & 752567 & 6.857 & 5.7361 & TRN & \\
\hline CHEMBL1603038 & 752567 & 5.697 & 5.5689 & TRN & \\
\hline CHEMBL1415374 & 752567 & 4.9209 & 5.7381 & TRN & \\
\hline CHEMBL123 & 752567 & 6.6364 & 5.4723 & TRN & \\
\hline CHEMBL1579933 & 752567 & 6.0434 & 5.7615 & TST & \\
\hline CHEMBL3189536 & 752567 & 4.8877 & 5.3403 & TRN & \\
\hline CHEMBL1479410 & 752567 & 5.0969 & 5.4819 & TRN & \\
\hline CHEMBL1301498 & 752567 & 5.2308 & 5.3886 & TRN & \\
\hline CHEMBL1366649 & 752567 & 6.058 & 5.2204 & TRN & \\
\hline CHEMBL3189492 & 752567 & 5.0995 & 5.4078 & TRN & \\
\hline CHEMBL1887373 & 752567 & 5.3136 & 5.6183 & TST & \\
\hline CHEMBL61505 & 752567 & 6.0731 & 5.6705 & TRN & \\
\hline CHEMBL3190706 & 752567 & $5.5120 e$ & 0000000 & 5.4803 & TST \\
\hline CHEMBL1348151 & 752567 & 5.1654 & 5.7591 & TST & \\
\hline CHEMBL1583398 & 752567 & 5.0954 & 5.3859 & TRN & \\
\hline CHEMBL3197126 & 752567 & 5.296 & 5.4986 & TRN & \\
\hline CHEMBL1327043 & 752567 & 5.3863 & 5.87299 & 9999999999 & TRN \\
\hline CHEMBL3197626 & 752567 & 6.9393 & 5.546 & TRN & \\
\hline CHEMBL1436882 & 752567 & 5.1732 & 5.449 & TRN & \\
\hline CHEMBL1714179 & 752567 & 5.3939 & 5.3501 & TRN & \\
\hline CHEMBL1613378 & 752567 & 6.7423 & 5.6267 & TRN & \\
\hline CHEMBL1714943 & 752567 & 4.8013 & 5.706 & TRN & \\
\hline CHEMBL1539917 & 752567 & 5.3798 & 5.1992 & TRN & \\
\hline CHEMBL1492194 & 752567 & 5.1231 & 5.1574 & TRN & \\
\hline CHEMBL1401585 & 752567 & 5.0809 & 5.4593 & TRN & \\
\hline CHEMBL1388409 & 752567 & 5.7395 & 5.6471 & TRN & \\
\hline CHEMBL1469056 & 752567 & 5.3048 & 5.1766 & TRN & \\
\hline CHEMBL1518866 & 752567 & 5.3077 & 5.4948 & TRN & \\
\hline CHEMBL1449886 & 752567 & 4.9054 & 5.57100 & 2000000001 & TRN \\
\hline CHEMBL1880434 & 752567 & 6.8928 & 5.9405 & TRN & \\
\hline CHEMBL1450534 & 752567 & 5.7178 & 5.3506 & TRN & \\
\hline CHEMBL1601848 & 752567 & 4.9428 & 5.1186 & TRN & \\
\hline CHEMBL1459532 & 752567 & 5.6741 & 5.3261 & TRN & \\
\hline CHEMBL1881824 & 752567 & 6.2062 & 5.9232 & TRN & \\
\hline CHEMBL1332033 & 752567 & 5.355 & 5.4376 & TRN & \\
\hline CHEMBL1576272 & 752567 & 4.5678 & 5.3687 & TRN & \\
\hline CHEMBL1412004 & 752567 & 6.1864 & 5.3716 & TRN & \\
\hline CHEMBL1571986 & 752567 & 5.4681 & 5.3788 & TRN & \\
\hline CHEMBL1360400 & 752567 & 5.4522 & 5.3547 & TRN & \\
\hline CHEMBL66879 & 752567 & 4.9645 & 5.894 & TRN & \\
\hline CHEMBL1569188 & 752567 & 5.2791 & 5.2983 & TRN & \\
\hline CHEMBL1352471 & 752567 & 5.4571 & 5.4036 & TRN & \\
\hline CHEMBL3195235 & 752567 & 5.439 & 5.6056 & TRN & \\
\hline CHEMBL1477662 & 752567 & 5.1145 & 5.4289 & TRN & \\
\hline CHEMBL1310556 & 752567 & 7.1079 & 5.7381 & TRN & \\
\hline CHEMBL1411504 & 752567 & 4.005 & 5.2294 & TST & \\
\hline CHEMBL1543870 & 752567 & 6.061 & 5.7343 & TST & \\
\hline
\end{tabular}


Supplemental Table S2.txt

\begin{tabular}{|c|c|c|c|c|}
\hline CHEMBL1727587 & 752567 & 6.9101 & 5.6754 & TRN \\
\hline CHEMBL1552012 & 752567 & 6.5768 & 5.7474 & TRN \\
\hline CHEMBL1462751 & 752567 & 5.5722 & 5.8441 & TRN \\
\hline CHEMBL1460201 & 752567 & 5.7025 & 5.5091 & TRN \\
\hline CHEMBL1546197 & 752567 & 7.6576 & 5.9406 & TRN \\
\hline CHEMBL1870201 & 752567 & 5.7426 & 5.5897 & TRN \\
\hline CHEMBL1363706 & 752567 & 4.6823 & 5.4747 & TST \\
\hline CHEMBL1424618 & 752567 & 4.4563 & 5.4221 & TRN \\
\hline CHEMBL1703897 & 752567 & 4.9629 & 5.4279 & TST \\
\hline CHEMBL170993 & 752567 & 4.6116 & 5.3694 & TRN \\
\hline CHEMBL1364536 & 752567 & 5.181 & 5.6378 & TRN \\
\hline CHEMBL1469700 & 752567 & 5.5611 & 5.3667 & TRN \\
\hline CHEMBL1585364 & 752567 & 6.2573 & 5.6108 & TST \\
\hline CHEMBL1528975 & 752567 & 5.0722 & 5.3643 & TRN \\
\hline CHEMBL1709767 & 752567 & 5.6863 & 5.8183 & TRN \\
\hline CHEMBL1501462 & 752567 & 5.0442 & 5.4561 & TRN \\
\hline CHEMBL1539077 & 752567 & 4.9962 & 5.3757 & TRN \\
\hline CHEMBL1443553 & 752567 & 5.5852 & 5.2722 & TRN \\
\hline CHEMBL340807 & 752567 & 5.90799 & 999999999 & 5.6317 \\
\hline CHEMBL1730949 & 752567 & 6.8447 & 5.612999 & 99999999995 \\
\hline CHEMBL1438167 & 752567 & 4.1846 & 5.4534 & TRN \\
\hline CHEMBL1442864 & 752567 & 6.1007 & 5.5855 & TRN \\
\hline CHEMBL177991 & 752567 & 6.3045 & 5.4211 & TRN \\
\hline CHEMBL1414790 & 752567 & 5.0857 & 5.6558 & TRN \\
\hline CHEMBL1500155 & 752567 & 6.9031 & 5.9064 & TRN \\
\hline CHEMBL1376017 & 752567 & 5.3816 & 5.4472 & TRN \\
\hline CHEMBL1487786 & 752567 & 4.6261 & 5.5291 & TST \\
\hline CHEMBL1553151 & 752567 & 5.1904 & 5.4664 & TST \\
\hline CHEMBL1580968 & 752567 & 5.1827 & 5.6982 & TST \\
\hline CHEMBL1734631 & 752567 & 5.1355 & 5.694 & TST \\
\hline CHEMBL1329994 & 752567 & 5.5481 & 5.4426 & TST \\
\hline CHEMBL1548715 & 752567 & 5.3932 & 5.7683 & TST \\
\hline CHEMBL1565911 & 752567 & 5.8935 & 5.4623 & TST \\
\hline CHEMBL1452621 & 752567 & 5.4689 & 5.6589 & TST \\
\hline CHEMBL1965956 & 752567 & 4.9974 & 5.5724 & TST \\
\hline CHEMBL1490818 & 752567 & 5.1656 & 5.3991 & TST \\
\hline CHEMBL16482 & 752567 & 5.6805 & 5.7665 & TST \\
\hline CHEMBL1425822 & 752567 & 5.0467 & 5.3292 & TST \\
\hline CHEMBL1722415 & 752567 & 4.8505 & 5.2879 & TST \\
\hline CHEMBL1390796 & 752567 & 5.6507 & 5.4444 & TST \\
\hline CHEMBL1610671 & 752567 & 6.4609 & 5.3751 & TST \\
\hline CHEMBL1303281 & 752567 & 5.0875 & 5.6598 & TST \\
\hline CHEMBL1342147 & 752567 & 4.8751 & 5.3843 & TST \\
\hline CHEMBL55814 & 752567 & 5.3427 & 5.6874 & TST \\
\hline CHEMBL1583267 & 752567 & 5.5585 & 5.4187 & TST \\
\hline CHEMBL1446001 & 752567 & 5.1676 & 5.7931 & TST \\
\hline CHEMBL1609641 & 752567 & 6.5003 & 6.0245 & TST \\
\hline CHEMBL1604973 & 752567 & 5.4187 & 5.4687 & TST \\
\hline
\end{tabular}


Supplemental Table S2.txt

\begin{tabular}{|c|c|c|c|c|}
\hline CHEMBL3195429 & 752567 & 5.3275 & 5.4837 & TST \\
\hline CHEMBL1301607 & 752567 & 5.4144 & 5.1412 & TST \\
\hline CHEMBL1583199 & 752567 & 6.5421 & 5.6659 & TST \\
\hline CHEMBL1469974 & 752567 & 2.9208 & 5.3347 & TST \\
\hline CHEMBL1329604 & 752567 & 9.2218 & 5.6664 & TST \\
\hline CHEMBL1408094 & 752567 & 5.0728 & 5.4892 & TST \\
\hline CHEMBL1561432 & 752567 & 4.8533 & 5.4264 & TST \\
\hline CHEMBL1430688 & 752567 & 5.1826 & 5.2582 & TST \\
\hline CHEMBL1545657 & 752567 & 5.011 & 5.3095 & TST \\
\hline CHEMBL3191763 & 752567 & 5.0133 & 5.574 & TST \\
\hline CHEMBL1390151 & 752567 & 5.5011 & 5.5559 & TST \\
\hline CHEMBL1379295 & 752567 & 5.5599 & 5.2731 & TST \\
\hline CHEMBL32579 & 752567 & 5.3898 & 5.7621 & TST \\
\hline CHEMBL1508872 & 752567 & 4.9911 & 5.4951 & TST \\
\hline CHEMBL1463659 & 752567 & 6.5467 & 5.3908 & TST \\
\hline CHEMBL1458609 & 752567 & 4.9809 & 5.6021 & TST \\
\hline CHEMBL209699 & 752567 & 5.5575 & 5.7213 & TST \\
\hline CHEMBL1891598 & 752567 & 5.4579 & 5.74200 & 0000000001 \\
\hline CHEMBL408982 & 752567 & 6.0 & 5.58700 & 0000000001 \\
\hline CHEMBL3208938 & 752567 & 5.2054 & 5.5093 & TST \\
\hline CHEMBL407874 & 752567 & 5.2967 & 5.5077 & TST \\
\hline CHEMBL1533622 & 752567 & 5.4362 & 5.791 & TST \\
\hline CHEMBL1884133 & 752567 & 6.04 & 5.5196 & TST \\
\hline CHEMBL1555880 & 752567 & 5.1444 & 5.3928 & TST \\
\hline CHEMBL1348329 & 752567 & 5.1419 & 5.7198 & TST \\
\hline CHEMBL1413051 & 752567 & 4.8595 & 5.2629 & TST \\
\hline CHEMBL1611020 & 752567 & 5.1028 & 5.5893 & TST \\
\hline CHEMBL1460452 & 752567 & 6.1688 & 5.5105 & TST \\
\hline CHEMBL1429797 & 752567 & 5.0733 & 5.5939 & TST \\
\hline CHEMBL1609015 & 752567 & 5.5054 & 5.6617 & TST \\
\hline CHEMBL1464228 & 752567 & 4.8388 & 5.6062 & TST \\
\hline CHEMBL375530 & 752567 & 5.4244 & 5.7443 & TST \\
\hline CHEMBL1505462 & 752567 & 4.5397 & 5.61299 & 79999999995 \\
\hline CHEMBL1492095 & 752567 & 5.0361 & 5.3085 & TST \\
\hline CHEMBL1543861 & 752567 & 5.16 & 5.1971 & TST \\
\hline CHEMBL1328892 & 752567 & 4.8675 & 5.3996 & TST \\
\hline CHEMBL1604112 & 752567 & 5.4522 & 5.5482 & TST \\
\hline CHEMBL1460413 & 752567 & 4.9958 & 5.6562 & TST \\
\hline CHEMBL1532994 & 752567 & 4.9012 & 5.2674 & TST \\
\hline CHEMBL1608304 & 752567 & 5.4455 & 5.3721 & TST \\
\hline CHEMBL1493400 & 752567 & 5.8204 & 5.6535 & TST \\
\hline CHEMBL 3190025 & 752567 & 5.1518 & 5.3891 & TST \\
\hline CHEMBL1430681 & 752567 & 6.0467 & 6.0626 & TST \\
\hline CHEMBL1594851 & 752567 & 5.0887 & 5.0875 & TST \\
\hline CHEMBL1608847 & 752567 & 5.1737 & 5.2214 & TST \\
\hline CHEMBL1309165 & 752567 & 5.6868 & 5.8403 & TST \\
\hline CHEMBL2369240 & 752567 & 5.2895 & 5.7201 & TST \\
\hline CHEMBL1518767 & 752567 & 6.2518 & 6.0566 & TST \\
\hline
\end{tabular}




\begin{tabular}{|c|c|c|c|c|c|c|}
\hline \multicolumn{7}{|c|}{ Supplemental Table S2.txt } \\
\hline CHEMBL1496630 & 752567 & 5.7701 & 5.4964 & TST & & \\
\hline CHEMBL1369135 & 752567 & $5.4920 e$ & 00000000 & & 5.5993 & TST \\
\hline CHEMBL1392459 & 752567 & 5.0005 & 5.5238 & TST & & \\
\hline CHEMBL527336 & 752567 & 4.9599 & 5.3191 & TST & & \\
\hline CHEMBL1343828 & 752567 & 5.9129 & 5.7676 & TST & & \\
\hline CHEMBL1565736 & 752567 & 5.9007 & 5.2864 & TST & & \\
\hline CHEMBL1586152 & 752567 & 5.5166 & 5.69600 & 000000000 & & TST \\
\hline CHEMBL1439898 & 752567 & 5.4817 & 5.2701 & TST & & \\
\hline CHEMBL1611317 & 752567 & $5.2970 e$ & 00000000 & $\partial 1$ & 5.2892 & TST \\
\hline CHEMBL1608645 & 752567 & 5.7064 & 5.1258 & TST & & \\
\hline CHEMBL1727014 & 752567 & 6.0575 & 5.8205 & TST & & \\
\hline CHEMBL1709889 & 752567 & 5.1627 & 5.7461 & TST & & \\
\hline CHEMBL1435418 & 752567 & 6.1688 & 5.7057 & TST & & \\
\hline CHEMBL1374748 & 752567 & 5.1795 & 5.1998 & TST & & \\
\hline CHEMBL1327484 & 752567 & 5.1011 & 5.4519 & TST & & \\
\hline CHEMBL1545978 & 752567 & 5.4646 & 5.2115 & TST & & \\
\hline CHEMBL426588 & 306176 & 4.4949 & 4.4387 & TRN & & \\
\hline CHEMBL424771 & 306176 & 4.1549 & 4.3167 & TRN & & \\
\hline CHEMBL179024 & 306176 & 3.0 & 2.9899 & TRN & & \\
\hline CHEMBL361631 & 306176 & 3.0 & 3.0722 & TRN & & \\
\hline CHEMBL414840 & 306176 & 4.0315 & 3.5511 & TRN & & \\
\hline CHEMBL175837 & 306176 & 3.0 & 3.5463 & TRN & & \\
\hline CHEMBL369513 & 306176 & 3.0 & 3.1376 & TRN & & \\
\hline CHEMBL175955 & 306176 & 4.8239 & 4.6685 & TRN & & \\
\hline CHEMBL180113 & 306176 & 4.0809 & 4.3524 & TRN & & \\
\hline CHEMBL175984 & 306176 & 4.0555 & 3.9797 & TRN & & \\
\hline CHEMBL179045 & 306176 & 3.0 & 3.3202 & TRN & & \\
\hline CHEMBL176125 & 306176 & 4.0655 & 4.1667 & TRN & & \\
\hline CHEMBL367845 & 306176 & 3.0 & 3.1613 & TRN & & \\
\hline CHEMBL368510 & 306176 & 4.2147 & 3.9168 & TRN & & \\
\hline CHEMBL175482 & 306176 & 4.1805 & 4.1509 & TST & & \\
\hline CHEMBL175828 & 306176 & 4.3979 & 4.0231 & TST & & \\
\hline CHEMBL369600 & 306176 & 4.0088 & 3.6048 & TRN & & \\
\hline CHEMBL179817 & 306176 & 4.0088 & 4.0013 & TRN & & \\
\hline CHEMBL 360014 & 306176 & 4.4437 & 4.4878 & TRN & & \\
\hline CHEMBL366397 & 306176 & 4.0132 & 4.2166 & TRN & & \\
\hline CHEMBL175480 & 306176 & 3.0 & 2.839 & TRN & & \\
\hline CHEMBL368194 & 306176 & 4.0044 & 3.917 & TRN & & \\
\hline CHEMBL175822 & 306176 & 3.0 & 3.2158 & TRN & & \\
\hline CHEMBL3706764 & 306176 & 4.8861 & 4.0799 & TST & & \\
\hline CHEMBL369010 & 306176 & 3.0 & 3.4899 & TRN & & \\
\hline CHEMBL175880 & 306176 & 4.7959 & 4.6939 & TST & & \\
\hline CHEMBL177242 & 306176 & 3.0 & 3.0144 & TRN & & \\
\hline CHEMBL176113 & 306176 & 4.8239 & 4.8404 & TRN & & \\
\hline CHEMBL176083 & 306176 & 4.699 & 4.3255 & TRN & & \\
\hline CHEMBL177335 & 306176 & 4.1079 & 3.8464 & TRN & & \\
\hline CHEMBL368303 & 306176 & 3.0 & 3.0832 & TRN & & \\
\hline CHEMBL175521 & 306176 & 4.7696 & 4.7319 & TRN & & \\
\hline
\end{tabular}




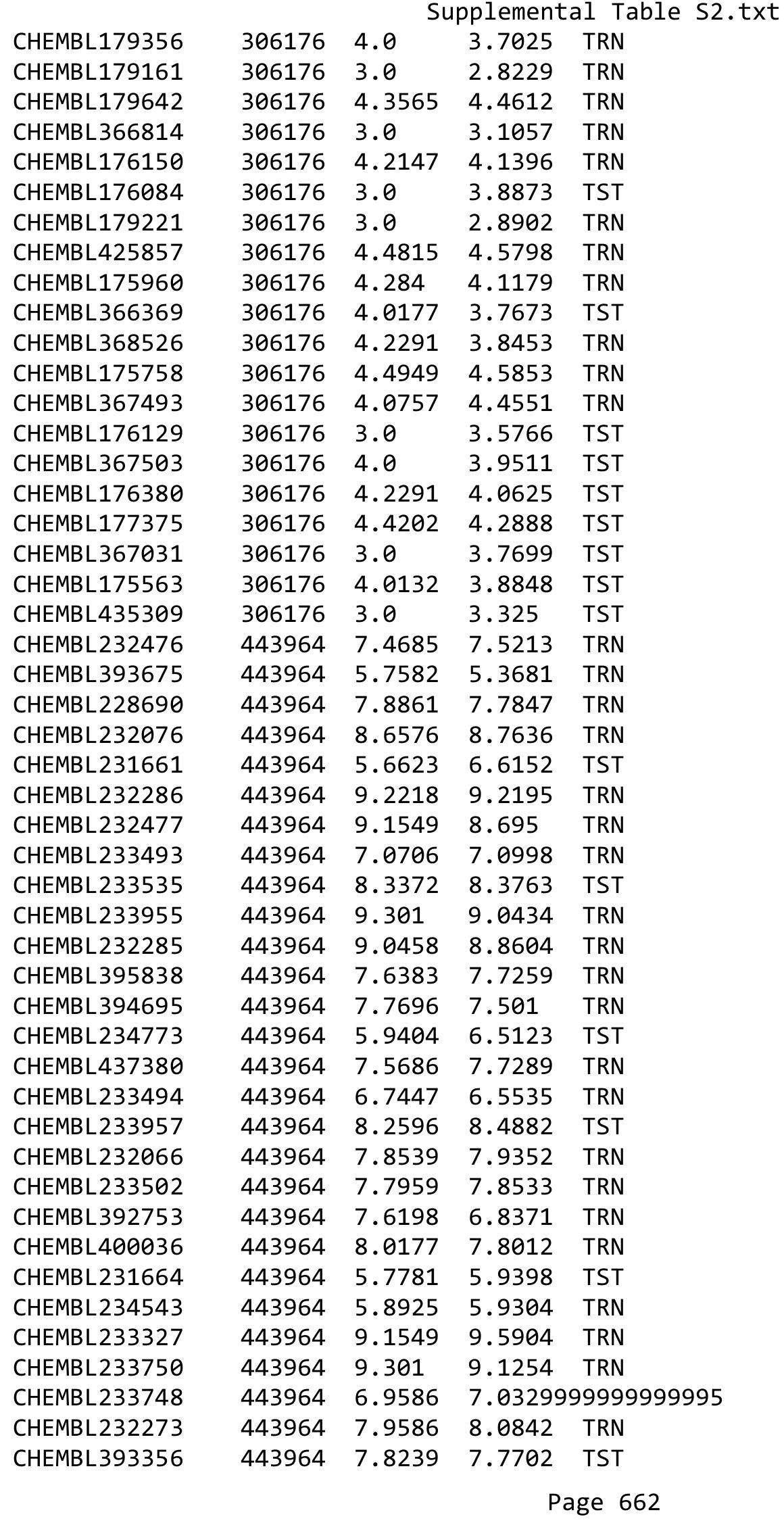

TRN 


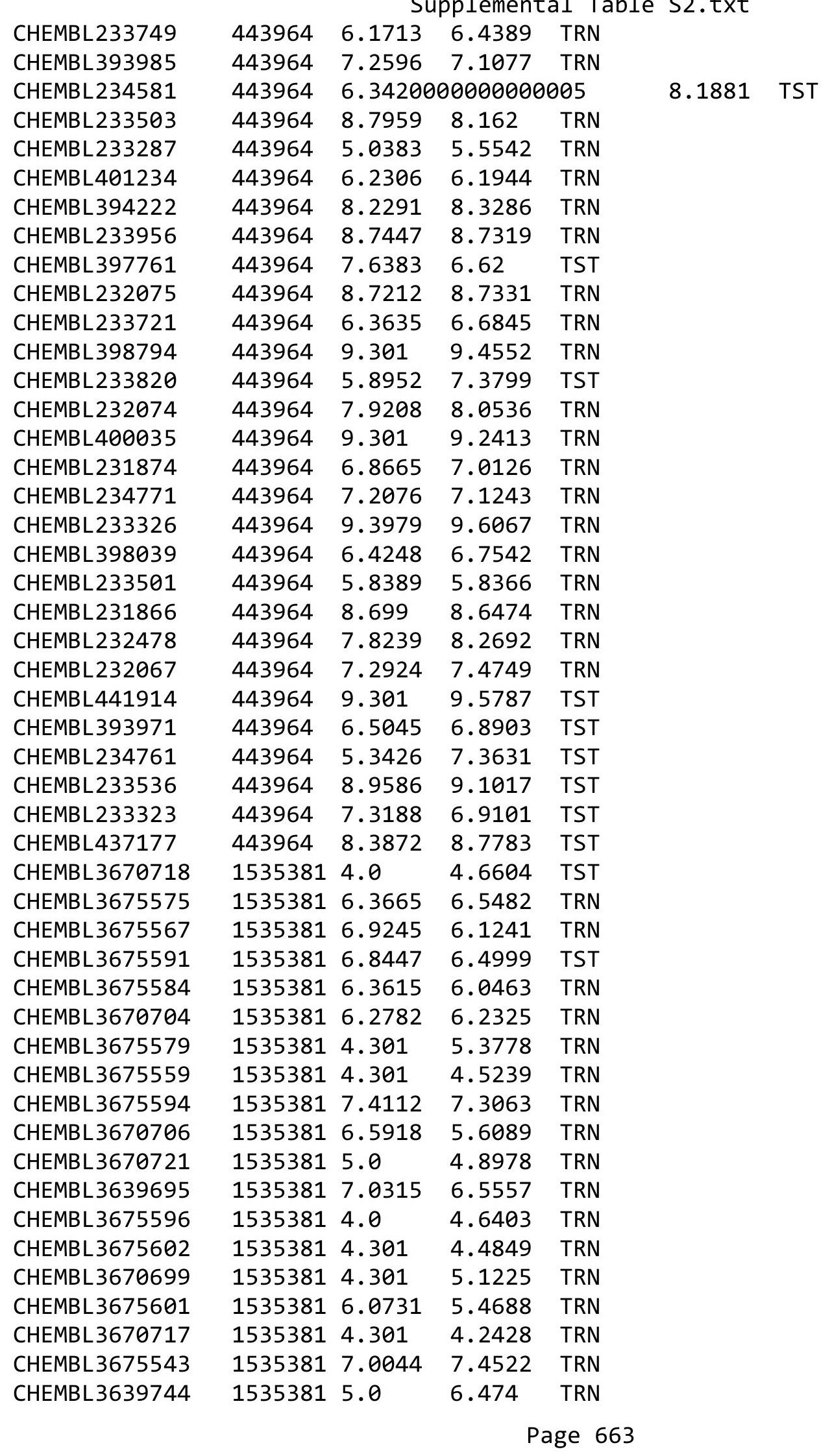


Supplemental Table S2.txt

\begin{tabular}{|c|c|c|c|c|}
\hline CHEMBL3675605 & 1535381 & 7.0969 & 6.8872 & TRN \\
\hline CHEMBL 3675548 & 1535381 & 5.0 & 6.1241 & TRN \\
\hline CHEMBL3675545 & 1535381 & 5.0 & 5.0053 & TRN \\
\hline CHEMBL3670716 & 1535381 & 5.0 & 4.8427 & TST \\
\hline CHEMBL3675583 & 1535381 & 5.0 & 5.2365 & TRN \\
\hline CHEMBL3675597 & 1535381 & 5.0 & 4.6403 & TRN \\
\hline CHEMBL3675554 & 1535381 & 6.3635 & 6.7663 & TST \\
\hline CHEMBL3675595 & 1535381 & 5.0 & 5.2305 & TRN \\
\hline CHEMBL 3675570 & 1535381 & 7.1487 & 6.125 & TRN \\
\hline CHEMBL3670710 & 1535381 & 5.0 & 4.9125 & TST \\
\hline CHEMBL3675581 & 1535381 & 6.4283 & 5.902 & TRN \\
\hline CHEMBL3675580 & 1535381 & 5.0 & 4.2634 & TRN \\
\hline CHEMBL 3675557 & 1535381 & 5.0 & 5.0096 & TRN \\
\hline CHEMBL3675558 & 1535381 & 4.0 & 4.0599 & TRN \\
\hline CHEMBL3675553 & 1535381 & 4.0 & 5.3492 & TST \\
\hline CHEMBL3670709 & 1535381 & 5.0 & 3.81 & TST \\
\hline CHEMBL 3675544 & 1535381 & 5.0 & 5.4331 & TRN \\
\hline CHEMBL 3675607 & 1535381 & 5.0 & 5.7811 & TRN \\
\hline CHEMBL3670696 & 1535381 & 6.284 & 6.3814 & TRN \\
\hline CHEMBL3675568 & 1535381 & 6.8861 & 5.9072 & TRN \\
\hline CHEMBL3675586 & 1535381 & 6.0783 & 5.5947 & TRN \\
\hline CHEMBL 3670708 & 1535381 & 6.5591 & 6.3828 & TRN \\
\hline CHEMBL3675571 & 1535381 & 6.4179 & 5.3012 & TRN \\
\hline CHEMBL 3675600 & 1535381 & 4.301 & 4.3856 & TRN \\
\hline CHEMBL 3675561 & 1535381 & 5.0 & 4.5778 & TRN \\
\hline CHEMBL3670705 & 1535381 & 4.301 & 5.6089 & TRN \\
\hline CHEMBL 3675562 & 1535381 & 4.301 & 4.4671 & TRN \\
\hline CHEMBL3675542 & 1535381 & 6.3507 & 6.0589 & TRN \\
\hline CHEMBL3670695 & 1535381 & 7.4559 & 6.8394 & TRN \\
\hline CHEMBL 3675574 & 1535381 & 5.0 & 5.0859 & TRN \\
\hline CHEMBL 3670714 & 1535381 & 5.0 & 4.7994 & TRN \\
\hline CHEMBL 3670703 & 1535381 & 6.7077 & 6.5068 & TST \\
\hline CHEMBL3670691 & 1535381 & 6.9136 & 6.5803 & TST \\
\hline CHEMBL3670701 & 1535381 & 6.9431 & 6.3583 & TST \\
\hline CHEMBL3675550 & 1535381 & 5.0 & 5.5524 & TRN \\
\hline CHEMBL3675552 & 1535381 & 4.301 & 5.3012 & TRN \\
\hline CHEMBL3675565 & 1535381 & 6.3497 & 5.0859 & TRN \\
\hline CHEMBL3670711 & 1535381 & 4.301 & 3.8907 & TST \\
\hline CHEMBL 3670700 & 1535381 & 4.301 & 5.1193 & TST \\
\hline CHEMBL 3675587 & 1535381 & 5.0 & 5.3173 & TRN \\
\hline CHEMBL3670698 & 1535381 & 7.2924 & 6.3216 & TST \\
\hline CHEMBL 3675585 & 1535381 & 6.289 & 6.17299 & 9999999999 \\
\hline CHEMBL 3675573 & 1535381 & 8.1135 & 6.7663 & TST \\
\hline CHEMBL 3670697 & 1535381 & 6.2549 & 4.5512 & TST \\
\hline CHEMBL3675541 & 1535381 & 5.0 & 4.6506 & TRN \\
\hline CHEMBL3675569 & 1535381 & 6.7747 & 5.5524 & TRN \\
\hline CHEMBL 3675604 & 1535381 & 5.0 & 4.7988 & TST \\
\hline CHEMBL 3675556 & 1535381 & 5.0 & 4.3898 & TRN \\
\hline
\end{tabular}


Supplemental Table S2.txt

\begin{tabular}{|c|c|c|c|c|}
\hline CHEMBL3675578 & 1535381 & 4.301 & 4.5538 & TRN \\
\hline CHEMBL3675592 & 1535381 & 6.4522 & 6.8337 & TRN \\
\hline CHEMBL3675599 & 1535381 & 6.2434 & 6.1308 & TRN \\
\hline CHEMBL3670715 & 1535381 & 5.0 & 5.2062 & TRN \\
\hline CHEMBL3670712 & 1535381 & 4.301 & 4.0924 & TST \\
\hline CHEMBL3675588 & 1535381 & 6.1296 & 5.7125 & TRN \\
\hline CHEMBL3675603 & 1535381 & 6.4976 & 6.532 & TST \\
\hline CHEMBL 3675566 & 1535381 & 7.4559 & 6.474 & TRN \\
\hline CHEMBL 3675572 & 1535381 & 6.3757 & 5.3492 & TST \\
\hline CHEMBL3675547 & 1535381 & 4.301 & 5.0859 & TRN \\
\hline CHEMBL3675564 & 1535381 & 6.9914 & 6.1726 & TRN \\
\hline CHEMBL3675546 & 1535381 & 4.301 & 4.8567 & TRN \\
\hline CHEMBL 3675582 & 1535381 & 6.1864 & 5.6543 & TRN \\
\hline CHEMBL3675593 & 1535381 & 6.8069 & 6.9064 & TRN \\
\hline CHEMBL 3675576 & 1535381 & 5.0 & 5.2812 & TRN \\
\hline CHEMBL3675598 & 1535381 & 5.0 & 5.858 & TRN \\
\hline CHEMBL3675555 & 1535381 & 5.0 & 4.5484 & TRN \\
\hline CHEMBL 3675549 & 1535381 & 5.0 & 5.9072 & TRN \\
\hline CHEMBL 3675560 & 1535381 & 5.0 & 4.8556 & TRN \\
\hline CHEMBL3675551 & 1535381 & 5.0 & 6.125 & TRN \\
\hline CHEMBL1232489 & 1535381 & 5.0 & 5.1992 & TST \\
\hline CHEMBL 3670702 & 1535381 & 5.0 & 6.0717 & TST \\
\hline CHEMBL3670719 & 1535381 & 5.0 & 4.3226 & TST \\
\hline CHEMBL3670713 & 1535381 & 5.0 & 4.7213 & TRN \\
\hline CHEMBL3675589 & 1535381 & 5.0 & 5.2931 & TRN \\
\hline CHEMBL3670707 & 1535381 & 4.0 & 4.4217 & TST \\
\hline CHEMBL 3675590 & 1535381 & 4.301 & 4.8314 & TST \\
\hline CHEMBL3670720 & 1535381 & 6.1681 & 5.87799 & э999999999 \\
\hline CHEMBL3675577 & 1535381 & 4.0 & 4.9359 & TRN \\
\hline CHEMBL1813084 & 762154 & 8.3979 & 8.736 & TRN \\
\hline CHEMBL1812881 & 762154 & 6.3372 & 6.3025 & TRN \\
\hline CHEMBL1812888 & 762154 & 8.3468 & 8.1799 & TRN \\
\hline CHEMBL1812883 & 762154 & 7.5528 & 7.0354 & TRN \\
\hline CHEMBL1812867 & 762154 & 8.1079 & 7.9037 & TST \\
\hline CHEMBL1813082 & 762154 & 8.8861 & 9.1202 & TRN \\
\hline CHEMBL1813093 & 762154 & 8.2924 & 8.0476 & TRN \\
\hline CHEMBL 85537 & 762154 & 5.3915 & 7.6064 & TST \\
\hline CHEMBL1812879 & 762154 & 5.7696 & 6.3469 & TRN \\
\hline CHEMBL1812898 & 762154 & 6.7696 & 6.359 & TRN \\
\hline CHEMBL1812889 & 762154 & 8.5376 & 8.1799 & TRN \\
\hline CHEMBL1812876 & 762154 & 6.426 & 6.9394 & TRN \\
\hline CHEMBL1812897 & 762154 & 7.0809 & 6.3545 & TRN \\
\hline CHEMBL1813089 & 762154 & 8.0809 & 8.1169 & TRN \\
\hline CHEMBL1811930 & 762154 & 5.2262 & 6.87299 & 9999999999 \\
\hline CHEMBL1813086 & 762154 & 8.2518 & 8.0849 & TRN \\
\hline CHEMBL1813088 & 762154 & 8.2147 & 8.4572 & TRN \\
\hline CHEMBL1813083 & 762154 & 8.5376 & 8.736 & TRN \\
\hline CHEMBL1813091 & 762154 & 7.8996 & 7.9313 & TRN \\
\hline
\end{tabular}




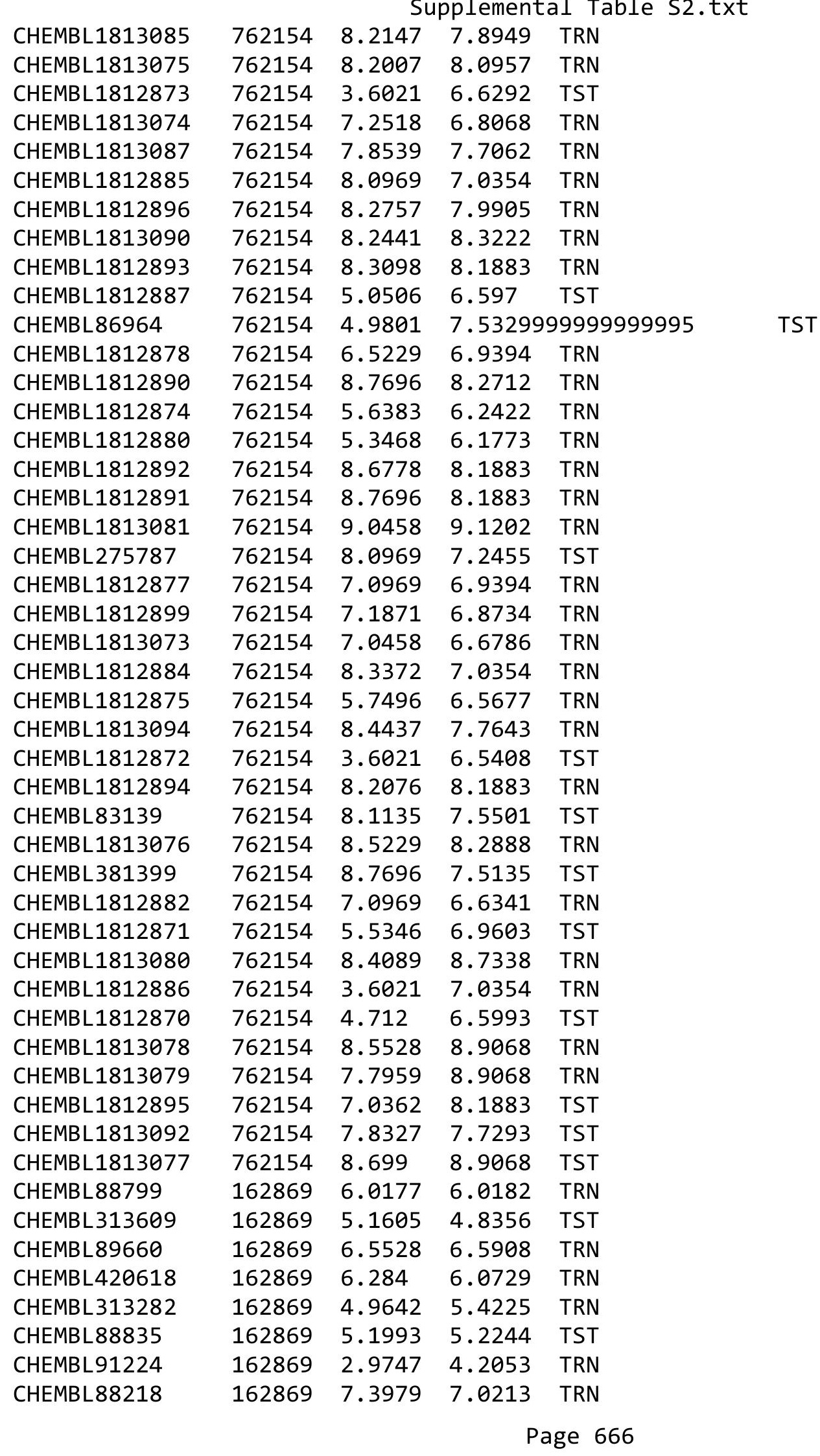




\begin{tabular}{|c|c|c|c|c|c|c|}
\hline \multirow[b]{2}{*}{ CHEMBL92264 } & \multicolumn{6}{|c|}{ Supplemental Table s2.txt } \\
\hline & 162869 & 6.9208 & 6.7103 & TRN & & \\
\hline CHEMBL91527 & 162869 & 7.699 & 8.0825 & TRN & & \\
\hline CHEMBL91478 & 162869 & 7.2596 & 6.7854 & TRN & & \\
\hline CHEMBL88707 & 162869 & 5.9706 & 5.6052 & TRN & & \\
\hline CHEMBL92158 & 162869 & 6.0223 & 5.8695 & TRN & & \\
\hline CHEMBL90168 & 162869 & 5.8761 & 5.7725 & TRN & & \\
\hline CHEMBL91127 & 162869 & 6.3565 & 6.3665 & TRN & & \\
\hline CHEMBL328755 & 162869 & 5.5302 & 5.7799 & TRN & & \\
\hline CHEMBL91368 & 162869 & 8.301 & 7.742006 & 0000000001 & & TRN \\
\hline CHEMBL88583 & 162869 & 6.4089 & 6.335 & TST & & \\
\hline CHEMBL330280 & 162869 & 5.21899 & 99999999 & & 5.1096 & TRN \\
\hline CHEMBL420980 & 162869 & 6.3665 & 5.9927 & TRN & & \\
\hline CHEMBL88265 & 162869 & 4.2 & 4.4078 & TRN & & \\
\hline CHEMBL88444 & 162869 & 7.699 & 7.5681 & TRN & & \\
\hline CHEMBL92363 & 162869 & 7.301 & 7.1057 & TRN & & \\
\hline CHEMBL431799 & 162869 & 8.301 & 8.0825 & TRN & & \\
\hline CHEMBL88708 & 162869 & 6.6778 & 6.7139 & TRN & & \\
\hline CHEMBL328149 & 162869 & 6.6778 & 6.7544 & TRN & & \\
\hline CHEMBL90102 & 162869 & 3.05800 & 300000006 & 203 & 3.2638 & TRN \\
\hline CHEMBL91579 & 162869 & 5.0264 & 4.669 & TRN & & \\
\hline CHEMBL90804 & 162869 & 8.2218 & 8.1302 & TRN & & \\
\hline CHEMBL93688 & 162869 & 6.4089 & 7.0213 & TRN & & \\
\hline CHEMBL91356 & 162869 & 6.7447 & 6.5908 & TRN & & \\
\hline CHEMBL 327580 & 162869 & 5.7799 & 6.1031 & TRN & & \\
\hline CHEMBL 88377 & 162869 & 5.8794 & 6.2254 & TRN & & \\
\hline CHEMBL91044 & 162869 & 6.8239 & 6.496 & TST & & \\
\hline CHEMBL90881 & 162869 & 6.2291 & 6.1985 & TRN & & \\
\hline CHEMBL 88525 & 162869 & 5.71899 & 99999999 & 99 & 5.835 & TRN \\
\hline CHEMBL91422 & 162869 & 7.1549 & 7.1057 & TST & & \\
\hline CHEMBL90677 & 162869 & 6.4089 & 6.3486 & TST & & \\
\hline CHEMBL313463 & 162869 & 5.983 & 5.5849 & TRN & & \\
\hline CHEMBL91843 & 162869 & 6.0223 & 6.5574 & TRN & & \\
\hline CHEMBL88224 & 162869 & 5.6073 & 5.699 & TRN & & \\
\hline CHEMBL91340 & 162869 & 4.5735 & 4.1604 & TST & & \\
\hline CHEMBL92269 & 162869 & 6.7447 & 6.6625 & TRN & & \\
\hline CHEMBL88877 & 162869 & 6.4437 & 5.7788 & TST & & \\
\hline CHEMBL91204 & 162869 & 6.3768 & 6.2756 & TRN & & \\
\hline CHEMBL90120 & 162869 & 5.2676 & 5.3084 & TST & & \\
\hline CHEMBL91837 & 162869 & 7.0458 & 6.5574 & TRN & & \\
\hline CHEMBL 88395 & 162869 & 5.0405 & 5.2784 & TST & & \\
\hline CHEMBL88698 & 162869 & 4.2984 & 4.2628 & TST & & \\
\hline CHEMBL90601 & 162869 & 3.0 & 3.1446 & TST & & \\
\hline CHEMBL330677 & 162869 & 6.1135 & 6.4292 & TRN & & \\
\hline CHEMBL88730 & 162869 & 6.3565 & 5.9226 & TST & & \\
\hline CHEMBL 91634 & 162869 & 5.7212 & 5.4934 & TST & & \\
\hline CHEMBL88697 & 162869 & 5.5702 & 5.84399 & 9999999999 & & TST \\
\hline CHEMBL91259 & 162869 & 6.3768 & 6.9677 & TRN & & \\
\hline CHEMBL91899 & 162869 & 5.3152 & 5.1831 & TRN & & \\
\hline & & & & ge 667 & & \\
\hline
\end{tabular}




\begin{tabular}{|c|c|c|c|c|c|}
\hline & & \multicolumn{4}{|c|}{ Supplemental Table S2.txt } \\
\hline CHEMBL421885 & 162869 & 2.9747 & 3.5024 & TST & \\
\hline CHEMBL314093 & 162869 & 5.8539 & 6.0736 & TRN & \\
\hline CHEMBL91570 & 162869 & 6.4202 & 6.4956 & TRN & \\
\hline CHEMBL90414 & 162869 & 6.9586 & 6.7953 & TRN & \\
\hline CHEMBL90195 & 162869 & 7.699 & 7.8709 & TRN & \\
\hline CHEMBL88955 & 162869 & 7.2218 & 7.74200 & 0000000001 & TRN \\
\hline CHEMBL327374 & 162869 & 6.4815 & 6.4564 & TRN & \\
\hline CHEMBL314763 & 162869 & 6.585 & 6.5178 & TRN & \\
\hline CHEMBL90566 & 162869 & 4.6144 & 4.615 & TRN & \\
\hline CHEMBL88136 & 162869 & 7.1805 & 6.8114 & TRN & \\
\hline CHEMBL91295 & 162869 & 5.4989 & 4.2053 & TRN & \\
\hline CHEMBL 88245 & 162869 & 6.7447 & 6.324 & TST & \\
\hline CHEMBL88108 & 162869 & 6.041 & 6.2389 & TRN & \\
\hline CHEMBL 90237 & 162869 & 8.0969 & 8.0825 & TRN & \\
\hline CHEMBL423864 & 162869 & 6.2007 & 6.2977 & TRN & \\
\hline CHEMBL89876 & 162869 & 6.0605 & 6.1987 & TRN & \\
\hline CHEMBL88764 & 162869 & 6.8539 & 6.496 & TST & \\
\hline CHEMBL89679 & 162869 & 6.6021 & 6.8325 & TST & \\
\hline CHEMBL1521044 & 737325 & 5.1403 & 4.6747 & TRN & \\
\hline CHEMBL1546342 & 737325 & 4.6038 & 4.2555 & TRN & \\
\hline CHEMBL3190354 & 737325 & 3.0969 & 3.9112 & TST & \\
\hline CHEMBL1424269 & 737325 & 3.0969 & 5.0295 & TRN & \\
\hline CHEMBL1584403 & 737325 & 4.3152 & 3.387 & TRN & \\
\hline CHEMBL1458282 & 737325 & 4.6021 & 3.7629 & TST & \\
\hline CHEMBL1352723 & 737325 & 3.0969 & 4.0837 & TRN & \\
\hline CHEMBL3192670 & 737325 & 4.4584 & 4.456 & TRN & \\
\hline CHEMBL1450096 & 737325 & 5.2111 & 4.0662 & TRN & \\
\hline CHEMBL1371372 & 737325 & 3.0969 & 3.8042 & TRN & \\
\hline CHEMBL1387790 & 737325 & 3.0969 & 4.4112 & TRN & \\
\hline CHEMBL1418371 & 737325 & 4.9914 & 5.0616 & TRN & \\
\hline CHEMBL1486790 & 737325 & 3.0969 & 4.1998 & TRN & \\
\hline CHEMBL1503607 & 737325 & 3.0969 & 3.6954 & TRN & \\
\hline CHEMBL1388241 & 737325 & 6.4437 & 4.933 & TRN & \\
\hline CHEMBL3194942 & 737325 & 4.7235 & 3.9852 & TRN & \\
\hline CHEMBL1311956 & 737325 & 3.0969 & 4.3704 & TRN & \\
\hline CHEMBL1533857 & 737325 & 4.8633 & 4.2746 & TRN & \\
\hline CHEMBL1476823 & 737325 & 4.7471 & 3.4822 & TRN & \\
\hline CHEMBL1527929 & 737325 & 4.9547 & 4.7519 & TRN & \\
\hline CHEMBL1344784 & 737325 & 3.0969 & 3.2961 & TRN & \\
\hline CHEMBL1555599 & 737325 & 3.0969 & 4.0413 & TRN & \\
\hline CHEMBL1301144 & 737325 & 4.4498 & 3.7437 & TRN & \\
\hline CHEMBL1414465 & 737325 & 6.4559 & 4.2259 & TRN & \\
\hline CHEMBL1568851 & 737325 & 3.0969 & 4.5241 & TRN & \\
\hline CHEMBL1413424 & 737325 & 6.5376 & 4.3445 & TRN & \\
\hline CHEMBL1484886 & 737325 & 5.0742 & 4.5016 & TRN & \\
\hline CHEMBL1724352 & 737325 & 4.5751 & 4.0422 & TRN & \\
\hline CHEMBL1313238 & 737325 & 4.15 & 4.3431 & TRN & \\
\hline CHEMBL1335749 & 737325 & 3.0969 & 3.8367 & TST & \\
\hline
\end{tabular}




\begin{tabular}{|c|c|c|c|c|}
\hline & & & oplement & al $\mathrm{T}$ \\
\hline CHEMBL1890899 & 737325 & 3.0969 & 3.7269 & TRN \\
\hline CHEMBL1373623 & 737325 & 3.0969 & 3.0159 & TRN \\
\hline CHEMBL1578584 & 737325 & 4.7235 & 3.9327 & TRN \\
\hline CHEMBL1598762 & 737325 & 4.5607 & 3.8273 & TRN \\
\hline CHEMBL1326942 & 737325 & 3.0969 & 3.3425 & TRN \\
\hline CHEMBL1409822 & 737325 & 5.2612 & 4.4451 & TRN \\
\hline CHEMBL1519454 & 737325 & 5.2197 & 4.5318 & TST \\
\hline CHEMBL1478054 & 737325 & 5.0783 & 4.0877 & TRN \\
\hline CHEMBL1412180 & 737325 & 4.2692 & 4.6093 & TST \\
\hline CHEMBL1487080 & 737325 & 3.0969 & 3.2243 & TRN \\
\hline CHEMBL1419363 & 737325 & 5.426 & 3.9038 & TRN \\
\hline CHEMBL3209192 & 737325 & 3.0969 & 3.66 & TRN \\
\hline CHEMBL2369258 & 737325 & 3.0969 & 3.5351 & TST \\
\hline CHEMBL1542873 & 737325 & 3.0969 & 3.7044 & TRN \\
\hline CHEMBL1300952 & 737325 & 5.7852 & 4.4496 & TRN \\
\hline CHEMBL1470315 & 737325 & 4.3575 & 4.0605 & TRN \\
\hline CHEMBL1423158 & 737325 & 3.0969 & 3.3186 & TRN \\
\hline CHEMBL1730681 & 737325 & 4.1818 & 4.7228 & TST \\
\hline CHEMBL1488229 & 737325 & 5.0467 & 5.2991 & TRN \\
\hline CHEMBL1423463 & 737325 & 5.063 & 4.0204 & TST \\
\hline CHEMBL1412855 & 737325 & 5.1469 & 4.4127 & TRN \\
\hline CHEMBL1519480 & 737325 & 4.4559 & 4.6907 & TRN \\
\hline CHEMBL1405953 & 737325 & 4.5317 & 4.1196 & TRN \\
\hline CHEMBL1485571 & 737325 & 4.7282 & 4.3439 & TRN \\
\hline CHEMBL1473114 & 737325 & 3.0969 & 3.4944 & TRN \\
\hline CHEMBL1533110 & 737325 & 3.0969 & 3.1917 & TRN \\
\hline CHEMBL1349387 & 737325 & 4.5114 & 4.433 & TRN \\
\hline CHEMBL1327993 & 737325 & 3.0969 & 3.9874 & TRN \\
\hline CHEMBL1598445 & 737325 & 4.2958 & 4.387 & TRN \\
\hline CHEMBL1360938 & 737325 & 3.0969 & 4.3778 & TRN \\
\hline CHEMBL1373738 & 737325 & 4.3429 & 4.4103 & TRN \\
\hline CHEMBL1381600 & 737325 & 5.6676 & 4.8217 & TRN \\
\hline CHEMBL1506962 & 737325 & 4.4685 & 4.3335 & TRN \\
\hline CHEMBL1388599 & 737325 & 4.9393 & 5.1556 & TRN \\
\hline CHEMBL1529883 & 737325 & 3.0969 & 4.3234 & TRN \\
\hline CHEMBL1353474 & 737325 & 6.0132 & 5.2099 & TRN \\
\hline CHEMBL1403324 & 737325 & 6.0472 & 5.0344 & TRN \\
\hline CHEMBL504142 & 737325 & 5.5331 & 4.7832 & TST \\
\hline CHEMBL1371241 & 737325 & 4.3686 & 3.8563 & TRN \\
\hline CHEMBL1419673 & 737325 & 4.6716 & 3.5262 & TST \\
\hline CHEMBL1428662 & 737325 & 3.0969 & 3.6223 & TRN \\
\hline CHEMBL3195661 & 737325 & 3.0969 & 4.152 & TRN \\
\hline CHEMBL1734009 & 737325 & 4.2269 & 4.525 & TRN \\
\hline CHEMBL1707441 & 737325 & 4.9747 & 3.7909 & TST \\
\hline CHEMBL1348824 & 737325 & 3.0969 & 3.6956 & TRN \\
\hline CHEMBL 2297588 & 737325 & 3.0969 & 3.864 & TRN \\
\hline CHEMBL1370849 & 737325 & 3.0969 & 4.9461 & TRN \\
\hline CHEMBL1471715 & 737325 & 3.0969 & 3.1801 & TRN \\
\hline
\end{tabular}




\begin{tabular}{|c|c|c|c|c|c|}
\hline \multirow{2}{*}{ CHEMBL1423968 } & \multicolumn{5}{|c|}{ Supplemental Table S2.txt } \\
\hline & 737325 & 4.5421 & 4.22199 & 99999999995 & TRN \\
\hline CHEMBL1424292 & 737325 & 3.0969 & 3.7455 & TRN & \\
\hline CHEMBL1483537 & 737325 & 4.2118 & 4.0264 & TRN & \\
\hline CHEMBL1363955 & 737325 & 4.9431 & 4.8758 & TRN & \\
\hline CHEMBL1607086 & 737325 & 4.9245 & 4.7457 & TRN & \\
\hline CHEMBL1407064 & 737325 & 4.3335 & 3.4951 & TRN & \\
\hline CHEMBL3189918 & 737325 & 4.8539 & 3.7135 & TRN & \\
\hline CHEMBL1479442 & 737325 & 3.0969 & 3.1741 & TRN & \\
\hline CHEMBL1533676 & 737325 & 4.9508 & 3.98199 & 99999999998 & TRN \\
\hline CHEMBL1490048 & 737325 & 4.7878 & 4.6415 & TRN & \\
\hline CHEMBL 2373711 & 737325 & 4.762 & 5.2946 & TST & \\
\hline CHEMBL1445424 & 737325 & 4.3585 & 3.8252 & TRN & \\
\hline CHEMBL1900850 & 737325 & 7.7959 & 6.6974 & TST & \\
\hline CHEMBL1441617 & 737325 & 4.1831 & 3.9579 & TRN & \\
\hline CHEMBL1518715 & 737325 & 4.3233 & 4.1101 & TRN & \\
\hline CHEMBL1572520 & 737325 & 3.0969 & 3.8452 & TRN & \\
\hline CHEMBL1477125 & 737325 & 3.0969 & 3.5971 & TRN & \\
\hline CHEMBL1711360 & 737325 & 6.2924 & 5.6879 & TST & \\
\hline CHEMBL1604602 & 737325 & 3.0969 & 3.8336 & TRN & \\
\hline CHEMBL1496657 & 737325 & 4.2557 & 3.6726 & TRN & \\
\hline CHEMBL1534546 & 737325 & 4.289 & 4.6556 & TRN & \\
\hline CHEMBL1552506 & 737325 & 5.055 & 4.7782 & TRN & \\
\hline CHEMBL1408398 & 737325 & 4.8125 & 4.7547 & TRN & \\
\hline CHEMBL1494391 & 737325 & 3.0969 & 3.4425 & TRN & \\
\hline CHEMBL1480464 & 737325 & 5.0339 & 4.8151 & TRN & \\
\hline CHEMBL1339546 & 737325 & 4.567 & 4.9932 & TRN & \\
\hline CHEMBL1610614 & 737325 & 3.0969 & 4.0869 & TRN & \\
\hline CHEMBL3197447 & 737325 & 6.1427 & 3.491 & TRN & \\
\hline CHEMBL1724339 & 737325 & 4.4157 & 4.8403 & TRN & \\
\hline CHEMBL 2003998 & 737325 & 4.8962 & 3.6983 & TRN & \\
\hline CHEMBL3210191 & 737325 & 3.0969 & 4.0507 & TRN & \\
\hline CHEMBL1518647 & 737325 & 3.0969 & 4.5632 & TRN & \\
\hline CHEMBL1447724 & 737325 & 4.5591 & 5.1542 & TRN & \\
\hline CHEMBL1568892 & 737325 & 6.2218 & 5.6878 & TRN & \\
\hline CHEMBL1733981 & 737325 & 3.0969 & 3.7749 & TRN & \\
\hline CHEMBL1429636 & 737325 & 3.0969 & 3.762 & TST & \\
\hline CHEMBL1700017 & 737325 & 4.6716 & 3.6774 & TRN & \\
\hline CHEMBL1498980 & 737325 & 3.0969 & 3.3953 & TRN & \\
\hline CHEMBL1362678 & 737325 & 3.0969 & 4.4516 & TRN & \\
\hline CHEMBL3210100 & 737325 & 3.0969 & 3.7593 & TRN & \\
\hline CHEMBL1504183 & 737325 & 3.0969 & 3.5912 & TST & \\
\hline CHEMBL1431151 & 737325 & 3.0969 & 4.5029 & TRN & \\
\hline CHEMBL1328214 & 737325 & 3.0969 & 4.2967 & TRN & \\
\hline CHEMBL1445134 & 737325 & 4.5157 & 4.2636 & TRN & \\
\hline CHEMBL1497097 & 737325 & 4.3893 & 4.4404 & TRN & \\
\hline CHEMBL1544054 & 737325 & 6.1675 & 3.9279 & TRN & \\
\hline CHEMBL1461601 & 737325 & 4.4815 & 3.8107 & TRN & \\
\hline CHEMBL1306343 & 737325 & 5.8539 & 5.0554 & TRN & \\
\hline
\end{tabular}


Supplemental Table S2.txt

\begin{tabular}{|c|c|c|c|c|}
\hline 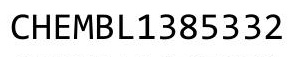 & & & & \\
\hline HEMBL1607931 & 325 & 0969 & 8493 & \\
\hline HEMBL1320514 & 37325 & .8477 & & \\
\hline 81 & 325 & 969 & 1631 & \\
\hline IEMBL1C & 7325 & 421 & & \\
\hline HEMBL1497909 & 37325 & 3125 & 2716 & \\
\hline HEMBL1732297 & 37325 & .0969 & 3.4329 & \\
\hline HEMBL1348010 & 325 & 969 & 7849 & \\
\hline AEMBL1: & 325 & 526 & 18 & \\
\hline EMMBL14 & 325 & 969 & & \\
\hline HEMBL1419661 & 37325 & 969 & 8589 & \\
\hline HEMBL1589649 & 325 & 9969 & & \\
\hline HEMBL1478067 & 25 & 113 & 7003 & \\
\hline HEMBL133 & 25 & 204 & 97 & \\
\hline HEMBL17: & 325 & 969 & & \\
\hline HEMBL 32 & 325 & 969 & 3507 & \\
\hline HEMBL16 & & 969 & & \\
\hline HEMBL14e & 25 & 969 & & \\
\hline HEMBL15 & & & & \\
\hline HEMBL15 & 5 & 969 & & RN \\
\hline HEMBL14 & & 377 & & - \\
\hline HEMBL158 & & & & RN \\
\hline HEMBL138 & 25 & 37 & & RN \\
\hline HEMBL13 & & & & \\
\hline 566 & 25 & 969 & & RN \\
\hline HEMBL16 & & 805 & & $2 \mathrm{~N}$ \\
\hline HEMBL13 & & 281 & & RN \\
\hline HEMBL14 & 25 & 969 & & RN \\
\hline HEME & & 96 & & KIV \\
\hline HEMBL17 & 25 & 69 & & ST \\
\hline HEMBL 31 & & & & RN \\
\hline HEMBL189 & 25 & 969 & & RN \\
\hline HEMBL5 & & 08 & & Niv \\
\hline 37 & & 55 & & ST \\
\hline HEMBL17 & & & & RN \\
\hline HEMBL 319 & & 969 & & RN \\
\hline HEMBL1545954 & 37325 & 597 & 3632 & RN \\
\hline 260 & 25 & 49 & & RN \\
\hline -2 1 & & & & RN \\
\hline HEMBL 320 & 37325 & 4.5952 & & RN \\
\hline HEMBL3198224 & 37325 & 969 & & RN \\
\hline HEMBL17 & 25 & 375 & & ST \\
\hline 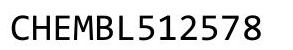 & 25 & 969 & & \\
\hline CHEMBL600313 & & & 2979 & ST \\
\hline HEMBL1405855 & 37325 & .266 & & ST \\
\hline HEMBL1506520 & 37325 & $\partial 969$ & 272 & RN \\
\hline-14 & & & & \\
\hline & & & & \\
\hline
\end{tabular}

Page 671 


\begin{tabular}{|c|c|c|c|c|c|c|}
\hline & & \multicolumn{5}{|c|}{ Supplemental Table s2.txt } \\
\hline CHEMBL514760 & 737325 & 3.0969 & 3.0944 & TRN & & \\
\hline CHEMBL1346443 & 737325 & 3.0969 & 3.4604 & TRN & & \\
\hline CHEMBL1402289 & 737325 & 4.6498 & 4.7762 & TRN & & \\
\hline CHEMBL1538560 & 737325 & 3.0969 & 3.7611 & TRN & & \\
\hline CHEMBL1454384 & 737325 & 3.0969 & 4.2662 & TRN & & \\
\hline CHEMBL1399076 & 737325 & 3.0969 & 3.4908 & TRN & & \\
\hline CHEMBL1369231 & 737325 & 5.8601 & 4.3664 & TRN & & \\
\hline CHEMBL1392896 & 737325 & 3.0969 & 3.7033 & TRN & & \\
\hline CHEMBL1455877 & 737325 & 5.4023 & 4.6339 & TRN & & \\
\hline CHEMBL1572914 & 737325 & 4.3778 & 4.9708 & TRN & & \\
\hline CHEMBL1545864 & 737325 & 4.9586 & 4.2804 & TRN & & \\
\hline CHEMBL1320575 & 737325 & 3.0969 & 3.4216 & TRN & & \\
\hline CHEMBL1428362 & 737325 & 3.0969 & 4.38899 & 999999999 & & TRN \\
\hline CHEMBL1452159 & 737325 & 4.4935 & 4.4207 & TRN & & \\
\hline CHEMBL1505655 & 737325 & 4.757 & 4.9201 & TRN & & \\
\hline CHEMBL1583137 & 737325 & 3.0969 & 3.8951 & TRN & & \\
\hline CHEMBL1436569 & 737325 & 4.6904 & 4.8009 & TRN & & \\
\hline CHEMBL1553841 & 737325 & 6.3279 & 4.3647 & TRN & & \\
\hline CHEMBL1497295 & 737325 & 4.9666 & 4.4497 & TST & & \\
\hline CHEMBL1580495 & 737325 & 4.2993 & 4.3823 & TRN & & \\
\hline CHEMBL1392403 & 737325 & 3.0969 & 4.2368 & TRN & & \\
\hline CHEMBL191750 & 737325 & 5.684 & 4.4811 & TRN & & \\
\hline CHEMBL1477756 & 737325 & 3.0969 & 4.1894 & TRN & & \\
\hline CHEMBL1302818 & 737325 & 4.6144 & 4.3589 & TRN & & \\
\hline CHEMBL1427350 & 737325 & 5.2299 & 5.1245 & TRN & & \\
\hline CHEMBL1461209 & 737325 & 5.4841 & 5.0379 & TRN & & \\
\hline CHEMBL1576870 & 737325 & 6.5686 & 6.5843 & TRN & & \\
\hline CHEMBL1494188 & 737325 & 4.3809 & 4.7646 & TRN & & \\
\hline CHEMBL1306844 & 737325 & 3.0969 & 3.2984 & TRN & & \\
\hline CHEMBL1430446 & 737325 & 3.0969 & 3.3969 & TRN & & \\
\hline CHEMBL1464197 & 737325 & 3.0969 & 3.6713 & TST & & \\
\hline CHEMBL1455409 & 737325 & 3.0969 & 3.7926 & TRN & & \\
\hline CHEMBL1456623 & 737325 & 4.6799 & 4.7385 & TST & & \\
\hline CHEMBL1351128 & 737325 & 4.6162 & 4.0336 & TRN & & \\
\hline CHEMBL1412162 & 737325 & 4.1568 & 4.1192 & TRN & & \\
\hline CHEMBL1342974 & 737325 & 4.6655 & 4.1471 & TRN & & \\
\hline CHEMBL1384673 & 737325 & 4.8962 & 4.5731 & TRN & & \\
\hline CHEMBL1318556 & 737325 & 4.8633 & 4.7627 & TRN & & \\
\hline CHEMBL1343497 & 737325 & 4.8827 & 3.3978 & TRN & & \\
\hline CHEMBL1404247 & 737325 & 3.0969 & 3.5641 & TRN & & \\
\hline CHEMBL602987 & 737325 & 5.0052 & 4.2056 & TST & & \\
\hline CHEMBL1541251 & 737325 & 4.9788 & 4.8183 & TRN & & \\
\hline CHEMBL1613126 & 737325 & 4.1226 & 4.5434 & TRN & & \\
\hline CHEMBL1559383 & 737325 & 4.9788 & 4.3344 & TRN & & \\
\hline CHEMBL1549107 & 737325 & $4.1530 e$ & 00000000 & 205 & 3.4558 & TRN \\
\hline CHEMBL1378086 & 737325 & 4.289 & 3.4666 & TRN & & \\
\hline CHEMBL1570747 & 737325 & 5.0429 & 4.3825 & TRN & & \\
\hline CHEMBL1596277 & 737325 & 5.4134 & 3.7532 & TST & & \\
\hline
\end{tabular}


Supplemental Table S2.txt

\begin{tabular}{|c|c|c|c|c|}
\hline The & & & & \\
\hline & 37325 & .1024 & & \\
\hline & & & & \\
\hline AEMBL1440051 & 7325 & & & $\mathrm{MI}$ \\
\hline AEMBL1526910 & 37325 & 511 & 082 & \\
\hline HEMBL1572139 & 37325 & 5556 & 8267 & \\
\hline HEMBL1313532 & 325 & & & \\
\hline IFMRI 17 & & & & \\
\hline AEMBL1446542 & 37325 & & & \\
\hline HEMBL117804 & 325 & & & \\
\hline AEMBL600121 & 325 & & & \\
\hline IEMBL155 & 25 & & & \\
\hline IEMBL13 & & & & \\
\hline HEMBL1364289 & 325 & & & \\
\hline AEMBL1485824 & 325 & & & \\
\hline AEMBL1304776 & 5 & 53 & 49 & \\
\hline AEMBL152 & 25 & & & \\
\hline HEMBL 140 & & & & \\
\hline HEMBL1377924 & 325 & & & \\
\hline IEMBL14 & & & & \\
\hline AEMBLIS & 5 & & & KIV \\
\hline AEMBL14 & & & & RN \\
\hline HEMBL17 & & & & \\
\hline AEMBL15 & & & & \\
\hline HEMBL171 & & & & (2) \\
\hline HEMBL14 & & & & KIV \\
\hline HEMBL1C & & & & RN \\
\hline HFMB| 17 & 25 & & & \\
\hline JEMBL14 & & & & TST \\
\hline HEMBL1348837 & & & & $\Gamma \mathrm{RN}$ \\
\hline HEMBL15 & & & & RN \\
\hline HEMBL1: & & & & RN \\
\hline HEMBL15 & 25 & & & ג \\
\hline HEMBL1566205 & & & & R \\
\hline HEMBL1438889 & 25 & & & TRN \\
\hline HEMBL15 & & & & RN \\
\hline HЕMP 1 & & & & TRN \\
\hline HEMBL14 & & & & RN \\
\hline HEMBL1413363 & 37325 & & & TRN \\
\hline AEMBL 58 & & & & $\mathrm{RN}$ \\
\hline HEMBL13 & 25 & & & DN \\
\hline HEMBL1366394 & & & & TRN \\
\hline HEMBL1523428 & 737325 & & 65 & $\Gamma R$ \\
\hline AEMBL1322190 & 37325 & 69 & 918 & TR \\
\hline HEMBL43 & 15 & & & ב \\
\hline CHEMBL13 & & & & \\
\hline LHEMBL3197039 & 37325 & & & \\
\hline CHEMBL1413514 & 737325 & 3.0969 & 3.9602 & \\
\hline
\end{tabular}

Page 673 
Supplemental Table S2.txt

\begin{tabular}{|c|c|c|c|c|}
\hline CHEMBL1517893 & 737325 & 3.0969 & 3.4325 & TRN \\
\hline CHEMBL1577938 & 737325 & 5.3958 & 5.1902 & TRN \\
\hline CHEMBL3190420 & 737325 & 3.0969 & 3.8958 & TRN \\
\hline CHEMBL1441974 & 737325 & 4.4318 & 4.6285 & TST \\
\hline CHEMBL1723778 & 737325 & 3.0969 & 4.1927 & TRN \\
\hline CHEMBL1581420 & 737325 & 5.0511 & 3.3358 & TST \\
\hline CHEMBL1507520 & 737325 & 3.0969 & 5.0288 & TRN \\
\hline CHEMBL3189935 & 737325 & 3.0969 & 3.122 & TRN \\
\hline CHEMBL1528979 & 737325 & 4.4711 & 3.9439 & TST \\
\hline CHEMBL 3197567 & 737325 & 3.0969 & 3.6642 & TRN \\
\hline CHEMBL1321343 & 737325 & 4.6289 & 3.9883 & TST \\
\hline CHEMBL1562012 & 737325 & 3.0969 & 3.6267 & TRN \\
\hline CHEMBL1541316 & 737325 & 4.8386 & 4.5075 & TRN \\
\hline CHEMBL3191187 & 737325 & 3.0969 & 3.466 & TRN \\
\hline CHEMBL1587181 & 737325 & 4.5143 & 4.993 & TST \\
\hline CHEMBL1705775 & 737325 & 3.0969 & 3.4371 & TRN \\
\hline CHEMBL1552306 & 737325 & 4.8928 & 4.4599 & TRN \\
\hline CHEMBL1610300 & 737325 & 6.4685 & 5.7091 & TRN \\
\hline CHEMBL1371504 & 737325 & 3.0969 & 4.2196 & TRN \\
\hline CHEMBL1426166 & 737325 & 4.2636 & 4.5934 & TRN \\
\hline CHEMBL1573524 & 737325 & 3.0969 & 3.7489 & TRN \\
\hline CHEMBL1727813 & 737325 & 4.163 & 3.8688 & TST \\
\hline CHEMBL1467489 & 737325 & 3.0969 & 3.5838 & TRN \\
\hline CHEMBL1383331 & 737325 & 3.0969 & 3.4639 & TRN \\
\hline CHEMBL 3199485 & 737325 & 3.0969 & 4.296 & TRN \\
\hline CHEMBL1447345 & 737325 & 4.9788 & 3.5357 & TRN \\
\hline CHEMBL1721523 & 737325 & 5.2277 & 3.9762 & TRN \\
\hline CHEMBL1362588 & 737325 & 4.9393 & 4.7625 & TRN \\
\hline CHEMBL1356345 & 737325 & 3.0969 & 3.616 & TRN \\
\hline CHEMBL1536689 & 737325 & 4.6253 & 4.3518 & TRN \\
\hline CHEMBL1602481 & 737325 & 4.6253 & 4.0428 & TRN \\
\hline CHEMBL1490470 & 737325 & 3.0969 & 4.6346 & TRN \\
\hline CHEMBL1379472 & 737325 & 4.7399 & 4.329 & TRN \\
\hline CHEMBL3197177 & 737325 & 4.2757 & 3.6226 & TRN \\
\hline CHEMBL1432867 & 737325 & 5.3605 & 3.7799 & TRN \\
\hline CHEMBL1310877 & 737325 & 4.5157 & 3.8061 & TRN \\
\hline CHEMBL1328161 & 737325 & 3.0969 & 4.3264 & TRN \\
\hline CHEMBL1331700 & 737325 & 3.0969 & 3.8868 & TRN \\
\hline CHEMBL1541771 & 737325 & 3.0969 & 4.1182 & TRN \\
\hline CHEMBL582073 & 737325 & 5.3116 & 4.3118 & TRN \\
\hline CHEMBL1456075 & 737325 & 4.7352 & 3.9535 & TRN \\
\hline CHEMBL1387015 & 737325 & 4.4698 & 4.3924 & TRN \\
\hline CHEMBL1415303 & 737325 & 4.2168 & 3.6967 & TRN \\
\hline CHEMBL3211093 & 737325 & 3.0969 & 4.2139 & TRN \\
\hline CHEMBL1350753 & 737325 & 4.1018 & 3.8774 & TRN \\
\hline CHEMBL1377807 & 737325 & 4.6968 & 4.375 & TRN \\
\hline CHEMBL1446437 & 737325 & 4.9355 & \multicolumn{2}{|c|}{3.6639999999999997} \\
\hline CHEMBL1393118 & 737325 & 3.0969 & 4.1945 & TST \\
\hline
\end{tabular}




\begin{tabular}{|c|c|c|c|c|}
\hline & & & oplement & al $\mathrm{Ta}$ \\
\hline CHEMBL1353529 & 737325 & 3.0969 & 3.8346 & TST \\
\hline CHEMBL1521793 & 737325 & 5.9031 & 5.1683 & TRN \\
\hline CHEMBL1411133 & 737325 & 4.3595 & 3.6241 & TRN \\
\hline CHEMBL1305438 & 737325 & 3.0969 & 3.8966 & TRN \\
\hline CHEMBL1575588 & 737325 & 6.1805 & 5.1909 & TRN \\
\hline CHEMBL1334041 & 737325 & 3.0969 & 3.9034 & TST \\
\hline CHEMBL1478292 & 737325 & 4.2 & 4.2401 & TRN \\
\hline CHEMBL1486981 & 737325 & 4.6615 & 4.3797 & TRN \\
\hline CHEMBL1382951 & 737325 & 4.7773 & 4.4188 & TST \\
\hline CHEMBL1578168 & 737325 & 3.0969 & 4.3525 & TST \\
\hline CHEMBL414840 & 737325 & 3.0969 & 3.196 & TRN \\
\hline CHEMBL1521435 & 737325 & 3.0969 & 3.7116 & TRN \\
\hline CHEMBL1366006 & 737325 & 3.0969 & 4.3347 & TRN \\
\hline CHEMBL1472889 & 737325 & 3.0969 & 3.6702 & TRN \\
\hline CHEMBL1338690 & 737325 & 4.279 & 4.4037 & TRN \\
\hline CHEMBL1711464 & 737325 & 3.0969 & 3.9085 & TRN \\
\hline CHEMBL1463050 & 737325 & 3.0969 & 4.3806 & TRN \\
\hline CHEMBL1527862 & 737325 & 3.0969 & 4.6567 & TRN \\
\hline CHEMBL1463249 & 737325 & 4.3635 & 4.8222 & TRN \\
\hline CHEMBL1305294 & 737325 & 3.0969 & 3.7067 & TRN \\
\hline CHEMBL1730563 & 737325 & 4.7721 & 3.2592 & TST \\
\hline CHEMBL1428877 & 737325 & 4.3883 & 3.5481 & TRN \\
\hline CHEMBL1608905 & 737325 & 3.0969 & 3.3784 & TRN \\
\hline CHEMBL1319621 & 737325 & 4.2967 & 3.7147 & TRN \\
\hline CHEMBL1730195 & 737325 & 3.0969 & 3.6633 & TRN \\
\hline CHEMBL1606813 & 737325 & 4.2218 & 3.7525 & TRN \\
\hline CHEMBL1310132 & 737325 & 7.7959 & 6.9598 & TRN \\
\hline CHEMBL1461080 & 737325 & 3.0969 & 3.7092 & TRN \\
\hline CHEMBL3207905 & 737325 & 3.0969 & 3.0327 & TRN \\
\hline CHEMBL1557372 & 737325 & 5.3197 & 3.4174 & TRN \\
\hline CHEMBL1401568 & 737325 & 3.0969 & 3.0347 & TRN \\
\hline CHEMBL3193468 & 737325 & 3.0969 & 3.81 & TRN \\
\hline CHEMBL580609 & 737325 & 5.4237 & 4.5759 & TRN \\
\hline CHEMBL1305586 & 737325 & 3.0969 & 3.8198 & TRN \\
\hline CHEMBL1469670 & 737325 & 3.0969 & 4.6182 & TRN \\
\hline CHEMBL1709070 & 737325 & 3.0969 & 3.8998 & TRN \\
\hline CHEMBL1565949 & 737325 & 4.8508 & 3.5773 & TST \\
\hline CHEMBL1608382 & 737325 & 4.2857 & 3.9891 & TRN \\
\hline CHEMBL1429513 & 737325 & 4.752 & 3.8274 & TRN \\
\hline CHEMBL1967256 & 737325 & 5.2733 & 4.0005 & TRN \\
\hline CHEMBL1702193 & 737325 & 4.1918 & 3.8887 & TST \\
\hline CHEMBL1351755 & 737325 & 4.6003 & 4.4133 & TRN \\
\hline CHEMBL1699107 & 737325 & 4.5719 & 3.6305 & TRN \\
\hline CHEMBL1443643 & 737325 & 3.0969 & 3.8959 & TRN \\
\hline CHEMBL1472194 & 737325 & 3.0969 & 3.9285 & TRN \\
\hline CHEMBL1382246 & 737325 & 5.059 & 3.9836 & TRN \\
\hline CHEMBL1321622 & 737325 & 5.1549 & 5.3934 & TRN \\
\hline CHEMBL1612757 & 737325 & 3.0969 & 4.3532 & TRN \\
\hline
\end{tabular}




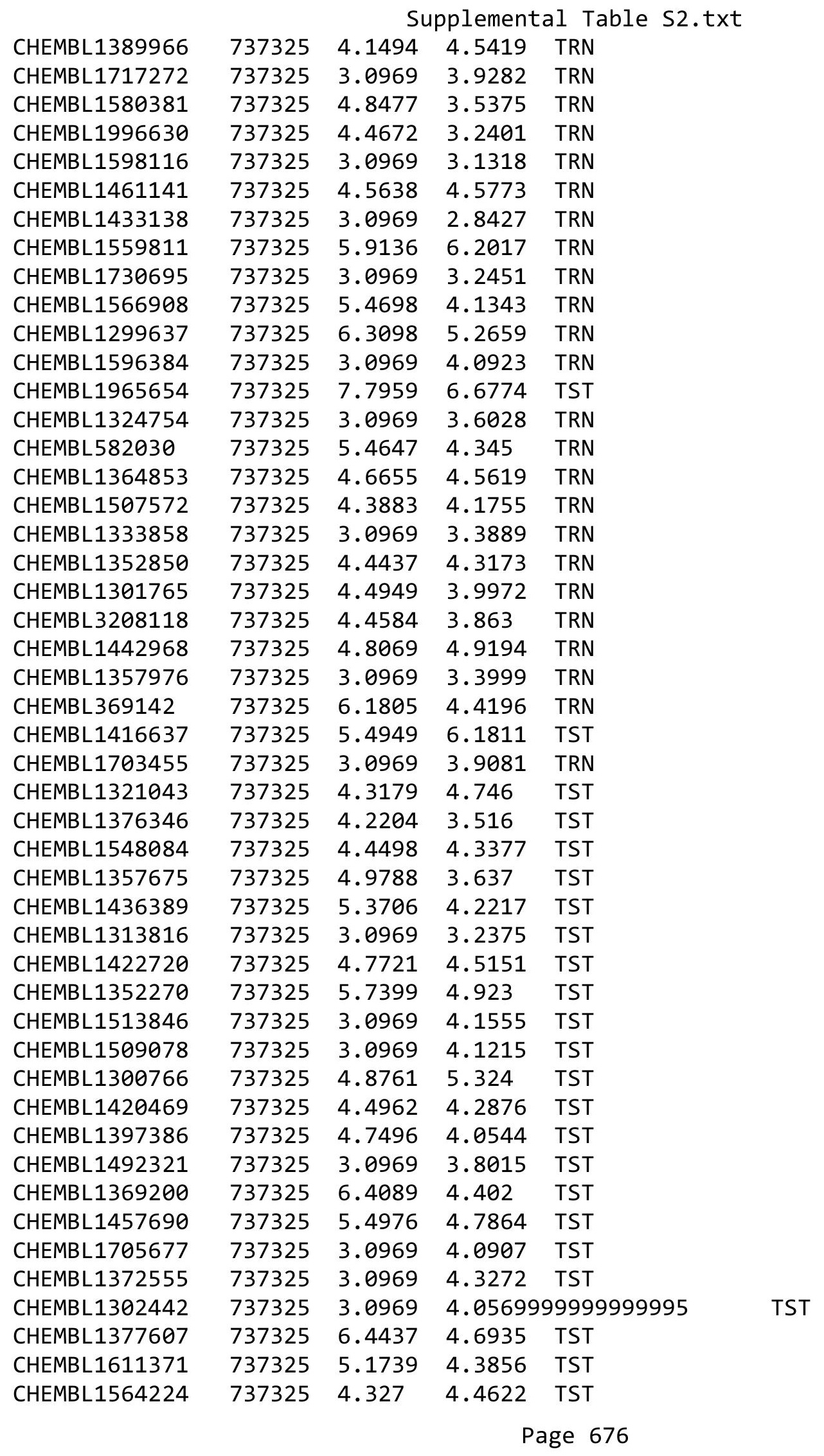


Supplemental Table S2.txt

\begin{tabular}{|c|c|c|c|c|}
\hline CHEMBL1385709 & 737325 & 4.1494 & 3.6684 & TST \\
\hline CHEMBL1719240 & 737325 & 4.289 & 4.0765 & TST \\
\hline CHEMBL1470695 & 737325 & 3.0969 & 3.4069 & TST \\
\hline CHEMBL1561496 & 737325 & 3.0969 & 4.0508 & TST \\
\hline CHEMBL1362969 & 737325 & 4.1858 & 4.4634 & TST \\
\hline CHEMBL1704298 & 737325 & 3.0969 & 3.3764 & TST \\
\hline CHEMBL77705 & 737325 & 3.0969 & 3.8349 & TST \\
\hline CHEMBL1560374 & 737325 & 4.5436 & 4.2009 & TST \\
\hline CHEMBL1698398 & 737325 & 3.0969 & 3.9425 & TST \\
\hline CHEMBL1454683 & 737325 & 4.3788 & 3.6426 & TST \\
\hline CHEMBL1730475 & 737325 & 4.5243 & 3.5724 & TST \\
\hline CHEMBL1582024 & 737325 & 3.0969 & 4.0687 & TST \\
\hline CHEMBL1416848 & 737325 & 4.9281 & 4.8766 & TST \\
\hline CHEMBL1431035 & 737325 & 4.3372 & 3.8484 & TST \\
\hline CHEMBL1547825 & 737325 & 3.0969 & 3.7742 & TST \\
\hline CHEMBL1350077 & 737325 & 5.4237 & 3.8004 & TST \\
\hline CHEMBL1347158 & 737325 & 4.7352 & 4.5885 & TST \\
\hline CHEMBL1412930 & 737325 & 4.433 & 4.1913 & TST \\
\hline CHEMBL1608402 & 737325 & 4.5003 & 4.5564 & TST \\
\hline CHEMBL1379416 & 737325 & 4.4145 & 3.7457 & TST \\
\hline CHEMBL1503124 & 737325 & 4.4572 & 5.0987 & TST \\
\hline CHEMBL1518428 & 737325 & 4.1605 & 4.202 & TST \\
\hline CHEMBL1472681 & 737325 & 4.7471 & 5.1677 & TST \\
\hline CHEMBL1324718 & 737325 & 3.0969 & 3.6183 & TST \\
\hline CHEMBL1520650 & 737325 & 3.0969 & 4.171 & TST \\
\hline CHEMBL1393156 & 737325 & 3.0969 & 4.1079 & TST \\
\hline CHEMBL1529687 & 737325 & 4.7932 & 4.8212 & TST \\
\hline CHEMBL1574176 & 737325 & 4.757 & 4.198 & TST \\
\hline CHEMBL1343551 & 737325 & 3.0969 & 3.2081 & TST \\
\hline CHEMBL1525213 & 737325 & 4.5171 & 3.637 & TST \\
\hline CHEMBL607309 & 737325 & 5.3382 & 4.2436 & TST \\
\hline CHEMBL1559707 & 737325 & 3.0969 & 3.8143 & TST \\
\hline CHEMBL1480380 & 737325 & 3.0969 & 3.5547 & TST \\
\hline CHEMBL1471436 & 737325 & 3.0969 & 3.7509 & TST \\
\hline CHEMBL1453819 & 737325 & 6.5376 & 3.855 & TST \\
\hline CHEMBL1539923 & 737325 & 4.109 & 4.5363 & TST \\
\hline CHEMBL1503612 & 737325 & 3.0969 & 4.0661 & TST \\
\hline CHEMBL1442817 & 737325 & 3.0969 & 3.9805 & TST \\
\hline CHEMBL1377943 & 737325 & 4.4318 & 3.456000 & 00000000004 \\
\hline CHEMBL1341261 & 737325 & 4.1349 & 4.415 & TST \\
\hline CHEMBL 1814143 & 762465 & 4.0 & 5.2893 & TRN \\
\hline CHEMBL1276549 & 762465 & 6.9208 & 6.5614 & TRN \\
\hline CHEMBL1814137 & 762465 & 5.9586 & 6.3472 & TRN \\
\hline CHEMBL1814125 & 762465 & 6.8861 & 6.4771 & TRN \\
\hline CHEMBL1814144 & 762465 & 4.0 & 5.0366 & TRN \\
\hline CHEMBL1813917 & 762465 & 4.0 & 4.3231 & TRN \\
\hline CHEMBL1814120 & 762465 & 4.0 & 6.2842 & TST \\
\hline CHEMBL1814139 & 762465 & 6.6576 & 6.3255 & TRN \\
\hline
\end{tabular}




\begin{tabular}{|c|c|c|c|c|c|}
\hline & & \multicolumn{4}{|c|}{ plemental } \\
\hline CHEMBL52210 & 762465 & 6.2757 & 6.8218 & TST & \\
\hline CHEMBL1813919 & 762465 & 5.2596 & 5.9124 & TST & \\
\hline CHEMBL1813916 & 762465 & 6.4318 & 6.1633 & TRN & \\
\hline CHEMBL1814110 & 762465 & 6.9586 & 7.2504 & TST & \\
\hline CHEMBL1813920 & 762465 & 6.0177 & 6.482 & TRN & \\
\hline CHEMBL1814136 & 762465 & 5.3279 & 5.9789 & TRN & \\
\hline CHEMBL1814112 & 762465 & 5.301 & 5.638 & TRN & \\
\hline CHEMBL49128 & 762465 & 6.4318 & 6.5974 & TRN & \\
\hline CHEMBL1813921 & 762465 & 6.2924 & 6.2292 & TRN & \\
\hline CHEMBL1275764 & 762465 & 7.0605 & 6.5674 & TRN & \\
\hline CHEMBL1814126 & 762465 & 4.0 & 4.1474 & TRN & \\
\hline CHEMBL1814124 & 762465 & 7.3468 & 7.2347 & TRN & \\
\hline CHEMBL1814114 & 762465 & 4.0 & 6.2988 & TST & \\
\hline CHEMBL450746 & 762465 & 6.9586 & 6.7011 & TST & \\
\hline CHEMBL1814115 & 762465 & 6.7696 & 6.2739 & TRN & \\
\hline CHEMBL1814131 & 762465 & 6.5686 & 6.3215 & TRN & \\
\hline CHEMBL1813922 & 762465 & 6.2076 & 5.86100 & 0000000001 & TRN \\
\hline CHEMBL1814119 & 762465 & 4.0 & 6.2284 & TST & \\
\hline CHEMBL1814121 & 762465 & 4.0 & 5.8832 & TST & \\
\hline CHEMBL1814123 & 762465 & 6.2291 & 6.1729 & TRN & \\
\hline CHEMBL1813914 & 762465 & 5.8539 & 6.1765 & TRN & \\
\hline CHEMBL1814118 & 762465 & 6.0458 & 6.1489 & TST & \\
\hline CHEMBL1814122 & 762465 & 6.6021 & 6.2587 & TRN & \\
\hline CHEMBL1814135 & 762465 & 6.3098 & 5.8924 & TRN & \\
\hline CHEMBL1814132 & 762465 & 5.5686 & 6.0757 & TRN & \\
\hline CHEMBL1814117 & 762465 & 5.4318 & 5.7178 & TRN & \\
\hline CHEMBL1814142 & 762465 & 6.5229 & 6.546 & TRN & \\
\hline CHEMBL416108 & 762465 & 6.5376 & 7.0858 & TRN & \\
\hline CHEMBL49894 & 762465 & 6.7959 & 6.8469 & TRN & \\
\hline CHEMBL1814129 & 762465 & 4.0 & 3.7317 & TRN & \\
\hline CHEMBL1814113 & 762465 & 6.7696 & 6.7702 & TRN & \\
\hline CHEMBL1814133 & 762465 & 4.0 & 4.0897 & TRN & \\
\hline CHEMBL1814130 & 762465 & 7.0223 & 5.8922 & TRN & \\
\hline CHEMBL48856 & 762465 & 6.2518 & 5.8365 & TRN & \\
\hline CHEMBL1814140 & 762465 & 6.1938 & 6.0851 & TRN & \\
\hline CHEMBL1814127 & 762465 & 5.6778 & 5.9958 & TRN & \\
\hline CHEMBL1814134 & 762465 & 4.0 & 3.4189 & TRN & \\
\hline CHEMBL1813915 & 762465 & 6.1308 & 6.1221 & TRN & \\
\hline CHEMBL1813918 & 762465 & 4.0 & 4.4746 & TRN & \\
\hline CHEMBL1814145 & 762465 & 6.4949 & 5.3019 & TRN & \\
\hline CHEMBL1814128 & 762465 & 4.0 & 3.7903 & TRN & \\
\hline CHEMBL1814111 & 762465 & 6.1549 & 6.5898 & TRN & \\
\hline CHEMBL1813913 & 762465 & 5.5086 & 6.4457 & TST & \\
\hline CHEMBL1814141 & 762465 & 6.0915 & 6.4198 & TST & \\
\hline CHEMBL1814138 & 762465 & 5.7696 & 6.3819 & TST & \\
\hline CHEMBL1614813 & 762465 & 4.0 & 5.5778 & TST & \\
\hline CHEMBL1814116 & 762465 & 6.6778 & 6.2777 & TST & \\
\hline CHEMBL191543 & 304976 & 5.8729 & 5.782 & TRN & \\
\hline
\end{tabular}




\begin{tabular}{|c|c|c|c|c|c|}
\hline \multicolumn{6}{|c|}{ Supplemental Table S2.txt } \\
\hline CHEMBL363155 & 304976 & 6.0031 & 5.1145 & TST & \\
\hline CHEMBL 370950 & 304976 & 4.301 & 5.3897 & TRN & \\
\hline CHEMBL190380 & 304976 & 5.0269 & 5.4966 & TRN & \\
\hline CHEMBL365146 & 304976 & 5.1675 & 6.0043 & TST & \\
\hline CHEMBL372035 & 304976 & 4.301 & 5.3884 & TRN & \\
\hline CHEMBL189538 & 304976 & 4.301 & 5.6203 & TRN & \\
\hline CHEMBL361265 & 304976 & 4.301 & 5.3771 & TRN & \\
\hline CHEMBL191204 & 304976 & 6.301 & 5.9456 & TRN & \\
\hline CHEMBL 372708 & 304976 & 7.0969 & 5.8045 & TRN & \\
\hline CHEMBL190597 & 304976 & 6.2924 & 5.7754 & TRN & \\
\hline CHEMBL189993 & 304976 & 4.301 & 5.8138 & TST & \\
\hline CHEMBL363253 & 304976 & 6.5638 & 5.8354 & TRN & \\
\hline CHEMBL370960 & 304976 & 5.8781 & 5.9704 & TRN & \\
\hline CHEMBL364757 & 304976 & 6.6021 & 5.0119 & TRN & \\
\hline CHEMBL191498 & 304976 & 4.301 & 4.0077 & TRN & \\
\hline CHEMBL191172 & 304976 & 4.301 & 5.3756 & TRN & \\
\hline CHEMBL191269 & 304976 & 6.0862 & 5.6891 & TRN & \\
\hline CHEMBL189421 & 304976 & 5.7423 & 5.2783 & TRN & \\
\hline CHEMBL188499 & 304976 & 5.5376 & 5.9494 & TST & \\
\hline CHEMBL 370516 & 304976 & 5.5114 & 5.3114 & TRN & \\
\hline CHEMBL189931 & 304976 & 4.301 & 5.5252 & TST & \\
\hline CHEMBL365191 & 304976 & 5.4271 & 6.3106 & TRN & \\
\hline CHEMBL425722 & 304976 & 4.301 & 4.6167 & TRN & \\
\hline CHEMBL191536 & 304976 & 5.1427 & 5.5696 & TST & \\
\hline CHEMBL189223 & 304976 & 6.4012 & 6.7077 & TRN & \\
\hline CHEMBL364637 & 304976 & 6.6021 & 6.1492 & TRN & \\
\hline CHEMBL 370899 & 304976 & 6.1192 & 6.4646 & TRN & \\
\hline CHEMBL365963 & 304976 & 6.3391 & 6.5215 & TRN & \\
\hline CHEMBL189841 & 304976 & 6.8327 & 6.984 & TRN & \\
\hline CHEMBL 364053 & 304976 & 5.1871 & 5.3001 & TRN & \\
\hline CHEMBL425902 & 304976 & 6.4559 & 4.4191 & TRN & \\
\hline CHEMBL425553 & 304976 & 5.8861 & 5.73799 & 99999999995 & TRN \\
\hline CHEMBL1788116 & 304976 & 6.9208 & 6.3433 & TRN & \\
\hline CHEMBL191581 & 304976 & 7.0969 & 6.4168 & TRN & \\
\hline CHEMBL190457 & 304976 & 5.1249 & 5.6006 & TRN & \\
\hline CHEMBL370889 & 304976 & 6.2343 & 6.4293 & TRN & \\
\hline CHEMBL 364940 & 304976 & 6.1871 & 5.9743 & TRN & \\
\hline CHEMBL 370477 & 304976 & 6.0223 & 5.7586 & TRN & \\
\hline CHEMBL190363 & 304976 & 4.301 & 4.7712 & TRN & \\
\hline CHEMBL 362926 & 304976 & 4.301 & 4.5303 & TST & \\
\hline CHEMBL190591 & 304976 & 4.301 & 5.1401 & TRN & \\
\hline CHEMBL190859 & 304976 & 5.7841 & 5.6954 & TRN & \\
\hline CHEMBL190742 & 304976 & 6.4724 & 6.1433 & TRN & \\
\hline CHEMBL371113 & 304976 & 6.8447 & 6.7785 & TRN & \\
\hline CHEMBL 363355 & 304976 & 7.3872 & 6.7289 & TRN & \\
\hline CHEMBL363556 & 304976 & 5.8268 & 5.8696 & TRN & \\
\hline CHEMBL 372933 & 304976 & 4.301 & 4.5067 & TRN & \\
\hline CHEMBL190067 & 304976 & 4.301 & 4.5769 & TST & \\
\hline
\end{tabular}




\begin{tabular}{|c|c|c|c|c|c|}
\hline \multicolumn{6}{|c|}{ Supplemental Table s2.txt } \\
\hline CHEMBL373086 & 304976 & 5.4559 & 5.6021 & TRN & \\
\hline CHEMBL362932 & 304976 & 4.301 & 5.0965 & TRN & \\
\hline CHEMBL191021 & 304976 & 6.1506 & 5.9179 & TRN & \\
\hline CHEMBL362934 & 304976 & 5.1805 & 5.8357 & TST & \\
\hline CHEMBL424815 & 304976 & 6.3251 & 6.3292 & TST & \\
\hline CHEMBL190250 & 304976 & 6.2218 & 6.6079 & TST & \\
\hline CHEMBL363254 & 304976 & 7.1871 & 6.5902 & TST & \\
\hline CHEMBL191465 & 304976 & 6.1805 & 5.7951 & TST & \\
\hline CHEMBL189852 & 304976 & 6.4685 & 6.0958 & TST & \\
\hline CHEMBL191376 & 304976 & 6.3904 & 6.5884 & TST & \\
\hline CHEMBL3642693 & 1535652 & 8.7212 & 8.8518 & TRN & \\
\hline CHEMBL 3642685 & 1535652 & 7.3665 & 7.4763 & TRN & \\
\hline CHEMBL 3642808 & 1535652 & 7.5735 & 7.5869 & TRN & \\
\hline CHEMBL3642777 & 1535652 & 8.1203 & 8.2168 & TST & \\
\hline CHEMBL3642722 & 1535652 & 7.9706 & 7.9454 & TRN & \\
\hline CHEMBL 3642720 & 1535652 & 6.9208 & 6.8986 & TRN & \\
\hline CHEMBL3642779 & 1535652 & 7.9281 & 8.1713 & TST & \\
\hline CHEMBL3642731 & 1535652 & 6.0 & 5.9874 & TRN & \\
\hline CHEMBL 3642723 & 1535652 & 7.8778 & 7.8839 & TRN & \\
\hline CHEMBL3642770 & 1535652 & 7.644 & 7.6048 & TRN & \\
\hline CHEMBL3642775 & 1535652 & 8.0246 & 8.0522 & TRN & \\
\hline CHEMBL 3642680 & 1535652 & 7.5406 & 7.5503 & TRN & \\
\hline CHEMBL3642802 & 1535652 & 7.3536 & 7.3534 & TRN & \\
\hline CHEMBL3642753 & 1535652 & 7.5952 & 7.6176 & TRN & \\
\hline CHEMBL3642733 & 1535652 & 7.3536 & 7.3433 & TRN & \\
\hline CHEMBL3642695 & 1535652 & 7.4815 & 7.407 & TST & \\
\hline CHEMBL3642690 & 1535652 & 6.8239 & 6.8187 & TRN & \\
\hline CHEMBL3642772 & 1535652 & 7.699 & 7.7116 & TRN & \\
\hline CHEMBL 3642817 & 1535652 & 7.5884 & 7.5976 & TRN & \\
\hline CHEMBL3642815 & 1535652 & 7.3915 & 7.3881 & TRN & \\
\hline CHEMBL 3642784 & 1535652 & 7.317 & 7.8065 & TST & \\
\hline CHEMBL3642694 & 1535652 & 7.5143 & 7.3508 & TST & \\
\hline CHEMBL 3642743 & 1535652 & 7.6038 & 7.6594 & TST & \\
\hline CHEMBL3642754 & 1535652 & 7.9172 & 7.9296 & TRN & \\
\hline CHEMBL 3642725 & 1535652 & 7.5003 & 7.7076 & TST & \\
\hline CHEMBL3642769 & 1535652 & 7.8125 & 7.8052 & TRN & \\
\hline CHEMBL3642686 & 1535652 & 7.1124 & 7.16100 & 00000000005 & TRN \\
\hline CHEMBL3642704 & 1535652 & 8.8539 & 8.7937 & TRN & \\
\hline CHEMBL3642774 & 1535652 & 7.8477 & 7.82799 & 9999999999 & TRN \\
\hline CHEMBL3642764 & 1535652 & 7.6655 & 7.6511 & TRN & \\
\hline CHEMBL3639415 & 1535652 & 7.7375 & 7.6654 & TRN & \\
\hline CHEMBL 3642710 & 1535652 & 7.4179 & 7.4163 & TRN & \\
\hline CHEMBL3639416 & 1535652 & 7.7282 & 7.9058 & TST & \\
\hline CHEMBL3642758 & 1535652 & 7.8894 & 7.885 & TRN & \\
\hline CHEMBL3642712 & 1535652 & 7.7595 & 7.7508 & TRN & \\
\hline CHEMBL 3642801 & 1535652 & 7.8416 & 7.8544 & TRN & \\
\hline CHEMBL3642716 & 1535652 & 8.0088 & 7.989 & TRN & \\
\hline CHEMBL3642728 & 1535652 & 8.295 & 8.1571 & TRN & \\
\hline
\end{tabular}


Supplemental Table S2.txt

\begin{tabular}{|c|c|c|c|c|c|c|c|}
\hline CHEMBL 3642700 & 1535652 & 8.4949 & 8.4316 & TRN & & & \\
\hline CHEMBL 3642786 & 1535652 & 7.1586 & 7.5105 & TST & & & \\
\hline CHEMBL3642805 & 1535652 & 7.8268 & 8.1734 & TST & & & \\
\hline CHEMBL 3642804 & 1535652 & 7.6882 & 7.6682 & TRN & & & \\
\hline CHEMBL 3642806 & 1535652 & \multicolumn{3}{|c|}{6.922999999999999} & 6.9116 & TRN & \\
\hline CHEMBL 3642788 & 1535652 & 7.4214 & 7.4384 & TRN & & & \\
\hline CHEMBL 3642800 & 1535652 & 6.7109 & 6.7018 & TRN & & & \\
\hline CHEMBL3642689 & 1535652 & 7.2541 & 7.2432 & TRN & & & \\
\hline CHEMBL 3642713 & 1535652 & 8.0132 & 8.0542 & TRN & & & \\
\hline CHEMBL 3642783 & 1535652 & 7.5229 & 8.1514 & TST & & & \\
\hline CHEMBL 3642776 & 1535652 & 8.3188 & 8.339 & TRN & & & \\
\hline CHEMBL3642755 & 1535652 & 7.0325 & 7.0337 & TRN & & & \\
\hline CHEMBL 3642726 & 1535652 & 7.6576 & 7.5573 & TST & & & \\
\hline CHEMBL 3642768 & 1535652 & 7.8477 & 7.8376 & TRN & & & \\
\hline CHEMBL 3642719 & 1535652 & 7.7399 & 7.73 & TRN & & & \\
\hline CHEMBL 3642749 & 1535652 & 7.7696 & 7.7841 & TRN & & & \\
\hline CHEMBL 3642787 & 1535652 & 7.3298 & 7.7896 & TST & & & \\
\hline CHEMBL 3642734 & 1535652 & 7.7721 & 7.7657 & TRN & & & \\
\hline CHEMBL 3642707 & 1535652 & 8.3665 & 8.7052 & TST & & & \\
\hline CHEMBL 3642736 & 1535652 & 8.1113 & 8.1166 & TRN & & & \\
\hline CHEMBL3642797 & 1535652 & 7.6615 & 7.6586 & TRN & & & \\
\hline CHEMBL 3642761 & 1535652 & 8.3969 & 8.3856 & TRN & & & \\
\hline CHEMBL 3642729 & 1535652 & 7.8041 & 7.8401 & TRN & & & \\
\hline CHEMBL 3642742 & 1535652 & \multicolumn{3}{|c|}{7.617999999999999} & 7.6605 & TRN & \\
\hline CHEMBL 3642782 & 1535652 & 7.4202 & 7.8395 & TST & & & \\
\hline CHEMBL 3642737 & 1535652 & 8.1838 & 8.1935 & TRN & & & \\
\hline CHEMBL 3642789 & 1535652 & 7.7144 & 7.74200 & 0000000001 & & TRN & \\
\hline CHEMBL 3642740 & 1535652 & 7.7328 & 7.7973 & TRN & & & \\
\hline CHEMBL 3642781 & 1535652 & 7.1385 & 7.5799 & TST & & & \\
\hline CHEMBL 3642711 & 1535652 & 7.6038 & 7.69 & TRN & & & \\
\hline CHEMBL 3642812 & 1535652 & \multicolumn{3}{|c|}{7.1579999999999995} & \multicolumn{2}{|c|}{7.1610000000000005} & TRN \\
\hline CHEMBL 3642696 & 1535652 & 8.7959 & 9.0732 & TST & & & \\
\hline CHEMBL 3642763 & 1535652 & 7.4248 & 7.4035 & TRN & & & \\
\hline CHEMBL3642746 & 1535652 & 6.0 & 6.035 & TRN & & & \\
\hline CHEMBL 3642717 & 1535652 & 7.7986 & 7.7471 & TRN & & & \\
\hline CHEMBL3642773 & 1535652 & 8.3335 & 8.3108 & TRN & & & \\
\hline CHEMBL 3642730 & 1535652 & 7.5406 & 7.5591 & TRN & & & \\
\hline CHEMBL 3642682 & 1535652 & 7.9281 & 7.8607 & TRN & & & \\
\hline CHEMBL 3642803 & 1535652 & 7.71 & 7.2206 & TST & & & \\
\hline CHEMBL 3642807 & 1535652 & 6.8336 & 6.8245 & TRN & & & \\
\hline CHEMBL 3642756 & 1535652 & 7.3251 & 7.3291 & TRN & & & \\
\hline CHEMBL 3642688 & 1535652 & 7.5186 & 7.487 & TRN & & & \\
\hline CHEMBL 3642709 & 1535652 & 7.8962 & \multicolumn{3}{|c|}{7.8260000000000005} & TRN & \\
\hline CHEMBL 3642767 & 1535652 & 7.7122 & 7.6882 & TRN & & & \\
\hline CHEMBL 3642692 & 1535652 & 7.4672 & 7.5285 & TST & & & \\
\hline CHEMBL 3642718 & 1535652 & 7.9393 & 7.9232 & TRN & & & \\
\hline CHEMBL 3642708 & 1535652 & 8.3665 & 8.5206 & TST & & & \\
\hline CHEMBL 3642683 & 1535652 & 7.6198 & 7.6209 & TRN & & & \\
\hline
\end{tabular}

Page 681 
Supplemental Table S2.txt

\begin{tabular}{|c|c|c|c|c|c|}
\hline CHEMBL 3642748 & 1535652 & 7.9626 & 7.9592 & TRN & \\
\hline CHEMBL3642727 & 1535652 & 8.1726 & 7.8314 & TST & \\
\hline CHEMBL3642757 & 1535652 & 7.8125 & 7.8218 & TRN & \\
\hline CHEMBL3642698 & 1535652 & 8.5229 & 8.7266 & TST & \\
\hline CHEMBL3642697 & 1535652 & 8.7212 & 8.8727 & TST & \\
\hline CHEMBL3642809 & 1535652 & 7.6126 & 7.6466 & TRN & \\
\hline CHEMBL3642759 & 1535652 & 7.7645 & 7.7556 & TRN & \\
\hline CHEMBL3642791 & 1535652 & 7.4711 & 7.7876 & TST & \\
\hline CHEMBL3642796 & 1535652 & 7.7932 & \multicolumn{2}{|c|}{ 7.787000000000001 } & TRN \\
\hline CHEMBL3642715 & 1535652 & 7.3429 & 7.3577 & TRN & \\
\hline CHEMBL3642798 & 1535652 & 7.7305 & 7.7337 & TRN & \\
\hline CHEMBL3642739 & 1535652 & 7.9706 & 7.9847 & TRN & \\
\hline CHEMBL3642706 & 1535652 & 7.6345 & 7.7116 & TST & \\
\hline CHEMBL 3642691 & 1535652 & 7.6615 & 7.6208 & TRN & \\
\hline CHEMBL3642684 & 1535652 & 7.7011 & 7.7291 & TRN & \\
\hline CHEMBL3642811 & 1535652 & 6.0 & 5.9851 & TRN & \\
\hline CHEMBL3642721 & 1535652 & 8.1158 & 8.1479 & TRN & \\
\hline CHEMBL3642752 & 1535652 & 7.7799 & 7.7899 & TRN & \\
\hline CHEMBL 3642778 & 1535652 & 7.4609 & 7.6391 & TST & \\
\hline CHEMBL3642760 & 1535652 & 7.5528 & \multicolumn{2}{|c|}{7.707999999999999} & TST \\
\hline CHEMBL3642780 & 1535652 & 7.6676 & 8.1895 & TST & \\
\hline CHEMBL3642681 & 1535652 & 7.2628 & 7.2459 & TRN & \\
\hline CHEMBL 3642750 & 1535652 & 8.0496 & 8.0892 & TRN & \\
\hline CHEMBL 3642735 & 1535652 & 7.567 & 7.5428 & TRN & \\
\hline CHEMBL 3642747 & 1535652 & 7.2277 & 7.2323 & TRN & \\
\hline CHEMBL3642765 & 1535652 & 7.7055 & 7.7019 & TRN & \\
\hline CHEMBL3642762 & 1535652 & 7.5072 & 7.5469 & TRN & \\
\hline CHEMBL 3642814 & 1535652 & 7.8097 & 7.9207 & TST & \\
\hline CHEMBL 3642794 & 1535652 & 7.8327 & 7.8224 & TRN & \\
\hline CHEMBL3642705 & 1535652 & 8.2218 & 8.4794 & TST & \\
\hline CHEMBL3642795 & 1535652 & 7.3497 & 7.3343 & TRN & \\
\hline CHEMBL 3642687 & 1535652 & 7.4855 & 7.5066 & TRN & \\
\hline CHEMBL 3642785 & 1535652 & 7.0057 & 7.2306 & TST & \\
\hline CHEMBL 3642793 & 1535652 & 7.5528 & 7.5447 & TRN & \\
\hline CHEMBL3642702 & 1535652 & 8.4437 & 8.3191 & TST & \\
\hline CHEMBL3642724 & 1535652 & 7.2441 & 7.2428 & TRN & \\
\hline CHEMBL3642792 & 1535652 & 7.2832 & 7.2653 & TRN & \\
\hline CHEMBL3642810 & 1535652 & 7.7305 & 7.7221 & TRN & \\
\hline CHEMBL 3642738 & 1535652 & 6.0 & 5.9966 & TRN & \\
\hline CHEMBL 3642701 & 1535652 & 8.5686 & 8.6006 & TST & \\
\hline CHEMBL3642799 & 1535652 & 6.8821 & 6.9288 & TRN & \\
\hline CHEMBL3642751 & 1535652 & 7.6234 & 7.6059 & TRN & \\
\hline CHEMBL3642771 & 1535652 & 7.7167 & 7.7333 & TRN & \\
\hline CHEMBL 3642790 & 1535652 & 7.1675 & 7.146 & TRN & \\
\hline CHEMBL279236 & 144153 & 5.4559 & 5.4775 & TRN & \\
\hline CHEMBL21019 & 144153 & 5.0506 & 5.0691 & TRN & \\
\hline CHEMBL 21071 & 144153 & 5.0 & 5.0423 & TRN & \\
\hline CHEMBL 21545 & 144153 & 4.5229 & 4.5788 & TRN & \\
\hline
\end{tabular}


Supplemental Table S2.txt

\begin{tabular}{|c|c|c|c|c|}
\hline CHEMBL21605 & 144153 & 5.6021 & 5.4835 & TRN \\
\hline CHEMBL282667 & 144153 & 4.6576 & 4.926 & TST \\
\hline CHEMBL279493 & 144153 & 4.5229 & 5.0226 & TST \\
\hline CHEMBL20549 & 144153 & 5.2757 & 5.2831 & TRN \\
\hline CHEMBL21523 & 144153 & 4.5229 & 4.4865 & TRN \\
\hline CHEMBL21679 & 144153 & 5.4949 & 5.4758 & TRN \\
\hline CHEMBL22046 & 144153 & 5.5528 & \multirow{2}{*}{\multicolumn{2}{|c|}{5.5760000000000005}} \\
\hline CHEMBL20965 & 144153 & 4.5229 & & \\
\hline CHEMBL414827 & 144153 & 5.3188 & 5.3772 & TRN \\
\hline CHEMBL20400 & 144153 & 4.9208 & 4.9205 & TRN \\
\hline CHEMBL279289 & 144153 & 4.585 & 4.6701 & TRN \\
\hline CHEMBL417100 & 144153 & 5.6383 & \multicolumn{2}{|c|}{5.5489999999999995} \\
\hline CHEMBL440278 & 144153 & 5.9586 & 5.9018 & TRN \\
\hline CHEMBL 282057 & 144153 & 4.7696 & 4.7736 & TRN \\
\hline CHEMBL281387 & 144153 & 5.8539 & 5.8939 & TRN \\
\hline CHEMBL21753 & 144153 & 5.4437 & 5.4304 & TRN \\
\hline CHEMBL21507 & 144153 & 6.2218 & 6.2391 & TRN \\
\hline CHEMBL278795 & 144153 & 4.5229 & 4.4807 & TRN \\
\hline CHEMBL 279044 & 144153 & 4.5229 & 4.5222 & TRN \\
\hline CHEMBL283106 & 144153 & 5.4815 & 5.4747 & TRN \\
\hline CHEMBL21907 & 144153 & 5.4437 & 5.5976 & TRN \\
\hline CHEMBL441516 & 144153 & 4.5229 & 4.5737 & TRN \\
\hline CHEMBL21502 & 144153 & 4.5229 & 4.5116 & TRN \\
\hline CHEMBL417641 & 144153 & 5.0362 & 5.0516 & TRN \\
\hline CHEMBL265065 & 144153 & 6.0969 & 6.1277 & TRN \\
\hline CHEMBL432651 & 144153 & 4.9208 & 5.5119 & TST \\
\hline CHEMBL429389 & 144153 & 5.3188 & 5.2429 & TRN \\
\hline CHEMBL 20553 & 144153 & 5.7212 & 5.6856 & TRN \\
\hline CHEMBL22056 & 144153 & 5.5229 & 5.4644 & TRN \\
\hline CHEMBL22105 & 144153 & 4.7447 & 4.7632 & TRN \\
\hline CHEMBL21670 & 144153 & 4.7959 & 4.7527 & TRN \\
\hline CHEMBL21992 & 144153 & 4.5376 & 4.8646 & TST \\
\hline CHEMBL21728 & 144153 & 5.9586 & 5.9294 & TRN \\
\hline CHEMBL21652 & 144153 & 5.4089 & 5.4076 & TRN \\
\hline CHEMBL 268554 & 144153 & 5.2366 & 5.2531 & TRN \\
\hline CHEMBL21935 & 144153 & 5.9586 & 5.9884 & TRN \\
\hline CHEMBL 21616 & 144153 & 4.5229 & 4.503 & TRN \\
\hline CHEMBL 22174 & 144153 & 4.5229 & 4.4975 & TRN \\
\hline CHEMBL 21941 & 144153 & 6.4559 & 6.2939 & TST \\
\hline CHEMBL21997 & 144153 & 4.757 & 5.1301 & TST \\
\hline CHEMBL22119 & 144153 & 4.8239 & 5.046 & TST \\
\hline CHEMBL20773 & 144153 & 5.5528 & 5.0846 & TST \\
\hline CHEMBL430532 & 144153 & 4.9586 & 4.6851 & TST \\
\hline CHEMBL 22840 & 144153 & 6.301 & 6.3888 & TST \\
\hline CHEMBL 22131 & 144153 & 4.9208 & 4.9234 & TST \\
\hline CHEMBL21877 & 144153 & 6.0 & 5.6126 & TST \\
\hline CHEMBL21737 & 144153 & 4.5229 & 4.9231 & TST \\
\hline CHEMBL492485 & 539657 & 2.0 & 2.1968 & TRN \\
\hline
\end{tabular}




\begin{tabular}{|c|c|c|c|c|}
\hline & & & oplement & al $\mathrm{Ta}$ \\
\hline CHEMBL492263 & 539657 & 2.0 & 2.5152 & TST \\
\hline CHEMBL493500 & 539657 & 2.0 & 1.1961 & TST \\
\hline CHEMBL494492 & 539657 & 5.1427 & 4.9104 & TRN \\
\hline CHEMBL492483 & 539657 & 2.0 & 0.455 & TST \\
\hline CHEMBL494705 & 539657 & 2.0 & 1.8012 & TRN \\
\hline CHEMBL492693 & 539657 & 2.0 & 1.7758 & TRN \\
\hline CHEMBL523997 & 539657 & 2.0 & 2.3355 & TRN \\
\hline CHEMBL523514 & 539657 & 2.0 & 1.4161 & TRN \\
\hline CHEMBL521813 & 539657 & 2.0 & 1.5558 & TST \\
\hline CHEMBL492494 & 539657 & 2.0 & 1.9231 & TRN \\
\hline CHEMBL492889 & 539657 & 2.0 & 1.6214 & TRN \\
\hline CHEMBL492657 & 539657 & 2.0 & 2.1303 & TRN \\
\hline CHEMBL494717 & 539657 & 5.2366 & 5.1851 & TRN \\
\hline CHEMBL492890 & 539657 & 2.0 & 2.1587 & TRN \\
\hline CHEMBL493896 & 539657 & 2.0 & 3.5133 & TRN \\
\hline CHEMBL494321 & 539657 & 2.0 & 0.5651 & TST \\
\hline CHEMBL493703 & 539657 & 4.1367 & 4.5428 & TRN \\
\hline CHEMBL495338 & 539657 & 2.0 & 2.1774 & TRN \\
\hline CHEMBL493490 & 539657 & 5.1249 & 4.1625 & TRN \\
\hline CHEMBL499809 & 539657 & 2.0 & -0.3161 & TST \\
\hline CHEMBL470153 & 539657 & 2.0 & 2.4951 & TST \\
\hline CHEMBL492684 & 539657 & 2.0 & 2.2329 & TRN \\
\hline CHEMBL493696 & 539657 & 2.0 & 2.9475 & TRN \\
\hline CHEMBL492873 & 539657 & 2.0 & 3.6086 & TRN \\
\hline CHEMBL522663 & 539657 & 2.0 & 2.3774 & TRN \\
\hline CHEMBL492665 & 539657 & 2.0 & 2.0276 & TRN \\
\hline CHEMBL492874 & 539657 & 2.0 & 1.6869 & TRN \\
\hline CHEMBL494912 & 539657 & 2.0 & 1.2785 & TST \\
\hline CHEMBL492875 & 539657 & 5.0757 & 4.3996 & TRN \\
\hline CHEMBL493713 & 539657 & 2.0 & 0.3942 & TST \\
\hline CHEMBL493904 & 539657 & 2.0 & 2.2775 & TRN \\
\hline CHEMBL492454 & 539657 & 2.0 & 2.1809 & TRN \\
\hline CHEMBL503048 & 539657 & 2.0 & 2.2368 & TRN \\
\hline CHEMBL492455 & 539657 & 2.0 & 1.9591 & TRN \\
\hline CHEMBL484451 & 539657 & 5.0 & 4.7799 & TRN \\
\hline CHEMBL494704 & 539657 & 2.0 & 2.1415 & TRN \\
\hline CHEMBL522833 & 539657 & 2.0 & 2.0625 & TRN \\
\hline CHEMBL493701 & 539657 & 2.0 & 4.2082 & TST \\
\hline CHEMBL494698 & 539657 & 5.6198 & 4.9122 & TRN \\
\hline CHEMBL449931 & 539657 & 2.0 & 2.3842 & TRN \\
\hline CHEMBL494493 & 539657 & 5.2366 & 5.5118 & TRN \\
\hline CHEMBL522823 & 539657 & 5.6021 & 4.7016 & TRN \\
\hline CHEMBL445785 & 539657 & 2.0 & 4.0268 & TRN \\
\hline CHEMBL158017 & 539657 & 2.0 & 2.6816 & TRN \\
\hline CHEMBL493695 & 539657 & 2.0 & 1.6402 & TRN \\
\hline CHEMBL521859 & 539657 & 2.0 & 2.1206 & TRN \\
\hline CHEMBL522354 & 539657 & 2.0 & 1.7983 & TRN \\
\hline CHEMBL523837 & 539657 & 2.0 & 1.7642 & TRN \\
\hline
\end{tabular}




\begin{tabular}{|c|c|c|c|c|}
\hline & & & Let & \\
\hline CHEMBL492493 & 539657 & 2.0 & 2.1282 & TRN \\
\hline CHEMBL452996 & 539657 & 2.0 & 1.7128 & TRN \\
\hline CHEMBL522341 & 539657 & 2.0 & 0.8438 & TST \\
\hline CHEMBL495135 & 539657 & 5.1192 & 4.8765 & TRN \\
\hline CHEMBL494319 & 539657 & 2.0 & 1.9465 & TRN \\
\hline CHEMBL523687 & 539657 & 2.0 & 0.8571 & TST \\
\hline CHEMBL494491 & 539657 & 5.1024 & 5.7218 & TRN \\
\hline CHEMBL494716 & 539657 & 2.0 & 0.9238 & TST \\
\hline CHEMBL493095 & 539657 & 2.0 & 1.873006 & $\partial 0000000002$ \\
\hline CHEMBL524027 & 539657 & 2.0 & 1.6402 & TRN \\
\hline CHEMBL352024 & 539657 & 4.7959 & 3.9726 & TST \\
\hline CHEMBL523380 & 539657 & 2.0 & 0.0189 & TST \\
\hline CHEMBL494911 & 539657 & 2.0 & 1.8141 & TRN \\
\hline CHEMBL498951 & 539657 & 2.0 & 1.8831 & TRN \\
\hline CHEMBL492262 & 539657 & 2.0 & 3.4879 & TST \\
\hline CHEMBL492297 & 539657 & 2.0 & 2.1468 & TRN \\
\hline CHEMBL448274 & 539657 & 2.0 & 2.1712 & TRN \\
\hline CHEMBL347927 & 539657 & 5.5528 & 5.0576 & TRN \\
\hline CHEMBL494122 & 539657 & 2.0 & -0.0128 & TST \\
\hline CHEMBL492685 & 539657 & 2.0 & 1.585999 & \\
\hline CHEMBL495337 & 539657 & 5.7696 & 5.2162 & TRN \\
\hline CHEMBL493097 & 539657 & 4.7959 & 3.796000 & 00000000003 \\
\hline CHEMBL507395 & 539657 & 2.0 & 4.1551 & TST \\
\hline CHEMBL443932 & 539657 & 2.0 & 2.1506 & TRN \\
\hline CHEMBL443774 & 539657 & 2.0 & 2.3864 & TRN \\
\hline CHEMBL494320 & 539657 & 2.0 & 2.5197 & TRN \\
\hline CHEMBL522995 & 539657 & 2.0 & 2.6152 & TRN \\
\hline CHEMBL494706 & 539657 & 5.2441 & 4.5781 & TRN \\
\hline CHEMBL522032 & 539657 & 2.0 & -0.2107 & TST \\
\hline CHEMBL522172 & 539657 & 2.0 & 3.153 & TRN \\
\hline CHEMBL523041 & 539657 & 2.0 & 1.7684 & TRN \\
\hline CHEMBL493501 & 539657 & 2.0 & 1.1094 & TRN \\
\hline CHEMBL494121 & 539657 & 5.3872 & 4.9364 & TRN \\
\hline CHEMBL522206 & 539657 & 2.0 & 1.9775 & TRN \\
\hline CHEMBL493903 & 539657 & 2.0 & 1.9794 & TRN \\
\hline CHEMBL492387 & 539657 & 2.0 & 2.6846 & TRN \\
\hline CHEMBL523698 & 539657 & 2.0 & 1.9478 & TRN \\
\hline CHEMBL493700 & 539657 & 2.0 & -0.2087 & TST \\
\hline CHEMBL495325 & 539657 & 2.0 & 1.986999 & \\
\hline CHEMBL492453 & 539657 & 2.0 & 0.8501 & TRN \\
\hline CHEMBL493702 & 539657 & 5.1249 & 4.4274 & TRN \\
\hline CHEMBL493304 & 539657 & 2.0 & 0.0451 & TST \\
\hline CHEMBL502155 & 539657 & 2.0 & 2.06 & TRN \\
\hline CHEMBL493096 & 539657 & 2.0 & 3.7813 & TRN \\
\hline CHEMBL495136 & 539657 & 2.0 & 1.9389 & TRN \\
\hline CHEMBL524173 & 539657 & 2.0 & 1.6243 & TRN \\
\hline CHEMBL495137 & 539657 & 2.0 & 1.4393 & TRN \\
\hline CHEMBL492456 & 539657 & 2.0 & 2.3852 & TRN \\
\hline
\end{tabular}




\begin{tabular}{|c|c|c|c|c|c|}
\hline \multicolumn{6}{|c|}{ Supplemental Table S2.txt } \\
\hline CHEMBL447755 & 539657 & 2.0 & 2.2657 & TRN & \\
\hline CHEMBL493502 & 539657 & 2.0 & -0.3731 & TST & \\
\hline CHEMBL495326 & 539657 & 5.6198 & 4.4741 & TRN & \\
\hline CHEMBL451143 & 539657 & 5.1427 & 3.825 & TRN & \\
\hline CHEMBL523707 & 539657 & 2.0 & 1.7684 & TRN & \\
\hline CHEMBL522542 & 539657 & 2.0 & 1.9389 & TRN & \\
\hline CHEMBL493897 & 539657 & 2.0 & 2.1673 & TRN & \\
\hline CHEMBL493694 & 539657 & 2.0 & 3.3034 & TST & \\
\hline CHEMBL400466 & 539657 & 2.0 & 2.8479 & TST & \\
\hline CHEMBL493714 & 539657 & 2.0 & 0.9081 & TST & \\
\hline CHEMBL523208 & 539657 & 2.0 & 2.8264 & TST & \\
\hline CHEMBL1381704 & 737469 & 3.6021 & 3.548 & TRN & \\
\hline CHEMBL1999160 & 737469 & 3.301 & 3.3848 & TRN & \\
\hline CHEMBL3208956 & 737469 & 3.301 & 3.2926 & TRN & \\
\hline CHEMBL1406652 & 737469 & 3.301 & 3.2482 & TRN & \\
\hline CHEMBL1390275 & 737469 & 8.0 & 8.1216 & TRN & \\
\hline CHEMBL1352584 & 737469 & 3.301 & 5.0336 & TST & \\
\hline CHEMBL1300014 & 737469 & 3.301 & 3.2686 & TRN & \\
\hline CHEMBL534244 & 737469 & 8.0 & 8.0377 & TRN & \\
\hline CHEMBL1332050 & 737469 & 8.0 & 7.9944 & TRN & \\
\hline CHEMBL1301472 & 737469 & 3.301 & 3.4467 & TST & \\
\hline CHEMBL1497379 & 737469 & 3.301 & 3.353999 & 99999999996 & TRN \\
\hline CHEMBL1528219 & 737469 & 8.0 & 7.8668 & TRN & \\
\hline CHEMBL1730158 & 737469 & 3.301 & 3.3236 & TRN & \\
\hline CHEMBL1406251 & 737469 & 8.0 & 8.017999 & 9999999999 & TRN \\
\hline CHEMBL1455279 & 737469 & 3.301 & 5.3575 & TST & \\
\hline CHEMBL1427178 & 737469 & 8.0 & 8.0434 & TRN & \\
\hline CHEMBL1571055 & 737469 & 3.301 & 3.2504 & TRN & \\
\hline CHEMBL1354123 & 737469 & 3.301 & 3.3408 & TRN & \\
\hline CHEMBL1426551 & 737469 & 3.301 & 3.2947 & TRN & \\
\hline CHEMBL1590745 & 737469 & 3.301 & 3.4389 & TRN & \\
\hline CHEMBL1383238 & 737469 & 3.301 & 3.3065 & TRN & \\
\hline CHEMBL1996299 & 737469 & 3.301 & 3.2732 & TRN & \\
\hline CHEMBL1570765 & 737469 & 3.6021 & 3.5644 & TRN & \\
\hline CHEMBL1387923 & 737469 & 3.301 & 3.313 & TRN & \\
\hline CHEMBL1489742 & 737469 & 3.301 & 3.3938 & TRN & \\
\hline CHEMBL1453498 & 737469 & 3.301 & 5.4914 & TST & \\
\hline CHEMBL1323142 & 737469 & 3.301 & 4.0602 & TST & \\
\hline CHEMBL1546184 & 737469 & 8.0 & 8.0879 & TRN & \\
\hline CHEMBL1353875 & 737469 & 3.301 & 3.265 & TRN & \\
\hline CHEMBL1578360 & 737469 & 3.301 & 3.3009 & TRN & \\
\hline CHEMBL1705878 & 737469 & 3.301 & 3.3786 & TRN & \\
\hline CHEMBL1533303 & 737469 & 8.0 & 8.0208 & TRN & \\
\hline CHEMBL1522368 & 737469 & 8.0 & 7.9902 & TRN & \\
\hline CHEMBL1403294 & 737469 & 3.301 & 3.2978 & TRN & \\
\hline CHEMBL1403035 & 737469 & 8.0 & 7.9857 & TRN & \\
\hline CHEMBL1475678 & 737469 & 8.0 & 8.0397 & TRN & \\
\hline CHEMBL 2007422 & 737469 & 3.301 & 3.3813 & TRN & \\
\hline
\end{tabular}




\begin{tabular}{|c|c|c|c|c|c|}
\hline \multicolumn{6}{|c|}{ Supplemental Table S2.txt } \\
\hline CHEMBL1400033 & 737469 & 8.0 & 8.0495 & TRN & \\
\hline CHEMBL1494007 & 737469 & 3.301 & 3.3201 & TRN & \\
\hline CHEMBL1332019 & 737469 & 3.301 & 3.2526 & TRN & \\
\hline CHEMBL1468136 & 737469 & 8.0 & 7.9519 & TRN & \\
\hline CHEMBL1342654 & 737469 & 3.301 & 3.3442 & TRN & \\
\hline CHEMBL1480613 & 737469 & 3.301 & 3.2834 & TRN & \\
\hline CHEMBL3197912 & 737469 & 8.0 & 8.1062 & TRN & \\
\hline CHEMBL1492697 & 737469 & 3.301 & 5.0211 & TST & \\
\hline CHEMBL1575626 & 737469 & 3.301 & 3.2242 & TRN & \\
\hline CHEMBL 2006594 & 737469 & 3.301 & 3.2137 & TRN & \\
\hline CHEMBL 3210438 & 737469 & 3.301 & 3.4825 & TST & \\
\hline CHEMBL 3190837 & 737469 & 3.301 & 3.3094 & TRN & \\
\hline CHEMBL1357892 & 737469 & 3.301 & 3.3206 & TRN & \\
\hline CHEMBL1509686 & 737469 & 3.301 & 3.3031 & TRN & \\
\hline CHEMBL1509387 & 737469 & 3.301 & 3.3312 & TRN & \\
\hline CHEMBL1499408 & 737469 & 3.301 & 3.2933 & TRN & \\
\hline CHEMBL1699978 & 737469 & 3.301 & 3.2798 & TRN & \\
\hline CHEMBL1375932 & 737469 & 3.301 & 3.5694 & TST & \\
\hline CHEMBL1567752 & 737469 & 3.301 & 3.2903 & TRN & \\
\hline CHEMBL3209339 & 737469 & 3.301 & 3.2066 & TRN & \\
\hline CHEMBL1526413 & 737469 & 3.301 & 3.3328 & TRN & \\
\hline CHEMBL1502128 & 737469 & 3.301 & 3.2263 & TRN & \\
\hline CHEMBL1346576 & 737469 & 3.301 & 5.2898 & TST & \\
\hline CHEMBL1425412 & 737469 & 3.301 & 3.3445 & TRN & \\
\hline CHEMBL3199370 & 737469 & 3.301 & 3.1678 & TRN & \\
\hline CHEMBL1594001 & 737469 & 3.301 & 3.27100 & 00000000004 & TRN \\
\hline CHEMBL1416089 & 737469 & 3.301 & 3.3003 & TRN & \\
\hline CHEMBL3198394 & 737469 & 8.0 & 7.8796 & TRN & \\
\hline CHEMBL1609163 & 737469 & 3.301 & 3.2073 & TRN & \\
\hline CHEMBL1534577 & 737469 & 3.301 & 3.3185 & TRN & \\
\hline CHEMBL1569550 & 737469 & 8.0 & 8.0432 & TRN & \\
\hline CHEMBL1400809 & 737469 & 8.0 & 7.8534 & TRN & \\
\hline CHEMBL3191958 & 737469 & 8.0 & 7.7959 & TRN & \\
\hline CHEMBL1575845 & 737469 & 3.301 & 3.3065 & TRN & \\
\hline CHEMBL1390716 & 737469 & 8.0 & 6.4125 & TST & \\
\hline CHEMBL1555589 & 737469 & 3.301 & 3.2861 & TRN & \\
\hline CHEMBL1563704 & 737469 & 3.301 & 3.36 & TRN & \\
\hline CHEMBL 252151 & 737469 & 3.301 & 3.4779 & TRN & \\
\hline CHEMBL1991431 & 737469 & 8.0 & 7.9417 & TRN & \\
\hline CHEMBL1586416 & 737469 & 8.0 & 8.1094 & TRN & \\
\hline CHEMBL1351508 & 737469 & 3.301 & 3.3239 & TRN & \\
\hline CHEMBL 3212874 & 737469 & 3.301 & 5.0598 & TST & \\
\hline CHEMBL1547725 & 737469 & 3.301 & 3.7876 & TST & \\
\hline CHEMBL1470448 & 737469 & 3.301 & 3.5524 & TST & \\
\hline CHEMBL1307469 & 737469 & 3.301 & 1.9058 & TST & \\
\hline CHEMBL1309573 & 737469 & 8.0 & 4.1155 & TST & \\
\hline CHEMBL1335672 & 737469 & 8.0 & 7.1099 & TST & \\
\hline CHEMBL1441940 & 737469 & 3.301 & 6.0224 & TST & \\
\hline
\end{tabular}




\begin{tabular}{|c|c|c|c|c|}
\hline \multicolumn{5}{|c|}{ Supplemental Table S2.txt } \\
\hline CHEMBL1540395 & 737469 & 3.301 & 3.7043 & TST \\
\hline CHEMBL1538021 & 737469 & 8.0 & 4.699 & TST \\
\hline CHEMBL1431440 & 737469 & 3.301 & 4.9717 & TST \\
\hline CHEMBL1425747 & 737469 & 3.301 & 6.1842 & TST \\
\hline CHEMBL1971379 & 737469 & 3.301 & 2.6909 & TST \\
\hline CHEMBL1424999 & 737469 & 8.0 & 7.9631 & TST \\
\hline CHEMBL1721094 & 809416 & 4.51 & 4.2465 & TRN \\
\hline CHEMBL1558648 & 809416 & 4.6819 & 4.3916 & TRN \\
\hline CHEMBL1993173 & 809416 & 5.0273 & 5.0344 & TRN \\
\hline CHEMBL358290 & 809416 & 3.0969 & 4.2702 & TRN \\
\hline CHEMBL1331149 & 809416 & 5.0953 & 4.8937 & TRN \\
\hline CHEMBL1502703 & 809416 & 4.3809 & 4.1962 & TST \\
\hline CHEMBL1721577 & 809416 & 3.0969 & 4.4131 & TST \\
\hline CHEMBL1545441 & 809416 & 4.857 & 4.4222 & TRN \\
\hline CHEMBL1991440 & 809416 & 4.5817 & 4.8391 & TRN \\
\hline CHEMBL1714422 & 809416 & 4.2832 & 4.83 & TRN \\
\hline CHEMBL1537922 & 809416 & 4.9355 & 4.9319 & TRN \\
\hline CHEMBL1451261 & 809416 & 4.3439 & 4.6853 & TRN \\
\hline CHEMBL1426299 & 809416 & 5.0482 & 5.1769 & TRN \\
\hline CHEMBL1986343 & 809416 & 4.5768 & 4.2305 & TRN \\
\hline CHEMBL1733383 & 809416 & 4.8729 & 4.7119 & TRN \\
\hline CHEMBL1421970 & 809416 & 5.3325 & 5.0592 & TST \\
\hline CHEMBL1460464 & 809416 & 3.0969 & 3.7836 & TST \\
\hline CHEMBL1580036 & 809416 & 4.6308 & 4.524 & TRN \\
\hline CHEMBL1506021 & 809416 & 4.2457 & 4.2669 & TST \\
\hline CHEMBL1364175 & 809416 & 4.248 & 4.3275 & TRN \\
\hline CHEMBL1547640 & 809416 & 5.1726 & 4.493 & TRN \\
\hline CHEMBL1310336 & 809416 & 4.5482 & 4.0521 & TRN \\
\hline CHEMBL1586360 & 809416 & 4.5114 & 4.9723 & TRN \\
\hline CHEMBL1423213 & 809416 & 3.0969 & 3.4437 & TRN \\
\hline CHEMBL1550032 & 809416 & 5.5317 & 5.21 & TRN \\
\hline CHEMBL1350887 & 809416 & 3.0969 & 4.2696 & TRN \\
\hline CHEMBL1433062 & 809416 & 4.6126 & 4.8881 & TRN \\
\hline CHEMBL1893914 & 809416 & 5.0482 & 5.1099 & TRN \\
\hline CHEMBL1429265 & 809416 & 3.0969 & 3.9043 & TRN \\
\hline CHEMBL1344075 & 809416 & 4.6271 & 4.8505 & TRN \\
\hline CHEMBL1540317 & 809416 & 5.0645 & 4.9427 & TRN \\
\hline CHEMBL1597485 & 809416 & 4.556 & 4.4796 & TRN \\
\hline CHEMBL1301519 & 809416 & 4.4921 & 4.5914 & TRN \\
\hline CHEMBL1334491 & 809416 & 4.4112 & 4.5631 & TRN \\
\hline CHEMBL1461216 & 809416 & 5.7033 & 5.4748 & TRN \\
\hline CHEMBL1515727 & 809416 & 4.6038 & 4.5425 & TRN \\
\hline CHEMBL1528986 & 809416 & 4.7721 & 5.0421 & TRN \\
\hline CHEMBL1470628 & 809416 & 4.6091 & 4.1768 & TRN \\
\hline CHEMBL1367604 & 809416 & 4.6091 & 4.7752 & TRN \\
\hline CHEMBL1996139 & 809416 & 4.7825 & 4.2151 & TRN \\
\hline CHEMBL1985932 & 809416 & 5.0123 & 5.184 & TRN \\
\hline CHEMBL1973036 & 809416 & 4.9318 & 5.0494 & TRN \\
\hline
\end{tabular}




\begin{tabular}{|c|c|c|c|c|c|c|}
\hline & & \multicolumn{5}{|c|}{ Supplemental Table S2.txt } \\
\hline CHEMBL1381413 & 809416 & 3.0969 & 4.1973 & TRN & & \\
\hline CHEMBL1432675 & 809416 & 4.2757 & 4.3439 & TRN & & \\
\hline CHEMBL1888617 & 809416 & 4.8477 & 4.942 & TRN & & \\
\hline CHEMBL1982044 & 809416 & 5.1367 & 4.9725 & TRN & & \\
\hline CHEMBL1302298 & 809416 & 5.1367 & 4.5969 & TRN & & \\
\hline CHEMBL1993711 & 809416 & 4.9318 & 4.8053 & TRN & & \\
\hline CHEMBL1731009 & 809416 & 4.5436 & 4.4263 & TRN & & \\
\hline CHEMBL1986392 & 809416 & \multicolumn{3}{|c|}{ 4.76699999999999995 } & 4.4203 & TRN \\
\hline CHEMBL1966746 & 809416 & 4.857 & 4.745 & TRN & & \\
\hline CHEMBL1407203 & 809416 & 4.7696 & 4.7469 & TRN & & \\
\hline CHEMBL1349800 & 809416 & 5.1141 & 4.6253 & TST & & \\
\hline CHEMBL1304345 & 809416 & 5.0039 & 4.7268 & TRN & & \\
\hline CHEMBL1993643 & 809416 & 3.0969 & 3.2882 & TRN & & \\
\hline CHEMBL1478082 & 809416 & 4.8416 & 4.2888 & TRN & & \\
\hline CHEMBL1585855 & 809416 & 4.2062 & 4.1305 & TRN & & \\
\hline CHEMBL1329712 & 809416 & 5.4001 & 4.6332 & TRN & & \\
\hline CHEMBL1528944 & 809416 & 4.6459 & 4.6138 & TST & & \\
\hline CHEMBL1586977 & 809416 & 4.4078 & 4.5414 & TRN & & \\
\hline CHEMBL1500616 & 809416 & 4.2464 & 4.0587 & TRN & & \\
\hline CHEMBL1412602 & 809416 & 4.2449 & 5.0205 & TST & & \\
\hline CHEMBL1417141 & 809416 & 5.2534 & 5.142 & TRN & & \\
\hline CHEMBL 3145017 & 809416 & 4.2306 & 4.416 & TRN & & \\
\hline CHEMBL1506538 & 809416 & 4.7852 & 4.8496 & TRN & & \\
\hline CHEMBL1485717 & 809416 & 4.7399 & 5.2521 & TRN & & \\
\hline CHEMBL1569105 & 809416 & 4.5654 & 4.7345 & TRN & & \\
\hline CHEMBL1735536 & 809416 & 4.5317 & 4.5477 & TST & & \\
\hline CHEMBL1505300 & 809416 & 5.3799 & 4.73 & TRN & & \\
\hline CHEMBL1523808 & 809416 & 4.7447 & 4.046 & TRN & & \\
\hline CHEMBL1271266 & 809416 & 5.1878 & 5.2114 & TRN & & \\
\hline CHEMBL1406679 & 809416 & 3.0969 & 3.9253 & TRN & & \\
\hline CHEMBL1368444 & 809416 & 5.1618 & 4.8181 & TRN & & \\
\hline CHEMBL1489399 & 809416 & 4.6968 & 5.2162 & TRN & & \\
\hline CHEMBL1733061 & 809416 & 3.0969 & 5.0212 & TST & & \\
\hline CHEMBL1973855 & 809416 & 3.0969 & 4.0675 & TRN & & \\
\hline CHEMBL1605157 & 809416 & 4.8761 & 4.8477 & TRN & & \\
\hline CHEMBL1535692 & 809416 & 4.4389 & 4.7176 & TRN & & \\
\hline CHEMBL1985091 & 809416 & 5.0883 & 4.9804 & TRN & & \\
\hline CHEMBL1407021 & 809416 & 4.6402 & 4.0339 & TRN & & \\
\hline CHEMBL1489711 & 809416 & 4.8097 & 4.3629 & TRN & & \\
\hline CHEMBL1529345 & 809416 & 4.5952 & 4.6353 & TRN & & \\
\hline CHEMBL1996666 & 809416 & 5.1824 & 4.8306 & TRN & & \\
\hline CHEMBL1509369 & 809416 & 4.2765 & 4.408 & TRN & & \\
\hline CHEMBL1484595 & 809416 & 4.5607 & 4.6143 & TST & & \\
\hline CHEMBL1466912 & 809416 & 4.5935 & 4.7685 & TRN & & \\
\hline CHEMBL1467623 & 809416 & 5.4012 & 5.1431 & TRN & & \\
\hline CHEMBL1487101 & 809416 & 4.6968 & 4.8978 & TRN & & \\
\hline CHEMBL1405311 & 809416 & 4.8508 & 4.8308 & TRN & & \\
\hline CHEMBL1533277 & 809416 & 4.5528 & 4.7089 & TRN & & \\
\hline
\end{tabular}


Supplemental Table S2.txt

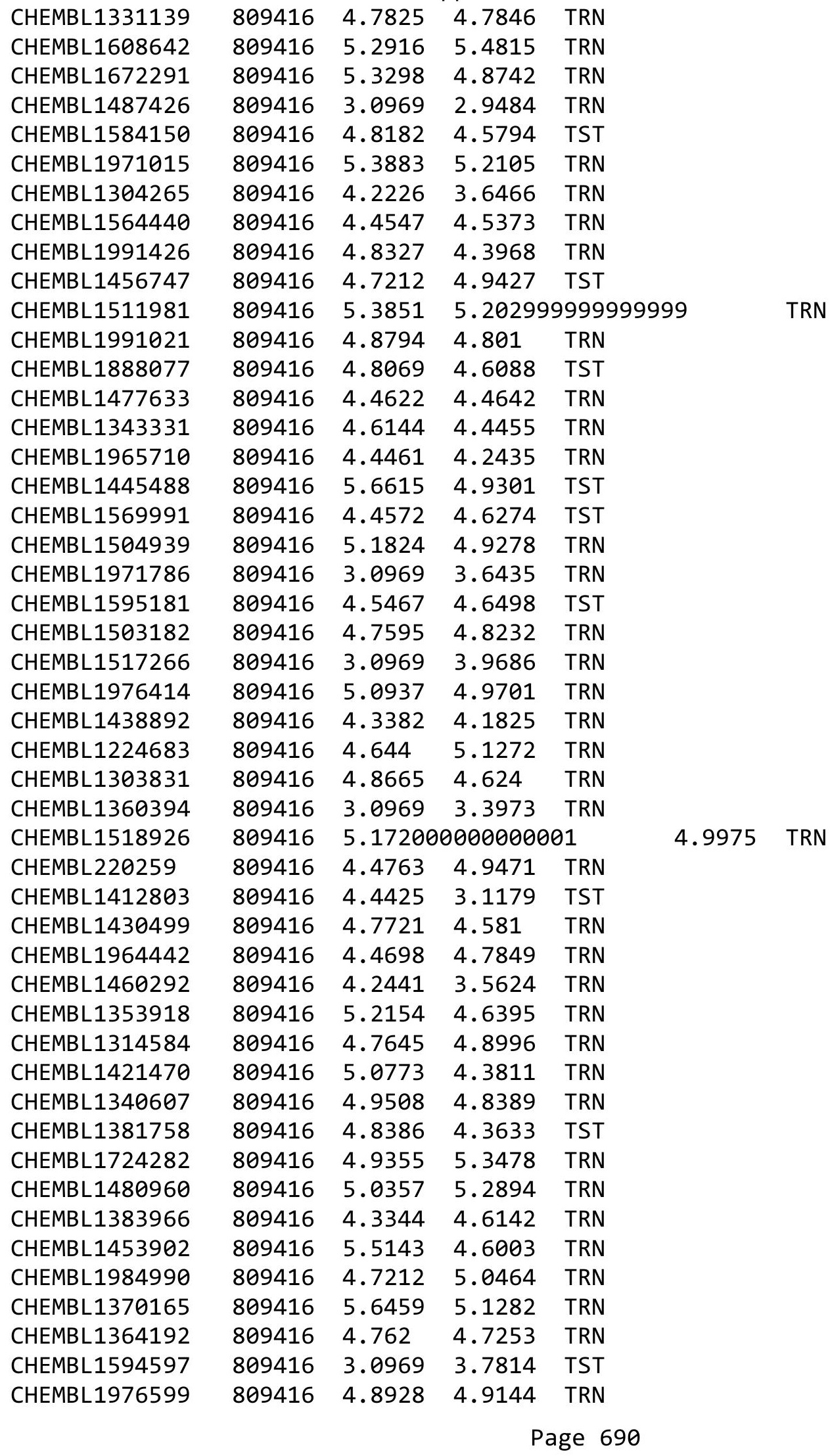




\begin{tabular}{|c|c|c|c|c|c|}
\hline & & \multicolumn{4}{|c|}{ Supplemental Table S2.txt } \\
\hline CHEMBL1529185 & 809416 & 4.71 & 4.5568 & TRN & \\
\hline CHEMBL1398814 & 809416 & 3.0969 & 4.4039 & TRN & \\
\hline CHEMBL1308781 & 809416 & 4.4413 & 4.3633 & TRN & \\
\hline CHEMBL1314093 & 809416 & 3.0969 & 3.1756 & TRN & \\
\hline CHEMBL1359614 & 809416 & 4.6882 & 4.8825 & TRN & \\
\hline CHEMBL1893949 & 809416 & 4.5287 & 4.5937 & TST & \\
\hline CHEMBL1898589 & 809416 & 3.0969 & 4.9769 & TST & \\
\hline CHEMBL1971404 & 809416 & 5.1656 & 4.6115 & TST & \\
\hline CHEMBL1608180 & 809416 & 4.6345 & 4.7407 & TST & \\
\hline CHEMBL1405203 & 809416 & 4.4045 & 5.0159 & TST & \\
\hline CHEMBL1383849 & 809416 & 3.0969 & 4.5763 & TST & \\
\hline CHEMBL1387238 & 809416 & 4.3737 & 4.3202 & TST & \\
\hline CHEMBL1419452 & 809416 & 4.2549 & 4.5149 & TST & \\
\hline CHEMBL1385949 & 809416 & 5.4134 & 4.7972 & TST & \\
\hline CHEMBL1531641 & 809416 & 5.0953 & 4.8195 & TST & \\
\hline CHEMBL1408579 & 809416 & 4.8386 & 4.7518 & TST & \\
\hline CHEMBL1982391 & 809416 & 5.0996 & 4.9419 & TST & \\
\hline CHEMBL1566674 & 809416 & 3.0969 & 4.7329 & TST & \\
\hline CHEMBL1725497 & 809416 & 4.9957 & 4.92899 & 9999999999 & TST \\
\hline CHEMBL1434855 & 809416 & 4.6716 & 4.6752 & TST & \\
\hline CHEMBL1331791 & 809416 & 3.0969 & 4.2998 & TST & \\
\hline CHEMBL1345966 & 809416 & 4.5272 & 4.992 & TST & \\
\hline CHEMBL1330962 & 809416 & 3.0969 & 3.7089 & TST & \\
\hline CHEMBL1540065 & 809416 & 5.1593 & 4.4767 & TST & \\
\hline CHEMBL1463248 & 809416 & 5.5638 & 4.8371 & TST & \\
\hline CHEMBL1875123 & 809416 & 5.0119 & 4.9117 & TST & \\
\hline CHEMBL1410244 & 809416 & 5.0501 & 5.4081 & TST & \\
\hline CHEMBL3938138 & 1641767 & 4.0 & 4.7237 & TRN & \\
\hline CHEMBL 3928707 & 1641767 & 6.6696 & 5.4487 & TST & \\
\hline CHEMBL3935962 & 1641767 & 4.0 & 3.9976 & TRN & \\
\hline CHEMBL3906169 & 1641767 & 5.9393 & 5.9332 & TRN & \\
\hline CHEMBL3946486 & 1641767 & $6.3270 e$ & 00000000 & 5.9997 & TRN \\
\hline CHEMBL3924938 & 1641767 & 4.0 & 4.6367 & TRN & \\
\hline CHEMBL3893102 & 1641767 & 5.9431 & 5.9042 & TRN & \\
\hline CHEMBL3944754 & 1641767 & 4.0 & 4.5345 & TST & \\
\hline CHEMBL3955748 & 1641767 & 4.0 & 4.5929 & TRN & \\
\hline CHEMBL3929862 & 1641767 & 4.0 & 5.0427 & TRN & \\
\hline CHEMBL3983609 & 1641767 & 5.6968 & 5.0286 & TRN & \\
\hline CHEMBL3933849 & 1641767 & 5.1198 & 4.8981 & TRN & \\
\hline CHEMBL3972706 & 1641767 & 4.0 & 4.0157 & TRN & \\
\hline CHEMBL3931583 & 1641767 & 4.0 & 4.0977 & TST & \\
\hline CHEMBL3895145 & 1641767 & 4.0 & 4.8357 & TST & \\
\hline CHEMBL3940662 & 1641767 & 4.0 & 4.7585 & TRN & \\
\hline CHEMBL3920490 & 1641767 & 4.0 & 4.5583 & TRN & \\
\hline CHEMBL3909582 & 1641767 & 4.0 & 4.9516 & TRN & \\
\hline CHEMBL3983393 & 1641767 & 4.0 & 4.1101 & TRN & \\
\hline CHEMBL3913628 & 1641767 & 4.0 & 4.6245 & TRN & \\
\hline CHEMBL3962721 & 1641767 & 4.0 & 5.2396 & TST & \\
\hline
\end{tabular}




\begin{tabular}{|c|c|c|c|c|c|}
\hline \multirow[b]{2}{*}{ CHEMBL3909976 } & \multicolumn{5}{|c|}{ Supplemental Table S2.txt } \\
\hline & 1641767 & 4.0 & 4.5018 & TRN & \\
\hline CHEMBL3921636 & 1641767 & 5.1805 & 4.9956 & TRN & \\
\hline CHEMBL3975139 & 1641767 & 4.0 & 5.0868 & TRN & \\
\hline CHEMBL 3926642 & 1641767 & 5.7258 & 5.3898 & TRN & \\
\hline CHEMBL3951692 & 1641767 & 5.4168 & 4.4889 & TRN & \\
\hline CHEMBL 3895680 & 1641767 & 5.0835 & 3.72399 & 99999999998 & TST \\
\hline CHEMBL3922776 & 1641767 & 5.1911 & 4.5047 & TRN & \\
\hline CHEMBL3952945 & 1641767 & 6.5143 & 5.5971 & TST & \\
\hline CHEMBL 3933266 & 1641767 & 4.0 & 4.64199 & 99999999995 & TRN \\
\hline CHEMBL3919882 & 1641767 & 5.0182 & 4.7543 & TST & \\
\hline CHEMBL3937896 & 1641767 & 4.0 & 4.8386 & TRN & \\
\hline CHEMBL 3900187 & 1641767 & 4.0 & 4.702 & TRN & \\
\hline CHEMBL3960584 & 1641767 & 5.7328 & 5.1425 & TRN & \\
\hline CHEMBL3961669 & 1641767 & 4.0 & 4.3 & TRN & \\
\hline CHEMBL3915316 & 1641767 & 4.0 & 4.3506 & TRN & \\
\hline CHEMBL3943111 & 1641767 & 5.8761 & 5.2875 & TST & \\
\hline CHEMBL3955185 & 1641767 & 4.0 & 4.3253 & TRN & \\
\hline CHEMBL3949406 & 1641767 & 5.433 & 5.6087 & TRN & \\
\hline CHEMBL3896891 & 1641767 & 5.4413 & 5.1585 & TRN & \\
\hline CHEMBL3986882 & 1641767 & 5.6021 & 4.3967 & TRN & \\
\hline CHEMBL3958343 & 1641767 & 4.0 & 4.7073 & TST & \\
\hline CHEMBL3946087 & 1641767 & 5.6402 & 5.4396 & TST & \\
\hline CHEMBL3958250 & 1641767 & 4.0 & 4.481 & TRN & \\
\hline CHEMBL3911405 & 1641767 & 5.7932 & 5.4745 & TRN & \\
\hline CHEMBL3975287 & 1641767 & 4.0 & 4.4212 & TST & \\
\hline CHEMBL3896276 & 1641767 & 4.0 & $3.89600 t$ & 00000000004 & TRN \\
\hline CHEMBL3890100 & 1641767 & 5.5186 & 4.7818 & TRN & \\
\hline CHEMBL3341981 & 1641767 & 4.0 & 4.77800 & 00000000005 & TRN \\
\hline CHEMBL3961261 & 1641767 & 4.0 & 3.8123 & TRN & \\
\hline CHEMBL3929582 & 1641767 & 6.5952 & 5.9569 & TRN & \\
\hline CHEMBL3937046 & 1641767 & 4.0 & $4.16100 t$ & 00000000005 & TRN \\
\hline CHEMBL 3983724 & 1641767 & 5.7011 & 5.3226 & TRN & \\
\hline CHEMBL3932638 & 1641767 & 4.0 & 4.6917 & TRN & \\
\hline CHEMBL 3928200 & 1641767 & 4.0 & 4.412 & TRN & \\
\hline CHEMBL3945942 & 1641767 & 4.0 & 4.4794 & TST & \\
\hline CHEMBL 3905774 & 1641767 & 4.0 & 4.3173 & TRN & \\
\hline CHEMBL3908279 & 1641767 & 5.1319 & 4.6655 & TRN & \\
\hline CHEMBL3939634 & 1641767 & 5.1331 & 4.7852 & TRN & \\
\hline CHEMBL3911657 & 1641767 & 5.1118 & 4.7516 & TRN & \\
\hline CHEMBL3959387 & 1641767 & 4.0 & 4.687 & TRN & \\
\hline CHEMBL3901597 & 1641767 & 4.0 & 4.9929 & TRN & \\
\hline CHEMBL3934231 & 1641767 & 4.0 & 3.832 & TRN & \\
\hline CHEMBL3969101 & 1641767 & 5.2161 & 4.3211 & TRN & \\
\hline CHEMBL3918153 & 1641767 & 4.0 & 4.3388 & TRN & \\
\hline CHEMBL3970163 & 1641767 & 4.0 & 3.5627 & TRN & \\
\hline CHEMBL3928011 & 1641767 & 5.4449 & 5.7883 & TRN & \\
\hline CHEMBL3963974 & 1641767 & 4.0 & 4.1246 & TRN & \\
\hline CHEMBL3945380 & 1641767 & 5.2007 & 4.80399 & 999999 & TRN \\
\hline & & & & 69 & \\
\hline
\end{tabular}


Supplemental Table S2.txt

\begin{tabular}{|c|c|c|c|c|c|}
\hline CHEMBL3977404 & 1641767 & 4.0 & 4.9713 & TST & \\
\hline CHEMBL3969238 & 1641767 & 5.6459 & 4.7738 & TRN & \\
\hline CHEMBL3909713 & 1641767 & 5.3197 & 5.5561 & TRN & \\
\hline CHEMBL 3900228 & 1641767 & 4.0 & 4.675 & TRN & \\
\hline CHEMBL3910221 & 1641767 & 4.0 & 4.5683 & TRN & \\
\hline CHEMBL3963432 & 1641767 & 4.0 & 5.2387 & TRN & \\
\hline CHEMBL3939564 & 1641767 & 4.0 & 3.9088 & TRN & \\
\hline CHEMBL3955931 & 1641767 & 4.0 & 5.0999 & TRN & \\
\hline CHEMBL3977812 & 1641767 & 5.1124 & 5.1492 & TRN & \\
\hline CHEMBL3922625 & 1641767 & 5.2534 & 4.8403 & TRN & \\
\hline CHEMBL3889675 & 1641767 & 5.9136 & 5.6246 & TRN & \\
\hline CHEMBL3939383 & 1641767 & 4.0 & 4.9033 & TRN & \\
\hline CHEMBL3937678 & 1641767 & 4.0 & 4.5526 & TRN & \\
\hline CHEMBL3941069 & 1641767 & 6.1637 & 5.3891 & TRN & \\
\hline CHEMBL3920827 & 1641767 & 5.8827 & 5.6324 & TRN & \\
\hline CHEMBL3912273 & 1641767 & 4.0 & 3.6035 & TST & \\
\hline CHEMBL3928121 & 1641767 & 5.9431 & 5.031000 & 0000000001 & TRN \\
\hline CHEMBL3958044 & 1641767 & 4.0 & 4.3484 & TST & \\
\hline CHEMBL3964144 & 1641767 & 4.0 & 4.673 & TST & \\
\hline CHEMBL3955295 & 1641767 & 5.3072 & 4.7348 & TRN & \\
\hline CHEMBL3954108 & 1641767 & 4.0 & 4.4375 & TST & \\
\hline CHEMBL3949355 & 1641767 & 5.21399 & 999999999 & 5.5974 & TST \\
\hline CHEMBL3900718 & 1641767 & 4.0 & 4.4368 & TRN & \\
\hline CHEMBL3981707 & 1641767 & 5.1524 & 4.675 & TRN & \\
\hline CHEMBL3902709 & 1641767 & 6.025 & 5.5675 & TST & \\
\hline CHEMBL3904074 & 1641767 & 5.9626 & 5.5742 & TRN & \\
\hline CHEMBL3933789 & 1641767 & 4.0 & 4.0438 & TST & \\
\hline CHEMBL3926166 & 1641767 & 4.0 & 5.312 & TST & \\
\hline CHEMBL3900671 & 1641767 & 4.0 & 4.1513 & TST & \\
\hline CHEMBL3918953 & 1641767 & 4.0 & 3.5698 & TRN & \\
\hline CHEMBL3891509 & 1641767 & 4.0 & 4.6384 & TST & \\
\hline CHEMBL3898405 & 1641767 & 4.0 & 4.8367 & TRN & \\
\hline CHEMBL3912701 & 1641767 & 4.0 & 4.1684 & TRN & \\
\hline CHEMBL3943116 & 1641767 & 4.0 & 4.7755 & TST & \\
\hline CHEMBL3951340 & 1641767 & 4.0 & 4.6331 & TRN & \\
\hline CHEMBL3937730 & 1641767 & 5.2668 & 5.2843 & TST & \\
\hline CHEMBL3922400 & 1641767 & 6.4572 & 5.7506 & TST & \\
\hline CHEMBL3944898 & 1641767 & 5.2941 & 5.0862 & TRN & \\
\hline CHEMBL3948159 & 1641767 & 5.8069 & 5.2229 & TRN & \\
\hline CHEMBL3948638 & 1641767 & 6.4145 & 5.7683 & TRN & \\
\hline CHEMBL3982445 & 1641767 & 4.0 & 4.4747 & TST & \\
\hline CHEMBL3911712 & 1641767 & 5.1007 & 4.5928 & TRN & \\
\hline CHEMBL3930401 & 1641767 & 5.3215 & 4.2588 & TRN & \\
\hline CHEMBL3985774 & 1641767 & 5.3526 & 4.2889 & TRN & \\
\hline CHEMBL3912549 & 1641767 & 4.0 & 4.2762 & TRN & \\
\hline CHEMBL3958187 & 1641767 & 4.0 & 4.6517 & TRN & \\
\hline CHEMBL3890316 & 1641767 & 4.0 & 4.1625 & TRN & \\
\hline \multirow[t]{2}{*}{ CHEMBL3980561 } & 1641767 & 4.0 & \multicolumn{2}{|c|}{4.9510000000000005} & I TIV \\
\hline & & & & 693 & \\
\hline
\end{tabular}


Supplemental Table S2.txt

\begin{tabular}{|c|c|c|c|c|}
\hline EMBL 3950672 & & 4.0 & & . \\
\hline CHEMBL 3911479 & 641767 & 5.13 & & \\
\hline AEMBL 3939862 & 541767 & 4.0 & & \\
\hline AEMBL 3925263 & 541767 & 5.1838 & 5165 & \\
\hline HEMBL3900428 & 641767 & 6.0191 & 5595 & \\
\hline AEMBL3912845 & 541767 & 5.153 & 132 & \\
\hline 997 & 641767 & 4.0 & & \\
\hline AEMBL3939863 & 767 & 4.0 & 8982 & \\
\hline HEMBL3923857 & 767 & 5.4449 & 5.1339 & \\
\hline HEMBL3902690 & 767 & 5.3161 & 4.3841 & \\
\hline AEMBL 3944281 & 767 & 4.0 & 328 & \\
\hline IEMBL & 767 & & 911 & \\
\hline AEMBL3906360 & 767 & 4.0 & 132 & \\
\hline AEMBL 3943628 & 767 & 5.4056 & 3338 & \\
\hline AEMBL3934179 & 67 & 5.9208 & 56 & \\
\hline AEMBL & 57 & 5.2774 & & \\
\hline AEMBL & 57 & & & $\mathrm{RN}$ \\
\hline HEMBL & 767 & 6.1959 & 909 & DN \\
\hline IEMBL: & 767 & 4.0 & 117 & \\
\hline AEMBL3950422 & 57 & 4. & 148 & DI \\
\hline EMBL & 57 & & 05 & RI \\
\hline EMBL & 57 & 4.0 & & \\
\hline AEMBL & 67 & 5.17 & 229 & \\
\hline IEMBL & 767 & 5 . & & \\
\hline AEMBL & 57 & 5.6326 & 277 & $N$ \\
\hline IEMBL & 57 & & 75 & RI \\
\hline EMBI & 57 & & & . \\
\hline 23 & & 4. & & \\
\hline IEMBL & 57 & & & 21 \\
\hline IEMBL 3939449 & 67 & 5.2197 & 747 & $\lceil\mathrm{R} \mid$ \\
\hline 3706 & 57 & 5 . & 65 & RI \\
\hline 34 & 57 & & & RIV \\
\hline & & 6. & & $\mathrm{RN}$ \\
\hline 48091 & 57 & & & ГS1 1 \\
\hline 34299 & 767 & 5 . & 328 & RI \\
\hline 4297 & 57 & 5 . & 14 & Tiv \\
\hline 9 & & & & I \\
\hline 42 & 67 & 4 . & & RI \\
\hline AEMBL 3957302 & 16 & 4. & 29 & TS \\
\hline 59065 & 67 & & & $S$ \\
\hline HEMBL & 67 & 5.29 & 5.2588 & \\
\hline & & 4.0 & 4.6415 & RN \\
\hline HEMBL3944914 & 767 & 5.2733 & 4.6556 & RI \\
\hline AEMBL3982796 & 67 & 5.2541 & 586 & $\mathrm{R}$ \\
\hline 21048 & & 4. & & \\
\hline CHEMBL 3982207 & 767 & 4. & 3.7159 & \\
\hline CHEMBL 3895556 & 767 & 4.0 & 4.8642 & \\
\hline CHEMBL3965708 & 1641767 & 4.0 & 4.4437 & \\
\hline
\end{tabular}

Page 694 
Supplemental Table S2.txt

\begin{tabular}{|c|c|c|c|c|}
\hline$\partial 18$ & 641767 & 5.4191 & & \\
\hline & 641767 & 5.3947 & 4.9675 & \\
\hline 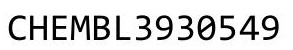 & 767 & 1 & & \\
\hline IEMBL 3986073 & 641767 & 4.0 & 786 & \\
\hline AEMBL3929996 & 641767 & 5.2076 & 371 & \\
\hline AEMBL & 767 & 4.0 & & \\
\hline 923 & 67 & 4.0 & & \\
\hline IEMB & 67 & 5.23 & & \\
\hline AEMBL 3972621 & 767 & 4.0 & & \\
\hline AEMBL3948444 & 767 & 6.1361 & 271 & \\
\hline 240 & 57 & & & \\
\hline 199 & 67 & 4.0 & & \\
\hline 150 & 67 & & & \\
\hline AEMBL & 767 & 4.0 & & \\
\hline 025 & 67 & & & \\
\hline 9 & 16 & 4. & & \\
\hline 19 & & & & \\
\hline 373 & 16 & & & \\
\hline 4688 & 67 & 4.0 & & \\
\hline 218 & & 4. & & \\
\hline 61 & 57 & 4. & & \\
\hline 2 & & & & \\
\hline 10 & 16 & & & \\
\hline 799 & & & & \\
\hline 217 & & 4.0 & & \\
\hline$?$ & & & & \\
\hline & & 5 . & & \\
\hline 15 & 16 & 4.0 & & \\
\hline 594 & & 5.31 & & \\
\hline 4058 & & 4.0 & & \\
\hline & & & & \\
\hline 9 & & 4.6 & & \\
\hline 6 & & 4.0 & & \\
\hline 5933 & & 4.0 & & \\
\hline 1824 & & 4. & & \\
\hline & & & & \\
\hline & & 6. & & \\
\hline & & 4.0 & & \\
\hline CHEMBL & 67 & 6.0685 & & - \\
\hline & & & & \\
\hline $\mathrm{CHE}$ & & & & \\
\hline CHEMBL & & 5.7 & & \\
\hline CHEMBL & & 2.8 & & TR \\
\hline IEMBL & 76 & 4.7779 & 575 & TS \\
\hline 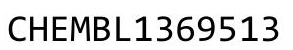 & & 2.8239 & & \\
\hline CHEMBL & & 2.8239 & & \\
\hline CHEMBL: & 688776 & 4.435 & 4.7061 & \\
\hline CHEMBL158251 & 688776 & 2.8239 & 2.0399 & \\
\hline
\end{tabular}

Page 695 


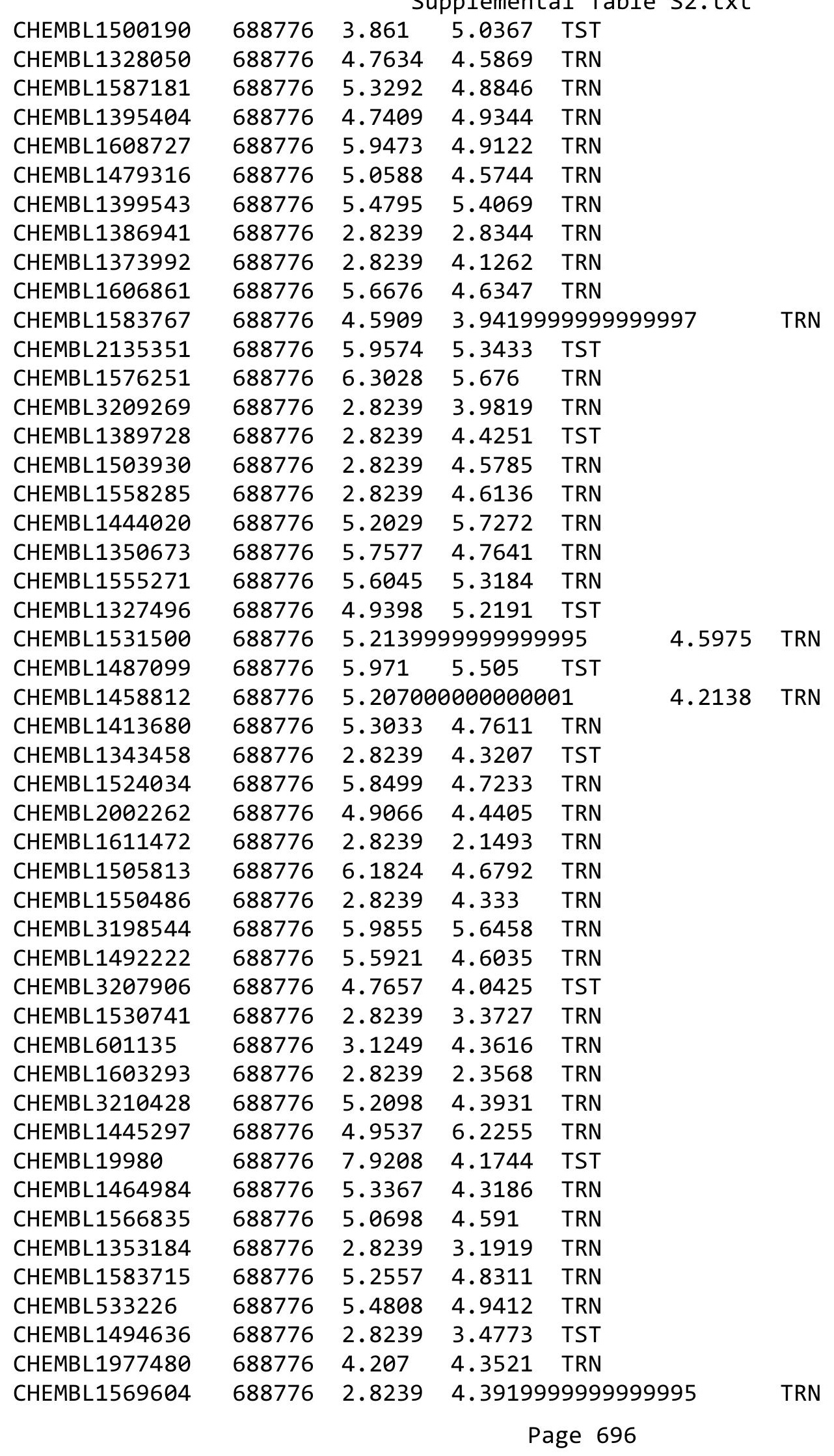




\begin{tabular}{|c|c|c|c|c|c|}
\hline \multicolumn{6}{|c|}{ Supplemental Table S2.txt } \\
\hline CHEMBL3199198 & 688776 & 2.8239 & 3.375 & TRN & \\
\hline CHEMBL1372356 & 688776 & 2.8239 & 3.656 & TRN & \\
\hline CHEMBL1516637 & 688776 & 4.9718 & 4.5513 & TRN & \\
\hline CHEMBL1505604 & 688776 & 2.8239 & 4.4978 & TRN & \\
\hline CHEMBL1330058 & 688776 & 4.7741 & 4.9952 & TRN & \\
\hline CHEMBL1485562 & 688776 & 2.8239 & 3.8099 & TRN & \\
\hline CHEMBL1524608 & 688776 & 2.8239 & 2.3951 & TRN & \\
\hline CHEMBL1352313 & 688776 & 5.6611 & 4.9473 & TRN & \\
\hline CHEMBL1611614 & 688776 & 6.066 & 5.42700 & 00000000005 & TST \\
\hline CHEMBL1322645 & 688776 & 5.3098 & 4.0051 & TST & \\
\hline CHEMBL1337919 & 688776 & 2.8239 & 2.998 & TRN & \\
\hline CHEMBL1595632 & 688776 & 4.9218 & 5.0545 & TRN & \\
\hline CHEMBL1993934 & 688776 & 5.2912 & 5.1609 & TRN & \\
\hline CHEMBL1406462 & 688776 & 2.8239 & 2.0764 & TRN & \\
\hline CHEMBL1994078 & 688776 & 4.7758 & 4.6679 & TRN & \\
\hline CHEMBL124006 & 688776 & 5.2548 & 5.0742 & TRN & \\
\hline CHEMBL1490339 & 688776 & 6.4112 & 5.7418 & TRN & \\
\hline CHEMBL330320 & 688776 & 6.6038 & 6.3555 & TST & \\
\hline CHEMBL1399938 & 688776 & 2.8239 & 5.4749 & TRN & \\
\hline CHEMBL512749 & 688776 & 2.8239 & 4.7753 & TRN & \\
\hline CHEMBL1408268 & 688776 & 6.1618 & 5.3376 & TST & \\
\hline CHEMBL1312720 & 688776 & 2.8239 & 3.7936 & TRN & \\
\hline CHEMBL1982032 & 688776 & 5.1701 & 4.8489 & TRN & \\
\hline CHEMBL1335177 & 688776 & 5.5732 & 4.6474 & TRN & \\
\hline CHEMBL1457139 & 688776 & 5.0406 & 4.6555 & TRN & \\
\hline CHEMBL1570706 & 688776 & 5.3463 & 5.0042 & TRN & \\
\hline CHEMBL1971248 & 688776 & 4.8148 & 4.4226 & TRN & \\
\hline CHEMBL1506351 & 688776 & 2.8239 & 2.6724 & TRN & \\
\hline CHEMBL1445386 & 688776 & 5.9197 & 4.8842 & TST & \\
\hline CHEMBL1319676 & 688776 & 5.2392 & 4.86100 & 0000000001 & TRN \\
\hline CHEMBL1332139 & 688776 & 5.777 & 5.6922 & TRN & \\
\hline CHEMBL1461858 & 688776 & 2.8239 & 2.1936 & TRN & \\
\hline CHEMBL 6742 & 688776 & 2.8239 & 3.9275 & TRN & \\
\hline CHEMBL1312676 & 688776 & 2.8239 & 3.6703 & TRN & \\
\hline CHEMBL1993058 & 688776 & 2.8239 & 4.1253 & TRN & \\
\hline CHEMBL3191855 & 688776 & 5.5334 & 5.26 & TRN & \\
\hline CHEMBL1366347 & 688776 & 2.8239 & 4.5243 & TRN & \\
\hline CHEMBL1544402 & 688776 & 2.8239 & 4.3961 & TRN & \\
\hline CHEMBL1396519 & 688776 & 4.7265 & 4.6843 & TRN & \\
\hline CHEMBL 290077 & 688776 & 6.3372 & 5.7589 & TST & \\
\hline CHEMBL546170 & 688776 & 5.0961 & 4.5331 & TRN & \\
\hline CHEMBL1599070 & 688776 & 2.8239 & 3.5562 & TRN & \\
\hline CHEMBL1598561 & 688776 & 5.3887 & 5.3061 & TRN & \\
\hline CHEMBL1505003 & 688776 & 4.8613 & 4.6665 & TRN & \\
\hline CHEMBL1521348 & 688776 & 2.8239 & 5.659 & TRN & \\
\hline CHEMBL1606521 & 688776 & 4.7367 & 5.0482 & TRN & \\
\hline CHEMBL1529978 & 688776 & 5.5787 & 5.0805 & TRN & \\
\hline CHEMBL1341680 & 688776 & 4.7465 & 3.7083 & TRN & \\
\hline
\end{tabular}




\begin{tabular}{|c|c|c|c|c|}
\hline \multirow[b]{2}{*}{ CHEMBL1462675 } & \multicolumn{4}{|c|}{ Supplemental Tabl } \\
\hline & 688776 & 2.8239 & 4.39 & TRN \\
\hline CHEMBL1987894 & 688776 & 5.5476 & 5.1795 & TRN \\
\hline CHEMBL1393126 & 688776 & 5.8931 & 5.5095 & TST \\
\hline CHEMBL1404493 & 688776 & 4.8645 & 5.6222 & TRN \\
\hline CHEMBL1481538 & 688776 & 6.3556 & 5.1635 & TRN \\
\hline CHEMBL3192894 & 688776 & 5.407 & 5.0833 & TRN \\
\hline CHEMBL1539745 & 688776 & 2.8239 & 2.3399 & TRN \\
\hline CHEMBL1407996 & 688776 & 2.8239 & 4.4564 & TRN \\
\hline CHEMBL1607906 & 688776 & 4.8922 & 5.0651 & TRN \\
\hline CHEMBL1977570 & 688776 & 3.1249 & 4.5444 & TRN \\
\hline CHEMBL1447885 & 688776 & 2.8239 & 4.3645 & TRN \\
\hline CHEMBL1576754 & 688776 & 5.0146 & 4.777 & TRN \\
\hline CHEMBL1610540 & 688776 & 4.5624 & 4.8515 & TRN \\
\hline CHEMBL1370884 & 688776 & 5.763 & 5.0784 & TRN \\
\hline CHEMBL1422429 & 688776 & 5.3977 & 5.5479 & TRN \\
\hline CHEMBL533602 & 688776 & 5.183 & 5.0452 & TST \\
\hline CHEMBL3198720 & 688776 & 5.2175 & 4.8379 & TRN \\
\hline CHEMBL1345835 & 688776 & 2.8239 & 4.7455 & TRN \\
\hline CHEMBL1394314 & 688776 & 5.1006 & 4.5617 & TRN \\
\hline CHEMBL3199573 & 688776 & 2.8239 & 3.1196 & TRN \\
\hline CHEMBL1531170 & 688776 & 4.1107 & 4.1939 & TRN \\
\hline CHEMBL1457201 & 688776 & 5.6284 & 5.0642 & TRN \\
\hline CHEMBL1389248 & 688776 & 5.2946 & 5.4735 & TRN \\
\hline CHEMBL1558695 & 688776 & 5.5541 & 4.7347 & TRN \\
\hline CHEMBL1328069 & 688776 & 5.5474 & 4.8876 & TRN \\
\hline CHEMBL1482663 & 688776 & 5.3093 & 4.9524 & TST \\
\hline CHEMBL1305612 & 688776 & 5.362 & 4.4056 & TRN \\
\hline CHEMBL1317682 & 688776 & 2.8239 & 2.9217 & TRN \\
\hline CHEMBL578487 & 688776 & 2.8239 & 4.6436 & TRN \\
\hline CHEMBL379179 & 688776 & 4.6445 & 4.6631 & TRN \\
\hline CHEMBL1609900 & 688776 & 2.8239 & 1.7599 & TRN \\
\hline CHEMBL1553717 & 688776 & 5.5387 & 4.9724 & TRN \\
\hline CHEMBL1536118 & 688776 & 4.9914 & 5.2478 & TRN \\
\hline CHEMBL1876078 & 688776 & 6.2725 & 4.5824 & TRN \\
\hline CHEMBL604321 & 688776 & 5.1807 & 4.873 & TST \\
\hline CHEMBL1346521 & 688776 & 2.8239 & 3.2017 & TRN \\
\hline CHEMBL1388459 & 688776 & 2.8239 & 1.9436 & TRN \\
\hline CHEMBL1998716 & 688776 & 6.3261 & 5.8521 & TRN \\
\hline CHEMBL1587981 & 688776 & 5.1098 & 3.4993 & TRN \\
\hline CHEMBL1373969 & 688776 & 5.1511 & 5.5795 & TRN \\
\hline CHEMBL1301647 & 688776 & 2.8239 & 4.1203 & TRN \\
\hline CHEMBL1528258 & 688776 & 3.1249 & 5.2591 & TRN \\
\hline CHEMBL1394035 & 688776 & 2.8239 & 2.5588 & TRN \\
\hline CHEMBL3198970 & 688776 & 6.1349 & 5.4531 & TRN \\
\hline CHEMBL1402096 & 688776 & 4.6606 & 4.596 & TRN \\
\hline CHEMBL1393944 & 688776 & 2.8239 & 3.6761 & TRN \\
\hline CHEMBL1983871 & 688776 & 2.8239 & 4.5128 & TRN \\
\hline CHEMBL1580848 & 688776 & 5.1769 & 4.8485 & TRN \\
\hline
\end{tabular}




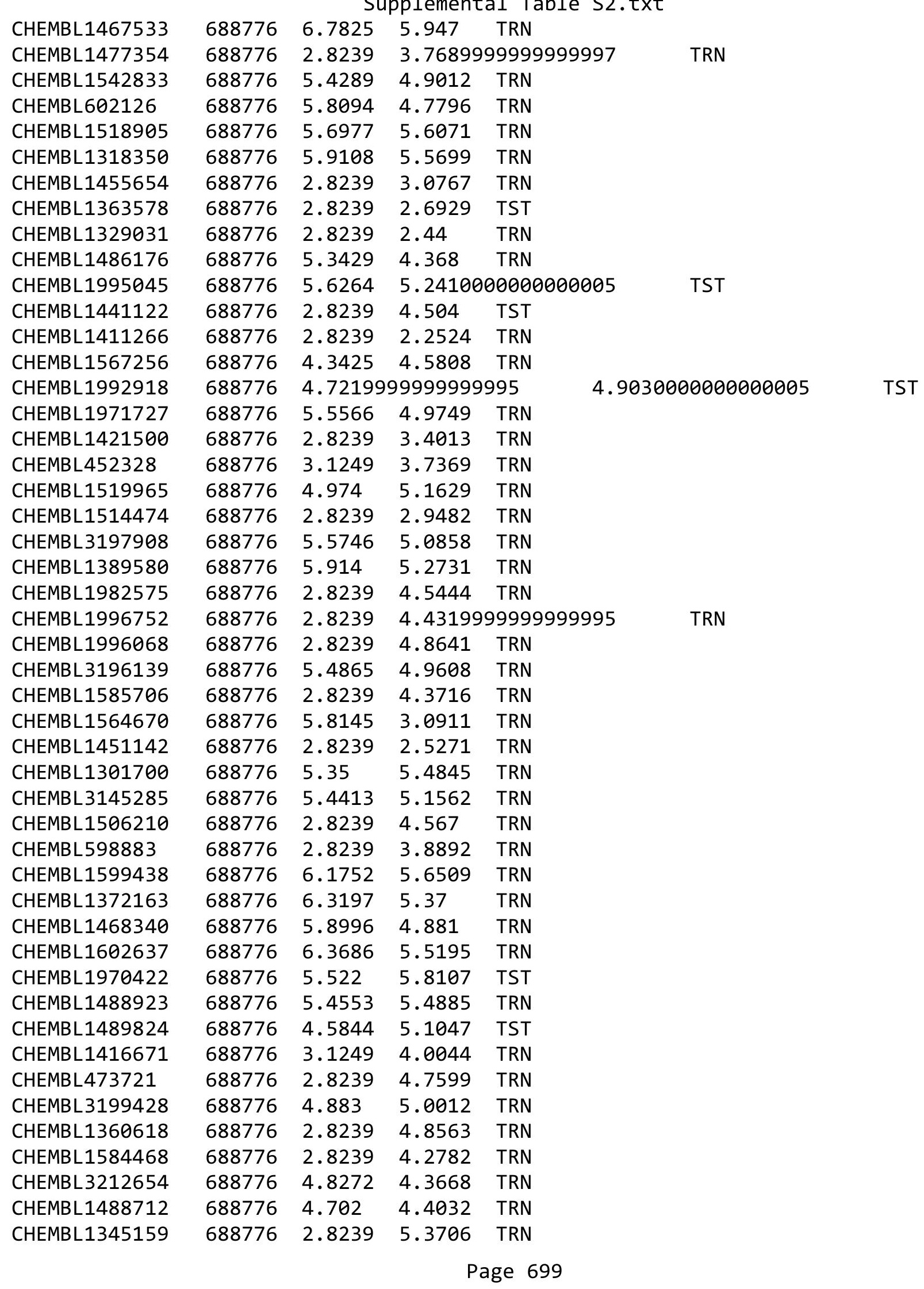




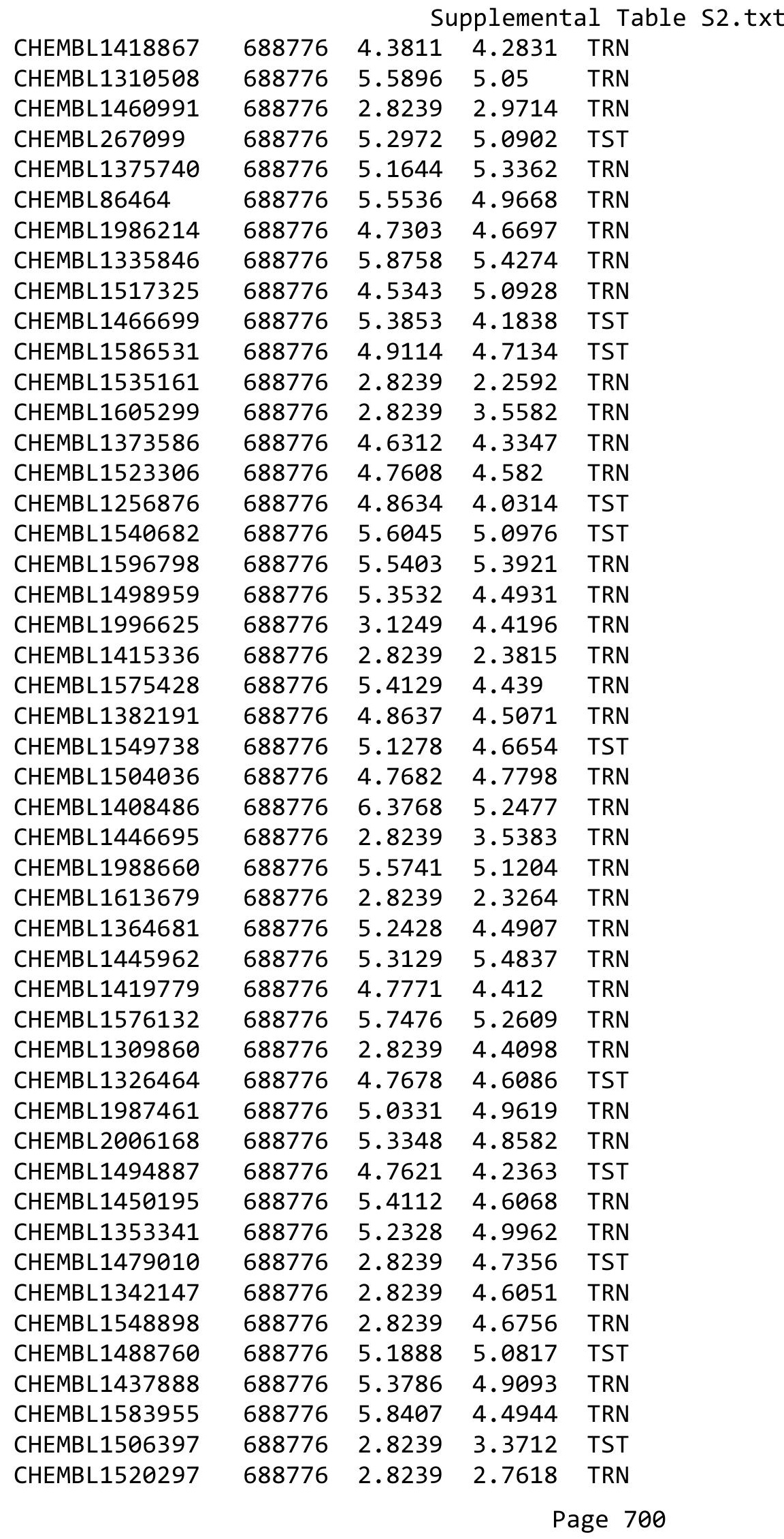




\begin{tabular}{|c|c|c|c|c|c|c|}
\hline \multirow[b]{2}{*}{ CHEMBL1600403 } & \multicolumn{6}{|c|}{ supp } \\
\hline & 688776 & 4.0115 & 2.8473 & TRN & & \\
\hline CHEMBL1544508 & 688776 & 5.7187 & 4.7145 & TRN & & \\
\hline CHEMBL1320414 & 688776 & 2.8239 & 4.5716 & TRN & & \\
\hline CHEMBL1491711 & 688776 & 2.8239 & 4.0634 & TRN & & \\
\hline CHEMBL1609770 & 688776 & 5.9007 & 5.2831 & TRN & & \\
\hline CHEMBL1326803 & 688776 & 5.3247 & 5.4488 & TRN & & \\
\hline CHEMBL1511371 & 688776 & 5.7577 & 5.126 & TST & & \\
\hline CHEMBL1457561 & 688776 & 5.5366 & 4.9481 & TRN & & \\
\hline CHEMBL1579277 & 688776 & 2.8239 & 4.09 & TRN & & \\
\hline CHEMBL1548542 & 688776 & 5.1202 & 4.6816 & TRN & & \\
\hline CHEMBL1399388 & 688776 & 5.8362 & 5.1646 & TRN & & \\
\hline CHEMBL1544837 & 688776 & 2.8239 & 2.0254 & TRN & & \\
\hline CHEMBL1519655 & 688776 & 5.249 & 4.716 & TRN & & \\
\hline CHEMBL1368752 & 688776 & 2.8239 & 2.3448 & TRN & & \\
\hline CHEMBL1417726 & 688776 & 2.8239 & 3.1469 & TRN & & \\
\hline CHEMBL1411388 & 688776 & 5.0301 & 4.7186 & TRN & & \\
\hline CHEMBL1387610 & 688776 & 5.2011 & 5.279 & TRN & & \\
\hline CHEMBL1497549 & 688776 & 5.2482 & 5.3059 & TRN & & \\
\hline CHEMBL1442056 & 688776 & 5.1496 & 4.8436 & TST & & \\
\hline CHEMBL1447362 & 688776 & 2.8239 & 2.8683 & TRN & & \\
\hline CHEMBL1431376 & 688776 & 5.3571 & 4.4136 & TRN & & \\
\hline CHEMBL1403322 & 688776 & 5.8511 & 4.9543 & TRN & & \\
\hline CHEMBL1330879 & 688776 & 5.6133 & 4.9079 & TRN & & \\
\hline CHEMBL1610510 & 688776 & 5.8377 & 4.8046 & TRN & & \\
\hline CHEMBL117966 & 688776 & 2.8239 & 4.2383 & TRN & & \\
\hline CHEMBL1334307 & 688776 & 5.1264 & 4.1327 & TRN & & \\
\hline CHEMBL1419227 & 688776 & 2.8239 & 2.2393 & TRN & & \\
\hline CHEMBL1424468 & 688776 & 6.45100 & 30000000 & 205 & 5.9966 & TRN \\
\hline CHEMBL1586263 & 688776 & 5.2965 & 4.3528 & TRN & & \\
\hline CHEMBL1611182 & 688776 & 5.3721 & 4.9763 & TRN & & \\
\hline CHEMBL1301313 & 688776 & 2.8239 & 2.2539 & TRN & & \\
\hline CHEMBL587801 & 688776 & 5.1575 & 4.7246 & TRN & & \\
\hline CHEMBL1520030 & 688776 & 2.8239 & 3.844 & TST & & \\
\hline CHEMBL1514187 & 688776 & 2.8239 & 3.8618 & TRN & & \\
\hline CHEMBL 2354875 & 688776 & 4.9961 & 4.5815 & TRN & & \\
\hline CHEMBL1378489 & 688776 & 5.3851 & 4.7116 & TST & & \\
\hline CHEMBL1439227 & 688776 & 5.92299 & 99999999 & & 5.0972 & TRN \\
\hline CHEMBL1342038 & 688776 & 5.02800 & 00000000 & 205 & 4.8179 & TRN \\
\hline CHEMBL1421333 & 688776 & 2.8239 & 2.3878 & TRN & & \\
\hline CHEMBL405317 & 688776 & 5.0276 & 5.1208 & TRN & & \\
\hline CHEMBL 3212271 & 688776 & 3.1249 & 4.0682 & TRN & & \\
\hline CHEMBL1529669 & 688776 & 3.1249 & 3.3419 & TRN & & \\
\hline CHEMBL1523206 & 688776 & 5.61799 & 99999999 & 99 & 4.9718 & TST \\
\hline CHEMBL1462711 & 688776 & 2.8239 & 3.7745 & TRN & & \\
\hline CHEMBL1492289 & 688776 & 5.358 & 4.6949 & TRN & & \\
\hline CHEMBL1608077 & 688776 & 5.3085 & 4.5249 & TRN & & \\
\hline CHEMBL1332450 & 688776 & 5.0885 & 4.5289 & TRN & & \\
\hline CHEMBL1467284 & 688776 & 5.3239 & 4.80399 & 9999999999 & & TRN \\
\hline & & & & e 701 & & \\
\hline
\end{tabular}




\begin{tabular}{|c|c|c|c|c|c|}
\hline & & & & & \\
\hline CHEMBL1368526 & 688776 & 5.4787 & 4.8911 & TRN & \\
\hline CHEMBL3193945 & 688776 & 2.8239 & 3.7868 & TRN & \\
\hline CHEMBL1501720 & 688776 & 2.8239 & 3.5264 & TST & \\
\hline CHEMBL3195477 & 688776 & 5.3989 & 5.0029 & TRN & \\
\hline CHEMBL1580774 & 688776 & 2.8239 & 4.61600 & 00000000005 & TRN \\
\hline CHEMBL3199286 & 688776 & 5.2179 & 4.7644 & TRN & \\
\hline CHEMBL1349727 & 688776 & 5.063 & 4.052 & TRN & \\
\hline CHEMBL1567896 & 688776 & 2.8239 & 2.7324 & TRN & \\
\hline CHEMBL1586733 & 688776 & 6.4572 & 5.1404 & TRN & \\
\hline CHEMBL1448905 & 688776 & 5.0436 & 4.7047 & TRN & \\
\hline CHEMBL1994372 & 688776 & 5.6183 & 4.9836 & TRN & \\
\hline CHEMBL1455421 & 688776 & 4.652 & 4.6377 & TRN & \\
\hline CHEMBL1596609 & 688776 & 2.8239 & 3.4183 & TRN & \\
\hline CHEMBL199868 & 688776 & 5.575 & 5.1223 & TRN & \\
\hline CHEMBL 29711 & 688776 & 2.8239 & 3.6856 & TST & \\
\hline CHEMBL1523845 & 688776 & 2.8239 & 4.2714 & TRN & \\
\hline CHEMBL1484547 & 688776 & 5.9654 & 5.2531 & TRN & \\
\hline CHEMBL1608535 & 688776 & 2.8239 & 4.4316 & TRN & \\
\hline CHEMBL1546843 & 688776 & 5.4684 & 4.4658 & TRN & \\
\hline CHEMBL1351755 & 688776 & 5.3859 & 5.9319 & TRN & \\
\hline CHEMBL1413355 & 688776 & 4.8278 & 4.7889 & TRN & \\
\hline CHEMBL1580075 & 688776 & 6.0555 & 3.5607 & TRN & \\
\hline CHEMBL1369945 & 688776 & 5.1061 & 4.606 & TRN & \\
\hline CHEMBL1430094 & 688776 & 4.7676 & 4.7636 & TRN & \\
\hline CHEMBL1305475 & 688776 & 2.8239 & 4.7511 & TRN & \\
\hline CHEMBL1427709 & 688776 & 3.1249 & 4.1879 & TRN & \\
\hline CHEMBL1526851 & 688776 & 2.8239 & 4.8704 & TST & \\
\hline CHEMBL1542809 & 688776 & 3.1249 & 4.4877 & TRN & \\
\hline CHEMBL417727 & 688776 & 5.5058 & 5.0999 & TRN & \\
\hline CHEMBL1471587 & 688776 & 4.7413 & 4.1993 & TRN & \\
\hline CHEMBL3192181 & 688776 & 5.8626 & 5.404 & TRN & \\
\hline CHEMBL1521127 & 688776 & 2.8239 & 2.4331 & TRN & \\
\hline CHEMBL1528867 & 688776 & 3.1249 & 4.1114 & TRN & \\
\hline CHEMBL1367034 & 688776 & 6.2104 & 4.9929 & TST & \\
\hline CHEMBL1535695 & 688776 & 3.1249 & 3.9899 & TST & \\
\hline CHEMBL3191127 & 688776 & 5.5367 & 4.618 & TRN & \\
\hline CHEMBL 82134 & 688776 & 4.9275 & 4.9634 & TRN & \\
\hline CHEMBL1582024 & 688776 & 2.8239 & 2.8548 & TRN & \\
\hline CHEMBL3182775 & 688776 & 6.0372 & 5.3943 & TST & \\
\hline CHEMBL1303034 & 688776 & 6.1805 & 5.0104 & TST & \\
\hline CHEMBL1339398 & 688776 & 2.8239 & 4.4234 & TST & \\
\hline CHEMBL1573883 & 688776 & 2.8239 & 4.7859 & TRN & \\
\hline CHEMBL1349455 & 688776 & 5.5216 & 4.3818 & TRN & \\
\hline CHEMBL3190220 & 688776 & 3.4202 & 4.3116 & TRN & \\
\hline CHEMBL1340058 & 688776 & 6.224 & 5.3243 & TRN & \\
\hline CHEMBL1396209 & 688776 & 5.568 & 5.4613 & TRN & \\
\hline CHEMBL1569918 & 688776 & 2.8239 & 4.33899 & 99999999995 & TRN \\
\hline CHEMBL328834 & 688776 & 5.9259 & 5.4467 & TST & \\
\hline & & & & 702 & \\
\hline
\end{tabular}




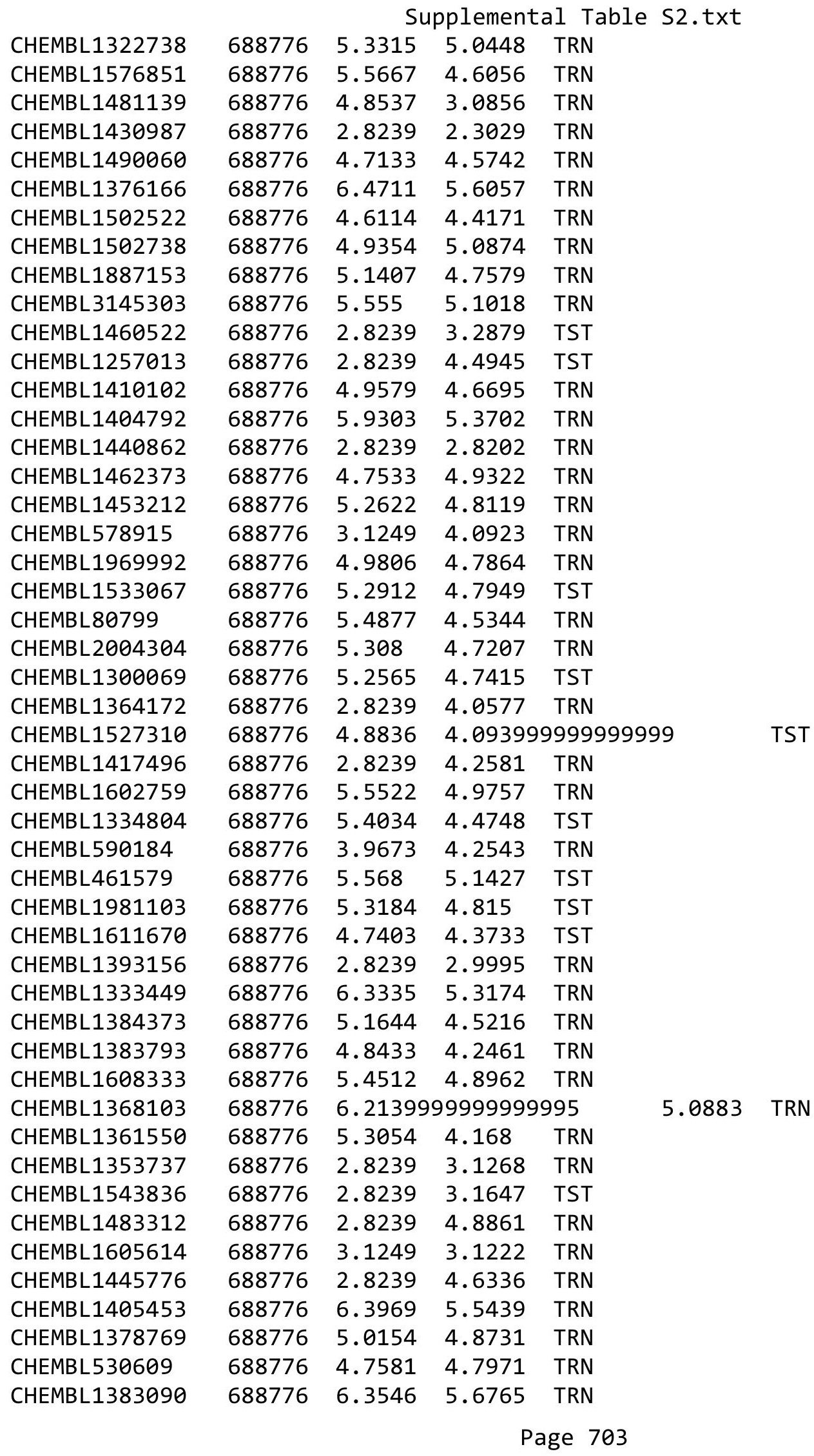




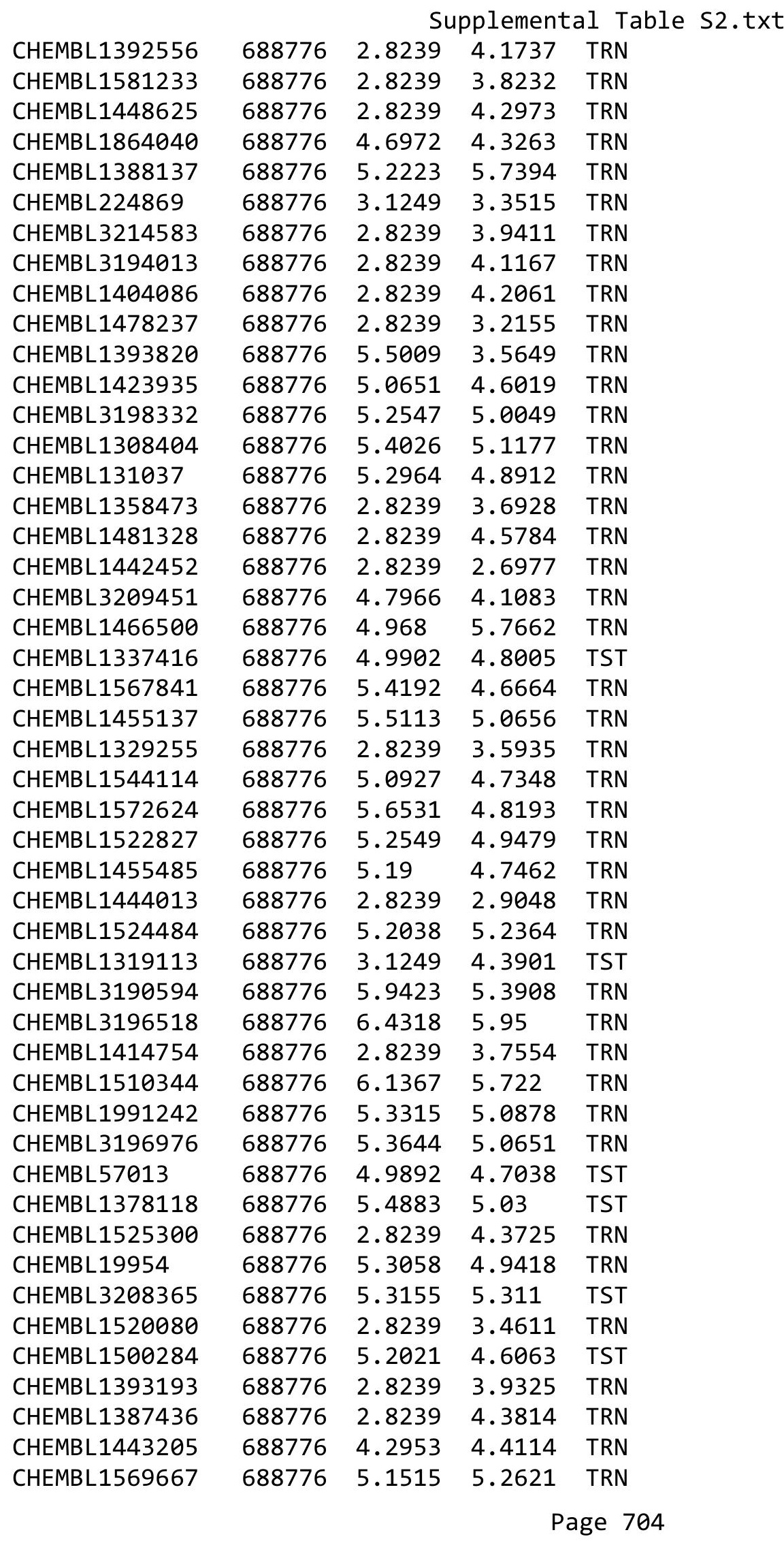




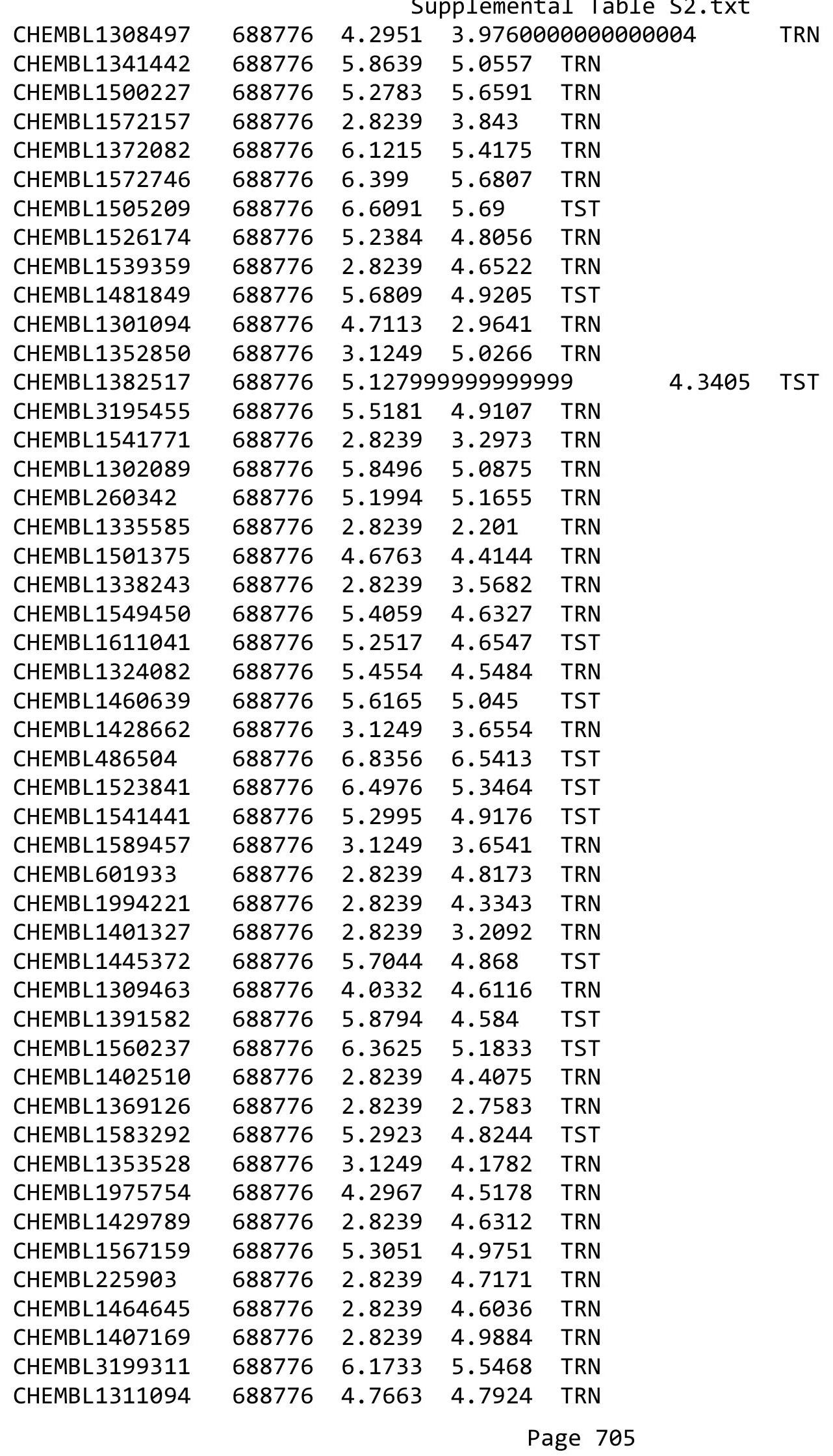




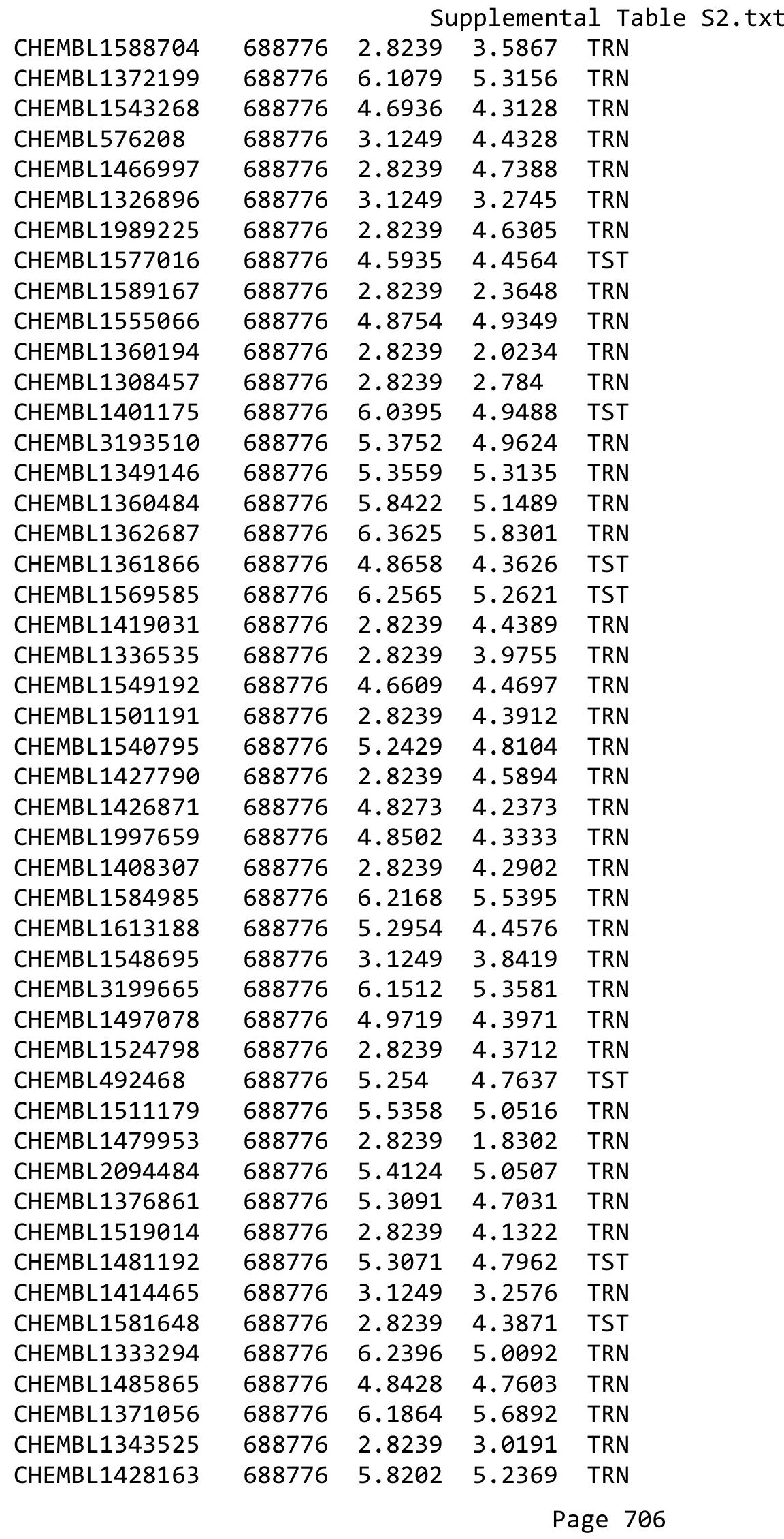




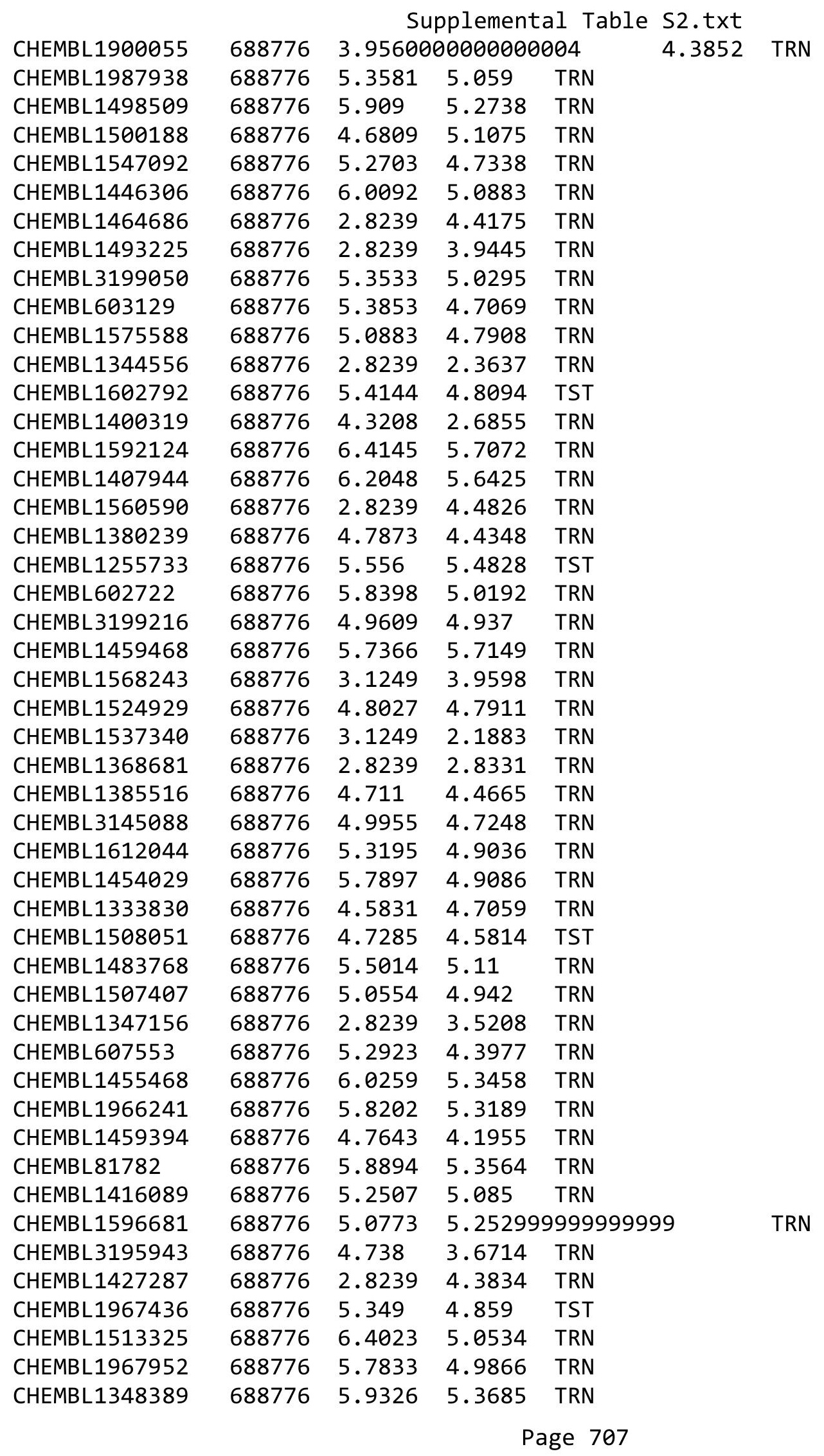




\begin{tabular}{|c|c|c|c|c|c|c|}
\hline & & \multicolumn{5}{|c|}{ Supplemental Table S2.txt } \\
\hline CHEMBL1380406 & 688776 & 5.0179 & 4.442 & TRN & & \\
\hline CHEMBL1315921 & 688776 & 2.8239 & 4.5898 & TRN & & \\
\hline CHEMBL1446353 & 688776 & 4.9739 & 4.293 & TRN & & \\
\hline CHEMBL1325021 & 688776 & 2.8239 & 5.0501 & TRN & & \\
\hline CHEMBL1309091 & 688776 & 4.703 & 4.86 & TRN & & \\
\hline CHEMBL1491717 & 688776 & 5.3204 & 5.196006 & 0000000001 & & TRN \\
\hline CHEMBL1549611 & 688776 & 4.9378 & 4.5436 & TST & & \\
\hline CHEMBL1458479 & 688776 & 5.1526 & 5.4609 & TRN & & \\
\hline CHEMBL1359872 & 688776 & 6.4609 & 5.648 & TRN & & \\
\hline CHEMBL1546134 & 688776 & 4.8871 & 4.6684 & TRN & & \\
\hline CHEMBL1497939 & 688776 & 4.7598 & 4.9183 & TRN & & \\
\hline CHEMBL3197070 & 688776 & \multicolumn{3}{|c|}{5.452000000000001} & 5.3138 & TRN \\
\hline CHEMBL1528030 & 688776 & 2.8239 & 2.435 & TRN & & \\
\hline CHEMBL1597628 & 688776 & 2.8239 & 4.4207 & TRN & & \\
\hline CHEMBL1332756 & 688776 & 5.1409 & 4.902 & TRN & & \\
\hline CHEMBL1563136 & 688776 & 2.8239 & 2.7663 & TRN & & \\
\hline CHEMBL600778 & 688776 & 5.5491 & 5.3785 & TRN & & \\
\hline CHEMBL1987454 & 688776 & 6.1746 & 5.4171 & TRN & & \\
\hline CHEMBL1611922 & 688776 & 4.9539 & 4.8184 & TRN & & \\
\hline CHEMBL1405940 & 688776 & 4.2556 & 4.3953 & TRN & & \\
\hline CHEMBL1547295 & 688776 & 3.1249 & 3.6858 & TRN & & \\
\hline CHEMBL1586371 & 688776 & 6.1152 & 3.8264 & TRN & & \\
\hline CHEMBL1511219 & 688776 & 5.6467 & 5.6635 & TRN & & \\
\hline CHEMBL1989858 & 688776 & 5.1933 & 4.8955 & TST & & \\
\hline CHEMBL1546374 & 688776 & 5.5259 & 5.285 & TRN & & \\
\hline CHEMBL3190965 & 688776 & 5.3751 & 5.195 & TRN & & \\
\hline CHEMBL1596197 & 688776 & 2.8239 & 3.7156 & TRN & & \\
\hline CHEMBL3210936 & 688776 & 2.8239 & 3.8958 & TST & & \\
\hline CHEMBL1543599 & 688776 & 5.5563 & 4.058 & TRN & & \\
\hline CHEMBL1558993 & 688776 & 3.1249 & 3.7772 & TRN & & \\
\hline CHEMBL3189519 & 688776 & 5.4864 & 5.2223 & TRN & & \\
\hline CHEMBL1612556 & 688776 & 2.8239 & 3.2206 & TRN & & \\
\hline CHEMBL1533738 & 688776 & 2.8239 & 4.3322 & TST & & \\
\hline CHEMBL1339289 & 688776 & 4.6996 & 5.5249 & TST & & \\
\hline CHEMBL1476215 & 688776 & 6.5467 & 4.9903 & TRN & & \\
\hline CHEMBL1556634 & 688776 & 2.8239 & 4.0646 & TST & & \\
\hline CHEMBL1613639 & 688776 & \multicolumn{3}{|c|}{5.742999999999999} & 4.9931 & TRN \\
\hline CHEMBL1523954 & 688776 & 2.8239 & 3.4263 & TRN & & \\
\hline CHEMBL1587596 & 688776 & 4.1184 & 4.4825 & TRN & & \\
\hline CHEMBL1998521 & 688776 & 6.1226 & 5.409 & TRN & & \\
\hline CHEMBL1486332 & 688776 & 5.1396 & 5.3631 & TRN & & \\
\hline CHEMBL1501508 & 688776 & 5.3134 & 4.6209 & TRN & & \\
\hline CHEMBL1313766 & 688776 & 2.8239 & 3.4903 & TRN & & \\
\hline CHEMBL1605372 & 688776 & \multicolumn{3}{|c|}{5.382999999999999} & 4.5577 & TST \\
\hline CHEMBL1360793 & 688776 & 5.4329 & 4.8841 & TRN & & \\
\hline CHEMBL1379740 & 688776 & 4.9144 & 5.0825 & TRN & & \\
\hline CHEMBL1566559 & 688776 & 2.8239 & 2.4283 & TRN & & \\
\hline CHEMBL89445 & 688776 & 5.365 & 4.6269 & TRN & & \\
\hline
\end{tabular}




\begin{tabular}{|c|c|c|c|c|c|}
\hline & & \multicolumn{4}{|c|}{ Supplemental Table S2.txt } \\
\hline CHEMBL1572558 & 688776 & 5.8228 & 5.3412 & TST & \\
\hline CHEMBL1321240 & 688776 & 5.8755 & 4.9992 & TRN & \\
\hline CHEMBL1361005 & 688776 & 2.8239 & 2.318 & TRN & \\
\hline CHEMBL1565600 & 688776 & 4.9035 & 4.402 & TST & \\
\hline CHEMBL1437683 & 688776 & 4.9674 & 4.81 & TRN & \\
\hline CHEMBL1311226 & 688776 & 2.8239 & 4.3077 & TST & \\
\hline CHEMBL1323828 & 688776 & 2.8239 & 3.0954 & TRN & \\
\hline CHEMBL1986514 & 688776 & 2.8239 & 4.3299 & TRN & \\
\hline CHEMBL1608301 & 688776 & 2.8239 & 4.2875 & TRN & \\
\hline CHEMBL1967744 & 688776 & 4.9521 & 4.7028 & TRN & \\
\hline CHEMBL1424269 & 688776 & 5.3773 & 3.6948 & TRN & \\
\hline CHEMBL1469827 & 688776 & 2.8239 & 3.7624 & TRN & \\
\hline CHEMBL1329069 & 688776 & 5.2857 & 4.8389 & TRN & \\
\hline CHEMBL1369671 & 688776 & 2.8239 & 4.3274 & TRN & \\
\hline CHEMBL1610036 & 688776 & 5.6951 & 3.4058 & TRN & \\
\hline CHEMBL1583677 & 688776 & 5.7757 & 4.629 & TRN & \\
\hline CHEMBL599098 & 688776 & 4.5478 & 4.8817 & TRN & \\
\hline CHEMBL1334919 & 688776 & 5.3948 & 4.8242 & TRN & \\
\hline CHEMBL1466523 & 688776 & 5.8359 & 5.0374 & TRN & \\
\hline CHEMBL1307506 & 688776 & 2.8239 & 4.2775 & TRN & \\
\hline CHEMBL 1403980 & 688776 & 5.2993 & 4.8892 & TRN & \\
\hline CHEMBL1380099 & 688776 & 2.8239 & 4.532 & TST & \\
\hline CHEMBL1472773 & 688776 & 4.9789 & 4.8885 & TST & \\
\hline CHEMBL1386058 & 688776 & 2.8239 & 2.6487 & TRN & \\
\hline CHEMBL1416406 & 688776 & 2.8239 & 3.6431 & TRN & \\
\hline CHEMBL1487444 & 688776 & 5.2521 & 4.7576 & TRN & \\
\hline CHEMBL1347277 & 688776 & 2.8239 & 4.6284 & TRN & \\
\hline CHEMBL1321754 & 688776 & 2.8239 & 4.26699 & 99999999995 & TRN \\
\hline CHEMBL1522007 & 688776 & 4.2605 & 4.6632 & TRN & \\
\hline CHEMBL1336467 & 688776 & 4.9475 & 3.8234 & TRN & \\
\hline CHEMBL1548433 & 688776 & 2.8239 & 4.1426 & TRN & \\
\hline CHEMBL1331514 & 688776 & 4.6634 & 4.6329 & TRN & \\
\hline CHEMBL1481030 & 688776 & 4.9176 & 5.6126 & TRN & \\
\hline CHEMBL1582760 & 688776 & 6.4023 & 5.8086 & TST & \\
\hline CHEMBL 1475774 & 688776 & 4.7692 & 4.7312 & TRN & \\
\hline CHEMBL1466305 & 688776 & 4.9425 & 4.7921 & TRN & \\
\hline CHEMBL15968 & 688776 & 5.8477 & 5.1365 & TRN & \\
\hline CHEMBL1576791 & 688776 & 3.1249 & 4.3551 & TRN & \\
\hline CHEMBL1436988 & 688776 & 5.0894 & 5.1682 & TRN & \\
\hline CHEMBL1537417 & 688776 & 5.3688 & 4.7943 & TST & \\
\hline CHEMBL568092 & 688776 & 5.2703 & 4.8173 & TRN & \\
\hline CHEMBL1430060 & 688776 & 4.7022 & 4.6062 & TRN & \\
\hline CHEMBL1544486 & 688776 & 5.8847 & 5.1395 & TRN & \\
\hline CHEMBL1565526 & 688776 & 5.6692 & 4.9066 & TRN & \\
\hline CHEMBL1586895 & 688776 & 5.1058 & 4.8522 & TRN & \\
\hline CHEMBL37570 & 688776 & 4.8223 & 5.2728 & TRN & \\
\hline CHEMBL1391387 & 688776 & 6.0721 & 5.5252 & TRN & \\
\hline CHEMBL1572278 & 688776 & 5.8617 & 4.9931 & TRN & \\
\hline
\end{tabular}




\begin{tabular}{|c|c|c|c|c|c|}
\hline & & \multicolumn{4}{|c|}{ Supplemental Table S2.txt } \\
\hline CHEMBL1469642 & 688776 & 4.9548 & 4.4898 & TST & \\
\hline CHEMBL1579636 & 688776 & 5.8505 & 5.1118 & TRN & \\
\hline CHEMBL1372924 & 688776 & 5.4845 & 4.7159 & TST & \\
\hline CHEMBL1323140 & 688776 & 5.9539 & 4.8904 & TRN & \\
\hline CHEMBL2004475 & 688776 & 4.9712 & 4.7694 & TST & \\
\hline CHEMBL1380592 & 688776 & 4.7793 & 4.2053 & TRN & \\
\hline CHEMBL1460869 & 688776 & 5.0411 & 4.7755 & TRN & \\
\hline CHEMBL1392026 & 688776 & 4.9567 & 4.4972 & TRN & \\
\hline CHEMBL1469579 & 688776 & 2.8239 & 4.0554 & TRN & \\
\hline CHEMBL1539486 & 688776 & 6.3288 & 5.0415 & TRN & \\
\hline CHEMBL512048 & 688776 & 2.8239 & 4.6233 & TRN & \\
\hline CHEMBL1312644 & 688776 & 2.8239 & 1.8013 & TRN & \\
\hline CHEMBL 2000499 & 688776 & 2.8239 & 4.6903 & TRN & \\
\hline CHEMBL1544726 & 688776 & 4.7647 & 4.2631 & TRN & \\
\hline CHEMBL1419082 & 688776 & 5.7156 & 4.9094 & TRN & \\
\hline CHEMBL31840 & 688776 & 6.5272 & 5.1528 & TRN & \\
\hline CHEMBL1376974 & 688776 & 2.8239 & 5.0248 & TST & \\
\hline CHEMBL3196369 & 688776 & 2.8239 & 3.4371 & TRN & \\
\hline CHEMBL1514238 & 688776 & 2.8239 & 3.2639 & TRN & \\
\hline CHEMBL1577495 & 688776 & 5.1388 & 4.3229 & TRN & \\
\hline CHEMBL1547278 & 688776 & 3.1249 & 3.29 & TRN & \\
\hline CHEMBL1404398 & 688776 & 2.8239 & 3.8615 & TRN & \\
\hline CHEMBL1516533 & 688776 & 6.2798 & 5.21700 & 00000000005 & TRN \\
\hline CHEMBL600121 & 688776 & 2.8239 & 4.4563 & TRN & \\
\hline CHEMBL1572446 & 688776 & 2.8239 & 2.7577 & TST & \\
\hline CHEMBL1414112 & 688776 & 6.1451 & 5.4648 & TRN & \\
\hline CHEMBL1422078 & 688776 & 5.1778 & 4.625 & TRN & \\
\hline CHEMBL1544633 & 688776 & 6.3401 & 5.1459 & TRN & \\
\hline CHEMBL1341399 & 688776 & 5.2402 & 4.6899 & TST & \\
\hline CHEMBL1451736 & 688776 & 5.7552 & 5.2282 & TRN & \\
\hline CHEMBL1349116 & 688776 & 6.8962 & 5.6449 & TRN & \\
\hline CHEMBL1573720 & 688776 & 2.8239 & 5.0796 & TRN & \\
\hline CHEMBL1386228 & 688776 & 6.4522 & 5.5001 & TRN & \\
\hline CHEMBL1610733 & 688776 & 3.1249 & 4.3955 & TST & \\
\hline CHEMBL1347192 & 688776 & 4.7689 & 4.4366 & TST & \\
\hline CHEMBL1789993 & 688776 & 5.2205 & 4.1634 & TST & \\
\hline CHEMBL1462938 & 688776 & 2.8239 & 5.4224 & TRN & \\
\hline CHEMBL1372889 & 688776 & 4.7406 & 4.7698 & TRN & \\
\hline CHEMBL1543387 & 688776 & 6.0947 & 5.1687 & TRN & \\
\hline CHEMBL1481347 & 688776 & 5.2421 & 5.25299 & 9999999999 & TRN \\
\hline CHEMBL3191151 & 688776 & 4.8214 & 5.1416 & TRN & \\
\hline CHEMBL1587031 & 688776 & 5.2658 & 4.2872 & TST & \\
\hline CHEMBL1438717 & 688776 & 5.4052 & 4.1296 & TRN & \\
\hline CHEMBL1325943 & 688776 & 4.6206 & 4.526 & TRN & \\
\hline CHEMBL1420037 & 688776 & 5.4543 & 5.0406 & TRN & \\
\hline CHEMBL1365523 & 688776 & 2.8239 & 2.945 & TST & \\
\hline CHEMBL601757 & 688776 & 5.3053 & 4.8989 & TST & \\
\hline CHEMBL1509637 & 688776 & 3.1249 & 2.5506 & TRN & \\
\hline
\end{tabular}




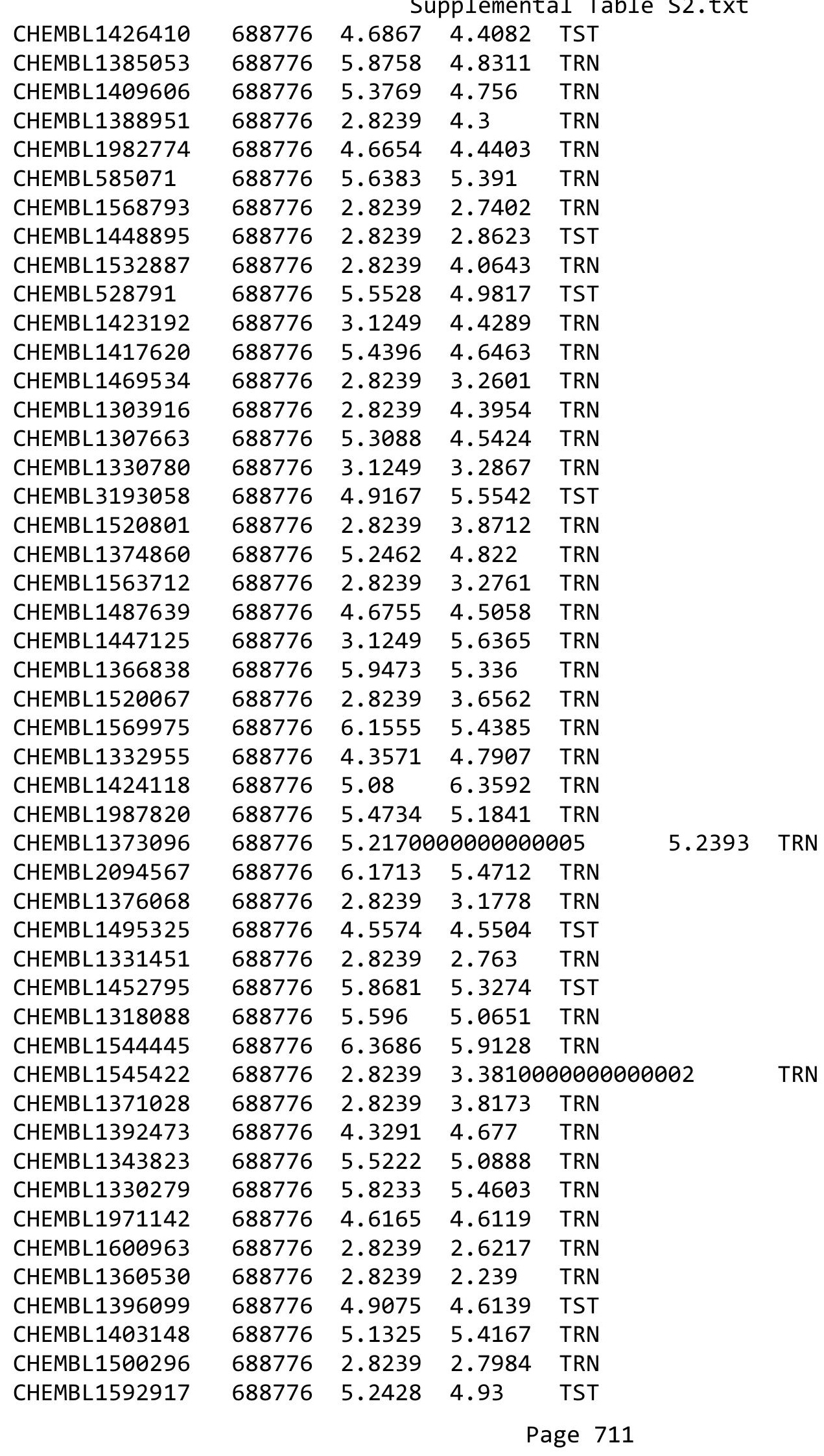




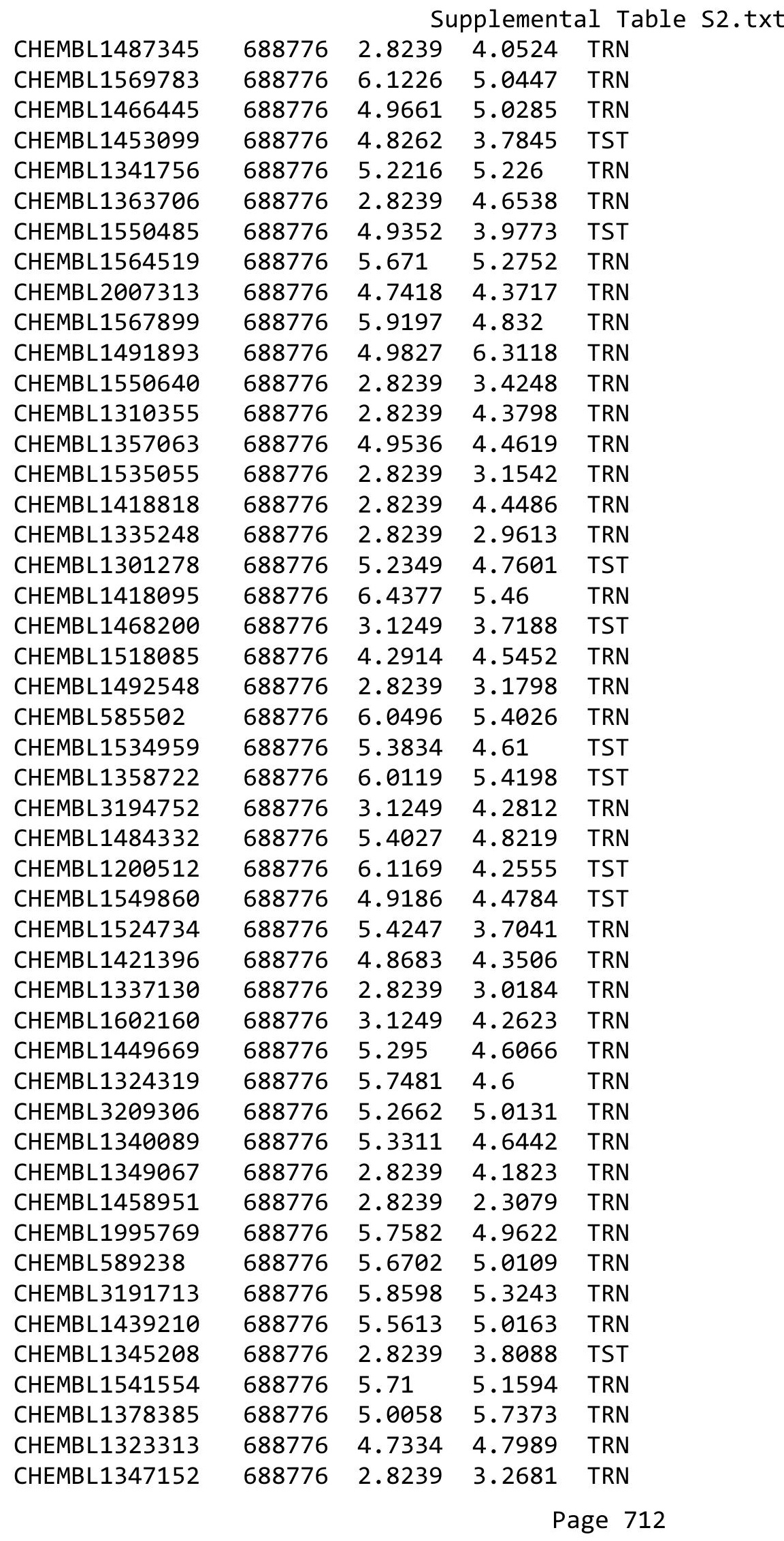




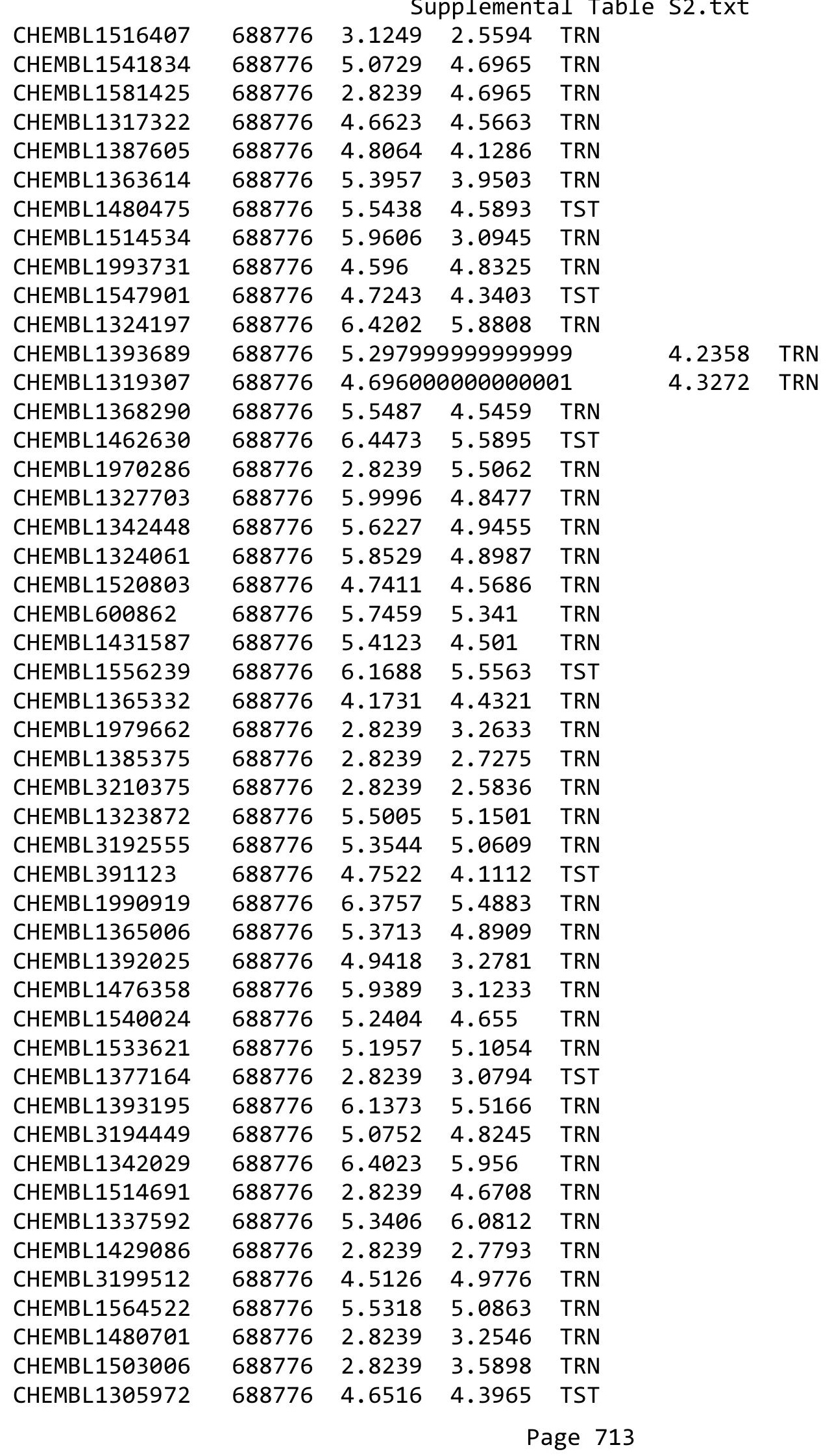




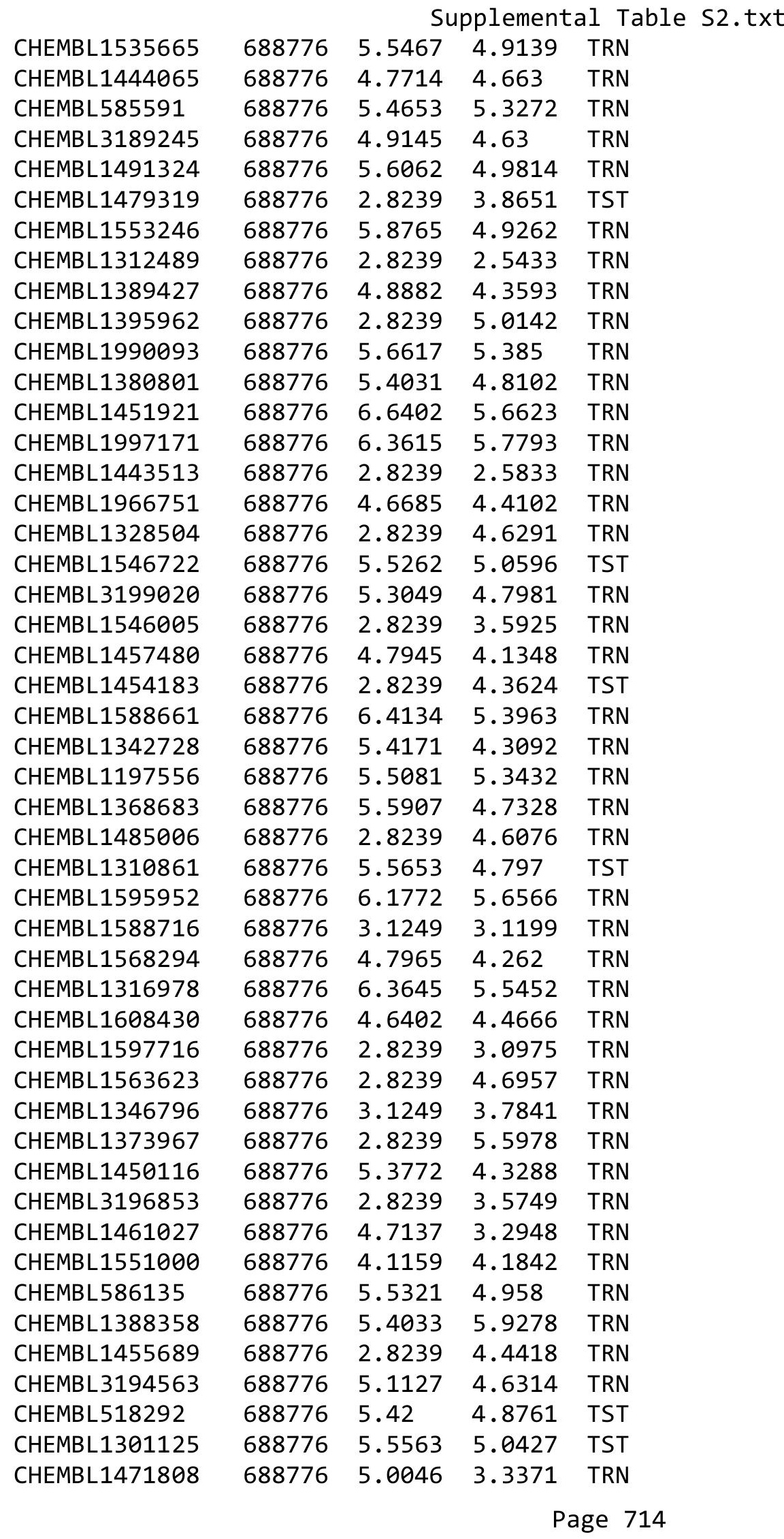




\begin{tabular}{|c|c|c|c|c|c|c|}
\hline & & \multicolumn{5}{|c|}{ Supplemental Table S2.txt } \\
\hline CHEMBL1359327 & 688776 & 2.8239 & 2.4801 & TRN & & \\
\hline CHEMBL1373253 & 688776 & 6.153 & 5.0076 & TRN & & \\
\hline CHEMBL1522486 & 688776 & 5.1183 & 4.6818 & TRN & & \\
\hline CHEMBL1430460 & 688776 & 2.8239 & 2.7353 & TRN & & \\
\hline CHEMBL1504701 & 688776 & 5.5459 & 5.2969 & TRN & & \\
\hline CHEMBL1978117 & 688776 & 6.2211 & 5.7765 & TRN & & \\
\hline CHEMBL1584364 & 688776 & 4.7256 & 2.8328 & TRN & & \\
\hline CHEMBL1502098 & 688776 & 3.1249 & 4.2996 & TRN & & \\
\hline CHEMBL1350780 & 688776 & 5.4288 & 4.6635 & TRN & & \\
\hline CHEMBL1477197 & 688776 & 5.7894 & 4.9099 & TRN & & \\
\hline CHEMBL1459746 & 688776 & 5.9014 & 5.4241 & TRN & & \\
\hline CHEMBL1417929 & 688776 & 3.1249 & 4.5286 & TST & & \\
\hline CHEMBL1464824 & 688776 & 2.8239 & 2.8224 & TRN & & \\
\hline CHEMBL1420007 & 688776 & 4.6486 & 4.1464 & TRN & & \\
\hline CHEMBL3191962 & 688776 & 4.8081 & 5.0322 & TRN & & \\
\hline CHEMBL1501238 & 688776 & 3.1249 & 4.6614 & TST & & \\
\hline CHEMBL1606557 & 688776 & 2.8239 & 3.2358 & TRN & & \\
\hline CHEMBL3189394 & 688776 & 2.8239 & 4.1156 & TRN & & \\
\hline CHEMBL1525381 & 688776 & 4.8578 & 4.5452 & TRN & & \\
\hline CHEMBL1344025 & 688776 & 2.8239 & 2.7406 & TST & & \\
\hline CHEMBL1541779 & 688776 & 4.6274 & 4.6028 & TRN & & \\
\hline CHEMBL1613644 & 688776 & 2.8239 & 3.968 & TRN & & \\
\hline CHEMBL578944 & 688776 & \multicolumn{3}{|c|}{5.292999999999999} & 4.8183 & TS \\
\hline CHEMBL1346284 & 688776 & 6.2832 & 5.5672 & TRN & & \\
\hline CHEMBL1527242 & 688776 & 2.8239 & 4.5443 & TRN & & \\
\hline CHEMBL1583976 & 688776 & 6.0794 & 5.0422 & TRN & & \\
\hline CHEMBL523200 & 688776 & 5.2559 & 4.6394 & TRN & & \\
\hline CHEMBL1384771 & 688776 & 2.8239 & 4.3738 & TST & & \\
\hline CHEMBL1429164 & 688776 & 2.8239 & 4.4514 & TRN & & \\
\hline CHEMBL1500581 & 688776 & 5.8661 & 5.0891 & TST & & \\
\hline CHEMBL1302639 & 688776 & 4.7773 & 3.9513 & TRN & & \\
\hline CHEMBL3199403 & 688776 & 5.3535 & 4.6861 & TRN & & \\
\hline CHEMBL1406552 & 688776 & 2.8239 & 4.1576 & TST & & \\
\hline CHEMBL583584 & 688776 & 2.8239 & 4.4489 & TRN & & \\
\hline CHEMBL1544797 & 688776 & 5.6517 & 5.1875 & TRN & & \\
\hline CHEMBL1530911 & 688776 & 5.5399 & 5.1347 & TRN & & \\
\hline CHEMBL1563218 & 688776 & 2.8239 & 4.504 & TRN & & \\
\hline CHEMBL1440293 & 688776 & 5.4377 & 4.8736 & TST & & \\
\hline CHEMBL1967031 & 688776 & 2.8239 & 4.3751 & TRN & & \\
\hline CHEMBL1392527 & 688776 & \multicolumn{3}{|c|}{6.3420000000000005} & 5.6151 & TRN \\
\hline CHEMBL1460638 & 688776 & 2.8239 & 2.9131 & TST & & \\
\hline CHEMBL1419369 & 688776 & 4.5338 & 4.7892 & TRN & & \\
\hline CHEMBL1386418 & 688776 & 3.1249 & 3.7621 & TRN & & \\
\hline CHEMBL1361821 & 688776 & 5.3987 & 4.604 & TRN & & \\
\hline CHEMBL1432727 & 688776 & 2.8239 & 2.5008 & TRN & & \\
\hline CHEMBL1303910 & 688776 & 6.0531 & 5.2475 & TRN & & \\
\hline CHEMBL1386838 & 688776 & 4.68 & 4.7266 & TST & & \\
\hline CHEMBL261114 & 688776 & 6.1051 & 5.2613 & TRN & & \\
\hline
\end{tabular}




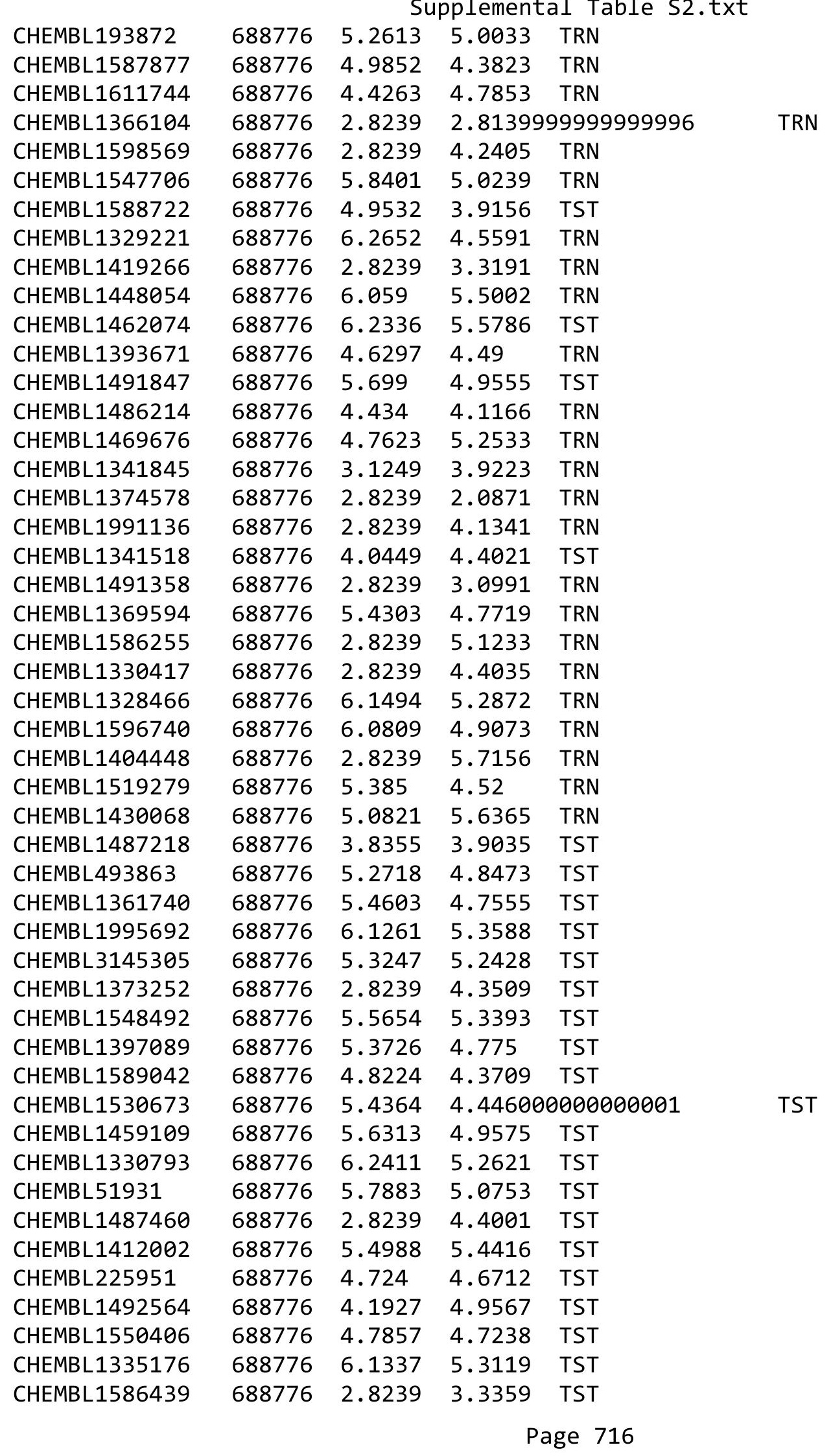




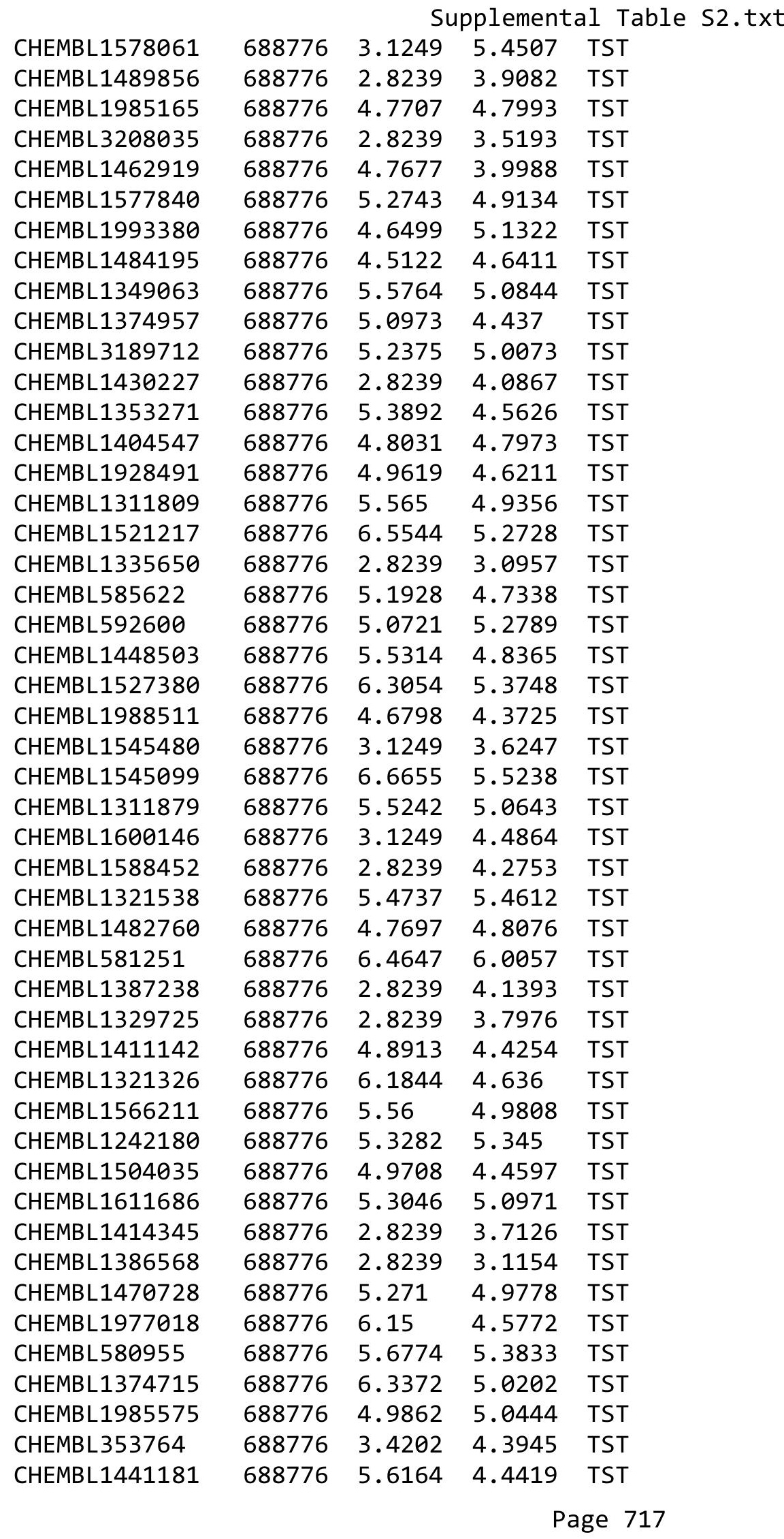




\begin{tabular}{|c|c|c|c|c|c|}
\hline \multicolumn{6}{|c|}{ suppte } \\
\hline CHEMBL 309016 & 688776 & 3.1249 & 4.5325 & TST & \\
\hline CHEMBL570345 & 688776 & 5.138 & 5.1558 & TST & \\
\hline CHEMBL1974506 & 688776 & 5.3543 & 4.6626 & TST & \\
\hline CHEMBL1390868 & 688776 & 2.8239 & 4.5628 & TST & \\
\hline CHEMBL1537106 & 688776 & 5.1866 & 4.8445 & TST & \\
\hline CHEMBL1305304 & 688776 & 2.8239 & 3.4793 & TST & \\
\hline CHEMBL1503190 & 688776 & 5.0769 & 4.5843 & TST & \\
\hline CHEMBL1584727 & 688776 & 2.8239 & 2.1932 & TST & \\
\hline CHEMBL1999480 & 688776 & 5.7395 & 5.16299 & 9999999999 & TST \\
\hline CHEMBL1493731 & 688776 & 5.9215 & 5.2922 & TST & \\
\hline CHEMBL3194964 & 688776 & 5.1138 & 5.0139 & TST & \\
\hline CHEMBL1452391 & 688776 & 5.6149 & 5.0822 & TST & \\
\hline CHEMBL1442431 & 688776 & 5.5807 & 5.0705 & TST & \\
\hline CHEMBL1408708 & 688776 & 5.8441 & 4.786006 & 00000000005 & TST \\
\hline CHEMBL1543337 & 688776 & 4.8842 & 4.8752 & TST & \\
\hline CHEMBL1978479 & 688776 & 2.8239 & 4.1357 & TST & \\
\hline CHEMBL3189320 & 688776 & 3.1249 & 3.9005 & TST & \\
\hline CHEMBL1483324 & 688776 & 2.8239 & 4.3011 & TST & \\
\hline CHEMBL1347563 & 688776 & 2.8239 & 4.3354 & TST & \\
\hline CHEMBL1539678 & 688776 & 4.4741 & 4.5421 & TST & \\
\hline CHEMBL1313990 & 688776 & 4.7881 & 4.9701 & TST & \\
\hline CHEMBL1447563 & 688776 & 5.175 & 4.8894 & TST & \\
\hline CHEMBL1993287 & 688776 & 4.0294 & 4.8376 & TST & \\
\hline CHEMBL1566108 & 688776 & 5.7838 & 4.8954 & TST & \\
\hline CHEMBL1606328 & 688776 & 2.8239 & 4.1552 & TST & \\
\hline CHEMBL1609431 & 688776 & 5.4199 & 4.8542 & TST & \\
\hline CHEMBL1385784 & 688776 & 5.5743 & 5.8242 & TST & \\
\hline CHEMBL1426340 & 688776 & 5.1997 & 4.7257 & TST & \\
\hline CHEMBL1569698 & 688776 & 6.0857 & 5.2735 & TST & \\
\hline CHEMBL1529883 & 688776 & 5.8996 & 5.1698 & TST & \\
\hline CHEMBL1302266 & 688776 & 2.8239 & 4.3791 & TST & \\
\hline CHEMBL1539572 & 688776 & 5.8658 & 4.7433 & TST & \\
\hline CHEMBL1399212 & 688776 & 3.1249 & 4.2354 & TST & \\
\hline CHEMBL1388469 & 688776 & 5.218 & 5.2536 & TST & \\
\hline CHEMBL528694 & 688776 & 5.2056 & 4.9672 & TST & \\
\hline CHEMBL1543383 & 688776 & 4.849 & 4.5629 & TST & \\
\hline CHEMBL257286 & 688776 & 2.8239 & 4.2216 & TST & \\
\hline CHEMBL1567957 & 688776 & 4.4952 & 3.6003 & TST & \\
\hline CHEMBL1609270 & 688776 & 4.6801 & 4.2838 & TST & \\
\hline CHEMBL1425008 & 688776 & 2.8239 & 2.0938 & TST & \\
\hline CHEMBL1607187 & 688776 & 2.8239 & 3.9636 & TST & \\
\hline CHEMBL1344300 & 688776 & 2.8239 & 3.5131 & TST & \\
\hline CHEMBL1416693 & 688776 & 2.8239 & 2.0842 & TST & \\
\hline CHEMBL1392509 & 688776 & 2.8239 & 4.0605 & TST & \\
\hline CHEMBL513150 & 688776 & 5.8108 & 4.6044 & TST & \\
\hline CHEMBL1424127 & 688776 & 6.0894 & 5.1409 & TST & \\
\hline CHEMBL1472126 & 688776 & 5.3367 & 5.2976 & TST & \\
\hline CHEMBL1545160 & 688451 & 4.6269 & 4.3044 & TRN & \\
\hline
\end{tabular}




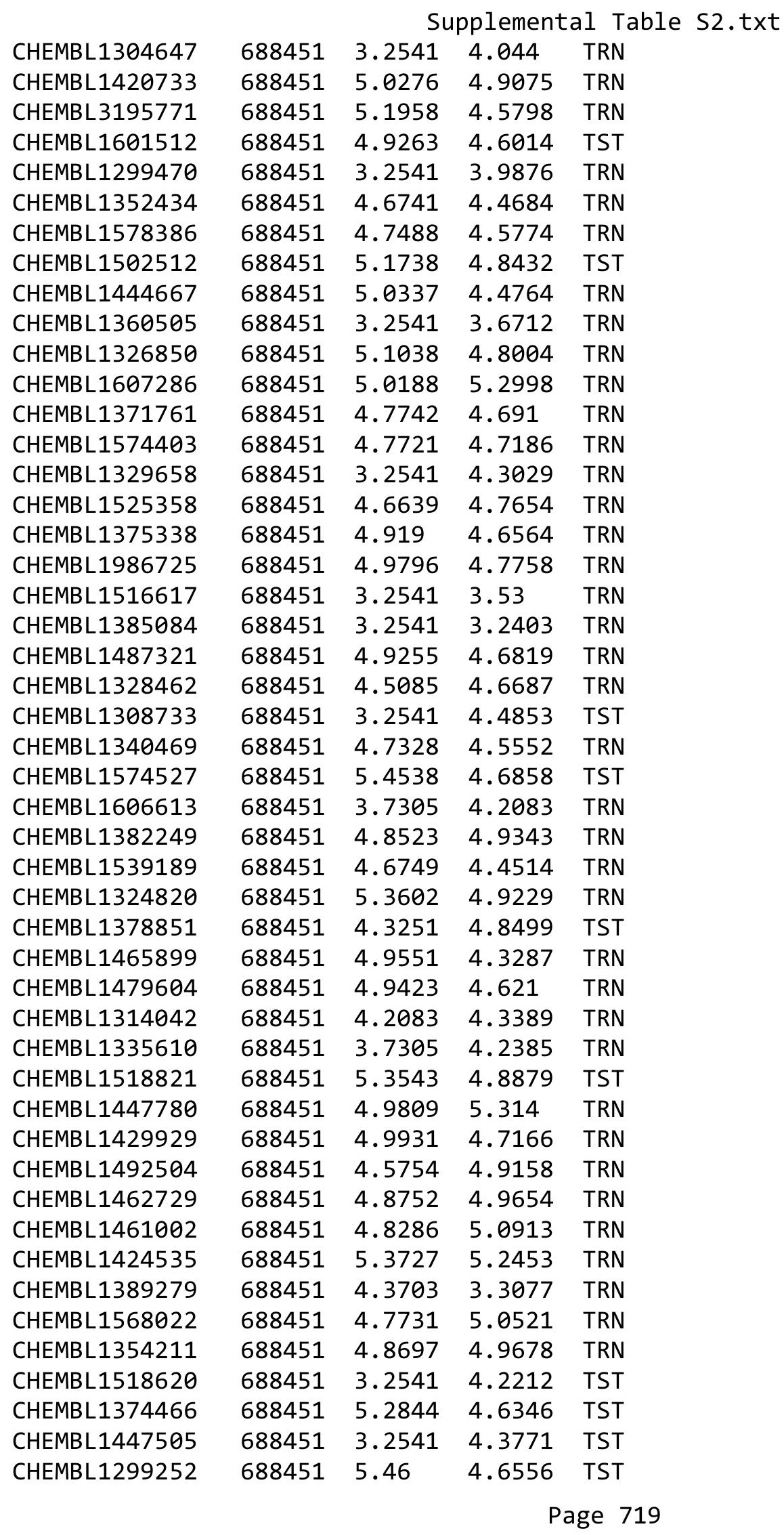


Supplemental Table S2.txt

\begin{tabular}{|c|c|c|c|c|c|}
\hline CHEMBL1444859 & 688451 & 3.7305 & 4.5548 & TST & \\
\hline CHEMBL1541307 & 688451 & 5.0743 & 4.7499 & TST & \\
\hline CHEMBL1492648 & 688451 & 5.0012 & 4.541 & TST & \\
\hline CHEMBL1370681 & 688451 & 4.9727 & 4.7559 & TST & \\
\hline CHEMBL181893 & 304931 & 7.0862 & 6.9254 & TRN & \\
\hline CHEMBL179132 & 304931 & 6.4949 & 6.5623 & TRN & \\
\hline CHEMBL181723 & 304931 & 6.4318 & 6.48 & TRN & \\
\hline CHEMBL178524 & 304931 & 7.2676 & 7.3659 & TRN & \\
\hline CHEMBL178555 & 304931 & 4.0 & 3.8606 & TRN & \\
\hline CHEMBL180757 & 304931 & 6.8861 & 6.9732 & TRN & \\
\hline CHEMBL180652 & 304931 & 7.3768 & 7.3024 & TRN & \\
\hline CHEMBL361389 & 304931 & 6.2924 & 6.1991 & TRN & \\
\hline CHEMBL181456 & 304931 & 7.0177 & 6.9474 & TRN & \\
\hline CHEMBL180666 & 304931 & 6.699 & 6.5922 & TRN & \\
\hline CHEMBL360236 & 304931 & 6.6778 & 6.6648 & TRN & \\
\hline CHEMBL361645 & 304931 & 6.2924 & 6.3208 & TRN & \\
\hline CHEMBL361133 & 304931 & 6.9208 & 7.1034 & TRN & \\
\hline CHEMBL178906 & 304931 & 6.6021 & 6.5533 & TRN & \\
\hline CHEMBL179438 & 304931 & 6.1739 & 6.269 & TRN & \\
\hline CHEMBL179485 & 304931 & 7.9208 & 7.6096 & TRN & \\
\hline CHEMBL179609 & 304931 & 6.4559 & 6.3241 & TRN & \\
\hline CHEMBL179368 & 304931 & 6.6778 & 6.9254 & TRN & \\
\hline CHEMBL361780 & 304931 & 6.6778 & 6.6688 & TRN & \\
\hline CHEMBL359689 & 304931 & 5.7212 & 5.6803 & TRN & \\
\hline CHEMBL181473 & 304931 & 6.8539 & 6.8499 & TRN & \\
\hline CHEMBL360993 & 304931 & 6.5376 & 6.4986 & TRN & \\
\hline CHEMBL180654 & 304931 & 5.9586 & 6.0126 & TRN & \\
\hline CHEMBL181844 & 304931 & 7.0 & 6.9009 & TRN & \\
\hline CHEMBL178648 & 304931 & 5.6778 & 5.6478 & TRN & \\
\hline CHEMBL181626 & 304931 & 6.4815 & 6.4661 & TRN & \\
\hline CHEMBL180881 & 304931 & 5.3372 & 5.3795 & TRN & \\
\hline CHEMBL180914 & 304931 & 5.5229 & 5.5463 & TRN & \\
\hline CHEMBL433950 & 304931 & 6.3872 & 6.2403 & TRN & \\
\hline CHEMBL362440 & 304931 & 5.8861 & 6.24 & TRN & \\
\hline CHEMBL181553 & 304931 & 6.585 & \multicolumn{2}{|c|}{6.5489999999999995} & TRN \\
\hline CHEMBL361998 & 304931 & 6.4949 & 6.6974 & TRN & \\
\hline CHEMBL178288 & 304931 & 6.6778 & 6.7448 & TRN & \\
\hline CHEMBL178253 & 304931 & 6.3279 & 6.4112 & TRN & \\
\hline CHEMBL178160 & 304931 & 6.6778 & 6.5202 & TRN & \\
\hline CHEMBL178181 & 304931 & 5.7959 & 5.9019 & TRN & \\
\hline CHEMBL182204 & 304931 & 5.9208 & 5.8979 & TRN & \\
\hline CHEMBL178386 & 304931 & 6.8239 & 6.7276 & TRN & \\
\hline CHEMBL178497 & 304931 & 6.6383 & 6.6556 & TRN & \\
\hline CHEMBL 264201 & 304931 & 5.7212 & 5.8329 & TRN & \\
\hline CHEMBL182239 & 304931 & 6.8239 & 6.9079 & TRN & \\
\hline CHEMBL179564 & 304931 & 7.0862 & 7.13399 & 99999999995 & TRN \\
\hline CHEMBL180775 & 304931 & 5.301 & 5.3857 & TRN & \\
\hline CHEMBL425526 & 304931 & 7.5229 & 6.9254 & TRN & \\
\hline
\end{tabular}




\begin{tabular}{|c|c|c|c|c|c|}
\hline \multicolumn{6}{|c|}{ Supplemental Table s2.txt } \\
\hline CHEMBL181117 & 304931 & 5.0132 & 5.0571 & TRN & \\
\hline CHEMBL179127 & 304931 & 6.6778 & 6.7119 & TRN & \\
\hline CHEMBL181072 & 304931 & 7.4949 & 6.9254 & TRN & \\
\hline CHEMBL178173 & 304931 & 5.9586 & 6.0714 & TRN & \\
\hline CHEMBL181737 & 304931 & 7.2596 & 7.3103 & TRN & \\
\hline CHEMBL178256 & 304931 & 6.7696 & 6.7092 & TRN & \\
\hline CHEMBL433766 & 304931 & 7.5229 & 7.7177 & TRN & \\
\hline CHEMBL181023 & 304931 & 6.4685 & 6.461 & TRN & \\
\hline CHEMBL178212 & 304931 & 5.8239 & 6.5409 & TST & \\
\hline CHEMBL178586 & 304931 & 6.3665 & 6.2242 & TST & \\
\hline CHEMBL180776 & 304931 & 7.7959 & 7.9172 & TRN & \\
\hline CHEMBL179764 & 304931 & 5.7959 & 5.7025 & TRN & \\
\hline CHEMBL360287 & 304931 & 6.2596 & 6.2241 & TRN & \\
\hline CHEMBL 367799 & 304931 & 6.8239 & 6.6974 & TRN & \\
\hline CHEMBL361767 & 304931 & 6.0315 & 5.8297 & TRN & \\
\hline CHEMBL181081 & 304931 & 5.8239 & 6.0613 & TST & \\
\hline CHEMBL181876 & 304931 & 7.3098 & 6.6644 & TST & \\
\hline CHEMBL181386 & 304931 & 6.4685 & 6.0638 & TST & \\
\hline CHEMBL427311 & 304931 & 6.585 & 7.0401 & TST & \\
\hline CHEMBL181326 & 304931 & 6.9208 & 6.7891 & TRN & \\
\hline CHEMBL361006 & 304931 & 6.2757 & 6.2892 & TRN & \\
\hline CHEMBL181228 & 304931 & 6.1739 & 6.1491 & TRN & \\
\hline CHEMBL178699 & 304931 & 6.0223 & 6.9254 & TRN & \\
\hline CHEMBL178569 & 304931 & 6.6021 & 6.4 & TRN & \\
\hline CHEMBL361555 & 304931 & 6.8239 & 6.8127 & TRN & \\
\hline CHEMBL182238 & 304931 & 5.0757 & 5.3936 & TRN & \\
\hline CHEMBL181455 & 304931 & 6.7959 & 6.7802 & TRN & \\
\hline CHEMBL179439 & 304931 & 5.0177 & 6.8177 & TST & \\
\hline CHEMBL362828 & 304931 & 6.3872 & 6.54700 & 0000000001 & TST \\
\hline CHEMBL179486 & 304931 & 6.2441 & 6.2783 & TST & \\
\hline CHEMBL180985 & 304931 & 7.0809 & 6.6823 & TST & \\
\hline CHEMBL361860 & 304931 & 6.7447 & 7.1761 & TST & \\
\hline CHEMBL319136 & 304931 & 6.9586 & 6.79799 & 9999999999 & TST \\
\hline CHEMBL 178171 & 304931 & 6.2596 & 6.976 & TST & \\
\hline CHEMBL181380 & 304931 & 6.1805 & 6.7788 & TST & \\
\hline CHEMBL362806 & 304931 & 7.0044 & 6.9254 & TST & \\
\hline CHEMBL178752 & 304931 & 5.7959 & 5.57700 & 0000000001 & TST \\
\hline CHEMBL181996 & 304931 & 6.6383 & 6.8163 & TST & \\
\hline CHEMBL178357 & 304931 & 6.4685 & 7.0522 & TST & \\
\hline CHEMBL180915 & 304931 & 5.4089 & 7.3807 & TST & \\
\hline CHEMBL182205 & 304931 & 6.1739 & 6.8226 & TST & \\
\hline CHEMBL359658 & 304931 & 7.2596 & 6.5931 & TST & \\
\hline CHEMBL179563 & 304931 & 6.2441 & 6.8524 & TST & \\
\hline CHEMBL1469916 & 737421 & 5.0 & 4.615 & TRN & \\
\hline CHEMBL1472426 & 737421 & 5.0 & 4.4426 & TRN & \\
\hline CHEMBL1545361 & 737421 & 4.0 & 4.4635 & TRN & \\
\hline CHEMBL1538215 & 737421 & 5.4112 & 4.8966 & TRN & \\
\hline CHEMBL1565993 & 737421 & 5.0 & 4.54899 & 99999999995 & TRN \\
\hline & & & & 721 & \\
\hline
\end{tabular}




\begin{tabular}{|c|c|c|c|c|c|}
\hline & & \multicolumn{4}{|c|}{ Supplemental Table S2.txt } \\
\hline CHEMBL1561150 & 737421 & 4.0975 & 4.5339 & TRN & \\
\hline CHEMBL69612 & 737421 & 4.032 & 4.7871 & TRN & \\
\hline CHEMBL1613615 & 737421 & 5.015 & 4.7703 & TRN & \\
\hline CHEMBL3190063 & 737421 & 5.0348 & 4.886 & TRN & \\
\hline CHEMBL1335224 & 737421 & 4.0209 & 5.0526 & TRN & \\
\hline CHEMBL1420682 & 737421 & 5.0 & 4.5506 & TRN & \\
\hline CHEMBL3197425 & 737421 & 4.2104 & 4.9991 & TRN & \\
\hline CHEMBL578716 & 737421 & 4.0 & 4.9553 & TST & \\
\hline CHEMBL1421112 & 737421 & 5.0 & 4.5983 & TRN & \\
\hline CHEMBL1329798 & 737421 & 7.7959 & 6.1011 & TRN & \\
\hline CHEMBL1576110 & 737421 & 4.0031 & 4.9119 & TRN & \\
\hline CHEMBL1388831 & 737421 & 5.0 & 4.6471 & TRN & \\
\hline CHEMBL3189304 & 737421 & 5.0 & 4.8141 & TRN & \\
\hline CHEMBL1308168 & 737421 & 5.1403 & 4.5072 & TRN & \\
\hline CHEMBL570400 & 737421 & 4.0035 & 5.0069 & TRN & \\
\hline CHEMBL1344294 & 737421 & 5.1549 & 4.3586 & TRN & \\
\hline CHEMBL1414873 & 737421 & 4.0545 & 4.5967 & TRN & \\
\hline CHEMBL1517752 & 737421 & 5.3188 & 4.6132 & TRN & \\
\hline CHEMBL3196611 & 737421 & 4.0074 & 4.7924 & TRN & \\
\hline CHEMBL1497549 & 737421 & 7.0605 & 6.0631 & TRN & \\
\hline CHEMBL1606938 & 737421 & 5.0 & 4.8065 & TST & \\
\hline CHEMBL1404541 & 737421 & 4.0726 & 4.4713 & TRN & \\
\hline CHEMBL1363322 & 737421 & 5.0 & 4.7838 & TRN & \\
\hline CHEMBL3190923 & 737421 & 4.0255 & 5.0523 & TRN & \\
\hline CHEMBL1340713 & 737421 & 4.0 & 4.5941 & TRN & \\
\hline CHEMBL1402473 & 737421 & 4.0 & 4.7902 & TRN & \\
\hline CHEMBL1352586 & 737421 & 5.2716 & 4.801 & TRN & \\
\hline CHEMBL1547342 & 737421 & 5.2644 & 4.8041 & TRN & \\
\hline CHEMBL1345518 & 737421 & 4.4045 & 4.428 & TRN & \\
\hline CHEMBL523200 & 737421 & 5.0 & 4.9362 & TRN & \\
\hline CHEMBL1346640 & 737421 & 5.3391 & 4.8061 & TRN & \\
\hline CHEMBL1570216 & 737421 & 4.2182 & 5.9108 & TRN & \\
\hline CHEMBL1402510 & 737421 & 6.0605 & 6.8394 & TRN & \\
\hline CHEMBL1518874 & 737421 & 5.2262 & 4.9114 & TRN & \\
\hline CHEMBL1374298 & 737421 & 5.6144 & 4.8744 & TRN & \\
\hline CHEMBL1445962 & 737421 & 4.0273 & 4.5871 & TRN & \\
\hline CHEMBL1545727 & 737421 & 6.0 & 4.5159 & TRN & \\
\hline CHEMBL1412369 & 737421 & 4.0 & 4.628 & TRN & \\
\hline CHEMBL1419822 & 737421 & 5.3335 & 4.5359 & TRN & \\
\hline CHEMBL1550734 & 737421 & 4.1965 & 5.24100 & 00000000005 & TRN \\
\hline CHEMBL1392570 & 737421 & 5.5058 & 4.916 & TRN & \\
\hline CHEMBL 2006154 & 737421 & 5.3116 & 5.2451 & TRN & \\
\hline CHEMBL1537098 & 737421 & 6.7959 & 6.6956 & TRN & \\
\hline CHEMBL1888628 & 737421 & 5.1002 & 4.9692 & TRN & \\
\hline CHEMBL1387110 & 737421 & 4.1284 & 4.735 & TRN & \\
\hline CHEMBL1348803 & 737421 & 4.0 & 4.9269 & TRN & \\
\hline CHEMBL1353886 & 737421 & 4.0146 & 4.4863 & TRN & \\
\hline CHEMBL1564569 & 737421 & 4.2798 & 4.8748 & TRN & \\
\hline
\end{tabular}




\begin{tabular}{|c|c|c|c|c|c|}
\hline \multirow{3}{*}{$\begin{array}{l}\text { CHEMBL1469567 } \\
\text { CHEMBL1446971 }\end{array}$} & & \multicolumn{4}{|c|}{ Supplemental Table S2.txt } \\
\hline & 737421 & 5.0 & 4.40600 & 0000000001 & TRN \\
\hline & 737421 & 4.3045 & 5.3032 & TRN & \\
\hline CHEMBL1449794 & 737421 & 5.3969 & 5.2675 & TRN & \\
\hline CHEMBL1602581 & 737421 & 4.0283 & 4.9395 & TRN & \\
\hline CHEMBL1462568 & 737421 & 4.0044 & 4.9007 & TST & \\
\hline CHEMBL1377682 & 737421 & 5.0 & 4.7444 & TRN & \\
\hline CHEMBL3207920 & 737421 & 4.6576 & 4.9555 & TRN & \\
\hline CHEMBL1411912 & 737421 & 6.7959 & 4.7608 & TRN & \\
\hline CHEMBL1585404 & 737421 & 5.0 & 4.9128 & TRN & \\
\hline CHEMBL3196976 & 737421 & 5.6716 & 5.2742 & TRN & \\
\hline CHEMBL1459578 & 737421 & 6.7959 & 6.1443 & TRN & \\
\hline CHEMBL1545584 & 737421 & 4.0173 & 4.8184 & TRN & \\
\hline CHEMBL3190960 & 737421 & 5.2757 & 4.8858 & TRN & \\
\hline CHEMBL1526855 & 737421 & 4.0926 & 4.974 & TRN & \\
\hline CHEMBL1445372 & 737421 & 5.6038 & 5.1293 & TRN & \\
\hline CHEMBL1377193 & 737421 & 5.2007 & 4.8115 & TRN & \\
\hline CHEMBL1578101 & 737421 & 5.0 & 4.8157 & TST & \\
\hline CHEMBL1367316 & 737421 & 5.2588 & 4.7286 & TRN & \\
\hline CHEMBL1500887 & 737421 & 4.0506 & 4.822 & TRN & \\
\hline CHEMBL1525530 & 737421 & 4.0209 & 4.6421 & TRN & \\
\hline CHEMBL1505922 & 737421 & 4.0214 & 4.8424 & TRN & \\
\hline CHEMBL1453673 & 737421 & 4.0958 & 4.9479 & TRN & \\
\hline CHEMBL1573994 & 737421 & 6.7959 & 6.3633 & TRN & \\
\hline CHEMBL1364960 & 737421 & 5.0348 & 4.3738 & TRN & \\
\hline CHEMBL3191416 & 737421 & 4.2218 & 5.2065 & TRN & \\
\hline CHEMBL1974389 & 737421 & 4.4342 & 5.2568 & TRN & \\
\hline CHEMBL1312016 & 737421 & 5.2541 & 5.0326 & TRN & \\
\hline CHEMBL1302406 & 737421 & 5.0 & 4.9577 & TRN & \\
\hline CHEMBL1310221 & 737421 & 5.055 & 4.7197 & TRN & \\
\hline CHEMBL1386876 & 737421 & 5.0 & 4.5632 & TRN & \\
\hline CHEMBL1510714 & 737421 & 4.0 & 4.5246 & TRN & \\
\hline CHEMBL1309232 & 737421 & 4.0 & 5.3155 & TRN & \\
\hline CHEMBL1453108 & 737421 & 6.0 & 5.0896 & TRN & \\
\hline CHEMBL1460004 & 737421 & 4.0 & 4.8871 & TRN & \\
\hline CHEMBL1310804 & 737421 & 4.1851 & 4.6499 & TRN & \\
\hline CHEMBL1345961 & 737421 & 5.0 & 4.5722 & TRN & \\
\hline CHEMBL1382438 & 737421 & 7.5229 & 5.7997 & TRN & \\
\hline CHEMBL1519585 & 737421 & 4.4168 & 4.5663 & TRN & \\
\hline CHEMBL1305292 & 737421 & 5.3372 & 4.677 & TRN & \\
\hline CHEMBL1380000 & 737421 & 4.1198 & 4.9469 & TRN & \\
\hline CHEMBL1370379 & 737421 & 5.209 & 4.7826 & TRN & \\
\hline CHEMBL1533351 & 737421 & 5.2328 & 4.6321 & TRN & \\
\hline CHEMBL1522800 & 737421 & 4.0173 & 4.44300 & 00000000005 & TRN \\
\hline CHEMBL1431118 & 737421 & 4.0 & 4.4874 & TRN & \\
\hline CHEMBL1732236 & 737421 & 5.3401 & 4.6834 & TRN & \\
\hline CHEMBL1518672 & 737421 & 6.1487 & 5.2424 & TRN & \\
\hline CHEMBL1556055 & 737421 & 4.4425 & 5.0442 & TRN & \\
\hline CHEMBL1460029 & 737421 & 4.0334 & 4.4037 & TRN & \\
\hline
\end{tabular}




\begin{tabular}{|c|c|c|c|c|c|}
\hline \multicolumn{6}{|c|}{ Supplemental Table s2.txt } \\
\hline CHEMBL1364411 & 737421 & 5.0 & 4.762 & TST & \\
\hline CHEMBL 259784 & 737421 & 5.0004 & 5.4654 & TRN & \\
\hline CHEMBL1471146 & 737421 & 5.0 & 5.1276 & TRN & \\
\hline CHEMBL1363219 & 737421 & 5.3439 & 4.8436 & TRN & \\
\hline CHEMBL1470914 & 737421 & 4.0223 & 4.5991 & TRN & \\
\hline CHEMBL1507523 & 737421 & 5.2848 & 4.7303 & TRN & \\
\hline CHEMBL1335176 & 737421 & 6.0862 & 5.4298 & TST & \\
\hline CHEMBL1402055 & 737421 & 4.2351 & 4.9289 & TST & \\
\hline CHEMBL1562277 & 737421 & 5.1713 & 4.4509 & TRN & \\
\hline CHEMBL1372914 & 737421 & 5.0438 & 4.5414 & TRN & \\
\hline CHEMBL1428228 & 737421 & 5.6737 & 5.0556 & TRN & \\
\hline CHEMBL1977082 & 737421 & 5.2782 & 4.377 & TRN & \\
\hline CHEMBL1595864 & 737421 & 5.0 & 4.8051 & TRN & \\
\hline CHEMBL1581932 & 737421 & 4.0287 & 4.8669 & TRN & \\
\hline CHEMBL1405952 & 737421 & 7.7959 & 6.3077 & TRN & \\
\hline CHEMBL1319933 & 737421 & 5.2907 & 5.0239 & TRN & \\
\hline CHEMBL1413963 & 737421 & 4.0173 & 5.0092 & TRN & \\
\hline CHEMBL1358722 & 737421 & 5.7959 & 6.2032 & TST & \\
\hline CHEMBL1581024 & 737421 & 4.2449 & 5.1598 & TST & \\
\hline CHEMBL1508875 & 737421 & 4.0 & 4.6262 & TRN & \\
\hline CHEMBL1439938 & 737421 & 5.4609 & 5.181 & TRN & \\
\hline CHEMBL1460889 & 737421 & 5.82100 & 00000000 & 01 & 5.6487 \\
\hline CHEMBL1456676 & 737421 & 5.0 & 4.7746 & TST & \\
\hline CHEMBL1365185 & 737421 & 4.2882 & 4.984 & TST & \\
\hline CHEMBL1423839 & 737421 & 4.0186 & 4.8604 & TRN & \\
\hline CHEMBL1585480 & 737421 & 4.0329 & 4.606 & TRN & \\
\hline CHEMBL1481551 & 737421 & 4.0 & 4.5632 & TRN & \\
\hline CHEMBL1567008 & 737421 & 4.2197 & 4.3647 & TRN & \\
\hline CHEMBL1385055 & 737421 & 5.0 & 4.8718 & TRN & \\
\hline CHEMBL 3190220 & 737421 & 4.0123 & 4.5954 & TRN & \\
\hline CHEMBL 3192554 & 737421 & 5.2175 & 4.4695 & TRN & \\
\hline CHEMBL1448732 & 737421 & 4.4056 & 4.7748 & TRN & \\
\hline CHEMBL1437997 & 737421 & 5.0516 & 4.9396 & TRN & \\
\hline CHEMBL1457594 & 737421 & 4.0904 & 4.8418 & TRN & \\
\hline CHEMBL1524393 & 737421 & 5.0721 & 4.8552 & TRN & \\
\hline CHEMBL1427279 & 737421 & 4.0655 & 5.2019 & TRN & \\
\hline CHEMBL1347962 & 737421 & 5.0 & 4.7386 & TRN & \\
\hline CHEMBL1393615 & 737421 & 5.0 & 5.0779 & TRN & \\
\hline CHEMBL1601788 & 737421 & 4.0218 & 4.6128 & TRN & \\
\hline CHEMBL1392142 & 737421 & 5.7959 & 5.7815 & TRN & \\
\hline CHEMBL1340447 & 737421 & 5.0 & 4.8891 & TRN & \\
\hline CHEMBL417727 & 737421 & 5.2941 & 4.9331 & TRN & \\
\hline CHEMBL1366942 & 737421 & 4.9431 & 5.2956 & TST & \\
\hline CHEMBL1387474 & 737421 & 5.6216 & 4.8947 & TRN & \\
\hline CHEMBL1360493 & 737421 & 4.0 & 4.9724 & TST & \\
\hline CHEMBL1303810 & 737421 & 5.5467 & 5.1605 & TRN & \\
\hline CHEMBL1566829 & 737421 & 5.3487 & 4.586 & TRN & \\
\hline CHEMBL1586169 & 737421 & 4.0 & 4.8162 & TRN & \\
\hline
\end{tabular}




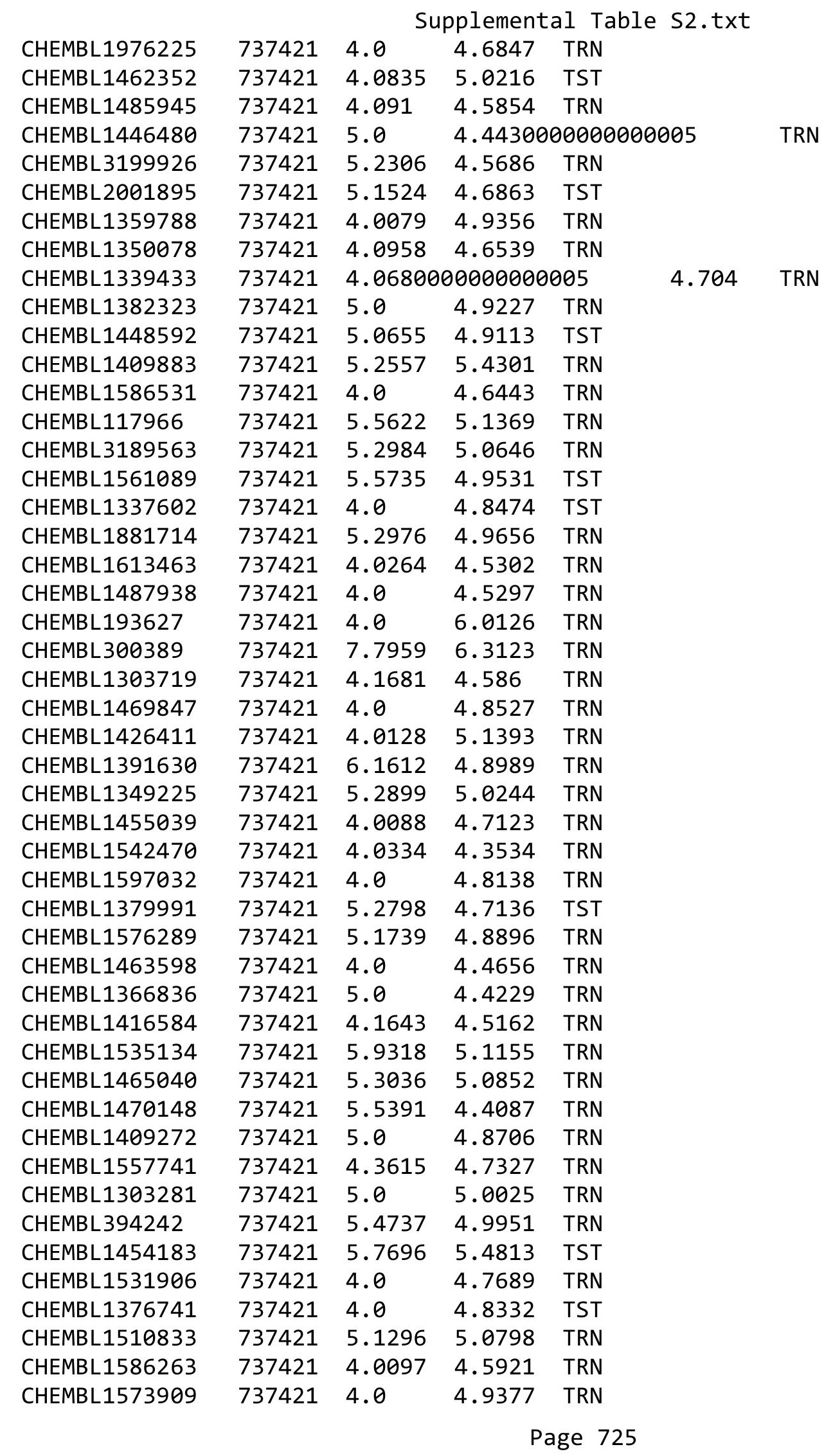




\begin{tabular}{|c|c|c|c|c|}
\hline \multicolumn{5}{|c|}{ Supplemental Table S2.txt } \\
\hline CHEMBL1589526 & 737421 & 4.0 & 5.0168 & TRN \\
\hline CHEMBL1532668 & 737421 & 5.2299 & 5.0149 & TRN \\
\hline CHEMBL1382884 & 737421 & 5.2958 & 4.982 & TRN \\
\hline CHEMBL1441545 & 737421 & 5.4377 & 4.5123 & TRN \\
\hline CHEMBL1557782 & 737421 & 4.0306 & 4.8304 & TRN \\
\hline CHEMBL1481836 & 737421 & 4.0768 & 4.7556 & TRN \\
\hline CHEMBL3191488 & 737421 & 5.0 & 4.901 & TRN \\
\hline CHEMBL1584796 & 737421 & 4.0214 & 4.9789 & TST \\
\hline CHEMBL1567389 & 737421 & 4.0 & 5.2228 & TRN \\
\hline CHEMBL1327721 & 737421 & 5.0 & 5.098 & TRN \\
\hline CHEMBL1482998 & 737421 & 5.1765 & 4.9938 & TRN \\
\hline CHEMBL1511795 & 737421 & 5.0726 & 4.8527 & TRN \\
\hline CHEMBL1519411 & 737421 & 4.0315 & 4.4011 & TRN \\
\hline CHEMBL3190201 & 737421 & 5.0 & 4.5152 & TRN \\
\hline CHEMBL3197754 & 737421 & 4.4976 & 4.9327 & TRN \\
\hline CHEMBL1584002 & 737421 & 5.0391 & 4.6907 & TRN \\
\hline CHEMBL1539307 & 737421 & 4.0119 & 4.9853 & TST \\
\hline CHEMBL1572026 & 737421 & 5.6946 & 4.9737 & TRN \\
\hline CHEMBL1392160 & 737421 & 5.0 & 4.8184 & TRN \\
\hline CHEMBL1562304 & 737421 & 5.0 & 4.9438 & TST \\
\hline CHEMBL1563483 & 737421 & 5.6737 & 5.3416 & TST \\
\hline CHEMBL1467956 & 737421 & 5.2233 & 4.9814 & TST \\
\hline CHEMBL3193107 & 737421 & 5.1739 & 5.3392 & TRN \\
\hline CHEMBL1444859 & 737421 & 5.0 & 4.7133 & TRN \\
\hline CHEMBL1708334 & 737421 & 5.2041 & 5.0316 & TST \\
\hline CHEMBL1362109 & 737421 & 4.0752 & 4.9424 & TRN \\
\hline CHEMBL1971234 & 737421 & 5.0 & 4.8184 & TRN \\
\hline CHEMBL1504590 & 737421 & 5.0 & 4.9722 & TST \\
\hline CHEMBL1989704 & 737421 & 5.0 & 4.9261 & TRN \\
\hline CHEMBL1460352 & 737421 & 5.6421 & 5.3179 & TRN \\
\hline CHEMBL 3210044 & 737421 & 5.0 & 4.7495 & TRN \\
\hline CHEMBL1984336 & 737421 & 5.1952 & 4.8406 & TRN \\
\hline CHEMBL1567571 & 737421 & 5.2541 & 5.2398 & TRN \\
\hline CHEMBL1448941 & 737421 & 4.0155 & 4.7877 & TRN \\
\hline CHEMBL1453996 & 737421 & 5.7959 & 6.1694 & TST \\
\hline CHEMBL1489294 & 737421 & 5.6819 & 5.1429 & TRN \\
\hline CHEMBL1508182 & 737421 & 5.2526 & 5.1884 & TRN \\
\hline CHEMBL3189258 & 737421 & 4.1261 & 5.0245 & TRN \\
\hline CHEMBL1399102 & 737421 & 5.2277 & 4.6282 & TRN \\
\hline CHEMBL1441304 & 737421 & 4.0 & 4.7561 & TRN \\
\hline CHEMBL1469035 & 737421 & 5.0 & 5.0085 & TRN \\
\hline CHEMBL1388639 & 737421 & 4.0009 & 4.6195 & TRN \\
\hline CHEMBL1369492 & 737421 & 5.0 & 4.8653 & TRN \\
\hline CHEMBL1492098 & 737421 & 4.0 & 4.481 & TRN \\
\hline CHEMBL1547559 & 737421 & 5.8996 & 5.723 & TRN \\
\hline CHEMBL1498509 & 737421 & 5.4737 & 5.2426 & TRN \\
\hline CHEMBL3197580 & 737421 & 5.0367 & 5.0729 & TRN \\
\hline CHEMBL1516857 & 737421 & 5.7055 & 4.9485 & TST \\
\hline
\end{tabular}


Supplemental Table S2.txt

\begin{tabular}{|c|c|c|c|c|}
\hline CHEMBL1578584 & 737421 & 7.7959 & 6.1429 & TRN \\
\hline CHEMBL1487444 & 737421 & 4.0052 & 4.9639 & TRN \\
\hline CHEMBL1381814 & 737421 & 5.0453 & 5.1438 & TRN \\
\hline CHEMBL1586425 & 737421 & 5.3947 & 4.9502 & TRN \\
\hline CHEMBL1429297 & 737421 & 5.0 & 4.8723 & TST \\
\hline CHEMBL1501680 & 737421 & 5.0 & 4.5848 & TRN \\
\hline CHEMBL414890 & 737421 & 5.5884 & 5.2618 & TST \\
\hline CHEMBL3195389 & 737421 & 6.7959 & 6.4106 & TRN \\
\hline CHEMBL1518905 & 737421 & 5.4949 & 5.6228 & TRN \\
\hline CHEMBL1425486 & 737421 & 4.0 & 5.0315 & TRN \\
\hline CHEMBL1468721 & 737421 & 4.0 & 4.9791 & TRN \\
\hline CHEMBL1337592 & 737421 & 4.0191 & 4.8411 & TRN \\
\hline CHEMBL1420717 & 737421 & 4.0 & 4.6753 & TRN \\
\hline CHEMBL1422030 & 737421 & 5.0 & 4.8078 & TRN \\
\hline CHEMBL142868 & 737421 & 4.0 & 4.8403 & TRN \\
\hline CHEMBL1602759 & 737421 & 5.3625 & 5.3951 & TRN \\
\hline CHEMBL1446234 & 737421 & 4.1057 & 4.6417 & TRN \\
\hline CHEMBL3194091 & 737421 & 4.0 & 4.7876 & TRN \\
\hline CHEMBL1325823 & 737421 & 5.2924 & 5.0001 & TRN \\
\hline CHEMBL1449103 & 737421 & 4.4202 & 4.7143 & TRN \\
\hline CHEMBL1586274 & 737421 & 4.0 & 4.6332 & TRN \\
\hline CHEMBL1310617 & 737421 & 6.5229 & 5.9463 & TRN \\
\hline CHEMBL1524306 & 737421 & 5.6216 & 5.5857 & TRN \\
\hline CHEMBL155563 & 737421 & 4.0 & 5.0678 & TRN \\
\hline CHEMBL1369671 & 737421 & 5.0 & 4.7573 & TRN \\
\hline CHEMBL1313521 & 737421 & 5.4535 & 4.6219 & TRN \\
\hline CHEMBL1341970 & 737421 & 4.02 & 4.4711 & TRN \\
\hline CHEMBL1567593 & 737421 & 4.2668 & 4.88899 & 9999999999 \\
\hline CHEMBL498373 & 737421 & 5.7352 & 4.8774 & TRN \\
\hline CHEMBL1561240 & 737421 & 4.0 & 4.614 & TRN \\
\hline CHEMBL1439773 & 737421 & 5.0315 & 4.8321 & TRN \\
\hline CHEMBL1497463 & 737421 & 5.7423 & 5.1512 & TRN \\
\hline CHEMBL1448771 & 737421 & 5.0 & 4.8387 & TST \\
\hline CHEMBL1976507 & 737421 & 5.2175 & 5.8597 & TRN \\
\hline CHEMBL1387790 & 737421 & 6.7959 & 6.7813 & TRN \\
\hline CHEMBL1492922 & 737421 & 5.3072 & 5.3672 & TRN \\
\hline CHEMBL1451348 & 737421 & 4.1662 & 4.754 & TRN \\
\hline CHEMBL1964338 & 737421 & 5.0835 & 4.8333 & TST \\
\hline CHEMBL1588525 & 737421 & 6.4949 & 5.3958 & TRN \\
\hline CHEMBL1361821 & 737421 & 4.0218 & 4.7266 & TRN \\
\hline CHEMBL1299463 & 737421 & 5.279 & 4.3997 & TRN \\
\hline CHEMBL1337500 & 737421 & 5.4001 & 5.0714 & TST \\
\hline CHEMBL3856090 & 737421 & 5.3565 & 4.9667 & TRN \\
\hline CHEMBL1375338 & 737421 & 5.0 & 4.6883 & TRN \\
\hline CHEMBL3192138 & 737421 & 5.7959 & 5.875 & TST \\
\hline CHEMBL1335988 & 737421 & 4.0315 & 5.1415 & TST \\
\hline CHEMBL451574 & 737421 & 4.2248 & 5.3261 & TST \\
\hline CHEMBL1375155 & 737421 & 5.0605 & 5.0032 & TST \\
\hline
\end{tabular}


Supplemental Table S2.txt

\begin{tabular}{|c|c|c|c|c|c|}
\hline CHEMBL1349180 & 737421 & 5.2306 & 4.8838 & TRN & \\
\hline CHEMBL1566334 & 737421 & 5.1361 & 4.7123 & TRN & \\
\hline CHEMBL1493101 & 737421 & 4.0894 & 4.8216 & TRN & \\
\hline CHEMBL1545556 & 737421 & 5.6144 & 5.1068 & TRN & \\
\hline CHEMBL1544093 & 737421 & 5.0 & 4.9918 & TRN & \\
\hline CHEMBL1570857 & 737421 & 5.2457 & 4.4089 & TRN & \\
\hline CHEMBL1441792 & 737421 & 5.0362 & 4.9988 & TRN & \\
\hline CHEMBL1490677 & 737421 & 4.0 & 5.0308 & TST & \\
\hline CHEMBL1572967 & 737421 & 5.475 & 5.15799 & 99999999995 & TRN \\
\hline CHEMBL1407650 & 737421 & 4.1469 & 4.7376 & TRN & \\
\hline CHEMBL1324256 & 737421 & 5.4449 & 4.8641 & TRN & \\
\hline CHEMBL1598287 & 737421 & 5.0241 & 4.7106 & TRN & \\
\hline CHEMBL1367885 & 737421 & 4.0 & 4.8656 & TRN & \\
\hline CHEMBL1306258 & 737421 & 5.0 & 5.2393 & TRN & \\
\hline CHEMBL1406703 & 737421 & 5.0132 & 4.4675 & TRN & \\
\hline CHEMBL1586817 & 737421 & 4.0195 & 4.5817 & TRN & \\
\hline CHEMBL1458022 & 737421 & 5.983 & 5.2426 & TRN & \\
\hline CHEMBL1499951 & 737421 & 5.4763 & 4.9197 & TRN & \\
\hline CHEMBL607309 & 737421 & 4.0635 & 4.6636 & TRN & \\
\hline CHEMBL2095095 & 737421 & 5.585 & 5.696006 & 3000000001 & TRN \\
\hline CHEMBL1578503 & 737421 & 5.1752 & 4.6244 & TRN & \\
\hline CHEMBL1312928 & 737421 & 7.7696 & 6.2468 & TRN & \\
\hline CHEMBL270297 & 737421 & 5.6055 & 5.6349 & TST & \\
\hline CHEMBL1479340 & 737421 & 4.0182 & 4.4059 & TRN & \\
\hline CHEMBL1373339 & 737421 & 5.0 & 4.8394 & TST & \\
\hline CHEMBL1519375 & 737421 & 5.0 & 4.5376 & TRN & \\
\hline CHEMBL1415841 & 737421 & 4.0462 & 4.8272 & TRN & \\
\hline CHEMBL1374835 & 737421 & 5.0 & 4.609 & TRN & \\
\hline CHEMBL1555935 & 737421 & 7.7959 & 6.2665 & TRN & \\
\hline CHEMBL1487337 & 737421 & 4.0074 & 4.815 & TST & \\
\hline CHEMBL1372889 & 737421 & 4.7496 & 5.5588 & TRN & \\
\hline CHEMBL1304919 & 737421 & 4.0 & 4.6457 & TRN & \\
\hline CHEMBL1544664 & 737421 & 4.0 & 4.8392 & TRN & \\
\hline CHEMBL1482670 & 737421 & 4.0048 & 4.4938 & TRN & \\
\hline CHEMBL1526751 & 737421 & 4.0292 & 4.9847 & TRN & \\
\hline CHEMBL1558210 & 737421 & 4.0159 & 5.1556 & TRN & \\
\hline CHEMBL1587373 & 737421 & 4.0159 & 4.7691 & TRN & \\
\hline CHEMBL193872 & 737421 & 6.7959 & 5.024 & TRN & \\
\hline CHEMBL 2003943 & 737421 & 5.5243 & 4.9126 & TRN & \\
\hline CHEMBL1501078 & 737421 & 6.0 & 4.4918 & TRN & \\
\hline CHEMBL1311185 & 737421 & 4.0146 & 5.3719 & TRN & \\
\hline CHEMBL1406161 & 737421 & 4.0 & 4.867 & TRN & \\
\hline CHEMBL3211865 & 737421 & 4.0 & 4.8944 & TRN & \\
\hline CHEMBL1385295 & 737421 & 4.1549 & 4.902 & TST & \\
\hline CHEMBL1588356 & 737421 & 4.2147 & 4.7089 & TRN & \\
\hline CHEMBL1465353 & 737421 & 5.2798 & 4.7136 & TRN & \\
\hline CHEMBL1989225 & 737421 & 5.0 & 4.9595 & TRN & \\
\hline CHEMBL1985061 & 737421 & 7.4202 & 5.5844 & TRN & \\
\hline
\end{tabular}




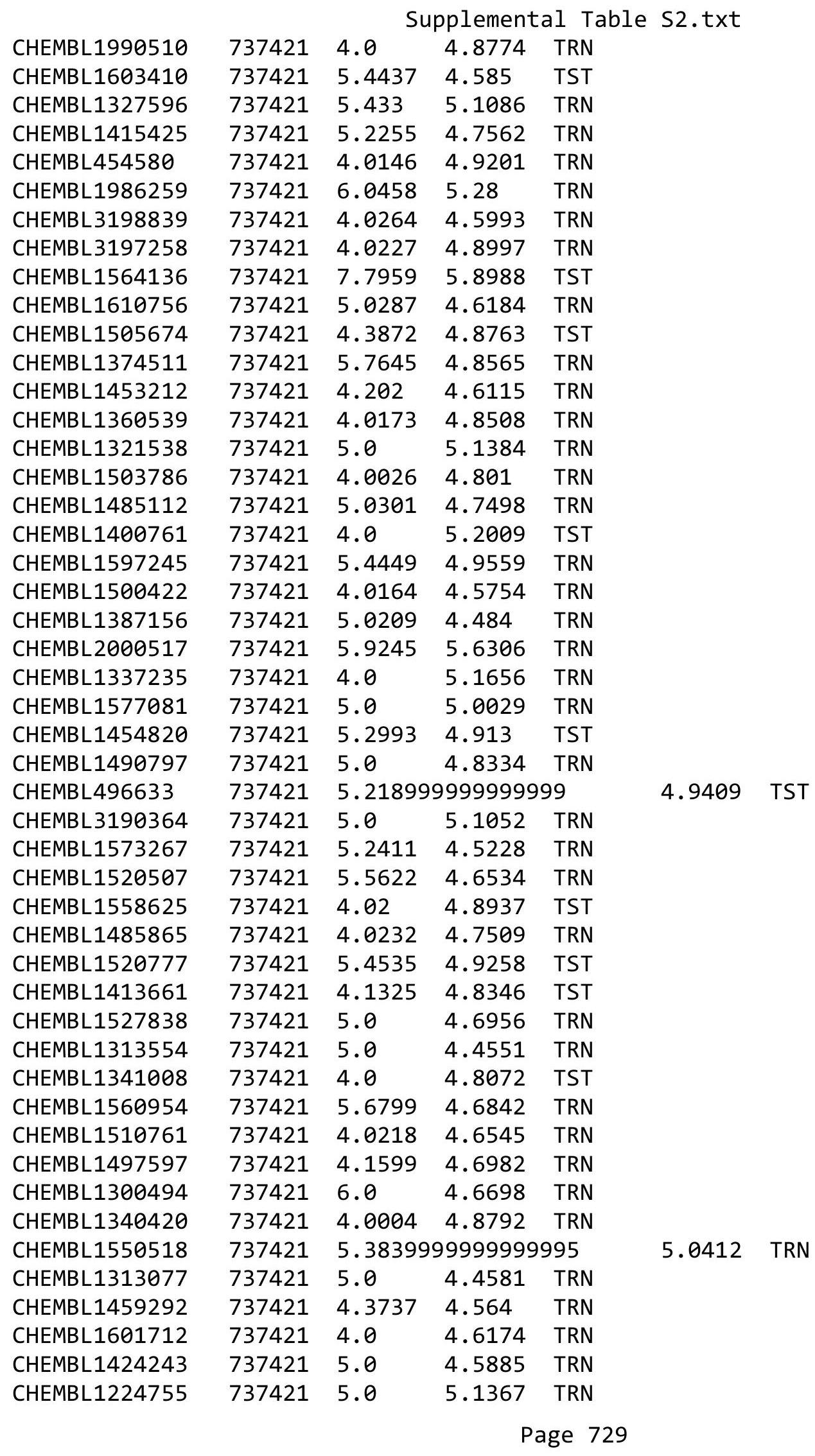


Supplemental Table S2.txt

\begin{tabular}{|c|c|c|c|c|c|}
\hline CHEMBL1603615 & 737421 & 5.6308 & 5.016 & TRN & \\
\hline CHEMBL1321531 & 737421 & 5.3045 & 4.8782 & TRN & \\
\hline CHEMBL1311729 & 737421 & 4.3372 & 4.5328 & TRN & \\
\hline CHEMBL1457060 & 737421 & 5.0665 & 4.7914 & TRN & \\
\hline CHEMBL1463847 & 737421 & 5.0 & 4.7468 & TRN & \\
\hline CHEMBL1371946 & 737421 & 4.51 & 5.0454 & TST & \\
\hline CHEMBL1309733 & 737421 & 5.0264 & 4.5573 & TRN & \\
\hline CHEMBL1407622 & 737421 & 4.2993 & 4.6365 & TRN & \\
\hline CHEMBL1455813 & 737421 & 4.0 & 4.8019 & TRN & \\
\hline CHEMBL1486651 & 737421 & 7.7959 & 6.4208 & TRN & \\
\hline CHEMBL1465527 & 737421 & 4.0 & 5.1695 & TST & \\
\hline CHEMBL1324125 & 737421 & 7.7959 & 6.2672 & TRN & \\
\hline CHEMBL1594720 & 737421 & 5.0 & 5.0243 & TRN & \\
\hline CHEMBL1365696 & 737421 & 5.3206 & 5.1946 & TRN & \\
\hline CHEMBL3185655 & 737421 & 6.7959 & 6.7296 & TRN & \\
\hline CHEMBL1319618 & 737421 & 5.4237 & 5.0762 & TRN & \\
\hline CHEMBL1490887 & 737421 & 4.0177 & 4.5772 & TST & \\
\hline CHEMBL1418598 & 737421 & 4.6038 & 4.5272 & TRN & \\
\hline CHEMBL1969593 & 737421 & 5.0 & 4.8607 & TRN & \\
\hline CHEMBL524222 & 737421 & 5.1759 & 4.4937 & TRN & \\
\hline CHEMBL1422386 & 737421 & 4.0 & 5.4114 & TRN & \\
\hline CHEMBL1491402 & 737421 & 5.0088 & 4.9828 & TRN & \\
\hline CHEMBL1367089 & 737421 & 4.0237 & 4.7829 & TRN & \\
\hline CHEMBL1558847 & 737421 & 5.0448 & 4.6065 & TST & \\
\hline CHEMBL1336745 & 737421 & 4.0209 & 4.5165 & TRN & \\
\hline CHEMBL1988416 & 737421 & 5.2299 & 4.9261 & TST & \\
\hline CHEMBL1994838 & 737421 & 5.7496 & 5.0544 & TRN & \\
\hline CHEMBL1347144 & 737421 & 5.0146 & 4.9497 & TRN & \\
\hline CHEMBL1608078 & 737421 & 5.3206 & \multicolumn{2}{|c|}{5.1370000000000005} & TRN \\
\hline CHEMBL1583552 & 737421 & 5.0 & 4.8615 & TRN & \\
\hline CHEMBL1561287 & 737421 & 4.0 & 4.547 & TRN & \\
\hline CHEMBL1521960 & 737421 & 5.3872 & 5.5597 & TRN & \\
\hline CHEMBL1994372 & 737421 & 5.0 & 4.6585 & TRN & \\
\hline CHEMBL1332979 & 737421 & 5.5901 & 4.8514 & TRN & \\
\hline CHEMBL1607568 & 737421 & 4.5918 & 5.1719 & TRN & \\
\hline CHEMBL1472409 & 737421 & 4.0 & 4.756 & TRN & \\
\hline CHEMBL1379970 & 737421 & 4.9547 & 5.3297 & TRN & \\
\hline CHEMBL1403242 & 737421 & 5.2725 & 4.7001 & TRN & \\
\hline CHEMBL1518326 & 737421 & 4.0173 & 5.0559 & TRN & \\
\hline CHEMBL610198 & 737421 & 4.0246 & 5.1453 & TRN & \\
\hline CHEMBL1445889 & 737421 & 5.0367 & 4.5969 & TST & \\
\hline CHEMBL1349113 & 737421 & 5.3883 & 4.694 & TRN & \\
\hline CHEMBL3212285 & 737421 & 5.5272 & \multicolumn{2}{|c|}{4.9239999999999995} & TRN \\
\hline CHEMBL1500565 & 737421 & 5.3143 & 4.7182 & TRN & \\
\hline CHEMBL1493251 & 737421 & 4.0 & 5.0263 & TRN & \\
\hline CHEMBL1471141 & 737421 & 5.0 & 4.9691 & TRN & \\
\hline CHEMBL 2000338 & 737421 & 4.0123 & 4.6113 & TRN & \\
\hline CHEMBL1406097 & 737421 & 5.0168 & 4.5464 & TRN & \\
\hline
\end{tabular}


Supplemental Table S2.txt

\begin{tabular}{|c|c|c|c|c|c|}
\hline CHEMBL1451950 & 737421 & 5.289 & 4.5004 & TST & \\
\hline CHEMBL1561080 & 737421 & 4.0278 & 4.8541 & TRN & \\
\hline CHEMBL1506527 & 737421 & 5.3045 & 4.8777 & TRN & \\
\hline CHEMBL1381257 & 737421 & 5.3862 & 4.7924 & TRN & \\
\hline CHEMBL1464853 & 737421 & 5.0132 & 4.5839 & TST & \\
\hline CHEMBL1329610 & 737421 & 5.0 & 4.8359 & TRN & \\
\hline CHEMBL1499792 & 737421 & 5.5086 & 4.7078 & TRN & \\
\hline CHEMBL1414964 & 737421 & 5.0 & 4.8037 & TRN & \\
\hline CHEMBL1450948 & 737421 & 5.5243 & 4.7955 & TRN & \\
\hline CHEMBL1499893 & 737421 & 5.3526 & 5.0437 & TRN & \\
\hline CHEMBL 2006634 & 737421 & 4.0079 & 4.6016 & TRN & \\
\hline CHEMBL1540112 & 737421 & 4.1261 & 5.3718 & TRN & \\
\hline CHEMBL3197371 & 737421 & 5.015 & 4.8795 & TRN & \\
\hline CHEMBL1323248 & 737421 & 4.0079 & 4.8784 & TRN & \\
\hline CHEMBL1411089 & 737421 & 5.0 & 4.5768 & TRN & \\
\hline CHEMBL1385193 & 737421 & 5.0 & 5.4545 & TRN & \\
\hline CHEMBL3195173 & 737421 & 5.0 & 4.7708 & TRN & \\
\hline CHEMBL1448637 & 737421 & 5.0 & 5.0227 & TRN & \\
\hline CHEMBL3856095 & 737421 & 5.2411 & 5.237999 & 99999999995 & TRN \\
\hline CHEMBL607299 & 737421 & 4.0 & 4.7526 & TST & \\
\hline CHEMBL1338150 & 737421 & 5.2668 & 4.7598 & TRN & \\
\hline CHEMBL1425823 & 737421 & 4.0114 & 4.8822 & TRN & \\
\hline CHEMBL1319488 & 737421 & 5.5654 & 5.1729 & TRN & \\
\hline CHEMBL1421518 & 737421 & 4.0376 & 5.1991 & TRN & \\
\hline CHEMBL1532453 & 737421 & 5.0 & 4.6612 & TST & \\
\hline CHEMBL3194760 & 737421 & 5.3788 & 4.8116 & TRN & \\
\hline CHEMBL1493396 & 737421 & 4.2464 & 4.901 & TST & \\
\hline CHEMBL1442537 & 737421 & 5.224 & 4.5894 & TRN & \\
\hline CHEMBL1540036 & 737421 & 5.0 & 4.5338 & TRN & \\
\hline CHEMBL1399698 & 737421 & 4.0 & 4.9618 & TRN & \\
\hline CHEMBL1361774 & 737421 & 5.0 & 4.862 & TRN & \\
\hline CHEMBL1452795 & 737421 & 5.3757 & 5.5369 & TRN & \\
\hline CHEMBL1363614 & 737421 & 4.011 & 4.4855 & TRN & \\
\hline CHEMBL1419438 & 737421 & 5.2175 & 4.5866 & TRN & \\
\hline CHEMBL1981103 & 737421 & 4.0137 & 5.0774 & TST & \\
\hline CHEMBL1390659 & 737421 & 5.7167 & 4.9933 & TRN & \\
\hline CHEMBL1373822 & 737421 & 5.0 & 5.295 & TRN & \\
\hline CHEMBL1412583 & 737421 & 4.4949 & 5.033 & TST & \\
\hline CHEMBL1429129 & 737421 & 5.0 & 5.1224 & TST & \\
\hline CHEMBL3209649 & 737421 & \multicolumn{2}{|c|}{5.382000000000001} & 4.5336 & TRN \\
\hline CHEMBL1352270 & 737421 & 4.2716 & 5.4028 & TRN & \\
\hline CHEMBL1610049 & 737421 & 4.0 & 4.9887 & TRN & \\
\hline CHEMBL3197151 & 737421 & 5.0 & 4.4982 & TRN & \\
\hline CHEMBL1582580 & 737421 & 4.0 & 4.5291 & TRN & \\
\hline CHEMBL1410479 & 737421 & 4.0 & 5.0127 & TRN & \\
\hline CHEMBL1528880 & 737421 & 5.0 & 4.7831 & TST & \\
\hline CHEMBL1505206 & 737421 & 5.3979 & 4.5027 & TRN & \\
\hline CHEMBL1517738 & 737421 & 4.0141 & 4.6571 & TST & \\
\hline
\end{tabular}




\begin{tabular}{|c|c|c|c|c|}
\hline \multicolumn{5}{|c|}{ Supplemental Table S2.txt } \\
\hline CHEMBL1401645 & 737421 & 5.2449 & 4.8307 & TRN \\
\hline CHEMBL1438983 & 737421 & 5.7471 & 4.8145 & TRN \\
\hline CHEMBL1440300 & 737421 & 5.6198 & 5.5454 & TRN \\
\hline CHEMBL1543875 & 737421 & 4.0804 & 4.3453 & TRN \\
\hline CHEMBL1509108 & 737421 & 5.0 & 4.8338 & TRN \\
\hline CHEMBL1461400 & 737421 & 7.7212 & 5.3628 & TRN \\
\hline CHEMBL3211781 & 737421 & 5.153 & 4.836 & TRN \\
\hline CHEMBL1501495 & 737421 & 5.1593 & 4.7221 & TRN \\
\hline CHEMBL1303714 & 737421 & 5.2007 & 4.7812 & TRN \\
\hline CHEMBL3192609 & 737421 & 5.3206 & 4.9789 & TRN \\
\hline CHEMBL1602157 & 737421 & 5.5817 & 4.6092 & TRN \\
\hline CHEMBL1464968 & 737421 & 5.0 & 4.7159 & TRN \\
\hline CHEMBL1607086 & 737421 & 6.0706 & 6.2143 & TRN \\
\hline CHEMBL1602192 & 737421 & 4.0 & 4.7119 & TRN \\
\hline CHEMBL1535252 & 737421 & 5.3206 & 4.785 & TRN \\
\hline CHEMBL1300317 & 737421 & 4.7055 & 5.1131 & TRN \\
\hline CHEMBL1562575 & 737421 & 6.4685 & 6.7961 & TRN \\
\hline CHEMBL1544559 & 737421 & 4.0 & 4.775 & TRN \\
\hline CHEMBL1613636 & 737421 & 5.0 & 4.8834 & TST \\
\hline CHEMBL1438319 & 737421 & 4.0 & 4.8179 & TRN \\
\hline CHEMBL3189719 & 737421 & 4.0386 & 4.6269 & TRN \\
\hline CHEMBL1537509 & 737421 & 6.7959 & 5.5209 & TST \\
\hline CHEMBL1371362 & 737421 & 4.0004 & 4.6801 & TST \\
\hline CHEMBL1344875 & 737421 & 5.0506 & 4.4512 & TRN \\
\hline CHEMBL 388978 & 737421 & 6.7959 & 5.8586 & TST \\
\hline CHEMBL1309448 & 737421 & 5.0395 & 4.7799 & TST \\
\hline CHEMBL1384974 & 737421 & 4.0 & 4.7394 & TRN \\
\hline CHEMBL1346096 & 737421 & 5.3726 & 5.401 & TST \\
\hline CHEMBL1440507 & 737421 & 4.0 & 5.0813 & TRN \\
\hline CHEMBL1339398 & 737421 & 5.0 & 4.7392 & TST \\
\hline CHEMBL1569824 & 737421 & 5.2269 & 4.8544 & TRN \\
\hline CHEMBL1580910 & 737421 & 5.4202 & 4.9009 & TST \\
\hline CHEMBL1572119 & 737421 & 4.2007 & 4.6894 & TRN \\
\hline CHEMBL1570874 & 737421 & 5.0 & 4.6438 & TRN \\
\hline CHEMBL1498599 & 737421 & 5.3279 & 4.6511 & TRN \\
\hline CHEMBL1457194 & 737421 & 5.0 & 4.7892 & TST \\
\hline CHEMBL1301125 & 737421 & 5.6655 & 5.3124 & TST \\
\hline CHEMBL1444103 & 737421 & 5.3325 & 4.6929 & TST \\
\hline CHEMBL1410689 & 737421 & 5.0 & 4.7972 & TST \\
\hline CHEMBL1576870 & 737421 & 6.7959 & 5.9953 & TRN \\
\hline CHEMBL1450616 & 737421 & 4.0 & 4.5576 & TRN \\
\hline CHEMBL1494120 & 737421 & 5.7011 & 5.6957 & TRN \\
\hline CHEMBL3199050 & 737421 & 5.8447 & 5.2697 & TRN \\
\hline CHEMBL1520595 & 737421 & 5.5467 & 4.6649 & TRN \\
\hline CHEMBL1421347 & 737421 & 4.0083 & 4.62 & TST \\
\hline CHEMBL3193792 & 737421 & 5.0 & 4.4411 & TRN \\
\hline CHEMBL1389966 & 737421 & 4.2284 & 5.49 & TRN \\
\hline CHEMBL1443632 & 737421 & 5.015 & 5.1388 & TRN \\
\hline
\end{tabular}




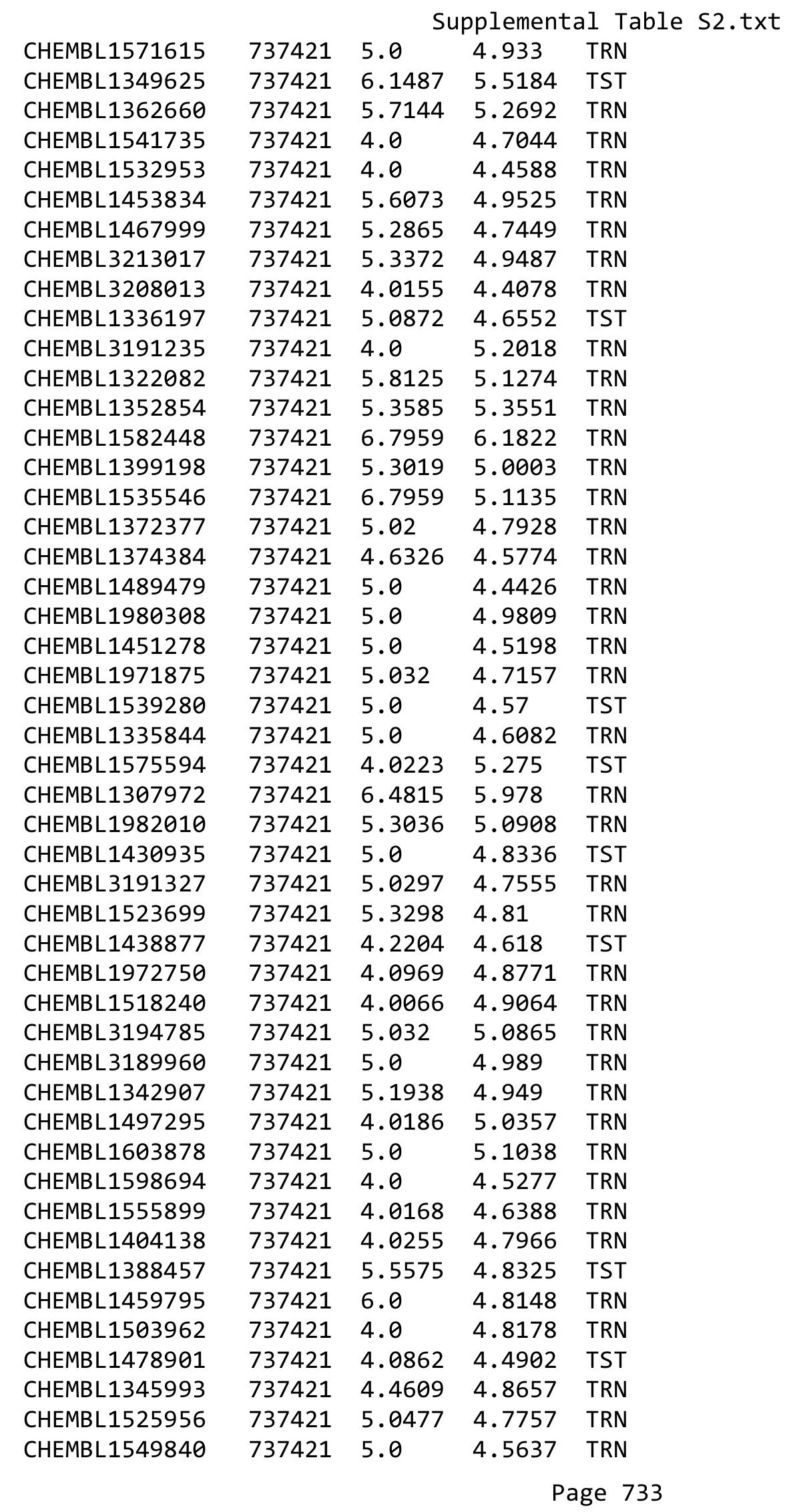




\begin{tabular}{|c|c|c|c|c|c|c|}
\hline \multicolumn{7}{|c|}{ Supplemental Table S2.txt } \\
\hline CHEMBL1319204 & 737421 & 5.0 & 4.7617 & TRN & & \\
\hline CHEMBL1496754 & 737421 & 4.0 & 5.109 & TRN & & \\
\hline CHEMBL1345063 & 737421 & 4.1403 & 5.0988 & TRN & & \\
\hline CHEMBL1499127 & 737421 & 4.0255 & 4.6111 & TRN & & \\
\hline CHEMBL1990598 & 737421 & 5.6904 & 5.4702 & TRN & & \\
\hline CHEMBL1597042 & 737421 & 5.0 & 4.791 & TRN & & \\
\hline CHEMBL1349727 & 737421 & 5.3251 & 5.0549 & TRN & & \\
\hline CHEMBL1524484 & 737421 & 6.7959 & 5.8259 & TRN & & \\
\hline CHEMBL1505902 & 737421 & 4.4214 & 4.5205 & TRN & & \\
\hline CHEMBL1523938 & 737421 & 4.0259 & 4.9358 & TST & & \\
\hline CHEMBL1532114 & 737421 & 4.1373 & 4.3868 & TRN & & \\
\hline CHEMBL 3213235 & 737421 & \multicolumn{3}{|c|}{5.617999999999999} & 4.4354 & TRN \\
\hline CHEMBL3193201 & 737421 & 4.0214 & 4.5521 & TRN & & \\
\hline CHEMBL1484741 & 737421 & 6.0862 & 4.7072 & TRN & & \\
\hline CHEMBL1334593 & 737421 & 5.1361 & 4.8947 & TRN & & \\
\hline CHEMBL1470373 & 737421 & 4.0182 & 4.7909 & TRN & & \\
\hline CHEMBL1445710 & 737421 & \multicolumn{3}{|c|}{5.3839999999999995} & 5.1214 & TRN \\
\hline CHEMBL1566847 & 737421 & 4.1096 & 4.8922 & TRN & & \\
\hline CHEMBL3198659 & 737421 & 4.27 & 4.8716 & TST & & \\
\hline CHEMBL1541829 & 737421 & 5.0 & 4.5293 & TRN & & \\
\hline CHEMBL3211808 & 737421 & 4.0511 & 5.0603 & TRN & & \\
\hline CHEMBL1384167 & 737421 & 5.6819 & 5.3729 & TRN & & \\
\hline CHEMBL1608347 & 737421 & 5.0 & 4.879 & TRN & & \\
\hline CHEMBL1334404 & 737421 & 4.0044 & 4.9463 & TST & & \\
\hline CHEMBL1463172 & 737421 & 4.0283 & 4.3109 & TST & & \\
\hline CHEMBL1598843 & 737421 & 4.0232 & 4.6633 & TRN & & \\
\hline CHEMBL1430425 & 737421 & 5.0 & 4.9141 & TRN & & \\
\hline CHEMBL3195749 & 737421 & 4.0 & 5.3661 & TRN & & \\
\hline CHEMBL1334984 & 737421 & 6.1192 & 5.2741 & TRN & & \\
\hline CHEMBL1337445 & 737421 & 4.0 & 4.4304 & TRN & & \\
\hline CHEMBL1452159 & 737421 & 6.3768 & 6.5598 & TRN & & \\
\hline CHEMBL1491705 & 737421 & 6.2676 & 5.3273 & TRN & & \\
\hline CHEMBL1411310 & 737421 & 4.0794 & 4.82100 & 0000000001 & & TRN \\
\hline CHEMBL1884996 & 737421 & 6.7959 & 6.1577 & TRN & & \\
\hline CHEMBL1349747 & 737421 & 5.0 & 4.7671 & TST & & \\
\hline CHEMBL1494650 & 737421 & 4.7545 & 5.4948 & TRN & & \\
\hline CHEMBL1973629 & 737421 & 5.4089 & 4.9359 & TRN & & \\
\hline CHEMBL1580520 & 737421 & 4.0074 & 4.9035 & TRN & & \\
\hline CHEMBL1565496 & 737421 & 5.1746 & 4.6102 & TRN & & \\
\hline CHEMBL1446421 & 737421 & 5.2381 & 4.67899 & 9999999999 & & TRN \\
\hline CHEMBL3191430 & 737421 & 5.4547 & 4.9021 & TRN & & \\
\hline CHEMBL1420393 & 737421 & 5.2708 & 5.0273 & TRN & & \\
\hline CHEMBL338474 & 737421 & 5.5834 & 5.494 & TST & & \\
\hline CHEMBL1541339 & 737421 & 7.5229 & 5.4717 & TRN & & \\
\hline CHEMBL1425166 & 737421 & 5.6696 & 4.9022 & TRN & & \\
\hline CHEMBL1385413 & 737421 & 4.02 & 5.1393 & TRN & & \\
\hline CHEMBL1497950 & 737421 & 5.0 & 4.8316 & TRN & & \\
\hline CHEMBL601952 & 737421 & 5.0 & 4.4548 & TRN & & \\
\hline
\end{tabular}


Supplemental Table S2.txt

\begin{tabular}{|c|c|c|c|c|c|c|}
\hline CHEMBL1323101 & 737421 & 4.0132 & 4.8185 & TRN & & \\
\hline CHEMBL1565040 & 737421 & 4.0128 & 4.5414 & TRN & & \\
\hline CHEMBL1532377 & 737421 & 5.6925 & 5.1046 & TRN & & \\
\hline CHEMBL1460235 & 737421 & 5.2676 & 4.7584 & TRN & & \\
\hline CHEMBL1384702 & 737421 & 5.0241 & 4.7829 & TRN & & \\
\hline CHEMBL1508982 & 737421 & 4.2765 & 5.3451 & TRN & & \\
\hline CHEMBL1607896 & 737421 & 5.1101 & 4.8815 & TRN & & \\
\hline CHEMBL1497939 & 737421 & 5.3497 & 5.3034 & TRN & & \\
\hline CHEMBL1517755 & 737421 & 4.0123 & 4.4516 & TRN & & \\
\hline CHEMBL1467896 & 737421 & 4.3288 & 4.7374 & TRN & & \\
\hline CHEMBL1988798 & 737421 & 5.1013 & 4.4211 & TRN & & \\
\hline CHEMBL1507704 & 737421 & 4.0278 & 4.5452 & TRN & & \\
\hline CHEMBL1427549 & 737421 & 5.21899 & 799999999 & & 4.5254 & TRN \\
\hline CHEMBL1413495 & 737421 & 6.0 & 4.5287 & TRN & & \\
\hline CHEMBL1363662 & 737421 & 4.0878 & 4.8804 & TST & & \\
\hline CHEMBL433680 & 737421 & 5.7959 & 6.5275 & TST & & \\
\hline CHEMBL1541840 & 737421 & 5.0 & 4.9877 & TRN & & \\
\hline CHEMBL1450266 & 737421 & 5.5901 & 4.8642 & TRN & & \\
\hline CHEMBL1387563 & 737421 & 5.0 & 4.5296 & TRN & & \\
\hline CHEMBL1482663 & 737421 & 5.3696 & 5.3781 & TST & & \\
\hline CHEMBL1328169 & 737421 & 5.0297 & 5.2145 & TRN & & \\
\hline CHEMBL1477778 & 737421 & 5.7122 & 4.5201 & TRN & & \\
\hline CHEMBL1594232 & 737421 & 5.0 & 4.9687 & TRN & & \\
\hline CHEMBL1431662 & 737421 & 5.0218 & 4.3819 & TRN & & \\
\hline CHEMBL1524152 & 737421 & 5.0 & 4.3942 & TRN & & \\
\hline CHEMBL1496362 & 737421 & 5.0 & 4.8128 & TST & & \\
\hline CHEMBL 2369275 & 737421 & 5.0 & 4.5564 & TRN & & \\
\hline CHEMBL1544737 & 737421 & 5.0306 & 4.6204 & TRN & & \\
\hline CHEMBL1390139 & 737421 & 4.0315 & 4.9273 & TRN & & \\
\hline CHEMBL582081 & 737421 & 5.0088 & 4.4231 & TRN & & \\
\hline CHEMBL1604527 & 737421 & 5.0 & 4.7671 & TRN & & \\
\hline CHEMBL1580532 & 737421 & 5.025 & 4.4545 & TRN & & \\
\hline CHEMBL570399 & 737421 & 5.0 & 5.0156 & TRN & & \\
\hline CHEMBL1318970 & 737421 & 5.0 & 4.9836 & TRN & & \\
\hline CHEMBL1564660 & 737421 & 4.0146 & 4.7406 & TRN & & \\
\hline CHEMBL1479316 & 737421 & \multicolumn{3}{|c|}{4.053999999999999} & 5.3077 & TRN \\
\hline CHEMBL1555913 & 737421 & 4.0 & 5.0152 & TST & & \\
\hline CHEMBL3192030 & 737421 & 4.1959 & 4.7016 & TRN & & \\
\hline CHEMBL1455786 & 737421 & 5.0 & 4.8818 & TRN & & \\
\hline CHEMBL3189663 & 737421 & 5.0 & 4.5057 & TRN & & \\
\hline CHEMBL584269 & 737421 & 5.0 & 4.7571 & TRN & & \\
\hline CHEMBL1430166 & 737421 & 5.2749 & 4.9088 & TST & & \\
\hline CHEMBL1492648 & 737421 & 5.0 & 4.8428 & TRN & & \\
\hline CHEMBL3193216 & 737421 & 5.2418 & 4.9837 & TRN & & \\
\hline CHEMBL1509120 & 737421 & 5.2255 & 4.7993 & TRN & & \\
\hline CHEMBL 2006503 & 737421 & 5.4045 & 5.1965 & TRN & & \\
\hline CHEMBL1500489 & 737421 & 4.1681 & 4.7379 & TST & & \\
\hline CHEMBL1581696 & 737421 & 4.1118 & 4.9313 & TRN & & \\
\hline
\end{tabular}




\begin{tabular}{|c|c|c|c|c|c|}
\hline \multicolumn{6}{|c|}{ Supplemental Table S2.txt } \\
\hline CHEMBL1353664 & 737421 & 5.0 & 4.3746 & TRN & \\
\hline CHEMBL1731165 & 737421 & 5.0 & 4.4007 & TRN & \\
\hline CHEMBL1453722 & 737421 & 5.6038 & 5.4421 & TRN & \\
\hline CHEMBL1346062 & 737421 & 5.1945 & 4.4907 & TRN & \\
\hline CHEMBL1417937 & 737421 & 4.0 & 4.8014 & TRN & \\
\hline CHEMBL1338958 & 737421 & 4.0 & 5.1344 & TRN & \\
\hline CHEMBL3198512 & 737421 & 5.0 & 4.6947 & TRN & \\
\hline CHEMBL1544131 & 737421 & 5.3206 & 5.1533 & TRN & \\
\hline CHEMBL1365290 & 737421 & 5.0 & 4.6731 & TRN & \\
\hline CHEMBL1422689 & 737421 & 4.0 & 4.6004 & TRN & \\
\hline CHEMBL1572266 & 737421 & 5.9666 & 4.9479 & TST & \\
\hline CHEMBL1470367 & 737421 & 5.3036 & 4.5307 & TRN & \\
\hline CHEMBL1322557 & 737421 & 4.0114 & 4.9725 & TRN & \\
\hline CHEMBL1493351 & 737421 & 5.0 & 4.7903 & TRN & \\
\hline CHEMBL1442661 & 737421 & 5.0273 & 5.0444 & TRN & \\
\hline CHEMBL1424264 & 737421 & 6.7959 & 4.9282 & TRN & \\
\hline CHEMBL1445776 & 737421 & 4.0159 & 4.5529 & TST & \\
\hline CHEMBL3190415 & 737421 & 5.0 & 4.5221 & TRN & \\
\hline CHEMBL1532375 & 737421 & 5.0 & 4.7531 & TRN & \\
\hline CHEMBL3193769 & 737421 & 4.0958 & 4.9171 & TRN & \\
\hline CHEMBL1533366 & 737421 & 5.2336 & 4.5275 & TRN & \\
\hline CHEMBL1559968 & 737421 & 4.0 & 4.8522 & TST & \\
\hline CHEMBL1523019 & 737421 & 4.0123 & 5.3021 & TRN & \\
\hline CHEMBL19954 & 737421 & 5.2774 & 4.6688 & TST & \\
\hline CHEMBL1521702 & 737421 & 4.3478 & 5.0215 & TRN & \\
\hline CHEMBL 3194371 & 737421 & 5.0 & 4.6707 & TRN & \\
\hline CHEMBL1558724 & 737421 & 5.0969 & 4.4215 & TRN & \\
\hline CHEMBL1470112 & 737421 & 4.0164 & 4.6423 & TST & \\
\hline CHEMBL1422158 & 737421 & 4.0255 & 4.7686 & TRN & \\
\hline CHEMBL1422414 & 737421 & 5.2495 & 4.742 & TRN & \\
\hline CHEMBL1541177 & 737421 & 5.0 & 4.7654 & TRN & \\
\hline CHEMBL1497323 & 737421 & 5.295 & 4.6191 & TST & \\
\hline CHEMBL1361883 & 737421 & 4.0137 & 4.6553 & TRN & \\
\hline CHEMBL1467102 & 737421 & 4.0061 & 4.8466 & TRN & \\
\hline CHEMBL3191021 & 737421 & 5.0625 & 4.8113 & TRN & \\
\hline CHEMBL1607895 & 737421 & 4.5272 & 4.90300 & 00000000005 & TRN \\
\hline CHEMBL1558051 & 737421 & 5.0 & 4.8347 & TRN & \\
\hline CHEMBL1586432 & 737421 & 5.0 & 4.5672 & TRN & \\
\hline CHEMBL 1374860 & 737421 & 5.2612 & 4.8962 & TRN & \\
\hline CHEMBL1493204 & 737421 & 5.1561 & 4.6236 & TRN & \\
\hline CHEMBL1569585 & 737421 & 5.9355 & 5.4247 & TST & \\
\hline CHEMBL1583137 & 737421 & 4.0259 & 4.7839 & TRN & \\
\hline CHEMBL1404904 & 737421 & 5.0 & 4.4916 & TRN & \\
\hline CHEMBL1326118 & 737421 & 5.0232 & 4.6864 & TRN & \\
\hline CHEMBL1467284 & 737421 & 4.0209 & 4.7858 & TRN & \\
\hline CHEMBL1429929 & 737421 & 6.7959 & 4.6772 & TRN & \\
\hline CHEMBL1372052 & 737421 & 4.1445 & 5.0358 & TRN & \\
\hline CHEMBL1381567 & 737421 & 4.0164 & 4.8719 & TRN & \\
\hline
\end{tabular}




\begin{tabular}{|c|c|c|c|c|}
\hline \multicolumn{5}{|c|}{ Supplemental Table S2.txt } \\
\hline CHEMBL1611733 & 737421 & 5.4342 & 5.1161 & TRN \\
\hline CHEMBL1613695 & 737421 & 5.2062 & 4.6607 & TRN \\
\hline CHEMBL1530161 & 737421 & 5.1397 & 4.8383 & TRN \\
\hline CHEMBL1301480 & 737421 & 5.0 & 4.7622 & TRN \\
\hline CHEMBL1503834 & 737421 & 5.3188 & 4.5566 & TRN \\
\hline CHEMBL1438881 & 737421 & 6.3872 & 5.2192 & TRN \\
\hline CHEMBL1584933 & 737421 & 5.0 & 4.9291 & TRN \\
\hline CHEMBL1600882 & 737421 & 5.0 & 4.7847 & TRN \\
\hline CHEMBL1398660 & 737421 & 4.0 & 4.7106 & TRN \\
\hline CHEMBL1352375 & 737421 & 5.0768 & 4.3583 & TRN \\
\hline CHEMBL1420175 & 737421 & 4.1759 & 4.9151 & TRN \\
\hline CHEMBL1539180 & 737421 & 5.2255 & 4.5926 & TRN \\
\hline CHEMBL1371873 & 737421 & 4.0132 & 4.7954 & TRN \\
\hline CHEMBL1500719 & 737421 & 5.0 & 4.887 & TRN \\
\hline CHEMBL3194916 & 737421 & 5.0 & 4.6434 & TRN \\
\hline CHEMBL1345414 & 737421 & 5.0 & 4.7421 & TRN \\
\hline CHEMBL1900850 & 737421 & 6.7959 & 6.987 & TRN \\
\hline CHEMBL3210104 & 737421 & 5.0 & 4.8283 & TRN \\
\hline CHEMBL1523651 & 737421 & 5.0 & 4.9722 & TRN \\
\hline CHEMBL1973525 & 737421 & 4.5735 & 5.0854 & TRN \\
\hline CHEMBL3192431 & 737421 & 5.2007 & 4.8311 & TRN \\
\hline CHEMBL1596965 & 737421 & 5.0 & 4.7391 & TRN \\
\hline CHEMBL1991215 & 737421 & 5.2882 & 4.8639 & TRN \\
\hline CHEMBL1310132 & 737421 & 5.0195 & 5.0371 & TRN \\
\hline CHEMBL1450615 & 737421 & 4.0 & 4.9373 & TRN \\
\hline CHEMBL1503152 & 737421 & 4.0114 & 4.575 & TRN \\
\hline CHEMBL1589652 & 737421 & 4.0 & 4.817 & TRN \\
\hline CHEMBL582444 & 737421 & 5.5969 & 4.9892 & TST \\
\hline CHEMBL1456379 & 737421 & 5.0 & 4.5421 & TRN \\
\hline CHEMBL3197224 & 737421 & 5.1409 & 4.6022 & TST \\
\hline CHEMBL1480939 & 737421 & 5.0 & 4.9252 & TRN \\
\hline CHEMBL1567274 & 737421 & 4.1612 & 4.7342 & TRN \\
\hline CHEMBL1399191 & 737421 & 5.0 & 4.489 & TST \\
\hline CHEMBL1566903 & 737421 & 5.0 & 4.9009 & TST \\
\hline CHEMBL1447697 & 737421 & 5.3726 & 5.0478 & TRN \\
\hline CHEMBL1337193 & 737421 & 5.5918 & 4.9518 & TRN \\
\hline CHEMBL1574908 & 737421 & 4.0223 & 4.5787 & TRN \\
\hline CHEMBL1341040 & 737421 & 4.0 & 4.9455 & TRN \\
\hline CHEMBL1539224 & 737421 & 4.6253 & 4.8941 & TST \\
\hline CHEMBL1480424 & 737421 & 4.0205 & 4.8145 & TRN \\
\hline CHEMBL1426059 & 737421 & 5.3936 & 4.6015 & TRN \\
\hline CHEMBL1531073 & 737421 & 5.5361 & 5.3604 & TRN \\
\hline CHEMBL1520407 & 737421 & 5.0434 & 4.5275 & TRN \\
\hline CHEMBL1420589 & 737421 & 5.8894 & 5.0162 & TRN \\
\hline CHEMBL1325168 & 737421 & 4.0106 & 4.6491 & TST \\
\hline CHEMBL3190181 & 737421 & 5.3526 & 5.605 & TRN \\
\hline CHEMBL3192732 & 737421 & 5.6364 & 4.9566 & TRN \\
\hline CHEMBL1563911 & 737421 & 5.0 & 4.4855 & TRN \\
\hline
\end{tabular}




\begin{tabular}{|c|c|c|c|c|c|c|}
\hline & & \multicolumn{5}{|c|}{ Supplemental Table S2.txt } \\
\hline CHEMBL1341981 & 737421 & 5.3344 & 5.1419 & TRN & & \\
\hline CHEMBL1600073 & 737421 & 5.1549 & 5.34 & TRN & & \\
\hline CHEMBL518292 & 737421 & 6.0706 & 5.4134 & TST & & \\
\hline CHEMBL3191034 & 737421 & 5.0 & 4.5827 & TRN & & \\
\hline CHEMBL1541967 & 737421 & 5.4547 & 4.8354 & TRN & & \\
\hline CHEMBL1539520 & 737421 & 4.0026 & 4.8767 & TRN & & \\
\hline CHEMBL1392313 & 737421 & 5.0 & 4.9094 & TST & & \\
\hline CHEMBL1427221 & 737421 & 4.1778 & 4.7369 & TRN & & \\
\hline CHEMBL1530031 & 737421 & 4.0191 & 4.7898 & TRN & & \\
\hline CHEMBL1360959 & 737421 & 5.1891 & 5.0428 & TRN & & \\
\hline CHEMBL1335610 & 737421 & 4.0 & 4.9377 & TRN & & \\
\hline CHEMBL3199901 & 737421 & 5.0 & 4.8632 & TRN & & \\
\hline CHEMBL1450156 & 737421 & \multicolumn{3}{|c|}{5.2620000000000005} & 4.9296 & TRN \\
\hline CHEMBL1524500 & 737421 & 5.1221 & 5.0391 & TRN & & \\
\hline CHEMBL1426695 & 737421 & 5.2874 & 4.416 & TRN & & \\
\hline CHEMBL494255 & 737421 & 5.0 & 5.2314 & TST & & \\
\hline CHEMBL1482292 & 737421 & 5.6126 & 4.928 & TST & & \\
\hline CHEMBL1576094 & 737421 & 4.0 & 4.4965 & TRN & & \\
\hline CHEMBL1347390 & 737421 & 5.3307 & 4.692 & TRN & & \\
\hline CHEMBL1428071 & 737421 & 4.0 & 5.0835 & TRN & & \\
\hline CHEMBL1524101 & 737421 & 4.0 & 4.6752 & TRN & & \\
\hline CHEMBL1459746 & 737421 & 5.2733 & 5.1097 & TRN & & \\
\hline CHEMBL1329054 & 737421 & 4.248 & 5.0188 & TRN & & \\
\hline CHEMBL1428417 & 737421 & 5.6308 & 4.9414 & TRN & & \\
\hline CHEMBL1417604 & 737421 & 4.279 & 4.5331 & TRN & & \\
\hline CHEMBL1347846 & 737421 & 4.0 & 5.0107 & TRN & & \\
\hline CHEMBL1562986 & 737421 & 5.0 & 4.9112 & TRN & & \\
\hline CHEMBL1578591 & 737421 & 4.1549 & 4.7637 & TRN & & \\
\hline CHEMBL1579803 & 737421 & 5.0 & 4.7986 & TRN & & \\
\hline CHEMBL1555650 & 737421 & 5.0434 & 4.7269 & TRN & & \\
\hline CHEMBL1500686 & 737421 & 5.0526 & 4.2653 & TRN & & \\
\hline CHEMBL1603547 & 737421 & 4.0 & 4.8434 & TRN & & \\
\hline CHEMBL1392551 & 737421 & 5.1561 & 4.8952 & TST & & \\
\hline CHEMBL1400196 & 737421 & 5.1993 & 4.9685 & TRN & & \\
\hline CHEMBL1984247 & 737421 & 4.0097 & 4.7795 & TRN & & \\
\hline CHEMBL3191594 & 737421 & 4.1851 & 4.7944 & TRN & & \\
\hline CHEMBL1386604 & 737421 & 4.0237 & 4.732 & TRN & & \\
\hline CHEMBL1323864 & 737421 & 4.0232 & 4.5409 & TST & & \\
\hline CHEMBL1424968 & 737421 & 5.2676 & 4.885 & TRN & & \\
\hline CHEMBL1545250 & 737421 & 4.0386 & 5.1054 & TRN & & \\
\hline CHEMBL3210051 & 737421 & 4.3036 & 4.5066 & TRN & & \\
\hline CHEMBL1596373 & 737421 & 4.0814 & 4.6885 & TRN & & \\
\hline CHEMBL1384253 & 737421 & 5.6234 & 5.5405 & TRN & & \\
\hline CHEMBL 2004918 & 737421 & 4.0 & 4.8956 & TRN & & \\
\hline CHEMBL1562493 & 737421 & 4.0168 & 4.659 & TST & & \\
\hline CHEMBL1587837 & 737421 & 5.1555 & 4.4067 & TRN & & \\
\hline CHEMBL1968732 & 737421 & 5.0 & 4.8872 & TRN & & \\
\hline CHEMBL1427397 & 737421 & 5.0 & 4.2892 & TRN & & \\
\hline
\end{tabular}


Supplemental Table S2.txt

\begin{tabular}{|c|c|c|c|c|c|c|}
\hline CHEMBL3192274 & 737421 & 5.1884 & 5.0045 & TRN & & \\
\hline CHEMBL1458479 & 737421 & 5.2774 & 4.996 & TRN & & \\
\hline CHEMBL3197230 & 737421 & 4.0 & 4.7489 & TST & & \\
\hline CHEMBL1464261 & 737421 & 5.4498 & 4.3272 & TST & & \\
\hline CHEMBL1405964 & 737421 & 4.0146 & 4.4588 & TST & & \\
\hline CHEMBL1393914 & 737421 & 5.5784 & 5.1161 & TST & & \\
\hline CHEMBL1611013 & 737421 & 5.4461 & 4.9357 & TST & & \\
\hline CHEMBL1471930 & 737421 & 5.3862 & 4.8463 & TST & & \\
\hline CHEMBL1541441 & 737421 & 5.3439 & 4.8127 & TST & & \\
\hline CHEMBL1882125 & 737421 & 5.3242 & 5.4838 & TST & & \\
\hline CHEMBL1984130 & 737421 & 4.0214 & 4.7767 & TST & & \\
\hline CHEMBL1430895 & 737421 & 6.7959 & 4.8582 & TST & & \\
\hline CHEMBL1477760 & 737421 & 5.0 & 4.9523 & TST & & \\
\hline CHEMBL1483047 & 737421 & 5.0 & 4.7409 & TST & & \\
\hline CHEMBL567422 & 737421 & 5.3063 & 5.2607 & TST & & \\
\hline CHEMBL1363514 & 737421 & 4.0123 & 4.8186 & TST & & \\
\hline CHEMBL1698464 & 737421 & 5.2628 & 5.146 & TST & & \\
\hline CHEMBL259018 & 737421 & 4.0 & 5.0079 & TST & & \\
\hline CHEMBL1522184 & 737421 & 5.3696 & 5.0227 & TST & & \\
\hline CHEMBL1383635 & 737421 & 4.0168 & 4.5463 & TST & & \\
\hline CHEMBL1351269 & 737421 & 4.0155 & 4.8825 & TST & & \\
\hline CHEMBL1576787 & 737421 & 5.0 & 4.541 & TST & & \\
\hline CHEMBL1572006 & 737421 & 4.0 & 4.4718 & TST & & \\
\hline CHEMBL1387767 & 737421 & 5.0 & 4.4745 & TST & & \\
\hline CHEMBL1527794 & 737421 & 5.4001 & 4.4983 & TST & & \\
\hline CHEMBL2005602 & 737421 & 5.0585 & 4.6417 & TST & & \\
\hline CHEMBL1370884 & 737421 & 5.8996 & 5.4756 & TST & & \\
\hline CHEMBL1377095 & 737421 & 5.0 & 5.0395 & TST & & \\
\hline CHEMBL1596234 & 737421 & 4.0 & 5.0106 & TST & & \\
\hline CHEMBL1545093 & 737421 & 4.0 & 4.5807 & TST & & \\
\hline CHEMBL1303463 & 737421 & 4.2815 & 4.8195 & TST & & \\
\hline CHEMBL1425525 & 737421 & 5.0 & 4.6259 & TST & & \\
\hline CHEMBL1422678 & 737421 & 4.0 & 4.9853 & TST & & \\
\hline CHEMBL 3198248 & 737421 & 5.2984 & 4.5227 & TST & & \\
\hline CHEMBL1555483 & 737421 & \multicolumn{3}{|c|}{5.4510000000000005} & 4.5362 & TST \\
\hline CHEMBL1511363 & 737421 & 5.7235 & 5.2358 & TST & & \\
\hline CHEMBL3193885 & 737421 & 4.0 & 4.705 & TST & & \\
\hline CHEMBL1569192 & 737421 & 5.0 & 4.6049 & TST & & \\
\hline CHEMBL1323139 & 737421 & 5.3429 & 5.1961 & TST & & \\
\hline CHEMBL1496662 & 737421 & 4.0 & 5.0453 & TST & & \\
\hline CHEMBL3193507 & 737421 & 5.0 & 4.484 & TST & & \\
\hline CHEMBL3192555 & 737421 & 5.3449 & 5.6122 & TST & & \\
\hline CHEMBL261693 & 737421 & 4.2197 & 4.7094 & TST & & \\
\hline CHEMBL1544818 & 737421 & 6.7959 & 6.1541 & TST & & \\
\hline CHEMBL1459155 & 737421 & 5.3893 & 4.9843 & TST & & \\
\hline CHEMBL1582152 & 737421 & 5.1871 & 4.8406 & TST & & \\
\hline CHEMBL1556017 & 737421 & 4.0 & 4.8526 & TST & & \\
\hline CHEMBL1328168 & 737421 & 4.0186 & 5.0003 & TST & & \\
\hline
\end{tabular}

Page 739 
Supplemental Table S2.txt

\begin{tabular}{|c|c|c|c|c|c|}
\hline CHEMBL3199665 & 737421 & 5.2916 & 4.9867 & TST & \\
\hline CHEMBL1594604 & 737421 & 5.7959 & 5.0236 & TST & \\
\hline CHEMBL1562044 & 737421 & 4.0 & 5.01399 & 9999999999 & TST \\
\hline CHEMBL1438038 & 737421 & 6.6198 & 4.7406 & TST & \\
\hline CHEMBL1541809 & 737421 & 5.0 & 4.8873 & TST & \\
\hline CHEMBL1307404 & 737421 & 5.0 & 4.9098 & TST & \\
\hline CHEMBL3192328 & 737421 & 4.2774 & 5.1675 & TST & \\
\hline CHEMBL3193204 & 737421 & 5.2366 & $4.53600 t$ & 00000000005 & TST \\
\hline CHEMBL1352168 & 737421 & 5.7959 & 5.0597 & TST & \\
\hline CHEMBL1427542 & 737421 & 5.0 & 4.8337 & TST & \\
\hline CHEMBL1612558 & 737421 & 5.0794 & 4.7891 & TST & \\
\hline CHEMBL1588660 & 737421 & 5.067 & 4.6203 & TST & \\
\hline CHEMBL1332308 & 737421 & 4.0039 & 5.1274 & TST & \\
\hline CHEMBL3194467 & 737421 & 5.0 & 4.6765 & TST & \\
\hline CHEMBL1422635 & 737421 & 5.6253 & 4.7978 & TST & \\
\hline CHEMBL1374970 & 737421 & 4.063 & 4.5601 & TST & \\
\hline CHEMBL1508896 & 737421 & 4.1524 & 4.6076 & TST & \\
\hline CHEMBL1335165 & 737421 & 5.0 & 4.8522 & TST & \\
\hline CHEMBL1444031 & 737421 & 4.0035 & 5.29299 & 9999999999 & TST \\
\hline CHEMBL1885024 & 737421 & 4.0 & 4.8506 & TST & \\
\hline CHEMBL1605094 & 737421 & 5.0241 & 4.7518 & TST & \\
\hline CHEMBL1337226 & 737421 & 5.3036 & 5.0089 & TST & \\
\hline CHEMBL1506229 & 737421 & 5.0405 & 4.9132 & TST & \\
\hline CHEMBL1319676 & 737421 & 5.3429 & 5.0886 & TST & \\
\hline CHEMBL1310036 & 737421 & 6.0 & 4.9189 & TST & \\
\hline CHEMBL1367572 & 737421 & 5.0348 & 4.7701 & TST & \\
\hline CHEMBL1583461 & 737421 & 4.3391 & 4.947 & TST & \\
\hline CHEMBL1471737 & 737421 & 5.4584 & 4.9934 & TST & \\
\hline CHEMBL1420411 & 737421 & 4.0947 & 4.7892 & TST & \\
\hline CHEMBL1429906 & 737421 & 5.011 & 4.6169 & TST & \\
\hline CHEMBL1447341 & 737421 & 4.0182 & 4.7926 & TST & \\
\hline CHEMBL1427233 & 737421 & 5.0 & 4.4705 & TST & \\
\hline CHEMBL1334291 & 737421 & 4.0773 & 5.1254 & TST & \\
\hline CHEMBL1464634 & 737421 & 4.0269 & 4.9039 & TST & \\
\hline CHEMBL1351052 & 737421 & 5.2343 & 4.6104 & TST & \\
\hline CHEMBL1256686 & 737421 & 6.7959 & 5.5259 & TST & \\
\hline CHEMBL1507250 & 737421 & 6.7959 & 6.2118 & TST & \\
\hline CHEMBL1405957 & 737421 & 5.1844 & 4.8194 & TST & \\
\hline CHEMBL1546628 & 737421 & 5.0 & 4.9004 & TST & \\
\hline CHEMBL1330736 & 737421 & 5.0 & 4.9175 & TST & \\
\hline CHEMBL1518766 & 737421 & 4.2 & 4.5737 & TST & \\
\hline CHEMBL1568747 & 737421 & 5.2588 & 5.0347 & TST & \\
\hline CHEMBL1342665 & 737421 & 4.0 & 4.8635 & TST & \\
\hline CHEMBL1501217 & 737421 & 5.0269 & 4.5215 & TST & \\
\hline CHEMBL1379136 & 737421 & 5.056 & 4.9632 & TST & \\
\hline CHEMBL1587592 & 737421 & 4.0 & 4.6386 & TST & \\
\hline CHEMBL1415413 & 737421 & 5.2612 & 4.8601 & TST & \\
\hline CHEMBL1451738 & 737421 & 4.0 & 4.9229 & TST & \\
\hline
\end{tabular}




\begin{tabular}{|c|c|c|c|c|c|c|}
\hline \multicolumn{7}{|c|}{ Supplemental Table S2.txt } \\
\hline CHEMBL1526304 & 737421 & 4.0 & 4.8005 & TST & & \\
\hline CHEMBL1330556 & 737421 & 5.7959 & 5.9066 & TST & & \\
\hline CHEMBL528181 & 737421 & 4.0 & 5.1737 & TST & & \\
\hline CHEMBL1326110 & 737421 & 4.0 & 5.0022 & TST & & \\
\hline CHEMBL3207582 & 737421 & 4.1568 & 4.836 & TST & & \\
\hline CHEMBL1595015 & 737421 & 5.0 & 5.2093 & TST & & \\
\hline CHEMBL1458548 & 737421 & 5.6946 & 5.3083 & TST & & \\
\hline CHEMBL1505552 & 737421 & 5.2757 & 5.08899 & 9999999 & 995 & TST \\
\hline CHEMBL597251 & 737421 & 5.0862 & 4.4395 & TST & & \\
\hline CHEMBL1507337 & 737421 & 5.0 & 4.5349 & TST & & \\
\hline CHEMBL1545384 & 737421 & 4.0241 & 4.7239 & TST & & \\
\hline CHEMBL3196367 & 737421 & 4.0391 & 5.1946 & TST & & \\
\hline CHEMBL1546843 & 737421 & 5.3809 & 5.2716 & TST & & \\
\hline CHEMBL1488563 & 737421 & 4.0 & 4.7376 & TST & & \\
\hline CHEMBL 3674038 & 1528133 & 7.4377 & 7.4176 & TRN & & \\
\hline CHEMBL 3674124 & 1528133 & 6.45200 & 30000000 & & 6.5588 & TRN \\
\hline CHEMBL3674122 & 1528133 & 7.9172 & 7.7972 & TST & & \\
\hline CHEMBL3909169 & 1528133 & 7.5086 & 6.9934 & TST & & \\
\hline CHEMBL 3674069 & 1528133 & 7.4584 & 7.3952 & TRN & & \\
\hline CHEMBL 3674058 & 1528133 & 6.345 & 6.2737 & TRN & & \\
\hline CHEMBL 3674095 & 1528133 & 6.0 & 5.6858 & TRN & & \\
\hline CHEMBL 3674042 & 1528133 & 7.684 & 7.599 & TRN & & \\
\hline CHEMBL 3674056 & 1528133 & 7.9245 & 8.0901 & TST & & \\
\hline CHEMBL 3674092 & 1528133 & 7.015 & 6.8122 & TST & & \\
\hline CHEMBL 3674133 & 1528133 & 6.0 & 5.5981 & TST & & \\
\hline CHEMBL 3674074 & 1528133 & 7.3382 & 7.3593 & TRN & & \\
\hline CHEMBL 3674088 & 1528133 & 6.0 & 5.9178 & TRN & & \\
\hline CHEMBL 3674127 & 1528133 & 6.0 & 5.8077 & TST & & \\
\hline CHEMBL 3674065 & 1528133 & 7.1979 & 7.4298 & TST & & \\
\hline CHEMBL 3674060 & 1528133 & 6.5764 & 6.9568 & TRN & & \\
\hline CHEMBL 3674141 & 1528133 & 7.7595 & 7.7191 & TRN & & \\
\hline CHEMBL 3674043 & 1528133 & 6.61299 & 79999999 & 995 & 6.6141 & TRN \\
\hline CHEMBL 3674039 & 1528133 & 6.098 & 6.2546 & TRN & & \\
\hline CHEMBL 3674046 & 1528133 & 7.5513 & 7.3376 & TRN & & \\
\hline CHEMBL 3674146 & 1528133 & 6.308 & 6.3986 & TRN & & \\
\hline CHEMBL 3674128 & 1528133 & 6.0 & 6.0354 & TST & & \\
\hline CHEMBL3674066 & 1528133 & 7.0 & 7.0736 & TRN & & \\
\hline CHEMBL 3674047 & 1528133 & 7.6003 & 7.5979 & TRN & & \\
\hline CHEMBL 3674142 & 1528133 & 4.94300 & 90000000 & 205 & 4.9371 & TRN \\
\hline CHEMBL 3674062 & 1528133 & 7.065 & 7.0787 & TRN & & \\
\hline CHEMBL 3674044 & 1528133 & 7.3363 & 7.3824 & TRN & & \\
\hline CHEMBL 3674072 & 1528133 & 7.0788 & 7.2814 & TRN & & \\
\hline CHEMBL3674052 & 1528133 & 8.2291 & 8.0 & TRN & & \\
\hline CHEMBL3674040 & 1528133 & 6.4109 & 6.3706 & TRN & & \\
\hline CHEMBL 3639729 & 1528133 & 7.3161 & 7.2249 & TRN & & \\
\hline CHEMBL 3674050 & 1528133 & 7.9872 & 8.2441 & TRN & & \\
\hline CHEMBL 3674068 & 1528133 & 7.8013 & 7.8367 & TRN & & \\
\hline CHEMBL3674053 & 1528133 & 6.553 & 6.3748 & TRN & & \\
\hline
\end{tabular}




\begin{tabular}{|c|c|c|c|c|c|c|}
\hline & & \multicolumn{5}{|c|}{ Supplemental Table S2.txt } \\
\hline CHEMBL 3674143 & 1528133 & 6.274 & 6.2318 & TRN & & \\
\hline CHEMBL 3674064 & 1528133 & 7.9172 & 8.0102 & TST & & \\
\hline CHEMBL3674102 & 1528133 & 6.0 & 5.94 & TRN & & \\
\hline CHEMBL 3674107 & 1528133 & 6.0 & 6.1652 & TRN & & \\
\hline CHEMBL3674051 & 1528133 & 7.5834 & 7.5575 & TRN & & \\
\hline CHEMBL 3674037 & 1528133 & 7.5243 & 7.5382 & TRN & & \\
\hline CHEMBL 3674045 & 1528133 & 6.381 & 6.6977 & TRN & & \\
\hline CHEMBL 3674145 & 1528133 & 6.48 & 6.459 & TRN & & \\
\hline CHEMBL3674049 & 1528133 & 4.88 & 7.0368 & TST & & \\
\hline CHEMBL3674091 & 1528133 & 6.0 & 6.2267 & TRN & & \\
\hline CHEMBL 3674114 & 1528133 & 6.7791 & 6.7694 & TRN & & \\
\hline CHEMBL3674061 & 1528133 & 8.0969 & 7.8538 & TRN & & \\
\hline CHEMBL 3674080 & 1528133 & 6.349 & 6.2895 & TRN & & \\
\hline CHEMBL3674055 & 1528133 & 8.3468 & 7.3895 & TST & & \\
\hline CHEMBL3674121 & 1528133 & \multicolumn{3}{|c|}{7.718999999999999} & 7.6065 & TRN \\
\hline CHEMBL 3674073 & 1528133 & 7.6778 & 7.6536 & TRN & & \\
\hline CHEMBL3674118 & 1528133 & 6.0 & 6.0099 & TRN & & \\
\hline CHEMBL 3674057 & 1528133 & 6.9318 & 6.6106 & TRN & & \\
\hline CHEMBL3674059 & 1528133 & 6.099 & 6.1287 & TRN & & \\
\hline CHEMBL3674076 & 1528133 & 7.7825 & 7.7626 & TRN & & \\
\hline CHEMBL 3674113 & 1528133 & 7.301 & 7.33 & TRN & & \\
\hline CHEMBL 3674123 & 1528133 & 4.0 & 6.3928 & TST & & \\
\hline CHEMBL 3674041 & 1528133 & 4.894 & 4.8805 & TRN & & \\
\hline CHEMBL 3674075 & 1528133 & 6.0 & 6.0617 & TRN & & \\
\hline CHEMBL 3674081 & 1528133 & 8.1079 & 8.0811 & TRN & & \\
\hline CHEMBL 3674070 & 1528133 & 7.8013 & 7.9975 & TST & & \\
\hline CHEMBL3674101 & 1528133 & 6.0 & 5.8771 & TRN & & \\
\hline CHEMBL 3674115 & 1528133 & 6.0 & 6.0048 & TRN & & \\
\hline CHEMBL 3674144 & 1528133 & \multicolumn{3}{|c|}{6.037000000000001} & 5.9958 & TRN \\
\hline CHEMBL3674067 & 1528133 & 7.699 & 7.7201 & TRN & & \\
\hline CHEMBL 3674136 & 1528133 & 6.0 & 6.0573 & TST & & \\
\hline CHEMBL 3674048 & 1528133 & 7.5003 & 7.4609 & TST & & \\
\hline CHEMBL 3674109 & 1528133 & 6.0 & 6.1785 & TRN & & \\
\hline CHEMBL 3674054 & 1528133 & 6.704 & 6.6281 & TST & & \\
\hline CHEMBL3674079 & 1528133 & 7.1838 & 7.2386 & TRN & & \\
\hline CHEMBL3674071 & 1528133 & 5.3 & 5.5769 & TST & & \\
\hline CHEMBL 3674140 & 1528133 & 6.9739 & 7.0576 & TRN & & \\
\hline CHEMBL 3674082 & 1528133 & 6.5 & 7.097 & TST & & \\
\hline CHEMBL569319 & 595037 & 5.585 & 5.0029 & TRN & & \\
\hline CHEMBL567740 & 595037 & 6.0315 & 6.2833 & TRN & & \\
\hline CHEMBL569617 & 595037 & 5.5229 & 5.0001 & TRN & & \\
\hline CHEMBL566613 & 595037 & 5.8539 & 5.3659 & TRN & & \\
\hline CHEMBL565974 & 595037 & 6.0655 & 6.0048 & TRN & & \\
\hline CHEMBL568384 & 595037 & 5.7696 & 5.6847 & TRN & & \\
\hline CHEMBL569995 & 595037 & 6.0555 & 5.8874 & TRN & & \\
\hline CHEMBL570020 & 595037 & 4.0 & 4.8833 & TRN & & \\
\hline CHEMBL567050 & 595037 & 6.1135 & 5.361000 & 0000000001 & & TRN \\
\hline CHEMBL567915 & 595037 & 6.2518 & 6.449 & TRN & & \\
\hline
\end{tabular}




\begin{tabular}{|c|c|c|c|c|c|}
\hline \multicolumn{6}{|c|}{ Supplemental Table S2.txt } \\
\hline CHEMBL570238 & 595037 & 5.585 & 6.0159 & TRN & \\
\hline CHEMBL570384 & 595037 & 4.0 & 5.0154 & TRN & \\
\hline CHEMBL570093 & 595037 & 5.8861 & 5.7096 & TRN & \\
\hline CHEMBL569681 & 595037 & 5.3565 & 5.4646 & TST & \\
\hline CHEMBL569815 & 595037 & 5.4202 & 4.9631 & TST & \\
\hline CHEMBL567133 & 595037 & 6.4089 & 6.4815 & TRN & \\
\hline CHEMBL569913 & 595037 & 4.0 & 5.6172 & TST & \\
\hline CHEMBL566309 & 595037 & 4.0 & 4.8001 & TRN & \\
\hline CHEMBL570154 & 595037 & 6.2076 & 5.9425 & TRN & \\
\hline CHEMBL570045 & 595037 & 6.2757 & 5.7886 & TRN & \\
\hline CHEMBL567064 & 595037 & 5.8539 & 5.5885 & TRN & \\
\hline CHEMBL569912 & 595037 & 4.0 & 5.6262 & TST & \\
\hline CHEMBL570150 & 595037 & 5.4437 & 5.0658 & TRN & \\
\hline CHEMBL570053 & 595037 & 5.5229 & 5.17299 & & TRN \\
\hline CHEMBL567280 & 595037 & 6.0915 & 6.2959 & TRN & \\
\hline CHEMBL569679 & 595037 & 5.1024 & 5.1015 & TRN & \\
\hline CHEMBL565363 & 595037 & 5.8239 & 6.3318 & TRN & \\
\hline CHEMBL570128 & 595037 & 6.0269 & 5.7358 & TRN & \\
\hline CHEMBL570155 & 595037 & 5.7447 & 5.6608 & TRN & \\
\hline CHEMBL566176 & 595037 & 5.6778 & 5.6626 & TRN & \\
\hline CHEMBL568250 & 595037 & 5.585 & 5.1345 & TST & \\
\hline CHEMBL569914 & 595037 & 5.2007 & 5.5088 & TRN & \\
\hline CHEMBL569053 & 595037 & 4.8239 & 5.0643 & TRN & \\
\hline CHEMBL569908 & 595037 & 4.0 & 4.6225 & TST & \\
\hline CHEMBL569889 & 595037 & 5.1549 & 4.6534 & TST & \\
\hline CHEMBL567883 & 595037 & 5.5686 & 5.6088 & TRN & \\
\hline CHEMBL570242 & 595037 & 5.699 & 5.5887 & TRN & \\
\hline CHEMBL567271 & 595037 & 6.3979 & 5.9918 & TRN & \\
\hline CHEMBL567709 & 595037 & 5.8861 & 5.8332 & TRN & \\
\hline CHEMBL566745 & 595037 & 5.3872 & 5.7058 & TRN & \\
\hline CHEMBL570271 & 595037 & 4.0 & 5.0273 & TRN & \\
\hline CHEMBL569781 & 595037 & 5.5229 & 5.3446 & TRN & \\
\hline CHEMBL570028 & 595037 & 5.6576 & 5.5041 & TRN & \\
\hline CHEMBL568128 & 595037 & 5.9208 & 5.3542 & TRN & \\
\hline CHEMBL565836 & 595037 & 5.7959 & 6.0455 & TRN & \\
\hline CHEMBL570256 & 595037 & 5.9208 & 5.653 & TRN & \\
\hline CHEMBL565249 & 595037 & 4.0 & 5.2692 & TST & \\
\hline CHEMBL569884 & 595037 & 5.0605 & 5.1249 & TST & \\
\hline CHEMBL568059 & 595037 & 6.1427 & 5.9728 & TRN & \\
\hline CHEMBL570423 & 595037 & 4.0 & 5.2559 & TST & \\
\hline CHEMBL569732 & 595037 & 5.8861 & 5.5175 & TST & \\
\hline CHEMBL570388 & 595037 & 5.8239 & 5.811 & TRN & \\
\hline CHEMBL571583 & 595037 & 5.5686 & 5.2368 & TRN & \\
\hline CHEMBL566520 & 595037 & 5.4559 & 5.6412 & TRN & \\
\hline CHEMBL570151 & 595037 & 5.9586 & 6.044 & TRN & \\
\hline CHEMBL569915 & 595037 & 5.585 & 5.3172 & TST & \\
\hline CHEMBL568498 & 595037 & 4.0 & 4.9367 & TST & \\
\hline CHEMBL569742 & 595037 & 5.4318 & 5.4578 & TST & \\
\hline
\end{tabular}




\begin{tabular}{|c|c|c|c|c|c|}
\hline \multicolumn{6}{|c|}{ Supplemental Table S } \\
\hline CHEMBL565409 & 595037 & 5.9586 & 6.0601 & TRN & \\
\hline CHEMBL569764 & 595037 & 5.7696 & 5.5199 & TST & \\
\hline CHEMBL570153 & 595037 & 6.1135 & 6.0214 & TRN & \\
\hline CHEMBL570385 & 595037 & 6.1612 & 6.1556 & TRN & \\
\hline CHEMBL570152 & 595037 & 6.2924 & 6.3246 & TRN & \\
\hline CHEMBL569771 & 595037 & 5.0269 & 5.0182 & TST & \\
\hline CHEMBL565300 & 595037 & 4.0 & 4.9912 & TRN & \\
\hline CHEMBL570275 & 595037 & 5.7959 & 6.1158 & TRN & \\
\hline CHEMBL569629 & 595037 & 5.8239 & 5.6579 & TRN & \\
\hline CHEMBL570285 & 595037 & 5.6383 & 5.5505 & TRN & \\
\hline CHEMBL567561 & 595037 & 6.5686 & 6.4935 & TRN & \\
\hline CHEMBL567840 & 595037 & 5.0915 & 4.9561 & TRN & \\
\hline CHEMBL567189 & 595037 & 5.585 & 5.7518 & TST & \\
\hline CHEMBL567468 & 595037 & 5.699 & 5.6001 & TRN & \\
\hline CHEMBL569910 & 595037 & 5.4437 & 5.4002 & TST & \\
\hline CHEMBL569680 & 595037 & 4.0 & 4.6926 & TST & \\
\hline CHEMBL569988 & 595037 & 5.7959 & 5.5446 & TRN & \\
\hline CHEMBL566913 & 595037 & 6.6383 & 6.4979 & TRN & \\
\hline CHEMBL568824 & 595037 & 5.9208 & 5.4144 & TST & \\
\hline CHEMBL567416 & 595037 & 6.1308 & 6.0153 & TRN & \\
\hline CHEMBL570149 & 595037 & 5.284 & 4.9897 & TRN & \\
\hline CHEMBL569911 & 595037 & 4.0 & 5.29299 & 9999999999 & TST \\
\hline CHEMBL570386 & 595037 & 6.4318 & 6.1913 & TRN & \\
\hline CHEMBL565470 & 595037 & 5.8539 & 5.6241 & TRN & \\
\hline CHEMBL570064 & 595037 & 6.1805 & 6.3224 & TRN & \\
\hline CHEMBL568211 & 595037 & 6.5528 & 6.3221 & TRN & \\
\hline CHEMBL570156 & 595037 & 5.2757 & 4.9973 & TRN & \\
\hline CHEMBL570387 & 595037 & 6.3979 & 6.2972 & TRN & \\
\hline CHEMBL571584 & 595037 & 6.3098 & 6.006 & TRN & \\
\hline CHEMBL568257 & 595037 & 4.0 & 4.6524 & TST & \\
\hline CHEMBL571929 & 595037 & 4.0 & 5.7742 & TRN & \\
\hline CHEMBL569909 & 595037 & 5.7447 & 5.4082 & TST & \\
\hline CHEMBL571812 & 595037 & 5.1675 & 5.0286 & TRN & \\
\hline CHEMBL571599 & 595037 & 6.0 & 6.1928 & TRN & \\
\hline CHEMBL569127 & 595037 & 4.0 & 5.2054 & TST & \\
\hline CHEMBL566720 & 595037 & 4.3098 & 5.2187 & TST & \\
\hline CHEMBL569722 & 595037 & 5.8861 & 5.3124 & TRN & \\
\hline CHEMBL565573 & 595037 & 4.0 & 5.1143 & TRN & \\
\hline CHEMBL566753 & 595037 & 4.0 & 4.8093 & TST & \\
\hline CHEMBL570295 & 595037 & 6.3098 & 5.7803 & TST & \\
\hline CHEMBL567772 & 595037 & 5.8861 & 5.6638 & TRN & \\
\hline CHEMBL570263 & 595037 & 5.2007 & 5.5763 & TRN & \\
\hline CHEMBL570108 & 595037 & 5.1871 & 4.9437 & TRN & \\
\hline CHEMBL570060 & 595037 & 5.2924 & 4.8481 & TRN & \\
\hline CHEMBL566599 & 595037 & 6.1079 & 5.8435 & TRN & \\
\hline CHEMBL565542 & 595037 & 5.5229 & 5.2244 & TRN & \\
\hline CHEMBL570289 & 595037 & 5.8239 & 6.2155 & TRN & \\
\hline CHEMBL1186585 & 954818 & 4.37 & 4.3681 & TRN & \\
\hline
\end{tabular}




\begin{tabular}{|c|c|c|c|c|c|c|}
\hline & & \multicolumn{5}{|c|}{ Supplemental Table S2.txt } \\
\hline CHEMBL300389 & 954818 & 5.9828 & 5.9837 & TRN & & \\
\hline CHEMBL1256459 & 954818 & 4.7996 & 4.8014 & TRN & & \\
\hline CHEMBL9470 & 954818 & 4.2407 & 4.6389 & TST & & \\
\hline CHEMBL472940 & 954818 & 2.9945 & 2.99399 & 9999999 & 998 & TRN \\
\hline CHEMBL180127 & 954818 & 3.5047 & 3.5061 & TRN & & \\
\hline CHEMBL221137 & 954818 & 3.6076 & 4.418 & TST & & \\
\hline CHEMBL1590308 & 954818 & \multicolumn{3}{|c|}{2.4930000000000003} & 2.6384 & TST \\
\hline CHEMBL65 & 954818 & 8.1022 & 8.1025 & TRN & & \\
\hline CHEMBL373751 & 954818 & 3.4085 & 3.4134 & TRN & & \\
\hline CHEMBL135561 & 954818 & 3.8945 & 3.8946 & TRN & & \\
\hline CHEMBL1404918 & 954818 & 2.484 & 2.4837 & TRN & & \\
\hline CHEMBL3199475 & 954818 & 3.3192 & 3.3175 & TRN & & \\
\hline CHEMBL 2005886 & 954818 & 2.8519 & 2.8507 & TRN & & \\
\hline CHEMBL1970879 & 954818 & 2.9104 & 2.9089 & TRN & & \\
\hline CHEMBL 3392440 & 954818 & 3.4314 & 3.4305 & TRN & & \\
\hline CHEMBL412142 & 954818 & 3.2992 & 3.2996 & TRN & & \\
\hline CHEMBL 2144069 & 954818 & 3.3059 & 3.3061 & TRN & & \\
\hline CHEMBL449158 & 954818 & \multicolumn{3}{|c|}{5.962000000000001} & 6.7489 & TST \\
\hline CHEMBL1357247 & 954818 & 2.7458 & 2.7444 & TRN & & \\
\hline CHEMBL399530 & 954818 & 5.3958 & 5.3986 & TRN & & \\
\hline CHEMBL1788116 & 954818 & 3.8195 & 3.8211 & TRN & & \\
\hline CHEMBL 217354 & 954818 & 6.3281 & 6.3293 & TRN & & \\
\hline CHEMBL585951 & 954818 & 5.6499 & 5.6499 & TRN & & \\
\hline CHEMBL192566 & 954818 & 6.4496 & 7.585 & TST & & \\
\hline CHEMBL515416 & 954818 & 3.4677 & 3.4644 & TRN & & \\
\hline CHEMBL220241 & 954818 & 4.354 & 4.353 & TRN & & \\
\hline CHEMBL1242367 & 954818 & 2.9587 & 2.9598 & TRN & & \\
\hline CHEMBL 209148 & 954818 & 2.5876 & 2.5885 & TRN & & \\
\hline CHEMBL509032 & 954818 & 3.2427 & 3.242 & TRN & & \\
\hline CHEMBL 379300 & 954818 & 5.6095 & 5.6085 & TRN & & \\
\hline CHEMBL512504 & 954818 & 3.7321 & 3.7316 & TRN & & \\
\hline CHEMBL92309 & 954818 & 2.1568 & 1.9196 & TST & & \\
\hline CHEMBL213100 & 954818 & 3.3639 & 3.3639 & TRN & & \\
\hline CHEMBL255342 & 954818 & 3.7795 & 3.4567 & TST & & \\
\hline CHEMBL1643959 & 954818 & 3.4984 & 3.4972 & TRN & & \\
\hline CHEMBL3186408 & 954818 & 3.3488 & 2.9911 & TST & & \\
\hline CHEMBL102714 & 954818 & 3.1922 & 3.1967 & TRN & & \\
\hline CHEMBL558642 & 954818 & \multicolumn{3}{|c|}{2.8539999999999996} & 2.8562 & T \\
\hline CHEMBL1516890 & 954818 & 4.0785 & 4.0731 & TRN & & \\
\hline CHEMBL1673039 & 954818 & 2.7255 & 2.727 & TRN & & \\
\hline CHEMBL259181 & 954818 & 3.2445 & 3.2447 & TRN & & \\
\hline CHEMBL2363137 & 954818 & 4.948 & 4.9461 & TRN & & \\
\hline CHEMBL483849 & 954818 & 2.4058 & 2.406 & TRN & & \\
\hline CHEMBL514499 & 954818 & 6.2202 & 6.2193 & TRN & & \\
\hline CHEMBL 258844 & 954818 & 3.2514 & 3.2509 & TRN & & \\
\hline CHEMBL 2137530 & 954818 & 4.5643 & 4.4538 & TST & & \\
\hline CHEMBL2134202 & 954818 & 3.9446 & 4.1131 & TST & & \\
\hline CHEMBL483847 & 954818 & 3.7354 & 3.8523 & TST & & \\
\hline
\end{tabular}


Supplemental Table S2.txt

\begin{tabular}{|c|c|c|c|c|}
\hline 595 & & & & \\
\hline 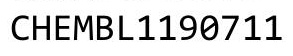 & & & & \\
\hline HFMRI & 243 & 59 & 29 & \\
\hline AEMBL & 243 & 96 & 76 & \\
\hline AEMBL3650140 & 528243 & .0605 & 9249 & \\
\hline HEMBL3650114 & 243 & 7.82 & 7642 & \\
\hline 084 & 243 & & 9646 & \\
\hline 0119 & & & & \\
\hline HEMBL3650112 & 528243 & 8.2757 & 2429 & \\
\hline HEMBL3650090 & 528243 & 8.3665 & 3822 & \\
\hline HEMBL3639489 & 243 & 7.1871 & 1247 & \\
\hline 132 & 43 & 7 & 3083 & \\
\hline AEMBL & & 5.6 & 3002 & \\
\hline HEMBL3650128 & 243 & 9.05 & 1312 & \\
\hline HEMBL3650097 & 43 & & 2736 & \\
\hline HEMBL3 & 13 & 9. & 3992 & \\
\hline HEMBL & 13 & & 646 & \\
\hline HEMBL; & & & 608 & \\
\hline 50082 & & & 5489 & \\
\hline AEMBL3650091 & & 7. & 5527 & I KIV \\
\hline HEMBL & +3 & & 3926 & RN \\
\hline HEM & & & 196 & \\
\hline HEMBL & 43 & & 539 & \\
\hline 50138 & & & 1407 & \\
\hline AEMBL3650129 & 43 & 9. & 147 & RN \\
\hline HEMBL3 & & & 552 & RI \\
\hline HFMP & & & 16 & NIV \\
\hline 36 & & 7. & 9769 & \\
\hline AEMBL & & & 5148 & IRN \\
\hline AEMBL3650102 & 3 & 7.7 & 3837 & RN \\
\hline AEMBL & & & 349 & RN \\
\hline 5 & & & 71 & \\
\hline 7 & & & 3847 & 「RN \\
\hline HEMBL3650118 & & 9 & 231 & $\mathrm{~K}$ \\
\hline HEMBL3967152 & 3 & & 84 & ST \\
\hline 97 & & & 545 & TRN \\
\hline 4 & & & 521 & ST \\
\hline HEMBL3 & & 8. & 2417 & TRN \\
\hline HEMBL3650120 & +3 & & 5667 & $\Gamma R$ \\
\hline TIDL & & & 1488 & RN \\
\hline HEMBL3 & & & & RIV \\
\hline HEMBL3 & & & 1965 & $\mathrm{RN}$ \\
\hline HEMBL3650105 & & 7.5 & 9597 & $\Gamma R$ \\
\hline HEMBL3650087 & +3 & 8 . & 729 & TS \\
\hline 2 & & & & \\
\hline HEMBL3650101 & & & & \\
\hline CHEMBL 3650098 & & 7.7959 & 284 & \\
\hline CHEMBL3650079 & 1528243 & 7.9586 & 8.2424 & \\
\hline
\end{tabular}

Page 746 
Supplemental Table S2.txt

\begin{tabular}{|c|c|c|c|c|c|}
\hline CHEMBL3650136 & 1528243 & 9.1549 & 8.2382 & TST & \\
\hline CHEMBL3650088 & 1528243 & 7.1135 & 7.3234 & TST & \\
\hline CHEMBL3650104 & 1528243 & 8.5528 & 8.5698 & TRN & \\
\hline CHEMBL3650089 & 1528243 & 6.6655 & 6.7043 & TRN & \\
\hline CHEMBL3984648 & 1528243 & 7.0555 & 7.3105 & TST & \\
\hline CHEMBL3650086 & 1528243 & 8.7696 & 8.6531 & TRN & \\
\hline CHEMBL3650115 & 1528243 & 5.0 & 6.1628 & TST & \\
\hline CHEMBL3650133 & 1528243 & 8.9586 & 8.9683 & TRN & \\
\hline CHEMBL3650111 & 1528243 & 8.2076 & 8.2348 & TRN & \\
\hline CHEMBL3650131 & 1528243 & 7.9208 & 5.9585 & TST & \\
\hline CHEMBL3650141 & 1528243 & 7.3565 & 6.9576 & TST & \\
\hline CHEMBL3650134 & 1528243 & 9.3979 & 8.2972 & TST & \\
\hline CHEMBL3902425 & 1528243 & 6.8928 & 7.3867 & TST & \\
\hline CHEMBL3650108 & 1528243 & 6.8962 & 6.8524 & TRN & \\
\hline CHEMBL3650139 & 1528243 & 7.1675 & 7.11100 & 0000000001 & TRN \\
\hline CHEMBL3650121 & 1528243 & 6.5544 & 6.9361 & TST & \\
\hline CHEMBL3650095 & 1528243 & 7.1675 & 6.9788 & TST & \\
\hline CHEMBL3650081 & 1528243 & 9.4949 & 9.3682 & TRN & \\
\hline CHEMBL3747665 & 1545040 & 5.2062 & 5.5439 & TRN & \\
\hline CHEMBL3747200 & 1545040 & 3.699 & 3.8762 & TRN & \\
\hline CHEMBL3746933 & 1545040 & 5.644 & 5.5086 & TRN & \\
\hline CHEMBL3745908 & 1545040 & 5.3947 & 5.3841 & TRN & \\
\hline CHEMBL3747745 & 1545040 & 3.699 & 3.3527 & TST & \\
\hline CHEMBL3746698 & 1545040 & 5.3197 & 4.7458 & TRN & \\
\hline CHEMBL 3746970 & 1545040 & 5.2226 & 5.1885 & TRN & \\
\hline CHEMBL3746813 & 1545040 & 5.2381 & 5.3275 & TRN & \\
\hline CHEMBL3746005 & 1545040 & 3.699 & 3.9286 & TRN & \\
\hline CHEMBL 3746704 & 1545040 & 4.9682 & 4.6587 & TRN & \\
\hline CHEMBL3746903 & 1545040 & 3.699 & 3.4162 & TST & \\
\hline CHEMBL 3747127 & 1545040 & 3.699 & 3.5056 & TST & \\
\hline CHEMBL3746132 & 1545040 & 4.7102 & 4.6192 & TRN & \\
\hline CHEMBL3746684 & 1545040 & 5.7645 & 5.8187 & TRN & \\
\hline CHEMBL3746501 & 1545040 & 3.699 & 4.065 & TRN & \\
\hline CHEMBL3747335 & 1545040 & 5.3449 & 5.2643 & TRN & \\
\hline CHEMBL3747598 & 1545040 & 5.644 & 5.7952 & TRN & \\
\hline CHEMBL3746641 & 1545040 & 3.699 & 3.6697 & TST & \\
\hline CHEMBL3747564 & 1545040 & 5.1255 & 4.8692 & TRN & \\
\hline CHEMBL 3746744 & 1545040 & 4.9987 & 4.7152 & TRN & \\
\hline CHEMBL3746500 & 1545040 & 3.699 & 3.5395 & TST & \\
\hline CHEMBL 3747725 & 1545040 & 5.3028 & 5.2021 & TRN & \\
\hline CHEMBL3747409 & 1545040 & 5.1278 & 4.7737 & TRN & \\
\hline CHEMBL3746403 & 1545040 & 5.3625 & 5.276 & TRN & \\
\hline CHEMBL3746905 & 1545040 & 5.4449 & 5.4938 & TRN & \\
\hline CHEMBL3746503 & 1545040 & 3.699 & 3.7078 & TRN & \\
\hline CHEMBL3746688 & 1545040 & 5.0742 & 4.9969 & TRN & \\
\hline CHEMBL 3746767 & 1545040 & 3.699 & 3.8571 & TRN & \\
\hline CHEMBL3745971 & 1545040 & 3.699 & 3.4649 & TRN & \\
\hline CHEMBL3747163 & 1545040 & 3.699 & 3.4599 & TST & \\
\hline
\end{tabular}


Supplemental Table S2.txt

\begin{tabular}{|c|c|c|c|c|}
\hline CHEMBL 3747731 & 1545040 & 3.699 & 3.5681 & TST \\
\hline CHEMBL 3745972 & 1545040 & 3.699 & 3.6245 & TST \\
\hline CHEMBL 3747251 & 1545040 & 3.699 & 3.7728 & TRN \\
\hline CHEMBL 3745869 & 1545040 & 5.1494 & 5.0184 & TRN \\
\hline CHEMBL 3747101 & 1545040 & 5.3288 & 5.3405 & TRN \\
\hline CHEMBL3746937 & 1545040 & 5.7595 & 5.6491 & TRN \\
\hline CHEMBL 3747232 & 1545040 & 5.2449 & \multicolumn{2}{|c|}{5.071000000000001} \\
\hline CHEMBL 3747572 & 1545040 & 3.699 & 3.5151 & TST \\
\hline CHEMBL 3746326 & 1545040 & 3.699 & 4.1451 & TRN \\
\hline CHEMBL 3746987 & 1545040 & 3.699 & 3.4648 & TRN \\
\hline CHEMBL 3747374 & 1545040 & 3.699 & 3.6347 & TST \\
\hline CHEMBL 3747242 & 1545040 & 3.699 & 3.8705 & TRN \\
\hline CHEMBL 3746788 & 1545040 & 5.0595 & 4.8213 & TRN \\
\hline CHEMBL 3745820 & 1545040 & \multicolumn{3}{|c|}{5.053999999999999} \\
\hline CHEMBL 3747671 & 1545040 & 3.699 & 3.7371 & TRN \\
\hline CHEMBL 3746216 & 1545040 & 3.699 & 4.5742 & TRN \\
\hline CHEMBL3746096 & 1545040 & 5.295 & 5.5351 & TRN \\
\hline CHEMBL 3746319 & 1545040 & 4.8398 & 4.6668 & TRN \\
\hline CHEMBL3746360 & 1545040 & 3.699 & 3.5973 & TST \\
\hline CHEMBL540 & 1545040 & 3.699 & 3.8469 & TST \\
\hline CHEMBL 3747164 & 1545040 & 5.5272 & 5.8361 & TRN \\
\hline CHEMBL3747686 & 1545040 & 5.2924 & 5.4828 & TRN \\
\hline CHEMBL 3747635 & 1545040 & 3.699 & 3.6015 & TST \\
\hline CHEMBL 3747658 & 1545040 & 3.699 & 3.6128 & TST \\
\hline CHEMBL 3746061 & 1545040 & 5.251 & 5.3479 & TRN \\
\hline CHEMBL 3746811 & 1545040 & 5.118 & 5.1029 & TRN \\
\hline CHEMBL 3747176 & 1545040 & 5.0953 & 4.5544 & TRN \\
\hline CHEMBL 3746790 & 1545040 & 3.699 & 3.7162 & TRN \\
\hline CHEMBL3746668 & 1545040 & 5.0325 & 5.1286 & TRN \\
\hline CHEMBL 3746367 & 1545040 & 3.699 & 3.6882 & TRN \\
\hline CHEMBL 3746718 & 1545040 & 3.699 & 3.6656 & TRN \\
\hline CHEMBL 3746194 & 1545040 & 3.699 & 3.3503 & TST \\
\hline CHEMBL 3747142 & 1545040 & 5.7447 & 5.6973 & TRN \\
\hline CHEMBL3746628 & 1545040 & 5.1232 & 4.9678 & TRN \\
\hline CHEMBL 3747627 & 1545040 & 3.699 & 4.0957 & TRN \\
\hline CHEMBL 3746720 & 1545040 & 3.699 & 4.1238 & TRN \\
\hline CHEMBL 3746560 & 1545040 & 3.699 & 3.6269 & TRN \\
\hline CHEMBL 3747384 & 1545040 & 3.699 & 3.6141 & TST \\
\hline CHEMBL 3746020 & 1545040 & 3.699 & 3.383 & TRN \\
\hline CHEMBL 3746023 & 1545040 & 3.699 & 3.469 & TST \\
\hline CHEMBL 3747035 & 1545040 & 5.5452 & 5.3755 & TRN \\
\hline CHEMBL 3747202 & 1545040 & 3.699 & 3.7148 & TST \\
\hline CHEMBL 3684690 & 1527880 & 7.9586 & 8.1417 & TRN \\
\hline CHEMBL3684701 & 1527880 & 7.9066 & 7.6383 & TST \\
\hline CHEMBL 3684733 & 1527880 & 7.0809 & 7.2313 & TRN \\
\hline CHEMBL 3684719 & 1527880 & 8.5086 & 8.4484 & TST \\
\hline CHEMBL 3689109 & 1527880 & 6.9208 & 7.3067 & TRN \\
\hline CHEMBL 3689139 & 1527880 & 7.284 & 7.401 & TRN \\
\hline
\end{tabular}


Supplemental Table S2.txt

\begin{tabular}{|c|c|c|c|c|c|}
\hline CHEMBL 3684740 & 1527880 & 8.1308 & 7.5639 & TRN & \\
\hline CHEMBL 3689148 & 1527880 & 7.9586 & 7.5047 & TRN & \\
\hline CHEMBL3689136 & 1527880 & 7.1805 & 7.3749 & TRN & \\
\hline CHEMBL 3684694 & 1527880 & 8.0362 & 7.4492 & TST & \\
\hline CHEMBL3689096 & 1527880 & 7.2596 & 7.1545 & TRN & \\
\hline CHEMBL3689110 & 1527880 & 7.6198 & 7.4716 & TRN & \\
\hline CHEMBL 3689116 & 1527880 & 7.3188 & 7.7267 & TRN & \\
\hline CHEMBL 3684698 & 1527880 & 6.9586 & 7.422999 & 9999999999 & TRN \\
\hline CHEMBL 3684731 & 1527880 & 8.6198 & 7.9368 & TRN & \\
\hline CHEMBL3689124 & 1527880 & 8.3665 & 8.282 & TRN & \\
\hline CHEMBL 3684683 & 1527880 & 8.5376 & 8.0933 & TRN & \\
\hline CHEMBL 3689174 & 1527880 & 7.4815 & 7.5832 & TRN & \\
\hline CHEMBL 3689147 & 1527880 & 7.8239 & 7.6735 & TRN & \\
\hline CHEMBL 3689150 & 1527880 & 7.8539 & 7.2566 & TRN & \\
\hline CHEMBL 3684730 & 1527880 & 8.4949 & 8.274 & TRN & \\
\hline CHEMBL3684708 & 1527880 & 7.3979 & 8.0915 & TST & \\
\hline CHEMBL 3684695 & 1527880 & 8.585 & 8.4617 & TRN & \\
\hline CHEMBL 3689106 & 1527880 & 7.7212 & 7.6058 & TST & \\
\hline CHEMBL 3689121 & 1527880 & 8.6198 & 8.3211 & TRN & \\
\hline CHEMBL 3684712 & 1527880 & 8.4949 & 8.4585 & TST & \\
\hline CHEMBL 3684748 & 1527880 & 8.3468 & 8.0749 & TRN & \\
\hline CHEMBL3684752 & 1527880 & 8.3979 & 8.1233 & TST & \\
\hline CHEMBL 3689157 & 1527880 & 7.7447 & 7.4356 & TRN & \\
\hline CHEMBL 3689099 & 1527880 & 8.1549 & 7.6209 & TRN & \\
\hline CHEMBL 3684726 & 1527880 & 8.585 & 8.2605 & TRN & \\
\hline CHEMBL3689165 & 1527880 & 7.0809 & 7.2251 & TRN & \\
\hline CHEMBL3684710 & 1527880 & 8.2291 & 8.2911 & TST & \\
\hline CHEMBL 3689178 & 1527880 & 6.0809 & 7.1617 & TRN & \\
\hline CHEMBL 3689135 & 1527880 & 7.3979 & \multicolumn{2}{|c|}{ 7.492999999999999 } & TRN \\
\hline CHEMBL 3684746 & 1527880 & 6.2147 & 7.1205 & TRN & \\
\hline CHEMBL 3689168 & 1527880 & 6.8861 & 7.3099 & TRN & \\
\hline CHEMBL3689141 & 1527880 & 7.3665 & 8.1284 & TST & \\
\hline CHEMBL 3684717 & 1527880 & 6.0 & 8.1558 & TRN & \\
\hline CHEMBL 3689140 & 1527880 & 7.3372 & 7.8866 & TST & \\
\hline CHEMBL 3684677 & 1527880 & 8.5686 & 8.7983 & TRN & \\
\hline CHEMBL 3689159 & 1527880 & 7.4685 & 7.5491 & TRN & \\
\hline CHEMBL3689169 & 1527880 & 6.9586 & 7.4893 & TRN & \\
\hline CHEMBL 3684705 & 1527880 & 8.7212 & 7.9871 & TRN & \\
\hline CHEMBL 3684678 & 1527880 & 7.7696 & 7.4997 & TRN & \\
\hline CHEMBL 3684704 & 1527880 & 7.4815 & 7.626 & TRN & \\
\hline CHEMBL 3689103 & 1527880 & 8.0915 & 7.6946 & TST & \\
\hline CHEMBL3689130 & 1527880 & 7.5528 & 7.4674 & TRN & \\
\hline CHEMBL 3689144 & 1527880 & 6.2366 & 7.345 & TST & \\
\hline CHEMBL 3684742 & 1527880 & 8.2147 & 7.5658 & TRN & \\
\hline CHEMBL 3689097 & 1527880 & 8.1367 & 7.4783 & TRN & \\
\hline CHEMBL 3684741 & 1527880 & 8.0223 & 7.5975 & TRN & \\
\hline CHEMBL3684699 & 1527880 & 8.3979 & 7.2156 & TST & \\
\hline CHEMBL3689171 & 1527880 & 7.1367 & 7.4624 & TRN & \\
\hline
\end{tabular}


Supplemental Table S2.txt

\begin{tabular}{|c|c|c|c|c|}
\hline 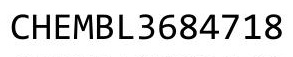 & 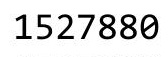 & 6.0 & 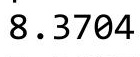 & \\
\hline HEMBL3689100 & 527880 & 7.6198 & 5687 & \\
\hline HEMBL3684758 & 527880 & 7.7447 & 3554 & \\
\hline 725 & & & & \\
\hline AEMBL3 & 27880 & & 786 & \\
\hline AEMBL3684756 & 527880 & 8.3872 & 4566 & \\
\hline HEMBL3689098 & 527880 & 8.5686 & .4796 & \\
\hline HEMBL3684751 & 527880 & 24 & 561 & \\
\hline AEMBL3 & 27880 & 7.8861 & 288 & \\
\hline IEMBL 36 & 880 & & 851 & \\
\hline HEMBL3689162 & 527880 & 7.0132 & 2163 & \\
\hline HEMBL3689166 & 527880 & 7.0223 & 7.2148 & \\
\hline HEMBL3684753 & 527880 & 8.2596 & 7.8376 & \\
\hline 175 & 880 & 88 & 4748 & \\
\hline AEMBL36 & 880 & & 519 & \\
\hline HEMBL3684689 & 527880 & 6.5528 & 2438 & \\
\hline HEMBL3684687 & 880 & & & \\
\hline HEMBL 368 & 880 & 8. & 019 & \\
\hline 112 & 880 & & 184 & \\
\hline 723 & 880 & & 338 & \\
\hline HEMBL3689154 & 527880 & 71 & 392 & \\
\hline AEMBL3689119 & & & & \\
\hline HEMBL36 & 380 & 7. & 771 & \\
\hline 120 & 880 & & 16 & \\
\hline 167 & 380 & & 87 & ST \\
\hline L3684755 & 880 & & & 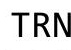 \\
\hline HEMBL 368 & & & & 10 \\
\hline HEMBL 368 & 80 & & & \\
\hline 11 & 80 & & & \\
\hline 721 & 380 & 8 . & 847 & RN \\
\hline HEMBL 368 & & & 3895 & RN \\
\hline HEMBL3689153 & 80 & 7. & 594 & RN \\
\hline AEMBL36 & & & & \\
\hline 6 & 30 & & & RN \\
\hline 86 & 80 & 8. & 37 & RN \\
\hline AEMBL3689125 & 527880 & 8. & 279 & RN \\
\hline AEMBL3689145 & 527880 & & 615 & ST \\
\hline 127 & & & 806 & RN \\
\hline 2 & & & 33 & RN \\
\hline 149 & & 7. & 643 & RN \\
\hline AEMBL3689115 & 527880 & 6 & 263 & RN \\
\hline HEMBL3 & 80 & & & \\
\hline 739 & & & 563 & \\
\hline HEMBL 36 & & & & \\
\hline HEMBL3684757 & & 7.6778 & 7.3524 & RN \\
\hline AEMBL3684693 & 380 & 66 & 2936 & \\
\hline & & & & \\
\hline & 152788 & & & \\
\hline
\end{tabular}


Supplemental Table S2.txt

\begin{tabular}{|c|c|c|c|c|}
\hline 06 & 527880 & 8.5376 & & \\
\hline HEMBL3684711 & 527880 & 6.9586 & & \\
\hline 27 & 527880 & & & \\
\hline IEMBL3 & 527880 & & & \\
\hline AEMBL & 527880 & 089 & & \\
\hline AEMBL3689126 & 527880 & 8.5528 & 848 & \\
\hline AEMBL & 880 & 528 & & \\
\hline EMBL & & & & \\
\hline AEMBL3689118 & 527880 & 8.6198 & & \\
\hline AEMBL368 & 527880 & 7.3665 & & \\
\hline AEMBL368 & 880 & 8.7447 & & \\
\hline IEMBL & 880 & 528 & & \\
\hline EMBL & 380 & & & \\
\hline AEMBL. & 380 & 586 & & \\
\hline IEMBL368 & 880 & 079 & & \\
\hline IEMBL368 & 380 & 539 & & \\
\hline AEMBL & 880 & 447 & & \\
\hline EMBL & 880 & 586 & & \\
\hline IEMBL & 527880 & 021 & & \\
\hline IEMBL & 80 & & & \\
\hline IEMBL & 30 & 56 & & \\
\hline EMB & 80 & 1 & & \\
\hline EMB & 30 & $\partial 2$ & & \\
\hline IEMBL & 80 & 249 & & \\
\hline IEMBL 368 & 80 & & & KN \\
\hline IEMBL & 30 & 51 & & \\
\hline EMB & $\theta$ & 9 & & RN \\
\hline 6 & 30 & 96 & & RN \\
\hline IEMBL & 30 & 021 & & \\
\hline HEMBL368ऽ & 30 & & & RN \\
\hline AEMBL: & 80 & 9 & 25 & $\mathrm{RI}$ \\
\hline 1 & $\theta$ & 6 & 7. & . \\
\hline IEMBL368 & 30 & 29 & & RN \\
\hline IEMBL368ऽ & ר & & & RN \\
\hline AEMBL3689 & 527 & 7.5086 & & RI \\
\hline IEMBL & 880 & & & RI \\
\hline 0 & & 565 & & 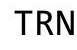 \\
\hline & 0 & & & ST \\
\hline HEMBL368ऽ & $527 \varepsilon$ & & & $\mathrm{RI}$ \\
\hline IEMBL 368 & ר? & 605 & 92 & \\
\hline HEMBL 368 & 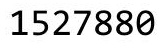 & 959 & & \\
\hline HEMBL; & & & & \\
\hline HEMBL368 & 527880 & 7.1675 & & RI \\
\hline HEMBL3689 & 27886 & & 354 & $\mathrm{R}$ \\
\hline 7 & 5278 & & & \\
\hline CHEMBL3689173 & & & & \\
\hline CHEMBL3689 & 527 & 7.6383 & 7.6431 & \\
\hline CHEMBL3689122 & 15278 & 8.8239 & 8.2525 & \\
\hline
\end{tabular}

Page 751 
Supplemental Table S2.txt

\begin{tabular}{|c|c|c|c|c|}
\hline 然 & & & & \\
\hline HEMBL3689163 & 527880 & 7.1024 & 7.4088 & \\
\hline & & & & \\
\hline 34750 & 7880 & & 344 & \\
\hline JEMBL3684703 & 527880 & 559 & 5323 & \\
\hline AEMBL3684697 & 527880 & 7.585 & 5238 & \\
\hline HEMBL3689160 & 527880 & 696 & 5917 & \\
\hline 44 & 880 & & & \\
\hline IEMBL & 880 & & & \\
\hline AEMBL3689143 & 527880 & 2676 & 7.8293 & \\
\hline HEMBL3684707 & 527880 & 8.6576 & 8.4216 & \\
\hline AEMBL3689107 & 527880 & 586 & 72 & \\
\hline AEMBL & 880 & & & \\
\hline AEMBL & 880 & & & \\
\hline AEMBL3684732 & 527880 & & 387 & \\
\hline AEMBL3684692 & 527880 & 47 & 08 & \\
\hline HEMBL 3684 & 880 & 92 & 12 & \\
\hline HEMBL3 & & & & \\
\hline HEMBL 3 & 68 & & & \\
\hline AEMBL3935310 & 268 & 6 . & 177 & ST \\
\hline ALIMISL & 268 & 17 & 12 & \\
\hline HEMBL3 & 68 & 8 & 53 & \\
\hline HEMBL3S & 68 & 6 & & \\
\hline 47 & 268 & & & \\
\hline AEMBL38897 & 68 & & & \\
\hline 3 & 58 & & 71 & \\
\hline 3017 & 68 & 51 & & \\
\hline HEN & & & & \\
\hline AEMBL 3963 & 68 & & & RN \\
\hline AEMBL 3912 & 68 & 6 & 17 & RIN \\
\hline AEMBL 392S & 68 & 6 & 49 & \\
\hline AFMBI 30 & & & & $2 \mathrm{~N}$ \\
\hline 9 & & & & RN \\
\hline HEMBL3955034 & 68 & & & RN \\
\hline AEMBL39231 & 68 & 6. & 44 & RN \\
\hline HEMBL 3914 & 68 & & & \\
\hline HEMRI 3 & & & & RN \\
\hline HEMBL3952396 & 268 & 6. & & ST \\
\hline HEMBL3970378 & 642268 & 9.36 & 546 & RN \\
\hline IEMBL39322 & 68 & 6 & & RN \\
\hline HEMBL39727 & 268 & 9. & 983 & \\
\hline HEMBL3957991 & & & & RN \\
\hline HEMBL3961688 & 268 & 9. & 8.9857 & RN \\
\hline AEMBL3974856 & 642268 & 9 . & 8.9346 & RN \\
\hline IFMPI 2005 & & & & \\
\hline HEMBL3932 & 1642268 & & & \\
\hline HEMBL3984782 & 1642268 & 9.2464 & 9.1036 & \\
\hline CHEMBL3947316 & 1642268 & 6.0 & 6.0152 & ГRN \\
\hline
\end{tabular}


Supplemental Table S2.txt

\begin{tabular}{|c|c|c|c|c|}
\hline 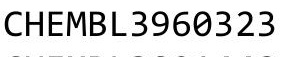 & 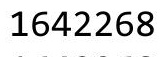 & & & \\
\hline HEMBL3891448 & 1642268 & 8.9914 & & \\
\hline HEMBL3968419 & 642268 & 6.6655 & 4262 & \\
\hline HEMBL3936734 & 542268 & & 316 & \\
\hline 825 & 542268 & & & \\
\hline AEMBL 3898577 & 642268 & 8.5817 & 392 & \\
\hline AEMBL3937842 & 642268 & 5.4609 & 4466 & \\
\hline HEMBL3979811 & 542268 & 9.5346 & 4404 & \\
\hline AEMBL39 & 542268 & 8.9788 & 359 & \\
\hline IEMBL: & 268 & 1302 & & \\
\hline HEMBL3964241 & 642268 & 6.0 & 5036 & \\
\hline AEMBL3946658 & 642268 & 7.5768 & 9848 & \\
\hline AEMBL 3898165 & 268 & 9.3497 & 244 & \\
\hline AEMBL39 & 268 & 545 & 885 & \\
\hline AEMBL & 268 & & & \\
\hline HEMBL3946515 & 642268 & 8.9586 & 5322 & \\
\hline AEMBL38 & 268 & & 303 & \\
\hline AEMBL 3890119 & 268 & & 3289 & \\
\hline IEMBL3 & 68 & 208 & 364 & \\
\hline AEMBL & 58 & 31 & & \\
\hline AEMBL3 & 268 & 214 & 755 & \\
\hline IEMBL39 & 58 & 38 & & \\
\hline AEMBL3 & 16 & & 25 & \\
\hline EMBL & 16 & & & \\
\hline IEME & 16 & & & \\
\hline 53 & & 872 & & \\
\hline IEMBL 389 & 58 & & & \\
\hline IEMBL3431 & 147 & 073 & 01 & \\
\hline IEMBL & 147 & 551 & 58 & \\
\hline 5 & 41 & 979 & & \\
\hline & & 654 & & \\
\hline IEMBL34 & & 941 & & \\
\hline IEMBL: & & 93 & 302 & \\
\hline IEMBL: & 41 & 03 & 89 & \\
\hline 7 & 41 & 14 & & \\
\hline & 41 & 7.3778 & & \\
\hline AEMBL 3431588 & & 6.0185 & & \\
\hline EMB & & 86 & & \\
\hline |FMBI $=$ & 41 & 96 & 88 & \\
\hline & & 68 & & \\
\hline HEMBL3431537 & 041 & 6.3231 & 261 & RI \\
\hline AEMBL3 3 & & 615 & 821 & \\
\hline ILTIDL & & 768 & & \\
\hline CHEMBL $3 \angle$ & & 7.2581 & & \\
\hline CHEMBL3431909 & & 7.2857 & 7.6942 & \\
\hline HEMBL3431886 & 479041 & 7.0048 & 6.6281 & \\
\hline HEMBL3431680 & & 1816 & & \\
\hline CHFMRI 343173 & (7) & & & \\
\hline
\end{tabular}

Page 753 
Supplemental Table S2.txt

\begin{tabular}{|c|c|c|c|c|c|}
\hline CHEMBL3431819 & 1479041 & 6.6229 & 6.7319 & TRN & \\
\hline CHEMBL3431912 & 1479041 & 7.2464 & 7.1463 & TRN & \\
\hline CHEMBL 3431884 & 1479041 & 7.066 & 6.8348 & TRN & \\
\hline CHEMBL 3431654 & 1479041 & 6.4765 & 6.5419 & TRN & \\
\hline CHEMBL 3431611 & 1479041 & 7.0467 & 7.2606 & TRN & \\
\hline CHEMBL 3431835 & 1479041 & 7.0004 & 6.8458 & TRN & \\
\hline CHEMBL 3431913 & 1479041 & 6.7796 & 7.2102 & TRN & \\
\hline CHEMBL3431698 & 1479041 & 6.5278 & 6.4377 & TRN & \\
\hline CHEMBL 3431660 & 1479041 & 6.3389 & 6.9241 & TRN & \\
\hline CHEMBL 3431850 & 1479041 & 6.8128 & 6.5676 & TRN & \\
\hline CHEMBL 3431562 & 1479041 & 5.3462 & 6.2352 & TRN & \\
\hline CHEMBL 3431491 & 1479041 & 6.7387 & 6.8567 & TRN & \\
\hline CHEMBL 3431631 & 1479041 & 7.0491 & 6.9862 & TRN & \\
\hline CHEMBL 3431877 & 1479041 & 6.199 & 6.471 & TRN & \\
\hline CHEMBL 3431770 & 1479041 & 6.9817 & 7.1104 & TST & \\
\hline CHEMBL 3431761 & 1479041 & 6.3412 & 6.5882 & TRN & \\
\hline CHEMBL 3431871 & 1479041 & 5.4414 & 6.3622 & TST & \\
\hline CHEMBL 3431701 & 1479041 & 6.6026 & 6.3657 & TRN & \\
\hline CHEMBL3431815 & 1479041 & 8.1427 & 7.752999 & 9999999999 & \\
\hline CHEMBL 3431836 & 1479041 & 7.6126 & 7.5236 & TRN & \\
\hline CHEMBL 3431902 & 1479041 & 6.8339 & 6.5539 & TRN & \\
\hline CHEMBL3431688 & 1479041 & 6.3688 & 6.2295 & TRN & \\
\hline CHEMBL 3431917 & 1479041 & 7.4622 & 7.147 & TRN & \\
\hline CHEMBL3431719 & 1479041 & 7.4168 & 7.3757 & TRN & \\
\hline CHEMBL 3431516 & 1479041 & 6.6878 & 6.7449 & TRN & \\
\hline CHEMBL3431727 & 1479041 & 7.2277 & 7.1526 & TRN & \\
\hline CHEMBL 3431704 & 1479041 & 6.0 & 7.0251 & TRN & \\
\hline CHEMBL 3431621 & 1479041 & 6.8798 & 6.8118 & TRN & \\
\hline CHEMBL 3431579 & 1479041 & 6.1597 & 6.1127 & TRN & \\
\hline CHEMBL3431649 & 1479041 & 7.0814 & 7.4106 & TRN & \\
\hline CHEMBL3431832 & 1479041 & 7.9957 & 7.7136 & TRN & \\
\hline CHEMBL3431852 & 1479041 & 6.6432 & 6.5954 & TRN & \\
\hline CHEMBL 3431665 & 1479041 & 6.5943 & 6.6379 & TRN & \\
\hline CHEMBL3431512 & 1479041 & 7.4711 & 7.4677 & TRN & \\
\hline CHEMBL 3431885 & 1479041 & 6.4563 & 6.1277 & TRN & \\
\hline CHEMBL3431800 & 1479041 & 6.9747 & 6.4895 & TST & \\
\hline CHEMBL3431552 & 1479041 & 7.3215 & 7.1447 & TRN & \\
\hline CHEMBL3431769 & 1479041 & 6.5962 & 6.676 & TRN & \\
\hline CHEMBL 3431849 & 1479041 & 6.7645 & 6.5095 & TRN & \\
\hline CHEMBL3431515 & 1479041 & 6.5938 & 6.5003 & TRN & \\
\hline CHEMBL3431831 & 1479041 & 7.6882 & 7.6622 & TRN & \\
\hline CHEMBL3431670 & 1479041 & 6.428999 & 999999999 & 6.5394 & $1 \mathrm{~N}$ \\
\hline CHEMBL3431606 & 1479041 & 6.8051 & 7.1368 & TRN & \\
\hline CHEMBL3431637 & 1479041 & 6.9731 & 6.5636 & TRN & \\
\hline CHEMBL 3431747 & 1479041 & 6.4817 & 6.6831 & TRN & \\
\hline CHEMBL3431882 & 1479041 & 7.2676 & 7.4717 & TRN & \\
\hline CHEMBL3431824 & 1479041 & 6.8706 & 6.7055 & TRN & \\
\hline CHEMBL3431873 & 1479041 & 6.9666 & 6.3681 & TRN & \\
\hline
\end{tabular}


Supplemental Table S2.txt

\begin{tabular}{|c|c|c|c|c|c|}
\hline CHEMBL3431506 & 1479041 & 7.0141 & 6.9384 & TST & \\
\hline CHEMBL3431891 & 1479041 & 6.5983 & 6.1909 & TRN & \\
\hline CHEMBL3431493 & 1479041 & 6.5158 & 6.3786 & TRN & \\
\hline CHEMBL3431825 & 1479041 & 7.2038 & 7.096 & TRN & \\
\hline CHEMBL3431485 & 1479041 & 6.6282 & 6.665 & TRN & \\
\hline CHEMBL3431615 & 1479041 & 6.1195 & 6.2379 & TRN & \\
\hline CHEMBL 3431874 & 1479041 & 6.3569 & 6.4172 & TRN & \\
\hline CHEMBL3431468 & 1479041 & 6.5993 & 6.43 & TRN & \\
\hline CHEMBL3431690 & 1479041 & 6.8748 & 6.8572 & TRN & \\
\hline CHEMBL3431635 & 1479041 & 7.1537 & 6.7317 & TRN & \\
\hline CHEMBL3431539 & 1479041 & 7.26200 & 000000000 & 6.0879 & TST \\
\hline CHEMBL3431657 & 1479041 & 6.5918 & 6.4303 & TST & \\
\hline CHEMBL3431525 & 1479041 & 6.3915 & 6.643 & TRN & \\
\hline CHEMBL3431494 & 1479041 & 6.8658 & 6.8241 & TRN & \\
\hline CHEMBL3431908 & 1479041 & 7.1308 & 7.0554 & TRN & \\
\hline CHEMBL3431584 & 1479041 & 6.4256 & 6.4081 & TST & \\
\hline CHEMBL3431517 & 1479041 & 5.8263 & 6.4409 & TRN & \\
\hline CHEMBL3431488 & 1479041 & 6.8315 & 6.8126 & TRN & \\
\hline CHEMBL3431623 & 1479041 & 6.8085 & 6.8833 & TRN & \\
\hline CHEMBL3431739 & 1479041 & 7.1124 & 6.4618 & TST & \\
\hline CHEMBL3431636 & 1479041 & 6.7647 & 6.8489 & TST & \\
\hline CHEMBL3431460 & 1479041 & 6.9901 & 6.7933 & TRN & \\
\hline CHEMBL3431924 & 1479041 & 6.8049 & 6.6668 & TRN & \\
\hline CHEMBL 3431644 & 1479041 & 6.7201 & 6.5654 & TST & \\
\hline CHEMBL 3431758 & 1479041 & 7.2233 & 6.7008 & TRN & \\
\hline CHEMBL3431632 & 1479041 & 7.7055 & 7.337000 & 0000000001 & TST \\
\hline CHEMBL3431472 & 1479041 & 7.2449 & 7.1591 & TRN & \\
\hline CHEMBL 3431745 & 1479041 & 6.6486 & 6.7272 & TRN & \\
\hline CHEMBL 3431898 & 1479041 & 7.3307 & 7.229 & TRN & \\
\hline CHEMBL3431759 & 1479041 & 7.2069 & 6.7403 & TRN & \\
\hline CHEMBL3431560 & 1479041 & 6.5768 & 6.3889 & TRN & \\
\hline CHEMBL3431817 & 1479041 & 4.0 & 6.903 & TST & \\
\hline CHEMBL3431893 & 1479041 & 5.9607 & 6.0259 & TRN & \\
\hline CHEMBL 3431672 & 1479041 & 7.1831 & 6.419 & TRN & \\
\hline CHEMBL 3431476 & 1479041 & 6.3198 & 6.5569 & TRN & \\
\hline CHEMBL3431470 & 1479041 & 7.7352 & 7.4281 & TRN & \\
\hline CHEMBL3431830 & 1479041 & 7.9957 & 7.8756 & TRN & \\
\hline CHEMBL3431589 & 1479041 & 6.6245 & 6.4875 & TST & \\
\hline CHEMBL3431862 & 1479041 & 5.9799 & 6.3179 & TRN & \\
\hline CHEMBL3431755 & 1479041 & 6.0757 & 6.3705 & TRN & \\
\hline CHEMBL3431848 & 1479041 & 6.48600 & 000000000 & 6.6837 & $\mathrm{TN}$ \\
\hline CHEMBL3431897 & 1479041 & 6.9087 & 7.2527 & TRN & \\
\hline CHEMBL3431839 & 1479041 & 7.8013 & 7.4382 & TRN & \\
\hline CHEMBL3431794 & 1479041 & 7.3665 & 7.5001 & TST & \\
\hline CHEMBL3431863 & 1479041 & 6.8887 & 6.5196 & TRN & \\
\hline CHEMBL3431656 & 1479041 & 7.1141 & 6.4075 & TST & \\
\hline CHEMBL3431921 & 1479041 & 5.2203 & 5.9778 & TRN & \\
\hline CHEMBL3431483 & 1479041 & 6.7231 & 6.6066 & TRN & \\
\hline
\end{tabular}


Supplemental Table S2.txt

\begin{tabular}{|c|c|c|c|c|}
\hline CHEMBL3431625 & 1479041 & 7.066 & 7.1121 & TST \\
\hline CHEMBL3431818 & 1479041 & 6.3564 & 6.9003 & TST \\
\hline CHEMBL3431918 & 1479041 & 6.8063 & 6.8737 & TRN \\
\hline CHEMBL3431729 & 1479041 & 6.9578 & 6.586 & TST \\
\hline CHEMBL 3431801 & 1479041 & 7.1385 & 6.3579 & TST \\
\hline CHEMBL3431896 & 1479041 & 7.0737 & 7.1846 & TRN \\
\hline CHEMBL3431620 & 1479041 & 6.4111 & 6.7004 & TRN \\
\hline CHEMBL 3431700 & 1479041 & 6.7284 & 6.1766 & TRN \\
\hline CHEMBL3431462 & 1479041 & 6.2468 & 6.4598 & TST \\
\hline CHEMBL 3431714 & 1479041 & 6.9914 & 7.05 & TRN \\
\hline CHEMBL 3431554 & 1479041 & 7.1261 & 7.0393 & TRN \\
\hline CHEMBL3431609 & 1479041 & 5.9607 & 6.4824 & TST \\
\hline CHEMBL 3431734 & 1479041 & 7.1765 & 6.5643 & TST \\
\hline CHEMBL3431757 & 1479041 & 6.2629 & 6.3169 & TRN \\
\hline CHEMBL 3431663 & 1479041 & 7.2104 & 6.5166 & TRN \\
\hline CHEMBL 3431875 & 1479041 & 5.9175 & 6.3065 & TRN \\
\hline CHEMBL 3431572 & 1479041 & 6.6014 & 6.2899 & TRN \\
\hline CHEMBL3431860 & 1479041 & 6.7462 & 6.5027 & TRN \\
\hline CHEMBL3431633 & 1479041 & 6.8989 & 6.9801 & TST \\
\hline CHEMBL 3431842 & 1479041 & 7.6536 & 7.7384 & TST \\
\hline CHEMBL 3431551 & 1479041 & 7.0414 & 7.1066 & TRN \\
\hline CHEMBL 3431568 & 1479041 & 6.1783 & 6.3784 & TRN \\
\hline CHEMBL3431876 & 1479041 & 5.6522 & 6.3221 & TRN \\
\hline CHEMBL3431473 & 1479041 & 6.1779 & 6.5575 & TRN \\
\hline CHEMBL 3431925 & 1479041 & 6.1012 & 6.1576 & TRN \\
\hline CHEMBL 3431581 & 1479041 & 6.9813 & 6.9853 & TRN \\
\hline CHEMBL3431500 & 1479041 & 6.4697 & 6.3032 & TRN \\
\hline CHEMBL 3431878 & 1479041 & 6.9292 & 6.4597 & TRN \\
\hline CHEMBL3431505 & 1479041 & 7.0731 & 7.2032 & TRN \\
\hline CHEMBL3431699 & 1479041 & 6.2479 & 6.1074 & TRN \\
\hline CHEMBL 3431648 & 1479041 & 6.3161 & 6.694 & TRN \\
\hline CHEMBL 3431661 & 1479041 & 6.9763 & 6.8592 & TRN \\
\hline CHEMBL3431639 & 1479041 & 6.7126 & 5.9608 & TST \\
\hline CHEMBL3431653 & 1479041 & 6.2994 & 6.7536 & TRN \\
\hline CHEMBL3431756 & 1479041 & 6.7345 & 7.07799 & 999999999 \\
\hline CHEMBL3431905 & 1479041 & 6.3846 & 6.7795 & TRN \\
\hline CHEMBL 3431787 & 1479041 & 6.4193 & 7.1717 & TRN \\
\hline CHEMBL 3431781 & 1479041 & 6.4701 & 6.803 & TRN \\
\hline CHEMBL3431543 & 1479041 & 6.4043 & 6.5939 & TST \\
\hline CHEMBL3431713 & 1479041 & 6.4763 & 6.8005 & TRN \\
\hline CHEMBL 2216779 & 1479041 & 7.2596 & 7.185 & TRN \\
\hline CHEMBL3431601 & 1479041 & 6.4113 & 6.48 & TRN \\
\hline CHEMBL3431612 & 1479041 & 6.8729 & 7.0853 & TRN \\
\hline CHEMBL3431532 & 1479041 & 6.2895 & 6.704 & TST \\
\hline CHEMBL3431807 & 1479041 & 7.0159 & 6.3976 & TRN \\
\hline CHEMBL 3431477 & 1479041 & 6.3253 & 6.7947 & TRN \\
\hline CHEMBL 3431802 & 1479041 & 6.0 & 6.3836 & TST \\
\hline CHEMBL 3431524 & 1479041 & 6.8056 & 6.5062 & TRN \\
\hline
\end{tabular}

Page 756 
Supplemental Table S2.txt

\begin{tabular}{|c|c|c|c|c|}
\hline CHEMBL3431809 & 1479041 & 6.1188 & 6.3009 & TRN \\
\hline CHEMBL3431479 & 1479041 & 6.6077 & 6.7829 & TST \\
\hline CHEMBL3431774 & 1479041 & 6.2306 & 6.4145 & TST \\
\hline CHEMBL3431533 & 1479041 & 7.8386 & 7.2911 & TST \\
\hline CHEMBL3431542 & 1479041 & 6.9743 & 6.3766 & TRN \\
\hline CHEMBL3431610 & 1479041 & 6.7918 & 6.9969 & TRN \\
\hline CHEMBL3431549 & 1479041 & 7.0334 & 7.2707 & TRN \\
\hline CHEMBL3431521 & 1479041 & 6.8573 & 7.2898 & TST \\
\hline CHEMBL3431545 & 1479041 & 5.9385 & 6.5198 & TRN \\
\hline CHEMBL3431566 & 1479041 & 6.3872 & 6.2386 & TRN \\
\hline CHEMBL3431482 & 1479041 & 7.0083 & 6.7504 & TRN \\
\hline CHEMBL3431664 & 1479041 & 6.5053 & 6.2265 & TRN \\
\hline CHEMBL3431867 & 1479041 & 5.5375 & 6.0227 & TRN \\
\hline CHEMBL3431851 & 1479041 & 6.9219 & 6.6015 & TRN \\
\hline CHEMBL3431565 & 1479041 & 6.1655 & 6.0899 & TRN \\
\hline CHEMBL3431696 & 1479041 & 6.2168 & 6.5726 & TST \\
\hline CHEMBL3431484 & 1479041 & 7.5171 & 6.9185 & TRN \\
\hline CHEMBL3431720 & 1479041 & 6.9914 & 7.2074 & TRN \\
\hline CHEMBL3431923 & 1479041 & 6.3437 & 6.1647 & TRN \\
\hline CHEMBL3431679 & 1479041 & 7.4962 & 7.4965 & TRN \\
\hline CHEMBL3431600 & 1479041 & 6.4356 & 6.3647 & TRN \\
\hline CHEMBL3431597 & 1479041 & 5.789 & 6.0321 & TRN \\
\hline CHEMBL3431538 & 1479041 & 5.5423 & 6.7051 & TST \\
\hline CHEMBL 3431782 & 1479041 & 7.1884 & 7.3257 & TRN \\
\hline CHEMBL3431478 & 1479041 & 7.27 & 7.4288 & TRN \\
\hline CHEMBL3431651 & 1479041 & 6.2008 & 6.6857 & TRN \\
\hline CHEMBL3431658 & 1479041 & 6.9863 & 6.3542 & TST \\
\hline CHEMBL3431502 & 1479041 & 6.655 & 6.4227 & TRN \\
\hline CHEMBL 3431676 & 1479041 & 6.9923 & 7.0808 & TRN \\
\hline CHEMBL3431547 & 1479041 & 7.15799 & 999999999 & 7.1825 \\
\hline CHEMBL3431642 & 1479041 & 7.9508 & 7.991000 & 00000000005 \\
\hline CHEMBL3431892 & 1479041 & 6.7256 & 6.7283 & TRN \\
\hline CHEMBL3431507 & 1479041 & 7.224 & 7.3034 & TST \\
\hline CHEMBL3431608 & 1479041 & 6.6874 & 6.7494 & TRN \\
\hline CHEMBL3431666 & 1479041 & 6.6068 & 6.7255 & TRN \\
\hline CHEMBL3431667 & 1479041 & 7.0311 & 6.7373 & TRN \\
\hline CHEMBL3431634 & 1479041 & 7.6308 & 6.8679 & TRN \\
\hline CHEMBL3431531 & 1479041 & 6.2493 & 6.0768 & TRN \\
\hline CHEMBL 3431594 & 1479041 & 5.8758 & 5.9109 & TRN \\
\hline CHEMBL 3431780 & 1479041 & 5.9087 & 6.3338 & TRN \\
\hline CHEMBL3431541 & 1479041 & 7.0698 & 7.2469 & TST \\
\hline CHEMBL3431861 & 1479041 & 6.442 & 6.5196 & TRN \\
\hline CHEMBL3431527 & 1479041 & 6.6214 & 6.4243 & TRN \\
\hline CHEMBL 3431624 & 1479041 & 7.6904 & 7.5152 & TRN \\
\hline CHEMBL3431872 & 1479041 & 6.9666 & 6.6764 & TRN \\
\hline CHEMBL3431721 & 1479041 & 7.1844 & 7.4224 & TRN \\
\hline CHEMBL3431907 & 1479041 & 6.8292 & 6.7133 & TST \\
\hline CHEMBL3431823 & 1479041 & 7.098 & 7.3457 & TST \\
\hline
\end{tabular}


Supplemental Table S2.txt

\begin{tabular}{|c|c|c|c|c|c|}
\hline CHEMBL3431528 & 1479041 & 6.0886 & \multicolumn{2}{|c|}{6.162000000000001} & TRN \\
\hline CHEMBL3431492 & 1479041 & 6.8147 & 6.6101 & TRN & \\
\hline CHEMBL3431846 & 1479041 & 6.2559 & 6.0644 & TRN & \\
\hline CHEMBL 3431792 & 1479041 & 6.9045 & 7.0323 & TRN & \\
\hline CHEMBL 3431838 & 1479041 & 6.7678 & 6.7214 & TRN & \\
\hline CHEMBL 3431754 & 1479041 & 7.4134 & 7.1954 & TRN & \\
\hline CHEMBL3431522 & 1479041 & 6.5971 & 7.2542 & TST & \\
\hline CHEMBL 3431887 & 1479041 & 6.1634 & 6.1383 & TRN & \\
\hline CHEMBL 3431646 & 1479041 & 7.1198 & 7.1857 & TST & \\
\hline CHEMBL3431511 & 1479041 & 7.0721 & 6.8042 & TRN & \\
\hline CHEMBL 3431674 & 1479041 & 6.8824 & 6.7635 & TRN & \\
\hline CHEMBL 3431748 & 1479041 & 6.8351 & 6.6092 & TRN & \\
\hline CHEMBL 3431555 & 1479041 & 7.0945 & 7.4295 & TST & \\
\hline CHEMBL 2216774 & 1479041 & 6.8941 & 6.3544 & TRN & \\
\hline CHEMBL 3431463 & 1479041 & 7.2147 & 7.5823 & TRN & \\
\hline CHEMBL 3431736 & 1479041 & 6.6349 & 6.3398 & TST & \\
\hline CHEMBL3431486 & 1479041 & 6.9034 & 7.0557 & TRN & \\
\hline CHEMBL 3431480 & 1479041 & 6.8908 & 6.7088 & TRN & \\
\hline CHEMBL 3431558 & 1479041 & 6.5141 & 6.6588 & TRN & \\
\hline CHEMBL 3431627 & 1479041 & 7.8182 & 7.5249 & TRN & \\
\hline CHEMBL 3431647 & 1479041 & 6.9778 & 7.106 & TRN & \\
\hline CHEMBL3431564 & 1479041 & 6.5842 & 7.2678 & TST & \\
\hline CHEMBL3431571 & 1479041 & 6.6598 & 6.2034 & TRN & \\
\hline CHEMBL 3431556 & 1479041 & 5.0158 & 6.2906 & TRN & \\
\hline CHEMBL 3431622 & 1479041 & 7.2815 & 7.494 & TRN & \\
\hline CHEMBL 3431592 & 1479041 & 6.4722 & 6.3975 & TRN & \\
\hline CHEMBL 3431702 & 1479041 & 6.2237 & 6.2437 & TRN & \\
\hline CHEMBL3431796 & 1479041 & 7.2403 & 7.3194 & TST & \\
\hline CHEMBL 3431816 & 1479041 & 8.5229 & 7.9276 & TRN & \\
\hline CHEMBL3431695 & 1479041 & 6.0287 & 6.4602 & TST & \\
\hline CHEMBL3431888 & 1479041 & 6.8834 & 6.9211 & TRN & \\
\hline CHEMBL 3431841 & 1479041 & 7.6635 & 7.6247 & TST & \\
\hline CHEMBL 3431743 & 1479041 & 5.7782 & 6.3664 & TST & \\
\hline CHEMBL 3431467 & 1479041 & 6.2949 & 6.3638 & TRN & \\
\hline CHEMBL 3431508 & 1479041 & 7.1463 & 6.6482 & TST & \\
\hline CHEMBL3431857 & 1479041 & 5.8656 & 6.4386 & TRN & \\
\hline CHEMBL 3431709 & 1479041 & 6.3229 & 6.5261 & TST & \\
\hline CHEMBL 3431827 & 1479041 & 6.9598 & 7.1026 & TRN & \\
\hline CHEMBL 3431650 & 1479041 & 5.8462 & 6.5351 & TST & \\
\hline CHEMBL3431596 & 1479041 & 6.7435 & 7.1114 & TRN & \\
\hline CHEMBL 3431799 & 1479041 & 7.1146 & 6.3651 & TST & \\
\hline CHEMBL3431859 & 1479041 & 6.3151 & 6.4688 & TRN & \\
\hline CHEMBL 3431854 & 1479041 & 6.6108 & 6.4286 & TRN & \\
\hline CHEMBL 3431870 & 1479041 & 6.6603 & 6.1646 & TRN & \\
\hline CHEMBL 3431689 & 1479041 & 6.7592 & 6.7946 & TRN & \\
\hline CHEMBL 3431889 & 1479041 & 6.7359 & 6.20200 & 0000000001 & TRN \\
\hline CHEMBL 3431858 & 1479041 & 6.5222 & 6.551 & TRN & \\
\hline CHEMBL 3431471 & 1479041 & 6.7828 & 6.7362 & TRN & \\
\hline
\end{tabular}


Supplemental Table S2.txt

\begin{tabular}{|c|c|c|c|c|c|}
\hline CHEMBL 3431574 & 1479041 & 6.9987 & 7.1137 & TRN & \\
\hline CHEMBL 3431776 & 1479041 & 6.4109 & 6.4693 & TST & \\
\hline CHEMBL3431890 & 1479041 & 7.2083 & 6.7103 & TRN & \\
\hline CHEMBL3431659 & 1479041 & 7.4342 & 7.2204 & TRN & \\
\hline CHEMBL 3431535 & 1479041 & 7.4908 & 7.2205 & TRN & \\
\hline CHEMBL3431475 & 1479041 & 6.5085 & 6.6243 & TRN & \\
\hline CHEMBL 3431490 & 1479041 & 6.6981 & 6.6325 & TRN & \\
\hline CHEMBL3431550 & 1479041 & 7.1864 & 7.3381 & TRN & \\
\hline CHEMBL 3431798 & 1479041 & 7.266 & 7.2713 & TST & \\
\hline CHEMBL3431821 & 1479041 & 7.7696 & 7.4295 & TRN & \\
\hline CHEMBL3431811 & 1479041 & 6.8297 & 6.9005 & TST & \\
\hline CHEMBL 3431645 & 1479041 & 6.4855 & 6.7483 & TRN & \\
\hline CHEMBL 3431548 & 1479041 & 7.1785 & 7.2386 & TRN & \\
\hline CHEMBL3431519 & 1479041 & 5.9847 & 6.3854 & TRN & \\
\hline CHEMBL3431879 & 1479041 & 6.4409 & 6.3657 & TRN & \\
\hline CHEMBL3431711 & 1479041 & 7.2612 & 7.489 & TRN & \\
\hline CHEMBL3431602 & 1479041 & 7.0166 & 7.1292 & TRN & \\
\hline CHEMBL 3431710 & 1479041 & 6.7716 & 6.4039 & TST & \\
\hline CHEMBL 3431786 & 1479041 & 7.5346 & 7.5371 & TRN & \\
\hline CHEMBL 3431716 & 1479041 & 6.7815 & 6.963999 & 99999999995 & TRN \\
\hline CHEMBL3431914 & 1479041 & 7.3063 & 7.1897 & TRN & \\
\hline CHEMBL 2216778 & 1479041 & 7.5214 & 7.1154 & TRN & \\
\hline CHEMBL 3431489 & 1479041 & 6.7627 & 6.7443 & TRN & \\
\hline CHEMBL3431735 & 1479041 & 6.9183 & 6.465 & TST & \\
\hline CHEMBL 3431767 & 1479041 & 6.9876 & 7.2776 & TRN & \\
\hline CHEMBL 3431728 & 1479041 & 6.8342 & 6.5283 & TRN & \\
\hline CHEMBL 3431510 & 1479041 & 6.79700 & 00000006 & 6.8562 & TRN \\
\hline CHEMBL 3431697 & 1479041 & 6.4247 & 6.3971 & TRN & \\
\hline CHEMBL3431762 & 1479041 & 4.0 & 6.6074 & TST & \\
\hline CHEMBL 3431618 & 1479041 & 6.3284 & 6.2229 & TRN & \\
\hline CHEMBL 3431777 & 1479041 & 6.6325 & 6.6207 & TST & \\
\hline CHEMBL 3431501 & 1479041 & 6.7731 & 6.6989 & TRN & \\
\hline CHEMBL3431577 & 1479041 & 6.2402 & 6.9118 & TRN & \\
\hline CHEMBL3431461 & 1479041 & 7.7235 & 7.4981 & TRN & \\
\hline CHEMBL3431928 & 1479041 & 5.7656 & 6.7681 & TST & \\
\hline CHEMBL3431536 & 1479041 & 7.45100 & 000000006 & 7.0752 & TRN \\
\hline CHEMBL 3431853 & 1479041 & 6.6494 & 6.2989 & TRN & \\
\hline CHEMBL 3431465 & 1479041 & 6.7857 & 6.447999 & 99999999995 & TRN \\
\hline CHEMBL3431640 & 1479041 & 6.5498 & 6.6188 & TRN & \\
\hline CHEMBL 3431523 & 1479041 & 6.6424 & 6.4229 & TRN & \\
\hline CHEMBL 3431768 & 1479041 & 5.098 & 6.7425 & TST & \\
\hline CHEMBL 3431561 & 1479041 & 5.9714 & 6.3577 & TRN & \\
\hline CHEMBL 3431540 & 1479041 & 7.15 & 6.7456 & TRN & \\
\hline CHEMBL 3431793 & 1479041 & 7.585 & 7.3792 & TST & \\
\hline CHEMBL 3431730 & 1479041 & 6.4351 & 6.5236 & TST & \\
\hline CHEMBL 3431864 & 1479041 & 6.0064 & 6.3361 & TRN & \\
\hline CHEMBL 3431843 & 1479041 & 7.5784 & 7.2931 & TST & \\
\hline CHEMBL 3431580 & 1479041 & 6.0304 & 6.4662 & TST & \\
\hline
\end{tabular}


Supplemental Table S2.txt

\begin{tabular}{|c|c|c|c|c|c|}
\hline CHEMBL3431604 & 1479041 & 7.1524 & 7.1925 & TRN & \\
\hline CHEMBL3431518 & 1479041 & 6.9151 & 7.0057 & TRN & \\
\hline CHEMBL3431899 & 1479041 & 7.2007 & 7.2591 & TRN & \\
\hline CHEMBL 3431775 & 1479041 & 6.4917 & 6.3506 & TST & \\
\hline CHEMBL3431578 & 1479041 & 6.4814 & 6.3567 & TRN & \\
\hline CHEMBL3431744 & 1479041 & 6.2555 & 6.6558 & TRN & \\
\hline CHEMBL3431582 & 1479041 & 6.0909 & 6.2736 & TRN & \\
\hline CHEMBL3431509 & 1479041 & 6.511 & 6.772 & TRN & \\
\hline CHEMBL 2216777 & 1479041 & 6.7307 & 6.7771 & TRN & \\
\hline CHEMBL3431570 & 1479041 & 5.8872 & 6.1422 & TRN & \\
\hline CHEMBL3431673 & 1479041 & 6.4255 & 6.374 & TRN & \\
\hline CHEMBL3431752 & 1479041 & 7.4949 & 7.6012 & TRN & \\
\hline CHEMBL3431691 & 1479041 & 7.098 & 7.0455 & TRN & \\
\hline CHEMBL3431629 & 1479041 & 8.0132 & 7.4653 & TST & \\
\hline CHEMBL3431753 & 1479041 & 7.5884 & 7.7499 & TRN & \\
\hline CHEMBL 3431481 & 1479041 & 7.0164 & 6.78600 & 30000000005 & TRN \\
\hline CHEMBL3431855 & 1479041 & 6.8945 & 6.4768 & TRN & \\
\hline CHEMBL3431869 & 1479041 & 7.2027 & 6.5528 & TRN & \\
\hline CHEMBL3431575 & 1479041 & 6.9508 & 7.0027 & TRN & \\
\hline CHEMBL 3431544 & 1479041 & 6.8182 & 7.1961 & TRN & \\
\hline CHEMBL 3431563 & 1479041 & 6.3988 & 6.1125 & TRN & \\
\hline CHEMBL3431789 & 1479041 & 7.7423 & 7.3544 & TRN & \\
\hline CHEMBL3431797 & 1479041 & 7.4584 & 7.2317 & TST & \\
\hline CHEMBL3431749 & 1479041 & 6.8407 & 6.851 & TRN & \\
\hline CHEMBL3431829 & 1479041 & 6.9151 & 6.7384 & TST & \\
\hline CHEMBL3431926 & 1479041 & 7.4295 & 7.2599 & TRN & \\
\hline CHEMBL3431585 & 1479041 & 7.3904 & 7.1354 & TRN & \\
\hline CHEMBL3431820 & 1479041 & 7.9208 & 7.3284 & TRN & \\
\hline CHEMBL3431828 & 1479041 & 7.5986 & 7.6317 & TRN & \\
\hline CHEMBL 3431495 & 1479041 & 6.0382 & 6.6139 & TRN & \\
\hline CHEMBL3431765 & 1479041 & 6.9073 & 7.2834 & TRN & \\
\hline CHEMBL3431746 & 1479041 & 6.3482 & 6.6457 & TRN & \\
\hline CHEMBL3431591 & 1479041 & 7.0092 & 6.7359 & TRN & \\
\hline CHEMBL 3431607 & 1479041 & 6.6135 & 6.5043 & TST & \\
\hline CHEMBL3431741 & 1479041 & 6.3391 & 6.8539 & TRN & \\
\hline CHEMBL3431685 & 1479041 & 7.2636 & 8.109 & TST & \\
\hline CHEMBL3431880 & 1479041 & 7.4145 & 6.8617 & TST & \\
\hline CHEMBL3431919 & 1479041 & 7.6925 & 7.2264 & TRN & \\
\hline CHEMBL3431865 & 1479041 & 5.6993 & 5.9831 & TRN & \\
\hline CHEMBL3431920 & 1479041 & 6.4277 & 6.5146 & TST & \\
\hline CHEMBL 3431723 & 1479041 & 7.1415 & 6.2053 & TST & \\
\hline CHEMBL3431587 & 1479041 & 6.7405 & 7.1455 & TRN & \\
\hline CHEMBL3431529 & 1479041 & 6.4681 & 6.4272 & TRN & \\
\hline CHEMBL3431927 & 1479041 & 6.841 & 6.7988 & TRN & \\
\hline CHEMBL 3431904 & 1479041 & 6.8447 & \multicolumn{2}{|c|}{6.797999999999999} & TRN \\
\hline CHEMBL 3431715 & 1479041 & 6.7899 & 6.916 & TRN & \\
\hline CHEMBL 3431474 & 1479041 & 6.6538 & 6.5539 & TRN & \\
\hline CHEMBL3431911 & 1479041 & 7.0419 & 6.5724 & TST & \\
\hline
\end{tabular}




\begin{tabular}{|c|c|c|c|c|c|c|}
\hline \multicolumn{7}{|c|}{ Supplemental Table s2.txt } \\
\hline CHEMBL 3431778 & 1479041 & 6.707999 & 999999999 & & 6.3761 & TST \\
\hline CHEMBL 3431503 & 1479041 & 6.631 & 6.6852 & TRN & & \\
\hline CHEMBL3431751 & 1479041 & 6.8116 & 6.5693 & TRN & & \\
\hline CHEMBL3431681 & 1479041 & 7.082000 & 20000000e & & 6.7823 & TST \\
\hline CHEMBL3431740 & 1479041 & 6.6931 & 7.177000 & 0000000000 & 05 & TST \\
\hline CHEMBL3431760 & 1479041 & 6.987999 & 999999999 & 995 & 6.8196 & TRN \\
\hline CHEMBL 3431708 & 1479041 & 6.7899 & 6.2246 & TST & & \\
\hline CHEMBL3431822 & 1479041 & 7.3788 & 7.4189 & TRN & & \\
\hline CHEMBL3431706 & 1479041 & 7.0768 & 6.4224 & TST & & \\
\hline CHEMBL3431856 & 1479041 & 6.5158 & 6.5085 & TRN & & \\
\hline CHEMBL3431662 & 1479041 & 7.0467 & 7.2628 & TST & & \\
\hline CHEMBL3431590 & 1479041 & 5.8011 & 6.4678 & TST & & \\
\hline CHEMBL3431791 & 1479041 & 6.9914 & 7.2393 & TRN & & \\
\hline CHEMBL3431487 & 1479041 & 6.5955 & 6.8842 & TRN & & \\
\hline CHEMBL 3431738 & 1479041 & 6.5802 & 6.4535 & TST & & \\
\hline CHEMBL3431626 & 1479041 & 7.4908 & 6.8262 & TRN & & \\
\hline CHEMBL 3431883 & 1479041 & 6.9987 & 6.7833 & TRN & & \\
\hline CHEMBL 3431784 & 1479041 & 6.7729 & 6.9812 & TRN & & \\
\hline CHEMBL3431785 & 1479041 & 6.8837 & 6.9104 & TRN & & \\
\hline CHEMBL 3431504 & 1479041 & 7.8996 & 7.1621 & TRN & & \\
\hline CHEMBL3431576 & 1479041 & 6.7231 & 6.9734 & TRN & & \\
\hline CHEMBL3431795 & 1479041 & 7.02 & 7.4331 & TST & & \\
\hline CHEMBL 3431643 & 1479041 & 6.6228 & 6.7548 & TRN & & \\
\hline CHEMBL3431845 & 1479041 & 7.8539 & 7.2562 & TRN & & \\
\hline CHEMBL3431619 & 1479041 & 5.9993 & 6.1437 & TRN & & \\
\hline CHEMBL3431712 & 1479041 & 6.922999 & 999999999 & & 6.8764 & TRN \\
\hline CHEMBL3431717 & 1479041 & 6.6869 & 6.6761 & TRN & & \\
\hline CHEMBL3431614 & 1479041 & 5.9032 & 6.165 & TRN & & \\
\hline CHEMBL3431750 & 1479041 & 6.4107 & 6.592000 & 0000000000 & 05 & TRN \\
\hline CHEMBL3431595 & 1479041 & 7.0237 & 7.1386 & TRN & & \\
\hline CHEMBL3431466 & 1479041 & 6.6029 & 6.5452 & TRN & & \\
\hline CHEMBL3431682 & 1479041 & 6.9266 & 6.7749 & TST & & \\
\hline CHEMBL3431922 & 1479041 & 6.8111 & $6.88200 e$ & 0000000001 & & TST \\
\hline CHEMBL3431567 & 1479041 & 6.3387 & 6.1953 & TRN & & \\
\hline CHEMBL3431916 & 1479041 & 7.1002 & 7.1505 & TRN & & \\
\hline CHEMBL3431764 & 1479041 & 7.1518 & 7.2766 & TRN & & \\
\hline CHEMBL3431613 & 1479041 & 6.7258 & 7.1248 & TRN & & \\
\hline CHEMBL3431464 & 1479041 & 5.7766 & 6.5185 & TRN & & \\
\hline CHEMBL3431603 & 1479041 & 7.1409 & 7.3004 & TRN & & \\
\hline CHEMBL3431546 & 1479041 & 7.0996 & 7.0284 & TRN & & \\
\hline CHEMBL3431915 & 1479041 & 7.383999 & 999999999 & 995 & 7.1095 & TRN \\
\hline CHEMBL3431557 & 1479041 & 6.5157 & 6.7485 & TRN & & \\
\hline CHEMBL3431868 & 1479041 & 7.2182 & 6.7014 & TRN & & \\
\hline CHEMBL3431881 & 1479041 & 6.2783 & 6.3307 & TST & & \\
\hline CHEMBL3431826 & 1479041 & 6.604 & 6.8066 & TST & & \\
\hline CHEMBL3431910 & 1479041 & 5.807 & 6.434 & TST & & \\
\hline CHEMBL3431707 & 1479041 & 6.6891 & 6.4611 & TST & & \\
\hline CHEMBL3431788 & 1479041 & 7.4034 & 7.4823 & TRN & & \\
\hline
\end{tabular}


Supplemental Table S2.txt

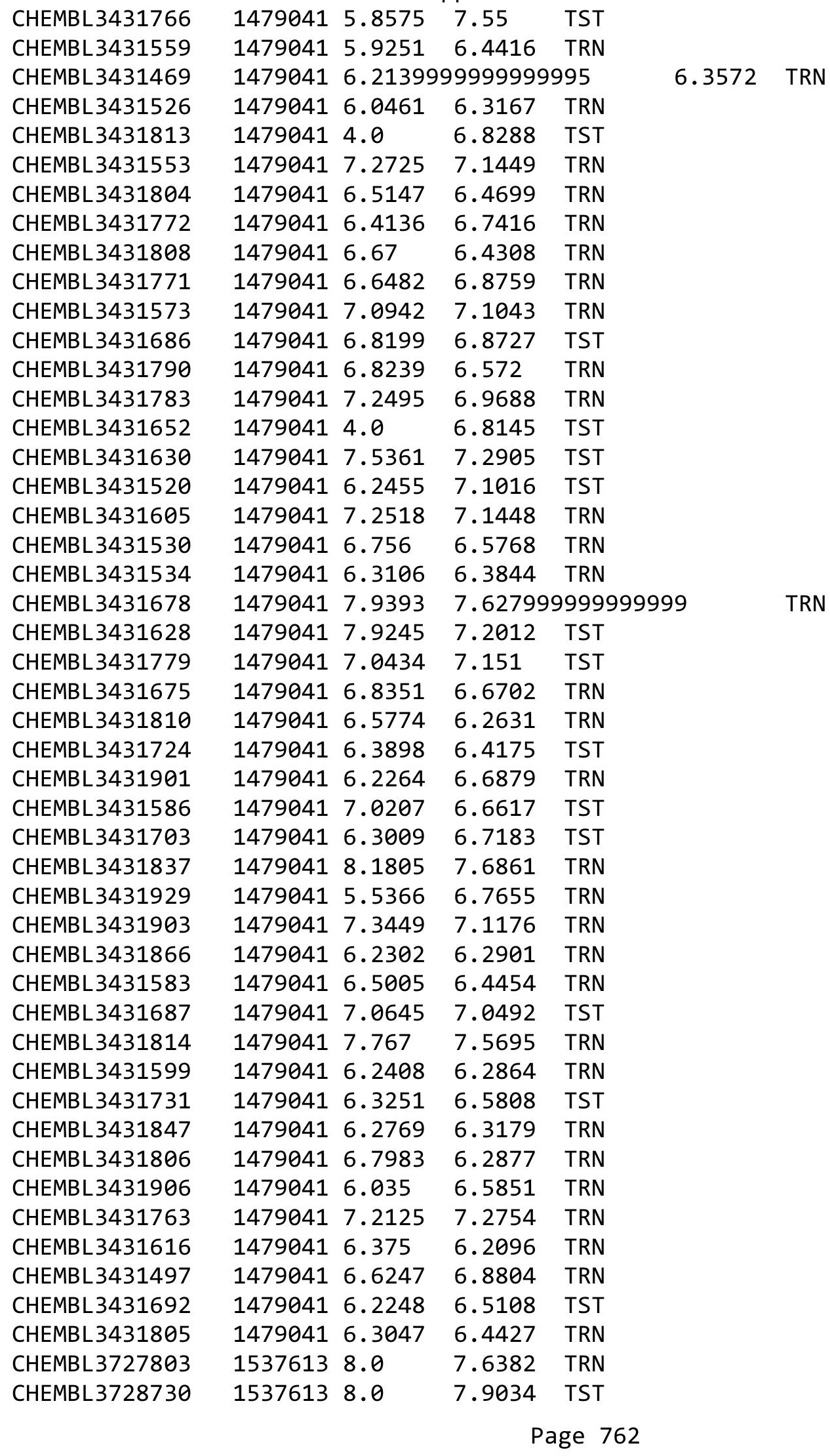




\begin{tabular}{|c|c|c|c|c|c|}
\hline \multicolumn{6}{|c|}{ Supplemental Table S2.txt } \\
\hline CHEMBL3728183 & 1537613 & 8.0 & 7.4996 & TRN & \\
\hline CHEMBL3728339 & 1537613 & 6.9957 & 7.3368 & TRN & \\
\hline CHEMBL3728131 & 1537613 & 8.0 & 7.5916 & TRN & \\
\hline CHEMBL3731821 & 1537613 & 8.0 & 7.7516 & TRN & \\
\hline CHEMBL3732587 & 1537613 & 8.0 & 7.7446 & TRN & \\
\hline CHEMBL3730556 & 1537613 & 5.9957 & 5.8605 & TRN & \\
\hline CHEMBL3729685 & 1537613 & 8.0 & 8.0626 & TRN & \\
\hline CHEMBL3732176 & 1537613 & 8.0 & 7.9962 & TRN & \\
\hline CHEMBL 3727867 & 1537613 & 8.0 & 7.8772 & TST & \\
\hline CHEMBL3727380 & 1537613 & 6.9957 & 7.7937 & TRN & \\
\hline CHEMBL3733007 & 1537613 & 8.0 & 7.7563 & TRN & \\
\hline CHEMBL 3732143 & 1537613 & 6.9957 & 7.63399 & 99999999995 & TRN \\
\hline CHEMBL3732065 & 1537613 & 8.0 & 8.0013 & TRN & \\
\hline CHEMBL3729064 & 1537613 & 6.9957 & 7.9978 & TST & \\
\hline CHEMBL3729025 & 1537613 & 8.0 & 7.7212 & TRN & \\
\hline CHEMBL3733100 & 1537613 & 6.9957 & 6.9122 & TST & \\
\hline CHEMBL3728122 & 1537613 & 6.9957 & 7.4505 & TRN & \\
\hline CHEMBL 3730284 & 1537613 & 8.0 & 7.7065 & TRN & \\
\hline CHEMBL3729450 & 1537613 & 8.0 & 8.0453 & TST & \\
\hline CHEMBL3729684 & 1537613 & 6.9957 & 7.2752 & TRN & \\
\hline CHEMBL3732573 & 1537613 & 8.0 & 8.0309 & TRN & \\
\hline CHEMBL3731546 & 1537613 & 8.0 & 7.4833 & TRN & \\
\hline CHEMBL3728835 & 1537613 & 5.9957 & 6.8657 & TRN & \\
\hline CHEMBL3730709 & 1537613 & 8.0 & 7.4119 & TST & \\
\hline CHEMBL3729836 & 1537613 & 8.0 & 8.0642 & TRN & \\
\hline CHEMBL3729496 & 1537613 & 8.0 & 8.0505 & TRN & \\
\hline CHEMBL3730769 & 1537613 & 8.0 & 7.6379 & TRN & \\
\hline CHEMBL3732749 & 1537613 & 6.9957 & 7.6015 & TRN & \\
\hline CHEMBL 3730171 & 1537613 & 6.9957 & 7.5989 & TRN & \\
\hline CHEMBL3733226 & 1537613 & 8.0 & 7.6321 & TRN & \\
\hline CHEMBL3733115 & 1537613 & 8.0 & 8.2011 & TRN & \\
\hline CHEMBL 3727870 & 1537613 & 8.0 & 7.9879 & TRN & \\
\hline CHEMBL 3730546 & 1537613 & 6.9957 & 7.5592 & TRN & \\
\hline CHEMBL3732830 & 1537613 & 8.0 & 7.6648 & TRN & \\
\hline CHEMBL3732452 & 1537613 & 6.9957 & 7.4356 & TST & \\
\hline CHEMBL3732598 & 1537613 & 8.0 & 7.5512 & TRN & \\
\hline CHEMBL3729906 & 1537613 & 8.0 & 8.0826 & TRN & \\
\hline CHEMBL3729057 & 1537613 & 6.9957 & 7.53799 & 9999999999 & TRN \\
\hline CHEMBL3729712 & 1537613 & 5.9957 & 7.0259 & TRN & \\
\hline CHEMBL3733291 & 1537613 & 8.0 & 8.1287 & TRN & \\
\hline CHEMBL3731224 & 1537613 & 8.0 & 7.7729 & TRN & \\
\hline CHEMBL3732561 & 1537613 & 6.9957 & 7.8269 & TRN & \\
\hline CHEMBL3732746 & 1537613 & 6.9957 & 7.6977 & TRN & \\
\hline CHEMBL3730681 & 1537613 & 6.9957 & 7.0763 & TRN & \\
\hline CHEMBL3730288 & 1537613 & 8.0 & 7.848 & TST & \\
\hline CHEMBL3728928 & 1537613 & 8.0 & 7.6862 & TRN & \\
\hline CHEMBL3729011 & 1537613 & 8.0 & 7.5705 & TRN & \\
\hline CHEMBL3728780 & 1537613 & 8.0 & 7.7915 & TRN & \\
\hline
\end{tabular}


Supplemental Table S2.txt

\begin{tabular}{|c|c|c|c|c|c|}
\hline CHEMBL3727671 & 1537613 & 6.9957 & 7.2617 & TRN & \\
\hline CHEMBL3731188 & 1537613 & 8.0 & 7.904 & TRN & \\
\hline CHEMBL3728648 & 1537613 & 6.9957 & 7.5984 & TRN & \\
\hline CHEMBL3727633 & 1537613 & 8.0 & 7.5289 & TRN & \\
\hline CHEMBL3731762 & 1537613 & 6.9957 & \multicolumn{2}{|c|}{7.1739999999999995} & TST \\
\hline CHEMBL3731904 & 1537613 & 6.9957 & 7.5653 & TRN & \\
\hline CHEMBL3728151 & 1537613 & 8.0 & 7.9169 & TRN & \\
\hline CHEMBL3727972 & 1537613 & 8.0 & 7.7326 & TRN & \\
\hline CHEMBL3729848 & 1537613 & 8.0 & 7.9267 & TRN & \\
\hline CHEMBL3730000 & 1537613 & 6.9957 & 7.237 & TST & \\
\hline CHEMBL3731974 & 1537613 & 8.0 & 7.9751 & TRN & \\
\hline CHEMBL3732412 & 1537613 & 8.0 & 8.1829 & TRN & \\
\hline CHEMBL3729298 & 1537613 & 6.9957 & 7.379 & TST & \\
\hline CHEMBL3731187 & 1537613 & 8.0 & \multicolumn{2}{|c|}{7.6370000000000005} & TRN \\
\hline CHEMBL3728609 & 1537613 & 8.0 & 7.9927 & TRN & \\
\hline CHEMBL3729860 & 1537613 & 8.0 & 7.5615 & TRN & \\
\hline CHEMBL3732299 & 1537613 & 8.0 & 8.1881 & TRN & \\
\hline CHEMBL3732399 & 1537613 & 5.9957 & 7.4146 & TRN & \\
\hline CHEMBL3731645 & 1537613 & 8.0 & 7.8416 & TRN & \\
\hline CHEMBL 3727658 & 1537613 & 8.0 & 7.9218 & TRN & \\
\hline CHEMBL3728269 & 1537613 & 8.0 & 7.6477 & TRN & \\
\hline CHEMBL3728569 & 1537613 & 6.9957 & 7.438 & TST & \\
\hline CHEMBL3732776 & 1537613 & 8.0 & 7.6548 & TST & \\
\hline CHEMBL3729452 & 1537613 & 5.9957 & 6.8964 & TRN & \\
\hline CHEMBL 3732495 & 1537613 & 8.0 & 7.9799 & TRN & \\
\hline CHEMBL3733161 & 1537613 & 8.0 & 7.685 & TST & \\
\hline CHEMBL3732459 & 1537613 & 8.0 & 7.9502 & TRN & \\
\hline CHEMBL3729290 & 1537613 & 8.0 & 7.1621 & TRN & \\
\hline CHEMBL3731801 & 1537613 & 8.0 & 7.6998 & TRN & \\
\hline CHEMBL 3732693 & 1537613 & 8.0 & 7.6876 & TRN & \\
\hline CHEMBL3728233 & 1537613 & 8.0 & 7.9763 & TRN & \\
\hline CHEMBL3731496 & 1537613 & 8.0 & 7.4308 & TST & \\
\hline CHEMBL3731565 & 1537613 & 8.0 & 8.0971 & TRN & \\
\hline CHEMBL3731643 & 1537613 & 8.0 & 7.7036 & TRN & \\
\hline CHEMBL3727429 & 1537613 & 6.9957 & 7.0007 & TRN & \\
\hline CHEMBL3732435 & 1537613 & 8.0 & 7.7653 & TRN & \\
\hline CHEMBL3728469 & 1537613 & 8.0 & 7.7244 & TRN & \\
\hline CHEMBL3731747 & 1537613 & 8.0 & 8.1308 & TRN & \\
\hline CHEMBL3727458 & 1537613 & 8.0 & 7.9155 & TRN & \\
\hline CHEMBL 3728828 & 1537613 & 8.0 & 8.0123 & TRN & \\
\hline CHEMBL3733360 & 1537613 & 8.0 & 7.9021 & TRN & \\
\hline CHEMBL3729439 & 1537613 & 6.9957 & 7.6419 & TST & \\
\hline CHEMBL3732969 & 1537613 & 8.0 & 7.5054 & TRN & \\
\hline CHEMBL3732269 & 1537613 & 6.9957 & 7.2933 & TRN & \\
\hline CHEMBL3730962 & 1537613 & 6.9957 & 7.4081 & TRN & \\
\hline CHEMBL3732867 & 1537613 & 8.0 & 7.9162 & TRN & \\
\hline CHEMBL3731897 & 1537613 & 8.0 & 8.0846 & TRN & \\
\hline CHEMBL3733188 & 1537613 & 6.9957 & 7.456 & TRN & \\
\hline
\end{tabular}


Supplemental Table S2.txt

\begin{tabular}{|c|c|c|c|c|c|}
\hline CHEMBL3728823 & 1537613 & 6.9957 & 7.4442 & TRN & \\
\hline CHEMBL3731497 & 1537613 & 6.9957 & 7.4615 & TRN & \\
\hline CHEMBL3730243 & 1537613 & 6.9957 & 7.0069 & TRN & \\
\hline CHEMBL3728052 & 1537613 & 8.0 & 8.0949 & TRN & \\
\hline CHEMBL3731630 & 1537613 & 8.0 & 7.9747 & TRN & \\
\hline CHEMBL3732139 & 1537613 & 8.0 & 7.5952 & TRN & \\
\hline CHEMBL3732405 & 1537613 & 8.0 & \multicolumn{2}{|c|}{8.017000000000001} & TRN \\
\hline CHEMBL3729744 & 1537613 & 8.0 & 7.9481 & TST & \\
\hline CHEMBL 3730038 & 1537613 & 8.0 & 7.3576 & TST & \\
\hline CHEMBL3730101 & 1537613 & 8.0 & 7.7865 & TRN & \\
\hline CHEMBL3728962 & 1537613 & 8.0 & 7.4084 & TRN & \\
\hline CHEMBL3728225 & 1537613 & 6.9957 & 7.6967 & TST & \\
\hline CHEMBL3731420 & 1537613 & 8.0 & 7.5728 & TRN & \\
\hline CHEMBL 3730708 & 1537613 & 8.0 & 7.8379 & TRN & \\
\hline CHEMBL 3727837 & 1537613 & 8.0 & 7.9995 & TRN & \\
\hline CHEMBL 3732340 & 1537613 & 8.0 & 7.704 & TRN & \\
\hline CHEMBL3729727 & 1537613 & 8.0 & 7.9472 & TRN & \\
\hline CHEMBL3728498 & 1537613 & 8.0 & 7.5949 & TRN & \\
\hline CHEMBL3731218 & 1537613 & 8.0 & 7.6424 & TRN & \\
\hline CHEMBL3730677 & 1537613 & 6.9957 & 7.5018 & TRN & \\
\hline CHEMBL 3732945 & 1537613 & 8.0 & 7.6548 & TRN & \\
\hline CHEMBL3729893 & 1537613 & 6.9957 & 7.4852 & TST & \\
\hline CHEMBL3727825 & 1537613 & 6.9957 & 7.3256 & TST & \\
\hline CHEMBL3728251 & 1537613 & 6.9957 & 7.447 & TRN & \\
\hline CHEMBL3733139 & 1537613 & 6.9957 & 7.4161 & TST & \\
\hline CHEMBL 3729821 & 1537613 & 8.0 & 7.4542 & TRN & \\
\hline CHEMBL3733051 & 1537613 & 8.0 & 7.5216 & TST & \\
\hline CHEMBL3731126 & 1537613 & 6.9957 & 6.8731 & TRN & \\
\hline CHEMBL3729041 & 1537613 & 6.9957 & 7.8349 & TRN & \\
\hline CHEMBL3731502 & 1537613 & 8.0 & 7.9993 & TRN & \\
\hline CHEMBL3728057 & 1537613 & 6.9957 & 7.2935 & TRN & \\
\hline CHEMBL3732133 & 1537613 & 8.0 & 8.1538 & TRN & \\
\hline CHEMBL3729570 & 1537613 & 8.0 & \multicolumn{2}{|c|}{7.9670000000000005} & TRN \\
\hline CHEMBL 3727751 & 1537613 & 8.0 & 8.1357 & TRN & \\
\hline CHEMBL3727915 & 1537613 & 6.9957 & 7.6562 & TRN & \\
\hline CHEMBL3731540 & 1537613 & 8.0 & 7.8165 & TRN & \\
\hline CHEMBL3729454 & 1537613 & 8.0 & 7.9077 & TRN & \\
\hline CHEMBL3732101 & 1537613 & 8.0 & 7.6031 & TRN & \\
\hline CHEMBL3729689 & 1537613 & 8.0 & 8.0731 & TRN & \\
\hline CHEMBL3728102 & 1537613 & 6.9957 & 7.2664 & TST & \\
\hline CHEMBL3729049 & 1537613 & 8.0 & 7.7043 & TRN & \\
\hline CHEMBL3728691 & 1537613 & 8.0 & 7.5025 & TRN & \\
\hline CHEMBL3732332 & 1537613 & 8.0 & 7.4436 & TRN & \\
\hline CHEMBL3732710 & 1537613 & 8.0 & 7.8478 & TRN & \\
\hline CHEMBL3731856 & 1537613 & 8.0 & 7.6002 & TRN & \\
\hline CHEMBL 3729403 & 1537613 & 6.9957 & 7.3323 & TRN & \\
\hline CHEMBL 3727804 & 1537613 & 8.0 & 7.7418 & TRN & \\
\hline CHEMBL3728399 & 1537613 & 8.0 & 7.5554 & TST & \\
\hline
\end{tabular}


Supplemental Table S2.txt

\begin{tabular}{|c|c|c|c|c|c|}
\hline CHEMBL 3729037 & 1537613 & 8.0 & 7.8976 & TRN & \\
\hline CHEMBL3731144 & 1537613 & 6.9957 & 7.6206 & TRN & \\
\hline CHEMBL3733045 & 1537613 & 8.0 & 7.7892 & TRN & \\
\hline CHEMBL3727855 & 1537613 & 8.0 & 8.1522 & TRN & \\
\hline CHEMBL3727945 & 1537613 & 6.9957 & 7.3832 & TRN & \\
\hline CHEMBL3731155 & 1537613 & 6.9957 & 7.4285 & TRN & \\
\hline CHEMBL3728608 & 1537613 & 6.9957 & 7.6118 & TRN & \\
\hline CHEMBL3729315 & 1537613 & 6.9957 & 6.2107 & TRN & \\
\hline CHEMBL 3732251 & 1537613 & 8.0 & 7.6114 & TRN & \\
\hline CHEMBL3733140 & 1537613 & 8.0 & 7.8778 & TRN & \\
\hline CHEMBL 3727743 & 1537613 & 8.0 & 7.1342 & TST & \\
\hline CHEMBL 3732526 & 1537613 & 8.0 & 7.6572 & TRN & \\
\hline CHEMBL3729704 & 1537613 & 8.0 & 7.4599 & TST & \\
\hline CHEMBL 3732647 & 1537613 & 8.0 & 7.8488 & TRN & \\
\hline CHEMBL3729745 & 1537613 & 6.9957 & 6.952000 & 0000000001 & TRN \\
\hline CHEMBL3729994 & 1537613 & 6.9957 & 7.3544 & TRN & \\
\hline CHEMBL3731935 & 1537613 & 6.9957 & 7.6819 & TST & \\
\hline CHEMBL 3728243 & 1537613 & 8.0 & 7.9884 & TRN & \\
\hline CHEMBL3729336 & 1537613 & 6.9957 & 7.5108 & TRN & \\
\hline CHEMBL3728355 & 1537613 & 6.9957 & 7.308 & TRN & \\
\hline CHEMBL3730039 & 1537613 & 8.0 & 7.8074 & TST & \\
\hline CHEMBL3728124 & 1537613 & 8.0 & 8.107999 & 9999999999 & TRN \\
\hline CHEMBL3729954 & 1537613 & 6.9957 & 7.0396 & TRN & \\
\hline CHEMBL3729438 & 1537613 & 6.9957 & 7.3113 & TST & \\
\hline CHEMBL 3731243 & 1537613 & 6.9957 & 7.5351 & TRN & \\
\hline CHEMBL3731923 & 1537613 & 8.0 & 8.1547 & TRN & \\
\hline CHEMBL 3730249 & 1537613 & 8.0 & 7.6816 & TST & \\
\hline CHEMBL3727693 & 1537613 & 8.0 & 7.2697 & TRN & \\
\hline CHEMBL 3728331 & 1537613 & 8.0 & 7.513 & TST & \\
\hline CHEMBL3731941 & 1537613 & 8.0 & 6.8971 & TRN & \\
\hline CHEMBL3731819 & 1537613 & 6.9957 & 7.3087 & TRN & \\
\hline CHEMBL3732662 & 1537613 & 8.0 & 7.9472 & TRN & \\
\hline CHEMBL3731863 & 1537613 & 8.0 & 7.9221 & TRN & \\
\hline CHEMBL3729723 & 1537613 & 6.9957 & 7.4924 & TRN & \\
\hline CHEMBL3727977 & 1537613 & 8.0 & 7.7365 & TRN & \\
\hline CHEMBL3729081 & 1537613 & 8.0 & 7.5601 & TRN & \\
\hline CHEMBL3728465 & 1537613 & 8.0 & 7.4451 & TRN & \\
\hline CHEMBL3728514 & 1537613 & 8.0 & 7.7163 & TRN & \\
\hline CHEMBL 3730388 & 1537613 & 8.0 & 7.8178 & TRN & \\
\hline CHEMBL3731824 & 1537613 & 5.9957 & 7.0965 & TST & \\
\hline CHEMBL3730678 & 1537613 & 8.0 & 7.5729 & TST & \\
\hline CHEMBL3730449 & 1537613 & 8.0 & 7.0663 & TST & \\
\hline CHEMBL3729451 & 1537613 & 6.9957 & 7.2818 & TST & \\
\hline CHEMBL3729506 & 1537613 & 8.0 & 7.6155 & TST & \\
\hline CHEMBL3728504 & 1537613 & 8.0 & 7.4413 & TST & \\
\hline CHEMBL3732372 & 1537613 & 8.0 & 7.4503 & TST & \\
\hline CHEMBL3733113 & 1537613 & 8.0 & 7.9101 & TST & \\
\hline CHEMBL3729395 & 1537613 & 6.9957 & 7.3875 & TST & \\
\hline
\end{tabular}


Supplemental Table S2.txt

\begin{tabular}{|c|c|c|c|c|}
\hline CHEMBL 3732558 & 1537613 & 6.9957 & 7.6874 & TST \\
\hline CHEMBL3728388 & 1537613 & 8.0 & 7.7661 & \\
\hline HEMBL3733174 & 537613 & 8.0 & 7.6323 & ST \\
\hline CHEMBL 3731675 & 537613 & 8.0 & 7.6996 & ST \\
\hline HEMBL3728841 & 537613 & 8.0 & 8.0582 & $\mathrm{~T}$ \\
\hline CHEMBL3733227 & .537613 & 6.9957 & 7.6078 & ST \\
\hline CHEMBL3728532 & 537613 & 6.9957 & 7.4988 & \\
\hline HEMBL3732377 & 537613 & 8.0 & 7.9237 & \\
\hline HEMBL3732980 & 1537613 & 8.0 & 7.6922 & \\
\hline HEMBL3729108 & 537613 & 6.9957 & 7.1339 & ST \\
\hline CHEMBL1964290 & 809194 & 5.5 & 5.57 & \\
\hline HEMBL 213505 & 309194 & 4.4 & 4.6408 & \\
\hline HEMBL 202721 & 809194 & 4.4 & 4.4713 & \\
\hline HEMBL1825138 & 809194 & 4.4 & 4.8649 & \\
\hline HEMBL1987034 & 809194 & 8.2 & 7.4605 & \\
\hline HEMBL1993941 & 809194 & 4.4 & 4.7043 & \\
\hline HEMBL377383 & 809194 & 8.0 & 7.3784 & 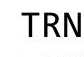 \\
\hline HEMBL2005886 & 809194 & 4.4 & 4.7816 & \\
\hline HEMBL481491 & 809194 & 4.4 & 4.5708 & \\
\hline HEMBL1682345 & 809194 & 4.4 & 4.5622 & RIN \\
\hline HEMBL1973142 & 809194 & 4.4 & 4.8351 & . \\
\hline CHEMBL 388311 & 809194 & 5.9 & 6.1225 & 西 \\
\hline CHEMBL1973145 & 809194 & 4.4 & 4.5289 & RN \\
\hline HEMBL1982924 & 809194 & 4.4 & 4.8853 & $2 \mathrm{~N}$ \\
\hline CHEMBL 2005936 & 809194 & 6.1 & 5.6526 & SIV \\
\hline CHEMBL1807515 & 809194 & 6. & 6.7981 & KIV \\
\hline HEMBL1964948 & 809194 & 4.4 & 5.1233 & Niv \\
\hline CHEMBL1971141 & 809194 & 4.4 & 4.4999 & RN \\
\hline HEMBL1995813 & 809194 & 4.4 & 5.3091 & TRN \\
\hline CHEMBL1979718 & 809194 & 4.4 & 4.7484 & IRN \\
\hline CHEMBL206236 & 809194 & 4.4 & 4.6465 & RN \\
\hline CHEMBL1989834 & 809194 & 5.8 & 4.02 & Niv \\
\hline CHEMBL523823 & 809194 & 4.4 & 5.0058 & ST \\
\hline CHEMBL1562756 & 809194 & 4.4 & 5.0116 & TST \\
\hline CHEMBL1987430 & 809194 & 4.4 & 4.3405 & TRN \\
\hline CHEMBL244378 & 809194 & 8.8 & 76 & TRN \\
\hline CHEMBL 20 & 809194 & 8.2 & 8.3697 & TRN \\
\hline CHEMBL1969372 & 809194 & 6.4 & 6.1937 & TRN \\
\hline CHEMBL1993413 & 809194 & 4.4 & 4.7455 & TRN \\
\hline CHEMBL1990583 & 809194 & 6.1 & 4.6458 & TRN \\
\hline CHEMBL1986943 & 809194 & 6.6 & 6.4108 & $1 \mathrm{KI}$ \\
\hline CHEMBL 2006263 & 809194 & 4.4 & 5.3738 & \\
\hline CHEMBL1993584 & 809194 & 4.4 & 4.4976 & RN \\
\hline CHEMBL1986263 & 809194 & 6.6 & 6.5254 & TRN \\
\hline CHEMBL 2000114 & 809194 & 4.4 & 4.8005 & $1 \pi$ \\
\hline CHEMBL210618 & 809194 & 8.4 & 7.2686 & \\
\hline CHEMBL1986265 & 809194 & 4.4 & 4.3147 & \\
\hline CHEMBL1975647 & 809194 & 4.4 & 4.4862 & 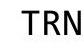 \\
\hline
\end{tabular}




\begin{tabular}{|c|c|c|c|c|c|}
\hline & & & & & \\
\hline CHEMBL1968380 & 809194 & 4.4 & 4.8677 & TRN & \\
\hline CHEMBL1964644 & 809194 & 4.4 & 4.5484 & TRN & \\
\hline CHEMBL1991734 & 809194 & 5.6 & 5.6356 & TST & \\
\hline CHEMBL1981782 & 809194 & 4.4 & 4.579 & TRN & \\
\hline CHEMBL1977681 & 809194 & 6.4 & 4.9286 & TRN & \\
\hline CHEMBL1970142 & 809194 & 4.4 & 4.544 & TRN & \\
\hline CHEMBL1990912 & 809194 & 4.4 & 4.6398 & TRN & \\
\hline CHEMBL1991782 & 809194 & 3.1 & 4.2558 & TRN & \\
\hline CHEMBL1983348 & 809194 & 6.6 & 5.9632 & TRN & \\
\hline CHEMBL1988163 & 809194 & 7.4 & 6.73600 & 3000000001 & TRN \\
\hline CHEMBL1995592 & 809194 & 6.1 & 5.7361 & TST & \\
\hline CHEMBL1980671 & 809194 & 4.5 & 5.003 & TRN & \\
\hline CHEMBL 2006493 & 809194 & 4.4 & 4.5907 & TST & \\
\hline CHEMBL1986177 & 809194 & 4.4 & 4.455 & TRN & \\
\hline CHEMBL1996923 & 809194 & 4.4 & 4.5316 & TST & \\
\hline CHEMBL1983449 & 809194 & 4.4 & 4.4188 & TRN & \\
\hline CHEMBL1992323 & 809194 & 4.4 & 4.5414 & TRN & \\
\hline CHEMBL1969735 & 809194 & 7.2 & 7.6327 & TRN & \\
\hline CHEMBL 2003524 & 809194 & 4.4 & 4.7204 & TST & \\
\hline CHEMBL 2002649 & 809194 & 5.8 & 4.7128 & TRN & \\
\hline CHEMBL1989423 & 809194 & 4.1 & 4.7807 & TRN & \\
\hline CHEMBL1985367 & 809194 & 5.5 & 5.5947 & TST & \\
\hline CHEMBL1996510 & 809194 & 4.4 & 4.6171 & TST & \\
\hline CHEMBL437747 & 809194 & 7.7 & 7.02 & TRN & \\
\hline CHEMBL1995172 & 809194 & 4.4 & 4.5176 & TST & \\
\hline CHEMBL 2001584 & 809194 & 4.4 & 4.434 & TRN & \\
\hline CHEMBL507936 & 809194 & 4.4 & 4.6844 & TRN & \\
\hline CHEMBL1971227 & 809194 & 5.5 & 5.2919 & TST & \\
\hline CHEMBL104264 & 809194 & 4.4 & 4.7814 & TST & \\
\hline CHEMBL1967998 & 809194 & 7.0 & 6.8276 & TRN & \\
\hline CHEMBL1994321 & 809194 & 6.2 & 4.6093 & TRN & \\
\hline CHEMBL1978562 & 809194 & 5.8 & 5.649 & TST & \\
\hline CHEMBL1997129 & 809194 & 7.1 & 6.5289 & TRN & \\
\hline CHEMBL1984788 & 809194 & 4.4 & 4.651 & TRN & \\
\hline CHEMBL451964 & 809194 & 4.4 & 4.7262 & TRN & \\
\hline CHEMBL1964307 & 809194 & 4.4 & 4.5652 & TRN & \\
\hline CHEMBL1989471 & 809194 & 5.6 & 5.7031 & TST & \\
\hline CHEMBL 2002099 & 809194 & 4.4 & 4.4652 & TRN & \\
\hline CHEMBL 2000508 & 809194 & 6.8 & 6.1619 & TRN & \\
\hline CHEMBL1971694 & 809194 & 4.4 & 4.5798 & TST & \\
\hline CHEMBL 2001547 & 809194 & 6.8 & 6.3729 & TRN & \\
\hline CHEMBL210928 & 809194 & 8.0 & 7.3125 & TRN & \\
\hline CHEMBL1978195 & 809194 & 4.4 & 5.5573 & TRN & \\
\hline CHEMBL1994361 & 809194 & 4.4 & 4.8864 & TRN & \\
\hline CHEMBL1986603 & 809194 & 4.4 & 4.655 & TST & \\
\hline CHEMBL1972840 & 809194 & 4.4 & 5.6471 & TRN & \\
\hline CHEMBL1977148 & 809194 & 4.4 & 4.6481 & TRN & \\
\hline CHEMBL 2003286 & 809194 & 4.4 & 4.6318 & TRN & \\
\hline & & & & e 768 & \\
\hline
\end{tabular}




\begin{tabular}{|c|c|c|c|c|}
\hline \multicolumn{5}{|c|}{ lemental T } \\
\hline CHEMBL1992306 & 809194 & 5.4 & 4.5248 & TRN \\
\hline CHEMBL 2002165 & 809194 & 5.8 & 4.71 & TRN \\
\hline CHEMBL1979318 & 809194 & 4.4 & 4.5558 & TRN \\
\hline CHEMBL206382 & 809194 & 4.4 & 4.4873 & TRN \\
\hline CHEMBL1998585 & 809194 & 6.9 & 4.7855 & TRN \\
\hline CHEMBL127898 & 809194 & 4.4 & 4.7471 & TST \\
\hline CHEMBL519697 & 809194 & 4.4 & 4.6101 & TRN \\
\hline CHEMBL 2004934 & 809194 & 4.4 & 4.3353 & TRN \\
\hline CHEMBL1973516 & 809194 & 6.1 & 6.5435 & TRN \\
\hline CHEMBL1996345 & 809194 & 4.4 & 4.675 & TST \\
\hline CHEMBL1975128 & 809194 & 5.5 & 5.5769 & TRN \\
\hline CHEMBL 2004025 & 809194 & 5.5 & 5.3158 & TRN \\
\hline CHEMBL1996048 & 809194 & 4.4 & 4.5066 & TST \\
\hline CHEMBL1970369 & 809194 & 4.4 & 4.6623 & TRN \\
\hline CHEMBL461876 & 809194 & 6.2 & 6.1629 & TRN \\
\hline CHEMBL1965033 & 809194 & 4.4 & 4.8408 & TRN \\
\hline CHEMBL 2001485 & 809194 & 4.4 & 4.5607 & TRN \\
\hline CHEMBL1971519 & 809194 & 4.3 & 4.3533 & TRN \\
\hline CHEMBL504950 & 809194 & 4.4 & 4.8186 & TRN \\
\hline CHEMBL1997335 & 809194 & 5.5 & 4.9552 & TRN \\
\hline CHEMBL1966425 & 809194 & 4.4 & 4.7848 & TRN \\
\hline CHEMBL1984363 & 809194 & 4.4 & 4.6306 & TRN \\
\hline CHEMBL1978099 & 809194 & 7.0 & 6.3704 & TRN \\
\hline CHEMBL1977041 & 809194 & 5.6 & 5.5355 & TRN \\
\hline CHEMBL1968070 & 809194 & 4.4 & 4.7118 & TRN \\
\hline CHEMBL1988608 & 809194 & 4.4 & 4.6188 & TRN \\
\hline CHEMBL184847 & 809194 & 4.4 & 4.262 & TRN \\
\hline CHEMBL1984367 & 809194 & 5.8 & 5.4263 & TRN \\
\hline CHEMBL178737 & 809194 & 4.4 & 4.5598 & TST \\
\hline CHEMBL226898 & 809194 & 4.4 & 5.1865 & TRN \\
\hline CHEMBL1982563 & 809194 & 7.6 & 7.597 & TRN \\
\hline CHEMBL539474 & 809194 & 4.4 & 4.7215 & TST \\
\hline CHEMBL575824 & 809194 & 4.4 & 4.8825 & TRN \\
\hline CHEMBL1988387 & 809194 & 5.7 & 4.9216 & TRN \\
\hline CHEMBL1973868 & 809194 & 4.4 & 4.4454 & TRN \\
\hline CHEMBL1972462 & 809194 & 4.4 & 4.3705 & TRN \\
\hline CHEMBL1997759 & 809194 & 4.4 & 4.5438 & TRN \\
\hline CHEMBL1974803 & 809194 & 4.4 & 4.6689 & TST \\
\hline CHEMBL1970074 & 809194 & 4.4 & 4.5676 & TRN \\
\hline CHEMBL1984500 & 809194 & 3.1 & 4.1168 & TRN \\
\hline CHEMBL1986970 & 809194 & 4.4 & 4.6176 & TRN \\
\hline CHEMBL1958401 & 809194 & 4.4 & 4.6221 & TRN \\
\hline CHEMBL2003456 & 809194 & 4.4 & 4.5286 & TRN \\
\hline CHEMBL1966816 & 809194 & 4.4 & 4.3881 & TRN \\
\hline CHEMBL1972584 & 809194 & 4.4 & 4.8903 & TRN \\
\hline CHEMBL 2002992 & 809194 & 4.4 & 4.6316 & TRN \\
\hline CHEMBL560813 & 809194 & 4.4 & 4.4346 & TRN \\
\hline CHEMBL207253 & 809194 & 5.6 & 5.4823 & TST \\
\hline
\end{tabular}




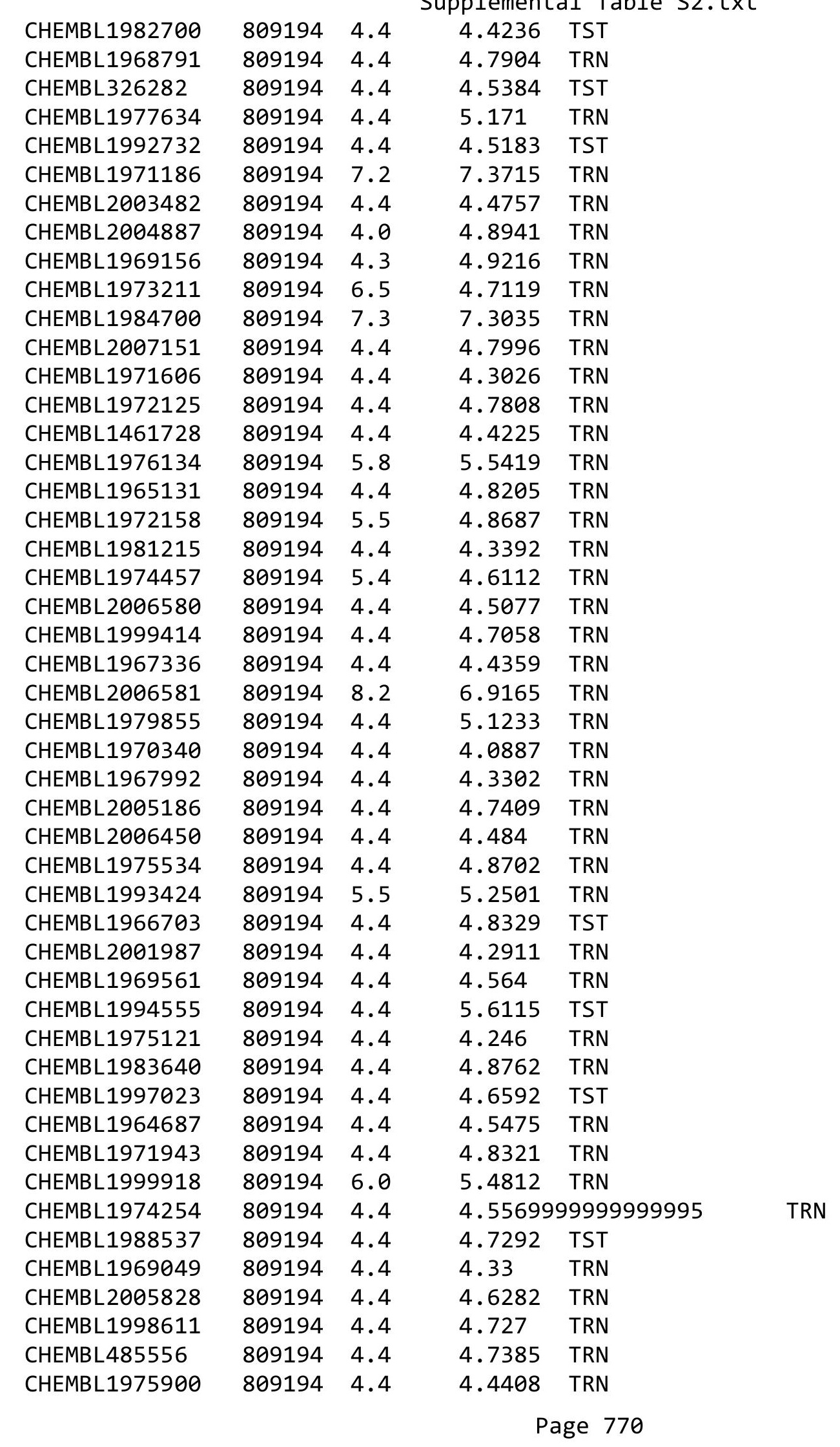




\begin{tabular}{|c|c|c|c|c|}
\hline \multicolumn{5}{|c|}{ plemental T } \\
\hline CHEMBL255822 & 809194 & 4.4 & 4.6971 & TRN \\
\hline CHEMBL1972221 & 809194 & 5.7 & 5.3327 & TRN \\
\hline CHEMBL 2006778 & 809194 & 4.4 & 4.8925 & TRN \\
\hline CHEMBL378627 & 809194 & 8.5 & 7.4313 & TRN \\
\hline CHEMBL1996979 & 809194 & 6.2 & 4.7697 & TRN \\
\hline CHEMBL1997025 & 809194 & 4.4 & 4.757 & TRN \\
\hline CHEMBL1968406 & 809194 & 4.4 & 4.5662 & TRN \\
\hline CHEMBL1982476 & 809194 & 6.1 & 4.7389 & TRN \\
\hline CHEMBL1998545 & 809194 & 4.4 & 4.3957 & TRN \\
\hline CHEMBL1986869 & 809194 & 4.4 & 4.7221 & TRN \\
\hline CHEMBL1975923 & 809194 & 4.7 & 5.6358 & TST \\
\hline CHEMBL 2005449 & 809194 & 5.7 & 5.6462 & TRN \\
\hline CHEMBL1987998 & 809194 & 4.4 & 4.3106 & TRN \\
\hline CHEMBL 2006010 & 809194 & 4.4 & 4.3959 & TRN \\
\hline CHEMBL1682558 & 809194 & 5.8 & 4.8634 & TRN \\
\hline CHEMBL 1990496 & 809194 & 7.1 & 7.1032 & TRN \\
\hline CHEMBL242865 & 809194 & 8.3 & 8.1507 & TRN \\
\hline CHEMBL1997623 & 809194 & 4.4 & 4.5099 & TRN \\
\hline CHEMBL 2002479 & 809194 & 5.6 & 5.2258 & TRN \\
\hline CHEMBL1993166 & 809194 & 4.4 & 4.6143 & TRN \\
\hline CHEMBL1967094 & 809194 & 6.4 & 5.5361 & TRN \\
\hline CHEMBL1966035 & 809194 & 4.4 & 4.6168 & TRN \\
\hline CHEMBL 2003341 & 809194 & 4.4 & 4.3992 & TRN \\
\hline CHEMBL1992645 & 809194 & 4.4 & 4.7921 & TST \\
\hline CHEMBL1982992 & 809194 & 4.4 & 4.6547 & TRN \\
\hline CHEMBL1974363 & 809194 & 6.1 & 4.5716 & TRN \\
\hline CHEMBL1998110 & 809194 & 4.4 & 4.1857 & TRN \\
\hline CHEMBL1999590 & 809194 & 5.7 & 4.7512 & TST \\
\hline CHEMBL1981079 & 809194 & 5.8 & 5.8093 & TRN \\
\hline CHEMBL1978166 & 809194 & 5.5 & 5.5229 & TRN \\
\hline CHEMBL1972276 & 809194 & 4.4 & 4.6388 & TRN \\
\hline CHEMBL1980489 & 809194 & 4.4 & 4.3611 & TRN \\
\hline CHEMBL 2000832 & 809194 & 4.4 & 5.9428 & TRN \\
\hline CHEMBL1967116 & 809194 & 6.2 & 4.6302 & TRN \\
\hline CHEMBL1990590 & 809194 & 4.4 & 4.3916 & TRN \\
\hline CHEMBL1977814 & 809194 & 4.4 & 5.3737 & TST \\
\hline CHEMBL513846 & 809194 & 6.0 & 5.6705 & TRN \\
\hline CHEMBL 86755 & 809194 & 5.9 & 5.3334 & TRN \\
\hline CHEMBL1970709 & 809194 & 4.4 & 4.4469 & TRN \\
\hline CHEMBL1974617 & 809194 & 4.1 & 4.6369 & TRN \\
\hline CHEMBL1965660 & 809194 & 6.3 & 6.1058 & TRN \\
\hline CHEMBL1998112 & 809194 & 4.4 & 4.7911 & TRN \\
\hline CHEMBL1969126 & 809194 & 6.4 & 5.3061 & TRN \\
\hline CHEMBL1980896 & 809194 & 4.4 & 4.7438 & TRN \\
\hline CHEMBL1975208 & 809194 & 4.4 & 4.7123 & TST \\
\hline CHEMBL1970104 & 809194 & 4.6 & 5.5558 & TRN \\
\hline CHEMBL1991429 & 809194 & 7.9 & 6.9684 & TRN \\
\hline CHEMBL1964777 & 809194 & 4.4 & 4.6467 & TRN \\
\hline
\end{tabular}




\begin{tabular}{|c|c|c|c|c|}
\hline & & & pplement & \\
\hline CHEMBL1971149 & 809194 & 7.0 & 7.2142 & TRN \\
\hline CHEMBL1999714 & 809194 & 4.4 & 4.417 & TRN \\
\hline CHEMBL1987533 & 809194 & 4.4 & 4.42 & TRN \\
\hline CHEMBL1994040 & 809194 & 7.4 & 6.9882 & TRN \\
\hline CHEMBL388978 & 809194 & 5.7 & 6.1344 & TST \\
\hline CHEMBL579246 & 809194 & 4.4 & 4.9092 & TRN \\
\hline CHEMBL398951 & 809194 & 4.4 & 4.3486 & TST \\
\hline CHEMBL1982506 & 809194 & 4.4 & 5.1416 & TST \\
\hline CHEMBL2004716 & 809194 & 5.9 & 4.8648 & TRN \\
\hline CHEMBL1968127 & 809194 & 6.8 & 6.8309 & TRN \\
\hline CHEMBL1975233 & 809194 & 4.4 & 4.4093 & TRN \\
\hline CHEMBL1985406 & 809194 & 6.1 & 5.6192 & TRN \\
\hline CHEMBL 207400 & 809194 & 6.5 & 5.9685 & TST \\
\hline CHEMBL 2000894 & 809194 & 4.4 & 4.708 & TST \\
\hline CHEMBL1421720 & 809194 & 5.5 & 5.551 & TRN \\
\hline CHEMBL1982135 & 809194 & 4.4 & 4.5345 & TRN \\
\hline CHEMBL1976090 & 809194 & 4.4 & 4.6927 & TRN \\
\hline CHEMBL1993243 & 809194 & 4.4 & 4.7871 & TRN \\
\hline CHEMBL 2004771 & 809194 & 4.4 & 4.3386 & TRN \\
\hline CHEMBL1992922 & 809194 & 4.4 & 4.5937 & TRN \\
\hline CHEMBL399021 & 809194 & 4.4 & 4.7861 & TRN \\
\hline CHEMBL1997597 & 809194 & 4.4 & 4.5776 & TRN \\
\hline CHEMBL1969537 & 809194 & 4.4 & 4.7113 & TST \\
\hline CHEMBL1976093 & 809194 & 6.0 & 6.3453 & TRN \\
\hline CHEMBL210032 & 809194 & 5.7 & 5.8944 & TRN \\
\hline CHEMBL1996543 & 809194 & 4.4 & 4.7037 & TRN \\
\hline CHEMBL1975256 & 809194 & 4.4 & 4.4592 & TST \\
\hline CHEMBL508928 & 809194 & 4.4 & 4.5988 & TRN \\
\hline CHEMBL1991356 & 809194 & 4.4 & 4.908 & TST \\
\hline CHEMBL 2004892 & 809194 & 4.4 & 4.5883 & TRN \\
\hline CHEMBL1949855 & 809194 & 4.2 & 4.5916 & TRN \\
\hline CHEMBL1997503 & 809194 & 4.4 & 4.7597 & TST \\
\hline CHEMBL116070 & 809194 & 5.4 & 4.6429 & TRN \\
\hline CHEMBL1990821 & 809194 & 4.4 & 4.562 & TST \\
\hline CHEMBL1970314 & 809194 & 4.4 & 4.6267 & TRN \\
\hline CHEMBL2004871 & 809194 & 6.1 & 5.0165 & TRN \\
\hline CHEMBL2004872 & 809194 & 4.4 & 4.4133 & TRN \\
\hline CHEMBL1990223 & 809194 & 4.4 & 4.3532 & TRN \\
\hline CHEMBL1969879 & 809194 & 4.4 & 4.4694 & TRN \\
\hline CHEMBL1964382 & 809194 & 4.4 & 5.3413 & TST \\
\hline CHEMBL101311 & 809194 & 5.8 & 6.3641 & TRN \\
\hline CHEMBL1981720 & 809194 & 4.4 & 4.5699 & TRN \\
\hline CHEMBL419932 & 809194 & 4.4 & 4.6102 & TRN \\
\hline CHEMBL 262433 & 809194 & 4.4 & 4.636 & TRN \\
\hline CHEMBL 306380 & 809194 & 5.6 & 5.2179 & TRN \\
\hline CHEMBL1966722 & 809194 & 4.4 & 4.5916 & TST \\
\hline CHEMBL1988581 & 809194 & 7.1 & 6.4431 & TST \\
\hline CHEMBL 2005699 & 809194 & 6.1 & 5.2908 & TRN \\
\hline
\end{tabular}




\begin{tabular}{|c|c|c|c|c|}
\hline & & & pमeme & al Ta \\
\hline CHEMBL1975500 & 809194 & 5.6 & 5.9453 & TRN \\
\hline CHEMBL1976328 & 809194 & 4.4 & 4.516 & TRN \\
\hline CHEMBL394619 & 809194 & 5.8 & 4.5799 & TRN \\
\hline CHEMBL 2006564 & 809194 & 6.3 & 6.2987 & TRN \\
\hline CHEMBL1964399 & 809194 & 5.6 & 5.7328 & TRN \\
\hline CHEMBL1996831 & 809194 & 4.4 & 4.6908 & TST \\
\hline CHEMBL411903 & 809194 & 5.8 & 4.8681 & TRN \\
\hline CHEMBL1978167 & 809194 & 4.4 & 4.7312 & TST \\
\hline CHEMBL1965988 & 809194 & 5.9 & 4.7161 & TRN \\
\hline CHEMBL418203 & 809194 & 4.4 & 4.8233 & TST \\
\hline CHEMBL1989646 & 809194 & 4.4 & 4.8383 & TRN \\
\hline CHEMBL1682357 & 809194 & 4.4 & 4.4544 & TRN \\
\hline CHEMBL 225519 & 809194 & 4.4 & 4.9147 & TRN \\
\hline CHEMBL209534 & 809194 & 7.7 & 7.4198 & TRN \\
\hline CHEMBL1978200 & 809194 & 6.9 & 7.1821 & TRN \\
\hline CHEMBL1970522 & 809194 & 5.5 & 4.7371 & TRN \\
\hline CHEMBL1990415 & 809194 & 4.4 & 4.4601 & TRN \\
\hline CHEMBL1966087 & 809194 & 4.4 & 4.4924 & TRN \\
\hline CHEMBL1964692 & 809194 & 4.4 & 4.8095 & TRN \\
\hline CHEMBL1996931 & 809194 & 4.4 & 4.4272 & TRN \\
\hline CHEMBL1964413 & 809194 & 4.4 & 4.5488 & TRN \\
\hline CHEMBL1973483 & 809194 & 4.4 & 4.4134 & TRN \\
\hline CHEMBL1992354 & 809194 & 5.5 & 5.0881 & TRN \\
\hline CHEMBL1998470 & 809194 & 4.4 & 4.5012 & TRN \\
\hline CHEMBL1984432 & 809194 & 4.4 & 4.4994 & TRN \\
\hline CHEMBL1970735 & 809194 & 4.4 & 6.1573 & TRN \\
\hline CHEMBL 219722 & 809194 & 4.4 & 4.4995 & TRN \\
\hline CHEMBL1975903 & 809194 & 5.6 & 5.9596 & TRN \\
\hline CHEMBL1997340 & 809194 & 4.4 & 4.547 & TRN \\
\hline CHEMBL 2004365 & 809194 & 4.4 & 4.7483 & TST \\
\hline CHEMBL1522508 & 809194 & 4.4 & 4.2648 & TRN \\
\hline CHEMBL1989474 & 809194 & 5.6 & 4.7356 & TRN \\
\hline CHEMBL1090360 & 809194 & 7.6 & 7.016 & TRN \\
\hline CHEMBL210887 & 809194 & 4.4 & 4.7002 & TRN \\
\hline CHEMBL1988805 & 809194 & 4.4 & 5.2491 & TST \\
\hline CHEMBL458997 & 809194 & 7.5 & 7.4974 & TRN \\
\hline CHEMBL1971021 & 809194 & 5.5 & 4.2545 & TRN \\
\hline CHEMBL227271 & 809194 & 4.4 & 5.2181 & TRN \\
\hline CHEMBL583144 & 809194 & 4.4 & 4.5821 & TRN \\
\hline CHEMBL1974310 & 809194 & 5.4 & 5.6126 & TRN \\
\hline CHEMBL1969942 & 809194 & 4.4 & 4.3051 & TRN \\
\hline CHEMBL1978567 & 809194 & 4.4 & 4.1857 & TRN \\
\hline CHEMBL1982660 & 809194 & 4.4 & 4.3286 & TRN \\
\hline CHEMBL1994693 & 809194 & 4.4 & 4.5976 & TRN \\
\hline CHEMBL1982957 & 809194 & 6.3 & 5.7854 & TRN \\
\hline CHEMBL1725279 & 809194 & 7.3 & 5.9433 & TST \\
\hline CHEMBL1975138 & 809194 & 4.4 & 4.6424 & TST \\
\hline CHEMBL 424872 & 809194 & 7.9 & 7.739 & TRN \\
\hline
\end{tabular}




\begin{tabular}{|c|c|c|c|c|c|}
\hline \\
\hline CHEMBL 2006836 & 809194 & 4.4 & 4.6199 & TST & \\
\hline CHEMBL1971947 & 809194 & 4.4 & 4.6829 & TRN & \\
\hline CHEMBL412142 & 809194 & 4.4 & 5.0827 & TST & \\
\hline CHEMBL1980704 & 809194 & 4.4 & 4.6604 & TST & \\
\hline CHEMBL 2003271 & 809194 & 4.4 & 4.8255 & TRN & \\
\hline CHEMBL1966808 & 809194 & 4.4 & 4.5699 & TST & \\
\hline CHEMBL 2004447 & 809194 & 4.4 & 4.4653 & TRN & \\
\hline CHEMBL1983111 & 809194 & 6.1 & 6.2904 & TRN & \\
\hline CHEMBL1973860 & 809194 & 4.4 & 4.7094 & TRN & \\
\hline CHEMBL260135 & 809194 & 4.4 & 4.543 & TRN & \\
\hline CHEMBL 220241 & 809194 & 4.4 & 4.794 & TRN & \\
\hline CHEMBL 2004544 & 809194 & 4.4 & 4.6025 & TST & \\
\hline CHEMBL1988141 & 809194 & 6.4 & 5.8616 & TST & \\
\hline CHEMBL1982610 & 809194 & 4.4 & 4.7858 & TST & \\
\hline CHEMBL1977134 & 809194 & 4.4 & 4.4551 & TRN & \\
\hline CHEMBL1999496 & 809194 & 4.4 & 4.5392 & TRN & \\
\hline CHEMBL2006933 & 809194 & 4.4 & 4.7259 & TST & \\
\hline CHEMBL1985206 & 809194 & 4.4 & 5.2113 & TST & \\
\hline CHEMBL1988300 & 809194 & 4.4 & 4.7518 & TRN & \\
\hline CHEMBL1991078 & 809194 & 6.6 & 5.9334 & TRN & \\
\hline CHEMBL1987359 & 809194 & 4.4 & 4.4678 & TST & \\
\hline CHEMBL1977749 & 809194 & 6.2 & 5.6858 & TST & \\
\hline CHEMBL1975212 & 809194 & 4.5 & 4.5616 & TRN & \\
\hline CHEMBL 2000685 & 809194 & 5.9 & 5.2751 & TRN & \\
\hline CHEMBL1997275 & 809194 & 4.4 & 4.5571 & TRN & \\
\hline CHEMBL1993904 & 809194 & 6.2 & 6.5405 & TRN & \\
\hline CHEMBL1967513 & 809194 & 4.4 & 4.2508 & TRN & \\
\hline CHEMBL2000724 & 809194 & 4.4 & 4.3984 & TRN & \\
\hline CHEMBL1985311 & 809194 & 4.4 & 4.663 & TRN & \\
\hline CHEMBL1989265 & 809194 & 4.4 & 4.6426 & TST & \\
\hline CHEMBL1982413 & 809194 & 5.5 & 5.1201 & TST & \\
\hline CHEMBL1969502 & 809194 & 4.4 & 4.7931 & TRN & \\
\hline CHEMBL1965910 & 809194 & 4.4 & 4.824 & TRN & \\
\hline CHEMBL1682553 & 809194 & 4.4 & 4.7871 & TRN & \\
\hline CHEMBL1971430 & 809194 & 6.7 & 6.024 & TRN & \\
\hline CHEMBL1983963 & 809194 & 5.5 & 4.6331 & TRN & \\
\hline CHEMBL1997764 & 809194 & 5.5 & 4.8473 & TRN & \\
\hline CHEMBL2000271 & 809194 & 5.4 & 5.9137 & TRN & \\
\hline CHEMBL1981792 & 809194 & 5.7 & 4.89199 & 99999999995 & TRN \\
\hline CHEMBL1987535 & 809194 & 4.4 & 5.329 & TRN & \\
\hline CHEMBL1985092 & 809194 & 4.4 & 4.8016 & TRN & \\
\hline CHEMBL 2004692 & 809194 & 4.4 & 4.4449 & TST & \\
\hline CHEMBL1981410 & 809194 & 4.4 & 4.7204 & TRN & \\
\hline CHEMBL 2002586 & 809194 & 4.4 & 5.8287 & TRN & \\
\hline CHEMBL1987815 & 809194 & 4.4 & 4.816 & TST & \\
\hline CHEMBL1996234 & 809194 & 5.7 & 4.9322 & TRN & \\
\hline CHEMBL383264 & 809194 & 4.4 & 4.7842 & TRN & \\
\hline CHEMBL2007421 & 809194 & 4.4 & 5.0823 & TST & \\
\hline & & & & 774 & \\
\hline
\end{tabular}




\begin{tabular}{|c|c|c|c|c|c|}
\hline & & & & & \\
\hline CHEMBL1991434 & 809194 & 4.4 & 4.5364 & TST & \\
\hline CHEMBL1967544 & 809194 & 4.4 & 4.7579 & TRN & \\
\hline CHEMBL1973138 & 809194 & 4.4 & 4.4033 & TRN & \\
\hline CHEMBL223367 & 809194 & 4.4 & 4.4746 & TST & \\
\hline CHEMBL340384 & 809194 & 4.4 & 4.9262 & TST & \\
\hline CHEMBL1969151 & 809194 & 4.4 & 6.0521 & TRN & \\
\hline CHEMBL1996587 & 809194 & 5.9 & 5.2532 & TRN & \\
\hline CHEMBL1981492 & 809194 & 4.5 & 4.8647 & TRN & \\
\hline CHEMBL1993335 & 809194 & 5.5 & 5.75299 & 9999999999 & TST \\
\hline CHEMBL1988692 & 809194 & 4.4 & 5.15600 & 0000000001 & TRN \\
\hline CHEMBL 2007574 & 809194 & 4.4 & 5.4241 & TRN & \\
\hline CHEMBL1964804 & 809194 & 4.4 & 4.6842 & TRN & \\
\hline CHEMBL443962 & 809194 & 4.4 & 4.4681 & TST & \\
\hline CHEMBL 2000354 & 809194 & 4.4 & 4.7123 & TRN & \\
\hline CHEMBL1965507 & 809194 & 4.4 & 4.4498 & TRN & \\
\hline CHEMBL274064 & 809194 & 5.6 & 5.3097 & TRN & \\
\hline CHEMBL1998680 & 809194 & 5.9 & 5.2962 & TRN & \\
\hline CHEMBL1967564 & 809194 & 4.4 & 4.4655 & TRN & \\
\hline CHEMBL592030 & 809194 & 4.7 & 5.4803 & TST & \\
\hline CHEMBL 2000071 & 809194 & 4.4 & 4.7179 & TRN & \\
\hline CHEMBL1979176 & 809194 & 4.4 & 4.4327 & TRN & \\
\hline CHEMBL1970317 & 809194 & 5.7 & 4.7541 & TRN & \\
\hline CHEMBL 2000408 & 809194 & 7.3 & 7.4468 & TRN & \\
\hline CHEMBL248757 & 809194 & 4.4 & 4.5276 & TST & \\
\hline CHEMBL1978014 & 809194 & 4.4 & 4.6562 & TRN & \\
\hline CHEMBL1997007 & 809194 & 5.6 & 6.0282 & TRN & \\
\hline CHEMBL1994538 & 809194 & 4.4 & 4.4784 & TRN & \\
\hline CHEMBL1983195 & 809194 & 4.4 & 4.539 & TST & \\
\hline CHEMBL1975490 & 809194 & 4.4 & 4.7672 & TRN & \\
\hline CHEMBL1964444 & 809194 & 4.4 & 4.3934 & TRN & \\
\hline CHEMBL 2002690 & 809194 & 4.4 & 4.6938 & TRN & \\
\hline CHEMBL 2006567 & 809194 & 6.3 & 6.3886 & TRN & \\
\hline CHEMBL1986139 & 809194 & 4.4 & 4.3683 & TRN & \\
\hline CHEMBL383527 & 809194 & 4.4 & 4.51 & TRN & \\
\hline CHEMBL1980540 & 809194 & 4.4 & 4.3675 & TRN & \\
\hline CHEMBL278041 & 809194 & 6.6 & 6.7618 & TRN & \\
\hline CHEMBL1979883 & 809194 & 6.1 & 4.6679 & TRN & \\
\hline CHEMBL1984162 & 809194 & 5.5 & 5.0229 & TRN & \\
\hline CHEMBL491758 & 809194 & 6.5 & 6.2455 & TRN & \\
\hline CHEMBL1986590 & 809194 & 4.4 & 4.9812 & TRN & \\
\hline CHEMBL549730 & 809194 & 4.4 & 4.4119 & TRN & \\
\hline CHEMBL1682360 & 809194 & 4.4 & 4.5622 & TRN & \\
\hline CHEMBL1970189 & 809194 & 4.4 & 4.4547 & TRN & \\
\hline CHEMBL1870106 & 809194 & 4.4 & 4.4843 & TRN & \\
\hline CHEMBL1996791 & 809194 & 4.4 & 4.8298 & TRN & \\
\hline CHEMBL371206 & 809194 & 5.8 & 4.5972 & TRN & \\
\hline CHEMBL1974664 & 809194 & 4.4 & 4.59399 & 9999999999 & TST \\
\hline CHEMBL406845 & 809194 & 5.8 & 5.558 & TRN & \\
\hline & & & & 775 & \\
\hline
\end{tabular}




\begin{tabular}{|c|c|c|c|c|}
\hline \multicolumn{5}{|c|}{ lemental T } \\
\hline CHEMBL1974288 & 809194 & 4.4 & 4.3072 & TRN \\
\hline CHEMBL1984296 & 809194 & 4.4 & 4.4765 & TST \\
\hline CHEMBL196363 & 809194 & 6.0 & 4.4842 & TRN \\
\hline CHEMBL1190711 & 809194 & 4.4 & 4.9436 & TRN \\
\hline CHEMBL1990346 & 809194 & 4.4 & 4.4146 & TRN \\
\hline CHEMBL1968705 & 809194 & 4.4 & 4.5947 & TRN \\
\hline CHEMBL1964441 & 809194 & 4.4 & 4.4936 & TRN \\
\hline CHEMBL1991410 & 809194 & 4.4 & 4.52 & TRN \\
\hline CHEMBL546797 & 809194 & 4.4 & 4.4109 & TRN \\
\hline CHEMBL404367 & 809194 & 5.8 & 5.2809 & TRN \\
\hline CHEMBL 1966343 & 809194 & 4.4 & 4.6501 & TRN \\
\hline CHEMBL1978271 & 809194 & 6.5 & 5.0721 & TRN \\
\hline CHEMBL1967887 & 809194 & 4.4 & 5.0487 & TRN \\
\hline CHEMBL 2007266 & 809194 & 4.4 & 4.4979 & TRN \\
\hline CHEMBL 2000568 & 809194 & 4.5 & 5.4589 & TRN \\
\hline CHEMBL1994308 & 809194 & 4.4 & 4.4255 & TRN \\
\hline CHEMBL 2000335 & 809194 & 4.4 & 4.5331 & TRN \\
\hline CHEMBL1988717 & 809194 & 4.4 & 4.5103 & TRN \\
\hline CHEMBL1974328 & 809194 & 4.5 & 4.8621 & TRN \\
\hline CHEMBL509032 & 809194 & 6.4 & 6.3929 & TRN \\
\hline CHEMBL 1973808 & 809194 & 4.4 & 4.4078 & TRN \\
\hline CHEMBL 2000429 & 809194 & 8.2 & 8.2472 & TRN \\
\hline CHEMBL1972576 & 809194 & 4.4 & 4.4465 & TRN \\
\hline CHEMBL1992555 & 809194 & 6.1 & 4.8944 & TRN \\
\hline CHEMBL1990254 & 809194 & 4.4 & 4.3798 & TRN \\
\hline CHEMBL1992342 & 809194 & 4.4 & 4.6221 & TRN \\
\hline CHEMBL1988173 & 809194 & 4.4 & 4.6228 & TST \\
\hline CHEMBL1973013 & 809194 & 6.7 & 6.3092 & TST \\
\hline CHEMBL535331 & 809194 & 4.4 & 4.7047 & TRN \\
\hline CHEMBL1989805 & 809194 & 4.4 & 4.7328 & TST \\
\hline CHEMBL1982980 & 809194 & 4.4 & 4.8545 & TST \\
\hline CHEMBL1965423 & 809194 & 7.8 & 6.7161 & TRN \\
\hline CHEMBL1983025 & 809194 & 5.7 & 4.6785 & TRN \\
\hline CHEMBL1975927 & 809194 & 6.4 & 6.2346 & TRN \\
\hline CHEMBL205415 & 809194 & 4.4 & 4.4948 & TRN \\
\hline CHEMBL1977135 & 809194 & 4.4 & 4.3374 & TRN \\
\hline CHEMBL 2001920 & 809194 & 5.8 & 5.4168 & TRN \\
\hline CHEMBL 2002322 & 809194 & 4.4 & 4.83 & TRN \\
\hline CHEMBL1977138 & 809194 & 5.8 & 5.8869 & TST \\
\hline CHEMBL 2002323 & 809194 & 4.4 & 4.6531 & TST \\
\hline CHEMBL1241473 & 809194 & 7.8 & 7.3734 & TRN \\
\hline CHEMBL1978448 & 809194 & 4.4 & 4.8164 & TST \\
\hline CHEMBL1972258 & 809194 & 4.4 & 4.4393 & TRN \\
\hline CHEMBL1980329 & 809194 & 4.4 & 5.0193 & TRN \\
\hline CHEMBL 2001257 & 809194 & 5.9 & 4.7395 & TRN \\
\hline CHEMBL1992042 & 809194 & 4.4 & 5.1456 & TRN \\
\hline CHEMBL 2005548 & 809194 & 4.4 & 4.7268 & TRN \\
\hline CHEMBL1987793 & 809194 & 4.4 & 4.6798 & TST \\
\hline
\end{tabular}




\begin{tabular}{|c|c|c|c|c|c|}
\hline \multirow[b]{2}{*}{ CHEMBL1992536 } & \multirow[b]{2}{*}{809194} & \multirow[b]{2}{*}{4.4} & \\
\hline & & & 4.4726 & TRN & \\
\hline CHEMBL1968727 & 809194 & 5.7 & 5.3234 & TRN & \\
\hline CHEMBL21156 & 809194 & 7.1 & 6.245 & TST & \\
\hline CHEMBL1992740 & 809194 & 4.4 & 4.6409 & TRN & \\
\hline CHEMBL1994724 & 809194 & 4.4 & 4.2605 & TRN & \\
\hline CHEMBL1989267 & 809194 & 4.4 & 5.3807 & TRN & \\
\hline CHEMBL 2002373 & 809194 & 6.3 & 4.8198 & TRN & \\
\hline CHEMBL439340 & 809194 & 4.4 & 4.6723 & TRN & \\
\hline CHEMBL1974574 & 809194 & 4.4 & 4.43 & TST & \\
\hline CHEMBL 2006188 & 809194 & 4.4 & 4.4249 & TRN & \\
\hline CHEMBL1970290 & 809194 & 4.4 & 5.2057 & TRN & \\
\hline CHEMBL1967531 & 809194 & 4.4 & 4.5994 & TRN & \\
\hline CHEMBL1970913 & 809194 & 4.4 & 4.5331 & TRN & \\
\hline CHEMBL1973893 & 809194 & 4.4 & 4.7733 & TRN & \\
\hline CHEMBL1995736 & 809194 & 4.4 & 4.7966 & TRN & \\
\hline CHEMBL1997534 & 809194 & 4.4 & 4.7168 & TRN & \\
\hline CHEMBL1993877 & 809194 & 4.4 & 5.0555 & TRN & \\
\hline CHEMBL1996500 & 809194 & 6.8 & 6.9164 & TRN & \\
\hline CHEMBL1985095 & 809194 & 5.9 & 6.5294 & TST & \\
\hline CHEMBL1977374 & 809194 & 5.7 & 5.2291 & TRN & \\
\hline CHEMBL1991180 & 809194 & 4.4 & 4.7545 & TST & \\
\hline CHEMBL1682540 & 809194 & 4.4 & 4.6497 & TRN & \\
\hline CHEMBL1976420 & 809194 & 4.5 & 5.3648 & TST & \\
\hline CHEMBL1998253 & 809194 & 4.4 & 4.3534 & TST & \\
\hline CHEMBL413779 & 809194 & 4.4 & 4.4914 & TST & \\
\hline CHEMBL1981744 & 809194 & 4.4 & 4.2643 & TRN & \\
\hline CHEMBL1994864 & 809194 & 4.4 & 4.4399 & TRN & \\
\hline CHEMBL2002446 & 809194 & 4.4 & 4.7199 & TST & \\
\hline CHEMBL497151 & 809194 & 4.4 & 5.2739 & TRN & \\
\hline CHEMBL2000029 & 809194 & 4.4 & 5.4914 & TRN & \\
\hline CHEMBL1973961 & 809194 & 4.4 & 5.3522 & TRN & \\
\hline CHEMBL 246970 & 809194 & 4.4 & 4.977 & TRN & \\
\hline CHEMBL340921 & 809194 & 4.4 & 4.6903 & TST & \\
\hline CHEMBL1994977 & 809194 & 4.4 & 5.0945 & TRN & \\
\hline CHEMBL373598 & 809194 & 4.4 & 4.50899 & 99999999995 & TST \\
\hline CHEMBL2001149 & 809194 & 4.4 & 5.19799 & 99999999995 & TRN \\
\hline CHEMBL1999718 & 809194 & 4.4 & 4.4342 & TRN & \\
\hline CHEMBL2005478 & 809194 & 5.4 & 5.7377 & TST & \\
\hline CHEMBL1276446 & 809194 & 6.9 & 6.3406 & TST & \\
\hline CHEMBL1996646 & 809194 & 5.4 & 5.3224 & TRN & \\
\hline CHEMBL1979773 & 809194 & 4.4 & 4.9755 & TRN & \\
\hline CHEMBL1977346 & 809194 & 4.4 & 4.7293 & TRN & \\
\hline CHEMBL2003657 & 809194 & 7.7 & 6.7247 & TRN & \\
\hline CHEMBL1971649 & 809194 & 4.4 & 4.7131 & TRN & \\
\hline CHEMBL1996702 & 809194 & 5.6 & 5.7323 & TRN & \\
\hline CHEMBL2007124 & 809194 & 4.4 & 4.4086 & TRN & \\
\hline CHEMBL 2006439 & 809194 & 5.5 & 5.3365 & TRN & \\
\hline CHEMBL1985681 & 809194 & 4.4 & 5.4231 & TST & \\
\hline & & & & 777 & \\
\hline
\end{tabular}




\begin{tabular}{|c|c|c|c|c|}
\hline & & & & al Table S2 \\
\hline CHEMBL1969190 & 809194 & 4.4 & 4.5436 & TRN \\
\hline CHEMBL1973937 & 809194 & 6.1 & 4.5014 & TRN \\
\hline CHEMBL1991674 & 809194 & 5.5 & 5.6294 & TRN \\
\hline CHEMBL1982711 & 809194 & 4.5 & 5.479 & TRN \\
\hline CHEMBL1984842 & 809194 & 7.4 & 8.5788 & TRN \\
\hline CHEMBL1969102 & 809194 & 6.1 & 4.7418 & TRN \\
\hline CHEMBL 2004118 & 809194 & 5.6 & 6.2904 & TRN \\
\hline CHEMBL1682346 & 809194 & 4.4 & 4.7969 & TRN \\
\hline CHEMBL 2007044 & 809194 & 4.4 & 4.5779 & TST \\
\hline CHEMBL2001998 & 809194 & 4.4 & 4.4983 & TST \\
\hline CHEMBL1994241 & 809194 & 5.9 & 4.6043 & TRN \\
\hline CHEMBL 223460 & 809194 & 4.4 & 4.5212 & TST \\
\hline CHEMBL1998829 & 809194 & 4.4 & 4.6769 & TRN \\
\hline CHEMBL50894 & 809194 & 4.4 & 4.4854 & TRN \\
\hline CHEMBL1995211 & 809194 & 4.4 & 5.1099 & TRN \\
\hline CHEMBL1988838 & 809194 & 6.9 & 6.3244 & TRN \\
\hline CHEMBL1981725 & 809194 & 6.9 & 6.3642 & TRN \\
\hline CHEMBL 375284 & 809194 & 4.4 & 4.5071 & TRN \\
\hline CHEMBL 2006299 & 809194 & 4.4 & 4.3064 & TRN \\
\hline CHEMBL1965169 & 809194 & 4.4 & 4.569 & TST \\
\hline CHEMBL1081312 & 809194 & 5.9 & 5.6327 & TRN \\
\hline CHEMBL1965170 & 809194 & 5.6 & 4.4646 & TRN \\
\hline CHEMBL1982866 & 809194 & 5.6 & 4.7662 & TRN \\
\hline CHEMBL 2005792 & 809194 & 7.1 & 8.6081 & TRN \\
\hline CHEMBL1968926 & 809194 & 4.4 & 4.5122 & TRN \\
\hline CHEMBL1984206 & 809194 & 7.4 & 7.3124 & TRN \\
\hline CHEMBL462120 & 809194 & 4.4 & 4.40300 & 00000000005 \\
\hline CHEMBL1991577 & 809194 & 4.4 & 4.4445 & TRN \\
\hline CHEMBL1986503 & 809194 & 4.4 & 4.7126 & TST \\
\hline CHEMBL1965570 & 809194 & 4.4 & 4.7548 & TRN \\
\hline CHEMBL 2007592 & 809194 & 5.8 & 5.1143 & TST \\
\hline CHEMBL1972355 & 809194 & 5.6 & 5.6645 & TRN \\
\hline CHEMBL1997892 & 809194 & 4.4 & 5.067 & TRN \\
\hline CHEMBL1997193 & 809194 & 4.4 & 5.8229 & TST \\
\hline CHEMBL210963 & 809194 & 8.2 & 7.6091 & TRN \\
\hline CHEMBL1964902 & 809194 & 6.7 & 5.3599 & TRN \\
\hline CHEMBL1082440 & 809194 & 4.4 & 4.6737 & TST \\
\hline CHEMBL1614705 & 809194 & 6.0 & 4.9632 & TRN \\
\hline CHEMBL1972362 & 809194 & 6.0 & 5.6276 & TRN \\
\hline CHEMBL1984633 & 809194 & 4.4 & 4.4072 & TRN \\
\hline CHEMBL1965845 & 809194 & 4.4 & 4.6505 & TRN \\
\hline CHEMBL 2007372 & 809194 & 6.5 & 6.9195 & TRN \\
\hline CHEMBL1983715 & 809194 & 7.4 & 7.7343 & TRN \\
\hline CHEMBL1982167 & 809194 & 5.6 & 4.6192 & TRN \\
\hline CHEMBL1971017 & 809194 & 5.8 & 4.8977 & TRN \\
\hline CHEMBL 2006715 & 809194 & 7.0 & 5.8415 & TRN \\
\hline CHEMBL1986597 & 809194 & 5.5 & 4.7233 & TRN \\
\hline CHEMBL1990482 & 809194 & 4.4 & 4.7421 & TRN \\
\hline
\end{tabular}




\begin{tabular}{|c|c|c|c|c|}
\hline & & & pplement & al $\mathrm{Ta}$ \\
\hline CHEMBL1990904 & 809194 & 7.3 & 6.9423 & TRN \\
\hline CHEMBL 2000104 & 809194 & 5.8 & 6.2756 & TRN \\
\hline CHEMBL2005475 & 809194 & 6.4 & 5.0095 & TRN \\
\hline CHEMBL402846 & 809194 & 5.9 & 4.9658 & TRN \\
\hline CHEMBL1997349 & 809194 & 4.4 & 4.5815 & TST \\
\hline CHEMBL183844 & 809194 & 4.4 & 4.3291 & TRN \\
\hline CHEMBL 220057 & 809194 & 5.8 & 4.5416 & TRN \\
\hline CHEMBL1682545 & 809194 & 4.4 & 4.595 & TRN \\
\hline CHEMBL383541 & 809194 & 4.4 & 4.6321 & TRN \\
\hline CHEMBL 2001224 & 809194 & 4.4 & 4.3647 & TRN \\
\hline CHEMBL10 & 809194 & 6.7 & 6.6113 & TRN \\
\hline CHEMBL1976732 & 809194 & 5.7 & 5.2811 & TRN \\
\hline CHEMBL1969506 & 809194 & 4.4 & 4.8259 & TRN \\
\hline CHEMBL1980763 & 809194 & 5.8 & 6.271 & TRN \\
\hline CHEMBL1964937 & 809194 & 4.4 & 4.8163 & TRN \\
\hline CHEMBL1980163 & 809194 & 4.4 & 4.2907 & TRN \\
\hline CHEMBL590109 & 809194 & 5.8 & 6.0568 & TST \\
\hline CHEMBL1970879 & 809194 & 4.4 & 4.8533 & TRN \\
\hline CHEMBL1989856 & 809194 & 4.4 & 4.6219 & TST \\
\hline CHEMBL2005899 & 809194 & 4.4 & 4.5397 & TRN \\
\hline CHEMBL1682552 & 809194 & 4.4 & 4.8142 & TRN \\
\hline CHEMBL 259850 & 809194 & 4.4 & 4.4863 & TRN \\
\hline CHEMBL1972568 & 809194 & 4.4 & 4.3632 & TRN \\
\hline CHEMBL 2007479 & 809194 & 4.4 & 4.456 & TRN \\
\hline CHEMBL1996155 & 809194 & 4.4 & 4.5621 & TRN \\
\hline CHEMBL229799 & 809194 & 5.4 & 5.7645 & TRN \\
\hline CHEMBL1971223 & 809194 & 6.5 & 4.9987 & TRN \\
\hline CHEMBL105739 & 809194 & 4.4 & 4.6266 & TRN \\
\hline CHEMBL1682359 & 809194 & 4.4 & 4.609 & TRN \\
\hline CHEMBL1972220 & 809194 & 6.0 & 5.5038 & TRN \\
\hline CHEMBL379300 & 809194 & 5.7 & 5.7323 & TRN \\
\hline CHEMBL 203673 & 809194 & 4.4 & 4.7152 & TRN \\
\hline CHEMBL 2003785 & 809194 & 4.3 & 4.8858 & TST \\
\hline CHEMBL1973720 & 809194 & 5.5 & 6.4241 & TRN \\
\hline CHEMBL1969523 & 809194 & 5.6 & 5.2261 & TRN \\
\hline CHEMBL1988995 & 809194 & 5.7 & 5.2846 & TRN \\
\hline CHEMBL207995 & 809194 & 4.4 & 4.5067 & TRN \\
\hline CHEMBL 2001923 & 809194 & 4.4 & 4.7638 & TRN \\
\hline CHEMBL1986781 & 809194 & 7.7 & 7.4547 & TRN \\
\hline CHEMBL1983070 & 809194 & 4.4 & 4.4765 & TRN \\
\hline CHEMBL526133 & 809194 & 4.4 & 4.6111 & TRN \\
\hline CHEMBL 2003514 & 809194 & 4.4 & 4.1937 & TRN \\
\hline CHEMBL1989043 & 809194 & 4.4 & 4.7542 & TRN \\
\hline CHEMBL1979057 & 809194 & 4.4 & 4.3218 & TRN \\
\hline CHEMBL1981045 & 809194 & 4.4 & 5.7604 & TRN \\
\hline CHEMBL387971 & 809194 & 4.4 & 4.7013 & TST \\
\hline CHEMBL1975418 & 809194 & 5.8 & 4.9804 & TRN \\
\hline CHEMBL1992796 & 809194 & 4.4 & 4.6211 & TST \\
\hline
\end{tabular}




\begin{tabular}{|c|c|c|c|c|c|}
\hline \\
\hline CHEMBL1164180 & 809194 & 4.4 & 4.6735 & TST & \\
\hline CHEMBL223257 & 809194 & 4.4 & 4.5514 & TST & \\
\hline CHEMBL1999428 & 809194 & 4.4 & 4.2911 & TRN & \\
\hline CHEMBL1967560 & 809194 & 4.4 & 4.7845 & TRN & \\
\hline CHEMBL1997611 & 809194 & 4.4 & 4.5565 & TST & \\
\hline CHEMBL1516890 & 809194 & 5.9 & 4.7663 & TRN & \\
\hline CHEMBL 211378 & 809194 & 4.4 & 4.6001 & TRN & \\
\hline CHEMBL1982465 & 809194 & 5.8 & 4.6938 & TRN & \\
\hline CHEMBL 2001751 & 809194 & 6.4 & 6.0843 & TRN & \\
\hline CHEMBL 2003420 & 809194 & 4.4 & 4.4273 & TRN & \\
\hline CHEMBL1984586 & 809194 & 4.4 & 4.5944 & TRN & \\
\hline CHEMBL1999774 & 809194 & 4.4 & 4.6305 & TST & \\
\hline CHEMBL1972659 & 809194 & 4.4 & 4.6014 & TST & \\
\hline CHEMBL 2002723 & 809194 & 5.5 & 5.4282 & TST & \\
\hline CHEMBL1973395 & 809194 & 4.4 & 4.6325 & TRN & \\
\hline CHEMBL 272453 & 809194 & 4.4 & 4.4548 & TRN & \\
\hline CHEMBL1970217 & 809194 & 4.4 & 4.3076 & TRN & \\
\hline CHEMBL1971801 & 809194 & 4.4 & 5.1788 & TRN & \\
\hline CHEMBL1968850 & 809194 & 5.5 & 4.6308 & TRN & \\
\hline CHEMBL 2005528 & 809194 & 4.4 & 5.2473 & TST & \\
\hline CHEMBL1984686 & 809194 & 4.4 & 4.3944 & TRN & \\
\hline CHEMBL185569 & 809194 & 4.4 & 4.2609 & TRN & \\
\hline CHEMBL1969843 & 809194 & 4.4 & 4.4474 & TRN & \\
\hline CHEMBL 2007002 & 809194 & 4.4 & 4.7933 & TRN & \\
\hline CHEMBL1987007 & 809194 & 5.5 & 5.1728 & TRN & \\
\hline CHEMBL1973793 & 809194 & 4.4 & 4.7856 & TST & \\
\hline CHEMBL1969588 & 809194 & 5.7 & 4.9499 & TRN & \\
\hline CHEMBL1984711 & 809194 & 6.3 & 6.5355 & TRN & \\
\hline CHEMBL1992073 & 809194 & 4.4 & 4.5891 & TRN & \\
\hline CHEMBL484390 & 809194 & 4.4 & 4.6086 & TRN & \\
\hline CHEMBL1979252 & 809194 & 4.4 & 4.4526 & TRN & \\
\hline CHEMBL1986143 & 809194 & 4.4 & 4.2405 & TRN & \\
\hline CHEMBL2007559 & 809194 & 4.4 & 5.938 & TRN & \\
\hline CHEMBL1992581 & 809194 & 4.4 & 4.5406 & TRN & \\
\hline CHEMBL1682341 & 809194 & 4.4 & 4.574 & TRN & \\
\hline CHEMBL 2004290 & 809194 & 4.4 & 4.5114 & TRN & \\
\hline CHEMBL1986499 & 809194 & 4.4 & 4.82600 & 30000000005 & TRN \\
\hline CHEMBL1972937 & 809194 & 4.4 & 4.6068 & TRN & \\
\hline CHEMBL1972250 & 809194 & 4.4 & 4.4648 & TST & \\
\hline CHEMBL 2000393 & 809194 & 4.4 & 4.9896 & TST & \\
\hline CHEMBL 2004311 & 809194 & 4.4 & 4.2244 & TRN & \\
\hline CHEMBL1992634 & 809194 & 4.4 & 5.3786 & TRN & \\
\hline CHEMBL1242373 & 809194 & 4.4 & 4.5618 & TRN & \\
\hline CHEMBL1984847 & 809194 & 4.4 & 4.5809 & TST & \\
\hline CHEMBL316264 & 809194 & 6.3 & 5.7928 & TRN & \\
\hline CHEMBL1988075 & 809194 & 4.4 & 4.6635 & TRN & \\
\hline CHEMBL1996576 & 809194 & 4.4 & 4.5429 & TST & \\
\hline CHEMBL1991678 & 809194 & 7.4 & 8.2583 & TRN & \\
\hline
\end{tabular}




\begin{tabular}{|c|c|c|c|c|}
\hline \multicolumn{5}{|c|}{ pplemental $\mathrm{T}$} \\
\hline CHEMBL2001239 & 809194 & 4.4 & 4.9568 & TST \\
\hline CHEMBL1988594 & 809194 & 4.4 & 4.4579 & TRN \\
\hline CHEMBL 2001288 & 809194 & 4.4 & 4.9399 & TRN \\
\hline CHEMBL260092 & 809194 & 5.6 & 4.8519 & TRN \\
\hline CHEMBL1999811 & 809194 & 5.6 & 4.6665 & TRN \\
\hline CHEMBL1965495 & 809194 & 4.4 & 4.6034 & TRN \\
\hline CHEMBL235157 & 809194 & 4.4 & 4.604 & TST \\
\hline CHEMBL1985074 & 809194 & 4.4 & 4.5473 & TST \\
\hline CHEMBL2000481 & 809194 & 4.4 & 4.5804 & TRN \\
\hline CHEMBL1982874 & 809194 & 7.6 & 6.5861 & TRN \\
\hline CHEMBL1991725 & 809194 & 5.4 & 5.5485 & TRN \\
\hline CHEMBL1992242 & 809194 & 4.4 & 4.5929 & TRN \\
\hline CHEMBL 2007296 & 809194 & 4.4 & 4.3374 & TRN \\
\hline CHEMBL208637 & 809194 & 6.4 & 6.3365 & TRN \\
\hline CHEMBL396523 & 809194 & 8.6 & 8.0916 & TRN \\
\hline CHEMBL 2004159 & 809194 & 4.4 & 4.3331 & TRN \\
\hline CHEMBL1978371 & 809194 & 6.5 & 5.4895 & TST \\
\hline CHEMBL1970203 & 809194 & 4.4 & 4.412 & TRN \\
\hline CHEMBL1986530 & 809194 & 4.4 & 4.5844 & TST \\
\hline CHEMBL440084 & 809194 & 4.4 & 4.6749 & TRN \\
\hline CHEMBL1999321 & 809194 & 4.4 & 4.5093 & TRN \\
\hline CHEMBL1968590 & 809194 & 4.4 & 4.9896 & TRN \\
\hline CHEMBL1999749 & 809194 & 4.4 & 4.6604 & TRN \\
\hline CHEMBL 2005375 & 809194 & 4.4 & 4.7683 & TRN \\
\hline CHEMBL1984191 & 809194 & 6.1 & 4.5688 & TRN \\
\hline CHEMBL1983006 & 809194 & 4.4 & 4.5055 & TRN \\
\hline CHEMBL1972183 & 809194 & 4.4 & 4.5845 & TRN \\
\hline CHEMBL1971029 & 809194 & 6.1 & 6.3705 & TRN \\
\hline CHEMBL394790 & 809194 & 4.4 & 4.5769 & TRN \\
\hline CHEMBL226471 & 809194 & 6.5 & 6.3538 & TRN \\
\hline CHEMBL1974702 & 809194 & 4.4 & 4.5362 & TRN \\
\hline CHEMBL1996111 & 809194 & 4.4 & 4.5767 & TRN \\
\hline CHEMBL1966175 & 809194 & 4.4 & 4.6087 & TRN \\
\hline CHEMBL1965589 & 809194 & 6.7 & 7.1376 & TRN \\
\hline CHEMBL 2007375 & 809194 & 4.4 & 4.2732 & TRN \\
\hline CHEMBL1998193 & 809194 & 4.4 & 4.3887 & TRN \\
\hline CHEMBL379975 & 809194 & 4.4 & 4.465 & TST \\
\hline CHEMBL474432 & 809194 & 4.4 & 4.5277 & TST \\
\hline CHEMBL1973016 & 809194 & 4.4 & 4.5902 & TRN \\
\hline CHEMBL1965387 & 809194 & 4.4 & 4.4367 & TRN \\
\hline CHEMBL2001539 & 809194 & 5.1 & 5.4801 & TST \\
\hline CHEMBL1988153 & 809194 & 4.4 & 4.5244 & TRN \\
\hline CHEMBL550418 & 809194 & 4.4 & 5.358 & TRN \\
\hline CHEMBL1971289 & 809194 & 4.4 & 5.1043 & TRN \\
\hline CHEMBL1999556 & 809194 & 5.9 & 5.4025 & TRN \\
\hline CHEMBL1988437 & 809194 & 4.4 & 5.0726 & TST \\
\hline CHEMBL1968245 & 809194 & 4.4 & 4.5453 & TRN \\
\hline CHEMBL1979577 & 809194 & 5.9 & 4.6909 & TRN \\
\hline
\end{tabular}




\begin{tabular}{|c|c|c|c|c|}
\hline \multicolumn{5}{|c|}{ Supplemental T } \\
\hline CHEMBL1998121 & 809194 & 4.4 & 5.3458 & TRN \\
\hline CHEMBL1233887 & 809194 & 4.4 & 4.6237 & TST \\
\hline CHEMBL1991800 & 809194 & 7.5 & 7.3181 & TRN \\
\hline CHEMBL52387 & 809194 & 4.4 & 5.0087 & TST \\
\hline CHEMBL 2003689 & 809194 & 4.4 & 5.1789 & TRN \\
\hline CHEMBL379835 & 809194 & 6.3 & 5.9085 & TST \\
\hline CHEMBL1979357 & 809194 & 4.4 & 4.5581 & TRN \\
\hline CHEMBL1980802 & 809194 & 4.4 & 4.4645 & TST \\
\hline CHEMBL1996649 & 809194 & 4.4 & 4.6948 & TRN \\
\hline CHEMBL1996817 & 809194 & 4.4 & 4.8755 & TRN \\
\hline CHEMBL1979554 & 809194 & 4.4 & 4.607 & TRN \\
\hline CHEMBL1973324 & 809194 & 5.4 & 5.2376 & TRN \\
\hline CHEMBL1986756 & 809194 & 4.4 & 4.276 & TRN \\
\hline CHEMBL3197315 & 809194 & 4.4 & 4.4939 & TST \\
\hline CHEMBL 2004355 & 809194 & 8.2 & 7.8011 & TRN \\
\hline CHEMBL468280 & 809194 & 4.4 & 4.6333 & TST \\
\hline CHEMBL1990884 & 809194 & 4.4 & 4.6905 & TRN \\
\hline CHEMBL3109278 & 809194 & 4.4 & 4.7375 & TRN \\
\hline CHEMBL 256835 & 809194 & 6.2 & 5.1989 & TRN \\
\hline CHEMBL1974998 & 809194 & 4.4 & 5.0731 & TRN \\
\hline CHEMBL1980142 & 809194 & 4.4 & 4.3594 & TRN \\
\hline CHEMBL41783 & 809194 & 4.4 & 4.6189 & TRN \\
\hline CHEMBL 2004438 & 809194 & 4.4 & 4.8764 & TRN \\
\hline CHEMBL 2006276 & 809194 & 4.4 & 4.5341 & TRN \\
\hline CHEMBL191003 & 809194 & 4.4 & 5.7609 & TRN \\
\hline CHEMBL271381 & 809194 & 4.7 & 4.4574 & TRN \\
\hline CHEMBL 2006785 & 809194 & 4.4 & 4.5516 & TRN \\
\hline CHEMBL1982466 & 809194 & 4.4 & 4.5422 & TRN \\
\hline CHEMBL1973359 & 809194 & 6.4 & 5.5438 & TST \\
\hline CHEMBL1995740 & 809194 & 4.4 & 4.9376 & TRN \\
\hline CHEMBL1996390 & 809194 & 5.7 & 4.6504 & TRN \\
\hline CHEMBL1979690 & 809194 & 6.9 & 6.7841 & TRN \\
\hline CHEMBL234085 & 809194 & 4.4 & 4.36 & TRN \\
\hline CHEMBL1998414 & 809194 & 4.4 & 4.9713 & TRN \\
\hline CHEMBL1995832 & 809194 & 7.9 & 8.2468 & TRN \\
\hline CHEMBL1969042 & 809194 & 4.4 & 4.6955 & TRN \\
\hline CHEMBL 2000345 & 809194 & 5.4 & 4.6474 & TRN \\
\hline CHEMBL1999931 & 809194 & 7.1 & 6.0003 & TRN \\
\hline CHEMBL1976376 & 809194 & 4.4 & 4.6418 & TRN \\
\hline CHEMBL1991640 & 809194 & 4.4 & 4.6957 & TST \\
\hline CHEMBL1983575 & 809194 & 5.9 & 5.5127 & TRN \\
\hline CHEMBL1968868 & 809194 & 4.4 & 4.3361 & TRN \\
\hline CHEMBL1375418 & 809194 & 4.4 & 4.6826 & TRN \\
\hline CHEMBL 302449 & 809194 & 5.4 & 6.0739 & TST \\
\hline CHEMBL 2007064 & 809194 & 5.5 & 4.7023 & TRN \\
\hline CHEMBL1981047 & 809194 & 4.4 & 4.6606 & TRN \\
\hline CHEMBL229968 & 809194 & 5.5 & 5.8313 & TRN \\
\hline CHEMBL1976196 & 809194 & 4.4 & 5.2888 & TST \\
\hline
\end{tabular}




\begin{tabular}{|c|c|c|c|c|c|}
\hline \\
\hline CHEMBL1976240 & 809194 & 4.4 & 4.3343 & TRN & \\
\hline CHEMBL1997197 & 809194 & 4.4 & 4.8281 & TRN & \\
\hline CHEMBL1979093 & 809194 & 4.4 & 4.5434 & TRN & \\
\hline CHEMBL1968151 & 809194 & 4.4 & 4.4413 & TST & \\
\hline CHEMBL1381197 & 809194 & 4.4 & 4.6207 & TRN & \\
\hline CHEMBL1987009 & 809194 & 6.5 & 6.0997 & TRN & \\
\hline CHEMBL379218 & 809194 & 4.4 & 5.334 & TRN & \\
\hline CHEMBL2003817 & 809194 & 4.4 & 4.4892 & TRN & \\
\hline CHEMBL336961 & 809194 & 4.4 & 4.4622 & TRN & \\
\hline CHEMBL1994830 & 809194 & 4.4 & 4.5054 & TRN & \\
\hline CHEMBL1987054 & 809194 & 5.5 & 4.9838 & TRN & \\
\hline CHEMBL1970083 & 809194 & 6.6 & 4.8611 & TRN & \\
\hline CHEMBL226403 & 809194 & 6.4 & 6.3153 & TRN & \\
\hline CHEMBL 2005631 & 809194 & 5.4 & 4.7582 & TRN & \\
\hline CHEMBL1994938 & 809194 & 4.4 & 4.9453 & TRN & \\
\hline CHEMBL1977223 & 809194 & 6.8 & 4.9132 & TRN & \\
\hline CHEMBL1966279 & 809194 & 4.4 & 4.5592 & TRN & \\
\hline CHEMBL1236126 & 809194 & 4.4 & 4.8627 & TRN & \\
\hline CHEMBL1997846 & 809194 & 5.5 & 5.4766 & TRN & \\
\hline CHEMBL1984760 & 809194 & 5.6 & 6.0328 & TRN & \\
\hline CHEMBL 2004419 & 809194 & 7.5 & 6.4375 & TRN & \\
\hline CHEMBL1991728 & 809194 & 4.4 & 4.6036 & TRN & \\
\hline CHEMBL360847 & 809194 & 4.4 & 4.4624 & TST & \\
\hline CHEMBL 2007073 & 809194 & 5.9 & 5.0704 & TRN & \\
\hline CHEMBL1995811 & 809194 & 6.0 & 5.8964 & TRN & \\
\hline CHEMBL1975787 & 809194 & 5.9 & 5.8528 & TRN & \\
\hline CHEMBL 2002407 & 809194 & 4.4 & 4.8089 & TRN & \\
\hline CHEMBL1972489 & 809194 & 4.4 & 4.3727 & TRN & \\
\hline CHEMBL1994074 & 809194 & 6.2 & 4.8634 & TRN & \\
\hline CHEMBL1992937 & 809194 & 4.7 & 5.5907 & TST & \\
\hline CHEMBL1985566 & 809194 & 4.4 & 5.2861 & TRN & \\
\hline CHEMBL1972119 & 809194 & 4.4 & 4.4982 & TRN & \\
\hline CHEMBL1986328 & 809194 & 4.4 & 4.52800 & 00000000005 & TST \\
\hline CHEMBL95692 & 809194 & 4.4 & 5.1911 & TRN & \\
\hline CHEMBL1090356 & 809194 & 8.0 & 7.5109 & TRN & \\
\hline CHEMBL1976455 & 809194 & 4.4 & 4.5771 & TRN & \\
\hline CHEMBL 261849 & 809194 & 4.4 & 4.5103 & TST & \\
\hline CHEMBL1983923 & 809194 & 4.4 & 4.5998 & TRN & \\
\hline CHEMBL1983534 & 809194 & 4.4 & 4.5603 & TRN & \\
\hline CHEMBL1982361 & 809194 & 4.4 & 4.4388 & TRN & \\
\hline CHEMBL1999112 & 809194 & 4.4 & 4.6785 & TST & \\
\hline CHEMBL1982122 & 809194 & 4.4 & 4.5728 & TRN & \\
\hline CHEMBL 2000801 & 809194 & 4.4 & 4.6574 & TRN & \\
\hline CHEMBL1682546 & 809194 & 4.4 & 4.4799 & TRN & \\
\hline CHEMBL1991395 & 809194 & 7.3 & 7.3069 & TRN & \\
\hline CHEMBL1971245 & 809194 & 4.4 & 5.4049 & TRN & \\
\hline CHEMBL1987648 & 809194 & 6.9 & 7.7745 & TRN & \\
\hline CHEMBL1996780 & 809194 & 4.4 & 4.6816 & TST & \\
\hline
\end{tabular}




\begin{tabular}{|c|c|c|c|c|}
\hline \multicolumn{5}{|c|}{ plemental T } \\
\hline CHEMBL1972142 & 809194 & 5.9 & 4.6395 & TRN \\
\hline CHEMBL1966514 & 809194 & 5.4 & 4.7592 & TRN \\
\hline CHEMBL 2003638 & 809194 & 6.7 & 5.9347 & TRN \\
\hline CHEMBL296586 & 809194 & 4.4 & 4.4701 & TRN \\
\hline CHEMBL1996066 & 809194 & 4.4 & 4.8227 & TST \\
\hline CHEMBL1983393 & 809194 & 4.4 & 4.3089 & TRN \\
\hline CHEMBL516429 & 809194 & 4.4 & 5.6331 & TRN \\
\hline CHEMBL1993722 & 809194 & 4.4 & 4.5956 & TST \\
\hline CHEMBL1970806 & 809194 & 4.4 & 4.6092 & TST \\
\hline CHEMBL 2006674 & 809194 & 4.4 & 4.5849 & TST \\
\hline CHEMBL1984236 & 809194 & 4.4 & 4.4978 & TST \\
\hline CHEMBL1992371 & 809194 & 4.4 & 4.9424 & TST \\
\hline CHEMBL1375640 & 809194 & 5.4 & 4.9993 & TST \\
\hline CHEMBL1979970 & 809194 & 4.4 & 5.183 & TST \\
\hline CHEMBL 2002599 & 809194 & 4.4 & 4.5315 & TST \\
\hline CHEMBL 249282 & 809194 & 4.4 & 4.4202 & TST \\
\hline CHEMBL1967252 & 809194 & 4.7 & 5.0907 & TST \\
\hline CHEMBL 2004637 & 809194 & 4.4 & 5.1589 & TST \\
\hline CHEMBL1993374 & 809194 & 6.5 & 6.169 & TST \\
\hline CHEMBL1969264 & 809194 & 5.4 & 4.6072 & TST \\
\hline CHEMBL1994318 & 809194 & 4.4 & 5.0923 & TST \\
\hline CHEMBL1973711 & 809194 & 4.4 & 4.7469 & TST \\
\hline CHEMBL 2006237 & 809194 & 4.4 & 4.7678 & TST \\
\hline CHEMBL1999506 & 809194 & 4.4 & 5.0696 & TST \\
\hline CHEMBL1967720 & 809194 & 6.1 & 4.8445 & TST \\
\hline CHEMBL1572266 & 809194 & 4.4 & 4.6897 & TST \\
\hline CHEMBL1991138 & 809194 & 4.4 & 4.8862 & TST \\
\hline CHEMBL1969755 & 809194 & 4.4 & 4.4334 & TST \\
\hline CHEMBL1979516 & 809194 & 4.4 & 4.6174 & TST \\
\hline CHEMBL1972820 & 809194 & 4.4 & 4.5587 & TST \\
\hline CHEMBL1605605 & 809194 & 4.4 & 4.4145 & TST \\
\hline CHEMBL1989029 & 809194 & 4.4 & 4.5799 & TST \\
\hline CHEMBL1980091 & 809194 & 5.6 & 4.9638 & TST \\
\hline CHEMBL392642 & 809194 & 5.4 & 5.0004 & TST \\
\hline CHEMBL514499 & 809194 & 4.4 & 4.4868 & TST \\
\hline CHEMBL1970352 & 809194 & 5.6 & 5.593 & TST \\
\hline CHEMBL1965631 & 809194 & 5.8 & 4.8044 & TST \\
\hline CHEMBL1980144 & 809194 & 4.4 & 4.426 & TST \\
\hline CHEMBL1991188 & 809194 & 4.4 & 4.4367 & TST \\
\hline CHEMBL1980167 & 809194 & 4.4 & 5.8519 & TST \\
\hline CHEMBL1972849 & 809194 & 4.4 & 5.5118 & TST \\
\hline CHEMBL377408 & 809194 & 8.4 & 7.4553 & TST \\
\hline CHEMBL215152 & 809194 & 4.4 & 4.5175 & TST \\
\hline CHEMBL231209 & 809194 & 4.4 & 4.6341 & TST \\
\hline CHEMBL1976220 & 809194 & 4.4 & 4.6045 & TST \\
\hline CHEMBL 2006765 & 809194 & 6.7 & 6.5266 & TST \\
\hline CHEMBL259922 & 809194 & 4.4 & 4.5912 & TST \\
\hline CHEMBL1997617 & 809194 & 4.4 & 4.8862 & TST \\
\hline
\end{tabular}




\begin{tabular}{|c|c|c|c|c|c|}
\hline & & & & & \\
\hline CHEMBL1969301 & 809194 & 4.4 & 4.6942 & TST & \\
\hline CHEMBL1982383 & 809194 & 6.7 & 6.903 & TST & \\
\hline CHEMBL17370 & 809194 & 6.4 & 5.7039 & TST & \\
\hline CHEMBL1980246 & 809194 & 4.4 & 4.5937 & TST & \\
\hline CHEMBL1987910 & 809194 & 4.4 & 4.6255 & TST & \\
\hline CHEMBL1983932 & 809194 & 4.4 & 4.4574 & TST & \\
\hline CHEMBL1983980 & 809194 & 5.5 & 5.8376 & TST & \\
\hline CHEMBL1999484 & 809194 & 7.1 & 7.0214 & TST & \\
\hline CHEMBL1966069 & 809194 & 4.4 & 4.8082 & TST & \\
\hline CHEMBL1986899 & 809194 & 4.4 & 5.4984 & TST & \\
\hline CHEMBL1991285 & 809194 & 4.4 & 4.4969 & TST & \\
\hline CHEMBL1997822 & 809194 & 4.4 & 4.7945 & TST & \\
\hline CHEMBL243088 & 809194 & 8.4 & 7.8686 & TST & \\
\hline CHEMBL1984038 & 809194 & 4.4 & 4.7417 & TST & \\
\hline CHEMBL1993661 & 809194 & 7.0 & 6.436 & TST & \\
\hline CHEMBL1974416 & 809194 & 5.8 & 4.9427 & TST & \\
\hline CHEMBL2004615 & 809194 & 4.4 & 4.6415 & TST & \\
\hline CHEMBL1997872 & 809194 & 4.4 & 4.7018 & TST & \\
\hline CHEMBL327821 & 1638066 & 8.4685 & 8.1869 & TRN & \\
\hline CHEMBL430839 & 1638066 & 8.2757 & 8.2886 & TRN & \\
\hline CHEMBL194235 & 1638066 & 7.8539 & 7.7609 & TRN & \\
\hline CHEMBL 3951248 & 1638066 & 7.5376 & 8.1691 & TRN & \\
\hline CHEMBL3944828 & 1638066 & 8.3979 & 8.6905 & TRN & \\
\hline CHEMBL440211 & 1638066 & 7.8861 & 7.7044 & TRN & \\
\hline CHEMBL1199648 & 1638066 & 6.8041 & 7.1608 & TRN & \\
\hline CHEMBL92355 & 1638066 & 7.4437 & 7.5256 & TRN & \\
\hline CHEMBL90185 & 1638066 & 8.2218 & 8.3274 & TRN & \\
\hline CHEMBL3926784 & 1638066 & 7.6383 & 7.9779 & TRN & \\
\hline CHEMBL3976524 & 1638066 & 8.0915 & 8.1751 & TRN & \\
\hline CHEMBL3922955 & 1638066 & 7.9208 & 8.1292 & TRN & \\
\hline CHEMBL3909635 & 1638066 & 8.3872 & 8.2033 & TRN & \\
\hline CHEMBL3917557 & 1638066 & 8.585 & 8.3695 & TRN & \\
\hline CHEMBL3914770 & 1638066 & 8.6021 & 8.4853 & TST & \\
\hline CHEMBL3983710 & 1638066 & 7.1549 & 7.2195 & TRN & \\
\hline CHEMBL90589 & 1638066 & 8.5229 & 8.2654 & TRN & \\
\hline CHEMBL382967 & 1638066 & 8.3372 & 8.3096 & TRN & \\
\hline CHEMBL3966591 & 1638066 & 8.0132 & 8.2389 & TRN & \\
\hline CHEMBL3907290 & 1638066 & 7.3979 & 7.4556 & TRN & \\
\hline CHEMBL3927125 & 1638066 & 8.2596 & 7.742999 & 9999999999 & TST \\
\hline CHEMBL327207 & 1638066 & 8.301 & 8.0992 & TRN & \\
\hline CHEMBL330534 & 1638066 & 8.283999 & 999999999 & 8.4601 & TST \\
\hline CHEMBL3954160 & 1638066 & 6.8928 & 6.9257 & TRN & \\
\hline CHEMBL197579 & 1638066 & 7.8861 & 7.5128 & TRN & \\
\hline CHEMBL3917051 & 1638066 & 6.8416 & 7.002999 & 9999999999 & TRN \\
\hline CHEMBL3945053 & 1638066 & 7.3468 & 7.5852 & TRN & \\
\hline CHEMBL197674 & 1638066 & 7.6576 & 7.9807 & TRN & \\
\hline CHEMBL194207 & 1638066 & 8.6778 & 8.435 & TRN & \\
\hline CHEMBL3913186 & 1638066 & 8.2366 & 7.5218 & TRN & \\
\hline
\end{tabular}


Supplemental Table S2.txt

\begin{tabular}{|c|c|c|c|c|}
\hline HEMB & 538066 & 7.8239 & 7.9258 & (1) \\
\hline HEMBL 88540 & 638066 & 8.4318 & 8.4742 & \\
\hline HEMBL3910815 & 38066 & & & \\
\hline AEMBL316101 & 38066 & 208 & 8094 & \\
\hline HEMBL 205821 & 638066 & 7.7447 & 8336 & \\
\hline HEMBL391 & 638066 & 8.0915 & .0672 & \\
\hline HEMBL92848 & 538066 & 7.284 & .2688 & \\
\hline HEMBL3961549 & 538066 & 8.3768 & & \\
\hline HEMBL1199647 & 638066 & 8.3279 & 8.0686 & \\
\hline HEMBL3947447 & 638066 & 7.1308 & .0671 & \\
\hline HEMBL90516 & 638066 & & & \\
\hline AEMBL3 & 638066 & 8.3979 & 275 & \\
\hline HEMBL9 & 538066 & & .61 & \\
\hline HEMBL3977587 & 638066 & 8.3979 & 8.0664 & \\
\hline HEMBL3930460 & 538066 & 969 & & \\
\hline HEMBL9 & 038000 & 9 & 15 & 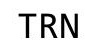 \\
\hline HEMBL 9 & & & & 等 \\
\hline HEMBL1 & 538066 & 97 & 469 & $\mathrm{RN}$ \\
\hline HEMBL3 & 538066 & 96 & 7.819 & \\
\hline HEMBL3 & 8066 & & 72 & $T_{1}$ \\
\hline HEMBL & D6 & 7. & 7.8 & RIN \\
\hline HEME & 6 & 8 & 62 & RN \\
\hline HEMBL & 638066 & & 7.4096 & IST \\
\hline HEMBL9 & 538066 & & 8.3435 & TRN \\
\hline HEMBL392 & 38066 & 7. & 0595 & I RN \\
\hline HEMBL3 & 3066 & 7. & 44 & 「RN \\
\hline HEME & 56 & & 38 & $\mathrm{RN}$ \\
\hline HFME & 66 & 7. & 39 & $\mathrm{RN}$ \\
\hline HEMBL3 & & & & $|S|$ \\
\hline AEMBL314 & 538066 & 8.3979 & 8.2515 & TRN \\
\hline HEMBL & 066 & & 15 & 「RN \\
\hline HFM & 56 & & 46 & ST \\
\hline HEMBL & & & 05 & TRN \\
\hline HEMBL9 & & & 13 & 「RN \\
\hline HEMBL 32 & 638066 & 7. & 7.5714 & TST \\
\hline HEMBL & 56 & 51 & 08 & TRN \\
\hline HFM & 56 & & 33 & TST \\
\hline HEMBL9 & & & & TST \\
\hline HEMBL 3 & 538066 & 8.30 & & TST \\
\hline HEMBL3 & 3066 & 8 & & TST \\
\hline HEMBL3 & 638066 & 7. & 7.7752 & וכו \\
\hline HEMBL3 & 66 & 6. & 6.7259 & TST \\
\hline HEMBL262735 & 638066 & 8.0605 & 8.0784 & TST \\
\hline CHEMBL3 & 638066 & 8 . & 5269 & TS \\
\hline 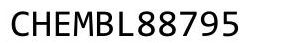 & & & & $|\mathrm{I}|$ \\
\hline HEMBL1 & 638066 & 09 & 5.7183 & \\
\hline THEMBL 316450 & 638066 & 6.7905 & 7.2298 & ST \\
\hline CHEMBL3648963 & 1528018 & 8.0269 & 7.5141 & $\Gamma R$ \\
\hline
\end{tabular}

Page 786 
Supplemental Table S2.txt

\begin{tabular}{|c|c|c|c|c|c|}
\hline CHEMBL 3648965 & 1528018 & 6.3279 & 6.3538 & TRN & \\
\hline CHEMBL3648969 & 1528018 & 6.8861 & \multicolumn{2}{|c|}{7.382000000000001} & TRN \\
\hline CHEMBL 3652245 & 1528018 & 6.0 & 6.2291 & TRN & \\
\hline CHEMBL3648952 & 1528018 & 6.5686 & 6.8736 & TRN & \\
\hline CHEMBL 2375964 & 1528018 & 6.0 & 6.8022 & TRN & \\
\hline CHEMBL 3649003 & 1528018 & 8.0 & 8.0286 & TRN & \\
\hline CHEMBL3649016 & 1528018 & 8.3979 & 7.6868 & TRN & \\
\hline CHEMBL 3648932 & 1528018 & 9.1361 & 8.9398 & TRN & \\
\hline CHEMBL 3652256 & 1528018 & 6.0 & 7.0587 & TRN & \\
\hline CHEMBL3648930 & 1528018 & 8.9957 & 9.5213 & TRN & \\
\hline CHEMBL3648995 & 1528018 & 7.9586 & 7.8016 & TRN & \\
\hline CHEMBL 3648980 & 1528018 & 8.7959 & 8.6729 & TRN & \\
\hline CHEMBL 3652248 & 1528018 & 9.1035 & 7.6511 & TRN & \\
\hline CHEMBL3648919 & 1528018 & 6.5607 & 7.6719 & TST & \\
\hline CHEMBL3649014 & 1528018 & 7.0555 & 7.8642 & TRN & \\
\hline CHEMBL3649011 & 1528018 & 8.699 & 7.5537 & TRN & \\
\hline CHEMBL3648978 & 1528018 & 8.2218 & 8.1271 & TRN & \\
\hline CHEMBL3648976 & 1528018 & 7.7696 & 7.7566 & TRN & \\
\hline CHEMBL3218405 & 1528018 & 8.1249 & 7.7711 & TRN & \\
\hline CHEMBL3649012 & 1528018 & 8.5086 & 8.2522 & TRN & \\
\hline CHEMBL1614778 & 1528018 & 8.0223 & 8.0637 & TRN & \\
\hline CHEMBL 3648917 & 1528018 & 6.0675 & 7.7606 & TST & \\
\hline CHEMBL 3652250 & 1528018 & 8.8861 & 6.6096 & TST & \\
\hline CHEMBL3648915 & 1528018 & 6.5086 & 8.487 & TST & \\
\hline CHEMBL 2375957 & 1528018 & 6.0 & 6.8305 & TRN & \\
\hline CHEMBL 3648951 & 1528018 & 7.8239 & 7.5446 & TRN & \\
\hline CHEMBL 3652274 & 1528018 & 8.2284 & 7.0879 & TRN & \\
\hline CHEMBL 3652251 & 1528018 & 8.5376 & 7.6021 & TST & \\
\hline CHEMBL3648985 & 1528018 & 7.0 & 7.5072 & TST & \\
\hline CHEMBL3648911 & 1528018 & 7.7696 & 7.8186 & TRN & \\
\hline CHEMBL 3648988 & 1528018 & 8.2676 & 8.0582 & TRN & \\
\hline CHEMBL 3648939 & 1528018 & 6.8239 & 6.0618 & TRN & \\
\hline CHEMBL 3652270 & 1528018 & 8.5072 & 8.5276 & TRN & \\
\hline CHEMBL3652258 & 1528018 & 6.0 & 7.2044 & TRN & \\
\hline CHEMBL3649009 & 1528018 & 7.7212 & 7.0055 & TRN & \\
\hline CHEMBL3648996 & 1528018 & 7.4089 & 7.8053 & TRN & \\
\hline CHEMBL3648909 & 1528018 & 6.3979 & 8.0327 & TST & \\
\hline CHEMBL3648992 & 1528018 & 7.699 & 8.0873 & TST & \\
\hline CHEMBL3652269 & 1528018 & 7.9914 & 8.5404 & TRN & \\
\hline CHEMBL3649015 & 1528018 & 7.3468 & 7.4632 & TRN & \\
\hline CHEMBL3648960 & 1528018 & 8.0458 & 7.5732 & TRN & \\
\hline CHEMBL3648933 & 1528018 & 7.7447 & 6.5424 & TRN & \\
\hline CHEMBL3648913 & 1528018 & 9.1249 & 8.5543 & TRN & \\
\hline CHEMBL 2057725 & 1528018 & 8.5287 & 8.0122 & TRN & \\
\hline CHEMBL 3652272 & 1528018 & 8.3261 & 7.6873 & TRN & \\
\hline CHEMBL 3648962 & 1528018 & 7.7447 & 7.61100 & 0000000001 & TRN \\
\hline CHEMBL3648977 & 1528018 & 7.3188 & 8.0748 & TST & \\
\hline CHEMBL3648972 & 1528018 & 6.6383 & 7.5411 & TRN & \\
\hline
\end{tabular}


Supplemental Table S2.txt

\begin{tabular}{|c|c|c|c|c|}
\hline The & 528018 & 6.0 & 398 & \\
\hline & 528018 & 6 & & \\
\hline$A$ AEMRI & 28018 & & 951 & \\
\hline AEMBL & 8018 & 699 & 76 & \\
\hline AEMBL3652252 & 528018 & 8.4089 & 508 & \\
\hline HEMBL365 & 528018 & 5.9208 & 3866 & \\
\hline 78 & 28018 & & 381 & \\
\hline AEMBL: & 28018 & & 7511 & \\
\hline HEMBL3648937 & 528018 & 6.0 & 7.1108 & \\
\hline HEMBL 364 & 528018 & 8.2984 & 5685 & \\
\hline HEMBL3 & 528018 & 7.5272 & 7383 & \\
\hline EM & 528018 & 6.0 & 8932 & \\
\hline AEMBL & 8018 & & 2555 & \\
\hline HEMBL3 & 528018 & 6 . & 2551 & \\
\hline AEMBL3 & 528018 & 6. & 3632 & \\
\hline HEMBL; & 28018 & 7 & 978 & $R / N$ \\
\hline AEMBL & $\partial 18$ & & 304 & Niv \\
\hline AEMBL. & 528018 & 6. & 699 & \\
\hline HFMBI 3 & 528018 & & 9006 & \\
\hline AEMBL2 & 528018 & 6. & 5777 & niv \\
\hline AEMBL & 8018 & & 3923 & RN \\
\hline HEMBL & 8 & & 965 & NIV \\
\hline AEMBL & 918 & & 7182 & \\
\hline HEMBL & 018 & & 549 & \\
\hline AEMBL3 & 8018 & 7. & 615 & RN \\
\hline HEMBL; & 8018 & & 621 & RN \\
\hline HFM & 18 & & 07 & $\mathrm{~K} / \mathrm{V}$ \\
\hline 58 & & & 192 & \\
\hline AEMBL & & & & $\Gamma \mathrm{RN}$ \\
\hline AEMBL3 & 528018 & 7. & 294 & RN \\
\hline AEMBL & 3018 & & 64 & RN \\
\hline 9 & 18 & & 06 & RN \\
\hline & & & & RN \\
\hline HEMBL3 & 28018 & 6 & 353 & 「RN \\
\hline AEMBL3 & 28018 & 7. & 976 & RN \\
\hline 40 & 3018 & 6 & 349 & TRN \\
\hline & & & 54 & RN \\
\hline HEMBL 2 & & & 9903 & 「RN \\
\hline HEMBL & 528018 & 7. & 442 & $\Gamma R$ \\
\hline 91 & 18 & & 522 & RN \\
\hline HEMBL3 & 8 & 5 . & 243 & \\
\hline HEMBL3 & & & 078 & 「RN \\
\hline HEMBL3 & 528018 & & 7632 & $\Gamma R$ \\
\hline HEMBL3 & 18 & & 209 & TS \\
\hline 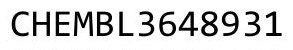 & & & 569 & \\
\hline HEMBL3 & 528018 & 7.8239 & 7.9254 & \\
\hline CHEMBL3 & .528018 & 8.1135 & 8.1048 & \\
\hline CHEMBL3652261 & 1528018 & 8.0325 & 7.6832 & \\
\hline
\end{tabular}

Page 788 
Supplemental Table S2.txt

\begin{tabular}{|c|c|c|c|c|}
\hline CHEMBL3649002 & 1528018 & 7.0506 & 7.4652 & TRN \\
\hline CHEMBL 3652260 & 1528018 & 7.2581 & 7.2099 & TRN \\
\hline CHEMBL3648986 & 1528018 & 7.6576 & 7.6838 & TRN \\
\hline CHEMBL 3648959 & 1528018 & 8.2076 & 7.5043 & TRN \\
\hline CHEMBL 3648908 & 1528018 & 7.8239 & 8.1757 & TST \\
\hline CHEMBL 3648918 & 1528018 & 9.3188 & 8.463 & TRN \\
\hline CHEMBL 2057736 & 1528018 & 8.3468 & 8.0684 & TRN \\
\hline CHEMBL 3648958 & 1528018 & 6.0 & 6.9371 & TRN \\
\hline CHEMBL 3648973 & 1528018 & 7.699 & 7.8506 & TRN \\
\hline CHEMBL 3648927 & 1528018 & 5.15 & 5.7547 & TRN \\
\hline CHEMBL 3649005 & 1528018 & 7.7447 & 7.8856 & TRN \\
\hline CHEMBL 3652244 & 1528018 & 8.0862 & 6.5157 & TRN \\
\hline CHEMBL 3648922 & 1528018 & 8.752 & 9.15 & TRN \\
\hline CHEMBL3648946 & 1528018 & 6.1675 & 7.013999 & 7999999999 \\
\hline CHEMBL 3652271 & 1528018 & 8.1772 & 7.9437 & TRN \\
\hline CHEMBL3648989 & 1528018 & 6.9208 & 7.2778 & TRN \\
\hline CHEMBL 3649010 & 1528018 & 8.7696 & 8.2249 & TRN \\
\hline CHEMBL 2057727 & 1528018 & 8.0862 & 7.9428 & TRN \\
\hline CHEMBL3652255 & 1528018 & 8.301 & 7.3013 & TST \\
\hline CHEMBL 3648953 & 1528018 & 8.3665 & 7.91 & TRN \\
\hline CHEMBL3218404 & 1528018 & 8.1805 & 7.9258 & TRN \\
\hline CHEMBL 2057729 & 1528018 & 7.2518 & 7.3206 & TRN \\
\hline CHEMBL 3648981 & 1528018 & 7.0269 & 7.9837 & TST \\
\hline CHEMBL 3652273 & 1528018 & 8.6696 & 7.6879 & TRN \\
\hline CHEMBL 3648997 & 1528018 & 7.4949 & 7.8312 & TRN \\
\hline CHEMBL 3648984 & 1528018 & 8.5528 & 8.5201 & TRN \\
\hline CHEMBL3648924 & 1528018 & 9.0048 & 8.9541 & TRN \\
\hline CHEMBL3652265 & 1528018 & 7.5272 & 7.5452 & TRN \\
\hline CHEMBL3648912 & 1528018 & 7.4078 & 7.726 & TRN \\
\hline CHEMBL 3648923 & 1528018 & 8.5114 & 9.4822 & TRN \\
\hline CHEMBL 3648964 & 1528018 & 8.5686 & 7.2673 & TRN \\
\hline CHEMBL 3649008 & 1528018 & 7.5686 & 7.3502 & TRN \\
\hline CHEMBL3652259 & 1528018 & 8.1203 & 7.8445 & TRN \\
\hline CHEMBL3648956 & 1528018 & 7.5086 & 7.1912 & TRN \\
\hline CHEMBL3648982 & 1528018 & 7.8539 & 8.1536 & TRN \\
\hline CHEMBL3648920 & 1528018 & 5.4685 & 8.1311 & TST \\
\hline CHEMBL 3649020 & 1528018 & 6.5229 & 7.584 & TRN \\
\hline CHEMBL3648936 & 1528018 & 6.0 & 6.4499 & TRN \\
\hline CHEMBL 3648998 & 1528018 & 7.3372 & 8.2871 & TST \\
\hline CHEMBL2057731 & 1528018 & 7.5317 & 7.8572 & TST \\
\hline CHEMBL3652249 & 1528018 & 8.7986 & 6.9513 & TST \\
\hline CHEMBL 3649018 & 1528018 & 8.8447 & 8.0828 & TST \\
\hline CHEMBL3648910 & 1528018 & 8.8041 & 8.881 & TST \\
\hline CHEMBL3648916 & 1528018 & 8.0969 & 8.0018 & TST \\
\hline CHEMBL3218403 & 1528018 & 8.1192 & 6.8588 & TST \\
\hline CHEMBL3649019 & 1528018 & 8.6576 & 7.473 & TST \\
\hline CHEMBL2375959 & 1528018 & 6.0 & 6.327999 & 7999999999 \\
\hline CHEMBL3648957 & 1528018 & 8.7959 & 7.7135 & TST \\
\hline
\end{tabular}


Supplemental Table S2.txt

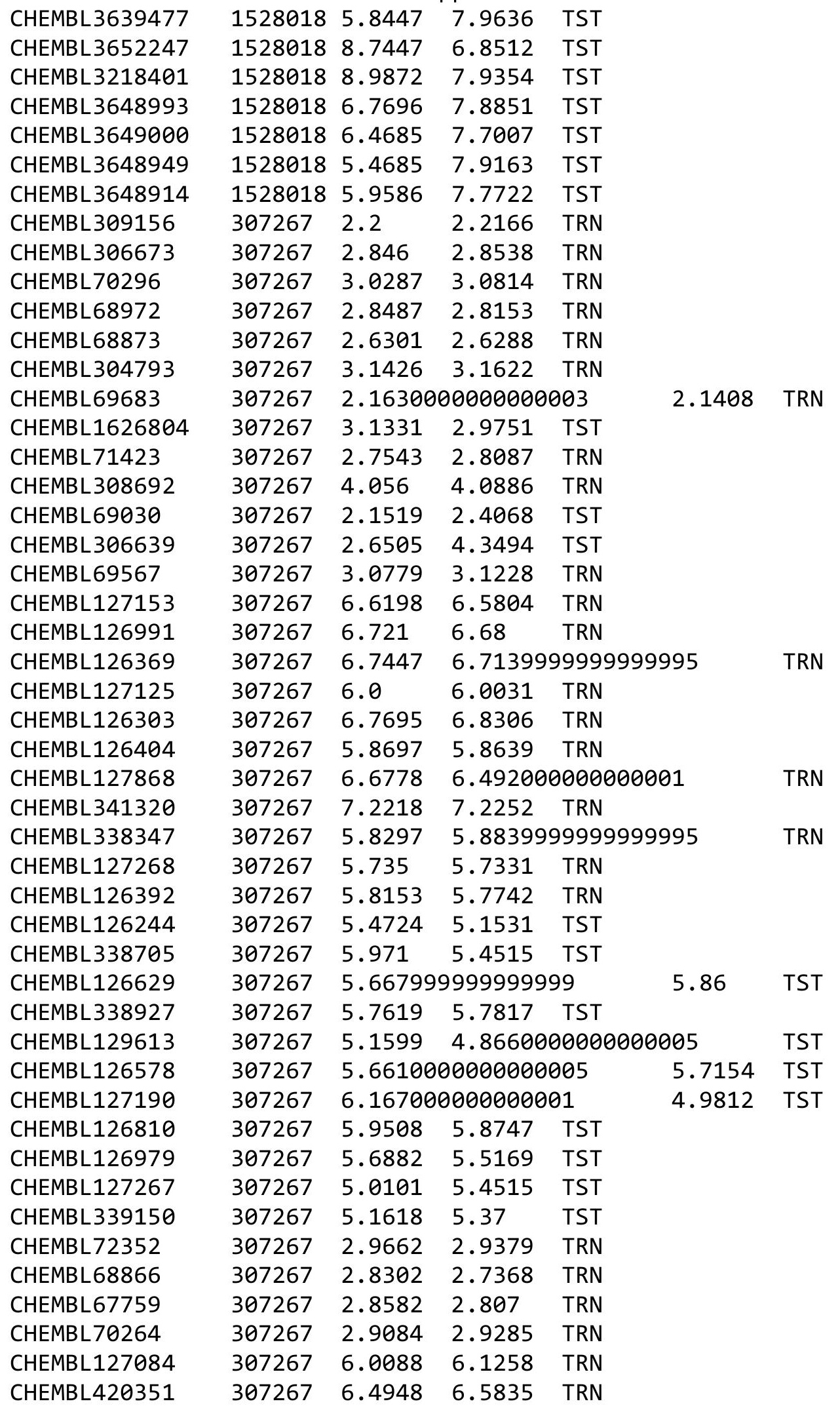




\begin{tabular}{|c|c|c|c|c|c|c|}
\hline \multirow[b]{2}{*}{ CHEMBL127514 } & \multicolumn{6}{|c|}{ Supplemental Table S2.txt } \\
\hline & 307267 & 6.444 & 6.5017 & TRN & & \\
\hline CHEMBL126683 & 307267 & 6.3872 & 6.3965 & TRN & & \\
\hline CHEMBL339258 & 307267 & 5.61100 & 00000000 & & 5.5541 & TRN \\
\hline CHEMBL127560 & 307267 & 5.61100 & 00000000 & & 5.638 & TRN \\
\hline CHEMBL129473 & 307267 & 5.399 & 5.4091 & TRN & & \\
\hline CHEMBL127211 & 307267 & 7.0969 & 7.0163 & TRN & & \\
\hline CHEMBL127210 & 307267 & 5.3536 & 5.3072 & TRN & & \\
\hline CHEMBL362149 & 307267 & 5.471 & 5.5548 & TRN & & \\
\hline CHEMBL442767 & 307267 & 6.699 & 6.6706 & TRN & & \\
\hline CHEMBL125460 & 307267 & 6.824 & 6.95299 & 9999999999 & & TRN \\
\hline CHEMBL338457 & 307267 & 6.5086 & 6.4172 & TRN & & \\
\hline CHEMBL129640 & 307267 & 6.7447 & 6.7305 & TRN & & \\
\hline CHEMBL3925946 & 1640353 & 8.3279 & 7.9267 & TRN & & \\
\hline CHEMBL3921766 & 1640353 & 7.7825 & 7.6997 & TRN & & \\
\hline CHEMBL3920964 & 1640353 & 7.0088 & 7.2717 & TRN & & \\
\hline CHEMBL3952226 & 1640353 & 7.0079 & 7.63200 & 0000000001 & & TRN \\
\hline CHEMBL3939755 & 1640353 & 7.2596 & 7.3313 & TST & & \\
\hline CHEMBL 3904394 & 1640353 & 7.8761 & 7.5358 & TRN & & \\
\hline CHEMBL 3908842 & 1640353 & 7.8633 & 7.4888 & TRN & & \\
\hline CHEMBL3959200 & 1640353 & 8.3188 & 8.63600 & 0000000001 & & TRN \\
\hline CHEMBL3892605 & 1640353 & 8.7696 & 8.984 & TRN & & \\
\hline CHEMBL3958112 & 1640353 & 7.2411 & 7.3047 & TRN & & \\
\hline CHEMBL 3977715 & 1640353 & 7.5544 & 7.7804 & TRN & & \\
\hline CHEMBL 3909611 & 1640353 & 7.3279 & 7.4095 & TRN & & \\
\hline CHEMBL 3964274 & 1640353 & 6.0 & 6.6705 & TRN & & \\
\hline CHEMBL3928713 & 1640353 & 7.2733 & 7.2798 & TRN & & \\
\hline CHEMBL3892335 & 1640353 & 7.5452 & 7.2048 & TRN & & \\
\hline CHEMBL 3979280 & 1640353 & 7.8153 & 7.5803 & TST & & \\
\hline CHEMBL 3976582 & 1640353 & 7.9957 & 7.7808 & TRN & & \\
\hline CHEMBL3961601 & 1640353 & 8.3768 & 8.3697 & TRN & & \\
\hline CHEMBL 3904564 & 1640353 & 7.9172 & 7.6691 & TRN & & \\
\hline CHEMBL3972009 & 1640353 & 8.2007 & 7.7558 & TRN & & \\
\hline CHEMBL3965146 & 1640353 & 7.3468 & 7.29299 & 9999999999 & & TRN \\
\hline CHEMBL3912228 & 1640353 & 7.1107 & 6.8524 & TST & & \\
\hline CHEMBL3950417 & 1640353 & 8.1249 & 7.7205 & TRN & & \\
\hline CHEMBL3960808 & 1640353 & 7.5086 & 7.6254 & TRN & & \\
\hline CHEMBL3972530 & 1640353 & 8.6576 & 8.59 & TRN & & \\
\hline CHEMBL3938957 & 1640353 & 7.8 & 7.8412 & TRN & & \\
\hline CHEMBL 3914850 & 1640353 & 6.8133 & 7.2859 & TST & & \\
\hline CHEMBL3931707 & 1640353 & 7.2798 & 7.7669 & TRN & & \\
\hline CHEMBL3890360 & 1640353 & 7.9469 & 7.9125 & TRN & & \\
\hline CHEMBL3909097 & 1640353 & 8.5229 & 8.5462 & TRN & & \\
\hline CHEMBL3940310 & 1640353 & 7.6946 & 7.0519 & TRN & & \\
\hline CHEMBL 3931550 & 1640353 & 7.8153 & 7.6624 & TST & & \\
\hline CHEMBL 3916820 & 1640353 & 8.1308 & 8.1519 & TST & & \\
\hline CHEMBL3917663 & 1640353 & 7.4921 & 6.95299 & 9999999999 & & TRN \\
\hline CHEMBL3910457 & 1640353 & 8.1163 & 8.2354 & TRN & & \\
\hline CHEMBL3925856 & 1640353 & 8.3279 & 8.0801 & TRN & & \\
\hline
\end{tabular}


Supplemental Table S2.txt

\begin{tabular}{|c|c|c|c|c|c|c|}
\hline CHEMBL3931315 & 1640353 & 6.0858 & 6.2676 & TRN & & \\
\hline CHEMBL 3978342 & 1640353 & 8.3979 & 8.7261 & TRN & & \\
\hline CHEMBL 3955856 & 1640353 & 7.4283 & 7.3972 & TST & & \\
\hline CHEMBL 3969188 & 1640353 & 8.5086 & 8.5496 & TRN & & \\
\hline CHEMBL 3944177 & 1640353 & 6.0 & 6.3407 & TRN & & \\
\hline CHEMBL 3952724 & 1640353 & 7.7167 & 7.5565 & TST & & \\
\hline CHEMBL 3924680 & 1640353 & 7.9066 & 7.7944 & TRN & & \\
\hline CHEMBL 3902763 & 1640353 & 8.0706 & 7.3518 & TST & & \\
\hline CHEMBL 3909345 & 1640353 & 7.8477 & 7.6746 & TRN & & \\
\hline CHEMBL 3937084 & 1640353 & 8.5086 & 7.6964 & TST & & \\
\hline CHEMBL 3969298 & 1640353 & 7.3799 & 6.9352 & TRN & & \\
\hline CHEMBL 3935820 & 1640353 & 8.3372 & 8.0133 & TRN & & \\
\hline CHEMBL 3895227 & 1640353 & 8.2441 & 8.2507 & TST & & \\
\hline CHEMBL 3916979 & 1640353 & 8.3325 & 8.0041 & TRN & & \\
\hline CHEMBL 3960393 & 1640353 & 8.3979 & 8.8599 & TRN & & \\
\hline CHEMBL 3951249 & 1640353 & \multicolumn{3}{|c|}{8.283999999999999} & 7.7564 & TRN \\
\hline CHEMBL 3972124 & 1640353 & 6.9718 & 7.1496 & TRN & & \\
\hline CHEMBL 3944802 & 1640353 & 6.7206 & 7.3276 & TST & & \\
\hline CHEMBL 3908178 & 1640353 & 6.0 & \multicolumn{3}{|c|}{7.207000000000001} & TD \\
\hline CHEMBL 3906762 & 1640353 & 7.3238 & 7.6348 & TRN & & \\
\hline CHEMBL 3945338 & 1640353 & 6.0 & 6.0994 & TRN & & \\
\hline CHEMBL 3986525 & 1640353 & 7.1439 & 7.3424 & TST & & \\
\hline CHEMBL 3914949 & 1640353 & 6.4946 & 7.6104 & TST & & \\
\hline CHEMBL 3957212 & 1640353 & 7.9957 & 8.4085 & TRN & & \\
\hline CHEMBL 3903332 & 1640353 & 6.7261 & 7.0884 & TST & & \\
\hline CHEMBL 3926625 & 1640353 & 6.767 & 7.3107 & TRN & & \\
\hline CHEMBL 3905188 & 1640353 & 6.0 & 7.2098 & TRN & & \\
\hline CHEMBL 3961013 & 1640353 & 7.8416 & 7.693 & TRN & & \\
\hline CHEMBL 3922624 & 1640353 & \multicolumn{3}{|c|}{7.3420000000000005} & 7.1876 & S15 \\
\hline CHEMBL 3902136 & 1640353 & 7.5768 & 6.9801 & TRN & & \\
\hline CHEMBL 3954631 & 1640353 & 8.1163 & 7.9335 & TRN & & \\
\hline CHEMBL 3977511 & 1640353 & 8.7696 & \multicolumn{3}{|c|}{8.767999999999999} & TRN \\
\hline CHEMBL 3939888 & 1640353 & 8.3979 & 8.2473 & TST & & \\
\hline CHEMBL 3975958 & 1640353 & \multicolumn{3}{|c|}{7.053999999999999} & 7.1374 & $\mathrm{TR}$ \\
\hline CHEMBL 3978619 & 1640353 & 7.5482 & 7.4792 & TRN & & \\
\hline CHEMBL 3965882 & 1640353 & 7.068 & 6.9637 & TRN & & \\
\hline CHEMBL 3928023 & 1640353 & \multicolumn{3}{|c|}{7.4510000000000005} & 7.6705 & וכנו \\
\hline CHEMBL 3945085 & 1640353 & 7.9393 & 7.7253 & TRN & & \\
\hline CHEMBL 3921554 & 1640353 & 8.2076 & 8.059 & TST & & \\
\hline CHEMBL 3922169 & 1640353 & 7.5622 & 7.4099 & TRN & & \\
\hline CHEMBL 3917425 & 1640353 & 7.8013 & \multicolumn{3}{|c|}{7.497999999999999} & $\mathrm{TR}$ \\
\hline CHEMBL 3915402 & 1640353 & 6.937 & 6.818 & TRN & & \\
\hline CHEMBL 3985415 & 1640353 & 6.0 & 6.1204 & TRN & & \\
\hline CHEMBL 3972037 & 1640353 & 7.5607 & 7.8179 & TRN & & \\
\hline CHEMBL 3951512 & 1640353 & 7.5346 & 7.4416 & TST & & \\
\hline CHEMBL 3978249 & 1640353 & 7.6536 & 7.653 & TRN & & \\
\hline CHEMBL 3933215 & 1640353 & \multicolumn{3}{|c|}{6.968999999999999} & 7.2896 & וS1 \\
\hline CHEMBL 3935975 & 1640353 & 7.2549 & 7.1772 & TST & & \\
\hline
\end{tabular}


Supplemental Table S2.txt

\begin{tabular}{|c|c|c|c|c|c|}
\hline CHEMBL3966401 & 1640353 & 7.8945 & 7.5445 & TRN & \\
\hline CHEMBL3894615 & 1640353 & 8.4559 & 8.5484 & TRN & \\
\hline CHEMBL3957096 & 1640353 & 7.0846 & 7.0998 & TRN & \\
\hline CHEMBL3938395 & 1640353 & 7.0841 & 7.1974 & TRN & \\
\hline CHEMBL 3980553 & 1640353 & 7.684 & 7.5118 & TRN & \\
\hline CHEMBL 3923976 & 1640353 & 8.1805 & 7.8932 & TST & \\
\hline CHEMBL3972751 & 1640353 & 8.301 & 7.9476 & TST & \\
\hline CHEMBL 3972027 & 1640353 & 7.7055 & 7.7469 & TRN & \\
\hline CHEMBL3904781 & 1640353 & 7.9914 & 7.8702 & TRN & \\
\hline CHEMBL 3891891 & 1640353 & 8.3768 & 7.9738 & TRN & \\
\hline CHEMBL1572574 & 1301606 & 8.0969 & 7.2776 & TST & \\
\hline CHEMBL 3186456 & 1301606 & 7.06 & 7.664 & TRN & \\
\hline CHEMBL 3184637 & 1301606 & 3.699 & 3.6854 & TRN & \\
\hline CHEMBL1360904 & 1301606 & 3.699 & \multicolumn{2}{|c|}{7.0760000000000005} & TST \\
\hline CHEMBL 3184165 & 1301606 & 6.2204 & 6.6312 & TRN & \\
\hline CHEMBL1365786 & 1301606 & 5.3645 & 5.0035 & TRN & \\
\hline CHEMBL3183243 & 1301606 & 6.1273 & 6.3769 & TRN & \\
\hline CHEMBL 3184923 & 1301606 & 4.8438 & 7.0043 & TST & \\
\hline CHEMBL3188784 & 1301606 & 5.1403 & 6.7638 & TST & \\
\hline CHEMBL1455653 & 1301606 & 8.0969 & 5.8895 & TRN & \\
\hline CHEMBL3181862 & 1301606 & 6.8239 & 6.5283 & TRN & \\
\hline CHEMBL3185233 & 1301606 & 3.699 & 4.8511 & TRN & \\
\hline CHEMBL 3186664 & 1301606 & 5.118 & 6.5721 & TST & \\
\hline CHEMBL3186054 & 1301606 & 3.699 & 4.1044 & TRN & \\
\hline CHEMBL 3188785 & 1301606 & 6.6091 & 7.3863 & TRN & \\
\hline CHEMBL 3182546 & 1301606 & 6.1244 & 6.4184 & TRN & \\
\hline CHEMBL 3185426 & 1301606 & 5.3635 & 4.8338 & TRN & \\
\hline CHEMBL1428856 & 1301606 & 6.5986 & 6.8108 & TRN & \\
\hline CHEMBL1445749 & 1301606 & 3.699 & 4.1481 & TRN & \\
\hline CHEMBL1871114 & 1301606 & 6.9393 & 6.4046 & TST & \\
\hline CHEMBL1894621 & 1301606 & 8.0969 & 6.709 & TST & \\
\hline CHEMBL3186915 & 1301606 & 6.5229 & 6.5866 & TRN & \\
\hline CHEMBL3181936 & 1301606 & 8.0969 & 7.6417 & TRN & \\
\hline CHEMBL3188495 & 1301606 & 6.8761 & 5.7386 & TRN & \\
\hline CHEMBL 3187582 & 1301606 & 5.1785 & 4.8129 & TRN & \\
\hline CHEMBL1527531 & 1301606 & 5.8356 & 6.0104 & TRN & \\
\hline CHEMBL3185889 & 1301606 & 5.8928 & 6.353 & TRN & \\
\hline CHEMBL 3188331 & 1301606 & 8.0969 & 7.7623 & TRN & \\
\hline CHEMBL1464894 & 1301606 & 6.9706 & 5.9522 & TST & \\
\hline CHEMBL1324387 & 1301606 & 6.7423 & 6.7251 & TST & \\
\hline CHEMBL3187644 & 1301606 & 4.8395 & 6.8053 & TST & \\
\hline CHEMBL1600842 & 1301606 & $6.1720 e$ & 000000000 & 6.2604 & TRN \\
\hline CHEMBL 3184062 & 1301606 & 4.9602 & 5.0007 & TRN & \\
\hline CHEMBL3183630 & 1301606 & 3.699 & 4.7094 & TRN & \\
\hline CHEMBL3185429 & 1301606 & 4.8867 & 5.0842 & TRN & \\
\hline CHEMBL 3187594 & 1301606 & 5.5482 & 5.987999 & 99999999995 & TRN \\
\hline CHEMBL3184589 & 1301606 & 6.7932 & 5.9634 & TRN & \\
\hline CHEMBL3185739 & 1301606 & 5.6904 & 6.904 & TRN & \\
\hline
\end{tabular}


Supplemental Table S2.txt

\begin{tabular}{|c|c|c|c|c|c|c|}
\hline CHEMBL1882055 & 1301606 & 6.7905 & 6.4913 & TRN & & \\
\hline CHEMBL1462984 & 1301606 & 3.699 & 4.5464 & TRN & & \\
\hline CHEMBL1701152 & 1301606 & 6.0477 & 5.9989 & TRN & & \\
\hline CHEMBL 3183329 & 1301606 & 7.02 & 6.982 & TRN & & \\
\hline CHEMBL 3182452 & 1301606 & 6.3726 & 6.3167 & TRN & & \\
\hline CHEMBL1558383 & 1301606 & 6.6478 & 6.4196 & TRN & & \\
\hline CHEMBL 3188230 & 1301606 & 6.0052 & 7.1844 & TST & & \\
\hline CHEMBL1376995 & 1301606 & 8.0969 & 5.8071 & TRN & & \\
\hline CHEMBL 3188534 & 1301606 & 6.1361 & 6.8614 & TRN & & \\
\hline CHEMBL1886714 & 1301606 & 5.2741 & 4.9477 & TRN & & \\
\hline CHEMBL1301524 & 1301606 & 8.0969 & 6.3666 & TST & & \\
\hline CHEMBL 3184594 & 1301606 & 6.0209 & 7.1646 & TST & & \\
\hline CHEMBL 2170628 & 862404 & 6.8601 & 6.8592 & TRN & & \\
\hline CHEMBL 2170644 & 862404 & 6.2684 & 6.2682 & TRN & & \\
\hline CHEMBL 2170632 & 862404 & 7.0315 & 7.0306 & TRN & & \\
\hline CHEMBL 2170649 & 862404 & 6.4342 & 6.4341 & TRN & & \\
\hline CHEMBL 2170636 & 862404 & 7.4949 & 7.4948 & TRN & & \\
\hline CHEMBL 2170646 & 862404 & 6.0048 & 6.0041 & TRN & & \\
\hline CHEMBL 2170605 & 862404 & 6.8962 & 6.8967 & TRN & & \\
\hline CHEMBL 2170642 & 862404 & 6.9626 & 6.9626 & TRN & & \\
\hline CHEMBL 2170631 & 862404 & 6.699 & 6.6985 & TRN & & \\
\hline CHEMBL 2170612 & 862404 & 6.3645 & 7.2353 & TST & & \\
\hline CHEMBL 2170623 & 862404 & 6.61799 & 999999999 & 9 & 6.619 & TRN \\
\hline CHEMBL 2170629 & 862404 & 6.8182 & 6.8177 & TRN & & \\
\hline CHEMBL 2169894 & 862404 & 7.0555 & 7.3949 & TST & & \\
\hline CHEMBL 2170647 & 862404 & 6.3054 & 6.3053 & TRN & & \\
\hline CHEMBL 2170630 & 862404 & 6.9547 & 6.9552 & TRN & & \\
\hline CHEMBL 2170609 & 862404 & 7.5086 & 7.5077 & TRN & & \\
\hline CHEMBL 2170626 & 862404 & 6.4522 & 6.4523 & TRN & & \\
\hline CHEMBL 2170622 & 862404 & 7.0555 & 7.0562 & TRN & & \\
\hline CHEMBL 2170625 & 862404 & 6.6556 & 6.655 & TRN & & \\
\hline CHEMBL 2170615 & 862404 & 7.6383 & 7.6381 & TRN & & \\
\hline CHEMBL 2170613 & 862404 & 6.5751 & 7.4675 & TST & & \\
\hline CHEMBL 2170633 & 862404 & 7.301 & 7.301 & TRN & & \\
\hline CHEMBL 2170640 & 862404 & 6.0223 & 6.8905 & TST & & \\
\hline CHEMBL 2170606 & 862404 & 7.1024 & 7.1027 & TRN & & \\
\hline CHEMBL 2170634 & 862404 & 6.5702 & 6.5706 & TRN & & \\
\hline CHEMBL 2170635 & 862404 & 7.1549 & 7.1554 & TRN & & \\
\hline CHEMBL 2170624 & 862404 & 6.3809 & 6.3804 & TRN & & \\
\hline CHEMBL 2170607 & 862404 & 7.301 & 7.3019 & TRN & & \\
\hline CHEMBL2170608 & 862404 & 7.3188 & 7.3188 & TRN & & \\
\hline CHEMBL2170604 & 862404 & 6.6968 & 6.6976 & TRN & & \\
\hline CHEMBL2170637 & 862404 & 7.1024 & 7.1024 & TRN & & \\
\hline CHEMBL 2170621 & 862404 & 7.1135 & 7.1128 & TRN & & \\
\hline CHEMBL 2170627 & 862404 & 6.7721 & 6.7719 & TRN & & \\
\hline CHEMBL 2170641 & 862404 & \multicolumn{3}{|c|}{6.617999999999999} & 6.6189 & TRN \\
\hline CHEMBL 2170614 & 862404 & 6.7235 & 7.3943 & TST & & \\
\hline CHEMBL 2170620 & 862404 & 6.6696 & 6.6696 & TRN & & \\
\hline
\end{tabular}


Supplemental Table S2.txt

\begin{tabular}{|c|c|c|c|c|c|}
\hline CHEMBL 2170616 & 862404 & 6.9393 & 7.2954 & TST & \\
\hline CHEMBL 2170645 & 862404 & 5.9469 & 5.9472 & TRN & \\
\hline CHEMBL2170611 & 862404 & 7.5528 & 7.3722 & TST & \\
\hline CHEMBL2170610 & 862404 & 7.5086 & 7.5087 & TRN & \\
\hline CHEMBL 2170650 & 862404 & 5.7997 & 6.468 & TST & \\
\hline CHEMBL 2170617 & 862404 & 6.9547 & 7.4857 & TST & \\
\hline CHEMBL 2170648 & 862404 & 4.0 & 4.0 & TRN & \\
\hline CHEMBL 2170638 & 862404 & 7.4437 & 7.4441 & TRN & \\
\hline CHEMBL 2170651 & 862404 & 5.4588 & 5.9942 & TST & \\
\hline CHEMBL2170619 & 862404 & 6.3028 & 6.3027 & TRN & \\
\hline CHEMBL2170639 & 862404 & 7.6021 & 7.6019 & TRN & \\
\hline CHEMBL 2170643 & 862404 & 6.7352 & 6.62 & TST & \\
\hline CHEMBL 2170618 & 862404 & 7.2076 & 7.1368 & TST & \\
\hline CHEMBL 2170603 & 862404 & 7.2518 & 7.3385 & TST & \\
\hline CHEMBL600412 & 610312 & 4.7258 & 5.3377 & TRN & \\
\hline CHEMBL101908 & 610312 & 4.3468 & 4.5752 & TST & \\
\hline CHEMBL17431 & 610312 & 5.585 & 5.5052 & TRN & \\
\hline CHEMBL597383 & 610312 & 5.9066 & 5.4137 & TRN & \\
\hline CHEMBL598605 & 610312 & 4.5575 & 4.447 & TRN & \\
\hline CHEMBL17453 & 610312 & 5.4685 & 5.4016 & TRN & \\
\hline CHEMBL 23960 & 610312 & 4.3429 & 4.2279 & TRN & \\
\hline CHEMBL 277438 & 610312 & 3.3279 & 3.8904 & TRN & \\
\hline CHEMBL602913 & 610312 & 6.0915 & 6.2121 & TRN & \\
\hline CHEMBL 278013 & 610312 & 6.0 & 5.489 & TST & \\
\hline CHEMBL 274278 & 610312 & 4.0491 & 4.1575 & TRN & \\
\hline CHEMBL597961 & 610312 & 5.7959 & 5.9955 & TRN & \\
\hline CHEMBL105759 & 610312 & 5.7447 & 5.3538 & TST & \\
\hline CHEMBL597583 & 610312 & 5.9872 & 5.98799 & 99999999995 & TRN \\
\hline CHEMBL600413 & 610312 & 4.4976 & 4.2639 & TRN & \\
\hline CHEMBL48648 & 610312 & 5.9586 & 5.7866 & TRN & \\
\hline CHEMBL103474 & 610312 & 6.0757 & 5.3062 & TST & \\
\hline CHEMBL 22820 & 610312 & 3.585 & 3.9241 & TRN & \\
\hline CHEMBL103203 & 610312 & 4.4828 & 4.7059 & TST & \\
\hline CHEMBL17323 & 610312 & 5.7696 & 5.1857 & TRN & \\
\hline CHEMBL105906 & 610312 & 4.5686 & 4.3894 & TST & \\
\hline CHEMBL17235 & 610312 & 4.4089 & 4.1788 & TRN & \\
\hline CHEMBL596969 & 610312 & 3.4067 & 4.934 & TST & \\
\hline CHEMBL17430 & 610312 & 4.9355 & 5.1562 & TRN & \\
\hline CHEMBL597382 & 610312 & 4.0605 & 4.6768 & TRN & \\
\hline CHEMBL106070 & 610312 & 5.7696 & 5.2535 & TST & \\
\hline CHEMBL591935 & 610312 & 4.7212 & 4.3131 & TRN & \\
\hline CHEMBL105323 & 610312 & 5.5229 & 4.7787 & TST & \\
\hline CHEMBL278110 & 610312 & 4.6676 & 4.3651 & TRN & \\
\hline CHEMBL608143 & 610312 & 4.0915 & 4.2726 & TRN & \\
\hline CHEMBL334198 & 610312 & 5.1586 & 5.0457 & TRN & \\
\hline CHEMBL608428 & 610312 & 5.3925 & 5.8343 & TRN & \\
\hline CHEMBL23846 & 610312 & 4.4318 & 4.6909 & TRN & \\
\hline CHEMBL123984 & 610312 & 5.3224 & 5.6458 & TRN & \\
\hline
\end{tabular}


Supplemental Table S2.txt

\begin{tabular}{|c|c|c|c|c|}
\hline CHEMBL598604 & 610312 & 4.8125 & 4.2884 & TRN \\
\hline CHEMBL604090 & 610312 & 4.6383 & 4.4411 & TRN \\
\hline CHEMBL420172 & 610312 & 5.0491 & 5.0035 & TRN \\
\hline CHEMBL331986 & 610312 & 6.7696 & 5.7158 & TRN \\
\hline CHEMBL 22561 & 610312 & 4.6271 & 4.5176 & TRN \\
\hline CHEMBL69681 & 610312 & 5.0915 & 5.2631 & TRN \\
\hline CHEMBL68439 & 610312 & 5.3665 & 5.268 & TRN \\
\hline CHEMBL102518 & 610312 & 4.8477 & 4.8899 & TST \\
\hline CHEMBL 22477 & 610312 & 3.3768 & 3.9868 & TRN \\
\hline CHEMBL66077 & 610312 & 4.5528 & 4.5034 & TST \\
\hline CHEMBL609914 & 610312 & 6.7959 & 6.2314 & TRN \\
\hline CHEMBL605782 & 610312 & 4.5086 & 4.6902 & TRN \\
\hline CHEMBL279914 & 610312 & 4.4202 & 4.2966 & TRN \\
\hline CHEMBL608865 & 610312 & 4.1146 & 4.3251 & TRN \\
\hline CHEMBL283515 & 610312 & 4.7212 & 4.7004 & TRN \\
\hline CHEMBL283311 & 610312 & 4.9355 & 4.2736 & TRN \\
\hline CHEMBL421594 & 610312 & 5.6198 & 5.4053 & TST \\
\hline CHEMBL105523 & 610312 & 5.8239 & 5.1503 & TST \\
\hline CHEMBL432136 & 610312 & 5.4089 & 4.7661 & TRN \\
\hline CHEMBL331456 & 610312 & 4.699 & 4.9763 & TRN \\
\hline CHEMBL601520 & 610312 & 5.3468 & 5.1194 & TRN \\
\hline CHEMBL597346 & 610312 & 4.1024 & 3.9077 & TRN \\
\hline CHEMBL607583 & 610312 & 5.5686 & 5.8521 & TRN \\
\hline CHEMBL589525 & 610312 & 6.0605 & 6.1824 & TRN \\
\hline CHEMBL590502 & 610312 & 4.7747 & 4.9121 & TST \\
\hline CHEMBL596970 & 610312 & 3.9788 & 4.3584 & TRN \\
\hline CHEMBL605980 & 610312 & 3.5867 & 3.963 & TRN \\
\hline CHEMBL68673 & 610312 & 5.2218 & 5.1225 & TRN \\
\hline CHEMBL312688 & 610312 & 5.1739 & 4.2652 & TST \\
\hline CHEMBL102303 & 610312 & 6.301 & 5.1786 & TST \\
\hline CHEMBL331314 & 610312 & 5.9914 & 6.0621 & TRN \\
\hline CHEMBL431257 & 610312 & 5.6576 & 5.0951 & TST \\
\hline CHEMBL604709 & 610312 & 4.6459 & 5.0995 & TRN \\
\hline CHEMBL597784 & 610312 & 4.2007 & 4.305 & TRN \\
\hline CHEMBL598190 & 610312 & 5.0362 & 5.3266 & TRN \\
\hline CHEMBL69363 & 610312 & 5.2757 & 5.0916 & TRN \\
\hline CHEMBL17873 & 610312 & 5.8539 & 5.1173 & TRN \\
\hline CHEMBL103108 & 610312 & 4.5157 & 4.905 & TST \\
\hline CHEMBL123892 & 610312 & 5.5702 & 5.2819 & TRN \\
\hline CHEMBL591930 & 610312 & 5.8861 & 6.4733 & TRN \\
\hline CHEMBL105020 & 610312 & 6.0 & 5.14 & TST \\
\hline CHEMBL597962 & 610312 & 5.9957 & 6.1525 & TRN \\
\hline CHEMBL23297 & 610312 & 4.4895 & 4.3098 & TRN \\
\hline CHEMBL610498 & 610312 & 4.5498 & 4.4244 & TST \\
\hline CHEMBL597347 & 610312 & 4.4202 & 4.6353 & TRN \\
\hline CHEMBL102432 & 610312 & 4.3098 & 4.6948 & TRN \\
\hline CHEMBL 302931 & 195220 & 6.1871 & 6.052006 & 00000000005 \\
\hline CHEMBL 70881 & 195220 & 5.0 & 4.8442 & TST \\
\hline
\end{tabular}




\begin{tabular}{|c|c|c|c|c|}
\hline & & & oplement & al $\mathrm{Tc}$ \\
\hline CHEMBL39505 & 195220 & 4.9586 & 5.0697 & TRN \\
\hline CHEMBL 70930 & 195220 & 6.3768 & 5.7625 & TRN \\
\hline CHEMBL289429 & 195220 & 5.7212 & 6.1205 & TRN \\
\hline CHEMBL 71310 & 195220 & 5.6778 & 5.7824 & TRN \\
\hline CHEMBL71927 & 195220 & 6.3979 & 6.1977 & TRN \\
\hline CHEMBL305041 & 195220 & 5.0 & 5.7455 & TRN \\
\hline CHEMBL 72545 & 195220 & 5.0 & 4.6305 & TRN \\
\hline CHEMBL439943 & 195220 & 7.3979 & 6.9001 & TRN \\
\hline CHEMBL 70532 & 195220 & 5.0 & 5.5259 & TRN \\
\hline CHEMBL 74240 & 195220 & 5.0 & 5.4188 & TRN \\
\hline CHEMBL 70483 & 195220 & 6.699 & 6.1089 & TRN \\
\hline CHEMBL 72916 & 195220 & 5.0 & 4.7663 & TRN \\
\hline CHEMBL306167 & 195220 & 5.0 & 4.3783 & TST \\
\hline CHEMBL70702 & 195220 & 5.0 & 5.1956 & TST \\
\hline CHEMBL291113 & 195220 & 5.9031 & 4.364 & TST \\
\hline CHEMBL39343 & 195220 & 5.5229 & 4.9495 & TST \\
\hline CHEMBL305965 & 195220 & 6.7696 & 6.6901 & TRN \\
\hline CHEMBL72392 & 195220 & 5.0 & 5.1582 & TRN \\
\hline CHEMBL304158 & 195220 & 5.0 & 5.4946 & TST \\
\hline CHEMBL 305010 & 195220 & 6.301 & 6.0897 & TRN \\
\hline CHEMBL290957 & 195220 & 6.3468 & 6.5265 & TRN \\
\hline CHEMBL289816 & 195220 & 6.3468 & 4.7646 & TST \\
\hline CHEMBL70753 & 195220 & 5.0 & 5.1279 & TRN \\
\hline CHEMBL73568 & 195220 & 5.0458 & 4.59 & TRN \\
\hline CHEMBL73753 & 195220 & 5.0 & 5.3449 & TRN \\
\hline CHEMBL307792 & 195220 & 5.0 & 5.0506 & TST \\
\hline CHEMBL305416 & 195220 & 6.0506 & 5.294 & TRN \\
\hline CHEMBL70850 & 195220 & 6.6198 & 6.8138 & TRN \\
\hline CHEMBL 70719 & 195220 & 7.2076 & 7.028 & TRN \\
\hline CHEMBL 37842 & 195220 & 7.0223 & 7.1712 & TRN \\
\hline CHEMBL71631 & 195220 & 5.0 & 5.1845 & TRN \\
\hline CHEMBL302957 & 195220 & 5.0969 & 5.9094 & TRN \\
\hline CHEMBL304965 & 195220 & 5.0 & 4.5434 & TRN \\
\hline CHEMBL72135 & 195220 & 5.0 & 4.8082 & TST \\
\hline CHEMBL 70324 & 195220 & 5.3468 & 5.4159 & TRN \\
\hline CHEMBL290410 & 195220 & 6.0706 & 5.5978 & TRN \\
\hline CHEMBL305243 & 195220 & 5.0 & 5.3197 & TRN \\
\hline CHEMBL310490 & 195220 & 6.0706 & 5.8472 & TRN \\
\hline CHEMBL308549 & 195220 & 5.1805 & 5.4489 & TRN \\
\hline CHEMBL 70562 & 195220 & 6.1612 & 5.9175 & TRN \\
\hline CHEMBL304563 & 195220 & 5.0 & 5.843 & TST \\
\hline CHEMBL70743 & 195220 & 6.0706 & 5.8097 & TRN \\
\hline CHEMBL306895 & 195220 & 5.0 & 5.0462 & TRN \\
\hline CHEMBL311349 & 195220 & 6.3872 & 6.6226 & TRN \\
\hline CHEMBL312340 & 195220 & 6.2366 & 6.4675 & TRN \\
\hline CHEMBL71306 & 195220 & 5.0 & 5.6329 & TRN \\
\hline CHEMBL291267 & 195220 & 5.0 & 4.8385 & TRN \\
\hline CHEMBL 70572 & 195220 & 5.0 & 6.2518 & TST \\
\hline
\end{tabular}




\begin{tabular}{|c|c|c|c|c|c|}
\hline & & & oplement & al Table S2 & \\
\hline CHEMBL306225 & 195220 & 5.0 & 5.7493 & TRN & \\
\hline CHEMBL308229 & 195220 & 5.0 & 5.6691 & TRN & \\
\hline CHEMBL418885 & 195220 & 5.9586 & 5.79200 & 0000000001 & TRN \\
\hline CHEMBL307451 & 195220 & 5.0 & 5.5185 & TRN & \\
\hline CHEMBL311814 & 195220 & 5.0 & 5.6569 & TST & \\
\hline CHEMBL72150 & 195220 & 5.0 & 5.2025 & TRN & \\
\hline CHEMBL305754 & 195220 & 5.0 & 4.8425 & TRN & \\
\hline CHEMBL37628 & 195220 & 7.4559 & 7.2738 & TRN & \\
\hline CHEMBL419629 & 195220 & 6.0 & 5.5781 & TRN & \\
\hline CHEMBL305521 & 195220 & 6.6198 & 6.3979 & TRN & \\
\hline CHEMBL306794 & 195220 & 5.0 & 5.38299 & 9999999999 & TRN \\
\hline CHEMBL308491 & 195220 & 5.0 & 5.1318 & TRN & \\
\hline CHEMBL412157 & 195220 & 5.0 & 4.6365 & TRN & \\
\hline CHEMBL69894 & 195220 & 6.7696 & 7.0895 & TRN & \\
\hline CHEMBL70255 & 195220 & 6.5376 & 6.1979 & TRN & \\
\hline CHEMBL71063 & 195220 & 5.0 & 4.5846 & TST & \\
\hline CHEMBL303466 & 195220 & 6.1871 & 5.4215 & TRN & \\
\hline CHEMBL310699 & 195220 & 5.0 & 5.0797 & TST & \\
\hline CHEMBL 71023 & 195220 & 6.2291 & 6.2067 & TST & \\
\hline CHEMBL 72225 & 195220 & 5.0 & 5.055 & TST & \\
\hline CHEMBL 70720 & 195220 & 5.0 & 5.0884 & TRN & \\
\hline CHEMBL70629 & 195220 & 7.4437 & 7.09200 & 00000000005 & TRN \\
\hline CHEMBL291024 & 195220 & 6.3565 & 6.1621 & TRN & \\
\hline CHEMBL73672 & 195220 & 6.9586 & 6.819 & TRN & \\
\hline CHEMBL 72272 & 195220 & 5.1192 & 4.7667 & TRN & \\
\hline CHEMBL312072 & 195220 & 5.0 & 5.4551 & TRN & \\
\hline CHEMBL302498 & 195220 & 5.0 & 5.482 & TST & \\
\hline CHEMBL 289072 & 195220 & 5.0 & 5.5897 & TRN & \\
\hline CHEMBL306247 & 195220 & 5.0 & 5.3478 & TRN & \\
\hline CHEMBL37343 & 195220 & 6.9031 & 6.2144 & TRN & \\
\hline CHEMBL418886 & 195220 & 5.0 & 4.4762 & TST & \\
\hline CHEMBL 308248 & 195220 & 6.6383 & 6.2372 & TRN & \\
\hline CHEMBL37722 & 195220 & 5.5376 & 5.7782 & TRN & \\
\hline CHEMBL73015 & 195220 & 6.0 & 6.2923 & TRN & \\
\hline CHEMBL308686 & 195220 & 6.6383 & 6.2977 & TRN & \\
\hline CHEMBL 72535 & 195220 & 5.8539 & 5.1209 & TST & \\
\hline CHEMBL290781 & 195220 & 4.8153 & 5.1121 & TRN & \\
\hline CHEMBL70047 & 195220 & 5.0 & 4.9607 & TRN & \\
\hline CHEMBL 73845 & 195220 & 6.4202 & 6.2407 & TRN & \\
\hline CHEMBL304615 & 195220 & 5.0 & 4.8636 & TRN & \\
\hline CHEMBL 70754 & 195220 & 5.0 & 5.1548 & TRN & \\
\hline CHEMBL312019 & 195220 & 5.0 & 5.0452 & TRN & \\
\hline CHEMBL424046 & 195220 & 6.3665 & 4.681 & TST & \\
\hline CHEMBL302034 & 195220 & 5.0 & 4.0971 & TST & \\
\hline CHEMBL69666 & 195220 & 5.0 & 4.8952 & TRN & \\
\hline CHEMBL 71311 & 195220 & 6.7212 & 6.7685 & TRN & \\
\hline CHEMBL 70854 & 195220 & 5.0 & 4.7271 & TRN & \\
\hline CHEMBL 74690 & 195220 & 6.8539 & 7.0562 & TRN & \\
\hline
\end{tabular}




\begin{tabular}{|c|c|c|c|c|}
\hline \multicolumn{5}{|c|}{ Supplemental Table S2.txt } \\
\hline CHEMBL73468 & 195220 & 5.0 & 4.9797 & TRN \\
\hline CHEMBL309574 & 195220 & 6.4437 & 6.0526 & TRN \\
\hline CHEMBL 305503 & 195220 & 4.5686 & 4.5658 & TRN \\
\hline CHEMBL 70401 & 195220 & 5.0 & 4.9786 & TRN \\
\hline CHEMBL72874 & 195220 & 5.0 & 5.7832 & TRN \\
\hline CHEMBL 288305 & 195220 & 6.7696 & 6.3824 & TRN \\
\hline CHEMBL72920 & 195220 & 4.7959 & 5.023 & TRN \\
\hline CHEMBL 307162 & 195220 & 5.0 & 4.2309 & TST \\
\hline CHEMBL70511 & 195220 & 5.0 & 5.4315 & TRN \\
\hline CHEMBL71766 & 195220 & 5.4559 & 4.9778 & TRN \\
\hline CHEMBL73477 & 195220 & 5.0 & 4.5866 & TST \\
\hline CHEMBL 307220 & 195220 & 7.4202 & 7.3709 & TRN \\
\hline CHEMBL39950 & 195220 & 6.1192 & 5.9972 & TRN \\
\hline CHEMBL 306079 & 195220 & 5.5376 & 5.2622 & TST \\
\hline CHEMBL311908 & 195220 & 5.0 & 4.9327 & TST \\
\hline CHEMBL 70312 & 195220 & 6.4202 & 5.7787 & TST \\
\hline CHEMBL70258 & 195220 & 5.0 & 4.6587 & TST \\
\hline CHEMBL 306032 & 195220 & 6.4559 & 6.1079 & TST \\
\hline CHEMBL 70538 & 195220 & 5.0 & 5.0252 & TST \\
\hline CHEMBL 303837 & 195220 & 5.0 & 5.6422 & TST \\
\hline CHEMBL347088 & 55100 & 9.0605 & 8.9407 & TRN \\
\hline CHEMBL149101 & 55100 & 8.9208 & 9.1721 & TRN \\
\hline CHEMBL22677 & 55100 & 8.4437 & 8.2852 & TRN \\
\hline CHEMBL151947 & 55100 & 9.0315 & 8.8896 & TRN \\
\hline CHEMBL 22924 & 55100 & 7.0655 & 8.3332 & TST \\
\hline CHEMBL150317 & 55100 & 9.3665 & 9.3314 & TRN \\
\hline CHEMBL147124 & 55100 & 9.0862 & 9.1643 & TRN \\
\hline CHEMBL 277217 & 55100 & 8.5686 & 8.4013 & TRN \\
\hline CHEMBL 282948 & 55100 & 9.0315 & 8.8468 & TRN \\
\hline CHEMBL 279705 & 55100 & 9.0655 & 8.8371 & TRN \\
\hline CHEMBL 24007 & 55100 & 8.4089 & 8.5302 & TRN \\
\hline CHEMBL348209 & 55100 & 8.9586 & 8.8393 & TRN \\
\hline CHEMBL23076 & 55100 & 8.9208 & 9.0172 & TRN \\
\hline CHEMBL23492 & 55100 & 7.1367 & 7.7852 & TST \\
\hline CHEMBL23867 & 55100 & 9.0915 & 9.0906 & TRN \\
\hline CHEMBL 279679 & 55100 & 9.0757 & 8.9148 & TRN \\
\hline CHEMBL23569 & 55100 & 7.699 & 8.7152 & TRN \\
\hline CHEMBL151673 & 55100 & 6.2596 & 5.9186 & TRN \\
\hline CHEMBL356620 & 55100 & 9.041 & 8.8611 & TRN \\
\hline CHEMBL150247 & 55100 & 7.6383 & 8.1271 & TRN \\
\hline CHEMBL 23021 & 55100 & 8.9586 & 8.9763 & TRN \\
\hline CHEMBL147257 & 55100 & 9.0506 & 9.0911 & TRN \\
\hline CHEMBL23383 & 55100 & 9.0362 & 9.0126 & TRN \\
\hline CHEMBL151312 & 55100 & 9.0 & 8.773 & TRN \\
\hline CHEMBL346666 & 55100 & 9.0605 & 9.0164 & TRN \\
\hline CHEMBL151451 & 55100 & 9.0 & 9.2 & TRN \\
\hline CHEMBL149273 & 55100 & 9.0223 & 8.8884 & TRN \\
\hline CHEMBL147006 & 55100 & 8.2757 & 8.2774 & TRN \\
\hline
\end{tabular}




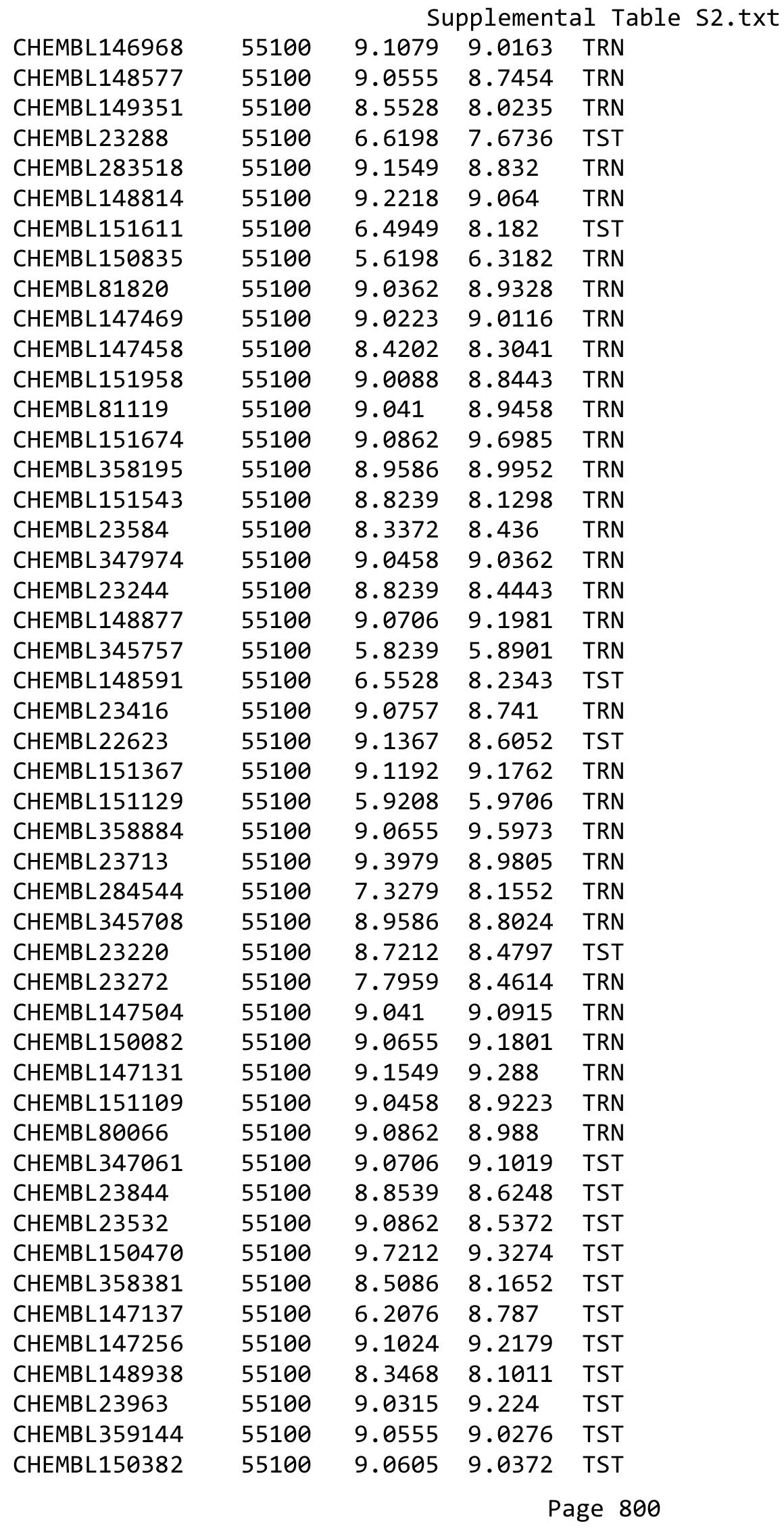




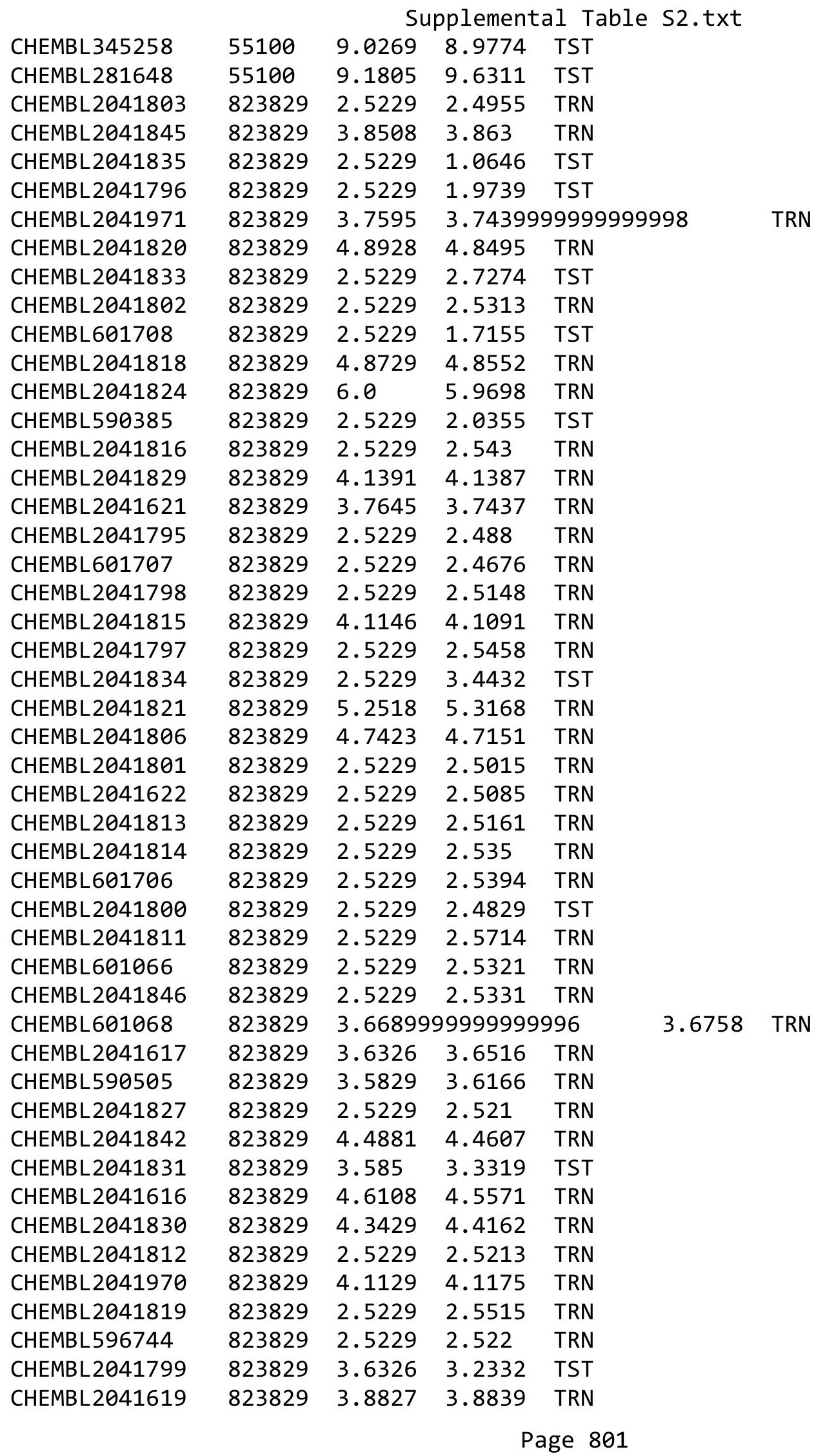


Supplemental Table S2.txt

\begin{tabular}{|c|c|c|c|c|c|}
\hline CHEMBL 2041828 & 823829 & 2.5229 & 4.5136 & TST & \\
\hline CHEMBL590504 & 823829 & 2.5229 & 2.5332 & TRN & \\
\hline CHEMBL598176 & 823829 & 2.5229 & 2.5207 & TRN & \\
\hline CHEMBL590266 & 823829 & 4.5686 & 4.6935 & TRN & \\
\hline CHEMBL 2041807 & 823829 & 4.7799 & 4.6935 & TRN & \\
\hline CHEMBL 2041624 & 823829 & 3.6192 & 3.6173 & TRN & \\
\hline CHEMBL 2041618 & 823829 & 3.6904 & 3.6838 & TRN & \\
\hline CHEMBL 2041837 & 823829 & 4.0362 & 3.0823 & TST & \\
\hline CHEMBL 2041838 & 823829 & 3.7878 & 3.1773 & TST & \\
\hline CHEMBL 2041826 & 823829 & 4.067 & 4.0664 & TRN & \\
\hline CHEMBL 2041843 & 823829 & 4.7545 & 4.7919 & TRN & \\
\hline CHEMBL 2041805 & 823829 & 4.6556 & 4.6598 & TRN & \\
\hline CHEMBL 2041832 & 823829 & 2.5229 & 2.5529 & TRN & \\
\hline CHEMBL 2041844 & 823829 & 4.317 & 4.2895 & TRN & \\
\hline CHEMBL 2041810 & 823829 & 2.5229 & 2.5021 & TRN & \\
\hline CHEMBL601067 & 823829 & 2.5229 & 2.5245 & TRN & \\
\hline CHEMBL 2041836 & 823829 & 2.5229 & 1.8802 & TST & \\
\hline CHEMBL601065 & 823829 & 2.5229 & 2.4948 & TRN & \\
\hline CHEMBL539632 & 823829 & 4.1752 & 4.1625 & TRN & \\
\hline CHEMBL2041839 & 823829 & 3.9431 & 3.5659 & TST & \\
\hline CHEMBL 2041817 & 823829 & 4.1993 & 4.2813 & TST & \\
\hline CHEMBL2041623 & 823829 & 4.2007 & 4.2226 & TST & \\
\hline CHEMBL 2041804 & 823829 & 2.5229 & 1.2993 & TST & \\
\hline CHEMBL 2041620 & 823829 & 3.9706 & 4.0613 & TST & \\
\hline CHEMBL1549844 & 688691 & 4.8 & 4.7192 & TST & \\
\hline CHEMBL1526319 & 688691 & 4.5 & 4.4647 & TRN & \\
\hline CHEMBL192627 & 688691 & 4.6 & 4.809 & TST & \\
\hline CHEMBL1602699 & 688691 & 5.3 & 5.2093 & TRN & \\
\hline CHEMBL1612246 & 688691 & 4.3 & 4.2746 & TRN & \\
\hline CHEMBL1200471 & 688691 & 6.4 & \multicolumn{2}{|c|}{6.587999999999999} & TRN \\
\hline CHEMBL935 & 688691 & 4.3 & 4.3234 & TRN & \\
\hline CHEMBL462576 & 688691 & 6.0 & 4.4834 & TST & \\
\hline CHEMBL70582 & 688691 & 5.0 & 4.74 & TRN & \\
\hline CHEMBL84685 & 688691 & 4.5 & 4.5697 & TRN & \\
\hline CHEMBL1569226 & 688691 & 5.1 & 5.1551 & TRN & \\
\hline CHEMBL 140 & 688691 & 4.4 & 4.3888 & TRN & \\
\hline CHEMBL402063 & 688691 & 4.4 & 5.098 & TST & \\
\hline CHEMBL1304981 & 688691 & 4.3 & 4.2262 & TRN & \\
\hline CHEMBL251389 & 688691 & 4.3 & 4.4432 & TRN & \\
\hline CHEMBL1471289 & 688691 & 4.4 & 4.4423 & TRN & \\
\hline CHEMBL 230156 & 688691 & 4.4 & 4.4528 & TRN & \\
\hline CHEMBL195953 & 688691 & 4.1 & 4.3376 & TST & \\
\hline CHEMBL144530 & 688691 & 4.5 & 4.6074 & TRN & \\
\hline CHEMBL1485360 & 688691 & 4.9 & 4.8571 & TST & \\
\hline CHEMBL1566504 & 688691 & 4.3 & 4.4875 & TST & \\
\hline CHEMBL1530684 & 688691 & 4.3 & 4.2445 & TRN & \\
\hline CHEMBL334255 & 688691 & 4.8 & 4.8842 & TRN & \\
\hline CHEMBL1492104 & 688691 & 4.9 & 5.0313 & TRN & \\
\hline
\end{tabular}




\begin{tabular}{|c|c|c|c|c|c|}
\hline \\
\hline CHEMBL1558796 & 688691 & 4.4 & 4.4802 & TRN & \\
\hline CHEMBL162598 & 688691 & 4.3 & 4.3756 & TST & \\
\hline CHEMBL1399151 & 688691 & 4.7 & 4.69300 & 00000000005 & TRN \\
\hline CHEMBL1447588 & 688691 & 5.1 & 5.0135 & TST & \\
\hline CHEMBL1450607 & 688691 & 4.6 & 4.77 & TST & \\
\hline CHEMBL1331245 & 688691 & 4.3 & 4.2882 & TRN & \\
\hline CHEMBL194399 & 688691 & 4.3 & 4.4022 & TST & \\
\hline CHEMBL1580759 & 688691 & 4.7 & 4.6438 & TRN & \\
\hline CHEMBL1338613 & 688691 & 4.4 & 4.4011 & TRN & \\
\hline CHEMBL1499545 & 688691 & 5.1 & 5.1819 & TRN & \\
\hline CHEMBL509531 & 688691 & 4.6 & 4.5077 & TST & \\
\hline CHEMBL1562104 & 688691 & 5.2 & 5.1604 & TRN & \\
\hline CHEMBL1142 & 688691 & 4.4 & 4.284 & TRN & \\
\hline CHEMBL443949 & 688691 & 4.3 & 4.1343 & TRN & \\
\hline CHEMBL1576086 & 688691 & 4.1 & 4.2567 & TRN & \\
\hline CHEMBL194400 & 688691 & 4.1 & 4.4698 & TST & \\
\hline CHEMBL1403428 & 688691 & 4.8 & 4.7946 & TRN & \\
\hline CHEMBL1485974 & 688691 & 4.7 & 4.7477 & TRN & \\
\hline CHEMBL1569493 & 688691 & 5.6 & 5.6272 & TRN & \\
\hline CHEMBL1526721 & 688691 & 5.2 & 5.25899 & 99999999995 & TST \\
\hline CHEMBL1535689 & 688691 & 4.4 & 4.4119 & TRN & \\
\hline CHEMBL1364985 & 688691 & 4.3 & 4.4161 & TRN & \\
\hline CHEMBL 289277 & 688691 & 4.6 & 4.4613 & TRN & \\
\hline CHEMBL1414154 & 688691 & 4.3 & 4.2245 & TRN & \\
\hline CHEMBL1492884 & 688691 & 4.4 & 4.4289 & TRN & \\
\hline CHEMBL1309179 & 688691 & 5.0 & 5.0574 & TRN & \\
\hline CHEMBL220845 & 688691 & 4.3 & 4.2331 & TRN & \\
\hline CHEMBL1308088 & 688691 & 5.1 & 5.0336 & TRN & \\
\hline CHEMBL1559341 & 688691 & 4.4 & 4.4444 & TRN & \\
\hline CHEMBL1609459 & 688691 & 5.1 & 5.0262 & TRN & \\
\hline CHEMBL1407826 & 688691 & 4.5 & 4.7096 & TST & \\
\hline CHEMBL1519327 & 688691 & 6.3 & 6.3084 & TRN & \\
\hline CHEMBL1489064 & 688691 & 4.3 & 4.2741 & TRN & \\
\hline CHEMBL280998 & 688691 & 4.4 & 4.5085 & TRN & \\
\hline CHEMBL1319452 & 688691 & 4.9 & 4.8002 & TRN & \\
\hline CHEMBL1449018 & 688691 & 4.6 & 4.5659 & TRN & \\
\hline CHEMBL1524617 & 688691 & 5.0 & 5.2234 & TST & \\
\hline CHEMBL 1484480 & 688691 & 4.3 & 4.1837 & TRN & \\
\hline CHEMBL 36296 & 688691 & 4.1 & 4.0714 & TRN & \\
\hline CHEMBL1409985 & 688691 & 5.4 & 5.2381 & TRN & \\
\hline CHEMBL1600998 & 688691 & 5.3 & 5.3352 & TRN & \\
\hline CHEMBL1496957 & 688691 & 4.6 & 4.6471 & TRN & \\
\hline CHEMBL1545634 & 688691 & 6.4 & 6.1416 & TRN & \\
\hline CHEMBL44072 & 688691 & 4.5 & 4.4109 & TST & \\
\hline CHEMBL1527567 & 688691 & 4.1 & 4.1437 & TRN & \\
\hline CHEMBL418068 & 688691 & 4.1 & 4.2947 & TRN & \\
\hline CHEMBL1408847 & 688691 & 5.1 & 5.1403 & TRN & \\
\hline CHEMBL1452158 & 688691 & 4.3 & 4.2336 & TRN & \\
\hline
\end{tabular}




\begin{tabular}{|c|c|c|c|c|}
\hline & & & oplement & al \\
\hline CHEMBL1522486 & 688691 & 4.9 & 4.8597 & TRN \\
\hline CHEMBL1451833 & 688691 & 4.4 & 4.6576 & TST \\
\hline CHEMBL440287 & 688691 & 4.4 & 4.4086 & TRN \\
\hline CHEMBL1303139 & 688691 & 5.0 & 4.9366 & TRN \\
\hline CHEMBL105712 & 688691 & 4.9 & 4.948 & TRN \\
\hline CHEMBL1579130 & 688691 & 6.0 & 5.4791 & TST \\
\hline CHEMBL1430204 & 688691 & 4.1 & 4.2842 & TRN \\
\hline CHEMBL1611235 & 688691 & 4.4 & 4.4826 & TST \\
\hline CHEMBL1448387 & 688691 & 4.4 & 4.492 & TST \\
\hline CHEMBL1984162 & 809145 & 5.9 & 5.5974 & TRN \\
\hline CHEMBL491758 & 809145 & 6.1 & 4.9522 & TRN \\
\hline CHEMBL549730 & 809145 & 6.0 & 5.9531 & TRN \\
\hline CHEMBL1682360 & 809145 & 4.1 & 4.3276 & TRN \\
\hline CHEMBL1970189 & 809145 & 4.1 & 3.9883 & TRN \\
\hline CHEMBL1996791 & 809145 & 4.1 & 3.7553 & TRN \\
\hline CHEMBL371206 & 809145 & 6.2 & 6.3168 & TRN \\
\hline CHEMBL1974664 & 809145 & 4.1 & 3.6511 & TST \\
\hline CHEMBL1970104 & 809145 & 4.1 & 4.3909 & TRN \\
\hline CHEMBL1974288 & 809145 & 4.1 & 4.2434 & TRN \\
\hline CHEMBL196363 & 809145 & 6.5 & 6.3398 & TRN \\
\hline CHEMBL1996837 & 809145 & 3.1 & 2.9514 & TRN \\
\hline CHEMBL1190711 & 809145 & 4.1 & 4.2901 & TRN \\
\hline CHEMBL1990346 & 809145 & 4.1 & 4.0327 & TRN \\
\hline CHEMBL404367 & 809145 & 4.2 & 4.6185 & TRN \\
\hline CHEMBL1966343 & 809145 & 5.3 & 4.7565 & TRN \\
\hline CHEMBL1967887 & 809145 & 4.1 & 3.8699 & TRN \\
\hline CHEMBL 2000568 & 809145 & 4.1 & 3.8301 & TRN \\
\hline CHEMBL 2000335 & 809145 & 7.4 & 6.8046 & TRN \\
\hline CHEMBL1977604 & 809145 & 4.1 & 5.189 & TST \\
\hline CHEMBL1980161 & 809145 & 5.0 & 4.1055 & TRN \\
\hline CHEMBL1988717 & 809145 & 4.1 & 4.4883 & TRN \\
\hline CHEMBL1974328 & 809145 & 4.1 & 5.3879 & TST \\
\hline CHEMBL509032 & 809145 & 5.5 & 5.5741 & TRN \\
\hline CHEMBL573339 & 809145 & 4.1 & 4.6181 & TRN \\
\hline CHEMBL143703 & 809145 & 3.1 & 3.1713 & TRN \\
\hline CHEMBL1973808 & 809145 & 4.1 & 3.7482 & TRN \\
\hline CHEMBL 2000429 & 809145 & 4.1 & 4.5337 & TRN \\
\hline CHEMBL1972576 & 809145 & 4.1 & 4.8137 & TRN \\
\hline CHEMBL1992555 & 809145 & 4.1 & 4.6964 & TST \\
\hline CHEMBL1990254 & 809145 & 4.1 & 4.4285 & TRN \\
\hline CHEMBL1992342 & 809145 & 4.1 & 3.9257 & TRN \\
\hline CHEMBL1988173 & 809145 & 7.0 & 6.8583 & TRN \\
\hline CHEMBL535331 & 809145 & 4.1 & 3.9182 & TRN \\
\hline CHEMBL1989805 & 809145 & 6.2 & 6.1171 & TST \\
\hline CHEMBL1965423 & 809145 & 4.1 & 4.376 & TRN \\
\hline CHEMBL1982980 & 809145 & 5.3 & 4.8553 & TST \\
\hline CHEMBL1983025 & 809145 & 4.1 & 4.6883 & TRN \\
\hline CHEMBL 205415 & 809145 & 4.1 & 4.187 & TRN \\
\hline
\end{tabular}




\begin{tabular}{|c|c|c|c|c|c|}
\hline \\
\hline CHEMBL1977135 & 809145 & 4.1 & 4.0789 & TRN & \\
\hline CHEMBL 2001920 & 809145 & 5.5 & 5.3454 & TRN & \\
\hline CHEMBL 2002322 & 809145 & 4.1 & 4.5959 & TRN & \\
\hline CHEMBL 2002323 & 809145 & 4.1 & 3.7869 & TST & \\
\hline CHEMBL1241473 & 809145 & 7.9 & 7.5168 & TRN & \\
\hline CHEMBL1978448 & 809145 & 7.8 & 3.8665 & TST & \\
\hline CHEMBL 2004513 & 809145 & 4.1 & 3.9333 & TRN & \\
\hline CHEMBL1972258 & 809145 & 4.1 & 4.0109 & TRN & \\
\hline CHEMBL 2001257 & 809145 & 4.1 & 4.2425 & TRN & \\
\hline CHEMBL 2005548 & 809145 & 4.1 & 4.0226 & TRN & \\
\hline CHEMBL1992536 & 809145 & 4.1 & 4.2726 & TRN & \\
\hline CHEMBL1992740 & 809145 & 5.3 & 4.8744 & TRN & \\
\hline CHEMBL 2002373 & 809145 & 4.1 & 4.1981 & TRN & \\
\hline CHEMBL439340 & 809145 & 4.1 & 3.8592 & TRN & \\
\hline CHEMBL 2006188 & 809145 & 4.1 & 3.7061 & TRN & \\
\hline CHEMBL1967531 & 809145 & 5.6 & 5.9073 & TRN & \\
\hline CHEMBL1970913 & 809145 & 4.1 & 4.0602 & TRN & \\
\hline CHEMBL1973893 & 809145 & 4.1 & 4.3705 & TRN & \\
\hline CHEMBL1995736 & 809145 & 4.1 & 3.8949 & TRN & \\
\hline CHEMBL1997534 & 809145 & 4.1 & 3.92199 & 99999999997 & TRN \\
\hline CHEMBL1996500 & 809145 & 4.1 & 3.9786 & TRN & \\
\hline CHEMBL1985095 & 809145 & 4.1 & 4.9391 & TST & \\
\hline CHEMBL1998551 & 809145 & 4.1 & 4.2167 & TRN & \\
\hline CHEMBL1991180 & 809145 & 5.8 & 4.599 & TST & \\
\hline CHEMBL1682540 & 809145 & 4.1 & 3.983 & TRN & \\
\hline CHEMBL1978656 & 809145 & 4.1 & 4.2323 & TRN & \\
\hline CHEMBL1976420 & 809145 & 4.1 & 4.0276 & TST & \\
\hline CHEMBL1994864 & 809145 & 4.1 & 4.3962 & TRN & \\
\hline CHEMBL413779 & 809145 & 6.1 & 5.5637 & TST & \\
\hline CHEMBL 2002446 & 809145 & 4.1 & 4.4722 & TST & \\
\hline CHEMBL497151 & 809145 & 5.6 & 5.8015 & TRN & \\
\hline CHEMBL340921 & 809145 & 4.1 & 4.0337 & TST & \\
\hline CHEMBL373598 & 809145 & 6.1 & 5.5733 & TST & \\
\hline CHEMBL1999718 & 809145 & 4.1 & 3.7356 & TRN & \\
\hline CHEMBL1977346 & 809145 & 4.1 & 4.579 & TRN & \\
\hline CHEMBL1971649 & 809145 & 4.1 & 3.7262 & TRN & \\
\hline CHEMBL 2003657 & 809145 & 4.1 & 4.1315 & TRN & \\
\hline CHEMBL1998435 & 809145 & 4.1 & 3.9061 & TRN & \\
\hline CHEMBL 2006439 & 809145 & 4.1 & 3.9192 & TRN & \\
\hline CHEMBL 2006156 & 809145 & 5.7 & 5.3317 & TST & \\
\hline CHEMBL1969190 & 809145 & 5.4 & 5.2361 & TRN & \\
\hline CHEMBL1973937 & 809145 & 4.3 & 4.8828 & TRN & \\
\hline CHEMBL1991674 & 809145 & 5.4 & 5.2566 & TRN & \\
\hline CHEMBL1982711 & 809145 & 4.1 & 4.3785 & TRN & \\
\hline CHEMBL1987982 & 809145 & 4.1 & 3.31600 & 00000000003 & TST \\
\hline CHEMBL1984842 & 809145 & 4.1 & 4.226 & TRN & \\
\hline CHEMBL1969102 & 809145 & 6.2 & 5.8036 & TRN & \\
\hline CHEMBL1682346 & 809145 & 4.1 & 4.4027 & TRN & \\
\hline
\end{tabular}




\begin{tabular}{|c|c|c|c|c|}
\hline & & & ipplemen & al Ta \\
\hline CHEMBL 2007044 & 809145 & 4.1 & 3.7296 & TST \\
\hline CHEMBL 2001998 & 809145 & 4.1 & 3.8878 & TST \\
\hline CHEMBL1994241 & 809145 & 4.1 & 4.1705 & TRN \\
\hline CHEMBL223460 & 809145 & 4.1 & 5.0808 & TST \\
\hline CHEMBL1998829 & 809145 & 4.1 & 4.319 & TRN \\
\hline CHEMBL50894 & 809145 & 4.1 & 4.3919 & TRN \\
\hline CHEMBL1981725 & 809145 & 4.1 & 4.7376 & TRN \\
\hline CHEMBL 375284 & 809145 & 5.7 & 4.9848 & TRN \\
\hline CHEMBL1982866 & 809145 & 4.1 & 4.1024 & TRN \\
\hline CHEMBL 2005792 & 809145 & 4.1 & 4.3791 & TRN \\
\hline CHEMBL1968926 & 809145 & 4.1 & 4.4999 & TRN \\
\hline CHEMBL462120 & 809145 & 5.3 & 4.2147 & TST \\
\hline CHEMBL1984206 & 809145 & 5.5 & 4.934 & TRN \\
\hline CHEMBL1991577 & 809145 & 6.0 & 5.2881 & TRN \\
\hline CHEMBL1991867 & 809145 & 3.1 & 3.7632 & TST \\
\hline CHEMBL1965570 & 809145 & 5.8 & 5.7562 & TRN \\
\hline CHEMBL 2007592 & 809145 & 4.1 & 4.7916 & TST \\
\hline CHEMBL210963 & 809145 & 4.1 & 3.735 & TRN \\
\hline CHEMBL1082440 & 809145 & 4.1 & 3.8287 & TST \\
\hline CHEMBL1614705 & 809145 & 4.1 & 3.9126 & TRN \\
\hline CHEMBL1972362 & 809145 & 4.1 & 4.3859 & TRN \\
\hline CHEMBL1984633 & 809145 & 4.1 & 3.957 & TRN \\
\hline CHEMBL 2007372 & 809145 & 4.1 & 4.0192 & TRN \\
\hline CHEMBL1965845 & 809145 & 4.1 & 4.0896 & TRN \\
\hline CHEMBL1982167 & 809145 & 5.1 & 4.5997 & TRN \\
\hline CHEMBL 2006715 & 809145 & 7.2 & 6.0287 & TRN \\
\hline CHEMBL1971017 & 809145 & 6.4 & 6.2016 & TRN \\
\hline CHEMBL1990482 & 809145 & 4.1 & 4.4222 & TRN \\
\hline CHEMBL1990904 & 809145 & 4.1 & 4.0201 & TRN \\
\hline CHEMBL1975121 & 809145 & 4.1 & 3.8937 & TRN \\
\hline CHEMBL 2005475 & 809145 & 5.3 & 4.8269 & TRN \\
\hline CHEMBL 2000104 & 809145 & 4.1 & 4.5226 & TRN \\
\hline CHEMBL402846 & 809145 & 4.2 & 4.4642 & TRN \\
\hline CHEMBL1997349 & 809145 & 6.5 & 5.6825 & TST \\
\hline CHEMBL183844 & 809145 & 4.1 & 4.2672 & TRN \\
\hline CHEMBL220057 & 809145 & 6.0 & 4.9698 & TRN \\
\hline CHEMBL1682545 & 809145 & 4.1 & 4.205 & TRN \\
\hline CHEMBL383541 & 809145 & 4.1 & 4.004 & TRN \\
\hline CHEMBL 2001224 & 809145 & 4.1 & 4.0836 & TRN \\
\hline CHEMBL10 & 809145 & 4.1 & 3.8924 & TRN \\
\hline CHEMBL1976732 & 809145 & 4.1 & 4.0231 & TRN \\
\hline CHEMBL1969506 & 809145 & 4.1 & 3.8555 & TRN \\
\hline CHEMBL1980163 & 809145 & 4.1 & 3.9925 & TRN \\
\hline CHEMBL590109 & 809145 & 4.1 & 4.8486 & TST \\
\hline CHEMBL1970879 & 809145 & 4.1 & 3.903 & TRN \\
\hline CHEMBL1989856 & 809145 & 6.1 & 4.477 & TST \\
\hline CHEMBL 2005899 & 809145 & 6.0 & 5.3863 & TRN \\
\hline CHEMBL1682552 & 809145 & 4.1 & 3.7427 & TRN \\
\hline
\end{tabular}




\begin{tabular}{|c|c|c|c|c|c|}
\hline \multicolumn{6}{|c|}{ Supplemental Table S2.txt } \\
\hline CHEMBL259850 & 809145 & 4.1 & 4.3555 & TRN & \\
\hline CHEMBL1972568 & 809145 & 4.1 & 3.8614 & TRN & \\
\hline CHEMBL1996155 & 809145 & 4.1 & 4.1695 & TRN & \\
\hline CHEMBL229799 & 809145 & 4.1 & 4.3524 & TRN & \\
\hline CHEMBL1682359 & 809145 & 4.1 & 4.4775 & TRN & \\
\hline CHEMBL105739 & 809145 & 4.1 & 4.1524 & TRN & \\
\hline CHEMBL379300 & 809145 & 4.1 & 3.9314 & TRN & \\
\hline CHEMBL203673 & 809145 & 4.1 & 3.7199 & TRN & \\
\hline CHEMBL1969523 & 809145 & 7.8 & 7.94600 & 2000000001 & TRN \\
\hline CHEMBL207995 & 809145 & 4.1 & 4.1832 & TRN & \\
\hline CHEMBL1988995 & 809145 & 4.1 & 3.9165 & TRN & \\
\hline CHEMBL 2001923 & 809145 & 4.1 & 4.0406 & TRN & \\
\hline CHEMBL1986781 & 809145 & 4.1 & 4.0798 & TRN & \\
\hline CHEMBL526133 & 809145 & 5.9 & 5.5962 & TRN & \\
\hline CHEMBL1967538 & 809145 & 3.1 & 3.4855 & TRN & \\
\hline CHEMBL1979057 & 809145 & 5.2 & 4.3223 & TRN & \\
\hline CHEMBL1981045 & 809145 & 4.1 & 4.8477 & TRN & \\
\hline CHEMBL387971 & 809145 & 4.1 & 3.8884 & TST & \\
\hline CHEMBL1975418 & 809145 & 4.1 & 4.567 & TRN & \\
\hline CHEMBL1992796 & 809145 & 4.1 & 4.0997 & TST & \\
\hline CHEMBL1999428 & 809145 & 5.7 & 4.4321 & TRN & \\
\hline CHEMBL223257 & 809145 & 5.8 & 5.3041 & TST & \\
\hline CHEMBL1967560 & 809145 & 7.3 & 7.4925 & TRN & \\
\hline CHEMBL1516890 & 809145 & 4.1 & 3.6667 & TRN & \\
\hline CHEMBL 211378 & 809145 & 6.7 & 6.3881 & TRN & \\
\hline CHEMBL1982465 & 809145 & 4.1 & 4.1397 & TRN & \\
\hline CHEMBL 2001751 & 809145 & 6.3 & 5.5757 & TRN & \\
\hline CHEMBL1984586 & 809145 & 5.2 & 5.5496 & TRN & \\
\hline CHEMBL1999774 & 809145 & 4.1 & 4.218 & TST & \\
\hline CHEMBL1972659 & 809145 & 4.1 & 4.1874 & TST & \\
\hline CHEMBL1973395 & 809145 & 4.1 & 3.9239 & TRN & \\
\hline CHEMBL 272453 & 809145 & 5.9 & 5.528 & TRN & \\
\hline CHEMBL1987143 & 809145 & 3.1 & 4.0191 & TST & \\
\hline CHEMBL1970217 & 809145 & 4.1 & 3.8217 & TRN & \\
\hline CHEMBL1971801 & 809145 & 4.1 & 3.9644 & TRN & \\
\hline CHEMBL1968850 & 809145 & 4.1 & 4.5145 & TRN & \\
\hline CHEMBL 2005528 & 809145 & 5.3 & 4.6376 & TST & \\
\hline CHEMBL185569 & 809145 & 4.1 & 4.6867 & TRN & \\
\hline CHEMBL1969843 & 809145 & 4.1 & 4.0349 & TRN & \\
\hline CHEMBL 2007002 & 809145 & 4.1 & 3.8436 & TRN & \\
\hline CHEMBL1990288 & 809145 & 4.1 & 4.4237 & TRN & \\
\hline CHEMBL1987007 & 809145 & 4.1 & 4.7135 & TRN & \\
\hline CHEMBL1969588 & 809145 & 4.1 & 4.6159 & TRN & \\
\hline CHEMBL1984711 & 809145 & 5.6 & 6.0601 & TRN & \\
\hline CHEMBL1990212 & 809145 & 5.1 & 4.9505 & TRN & \\
\hline CHEMBL484390 & 809145 & 4.1 & 4.4432 & TST & \\
\hline CHEMBL1979252 & 809145 & 4.1 & 4.8723 & TRN & \\
\hline CHEMBL1682341 & 809145 & 4.1 & 4.0429 & TRN & \\
\hline
\end{tabular}




\begin{tabular}{|c|c|c|c|c|}
\hline & & & ipplemen & \\
\hline CHEMBL1986499 & 809145 & 4.1 & 4.5521 & TRN \\
\hline CHEMBL 2004290 & 809145 & 5.5 & 5.277 & TRN \\
\hline CHEMBL1972937 & 809145 & 4.1 & 4.5887 & TRN \\
\hline CHEMBL1972250 & 809145 & 4.1 & 3.7645 & TST \\
\hline CHEMBL 2000393 & 809145 & 4.1 & 4.7881 & TST \\
\hline CHEMBL 2004072 & 809145 & 4.1 & 4.9321 & TRN \\
\hline CHEMBL1992634 & 809145 & 4.1 & 4.4981 & TRN \\
\hline CHEMBL1242373 & 809145 & 5.7 & 6.2257 & TRN \\
\hline CHEMBL 2000433 & 809145 & 5.3 & 3.8929 & TST \\
\hline CHEMBL56543 & 809145 & 6.2 & 5.4152 & TRN \\
\hline CHEMBL1988075 & 809145 & 4.1 & 5.0439 & TRN \\
\hline CHEMBL316264 & 809145 & 4.1 & 4.1993 & TRN \\
\hline CHEMBL1991678 & 809145 & 4.1 & 4.1836 & TRN \\
\hline CHEMBL2001239 & 809145 & 5.1 & 5.0306 & TST \\
\hline CHEMBL1988594 & 809145 & 4.1 & 4.232 & TRN \\
\hline CHEMBL 2001288 & 809145 & 4.1 & 3.9621 & TRN \\
\hline CHEMBL 260092 & 809145 & 5.4 & 5.3303 & TRN \\
\hline CHEMBL1999811 & 809145 & 5.7 & 4.7589 & TST \\
\hline CHEMBL1965495 & 809145 & 4.1 & 4.6538 & TRN \\
\hline CHEMBL1985074 & 809145 & 4.1 & 4.7591 & TST \\
\hline CHEMBL1982874 & 809145 & 4.1 & 4.0225 & TRN \\
\hline CHEMBL 2000481 & 809145 & 4.1 & 4.383 & TRN \\
\hline CHEMBL1991725 & 809145 & 4.1 & 3.4788 & TRN \\
\hline CHEMBL1992242 & 809145 & 4.1 & 4.7182 & TRN \\
\hline CHEMBL 2007296 & 809145 & 4.1 & 4.0933 & TRN \\
\hline CHEMBL396523 & 809145 & 7.6 & 7.7039 & TRN \\
\hline CHEMBL 2007138 & 809145 & 3.7 & 3.985 & TRN \\
\hline CHEMBL 208637 & 809145 & 4.1 & 4.1655 & TRN \\
\hline CHEMBL1970203 & 809145 & 5.2 & 4.9466 & TRN \\
\hline CHEMBL1986530 & 809145 & 4.1 & 3.8064 & TST \\
\hline CHEMBL385478 & 809145 & 4.1 & 4.2507 & TRN \\
\hline CHEMBL1968590 & 809145 & 4.1 & 4.2765 & TRN \\
\hline CHEMBL1999749 & 809145 & 4.1 & 3.8825 & TRN \\
\hline CHEMBL 2005375 & 809145 & 7.9 & 8.0612 & TRN \\
\hline CHEMBL1984191 & 809145 & 4.1 & 4.2249 & TRN \\
\hline CHEMBL1983006 & 809145 & 4.1 & 4.149 & TRN \\
\hline CHEMBL1972183 & 809145 & 4.1 & 3.7874 & TRN \\
\hline CHEMBL1971029 & 809145 & 5.8 & 5.4397 & TRN \\
\hline CHEMBL1995391 & 809145 & 3.7 & 3.739 & TRN \\
\hline CHEMBL 383527 & 809145 & 4.1 & 4.1864 & TRN \\
\hline CHEMBL394790 & 809145 & 5.2 & 5.4017 & TRN \\
\hline CHEMBL 226471 & 809145 & 4.1 & 4.6238 & TRN \\
\hline CHEMBL1974702 & 809145 & 4.1 & 4.6927 & TRN \\
\hline CHEMBL1996111 & 809145 & 4.1 & 4.3387 & TRN \\
\hline CHEMBL1965589 & 809145 & 4.1 & 3.7927 & TRN \\
\hline CHEMBL474432 & 809145 & 7.5 & 5.4545 & TST \\
\hline CHEMBL 2001539 & 809145 & 4.5 & 3.6738 & TST \\
\hline CHEMBL1988153 & 809145 & 4.1 & 3.9996 & TRN \\
\hline
\end{tabular}




\begin{tabular}{|c|c|c|c|c|}
\hline \multicolumn{5}{|c|}{ Supplemental Table } \\
\hline CHEMBL1972584 & 809145 & 4.1 & 3.7087 & TRN \\
\hline CHEMBL1999556 & 809145 & 6.2 & 5.9181 & TRN \\
\hline CHEMBL1988437 & 809145 & 4.1 & 4.1946 & TST \\
\hline CHEMBL1968245 & 809145 & 4.1 & 3.815 & TRN \\
\hline CHEMBL1998121 & 809145 & 5.5 & 5.0777 & TRN \\
\hline CHEMBL1979577 & 809145 & 4.1 & 4.91 & TRN \\
\hline CHEMBL1991800 & 809145 & 4.1 & 4.0604 & TRN \\
\hline CHEMBL1985566 & 809145 & 6.0 & 5.1193 & TRN \\
\hline CHEMBL52387 & 809145 & 4.1 & 4.2881 & TST \\
\hline CHEMBL379835 & 809145 & 4.1 & 3.7773 & TST \\
\hline CHEMBL1979357 & 809145 & 4.1 & 3.9906 & TRN \\
\hline CHEMBL1980802 & 809145 & 4.1 & 4.699 & TST \\
\hline CHEMBL1979554 & 809145 & 4.1 & 4.0186 & TRN \\
\hline CHEMBL1996817 & 809145 & 4.1 & 4.4028 & TRN \\
\hline CHEMBL3197315 & 809145 & 4.1 & 4.854 & TST \\
\hline CHEMBL 2004355 & 809145 & 4.1 & 4.1527 & TRN \\
\hline CHEMBL468280 & 809145 & 4.1 & 4.6048 & TST \\
\hline CHEMBL1990884 & 809145 & 4.1 & 4.2896 & TRN \\
\hline CHEMBL3109278 & 809145 & 4.1 & 3.9305 & TRN \\
\hline CHEMBL 256835 & 809145 & 4.1 & 3.7098 & TRN \\
\hline CHEMBL1980142 & 809145 & 4.1 & 4.4429 & TRN \\
\hline CHEMBL41783 & 809145 & 4.1 & 4.2882 & TRN \\
\hline CHEMBL 2004438 & 809145 & 4.1 & 3.6435 & TRN \\
\hline CHEMBL 2006276 & 809145 & 4.1 & 4.8532 & TRN \\
\hline CHEMBL 271381 & 809145 & 6.4 & 5.7688 & TRN \\
\hline CHEMBL 2006785 & 809145 & 4.1 & 4.1605 & TRN \\
\hline CHEMBL1995740 & 809145 & 5.9 & 5.2809 & TRN \\
\hline CHEMBL1996390 & 809145 & 5.6 & 5.6755 & TRN \\
\hline CHEMBL1986943 & 809145 & 4.1 & 4.6537 & TRN \\
\hline CHEMBL 234085 & 809145 & 4.1 & 4.4255 & TRN \\
\hline CHEMBL1995832 & 809145 & 5.3 & 4.5542 & TRN \\
\hline CHEMBL1998414 & 809145 & 4.1 & 3.8663 & TRN \\
\hline CHEMBL1969042 & 809145 & 4.1 & 4.0923 & TST \\
\hline CHEMBL 2000345 & 809145 & 4.1 & 4.0836 & TRN \\
\hline CHEMBL1999931 & 809145 & 5.2 & 5.027 & TRN \\
\hline CHEMBL1991640 & 809145 & 6.1 & 4.6287 & TST \\
\hline CHEMBL1375418 & 809145 & 4.1 & 3.9465 & TRN \\
\hline CHEMBL302449 & 809145 & 4.1 & 4.8656 & TST \\
\hline CHEMBL 2007064 & 809145 & 4.1 & 4.5451 & TRN \\
\hline CHEMBL1981047 & 809145 & 4.1 & 4.253 & TST \\
\hline CHEMBL 229968 & 809145 & 4.1 & 4.1758 & TRN \\
\hline CHEMBL1979093 & 809145 & 4.1 & 5.0179 & TRN \\
\hline CHEMBL1968151 & 809145 & 4.1 & 5.3199 & TST \\
\hline CHEMBL1381197 & 809145 & 4.1 & 3.7324 & TRN \\
\hline CHEMBL1987009 & 809145 & 4.1 & 4.6024 & TRN \\
\hline CHEMBL 379218 & 809145 & 4.1 & 3.8811 & TRN \\
\hline CHEMBL 2003817 & 809145 & 4.1 & 3.9736 & TRN \\
\hline CHEMBL336961 & 809145 & 4.1 & 3.9873 & TRN \\
\hline
\end{tabular}




\begin{tabular}{|c|c|c|c|c|}
\hline & & & ipplemen & al $\mathrm{Ta}$ \\
\hline CHEMBL1994830 & 809145 & 4.1 & 4.3163 & TRN \\
\hline CHEMBL1987054 & 809145 & 5.3 & 5.5113 & TRN \\
\hline CHEMBL1970083 & 809145 & 7.1 & 6.0989 & TRN \\
\hline CHEMBL 226403 & 809145 & 4.1 & 4.593 & TRN \\
\hline CHEMBL 2005631 & 809145 & 5.2 & 5.0592 & TRN \\
\hline CHEMBL1994938 & 809145 & 4.1 & 4.2635 & TRN \\
\hline CHEMBL1825138 & 809145 & 4.1 & 3.4786 & TST \\
\hline CHEMBL1977223 & 809145 & 4.1 & 4.4741 & TRN \\
\hline CHEMBL1236126 & 809145 & 4.1 & 4.262 & TST \\
\hline CHEMBL1966279 & 809145 & 4.1 & 4.0866 & TRN \\
\hline CHEMBL1997846 & 809145 & 5.4 & 4.7537 & TRN \\
\hline CHEMBL 2004419 & 809145 & 4.1 & 4.4896 & TRN \\
\hline CHEMBL1991728 & 809145 & 5.2 & 5.1801 & TRN \\
\hline CHEMBL1975787 & 809145 & 5.8 & 5.7453 & TRN \\
\hline CHEMBL 2002407 & 809145 & 4.1 & 4.1605 & TRN \\
\hline CHEMBL1972489 & 809145 & 4.1 & 4.11 & TRN \\
\hline CHEMBL1994074 & 809145 & 4.1 & 4.0682 & TRN \\
\hline CHEMBL1992937 & 809145 & 4.1 & 4.0039 & TST \\
\hline CHEMBL451401 & 809145 & 3.1 & 3.8908 & TRN \\
\hline CHEMBL1972119 & 809145 & 4.1 & 4.4319 & TRN \\
\hline CHEMBL1986328 & 809145 & 6.1 & 5.3729 & TST \\
\hline CHEMBL95692 & 809145 & 4.1 & 3.5873 & TRN \\
\hline CHEMBL1090356 & 809145 & 4.1 & 4.4971 & TRN \\
\hline CHEMBL1976455 & 809145 & 4.1 & 3.9843 & TRN \\
\hline CHEMBL1983923 & 809145 & 4.1 & 5.1392 & TST \\
\hline CHEMBL1983534 & 809145 & 4.1 & 3.7014 & TRN \\
\hline CHEMBL1982361 & 809145 & 5.6 & 4.9268 & TRN \\
\hline CHEMBL1999112 & 809145 & 4.1 & 5.6423 & TST \\
\hline CHEMBL1982122 & 809145 & 4.1 & 4.216 & TRN \\
\hline CHEMBL 2000801 & 809145 & 4.1 & 4.5009 & TRN \\
\hline CHEMBL1682546 & 809145 & 4.1 & 3.8553 & TRN \\
\hline CHEMBL1991395 & 809145 & 4.1 & 4.0576 & TRN \\
\hline CHEMBL1971245 & 809145 & 4.1 & 4.1367 & TRN \\
\hline CHEMBL1987648 & 809145 & 4.1 & 4.1679 & TRN \\
\hline CHEMBL1996780 & 809145 & 4.1 & 3.9193 & TST \\
\hline CHEMBL1972142 & 809145 & 4.1 & 3.6847 & TRN \\
\hline CHEMBL1966514 & 809145 & 5.4 & 5.4362 & TRN \\
\hline CHEMBL 2003638 & 809145 & 4.1 & 4.5564 & TRN \\
\hline CHEMBL 296586 & 809145 & 4.1 & 4.1534 & TRN \\
\hline CHEMBL1996066 & 809145 & 4.1 & 4.3184 & TST \\
\hline CHEMBL516429 & 809145 & 6.1 & 4.9307 & TRN \\
\hline CHEMBL1993722 & 809145 & 5.6 & 5.7289 & TRN \\
\hline CHEMBL1970806 & 809145 & 4.1 & 4.7972 & TST \\
\hline CHEMBL1375640 & 809145 & 5.1 & 3.5929 & TST \\
\hline CHEMBL1979970 & 809145 & 4.1 & 4.5152 & TRN \\
\hline CHEMBL 249282 & 809145 & 4.1 & 4.0475 & TST \\
\hline CHEMBL1969264 & 809145 & 4.1 & 4.53 & TRN \\
\hline CHEMBL1973711 & 809145 & 6.1 & 5.9361 & TRN \\
\hline
\end{tabular}




\begin{tabular}{|c|c|c|c|c|}
\hline & & & ipplemen & \\
\hline CHEMBL 2006237 & 809145 & 4.1 & 4.4037 & TRN \\
\hline CHEMBL1967720 & 809145 & 4.1 & 5.2839 & TRN \\
\hline CHEMBL1991138 & 809145 & 4.1 & 4.0178 & TRN \\
\hline CHEMBL1969755 & 809145 & 4.1 & 3.5185 & TRN \\
\hline CHEMBL1979516 & 809145 & 4.1 & 4.2019 & TRN \\
\hline CHEMBL1605605 & 809145 & 4.1 & 4.2183 & TRN \\
\hline CHEMBL1972820 & 809145 & 4.1 & 4.6425 & TST \\
\hline CHEMBL1989029 & 809145 & 4.1 & 4.6381 & TRN \\
\hline CHEMBL392642 & 809145 & 4.1 & 4.0739 & TRN \\
\hline CHEMBL514499 & 809145 & 8.1 & 4.7651 & TST \\
\hline CHEMBL1965631 & 809145 & 4.1 & 4.2502 & TRN \\
\hline CHEMBL1980144 & 809145 & 5.1 & 4.5203 & TRN \\
\hline CHEMBL1991188 & 809145 & 4.1 & 3.6436 & TRN \\
\hline CHEMBL1972849 & 809145 & 4.1 & 3.9391 & TRN \\
\hline CHEMBL 377408 & 809145 & 4.1 & 4.0271 & TRN \\
\hline CHEMBL215152 & 809145 & 4.1 & 4.2827 & TST \\
\hline CHEMBL231209 & 809145 & 5.7 & 5.4574 & TRN \\
\hline CHEMBL1975357 & 809145 & 4.1 & 3.9552 & TST \\
\hline CHEMBL1976220 & 809145 & 6.2 & 5.9289 & TRN \\
\hline CHEMBL 259922 & 809145 & 4.2 & 5.1253 & TST \\
\hline CHEMBL1997617 & 809145 & 4.1 & 4.0665 & TRN \\
\hline CHEMBL1982383 & 809145 & 4.1 & 4.1993 & TRN \\
\hline CHEMBL1969301 & 809145 & 4.1 & 4.4076 & TST \\
\hline CHEMBL17370 & 809145 & 4.1 & 4.2772 & TRN \\
\hline CHEMBL1983932 & 809145 & 4.1 & 4.3361 & TRN \\
\hline CHEMBL1973399 & 809145 & 3.1 & 3.8545 & TST \\
\hline CHEMBL1966069 & 809145 & 4.1 & 3.8893 & TRN \\
\hline CHEMBL1997822 & 809145 & 4.1 & 4.4254 & TRN \\
\hline CHEMBL1991285 & 809145 & 4.1 & 4.0142 & TRN \\
\hline CHEMBL1984038 & 809145 & 4.1 & 4.3968 & TRN \\
\hline CHEMBL243088 & 809145 & 7.3 & 7.6793 & TRN \\
\hline CHEMBL1993661 & 809145 & 6.6 & 6.5465 & TRN \\
\hline CHEMBL1974416 & 809145 & 4.1 & 4.29 & TRN \\
\hline CHEMBL 2004615 & 809145 & 4.1 & 3.6417 & TST \\
\hline CHEMBL1997872 & 809145 & 4.1 & 3.8615 & TRN \\
\hline CHEMBL1964290 & 809145 & 5.3 & 4.6644 & TRN \\
\hline CHEMBL 2003768 & 809145 & 4.1 & 4.3398 & TRN \\
\hline CHEMBL213505 & 809145 & 7.2 & 6.4282 & TRN \\
\hline CHEMBL1982880 & 809145 & 4.1 & 4.9883 & TRN \\
\hline CHEMBL1987034 & 809145 & 6.3 & 6.1543 & TRN \\
\hline CHEMBL1993941 & 809145 & 5.2 & 5.1943 & TRN \\
\hline CHEMBL377383 & 809145 & 4.1 & 4.2314 & TRN \\
\hline CHEMBL578061 & 809145 & 5.0 & 4.9411 & TRN \\
\hline CHEMBL 2005886 & 809145 & 4.1 & 4.1397 & TRN \\
\hline CHEMBL481491 & 809145 & 6.9 & 3.9645 & TST \\
\hline CHEMBL1682345 & 809145 & 4.1 & 4.647 & TRN \\
\hline CHEMBL1973142 & 809145 & 4.1 & 3.6168 & TRN \\
\hline CHEMBL1973145 & 809145 & 4.1 & 4.9057 & TRN \\
\hline
\end{tabular}




\begin{tabular}{|c|c|c|c|c|}
\hline & & & Supplement & \\
\hline CHEMBL1982924 & 809145 & 4.1 & 3.8886 & TRN \\
\hline CHEMBL2005936 & 809145 & 4.1 & 4.1336 & TRN \\
\hline CHEMBL1807515 & 809145 & 4.1 & 4.1729 & TRN \\
\hline CHEMBL1971141 & 809145 & 4.1 & 4.4778 & TRN \\
\hline CHEMBL1995813 & 809145 & 4.1 & 4.1757 & TRN \\
\hline CHEMBL1979718 & 809145 & 4.1 & 4.2176 & TRN \\
\hline CHEMBL206236 & 809145 & 4.1 & 4.0743 & TRN \\
\hline CHEMBL1989834 & 809145 & 3.1 & 3.4949 & TRN \\
\hline CHEMBL523823 & 809145 & 4.1 & 5.0344 & TST \\
\hline CHEMBL1562756 & 809145 & 4.1 & 4.3173 & TST \\
\hline CHEMBL244378 & 809145 & 8.2 & 8.0871 & TRN \\
\hline CHEMBL 2001957 & 809145 & 4.1 & 4.3812 & TRN \\
\hline CHEMBL1969372 & 809145 & 4.1 & 3.793 & TRN \\
\hline CHEMBL1990583 & 809145 & 4.1 & 4.5032 & TRN \\
\hline CHEMBL289959 & 809145 & 3.1 & 3.4062 & TRN \\
\hline CHEMBL 2006263 & 809145 & 7.0 & 4.6695 & TST \\
\hline CHEMBL2001646 & 809145 & 5.7 & 4.7454 & TST \\
\hline CHEMBL1993584 & 809145 & 4.1 & 3.8178 & TRN \\
\hline CHEMBL1986263 & 809145 & 6.6 & 6.3166 & TRN \\
\hline CHEMBL 2000114 & 809145 & 4.1 & 3.8652 & TRN \\
\hline CHEMBL210618 & 809145 & 4.1 & 4.4834 & TRN \\
\hline CHEMBL1998975 & 809145 & 5.6 & 4.1126 & TRN \\
\hline CHEMBL1975647 & 809145 & 4.1 & 4.3276 & TRN \\
\hline CHEMBL1968380 & 809145 & 8.3 & 8.3984 & TRN \\
\hline CHEMBL1964644 & 809145 & 4.1 & 4.3003 & TRN \\
\hline CHEMBL1981782 & 809145 & 4.1 & 4.4056 & TRN \\
\hline CHEMBL1977681 & 809145 & 4.1 & 3.9712 & TRN \\
\hline CHEMBL1990912 & 809145 & 4.1 & 3.6733 & TRN \\
\hline CHEMBL1988163 & 809145 & 4.1 & 4.5971 & TRN \\
\hline CHEMBL1995592 & 809145 & 5.2 & 4.2868 & TST \\
\hline CHEMBL 2006493 & 809145 & 4.1 & 4.897 & TST \\
\hline CHEMBL1982541 & 809145 & 4.1 & 4.4566 & TRN \\
\hline CHEMBL1996923 & 809145 & 4.1 & 3.8778 & TST \\
\hline CHEMBL1983449 & 809145 & 4.1 & 4.5763 & TRN \\
\hline CHEMBL1992323 & 809145 & 4.1 & 4.6765 & TRN \\
\hline CHEMBL1969735 & 809145 & 4.1 & 4.184 & TRN \\
\hline CHEMBL 2003524 & 809145 & 4.1 & 4.512 & TST \\
\hline CHEMBL1989423 & 809145 & 3.1 & 3.2183 & TRN \\
\hline CHEMBL437747 & 809145 & 4.1 & 4.4133 & TRN \\
\hline CHEMBL1995172 & 809145 & 3.4 & 3.6489 & TST \\
\hline CHEMBL507936 & 809145 & 4.1 & 4.0441 & TRN \\
\hline CHEMBL104264 & 809145 & 4.1 & 3.9907 & TST \\
\hline CHEMBL1994321 & 809145 & 5.7 & 4.506 & TRN \\
\hline CHEMBL1997129 & 809145 & 6.0 & 5.8577 & TRN \\
\hline CHEMBL1984788 & 809145 & 4.1 & 4.0246 & TRN \\
\hline CHEMBL451964 & 809145 & 4.1 & 3.6085 & TRN \\
\hline CHEMBL1964307 & 809145 & 4.1 & 4.5866 & TRN \\
\hline CHEMBL 2000508 & 809145 & 4.1 & 4.6172 & TRN \\
\hline
\end{tabular}




\begin{tabular}{|c|c|c|c|c|c|}
\hline \multicolumn{6}{|c|}{ Supplemental Table S2.txt } \\
\hline CHEMBL1971694 & 809145 & 4.1 & 4.7349 & TST & \\
\hline CHEMBL 2001547 & 809145 & 4.1 & 3.968 & TRN & \\
\hline CHEMBL 210928 & 809145 & 4.1 & 3.9563 & TRN & \\
\hline CHEMBL1994361 & 809145 & 4.1 & 4.3204 & TRN & \\
\hline CHEMBL1986603 & 809145 & 4.1 & 3.7584 & TST & \\
\hline CHEMBL1972840 & 809145 & 4.1 & 4.6962 & TRN & \\
\hline CHEMBL1977148 & 809145 & 5.5 & \multicolumn{2}{|c|}{5.156000000000001} & TRN \\
\hline CHEMBL 2003286 & 809145 & 4.1 & 4.9797 & TRN & \\
\hline CHEMBL1992306 & 809145 & 4.1 & 4.0675 & TRN & \\
\hline CHEMBL 2002165 & 809145 & 5.6 & 5.3502 & TRN & \\
\hline CHEMBL 2001668 & 809145 & 4.1 & 5.1835 & TST & \\
\hline CHEMBL1979318 & 809145 & 4.1 & 4.2327 & TRN & \\
\hline CHEMBL 206382 & 809145 & 4.1 & 4.0182 & TRN & \\
\hline CHEMBL1998585 & 809145 & 7.2 & \multicolumn{2}{|c|}{7.002999999999999} & TRN \\
\hline CHEMBL519697 & 809145 & 4.1 & 4.0329 & TST & \\
\hline CHEMBL 2004934 & 809145 & 4.1 & \multicolumn{2}{|c|}{4.1930000000000005} & TRN \\
\hline CHEMBL1977619 & 809145 & 4.1 & 4.7815 & TST & \\
\hline CHEMBL1975128 & 809145 & 5.6 & 5.5019 & TRN & \\
\hline CHEMBL1970369 & 809145 & 4.1 & 4.1966 & TRN & \\
\hline CHEMBL504950 & 809145 & 4.1 & 3.7742 & TRN & \\
\hline CHEMBL1984363 & 809145 & 4.1 & 4.3626 & TRN & \\
\hline CHEMBL1977041 & 809145 & 5.8 & 5.5981 & TRN & \\
\hline CHEMBL1968070 & 809145 & 5.7 & 5.482 & TRN & \\
\hline CHEMBL1988608 & 809145 & 5.1 & 5.0436 & TRN & \\
\hline CHEMBL184847 & 809145 & 4.1 & 4.2561 & TRN & \\
\hline CHEMBL1984367 & 809145 & 4.1 & 3.9947 & TRN & \\
\hline CHEMBL178737 & 809145 & 4.1 & 4.2255 & TST & \\
\hline CHEMBL1982563 & 809145 & 4.1 & 4.3966 & TRN & \\
\hline CHEMBL539474 & 809145 & 7.1 & \multicolumn{2}{|c|}{5.718999999999999} & TST \\
\hline CHEMBL575824 & 809145 & 4.1 & 4.3112 & TRN & \\
\hline CHEMBL1997759 & 809145 & 4.1 & 3.9845 & TRN & \\
\hline CHEMBL1974803 & 809145 & 5.5 & 4.9776 & TST & \\
\hline CHEMBL1970074 & 809145 & 6.2 & 4.9579 & TRN & \\
\hline CHEMBL2002635 & 809145 & 5.2 & 4.1515 & TST & \\
\hline CHEMBL1984500 & 809145 & 3.1 & 3.4735 & TRN & \\
\hline CHEMBL1986970 & 809145 & 4.1 & 4.1139 & TRN & \\
\hline CHEMBL 2005112 & 809145 & 5.2 & 5.4804 & TST & \\
\hline CHEMBL1958401 & 809145 & 4.1 & 4.6052 & TRN & \\
\hline CHEMBL1984044 & 809145 & 4.1 & 4.2809 & TRN & \\
\hline CHEMBL 2003456 & 809145 & 4.1 & 3.9372 & TRN & \\
\hline CHEMBL1966816 & 809145 & 5.6 & 4.9729 & TRN & \\
\hline CHEMBL 2002992 & 809145 & 4.1 & 4.0053 & TRN & \\
\hline CHEMBL560813 & 809145 & 5.5 & 5.0009 & TRN & \\
\hline CHEMBL207253 & 809145 & 4.1 & 4.1768 & TST & \\
\hline CHEMBL1968791 & 809145 & 4.1 & \multicolumn{2}{|c|}{4.1339999999999995} & TRN \\
\hline CHEMBL326282 & 809145 & 4.1 & 4.5913 & TST & \\
\hline CHEMBL 2002682 & 809145 & 4.1 & 4.6485 & TST & \\
\hline CHEMBL1992732 & 809145 & 4.1 & 4.9858 & TST & \\
\hline
\end{tabular}




\begin{tabular}{|c|c|c|c|c|c|}
\hline \multicolumn{6}{|c|}{ Supplemental Table S2.txt } \\
\hline CHEMBL1971186 & 809145 & 4.1 & 3.9568 & TRN & \\
\hline CHEMBL 2003482 & 809145 & 4.1 & 4.0199 & TRN & \\
\hline CHEMBL1976872 & 809145 & 3.1 & 3.0655 & TRN & \\
\hline CHEMBL1969156 & 809145 & 3.1 & 3.4882 & TST & \\
\hline CHEMBL1973211 & 809145 & 4.1 & 4.1543 & TRN & \\
\hline CHEMBL1984700 & 809145 & 4.1 & 4.3825 & TRN & \\
\hline CHEMBL 2007151 & 809145 & 4.1 & 4.1308 & TRN & \\
\hline CHEMBL1972125 & 809145 & 4.1 & 4.0085 & TRN & \\
\hline CHEMBL1461728 & 809145 & 4.1 & 3.87399 & 99999999997 & TRN \\
\hline CHEMBL1976134 & 809145 & 4.1 & 4.4359 & TRN & \\
\hline CHEMBL1965131 & 809145 & 4.1 & 3.7883 & TRN & \\
\hline CHEMBL1995448 & 809145 & 4.1 & 4.5864 & TRN & \\
\hline CHEMBL1972158 & 809145 & 4.1 & 4.5443 & TRN & \\
\hline CHEMBL1974457 & 809145 & 5.8 & 5.8144 & TRN & \\
\hline CHEMBL 2006580 & 809145 & 4.1 & 4.2135 & TRN & \\
\hline CHEMBL 2006581 & 809145 & 4.1 & 4.191 & TRN & \\
\hline CHEMBL 2006481 & 809145 & 4.1 & 4.3755 & TRN & \\
\hline CHEMBL1978645 & 809145 & 5.5 & 4.9158 & TST & \\
\hline CHEMBL1970340 & 809145 & 4.1 & 4.3947 & TRN & \\
\hline CHEMBL1995927 & 809145 & 4.1 & 3.8968 & TST & \\
\hline CHEMBL1975534 & 809145 & 4.1 & 4.4751 & TRN & \\
\hline CHEMBL1993424 & 809145 & 4.1 & 4.3833 & TRN & \\
\hline CHEMBL1966703 & 809145 & 4.1 & 4.4888 & TST & \\
\hline CHEMBL1969561 & 809145 & 4.1 & 4.3513 & TRN & \\
\hline CHEMBL1997023 & 809145 & 4.1 & 5.104 & TST & \\
\hline CHEMBL1964687 & 809145 & 6.3 & 6.2862 & TRN & \\
\hline CHEMBL1971943 & 809145 & 4.1 & 3.61 & TRN & \\
\hline CHEMBL1999918 & 809145 & 6.1 & 5.9843 & TRN & \\
\hline CHEMBL1974254 & 809145 & 5.3 & 5.6151 & TRN & \\
\hline CHEMBL1988537 & 809145 & 4.1 & 5.1439 & TST & \\
\hline CHEMBL1969049 & 809145 & 4.1 & 4.0548 & TRN & \\
\hline CHEMBL 2005828 & 809145 & 5.9 & 5.6917 & TRN & \\
\hline CHEMBL 2002240 & 809145 & 4.1 & 3.7714 & TRN & \\
\hline CHEMBL1991143 & 809145 & 5.6 & 3.9748 & TST & \\
\hline CHEMBL1998611 & 809145 & 4.1 & 4.415 & TRN & \\
\hline CHEMBL485556 & 809145 & 4.1 & 3.9248 & TST & \\
\hline CHEMBL1975900 & 809145 & 6.0 & 5.12799 & 9999999999 & TRN \\
\hline CHEMBL255822 & 809145 & 5.9 & 5.251 & TRN & \\
\hline CHEMBL1972221 & 809145 & 4.1 & 4.2894 & TRN & \\
\hline CHEMBL 2006778 & 809145 & 4.1 & 4.7395 & TRN & \\
\hline CHEMBL378627 & 809145 & 4.1 & 3.5141 & TRN & \\
\hline CHEMBL1996979 & 809145 & 6.2 & 5.0055 & TRN & \\
\hline CHEMBL1997025 & 809145 & 4.1 & 4.0778 & TRN & \\
\hline CHEMBL1968406 & 809145 & 5.5 & 5.9537 & TRN & \\
\hline CHEMBL1982476 & 809145 & 4.1 & 4.5348 & TRN & \\
\hline CHEMBL1984274 & 809145 & 5.9 & 4.9594 & TST & \\
\hline CHEMBL1998545 & 809145 & 4.1 & 3.8353 & TRN & \\
\hline CHEMBL2006010 & 809145 & 5.5 & 4.7662 & TRN & \\
\hline
\end{tabular}




\begin{tabular}{|c|c|c|c|c|}
\hline \multicolumn{5}{|c|}{ Supplemental Table S2.txt } \\
\hline CHEMBL1682558 & 809145 & 4.1 & 4.2796 & TRN \\
\hline CHEMBL1990496 & 809145 & 4.1 & 4.0909 & TRN \\
\hline CHEMBL1997623 & 809145 & 4.1 & 4.7329 & TRN \\
\hline CHEMBL1472492 & 809145 & 4.1 & 3.8831 & TST \\
\hline CHEMBL1993166 & 809145 & 4.1 & 4.9057 & TRN \\
\hline CHEMBL1967094 & 809145 & 4.1 & 4.311 & TRN \\
\hline CHEMBL1966035 & 809145 & 4.1 & 4.8677 & TRN \\
\hline CHEMBL 2003341 & 809145 & 4.1 & 4.1936 & TRN \\
\hline CHEMBL1992644 & 809145 & 3.7 & 4.0439 & TRN \\
\hline CHEMBL1992645 & 809145 & 6.0 & 5.3641 & TST \\
\hline CHEMBL1982992 & 809145 & 4.1 & 4.1854 & TRN \\
\hline CHEMBL1999590 & 809145 & 4.1 & 4.6694 & TST \\
\hline CHEMBL1981079 & 809145 & 4.1 & 4.3899 & TRN \\
\hline CHEMBL1972276 & 809145 & 4.1 & 4.2991 & TRN \\
\hline CHEMBL1980489 & 809145 & 4.1 & 4.4494 & TRN \\
\hline CHEMBL1967116 & 809145 & 6.5 & 5.8012 & TRN \\
\hline CHEMBL 2000832 & 809145 & 6.1 & 5.455 & TRN \\
\hline CHEMBL1977814 & 809145 & 4.1 & 4.0972 & TST \\
\hline CHEMBL1970709 & 809145 & 4.1 & 4.1828 & TRN \\
\hline CHEMBL1965660 & 809145 & 4.1 & 4.4221 & TRN \\
\hline CHEMBL1998112 & 809145 & 4.1 & 4.499 & TRN \\
\hline CHEMBL1969126 & 809145 & 4.1 & 4.1021 & TRN \\
\hline CHEMBL1980896 & 809145 & 6.2 & 5.5756 & TRN \\
\hline CHEMBL1975208 & 809145 & 4.1 & 4.4966 & TST \\
\hline CHEMBL1991429 & 809145 & 4.1 & 5.1802 & TRN \\
\hline CHEMBL1964777 & 809145 & 6.0 & 5.5296 & TRN \\
\hline CHEMBL1971149 & 809145 & 4.1 & 4.5884 & TRN \\
\hline CHEMBL1999714 & 809145 & 4.1 & 4.0398 & TRN \\
\hline CHEMBL1987533 & 809145 & 4.1 & 4.2135 & TRN \\
\hline CHEMBL1994040 & 809145 & 4.1 & 4.0661 & TRN \\
\hline CHEMBL388978 & 809145 & 5.7 & 5.5943 & TST \\
\hline CHEMBL579246 & 809145 & 4.1 & 3.9407 & TRN \\
\hline CHEMBL398951 & 809145 & 4.1 & 4.3044 & TST \\
\hline CHEMBL1982506 & 809145 & 4.1 & 4.4988 & TST \\
\hline CHEMBL1968127 & 809145 & 4.1 & 4.0329 & TRN \\
\hline CHEMBL1975233 & 809145 & 4.2 & 4.2371 & TRN \\
\hline CHEMBL1985406 & 809145 & 4.1 & 4.1755 & TRN \\
\hline CHEMBL 207400 & 809145 & 4.1 & 3.9872 & TST \\
\hline CHEMBL 2000894 & 809145 & 4.1 & 3.595 & TST \\
\hline CHEMBL1982135 & 809145 & 5.9 & 5.7693 & TRN \\
\hline CHEMBL1976090 & 809145 & 4.1 & 4.3732 & TRN \\
\hline CHEMBL1993243 & 809145 & 4.1 & 4.2697 & TRN \\
\hline CHEMBL1992922 & 809145 & 4.1 & 3.6746 & TRN \\
\hline CHEMBL399021 & 809145 & 4.1 & 4.1273 & TRN \\
\hline CHEMBL1997597 & 809145 & 4.1 & 3.8197 & TRN \\
\hline CHEMBL1969537 & 809145 & 6.4 & 5.6802 & TST \\
\hline CHEMBL1976093 & 809145 & 4.1 & 3.9279 & TRN \\
\hline CHEMBL210032 & 809145 & 4.1 & 4.1209 & TRN \\
\hline
\end{tabular}




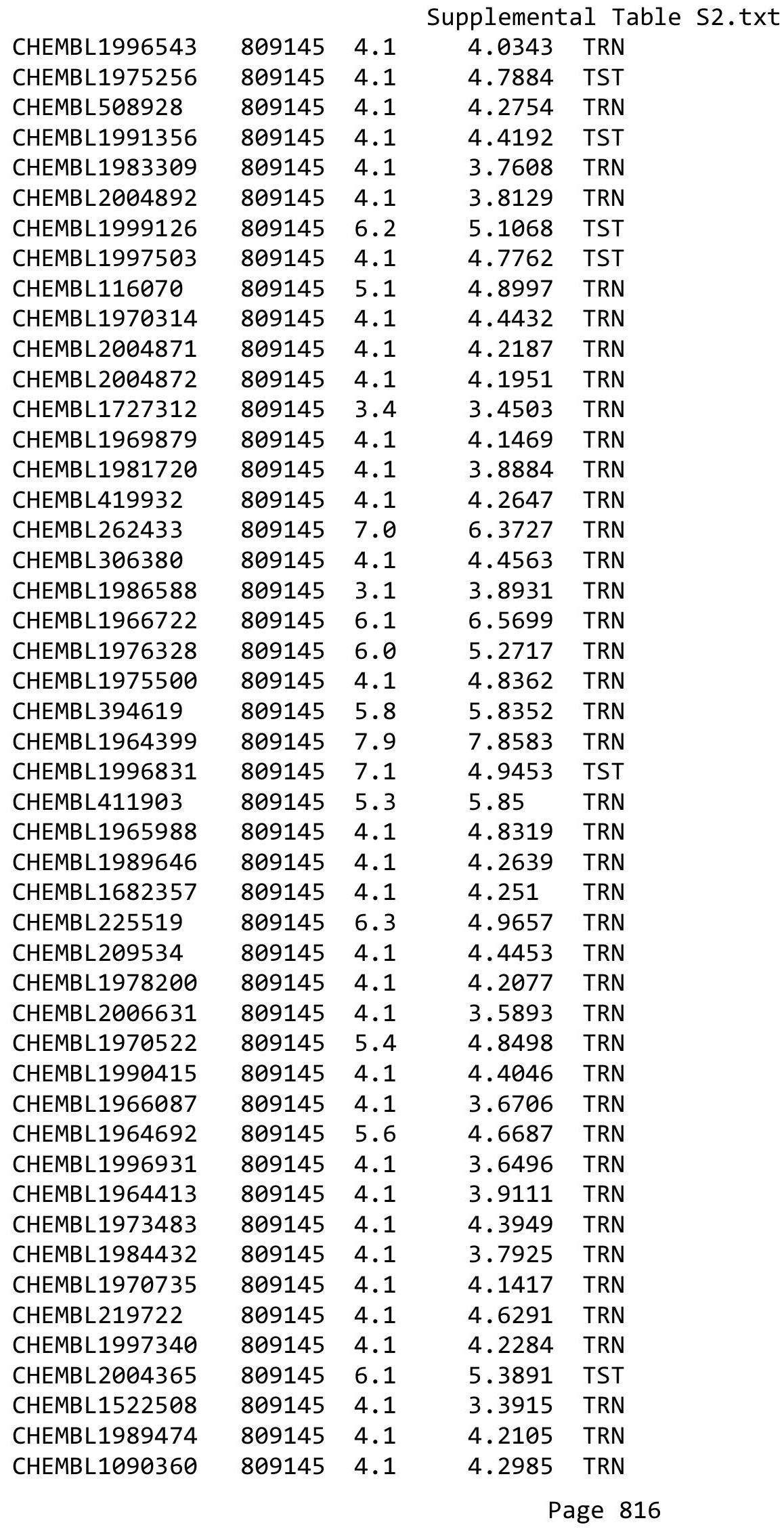




\begin{tabular}{|c|c|c|c|c|c|}
\hline \\
\hline CHEMBL210887 & 809145 & 5.2 & 3.9201 & TST & \\
\hline CHEMBL458997 & 809145 & 5.7 & 5.6482 & TRN & \\
\hline CHEMBL227271 & 809145 & 4.1 & 4.0736 & TRN & \\
\hline CHEMBL583144 & 809145 & 5.1 & 4.6903 & TRN & \\
\hline CHEMBL1974310 & 809145 & 6.4 & 5.9506 & TRN & \\
\hline CHEMBL1982660 & 809145 & 4.1 & 4.2759 & TRN & \\
\hline CHEMBL1994693 & 809145 & 6.0 & 6.0627 & TRN & \\
\hline CHEMBL1982957 & 809145 & 5.3 & 5.434 & TRN & \\
\hline CHEMBL1975138 & 809145 & 6.1 & 6.6312 & TRN & \\
\hline CHEMBL2002346 & 809145 & 4.1 & 4.5167 & TRN & \\
\hline CHEMBL424872 & 809145 & 4.1 & 4.1554 & TRN & \\
\hline CHEMBL 2006836 & 809145 & 6.3 & 5.5272 & TST & \\
\hline CHEMBL1971947 & 809145 & 5.6 & 4.9307 & TRN & \\
\hline CHEMBL412142 & 809145 & 4.1 & 3.2634 & TST & \\
\hline CHEMBL1980704 & 809145 & 4.1 & 4.2481 & TST & \\
\hline CHEMBL 2003271 & 809145 & 4.1 & 3.9885 & TRN & \\
\hline CHEMBL1972365 & 809145 & 3.1 & 4.3481 & TST & \\
\hline CHEMBL1966808 & 809145 & 4.1 & 5.45200 & $\partial 000000001$ & TST \\
\hline CHEMBL 2004447 & 809145 & 4.1 & 3.88 & TRN & \\
\hline CHEMBL1983111 & 809145 & 4.1 & 6.1795 & TST & \\
\hline CHEMBL1973860 & 809145 & 4.1 & 4.2714 & TRN & \\
\hline CHEMBL1977713 & 809145 & 4.1 & 4.456 & TRN & \\
\hline CHEMBL260135 & 809145 & 4.1 & 4.0813 & TRN & \\
\hline CHEMBL220241 & 809145 & 4.1 & 5.4759 & TST & \\
\hline CHEMBL2004544 & 809145 & 6.6 & 4.5812 & TST & \\
\hline CHEMBL1982610 & 809145 & 4.1 & 5.3444 & TST & \\
\hline CHEMBL1986996 & 809145 & 5.3 & 4.7753 & TST & \\
\hline CHEMBL1999496 & 809145 & 6.8 & 5.5558 & TRN & \\
\hline CHEMBL1970873 & 809145 & 3.4 & 3.661 & TRN & \\
\hline CHEMBL2006933 & 809145 & 5.6 & 4.6957 & TST & \\
\hline CHEMBL1988300 & 809145 & 4.1 & 4.2217 & TRN & \\
\hline CHEMBL 2000685 & 809145 & 5.9 & 5.4932 & TRN & \\
\hline CHEMBL1985311 & 809145 & 6.0 & 5.3747 & TRN & \\
\hline CHEMBL1989265 & 809145 & 4.1 & 5.1501 & TST & \\
\hline CHEMBL 2004647 & 809145 & 4.1 & 4.5464 & TST & \\
\hline CHEMBL1969502 & 809145 & 5.7 & 6.0432 & TRN & \\
\hline CHEMBL1965910 & 809145 & 4.1 & 3.95899 & 99999999996 & TRN \\
\hline CHEMBL1682553 & 809145 & 4.1 & 3.9324 & TRN & \\
\hline CHEMBL1971430 & 809145 & 4.1 & 4.3284 & TRN & \\
\hline CHEMBL1997764 & 809145 & 4.1 & 4.2686 & TRN & \\
\hline CHEMBL1983963 & 809145 & 6.6 & 6.6834 & TRN & \\
\hline CHEMBL 2000271 & 809145 & 4.1 & 3.3465 & TST & \\
\hline CHEMBL562488 & 809145 & 3.1 & 4.4249 & TST & \\
\hline CHEMBL354676 & 809145 & 3.3 & 3.8171 & TST & \\
\hline CHEMBL1985092 & 809145 & 5.2 & 4.0532 & TST & \\
\hline CHEMBL2004692 & 809145 & 4.1 & 4.7338 & TST & \\
\hline CHEMBL1981410 & 809145 & 4.1 & 4.2168 & TST & \\
\hline CHEMBL1996234 & 809145 & 4.1 & 3.9024 & TST & \\
\hline & & & & 817 & \\
\hline
\end{tabular}




\begin{tabular}{|c|c|c|c|c|c|}
\hline \multicolumn{6}{|c|}{ Supplemental Table S2.txt } \\
\hline CHEMBL1991434 & 809145 & 4.1 & 5.3332 & TST & \\
\hline CHEMBL1967544 & 809145 & 4.1 & 3.4555 & TST & \\
\hline CHEMBL223367 & 809145 & 6.2 & 5.5999 & TST & \\
\hline CHEMBL340384 & 809145 & 5.2 & 4.5725 & TST & \\
\hline CHEMBL1996587 & 809145 & 4.1 & 3.801 & TST & \\
\hline CHEMBL1964804 & 809145 & 4.1 & 3.3295 & TST & \\
\hline CHEMBL443962 & 809145 & 4.1 & 4.1696 & TST & \\
\hline CHEMBL 2000354 & 809145 & 4.1 & 5.1204 & TST & \\
\hline CHEMBL1965507 & 809145 & 4.1 & 4.9646 & TST & \\
\hline CHEMBL1981107 & 809145 & 5.7 & 3.7221 & TST & \\
\hline CHEMBL274064 & 809145 & 4.1 & 3.3891 & TST & \\
\hline CHEMBL1967564 & 809145 & 4.1 & 4.1602 & TST & \\
\hline CHEMBL592030 & 809145 & 4.1 & 4.8558 & TST & \\
\hline CHEMBL2000071 & 809145 & 4.1 & 3.6867 & TST & \\
\hline CHEMBL1979176 & 809145 & 4.1 & 3.9498 & TST & \\
\hline CHEMBL1970317 & 809145 & 6.3 & 5.0544 & TST & \\
\hline CHEMBL2000408 & 809145 & 4.1 & 4.2624 & TST & \\
\hline CHEMBL 248757 & 809145 & 6.0 & 5.4541 & TST & \\
\hline CHEMBL1978014 & 809145 & 4.1 & 4.4213 & TST & \\
\hline CHEMBL1994538 & 809145 & 4.1 & 3.8574 & TST & \\
\hline CHEMBL1983195 & 809145 & 6.0 & 5.3511 & TST & \\
\hline CHEMBL1964444 & 809145 & 4.1 & 4.1045 & TST & \\
\hline CHEMBL1989957 & 809145 & 4.1 & 3.6991 & TST & \\
\hline CHEMBL2006567 & 809145 & 4.1 & 4.449 & TST & \\
\hline CHEMBL1986139 & 809145 & 4.1 & 4.0283 & TST & \\
\hline CHEMBL1980540 & 809145 & 4.1 & 4.748 & TST & \\
\hline CHEMBL1979883 & 809145 & 4.1 & 4.5212 & TST & \\
\hline CHEMBL3701357 & 1528286 & 8.1549 & 8.10799 & 9999999999 & TRN \\
\hline CHEMBL3701393 & 1528286 & 8.4089 & 7.9297 & TRN & \\
\hline CHEMBL3701293 & 1528286 & 7.6737 & 8.8542 & TST & \\
\hline CHEMBL3701408 & 1528286 & 8.5229 & 8.4504 & TRN & \\
\hline CHEMBL3701373 & 1528286 & 7.7423 & 7.9396 & TRN & \\
\hline CHEMBL3704792 & 1528286 & 8.2596 & 8.1595 & TRN & \\
\hline CHEMBL3701348 & 1528286 & 7.7721 & 9.0198 & TST & \\
\hline CHEMBL3701309 & 1528286 & 6.0 & 7.4621 & TRN & \\
\hline CHEMBL3704789 & 1528286 & 8.585 & 8.5908 & TRN & \\
\hline CHEMBL3704796 & 1528286 & 8.0809 & 8.1648 & TRN & \\
\hline CHEMBL3701292 & 1528286 & 7.6091 & 8.7576 & TST & \\
\hline CHEMBL3701374 & 1528286 & 8.3372 & 7.7966 & TRN & \\
\hline CHEMBL3701388 & 1528286 & 8.6778 & 8.4118 & TRN & \\
\hline CHEMBL3701310 & 1528286 & 8.3872 & 8.2766 & TRN & \\
\hline CHEMBL3701413 & 1528286 & 7.9318 & 8.0775 & TRN & \\
\hline CHEMBL3704793 & 1528286 & 8.1079 & 7.9006 & TRN & \\
\hline CHEMBL3701372 & 1528286 & 8.2757 & 8.0402 & TRN & \\
\hline CHEMBL3701313 & 1528286 & 8.1805 & 8.2636 & TST & \\
\hline CHEMBL3701294 & 1528286 & 7.5986 & 8.5936 & TST & \\
\hline CHEMBL3701327 & 1528286 & 8.2924 & 8.3211 & TRN & \\
\hline CHEMBL3701312 & 1528286 & 8.1249 & 8.2196 & TRN & \\
\hline
\end{tabular}


Supplemental Table S2.txt

\begin{tabular}{|c|c|c|c|c|c|}
\hline CHEMBL3701360 & 1528286 & 8.1192 & 8.547 & TRN & \\
\hline CHEMBL3704800 & 1528286 & 8.5686 & 8.3444 & TST & \\
\hline CHEMBL3704783 & 1528286 & 8.4559 & 8.2507 & TRN & \\
\hline CHEMBL3701384 & 1528286 & 8.4437 & 8.1666 & TRN & \\
\hline CHEMBL 3701323 & 1528286 & 8.1427 & 8.0798 & TRN & \\
\hline CHEMBL 3701370 & 1528286 & 8.4685 & 8.3648 & TRN & \\
\hline CHEMBL3701297 & 1528286 & 7.7905 & 7.938 & TRN & \\
\hline CHEMBL3701395 & 1528286 & 7.3098 & 7.6577 & TRN & \\
\hline CHEMBL3701320 & 1528286 & 7.1463 & 8.7794 & TST & \\
\hline CHEMBL3701350 & 1528286 & 8.6778 & 8.329 & TRN & \\
\hline CHEMBL 3701378 & 1528286 & 8.2924 & 7.8929 & TRN & \\
\hline CHEMBL3701399 & 1528286 & 8.3768 & 8.4094 & TRN & \\
\hline CHEMBL3701353 & 1528286 & 7.71 & 8.5281 & TST & \\
\hline CHEMBL3701333 & 1528286 & 8.3979 & 8.3876 & TRN & \\
\hline CHEMBL3701319 & 1528286 & 7.301 & 8.6711 & TST & \\
\hline CHEMBL3701305 & 1528286 & 8.3279 & 7.7387 & TRN & \\
\hline CHEMBL3701356 & 1528286 & 8.0655 & 8.0036 & TRN & \\
\hline CHEMBL 3701410 & 1528286 & 8.5528 & 8.1869 & TRN & \\
\hline CHEMBL3704804 & 1528286 & 8.5086 & 8.3514 & TRN & \\
\hline CHEMBL3704809 & 1528286 & 7.9547 & 8.0958 & TRN & \\
\hline CHEMBL3704787 & 1528286 & 7.9469 & 7.6057 & TRN & \\
\hline CHEMBL3701295 & 1528286 & 7.5918 & 9.0148 & TST & \\
\hline CHEMBL 3701403 & 1528286 & 8.0044 & 8.2017 & TRN & \\
\hline CHEMBL3701386 & 1528286 & 7.6737 & 7.7125 & TRN & \\
\hline CHEMBL3701330 & 1528286 & 7.1158 & 8.5969 & TST & \\
\hline CHEMBL3704777 & 1528286 & 8.4559 & 8.3933 & TRN & \\
\hline CHEMBL3704788 & 1528286 & 8.2147 & 8.2215 & TRN & \\
\hline CHEMBL 3701322 & 1528286 & 8.1249 & 8.0001 & TST & \\
\hline CHEMBL3701377 & 1528286 & 8.2007 & 8.4971 & TRN & \\
\hline CHEMBL 3701345 & 1528286 & 7.8447 & 8.3221 & TRN & \\
\hline CHEMBL3701379 & 1528286 & 7.8297 & 8.3012 & TRN & \\
\hline CHEMBL3704814 & 1528286 & 7.2765 & 8.315 & TST & \\
\hline CHEMBL3701362 & 1528286 & 7.6402 & 7.9174 & TST & \\
\hline CHEMBL3701291 & 1528286 & 8.301 & 8.0312 & TRN & \\
\hline CHEMBL3704797 & 1528286 & 8.1612 & 8.443999 & 9999999999 & TRN \\
\hline CHEMBL3701318 & 1528286 & 8.0862 & 7.9161 & TRN & \\
\hline CHEMBL3701325 & 1528286 & 8.0 & 8.4242 & TRN & \\
\hline CHEMBL3701354 & 1528286 & 8.0757 & 8.0418 & TRN & \\
\hline CHEMBL 3701371 & 1528286 & 8.3768 & 7.9505 & TRN & \\
\hline CHEMBL 3701412 & 1528286 & 8.0362 & 7.5982 & TRN & \\
\hline CHEMBL3704799 & 1528286 & 8.7212 & 8.3739 & TST & \\
\hline CHEMBL3701363 & 1528286 & 7.6757 & 7.7352 & TRN & \\
\hline CHEMBL3701367 & 1528286 & 8.0706 & 7.71 & TRN & \\
\hline CHEMBL3701382 & 1528286 & 6.0 & 8.208 & TRN & \\
\hline CHEMBL 3701361 & 1528286 & 8.1938 & 8.2078 & TRN & \\
\hline CHEMBL3701409 & 1528286 & 7.9957 & 7.6971 & TRN & \\
\hline CHEMBL3704782 & 1528286 & 8.585 & 7.8474 & TRN & \\
\hline CHEMBL3704815 & 1528286 & 7.7986 & 8.2011 & TRN & \\
\hline
\end{tabular}


Supplemental Table S2.txt

\begin{tabular}{|c|c|c|c|c|c|c|}
\hline CHEMBL3701321 & 1528286 & \multicolumn{3}{|c|}{7.218999999999999} & \multirow[t]{2}{*}{8.7299} & TST \\
\hline CHEMBL3701375 & 1528286 & 8.1308 & 8.2047 & TRN & & \\
\hline CHEMBL3701311 & 1528286 & 8.28399 & 99999999 & & 8.3773 & TRN \\
\hline CHEMBL3701306 & 1528286 & 8.1805 & 7.9853 & TRN & & \\
\hline CHEMBL3701296 & 1528286 & 7.6498 & 8.89299 & 999999999 & & TST \\
\hline CHEMBL3701324 & 1528286 & 7.1911 & 8.5786 & TST & & \\
\hline CHEMBL3704780 & 1528286 & 8.5229 & 8.0806 & TRN & & \\
\hline CHEMBL3701387 & 1528286 & 8.4202 & 8.0743 & TRN & & \\
\hline CHEMBL3701344 & 1528286 & 8.3468 & 8.279 & TRN & & \\
\hline CHEMBL3701349 & 1528286 & 6.0 & 7.5569 & TRN & & \\
\hline CHEMBL3701376 & 1528286 & 8.0555 & 8.4884 & TRN & & \\
\hline CHEMBL3701328 & 1528286 & 8.5229 & 8.2763 & TRN & & \\
\hline CHEMBL3701316 & 1528286 & 7.8761 & 8.5955 & TST & & \\
\hline CHEMBL3701301 & 1528286 & 7.8996 & 8.2069 & TRN & & \\
\hline CHEMBL3701400 & 1528286 & 7.6861 & 7.8045 & TRN & & \\
\hline CHEMBL3701329 & 1528286 & 7.4101 & 8.8486 & TST & & \\
\hline CHEMBL3701332 & 1528286 & 8.3565 & 8.5059 & TST & & \\
\hline CHEMBL3701383 & 1528286 & 7.6861 & 8.5219 & TST & & \\
\hline CHEMBL3704801 & 1528286 & 7.9788 & 7.7853 & TRN & & \\
\hline CHEMBL3701404 & 1528286 & 8.2596 & 8.0416 & TST & & \\
\hline CHEMBL3701351 & 1528286 & 8.2757 & 8.4558 & TRN & & \\
\hline CHEMBL3704795 & 1528286 & 8.5376 & 7.9328 & TRN & & \\
\hline CHEMBL3704794 & 1528286 & 8.5686 & 8.1459 & TRN & & \\
\hline CHEMBL3701340 & 1528286 & 7.1249 & 8.8999 & TST & & \\
\hline CHEMBL3701358 & 1528286 & 7.8697 & 8.4003 & TST & & \\
\hline CHEMBL3704808 & 1528286 & 8.4318 & 8.3406 & TRN & & \\
\hline CHEMBL3704791 & 1528286 & 8.5229 & 8.0204 & TRN & & \\
\hline CHEMBL3701390 & 1528286 & 8.4559 & 8.2374 & TRN & & \\
\hline CHEMBL3701389 & 1528286 & 8.6021 & 8.6324 & TRN & & \\
\hline CHEMBL3704785 & 1528286 & 7.3089 & 7.809 & TRN & & \\
\hline CHEMBL3701380 & 1528286 & 8.0132 & 7.8621 & TRN & & \\
\hline CHEMBL3704786 & 1528286 & 8.3565 & 8.1284 & TRN & & \\
\hline CHEMBL3704806 & 1528286 & 7.4365 & 7.7562 & TRN & & \\
\hline CHEMBL3701339 & 1528286 & 6.6786 & 9.1731 & TST & & \\
\hline CHEMBL3701304 & 1528286 & 8.3098 & 8.5019 & TST & & \\
\hline CHEMBL3701300 & 1528286 & 8.3565 & 8.4742 & TRN & & \\
\hline CHEMBL3701343 & 1528286 & 6.8729 & 9.5426 & TST & & \\
\hline CHEMBL3701302 & 1528286 & 8.0969 & 7.6338 & TRN & & \\
\hline CHEMBL3704813 & 1528286 & 8.0969 & 8.0221 & TRN & & \\
\hline CHEMBL3701366 & 1528286 & 7.0386 & 7.4548 & TRN & & \\
\hline CHEMBL3701392 & 1528286 & 8.3468 & 7.9876 & TRN & & \\
\hline CHEMBL3701359 & 1528286 & 7.7212 & 8.6071 & TST & & \\
\hline CHEMBL3701398 & 1528286 & 7.6126 & 7.4644 & TRN & & \\
\hline CHEMBL3701314 & 1528286 & 8.3279 & 8.1855 & TST & & \\
\hline CHEMBL3701308 & 1528286 & 8.2076 & 7.8219 & TRN & & \\
\hline CHEMBL3704798 & 1528286 & 8.1871 & 8.0661 & TST & & \\
\hline CHEMBL3640002 & 1528286 & 7.5186 & 7.5338 & TRN & & \\
\hline CHEMBL3701411 & 1528286 & 8.6021 & 8.463 & TRN & & \\
\hline
\end{tabular}


Supplemental Table S2.txt

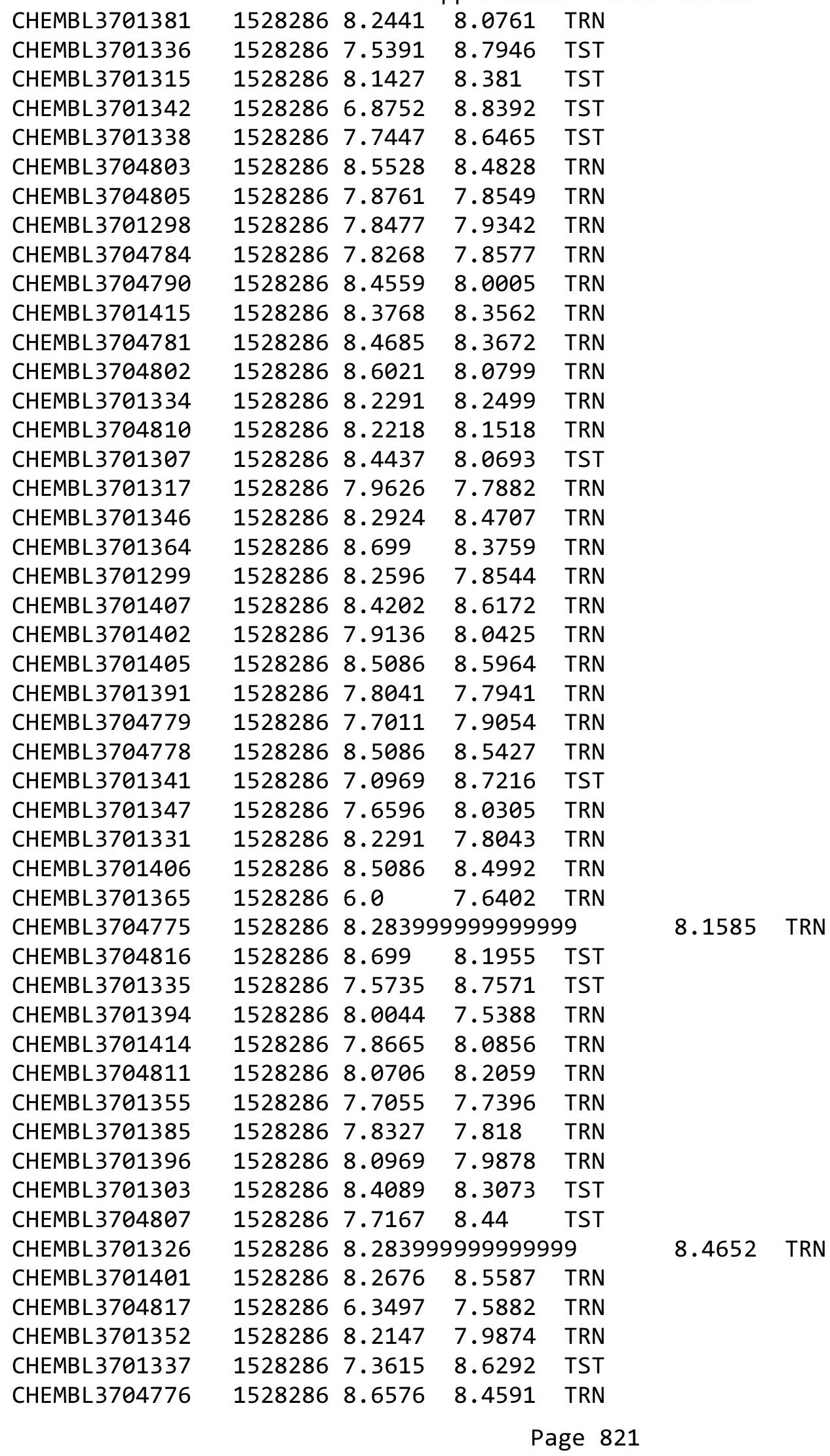


Supplemental Table S2.txt

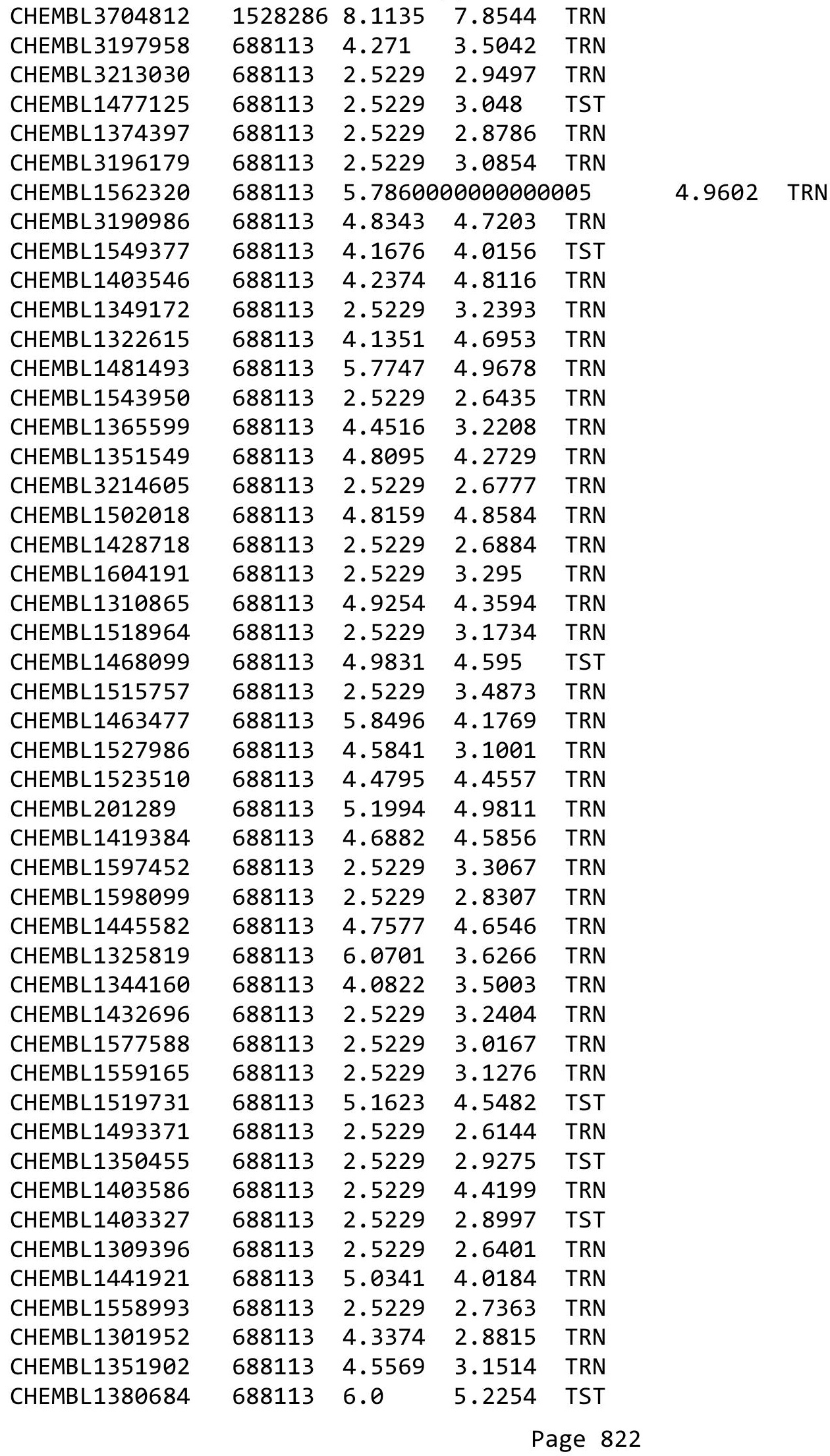


Supplemental Table S2.txt

\begin{tabular}{|c|c|c|c|c|}
\hline CHEMBL1447137 & 688113 & 2.5229 & 3.6834 & TRN \\
\hline CHEMBL1421081 & 688113 & 4.6334 & 3.4407 & TST \\
\hline CHEMBL1371292 & 688113 & 3.7815 & 4.691 & TRN \\
\hline CHEMBL1551695 & 688113 & 2.5229 & 3.6508 & TRN \\
\hline CHEMBL371107 & 688113 & 2.5229 & 2.9135 & TRN \\
\hline CHEMBL1401406 & 688113 & 4.5735 & 4.8633 & TRN \\
\hline CHEMBL1501269 & 688113 & 2.5229 & 3.1626 & TST \\
\hline CHEMBL1555657 & 688113 & 4.3419 & 3.1987 & TRN \\
\hline CHEMBL1318390 & 688113 & 4.7899 & 4.7667 & TRN \\
\hline CHEMBL1385559 & 688113 & 5.0586 & 4.84699 & 99999999995 \\
\hline CHEMBL1356088 & 688113 & 2.5229 & 3.4385 & TRN \\
\hline CHEMBL1522702 & 688113 & 2.5229 & 2.9773 & TRN \\
\hline CHEMBL 2007274 & 688113 & 2.5229 & 2.9595 & TRN \\
\hline CHEMBL1481257 & 688113 & 2.5229 & 2.7102 & TRN \\
\hline CHEMBL1405606 & 688113 & 4.3776 & 4.6448 & TRN \\
\hline CHEMBL1465545 & 688113 & 3.8132 & 4.5202 & TST \\
\hline CHEMBL1394204 & 688113 & 2.5229 & 3.1677 & TRN \\
\hline CHEMBL1418857 & 688113 & 4.2337 & 2.984 & TST \\
\hline CHEMBL1565141 & 688113 & 2.5229 & 2.67 & TRN \\
\hline CHEMBL1380331 & 688113 & 2.5229 & 2.9309 & TRN \\
\hline CHEMBL1586114 & 688113 & 2.5229 & 2.8591 & TRN \\
\hline CHEMBL1529192 & 688113 & 4.591 & 4.7774 & TRN \\
\hline CHEMBL1565291 & 688113 & 4.4242 & 2.9399 & TST \\
\hline CHEMBL1475386 & 688113 & 2.5229 & 2.8078 & TRN \\
\hline CHEMBL1524622 & 688113 & 4.8921 & 4.7589 & TRN \\
\hline CHEMBL1421529 & 688113 & 2.5229 & 2.7913 & TRN \\
\hline CHEMBL 3193220 & 688113 & 2.5229 & 3.0721 & TRN \\
\hline CHEMBL1310353 & 688113 & 4.686 & 4.5933 & TRN \\
\hline CHEMBL1565662 & 688113 & 4.1707 & 3.1014 & TRN \\
\hline CHEMBL1437786 & 688113 & 2.5229 & 2.6566 & TRN \\
\hline CHEMBL36654 & 688113 & 4.6685 & 4.7164 & TST \\
\hline CHEMBL1563000 & 688113 & 2.5229 & 2.8947 & TRN \\
\hline CHEMBL1457473 & 688113 & 2.5229 & 2.6797 & TRN \\
\hline CHEMBL 3198724 & 688113 & 3.641 & 2.9695 & TRN \\
\hline CHEMBL1332421 & 688113 & 4.7325 & 4.2021 & TRN \\
\hline CHEMBL1425931 & 688113 & 2.5229 & 2.9458 & TRN \\
\hline CHEMBL 3197324 & 688113 & 5.0511 & 4.763 & TRN \\
\hline CHEMBL1469130 & 688113 & 2.5229 & 2.7522 & TRN \\
\hline CHEMBL1438019 & 688113 & 5.3195 & 4.4717 & TRN \\
\hline CHEMBL52 & 688113 & 5.0577 & 5.1052 & TRN \\
\hline CHEMBL 3189447 & 688113 & 4.753 & 2.972 & TRN \\
\hline CHEMBL122330 & 688113 & 5.0796 & 5.4627 & TRN \\
\hline CHEMBL1536243 & 688113 & 4.9069 & 3.4536 & TRN \\
\hline CHEMBL1398799 & 688113 & 2.5229 & 3.7835 & TRN \\
\hline CHEMBL1508544 & 688113 & 2.5229 & 2.8466 & TST \\
\hline CHEMBL1999960 & 688113 & 2.5229 & 3.5145 & TRN \\
\hline CHEMBL1451032 & 688113 & 5.11 & 5.0745 & TST \\
\hline CHEMBL1348800 & 688113 & 2.5229 & 4.404 & TRN \\
\hline
\end{tabular}


Supplemental Table S2.txt

\begin{tabular}{|c|c|c|c|c|c|}
\hline CHEMBL1484753 & 688113 & 2.5229 & 2.9014 & TRN & \\
\hline CHEMBL1352343 & 688113 & 2.5229 & 2.6613 & TRN & \\
\hline CHEMBL1605668 & 688113 & 2.5229 & 2.7011 & TRN & \\
\hline CHEMBL1381318 & 688113 & 4.9846 & 3.8279 & TRN & \\
\hline CHEMBL1976044 & 688113 & 2.5229 & 3.1658 & TRN & \\
\hline CHEMBL1409666 & 688113 & 2.5229 & 2.5863 & TRN & \\
\hline CHEMBL1392590 & 688113 & 2.5229 & 2.641 & TRN & \\
\hline CHEMBL1419164 & 688113 & 6.7375 & 5.6302 & TRN & \\
\hline CHEMBL1561889 & 688113 & 4.4614 & 4.5606 & TST & \\
\hline CHEMBL1399199 & 688113 & 2.5229 & 2.8672 & TRN & \\
\hline CHEMBL1333824 & 688113 & 4.2385 & 4.7915 & TRN & \\
\hline CHEMBL1548928 & 688113 & 2.5229 & 3.1522 & TRN & \\
\hline CHEMBL1471997 & 688113 & 2.5229 & 2.7715 & TRN & \\
\hline CHEMBL1378605 & 688113 & 2.5229 & 2.5776 & TRN & \\
\hline CHEMBL1401848 & 688113 & 2.5229 & 4.5033 & TST & \\
\hline CHEMBL1338320 & 688113 & 2.5229 & 3.1244 & TRN & \\
\hline CHEMBL3192454 & 688113 & 4.488 & 5.0602 & TRN & \\
\hline CHEMBL1358861 & 688113 & 2.5229 & 2.6439 & TRN & \\
\hline CHEMBL1312514 & 688113 & 4.4587 & 4.3244 & TRN & \\
\hline CHEMBL1602261 & 688113 & 4.2565 & 2.9489 & TRN & \\
\hline CHEMBL1547446 & 688113 & 4.4255 & 4.5283 & TRN & \\
\hline CHEMBL1442704 & 688113 & 2.5229 & 3.1679 & TRN & \\
\hline CHEMBL297453 & 688113 & 6.1385 & 5.2881 & TST & \\
\hline CHEMBL1574316 & 688113 & 2.5229 & 2.8817 & TRN & \\
\hline CHEMBL1402992 & 688113 & 2.5229 & 2.7354 & TRN & \\
\hline CHEMBL1311625 & 688113 & 2.5229 & 3.0659 & TST & \\
\hline CHEMBL1520689 & 688113 & 2.5229 & 2.9003 & TRN & \\
\hline CHEMBL1430110 & 688113 & 4.8755 & 3.1892 & TRN & \\
\hline CHEMBL1400829 & 688113 & 2.5229 & 2.9861 & TST & \\
\hline CHEMBL1566684 & 688113 & 5.7044 & 2.9547 & TRN & \\
\hline CHEMBL1429070 & 688113 & 5.7773 & 5.3936 & TRN & \\
\hline CHEMBL1459555 & 688113 & 4.4022 & 4.3474 & TRN & \\
\hline CHEMBL1976839 & 688113 & 2.5229 & 3.2826 & TRN & \\
\hline CHEMBL1372920 & 688113 & 6.5391 & \multicolumn{2}{|c|}{5.377000000000001} & TRN \\
\hline CHEMBL1414875 & 688113 & 3.9865 & 3.8365 & TRN & \\
\hline CHEMBL1544326 & 688113 & 2.5229 & 2.5272 & TRN & \\
\hline CHEMBL1392231 & 688113 & 4.5841 & 4.9429 & TRN & \\
\hline CHEMBL1378567 & 688113 & 2.5229 & 2.7859 & TRN & \\
\hline CHEMBL66966 & 688113 & 5.0579 & 5.1072 & TRN & \\
\hline CHEMBL1447403 & 688113 & 4.7787 & 4.8819 & TRN & \\
\hline CHEMBL1526069 & 688113 & 4.6373 & 3.4212 & TRN & \\
\hline CHEMBL1311929 & 688113 & 5.1972 & 4.5409 & TRN & \\
\hline CHEMBL1582721 & 688113 & 2.5229 & 2.9688 & TRN & \\
\hline CHEMBL1609014 & 688113 & 3.7212 & 3.4827 & TRN & \\
\hline CHEMBL1532663 & 688113 & 4.2123 & 4.1362 & TRN & \\
\hline CHEMBL1610224 & 688113 & 2.5229 & 2.7098 & TRN & \\
\hline CHEMBL 3197553 & 688113 & 2.5229 & 3.2235 & TRN & \\
\hline CHEMBL1342337 & 688113 & 4.4135 & 3.3269 & TRN & \\
\hline
\end{tabular}

Page 824 
Supplemental Table S2.txt

\begin{tabular}{|c|c|c|c|c|c|c|}
\hline CHEMBL1538427 & 688113 & 2.5229 & 2.6106 & TRN & & \\
\hline CHEMBL1488981 & 688113 & 4.5738 & 4.7883 & TRN & & \\
\hline CHEMBL1576762 & 688113 & 5.7637 & 4.9138 & TRN & & \\
\hline CHEMBL1459011 & 688113 & 2.5229 & 2.9619 & TRN & & \\
\hline CHEMBL1349197 & 688113 & 5.1117 & 4.7294 & TRN & & \\
\hline CHEMBL1307487 & 688113 & 4.1292 & 2.6761 & TRN & & \\
\hline CHEMBL1387790 & 688113 & 4.6096 & 4.341 & TRN & & \\
\hline CHEMBL1541254 & 688113 & 4.1225 & 4.2067 & TRN & & \\
\hline CHEMBL1495485 & 688113 & 4.7592 & 4.5601 & TRN & & \\
\hline CHEMBL1386096 & 688113 & 4.2469 & 3.0921 & TRN & & \\
\hline CHEMBL1401266 & 688113 & 2.5229 & 2.9757 & TRN & & \\
\hline CHEMBL1321993 & 688113 & 2.5229 & 2.5899 & TRN & & \\
\hline CHEMBL1459459 & 688113 & 2.5229 & 2.9625 & TST & & \\
\hline CHEMBL1378352 & 688113 & 2.5229 & 2.6697 & TRN & & \\
\hline CHEMBL3216654 & 688113 & 4.4649 & 4.3541 & TST & & \\
\hline CHEMBL1342667 & 688113 & 4.4354 & 4.832 & TRN & & \\
\hline CHEMBL1990742 & 688113 & 4.2155 & 3.9538 & TRN & & \\
\hline CHEMBL1310138 & 688113 & 5.3204 & 5.2683 & TST & & \\
\hline CHEMBL1313485 & 688113 & 6.0615 & 4.6232 & TRN & & \\
\hline CHEMBL1578931 & 688113 & 4.6785 & 3.3363 & TRN & & \\
\hline CHEMBL1425000 & 688113 & 2.5229 & 2.7698 & TRN & & \\
\hline CHEMBL1972190 & 688113 & 2.5229 & 2.9048 & TRN & & \\
\hline CHEMBL1325374 & 688113 & 2.5229 & 2.7507 & TRN & & \\
\hline CHEMBL1444054 & 688113 & 2.5229 & 2.5453 & TRN & & \\
\hline CHEMBL1555752 & 688113 & 4.8131 & 3.4539 & TRN & & \\
\hline CHEMBL1427125 & 688113 & 2.5229 & 2.8037 & TRN & & \\
\hline CHEMBL1481627 & 688113 & 2.5229 & 2.9676 & TRN & & \\
\hline CHEMBL1364329 & 688113 & 2.5229 & 2.9702 & TRN & & \\
\hline CHEMBL 3198297 & 688113 & 2.5229 & 3.0436 & TRN & & \\
\hline CHEMBL1581048 & 688113 & 3.6958 & 4.4763 & TRN & & \\
\hline CHEMBL1462002 & 688113 & 5.9884 & 5.1458 & TRN & & \\
\hline CHEMBL1302827 & 688113 & 2.5229 & 3.2508 & TRN & & \\
\hline CHEMBL3189865 & 688113 & 4.0883 & 4.5506 & TRN & & \\
\hline CHEMBL3189823 & 688113 & \multicolumn{3}{|c|}{5.372999999999999} & 4.8301 & TRN \\
\hline CHEMBL1382785 & 688113 & 5.2538 & 5.005 & TRN & & \\
\hline CHEMBL1369958 & 688113 & 2.5229 & 2.7926 & TRN & & \\
\hline CHEMBL1501508 & 688113 & 5.9602 & 5.0119 & TRN & & \\
\hline CHEMBL1372505 & 688113 & 3.7453 & 4.6531 & TRN & & \\
\hline CHEMBL1597974 & 688113 & 4.846 & 4.9809 & TRN & & \\
\hline CHEMBL1331211 & 688113 & 5.0876 & 4.9094 & TRN & & \\
\hline CHEMBL1340338 & 688113 & 6.5317 & 4.7483 & TRN & & \\
\hline CHEMBL1572210 & 688113 & \multicolumn{3}{|c|}{4.1160000000000005} & 3.2273 & TRN \\
\hline CHEMBL1363642 & 688113 & 2.5229 & 3.1818 & TRN & & \\
\hline CHEMBL1369175 & 688113 & 2.5229 & 2.4456 & TRN & & \\
\hline CHEMBL1549526 & 688113 & 2.5229 & 2.8555 & TRN & & \\
\hline CHEMBL1328856 & 688113 & 4.8447 & 4.7651 & TRN & & \\
\hline CHEMBL 3194876 & 688113 & 7.0655 & 4.749 & TRN & & \\
\hline CHEMBL3193122 & 688113 & 2.5229 & 2.8343 & TRN & & \\
\hline
\end{tabular}

Page 825 


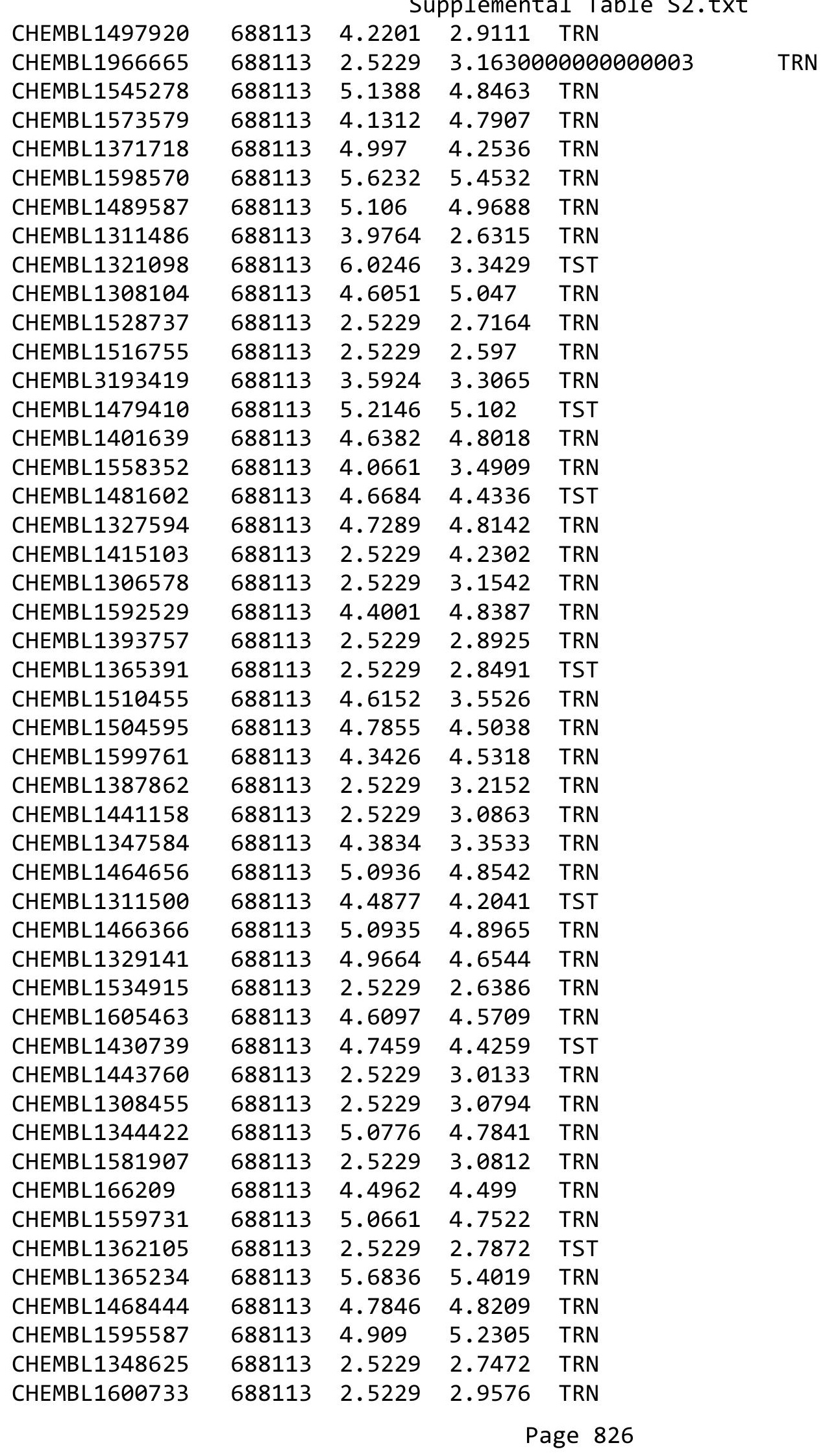


Supplemental Table S2.txt

\begin{tabular}{|c|c|c|c|c|}
\hline- & 113 & & & \\
\hline HЕMPI 1420706 & 88113 & .5229 & 7606 & \\
\hline & & & & \\
\hline EMPI 27 & 3113 & 29 & & \\
\hline IEMBL1513075 & 88113 & 643 & 1206 & \\
\hline AEMBL3193785 & 88113 & 7407 & 7146 & \\
\hline HEMBL15 & 88113 & 7902 & 7027 & \\
\hline IFN & & 229 & 6812 & \\
\hline IEMBL1549772 & 88113 & 2.5229 & .7836 & \\
\hline AEMBL3191703 & 88113 & 229 & .0859 & \\
\hline HEMBL1312974 & 88113 & 2697 & 4447 & \\
\hline AEMBL3208527 & 88113 & 229 & .8964 & \\
\hline AEMBL & 113 & & & \\
\hline AEMBL1386348 & 88113 & 888 & .5086 & \\
\hline JEMBL1354008 & 88113 & 229 & 9868 & \\
\hline IEMBL1410740 & 88113 & 229 & 105 & \\
\hline JEMBL142 & 88113 & 59 & 1301 & \\
\hline HEMBL135 & 38113 & & 1262 & \\
\hline AEMBL1365457 & 88113 & 383 & 991 & \\
\hline AEMBL1517505 & 38113 & & 512 & \\
\hline AEMBL1612714 & 8113 & 229 & 2.9192 & \\
\hline HEMBL1530689 & 38113 & 9 & 043 & RN \\
\hline 51 & & & & \\
\hline 500 & 88113 & & 714 & \\
\hline IEMBL 200 & 13 & & 25 & SI \\
\hline L3196 & 3 & 29 & 924 & RN \\
\hline L1312212 & 38113 & & 144 & RN \\
\hline 3 & 13 & & & RN \\
\hline 928 & & & 788 & 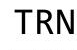 \\
\hline IEMBL14 & 88113 & & 36 & RN \\
\hline IEMBL13 & 13 & 29 & 268 & RN \\
\hline 3 & 3 & & 82 & \\
\hline- & & & & ST \\
\hline HEMBL3212916 & & & 21 & ST \\
\hline IEMBL13654 & 88113 & & 125 & RN \\
\hline AEMBL14384 & 38113 & 29 & 034 & \\
\hline HEMDI 10 & & & & RN \\
\hline HEMBL1478572 & & & 4.5839 & ST \\
\hline HEMBL1325348 & 88113 & & 3.9932 & RN \\
\hline EMBL15202 & 88113 & & 781 & RN \\
\hline HEMBL 318973 & 13 & 29 & 2.8374 & 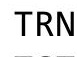 \\
\hline HEMBL1522718 & & & & ST \\
\hline HEMBL1332375 & 8113 & & 2.6021 & $\mathrm{RN}$ \\
\hline AEMBL1570774 & 88113 & 29 & 5 & RN \\
\hline IFMRI 1971 & & & 1277 & \\
\hline HEMBL239103 & 588113 & & 5.2765 & \\
\hline 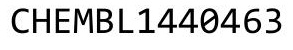 & 88113 & 2.5229 & 3.0585 & \\
\hline HEMBL143180 & 688113 & 4.4691 & 4.3568 & \\
\hline
\end{tabular}


Supplemental Table S2.txt

\begin{tabular}{|c|c|c|c|c|}
\hline HEMBL21353 & & 29 & & \\
\hline UГMDI 1400616 & 88113 & .9506 & 3.2262 & \\
\hline & & & & \\
\hline AEMBL15 & & 229 & & \\
\hline AEMBL1313065 & 8113 & 229 & 9984 & \\
\hline HEMBL1408193 & 88113 & 5229 & 7723 & \\
\hline HEMBL1: & 8113 & & 477 & \\
\hline IEMBL1486886 & & & & \\
\hline AEMBL1387618 & 88113 & & 4.4664 & \\
\hline HEMBL1453783 & 88113 & 229 & .0678 & \\
\hline HEMBL1317867 & 88113 & & 6211 & \\
\hline IEMBL14 & 113 & & .7953 & \\
\hline IEMBL14 & & & & \\
\hline AEMBL3195145 & 88113 & & 2.7867 & \\
\hline AEMBL102714 & 13 & & .7714 & \\
\hline IEMBL14 & 13 & 29 & 2.8883 & \\
\hline AEMBL13 & 113 & & 4.9314 & \\
\hline HEMBL 14 & & & 3.1555 & \\
\hline JEMBL14 & & & 3.6609 & \\
\hline AEMBL15 & 3 & & & ST \\
\hline IEIMBL3. & & & 664 & \\
\hline AEMBL1 & & & 36 & \\
\hline AEMBL32 & 13 & & 456 & \\
\hline$A F M R I \triangle$ & & & 5.3811 & \\
\hline AEMBL13 & & & & NIV \\
\hline HEMBL1 & & & 27 & RI \\
\hline AEMBL1 & & & 41 & \\
\hline HEMBL14 & 13 & & 36 & RN \\
\hline HEMBL13 & & & & $\mathrm{RN}$ \\
\hline HEMBL3210868 & 3 & & & RIN \\
\hline HEMBL1 & & & 45 & \\
\hline HEMBL1 & & & 01 & \\
\hline HFMRI 1 & & & & RN \\
\hline HEMBL1481714 & & & 2.9312 & RN \\
\hline HEMBL1309512 & & & & $\mathrm{RN}$ \\
\hline HEMBL1: & & & 4.4487 & \\
\hline HᄃMP 1 & & & 44 & RN \\
\hline HEMBL1 & & & 4.7091 & RN \\
\hline HEMBL1428662 & 88113 & & 1.0254 & $\Gamma \mathrm{RN}$ \\
\hline EMBL3: & & & 4.2984 & RN \\
\hline HEMBL15 & & & 3.6147 & \\
\hline HEMBL14 & & & 2.4923 & RN \\
\hline HEMBL15 & & & 3.0079 & RN \\
\hline AEMBL3192138 & 8113 & & .9519 & RN \\
\hline MBL1 & & & 3.0993 & \\
\hline CHEMBL1497731 & & & 2.8586 & \\
\hline CHEMBL1571298 & & 2.5229 & 3.2606 & \\
\hline HEMBL150335 & 688113 & 4.747 & 4.7812 & ГRN \\
\hline
\end{tabular}

Page 828 


\begin{tabular}{|c|c|c|c|c|c|}
\hline & & \multicolumn{4}{|c|}{ Supplemental Table S2.txt } \\
\hline CHEMBL1528899 & 688113 & 5.4259 & 3.7258 & TRN & \\
\hline CHEMBL1479366 & 688113 & 4.8581 & 4.6836 & TRN & \\
\hline CHEMBL1499978 & 688113 & 4.4588 & 3.3878 & TRN & \\
\hline CHEMBL1483025 & 688113 & 4.6261 & 3.0418 & TRN & \\
\hline CHEMBL1299808 & 688113 & 4.9527 & 4.8343 & TST & \\
\hline CHEMBL1520090 & 688113 & 4.5829 & 4.4421 & TST & \\
\hline CHEMBL1351297 & 688113 & 5.062 & 4.5401 & TRN & \\
\hline CHEMBL1570453 & 688113 & 2.5229 & 2.8954 & TRN & \\
\hline CHEMBL1327409 & 688113 & 5.8374 & 3.0352 & TRN & \\
\hline CHEMBL1511743 & 688113 & 2.5229 & 2.6344 & TRN & \\
\hline CHEMBL1608853 & 688113 & 4.4932 & 3.5094 & TRN & \\
\hline CHEMBL1348355 & 688113 & 4.4923 & 4.9519 & TRN & \\
\hline CHEMBL1536155 & 688113 & 2.5229 & 3.1303 & TST & \\
\hline CHEMBL 3212322 & 688113 & 2.5229 & 3.1735 & TRN & \\
\hline CHEMBL1303235 & 688113 & 4.6223 & 4.7023 & TRN & \\
\hline CHEMBL1333169 & 688113 & 4.4449 & 3.3049 & TRN & \\
\hline CHEMBL1526699 & 688113 & 4.5872 & 4.4942 & TRN & \\
\hline CHEMBL1401755 & 688113 & 3.8474 & 3.1514 & TRN & \\
\hline CHEMBL1530303 & 688113 & 2.5229 & 2.8361 & TRN & \\
\hline CHEMBL1312167 & 688113 & 4.5267 & 2.8752 & TRN & \\
\hline CHEMBL1353270 & 688113 & 2.5229 & 3.0715 & TST & \\
\hline CHEMBL1301852 & 688113 & 2.5229 & 3.1271 & TST & \\
\hline CHEMBL3191954 & 688113 & 2.5229 & 2.7071 & TRN & \\
\hline CHEMBL1601175 & 688113 & 4.4484 & 3.458 & TRN & \\
\hline CHEMBL1523364 & 688113 & 3.7624 & 2.7769 & TRN & \\
\hline CHEMBL1569474 & 688113 & 2.5229 & 2.5102 & TRN & \\
\hline CHEMBL3210094 & 688113 & 4.8993 & 4.5958 & TRN & \\
\hline CHEMBL1310269 & 688113 & 4.3827 & 4.2434 & TRN & \\
\hline CHEMBL1485368 & 688113 & 2.8239 & 3.9112 & TRN & \\
\hline CHEMBL1398596 & 688113 & 2.5229 & 2.9871 & TRN & \\
\hline CHEMBL1380676 & 688113 & 2.5229 & 4.7543 & TRN & \\
\hline CHEMBL1528856 & 688113 & 4.6869 & 4.7084 & TRN & \\
\hline CHEMBL1324317 & 688113 & 2.5229 & 2.8818 & TRN & \\
\hline CHEMBL1517522 & 688113 & 2.5229 & 2.9663 & TRN & \\
\hline CHEMBL1409269 & 688113 & 4.6297 & 4.6512 & TRN & \\
\hline CHEMBL27871 & 688113 & 4.9921 & 4.6382 & TST & \\
\hline CHEMBL1301297 & 688113 & 2.5229 & 2.4753 & TRN & \\
\hline CHEMBL391877 & 688113 & 7.0 & 6.0511 & TRN & \\
\hline CHEMBL1418763 & 688113 & 2.5229 & 3.1202 & TRN & \\
\hline CHEMBL1346615 & 688113 & 2.5229 & 2.82899 & 99999999997 & TRN \\
\hline CHEMBL1312377 & 688113 & 2.5229 & 4.5558 & TRN & \\
\hline CHEMBL1492148 & 688113 & 4.5933 & 2.81100 & 00000000004 & TRN \\
\hline CHEMBL1505230 & 688113 & 3.6274 & 3.4225 & TRN & \\
\hline CHEMBL1582163 & 688113 & 2.5229 & 2.6622 & TRN & \\
\hline CHEMBL1546791 & 688113 & 5.2576 & 3.2758 & TRN & \\
\hline CHEMBL1575375 & 688113 & 5.1273 & 4.5524 & TRN & \\
\hline CHEMBL1370447 & 688113 & 5.5452 & 4.7 & TRN & \\
\hline CHEMBL3192451 & 688113 & 4.1772 & 4.8947 & TRN & \\
\hline
\end{tabular}




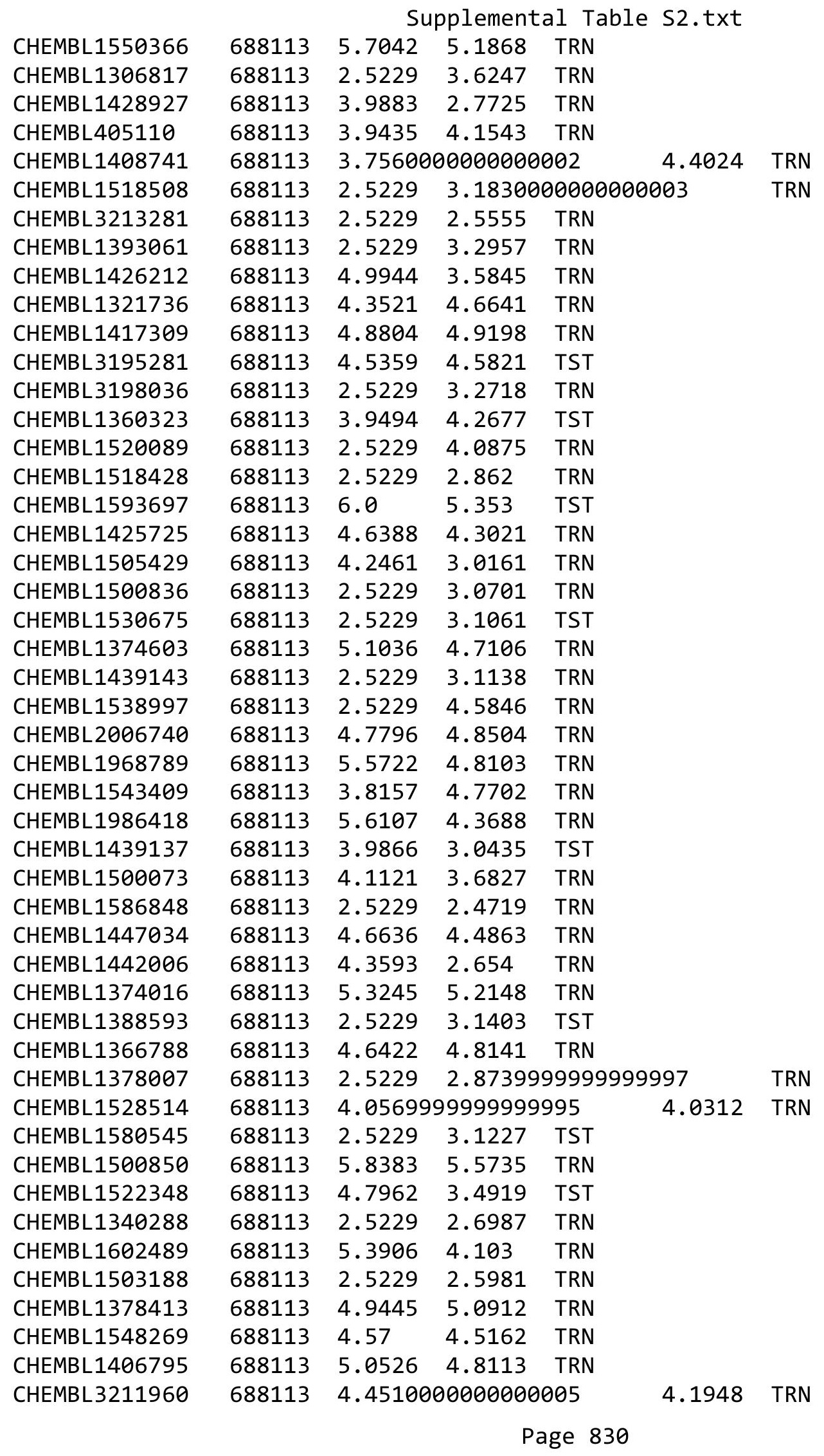


Supplemental Table S2.txt

\begin{tabular}{|c|c|c|c|c|}
\hline CHEMBL1304684 & 688113 & 2.5229 & 2.8982 & TRN \\
\hline CHEMBL1393490 & 688113 & 2.5229 & 2.6298 & TRN \\
\hline CHEMBL1488693 & 688113 & 4.9119 & 4.8609 & TRN \\
\hline CHEMBL1450930 & 688113 & 4.6942 & 3.6556 & TRN \\
\hline CHEMBL1449875 & 688113 & 4.5289 & 5.0232 & TRN \\
\hline CHEMBL1491562 & 688113 & 5.1991 & 4.7232 & TRN \\
\hline CHEMBL1402117 & 688113 & 5.34399 & 999999999 & 5.1856 \\
\hline CHEMBL1390702 & 688113 & 4.7482 & 3.477 & TRN \\
\hline CHEMBL1568292 & 688113 & 4.5626 & 4.2773 & TRN \\
\hline CHEMBL1479391 & 688113 & 2.5229 & 2.8156 & TRN \\
\hline CHEMBL1603748 & 688113 & 2.5229 & 2.8114 & TRN \\
\hline CHEMBL1310375 & 688113 & 4.7204 & 5.1199 & TRN \\
\hline CHEMBL 3199468 & 688113 & 5.9531 & 4.7179 & TRN \\
\hline CHEMBL1565096 & 688113 & 2.5229 & 2.9423 & TRN \\
\hline CHEMBL 3190785 & 688113 & 4.4538 & 3.0245 & TRN \\
\hline CHEMBL1529516 & 688113 & 2.5229 & 2.8746 & TRN \\
\hline CHEMBL3145010 & 688113 & 5.4347 & 4.9435 & TRN \\
\hline CHEMBL1369950 & 688113 & 2.5229 & 4.343999 & 9999999999 \\
\hline CHEMBL1373237 & 688113 & 2.5229 & 2.5136 & TRN \\
\hline CHEMBL1401536 & 688113 & 4.6514 & 4.5256 & TST \\
\hline CHEMBL1330710 & 688113 & 4.3476 & 4.8792 & TRN \\
\hline CHEMBL1544349 & 688113 & 4.2271 & 4.6902 & TST \\
\hline CHEMBL3198578 & 688113 & 4.1956 & 3.2897 & TRN \\
\hline CHEMBL1508001 & 688113 & 4.4147 & 4.6174 & TRN \\
\hline CHEMBL1518895 & 688113 & 4.4165 & 4.1423 & TRN \\
\hline CHEMBL1341918 & 688113 & 2.5229 & 2.5365 & TRN \\
\hline CHEMBL1561932 & 688113 & 2.5229 & 2.8486 & TRN \\
\hline CHEMBL1322709 & 688113 & 4.2112 & 4.1494 & TRN \\
\hline CHEMBL1497838 & 688113 & 4.8288 & 4.7904 & TST \\
\hline CHEMBL1570066 & 688113 & 2.8239 & 4.7125 & TRN \\
\hline CHEMBL1329990 & 688113 & 4.7327 & 4.425 & TST \\
\hline CHEMBL1403110 & 688113 & 2.5229 & 2.6265 & TRN \\
\hline CHEMBL1408817 & 688113 & 2.5229 & 2.9303 & TRN \\
\hline CHEMBL1519231 & 688113 & 4.4126 & 2.8091 & TRN \\
\hline CHEMBL1369102 & 688113 & 4.8435 & 4.2268 & TRN \\
\hline CHEMBL1300484 & 688113 & 2.5229 & 2.7463 & TRN \\
\hline CHEMBL1332240 & 688113 & 4.5161 & 4.1178 & TRN \\
\hline CHEMBL199868 & 688113 & 2.5229 & 3.4053 & TRN \\
\hline CHEMBL1369329 & 688113 & 3.6768 & 3.2162 & TRN \\
\hline CHEMBL1973532 & 688113 & 4.3955 & 3.4757 & TRN \\
\hline CHEMBL 3211410 & 688113 & 2.5229 & 2.778 & TST \\
\hline CHEMBL1468490 & 688113 & 4.6583 & 4.666 & TRN \\
\hline CHEMBL1339485 & 688113 & 2.5229 & 3.0196 & TRN \\
\hline CHEMBL1438081 & 688113 & 4.8357 & 4.434 & TRN \\
\hline CHEMBL1981657 & 688113 & 4.5831 & 4.837 & TRN \\
\hline CHEMBL483531 & 688113 & 2.5229 & 4.6873 & TST \\
\hline CHEMBL1338176 & 688113 & 3.8152 & 4.0946 & TST \\
\hline CHEMBL1302189 & 688113 & 2.5229 & 3.0817 & TST \\
\hline
\end{tabular}


Supplemental Table S2.txt

\begin{tabular}{|c|c|c|c|c|}
\hline 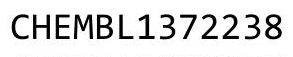 & & & & \\
\hline HEMBL1098875 & 88113 & 5229 & 3017 & \\
\hline HEMBL1509548 & 88113 & 5229 & & \\
\hline IEMBL3. & & 25 & & \\
\hline EMBL14 & & & & \\
\hline HEMBL1494729 & 88113 & 4.6484 & 024 & \\
\hline HEMBL1429733 & 88113 & 2.5229 & 2752 & \\
\hline HEMBL198 & 88113 & & 5034 & \\
\hline AEMBL 2 & 13 & & 1112 & \\
\hline IEMBL148 & 13 & & 979 & \\
\hline HEMBL1444791 & 88113 & 2.5229 & 3587 & \\
\hline HEMBL1455361 & 88113 & & 9397 & \\
\hline HEMBL542 & 13 & 4.62 & 198 & \\
\hline HEMBL14 & 13 & & 55 & \\
\hline HEMBL13 & 3 & & & \\
\hline HEMBL138 & 13 & 29 & 462 & \\
\hline HEMBL13e & 88113 & 61 & 566 & \\
\hline HEMBL142 & 88 & & 9502 & \\
\hline HEMBL13 & & & 507 & \\
\hline HEMBL1C & 13 & & 202 & \\
\hline HEMBL 14 & 3 & & & \\
\hline HEMBL136 & 88 & & 7661 & \\
\hline HEMBL13. & 88 & & 7563 & \\
\hline HEMBL14 & & & 5566 & \\
\hline HEM & 3 & & 307 & RN \\
\hline HEMBL 319 & 3 & & & RN \\
\hline HEMBL1301464 & 3 & & 7728 & RN \\
\hline HEMBL198 & 88 & & 66 & \\
\hline HEME & 3 & & 362 & RN \\
\hline HEMBL15 & 3 & & 558 & RN \\
\hline HEMBL132 & 3 & & & RN \\
\hline HEMBL1577292 & 88 & & 558 & RN \\
\hline HEMBL138 & 3 & 12 & 165 & II \\
\hline 3 & 3 & & 38 & RN \\
\hline HEMBL143 & & & 2231 & RN \\
\hline HEMBL1375078 & 88 & & 412 & ST \\
\hline HEMBL1502090 & 881 & & 119 & RN \\
\hline HEMBL3195762 & כ2 & & 201 & RN \\
\hline 30 & 3 & & & RN \\
\hline HEMBL 319 & & & & RN \\
\hline HEMBL131S & 88113 & & 5923 & RN \\
\hline HEMBL 14 & 3 & & 3656 & RN \\
\hline HEMBL146 & 13 & & & \\
\hline CHEMBL1398098 & 88113 & & & RN \\
\hline HEMBL1379433 & & & 5823 & RN \\
\hline HEMBL3189263 & 88113 & 29 & 333 & RN \\
\hline 13 & & & & \\
\hline 1 1 & & & & \\
\hline
\end{tabular}

Page 832 
Supplemental Table S2.txt

\begin{tabular}{|c|c|c|c|c|}
\hline CHEMBL1449697 & 688113 & 2.5229 & 3.6773 & TRN \\
\hline CHEMBL246446 & 688113 & 4.9935 & 4.8041 & TRN \\
\hline CHEMBL1469444 & 688113 & 5.1204 & 5.2254 & TRN \\
\hline CHEMBL1423851 & 688113 & 2.5229 & 2.8744 & TRN \\
\hline CHEMBL1413087 & 688113 & 4.712 & 4.9191 & TRN \\
\hline CHEMBL1429861 & 688113 & 5.1576 & 3.0453 & TRN \\
\hline CHEMBL1582403 & 688113 & 5.1642 & 4.8017 & TRN \\
\hline CHEMBL1584753 & 688113 & 5.2968 & 4.5002 & TRN \\
\hline CHEMBL1509330 & 688113 & 2.5229 & 2.5848 & TRN \\
\hline CHEMBL1443882 & 688113 & 4.6763 & 4.9571 & TRN \\
\hline CHEMBL1524225 & 688113 & 5.9382 & 5.7665 & TRN \\
\hline CHEMBL1519456 & 688113 & 2.5229 & 2.9242 & TRN \\
\hline CHEMBL1301239 & 688113 & 4.2535 & 2.867 & TRN \\
\hline CHEMBL463563 & 688113 & 5.1502 & 4.4879 & TRN \\
\hline CHEMBL1303193 & 688113 & 2.5229 & 2.8703 & TRN \\
\hline CHEMBL1447098 & 688113 & 2.5229 & 4.1103 & TRN \\
\hline CHEMBL418068 & 688113 & 4.6662 & 4.809 & TRN \\
\hline CHEMBL1380856 & 688113 & 5.2849 & 5.1425 & TRN \\
\hline CHEMBL1312488 & 688113 & 2.5229 & 3.042 & TST \\
\hline CHEMBL1612106 & 688113 & 4.9741 & 4.9635 & TRN \\
\hline CHEMBL1386130 & 688113 & 2.5229 & 2.9371 & TRN \\
\hline CHEMBL1304952 & 688113 & 4.3885 & 4.3224 & TRN \\
\hline CHEMBL1523709 & 688113 & 2.5229 & 3.0676 & TRN \\
\hline CHEMBL1343563 & 688113 & 3.8152 & 3.1003 & TRN \\
\hline CHEMBL1542314 & 688113 & 2.5229 & 2.5236 & TRN \\
\hline CHEMBL3191761 & 688113 & 4.4233 & 2.9496 & TRN \\
\hline CHEMBL1368153 & 688113 & 2.5229 & 3.2024 & TRN \\
\hline CHEMBL1508945 & 688113 & 2.5229 & 3.0371 & TRN \\
\hline CHEMBL1305525 & 688113 & 4.9491 & 4.8667 & TST \\
\hline CHEMBL1454835 & 688113 & 5.1574 & 2.4866 & TRN \\
\hline CHEMBL1391513 & 688113 & 2.5229 & 3.9411 & TRN \\
\hline CHEMBL 2005207 & 688113 & 2.5229 & 2.9191 & TRN \\
\hline CHEMBL1536407 & 688113 & 2.5229 & 2.8457 & TRN \\
\hline CHEMBL1571079 & 688113 & 4.3905 & 4.0031 & TRN \\
\hline CHEMBL1545894 & 688113 & 3.9456 & 4.1302 & TRN \\
\hline CHEMBL1583777 & 688113 & 2.5229 & 2.8739 & TRN \\
\hline CHEMBL1998521 & 688113 & 4.3307 & 4.5945 & TST \\
\hline CHEMBL1612493 & 688113 & 4.2129 & 2.9325 & TST \\
\hline CHEMBL1563370 & 688113 & 4.2325 & 3.3975 & TRN \\
\hline CHEMBL1344572 & 688113 & 3.7096 & 3.8941 & TRN \\
\hline CHEMBL1313324 & 688113 & 4.6607 & 4.8777 & TRN \\
\hline CHEMBL1549255 & 688113 & 2.5229 & \multicolumn{2}{|c|}{2.9560000000000004} \\
\hline CHEMBL449081 & 688113 & 5.0619 & 4.7574 & TST \\
\hline CHEMBL1446753 & 688113 & 2.5229 & 2.9866 & TRN \\
\hline CHEMBL1459241 & 688113 & 3.9191 & 3.1176 & TRN \\
\hline CHEMBL1585863 & 688113 & 2.5229 & 2.5004 & TRN \\
\hline CHEMBL3210299 & 688113 & 2.5229 & 2.6663 & TRN \\
\hline CHEMBL1490148 & 688113 & 2.5229 & 3.2305 & TRN \\
\hline
\end{tabular}

Page 833 
Supplemental Table S2.txt

\begin{tabular}{|c|c|c|c|c|}
\hline CHEMBL1510513 & 688113 & 4.3889 & 3.2046 & TST \\
\hline CHEMBL1303188 & 688113 & 5.2749 & 5.0804 & TRN \\
\hline CHEMBL1556332 & 688113 & 4.9781 & 4.7839 & TST \\
\hline CHEMBL1584874 & 688113 & 2.5229 & 2.9044 & TRN \\
\hline CHEMBL1328497 & 688113 & 3.7614 & 3.1044 & TRN \\
\hline CHEMBL1319488 & 688113 & 4.3968 & 3.5351 & TRN \\
\hline CHEMBL1707818 & 688113 & 2.5229 & 4.3709 & TRN \\
\hline CHEMBL1403999 & 688113 & 4.3368 & 4.3321 & TRN \\
\hline CHEMBL1368206 & 688113 & 2.5229 & 2.8898 & TRN \\
\hline CHEMBL1549900 & 688113 & 4.4562 & 4.6381 & TRN \\
\hline CHEMBL1302462 & 688113 & 4.4074 & 2.9933 & TRN \\
\hline CHEMBL1455143 & 688113 & 2.5229 & 2.9112 & TRN \\
\hline CHEMBL1412067 & 688113 & 6.9355 & 6.1067 & TRN \\
\hline CHEMBL1544695 & 688113 & 2.5229 & 4.5338 & TRN \\
\hline CHEMBL1341090 & 688113 & 3.7723 & 4.2409 & TST \\
\hline CHEMBL1462806 & 688113 & 2.5229 & 3.0169 & TST \\
\hline CHEMBL1424710 & 688113 & 2.5229 & 2.4962 & TRN \\
\hline CHEMBL1420189 & 688113 & 5.2545 & 4.8749 & TRN \\
\hline CHEMBL 2006431 & 688113 & 3.9373 & 2.787 & TST \\
\hline CHEMBL1544034 & 688113 & 2.5229 & 2.6531 & TRN \\
\hline CHEMBL3198142 & 688113 & 2.5229 & 3.1016 & TRN \\
\hline CHEMBL1484956 & 688113 & 5.7562 & 4.1873 & TRN \\
\hline CHEMBL1309836 & 688113 & 2.5229 & 4.5371 & TRN \\
\hline CHEMBL1257041 & 688113 & 5.4985 & 5.1194 & TST \\
\hline CHEMBL1577198 & 688113 & 4.4363 & 4.1644 & TRN \\
\hline CHEMBL1326075 & 688113 & 2.5229 & 3.0019 & TRN \\
\hline CHEMBL1533590 & 688113 & 4.9062 & 4.3585 & TRN \\
\hline CHEMBL1414842 & 688113 & 4.5229 & 5.0045 & TRN \\
\hline CHEMBL1422472 & 688113 & 2.5229 & 3.3171 & TRN \\
\hline CHEMBL1416658 & 688113 & 2.5229 & 3.1504 & TRN \\
\hline CHEMBL1329597 & 688113 & 5.2901 & 4.9571 & TRN \\
\hline CHEMBL3209631 & 688113 & 2.5229 & 3.06100 & 0000000004 \\
\hline CHEMBL3198213 & 688113 & 5.012 & 4.2586 & TST \\
\hline CHEMBL1364729 & 688113 & 4.8875 & 4.6742 & TST \\
\hline CHEMBL1339509 & 688113 & 2.5229 & 3.1199 & TRN \\
\hline CHEMBL1573071 & 688113 & 2.5229 & 3.1507 & TST \\
\hline CHEMBL1306005 & 688113 & 4.5137 & 4.6054 & TST \\
\hline CHEMBL1502526 & 688113 & 2.5229 & 2.8994 & TRN \\
\hline CHEMBL1559737 & 688113 & 2.5229 & 4.1076 & TRN \\
\hline CHEMBL1507021 & 688113 & 5.0048 & 4.4709 & TRN \\
\hline CHEMBL515248 & 688113 & 4.6768 & 4.6319 & TRN \\
\hline CHEMBL3211556 & 688113 & 2.5229 & 2.4819 & TRN \\
\hline CHEMBL1521764 & 688113 & 2.5229 & 2.9736 & TST \\
\hline CHEMBL1579691 & 688113 & 2.5229 & 3.0901 & TRN \\
\hline CHEMBL1456904 & 688113 & 4.5859 & 3.00100 & 00000000003 \\
\hline CHEMBL1396089 & 688113 & 5.032 & 4.9473 & TRN \\
\hline CHEMBL1326683 & 688113 & 5.0691 & 4.934 & TST \\
\hline CHEMBL1529238 & 688113 & 4.7318 & 4.7562 & TRN \\
\hline
\end{tabular}

Page 834 
Supplemental Table S2.txt

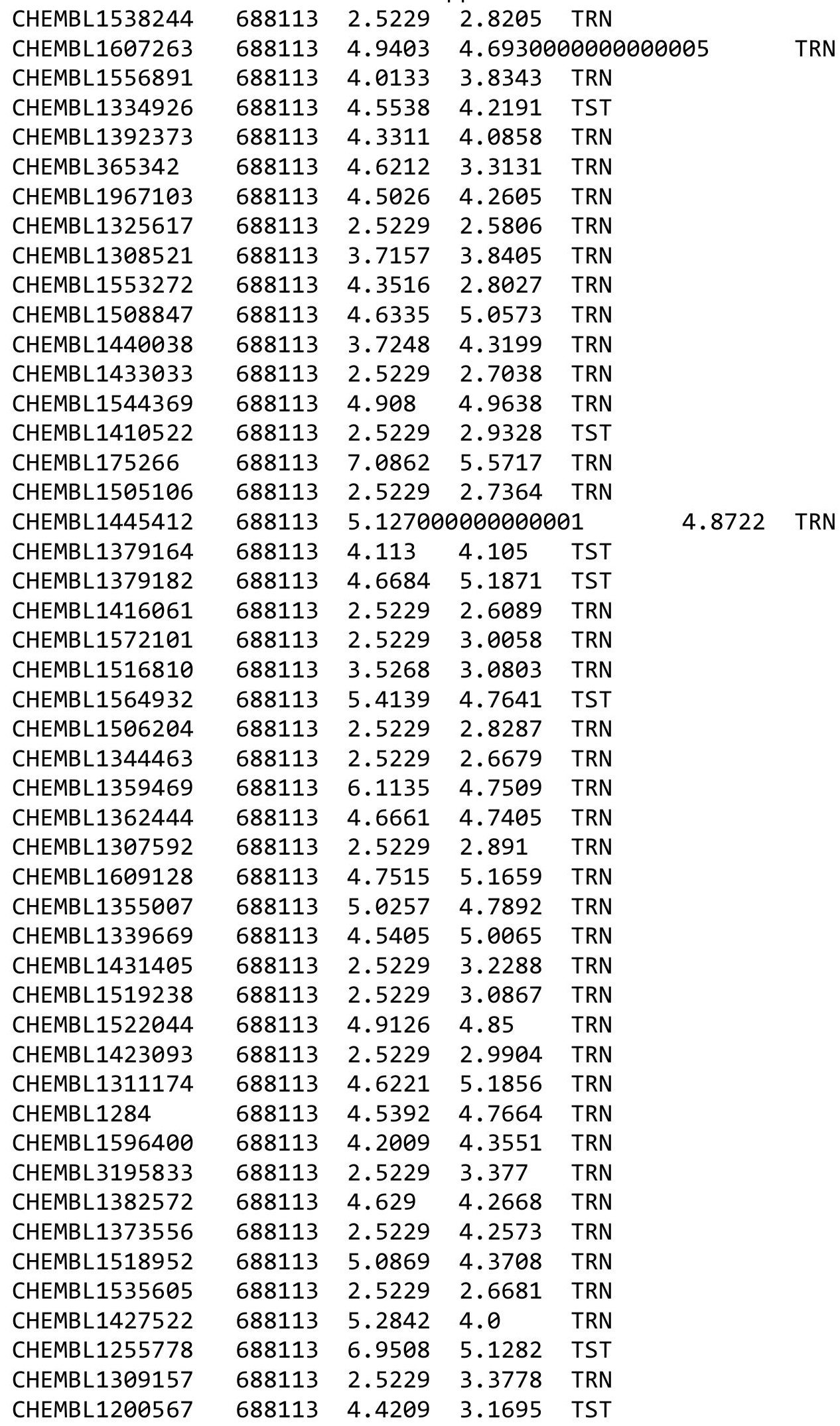

Page 835 
Supplemental Table S2.txt

\begin{tabular}{|c|c|c|c|c|}
\hline CHEMBL1368728 & 688113 & 5.1967 & 4.7551 & TRN \\
\hline CHEMBL1347643 & 688113 & 2.5229 & 3.1021 & TRN \\
\hline CHEMBL1344078 & 688113 & 2.5229 & 2.8945 & TRN \\
\hline CHEMBL1548669 & 688113 & 2.5229 & 3.0329 & TRN \\
\hline CHEMBL 3235884 & 688113 & 2.5229 & 2.7049 & TRN \\
\hline CHEMBL1545858 & 688113 & 5.6851 & 3.1363 & TRN \\
\hline CHEMBL1353004 & 688113 & 5.9488 & 3.3255 & TRN \\
\hline CHEMBL3145379 & 688113 & 4.617 & 3.09 & TRN \\
\hline CHEMBL 3208977 & 688113 & 2.5229 & 3.2008 & TST \\
\hline CHEMBL1481671 & 688113 & 4.3658 & 4.3756 & TRN \\
\hline CHEMBL1428153 & 688113 & 4.5489 & 4.5494 & TST \\
\hline CHEMBL1311214 & 688113 & 4.0551 & 4.0913 & TRN \\
\hline CHEMBL1543180 & 688113 & 5.6904 & 4.6687 & TRN \\
\hline CHEMBL1560267 & 688113 & 4.7253 & 4.864 & TRN \\
\hline CHEMBL1452684 & 688113 & 5.4716 & 4.6222 & TRN \\
\hline CHEMBL 2001761 & 688113 & 2.5229 & 4.8104 & TRN \\
\hline CHEMBL1492585 & 688113 & 2.5229 & 3.0477 & TRN \\
\hline CHEMBL1503219 & 688113 & 2.5229 & 2.79100 & 00000000004 \\
\hline CHEMBL3209532 & 688113 & 2.5229 & 3.3106 & TRN \\
\hline CHEMBL1397898 & 688113 & 2.5229 & 2.8289 & TRN \\
\hline CHEMBL1503564 & 688113 & 2.5229 & 3.0166 & TRN \\
\hline CHEMBL1362935 & 688113 & 5.1397 & 3.3153 & TRN \\
\hline CHEMBL3196884 & 688113 & $5.2010 e$ & 00000000 & 4.7932 \\
\hline CHEMBL1595818 & 688113 & 2.5229 & 2.5647 & TRN \\
\hline CHEMBL1384247 & 688113 & 4.3092 & 4.1617 & TRN \\
\hline CHEMBL 3195671 & 688113 & 4.6605 & 4.765 & TRN \\
\hline CHEMBL1392519 & 688113 & 3.5945 & 2.9311 & TRN \\
\hline CHEMBL1998057 & 688113 & 2.8239 & 4.1119 & TRN \\
\hline CHEMBL 2003651 & 688113 & 4.2162 & 4.1096 & TRN \\
\hline CHEMBL 332770 & 688113 & 5.0373 & 3.3241 & TST \\
\hline CHEMBL1322518 & 688113 & 4.3192 & 2.764 & TRN \\
\hline CHEMBL456295 & 688113 & 5.316 & 4.5813 & TST \\
\hline CHEMBL1460765 & 688113 & 2.5229 & 3.1706 & TRN \\
\hline CHEMBL1364410 & 688113 & 4.6836 & 4.6289 & TRN \\
\hline CHEMBL3189964 & 688113 & 2.5229 & 3.2935 & TRN \\
\hline CHEMBL1977082 & 688113 & 4.9896 & 4.6717 & TRN \\
\hline CHEMBL1588786 & 688113 & 3.9458 & 3.5998 & TRN \\
\hline CHEMBL1368277 & 688113 & 2.5229 & 2.8464 & TRN \\
\hline CHEMBL1444958 & 688113 & 4.7718 & 4.885 & TRN \\
\hline CHEMBL1462008 & 688113 & 2.5229 & 2.6386 & TRN \\
\hline CHEMBL1362862 & 688113 & 4.7465 & 4.6437 & TRN \\
\hline CHEMBL1561077 & 688113 & 4.5367 & 4.9285 & TRN \\
\hline CHEMBL1543734 & 688113 & 2.5229 & 4.1648 & TST \\
\hline CHEMBL1980226 & 688113 & 5.2713 & 3.3851 & TRN \\
\hline CHEMBL470881 & 688113 & 6.0788 & 4.4225 & TST \\
\hline CHEMBL3193300 & 688113 & 2.5229 & 4.518 & TRN \\
\hline CHEMBL1585982 & 688113 & 5.0265 & 4.9997 & TST \\
\hline CHEMBL1565767 & 688113 & 5.2347 & 4.9777 & TRN \\
\hline
\end{tabular}




\begin{tabular}{|c|c|c|c|c|c|c|}
\hline & & \multicolumn{5}{|c|}{ Supplemental Table S2.txt } \\
\hline CHEMBL1423828 & 688113 & 5.3158 & 3.5723 & TRN & & \\
\hline CHEMBL1523528 & 688113 & 2.5229 & 3.0158 & TRN & & \\
\hline CHEMBL1319154 & 688113 & 2.5229 & 2.8958 & TRN & & \\
\hline CHEMBL1339859 & 688113 & 2.5229 & 2.5352 & TRN & & \\
\hline CHEMBL232148 & 688113 & 4.4765 & 3.5411 & TRN & & \\
\hline CHEMBL1326814 & 688113 & 4.779 & 4.479 & TRN & & \\
\hline CHEMBL1594490 & 688113 & 4.9289 & 4.6306 & TRN & & \\
\hline CHEMBL1606453 & 688113 & 2.5229 & 2.5596 & TRN & & \\
\hline CHEMBL1446838 & 688113 & 2.5229 & 2.6022 & TRN & & \\
\hline CHEMBL1426306 & 688113 & 4.6863 & 4.3942 & TST & & \\
\hline CHEMBL1415136 & 688113 & 4.4659 & 4.1306 & TRN & & \\
\hline CHEMBL225230 & 688113 & 5.5056 & 5.0628 & TST & & \\
\hline CHEMBL1366593 & 688113 & 5.1046 & 4.5597 & TRN & & \\
\hline CHEMBL1600440 & 688113 & 4.8932 & 5.0411 & TRN & & \\
\hline CHEMBL1520667 & 688113 & 2.5229 & 3.5542 & TRN & & \\
\hline CHEMBL1332539 & 688113 & 4.4819 & 4.538 & TRN & & \\
\hline CHEMBL1400426 & 688113 & 4.6992 & 4.8094 & TRN & & \\
\hline CHEMBL1507424 & 688113 & 2.5229 & 2.7424 & TRN & & \\
\hline CHEMBL1369743 & 688113 & 2.5229 & 2.7388 & TRN & & \\
\hline CHEMBL1451040 & 688113 & 4.5717 & 3.5009 & TRN & & \\
\hline CHEMBL3196505 & 688113 & 2.5229 & 2.9765 & TRN & & \\
\hline CHEMBL1524306 & 688113 & 2.5229 & 2.6924 & TRN & & \\
\hline CHEMBL3192348 & 688113 & 2.5229 & 3.261 & TRN & & \\
\hline CHEMBL1970867 & 688113 & 5.808 & 4.148 & TRN & & \\
\hline CHEMBL1485960 & 688113 & 2.5229 & 3.1158 & TRN & & \\
\hline CHEMBL1595909 & 688113 & 4.54899 & 99999999 & 995 & 1702 & TRN \\
\hline CHEMBL1439218 & 688113 & 4.3844 & 4.2269 & TRN & & \\
\hline CHEMBL1424050 & 688113 & 4.7932 & 4.4867 & TRN & & \\
\hline CHEMBL246657 & 688113 & 4.4108 & 3.0316 & TST & & \\
\hline CHEMBL1399700 & 688113 & 4.3426 & 3.2018 & TRN & & \\
\hline CHEMBL1388156 & 688113 & 2.5229 & 3.117 & TRN & & \\
\hline CHEMBL1421318 & 688113 & 2.5229 & 2.9032 & TST & & \\
\hline CHEMBL1541029 & 688113 & 4.0942 & 3.0167 & TRN & & \\
\hline CHEMBL1490217 & 688113 & 2.5229 & 2.8541 & TRN & & \\
\hline CHEMBL1319026 & 688113 & 4.645 & 4.8099 & TRN & & \\
\hline CHEMBL1320111 & 688113 & 4.6101 & 2.9999 & TRN & & \\
\hline CHEMBL1545689 & 688113 & 4.9977 & 2.9599 & TRN & & \\
\hline CHEMBL339587 & 688113 & 4.374 & 3.3947 & TRN & & \\
\hline CHEMBL1468268 & 688113 & 2.5229 & 3.286 & TRN & & \\
\hline CHEMBL1570659 & 688113 & 4.672 & 4.2279 & TRN & & \\
\hline CHEMBL1423675 & 688113 & 4.641 & 4.9013 & TRN & & \\
\hline CHEMBL1527214 & 688113 & 4.868 & 3.4443 & TST & & \\
\hline CHEMBL1399551 & 688113 & 2.5229 & 2.9357 & TRN & & \\
\hline CHEMBL1323719 & 688113 & 4.505 & 4.5056 & TRN & & \\
\hline CHEMBL 269410 & 688113 & 4.9784 & 4.6215 & TRN & & \\
\hline CHEMBL246656 & 688113 & 4.2757 & 3.1785 & TST & & \\
\hline CHEMBL1445410 & 688113 & 4.2102 & 4.0197 & TST & & \\
\hline CHEMBL3199799 & 688113 & 2.5229 & 3.0637 & TRN & & \\
\hline
\end{tabular}

Page 837 


\begin{tabular}{|c|c|c|c|c|c|c|}
\hline \multirow[b]{2}{*}{ CHEMBL1986342 } & & \multicolumn{5}{|c|}{ Supplemental Table S2.txt } \\
\hline & 688113 & 6.0462 & 6.0839 & TST & & \\
\hline CHEMBL1310926 & 688113 & 4.1 & 3.9423 & TRN & & \\
\hline CHEMBL1606686 & 688113 & 4.896 & 3.1383 & TRN & & \\
\hline CHEMBL1420395 & 688113 & 4.1575 & 4.2555 & TRN & & \\
\hline CHEMBL1569384 & 688113 & 4.437 & 3.1422 & TRN & & \\
\hline CHEMBL1579763 & 688113 & 2.5229 & 2.7425 & TRN & & \\
\hline CHEMBL1410838 & 688113 & 2.5229 & 3.3721 & TRN & & \\
\hline CHEMBL1346865 & 688113 & \multicolumn{3}{|c|}{5.2860000000000005} & 5.114 & TRN \\
\hline CHEMBL1565114 & 688113 & 2.5229 & 2.5728 & TRN & & \\
\hline CHEMBL1301252 & 688113 & 2.5229 & 3.304 & TRN & & \\
\hline CHEMBL1300605 & 688113 & 2.5229 & 4.4187 & TRN & & \\
\hline CHEMBL1459194 & 688113 & 2.5229 & 2.6391 & TRN & & \\
\hline CHEMBL1391547 & 688113 & 4.5069 & 5.0882 & TRN & & \\
\hline CHEMBL3145161 & 688113 & 5.3883 & 5.0527 & TRN & & \\
\hline CHEMBL1524932 & 688113 & 4.3918 & 4.5934 & TRN & & \\
\hline CHEMBL1501465 & 688113 & 4.1566 & 4.5267 & TRN & & \\
\hline CHEMBL1508769 & 688113 & 2.5229 & 2.6817 & TRN & & \\
\hline CHEMBL 3198643 & 688113 & 4.0994 & 5.3287 & TRN & & \\
\hline CHEMBL 305978 & 688113 & 4.92 & 5.0885 & TRN & & \\
\hline CHEMBL1433911 & 688113 & 4.6325 & 4.4349 & TRN & & \\
\hline CHEMBL1570306 & 688113 & 2.5229 & 3.1491 & TST & & \\
\hline CHEMBL1434839 & 688113 & 2.5229 & 2.821 & TRN & & \\
\hline CHEMBL1611689 & 688113 & 3.5958 & 3.051 & TRN & & \\
\hline CHEMBL1486880 & 688113 & 2.5229 & 2.6247 & TRN & & \\
\hline CHEMBL3198022 & 688113 & 2.5229 & 3.1294 & TRN & & \\
\hline CHEMBL1522811 & 688113 & 5.1026 & 3.9727 & TRN & & \\
\hline CHEMBL1341586 & 688113 & 3.8668 & 4.1556 & TRN & & \\
\hline CHEMBL1307886 & 688113 & \multicolumn{3}{|c|}{6.617999999999999} & 5.7052 & TRN \\
\hline CHEMBL3199707 & 688113 & 2.8239 & 3.2094 & TRN & & \\
\hline CHEMBL1307262 & 688113 & 4.6506 & 4.8283 & TRN & & \\
\hline CHEMBL1607959 & 688113 & 4.0928 & 3.1297 & TST & & \\
\hline CHEMBL1400103 & 688113 & 4.53 & 4.7366 & TRN & & \\
\hline CHEMBL1576943 & 688113 & 4.0805 & 2.4828 & TRN & & \\
\hline CHEMBL1370349 & 688113 & 2.5229 & 3.1132 & TRN & & \\
\hline CHEMBL1466200 & 688113 & 5.2623 & 4.6743 & TRN & & \\
\hline CHEMBL1417291 & 688113 & 2.5229 & 2.6025 & TRN & & \\
\hline CHEMBL3198823 & 688113 & 2.5229 & 3.6232 & TRN & & \\
\hline CHEMBL1378424 & 688113 & 2.5229 & 2.838 & TRN & & \\
\hline CHEMBL1370952 & 688113 & 4.5934 & 4.511 & TRN & & \\
\hline CHEMBL1570806 & 688113 & 2.5229 & 2.867 & TRN & & \\
\hline CHEMBL3198930 & 688113 & 2.5229 & 4.1236 & TRN & & \\
\hline CHEMBL172350 & 688113 & 4.4433 & 4.5636 & TRN & & \\
\hline CHEMBL1459412 & 688113 & 2.5229 & 3.1101 & TST & & \\
\hline CHEMBL1563623 & 688113 & 4.6053 & 3.7518 & TRN & & \\
\hline CHEMBL1346060 & 688113 & 4.2615 & 4.2041 & TRN & & \\
\hline CHEMBL1354279 & 688113 & 2.5229 & 2.5689 & TRN & & \\
\hline CHEMBL1428824 & 688113 & 2.5229 & 3.8844 & TRN & & \\
\hline CHEMBL3196023 & 688113 & 2.8239 & 3.1648 & TRN & & \\
\hline
\end{tabular}


Supplemental Table S2.txt

\begin{tabular}{|c|c|c|c|c|}
\hline CHEMBL1507529 & 688113 & 4.0827 & 4.242 & TRN \\
\hline CHEMBL1574785 & 688113 & 4.3095 & 4.6268 & TRN \\
\hline CHEMBL1331797 & 688113 & 2.5229 & 2.5782 & TRN \\
\hline CHEMBL1085162 & 688113 & 2.5229 & 2.7784 & TRN \\
\hline CHEMBL1606823 & 688113 & 5.0304 & 4.9046 & TRN \\
\hline CHEMBL1310901 & 688113 & 2.5229 & 3.7215 & TST \\
\hline CHEMBL1548111 & 688113 & 4.8602 & 4.9867 & TRN \\
\hline CHEMBL1598948 & 688113 & 2.5229 & 2.6369 & TRN \\
\hline CHEMBL1534274 & 688113 & 2.5229 & 2.6109 & TRN \\
\hline CHEMBL1329106 & 688113 & 3.8246 & 4.023 & TRN \\
\hline CHEMBL1405177 & 688113 & 4.7813 & 4.9789 & TRN \\
\hline CHEMBL1469594 & 688113 & 4.6298 & 4.7846 & TRN \\
\hline CHEMBL1537711 & 688113 & 2.5229 & 3.0284 & TRN \\
\hline CHEMBL1456636 & 688113 & 2.5229 & 2.7359 & TRN \\
\hline CHEMBL1511669 & 688113 & 2.5229 & 2.871000 & 0000000004 \\
\hline CHEMBL1505358 & 688113 & 4.7775 & 5.0616 & TRN \\
\hline CHEMBL1390797 & 688113 & 4.9573 & 4.7345 & TRN \\
\hline CHEMBL1479965 & 688113 & 4.5898 & 4.4171 & TST \\
\hline CHEMBL1381289 & 688113 & 4.4221 & 3.1515 & TRN \\
\hline CHEMBL1601929 & 688113 & 2.5229 & 2.4972 & TRN \\
\hline CHEMBL 278037 & 688113 & 4.8461 & 4.9896 & TRN \\
\hline CHEMBL1364849 & 688113 & 5.1808 & 2.9064 & TST \\
\hline CHEMBL1365813 & 688113 & 4.84399 & 999999999 & 4.3724 \\
\hline CHEMBL1386945 & 688113 & 4.3423 & 4.3586 & TRN \\
\hline CHEMBL1325563 & 688113 & 4.2971 & 4.1072 & TRN \\
\hline CHEMBL1589514 & 688113 & 5.409 & 5.0225 & TRN \\
\hline CHEMBL 1450570 & 688113 & 4.9113 & 5.0307 & TRN \\
\hline CHEMBL1573707 & 688113 & 3.9039 & 4.6845 & TRN \\
\hline CHEMBL1380513 & 688113 & 4.461 & 3.1365 & TRN \\
\hline CHEMBL1369478 & 688113 & 2.5229 & 3.0728 & TST \\
\hline CHEMBL1580198 & 688113 & 4.1113 & 4.191 & TRN \\
\hline CHEMBL1301619 & 688113 & 2.5229 & 2.8088 & TRN \\
\hline CHEMBL1457676 & 688113 & 4.6147 & 4.3397 & TRN \\
\hline CHEMBL1442096 & 688113 & 2.8239 & 2.9432 & TRN \\
\hline CHEMBL1563808 & 688113 & 4.5265 & 3.7554 & TRN \\
\hline CHEMBL1588346 & 688113 & 2.5229 & 2.5662 & TRN \\
\hline CHEMBL1518696 & 688113 & 4.9524 & 4.8403 & TRN \\
\hline CHEMBL1417293 & 688113 & 4.3153 & 3.1293 & TRN \\
\hline CHEMBL 3190891 & 688113 & 2.5229 & 4.9462 & TRN \\
\hline CHEMBL1992540 & 688113 & 2.5229 & 3.2656 & TRN \\
\hline CHEMBL3209168 & 688113 & 2.5229 & 3.5445 & TRN \\
\hline CHEMBL35228 & 688113 & 4.6585 & 4.4098 & TRN \\
\hline CHEMBL3212133 & 688113 & 2.5229 & 2.8291 & TRN \\
\hline CHEMBL1586651 & 688113 & 5.1809 & 5.0261 & TRN \\
\hline CHEMBL1526855 & 688113 & 5.0874 & 3.8502 & TRN \\
\hline CHEMBL1491266 & 688113 & 4.4138 & 2.8238 & TST \\
\hline CHEMBL1609156 & 688113 & 2.5229 & 3.1746 & TRN \\
\hline CHEMBL1350841 & 688113 & 2.5229 & 3.2381 & TRN \\
\hline
\end{tabular}




\begin{tabular}{|c|c|c|c|c|c|}
\hline & & \multicolumn{4}{|c|}{ Supplemental Table S2.txt } \\
\hline CHEMBL1408810 & 688113 & 4.2538 & 3.9187 & TRN & \\
\hline CHEMBL1431657 & 688113 & 2.5229 & 2.8517 & TST & \\
\hline CHEMBL1334452 & 688113 & 4.7558 & 3.4539 & TRN & \\
\hline CHEMBL1583293 & 688113 & 3.975 & 4.1922 & TRN & \\
\hline CHEMBL212414 & 688113 & 4.2676 & 2.4519 & TRN & \\
\hline CHEMBL1409827 & 688113 & 2.5229 & 2.6213 & TRN & \\
\hline CHEMBL1310100 & 688113 & 2.5229 & 3.26899 & 99999999997 & TRN \\
\hline CHEMBL1543588 & 688113 & 2.5229 & 2.7927 & TRN & \\
\hline CHEMBL 1471750 & 688113 & 2.5229 & 3.1663 & TST & \\
\hline CHEMBL1323502 & 688113 & 2.5229 & 2.6667 & TRN & \\
\hline CHEMBL1560629 & 688113 & 2.5229 & 2.5592 & TRN & \\
\hline CHEMBL1493686 & 688113 & 4.5116 & 4.6216 & TRN & \\
\hline CHEMBL1270192 & 688113 & 2.5229 & 2.887 & TRN & \\
\hline CHEMBL1565581 & 688113 & 5.0062 & 4.6034 & TST & \\
\hline CHEMBL1537327 & 688113 & 2.5229 & 3.1506 & TRN & \\
\hline CHEMBL1564075 & 688113 & 4.064 & 4.3312 & TRN & \\
\hline CHEMBL1497153 & 688113 & 5.038 & 5.2653 & TRN & \\
\hline CHEMBL1423165 & 688113 & 2.5229 & 4.3108 & TRN & \\
\hline CHEMBL1392292 & 688113 & 3.8153 & 4.1568 & TRN & \\
\hline CHEMBL1447871 & 688113 & 4.667 & 3.6126 & TRN & \\
\hline CHEMBL1613004 & 688113 & 5.7525 & 5.4405 & TST & \\
\hline CHEMBL1372723 & 688113 & 2.5229 & 2.8707 & TRN & \\
\hline CHEMBL1430473 & 688113 & 4.7179 & 4.1619 & TRN & \\
\hline CHEMBL1582178 & 688113 & 4.227 & 4.2367 & TST & \\
\hline CHEMBL1577264 & 688113 & 2.5229 & 3.1329 & TRN & \\
\hline CHEMBL1438779 & 688113 & 4.9713 & 3.7658 & TRN & \\
\hline CHEMBL1487945 & 688113 & 4.5498 & 4.7022 & TRN & \\
\hline CHEMBL1541438 & 688113 & 2.5229 & 2.6171 & TRN & \\
\hline CHEMBL1464200 & 688113 & 2.5229 & 3.906 & TST & \\
\hline CHEMBL1424261 & 688113 & 5.515 & 4.9109 & TRN & \\
\hline CHEMBL1560309 & 688113 & 2.5229 & 2.94100 & 00000000003 & TRN \\
\hline CHEMBL438909 & 688113 & 2.5229 & 3.2117 & TRN & \\
\hline CHEMBL1571307 & 688113 & 4.4072 & 3.2453 & TRN & \\
\hline CHEMBL1542208 & 688113 & 4.0358 & 3.4386 & TRN & \\
\hline CHEMBL1472229 & 688113 & 2.5229 & 2.7283 & TRN & \\
\hline CHEMBL1421995 & 688113 & 4.8528 & 4.959 & TST & \\
\hline CHEMBL1304721 & 688113 & 2.5229 & 5.33700 & 0000000001 & TRN \\
\hline CHEMBL1391884 & 688113 & 2.5229 & 2.5273 & TRN & \\
\hline CHEMBL1519638 & 688113 & 2.5229 & 2.7695 & TRN & \\
\hline CHEMBL1571367 & 688113 & 2.5229 & 2.6237 & TRN & \\
\hline CHEMBL1559190 & 688113 & 2.5229 & 3.0065 & TRN & \\
\hline CHEMBL495123 & 688113 & 4.6712 & 4.7557 & TST & \\
\hline CHEMBL1416049 & 688113 & 5.0812 & 4.9976 & TST & \\
\hline CHEMBL1436090 & 688113 & 2.5229 & 2.9285 & TRN & \\
\hline CHEMBL1732424 & 688113 & 5.2496 & 5.03 & TRN & \\
\hline CHEMBL1578045 & 688113 & 4.9607 & 3.549 & TRN & \\
\hline CHEMBL1455582 & 688113 & 2.5229 & 2.6331 & TRN & \\
\hline CHEMBL1449832 & 688113 & 4.7443 & 5.0915 & TST & \\
\hline
\end{tabular}


Supplemental Table S2.txt

\begin{tabular}{|c|c|c|c|c|}
\hline HEl & & 229 & & \\
\hline HEMPI 1145020 & & .5229 & 2.5241 & \\
\hline & & & & \\
\hline IEMBL13e & & & & \\
\hline AEMBL1457752 & 8113 & & 3814 & \\
\hline HEMBL1343099 & 88113 & 049 & 1864 & \\
\hline HEMBL13 & 8113 & & 41 & \\
\hline 231 & & & 7773 & \\
\hline AEMBL1313262 & 113 & & 3.45 & \\
\hline HEMBL1553837 & 38113 & & .6699 & \\
\hline AEMBL1453634 & 88113 & & 57 & \\
\hline IEMBL13. & 113 & & 251 & \\
\hline IEMBL14 & & & & \\
\hline HEMBL14 & 3113 & & 3.0133 & \\
\hline IEMBL13 & 13 & & 531 & \\
\hline IEMBL137 & 13 & 29 & 2.7042 & \\
\hline AEMBL15\& & & & 105 & \\
\hline HEMBL133 & & & & \\
\hline AEMBL150 & & & 2.7158 & \\
\hline HEMBL149 & 3 & & 78 & \\
\hline AEMBLIL & & & 29 & \\
\hline AEMBL13 & & & 25 & \\
\hline JEMBL15 & 13 & & & \\
\hline 731 & & & & \\
\hline IEMBL140 & & & $\partial 6$ & \\
\hline HEMBL158 & & & 968 & RI \\
\hline AEMBL: & & & 33 & \\
\hline AFMBI 66 & 13 & & 338 & RN \\
\hline HEMBL131 & & & 4.7521 & \\
\hline HEMBL1322202 & 3 & & 3.089 & IS \\
\hline HEMBL15 & & & 355 & RN \\
\hline HEMBL1 & & & 93 & RIV \\
\hline 98 & & & 4.8474 & RN \\
\hline HEMBL1539300 & & & 3.0353 & RN \\
\hline HEMBL1484906 & & & 3.4316 & RN \\
\hline HEMBL148 & 3 & & 5.0769 & DN \\
\hline HFMRI 13 & & & 5.12 & RN \\
\hline HEMBL 14 & & & 2.8466 & RN \\
\hline HEMBL1309068 & 88113 & & 4.8005 & TRN \\
\hline IEMBL147 & & & 4.1673 & RN \\
\hline HEMBL197 & & & 2.7541 & \\
\hline HEMBL1344339 & & & & ST \\
\hline HEMBL1410130 & & & 3.2651 & RN \\
\hline AEMBL1373732 & 8113 & & 3.0077 & RN \\
\hline MBL 1 & & & 3.4118 & \\
\hline HEMBL1501121 & & & 2.9547 & \\
\hline LHEMBL1462267 & 88113 & & 5.3378 & \\
\hline HEMBL1410936 & 688113 & 2.5229 & 2.525 & RN \\
\hline
\end{tabular}


Supplemental Table S2.txt

\begin{tabular}{|c|c|c|c|c|c|}
\hline CHEMBL1545104 & 688113 & 2.5229 & \multicolumn{2}{|c|}{3.1910000000000003} & TRN \\
\hline CHEMBL1448972 & 688113 & 2.5229 & 4.4152 & TRN & \\
\hline CHEMBL1967734 & 688113 & 4.6934 & 4.6422 & TRN & \\
\hline CHEMBL1587179 & 688113 & 2.5229 & 3.1392 & TST & \\
\hline CHEMBL1508788 & 688113 & 5.5634 & 5.7138 & TRN & \\
\hline CHEMBL1580081 & 688113 & 2.5229 & 3.0977 & TRN & \\
\hline CHEMBL511385 & 688113 & 3.8211 & 4.2673 & TRN & \\
\hline CHEMBL1461518 & 688113 & 5.0448 & 4.7754 & TRN & \\
\hline CHEMBL1577208 & 688113 & 2.5229 & 3.0068 & TRN & \\
\hline CHEMBL136344 & 688113 & 2.8239 & 4.3613 & TRN & \\
\hline CHEMBL3212362 & 688113 & 3.8833 & 3.8008 & TRN & \\
\hline CHEMBL1408747 & 688113 & 4.107 & 3.6483 & TRN & \\
\hline CHEMBL2006357 & 688113 & 4.5623 & 3.5707 & TRN & \\
\hline CHEMBL1494787 & 688113 & 2.5229 & 3.0836 & TRN & \\
\hline CHEMBL1518827 & 688113 & 5.4048 & 5.1867 & TRN & \\
\hline CHEMBL1383134 & 688113 & 2.5229 & 3.1194 & TRN & \\
\hline CHEMBL1451538 & 688113 & 4.3688 & 4.511 & TRN & \\
\hline CHEMBL1978903 & 688113 & 4.4075 & 4.0494 & TRN & \\
\hline CHEMBL223453 & 688113 & 5.3433 & 3.2867 & TST & \\
\hline CHEMBL451748 & 688113 & 2.5229 & 3.2837 & TRN & \\
\hline CHEMBL1536438 & 688113 & 4.2965 & 4.2129 & TRN & \\
\hline CHEMBL3191029 & 688113 & 4.6158 & 4.1886 & TRN & \\
\hline CHEMBL1458456 & 688113 & 5.2978 & 5.2815 & TRN & \\
\hline CHEMBL1409714 & 688113 & 4.6525 & 4.8177 & TRN & \\
\hline CHEMBL1440889 & 688113 & 4.4 & 4.0798 & TRN & \\
\hline CHEMBL1430927 & 688113 & 2.5229 & 4.2334 & TRN & \\
\hline CHEMBL1542593 & 688113 & 2.5229 & 2.541 & TRN & \\
\hline CHEMBL1388398 & 688113 & 3.9547 & 4.8119 & TRN & \\
\hline CHEMBL1587891 & 688113 & 4.0045 & 3.5855 & TRN & \\
\hline CHEMBL1997990 & 688113 & 5.3133 & 5.0939 & TRN & \\
\hline CHEMBL1505874 & 688113 & 4.519 & 4.3709 & TRN & \\
\hline CHEMBL1537601 & 688113 & 5.0899 & 4.6966 & TRN & \\
\hline CHEMBL1555214 & 688113 & 4.4598 & 4.2536 & TRN & \\
\hline CHEMBL1383060 & 688113 & 2.5229 & 3.5461 & TRN & \\
\hline CHEMBL1557268 & 688113 & 5.0183 & 4.4977 & TRN & \\
\hline CHEMBL1599000 & 688113 & 2.5229 & 2.8218 & TRN & \\
\hline CHEMBL1379179 & 688113 & 2.5229 & 3.3824 & TRN & \\
\hline CHEMBL1455121 & 688113 & 5.2345 & 4.4581 & TRN & \\
\hline CHEMBL1438006 & 688113 & 4.5464 & 4.7307 & TRN & \\
\hline CHEMBL1525895 & 688113 & 2.5229 & 2.7745 & TRN & \\
\hline CHEMBL1479865 & 688113 & 2.5229 & 3.3547 & TRN & \\
\hline CHEMBL1381495 & 688113 & 4.9053 & 4.4678 & TST & \\
\hline CHEMBL3188273 & 688113 & 4.6465 & 4.6681 & TRN & \\
\hline CHEMBL1531495 & 688113 & 4.7374 & 5.02800 & 00000000005 & TRN \\
\hline CHEMBL1452077 & 688113 & 2.5229 & 3.1275 & TST & \\
\hline CHEMBL1453752 & 688113 & 2.5229 & 3.1735 & TST & \\
\hline CHEMBL1322274 & 688113 & 4.3561 & 2.7717 & TRN & \\
\hline CHEMBL1568754 & 688113 & 2.5229 & 3.029 & TRN & \\
\hline
\end{tabular}




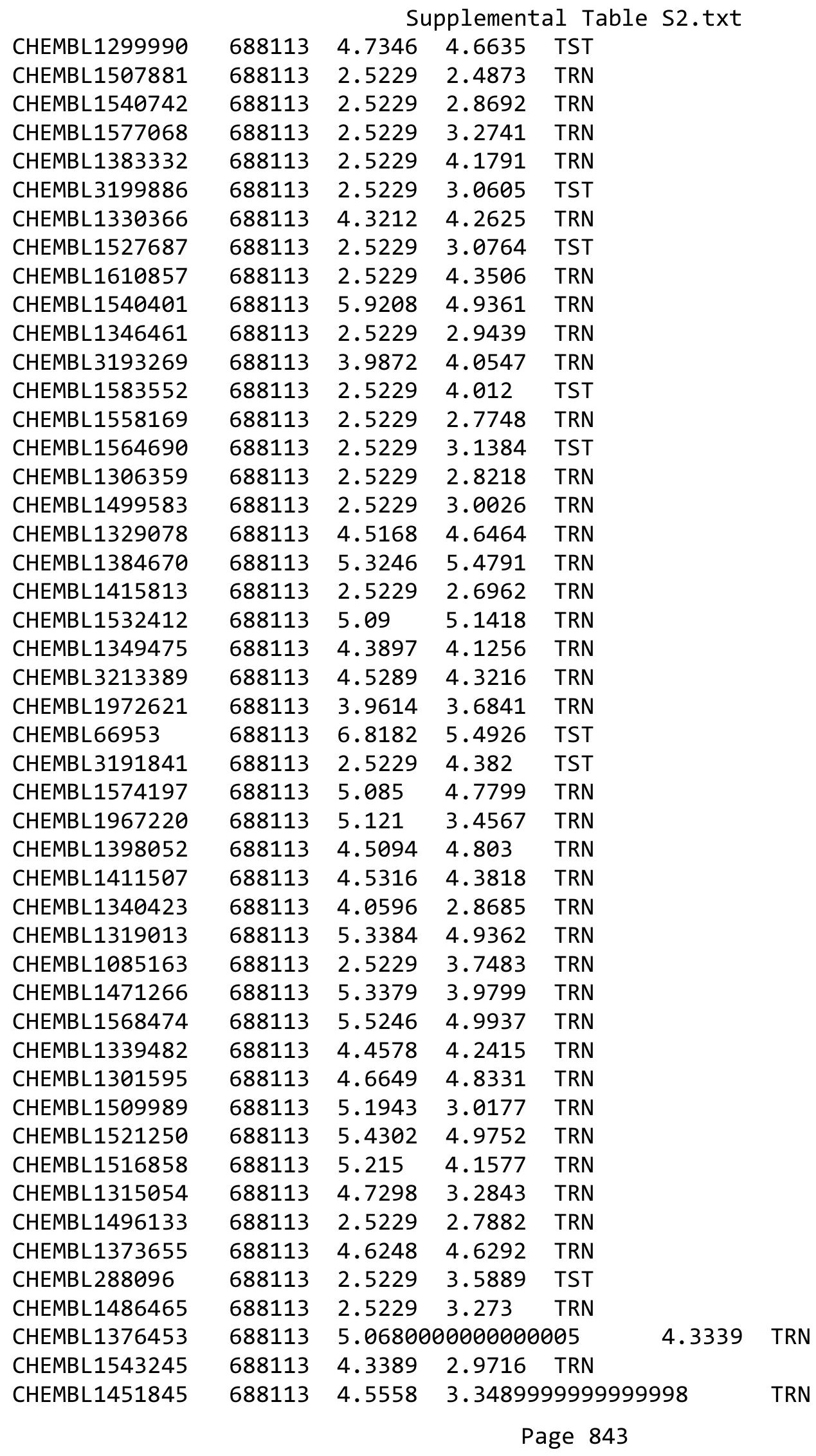




\begin{tabular}{|c|c|c|c|c|c|}
\hline & & \multicolumn{4}{|c|}{ Supplemental Table S2.txt } \\
\hline CHEMBL1511605 & 688113 & 4.6189 & 4.5664 & TRN & \\
\hline CHEMBL1511185 & 688113 & 3.8265 & 4.3325 & TRN & \\
\hline CHEMBL3195049 & 688113 & 4.3769 & 3.0472 & TRN & \\
\hline CHEMBL 2003195 & 688113 & 4.0248 & 3.4178 & TRN & \\
\hline CHEMBL1454853 & 688113 & 4.641 & 4.5749 & TRN & \\
\hline CHEMBL1333357 & 688113 & 2.5229 & 2.5594 & TRN & \\
\hline CHEMBL3210632 & 688113 & 2.5229 & 2.6759 & TRN & \\
\hline CHEMBL1977043 & 688113 & 2.5229 & 4.2735 & TRN & \\
\hline CHEMBL 1325440 & 688113 & 4.1964 & 4.0435 & TRN & \\
\hline CHEMBL1370073 & 688113 & 4.7146 & 3.0267 & TRN & \\
\hline CHEMBL1407246 & 688113 & 2.5229 & 2.9984 & TRN & \\
\hline CHEMBL3197284 & 688113 & 4.8873 & 3.20399 & 99999999997 & TST \\
\hline CHEMBL1333404 & 688113 & 2.5229 & 3.042 & TST & \\
\hline CHEMBL1556346 & 688113 & 2.5229 & 3.3377 & TRN & \\
\hline CHEMBL1516208 & 688113 & 2.5229 & 2.945 & TRN & \\
\hline CHEMBL1349942 & 688113 & 2.5229 & 3.8909 & TRN & \\
\hline CHEMBL585654 & 688113 & 4.8691 & 4.5859 & TRN & \\
\hline CHEMBL1414321 & 688113 & 2.5229 & 2.8245 & TRN & \\
\hline CHEMBL1315464 & 688113 & 2.5229 & 2.9479 & TST & \\
\hline CHEMBL1346124 & 688113 & 2.5229 & 2.7587 & TRN & \\
\hline CHEMBL3194688 & 688113 & 2.5229 & 3.1383 & TRN & \\
\hline CHEMBL1501369 & 688113 & 2.5229 & 2.8715 & TRN & \\
\hline CHEMBL1609016 & 688113 & 4.3684 & 3.3637 & TST & \\
\hline CHEMBL1442893 & 688113 & 4.5657 & 4.4467 & TRN & \\
\hline CHEMBL1325143 & 688113 & 4.9947 & 4.7654 & TST & \\
\hline CHEMBL 2005721 & 688113 & 2.5229 & 3.2075 & TRN & \\
\hline CHEMBL1536221 & 688113 & 2.5229 & 2.9979 & TRN & \\
\hline CHEMBL1393975 & 688113 & 2.5229 & 2.5239 & TRN & \\
\hline CHEMBL1594685 & 688113 & 2.5229 & 2.6643 & TRN & \\
\hline CHEMBL1572536 & 688113 & 2.5229 & 3.1874 & TRN & \\
\hline CHEMBL1587291 & 688113 & 3.9165 & 2.8259 & TRN & \\
\hline CHEMBL213017 & 688113 & 4.2997 & 2.9841 & TRN & \\
\hline CHEMBL1398190 & 688113 & 4.328 & 4.4394 & TRN & \\
\hline CHEMBL 1448410 & 688113 & 4.413 & 4.5698 & TRN & \\
\hline CHEMBL1473591 & 688113 & 5.235 & 5.3174 & TRN & \\
\hline CHEMBL1594443 & 688113 & 2.5229 & 2.8621 & TRN & \\
\hline CHEMBL3210188 & 688113 & 3.7947 & 2.7287 & TRN & \\
\hline CHEMBL1312576 & 688113 & 3.7967 & 2.8397 & TRN & \\
\hline CHEMBL1489173 & 688113 & 2.5229 & 4.0373 & TRN & \\
\hline CHEMBL1326103 & 688113 & 2.5229 & 2.8741 & TST & \\
\hline CHEMBL1414498 & 688113 & 2.5229 & 4.5399 & TRN & \\
\hline CHEMBL3198393 & 688113 & 2.5229 & 3.2444 & TRN & \\
\hline CHEMBL1412988 & 688113 & 2.5229 & 2.5519 & TRN & \\
\hline CHEMBL1308784 & 688113 & 3.8908 & 3.6361 & TRN & \\
\hline CHEMBL1385400 & 688113 & 2.5229 & 2.8229 & TRN & \\
\hline CHEMBL3145312 & 688113 & 2.5229 & 2.9102 & TRN & \\
\hline CHEMBL1446187 & 688113 & 2.5229 & 3.3339 & TRN & \\
\hline CHEMBL1300007 & 688113 & 4.7417 & 3.4642 & TRN & \\
\hline
\end{tabular}


Supplemental Table S2.txt

\begin{tabular}{|c|c|c|c|c|c|}
\hline CHEMBL1570573 & 688113 & 4.7379 & 4.7175 & TRN & \\
\hline CHEMBL1569232 & 688113 & 8.2218 & \multicolumn{2}{|c|}{6.3020000000000005} & TRN \\
\hline CHEMBL1588976 & 688113 & 2.5229 & 3.2625 & TRN & \\
\hline CHEMBL1521165 & 688113 & 2.5229 & 2.5184 & TRN & \\
\hline CHEMBL1989090 & 688113 & 4.38 & 4.3555 & TRN & \\
\hline CHEMBL1337325 & 688113 & 4.8448 & 4.4338 & TST & \\
\hline CHEMBL1539255 & 688113 & 4.3793 & 3.4933 & TRN & \\
\hline CHEMBL1375636 & 688113 & 4.9038 & 4.6197 & TST & \\
\hline CHEMBL 3189163 & 688113 & \multicolumn{2}{|c|}{5.242999999999999} & 3.5554 & TRN \\
\hline CHEMBL1352344 & 688113 & 2.5229 & 3.0061 & TRN & \\
\hline CHEMBL1460841 & 688113 & 4.4566 & 4.2638 & TRN & \\
\hline CHEMBL1417099 & 688113 & 4.3983 & 4.1387 & TST & \\
\hline CHEMBL1447301 & 688113 & 4.9249 & 4.5878 & TRN & \\
\hline CHEMBL1200938 & 688113 & 6.0 & 5.4985 & TST & \\
\hline CHEMBL1569909 & 688113 & 4.7506 & 4.5479 & TRN & \\
\hline CHEMBL1964868 & 688113 & 4.4043 & 3.5233 & TRN & \\
\hline CHEMBL1450444 & 688113 & 2.5229 & 2.965 & TRN & \\
\hline CHEMBL1580714 & 688113 & 4.9578 & 4.7902 & TST & \\
\hline CHEMBL1392426 & 688113 & 4.2856 & 4.3458 & TRN & \\
\hline CHEMBL1377284 & 688113 & 2.5229 & 3.1128 & TRN & \\
\hline CHEMBL1302328 & 688113 & 3.72 & 3.8226 & TRN & \\
\hline CHEMBL1529460 & 688113 & 4.5623 & 4.4768 & TST & \\
\hline CHEMBL156383 & 688113 & 5.2651 & 5.5087 & TRN & \\
\hline CHEMBL1381601 & 688113 & 2.5229 & 3.1625 & TRN & \\
\hline CHEMBL1382870 & 688113 & 2.5229 & 2.6238 & TRN & \\
\hline CHEMBL1303246 & 688113 & 4.4307 & 4.5084 & TST & \\
\hline CHEMBL1526323 & 688113 & 2.5229 & 2.80899 & 99999999997 & TRN \\
\hline CHEMBL1359261 & 688113 & 4.9774 & 3.217 & TRN & \\
\hline CHEMBL1392176 & 688113 & 5.2649 & 4.8354 & TRN & \\
\hline CHEMBL1600888 & 688113 & 2.5229 & 2.4552 & TRN & \\
\hline CHEMBL1458441 & 688113 & 2.5229 & 3.2883 & TRN & \\
\hline CHEMBL1543134 & 688113 & 5.2602 & 5.0496 & TRN & \\
\hline CHEMBL1365400 & 688113 & 4.4964 & 4.3076 & TRN & \\
\hline CHEMBL1346486 & 688113 & 4.8696 & 4.4344 & TST & \\
\hline CHEMBL1570293 & 688113 & 4.7307 & 4.3301 & TRN & \\
\hline CHEMBL1563624 & 688113 & 4.8447 & 4.7671 & TRN & \\
\hline CHEMBL 3189560 & 688113 & 4.2806 & 3.2299 & TST & \\
\hline CHEMBL1584895 & 688113 & 5.3258 & 3.2592 & TRN & \\
\hline CHEMBL3191157 & 688113 & 4.1516 & 4.4661 & TRN & \\
\hline CHEMBL1389358 & 688113 & 8.2218 & 3.696 & TRN & \\
\hline CHEMBL1453122 & 688113 & 2.5229 & 3.0006 & TRN & \\
\hline CHEMBL1318199 & 688113 & 2.5229 & 2.5566 & TRN & \\
\hline CHEMBL1494087 & 688113 & 2.5229 & 3.3593 & TRN & \\
\hline CHEMBL1575124 & 688113 & 2.5229 & 3.0151 & TRN & \\
\hline CHEMBL1353221 & 688113 & 4.4235 & 3.2646 & TST & \\
\hline CHEMBL3196206 & 688113 & 2.5229 & 3.0207 & TRN & \\
\hline CHEMBL 1574512 & 688113 & 2.5229 & 2.989 & TRN & \\
\hline CHEMBL1439525 & 688113 & 4.4721 & 3.91 & TST & \\
\hline & & & & e 845 & \\
\hline
\end{tabular}




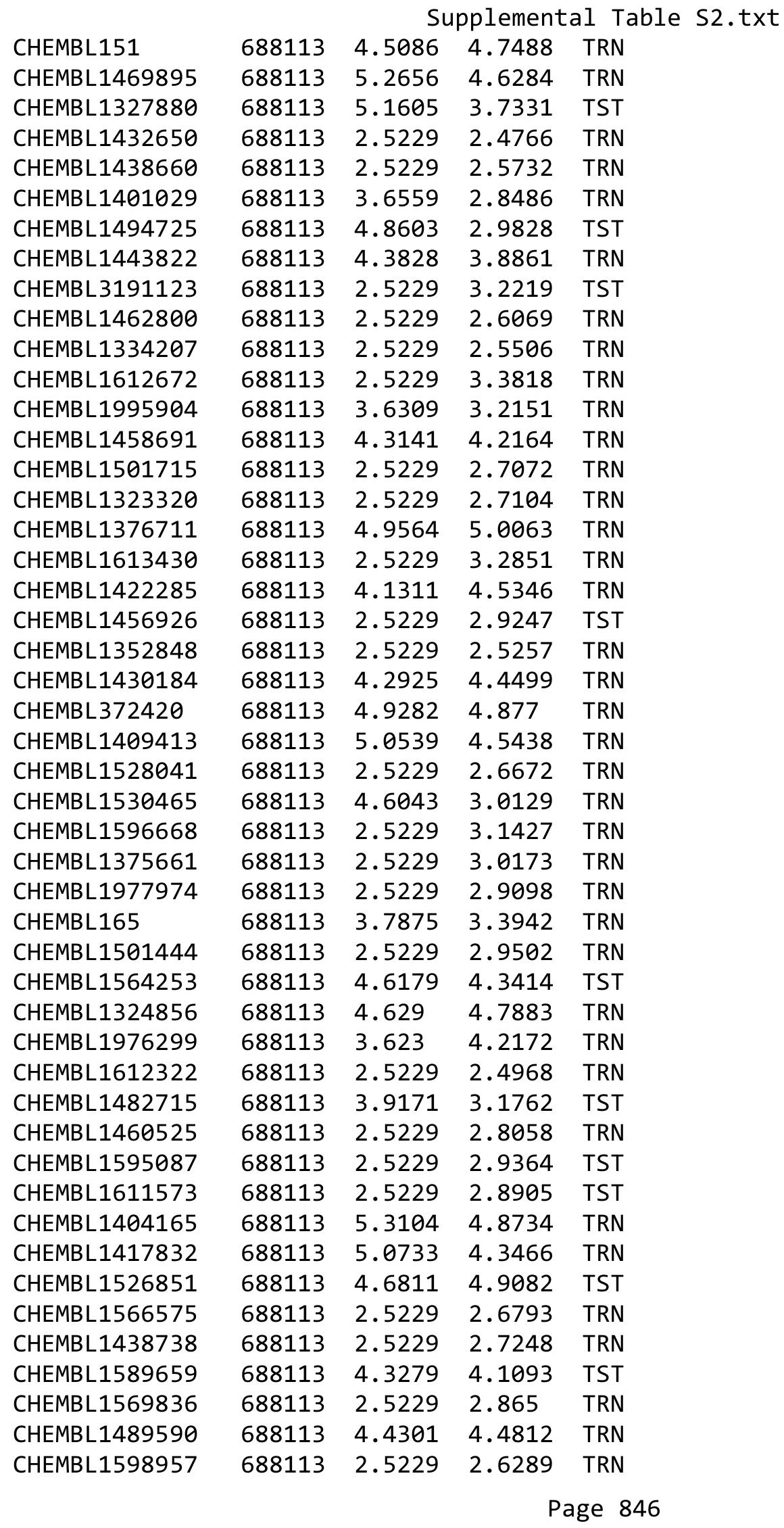




\begin{tabular}{|c|c|c|c|c|c|}
\hline \multicolumn{6}{|c|}{ Supplemental Table S2.txt } \\
\hline CHEMBL1331639 & 688113 & 4.4261 & 3.4262 & TRN & \\
\hline CHEMBL1320574 & 688113 & 4.3742 & 3.917 & TRN & \\
\hline CHEMBL1392399 & 688113 & 2.5229 & 3.0016 & TRN & \\
\hline CHEMBL1561729 & 688113 & 4.1482 & 2.8637 & TRN & \\
\hline CHEMBL1335000 & 688113 & 3.9018 & 4.2492 & TRN & \\
\hline CHEMBL1506185 & 688113 & 8.2218 & 5.8158 & TST & \\
\hline CHEMBL1468179 & 688113 & 4.3904 & 2.7261 & TRN & \\
\hline CHEMBL1971815 & 688113 & 2.5229 & 2.8044 & TRN & \\
\hline CHEMBL1348235 & 688113 & 2.5229 & 3.0845 & TRN & \\
\hline CHEMBL1556775 & 688113 & 2.5229 & 3.0289 & TRN & \\
\hline CHEMBL1884996 & 688113 & 2.5229 & 3.0023 & TRN & \\
\hline CHEMBL1346195 & 688113 & 4.0273 & 4.1451 & TRN & \\
\hline CHEMBL1481417 & 688113 & 5.7595 & 5.1721 & TST & \\
\hline CHEMBL1327262 & 688113 & 5.3616 & 4.7146 & TRN & \\
\hline CHEMBL1995948 & 688113 & 2.5229 & 2.7945 & TRN & \\
\hline CHEMBL1456923 & 688113 & 2.5229 & 2.7259 & TST & \\
\hline CHEMBL1505809 & 688113 & 2.5229 & 4.0905 & TST & \\
\hline CHEMBL1377441 & 688113 & 4.6284 & 4.5841 & TRN & \\
\hline CHEMBL1583536 & 688113 & 2.5229 & 2.8281 & TRN & \\
\hline CHEMBL 1436378 & 688113 & 2.5229 & 3.0288 & TRN & \\
\hline CHEMBL1583157 & 688113 & 2.5229 & 2.73100 & 00000000003 & TRN \\
\hline CHEMBL1529274 & 688113 & 2.5229 & 3.0437 & TRN & \\
\hline CHEMBL1559324 & 688113 & 4.9502 & 4.5884 & TRN & \\
\hline CHEMBL1302104 & 688113 & 2.5229 & 2.9546 & TRN & \\
\hline CHEMBL1310909 & 688113 & 4.3432 & 4.5716 & TRN & \\
\hline CHEMBL1607746 & 688113 & 2.5229 & 3.4091 & TRN & \\
\hline CHEMBL1392191 & 688113 & 2.5229 & 3.2462 & TRN & \\
\hline CHEMBL1545814 & 688113 & 5.5178 & 4.9548 & TRN & \\
\hline CHEMBL1406528 & 688113 & 4.6444 & 4.3101 & TRN & \\
\hline CHEMBL1598843 & 688113 & 4.4282 & 4.4027 & TRN & \\
\hline CHEMBL1366453 & 688113 & 4.593 & 4.3726 & TRN & \\
\hline CHEMBL1523304 & 688113 & 2.5229 & 2.6518 & TRN & \\
\hline CHEMBL1408276 & 688113 & 4.7622 & 4.6528 & TST & \\
\hline CHEMBL1583064 & 688113 & 2.5229 & 2.8795 & TST & \\
\hline CHEMBL 3198220 & 688113 & 2.5229 & 2.8996 & TRN & \\
\hline CHEMBL1417203 & 688113 & 2.8239 & 2.6182 & TRN & \\
\hline CHEMBL1504586 & 688113 & 4.8972 & 4.0062 & TST & \\
\hline CHEMBL1472200 & 688113 & 5.7905 & 4.4199 & TRN & \\
\hline CHEMBL1543190 & 688113 & 4.683 & 4.8725 & TRN & \\
\hline CHEMBL1562537 & 688113 & 2.5229 & 2.9593 & TRN & \\
\hline CHEMBL1449738 & 688113 & 2.5229 & 2.7497 & TRN & \\
\hline CHEMBL1326929 & 688113 & 3.9763 & 4.1294 & TRN & \\
\hline CHEMBL1592105 & 688113 & 4.4411 & 4.4477 & TRN & \\
\hline CHEMBL1464230 & 688113 & 2.5229 & 3.0473 & TRN & \\
\hline CHEMBL1597773 & 688113 & 2.5229 & 2.9122 & TST & \\
\hline CHEMBL3192866 & 688113 & 4.4395 & 3.1696 & TRN & \\
\hline CHEMBL 1450422 & 688113 & 4.1809 & 2.5847 & TRN & \\
\hline CHEMBL1560144 & 688113 & 2.5229 & 2.5794 & TRN & \\
\hline
\end{tabular}




\begin{tabular}{|c|c|c|c|c|c|c|}
\hline & & \multicolumn{5}{|c|}{ Supplemental Table S2.txt } \\
\hline CHEMBL444478 & 688113 & 5.0075 & 4.6014 & TRN & & \\
\hline CHEMBL1412227 & 688113 & 5.2701 & 3.1628 & TRN & & \\
\hline CHEMBL1597190 & 688113 & 2.5229 & 3.0002 & TST & & \\
\hline CHEMBL1359225 & 688113 & 2.5229 & 2.7348 & TRN & & \\
\hline CHEMBL1343532 & 688113 & \multicolumn{3}{|c|}{3.9610000000000003} & .9069 & TRN \\
\hline CHEMBL3213435 & 688113 & 2.5229 & 2.5903 & TRN & & \\
\hline CHEMBL 2001481 & 688113 & 5.2825 & 4.9736 & TRN & & \\
\hline CHEMBL1304449 & 688113 & 2.5229 & 3.3146 & TRN & & \\
\hline CHEMBL1533614 & 688113 & 2.5229 & 2.5015 & TRN & & \\
\hline CHEMBL1308318 & 688113 & 2.5229 & 3.0838 & TRN & & \\
\hline CHEMBL1567207 & 688113 & 3.6655 & 3.9723 & TRN & & \\
\hline CHEMBL1568537 & 688113 & 2.5229 & 2.7821 & TRN & & \\
\hline CHEMBL3199002 & 688113 & 4.5073 & 4.5982 & TRN & & \\
\hline CHEMBL1374575 & 688113 & 2.5229 & 2.775 & TRN & & \\
\hline CHEMBL1480672 & 688113 & 2.5229 & 2.7413 & TRN & & \\
\hline CHEMBL1421193 & 688113 & 4.2674 & 4.4745 & TRN & & \\
\hline CHEMBL1382089 & 688113 & 2.5229 & 2.7478 & TRN & & \\
\hline CHEMBL1989592 & 688113 & 2.5229 & 3.5035 & TRN & & \\
\hline CHEMBL1516769 & 688113 & 5.0556 & 4.7348 & TRN & & \\
\hline CHEMBL3191780 & 688113 & 4.1735 & 3.5855 & TRN & & \\
\hline CHEMBL1384352 & 688113 & 2.5229 & 2.8488 & TRN & & \\
\hline CHEMBL3192762 & 688113 & 2.5229 & 3.054 & TRN & & \\
\hline CHEMBL1569253 & 688113 & 2.5229 & 2.6307 & TRN & & \\
\hline CHEMBL1413736 & 688113 & 2.5229 & 3.1692 & TRN & & \\
\hline CHEMBL1412552 & 688113 & 2.5229 & 2.5685 & TRN & & \\
\hline CHEMBL1491588 & 688113 & 5.0715 & 5.4014 & TRN & & \\
\hline CHEMBL1589492 & 688113 & 2.5229 & 2.8349 & TST & & \\
\hline CHEMBL1564532 & 688113 & 4.2321 & 3.933006 & 0000000000 & & TRN \\
\hline CHEMBL1383957 & 688113 & 2.5229 & 3.1228 & TRN & & \\
\hline CHEMBL1503175 & 688113 & 5.0589 & 5.0206 & TRN & & \\
\hline CHEMBL1376421 & 688113 & 4.3242 & 4.5923 & TRN & & \\
\hline CHEMBL1401494 & 688113 & 4.3625 & 3.25699 & 7999999999 & & TST \\
\hline CHEMBL1488502 & 688113 & 2.5229 & 2.7609 & TRN & & \\
\hline CHEMBL1578039 & 688113 & 5.0137 & 4.5046 & TRN & & \\
\hline CHEMBL1595976 & 688113 & 2.5229 & 2.7307 & TRN & & \\
\hline CHEMBL1455287 & 688113 & 2.5229 & 2.9008 & TRN & & \\
\hline CHEMBL1363989 & 688113 & 4.5011 & 4.5215 & TRN & & \\
\hline CHEMBL1389990 & 688113 & 2.5229 & 3.0996 & TRN & & \\
\hline CHEMBL1581512 & 688113 & 4.5812 & 4.7609 & TRN & & \\
\hline CHEMBL1549499 & 688113 & 2.5229 & 2.8321 & TST & & \\
\hline CHEMBL1305441 & 688113 & 4.2389 & 2.8529 & TRN & & \\
\hline CHEMBL1408827 & 688113 & 4.8184 & 4.4946 & TRN & & \\
\hline CHEMBL1380440 & 688113 & 2.5229 & 2.9153 & TRN & & \\
\hline CHEMBL1492475 & 688113 & 2.5229 & 2.4741 & TRN & & \\
\hline CHEMBL1522846 & 688113 & 4.8278 & 4.2732 & TST & & \\
\hline CHEMBL1309980 & 688113 & 3.8286 & 4.1627 & TRN & & \\
\hline CHEMBL1607621 & 688113 & 2.5229 & 2.6269 & TRN & & \\
\hline CHEMBL1539325 & 688113 & 4.1654 & 2.7055 & TRN & & \\
\hline
\end{tabular}


Supplemental Table S2.txt

\begin{tabular}{|c|c|c|c|c|}
\hline 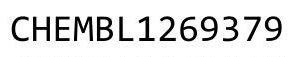 & & 229 & & \\
\hline & 88113 & 4.4109 & 4.0682 & \\
\hline & & & & \\
\hline IEMBL1490535 & & & & S \\
\hline AEMBL1443797 & 8113 & & 3374 & \\
\hline HEMBL1339776 & 88113 & 5586 & 1621 & \\
\hline 92999 & 113 & & 747 & \\
\hline 661 & & & 148 & RN \\
\hline AEMBL1396733 & 88113 & & 8487 & \\
\hline HEMBL1586152 & 38113 & & 3948 & \\
\hline HEMBL1485442 & 88113 & & & \\
\hline IEMBL1502246 & 113 & & & \\
\hline IEMBL1 & & & & \\
\hline HEMBL1430625 & 3113 & & 5495 & \\
\hline AEMBL2006012 & 13 & & 214 & \\
\hline AEMBL1401955 & 13 & & 515 & \\
\hline AEMBL1: & 113 & & & \\
\hline HEMBL1533201 & & & & \\
\hline AEMBL1492305 & 113 & & 377 & \\
\hline IEMBL1347789 & 13 & & 85 & \\
\hline EMBLI & & & & \\
\hline AEMBL & & & 98 & 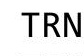 \\
\hline HEMBLI & 13 & & & \\
\hline 69154 & & & 847 & \\
\hline AEMBL1432420 & & & & I NIV \\
\hline HEMBL1 & & & 471 & II \\
\hline AEMBL: & & & 93 & ST \\
\hline AFMBI 1 & 13 & & 812 & \\
\hline AEMBL1 & & & 377 & r \\
\hline HEMBL1440636 & & & & s \\
\hline HEMBL1 & & & 275 & RIV \\
\hline HEMBL1 & & & 383 & KIN \\
\hline 91 & & & 124 & \\
\hline HEMBL1528814 & & & 5906 & T \\
\hline HEMBL1360038 & & & 9913 & TRN \\
\hline HEMBL1 & & & 718 & 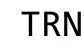 \\
\hline - & & & 413 & RIV \\
\hline & & & & $\mathrm{RN}$ \\
\hline HEMBL1605770 & 88113 & & 439 & $\Gamma \mathrm{RN}$ \\
\hline AEMBL13 & & & 315 & TST \\
\hline HEMBL3 & & & 875 & \\
\hline HEMBL1450347 & & & 2.5843 & TRN \\
\hline HEMBL1348294 & & & 7069 & RN \\
\hline AEMBL1540881 & 8113 & & 8768 & TRN \\
\hline 1 & & & 814 & \\
\hline HEMBL1389032 & & & .4946 & \\
\hline CHEMBL1360263 & & 2.5229 & 4.2544 & \\
\hline CHEMBL1588042 & 688113 & 3.9681 & 3.9229 & \\
\hline
\end{tabular}

Page 849 
Supplemental Table S2.txt

\begin{tabular}{|c|c|c|c|c|}
\hline CHEMBL1984130 & 688113 & 2.5229 & 2.7518 & TRN \\
\hline CHEMBL1489949 & 688113 & 2.5229 & 3.2099 & TRN \\
\hline CHEMBL3193719 & 688113 & 2.5229 & 2.8001 & TRN \\
\hline CHEMBL1343123 & 688113 & 2.5229 & 3.1672 & TRN \\
\hline CHEMBL1418504 & 688113 & 2.5229 & 3.3764 & TST \\
\hline CHEMBL1608866 & 688113 & 2.5229 & 3.3411 & TRN \\
\hline CHEMBL1997564 & 688113 & 2.5229 & 3.0128 & TRN \\
\hline CHEMBL1337737 & 688113 & 2.5229 & 2.9686 & TST \\
\hline CHEMBL1375215 & 688113 & 2.5229 & 2.7215 & TRN \\
\hline CHEMBL1596184 & 688113 & 4.1296 & 2.9399 & TST \\
\hline CHEMBL1335905 & 688113 & 5.9169 & 4.0492 & TRN \\
\hline CHEMBL1541803 & 688113 & 4.6077 & 4.3574 & TRN \\
\hline CHEMBL212827 & 688113 & 4.6877 & 4.4282 & TRN \\
\hline CHEMBL1605357 & 688113 & 4.5755 & 4.8437 & TRN \\
\hline CHEMBL420385 & 688113 & 2.5229 & 2.9057 & TRN \\
\hline CHEMBL1520655 & 688113 & 2.5229 & 2.8095 & TRN \\
\hline CHEMBL1492232 & 688113 & 3.9447 & 4.2629 & TRN \\
\hline CHEMBL1601229 & 688113 & 5.7652 & 5.1138 & TRN \\
\hline CHEMBL3189520 & 688113 & 2.5229 & 3.1996 & TST \\
\hline CHEMBL1400010 & 688113 & 2.5229 & 2.8526 & TRN \\
\hline CHEMBL1409312 & 688113 & 2.5229 & 2.7419 & TRN \\
\hline CHEMBL1459156 & 688113 & 2.5229 & 2.799 & TRN \\
\hline CHEMBL1495771 & 688113 & 2.5229 & 3.0186 & TRN \\
\hline CHEMBL3194726 & 688113 & 2.5229 & 2.8042 & TRN \\
\hline CHEMBL401743 & 688113 & 4.2218 & 2.5393 & TRN \\
\hline CHEMBL1598223 & 688113 & 5.6098 & 5.2902 & TST \\
\hline CHEMBL1475027 & 688113 & 2.5229 & 3.1678 & TRN \\
\hline CHEMBL3189592 & 688113 & 4.1837 & 4.8023 & TRN \\
\hline CHEMBL1602750 & 688113 & 2.5229 & 2.7705 & TRN \\
\hline CHEMBL1326666 & 688113 & 3.8964 & 3.0139 & TRN \\
\hline CHEMBL1463475 & 688113 & 2.5229 & 2.636 & TRN \\
\hline CHEMBL1488551 & 688113 & 5.2649 & 4.7632 & TRN \\
\hline CHEMBL1482955 & 688113 & 2.5229 & 2.9124 & TRN \\
\hline CHEMBL1413142 & 688113 & 6.0315 & 3.8631 & TRN \\
\hline CHEMBL3191304 & 688113 & 5.197 & 5.0365 & TRN \\
\hline CHEMBL1421819 & 688113 & 5.9027 & 4.8473 & TRN \\
\hline CHEMBL1361188 & 688113 & 5.0857 & 4.5497 & TRN \\
\hline CHEMBL1584730 & 688113 & 5.8 & 5.0427 & TRN \\
\hline CHEMBL1389549 & 688113 & 4.9086 & 5.1898 & TRN \\
\hline CHEMBL1449573 & 688113 & 2.5229 & 3.2911 & TRN \\
\hline CHEMBL1562170 & 688113 & 4.5903 & 4.8582 & TRN \\
\hline CHEMBL1536229 & 688113 & 2.5229 & 3.1138 & TRN \\
\hline CHEMBL1452132 & 688113 & 2.5229 & 3.0191 & TRN \\
\hline CHEMBL1306697 & 688113 & 4.1365 & 3.2636 & TRN \\
\hline CHEMBL1589299 & 688113 & 4.5825 & 3.9575 & TRN \\
\hline CHEMBL1576876 & 688113 & 2.5229 & 3.1669 & TRN \\
\hline CHEMBL1543994 & 688113 & 4.6112 & 4.2871 & TRN \\
\hline \multirow[t]{2}{*}{ CHEMBL1497773 } & 688113 & 5.2682 & 4.86100 & 3000000001 \\
\hline & & \multicolumn{3}{|c|}{ Page 850} \\
\hline
\end{tabular}




\begin{tabular}{|c|c|c|c|c|c|}
\hline \multirow[b]{2}{*}{ CHEMBL1572084 } & \multicolumn{5}{|c|}{ Supplemental Table S2.txt } \\
\hline & 688113 & 4.3845 & 2.7457 & TRN & \\
\hline CHEMBL1995336 & 688113 & 3.9443 & 3.8148 & TRN & \\
\hline CHEMBL1413137 & 688113 & 2.5229 & 3.0137 & TRN & \\
\hline CHEMBL1611294 & 688113 & 2.5229 & 2.9737 & TRN & \\
\hline CHEMBL1342581 & 688113 & 2.5229 & 3.1489 & TRN & \\
\hline CHEMBL1583456 & 688113 & 2.5229 & 2.4109 & TRN & \\
\hline CHEMBL1392395 & 688113 & 4.2856 & 3.3554 & TRN & \\
\hline CHEMBL151146 & 688113 & 4.5283 & 3.2797 & TST & \\
\hline CHEMBL1580273 & 688113 & 2.5229 & 2.6407 & TRN & \\
\hline CHEMBL1457785 & 688113 & 2.5229 & 3.2877 & TST & \\
\hline CHEMBL1470314 & 688113 & 2.5229 & 3.0926 & TRN & \\
\hline CHEMBL1328139 & 688113 & 2.5229 & 3.1723 & TRN & \\
\hline CHEMBL3197005 & 688113 & 4.968 & 5.4234 & TRN & \\
\hline CHEMBL1429365 & 688113 & 4.4488 & 2.9663 & TRN & \\
\hline CHEMBL1541028 & 688113 & 2.5229 & 2.4707 & TRN & \\
\hline CHEMBL1334711 & 688113 & 4.1582 & 3.7223 & TRN & \\
\hline CHEMBL1604408 & 688113 & 4.2193 & 4.2316 & TRN & \\
\hline CHEMBL1541428 & 688113 & 4.3889 & 4.4826 & TRN & \\
\hline CHEMBL1514691 & 688113 & 4.6841 & 4.7622 & TRN & \\
\hline CHEMBL1384354 & 688113 & 4.9084 & 4.5445 & TRN & \\
\hline CHEMBL1559983 & 688113 & 2.5229 & 2.6003 & TRN & \\
\hline CHEMBL1564699 & 688113 & 5.2007 & 4.6444 & TRN & \\
\hline CHEMBL1529932 & 688113 & 2.5229 & 3.3228 & TRN & \\
\hline CHEMBL1482438 & 688113 & 4.0658 & 3.0025 & TRN & \\
\hline CHEMBL3207893 & 688113 & 2.5229 & 3.5418 & TRN & \\
\hline CHEMBL1361794 & 688113 & 2.5229 & 2.7695 & TRN & \\
\hline CHEMBL1609922 & 688113 & 2.5229 & 2.7505 & TRN & \\
\hline CHEMBL1356209 & 688113 & 2.5229 & 2.7459 & TRN & \\
\hline CHEMBL1517097 & 688113 & 4.7761 & 4.9042 & TRN & \\
\hline CHEMBL1409344 & 688113 & 4.8439 & 4.7624 & TRN & \\
\hline CHEMBL1466059 & 688113 & 2.5229 & 3.1523 & TRN & \\
\hline CHEMBL1323245 & 688113 & 4.6617 & 4.7085 & TRN & \\
\hline CHEMBL 3190454 & 688113 & 2.5229 & 3.2317 & TRN & \\
\hline CHEMBL1472773 & 688113 & 5.2706 & 4.6868 & TRN & \\
\hline CHEMBL1464243 & 688113 & 2.5229 & 4.1349 & TRN & \\
\hline CHEMBL1384200 & 688113 & 2.5229 & 3.1094 & TRN & \\
\hline CHEMBL1328436 & 688113 & 4.2333 & 4.31 & TRN & \\
\hline CHEMBL565657 & 688113 & 2.5229 & 3.0138 & TRN & \\
\hline CHEMBL1342159 & 688113 & 3.7227 & 3.8584 & TRN & \\
\hline CHEMBL1450204 & 688113 & 2.5229 & 3.8564 & TRN & \\
\hline CHEMBL1446410 & 688113 & 2.5229 & 3.3201 & TRN & \\
\hline CHEMBL1462735 & 688113 & 2.5229 & 2.61899 & 99999999998 & TRN \\
\hline CHEMBL1578944 & 688113 & 4.8225 & 5.1954 & TRN & \\
\hline CHEMBL3198237 & 688113 & 4.2674 & 3.4638 & TRN & \\
\hline CHEMBL1340752 & 688113 & 2.5229 & 2.863 & TRN & \\
\hline CHEMBL1347598 & 688113 & 5.0732 & 4.8372 & TST & \\
\hline CHEMBL3195238 & 688113 & 2.5229 & 3.286 & TST & \\
\hline CHEMBL 2000240 & 688113 & 2.5229 & 3.1177 & TRN & \\
\hline
\end{tabular}

Page 851 
Supplemental Table S2.txt

\begin{tabular}{|c|c|c|c|c|}
\hline CHEMBL1567874 & 688113 & 4.4593 & 3.9851 & TRN \\
\hline CHEMBL1398855 & 688113 & 4.4684 & 4.1464 & TST \\
\hline CHEMBL1516723 & 688113 & 5.0074 & 5.5839 & TRN \\
\hline CHEMBL1333659 & 688113 & 3.7481 & 4.4514 & TRN \\
\hline CHEMBL1968273 & 688113 & 5.2494 & 5.0417 & TST \\
\hline CHEMBL1304473 & 688113 & 2.5229 & 2.6841 & TRN \\
\hline CHEMBL1308830 & 688113 & 5.4058 & 5.1523 & TRN \\
\hline CHEMBL1348958 & 688113 & 4.6096 & 3.3769 & TRN \\
\hline CHEMBL1450775 & 688113 & 4.263 & 4.4197 & TRN \\
\hline CHEMBL1532054 & 688113 & 2.5229 & 2.9285 & TRN \\
\hline CHEMBL1582332 & 688113 & 2.8239 & 3.9504 & TRN \\
\hline CHEMBL 3199005 & 688113 & 2.5229 & 3.052 & TRN \\
\hline CHEMBL1573238 & 688113 & 2.5229 & 2.7162 & TRN \\
\hline CHEMBL1425829 & 688113 & 2.5229 & 2.6119 & TRN \\
\hline CHEMBL1544403 & 688113 & 4.5891 & 4.4148 & TRN \\
\hline CHEMBL1387109 & 688113 & 4.0573 & 3.9932 & TRN \\
\hline CHEMBL1439896 & 688113 & 2.5229 & 2.6441 & TRN \\
\hline CHEMBL1363496 & 688113 & 4.5213 & 4.8143 & TRN \\
\hline CHEMBL1571941 & 688113 & 2.5229 & 3.0204 & TRN \\
\hline CHEMBL3190482 & 688113 & 2.5229 & 3.3219 & TST \\
\hline CHEMBL1460470 & 688113 & 4.7235 & 4.6956 & TST \\
\hline CHEMBL1378622 & 688113 & 5.0143 & 3.2754 & TST \\
\hline CHEMBL1443685 & 688113 & 2.5229 & 2.7361 & TST \\
\hline CHEMBL1448592 & 688113 & 2.5229 & 3.0103 & TST \\
\hline CHEMBL1602950 & 688113 & 4.4549 & 5.3035 & TST \\
\hline CHEMBL1539176 & 688113 & 2.5229 & 4.0003 & TST \\
\hline CHEMBL1992547 & 688113 & 2.8239 & 2.9943 & TST \\
\hline CHEMBL1969046 & 688113 & 4.4989 & 4.0976 & TST \\
\hline CHEMBL1544064 & 688113 & 2.5229 & 2.9191 & TST \\
\hline CHEMBL1335833 & 688113 & 2.5229 & 3.046000 & 0000000003 \\
\hline CHEMBL1488688 & 688113 & 2.5229 & 3.2203 & TST \\
\hline CHEMBL1509842 & 688113 & 5.5458 & 5.3468 & TST \\
\hline CHEMBL1477950 & 688113 & 2.5229 & 3.0705 & TST \\
\hline CHEMBL1543214 & 688113 & 2.5229 & 2.6194 & TST \\
\hline CHEMBL1483095 & 688113 & 5.6463 & 5.0982 & TST \\
\hline CHEMBL1510955 & 688113 & 2.5229 & 3.3697 & TST \\
\hline CHEMBL1350299 & 688113 & 2.5229 & 3.0523 & TST \\
\hline CHEMBL1334970 & 688113 & 2.5229 & 2.5013 & TST \\
\hline CHEMBL1353112 & 688113 & 2.5229 & 4.2592 & TST \\
\hline CHEMBL1612744 & 688113 & 2.5229 & 2.9156 & TST \\
\hline CHEMBL1609926 & 688113 & 3.8477 & 3.1607 & TST \\
\hline CHEMBL1353916 & 688113 & 4.4523 & 4.1154 & TST \\
\hline CHEMBL1377074 & 688113 & 2.5229 & 2.5812 & TST \\
\hline CHEMBL1405716 & 688113 & 4.5383 & 3.2123 & TST \\
\hline CHEMBL1494599 & 688113 & 4.4778 & 4.1164 & TST \\
\hline CHEMBL1419259 & 688113 & 2.5229 & 3.0832 & TST \\
\hline CHEMBL1539384 & 688113 & 4.8158 & 5.1551 & TST \\
\hline CHEMBL3195188 & 688113 & 5.096 & 3.1187 & TST \\
\hline
\end{tabular}




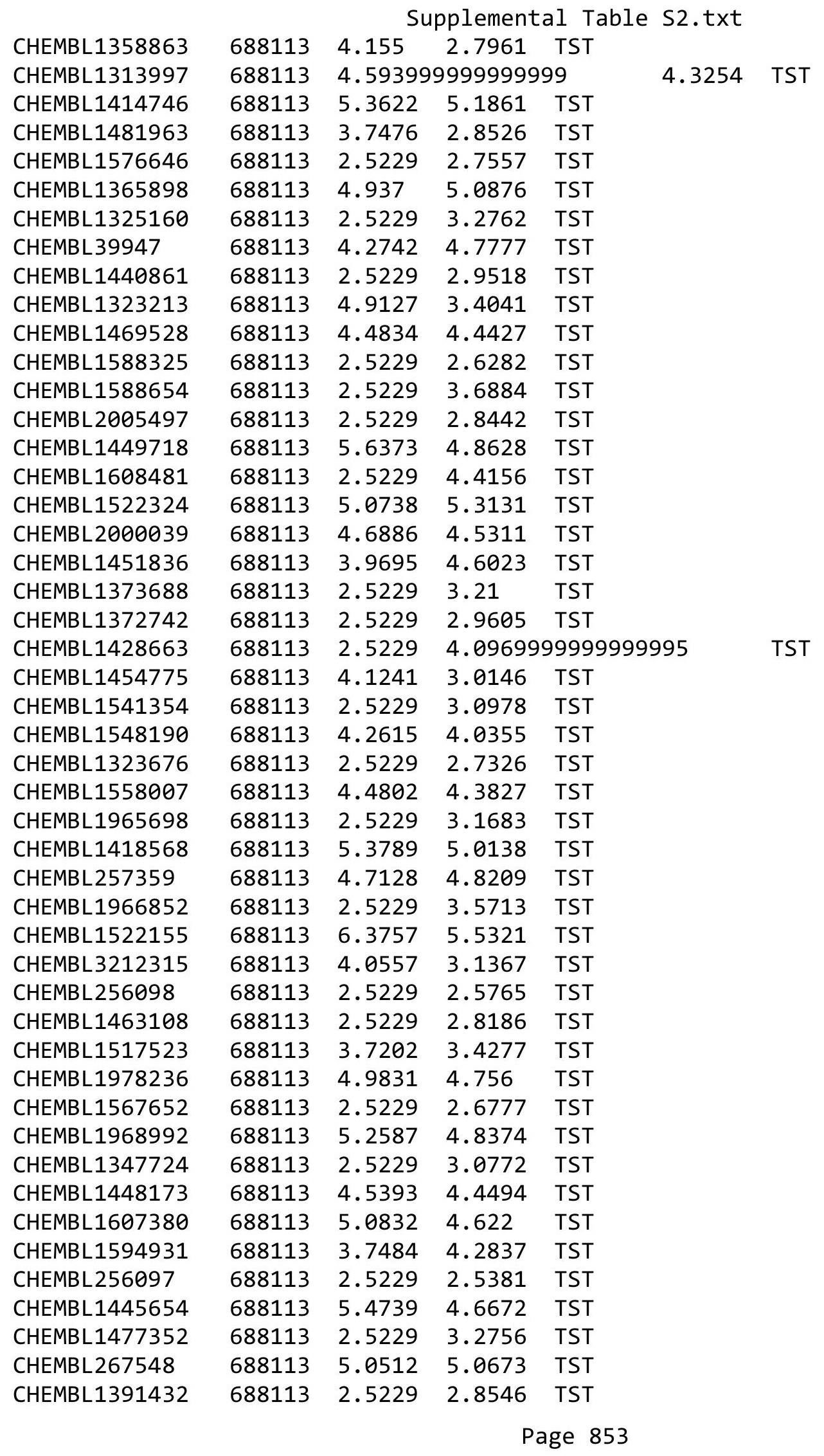


Supplemental Table S2.txt

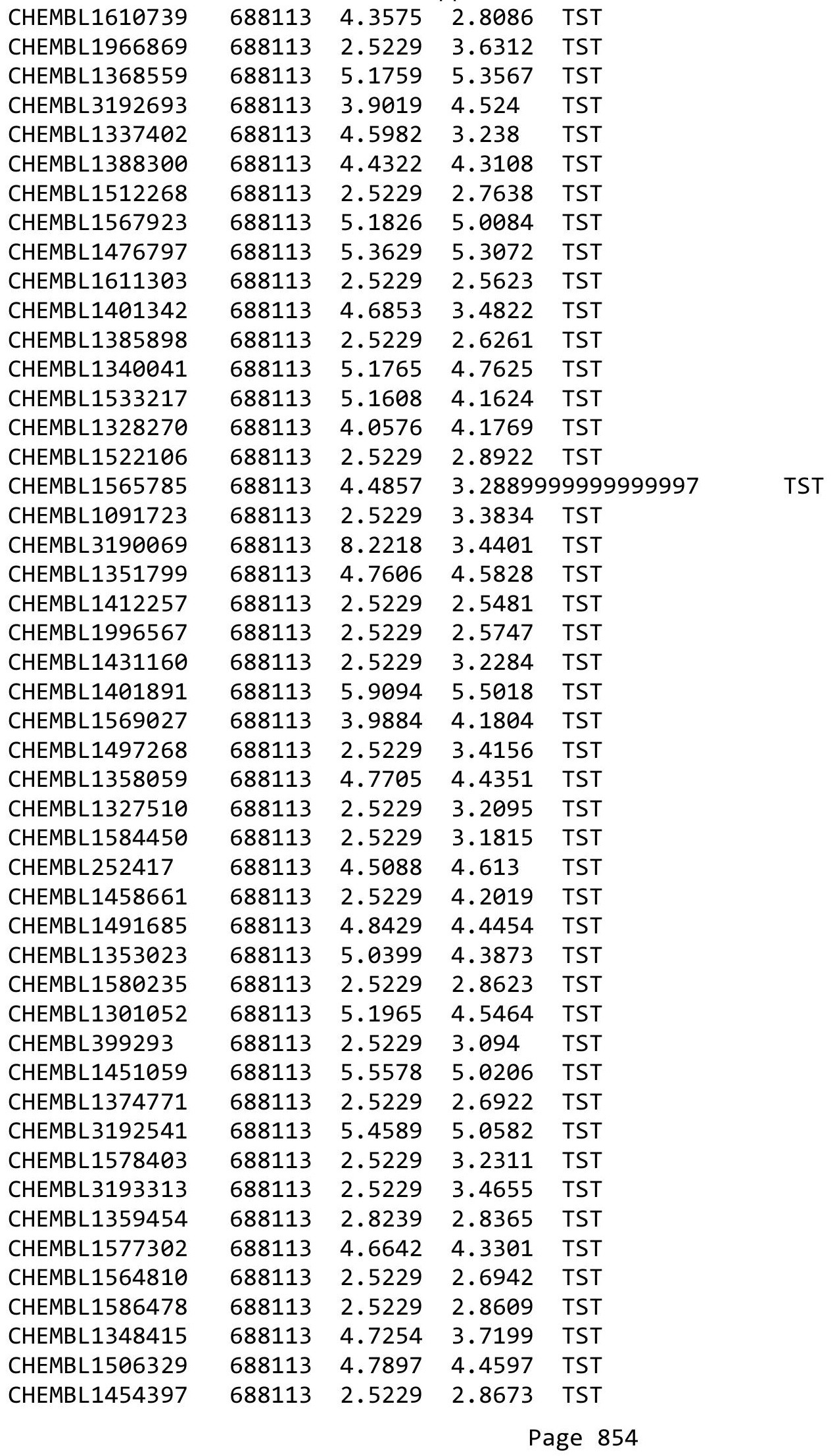




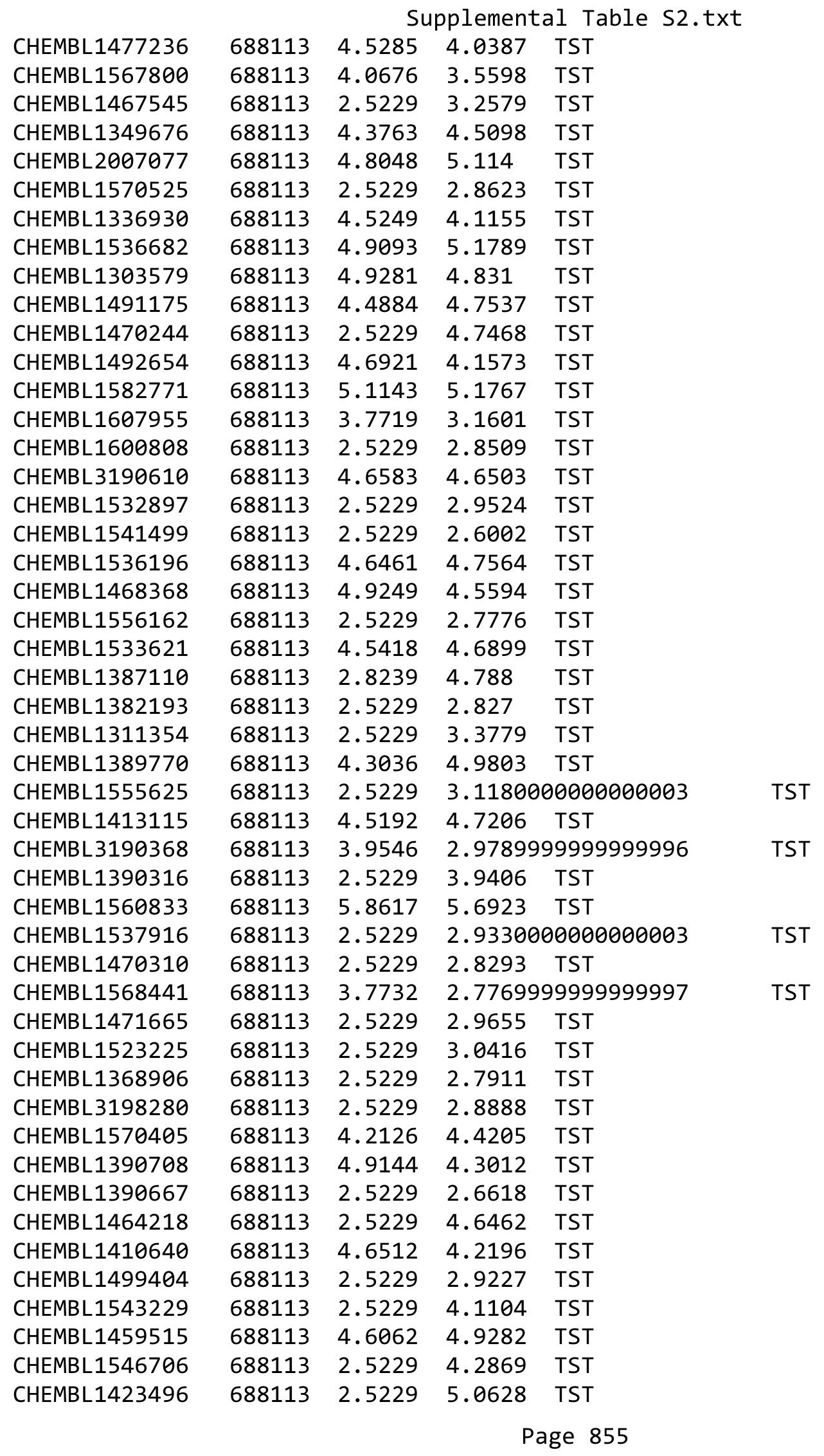




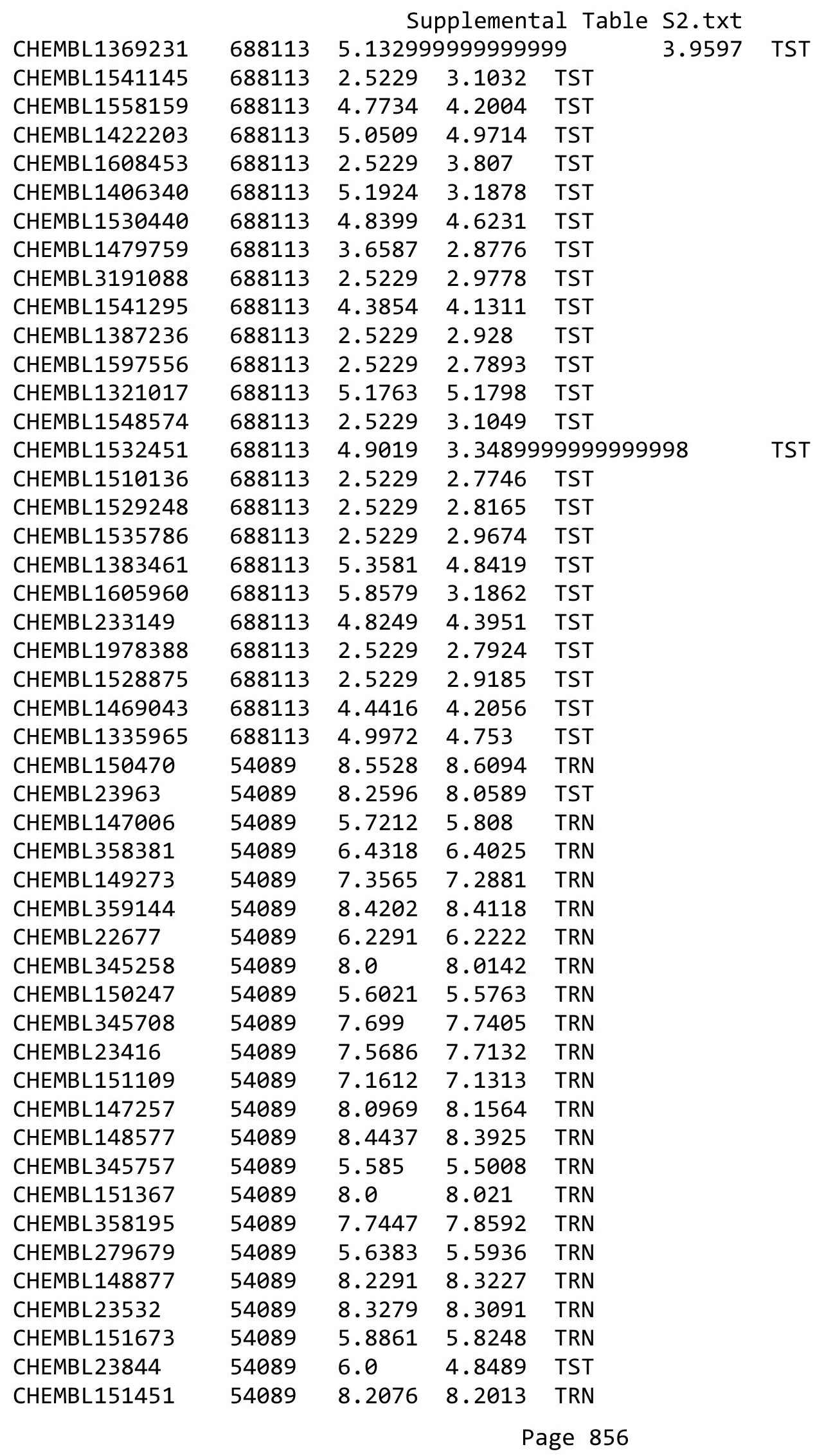




\begin{tabular}{|c|c|c|c|c|c|}
\hline & & \multicolumn{4}{|c|}{ Supplemental Table s2.txt } \\
\hline CHEMBL151312 & 54089 & 5.1367 & 5.1311 & TRN & \\
\hline CHEMBL149101 & 54089 & 7.9208 & 7.9468 & TRN & \\
\hline CHEMBL151611 & 54089 & 5.2757 & 6.4962 & TST & \\
\hline CHEMBL147469 & 54089 & 8.1487 & 8.1306 & TRN & \\
\hline CHEMBL147256 & 54089 & 8.2147 & 8.1993 & TRN & \\
\hline CHEMBL151129 & 54089 & 5.2147 & 5.4867 & TRN & \\
\hline CHEMBL348209 & 54089 & 6.6021 & 6.6497 & TRN & \\
\hline CHEMBL147131 & 54089 & 8.3372 & 8.21600 & 2000000001 & TRN \\
\hline CHEMBL358884 & 54089 & 8.3872 & 8.3339 & TRN & \\
\hline CHEMBL24007 & 54089 & 6.3768 & 6.4049 & TRN & \\
\hline CHEMBL23244 & 54089 & 6.3565 & 6.3113 & TRN & \\
\hline CHEMBL151543 & 54089 & 6.0044 & 5.9126 & TRN & \\
\hline CHEMBL281648 & 54089 & 8.5686 & 8.5567 & TRN & \\
\hline CHEMBL149351 & 54089 & 6.0 & 5.9657 & TRN & \\
\hline CHEMBL151958 & 54089 & 8.3665 & 8.3424 & TRN & \\
\hline CHEMBL151674 & 54089 & 8.4949 & 8.686 & TRN & \\
\hline CHEMBL346666 & 54089 & 8.3979 & 8.3766 & TRN & \\
\hline CHEMBL22623 & 54089 & 8.0605 & 8.0977 & TRN & \\
\hline CHEMBL148814 & 54089 & 8.4318 & 8.3121 & TRN & \\
\hline CHEMBL147124 & 54089 & 8.28399 & 99999999 & 8.3259 & TRN \\
\hline CHEMBL 23272 & 54089 & 6.0706 & 6.0454 & TRN & \\
\hline CHEMBL356620 & 54089 & 7.8539 & 7.8666 & TRN & \\
\hline CHEMBL80066 & 54089 & 7.7696 & 7.6958 & TRN & \\
\hline CHEMBL277217 & 54089 & 6.301 & 6.303 & TRN & \\
\hline CHEMBL347974 & 54089 & 8.1739 & 8.1507 & TRN & \\
\hline CHEMBL282948 & 54089 & 6.8477 & 6.7953 & TRN & \\
\hline CHEMBL148938 & 54089 & 5.9208 & 6.0701 & TRN & \\
\hline CHEMBL347088 & 54089 & 6.5575 & 6.5251 & TRN & \\
\hline CHEMBL23492 & 54089 & 6.1739 & 5.5111 & TST & \\
\hline CHEMBL23713 & 54089 & 6.8239 & 6.8942 & TRN & \\
\hline CHEMBL23021 & 54089 & 6.0 & 6.0137 & TRN & \\
\hline CHEMBL347061 & 54089 & 7.7212 & 7.6705 & TRN & \\
\hline CHEMBL283518 & 54089 & 8.2924 & 8.1547 & TRN & \\
\hline CHEMBL 23220 & 54089 & 6.1487 & 6.4059 & TST & \\
\hline CHEMBL150317 & 54089 & 8.699 & 8.742 & TRN & \\
\hline CHEMBL 23076 & 54089 & 7.4437 & 7.3521 & TRN & \\
\hline CHEMBL23383 & 54089 & 7.2441 & 7.1492 & TRN & \\
\hline CHEMBL147458 & 54089 & 6.0706 & 6.0633 & TRN & \\
\hline CHEMBL81820 & 54089 & 8.301 & 8.3203 & TRN & \\
\hline CHEMBL23584 & 54089 & 6.3565 & 6.9291 & TST & \\
\hline CHEMBL150082 & 54089 & 8.1739 & 7.5204 & TST & \\
\hline CHEMBL23867 & 54089 & 8.3665 & 8.2119 & TST & \\
\hline CHEMBL284544 & 54089 & 5.5686 & 4.71899 & 9999999999 & TST \\
\hline CHEMBL22924 & 54089 & 6.0862 & 5.9596 & TST & \\
\hline CHEMBL151947 & 54089 & 7.8239 & 7.487 & TST & \\
\hline CHEMBL279705 & 54089 & 6.5229 & 6.7393 & TST & \\
\hline CHEMBL23288 & 54089 & 5.4089 & 5.646 & TST & \\
\hline CHEMBL150382 & 54089 & 8.2147 & 8.0961 & TST & \\
\hline
\end{tabular}




\begin{tabular}{|c|c|c|c|c|c|}
\hline & & \multicolumn{4}{|c|}{ Supplemental Table s2.txt } \\
\hline CHEMBL81119 & 54089 & 6.9208 & 7.9317 & TST & \\
\hline CHEMBL148591 & 54089 & 5.4685 & 5.95 & TST & \\
\hline CHEMBL146968 & 54089 & 7.4815 & 7.8377 & TST & \\
\hline CHEMBL150835 & 54089 & 4.5086 & 3.8828 & TST & \\
\hline CHEMBL147504 & 54089 & 7.1675 & 6.2252 & TST & \\
\hline CHEMBL3410592 & 1470241 & 6.1858 & 6.1645 & TRN & \\
\hline CHEMBL3410604 & 1470241 & 6.7595 & 6.8047 & TRN & \\
\hline CHEMBL3410576 & 1470241 & 6.2503 & 5.3776 & TST & \\
\hline CHEMBL 3410571 & 1470241 & 5.4378 & 4.0475 & TST & \\
\hline CHEMBL3410599 & 1470241 & 6.6216 & 6.6052 & TRN & \\
\hline CHEMBL 3410585 & 1470241 & 5.21899 & 99999999 & 5.204 & TRN \\
\hline CHEMBL3410583 & 1470241 & 4.0 & 4.044 & TRN & \\
\hline CHEMBL3410617 & 1470241 & 4.0 & 4.0362 & TRN & \\
\hline CHEMBL 3410577 & 1470241 & 4.0 & 4.2029 & TST & \\
\hline CHEMBL3410594 & 1470241 & 7.2366 & 7.3354 & TRN & \\
\hline CHEMBL3410616 & 1470241 & 6.5072 & 6.5559 & TRN & \\
\hline CHEMBL3410596 & 1470241 & 7.4559 & 7.4544 & TRN & \\
\hline CHEMBL3410602 & 1470241 & 6.8827 & 6.7698 & TRN & \\
\hline CHEMBL3410603 & 1470241 & 6.8928 & 6.8855 & TRN & \\
\hline CHEMBL3410582 & 1470241 & 5.6755 & 5.5888 & TRN & \\
\hline CHEMBL3410607 & 1470241 & 7.585 & 7.5613 & TRN & \\
\hline CHEMBL3410597 & 1470241 & 6.1057 & 6.2029 & TRN & \\
\hline CHEMBL3410618 & 1470241 & 4.0 & 3.9973 & TRN & \\
\hline CHEMBL3410579 & 1470241 & 5.7018 & 5.5396 & TRN & \\
\hline CHEMBL3410570 & 1470241 & 4.0 & 2.5048 & TST & \\
\hline CHEMBL3410578 & 1470241 & 5.8671 & 5.9911 & TRN & \\
\hline CHEMBL3410588 & 1470241 & 6.4881 & 6.5344 & TRN & \\
\hline CHEMBL1460972 & 1470241 & 5.0422 & 3.39899 & 99999999996 & TST \\
\hline CHEMBL3410614 & 1470241 & 4.0 & 3.9376 & TRN & \\
\hline CHEMBL3410601 & 1470241 & 6.5467 & 6.4928 & TRN & \\
\hline CHEMBL1235108 & 1470241 & 4.0 & 4.0242 & TST & \\
\hline CHEMBL3410575 & 1470241 & 5.7153 & 4.0535 & TST & \\
\hline CHEMBL 3410580 & 1470241 & 6.0137 & 5.9919 & TRN & \\
\hline CHEMBL3410593 & 1470241 & 6.2581 & 6.305 & TRN & \\
\hline CHEMBL3410573 & 1470241 & 4.0 & 4.2075 & TRN & \\
\hline CHEMBL3410611 & 1470241 & 6.3439 & 6.2264 & TRN & \\
\hline CHEMBL3410608 & 1470241 & 5.9555 & 6.0485 & TRN & \\
\hline CHEMBL3410610 & 1470241 & 7.5376 & 7.4843 & TRN & \\
\hline CHEMBL3410586 & 1470241 & 5.0444 & 4.6052 & TST & \\
\hline CHEMBL3410581 & 1470241 & 6.0521 & 6.2113 & TRN & \\
\hline CHEMBL3410606 & 1470241 & 4.0 & 5.0785 & TST & \\
\hline CHEMBL3410598 & 1470241 & 5.8416 & 5.7017 & TRN & \\
\hline CHEMBL3410589 & 1470241 & 6.1904 & 6.206 & TRN & \\
\hline CHEMBL3410612 & 1470241 & 4.0 & 3.9232 & TRN & \\
\hline CHEMBL3410595 & 1470241 & 7.3098 & 7.2598 & TRN & \\
\hline CHEMBL3410572 & 1470241 & 5.4148 & 5.2127 & TRN & \\
\hline CHEMBL3410587 & 1470241 & 4.0 & 3.9746 & TRN & \\
\hline CHEMBL3410600 & 1470241 & 6.3893 & 6.4718 & TRN & \\
\hline
\end{tabular}


Supplemental Table S2.txt

\begin{tabular}{|c|c|c|c|c|c|}
\hline CHEMBL3410590 & 1470241 & 6.4295 & 6.3965 & TRN & \\
\hline CHEMBL3410613 & 1470241 & 4.0 & 4.075 & TRN & \\
\hline CHEMBL2178108 & 1470241 & 5.4048 & 5.3944 & TRN & \\
\hline CHEMBL3410619 & 1470241 & 4.0 & 4.0309 & TRN & \\
\hline CHEMBL3410574 & 1470241 & 5.6297 & 3.958999 & 99999999996 & TST \\
\hline CHEMBL3410609 & 1470241 & 7.7447 & 7.7899 & TRN & \\
\hline CHEMBL3410591 & 1470241 & 6.2882 & 6.4582 & TST & \\
\hline CHEMBL3410584 & 1470241 & 4.0 & 6.4035 & TST & \\
\hline CHEMBL3410615 & 1470241 & 4.0 & 4.6003 & TST & \\
\hline CHEMBL3410605 & 1470241 & 6.4056 & 6.7618 & TST & \\
\hline CHEMBL220241 & 954710 & 4.1829 & 4.8277 & TRN & \\
\hline CHEMBL210618 & 954710 & 3.0695 & 3.3842 & TRN & \\
\hline CHEMBL 213100 & 954710 & 5.9649 & 6.2366 & TRN & \\
\hline CHEMBL217354 & 954710 & 6.3353 & 6.3715 & TRN & \\
\hline CHEMBL1230020 & 954710 & 4.1189 & 4.015 & TRN & \\
\hline CHEMBL1788116 & 954710 & 5.4271 & 4.7891 & TRN & \\
\hline CHEMBL3392440 & 954710 & 3.6297 & 3.9764 & TRN & \\
\hline CHEMBL2144069 & 954710 & 5.1773 & 5.3212 & TRN & \\
\hline CHEMBL240954 & 954710 & 3.8579 & 3.551 & TST & \\
\hline CHEMBL1186585 & 954710 & 4.6994 & 4.0131 & TRN & \\
\hline CHEMBL514499 & 954710 & 7.0416 & 7.0946 & TRN & \\
\hline CHEMBL585951 & 954710 & 5.9237 & 6.1288 & TRN & \\
\hline CHEMBL483849 & 954710 & 1.7788 & 2.2528 & TST & \\
\hline CHEMBL393929 & 954710 & 3.7085 & 3.8063 & TRN & \\
\hline CHEMBL573107 & 954710 & 5.2708 & 4.9651 & TRN & \\
\hline CHEMBL3199475 & 954710 & 5.3206 & 4.4435 & TRN & \\
\hline CHEMBL135561 & 954710 & 4.5463 & 4.6816 & TRN & \\
\hline CHEMBL189584 & 954710 & 4.5491 & 4.4155 & TRN & \\
\hline CHEMBL512504 & 954710 & 4.1597 & 4.1538 & TRN & \\
\hline CHEMBL2137530 & 954710 & 5.1714 & 4.7946 & TRN & \\
\hline CHEMBL3186408 & 954710 & 3.9811 & 3.927 & TST & \\
\hline CHEMBL9470 & 954710 & 5.9122 & 5.8473 & TST & \\
\hline CHEMBL1970879 & 954710 & 6.2245 & 5.7807 & TRN & \\
\hline CHEMBL2134202 & 954710 & 3.6327 & 4.016 & TRN & \\
\hline CHEMBL509032 & 954710 & 5.9786 & 6.0248 & TRN & \\
\hline CHEMBL1516890 & 954710 & 4.3156 & 4.0858 & TRN & \\
\hline CHEMBL258844 & 954710 & 4.212 & 4.5294 & TRN & \\
\hline CHEMBL 300389 & 954710 & 7.2443 & 7.0232 & TRN & \\
\hline CHEMBL1643959 & 954710 & 4.0158 & 4.1562 & TRN & \\
\hline CHEMBL2363137 & 954710 & \multicolumn{3}{|c|}{4.9910000000000005} & TRN \\
\hline CHEMBL2005886 & 954710 & 5.6453 & 5.9718 & TRN & \\
\hline CHEMBL1909414 & 954710 & 3.4299 & 3.7671 & TRN & \\
\hline CHEMBL221137 & 954710 & 4.4271 & 4.7906 & TST & \\
\hline CHEMBL399530 & 954710 & \multicolumn{3}{|c|}{4.111000000000001} & TRN \\
\hline CHEMBL222102 & 954710 & 3.9786 & 3.7239 & TRN & \\
\hline CHEMBL373751 & 954710 & 3.6019 & 3.9266 & TRN & \\
\hline CHEMBL188678 & 954710 & 4.7693 & 4.3157 & TRN & \\
\hline CHEMBL180127 & 954710 & 3.8018 & 4.302 & TRN & \\
\hline
\end{tabular}




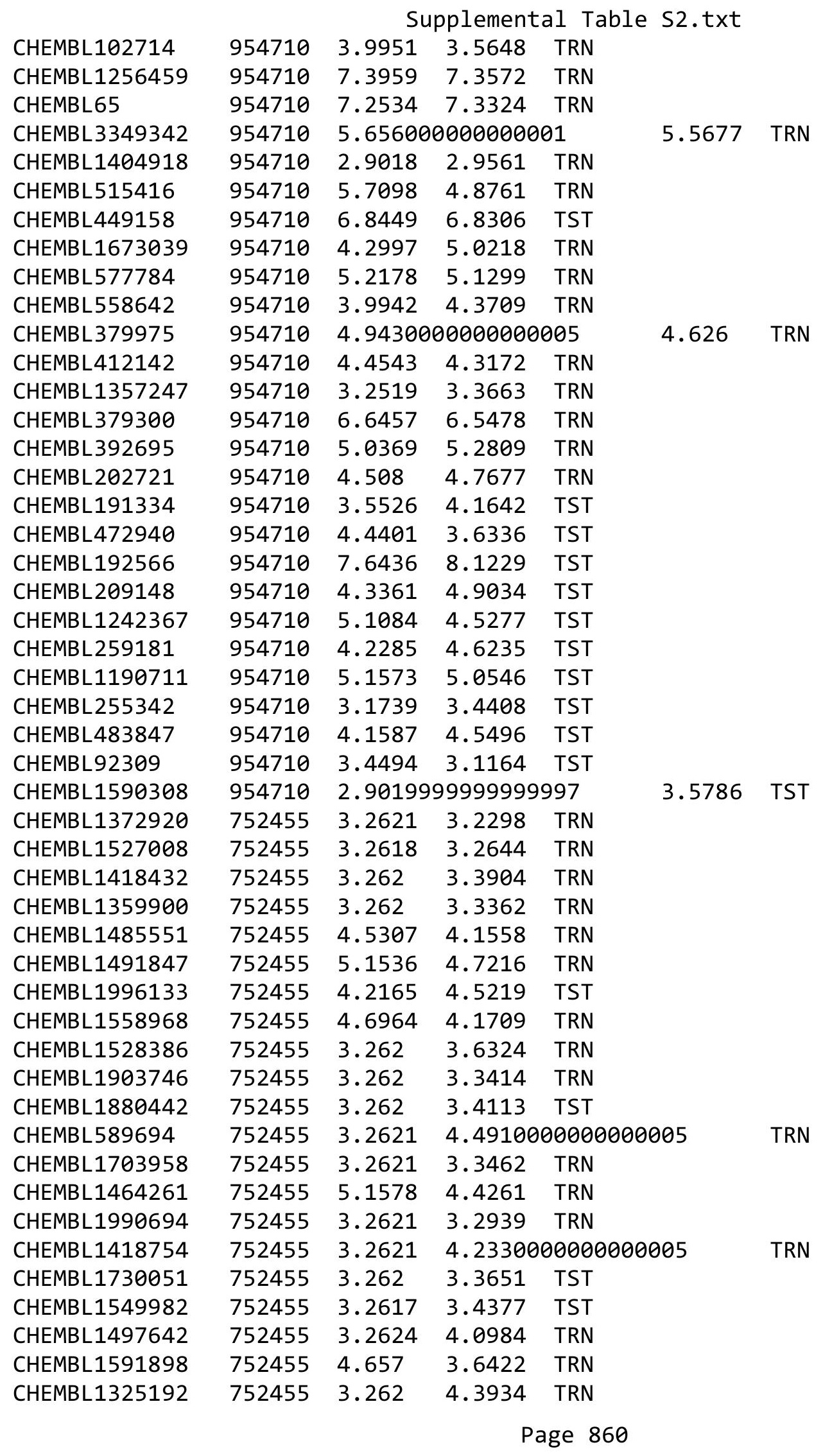




\begin{tabular}{|c|c|c|c|c|c|c|}
\hline \multirow[b]{2}{*}{ CHEMBL1572827 } & & \multicolumn{5}{|c|}{ Supplemental Table S2.txt } \\
\hline & 752455 & 3.262 & 4.5566 & TRN & & \\
\hline CHEMBL1361615 & 752455 & 3.2621 & 3.7695 & TRN & & \\
\hline CHEMBL1472131 & 752455 & 3.2623 & 3.3174 & TRN & & \\
\hline CHEMBL1578991 & 752455 & 3.2616 & 3.3211 & TRN & & \\
\hline CHEMBL1719363 & 752455 & 3.262 & 3.4456 & TRN & & \\
\hline CHEMBL1418096 & 752455 & 3.2617 & 3.2928 & TRN & & \\
\hline CHEMBL1605224 & 752455 & 4.8209 & 4.3395 & TRN & & \\
\hline CHEMBL1713873 & 752455 & 3.2624 & 3.3195 & TRN & & \\
\hline CHEMBL1368701 & 752455 & 3.2619 & 3.3653 & TST & & \\
\hline CHEMBL1547938 & 752455 & 3.2618 & 3.2376 & TRN & & \\
\hline CHEMBL1489159 & 752455 & 3.2621 & 3.3023 & TST & & \\
\hline CHEMBL1442125 & 752455 & 4.6515 & 3.7349 & TRN & & \\
\hline CHEMBL1528271 & 752455 & 3.2621 & 3.3304 & TST & & \\
\hline CHEMBL1544339 & 752455 & 3.2621 & 4.1659 & TRN & & \\
\hline CHEMBL1332522 & 752455 & 3.2622 & 3.2891 & TST & & \\
\hline CHEMBL 1491750 & 752455 & 3.262 & 3.3874 & TST & & \\
\hline CHEMBL1492019 & 752455 & 3.2618 & 3.3299 & TST & & \\
\hline CHEMBL1731264 & 752455 & 3.2616 & 3.2737 & TRN & & \\
\hline CHEMBL1462480 & 752455 & 3.262 & 3.4247 & TRN & & \\
\hline CHEMBL1360013 & 752455 & 3.262 & 3.5086 & TRN & & \\
\hline CHEMBL1361924 & 752455 & 4.2162 & 4.4465 & TRN & & \\
\hline CHEMBL1401226 & 752455 & 3.2619 & 3.8698 & TRN & & \\
\hline CHEMBL1721855 & 752455 & 3.2618 & 3.2543 & TST & & \\
\hline CHEMBL1723816 & 752455 & 3.2621 & 3.2609 & TRN & & \\
\hline CHEMBL1513972 & 752455 & 5.1238 & 4.4621 & TRN & & \\
\hline CHEMBL1553406 & 752455 & 3.2617 & 3.3872 & TRN & & \\
\hline CHEMBL1497597 & 752455 & 4.9517 & 4.7298 & TRN & & \\
\hline CHEMBL1707076 & 752455 & 3.2621 & 3.3321 & TRN & & \\
\hline CHEMBL1610752 & 752455 & 3.2621 & 3.4037 & TRN & & \\
\hline CHEMBL1557185 & 752455 & 3.2623 & 3.3475 & TRN & & \\
\hline CHEMBL1496705 & 752455 & 4.2163 & 4.8424 & TRN & & \\
\hline CHEMBL1586096 & 752455 & 3.262 & 3.2642 & TRN & & \\
\hline CHEMBL1398001 & 752455 & 3.262 & 3.2972 & TRN & & \\
\hline CHEMBL1484277 & 752455 & 3.2621 & 3.31 & TRN & & \\
\hline CHEMBL1419164 & 752455 & 3.2622 & 3.2605 & TRN & & \\
\hline CHEMBL1367036 & 752455 & 3.2621 & 3.3507 & TST & & \\
\hline CHEMBL1966241 & 752455 & 3.2621 & 3.3873 & TST & & \\
\hline CHEMBL1337599 & 752455 & 3.262 & 3.4167 & TRN & & \\
\hline CHEMBL1982108 & 752455 & 3.262 & 4.747 & TST & & \\
\hline CHEMBL1394552 & 752455 & 3.2624 & 3.3752 & TST & & \\
\hline CHEMBL1536835 & 752455 & 4.4907 & 3.68 & TRN & & \\
\hline CHEMBL1452296 & 752455 & 3.262 & 3.3675 & TST & & \\
\hline CHEMBL589245 & 752455 & 3.262 & 3.9199 & TRN & & \\
\hline CHEMBL1314272 & 752455 & 3.2618 & 3.4667 & TRN & & \\
\hline CHEMBL1458111 & 752455 & 5.13200 & 00000000 & $\partial 1$ & 3.9068 & TRN \\
\hline CHEMBL3195513 & 752455 & 3.2621 & 3.4318 & TRN & & \\
\hline CHEMBL1474759 & 752455 & 4.7552 & 4.4816 & TRN & & \\
\hline CHEMBL1498210 & 752455 & 3.2619 & 3.2409 & TST & & \\
\hline
\end{tabular}




\begin{tabular}{|c|c|c|c|c|c|}
\hline & & \multicolumn{4}{|c|}{ Supplemental Table S2.txt } \\
\hline CHEMBL1367989 & 752455 & 3.262 & 4.1642 & TRN & \\
\hline CHEMBL1345866 & 752455 & 3.2621 & 3.3381 & TRN & \\
\hline CHEMBL1381946 & 752455 & 3.262 & 3.4264 & TRN & \\
\hline CHEMBL1370456 & 752455 & 3.2623 & 3.7435 & TST & \\
\hline CHEMBL1410739 & 752455 & 3.262 & 4.1498 & TRN & \\
\hline CHEMBL250711 & 752455 & 5.0485 & 4.0659 & TRN & \\
\hline CHEMBL1397114 & 752455 & 3.2618 & 3.283 & TST & \\
\hline CHEMBL1571034 & 752455 & 3.2621 & 3.2791 & TRN & \\
\hline CHEMBL1471509 & 752455 & 3.262 & 3.4466 & TST & \\
\hline CHEMBL1893003 & 752455 & 3.2624 & 3.3612 & TRN & \\
\hline CHEMBL1708021 & 752455 & 3.2621 & 3.3575 & TRN & \\
\hline CHEMBL1572055 & 752455 & 3.2621 & 3.2746 & TRN & \\
\hline CHEMBL1726318 & 752455 & 3.262 & 3.3892 & TRN & \\
\hline CHEMBL1232381 & 752455 & 5.1081 & 3.8002 & TRN & \\
\hline CHEMBL1591708 & 752455 & 3.2618 & 3.3349 & TRN & \\
\hline CHEMBL1510721 & 752455 & 3.262 & 3.2595 & TRN & \\
\hline CHEMBL1979061 & 752455 & 3.2624 & 3.3528 & TRN & \\
\hline CHEMBL1341102 & 752455 & 3.2619 & 3.2994 & TRN & \\
\hline CHEMBL1331195 & 752455 & 3.2618 & 3.2728 & TRN & \\
\hline CHEMBL1403262 & 752455 & 4.9145 & 3.7669 & TRN & \\
\hline CHEMBL1974537 & 752455 & 3.2621 & 4.7619 & TST & \\
\hline CHEMBL1369287 & 752455 & 5.003 & 4.3892 & TRN & \\
\hline CHEMBL1409608 & 752455 & 3.2621 & 3.3331 & TRN & \\
\hline CHEMBL1415720 & 752455 & 4.2636 & 4.263 & TRN & \\
\hline CHEMBL1492044 & 752455 & 3.2619 & 3.3173 & TRN & \\
\hline CHEMBL1576297 & 752455 & 3.2617 & 3.4027 & TRN & \\
\hline CHEMBL1393761 & 752455 & 4.79899 & 99999999 & 4.1629 & TST \\
\hline CHEMBL1973159 & 752455 & 4.6936 & 5.6257 & TST & \\
\hline CHEMBL1486421 & 752455 & 3.2622 & 3.4149 & TRN & \\
\hline CHEMBL1303339 & 752455 & 3.2621 & 3.3729 & TRN & \\
\hline CHEMBL1376516 & 752455 & 4.3714 & 4.5187 & TRN & \\
\hline CHEMBL1704902 & 752455 & 3.2622 & 3.265 & TRN & \\
\hline CHEMBL 86464 & 752455 & 3.2621 & 4.475 & TRN & \\
\hline CHEMBL1979800 & 752455 & 3.262 & 4.0528 & TST & \\
\hline CHEMBL1575701 & 752455 & 3.2617 & 3.3793 & TST & \\
\hline CHEMBL3213565 & 752455 & 3.2624 & 3.365 & TRN & \\
\hline CHEMBL1481849 & 752455 & 5.1791 & 4.5442 & TRN & \\
\hline CHEMBL1390912 & 752455 & 3.262 & 3.36899 & 99999999998 & TRN \\
\hline CHEMBL1995720 & 752455 & 4.2161 & 5.2174 & TST & \\
\hline CHEMBL1510317 & 752455 & 3.2621 & 3.307 & TRN & \\
\hline CHEMBL1725771 & 752455 & 3.2617 & 3.25600 & 00000000002 & TRN \\
\hline CHEMBL1542526 & 752455 & 4.6418 & 3.4248 & TRN & \\
\hline CHEMBL1303641 & 752455 & 3.2621 & 3.3543 & TRN & \\
\hline CHEMBL1455530 & 752455 & 4.9554 & 4.4292 & TRN & \\
\hline CHEMBL1611041 & 752455 & 3.262 & 4.2573 & TST & \\
\hline CHEMBL1208858 & 752455 & 4.6934 & 4.6046 & TST & \\
\hline CHEMBL1562133 & 752455 & 3.2621 & 3.3774 & TRN & \\
\hline CHEMBL1321530 & 752455 & 3.2623 & 3.2733 & TRN & \\
\hline
\end{tabular}




\begin{tabular}{|c|c|c|c|c|}
\hline \multicolumn{5}{|c|}{ Supplemental Table S2.txt } \\
\hline CHEMBL3198737 & 752455 & 3.2624 & 3.3869 & TRN \\
\hline CHEMBL1369972 & 752455 & 3.262 & 3.3702 & TRN \\
\hline CHEMBL532160 & 752455 & 4.8104 & 4.3508 & TRN \\
\hline CHEMBL3196438 & 752455 & 3.262 & 3.6487 & TRN \\
\hline CHEMBL1362746 & 752455 & 3.2621 & 3.2386 & TST \\
\hline CHEMBL601385 & 752455 & 3.2619 & 3.4135 & TRN \\
\hline CHEMBL1423359 & 752455 & 3.2624 & 3.3236 & TRN \\
\hline CHEMBL1500686 & 752455 & 5.0273 & 4.2702 & TRN \\
\hline CHEMBL3189224 & 752455 & 4.8576 & 4.0879 & TRN \\
\hline CHEMBL1360535 & 752455 & 3.262 & 4.1003 & TST \\
\hline CHEMBL1576059 & 752455 & 4.3589 & 3.3191 & TRN \\
\hline CHEMBL1454203 & 752455 & 3.2619 & 3.2743 & TRN \\
\hline CHEMBL1709883 & 752455 & 3.2621 & 3.4044 & TST \\
\hline CHEMBL1460004 & 752455 & 4.8085 & 4.3689 & TRN \\
\hline CHEMBL1526165 & 752455 & 4.5978 & 4.4128 & TRN \\
\hline CHEMBL1331762 & 752455 & 3.262 & 3.355 & TRN \\
\hline CHEMBL1474602 & 752455 & 3.262 & 3.3439 & TRN \\
\hline CHEMBL1729450 & 752455 & 3.262 & 3.4041 & TRN \\
\hline CHEMBL496633 & 752455 & 4.3872 & 4.1941 & TST \\
\hline CHEMBL1527356 & 752455 & 3.2621 & 3.3175 & TRN \\
\hline CHEMBL1548876 & 752455 & 3.2624 & 3.2692 & TRN \\
\hline CHEMBL1553368 & 752455 & 3.2619 & 3.3374 & TRN \\
\hline CHEMBL1309448 & 752455 & 4.8433 & 4.1737 & TST \\
\hline CHEMBL1574420 & 752455 & 5.0973 & 3.6521 & TRN \\
\hline CHEMBL3192838 & 752455 & 3.262 & 3.9861 & TRN \\
\hline CHEMBL422692 & 752455 & 3.262 & 3.3226 & TRN \\
\hline CHEMBL1302748 & 752455 & 3.2618 & 3.324 & TRN \\
\hline CHEMBL3191688 & 752455 & 4.7787 & 4.1108 & TST \\
\hline CHEMBL1904073 & 752455 & 3.262 & 3.4164 & TRN \\
\hline CHEMBL1365476 & 752455 & 3.262 & 4.3096 & TRN \\
\hline CHEMBL1378134 & 752455 & 3.262 & 3.2479 & TRN \\
\hline CHEMBL1724937 & 752455 & 3.2623 & 3.3002 & TRN \\
\hline CHEMBL1387366 & 752455 & 3.2615 & 3.259 & TRN \\
\hline CHEMBL1873186 & 752455 & 3.262 & 3.5306 & TRN \\
\hline CHEMBL1880132 & 752455 & 3.262 & 3.3724 & TRN \\
\hline CHEMBL1706025 & 752455 & 3.262 & 3.4167 & TRN \\
\hline CHEMBL1604962 & 752455 & 3.2623 & 3.2494 & TST \\
\hline CHEMBL1391773 & 752455 & 3.2619 & 3.3752 & TRN \\
\hline CHEMBL1525340 & 752455 & 3.2618 & 3.4086 & TRN \\
\hline CHEMBL1484627 & 752455 & 3.262 & 4.2621 & TRN \\
\hline CHEMBL1378294 & 752455 & 3.2619 & 3.345 & TRN \\
\hline CHEMBL1500754 & 752455 & 3.2623 & 3.3511 & TRN \\
\hline CHEMBL1386534 & 752455 & 3.262 & 3.3446 & TRN \\
\hline CHEMBL1984581 & 752455 & 5.2581 & 5.8829 & TST \\
\hline CHEMBL1713654 & 752455 & 3.262 & 3.3349 & TST \\
\hline CHEMBL1545021 & 752455 & 3.2623 & 3.39899 & 99999999996 \\
\hline CHEMBL1322645 & 752455 & 5.0128 & 4.495 & TRN \\
\hline CHEMBL1986183 & 752455 & 4.6936 & 5.6787 & TST \\
\hline
\end{tabular}


Supplemental Table S2.txt

\begin{tabular}{|c|c|c|c|c|c|}
\hline CHEMBL1989158 & 752455 & 4.6931 & 5.7019 & TST & \\
\hline CHEMBL1584270 & 752455 & 3.2621 & 4.0489 & TRN & \\
\hline CHEMBL1605743 & 752455 & 3.2624 & 3.2778 & TRN & \\
\hline CHEMBL1518886 & 752455 & 3.2623 & \multicolumn{2}{|c|}{3.2260000000000004} & TST \\
\hline CHEMBL1504972 & 752455 & 4.683 & 4.0193 & TRN & \\
\hline CHEMBL1545734 & 752455 & 3.2619 & 4.1475 & TRN & \\
\hline CHEMBL1578670 & 752455 & 5.0555 & 3.7842 & TRN & \\
\hline CHEMBL1597733 & 752455 & 3.262 & 3.4583 & TRN & \\
\hline CHEMBL1389301 & 752455 & 3.2617 & 3.3975 & TRN & \\
\hline CHEMBL1486690 & 752455 & 3.2618 & 4.4391 & TST & \\
\hline CHEMBL1429269 & 752455 & 3.2619 & 3.3444 & TRN & \\
\hline CHEMBL1707833 & 752455 & 3.2621 & 3.2992 & TRN & \\
\hline CHEMBL1980281 & 752455 & 4.2161 & 4.7548 & TST & \\
\hline CHEMBL1598570 & 752455 & 3.262 & 3.2635 & TRN & \\
\hline CHEMBL1318510 & 752455 & 3.2617 & 3.3484 & TRN & \\
\hline CHEMBL1733182 & 752455 & 3.2623 & 3.3716 & TST & \\
\hline CHEMBL1331010 & 752455 & 3.2621 & 3.3367 & TRN & \\
\hline CHEMBL1587031 & 752455 & 3.2618 & 4.3784 & TRN & \\
\hline CHEMBL1514790 & 752455 & 5.1931 & 4.573 & TRN & \\
\hline CHEMBL1448906 & 752455 & 3.262 & 3.2801 & TRN & \\
\hline CHEMBL1522563 & 752455 & 3.2622 & 3.2586 & TST & \\
\hline CHEMBL1992490 & 752455 & 3.262 & 5.0382 & TST & \\
\hline CHEMBL1527972 & 752455 & 4.9537 & 3.73 & TRN & \\
\hline CHEMBL1370322 & 752455 & 3.262 & 3.7505 & TRN & \\
\hline CHEMBL1568474 & 752455 & 6.0499 & 4.0646 & TRN & \\
\hline CHEMBL1705738 & 752455 & 5.5003 & 3.8285 & TRN & \\
\hline CHEMBL1412077 & 752455 & 3.2623 & 3.2314 & TRN & \\
\hline CHEMBL1452571 & 752455 & 3.2621 & 3.4011 & TRN & \\
\hline CHEMBL3391764 & 752455 & 3.2622 & 3.4466 & TST & \\
\hline CHEMBL1313831 & 752455 & 3.2619 & 3.2976 & TRN & \\
\hline CHEMBL1503093 & 752455 & 3.2621 & 3.8184 & TRN & \\
\hline CHEMBL1328504 & 752455 & 3.2624 & 3.3129 & TRN & \\
\hline CHEMBL1565682 & 752455 & 3.2621 & 3.412 & TRN & \\
\hline CHEMBL1971127 & 752455 & 4.6934 & 5.472 & TST & \\
\hline CHEMBL1312403 & 752455 & 3.7391 & 3.3749 & TRN & \\
\hline CHEMBL1358613 & 752455 & 3.2618 & 3.3259 & TRN & \\
\hline CHEMBL1353338 & 752455 & 3.2621 & 4.1037 & TRN & \\
\hline CHEMBL1393633 & 752455 & 3.2624 & 3.40199 & 99999999997 & TRN \\
\hline CHEMBL1349596 & 752455 & 3.2623 & 3.2492 & TST & \\
\hline CHEMBL1530087 & 752455 & 4.6625 & 4.3477 & TRN & \\
\hline CHEMBL1473205 & 752455 & 3.2627 & 3.347 & TST & \\
\hline CHEMBL1511114 & 752455 & 3.2621 & 3.2978 & TRN & \\
\hline CHEMBL3193419 & 752455 & 3.2617 & 3.40199 & 99999999997 & TRN \\
\hline CHEMBL1497035 & 752455 & 3.2621 & 3.3689 & TRN & \\
\hline CHEMBL1388543 & 752455 & 4.6354 & 4.2616 & TRN & \\
\hline CHEMBL1577275 & 752455 & 3.2623 & 3.3539 & TRN & \\
\hline CHEMBL 1732485 & 752455 & 3.262 & 3.2989 & TRN & \\
\hline CHEMBL1392848 & 752455 & 3.2618 & 3.26899 & 99999999997 & TST \\
\hline & & & & 864 & \\
\hline
\end{tabular}




\begin{tabular}{|c|c|c|c|c|c|}
\hline \multicolumn{6}{|c|}{ Supplemental Table S2.txt } \\
\hline CHEMBL1416701 & 752455 & 3.2617 & 3.2492 & TST & \\
\hline CHEMBL1602206 & 752455 & 3.2619 & 4.3556 & TST & \\
\hline CHEMBL1355072 & 752455 & 3.262 & 4.2341 & TST & \\
\hline CHEMBL1991601 & 752455 & 3.2622 & 4.1496 & TST & \\
\hline CHEMBL1448282 & 752412 & 5.4868 & 5.4879 & TRN & \\
\hline CHEMBL1878645 & 752412 & 3.1024 & 4.6386 & TRN & \\
\hline CHEMBL1578584 & 752412 & 3.1024 & 4.9591 & TST & \\
\hline CHEMBL1864059 & 752412 & 4.3116 & 4.6107 & TRN & \\
\hline CHEMBL1735962 & 752412 & 4.5583 & 4.567 & TRN & \\
\hline CHEMBL1894788 & 752412 & 3.1024 & 4.7022 & TST & \\
\hline CHEMBL580955 & 752412 & 5.5884 & 5.5455 & TRN & \\
\hline CHEMBL1496891 & 752412 & 3.1024 & 4.9401 & TST & \\
\hline CHEMBL1890613 & 752412 & 5.5768 & 5.5179 & TRN & \\
\hline CHEMBL1503124 & 752412 & 3.1024 & 4.9823 & TST & \\
\hline CHEMBL1890797 & 752412 & 3.1024 & 4.6477 & TST & \\
\hline CHEMBL1885380 & 752412 & 5.5986 & 5.4142 & TRN & \\
\hline CHEMBL1875095 & 752412 & 4.3054 & 4.586 & TRN & \\
\hline CHEMBL1373096 & 752412 & 5.7235 & 5.4405 & TRN & \\
\hline CHEMBL590927 & 752412 & 5.5072 & 5.4952 & TRN & \\
\hline CHEMBL1330279 & 752412 & 5.4989 & 5.5432 & TRN & \\
\hline CHEMBL1443069 & 752412 & 4.6611 & 4.7455 & TRN & \\
\hline CHEMBL1902332 & 752412 & 4.4715 & 4.5996 & TRN & \\
\hline CHEMBL1866926 & 752412 & 4.7423 & 4.572 & TRN & \\
\hline CHEMBL1876834 & 752412 & 5.6498 & 5.3712 & TRN & \\
\hline CHEMBL1572920 & 752412 & 4.5635 & 4.6451 & TRN & \\
\hline CHEMBL1514530 & 752412 & 5.2774 & 5.52 & TRN & \\
\hline CHEMBL1885971 & 752412 & 5.3788 & 5.4772 & TRN & \\
\hline CHEMBL1903426 & 752412 & 5.2612 & 5.4208 & TRN & \\
\hline CHEMBL602720 & 752412 & 5.5735 & 5.4898 & TRN & \\
\hline CHEMBL1872492 & 752412 & 4.3206 & 4.9532 & TST & \\
\hline CHEMBL1899890 & 752412 & 5.2197 & 4.7134 & TRN & \\
\hline CHEMBL1555271 & 752412 & 5.3675 & 5.5113 & TRN & \\
\hline CHEMBL1339830 & 752412 & 6.0706 & 4.6605 & TRN & \\
\hline CHEMBL1430579 & 752412 & 3.1024 & 4.9698 & TST & \\
\hline CHEMBL1865457 & 752412 & 3.1024 & 4.6748 & TST & \\
\hline CHEMBL1576870 & 752412 & 6.585 & 4.9551 & TST & \\
\hline CHEMBL1864401 & 752412 & 3.1024 & 4.9227 & TST & \\
\hline CHEMBL1902496 & 752412 & 5.466 & 4.7125 & TRN & \\
\hline CHEMBL548670 & 752412 & 5.5817 & 5.3713 & TRN & \\
\hline CHEMBL1529188 & 752412 & 4.5072 & 4.6263 & TRN & \\
\hline CHEMBL1313101 & 752412 & 5.1637 & 4.654 & TRN & \\
\hline CHEMBL1412002 & 752412 & 5.7696 & 5.5172 & TRN & \\
\hline CHEMBL1604735 & 752412 & 4.8022 & 4.67899 & 9999999999 & TRN \\
\hline CHEMBL1379163 & 752412 & 4.7496 & 4.6383 & TRN & \\
\hline CHEMBL1491842 & 752412 & 4.4101 & 4.6486 & TRN & \\
\hline CHEMBL1530766 & 752412 & 4.4531 & 4.5479 & TRN & \\
\hline CHEMBL601768 & 752412 & 5.5467 & 5.5268 & TRN & \\
\hline CHEMBL1525213 & 752412 & 3.1024 & 4.9956 & TST & \\
\hline
\end{tabular}


Supplemental Table S2.txt

\begin{tabular}{|c|c|c|c|c|c|}
\hline CHEMBL1522618 & 752412 & 3.1024 & 4.5812 & TRN & \\
\hline CHEMBL1503612 & 752412 & 5.1739 & 4.8043 & TST & \\
\hline CHEMBL600862 & 752412 & 5.5058 & 5.5052 & TRN & \\
\hline CHEMBL1906106 & 752412 & 5.6038 & 5.5009 & TRN & \\
\hline CHEMBL1519450 & 752412 & 5.6234 & 5.438 & TRN & \\
\hline CHEMBL1906519 & 752412 & 4.8523 & 4.7356 & TRN & \\
\hline CHEMBL1902224 & 752412 & 5.4868 & 5.4635 & TRN & \\
\hline CHEMBL1887169 & 752412 & 4.7592 & 4.588 & TRN & \\
\hline CHEMBL1316506 & 752412 & 4.9755 & 4.7426 & TRN & \\
\hline CHEMBL1880835 & 752412 & 4.7122 & 4.72199 & 99999999995 & TRN \\
\hline CHEMBL1899180 & 752412 & 5.1494 & 5.3931 & TRN & \\
\hline CHEMBL1891946 & 752412 & 4.1169 & 5.17700 & 00000000005 & TRN \\
\hline CHEMBL1419414 & 752412 & 4.2557 & 4.5713 & TRN & \\
\hline CHEMBL580530 & 752412 & 5.5317 & 5.4005 & TRN & \\
\hline CHEMBL1902698 & 752412 & 5.5575 & 4.959 & TST & \\
\hline CHEMBL1879735 & 752412 & 3.1024 & 4.65300 & 00000000005 & TST \\
\hline CHEMBL1438842 & 752412 & 3.1024 & 4.9257 & TST & \\
\hline CHEMBL251603 & 752412 & 4.605 & 4.6728 & TRN & \\
\hline CHEMBL1885580 & 752412 & 4.1152 & 4.5543 & TST & \\
\hline CHEMBL590665 & 752412 & 5.4318 & 5.5084 & TRN & \\
\hline CHEMBL591412 & 752412 & 5.2874 & 5.4541 & TRN & \\
\hline CHEMBL592600 & 752412 & 5.585 & 5.4857 & TRN & \\
\hline CHEMBL1589983 & 752412 & 3.1024 & 4.8887 & TST & \\
\hline CHEMBL1889367 & 752412 & 5.4921 & 5.4862 & TRN & \\
\hline CHEMBL1863881 & 752412 & 6.3468 & 4.7028 & TRN & \\
\hline CHEMBL547285 & 752412 & 5.5986 & 5.5232 & TRN & \\
\hline CHEMBL1598785 & 752412 & 5.2027 & 5.5117 & TRN & \\
\hline CHEMBL1877680 & 752412 & 3.1024 & 5.0148 & TST & \\
\hline CHEMBL1393944 & 752412 & 6.2518 & 4.7843 & TST & \\
\hline CHEMBL1522043 & 752412 & 4.4123 & 4.5696 & TRN & \\
\hline CHEMBL1452490 & 752412 & 4.6434 & 4.7353 & TRN & \\
\hline CHEMBL1416756 & 752412 & 4.4134 & 4.6897 & TST & \\
\hline CHEMBL585827 & 752412 & 5.2503 & 5.5111 & TRN & \\
\hline CHEMBL446205 & 521897 & 10.0 & 8.7115 & TST & \\
\hline CHEMBL483265 & 521897 & 6.0 & 6.1044 & TRN & \\
\hline CHEMBL520452 & 521897 & 10.08 & 10.3853 & TRN & \\
\hline CHEMBL482641 & 521897 & 8.52 & 8.5802 & TRN & \\
\hline CHEMBL484285 & 521897 & 8.52 & 8.3385 & TRN & \\
\hline CHEMBL484286 & 521897 & 9.82 & 8.5156 & TST & \\
\hline CHEMBL485649 & 521897 & 9.77 & 9.7255 & TRN & \\
\hline CHEMBL450116 & 521897 & 8.2 & 8.1407 & TRN & \\
\hline CHEMBL445542 & 521897 & 8.27 & 8.4725 & TRN & \\
\hline CHEMBL482450 & 521897 & 9.55 & 8.708 & TST & \\
\hline CHEMBL520618 & 521897 & 8.22 & 8.1443 & TRN & \\
\hline CHEMBL2304846 & 521897 & 8.77 & 8.9336 & TST & \\
\hline CHEMBL482658 & 521897 & 9.77 & 9.8346 & TRN & \\
\hline CHEMBL519164 & 521897 & 10.12 & 9.9968 & TRN & \\
\hline CHEMBL483482 & 521897 & 9.85 & 9.8763 & TRN & \\
\hline
\end{tabular}




\begin{tabular}{|c|c|c|c|c|c|}
\hline \multicolumn{6}{|c|}{ Supplemental Table S2.txt } \\
\hline CHEMBL490257 & 521897 & 8.89 & 8.7451 & TRN & \\
\hline CHEMBL490256 & 521897 & 9.29 & 9.3049 & TRN & \\
\hline CHEMBL 2304744 & 521897 & 9.14 & 8.9468 & TRN & \\
\hline CHEMBL482630 & 521897 & 9.09 & 9.2976 & TRN & \\
\hline CHEMBL520295 & 521897 & 8.2 & 8.3778 & TRN & \\
\hline CHEMBL484687 & 521897 & 9.72 & 9.7057 & TRN & \\
\hline CHEMBL484688 & 521897 & 8.66 & 8.6263 & TRN & \\
\hline CHEMBL521154 & 521897 & 6.19 & 6.2105 & TRN & \\
\hline CHEMBL484081 & 521897 & 8.66 & 8.6489 & TRN & \\
\hline CHEMBL484082 & 521897 & 8.7 & 8.7926 & TRN & \\
\hline CHEMBL484282 & 521897 & 10.06 & 10.1835 & TRN & \\
\hline CHEMBL520965 & 521897 & 9.02 & 8.88600 & 0000000001 & TRN \\
\hline CHEMBL483060 & 521897 & 9.6 & 9.5238 & TRN & \\
\hline CHEMBL483061 & 521897 & 8.85 & 8.8205 & TRN & \\
\hline CHEMBL483266 & 521897 & 9.38 & 9.2861 & TRN & \\
\hline CHEMBL519975 & 521897 & 9.12 & 9.1476 & TRN & \\
\hline CHEMBL484903 & 521897 & 8.96 & 8.8633 & TST & \\
\hline CHEMBL484701 & 521897 & 9.85 & 9.9121 & TRN & \\
\hline CHEMBL484902 & 521897 & 7.5 & 6.5604 & TST & \\
\hline CHEMBL2304766 & 521897 & 9.82 & 9.7722 & TRN & \\
\hline CHEMBL483062 & 521897 & 9.82 & 9.7675 & TRN & \\
\hline CHEMBL520966 & 521897 & 9.89 & 9.4362 & TRN & \\
\hline CHEMBL483063 & 521897 & 9.85 & 9.9121 & TRN & \\
\hline CHEMBL483273 & 521897 & 8.15 & 8.1643 & TRN & \\
\hline CHEMBL520139 & 521897 & 8.36 & 8.9513 & TST & \\
\hline CHEMBL483275 & 521897 & 9.02 & 8.9876 & TRN & \\
\hline CHEMBL2304777 & 521897 & 9.08 & 9.1544 & TRN & \\
\hline CHEMBL482870 & 521897 & 9.7 & 9.7852 & TRN & \\
\hline CHEMBL519733 & 521897 & 6.92 & 7.5494 & TST & \\
\hline CHEMBL483284 & 521897 & 7.6 & 7.5966 & TRN & \\
\hline CHEMBL483285 & 521897 & 6.82 & 6.8363 & TRN & \\
\hline CHEMBL483286 & 521897 & 8.24 & 8.3241 & TRN & \\
\hline CHEMBL520310 & 521897 & 8.89 & 8.8735 & TRN & \\
\hline CHEMBL527210 & 521897 & 9.64 & 9.6353 & TRN & \\
\hline CHEMBL488938 & 521897 & 7.0 & 7.4163 & TST & \\
\hline CHEMBL488939 & 521897 & 8.55 & 8.8871 & TST & \\
\hline CHEMBL485865 & 521897 & 10.52 & 9.9632 & TST & \\
\hline CHEMBL487918 & 521897 & 8.96 & 9.6485 & TST & \\
\hline CHEMBL487919 & 521897 & 7.54 & 8.1528 & TST & \\
\hline CHEMBL487920 & 521897 & 9.77 & 9.4219 & TST & \\
\hline CHEMBL495141 & 1636927 & 4.0 & 5.0509 & TRN & \\
\hline CHEMBL458061 & 1636927 & 6.0595 & 5.8117 & TRN & \\
\hline CHEMBL3910419 & 1636927 & 7.3872 & 7.2873 & TRN & \\
\hline CHEMBL483615 & 1636927 & 7.8239 & 7.273 & TRN & \\
\hline CHEMBL1089604 & 1636927 & 6.5622 & 5.87700 & 2000000001 & TRN \\
\hline CHEMBL1091488 & 1636927 & 6.2226 & 6.4164 & TST & \\
\hline CHEMBL513771 & 1636927 & 6.7932 & 6.245 & TRN & \\
\hline CHEMBL3960412 & 1636927 & 4.0 & 3.9981 & TRN & \\
\hline
\end{tabular}


Supplemental Table S2.txt

\begin{tabular}{|c|c|c|c|c|c|}
\hline CHEMBL493725 & 1636927 & 8.0969 & 8.0282 & TRN & \\
\hline CHEMBL3930911 & 1636927 & 4.0 & 4.4628 & TRN & \\
\hline CHEMBL1089028 & 1636927 & 6.1337 & 6.1461 & TRN & \\
\hline CHEMBL442844 & 1636927 & 6.3242 & 5.994 & TRN & \\
\hline CHEMBL3910660 & 1636927 & 4.0 & 3.8103 & TRN & \\
\hline CHEMBL3910844 & 1636927 & 9.0 & 8.8072 & TRN & \\
\hline CHEMBL3894657 & 1636927 & 6.4145 & 6.7228 & TRN & \\
\hline CHEMBL3976538 & 1636927 & 4.0 & 4.2359 & TRN & \\
\hline CHEMBL 3928402 & 1636927 & 4.0 & 3.9459 & TRN & \\
\hline CHEMBL3917342 & 1636927 & 5.5698 & 5.7841 & TRN & \\
\hline CHEMBL3922337 & 1636927 & 8.0969 & 8.0282 & TRN & \\
\hline CHEMBL474387 & 1636927 & 8.699 & 8.0622 & TRN & \\
\hline CHEMBL457396 & 1636927 & 6.6596 & 7.0575 & TRN & \\
\hline CHEMBL3956411 & 1636927 & 7.2366 & 6.9546 & TRN & \\
\hline CHEMBL3933661 & 1636927 & 5.5327 & 5.2955 & TST & \\
\hline CHEMBL3896928 & 1636927 & 4.0 & 3.9335 & TRN & \\
\hline CHEMBL1093694 & 1636927 & 8.1549 & 7.4615 & TRN & \\
\hline CHEMBL3902567 & 1636927 & 8.0969 & 8.0675 & TRN & \\
\hline CHEMBL 3962044 & 1636927 & 4.0 & \multicolumn{2}{|c|}{2.8560000000000003} & TRN \\
\hline CHEMBL3979071 & 1636927 & 4.0 & 3.9797 & TRN & \\
\hline CHEMBL456374 & 1636927 & 4.0 & 4.0973 & TRN & \\
\hline CHEMBL493724 & 1636927 & 7.7959 & 7.2093 & TRN & \\
\hline CHEMBL3915076 & 1636927 & 7.5229 & \multicolumn{2}{|c|}{ 7.702999999999999 } & TST \\
\hline CHEMBL1091825 & 1636927 & 7.7447 & 7.2851 & TST & \\
\hline CHEMBL3905630 & 1636927 & 4.0 & 4.8121 & TRN & \\
\hline CHEMBL506330 & 1636927 & 7.8539 & 8.4911 & TRN & \\
\hline CHEMBL3934245 & 1636927 & 6.2581 & 5.8493 & TST & \\
\hline CHEMBL3949718 & 1636927 & 4.0 & 4.7812 & TST & \\
\hline CHEMBL3905892 & 1636927 & 7.2518 & 6.7312 & TST & \\
\hline CHEMBL1093693 & 1636927 & 8.3979 & 8.2646 & TRN & \\
\hline CHEMBL1089030 & 1636927 & 7.7959 & 7.1798 & TST & \\
\hline CHEMBL453919 & 1636927 & 7.2596 & 6.9848 & TRN & \\
\hline CHEMBL458032 & 1636927 & 6.3002 & 6.6277 & TRN & \\
\hline CHEMBL 3908727 & 1636927 & 6.5287 & 4.8649 & TST & \\
\hline CHEMBL3928467 & 1636927 & 7.3768 & 7.2208 & TST & \\
\hline CHEMBL512022 & 1636927 & 8.1549 & 7.8147 & TRN & \\
\hline CHEMBL3971425 & 1636927 & 6.2549 & \multicolumn{2}{|c|}{6.622000000000001} & TRN \\
\hline CHEMBL474386 & 1636927 & 8.301 & 8.0283 & TRN & \\
\hline CHEMBL 3985238 & 1636927 & 4.0 & 5.5009 & TST & \\
\hline CHEMBL483616 & 1636927 & 6.8508 & 6.7506 & TRN & \\
\hline CHEMBL3966707 & 1636927 & 7.5376 & 7.3634 & TRN & \\
\hline CHEMBL3977325 & 1636927 & 4.0 & 4.4928 & TST & \\
\hline CHEMBL450582 & 1636927 & 8.0969 & \multicolumn{2}{|c|}{8.027999999999999} & TRN \\
\hline CHEMBL3964774 & 1636927 & 4.0 & 4.6979 & TRN & \\
\hline CHEMBL3917515 & 1636927 & 4.0 & 4.3748 & TST & \\
\hline CHEMBL 3957072 & 1636927 & 4.0 & 4.0118 & TST & \\
\hline CHEMBL3909783 & 1636927 & 5.8713 & 6.0744 & TRN & \\
\hline CHEMBL3922715 & 1636927 & 6.5498 & 7.3876 & TRN & \\
\hline
\end{tabular}




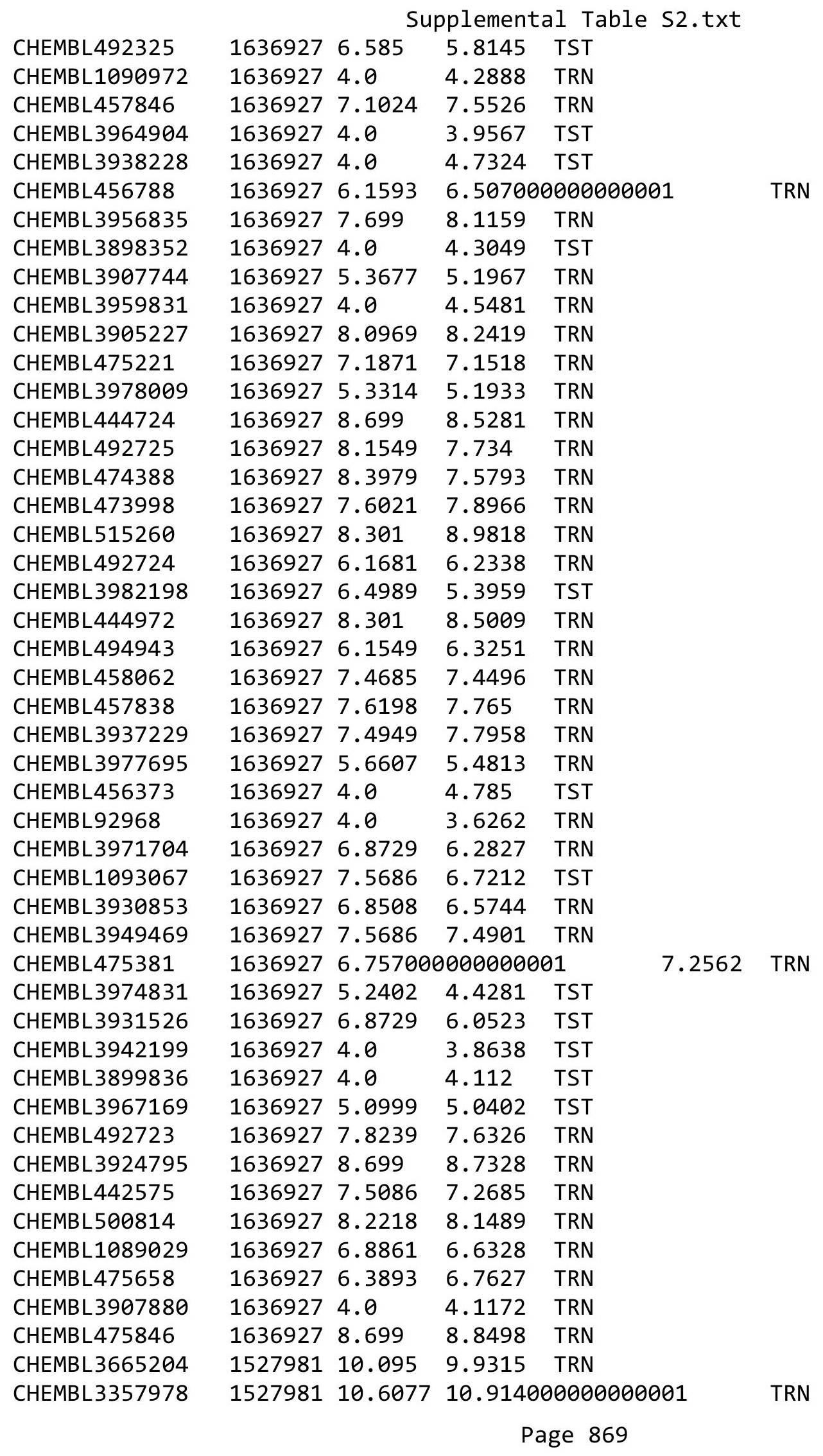


Supplemental Table S2.txt

\begin{tabular}{|c|c|c|c|c|c|c|}
\hline CHEMBL 3665177 & 1527981 & 10.6214 & 10.2587 & TRN & & \\
\hline CHEMBL 3665186 & 1527981 & 10.5471 & 10.8736 & TRN & & \\
\hline CHEMBL 3665171 & 1527981 & 11.06200 & 00000000 & 01 & 10.7019 & TST \\
\hline CHEMBL 3665222 & 1527981 & 11.585 & 11.9646 & TRN & & \\
\hline CHEMBL 3665220 & 1527981 & 10.3012 & 10.3285 & TST & & \\
\hline CHEMBL 3665139 & 1527981 & 9.7537 & 9.7283 & TRN & & \\
\hline CHEMBL 3665172 & 1527981 & 11.2314 & 11.1555 & TST & & \\
\hline CHEMBL 3665143 & 1527981 & 9.5521 & 9.5351 & TRN & & \\
\hline CHEMBL 3665198 & 1527981 & 10.5989 & 10.6278 & TRN & & \\
\hline CHEMBL 3665182 & 1527981 & 12.0269 & 11.4482 & TRN & & \\
\hline CHEMBL 3665158 & 1527981 & 9.8265 & 9.1269 & TRN & & \\
\hline CHEMBL 3665167 & 1527981 & 10.9285 & 11.1447 & TRN & & \\
\hline CHEMBL 3335693 & 1527981 & 10.7263 & 10.6163 & TRN & & \\
\hline CHEMBL 3665136 & 1527981 & 9.2267 & 9.7407 & TRN & & \\
\hline CHEMBL3665148 & 1527981 & 10.5936 & 10.6424 & TRN & & \\
\hline CHEMBL 3665187 & 1527981 & 9.6494 & 10.2703 & TST & & \\
\hline CHEMBL 3665147 & 1527981 & 9.9876 & 11.2955 & TST & & \\
\hline CHEMBL 3335695 & 1527981 & 11.0655 & 11.0975 & TRN & & \\
\hline CHEMBL 3665205 & 1527981 & 6.0 & 6.5354 & TRN & & \\
\hline CHEMBL3665203 & 1527981 & 10.8891 & 10.7697 & TRN & & \\
\hline CHEMBL 3665190 & 1527981 & 10.5817 & 10.6695 & TRN & & \\
\hline CHEMBL 3665152 & 1527981 & 11.4283 & 11.2645 & TRN & & \\
\hline CHEMBL 3665223 & 1527981 & 9.7929 & 10.3242 & TST & & \\
\hline CHEMBL 3335694 & 1527981 & 11.0491 & 11.2944 & TRN & & \\
\hline CHEMBL 3665119 & 1527981 & 6.0 & 6.4929 & TRN & & \\
\hline CHEMBL3335692 & 1527981 & 11.4641 & 11.2408 & TRN & & \\
\hline CHEMBL 3665137 & 1527981 & 10.0002 & 10.4696 & TRN & & \\
\hline CHEMBL 3665156 & 1527981 & 9.9003 & 8.8735 & TRN & & \\
\hline CHEMBL 3665219 & 1527981 & 10.1719 & 10.0266 & TRN & & \\
\hline CHEMBL 3665157 & 1527981 & 10.1864 & 9.0674 & TRN & & \\
\hline CHEMBL 3665145 & 1527981 & 10.5176 & 10.7554 & TST & & \\
\hline CHEMBL 3665201 & 1527981 & 10.90200 & 00000000 & 001 & 11.0298 & TRN \\
\hline CHEMBL 3665217 & 1527981 & 10.8732 & 10.8652 & TRN & & \\
\hline CHEMBL 3665207 & 1527981 & 11.1681 & 10.8513 & TRN & & \\
\hline CHEMBL 3665175 & 1527981 & 11.6778 & 11.0386 & TRN & & \\
\hline CHEMBL3665150 & 1527981 & 11.0766 & 11.1301 & TRN & & \\
\hline CHEMBL 3665125 & 1527981 & 9.5082 & 9.8501 & TST & & \\
\hline CHEMBL 3665161 & 1527981 & 9.4135 & 9.1658 & TST & & \\
\hline CHEMBL 3665191 & 1527981 & 10.7875 & 10.7607 & TRN & & \\
\hline CHEMBL 3665213 & 1527981 & 10.9662 & 10.6213 & TRN & & \\
\hline CHEMBL 3665194 & 1527981 & 9.3745 & 10.5711 & TST & & \\
\hline CHEMBL 3665132 & 1527981 & 9.3983 & 9.38 & TRN & & \\
\hline CHEMBL 3665184 & 1527981 & 11.2798 & 11.7061 & TRN & & \\
\hline CHEMBL 3665129 & 1527981 & 10.2589 & 11.5874 & TST & & \\
\hline CHEMBL 3665183 & 1527981 & 11.3487 & 11.3411 & TRN & & \\
\hline CHEMBL3335691 & 1527981 & 12.1261 & 11.1571 & TRN & & \\
\hline CHEMBL 3665144 & 1527981 & 10.819 & 10.6915 & TRN & & \\
\hline CHEMBL3665135 & 1527981 & 9.3841 & 9.5906 & TRN & & \\
\hline
\end{tabular}




\begin{tabular}{|c|c|c|c|c|c|c|c|}
\hline \multicolumn{7}{|c|}{ Supplemental Table S2.txt } & \\
\hline CHEMBL3665154 & 1527981 & 8.7886 & 8.4768 & TST & & & \\
\hline CHEMBL3665120 & 1527981 & 6.0 & 6.1803 & TST & & & \\
\hline CHEMBL3665131 & 1527981 & 10.2957 & 10.3534 & TRN & & & \\
\hline CHEMBL 3665188 & 1527981 & 11.9172 & 11.8541 & TRN & & & \\
\hline CHEMBL3665211 & 1527981 & 10.7867 & 10.6463 & TRN & & & \\
\hline CHEMBL3665178 & 1527981 & 10.4901 & 10.1936 & TRN & & & \\
\hline CHEMBL3665146 & 1527981 & 11.0138 & 11.0765 & TRN & & & \\
\hline CHEMBL3665215 & 1527981 & 10.7875 & 11.47 & TRN & & & \\
\hline CHEMBL3665202 & 1527981 & 11.9626 & 12.2546 & TRN & & & \\
\hline CHEMBL3665209 & 1527981 & 10.9329 & 11.02799 & 99999999999 & & TRN & \\
\hline CHEMBL3665192 & 1527981 & 11.3958 & 11.1817 & TRN & & & \\
\hline CHEMBL3665193 & 1527981 & 11.2716 & 11.116 & TRN & & & \\
\hline CHEMBL3665199 & 1527981 & 11.5768 & 11.94700 & 00000000001 & & TRN & \\
\hline CHEMBL3665197 & 1527981 & 10.8228 & 11.0076 & TRN & & & \\
\hline CHEMBL3665168 & 1527981 & 9.2475 & 10.1225 & TRN & & & \\
\hline CHEMBL3639640 & 1527981 & 10.4525 & 10.1096 & TST & & & \\
\hline CHEMBL3665181 & 1527981 & 11.6055 & 11.4993 & TRN & & & \\
\hline CHEMBL3665142 & 1527981 & 11.4 & 11.3327 & TRN & & & \\
\hline CHEMBL3665210 & 1527981 & 10.1161 & 10.196 & TRN & & & \\
\hline CHEMBL3665141 & 1527981 & 10.7201 & 10.73 & TRN & & & \\
\hline CHEMBL3665195 & 1527981 & 10.7036 & 10.7554 & TRN & & & \\
\hline CHEMBL3665173 & 1527981 & 10.96900 & 000000000 & 01 & 1.3920 & 00000000001 & TST \\
\hline CHEMBL3335690 & 1527981 & 11.9208 & 11.8079 & TRN & & & \\
\hline CHEMBL3665149 & 1527981 & 10.7016 & 10.6409 & TRN & & & \\
\hline CHEMBL3665216 & 1527981 & 11.68400 & 000000000 & 01 & 1.5785 & TRN & \\
\hline CHEMBL3335698 & 1527981 & 11.0311 & 11.0028 & TRN & & & \\
\hline CHEMBL 3665208 & 1527981 & 10.4891 & 10.3103 & TRN & & & \\
\hline CHEMBL3665176 & 1527981 & 11.4202 & 11.1873 & TRN & & & \\
\hline CHEMBL3665138 & 1527981 & 9.4447 & 10.624 & TST & & & \\
\hline CHEMBL3665185 & 1527981 & 10.6256 & 10.8416 & TRN & & & \\
\hline CHEMBL3335689 & 1527981 & 10.9805 & 10.6856 & TRN & & & \\
\hline CHEMBL3665221 & 1527981 & 10.0229 & 10.29099 & 79999999999 & & TST & \\
\hline CHEMBL3665121 & 1527981 & 6.0 & 5.8045 & TST & & & \\
\hline CHEMBL 3665174 & 1527981 & 11.4134 & 11.0902 & TST & & & \\
\hline CHEMBL3665160 & 1527981 & 8.9889 & 8.7904 & TST & & & \\
\hline CHEMBL3665189 & 1527981 & 10.8677 & 11.0001 & TRN & & & \\
\hline CHEMBL3665124 & 1527981 & 9.7948 & 9.8977 & TST & & & \\
\hline CHEMBL3665218 & 1527981 & 9.7089 & 9.6788 & TRN & & & \\
\hline CHEMBL3665196 & 1527981 & 10.6036 & 10.5263 & TRN & & & \\
\hline CHEMBL3665214 & 1527981 & 11.4724 & 11.6733 & TRN & & & \\
\hline CHEMBL3665206 & 1527981 & 11.2041 & 11.2251 & TRN & & & \\
\hline CHEMBL3335699 & 1527981 & 10.9767 & 11.3036 & TRN & & & \\
\hline CHEMBL3665151 & 1527981 & 10.7058 & 11.2372 & TRN & & & \\
\hline CHEMBL3665133 & 1527981 & 10.0069 & 10.177 & TRN & & & \\
\hline CHEMBL3665153 & 1527981 & 10.75599 & 999999999 & 998 & 0.4371 & TST & \\
\hline CHEMBL 3665179 & 1527981 & 12.0088 & 11.5816 & TRN & & & \\
\hline CHEMBL3665134 & 1527981 & 9.5558 & 10.0301 & TRN & & & \\
\hline CHEMBL3665155 & 1527981 & 8.9263 & 8.6977 & TST & & & \\
\hline
\end{tabular}


Supplemental Table S2.txt

CHEMBL 3665130

CHEMBL 3665159

CHEMBL3665123

CHEMBL 3665212

CHEMBL3665170

CHEMBL 3665180

CHEMBL 3775894

CHEMBL2098433

CHEMBL 3775814

CHEMBL 3775545

CHEMBL 3774922

CHEMBL 3775516

CHEMBL 3774798

CHEMBL 3775277

CHEMBL 2098408

CHEMBL 3775637

CHEMBL 3775615

CHEMBL164087

CHEMBL3775454

CHEMBL 3775465

CHEMBL 3774747

CHEMBL3775145

CHEMBL 3775802

CHEMBL 3775135

CHEMBL 3775453

CHEMBL 3775040

CHEMBL 3775636

CHEMBL 3775668

CHEMBL 3774765

CHEMBL 3774749

CHEMBL 3775987

CHEMBL 3775493

CHEMBL 3774418

CHEMBL 3775977

CHEMBL 3775953

CHEMBL 2094865

CHEMBL 3775782

CHEMBL 3774701

CHEMBL 3775500

CHEMBL 3774437

CHEMBL 3775130

CHEMBL 3774710

CHEMBL 3774456

CHEMBL 3775933

CHEMBL 3775899

CHEMBL 3775095

CHEMBL3774457

$\begin{array}{lll}1527981 & 10.5971 & 10.9199\end{array}$

$\begin{array}{llll}1527981 & 9.2763 & 9.7956 & \text { TRN }\end{array}$

$\begin{array}{lll}1527981 & 11.1823 & 10.8676\end{array}$

$\begin{array}{lll}1527981 & 10.6149 & 10.7143\end{array}$

$\begin{array}{llll}1527981 & 8.631 & 8.2498 & \text { TST }\end{array}$

$\begin{array}{lll}1527981 & 12.2381 & 12.0925\end{array}$

$\begin{array}{llll}1561971 & 7.8539 & 7.8697 & \text { TRN }\end{array}$

$\begin{array}{llll}1561971 & 4.644 & 4.6645 & \text { TRN }\end{array}$

$\begin{array}{llll}1561971 & 8.1549 & 8.1254 & \text { TRN }\end{array}$

$\begin{array}{llll}15619718.0 & 8.0036 & \text { TRN }\end{array}$

$\begin{array}{llll}1561971 & 7.3188 & 7.3251 & \text { TRN }\end{array}$

$\begin{array}{llll}1561971 & 7.8239 & 7.8158 & \text { TRN }\end{array}$

$\begin{array}{llll}1561971 & 6.9066 & 5.9193 & \text { TST }\end{array}$

$\begin{array}{llll}1561971 & 7.8239 & 7.8428 & \text { TRN }\end{array}$

$\begin{array}{llll}1561971 & 4.279 & 4.2684 & \text { TRN }\end{array}$

$\begin{array}{llll}1561971 & 6.2291 & 6.223 & \text { TRN }\end{array}$

$\begin{array}{llll}1561971 & 6.1612 & 5.6282 & \text { TST }\end{array}$

$\begin{array}{llll}1561971 & 4.2907 & 4.2901 & \text { TRN }\end{array}$

$\begin{array}{lllll}1561971 & 6.4559 & 6.4595 & \text { TRN }\end{array}$

$\begin{array}{llll}1561971 & 7.5528 & 7.5436 & \text { TRN }\end{array}$

$\begin{array}{llll}1561971 & 7.3768 & 7.3444 & \text { TRN }\end{array}$

$\begin{array}{llll}1561971 & 7.3188 & 7.3288 & \text { TRN }\end{array}$

$\begin{array}{llll}1561971 & 5.3872 & 4.9505 & \text { TST }\end{array}$

$\begin{array}{llll}1561971 & 7.3188 & 7.336 & \text { TRN }\end{array}$

$\begin{array}{llll}1561971 & 5.8539 & 5.8754 & \text { TST }\end{array}$

$\begin{array}{llll}1561971 & 7.7696 & 7.8206 & \text { TRN }\end{array}$

$\begin{array}{llll}1561971 & 6.5086 & 5.2901 & \text { TST }\end{array}$

$\begin{array}{llll}1561971 & 7.585 & 7.5741 & \text { TRN }\end{array}$

$\begin{array}{llll}1561971 & 6.2007 & 5.6876 & \text { TST }\end{array}$

$\begin{array}{llll}1561971 & 5.1549 & 5.155 & \text { TRN }\end{array}$

$\begin{array}{llll}1561971 & 4.6696 & 5.1466 & \text { TST }\end{array}$

$\begin{array}{llll}1561971 & 5.1549 & 5.4796 & \text { TST }\end{array}$

$\begin{array}{lllll}1561971 & 4.1805 & 4.6116 & \text { TST }\end{array}$

$\begin{array}{llll}1561971 & 7.5229 & 7.5757 & \text { TRN }\end{array}$

$\begin{array}{llll}1561971 & 7.7447 & 7.7171 & \text { TRN }\end{array}$

$\begin{array}{llll}1561971 & 4.5272 & 4.5242 & \text { TRN }\end{array}$

$\begin{array}{llll}1561971 & 5.6576 & 5.6591 & \text { TRN }\end{array}$

$\begin{array}{llll}1561971 & 7.1427 & 7.1323 & \text { TRN }\end{array}$

$\begin{array}{llll}1561971 & 6.7011 & 6.7118 & \text { TRN }\end{array}$

$\begin{array}{llll}1561971 & 5.8861 & 5.8893 & \text { TRN }\end{array}$

$\begin{array}{llll}1561971 & 7.3665 & 7.3516 & \text { TRN }\end{array}$

$\begin{array}{llll}1561971 & 7.1487 & 7.1501 & \text { TRN }\end{array}$

$\begin{array}{llll}1561971 & 7.3665 & 7.3647 & \text { TRN }\end{array}$

$\begin{array}{llll}1561971 & 7.0088 & 7.0043 & \text { TRN }\end{array}$

$\begin{array}{llll}1561971 & 7.8539 & 7.8051 & \text { TRN }\end{array}$

$\begin{array}{llll}1561971 & 6.8861 & 6.2752 & \text { TST }\end{array}$

$\begin{array}{llll}1561971 & 7.2366 & 7.231 & \text { TRN }\end{array}$

$\begin{array}{lllll}\text { CHEMBL3775451 } & 1561971 & 7.7959 & 7.8047 & \text { TRN }\end{array}$

Page 872 
Supplemental Table S2.txt

\begin{tabular}{|c|c|c|c|c|}
\hline CHEMBL 3775295 & 1561971 & 5.4089 & 4.6972 & TST \\
\hline CHEMBL 3774940 & 1561971 & 7.8239 & 7.8316 & TRN \\
\hline CHEMBL3774692 & 1561971 & 7.9208 & 7.9211 & TRN \\
\hline CHEMBL 3775121 & 1561971 & 7.9586 & 7.9671 & TRN \\
\hline CHEMBL 3775823 & 1561971 & 7.2518 & 7.2388 & TRN \\
\hline CHEMBL3774392 & 1561971 & 7.6778 & 7.704 & TRN \\
\hline CHEMBL 3774672 & 1561971 & 5.3372 & 5.3343 & TRN \\
\hline CHEMBL3774688 & 1561971 & 5.699 & 4.8227 & TST \\
\hline CHEMBL3774537 & 1561971 & 7.6383 & 7.6083 & TRN \\
\hline CHEMBL3770256 & 1561971 & 5.8861 & \multicolumn{2}{|c|}{5.622999999999999} \\
\hline CHEMBL 3775548 & 1561971 & 7.7447 & 7.7539 & TRN \\
\hline CHEMBL 3775362 & 1561971 & 7.3979 & 6.3941 & TST \\
\hline CHEMBL3774665 & 1561971 & 8.0 & 8.0054 & TRN \\
\hline CHEMBL3775956 & 1561971 & 7.585 & 7.5722 & TRN \\
\hline CHEMBL1304169 & 688431 & 5.6254 & 4.8086 & TRN \\
\hline CHEMBL1432251 & 688431 & 5.7357 & 6.1695 & TRN \\
\hline CHEMBL1347469 & 688431 & 6.2449 & 6.1125 & TRN \\
\hline CHEMBL1355464 & 688431 & 3.3979 & 3.4041 & TRN \\
\hline CHEMBL1316410 & 688431 & 3.3979 & 3.2376 & TRN \\
\hline CHEMBL1503266 & 688431 & 3.3979 & 3.3615 & TRN \\
\hline CHEMBL1344225 & 688431 & 6.1238 & 6.3765 & TRN \\
\hline CHEMBL1533366 & 688431 & 4.5358 & 4.7117 & TRN \\
\hline CHEMBL1607568 & 688431 & 5.9003 & 5.9134 & TRN \\
\hline CHEMBL1420175 & 688431 & 5.534 & 5.3999 & TRN \\
\hline CHEMBL1404792 & 688431 & 6.1637 & 6.0984 & TST \\
\hline CHEMBL1481347 & 688431 & 6.4776 & \multicolumn{2}{|c|}{6.361000000000001} \\
\hline CHEMBL601757 & 688431 & 5.8948 & 6.0957 & TRN \\
\hline CHEMBL1413625 & 688431 & 6.1938 & 6.1668 & TRN \\
\hline CHEMBL1596681 & 688431 & 6.3382 & \multicolumn{2}{|c|}{6.361000000000001} \\
\hline CHEMBL1428153 & 688431 & 5.0967 & 4.8311 & TRN \\
\hline CHEMBL1309450 & 688431 & 6.1007 & 5.7364 & TST \\
\hline CHEMBL1334062 & 688431 & 6.1979 & 6.4878 & TRN \\
\hline CHEMBL1519087 & 688431 & 3.3979 & 3.9835 & TRN \\
\hline CHEMBL1605274 & 688431 & 5.2403 & 4.7178 & TST \\
\hline CHEMBL1343392 & 688431 & 5.5116 & 5.6527 & TRN \\
\hline CHEMBL1531343 & 688431 & 3.3979 & 3.2118 & TRN \\
\hline CHEMBL1356269 & 688431 & 3.3979 & 3.2539 & TRN \\
\hline CHEMBL1304582 & 688431 & 6.0915 & 5.6483 & TRN \\
\hline CHEMBL1546374 & 688431 & 5.8274 & 5.7241 & TRN \\
\hline CHEMBL1341270 & 688431 & 5.9208 & 6.2513 & TRN \\
\hline CHEMBL1986259 & 688431 & 5.6218 & 5.6701 & TRN \\
\hline CHEMBL1393783 & 688431 & 5.7428 & 6.0831 & TRN \\
\hline CHEMBL1566928 & 688431 & 5.3594 & 5.6743 & TST \\
\hline CHEMBL1470979 & 688431 & 6.059 & 5.7136 & TRN \\
\hline CHEMBL1563483 & 688431 & 5.7069 & 6.1127 & TST \\
\hline CHEMBL1985061 & 688431 & 6.4413 & 5.8054 & TRN \\
\hline CHEMBL1881714 & 688431 & 5.7406 & 5.7601 & TRN \\
\hline CHEMBL1553842 & 688431 & 3.3979 & 3.5221 & TRN \\
\hline
\end{tabular}


Supplemental Table S2.txt

\begin{tabular}{|c|c|c|c|c|}
\hline CHEMBL3196976 & 688431 & 5.5763 & 5.4507 & TRN \\
\hline CHEMBL1356613 & 688431 & 3.3979 & 3.2735 & TRN \\
\hline CHEMBL1443201 & 688431 & 3.3979 & 3.1471 & TRN \\
\hline CHEMBL1197556 & 688431 & 5.9662 & 5.7436 & TST \\
\hline CHEMBL1540682 & 688431 & 6.2168 & 6.0375 & TRN \\
\hline CHEMBL1353442 & 688431 & 3.3979 & 3.4812 & TRN \\
\hline CHEMBL1572967 & 688431 & 5.4192 & 5.2051 & TRN \\
\hline CHEMBL1322078 & 688431 & 5.9706 & 5.94600 & 0000000001 \\
\hline CHEMBL1563943 & 688431 & 7.3771 & 6.61 & TRN \\
\hline CHEMBL1393625 & 688431 & 5.8271 & 5.6354 & TRN \\
\hline CHEMBL3199050 & 688431 & 5.5345 & 5.6 & TRN \\
\hline CHEMBL1307319 & 688431 & 5.7442 & 5.2975 & TRN \\
\hline CHEMBL1369655 & 688431 & 5.8083 & 5.7794 & TRN \\
\hline CHEMBL1414715 & 688431 & 3.3979 & 3.4075 & TRN \\
\hline CHEMBL1309232 & 688431 & 5.8447 & 6.3265 & TRN \\
\hline CHEMBL1488339 & 688431 & 3.3979 & 3.1654 & TRN \\
\hline CHEMBL1459140 & 688431 & 5.5349 & 5.9039 & TRN \\
\hline CHEMBL1467961 & 688431 & 5.0009 & 4.9425 & TRN \\
\hline CHEMBL1450007 & 688431 & 3.301 & 4.1159 & TRN \\
\hline CHEMBL1329973 & 688431 & 3.3979 & 3.303 & TRN \\
\hline CHEMBL1424968 & 688431 & 5.53 & 5.4399 & TRN \\
\hline CHEMBL1411912 & 688431 & 6.1118 & 5.9844 & TRN \\
\hline CHEMBL1565349 & 688431 & 5.6482 & 6.0153 & TRN \\
\hline CHEMBL533602 & 688431 & 7.0458 & 5.9125 & TST \\
\hline CHEMBL1531073 & 688431 & 5.3939 & 5.7219 & TST \\
\hline CHEMBL1465527 & 688431 & 5.431 & 5.2703 & TRN \\
\hline CHEMBL1422386 & 688431 & 5.7567 & 5.9955 & TRN \\
\hline CHEMBL1555086 & 688431 & 3.3979 & 3.2349 & TRN \\
\hline CHEMBL1496004 & 688431 & 5.8523 & 6.1705 & TRN \\
\hline CHEMBL1606330 & 688431 & 5.0147 & 5.345 & TST \\
\hline CHEMBL1395037 & 688431 & 3.3979 & 3.9119 & TRN \\
\hline CHEMBL1417204 & 688431 & 5.6442 & 5.33799 & 9999999999 \\
\hline CHEMBL1508593 & 688431 & 5.901 & 5.5764 & TRN \\
\hline CHEMBL1518905 & 688431 & 7.1938 & 5.8987 & TST \\
\hline CHEMBL1570449 & 688431 & 3.3979 & 3.3572 & TRN \\
\hline CHEMBL1317987 & 688431 & 3.3979 & 4.1053 & TRN \\
\hline CHEMBL1481335 & 688431 & 3.301 & 4.0401 & TRN \\
\hline CHEMBL1535539 & 688431 & 4.978 & 4.6906 & TRN \\
\hline CHEMBL1323894 & 688431 & 3.3979 & 3.2217 & TST \\
\hline CHEMBL1518487 & 688431 & 3.3979 & 3.22 & TST \\
\hline CHEMBL1440703 & 688431 & 5.4765 & 5.3406 & TST \\
\hline CHEMBL1504701 & 688431 & 6.9957 & 5.0822 & TST \\
\hline CHEMBL1333355 & 688431 & 3.3979 & 3.1471 & TST \\
\hline CHEMBL1574879 & 688431 & 5.8938 & 5.876 & TST \\
\hline CHEMBL1376109 & 688431 & 3.3979 & 3.7761 & TST \\
\hline CHEMBL1543839 & 688431 & 5.5882 & 5.3227 & TST \\
\hline CHEMBL 3398007 & 1463307 & 5.4089 & 3.9616 & TRN \\
\hline CHEMBL3398028 & 1463307 & 3.0 & 4.2063 & TST \\
\hline
\end{tabular}


Supplemental Table S2.txt

\begin{tabular}{|c|c|c|c|c|}
\hline - & & & & \\
\hline HEMBL3398039 & 463307 & 5.3468 & 5.245 & \\
\hline & & & & \\
\hline 8071 & 307 & & 557 & \\
\hline IEMBL3398056 & 3307 & 3239 & 235 & \\
\hline AEMBL3398034 & 463307 & 5.2676 & 0247 & \\
\hline HEMBL3398075 & 307 & 5.2924 & .1536 & \\
\hline 98066 & & 528 & & \\
\hline AEMBL3398078 & 307 & 872 & 64 & \\
\hline AEMBL3397056 & 3307 & 88 & 5435 & \\
\hline HEMBL3398033 & 463307 & $5.2-3 x-1$ & 16 & \\
\hline AEMBL3398022 & 3307 & 79 & 67 & \\
\hline AEMBL3398079 & & & & ST \\
\hline HEMBL3398016 & 307 & 3. & & \\
\hline AEMBL3398074 & 307 & & & \\
\hline AEMBL3398057 & 307 & 07 & 78 & \\
\hline HEMBL3398017 & 307 & 85 & & \\
\hline HEMBL3398081 & & & & ST \\
\hline HEMBL3398055 & 307 & & & \\
\hline AEMBL3398073 & 307 & & & \\
\hline EEML 3398025 & 307 & 3 & 65 & 31 \\
\hline HEMBL3398064 & 307 & & & RN \\
\hline HEMBL3398008 & 307 & & & \\
\hline AEMBL3398047 & 307 & 3. & & \\
\hline AEMBL 339 & & & & RIV \\
\hline AEMBL3398045 & 307 & 3 & 05 & RN \\
\hline AEMBL3398070 & $\partial 7$ & & 14 & RN \\
\hline 65 & & & & \\
\hline AEMBL33 & & 3 & & RN \\
\hline AEMBL3398072 & & & & RN \\
\hline AEMBL3398043 & & & & RN \\
\hline AEMBL3398012 & & 6 & & RN \\
\hline 05 & & & & $-T$ \\
\hline HEMBL3398014 & & & & IRN \\
\hline AEMBL3398049 & & 3 & 57 & RN \\
\hline AEMBL3398029 & 07 & 3 & 91 & ST \\
\hline 98080 & & & & ST \\
\hline 40 & & & & RN \\
\hline HEMBL3398063 & 3307 & 4. & 405 & TRN \\
\hline AEMBL3398051 & & & & RN \\
\hline HEMBL3398038 & 07 & & 32 & RN \\
\hline HEMBL3398021 & & & & RN \\
\hline HEMBL3398023 & 3307 & & 5965 & ST \\
\hline HEMBL3398077 & 53307 & 4.2366 & 835 & $R$ \\
\hline EMBL3398068 & & 4 . & & KIV \\
\hline HEMBL 3398024 & 1463307 & & 3.9504 & \\
\hline HEMBL3398052 & & 5.366 & 4.9341 & \\
\hline CHEMBL3398054 & 1463307 & 3.0 & 3.4777 & RN \\
\hline
\end{tabular}


Supplemental Table S2.txt

\begin{tabular}{|c|c|c|c|c|c|}
\hline CHEMBL3398053 & 1463307 & 5.3979 & 4.8686 & TRN & \\
\hline CHEMBL3398062 & 1463307 & 5.0706 & 4.8402 & TRN & \\
\hline CHEMBL3398018 & 1463307 & 3.0 & 4.2027 & TRN & \\
\hline CHEMBL3398044 & 1463307 & 3.0 & 4.9641 & TRN & \\
\hline CHEMBL3398006 & 1463307 & 3.0 & 3.7586 & TST & \\
\hline CHEMBL3398026 & 1463307 & 4.3468 & 4.336 & TST & \\
\hline CHEMBL3398058 & 1463307 & 5.0706 & 4.8211 & TRN & \\
\hline CHEMBL3398036 & 1463307 & 5.4089 & 5.1747 & TRN & \\
\hline CHEMBL3398069 & 1463307 & 5.2218 & 5.1196 & TRN & \\
\hline CHEMBL3398015 & 1463307 & 3.0 & 3.8913 & TST & \\
\hline CHEMBL3398060 & 1463307 & 5.0362 & 4.8217 & TRN & \\
\hline CHEMBL3398009 & 1463307 & 3.0 & 4.0844 & TST & \\
\hline CHEMBL3398035 & 1463307 & 5.3565 & 5.2132 & TRN & \\
\hline CHEMBL3398013 & 1463307 & 4.1549 & 4.0645 & TST & \\
\hline CHEMBL3398042 & 1463307 & 5.2366 & 5.0384 & TRN & \\
\hline CHEMBL3398059 & 1463307 & 5.0177 & 4.8771 & TRN & \\
\hline CHEMBL3398048 & 1463307 & 4.5452 & 3.9257 & TRN & \\
\hline CHEMBL3398019 & 1463307 & 3.0 & 3.9685 & TST & \\
\hline CHEMBL3398027 & 1463307 & 4.4685 & 4.5657 & TST & \\
\hline CHEMBL3398041 & 1463307 & 5.2218 & 5.3384 & TRN & \\
\hline CHEMBL3398076 & 1463307 & 5.0223 & 5.49700 & 0000000001 & TRN \\
\hline CHEMBL 3398037 & 1463307 & 5.4559 & 5.357 & TRN & \\
\hline CHEMBL3398046 & 1463307 & 4.9208 & 4.3041 & TRN & \\
\hline CHEMBL3929664 & 1641073 & 6.57299 & 99999999 & 6.6363 & TST \\
\hline CHEMBL3917067 & 1641073 & 6.0 & 7.3926 & TRN & \\
\hline CHEMBL 3976443 & 1641073 & 7.0921 & 7.8959 & TRN & \\
\hline CHEMBL3964468 & 1641073 & 6.7794 & 6.8619 & TST & \\
\hline CHEMBL 3953694 & 1641073 & 7.5897 & 7.5605 & TRN & \\
\hline CHEMBL3924739 & 1641073 & 8.2757 & 8.0918 & TRN & \\
\hline CHEMBL 3927594 & 1641073 & 8.8861 & 8.4247 & TRN & \\
\hline CHEMBL3945325 & 1641073 & 6.8545 & 7.1714 & TRN & \\
\hline CHEMBL3938771 & 1641073 & 7.7747 & 7.8061 & TRN & \\
\hline CHEMBL3920361 & 1641073 & 6.9606 & 7.2575 & TRN & \\
\hline CHEMBL3984130 & 1641073 & 7.6253 & 8.0081 & TRN & \\
\hline CHEMBL3939730 & 1641073 & 8.8861 & 8.1544 & TRN & \\
\hline CHEMBL 3947180 & 1641073 & 8.7212 & 8.1157 & TRN & \\
\hline CHEMBL 3945511 & 1641073 & 8.7212 & 7.8715 & TRN & \\
\hline CHEMBL3896247 & 1641073 & 8.3872 & 7.3217 & TRN & \\
\hline CHEMBL3919928 & 1641073 & 6.8539 & 7.1483 & TRN & \\
\hline CHEMBL3965586 & 1641073 & 7.9245 & 6.7391 & TRN & \\
\hline CHEMBL3964381 & 1641073 & 7.7212 & 7.7953 & TST & \\
\hline CHEMBL 3961777 & 1641073 & 7.5072 & 8.2939 & TRN & \\
\hline CHEMBL3978479 & 1641073 & 7.5834 & 7.0125 & TST & \\
\hline CHEMBL 3905413 & 1641073 & 8.0315 & 8.5041 & TRN & \\
\hline CHEMBL3941331 & 1641073 & 7.9223 & 7.1903 & TRN & \\
\hline CHEMBL3927111 & 1641073 & 7.8928 & 7.3159 & TRN & \\
\hline CHEMBL 3954898 & 1641073 & 6.5691 & 7.6515 & TST & \\
\hline CHEMBL3952613 & 1641073 & 6.0 & 7.3772 & TRN & \\
\hline
\end{tabular}


Supplemental Table S2.txt

\begin{tabular}{|c|c|c|c|c|}
\hline CHEMBL3956761 & 1641073 & 6.0 & 7.1751 & TST \\
\hline CHEMBL3918004 & 1641073 & 6.8928 & 7.442 & TRN \\
\hline CHEMBL3891147 & 1641073 & 7.8633 & 7.334 & TRN \\
\hline CHEMBL3979382 & 1641073 & 7.3665 & 7.4133 & TST \\
\hline CHEMBL 3946726 & 1641073 & 7.2976 & 7.7494 & TRN \\
\hline CHEMBL3985137 & 1641073 & 8.7959 & 8.1027 & TRN \\
\hline CHEMBL3947725 & 1641073 & 7.7447 & 7.7782 & TRN \\
\hline CHEMBL3929032 & 1641073 & 6.0 & 6.904 & TRN \\
\hline CHEMBL 3904585 & 1641073 & 8.2366 & 6.5157 & TST \\
\hline CHEMBL 3937367 & 1641073 & 8.8861 & 6.4339 & TRN \\
\hline CHEMBL3951342 & 1641073 & 7.5918 & 7.4805 & TRN \\
\hline CHEMBL3936669 & 1641073 & 6.7215 & 8.4077 & TRN \\
\hline CHEMBL 3954392 & 1641073 & 8.0269 & 6.8114 & TST \\
\hline CHEMBL3962262 & 1641073 & 7.5969 & 7.0827 & TRN \\
\hline CHEMBL 3941553 & 1641073 & 6.0 & 8.3069 & TRN \\
\hline CHEMBL3922885 & 1641073 & 8.7447 & 7.4168 & TST \\
\hline CHEMBL3921254 & 1641073 & 8.9208 & 8.3453 & TRN \\
\hline CHEMBL3907982 & 1641073 & 7.6055 & \multicolumn{2}{|c|}{7.117000000000001} \\
\hline CHEMBL 3937971 & 1641073 & 9.1549 & 8.3611 & TRN \\
\hline CHEMBL 3895631 & 1641073 & 6.0 & 6.415 & TST \\
\hline CHEMBL3919851 & 1641073 & 8.4559 & 7.5551 & TRN \\
\hline CHEMBL3975512 & 1641073 & 6.0 & 7.4751 & TRN \\
\hline CHEMBL3895165 & 1641073 & 7.9431 & \multicolumn{2}{|c|}{8.232999999999999} \\
\hline CHEMBL 3909735 & 1641073 & 7.3036 & 7.5948 & TST \\
\hline CHEMBL 3973553 & 1641073 & 7.1331 & 7.0824 & TST \\
\hline CHEMBL 3948992 & 1641073 & 9.2218 & 7.8788 & TST \\
\hline CHEMBL 3925308 & 1641073 & 7.5391 & 7.2886 & TRN \\
\hline CHEMBL3981423 & 1641073 & 6.8752 & 7.0842 & TST \\
\hline CHEMBL3910127 & 1641073 & 8.2757 & 7.593 & TRN \\
\hline CHEMBL 3962310 & 1641073 & 8.2782 & 7.7718 & TRN \\
\hline CHEMBL 3971735 & 1641073 & 9.301 & 7.6195 & TST \\
\hline CHEMBL3909516 & 1641073 & 8.9208 & 7.6712 & TST \\
\hline CHEMBL3891992 & 1641073 & 7.2 & 6.6893 & TRN \\
\hline CHEMBL3961286 & 1641073 & 6.0 & 6.8575 & TRN \\
\hline CHEMBL 3892374 & 1641073 & 8.3862 & 8.3718 & TRN \\
\hline CHEMBL3974739 & 1641073 & 6.5511 & 6.5622 & TRN \\
\hline CHEMBL 3952538 & 1641073 & 7.8729 & 6.0647 & TRN \\
\hline CHEMBL 3916244 & 1641073 & 7.3645 & 7.3022 & TST \\
\hline CHEMBL 3926641 & 1641073 & 9.0969 & 8.9844 & TRN \\
\hline CHEMBL 3976402 & 1641073 & 7.9626 & 7.5801 & TRN \\
\hline CHEMBL 3924000 & 1641073 & 8.6576 & 7.9801 & TRN \\
\hline CHEMBL 3931325 & 1641073 & 8.7696 & 8.7285 & TRN \\
\hline CHEMBL 3952663 & 1641073 & 8.9101 & 8.3483 & TRN \\
\hline CHEMBL 3926744 & 1641073 & 8.9208 & \multicolumn{2}{|c|}{7.6160000000000005} \\
\hline CHEMBL 3914867 & 1641073 & 8.9586 & 8.3974 & TRN \\
\hline CHEMBL 3909780 & 1641073 & 8.8539 & 8.2919 & TRN \\
\hline CHEMBL 3960326 & 1641073 & 7.061 & 7.5128 & TRN \\
\hline CHEMBL3969395 & 1641073 & 6.6859 & 7.6265 & TRN \\
\hline
\end{tabular}


Supplemental Table S2.txt

\begin{tabular}{|c|c|c|c|c|c|c|}
\hline CHEMBL 3893101 & 1641073 & 8.3768 & 7.9698 & TST & & \\
\hline CHEMBL 3921781 & 1641073 & 7.1349 & 7.3515 & TRN & & \\
\hline CHEMBL 3932591 & 1641073 & 9.5229 & 9.0743 & TRN & & \\
\hline CHEMBL 3896843 & 1641073 & 6.9165 & 7.3297 & TRN & & \\
\hline CHEMBL 3899057 & 1641073 & 8.3279 & 7.2359 & TRN & & \\
\hline CHEMBL 3928733 & 1641073 & 7.1451 & 5.7481 & TST & & \\
\hline CHEMBL 3976263 & 1641073 & 6.6726 & 6.8109 & TRN & & \\
\hline CHEMBL 3933660 & 1641073 & 6.2642 & 7.3571 & TST & & \\
\hline CHEMBL 3920471 & 1641073 & 7.1811 & 6.7415 & TST & & \\
\hline CHEMBL 3906888 & 1641073 & 6.0 & 7.7403 & TRN & & \\
\hline CHEMBL 3890995 & 1641073 & 7.015 & 6.2347 & TST & & \\
\hline CHEMBL 3902559 & 1641073 & 5.8996 & 6.9505 & TST & & \\
\hline CHEMBL 3890134 & 1641073 & 7.6536 & 7.4138 & TRN & & \\
\hline CHEMBL 3964047 & 1641073 & 7.1979 & 6.8293 & TST & & \\
\hline CHEMBL 3909437 & 1641073 & 6.0 & 7.7059 & TRN & & \\
\hline CHEMBL 3981346 & 1641073 & 5.74299 & 799999999 & 99 & 7.6234 & TST \\
\hline CHEMBL 3971306 & 1641073 & 9.5229 & 8.9032 & TRN & & \\
\hline CHEMBL 3946769 & 1641073 & 6.0 & 7.4378 & TRN & & \\
\hline CHEMBL 3913205 & 1641073 & 9.0458 & 7.8706 & TST & & \\
\hline CHEMBL 3903104 & 1641073 & 6.5748 & 7.9245 & TRN & & \\
\hline CHEMBL 3986295 & 1641073 & 8.0625 & 7.5222 & TRN & & \\
\hline CHEMBL 3975573 & 1641073 & 8.0516 & 7.8766 & TRN & & \\
\hline CHEMBL 3946986 & 1641073 & 8.7447 & 7.9101 & TRN & & \\
\hline CHEMBL 3904162 & 1641073 & 6.0 & 6.581 & TRN & & \\
\hline CHEMBL 3966514 & 1641073 & 7.5952 & 6.8523 & TRN & & \\
\hline CHEMBL 3908429 & 1641073 & 9.3979 & 7.2674 & TRN & & \\
\hline CHEMBL 3932545 & 1641073 & 6.8671 & 7.2771 & TRN & & \\
\hline CHEMBL 3981912 & 1641073 & 9.3979 & 8.7187 & TRN & & \\
\hline CHEMBL 3950685 & 1641073 & 8.0883 & 7.8356 & TRN & & \\
\hline CHEMBL 3907934 & 1641073 & 8.6198 & 8.0953 & TRN & & \\
\hline CHEMBL 3910096 & 1641073 & 8.9208 & 8.1748 & TST & & \\
\hline CHEMBL 3944883 & 1641073 & 6.0 & 6.5368 & TST & & \\
\hline CHEMBL 3973575 & 1641073 & 9.0 & 6.5778 & TST & & \\
\hline CHEMBL 3973286 & 1641073 & 8.2007 & 7.9293 & TRN & & \\
\hline CHEMBL 3981415 & 1641073 & 7.5302 & 7.2226 & TRN & & \\
\hline CHEMBL 3892731 & 1641073 & 6.0 & 7.8438 & TRN & & \\
\hline CHEMBL 3979074 & 1641073 & 8.9031 & 7.3493 & TST & & \\
\hline CHEMBL 3918662 & 1641073 & 6.4884 & 6.9938 & TST & & \\
\hline CHEMBL 3904545 & 1641073 & 9.0969 & 7.5214 & TST & & \\
\hline CHEMBL 3985180 & 1641073 & 7.8327 & 7.2915 & TRN & & \\
\hline CHEMBL 3960612 & 1641073 & 6.4454 & 7.5007 & TST & & \\
\hline CHEMBL 3904567 & 1641073 & 9.0969 & 8.4439 & TRN & & \\
\hline CHEMBL 3967760 & 1641073 & 6.3275 & 6.7179 & TRN & & \\
\hline CHEMBL 3970268 & 1641073 & 7.4001 & 7.2843 & TST & & \\
\hline CHEMBL 3949688 & 1641073 & \multicolumn{3}{|c|}{7.617999999999999} & 8.2235 & TRN \\
\hline CHEMBL 3899682 & 1641073 & 8.7696 & 7.5138 & TST & & \\
\hline CHEMBL 3934201 & 1641073 & 8.1024 & 7.5609 & TRN & & \\
\hline CHEMBL 3895260 & 1641073 & 8.8477 & 8.4874 & TRN & & \\
\hline
\end{tabular}


Supplemental Table S2.txt

\begin{tabular}{|c|c|c|c|c|c|}
\hline CHEMBL3892371 & 1641073 & 7.556 & 7.9112 & TRN & \\
\hline CHEMBL3940997 & 1641073 & 8.0177 & 7.6891 & TRN & \\
\hline CHEMBL3959321 & 1641073 & 7.1993 & 7.0067 & TRN & \\
\hline CHEMBL3893230 & 1641073 & 6.0 & 7.1136 & TRN & \\
\hline CHEMBL3986009 & 1641073 & 6.0 & 6.471 & TST & \\
\hline CHEMBL3973831 & 1641073 & 6.0 & 7.2891 & TRN & \\
\hline CHEMBL3946066 & 1641073 & 5.9165 & 6.947 & TRN & \\
\hline CHEMBL3943812 & 1641073 & 9.301 & 8.3171 & TRN & \\
\hline CHEMBL3969805 & 1641073 & 7.767 & 8.1022 & TRN & \\
\hline CHEMBL3916027 & 1641073 & 6.0 & 6.7278 & TRN & \\
\hline CHEMBL3980249 & 1641073 & 7.7328 & 7.0179 & TRN & \\
\hline CHEMBL3984298 & 1641073 & 8.7696 & 8.3592 & TRN & \\
\hline CHEMBL3929876 & 1641073 & 8.1135 & 7.2797 & TRN & \\
\hline CHEMBL3961552 & 1641073 & 8.6576 & 8.3512 & TRN & \\
\hline CHEMBL3946516 & 1641073 & 7.0757 & 7.6331 & TST & \\
\hline CHEMBL3965201 & 1641073 & 7.0711 & 5.86600 & 30000000005 & TRN \\
\hline CHEMBL3898007 & 1641073 & 7.2125 & 8.2009 & TRN & \\
\hline CHEMBL3899202 & 1641073 & 8.6021 & 7.6785 & TRN & \\
\hline CHEMBL3900586 & 1641073 & 6.0 & 7.8137 & TST & \\
\hline CHEMBL3981438 & 1641073 & 9.0 & 8.8242 & TRN & \\
\hline CHEMBL3908114 & 1641073 & 6.0 & 7.6214 & TST & \\
\hline CHEMBL3948189 & 1641073 & 6.0 & 7.2663 & TRN & \\
\hline CHEMBL3905854 & 1641073 & 6.5223 & 6.1605 & TRN & \\
\hline CHEMBL3899066 & 1641073 & 6.9805 & 7.4261 & TST & \\
\hline CHEMBL3928671 & 1641073 & 5.8533 & 7.6776 & TST & \\
\hline CHEMBL3977420 & 1641073 & 8.3098 & 7.6869 & TRN & \\
\hline CHEMBL3919166 & 1641073 & 7.9813 & 7.4036 & TRN & \\
\hline CHEMBL3910401 & 1641073 & 9.2218 & 6.796 & TRN & \\
\hline CHEMBL3978024 & 1641073 & 8.1831 & 8.5422 & TRN & \\
\hline CHEMBL 3957125 & 1641073 & 6.0 & 6.7519 & TRN & \\
\hline CHEMBL3922563 & 1641073 & 8.3372 & 8.1538 & TRN & \\
\hline CHEMBL3973360 & 1641073 & 5.7932 & 6.9731 & TRN & \\
\hline CHEMBL3895959 & 1641073 & 8.5229 & 8.3262 & TRN & \\
\hline CHEMBL3955719 & 1641073 & 7.3716 & 7.3628 & TRN & \\
\hline CHEMBL3923630 & 1641073 & 5.8219 & 6.9883 & TRN & \\
\hline CHEMBL3965054 & 1641073 & 7.1085 & 7.2818 & TRN & \\
\hline CHEMBL3978499 & 1641073 & 8.7959 & 8.6113 & TRN & \\
\hline CHEMBL3979344 & 1641073 & 6.3663 & 7.1892 & TST & \\
\hline CHEMBL3901605 & 1641073 & 6.0 & 6.5173 & TST & \\
\hline CHEMBL3904578 & 1641073 & 7.983 & 6.9061 & TRN & \\
\hline CHEMBL3977327 & 1641073 & 8.5376 & 7.7295 & TST & \\
\hline CHEMBL3920107 & 1641073 & 6.0 & 5.6151 & TRN & \\
\hline CHEMBL3942393 & 1641073 & 8.0655 & 8.5735 & TRN & \\
\hline CHEMBL3947147 & 1641073 & 9.301 & 8.7904 & TRN & \\
\hline CHEMBL3922745 & 1641073 & 6.0 & 7.5445 & TRN & \\
\hline CHEMBL3975400 & 1641073 & 7.3206 & 6.9744 & TRN & \\
\hline CHEMBL3972007 & 1641073 & 7.7469 & 7.0408 & TST & \\
\hline CHEMBL3906632 & 1641073 & 6.8732 & 7.0546 & TST & \\
\hline
\end{tabular}


Supplemental Table S2.txt

\begin{tabular}{|c|c|c|c|c|}
\hline th & 541073 & .9586 & & \\
\hline & 641073 & 7.8239 & & \\
\hline (II) & & & & \\
\hline AEMBL & 073 & & & A \\
\hline AEMBL3958340 & 541073 & 2765 & 1427 & \\
\hline HEMBL3918549 & 641073 & 8.6198 & .8747 & \\
\hline HEMBL 389 & 973 & 239 & 28 & \\
\hline IFMBI 392 & & & & \\
\hline AEMBL3890256 & 073 & 7878 & & \\
\hline HEMBL3978575 & 073 & 6.841 & 1974 & \\
\hline HEMBL3931618 & $\partial 73$ & 8.2076 & .2831 & \\
\hline IEMBL 3913020 & 73 & 59 & 732 & \\
\hline AEMBL3891686 & & & & RN \\
\hline HEMBL3913568 & 973 & 8.1308 & 6.7842 & \\
\hline AEMBL3962933 & 73 & 12 & & \\
\hline AEMBL3983261 & 62 & 7.6674 & & \\
\hline AEMBL3 & 3 & 747 & 55 & KIV \\
\hline AEMBL3S & & & & \\
\hline HEMBL39 & & 6.0 & & \\
\hline AEMBL3S & & 6 & & \\
\hline HEIMBLSS & 6 & 8 . & & I RIV \\
\hline AEMBL & & & & RN \\
\hline HEMBL3S & & & & \\
\hline 038 & & & & \\
\hline AEMBL3S & & & & ISI \\
\hline HEMBL3S & 6 & 8. & & ГRN \\
\hline HEMBL3 & & 9 & & RN \\
\hline HFMBI 36 & 73 & & 87 & \\
\hline HEMBL3 & & & & in \\
\hline HEMBL 397 & & & & IK \\
\hline HEMBL3S & 62 & 7. & & RN \\
\hline HEMBL; & & 6 & & RN \\
\hline AEMBL; & & 6 & 04 & TRN \\
\hline HEMBL3935934 & & & & 15 \\
\hline HEMBL3958718 & 64 & 8.03 & 364 & TST \\
\hline HEMBL3889673 & 61 & & & RN \\
\hline HFMRI & 3 & & & $\Gamma \mathrm{RN}$ \\
\hline HEMBL & & & & IRN \\
\hline HEMBL3934614 & 3 & 6 . & 341 & TST \\
\hline AEMBL39 & 3 & 8 & & TRN \\
\hline HEMBL 39 & 6 & & & \\
\hline CHEMBL 3966700 & & & & RN \\
\hline HEMBL3932165 & 73 & 7.7595 & 8.0654 & ГST \\
\hline AEMBL3900367 & $\partial 73$ & 8.6383 & 27 & TRN \\
\hline MBL & & & & $\mathrm{N}$ \\
\hline HEMBL 38989 & & כב כב & & \\
\hline CHEMBL 3952247 & & .1878 & 9.0625 & \\
\hline HEMBL3936722 & 1641073 & 9.1549 & 9.0091 & ГRN \\
\hline
\end{tabular}

Page 880 


\begin{tabular}{|c|c|c|c|c|c|c|}
\hline \multicolumn{7}{|c|}{ Supplemental Table S2.txt } \\
\hline CHEMBL3920631 & 1641073 & 6.0 & 7.7169 & TST & & \\
\hline CHEMBL3955904 & 1641073 & 8.98299 & 999999999 & & 7.8499 & TRN \\
\hline CHEMBL3953499 & 1641073 & 9.1549 & 8.6086 & TRN & & \\
\hline CHEMBL3917591 & 1641073 & 6.3336 & 8.0768 & TST & & \\
\hline CHEMBL3930520 & 1641073 & 8.2291 & 8.0413 & TRN & & \\
\hline CHEMBL3956320 & 1641073 & 8.7447 & 8.3796 & TRN & & \\
\hline CHEMBL 3951055 & 1641073 & 6.0 & 7.9785 & TRN & & \\
\hline CHEMBL3955546 & 1641073 & 8.8239 & 8.3548 & TST & & \\
\hline CHEMBL3956179 & 1641073 & 6.7711 & 7.0608 & TRN & & \\
\hline CHEMBL3937709 & 1641073 & 6.0 & 6.5796 & TRN & & \\
\hline CHEMBL3941892 & 1641073 & 9.0 & 7.6871 & TST & & \\
\hline CHEMBL 3955580 & 1641073 & 6.0 & 6.6385 & TRN & & \\
\hline CHEMBL3945974 & 1641073 & 8.5686 & 8.1935 & TRN & & \\
\hline CHEMBL3938908 & 1641073 & 7.9281 & 7.925 & TRN & & \\
\hline CHEMBL3962723 & 1641073 & 8.8239 & 7.5461 & TRN & & \\
\hline CHEMBL3960214 & 1641073 & 7.51 & 7.3484 & TRN & & \\
\hline CHEMBL3897779 & 1641073 & 6.0 & 6.7986 & TST & & \\
\hline CHEMBL3939623 & 1641073 & 7.7533 & 7.1151 & TRN & & \\
\hline CHEMBL3917168 & 1641073 & 6.0 & 7.8648 & TRN & & \\
\hline CHEMBL 3894412 & 1641073 & 9.2441 & 9.135 & TST & & \\
\hline CHEMBL3943997 & 1641073 & 8.5086 & 7.8669 & TRN & & \\
\hline CHEMBL3895154 & 1641073 & 6.0 & 7.825 & TRN & & \\
\hline CHEMBL3928199 & 1641073 & 7.1998 & 8.1214 & TRN & & \\
\hline CHEMBL3914309 & 1641073 & 7.8182 & 7.4527 & TRN & & \\
\hline CHEMBL 3905776 & 1641073 & 6.3056 & 7.4112 & TRN & & \\
\hline CHEMBL3944087 & 1641073 & 8.3665 & 8.1136 & TST & & \\
\hline CHEMBL 3902207 & 1641073 & 6.5578 & 7.0579 & TRN & & \\
\hline CHEMBL3929367 & 1641073 & 9.3979 & 8.9261 & TRN & & \\
\hline CHEMBL3910978 & 1641073 & 8.0506 & 7.9947 & TRN & & \\
\hline CHEMBL 3895804 & 1641073 & 8.5686 & 6.4649 & TST & & \\
\hline CHEMBL3932015 & 1641073 & 5.8005 & 8.2283 & TRN & & \\
\hline CHEMBL 3899365 & 1641073 & 9.3979 & 8.9436 & TRN & & \\
\hline CHEMBL 3912743 & 1641073 & 7.5137 & 8.2004 & TRN & & \\
\hline CHEMBL3893061 & 1641073 & 8.2596 & 7.88 & TRN & & \\
\hline CHEMBL3976585 & 1641073 & 6.7948 & 6.9917 & TRN & & \\
\hline CHEMBL3904513 & 1641073 & 8.4179 & 8.7606 & TST & & \\
\hline CHEMBL3935117 & 1641073 & 6.01399 & 999999999 & 9 & 6.8071 & TST \\
\hline CHEMBL 3936883 & 1641073 & 9.301 & 8.2909 & TRN & & \\
\hline CHEMBL3955406 & 1641073 & 8.0458 & 8.6532 & TST & & \\
\hline CHEMBL3895406 & 1641073 & 9.301 & 8.7731 & TRN & & \\
\hline CHEMBL3960094 & 1641073 & 9.0969 & 8.6552 & TST & & \\
\hline CHEMBL 3943583 & 1641073 & 7.0794 & 7.1479 & TRN & & \\
\hline CHEMBL 3972726 & 1641073 & 8.1675 & 7.4569 & TRN & & \\
\hline CHEMBL3909069 & 1641073 & 6.9867 & 7.1697 & TST & & \\
\hline CHEMBL3952296 & 1641073 & 7.0128 & 6.8861 & TRN & & \\
\hline CHEMBL3971980 & 1641073 & 9.301 & 8.6127 & TRN & & \\
\hline CHEMBL3948751 & 1641073 & 8.0605 & 8.0207 & TRN & & \\
\hline CHEMBL3896770 & 1641073 & 8.0701 & 7.4462 & TRN & & \\
\hline
\end{tabular}


Supplemental Table S2.txt

\begin{tabular}{|c|c|c|c|c|c|}
\hline CHEMBL3946607 & 1641073 & 8.0555 & 7.8626 & TST & \\
\hline CHEMBL 3982882 & 1641073 & 6.0 & \multicolumn{2}{|c|}{6.667000000000001} & TRN \\
\hline CHEMBL3897465 & 1641073 & 8.4868 & \multicolumn{2}{|c|}{7.946000000000001} & TRN \\
\hline CHEMBL3935846 & 1641073 & 8.2076 & 7.7801 & TRN & \\
\hline CHEMBL3896262 & 1641073 & 7.6861 & 7.5019 & TRN & \\
\hline CHEMBL3914218 & 1641073 & 8.8239 & 8.4711 & TRN & \\
\hline CHEMBL3919408 & 1641073 & 9.5229 & 8.9293 & TRN & \\
\hline CHEMBL3909230 & 1641073 & 8.7447 & 7.8191 & TST & \\
\hline CHEMBL 3985412 & 1641073 & 9.0969 & 8.1083 & TST & \\
\hline CHEMBL3937149 & 1641073 & 7.067 & 8.2605 & TRN & \\
\hline CHEMBL3920232 & 1641073 & 8.0655 & 8.1444 & TRN & \\
\hline CHEMBL3914267 & 1641073 & 8.6198 & 7.843 & TRN & \\
\hline CHEMBL3942686 & 1641073 & 8.3372 & 8.2164 & TST & \\
\hline CHEMBL 3932507 & 1641073 & 6.8459 & 7.1465 & TRN & \\
\hline CHEMBL3900195 & 1641073 & 8.2596 & 7.5025 & TST & \\
\hline CHEMBL3930551 & 1641073 & 9.0362 & 8.6736 & TRN & \\
\hline CHEMBL3931701 & 1641073 & 6.6755 & 7.597 & TST & \\
\hline CHEMBL3946015 & 1641073 & 8.6615 & 7.8678 & TRN & \\
\hline CHEMBL3919174 & 1641073 & 8.1135 & 8.1387 & TRN & \\
\hline CHEMBL 3972253 & 1641073 & 8.0757 & 7.5047 & TRN & \\
\hline CHEMBL3949641 & 1641073 & 7.3063 & 7.2252 & TRN & \\
\hline CHEMBL 3984234 & 1641073 & 7.6676 & 7.6768 & TRN & \\
\hline CHEMBL 3972531 & 1641073 & 8.3468 & 8.1078 & TRN & \\
\hline CHEMBL3909381 & 1641073 & 6.7755 & 7.9157 & TRN & \\
\hline CHEMBL3981296 & 1641073 & 7.9914 & 6.6605 & TRN & \\
\hline CHEMBL3941575 & 1641073 & 7.2749 & 7.2996 & TRN & \\
\hline CHEMBL3959402 & 1641073 & 8.4828 & 7.7462 & TRN & \\
\hline CHEMBL3975347 & 1641073 & 7.8901 & 8.3768 & TST & \\
\hline CHEMBL3911276 & 1641073 & 6.7975 & 7.022 & TRN & \\
\hline CHEMBL 3924351 & 1641073 & 8.5086 & 8.3096 & TRN & \\
\hline CHEMBL3902183 & 1641073 & 8.3979 & 8.432 & TRN & \\
\hline CHEMBL3927703 & 1641073 & 7.6946 & 7.6452 & TST & \\
\hline CHEMBL3928337 & 1641073 & 6.0 & 8.1204 & TST & \\
\hline CHEMBL 3894768 & 1641073 & 7.7033 & 7.9555 & TRN & \\
\hline CHEMBL3978911 & 1641073 & 9.0969 & 8.4217 & TRN & \\
\hline CHEMBL3975320 & 1641073 & 9.0 & 7.6353 & TST & \\
\hline CHEMBL3972304 & 1641073 & 8.6778 & 8.2005 & TRN & \\
\hline CHEMBL3910095 & 1641073 & 8.2291 & 7.2063 & TST & \\
\hline CHEMBL3921562 & 1641073 & 5.7747 & 7.6087 & TST & \\
\hline CHEMBL3956757 & 1641073 & 6.0 & 5.6714 & TRN & \\
\hline CHEMBL3912479 & 1641073 & 7.7149 & 6.9302 & TRN & \\
\hline CHEMBL 3925537 & 1641073 & 7.6455 & 7.4512 & TRN & \\
\hline CHEMBL3919739 & 1641073 & 8.7959 & 8.3103 & TRN & \\
\hline CHEMBL3970924 & 1641073 & 7.4149 & 7.1373 & TRN & \\
\hline CHEMBL3949612 & 1641073 & 8.6576 & 8.1102 & TRN & \\
\hline CHEMBL3938799 & 1641073 & 8.301 & 7.6277 & TRN & \\
\hline CHEMBL 3964427 & 1641073 & 8.8539 & 8.9897 & TRN & \\
\hline CHEMBL3969653 & 1641073 & 9.3768 & 9.5933 & TST & \\
\hline
\end{tabular}


Supplemental Table S2.txt

\begin{tabular}{|c|c|c|c|c|c|}
\hline CHEMBL 3892846 & 1641073 & 8.2676 & 7.9099 & TRN & \\
\hline CHEMBL 3936914 & 1641073 & 6.2116 & 7.8018 & TRN & \\
\hline CHEMBL3948256 & 1641073 & 8.1249 & 7.6414 & TRN & \\
\hline CHEMBL 3920941 & 1641073 & 8.5376 & 7.7183 & TRN & \\
\hline CHEMBL 3985532 & 1641073 & 6.0 & 6.9827 & TRN & \\
\hline CHEMBL 3938182 & 1641073 & 7.1811 & 6.9591 & TRN & \\
\hline CHEMBL 3969068 & 1641073 & 8.7235 & 8.9746 & TST & \\
\hline CHEMBL3902259 & 1641073 & 8.5867 & 8.3003 & TRN & \\
\hline CHEMBL3927949 & 1641073 & 8.5575 & 8.1495 & TRN & \\
\hline CHEMBL 3902881 & 1641073 & 7.1925 & 7.9108 & TRN & \\
\hline CHEMBL 3904845 & 1641073 & 8.3665 & 7.7242 & TST & \\
\hline CHEMBL 3945978 & 1641073 & 5.8608 & 7.487999 & 79999999995 & TRN \\
\hline CHEMBL 3980867 & 1641073 & 8.8539 & 8.8868 & TRN & \\
\hline CHEMBL 3943581 & 1641073 & 6.0 & 7.8942 & TRN & \\
\hline CHEMBL 3950485 & 1641073 & 8.2984 & 7.4467 & TRN & \\
\hline CHEMBL 3956401 & 1641073 & 6.0 & 7.6109 & TRN & \\
\hline CHEMBL3904922 & 1641073 & 7.6308 & 7.6025 & TRN & \\
\hline CHEMBL 3923306 & 1641073 & 6.0 & 8.1028 & TRN & \\
\hline CHEMBL 3910236 & 1641073 & 6.0185 & 7.4361 & TRN & \\
\hline CHEMBL 3894728 & 1641073 & 8.0297 & 7.4308 & TRN & \\
\hline CHEMBL 3904167 & 1641073 & 8.7959 & 8.8595 & TRN & \\
\hline CHEMBL 3954207 & 1641073 & 6.0 & 8.1561 & TRN & \\
\hline CHEMBL 3929819 & 1641073 & 6.0 & 8.032 & TRN & \\
\hline CHEMBL 3929048 & 1641073 & 6.0 & 8.2057 & TRN & \\
\hline CHEMBL 3950851 & 1641073 & 6.0 & 7.6824 & TRN & \\
\hline CHEMBL 3956894 & 1641073 & 7.9281 & 8.3735 & TRN & \\
\hline CHEMBL3900694 & 1641073 & 8.6383 & 7.9593 & TRN & \\
\hline CHEMBL 3933414 & 1641073 & 7.9957 & 8.0915 & TRN & \\
\hline CHEMBL3924394 & 1641073 & 9.301 & 8.924 & TRN & \\
\hline CHEMBL 3968229 & 1641073 & 8.4685 & 6.7452 & TST & \\
\hline CHEMBL 3953831 & 1641073 & 6.0 & 6.7629 & TRN & \\
\hline CHEMBL 3904955 & 1641073 & 9.0969 & 8.6711 & TRN & \\
\hline CHEMBL 3920282 & 1641073 & 6.0 & 7.3901 & TST & \\
\hline CHEMBL3977841 & 1641073 & 8.4202 & 7.737 & TRN & \\
\hline CHEMBL3967091 & 1641073 & 7.1821 & 7.6797 & TRN & \\
\hline CHEMBL3982728 & 1641073 & 8.0757 & 7.2483 & TRN & \\
\hline CHEMBL3907956 & 1641073 & 6.0132 & 7.7441 & TRN & \\
\hline CHEMBL 3950876 & 1641073 & 7.9914 & 7.9318 & TRN & \\
\hline CHEMBL3914846 & 1641073 & 7.6925 & 7.1538 & TRN & \\
\hline CHEMBL 3984509 & 1641073 & 6.6459 & 7.1996 & TRN & \\
\hline CHEMBL 3920606 & 1641073 & 9.5229 & 9.4614 & TRN & \\
\hline CHEMBL 3966825 & 1641073 & 7.38399 & 999999999 & 7.1429 & TRN \\
\hline CHEMBL 3978772 & 1641073 & 7.3925 & 7.4578 & TRN & \\
\hline CHEMBL3914132 & 1641073 & 6.0 & 7.3444 & TRN & \\
\hline CHEMBL 3940733 & 1641073 & 7.445 & 8.1174 & TRN & \\
\hline CHEMBL 3958284 & 1641073 & 6.0 & 7.6632 & TRN & \\
\hline CHEMBL 3910027 & 1641073 & 9.301 & 8.4421 & TRN & \\
\hline CHEMBL 3891206 & 1641073 & 8.4089 & 8.5545 & TST & \\
\hline
\end{tabular}


Supplemental Table S2.txt

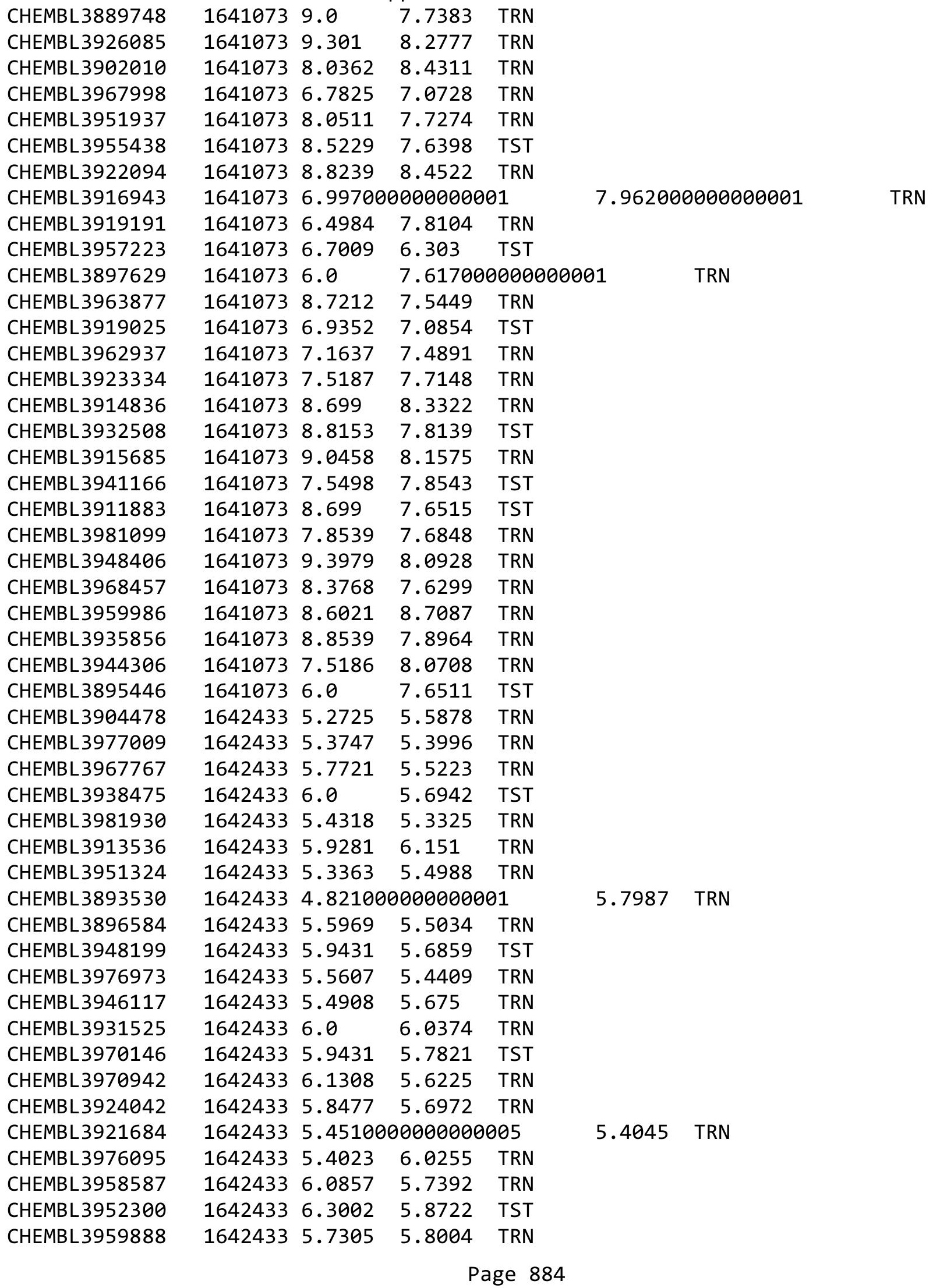


Supplemental Table S2.txt

\begin{tabular}{|c|c|c|c|c|c|}
\hline CHEMBL3956615 & 1642433 & 3.699 & 5.6641 & TST & \\
\hline CHEMBL3924034 & 1642433 & 6.4179 & 5.9329 & TRN & \\
\hline CHEMBL3986805 & 1642433 & 5.75700 & 000000000 & 5.944 & TRN \\
\hline CHEMBL 3949462 & 1642433 & 3.699 & 5.6564 & TST & \\
\hline CHEMBL 3975363 & 1642433 & 5.3737 & 5.4569 & TRN & \\
\hline CHEMBL3960313 & 1642433 & 6.0 & 6.2476 & TRN & \\
\hline CHEMBL3969113 & 1642433 & 5.8153 & 5.5436 & TST & \\
\hline CHEMBL3952831 & 1642433 & 5.6819 & 5.9882 & TRN & \\
\hline CHEMBL3909018 & 1642433 & 6.3298 & 5.6349 & TST & \\
\hline CHEMBL 3902587 & 1642433 & 5.6383 & 5.4329 & TRN & \\
\hline CHEMBL3939555 & 1642433 & 5.5467 & 5.6059 & TST & \\
\hline CHEMBL3929628 & 1642433 & 6.1884 & 5.6581 & TST & \\
\hline CHEMBL3942780 & 1642433 & 5.8539 & 6.1194 & TRN & \\
\hline CHEMBL3927469 & 1642433 & 5.7235 & 6.042999 & 999999999 & TRN \\
\hline CHEMBL3961516 & 1642433 & 6.0605 & 5.8596 & TRN & \\
\hline CHEMBL 3933392 & 1642433 & 6.0283 & 5.5758 & TRN & \\
\hline CHEMBL3932839 & 1642433 & 6.9208 & 6.2395 & TRN & \\
\hline CHEMBL 3896768 & 1642433 & 6.1739 & 5.4869 & TRN & \\
\hline CHEMBL3898321 & 1642433 & 5.5361 & 5.5553 & TRN & \\
\hline CHEMBL 3915627 & 1642433 & 6.1537 & 5.9431 & TRN & \\
\hline CHEMBL3930563 & 1642433 & 5.8268 & 5.8665 & TRN & \\
\hline CHEMBL3959876 & 1642433 & 5.466 & 5.6798 & TRN & \\
\hline CHEMBL3920923 & 1642433 & 3.699 & 5.2741 & TRN & \\
\hline CHEMBL3957193 & 1642433 & 5.8097 & 5.5578 & TRN & \\
\hline CHEMBL 3946981 & 1642433 & 6.1113 & 5.4409 & TST & \\
\hline CHEMBL3960456 & 1642433 & 6.0 & 5.7529 & TRN & \\
\hline CHEMBL3924612 & 1642433 & 6.4763 & 5.7358 & TRN & \\
\hline CHEMBL3892912 & 1642433 & 5.7825 & 5.6835 & TRN & \\
\hline CHEMBL3908457 & 1642433 & 5.6421 & 5.4977 & TST & \\
\hline CHEMBL 3944781 & 1642433 & 4.9586 & 5.5982 & TST & \\
\hline CHEMBL6534 & 89064 & 5.0 & 5.3609 & TRN & \\
\hline CHEMBL 6523 & 89064 & 5.1805 & 4.1909 & TST & \\
\hline CHEMBL6229 & 89064 & 5.2007 & 4.9626 & TST & \\
\hline CHEMBL6248 & 89064 & 6.8539 & 6.5213 & TST & \\
\hline CHEMBL6612 & 89064 & 7.4318 & 7.1382 & TRN & \\
\hline CHEMBL6264 & 89064 & 5.8539 & 5.7303 & TRN & \\
\hline CHEMBL268567 & 89064 & 7.3188 & 7.4993 & TRN & \\
\hline CHEMBL6370 & 89064 & 5.4318 & 5.6487 & TRN & \\
\hline CHEMBL269598 & 89064 & 7.4949 & 7.1463 & TRN & \\
\hline CHEMBL 266572 & 89064 & 5.7447 & 5.7389 & TST & \\
\hline CHEMBL268530 & 89064 & 6.2676 & 6.4356 & TRN & \\
\hline CHEMBL6258 & 89064 & 5.7212 & 5.4025 & TRN & \\
\hline CHEMBL6381 & 89064 & 5.7212 & 5.9075 & TRN & \\
\hline CHEMBL6371 & 89064 & 5.8539 & 6.18 & TRN & \\
\hline CHEMBL 269495 & 89064 & 4.0362 & 3.8525 & TST & \\
\hline CHEMBL6442 & 89064 & 4.7212 & 4.9322 & TRN & \\
\hline CHEMBL6215 & 89064 & 3.0 & 2.8418 & TST & \\
\hline CHEMBL6316 & 89064 & 4.3979 & 4.1289 & TRN & \\
\hline
\end{tabular}




\begin{tabular}{|c|c|c|c|c|}
\hline & & & oplement & al Table S2 \\
\hline CHEMBL6417 & 89064 & 3.0 & 3.5011 & TRN \\
\hline CHEMBL263080 & 89064 & 5.6383 & 6.2351 & TRN \\
\hline CHEMBL262570 & 89064 & 7.0706 & 6.9512 & TRN \\
\hline CHEMBL267938 & 89064 & 6.2441 & 6.3044 & TRN \\
\hline CHEMBL268070 & 89064 & 4.9208 & 5.0847 & TRN \\
\hline CHEMBL263081 & 89064 & 6.8539 & 7.0481 & TRN \\
\hline CHEMBL268667 & 89064 & 4.3979 & 4.5206 & TRN \\
\hline CHEMBL266798 & 89064 & 4.3979 & 4.0843 & TRN \\
\hline CHEMBL6275 & 89064 & 4.3979 & 4.9076 & TRN \\
\hline CHEMBL269497 & 89064 & 6.8539 & 7.0428 & TRN \\
\hline CHEMBL267125 & 89064 & 8.0969 & 7.8044 & TRN \\
\hline CHEMBL6324 & 89064 & 4.3979 & 4.0063 & TRN \\
\hline CHEMBL266198 & 89064 & 8.0 & 8.2539 & TRN \\
\hline CHEMBL6517 & 89064 & 7.0044 & 6.9006 & TRN \\
\hline CHEMBL6257 & 89064 & 6.4437 & 5.9709 & TRN \\
\hline CHEMBL6369 & 89064 & 4.9586 & 5.3662 & TRN \\
\hline CHEMBL268099 & 89064 & 6.0757 & 4.9641 & TRN \\
\hline CHEMBL267127 & 89064 & 5.301 & 4.7631 & TST \\
\hline CHEMBL6430 & 89064 & 4.2518 & 3.6472 & TST \\
\hline CHEMBL6278 & 89064 & 7.3979 & 7.1683 & TRN \\
\hline CHEMBL6830 & 89064 & 7.2676 & 7.3944 & TRN \\
\hline CHEMBL267456 & 89064 & 7.6021 & 7.4244 & TRN \\
\hline CHEMBL269570 & 89064 & 6.1612 & 6.1436 & TRN \\
\hline CHEMBL266460 & 89064 & 4.3979 & 4.7255 & TRN \\
\hline CHEMBL6320 & 89064 & 4.3979 & 4.3108 & TST \\
\hline CHEMBL269075 & 89064 & 6.7696 & 6.7784 & TRN \\
\hline CHEMBL266799 & 89064 & 5.4437 & 4.8824 & TST \\
\hline CHEMBL6542 & 89064 & 7.4089 & 7.5319 & TRN \\
\hline CHEMBL428508 & 89064 & 6.2218 & 6.0868 & TRN \\
\hline CHEMBL266197 & 89064 & 5.6383 & 5.6362 & TRN \\
\hline CHEMBL267914 & 89064 & 4.4089 & 4.4913 & TRN \\
\hline CHEMBL6249 & 89064 & 4.3979 & 4.001 & TRN \\
\hline CHEMBL6762 & 89064 & 4.3979 & 4.4737 & TRN \\
\hline CHEMBL267678 & 89064 & 7.6021 & 7.3271 & TRN \\
\hline CHEMBL266429 & 89064 & 6.7959 & 6.637006 & 00000000005 \\
\hline CHEMBL266708 & 89064 & 6.6021 & 6.8444 & TST \\
\hline CHEMBL269056 & 89064 & 3.0 & 3.9649 & TST \\
\hline CHEMBL266064 & 89064 & 4.0044 & 3.5705 & TST \\
\hline CHEMBL1364757 & 688251 & 3.0004 & 3.2487 & TRN \\
\hline CHEMBL1417829 & 688251 & 3.0004 & 3.2212 & TRN \\
\hline CHEMBL1607428 & 688251 & 3.0004 & 3.2181 & TST \\
\hline CHEMBL1529715 & 688251 & 3.0004 & 3.7629 & TRN \\
\hline CHEMBL1505198 & 688251 & 3.0004 & 3.4585 & TST \\
\hline CHEMBL1535276 & 688251 & 3.0004 & 3.3826 & TRN \\
\hline CHEMBL1501751 & 688251 & 3.0004 & 3.1904 & TRN \\
\hline CHEMBL1605701 & 688251 & 4.2083 & 3.7205 & TRN \\
\hline CHEMBL1300798 & 688251 & 3.0004 & 3.2458 & TRN \\
\hline CHEMBL1413054 & 688251 & 3.0004 & 3.3225 & TRN \\
\hline
\end{tabular}




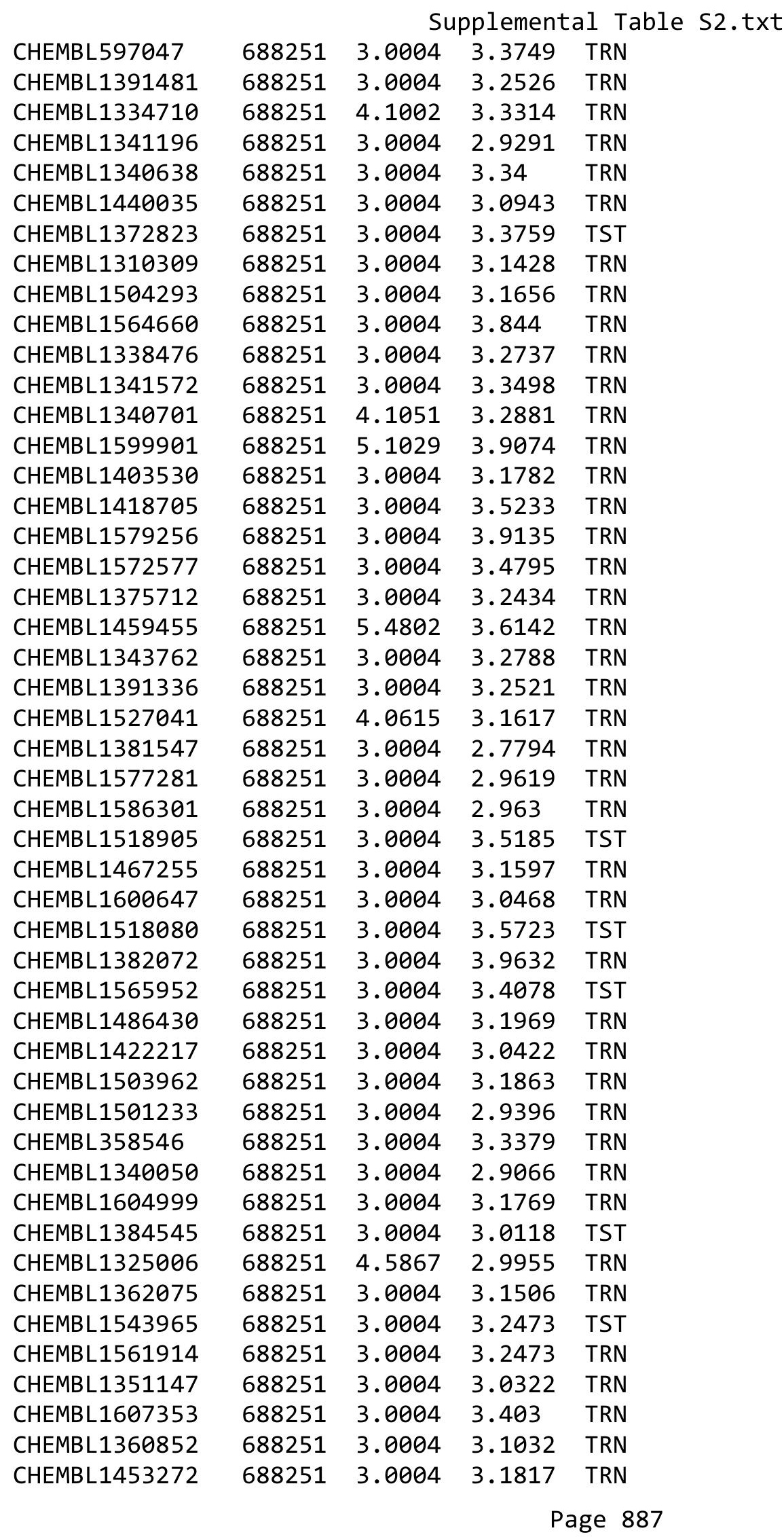




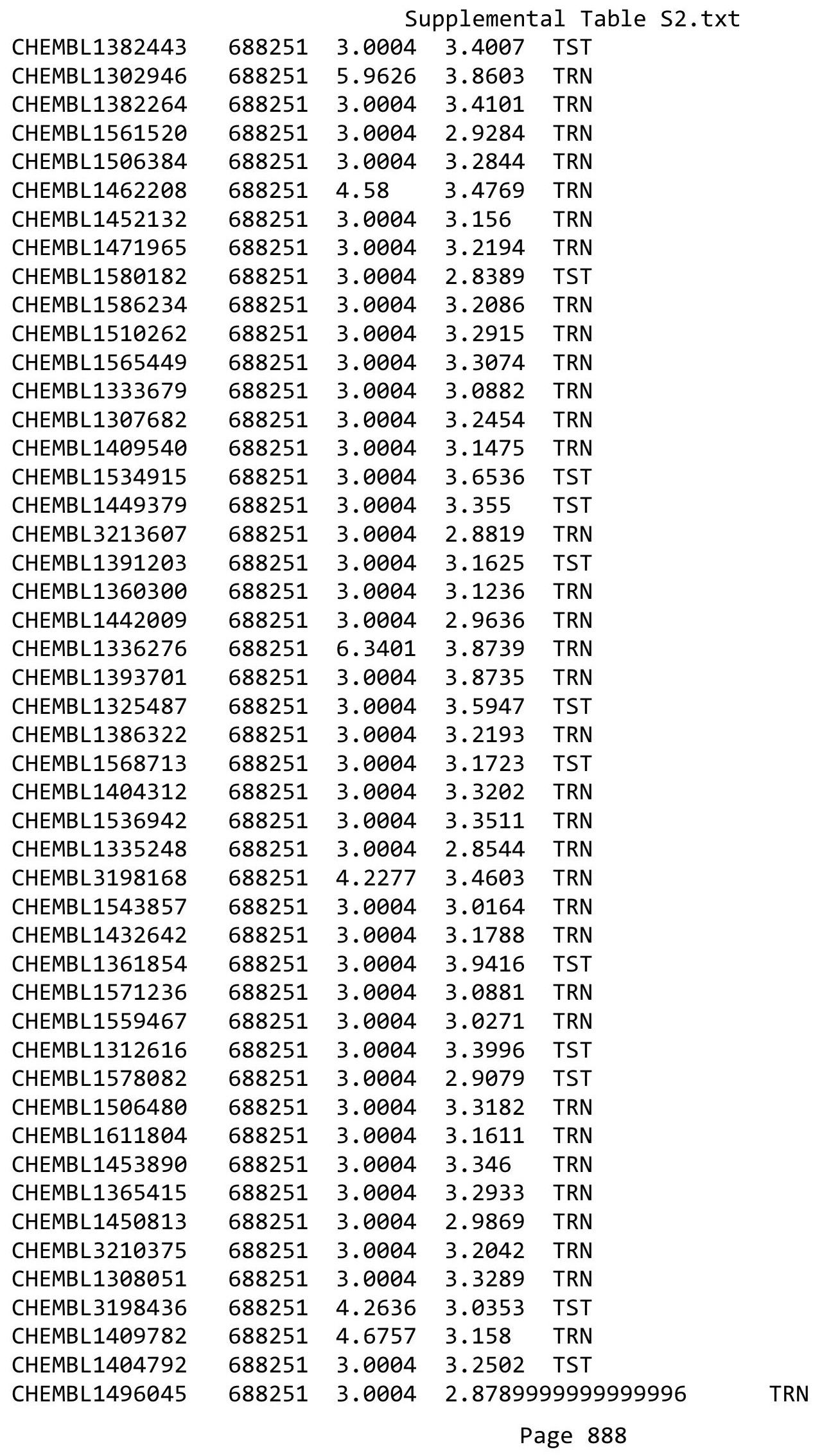




\begin{tabular}{|c|c|c|c|c|c|}
\hline & & \multicolumn{4}{|c|}{ Supplemental Table S2.txt } \\
\hline CHEMBL566931 & 688251 & 3.0004 & 3.1413 & TRN & \\
\hline CHEMBL1581153 & 688251 & 3.0004 & 3.3036 & TRN & \\
\hline CHEMBL1531156 & 688251 & 3.0004 & 3.347 & TRN & \\
\hline CHEMBL1583567 & 688251 & 3.0004 & 3.2055 & TRN & \\
\hline CHEMBL1353223 & 688251 & 3.0004 & 3.1029 & TRN & \\
\hline CHEMBL1410280 & 688251 & 3.0004 & 3.2813 & TRN & \\
\hline CHEMBL1980031 & 688251 & 3.0004 & 3.2688 & TRN & \\
\hline CHEMBL1321811 & 688251 & 3.0004 & 3.0635 & TST & \\
\hline CHEMBL1446839 & 688251 & 3.0004 & 3.1074 & TRN & \\
\hline CHEMBL1392552 & 688251 & 4.4318 & 3.2742 & TRN & \\
\hline CHEMBL1439775 & 688251 & 4.082 & 3.0664 & TRN & \\
\hline CHEMBL1338021 & 688251 & 3.0004 & 3.08699 & 99999999997 & TRN \\
\hline CHEMBL1326215 & 688251 & 3.0004 & 3.2805 & TRN & \\
\hline CHEMBL1430116 & 688251 & 3.0004 & 3.1566 & TRN & \\
\hline CHEMBL1478852 & 688251 & 3.0004 & 3.52699 & 99999999997 & TRN \\
\hline CHEMBL1400955 & 688251 & 4.1586 & 3.4846 & TRN & \\
\hline CHEMBL1386914 & 688251 & 3.0004 & 2.9728 & TRN & \\
\hline CHEMBL1529932 & 688251 & 3.0004 & 3.0003 & TRN & \\
\hline CHEMBL254255 & 688251 & 3.0004 & 3.077 & TRN & \\
\hline CHEMBL1594922 & 688251 & 4.2924 & 3.6527 & TRN & \\
\hline CHEMBL1302459 & 688251 & 3.0004 & 3.5068 & TST & \\
\hline CHEMBL1524101 & 688251 & 3.0004 & 3.4016 & TRN & \\
\hline CHEMBL1458324 & 688251 & 4.752 & 3.3522 & TRN & \\
\hline CHEMBL1472214 & 688251 & 3.0004 & 3.4711 & TRN & \\
\hline CHEMBL1338487 & 688251 & 3.0004 & 3.6469 & TRN & \\
\hline CHEMBL1454476 & 688251 & 4.6364 & 3.9243 & TRN & \\
\hline CHEMBL1703256 & 688251 & 3.0004 & 3.3719 & TRN & \\
\hline CHEMBL3195874 & 688251 & 3.0004 & 3.1219 & TRN & \\
\hline CHEMBL1572087 & 688251 & 3.0004 & 3.1209 & TRN & \\
\hline CHEMBL1339368 & 688251 & 3.0004 & 3.2827 & TRN & \\
\hline CHEMBL1393912 & 688251 & 3.0004 & 2.989 & TRN & \\
\hline CHEMBL1431089 & 688251 & 3.0004 & 3.0446 & TRN & \\
\hline CHEMBL1518885 & 688251 & 3.0004 & 3.5689 & TRN & \\
\hline CHEMBL1991234 & 688251 & 4.317 & 3.6828 & TST & \\
\hline CHEMBL1340713 & 688251 & 3.0004 & 3.1603 & TRN & \\
\hline CHEMBL1550080 & 688251 & 3.0004 & 3.5184 & TRN & \\
\hline CHEMBL1439674 & 688251 & 3.0004 & 3.4866 & TRN & \\
\hline CHEMBL1415997 & 688251 & 3.0004 & 3.3199 & TRN & \\
\hline CHEMBL1499077 & 688251 & 4.1746 & 3.2492 & TRN & \\
\hline CHEMBL1311684 & 688251 & 3.0004 & 3.1751 & TRN & \\
\hline CHEMBL1425463 & 688251 & 3.0004 & 3.5915 & TRN & \\
\hline CHEMBL1303708 & 688251 & 4.1124 & 3.2272 & TRN & \\
\hline CHEMBL1489460 & 688251 & 3.0004 & 3.1254 & TRN & \\
\hline CHEMBL1331632 & 688251 & 3.0004 & 3.0973 & TRN & \\
\hline CHEMBL1484384 & 688251 & 3.0004 & 3.2394 & TRN & \\
\hline CHEMBL1399643 & 688251 & 3.0004 & 3.4936 & TRN & \\
\hline CHEMBL1452494 & 688251 & 3.0004 & 3.5261 & TRN & \\
\hline CHEMBL1439696 & 688251 & 3.0004 & 2.8678 & TRN & \\
\hline
\end{tabular}




\begin{tabular}{|c|c|c|c|c|c|}
\hline & & \multicolumn{4}{|c|}{ Supplemental Table S2.txt } \\
\hline CHEMBL1489035 & 688251 & 3.0004 & 3.5293 & TRN & \\
\hline CHEMBL1407614 & 688251 & 4.2 & 3.3365 & TRN & \\
\hline CHEMBL1508485 & 688251 & 3.0004 & 3.0363 & TRN & \\
\hline CHEMBL1539483 & 688251 & 3.0004 & 3.2108 & TRN & \\
\hline CHEMBL1430013 & 688251 & 3.0004 & 3.1825 & TRN & \\
\hline CHEMBL1495574 & 688251 & 4.1079 & 3.39399 & 99999999997 & TRN \\
\hline CHEMBL1579513 & 688251 & 5.0696 & 3.3677 & TRN & \\
\hline CHEMBL1495555 & 688251 & 4.6308 & 3.502 & TRN & \\
\hline CHEMBL1567438 & 688251 & 3.0004 & 3.0355 & TRN & \\
\hline CHEMBL1469835 & 688251 & 3.0004 & 3.5413 & TRN & \\
\hline CHEMBL1526624 & 688251 & 3.0004 & 3.2182 & TRN & \\
\hline CHEMBL1405731 & 688251 & 3.0004 & 3.2047 & TRN & \\
\hline CHEMBL1374814 & 688251 & 3.0004 & 3.2308 & TRN & \\
\hline CHEMBL1564105 & 688251 & 3.0004 & 3.0858 & TST & \\
\hline CHEMBL 3208268 & 688251 & 3.0004 & 2.7543 & TRN & \\
\hline CHEMBL1299971 & 688251 & 3.0004 & 3.2437 & TRN & \\
\hline CHEMBL3193915 & 688251 & 4.1421 & 3.3436 & TRN & \\
\hline CHEMBL1302272 & 688251 & 6.6925 & 3.3775 & TST & \\
\hline CHEMBL1489864 & 688251 & 3.0004 & 3.1753 & TRN & \\
\hline CHEMBL1468368 & 688251 & 3.0004 & 3.4315 & TRN & \\
\hline CHEMBL1387349 & 688251 & 3.0004 & 3.1053 & TST & \\
\hline CHEMBL240331 & 688251 & 3.0004 & 3.2306 & TRN & \\
\hline CHEMBL1718423 & 688251 & 3.0004 & 3.1068 & TRN & \\
\hline CHEMBL1601093 & 688251 & 4.0264 & 3.1439 & TRN & \\
\hline CHEMBL1311641 & 688251 & 4.3143 & 3.3493 & TRN & \\
\hline CHEMBL1568847 & 688251 & 3.0004 & 3.1328 & TRN & \\
\hline CHEMBL1585024 & 688251 & 3.0004 & 3.4758 & TRN & \\
\hline CHEMBL 3194168 & 688251 & 3.0004 & 3.1075 & TRN & \\
\hline CHEMBL1385608 & 688251 & 4.0017 & 3.4323 & TRN & \\
\hline CHEMBL1379607 & 688251 & 4.6055 & 3.3192 & TRN & \\
\hline CHEMBL1492221 & 688251 & 3.0004 & 3.1746 & TRN & \\
\hline CHEMBL1602873 & 688251 & 3.0004 & 3.3159 & TRN & \\
\hline CHEMBL1368995 & 688251 & 3.0004 & 3.0672 & TRN & \\
\hline CHEMBL1499248 & 688251 & 3.0004 & 3.1592 & TRN & \\
\hline CHEMBL474933 & 688251 & 3.0004 & 3.1575 & TST & \\
\hline CHEMBL1342386 & 688251 & 3.0004 & 2.9183 & TRN & \\
\hline CHEMBL1560072 & 688251 & 3.0004 & 3.1104 & TRN & \\
\hline CHEMBL1323944 & 688251 & 3.0004 & 3.1728 & TRN & \\
\hline CHEMBL1320577 & 688251 & 3.0004 & 3.2686 & TRN & \\
\hline CHEMBL1197556 & 688251 & 3.0004 & 3.2769 & TST & \\
\hline CHEMBL1497124 & 688251 & 3.0004 & 3.0332 & TRN & \\
\hline CHEMBL3194926 & 688251 & 3.0004 & 3.117 & TRN & \\
\hline CHEMBL1471358 & 688251 & 3.0004 & 3.0969 & TRN & \\
\hline CHEMBL610508 & 688251 & 4.5969 & 3.4315 & TRN & \\
\hline CHEMBL 3212503 & 688251 & 3.0004 & 3.1067 & TRN & \\
\hline CHEMBL1342156 & 688251 & 3.0004 & 2.9461 & TRN & \\
\hline CHEMBL1585156 & 688251 & 3.0004 & 3.2465 & TST & \\
\hline CHEMBL1605622 & 688251 & 3.0004 & 3.1913 & TST & \\
\hline
\end{tabular}




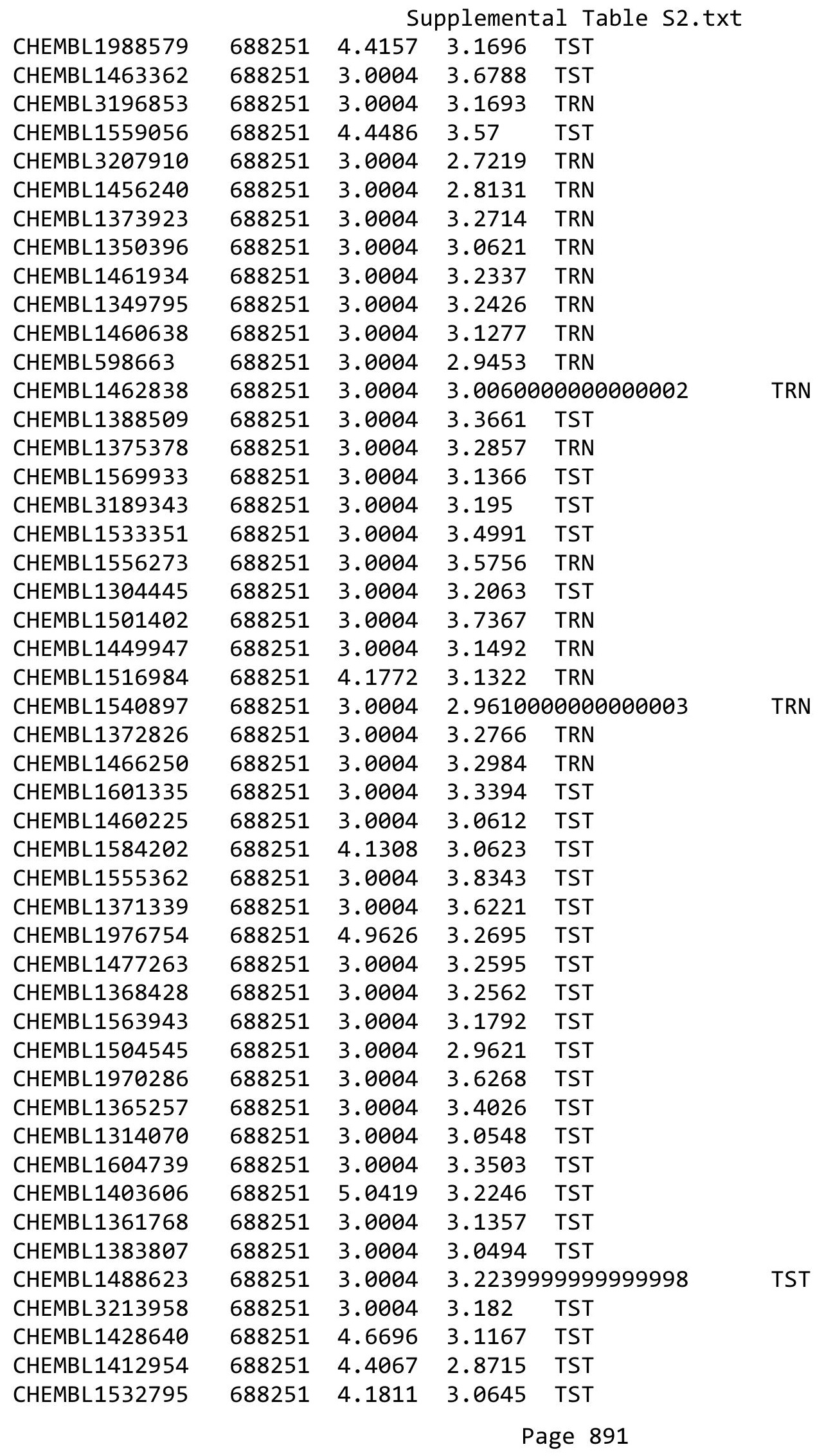




\begin{tabular}{|c|c|c|c|c|c|}
\hline \multicolumn{6}{|c|}{ Supplemental Table S2.txt } \\
\hline CHEMBL1504364 & 688251 & 3.0004 & 3.1394 & TST & \\
\hline CHEMBL1483757 & 688251 & 3.0004 & 3.125 & TST & \\
\hline CHEMBL1572262 & 688251 & 5.5768 & 3.0901 & TST & \\
\hline CHEMBL1463369 & 688251 & 3.0004 & 3.0631 & TST & \\
\hline CHEMBL99199 & 159749 & 7.301 & 7.2298 & TRN & \\
\hline CHEMBL95311 & 159749 & 7.2218 & 7.0458 & TRN & \\
\hline CHEMBL 320140 & 159749 & 5.6021 & 6.542999 & 9999999999 & TST \\
\hline CHEMBL97411 & 159749 & 7.0458 & 7.2983 & TRN & \\
\hline CHEMBL327751 & 159749 & 6.8539 & 7.1174 & TRN & \\
\hline CHEMBL330194 & 159749 & 7.3979 & 7.2983 & TRN & \\
\hline CHEMBL421385 & 159749 & 7.301 & 6.6325 & TRN & \\
\hline CHEMBL265078 & 159749 & 7.2596 & 7.0398 & TRN & \\
\hline CHEMBL319359 & 159749 & 7.2218 & 7.7582 & TRN & \\
\hline CHEMBL328161 & 159749 & 5.0 & 5.6082 & TRN & \\
\hline CHEMBL95479 & 159749 & 6.0 & 6.0644 & TRN & \\
\hline CHEMBL95558 & 159749 & 7.2366 & 7.5852 & TRN & \\
\hline CHEMBL96011 & 159749 & 6.9208 & 7.3366 & TRN & \\
\hline CHEMBL330162 & 159749 & 7.0969 & 6.5838 & TRN & \\
\hline CHEMBL95625 & 159749 & 7.2218 & 6.8778 & TRN & \\
\hline CHEMBL319766 & 159749 & 6.1871 & 5.8922 & TRN & \\
\hline CHEMBL95640 & 159749 & 3.1805 & 6.5768 & TST & \\
\hline CHEMBL100331 & 159749 & 7.3979 & 7.0587 & TRN & \\
\hline CHEMBL 94944 & 159749 & 5.3979 & 5.638 & TRN & \\
\hline CHEMBL96057 & 159749 & 6.5229 & 6.7381 & TRN & \\
\hline CHEMBL318881 & 159749 & 7.1249 & 7.0082 & TRN & \\
\hline CHEMBL330200 & 159749 & 4.0969 & 4.2016 & TRN & \\
\hline CHEMBL73572 & 159749 & 6.6021 & 6.4087 & TRN & \\
\hline CHEMBL318495 & 159749 & 6.1549 & 6.1851 & TRN & \\
\hline CHEMBL317321 & 159749 & 6.1549 & 6.3141 & TST & \\
\hline CHEMBL97467 & 159749 & 4.0969 & 4.5706 & TRN & \\
\hline CHEMBL95380 & 159749 & 6.7212 & 5.1226 & TST & \\
\hline CHEMBL96954 & 159749 & 7.301 & 6.381 & TRN & \\
\hline CHEMBL97088 & 159749 & 5.301 & 5.4845 & TRN & \\
\hline CHEMBL95469 & 159749 & 6.9208 & 7.0107 & TRN & \\
\hline CHEMBL318410 & 159749 & 6.9208 & 7.1146 & TRN & \\
\hline CHEMBL316866 & 159749 & 7.3979 & 6.2424 & TRN & \\
\hline CHEMBL95659 & 159749 & 5.6021 & 6.0383 & TRN & \\
\hline CHEMBL 72631 & 159749 & 3.4815 & 4.6625 & TST & \\
\hline CHEMBL95988 & 159749 & 6.6021 & 7.0505 & TRN & \\
\hline CHEMBL100092 & 159749 & 7.2218 & 7.2983 & TRN & \\
\hline CHEMBL97562 & 159749 & 7.301 & 7.3967 & TRN & \\
\hline CHEMBL97808 & 159749 & 5.3979 & 5.4907 & TRN & \\
\hline CHEMBL97834 & 159749 & 4.7447 & 4.5928 & TRN & \\
\hline CHEMBL319825 & 159749 & 6.3979 & 6.3413 & TRN & \\
\hline CHEMBL328864 & 159749 & 7.0 & 6.7287 & TRN & \\
\hline CHEMBL318053 & 159749 & 6.9208 & 6.9782 & TRN & \\
\hline CHEMBL421570 & 159749 & 7.2218 & 7.5414 & TRN & \\
\hline CHEMBL433160 & 159749 & 7.3468 & 7.2654 & TRN & \\
\hline
\end{tabular}




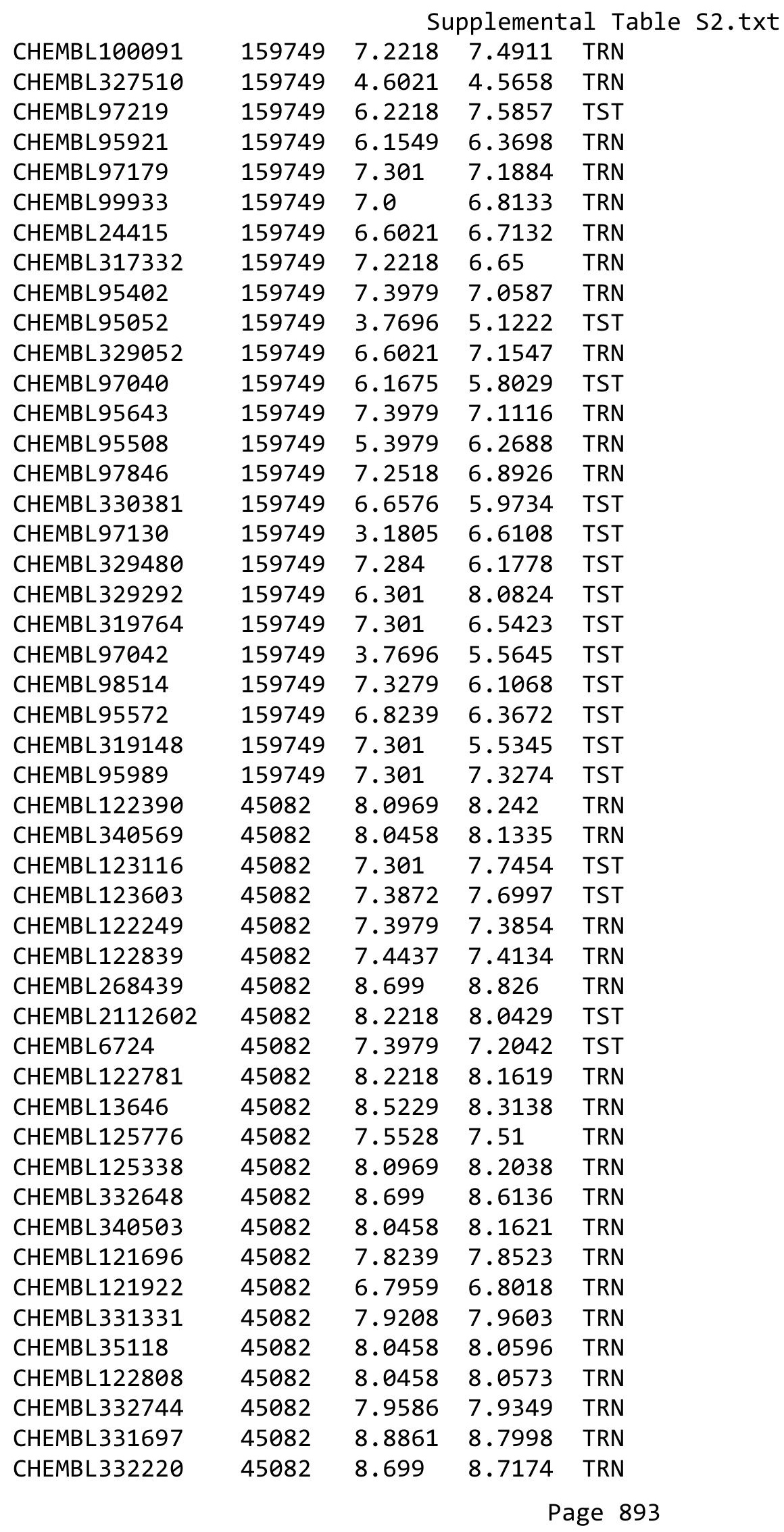




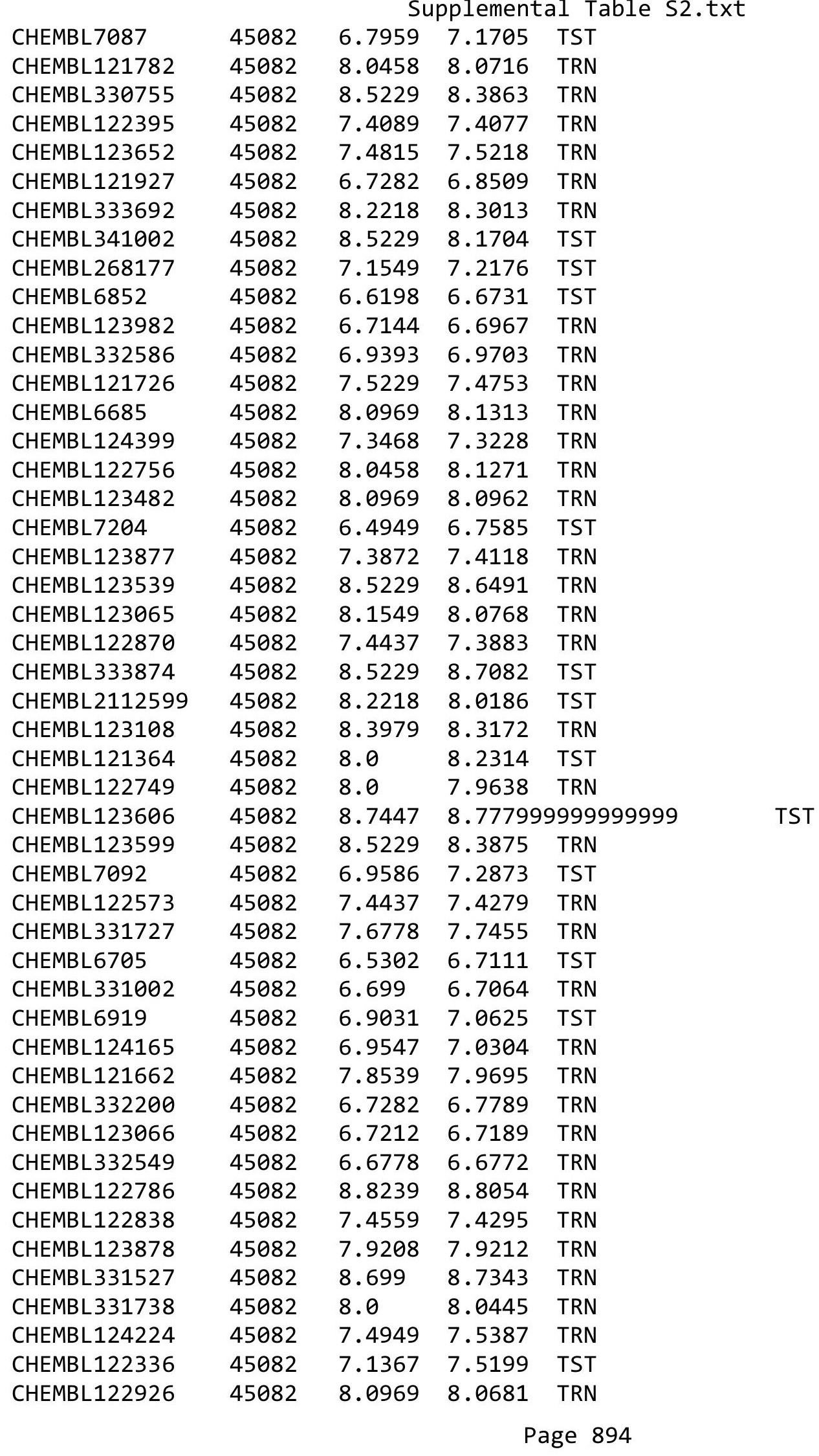




\begin{tabular}{|c|c|c|c|c|c|}
\hline \multicolumn{6}{|c|}{ Supplemental Table S2.txt } \\
\hline CHEMBL122951 & 45082 & 8.2218 & 8.2488 & TRN & \\
\hline CHEMBL122720 & 45082 & 8.5229 & 8.3323 & TRN & \\
\hline CHEMBL 265674 & 45082 & 7.2218 & 7.7235 & TST & \\
\hline CHEMBL122795 & 45082 & 8.0 & 8.0057 & TRN & \\
\hline CHEMBL 266240 & 45082 & 7.1249 & 7.601 & TST & \\
\hline CHEMBL126179 & 45082 & 8.301 & 8.2758 & TRN & \\
\hline CHEMBL451190 & 45082 & 8.699 & 8.7065 & TRN & \\
\hline CHEMBL6633 & 45082 & 7.9208 & 7.7118 & TRN & \\
\hline CHEMBL 269628 & 45082 & 7.5528 & 7.6834 & TST & \\
\hline CHEMBL122074 & 45082 & 8.0458 & 7.9806 & TRN & \\
\hline CHEMBL122730 & 45082 & 7.5229 & 7.5152 & TRN & \\
\hline CHEMBL125376 & 45082 & 6.699 & 6.6471 & TRN & \\
\hline CHEMBL 334088 & 45082 & 7.8861 & 7.8614 & TRN & \\
\hline CHEMBL13630 & 45082 & 9.2218 & 8.9006 & TST & \\
\hline CHEMBL419604 & 45082 & 8.9586 & 8.8233 & TRN & \\
\hline CHEMBL122484 & 45082 & 6.9066 & 6.8624 & TRN & \\
\hline CHEMBL122767 & 45082 & 6.699 & 6.6961 & TRN & \\
\hline CHEMBL332221 & 45082 & 8.5229 & 8.5468 & TRN & \\
\hline CHEMBL121393 & 45082 & 8.0458 & 8.1613 & TRN & \\
\hline CHEMBL332119 & 45082 & 7.5376 & 7.5066 & TRN & \\
\hline CHEMBL6784 & 45082 & 6.9586 & 7.1174 & TST & \\
\hline CHEMBL123827 & 45082 & 8.0 & 7.9895 & TRN & \\
\hline CHEMBL123535 & 45082 & 7.2147 & 7.6346 & TST & \\
\hline CHEMBL331386 & 45082 & 8.3979 & 8.5385 & TRN & \\
\hline CHEMBL6853 & 45082 & 7.2218 & 7.7326 & TST & \\
\hline CHEMBL 287117 & 45082 & 8.1549 & 8.1857 & TRN & \\
\hline CHEMBL14182 & 45082 & 8.0458 & 8.0737 & TRN & \\
\hline CHEMBL121809 & 45082 & 7.7212 & 7.8287 & TRN & \\
\hline CHEMBL6753 & 45082 & 7.7212 & 8.0121 & TST & \\
\hline CHEMBL125729 & 45082 & 8.0 & 8.0226 & TRN & \\
\hline CHEMBL122961 & 45082 & 7.4202 & 7.3693 & TRN & \\
\hline CHEMBL122762 & 45082 & 6.6021 & 6.5458 & TRN & \\
\hline CHEMBL121777 & 45082 & 7.2441 & 7.6741 & TST & \\
\hline CHEMBL124450 & 45082 & 7.9208 & 7.8887 & TRN & \\
\hline CHEMBL331932 & 45082 & 6.7447 & 6.7374 & TRN & \\
\hline CHEMBL122176 & 45082 & 7.6383 & 7.71399 & 99999999995 & TRN \\
\hline CHEMBL333954 & 45082 & 7.3979 & 7.7648 & TST & \\
\hline CHEMBL122394 & 45082 & 7.1675 & 7.5746 & TST & \\
\hline CHEMBL123047 & 45082 & 8.1549 & 8.3134 & TST & \\
\hline CHEMBL 332225 & 45082 & 7.5686 & 7.5452 & TRN & \\
\hline CHEMBL122817 & 45082 & 7.5229 & 7.5353 & TRN & \\
\hline CHEMBL122444 & 45082 & 8.2218 & 8.3496 & TST & \\
\hline CHEMBL125980 & 45082 & 7.3979 & 7.3518 & TRN & \\
\hline CHEMBL122953 & 45082 & 7.4437 & 7.439 & TRN & \\
\hline CHEMBL338513 & 45082 & 7.8861 & 7.9779 & TRN & \\
\hline CHEMBL 2112600 & 45082 & 8.699 & 8.0001 & TST & \\
\hline CHEMBL124168 & 45082 & 7.4815 & 7.4537 & TRN & \\
\hline CHEMBL123398 & 45082 & 8.0969 & 8.0943 & TRN & \\
\hline
\end{tabular}




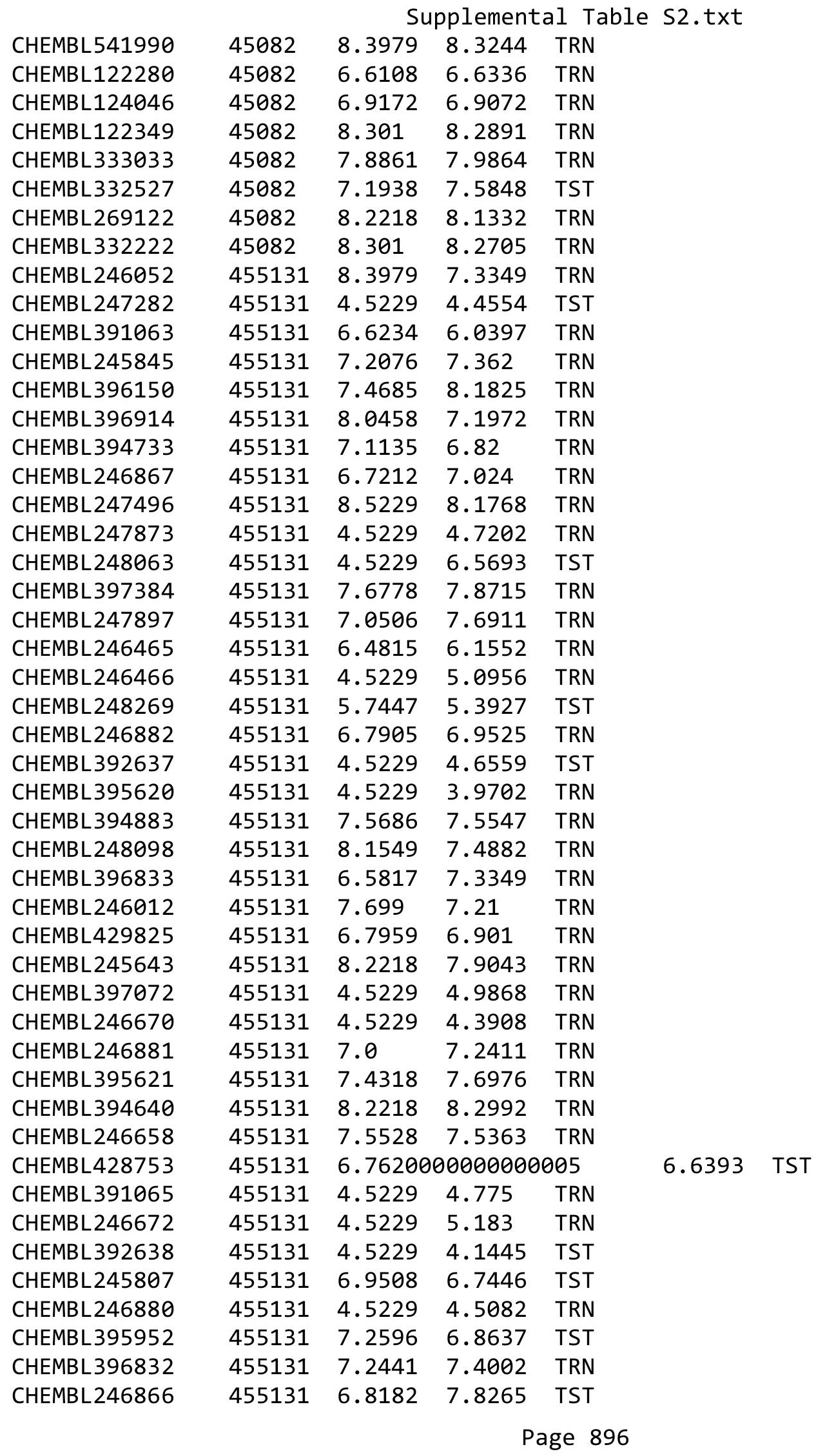




\begin{tabular}{|c|c|c|c|c|c|c|}
\hline & & \multicolumn{5}{|c|}{ Supplemental Table s2.txt } \\
\hline CHEMBL395189 & 455131 & 8.2218 & 7.6522 & TRN & & \\
\hline CHEMBL 246868 & 455131 & 6.6819 & 6.506 & TST & & \\
\hline CHEMBL248072 & 455131 & 4.5229 & 3.909 & TRN & & \\
\hline CHEMBL 395953 & 455131 & 4.5229 & 6.8637 & TST & & \\
\hline CHEMBL393141 & 455131 & 5.585 & 6.4658 & TRN & & \\
\hline CHEMBL 248099 & 455131 & 8.2218 & 7.6433 & TRN & & \\
\hline CHEMBL 247884 & 455131 & 6.7375 & 6.9218 & TST & & \\
\hline CHEMBL410383 & 455131 & 6.7696 & 7.4116 & TST & & \\
\hline CHEMBL 246671 & 455131 & 4.5229 & 4.8416 & TRN & & \\
\hline CHEMBL247078 & 455131 & \multicolumn{3}{|c|}{6.718999999999999} & 6.5738 & TST \\
\hline CHEMBL393968 & 455131 & 4.5229 & 4.2618 & TRN & & \\
\hline CHEMBL 246260 & 455131 & 7.0458 & 7.3932 & TRN & & \\
\hline CHEMBL391064 & 455131 & 6.5361 & 6.7648 & TRN & & \\
\hline CHEMBL9470 & 954860 & 7.4439 & \multicolumn{3}{|c|}{6.071000000000001} & TST \\
\hline CHEMBL 258844 & 954860 & 4.2907 & 4.2233 & TRN & & \\
\hline CHEMBL 222102 & 954860 & 4.7749 & 4.7875 & TRN & & \\
\hline CHEMBL573107 & 954860 & \multicolumn{3}{|c|}{5.327000000000001} & 5.3605 & TRN \\
\hline CHEMBL1909414 & 954860 & 3.2008 & 3.1704 & TRN & & \\
\hline CHEMBL512504 & 954860 & 4.0738 & 4.0707 & TRN & & \\
\hline CHEMBL449158 & 954860 & 6.7367 & 7.5173 & TST & & \\
\hline CHEMBL1590308 & 954860 & 4.0039 & 4.1308 & TST & & \\
\hline CHEMBL1516890 & 954860 & 3.6325 & 3.6368 & TRN & & \\
\hline CHEMBL 2363137 & 954860 & \multicolumn{3}{|c|}{5.531000000000001} & 5.6099 & TRN \\
\hline CHEMBL192566 & 954860 & 7.272 & 8.2478 & TST & & \\
\hline CHEMBL515416 & 954860 & 5.0774 & 5.0105 & TRN & & \\
\hline CHEMBL 259181 & 954860 & 4.8244 & 4.8539 & TRN & & \\
\hline CHEMBL1404918 & 954860 & 3.0457 & 2.9527 & TRN & & \\
\hline CHEMBL1186585 & 954860 & 4.7876 & 4.7233 & TRN & & \\
\hline CHEMBL220241 & 954860 & 5.0086 & 4.9794 & TRN & & \\
\hline CHEMBL2134202 & 954860 & 4.3657 & 4.2416 & TRN & & \\
\hline CHEMBL1643959 & 954860 & 3.7829 & 3.8883 & TRN & & \\
\hline CHEMBL2005886 & 954860 & 6.3933 & 6.3753 & TRN & & \\
\hline CHEMBL189584 & 954860 & 3.8644 & 3.9382 & TRN & & \\
\hline CHEMBL509032 & 954860 & 6.0199 & 5.9552 & TRN & & \\
\hline CHEMBL1190711 & 954860 & 3.3038 & 3.2509 & TRN & & \\
\hline CHEMBL472940 & 954860 & 2.7325 & 2.7883 & TRN & & \\
\hline CHEMBL210618 & 954860 & 3.3587 & 3.3529 & TRN & & \\
\hline CHEMBL1256459 & 954860 & \multicolumn{3}{|c|}{7.997000000000001} & 7.8043 & TRN \\
\hline CHEMBL202721 & 954860 & 3.7235 & 3.57 & TRN & & \\
\hline CHEMBL1788116 & 954860 & 5.2614 & 5.2572 & TRN & & \\
\hline CHEMBL300389 & 954860 & 5.9446 & 5.9945 & TRN & & \\
\hline CHEMBL577784 & 954860 & 5.1183 & 5.2034 & TRN & & \\
\hline CHEMBL1970879 & 954860 & 5.3942 & 5.4337 & TRN & & \\
\hline CHEMBL240954 & 954860 & 3.4348 & 3.3306 & TST & & \\
\hline CHEMBL379975 & 954860 & 3.7377 & 3.7468 & TRN & & \\
\hline CHEMBL585951 & 954860 & 6.888 & 6.9978 & TRN & & \\
\hline CHEMBL188678 & 954860 & 5.2586 & 5.2909 & TRN & & \\
\hline CHEMBL213100 & 954860 & 5.9101 & 5.9079 & TRN & & \\
\hline
\end{tabular}




\begin{tabular}{|c|c|c|c|c|}
\hline \multicolumn{5}{|c|}{ Supplemental Table S2.txt } \\
\hline CHEMBL3392440 & 954860 & 3.7123 & 3.7958 & TRN \\
\hline CHEMBL 379300 & 954860 & 6.5828 & 6.6323 & TRN \\
\hline CHEMBL2144069 & 954860 & 4.1917 & 4.1593 & TRN \\
\hline CHEMBL92309 & 954860 & 3.9615 & 3.2165 & TST \\
\hline CHEMBL558642 & 954860 & 4.0601 & 4.0236 & TRN \\
\hline CHEMBL1673039 & 954860 & 3.8501 & 4.0601 & TRN \\
\hline CHEMBL209148 & 954860 & 4.7311 & 4.6655 & TRN \\
\hline CHEMBL255342 & 954860 & 4.5114 & 4.3352 & TRN \\
\hline CHEMBL399530 & 954860 & 4.5863 & 4.5874 & TRN \\
\hline CHEMBL392695 & 954860 & 5.7403 & 5.8038 & TRN \\
\hline CHEMBL483847 & 954860 & 4.2866 & 4.2521 & TRN \\
\hline CHEMBL180127 & 954860 & 4.3654 & 4.3467 & TRN \\
\hline CHEMBL1242367 & 954860 & 4.6573 & 4.5044 & TRN \\
\hline CHEMBL393929 & 954860 & 3.57 & 3.7498 & TRN \\
\hline CHEMBL373751 & 954860 & 3.214 & 3.3318 & TRN \\
\hline CHEMBL1357247 & 954860 & 3.6281 & 3.6523 & TRN \\
\hline CHEMBL217354 & 954860 & 7.6813 & 7.7308 & TRN \\
\hline CHEMBL483849 & 954860 & 0.7612 & 2.2417 & TST \\
\hline CHEMBL3186408 & 954860 & 5.2233 & 4.3313 & TST \\
\hline CHEMBL412142 & 954860 & 3.8303 & 3.8546 & TRN \\
\hline CHEMBL102714 & 954860 & 3.1794 & 3.1455 & TRN \\
\hline CHEMBL3349342 & 954860 & 5.9277 & 5.5073 & TST \\
\hline CHEMBL 2137530 & 954860 & 4.1596 & 4.8988 & TST \\
\hline CHEMBL135561 & 954860 & 4.3592 & 4.6934 & TST \\
\hline CHEMBL221137 & 954860 & 4.9943 & 5.002 & TST \\
\hline CHEMBL3199475 & 954860 & 4.8868 & 4.4033 & TST \\
\hline CHEMBL514499 & 954860 & 7.3189 & 6.5839 & TST \\
\hline CHEMBL65 & 954860 & 7.1795 & 7.1945 & TST \\
\hline CHEMBL191334 & 954860 & 3.3888 & 3.8397 & TST \\
\hline CHEMBL1230020 & 954860 & 3.205 & 3.6913 & TST \\
\hline CHEMBL1964290 & 809243 & 5.5 & 5.68 & TRN \\
\hline CHEMBL 2003768 & 809243 & 4.1 & 4.0874 & TRN \\
\hline CHEMBL213505 & 809243 & 5.4 & 5.0526 & TRN \\
\hline CHEMBL1987034 & 809243 & 6.5 & 6.3444 & TRN \\
\hline CHEMBL1993941 & 809243 & 6.6 & 6.6265 & TRN \\
\hline CHEMBL1980435 & 809243 & 5.7 & 5.4881 & TRN \\
\hline CHEMBL377383 & 809243 & 4.1 & 4.0167 & TRN \\
\hline CHEMBL 2005886 & 809243 & 6.6 & 6.2943 & TRN \\
\hline CHEMBL481491 & 809243 & 4.1 & 5.1324 & TST \\
\hline CHEMBL1973142 & 809243 & 5.5 & 5.4197 & TRN \\
\hline CHEMBL1973145 & 809243 & 4.1 & 4.0375 & TRN \\
\hline CHEMBL1982924 & 809243 & 6.0 & 5.8209 & TRN \\
\hline CHEMBL 2005936 & 809243 & 5.3 & 5.2334 & TRN \\
\hline CHEMBL1807515 & 809243 & 6.6 & 7.5008 & TRN \\
\hline CHEMBL1971141 & 809243 & 4.1 & 4.0456 & TRN \\
\hline CHEMBL1995813 & 809243 & 6.9 & 7.4152 & TRN \\
\hline CHEMBL 206236 & 809243 & 4.1 & 4.4318 & TRN \\
\hline CHEMBL244378 & 809243 & 6.9 & 6.8946 & TRN \\
\hline
\end{tabular}




\begin{tabular}{|c|c|c|c|c|c|}
\hline \multirow{2}{*}{ CHEMBL2001957 } & \multirow[b]{2}{*}{809243} & \\
\hline & & 4.1 & 5.3142 & TRN & \\
\hline CHEMBL1969372 & 809243 & 5.5 & 5.0514 & TRN & \\
\hline CHEMBL1993413 & 809243 & 4.6 & 5.3819 & TRN & \\
\hline CHEMBL1986943 & 809243 & 8.5 & 8.147 & TRN & \\
\hline CHEMBL 2006263 & 809243 & 5.6 & 4.7066 & TST & \\
\hline CHEMBL 2001646 & 809243 & 5.8 & 4.9387 & TST & \\
\hline CHEMBL1993584 & 809243 & 6.0 & 5.2945 & TRN & \\
\hline CHEMBL1986263 & 809243 & 6.5 & 6.0397 & TRN & \\
\hline CHEMBL 2000114 & 809243 & 5.3 & 5.4478 & TRN & \\
\hline CHEMBL 210618 & 809243 & 4.1 & 4.2006 & TRN & \\
\hline CHEMBL1971172 & 809243 & 6.8 & 6.7342 & TRN & \\
\hline CHEMBL1975647 & 809243 & 5.3 & 4.70100 & 00000000005 & TRN \\
\hline CHEMBL1968380 & 809243 & 5.6 & 4.7777 & TRN & \\
\hline CHEMBL1964644 & 809243 & 4.1 & 3.8761 & TRN & \\
\hline CHEMBL1981782 & 809243 & 4.1 & 3.804 & TRN & \\
\hline CHEMBL1977681 & 809243 & 5.9 & 5.6579 & TRN & \\
\hline CHEMBL1970142 & 809243 & 7.6 & 7.2274 & TRN & \\
\hline CHEMBL1990912 & 809243 & 5.7 & 4.9716 & TRN & \\
\hline CHEMBL1988163 & 809243 & 6.3 & 6.3233 & TRN & \\
\hline CHEMBL2006493 & 809243 & 4.1 & 4.1354 & TST & \\
\hline CHEMBL1996923 & 809243 & 4.1 & 3.9921 & TST & \\
\hline CHEMBL1983449 & 809243 & 4.1 & 3.9007 & TRN & \\
\hline CHEMBL1992323 & 809243 & 4.1 & 3.8902 & TRN & \\
\hline CHEMBL1969735 & 809243 & 5.2 & 5.2864 & TRN & \\
\hline CHEMBL2002649 & 809243 & 6.0 & 5.9688 & TRN & \\
\hline CHEMBL1983589 & 809243 & 7.9 & 7.9877 & TRN & \\
\hline CHEMBL 2005718 & 809243 & 7.9 & 7.1834 & TRN & \\
\hline CHEMBL1995172 & 809243 & 5.1 & 4.3762 & TST & \\
\hline CHEMBL1994321 & 809243 & 5.8 & 5.9519 & TRN & \\
\hline CHEMBL1997129 & 809243 & 7.2 & 6.487 & TRN & \\
\hline CHEMBL1984788 & 809243 & 6.3 & 5.8255 & TRN & \\
\hline CHEMBL2000508 & 809243 & 5.8 & 5.5993 & TRN & \\
\hline CHEMBL1971694 & 809243 & 4.1 & 3.6358 & TST & \\
\hline CHEMBL2001547 & 809243 & 5.1 & 5.1542 & TRN & \\
\hline CHEMBL210928 & 809243 & 4.1 & 3.84899 & 99999999998 & TRN \\
\hline CHEMBL1986603 & 809243 & 6.1 & 5.0305 & TST & \\
\hline CHEMBL1977148 & 809243 & 4.1 & 5.5757 & TRN & \\
\hline CHEMBL1966842 & 809243 & 5.3 & 5.042 & TRN & \\
\hline CHEMBL2003286 & 809243 & 5.2 & 4.8038 & TRN & \\
\hline CHEMBL1992306 & 809243 & 5.1 & 4.7243 & TRN & \\
\hline CHEMBL2002165 & 809243 & 6.5 & 6.9038 & TRN & \\
\hline CHEMBL 2001668 & 809243 & 4.1 & 4.0459 & TST & \\
\hline CHEMBL1979318 & 809243 & 4.1 & 3.9619 & TST & \\
\hline CHEMBL206382 & 809243 & 4.1 & 4.5075 & TRN & \\
\hline CHEMBL1998585 & 809243 & 6.4 & 6.2187 & TRN & \\
\hline CHEMBL127898 & 809243 & 4.1 & 4.2835 & TST & \\
\hline CHEMBL519697 & 809243 & 4.1 & 5.2683 & TST & \\
\hline CHEMBL1987261 & 809243 & 6.8 & 6.5805 & TRN & \\
\hline & & & & 899 & \\
\hline
\end{tabular}




\begin{tabular}{|c|c|c|c|c|c|}
\hline & & & & & \\
\hline CHEMBL1981947 & 809243 & 5.6 & 5.3287 & TST & \\
\hline CHEMBL1975128 & 809243 & 6.0 & 5.9236 & TRN & \\
\hline CHEMBL1996048 & 809243 & 7.2 & 6.6403 & TST & \\
\hline CHEMBL1970369 & 809243 & 4.1 & 3.8299 & TRN & \\
\hline CHEMBL461876 & 809243 & 5.4 & 4.3888 & TRN & \\
\hline CHEMBL 2001485 & 809243 & 7.0 & 6.956 & TRN & \\
\hline CHEMBL1966425 & 809243 & 4.1 & 4.3422 & TRN & \\
\hline CHEMBL1984363 & 809243 & 4.1 & 4.6064 & TRN & \\
\hline CHEMBL1978099 & 809243 & 5.2 & 5.3887 & TRN & \\
\hline CHEMBL1988608 & 809243 & 4.1 & 3.8631 & TRN & \\
\hline CHEMBL184847 & 809243 & 4.1 & 4.9316 & TRN & \\
\hline CHEMBL1984367 & 809243 & 5.6 & 4.9882 & TRN & \\
\hline CHEMBL1985723 & 809243 & 7.2 & 6.7711 & TRN & \\
\hline CHEMBL178737 & 809243 & 4.1 & 4.4486 & TST & \\
\hline CHEMBL226898 & 809243 & 8.4 & 7.2148 & TRN & \\
\hline CHEMBL1982563 & 809243 & 5.5 & 5.284 & TRN & \\
\hline CHEMBL539474 & 809243 & 4.1 & 5.4112 & TST & \\
\hline CHEMBL575824 & 809243 & 4.2 & 4.7588 & TRN & \\
\hline CHEMBL1988387 & 809243 & 7.0 & 7.5537 & TRN & \\
\hline CHEMBL1977128 & 809243 & 5.8 & 4.7553 & TRN & \\
\hline CHEMBL1974803 & 809243 & 5.8 & 4.6172 & TST & \\
\hline CHEMBL1970074 & 809243 & 4.1 & 4.7668 & TRN & \\
\hline CHEMBL1965702 & 809243 & 6.2 & 7.1691 & TRN & \\
\hline CHEMBL1986970 & 809243 & 4.1 & 4.06 & TRN & \\
\hline CHEMBL 2005112 & 809243 & 4.1 & 4.301 & TST & \\
\hline CHEMBL1958401 & 809243 & 5.9 & 5.7672 & TRN & \\
\hline CHEMBL1984044 & 809243 & 5.8 & 5.0839 & TRN & \\
\hline CHEMBL 2003456 & 809243 & 5.3 & 4.9132 & TRN & \\
\hline CHEMBL1966816 & 809243 & 4.1 & 5.0006 & TRN & \\
\hline CHEMBL1972584 & 809243 & 4.1 & 4.985 & TRN & \\
\hline CHEMBL 2002992 & 809243 & 5.5 & 5.3204 & TRN & \\
\hline CHEMBL560813 & 809243 & 5.2 & 4.4859 & TRN & \\
\hline CHEMBL 207253 & 809243 & 5.3 & 4.7649 & TST & \\
\hline CHEMBL1990635 & 809243 & 5.1 & 5.3873 & TST & \\
\hline CHEMBL1968791 & 809243 & 4.1 & 4.4139 & TRN & \\
\hline CHEMBL 2002682 & 809243 & 4.1 & 5.5973 & TST & \\
\hline CHEMBL1971186 & 809243 & 5.4 & $5.4220 e$ & 0000000001 & TRN \\
\hline CHEMBL 2003482 & 809243 & 4.1 & 4.0965 & TRN & \\
\hline CHEMBL 2006456 & 809243 & 6.9 & 7.5654 & TRN & \\
\hline CHEMBL1973211 & 809243 & 6.0 & 5.869 & TRN & \\
\hline CHEMBL1984700 & 809243 & 5.5 & 5.4225 & TRN & \\
\hline CHEMBL1972125 & 809243 & 4.1 & 3.9357 & TRN & \\
\hline CHEMBL1461728 & 809243 & 4.1 & 4.2776 & TRN & \\
\hline CHEMBL1976134 & 809243 & 6.4 & 6.00299 & 9999999999 & TRN \\
\hline CHEMBL1965131 & 809243 & 5.5 & 5.5905 & TRN & \\
\hline CHEMBL 2006580 & 809243 & 5.1 & 4.607 & TRN & \\
\hline CHEMBL 2001228 & 809243 & 5.4 & 4.5094 & TRN & \\
\hline CHEMBL2006481 & 809243 & 4.1 & 3.7363 & TRN & \\
\hline & & & & 900 & \\
\hline
\end{tabular}




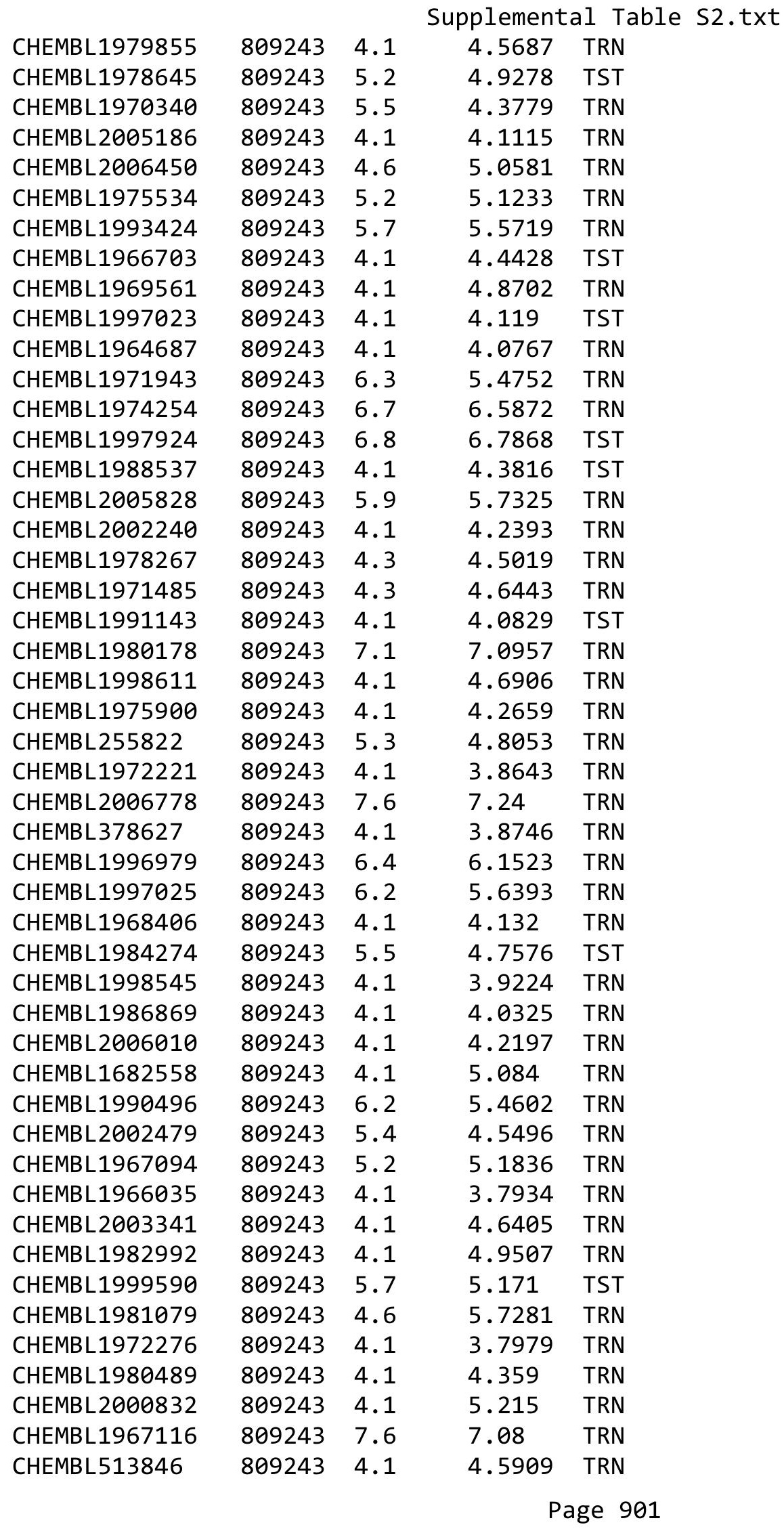




\begin{tabular}{|c|c|c|c|c|c|}
\hline \\
\hline CHEMBL1970709 & 809243 & 4.1 & 3.8071 & TRN & \\
\hline CHEMBL1965660 & 809243 & 5.8 & 5.8465 & TRN & \\
\hline CHEMBL1972290 & 809243 & 6.7 & 7.0577 & TRN & \\
\hline CHEMBL1969126 & 809243 & 6.2 & 6.0653 & TRN & \\
\hline CHEMBL1980896 & 809243 & 4.1 & 4.4585 & TRN & \\
\hline CHEMBL1975208 & 809243 & 4.1 & 4.1257 & TST & \\
\hline CHEMBL1970104 & 809243 & 5.9 & 5.8144 & TRN & \\
\hline CHEMBL1991429 & 809243 & 6.4 & 5.5737 & TRN & \\
\hline CHEMBL1964777 & 809243 & 5.5 & 5.8719 & TST & \\
\hline CHEMBL1971149 & 809243 & 4.1 & 4.5603 & TRN & \\
\hline CHEMBL1999714 & 809243 & 4.1 & 4.2391 & TRN & \\
\hline CHEMBL1987533 & 809243 & 4.1 & 3.927 & TRN & \\
\hline CHEMBL1994040 & 809243 & 5.3 & 5.28799 & 9999999999 & TRN \\
\hline CHEMBL1984548 & 809243 & 7.5 & 7.1526 & TRN & \\
\hline CHEMBL579246 & 809243 & 5.5 & 4.5341 & TRN & \\
\hline CHEMBL398951 & 809243 & 4.6 & 4.1283 & TST & \\
\hline CHEMBL1982506 & 809243 & 4.1 & 4.512 & TST & \\
\hline CHEMBL2004716 & 809243 & 7.0 & 7.0138 & TRN & \\
\hline CHEMBL1968127 & 809243 & 4.1 & 4.8403 & TRN & \\
\hline CHEMBL1975233 & 809243 & 4.1 & 4.5953 & TRN & \\
\hline CHEMBL1985406 & 809243 & 5.4 & 4.7691 & TRN & \\
\hline CHEMBL 207400 & 809243 & 4.1 & 3.9082 & TST & \\
\hline CHEMBL 2000894 & 809243 & 4.1 & 4.7909 & TST & \\
\hline CHEMBL 2002553 & 809243 & 4.1 & 4.1862 & TST & \\
\hline CHEMBL1982135 & 809243 & 4.1 & 4.5646 & TRN & \\
\hline CHEMBL1976090 & 809243 & 5.3 & 5.087 & TRN & \\
\hline CHEMBL1993243 & 809243 & 7.0 & 6.7029 & TRN & \\
\hline CHEMBL1992922 & 809243 & 5.8 & 6.17299 & 9999999999 & TRN \\
\hline CHEMBL 2004771 & 809243 & 4.1 & 4.6322 & TRN & \\
\hline CHEMBL1997597 & 809243 & 4.1 & 4.5783 & TRN & \\
\hline CHEMBL1969537 & 809243 & 4.1 & 5.5485 & TST & \\
\hline CHEMBL1976093 & 809243 & 4.1 & 4.5336 & TRN & \\
\hline CHEMBL 210032 & 809243 & 4.1 & 4.4688 & TRN & \\
\hline CHEMBL1975256 & 809243 & 4.1 & 3.7827 & TST & \\
\hline CHEMBL508928 & 809243 & 5.9 & 5.6162 & TRN & \\
\hline CHEMBL1991356 & 809243 & 4.1 & 5.0021 & TST & \\
\hline CHEMBL1983309 & 809243 & 4.1 & 4.6541 & TRN & \\
\hline CHEMBL 2004892 & 809243 & 4.1 & 4.4669 & TRN & \\
\hline CHEMBL1999126 & 809243 & 4.1 & 4.0728 & TST & \\
\hline CHEMBL1997503 & 809243 & 6.3 & 5.5939 & TST & \\
\hline CHEMBL1972339 & 809243 & 6.8 & 6.528 & TRN & \\
\hline CHEMBL116070 & 809243 & 4.1 & 5.416 & TST & \\
\hline CHEMBL1990821 & 809243 & 6.1 & 4.7752 & TST & \\
\hline CHEMBL1970314 & 809243 & 5.4 & 4.7097 & TRN & \\
\hline CHEMBL 2004871 & 809243 & 4.1 & 5.0827 & TRN & \\
\hline CHEMBL 2004872 & 809243 & 4.1 & 4.2948 & TRN & \\
\hline CHEMBL1727312 & 809243 & 4.1 & 4.2045 & TRN & \\
\hline CHEMBL1981720 & 809243 & 5.8 & 5.0783 & TRN & \\
\hline
\end{tabular}




\begin{tabular}{|c|c|c|c|c|}
\hline & & & & $a+1 a$ \\
\hline CHEMBL419932 & 809243 & 5.5 & 5.1991 & TRN \\
\hline CHEMBL262433 & 809243 & 4.1 & 4.7874 & TRN \\
\hline CHEMBL306380 & 809243 & 4.1 & 4.4172 & TRN \\
\hline CHEMBL1966722 & 809243 & 4.1 & 5.1436 & TST \\
\hline CHEMBL1983595 & 809243 & 4.6 & 4.9271 & TRN \\
\hline CHEMBL1975500 & 809243 & 4.1 & 5.0526 & TRN \\
\hline CHEMBL394619 & 809243 & 5.3 & 4.8469 & TRN \\
\hline CHEMBL1996831 & 809243 & 5.2 & 4.7724 & TST \\
\hline CHEMBL411903 & 809243 & 6.5 & 6.4545 & TRN \\
\hline CHEMBL1980253 & 809243 & 7.8 & 7.6946 & TRN \\
\hline CHEMBL1965988 & 809243 & 6.0 & 5.8874 & TRN \\
\hline CHEMBL418203 & 809243 & 4.1 & 4.8636 & TST \\
\hline CHEMBL1989646 & 809243 & 4.1 & 5.4983 & TRN \\
\hline CHEMBL225519 & 809243 & 6.3 & 5.6136 & TRN \\
\hline CHEMBL1978200 & 809243 & 5.6 & 5.3903 & TRN \\
\hline CHEMBL 2006631 & 809243 & 4.1 & 4.3287 & TRN \\
\hline CHEMBL1970522 & 809243 & 4.1 & 4.824 & TRN \\
\hline CHEMBL1990415 & 809243 & 4.1 & 4.7658 & TRN \\
\hline CHEMBL1966087 & 809243 & 4.1 & 4.7868 & TRN \\
\hline CHEMBL1964692 & 809243 & 6.2 & 5.6224 & TRN \\
\hline CHEMBL1996931 & 809243 & 4.1 & 4.0298 & TRN \\
\hline CHEMBL1964413 & 809243 & 4.1 & 4.1495 & TRN \\
\hline CHEMBL1998470 & 809243 & 7.0 & 5.7054 & TRN \\
\hline CHEMBL1996980 & 809243 & 8.3 & 8.10799 & 9999999999 \\
\hline CHEMBL1995428 & 809243 & 4.3 & 4.6274 & TRN \\
\hline CHEMBL1970735 & 809243 & 4.1 & 4.8062 & TRN \\
\hline CHEMBL1997340 & 809243 & 4.1 & 3.8487 & TRN \\
\hline CHEMBL1994669 & 809243 & 7.8 & 7.2883 & TRN \\
\hline CHEMBL 2004365 & 809243 & 5.3 & 5.0905 & TST \\
\hline CHEMBL1522508 & 809243 & 4.1 & 4.1632 & TRN \\
\hline CHEMBL1989474 & 809243 & 4.1 & 4.7456 & TRN \\
\hline CHEMBL1090360 & 809243 & 5.8 & 5.4387 & TRN \\
\hline CHEMBL 210887 & 809243 & 5.6 & 5.2736 & TST \\
\hline CHEMBL458997 & 809243 & 5.3 & 4.4752 & TRN \\
\hline CHEMBL1971021 & 809243 & 4.1 & 4.2671 & TRN \\
\hline CHEMBL227271 & 809243 & 7.2 & 7.4403 & TRN \\
\hline CHEMBL583144 & 809243 & 4.1 & 4.4757 & TRN \\
\hline CHEMBL1974310 & 809243 & 4.1 & 6.2827 & TST \\
\hline CHEMBL1982660 & 809243 & 5.8 & 5.1996 & TRN \\
\hline CHEMBL1994693 & 809243 & 4.1 & 4.2884 & TRN \\
\hline CHEMBL1982957 & 809243 & 4.1 & 4.7897 & TRN \\
\hline CHEMBL1725279 & 809243 & 6.7 & 5.09 & TST \\
\hline CHEMBL1975138 & 809243 & 5.9 & 4.9858 & TST \\
\hline CHEMBL424872 & 809243 & 4.1 & 4.0796 & TRN \\
\hline CHEMBL 2006836 & 809243 & 4.1 & 3.6722 & TST \\
\hline CHEMBL412142 & 809243 & 4.1 & 4.3684 & TST \\
\hline CHEMBL1980704 & 809243 & 4.1 & 3.8922 & TST \\
\hline CHEMBL 2003271 & 809243 & 5.7 & 5.6786 & TRN \\
\hline
\end{tabular}

TRN 


\begin{tabular}{|c|c|c|c|c|}
\hline \multicolumn{5}{|c|}{ lemental T } \\
\hline CHEMBL 2004447 & 809243 & 4.1 & 4.1071 & TST \\
\hline CHEMBL1992231 & 809243 & 5.7 & 4.2048 & TRN \\
\hline CHEMBL1983111 & 809243 & 6.8 & 6.6925 & TST \\
\hline CHEMBL1973860 & 809243 & 6.0 & 4.6632 & TRN \\
\hline CHEMBL1977713 & 809243 & 4.1 & 4.0517 & TRN \\
\hline CHEMBL 260135 & 809243 & 4.1 & 3.9629 & TRN \\
\hline CHEMBL 2004544 & 809243 & 5.4 & 4.7031 & TST \\
\hline CHEMBL1982610 & 809243 & 4.1 & 4.3816 & TST \\
\hline CHEMBL1999496 & 809243 & 4.1 & 4.2396 & TRN \\
\hline CHEMBL1988300 & 809243 & 6.0 & 5.9522 & TRN \\
\hline CHEMBL1991078 & 809243 & 6.6 & 5.9083 & TRN \\
\hline CHEMBL1987359 & 809243 & 4.1 & 4.3767 & TST \\
\hline CHEMBL1994438 & 809243 & 6.7 & 7.5374 & TRN \\
\hline CHEMBL1989265 & 809243 & 4.1 & 4.0362 & TST \\
\hline CHEMBL 2004647 & 809243 & 4.1 & 4.2087 & TST \\
\hline CHEMBL1969502 & 809243 & 5.6 & 5.6881 & TRN \\
\hline CHEMBL1682553 & 809243 & 4.1 & 4.5484 & TRN \\
\hline CHEMBL1971430 & 809243 & 5.1 & 5.1121 & TRN \\
\hline CHEMBL1983963 & 809243 & 5.6 & 5.2198 & TRN \\
\hline CHEMBL1997764 & 809243 & 6.1 & 5.9146 & TRN \\
\hline CHEMBL 1985092 & 809243 & 5.8 & 5.5254 & TRN \\
\hline CHEMBL 2004692 & 809243 & 4.1 & 3.7146 & TST \\
\hline CHEMBL1981410 & 809243 & 5.9 & 5.2461 & TRN \\
\hline CHEMBL1991434 & 809243 & 4.1 & 4.8427 & TST \\
\hline CHEMBL1967544 & 809243 & 4.1 & 4.3418 & TRN \\
\hline CHEMBL 223367 & 809243 & 4.1 & 5.635 & TST \\
\hline CHEMBL340384 & 809243 & 5.6 & 5.2924 & TST \\
\hline CHEMBL1969151 & 809243 & 7.5 & 7.7664 & TRN \\
\hline CHEMBL1964804 & 809243 & 4.1 & 4.8703 & TRN \\
\hline CHEMBL443962 & 809243 & 5.6 & 5.2136 & TST \\
\hline CHEMBL 2000354 & 809243 & 5.5 & 5.5223 & TRN \\
\hline CHEMBL1965507 & 809243 & 6.5 & 6.4489 & TRN \\
\hline CHEMBL274064 & 809243 & 5.9 & 5.7173 & TRN \\
\hline CHEMBL1967564 & 809243 & 4.1 & 4.1678 & TRN \\
\hline CHEMBL592030 & 809243 & 7.0 & 5.7367 & TST \\
\hline CHEMBL 2000071 & 809243 & 6.5 & 6.3218 & TRN \\
\hline CHEMBL 2002613 & 809243 & 4.6 & 4.8403 & TRN \\
\hline CHEMBL 2000408 & 809243 & 5.6 & 5.5018 & TRN \\
\hline CHEMBL 248757 & 809243 & 4.1 & 6.1809 & TST \\
\hline CHEMBL1978014 & 809243 & 4.1 & 4.1551 & TRN \\
\hline CHEMBL1994538 & 809243 & 4.1 & 4.4944 & TRN \\
\hline CHEMBL1983195 & 809243 & 5.1 & 4.631 & TST \\
\hline CHEMBL1975490 & 809243 & 4.1 & 4.3012 & TRN \\
\hline CHEMBL1964444 & 809243 & 6.7 & 4.3915 & TRN \\
\hline CHEMBL1989957 & 809243 & 5.3 & 4.6029 & TRN \\
\hline CHEMBL1986139 & 809243 & 4.1 & 4.5515 & TRN \\
\hline CHEMBL1980540 & 809243 & 4.1 & 4.9654 & TRN \\
\hline CHEMBL1979883 & 809243 & 6.1 & 5.8364 & TRN \\
\hline
\end{tabular}




\begin{tabular}{|c|c|c|c|c|c|}
\hline \multirow{3}{*}{$\begin{array}{l}\text { CHEMBL1984162 } \\
\text { CHEMBL1997051 }\end{array}$} & \multirow{3}{*}{$\begin{array}{l}809243 \\
809243\end{array}$} & \multicolumn{4}{|c|}{ Supplemental Table S2.txt } \\
\hline & & 5.6 & 4.9639 & 99999999995 & TRN \\
\hline & & 4.3 & 5.2852 & TRN & \\
\hline CHEMBL1998432 & 809243 & 7.7 & 7.5973 & TRN & \\
\hline CHEMBL491758 & 809243 & 5.6 & 5.3596 & TRN & \\
\hline CHEMBL549730 & 809243 & 4.1 & 3.6334 & TRN & \\
\hline CHEMBL1970189 & 809243 & 4.1 & 4.2431 & TST & \\
\hline CHEMBL1996791 & 809243 & 5.1 & 5.1447 & TRN & \\
\hline CHEMBL371206 & 809243 & 5.2 & 5.1586 & TRN & \\
\hline CHEMBL1974664 & 809243 & 4.1 & 4.6126 & TST & \\
\hline CHEMBL1974288 & 809243 & 5.1 & 4.5689 & TRN & \\
\hline CHEMBL196363 & 809243 & 5.1 & 5.1472 & TRN & \\
\hline CHEMBL1190711 & 809243 & 5.7 & 5.8809 & TRN & \\
\hline CHEMBL1968705 & 809243 & 4.1 & 4.5408 & TRN & \\
\hline CHEMBL1991410 & 809243 & 4.6 & 4.9549 & TRN & \\
\hline CHEMBL404367 & 809243 & 5.3 & 5.0673 & TRN & \\
\hline CHEMBL1966343 & 809243 & 4.1 & 5.0826 & TRN & \\
\hline CHEMBL1967887 & 809243 & 6.5 & 6.165 & TRN & \\
\hline CHEMBL 2000568 & 809243 & 5.7 & 5.6364 & TRN & \\
\hline CHEMBL 2000335 & 809243 & 4.1 & 5.5651 & TRN & \\
\hline CHEMBL1977604 & 809243 & 4.1 & 3.9924 & TST & \\
\hline CHEMBL1988717 & 809243 & 4.1 & 5.4663 & TRN & \\
\hline CHEMBL1974328 & 809243 & 7.0 & 7.3594 & TRN & \\
\hline CHEMBL1985507 & 809243 & 5.3 & 4.2172 & TST & \\
\hline CHEMBL509032 & 809243 & 6.0 & 5.7252 & TRN & \\
\hline CHEMBL243298 & 809243 & 4.6 & 4.9526 & TRN & \\
\hline CHEMBL573339 & 809243 & 4.1 & 4.7055 & TRN & \\
\hline CHEMBL1973808 & 809243 & 4.1 & 4.2563 & TRN & \\
\hline CHEMBL 2000429 & 809243 & 5.8 & 5.6299 & TRN & \\
\hline CHEMBL1972576 & 809243 & 6.6 & 6.608 & TRN & \\
\hline CHEMBL1992555 & 809243 & 4.1 & 3.9794 & TST & \\
\hline CHEMBL1992342 & 809243 & 4.1 & 4.6431 & TRN & \\
\hline CHEMBL1988173 & 809243 & 6.1 & 5.5359 & TST & \\
\hline CHEMBL1164265 & 809243 & 6.4 & 6.0677 & TST & \\
\hline CHEMBL535331 & 809243 & 4.1 & 4.9679 & TRN & \\
\hline CHEMBL1989805 & 809243 & 4.1 & 4.7912 & TST & \\
\hline CHEMBL1966204 & 809243 & 4.6 & 5.778 & TRN & \\
\hline CHEMBL1965423 & 809243 & 6.2 & 6.3627 & TRN & \\
\hline CHEMBL1982980 & 809243 & 5.8 & 4.9044 & TST & \\
\hline CHEMBL1983025 & 809243 & 5.2 & 5.4773 & TRN & \\
\hline CHEMBL 205415 & 809243 & 4.1 & 4.2304 & TRN & \\
\hline CHEMBL1977135 & 809243 & 4.1 & 4.4943 & TRN & \\
\hline CHEMBL 2001920 & 809243 & 4.1 & 4.7809 & TRN & \\
\hline CHEMBL1241473 & 809243 & 6.7 & 7.0422 & TRN & \\
\hline CHEMBL1978448 & 809243 & 4.1 & 5.4015 & TST & \\
\hline CHEMBL 2004513 & 809243 & 4.1 & 4.2002 & TRN & \\
\hline CHEMBL1972258 & 809243 & 4.1 & 4.4203 & TRN & \\
\hline CHEMBL1969483 & 809243 & 4.3 & 4.2505 & TRN & \\
\hline CHEMBL 2001257 & 809243 & 5.9 & 5.5718 & TRN & \\
\hline
\end{tabular}




\begin{tabular}{|c|c|c|c|c|c|}
\hline \multicolumn{6}{|c|}{ Supplemental Table S2.txt } \\
\hline CHEMBL1992536 & 809243 & 4.1 & 3.6001 & TRN & \\
\hline CHEMBL1987793 & 809243 & 6.1 & 5.3363 & TST & \\
\hline CHEMBL1992740 & 809243 & 4.1 & 3.7507 & TRN & \\
\hline CHEMBL439340 & 809243 & 4.1 & 3.989 & TRN & \\
\hline CHEMBL 2002373 & 809243 & 4.1 & 4.9731 & TRN & \\
\hline CHEMBL 2006188 & 809243 & 4.1 & 4.3738 & TRN & \\
\hline CHEMBL1967531 & 809243 & 5.9 & 5.6833 & TRN & \\
\hline CHEMBL1970913 & 809243 & 4.1 & 4.2032 & TRN & \\
\hline CHEMBL1973893 & 809243 & 4.1 & 3.9241 & TRN & \\
\hline CHEMBL1995736 & 809243 & 4.1 & 4.7304 & TRN & \\
\hline CHEMBL1997534 & 809243 & 6.6 & 6.5131 & TRN & \\
\hline CHEMBL1996500 & 809243 & 5.3 & 5.41100 & 00000000005 & TRN \\
\hline CHEMBL1985095 & 809243 & 6.3 & 5.8024 & TST & \\
\hline CHEMBL1977374 & 809243 & 6.5 & 5.7527 & TRN & \\
\hline CHEMBL1682540 & 809243 & 4.1 & 4.1006 & TRN & \\
\hline CHEMBL1976420 & 809243 & 6.3 & 5.6457 & TST & \\
\hline CHEMBL1994864 & 809243 & 4.1 & 4.0789 & TRN & \\
\hline CHEMBL 2002446 & 809243 & 6.0 & 5.1579 & TST & \\
\hline CHEMBL497151 & 809243 & 5.6 & 5.8785 & TST & \\
\hline CHEMBL1973961 & 809243 & 4.4 & 4.7868 & TRN & \\
\hline CHEMBL246970 & 809243 & 6.2 & 5.7565 & TRN & \\
\hline CHEMBL340921 & 809243 & 4.1 & 4.845 & TST & \\
\hline CHEMBL1999718 & 809243 & 4.1 & 3.9367 & TRN & \\
\hline CHEMBL1987073 & 809243 & 4.6 & 5.0282 & TRN & \\
\hline CHEMBL 2000078 & 809243 & 4.3 & 4.2396 & TRN & \\
\hline CHEMBL1995712 & 809243 & 6.2 & 6.9044 & TRN & \\
\hline CHEMBL1977346 & 809243 & 4.1 & 4.5015 & TRN & \\
\hline CHEMBL1971649 & 809243 & 4.1 & 4.546 & TRN & \\
\hline CHEMBL2005482 & 809243 & 6.8 & 5.1569 & TRN & \\
\hline CHEMBL1997909 & 809243 & 4.3 & 4.5645 & TRN & \\
\hline CHEMBL1998435 & 809243 & 4.1 & 4.5122 & TRN & \\
\hline CHEMBL 2006439 & 809243 & 8.1 & 7.33299 & & TRN \\
\hline CHEMBL 2006156 & 809243 & 6.0 & 5.2412 & TST & \\
\hline CHEMBL1969190 & 809243 & 5.7 & 5.3399 & TRN & \\
\hline CHEMBL1973937 & 809243 & 5.3 & 5.0384 & TRN & \\
\hline CHEMBL1991674 & 809243 & 8.4 & 8.2831 & TRN & \\
\hline CHEMBL1982711 & 809243 & 7.0 & 6.7202 & TRN & \\
\hline CHEMBL1987982 & 809243 & 4.1 & 4.9446 & TST & \\
\hline CHEMBL 2007044 & 809243 & 4.1 & 4.5896 & TST & \\
\hline CHEMBL1994241 & 809243 & 5.7 & 6.678 & TST & \\
\hline CHEMBL223460 & 809243 & 4.1 & 6.0184 & TST & \\
\hline CHEMBL1998829 & 809243 & 5.8 & 5.8985 & TRN & \\
\hline CHEMBL50894 & 809243 & 7.1 & 6.3271 & TST & \\
\hline CHEMBL1988838 & 809243 & 5.6 & 5.7152 & TRN & \\
\hline CHEMBL1980562 & 809243 & 7.4 & 7.8686 & TRN & \\
\hline CHEMBL1982866 & 809243 & 4.1 & 4.7674 & TRN & \\
\hline CHEMBL1968926 & 809243 & 4.1 & 4.6775 & TRN & \\
\hline CHEMBL462120 & 809243 & 4.1 & 4.2701 & TST & \\
\hline
\end{tabular}




\begin{tabular}{|c|c|c|c|c|c|}
\hline \multicolumn{6}{|c|}{ Supplemental Table S2.txt } \\
\hline CHEMBL1979933 & 809243 & 4.6 & 4.2976 & TRN & \\
\hline CHEMBL1965570 & 809243 & 6.6 & 6.216 & TRN & \\
\hline CHEMBL 2007592 & 809243 & 5.2 & 4.2113 & TST & \\
\hline CHEMBL1976936 & 809243 & 8.2 & 8.1891 & TRN & \\
\hline CHEMBL210963 & 809243 & 4.1 & 3.7889 & TRN & \\
\hline CHEMBL1082440 & 809243 & 5.2 & 5.232 & TST & \\
\hline CHEMBL1614705 & 809243 & 5.4 & 5.2914 & TRN & \\
\hline CHEMBL1984633 & 809243 & 4.1 & 4.1408 & TRN & \\
\hline CHEMBL1972988 & 809243 & 6.1 & 5.75299 & 9999999999 & TRN \\
\hline CHEMBL 2007372 & 809243 & 4.1 & 4.6421 & TRN & \\
\hline CHEMBL 2006715 & 809243 & 5.6 & 5.6742 & TRN & \\
\hline CHEMBL1986597 & 809243 & 5.4 & 5.0468 & TRN & \\
\hline CHEMBL1990482 & 809243 & 4.1 & 4.8532 & TRN & \\
\hline CHEMBL1990904 & 809243 & 6.0 & 5.686 & TRN & \\
\hline CHEMBL1987448 & 809243 & 6.3 & 6.6785 & TRN & \\
\hline CHEMBL 2005475 & 809243 & 4.1 & 5.06 & TRN & \\
\hline CHEMBL402846 & 809243 & 5.1 & 4.9575 & TRN & \\
\hline CHEMBL1997349 & 809243 & 4.1 & 4.5668 & TST & \\
\hline CHEMBL183844 & 809243 & 4.1 & 3.6452 & TRN & \\
\hline CHEMBL220057 & 809243 & 5.1 & 4.8086 & TRN & \\
\hline CHEMBL1682545 & 809243 & 5.5 & 4.6405 & TRN & \\
\hline CHEMBL383541 & 809243 & 4.1 & 5.0756 & TRN & \\
\hline CHEMBL 2001224 & 809243 & 4.1 & 4.1557 & TRN & \\
\hline CHEMBL10 & 809243 & 5.6 & 5.3084 & TRN & \\
\hline CHEMBL1976732 & 809243 & 6.9 & 5.3083 & TRN & \\
\hline CHEMBL 2005216 & 809243 & 7.9 & 8.1428 & TRN & \\
\hline CHEMBL1969506 & 809243 & 4.1 & 4.2298 & TRN & \\
\hline CHEMBL1964937 & 809243 & 6.4 & 6.188 & TRN & \\
\hline CHEMBL1980163 & 809243 & 4.1 & 3.6711 & TRN & \\
\hline CHEMBL 2005899 & 809243 & 4.1 & 3.5261 & TRN & \\
\hline CHEMBL1682552 & 809243 & 4.1 & 4.482 & TRN & \\
\hline CHEMBL1972568 & 809243 & 4.1 & 4.5509 & TRN & \\
\hline CHEMBL1995635 & 809243 & 5.2 & 4.8355 & TST & \\
\hline CHEMBL229799 & 809243 & 7.6 & 7.4124 & TRN & \\
\hline CHEMBL105739 & 809243 & 5.9 & 5.5191 & TRN & \\
\hline CHEMBL379300 & 809243 & 7.7 & 6.928 & TRN & \\
\hline CHEMBL1973720 & 809243 & 7.7 & 7.8484 & TRN & \\
\hline CHEMBL1969523 & 809243 & 4.1 & 5.0808 & TRN & \\
\hline CHEMBL1988995 & 809243 & 5.7 & 5.5202 & TRN & \\
\hline CHEMBL1986781 & 809243 & 5.4 & 5.2811 & TRN & \\
\hline CHEMBL387971 & 809243 & 5.7 & 4.3509 & TST & \\
\hline CHEMBL1979057 & 809243 & 5.4 & 5.1974 & TRN & \\
\hline CHEMBL1164180 & 809243 & 4.6 & 5.9893 & TST & \\
\hline CHEMBL1999428 & 809243 & 4.1 & 4.427 & TRN & \\
\hline CHEMBL1967560 & 809243 & 4.1 & 4.3513 & TRN & \\
\hline CHEMBL211378 & 809243 & 4.1 & 4.5687 & TRN & \\
\hline CHEMBL1516890 & 809243 & 6.1 & 5.2998 & TRN & \\
\hline CHEMBL1982465 & 809243 & 6.0 & 5.7903 & TRN & \\
\hline
\end{tabular}




\begin{tabular}{|c|c|c|c|c|}
\hline & & & & \\
\hline CHEMBL2001751 & 809243 & 7.4 & 7.0084 & TRN \\
\hline CHEMBL2003420 & 809243 & 4.1 & 4.0684 & TRN \\
\hline CHEMBL1984586 & 809243 & 6.0 & 5.4747 & TRN \\
\hline CHEMBL1972659 & 809243 & 4.1 & 4.4582 & TST \\
\hline CHEMBL272453 & 809243 & 4.1 & 4.5962 & TRN \\
\hline CHEMBL2005528 & 809243 & 5.7 & 4.6116 & TST \\
\hline CHEMBL185569 & 809243 & 4.1 & 4.6418 & TRN \\
\hline CHEMBL1969843 & 809243 & 4.1 & 3.9655 & TRN \\
\hline CHEMBL 2006113 & 809243 & 5.2 & 5.2072 & TST \\
\hline CHEMBL2007002 & 809243 & 6.4 & 5.6505 & TRN \\
\hline CHEMBL1987007 & 809243 & 4.1 & 4.628 & TRN \\
\hline CHEMBL1984711 & 809243 & 5.1 & 4.6648 & TRN \\
\hline CHEMBL484390 & 809243 & 4.1 & 5.4528 & TST \\
\hline CHEMBL1979252 & 809243 & 4.1 & 4.1249 & TRN \\
\hline CHEMBL 2004290 & 809243 & 6.8 & 6.2032 & TRN \\
\hline CHEMBL1986499 & 809243 & 6.6 & 5.7156 & TRN \\
\hline CHEMBL1972937 & 809243 & 4.1 & 4.1683 & TRN \\
\hline CHEMBL 2000393 & 809243 & 5.3 & 5.1797 & TST \\
\hline CHEMBL1089101 & 809243 & 5.9 & 5.4351 & TRN \\
\hline CHEMBL 2004311 & 809243 & 5.1 & 4.5327 & TRN \\
\hline CHEMBL1992634 & 809243 & 7.4 & 6.7828 & TRN \\
\hline CHEMBL1242373 & 809243 & 4.1 & 4.0274 & TRN \\
\hline CHEMBL56543 & 809243 & 5.5 & 4.76399 & 9999999999 \\
\hline CHEMBL1988075 & 809243 & 6.5 & 6.5367 & TRN \\
\hline CHEMBL316264 & 809243 & 4.1 & 5.235 & TRN \\
\hline CHEMBL1988076 & 809243 & 4.3 & 4.9857 & TRN \\
\hline CHEMBL1991678 & 809243 & 5.9 & 5.2579 & TRN \\
\hline CHEMBL2001239 & 809243 & 5.1 & 5.2472 & TST \\
\hline CHEMBL1988594 & 809243 & 6.5 & 6.4206 & TRN \\
\hline CHEMBL 2001288 & 809243 & 4.1 & 4.238 & TRN \\
\hline CHEMBL1992363 & 809243 & 7.1 & 6.3449 & TRN \\
\hline CHEMBL1999811 & 809243 & 5.8 & 5.2009 & TST \\
\hline CHEMBL1985074 & 809243 & 4.1 & 4.4356 & TST \\
\hline CHEMBL1982874 & 809243 & 6.7 & 6.3366 & TRN \\
\hline CHEMBL 2000481 & 809243 & 4.1 & 4.6779 & TRN \\
\hline CHEMBL1991725 & 809243 & 4.1 & 3.995 & TRN \\
\hline CHEMBL1992242 & 809243 & 4.1 & 3.9262 & TRN \\
\hline CHEMBL1982271 & 809243 & 8.0 & 7.8399 & TRN \\
\hline CHEMBL 2007296 & 809243 & 6.6 & 4.231 & TRN \\
\hline CHEMBL396523 & 809243 & 7.0 & 6.6047 & TRN \\
\hline CHEMBL208637 & 809243 & 4.1 & 4.5329 & TRN \\
\hline CHEMBL1970203 & 809243 & 6.6 & 6.6654 & TRN \\
\hline CHEMBL1965351 & 809243 & 4.1 & 4.8153 & TST \\
\hline CHEMBL1999321 & 809243 & 4.1 & 3.9341 & TRN \\
\hline CHEMBL1968590 & 809243 & 6.2 & 6.3764 & TRN \\
\hline CHEMBL 2005375 & 809243 & 4.1 & 4.7547 & TRN \\
\hline CHEMBL1984191 & 809243 & 5.8 & 5.0902 & TRN \\
\hline CHEMBL1972183 & 809243 & 4.1 & 4.1853 & TST \\
\hline
\end{tabular}




\begin{tabular}{|c|c|c|c|c|}
\hline & & & pplement & al $\mathrm{Ta}$ \\
\hline CHEMBL1971029 & 809243 & 6.7 & 6.7167 & TRN \\
\hline CHEMBL394790 & 809243 & 5.4 & 4.8701 & TRN \\
\hline CHEMBL226471 & 809243 & 6.6 & 6.5328 & TRN \\
\hline CHEMBL1974702 & 809243 & 4.1 & 3.8264 & TRN \\
\hline CHEMBL1996111 & 809243 & 4.1 & 4.6043 & TRN \\
\hline CHEMBL1965589 & 809243 & 4.2 & 5.1484 & TRN \\
\hline CHEMBL1998193 & 809243 & 4.1 & 4.33 & TRN \\
\hline CHEMBL379975 & 809243 & 8.9 & 6.7685 & TST \\
\hline CHEMBL474432 & 809243 & 4.1 & 4.7122 & TST \\
\hline CHEMBL1988153 & 809243 & 5.6 & 5.465 & TST \\
\hline CHEMBL1986666 & 809243 & 4.6 & 5.4295 & TRN \\
\hline CHEMBL1988437 & 809243 & 6.4 & 6.3714 & TST \\
\hline CHEMBL1998121 & 809243 & 4.1 & 4.732 & TRN \\
\hline CHEMBL1979577 & 809243 & 5.9 & 5.8832 & TRN \\
\hline CHEMBL1991800 & 809243 & 5.5 & 5.2655 & TRN \\
\hline CHEMBL52387 & 809243 & 4.1 & 3.7566 & TST \\
\hline CHEMBL379835 & 809243 & 4.1 & 3.9444 & TST \\
\hline CHEMBL1979357 & 809243 & 4.1 & 4.4127 & TRN \\
\hline CHEMBL1996817 & 809243 & 6.4 & 6.629 & TRN \\
\hline CHEMBL 3197315 & 809243 & 4.1 & 3.8402 & TST \\
\hline CHEMBL468280 & 809243 & 4.1 & 3.8714 & TST \\
\hline CHEMBL1990884 & 809243 & 4.1 & 4.5247 & TRN \\
\hline CHEMBL3109278 & 809243 & 7.1 & 6.2462 & TRN \\
\hline CHEMBL256835 & 809243 & 6.4 & 6.2836 & TRN \\
\hline CHEMBL41783 & 809243 & 4.1 & 3.8442 & TRN \\
\hline CHEMBL 2006276 & 809243 & 5.3 & 5.0544 & TRN \\
\hline CHEMBL271381 & 809243 & 5.8 & 5.0535 & TRN \\
\hline CHEMBL 2006785 & 809243 & 4.1 & 4.2266 & TRN \\
\hline CHEMBL1982466 & 809243 & 6.1 & 7.2421 & TRN \\
\hline CHEMBL1995740 & 809243 & 4.1 & 4.3889 & TRN \\
\hline CHEMBL1990162 & 809243 & 4.6 & 5.0275 & TRN \\
\hline CHEMBL1992220 & 809243 & 8.2 & 8.2611 & TRN \\
\hline CHEMBL 234085 & 809243 & 4.1 & 4.4651 & TST \\
\hline CHEMBL1995832 & 809243 & 5.9 & 5.7544 & TRN \\
\hline CHEMBL1998414 & 809243 & 4.1 & 4.5505 & TRN \\
\hline CHEMBL1969042 & 809243 & 5.8 & 5.3424 & TRN \\
\hline CHEMBL 2000345 & 809243 & 6.5 & 6.6205 & TST \\
\hline CHEMBL1076555 & 809243 & 5.6 & 4.966 & TRN \\
\hline CHEMBL1375418 & 809243 & 4.1 & 4.2484 & TRN \\
\hline CHEMBL 2007064 & 809243 & 5.4 & 4.8514 & TRN \\
\hline CHEMBL229968 & 809243 & 7.7 & 7.3058 & TRN \\
\hline CHEMBL1976240 & 809243 & 5.1 & 4.8773 & TRN \\
\hline CHEMBL1987948 & 809243 & 6.9 & 7.1665 & TRN \\
\hline CHEMBL1979093 & 809243 & 5.7 & 5.1915 & TRN \\
\hline CHEMBL1987009 & 809243 & 5.9 & 5.3203 & TRN \\
\hline CHEMBL379218 & 809243 & 7.3 & 7.3948 & TRN \\
\hline CHEMBL2003817 & 809243 & 4.1 & 4.4869 & TRN \\
\hline CHEMBL1994830 & 809243 & 4.1 & 5.3747 & TST \\
\hline
\end{tabular}




\begin{tabular}{|c|c|c|c|c|c|}
\hline \multirow{3}{*}{$\begin{array}{l}\text { CHEMBL } 226403 \\
\text { CHEMBL } 2005631\end{array}$} & \multirow{3}{*}{$\begin{array}{l}809243 \\
809243\end{array}$} & \multicolumn{4}{|c|}{ Supplemental Table S2.txt } \\
\hline & & 5.5 & \multicolumn{2}{|c|}{5.718999999999999} & \multirow[t]{2}{*}{ TRN } \\
\hline & & 6.5 & 6.8365 & TRN & \\
\hline CHEMBL1994938 & 809243 & 6.8 & 6.6718 & TRN & \\
\hline CHEMBL1977223 & 809243 & 4.1 & 4.3915 & TRN & \\
\hline CHEMBL1236126 & 809243 & 4.1 & 4.8602 & TST & \\
\hline CHEMBL1966279 & 809243 & 5.2 & 4.6633 & TRN & \\
\hline CHEMBL1997846 & 809243 & 8.2 & 7.5398 & TRN & \\
\hline CHEMBL 2004419 & 809243 & 5.2 & 5.479 & TRN & \\
\hline CHEMBL1995811 & 809243 & 4.6 & 5.5007 & TRN & \\
\hline CHEMBL1972489 & 809243 & 4.1 & 4.3214 & TRN & \\
\hline CHEMBL1994074 & 809243 & 5.8 & 5.7286 & TRN & \\
\hline CHEMBL1992937 & 809243 & 5.9 & 5.1691 & TST & \\
\hline CHEMBL1968930 & 809243 & 6.9 & 7.1343 & TRN & \\
\hline CHEMBL1972119 & 809243 & 4.1 & 4.1602 & TRN & \\
\hline CHEMBL1986328 & 809243 & 4.1 & 4.7114 & TST & \\
\hline CHEMBL95692 & 809243 & 5.4 & 5.9889 & TRN & \\
\hline CHEMBL1090356 & 809243 & 4.1 & 4.5012 & TRN & \\
\hline CHEMBL1976455 & 809243 & 4.1 & 4.7322 & TRN & \\
\hline CHEMBL1983923 & 809243 & 5.4 & 4.952 & TST & \\
\hline CHEMBL1982361 & 809243 & 4.1 & 4.4009 & TRN & \\
\hline CHEMBL1999112 & 809243 & 5.7 & 5.2785 & TST & \\
\hline CHEMBL 2000801 & 809243 & 4.1 & 3.9466 & TRN & \\
\hline CHEMBL1682546 & 809243 & 4.1 & 3.968 & TRN & \\
\hline CHEMBL1991395 & 809243 & 5.4 & 5.2393 & TRN & \\
\hline CHEMBL1972142 & 809243 & 6.1 & 6.0595 & TRN & \\
\hline CHEMBL1966514 & 809243 & 6.0 & 6.3678 & TRN & \\
\hline CHEMBL2003638 & 809243 & 6.3 & 6.0445 & TRN & \\
\hline CHEMBL1972152 & 809243 & 4.1 & 4.4276 & TST & \\
\hline CHEMBL1993722 & 809243 & 5.1 & 5.4214 & TRN & \\
\hline CHEMBL1970806 & 809243 & 4.1 & 3.9475 & TST & \\
\hline CHEMBL1375640 & 809243 & 5.3 & 5.3598 & TST & \\
\hline CHEMBL1979970 & 809243 & 4.2 & 3.7245 & TRN & \\
\hline CHEMBL249282 & 809243 & 5.8 & 4.4872 & TST & \\
\hline CHEMBL1992473 & 809243 & 4.3 & 5.0131 & TRN & \\
\hline CHEMBL 2006237 & 809243 & 4.1 & 3.5758 & TRN & \\
\hline CHEMBL1967720 & 809243 & 6.3 & 6.5134 & TRN & \\
\hline CHEMBL 2005509 & 809243 & 8.2 & 8.244 & TRN & \\
\hline CHEMBL1572266 & 809243 & 4.1 & 4.4581 & TST & \\
\hline CHEMBL1991138 & 809243 & 4.1 & 3.8689 & TRN & \\
\hline CHEMBL1969755 & 809243 & 4.1 & 4.0326 & TRN & \\
\hline CHEMBL1979516 & 809243 & 4.3 & 6.0272 & TRN & \\
\hline CHEMBL1605605 & 809243 & 4.1 & 4.2277 & TRN & \\
\hline CHEMBL1972820 & 809243 & 4.1 & 4.1528 & TST & \\
\hline CHEMBL1996208 & 809243 & 4.1 & 4.3614 & TST & \\
\hline CHEMBL1989029 & 809243 & 5.5 & 4.9499 & TRN & \\
\hline CHEMBL392642 & 809243 & 5.9 & 5.9225 & TRN & \\
\hline CHEMBL514499 & 809243 & 4.1 & 5.4441 & TST & \\
\hline CHEMBL1965631 & 809243 & 4.1 & 4.05699 & 99999999995 & TRN \\
\hline & & & & ge 910 & \\
\hline
\end{tabular}




\begin{tabular}{|c|c|c|c|c|c|}
\hline \multicolumn{6}{|c|}{ Supplemental Table S } \\
\hline CHEMBL1980144 & 809243 & 6.7 & 6.3209 & TST & \\
\hline CHEMBL1991188 & 809243 & 4.1 & 4.9274 & TST & \\
\hline CHEMBL1972849 & 809243 & 7.0 & 5.5719 & TST & \\
\hline CHEMBL377408 & 809243 & 5.3 & 4.7431 & TST & \\
\hline CHEMBL1986855 & 809243 & 8.1 & 7.4513 & TST & \\
\hline CHEMBL231209 & 809243 & 5.5 & 5.0065 & TST & \\
\hline CHEMBL1975357 & 809243 & 4.1 & 4.4923 & TST & \\
\hline CHEMBL1976220 & 809243 & 5.2 & 4.8854 & TST & \\
\hline CHEMBL259922 & 809243 & 4.1 & 3.9192 & TST & \\
\hline CHEMBL1997617 & 809243 & 5.6 & 5.9476 & TST & \\
\hline CHEMBL1982383 & 809243 & 5.3 & 5.3116 & TST & \\
\hline CHEMBL1969301 & 809243 & 5.4 & 5.867006 & 0000000001 & TST \\
\hline CHEMBL17370 & 809243 & 5.5 & 5.2898 & TST & \\
\hline CHEMBL1987910 & 809243 & 4.1 & 5.4138 & TST & \\
\hline CHEMBL1997822 & 809243 & 7.1 & 6.6417 & TST & \\
\hline CHEMBL1991285 & 809243 & 4.1 & 4.599 & TST & \\
\hline CHEMBL243088 & 809243 & 6.1 & 6.0191 & TST & \\
\hline CHEMBL1984038 & 809243 & 4.1 & 4.5218 & TST & \\
\hline CHEMBL1993661 & 809243 & 7.2 & 6.3843 & TST & \\
\hline CHEMBL1974416 & 809243 & 5.8 & 5.8529 & TST & \\
\hline CHEMBL 2004615 & 809243 & 4.1 & 4.494 & TST & \\
\hline CHEMBL1984039 & 809243 & 4.1 & 4.5315 & TST & \\
\hline CHEMBL1997872 & 809243 & 6.1 & 5.6062 & TST & \\
\hline CHEMBL1688305 & 736488 & 4.7959 & 4.9558 & TST & \\
\hline CHEMBL1688290 & 736488 & 3.699 & 4.5763 & TRN & \\
\hline CHEMBL1688255 & 736488 & 5.8239 & 5.2841 & TST & \\
\hline CHEMBL1688154 & 736488 & 3.699 & 3.7572 & TRN & \\
\hline CHEMBL1688152 & 736488 & 4.3279 & 3.3831 & TST & \\
\hline CHEMBL1688164 & 736488 & 2.699 & 3.2087 & TRN & \\
\hline CHEMBL1688292 & 736488 & 3.301 & 3.9382 & TRN & \\
\hline CHEMBL1688160 & 736488 & 3.0 & 3.3077 & TRN & \\
\hline CHEMBL1688259 & 736488 & 6.3468 & 6.0772 & TRN & \\
\hline CHEMBL1688299 & 736488 & 2.699 & 2.6333 & TRN & \\
\hline CHEMBL1688166 & 736488 & 2.699 & 2.6444 & TRN & \\
\hline CHEMBL1688276 & 736488 & 6.5086 & 5.8235 & TST & \\
\hline CHEMBL3675201 & 736488 & 6.4202 & 5.6409 & TST & \\
\hline CHEMBL1688169 & 736488 & 3.699 & 4.7066 & TST & \\
\hline CHEMBL1688283 & 736488 & 5.5528 & 5.8345 & TRN & \\
\hline CHEMBL1688168 & 736488 & 2.699 & 2.6528 & TRN & \\
\hline CHEMBL1688294 & 736488 & 3.0 & 3.9418 & TRN & \\
\hline CHEMBL1688144 & 736488 & 4.0605 & 4.5619 & TRN & \\
\hline CHEMBL1688268 & 736488 & 6.2366 & 6.561 & TRN & \\
\hline CHEMBL1688288 & 736488 & 3.6696 & 3.8424 & TRN & \\
\hline CHEMBL1688262 & 736488 & 6.0 & 5.0029 & TST & \\
\hline CHEMBL1688157 & 736488 & 3.0 & 2.9818 & TRN & \\
\hline CHEMBL1688256 & 736488 & 5.8539 & 5.7292 & TST & \\
\hline CHEMBL1688279 & 736488 & 5.6383 & 5.0767 & TRN & \\
\hline CHEMBL1688296 & 736488 & 4.5376 & 3.7985 & TRN & \\
\hline
\end{tabular}




\begin{tabular}{|c|c|c|c|c|c|c|}
\hline & & \multicolumn{5}{|c|}{ Supplemental Table S2.txt } \\
\hline CHEMBL1688293 & 736488 & 4.7696 & 4.4074 & TRN & & \\
\hline CHEMBL1688254 & 736488 & 5.3279 & 4.6519 & TST & & \\
\hline CHEMBL1688282 & 736488 & 5.6383 & 5.4959 & TRN & & \\
\hline CHEMBL1688146 & 736488 & 5.6198 & 5.0795 & TRN & & \\
\hline CHEMBL1688163 & 736488 & 3.699 & 3.557 & TRN & & \\
\hline CHEMBL1688151 & 736488 & 5.2076 & 5.015 & TRN & & \\
\hline CHEMBL1688150 & 736488 & 5.2076 & 5.6364 & TRN & & \\
\hline CHEMBL1688267 & 736488 & 6.0088 & 6.3132 & TRN & & \\
\hline CHEMBL1688258 & 736488 & 6.3979 & \multicolumn{3}{|c|}{6.337000000000001} & TRN \\
\hline CHEMBL1688170 & 736488 & 5.5229 & 4.6897 & TST & & \\
\hline CHEMBL1688302 & 736488 & 3.301 & 3.3703 & TRN & & \\
\hline CHEMBL1688253 & 736488 & 5.6383 & 6.0007 & TST & & \\
\hline CHEMBL1688286 & 736488 & 4.3098 & 4.0051 & TRN & & \\
\hline CHEMBL1688295 & 736488 & 3.5986 & 4.1188 & TRN & & \\
\hline CHEMBL1688165 & 736488 & 2.699 & 3.9951 & TST & & \\
\hline CHEMBL1688148 & 736488 & 4.2676 & 3.9925 & TRN & & \\
\hline CHEMBL1688158 & 736488 & 3.0 & 3.2092 & TRN & & \\
\hline CHEMBL1688251 & 736488 & 6.0 & 5.8171 & TST & & \\
\hline CHEMBL1688298 & 736488 & 2.699 & 3.2704 & TRN & & \\
\hline CHEMBL1688139 & 736488 & 5.3768 & 4.5296 & TRN & & \\
\hline CHEMBL1688271 & 736488 & 6.1805 & 6.181 & TRN & & \\
\hline CHEMBL1688159 & 736488 & 4.9586 & 4.4334 & TRN & & \\
\hline CHEMBL1688272 & 736488 & 6.2441 & 6.204 & TRN & & \\
\hline CHEMBL1688300 & 736488 & 4.4815 & 3.1944 & TRN & & \\
\hline CHEMBL1688269 & 736488 & 6.1367 & 5.9373 & TRN & & \\
\hline CHEMBL1688138 & 736488 & 3.699 & 4.3659 & TRN & & \\
\hline CHEMBL1688281 & 736488 & 5.8239 & 4.8332 & TRN & & \\
\hline CHEMBL1688143 & 736488 & 5.2218 & \multicolumn{3}{|c|}{5.382000000000001} & TRN \\
\hline CHEMBL1688287 & 736488 & 4.3279 & 4.0461 & TRN & & \\
\hline CHEMBL1688147 & 736488 & 5.5086 & 5.3811 & TRN & & \\
\hline CHEMBL1688301 & 736488 & 3.699 & 4.2071 & TRN & & \\
\hline CHEMBL1688156 & 736488 & 3.0 & 3.0963 & TRN & & \\
\hline CHEMBL1688297 & 736488 & 4.9586 & 4.5533 & TRN & & \\
\hline CHEMBL1688277 & 736488 & 5.7447 & 5.7845 & TRN & & \\
\hline CHEMBL1688136 & 736488 & 4.1612 & 4.7863 & TRN & & \\
\hline CHEMBL1688266 & 736488 & 6.2441 & 6.4113 & TRN & & \\
\hline CHEMBL1688141 & 736488 & 3.699 & 4.2612 & TRN & & \\
\hline CHEMBL1688140 & 736488 & 5.3468 & 5.0928 & TRN & & \\
\hline CHEMBL1688155 & 736488 & 3.0 & 3.7312 & TRN & & \\
\hline CHEMBL1688142 & 736488 & 4.8239 & 5.0511 & TRN & & \\
\hline CHEMBL1688264 & 736488 & 5.4949 & 6.2384 & TST & & \\
\hline CHEMBL1688161 & 736488 & 4.0555 & 3.9751 & TRN & & \\
\hline CHEMBL1688289 & 736488 & \multicolumn{3}{|c|}{ 3.7569999999999997 } & 4.3535 & TRN \\
\hline CHEMBL191334 & 736488 & 7.2147 & 5.4463 & TST & & \\
\hline CHEMBL1688145 & 736488 & 5.0223 & 4.7571 & TRN & & \\
\hline CHEMBL1688291 & 736488 & 3.699 & 3.8955 & TRN & & \\
\hline CHEMBL1688265 & 736488 & 5.8539 & 6.4637 & TST & & \\
\hline CHEMBL1688167 & 736488 & 2.699 & 2.0429 & TRN & & \\
\hline
\end{tabular}


Supplemental Table S2.txt

\begin{tabular}{|c|c|c|c|c|}
\hline CHEMBL1688280 & 736488 & 5.9208 & 5.5401 & TRN \\
\hline CHEMBL1688257 & 736488 & 5.7212 & 5.7759 & TST \\
\hline CHEMBL1688273 & 736488 & 6.3979 & 5.3036 & TST \\
\hline CHEMBL1688137 & 736488 & 4.1308 & 3.9073 & TRN \\
\hline CHEMBL 3928363 & 736488 & 6.4089 & 5.7411 & TST \\
\hline CHEMBL1688261 & 736488 & 5.4559 & 6.2161 & TST \\
\hline CHEMBL1688278 & 736488 & 5.585 & 4.9335 & TRN \\
\hline CHEMBL1688153 & 736488 & 3.0 & 3.6611 & TRN \\
\hline CHEMBL1688162 & 736488 & 3.699 & 3.3792 & TRN \\
\hline CHEMBL1688149 & 736488 & 5.1427 & 4.4986 & TRN \\
\hline CHEMBL1688260 & 736488 & 6.4437 & 5.9989 & TST \\
\hline CHEMBL423444 & 51114 & 8.4559 & 8.4514 & TRN \\
\hline CHEMBL 296641 & 51114 & 9.0757 & 6.5497 & TST \\
\hline CHEMBL168554 & 51114 & 9.0458 & 8.902000 & 000000001 \\
\hline CHEMBL169365 & 51114 & 5.9889 & 6.0166 & TRN \\
\hline CHEMBL168936 & 51114 & 8.7212 & 8.6792 & TRN \\
\hline CHEMBL169781 & 51114 & 8.3468 & 8.3057 & TRN \\
\hline CHEMBL169711 & 51114 & 7.9788 & 7.9516 & TRN \\
\hline CHEMBL169070 & 51114 & 6.9101 & 6.902 & TRN \\
\hline CHEMBL169577 & 51114 & 8.28399 & 999999999 & 8.3818 \\
\hline CHEMBL167024 & 51114 & 5.4609 & 5.4679 & TRN \\
\hline CHEMBL168388 & 51114 & 7.8153 & 7.8726 & TRN \\
\hline CHEMBL354398 & 51114 & 7.5969 & 7.6251 & TRN \\
\hline CHEMBL167017 & 51114 & 8.5376 & 8.5379 & TRN \\
\hline CHEMBL 170791 & 51114 & 7.6576 & 7.6776 & TRN \\
\hline CHEMBL434689 & 51114 & 7.1938 & 7.144 & TRN \\
\hline CHEMBL168676 & 51114 & 8.3565 & 8.4142 & TRN \\
\hline CHEMBL172684 & 51114 & 8.2924 & 8.3734 & TRN \\
\hline CHEMBL170844 & 51114 & 7.0 & 7.017 & TRN \\
\hline CHEMBL169280 & 51114 & 8.1487 & 7.8663 & TST \\
\hline CHEMBL168353 & 51114 & 7.9066 & 7.8913 & TRN \\
\hline CHEMBL353098 & 51114 & 6.8761 & 6.8668 & TRN \\
\hline CHEMBL168883 & 51114 & 6.5361 & 6.605 & TRN \\
\hline CHEMBL354982 & 51114 & 8.8539 & 8.8746 & TRN \\
\hline CHEMBL 354940 & 51114 & 8.4559 & 8.3948 & TRN \\
\hline CHEMBL168788 & 51114 & 7.684 & 6.5805 & TST \\
\hline CHEMBL423833 & 51114 & 6.9208 & 7.5691 & TST \\
\hline CHEMBL168823 & 51114 & 8.2147 & 8.2526 & TRN \\
\hline CHEMBL169010 & 51114 & 8.6576 & 8.6305 & TRN \\
\hline CHEMBL169528 & 51114 & 7.4353 & 7.4084 & TRN \\
\hline CHEMBL 353050 & 51114 & 7.6778 & 7.629 & TRN \\
\hline CHEMBL169979 & 51114 & 8.1192 & 7.8163 & TST \\
\hline CHEMBL166431 & 51114 & 7.1871 & 6.4194 & TST \\
\hline CHEMBL353393 & 51114 & 6.6289 & 6.6498 & TRN \\
\hline CHEMBL 352353 & 51114 & 8.3279 & 8.2348 & TRN \\
\hline CHEMBL355394 & 51114 & 6.6925 & 6.7573 & TRN \\
\hline CHEMBL169430 & 51114 & 8.4437 & 8.424 & TRN \\
\hline CHEMBL167777 & 51114 & 8.2291 & 8.17 & TRN \\
\hline
\end{tabular}




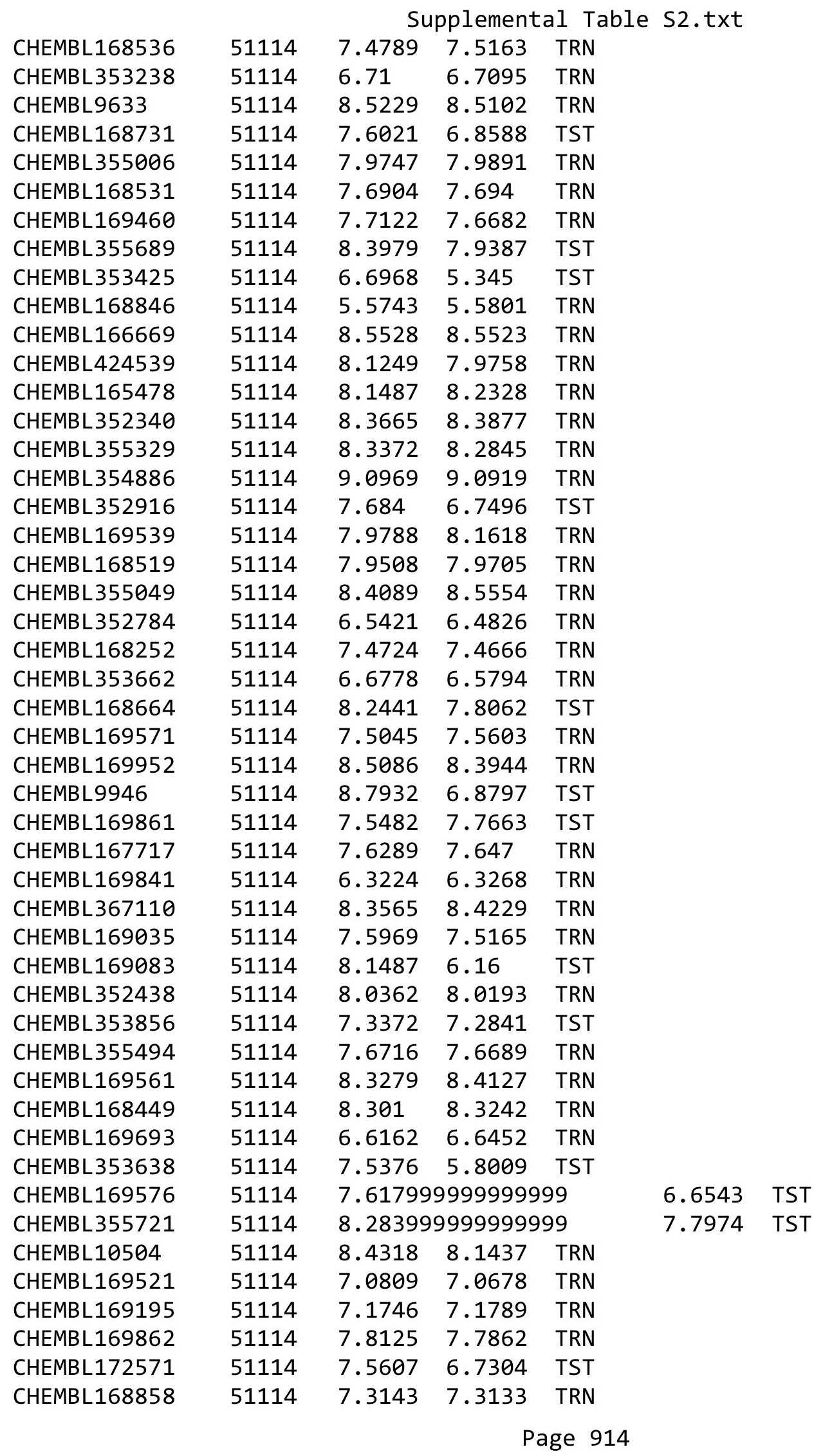




\begin{tabular}{|c|c|c|c|c|c|}
\hline & & \multicolumn{4}{|c|}{ Supplemental Table S2.txt } \\
\hline CHEMBL169421 & 51114 & 7.4123 & 7.4207 & TRN & \\
\hline CHEMBL169641 & 51114 & 8.0088 & 7.9105 & TRN & \\
\hline CHEMBL169629 & 51114 & 6.7122 & 7.2685 & TST & \\
\hline CHEMBL435468 & 51114 & 8.4559 & 8.3862 & TRN & \\
\hline CHEMBL169418 & 51114 & 7.5638 & 6.2849 & TST & \\
\hline CHEMBL169955 & 51114 & 8.1308 & 8.1028 & TRN & \\
\hline CHEMBL172570 & 51114 & 6.3809 & 6.2773 & TST & \\
\hline CHEMBL168646 & 51114 & 7.4881 & 7.6455 & TRN & \\
\hline CHEMBL168476 & 51114 & 8.1739 & 8.3362 & TRN & \\
\hline CHEMBL170788 & 51114 & 8.0132 & 8.0148 & TRN & \\
\hline CHEMBL354256 & 51114 & 7.2262 & 7.6928 & TST & \\
\hline CHEMBL352436 & 51114 & 5.9194 & 5.3414 & TST & \\
\hline CHEMBL354280 & 51114 & 7.317 & 7.32 & TST & \\
\hline CHEMBL 355214 & 51114 & 8.8239 & 8.8454 & TRN & \\
\hline CHEMBL168459 & 51114 & 7.6234 & 6.1751 & TST & \\
\hline CHEMBL353891 & 51114 & 8.0969 & 8.104 & TRN & \\
\hline CHEMBL353732 & 51114 & 8.3665 & 8.4017 & TRN & \\
\hline CHEMBL169538 & 51114 & 7.5575 & 6.7197 & TST & \\
\hline CHEMBL169248 & 51114 & 8.7212 & 8.774 & TRN & \\
\hline CHEMBL169751 & 51114 & 7.4012 & 7.3438 & TRN & \\
\hline CHEMBL169998 & 51114 & 7.9872 & 8.0145 & TRN & \\
\hline CHEMBL354579 & 51114 & 7.1574 & 7.1742 & TRN & \\
\hline CHEMBL 355008 & 51114 & 5.4069 & 5.4096 & TRN & \\
\hline CHEMBL 1595580 & 688116 & 5.95 & 5.4584 & TRN & \\
\hline CHEMBL1465189 & 688116 & 5.65 & 5.8318 & TRN & \\
\hline CHEMBL1498551 & 688116 & 5.85 & 5.6609 & TRN & \\
\hline CHEMBL1521589 & 688116 & 6.0 & 6.3002 & TRN & \\
\hline CHEMBL1446335 & 688116 & 6.95 & 5.5511 & TST & \\
\hline CHEMBL1340885 & 688116 & 6.25 & 6.4774 & TRN & \\
\hline CHEMBL1480787 & 688116 & 6.15 & 6.50799 & 9999999999 & TRN \\
\hline CHEMBL1585191 & 688116 & 6.35 & 5.7286 & TST & \\
\hline CHEMBL1459903 & 688116 & 6.25 & 6.6521 & TRN & \\
\hline CHEMBL1501376 & 688116 & 5.95 & 5.695 & TST & \\
\hline CHEMBL1601377 & 688116 & 5.9 & 5.9912 & TRN & \\
\hline CHEMBL1489593 & 688116 & 6.2 & 6.2658 & TRN & \\
\hline CHEMBL1968458 & 688116 & 6.3 & 5.8571 & TST & \\
\hline CHEMBL1588426 & 688116 & 6.4 & 6.3026 & TRN & \\
\hline CHEMBL1426552 & 688116 & 6.6 & 6.916 & TRN & \\
\hline CHEMBL1480691 & 688116 & 5.4 & 5.3864 & TRN & \\
\hline CHEMBL1471007 & 688116 & 7.0501 & 6.7512 & TRN & \\
\hline CHEMBL1408258 & 688116 & 7.0501 & 6.7053 & TST & \\
\hline CHEMBL103469 & 688116 & 7.2 & 6.7216 & TRN & \\
\hline CHEMBL1366093 & 688116 & 4.75 & 5.1203 & TRN & \\
\hline CHEMBL1605811 & 688116 & 6.3 & 6.5048 & TRN & \\
\hline CHEMBL1568889 & 688116 & 6.6 & 6.3396 & TRN & \\
\hline CHEMBL1579618 & 688116 & 6.05 & 5.8313 & TRN & \\
\hline CHEMBL1540929 & 688116 & 6.45 & 6.3657 & TRN & \\
\hline CHEMBL1462203 & 688116 & 4.8 & 5.6471 & TRN & \\
\hline
\end{tabular}




\begin{tabular}{|c|c|c|c|c|c|}
\hline \\
\hline CHEMBL1581982 & 688116 & 6.0 & 6.0218 & TRN & \\
\hline CHEMBL1332808 & 688116 & 4.85 & 4.9173 & TRN & \\
\hline CHEMBL1255648 & 688116 & 6.6499 & 6.5689 & TRN & \\
\hline CHEMBL1581385 & 688116 & 5.5 & 5.7169 & TST & \\
\hline CHEMBL1453299 & 688116 & 5.95 & 5.7452 & TRN & \\
\hline CHEMBL1303336 & 688116 & 4.95 & 4.8923 & TRN & \\
\hline CHEMBL1377749 & 688116 & 5.6 & 5.7824 & TRN & \\
\hline CHEMBL1595121 & 688116 & 6.35 & 6.0198 & TST & \\
\hline CHEMBL1577842 & 688116 & 5.2 & 4.8677 & TRN & \\
\hline CHEMBL1306759 & 688116 & 4.8 & 5.1574 & TRN & \\
\hline CHEMBL1514272 & 688116 & 4.85 & 5.1004 & TST & \\
\hline CHEMBL608699 & 688116 & 5.5 & 6.1894 & TST & \\
\hline CHEMBL1536448 & 688116 & 6.5501 & 6.3685 & TRN & \\
\hline CHEMBL1342410 & 688116 & 6.4 & 5.8929 & TRN & \\
\hline CHEMBL1320088 & 688116 & 6.1 & 5.851 & TRN & \\
\hline CHEMBL1471681 & 688116 & 5.65 & 5.9714 & TRN & \\
\hline CHEMBL1387773 & 688116 & 6.4 & 6.4153 & TRN & \\
\hline CHEMBL260370 & 688116 & 6.2 & 5.8014 & TRN & \\
\hline CHEMBL1503736 & 688116 & 5.65 & 5.1711 & TRN & \\
\hline CHEMBL1610843 & 688116 & 6.7001 & 6.9047 & TRN & \\
\hline CHEMBL1484209 & 688116 & 5.8 & 5.9239 & TRN & \\
\hline CHEMBL1363920 & 688116 & 5.6 & 5.4293 & TST & \\
\hline CHEMBL1543197 & 688116 & 5.2 & 5.1371 & TRN & \\
\hline CHEMBL1479674 & 688116 & 5.15 & 5.4048 & TRN & \\
\hline CHEMBL1488995 & 688116 & 5.0 & 5.6761 & TST & \\
\hline CHEMBL1451386 & 688116 & 6.8 & 6.0713 & TST & \\
\hline CHEMBL1368293 & 688116 & 5.4 & 5.9436 & TRN & \\
\hline CHEMBL3208556 & 688116 & 6.3 & 5.6433 & TST & \\
\hline CHEMBL1389685 & 688116 & 6.9 & 6.6453 & TRN & \\
\hline CHEMBL1458760 & 688116 & 6.1 & 6.2813 & TRN & \\
\hline CHEMBL1547070 & 688116 & 6.0 & 5.8871 & TST & \\
\hline CHEMBL1337096 & 688116 & 5.6 & 5.7073 & TRN & \\
\hline CHEMBL1343518 & 688116 & 5.7 & 5.4695 & TRN & \\
\hline CHEMBL1974538 & 688116 & 5.8 & 6.0396 & TST & \\
\hline CHEMBL1489314 & 688116 & 6.6499 & 6.527 & TRN & \\
\hline CHEMBL1340021 & 688116 & 6.6499 & 6.4153 & TRN & \\
\hline CHEMBL1373458 & 688116 & 4.85 & 4.9644 & TRN & \\
\hline CHEMBL1441053 & 688116 & 5.3 & 5.92200 & 0000000001 & TRN \\
\hline CHEMBL1332617 & 688116 & 6.8499 & 6.2115 & TRN & \\
\hline CHEMBL1432063 & 688116 & 6.15 & 6.0414 & TRN & \\
\hline CHEMBL1343061 & 688116 & 7.2503 & 6.9295 & TRN & \\
\hline CHEMBL1406538 & 688116 & 6.5501 & 6.8039 & TRN & \\
\hline CHEMBL1451996 & 688116 & 5.6 & 5.6962 & TRN & \\
\hline CHEMBL1338317 & 688116 & 5.6 & 6.2601 & TST & \\
\hline CHEMBL1511082 & 688116 & 6.5 & 6.2835 & TRN & \\
\hline CHEMBL1595431 & 688116 & 6.9 & 5.943 & TST & \\
\hline CHEMBL1320257 & 688116 & 6.0 & 5.7797 & TST & \\
\hline CHEMBL1540304 & 688116 & 6.45 & 6.1677 & TRN & \\
\hline
\end{tabular}




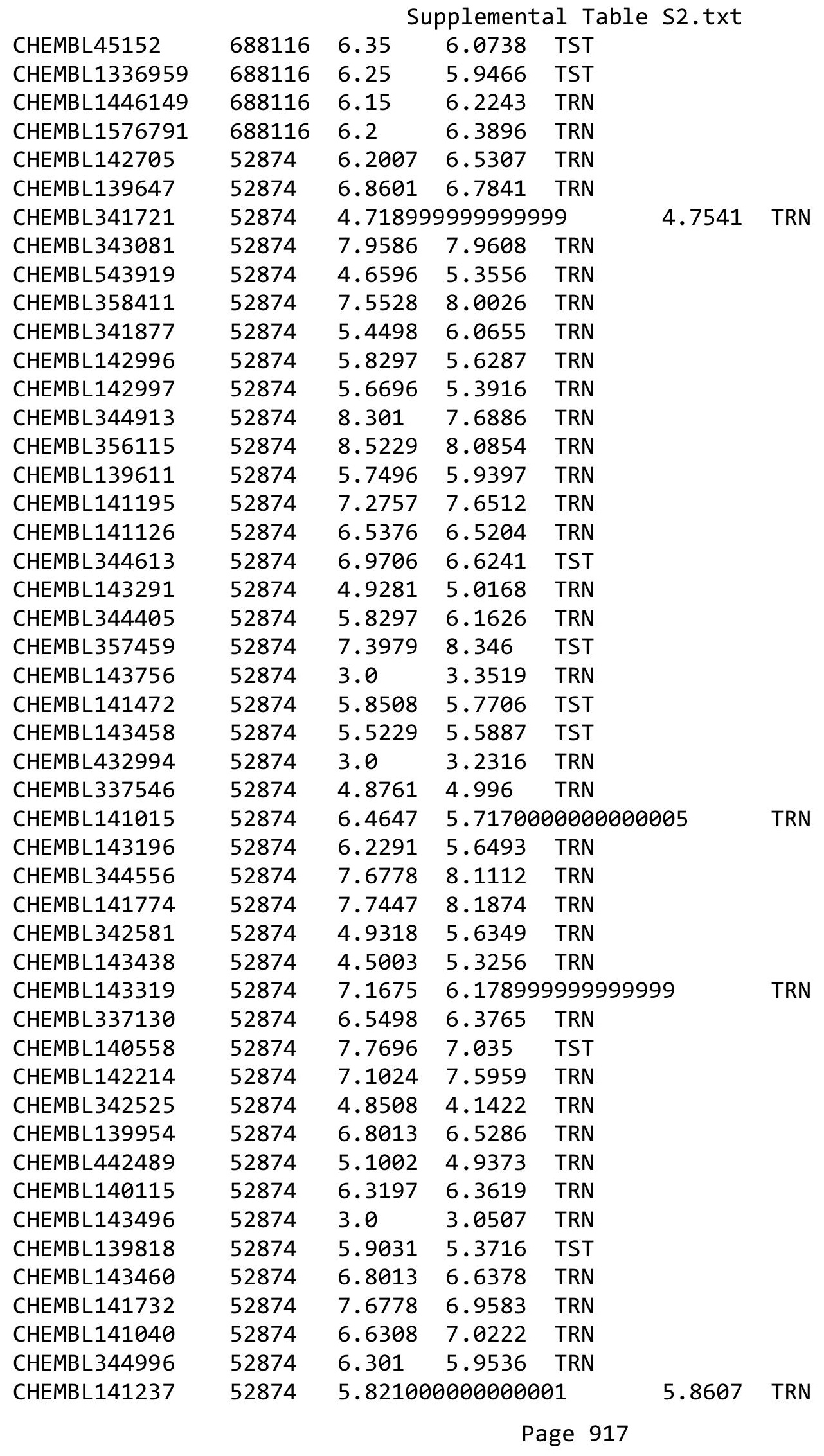




\begin{tabular}{|c|c|c|c|c|c|}
\hline \multirow{3}{*}{$\begin{array}{l}\text { CHEMBL141074 } \\
\text { CHEMBL } 358621\end{array}$} & \multicolumn{5}{|c|}{ Supplemental Table S2.txt } \\
\hline & 52874 & 6.2 & 5.87200 & 0000000001 & TRN \\
\hline & 52874 & 7.7959 & 7.5362 & TRN & \\
\hline CHEMBL141041 & 52874 & 5.699 & 6.2943 & TRN & \\
\hline CHEMBL143237 & 52874 & 7.4318 & 7.5037 & TST & \\
\hline CHEMBL143816 & 52874 & 7.8861 & 7.6186 & TRN & \\
\hline CHEMBL334922 & 52874 & 6.7305 & 6.37200 & 0000000001 & TRN \\
\hline CHEMBL143437 & 52874 & 5.3497 & 4.955 & TRN & \\
\hline CHEMBL143052 & 52874 & 7.1192 & 6.4739 & TST & \\
\hline CHEMBL143518 & 52874 & 7.2007 & 6.4985 & TRN & \\
\hline CHEMBL142074 & 52874 & 7.301 & 7.7311 & TRN & \\
\hline CHEMBL139937 & 52874 & 7.9586 & 7.8104 & TRN & \\
\hline CHEMBL139699 & 52874 & 4.7496 & 5.4276 & TRN & \\
\hline CHEMBL141104 & 52874 & 7.1024 & 6.9037 & TST & \\
\hline CHEMBL141248 & 52874 & 8.301 & 8.1247 & TST & \\
\hline CHEMBL342124 & 52874 & 5.3696 & 5.6548 & TST & \\
\hline CHEMBL140210 & 52874 & 5.3401 & 5.9596 & TST & \\
\hline CHEMBL141047 & 52874 & 7.6383 & 6.4718 & TST & \\
\hline CHEMBL357498 & 52874 & 6.0799 & 6.2032 & TST & \\
\hline CHEMBL141086 & 52874 & 6.6003 & 6.4569 & TST & \\
\hline CHEMBL143116 & 52874 & 7.4815 & 7.6033 & TST & \\
\hline CHEMBL141144 & 52874 & 3.0 & 4.9871 & TST & \\
\hline CHEMBL1378232 & 1301715 & 4.2315 & 4.8071 & TST & \\
\hline CHEMBL1375884 & 1301715 & 4.8959 & 4.8633 & TRN & \\
\hline CHEMBL1405749 & 1301715 & 5.2708 & 4.9487 & TRN & \\
\hline CHEMBL1445297 & 1301715 & 5.2449 & 5.0205 & TRN & \\
\hline CHEMBL 2358729 & 1301715 & 4.9978 & 4.9479 & TRN & \\
\hline CHEMBL 2355378 & 1301715 & 4.4522 & 5.145 & TRN & \\
\hline CHEMBL1602637 & 1301715 & 4.9158 & 4.9295 & TST & \\
\hline CHEMBL1536108 & 1301715 & 4.2958 & 4.8091 & TRN & \\
\hline CHEMBL2356872 & 1301715 & 4.505 & 4.3548 & TRN & \\
\hline CHEMBL 2138714 & 1301715 & 5.6556 & 5.0029 & TRN & \\
\hline CHEMBL3184311 & 1301715 & 4.9755 & 4.9569 & TRN & \\
\hline CHEMBL1321427 & 1301715 & 4.6574 & 4.7196 & TST & \\
\hline CHEMBL1568022 & 1301715 & 4.7303 & 4.7352 & TRN & \\
\hline CHEMBL2359612 & 1301715 & 4.6162 & 4.3388 & TRN & \\
\hline CHEMBL1375289 & 1301715 & 4.768 & 4.9726 & TRN & \\
\hline CHEMBL 2359110 & 1301715 & 4.5936 & 4.5388 & TRN & \\
\hline CHEMBL2362650 & 1301715 & 5.4134 & 5.0128 & TRN & \\
\hline CHEMBL1371507 & 1301715 & 3.0 & 4.6864 & TRN & \\
\hline CHEMBL1704298 & 1301715 & 4.4054 & 4.8405 & TST & \\
\hline CHEMBL1544797 & 1301715 & 5.0306 & 4.843 & TST & \\
\hline CHEMBL2359502 & 1301715 & 4.8416 & 4.3401 & TRN & \\
\hline CHEMBL3187821 & 1301715 & 4.9255 & 5.1131 & TRN & \\
\hline CHEMBL1580784 & 1301715 & 4.9662 & 4.6703 & TST & \\
\hline CHEMBL1483562 & 1301715 & 5.3958 & 5.0238 & TRN & \\
\hline CHEMBL1579170 & 1301715 & 4.3301 & 4.7981 & TST & \\
\hline CHEMBL3186440 & 1301715 & 4.2111 & 5.0092 & TRN & \\
\hline CHEMBL3182522 & 1301715 & 6.0 & 5.1308 & TRN & \\
\hline
\end{tabular}


Supplemental Table S2.txt

\begin{tabular}{|c|c|c|c|c|c|}
\hline CHEMBL1625031 & 1301715 & 4.967 & 4.7708 & TRN & \\
\hline CHEMBL 2357535 & 1301715 & 5.3458 & 4.5845 & TRN & \\
\hline CHEMBL2355506 & 1301715 & 6.0 & 5.2321 & TRN & \\
\hline CHEMBL1350915 & 1301715 & 5.066 & 4.71 & TRN & \\
\hline CHEMBL 2354788 & 1301715 & 4.997 & 4.2596 & TRN & \\
\hline CHEMBL1305372 & 1301715 & 4.3475 & 4.83 & TRN & \\
\hline CHEMBL1904071 & 1301715 & 4.2542 & 4.81 & TST & \\
\hline CHEMBL 2357173 & 1301715 & 4.4235 & 4.4209 & TRN & \\
\hline CHEMBL1344930 & 1301715 & 4.9245 & 4.762 & TRN & \\
\hline CHEMBL 3182148 & 1301715 & 5.1284 & 4.6791 & TRN & \\
\hline CHEMBL1321754 & 1301715 & 4.8083 & 4.9964 & TRN & \\
\hline CHEMBL1559741 & 1301715 & 4.7022 & 4.6044 & TST & \\
\hline CHEMBL1711200 & 1301715 & 4.8928 & 4.9204 & TRN & \\
\hline CHEMBL1396619 & 1301715 & 4.8844 & 5.1074 & TST & \\
\hline CHEMBL 2137170 & 1301715 & 3.1549 & 4.0018 & TRN & \\
\hline CHEMBL 3182281 & 1301715 & 4.7545 & 4.8893 & TRN & \\
\hline CHEMBL 2359406 & 1301715 & 5.0079 & 4.5417 & TRN & \\
\hline CHEMBL1617452 & 1301715 & 4.8788 & 4.6721 & TRN & \\
\hline CHEMBL1451348 & 1301715 & 4.6364 & 4.8172 & TRN & \\
\hline CHEMBL1560774 & 1301715 & 4.376 & 4.7363 & TRN & \\
\hline CHEMBL1489779 & 1301715 & 5.4191 & 4.9671 & TRN & \\
\hline CHEMBL 2361967 & 1301715 & 4.4018 & 4.8507 & TRN & \\
\hline CHEMBL585827 & 1301715 & 5.0405 & 4.8248 & TRN & \\
\hline CHEMBL 3182041 & 1301715 & 4.0598 & 4.1007 & TRN & \\
\hline CHEMBL 3187483 & 1301715 & 3.0 & 4.1846 & TRN & \\
\hline CHEMBL1299769 & 1301715 & 4.4647 & 4.7946 & TRN & \\
\hline CHEMBL 2358863 & 1301715 & 4.6934 & 4.7627 & TRN & \\
\hline CHEMBL 3186226 & 1301715 & 4.522 & 5.2548 & TRN & \\
\hline CHEMBL2356549 & 1301715 & 3.1549 & 4.9267 & TRN & \\
\hline CHEMBL 2354497 & 1301715 & 6.0 & 4.2526 & TRN & \\
\hline CHEMBL 2356442 & 1301715 & 4.6494 & 4.3401 & TRN & \\
\hline CHEMBL1337726 & 1301715 & 4.7959 & 5.1238 & TST & \\
\hline CHEMBL 257286 & 1301715 & 4.6832 & 4.9916 & TRN & \\
\hline CHEMBL 3188935 & 1301715 & 4.6598 & 4.4346 & TRN & \\
\hline CHEMBL 2355735 & 1301715 & 4.5166 & 4.0663 & TRN & \\
\hline CHEMBL1544186 & 1301715 & 5.24799 & 99999999 & 99 & 4.8799 \\
\hline CHEMBL1551808 & 1301715 & 4.7962 & 4.7888 & TRN & \\
\hline CHEMBL 2354539 & 1301715 & 4.7875 & 4.9421 & TRN & \\
\hline CHEMBL1564801 & 1301715 & 4.7498 & 4.6077 & TRN & \\
\hline CHEMBL1472681 & 1301715 & 4.0552 & 4.9607 & TST & \\
\hline CHEMBL 2137524 & 1301715 & 4.3549 & 4.0201 & TRN & \\
\hline CHEMBL 2358770 & 1301715 & 6.0 & 4.4096 & TRN & \\
\hline CHEMBL591363 & 1301715 & 5.0696 & 5.1373 & TRN & \\
\hline CHEMBL 2356728 & 1301715 & 5.2388 & 5.2143 & TRN & \\
\hline CHEMBL 2355635 & 1301715 & 4.3903 & 4.9977 & TRN & \\
\hline CHEMBL1622981 & 1301715 & 4.7111 & 5.0307 & TRN & \\
\hline CHEMBL1378851 & 1301715 & 4.5759 & 4.9143 & TST & \\
\hline CHEMBL1578386 & 1301715 & 4.7908 & 4.5199 & TRN & \\
\hline
\end{tabular}

Page 919 
Supplemental Table S2.txt

$\begin{array}{lllll}\text { CHEMBL1420472 } & 1301715 & 4.8245 & 4.933 & \text { TRN } \\ \text { CHEMBL2355724 } & 1301715 & 4.8857 & 4.7983 & \text { TRN } \\ \text { CHEMBL2356002 } & 1301715 & 4.8102 & 4.875 & \text { TRN } \\ \text { CHEMBL1574530 } & 1301715 & 4.8847 & 4.6877 & \text { TST } \\ \text { CHEMBL2359622 } & 1301715 & 4.7397 & 4.3816 & \text { TRN } \\ \text { CHEMBL1379675 } & 1301715 & 4.9329 & 5.0921 & \text { TRN } \\ \text { CHEMBL3186267 } & 1301715 & 3.1549 & 4.8071 & \text { TRN } \\ \text { CHEMBL3183001 } & 1301715 & 4.9119 & 5.0219 & \text { TRN } \\ \text { CHEMBL1582221 } & 1301715 & 4.6014 & 4.7484 & \text { TST } \\ \text { CHEMBL2357640 } & 1301715 & 3.1549 & 3.9795 & \text { TRN } \\ \text { CHEMBL2361346 } & 1301715 & 4.6927 & 4.5475 & \text { TST } \\ \text { CHEMBL1873627 } & 1301715 & 3.1549 & 4.0978 & \text { TRN } \\ \text { CHEMBL1345220 } & 1301715 & 5.2549 & 4.8303 & \text { TST } \\ \text { CHEMBL2359040 } & 1301715 & 6.0 & 5.2888 & \text { TRN } \\ \text { CHEMBL1418341 } & 1301715 & 5.1152 & 4.7195 & \text { TST } \\ \text { CHEMBL1519285 } & 1301715 & 4.0247 & 4.7228 & \text { TST } \\ \text { CHEMBL1866791 } & 1301715 & 4.8202 & 4.6324 & \text { TRN } \\ \text { CHEMBL2131792 } & 1301715 & 5.7825 & 4.3868 & \text { TRN } \\ \text { CHEMBL1347023 } & 1301715 & 5.0372 & 4.7995 & \text { TST } \\ \text { CHEMBL2355890 } & 1301715 & 3.1549 & 4.1706 & \text { TRN } \\ \text { CHEMBL3188673 } & 1301715 & 6.0 & 5.1087 & \text { TRN } \\ \text { CHEMBL2354712 } & 1301715 & 6.0 & 5.2136 & \text { TRN } \\ \text { CHEMBL1321622 } & 1301715 & 3.0 & 4.9207 & \text { TST } \\ \text { CHEMBL1459394 } & 1301715 & 4.9158 & 4.9582 & \text { TRN } \\ \text { CHEMBL1584985 } & 1301715 & 5.1409 & 4.9412 & \text { TST } \\ \text { CHEMBL1392527 } & 1301715 & 6.4134 & 5.0916 & \text { TST } \\ \text { CHEMBL1390112 } & 1301715 & 5.0306 & 4.8253 & \text { TST } \\ \text { CHEMBL1428095 } & 1301715 & 4.7545 & 4.6585 & \text { TST } \\ \text { CHEMBL3185444 } & 1301715 & 4.7314 & 5.3265 & \text { TRN } \\ \text { CHEMBL2361006 } & 1301715 & 4.8551 & 4.4151 & \text { TRN } \\ \text { CHEMBL2362298 } & 1301715 & 4.3404 & 4.8811 & \text { TRN } \\ \text { CHEMBEM } 141466 & 809380 & 4.3521 & 4.2485 & \text { TRN } \\ \text { CHEMBL1409055 } & 809380 & 2.9829 & 3.355 & \text { TST } \\ \text { CHEMBL1530866 } & 1301715 & 4.7956 & 5.0068 & \text { TRN } \\ \text { CHEMBEMB } & & & \end{array}$

Page 920 
Supplemental Table S2.txt

\begin{tabular}{|c|c|c|c|c|c|}
\hline CHEMBL1553409 & 809380 & 2.9832 & 2.9423 & TRN & \\
\hline CHEMBL1982304 & 809380 & 2.9834 & 2.8885 & TRN & \\
\hline CHEMBL1728280 & 809380 & 4.8512 & 4.7356 & TRN & \\
\hline CHEMBL 290545 & 809380 & 2.9831 & 3.2172 & TRN & \\
\hline CHEMBL45152 & 809380 & 4.1008 & 3.805 & TRN & \\
\hline CHEMBL1468954 & 809380 & 4.2085 & 4.0565 & TRN & \\
\hline CHEMBL1519374 & 809380 & 2.9833 & 2.8105 & TRN & \\
\hline CHEMBL1995994 & 809380 & 2.9834 & 2.9982 & TST & \\
\hline CHEMBL1506226 & 809380 & 2.9839 & 2.7544 & TST & \\
\hline CHEMBL1578029 & 809380 & 4.5649 & 4.3007 & TRN & \\
\hline CHEMBL1703200 & 809380 & 2.9838 & 3.161 & TRN & \\
\hline CHEMBL1709564 & 809380 & 2.9836 & 3.237 & TRN & \\
\hline CHEMBL1451931 & 809380 & 4.1983 & 4.3253 & TRN & \\
\hline CHEMBL1385603 & 809380 & 2.9833 & 3.1851 & TRN & \\
\hline CHEMBL 2373711 & 809380 & 4.8019 & 3.9694 & TST & \\
\hline CHEMBL1991736 & 809380 & 2.9836 & 2.8446 & TRN & \\
\hline CHEMBL1307717 & 809380 & 2.9833 & 3.0432 & TRN & \\
\hline CHEMBL1314677 & 809380 & 4.6061 & 4.5279 & TRN & \\
\hline CHEMBL1895397 & 809380 & 2.9833 & 3.1499 & TRN & \\
\hline CHEMBL1338258 & 809380 & 2.9832 & 2.9561 & TRN & \\
\hline CHEMBL421088 & 809380 & 2.9837 & 3.1367 & TRN & \\
\hline CHEMBL1419232 & 809380 & 2.9833 & 3.0389 & TRN & \\
\hline CHEMBL1605599 & 809380 & 4.4237 & 4.4419 & TRN & \\
\hline CHEMBL1300672 & 809380 & 2.9831 & 3.1543 & TST & \\
\hline CHEMBL1493528 & 809380 & 4.2753 & 4.3429 & TRN & \\
\hline CHEMBL1331954 & 809380 & 2.9833 & 3.2081 & TST & \\
\hline CHEMBL1731722 & 809380 & 4.3326 & 4.3797 & TST & \\
\hline CHEMBL601757 & 809380 & 4.19600 & 000000000 & $\partial 1$ & 4.0748 \\
\hline CHEMBL1709883 & 809380 & 4.4835 & 4.4716 & TRN & \\
\hline CHEMBL1464949 & 809380 & 4.4049 & 4.3703 & TRN & \\
\hline CHEMBL1729297 & 809380 & 4.0197 & 4.0104 & TRN & \\
\hline CHEMBL1420427 & 809380 & 2.9825 & 4.1721 & TST & \\
\hline CHEMBL1458444 & 809380 & 2.9834 & 3.0761 & TRN & \\
\hline CHEMBL1716155 & 809380 & 2.9836 & 3.0815 & TRN & \\
\hline CHEMBL1599646 & 809380 & 2.9833 & 2.8422 & TRN & \\
\hline CHEMBL1717890 & 809380 & 4.4667 & 4.4043 & TRN & \\
\hline CHEMBL1701182 & 809380 & 4.4427 & 4.6556 & TRN & \\
\hline CHEMBL1520233 & 809380 & 4.2618 & 3.7936 & TRN & \\
\hline CHEMBL1339245 & 809380 & 2.9833 & 3.1282 & TRN & \\
\hline CHEMBL1435590 & 809380 & 2.9834 & 3.0992 & TRN & \\
\hline CHEMBL1470135 & 809380 & 4.1992 & 4.3894 & TRN & \\
\hline CHEMBL1979040 & 809380 & 2.9833 & 2.9889 & TRN & \\
\hline CHEMBL1979558 & 809380 & 2.9837 & 2.7451 & TRN & \\
\hline CHEMBL1976219 & 809380 & 2.9834 & 2.6777 & TRN & \\
\hline CHEMBL1441363 & 809380 & 4.4845 & 4.5768 & TRN & \\
\hline CHEMBL1325300 & 809380 & 2.9833 & 3.0018 & TST & \\
\hline CHEMBL1875561 & 809380 & 4.0203 & 3.9221 & TRN & \\
\hline CHEMBL1504853 & 809380 & 4.2402 & 4.1388 & TRN & \\
\hline
\end{tabular}


Supplemental Table S2.txt

\begin{tabular}{|c|c|c|c|c|}
\hline CHEMBL1520143 & 809380 & 4.0065 & 3.3582 & TRN \\
\hline CHEMBL1704614 & 809380 & 2.9832 & 3.3906 & TRN \\
\hline CHEMBL 2003806 & 809380 & 2.9833 & 2.9187 & TRN \\
\hline CHEMBL1521296 & 809380 & 4.6549 & 4.8746 & TRN \\
\hline CHEMBL1532997 & 809380 & 2.9834 & 3.0048 & TRN \\
\hline CHEMBL1374291 & 809380 & 2.9834 & 3.043 & TRN \\
\hline CHEMBL1558285 & 809380 & 4.7165 & 4.8946 & TRN \\
\hline CHEMBL118678 & 809380 & 2.9835 & 3.1881 & TRN \\
\hline CHEMBL1424332 & 809380 & 2.9832 & 2.7656 & TRN \\
\hline CHEMBL1976412 & 809380 & 2.9832 & 3.14399 & 99999999997 \\
\hline CHEMBL1473955 & 809380 & 4.1968 & 3.9761 & TRN \\
\hline CHEMBL156174 & 809380 & 3.4614 & 4.1674 & TRN \\
\hline CHEMBL1489745 & 809380 & 4.8013 & 4.78 & TRN \\
\hline CHEMBL1456330 & 809380 & 2.9833 & 3.5653 & TST \\
\hline CHEMBL1974348 & 809380 & 2.9833 & 3.0143 & TRN \\
\hline CHEMBL1542926 & 809380 & 2.9834 & 3.0514 & TRN \\
\hline CHEMBL1485159 & 809380 & 5.4517 & 5.3302 & TRN \\
\hline CHEMBL1567800 & 809380 & 2.9835 & 3.1192 & TRN \\
\hline CHEMBL1988648 & 809380 & 4.677 & 4.7427 & TRN \\
\hline CHEMBL1605787 & 809380 & 2.9837 & 3.0577 & TRN \\
\hline CHEMBL 235504 & 809380 & 5.4393 & 4.4442 & TRN \\
\hline CHEMBL1521600 & 809380 & 4.1524 & 3.9962 & TRN \\
\hline CHEMBL1708891 & 809380 & 2.9828 & 2.8913 & TRN \\
\hline CHEMBL1472879 & 809380 & 2.984 & 2.7161 & TRN \\
\hline CHEMBL1334768 & 809380 & 2.9834 & 3.0796 & TST \\
\hline CHEMBL1324193 & 809380 & 2.9833 & 2.7962 & TRN \\
\hline CHEMBL 2005270 & 809380 & 2.9832 & 3.2285 & TRN \\
\hline CHEMBL417727 & 809380 & 5.0415 & 4.9321 & TRN \\
\hline CHEMBL1367036 & 809380 & 4.2646 & 4.2429 & TRN \\
\hline CHEMBL1698877 & 809380 & 2.9832 & 2.9837 & TRN \\
\hline CHEMBL1353102 & 809380 & 2.9833 & 2.9083 & TRN \\
\hline CHEMBL1701124 & 809380 & 2.9835 & 2.5574 & TST \\
\hline CHEMBL1887807 & 809380 & 4.8894 & 3.7051 & TST \\
\hline CHEMBL1899240 & 809380 & 2.983 & 3.1786 & TRN \\
\hline CHEMBL1591913 & 809380 & 4.6398 & 4.6915 & TRN \\
\hline CHEMBL1335002 & 809380 & 2.9834 & 2.9941 & TRN \\
\hline CHEMBL1484618 & 809380 & 4.4387 & 4.6856 & TRN \\
\hline CHEMBL1308477 & 809380 & 2.9836 & 3.6129 & TST \\
\hline CHEMBL1481417 & 809380 & 4.2757 & 4.3037 & TRN \\
\hline CHEMBL1710798 & 809380 & 2.9833 & 3.0434 & TRN \\
\hline CHEMBL1557212 & 809380 & 2.9835 & 3.4592 & TST \\
\hline CHEMBL1996376 & 809380 & 2.9833 & 2.9265 & TRN \\
\hline CHEMBL1497838 & 809380 & 5.6722 & 5.6871 & TRN \\
\hline CHEMBL1702711 & 809380 & 2.9834 & 2.7903 & TRN \\
\hline CHEMBL1698123 & 809380 & 2.983 & 3.2878 & TRN \\
\hline CHEMBL1357999 & 809380 & 2.9834 & 2.958 & TST \\
\hline CHEMBL1310318 & 809380 & 2.9832 & 3.4943 & TST \\
\hline CHEMBL1473428 & 809380 & 4.4798 & 3.8684 & TST \\
\hline
\end{tabular}




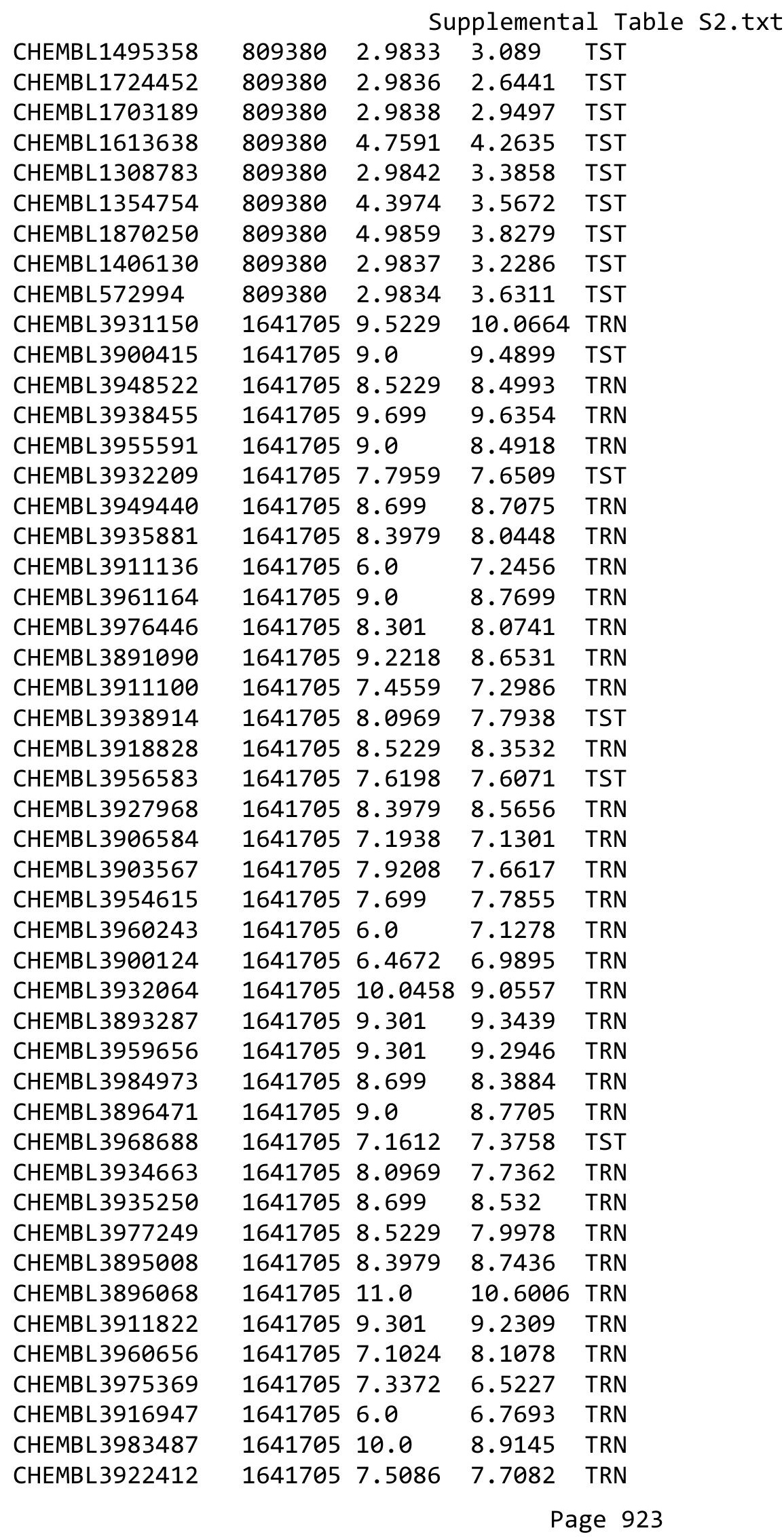




\begin{tabular}{|c|c|c|c|c|c|}
\hline \multicolumn{6}{|c|}{ Supplemental Table S2.txt } \\
\hline CHEMBL3916449 & 1641705 & 6.0 & 7.1116 & TRN & \\
\hline CHEMBL 3982398 & 1641705 & 10.0 & 9.4662 & TRN & \\
\hline CHEMBL3919793 & 1641705 & 8.3979 & 8.3257 & TRN & \\
\hline CHEMBL 3937127 & 1641705 & 6.0 & 6.5159 & TRN & \\
\hline CHEMBL 3947161 & 1641705 & 6.5129 & 5.6522 & TRN & \\
\hline CHEMBL3983711 & 1641705 & 6.0 & 7.0953 & TST & \\
\hline CHEMBL 3894262 & 1641705 & 9.0 & 8.885 & TRN & \\
\hline CHEMBL3968639 & 1641705 & 8.2218 & 8.1664 & TRN & \\
\hline CHEMBL 3953465 & 1641705 & 8.699 & 9.0834 & TRN & \\
\hline CHEMBL3901812 & 1641705 & 9.699 & 9.6447 & TRN & \\
\hline CHEMBL 3912678 & 1641705 & 9.0969 & 9.7619 & TST & \\
\hline CHEMBL3916994 & 1641705 & 6.9393 & 7.4636 & TST & \\
\hline CHEMBL3958399 & 1641705 & 9.5229 & 9.1557 & TRN & \\
\hline CHEMBL 3892955 & 1641705 & 8.5229 & 8.6761 & TRN & \\
\hline CHEMBL3892313 & 1641705 & 6.0 & 6.6203 & TRN & \\
\hline CHEMBL3943338 & 1641705 & 8.2218 & 8.1628 & TRN & \\
\hline CHEMBL3941235 & 1641705 & 7.5528 & 7.5718 & TRN & \\
\hline CHEMBL3924664 & 1641705 & 8.0 & 8.7108 & TST & \\
\hline CHEMBL 3986677 & 1641705 & 8.5229 & 7.456 & TST & \\
\hline CHEMBL3967557 & 1641705 & 8.2218 & 7.6523 & TST & \\
\hline CHEMBL3938961 & 1641705 & 8.2218 & 8.262 & TST & \\
\hline CHEMBL 3914684 & 1641705 & 8.0458 & 8.2142 & TRN & \\
\hline CHEMBL3932767 & 1641705 & 9.0 & 7.7655 & TRN & \\
\hline CHEMBL 3971587 & 1641705 & 9.699 & 9.868 & TRN & \\
\hline CHEMBL3953692 & 1641705 & 7.6778 & 7.5978 & TST & \\
\hline CHEMBL3979025 & 1641705 & 8.5229 & 9.7636 & TST & \\
\hline CHEMBL3949065 & 1641705 & 9.699 & 9.9483 & TRN & \\
\hline CHEMBL3983423 & 1641705 & 8.3979 & 7.9503 & TRN & \\
\hline CHEMBL 3923856 & 1641705 & 7.9586 & 7.7152 & TRN & \\
\hline CHEMBL3892219 & 1641705 & 9.0 & 8.9172 & TRN & \\
\hline CHEMBL 3984300 & 1641705 & 10.2218 & 10.62099 & 99999999999 & TRN \\
\hline CHEMBL 3950104 & 1641705 & 8.2218 & 8.1993 & TRN & \\
\hline CHEMBL3892636 & 1641705 & 7.7212 & 7.3121 & TRN & \\
\hline CHEMBL 3947540 & 1641705 & 6.0 & 6.6278 & TRN & \\
\hline CHEMBL3944827 & 1641705 & 8.699 & 8.455 & TRN & \\
\hline CHEMBL3955861 & 1641705 & 8.3979 & 8.8657 & TRN & \\
\hline CHEMBL3922614 & 1641705 & 9.0 & 8.2949 & TST & \\
\hline CHEMBL3951569 & 1641705 & 6.426 & 6.8971 & TRN & \\
\hline CHEMBL3955398 & 1641705 & 9.699 & 9.6752 & TRN & \\
\hline CHEMBL3915696 & 1641705 & 9.0969 & 7.5542 & TRN & \\
\hline CHEMBL3903172 & 1641705 & 9.3979 & 9.9729 & TST & \\
\hline CHEMBL3898987 & 1641705 & 7.8539 & 6.6028 & TRN & \\
\hline CHEMBL3909471 & 1641705 & 9.5229 & 9.3774 & TRN & \\
\hline CHEMBL3906978 & 1641705 & 9.699 & 9.3023 & TRN & \\
\hline CHEMBL3956020 & 1641705 & 6.0 & 6.2902 & TRN & \\
\hline CHEMBL3890579 & 1641705 & 8.3979 & 8.1601 & TRN & \\
\hline CHEMBL3971438 & 1641705 & 6.6904 & 6.3719 & TRN & \\
\hline CHEMBL3977196 & 1641705 & 9.3979 & 9.4642 & TRN & \\
\hline
\end{tabular}


Supplemental Table S2.txt

\begin{tabular}{|c|c|c|c|c|}
\hline & & & 54 & \\
\hline FHFMBI 3984504 & & & & \\
\hline IEMBL 3905904 & & 301 & & \\
\hline IEMBL 3946128 & 705 & 1549 & & \\
\hline AEMBL3923485 & 705 & 8.699 & 186 & \\
\hline 765 & & 739 & & \\
\hline & & & 334 & \\
\hline AEMBL3891000 & 105 & 218 & 812 & \\
\hline AEMBL3976766 & 705 & 7.7447 & 01 & \\
\hline HEMBL3938918 & 705 & 9.5229 & 53 & \\
\hline HEMBL389 & 705 & 979 & 93 & \\
\hline EMBL & & & & \\
\hline HEMBL 391 & 705 & & 09 & \\
\hline HEMBL 389 & 705 & & & \\
\hline AEMBL & & & & \\
\hline 5 & & & & \\
\hline 6 & & & & \\
\hline HEMBL & 05 & & 79 & \\
\hline 03 & & & 154 & \\
\hline AEMBL & & & & $\mathrm{NT}$ \\
\hline 0 & & & & RN \\
\hline & & & & \\
\hline 67 & 05 & 6 . & & \\
\hline 39 & & & & \\
\hline MBL & & & & $\mathrm{KI}$ \\
\hline & & & & 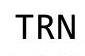 \\
\hline & & & & \\
\hline & & & & \\
\hline & & & & RI \\
\hline & & & & R \\
\hline & & & 94 & RI \\
\hline 1 & & & & \\
\hline & & & & \\
\hline & & & & TR \\
\hline AEMBL 393 & & & & RI \\
\hline & & & & $\mathrm{RN}$ \\
\hline 7 & & & & \\
\hline & & & & TST \\
\hline HEMBL 390 & 05 & & & $\mathrm{R}$ \\
\hline MBL & & & & \\
\hline 8 & & 6 . & & $S$ \\
\hline CHEMBL397 & & 6.90 & & RN \\
\hline HEMBL392 & & 7.8539 & & $\mathrm{R}$ \\
\hline EMBL39 & 05 & 8.2 & 65 & \\
\hline 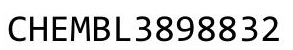 & & & & \\
\hline & & 0.0 & 849 & \\
\hline CHEMBL3972 & 705 & 8.522 & 8.1166 & \\
\hline CHEMBL3910522 & 1641705 & 9.5229 & 10.5605 & \\
\hline
\end{tabular}

Page 925 
Supplemental Table S2.txt

\begin{tabular}{|c|c|c|c|c|c|}
\hline CHEMBL3934244 & 1641705 & 7.3768 & 7.6598 & TRN & \\
\hline CHEMBL3935528 & 1641705 & 8.2218 & 8.3536 & TRN & \\
\hline CHEMBL3896424 & 1641705 & 8.2218 & 8.3973 & TRN & \\
\hline CHEMBL3940586 & 1641705 & 9.5229 & 9.2103 & TRN & \\
\hline CHEMBL3944048 & 1641705 & 9.5229 & 9.2154 & TST & \\
\hline CHEMBL3920087 & 1641705 & 8.5229 & 8.5639 & TRN & \\
\hline CHEMBL3972223 & 1641705 & 9.1549 & 9.0597 & TRN & \\
\hline CHEMBL3969749 & 1641705 & 8.699 & 8.4446 & TRN & \\
\hline CHEMBL3925830 & 1641705 & 8.301 & 8.1872 & TRN & \\
\hline CHEMBL3935566 & 1641705 & 7.7212 & 7.7955 & TST & \\
\hline CHEMBL3930094 & 1641705 & 8.2218 & 7.9396 & TRN & \\
\hline CHEMBL3891348 & 1641705 & 9.1549 & 9.3623 & TRN & \\
\hline CHEMBL3911561 & 1641705 & 7.699 & 7.704 & TRN & \\
\hline CHEMBL3950247 & 1641705 & 9.5229 & 9.5165 & TRN & \\
\hline CHEMBL 3934229 & 1641705 & 7.301 & 7.2851 & TST & \\
\hline CHEMBL3893183 & 1641705 & 8.699 & 8.6767 & TRN & \\
\hline CHEMBL3914703 & 1641705 & 6.0 & 6.6471 & TST & \\
\hline CHEMBL3977586 & 1641705 & 8.2218 & 7.9659 & TRN & \\
\hline CHEMBL3929641 & 1641705 & 10.2218 & 8.9059 & TRN & \\
\hline CHEMBL3953347 & 1641705 & 9.3979 & 9.4577 & TRN & \\
\hline CHEMBL3916587 & 1641705 & 9.699 & 9.2586 & TST & \\
\hline CHEMBL3943646 & 1641705 & 8.5229 & 8.1334 & TRN & \\
\hline CHEMBL3950965 & 1641705 & 6.0 & 6.8491 & TST & \\
\hline CHEMBL3966245 & 1641705 & 8.1549 & 8.041 & TST & \\
\hline CHEMBL3909805 & 1641705 & 8.0 & 8.0517 & TST & \\
\hline CHEMBL3974409 & 1641705 & 8.3979 & 8.1541 & TST & \\
\hline CHEMBL3922069 & 1641705 & 10.0 & 10.439 & TST & \\
\hline CHEMBL3894605 & 1641705 & 7.6198 & 6.6769 & TST & \\
\hline CHEMBL3974509 & 1641705 & 7.2147 & 7.2108 & TRN & \\
\hline CHEMBL3907066 & 1641705 & 8.699 & 9.6052 & TST & \\
\hline CHEMBL3909143 & 1641705 & 6.0 & 7.0049 & TRN & \\
\hline CHEMBL3914600 & 1641705 & 10.0 & \multicolumn{2}{|c|}{10.062000000000001} & TRN \\
\hline CHEMBL3895300 & 1641705 & 6.7033 & 6.7593 & TRN & \\
\hline CHEMBL3939999 & 1641705 & 6.3478 & 5.5511 & TST & \\
\hline CHEMBL3932521 & 1641705 & 6.0 & 7.2471 & TRN & \\
\hline CHEMBL3918263 & 1641705 & 8.0 & 8.2346 & TST & \\
\hline CHEMBL3926301 & 1641705 & 8.5229 & 8.2189 & TRN & \\
\hline CHEMBL3974477 & 1641705 & 9.699 & \multicolumn{2}{|c|}{9.597000000000001} & TRN \\
\hline CHEMBL3921194 & 1641705 & 8.3979 & 8.5285 & TST & \\
\hline CHEMBL 3894307 & 1641705 & 8.1549 & 8.0073 & TRN & \\
\hline CHEMBL3905110 & 1641705 & 8.2218 & 8.6422 & TRN & \\
\hline CHEMBL3985566 & 1641705 & 9.0458 & 9.1733 & TRN & \\
\hline CHEMBL3930602 & 1641705 & 7.4559 & 7.7057 & TRN & \\
\hline CHEMBL3974257 & 1641705 & 8.3979 & 8.2566 & TRN & \\
\hline CHEMBL3949820 & 1641705 & 8.2218 & 8.4874 & TST & \\
\hline CHEMBL 3930143 & 1641705 & 7.9208 & 7.6785 & TST & \\
\hline CHEMBL3936727 & 1641705 & 9.0458 & 8.5742 & TRN & \\
\hline CHEMBL3982364 & 1641705 & 8.699 & 8.8836 & TRN & \\
\hline
\end{tabular}


Supplemental Table S2.txt

\begin{tabular}{|c|c|c|c|c|}
\hline CHEMBL3936802 & 1641705 & 8.699 & 8.5527 & TRN \\
\hline CHEMBL3956546 & 1641705 & 9.1549 & 9.1663 & TRN \\
\hline CHEMBL3983063 & 1641705 & 7.8861 & 8.1055 & TRN \\
\hline CHEMBL 3940150 & 1641705 & 7.5376 & 7.819 & TRN \\
\hline CHEMBL3939808 & 1641705 & 9.2218 & 9.2028 & TRN \\
\hline CHEMBL3961250 & 1641705 & 7.8861 & 7.9674 & TRN \\
\hline CHEMBL3908325 & 1641705 & 7.8861 & \multicolumn{2}{|c|}{7.821000000000001} \\
\hline CHEMBL 3950253 & 1641705 & 6.0 & 6.4324 & TRN \\
\hline CHEMBL 3933473 & 1641705 & 6.0 & 6.4794 & TRN \\
\hline CHEMBL3899737 & 1641705 & 8.2218 & 8.2559 & TRN \\
\hline CHEMBL 3908148 & 1641705 & 7.8239 & 8.9557 & TST \\
\hline CHEMBL3946164 & 1641705 & 8.5229 & 8.6763 & TRN \\
\hline CHEMBL3958723 & 1641705 & 6.8297 & 6.5558 & TRN \\
\hline CHEMBL 3938472 & 1641705 & 8.3979 & 8.3676 & TRN \\
\hline CHEMBL3944536 & 1641705 & 9.5229 & 9.5028 & TRN \\
\hline CHEMBL3905278 & 1641705 & 9.699 & 9.8262 & TRN \\
\hline CHEMBL3931224 & 1641705 & 7.2924 & 7.2087 & TRN \\
\hline CHEMBL3945594 & 1641705 & 10.2218 & 10.1094 & TRN \\
\hline CHEMBL3931559 & 1641705 & 7.8239 & 8.0688 & TST \\
\hline CHEMBL3950086 & 1641705 & 8.699 & 8.6843 & TRN \\
\hline CHEMBL3962864 & 1641705 & 8.3979 & 8.3168 & TRN \\
\hline CHEMBL3931158 & 1641705 & 9.0 & 8.8416 & TRN \\
\hline CHEMBL3933592 & 1641705 & 9.5229 & 9.2731 & TRN \\
\hline CHEMBL 3951300 & 1641705 & 6.0 & 6.3758 & TRN \\
\hline CHEMBL 3892346 & 1641705 & 8.2218 & 8.059 & TST \\
\hline CHEMBL3920686 & 1641705 & 9.2218 & 9.1172 & TST \\
\hline CHEMBL3905818 & 1641705 & 9.0 & 8.6267 & TRN \\
\hline CHEMBL3947490 & 1641705 & 7.7447 & 7.4421 & TRN \\
\hline CHEMBL 3896341 & 1641705 & 8.301 & 7.7557 & TST \\
\hline CHEMBL3933138 & 1641705 & 7.6576 & 7.3141 & TRN \\
\hline CHEMBL3924108 & 1641705 & 9.3979 & 9.1097 & TRN \\
\hline CHEMBL3971240 & 1641705 & 6.0 & 7.3997 & TST \\
\hline CHEMBL3900229 & 1641705 & 7.0269 & 7.1414 & TST \\
\hline CHEMBL3973983 & 1641705 & 8.0969 & 8.2096 & TRN \\
\hline CHEMBL 3889558 & 1641705 & 7.7212 & 7.3078 & TST \\
\hline CHEMBL3924793 & 1641705 & 9.699 & 9.4944 & TRN \\
\hline CHEMBL3909334 & 1641705 & 7.7212 & 8.0785 & TRN \\
\hline CHEMBL3936674 & 1641705 & 8.3979 & 8.6091 & TST \\
\hline CHEMBL3901593 & 1641705 & 9.699 & 9.562999 & э999999999 \\
\hline CHEMBL 3922288 & 1641705 & 9.3979 & 9.4032 & TRN \\
\hline CHEMBL3889509 & 1641705 & 6.6716 & 6.4604 & TRN \\
\hline CHEMBL3950370 & 1641705 & 6.0 & 7.4905 & TST \\
\hline CHEMBL3910324 & 1641705 & 7.6383 & 6.5405 & TRN \\
\hline CHEMBL 3901464 & 1641705 & 9.0458 & 8.3355 & TST \\
\hline CHEMBL 3929898 & 1641705 & 7.1612 & 6.8259 & TST \\
\hline CHEMBL3947800 & 1641705 & 7.0655 & 6.3605 & TRN \\
\hline CHEMBL3920825 & 1641705 & 9.0 & 9.1471 & TRN \\
\hline CHEMBL3957604 & 1641705 & 8.5229 & 8.3019 & TRN \\
\hline
\end{tabular}




\begin{tabular}{|c|c|c|c|c|c|}
\hline \multirow[b]{2}{*}{ CHEMBL3919665 } & \multicolumn{5}{|c|}{ Supplemental Table S2.txt } \\
\hline & 1641705 & 6.0 & 6.8985 & TST & \\
\hline CHEMBL3924304 & 1641705 & 8.0969 & 7.7974 & TRN & \\
\hline CHEMBL3916939 & 1641705 & 9.699 & 9.7733 & TRN & \\
\hline CHEMBL3967309 & 1641705 & 9.3979 & 9.3942 & TRN & \\
\hline CHEMBL 3945721 & 1641705 & 8.301 & 8.3558 & TRN & \\
\hline CHEMBL3976451 & 1641705 & 7.6778 & 7.571006 & 0000000001 & TRN \\
\hline CHEMBL3929554 & 1641705 & 9.2218 & 10.1784 & TST & \\
\hline CHEMBL3960876 & 1641705 & 9.3979 & 9.1817 & TRN & \\
\hline CHEMBL3915170 & 1641705 & 8.301 & 9.2195 & TST & \\
\hline CHEMBL3941640 & 1641705 & 8.699 & 8.1225 & TST & \\
\hline CHEMBL3909826 & 1641705 & 7.0555 & 6.0002 & TST & \\
\hline CHEMBL3948386 & 1641705 & 9.0969 & 8.759 & TRN & \\
\hline CHEMBL3896338 & 1641705 & 9.301 & 9.5438 & TRN & \\
\hline CHEMBL3940215 & 1641705 & 7.8861 & 8.087 & TRN & \\
\hline CHEMBL3917637 & 1641705 & 9.2218 & 10.3858 & TST & \\
\hline CHEMBL3938017 & 1641705 & 9.699 & 9.4254 & TRN & \\
\hline CHEMBL3965448 & 1641705 & 10.5229 & 10.8712 & TRN & \\
\hline CHEMBL3889517 & 1641705 & 9.0 & 9.026 & TRN & \\
\hline CHEMBL3917002 & 1641705 & 10.0 & 9.6376 & TRN & \\
\hline CHEMBL3901595 & 1641705 & 9.1549 & 9.788 & TST & \\
\hline CHEMBL3906783 & 1641705 & 9.3979 & 10.1776 & TST & \\
\hline CHEMBL 3948843 & 1641705 & 8.0 & 8.2204 & TST & \\
\hline CHEMBL3893763 & 1641705 & 8.301 & 8.3356 & TRN & \\
\hline CHEMBL3911885 & 1641705 & 7.8239 & 7.5287 & TRN & \\
\hline CHEMBL3957158 & 1641705 & 9.301 & 9.1342 & TST & \\
\hline CHEMBL3905158 & 1641705 & 7.8861 & 6.7368 & TRN & \\
\hline CHEMBL3951181 & 1641705 & 6.0 & 7.1342 & TST & \\
\hline CHEMBL3939566 & 1641705 & 8.5229 & 7.8528 & TRN & \\
\hline CHEMBL3962716 & 1641705 & 6.0 & 7.4002 & TRN & \\
\hline CHEMBL3965904 & 1641705 & 10.0 & 9.9667 & TST & \\
\hline CHEMBL3981419 & 1641705 & 8.0458 & 7.0921 & TST & \\
\hline CHEMBL3927869 & 1641705 & 8.5229 & 8.5159 & TRN & \\
\hline CHEMBL 3944488 & 1641705 & 10.0 & 9.8374 & TRN & \\
\hline CHEMBL3979560 & 1641705 & 7.7959 & 6.9335 & TRN & \\
\hline CHEMBL3920671 & 1641705 & 8.5229 & 8.687999 & 9999999999 & TRN \\
\hline CHEMBL3915503 & 1641705 & 7.585 & 7.4196 & TST & \\
\hline CHEMBL3946652 & 1641705 & 7.9586 & 8.0612 & TRN & \\
\hline CHEMBL3899688 & 1641705 & 9.0 & 9.035 & TRN & \\
\hline CHEMBL 3975194 & 1641705 & 7.4089 & 7.2002 & TST & \\
\hline CHEMBL3899162 & 1641705 & 9.5229 & 9.7062 & TRN & \\
\hline CHEMBL3915313 & 1641705 & 6.0 & 6.5424 & TRN & \\
\hline CHEMBL3952017 & 1641705 & 8.699 & 8.5613 & TRN & \\
\hline CHEMBL3958861 & 1641705 & 9.3979 & 9.0034 & TRN & \\
\hline CHEMBL3909605 & 1641705 & 6.0 & 7.392 & TRN & \\
\hline CHEMBL3986584 & 1641705 & 9.0 & 8.9198 & TRN & \\
\hline CHEMBL3985102 & 1641705 & 8.0 & 7.1145 & TRN & \\
\hline CHEMBL3980737 & 1641705 & 6.0 & 6.5677 & TRN & \\
\hline CHEMBL3891937 & 1641705 & 6.0 & 6.8545 & TRN & \\
\hline
\end{tabular}


Supplemental Table S2.txt

\begin{tabular}{|c|c|c|c|c|c|}
\hline CHEMBL3944525 & 1641705 & 8.699 & 8.3084 & TST & \\
\hline CHEMBL3952926 & 1641705 & 9.1549 & 9.1648 & TRN & \\
\hline CHEMBL3960177 & 1641705 & 6.4868 & 5.8304 & TST & \\
\hline CHEMBL3912257 & 1641705 & 7.9208 & 8.4621 & TRN & \\
\hline CHEMBL3914049 & 1641705 & 9.3979 & 8.9959 & TRN & \\
\hline CHEMBL3926220 & 1641705 & 9.0 & 8.7293 & TRN & \\
\hline CHEMBL3928955 & 1641705 & 7.3565 & 8.1456 & TRN & \\
\hline CHEMBL3953754 & 1641705 & 6.0 & 6.7471 & TRN & \\
\hline CHEMBL3890238 & 1641705 & 9.0 & 7.181 & TST & \\
\hline CHEMBL3964431 & 1641705 & 7.1192 & 6.9666 & TRN & \\
\hline CHEMBL3933102 & 1641705 & 10.3979 & 10.7239 & TRN & \\
\hline CHEMBL3904265 & 1641705 & 6.0 & 6.2923 & TRN & \\
\hline CHEMBL3981780 & 1641705 & 10.0 & 9.5791 & TRN & \\
\hline CHEMBL 3911044 & 1641705 & 6.0 & 7.1375 & TRN & \\
\hline CHEMBL3976884 & 1641705 & 8.301 & 8.4818 & TRN & \\
\hline CHEMBL3946178 & 1641705 & 9.0969 & 8.0075 & TST & \\
\hline CHEMBL3915901 & 1641705 & 9.2218 & 9.1547 & TRN & \\
\hline CHEMBL3954705 & 1641705 & 6.0 & 7.1646 & TRN & \\
\hline CHEMBL3926489 & 1641705 & 8.1549 & 8.2861 & TRN & \\
\hline CHEMBL3938195 & 1641705 & 10.0 & 8.75 & TST & \\
\hline CHEMBL3894399 & 1641705 & 7.3872 & 7.5564 & TRN & \\
\hline CHEMBL3981986 & 1641705 & 8.1549 & 7.9134 & TRN & \\
\hline CHEMBL3922799 & 1641705 & 9.301 & 9.5989 & TRN & \\
\hline CHEMBL3893139 & 1641705 & 9.1549 & 10.4481 & TST & \\
\hline CHEMBL3956545 & 1641705 & 8.699 & 8.138 & TRN & \\
\hline CHEMBL3944548 & 1641705 & 7.1308 & 7.3187 & TRN & \\
\hline CHEMBL3896885 & 1641705 & 8.3979 & 8.3402 & TRN & \\
\hline CHEMBL3984895 & 1641705 & 9.699 & 9.9165 & TRN & \\
\hline CHEMBL3911564 & 1641705 & 7.9208 & 7.1965 & TST & \\
\hline CHEMBL3908689 & 1641705 & 8.5229 & 9.4839 & TST & \\
\hline CHEMBL3980335 & 1641705 & 7.5086 & 7.2621 & TRN & \\
\hline CHEMBL3900088 & 1641705 & 6.0 & 7.7589 & TST & \\
\hline CHEMBL3897977 & 1641705 & 6.0 & 6.5028 & TRN & \\
\hline CHEMBL3929513 & 1641705 & 10.5229 & 10.6332 & TRN & \\
\hline CHEMBL3971268 & 1641705 & 9.1549 & 9.1268 & TRN & \\
\hline CHEMBL3939054 & 1641705 & 8.699 & 8.6236 & TRN & \\
\hline CHEMBL3982937 & 1641705 & 8.699 & 8.738999 & 9999999999 & TRN \\
\hline CHEMBL3946481 & 1641705 & 6.0 & 6.3775 & TST & \\
\hline CHEMBL3902783 & 1641705 & 9.0 & 8.7714 & TRN & \\
\hline CHEMBL3969943 & 1641705 & 8.699 & 8.9856 & TRN & \\
\hline CHEMBL3954866 & 1641705 & 7.9208 & 7.5798 & TST & \\
\hline CHEMBL3930265 & 1641705 & 9.0 & 9.0242 & TRN & \\
\hline CHEMBL3903806 & 1641705 & 6.9208 & 6.754 & TRN & \\
\hline CHEMBL3905548 & 1641705 & 7.8539 & 7.9705 & TRN & \\
\hline CHEMBL3958613 & 1641705 & 7.699 & 6.9484 & TST & \\
\hline CHEMBL3957645 & 1641705 & 7.7447 & 8.1108 & TRN & \\
\hline CHEMBL3982094 & 1641705 & 10.0 & 9.6549 & TRN & \\
\hline CHEMBL3895727 & 1641705 & 6.0 & 6.5681 & TRN & \\
\hline
\end{tabular}


Supplemental Table s2.txt

\begin{tabular}{|c|c|c|c|c|c|}
\hline CHEMBL3945544 & 1641705 & 8.0969 & 8.0104 & TRN & \\
\hline CHEMBL3907923 & 1641705 & 7.3468 & 7.526 & TRN & \\
\hline CHEMBL3945825 & 1641705 & 9.0969 & 8.7299 & TRN & \\
\hline CHEMBL3939451 & 1641705 & 7.4949 & 7.9441 & TRN & \\
\hline CHEMBL3926188 & 1641705 & 10.0 & 8.4208 & TST & \\
\hline CHEMBL3935010 & 1641705 & 9.3979 & 8.6386 & TST & \\
\hline CHEMBL3980147 & 1641705 & 8.0969 & 8.6176 & TRN & \\
\hline CHEMBL3930874 & 1641705 & 7.8861 & 8.1791 & TRN & \\
\hline CHEMBL3922934 & 1641705 & 9.301 & 9.0689 & TRN & \\
\hline CHEMBL3912624 & 1641705 & 7.9208 & 7.3235 & TRN & \\
\hline CHEMBL3942917 & 1641705 & 9.699 & 10.1248 & TRN & \\
\hline CHEMBL3899546 & 1641705 & 9.0458 & 9.4444 & TRN & \\
\hline CHEMBL3905407 & 1641705 & 9.699 & 9.3907 & TRN & \\
\hline CHEMBL3901174 & 1641705 & 7.7696 & 7.7859 & TRN & \\
\hline CHEMBL3962407 & 1641705 & 9.0 & 8.3858 & TRN & \\
\hline CHEMBL3892599 & 1641705 & 6.0 & 7.3423 & TST & \\
\hline CHEMBL3943909 & 1641705 & 6.0 & 6.5589 & TRN & \\
\hline CHEMBL3948482 & 1641705 & 8.699 & 8.552999 & 9999999999 & TRN \\
\hline CHEMBL3931541 & 1641705 & 9.0 & 7.9223 & TST & \\
\hline CHEMBL3931773 & 1641705 & 8.699 & 7.6268 & TST & \\
\hline CHEMBL3952853 & 1641705 & 9.0 & 8.6811 & TST & \\
\hline CHEMBL3963309 & 1641705 & 8.0969 & 8.5583 & TRN & \\
\hline CHEMBL3896010 & 1641705 & 6.0 & 6.7713 & TST & \\
\hline CHEMBL3897673 & 1641705 & 7.8861 & 8.0125 & TRN & \\
\hline CHEMBL3892372 & 1641705 & 8.0969 & 8.1076 & TST & \\
\hline CHEMBL3960898 & 1641705 & 8.1549 & 7.883999 & 799999999995 & TST \\
\hline CHEMBL3976529 & 1641705 & 8.5229 & 8.3434 & TRN & \\
\hline CHEMBL3984315 & 1641705 & 9.699 & 9.31 & TST & \\
\hline CHEMBL3947052 & 1641705 & 6.0 & 7.1344 & TRN & \\
\hline CHEMBL 3902563 & 1641705 & 9.5229 & 10.0858 & TRN & \\
\hline CHEMBL3935178 & 1641705 & 10.0458 & 9.95 & TRN & \\
\hline CHEMBL3945622 & 1641705 & 9.5229 & 9.895 & TRN & \\
\hline CHEMBL3916493 & 1641705 & 8.699 & 8.982999 & 9999999999 & TRN \\
\hline CHEMBL 3940820 & 1641705 & 7.4437 & 6.7973 & TRN & \\
\hline CHEMBL3980404 & 1641705 & 8.301 & 8.7247 & TRN & \\
\hline CHEMBL3966967 & 1641705 & 7.0706 & 7.0924 & TRN & \\
\hline CHEMBL 3889521 & 1641705 & 8.5229 & 8.8903 & TRN & \\
\hline CHEMBL3940671 & 1641705 & 9.0969 & 9.5444 & TRN & \\
\hline CHEMBL3978395 & 1641705 & 7.8239 & 8.1255 & TST & \\
\hline CHEMBL3954311 & 1641705 & 8.301 & 8.2966 & TRN & \\
\hline CHEMBL3930998 & 1641705 & 9.0458 & 8.8862 & TRN & \\
\hline CHEMBL3918566 & 1641705 & 9.5229 & 9.0176 & TRN & \\
\hline CHEMBL3973093 & 1641705 & 7.8861 & 7.5748 & TST & \\
\hline CHEMBL3973507 & 1641705 & 8.699 & 6.9809 & TST & \\
\hline CHEMBL3911829 & 1641705 & 8.699 & 8.9829 & TRN & \\
\hline CHEMBL3954817 & 1641705 & 6.1911 & 6.9571 & TRN & \\
\hline CHEMBL3935066 & 1641705 & 7.4949 & 7.7458 & TRN & \\
\hline CHEMBL3955361 & 1641705 & 7.3372 & 7.5718 & TST & \\
\hline
\end{tabular}


Supplemental Table S2.txt

\begin{tabular}{|c|c|c|c|c|c|}
\hline CHEMBL 3938257 & 1641705 & 7.9208 & 7.1065 & TRN & \\
\hline CHEMBL 3956730 & 1641705 & 7.4815 & 7.916 & TRN & \\
\hline CHEMBL3917536 & 1641705 & 8.5229 & 8.8492 & TRN & \\
\hline CHEMBL 3907084 & 1641705 & 6.857 & 5.5901 & TST & \\
\hline CHEMBL 3924220 & 1641705 & 9.3979 & 9.4555 & TRN & \\
\hline CHEMBL3968775 & 1641705 & 8.699 & 8.4907 & TST & \\
\hline CHEMBL 3947883 & 1641705 & 7.301 & 7.9319 & TRN & \\
\hline CHEMBL3953419 & 1641705 & 8.0 & 8.0538 & TRN & \\
\hline CHEMBL3908774 & 1641705 & 9.0 & 8.9041 & TRN & \\
\hline CHEMBL3973935 & 1641705 & 7.0 & 6.0221 & TST & \\
\hline CHEMBL3971783 & 1641705 & 8.2218 & 8.3286 & TRN & \\
\hline CHEMBL3893735 & 1641705 & 6.0 & 6.3568 & TRN & \\
\hline CHEMBL3906618 & 1641705 & 10.0 & 9.859 & TRN & \\
\hline CHEMBL3982019 & 1641705 & 9.0458 & 8.876 & TRN & \\
\hline CHEMBL 3973424 & 1641705 & 10.0969 & 10.2271 & TRN & \\
\hline CHEMBL3972275 & 1641705 & 6.7932 & 6.6928 & TRN & \\
\hline CHEMBL3948006 & 1641705 & 8.301 & 8.3454 & TRN & \\
\hline CHEMBL3969454 & 1641705 & 8.2218 & 8.4197 & TRN & \\
\hline CHEMBL 3941871 & 1641705 & 8.0969 & 7.4372 & TRN & \\
\hline CHEMBL3969761 & 1641705 & 7.9586 & 7.8204 & TRN & \\
\hline CHEMBL 3892891 & 1641705 & 7.8861 & 7.5914 & TRN & \\
\hline CHEMBL 3968473 & 1641705 & 9.301 & 9.735 & TRN & \\
\hline CHEMBL3909103 & 1641705 & 8.699 & 9.1389 & TRN & \\
\hline CHEMBL 3962314 & 1641705 & 9.0 & 8.6366 & TRN & \\
\hline CHEMBL3958942 & 1641705 & 9.5229 & 9.6347 & TRN & \\
\hline CHEMBL 3953411 & 1641705 & 8.301 & 8.052 & TRN & \\
\hline CHEMBL 3911273 & 1641705 & 8.5229 & 8.9588 & TRN & \\
\hline CHEMBL3959005 & 1641705 & 6.0 & 6.9358 & TST & \\
\hline CHEMBL3952618 & 1641705 & 8.0969 & 8.405 & TRN & \\
\hline CHEMBL3976977 & 1641705 & 9.699 & 9.5373 & TRN & \\
\hline CHEMBL 3900321 & 1641705 & 8.1549 & 8.0401 & TRN & \\
\hline CHEMBL3926055 & 1641705 & 7.4089 & 7.6064 & TRN & \\
\hline CHEMBL3964457 & 1641705 & 8.699 & 8.636006 & $\partial 000000001$ & TRN \\
\hline CHEMBL 3946078 & 1641705 & 8.699 & 7.775 & TST & \\
\hline CHEMBL3981696 & 1641705 & 8.3979 & 7.5533 & TST & \\
\hline CHEMBL 3933722 & 1641705 & 9.3979 & 9.4525 & TRN & \\
\hline CHEMBL3931206 & 1641705 & 8.3979 & 8.4805 & TST & \\
\hline CHEMBL3954129 & 1641705 & 7.8539 & 7.778 & TRN & \\
\hline CHEMBL 3986976 & 1641705 & 9.699 & 9.8279 & TRN & \\
\hline CHEMBL3951724 & 1641705 & 7.4202 & 7.2062 & TST & \\
\hline CHEMBL 3914149 & 1641705 & 10.1549 & 10.0991 & TRN & \\
\hline CHEMBL3969967 & 1641705 & 7.7447 & 7.7562 & TST & \\
\hline CHEMBL3971912 & 1641705 & 7.6383 & 7.82299 & 99999999995 & TRN \\
\hline CHEMBL 3925801 & 1641705 & 6.9393 & 5.9318 & TRN & \\
\hline CHEMBL3901465 & 1641705 & 9.5229 & 9.2065 & TST & \\
\hline CHEMBL 3914006 & 1641705 & 8.699 & 8.7874 & TRN & \\
\hline CHEMBL 3935508 & 1641705 & 9.301 & 9.9141 & TRN & \\
\hline CHEMBL 3933191 & 1641705 & 8.5229 & 8.9238 & TRN & \\
\hline
\end{tabular}




\begin{tabular}{|c|c|c|c|c|}
\hline \multicolumn{5}{|c|}{ Supplemental Table S2.txt } \\
\hline CHEMBL3920186 & 1641705 & 10.0 & 9.8872 & TRN \\
\hline CHEMBL3957574 & 1641705 & 8.699 & 7.6239 & TRN \\
\hline CHEMBL3948300 & 1641705 & 9.5229 & 9.4068 & TRN \\
\hline CHEMBL3947600 & 1641705 & 8.5229 & 9.0949 & TRN \\
\hline CHEMBL3905008 & 1641705 & 10.0 & 9.6797 & TRN \\
\hline CHEMBL 3951449 & 1641705 & 7.9586 & 7.9991 & TRN \\
\hline CHEMBL3942252 & 1641705 & 9.301 & 9.6813 & TRN \\
\hline CHEMBL3898144 & 1641705 & 8.699 & 8.7005 & TRN \\
\hline CHEMBL3930900 & 1641705 & 10.0 & 9.639 & TRN \\
\hline CHEMBL3920283 & 1641705 & 8.5229 & 8.6376 & TRN \\
\hline CHEMBL3918038 & 1641705 & 8.2218 & 8.2584 & TRN \\
\hline CHEMBL 3942738 & 1641705 & 9.2218 & 9.1253 & TST \\
\hline CHEMBL3953266 & 1641705 & 8.3979 & 8.7088 & TRN \\
\hline CHEMBL3946403 & 1641705 & 6.0 & 7.1871 & TST \\
\hline CHEMBL3956972 & 1641705 & 6.0 & 6.7758 & TST \\
\hline CHEMBL3923710 & 1641705 & 9.0 & 9.2431 & TRN \\
\hline CHEMBL3904021 & 1641705 & 9.1549 & 9.7188 & TRN \\
\hline CHEMBL3927787 & 1641705 & 10.0 & 10.1232 & TRN \\
\hline CHEMBL3984652 & 1641705 & 8.1549 & 8.2413 & TST \\
\hline CHEMBL3939638 & 1641705 & 9.3979 & 9.2669 & TRN \\
\hline CHEMBL3974368 & 1641705 & 7.8861 & 7.7734 & TST \\
\hline CHEMBL3923034 & 1641705 & 6.0 & 6.5953 & TRN \\
\hline CHEMBL3960707 & 1641705 & 9.0 & 8.5699 & TRN \\
\hline CHEMBL 3891171 & 1641705 & 9.1549 & 9.1476 & TRN \\
\hline CHEMBL3979073 & 1641705 & 8.1549 & 8.3655 & TRN \\
\hline CHEMBL3939533 & 1641705 & 7.5686 & 7.9994 & TST \\
\hline CHEMBL3985654 & 1641705 & 8.699 & 9.3712 & TST \\
\hline CHEMBL3899110 & 1641705 & 9.699 & 9.6453 & TRN \\
\hline CHEMBL3897680 & 1641705 & 7.585 & 8.0896 & TST \\
\hline CHEMBL3902263 & 1641705 & 9.5229 & 9.4741 & TRN \\
\hline CHEMBL3979997 & 1641705 & 9.699 & 9.5885 & TRN \\
\hline CHEMBL3903692 & 1641705 & 8.699 & 9.059 & TRN \\
\hline CHEMBL3899765 & 1641705 & 8.301 & 9.4508 & TST \\
\hline CHEMBL3946034 & 1641705 & 7.3468 & 6.6412 & TRN \\
\hline CHEMBL3907706 & 1641705 & 9.0 & 9.1496 & TRN \\
\hline CHEMBL3977394 & 1641705 & 9.0 & 9.4328 & TRN \\
\hline CHEMBL3941105 & 1641705 & 8.2218 & 8.4333 & TRN \\
\hline CHEMBL3953137 & 1641705 & 7.5229 & 7.6045 & TST \\
\hline CHEMBL3938031 & 1641705 & 6.0 & 7.1023 & TST \\
\hline CHEMBL3955899 & 1641705 & 7.5528 & 6.5922 & TRN \\
\hline CHEMBL3893756 & 1641705 & 6.9788 & 7.254 & TST \\
\hline CHEMBL3931250 & 1641705 & 10.0 & 10.3354 & TRN \\
\hline CHEMBL3951407 & 1641705 & 8.3979 & 8.4243 & TRN \\
\hline CHEMBL 3894383 & 1641705 & 6.0 & 6.8624 & TRN \\
\hline CHEMBL3923655 & 1641705 & 6.0 & 6.706 & TST \\
\hline CHEMBL3940414 & 1641705 & 6.0 & 7.3021 & TST \\
\hline CHEMBL3975786 & 1641705 & 9.0 & 8.8612 & TRN \\
\hline CHEMBL3965345 & 1641705 & 9.0 & 8.9616 & TRN \\
\hline
\end{tabular}


Supplemental Table S2.txt

\begin{tabular}{|c|c|c|c|c|}
\hline 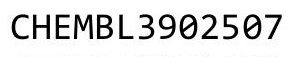 & - & & 7707 & 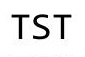 \\
\hline HEMBL3951123 & 641705 & 9.0969 & 9.6386 & -5 \\
\hline HEMBL3950882 & 541705 & 8.0458 & 9051 & \\
\hline & 705 & & 3381 & \\
\hline AEMBL & 705 & 6.0 & 0877 & $\mathrm{RN}$ \\
\hline AEMBL3973996 & 641705 & 9.0 & 603 & \\
\hline HEMBL3909449 & 641705 & 7.8539 & .2942 & \\
\hline HEMBL3919061 & 705 & 9.5229 & 1141 & \\
\hline AEMBL3S & 705 & 7.7447 & 6644 & \\
\hline HEMBL3982523 & 705 & 6.4123 & 0578 & \\
\hline HEMBL3960729 & 705 & 8.5229 & 7173 & \\
\hline HEMBL3892967 & 705 & 7.2076 & 2333 & \\
\hline HEMBL3958656 & 64 & 8.0969 & 8235 & \\
\hline HEMBL3 & 05 & 301 & 8981 & \\
\hline HEMBL3 & 105 & 599 & 757 & \\
\hline HEMBL3890345 & 705 & 6.0 & 9278 & \\
\hline HEMBL3933330 & 705 & 9.5229 & 7753 & \\
\hline HEMBL3S & 164 & 10 & 2598 & \\
\hline HEM & 6 & 99 & 525 & \\
\hline HEMBL3 & 05 & 9. & 956 & \\
\hline HEMBL3905579 & 705 & 9.699 & 5941 & \\
\hline AEMBL3961060 & 25 & 655 & & \\
\hline HEMBL3 & 164 & 9.5229 & 467 & KIV \\
\hline HEN & 6 & 9. & 911 & \\
\hline HEM & 25 & 218 & & \\
\hline HEMBL3901898 & $\partial 5$ & 7.0362 & 751 & \\
\hline AEMBL3951373 & 62 & 8.0969 & & \\
\hline HEMBL3S & 64 & 6 & 18 & I \\
\hline HEN & - & 99 & 07 & RN \\
\hline 608 & 25 & 10.0 & 49 & RN \\
\hline HEMBL3983335 & 05 & 9.0 & 891 & $\mathrm{RN}$ \\
\hline HEMBL3954853 & 35 & 9. & 1091 & ГRN \\
\hline AEMBL3 & 64 & & 078 & $\mathrm{RN}$ \\
\hline 28 & 5 & 309 & 44 & ST \\
\hline 76 & 25 & 8. & 859 & $\mathrm{RN}$ \\
\hline AEMBL3906220 & 25 & 7.4685 & 802 & TRN \\
\hline HEMBL3892613 & 05 & 9.699 & 918 & TRN \\
\hline HEN & & & 803 & RN \\
\hline 472 & 164 & 10 & 2167 & TRN \\
\hline HEMBL3 & & 9 . & 102 & TRN \\
\hline AEMBL3912216 & 105 & 7.0506 & 664 & TRN \\
\hline HEMBL3933703 & 705 & 8.2218 & 687 & RN \\
\hline & & & & (DN \\
\hline HEMBL3 & 164 & 8.5229 & 9677 & (2) \\
\hline HEMBL 3898201 & 105 & 7.8239 & 6955 & ST \\
\hline AEMBL3907611 & 705 & 8.5229 & 52 & $\mathrm{R}$ \\
\hline LHEMBL 394 & & & & \\
\hline בתחמבת & 54170 & & & \\
\hline
\end{tabular}

Page 933 


\begin{tabular}{|c|c|c|c|c|c|c|}
\hline & & \multicolumn{5}{|c|}{ Supplemental Table S2.txt } \\
\hline CHEMBL3985138 & 1641705 & 9.699 & 9.6558 & TRN & & \\
\hline CHEMBL3944980 & 1641705 & 8.0 & 8.5499 & TRN & & \\
\hline CHEMBL3951216 & 1641705 & 9.0 & 8.8976 & TRN & & \\
\hline CHEMBL3963918 & 1641705 & 9.3979 & 9.4364 & TRN & & \\
\hline CHEMBL3927483 & 1641705 & 6.0 & 7.6701 & TST & & \\
\hline CHEMBL3903224 & 1641705 & 7.9208 & 7.7304 & TRN & & \\
\hline CHEMBL3967827 & 1641705 & 8.0 & 8.1086 & TST & & \\
\hline CHEMBL3911395 & 1641705 & 6.71899 & 999999995 & 99 & 6.4501 & TRN \\
\hline CHEMBL3909552 & 1641705 & 8.0969 & 7.4256 & TST & & \\
\hline CHEMBL3948102 & 1641705 & 9.2218 & 9.2137 & TRN & & \\
\hline CHEMBL3962429 & 1641705 & 8.5229 & 8.7426 & TRN & & \\
\hline CHEMBL3952669 & 1641705 & 9.699 & 9.0011 & TST & & \\
\hline CHEMBL3963750 & 1641705 & 8.5229 & 8.4373 & TRN & & \\
\hline CHEMBL3903164 & 1641705 & 8.0458 & 7.9288 & TRN & & \\
\hline CHEMBL374960 & 379860 & 7.3188 & 7.284 & TRN & & \\
\hline CHEMBL215145 & 379860 & 7.4685 & 7.2869 & TRN & & \\
\hline CHEMBL216046 & 379860 & 6.5817 & 6.9439 & TST & & \\
\hline CHEMBL219414 & 379860 & 7.5686 & 7.4611 & TRN & & \\
\hline CHEMBL385984 & 379860 & 6.8928 & 7.5423 & TRN & & \\
\hline CHEMBL213319 & 379860 & 6.8356 & 6.8463 & TRN & & \\
\hline CHEMBL218875 & 379860 & 6.5834 & 6.8556 & TRN & & \\
\hline CHEMBL219365 & 379860 & 6.7545 & 6.8556 & TRN & & \\
\hline CHEMBL407659 & 379860 & 6.8297 & 7.284 & TRN & & \\
\hline CHEMBL216017 & 379860 & 7.7447 & 7.4811 & TRN & & \\
\hline CHEMBL215679 & 379860 & 7.3279 & 6.8556 & TRN & & \\
\hline CHEMBL264837 & 379860 & 7.7212 & 7.5423 & TRN & & \\
\hline CHEMBL269324 & 379860 & 7.1805 & 6.8857 & TRN & & \\
\hline CHEMBL220235 & 379860 & 7.0458 & 6.9009 & TRN & & \\
\hline CHEMBL 213366 & 379860 & 7.0862 & 7.0647 & TRN & & \\
\hline CHEMBL409178 & 379860 & 6.9393 & 6.7062 & TRN & & \\
\hline CHEMBL213418 & 379860 & 5.21899 & 999999999 & 99 & 6.9373 & וב \\
\hline CHEMBL438644 & 379860 & 7.0809 & 7.4611 & TRN & & \\
\hline CHEMBL378173 & 379860 & 5.8941 & 6.9787 & TST & & \\
\hline CHEMBL384093 & 379860 & 5.9176 & 6.9759 & TST & & \\
\hline CHEMBL386206 & 379860 & 6.585 & 6.688 & TRN & & \\
\hline CHEMBL 219563 & 379860 & 7.0605 & 7.2998 & TRN & & \\
\hline CHEMBL265173 & 379860 & 7.699 & 7.5423 & TRN & & \\
\hline CHEMBL 384621 & 379860 & 6.4622 & 6.8857 & TRN & & \\
\hline CHEMBL212353 & 379860 & 6.7423 & 6.7062 & TRN & & \\
\hline CHEMBL261904 & 379860 & 7.0506 & 7.3291 & TRN & & \\
\hline CHEMBL386531 & 379860 & 7.4202 & 6.9767 & TST & & \\
\hline CHEMBL215358 & 379860 & 7.8539 & 7.3687 & TRN & & \\
\hline CHEMBL265035 & 379860 & 6.9469 & 7.1251 & TRN & & \\
\hline CHEMBL220084 & 379860 & 7.1024 & 7.3239 & TRN & & \\
\hline CHEMBL379870 & 379860 & 6.9547 & 6.9982 & TRN & & \\
\hline CHEMBL405750 & 379860 & 7.0177 & 6.8463 & TRN & & \\
\hline CHEMBL415578 & 379860 & 6.699 & 6.8674 & TRN & & \\
\hline CHEMBL 379992 & 379860 & 6.0 & 6.9777 & TST & & \\
\hline
\end{tabular}




\begin{tabular}{|c|c|c|c|c|}
\hline \multicolumn{5}{|c|}{ Supplemental Table s2.txt } \\
\hline CHEMBL378486 & 379860 & 7.6198 & 7.4611 & TRN \\
\hline CHEMBL 210024 & 379860 & 8.0 & 6.9639 & TST \\
\hline CHEMBL219360 & 379860 & 7.5686 & 7.4611 & TRN \\
\hline CHEMBL384338 & 379860 & 6.9508 & 7.2119 & TRN \\
\hline CHEMBL 213768 & 379860 & 7.2147 & 7.3874 & TRN \\
\hline CHEMBL267717 & 379860 & 6.7878 & 6.9009 & TRN \\
\hline CHEMBL 213268 & 379860 & 7.8861 & 7.1528 & TRN \\
\hline CHEMBL213096 & 379860 & 7.3872 & 7.3442 & TRN \\
\hline CHEMBL385376 & 379860 & 7.4949 & 7.4191 & TRN \\
\hline CHEMBL428164 & 379860 & 6.5884 & 6.8556 & TRN \\
\hline CHEMBL407658 & 379860 & 6.8996 & 6.688 & TRN \\
\hline CHEMBL 386739 & 379860 & 6.8601 & 6.8463 & TST \\
\hline CHEMBL373615 & 379860 & 7.0223 & 6.8556 & TST \\
\hline CHEMBL375136 & 379860 & 7.1079 & 6.8674 & TST \\
\hline CHEMBL 386152 & 379860 & 6.0545 & 6.9462 & TST \\
\hline CHEMBL402882 & 379860 & 6.8097 & 7.0647 & TRN \\
\hline CHEMBL441694 & 379860 & 7.7212 & 7.5663 & TRN \\
\hline CHEMBL212405 & 379860 & 8.699 & 7.0328 & TST \\
\hline CHEMBL 215347 & 379860 & 7.8239 & 7.4981 & TRN \\
\hline CHEMBL 211895 & 379860 & 6.4634 & 6.8463 & TST \\
\hline CHEMBL219863 & 379860 & 6.9666 & 6.8674 & TST \\
\hline CHEMBL 300389 & 954563 & 6.5855 & 6.6835 & TRN \\
\hline CHEMBL191334 & 954563 & 3.4787 & 3.5634 & TRN \\
\hline CHEMBL135561 & 954563 & 3.7671 & 3.9499 & TRN \\
\hline CHEMBL1516890 & 954563 & 4.8445 & 4.3766 & TRN \\
\hline CHEMBL 2005886 & 954563 & 3.7446 & 4.1684 & TRN \\
\hline CHEMBL 240954 & 954563 & 3.0445 & 3.4591 & TST \\
\hline CHEMBL1643959 & 954563 & 3.5601 & 3.2337 & TRN \\
\hline CHEMBL1190711 & 954563 & 4.4685 & 3.5665 & TRN \\
\hline CHEMBL 259181 & 954563 & 2.6175 & 2.7586 & TRN \\
\hline CHEMBL1909414 & 954563 & 3.2784 & 3.6851 & TRN \\
\hline CHEMBL3186408 & 954563 & 3.5099 & 3.3065 & TST \\
\hline CHEMBL 379300 & 954563 & 6.0733 & 6.1754 & TRN \\
\hline CHEMBL399530 & 954563 & 4.5895 & 4.4975 & TRN \\
\hline CHEMBL558642 & 954563 & 2.3956 & 2.0792 & TRN \\
\hline CHEMBL192566 & 954563 & 7.0543 & 6.5194 & TST \\
\hline CHEMBL 213100 & 954563 & 3.4779 & 3.9509 & TRN \\
\hline CHEMBL92309 & 954563 & 1.2914 & 1.7143 & TST \\
\hline CHEMBL472940 & 954563 & 2.3221 & 1.9799 & TRN \\
\hline CHEMBL 373751 & 954563 & 3.2045 & 3.733 & TRN \\
\hline CHEMBL392695 & 954563 & 5.5 & 4.8519 & TRN \\
\hline CHEMBL1242367 & 954563 & 3.9118 & 3.5981 & TRN \\
\hline CHEMBL189584 & 954563 & 3.8473 & 4.0762 & TRN \\
\hline CHEMBL188678 & 954563 & 3.8764 & 4.0897 & TRN \\
\hline CHEMBL512504 & 954563 & 5.602 & 5.1754 & TRN \\
\hline CHEMBL3392440 & 954563 & 3.4412 & 3.8023 & TRN \\
\hline CHEMBL2134202 & 954563 & 4.2268 & 3.9341 & TRN \\
\hline CHEMBL577784 & 954563 & 3.4603 & 4.1421 & TRN \\
\hline
\end{tabular}




\begin{tabular}{|c|c|c|c|c|c|c|}
\hline & & \multicolumn{5}{|c|}{ Supplemental Table S2.txt } \\
\hline CHEMBL3349342 & 954563 & 5.7248 & 5.6461 & TRN & & \\
\hline CHEMBL1230020 & 954563 & 3.0257 & 3.4916 & TRN & & \\
\hline CHEMBL258844 & 954563 & 3.6015 & 3.3733 & TRN & & \\
\hline CHEMBL1673039 & 954563 & 3.5793 & \multicolumn{3}{|c|}{3.9010000000000002} & TRN \\
\hline CHEMBL483849 & 954563 & 0.6791 & 1.8959 & TST & & \\
\hline CHEMBL1357247 & 954563 & 2.4406 & 2.512 & TRN & & \\
\hline CHEMBL102714 & 954563 & 3.7545 & 3.8528 & TRN & & \\
\hline CHEMBL9470 & 954563 & 5.1139 & 4.7301 & TST & & \\
\hline CHEMBL1788116 & 954563 & 3.6849 & 3.5889 & TRN & & \\
\hline CHEMBL221137 & 954563 & 3.6206 & 3.8194 & TST & & \\
\hline CHEMBL449158 & 954563 & 6.0073 & 6.7207 & TST & & \\
\hline CHEMBL515416 & 954563 & 4.3394 & \multicolumn{3}{|c|}{4.428999999999999} & TRN \\
\hline CHEMBL65 & 954563 & 6.9722 & 6.4088 & TRN & & \\
\hline CHEMBL202721 & 954563 & 3.4515 & 3.7975 & TRN & & \\
\hline CHEMBL3199475 & 954563 & 3.2964 & 3.4312 & TRN & & \\
\hline CHEMBL1970879 & 954563 & 4.3788 & 4.1744 & TRN & & \\
\hline CHEMBL217354 & 954563 & 6.4845 & 6.32799 & 99999999 & & TRN \\
\hline CHEMBL379975 & 954563 & 5.2217 & 4.7034 & TRN & & \\
\hline CHEMBL573107 & 954563 & 4.5831 & 4.7663 & TRN & & \\
\hline CHEMBL220241 & 954563 & \multicolumn{3}{|c|}{3.5780000000000003} & 3.8114 & TRN \\
\hline CHEMBL255342 & 954563 & 3.4453 & 3.4125 & TRN & & \\
\hline CHEMBL509032 & 954563 & 5.18 & 4.8826 & TRN & & \\
\hline CHEMBL210618 & 954563 & 3.7871 & 3.3391 & TRN & & \\
\hline CHEMBL585951 & 954563 & 4.1124 & 5.1953 & TRN & & \\
\hline CHEMBL222102 & 954563 & 3.7058 & 3.4591 & TRN & & \\
\hline CHEMBL209148 & 954563 & 3.7684 & 3.6723 & TRN & & \\
\hline CHEMBL 2137530 & 954563 & 4.5046 & 4.6026 & TRN & & \\
\hline CHEMBL483847 & 954563 & 4.2195 & 4.0872 & TRN & & \\
\hline CHEMBL1186585 & 954563 & 3.7979 & 3.9731 & TRN & & \\
\hline CHEMBL 2363137 & 954563 & 4.777 & 4.333 & TST & & \\
\hline CHEMBL412142 & 954563 & 3.4915 & 3.6925 & TST & & \\
\hline CHEMBL1256459 & 954563 & 5.5601 & 6.5273 & TST & & \\
\hline CHEMBL514499 & 954563 & 6.6348 & 6.8305 & TST & & \\
\hline CHEMBL180127 & 954563 & 3.9669 & 3.6666 & TST & & \\
\hline CHEMBL1404918 & 954563 & 2.8755 & 2.4434 & TST & & \\
\hline CHEMBL 2144069 & 954563 & 4.4166 & 4.5516 & TST & & \\
\hline CHEMBL393929 & 954563 & 5.0261 & 3.7922 & TST & & \\
\hline CHEMBL1590308 & 954563 & 2.4692 & 3.0997 & TST & & \\
\hline CHEMBL367356 & 305652 & 9.8861 & 9.8587 & TRN & & \\
\hline CHEMBL369290 & 305652 & 9.2218 & 9.1852 & TRN & & \\
\hline CHEMBL360915 & 305652 & 7.0 & 7.0554 & TRN & & \\
\hline CHEMBL180763 & 305652 & 8.5952 & 8.6195 & TRN & & \\
\hline CHEMBL360956 & 305652 & 8.3298 & 8.3068 & TRN & & \\
\hline CHEMBL362213 & 305652 & 8.4841 & 7.6364 & TST & & \\
\hline CHEMBL361613 & 305652 & 9.0915 & 9.0949 & TRN & & \\
\hline CHEMBL362191 & 305652 & 8.2865 & 8.27 & TRN & & \\
\hline CHEMBL181775 & 305652 & 8.6162 & 7.0269 & TST & & \\
\hline CHEMBL182103 & 305652 & 7.0 & 7.0131 & TRN & & \\
\hline
\end{tabular}




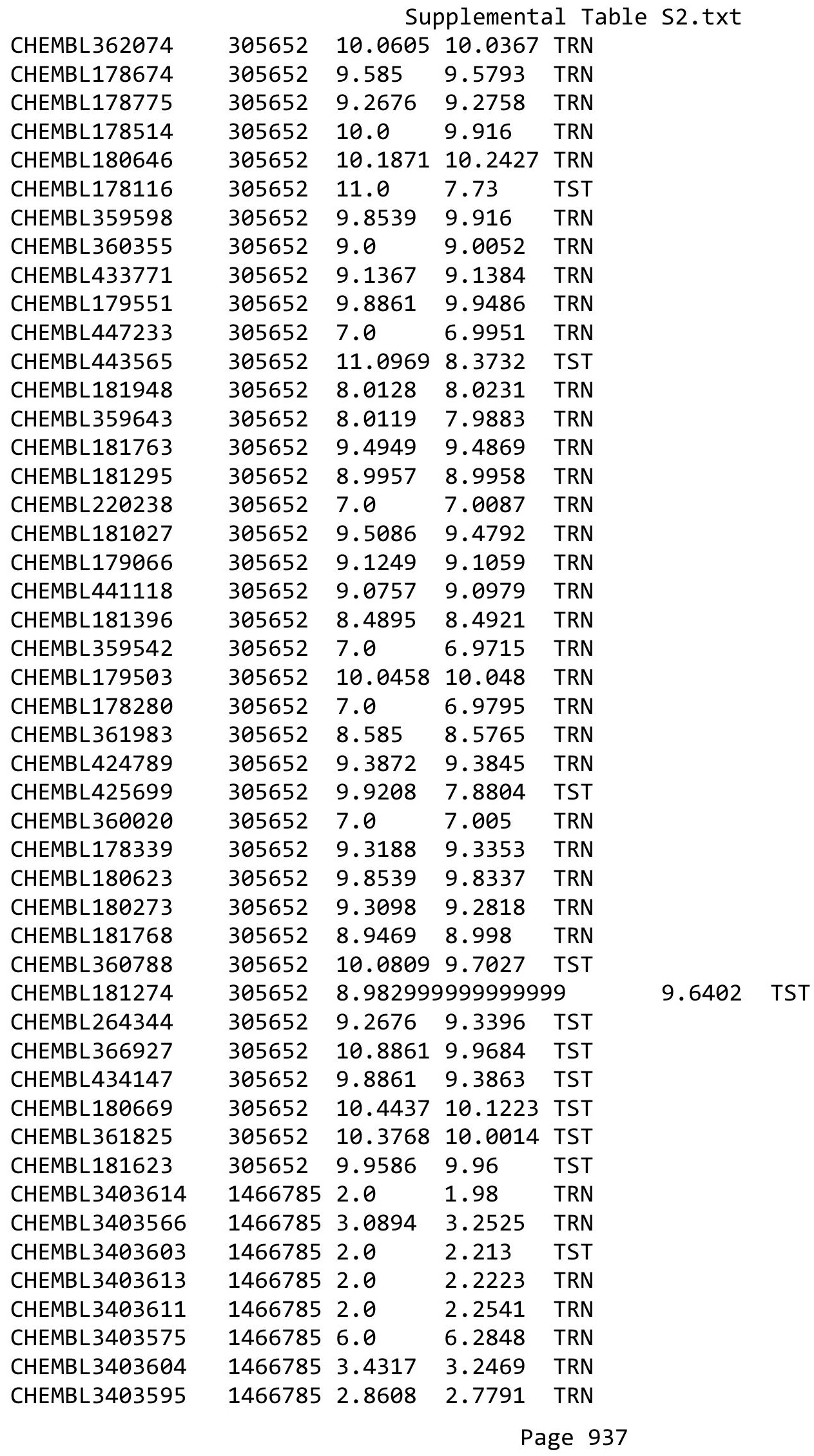


Supplemental Table S2.txt

\begin{tabular}{|c|c|c|c|c|c|}
\hline CHEMBL3403593 & 1466785 & 3.2976 & 3.0875 & TRN & \\
\hline CHEMBL3403579 & 1466785 & 6.0 & 5.48 & TRN & \\
\hline CHEMBL3403586 & 1466785 & 2.0 & 2.6599 & TRN & \\
\hline CHEMBL3403583 & 1466785 & 3.7471 & 4.1228 & TRN & \\
\hline CHEMBL3403601 & 1466785 & 2.0 & 2.2902 & TRN & \\
\hline CHEMBL3403563 & 1466785 & 6.0 & 6.1497 & TRN & \\
\hline CHEMBL3403577 & 1466785 & 6.0 & 5.7719 & TRN & \\
\hline CHEMBL3403581 & 1466785 & 6.0 & 5.6344 & TRN & \\
\hline CHEMBL3403597 & 1466785 & 2.1238 & 2.1222 & TRN & \\
\hline CHEMBL3403571 & 1466785 & 6.0 & 5.5876 & TRN & \\
\hline CHEMBL 2326022 & 1466785 & 6.0 & 6.3552 & TRN & \\
\hline CHEMBL1446457 & 1466785 & 5.8539 & 2.7377 & TST & \\
\hline CHEMBL3403584 & 1466785 & 3.3665 & 3.3111 & TRN & \\
\hline CHEMBL3403599 & 1466785 & 2.0 & 1.8623 & TRN & \\
\hline CHEMBL3403615 & 1466785 & 2.0 & 1.929 & TRN & \\
\hline CHEMBL3403573 & 1466785 & 6.0 & 6.2522 & TRN & \\
\hline CHEMBL3403594 & 1466785 & 2.0 & 2.1701 & TRN & \\
\hline CHEMBL 3403587 & 1466785 & 2.0 & 1.5696 & TRN & \\
\hline CHEMBL3403588 & 1466785 & 3.3969 & 3.1378 & TRN & \\
\hline CHEMBL3403565 & 1466785 & 6.0 & 6.1958 & TRN & \\
\hline CHEMBL3403596 & 1466785 & 3.0283 & 3.018000 & 00000000002 & TRN \\
\hline CHEMBL3403585 & 1466785 & 3.7212 & 4.6589 & TST & \\
\hline CHEMBL3403605 & 1466785 & 3.4983 & 3.1603 & TRN & \\
\hline CHEMBL3403600 & 1466785 & 2.0 & 2.2798 & TRN & \\
\hline CHEMBL3403589 & 1466785 & 2.0 & 3.4276 & TST & \\
\hline CHEMBL3403609 & 1466785 & 3.5099 & 3.6274 & TRN & \\
\hline CHEMBL3403602 & 1466785 & 1.699 & 1.4609 & TRN & \\
\hline CHEMBL3403561 & 1466785 & 6.0 & 5.4353 & TRN & \\
\hline CHEMBL3403608 & 1466785 & 3.7967 & 3.4778 & TRN & \\
\hline CHEMBL3403590 & 1466785 & 2.8536 & 2.9156 & TRN & \\
\hline CHEMBL3403578 & 1466785 & 3.9431 & 4.6306 & TRN & \\
\hline CHEMBL3403616 & 1466785 & 2.0 & 2.0499 & TRN & \\
\hline CHEMBL3403567 & 1466785 & 4.0915 & 3.9693 & TRN & \\
\hline CHEMBL3403612 & 1466785 & 2.0 & 2.3575 & TST & \\
\hline CHEMBL3403607 & 1466785 & 4.0935 & 2.8939 & TST & \\
\hline CHEMBL3403610 & 1466785 & 2.0 & 2.9952 & TST & \\
\hline CHEMBL 3403568 & 1466785 & 3.9706 & 4.2613 & TST & \\
\hline CHEMBL3403606 & 1466785 & 3.796999 & 999999999 & 2.9751 & TST \\
\hline CHEMBL3403598 & 1466785 & 3.1337 & 2.9182 & TST & \\
\hline CHEMBL3403591 & 1466785 & 2.0 & 2.3585 & TST & \\
\hline CHEMBL 75035 & 1466785 & 4.6576 & 4.2389 & TST & \\
\hline CHEMBL3403592 & 1466785 & 2.0 & 3.8279 & TST & \\
\hline CHEMBL87381 & 1503356 & 6.9245 & 6.9001 & TRN & \\
\hline CHEMBL3589735 & 1503356 & 6.2034 & 5.9557 & TRN & \\
\hline CHEMBL3589874 & 1503356 & 7.2 & 7.412999 & 7999999999 & TRN \\
\hline CHEMBL3589878 & 1503356 & 6.2573 & 6.4828 & TRN & \\
\hline CHEMBL3589725 & 1503356 & 7.0106 & 7.2147 & TRN & \\
\hline CHEMBL3589879 & 1503356 & 7.2262 & 7.0758 & TRN & \\
\hline
\end{tabular}


Supplemental Table S2.txt

\begin{tabular}{|c|c|c|c|c|c|}
\hline CHEMBL3589865 & 1503356 & 7.6968 & 7.5922 & TRN & \\
\hline CHEMBL 3589734 & 1503356 & 5.7513 & 5.8061 & TRN & \\
\hline CHEMBL3589728 & 1503356 & 7.1739 & 6.7829 & TST & \\
\hline CHEMBL 3589729 & 1503356 & 7.1871 & 7.7556 & TRN & \\
\hline CHEMBL 3589718 & 1503356 & 6.1331 & 6.1017 & TRN & \\
\hline CHEMBL 3589722 & 1503356 & 7.1844 & 6.9051 & TRN & \\
\hline CHEMBL3589876 & 1503356 & 7.5986 & 7.7855 & TRN & \\
\hline CHEMBL3589716 & 1503356 & 7.5086 & 6.9154 & TRN & \\
\hline CHEMBL 3589868 & 1503356 & 5.0 & 6.4017 & TRN & \\
\hline CHEMBL 3589875 & 1503356 & 6.341 & 6.2188 & TRN & \\
\hline CHEMBL 3589721 & 1503356 & 6.5229 & 6.5122 & TRN & \\
\hline CHEMBL 3589863 & 1503356 & 7.6478 & 6.9228 & TST & \\
\hline CHEMBL 3589732 & 1503356 & 7.2573 & 6.8995 & TRN & \\
\hline CHEMBL 3589712 & 1503356 & 7.7747 & 7.7168 & TRN & \\
\hline CHEMBL 3589724 & 1503356 & 7.5867 & 7.4668 & TRN & \\
\hline CHEMBL 3589714 & 1503356 & 7.7986 & 7.8511 & TRN & \\
\hline CHEMBL3590031 & 1503356 & 6.9393 & 6.7533 & TST & \\
\hline CHEMBL 3589877 & 1503356 & 7.2291 & 7.6188 & TRN & \\
\hline CHEMBL1271793 & 1503356 & 6.6799 & 6.7458 & TRN & \\
\hline CHEMBL 3589720 & 1503356 & 7.6364 & 7.6253 & TRN & \\
\hline CHEMBL473129 & 1503356 & 6.6676 & 7.396 & TRN & \\
\hline CHEMBL3589736 & 1503356 & 6.5287 & 5.8937 & TRN & \\
\hline CHEMBL3589869 & 1503356 & 7.7799 & 7.7623 & TRN & \\
\hline CHEMBL3589731 & 1503356 & 8.0506 & 7.3733 & TRN & \\
\hline CHEMBL 3589872 & 1503356 & 7.9788 & 7.2089 & TST & \\
\hline CHEMBL 3589733 & 1503356 & 5.1917 & 5.7719 & TRN & \\
\hline CHEMBL 3589870 & 1503356 & 6.9872 & 7.0514 & TRN & \\
\hline CHEMBL3589871 & 1503356 & 7.5243 & 7.8323 & TRN & \\
\hline CHEMBL3590029 & 1503356 & 7.0762 & 6.7513 & TRN & \\
\hline CHEMBL 3589727 & 1503356 & 7.6198 & 7.5678 & TST & \\
\hline CHEMBL 3589730 & 1503356 & 6.6055 & 6.7067 & TRN & \\
\hline CHEMBL 3589719 & 1503356 & 8.0362 & 7.607 & TRN & \\
\hline CHEMBL 3589864 & 1503356 & 7.3645 & 6.3117 & TST & \\
\hline CHEMBL 264437 & 1503356 & 8.2366 & 7.9408 & TRN & \\
\hline CHEMBL 3589723 & 1503356 & 7.3862 & 7.23799 & 99999999995 & TRN \\
\hline CHEMBL3589711 & 1503356 & 7.5784 & 7.3794 & TRN & \\
\hline CHEMBL 3589713 & 1503356 & 6.7235 & 6.8017 & TRN & \\
\hline CHEMBL 3589726 & 1503356 & 6.3316 & 6.7623 & TST & \\
\hline CHEMBL 3589862 & 1503356 & 6.3429 & 6.5245 & TST & \\
\hline CHEMBL 3589715 & 1503356 & 7.7055 & 7.0463 & TST & \\
\hline CHEMBL1089853 & 1503356 & 7.2154 & 6.9174 & TRN & \\
\hline CHEMBL 3589873 & 1503356 & 7.3251 & 7.0024 & TRN & \\
\hline CHEMBL 3589867 & 1503356 & 5.0 & 5.8554 & TST & \\
\hline CHEMBL3589717 & 1503356 & 6.9208 & 7.1561 & TRN & \\
\hline CHEMBL 20730 & 1503356 & 7.6904 & 7.525 & TST & \\
\hline CHEMBL87379 & 1503356 & 7.5834 & 7.6256 & TST & \\
\hline CHEMBL 3590030 & 1503356 & 8.0132 & 7.5214 & TST & \\
\hline CHEMBL 3589866 & 1503356 & 7.2652 & 6.9654 & TST & \\
\hline
\end{tabular}




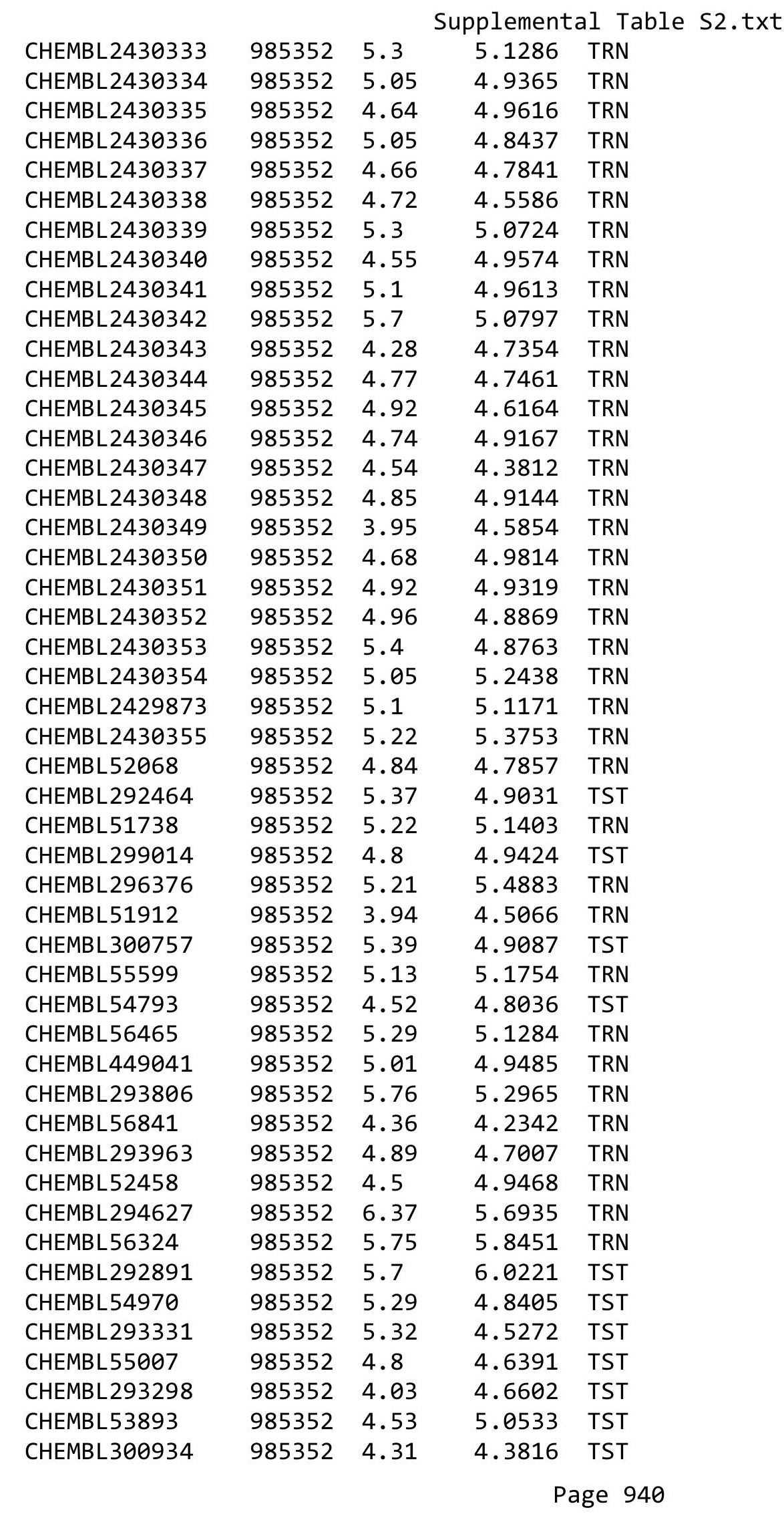




\begin{tabular}{|c|c|c|c|c|c|}
\hline \multirow[b]{2}{*}{ CHEMBL299781 } & \multicolumn{5}{|c|}{ Supplemental Table S2.txt } \\
\hline & 985352 & 4.41 & 4.6914 & TST & \\
\hline CHEMBL55998 & 985352 & 7.1 & 5.1614 & TST & \\
\hline CHEMBL56178 & 985352 & 4.69 & 4.6335 & TST & \\
\hline CHEMBL294212 & 985352 & 5.41 & 4.592 & TST & \\
\hline CHEMBL293553 & 985352 & 4.85 & 4.7597 & TST & \\
\hline CHEMBL292644 & 985352 & 4.4 & 4.5767 & TST & \\
\hline CHEMBL54318 & 985352 & 6.47 & 5.7463 & TST & \\
\hline CHEMBL292012 & 985352 & 5.01 & 5.3215 & TST & \\
\hline CHEMBL55862 & 985352 & 6.49 & 6.0379 & TST & \\
\hline CHEMBL55387 & 985352 & 5.68 & 5.1165 & TST & \\
\hline CHEMBL55271 & 985352 & 5.7 & 5.0825 & TRN & \\
\hline CHEMBL55308 & 985352 & 6.22 & 5.4387 & TST & \\
\hline CHEMBL55199 & 985352 & 6.04 & 5.8237 & TRN & \\
\hline CHEMBL55043 & 985352 & 4.6 & 4.5669 & TRN & \\
\hline CHEMBL54444 & 985352 & 5.64 & 5.3947 & TRN & \\
\hline CHEMBL54600 & 985352 & 6.4 & 6.4296 & TRN & \\
\hline CHEMBL53896 & 985352 & 5.02 & 4.698 & TRN & \\
\hline CHEMBL301086 & 985352 & 5.39 & 5.4798 & TRN & \\
\hline CHEMBL 291532 & 985352 & 6.23 & 6.4151 & TRN & \\
\hline CHEMBL433488 & 985352 & 5.52 & 5.4939 & TRN & \\
\hline CHEMBL 293780 & 985352 & 5.3 & 5.3757 & TRN & \\
\hline CHEMBL 293989 & 985352 & 6.27 & 6.4211 & TRN & \\
\hline CHEMBL57223 & 985352 & 4.7 & 4.9615 & TRN & \\
\hline CHEMBL53684 & 985352 & 5.52 & 5.4379 & TRN & \\
\hline CHEMBL58988 & 985352 & 5.52 & 5.7864 & TRN & \\
\hline CHEMBL 298823 & 985352 & 5.27 & 5.2154 & TRN & \\
\hline CHEMBL 299271 & 985352 & 5.62 & 5.6354 & TRN & \\
\hline CHEMBL292436 & 985352 & 4.1 & 4.47 & TRN & \\
\hline CHEMBL432894 & 985352 & 4.46 & 5.2086 & TRN & \\
\hline CHEMBL 301055 & 985352 & 6.52 & 6.6072 & TRN & \\
\hline CHEMBL55951 & 985352 & 7.15 & 7.2554 & TRN & \\
\hline CHEMBL 299001 & 985352 & 8.0 & 7.4791 & TRN & \\
\hline CHEMBL56135 & 985352 & 7.7 & 7.766 & TRN & \\
\hline CHEMBL 291983 & 985352 & 7.52 & 7.8446 & TRN & \\
\hline CHEMBL55187 & 985352 & 7.3 & 7.36600 & 00000000005 & TRN \\
\hline CHEMBL55186 & 985352 & 7.05 & 6.3012 & TRN & \\
\hline CHEMBL57064 & 985352 & 6.37 & 7.20100 & 00000000005 & TRN \\
\hline CHEMBL 300851 & 985352 & 7.22 & 7.005 & TRN & \\
\hline CHEMBL55757 & 985352 & 7.22 & 6.7685 & TRN & \\
\hline CHEMBL55997 & 985352 & 6.22 & 6.3176 & TRN & \\
\hline CHEMBL3982142 & 1641457 & 9.1549 & 9.5784 & TST & \\
\hline CHEMBL3919357 & 1641457 & 9.0 & 8.9101 & TRN & \\
\hline CHEMBL3967824 & 1641457 & 9.5229 & 9.9017 & TRN & \\
\hline CHEMBL 2177191 & 1641457 & 8.699 & 8.8957 & TRN & \\
\hline CHEMBL3950476 & 1641457 & 9.301 & 8.9992 & TRN & \\
\hline CHEMBL3953658 & 1641457 & 9.0 & 9.5546 & TRN & \\
\hline CHEMBL3915213 & 1641457 & 9.699 & 9.8011 & TRN & \\
\hline CHEMBL3125518 & 1641457 & 8.7447 & 8.7127 & TRN & \\
\hline
\end{tabular}

Page 941 
Supplemental Table S2.txt

\begin{tabular}{|c|c|c|c|c|}
\hline CHEMBL3965232 & 1641457 & 10.0 & 10.013 & TRN \\
\hline CHEMBL3904865 & 1641457 & 8.699 & 8.5266 & TST \\
\hline CHEMBL3958379 & 1641457 & 9.699 & 9.1777 & TRN \\
\hline CHEMBL 3891492 & 1641457 & 10.0 & 9.3706 & TRN \\
\hline CHEMBL3932076 & 1641457 & 6.0 & 7.6441 & TST \\
\hline CHEMBL3970789 & 1641457 & 9.301 & 9.5088 & TRN \\
\hline CHEMBL3955779 & 1641457 & 8.5229 & 8.9187 & TRN \\
\hline CHEMBL 3903481 & 1641457 & 9.5229 & 9.5206 & TRN \\
\hline CHEMBL 3927948 & 1641457 & 9.2218 & 9.3951 & TRN \\
\hline CHEMBL3927069 & 1641457 & 9.0 & 8.9556 & TRN \\
\hline CHEMBL3970501 & 1641457 & 8.8539 & 8.6665 & TRN \\
\hline CHEMBL 3953174 & 1641457 & 8.699 & 8.5357 & TRN \\
\hline CHEMBL3950753 & 1641457 & 8.0 & 8.9575 & TST \\
\hline CHEMBL3929164 & 1641457 & 8.301 & 9.2122 & TST \\
\hline CHEMBL3945887 & 1641457 & 9.0 & 8.8091 & TRN \\
\hline CHEMBL3949319 & 1641457 & 8.699 & 8.478 & TRN \\
\hline CHEMBL3935746 & 1641457 & 9.2218 & 9.1741 & TRN \\
\hline CHEMBL3899788 & 1641457 & 8.3979 & 8.7055 & TST \\
\hline CHEMBL3963943 & 1641457 & 8.699 & 7.3599 & TST \\
\hline CHEMBL3891309 & 1641457 & 8.3565 & 8.297 & TRN \\
\hline CHEMBL3905634 & 1641457 & 9.5229 & 9.5843 & TRN \\
\hline CHEMBL3948736 & 1641457 & 8.699 & 8.279 & TRN \\
\hline CHEMBL3894232 & 1641457 & 9.5229 & 9.3895 & TRN \\
\hline CHEMBL3929499 & 1641457 & 8.699 & 9.4 & TRN \\
\hline CHEMBL 3986817 & 1641457 & 9.3979 & 9.1367 & TRN \\
\hline CHEMBL3923297 & 1641457 & 8.3979 & 9.5257 & TST \\
\hline CHEMBL3979336 & 1641457 & 7.585 & 7.3133 & TRN \\
\hline CHEMBL3904550 & 1641457 & 8.0969 & 8.0928 & TRN \\
\hline CHEMBL3971528 & 1641457 & 8.1549 & 8.6302 & TST \\
\hline CHEMBL 3897481 & 1641457 & 8.8861 & 8.9509 & TRN \\
\hline CHEMBL 3953228 & 1641457 & 8.2596 & 8.9228 & TST \\
\hline CHEMBL3934002 & 1641457 & 9.699 & 9.7536 & TRN \\
\hline CHEMBL3969208 & 1641457 & 8.2218 & 7.5535 & TRN \\
\hline CHEMBL3963132 & 1641457 & 8.3979 & 8.8737 & TRN \\
\hline CHEMBL3961096 & 1641457 & 9.5229 & 9.5799 & TRN \\
\hline CHEMBL 3893802 & 1641457 & 9.0 & 8.5043 & TRN \\
\hline CHEMBL3910494 & 1641457 & 8.5229 & 6.9953 & TST \\
\hline CHEMBL 3896895 & 1641457 & 6.9747 & 7.2202 & TRN \\
\hline CHEMBL3919318 & 1641457 & 8.0458 & 8.2669 & TRN \\
\hline CHEMBL 3125537 & 1641457 & 10.0 & 9.7179 & TRN \\
\hline CHEMBL3910330 & 1641457 & 8.2218 & 8.3913 & TRN \\
\hline CHEMBL3983498 & 1641457 & 10.0 & 9.3111 & TRN \\
\hline CHEMBL3929489 & 1641457 & 9.0458 & 8.9427 & TRN \\
\hline CHEMBL3933541 & 1641457 & 9.2218 & 8.0241 & TRN \\
\hline CHEMBL3904755 & 1641457 & 8.0969 & 7.5693 & TRN \\
\hline CHEMBL3952401 & 1641457 & 10.0 & 9.5551 & TRN \\
\hline CHEMBL3968648 & 1641457 & 9.3979 & \multicolumn{2}{|c|}{9.722999999999999} \\
\hline CHEMBL3914715 & 1641457 & 8.5229 & \multicolumn{2}{|c|}{8.556000000000001} \\
\hline
\end{tabular}




$$
\text { Supplemental Table S2.txt }
$$

\begin{tabular}{|c|c|c|c|c|}
\hline IEI & 457 & & & $\mathrm{~T}$ \\
\hline & 641457 & 9.1549 & & \\
\hline $\mathrm{AFN}$ & & & & \\
\hline AEMBL & 457 & 6.0 & & $2 \mathrm{~N}$ \\
\hline AEMBL3967671 & 457 & 7.2757 & & \\
\hline HEMBL3125521 & 641457 & 10.0 & . 9118 & \\
\hline HEMBL & 57 & 8.1549 & & \\
\hline AEMBL: & & & & RN \\
\hline AEMBL3S & 457 & 10.0 & & \\
\hline HEMBL3975518 & 457 & 6.0 & & \\
\hline HEMBL3974184 & 457 & 6.9101 & 63 & \\
\hline AEMBL3 & 57 & 10.0 & 62 & \\
\hline AEMBL3 & & & & RN \\
\hline HEMBL3 & 57 & 8.301 & & \\
\hline AEMBL3 & 57 & 599 & & \\
\hline AEMBL & 57 & 8.3979 & 99 & RN \\
\hline AEMBL3 & 1 & 9 . & & . \\
\hline HEMBL3 & & 01 & & \\
\hline HEMBL3 & & 8.8239 & & \\
\hline HEMBL3 & 57 & 7.2757 & 97 & ונ \\
\hline IEMBL & 57 & 9 & & RT \\
\hline HEMBL. & & 9. & & RI \\
\hline HEMBL; & & 98 & & \\
\hline HEMBL & & 10.0 & & $\Gamma \mathrm{RN}$ \\
\hline HEMBL3 & 1 & 01 & 26 & RIV \\
\hline AEMBL: & & 9 & & RN \\
\hline HEMBL. & & & & RN \\
\hline HFMBI & & 16 & & $2 N$ \\
\hline HEMBL3 & & 8 & & TST \\
\hline HEMBL3 & 1 & 7.3565 & 64 & RN \\
\hline HEMBL & 6 & 99 & & RN \\
\hline AFMB & & 29 & & \\
\hline EMBL & & & 247 & $\mathrm{~N}$ \\
\hline HEMBL3 & & 8.699 & & IRN \\
\hline HEMBL3 & 57 & 8.5229 & & TRN \\
\hline HEMBL3 & & 229 & & RN \\
\hline HEMRI & & 59 & & \\
\hline HEMBL3 & & & & ST \\
\hline HEMBL3954881 & 57 & 7.5229 & 77 & TST \\
\hline AEMBL3 & 57 & 539 & & RN \\
\hline HEMBL3 & 6 & & 6.6256 & DA \\
\hline CHEMBL3 & & & & RIV \\
\hline HEMBL3 & 57 & 8.3372 & 7.7434 & RN \\
\hline HEMBL 392 & 57 & 8.301 & 8.1458 & ST \\
\hline MBL3 & & & & \\
\hline HEMBL3 & & 8.522 & 8.8265 & \\
\hline CHEMBL3 & 6 & 9.0 & 9.6796 & \\
\hline SHEMBL3329620 & 1641457 & 8.2218 & 8.5882 & RN \\
\hline
\end{tabular}


Supplemental Table S2.txt

\begin{tabular}{|c|c|c|c|c|}
\hline CHEMBL3968680 & 1641457 & 9.699 & 10.1271 & TRN \\
\hline CHEMBL3984721 & 1641457 & 10.0 & 9.8392 & TRN \\
\hline CHEMBL3931236 & 1641457 & 9.301 & 9.1539 & TRN \\
\hline CHEMBL3968199 & 1641457 & 9.699 & 9.9554 & TRN \\
\hline CHEMBL 3898253 & 1641457 & 10.0 & 9.7961 & TRN \\
\hline CHEMBL3967015 & 1641457 & 7.5528 & 7.034 & TRN \\
\hline CHEMBL3896807 & 1641457 & 9.0 & 9.0421 & TRN \\
\hline CHEMBL3930133 & 1641457 & 10.0 & 9.8208 & TRN \\
\hline CHEMBL3892439 & 1641457 & 7.7932 & 8.3104 & TRN \\
\hline CHEMBL3329613 & 1641457 & 9.0 & 8.1755 & TST \\
\hline CHEMBL 3895254 & 1641457 & 8.6198 & 9.2775 & TST \\
\hline CHEMBL3940186 & 1641457 & 8.5376 & 8.6891 & TRN \\
\hline CHEMBL3956221 & 1641457 & 10.0 & 9.7701 & TRN \\
\hline CHEMBL 3125524 & 1641457 & 9.5229 & 9.6647 & TRN \\
\hline CHEMBL3958080 & 1641457 & 8.8239 & 9.6812 & TST \\
\hline CHEMBL3980222 & 1641457 & 8.5229 & 8.6622 & TRN \\
\hline CHEMBL3125513 & 1641457 & 8.699 & 8.6404 & TRN \\
\hline CHEMBL3924621 & 1641457 & 6.0 & 6.2437 & TRN \\
\hline CHEMBL3967551 & 1641457 & 8.5229 & 8.074 & TST \\
\hline CHEMBL3958512 & 1641457 & 6.0 & 8.1447 & TST \\
\hline CHEMBL3950302 & 1641457 & 7.3565 & 7.396 & TRN \\
\hline CHEMBL3942755 & 1641457 & 9.301 & 9.3668 & TRN \\
\hline CHEMBL3937570 & 1641457 & 6.0 & 8.0741 & TST \\
\hline CHEMBL3932147 & 1641457 & 8.4202 & 8.5594 & TRN \\
\hline CHEMBL3950450 & 1641457 & 8.6198 & 8.2456 & TRN \\
\hline CHEMBL3926559 & 1641457 & 8.0458 & 8.3306 & TST \\
\hline CHEMBL3967148 & 1641457 & 9.0 & 8.8841 & TRN \\
\hline CHEMBL3913854 & 1641457 & 10.0 & 9.7136 & TRN \\
\hline CHEMBL3951659 & 1641457 & 7.9208 & 7.6631 & TST \\
\hline CHEMBL3921531 & 1641457 & 9.0 & 8.6371 & TRN \\
\hline CHEMBL3975667 & 1641457 & 8.301 & 8.6445 & TST \\
\hline CHEMBL3941328 & 1641457 & 9.699 & 9.9721 & TRN \\
\hline CHEMBL3329607 & 1641457 & 8.0458 & 7.923999 & 99999999995 \\
\hline CHEMBL 3927464 & 1641457 & 7.7212 & 7.8041 & TRN \\
\hline CHEMBL3912962 & 1641457 & 9.3979 & 9.6636 & TRN \\
\hline CHEMBL3899963 & 1641457 & 9.0969 & 9.2381 & TRN \\
\hline CHEMBL3941277 & 1641457 & 9.1549 & 9.1014 & TRN \\
\hline CHEMBL3918023 & 1641457 & 8.3872 & 8.5684 & TRN \\
\hline CHEMBL3947547 & 1641457 & 7.8861 & 7.8646 & TRN \\
\hline CHEMBL3966228 & 1641457 & 8.301 & 8.45 & TRN \\
\hline CHEMBL3926383 & 1641457 & 8.5229 & 8.7766 & TRN \\
\hline CHEMBL3976643 & 1641457 & 9.699 & 9.548 & TRN \\
\hline CHEMBL3125705 & 1641457 & 9.0 & 8.1609 & TRN \\
\hline CHEMBL3965712 & 1641457 & 9.3979 & 9.0758 & TRN \\
\hline CHEMBL3963590 & 1641457 & 10.0 & 10.0769 & TRN \\
\hline CHEMBL3975677 & 1641457 & 10.0 & 9.4582 & TRN \\
\hline CHEMBL3972181 & 1641457 & 8.0458 & 8.0877 & TRN \\
\hline CHEMBL3895235 & 1641457 & 7.9586 & 8.515 & TST \\
\hline
\end{tabular}




\begin{tabular}{|c|c|c|c|c|}
\hline \multicolumn{5}{|c|}{ Supplemental Table S2.txt } \\
\hline CHEMBL 2059435 & 1641457 & 6.0 & 6.4881 & TRN \\
\hline CHEMBL3944399 & 1641457 & 9.699 & 9.5 & TRN \\
\hline CHEMBL3950087 & 1641457 & 6.0 & 8.4118 & TST \\
\hline CHEMBL 3922286 & 1641457 & 7.9208 & 8.4292 & TST \\
\hline CHEMBL3978594 & 1641457 & 9.699 & 9.754 & TRN \\
\hline CHEMBL 3897410 & 1641457 & 9.699 & 9.8808 & TRN \\
\hline CHEMBL3957184 & 1641457 & 8.7447 & 9.0167 & TRN \\
\hline CHEMBL 3970386 & 1641457 & 9.0 & 9.1777 & TRN \\
\hline CHEMBL 3977478 & 1641457 & 9.0969 & 9.3749 & TRN \\
\hline CHEMBL3959155 & 1641457 & 8.7959 & 8.5094 & TRN \\
\hline CHEMBL 3937087 & 1641457 & 8.5229 & 7.9319 & TRN \\
\hline CHEMBL3922642 & 1641457 & 9.699 & 9.8998 & TRN \\
\hline CHEMBL3981404 & 1641457 & 7.8239 & 7.4765 & TRN \\
\hline CHEMBL3982143 & 1641457 & 9.5229 & 9.5973 & TRN \\
\hline CHEMBL3917573 & 1641457 & 8.0458 & 8.1881 & TST \\
\hline CHEMBL 3892453 & 1641457 & 9.3979 & 8.8617 & TRN \\
\hline CHEMBL3965284 & 1641457 & 9.5229 & 9.7206 & TRN \\
\hline CHEMBL 3125520 & 1641457 & 9.699 & 9.8503 & TRN \\
\hline CHEMBL 3125540 & 1641457 & 9.0969 & 9.611 & TRN \\
\hline CHEMBL 2177189 & 1641457 & 9.0 & 7.9919 & TST \\
\hline CHEMBL3125530 & 1641457 & 9.5229 & 9.5712 & TRN \\
\hline CHEMBL 3125528 & 1641457 & 9.5229 & 9.3154 & TRN \\
\hline CHEMBL3961423 & 1641457 & 8.8861 & 8.7141 & TRN \\
\hline CHEMBL 3898961 & 1641457 & 8.699 & 8.2852 & TRN \\
\hline CHEMBL3960491 & 1641457 & 8.0 & 7.9807 & TRN \\
\hline CHEMBL3932633 & 1641457 & 9.0 & 7.7153 & TST \\
\hline CHEMBL3899019 & 1641457 & 10.0 & 10.624 & TRN \\
\hline CHEMBL3956765 & 1641457 & 9.699 & 9.8427 & TRN \\
\hline CHEMBL 3890387 & 1641457 & 9.0 & 9.2759 & TRN \\
\hline CHEMBL3942011 & 1641457 & 9.301 & 9.2047 & TRN \\
\hline CHEMBL3968058 & 1641457 & 8.699 & 8.2392 & TRN \\
\hline CHEMBL3944616 & 1641457 & 9.2218 & 9.7885 & TRN \\
\hline CHEMBL 3895410 & 1641457 & 8.585 & 8.9616 & TRN \\
\hline CHEMBL 3892226 & 1641457 & 9.0 & 8.71 & TRN \\
\hline CHEMBL3968189 & 1641457 & 8.9208 & 8.9778 & TRN \\
\hline CHEMBL3956742 & 1641457 & 8.2218 & 7.7955 & TRN \\
\hline CHEMBL3980413 & 1641457 & 8.699 & 8.7668 & TRN \\
\hline CHEMBL 3125710 & 1641457 & 9.0 & 9.1739 & TRN \\
\hline CHEMBL3125531 & 1641457 & 9.5229 & 9.5483 & TRN \\
\hline CHEMBL 3898721 & 1641457 & 9.5229 & 9.4563 & TRN \\
\hline CHEMBL3931331 & 1641457 & 8.2218 & 8.7607 & TST \\
\hline CHEMBL3125519 & 1641457 & 9.699 & 9.6971 & TRN \\
\hline CHEMBL3962217 & 1641457 & 8.8539 & 9.0162 & TST \\
\hline CHEMBL 3125700 & 1641457 & 9.5229 & 9.1531 & TRN \\
\hline CHEMBL3918280 & 1641457 & 8.3979 & 8.7681 & TST \\
\hline CHEMBL3940783 & 1641457 & 8.699 & 8.4514 & TRN \\
\hline CHEMBL 3896849 & 1641457 & 8.7447 & 8.7674 & TST \\
\hline CHEMBL3935799 & 1641457 & 9.301 & 9.6923 & TRN \\
\hline
\end{tabular}




$$
\text { Supplemental Table S2.txt }
$$

\begin{tabular}{|c|c|c|c|c|c|}
\hline CHEMBL3943183 & 1641457 & 9.699 & 9.8241 & TRN & \\
\hline CHEMBL3125515 & 1641457 & 8.3979 & 8.4157 & TRN & \\
\hline CHEMBL3970576 & 1641457 & 9.0 & 8.8161 & TRN & \\
\hline CHEMBL3941666 & 1641457 & 8.2218 & 8.2574 & TRN & \\
\hline CHEMBL3930864 & 1641457 & 8.699 & 8.6962 & TRN & \\
\hline CHEMBL3937202 & 1641457 & 7.8697 & 8.1422 & TRN & \\
\hline CHEMBL3966894 & 1641457 & 8.699 & 8.5621 & TRN & \\
\hline CHEMBL3962770 & 1641457 & 9.0 & 8.5479 & TRN & \\
\hline CHEMBL3964874 & 1641457 & 8.2218 & 8.0729 & TRN & \\
\hline CHEMBL3894720 & 1641457 & 10.0 & 10.1606 & TRN & \\
\hline CHEMBL3963123 & 1641457 & 9.5229 & 9.5528 & TRN & \\
\hline CHEMBL3930665 & 1641457 & 9.0 & 9.267999 & 9999999999 & TRN \\
\hline CHEMBL3125527 & 1641457 & 10.0 & 9.5593 & TRN & \\
\hline CHEMBL3894532 & 1641457 & 8.3979 & 8.5215 & TRN & \\
\hline CHEMBL3942141 & 1641457 & 9.5229 & 9.0618 & TRN & \\
\hline CHEMBL3957985 & 1641457 & 8.5229 & 8.2222 & TRN & \\
\hline CHEMBL3897931 & 1641457 & 9.699 & 9.1538 & TRN & \\
\hline CHEMBL3931077 & 1641457 & 9.0458 & 8.964 & TRN & \\
\hline CHEMBL3917945 & 1641457 & 9.699 & 9.408999 & 9999999999 & TRN \\
\hline CHEMBL3125529 & 1641457 & 9.699 & 9.5288 & TRN & \\
\hline CHEMBL3916712 & 1641457 & 9.5229 & 9.746 & TRN & \\
\hline CHEMBL3952928 & 1641457 & 8.3979 & 7.928 & TRN & \\
\hline CHEMBL3977905 & 1641457 & 6.0 & 6.6527 & TRN & \\
\hline CHEMBL 3950037 & 1641457 & 8.301 & 7.4268 & TST & \\
\hline CHEMBL3895600 & 1641457 & 8.3979 & 8.5144 & TRN & \\
\hline CHEMBL3971665 & 1641457 & 9.301 & 9.3851 & TRN & \\
\hline CHEMBL 3982594 & 1641457 & 8.5376 & 8.2973 & TRN & \\
\hline CHEMBL3891247 & 1641457 & 8.7447 & 8.3103 & TST & \\
\hline CHEMBL3924685 & 1641457 & 6.0 & 8.3197 & TST & \\
\hline CHEMBL3979320 & 1641457 & 7.6234 & 7.789 & TRN & \\
\hline CHEMBL3941543 & 1641457 & 9.0 & 9.042 & TRN & \\
\hline CHEMBL 3909721 & 1641457 & 10.0 & 9.7942 & TRN & \\
\hline CHEMBL3961000 & 1641457 & 6.0 & 7.2371 & TRN & \\
\hline CHEMBL3980529 & 1641457 & 10.0 & 9.8867 & TRN & \\
\hline CHEMBL3953498 & 1641457 & 9.5229 & 9.9232 & TRN & \\
\hline CHEMBL3919529 & 1641457 & 9.699 & 9.732000 & 0000000001 & TRN \\
\hline CHEMBL 3902491 & 1641457 & 8.5229 & 8.8992 & TRN & \\
\hline CHEMBL3958840 & 1641457 & 7.0 & 7.9351 & TST & \\
\hline CHEMBL3125703 & 1641457 & 8.699 & 8.5137 & TRN & \\
\hline CHEMBL3125701 & 1641457 & 10.0 & 9.9499 & TRN & \\
\hline CHEMBL3960066 & 1641457 & 9.699 & 9.6039 & TRN & \\
\hline CHEMBL3125535 & 1641457 & 9.2218 & 8.9493 & TST & \\
\hline CHEMBL3915592 & 1641457 & 7.9586 & 7.8993 & TST & \\
\hline CHEMBL3964087 & 1641457 & 9.699 & 9.772 & TST & \\
\hline CHEMBL3932275 & 1641457 & 6.0 & 7.4163 & TST & \\
\hline CHEMBL3941874 & 1641457 & 8.5229 & 8.4188 & TST & \\
\hline CHEMBL3940745 & 1641457 & 9.301 & 9.3146 & TST & \\
\hline CHEMBL3948045 & 1641457 & 8.8861 & 7.5331 & TST & \\
\hline
\end{tabular}


Supplemental Table S2.txt

\begin{tabular}{|c|c|c|c|c|}
\hline & & & 771 & \\
\hline HEMBL3906854 & 641457 & 9.0458 & 9.2654 & \\
\hline AEMBL3 & 541457 & 49 & & \\
\hline 525 & & & 592 & \\
\hline EMBL3967652 & 541457 & 6.0 & & \\
\hline IEMBL3959436 & 541457 & 699 & 1483 & \\
\hline AEMBL3915847 & 641457 & 10.0 & 8505 & \\
\hline HEMBL3960885 & 641457 & & 54 & \\
\hline IEMBL39 & 641457 & 8.699 & 799 & \\
\hline IEMBL 3951924 & 457 & 7959 & & \\
\hline AEMBL3923124 & 641457 & 6.0 & 4369 & \\
\hline AEMBL3946498 & 641457 & 8.3979 & 514 & \\
\hline HEMBL3974607 & 641457 & & & \\
\hline IEMBL3125522 & 7 & 9.5229 & 815 & \\
\hline AEMBL 3974584 & 57 & & & \\
\hline AEMBL 3899040 & 641457 & 10.0 & 7951 & \\
\hline AEMBL3946425 & 457 & & & \\
\hline HEMBL3961625 & 57 & 99 & & \\
\hline AEMBL] & $8 \varepsilon$ & 62 & & \\
\hline 881 & בקנ & 62 & & \\
\hline IEMBL1409742 & 39 & 1362 & & \\
\hline AEMBL1479746 & 39 & 862 & & \\
\hline HEMBL1: & 39 & 1862 & 28 & \\
\hline 910 & 39 & 862 & & \\
\hline 526 & 39 & 362 & & \\
\hline 5005 & & 862 & & \\
\hline AEMBL1585707 & 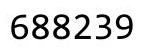 & 362 & & \\
\hline AEMBL1541045 & 9 & 5862 & & \\
\hline 09 & & 52 & & \\
\hline 979 & 39 & 862 & 52 & \\
\hline 503 & & 362 & & \\
\hline AEMBL1386732 & 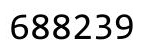 & 862 & & \\
\hline 155 & & 2 & & $S$ \\
\hline 35 & 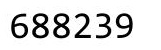 & 53 & & \\
\hline 84 & & 62 & & \\
\hline 91674 & or & 862 & & \\
\hline IEMBL1404870 & 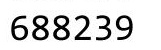 & 362 & & \\
\hline 88 & & & & RI \\
\hline 39 & & 2 & & \\
\hline 437 & & & & RN \\
\hline AEMBL 3210315 & & 361 & 792 & R \\
\hline AEMBL: & 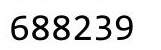 & 362 & & \\
\hline 37 & & & & \\
\hline 83030 & & & & \\
\hline HEMBL1497129 & & 362 & & $R$ \\
\hline 00557 & 9 & 3362 & 29 & $\mathrm{~F}$ \\
\hline HEMBL & & & & \\
\hline CHEMBL136045 & & & 5.4644 & \\
\hline
\end{tabular}


Supplemental Table S2.txt

\begin{tabular}{|c|c|c|c|c|c|}
\hline CHEMBL1358951 & 688239 & 4.7362 & 5.4303 & TRN & \\
\hline CHEMBL1575714 & 688239 & 5.1362 & 5.3785 & TRN & \\
\hline CHEMBL 3209331 & 688239 & 4.6362 & 5.4093 & TRN & \\
\hline CHEMBL1364657 & 688239 & 5.9862 & 5.4967 & TST & \\
\hline CHEMBL1316230 & 688239 & 8.2366 & 5.4772 & TRN & \\
\hline CHEMBL1425584 & 688239 & 4.5362 & 5.441 & TST & \\
\hline CHEMBL1588570 & 688239 & 4.5362 & 5.4602 & TRN & \\
\hline CHEMBL1437233 & 688239 & 5.4862 & 5.4809 & TRN & \\
\hline CHEMBL1528951 & 688239 & 6.9363 & 5.4912 & TRN & \\
\hline CHEMBL1424905 & 688239 & 5.4362 & 5.6127 & TRN & \\
\hline CHEMBL1485717 & 688239 & 6.6861 & 5.4597 & TRN & \\
\hline CHEMBL1993522 & 688239 & 5.7362 & 5.3185 & TRN & \\
\hline CHEMBL1415363 & 688239 & 4.5862 & 5.4919 & TRN & \\
\hline CHEMBL1474899 & 688239 & 5.7362 & 5.4957 & TRN & \\
\hline CHEMBL1529505 & 688239 & 6.9363 & 5.3191 & TST & \\
\hline CHEMBL1375465 & 688239 & 4.8862 & 5.5444 & TRN & \\
\hline CHEMBL1599444 & 688239 & 5.9362 & 5.519 & TST & \\
\hline CHEMBL1343071 & 688239 & 5.1862 & 5.5075 & TRN & \\
\hline CHEMBL1585558 & 688239 & 6.4862 & 5.401 & TRN & \\
\hline CHEMBL1418786 & 688239 & 5.1362 & 5.5236 & TRN & \\
\hline CHEMBL1529303 & 688239 & 6.7361 & 5.3759 & TST & \\
\hline CHEMBL1604436 & 688239 & 6.7361 & 5.5293 & TRN & \\
\hline CHEMBL1562373 & 688239 & 6.2862 & 5.4402 & TRN & \\
\hline CHEMBL1366264 & 688239 & 6.3362 & 5.4369 & TRN & \\
\hline CHEMBL1378529 & 688239 & 6.5363 & 5.632000 & 0000000001 & m \\
\hline CHEMBL1317015 & 688239 & 5.9862 & 5.5608 & TRN & \\
\hline CHEMBL1584628 & 688239 & 5.3362 & 5.5283 & TRN & \\
\hline CHEMBL1548618 & 688239 & 5.6862 & 5.5265 & TST & \\
\hline CHEMBL1422847 & 688239 & 4.5362 & 5.4198 & TRN & \\
\hline CHEMBL1584845 & 688239 & 5.3862 & 5.6481 & TRN & \\
\hline CHEMBL1543737 & 688239 & 5.2362 & 5.548999 & 99999999995 & TST \\
\hline CHEMBL1505829 & 688239 & 5.4362 & 5.5757 & TRN & \\
\hline CHEMBL1407404 & 688239 & 5.7362 & 5.4059 & TRN & \\
\hline CHEMBL1486974 & 688239 & 6.5363 & 5.5334 & TRN & \\
\hline CHEMBL1393193 & 688239 & 6.4862 & 5.6461 & TRN & \\
\hline CHEMBL1529277 & 688239 & 6.1862 & 5.3979 & TRN & \\
\hline CHEMBL1319314 & 688239 & 5.1362 & 5.6538 & TRN & \\
\hline CHEMBL1419479 & 688239 & 4.7862 & 5.4051 & TRN & \\
\hline CHEMBL1591267 & 688239 & 8.283999 & 99999999 & 5.3686 & TST \\
\hline CHEMBL1340638 & 688239 & 4.5862 & 5.4976 & TST & \\
\hline CHEMBL1387139 & 688239 & 6.2362 & 5.5543 & TRN & \\
\hline CHEMBL1324179 & 688239 & 5.9362 & 5.5293 & TRN & \\
\hline CHEMBL1550345 & 688239 & 4.7362 & 5.417999 & 7999999999 & ובו \\
\hline CHEMBL1471222 & 688239 & 4.7362 & 5.4606 & TRN & \\
\hline CHEMBL1432632 & 688239 & 4.7362 & 5.6366 & TRN & \\
\hline CHEMBL1505361 & 688239 & 6.1862 & 5.3967 & TRN & \\
\hline CHEMBL1380563 & 688239 & 4.7862 & 5.5736 & TRN & \\
\hline CHEMBL1418380 & 688239 & 5.1862 & 5.5964 & TRN & \\
\hline
\end{tabular}


Supplemental Table S2.txt

\begin{tabular}{|c|c|c|c|c|c|}
\hline CHEMBL1523557 & 688239 & 4.6362 & 5.4137 & TRN & \\
\hline CHEMBL1448568 & 688239 & 4.6862 & 5.4355 & TST & \\
\hline CHEMBL1408513 & 688239 & 4.9362 & 5.5252 & TRN & \\
\hline CHEMBL1466056 & 688239 & 4.5362 & 5.4957 & TRN & \\
\hline CHEMBL1470492 & 688239 & 4.7862 & 5.5099 & TRN & \\
\hline CHEMBL1379991 & 688239 & 5.1862 & 5.3882 & TST & \\
\hline CHEMBL1402686 & 688239 & 6.1362 & 5.4893 & TRN & \\
\hline CHEMBL1379682 & 688239 & 6.7862 & 5.6195 & TRN & \\
\hline CHEMBL1429085 & 688239 & 7.7852 & 5.4699 & TRN & \\
\hline CHEMBL1164527 & 688239 & 5.1862 & 5.4443 & TRN & \\
\hline CHEMBL1480557 & 688239 & 6.4362 & 5.4207 & TRN & \\
\hline CHEMBL1606900 & 688239 & 4.6862 & 5.5463 & TST & \\
\hline CHEMBL1450564 & 688239 & 4.8362 & 5.5446 & TST & \\
\hline CHEMBL1430705 & 688239 & 6.1862 & 5.5258 & TST & \\
\hline CHEMBL1419127 & 688239 & 5.9362 & 5.4962 & TRN & \\
\hline CHEMBL1390574 & 688239 & 6.5363 & 5.4254 & TRN & \\
\hline CHEMBL1457825 & 688239 & 5.4862 & 5.5426 & TRN & \\
\hline CHEMBL1410941 & 688239 & 5.4362 & 5.6342 & TRN & \\
\hline CHEMBL1522452 & 688239 & 5.4862 & 5.542999 & 999999999 & \\
\hline CHEMBL1313928 & 688239 & 5.1862 & 5.6893 & TRN & \\
\hline CHEMBL1322920 & 688239 & 4.5362 & 5.7912 & TRN & \\
\hline CHEMBL1479989 & 688239 & 4.5362 & 5.5564 & TRN & \\
\hline CHEMBL1354992 & 688239 & 5.9362 & 5.5221 & TRN & \\
\hline CHEMBL1521587 & 688239 & 5.0362 & 5.4948 & TRN & \\
\hline CHEMBL1567980 & 688239 & 4.9362 & 5.4193 & TRN & \\
\hline CHEMBL1538755 & 688239 & 6.0362 & 5.5166 & TRN & \\
\hline CHEMBL1310425 & 688239 & 6.3863 & 5.512006 & 0000000005 & TRN \\
\hline CHEMBL1428815 & 688239 & 5.7862 & 5.5679 & TRN & \\
\hline CHEMBL1342837 & 688239 & 5.4862 & 5.4432 & TRN & \\
\hline CHEMBL1452831 & 688239 & 6.2362 & 5.5926 & TST & \\
\hline CHEMBL1366963 & 688239 & 4.5362 & 5.4142 & TRN & \\
\hline CHEMBL3189312 & 688239 & 4.5862 & 5.4325 & TRN & \\
\hline CHEMBL3197179 & 688239 & 7.0362 & 5.4677 & TRN & \\
\hline CHEMBL1571386 & 688239 & 5.2362 & 5.4283 & TRN & \\
\hline CHEMBL1567754 & 688239 & 4.5362 & 5.6858 & TRN & \\
\hline CHEMBL1490580 & 688239 & \multicolumn{3}{|c|}{8.283999999999999} & RN \\
\hline CHEMBL1427214 & 688239 & 6.1862 & 5.517 & TRN & \\
\hline CHEMBL1379247 & 688239 & 4.5362 & 5.522 & TRN & \\
\hline CHEMBL1333684 & 688239 & 4.7362 & 5.5561 & TRN & \\
\hline CHEMBL1342120 & 688239 & 6.6362 & 5.5394 & TRN & \\
\hline CHEMBL1303592 & 688239 & 4.5362 & 5.5175 & TRN & \\
\hline CHEMBL1401865 & 688239 & 4.5362 & 5.4291 & TRN & \\
\hline CHEMBL3190960 & 688239 & 4.6362 & 5.4711 & TRN & \\
\hline CHEMBL1548680 & 688239 & 4.4862 & 5.6514 & TRN & \\
\hline CHEMBL1453666 & 688239 & 4.5362 & 5.477 & TRN & \\
\hline CHEMBL1434621 & 688239 & 4.5362 & 5.4332 & TRN & \\
\hline CHEMBL1397537 & 688239 & 5.6862 & 5.4452 & TRN & \\
\hline CHEMBL1529242 & 688239 & 7.7352 & 5.5525 & TRN & \\
\hline
\end{tabular}




\begin{tabular}{|c|c|c|c|c|c|}
\hline & & \multicolumn{4}{|c|}{ Supplemental Table s2.txt } \\
\hline CHEMBL1419844 & 688239 & 7.2366 & 5.4917 & TRN & \\
\hline CHEMBL1329852 & 688239 & 5.3362 & 5.5263 & TRN & \\
\hline CHEMBL1586835 & 688239 & 6.5862 & 5.506 & TRN & \\
\hline CHEMBL3190009 & 688239 & 4.8862 & 5.4574 & TRN & \\
\hline CHEMBL1368769 & 688239 & 4.5362 & 5.5458 & TRN & \\
\hline CHEMBL1482699 & 688239 & 5.0862 & 5.4748 & TRN & \\
\hline CHEMBL1382157 & 688239 & 6.4362 & 5.4927 & TRN & \\
\hline CHEMBL1418808 & 688239 & 8.3372 & 5.4942 & TRN & \\
\hline CHEMBL1593867 & 688239 & 7.1361 & 5.4708 & TST & \\
\hline CHEMBL1344911 & 688239 & 5.1862 & 5.5153 & TRN & \\
\hline CHEMBL1341280 & 688239 & 5.1362 & 5.3238 & TST & \\
\hline CHEMBL1347288 & 688239 & 5.2862 & 5.4856 & TRN & \\
\hline CHEMBL1445637 & 688239 & 4.6362 & 5.4991 & TRN & \\
\hline CHEMBL1470576 & 688239 & 6.1862 & 5.4539 & TRN & \\
\hline CHEMBL1576699 & 688239 & 5.5862 & 5.6262 & TRN & \\
\hline CHEMBL1523652 & 688239 & 5.6362 & 5.2662 & TST & \\
\hline CHEMBL1505531 & 688239 & 5.6862 & 5.5353 & TRN & \\
\hline CHEMBL3191860 & 688239 & 4.9862 & 5.4974 & TRN & \\
\hline CHEMBL1313449 & 688239 & 4.7362 & 5.3431 & TRN & \\
\hline CHEMBL1328234 & 688239 & 5.2862 & 5.5301 & TRN & \\
\hline CHEMBL1583881 & 688239 & 4.5362 & 5.5823 & TST & \\
\hline CHEMBL1369745 & 688239 & 6.0862 & 5.4126 & TRN & \\
\hline CHEMBL1359495 & 688239 & 6.9863 & 5.6466 & TRN & \\
\hline CHEMBL1340187 & 688239 & 6.6362 & 5.3434 & TRN & \\
\hline CHEMBL1483446 & 688239 & 6.1862 & 5.5536 & TRN & \\
\hline CHEMBL1473388 & 688239 & 5.2362 & 5.4352 & TRN & \\
\hline CHEMBL1352777 & 688239 & 4.7362 & 5.5318 & TRN & \\
\hline CHEMBL1414775 & 688239 & 5.3862 & 5.6005 & TRN & \\
\hline CHEMBL1557590 & 688239 & 4.6862 & 5.3761 & TST & \\
\hline CHEMBL1354710 & 688239 & 4.5362 & 5.29899 & 99999999995 & TRN \\
\hline CHEMBL1310831 & 688239 & 4.8362 & 5.6296 & TST & \\
\hline CHEMBL1537936 & 688239 & 5.1862 & 5.5693 & TRN & \\
\hline CHEMBL1347626 & 688239 & 4.7362 & 5.55399 & 9999999999 & TRN \\
\hline CHEMBL1399060 & 688239 & 4.6362 & 5.3424 & TRN & \\
\hline CHEMBL1570684 & 688239 & 8.3372 & 5.3808 & TRN & \\
\hline CHEMBL1467382 & 688239 & 6.8861 & 5.5428 & TRN & \\
\hline CHEMBL1458848 & 688239 & 4.5362 & 5.3695 & TRN & \\
\hline CHEMBL3214332 & 688239 & 5.7862 & 5.4654 & TST & \\
\hline CHEMBL1540047 & 688239 & 4.5362 & 5.5656 & TRN & \\
\hline CHEMBL1587150 & 688239 & 8.3372 & 5.5344 & TRN & \\
\hline CHEMBL1508189 & 688239 & 6.1362 & 5.46299 & 9999999999 & TRN \\
\hline CHEMBL1606783 & 688239 & 5.4862 & 5.46299 & 9999999999 & TST \\
\hline CHEMBL1410319 & 688239 & 4.8362 & 5.4483 & TRN & \\
\hline CHEMBL1341008 & 688239 & 4.5362 & 5.3883 & TST & \\
\hline CHEMBL1491084 & 688239 & 8.28399 & 99999999 & 5.6176 & TST \\
\hline CHEMBL1369774 & 688239 & 4.5362 & 5.4306 & TRN & \\
\hline CHEMBL1325414 & 688239 & 5.3862 & 5.6512 & TST & \\
\hline CHEMBL1515620 & 688239 & 5.5362 & 5.4663 & TRN & \\
\hline
\end{tabular}


Supplemental Table S2.txt

\begin{tabular}{|c|c|c|c|c|}
\hline CHEMBL3190415 & 688239 & 5.2362 & 5.5678 & TRN \\
\hline CHEMBL3210088 & 688239 & 4.9362 & 5.477 & TRN \\
\hline CHEMBL1607571 & 688239 & 5.8362 & 5.518 & TRN \\
\hline CHEMBL1597921 & 688239 & 5.4862 & 5.5859 & TRN \\
\hline CHEMBL1523278 & 688239 & 6.3362 & 5.5291 & TRN \\
\hline CHEMBL1312201 & 688239 & 6.2862 & 5.6391 & TRN \\
\hline CHEMBL1357953 & 688239 & 6.6861 & 5.4346 & TRN \\
\hline CHEMBL1359599 & 688239 & 5.2862 & 5.4121 & TRN \\
\hline CHEMBL1319854 & 688239 & 4.7862 & 5.7043 & TRN \\
\hline CHEMBL1341079 & 688239 & 5.2362 & 5.4163 & TST \\
\hline CHEMBL1528802 & 688239 & 4.7862 & 5.4612 & TRN \\
\hline CHEMBL1464026 & 688239 & 8.3872 & 5.3576 & TRN \\
\hline CHEMBL1586030 & 688239 & 6.8362 & 5.5675 & TRN \\
\hline CHEMBL 270337 & 688239 & 8.2366 & 5.3928 & TRN \\
\hline CHEMBL1993778 & 688239 & 5.6862 & 5.5336 & TRN \\
\hline CHEMBL1421420 & 688239 & 6.3362 & 5.3865 & TST \\
\hline CHEMBL1467339 & 688239 & 5.7862 & 5.4483 & TRN \\
\hline CHEMBL1411149 & 688239 & 5.4362 & 5.6102 & TRN \\
\hline CHEMBL1317904 & 688239 & 4.7862 & 5.3262 & TST \\
\hline CHEMBL1270605 & 688239 & 6.2862 & 5.5472 & TRN \\
\hline CHEMBL1502257 & 688239 & 4.5362 & 5.4418 & TRN \\
\hline CHEMBL1447809 & 688239 & 4.7362 & 5.6101 & TRN \\
\hline CHEMBL1593612 & 688239 & 4.6862 & 5.3965 & TRN \\
\hline CHEMBL1351313 & 688239 & 4.7862 & 5.4096 & TRN \\
\hline CHEMBL1481421 & 688239 & 7.0362 & 5.4833 & TRN \\
\hline CHEMBL1420067 & 688239 & 5.6862 & 5.3742 & TST \\
\hline CHEMBL3212335 & 688239 & 6.8861 & 5.4559 & TST \\
\hline CHEMBL1423409 & 688239 & 8.3372 & 5.417999 & 9999999999 \\
\hline CHEMBL1342597 & 688239 & 4.5362 & 5.6128 & TST \\
\hline CHEMBL1568059 & 688239 & 5.8362 & 5.4747 & TRN \\
\hline CHEMBL1517612 & 688239 & 4.7362 & 5.3185 & TRN \\
\hline CHEMBL1508571 & 688239 & 4.8362 & 5.5107 & TST \\
\hline CHEMBL1595773 & 688239 & 5.3862 & 5.5241 & TRN \\
\hline CHEMBL1583399 & 688239 & 5.9362 & 5.5433 & TRN \\
\hline CHEMBL1543639 & 688239 & 4.5862 & 5.4701 & TRN \\
\hline CHEMBL1558622 & 688239 & 6.0362 & 5.5547 & TRN \\
\hline CHEMBL1589411 & 688239 & 7.1864 & 5.3839 & TRN \\
\hline CHEMBL3193199 & 688239 & 6.9863 & 5.4773 & TST \\
\hline CHEMBL1362556 & 688239 & 4.7862 & 5.3537 & TRN \\
\hline CHEMBL1418972 & 688239 & 5.2362 & 5.3716 & TRN \\
\hline CHEMBL1351885 & 688239 & 6.2362 & 5.3684 & TST \\
\hline CHEMBL1375268 & 688239 & 4.5362 & 5.4092 & TRN \\
\hline CHEMBL1547907 & 688239 & 4.5362 & 5.5575 & TRN \\
\hline CHEMBL1605574 & 688239 & 4.4862 & 5.4524 & TRN \\
\hline CHEMBL1566361 & 688239 & 5.4362 & 5.5286 & TRN \\
\hline CHEMBL1606938 & 688239 & 4.6362 & 5.3596 & TST \\
\hline CHEMBL1552392 & 688239 & 5.1862 & 5.5045 & TST \\
\hline CHEMBL3190550 & 688239 & 4.8362 & 5.5806 & TRN \\
\hline
\end{tabular}




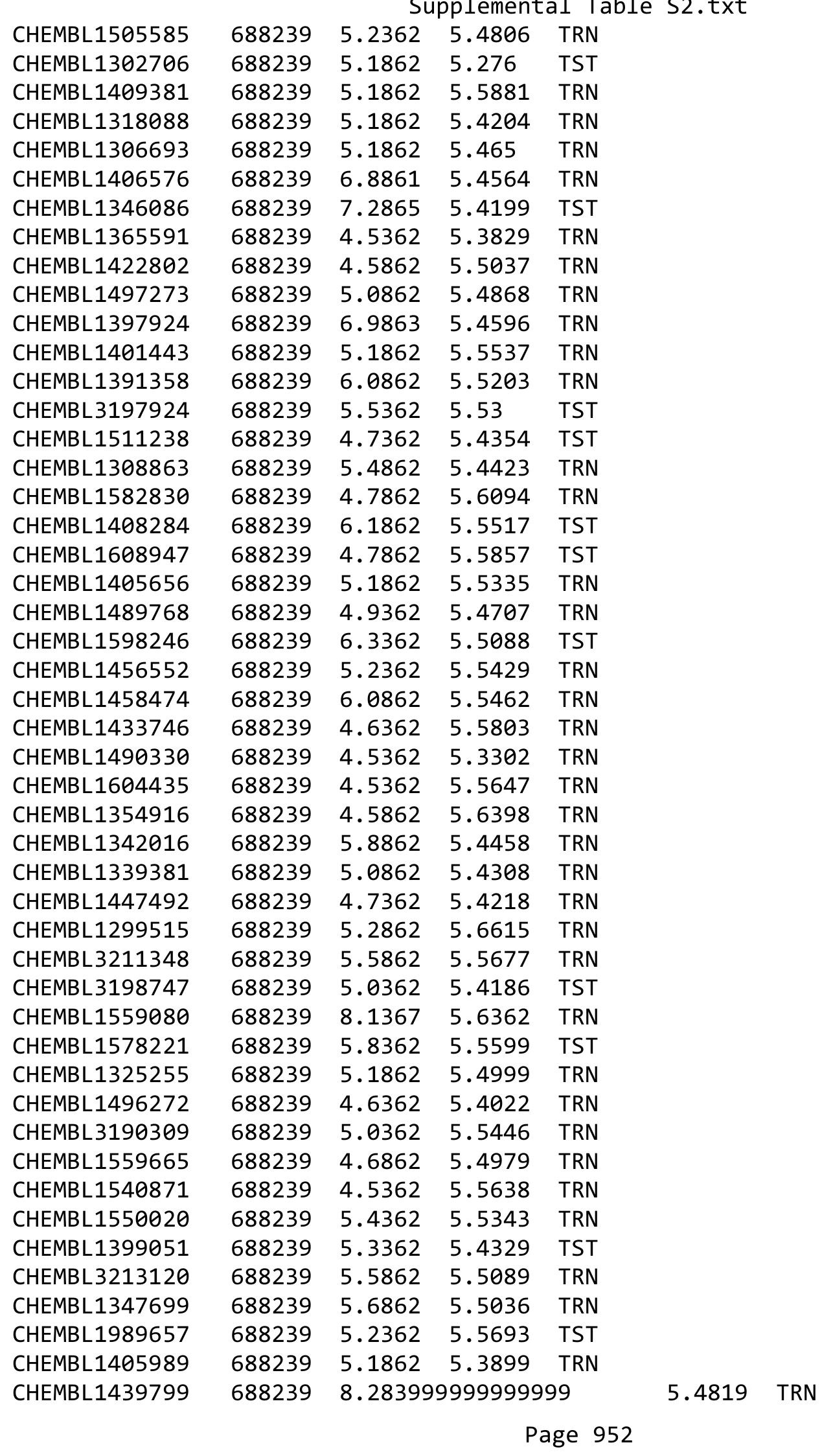


Supplemental Table S2.txt

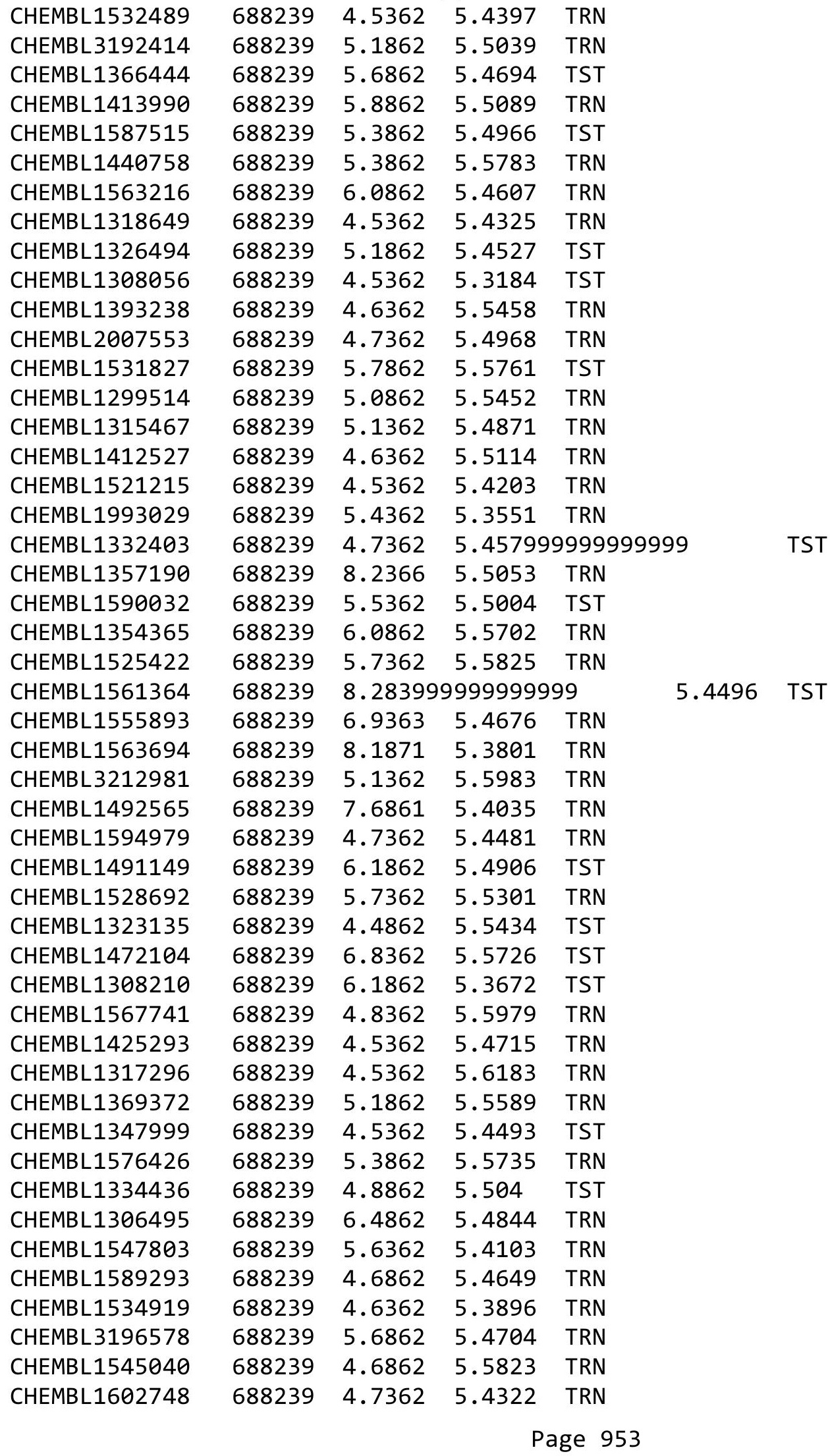


Supplemental Table S2.txt

\begin{tabular}{|c|c|c|c|c|}
\hline CHEMBL1539437 & 688239 & 5.0362 & 5.3597 & TRN \\
\hline CHEMBL1427646 & 688239 & 6.1362 & 5.4191 & TST \\
\hline CHEMBL1348894 & 688239 & 4.7362 & 5.5151 & TRN \\
\hline CHEMBL1301071 & 688239 & 4.5362 & 5.4954 & TRN \\
\hline CHEMBL1533415 & 688239 & 4.5362 & 5.4325 & TRN \\
\hline CHEMBL1487118 & 688239 & 4.7362 & \multicolumn{2}{|c|}{5.377000000000001} \\
\hline CHEMBL1446004 & 688239 & 8.3872 & 5.3426 & TST \\
\hline CHEMBL1489282 & 688239 & 5.7362 & 5.5005 & TRN \\
\hline CHEMBL1501644 & 688239 & 5.1862 & 5.4005 & TRN \\
\hline CHEMBL1310708 & 688239 & 5.3862 & 5.6054 & TRN \\
\hline CHEMBL1490653 & 688239 & 4.7362 & 5.5677 & TRN \\
\hline CHEMBL1553276 & 688239 & 6.9863 & 5.5173 & TRN \\
\hline CHEMBL3212905 & 688239 & 6.1862 & 5.5168 & TST \\
\hline CHEMBL1370101 & 688239 & 4.5362 & 5.5345 & TRN \\
\hline CHEMBL1444124 & 688239 & 6.7862 & 5.4573 & TRN \\
\hline CHEMBL1304192 & 688239 & 4.6862 & 5.5743 & TST \\
\hline CHEMBL1562654 & 688239 & 4.7362 & 5.5795 & TST \\
\hline CHEMBL1559849 & 688239 & 4.5362 & 5.6314 & TRN \\
\hline CHEMBL3199725 & 688239 & 4.6862 & 5.4228 & TST \\
\hline CHEMBL1485233 & 688239 & 4.6862 & 5.4269 & TRN \\
\hline CHEMBL1368291 & 688239 & 4.6862 & 5.4566 & TRN \\
\hline CHEMBL1430710 & 688239 & 5.4362 & 5.4721 & TRN \\
\hline CHEMBL1409985 & 688239 & 8.3372 & 5.4663 & TST \\
\hline CHEMBL1545267 & 688239 & 4.4862 & 5.5433 & TST \\
\hline CHEMBL1489773 & 688239 & 5.1362 & 5.4438 & TRN \\
\hline CHEMBL1563067 & 688239 & 4.6362 & 5.5617 & TRN \\
\hline CHEMBL1476673 & 688239 & 4.6862 & 5.4478 & TRN \\
\hline CHEMBL1510704 & 688239 & 4.7362 & 5.4736 & TRN \\
\hline CHEMBL1344044 & 688239 & 4.9362 & 5.4303 & TST \\
\hline CHEMBL1482455 & 688239 & 4.5362 & 5.4592 & TRN \\
\hline CHEMBL1363218 & 688239 & 4.5362 & 5.4576 & TRN \\
\hline CHEMBL1538925 & 688239 & 8.3372 & 5.5402 & TRN \\
\hline CHEMBL1560497 & 688239 & 7.0362 & 5.2821 & TST \\
\hline CHEMBL1503237 & 688239 & 6.0862 & 5.4263 & TST \\
\hline CHEMBL1355655 & 688239 & 5.1862 & 5.4281 & TRN \\
\hline CHEMBL1536523 & 688239 & 6.7862 & 5.4663 & TST \\
\hline CHEMBL1334412 & 688239 & 4.9862 & 5.4615 & TRN \\
\hline CHEMBL1572725 & 688239 & 5.1862 & 5.6715 & TRN \\
\hline CHEMBL1505368 & 688239 & 5.2362 & 5.4969 & TST \\
\hline CHEMBL1403316 & 688239 & 6.9363 & 5.5279 & TRN \\
\hline CHEMBL1585755 & 688239 & 5.1362 & 5.4642 & TRN \\
\hline CHEMBL1477347 & 688239 & 6.1362 & 5.5505 & TRN \\
\hline CHEMBL1455697 & 688239 & 5.1862 & 5.3663 & TRN \\
\hline CHEMBL1302237 & 688239 & 5.2362 & 5.5626 & TRN \\
\hline CHEMBL1332778 & 688239 & 6.9863 & 5.511 & TRN \\
\hline CHEMBL1522383 & 688239 & 5.0362 & 5.3927 & TRN \\
\hline CHEMBL1429796 & 688239 & 4.5362 & 5.6877 & TRN \\
\hline CHEMBL1470082 & 688239 & 5.1862 & 5.45700 & 20000 \\
\hline & & & & se 954 \\
\hline
\end{tabular}




\begin{tabular}{|c|c|c|c|c|c|c|}
\hline & & \multicolumn{5}{|c|}{ Supplemental Table s2.txt } \\
\hline CHEMBL3193756 & 688239 & 6.3362 & 5.3963 & TRN & & \\
\hline CHEMBL1438839 & 688239 & 4.5362 & 5.4832 & TST & & \\
\hline CHEMBL1378972 & 688239 & 5.6362 & 5.6437 & TRN & & \\
\hline CHEMBL1529737 & 688239 & 5.1862 & 5.4922 & TRN & & \\
\hline CHEMBL1448181 & 688239 & 4.5862 & 5.4485 & TRN & & \\
\hline CHEMBL1088193 & 688239 & 8.2366 & 5.5461 & TRN & & \\
\hline CHEMBL1510861 & 688239 & 5.2362 & 5.5195 & TRN & & \\
\hline CHEMBL1339055 & 688239 & \multicolumn{3}{|c|}{8.283999999999999} & 5.5884 & TRN \\
\hline CHEMBL1341460 & 688239 & 7.1864 & 5.362 & TRN & & \\
\hline CHEMBL1381133 & 688239 & 4.5362 & 5.6218 & TST & & \\
\hline CHEMBL1323695 & 688239 & 6.0862 & 5.4642 & TRN & & \\
\hline CHEMBL1362920 & 688239 & 8.2366 & 5.4916 & TRN & & \\
\hline CHEMBL3210486 & 688239 & 4.7362 & 5.5238 & TRN & & \\
\hline CHEMBL1604353 & 688239 & 5.7862 & 5.6213 & TRN & & \\
\hline CHEMBL1606213 & 688239 & 4.9362 & 5.6252 & TRN & & \\
\hline CHEMBL1310295 & 688239 & 5.8362 & 5.5918 & TRN & & \\
\hline CHEMBL1442305 & 688239 & 4.5362 & 5.4549 & TST & & \\
\hline CHEMBL1458001 & 688239 & 4.5362 & 5.5815 & TRN & & \\
\hline CHEMBL1335380 & 688239 & 4.5362 & 5.5159 & TST & & \\
\hline CHEMBL1402689 & 688239 & 5.6862 & 5.6894 & TST & & \\
\hline CHEMBL1313509 & 688239 & \multicolumn{3}{|c|}{8.283999999999999} & 5.4252 & TRN \\
\hline CHEMBL1338699 & 688239 & 5.1862 & 5.511 & TRN & & \\
\hline CHEMBL1497081 & 688239 & 4.4862 & 5.3681 & TST & & \\
\hline CHEMBL1418644 & 688239 & 4.5362 & 5.5556 & TRN & & \\
\hline CHEMBL3191435 & 688239 & 6.2362 & 5.6632 & TRN & & \\
\hline CHEMBL1550919 & 688239 & 4.5362 & 5.5028 & TST & & \\
\hline CHEMBL1562673 & 688239 & 5.4862 & 5.4186 & TRN & & \\
\hline CHEMBL3195239 & 688239 & 4.5362 & 5.3182 & TRN & & \\
\hline CHEMBL1300514 & 688239 & 6.1862 & 5.3743 & TRN & & \\
\hline CHEMBL1611068 & 688239 & 4.7862 & 5.5292 & TRN & & \\
\hline CHEMBL1502222 & 688239 & 5.35 & 5.4244 & TST & & \\
\hline CHEMBL3211640 & 688239 & 5.1862 & 5.5147 & TST & & \\
\hline CHEMBL1423682 & 688239 & 6.9863 & 5.5944 & TRN & & \\
\hline CHEMBL1446098 & 688239 & 5.9362 & 5.4866 & TRN & & \\
\hline CHEMBL1603451 & 688239 & 5.1862 & 5.4994 & TRN & & \\
\hline CHEMBL1556460 & 688239 & 4.8362 & 5.4995 & TRN & & \\
\hline CHEMBL1489002 & 688239 & 5.7362 & 5.42399 & 9999999999 & 95 & TST \\
\hline CHEMBL1537648 & 688239 & 5.1862 & 5.5118 & TRN & & \\
\hline CHEMBL1445374 & 688239 & \multicolumn{3}{|c|}{8.283999999999999} & 5.5012 & TST \\
\hline CHEMBL1373985 & 688239 & 4.4862 & 5.3517 & TST & & \\
\hline CHEMBL1299600 & 688239 & 4.7362 & 5.4022 & TST & & \\
\hline CHEMBL458094 & 688239 & 4.5362 & 5.4391 & TST & & \\
\hline CHEMBL1340096 & 688239 & 6.9863 & 5.4728 & TRN & & \\
\hline CHEMBL1470720 & 688239 & 6.7361 & 5.5581 & TRN & & \\
\hline CHEMBL1573754 & 688239 & 6.2362 & 5.3273 & TST & & \\
\hline CHEMBL1440233 & 688239 & 5.1862 & 5.4683 & TRN & & \\
\hline CHEMBL1442891 & 688239 & 8.2366 & 5.5393 & TRN & & \\
\hline CHEMBL1388965 & 688239 & 4.6362 & 5.4527 & TRN & & \\
\hline
\end{tabular}


Supplemental Table S2.txt

\begin{tabular}{|c|c|c|c|c|c|}
\hline CHEMBL1554621 & 688239 & 6.1862 & \multicolumn{2}{|c|}{5.5120000000000005} & TRN \\
\hline CHEMBL1359526 & 688239 & 8.3372 & 5.3866 & TST & \\
\hline CHEMBL1544138 & 688239 & 6.0362 & 5.4643 & TRN & \\
\hline CHEMBL1573205 & 688239 & 5.1862 & 5.4351 & TRN & \\
\hline CHEMBL256098 & 688239 & 4.5362 & 5.4256 & TRN & \\
\hline CHEMBL1347606 & 688239 & 4.7862 & 5.4208 & TRN & \\
\hline CHEMBL1604853 & 688239 & 4.6362 & 5.5419 & TRN & \\
\hline CHEMBL1438930 & 688239 & 6.5363 & 5.5615 & TRN & \\
\hline CHEMBL1498410 & 688239 & 6.1862 & 5.5206 & TRN & \\
\hline CHEMBL1397434 & 688239 & 5.1862 & 5.5203 & TRN & \\
\hline CHEMBL1548868 & 688239 & 7.9355 & 5.4858 & TRN & \\
\hline CHEMBL1480486 & 688239 & 6.2862 & 5.4629 & TST & \\
\hline CHEMBL1483373 & 688239 & 4.5362 & 5.6063 & TRN & \\
\hline CHEMBL3209035 & 688239 & 6.3362 & 5.5223 & TRN & \\
\hline CHEMBL1368328 & 688239 & 4.6362 & 5.4658 & TRN & \\
\hline CHEMBL1346367 & 688239 & 4.7362 & 5.4593 & TRN & \\
\hline CHEMBL1419676 & 688239 & 5.1862 & 5.6367 & TST & \\
\hline CHEMBL1341352 & 688239 & 8.3372 & 5.5177 & TRN & \\
\hline CHEMBL1380724 & 688239 & 5.7362 & 5.4283 & TRN & \\
\hline CHEMBL1511058 & 688239 & 4.5362 & 5.5256 & TRN & \\
\hline CHEMBL1588468 & 688239 & 4.6862 & 5.6852 & TRN & \\
\hline CHEMBL1978808 & 688239 & 6.2862 & 5.3743 & TRN & \\
\hline CHEMBL1320023 & 688239 & 4.8362 & 5.5815 & TST & \\
\hline CHEMBL1499210 & 688239 & 5.7362 & 5.4468 & TRN & \\
\hline CHEMBL1333210 & 688239 & 6.9363 & 5.4765 & TRN & \\
\hline CHEMBL1408196 & 688239 & 6.2862 & 5.5407 & TRN & \\
\hline CHEMBL1560795 & 688239 & 5.6362 & 5.5119 & TRN & \\
\hline CHEMBL1415082 & 688239 & 5.1862 & 5.4414 & TRN & \\
\hline CHEMBL1256845 & 688239 & 6.2862 & 5.414 & TST & \\
\hline CHEMBL1384937 & 688239 & 4.8362 & 5.6513 & TRN & \\
\hline CHEMBL1470503 & 688239 & 5.3862 & 5.5401 & TST & \\
\hline CHEMBL1554085 & 688239 & 5.7362 & 5.5179 & TRN & \\
\hline CHEMBL1530378 & 688239 & 4.6862 & 5.5442 & TRN & \\
\hline CHEMBL 3209348 & 688239 & 6.1862 & 5.5525 & TRN & \\
\hline CHEMBL1302999 & 688239 & 4.5362 & 5.4675 & TRN & \\
\hline CHEMBL 3195322 & 688239 & 5.5862 & 5.2531 & TRN & \\
\hline CHEMBL1499929 & 688239 & 5.1862 & 5.4739 & TST & \\
\hline CHEMBL1535213 & 688239 & 4.5362 & 5.4963 & TRN & \\
\hline CHEMBL1479553 & 688239 & 5.1862 & 5.3202 & TST & \\
\hline CHEMBL1608665 & 688239 & 4.5862 & 5.5164 & TRN & \\
\hline CHEMBL1586667 & 688239 & 4.7362 & 5.5566 & TRN & \\
\hline CHEMBL1381398 & 688239 & 6.4862 & 5.4787 & TRN & \\
\hline CHEMBL1455658 & 688239 & 6.8861 & 5.4287 & TRN & \\
\hline CHEMBL1490704 & 688239 & 6.0362 & 5.4175 & TRN & \\
\hline CHEMBL1378971 & 688239 & 4.6362 & 5.4062 & TRN & \\
\hline CHEMBL1310880 & 688239 & 4.8362 & 5.4865 & TRN & \\
\hline CHEMBL1591385 & 688239 & 5.5362 & 5.565 & TRN & \\
\hline CHEMBL1579400 & 688239 & 4.8362 & 5.5553 & TRN & \\
\hline
\end{tabular}

Page 956 
Supplemental Table S2.txt

\begin{tabular}{|c|c|c|c|c|}
\hline & & & & \\
\hline HEMBL1524807 & 38239 & 862 & & \\
\hline AEMBL1539710 & 239 & 362 & & \\
\hline & & & & \\
\hline IEMBL 321 & & & & \\
\hline AEMBL1546837 & 88239 & 862 & & \\
\hline AEMBL3198032 & 88239 & 362 & 706 & \\
\hline HEMBL1569494 & & & & \\
\hline IEMBL1350582 & 39 & 362 & & \\
\hline IEMBL13 & & & & \\
\hline AEMBL1491034 & 39 & 362 & 507 & \\
\hline AEMBL1446444 & & 862 & & \\
\hline AEMBL1441776 & & 63 & & \\
\hline IEMBL16 & & & & \\
\hline HEMBL1342667 & & & & \\
\hline AEMBL1386422 & & 362 & & \\
\hline AEMBL1612561 & & 861 & & \\
\hline IEMBL1375 & & & & \\
\hline AEMBL3193253 & & & & \\
\hline AEMBL14 & & & & \\
\hline AEMBL1482105 & & 61 & & \\
\hline JEMBL14 & & & & \\
\hline IEMBL13 & & & & \\
\hline AFMRI 15 & & & & \\
\hline 64 & & & & \\
\hline 9095 & & 62 & & \\
\hline IEMBL1327688 & & & & \\
\hline IEMBL1531311 & & & & \\
\hline 3 & & & & \\
\hline 1 & & 52 & & \\
\hline AEMBL15341 & & & & \\
\hline HEMBL1559388 & & & & \\
\hline & & & & \\
\hline 4 & & & & \\
\hline & & & & \\
\hline AEMBL1441522 & & & & \\
\hline AEMBL1367633 & & 62 & & \\
\hline & & & & \\
\hline DOM & & & & \\
\hline HEMBL1603822 & & & & RN \\
\hline AEMBL1303221 & & & & TS \\
\hline BL1531 & & & & \\
\hline & & & & \\
\hline HEMBL1422386 & & & & \\
\hline AEMBL1382754 & & & & RN \\
\hline MBL1375974 & & 363 & & 11 \\
\hline זירס & & & & \\
\hline HEMBL157584 & & & .4884 & \\
\hline
\end{tabular}


Supplemental Table S2.txt

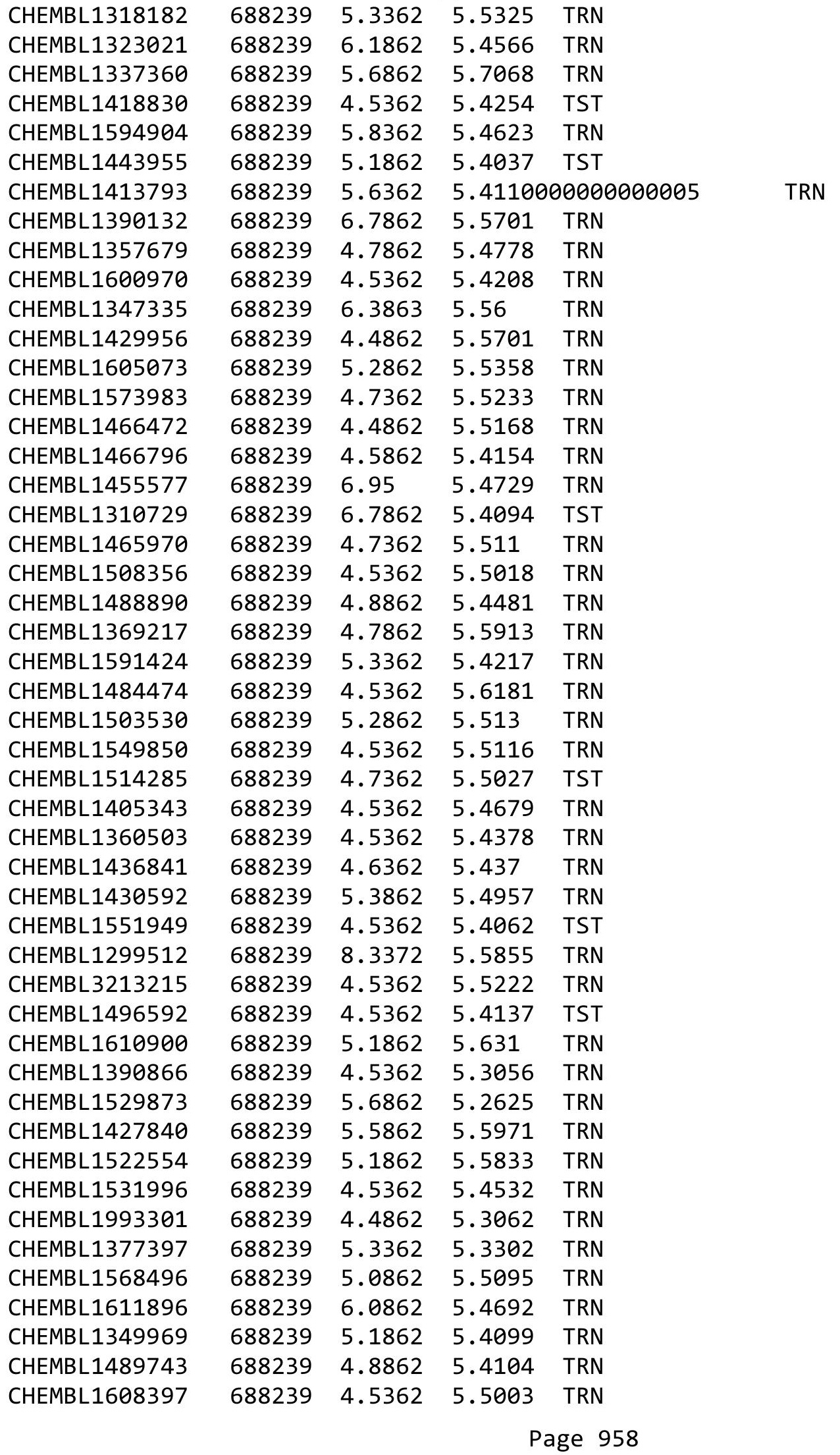




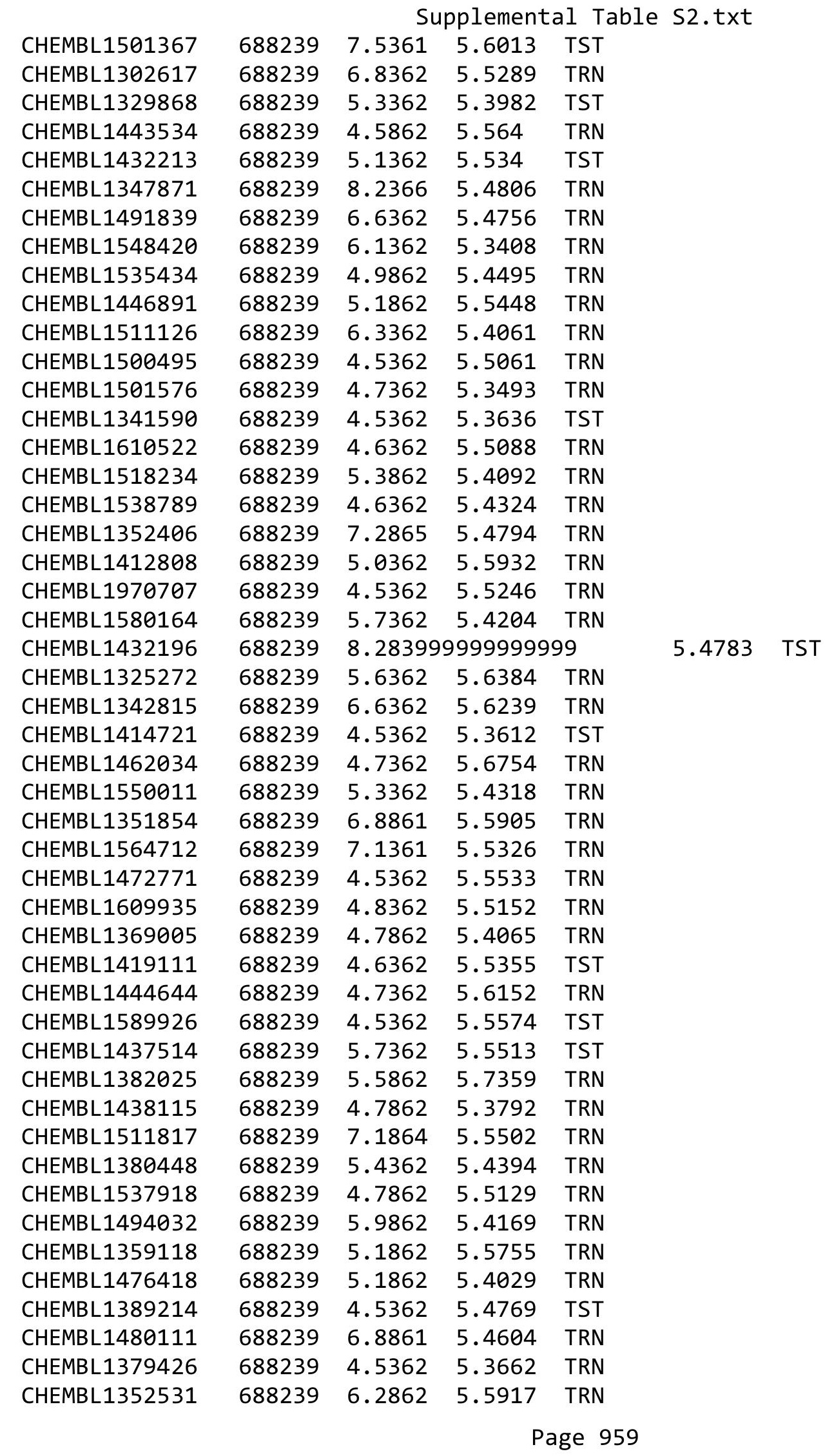


Supplemental Table S2.txt

\begin{tabular}{|c|c|c|c|c|c|}
\hline CHEMBL1369332 & 688239 & 4.9362 & 5.2803 & TRN & \\
\hline CHEMBL1607692 & 688239 & 5.1862 & 5.4384 & TST & \\
\hline CHEMBL1545844 & 688239 & 5.4362 & 5.5604 & TRN & \\
\hline CHEMBL1320095 & 688239 & 6.3362 & 5.4271 & TRN & \\
\hline CHEMBL1503258 & 688239 & 4.7862 & \multicolumn{2}{|c|}{5.4910000000000005} & TRN \\
\hline CHEMBL1310715 & 688239 & 6.0362 & 5.461 & TRN & \\
\hline CHEMBL1586837 & 688239 & 6.5363 & 5.4985 & TRN & \\
\hline CHEMBL1503025 & 688239 & 4.5862 & 5.5215 & TRN & \\
\hline CHEMBL1432041 & 688239 & 6.2862 & 5.6556 & TST & \\
\hline CHEMBL1372720 & 688239 & 4.5362 & 5.4013 & TST & \\
\hline CHEMBL1315709 & 688239 & 5.1862 & 5.4359 & TRN & \\
\hline CHEMBL1321376 & 688239 & 5.0862 & 5.4071 & TRN & \\
\hline CHEMBL1562019 & 688239 & 4.5362 & 5.5228 & TRN & \\
\hline CHEMBL1372921 & 688239 & 5.2362 & 5.5416 & TRN & \\
\hline CHEMBL 3211692 & 688239 & 5.0862 & 5.4167 & TST & \\
\hline CHEMBL3194417 & 688239 & 4.5362 & 5.5679 & TRN & \\
\hline CHEMBL1469109 & 688239 & 5.1862 & 5.4729 & TRN & \\
\hline CHEMBL1481697 & 688239 & 4.6862 & 5.4346 & TRN & \\
\hline CHEMBL3195271 & 688239 & 4.8362 & 5.4367 & TRN & \\
\hline CHEMBL1576747 & 688239 & 4.5362 & 5.4172 & TST & \\
\hline CHEMBL1479008 & 688239 & 4.5362 & 5.5095 & TRN & \\
\hline CHEMBL1333198 & 688239 & 6.7361 & 5.4927 & TST & \\
\hline CHEMBL1425278 & 688239 & 5.1362 & 5.5284 & TRN & \\
\hline CHEMBL1558968 & 688239 & 5.3862 & 5.5205 & TST & \\
\hline CHEMBL1335258 & 688239 & 5.3862 & 5.3228 & TRN & \\
\hline CHEMBL1416599 & 688239 & 5.8862 & 5.4776 & TRN & \\
\hline CHEMBL1302614 & 688239 & 6.7361 & 5.4696 & TRN & \\
\hline CHEMBL1569950 & 688239 & 4.5362 & 5.3806 & TRN & \\
\hline CHEMBL1328304 & 688239 & 6.8861 & 5.5685 & TRN & \\
\hline CHEMBL1542314 & 688239 & 6.4862 & \multicolumn{2}{|c|}{5.531000000000001} & TRN \\
\hline CHEMBL1398621 & 688239 & 5.3362 & 5.4309 & TRN & \\
\hline CHEMBL1361525 & 688239 & 4.6362 & 5.5381 & TRN & \\
\hline CHEMBL1463436 & 688239 & 6.1362 & 5.4869 & TRN & \\
\hline CHEMBL1487176 & 688239 & 5.1362 & 5.4906 & TST & \\
\hline CHEMBL1984056 & 688239 & 5.9362 & \multicolumn{2}{|c|}{5.263999999999999} & TRN \\
\hline CHEMBL1558012 & 688239 & 6.7862 & 5.6087 & TST & \\
\hline CHEMBL1341810 & 688239 & 6.1862 & 5.4016 & TRN & \\
\hline CHEMBL1464878 & 688239 & 5.9862 & 5.4708 & TRN & \\
\hline CHEMBL1361034 & 688239 & 5.6862 & 5.4023 & TRN & \\
\hline CHEMBL1585304 & 688239 & 4.6362 & 5.4739 & TRN & \\
\hline CHEMBL1529501 & 688239 & 8.1871 & 5.5433 & TRN & \\
\hline CHEMBL1564674 & 688239 & 5.7362 & 5.385 & TST & \\
\hline CHEMBL1546418 & 688239 & 5.1862 & 5.4469 & TRN & \\
\hline CHEMBL1468538 & 688239 & 4.5862 & \multicolumn{2}{|c|}{5.492999999999999} & TRN \\
\hline CHEMBL1317985 & 688239 & 4.5862 & 5.5886 & TRN & \\
\hline CHEMBL1506425 & 688239 & 5.9362 & 5.5701 & TRN & \\
\hline CHEMBL1483401 & 688239 & 5.3862 & 5.4705 & TRN & \\
\hline CHEMBL1543075 & 688239 & 4.9862 & 5.4817 & TST & \\
\hline
\end{tabular}




\begin{tabular}{|c|c|c|c|c|c|}
\hline \\
\hline CHEMBL3208982 & 688239 & 7.1361 & 5.4821 & TST & \\
\hline CHEMBL3199887 & 688239 & 6.7361 & 5.3728 & TST & \\
\hline CHEMBL1503497 & 688239 & 6.8861 & 5.5922 & TRN & \\
\hline CHEMBL1346836 & 688239 & 5.8862 & 5.3732 & TRN & \\
\hline CHEMBL1583864 & 688239 & 4.95 & 5.581 & TRN & \\
\hline CHEMBL1421360 & 688239 & 5.1862 & 5.7296 & TRN & \\
\hline CHEMBL1528052 & 688239 & 5.1862 & 5.35 & TST & \\
\hline CHEMBL1599129 & 688239 & 4.5362 & 5.5462 & TRN & \\
\hline CHEMBL1461748 & 688239 & 4.7862 & 5.4844 & TRN & \\
\hline CHEMBL1608419 & 688239 & 4.5362 & 5.6709 & TRN & \\
\hline CHEMBL1334595 & 688239 & 4.4862 & 5.4809 & TRN & \\
\hline CHEMBL1336686 & 688239 & 5.1362 & 5.4252 & TRN & \\
\hline CHEMBL1386446 & 688239 & 5.4862 & $5.46200 t$ & 0000000001 & TST \\
\hline CHEMBL3213304 & 688239 & 4.5862 & 5.5987 & TRN & \\
\hline CHEMBL1569489 & 688239 & 6.1362 & 5.3665 & TST & \\
\hline CHEMBL1419709 & 688239 & 5.3862 & 5.5789 & TRN & \\
\hline CHEMBL1464890 & 688239 & 4.8862 & 5.5434 & TRN & \\
\hline CHEMBL1345719 & 688239 & 5.0862 & 5.5174 & TRN & \\
\hline CHEMBL1538839 & 688239 & 5.2362 & 5.5183 & TRN & \\
\hline CHEMBL1331798 & 688239 & 4.5362 & 5.2982 & TRN & \\
\hline CHEMBL1334620 & 688239 & 5.7862 & 5.402 & TRN & \\
\hline CHEMBL1613213 & 688239 & 4.7862 & 5.506 & TRN & \\
\hline CHEMBL1346029 & 688239 & 6.2362 & 5.5566 & TST & \\
\hline CHEMBL1527707 & 688239 & 5.3862 & 5.4523 & TRN & \\
\hline CHEMBL1549776 & 688239 & 4.6362 & 5.4606 & TRN & \\
\hline CHEMBL1453429 & 688239 & 4.7862 & 5.3842 & TRN & \\
\hline CHEMBL1541036 & 688239 & 4.7862 & 5.4293 & TST & \\
\hline CHEMBL1369861 & 688239 & 5.3362 & 5.6068 & TRN & \\
\hline CHEMBL1315985 & 688239 & 4.5362 & 5.4729 & TRN & \\
\hline CHEMBL 73441 & 688239 & 5.5362 & 5.5592 & TRN & \\
\hline CHEMBL1389736 & 688239 & 5.4362 & 5.5503 & TST & \\
\hline CHEMBL1541217 & 688239 & 7.1864 & 5.4872 & TRN & \\
\hline CHEMBL1425057 & 688239 & 6.2362 & 5.5025 & TRN & \\
\hline CHEMBL1420550 & 688239 & 5.7362 & 5.6667 & TRN & \\
\hline CHEMBL1338296 & 688239 & 5.0362 & 5.5139 & TRN & \\
\hline CHEMBL1415154 & 688239 & 5.6362 & 5.5703 & TRN & \\
\hline CHEMBL1534216 & 688239 & 4.4862 & 5.3587 & TRN & \\
\hline CHEMBL1533050 & 688239 & 6.3863 & 5.6619 & TRN & \\
\hline CHEMBL3210463 & 688239 & 5.2362 & 5.3335 & TST & \\
\hline CHEMBL 1465742 & 688239 & 4.7362 & 5.6122 & TRN & \\
\hline CHEMBL1601598 & 688239 & 4.9862 & 5.4801 & TRN & \\
\hline CHEMBL1399616 & 688239 & 5.6862 & 5.5911 & TRN & \\
\hline CHEMBL1392226 & 688239 & 5.1862 & 5.4835 & TRN & \\
\hline CHEMBL1976446 & 688239 & 4.5362 & 5.3593 & TRN & \\
\hline CHEMBL1422602 & 688239 & 5.0862 & 5.6082 & TRN & \\
\hline CHEMBL1420684 & 688239 & 4.7862 & 5.3731 & TST & \\
\hline CHEMBL1383327 & 688239 & 4.7362 & 5.3022 & TRN & \\
\hline CHEMBL1460839 & 688239 & 6.2362 & 5.4903 & TRN & \\
\hline
\end{tabular}


Supplemental Table S2.txt

\begin{tabular}{|c|c|c|c|c|}
\hline CHEMBL1458541 & 688239 & 6.1862 & 5.354 & TRN \\
\hline CHEMBL1367160 & 688239 & 4.6862 & 5.3881 & TRN \\
\hline CHEMBL1341532 & 688239 & 4.6862 & 5.4893 & TRN \\
\hline CHEMBL1520525 & 688239 & 4.9862 & 5.3884 & TRN \\
\hline CHEMBL1400678 & 688239 & 5.2862 & 5.3709 & TRN \\
\hline CHEMBL1437637 & 688239 & 4.8362 & 5.6437 & TRN \\
\hline CHEMBL1586333 & 688239 & 5.1862 & 5.5615 & TRN \\
\hline CHEMBL1561464 & 688239 & 4.7362 & 5.4977 & TRN \\
\hline CHEMBL3192332 & 688239 & 4.4862 & 5.5589 & TST \\
\hline CHEMBL1604017 & 688239 & 4.5862 & 5.4927 & TRN \\
\hline CHEMBL1389533 & 688239 & 5.0362 & \multicolumn{2}{|c|}{5.507999999999999} \\
\hline CHEMBL1303778 & 688239 & 4.7862 & 5.4887 & TRN \\
\hline CHEMBL1585949 & 688239 & 8.2366 & 5.4322 & TST \\
\hline CHEMBL1405660 & 688239 & 6.4362 & 5.5409 & TRN \\
\hline CHEMBL1361694 & 688239 & 5.1862 & 5.4747 & TST \\
\hline CHEMBL1345865 & 688239 & 4.6862 & 5.4105 & TRN \\
\hline CHEMBL3196855 & 688239 & 6.0362 & 5.4174 & TRN \\
\hline CHEMBL1432741 & 688239 & 4.4862 & 5.3926 & TRN \\
\hline CHEMBL1510667 & 688239 & 5.1862 & 5.5078 & TST \\
\hline CHEMBL1573004 & 688239 & 6.7361 & 5.515 & TRN \\
\hline CHEMBL1307100 & 688239 & 5.3862 & 5.4814 & TRN \\
\hline CHEMBL1495556 & 688239 & 4.5362 & 5.4832 & TRN \\
\hline CHEMBL1381561 & 688239 & 5.7362 & 5.3423 & TRN \\
\hline CHEMBL1393646 & 688239 & 7.2366 & 5.5354 & TRN \\
\hline CHEMBL1606446 & 688239 & 5.7862 & 5.4086 & TST \\
\hline CHEMBL1472200 & 688239 & 4.7362 & 5.5527 & TRN \\
\hline CHEMBL1379356 & 688239 & 6.2862 & 5.5751 & TST \\
\hline CHEMBL1305591 & 688239 & 5.8362 & 5.3083 & TRN \\
\hline CHEMBL1583667 & 688239 & 4.7362 & 5.4888 & TRN \\
\hline CHEMBL1344699 & 688239 & 5.2362 & 5.4836 & TST \\
\hline CHEMBL1545326 & 688239 & 4.8362 & 5.5536 & TRN \\
\hline CHEMBL1559227 & 688239 & 5.4362 & 5.5167 & TRN \\
\hline CHEMBL1375768 & 688239 & 4.6862 & 5.5796 & TRN \\
\hline CHEMBL1490562 & 688239 & 5.3362 & 5.6226 & TRN \\
\hline CHEMBL1473892 & 688239 & 5.4862 & 5.441 & TRN \\
\hline CHEMBL1512447 & 688239 & 5.1862 & 5.5461 & TRN \\
\hline CHEMBL1468641 & 688239 & 4.5362 & 5.6204 & TRN \\
\hline CHEMBL1491255 & 688239 & 6.7862 & 5.4865 & TST \\
\hline CHEMBL1466211 & 688239 & 5.7862 & 5.5797 & TRN \\
\hline CHEMBL1530034 & 688239 & 6.7361 & 5.4563 & TRN \\
\hline CHEMBL3209685 & 688239 & 5.4862 & 5.4062 & TST \\
\hline CHEMBL1505715 & 688239 & 6.1862 & 5.4681 & TST \\
\hline CHEMBL1517016 & 688239 & 4.8862 & 5.4486 & TRN \\
\hline CHEMBL1533714 & 688239 & 6.5862 & 5.545 & TRN \\
\hline CHEMBL1380720 & 688239 & 6.0362 & 5.492999 & 999999999 \\
\hline CHEMBL1450650 & 688239 & 7.0362 & 5.4807 & TST \\
\hline CHEMBL1508539 & 688239 & 6.3863 & 5.441 & TRN \\
\hline CHEMBL1340405 & 688239 & 4.8862 & 5.5585 & TRN \\
\hline
\end{tabular}

Page 962 
Supplemental Table S2.txt

\begin{tabular}{|c|c|c|c|c|}
\hline CHEMBL1589871 & 688239 & 4.6862 & 5.4086 & TST \\
\hline CHEMBL1560004 & 688239 & 5.0862 & 5.3557 & TRN \\
\hline CHEMBL1530045 & 688239 & 5.4862 & 5.4645 & TRN \\
\hline CHEMBL3211969 & 688239 & 4.5362 & 5.6785 & TRN \\
\hline CHEMBL1586920 & 688239 & 7.0362 & 5.5041 & TST \\
\hline CHEMBL1482325 & 688239 & 4.5862 & 5.5422 & TRN \\
\hline CHEMBL1356413 & 688239 & 4.5362 & 5.3773 & TRN \\
\hline CHEMBL1500278 & 688239 & 6.0862 & 5.4927 & TRN \\
\hline CHEMBL1363810 & 688239 & 6.7862 & 5.3427 & TRN \\
\hline CHEMBL1314320 & 688239 & 4.9862 & 5.4121 & TRN \\
\hline CHEMBL1386256 & 688239 & 5.4362 & 5.5139 & TST \\
\hline CHEMBL1319941 & 688239 & 5.5362 & 5.5598 & TRN \\
\hline CHEMBL1426505 & 688239 & 4.7362 & 5.4438 & TST \\
\hline CHEMBL1531476 & 688239 & 6.1862 & 5.5206 & TRN \\
\hline CHEMBL1471601 & 688239 & 6.1862 & 5.5731 & TST \\
\hline CHEMBL1587213 & 688239 & 4.9362 & 5.5105 & TST \\
\hline CHEMBL1482824 & 688239 & 8.3372 & 5.5555 & TRN \\
\hline CHEMBL1558995 & 688239 & 6.8861 & 5.4041 & TRN \\
\hline CHEMBL1535736 & 688239 & 6.0862 & 5.5381 & TRN \\
\hline CHEMBL1526845 & 688239 & 5.1862 & 5.6155 & TST \\
\hline CHEMBL1594278 & 688239 & 6.0362 & 5.5722 & TRN \\
\hline CHEMBL1493961 & 688239 & 7.1361 & 5.4206 & TRN \\
\hline CHEMBL1390187 & 688239 & 4.6362 & 5.4749 & TRN \\
\hline CHEMBL1326656 & 688239 & 8.3872 & 5.4935 & TRN \\
\hline CHEMBL1521237 & 688239 & 6.9363 & 5.4177 & TRN \\
\hline CHEMBL1310264 & 688239 & 6.4862 & $5.45700 e$ & 0000000001 \\
\hline CHEMBL1444991 & 688239 & 5.6362 & 5.5052 & TST \\
\hline CHEMBL1436941 & 688239 & 7.2865 & 5.4977 & TRN \\
\hline CHEMBL1408987 & 688239 & 6.3863 & 5.5464 & TST \\
\hline CHEMBL1311577 & 688239 & 6.1362 & 5.4964 & TRN \\
\hline CHEMBL1569353 & 688239 & 5.4862 & 5.4967 & TST \\
\hline CHEMBL1508068 & 688239 & 4.5362 & 5.5233 & TRN \\
\hline CHEMBL3212333 & 688239 & 4.7862 & 5.402 & TRN \\
\hline CHEMBL1459808 & 688239 & 4.5362 & 5.5256 & TRN \\
\hline CHEMBL1610073 & 688239 & 4.5362 & 5.407 & TRN \\
\hline CHEMBL1407390 & 688239 & 4.7362 & 5.4489 & TRN \\
\hline CHEMBL1525274 & 688239 & 5.4362 & 5.5526 & TST \\
\hline CHEMBL1416516 & 688239 & 5.1862 & 5.4351 & TRN \\
\hline CHEMBL1384696 & 688239 & 6.7001 & 5.3822 & TRN \\
\hline CHEMBL1515321 & 688239 & 5.2862 & 5.3885 & TRN \\
\hline CHEMBL 1607136 & 688239 & 4.7862 & 5.5628 & TRN \\
\hline CHEMBL1535348 & 688239 & 4.7862 & 5.4564 & TRN \\
\hline CHEMBL1441046 & 688239 & 4.5362 & 5.7407 & TRN \\
\hline CHEMBL1458499 & 688239 & 4.5362 & 5.3181 & TRN \\
\hline CHEMBL1502670 & 688239 & 5.1362 & 5.392 & TST \\
\hline CHEMBL1448623 & 688239 & 4.5362 & 5.5243 & TST \\
\hline CHEMBL1338895 & 688239 & 4.7862 & 5.4511 & TRN \\
\hline CHEMBL1309288 & 688239 & 4.7362 & 5.3782 & TRN \\
\hline
\end{tabular}


Supplemental Table S2.txt

\begin{tabular}{|c|c|c|c|c|}
\hline CHEMBL1581818 & 688239 & 4.5862 & 5.3504 & TRN \\
\hline CHEMBL1521381 & 688239 & 4.5362 & 5.4505 & TRN \\
\hline CHEMBL1350785 & 688239 & 4.5362 & 5.4133 & TST \\
\hline CHEMBL1458044 & 688239 & 4.5362 & 5.4321 & TRN \\
\hline CHEMBL1339170 & 688239 & 4.7862 & 5.4372 & TRN \\
\hline CHEMBL1419109 & 688239 & 4.5362 & 5.4068 & TRN \\
\hline CHEMBL1546354 & 688239 & 4.7362 & 5.4409 & TRN \\
\hline CHEMBL1455052 & 688239 & 5.2362 & 5.6609 & TRN \\
\hline CHEMBL1472648 & 688239 & 5.7362 & 5.5379 & TRN \\
\hline CHEMBL1360805 & 688239 & 6.0862 & 5.574 & TRN \\
\hline CHEMBL1365783 & 688239 & 5.1862 & 5.5425 & TRN \\
\hline CHEMBL1541620 & 688239 & 6.2362 & 5.3974 & TST \\
\hline CHEMBL1430520 & 688239 & 5.2862 & 5.3568 & TRN \\
\hline CHEMBL1312566 & 688239 & 7.6364 & 5.4734 & TST \\
\hline CHEMBL1579098 & 688239 & 6.1862 & 5.4519 & TRN \\
\hline CHEMBL1382749 & 688239 & 5.1862 & 5.4213 & TST \\
\hline CHEMBL1430660 & 688239 & 6.3863 & 5.3559 & TRN \\
\hline CHEMBL1597860 & 688239 & 6.0862 & 5.474 & TST \\
\hline CHEMBL1597004 & 688239 & 4.7362 & 5.3072 & TST \\
\hline CHEMBL1608341 & 688239 & 6.8861 & 5.7032 & TRN \\
\hline CHEMBL1557030 & 688239 & 5.1862 & 5.4653 & TRN \\
\hline CHEMBL1566732 & 688239 & 4.9862 & 5.5249 & TRN \\
\hline CHEMBL1318719 & 688239 & 4.6862 & 5.6157 & TRN \\
\hline CHEMBL1408190 & 688239 & 6.0862 & 5.4738 & TRN \\
\hline CHEMBL1497286 & 688239 & 4.5362 & 5.364 & TRN \\
\hline CHEMBL3191985 & 688239 & 5.8362 & 5.475 & TST \\
\hline CHEMBL1599538 & 688239 & 6.4362 & 5.553999 & 9999999999 \\
\hline CHEMBL 2004745 & 688239 & 5.6362 & 5.335 & TRN \\
\hline CHEMBL1492668 & 688239 & 4.5362 & 5.5119 & TRN \\
\hline CHEMBL1608077 & 688239 & 5.1862 & 5.4685 & TRN \\
\hline CHEMBL1479423 & 688239 & 5.8362 & 5.5309 & TRN \\
\hline CHEMBL1419754 & 688239 & 4.5362 & 5.546 & TST \\
\hline CHEMBL3198332 & 688239 & 5.3362 & 5.5391 & TST \\
\hline CHEMBL1588126 & 688239 & 4.7362 & 5.3849 & TRN \\
\hline CHEMBL1342993 & 688239 & 4.7862 & 5.5065 & TST \\
\hline CHEMBL48310 & 688239 & 5.7362 & 5.3854 & TST \\
\hline CHEMBL1372115 & 688239 & 5.1362 & 5.6782 & TRN \\
\hline CHEMBL1301236 & 688239 & 4.7362 & 5.4713 & TRN \\
\hline CHEMBL1527725 & 688239 & 4.5362 & 5.6821 & TST \\
\hline CHEMBL 3189644 & 688239 & 5.1862 & 5.3994 & TRN \\
\hline CHEMBL1471085 & 688239 & 8.3372 & 5.5669 & TRN \\
\hline CHEMBL1518567 & 688239 & 4.7362 & 5.4185 & TRN \\
\hline CHEMBL1450381 & 688239 & 6.7361 & 5.3924 & TST \\
\hline CHEMBL1333715 & 688239 & 6.0362 & 5.5194 & TST \\
\hline CHEMBL1546642 & 688239 & 4.7362 & 5.4376 & TRN \\
\hline CHEMBL1425068 & 688239 & 5.5862 & 5.4877 & TRN \\
\hline CHEMBL1594139 & 688239 & 6.2862 & 5.5085 & TRN \\
\hline CHEMBL1416330 & 688239 & 4.5362 & 5.5498 & TST \\
\hline
\end{tabular}


Supplemental Table S2.txt

\begin{tabular}{|c|c|c|c|c|c|}
\hline CHEMBL1319684 & 688239 & 4.4862 & 5.4807 & TRN & \\
\hline CHEMBL1416403 & 688239 & 4.8362 & 5.4937 & TRN & \\
\hline CHEMBL1608273 & 688239 & 4.5362 & 5.4837 & TRN & \\
\hline CHEMBL1495705 & 688239 & 6.9863 & 5.5175 & TRN & \\
\hline CHEMBL1412636 & 688239 & 5.0862 & 5.476 & TRN & \\
\hline CHEMBL1468458 & 688239 & 6.2362 & 5.3829 & TST & \\
\hline CHEMBL1550063 & 688239 & 4.7362 & 5.4778 & TRN & \\
\hline CHEMBL1400453 & 688239 & 4.7862 & 5.6673 & TST & \\
\hline CHEMBL1467741 & 688239 & 4.5362 & 5.5462 & TRN & \\
\hline CHEMBL1402384 & 688239 & 4.8362 & 5.4992 & TST & \\
\hline CHEMBL1441147 & 688239 & 5.3862 & 5.5309 & TRN & \\
\hline CHEMBL1535229 & 688239 & 6.0862 & 5.5789 & TRN & \\
\hline CHEMBL1987816 & 688239 & 4.7862 & 5.377000 & 0000000001 & TST \\
\hline CHEMBL1334129 & 688239 & 6.5363 & 5.5615 & TRN & \\
\hline CHEMBL1307842 & 688239 & 5.5362 & 5.6622 & TRN & \\
\hline CHEMBL1365447 & 688239 & 4.5362 & 5.559 & TRN & \\
\hline CHEMBL3208357 & 688239 & 8.1871 & 5.4968 & TRN & \\
\hline CHEMBL1345361 & 688239 & 4.5362 & 5.4633 & TRN & \\
\hline CHEMBL1583433 & 688239 & 4.9862 & 5.4349 & TST & \\
\hline CHEMBL1550878 & 688239 & 6.2862 & 5.4713 & TRN & \\
\hline CHEMBL1592285 & 688239 & 6.7862 & 5.3312 & TRN & \\
\hline CHEMBL1320417 & 688239 & 4.4862 & 5.5869 & TRN & \\
\hline CHEMBL1333955 & 688239 & 5.1862 & 5.5658 & TRN & \\
\hline CHEMBL1454580 & 688239 & 4.5362 & 5.3745 & TST & \\
\hline CHEMBL1309098 & 688239 & 6.2362 & 5.4866 & TRN & \\
\hline CHEMBL1429009 & 688239 & 5.1862 & 5.3345 & TST & \\
\hline CHEMBL1336282 & 688239 & 5.0862 & 5.4355 & TST & \\
\hline CHEMBL1480712 & 688239 & 4.8862 & 5.4347 & TRN & \\
\hline CHEMBL1600235 & 688239 & 4.5362 & 5.444 & TRN & \\
\hline CHEMBL1392237 & 688239 & 8.2366 & 5.4092 & TRN & \\
\hline CHEMBL1376777 & 688239 & 5.4862 & 5.4072 & TRN & \\
\hline CHEMBL1355894 & 688239 & 6.5363 & 5.5853 & TRN & \\
\hline CHEMBL1493783 & 688239 & 4.8362 & 5.3177 & TRN & \\
\hline CHEMBL1390918 & 688239 & 8.3372 & 5.4522 & TRN & \\
\hline CHEMBL122355 & 688239 & 4.7862 & 5.5381 & TST & \\
\hline CHEMBL1406203 & 688239 & 6.1862 & 5.5306 & TRN & \\
\hline CHEMBL1613356 & 688239 & 6.0862 & 5.3703 & TRN & \\
\hline CHEMBL1452067 & 688239 & 4.8362 & 5.4882 & TRN & \\
\hline CHEMBL1494824 & 688239 & 6.9863 & 5.5563 & TRN & \\
\hline CHEMBL1463187 & 688239 & 6.0862 & 5.6066 & TRN & \\
\hline CHEMBL 3209734 & 688239 & 4.6362 & 5.4867 & TRN & \\
\hline CHEMBL3196370 & 688239 & 4.6862 & 5.5281 & TRN & \\
\hline CHEMBL1574500 & 688239 & 4.7362 & 5.4215 & TRN & \\
\hline CHEMBL1453826 & 688239 & 4.8362 & 5.3891 & TST & \\
\hline CHEMBL1986425 & 688239 & 5.4862 & 5.5391 & TRN & \\
\hline CHEMBL1463279 & 688239 & 5.4862 & 5.3518 & TST & \\
\hline CHEMBL3197051 & 688239 & 5.7362 & 5.5421 & TRN & \\
\hline CHEMBL1347460 & 688239 & 4.8862 & 5.5405 & TRN & \\
\hline
\end{tabular}


Supplemental Table S2.txt

\begin{tabular}{|c|c|c|c|c|}
\hline . & & & & \\
\hline HEMBL1402699 & 38239 & 862 & & \\
\hline AEMBL1381104 & 239 & & 273 & \\
\hline 210 & 39 & & & \\
\hline IEMBL13 & 39 & & & \\
\hline AEMBL1306775 & 88239 & 862 & & \\
\hline AEMBL1504092 & 88239 & 862 & 137 & \\
\hline HEMBL1990783 & & & & \\
\hline AEMBL319 & 39 & 362 & & \\
\hline IEMBL1432478 & & & & \\
\hline AEMBL1408907 & 39 & 362 & & \\
\hline AEMBL1390095 & & 362 & & \\
\hline AEMBL3190227 & & 62 & & \\
\hline AEMBL1578961 & & & & \\
\hline HEMBL1439716 & & & & \\
\hline AEMBL405317 & & 362 & & \\
\hline AEMBL1494756 & & & & \\
\hline IEMBL1479880 & & & & \\
\hline AEMBL146 & & & & \\
\hline IEMBL1526945 & & & & \\
\hline AEMBL1415347 & & 62 & & \\
\hline AEMBL1610042 & & & & \\
\hline IEMBL1575926 & & & & \\
\hline AEMBL1607396 & & & & \\
\hline 1602854 & & & & \\
\hline AEMBL1420800 & & & & \\
\hline IEMBL1550958 & & & & \\
\hline AEMBL1342302 & & & & \\
\hline AEMBL1390120 & & & & \\
\hline AEMBL1480782 & & & & \\
\hline AEMBL1349172 & & & & \\
\hline HEMBL1867074 & & & & \\
\hline 89 & & & & \\
\hline 57 & & & & \\
\hline AEMBL1537934 & & & & ST \\
\hline AEMBL1338958 & & & & $S$ \\
\hline AEMBL1608108 & & & & \\
\hline & & & & \\
\hline 90 & & & & \\
\hline L1562502 & & & & RN \\
\hline AEMBL1358831 & & & & \\
\hline AEMBL1396260 & & & & \\
\hline & & & & \\
\hline HEMBL1376066 & & & & \\
\hline AEMBL1497143 & & & & RN \\
\hline IEMBL1326874 & & 62 & & \\
\hline 1542165 & & & & \\
\hline HEMBL142030 & & & .5748 & \\
\hline
\end{tabular}

Page 966 
Supplemental Table S2.txt

\begin{tabular}{|c|c|c|c|c|}
\hline & & & 5.43 & \\
\hline CHEMBL1416637 & 38239 & 3862 & 5.359 & \\
\hline HEMBL1452678 & 3239 & 5362 & & \\
\hline EMBL1 & 239 & & & \\
\hline EMBL13 & 3239 & 5362 & & \\
\hline AEMBL1359443 & 88239 & 2862 & 4832 & \\
\hline HEMBL1588191 & 88239 & .7362 & .5361 & \\
\hline HEMBL1 & & & & \\
\hline EMBL & 239 & 7362 & & \\
\hline IEMBL: & 239 & 1862 & & \\
\hline AEMBL13 & 88239 & 2362 & 5.5198 & \\
\hline AEMBL13 & 3239 & .5362 & & \\
\hline HEMBL 1 & 39 & & & \\
\hline AEMBL: & 239 & 862 & & \\
\hline AEMBL: & 239 & 862 & & \\
\hline AEMBL: & 239 & .6862 & & \\
\hline HEMBL: & & 861 & & \\
\hline HEMBL & & 53 & & \\
\hline HEMBL & & 62 & & \\
\hline HEMB & 39 & 862 & & \\
\hline IEMBL? & & 862 & & \\
\hline AEMBL: & & 62 & & \\
\hline AEMBL: & & 52 & & \\
\hline HEMBL & & 62 & & \\
\hline HEMB & & & & \\
\hline EMBL & & & & \\
\hline AEMBL] & & & & \\
\hline AEMBL: & & & & \\
\hline IEMB & & & & \\
\hline 99 & & 62 & & $\Gamma R N$ \\
\hline 3452 & & & & R \\
\hline HEMBL: & & 62 & & \\
\hline IEMBL & & & & t \\
\hline 2 & & & & \\
\hline 73 & & & & TRN \\
\hline AEMBL] & & & & TRI \\
\hline HEMBL] & & 62 & & \\
\hline 24 & & & & \\
\hline 251 & & & & \\
\hline & & & & \\
\hline IEMBL: & & 862 & 304 & F \\
\hline AEMBL & & 362 & & \\
\hline & & & & \\
\hline HEMBL & & & & \\
\hline CHEMBL & & & & RI \\
\hline IEMBL: & & 362 & & \\
\hline 21 & & & & \\
\hline CHEMBL 1 & & & 5.6148 & \\
\hline
\end{tabular}


Supplemental Table S2.txt

\begin{tabular}{|c|c|c|c|c|}
\hline & & & & \\
\hline HEMBL1444176 & 38239 & 362 & & \\
\hline AEMBL1340597 & 239 & 361 & & \\
\hline & 39 & 865 & & \\
\hline IEMBL14 & & 862 & & \\
\hline AEMBL1507455 & 88239 & 862 & & \\
\hline AEMBL1455087 & 88239 & 862 & 893 & \\
\hline HEMBL1369254 & & 862 & & \\
\hline IEMBL13 & 39 & 362 & & \\
\hline IEMBL15 & & 862 & & \\
\hline AEMBL1556205 & 39 & 872 & & \\
\hline AEMBL1608977 & & 862 & & \\
\hline AEMBL1402294 & & 63 & & \\
\hline AEMBL13 & & 62 & & \\
\hline HEMBL 14 & & 62 & & \\
\hline HEMBL136 & & 372 & & \\
\hline AEMBL1412823 & & 366 & & \\
\hline HEMBL14 & & 62 & & \\
\hline JEMBL14 & & & & \\
\hline JEMBL15 & & 62 & & \\
\hline HEMBL130 & & 863 & & \\
\hline HEMBL144 & & 362 & & \\
\hline HEMBL14 & & 62 & & \\
\hline HFMBI 14 & & 62 & & \\
\hline 92 & & 62 & & \\
\hline בר 1 & & 362 & & \\
\hline AEMBL532 & & & & \\
\hline EMBL32 & & 62 & & \\
\hline AEMP & & & & \\
\hline AEMBL15 & & 62 & & \\
\hline HEMBL142 & & 62 & & \\
\hline HEMBL1583970 & & 362 & & \\
\hline & & 62 & & \\
\hline 5 & & 52 & & \\
\hline HEMBL131 & & & & RI \\
\hline AEMBL1459276 & & 362 & & \\
\hline AEMBL239103 & & 862 & & 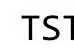 \\
\hline & & 362 & & \\
\hline (2MO & & & & ل \\
\hline HEMBL155 & & & & RN \\
\hline AEMBL1588591 & & 362 & & $\mathrm{R}$ \\
\hline JEMBL14] & & 62 & & \\
\hline . & & & & \\
\hline HEMBL152 & & 62 & & \\
\hline HEMBL1353988 & & 862 & & $\cdots$ \\
\hline AEMBL137 & & 362 & 312 & TR \\
\hline רי12019 1 & & 5.4862 & & \\
\hline HEMBL146799 & & & .4551 & \\
\hline
\end{tabular}

Page 968 
Supplemental Table S2.txt

\begin{tabular}{|c|c|c|c|c|c|c|}
\hline CHEMBL1527407 & 688239 & 5.9362 & 5.4968 & TRN & & \\
\hline CHEMBL1464850 & 688239 & 5.5862 & 5.4816 & TST & & \\
\hline CHEMBL396366 & 688239 & 4.7362 & 5.566 & TST & & \\
\hline CHEMBL1427684 & 688239 & 4.7362 & 5.4857 & TST & & \\
\hline CHEMBL1562033 & 688239 & 4.5362 & 5.3146 & TST & & \\
\hline CHEMBL1299872 & 688239 & 4.9362 & 5.5166 & TRN & & \\
\hline CHEMBL1575493 & 688239 & 4.5362 & 5.5109 & TRN & & \\
\hline CHEMBL1340758 & 688239 & 6.8861 & 5.5972 & TRN & & \\
\hline CHEMBL1570081 & 688239 & 4.5362 & 5.4954 & TST & & \\
\hline CHEMBL1380844 & 688239 & 6.7361 & 5.5201 & TST & & \\
\hline CHEMBL1528697 & 688239 & 5.0862 & 5.4605 & TRN & & \\
\hline CHEMBL1334940 & 688239 & 4.7862 & 5.6496 & TRN & & \\
\hline CHEMBL1490880 & 688239 & 4.7362 & 5.4368 & TRN & & \\
\hline CHEMBL1536580 & 688239 & 4.6362 & 5.487 & TRN & & \\
\hline CHEMBL1333354 & 688239 & 5.1362 & 5.619 & TRN & & \\
\hline CHEMBL1584620 & 688239 & 4.7362 & 5.3379 & TRN & & \\
\hline CHEMBL1587063 & 688239 & 5.1862 & 5.501 & TRN & & \\
\hline CHEMBL1590370 & 688239 & 4.5362 & 5.5267 & TRN & & \\
\hline CHEMBL1489174 & 688239 & 5.7862 & 5.5763 & TRN & & \\
\hline CHEMBL1451667 & 688239 & 5.2362 & 5.5286 & TST & & \\
\hline CHEMBL1387452 & 688239 & 8.28399 & 99999999 & 99 & 5.4218 & TST \\
\hline CHEMBL1572414 & 688239 & 6.5862 & 5.4898 & TRN & & \\
\hline CHEMBL1365279 & 688239 & 4.5362 & 5.3939 & TRN & & \\
\hline CHEMBL1993796 & 688239 & 5.3862 & 5.4541 & TRN & & \\
\hline CHEMBL3211791 & 688239 & 5.3362 & 5.5457 & TRN & & \\
\hline CHEMBL394657 & 688239 & 7.6364 & 5.4786 & TRN & & \\
\hline CHEMBL1389048 & 688239 & 6.0862 & 5.4934 & TRN & & \\
\hline CHEMBL1451379 & 688239 & 4.5362 & 5.3813 & TRN & & \\
\hline CHEMBL1549697 & 688239 & 5.9362 & 5.4408 & TRN & & \\
\hline CHEMBL1554757 & 688239 & 5.9362 & 5.3161 & TRN & & \\
\hline CHEMBL1600692 & 688239 & 5.5862 & 5.5438 & TRN & & \\
\hline CHEMBL1470100 & 688239 & 6.0862 & 5.5653 & TST & & \\
\hline CHEMBL1439352 & 688239 & 5.3362 & 5.5273 & TST & & \\
\hline CHEMBL1477859 & 688239 & 5.8362 & 5.6183 & TST & & \\
\hline CHEMBL3208633 & 688239 & 4.5362 & 5.4265 & TRN & & \\
\hline CHEMBL1442176 & 688239 & 6.7361 & 5.4564 & TRN & & \\
\hline CHEMBL1312163 & 688239 & 5.6362 & 5.5779 & TRN & & \\
\hline CHEMBL1325124 & 688239 & 4.5362 & 5.4035 & TST & & \\
\hline CHEMBL 3207594 & 688239 & 5.1862 & 5.5213 & TRN & & \\
\hline CHEMBL1529778 & 688239 & 8.3372 & 5.4556 & TRN & & \\
\hline CHEMBL1422031 & 688239 & 4.5362 & 5.4364 & TRN & & \\
\hline CHEMBL3212906 & 688239 & 6.1862 & 5.3987 & TRN & & \\
\hline CHEMBL1344869 & 688239 & 4.5362 & 5.4825 & TRN & & \\
\hline CHEMBL1491793 & 688239 & 4.6362 & 5.6542 & TRN & & \\
\hline CHEMBL1406392 & 688239 & 5.8862 & 5.4481 & TRN & & \\
\hline CHEMBL1349903 & 688239 & 5.0362 & 5.5988 & TRN & & \\
\hline CHEMBL1528035 & 688239 & 5.1862 & 5.4012 & TRN & & \\
\hline CHEMBL1535618 & 688239 & 4.7862 & 5.5063 & TRN & & \\
\hline
\end{tabular}

Page 969 
Supplemental Table S2.txt

\begin{tabular}{|c|c|c|c|c|c|}
\hline CHEMBL1595527 & 688239 & 6.5363 & 5.6457 & TRN & \\
\hline CHEMBL1499534 & 688239 & 5.7862 & 5.5763 & TRN & \\
\hline CHEMBL1374639 & 688239 & 4.4862 & 5.4475 & TST & \\
\hline CHEMBL1604507 & 688239 & 4.6862 & 5.4821 & TRN & \\
\hline CHEMBL1581468 & 688239 & 6.1862 & 5.54799 & 9999999999 & TRN \\
\hline CHEMBL1446589 & 688239 & 6.8362 & 5.5847 & TRN & \\
\hline CHEMBL487894 & 688239 & 4.6362 & 5.5515 & TRN & \\
\hline CHEMBL3193888 & 688239 & 4.5362 & 5.4777 & TST & \\
\hline CHEMBL1594104 & 688239 & 4.7862 & 5.4517 & TST & \\
\hline CHEMBL1411911 & 688239 & 4.7862 & 5.3198 & TRN & \\
\hline CHEMBL1436469 & 688239 & 6.8362 & 5.3954 & TRN & \\
\hline CHEMBL1465036 & 688239 & 5.7362 & 5.5734 & TRN & \\
\hline CHEMBL114957 & 688239 & 6.8362 & 5.5814 & TRN & \\
\hline CHEMBL1385663 & 688239 & 6.2362 & 5.3764 & TRN & \\
\hline CHEMBL1499740 & 688239 & 6.1862 & 5.4112 & TRN & \\
\hline CHEMBL1468176 & 688239 & 5.9362 & 5.5504 & TST & \\
\hline CHEMBL1493957 & 688239 & 5.9362 & 5.46200 & 0000000001 & TST \\
\hline CHEMBL1444425 & 688239 & 6.1362 & 5.5358 & TRN & \\
\hline CHEMBL1588517 & 688239 & 6.4362 & 5.4056 & TST & \\
\hline CHEMBL1457422 & 688239 & 5.8362 & 5.4799 & TRN & \\
\hline CHEMBL1603523 & 688239 & 4.5362 & 5.4232 & TST & \\
\hline CHEMBL1367007 & 688239 & 4.8362 & 5.6929 & TRN & \\
\hline CHEMBL1389230 & 688239 & 4.6362 & 5.48799 & 99999999995 & TST \\
\hline CHEMBL1305997 & 688239 & 4.8362 & 5.3946 & TRN & \\
\hline CHEMBL1363562 & 688239 & 5.7862 & 5.5043 & TRN & \\
\hline CHEMBL1555938 & 688239 & 4.7362 & 5.5685 & TRN & \\
\hline CHEMBL1422312 & 688239 & 5.2862 & 5.4256 & TRN & \\
\hline CHEMBL1611800 & 688239 & 4.9862 & 5.3894 & TRN & \\
\hline CHEMBL1305218 & 688239 & 6.7862 & 5.5665 & TST & \\
\hline CHEMBL1510334 & 688239 & 5.4362 & 5.4026 & TRN & \\
\hline CHEMBL1375197 & 688239 & 5.1862 & 5.5998 & TRN & \\
\hline CHEMBL1361854 & 688239 & 5.1862 & 5.4731 & TRN & \\
\hline CHEMBL1421571 & 688239 & 5.6862 & 5.568 & TRN & \\
\hline CHEMBL1340743 & 688239 & 4.6362 & 5.655 & TRN & \\
\hline CHEMBL1491246 & 688239 & 4.5362 & 5.5022 & TRN & \\
\hline CHEMBL1587872 & 688239 & 4.5862 & 5.3969 & TRN & \\
\hline CHEMBL1391039 & 688239 & 5.3862 & 5.4249 & TST & \\
\hline CHEMBL3196198 & 688239 & 5.7362 & 5.4672 & TST & \\
\hline CHEMBL1463514 & 688239 & 4.5 & 5.5002 & TRN & \\
\hline CHEMBL1497797 & 688239 & 5.8362 & 5.3462 & TST & \\
\hline CHEMBL1993746 & 688239 & 6.6861 & 5.4051 & TRN & \\
\hline CHEMBL 2373645 & 688239 & 6.0362 & 5.4802 & TRN & \\
\hline CHEMBL1394332 & 688239 & 4.5862 & 5.4222 & TRN & \\
\hline CHEMBL3208829 & 688239 & 6.2862 & 5.4385 & TRN & \\
\hline CHEMBL1457573 & 688239 & 5.1362 & 5.5425 & TRN & \\
\hline CHEMBL1599319 & 688239 & 6.9363 & 5.4551 & TST & \\
\hline CHEMBL270297 & 688239 & 5.1862 & 5.4805 & TRN & \\
\hline CHEMBL1496206 & 688239 & 4.9362 & 5.4255 & TRN & \\
\hline
\end{tabular}


Supplemental Table S2.txt

\begin{tabular}{|c|c|c|c|c|c|}
\hline CHEMBL1472958 & 688239 & 5.2862 & 5.3103 & TRN & \\
\hline CHEMBL1365627 & 688239 & 4.7862 & 5.3831 & TST & \\
\hline CHEMBL1359858 & 688239 & 4.4862 & 5.4656 & TRN & \\
\hline CHEMBL1336951 & 688239 & 4.5362 & 5.6336 & TST & \\
\hline CHEMBL1447273 & 688239 & 4.7362 & 5.506 & TST & \\
\hline CHEMBL1578862 & 688239 & 4.4862 & 5.6495 & TRN & \\
\hline CHEMBL1533175 & 688239 & 6.4362 & 5.6528 & TST & \\
\hline CHEMBL1340193 & 688239 & 5.1862 & 5.4273 & TST & \\
\hline CHEMBL1563150 & 688239 & 5.5862 & 5.4947 & TRN & \\
\hline CHEMBL1452614 & 688239 & 4.6862 & 5.4739 & TRN & \\
\hline CHEMBL1461831 & 688239 & 4.6362 & 5.6207 & TRN & \\
\hline CHEMBL1557203 & 688239 & 5.1862 & 5.5562 & TRN & \\
\hline CHEMBL1506221 & 688239 & 8.3372 & 5.4695 & TRN & \\
\hline CHEMBL1479538 & 688239 & 6.8362 & 5.5222 & TRN & \\
\hline CHEMBL1445009 & 688239 & 5.1862 & 5.4682 & TRN & \\
\hline CHEMBL1407288 & 688239 & 4.5862 & 5.4859 & TRN & \\
\hline CHEMBL1510572 & 688239 & 4.5362 & 5.4543 & TRN & \\
\hline CHEMBL1548496 & 688239 & 6.8861 & 5.5498 & TRN & \\
\hline CHEMBL1575846 & 688239 & 5.6362 & 5.449 & TRN & \\
\hline CHEMBL1369303 & 688239 & 5.1862 & 5.6373 & TRN & \\
\hline CHEMBL1393795 & 688239 & 6.7862 & 5.4808 & TRN & \\
\hline CHEMBL1583230 & 688239 & 6.5363 & 5.5509 & TRN & \\
\hline CHEMBL1474022 & 688239 & 5.4862 & 5.4845 & TRN & \\
\hline CHEMBL1476976 & 688239 & 4.5862 & 5.5238 & TRN & \\
\hline CHEMBL3211359 & 688239 & 5.9862 & 5.5409 & TRN & \\
\hline CHEMBL1342493 & 688239 & 7.2366 & 5.4417 & TRN & \\
\hline CHEMBL1344897 & 688239 & 5.1362 & 5.3821 & TRN & \\
\hline CHEMBL1571256 & 688239 & 5.0362 & 5.4592 & TRN & \\
\hline CHEMBL1365731 & 688239 & 5.3862 & 5.5521 & TRN & \\
\hline CHEMBL 3208327 & 688239 & 5.7862 & 5.5357 & TRN & \\
\hline CHEMBL1496572 & 688239 & 6.9363 & 5.6476 & TRN & \\
\hline CHEMBL1393066 & 688239 & 4.5862 & 5.437 & TRN & \\
\hline CHEMBL1546791 & 688239 & 5.3862 & 5.3724 & TST & \\
\hline CHEMBL1334570 & 688239 & 6.1362 & 5.695 & TRN & \\
\hline CHEMBL1369605 & 688239 & 4.5362 & 5.4906 & TRN & \\
\hline CHEMBL1403487 & 688239 & 5.0362 & 5.4519 & TRN & \\
\hline CHEMBL1429545 & 688239 & 4.6862 & 5.5738 & TRN & \\
\hline CHEMBL1563361 & 688239 & 5.1362 & 5.4568 & TST & \\
\hline CHEMBL1421717 & 688239 & 6.1862 & 5.5095 & TRN & \\
\hline CHEMBL1368564 & 688239 & 4.5362 & 5.5369 & TRN & \\
\hline CHEMBL1428694 & 688239 & 5.1862 & 5.48600 & 0000000001 & TRN \\
\hline CHEMBL1384241 & 688239 & 7.2865 & 5.5847 & TRN & \\
\hline CHEMBL1551504 & 688239 & 4.5862 & 5.5008 & TRN & \\
\hline CHEMBL 2369250 & 688239 & 6.8362 & 5.5659 & TST & \\
\hline CHEMBL3192525 & 688239 & 5.7362 & 5.4721 & TST & \\
\hline CHEMBL1503865 & 688239 & 5.3362 & 5.4401 & TRN & \\
\hline CHEMBL1576513 & 688239 & 4.6862 & 5.4761 & TRN & \\
\hline CHEMBL358546 & 688239 & 8.28399 & 79999999 & 5.4659 & TRN \\
\hline
\end{tabular}


Supplemental Table S2.txt

\begin{tabular}{|c|c|c|c|c|c|}
\hline CHEMBL1550946 & 688239 & 4.7862 & 5.5661 & TRN & \\
\hline CHEMBL1304399 & 688239 & 4.9362 & 5.3941 & TRN & \\
\hline CHEMBL1299997 & 688239 & 4.9862 & 5.5153 & TRN & \\
\hline CHEMBL1479122 & 688239 & 5.0362 & 5.4349 & TRN & \\
\hline CHEMBL1529460 & 688239 & 4.6862 & 5.497999 & 999999999 & TST \\
\hline CHEMBL1547598 & 688239 & 4.5362 & 5.587999 & (999999999 & TPN \\
\hline CHEMBL1477420 & 688239 & 6.9363 & 5.3298 & TRN & \\
\hline CHEMBL1518740 & 688239 & 7.0362 & 5.5636 & TRN & \\
\hline CHEMBL1427443 & 688239 & 4.4862 & 5.3649 & TRN & \\
\hline CHEMBL1492477 & 688239 & 5.0862 & 5.4291 & TRN & \\
\hline CHEMBL1543003 & 688239 & 4.5362 & 5.5363 & TST & \\
\hline CHEMBL 3195071 & 688239 & 5.1862 & 5.3161 & TRN & \\
\hline CHEMBL1300864 & 688239 & 5.1862 & 5.3814 & TRN & \\
\hline CHEMBL1328764 & 688239 & 5.2362 & 5.5638 & TRN & \\
\hline CHEMBL1482558 & 688239 & 4.9362 & 5.6202 & TRN & \\
\hline CHEMBL 3210584 & 688239 & 6.2362 & 5.433 & TRN & \\
\hline CHEMBL1541170 & 688239 & 5.2362 & 5.5499 & TRN & \\
\hline CHEMBL1489790 & 688239 & 4.5362 & 5.6074 & TRN & \\
\hline CHEMBL1581538 & 688239 & 5.3862 & 5.521 & TRN & \\
\hline CHEMBL1563810 & 688239 & 5.3362 & 5.495 & TRN & \\
\hline CHEMBL1478714 & 688239 & \multicolumn{2}{|c|}{8.283999999999999} & 5.5019 & TRN \\
\hline CHEMBL1511103 & 688239 & 4.7362 & 5.602 & TRN & \\
\hline CHEMBL1337209 & 688239 & 4.5362 & 5.3972 & TRN & \\
\hline CHEMBL1462268 & 688239 & 5.2862 & 5.3645 & TST & \\
\hline CHEMBL1450074 & 688239 & 4.5362 & 5.5043 & TST & \\
\hline CHEMBL 3213710 & 688239 & 5.0862 & 5.4051 & TST & \\
\hline CHEMBL1351600 & 688239 & 4.7862 & 5.4881 & TRN & \\
\hline CHEMBL1451508 & 688239 & 4.5862 & 5.4901 & TST & \\
\hline CHEMBL1313009 & 688239 & 5.2862 & 5.5322 & TRN & \\
\hline CHEMBL3208163 & 688239 & 4.8362 & 5.4048 & TRN & \\
\hline CHEMBL1402504 & 688239 & 5.1362 & 5.4149 & TRN & \\
\hline CHEMBL1322992 & 688239 & 4.5862 & 5.3746 & TRN & \\
\hline CHEMBL1479613 & 688239 & 5.3362 & 5.4468 & TRN & \\
\hline CHEMBL1529455 & 688239 & 6.0862 & 5.4443 & TST & \\
\hline CHEMBL1457433 & 688239 & 6.3362 & 5.6325 & TRN & \\
\hline CHEMBL3196521 & 688239 & 5.1862 & 5.3919 & TRN & \\
\hline CHEMBL1386665 & 688239 & 5.1862 & 5.4284 & TRN & \\
\hline CHEMBL1423444 & 688239 & 4.7862 & 5.3749 & TRN & \\
\hline CHEMBL1329369 & 688239 & 5.1362 & 5.5331 & TRN & \\
\hline CHEMBL1540345 & 688239 & 4.8862 & 5.5752 & TRN & \\
\hline CHEMBL1331086 & 688239 & 4.5362 & 5.6558 & TRN & \\
\hline CHEMBL1503346 & 688239 & 6.5363 & 5.4912 & TRN & \\
\hline CHEMBL1538496 & 688239 & 4.7862 & 5.6167 & TRN & \\
\hline CHEMBL3196148 & 688239 & 5.0362 & 5.4874 & TST & \\
\hline CHEMBL3190392 & 688239 & 5.5362 & 5.4108 & TRN & \\
\hline CHEMBL 3198972 & 688239 & 4.5362 & 5.505 & TRN & \\
\hline CHEMBL603522 & 688239 & 5.6362 & 5.3378 & TRN & \\
\hline CHEMBL1461436 & 688239 & 5.9362 & 5.5226 & TST & \\
\hline
\end{tabular}




\begin{tabular}{|c|c|c|c|c|c|}
\hline \multicolumn{6}{|c|}{ Supplemental Table s2.txt } \\
\hline CHEMBL1527055 & 688239 & 6.0 & 5.6507 & TRN & \\
\hline CHEMBL3210473 & 688239 & 8.3372 & 5.5105 & TRN & \\
\hline CHEMBL1539030 & 688239 & 5.0862 & 5.6437 & TST & \\
\hline CHEMBL3191932 & 688239 & 4.5362 & 5.415 & TST & \\
\hline CHEMBL1489380 & 688239 & 6.2362 & 5.351 & TRN & \\
\hline CHEMBL1404839 & 688239 & 6.7361 & 5.4653 & TST & \\
\hline CHEMBL3192043 & 688239 & 5.7362 & 5.4003 & TST & \\
\hline CHEMBL1578163 & 688239 & 4.4862 & 5.4443 & TRN & \\
\hline CHEMBL1403770 & 688239 & 5.3862 & 5.5887 & TRN & \\
\hline CHEMBL1328235 & 688239 & 5.2862 & 5.4928 & TRN & \\
\hline CHEMBL1456023 & 688239 & 4.8862 & 5.5183 & TRN & \\
\hline CHEMBL1565767 & 688239 & 5.2862 & 5.4357 & TST & \\
\hline CHEMBL1601097 & 688239 & 4.6362 & 5.4921 & TST & \\
\hline CHEMBL1376872 & 688239 & 4.7862 & 5.3815 & TRN & \\
\hline CHEMBL1389536 & 688239 & 4.6862 & 5.4558 & TRN & \\
\hline CHEMBL1543163 & 688239 & 4.5362 & 5.3523 & TST & \\
\hline CHEMBL3199102 & 688239 & 4.7862 & 5.593 & TRN & \\
\hline CHEMBL1344431 & 688239 & 6.7862 & 5.6961 & TRN & \\
\hline CHEMBL1319420 & 688239 & 6.1362 & 5.3796 & TRN & \\
\hline CHEMBL1484623 & 688239 & 5.3362 & 5.5754 & TST & \\
\hline CHEMBL1450058 & 688239 & 4.5362 & 5.5709 & TRN & \\
\hline CHEMBL1582028 & 688239 & 5.1862 & 5.5325 & TRN & \\
\hline CHEMBL1591708 & 688239 & 5.1862 & 5.5569 & TRN & \\
\hline CHEMBL13888 & 688239 & 6.9363 & 5.3967 & TRN & \\
\hline CHEMBL1591002 & 688239 & 5.0362 & 5.4271 & TST & \\
\hline CHEMBL1560014 & 688239 & 5.0362 & 5.4477 & TRN & \\
\hline CHEMBL1416861 & 688239 & 5.1862 & 5.5138 & TRN & \\
\hline CHEMBL1601995 & 688239 & 8.28399 & 79999999ऽ & 5.5519 & TST \\
\hline CHEMBL22996 & 688239 & 6.2362 & 5.4568 & TRN & \\
\hline CHEMBL1400054 & 688239 & 4.6862 & 5.73799 & 99999999995 & TRN \\
\hline CHEMBL1563913 & 688239 & 6.9863 & 5.3932 & TST & \\
\hline CHEMBL1310969 & 688239 & 4.5362 & 5.5541 & TRN & \\
\hline CHEMBL1460803 & 688239 & 5.3862 & 5.4921 & TST & \\
\hline CHEMBL1327914 & 688239 & 5.1862 & 5.4179 & TRN & \\
\hline CHEMBL1315087 & 688239 & 6.2862 & 5.7319 & TRN & \\
\hline CHEMBL1452610 & 688239 & 4.6862 & 5.3022 & TRN & \\
\hline CHEMBL1320670 & 688239 & 8.28399 & 79999999ऽ & 5.5873 & TRN \\
\hline CHEMBL1471131 & 688239 & 4.5362 & 5.4819 & TRN & \\
\hline CHEMBL1351558 & 688239 & 6.5363 & 5.672006 & 0000000001 & TRN \\
\hline CHEMBL1418330 & 688239 & 4.4862 & 5.3781 & TRN & \\
\hline CHEMBL1386174 & 688239 & 6.6861 & 5.5356 & TST & \\
\hline CHEMBL1610631 & 688239 & 5.5862 & 5.4772 & TST & \\
\hline CHEMBL1425047 & 688239 & 5.2362 & 5.5761 & TST & \\
\hline CHEMBL1310802 & 688239 & 4.7862 & 5.5438 & TRN & \\
\hline CHEMBL1447019 & 688239 & 4.5362 & 5.4335 & TST & \\
\hline CHEMBL1321424 & 688239 & 5.3862 & 5.4822 & TST & \\
\hline CHEMBL1379249 & 688239 & 5.3862 & 5.4878 & TRN & \\
\hline CHEMBL1544997 & 688239 & 4.6862 & 5.5333 & TRN & \\
\hline
\end{tabular}


Supplemental Table S2.txt

\begin{tabular}{|c|c|c|c|c|}
\hline 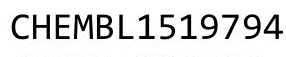 & & & & \\
\hline HEMBL 296536 & 88239 & 8362 & 5.6849 & \\
\hline HEMBL1378664 & 88239 & 6861 & & \\
\hline IEMBL1 & & & 079 & \\
\hline EMBL32: & & 862 & & \\
\hline HEMBL1318074 & 88239 & 362 & 5077 & \\
\hline HEMBL1552683 & 88239 & .1362 & .5397 & \\
\hline HEMBL1472329 & & & & \\
\hline IEMBL14 & 39 & 362 & .3027 & \\
\hline EMBL14 & 39 & 362 & .4321 & \\
\hline HEMBL1393201 & 88239 & 362 & 3981 & \\
\hline HEMBL1454379 & 39 & 1862 & .5307 & \\
\hline HEMBL151 & 39 & 62 & 5599 & \\
\hline HEMBL & 39 & & .4677 & \\
\hline HEMBL15 & 39 & 862 & & \\
\hline HEMBL1587534 & 39 & 362 & 4282 & \\
\hline HEMBL319 & 39 & 862 & & \\
\hline HEMBL153 & 9 & 862 & 13 & \\
\hline HEMBL 12 & 9 & 62 & & \\
\hline HEMBL60 & 39 & & 64 & \\
\hline HEMBL 144 & 39 & 862 & & \\
\hline HEMBL143 & 39 & 62 & & \\
\hline HEMBL13 & 39 & 862 & & \\
\hline HEMBL14 & & 72 & & \\
\hline 95 & 39 & 62 & & \\
\hline HEMBL 14 & 39 & & & \\
\hline AEMBL13马 & 39 & & & SI \\
\hline HEMBL15 & 39 & 62 & 13 & \\
\hline HEME & & & 29 & \\
\hline HEN & & 62 & 175 & RN \\
\hline HEMBL134 & 9 & & & RN \\
\hline HEMBL1587886 & 39 & 362 & 135 & RN \\
\hline HEMBL3 & & & & Niv \\
\hline 6 & 9 & & 61 & RN \\
\hline HEMBL13. & & & & RN \\
\hline HEMBL1611603 & 39 & & 5081 & IST \\
\hline HEMBL 530 & 39 & 862 & 5.5377 & RN \\
\hline 897 & 39 & 62 & 39 & $\mathrm{RN}$ \\
\hline 7 & 39 & & & RIV \\
\hline HEMBL15 & & & 5.4252 & ST \\
\hline HEMBL1585932 & 39 & 362 & 5.5372 & $\mathrm{RN}$ \\
\hline HEMBL 152 & 39 & 362 & 5.4974 & $\mathrm{RN}$ \\
\hline 98 & & & 5385 & \\
\hline CHEMBL 145 & & & 5.4856 & RIN \\
\hline HEMBL1338922 & & .4362 & .3753 & RN \\
\hline HEMBL1547815 & 39 & .5362 & & \\
\hline HEMBL 32 & & & & \\
\hline זררברו נחוזו & & & & \\
\hline
\end{tabular}

Page 974 
Supplemental Table S2.txt

\begin{tabular}{|c|c|c|c|c|c|}
\hline CHEMBL1423913 & 688239 & 5.6362 & 5.5527 & TRN & \\
\hline CHEMBL1516399 & 688239 & 5.1862 & 5.4949 & TRN & \\
\hline CHEMBL3199921 & 688239 & 5.0362 & 5.5164 & TST & \\
\hline CHEMBL1424911 & 688239 & 8.3372 & 5.5868 & TRN & \\
\hline CHEMBL1362523 & 688239 & 6.9363 & 5.4714 & TRN & \\
\hline CHEMBL1303731 & 688239 & 4.6362 & 5.7684 & TST & \\
\hline CHEMBL1367985 & 688239 & 4.5362 & 5.4841 & TRN & \\
\hline CHEMBL1476143 & 688239 & 4.8362 & 5.3527 & TRN & \\
\hline CHEMBL1381504 & 688239 & 4.5362 & 5.5177 & TRN & \\
\hline CHEMBL1398276 & 688239 & 5.9362 & 5.5719 & TRN & \\
\hline CHEMBL1452904 & 688239 & 4.5362 & 5.3234 & TST & \\
\hline CHEMBL1431491 & 688239 & 5.8862 & 5.3731 & TRN & \\
\hline CHEMBL1529901 & 688239 & 6.8861 & 5.4177 & TST & \\
\hline CHEMBL1564196 & 688239 & 4.6362 & 5.3407 & TRN & \\
\hline CHEMBL1429950 & 688239 & 7.5361 & 5.6197 & TRN & \\
\hline CHEMBL1334362 & 688239 & 4.7862 & 5.4475 & TRN & \\
\hline CHEMBL1606242 & 688239 & 6.1362 & 5.5187 & TRN & \\
\hline CHEMBL1432992 & 688239 & 4.7362 & 5.4624 & TRN & \\
\hline CHEMBL1347469 & 688239 & 4.9362 & 5.3683 & TRN & \\
\hline CHEMBL1594460 & 688239 & 6.2862 & 5.5968 & TRN & \\
\hline CHEMBL1489444 & 688239 & 5.5862 & 5.4831 & TST & \\
\hline CHEMBL1484039 & 688239 & 4.7362 & 5.5529 & TRN & \\
\hline CHEMBL1404110 & 688239 & 6.9363 & 5.4775 & TRN & \\
\hline CHEMBL1487135 & 688239 & 4.7862 & 5.25200 & 0000000001 & TRN \\
\hline CHEMBL1610862 & 688239 & 4.8862 & 5.5444 & TRN & \\
\hline CHEMBL1421619 & 688239 & 7.2366 & 5.4064 & TST & \\
\hline CHEMBL1510939 & 688239 & 6.9863 & 5.4501 & TST & \\
\hline CHEMBL1464131 & 688239 & 5.7862 & 5.5763 & TRN & \\
\hline CHEMBL1366577 & 688239 & 4.5862 & 5.3553 & TRN & \\
\hline CHEMBL1494611 & 688239 & 4.6862 & 5.5766 & TRN & \\
\hline CHEMBL1302075 & 688239 & 4.7362 & 5.5866 & TRN & \\
\hline CHEMBL1360737 & 688239 & 5.1862 & 5.5959 & TRN & \\
\hline CHEMBL1380811 & 688239 & 5.3362 & 5.59399 & 9999999999 & TRN \\
\hline CHEMBL1549666 & 688239 & 4.5362 & 5.3608 & TRN & \\
\hline CHEMBL1331567 & 688239 & 4.4862 & 5.4487 & TRN & \\
\hline CHEMBL1387150 & 688239 & 5.3362 & 5.5275 & TRN & \\
\hline CHEMBL1422892 & 688239 & 4.8362 & 5.5094 & TRN & \\
\hline CHEMBL1545818 & 688239 & 4.9862 & 5.58 & TRN & \\
\hline CHEMBL1306331 & 688239 & 5.7362 & 5.5485 & TRN & \\
\hline CHEMBL1332820 & 688239 & 4.5362 & 5.5497 & TST & \\
\hline CHEMBL1541530 & 688239 & 4.6862 & 5.4854 & TRN & \\
\hline CHEMBL1398891 & 688239 & 4.5362 & 5.5359 & TRN & \\
\hline CHEMBL1329979 & 688239 & 4.5862 & 5.5594 & TRN & \\
\hline CHEMBL1386106 & 688239 & 4.8362 & 5.5746 & TST & \\
\hline CHEMBL1479339 & 688239 & 5.5862 & 5.4854 & TRN & \\
\hline CHEMBL1551713 & 688239 & 8.0362 & 5.4534 & TRN & \\
\hline CHEMBL1339192 & 688239 & 5.8362 & 5.5582 & TRN & \\
\hline CHEMBL1469990 & 688239 & 5.1862 & 5.5791 & TST & \\
\hline
\end{tabular}




\begin{tabular}{|c|c|c|c|c|c|c|}
\hline & & \multicolumn{5}{|c|}{ Supplemental Table S2.txt } \\
\hline CHEMBL1339316 & 688239 & 6.8861 & 5.5274 & TRN & & \\
\hline CHEMBL1408681 & 688239 & 7.9355 & 5.5691 & TRN & & \\
\hline CHEMBL1606930 & 688239 & 6.1862 & 5.4445 & TST & & \\
\hline CHEMBL1448466 & 688239 & 4.6862 & 5.492006 & 000000000 & & TRN \\
\hline CHEMBL1507520 & 688239 & 4.4862 & 5.5409 & TST & & \\
\hline CHEMBL1566083 & 688239 & 4.7362 & 5.419 & TRN & & \\
\hline CHEMBL1305236 & 688239 & 4.8862 & 5.6542 & TRN & & \\
\hline CHEMBL1432000 & 688239 & 7.1864 & 5.5824 & TST & & \\
\hline CHEMBL1550056 & 688239 & 6.9863 & 5.409 & TST & & \\
\hline CHEMBL3199910 & 688239 & 5.0362 & 5.55 & TST & & \\
\hline CHEMBL1328886 & 688239 & 6.8861 & 5.4945 & TST & & \\
\hline CHEMBL1306602 & 688239 & 6.2362 & 5.4765 & TRN & & \\
\hline CHEMBL1417260 & 688239 & 4.5362 & 5.3033 & TRN & & \\
\hline CHEMBL1541015 & 688239 & 6.3863 & 5.4061 & TST & & \\
\hline CHEMBL1596083 & 688239 & 4.5362 & 5.4458 & TRN & & \\
\hline CHEMBL1389735 & 688239 & 6.8861 & 5.6034 & TRN & & \\
\hline CHEMBL1342530 & 688239 & 5.7362 & 5.5319 & TRN & & \\
\hline CHEMBL1414935 & 688239 & 4.8862 & 5.5141 & TRN & & \\
\hline CHEMBL1324804 & 688239 & 5.7862 & 5.45799 & 999999999 & & TST \\
\hline CHEMBL1575689 & 688239 & 4.8362 & 5.5247 & TST & & \\
\hline CHEMBL3192899 & 688239 & 6.8861 & 5.4029 & TST & & \\
\hline CHEMBL1335106 & 688239 & 5.1862 & 5.3437 & TST & & \\
\hline CHEMBL606166 & 688239 & 4.5362 & 5.4258 & TST & & \\
\hline CHEMBL1342625 & 688239 & 5.5862 & 5.5444 & TST & & \\
\hline CHEMBL1586151 & 688239 & 4.5362 & 5.4841 & TRN & & \\
\hline CHEMBL1337877 & 688239 & 6.3362 & 5.5028 & TRN & & \\
\hline CHEMBL1500720 & 688239 & 5.8862 & 5.3137 & TST & & \\
\hline CHEMBL1569119 & 688239 & 6.8861 & 5.4504 & TST & & \\
\hline CHEMBL1466629 & 688239 & 4.4862 & 5.6008 & TST & & \\
\hline CHEMBL1565575 & 688239 & 5.4862 & 5.312 & TST & & \\
\hline CHEMBL3211520 & 688239 & 4.5362 & 5.5449 & TRN & & \\
\hline CHEMBL1606810 & 688239 & 4.5362 & 5.3742 & TST & & \\
\hline CHEMBL1526510 & 688239 & 4.5862 & 5.5423 & TRN & & \\
\hline CHEMBL1464239 & 688239 & 5.1862 & 5.4563 & TRN & & \\
\hline CHEMBL1376871 & 688239 & 6.3362 & 5.3918 & TRN & & \\
\hline CHEMBL1471963 & 688239 & 6.4862 & 5.6649 & TST & & \\
\hline CHEMBL1539342 & 688239 & 5.4862 & 5.6367 & TST & & \\
\hline CHEMBL1445143 & 688239 & 4.7862 & 5.6431 & TRN & & \\
\hline CHEMBL1572237 & 688239 & 6.0862 & 5.6567 & TRN & & \\
\hline CHEMBL1491501 & 688239 & 6.0862 & 5.5307 & TRN & & \\
\hline CHEMBL1599282 & 688239 & 6.9863 & 5.3491 & TRN & & \\
\hline CHEMBL1425122 & 688239 & 6.0362 & 5.4908 & TRN & & \\
\hline CHEMBL1381284 & 688239 & 8.28399 & 99999999 & 99 & 5.2882 & TRN \\
\hline CHEMBL1590183 & 688239 & 5.2862 & 5.4558 & TST & & \\
\hline CHEMBL1369130 & 688239 & 6.9363 & 5.544 & TRN & & \\
\hline CHEMBL1447480 & 688239 & 4.8362 & 5.5257 & TRN & & \\
\hline CHEMBL1345265 & 688239 & 4.7362 & 5.4291 & TRN & & \\
\hline CHEMBL1462301 & 688239 & 4.8862 & 5.6184 & TRN & & \\
\hline
\end{tabular}


Supplemental Table S2.txt

\begin{tabular}{|c|c|c|c|c|}
\hline CHEMBL1603899 & 688239 & 4.4862 & 5.6432 & TRN \\
\hline CHEMBL1334202 & 688239 & 5.7362 & 5.5981 & TRN \\
\hline CHEMBL1602259 & 688239 & 6.6362 & 5.5354 & TRN \\
\hline CHEMBL1421840 & 688239 & 4.6362 & 5.5433 & TST \\
\hline CHEMBL1391082 & 688239 & 6.1862 & 5.5427 & TST \\
\hline CHEMBL1561155 & 688239 & 5.2362 & 5.4486 & TRN \\
\hline CHEMBL1546919 & 688239 & 8.3872 & 5.5794 & TRN \\
\hline CHEMBL1612320 & 688239 & 7.0362 & 5.5391 & TRN \\
\hline CHEMBL3195720 & 688239 & 4.5362 & 5.3426 & TRN \\
\hline CHEMBL1466391 & 688239 & 5.2362 & 5.485 & TRN \\
\hline CHEMBL1361838 & 688239 & 4.5362 & 5.4055 & TRN \\
\hline CHEMBL1489689 & 688239 & 6.2362 & 5.4143 & TRN \\
\hline CHEMBL1388888 & 688239 & 4.5362 & 5.4634 & TRN \\
\hline CHEMBL 3196047 & 688239 & 5.1362 & \multicolumn{2}{|c|}{5.382000000000001} \\
\hline CHEMBL1391821 & 688239 & 6.9363 & 5.5135 & TRN \\
\hline CHEMBL1407002 & 688239 & 4.6362 & 5.4156 & TST \\
\hline CHEMBL1407396 & 688239 & 5.3362 & 5.5217 & TRN \\
\hline CHEMBL1999900 & 688239 & 4.7362 & 5.4114 & TST \\
\hline CHEMBL1581592 & 688239 & 5.6362 & 5.5184 & TRN \\
\hline CHEMBL1412924 & 688239 & 6.6861 & \multicolumn{2}{|c|}{5.5329999999999995} \\
\hline CHEMBL1430578 & 688239 & 5.0362 & 5.4205 & TRN \\
\hline CHEMBL1558845 & 688239 & 4.5362 & 5.4511 & TRN \\
\hline CHEMBL1399578 & 688239 & 5.1862 & 5.6111 & TRN \\
\hline CHEMBL3196774 & 688239 & 5.1362 & 5.6048 & TRN \\
\hline CHEMBL1589880 & 688239 & 4.7862 & 5.5262 & TRN \\
\hline CHEMBL1445313 & 688239 & 5.1362 & 5.6598 & TRN \\
\hline CHEMBL1502908 & 688239 & 6.5862 & 5.4863 & TRN \\
\hline CHEMBL1323273 & 688239 & 5.1862 & 5.4664 & TRN \\
\hline CHEMBL1419596 & 688239 & 5.4362 & 5.6023 & TRN \\
\hline CHEMBL1564543 & 688239 & 5.1362 & \multicolumn{2}{|c|}{5.4270000000000005} \\
\hline CHEMBL1324389 & 688239 & 4.7862 & 5.46 & TST \\
\hline CHEMBL1528352 & 688239 & 5.4362 & 5.4616 & TRN \\
\hline CHEMBL1486202 & 688239 & 4.7362 & 5.4729 & TRN \\
\hline CHEMBL1317738 & 688239 & 6.5862 & 5.3934 & TST \\
\hline CHEMBL1370360 & 688239 & 7.0 & 5.4535 & TST \\
\hline CHEMBL1305741 & 688239 & 4.6362 & 5.4819 & TRN \\
\hline CHEMBL1527096 & 688239 & 5.7362 & 5.5553 & TST \\
\hline CHEMBL1591629 & 688239 & 5.1862 & 5.4798 & TRN \\
\hline CHEMBL1523165 & 688239 & 4.7362 & 5.58 & TST \\
\hline CHEMBL1342467 & 688239 & 5.7362 & 5.428 & TRN \\
\hline CHEMBL1334565 & 688239 & 5.4362 & 5.5136 & TST \\
\hline CHEMBL1588295 & 688239 & 5.1862 & 5.4314 & TST \\
\hline CHEMBL1568551 & 688239 & 4.5362 & 5.4781 & TST \\
\hline CHEMBL1400507 & 688239 & 5.1862 & 5.5157 & TRN \\
\hline CHEMBL1562234 & 688239 & 4.45 & 5.6331 & TRN \\
\hline CHEMBL1359609 & 688239 & 6.8861 & 5.4477 & TRN \\
\hline CHEMBL1403338 & 688239 & 4.8862 & 5.4053 & TRN \\
\hline CHEMBL1384082 & 688239 & 4.9362 & 5.5251 & TRN \\
\hline
\end{tabular}


Supplemental Table S2.txt

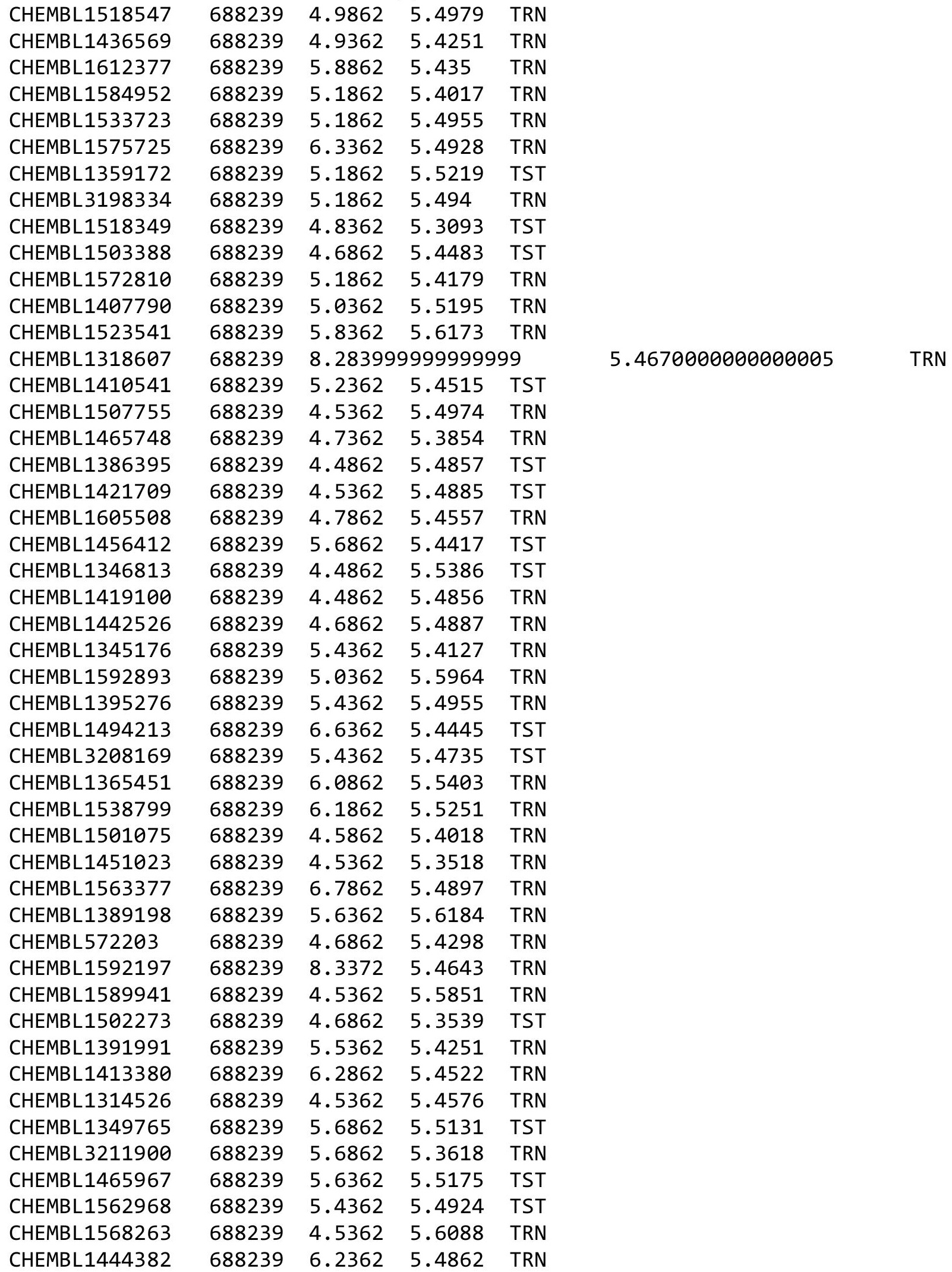

Page 978 
Supplemental Table S2.txt

\begin{tabular}{|c|c|c|c|c|}
\hline CHEMBL1323055 & 688239 & 5.1362 & 5.468 & TST \\
\hline CHEMBL1605645 & 688239 & 4.5862 & 5.566 & TST \\
\hline CHEMBL1994506 & 688239 & 6.0862 & 5.4179 & TRN \\
\hline CHEMBL1492269 & 688239 & 5.3862 & 5.496 & TRN \\
\hline CHEMBL1561342 & 688239 & 4.5362 & 5.4632 & TRN \\
\hline CHEMBL1362641 & 688239 & 4.4862 & 5.4094 & TRN \\
\hline CHEMBL1476776 & 688239 & 5.4362 & 5.4104 & TRN \\
\hline CHEMBL1510973 & 688239 & 5.1862 & 5.5121 & TRN \\
\hline CHEMBL1414862 & 688239 & 4.5862 & 5.5782 & TST \\
\hline CHEMBL1585171 & 688239 & 6.7361 & 5.5219 & TRN \\
\hline CHEMBL1391816 & 688239 & 7.2865 & 5.6826 & TRN \\
\hline CHEMBL1357914 & 688239 & 4.9862 & 5.4282 & TST \\
\hline CHEMBL1335857 & 688239 & 5.1862 & 5.4793 & TRN \\
\hline CHEMBL1597248 & 688239 & 5.1862 & 5.4423 & TST \\
\hline CHEMBL 3667549 & 688239 & 5.0862 & 5.3467 & TST \\
\hline CHEMBL1570744 & 688239 & 6.2362 & 5.4639 & TRN \\
\hline CHEMBL1609296 & 688239 & 4.5362 & 5.5143 & TST \\
\hline CHEMBL1308009 & 688239 & 4.4862 & 5.4433 & TRN \\
\hline CHEMBL1301484 & 688239 & 4.7862 & 5.4268 & TRN \\
\hline CHEMBL1579187 & 688239 & 6.2362 & 5.516 & TST \\
\hline CHEMBL 2003508 & 688239 & 5.2362 & 5.4735 & TRN \\
\hline CHEMBL1481679 & 688239 & 6.8362 & 5.5396 & TST \\
\hline CHEMBL1382820 & 688239 & 4.6362 & 5.5467 & TST \\
\hline CHEMBL1362547 & 688239 & 4.6862 & 5.4474 & TRN \\
\hline CHEMBL1411095 & 688239 & 7.1864 & 5.4365 & TST \\
\hline CHEMBL1497351 & 688239 & 5.6862 & 5.5031 & TST \\
\hline CHEMBL1431255 & 688239 & 6.1362 & 5.2699 & TRN \\
\hline CHEMBL1537886 & 688239 & 6.6362 & 5.5071 & TRN \\
\hline CHEMBL1574858 & 688239 & 6.1862 & 5.5911 & TRN \\
\hline CHEMBL1367520 & 688239 & 4.6862 & 5.4049 & TRN \\
\hline CHEMBL1516353 & 688239 & 4.9362 & 5.4561 & TRN \\
\hline CHEMBL1555768 & 688239 & 6.9363 & 5.5443 & TRN \\
\hline CHEMBL1458319 & 688239 & 4.7362 & 5.4465 & TST \\
\hline CHEMBL1531495 & 688239 & 5.1862 & 5.3694 & TRN \\
\hline CHEMBL1505721 & 688239 & 6.0362 & 5.5358 & TRN \\
\hline CHEMBL1314531 & 688239 & 6.5363 & 5.5798 & TRN \\
\hline CHEMBL 3213344 & 688239 & 5.8362 & 5.5778 & TRN \\
\hline CHEMBL1476008 & 688239 & 4.5862 & 5.3717 & TRN \\
\hline CHEMBL3213016 & 688239 & 4.4862 & 5.3946 & TST \\
\hline CHEMBL1505533 & 688239 & 5.2362 & 5.4274 & TRN \\
\hline CHEMBL1466232 & 688239 & 4.6862 & 5.4773 & TST \\
\hline CHEMBL1361692 & 688239 & 5.6362 & 5.5292 & TST \\
\hline CHEMBL1307065 & 688239 & 4.5362 & 5.4931 & TRN \\
\hline CHEMBL1385347 & 688239 & 4.5362 & 5.3758 & TST \\
\hline CHEMBL1464835 & 688239 & 4.6862 & 5.4594 & TRN \\
\hline CHEMBL1544863 & 688239 & 4.6862 & 5.6172 & TRN \\
\hline CHEMBL1616787 & 688239 & 4.6862 & 5.4278 & TRN \\
\hline \multirow[t]{2}{*}{ CHEMBL1412697 } & 688239 & 5.1862 & 5.50700 & 0000000001 \\
\hline & & \multicolumn{3}{|c|}{ Page 979} \\
\hline
\end{tabular}


Supplemental Table S2.txt

\begin{tabular}{|c|c|c|c|c|c|}
\hline CHEMBL3197258 & 688239 & 4.7862 & 5.3553 & TST & \\
\hline CHEMBL1367850 & 688239 & 5.2862 & 5.4274 & TRN & \\
\hline CHEMBL1505882 & 688239 & 6.1862 & 5.347 & TRN & \\
\hline CHEMBL3145033 & 688239 & 6.1362 & 5.4187 & TST & \\
\hline CHEMBL1449724 & 688239 & 4.5362 & 5.41200 & 0000000001 & TST \\
\hline CHEMBL1374590 & 688239 & 5.1862 & 5.478 & TRN & \\
\hline CHEMBL1445075 & 688239 & 5.2362 & 5.404 & TST & \\
\hline CHEMBL1413023 & 688239 & 6.0862 & 5.6167 & TST & \\
\hline CHEMBL1589281 & 688239 & 5.3862 & 5.5444 & TRN & \\
\hline CHEMBL1379168 & 688239 & 4.6362 & 5.4239 & TRN & \\
\hline CHEMBL1326361 & 688239 & 4.5362 & 5.4741 & TRN & \\
\hline CHEMBL1427427 & 688239 & 4.6362 & 5.5881 & TST & \\
\hline CHEMBL1331147 & 688239 & 5.0362 & 5.5015 & TST & \\
\hline CHEMBL1381817 & 688239 & 5.1862 & 5.45799 & 9999999999 & TRN \\
\hline CHEMBL1417318 & 688239 & 6.7862 & 5.4606 & TRN & \\
\hline CHEMBL1407749 & 688239 & 6.1862 & 5.4782 & TRN & \\
\hline CHEMBL1401112 & 688239 & 4.6862 & 5.4628 & TRN & \\
\hline CHEMBL1480452 & 688239 & 5.4862 & 5.41 & TST & \\
\hline CHEMBL1610665 & 688239 & 6.1362 & 5.483 & TRN & \\
\hline CHEMBL1537040 & 688239 & 4.5362 & 5.4115 & TRN & \\
\hline CHEMBL1343097 & 688239 & 4.7862 & 5.4924 & TRN & \\
\hline CHEMBL1577943 & 688239 & 5.2862 & 5.5223 & TRN & \\
\hline CHEMBL1613737 & 688239 & 4.5362 & 5.5355 & TST & \\
\hline CHEMBL1544481 & 688239 & 4.9862 & 5.4471 & TST & \\
\hline CHEMBL1343183 & 688239 & 5.0862 & 5.4511 & TRN & \\
\hline CHEMBL1344507 & 688239 & 5.1862 & 5.4575 & TRN & \\
\hline CHEMBL1599626 & 688239 & 5.1862 & 5.4376 & TRN & \\
\hline CHEMBL1489545 & 688239 & 6.1362 & 5.5791 & TRN & \\
\hline CHEMBL1600956 & 688239 & 5.7862 & 5.6297 & TST & \\
\hline CHEMBL1337778 & 688239 & 5.6862 & 5.6208 & TRN & \\
\hline CHEMBL1529328 & 688239 & 5.1862 & 5.3304 & TRN & \\
\hline CHEMBL3189642 & 688239 & 5.5362 & 5.5912 & TRN & \\
\hline CHEMBL1974351 & 688239 & 5.7862 & 5.525 & TST & \\
\hline CHEMBL1566790 & 688239 & 4.5362 & 5.5433 & TRN & \\
\hline CHEMBL1500093 & 688239 & 6.4862 & 5.6006 & TST & \\
\hline CHEMBL1554986 & 688239 & 5.1862 & 5.5784 & TRN & \\
\hline CHEMBL1539409 & 688239 & 4.6362 & 5.3684 & TST & \\
\hline CHEMBL1530894 & 688239 & 4.8862 & 5.4057 & TRN & \\
\hline CHEMBL1543936 & 688239 & 4.8362 & 5.5415 & TRN & \\
\hline CHEMBL3210173 & 688239 & 6.4862 & 5.5793 & TRN & \\
\hline CHEMBL1390841 & 688239 & 5.9362 & 5.4991 & TRN & \\
\hline CHEMBL1301877 & 688239 & 5.2862 & 5.4668 & TRN & \\
\hline CHEMBL1463236 & 688239 & 6.7862 & 5.5315 & TRN & \\
\hline CHEMBL3213572 & 688239 & 4.6862 & 5.6209 & TRN & \\
\hline CHEMBL1470781 & 688239 & 4.5862 & 5.4668 & TRN & \\
\hline CHEMBL1320577 & 688239 & 5.3362 & 5.5169 & TRN & \\
\hline CHEMBL1579029 & 688239 & 6.8362 & 5.5982 & TRN & \\
\hline CHEMBL1494593 & 688239 & 4.4862 & 5.5358 & TRN & \\
\hline
\end{tabular}


Supplemental Table S2.txt

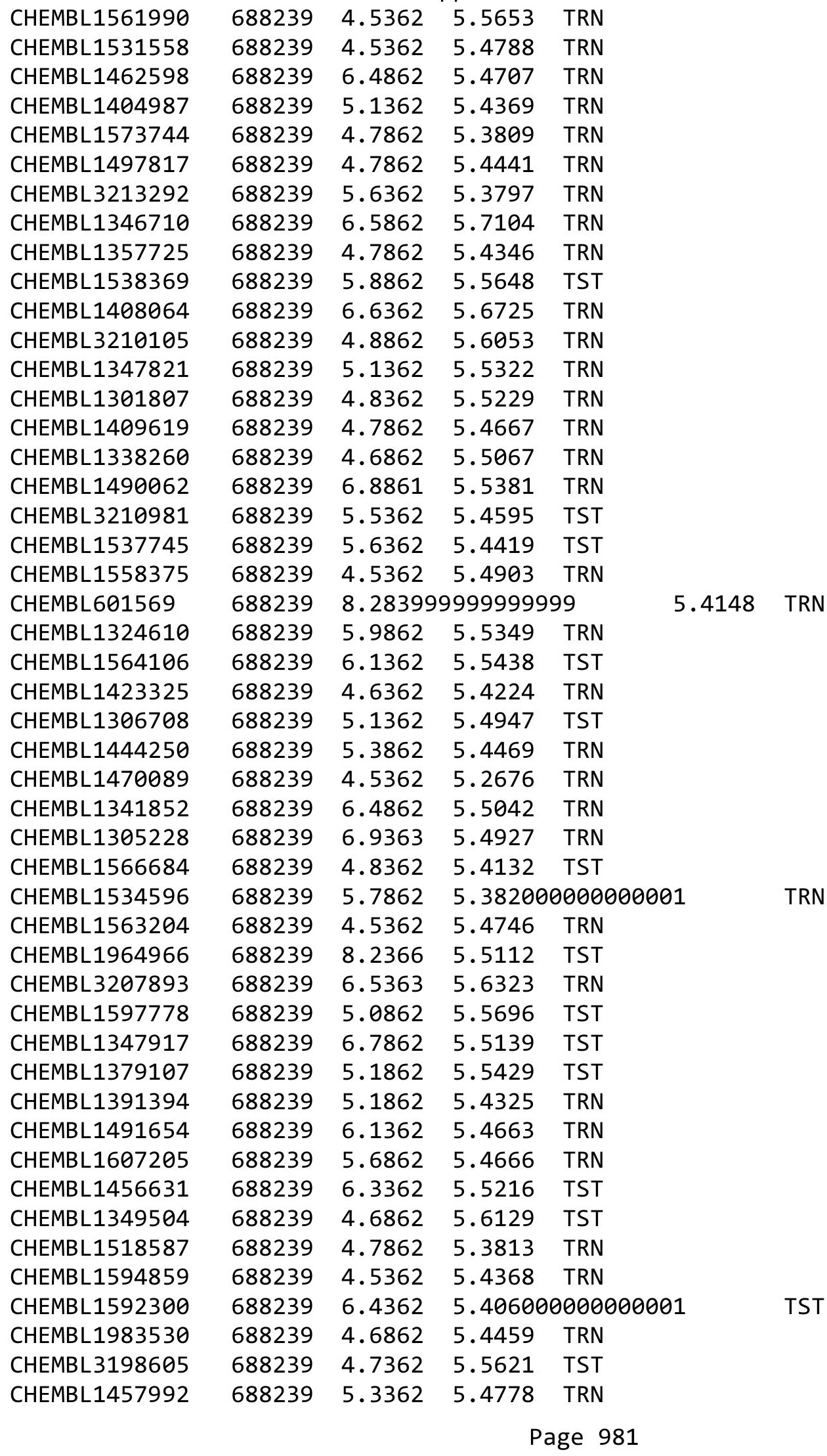


Supplemental Table S2.txt

\begin{tabular}{|c|c|c|c|c|c|}
\hline CHEMBL1333199 & 688239 & 5.0862 & 5.5196 & TRN & \\
\hline CHEMBL1599272 & 688239 & 4.9362 & 5.42399 & 99999999995 & TRN \\
\hline CHEMBL1575127 & 688239 & 4.5362 & 5.5587 & TST & \\
\hline CHEMBL1526824 & 688239 & 5.4362 & 5.5637 & TRN & \\
\hline CHEMBL1594364 & 688239 & 4.7862 & 5.3175 & TRN & \\
\hline CHEMBL1303984 & 688239 & 6.2862 & 5.6422 & TRN & \\
\hline CHEMBL1437766 & 688239 & 4.8362 & 5.48600 & 0000000001 & TRN \\
\hline CHEMBL1402815 & 688239 & 6.1 & 5.45700 & 0000000001 & TRN \\
\hline CHEMBL1595368 & 688239 & 8.3372 & 5.5508 & TRN & \\
\hline CHEMBL1612226 & 688239 & 6.5862 & 5.5926 & TRN & \\
\hline CHEMBL1541583 & 688239 & 5.6862 & 5.6378 & TRN & \\
\hline CHEMBL1304976 & 688239 & 5.9362 & 5.63399 & 99999999995 & TST \\
\hline CHEMBL1331278 & 688239 & 5.2362 & 5.5455 & TRN & \\
\hline CHEMBL1411910 & 688239 & 5.8362 & 5.6751 & TRN & \\
\hline CHEMBL3207953 & 688239 & 4.7362 & 5.4123 & TST & \\
\hline CHEMBL1510445 & 688239 & 4.7862 & 5.4336 & TRN & \\
\hline CHEMBL1582927 & 688239 & 6.9863 & 5.4032 & TRN & \\
\hline CHEMBL1461863 & 688239 & 5.3862 & 5.4422 & TRN & \\
\hline CHEMBL1391536 & 688239 & 6.1362 & 5.4783 & TRN & \\
\hline CHEMBL1498041 & 688239 & 5.4362 & 5.4502 & TRN & \\
\hline CHEMBL1394982 & 688239 & 5.4362 & 5.31 & TRN & \\
\hline CHEMBL1347353 & 688239 & 5.1362 & 5.5532 & TRN & \\
\hline CHEMBL1460998 & 688239 & 5.9362 & 5.3952 & TRN & \\
\hline CHEMBL1367948 & 688239 & 4.5362 & 5.501 & TRN & \\
\hline CHEMBL3197496 & 688239 & 5.1862 & 5.4288 & TRN & \\
\hline CHEMBL1341281 & 688239 & 4.7362 & 5.4829 & TST & \\
\hline CHEMBL1548078 & 688239 & 5.5862 & 5.4459 & TRN & \\
\hline CHEMBL1445923 & 688239 & 5.5862 & 5.5501 & TST & \\
\hline CHEMBL3208338 & 688239 & 5.9362 & 5.3381 & TRN & \\
\hline CHEMBL1425876 & 688239 & 8.3372 & 5.3422 & TST & \\
\hline CHEMBL1327408 & 688239 & 4.6362 & 5.4921 & TRN & \\
\hline CHEMBL1611327 & 688239 & 5.0362 & 5.5781 & TRN & \\
\hline CHEMBL1313732 & 688239 & 5.4362 & 5.4336 & TST & \\
\hline CHEMBL1411561 & 688239 & 5.4862 & 5.4356 & TRN & \\
\hline CHEMBL1489520 & 688239 & 8.3372 & 5.4186 & TST & \\
\hline CHEMBL1381471 & 688239 & 5.4362 & 5.409 & TRN & \\
\hline CHEMBL1468531 & 688239 & 4.5362 & 5.6587 & TRN & \\
\hline CHEMBL1421347 & 688239 & 5.1862 & 5.4221 & TST & \\
\hline CHEMBL1391946 & 688239 & 6.9863 & 5.5278 & TRN & \\
\hline CHEMBL1511181 & 688239 & 4.5362 & 5.4136 & TRN & \\
\hline CHEMBL1539203 & 688239 & 4.6362 & 5.6045 & TRN & \\
\hline CHEMBL1299669 & 688239 & 6.5862 & 5.5166 & TRN & \\
\hline CHEMBL1464002 & 688239 & 5.3362 & 5.5744 & TRN & \\
\hline CHEMBL1457429 & 688239 & 5.2362 & 5.5086 & TRN & \\
\hline CHEMBL1457936 & 688239 & 6.1362 & 5.572 & TST & \\
\hline CHEMBL1437938 & 688239 & 6.1362 & 5.5424 & TRN & \\
\hline CHEMBL1452129 & 688239 & 4.7862 & 5.5783 & TRN & \\
\hline CHEMBL1459451 & 688239 & 6.4862 & 5.4251 & TRN & \\
\hline
\end{tabular}


Supplemental Table S2.txt

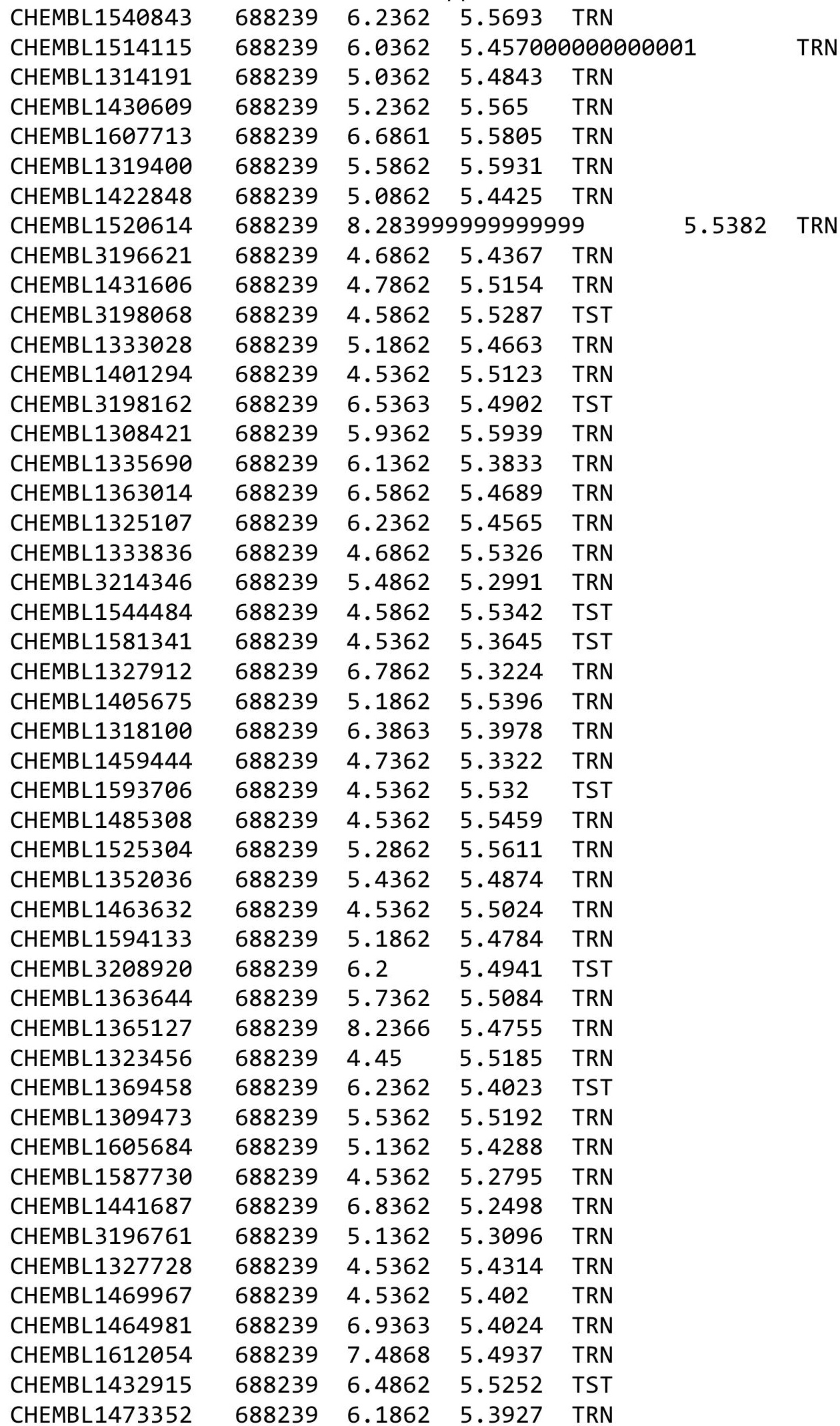

Page 983 
Supplemental Table S2.txt

\begin{tabular}{|c|c|c|c|c|}
\hline CHEMBL1611035 & 688239 & 4.5362 & 5.5405 & TRN \\
\hline CHEMBL1361011 & 688239 & 4.9862 & 5.5699 & TRN \\
\hline CHEMBL1459599 & 688239 & 4.9862 & 5.5539 & TRN \\
\hline CHEMBL1564915 & 688239 & 5.9862 & 5.6648 & TRN \\
\hline CHEMBL1549319 & 688239 & 4.5862 & 5.4255 & TST \\
\hline CHEMBL1502679 & 688239 & 5.8362 & 5.4586 & TST \\
\hline CHEMBL1416808 & 688239 & 4.6362 & 5.5571 & TRN \\
\hline CHEMBL1401529 & 688239 & 5.3862 & 5.5721 & TRN \\
\hline CHEMBL1602775 & 688239 & 5.8362 & 5.4612 & TST \\
\hline CHEMBL1425667 & 688239 & 6.1362 & 5.4253 & TST \\
\hline CHEMBL1567062 & 688239 & 5.1862 & 5.4574 & TRN \\
\hline CHEMBL1521683 & 688239 & 6.7862 & 5.5646 & TST \\
\hline CHEMBL1317340 & 688239 & 4.5362 & 5.3957 & TRN \\
\hline CHEMBL1411034 & 688239 & 5.2862 & 5.5045 & TRN \\
\hline CHEMBL1543627 & 688239 & 4.5362 & 5.5232 & TST \\
\hline CHEMBL1551752 & 688239 & 5.0362 & 5.2407 & TRN \\
\hline CHEMBL227726 & 688239 & 5.9362 & 5.5555 & TRN \\
\hline CHEMBL1537899 & 688239 & 6.1362 & 5.4253 & TST \\
\hline CHEMBL1308541 & 688239 & 7.0862 & 5.5665 & TRN \\
\hline CHEMBL1574699 & 688239 & 6.2362 & 5.4234 & TRN \\
\hline CHEMBL1384423 & 688239 & 6.1862 & 5.3969 & TRN \\
\hline CHEMBL1308324 & 688239 & 8.28399 & 99999999 & 5.3969 \\
\hline CHEMBL1387024 & 688239 & 4.6862 & 5.4807 & TST \\
\hline CHEMBL1469756 & 688239 & 4.9362 & 5.5174 & TRN \\
\hline CHEMBL1523845 & 688239 & 4.6362 & 5.5507 & TRN \\
\hline CHEMBL1504608 & 688239 & 4.6362 & 5.5773 & TRN \\
\hline CHEMBL1446789 & 688239 & 7.0362 & 5.6526 & TRN \\
\hline CHEMBL1402697 & 688239 & 6.9363 & 5.5586 & TRN \\
\hline CHEMBL1343392 & 688239 & 5.3862 & 5.5695 & TRN \\
\hline CHEMBL1421398 & 688239 & 5.0862 & 5.688 & TRN \\
\hline CHEMBL1591795 & 688239 & 5.7362 & 5.451000 & 30000000005 \\
\hline CHEMBL1358177 & 688239 & 5.3362 & 5.4124 & TRN \\
\hline CHEMBL1966080 & 688239 & 4.6362 & 5.3747 & TST \\
\hline CHEMBL1505989 & 688239 & 4.5362 & 5.3819 & TST \\
\hline CHEMBL1320923 & 688239 & 8.2366 & 5.4962 & TRN \\
\hline CHEMBL1491694 & 688239 & 5.1862 & 5.5183 & TRN \\
\hline CHEMBL1606863 & 688239 & 4.7362 & 5.5755 & TST \\
\hline CHEMBL3199188 & 688239 & 5.2862 & 5.3604 & TRN \\
\hline CHEMBL1322368 & 688239 & 5.8362 & 5.5357 & TRN \\
\hline CHEMBL1407268 & 688239 & 4.5362 & 5.5044 & TST \\
\hline CHEMBL1482495 & 688239 & 5.1362 & 5.5029 & TRN \\
\hline CHEMBL1527870 & 688239 & 5.3862 & 5.3385 & TRN \\
\hline CHEMBL1376480 & 688239 & 6.2362 & 5.457999 & 9999999999 \\
\hline CHEMBL1338629 & 688239 & 4.8362 & 5.4776 & TRN \\
\hline CHEMBL1486637 & 688239 & 6.6861 & 5.6615 & TRN \\
\hline CHEMBL1402439 & 688239 & 4.8362 & 5.5005 & TRN \\
\hline CHEMBL1370865 & 688239 & 5.4362 & 5.5824 & TRN \\
\hline CHEMBL1496159 & 688239 & 5.5362 & 5.5008 & TRN \\
\hline
\end{tabular}


Supplemental Table S2.txt

\begin{tabular}{|c|c|c|c|c|c|}
\hline CHEMBL1462645 & 688239 & 4.5362 & 5.4806 & TRN & \\
\hline CHEMBL 3213960 & 688239 & 6.4362 & 5.5751 & TRN & \\
\hline CHEMBL1392077 & 688239 & 4.5362 & 5.5161 & TST & \\
\hline CHEMBL1474119 & 688239 & 5.4862 & 5.516 & TRN & \\
\hline CHEMBL1602844 & 688239 & 4.5362 & 5.3686 & TST & \\
\hline CHEMBL1522543 & 688239 & 6.6362 & 5.3126 & TRN & \\
\hline CHEMBL1339050 & 688239 & 6.9363 & 5.4854 & TRN & \\
\hline CHEMBL1455144 & 688239 & 5.1862 & 5.4139 & TRN & \\
\hline CHEMBL608673 & 688239 & 4.5362 & 5.5454 & TRN & \\
\hline CHEMBL1430372 & 688239 & 4.6362 & 5.3035 & TST & \\
\hline CHEMBL1586706 & 688239 & 4.5362 & 5.365 & TRN & \\
\hline CHEMBL1575107 & 688239 & 5.9862 & 5.5476 & TRN & \\
\hline CHEMBL1512743 & 688239 & 5.1362 & 5.3987 & TRN & \\
\hline CHEMBL1442158 & 688239 & 4.5362 & 5.4747 & TST & \\
\hline CHEMBL1465456 & 688239 & 8.0862 & 5.5033 & TRN & \\
\hline CHEMBL1510412 & 688239 & 5.6362 & 5.7058 & TRN & \\
\hline CHEMBL1451066 & 688239 & 5.5362 & 5.6156 & TST & \\
\hline CHEMBL1592654 & 688239 & 5.3862 & 5.45700 & 0000000001 & TRN \\
\hline CHEMBL 3213140 & 688239 & 4.7362 & 5.505 & TRN & \\
\hline CHEMBL1481458 & 688239 & 5.3362 & 5.5303 & TST & \\
\hline CHEMBL1583706 & 688239 & 4.5362 & 5.5585 & TST & \\
\hline CHEMBL1517563 & 688239 & 6.5862 & 5.5258 & TRN & \\
\hline CHEMBL1479876 & 688239 & 4.5362 & 5.2548 & TST & \\
\hline CHEMBL1346082 & 688239 & 5.1862 & 5.5083 & TRN & \\
\hline CHEMBL1552114 & 688239 & 4.7362 & 5.4782 & TRN & \\
\hline CHEMBL1465076 & 688239 & 6.9363 & 5.5753 & TRN & \\
\hline CHEMBL1440499 & 688239 & 7.6364 & 5.4321 & TRN & \\
\hline CHEMBL1515081 & 688239 & 5.2362 & 5.4363 & TRN & \\
\hline CHEMBL1585367 & 688239 & 4.5362 & 5.3888 & TST & \\
\hline CHEMBL1602164 & 688239 & 6.9363 & 5.5337 & TRN & \\
\hline CHEMBL1457383 & 688239 & 5.7362 & 5.3162 & TRN & \\
\hline CHEMBL1536449 & 688239 & 4.5362 & 5.4834 & TST & \\
\hline CHEMBL1472209 & 688239 & 5.5862 & 5.5974 & TRN & \\
\hline CHEMBL1444816 & 688239 & 5.1862 & 5.614 & TRN & \\
\hline CHEMBL1377154 & 688239 & 7.1361 & 5.425 & TRN & \\
\hline CHEMBL3192817 & 688239 & 5.6862 & 5.4592 & TRN & \\
\hline CHEMBL1443878 & 688239 & 4.5362 & 5.4741 & TRN & \\
\hline CHEMBL1353832 & 688239 & 6.8362 & 5.6212 & TST & \\
\hline CHEMBL1325946 & 688239 & 4.8862 & 5.4259 & TST & \\
\hline CHEMBL1299985 & 688239 & 5.1862 & 5.3111 & TST & \\
\hline CHEMBL1594248 & 688239 & 4.8362 & 5.4345 & TST & \\
\hline CHEMBL1302844 & 688239 & 6.1362 & 5.6422 & TRN & \\
\hline CHEMBL1460088 & 688239 & 4.7362 & 5.3487 & TRN & \\
\hline CHEMBL1612022 & 688239 & 4.8362 & 5.3475 & TRN & \\
\hline CHEMBL1494164 & 688239 & 4.5362 & 5.6804 & TRN & \\
\hline CHEMBL1487771 & 688239 & 7.2366 & 5.4353 & TRN & \\
\hline CHEMBL1300641 & 688239 & 4.5362 & 5.4824 & TST & \\
\hline CHEMBL1420436 & 688239 & 4.8862 & 5.5417 & TRN & \\
\hline
\end{tabular}


Supplemental Table S2.txt

\begin{tabular}{|c|c|c|c|c|c|}
\hline CHEMBL1362018 & 688239 & 6.0862 & 5.4327 & TST & \\
\hline CHEMBL1968983 & 688239 & 4.7362 & 5.3371 & TRN & \\
\hline CHEMBL1607908 & 688239 & 5.4862 & 5.4403 & TRN & \\
\hline CHEMBL1549377 & 688239 & 4.5362 & 5.4569 & TST & \\
\hline CHEMBL1505927 & 688239 & 5.5362 & 5.5334 & TRN & \\
\hline CHEMBL1303232 & 688239 & 5.1862 & 5.4736 & TRN & \\
\hline CHEMBL1380555 & 688239 & 5.4362 & 5.5416 & TRN & \\
\hline CHEMBL1461147 & 688239 & 4.6862 & 5.3891 & TRN & \\
\hline CHEMBL1500167 & 688239 & 5.4362 & 5.6014 & TRN & \\
\hline CHEMBL1325466 & 688239 & 6.7361 & 5.4147 & TRN & \\
\hline CHEMBL1566929 & 688239 & 4.6362 & 5.5639 & TRN & \\
\hline CHEMBL1421713 & 688239 & 4.5362 & 5.53799 & 9999999999 & TRN \\
\hline CHEMBL1422470 & 688239 & 4.5362 & 5.459 & TST & \\
\hline CHEMBL1365291 & 688239 & 5.6862 & 5.3851 & TRN & \\
\hline CHEMBL1365212 & 688239 & 6.8362 & 5.5152 & TRN & \\
\hline CHEMBL1459340 & 688239 & 6.3863 & 5.5157 & TRN & \\
\hline CHEMBL1603385 & 688239 & 6.8362 & 5.5474 & TST & \\
\hline CHEMBL1302753 & 688239 & 4.5362 & 5.5254 & TRN & \\
\hline CHEMBL3199093 & 688239 & 4.5362 & 5.2974 & TRN & \\
\hline CHEMBL1324370 & 688239 & 4.5362 & 5.4848 & TRN & \\
\hline CHEMBL1373684 & 688239 & 4.7862 & 5.54899 & 99999999995 & TRN \\
\hline CHEMBL1578811 & 688239 & 5.5362 & 5.4029 & TST & \\
\hline CHEMBL1536796 & 688239 & 6.3362 & 5.468 & TRN & \\
\hline CHEMBL1508121 & 688239 & 7.0862 & 5.4227 & TRN & \\
\hline CHEMBL394242 & 688239 & 4.6362 & 5.4426 & TRN & \\
\hline CHEMBL1489213 & 688239 & 5.3362 & 5.5701 & TRN & \\
\hline CHEMBL1365397 & 688239 & 4.7362 & 5.3909 & TRN & \\
\hline CHEMBL1608963 & 688239 & 6.3362 & 5.6178 & TST & \\
\hline CHEMBL1524286 & 688239 & 4.5362 & 5.5085 & TST & \\
\hline CHEMBL1499753 & 688239 & 5.4362 & 5.4851 & TST & \\
\hline CHEMBL 3193075 & 688239 & 4.5362 & 5.4406 & TST & \\
\hline CHEMBL1445504 & 688239 & 7.1864 & 5.4721 & TRN & \\
\hline CHEMBL1542062 & 688239 & 7.2865 & 5.5917 & TST & \\
\hline CHEMBL1365078 & 688239 & 4.6362 & 5.5536 & TRN & \\
\hline CHEMBL1359422 & 688239 & 5.1862 & 5.4553 & TRN & \\
\hline CHEMBL1310603 & 688239 & 4.7862 & 5.3463 & TRN & \\
\hline CHEMBL1550322 & 688239 & 5.4862 & 5.5443 & TRN & \\
\hline CHEMBL1459668 & 688239 & 5.9362 & 5.6471 & TRN & \\
\hline CHEMBL1530784 & 688239 & 4.8862 & 5.5754 & TRN & \\
\hline CHEMBL1327127 & 688239 & 4.5862 & 5.4591 & TRN & \\
\hline CHEMBL1559236 & 688239 & 5.8362 & 5.4665 & TRN & \\
\hline CHEMBL3210600 & 688239 & 4.7862 & 5.5453 & TRN & \\
\hline CHEMBL1578678 & 688239 & 4.5362 & 5.388 & TST & \\
\hline CHEMBL1528492 & 688239 & 5.8862 & 5.5311 & TST & \\
\hline CHEMBL1316612 & 688239 & 5.3362 & 5.5688 & TRN & \\
\hline CHEMBL1397591 & 688239 & 8.2366 & 5.4736 & TST & \\
\hline CHEMBL1543194 & 688239 & 5.1862 & 5.5011 & TRN & \\
\hline CHEMBL1351190 & 688239 & 5.5862 & 5.6031 & TRN & \\
\hline
\end{tabular}


Supplemental Table S2.txt

\begin{tabular}{|c|c|c|c|c|}
\hline CHEMBL3199267 & 688239 & 6.9863 & 5.4176 & TRN \\
\hline CHEMBL1497884 & 688239 & 6.9863 & 5.6016 & TRN \\
\hline CHEMBL1604640 & 688239 & 6.8861 & 5.4721 & TST \\
\hline CHEMBL1520268 & 688239 & 7.5867 & 5.356 & TRN \\
\hline CHEMBL1322876 & 688239 & 4.5362 & 5.4406 & TRN \\
\hline CHEMBL1368162 & 688239 & 5.1862 & 5.432 & TRN \\
\hline CHEMBL1600570 & 688239 & 8.3372 & 5.5409 & TRN \\
\hline CHEMBL1585763 & 688239 & 5.7362 & 5.3991 & TRN \\
\hline CHEMBL1348908 & 688239 & 4.5362 & 5.5338 & TST \\
\hline CHEMBL1333052 & 688239 & 7.1361 & 5.4772 & TRN \\
\hline CHEMBL1389946 & 688239 & 4.5362 & 5.5445 & TRN \\
\hline CHEMBL1568166 & 688239 & 6.4862 & 5.5393 & TRN \\
\hline CHEMBL3214419 & 688239 & 6.1862 & 5.3858 & TRN \\
\hline CHEMBL223449 & 688239 & 6.6861 & 5.4097 & TST \\
\hline CHEMBL1401549 & 688239 & 4.7362 & 5.5693 & TST \\
\hline CHEMBL1470616 & 688239 & 4.7862 & 5.4593 & TRN \\
\hline CHEMBL1602062 & 688239 & 4.5362 & 5.4464 & TRN \\
\hline CHEMBL195917 & 688239 & 6.2362 & 5.5092 & TRN \\
\hline CHEMBL1497477 & 688239 & 5.1862 & 5.4529 & TRN \\
\hline CHEMBL1486423 & 688239 & 5.3862 & 5.4712 & TST \\
\hline CHEMBL1606173 & 688239 & 4.5362 & 5.3866 & TRN \\
\hline CHEMBL3210081 & 688239 & 5.3862 & 5.4298 & TST \\
\hline CHEMBL1610342 & 688239 & 5.7862 & 5.4891 & TRN \\
\hline CHEMBL1398672 & 688239 & 6.3362 & 5.5919 & TRN \\
\hline CHEMBL1382646 & 688239 & 6.0862 & 5.5943 & TRN \\
\hline CHEMBL1301729 & 688239 & 6.4362 & 5.5641 & TRN \\
\hline CHEMBL1529185 & 688239 & 6.7361 & 5.4825 & TRN \\
\hline CHEMBL1507517 & 688239 & 4.4862 & 5.4385 & TRN \\
\hline CHEMBL1540785 & 688239 & 4.4862 & 5.5544 & TRN \\
\hline CHEMBL1336431 & 688239 & 4.7362 & 5.314 & TST \\
\hline CHEMBL1409178 & 688239 & 4.6862 & 5.5928 & TRN \\
\hline CHEMBL1577761 & 688239 & 8.3372 & 5.4958 & TRN \\
\hline CHEMBL1344129 & 688239 & 5.6862 & 5.5675 & TRN \\
\hline CHEMBL1318084 & 688239 & 7.0362 & 5.5027 & TRN \\
\hline CHEMBL1321703 & 688239 & 6.2362 & 5.3684 & TRN \\
\hline CHEMBL1451228 & 688239 & 6.2862 & 5.4839 & TRN \\
\hline CHEMBL1461815 & 688239 & 8.28399 & 999999999 & 5.3888 \\
\hline CHEMBL1316636 & 688239 & 6.3362 & 5.5307 & TRN \\
\hline CHEMBL1542728 & 688239 & 5.5862 & 5.3278 & TST \\
\hline CHEMBL1974640 & 688239 & 5.4862 & 5.4881 & TST \\
\hline CHEMBL1388500 & 688239 & 4.5362 & 5.4088 & TST \\
\hline CHEMBL1555525 & 688239 & 5.6862 & 5.4301 & TST \\
\hline CHEMBL1563261 & 688239 & 5.6362 & 5.336 & TRN \\
\hline CHEMBL1536560 & 688239 & 6.2362 & 5.4979 & TRN \\
\hline CHEMBL1330138 & 688239 & 5.1862 & 5.4922 & TRN \\
\hline CHEMBL1302024 & 688239 & 5.4862 & 5.4996 & TRN \\
\hline CHEMBL1472299 & 688239 & 5.9362 & 5.394 & TRN \\
\hline CHEMBL1314013 & 688239 & 6.2362 & 5.4579 & 9999999 \\
\hline
\end{tabular}


Supplemental Table S2.txt

\begin{tabular}{|c|c|c|c|c|}
\hline CHEMBL1532213 & 688239 & 4.8362 & 5.4662 & TST \\
\hline CHEMBL1312298 & 688239 & 4.5862 & 5.5954 & TRN \\
\hline CHEMBL1376759 & 688239 & 5.1862 & 5.5126 & TRN \\
\hline CHEMBL1606780 & 688239 & 4.7862 & 5.5593 & TRN \\
\hline CHEMBL1345470 & 688239 & 4.6362 & 5.6114 & TRN \\
\hline CHEMBL1516113 & 688239 & 8.28399 & 99999999 & 5.5117 \\
\hline CHEMBL1336854 & 688239 & 4.9862 & 5.4321 & TST \\
\hline CHEMBL1565640 & 688239 & 6.8861 & 5.4647 & TST \\
\hline CHEMBL1508900 & 688239 & 5.8362 & 5.5127 & TRN \\
\hline CHEMBL1451961 & 688239 & 5.1862 & 5.4471 & TRN \\
\hline CHEMBL1342739 & 688239 & 5.5862 & 5.4485 & TRN \\
\hline CHEMBL1553493 & 688239 & 5.7862 & 5.5272 & TRN \\
\hline CHEMBL1535624 & 688239 & 4.9862 & 5.395 & TRN \\
\hline CHEMBL1396382 & 688239 & 4.5362 & 5.5365 & TRN \\
\hline CHEMBL1370978 & 688239 & 5.0862 & 5.3675 & TST \\
\hline CHEMBL1345260 & 688239 & 5.3862 & 5.572999 & 9999999995 \\
\hline CHEMBL1347073 & 688239 & 5.0862 & 5.5688 & TRN \\
\hline CHEMBL1445797 & 688239 & 5.9362 & 5.3954 & TRN \\
\hline CHEMBL1415741 & 688239 & 4.5362 & 5.3649 & TRN \\
\hline CHEMBL1406484 & 688239 & 4.5862 & 5.4634 & TRN \\
\hline CHEMBL1391710 & 688239 & 4.5362 & 5.5034 & TRN \\
\hline CHEMBL1456307 & 688239 & 4.5862 & 5.3498 & TRN \\
\hline CHEMBL1454387 & 688239 & 4.5862 & 5.4819 & TRN \\
\hline CHEMBL1415649 & 688239 & 5.1362 & 5.4605 & TRN \\
\hline CHEMBL1320068 & 688239 & 5.1862 & 5.4422 & TRN \\
\hline CHEMBL1334057 & 688239 & 5.4862 & 5.4603 & TRN \\
\hline CHEMBL1459063 & 688239 & 6.1362 & 5.5158 & TRN \\
\hline CHEMBL1466510 & 688239 & 4.6362 & 5.426 & TRN \\
\hline CHEMBL1577067 & 688239 & 6.1862 & 5.5264 & TRN \\
\hline CHEMBL1459066 & 688239 & 5.1862 & 5.405 & TST \\
\hline CHEMBL1589216 & 688239 & 4.8362 & 5.5858 & TRN \\
\hline CHEMBL1577563 & 688239 & 6.1362 & 5.5525 & TRN \\
\hline CHEMBL1575838 & 688239 & 8.3872 & 5.5888 & TRN \\
\hline CHEMBL1348166 & 688239 & 6.1862 & 5.5606 & TRN \\
\hline CHEMBL1587487 & 688239 & 5.1862 & 5.4988 & TRN \\
\hline CHEMBL3195494 & 688239 & 6.8362 & 5.4993 & TRN \\
\hline CHEMBL1515220 & 688239 & 4.6862 & 5.3803 & TRN \\
\hline CHEMBL1468769 & 688239 & 4.5362 & 5.4758 & TRN \\
\hline CHEMBL1394963 & 688239 & 5.1862 & 5.4529 & TRN \\
\hline CHEMBL1425938 & 688239 & 4.5362 & 5.4548 & TRN \\
\hline CHEMBL1335817 & 688239 & 5.2362 & 5.4675 & TRN \\
\hline CHEMBL1336543 & 688239 & 5.4862 & 5.7505 & TRN \\
\hline CHEMBL1319728 & 688239 & 6.4862 & 5.5297 & TRN \\
\hline CHEMBL1359136 & 688239 & 5.1362 & 5.6049 & TST \\
\hline CHEMBL1432997 & 688239 & 5.0862 & 5.4564 & TRN \\
\hline CHEMBL1438816 & 688239 & 4.8362 & 5.4195 & TRN \\
\hline CHEMBL1333773 & 688239 & 4.6362 & 5.415 & TRN \\
\hline CHEMBL1323837 & 688239 & 6.1862 & 5.5018 & TST \\
\hline
\end{tabular}


Supplemental Table S2.txt

\begin{tabular}{|c|c|c|c|c|}
\hline CHEMBL1441894 & 688239 & 8.3372 & 5.3963 & TRN \\
\hline CHEMBL1448077 & 688239 & 6.1362 & 5.3089 & TST \\
\hline CHEMBL193627 & 688239 & 5.6362 & \multicolumn{2}{|c|}{5.281000000000001} \\
\hline CHEMBL1493665 & 688239 & 4.5362 & 5.671 & TRN \\
\hline CHEMBL1494911 & 688239 & 4.6862 & 5.597 & TST \\
\hline CHEMBL1315016 & 688239 & 4.7362 & 5.6471 & TST \\
\hline CHEMBL1429618 & 688239 & 5.4362 & 5.5379 & TST \\
\hline CHEMBL1325869 & 688239 & 5.5362 & 5.4087 & TST \\
\hline CHEMBL1338026 & 688239 & 6.9363 & 5.431 & TRN \\
\hline CHEMBL1561427 & 688239 & 5.1862 & 5.5763 & TRN \\
\hline CHEMBL1588681 & 688239 & 8.2366 & 5.6079 & TRN \\
\hline CHEMBL1979539 & 688239 & 4.5362 & 5.4635 & TRN \\
\hline CHEMBL1553886 & 688239 & 4.9362 & 5.4616 & TRN \\
\hline CHEMBL 3209684 & 688239 & 4.9362 & 5.3981 & TST \\
\hline CHEMBL1569037 & 688239 & 8.3372 & 5.4382 & TRN \\
\hline CHEMBL1312525 & 688239 & 6.1862 & 5.2846 & TRN \\
\hline CHEMBL1529606 & 688239 & 4.6362 & \multicolumn{2}{|c|}{5.428999999999999} \\
\hline CHEMBL1426147 & 688239 & 4.8362 & \multicolumn{2}{|c|}{5.428999999999999} \\
\hline CHEMBL1366355 & 688239 & 7.4868 & 5.4295 & TRN \\
\hline CHEMBL1317582 & 688239 & 5.3362 & 5.4684 & TRN \\
\hline CHEMBL1402990 & 688239 & 4.8862 & 5.2921 & TRN \\
\hline CHEMBL1512739 & 688239 & 4.4862 & 5.5132 & TRN \\
\hline CHEMBL1388108 & 688239 & 4.5362 & 5.6113 & TRN \\
\hline CHEMBL 3212372 & 688239 & 8.2366 & 5.4766 & TST \\
\hline CHEMBL1508989 & 688239 & 8.3372 & 5.6538 & TST \\
\hline CHEMBL1418744 & 688239 & 5.6362 & 5.3775 & TRN \\
\hline CHEMBL1415136 & 688239 & 6.0862 & 5.4253 & TST \\
\hline CHEMBL3191211 & 688239 & 5.1862 & 5.4368 & TST \\
\hline CHEMBL602997 & 688239 & 4.6362 & 5.5493 & TST \\
\hline CHEMBL1487411 & 688239 & 4.7362 & 5.4365 & TRN \\
\hline CHEMBL1585826 & 688239 & 5.8862 & 5.6053 & TRN \\
\hline CHEMBL1379274 & 688239 & 4.5362 & 5.3559 & TST \\
\hline CHEMBL3194117 & 688239 & 5.7362 & 5.4455 & TRN \\
\hline CHEMBL1345069 & 688239 & 5.4862 & 5.6316 & TRN \\
\hline CHEMBL1374167 & 688239 & 6.8362 & 5.6589 & TST \\
\hline CHEMBL1419207 & 688239 & 6.9363 & 5.4987 & TRN \\
\hline CHEMBL1345275 & 688239 & 6.0362 & 5.5608 & TRN \\
\hline CHEMBL1388763 & 688239 & 5.4862 & 5.5228 & TST \\
\hline CHEMBL1462658 & 688239 & 4.5362 & 5.5459 & TST \\
\hline CHEMBL1352451 & 688239 & 5.7362 & 5.5055 & TST \\
\hline CHEMBL1484284 & 688239 & 5.8862 & 5.5981 & TST \\
\hline CHEMBL1605868 & 688239 & 6.1862 & 5.5284 & TRN \\
\hline CHEMBL1589811 & 688239 & 4.8362 & 5.49 & TRN \\
\hline CHEMBL1555143 & 688239 & 4.4862 & 5.4314 & TRN \\
\hline CHEMBL1581792 & 688239 & 4.7862 & 5.5848 & TRN \\
\hline CHEMBL1307734 & 688239 & 6.7862 & 5.5278 & TRN \\
\hline CHEMBL1353368 & 688239 & 4.5362 & 5.5047 & TRN \\
\hline CHEMBL1535302 & 688239 & 6.8861 & 5.3715 & TRN \\
\hline
\end{tabular}

Page 989 
Supplemental Table S2.txt

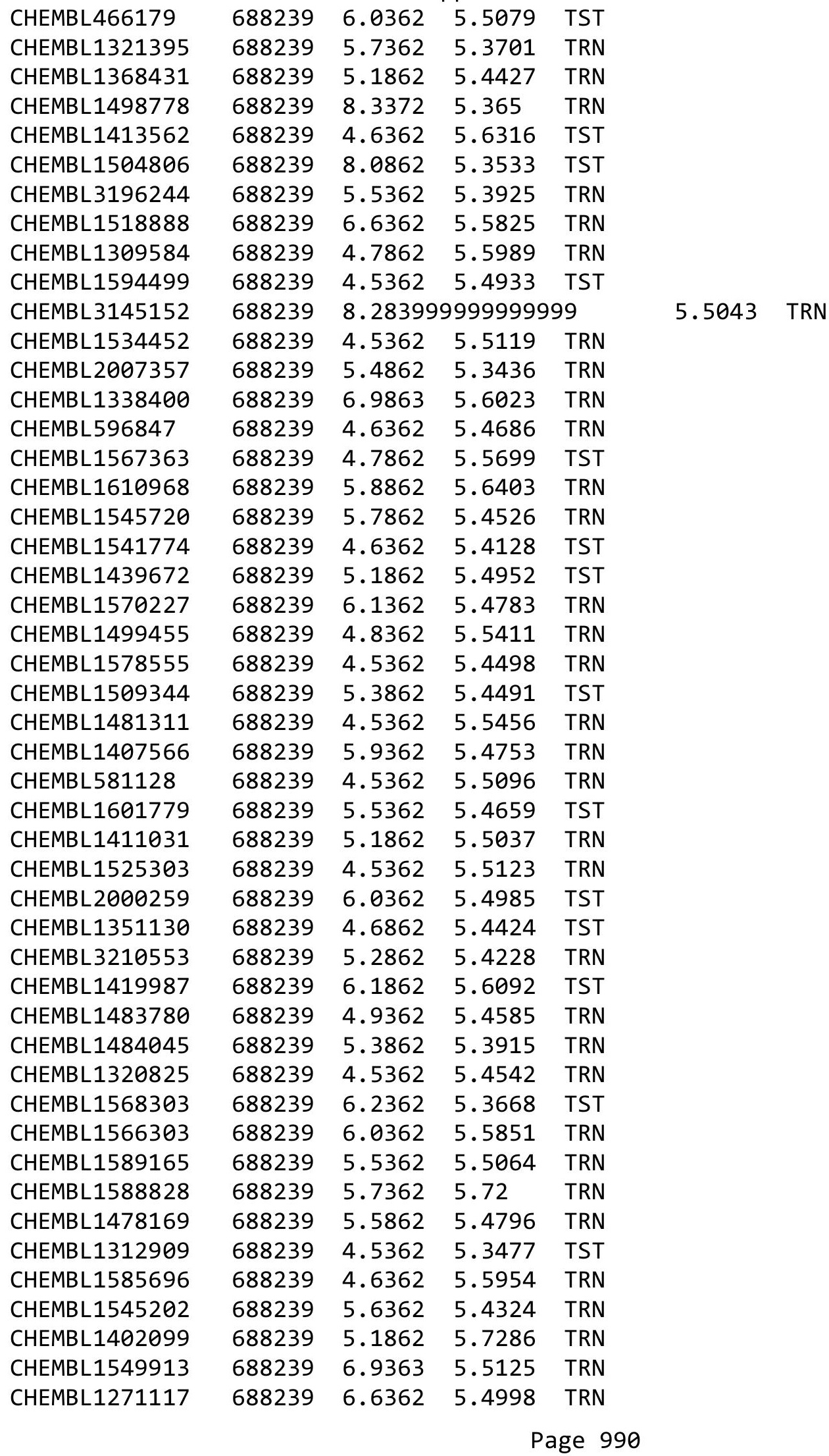


Supplemental Table S2.txt

\begin{tabular}{|c|c|c|c|c|}
\hline CHEMBL1301020 & 688239 & 5.2862 & 5.648 & TRN \\
\hline CHEMBL1507778 & 688239 & 4.6362 & 5.5774 & TST \\
\hline CHEMBL1504112 & 688239 & 5.9362 & 5.3334 & TRN \\
\hline CHEMBL1400979 & 688239 & 4.8362 & 5.5308 & TRN \\
\hline CHEMBL1518663 & 688239 & 4.5362 & 5.4356 & TRN \\
\hline CHEMBL1468960 & 688239 & 7.1864 & 5.4991 & TRN \\
\hline CHEMBL1368131 & 688239 & 5.0362 & 5.6391 & TRN \\
\hline CHEMBL1530523 & 688239 & 4.6362 & 5.6085 & TRN \\
\hline CHEMBL1558064 & 688239 & 5.1362 & 5.4842 & TRN \\
\hline CHEMBL1317211 & 688239 & 7.1864 & 5.376 & TRN \\
\hline CHEMBL1460344 & 688239 & 6.5363 & 5.4073 & TST \\
\hline CHEMBL1338056 & 688239 & 4.4862 & 5.4297 & TRN \\
\hline CHEMBL1306607 & 688239 & 5.9362 & 5.49700 & 000000001 \\
\hline CHEMBL1425889 & 688239 & 4.6862 & 5.3863 & TRN \\
\hline CHEMBL1544324 & 688239 & 7.6861 & 5.6651 & TRN \\
\hline CHEMBL6390 & 688239 & 8.3872 & 5.48600 & 000000001 \\
\hline CHEMBL1332562 & 688239 & 7.2366 & 5.4731 & TRN \\
\hline CHEMBL1424208 & 688239 & 4.5862 & 5.4414 & TRN \\
\hline CHEMBL1558210 & 688239 & 4.8862 & 5.3874 & TRN \\
\hline CHEMBL1530412 & 688239 & 5.6362 & 5.4306 & TRN \\
\hline CHEMBL1305680 & 688239 & 5.2362 & 5.5093 & TRN \\
\hline CHEMBL1488708 & 688239 & 4.7362 & 5.4032 & TRN \\
\hline CHEMBL1424335 & 688239 & 5.9362 & 5.529 & TRN \\
\hline CHEMBL1517373 & 688239 & 5.3362 & 5.4745 & TST \\
\hline CHEMBL3196314 & 688239 & 5.6862 & 5.4581 & TRN \\
\hline CHEMBL1416950 & 688239 & 6.6362 & 5.4093 & TRN \\
\hline CHEMBL1532978 & 688239 & 6.1362 & 5.4773 & TST \\
\hline CHEMBL1490417 & 688239 & 4.7862 & 5.3276 & TST \\
\hline CHEMBL1504520 & 688239 & 4.9862 & 5.3882 & TRN \\
\hline CHEMBL1324875 & 688239 & 4.6362 & 5.3599 & TST \\
\hline CHEMBL1522315 & 688239 & 5.6362 & 5.5327 & TRN \\
\hline CHEMBL1329757 & 688239 & 4.7862 & 5.3699 & TRN \\
\hline CHEMBL1472304 & 688239 & 5.6362 & 5.5344 & TRN \\
\hline CHEMBL1313621 & 688239 & 4.5362 & 5.4541 & TST \\
\hline CHEMBL1349286 & 688239 & 5.6862 & 5.4874 & TRN \\
\hline CHEMBL1443000 & 688239 & 6.3362 & 5.41799 & 999999999 \\
\hline CHEMBL1366468 & 688239 & 4.6362 & 5.6306 & TRN \\
\hline CHEMBL1510925 & 688239 & 7.2366 & 5.404 & TST \\
\hline CHEMBL1334656 & 688239 & 6.7361 & 5.6382 & TRN \\
\hline CHEMBL1464310 & 688239 & 5.8862 & 5.4994 & TRN \\
\hline CHEMBL3213487 & 688239 & 5.1362 & 5.4589 & TST \\
\hline CHEMBL1433426 & 688239 & 5.1362 & 5.3318 & TST \\
\hline CHEMBL1344733 & 688239 & 6.0862 & 5.3676 & TST \\
\hline CHEMBL1308938 & 688239 & 4.5362 & 5.553 & TST \\
\hline CHEMBL1506394 & 688239 & 5.0 & 5.454 & TRN \\
\hline CHEMBL1563021 & 688239 & 6.1362 & 5.5719 & TRN \\
\hline CHEMBL1453540 & 688239 & 6.8362 & 5.5705 & TRN \\
\hline CHEMBL1417482 & 688239 & 6.6861 & 5.5231 & TRN \\
\hline
\end{tabular}


Supplemental Table S2.txt

\begin{tabular}{|c|c|c|c|c|}
\hline CHEMBL1441439 & 688239 & 5.8862 & 5.473 & TST \\
\hline CHEMBL1579610 & 688239 & 5.0362 & 5.6471 & TST \\
\hline CHEMBL1315762 & 688239 & 4.5362 & 5.5541 & TRN \\
\hline CHEMBL1304023 & 688239 & 4.5362 & 5.5797 & TRN \\
\hline CHEMBL1545471 & 688239 & 5.1862 & 5.6722 & TRN \\
\hline CHEMBL1539809 & 688239 & 5.6362 & 5.421 & TRN \\
\hline CHEMBL1403060 & 688239 & 4.6862 & 5.6146 & TRN \\
\hline CHEMBL1564328 & 688239 & 8.28399 & 99999999 & 5.5084 \\
\hline CHEMBL1461579 & 688239 & 4.5862 & 5.5259 & TRN \\
\hline CHEMBL1525323 & 688239 & 4.6362 & 5.6619 & TRN \\
\hline CHEMBL1405274 & 688239 & 4.6362 & 5.3416 & TST \\
\hline CHEMBL1355178 & 688239 & 6.3362 & 5.4153 & TRN \\
\hline CHEMBL3195974 & 688239 & 4.6862 & 5.3778 & TRN \\
\hline CHEMBL1483164 & 688239 & 5.4862 & 5.5797 & TRN \\
\hline CHEMBL528373 & 688239 & 5.1362 & 5.3864 & TRN \\
\hline CHEMBL1386002 & 688239 & 5.1862 & 5.4903 & TRN \\
\hline CHEMBL1336158 & 688239 & 4.6362 & 5.3258 & TST \\
\hline CHEMBL1397157 & 688239 & 6.8362 & 5.5051 & TRN \\
\hline CHEMBL1558655 & 688239 & 7.6364 & 5.5736 & TST \\
\hline CHEMBL1609187 & 688239 & 5.1862 & 5.3857 & TRN \\
\hline CHEMBL1565744 & 688239 & 4.5862 & 5.5371 & TRN \\
\hline CHEMBL1408312 & 688239 & 4.5362 & 5.6604 & TRN \\
\hline CHEMBL1610196 & 688239 & 5.1862 & 5.5893 & TRN \\
\hline CHEMBL1573457 & 688239 & 4.5362 & 5.5316 & TRN \\
\hline CHEMBL1600283 & 688239 & 4.5362 & 5.407999 & \\
\hline CHEMBL1339849 & 688239 & 5.0362 & 5.53 & TRN \\
\hline CHEMBL1562566 & 688239 & 6.9363 & 5.5078 & TST \\
\hline CHEMBL1434122 & 688239 & 5.7362 & 5.4324 & TST \\
\hline CHEMBL1464699 & 688239 & 7.2366 & 5.5748 & TRN \\
\hline CHEMBL1559261 & 688239 & 4.5362 & 5.5766 & TRN \\
\hline CHEMBL1365726 & 688239 & 4.7862 & 5.5764 & TRN \\
\hline CHEMBL1395825 & 688239 & 8.2366 & 5.5713 & TRN \\
\hline CHEMBL1556852 & 688239 & 6.2362 & 5.5201 & TST \\
\hline CHEMBL1460071 & 688239 & 5.4862 & 5.5863 & TST \\
\hline CHEMBL1469772 & 688239 & 4.6362 & 5.4591 & TRN \\
\hline CHEMBL1480545 & 688239 & 5.3862 & 5.6019 & TRN \\
\hline CHEMBL1466420 & 688239 & 6.6861 & 5.6074 & TRN \\
\hline CHEMBL1505703 & 688239 & 4.5362 & 5.5405 & TRN \\
\hline CHEMBL1540756 & 688239 & 4.7362 & 5.4104 & TRN \\
\hline CHEMBL3212081 & 688239 & 5.5862 & 5.5323 & TRN \\
\hline CHEMBL1527501 & 688239 & 8.3372 & 5.3655 & TRN \\
\hline CHEMBL1510447 & 688239 & 5.8362 & 5.5592 & TRN \\
\hline CHEMBL1469743 & 688239 & 4.5362 & 5.4981 & TST \\
\hline CHEMBL1360257 & 688239 & 4.6862 & 5.6282 & TRN \\
\hline CHEMBL3208201 & 688239 & 6.9363 & 5.5122 & TRN \\
\hline CHEMBL1406542 & 688239 & 5.1862 & 5.4017 & TRN \\
\hline CHEMBL1499029 & 688239 & 4.7862 & 5.5679 & TRN \\
\hline CHEMBL1336184 & 688239 & 5.7362 & 5.6006 & TRN \\
\hline
\end{tabular}


Supplemental Table S2.txt

\begin{tabular}{|c|c|c|c|c|}
\hline 工 & & & & \\
\hline HEMBL 3214536 & 38239 & 1862 & 4706 & \\
\hline AEMBL1304146 & 239 & 362 & 86 & \\
\hline 3L156 & 39 & 362 & & \\
\hline AEMBL157 & 39 & 862 & & \\
\hline AEMBL1364462 & 88239 & 861 & 072 & \\
\hline AEMBL3194797 & 88239 & 4.7362 & 934 & \\
\hline HEMBL137 & & & & \\
\hline AEMBL149 & 39 & 361 & & \\
\hline AEMBL151 & & 361 & & \\
\hline AEMBL2373596 & 39 & 362 & & \\
\hline AEMBL1338603 & & 362 & & \\
\hline AEMBL147€ & & 862 & & \\
\hline IEMBL130 & & 362 & & \\
\hline AEMBL139 & & 62 & & \\
\hline HEMBL138 & & 862 & & \\
\hline AEMBL1423 & & 361 & & \\
\hline HEMBL130 & & 62 & & \\
\hline HEMBL149 & & & & \\
\hline HEMBL134 & & 362 & & \\
\hline HEMBL 144 & & 362 & & \\
\hline AEMBL14] & & 62 & & \\
\hline IEMBL142 & & 62 & & \\
\hline AFMRI $15^{\circ}$ & & & & \\
\hline 37 & & & & \\
\hline ר 15 15 & & 62 & & \\
\hline AEMBL199 & & & & \\
\hline EMBL136 & & 62 & & \\
\hline 4 & & 72 & & \\
\hline 14 & & 62 & & \\
\hline HEMBL 144 & & & & \\
\hline HEMBL1586 & & 362 & & \\
\hline & & & & \\
\hline 2 & & & & \\
\hline & & & & \\
\hline AEMBL1324995 & & & & \\
\hline AEMBL1533034 & & 862 & & \\
\hline & & & & \\
\hline 7 & & & & \\
\hline HEMBL155 & & & & RN \\
\hline AEMBL 320 & & 62 & & s \\
\hline רבי 15 & & 62 & & \\
\hline & & & & \\
\hline & & & & \\
\hline HEMBL 144 & & 6.7862 & & ST \\
\hline HEMBL130 & 68 & 366 & 308 & $\mathrm{R}$ \\
\hline & & & & \\
\hline HEMBL1608512 & & & & \\
\hline
\end{tabular}

Page 993 
Supplemental Table S2.txt

\begin{tabular}{|c|c|c|c|c|}
\hline CHEMBL1550428 & 688239 & 4.7362 & 5.4489 & TRN \\
\hline CHEMBL1612453 & 688239 & 5.9362 & 5.5147 & TST \\
\hline CHEMBL1507071 & 688239 & 7.0862 & 5.7086 & TRN \\
\hline CHEMBL3199724 & 688239 & 5.8862 & 5.3567 & TRN \\
\hline CHEMBL1425063 & 688239 & 5.8362 & 5.5514 & TST \\
\hline CHEMBL1359222 & 688239 & 4.7362 & 5.4882 & TRN \\
\hline CHEMBL588919 & 688239 & 5.0362 & 5.5004 & TRN \\
\hline CHEMBL1986055 & 688239 & 6.0862 & 5.3726 & TST \\
\hline CHEMBL3210485 & 688239 & 5.1862 & 5.4276 & TRN \\
\hline CHEMBL1531653 & 688239 & 6.6362 & 5.4299 & TRN \\
\hline CHEMBL1612546 & 688239 & 6.5862 & 5.4613 & TST \\
\hline CHEMBL1406283 & 688239 & 5.0362 & 5.5555 & TRN \\
\hline CHEMBL3189460 & 688239 & 5.1362 & 5.497000 & 0000000001 \\
\hline CHEMBL1334820 & 688239 & 4.5362 & 5.5025 & TST \\
\hline CHEMBL1311193 & 688239 & 4.4862 & 5.4753 & TRN \\
\hline CHEMBL1508298 & 688239 & 6.0862 & 5.4153 & TRN \\
\hline CHEMBL1536652 & 688239 & 4.5362 & 5.4569 & TRN \\
\hline CHEMBL1367435 & 688239 & 6.7361 & 5.5276 & TST \\
\hline CHEMBL1494410 & 688239 & 8.2366 & 5.5666 & TRN \\
\hline CHEMBL1458522 & 688239 & 6.3362 & 5.4815 & TRN \\
\hline CHEMBL1534499 & 688239 & 4.5362 & 5.3195 & TRN \\
\hline CHEMBL1569996 & 688239 & 5.4362 & 5.6646 & TST \\
\hline CHEMBL3191597 & 688239 & 6.2362 & 5.4622 & TST \\
\hline CHEMBL1444923 & 688239 & 4.9362 & 5.5163 & TRN \\
\hline CHEMBL1494021 & 688239 & 5.0862 & 5.5553 & TST \\
\hline CHEMBL1499538 & 688239 & 4.6862 & 5.5533 & TST \\
\hline CHEMBL1366839 & 688239 & 4.6862 & 5.4133 & TRN \\
\hline CHEMBL1337790 & 688239 & 4.5362 & 5.44 & TRN \\
\hline CHEMBL1365290 & 688239 & 4.9362 & 5.4437 & TRN \\
\hline CHEMBL1581525 & 688239 & 8.28399 & 999999999 & 5.6743 \\
\hline CHEMBL1307760 & 688239 & 4.5362 & 5.3347 & TST \\
\hline CHEMBL1478674 & 688239 & 5.7862 & 5.4513 & TRN \\
\hline CHEMBL1359860 & 688239 & 6.0862 & 5.5156 & TST \\
\hline CHEMBL1313201 & 688239 & 5.6862 & 5.4654 & TRN \\
\hline CHEMBL1480975 & 688239 & 5.0862 & 5.4805 & TST \\
\hline CHEMBL1528748 & 688239 & 4.6862 & 5.3882 & TRN \\
\hline CHEMBL1388477 & 688239 & 4.5862 & 5.4906 & TST \\
\hline CHEMBL1373048 & 688239 & 5.1862 & 5.3905 & TST \\
\hline CHEMBL1609400 & 688239 & 5.1862 & 5.5507 & TRN \\
\hline CHEMBL1413328 & 688239 & 5.1862 & 5.5562 & TST \\
\hline CHEMBL3197597 & 688239 & 4.6362 & 5.5405 & TRN \\
\hline CHEMBL1429622 & 688239 & 5.4362 & 5.4903 & TRN \\
\hline CHEMBL1426182 & 688239 & 5.5862 & 5.5463 & TST \\
\hline CHEMBL1526864 & 688239 & 5.1862 & 5.3535 & TST \\
\hline CHEMBL590706 & 688239 & 4.5362 & 5.4796 & TRN \\
\hline CHEMBL1466302 & 688239 & 4.7362 & 5.5899 & TRN \\
\hline CHEMBL1513783 & 688239 & 7.7852 & 5.4859 & TRN \\
\hline CHEMBL1338842 & 688239 & 6.0862 & 5.4492 & TRN \\
\hline
\end{tabular}


Supplemental Table S2.txt

\begin{tabular}{|c|c|c|c|c|}
\hline CHEMBL1605202 & 688239 & 6.0362 & 5.4762 & TRN \\
\hline CHEMBL1391923 & 688239 & 5.7362 & 5.4246 & TRN \\
\hline CHEMBL1369327 & 688239 & 4.6862 & 5.4466 & TRN \\
\hline CHEMBL1351803 & 688239 & 4.6862 & 5.4088 & TRN \\
\hline CHEMBL 3213440 & 688239 & 5.4362 & 5.3723 & TST \\
\hline CHEMBL1337167 & 688239 & 5.0362 & 5.5774 & TRN \\
\hline CHEMBL1379947 & 688239 & 6.0862 & \multicolumn{2}{|c|}{5.6339999999999995} \\
\hline CHEMBL1343186 & 688239 & 5.6862 & 5.5386 & TST \\
\hline CHEMBL1488259 & 688239 & 4.7362 & 5.5057 & TST \\
\hline CHEMBL1485580 & 688239 & 6.8362 & 5.4257 & TST \\
\hline CHEMBL1372339 & 688239 & 4.7362 & 5.5795 & TST \\
\hline CHEMBL1538396 & 688239 & 4.5362 & 5.4622 & TRN \\
\hline CHEMBL1510056 & 688239 & 4.8362 & 5.4154 & TRN \\
\hline CHEMBL1328140 & 688239 & 4.7862 & 5.3761 & TRN \\
\hline CHEMBL1590324 & 688239 & 7.2366 & 5.5763 & TST \\
\hline CHEMBL1478244 & 688239 & 6.2362 & 5.62 & TRN \\
\hline CHEMBL1569906 & 688239 & 5.2862 & 5.5211 & TRN \\
\hline CHEMBL1579843 & 688239 & 5.1362 & 5.3906 & TRN \\
\hline CHEMBL1383000 & 688239 & 4.6362 & 5.5779 & TRN \\
\hline CHEMBL1566558 & 688239 & 4.5362 & 5.4701 & TST \\
\hline CHEMBL1440832 & 688239 & 4.7362 & 5.4322 & TRN \\
\hline CHEMBL1372167 & 688239 & 4.7862 & 5.5868 & TRN \\
\hline CHEMBL1403639 & 688239 & 6.7862 & 5.3871 & TST \\
\hline CHEMBL1613029 & 688239 & 5.0362 & 5.4955 & TST \\
\hline CHEMBL1331966 & 688239 & 5.4862 & 5.4594 & TST \\
\hline CHEMBL1471399 & 688239 & 4.6862 & 5.4822 & TRN \\
\hline CHEMBL1350147 & 688239 & 6.1362 & 5.46 & TRN \\
\hline CHEMBL1482502 & 688239 & 6.2362 & 5.5285 & TST \\
\hline CHEMBL1443178 & 688239 & 4.9362 & 5.4251 & TRN \\
\hline CHEMBL1412447 & 688239 & 5.4362 & 5.6507 & TST \\
\hline CHEMBL1366604 & 688239 & 4.5362 & 5.4558 & TRN \\
\hline CHEMBL1393768 & 688239 & 5.6362 & 5.3991 & TRN \\
\hline CHEMBL1535114 & 688239 & 4.5362 & 5.532999 & 79999999995 \\
\hline CHEMBL1462310 & 688239 & 5.9862 & 5.5403 & TST \\
\hline CHEMBL1376950 & 688239 & 4.6362 & 5.6005 & TRN \\
\hline CHEMBL1301470 & 688239 & 6.8861 & 5.5422 & TRN \\
\hline CHEMBL1348984 & 688239 & 6.8861 & 5.4021 & TST \\
\hline CHEMBL1335209 & 688239 & 5.1862 & 5.5159 & TST \\
\hline CHEMBL1537419 & 688239 & 5.4862 & 5.4465 & TRN \\
\hline CHEMBL1419733 & 688239 & 4.7362 & 5.3753 & TRN \\
\hline CHEMBL1555116 & 688239 & 4.5362 & 5.4769 & TRN \\
\hline CHEMBL3194037 & 688239 & 4.5362 & 5.3465 & TST \\
\hline CHEMBL1361041 & 688239 & 5.7862 & 5.5583 & TRN \\
\hline CHEMBL1306488 & 688239 & 5.1862 & 5.3662 & TRN \\
\hline CHEMBL1435943 & 688239 & 5.3862 & 5.3206 & TRN \\
\hline CHEMBL1557945 & 688239 & 5.5362 & 5.3398 & TRN \\
\hline CHEMBL1602487 & 688239 & 5.2362 & 5.3469 & TST \\
\hline CHEMBL1405016 & 688239 & 5.9362 & 5.5788 & TRN \\
\hline
\end{tabular}


Supplemental Table S2.txt

\begin{tabular}{|c|c|c|c|c|c|c|}
\hline CHEMBL3190623 & 688239 & 5.1862 & 5.3708 & TRN & & \\
\hline CHEMBL1403218 & 688239 & 4.7362 & 5.6389 & TRN & & \\
\hline CHEMBL1480967 & 688239 & 7.9872 & 5.3898 & TRN & & \\
\hline CHEMBL1303060 & 688239 & 4.5362 & 5.4845 & TRN & & \\
\hline CHEMBL1528277 & 688239 & 6.3863 & 5.4231 & TRN & & \\
\hline CHEMBL1966657 & 688239 & 4.6862 & 5.4567 & TRN & & \\
\hline CHEMBL1440840 & 688239 & 6.2362 & 5.4237 & TRN & & \\
\hline CHEMBL1607983 & 688239 & 5.4862 & 5.511 & TRN & & \\
\hline CHEMBL1524270 & 688239 & 4.5362 & 5.3857 & TRN & & \\
\hline CHEMBL1394157 & 688239 & 5.5362 & 5.4827 & TRN & & \\
\hline CHEMBL1349710 & 688239 & 8.3372 & 5.5305 & TST & & \\
\hline CHEMBL1423480 & 688239 & 6.0862 & 5.629 & TST & & \\
\hline CHEMBL1415341 & 688239 & 5.1862 & 5.5893 & TRN & & \\
\hline CHEMBL1611801 & 688239 & 6.0 & 5.567 & TST & & \\
\hline CHEMBL1401862 & 688239 & 5.2862 & 5.5063 & TRN & & \\
\hline CHEMBL1540490 & 688239 & 5.9862 & 5.3432 & TRN & & \\
\hline CHEMBL3214326 & 688239 & 4.5362 & 5.5642 & TST & & \\
\hline CHEMBL1580463 & 688239 & 5.2362 & 5.5428 & TRN & & \\
\hline CHEMBL1465644 & 688239 & 6.1862 & 5.5051 & TST & & \\
\hline CHEMBL1591070 & 688239 & 4.5362 & 5.5196 & TRN & & \\
\hline CHEMBL1504314 & 688239 & 5.1862 & 5.4306 & TRN & & \\
\hline CHEMBL1351868 & 688239 & 4.5362 & 5.5742 & TRN & & \\
\hline CHEMBL1432052 & 688239 & 5.2362 & 5.6837 & TRN & & \\
\hline CHEMBL1489050 & 688239 & 5.4362 & 5.4466 & TST & & \\
\hline CHEMBL1470024 & 688239 & 5.2862 & 5.6223 & TRN & & \\
\hline CHEMBL1589261 & 688239 & 8.28399 & 999999999 & 99 & 5.3778 & TST \\
\hline CHEMBL338479 & 688239 & 4.5362 & 5.5783 & TRN & & \\
\hline CHEMBL3193915 & 688239 & 6.4862 & 5.4497 & TRN & & \\
\hline CHEMBL1515248 & 688239 & 5.1862 & 5.526 & TRN & & \\
\hline CHEMBL1538727 & 688239 & 6.8861 & 5.7497 & TRN & & \\
\hline CHEMBL1544557 & 688239 & 5.6862 & 5.4314 & TRN & & \\
\hline CHEMBL1414413 & 688239 & 5.1862 & 5.5907 & TST & & \\
\hline CHEMBL1367255 & 688239 & 4.9862 & 5.4564 & TRN & & \\
\hline CHEMBL1990091 & 688239 & 8.2366 & 5.5767 & TRN & & \\
\hline CHEMBL601994 & 688239 & 6.2362 & 5.6261 & TST & & \\
\hline CHEMBL1416762 & 688239 & 4.7862 & 5.5281 & TRN & & \\
\hline CHEMBL1527551 & 688239 & 6.3863 & 5.4752 & TRN & & \\
\hline CHEMBL1350834 & 688239 & 5.9362 & 5.4845 & TRN & & \\
\hline CHEMBL1337797 & 688239 & 5.1862 & 5.506 & TRN & & \\
\hline CHEMBL1499220 & 688239 & 4.5862 & 5.4327 & TST & & \\
\hline CHEMBL1429896 & 688239 & 6.6362 & 5.5162 & TST & & \\
\hline CHEMBL1535091 & 688239 & 8.1871 & 5.4953 & TRN & & \\
\hline CHEMBL1508288 & 688239 & 5.4862 & 5.5479 & TRN & & \\
\hline CHEMBL1401090 & 688239 & 4.6862 & 5.4835 & TRN & & \\
\hline CHEMBL1536980 & 688239 & 5.1862 & 5.5135 & TRN & & \\
\hline CHEMBL1553881 & 688239 & 4.6862 & 5.4052 & TRN & & \\
\hline CHEMBL3211510 & 688239 & 5.0362 & 5.5396 & TRN & & \\
\hline CHEMBL1592115 & 688239 & \multicolumn{3}{|c|}{8.283999999999999} & 5.6993 & TRN \\
\hline
\end{tabular}




\begin{tabular}{|c|c|c|c|c|c|}
\hline \multicolumn{6}{|c|}{ Supplemental Table S2.txt } \\
\hline CHEMBL1373330 & 688239 & 7.5361 & 5.6808 & TRN & \\
\hline CHEMBL1356151 & 688239 & 4.6862 & 5.4921 & TRN & \\
\hline CHEMBL1569755 & 688239 & 4.5362 & 5.4011 & TST & \\
\hline CHEMBL1457352 & 688239 & 4.8362 & 5.4251 & TRN & \\
\hline CHEMBL1423708 & 688239 & 6.6362 & 5.3922 & TST & \\
\hline CHEMBL1560555 & 688239 & 4.6362 & 5.4798 & TRN & \\
\hline CHEMBL1321962 & 688239 & 4.5362 & 5.4417 & TRN & \\
\hline CHEMBL1326630 & 688239 & 5.4362 & 5.3933 & TRN & \\
\hline CHEMBL 3212494 & 688239 & 5.0862 & 5.6608 & TRN & \\
\hline CHEMBL1527791 & 688239 & 5.7362 & 5.4761 & TRN & \\
\hline CHEMBL566474 & 688239 & 4.5362 & 5.4631 & TRN & \\
\hline CHEMBL1492912 & 688239 & 4.5362 & 5.5068 & TRN & \\
\hline CHEMBL1453451 & 688239 & 4.5862 & 5.4058 & TRN & \\
\hline CHEMBL1521691 & 688239 & 5.5862 & 5.4606 & TRN & \\
\hline CHEMBL1326053 & 688239 & 4.5362 & 5.3636 & TRN & \\
\hline CHEMBL1381860 & 688239 & 4.6862 & 5.3999 & TST & \\
\hline CHEMBL1532152 & 688239 & 8.0862 & 5.5585 & TST & \\
\hline CHEMBL1301682 & 688239 & 5.0862 & 5.5185 & TRN & \\
\hline CHEMBL1366498 & 688239 & 4.5362 & 5.3702 & TST & \\
\hline CHEMBL1558957 & 688239 & 5.1362 & 5.5062 & TRN & \\
\hline CHEMBL1444307 & 688239 & 4.5362 & 5.4165 & TST & \\
\hline CHEMBL1299532 & 688239 & 6.9863 & 5.4571 & TRN & \\
\hline CHEMBL1389930 & 688239 & 8.3372 & 5.4518 & TRN & \\
\hline CHEMBL1535384 & 688239 & 6.1862 & 5.4031 & TST & \\
\hline CHEMBL1359183 & 688239 & 4.6862 & 5.5526 & TRN & \\
\hline CHEMBL1373870 & 688239 & 7.2366 & 5.5022 & TRN & \\
\hline CHEMBL1365742 & 688239 & 6.4862 & 5.58799 & 9999999999 & TST \\
\hline CHEMBL1593681 & 688239 & 4.7362 & 5.5165 & TRN & \\
\hline CHEMBL1436878 & 688239 & 5.6862 & 5.4541 & TRN & \\
\hline CHEMBL1603921 & 688239 & 4.5862 & 5.541 & TRN & \\
\hline CHEMBL 3214484 & 688239 & 4.4862 & 5.5721 & TRN & \\
\hline CHEMBL1590200 & 688239 & 5.3362 & 5.4173 & TRN & \\
\hline CHEMBL1578386 & 688239 & 4.8862 & 5.5219 & TRN & \\
\hline CHEMBL1416104 & 688239 & 5.9362 & 5.433 & TRN & \\
\hline CHEMBL1313707 & 688239 & 5.2862 & 5.4011 & TST & \\
\hline CHEMBL1346893 & 688239 & 4.5862 & 5.4674 & TST & \\
\hline CHEMBL1409649 & 688239 & 4.4862 & 5.4704 & TRN & \\
\hline CHEMBL1464438 & 688239 & 5.8362 & 5.484 & TST & \\
\hline CHEMBL1369962 & 688239 & 7.2865 & 5.6945 & TRN & \\
\hline CHEMBL1401721 & 688239 & 5.6862 & 5.4605 & TRN & \\
\hline CHEMBL1481473 & 688239 & 6.2362 & 5.5819 & TRN & \\
\hline CHEMBL1536562 & 688239 & 4.5362 & 5.414 & TRN & \\
\hline CHEMBL1439901 & 688239 & 6.1862 & 5.4733 & TRN & \\
\hline CHEMBL1449642 & 688239 & 4.5362 & 5.67 & TRN & \\
\hline CHEMBL1609710 & 688239 & 5.4362 & 5.5358 & TST & \\
\hline CHEMBL1423821 & 688239 & 4.9362 & 5.5207 & TRN & \\
\hline CHEMBL1561803 & 688239 & 5.1862 & 5.6816 & TRN & \\
\hline CHEMBL1528610 & 688239 & 4.6362 & 5.3984 & TRN & \\
\hline
\end{tabular}




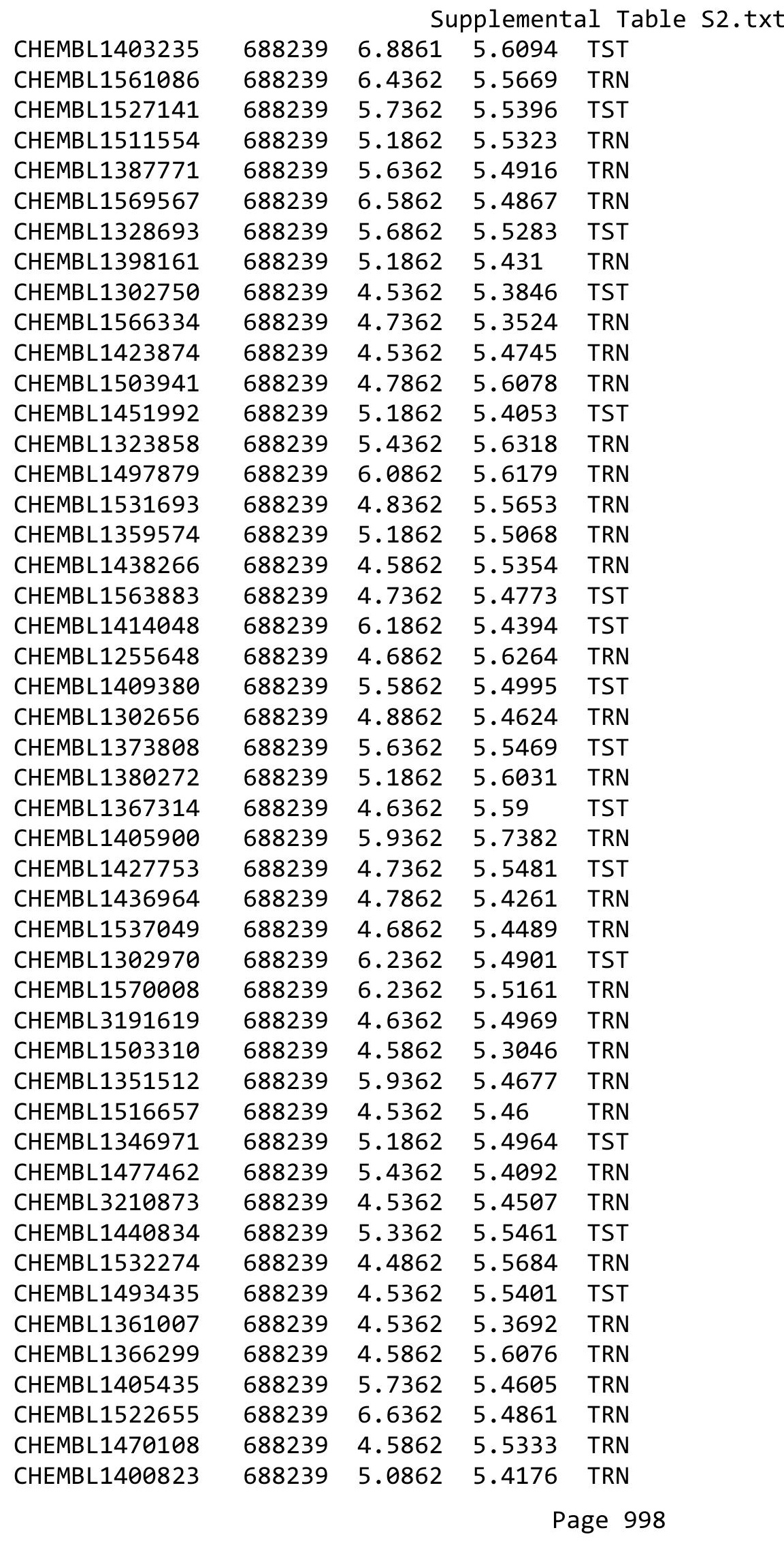




\begin{tabular}{|c|c|c|c|c|c|}
\hline \multirow[b]{2}{*}{ CHEMBL1388809 } & \multicolumn{5}{|c|}{ Supplemental Table S2.txt } \\
\hline & 688239 & 4.7362 & 5.5003 & TRN & \\
\hline CHEMBL1301427 & 688239 & 6.1862 & 5.5211 & TST & \\
\hline CHEMBL1544204 & 688239 & 4.5362 & 5.3859 & TST & \\
\hline CHEMBL1440613 & 688239 & 5.0862 & 5.4786 & TST & \\
\hline CHEMBL1365473 & 688239 & 4.5362 & 5.6238 & TRN & \\
\hline CHEMBL1302260 & 688239 & 4.8862 & 5.6625 & TRN & \\
\hline CHEMBL1402102 & 688239 & 4.5862 & 5.5796 & TRN & \\
\hline CHEMBL1490435 & 688239 & 5.1362 & 5.3172 & TRN & \\
\hline CHEMBL1569836 & 688239 & 5.1862 & 5.4698 & TRN & \\
\hline CHEMBL1463791 & 688239 & 6.7361 & 5.4615 & TRN & \\
\hline CHEMBL1390465 & 688239 & 5.3862 & 5.5155 & TRN & \\
\hline CHEMBL1383250 & 688239 & 7.3363 & 5.3744 & TRN & \\
\hline CHEMBL1369338 & 688239 & 5.7362 & 5.4965 & TRN & \\
\hline CHEMBL1610977 & 688239 & 4.5362 & 5.5896 & TRN & \\
\hline CHEMBL1328224 & 688239 & 6.9863 & 5.3656 & TST & \\
\hline CHEMBL1410465 & 688239 & 6.2362 & 5.435 & TRN & \\
\hline CHEMBL1595457 & 688239 & 6.1362 & 5.274 & TST & \\
\hline CHEMBL1568778 & 688239 & 5.2862 & 5.4612 & TST & \\
\hline CHEMBL1545688 & 688239 & 4.5862 & 5.494 & TST & \\
\hline CHEMBL1420177 & 688239 & 6.2362 & 5.51399 & 9999999999 & TST \\
\hline CHEMBL1385085 & 688239 & 4.5362 & 5.6432 & TRN & \\
\hline CHEMBL1533662 & 688239 & 5.5362 & 5.3949 & TRN & \\
\hline CHEMBL1609946 & 688239 & 5.3862 & 5.5521 & TRN & \\
\hline CHEMBL1597339 & 688239 & 5.7362 & 5.5344 & TRN & \\
\hline CHEMBL1577927 & 688239 & 8.1871 & 5.529 & TRN & \\
\hline CHEMBL1538269 & 688239 & 8.0862 & 5.3921 & TST & \\
\hline CHEMBL1579176 & 688239 & 6.5363 & 5.4436 & TRN & \\
\hline CHEMBL1271429 & 688239 & 6.2862 & 5.4933 & TRN & \\
\hline CHEMBL1439748 & 688239 & 5.8362 & 5.4241 & TRN & \\
\hline CHEMBL1353363 & 688239 & 5.6862 & 5.5797 & TRN & \\
\hline CHEMBL3192632 & 688239 & 6.7862 & 5.5629 & TRN & \\
\hline CHEMBL1360835 & 688239 & 5.3862 & 5.535 & TRN & \\
\hline CHEMBL1328213 & 688239 & 4.5362 & 5.5168 & TST & \\
\hline CHEMBL3209547 & 688239 & 5.5362 & 5.5232 & TRN & \\
\hline CHEMBL1441645 & 688239 & 6.0362 & 5.5036 & TRN & \\
\hline CHEMBL1535656 & 688239 & 5.1862 & 5.4853 & TRN & \\
\hline CHEMBL1377210 & 688239 & 4.5362 & 5.3487 & TRN & \\
\hline CHEMBL1576053 & 688239 & 8.3372 & 5.462006 & $\partial 000000001$ & TST \\
\hline CHEMBL1520157 & 688239 & 4.7362 & 5.4017 & TRN & \\
\hline CHEMBL1435679 & 688239 & 6.1862 & 5.5995 & TST & \\
\hline CHEMBL3197204 & 688239 & 5.0362 & 5.444 & TST & \\
\hline CHEMBL1352594 & 688239 & 5.3362 & 5.5715 & TRN & \\
\hline CHEMBL1429341 & 688239 & 5.1862 & 5.5531 & TRN & \\
\hline CHEMBL1466325 & 688239 & 5.4362 & 5.5763 & TRN & \\
\hline CHEMBL1524515 & 688239 & 4.6862 & 5.3075 & TST & \\
\hline CHEMBL1442580 & 688239 & 5.1862 & 5.4292 & TRN & \\
\hline CHEMBL1380058 & 688239 & 4.4862 & 5.532 & TRN & \\
\hline CHEMBL1453668 & 688239 & 5.1862 & 5.6643 & TRN & \\
\hline
\end{tabular}


Supplemental Table S2.txt

\begin{tabular}{|c|c|c|c|c|c|}
\hline CHEMBL1454716 & 688239 & 5.1862 & 5.6513 & TRN & \\
\hline CHEMBL1380673 & 688239 & 4.8362 & 5.3611 & TRN & \\
\hline CHEMBL1368155 & 688239 & 4.5362 & 5.3842 & TRN & \\
\hline CHEMBL1566285 & 688239 & 6.2362 & 5.3718 & TRN & \\
\hline CHEMBL1414237 & 688239 & 5.8862 & 5.4421 & TRN & \\
\hline CHEMBL1299604 & 688239 & 4.5362 & 5.454 & TRN & \\
\hline CHEMBL1390857 & 688239 & 5.2862 & 5.4539 & TRN & \\
\hline CHEMBL1380951 & 688239 & 7.9355 & 5.4758 & TRN & \\
\hline CHEMBL1497226 & 688239 & 5.4362 & 5.4328 & TST & \\
\hline CHEMBL1603437 & 688239 & 4.5362 & 5.377000 & 000000001 & TRA \\
\hline CHEMBL1997413 & 688239 & 4.5362 & 5.3525 & TST & \\
\hline CHEMBL1530938 & 688239 & 6.1362 & 5.5551 & TST & \\
\hline CHEMBL1399906 & 688239 & 6.8362 & 5.5457 & TRN & \\
\hline CHEMBL1511134 & 688239 & 6.6861 & 5.5818 & TRN & \\
\hline CHEMBL1365031 & 688239 & 4.6862 & 5.5227 & TRN & \\
\hline CHEMBL1569889 & 688239 & 6.0362 & 5.582999 & 999999999 & I \\
\hline CHEMBL1592128 & 688239 & 5.2862 & 5.5217 & TRN & \\
\hline CHEMBL1440658 & 688239 & 8.28399 & 99999999 & 5.5055 & \\
\hline CHEMBL1419090 & 688239 & 4.6862 & 5.5378 & TST & \\
\hline CHEMBL1380614 & 688239 & 6.9363 & 5.5227 & TRN & \\
\hline CHEMBL1362720 & 688239 & 4.6862 & 5.4892 & TST & \\
\hline CHEMBL1341070 & 688239 & 4.6862 & 5.2432 & TRN & \\
\hline CHEMBL1557291 & 688239 & 8.1871 & 5.3813 & TRN & \\
\hline CHEMBL1354037 & 688239 & 6.7862 & 5.4582 & TRN & \\
\hline CHEMBL1579515 & 688239 & 6.1862 & 5.5248 & TRN & \\
\hline CHEMBL1523838 & 688239 & 4.6862 & 5.5022 & TRN & \\
\hline CHEMBL 3207495 & 688239 & 5.1862 & 5.3963 & TRN & \\
\hline CHEMBL1404088 & 688239 & 4.4862 & 5.4183 & TST & \\
\hline CHEMBL1565551 & 688239 & 4.6362 & 5.5706 & TRN & \\
\hline CHEMBL1418139 & 688239 & 5.6862 & 5.6856 & TRN & \\
\hline CHEMBL1310314 & 688239 & 4.7362 & 5.4366 & TRN & \\
\hline CHEMBL1549092 & 688239 & 6.6861 & 5.542000 & 000000001 & \\
\hline CHEMBL1383741 & 688239 & 6.4362 & 5.4663 & TRN & \\
\hline CHEMBL1465588 & 688239 & 4.6862 & 5.3552 & TRN & \\
\hline CHEMBL1080178 & 688239 & 6.8362 & 5.5103 & TST & \\
\hline CHEMBL610056 & 688239 & 6.2862 & 5.3576 & TST & \\
\hline CHEMBL1432132 & 688239 & 5.1862 & 5.5533 & TRN & \\
\hline CHEMBL1431881 & 688239 & 6.1362 & 5.5554 & TRN & \\
\hline CHEMBL1560582 & 688239 & 5.7362 & 5.4556 & TRN & \\
\hline CHEMBL1545857 & 688239 & 4.5362 & 5.4623 & TST & \\
\hline CHEMBL1401118 & 688239 & 4.6862 & 5.4954 & TRN & \\
\hline CHEMBL3194152 & 688239 & 5.0862 & 5.4519 & TRN & \\
\hline CHEMBL1396062 & 688239 & 6.2862 & 5.4689 & TRN & \\
\hline CHEMBL1397709 & 688239 & 6.8861 & 5.44 & TRN & \\
\hline CHEMBL1405449 & 688239 & 4.4862 & 5.5079 & TST & \\
\hline CHEMBL1375383 & 688239 & 6.9363 & 5.4992 & TRN & \\
\hline CHEMBL1357701 & 688239 & 4.6862 & 5.4696 & TRN & \\
\hline CHEMBL1552356 & 688239 & 7.7852 & 5.5674 & TST & \\
\hline
\end{tabular}


Supplemental Table S2.txt

\begin{tabular}{|c|c|c|c|c|}
\hline CHEMBL1391525 & 688239 & 5.3862 & 5.3692 & TST \\
\hline CHEMBL1486790 & 688239 & 4.5362 & 5.4241 & TST \\
\hline CHEMBL1345251 & 688239 & 4.7862 & 5.5305 & TRN \\
\hline CHEMBL1456911 & 688239 & 4.9862 & 5.5934 & TRN \\
\hline CHEMBL1470336 & 688239 & 5.8862 & 5.5918 & TRN \\
\hline CHEMBL1371797 & 688239 & 6.4862 & 5.6873 & TRN \\
\hline CHEMBL1504525 & 688239 & 5.0862 & 5.3675 & TRN \\
\hline CHEMBL1345460 & 688239 & 5.0362 & 5.5241 & TST \\
\hline CHEMBL1392079 & 688239 & 6.9863 & 5.3188 & TST \\
\hline CHEMBL1451859 & 688239 & 7.2366 & 5.6589 & TRN \\
\hline CHEMBL1463316 & 688239 & 6.9863 & 5.3961 & TST \\
\hline CHEMBL1498453 & 688239 & 6.2362 & 5.5484 & TRN \\
\hline CHEMBL1360435 & 688239 & 5.1362 & 5.3829 & TRN \\
\hline CHEMBL1299891 & 688239 & 4.4862 & 5.4664 & TRN \\
\hline CHEMBL1474727 & 688239 & 5.3862 & 5.5163 & TRN \\
\hline CHEMBL1307838 & 688239 & 4.5362 & 5.4936 & TRN \\
\hline CHEMBL1516850 & 688239 & 4.6862 & 5.5921 & TST \\
\hline CHEMBL1528039 & 688239 & 6.0862 & 5.6992 & TRN \\
\hline CHEMBL1466309 & 688239 & 6.0862 & 5.478 & TRN \\
\hline CHEMBL1532836 & 688239 & 6.8861 & 5.5984 & TRN \\
\hline CHEMBL1582089 & 688239 & 5.4362 & 5.5823 & TRN \\
\hline CHEMBL1370468 & 688239 & 4.6862 & 5.4588 & TRN \\
\hline CHEMBL1355637 & 688239 & 5.1862 & 5.454 & TRN \\
\hline CHEMBL1368035 & 688239 & 6.1362 & 5.507999 & (999999999 \\
\hline CHEMBL1445065 & 688239 & 8.283999 & 999999999 & 5.5239 \\
\hline CHEMBL1521335 & 688239 & 4.5362 & 5.4404 & TRN \\
\hline CHEMBL1307812 & 688239 & 4.4862 & 5.5294 & TRN \\
\hline CHEMBL1540048 & 688239 & 4.4862 & 5.5357 & TRN \\
\hline CHEMBL1613484 & 688239 & 4.7862 & 5.5211 & TRN \\
\hline CHEMBL1362701 & 688239 & 4.5362 & 5.4703 & TST \\
\hline CHEMBL1458364 & 688239 & 6.1862 & 5.5685 & TRN \\
\hline CHEMBL1407045 & 688239 & 5.1862 & 5.4773 & TRN \\
\hline CHEMBL1305927 & 688239 & 6.1862 & 5.4142 & TST \\
\hline CHEMBL1320057 & 688239 & 5.4862 & 5.6284 & TST \\
\hline CHEMBL1396404 & 688239 & 6.0362 & 5.3512 & TRN \\
\hline CHEMBL1490575 & 688239 & 4.8862 & 5.56 & TRN \\
\hline CHEMBL1486468 & 688239 & 4.5362 & 5.4963 & TRN \\
\hline CHEMBL1377557 & 688239 & 5.3862 & 5.6255 & TRN \\
\hline CHEMBL1531405 & 688239 & 5.7362 & 5.4047 & TRN \\
\hline CHEMBL1355608 & 688239 & 5.1862 & 5.4784 & TRN \\
\hline CHEMBL1395952 & 688239 & 5.9362 & 5.5874 & TRN \\
\hline CHEMBL1349767 & 688239 & 4.5362 & 5.5824 & TRN \\
\hline CHEMBL 3194499 & 688239 & 4.7862 & 5.5083 & TST \\
\hline CHEMBL1490460 & 688239 & 4.8862 & 5.4331 & TRN \\
\hline CHEMBL1437312 & 688239 & 7.1864 & 5.5391 & TRN \\
\hline CHEMBL 1556370 & 688239 & 4.5362 & 5.433 & TRN \\
\hline CHEMBL1436790 & 688239 & 4.5362 & 5.4622 & TRN \\
\hline CHEMBL1434158 & 688239 & 5.4362 & 5.4347 & TST \\
\hline
\end{tabular}


Supplemental Table S2.txt

\begin{tabular}{|c|c|c|c|c|}
\hline & & & & \\
\hline AEMBL1605052 & 8239 & 9862 & & \\
\hline IEMBL309016 & 3239 & 3862 & & \\
\hline HEMBL1599708 & 239 & 862 & 873 & \\
\hline 621 & 239 & 363 & & \\
\hline AEMBL1435872 & 239 & 862 & & \\
\hline EMMBL1463240 & 88239 & 318 & 05 & \\
\hline AEMBL1348310 & 88239 & 362 & 04 & \\
\hline AEMBL3189671 & 239 & 362 & & \\
\hline IEMBL13 & 239 & 362 & & \\
\hline AEMBL143 & & & & \\
\hline HEMBL1342298 & 688239 & 362 & & \\
\hline AEMBL1571402 & 239 & 862 & & \\
\hline IEMBL1375 & & 62 & & \\
\hline EMBL1443244 & & 62 & & \\
\hline AEMBL1403309 & & & & \\
\hline AEMBL1311207 & 39 & 362 & & \\
\hline IEMBL14C & & 362 & & \\
\hline IEMBLI9 & & 62 & & \\
\hline IEMBL14 & & & & \\
\hline HEMBL16 & & 62 & & \\
\hline AEMBL3209842 & & 862 & & RN \\
\hline IEMBL1466923 & & 862 & & \\
\hline EMBL14 & & 62 & & $\mathrm{RN}$ \\
\hline EMBL14 & & 52 & & ST \\
\hline 1 & & 62 & & \\
\hline JEMBL13 & & & & RN \\
\hline AEMBL1484014 & & & & RI \\
\hline AEMBL1484764 & & 62 & & RI \\
\hline-14 & & 51 & & ST \\
\hline 35 & & 62 & & RN \\
\hline HEMBL1390119 & & & & S1 \\
\hline AEMBL1528547 & & & & RI \\
\hline IEMBL1544489 & & & & RI \\
\hline HEMBL14€ & & 52 & & 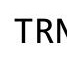 \\
\hline & & & & $\mathrm{ST}$ \\
\hline AEMBL1456062 & & & & RI \\
\hline AEMBL1481824 & & & & r \\
\hline EMBL1511 & & & & RI \\
\hline HEMBL1449806 & & & & ות \\
\hline & & 62 & & $S 1$ \\
\hline AEMBL1419578 & & 862 & 75 & RI \\
\hline IEMBL1439175 & & 62 & & $\Gamma R$ \\
\hline EMBL144 & & & & is \\
\hline HEMBL1520783 & & & & $S 1$ \\
\hline CHEMBL1509203 & & 362 & & RN \\
\hline AEMBL1354771 & 8239 & 5.3362 & 5.4345 & $T R$ \\
\hline HFMRI 1396991 & 688239 & 5.2362 & 5.5747 & \\
\hline
\end{tabular}


Supplemental Table S2.txt

\begin{tabular}{|c|c|c|c|c|c|}
\hline CHEMBL1439226 & 688239 & 6.0862 & 5.6171 & TRN & \\
\hline CHEMBL1462260 & 688239 & 5.1862 & 5.48600 & 0000000001 & TRN \\
\hline CHEMBL1409208 & 688239 & 4.5362 & 5.4396 & TRN & \\
\hline CHEMBL1367804 & 688239 & 5.1862 & 5.5729 & TST & \\
\hline CHEMBL1358715 & 688239 & 5.6862 & 5.3649 & TRN & \\
\hline CHEMBL1364185 & 688239 & 6.0362 & 5.4799 & TST & \\
\hline CHEMBL1354049 & 688239 & 4.9362 & 5.5692 & TRN & \\
\hline CHEMBL1544322 & 688239 & 5.4862 & 5.4646 & TRN & \\
\hline CHEMBL1487476 & 688239 & 4.5362 & 5.5006 & TST & \\
\hline CHEMBL1326700 & 688239 & 4.8362 & 5.3585 & TST & \\
\hline CHEMBL1530900 & 688239 & 7.0862 & 5.5152 & TST & \\
\hline CHEMBL1444626 & 688239 & 6.2362 & 5.6841 & TRN & \\
\hline CHEMBL1542368 & 688239 & 6.1862 & 5.4337 & TRN & \\
\hline CHEMBL1542127 & 688239 & 5.3862 & 5.5711 & TRN & \\
\hline CHEMBL1361432 & 688239 & 8.1367 & 5.6386 & TST & \\
\hline CHEMBL1500301 & 688239 & 4.5362 & 5.56 & TRN & \\
\hline CHEMBL1567861 & 688239 & 4.8862 & 5.3651 & TRN & \\
\hline CHEMBL1537650 & 688239 & 4.5362 & 5.5601 & TRN & \\
\hline CHEMBL1571347 & 688239 & 5.1862 & 5.4945 & TRN & \\
\hline CHEMBL1558216 & 688239 & 4.7362 & 5.4869 & TST & \\
\hline CHEMBL1417377 & 688239 & 5.5862 & 5.4414 & TRN & \\
\hline CHEMBL3194936 & 688239 & 4.5362 & 5.3459 & TRN & \\
\hline CHEMBL1316494 & 688239 & 4.6862 & 5.2649 & TRN & \\
\hline CHEMBL1572189 & 688239 & 6.9863 & 5.4521 & TRN & \\
\hline CHEMBL534214 & 688239 & 6.4862 & 5.3846 & TRN & \\
\hline CHEMBL1552901 & 688239 & 5.1362 & 5.5335 & TRN & \\
\hline CHEMBL1518874 & 688239 & 4.8362 & 5.3974 & TST & \\
\hline CHEMBL1520920 & 688239 & 7.0362 & 5.5049 & TRN & \\
\hline CHEMBL1593312 & 688239 & 4.5362 & 5.5356 & TRN & \\
\hline CHEMBL1568905 & 688239 & 6.0862 & 5.4772 & TST & \\
\hline CHEMBL1995870 & 688239 & 5.2862 & 5.4761 & TRN & \\
\hline CHEMBL1403760 & 688239 & 5.1862 & 5.4739 & TRN & \\
\hline CHEMBL1414007 & 688239 & 5.5862 & 5.5782 & TST & \\
\hline CHEMBL1517975 & 688239 & 6.9363 & 5.5162 & TRN & \\
\hline CHEMBL 1460250 & 688239 & 8.1871 & 5.354 & TST & \\
\hline CHEMBL1488408 & 688239 & 4.7862 & 5.4952 & TST & \\
\hline CHEMBL1493381 & 688239 & 6.6861 & 5.5185 & TRN & \\
\hline CHEMBL1416564 & 688239 & 4.5362 & 5.4927 & TRN & \\
\hline CHEMBL1421335 & 688239 & 4.5362 & 5.5805 & TRN & \\
\hline CHEMBL1469391 & 688239 & 6.1862 & 5.3828 & TST & \\
\hline CHEMBL1445018 & 688239 & 5.1862 & 5.5825 & TRN & \\
\hline CHEMBL1412788 & 688239 & 8.3372 & 5.3962 & TRN & \\
\hline CHEMBL1415737 & 688239 & 5.2862 & 5.4156 & TRN & \\
\hline CHEMBL1431369 & 688239 & 5.1862 & 5.3777 & TRN & \\
\hline CHEMBL1502703 & 688239 & 6.1362 & 5.5155 & TRN & \\
\hline CHEMBL1377003 & 688239 & 4.6862 & 5.4246 & TRN & \\
\hline CHEMBL 1487848 & 688239 & 6.2362 & 5.3667 & TRN & \\
\hline CHEMBL1505573 & 688239 & 6.9863 & 5.4621 & TRN & \\
\hline
\end{tabular}


Supplemental Table S2.txt

\begin{tabular}{|c|c|c|c|c|}
\hline 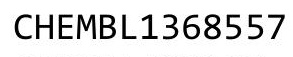 & & & & \\
\hline HEMBL492193 & 38239 & 862 & 86 & \\
\hline AEMBL1547135 & 239 & 362 & & \\
\hline 3862 & 39 & 362 & & \\
\hline IEMBL1507698 & 39 & 362 & & \\
\hline AEMBL1515935 & 88239 & 362 & & \\
\hline AEMBL1415950 & 88239 & 362 & 226 & \\
\hline HEMBL1377868 & & & & \\
\hline EMBL14C & 39 & 862 & & \\
\hline IEMBL133 & & 862 & & \\
\hline AEMBL1324375 & 39 & 362 & 29 & \\
\hline AEMBL1557632 & & 362 & & \\
\hline AEMBL1525844 & & 62 & & \\
\hline HEMBL147 & & 62 & & \\
\hline JEMB L454 & & 362 & & \\
\hline AEMBL1423389 & & 862 & & \\
\hline AEMBL1550485 & & 862 & & \\
\hline IEMBL132 & & 68 & & \\
\hline HEMBL133 & & 62 & & \\
\hline AEMBL16 & & 362 & & \\
\hline AEMBL1469621 & & 862 & & \\
\hline AEMBL1380879 & & 62 & & \\
\hline AEMBL 145 & & 62 & & \\
\hline HFMRI 156 & & & & \\
\hline 305 & & 62 & & \\
\hline 127 & & 862 & & \\
\hline IEMBL1573650 & & 62 & & \\
\hline EMBL1404468 & & 62 & & \\
\hline AFMRI 12 & & 62 & & \\
\hline IEMPI 11 & & 62 & & \\
\hline AEMBL1511778 & & & & \\
\hline HEMBL1336705 & & 862 & & \\
\hline & & 62 & & \\
\hline 7 & & 52 & & \\
\hline & & & & \\
\hline AEMBL1384176 & & & & \\
\hline AEMBL1592318 & & 862 & & \\
\hline & & & & \\
\hline 7 & & & & \\
\hline HEMBL1376218 & & & & $\mathrm{RI}$ \\
\hline AEMBL1510867 & & 362 & & \\
\hline AEMBL3190555 & & 62 & & \\
\hline 2 & & & & \\
\hline HEMBL1461937 & & & & \\
\hline AEMBL1416914 & & 4.5862 & & RN \\
\hline MBL160 & & 362 & 64 & \\
\hline 158 & & & & \\
\hline HEMBL143989 & & & & \\
\hline
\end{tabular}

Page 1004 
Supplemental Table S2.txt

\begin{tabular}{|c|c|c|c|c|}
\hline 597 & & & & \\
\hline HEMBL1573084 & 38239 & 5.1862 & & \\
\hline & & & 911 & \\
\hline 18 & 8239 & 4362 & & \\
\hline IEMBL152 & 38239 & 3362 & & \\
\hline AEMBL1555498 & 88239 & 7361 & 738 & \\
\hline AEMBL13 & 38239 & 0862 & & \\
\hline 14 & 239 & 862 & & \\
\hline IEMBL14 & 38239 & .5862 & & \\
\hline AEMBL1525527 & 88239 & 7862 & & \\
\hline JEMBL140 & 38239 & 0862 & & \\
\hline IEMBL1 & 8239 & 862 & & \\
\hline EMBL: & & & & \\
\hline EMBL1 & 39 & 861 & & \\
\hline IEMBL15 & 39 & 362 & & \\
\hline IEMBL15 & 39 & & & \\
\hline AEMBL3 & 39 & 54 & & \\
\hline AEMBL1 & & & & \\
\hline AEMBL: & 39 & & & \\
\hline EMBL1 & 39 & & & \\
\hline $\mathrm{H} \in \mathrm{MBL} 12$ & 39 & 62 & & \\
\hline IEMBL3 & 9 & 52 & & \\
\hline IEMBL1 & & & & \\
\hline 784 & 9 & & & \\
\hline EMBL1 & 9 & & & S \\
\hline IEMBL1 & 9 & 62 & & $S$ \\
\hline IEMBL] & 9 & 52 & & \\
\hline 22 & & & & \\
\hline 10 & & & & \\
\hline IEMBL13 & 9 & & & $\mathrm{RN}$ \\
\hline IEMBL: & 9 & 62 & & $\mathrm{RI}$ \\
\hline 09 & 9 & & & 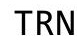 \\
\hline & & & & \\
\hline EMBL15 & & & & ST \\
\hline IEMBL15 & 9 & 62 & & ST \\
\hline IEMBL: & 9 & 62 & & $\mathrm{R} \wedge$ \\
\hline 24 & & & & NIV \\
\hline & & & & RN \\
\hline AEMBL1517193 & 88239 & 62 & & ST 1 \\
\hline EMBL] & 9 & & & ST \\
\hline IEMBL1 & 9 & & & $R_{2}>>$ \\
\hline & & & & ST \\
\hline 619 & & 362 & 03 & RI \\
\hline EMBL1510241 & 38239 & 862 & & RI \\
\hline 84 & & 62 & & $S$ \\
\hline HEMBL: & & & & $\mathrm{RI}$ \\
\hline (16) & & 4.7862 & 5.4509 & \\
\hline CHEMBL1448052 & 688239 & 5.8362 & 5.5411 & TS \\
\hline
\end{tabular}

Page 1005 
Supplemental Table S2.txt

\begin{tabular}{|c|c|c|c|c|}
\hline CHEMBL1342361 & 688239 & 5.2862 & 5.5923 & TRN \\
\hline CHEMBL1362132 & 688239 & 4.8362 & 5.5189 & TRN \\
\hline CHEMBL3193273 & 688239 & 6.5363 & 5.3874 & TRN \\
\hline CHEMBL3209591 & 688239 & 6.3362 & 5.5039 & TST \\
\hline CHEMBL3197695 & 688239 & 8.3372 & 5.4096 & TRN \\
\hline CHEMBL1525762 & 688239 & 5.5862 & 5.5281 & TST \\
\hline CHEMBL3191615 & 688239 & 6.1362 & 5.5516 & TST \\
\hline CHEMBL1407092 & 688239 & 5.3862 & 5.4417 & TRN \\
\hline CHEMBL1322213 & 688239 & 4.7362 & 5.5551 & TRN \\
\hline CHEMBL1472022 & 688239 & 4.4862 & 5.3415 & TST \\
\hline CHEMBL1522454 & 688239 & 4.7862 & 5.5292 & TRN \\
\hline CHEMBL1478751 & 688239 & 5.0862 & 5.5949 & TRN \\
\hline CHEMBL1571084 & 688239 & 5.7362 & 5.6411 & TRN \\
\hline CHEMBL1326820 & 688239 & 5.2862 & 5.7001 & TST \\
\hline CHEMBL1599729 & 688239 & 7.2865 & \multicolumn{2}{|c|}{5.617000000000001} \\
\hline CHEMBL1473979 & 688239 & 8.3872 & 5.6014 & TRN \\
\hline CHEMBL1459074 & 688239 & 6.8861 & 5.6219 & TRN \\
\hline CHEMBL1450255 & 688239 & 4.5362 & 5.5083 & TST \\
\hline CHEMBL1535740 & 688239 & 6.1362 & 5.6013 & TRN \\
\hline CHEMBL1419506 & 688239 & 4.5362 & 5.4196 & TST \\
\hline CHEMBL1348701 & 688239 & 4.6362 & 5.5183 & TRN \\
\hline CHEMBL1605301 & 688239 & 4.7862 & 5.6075 & TRN \\
\hline CHEMBL1490674 & 688239 & 5.6862 & 5.5465 & TRN \\
\hline CHEMBL147725 & 688239 & 4.7362 & 5.4534 & TST \\
\hline CHEMBL1345192 & 688239 & 4.5362 & 5.4379 & TST \\
\hline CHEMBL1345034 & 688239 & 5.8862 & 5.5721 & TRN \\
\hline CHEMBL1371738 & 688239 & 5.0362 & 5.5983 & TRN \\
\hline CHEMBL1563118 & 688239 & 4.6362 & 5.5475 & TRN \\
\hline CHEMBL1572132 & 688239 & 4.6362 & 5.5056 & TRN \\
\hline CHEMBL1368301 & 688239 & 6.1862 & 5.5998 & TRN \\
\hline CHEMBL1317926 & 688239 & 6.8861 & 5.4671 & TRN \\
\hline CHEMBL1610796 & 688239 & 4.5362 & 5.4692 & TRN \\
\hline CHEMBL1552741 & 688239 & 6.3863 & 5.459 & TST \\
\hline CHEMBL1555492 & 688239 & 5.7362 & 5.5881 & TST \\
\hline CHEMBL1506964 & 688239 & 4.8862 & 5.4051 & TRN \\
\hline CHEMBL1583893 & 688239 & 6.1362 & \multicolumn{2}{|c|}{5.5360000000000005} \\
\hline CHEMBL1444700 & 688239 & 5.4862 & 5.5771 & TRN \\
\hline CHEMBL1527235 & 688239 & 6.7862 & 5.4241 & TRN \\
\hline CHEMBL1602145 & 688239 & 5.8362 & 5.5479 & TRN \\
\hline CHEMBL1570371 & 688239 & 5.8862 & 5.4991 & TRN \\
\hline CHEMBL1403922 & 688239 & 6.1362 & 5.4627 & TRN \\
\hline CHEMBL1524533 & 688239 & 6.2862 & 5.4924 & TST \\
\hline CHEMBL1410096 & 688239 & 4.5362 & 5.5295 & TRN \\
\hline CHEMBL1513570 & 688239 & 5.9862 & 5.5402 & TRN \\
\hline CHEMBL1463195 & 688239 & 5.3862 & 5.5922 & TST \\
\hline CHEMBL1443751 & 688239 & 6.8861 & 5.4464 & TRN \\
\hline CHEMBL1484810 & 688239 & 4.7362 & 5.4147 & TST \\
\hline CHEMBL1328885 & 688239 & 5.6362 & 5.6307 & TRN \\
\hline
\end{tabular}


Supplemental Table S2.txt

\begin{tabular}{|c|c|c|c|c|}
\hline CHEMBL1421771 & 688239 & 5.2862 & 5.5904 & TRN \\
\hline CHEMBL1377577 & 688239 & 5.6362 & 5.5284 & TRN \\
\hline CHEMBL1440326 & 688239 & 6.2362 & 5.5147 & TST \\
\hline CHEMBL1478909 & 688239 & 5.2362 & 5.6126 & TRN \\
\hline CHEMBL1402636 & 688239 & 4.4862 & 5.4801 & TST \\
\hline CHEMBL1495034 & 688239 & 7.2865 & 5.4727 & TRN \\
\hline CHEMBL1311900 & 688239 & 5.5362 & 5.4534 & TRN \\
\hline CHEMBL1306983 & 688239 & 7.2366 & 5.4101 & TRN \\
\hline CHEMBL1567096 & 688239 & 5.1362 & 5.5005 & TRN \\
\hline CHEMBL1563714 & 688239 & 6.9363 & 5.539 & TRN \\
\hline CHEMBL1392445 & 688239 & 5.6862 & 5.4841 & TST \\
\hline CHEMBL1541453 & 688239 & 4.5362 & 5.6081 & TRN \\
\hline CHEMBL1508196 & 688239 & 4.7862 & 5.4048 & TRN \\
\hline CHEMBL1310211 & 688239 & 6.8362 & 5.4275 & TRN \\
\hline CHEMBL1386063 & 688239 & 8.1871 & 5.42 & TST \\
\hline CHEMBL1604283 & 688239 & 4.7862 & 5.4057 & TRN \\
\hline CHEMBL1596404 & 688239 & 5.1362 & 5.6482 & TRN \\
\hline CHEMBL1589591 & 688239 & 5.4862 & 5.5879 & TST \\
\hline CHEMBL1398561 & 688239 & 6.3863 & 5.4838 & TRN \\
\hline CHEMBL1338185 & 688239 & 6.1862 & 5.5271 & TST \\
\hline CHEMBL1607484 & 688239 & 4.5362 & 5.5682 & TRN \\
\hline CHEMBL1465890 & 688239 & 6.8861 & 5.4318 & TRN \\
\hline CHEMBL1346557 & 688239 & 4.7362 & 5.4885 & TRN \\
\hline CHEMBL1339669 & 688239 & 6.1862 & 5.3039 & TRN \\
\hline CHEMBL3195136 & 688239 & 4.4862 & 5.4312 & TRN \\
\hline CHEMBL1556787 & 688239 & 4.6862 & 5.4595 & TRN \\
\hline CHEMBL 3211048 & 688239 & 5.5862 & 5.3386 & TRN \\
\hline CHEMBL1354947 & 688239 & 6.7862 & 5.5198 & TRN \\
\hline CHEMBL1422877 & 688239 & 5.3862 & 5.5067 & TST \\
\hline CHEMBL1416459 & 688239 & 4.7362 & 5.6545 & TRN \\
\hline CHEMBL1529364 & 688239 & 4.5362 & 5.5722 & TRN \\
\hline CHEMBL1312196 & 688239 & 7.2366 & 5.4674 & TRN \\
\hline CHEMBL1418924 & 688239 & 7.2366 & 5.4449 & TRN \\
\hline CHEMBL1375761 & 688239 & 4.8362 & 5.5264 & TST \\
\hline CHEMBL1349622 & 688239 & 4.5362 & 5.5957 & TRN \\
\hline CHEMBL1309987 & 688239 & 5.1862 & 5.4358 & TST \\
\hline CHEMBL1301709 & 688239 & 4.5362 & 5.4261 & TST \\
\hline CHEMBL1583146 & 688239 & 4.5362 & 5.6981 & TRN \\
\hline CHEMBL1604593 & 688239 & 6.2862 & 5.5197 & TRN \\
\hline CHEMBL1503587 & 688239 & 4.7862 & 5.5527 & TRN \\
\hline CHEMBL1305915 & 688239 & 6.2862 & 5.42200 & 0000000001 \\
\hline CHEMBL1594709 & 688239 & 6.8861 & 5.6401 & TRN \\
\hline CHEMBL1382149 & 688239 & 5.1862 & 5.4233 & TRN \\
\hline CHEMBL1403492 & 688239 & 5.1362 & 5.4495 & TRN \\
\hline CHEMBL1548473 & 688239 & 6.2862 & 5.4666 & TST \\
\hline CHEMBL1531643 & 688239 & 6.5363 & 5.4662 & TRN \\
\hline CHEMBL1598131 & 688239 & 6.4362 & 5.4508 & TRN \\
\hline CHEMBL1395515 & 688239 & 5.0362 & 5.6463 & TRN \\
\hline
\end{tabular}


Supplemental Table S2.txt

\begin{tabular}{|c|c|c|c|c|}
\hline 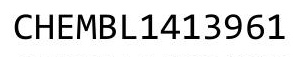 & & & & \\
\hline HEMBL1599386 & 38239 & 862 & 4555 & \\
\hline AEMBL1551552 & 239 & & 826 & \\
\hline & 39 & & & \\
\hline IEMBL14 & 39 & & & \\
\hline AEMBL1967273 & 88239 & 861 & 149 & \\
\hline AEMBL1323139 & 88239 & 862 & .3006 & \\
\hline AEMBL1313932 & & & & \\
\hline IEMBL1300521 & 39 & 362 & & \\
\hline IEMBL1433182 & & & & \\
\hline AEMBL3195616 & 239 & 362 & 982 & \\
\hline AEMBL1354624 & & 362 & & \\
\hline AEMBL1567443 & & & & \\
\hline HEMBL140 & & & & \\
\hline HEMBL132 & & & & \\
\hline AEMBL1393583 & & 362 & & \\
\hline AEMBL1402225 & & 6 & & \\
\hline AEMBL134; & & & & \\
\hline HEMBL 319 & & & & \\
\hline AEMBL142 & & & & \\
\hline HEMBL149 & & 61 & & \\
\hline AEMBL1484311 & & & & \\
\hline HEMBL1399 & & & & \\
\hline AFMRI 132 & & & & \\
\hline 27 & & & & \\
\hline AEMBL1513945 & & & & \\
\hline IEMBL1371346 & & & & \\
\hline AEMBL196 & & & & \\
\hline IEMPI 15 & & & & \\
\hline 65 & & & & \\
\hline AEMBL1994837 & & & & \\
\hline HEMBL1463410 & & & & \\
\hline & & & & \\
\hline$\theta$ & & & & \\
\hline & & & & \\
\hline AEMBL1601889 & & & & \\
\hline AEMBL1377302 & & & & \\
\hline & & & & \\
\hline 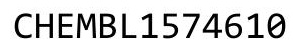 & & & & \\
\hline HEMBL1609790 & & & & RN \\
\hline AEMBL1389207 & & & & \\
\hline HEMBL 144 & & & & \\
\hline 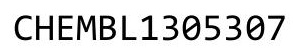 & & & & \\
\hline HEMBL1373712 & & & & \\
\hline AEMBL1536051 & & & & RN \\
\hline IEMBL1591618 & & & 22 & \\
\hline 1405259 & & & & \\
\hline HEMBL13734 & & & & \\
\hline
\end{tabular}

Page 1008 
Supplemental Table S2.txt

\begin{tabular}{|c|c|c|c|c|}
\hline CHEMBL1365632 & 688239 & 5.8362 & 5.4792 & TST \\
\hline CHEMBL1567083 & 688239 & 5.7362 & 5.5641 & TST \\
\hline CHEMBL1428839 & 688239 & 7.0862 & 5.5084 & TRN \\
\hline CHEMBL1419269 & 688239 & 6.7862 & 5.501 & TRN \\
\hline CHEMBL62270 & 688239 & 5.2362 & 5.5181 & TRN \\
\hline CHEMBL1365897 & 688239 & 6.2362 & 5.4156 & TRN \\
\hline CHEMBL1469216 & 688239 & 4.5862 & 5.3008 & TRN \\
\hline CHEMBL1352813 & 688239 & 5.1862 & 5.5002 & TRN \\
\hline CHEMBL1435040 & 688239 & 4.5362 & 5.4169 & TRN \\
\hline CHEMBL1388002 & 688239 & 4.8862 & 5.3988 & TRN \\
\hline CHEMBL1348382 & 688239 & 6.1362 & 5.4574 & TRN \\
\hline CHEMBL1460297 & 688239 & 4.5362 & 5.4197 & TRN \\
\hline CHEMBL1430260 & 688239 & 5.3862 & 5.486006 & 000000001 \\
\hline CHEMBL1334953 & 688239 & 6.9863 & 5.6846 & TRN \\
\hline CHEMBL1524935 & 688239 & 5.3362 & 5.5624 & TRN \\
\hline CHEMBL1466291 & 688239 & 4.9862 & 5.5012 & TST \\
\hline CHEMBL1559739 & 688239 & 5.3862 & 5.6004 & TRN \\
\hline CHEMBL1453497 & 688239 & 4.5362 & 5.3894 & TRN \\
\hline CHEMBL1483544 & 688239 & 5.6362 & 5.4135 & TRN \\
\hline CHEMBL1344451 & 688239 & 5.3362 & 5.4306 & TST \\
\hline CHEMBL1308815 & 688239 & 6.8861 & 5.4733 & TRN \\
\hline CHEMBL1416307 & 688239 & 6.5363 & 5.5215 & TRN \\
\hline CHEMBL1412857 & 688239 & 4.9362 & 5.6896 & TRN \\
\hline CHEMBL1338194 & 688239 & 4.9862 & 5.5776 & TRN \\
\hline CHEMBL1409582 & 688239 & 4.7362 & 5.4828 & TST \\
\hline CHEMBL1540487 & 688239 & 4.5362 & 5.3443 & TST \\
\hline CHEMBL1503538 & 688239 & 6.0862 & 5.6564 & TRN \\
\hline CHEMBL1545178 & 688239 & 4.7362 & 5.5828 & TRN \\
\hline CHEMBL1441049 & 688239 & 4.7862 & 5.3896 & TRN \\
\hline CHEMBL1387417 & 688239 & 4.5362 & 5.5353 & TST \\
\hline CHEMBL1460899 & 688239 & 5.9362 & 5.5168 & TRN \\
\hline CHEMBL1597671 & 688239 & 5.2362 & 5.3808 & TRN \\
\hline CHEMBL3192479 & 688239 & 4.4862 & 5.3413 & TRN \\
\hline CHEMBL1465268 & 688239 & 5.6862 & 5.5968 & TRN \\
\hline CHEMBL1548683 & 688239 & 5.1862 & 5.5249 & TST \\
\hline CHEMBL1543900 & 688239 & 6.8362 & 5.4311 & TST \\
\hline CHEMBL1438921 & 688239 & 5.5362 & 5.4627 & TRN \\
\hline CHEMBL1475321 & 688239 & 5.4862 & 5.4946 & TRN \\
\hline CHEMBL1467583 & 688239 & 5.9862 & 5.4325 & TRN \\
\hline CHEMBL1550313 & 688239 & 4.6362 & 5.4176 & TRN \\
\hline CHEMBL1546374 & 688239 & 5.6362 & 5.407 & TRN \\
\hline CHEMBL1595655 & 688239 & 5.1862 & 5.5208 & TRN \\
\hline CHEMBL1407488 & 688239 & 4.5362 & 5.4545 & TST \\
\hline CHEMBL1569585 & 688239 & 4.6862 & 5.3552 & TRN \\
\hline CHEMBL1392951 & 688239 & 4.9862 & 5.5161 & TRN \\
\hline CHEMBL1343181 & 688239 & 6.6362 & 5.5477 & TST \\
\hline CHEMBL1376760 & 688239 & 4.6862 & 5.5102 & TST \\
\hline CHEMBL1517504 & 688239 & 4.5362 & 5.4933 & TRN \\
\hline
\end{tabular}

Page 1009 
Supplemental Table S2.txt

\begin{tabular}{|c|c|c|c|c|}
\hline CHEMBL1308194 & 688239 & 6.0862 & 5.3713 & TRN \\
\hline CHEMBL1546458 & 688239 & 6.0862 & 5.5759 & TRN \\
\hline CHEMBL1518959 & 688239 & 5.3862 & 5.4319 & TRN \\
\hline CHEMBL1413195 & 688239 & 5.8362 & 5.5356 & TRN \\
\hline CHEMBL1440711 & 688239 & 6.8861 & 5.5144 & TRN \\
\hline CHEMBL1440614 & 688239 & 6.1362 & 5.3798 & TRN \\
\hline CHEMBL1519407 & 688239 & 5.6362 & 5.4228 & TST \\
\hline CHEMBL1577789 & 688239 & 5.8362 & 5.5567 & TRN \\
\hline CHEMBL1362299 & 688239 & 6.8861 & 5.4909 & TRN \\
\hline CHEMBL1425831 & 688239 & 6.0862 & 5.4559 & TST \\
\hline CHEMBL1474671 & 688239 & 5.7362 & 5.5303 & TRN \\
\hline CHEMBL1460630 & 688239 & 5.7362 & 5.6089 & TST \\
\hline CHEMBL1608697 & 688239 & 6.0862 & 5.587006 & 000000001 \\
\hline CHEMBL1598293 & 688239 & 4.4862 & 5.3669 & TRN \\
\hline CHEMBL1608676 & 688239 & 6.1362 & 5.5413 & TRN \\
\hline CHEMBL1513830 & 688239 & 5.1862 & 5.4585 & TRN \\
\hline CHEMBL1603049 & 688239 & 4.7862 & 5.5166 & TST \\
\hline CHEMBL1430205 & 688239 & 4.5862 & 5.3744 & TRN \\
\hline CHEMBL1606084 & 688239 & 4.7362 & 5.4533 & TRN \\
\hline CHEMBL1533026 & 688239 & 5.9362 & 5.4589 & TRN \\
\hline CHEMBL1578492 & 688239 & 5.9362 & 5.3704 & TRN \\
\hline CHEMBL3209146 & 688239 & 5.6362 & 5.4515 & TST \\
\hline CHEMBL1366441 & 688239 & 4.7362 & 5.4757 & TRN \\
\hline CHEMBL1307345 & 688239 & 4.5362 & 5.5318 & TRN \\
\hline CHEMBL601319 & 688239 & 6.1862 & 5.5503 & TST \\
\hline CHEMBL1512902 & 688239 & 5.1862 & 5.4579 & TRN \\
\hline CHEMBL1312557 & 688239 & 5.2362 & 5.4562 & TRN \\
\hline CHEMBL 3210067 & 688239 & 4.5362 & 5.2563 & TST \\
\hline CHEMBL1386663 & 688239 & 4.5362 & 5.3722 & TST \\
\hline CHEMBL3211229 & 688239 & 5.9362 & 5.3896 & TRN \\
\hline CHEMBL1502984 & 688239 & 4.5362 & 5.553999 & 999999999 \\
\hline CHEMBL1325449 & 688239 & 6.8861 & 5.386 & TST \\
\hline CHEMBL1473505 & 688239 & 6.1862 & 5.4317 & TST \\
\hline CHEMBL1417492 & 688239 & 4.7862 & 5.5436 & TRN \\
\hline CHEMBL 3197846 & 688239 & 6.1362 & 5.4998 & TST \\
\hline CHEMBL1585237 & 688239 & 4.5362 & 5.5272 & TRN \\
\hline CHEMBL1380259 & 688239 & 5.1862 & 5.4428 & TST \\
\hline CHEMBL1399617 & 688239 & 6.9363 & 5.5837 & TRN \\
\hline CHEMBL1606156 & 688239 & 4.5362 & 5.5739 & TRN \\
\hline CHEMBL1381146 & 688239 & 6.1362 & 5.4734 & TRN \\
\hline CHEMBL1365864 & 688239 & 4.9362 & 5.4872 & TST \\
\hline CHEMBL1391483 & 688239 & 5.6862 & 5.5513 & TRN \\
\hline CHEMBL1523296 & 688239 & 4.5362 & 5.5813 & TRN \\
\hline CHEMBL1438879 & 688239 & 4.7862 & 5.6325 & TRN \\
\hline CHEMBL1443475 & 688239 & 5.8862 & 5.3975 & TRN \\
\hline CHEMBL1555333 & 688239 & 5.4862 & 5.6066 & TRN \\
\hline CHEMBL1602780 & 688239 & 7.0362 & 5.4377 & TRN \\
\hline CHEMBL1603638 & 688239 & 5.3862 & 5.4372 & TRN \\
\hline
\end{tabular}




\begin{tabular}{|c|c|c|c|c|c|}
\hline \multirow[b]{2}{*}{ CHEMBL1333099 } & & \multicolumn{4}{|c|}{ Supplemental Table s2.txt } \\
\hline & 688239 & 4.5362 & 5.54899 & 99999999995 & TRN \\
\hline CHEMBL1538593 & 688239 & 5.6862 & 5.4676 & TST & \\
\hline CHEMBL1548120 & 688239 & 5.3362 & 5.5436 & TRN & \\
\hline CHEMBL 1428960 & 688239 & 5.1862 & 5.4835 & TST & \\
\hline CHEMBL1400297 & 688239 & 6.9863 & 5.541 & TRN & \\
\hline CHEMBL1981675 & 688239 & 4.9362 & 5.5813 & TST & \\
\hline CHEMBL1411705 & 688239 & 4.6362 & 5.4785 & TRN & \\
\hline CHEMBL1425267 & 688239 & 6.3362 & 5.5915 & TRN & \\
\hline CHEMBL1494890 & 688239 & 4.5362 & 5.5811 & TRN & \\
\hline CHEMBL1494483 & 688239 & 4.6862 & 5.4081 & TRN & \\
\hline CHEMBL1598522 & 688239 & 5.3862 & 5.5343 & TRN & \\
\hline CHEMBL1308270 & 688239 & 4.8862 & 5.6906 & TRN & \\
\hline CHEMBL1459180 & 688239 & 5.1862 & 5.5272 & TRN & \\
\hline CHEMBL1587711 & 688239 & 6.9863 & 5.4817 & TRN & \\
\hline CHEMBL1408746 & 688239 & 5.4862 & 5.6285 & TRN & \\
\hline CHEMBL1443673 & 688239 & 6.2362 & 5.4736 & TRN & \\
\hline CHEMBL1357737 & 688239 & 6.8861 & 5.5764 & TRN & \\
\hline CHEMBL1564516 & 688239 & 7.6861 & 5.5379 & TST & \\
\hline CHEMBL1494466 & 688239 & 4.5362 & 5.4272 & TRN & \\
\hline CHEMBL1542892 & 688239 & 4.7362 & 5.5135 & TRN & \\
\hline CHEMBL1429172 & 688239 & 4.7362 & 5.4534 & TRN & \\
\hline CHEMBL1488075 & 688239 & 6.2862 & 5.4714 & TST & \\
\hline CHEMBL1322608 & 688239 & 4.5862 & 5.4592 & TST & \\
\hline CHEMBL1306115 & 688239 & 8.3372 & 5.5484 & TST & \\
\hline CHEMBL1612715 & 688239 & 4.7862 & 5.4823 & TRN & \\
\hline CHEMBL1390776 & 688239 & 6.2362 & 5.6197 & TRN & \\
\hline CHEMBL1496996 & 688239 & 5.1862 & 5.5825 & TST & \\
\hline CHEMBL1499386 & 688239 & 5.1862 & 5.5977 & TST & \\
\hline CHEMBL1463743 & 688239 & 4.4862 & 5.4581 & TST & \\
\hline CHEMBL1579939 & 688239 & 4.5362 & 5.5003 & TRN & \\
\hline CHEMBL1312200 & 688239 & 6.1862 & 5.4778 & TRN & \\
\hline CHEMBL1599761 & 688239 & 4.9362 & 5.2519 & TRN & \\
\hline CHEMBL1390280 & 688239 & 4.7862 & 5.49299 & 9999999999 & TRN \\
\hline CHEMBL1336441 & 688239 & 5.9862 & 5.4942 & TRN & \\
\hline CHEMBL1598813 & 688239 & 5.0862 & 5.4314 & TRN & \\
\hline CHEMBL1554905 & 688239 & 4.9862 & 5.3915 & TRN & \\
\hline CHEMBL1405575 & 688239 & 5.8862 & 5.5684 & TRN & \\
\hline CHEMBL1403915 & 688239 & 4.5362 & 5.4203 & TRN & \\
\hline CHEMBL1315365 & 688239 & 4.7362 & 5.4104 & TRN & \\
\hline CHEMBL1514948 & 688239 & 5.1362 & 5.4078 & TRN & \\
\hline CHEMBL1568643 & 688239 & 6.2862 & 5.4027 & TRN & \\
\hline CHEMBL1469761 & 688239 & 4.8362 & 5.3645 & TRN & \\
\hline CHEMBL1460492 & 688239 & 4.4862 & 5.5429 & TRN & \\
\hline CHEMBL 2005761 & 688239 & 4.7862 & 5.5019 & TRN & \\
\hline CHEMBL1546738 & 688239 & 6.0862 & 5.4125 & TRN & \\
\hline CHEMBL1346351 & 688239 & 4.5362 & 5.6659 & TRN & \\
\hline CHEMBL1519126 & 688239 & 4.7362 & 5.3999 & TST & \\
\hline CHEMBL1427731 & 688239 & 5.8862 & 5.5575 & TRN & \\
\hline
\end{tabular}




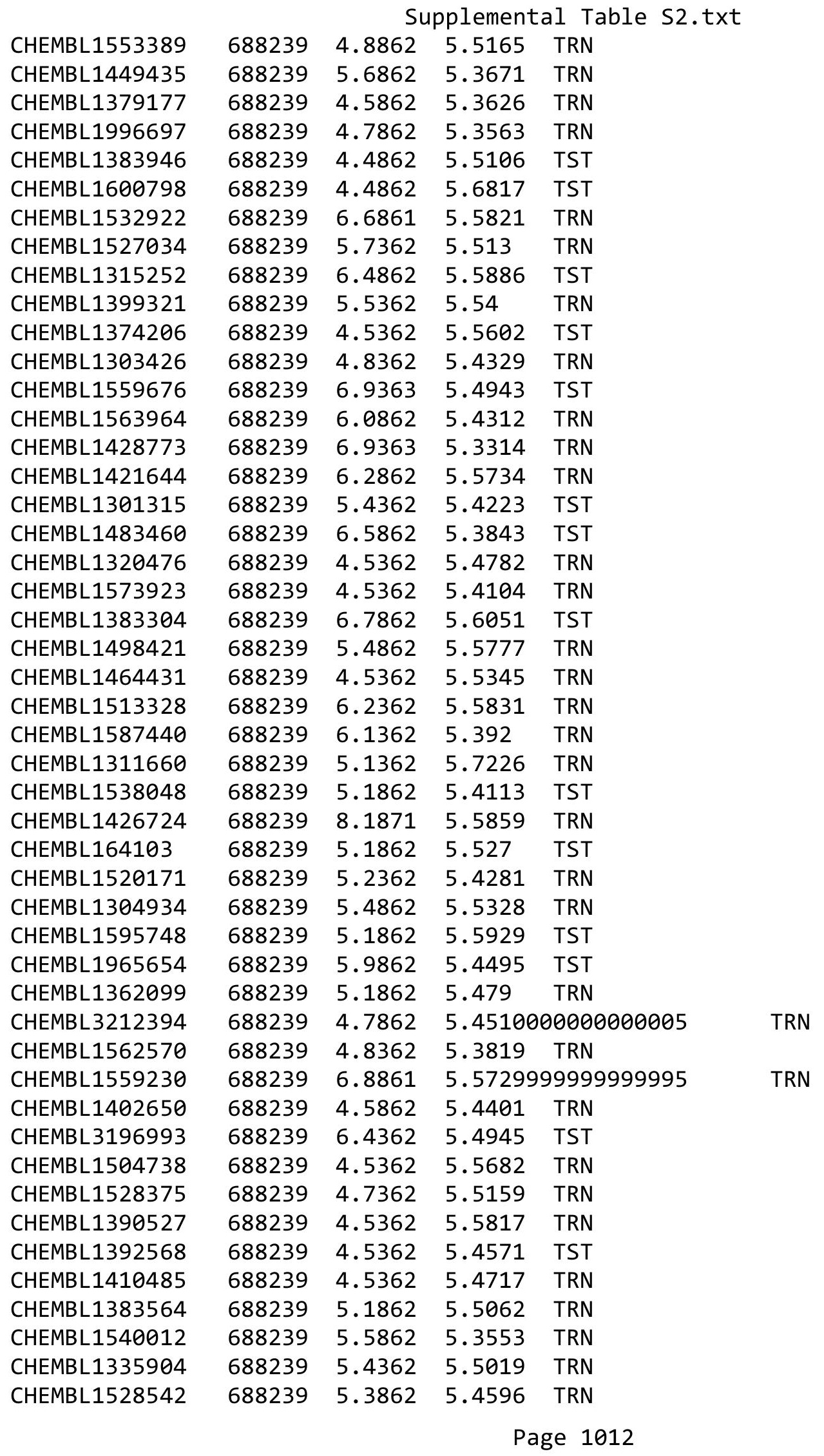




\begin{tabular}{|c|c|c|c|c|c|}
\hline \multicolumn{6}{|c|}{ Supplemental Table S } \\
\hline CHEMBL1485085 & 688239 & 5.4362 & 5.5629 & TRN & \\
\hline CHEMBL1602295 & 688239 & 8.3372 & 5.5618 & TRN & \\
\hline CHEMBL1410940 & 688239 & 4.6362 & 5.6493 & TRN & \\
\hline CHEMBL1407579 & 688239 & 5.5362 & 5.5769 & TRN & \\
\hline CHEMBL1373236 & 688239 & 7.0862 & 5.4352 & TRN & \\
\hline CHEMBL1492398 & 688239 & 5.5362 & 5.4947 & TRN & \\
\hline CHEMBL1479509 & 688239 & 5.1862 & 5.4791 & TRN & \\
\hline CHEMBL1351724 & 688239 & 4.7362 & 5.4458 & TRN & \\
\hline CHEMBL1379320 & 688239 & 5.8362 & 5.4265 & TRN & \\
\hline CHEMBL1347334 & 688239 & 4.7362 & 5.4093 & TRN & \\
\hline CHEMBL1384495 & 688239 & 6.1362 & 5.5103 & TRN & \\
\hline CHEMBL1506105 & 688239 & 5.6862 & 5.5786 & TST & \\
\hline CHEMBL1302478 & 688239 & 4.8362 & 5.4695 & TST & \\
\hline CHEMBL1460676 & 688239 & 4.8862 & 5.3794 & TRN & \\
\hline CHEMBL1416263 & 688239 & 4.5362 & 5.51 & TRN & \\
\hline CHEMBL1979756 & 688239 & 4.4862 & 5.2855 & TRN & \\
\hline CHEMBL1552894 & 688239 & 5.1862 & 5.421 & TRN & \\
\hline CHEMBL1586595 & 688239 & 4.4862 & 5.379 & TRN & \\
\hline CHEMBL1496465 & 688239 & 5.0362 & 5.6075 & TRN & \\
\hline CHEMBL1535440 & 688239 & 4.5362 & 5.4134 & TRN & \\
\hline CHEMBL1577314 & 688239 & 5.9362 & 5.3857 & TRN & \\
\hline CHEMBL1462656 & 688239 & 4.5862 & 5.4569 & TST & \\
\hline CHEMBL1510451 & 688239 & 4.6862 & 5.4976 & TST & \\
\hline CHEMBL3209079 & 688239 & 5.1362 & 5.3576 & TST & \\
\hline CHEMBL1545120 & 688239 & 6.8362 & 5.6236 & TRN & \\
\hline CHEMBL1459086 & 688239 & 4.7362 & 5.4643 & TRN & \\
\hline CHEMBL1522845 & 688239 & 5.3862 & 5.504 & TRN & \\
\hline CHEMBL1597509 & 688239 & 4.9862 & 5.4227 & TRN & \\
\hline CHEMBL1565230 & 688239 & 5.1862 & 5.4991 & TRN & \\
\hline CHEMBL1518407 & 688239 & 4.8362 & 5.7058 & TRN & \\
\hline CHEMBL1544413 & 688239 & 6.7862 & 5.4749 & TRN & \\
\hline CHEMBL1520505 & 688239 & 4.5862 & 5.4066 & TRN & \\
\hline CHEMBL1482857 & 688239 & 5.1862 & 5.4922 & TRN & \\
\hline CHEMBL1361251 & 688239 & 4.8362 & 5.5788 & TRN & \\
\hline CHEMBL1561530 & 688239 & 6.1862 & 5.3829 & TST & \\
\hline CHEMBL1566084 & 688239 & 4.5362 & 5.42399 & 99999999995 & TRN \\
\hline CHEMBL1349781 & 688239 & 8.3872 & 5.4542 & TRN & \\
\hline CHEMBL1410083 & 688239 & 4.5362 & 5.4299 & TST & \\
\hline CHEMBL1350984 & 688239 & 5.3362 & 5.4718 & TRN & \\
\hline CHEMBL1369326 & 688239 & 5.1862 & 5.4817 & TST & \\
\hline CHEMBL1464053 & 688239 & 5.1862 & 5.6904 & TRN & \\
\hline CHEMBL1320557 & 688239 & 5.9362 & 5.4651 & TST & \\
\hline CHEMBL1419134 & 688239 & 5.7362 & 5.5839 & TST & \\
\hline CHEMBL1344409 & 688239 & 6.2862 & 5.5003 & TRN & \\
\hline CHEMBL1488539 & 688239 & 5.2362 & 5.5445 & TRN & \\
\hline CHEMBL1547198 & 688239 & 5.3362 & 5.2775 & TST & \\
\hline CHEMBL1408070 & 688239 & 6.9863 & 5.5691 & TRN & \\
\hline CHEMBL1565960 & 688239 & 4.8362 & 5.4629 & TRN & \\
\hline
\end{tabular}


Supplemental Table S2.txt

\begin{tabular}{|c|c|c|c|c|c|}
\hline CHEMBL1376090 & 688239 & 4.5362 & 5.655 & TRN & \\
\hline CHEMBL1611965 & 688239 & 4.7362 & 5.3515 & TRN & \\
\hline CHEMBL1487974 & 688239 & 6.3863 & 5.4449 & TRN & \\
\hline CHEMBL1522764 & 688239 & 5.1862 & 5.5321 & TST & \\
\hline CHEMBL1414378 & 688239 & 5.3862 & 5.5488 & TRN & \\
\hline CHEMBL1532416 & 688239 & 5.0862 & 5.5042 & TRN & \\
\hline CHEMBL1514319 & 688239 & 6.8861 & 5.5144 & TRN & \\
\hline CHEMBL1545344 & 688239 & 5.7862 & 5.6628 & TRN & \\
\hline CHEMBL3209198 & 688239 & 5.2362 & 5.5118 & TST & \\
\hline CHEMBL1383034 & 688239 & 6.9363 & 5.5322 & TST & \\
\hline CHEMBL1555262 & 688239 & 4.9362 & 5.4702 & TRN & \\
\hline CHEMBL474933 & 688239 & 4.7862 & 5.431 & TST & \\
\hline CHEMBL1998940 & 688239 & 5.4862 & 5.3628 & TRN & \\
\hline CHEMBL1353976 & 688239 & 6.0862 & 5.6067 & TRN & \\
\hline CHEMBL 3196020 & 688239 & 5.3362 & 5.3712 & TRN & \\
\hline CHEMBL1378910 & 688239 & 6.3362 & 5.4665 & TRN & \\
\hline CHEMBL1493383 & 688239 & 4.8362 & 5.5575 & TRN & \\
\hline CHEMBL1523842 & 688239 & 4.6862 & 5.3136 & TST & \\
\hline CHEMBL1426073 & 688239 & 4.6862 & 5.5979 & TRN & \\
\hline CHEMBL1398277 & 688239 & 5.3862 & 5.46399 & 99999999995 & TRN \\
\hline CHEMBL1534247 & 688239 & 5.7862 & 5.5522 & TRN & \\
\hline CHEMBL1458732 & 688239 & 4.4862 & 5.5961 & TRN & \\
\hline CHEMBL1484212 & 688239 & 6.1862 & 5.5111 & TST & \\
\hline CHEMBL3192431 & 688239 & 4.7862 & 5.3983 & TRN & \\
\hline CHEMBL1378547 & 688239 & 6.6362 & 5.6 & TRN & \\
\hline CHEMBL1408305 & 688239 & 4.7362 & 5.5366 & TRN & \\
\hline CHEMBL1464540 & 688239 & 4.5362 & 5.4181 & TST & \\
\hline CHEMBL1423292 & 688239 & 6.6362 & 5.5083 & TRN & \\
\hline CHEMBL1425815 & 688239 & 4.5362 & 5.3424 & TRN & \\
\hline CHEMBL1560156 & 688239 & 4.7362 & 5.3769 & TST & \\
\hline CHEMBL1548332 & 688239 & 6.6861 & 5.4386 & TST & \\
\hline CHEMBL1319964 & 688239 & 6.2362 & 5.4587 & TRN & \\
\hline CHEMBL1439407 & 688239 & 5.7362 & 5.5864 & TRN & \\
\hline CHEMBL1568139 & 688239 & 5.3362 & 5.4191 & TRN & \\
\hline CHEMBL433680 & 688239 & 7.2865 & 5.5666 & TST & \\
\hline CHEMBL1558954 & 688239 & 4.5362 & 5.434 & TRN & \\
\hline CHEMBL1375783 & 688239 & 6.0862 & 5.5543 & TRN & \\
\hline CHEMBL1434274 & 688239 & 4.5362 & 5.5358 & TRN & \\
\hline CHEMBL1341251 & 688239 & 4.4862 & 5.3887 & TRN & \\
\hline CHEMBL1485264 & 688239 & 4.9862 & 5.5093 & TRN & \\
\hline CHEMBL1501399 & 688239 & 4.4862 & 5.6146 & TST & \\
\hline CHEMBL1512829 & 688239 & 4.9862 & 5.5755 & TRN & \\
\hline CHEMBL1450728 & 688239 & 5.1862 & 5.3672 & TRN & \\
\hline CHEMBL1324266 & 688239 & 5.8362 & 5.4088 & TST & \\
\hline CHEMBL1413439 & 688239 & 4.4862 & 5.5264 & TST & \\
\hline CHEMBL1423827 & 688239 & 5.1862 & 5.6142 & TRN & \\
\hline CHEMBL1484757 & 688239 & 6.7862 & 5.54299 & 9999999999 & TST \\
\hline CHEMBL1417867 & 688239 & 5.5862 & 5.4017 & TRN & \\
\hline
\end{tabular}


Supplemental Table S2.txt

\begin{tabular}{|c|c|c|c|c|}
\hline 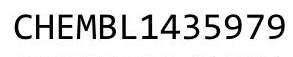 & & & & \\
\hline HEMBL1300620 & 38239 & 862 & 612 & \\
\hline AEMBL1454915 & 239 & 362 & 734 & \\
\hline AEMBL1518177 & 39 & 872 & & \\
\hline IEMBL13 & 39 & 362 & & \\
\hline AEMBL1312959 & 88239 & 862 & 703 & \\
\hline AEMBL1579133 & 88239 & 362 & 5764 & \\
\hline AEMBL1483576 & & & & \\
\hline EMBL14 & 39 & 362 & & \\
\hline IEMBL1604814 & & & & \\
\hline AEMBL1543664 & 39 & 862 & .72 & \\
\hline HEMBL1580999 & & 862 & & \\
\hline AEMBL1362229 & & 863 & & \\
\hline HEMBL1322124 & & 862 & & \\
\hline HEMBL1484324 & & 362 & & \\
\hline AEMBL1441062 & & 362 & & \\
\hline AEMBL1557474 & & 862 & & \\
\hline EMMBL1412340 & & 62 & & \\
\hline AEMBL1411878 & & 62 & & \\
\hline AEMBL1377169 & & & & \\
\hline AEMBL1490167 & & 362 & & \\
\hline AEMBL1348883 & & 62 & & \\
\hline AEMBL1327838 & & & & \\
\hline AEMBL1305099 & & & & \\
\hline 1395364 & & & & \\
\hline AEMBL1343795 & & 62 & & \\
\hline IEMBL1579787 & & & & \\
\hline IEMBL1444158 & & & & \\
\hline AEMBL1519162 & & & & \\
\hline 48 & & 62 & & \\
\hline AEMBL1586445 & & & & \\
\hline HEMBL1389598 & & & & \\
\hline & & & & \\
\hline 3 & & & & \\
\hline AEMBL1553375 & & & & RN \\
\hline AEMBL1576737 & & & & $S$ \\
\hline AEMBL3210136 & & 862 & & ST \\
\hline 38 & & & & \\
\hline 1381810 & & & & $\mathrm{RN}$ \\
\hline HEMBL1431776 & & & & $\mathrm{RI}$ \\
\hline AEMBL1423785 & & 62 & & $R$ \\
\hline AEMBL1525430 & & 52 & & s \\
\hline & & & & \\
\hline HEMBL1601444 & & & & r \\
\hline AEMBL1327202 & & & & ST \\
\hline MBL1385559 & & 862 & 45 & TR \\
\hline MBL1352836 & & & & \\
\hline HEMBL155736 & & & & \\
\hline
\end{tabular}

Page 1015 
Supplemental Table S2.txt

\begin{tabular}{|c|c|c|c|c|c|c|}
\hline CHEMBL1559991 & 688239 & 4.5362 & 5.6873 & TST & & \\
\hline CHEMBL1552459 & 688239 & 5.4862 & 5.5332 & TST & & \\
\hline CHEMBL1494758 & 688239 & 4.5362 & 5.4813 & TRN & & \\
\hline CHEMBL3193975 & 688239 & 7.8356 & 5.3288 & TRN & & \\
\hline CHEMBL1589145 & 688239 & 4.4862 & 5.5062 & TRN & & \\
\hline CHEMBL1604957 & 688239 & 4.5362 & 5.4159 & TRN & & \\
\hline CHEMBL1594119 & 688239 & 5.6862 & 5.5418 & TRN & & \\
\hline CHEMBL1545949 & 688239 & 6.3362 & 5.4818 & TRN & & \\
\hline CHEMBL1596298 & 688239 & 6.5363 & 5.5735 & TRN & & \\
\hline CHEMBL1515145 & 688239 & 4.7362 & 5.407 & TRN & & \\
\hline CHEMBL1494589 & 688239 & 4.6862 & 5.4824 & TRN & & \\
\hline CHEMBL1532027 & 688239 & 6.4862 & 5.6183 & TRN & & \\
\hline CHEMBL1582561 & 688239 & 6.9863 & 5.3243 & TRN & & \\
\hline CHEMBL1561943 & 688239 & 6.9863 & 5.6652 & TRN & & \\
\hline CHEMBL1316594 & 688239 & 5.2862 & 5.4729 & TRN & & \\
\hline CHEMBL1433015 & 688239 & 5.2362 & 5.3549 & TST & & \\
\hline CHEMBL1555683 & 688239 & 5.1362 & 5.4799 & TST & & \\
\hline CHEMBL1544183 & 688239 & 5.6362 & 5.4707 & TRN & & \\
\hline CHEMBL1426124 & 688239 & 6.3863 & 5.4119 & TRN & & \\
\hline CHEMBL1358746 & 688239 & 4.5362 & 5.5424 & TRN & & \\
\hline CHEMBL1380306 & 688239 & 5.1862 & 5.4183 & TST & & \\
\hline CHEMBL1396393 & 688239 & 8.28399 & 99999999 & 99 & 5.473 & TST \\
\hline CHEMBL1604510 & 688239 & 4.8862 & 5.5124 & TRN & & \\
\hline CHEMBL1450458 & 688239 & 5.3862 & 5.4624 & TRN & & \\
\hline CHEMBL1550786 & 688239 & 6.3863 & 5.5091 & TRN & & \\
\hline CHEMBL1381505 & 688239 & 5.4862 & 5.3969 & TRN & & \\
\hline CHEMBL1306430 & 688239 & 4.5362 & 5.5296 & TRN & & \\
\hline CHEMBL1341961 & 688239 & 4.8362 & 5.4017 & TRN & & \\
\hline CHEMBL1566681 & 688239 & 5.5862 & 5.5454 & TRN & & \\
\hline CHEMBL1463594 & 688239 & 5.1362 & 5.4272 & TST & & \\
\hline CHEMBL1495096 & 688239 & 5.1862 & 5.553 & TST & & \\
\hline CHEMBL1609997 & 688239 & 6.8362 & 5.6666 & TST & & \\
\hline CHEMBL1390577 & 688239 & 5.3862 & 5.392 & TRN & & \\
\hline CHEMBL1361870 & 688239 & 4.7362 & 5.3641 & TST & & \\
\hline CHEMBL1460565 & 688239 & 8.2366 & 5.4487 & TRN & & \\
\hline CHEMBL1453901 & 688239 & 5.1862 & 5.5274 & TRN & & \\
\hline CHEMBL1400415 & 688239 & 5.0862 & 5.5363 & TRN & & \\
\hline CHEMBL1527624 & 688239 & 4.6862 & 5.3652 & TST & & \\
\hline CHEMBL1337670 & 688239 & 6.4362 & 5.5245 & TST & & \\
\hline CHEMBL1480375 & 688239 & 5.1862 & 5.2995 & TRN & & \\
\hline CHEMBL1440337 & 688239 & 7.1361 & 5.4916 & TRN & & \\
\hline CHEMBL1490790 & 688239 & 5.1862 & 5.4593 & TRN & & \\
\hline CHEMBL1448985 & 688239 & 4.5362 & 5.5288 & TRN & & \\
\hline CHEMBL1596399 & 688239 & 5.1862 & 5.4899 & TST & & \\
\hline CHEMBL1321649 & 688239 & 4.6862 & 5.5326 & TRN & & \\
\hline CHEMBL1366193 & 688239 & 6.0362 & 5.4525 & TRN & & \\
\hline CHEMBL1325585 & 688239 & 6.2362 & 5.5463 & TST & & \\
\hline CHEMBL1499922 & 688239 & 5.1362 & 5.5344 & TRN & & \\
\hline
\end{tabular}


Supplemental Table S2.txt

\begin{tabular}{|c|c|c|c|c|c|}
\hline CHEMBL1363232 & 688239 & 6.1362 & 5.6966 & TRN & \\
\hline CHEMBL1312044 & 688239 & 6.9863 & 5.615 & TRN & \\
\hline CHEMBL1404273 & 688239 & 4.4862 & 5.4417 & TRN & \\
\hline CHEMBL1468291 & 688239 & 6.8861 & 5.7503 & TRN & \\
\hline CHEMBL1355028 & 688239 & 5.6862 & 5.3367 & TRN & \\
\hline CHEMBL1347390 & 688239 & 4.5362 & 5.3799 & TRN & \\
\hline CHEMBL1365432 & 688239 & 6.2362 & 5.4527 & TST & \\
\hline CHEMBL1608853 & 688239 & 5.4362 & 5.4483 & TRN & \\
\hline CHEMBL1604789 & 688239 & 6.2362 & 5.4379 & TRN & \\
\hline CHEMBL1472399 & 688239 & 5.7862 & 5.5044 & TST & \\
\hline CHEMBL1442737 & 688239 & 6.7862 & 5.6369 & TRN & \\
\hline CHEMBL1532907 & 688239 & 4.6862 & 5.5761 & TRN & \\
\hline CHEMBL1370999 & 688239 & 4.5362 & 5.4494 & TST & \\
\hline CHEMBL1399001 & 688239 & 5.7862 & 5.5316 & TRN & \\
\hline CHEMBL1563905 & 688239 & 4.6862 & 5.3152 & TRN & \\
\hline CHEMBL1563581 & 688239 & 5.7362 & 5.4835 & TRN & \\
\hline CHEMBL1435800 & 688239 & 4.8362 & 5.5496 & TRN & \\
\hline CHEMBL1523054 & 688239 & 5.4862 & 5.5203 & TRN & \\
\hline CHEMBL1411509 & 688239 & 5.4362 & 5.3886 & TRN & \\
\hline CHEMBL1342138 & 688239 & 6.1862 & 5.3763 & TST & \\
\hline CHEMBL1387938 & 688239 & 5.3362 & 5.3581 & TRN & \\
\hline CHEMBL3196101 & 688239 & 5.4862 & 5.6625 & TRN & \\
\hline CHEMBL1553418 & 688239 & 4.5362 & 5.4171 & TRN & \\
\hline CHEMBL1336979 & 688239 & 6.0862 & 5.5128 & TRN & \\
\hline CHEMBL1581303 & 688239 & 4.5362 & 5.4412 & TRN & \\
\hline CHEMBL1430549 & 688239 & 6.4862 & 5.4625 & TRN & \\
\hline CHEMBL1523425 & 688239 & 5.6362 & 5.4756 & TRN & \\
\hline CHEMBL3207438 & 688239 & 7.1864 & 5.6437 & TRN & \\
\hline CHEMBL1348098 & 688239 & 8.1367 & 5.5957 & TRN & \\
\hline CHEMBL1521664 & 688239 & 5.1862 & 5.291 & TRN & \\
\hline CHEMBL1565257 & 688239 & 4.5362 & 5.5178 & TRN & \\
\hline CHEMBL1605153 & 688239 & 4.6862 & 5.4534 & TRN & \\
\hline CHEMBL1499255 & 688239 & 6.0 & 5.5143 & TRN & \\
\hline CHEMBL1388298 & 688239 & 4.4362 & 5.3715 & TST & \\
\hline CHEMBL1477225 & 688239 & 6.7862 & 5.4786 & TRN & \\
\hline CHEMBL1434040 & 688239 & 4.4862 & 5.3438 & TRN & \\
\hline CHEMBL1363478 & 688239 & 4.8362 & 5.4555 & TRN & \\
\hline CHEMBL1421297 & 688239 & 5.1862 & 5.3678 & TRN & \\
\hline CHEMBL1585579 & 688239 & 4.7 & 5.5927 & TRN & \\
\hline CHEMBL1402253 & 688239 & 4.6362 & 5.4098 & TRN & \\
\hline CHEMBL1503091 & 688239 & 4.6362 & 5.42200 & 0000000001 & TRN \\
\hline CHEMBL1523866 & 688239 & 4.65 & 5.3594 & TST & \\
\hline CHEMBL1510836 & 688239 & 5.4362 & 5.346 & TRN & \\
\hline CHEMBL3192360 & 688239 & 5.2362 & 5.5226 & TST & \\
\hline CHEMBL1477915 & 688239 & 5.9362 & 5.4411 & TST & \\
\hline CHEMBL1535438 & 688239 & 6.1862 & 5.5079 & TRN & \\
\hline CHEMBL1587006 & 688239 & 5.7362 & 5.3942 & TRN & \\
\hline CHEMBL1544499 & 688239 & 4.5362 & 5.4172 & TST & \\
\hline
\end{tabular}


Supplemental Table S2.txt

\begin{tabular}{|c|c|c|c|c|c|}
\hline CHEMBL1400439 & 688239 & 5.1862 & 5.505 & TST & \\
\hline CHEMBL1522207 & 688239 & 5.3362 & 5.4025 & TRN & \\
\hline CHEMBL1382948 & 688239 & 4.5862 & 5.4752 & TRN & \\
\hline CHEMBL1324826 & 688239 & 5.4862 & 5.6156 & TRN & \\
\hline CHEMBL1308494 & 688239 & 8.3372 & 5.7088 & TRN & \\
\hline CHEMBL1320800 & 688239 & 5.5862 & 5.4869 & TST & \\
\hline CHEMBL1522322 & 688239 & 4.7862 & 5.4155 & TST & \\
\hline CHEMBL1546920 & 688239 & 4.9362 & 5.4885 & TRN & \\
\hline CHEMBL1368280 & 688239 & 4.5362 & 5.5355 & TRN & \\
\hline CHEMBL1387036 & 688239 & 6.2362 & 5.5042 & TRN & \\
\hline CHEMBL1329617 & 688239 & 6.6861 & 5.3734 & TRN & \\
\hline CHEMBL1516369 & 688239 & 6.2362 & 5.4345 & TRN & \\
\hline CHEMBL1363966 & 688239 & 5.1862 & 5.5608 & TRN & \\
\hline CHEMBL1500416 & 688239 & 7.7852 & 5.4968 & TST & \\
\hline CHEMBL1518887 & 688239 & 4.5362 & 5.6049 & TRN & \\
\hline CHEMBL1397430 & 688239 & 4.5362 & 5.4059 & TRN & \\
\hline CHEMBL1506928 & 688239 & 6.6861 & 5.5593 & TRN & \\
\hline CHEMBL1364203 & 688239 & 5.8362 & 5.5838 & TST & \\
\hline CHEMBL1545224 & 688239 & 4.7862 & 5.4604 & TRN & \\
\hline CHEMBL1546581 & 688239 & 5.4862 & 5.3742 & TRN & \\
\hline CHEMBL1453178 & 688239 & 5.2862 & 5.57299 & 99999999995 & TRN \\
\hline CHEMBL1422829 & 688239 & 6.2862 & 5.4722 & TST & \\
\hline CHEMBL1454568 & 688239 & 6.3362 & 5.34200 & $\partial 0000000005$ & TST \\
\hline CHEMBL1475445 & 688239 & 5.7362 & 5.4979 & TRN & \\
\hline CHEMBL1360798 & 688239 & 5.2862 & 5.5699 & TRN & \\
\hline CHEMBL1372370 & 688239 & 5.1362 & 5.5116 & TST & \\
\hline CHEMBL1415999 & 688239 & 4.6362 & 5.4013 & TRN & \\
\hline CHEMBL1349716 & 688239 & 4.4862 & 5.6011 & TRN & \\
\hline CHEMBL25090 & 688239 & 8.3872 & 5.6122 & TRN & \\
\hline CHEMBL1409339 & 688239 & 4.6862 & 5.4851 & TST & \\
\hline CHEMBL1605441 & 688239 & 5.2362 & 5.4133 & TST & \\
\hline CHEMBL1541549 & 688239 & 4.7862 & 5.3195 & TRN & \\
\hline CHEMBL1396151 & 688239 & 4.6362 & 5.432 & TRN & \\
\hline CHEMBL1374310 & 688239 & 4.6362 & 5.5567 & TRN & \\
\hline CHEMBL1332364 & 688239 & 5.9362 & 5.3012 & TRN & \\
\hline CHEMBL1324884 & 688239 & 4.5362 & 5.646 & TRN & \\
\hline CHEMBL1328988 & 688239 & 4.6362 & 5.5853 & TRN & \\
\hline CHEMBL1597742 & 688239 & 6.1862 & 5.6242 & TST & \\
\hline CHEMBL1384641 & 688239 & 5.5362 & 5.6263 & TST & \\
\hline CHEMBL1516370 & 688239 & 5.7862 & 5.54799 & 9999999999 & TRN \\
\hline CHEMBL1440340 & 688239 & 4.7362 & 5.2912 & TRN & \\
\hline CHEMBL1579495 & 688239 & 4.5362 & 5.5552 & TST & \\
\hline CHEMBL1524124 & 688239 & 4.5362 & 5.4686 & TRN & \\
\hline CHEMBL1305397 & 688239 & 7.4868 & 5.5631 & TRN & \\
\hline CHEMBL1384103 & 688239 & 4.5362 & 5.2787 & TRN & \\
\hline CHEMBL1325346 & 688239 & 7.7852 & 5.4697 & TRN & \\
\hline CHEMBL1458935 & 688239 & 5.8862 & 5.5065 & TRN & \\
\hline CHEMBL1537136 & 688239 & 4.7362 & 5.3197 & TRN & \\
\hline
\end{tabular}


Supplemental Table S2.txt

\begin{tabular}{|c|c|c|c|c|}
\hline 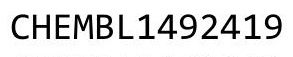 & & & & \\
\hline HEMBL1601860 & 88239 & 8362 & 1023 & \\
\hline HEMBL1610640 & 88239 & 1862 & & \\
\hline 83 & & & & \\
\hline EMBL13 & & 362 & & \\
\hline HEMBL1328859 & 88239 & 362 & 3978 & \\
\hline HEMBL1328245 & 88239 & 1862 & .55 & \\
\hline HEMBL1384507 & 39 & 862 & & \\
\hline EMBL15 & 39 & 862 & & \\
\hline IEMBL1379443 & 39 & 862 & & \\
\hline HEMBL1502811 & 88 & 5862 & . 4987 & \\
\hline HEMBL1522721 & 39 & .3362 & & \\
\hline HEMBL 290426 & 39 & 362 & & \\
\hline HEMBL1579105 & & & 45 & \\
\hline HEMBL1308926 & 9 & 862 & & \\
\hline HEMBL1600829 & 39 & 862 & & \\
\hline HEMBL1550820 & 88 & 4.7862 & .5578 & \\
\hline HEMBL1355087 & 39 & 862 & 93 & \\
\hline HEMBL156 & & & & \\
\hline HEMBL 319 & 39 & 862 & & \\
\hline HEMBL3191484 & 39 & 872 & & \\
\hline HEMBL1338218 & 39 & 4.8362 & & RN \\
\hline HEMBL1578285 & 39 & 362 & & \\
\hline HEMBL1308949 & & 62 & & \\
\hline 494325 & & 362 & 5. & \\
\hline 435 & 39 & 362 & & ST \\
\hline AEMBL1330239 & 39 & 862 & 83 & $\mathrm{R} N$ \\
\hline HEMBL1535242 & 39 & 362 & 86 & $\mathrm{RN}$ \\
\hline 7 & & 52 & & RN \\
\hline HEM & & & & RN \\
\hline HEMBL1401357 & & & & RN \\
\hline HEMBL1405261 & 88 & 362 & 319 & RN \\
\hline HEMBL137 & 39 & 362 & & Niv \\
\hline 4 & & & & ST \\
\hline HEMBL130 & & & & RN \\
\hline HEMBL1508674 & 39 & & & RN \\
\hline HEMBL1379321 & 39 & 362 & & RN \\
\hline HEMBL1998429 & 39 & 362 & & RIV \\
\hline 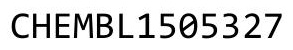 & & & & RN \\
\hline HEMBL1505590 & & & & RN \\
\hline HEMBL1541521 & 39 & 362 & .77 & RN \\
\hline HEMBL136 & 39 & 362 & & r \\
\hline HEMBL1312910 & & & & \\
\hline & & & & RN \\
\hline HEMBL 15 & & & & ST \\
\hline HEMBL1518204 & 39 & 862 & 295 & ST \\
\hline 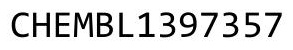 & & & & \\
\hline & & & & \\
\hline
\end{tabular}

Page 1019 
Supplemental Table S2.txt

\begin{tabular}{|c|c|c|c|c|}
\hline CHEMBL1585762 & 688239 & 7.5361 & 5.4602 & TST \\
\hline CHEMBL1563994 & 688239 & 5.1362 & 5.6113 & TRN \\
\hline CHEMBL1546445 & 688239 & 6.4362 & 5.459 & TST \\
\hline CHEMBL1575843 & 688239 & 4.7362 & 5.3414 & TRN \\
\hline CHEMBL1441973 & 688239 & 4.5862 & 5.4912 & TST \\
\hline CHEMBL 234180 & 688239 & 4.7362 & 5.5087 & TRN \\
\hline CHEMBL1459333 & 688239 & 7.2366 & 5.3384 & TRN \\
\hline CHEMBL1323429 & 688239 & 5.2862 & 5.4156 & TRN \\
\hline CHEMBL1566415 & 688239 & 4.4862 & 5.3832 & TST \\
\hline CHEMBL1421205 & 688239 & 6.8861 & 5.451000 & 0000000005 \\
\hline CHEMBL1367572 & 688239 & 4.5362 & 5.4354 & TRN \\
\hline CHEMBL1403578 & 688239 & 4.7362 & 5.5359 & TRN \\
\hline CHEMBL1530162 & 688239 & 4.6362 & 5.7055 & TRN \\
\hline CHEMBL1535340 & 688239 & 4.5362 & 5.4325 & TRN \\
\hline CHEMBL1462415 & 688239 & 8.3372 & 5.5934 & TRN \\
\hline CHEMBL1363042 & 688239 & 5.6362 & 5.5483 & TRN \\
\hline CHEMBL1324202 & 688239 & 4.5362 & 5.5151 & TST \\
\hline CHEMBL1310657 & 688239 & 4.5862 & 5.4759 & TRN \\
\hline CHEMBL1401075 & 688239 & 8.3872 & 5.4031 & TRN \\
\hline CHEMBL3209244 & 688239 & 5.0862 & 5.3882 & TRN \\
\hline CHEMBL1579916 & 688239 & 4.5362 & 5.4343 & TST \\
\hline CHEMBL1406472 & 688239 & 5.8362 & 5.4896 & TRN \\
\hline CHEMBL1409033 & 688239 & 5.7362 & 5.568 & TRN \\
\hline CHEMBL1561093 & 688239 & 4.6362 & 5.4926 & TRN \\
\hline CHEMBL1530361 & 688239 & 5.1862 & 5.5543 & TST \\
\hline CHEMBL1502761 & 688239 & 5.1362 & 5.3656 & TRN \\
\hline CHEMBL1430802 & 688239 & 6.1862 & 5.6101 & TST \\
\hline CHEMBL1330369 & 688239 & 8.28399 & 99999999 & 5.4942 \\
\hline CHEMBL1486208 & 688239 & 5.1362 & 5.4915 & TRN \\
\hline CHEMBL1404067 & 688239 & 4.8362 & 5.3781 & TRN \\
\hline CHEMBL1585451 & 688239 & 5.4362 & 5.5224 & TRN \\
\hline CHEMBL1992174 & 688239 & 5.5362 & 5.3657 & TST \\
\hline CHEMBL1526634 & 688239 & 4.6862 & 5.5598 & TRN \\
\hline CHEMBL1604741 & 688239 & 4.8362 & 5.4475 & TST \\
\hline CHEMBL1391080 & 688239 & 5.4362 & 5.4595 & TRN \\
\hline CHEMBL1539890 & 688239 & 6.1362 & 5.5285 & TRN \\
\hline CHEMBL1454967 & 688239 & 4.5362 & 5.4285 & TRN \\
\hline CHEMBL1461221 & 688239 & 4.5362 & 5.5052 & TRN \\
\hline CHEMBL1517871 & 688239 & 6.5862 & 5.4071 & TRN \\
\hline CHEMBL1314080 & 688239 & 4.5362 & 5.4898 & TRN \\
\hline CHEMBL1412920 & 688239 & 6.8362 & 5.5178 & TRN \\
\hline CHEMBL1549514 & 688239 & 4.6862 & 5.5085 & TST \\
\hline CHEMBL1535027 & 688239 & 6.7862 & 5.5581 & TRN \\
\hline CHEMBL1347789 & 688239 & 4.9862 & 5.365 & TST \\
\hline CHEMBL 2007190 & 688239 & 4.9862 & 5.5023 & TRN \\
\hline CHEMBL1545195 & 688239 & 4.9362 & 5.392 & TRN \\
\hline CHEMBL1403570 & 688239 & 4.5362 & 5.5812 & TRN \\
\hline CHEMBL1324621 & 688239 & 4.7862 & 5.447 & TRN \\
\hline
\end{tabular}


Supplemental Table S2.txt

\begin{tabular}{|c|c|c|c|c|c|}
\hline CHEMBL3211809 & 688239 & 5.6362 & 5.4373 & TRN & \\
\hline CHEMBL1348131 & 688239 & 4.9862 & 5.3874 & TRN & \\
\hline CHEMBL1397688 & 688239 & 5.1862 & 5.481 & TRN & \\
\hline CHEMBL1586822 & 688239 & 8.3372 & 5.4035 & TRN & \\
\hline CHEMBL1303435 & 688239 & 6.5862 & 5.4527 & TRN & \\
\hline CHEMBL1982202 & 688239 & 4.5362 & 5.3494 & TRN & \\
\hline CHEMBL1303486 & 688239 & 6.7862 & 5.5568 & TRN & \\
\hline CHEMBL1459427 & 688239 & 4.6862 & 5.4339 & TRN & \\
\hline CHEMBL1536615 & 688239 & 6.1362 & 5.5118 & TRN & \\
\hline CHEMBL1448063 & 688239 & 6.0862 & 5.432 & TST & \\
\hline CHEMBL1425292 & 688239 & 4.7862 & 5.4676 & TST & \\
\hline CHEMBL1611257 & 688239 & 4.5362 & 5.4349 & TRN & \\
\hline CHEMBL1612685 & 688239 & 4.5362 & 5.3875 & TRN & \\
\hline CHEMBL 3197317 & 688239 & 6.9363 & 5.46700 & 00000000005 & TST \\
\hline CHEMBL 3194322 & 688239 & 5.5862 & 5.4218 & TST & \\
\hline CHEMBL1439972 & 688239 & 5.8862 & 5.4325 & TST & \\
\hline CHEMBL1421982 & 688239 & 4.5362 & 5.57799 & 9999999999 & \\
\hline CHEMBL1347708 & 688239 & 4.7362 & 5.6583 & TRN & \\
\hline CHEMBL1319641 & 688239 & 5.1362 & 5.4628 & TRN & \\
\hline CHEMBL1528172 & 688239 & 5.1862 & 5.3455 & TRN & \\
\hline CHEMBL 3211949 & 688239 & 4.6862 & 5.574 & TST & \\
\hline CHEMBL1477324 & 688239 & 6.6861 & 5.4945 & TRN & \\
\hline CHEMBL1385194 & 688239 & 4.6362 & 5.5919 & TRN & \\
\hline CHEMBL1531281 & 688239 & 4.7362 & 5.6288 & TRN & \\
\hline CHEMBL1412366 & 688239 & 5.1862 & 5.3454 & TRN & \\
\hline CHEMBL1575717 & 688239 & 4.9362 & 5.4835 & TRN & \\
\hline CHEMBL1337143 & 688239 & 5.1862 & 5.2408 & TRN & \\
\hline CHEMBL1440373 & 688239 & 6.8861 & 5.6499 & TRN & \\
\hline CHEMBL1577117 & 688239 & 5.4362 & 5.5189 & TRN & \\
\hline CHEMBL1511179 & 688239 & 4.7362 & 5.3677 & TRN & \\
\hline CHEMBL1321730 & 688239 & 5.0362 & 5.5005 & TRN & \\
\hline CHEMBL1356191 & 688239 & 5.4362 & 5.4301 & TRN & \\
\hline CHEMBL1478041 & 688239 & 7.1864 & 5.5301 & TRN & \\
\hline CHEMBL1612370 & 688239 & 4.5862 & 5.4499 & TRN & \\
\hline CHEMBL1543372 & 688239 & \multicolumn{3}{|c|}{8.283999999999999} & TR \\
\hline CHEMBL1402849 & 688239 & 4.5862 & 5.5367 & TRN & \\
\hline CHEMBL1339652 & 688239 & 4.5362 & 5.4889 & TRN & \\
\hline CHEMBL1531820 & 688239 & 4.5362 & 5.5126 & TRN & \\
\hline CHEMBL1462576 & 688239 & 4.5862 & 5.4891 & TRN & \\
\hline CHEMBL1448644 & 688239 & 5.7362 & 5.4906 & TRN & \\
\hline CHEMBL1967436 & 688239 & 4.7362 & 5.3948 & TST & \\
\hline CHEMBL 3197754 & 688239 & 4.5362 & 5.3571 & TST & \\
\hline CHEMBL1537021 & 688239 & 4.5362 & 5.5167 & TRN & \\
\hline CHEMBL1582415 & 688239 & 8.3372 & 5.4794 & TRN & \\
\hline CHEMBL1379560 & 688239 & 6.9863 & 5.558 & TST & \\
\hline CHEMBL1498184 & 688239 & 4.7362 & 5.5882 & TRN & \\
\hline CHEMBL1342011 & 688239 & 6.6362 & 5.428 & TRN & \\
\hline CHEMBL1567175 & 688239 & 6.8861 & 5.5019 & TRN & \\
\hline
\end{tabular}


Supplemental Table S2.txt

\begin{tabular}{|c|c|c|c|c|c|c|}
\hline CHEMBL1572706 & 688239 & 4.5362 & 5.4747 & TST & & \\
\hline CHEMBL1333392 & 688239 & 5.0862 & 5.515 & TRN & & \\
\hline CHEMBL1425929 & 688239 & 4.5362 & 5.4867 & TRN & & \\
\hline CHEMBL3210329 & 688239 & 5.1862 & 5.476 & TST & & \\
\hline CHEMBL1345535 & 688239 & 4.5362 & 5.5641 & TRN & & \\
\hline CHEMBL1398722 & 688239 & 5.8862 & 5.4189 & TRN & & \\
\hline CHEMBL1403721 & 688239 & 6.0862 & 5.4399 & TRN & & \\
\hline CHEMBL1478847 & 688239 & 4.5362 & 5.4194 & TRN & & \\
\hline CHEMBL1341283 & 688239 & 6.2362 & 5.5401 & TRN & & \\
\hline CHEMBL1549531 & 688239 & 6.5862 & 5.4272 & TST & & \\
\hline CHEMBL1330348 & 688239 & 4.5362 & 5.4576 & TRN & & \\
\hline CHEMBL1361941 & 688239 & 4.7862 & 5.4371 & TRN & & \\
\hline CHEMBL1423503 & 688239 & 4.5362 & 5.441 & TRN & & \\
\hline CHEMBL1400832 & 688239 & 4.8862 & 5.4971 & TRN & & \\
\hline CHEMBL3214504 & 688239 & 5.7362 & 5.4547 & TRN & & \\
\hline CHEMBL1523503 & 688239 & 4.8862 & 5.4462 & TRN & & \\
\hline CHEMBL1431330 & 688239 & 6.8861 & 5.5027 & TRN & & \\
\hline CHEMBL1530436 & 688239 & 6.9363 & 5.5994 & TRN & & \\
\hline CHEMBL3192663 & 688239 & 4.5362 & 5.4311 & TST & & \\
\hline CHEMBL1353926 & 688239 & 4.5862 & 5.597 & TST & & \\
\hline CHEMBL1343842 & 688239 & 6.1862 & 5.3789 & TRN & & \\
\hline CHEMBL1982195 & 688239 & 5.7362 & 5.4203 & TST & & \\
\hline CHEMBL1414143 & 688239 & 7.2865 & 5.316 & TRN & & \\
\hline CHEMBL1494627 & 688239 & 6.2862 & 5.3873 & TRN & & \\
\hline CHEMBL1395621 & 688239 & 5.6362 & 5.4544 & TRN & & \\
\hline CHEMBL1591178 & 688239 & 4.5362 & 5.3891 & TST & & \\
\hline CHEMBL1318143 & 688239 & 4.5362 & 5.404 & TRN & & \\
\hline CHEMBL1560570 & 688239 & 6.2862 & 5.6438 & TRN & & \\
\hline CHEMBL1318133 & 688239 & 4.6362 & 5.3848 & TRN & & \\
\hline CHEMBL1332377 & 688239 & 5.6362 & 5.4118 & TRN & & \\
\hline CHEMBL1370820 & 688239 & 6.2362 & 5.5508 & TRN & & \\
\hline CHEMBL1597311 & 688239 & 4.7862 & 5.5546 & TRN & & \\
\hline CHEMBL1332018 & 688239 & 4.9362 & 5.4901 & TRN & & \\
\hline CHEMBL1406170 & 688239 & 4.4862 & 5.4184 & TST & & \\
\hline CHEMBL1349758 & 688239 & 4.7862 & 5.6645 & TRN & & \\
\hline CHEMBL1505477 & 688239 & 4.7862 & 5.3892 & TRN & & \\
\hline CHEMBL1403800 & 688239 & \multicolumn{3}{|c|}{8.283999999999999} & 5.4105 & TRN \\
\hline CHEMBL1568948 & 688239 & 5.1862 & 5.3224 & TRN & & \\
\hline CHEMBL1605196 & 688239 & 4.7862 & 5.4042 & TRN & & \\
\hline CHEMBL1317499 & 688239 & \multicolumn{3}{|c|}{8.283999999999999} & 5.4011 & TRN \\
\hline CHEMBL1595181 & 688239 & 5.6362 & 5.625 & TRN & & \\
\hline CHEMBL1326527 & 688239 & 6.1362 & 5.5049 & TRN & & \\
\hline CHEMBL1325607 & 688239 & 4.5362 & 5.5561 & TRN & & \\
\hline CHEMBL1522310 & 688239 & 5.2862 & 5.4729 & TST & & \\
\hline CHEMBL1354562 & 688239 & 5.4362 & 5.5175 & TRN & & \\
\hline CHEMBL1499792 & 688239 & 4.6862 & 5.3356 & TST & & \\
\hline CHEMBL1610031 & 688239 & 4.6862 & 5.4267 & TRN & & \\
\hline CHEMBL1501811 & 688239 & 5.1862 & 5.3177 & TRN & & \\
\hline
\end{tabular}

Page 1022 
Supplemental Table S2.txt

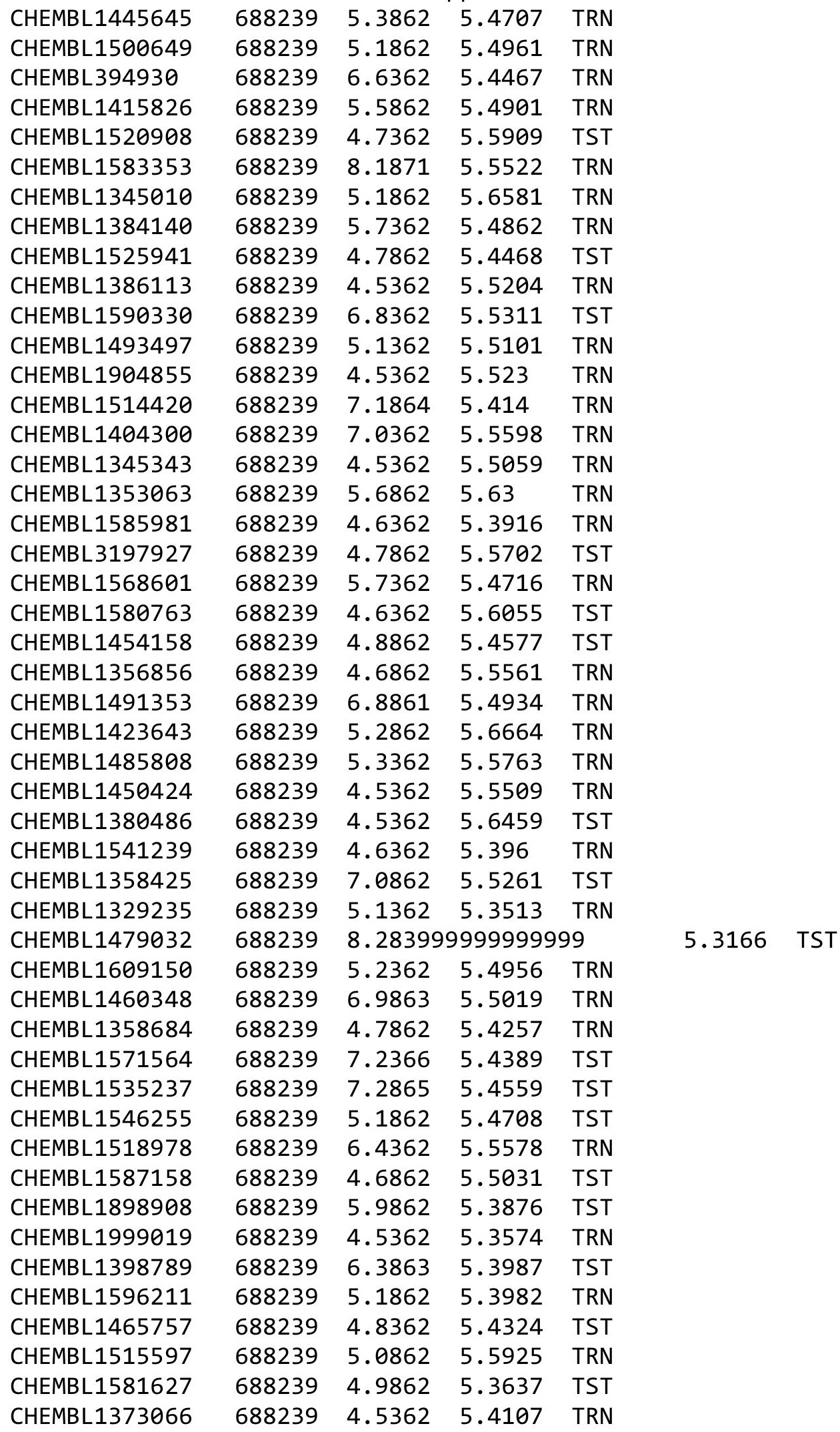

Page 1023 
Supplemental Table S2.txt

\begin{tabular}{|c|c|c|c|c|}
\hline CHEMBL1371610 & 688239 & 5.0862 & 5.4382 & TRN \\
\hline CHEMBL1466662 & 688239 & 5.2362 & 5.6908 & TRN \\
\hline CHEMBL1444541 & 688239 & 5.6362 & 5.4772 & TRN \\
\hline CHEMBL1540742 & 688239 & 4.5362 & 5.388 & TST \\
\hline CHEMBL1421998 & 688239 & 4.8362 & 5.4372 & TRN \\
\hline CHEMBL1366301 & 688239 & 4.5362 & \multicolumn{2}{|c|}{5.462000000000001} \\
\hline CHEMBL1558400 & 688239 & 4.6862 & 5.5548 & TST \\
\hline CHEMBL1612448 & 688239 & 6.3362 & 5.4545 & TRN \\
\hline CHEMBL1538952 & 688239 & 5.1862 & 5.6212 & TRN \\
\hline CHEMBL1583503 & 688239 & 6.1362 & 5.3997 & TRN \\
\hline CHEMBL1490267 & 688239 & 4.7362 & 5.3399 & TST \\
\hline CHEMBL1343825 & 688239 & 5.0362 & 5.4184 & TST \\
\hline CHEMBL1425901 & 688239 & 6.6362 & 5.4748 & TRN \\
\hline CHEMBL1371057 & 688239 & 4.9862 & 5.4803 & TRN \\
\hline CHEMBL1426890 & 688239 & 5.3362 & 5.6519 & TRN \\
\hline CHEMBL1432694 & 688239 & 6.2862 & 5.5664 & TRN \\
\hline CHEMBL1323954 & 688239 & 4.9862 & 5.3738 & TRN \\
\hline CHEMBL1493263 & 688239 & 5.5862 & 5.4526 & TRN \\
\hline CHEMBL1476557 & 688239 & 5.3362 & 5.5318 & TRN \\
\hline CHEMBL1479600 & 688239 & 5.5362 & 5.4084 & TRN \\
\hline CHEMBL1415499 & 688239 & 5.5862 & 5.6325 & TRN \\
\hline CHEMBL1503066 & 688239 & 4.5362 & 5.4192 & TRN \\
\hline CHEMBL1418862 & 688239 & 5.9862 & 5.6163 & TRN \\
\hline CHEMBL1337390 & 688239 & 4.5362 & 5.5401 & TRN \\
\hline CHEMBL1360771 & 688239 & 5.1862 & 5.7015 & TRN \\
\hline CHEMBL1418367 & 688239 & 5.2362 & 5.4725 & TRN \\
\hline CHEMBL1607346 & 688239 & 6.0362 & 5.4864 & TRN \\
\hline CHEMBL1429031 & 688239 & 4.9362 & 5.4755 & TRN \\
\hline CHEMBL3207612 & 688239 & 4.5362 & 5.3085 & TRN \\
\hline CHEMBL1363884 & 688239 & 4.9862 & 5.4407 & TRN \\
\hline CHEMBL1581464 & 688239 & 7.5867 & 5.505 & TST \\
\hline CHEMBL1450272 & 688239 & 5.4362 & 5.5294 & TRN \\
\hline CHEMBL1580166 & 688239 & 4.5362 & 5.351 & TST \\
\hline CHEMBL1389113 & 688239 & 5.0362 & 5.4428 & TST \\
\hline CHEMBL1476577 & 688239 & 6.0362 & 5.5996 & TST \\
\hline CHEMBL1329672 & 688239 & 7.0862 & 5.4823 & TRN \\
\hline CHEMBL1328782 & 688239 & 5.5862 & 5.5311 & TRN \\
\hline CHEMBL1540232 & 688239 & 8.3372 & 5.4854 & TST \\
\hline CHEMBL1599177 & 688239 & 4.5862 & 5.4221 & TRN \\
\hline CHEMBL579624 & 688239 & 6.1862 & 5.4817 & TRN \\
\hline CHEMBL1368215 & 688239 & 6.6362 & 5.5197 & TRN \\
\hline CHEMBL1313429 & 688239 & 4.6362 & 5.4046 & TST \\
\hline CHEMBL1440387 & 688239 & 5.6362 & 5.5668 & TRN \\
\hline CHEMBL1301663 & 688239 & 6.2362 & 5.5669 & TRN \\
\hline CHEMBL1550497 & 688239 & 5.1862 & 5.4795 & TRN \\
\hline CHEMBL1324707 & 688239 & 5.7862 & 5.5758 & TST \\
\hline CHEMBL1313261 & 688239 & 4.5362 & 5.40600 & 0000000001 \\
\hline CHEMBL1333154 & 688239 & 4.6862 & 5.4516 & TRN \\
\hline
\end{tabular}


Supplemental Table S2.txt

\begin{tabular}{|c|c|c|c|c|c|}
\hline CHEMBL1380943 & 688239 & 4.6862 & 5.2837 & TRN & \\
\hline CHEMBL1458570 & 688239 & 5.1862 & 5.6615 & TRN & \\
\hline CHEMBL1449545 & 688239 & 5.4862 & 5.5229 & TST & \\
\hline CHEMBL1397936 & 688239 & 5.0862 & 5.4506 & TRN & \\
\hline CHEMBL1414330 & 688239 & 5.1862 & 5.4441 & TRN & \\
\hline CHEMBL1978855 & 688239 & 6.0862 & 5.3903 & TST & \\
\hline CHEMBL1300653 & 688239 & 8.3372 & 5.4975 & TST & \\
\hline CHEMBL1408157 & 688239 & 4.8362 & 5.442 & TRN & \\
\hline CHEMBL3214288 & 688239 & 5.3862 & 5.4891 & TRN & \\
\hline CHEMBL1466149 & 688239 & 4.6362 & 5.5478 & TRN & \\
\hline CHEMBL1438223 & 688239 & 4.7362 & 5.4822 & TRN & \\
\hline CHEMBL1507834 & 688239 & 5.4862 & 5.5739 & TRN & \\
\hline CHEMBL1373665 & 688239 & 4.5362 & 5.2859 & TST & \\
\hline CHEMBL1529092 & 688239 & 5.2362 & 5.49299 & 9999999999 & TRN \\
\hline CHEMBL1308907 & 688239 & 6.9863 & 5.6147 & TRN & \\
\hline CHEMBL1384793 & 688239 & 8.1871 & 5.681 & TST & \\
\hline CHEMBL1314636 & 688239 & 5.0862 & 5.4034 & TRN & \\
\hline CHEMBL1417108 & 688239 & 4.7362 & 5.6397 & TRN & \\
\hline CHEMBL1389521 & 688239 & 4.5362 & 5.5076 & TRN & \\
\hline CHEMBL1364772 & 688239 & 4.8862 & 5.444 & TRN & \\
\hline CHEMBL1500478 & 688239 & 5.1862 & 5.4871 & TST & \\
\hline CHEMBL1596677 & 688239 & 4.6362 & 5.4169 & TRN & \\
\hline CHEMBL1448692 & 688239 & 6.0862 & 5.6761 & TRN & \\
\hline CHEMBL1339283 & 688239 & 7.2865 & 5.3873 & TRN & \\
\hline CHEMBL1334661 & 688239 & 5.1862 & 5.4792 & TRN & \\
\hline CHEMBL1424454 & 688239 & 5.1862 & 5.4351 & TRN & \\
\hline CHEMBL1393968 & 688239 & 6.0862 & 5.3958 & TST & \\
\hline CHEMBL1308899 & 688239 & 4.8362 & 5.4602 & TRN & \\
\hline CHEMBL1330787 & 688239 & 6.1862 & 5.5122 & TST & \\
\hline CHEMBL1534447 & 688239 & 4.6362 & 5.5968 & TRN & \\
\hline CHEMBL1318901 & 688239 & 4.8862 & 5.4807 & TRN & \\
\hline CHEMBL1418724 & 688239 & 4.5862 & 5.4657 & TRN & \\
\hline CHEMBL1571824 & 688239 & 5.8362 & 5.5737 & TST & \\
\hline CHEMBL1508659 & 688239 & 4.5362 & 5.6742 & TRN & \\
\hline CHEMBL3213024 & 688239 & 4.5362 & 5.3921 & TRN & \\
\hline CHEMBL1412984 & 688239 & 4.9862 & 5.5005 & TRN & \\
\hline CHEMBL1464312 & 688239 & 6.0862 & 5.4427 & TST & \\
\hline CHEMBL1520851 & 688239 & 4.6862 & 5.6611 & TRN & \\
\hline CHEMBL1563944 & 688239 & 5.4362 & 5.4838 & TRN & \\
\hline CHEMBL1425491 & 688239 & 5.1862 & 5.4734 & TRN & \\
\hline CHEMBL1413425 & 688239 & 6.6861 & 5.4225 & TST & \\
\hline CHEMBL1538908 & 688239 & 6.3362 & 5.7005 & TST & \\
\hline CHEMBL1599383 & 688239 & 4.5362 & 5.4577 & TST & \\
\hline CHEMBL 251005 & 688239 & 5.4862 & 5.5425 & TRN & \\
\hline CHEMBL1595590 & 688239 & 5.3862 & 5.6293 & TRN & \\
\hline CHEMBL3191962 & 688239 & 5.0862 & 5.4455 & TRN & \\
\hline CHEMBL1370528 & 688239 & 4.7862 & 5.4265 & TRN & \\
\hline CHEMBL1482879 & 688239 & 5.1362 & 5.4849 & TRN & \\
\hline
\end{tabular}


Supplemental Table S2.txt

\begin{tabular}{|c|c|c|c|c|}
\hline CHEMBL1407688 & 688239 & 4.7862 & 5.3915 & TRN \\
\hline CHEMBL1612002 & 688239 & 6.1362 & 5.5239 & TRN \\
\hline CHEMBL1477929 & 688239 & 4.5862 & 5.5247 & TRN \\
\hline CHEMBL1551521 & 688239 & 5.0362 & 5.4716 & TRN \\
\hline CHEMBL1535548 & 688239 & 7.3363 & 5.6128 & TRN \\
\hline CHEMBL1465894 & 688239 & 4.5862 & 5.4261 & TRN \\
\hline CHEMBL1449701 & 688239 & 4.5862 & 5.3501 & TRN \\
\hline CHEMBL1536499 & 688239 & 4.5362 & 5.4673 & TST \\
\hline CHEMBL1400518 & 688239 & 4.5362 & 5.5018 & TST \\
\hline CHEMBL1546424 & 688239 & 6.2862 & 5.3611 & TST \\
\hline CHEMBL1562670 & 688239 & 4.6862 & 5.5512 & TRN \\
\hline CHEMBL1589660 & 688239 & 4.5362 & 5.3827 & TRN \\
\hline CHEMBL1322024 & 688239 & 4.9862 & 5.5455 & TRN \\
\hline CHEMBL1392798 & 688239 & 6.1862 & 5.5115 & TST \\
\hline CHEMBL1429809 & 688239 & 5.2362 & 5.4552 & TRN \\
\hline CHEMBL1457592 & 688239 & 6.9363 & 5.4126 & TST \\
\hline CHEMBL1345047 & 688239 & 5.0362 & 5.4961 & TST \\
\hline CHEMBL1528655 & 688239 & 4.5362 & 5.5211 & TRN \\
\hline CHEMBL1416211 & 688239 & 5.3362 & 5.5057 & TST \\
\hline CHEMBL1556811 & 688239 & 5.0862 & 5.5093 & TRN \\
\hline CHEMBL1313915 & 688239 & 5.7362 & 5.3995 & TRN \\
\hline CHEMBL1393540 & 688239 & 6.5363 & 5.4618 & TRN \\
\hline CHEMBL1343576 & 688239 & 8.28399 & 99999999 & 5.3921 \\
\hline CHEMBL1370539 & 688239 & 5.1362 & 5.4707 & TRN \\
\hline CHEMBL1533563 & 688239 & 4.5362 & 5.3912 & TRN \\
\hline CHEMBL1559472 & 688239 & 8.3372 & 5.3707 & TRN \\
\hline CHEMBL1483580 & 688239 & 5.1862 & 5.5635 & TST \\
\hline CHEMBL1524355 & 688239 & 4.6862 & 5.6418 & TRN \\
\hline CHEMBL1318275 & 688239 & 7.1361 & 5.4849 & TRN \\
\hline CHEMBL1321634 & 688239 & 5.6362 & 5.4302 & TST \\
\hline CHEMBL1609909 & 688239 & 5.1862 & 5.4213 & TST \\
\hline CHEMBL1522544 & 688239 & 4.5862 & 5.3263 & TRN \\
\hline CHEMBL1484894 & 688239 & 4.7862 & 5.3647 & TRN \\
\hline CHEMBL1373081 & 688239 & 4.5862 & 5.5788 & TRN \\
\hline CHEMBL3208487 & 688239 & 4.7362 & 5.3972 & TRN \\
\hline CHEMBL1531254 & 688239 & 5.4862 & 5.441 & TRN \\
\hline CHEMBL1529467 & 688239 & 7.0362 & 5.4894 & TST \\
\hline CHEMBL1500692 & 688239 & 4.5862 & 5.4287 & TRN \\
\hline CHEMBL1305528 & 688239 & 5.1862 & 5.425 & TRN \\
\hline CHEMBL1413839 & 688239 & 4.5362 & 5.6335 & TST \\
\hline CHEMBL1428080 & 688239 & 5.1862 & 5.4882 & TRN \\
\hline CHEMBL43462 & 688239 & 4.5362 & 5.617999 & 9999999999 \\
\hline CHEMBL1532271 & 688239 & 4.5362 & 5.5932 & TRN \\
\hline CHEMBL1353921 & 688239 & 4.4862 & 5.4371 & TRN \\
\hline CHEMBL1343633 & 688239 & 5.5862 & 5.4654 & TST \\
\hline CHEMBL1506986 & 688239 & 5.1862 & 5.5142 & TRN \\
\hline CHEMBL1424951 & 688239 & 4.6362 & 5.2459 & TST \\
\hline CHEMBL1411066 & 688239 & 6.0362 & 5.4856 & TRN \\
\hline
\end{tabular}




\begin{tabular}{|c|c|c|c|c|c|}
\hline & & & & & \\
\hline CHEMBL1387805 & 688239 & 6.8861 & 5.3481 & TST & \\
\hline CHEMBL3190449 & 688239 & 6.7361 & 5.5927 & TRN & \\
\hline CHEMBL1452156 & 688239 & 5.3862 & 5.4412 & TRN & \\
\hline CHEMBL1492111 & 688239 & 5.1862 & 5.5728 & TRN & \\
\hline CHEMBL3189463 & 688239 & 6.2362 & 5.2876 & TRN & \\
\hline CHEMBL1312198 & 688239 & 5.8362 & 5.426 & TRN & \\
\hline CHEMBL3193300 & 688239 & 5.1862 & 5.4925 & TRN & \\
\hline CHEMBL1330840 & 688239 & 4.5362 & 5.5434 & TRN & \\
\hline CHEMBL1403374 & 688239 & 6.8861 & 5.6016 & TRN & \\
\hline CHEMBL1411275 & 688239 & 6.1862 & 5.5616 & TST & \\
\hline CHEMBL1461140 & 688239 & 4.5362 & 5.4045 & TST & \\
\hline CHEMBL1311097 & 688239 & 6.2362 & 5.5529 & TRN & \\
\hline CHEMBL1333873 & 688239 & 4.7362 & 5.4659 & TST & \\
\hline CHEMBL1327531 & 688239 & 6.1862 & 5.4085 & TST & \\
\hline CHEMBL1371090 & 688239 & 5.1862 & 5.6932 & TRN & \\
\hline CHEMBL1498848 & 688239 & 7.9355 & 5.3807 & TST & \\
\hline CHEMBL1374077 & 688239 & 5.6862 & 5.5133 & TRN & \\
\hline CHEMBL1497258 & 688239 & 4.9862 & 5.4154 & TRN & \\
\hline CHEMBL1399571 & 688239 & 5.1862 & 5.5312 & TRN & \\
\hline CHEMBL1357108 & 688239 & 4.5862 & 5.542006 & 0000000001 & TRN \\
\hline CHEMBL1368165 & 688239 & 4.5362 & 5.4379 & TST & \\
\hline CHEMBL1334461 & 688239 & 4.6862 & 5.4877 & TRN & \\
\hline CHEMBL1339350 & 688239 & 4.5362 & 5.4749 & TRN & \\
\hline CHEMBL1540674 & 688239 & 4.5362 & 5.5022 & TRN & \\
\hline CHEMBL1317529 & 688239 & 5.8362 & 5.5997 & TRN & \\
\hline CHEMBL1511801 & 688239 & 4.6862 & 5.4895 & TRN & \\
\hline CHEMBL1609831 & 688239 & 4.5362 & 5.3099 & TRN & \\
\hline CHEMBL1334396 & 688239 & 5.1862 & 5.4176 & TRN & \\
\hline CHEMBL1535215 & 688239 & 6.0362 & 5.4925 & TRN & \\
\hline CHEMBL1444561 & 688239 & 6.1362 & 5.4129 & TRN & \\
\hline CHEMBL1543827 & 688239 & 5.1862 & 5.5057 & TRN & \\
\hline CHEMBL1416236 & 688239 & 6.6861 & 5.4365 & TRN & \\
\hline CHEMBL1301008 & 688239 & 4.6362 & 5.501 & TRN & \\
\hline CHEMBL1611848 & 688239 & 8.2366 & 5.6662 & TRN & \\
\hline CHEMBL1360068 & 688239 & 4.7862 & 5.4789 & TRN & \\
\hline CHEMBL1300215 & 688239 & 4.4862 & 5.3828 & TRN & \\
\hline CHEMBL1606247 & 688239 & 7.0862 & 5.5237 & TRN & \\
\hline CHEMBL1571394 & 688239 & 4.7862 & 5.6127 & TRN & \\
\hline CHEMBL1612528 & 688239 & 4.4862 & 5.4657 & TRN & \\
\hline CHEMBL1462223 & 688239 & 5.1862 & 5.4086 & TST & \\
\hline CHEMBL1354582 & 688239 & 4.7862 & 5.3651 & TST & \\
\hline CHEMBL1504189 & 688239 & 4.5362 & 5.3041 & TRN & \\
\hline CHEMBL1355829 & 688239 & 4.5362 & 5.5844 & TRN & \\
\hline CHEMBL1315768 & 688239 & 5.1862 & 5.501 & TST & \\
\hline CHEMBL1458096 & 688239 & 7.1864 & 5.5827 & TRN & \\
\hline CHEMBL1424577 & 688239 & 4.5862 & 5.5601 & TRN & \\
\hline CHEMBL1347578 & 688239 & 4.9362 & 5.5704 & TST & \\
\hline CHEMBL1413910 & 688239 & 6.9863 & 5.5357 & TST & \\
\hline
\end{tabular}


Supplemental Table S2.txt

\begin{tabular}{|c|c|c|c|c|}
\hline & & & & \\
\hline HEMBL1456142 & 88239 & .7362 & & \\
\hline HEMBL1342082 & 3239 & 862 & 85 & \\
\hline 80 & & & & \\
\hline FMBI 14 & 239 & 862 & & \\
\hline AEMBL1528496 & 88239 & 9363 & & \\
\hline HEMBL1439166 & 88239 & 3862 & 4185 & \\
\hline AEMBL16 & 39 & 62 & & \\
\hline IEMBL1: & 239 & 8662 & & \\
\hline IEMBL1 & & 362 & & \\
\hline AEMBL13 & 88239 & 5862 & & \\
\hline HEMBL 592 & 88239 & 4.6862 & & \\
\hline HEMBL13 & & 62 & & \\
\hline IEMBL] & & 62 & & \\
\hline AEMBL: & & & & \\
\hline AEMBL1: & 88239 & 6.8362 & & \\
\hline HEMBL15 & & & & \\
\hline HEMBLI & 9 & 4. & & \\
\hline AEMBL: & & & & \\
\hline AEMBL: & & & & \\
\hline AEMBL: & & & & \\
\hline IEMBL15 & & & & \\
\hline HEMBL3 & 39 & 4. & & \\
\hline AEMBL: & & & & \\
\hline HEMB & & & & \\
\hline 74 & & & & \\
\hline AEMBL13 & & & & | \\
\hline HEMBL1 & & & & \\
\hline IEMB & & & & \\
\hline 37 & 39 & & & \\
\hline 206 & & & & \\
\hline AEMBL1 & & & & \\
\hline AEMBL & & & & \\
\hline EME & & & & \\
\hline EME & & & & \\
\hline & & & & \\
\hline AEMBL3: & & & & ГST \\
\hline 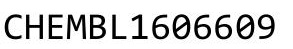 & & & & \\
\hline 19 & & & & \\
\hline HEMB & & & & \\
\hline AEMBL1 & 8239 & 4.6862 & & \\
\hline HEMBL: & & & & \\
\hline & & & & \\
\hline HEMBL & & & & \\
\hline CHEMBL 2 & & & & \\
\hline AEMBL1 & 39 & 863 & & \\
\hline CHEMBL: & & & & \\
\hline CHEMBL1. & & & 5.4141 & \\
\hline
\end{tabular}

Page 1028 
Supplemental Table S2.txt

\begin{tabular}{|c|c|c|c|c|c|}
\hline CHEMBL1497782 & 688239 & 6.6362 & 5.5248 & TRN & \\
\hline CHEMBL1328394 & 688239 & 5.2362 & \multicolumn{2}{|c|}{5.5520000000000005} & TRN \\
\hline CHEMBL109866 & 688239 & 5.4362 & 5.5367 & TST & \\
\hline CHEMBL1585752 & 688239 & 6.1862 & 5.4924 & TST & \\
\hline CHEMBL1406016 & 688239 & 7.0362 & 5.5341 & TRN & \\
\hline CHEMBL1389551 & 688239 & 4.7362 & 5.3939 & TRN & \\
\hline CHEMBL 3199104 & 688239 & 4.6362 & 5.2931 & TRN & \\
\hline CHEMBL1357226 & 688239 & 5.8862 & 5.5087 & TRN & \\
\hline CHEMBL 3210147 & 688239 & 5.1862 & 5.3357 & TST & \\
\hline CHEMBL1437699 & 688239 & 6.8362 & 5.5983 & TRN & \\
\hline CHEMBL1516797 & 688239 & 5.7362 & 5.3747 & TRN & \\
\hline CHEMBL1568376 & 688239 & 4.6862 & 5.4563 & TRN & \\
\hline CHEMBL1561044 & 688239 & 8.1871 & 5.3869 & TRN & \\
\hline CHEMBL1371195 & 688239 & 6.7862 & 5.4862 & TRN & \\
\hline CHEMBL1565101 & 688239 & 5.9862 & 5.595 & TRN & \\
\hline CHEMBL1606047 & 688239 & 6.3362 & 5.4891 & TRN & \\
\hline CHEMBL1381858 & 688239 & 6.1362 & 5.5429 & TRN & \\
\hline CHEMBL1331054 & 688239 & 4.5362 & 5.5158 & TRN & \\
\hline CHEMBL1607836 & 688239 & 6.1862 & 5.5134 & TST & \\
\hline CHEMBL498373 & 688239 & 4.7362 & 5.455 & TRN & \\
\hline CHEMBL1968326 & 688239 & 4.8862 & 5.4065 & TRN & \\
\hline CHEMBL1535067 & 688239 & 5.1362 & 5.4497 & TST & \\
\hline CHEMBL1384745 & 688239 & 6.2862 & 5.5723 & TRN & \\
\hline CHEMBL1392715 & 688239 & 6.1362 & 5.3127 & TRN & \\
\hline CHEMBL1589346 & 688239 & 5.1862 & 5.5924 & TRN & \\
\hline CHEMBL1319889 & 688239 & 4.6862 & \multicolumn{2}{|c|}{5.257000000000001} & TST \\
\hline CHEMBL1333173 & 688239 & 6.1862 & 5.5288 & TRN & \\
\hline CHEMBL1394590 & 688239 & 4.5862 & 5.4026 & TRN & \\
\hline CHEMBL1556062 & 688239 & 4.6362 & 5.4373 & TRN & \\
\hline CHEMBL1567951 & 688239 & 5.0362 & 5.5045 & TRN & \\
\hline CHEMBL1407726 & 688239 & 5.1362 & 5.5241 & TRN & \\
\hline CHEMBL1306347 & 688239 & 8.3872 & 5.4005 & TST & \\
\hline CHEMBL1562574 & 688239 & 4.5362 & 5.5423 & TRN & \\
\hline CHEMBL1603674 & 688239 & 4.95 & 5.4421 & TRN & \\
\hline CHEMBL1521089 & 688239 & 6.1362 & 5.4998 & TRN & \\
\hline CHEMBL1307279 & 688239 & 4.4862 & 5.4035 & TRN & \\
\hline CHEMBL1468664 & 688239 & 4.5362 & 5.5741 & TRN & \\
\hline CHEMBL1328966 & 688239 & 4.6362 & 5.487 & TRN & \\
\hline CHEMBL1445746 & 688239 & 7.2366 & 5.5737 & TRN & \\
\hline CHEMBL1471869 & 688239 & 8.3872 & 5.4859 & TRN & \\
\hline CHEMBL1998863 & 688239 & 4.6862 & 5.3702 & TRN & \\
\hline CHEMBL1504513 & 688239 & 6.0362 & 5.3569 & TRN & \\
\hline CHEMBL1495733 & 688239 & 6.7862 & 5.5274 & TRN & \\
\hline CHEMBL1392713 & 688239 & 7.9355 & 5.426 & TRN & \\
\hline CHEMBL1462130 & 688239 & 5.6362 & 5.6288 & TST & \\
\hline CHEMBL1500989 & 688239 & 6.0862 & 5.4345 & TRN & \\
\hline CHEMBL 3208805 & 688239 & 4.5362 & 5.4249 & TRN & \\
\hline CHEMBL1981886 & 688239 & 4.5362 & 5.5592 & TRN & \\
\hline
\end{tabular}


Supplemental Table S2.txt

\begin{tabular}{|c|c|c|c|c|}
\hline CHEMBL1359825 & 688239 & 4.4862 & 5.6085 & TRN \\
\hline CHEMBL1449604 & 688239 & 5.0862 & 5.4427 & TRN \\
\hline CHEMBL1599713 & 688239 & 4.8362 & 5.3842 & TST \\
\hline CHEMBL1319207 & 688239 & 6.3362 & 5.57 & TRN \\
\hline CHEMBL1456771 & 688239 & 6.2362 & 5.3648 & TRN \\
\hline CHEMBL1459371 & 688239 & 5.2862 & 5.4795 & TRN \\
\hline CHEMBL1363730 & 688239 & 5.1862 & 5.3585 & TST \\
\hline CHEMBL1521556 & 688239 & 5.2862 & 5.5225 & TRN \\
\hline CHEMBL1545864 & 688239 & 5.7862 & 5.575 & TRN \\
\hline CHEMBL1302547 & 688239 & 5.2362 & 5.5731 & TRN \\
\hline CHEMBL1410117 & 688239 & 5.7862 & 5.6017 & TRN \\
\hline CHEMBL1343671 & 688239 & 4.5362 & 5.6134 & TRN \\
\hline CHEMBL1574851 & 688239 & 4.6362 & 5.5144 & TST \\
\hline CHEMBL1379867 & 688239 & 5.1862 & 5.53600 & 00000000005 \\
\hline CHEMBL1459994 & 688239 & 6.5862 & 5.4215 & TRN \\
\hline CHEMBL1383510 & 688239 & 6.8362 & 5.5344 & TST \\
\hline CHEMBL1452785 & 688239 & 6.1862 & 5.4928 & TRN \\
\hline CHEMBL1525222 & 688239 & 5.4362 & 5.4817 & TRN \\
\hline CHEMBL1549552 & 688239 & 8.3372 & 5.4344 & TRN \\
\hline CHEMBL1612988 & 688239 & 4.5362 & 5.46700 & 30000000005 \\
\hline CHEMBL1390395 & 688239 & 6.0862 & 5.3389 & TST \\
\hline CHEMBL1322563 & 688239 & 4.7362 & 5.3589 & TRN \\
\hline CHEMBL1533111 & 688239 & 4.5862 & 5.6013 & TRN \\
\hline CHEMBL1608378 & 688239 & 8.3872 & 5.4497 & TRN \\
\hline CHEMBL1533577 & 688239 & 4.5362 & 5.4712 & TST \\
\hline CHEMBL1447989 & 688239 & 5.1862 & 5.5621 & TRN \\
\hline CHEMBL1550266 & 688239 & 8.3872 & 5.5231 & TRN \\
\hline CHEMBL1437289 & 688239 & 4.5362 & 5.3163 & TRN \\
\hline CHEMBL1351563 & 688239 & 4.6362 & 5.5961 & TST \\
\hline CHEMBL1411312 & 688239 & 7.6364 & 5.5162 & TRN \\
\hline CHEMBL1427022 & 688239 & 4.9362 & 5.5598 & TRN \\
\hline CHEMBL1503493 & 688239 & 5.3362 & 5.4901 & TRN \\
\hline CHEMBL1480871 & 688239 & 4.5362 & 5.42899 & \\
\hline CHEMBL1560535 & 688239 & 5.8362 & 5.4465 & TRN \\
\hline CHEMBL1475182 & 688239 & 4.9862 & 5.5273 & TRN \\
\hline CHEMBL1408482 & 688239 & 5.5362 & 5.499 & TRN \\
\hline CHEMBL1482946 & 688239 & 4.5362 & 5.4719 & TRN \\
\hline CHEMBL1496999 & 688239 & 4.7862 & 5.4519 & TRN \\
\hline CHEMBL1609303 & 688239 & 6.4862 & 5.5449 & TRN \\
\hline CHEMBL1501260 & 688239 & 8.3372 & 5.5444 & TRN \\
\hline CHEMBL1426477 & 688239 & 6.1862 & 5.5839 & TRN \\
\hline CHEMBL1503045 & 688239 & 5.6862 & 5.5885 & TRN \\
\hline CHEMBL1369518 & 688239 & 4.5862 & 5.4778 & TRN \\
\hline CHEMBL1379798 & 688239 & 5.1862 & 5.3806 & TRN \\
\hline CHEMBL1311023 & 688239 & 6.2362 & 5.5526 & TRN \\
\hline CHEMBL1381368 & 688239 & 5.0862 & 5.5235 & TRN \\
\hline CHEMBL1373814 & 688239 & 4.4862 & 5.4786 & TST \\
\hline CHEMBL1500628 & 688239 & 4.5362 & 5.4741 & TRN \\
\hline
\end{tabular}


Supplemental Table S2.txt

\begin{tabular}{|c|c|c|c|c|}
\hline CHEMBL1573876 & 688239 & 6.3362 & 5.6295 & TST \\
\hline CHEMBL1309079 & 688239 & 4.5362 & 5.4412 & TRN \\
\hline CHEMBL1993287 & 688239 & 4.7862 & 5.4313 & TRN \\
\hline CHEMBL 3195155 & 688239 & 5.6862 & 5.4881 & TST \\
\hline CHEMBL1608168 & 688239 & 5.0862 & 5.4861 & TRN \\
\hline CHEMBL1363899 & 688239 & 4.6862 & 5.5162 & TRN \\
\hline CHEMBL1543140 & 688239 & 5.0362 & 5.5459 & TST \\
\hline CHEMBL1508116 & 688239 & 8.1871 & 5.51 & TST \\
\hline CHEMBL1448753 & 688239 & 4.4862 & 5.4667 & TRN \\
\hline CHEMBL1445144 & 688239 & 4.7362 & 5.3882 & TST \\
\hline CHEMBL1586447 & 688239 & 4.5362 & 5.4689 & TST \\
\hline CHEMBL1446466 & 688239 & 4.5362 & 5.6519 & TRN \\
\hline CHEMBL1379362 & 688239 & 5.7362 & 5.4044 & TRN \\
\hline CHEMBL1382341 & 688239 & 5.1862 & 5.529 & TRN \\
\hline CHEMBL1319083 & 688239 & 6.2862 & 5.5972 & TST \\
\hline CHEMBL1613614 & 688239 & 4.5362 & 5.3682 & TRN \\
\hline CHEMBL1454014 & 688239 & 4.7362 & 5.4057 & TRN \\
\hline CHEMBL1502687 & 688239 & 4.5362 & 5.4067 & TRN \\
\hline CHEMBL1993575 & 688239 & 5.8862 & 5.547006 & 0000000001 \\
\hline CHEMBL1548030 & 688239 & 5.5862 & 5.5224 & TST \\
\hline CHEMBL1421215 & 688239 & 5.1862 & 5.5303 & TRN \\
\hline CHEMBL1563712 & 688239 & 7.1361 & 5.4615 & TST \\
\hline CHEMBL1579212 & 688239 & 5.8862 & 5.474 & TST \\
\hline CHEMBL1569684 & 688239 & 5.6862 & 5.4682 & TRN \\
\hline CHEMBL1325658 & 688239 & 5.1362 & 5.4427 & TRN \\
\hline CHEMBL1330811 & 688239 & 6.9363 & 5.5484 & TRN \\
\hline CHEMBL1410864 & 688239 & 5.0362 & 5.422999 & 9999999999 \\
\hline CHEMBL1534105 & 688239 & 6.8362 & 5.4979 & TRN \\
\hline CHEMBL1538667 & 688239 & 4.6362 & 5.4686 & TRN \\
\hline CHEMBL1385977 & 688239 & 5.4362 & 5.5651 & TST \\
\hline CHEMBL1419260 & 688239 & 4.5362 & 5.5579 & TRN \\
\hline CHEMBL1454489 & 688239 & 4.5362 & 5.4467 & TRN \\
\hline CHEMBL1478892 & 688239 & 6.5862 & 5.4827 & TST \\
\hline CHEMBL1593759 & 688239 & 4.6862 & 5.6209 & TRN \\
\hline CHEMBL1549800 & 688239 & 4.8862 & 5.4123 & TRN \\
\hline CHEMBL1331349 & 688239 & 5.6362 & 5.5542 & TRN \\
\hline CHEMBL1538339 & 688239 & 5.0362 & 5.4082 & TRN \\
\hline CHEMBL1406999 & 688239 & 6.9363 & 5.4103 & TST \\
\hline CHEMBL1587003 & 688239 & 4.7862 & 5.4303 & TRN \\
\hline CHEMBL1303755 & 688239 & 5.1862 & 5.4613 & TST \\
\hline CHEMBL1456708 & 688239 & 5.1862 & 5.5092 & TRN \\
\hline CHEMBL1330249 & 688239 & 5.6362 & 5.489 & TRN \\
\hline CHEMBL1484487 & 688239 & 4.8362 & 5.4408 & TRN \\
\hline CHEMBL1400504 & 688239 & 4.7862 & 5.4572 & TST \\
\hline CHEMBL1339587 & 688239 & 5.6862 & 5.5614 & TST \\
\hline CHEMBL1477137 & 688239 & 5.6862 & 5.5519 & TST \\
\hline CHEMBL1437799 & 688239 & 7.2865 & 5.4641 & TST \\
\hline CHEMBL1535692 & 688239 & 6.7862 & 5.4632 & TRN \\
\hline
\end{tabular}


Supplemental Table S2.txt

\begin{tabular}{|c|c|c|c|c|c|}
\hline CHEMBL1329660 & 688239 & 5.7362 & 5.6989 & TRN & \\
\hline CHEMBL1420909 & 688239 & 5.5362 & 5.4339 & TRN & \\
\hline CHEMBL1450219 & 688239 & 4.5362 & 5.3796 & TRN & \\
\hline CHEMBL1526880 & 688239 & 4.5362 & 5.5665 & TRN & \\
\hline CHEMBL1539955 & 688239 & 6.0862 & 5.4859 & TRN & \\
\hline CHEMBL1546640 & 688239 & 4.6362 & 5.5481 & TRN & \\
\hline CHEMBL1536130 & 688239 & 5.4362 & 5.4488 & TRN & \\
\hline CHEMBL1414156 & 688239 & 4.7362 & 5.6383 & TRN & \\
\hline CHEMBL1312904 & 688239 & 7.6364 & 5.4254 & TRN & \\
\hline CHEMBL1422260 & 688239 & 5.8862 & 5.5067 & TRN & \\
\hline CHEMBL1604497 & 688239 & 4.7862 & 5.5223 & TRN & \\
\hline CHEMBL1470211 & 688239 & 6.2362 & 5.4938 & TRN & \\
\hline CHEMBL1588850 & 688239 & 4.7362 & 5.4664 & TRN & \\
\hline CHEMBL1351794 & 688239 & 6.0862 & 5.6133 & TRN & \\
\hline CHEMBL1464832 & 688239 & 5.3362 & 5.3865 & TRN & \\
\hline CHEMBL1565463 & 688239 & 5.4862 & 5.5431 & TRN & \\
\hline CHEMBL1371194 & 688239 & 5.1862 & 5.3075 & TRN & \\
\hline CHEMBL1385832 & 688239 & 4.7862 & 5.4284 & TST & \\
\hline CHEMBL1423300 & 688239 & 6.2362 & 5.4594 & TST & \\
\hline CHEMBL1571376 & 688239 & 4.5362 & 5.4554 & TRN & \\
\hline CHEMBL3192641 & 688239 & 4.8862 & 5.4874 & TRN & \\
\hline CHEMBL1485438 & 688239 & 8.3372 & 5.5788 & TRN & \\
\hline CHEMBL1375894 & 688239 & 4.4862 & 5.303999 & 999999999 & TR \\
\hline CHEMBL1422731 & 688239 & 4.5362 & 5.5105 & TRN & \\
\hline CHEMBL1566989 & 688239 & 4.9362 & 5.4911 & TRN & \\
\hline CHEMBL1510390 & 688239 & 5.4362 & 5.272 & TRN & \\
\hline CHEMBL 3189973 & 688239 & 4.6862 & 5.3872 & TRN & \\
\hline CHEMBL1450847 & 688239 & 4.8362 & 5.5466 & TRN & \\
\hline CHEMBL1461746 & 688239 & 4.8362 & 5.5355 & TST & \\
\hline CHEMBL1345961 & 688239 & 6.6362 & 5.5469 & TRN & \\
\hline CHEMBL1529459 & 688239 & 6.0862 & 5.4841 & TRN & \\
\hline CHEMBL1574591 & 688239 & 5.1862 & 5.5727 & TRN & \\
\hline CHEMBL1368829 & 688239 & 5.3862 & 5.5754 & TRN & \\
\hline CHEMBL1416800 & 688239 & 8.1367 & 5.4826 & TRN & \\
\hline CHEMBL3189905 & 688239 & 4.5362 & 5.5501 & TRN & \\
\hline CHEMBL1613279 & 688239 & 4.5362 & 5.4134 & TRN & \\
\hline CHEMBL1497848 & 688239 & 6.1362 & 5.5359 & TRN & \\
\hline CHEMBL1459281 & 688239 & 7.9872 & 5.5497 & TRN & \\
\hline CHEMBL1364233 & 688239 & 4.5862 & 5.3833 & TRN & \\
\hline CHEMBL1511149 & 688239 & 5.1862 & 5.523 & TRN & \\
\hline CHEMBL1595346 & 688239 & 5.6862 & 5.4703 & TRN & \\
\hline CHEMBL1412455 & 688239 & 5.1362 & 5.5775 & TST & \\
\hline CHEMBL1368523 & 688239 & 5.1862 & 5.4279 & TST & \\
\hline CHEMBL3190043 & 688239 & 6.3362 & 5.3465 & TRN & \\
\hline CHEMBL1322430 & 688239 & 5.6862 & 5.4772 & TST & \\
\hline CHEMBL1471634 & 688239 & 5.1862 & 5.5938 & TST & \\
\hline CHEMBL1404145 & 688239 & 8.28399 & 99999999 & 5.6006 & $\mathrm{~T} \mathrm{KN}$ \\
\hline CHEMBL1384061 & 688239 & 4.7862 & 5.4231 & TST & \\
\hline
\end{tabular}


Supplemental Table S2.txt

\begin{tabular}{|c|c|c|c|c|c|}
\hline CHEMBL1343061 & 688239 & 7.1864 & 5.4868 & TST & \\
\hline CHEMBL1299837 & 688239 & 5.1862 & 5.5673 & TRN & \\
\hline CHEMBL1442938 & 688239 & 5.1862 & 5.5456 & TRN & \\
\hline CHEMBL1603407 & 688239 & 5.2362 & 5.6336 & TST & \\
\hline CHEMBL1318216 & 688239 & 4.6862 & 5.4644 & TRN & \\
\hline CHEMBL1479710 & 688239 & 7.2366 & 5.5452 & TRN & \\
\hline CHEMBL1607758 & 688239 & 4.5362 & 5.4898 & TRN & \\
\hline CHEMBL1389509 & 688239 & 4.7362 & 5.2989 & TRN & \\
\hline CHEMBL1986741 & 688239 & 4.5362 & 5.3003 & TST & \\
\hline CHEMBL1394309 & 688239 & 5.8862 & 5.5911 & TST & \\
\hline CHEMBL1346896 & 688239 & 8.1871 & 5.5376 & TRN & \\
\hline CHEMBL1315745 & 688239 & 4.6362 & 5.5658 & TRN & \\
\hline CHEMBL1533405 & 688239 & 4.6862 & 5.7081 & TRN & \\
\hline CHEMBL1332774 & 688239 & 5.7862 & 5.5427 & TRN & \\
\hline CHEMBL1612078 & 688239 & 4.5362 & 5.4141 & TRN & \\
\hline CHEMBL1519282 & 688239 & 4.6362 & 5.48600 & 2000000001 & TRN \\
\hline CHEMBL1459021 & 688239 & 4.9862 & 5.5847 & TRN & \\
\hline CHEMBL1588821 & 688239 & 4.6362 & 5.4819 & TST & \\
\hline CHEMBL1472395 & 688239 & 6.8362 & 5.7029 & TRN & \\
\hline CHEMBL1583921 & 688239 & 5.6862 & 5.4898 & TRN & \\
\hline CHEMBL1494082 & 688239 & 5.7862 & 5.4636 & TRN & \\
\hline CHEMBL1339346 & 688239 & 6.1862 & 5.7033 & TRN & \\
\hline CHEMBL1379124 & 688239 & 4.4862 & 5.3999 & TST & \\
\hline CHEMBL1996136 & 688239 & 7.0862 & 5.6255 & TRN & \\
\hline CHEMBL1419192 & 688239 & 4.7862 & 5.5174 & TST & \\
\hline CHEMBL1427195 & 688239 & 4.9362 & 5.5781 & TRN & \\
\hline CHEMBL1316274 & 688239 & 4.6862 & 5.4167 & TST & \\
\hline CHEMBL1313660 & 688239 & 4.5362 & 5.5259 & TRN & \\
\hline CHEMBL1299562 & 688239 & 5.1862 & 5.575 & TRN & \\
\hline CHEMBL1363043 & 688239 & 4.4862 & 5.5257 & TST & \\
\hline CHEMBL1592033 & 688239 & 8.3872 & 5.5323 & TRN & \\
\hline CHEMBL1588726 & 688239 & 6.2362 & 5.7149 & TRN & \\
\hline CHEMBL1588622 & 688239 & 4.5362 & 5.5648 & TRN & \\
\hline CHEMBL1452189 & 688239 & 5.9862 & 5.404 & TRN & \\
\hline CHEMBL1432841 & 688239 & 5.1862 & 5.3452 & TST & \\
\hline CHEMBL1527307 & 688239 & 6.9863 & 5.5174 & TST & \\
\hline CHEMBL1404362 & 688239 & 5.6862 & 5.4731 & TRN & \\
\hline CHEMBL1302817 & 688239 & 5.5362 & 5.5278 & TST & \\
\hline CHEMBL1527114 & 688239 & 6.1862 & 5.5447 & TRN & \\
\hline CHEMBL1324881 & 688239 & 4.8862 & 5.4758 & TST & \\
\hline CHEMBL1469206 & 688239 & 5.3362 & 5.4857 & TRN & \\
\hline CHEMBL1327931 & 688239 & 6.0862 & 5.4261 & TST & \\
\hline CHEMBL1379441 & 688239 & 5.1862 & 5.6624 & TRN & \\
\hline CHEMBL1439680 & 688239 & 6.5363 & 5.4572 & TRN & \\
\hline CHEMBL1541831 & 688239 & 5.2862 & 5.5403 & TST & \\
\hline CHEMBL1514642 & 688239 & 4.5362 & 5.6066 & TST & \\
\hline CHEMBL1420286 & 688239 & 4.6362 & 5.3209 & TRN & \\
\hline CHEMBL1566331 & 688239 & 6.1862 & 5.5663 & TRN & \\
\hline
\end{tabular}

Page 1033 
Supplemental Table S2.txt

\begin{tabular}{|c|c|c|c|c|}
\hline 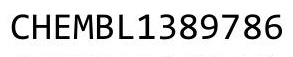 & & 862 & & \\
\hline HEMBL1609751 & 88239 & 7362 & 4 & \\
\hline HEMBL1476975 & 88239 & .8362 & & \\
\hline IEMBL1 & & 362 & & \\
\hline EMBL15 & & 862 & 3842 & \\
\hline HEMBL1490761 & 88239 & 362 & 4718 & \\
\hline HEMBL600495 & 88239 & .9862 & .409 & \\
\hline HEMBL1550683 & 239 & 862 & 589 & \\
\hline AEMBL: & 39 & 862 & & \\
\hline IEMBL131 & 39 & 862 & & \\
\hline HEMBL1327252 & 88239 & 362 & .4746 & \\
\hline HEMBL1509482 & 39 & .7362 & .4497 & \\
\hline HEMBL154 & 39 & 862 & .6806 & \\
\hline HEMBL14C & & & 54 & \\
\hline HEMBL13 & 39 & 862 & & \\
\hline HEMBL 148 & 39 & 356 & .4587 & \\
\hline HEMBL1324930 & 88 & 862 & .4528 & \\
\hline HEMBL142 & 39 & 62 & 37 & \\
\hline HEMBL151 & 9 & & & \\
\hline HEMBL15 & 39 & & & RN \\
\hline HEMBL14 & 39 & 62 & & ST \\
\hline HEMBL1568482 & 39 & 62 & 31 & RN \\
\hline HEMBL138 & 39 & 62 & 55 & \\
\hline HEMBL14 & & & & \\
\hline HEM & 39 & & & RN \\
\hline HEMBL 14 & 39 & & & RN \\
\hline HEMBL1431592 & 39 & 62 & 33 & RN \\
\hline HEMBL131 & 39 & 62 & 08 & RN \\
\hline HEM & & & & RN \\
\hline HEME & & & & RN \\
\hline HEMBL 138 & 9 & & & ST \\
\hline HEMBL1411797 & 88239 & 62 & 5 . & ST \\
\hline HEMBL 15 & 39 & 62 & & ST \\
\hline HEM & 9 & & & RN \\
\hline HEMBL133 & & & & RN \\
\hline HEMBL1395487 & 39 & & & RN \\
\hline HEMBL137. & 39 & 362 & 178 & RN \\
\hline HEMBL157 & 39 & 62 & 84 & RN \\
\hline 190 & & & & ST \\
\hline HEMBL156 & & & & RN \\
\hline HEMBL153 & 39 & 362 & 549 & ST \\
\hline HEMBL14 & 39 & 362 & & RN \\
\hline HEMBL13 & & 863 & & \\
\hline CHEMBL 147 & & & & RN \\
\hline HEMBL13 & & & 5.4317 & RN \\
\hline HEMBL135 & 88 & 862 & 317 & RN \\
\hline-14 & & & & \\
\hline & & & & \\
\hline
\end{tabular}

Page 1034 


\begin{tabular}{|c|c|c|c|c|c|}
\hline \multicolumn{6}{|c|}{ Supplemental Table S2.txt } \\
\hline CHEMBL1560255 & 688239 & 8.4318 & 5.5584 & TRN & \\
\hline CHEMBL1494282 & 688239 & 5.0862 & 5.3257 & TST & \\
\hline CHEMBL1579000 & 688239 & 6.0862 & 5.5658 & TRN & \\
\hline CHEMBL 3210988 & 688239 & 6.2362 & 5.456 & TRN & \\
\hline CHEMBL1467941 & 688239 & 7.8356 & 5.3749 & TST & \\
\hline CHEMBL1361931 & 688239 & 6.2362 & 5.4671 & TRN & \\
\hline CHEMBL1382610 & 688239 & 4.5362 & 5.4508 & TRN & \\
\hline CHEMBL1454698 & 688239 & 4.6362 & 5.4704 & TST & \\
\hline CHEMBL1525144 & 688239 & 4.7862 & 5.3997 & TRN & \\
\hline CHEMBL3193989 & 688239 & 7.8861 & 5.3623 & TRN & \\
\hline CHEMBL1558164 & 688239 & 5.6862 & 5.4706 & TRN & \\
\hline CHEMBL 3195952 & 688239 & 5.6362 & 5.5028 & TRN & \\
\hline CHEMBL1601955 & 688239 & 5.5862 & 5.5337 & TRN & \\
\hline CHEMBL1548664 & 688239 & 4.7362 & 5.4152 & TST & \\
\hline CHEMBL1588116 & 688239 & 5.6362 & 5.4889 & TST & \\
\hline CHEMBL1477300 & 688239 & 5.0362 & 5.6052 & TRN & \\
\hline CHEMBL1457829 & 688239 & 5.9362 & 5.5128 & TRN & \\
\hline CHEMBL1380757 & 688239 & 5.1862 & 5.4493 & TRN & \\
\hline CHEMBL1515123 & 688239 & 5.0362 & 5.4453 & TST & \\
\hline CHEMBL1427945 & 688239 & 7.0862 & 5.5867 & TRN & \\
\hline CHEMBL1564849 & 688239 & 6.0862 & 5.4719 & TRN & \\
\hline CHEMBL1450369 & 688239 & 6.2362 & 5.4864 & TRN & \\
\hline CHEMBL1456276 & 688239 & 4.5362 & 5.4734 & TRN & \\
\hline CHEMBL1367437 & 688239 & 5.1862 & 5.4899 & TRN & \\
\hline CHEMBL1586172 & 688239 & 4.6862 & 5.48799 & 99999999995 & TRN \\
\hline CHEMBL3196387 & 688239 & 5.2362 & 5.5286 & TRN & \\
\hline CHEMBL1348027 & 688239 & 4.6362 & 5.4772 & TRN & \\
\hline CHEMBL1500718 & 688239 & 5.3862 & 5.5194 & TST & \\
\hline CHEMBL1486618 & 688239 & 6.8861 & 5.3678 & TRN & \\
\hline CHEMBL1312868 & 688239 & 4.4862 & 5.5643 & TST & \\
\hline CHEMBL1350956 & 688239 & 5.1862 & 5.4428 & TRN & \\
\hline CHEMBL 3193824 & 688239 & 5.2362 & 5.395 & TRN & \\
\hline CHEMBL1370795 & 688239 & 5.2362 & 5.4882 & TRN & \\
\hline CHEMBL1530401 & 688239 & 5.2362 & 5.4002 & TRN & \\
\hline CHEMBL1345893 & 688239 & 8.3372 & 5.3083 & TRN & \\
\hline CHEMBL1304695 & 688239 & 4.6862 & 5.5403 & TST & \\
\hline CHEMBL1457998 & 688239 & 5.1862 & 5.4513 & TRN & \\
\hline CHEMBL1604562 & 688239 & 8.2366 & 5.4563 & TRN & \\
\hline CHEMBL1445728 & 688239 & 4.7362 & 5.4794 & TRN & \\
\hline CHEMBL1430489 & 688239 & 4.6862 & 5.4967 & TST & \\
\hline CHEMBL1314317 & 688239 & 4.9362 & 5.4256 & TRN & \\
\hline CHEMBL1484064 & 688239 & 6.1862 & 5.5768 & TRN & \\
\hline CHEMBL1429364 & 688239 & 5.6362 & 5.6051 & TRN & \\
\hline CHEMBL1442847 & 688239 & 5.0862 & 5.4788 & TRN & \\
\hline CHEMBL1398368 & 688239 & 5.3862 & 5.5169 & TRN & \\
\hline CHEMBL1345485 & 688239 & 5.1862 & 5.5425 & TRN & \\
\hline CHEMBL1542691 & 688239 & 4.5362 & 5.4678 & TST & \\
\hline CHEMBL242572 & 688239 & 4.5362 & 5.4195 & TRN & \\
\hline
\end{tabular}


Supplemental Table S2.txt

\begin{tabular}{|c|c|c|c|c|}
\hline & & & & \\
\hline AEMBL1306920 & 8239 & 362 & 3961 & \\
\hline IEMBL1462740 & 3239 & 862 & & \\
\hline AEMBL1313102 & 239 & 362 & 207 & \\
\hline & 239 & & & \\
\hline IEMBL1536014 & 239 & 362 & 305 & \\
\hline AEMBL1304006 & 88239 & 362 & 4024 & \\
\hline AEMBL1521766 & 88239 & 362 & 2941 & \\
\hline AEMBL1332279 & 239 & 862 & 013 & \\
\hline AEMBL1376 & 239 & 62 & & \\
\hline IEMBL1514912 & & & & \\
\hline AEMBL1580511 & 688239 & 862 & 298 & \\
\hline AEMBL1518473 & 239 & 862 & & \\
\hline IEMBL136] & & 362 & 572 & \\
\hline IEMBL142S & & & & \\
\hline AEMBL1327401 & & & & \\
\hline AEMBL1524280 & 39 & 362 & 251 & RN \\
\hline AEMBL1327956 & & 362 & & ST \\
\hline IEMBL152 & & 4. & & \\
\hline AEMBL319 & & & & \\
\hline FMBI $144 C$ & & & & \\
\hline AEMBL1444374 & & 362 & & \\
\hline IEMBL1607 & & & & \\
\hline IEMBL155 & & & & RI \\
\hline IEMBL143 & & & & ST \\
\hline AFMRI 1478 & & & & ST \\
\hline AEMBL1351164 & & & & RN \\
\hline AEMBL1331908 & & & & ST \\
\hline IEMBL1490 & & & & $\mathrm{RN}$ \\
\hline HEMBL13 & & & & . \\
\hline 18 & & 52 & & RN \\
\hline AEMBL1378193 & & & & RN \\
\hline AEMBL1548634 & & & & RI \\
\hline AEMBL1490 & & & & RI \\
\hline AFMRI 1553 & & 52 & & $\cdots$ \\
\hline & & & & $\cdots$ \\
\hline AEMBL1459039 & & & & $\mathrm{R}$ \\
\hline AEMBL1339884 & & & & \\
\hline EMBL3212 & & & & RI \\
\hline תריר יחוזו & & & & \\
\hline-14 & & & & RN \\
\hline AEMBL1367054 & & 362 & 14 & $\mathrm{R}$ \\
\hline IEMBL1407308 & & & & TS \\
\hline EMBL148 & & & & TS \\
\hline HEMBL1449240 & & & & \\
\hline CHEMBL1413288 & & 362 & 846 & $\mathrm{~T}$ \\
\hline HEMBL1399556 & 8239 & 5.5362 & 5.4433 & TST \\
\hline HFMBI 1326235 & 688239 & 4.5362 & 5.5021 & \\
\hline
\end{tabular}

Page 1036 
Supplemental Table S2.txt

\begin{tabular}{|c|c|c|c|c|}
\hline CHEMBL1417514 & 688239 & 4.5362 & 5.5166 & TRN \\
\hline CHEMBL1486130 & 688239 & 4.7862 & 5.4502 & TRN \\
\hline CHEMBL1324309 & 688239 & 4.5362 & 5.5497 & TRN \\
\hline CHEMBL3212581 & 688239 & 4.5362 & 5.4803 & TST \\
\hline CHEMBL1329403 & 688239 & 5.5862 & 5.5845 & TRN \\
\hline CHEMBL1412898 & 688239 & 4.5362 & 5.4505 & TRN \\
\hline CHEMBL1408162 & 688239 & 4.5362 & 5.3903 & TRN \\
\hline CHEMBL1487546 & 688239 & 6.1862 & 5.4882 & TRN \\
\hline CHEMBL1608705 & 688239 & 4.6362 & 5.4631 & TRN \\
\hline CHEMBL365558 & 688239 & 6.8861 & 5.4362 & TST \\
\hline CHEMBL1339389 & 688239 & 5.4362 & \multicolumn{2}{|c|}{5.3420000000000005} \\
\hline CHEMBL1454457 & 688239 & 4.7862 & 5.51399 & 9999999999 \\
\hline CHEMBL3192547 & 688239 & 4.6862 & 5.3977 & TRN \\
\hline CHEMBL1564870 & 688239 & 4.5362 & 5.5227 & TST \\
\hline CHEMBL1346039 & 688239 & 4.5362 & 5.5558 & TST \\
\hline CHEMBL1431664 & 688239 & 5.1362 & 5.5526 & TST \\
\hline CHEMBL1547226 & 688239 & 5.1362 & 5.6326 & TRN \\
\hline CHEMBL1361611 & 688239 & 8.3372 & 5.5511 & TRN \\
\hline CHEMBL 3210842 & 688239 & 5.1862 & 5.4127 & TRN \\
\hline CHEMBL581417 & 688239 & 5.7362 & 5.6212 & TRN \\
\hline CHEMBL1429225 & 688239 & 6.7862 & 5.5706 & TRN \\
\hline CHEMBL1430034 & 688239 & 6.7361 & 5.6899 & TRN \\
\hline CHEMBL1584119 & 688239 & 5.2362 & 5.4116 & TRN \\
\hline CHEMBL1567206 & 688239 & 5.9862 & 5.3704 & TRN \\
\hline CHEMBL1305563 & 688239 & 4.9362 & 5.6105 & TST \\
\hline CHEMBL1362577 & 688239 & 4.7862 & 5.4914 & TRN \\
\hline CHEMBL1454689 & 688239 & 6.2362 & 5.4545 & TRN \\
\hline CHEMBL1599796 & 688239 & 5.1862 & 5.5199 & TRN \\
\hline CHEMBL1375493 & 688239 & 6.3863 & 5.518 & TRN \\
\hline CHEMBL1483429 & 688239 & 5.3362 & 5.4446 & TST \\
\hline CHEMBL601335 & 688239 & 6.7361 & 5.414 & TRN \\
\hline CHEMBL1530648 & 688239 & 6.6861 & 5.5965 & TRN \\
\hline CHEMBL1566512 & 688239 & 5.4362 & 5.4003 & TRN \\
\hline CHEMBL1409210 & 688239 & 5.4862 & 5.4024 & TRN \\
\hline CHEMBL1379318 & 688239 & 5.2362 & 5.4894 & TRN \\
\hline CHEMBL1483311 & 688239 & 4.6862 & 5.3501 & TST \\
\hline CHEMBL1449196 & 688239 & 4.5362 & 5.5372 & TRN \\
\hline CHEMBL1453711 & 688239 & 5.3862 & 5.5271 & TRN \\
\hline CHEMBL1584475 & 688239 & 4.5362 & 5.4939 & TRN \\
\hline CHEMBL1559010 & 688239 & 5.6362 & 5.3879 & TRN \\
\hline CHEMBL1569341 & 688239 & 5.4862 & 5.4976 & TRN \\
\hline CHEMBL1487274 & 688239 & 7.0362 & 5.5265 & TRN \\
\hline CHEMBL1372809 & 688239 & 4.5362 & 5.5353 & TST \\
\hline CHEMBL1464905 & 688239 & 5.6862 & 5.518 & TRN \\
\hline CHEMBL1447014 & 688239 & 6.4862 & 5.3946 & TRN \\
\hline CHEMBL1445786 & 688239 & 4.5362 & 5.4127 & TRN \\
\hline CHEMBL1533476 & 688239 & 4.5362 & 5.4611 & TRN \\
\hline CHEMBL3194845 & 688239 & 5.1862 & 5.4189 & TRN \\
\hline
\end{tabular}


Supplemental Table S2.txt

\begin{tabular}{|c|c|c|c|c|}
\hline CHEMBL1404535 & 688239 & 5.0862 & 5.4692 & TRN \\
\hline CHEMBL1466716 & 688239 & 5.1362 & 5.6481 & TRN \\
\hline CHEMBL1464168 & 688239 & 5.8862 & 5.478 & TRN \\
\hline CHEMBL1499948 & 688239 & 5.1862 & 5.447 & TRN \\
\hline CHEMBL1579095 & 688239 & 5.2362 & 5.4238 & TRN \\
\hline CHEMBL 3198241 & 688239 & 4.6862 & 5.4331 & TRN \\
\hline CHEMBL1416496 & 688239 & 5.6862 & 5.5081 & TRN \\
\hline CHEMBL3194060 & 688239 & 5.7862 & 5.4447 & TRN \\
\hline CHEMBL1511884 & 688239 & 6.3362 & 5.5556 & TRN \\
\hline CHEMBL 3197368 & 688239 & 4.5362 & 5.3755 & TRN \\
\hline CHEMBL1353781 & 688239 & 6.5862 & 5.3725 & TST \\
\hline CHEMBL1394815 & 688239 & 4.6862 & 5.6032 & TRN \\
\hline CHEMBL1548074 & 688239 & 5.9362 & 5.394 & TST \\
\hline CHEMBL1508879 & 688239 & 4.7362 & 5.4336 & TRN \\
\hline CHEMBL1468760 & 688239 & 4.4862 & 5.6944 & TRN \\
\hline CHEMBL1408392 & 688239 & 6.1862 & 5.5214 & TRN \\
\hline CHEMBL1517391 & 688239 & 5.1862 & 5.5154 & TRN \\
\hline CHEMBL1603134 & 688239 & 5.6862 & 5.5435 & TRN \\
\hline CHEMBL1463323 & 688239 & 5.2862 & 5.5333 & TRN \\
\hline CHEMBL1518040 & 688239 & 4.5362 & 5.3225 & TST \\
\hline CHEMBL 3207932 & 688239 & 6.4862 & 5.6447 & TRN \\
\hline CHEMBL1334842 & 688239 & 6.9363 & 5.5387 & TST \\
\hline CHEMBL3209350 & 688239 & 5.4862 & 5.58299 & 9999999999 \\
\hline CHEMBL1418996 & 688239 & 5.1862 & 5.5262 & TRN \\
\hline CHEMBL1477616 & 688239 & 5.4362 & 5.5293 & TRN \\
\hline CHEMBL1546279 & 688239 & 6.3362 & 5.5296 & TRN \\
\hline CHEMBL1594165 & 688239 & 5.2862 & 5.40600 & 0000000001 \\
\hline CHEMBL1603351 & 688239 & 6.0862 & 5.5715 & TRN \\
\hline CHEMBL1425959 & 688239 & 5.2362 & 5.4516 & TRN \\
\hline CHEMBL1387224 & 688239 & 5.8362 & 5.5883 & TST \\
\hline CHEMBL3211472 & 688239 & 7.7352 & 5.3822 & TRN \\
\hline CHEMBL1607340 & 688239 & 4.9862 & 5.456 & TST \\
\hline CHEMBL1596077 & 688239 & 4.9362 & 5.4863 & TST \\
\hline CHEMBL1567116 & 688239 & 6.1362 & 5.3563 & TRN \\
\hline CHEMBL1527385 & 688239 & 6.2862 & 5.5413 & TRN \\
\hline CHEMBL1317903 & 688239 & 5.2862 & 5.6011 & TRN \\
\hline CHEMBL1468481 & 688239 & 5.2362 & 5.4896 & TRN \\
\hline CHEMBL3208411 & 688239 & 4.4862 & 5.3065 & TST \\
\hline CHEMBL1411118 & 688239 & 8.3872 & 5.6188 & TST \\
\hline CHEMBL1341068 & 688239 & 4.6862 & 5.5703 & TRN \\
\hline CHEMBL1406019 & 688239 & 5.3862 & 5.402 & TRN \\
\hline CHEMBL1411452 & 688239 & 4.5362 & 5.54899 & 99999999995 \\
\hline CHEMBL1590635 & 688239 & 6.1862 & 5.4629 & TRN \\
\hline CHEMBL1591920 & 688239 & 7.1864 & 5.53299 & 99999999995 \\
\hline CHEMBL1364256 & 688239 & 5.1862 & 5.606 & TRN \\
\hline CHEMBL3212833 & 688239 & 5.7362 & 5.2798 & TRN \\
\hline CHEMBL1558144 & 688239 & 7.1361 & 5.3906 & TRN \\
\hline CHEMBL1472140 & 688239 & 5.1862 & 5.5322 & TRN \\
\hline
\end{tabular}


Supplemental Table S2.txt

\begin{tabular}{|c|c|c|c|c|c|}
\hline CHEMBL1457434 & 688239 & 6.6362 & 5.3828 & TRN & \\
\hline CHEMBL1484191 & 688239 & 6.1362 & 5.5098 & TRN & \\
\hline CHEMBL1416358 & 688239 & 6.4362 & 5.5592 & TST & \\
\hline CHEMBL1452409 & 688239 & 4.5362 & 5.3038 & TRN & \\
\hline CHEMBL1315649 & 688239 & 5.0362 & 5.5785 & TRN & \\
\hline CHEMBL1522295 & 688239 & 6.0862 & 5.6245 & TRN & \\
\hline CHEMBL1608311 & 688239 & 5.7362 & 5.6376 & TRN & \\
\hline CHEMBL229190 & 688239 & 5.5862 & 5.4383 & TRN & \\
\hline CHEMBL1493843 & 688239 & 5.3362 & 5.6259 & TRN & \\
\hline CHEMBL1317442 & 688239 & 5.5362 & 5.5795 & TRN & \\
\hline CHEMBL1381464 & 688239 & 5.1362 & 5.5342 & TRN & \\
\hline CHEMBL1548350 & 688239 & 4.5362 & 5.5086 & TRN & \\
\hline CHEMBL1311861 & 688239 & 4.5362 & 5.5108 & TRN & \\
\hline CHEMBL1528417 & 688239 & 5.0 & 5.5524 & TRN & \\
\hline CHEMBL1423082 & 688239 & 4.5362 & 5.5909 & TRN & \\
\hline CHEMBL1473323 & 688239 & 6.1862 & 5.4962 & TRN & \\
\hline CHEMBL1454401 & 688239 & 7.3862 & 5.5302 & TRN & \\
\hline CHEMBL3198886 & 688239 & 4.6862 & 5.4262 & TRN & \\
\hline CHEMBL1515180 & 688239 & 5.6362 & 5.5833 & TRN & \\
\hline CHEMBL1459289 & 688239 & 4.5362 & 5.5136 & TRN & \\
\hline CHEMBL1428163 & 688239 & 4.7362 & 5.481 & TRN & \\
\hline CHEMBL1585669 & 688239 & 5.1362 & 5.4666 & TRN & \\
\hline CHEMBL1498682 & 688239 & 4.6862 & 5.5358 & TRN & \\
\hline CHEMBL1528520 & 688239 & 4.4862 & 5.5955 & TRN & \\
\hline CHEMBL1447065 & 688239 & 4.4862 & 5.4579 & TRN & \\
\hline CHEMBL1317900 & 688239 & 4.5362 & 5.4011 & TST & \\
\hline CHEMBL1521867 & 688239 & 5.2362 & 5.5255 & TRN & \\
\hline CHEMBL1310429 & 688239 & 5.9862 & 5.5717 & TRN & \\
\hline CHEMBL1446745 & 688239 & 5.1862 & 5.5134 & TRN & \\
\hline CHEMBL1449911 & 688239 & 4.7362 & 5.3799 & TRN & \\
\hline CHEMBL1535684 & 688239 & 5.5362 & 5.476 & TST & \\
\hline CHEMBL1430473 & 688239 & 8.3372 & 5.3172 & TST & \\
\hline CHEMBL 233149 & 688239 & 4.7362 & 5.4693 & TRN & \\
\hline CHEMBL1332538 & 688239 & 5.4862 & 5.4619 & TRN & \\
\hline CHEMBL1477395 & 688239 & 7.0362 & \multicolumn{2}{|c|}{5.587000000000001} & TRN \\
\hline CHEMBL1551819 & 688239 & 6.2862 & 5.3696 & TRN & \\
\hline CHEMBL1440338 & 688239 & 4.5362 & 5.5643 & TRN & \\
\hline CHEMBL1455422 & 688239 & 5.1862 & 5.465 & TST & \\
\hline CHEMBL1540205 & 688239 & 5.3362 & 5.354 & TRN & \\
\hline CHEMBL1565040 & 688239 & 6.9363 & 5.4542 & TST & \\
\hline CHEMBL1482475 & 688239 & 6.8861 & 5.4682 & TRN & \\
\hline CHEMBL1467108 & 688239 & 6.8362 & 5.4127 & TST & \\
\hline CHEMBL1341545 & 688239 & 6.7361 & 5.7047 & TRN & \\
\hline CHEMBL1474431 & 688239 & 4.5362 & 5.5167 & TRN & \\
\hline CHEMBL1513775 & 688239 & 4.6362 & 5.5447 & TRN & \\
\hline CHEMBL1524448 & 688239 & 7.1361 & 5.5938 & TRN & \\
\hline CHEMBL1500559 & 688239 & 5.2362 & 5.6086 & TST & \\
\hline CHEMBL1431171 & 688239 & 4.5362 & 5.4919 & TRN & \\
\hline
\end{tabular}


Supplemental Table S2.txt

\begin{tabular}{|c|c|c|c|c|c|}
\hline CHEMBL1472171 & 688239 & 5.3362 & 5.5524 & TRN & \\
\hline CHEMBL1478789 & 688239 & 6.9363 & 5.6031 & TRN & \\
\hline CHEMBL1415194 & 688239 & 4.6862 & 5.5315 & TST & \\
\hline CHEMBL1388542 & 688239 & 4.6862 & 5.4241 & TRN & \\
\hline CHEMBL1433329 & 688239 & 5.3862 & 5.3637 & TST & \\
\hline CHEMBL1385557 & 688239 & 4.5362 & \multicolumn{2}{|c|}{5.4879999999999995} & TRN \\
\hline CHEMBL1480025 & 688239 & 4.6362 & 5.4179 & TRN & \\
\hline CHEMBL1443883 & 688239 & 4.4862 & 5.6368 & TRN & \\
\hline CHEMBL1522609 & 688239 & 4.9362 & 5.5677 & TRN & \\
\hline CHEMBL1990194 & 688239 & 4.4862 & 5.5524 & TRN & \\
\hline CHEMBL1353904 & 688239 & 6.1362 & 5.5305 & TRN & \\
\hline CHEMBL1545167 & 688239 & 4.5362 & 5.4702 & TRN & \\
\hline CHEMBL1375920 & 688239 & 4.5362 & 5.6142 & TRN & \\
\hline CHEMBL1530160 & 688239 & 5.3362 & 5.3022 & TST & \\
\hline CHEMBL1485551 & 688239 & 4.5362 & 5.3638 & TRN & \\
\hline CHEMBL1579468 & 688239 & 6.8861 & 5.5392 & TRN & \\
\hline CHEMBL1600621 & 688239 & 4.6862 & 5.1649 & TRN & \\
\hline CHEMBL1496650 & 688239 & 8.3372 & 5.614 & TST & \\
\hline CHEMBL1487751 & 688239 & 5.1862 & 5.4715 & TRN & \\
\hline CHEMBL1566367 & 688239 & 6.8861 & 5.3828 & TRN & \\
\hline CHEMBL1575542 & 688239 & 4.6362 & 5.5503 & TRN & \\
\hline CHEMBL1364817 & 688239 & 5.9362 & 5.5814 & TRN & \\
\hline CHEMBL1443684 & 688239 & 4.7362 & 5.5725 & TRN & \\
\hline CHEMBL1301781 & 688239 & 4.5362 & 5.4953 & TST & \\
\hline CHEMBL1336408 & 688239 & 4.5362 & 5.5012 & TRN & \\
\hline CHEMBL1325914 & 688239 & 7.2366 & 5.5138 & TRN & \\
\hline CHEMBL1391335 & 688239 & 5.4862 & 5.4188 & TRN & \\
\hline CHEMBL1456896 & 688239 & 4.6862 & 5.4148 & TRN & \\
\hline CHEMBL1478456 & 688239 & 6.5363 & 5.5137 & TRN & \\
\hline CHEMBL3198609 & 688239 & 6.8861 & 5.4162 & TRN & \\
\hline CHEMBL1518651 & 688239 & 4.5362 & 5.4801 & TRN & \\
\hline CHEMBL1546103 & 688239 & 4.5362 & 5.5225 & TRN & \\
\hline CHEMBL1563022 & 688239 & 4.5862 & \multicolumn{2}{|c|}{5.6370000000000005} & TRN \\
\hline CHEMBL1488470 & 688239 & 6.9363 & 5.5686 & TRN & \\
\hline CHEMBL1558922 & 688239 & 4.6862 & 5.3497 & TRN & \\
\hline CHEMBL1550282 & 688239 & 4.7362 & 5.4442 & TRN & \\
\hline CHEMBL1593846 & 688239 & 5.5362 & 5.5257 & TRN & \\
\hline CHEMBL1369328 & 688239 & 6.8861 & 5.5779 & TST & \\
\hline CHEMBL1443409 & 688239 & 5.4862 & 5.4888 & TRN & \\
\hline CHEMBL1534928 & 688239 & 6.1862 & \multicolumn{2}{|c|}{5.577999999999999} & TRN \\
\hline CHEMBL1549045 & 688239 & 5.5862 & 5.3852 & TST & \\
\hline CHEMBL1565413 & 688239 & 4.5362 & 5.3085 & TRN & \\
\hline CHEMBL1395911 & 688239 & 6.9363 & 5.6469 & TRN & \\
\hline CHEMBL1335102 & 688239 & 5.2862 & 5.5097 & TRN & \\
\hline CHEMBL1378071 & 688239 & 6.0362 & 5.4819 & TRN & \\
\hline CHEMBL1356476 & 688239 & 5.1862 & 5.5007 & TRN & \\
\hline CHEMBL1402275 & 688239 & 6.4362 & 5.4271 & TRN & \\
\hline CHEMBL1382121 & 688239 & 5.3862 & 5.5045 & TRN & \\
\hline
\end{tabular}


Supplemental Table S2.txt

\begin{tabular}{|c|c|c|c|c|}
\hline CHEMBL1539428 & 688239 & 8.0862 & 5.5513 & TRN \\
\hline CHEMBL1406586 & 688239 & 5.6862 & 5.4908 & TST \\
\hline CHEMBL1374409 & 688239 & 7.5361 & 5.6172 & TRN \\
\hline CHEMBL1586276 & 688239 & 6.7361 & 5.5263 & TRN \\
\hline CHEMBL1413653 & 688239 & 5.5862 & 5.5432 & TRN \\
\hline CHEMBL1423341 & 688239 & 5.7862 & 5.4165 & TRN \\
\hline CHEMBL1301056 & 688239 & 5.2862 & 5.3981 & TRN \\
\hline CHEMBL1987820 & 688239 & 4.6362 & 5.3816 & TRN \\
\hline CHEMBL1385980 & 688239 & 4.5362 & 5.4616 & TST \\
\hline CHEMBL1503391 & 688239 & 5.1862 & 5.4522 & TST \\
\hline CHEMBL1588730 & 688239 & 5.3862 & 5.5153 & TRN \\
\hline CHEMBL1505754 & 688239 & 5.1862 & 5.4997 & TST \\
\hline CHEMBL1613177 & 688239 & 5.7362 & 5.5377 & TRN \\
\hline CHEMBL1372333 & 688239 & 4.8362 & 5.3688 & TRN \\
\hline CHEMBL1585263 & 688239 & 8.28399 & 99999999 & 5.6342 \\
\hline CHEMBL1389679 & 688239 & 5.4362 & 5.5294 & TRN \\
\hline CHEMBL1491219 & 688239 & 5.1362 & 5.5382 & TRN \\
\hline CHEMBL1417872 & 688239 & 5.2862 & 5.4463 & TRN \\
\hline CHEMBL1325687 & 688239 & 6.3362 & 5.575 & TRN \\
\hline CHEMBL1578354 & 688239 & 6.1862 & 5.454 & TST \\
\hline CHEMBL1304221 & 688239 & 7.2366 & 5.6271 & TRN \\
\hline CHEMBL3208868 & 688239 & 5.1862 & 5.5381 & TRN \\
\hline CHEMBL1420938 & 688239 & 6.2862 & 5.4862 & TST \\
\hline CHEMBL1380518 & 688239 & 4.5862 & 5.632000 & 0000000001 \\
\hline CHEMBL1302849 & 688239 & 8.28399 & 99999999 & 5.4356 \\
\hline CHEMBL1464008 & 688239 & 6.7361 & 5.4706 & TRN \\
\hline CHEMBL1584737 & 688239 & 6.9363 & 5.6354 & TRN \\
\hline CHEMBL1330182 & 688239 & 6.2362 & 5.6504 & TST \\
\hline CHEMBL1541703 & 688239 & 4.7362 & 5.4439 & TRN \\
\hline CHEMBL1555867 & 688239 & 4.5362 & 5.5588 & TRN \\
\hline CHEMBL1520227 & 688239 & 5.7862 & 5.4984 & TST \\
\hline CHEMBL1494617 & 688239 & 5.3862 & 5.5318 & TRN \\
\hline CHEMBL1409314 & 688239 & 6.4362 & 5.4547 & TST \\
\hline CHEMBL1498146 & 688239 & 4.5862 & 5.1913 & TRN \\
\hline CHEMBL1597888 & 688239 & 4.5362 & 5.2936 & TST \\
\hline CHEMBL1506439 & 688239 & 4.5362 & 5.432 & TRN \\
\hline CHEMBL1527827 & 688239 & 4.9862 & 5.7095 & TRN \\
\hline CHEMBL587919 & 688239 & 8.2366 & 5.456 & TRN \\
\hline CHEMBL1422506 & 688239 & 4.5362 & 5.6281 & TRN \\
\hline CHEMBL1504163 & 688239 & 6.1862 & 5.5916 & TST \\
\hline CHEMBL1487589 & 688239 & 5.1862 & 5.3767 & TRN \\
\hline CHEMBL1321477 & 688239 & 5.3362 & 5.4828 & TRN \\
\hline CHEMBL1445295 & 688239 & 5.1862 & 5.4111 & TRN \\
\hline CHEMBL1353725 & 688239 & 4.5362 & 5.449 & TRN \\
\hline CHEMBL 2374093 & 688239 & 6.6251 & 5.3669 & TST \\
\hline CHEMBL1504013 & 688239 & 4.7362 & 5.6678 & TRN \\
\hline CHEMBL1567994 & 688239 & 4.7862 & 5.5754 & TRN \\
\hline CHEMBL1561147 & 688239 & 6.7361 & 5.686 & TRN \\
\hline
\end{tabular}




\begin{tabular}{|c|c|c|c|c|c|}
\hline \multicolumn{6}{|c|}{ Supplemental Table S2.txt } \\
\hline CHEMBL1302946 & 688239 & 4.4862 & 5.4347 & TRN & \\
\hline CHEMBL1383610 & 688239 & 5.5362 & 5.5334 & TST & \\
\hline CHEMBL1409312 & 688239 & 4.5362 & 5.3505 & TRN & \\
\hline CHEMBL1352052 & 688239 & 5.1862 & 5.3676 & TRN & \\
\hline CHEMBL1329835 & 688239 & 5.8862 & 5.5678 & TRN & \\
\hline CHEMBL1600882 & 688239 & 6.6861 & 5.2504 & TRN & \\
\hline CHEMBL1332378 & 688239 & 5.8362 & 5.4472 & TRN & \\
\hline CHEMBL1378803 & 688239 & 5.1862 & 5.5306 & TRN & \\
\hline CHEMBL1544998 & 688239 & 4.4862 & 5.3842 & TRN & \\
\hline CHEMBL1534836 & 688239 & 7.2366 & 5.5428 & TST & \\
\hline CHEMBL1301402 & 688239 & 5.7862 & 5.4949 & TRN & \\
\hline CHEMBL1311140 & 688239 & 4.4862 & 5.5029 & TRN & \\
\hline CHEMBL1610530 & 688239 & 6.1862 & 5.4415 & TRN & \\
\hline CHEMBL1536428 & 688239 & 5.1362 & 5.4563 & TRN & \\
\hline CHEMBL1480083 & 688239 & 5.7862 & 5.5947 & TRN & \\
\hline CHEMBL1303641 & 688239 & 4.6862 & 5.3843 & TST & \\
\hline CHEMBL1539706 & 688239 & 4.6362 & 5.5178 & TRN & \\
\hline CHEMBL1308784 & 688239 & 6.3863 & 5.4202 & TST & \\
\hline CHEMBL1613647 & 688239 & 7.6861 & 5.6844 & TST & \\
\hline CHEMBL1332811 & 688239 & 5.6862 & 5.4725 & TST & \\
\hline CHEMBL1399626 & 688239 & 4.6862 & 5.5228 & TRN & \\
\hline CHEMBL1385314 & 688239 & 4.5362 & 5.49100 & 00000000005 & TST \\
\hline CHEMBL1539883 & 688239 & 6.9863 & 5.5419 & TRN & \\
\hline CHEMBL1353096 & 688239 & 4.8862 & 5.4897 & TRN & \\
\hline CHEMBL1451683 & 688239 & 5.9862 & 5.5359 & TRN & \\
\hline CHEMBL1608584 & 688239 & 4.6862 & 5.4702 & TRN & \\
\hline CHEMBL1364581 & 688239 & 4.5362 & 5.519 & TRN & \\
\hline CHEMBL1569018 & 688239 & 4.6862 & 5.3705 & TST & \\
\hline CHEMBL1417338 & 688239 & 6.1362 & 5.5392 & TRN & \\
\hline CHEMBL1477681 & 688239 & 7.0862 & 5.4984 & TST & \\
\hline CHEMBL1556999 & 688239 & 6.4862 & 5.4862 & TRN & \\
\hline CHEMBL1609870 & 688239 & 5.1862 & 5.4938 & TST & \\
\hline CHEMBL1409725 & 688239 & 4.7362 & 5.5103 & TRN & \\
\hline CHEMBL1445550 & 688239 & 4.5362 & 5.5197 & TRN & \\
\hline CHEMBL1588306 & 688239 & 4.9362 & 5.5451 & TST & \\
\hline CHEMBL1602791 & 688239 & 4.5362 & 5.4195 & TRN & \\
\hline CHEMBL1608983 & 688239 & 4.4862 & 5.376 & TRN & \\
\hline CHEMBL2003172 & 688239 & 4.8362 & 5.4002 & TST & \\
\hline CHEMBL1444360 & 688239 & 5.4862 & 5.6093 & TRN & \\
\hline CHEMBL1325053 & 688239 & 4.5362 & 5.5158 & TST & \\
\hline CHEMBL1397201 & 688239 & 4.5362 & 5.4215 & TRN & \\
\hline CHEMBL1493701 & 688239 & 6.5363 & 5.4116 & TRN & \\
\hline CHEMBL1572119 & 688239 & 5.3862 & 5.2947 & TRN & \\
\hline CHEMBL1515855 & 688239 & 5.1362 & 5.5243 & TRN & \\
\hline CHEMBL3195020 & 688239 & 4.5362 & 5.5273 & TST & \\
\hline CHEMBL1590741 & 688239 & 6.9863 & 5.5367 & TST & \\
\hline CHEMBL1417798 & 688239 & 5.2862 & 5.5469 & TRN & \\
\hline CHEMBL3192978 & 688239 & 5.7362 & 5.6731 & TST & \\
\hline
\end{tabular}


Supplemental Table S2.txt

\begin{tabular}{|c|c|c|c|c|}
\hline CHEMBL1306782 & 688239 & 4.8862 & 5.51 & TRN \\
\hline CHEMBL1443487 & 688239 & 5.1862 & 5.3972 & TST \\
\hline CHEMBL1461311 & 688239 & 4.5362 & 5.5873 & TRN \\
\hline CHEMBL1536849 & 688239 & 5.0362 & 5.6287 & TRN \\
\hline CHEMBL1473358 & 688239 & 5.1862 & 5.5197 & TRN \\
\hline CHEMBL1462505 & 688239 & 4.7362 & 5.3918 & TRN \\
\hline CHEMBL1487646 & 688239 & 5.6362 & 5.4238 & TST \\
\hline CHEMBL1339141 & 688239 & 4.8862 & 5.4 & TST \\
\hline CHEMBL1572152 & 688239 & 7.2366 & 5.5745 & TRN \\
\hline CHEMBL1330414 & 688239 & 5.0862 & 5.4813 & TRN \\
\hline CHEMBL1312901 & 688239 & 6.1862 & 5.474 & TRN \\
\hline CHEMBL1487734 & 688239 & 4.5362 & 5.4964 & TST \\
\hline CHEMBL1453603 & 688239 & 6.3362 & 5.4806 & TST \\
\hline CHEMBL1465336 & 688239 & 6.0362 & 5.5409 & TRN \\
\hline CHEMBL1594195 & 688239 & 4.5362 & 5.5442 & TRN \\
\hline CHEMBL1466036 & 688239 & 5.1862 & 5.5387 & TRN \\
\hline CHEMBL1299269 & 688239 & 5.4862 & 5.3623 & TST \\
\hline CHEMBL1480100 & 688239 & 6.1362 & 5.4217 & TRN \\
\hline CHEMBL1604028 & 688239 & 6.1862 & 5.6014 & TST \\
\hline CHEMBL1423965 & 688239 & 6.5363 & 5.5387 & TRN \\
\hline CHEMBL1611373 & 688239 & 5.65 & 5.4765 & TRN \\
\hline CHEMBL1382739 & 688239 & 6.8861 & 5.4849 & TRN \\
\hline CHEMBL1459221 & 688239 & 5.3362 & 5.5383 & TST \\
\hline CHEMBL1589814 & 688239 & 5.4362 & 5.5004 & TRN \\
\hline CHEMBL459931 & 688239 & 4.6362 & 5.5351 & TRN \\
\hline CHEMBL1314578 & 688239 & 4.8362 & 5.2269 & TST \\
\hline CHEMBL1418423 & 688239 & 6.4362 & 5.4663 & TST \\
\hline CHEMBL1476053 & 688239 & 6.2862 & 5.6037 & TRN \\
\hline CHEMBL1426213 & 688239 & 6.1862 & 5.6223 & TRN \\
\hline CHEMBL1597345 & 688239 & 4.9362 & 5.487999 & \\
\hline CHEMBL3212380 & 688239 & 8.3872 & 5.3816 & TRN \\
\hline CHEMBL3207956 & 688239 & 4.5362 & 5.5123 & TRN \\
\hline CHEMBL1475319 & 688239 & 6.7862 & 5.5085 & TST \\
\hline CHEMBL1330163 & 688239 & 6.3863 & 5.4877 & TST \\
\hline CHEMBL1369001 & 688239 & 7.1361 & 5.3637 & TRN \\
\hline CHEMBL1306856 & 688239 & 7.5867 & 5.58 & TRN \\
\hline CHEMBL1597522 & 688239 & 4.5362 & 5.4878 & TRN \\
\hline CHEMBL1424547 & 688239 & 7.1361 & 5.5499 & TRN \\
\hline CHEMBL1430049 & 688239 & 5.1862 & 5.4262 & TRN \\
\hline CHEMBL1548695 & 688239 & 4.6862 & 5.4036 & TRN \\
\hline CHEMBL1327592 & 688239 & 6.1362 & 5.6018 & TRN \\
\hline CHEMBL1508348 & 688239 & 6.1862 & 5.527 & TRN \\
\hline CHEMBL1389516 & 688239 & 4.9362 & 5.3945 & TRN \\
\hline CHEMBL1422963 & 688239 & 4.5362 & 5.5234 & TRN \\
\hline CHEMBL1320043 & 688239 & 6.5363 & 5.476 & TRN \\
\hline CHEMBL1544608 & 688239 & 5.5862 & 5.6496 & TST \\
\hline CHEMBL1388514 & 688239 & 6.5862 & 5.5652 & TRN \\
\hline CHEMBL1578066 & 688239 & 4.4862 & 5.584 & TRN \\
\hline
\end{tabular}


Supplemental Table S2.txt

\begin{tabular}{|c|c|c|c|c|c|}
\hline CHEMBL1363674 & 688239 & 6.1862 & 5.5791 & TRN & \\
\hline CHEMBL1599999 & 688239 & 6.7862 & 5.5081 & TST & \\
\hline CHEMBL1349109 & 688239 & 6.8861 & 5.513999 & 999999999 & TRN \\
\hline CHEMBL1449193 & 688239 & 5.1362 & 5.4967 & TST & \\
\hline CHEMBL1526218 & 688239 & 5.3362 & 5.5439 & TRN & \\
\hline CHEMBL1601003 & 688239 & 6.1362 & 5.4982 & TRN & \\
\hline CHEMBL1412000 & 688239 & 5.2862 & $5.57100 e$ & 000000001 & TRN \\
\hline CHEMBL1439968 & 688239 & 5.6862 & 5.3392 & TRN & \\
\hline CHEMBL1509569 & 688239 & 5.8362 & 5.4351 & TST & \\
\hline CHEMBL1343898 & 688239 & 4.6862 & 5.5024 & TST & \\
\hline CHEMBL1377624 & 688239 & 4.5362 & 5.4211 & TRN & \\
\hline CHEMBL 3212227 & 688239 & 6.1362 & 5.5453 & TRN & \\
\hline CHEMBL1345463 & 688239 & 6.1362 & 5.5102 & TRN & \\
\hline CHEMBL3199089 & 688239 & 4.8862 & 5.4153 & TST & \\
\hline CHEMBL1454754 & 688239 & 4.9862 & 5.4948 & TRN & \\
\hline CHEMBL 3197815 & 688239 & 4.6362 & 5.4505 & TRN & \\
\hline CHEMBL1426845 & 688239 & 4.5362 & 5.5076 & TRN & \\
\hline CHEMBL1564177 & 688239 & 4.5362 & 5.4876 & TST & \\
\hline CHEMBL1536176 & 688239 & 8.3372 & 5.4978 & TRN & \\
\hline CHEMBL1545147 & 688239 & 5.2862 & 5.4544 & TRN & \\
\hline CHEMBL1385139 & 688239 & 5.7862 & 5.3761 & TST & \\
\hline CHEMBL1528880 & 688239 & 4.5362 & 5.4176 & TRN & \\
\hline CHEMBL1442383 & 688239 & 6.0862 & 5.3871 & TST & \\
\hline CHEMBL1612192 & 688239 & 5.8862 & 5.5296 & TRN & \\
\hline CHEMBL1396042 & 688239 & 4.5862 & 5.4317 & TRN & \\
\hline CHEMBL1510228 & 688239 & 5.8862 & 5.4312 & TRN & \\
\hline CHEMBL1308312 & 688239 & 4.5362 & 5.401 & TST & \\
\hline CHEMBL1606294 & 688239 & 6.5862 & 5.4431 & TRN & \\
\hline CHEMBL1437967 & 688239 & 5.1862 & 5.5975 & TRN & \\
\hline CHEMBL1554518 & 688239 & 5.6862 & \multicolumn{2}{|c|}{5.5120000000000005} & TRN \\
\hline CHEMBL1301664 & 688239 & 6.2362 & 5.5454 & TRN & \\
\hline CHEMBL1427458 & 688239 & 5.7362 & 5.5891 & TRN & \\
\hline CHEMBL1572427 & 688239 & 4.5362 & 5.4937 & TRN & \\
\hline CHEMBL1526004 & 688239 & 6.2362 & 5.585 & TRN & \\
\hline CHEMBL1369629 & 688239 & 5.0362 & 5.5328 & TRN & \\
\hline CHEMBL1368540 & 688239 & 4.5362 & 5.5222 & TRN & \\
\hline CHEMBL1422488 & 688239 & 4.5362 & 5.5023 & TRN & \\
\hline CHEMBL3193365 & 688239 & 5.2362 & 5.4725 & TST & \\
\hline CHEMBL1445229 & 688239 & 4.8862 & 5.5063 & TRN & \\
\hline CHEMBL1354899 & 688239 & 5.3362 & 5.5891 & TRN & \\
\hline CHEMBL1549059 & 688239 & 5.3862 & 5.3415 & TST & \\
\hline CHEMBL1335607 & 688239 & 4.6862 & 5.5483 & TRN & \\
\hline CHEMBL1374288 & 688239 & 6.1862 & 5.5128 & TST & \\
\hline CHEMBL1610300 & 688239 & 5.8362 & 5.5157 & TRN & \\
\hline CHEMBL1589955 & 688239 & 4.6362 & 5.5588 & TRN & \\
\hline CHEMBL1572375 & 688239 & 5.6862 & 5.4868 & TRN & \\
\hline CHEMBL1345374 & 688239 & 5.1862 & 5.4808 & TRN & \\
\hline CHEMBL1330119 & 688239 & 6.2862 & 5.5497 & TST & \\
\hline
\end{tabular}




\begin{tabular}{|c|c|c|c|c|}
\hline & & & pplement & al Ta \\
\hline CHEMBL1403965 & 688239 & 5.9 & 5.4631 & TRN \\
\hline CHEMBL1612075 & 688239 & 4.4862 & 5.3746 & TRN \\
\hline CHEMBL1445899 & 688239 & 5.1862 & 5.4829 & TRN \\
\hline CHEMBL3196189 & 688239 & 5.7362 & 5.4544 & TRN \\
\hline CHEMBL1500166 & 688239 & 4.6862 & 5.4714 & TST \\
\hline CHEMBL1382167 & 688239 & 5.1862 & 5.5378 & TST \\
\hline CHEMBL1360592 & 688239 & 6.2362 & 5.5902 & TRN \\
\hline CHEMBL1463695 & 688239 & 6.7862 & 5.4767 & TST \\
\hline CHEMBL1412301 & 688239 & 5.1862 & 5.4937 & TST \\
\hline CHEMBL1387704 & 688239 & 4.7862 & 5.505 & TST \\
\hline CHEMBL1332433 & 688239 & 4.7862 & 5.3893 & TRN \\
\hline CHEMBL1482135 & 688239 & 4.8362 & 5.434 & TRN \\
\hline CHEMBL1477583 & 688239 & 5.4862 & 5.4764 & TST \\
\hline CHEMBL1452820 & 688239 & 6.2362 & 5.562 & TRN \\
\hline CHEMBL1534366 & 688239 & 7.1864 & 5.4179 & TRN \\
\hline CHEMBL1343950 & 688239 & 4.5362 & 5.5725 & TRN \\
\hline CHEMBL1307580 & 688239 & 5.9362 & 5.4736 & TRN \\
\hline CHEMBL3193998 & 688239 & 5.6362 & 5.3916 & TRN \\
\hline CHEMBL1386431 & 688239 & 7.6861 & 5.5777 & TST \\
\hline CHEMBL1491856 & 688239 & 4.6362 & 5.4414 & TRN \\
\hline CHEMBL1300468 & 688239 & 4.5362 & 5.4748 & TST \\
\hline CHEMBL1388467 & 688239 & 6.0362 & 5.4696 & TRN \\
\hline CHEMBL1574593 & 688239 & 4.5362 & 5.4226 & TRN \\
\hline CHEMBL1330386 & 688239 & 6.6362 & 5.6293 & TRN \\
\hline CHEMBL1412723 & 688239 & 4.5362 & 5.4855 & TRN \\
\hline CHEMBL1301130 & 688239 & 6.2862 & 5.597 & TST \\
\hline CHEMBL1407614 & 688239 & 5.3862 & 5.3227 & TRN \\
\hline CHEMBL1537855 & 688239 & 5.1862 & 5.4514 & TST \\
\hline CHEMBL 3191149 & 688239 & 4.6362 & 5.4028 & TRN \\
\hline CHEMBL1569871 & 688239 & 4.7862 & 5.544 & TRN \\
\hline CHEMBL1465177 & 688239 & 6.1362 & 5.5093 & TRN \\
\hline CHEMBL1349713 & 688239 & 5.0362 & 5.6021 & TRN \\
\hline CHEMBL1404003 & 688239 & 5.0862 & 5.5593 & TRN \\
\hline CHEMBL1541068 & 688239 & 5.1862 & 5.3815 & TST \\
\hline CHEMBL3213624 & 688239 & 5.0862 & 5.4841 & TRN \\
\hline CHEMBL1459625 & 688239 & 4.5362 & 5.5435 & TRN \\
\hline CHEMBL1391393 & 688239 & 7.1864 & 5.4092 & TRN \\
\hline CHEMBL1313492 & 688239 & 5.4862 & 5.5016 & TRN \\
\hline CHEMBL1426468 & 688239 & 5.6362 & 5.5989 & TRN \\
\hline CHEMBL1542159 & 688239 & 5.9362 & 5.5684 & TST \\
\hline CHEMBL1321447 & 688239 & 6.1862 & 5.5351 & TRN \\
\hline CHEMBL1398016 & 688239 & 5.6362 & 5.5194 & TRN \\
\hline CHEMBL1320046 & 688239 & 5.1862 & 5.4884 & TST \\
\hline CHEMBL1506491 & 688239 & 4.5862 & 5.4534 & TRN \\
\hline CHEMBL1372129 & 688239 & 5.6862 & 5.4241 & TRN \\
\hline CHEMBL1377484 & 688239 & 4.9362 & 5.5332 & TRN \\
\hline CHEMBL1330557 & 688239 & 6.3863 & 5.4733 & TRN \\
\hline CHEMBL1449499 & 688239 & 4.8862 & 5.4754 & TRN \\
\hline
\end{tabular}


Supplemental Table S2.txt

\begin{tabular}{|c|c|c|c|c|}
\hline CHEMBL1417468 & 688239 & 4.5362 & 5.5566 & TRN \\
\hline CHEMBL1482328 & 688239 & 4.6862 & 5.499 & TRN \\
\hline CHEMBL1368966 & 688239 & 5.6362 & 5.5205 & TST \\
\hline CHEMBL1599280 & 688239 & 6.3863 & 5.486006 & 0000000001 \\
\hline CHEMBL1486195 & 688239 & 5.4362 & 5.6439 & TRN \\
\hline CHEMBL1578446 & 688239 & 5.0362 & 5.595 & TST \\
\hline CHEMBL1387698 & 688239 & 6.0362 & 5.4219 & TST \\
\hline CHEMBL1348332 & 688239 & 5.3862 & 5.564 & TST \\
\hline CHEMBL1571185 & 688239 & 6.1362 & 5.4368 & TRN \\
\hline CHEMBL1565071 & 688239 & 5.2862 & 5.4607 & TRN \\
\hline CHEMBL1438538 & 688239 & 6.1862 & 5.3858 & TRN \\
\hline CHEMBL1592381 & 688239 & 4.5362 & 5.7801 & TRN \\
\hline CHEMBL1486927 & 688239 & 4.8862 & 5.5147 & TRN \\
\hline CHEMBL1539751 & 688239 & 4.8362 & 5.5894 & TST \\
\hline CHEMBL1567547 & 688239 & 5.5862 & 5.4694 & TST \\
\hline CHEMBL1333158 & 688239 & 5.5362 & 5.5665 & TRN \\
\hline CHEMBL1408795 & 688239 & 4.5362 & 5.4517 & TRN \\
\hline CHEMBL1418775 & 688239 & 5.9862 & 5.5449 & TRN \\
\hline CHEMBL1444671 & 688239 & 5.1862 & 5.4146 & TRN \\
\hline CHEMBL1336756 & 688239 & 6.5363 & 5.6007 & TRN \\
\hline CHEMBL1376419 & 688239 & 6.0862 & 5.4668 & TRN \\
\hline CHEMBL1532234 & 688239 & 4.6362 & 5.5675 & TST \\
\hline CHEMBL1587085 & 688239 & 5.1862 & 5.7104 & TRN \\
\hline CHEMBL1496134 & 688239 & 7.1361 & 5.3967 & TRN \\
\hline CHEMBL1547730 & 688239 & 6.7361 & 5.4752 & TST \\
\hline CHEMBL1465486 & 688239 & 4.6862 & 5.4169 & TRN \\
\hline CHEMBL1352071 & 688239 & 7.2366 & 5.6175 & TRN \\
\hline CHEMBL1440468 & 688239 & 5.2862 & 5.4748 & TST \\
\hline CHEMBL1592683 & 688239 & 5.8362 & 5.5644 & TRN \\
\hline CHEMBL1485883 & 688239 & 5.1862 & 5.4884 & TRN \\
\hline CHEMBL1451308 & 688239 & 5.0862 & 5.6347 & TRN \\
\hline CHEMBL1519650 & 688239 & 5.1862 & 5.5042 & TRN \\
\hline CHEMBL1543346 & 688239 & 5.0362 & 5.4877 & TRN \\
\hline CHEMBL1597468 & 688239 & 5.9362 & 5.5588 & TRN \\
\hline CHEMBL514760 & 688239 & 6.2362 & 5.3823 & TRN \\
\hline CHEMBL1554541 & 688239 & 4.4862 & 5.6769 & TST \\
\hline CHEMBL1590452 & 688239 & 5.1862 & 5.2856 & TRN \\
\hline CHEMBL1427356 & 688239 & 5.6862 & 5.3992 & TRN \\
\hline CHEMBL1506823 & 688239 & 4.7362 & 5.3858 & TRN \\
\hline CHEMBL534429 & 688239 & 5.6362 & 5.4747 & TRN \\
\hline CHEMBL1524923 & 688239 & 5.0862 & 5.5977 & TRN \\
\hline CHEMBL3209690 & 688239 & 6.5363 & 5.494 & TRN \\
\hline CHEMBL1301343 & 688239 & 6.1862 & 5.4901 & TRN \\
\hline CHEMBL1421391 & 688239 & 4.5862 & 5.5719 & TRN \\
\hline CHEMBL1454094 & 688239 & 6.4362 & 5.6441 & TST \\
\hline CHEMBL3144947 & 688239 & 4.5362 & 5.4319 & TST \\
\hline CHEMBL1593536 & 688239 & 6.9363 & 5.6598 & TRN \\
\hline CHEMBL1521235 & 688239 & 5.1862 & 5.5122 & TRN \\
\hline
\end{tabular}


Supplemental Table S2.txt

\begin{tabular}{|c|c|c|c|c|c|}
\hline CHEMBL1602330 & 688239 & 6.9363 & 5.51 & TST & \\
\hline CHEMBL1430619 & 688239 & 4.4862 & 5.4831 & TRN & \\
\hline CHEMBL1518710 & 688239 & 4.7362 & 5.5481 & TRN & \\
\hline CHEMBL1407863 & 688239 & 4.7362 & \multicolumn{2}{|c|}{5.627000000000001} & TRN \\
\hline CHEMBL1510543 & 688239 & 4.7362 & 5.4067 & TST & \\
\hline CHEMBL1526974 & 688239 & 5.6362 & 5.7211 & TST & \\
\hline CHEMBL1335327 & 688239 & 5.3862 & 5.6197 & TRN & \\
\hline CHEMBL1460859 & 688239 & 4.7362 & \multicolumn{2}{|c|}{5.542000000000001} & TRN \\
\hline CHEMBL1579082 & 688239 & 4.6362 & 5.6352 & TRN & \\
\hline CHEMBL1595867 & 688239 & 6.4862 & 5.6668 & TRN & \\
\hline CHEMBL3195905 & 688239 & 6.8861 & 5.4777 & TRN & \\
\hline CHEMBL1357114 & 688239 & 4.7862 & 5.4885 & TST & \\
\hline CHEMBL3197551 & 688239 & 7.1864 & 5.5047 & TRN & \\
\hline CHEMBL1550022 & 688239 & 5.0362 & 5.5373 & TRN & \\
\hline CHEMBL1523255 & 688239 & 4.5362 & \multicolumn{2}{|c|}{5.428999999999999} & TRN \\
\hline CHEMBL1460912 & 688239 & 4.5362 & 5.5777 & TRN & \\
\hline CHEMBL1584018 & 688239 & 5.6862 & 5.6077 & TRN & \\
\hline CHEMBL1461433 & 688239 & 5.7862 & 5.5301 & TST & \\
\hline CHEMBL1444582 & 688239 & 4.9862 & 5.7298 & TST & \\
\hline CHEMBL1388802 & 688239 & 4.5362 & 5.4915 & TRN & \\
\hline CHEMBL1461584 & 688239 & 4.7362 & 5.5292 & TRN & \\
\hline CHEMBL1346374 & 688239 & 6.0362 & 5.4162 & TRN & \\
\hline CHEMBL1339814 & 688239 & 5.1862 & 5.5307 & TRN & \\
\hline CHEMBL1524353 & 688239 & 4.7862 & 5.4831 & TST & \\
\hline CHEMBL1505232 & 688239 & 5.0362 & 5.494 & TRN & \\
\hline CHEMBL1441488 & 688239 & 5.2362 & 5.5699 & TST & \\
\hline CHEMBL1515499 & 688239 & 5.4862 & 5.4709 & TRN & \\
\hline CHEMBL1501700 & 688239 & 4.9362 & 5.3437 & TRN & \\
\hline CHEMBL1431068 & 688239 & 5.3862 & 5.4448 & TST & \\
\hline CHEMBL1313155 & 688239 & 5.1862 & 5.3366 & TST & \\
\hline CHEMBL1527294 & 688239 & 5.1862 & 5.4936 & TRN & \\
\hline CHEMBL1446069 & 688239 & 4.8362 & 5.4905 & TST & \\
\hline CHEMBL1464262 & 688239 & 4.7862 & 5.4659 & TRN & \\
\hline CHEMBL1322404 & 688239 & 6.4862 & \multicolumn{2}{|c|}{5.492999999999999} & TST \\
\hline CHEMBL1402789 & 688239 & 4.9362 & 5.4362 & TRN & \\
\hline CHEMBL3193938 & 688239 & 5.2862 & 5.4264 & TRN & \\
\hline CHEMBL1483247 & 688239 & 5.5362 & 5.4288 & TRN & \\
\hline CHEMBL1375848 & 688239 & 4.8862 & 5.4955 & TRN & \\
\hline CHEMBL1558556 & 688239 & 4.7362 & 5.6273 & TRN & \\
\hline CHEMBL1533257 & 688239 & 4.5362 & 5.6799 & TRN & \\
\hline CHEMBL1587488 & 688239 & 4.7862 & 5.6003 & TRN & \\
\hline CHEMBL1492019 & 688239 & 5.1862 & 5.5603 & TST & \\
\hline CHEMBL1520252 & 688239 & 5.6362 & 5.5221 & TRN & \\
\hline CHEMBL1323444 & 688239 & 6.6362 & 5.6432 & TRN & \\
\hline CHEMBL1423661 & 688239 & 6.5862 & 5.4873 & TST & \\
\hline CHEMBL1462707 & 688239 & 4.8362 & 5.3745 & TRN & \\
\hline CHEMBL1608506 & 688239 & 5.5362 & 5.5854 & TRN & \\
\hline CHEMBL1363110 & 688239 & 6.9863 & 5.4589 & TRN & \\
\hline
\end{tabular}




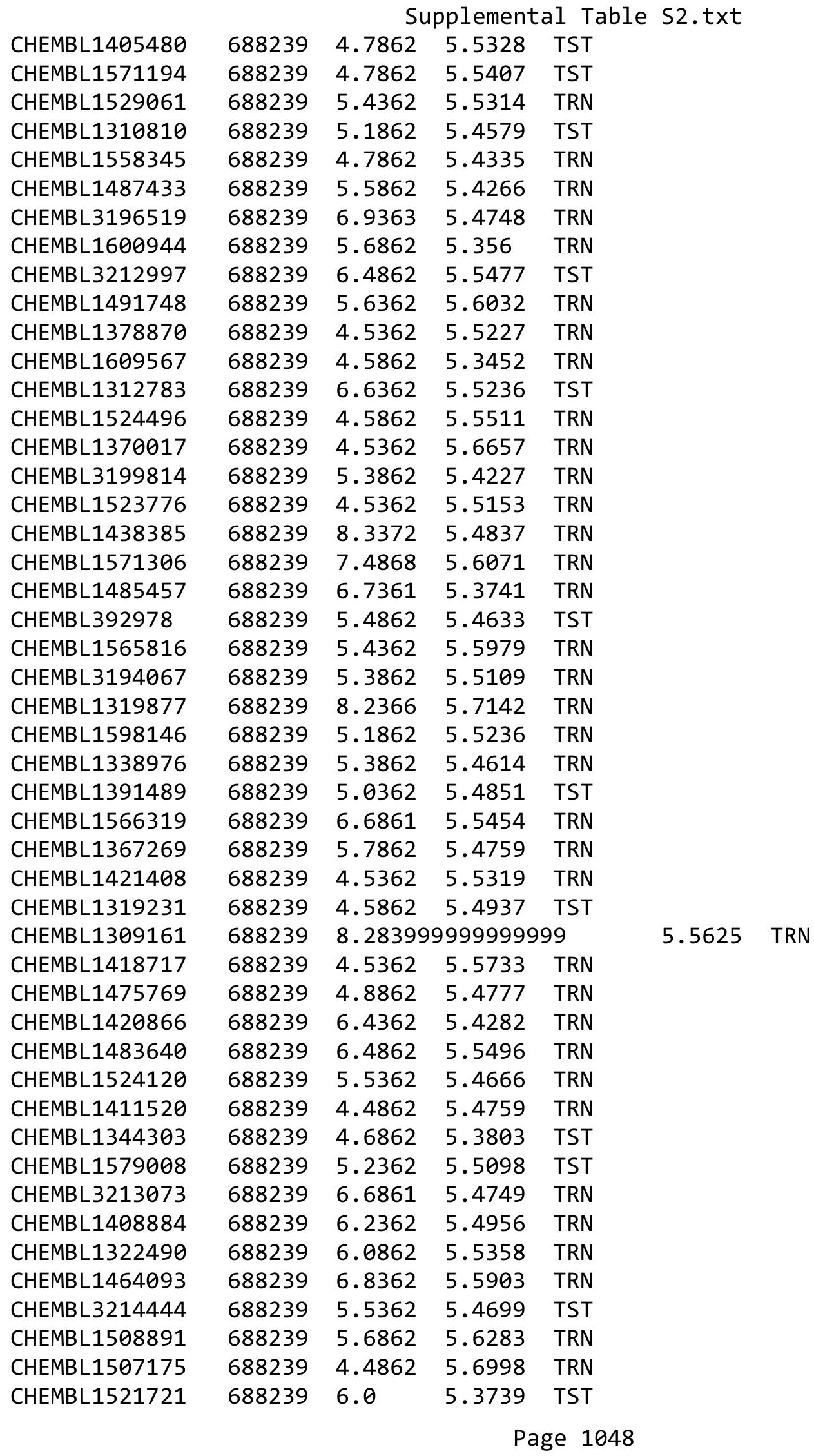


Supplemental Table S2.txt

\begin{tabular}{|c|c|c|c|c|c|}
\hline CHEMBL1549055 & 688239 & 6.2362 & 5.7414 & TRN & \\
\hline CHEMBL1388156 & 688239 & 6.2362 & 5.4486 & TST & \\
\hline CHEMBL1338724 & 688239 & 4.9862 & 5.4505 & TRN & \\
\hline CHEMBL1408727 & 688239 & 4.5362 & 5.5496 & TST & \\
\hline CHEMBL1317142 & 688239 & 5.0862 & 5.3884 & TRN & \\
\hline CHEMBL1354485 & 688239 & 5.6362 & 5.5595 & TRN & \\
\hline CHEMBL1529682 & 688239 & 5.8362 & 5.5393 & TRN & \\
\hline CHEMBL1334715 & 688239 & 7.4868 & 5.593 & TRN & \\
\hline CHEMBL1597011 & 688239 & 4.5362 & 5.5881 & TRN & \\
\hline CHEMBL1477037 & 688239 & 6.1362 & 5.5206 & TRN & \\
\hline CHEMBL3191251 & 688239 & 4.6862 & 5.3886 & TST & \\
\hline CHEMBL1544718 & 688239 & 4.5362 & 5.2956 & TST & \\
\hline CHEMBL573127 & 688239 & 4.5362 & 5.5629 & TRN & \\
\hline CHEMBL1363368 & 688239 & 4.9362 & 5.2655 & TRN & \\
\hline CHEMBL1388783 & 688239 & 4.7862 & 5.5231 & TRN & \\
\hline CHEMBL1314875 & 688239 & 5.1862 & 5.277 & TRN & \\
\hline CHEMBL1372377 & 688239 & 4.5362 & 5.5719 & TRN & \\
\hline CHEMBL1604324 & 688239 & 4.7362 & 5.513 & TRN & \\
\hline CHEMBL1324427 & 688239 & 5.1362 & 5.5382 & TRN & \\
\hline CHEMBL1582590 & 688239 & 4.9362 & 5.5486 & TST & \\
\hline CHEMBL1367329 & 688239 & 4.5362 & 5.5517 & TRN & \\
\hline CHEMBL1546822 & 688239 & 5.0862 & 5.5049 & TST & \\
\hline CHEMBL1558766 & 688239 & 6.1862 & 5.5671 & TRN & \\
\hline CHEMBL1607194 & 688239 & 4.7362 & 5.4362 & TRN & \\
\hline CHEMBL1463077 & 688239 & 6.0862 & 5.4981 & TRN & \\
\hline CHEMBL1608109 & 688239 & 5.1862 & 5.5758 & TRN & \\
\hline CHEMBL1543698 & 688239 & 4.6362 & 5.3758 & TRN & \\
\hline CHEMBL1445494 & 688239 & 4.4862 & 5.5446 & TRN & \\
\hline CHEMBL1598639 & 688239 & 4.9362 & 5.4846 & TRN & \\
\hline CHEMBL1471814 & 688239 & 5.4362 & 5.3391 & TST & \\
\hline CHEMBL1493746 & 688239 & 4.5362 & 5.3664 & TRN & \\
\hline CHEMBL1565222 & 688239 & 8.3372 & 5.6021 & TRN & \\
\hline CHEMBL1332293 & 688239 & 5.6362 & 5.6066 & TRN & \\
\hline CHEMBL1451631 & 688239 & 4.5362 & 5.4446 & TRN & \\
\hline CHEMBL1357865 & 688239 & 8.28399 & 99999999 & 99 & 5.4507 \\
\hline CHEMBL1299425 & 688239 & 5.3362 & 5.5948 & TRN & \\
\hline CHEMBL1506397 & 688239 & 6.3362 & 5.6043 & TRN & \\
\hline CHEMBL1570577 & 688239 & 4.8362 & 5.5747 & TRN & \\
\hline CHEMBL1425936 & 688239 & 6.8861 & 5.4709 & TST & \\
\hline CHEMBL1591423 & 688239 & 6.1862 & 5.4842 & TRN & \\
\hline CHEMBL1349646 & 688239 & 4.8362 & 5.4138 & TST & \\
\hline CHEMBL1417499 & 688239 & 5.3362 & 5.4377 & TRN & \\
\hline CHEMBL1504687 & 688239 & 6.0862 & 5.601 & TST & \\
\hline CHEMBL1459101 & 688239 & 5.3362 & 5.5555 & TRN & \\
\hline CHEMBL1360161 & 688239 & 6.0862 & 5.5083 & TRN & \\
\hline CHEMBL1447444 & 688239 & 6.5363 & 5.7207 & TRN & \\
\hline CHEMBL1367126 & 688239 & 6.1862 & 5.5793 & TRN & \\
\hline CHEMBL1407622 & 688239 & 4.7862 & 5.4674 & TST & \\
\hline
\end{tabular}


Supplemental Table S2.txt

\begin{tabular}{|c|c|c|c|c|c|}
\hline CHEMBL1456159 & 688239 & 8.3872 & 5.4582 & TRN & \\
\hline CHEMBL1307713 & 688239 & 5.8862 & 5.5973 & TRN & \\
\hline CHEMBL3214293 & 688239 & 4.6362 & 5.5907 & TST & \\
\hline CHEMBL1547643 & 688239 & 5.8862 & 5.3361 & TST & \\
\hline CHEMBL1440612 & 688239 & 6.7361 & 5.4892 & TRN & \\
\hline CHEMBL1584703 & 688239 & 5.4362 & 5.5633 & TRN & \\
\hline CHEMBL1528830 & 688239 & 6.9363 & 5.5572 & TRN & \\
\hline CHEMBL1363050 & 688239 & 4.7362 & 5.4707 & TRN & \\
\hline CHEMBL1454720 & 688239 & 4.5862 & 5.5231 & TRN & \\
\hline CHEMBL1460131 & 688239 & 6.7361 & 5.621 & TRN & \\
\hline CHEMBL1598735 & 688239 & 5.5862 & 5.3657 & TRN & \\
\hline CHEMBL1581266 & 688239 & 5.3362 & 5.3908 & TRN & \\
\hline CHEMBL1452642 & 688239 & 5.7862 & 5.5285 & TRN & \\
\hline CHEMBL1578463 & 688239 & 7.2865 & 5.5458 & TST & \\
\hline CHEMBL1350094 & 688239 & 5.0862 & 5.5311 & TRN & \\
\hline CHEMBL1309834 & 688239 & 4.5362 & 5.4342 & TST & \\
\hline CHEMBL1536784 & 688239 & 4.4862 & 5.5334 & TRN & \\
\hline CHEMBL1451525 & 688239 & 4.5362 & 5.452999 & 999999999 & TST \\
\hline CHEMBL1312711 & 688239 & 4.7862 & 5.5715 & TRN & \\
\hline CHEMBL1500394 & 688239 & 4.5362 & 5.4279 & TST & \\
\hline CHEMBL1550794 & 688239 & 8.1871 & 5.3898 & TST & \\
\hline CHEMBL3193740 & 688239 & 5.4362 & 5.5802 & TRN & \\
\hline CHEMBL1604858 & 688239 & 4.7862 & 5.5589 & TRN & \\
\hline CHEMBL1459470 & 688239 & 6.8362 & 5.6723 & TRN & \\
\hline CHEMBL1511321 & 688239 & 5.5362 & 5.5248 & TRN & \\
\hline CHEMBL1459640 & 688239 & 4.5362 & 5.5248 & TRN & \\
\hline CHEMBL1448276 & 688239 & 4.4862 & 5.4225 & TST & \\
\hline CHEMBL1458154 & 688239 & 4.7362 & 5.5053 & TRN & \\
\hline CHEMBL1386440 & 688239 & 4.5362 & 5.5055 & TRN & \\
\hline CHEMBL1445982 & 688239 & 5.1862 & 5.5692 & TRN & \\
\hline CHEMBL3190615 & 688239 & 7.2366 & 5.4684 & TRN & \\
\hline CHEMBL1367700 & 688239 & 6.3362 & 5.5346 & TST & \\
\hline CHEMBL1425374 & 688239 & 4.6862 & 5.617000 & 000000001 & TST \\
\hline CHEMBL1383734 & 688239 & 5.3862 & 5.5413 & TRN & \\
\hline CHEMBL1543903 & 688239 & 4.9862 & 5.4227 & TRN & \\
\hline CHEMBL1466657 & 688239 & 5.2362 & 5.5363 & TRN & \\
\hline CHEMBL1571464 & 688239 & 5.5362 & 5.4365 & TRN & \\
\hline CHEMBL1497459 & 688239 & 5.1862 & 5.3966 & TST & \\
\hline CHEMBL1491390 & 688239 & 7.1361 & 5.4163 & TRN & \\
\hline CHEMBL1508148 & 688239 & 6.5363 & 5.5308 & TRN & \\
\hline CHEMBL1511399 & 688239 & 5.1862 & 5.4019 & TRN & \\
\hline CHEMBL1325112 & 688239 & 4.7862 & 5.4646 & TST & \\
\hline CHEMBL1498635 & 688239 & 6.1362 & 5.4758 & TRN & \\
\hline CHEMBL1368356 & 688239 & 8.3872 & 5.3943 & TRN & \\
\hline CHEMBL1573437 & 688239 & 5.0862 & 5.577000 & 000000001 & TRN \\
\hline CHEMBL1394131 & 688239 & 8.28399 & 99999999 & 5.4366 & $1 \mathrm{KI}$ \\
\hline CHEMBL1530911 & 688239 & 5.8862 & 5.3887 & TRN & \\
\hline CHEMBL1544600 & 688239 & 6.1862 & 5.5782 & TRN & \\
\hline
\end{tabular}


Supplemental Table S2.txt

\begin{tabular}{|c|c|c|c|c|c|}
\hline CHEMBL1578647 & 688239 & 5.2862 & 5.4648 & TST & \\
\hline CHEMBL1465414 & 688239 & 4.8862 & 5.6918 & TRN & \\
\hline CHEMBL1430547 & 688239 & 4.8862 & 5.3736 & TRN & \\
\hline CHEMBL1431123 & 688239 & 4.8362 & 5.3009 & TRN & \\
\hline CHEMBL1610372 & 688239 & 5.1362 & 5.5164 & TRN & \\
\hline CHEMBL1587766 & 688239 & 5.0862 & 5.6029 & TST & \\
\hline CHEMBL1474925 & 688239 & 5.8362 & 5.3757 & TRN & \\
\hline CHEMBL1385091 & 688239 & 4.5362 & 5.6061 & TRN & \\
\hline CHEMBL1531065 & 688239 & 4.5362 & 5.5552 & TRN & \\
\hline CHEMBL1466447 & 688239 & 5.3362 & 5.4433 & TST & \\
\hline CHEMBL1601688 & 688239 & 5.3362 & 5.491000 & 20000000005 & TRN \\
\hline CHEMBL1375380 & 688239 & 5.2362 & 5.5361 & TRN & \\
\hline CHEMBL1377344 & 688239 & 4.5362 & 5.5109 & TRN & \\
\hline CHEMBL1504950 & 688239 & 5.9362 & 5.5921 & TRN & \\
\hline CHEMBL1611193 & 688239 & 4.5362 & 5.5244 & TRN & \\
\hline CHEMBL1335561 & 688239 & 5.2862 & 5.5516 & TRN & \\
\hline CHEMBL1600766 & 688239 & 4.5362 & 5.4464 & TST & \\
\hline CHEMBL1606377 & 688239 & 5.2362 & 5.5975 & TRN & \\
\hline CHEMBL3196011 & 688239 & 5.2362 & 5.2956 & TRN & \\
\hline CHEMBL 3196341 & 688239 & 4.9862 & 5.4629 & TRN & \\
\hline CHEMBL1496717 & 688239 & 4.6862 & 5.4314 & TST & \\
\hline CHEMBL1537398 & 688239 & 5.3862 & 5.541 & TRN & \\
\hline CHEMBL1581868 & 688239 & 4.6362 & 5.5888 & TRN & \\
\hline CHEMBL1413723 & 688239 & 6.1862 & 5.4981 & TRN & \\
\hline CHEMBL1523299 & 688239 & 4.6862 & 5.4932 & TRN & \\
\hline CHEMBL1397404 & 688239 & 6.0862 & 5.5521 & TRN & \\
\hline CHEMBL1417035 & 688239 & 4.5362 & 5.5142 & TRN & \\
\hline CHEMBL 3212032 & 688239 & 6.0362 & 5.4153 & TST & \\
\hline CHEMBL1333510 & 688239 & 4.4862 & 5.369 & TRN & \\
\hline CHEMBL1402741 & 688239 & 5.7362 & 5.4529 & TRN & \\
\hline CHEMBL1373298 & 688239 & 6.1362 & 5.6441 & TRN & \\
\hline CHEMBL1528472 & 688239 & 4.7362 & 5.4445 & TRN & \\
\hline CHEMBL1536128 & 688239 & 6.9863 & \multicolumn{2}{|c|}{5.531000000000001} & TRN \\
\hline CHEMBL1302505 & 688239 & 4.5862 & 5.6089 & TRN & \\
\hline CHEMBL 3189307 & 688239 & 4.6362 & 5.4123 & TST & \\
\hline CHEMBL1349849 & 688239 & 6.3863 & 5.4937 & TRN & \\
\hline CHEMBL1406883 & 688239 & 8.2366 & 5.4525 & TRN & \\
\hline CHEMBL1412035 & 688239 & 5.2362 & 5.4791 & TST & \\
\hline CHEMBL1595835 & 688239 & 5.3862 & 5.5833 & TRN & \\
\hline CHEMBL 3199759 & 688239 & 5.0862 & 5.4249 & TRN & \\
\hline CHEMBL1413532 & 688239 & 4.4862 & 5.4948 & TRN & \\
\hline CHEMBL1386228 & 688239 & 4.7862 & 5.4818 & TRN & \\
\hline CHEMBL1505800 & 688239 & 5.1862 & 5.4588 & TRN & \\
\hline CHEMBL1426876 & 688239 & 5.3862 & 5.4537 & TRN & \\
\hline CHEMBL1522365 & 688239 & 6.2362 & 5.3295 & TRN & \\
\hline CHEMBL1446762 & 688239 & 4.7362 & 5.4997 & TRN & \\
\hline CHEMBL1350994 & 688239 & 8.283999 & 999999999 & 5.2969 & RI \\
\hline CHEMBL1323577 & 688239 & 4.6862 & 5.6119 & TRN & \\
\hline
\end{tabular}




\begin{tabular}{|c|c|c|c|c|c|c|}
\hline & & \multicolumn{5}{|c|}{ Supplemental Table s2.txt } \\
\hline CHEMBL1330495 & 688239 & 7.5361 & 5.5673 & TRN & & \\
\hline CHEMBL1464317 & 688239 & 6.9363 & 5.32799 & 9999999999 & & TRN \\
\hline CHEMBL1476672 & 688239 & 6.6362 & 5.501 & TRN & & \\
\hline CHEMBL1546507 & 688239 & 5.1862 & 5.4077 & TRN & & \\
\hline CHEMBL1524348 & 688239 & 5.6362 & 5.4528 & TST & & \\
\hline CHEMBL1309068 & 688239 & 4.5362 & 5.3258 & TST & & \\
\hline CHEMBL1316824 & 688239 & 8.3872 & 5.5661 & TRN & & \\
\hline CHEMBL1594907 & 688239 & 7.9872 & 5.4611 & TRN & & \\
\hline CHEMBL1563198 & 688239 & 5.0862 & 5.3869 & TRN & & \\
\hline CHEMBL1605456 & 688239 & 5.1862 & 5.4712 & TST & & \\
\hline CHEMBL1353812 & 688239 & 5.4362 & 5.3745 & TST & & \\
\hline CHEMBL1561331 & 688239 & 4.5362 & 5.4988 & TRN & & \\
\hline CHEMBL1327446 & 688239 & 7.7352 & 5.5182 & TRN & & \\
\hline CHEMBL1305664 & 688239 & 5.6362 & 5.5174 & TRN & & \\
\hline CHEMBL1472220 & 688239 & 6.2362 & 5.5366 & TRN & & \\
\hline CHEMBL1493817 & 688239 & 6.6861 & 5.4073 & TRN & & \\
\hline CHEMBL1595234 & 688239 & 5.1862 & 5.4847 & TRN & & \\
\hline CHEMBL1467780 & 688239 & 5.5862 & 5.4513 & TRN & & \\
\hline CHEMBL1440752 & 688239 & 5.1862 & 5.5458 & TRN & & \\
\hline CHEMBL1609219 & 688239 & 6.0 & 5.4301 & TRN & & \\
\hline CHEMBL1507583 & 688239 & 5.5862 & 5.4407 & TRN & & \\
\hline CHEMBL1353122 & 688239 & 4.8862 & 5.5072 & TRN & & \\
\hline CHEMBL1304525 & 688239 & 4.4862 & 5.4028 & TRN & & \\
\hline CHEMBL1405741 & 688239 & 4.7862 & 5.3067 & TST & & \\
\hline CHEMBL1578636 & 688239 & 6.1362 & 5.4123 & TRN & & \\
\hline CHEMBL586628 & 688239 & 4.5362 & 5.5783 & TST & & \\
\hline CHEMBL1582107 & 688239 & 4.6862 & 5.3458 & TST & & \\
\hline CHEMBL1549996 & 688239 & 5.9862 & 5.4773 & TST & & \\
\hline CHEMBL1327285 & 688239 & 5.1862 & 5.6374 & TRN & & \\
\hline CHEMBL3214019 & 688239 & 5.1362 & 5.4603 & TRN & & \\
\hline CHEMBL3192413 & 688239 & 5.0362 & 5.4474 & TRN & & \\
\hline CHEMBL1530666 & 688239 & 4.5362 & 5.4645 & TRN & & \\
\hline CHEMBL1586543 & 688239 & 7.0862 & 5.4527 & TRN & & \\
\hline CHEMBL1575458 & 688239 & 5.0362 & 5.5396 & TRN & & \\
\hline CHEMBL1534355 & 688239 & 4.9 & 5.4483 & TRN & & \\
\hline CHEMBL1343980 & 688239 & 5.2862 & 5.4847 & TRN & & \\
\hline CHEMBL1369315 & 688239 & 7.0362 & 5.4926 & TRN & & \\
\hline CHEMBL1331029 & 688239 & 5.6362 & 5.3918 & TRN & & \\
\hline CHEMBL1300873 & 688239 & 8.28399 & 99999999 & 99 & 5.5813 & TST \\
\hline CHEMBL1467821 & 688239 & 5.1862 & 5.4601 & TRN & & \\
\hline CHEMBL1408082 & 688239 & 4.5362 & 5.4523 & TRN & & \\
\hline CHEMBL1439327 & 688239 & 5.4862 & 5.4646 & TRN & & \\
\hline CHEMBL1329259 & 688239 & 4.8362 & 5.5577 & TRN & & \\
\hline CHEMBL1422448 & 688239 & 6.9863 & 5.4408 & TRN & & \\
\hline CHEMBL1379955 & 688239 & 5.2862 & 5.4254 & TRN & & \\
\hline CHEMBL1367631 & 688239 & 4.8 & 5.4896 & TRN & & \\
\hline CHEMBL1503553 & 688239 & 4.5362 & 5.5672 & TRN & & \\
\hline CHEMBL1340042 & 688239 & 5.5362 & 5.4527 & TRN & & \\
\hline
\end{tabular}


Supplemental Table S2.txt

\begin{tabular}{|c|c|c|c|c|c|}
\hline CHEMBL1487443 & 688239 & 6.0862 & 5.5229 & TRN & \\
\hline CHEMBL1468484 & 688239 & 4.6362 & 5.4895 & TST & \\
\hline CHEMBL1360670 & 688239 & 5.3862 & 5.4911 & TST & \\
\hline CHEMBL1333443 & 688239 & 4.5362 & 5.5126 & TRN & \\
\hline CHEMBL1572709 & 688239 & 6.2362 & 5.4991 & TRN & \\
\hline CHEMBL1323041 & 688239 & 4.5362 & 5.5869 & TST & \\
\hline CHEMBL1519651 & 688239 & 6.2362 & 5.4869 & TRN & \\
\hline CHEMBL1403912 & 688239 & 4.5362 & 5.4467 & TRN & \\
\hline CHEMBL1474530 & 688239 & 6.6362 & 5.436 & TRN & \\
\hline CHEMBL1468122 & 688239 & 4.7862 & 5.3921 & TST & \\
\hline CHEMBL1535476 & 688239 & 5.3362 & 5.4523 & TRN & \\
\hline CHEMBL1438043 & 688239 & 4.5362 & 5.4383 & TRN & \\
\hline CHEMBL1403648 & 688239 & 4.5362 & 5.4872 & TST & \\
\hline CHEMBL1544964 & 688239 & 4.5362 & 5.5654 & TRN & \\
\hline CHEMBL1575702 & 688239 & 4.5362 & 5.5897 & TRN & \\
\hline CHEMBL 3211678 & 688239 & 6.5862 & 5.4896 & TRN & \\
\hline CHEMBL1433297 & 688239 & 6.0862 & 5.6502 & TRN & \\
\hline CHEMBL1517860 & 688239 & 5.8862 & 5.4705 & TRN & \\
\hline CHEMBL1337416 & 688239 & 5.0362 & 5.2898 & TRN & \\
\hline CHEMBL1322594 & 688239 & 4.5362 & 5.468 & TRN & \\
\hline CHEMBL1328840 & 688239 & 5.1862 & 5.6063 & TRN & \\
\hline CHEMBL578668 & 688239 & 4.7362 & 5.5523 & TRN & \\
\hline CHEMBL1425516 & 688239 & 6.8861 & 5.4783 & TRN & \\
\hline CHEMBL1485933 & 688239 & 5.2362 & 5.5419 & TRN & \\
\hline CHEMBL1446684 & 688239 & 7.1864 & 5.4221 & TRN & \\
\hline CHEMBL1609068 & 688239 & 4.6862 & 5.4751 & TST & \\
\hline CHEMBL1580945 & 688239 & 5.1862 & 5.6066 & TRN & \\
\hline CHEMBL1531949 & 688239 & 7.0862 & 5.4388 & TRN & \\
\hline CHEMBL 2000525 & 688239 & 5.1862 & 5.3019 & TST & \\
\hline CHEMBL1352233 & 688239 & 4.5362 & 5.5907 & TRN & \\
\hline CHEMBL1457303 & 688239 & 5.3862 & 5.5167 & TST & \\
\hline CHEMBL1381828 & 688239 & 5.8862 & 5.4757 & TRN & \\
\hline CHEMBL1400981 & 688239 & 5.9362 & 5.4967 & TRN & \\
\hline CHEMBL1580916 & 688239 & 6.1862 & 5.4505 & TRN & \\
\hline CHEMBL1555277 & 688239 & 5.1362 & 5.3813 & TRN & \\
\hline CHEMBL1493903 & 688239 & 4.7362 & 5.3092 & TST & \\
\hline CHEMBL1369325 & 688239 & 4.7862 & 5.6034 & TRN & \\
\hline CHEMBL1411684 & 688239 & 6.8861 & 5.3734 & TST & \\
\hline CHEMBL1398585 & 688239 & 5.6862 & 5.5718 & TRN & \\
\hline CHEMBL1494510 & 688239 & 5.1862 & 5.5908 & TRN & \\
\hline CHEMBL1348042 & 688239 & 4.5362 & 5.515 & TRN & \\
\hline CHEMBL1395971 & 688239 & 6.1362 & 5.3631 & TRN & \\
\hline CHEMBL1505712 & 688239 & 4.5362 & 5.5105 & TRN & \\
\hline CHEMBL1531471 & 688239 & 5.8862 & 5.3633 & TRN & \\
\hline CHEMBL1598669 & 688239 & 8.28399 & 999999999 & 99 & 5.4903 \\
\hline CHEMBL3189635 & 688239 & 5.4362 & 5.4431 & TRN & \\
\hline CHEMBL1399404 & 688239 & 5.6362 & 5.4997 & TRN & \\
\hline CHEMBL1568096 & 688239 & 4.5362 & 5.5032 & TRN & \\
\hline
\end{tabular}

Page 1053 
Supplemental Table S2.txt

\begin{tabular}{|c|c|c|c|c|}
\hline CHEMBL1989858 & 688239 & 4.8862 & 5.4088 & TST \\
\hline CHEMBL1305126 & 688239 & 8.3372 & 5.67 & TRN \\
\hline CHEMBL1326768 & 688239 & 5.8362 & 5.5711 & TRN \\
\hline CHEMBL1520500 & 688239 & 4.7362 & 5.57799 & 9999999999 \\
\hline CHEMBL435392 & 688239 & 6.8362 & 5.3767 & TST \\
\hline CHEMBL1425246 & 688239 & 4.7362 & 5.3836 & TRN \\
\hline CHEMBL1556211 & 688239 & 4.5362 & 5.643 & TST \\
\hline CHEMBL1537608 & 688239 & 4.7362 & 5.5851 & TRN \\
\hline CHEMBL1548884 & 688239 & 5.4362 & 5.4589 & TRN \\
\hline CHEMBL1388275 & 688239 & 5.7362 & 5.4359 & TST \\
\hline CHEMBL1382893 & 688239 & 4.5362 & 5.4362 & TRN \\
\hline CHEMBL1305261 & 688239 & 4.4862 & 5.4508 & TRN \\
\hline CHEMBL1423141 & 688239 & 4.5362 & 5.4945 & TRN \\
\hline CHEMBL584269 & 688239 & 4.5362 & 5.3189 & TRN \\
\hline CHEMBL1346623 & 688239 & 5.7362 & 5.3723 & TRN \\
\hline CHEMBL1566040 & 688239 & 6.8861 & 5.5737 & TRN \\
\hline CHEMBL1578798 & 688239 & 4.5362 & 5.5734 & TRN \\
\hline CHEMBL1371241 & 688239 & 5.1862 & 5.5278 & TRN \\
\hline CHEMBL1343851 & 688239 & 5.6862 & 5.3205 & TRN \\
\hline CHEMBL1549525 & 688239 & 6.9363 & 5.3737 & TRN \\
\hline CHEMBL1541655 & 688239 & 8.3872 & 5.5093 & TST \\
\hline CHEMBL1600740 & 688239 & 5.4862 & 5.3725 & TRN \\
\hline CHEMBL1507162 & 688239 & 4.5362 & 5.3402 & TRN \\
\hline CHEMBL1363844 & 688239 & 5.6862 & 5.5286 & TST \\
\hline CHEMBL1360730 & 688239 & 4.6862 & 5.556 & TST \\
\hline CHEMBL1389506 & 688239 & 4.8862 & 5.607 & TRN \\
\hline CHEMBL1558835 & 688239 & 5.1862 & 5.3923 & TST \\
\hline CHEMBL1443942 & 688239 & 6.1862 & 5.5087 & TRN \\
\hline CHEMBL1410811 & 688239 & 8.3372 & 5.4793 & TRN \\
\hline CHEMBL1611702 & 688239 & 5.1862 & 5.5194 & TRN \\
\hline CHEMBL1597471 & 688239 & 4.5362 & 5.5853 & TST \\
\hline CHEMBL1412217 & 688239 & 4.7362 & 5.5048 & TRN \\
\hline CHEMBL1425558 & 688239 & 5.1862 & 5.4645 & TRN \\
\hline CHEMBL1575406 & 688239 & 4.5362 & 5.6783 & TRN \\
\hline CHEMBL1355187 & 688239 & 6.2362 & 5.4391 & TRN \\
\hline CHEMBL1310929 & 688239 & 4.7362 & 5.4003 & TST \\
\hline CHEMBL1311858 & 688239 & 4.9362 & 5.5087 & TRN \\
\hline CHEMBL1431188 & 688239 & 6.1362 & 5.4277 & TRN \\
\hline CHEMBL1418566 & 688239 & 4.5362 & 5.4225 & TRN \\
\hline CHEMBL1576312 & 688239 & 6.2862 & 5.4354 & TRN \\
\hline CHEMBL1349376 & 688239 & 4.7362 & 5.4467 & TRN \\
\hline CHEMBL1589020 & 688239 & 5.8362 & 5.4114 & TRN \\
\hline CHEMBL1527282 & 688239 & 5.6862 & 5.5221 & TRN \\
\hline CHEMBL1506239 & 688239 & 6.5862 & 5.2589 & TRN \\
\hline CHEMBL1550846 & 688239 & 5.1862 & 5.3598 & TRN \\
\hline CHEMBL1504106 & 688239 & 5.1862 & 5.4826 & TRN \\
\hline CHEMBL1315458 & 688239 & 5.6362 & 5.4487 & TRN \\
\hline CHEMBL1603769 & 688239 & 6.1362 & 5.4796 & TRN \\
\hline
\end{tabular}




\begin{tabular}{|c|c|c|c|c|c|}
\hline \multicolumn{6}{|c|}{ lemental } \\
\hline CHEMBL1581559 & 688239 & 4.7362 & 5.5502 & TRN & \\
\hline CHEMBL1313115 & 688239 & 7.2865 & 5.5114 & TST & \\
\hline CHEMBL1329885 & 688239 & 5.5362 & 5.6414 & TRN & \\
\hline CHEMBL1400028 & 688239 & 6.3362 & 5.3382 & TRN & \\
\hline CHEMBL1344113 & 688239 & 5.0862 & 5.36299 & 99999999995 & TRN \\
\hline CHEMBL1564812 & 688239 & 4.5862 & 5.4739 & TRN & \\
\hline CHEMBL1413333 & 688239 & 5.4862 & 5.5209 & TRN & \\
\hline CHEMBL3210781 & 688239 & 5.7362 & 5.3899 & TRN & \\
\hline CHEMBL1499773 & 688239 & 4.5362 & 5.3554 & TRN & \\
\hline CHEMBL1474688 & 688239 & 6.1862 & 5.4229 & TST & \\
\hline CHEMBL1577643 & 688239 & 5.9862 & 5.3661 & TST & \\
\hline CHEMBL1373052 & 688239 & 6.8362 & 5.6606 & TRN & \\
\hline CHEMBL1490397 & 688239 & 4.6862 & 5.4109 & TST & \\
\hline CHEMBL1986027 & 688239 & 5.1362 & 5.2734 & TRN & \\
\hline CHEMBL1412522 & 688239 & 6.2862 & 5.3962 & TST & \\
\hline CHEMBL1538698 & 688239 & 5.1362 & 5.3067 & TRN & \\
\hline CHEMBL1311883 & 688239 & 6.3362 & 5.6167 & TRN & \\
\hline CHEMBL1382617 & 688239 & 4.5362 & 5.3632 & TRN & \\
\hline CHEMBL1549497 & 688239 & 6.9863 & 5.5008 & TRN & \\
\hline CHEMBL1472530 & 688239 & 4.8 & 5.4839 & TRN & \\
\hline CHEMBL3213965 & 688239 & 4.5862 & 5.4926 & TRN & \\
\hline CHEMBL1565280 & 688239 & 5.7862 & 5.5084 & TRN & \\
\hline CHEMBL1450443 & 688239 & 5.4362 & 5.5077 & TRN & \\
\hline CHEMBL1515514 & 688239 & 4.6862 & 5.5023 & TRN & \\
\hline CHEMBL1582537 & 688239 & 8.3372 & 5.5701 & TST & \\
\hline CHEMBL1568645 & 688239 & 4.5362 & 5.5302 & TRN & \\
\hline CHEMBL1414108 & 688239 & 4.7862 & 5.3902 & TST & \\
\hline CHEMBL1422635 & 688239 & 6.9863 & 5.3821 & TST & \\
\hline CHEMBL1534158 & 688239 & 5.5862 & 5.5726 & TRN & \\
\hline CHEMBL1490279 & 688239 & 4.9362 & 5.3941 & TRN & \\
\hline CHEMBL1446926 & 688239 & 4.5362 & 5.5609 & TRN & \\
\hline CHEMBL1471487 & 688239 & 5.4362 & 5.5087 & TRN & \\
\hline CHEMBL3197061 & 688239 & 5.1862 & 5.4398 & TST & \\
\hline CHEMBL1470904 & 688239 & 4.5862 & 5.5402 & TRN & \\
\hline CHEMBL1370902 & 688239 & 4.4862 & 5.3474 & TRN & \\
\hline CHEMBL1525742 & 688239 & 4.5362 & 5.3975 & TRN & \\
\hline CHEMBL1553241 & 688239 & 5.1362 & 5.5069 & TRN & \\
\hline CHEMBL1577392 & 688239 & 4.6862 & 5.3196 & TRN & \\
\hline CHEMBL1392291 & 688239 & 4.8362 & 5.5715 & TRN & \\
\hline CHEMBL1349450 & 688239 & 4.6862 & 5.5512 & TRN & \\
\hline CHEMBL1438983 & 688239 & 4.6862 & 5.2148 & TST & \\
\hline CHEMBL1412204 & 688239 & 4.5362 & 5.4507 & TST & \\
\hline CHEMBL1388788 & 688239 & 5.2362 & 5.4605 & TRN & \\
\hline CHEMBL1535973 & 688239 & 5.3862 & 5.5534 & TRN & \\
\hline CHEMBL1532659 & 688239 & 5.3362 & 5.562 & TRN & \\
\hline CHEMBL1540025 & 688239 & 4.7862 & 5.3507 & TST & \\
\hline CHEMBL1535458 & 688239 & 5.0362 & 5.3062 & TST & \\
\hline CHEMBL1382203 & 688239 & 4.5362 & 5.6174 & TRN & \\
\hline
\end{tabular}


Supplemental Table S2.txt

\begin{tabular}{|c|c|c|c|c|}
\hline 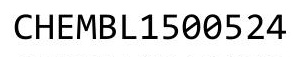 & & & & \\
\hline HEMBL3210339 & 38239 & 362 & 3924 & \\
\hline AEMBL1590978 & 239 & 862 & & \\
\hline & 39 & & & \\
\hline IEMBL1477973 & 39 & & & \\
\hline AEMBL1592822 & 88239 & 362 & & \\
\hline AEMBL1530071 & 88239 & 862 & 5751 & \\
\hline HEMBL1302406 & & & & \\
\hline EMBL1575335 & 39 & 362 & & \\
\hline IEMBL1352755 & & 362 & & \\
\hline AEMBL1543200 & 239 & 862 & 12 & \\
\hline HEMBL1392867 & & 862 & & \\
\hline HEMBL1388678 & & 62 & & \\
\hline AEMBL579028 & & & & \\
\hline HEMBL1488093 & & & & \\
\hline AEMBL1605583 & & 362 & & \\
\hline AEMBL1393903 & & 362 & & \\
\hline IEMBL156 & & & & \\
\hline AEMBL1445630 & & & & \\
\hline AEMBL1501815 & & & & \\
\hline AEMBL3210658 & & 862 & & \\
\hline AEMBL1458523 & & 62 & & \\
\hline AEMBL1501321 & & & & \\
\hline AEMBL3209762 & & & & \\
\hline 11 & & & & \\
\hline AEMBL1450488 & & & & \\
\hline IEMBL1492365 & & & & \\
\hline IEMBL137 & & & & \\
\hline ALMPI & & 52 & & \\
\hline ת 12 & & & & \\
\hline AEMBL1388660 & & & & \\
\hline AEMBL1546358 & & & & \\
\hline & & & & \\
\hline 7 & & & & \\
\hline & & & & \\
\hline AEMBL1610699 & & & & \\
\hline AEMBL1390564 & & 362 & & \\
\hline & & & & \\
\hline 0 & & & & \\
\hline HEMBL1440383 & & & & $\mathrm{RI}$ \\
\hline AEMBL1598490 & & & & \\
\hline AEMBL1525930 & & & & \\
\hline & & & & \\
\hline HEMBL1362180 & & & & \\
\hline HEMBL1398898 & & & & RN \\
\hline IEMBL1501428 & & 4. & & \\
\hline 2 & & & & \\
\hline אבתבזי & & & & \\
\hline
\end{tabular}

Page 1056 


\begin{tabular}{|c|c|c|c|c|c|c|}
\hline & & \multicolumn{5}{|c|}{ Supplemental Table s2.txt } \\
\hline CHEMBL1580770 & 688239 & 6.6861 & 5.5676 & TRN & & \\
\hline CHEMBL1470184 & 688239 & 6.9863 & 5.4969 & TST & & \\
\hline CHEMBL1331027 & 688239 & 6.3362 & 5.5857 & TRN & & \\
\hline CHEMBL1581775 & 688239 & 4.8862 & 5.4996 & TRN & & \\
\hline CHEMBL1404029 & 688239 & 4.5362 & 5.4901 & TRN & & \\
\hline CHEMBL1555971 & 688239 & 4.9862 & 5.4102 & TRN & & \\
\hline CHEMBL1325870 & 688239 & 6.5862 & 5.3345 & TST & & \\
\hline CHEMBL1418152 & 688239 & 5.6362 & 5.5394 & TRN & & \\
\hline CHEMBL1609031 & 688239 & 6.5862 & 5.4469 & TRN & & \\
\hline CHEMBL1412910 & 688239 & 5.1362 & 5.3666 & TST & & \\
\hline CHEMBL3211302 & 688239 & 5.4862 & 5.3828 & TRN & & \\
\hline CHEMBL1305905 & 688239 & 5.3862 & 5.54299 & 9999999999 & & TRN \\
\hline CHEMBL1396653 & 688239 & 4.5862 & 5.5106 & TRN & & \\
\hline CHEMBL1564711 & 688239 & 6.1362 & 5.5063 & TRN & & \\
\hline CHEMBL1582006 & 688239 & 4.6362 & 5.4024 & TST & & \\
\hline CHEMBL1331634 & 688239 & 6.0862 & 5.3527 & TRN & & \\
\hline CHEMBL1491537 & 688239 & 4.4862 & 5.4922 & TRN & & \\
\hline CHEMBL1613256 & 688239 & 5.3362 & 5.5087 & TST & & \\
\hline CHEMBL1526963 & 688239 & 5.7862 & 5.4936 & TRN & & \\
\hline CHEMBL1444990 & 688239 & 6.2362 & 5.4169 & TST & & \\
\hline CHEMBL1465648 & 688239 & 4.7362 & 5.3663 & TST & & \\
\hline CHEMBL1338355 & 688239 & 7.0362 & 5.4703 & TST & & \\
\hline CHEMBL1586303 & 688239 & 6.6362 & 5.3033 & TRN & & \\
\hline CHEMBL1361560 & 688239 & 4.7362 & 5.5242 & TRN & & \\
\hline CHEMBL1411612 & 688239 & 5.3862 & 5.5144 & TRN & & \\
\hline CHEMBL1594270 & 688239 & 5.1362 & $5.54200 t$ & 0000000001 & & TST \\
\hline CHEMBL1354452 & 688239 & 5.7862 & 5.5207 & TRN & & \\
\hline CHEMBL1343101 & 688239 & 4.5362 & 5.4197 & TST & & \\
\hline CHEMBL1457195 & 688239 & 5.0362 & 5.4855 & TRN & & \\
\hline CHEMBL1603953 & 688239 & 4.6862 & 5.5668 & TRN & & \\
\hline CHEMBL1607031 & 688239 & 4.8862 & 5.4482 & TRN & & \\
\hline CHEMBL3209137 & 688239 & 4.5362 & 5.3673 & TRN & & \\
\hline CHEMBL1374115 & 688239 & 4.6362 & 5.4955 & TRN & & \\
\hline CHEMBL1410737 & 688239 & 5.1862 & 5.5486 & TRN & & \\
\hline CHEMBL1490336 & 688239 & 4.5362 & 5.4042 & TRN & & \\
\hline CHEMBL1385355 & 688239 & 5.5862 & 5.5524 & TRN & & \\
\hline CHEMBL1539676 & 688239 & 5.2862 & 5.5485 & TST & & \\
\hline CHEMBL1305540 & 688239 & 4.5362 & 5.3034 & TRN & & \\
\hline CHEMBL1306493 & 688239 & 5.4362 & 5.5152 & TRN & & \\
\hline CHEMBL1332276 & 688239 & 6.2362 & 5.4596 & TRN & & \\
\hline CHEMBL1316519 & 688239 & 5.1862 & 5.5349 & TST & & \\
\hline CHEMBL1351381 & 688239 & 4.8862 & 5.4348 & TRN & & \\
\hline CHEMBL1604612 & 688239 & 8.28399 & 99999999 & 99 & 5.3704 & TRN \\
\hline CHEMBL1572951 & 688239 & 5.6362 & 5.4258 & TRN & & \\
\hline CHEMBL1337867 & 688239 & 6.9363 & 5.6086 & TRN & & \\
\hline CHEMBL1537196 & 688239 & 6.3863 & 5.4489 & TST & & \\
\hline CHEMBL1596820 & 688239 & 4.6862 & 5.4523 & TRN & & \\
\hline CHEMBL1539303 & 688239 & 5.3362 & 5.5696 & TRN & & \\
\hline
\end{tabular}


Supplemental Table S2.txt

\begin{tabular}{|c|c|c|c|c|c|}
\hline CHEMBL1413544 & 688239 & 4.5362 & 5.4178 & TRN & \\
\hline CHEMBL1396293 & 688239 & 6.3863 & 5.4746 & TRN & \\
\hline CHEMBL1530994 & 688239 & 4.5862 & 5.6381 & TRN & \\
\hline CHEMBL1327359 & 688239 & 6.4862 & 5.4071 & TRN & \\
\hline CHEMBL1565506 & 688239 & 4.6862 & 5.4306 & TRN & \\
\hline CHEMBL1567566 & 688239 & 5.7862 & 5.4728 & TRN & \\
\hline CHEMBL1362905 & 688239 & 4.5362 & 5.4309 & TRN & \\
\hline CHEMBL1370050 & 688239 & 6.6362 & 5.4818 & TRN & \\
\hline CHEMBL1433044 & 688239 & 8.3372 & 5.5165 & TRN & \\
\hline CHEMBL 3214440 & 688239 & 5.5862 & 5.7113 & TRN & \\
\hline CHEMBL1588177 & 688239 & 4.95 & 5.5306 & TRN & \\
\hline CHEMBL3208210 & 688239 & 6.9363 & 5.4648 & TRN & \\
\hline CHEMBL1409398 & 688239 & 4.7362 & 5.4248 & TST & \\
\hline CHEMBL1419978 & 688239 & 4.7362 & 5.4556 & TRN & \\
\hline CHEMBL1347556 & 688239 & 5.8862 & 5.5377 & TST & \\
\hline CHEMBL1526527 & 688239 & 5.15 & 5.5677 & TRN & \\
\hline CHEMBL1376488 & 688239 & 4.6362 & 5.3517 & TRN & \\
\hline CHEMBL1344969 & 688239 & 4.5362 & 5.6215 & TRN & \\
\hline CHEMBL1990096 & 688239 & 4.7362 & 5.4917 & TST & \\
\hline CHEMBL1462985 & 688239 & 4.5862 & 5.4067 & TST & \\
\hline CHEMBL1421922 & 688239 & 4.5362 & 5.5008 & TRN & \\
\hline CHEMBL3210632 & 688239 & 4.7362 & 5.4594 & TRN & \\
\hline CHEMBL1573144 & 688239 & 4.4862 & 5.4179 & TST & \\
\hline CHEMBL1387574 & 688239 & 5.0362 & 5.6299 & TRN & \\
\hline CHEMBL1590090 & 688239 & 5.8362 & 5.4501 & TRN & \\
\hline CHEMBL1316372 & 688239 & 4.5362 & 5.494 & TRN & \\
\hline CHEMBL1377155 & 688239 & 4.5362 & 5.5387 & TST & \\
\hline CHEMBL1477397 & 688239 & 5.1862 & 5.5411 & TRN & \\
\hline CHEMBL1587190 & 688239 & 5.6362 & 5.343999 & 999999999 & TST \\
\hline CHEMBL1374508 & 688239 & 5.9362 & 5.5746 & TRN & \\
\hline CHEMBL1595802 & 688239 & 4.9362 & 5.3533 & TST & \\
\hline CHEMBL1400779 & 688239 & 6.1362 & 5.6777 & TST & \\
\hline CHEMBL3199812 & 688239 & 4.5862 & 5.3492 & TRN & \\
\hline CHEMBL1598403 & 688239 & 4.6862 & 5.4911 & TRN & \\
\hline CHEMBL1318836 & 688239 & 6.2862 & 5.5816 & TRN & \\
\hline CHEMBL1326294 & 688239 & 6.3863 & 5.4538 & TRN & \\
\hline CHEMBL3194298 & 688239 & 6.7862 & 5.5482 & TRN & \\
\hline CHEMBL1540939 & 688239 & 5.6362 & 5.4893 & TRN & \\
\hline CHEMBL3209551 & 688239 & 4.5362 & 5.547000 & 000000001 & TRN \\
\hline CHEMBL1307601 & 688239 & 8.283999 & 999999999 & 5.6154 & TRN \\
\hline CHEMBL 3211366 & 688239 & 8.3372 & 5.4752 & TRN & \\
\hline CHEMBL 365161 & 688239 & 4.8362 & 5.4496 & TST & \\
\hline CHEMBL1527106 & 688239 & 4.4862 & 5.4231 & TRN & \\
\hline CHEMBL1445859 & 688239 & 5.3862 & 5.3958 & TRN & \\
\hline CHEMBL1533801 & 688239 & 6.0362 & 5.5828 & TRN & \\
\hline CHEMBL1431100 & 688239 & 4.6862 & 5.3587 & TST & \\
\hline CHEMBL1478480 & 688239 & 5.3362 & 5.3827 & TRN & \\
\hline CHEMBL1449387 & 688239 & 8.3372 & 5.4837 & TST & \\
\hline
\end{tabular}


Supplemental Table S2.txt

\begin{tabular}{|c|c|c|c|c|c|}
\hline CHEMBL1570359 & 688239 & 4.8362 & 5.4043 & TRN & \\
\hline CHEMBL1413731 & 688239 & 4.5862 & 5.5037 & TRN & \\
\hline CHEMBL1487596 & 688239 & 6.4862 & 5.6812 & TRN & \\
\hline CHEMBL1385592 & 688239 & 6.6362 & 5.4 & TRN & \\
\hline CHEMBL1380363 & 688239 & 5.1862 & 5.4121 & TRN & \\
\hline CHEMBL1561447 & 688239 & 5.1362 & 5.5166 & TRN & \\
\hline CHEMBL1377104 & 688239 & 5.6362 & 5.6329 & TRN & \\
\hline CHEMBL1346183 & 688239 & 4.4862 & 5.5065 & TST & \\
\hline CHEMBL1512089 & 688239 & 5.1862 & 5.5258 & TRN & \\
\hline CHEMBL1480253 & 688239 & 6.5363 & 5.6402 & TRN & \\
\hline CHEMBL1606447 & 688239 & 5.4862 & 5.6868 & TST & \\
\hline CHEMBL1507610 & 688239 & 5.8362 & 5.6712 & TRN & \\
\hline CHEMBL1383376 & 688239 & 4.7362 & 5.4181 & TRN & \\
\hline CHEMBL1447563 & 688239 & 4.5362 & 5.4943 & TST & \\
\hline CHEMBL1564638 & 688239 & 6.0862 & 5.4029 & TST & \\
\hline CHEMBL1479425 & 688239 & 5.4362 & 5.4385 & TRN & \\
\hline CHEMBL1361238 & 688239 & 5.6362 & 5.4162 & TRN & \\
\hline CHEMBL1332286 & 688239 & 5.4362 & 5.5061 & TST & \\
\hline CHEMBL1383583 & 688239 & 4.5362 & 5.4433 & TST & \\
\hline CHEMBL1339213 & 688239 & 4.5362 & 5.563 & TRN & \\
\hline CHEMBL1313336 & 688239 & 4.6362 & 5.5417 & TRN & \\
\hline CHEMBL1402274 & 688239 & 5.1862 & 5.4259 & TST & \\
\hline CHEMBL1389398 & 688239 & 4.7862 & 5.4903 & TRN & \\
\hline CHEMBL1551721 & 688239 & 5.4362 & 5.4634 & TRN & \\
\hline CHEMBL 3212034 & 688239 & 4.7862 & 5.5485 & TRN & \\
\hline CHEMBL1406886 & 688239 & 5.1862 & 5.5428 & TRN & \\
\hline CHEMBL1318504 & 688239 & 6.0862 & 5.5123 & TRN & \\
\hline CHEMBL1494052 & 688239 & 5.9862 & 5.5645 & TRN & \\
\hline CHEMBL1572961 & 688239 & 4.6862 & 5.4363 & TST & \\
\hline CHEMBL1374138 & 688239 & 6.9363 & 5.6175 & TRN & \\
\hline CHEMBL1415313 & 688239 & 4.7362 & 5.5201 & TRN & \\
\hline CHEMBL1585607 & 688239 & 5.7362 & 5.5623 & TRN & \\
\hline CHEMBL1377505 & 688239 & 6.3362 & 5.5037 & TRN & \\
\hline CHEMBL1457333 & 688239 & 6.1362 & 5.5276 & TRN & \\
\hline CHEMBL1361702 & 688239 & 7.4365 & 5.3924 & TST & \\
\hline CHEMBL1601293 & 688239 & 4.4862 & 5.4737 & TRN & \\
\hline CHEMBL1476170 & 688239 & 4.5362 & 5.3682 & TST & \\
\hline CHEMBL1345262 & 688239 & 4.5362 & 5.4444 & TRN & \\
\hline CHEMBL1415033 & 688239 & 6.2362 & 5.57799 & 9999999999 & TRN \\
\hline CHEMBL1447073 & 688239 & 7.5361 & 5.555 & TST & \\
\hline CHEMBL1518593 & 688239 & 5.1862 & 5.409 & TRN & \\
\hline CHEMBL1468142 & 688239 & 5.7362 & 5.5926 & TRN & \\
\hline CHEMBL1359223 & 688239 & 4.7862 & 5.4942 & TRN & \\
\hline CHEMBL1494414 & 688239 & 4.5862 & 5.466 & TST & \\
\hline CHEMBL1608001 & 688239 & 5.7862 & 5.3469 & TRN & \\
\hline CHEMBL1410233 & 688239 & 5.1862 & 5.44799 & 99999999995 & TRN \\
\hline CHEMBL1524976 & 688239 & 6.9863 & 5.5592 & TRN & \\
\hline CHEMBL1377928 & 688239 & 4.8362 & 5.4077 & TST & \\
\hline
\end{tabular}




\begin{tabular}{|c|c|c|c|c|c|}
\hline \multirow{3}{*}{$\begin{array}{l}\text { CHEMBL1466929 } \\
\text { CHFMBI } 1504829\end{array}$} & & \multicolumn{4}{|c|}{ Supplemental Table s2.txt } \\
\hline & 688239 & 4.5362 & \multicolumn{2}{|c|}{5.492000000000001} & TRN \\
\hline & 688239 & 5.6862 & 5.4235 & TRN & \\
\hline CHEMBL1523162 & 688239 & 6.0862 & 5.4889 & TRN & \\
\hline CHEMBL1494819 & 688239 & 5.4862 & 5.5127 & TRN & \\
\hline CHEMBL1430289 & 688239 & 4.7362 & 5.3116 & TST & \\
\hline CHEMBL1381566 & 688239 & 4.4862 & 5.49799 & 9999999999 & TRN \\
\hline CHEMBL1606571 & 688239 & 6.8861 & 5.4864 & TRN & \\
\hline CHEMBL1586404 & 688239 & 5.4362 & 5.2989 & TRN & \\
\hline CHEMBL1980530 & 688239 & 6.0362 & 5.3811 & TRN & \\
\hline CHEMBL1401903 & 688239 & 4.7362 & 5.4397 & TRN & \\
\hline CHEMBL1471186 & 688239 & 4.5362 & 5.436 & TRN & \\
\hline CHEMBL1473065 & 688239 & 7.7852 & 5.433 & TST & \\
\hline CHEMBL1384773 & 688239 & 5.0362 & 5.50299 & 9999999999 & TRN \\
\hline CHEMBL1580832 & 688239 & 4.6862 & 5.3142 & TRN & \\
\hline CHEMBL1421484 & 688239 & 5.1862 & 5.3808 & TRN & \\
\hline CHEMBL1541494 & 688239 & 4.5362 & 5.4361 & TRN & \\
\hline CHEMBL1552054 & 688239 & 4.7862 & 5.4939 & TRN & \\
\hline CHEMBL1610364 & 688239 & 5.2362 & 5.4552 & TRN & \\
\hline CHEMBL1527645 & 688239 & 7.6861 & 5.3295 & TRN & \\
\hline CHEMBL3190913 & 688239 & 5.7862 & 5.4298 & TRN & \\
\hline CHEMBL1453384 & 688239 & 4.6362 & 5.3766 & TST & \\
\hline CHEMBL1429770 & 688239 & 6.3863 & 5.5536 & TRN & \\
\hline CHEMBL1527130 & 688239 & 4.5362 & 5.425 & TRN & \\
\hline CHEMBL1306624 & 688239 & 5.4862 & 5.3545 & TRN & \\
\hline CHEMBL1326460 & 688239 & 4.5362 & 5.5557 & TST & \\
\hline CHEMBL1365413 & 688239 & 5.8362 & 5.4521 & TRN & \\
\hline CHEMBL1513960 & 688239 & 4.7362 & 5.5544 & TST & \\
\hline CHEMBL1538417 & 688239 & 5.5862 & 5.49299 & 9999999999 & TRN \\
\hline CHEMBL1311676 & 688239 & 4.7362 & 5.3559 & TRN & \\
\hline CHEMBL1533346 & 688239 & 6.7361 & 5.4189 & TST & \\
\hline CHEMBL1487695 & 688239 & 6.9363 & 5.5459 & TRN & \\
\hline CHEMBL1349146 & 688239 & 4.9862 & 5.407 & TST & \\
\hline CHEMBL1574181 & 688239 & 5.1362 & 5.4931 & TRN & \\
\hline CHEMBL1417731 & 688239 & 4.6862 & 5.4066 & TST & \\
\hline CHEMBL1574611 & 688239 & 5.4862 & 5.3934 & TRN & \\
\hline CHEMBL1488169 & 688239 & 5.0862 & 5.5658 & TRN & \\
\hline CHEMBL1497321 & 688239 & 5.7862 & 5.6298 & TRN & \\
\hline CHEMBL1449660 & 688239 & 4.5362 & 5.3174 & TRN & \\
\hline CHEMBL1479777 & 688239 & 4.5362 & 5.581 & TST & \\
\hline CHEMBL1497230 & 688239 & 5.2362 & 5.5746 & TST & \\
\hline CHEMBL1337556 & 688239 & 4.9862 & 5.5635 & TRN & \\
\hline CHEMBL1433083 & 688239 & 5.3362 & 5.5384 & TRN & \\
\hline CHEMBL1541685 & 688239 & 5.7862 & 5.4962 & TST & \\
\hline CHEMBL1429988 & 688239 & 6.0862 & 5.6211 & TRN & \\
\hline CHEMBL1300119 & 688239 & 6.0862 & 5.6461 & TRN & \\
\hline CHEMBL1471137 & 688239 & 5.1362 & 5.5541 & TRN & \\
\hline CHEMBL1473963 & 688239 & 5.4862 & 5.4223 & TRN & \\
\hline CHEMBL1377779 & 688239 & 5.6362 & 5.4419 & TST & \\
\hline
\end{tabular}


Supplemental Table S2.txt

\begin{tabular}{|c|c|c|c|c|}
\hline 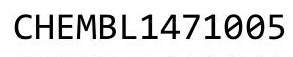 & & & & \\
\hline HEMBL1611204 & 38239 & 862 & 6 & \\
\hline HEMBL1459688 & 239 & 62 & 867 & \\
\hline & 39 & 362 & & \\
\hline IEMBL13 & 39 & 362 & & \\
\hline AEMBL1388906 & 88239 & 366 & 5032 & \\
\hline AEMBL1410961 & 88239 & 362 & 5746 & \\
\hline AEMBL1545612 & & & & \\
\hline EMBL14 & 39 & 862 & & \\
\hline IEMBL15 & & & 26 & \\
\hline AEMBL1355073 & 239 & 862 & 506 & \\
\hline AEMBL1575140 & 39 & 862 & 1918 & \\
\hline HEMBL1409730 & & 62 & 234 & \\
\hline AEMBL13 & & & 302 & \\
\hline AEMBL13 & & & & \\
\hline AEMBL1421407 & & 867 & 509 & \\
\hline AEMBL1591576 & & 362 & 279 & \\
\hline IEMBL14 & & & & \\
\hline AEMBL13 & & & & \\
\hline AEMBL14 & & & & \\
\hline AEMBL 15 & & 362 & 92 & \\
\hline AEMBL1312421 & & 61 & & \\
\hline HEMBL13 & & & & \\
\hline AEMBL 32 & & & & \\
\hline 935 & & & & \\
\hline 071 & & & & \\
\hline IEMBL15 & & & & \\
\hline EMBL13 & & & & \\
\hline 916 & & & & \\
\hline 451 & & & & \\
\hline 5268 & & & & \\
\hline HEMBL1548747 & & & & \\
\hline & & & & \\
\hline 43 & & & & \\
\hline AEMBL13 & & & & \\
\hline AEMBL1378233 & & & & \\
\hline AEMBL1482515 & & 62 & 04 & \\
\hline & & & & \\
\hline 929 & & & & \\
\hline HEMBL1412608 & & & & RN \\
\hline AEMBL1364363 & & & & \\
\hline JEMBL14 & & & & \\
\hline & & & & \\
\hline CHEMBL14 & & & & \\
\hline AEMBL143 & & & 4826 & RN \\
\hline MBL13 & & 62 & 339 & \\
\hline 1 & & & & \\
\hline HEMBL149953 & & & & \\
\hline
\end{tabular}

Page 1061 
Supplemental Table S2.txt

\begin{tabular}{|c|c|c|c|c|c|}
\hline CHEMBL1572135 & 688239 & 4.9362 & 5.7557 & TRN & \\
\hline CHEMBL435539 & 688239 & 5.4862 & 5.4667 & TRN & \\
\hline CHEMBL1456842 & 688239 & 5.9362 & 5.4923 & TST & \\
\hline CHEMBL1533374 & 688239 & 5.7862 & 5.5501 & TRN & \\
\hline CHEMBL1364887 & 688239 & 6.0862 & 5.4872 & TRN & \\
\hline CHEMBL3210282 & 688239 & 5.4362 & 5.5669 & TST & \\
\hline CHEMBL3145062 & 688239 & 5.6362 & 5.4272 & TRN & \\
\hline CHEMBL3214125 & 688239 & 8.3372 & 5.7264 & TRN & \\
\hline CHEMBL1417463 & 688239 & 4.5362 & 5.4644 & TRN & \\
\hline CHEMBL1380689 & 688239 & 8.2366 & 5.452000 & 000000001 & TRN \\
\hline CHEMBL1308586 & 688239 & 5.4362 & 5.3447 & TRN & \\
\hline CHEMBL1348843 & 688239 & 5.3362 & 5.5283 & TRN & \\
\hline CHEMBL1541608 & 688239 & 5.0362 & 5.5076 & TRN & \\
\hline CHEMBL1525683 & 688239 & 4.9362 & 5.3898 & TRN & \\
\hline CHEMBL1582261 & 688239 & 6.9863 & 5.4093 & TRN & \\
\hline CHEMBL1974301 & 688239 & 4.5362 & 5.4239 & TST & \\
\hline CHEMBL1573830 & 688239 & 5.1862 & 5.4947 & TRN & \\
\hline CHEMBL1580808 & 688239 & 5.7362 & 5.5811 & TRN & \\
\hline CHEMBL1404405 & 688239 & 5.5862 & 5.5121 & TRN & \\
\hline CHEMBL1341487 & 688239 & 5.4862 & 5.6004 & TRN & \\
\hline CHEMBL3212951 & 688239 & 5.8862 & 5.5257 & TST & \\
\hline CHEMBL1346260 & 688239 & 4.8862 & 5.5222 & TST & \\
\hline CHEMBL1364223 & 688239 & 4.5362 & 5.3199 & TST & \\
\hline CHEMBL1583127 & 688239 & 6.7862 & 5.4619 & TRN & \\
\hline CHEMBL1477939 & 688239 & 6.0862 & 5.4712 & TST & \\
\hline CHEMBL1404651 & 688239 & 4.9362 & 5.4446 & TRN & \\
\hline CHEMBL1541670 & 688239 & 6.1862 & 5.5561 & TRN & \\
\hline CHEMBL1499461 & 688239 & 4.5362 & 5.4403 & TST & \\
\hline CHEMBL1328410 & 688239 & 4.7862 & 5.691 & TRN & \\
\hline CHEMBL1381051 & 688239 & 5.2362 & 5.5068 & TRN & \\
\hline CHEMBL1537337 & 688239 & 6.1362 & 5.6148 & TRN & \\
\hline CHEMBL1493057 & 688239 & 5.8862 & 5.4575 & TST & \\
\hline CHEMBL1410944 & 688239 & 6.1362 & 5.665 & TRN & \\
\hline CHEMBL1378291 & 688239 & 4.8362 & 5.4075 & TST & \\
\hline CHEMBL1452473 & 688239 & 5.8862 & 5.6266 & TST & \\
\hline CHEMBL1483413 & 688239 & 5.4862 & 5.5876 & TRN & \\
\hline CHEMBL1390444 & 688239 & 4.6362 & 5.5737 & TRN & \\
\hline CHEMBL3212998 & 688239 & 4.7362 & 5.3719 & TST & \\
\hline CHEMBL1428215 & 688239 & 6.1862 & 5.4567 & TST & \\
\hline CHEMBL1411644 & 688239 & 6.9863 & 5.5002 & TRN & \\
\hline CHEMBL1502366 & 688239 & 8.28399 & 999999999 & 5.5636 & KI \\
\hline CHEMBL1386994 & 688239 & 6.2362 & 5.6152 & TRN & \\
\hline CHEMBL1572783 & 688239 & 8.3872 & 5.3884 & TST & \\
\hline CHEMBL1378594 & 688239 & 5.4362 & 5.4028 & TRN & \\
\hline CHEMBL1446090 & 688239 & 8.3372 & 5.3918 & TRN & \\
\hline CHEMBL1522934 & 688239 & 6.1362 & 5.6093 & TRN & \\
\hline CHEMBL3194689 & 688239 & 4.4862 & 5.3478 & TRN & \\
\hline CHEMBL1392129 & 688239 & 4.5362 & 5.5725 & TRN & \\
\hline
\end{tabular}


Supplemental Table S2.txt

\begin{tabular}{|c|c|c|c|c|}
\hline CHEMBL1465466 & 688239 & 4.5362 & 5.5007 & TRN \\
\hline CHEMBL1966728 & 688239 & 6.5363 & 5.518 & TRN \\
\hline CHEMBL1323009 & 688239 & 5.4362 & 5.5045 & TRN \\
\hline CHEMBL1338035 & 688239 & 4.8862 & 5.3811 & TRN \\
\hline CHEMBL1406278 & 688239 & 5.1862 & 5.5059 & TRN \\
\hline CHEMBL1433306 & 688239 & 6.0362 & 5.5697 & TRN \\
\hline CHEMBL1451691 & 688239 & 4.7362 & 5.4439 & TRN \\
\hline CHEMBL3209162 & 688239 & 5.4862 & 5.422006 & 0000000001 \\
\hline CHEMBL1299701 & 688239 & 6.8362 & 5.5584 & TRN \\
\hline CHEMBL1579953 & 688239 & 5.2362 & 5.6029 & TRN \\
\hline CHEMBL1311789 & 688239 & 4.8862 & 5.2421 & TRN \\
\hline CHEMBL1387733 & 688239 & 5.4862 & 5.3894 & TRN \\
\hline CHEMBL1577776 & 688239 & 4.5862 & 5.4036 & TST \\
\hline CHEMBL1448716 & 688239 & 6.0862 & 5.6362 & TST \\
\hline CHEMBL1330828 & 688239 & 5.6362 & 5.6003 & TRN \\
\hline CHEMBL1522600 & 688239 & 6.0862 & 5.5421 & TRN \\
\hline CHEMBL1412603 & 688239 & 4.2362 & 5.4735 & TST \\
\hline CHEMBL1607020 & 688239 & 6.5363 & 5.559 & TRN \\
\hline CHEMBL1508231 & 688239 & 4.9362 & 5.4864 & TRN \\
\hline CHEMBL1525400 & 688239 & 4.5362 & 5.4121 & TRN \\
\hline CHEMBL1564147 & 688239 & 5.6862 & 5.5126 & TRN \\
\hline CHEMBL1526462 & 688239 & 5.6862 & 5.3485 & TRN \\
\hline CHEMBL1411106 & 688239 & 6.9363 & 5.5529 & TRN \\
\hline CHEMBL1309950 & 688239 & 5.7362 & 5.4829 & TRN \\
\hline CHEMBL1587473 & 688239 & 4.7362 & 5.3272 & TRN \\
\hline CHEMBL1321530 & 688239 & 4.5362 & 5.5899 & TRN \\
\hline CHEMBL1525092 & 688239 & 4.7862 & 5.5684 & TRN \\
\hline CHEMBL1580151 & 688239 & 5.3362 & 5.551 & TRN \\
\hline CHEMBL1594007 & 688239 & 4.7862 & 5.4272 & TRN \\
\hline CHEMBL1451230 & 688239 & 4.6862 & 5.638 & TST \\
\hline CHEMBL1444989 & 688239 & 4.5362 & 5.4104 & TRN \\
\hline CHEMBL1337232 & 688239 & 5.1362 & 5.4837 & TRN \\
\hline CHEMBL1572320 & 688239 & 4.5362 & 5.4721 & TST \\
\hline CHEMBL1437115 & 688239 & 4.5362 & 5.4929 & TRN \\
\hline CHEMBL1373781 & 688239 & 4.6362 & 5.4581 & TRN \\
\hline CHEMBL1430877 & 688239 & 6.0862 & 5.5829 & TST \\
\hline CHEMBL1343315 & 688239 & 6.0362 & 5.5814 & TRN \\
\hline CHEMBL3189770 & 688239 & 4.5362 & 5.4777 & TST \\
\hline CHEMBL1527394 & 688239 & 7.9355 & 5.5451 & TRN \\
\hline CHEMBL3195786 & 688239 & 4.7362 & 5.3576 & TRN \\
\hline CHEMBL1549053 & 688239 & 5.7362 & 5.4645 & TST \\
\hline CHEMBL1487337 & 688239 & 4.5362 & 5.5393 & TST \\
\hline CHEMBL1320744 & 688239 & 7.0862 & 5.4789 & TRN \\
\hline CHEMBL592552 & 688239 & 6.2362 & 5.3894 & TRN \\
\hline CHEMBL1529904 & 688239 & 5.8862 & 5.6325 & TRN \\
\hline CHEMBL1571806 & 688239 & 5.1862 & 5.49 & TST \\
\hline CHEMBL1460907 & 688239 & 6.1362 & 5.4561 & TRN \\
\hline CHEMBL1361661 & 688239 & 5.5362 & 5.4902 & TRN \\
\hline
\end{tabular}


Supplemental Table S2.txt

\begin{tabular}{|c|c|c|c|c|c|}
\hline CHEMBL1448939 & 688239 & 5.6362 & 5.4484 & TRN & \\
\hline CHEMBL1380250 & 688239 & 5.6362 & 5.4077 & TRN & \\
\hline CHEMBL1437192 & 688239 & 8.3872 & 5.4092 & TRN & \\
\hline CHEMBL1412335 & 688239 & 4.5362 & 5.7139 & TRN & \\
\hline CHEMBL1459199 & 688239 & 4.5362 & 5.4304 & TRN & \\
\hline CHEMBL3196487 & 688239 & 4.6862 & 5.2343 & TST & \\
\hline CHEMBL3213658 & 688239 & 6.8861 & 5.4486 & TST & \\
\hline CHEMBL1317270 & 688239 & 5.0362 & 5.4583 & TRN & \\
\hline CHEMBL3199626 & 688239 & 5.6862 & 5.4051 & TRN & \\
\hline CHEMBL3195857 & 688239 & 8.3372 & 5.4323 & TST & \\
\hline CHEMBL1544144 & 688239 & 6.5862 & 5.4806 & TST & \\
\hline CHEMBL1603815 & 688239 & 4.6362 & 5.4842 & TRN & \\
\hline CHEMBL1566149 & 688239 & 5.8362 & 5.518 & TRN & \\
\hline CHEMBL1574641 & 688239 & 4.4862 & 5.5354 & TRN & \\
\hline CHEMBL1585569 & 688239 & 4.5362 & 5.4315 & TRN & \\
\hline CHEMBL1410908 & 688239 & 4.5362 & 5.5583 & TRN & \\
\hline CHEMBL1498429 & 688239 & 5.7862 & 5.6934 & TRN & \\
\hline CHEMBL1458390 & 688239 & 6.4362 & 5.598 & TRN & \\
\hline CHEMBL1542817 & 688239 & 5.3362 & 5.4361 & TRN & \\
\hline CHEMBL1461722 & 688239 & 6.3863 & 5.4773 & TST & \\
\hline CHEMBL1569721 & 688239 & 6.7361 & 5.5271 & TST & \\
\hline CHEMBL1547860 & 688239 & 4.5362 & 5.6786 & TRN & \\
\hline CHEMBL1402747 & 688239 & 4.8362 & 5.528 & TRN & \\
\hline CHEMBL1556181 & 688239 & 5.2362 & 5.4666 & TST & \\
\hline CHEMBL1563952 & 688239 & 5.6862 & 5.5364 & TRN & \\
\hline CHEMBL1593968 & 688239 & 4.5362 & 5.5201 & TRN & \\
\hline CHEMBL1418085 & 688239 & 5.8362 & 5.5886 & TRN & \\
\hline CHEMBL1456739 & 688239 & 4.5362 & 5.4527 & TRN & \\
\hline CHEMBL1305944 & 688239 & 4.8862 & 5.5061 & TST & \\
\hline CHEMBL1351611 & 688239 & 6.0862 & 5.4717 & TRN & \\
\hline CHEMBL1334501 & 688239 & 6.9363 & 5.3277 & TST & \\
\hline CHEMBL1302017 & 688239 & 5.1862 & 5.49200 & 2000000001 & TRN \\
\hline CHEMBL1417793 & 688239 & 5.1862 & 5.4307 & TRN & \\
\hline CHEMBL1587860 & 688239 & 4.5362 & 5.3887 & TRN & \\
\hline CHEMBL1375714 & 688239 & 5.6862 & 5.4081 & TRN & \\
\hline CHEMBL1484611 & 688239 & 5.3362 & 5.5359 & TRN & \\
\hline CHEMBL1537267 & 688239 & 5.0862 & 5.4155 & TRN & \\
\hline CHEMBL1513526 & 688239 & 5.4862 & 5.4005 & TRN & \\
\hline CHEMBL1300556 & 688239 & 6.1362 & 5.519 & TST & \\
\hline CHEMBL1351556 & 688239 & 4.5362 & 5.5716 & TRN & \\
\hline CHEMBL1345875 & 688239 & 5.7862 & 5.5676 & TST & \\
\hline CHEMBL1447203 & 688239 & 6.8362 & 5.4357 & TRN & \\
\hline CHEMBL1561287 & 688239 & 6.3362 & 5.6284 & TRN & \\
\hline CHEMBL1461497 & 688239 & 5.0862 & 5.6624 & TRN & \\
\hline CHEMBL1498353 & 688239 & 4.5862 & 5.1676 & TST & \\
\hline CHEMBL1442478 & 688239 & 4.8862 & 5.4131 & TRN & \\
\hline CHEMBL1542440 & 688239 & 4.5862 & 5.4872 & TRN & \\
\hline CHEMBL1398620 & 688239 & 5.5362 & 5.4362 & TRN & \\
\hline
\end{tabular}


Supplemental Table S2.txt

\begin{tabular}{|c|c|c|c|c|}
\hline IE & & 2 & & \\
\hline & & .8362 & 5.3576 & \\
\hline 60 & & & & \\
\hline IEMBL15080 & & & & \\
\hline AEMBL1427694 & 8239 & 372 & & \\
\hline HEMBL3194945 & 88239 & 5362 & 4227 & \\
\hline HEMBL1303963 & 239 & & & \\
\hline IFMRI 32 & & & & \\
\hline AEMBL3193734 & & & & \\
\hline HEMBL3211334 & 38239 & & & \\
\hline HEMBL1305792 & 39 & & 5261 & \\
\hline IEMBL150 & 39 & & & \\
\hline IEMBL13e & & & & \\
\hline HEMBL151 & & & & \\
\hline AEMBL3198683 & & & & \\
\hline AEMBL319] & 39 & & 46 & \\
\hline AEMBL16 & & & & \\
\hline HEMBL 14 & & & & \\
\hline AEMBL1392 & & 62 & & \\
\hline AEMBL136 & & & & \\
\hline HEIMBLIL & & & & \\
\hline AEMBL1C & & & & \\
\hline HEMBL31 & & & & \\
\hline AFMRI 1 & & & & \\
\hline AEMBL15 & & & & 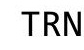 \\
\hline AEMBL13 & & & & \\
\hline AEMBLI & & & & \\
\hline HFMBI 1 & & & & \\
\hline HEMBL14 & & & & TRN \\
\hline HEMBL31996 & & & & ISI \\
\hline HEMBL13 & & & & TRN \\
\hline AFMBI 1 & & & & \\
\hline - ניסM & & & & ST \\
\hline HEMBL1420963 & & & & TST \\
\hline HEMBL134976 & & & 45 & $\Gamma \mathrm{RN}$ \\
\hline HEMBL16 & & & & \\
\hline 1 & & & & RIV \\
\hline HEMBL1: & & & & RN \\
\hline HEMBL3199127 & 88239 & & 57 & TRN \\
\hline EMBL] & & & & RIV \\
\hline HEMBL14 & & & 06 & \\
\hline HEMBL130 & & & & ST \\
\hline HEMBL 252403 & & & 5.5032 & RN \\
\hline AEMBL3214 & & 362 & 893 & TRN \\
\hline MBL1 & & & & RN \\
\hline CHEMBL3199006 & & & & \\
\hline CHEMBL15722 & & & 5.4811 & \\
\hline HEMBL137325 & 688239 & 5.3862 & 5.5885 & ГRN \\
\hline
\end{tabular}

Page 1065 
Supplemental Table S2.txt

\begin{tabular}{|c|c|c|c|c|c|}
\hline CHEMBL1598154 & 688239 & 4.9362 & 5.4967 & TRN & \\
\hline CHEMBL1454988 & 688239 & 4.7862 & 5.3791 & TST & \\
\hline CHEMBL1311764 & 688239 & 4.7362 & 5.5647 & TST & \\
\hline CHEMBL1568245 & 688239 & 4.5362 & 5.5802 & TRN & \\
\hline CHEMBL1431782 & 688239 & 6.7862 & 5.4968 & TRN & \\
\hline CHEMBL1319160 & 688239 & 4.7862 & 5.3919 & TRN & \\
\hline CHEMBL1400376 & 688239 & 5.0862 & 5.3883 & TRN & \\
\hline CHEMBL1373685 & 688239 & 4.6362 & 5.4959 & TRN & \\
\hline CHEMBL1308223 & 688239 & 5.8362 & 5.6756 & TRN & \\
\hline CHEMBL1523730 & 688239 & 4.8862 & 5.4664 & TRN & \\
\hline CHEMBL1305456 & 688239 & 6.6861 & 5.522 & TRN & \\
\hline CHEMBL1576092 & 688239 & 8.28399 & 99999999 & 5.4353 & TRN \\
\hline CHEMBL1390198 & 688239 & 4.4862 & 5.6435 & TRN & \\
\hline CHEMBL1365321 & 688239 & 4.6862 & 5.5171 & TRN & \\
\hline CHEMBL3209436 & 688239 & 6.8861 & 5.536000 & 0000000005 & \\
\hline CHEMBL1580958 & 688239 & 6.1862 & 5.5956 & TST & \\
\hline CHEMBL1400067 & 688239 & 4.7862 & 5.422000 & 000000001 & \\
\hline CHEMBL1463220 & 688239 & 5.5862 & 5.6741 & TRN & \\
\hline CHEMBL1333259 & 688239 & 5.5862 & 5.5145 & TST & \\
\hline CHEMBL1453231 & 688239 & 5.4362 & 5.4883 & TST & \\
\hline CHEMBL3197075 & 688239 & 4.5362 & 5.4988 & TRN & \\
\hline CHEMBL1513964 & 688239 & 5.8862 & 5.5921 & TRN & \\
\hline CHEMBL1400901 & 688239 & 5.8862 & 5.5335 & TRN & \\
\hline CHEMBL1398080 & 688239 & 4.7862 & 5.5193 & TRN & \\
\hline CHEMBL1323876 & 688239 & 4.5362 & 5.474 & TRN & \\
\hline CHEMBL1504458 & 688239 & 4.4362 & 5.7709 & TRN & \\
\hline CHEMBL1458758 & 688239 & 4.9362 & 5.4821 & TST & \\
\hline CHEMBL1427878 & 688239 & 4.6862 & 5.4085 & TRN & \\
\hline CHEMBL3189819 & 688239 & 6.4862 & 5.4552 & TST & \\
\hline CHEMBL1584777 & 688239 & 8.1871 & 5.5936 & TRN & \\
\hline CHEMBL1514691 & 688239 & 4.7862 & 5.5128 & TST & \\
\hline CHEMBL1422263 & 688239 & 6.8861 & 5.5836 & TST & \\
\hline CHEMBL1454269 & 688239 & 4.5362 & 5.3499 & TRN & \\
\hline CHEMBL1548779 & 688239 & 8.3372 & 5.4267 & TRN & \\
\hline CHEMBL1495841 & 688239 & 4.5362 & 5.3305 & TST & \\
\hline CHEMBL1448588 & 688239 & 5.1862 & 5.3468 & TRN & \\
\hline CHEMBL1307246 & 688239 & 4.7362 & 5.347 & TRN & \\
\hline CHEMBL1316531 & 688239 & 5.8362 & 5.5208 & TRN & \\
\hline CHEMBL1448813 & 688239 & 7.1864 & 5.4731 & TRN & \\
\hline CHEMBL1464165 & 688239 & 5.0862 & 5.4786 & TRN & \\
\hline CHEMBL1312501 & 688239 & 4.7362 & 5.5093 & TRN & \\
\hline CHEMBL1607358 & 688239 & 5.1862 & 5.612999 & 9999999995 & TRN \\
\hline CHEMBL1307410 & 688239 & 4.5362 & 5.5027 & TRN & \\
\hline CHEMBL3198339 & 688239 & 4.7862 & 5.5042 & TRN & \\
\hline CHEMBL1342296 & 688239 & 6.9363 & 5.5126 & TST & \\
\hline CHEMBL1481730 & 688239 & 6.8362 & 5.4605 & TRN & \\
\hline CHEMBL1336330 & 688239 & 4.8362 & 5.5305 & TRN & \\
\hline CHEMBL1482881 & 688239 & 5.4862 & 5.4447 & TRN & \\
\hline
\end{tabular}


Supplemental Table S2.txt

\begin{tabular}{|c|c|c|c|c|c|}
\hline CHEMBL1372434 & 688239 & 4.6362 & 5.6057 & TRN & \\
\hline CHEMBL1462566 & 688239 & 4.5362 & 5.4518 & TRN & \\
\hline CHEMBL1508269 & 688239 & 6.2862 & 5.4286 & TRN & \\
\hline CHEMBL1506054 & 688239 & 4.7362 & 5.5722 & TRN & \\
\hline CHEMBL1412379 & 688239 & 5.6362 & 5.4322 & TRN & \\
\hline CHEMBL1970925 & 688239 & 4.7362 & 5.3116 & TRN & \\
\hline CHEMBL1396594 & 688239 & 6.2862 & 5.5014 & TRN & \\
\hline CHEMBL3210411 & 688239 & 5.1862 & 5.5517 & TRN & \\
\hline CHEMBL1366260 & 688239 & 4.7862 & 5.285 & TRN & \\
\hline CHEMBL1367915 & 688239 & 6.2362 & 5.3756 & TRN & \\
\hline CHEMBL3189960 & 688239 & 5.2362 & 5.3951 & TST & \\
\hline CHEMBL1561791 & 688239 & 5.8362 & 5.5425 & TRN & \\
\hline CHEMBL1560462 & 688239 & 6.8362 & 5.5907 & TRN & \\
\hline CHEMBL1497243 & 688239 & 4.9362 & 5.4472 & TRN & \\
\hline CHEMBL1407639 & 688239 & 4.5362 & 5.5298 & TST & \\
\hline CHEMBL1389823 & 688239 & 4.5862 & 5.6002 & TST & \\
\hline CHEMBL1974032 & 688239 & 5.5862 & 5.6107 & TST & \\
\hline CHEMBL1535495 & 688239 & 6.4862 & 5.4667 & TRN & \\
\hline CHEMBL1416992 & 688239 & 4.5362 & 5.4308 & TST & \\
\hline CHEMBL3191592 & 688239 & 4.5362 & 5.4095 & TRN & \\
\hline CHEMBL1552728 & 688239 & 5.1362 & 5.4167 & TRN & \\
\hline CHEMBL1358413 & 688239 & 5.1862 & 5.4384 & TRN & \\
\hline CHEMBL1474233 & 688239 & 4.9862 & 5.5054 & TRN & \\
\hline CHEMBL1397631 & 688239 & 5.3862 & 5.4987 & TRN & \\
\hline CHEMBL1538469 & 688239 & 6.1362 & 5.6008 & TRN & \\
\hline CHEMBL1379312 & 688239 & 4.5362 & 5.4175 & TRN & \\
\hline CHEMBL1495169 & 688239 & 4.5362 & 5.3758 & TRN & \\
\hline CHEMBL1316926 & 688239 & 5.4862 & 5.3746 & TRN & \\
\hline CHEMBL1474837 & 688239 & 8.28399 & 79999999 & 5.3734 & TRN \\
\hline CHEMBL1589670 & 688239 & 5.5362 & 5.5161 & TRN & \\
\hline CHEMBL1390613 & 688239 & 4.7362 & 5.3841 & TRN & \\
\hline CHEMBL1490050 & 688239 & 5.5362 & 5.4859 & TRN & \\
\hline CHEMBL1367344 & 688239 & 6.1862 & 5.6736 & TRN & \\
\hline CHEMBL3213685 & 688239 & 5.6862 & 5.4396 & TRN & \\
\hline CHEMBL3144828 & 688239 & 4.7362 & 5.4316 & TST & \\
\hline CHEMBL3199718 & 688239 & 7.0362 & 5.38899 & 9999999999 & TST \\
\hline CHEMBL407294 & 688239 & 6.0362 & 5.4775 & TRN & \\
\hline CHEMBL1330963 & 688239 & 6.0862 & 5.3782 & TRN & \\
\hline CHEMBL1338712 & 688239 & 6.8861 & 5.6049 & TRN & \\
\hline CHEMBL1442578 & 688239 & 4.5362 & 5.502006 & $\partial 000000001$ & TRN \\
\hline CHEMBL1392322 & 688239 & 4.9862 & 5.4419 & TST & \\
\hline CHEMBL1405543 & 688239 & 6.3362 & 5.5569 & TRN & \\
\hline CHEMBL1446982 & 688239 & 6.0862 & 5.5221 & TRN & \\
\hline CHEMBL1438038 & 688239 & 5.4362 & 5.53100 & 0000000001 & TST \\
\hline CHEMBL1537906 & 688239 & 4.5362 & 5.3905 & TST & \\
\hline CHEMBL1359338 & 688239 & 5.3862 & 5.4515 & TRN & \\
\hline CHEMBL1330397 & 688239 & 5.45 & 5.4265 & TRN & \\
\hline CHEMBL1581710 & 688239 & 7.3363 & 5.3431 & TST & \\
\hline
\end{tabular}


Supplemental Table S2.txt

\begin{tabular}{|c|c|c|c|c|c|}
\hline CHEMBL1474921 & 688239 & 4.7362 & 5.3941 & TRN & \\
\hline CHEMBL1394549 & 688239 & 7.2865 & 5.3699 & TRN & \\
\hline CHEMBL1549893 & 688239 & 4.5362 & 5.4134 & TRN & \\
\hline CHEMBL1448646 & 688239 & 4.9862 & 5.4205 & TRN & \\
\hline CHEMBL1503289 & 688239 & 5.5862 & 5.5366 & TRN & \\
\hline CHEMBL1439630 & 688239 & 4.8862 & 5.4813 & TRN & \\
\hline CHEMBL1514178 & 688239 & 5.6862 & 5.3516 & TRN & \\
\hline CHEMBL1524254 & 688239 & 6.1862 & 5.4078 & TST & \\
\hline CHEMBL 3190821 & 688239 & 5.1862 & 5.7418 & TRN & \\
\hline CHEMBL1511782 & 688239 & 4.5362 & 5.383999 & 9999999995 & TST \\
\hline CHEMBL1528411 & 688239 & 6.2362 & 5.6737 & TRN & \\
\hline CHEMBL1349180 & 688239 & 4.8862 & 5.553999 & 999999999 & $1 \pi$ \\
\hline CHEMBL1410805 & 688239 & 4.5362 & 5.4855 & TRN & \\
\hline CHEMBL1452584 & 688239 & 4.5362 & 5.5463 & TRN & \\
\hline CHEMBL 3214009 & 688239 & 6.4362 & 5.4986 & TRN & \\
\hline CHEMBL1362104 & 688239 & 4.5362 & 5.4698 & TRN & \\
\hline CHEMBL1589778 & 688239 & 4.7362 & 5.3977 & TST & \\
\hline CHEMBL1413145 & 688239 & 5.3862 & 5.5613 & TRN & \\
\hline CHEMBL1458294 & 688239 & 5.1862 & 5.4932 & TRN & \\
\hline CHEMBL1578796 & 688239 & 5.1362 & 5.556 & TRN & \\
\hline CHEMBL1418161 & 688239 & 6.2362 & 5.552000 & 0000000005 & TRN \\
\hline CHEMBL1510471 & 688239 & 6.0862 & 5.6226 & TRN & \\
\hline CHEMBL1534386 & 688239 & 5.7362 & 5.5958 & TRN & \\
\hline CHEMBL1557402 & 688239 & 4.5362 & 5.5878 & TST & \\
\hline CHEMBL1550748 & 688239 & 5.1362 & 5.476 & TST & \\
\hline CHEMBL1495889 & 688239 & 4.5362 & 5.4248 & TRN & \\
\hline CHEMBL1592081 & 688239 & 7.1361 & 5.4816 & TRN & \\
\hline CHEMBL1603072 & 688239 & 4.6862 & 5.569 & TRN & \\
\hline CHEMBL1378390 & 688239 & 4.6362 & 5.4376 & TRN & \\
\hline CHEMBL1446626 & 688239 & 5.8862 & 5.4939 & TRN & \\
\hline CHEMBL1444073 & 688239 & 6.7862 & 5.566 & TST & \\
\hline CHEMBL1488749 & 688239 & 4.5362 & 5.5162 & TST & \\
\hline CHEMBL602633 & 688239 & 8.283999 & 99999999 & 5.5432 & נו \\
\hline CHEMBL1362871 & 688239 & 4.5362 & 5.2889 & TST & \\
\hline CHEMBL1430332 & 688239 & 4.5362 & 5.4592 & TRN & \\
\hline CHEMBL1390717 & 688239 & 5.1362 & 5.3708 & TST & \\
\hline CHEMBL 1484875 & 688239 & 6.7862 & 5.5419 & TRN & \\
\hline CHEMBL1489769 & 688239 & 5.7862 & 5.3368 & TST & \\
\hline CHEMBL1540074 & 688239 & 5.2862 & 5.5091 & TST & \\
\hline CHEMBL1467090 & 688239 & 4.5362 & 5.481 & TST & \\
\hline CHEMBL1515442 & 688239 & 5.1862 & 5.3908 & TRN & \\
\hline CHEMBL1373087 & 688239 & 5.6362 & 5.4467 & TRN & \\
\hline CHEMBL1466100 & 688239 & 8.2366 & 5.4521 & TRN & \\
\hline CHEMBL1432217 & 688239 & 4.5362 & 5.5791 & TST & \\
\hline CHEMBL1300442 & 688239 & 5.2362 & 5.457999 & 999999999 & Trv \\
\hline CHEMBL1451414 & 688239 & 7.7852 & 5.457000 & 000000001 & 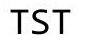 \\
\hline CHEMBL1535918 & 688239 & 4.5362 & 5.5704 & TST & \\
\hline CHEMBL1445709 & 688239 & 6.0862 & 5.6353 & TRN & \\
\hline
\end{tabular}

Page 1068 
Supplemental Table S2.txt

\begin{tabular}{|c|c|c|c|c|}
\hline 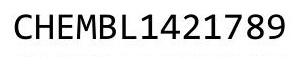 & & & & \\
\hline AEMBL1335545 & 38239 & 1862 & 6 & \\
\hline AEMBL3192150 & 239 & 361 & & \\
\hline & 39 & 862 & & \\
\hline IEMBL3191644 & 39 & 862 & & \\
\hline AEMBL1379024 & 88239 & 362 & & \\
\hline AEMBL1312579 & 88239 & 862 & 4731 & \\
\hline AEMBL1491422 & & & & \\
\hline EMBL16e & 39 & 862 & & \\
\hline IEMBL1453686 & & & & \\
\hline AEMBL1561595 & 239 & 362 & 92 & \\
\hline AEMBL1516364 & & 362 & 3951 & \\
\hline AEMBL1620590 & & & & \\
\hline HEMBL3209308 & & & & \\
\hline AEMBL133ऽ & & & & \\
\hline AEMBL1421534 & & 862 & & \\
\hline AEMBL1560809 & & 362 & & \\
\hline AEMBL1547 & & & & \\
\hline AEMBL1519 & & & & \\
\hline HEMBL137؟ & & & & \\
\hline AEMBL1596508 & & 862 & & \\
\hline AEMBL1331034 & & 62 & & \\
\hline IEMBL1584 & & 62 & & \\
\hline AFMRI $158=$ & & & & \\
\hline 32 & & & & \\
\hline AEMBL1567635 & & & & \\
\hline IEMBL1603078 & & & & \\
\hline EMBL14161 & & & & \\
\hline AFMRI 13 & & & & \\
\hline AEMBL1422353 & & & & \\
\hline AEMBL1383424 & & & & \\
\hline AEMBL1341289 & & & & \\
\hline & & & & \\
\hline 4 & & 52 & & \\
\hline & & & & ST \\
\hline AEMBL1594335 & & & & $S$ \\
\hline AEMBL1487085 & & 362 & & \\
\hline & & & & \\
\hline (2MO & & & & \\
\hline HEMBL1571853 & & & & $\mathrm{RI}$ \\
\hline AEMBL1325643 & & & & $S$ \\
\hline AEMBL14. & & & & $S$ \\
\hline & & & & \\
\hline HEMBL1515125 & & & & \\
\hline AEMBL1553349 & & & & RN \\
\hline IEMBL1491904 & & 862 & & \\
\hline MO 191 & & & & \\
\hline HEMBL152085 & & & & \\
\hline
\end{tabular}

Page 1069 
Supplemental Table S2.txt

\begin{tabular}{|c|c|c|c|c|}
\hline & & & & \\
\hline AEMBL1556834 & 88239 & 362 & & \\
\hline AEMBL1324154 & 39 & & & \\
\hline AEMBL1594445 & & & & \\
\hline AEMBL1341257 & & & & \\
\hline AEMBL1530884 & 88239 & & & \\
\hline AEMBL1563247 & 88239 & 362 & 5372 & \\
\hline HEMBL1589206 & & & & \\
\hline AEMBL131 & & & & \\
\hline IEMBL1368805 & & & & \\
\hline AEMBL1486119 & 39 & & & \\
\hline AEMBL1549426 & 39 & 62 & 204 & \\
\hline HEMBL1560 & & & & \\
\hline AEMBL 321 & & & & \\
\hline AEMBL145 & & & & \\
\hline AEMBL1527951 & & 61 & & \\
\hline AEMBL1498618 & & & & \\
\hline HEMBL151 & & & & \\
\hline IEMBL144 & & & & \\
\hline HEMBL13 & & & & \\
\hline AEMBL1479524 & & & & \\
\hline AEMBL1459393 & & & & \\
\hline AEMBL15 & & & & \\
\hline HEMBL13 & & & & \\
\hline AFMRI 13 & & & & \\
\hline 1612746 & & & & \\
\hline AEMBL1580219 & & & & \\
\hline AEMBL153363 & & & & \\
\hline AEM & & & & \\
\hline 39 & & & & \\
\hline AEMBL1564473 & & & & \\
\hline HEMBL1524693 & & & & \\
\hline 810 & & & & \\
\hline 2 & & & & \\
\hline 1 & & & & \\
\hline AEMBL1315120 & & & & \\
\hline AEMBL1511755 & & & & \\
\hline & & & & \\
\hline 2 & & & & \\
\hline JEMBL133 & & & & ST \\
\hline AEMBL1476154 & & & 89 & $R$ \\
\hline HEMBL15e & & & & \\
\hline & & & & \\
\hline HEMBL1399605 & & & & \\
\hline HEMBL 3210195 & & & & $\mathrm{RN}$ \\
\hline IEMBL1457977 & & & & \\
\hline-1531969 & & & & \\
\hline 1907 & & & 5.4346 & \\
\hline
\end{tabular}

Page 1070 
Supplemental Table S2.txt

\begin{tabular}{|c|c|c|c|c|}
\hline CHEMBL1594915 & 688239 & 5.6362 & 5.4577 & TRN \\
\hline CHEMBL1383687 & 688239 & 4.5362 & 5.5118 & TRN \\
\hline CHEMBL1588856 & 688239 & 4.7862 & 5.4845 & TRN \\
\hline CHEMBL1302777 & 688239 & 5.2862 & 5.3666 & TRN \\
\hline CHEMBL1342926 & 688239 & 6.7361 & 5.4168 & TRN \\
\hline CHEMBL1584079 & 688239 & 5.3862 & 5.4971 & TRN \\
\hline CHEMBL1374499 & 688239 & 4.6862 & 5.4048 & TST \\
\hline CHEMBL1572126 & 688239 & 5.2862 & 5.3684 & TRN \\
\hline CHEMBL1338942 & 688239 & 6.1362 & 5.6333 & TRN \\
\hline CHEMBL1533200 & 688239 & 5.1862 & 5.532999 & 9999999995 \\
\hline CHEMBL1324507 & 688239 & 5.3862 & 5.5774 & TRN \\
\hline CHEMBL1481572 & 688239 & 4.5362 & 5.4503 & TST \\
\hline CHEMBL1363820 & 688239 & 5.2362 & 5.5363 & TRN \\
\hline CHEMBL1597631 & 688239 & 4.4862 & 5.6693 & TRN \\
\hline CHEMBL1471430 & 688239 & 5.3862 & 5.456 & TST \\
\hline CHEMBL1458054 & 688239 & 6.3863 & 5.4977 & TRN \\
\hline CHEMBL1388878 & 688239 & 5.0862 & 5.4167 & TST \\
\hline CHEMBL1431526 & 688239 & 4.5362 & 5.5586 & TRN \\
\hline CHEMBL1547994 & 688239 & 4.6862 & 5.5924 & TRN \\
\hline CHEMBL1559557 & 688239 & 4.5362 & 5.4845 & TRN \\
\hline CHEMBL1309495 & 688239 & 4.9862 & 5.457999 & 999999999 \\
\hline CHEMBL1450630 & 688239 & 6.7361 & 5.5964 & TRN \\
\hline CHEMBL1348911 & 688239 & 4.7862 & 5.3897 & TST \\
\hline CHEMBL1987108 & 688239 & 4.5362 & 5.4339 & TRN \\
\hline CHEMBL1506710 & 688239 & 8.2366 & 5.6564 & TRN \\
\hline CHEMBL1347268 & 688239 & 7.1361 & 5.4549 & TRN \\
\hline CHEMBL1598114 & 688239 & 4.7362 & 5.5919 & TRN \\
\hline CHEMBL1606902 & 688239 & 7.4365 & 5.3857 & TST \\
\hline CHEMBL1610312 & 688239 & 4.5362 & 5.3975 & TST \\
\hline CHEMBL1510600 & 688239 & 4.8362 & 5.5162 & TST \\
\hline CHEMBL1576581 & 688239 & 5.1362 & 5.4337 & TST \\
\hline CHEMBL1474344 & 688239 & 4.4862 & 5.6515 & TRN \\
\hline CHEMBL1370042 & 688239 & 6.8861 & 5.5176 & TRN \\
\hline CHEMBL1369719 & 688239 & 6.5862 & 5.4017 & TRN \\
\hline CHEMBL1531865 & 688239 & 4.9862 & 5.461 & TST \\
\hline CHEMBL1397098 & 688239 & 4.5362 & 5.4059 & TRN \\
\hline CHEMBL1587026 & 688239 & 5.7362 & 5.5208 & TRN \\
\hline CHEMBL1487136 & 688239 & 6.2362 & 5.6055 & TRN \\
\hline CHEMBL1558233 & 688239 & 6.1362 & 5.505 & TRN \\
\hline CHEMBL1307866 & 688239 & 4.5362 & 5.632006 & 000000001 \\
\hline CHEMBL1504659 & 688239 & 4.8362 & 5.5953 & TST \\
\hline CHEMBL1302747 & 688239 & 4.5362 & 5.4296 & TRN \\
\hline CHEMBL1400455 & 688239 & 4.6362 & 5.5711 & TRN \\
\hline CHEMBL1493199 & 688239 & 4.5362 & 5.3019 & TST \\
\hline CHEMBL1306466 & 688239 & 4.7 & 5.6406 & TRN \\
\hline CHEMBL1330424 & 688239 & 4.7362 & 5.5254 & TRN \\
\hline CHEMBL1417527 & 688239 & 5.4362 & 5.5047 & TST \\
\hline CHEMBL1507196 & 688239 & 6.7361 & 5.5195 & TST \\
\hline
\end{tabular}


Supplemental Table S2.txt

\begin{tabular}{|c|c|c|c|c|}
\hline CHEMBL1301614 & 688239 & 5.0362 & 5.6458 & TRN \\
\hline CHEMBL1514152 & 688239 & 6.3362 & 5.5083 & TRN \\
\hline CHEMBL1400164 & 688239 & 5.1362 & 5.5056 & TRN \\
\hline CHEMBL1351746 & 688239 & 8.3372 & \multicolumn{2}{|c|}{5.468999999999999} \\
\hline CHEMBL1434876 & 688239 & 5.9362 & 5.5642 & TST \\
\hline CHEMBL1532042 & 688239 & 6.8861 & 5.5542 & TRN \\
\hline CHEMBL1312527 & 688239 & 5.4362 & 5.6005 & TRN \\
\hline CHEMBL1518224 & 688239 & 5.2362 & 5.4537 & TST \\
\hline CHEMBL3196416 & 688239 & 5.2362 & 5.4476 & TST \\
\hline CHEMBL1355713 & 688239 & 5.3862 & \multicolumn{2}{|c|}{5.507000000000001} \\
\hline CHEMBL1603363 & 688239 & 5.1362 & 5.4408 & TRN \\
\hline CHEMBL1365666 & 688239 & 4.6362 & 5.4573 & TRN \\
\hline CHEMBL1403302 & 688239 & 6.8861 & 5.4963 & TRN \\
\hline CHEMBL1571140 & 688239 & 6.3863 & 5.5892 & TRN \\
\hline CHEMBL1343857 & 688239 & 4.7362 & 5.4 & TST \\
\hline CHEMBL1407741 & 688239 & 4.4862 & 5.3303 & TRN \\
\hline CHEMBL1613465 & 688239 & 6.0862 & 5.334 & TRN \\
\hline CHEMBL1402980 & 688239 & 4.7862 & 5.5418 & TRN \\
\hline CHEMBL1417430 & 688239 & 5.1862 & 5.4407 & TRN \\
\hline CHEMBL1390310 & 688239 & 5.1862 & 5.5727 & TRN \\
\hline CHEMBL1577720 & 688239 & 4.5862 & 5.4763 & TRN \\
\hline CHEMBL1503380 & 688239 & 5.1862 & 5.4635 & TRN \\
\hline CHEMBL1359478 & 688239 & 4.7362 & 5.494 & TST \\
\hline CHEMBL1396030 & 688239 & 4.5362 & 5.2933 & TST \\
\hline CHEMBL1379197 & 688239 & 4.7362 & 5.4372 & TST \\
\hline CHEMBL1427205 & 688239 & 4.9862 & 5.5318 & TRN \\
\hline CHEMBL1547144 & 688239 & 5.1862 & 5.517 & TRN \\
\hline CHEMBL1543111 & 688239 & 5.8362 & 5.5397 & TRN \\
\hline CHEMBL3199679 & 688239 & 8.2366 & 5.3167 & TRN \\
\hline CHEMBL1440599 & 688239 & 5.8862 & 5.5445 & TRN \\
\hline CHEMBL1381789 & 688239 & 5.3862 & 5.4909 & TST \\
\hline CHEMBL1411649 & 688239 & 4.6862 & 5.5475 & TRN \\
\hline CHEMBL3196331 & 688239 & 6.3863 & 5.4694 & TST \\
\hline CHEMBL1344565 & 688239 & 5.1862 & 5.6112 & TRN \\
\hline CHEMBL1599757 & 688239 & 4.7862 & 5.4109 & TST \\
\hline CHEMBL1361445 & 688239 & 5.5362 & 5.5292 & TST \\
\hline CHEMBL3213426 & 688239 & 8.0362 & 5.30200 & 00000000005 \\
\hline CHEMBL1574525 & 688239 & 6.4362 & 5.4944 & TST \\
\hline CHEMBL1541596 & 688239 & 4.7362 & 5.5112 & TST \\
\hline CHEMBL1471807 & 688239 & 6.3863 & 5.5205 & TRN \\
\hline CHEMBL1461176 & 688239 & 7.1864 & 5.3899 & TST \\
\hline CHEMBL1314602 & 688239 & 5.3362 & 5.4607 & TRN \\
\hline CHEMBL1610800 & 688239 & 6.2362 & 5.6301 & TRN \\
\hline CHEMBL1541446 & 688239 & 4.5362 & 5.4744 & TRN \\
\hline CHEMBL1433286 & 688239 & 4.7362 & 5.4037 & TST \\
\hline CHEMBL443343 & 688239 & 5.8862 & 5.38899 & э999999999 \\
\hline CHEMBL1428907 & 688239 & 5.5862 & 5.4513 & TST \\
\hline CHEMBL1468569 & 688239 & 4.5362 & 5.5575 & TRN \\
\hline
\end{tabular}


Supplemental Table S2.txt

\begin{tabular}{|c|c|c|c|c|c|}
\hline CHEMBL1577963 & 688239 & 6.9863 & \multicolumn{2}{|c|}{5.382999999999999} & TRN \\
\hline CHEMBL1537917 & 688239 & 4.5862 & 5.5378 & TRN & \\
\hline CHEMBL1429141 & 688239 & 8.3872 & 5.5119 & TRN & \\
\hline CHEMBL1477207 & 688239 & 4.7862 & 5.46 & TRN & \\
\hline CHEMBL1350822 & 688239 & 5.1862 & 5.5255 & TST & \\
\hline CHEMBL 3210006 & 688239 & 5.4362 & 5.4023 & TRN & \\
\hline CHEMBL1557002 & 688239 & 4.5362 & 5.4096 & TRN & \\
\hline CHEMBL 3214570 & 688239 & 5.1362 & 5.4713 & TST & \\
\hline CHEMBL1564075 & 688239 & 4.5362 & 5.4932 & TST & \\
\hline CHEMBL1562480 & 688239 & 5.8362 & 5.5489 & TRN & \\
\hline CHEMBL1483863 & 688239 & 5.8862 & 5.3881 & TRN & \\
\hline CHEMBL1479239 & 688239 & 4.5862 & \multicolumn{2}{|c|}{5.6770000000000005} & \\
\hline CHEMBL1509822 & 688239 & 8.28399 & 99999999 & 5.4301 & \\
\hline CHEMBL1322697 & 688239 & 5.0862 & 5.4151 & TRN & \\
\hline CHEMBL1350981 & 688239 & 6.0862 & 5.5371 & TRN & \\
\hline CHEMBL1574570 & 688239 & 7.2865 & 5.4443 & TST & \\
\hline CHEMBL1586790 & 688239 & 8.28399 & 99999999 & 5.5664 & \\
\hline CHEMBL1432508 & 688239 & 6.8362 & 5.6411 & TST & \\
\hline CHEMBL1564172 & 688239 & 6.1862 & 5.4328 & TRN & \\
\hline CHEMBL1370008 & 688239 & 6.1862 & 5.6253 & TRN & \\
\hline CHEMBL1438768 & 688239 & 6.1362 & \multicolumn{2}{|c|}{5.4110000000000005} & \\
\hline CHEMBL1406869 & 688239 & 5.5862 & 5.5482 & TRN & \\
\hline CHEMBL1516732 & 688239 & 8.3872 & 5.5543 & TRN & \\
\hline CHEMBL1592310 & 688239 & 4.5362 & 5.5952 & TRN & \\
\hline CHEMBL1467694 & 688239 & 6.0862 & 5.5538 & TRN & \\
\hline CHEMBL1398426 & 688239 & 6.5363 & 5.3621 & TRN & \\
\hline CHEMBL1571937 & 688239 & 4.7862 & 5.3207 & TRN & \\
\hline CHEMBL1308965 & 688239 & 6.9863 & 5.3431 & TST & \\
\hline CHEMBL1366911 & 688239 & 5.2862 & 5.4279 & TRN & \\
\hline CHEMBL1377354 & 688239 & 5.6862 & 5.6029 & TRN & \\
\hline CHEMBL1487887 & 688239 & 4.9362 & 5.4743 & TRN & \\
\hline CHEMBL1301197 & 688239 & 4.5362 & \multicolumn{2}{|c|}{5.446000000000001} & \\
\hline CHEMBL1554732 & 688239 & 5.6862 & 5.608 & TRN & \\
\hline CHEMBL1491077 & 688239 & 4.5362 & 5.4133 & TRN & \\
\hline CHEMBL1505017 & 688239 & 5.1862 & 5.4407 & TRN & \\
\hline CHEMBL1570831 & 688239 & 4.9362 & 5.5303 & TST & \\
\hline CHEMBL1547390 & 688239 & 4.7862 & 5.6624 & TRN & \\
\hline CHEMBL1531026 & 688239 & 5.4362 & 5.5292 & TRN & \\
\hline CHEMBL1422328 & 688239 & 6.0862 & 5.4176 & TST & \\
\hline CHEMBL1414019 & 688239 & 5.2862 & 5.6212 & TRN & \\
\hline CHEMBL1493654 & 688239 & 5.5362 & 5.4321 & TRN & \\
\hline CHEMBL1584625 & 688239 & 5.1862 & 5.3918 & TRN & \\
\hline CHEMBL1342980 & 688239 & 5.1862 & 5.5817 & TRN & \\
\hline CHEMBL1336598 & 688239 & 4.5362 & 5.3726 & TST & \\
\hline CHEMBL1604904 & 688239 & 5.1362 & 5.6333 & TRN & \\
\hline CHEMBL1524046 & 688239 & 6.5862 & 5.5763 & TRN & \\
\hline CHEMBL1572895 & 688239 & 5.1862 & 5.4609 & TRN & \\
\hline CHEMBL1568620 & 688239 & 6.2362 & 5.4575 & TRN & \\
\hline
\end{tabular}


Supplemental Table S2.txt

\begin{tabular}{|c|c|c|c|c|}
\hline CHEMBL1558259 & 688239 & 5.5362 & 5.6759 & TRN \\
\hline CHEMBL1466706 & 688239 & 4.5362 & 5.5156 & TRN \\
\hline CHEMBL1421893 & 688239 & 5.1862 & 5.5163 & TST \\
\hline CHEMBL1318305 & 688239 & 5.5862 & 5.5913 & TRN \\
\hline CHEMBL1343180 & 688239 & 5.3862 & 5.4133 & TRN \\
\hline CHEMBL1732967 & 688239 & 4.5362 & 5.2544 & TRN \\
\hline CHEMBL3199796 & 688239 & 4.4862 & 5.6162 & TRN \\
\hline CHEMBL1534485 & 688239 & 6.1862 & 5.4851 & TRN \\
\hline CHEMBL1321195 & 688239 & 4.6862 & 5.3569 & TST \\
\hline CHEMBL1378018 & 688239 & 4.6362 & 5.5815 & TRN \\
\hline CHEMBL1532385 & 688239 & 4.7862 & 5.3633 & TRN \\
\hline CHEMBL1522255 & 688239 & 4.6862 & 5.5545 & TST \\
\hline CHEMBL1516319 & 688239 & 4.7362 & 5.5979 & TRN \\
\hline CHEMBL1486005 & 688239 & 4.45 & 5.5308 & TRN \\
\hline CHEMBL1347202 & 688239 & 5.1362 & 5.4357 & TRN \\
\hline CHEMBL1458108 & 688239 & 8.3372 & 5.5767 & TRN \\
\hline CHEMBL1380364 & 688239 & 4.7862 & 5.3297 & TRN \\
\hline CHEMBL1342988 & 688239 & 6.1362 & 5.4685 & TST \\
\hline CHEMBL1577536 & 688239 & 6.8362 & 5.5137 & TRN \\
\hline CHEMBL1455770 & 688239 & 4.5362 & 5.5815 & TRN \\
\hline CHEMBL1299207 & 688239 & 4.8862 & 5.5307 & TRN \\
\hline CHEMBL1350585 & 688239 & 5.6362 & 5.4543 & TRN \\
\hline CHEMBL1342414 & 688239 & 4.5362 & 5.3114 & TRN \\
\hline CHEMBL1549832 & 688239 & 5.4362 & 5.4243 & TRN \\
\hline CHEMBL1496284 & 688239 & 5.8862 & 5.522 & TST \\
\hline CHEMBL1338543 & 688239 & 5.3862 & 5.5156 & TRN \\
\hline CHEMBL1455910 & 688239 & 4.8362 & 5.5138 & TRN \\
\hline CHEMBL1582621 & 688239 & 8.28399 & 99999999 & 5.4627 \\
\hline CHEMBL1417541 & 688239 & 8.3372 & 5.4355 & TRN \\
\hline CHEMBL1601806 & 688239 & 5.0862 & 5.5535 & TRN \\
\hline CHEMBL1371247 & 688239 & 5.7362 & 5.6396 & TRN \\
\hline CHEMBL1516120 & 688239 & 4.5362 & 5.49 & TRN \\
\hline CHEMBL1581039 & 688239 & 4.8362 & 5.4974 & TST \\
\hline CHEMBL1302064 & 688239 & 4.5362 & 5.428 & TRN \\
\hline CHEMBL1527817 & 688239 & 4.7362 & 5.4288 & TST \\
\hline CHEMBL1585213 & 688239 & 5.9362 & 5.446000 & 000000001 \\
\hline CHEMBL1535615 & 688239 & 5.8862 & 5.624 & TRN \\
\hline CHEMBL1990081 & 688239 & 5.0362 & 5.523 & TRN \\
\hline CHEMBL1524529 & 688239 & 6.3362 & 5.3791 & TST \\
\hline CHEMBL1433808 & 688239 & 6.0362 & 5.5966 & TRN \\
\hline CHEMBL3192457 & 688239 & 4.5362 & 5.402 & TRN \\
\hline CHEMBL1573672 & 688239 & 4.7362 & 5.654 & TST \\
\hline CHEMBL1394142 & 688239 & 4.6362 & 5.4666 & TRN \\
\hline CHEMBL1385556 & 688239 & 5.0862 & 5.572999 & 9999999995 \\
\hline CHEMBL1307719 & 688239 & 5.2362 & 5.5303 & TRN \\
\hline CHEMBL1329953 & 688239 & 6.9863 & 5.5538 & TRN \\
\hline CHEMBL1523172 & 688239 & 4.4862 & 5.4294 & TST \\
\hline CHEMBL1452353 & 688239 & 6.4862 & 5.5608 & TRN \\
\hline
\end{tabular}


Supplemental Table S2.txt

\begin{tabular}{|c|c|c|c|c|c|}
\hline CHEMBL1363650 & 688239 & 5.5862 & 5.495 & TRN & \\
\hline CHEMBL1453942 & 688239 & 5.3362 & 5.2967 & TRN & \\
\hline CHEMBL1407254 & 688239 & 5.2362 & 5.3981 & TRN & \\
\hline CHEMBL1510086 & 688239 & 4.4862 & 5.4345 & TRN & \\
\hline CHEMBL1577239 & 688239 & 5.3362 & 5.6178 & TRN & \\
\hline CHEMBL1315687 & 688239 & 5.5862 & 5.4398 & TRN & \\
\hline CHEMBL1337199 & 688239 & 4.6862 & 5.5348 & TST & \\
\hline CHEMBL1458549 & 688239 & 4.8362 & 5.2948 & TRN & \\
\hline CHEMBL1423836 & 688239 & 4.4862 & 5.5342 & TST & \\
\hline CHEMBL1357207 & 688239 & 5.1862 & 5.4841 & TRN & \\
\hline CHEMBL 3208002 & 688239 & 4.6862 & 5.4504 & TRN & \\
\hline CHEMBL1410624 & 688239 & 5.7362 & 5.5522 & TRN & \\
\hline CHEMBL1532411 & 688239 & 4.7862 & 5.5249 & TRN & \\
\hline CHEMBL1319645 & 688239 & 5.1862 & 5.4135 & TST & \\
\hline CHEMBL1393836 & 688239 & 4.7362 & 5.6124 & TRN & \\
\hline CHEMBL1429246 & 688239 & 6.2362 & 5.4307 & TRN & \\
\hline CHEMBL1428506 & 688239 & 4.8862 & 5.5611 & TST & \\
\hline CHEMBL1557219 & 688239 & 4.5862 & 5.4853 & TST & \\
\hline CHEMBL1425967 & 688239 & 5.2362 & 5.4812 & TRN & \\
\hline CHEMBL1496435 & 688239 & 4.5362 & 5.4631 & TRN & \\
\hline CHEMBL1611873 & 688239 & 6.0862 & 5.41700 & 0000000001 & TRN \\
\hline CHEMBL1606775 & 688239 & 5.3362 & 5.5784 & TRN & \\
\hline CHEMBL1388069 & 688239 & 5.2362 & 5.3448 & TRN & \\
\hline CHEMBL1463637 & 688239 & 5.2862 & 5.4283 & TRN & \\
\hline CHEMBL1560368 & 688239 & 6.2862 & 5.5066 & TST & \\
\hline CHEMBL 259507 & 688239 & 5.4862 & 5.4341 & TST & \\
\hline CHEMBL1449978 & 688239 & 5.8862 & 5.5409 & TRN & \\
\hline CHEMBL1580877 & 688239 & 6.3863 & 5.4194 & TRN & \\
\hline CHEMBL1509498 & 688239 & 5.8362 & 5.5077 & TST & \\
\hline CHEMBL1522022 & 688239 & 4.5362 & 5.579 & TRN & \\
\hline CHEMBL3211798 & 688239 & 4.9362 & 5.506 & TRN & \\
\hline CHEMBL1359782 & 688239 & 4.5362 & 5.4316 & TRN & \\
\hline CHEMBL1486182 & 688239 & 4.5362 & 5.3964 & TRN & \\
\hline CHEMBL1478677 & 688239 & 6.0862 & 5.4328 & TRN & \\
\hline CHEMBL1497325 & 688239 & 5.0362 & 5.5043 & TRN & \\
\hline CHEMBL1452508 & 688239 & 5.4862 & 5.3738 & TRN & \\
\hline CHEMBL1599028 & 688239 & 4.5862 & 5.6292 & TRN & \\
\hline CHEMBL1584740 & 688239 & 4.5362 & 5.42 & TRN & \\
\hline CHEMBL1386270 & 688239 & 4.5362 & 5.497006 & 0000000001 & TRN \\
\hline CHEMBL1545165 & 688239 & 7.4868 & 5.5213 & TRN & \\
\hline CHEMBL1476092 & 688239 & 6.8362 & 5.4414 & TRN & \\
\hline CHEMBL1564067 & 688239 & 5.7862 & 5.5858 & TST & \\
\hline CHEMBL1423810 & 688239 & 5.9862 & 5.4503 & TRN & \\
\hline CHEMBL1326433 & 688239 & 5.0362 & 5.4777 & TRN & \\
\hline CHEMBL1310660 & 688239 & 5.1862 & 5.5513 & TRN & \\
\hline CHEMBL1329336 & 688239 & 4.5362 & 5.4791 & TRN & \\
\hline CHEMBL1453515 & 688239 & 5.3862 & 5.4415 & TRN & \\
\hline CHEMBL1380686 & 688239 & 6.6861 & 5.6264 & TRN & \\
\hline
\end{tabular}


Supplemental Table S2.txt

\begin{tabular}{|c|c|c|c|c|}
\hline CHEMBL1469342 & 688239 & 6.7862 & 5.4083 & TRN \\
\hline CHEMBL1358777 & 688239 & 4.5362 & 5.3783 & TST \\
\hline CHEMBL1372717 & 688239 & 5.2862 & 5.557 & TST \\
\hline CHEMBL1317849 & 688239 & 5.7862 & 5.388 & TRN \\
\hline CHEMBL1343105 & 688239 & 5.5362 & 5.4497 & TRN \\
\hline CHEMBL1500885 & 688239 & 5.0862 & 5.4572 & TRN \\
\hline CHEMBL1497037 & 688239 & 4.5362 & \multicolumn{2}{|c|}{5.5520000000000005} \\
\hline CHEMBL1566667 & 688239 & 4.7362 & 5.6238 & TRN \\
\hline CHEMBL1374327 & 688239 & 6.8861 & 5.608 & TRN \\
\hline CHEMBL1435625 & 688239 & 4.5862 & 5.6845 & TRN \\
\hline CHEMBL1467692 & 688239 & 5.6862 & 5.5076 & TRN \\
\hline CHEMBL1573863 & 688239 & 4.5362 & 5.481 & TST \\
\hline CHEMBL1321713 & 688239 & 4.5362 & 5.4523 & TRN \\
\hline CHEMBL 3195530 & 688239 & 8.3372 & 5.4342 & TRN \\
\hline CHEMBL1489656 & 688239 & 6.8861 & 5.4369 & TRN \\
\hline CHEMBL1345759 & 688239 & 5.8362 & 5.388 & TRN \\
\hline CHEMBL1513414 & 688239 & 4.7362 & 5.4214 & TRN \\
\hline CHEMBL1437943 & 688239 & 4.6862 & 5.6418 & TST \\
\hline CHEMBL1421824 & 688239 & 6.8861 & 5.5686 & TRN \\
\hline CHEMBL1368657 & 688239 & 6.4862 & 5.5125 & TRN \\
\hline CHEMBL1454317 & 688239 & 5.1862 & 5.5011 & TRN \\
\hline CHEMBL1302215 & 688239 & 6.1862 & 5.5647 & TST \\
\hline CHEMBL1459239 & 688239 & 4.5362 & 5.4628 & TRN \\
\hline CHEMBL1606151 & 688239 & 4.5362 & 5.6135 & TRN \\
\hline CHEMBL1461505 & 688239 & 4.5362 & 5.4142 & TRN \\
\hline CHEMBL1470804 & 688239 & 5.8862 & 5.3213 & TRN \\
\hline CHEMBL1387434 & 688239 & 4.4862 & 5.5449 & TRN \\
\hline CHEMBL1486589 & 688239 & 5.1362 & 5.4805 & TRN \\
\hline CHEMBL1534066 & 688239 & 6.3863 & 5.5263 & TRN \\
\hline CHEMBL1463470 & 688239 & 4.5362 & 5.3128 & TRN \\
\hline CHEMBL1532927 & 688239 & 4.9862 & 5.5425 & TRN \\
\hline CHEMBL 3195624 & 688239 & 4.5362 & 5.3924 & TRN \\
\hline CHEMBL1351658 & 688239 & 5.2362 & 5.5115 & TRN \\
\hline CHEMBL125730 & 688239 & 6.1362 & 5.7484 & TST \\
\hline CHEMBL1310819 & 688239 & 4.7862 & 5.581 & TST \\
\hline CHEMBL1319513 & 688239 & 4.9362 & 5.4775 & TRN \\
\hline CHEMBL1375818 & 688239 & 5.6362 & 5.3825 & TRN \\
\hline CHEMBL1559104 & 688239 & 5.4862 & 5.6629 & TRN \\
\hline CHEMBL1411111 & 688239 & 6.9363 & 5.4117 & TST \\
\hline CHEMBL1358123 & 688239 & 5.1862 & 5.5923 & TST \\
\hline CHEMBL1488623 & 688239 & 5.4362 & 5.5621 & TRN \\
\hline CHEMBL1368883 & 688239 & 4.7362 & 5.5098 & TRN \\
\hline CHEMBL1385725 & 688239 & 6.2862 & 5.4317 & TRN \\
\hline CHEMBL1376740 & 688239 & 5.1362 & 5.434 & TRN \\
\hline CHEMBL1404014 & 688239 & 5.5362 & 5.6478 & TST \\
\hline CHEMBL1398303 & 688239 & 4.4862 & 5.4866 & TRN \\
\hline CHEMBL1510284 & 688239 & 5.1862 & 5.4933 & TST \\
\hline CHEMBL1600160 & 688239 & 6.8861 & 5.6824 & TRN \\
\hline
\end{tabular}


Supplemental Table S2.txt

\begin{tabular}{|c|c|c|c|c|}
\hline CHEMBL1301377 & 688239 & 4.4862 & 5.5018 & TRN \\
\hline CHEMBL1389031 & 688239 & 6.6861 & 5.517 & TRN \\
\hline CHEMBL1453628 & 688239 & 4.5362 & 5.4204 & TRN \\
\hline CHEMBL1509397 & 688239 & 5.3362 & 5.517 & TRN \\
\hline CHEMBL1484391 & 688239 & 4.5362 & 5.5299 & TRN \\
\hline CHEMBL1546938 & 688239 & 4.7862 & 5.4278 & TST \\
\hline CHEMBL1394753 & 688239 & 5.5362 & 5.5437 & TRN \\
\hline CHEMBL1331378 & 688239 & 5.1862 & 5.5524 & TRN \\
\hline CHEMBL1469179 & 688239 & 6.1862 & 5.4097 & TRN \\
\hline CHEMBL1346749 & 688239 & 4.8362 & 5.6471 & TST \\
\hline CHEMBL1562721 & 688239 & 5.4862 & 5.4777 & TRN \\
\hline CHEMBL1445001 & 688239 & 7.2366 & 5.5891 & TRN \\
\hline CHEMBL1406211 & 688239 & 5.0862 & 5.4989 & TST \\
\hline CHEMBL1429531 & 688239 & 5.6862 & 5.5228 & TST \\
\hline CHEMBL1448480 & 688239 & 4.5362 & 5.329 & TST \\
\hline CHEMBL1566317 & 688239 & 5.1862 & 5.5441 & TRN \\
\hline CHEMBL1313777 & 688239 & 4.5362 & 5.4452 & TRN \\
\hline CHEMBL1359635 & 688239 & 5.7862 & 5.6582 & TRN \\
\hline CHEMBL1311134 & 688239 & 7.2366 & 5.5602 & TST \\
\hline CHEMBL1500168 & 688239 & 5.3362 & 5.5131 & TRN \\
\hline CHEMBL1344330 & 688239 & 5.6862 & 5.46299 & 999999999 \\
\hline CHEMBL1388369 & 688239 & 4.4862 & 5.356 & TST \\
\hline CHEMBL1595593 & 688239 & 4.9362 & 5.3316 & TRN \\
\hline CHEMBL1989823 & 688239 & 6.1862 & 5.4435 & TST \\
\hline CHEMBL1543070 & 688239 & 4.4862 & 5.3647 & TRN \\
\hline CHEMBL1551828 & 688239 & 8.2366 & 5.3984 & TRN \\
\hline CHEMBL1305688 & 688239 & 4.5362 & 5.4308 & TST \\
\hline CHEMBL1400032 & 688239 & 5.5362 & 5.4105 & TRN \\
\hline CHEMBL1472177 & 688239 & 5.7862 & 5.4806 & TRN \\
\hline CHEMBL1322862 & 688239 & 5.4862 & 5.5648 & TRN \\
\hline CHEMBL1569256 & 688239 & 6.7862 & 5.4726 & TST \\
\hline CHEMBL1985987 & 688239 & 4.5362 & 5.3806 & TRN \\
\hline CHEMBL3209854 & 688239 & 6.0862 & 5.5713 & TRN \\
\hline CHEMBL1429267 & 688239 & 6.7361 & 5.5273 & TRN \\
\hline CHEMBL1319891 & 688239 & 7.0862 & 5.4995 & TRN \\
\hline CHEMBL1378813 & 688239 & 5.3362 & 5.6108 & TST \\
\hline CHEMBL1479170 & 688239 & 5.4862 & 5.4517 & TRN \\
\hline CHEMBL1422259 & 688239 & 5.4862 & 5.6025 & TRN \\
\hline CHEMBL1326246 & 688239 & 5.8362 & 5.4327 & TST \\
\hline CHEMBL1402587 & 688239 & 4.5362 & 5.4778 & TRN \\
\hline CHEMBL1420804 & 688239 & 7.1361 & 5.5837 & TST \\
\hline CHEMBL1316857 & 688239 & 4.9862 & 5.6841 & TRN \\
\hline CHEMBL1325132 & 688239 & 4.9862 & 5.6021 & TRN \\
\hline CHEMBL1332318 & 688239 & 5.1862 & 5.44 & TST \\
\hline CHEMBL1337608 & 688239 & 4.4862 & 5.6594 & TRN \\
\hline CHEMBL1524929 & 688239 & 4.5362 & 5.5056 & TRN \\
\hline CHEMBL1582516 & 688239 & 4.4862 & 5.5237 & TRN \\
\hline CHEMBL1334638 & 688239 & 4.5362 & 5.4793 & TRN \\
\hline
\end{tabular}




\begin{tabular}{|c|c|c|c|c|c|c|}
\hline & & \multicolumn{5}{|c|}{ Supplemental Table S2.txt } \\
\hline CHEMBL1368870 & 688239 & 5.5862 & 5.5746 & TRN & & \\
\hline CHEMBL3208075 & 688239 & 6.1862 & 5.4695 & TST & & \\
\hline CHEMBL1370165 & 688239 & 8.3372 & 5.4432 & TRN & & \\
\hline CHEMBL1440855 & 688239 & 5.0862 & 5.5705 & TRN & & \\
\hline CHEMBL1542358 & 688239 & 5.9362 & 5.5622 & TRN & & \\
\hline CHEMBL1577642 & 688239 & 4.6362 & 5.5755 & TST & & \\
\hline CHEMBL1304383 & 688239 & 5.1362 & 5.6283 & TRN & & \\
\hline CHEMBL1578909 & 688239 & 8.28399 & 99999999 & 99 & 5.5131 & TRN \\
\hline CHEMBL1503787 & 688239 & 4.5862 & 5.5609 & TST & & \\
\hline CHEMBL1362635 & 688239 & 5.5362 & 5.3829 & TRN & & \\
\hline CHEMBL1313957 & 688239 & 4.6362 & 5.5539 & TRN & & \\
\hline CHEMBL1319181 & 688239 & 8.3372 & 5.6046 & TRN & & \\
\hline CHEMBL1352819 & 688239 & 7.1361 & 5.3345 & TST & & \\
\hline CHEMBL1527340 & 688239 & 6.6362 & 5.5874 & TRN & & \\
\hline CHEMBL1578075 & 688239 & 5.1862 & 5.5282 & TRN & & \\
\hline CHEMBL1375279 & 688239 & 5.4362 & 5.4387 & TRN & & \\
\hline CHEMBL1302941 & 688239 & 4.9862 & 5.6292 & TRN & & \\
\hline CHEMBL1579822 & 688239 & 4.4862 & 5.5818 & TST & & \\
\hline CHEMBL1330489 & 688239 & 5.6362 & 5.3341 & TRN & & \\
\hline CHEMBL1324759 & 688239 & 4.7362 & 5.4234 & TRN & & \\
\hline CHEMBL1372532 & 688239 & 5.5362 & 5.6575 & TRN & & \\
\hline CHEMBL1542241 & 688239 & 5.1862 & 5.5973 & TRN & & \\
\hline CHEMBL1319401 & 688239 & 4.5362 & 5.3388 & TRN & & \\
\hline CHEMBL1375406 & 688239 & 4.6362 & 5.2956 & TST & & \\
\hline CHEMBL1517966 & 688239 & 6.3362 & 5.3945 & TST & & \\
\hline CHEMBL3211290 & 688239 & 4.5362 & 5.5528 & TRN & & \\
\hline CHEMBL1580285 & 688239 & 6.1362 & 5.3384 & TRN & & \\
\hline CHEMBL1534436 & 688239 & 5.8362 & 5.4128 & TRN & & \\
\hline CHEMBL1299625 & 688239 & 7.1361 & 5.4274 & TRN & & \\
\hline CHEMBL1518153 & 688239 & 5.0362 & 5.2765 & TST & & \\
\hline CHEMBL1364734 & 688239 & 5.2362 & 5.3816 & TRN & & \\
\hline CHEMBL1567789 & 688239 & 4.6362 & 5.5514 & TRN & & \\
\hline CHEMBL1584749 & 688239 & 6.4862 & 5.3918 & TRN & & \\
\hline CHEMBL1341455 & 688239 & 5.7362 & 5.5347 & TRN & & \\
\hline CHEMBL1613415 & 688239 & 7.2366 & 5.5344 & TRN & & \\
\hline CHEMBL1355294 & 688239 & 5.4362 & 5.6099 & TST & & \\
\hline CHEMBL1308260 & 688239 & 6.9363 & 5.5737 & TRN & & \\
\hline CHEMBL1533051 & 688239 & 6.2862 & 5.4447 & TRN & & \\
\hline CHEMBL1584351 & 688239 & 8.3872 & 5.5241 & TRN & & \\
\hline CHEMBL3195368 & 688239 & 6.1362 & 5.4616 & TRN & & \\
\hline CHEMBL1598076 & 688239 & 5.2362 & 5.5669 & TRN & & \\
\hline CHEMBL1323413 & 688239 & 6.1362 & 5.4957 & TRN & & \\
\hline CHEMBL1484197 & 688239 & 4.7362 & 5.505 & TRN & & \\
\hline CHEMBL1379507 & 688239 & 7.2366 & 5.4472 & TRN & & \\
\hline CHEMBL1342130 & 688239 & 6.1862 & 5.3726 & TST & & \\
\hline CHEMBL1477176 & 688239 & 4.8862 & 5.6155 & TRN & & \\
\hline CHEMBL1580972 & 688239 & 6.1862 & 5.6032 & TST & & \\
\hline CHEMBL1318795 & 688239 & 6.6362 & 5.7735 & TRN & & \\
\hline
\end{tabular}


Supplemental Table S2.txt

\begin{tabular}{|c|c|c|c|c|}
\hline CHEMBL1331166 & 688239 & 4.5362 & 5.5203 & TST \\
\hline CHEMBL1372551 & 688239 & 5.6862 & 5.6168 & TRN \\
\hline CHEMBL1450915 & 688239 & 4.7362 & 5.4156 & TRN \\
\hline CHEMBL1310568 & 688239 & 5.4362 & 5.3975 & TRN \\
\hline CHEMBL1386030 & 688239 & 4.5362 & 5.4667 & TRN \\
\hline CHEMBL1326392 & 688239 & 6.1862 & 5.5321 & TRN \\
\hline CHEMBL1360480 & 688239 & 4.7862 & \multicolumn{2}{|c|}{5.4670000000000005} \\
\hline CHEMBL1481028 & 688239 & 4.5362 & 5.5833 & TRN \\
\hline CHEMBL1544226 & 688239 & 6.6362 & 5.5786 & TRN \\
\hline CHEMBL1426154 & 688239 & 5.2362 & 5.4444 & TST \\
\hline CHEMBL1411634 & 688239 & 4.5362 & 5.4834 & TRN \\
\hline CHEMBL1485887 & 688239 & 4.8362 & 5.4294 & TRN \\
\hline CHEMBL1575625 & 688239 & 6.1862 & 5.4083 & TRN \\
\hline CHEMBL1321690 & 688239 & 5.5862 & 5.4705 & TST \\
\hline CHEMBL1503935 & 688239 & 6.2362 & 5.6079 & TST \\
\hline CHEMBL1444657 & 688239 & 4.7362 & 5.6766 & TRN \\
\hline CHEMBL1494118 & 688239 & 6.3863 & 5.5283 & TST \\
\hline CHEMBL 3190330 & 688239 & 4.6362 & 5.4296 & TRN \\
\hline CHEMBL3198948 & 688239 & 4.7862 & 5.3516 & TST \\
\hline CHEMBL1533030 & 688239 & 5.3862 & 5.5395 & TST \\
\hline CHEMBL1477919 & 688239 & 8.2366 & 5.3828 & TRN \\
\hline CHEMBL3193803 & 688239 & 5.1862 & 5.4482 & TST \\
\hline CHEMBL1490075 & 688239 & 5.3362 & 5.433 & TRN \\
\hline CHEMBL1523793 & 688239 & 5.1862 & 5.6226 & TRN \\
\hline CHEMBL1390273 & 688239 & 5.4862 & 5.3641 & TRN \\
\hline CHEMBL1399836 & 688239 & 5.3862 & 5.5117 & TRN \\
\hline CHEMBL1461108 & 688239 & 6.1362 & 5.5257 & TRN \\
\hline CHEMBL1329799 & 688239 & 6.1862 & 5.5405 & TST \\
\hline CHEMBL1990355 & 688239 & 6.9363 & 5.4437 & TRN \\
\hline CHEMBL1452157 & 688239 & 5.1862 & 5.4868 & TRN \\
\hline CHEMBL1368302 & 688239 & 4.7862 & 5.5592 & TRN \\
\hline CHEMBL1491790 & 688239 & 6.9363 & 5.4797 & TRN \\
\hline CHEMBL1594279 & 688239 & 6.4362 & 5.4294 & TRN \\
\hline CHEMBL1506809 & 688239 & 4.5862 & 5.5243 & TRN \\
\hline CHEMBL1461590 & 688239 & 4.7862 & 5.4663 & TRN \\
\hline CHEMBL1515242 & 688239 & 4.5362 & 5.4559 & TRN \\
\hline CHEMBL1607920 & 688239 & 5.1862 & 5.5722 & TRN \\
\hline CHEMBL1413844 & 688239 & 4.9362 & 5.4096 & TRN \\
\hline CHEMBL1537225 & 688239 & 5.4362 & 5.5331 & TRN \\
\hline CHEMBL3192869 & 688239 & 4.7362 & 5.434 & TRN \\
\hline CHEMBL1561281 & 688239 & 5.6862 & 5.5227 & TRN \\
\hline CHEMBL1302138 & 688239 & 4.9862 & 5.63899 & 9999999999 \\
\hline CHEMBL1398312 & 688239 & 4.4862 & 5.4231 & TST \\
\hline CHEMBL1991936 & 688239 & 5.0862 & 5.4527 & TST \\
\hline CHEMBL1553970 & 688239 & 4.5862 & 5.5967 & TST \\
\hline CHEMBL1604414 & 688239 & 4.5862 & 5.4608 & TST \\
\hline CHEMBL1566920 & 688239 & 4.5362 & 5.5069 & TRN \\
\hline CHEMBL1385010 & 688239 & 5.3862 & 5.3752 & TRN \\
\hline
\end{tabular}


Supplemental Table S2.txt

\begin{tabular}{|c|c|c|c|c|}
\hline CHEMBL1413787 & 688239 & 5.3862 & 5.4723 & TRN \\
\hline CHEMBL1487620 & 688239 & 5.9362 & 5.5134 & TRN \\
\hline CHEMBL1324773 & 688239 & 5.9362 & 5.4725 & TRN \\
\hline CHEMBL1421666 & 688239 & 6.7361 & 5.5099 & TRN \\
\hline CHEMBL1454853 & 688239 & 5.3862 & 5.3602 & TRN \\
\hline CHEMBL1399581 & 688239 & 5.5862 & 5.6037 & TRN \\
\hline CHEMBL1331266 & 688239 & 8.3872 & 5.4339 & TST \\
\hline CHEMBL1566771 & 688239 & 6.9863 & 5.7785 & TRN \\
\hline CHEMBL1343297 & 688239 & 6.8362 & 5.4144 & TST \\
\hline CHEMBL1394542 & 688239 & 4.5362 & 5.4514 & TRN \\
\hline CHEMBL3195605 & 688239 & 4.6362 & 5.6213 & TRN \\
\hline CHEMBL1602443 & 688239 & 4.7862 & 5.4268 & TRN \\
\hline CHEMBL1506296 & 688239 & 4.6 & 5.4922 & TRN \\
\hline CHEMBL1442789 & 688239 & 4.4862 & 5.4792 & TRN \\
\hline CHEMBL1589906 & 688239 & 6.8861 & 5.7642 & TRN \\
\hline CHEMBL1340046 & 688239 & 4.8362 & 5.2896 & TST \\
\hline CHEMBL1454832 & 688239 & 5.0362 & 5.4465 & TRN \\
\hline CHEMBL1612169 & 688239 & 4.5362 & 5.4738 & TST \\
\hline CHEMBL1578650 & 688239 & 5.0862 & 5.474 & TRN \\
\hline CHEMBL1524020 & 688239 & 5.4362 & 5.5018 & TST \\
\hline CHEMBL1318142 & 688239 & 6.3863 & 5.6472 & TRN \\
\hline CHEMBL1559689 & 688239 & 5.1862 & 5.3407 & TRN \\
\hline CHEMBL1305421 & 688239 & 4.5362 & 5.51200 & 00000000005 \\
\hline CHEMBL1461415 & 688239 & 4.5362 & 5.4998 & TST \\
\hline CHEMBL3191728 & 688239 & 5.7362 & 5.4152 & TRN \\
\hline CHEMBL1568272 & 688239 & 4.5362 & 5.4646 & TRN \\
\hline CHEMBL1348747 & 688239 & 6.0362 & 5.5402 & TRN \\
\hline CHEMBL1597547 & 688239 & 8.28399 & 99999999 & 5.4368 \\
\hline CHEMBL1449299 & 688239 & 4.7362 & 5.5484 & TRN \\
\hline CHEMBL1546528 & 688239 & 4.5362 & 5.3981 & TRN \\
\hline CHEMBL1548756 & 688239 & 6.5363 & 5.5164 & TRN \\
\hline CHEMBL1594522 & 688239 & 5.3862 & 5.4401 & TRN \\
\hline CHEMBL1312040 & 688239 & 6.2862 & 5.4471 & TRN \\
\hline CHEMBL1317664 & 688239 & 5.0862 & 5.4617 & TRN \\
\hline CHEMBL1577843 & 688239 & 5.0362 & 5.4013 & TRN \\
\hline CHEMBL585465 & 688239 & 5.5362 & 5.4314 & TST \\
\hline CHEMBL1530318 & 688239 & 6.2362 & 5.694 & TRN \\
\hline CHEMBL1399358 & 688239 & 6.7862 & 5.5212 & TST \\
\hline CHEMBL1480362 & 688239 & 6.8362 & 5.5875 & TRN \\
\hline CHEMBL1596681 & 688239 & 5.5862 & 5.434 & TRN \\
\hline CHEMBL1589512 & 688239 & 5.2362 & 5.4992 & TRN \\
\hline CHEMBL1393184 & 688239 & 5.3362 & 5.4291 & TRN \\
\hline CHEMBL1307057 & 688239 & 4.9362 & 5.4221 & TRN \\
\hline CHEMBL1417816 & 688239 & 8.3872 & 5.4441 & TRN \\
\hline CHEMBL1449358 & 688239 & 4.5362 & 5.5981 & TRN \\
\hline CHEMBL1457113 & 688239 & 5.7362 & 5.4826 & TST \\
\hline CHEMBL1584940 & 688239 & 5.3862 & 5.5385 & TRN \\
\hline CHEMBL1526672 & 688239 & 5.0862 & 5.49299 & 9999999999 \\
\hline
\end{tabular}


Supplemental Table S2.txt

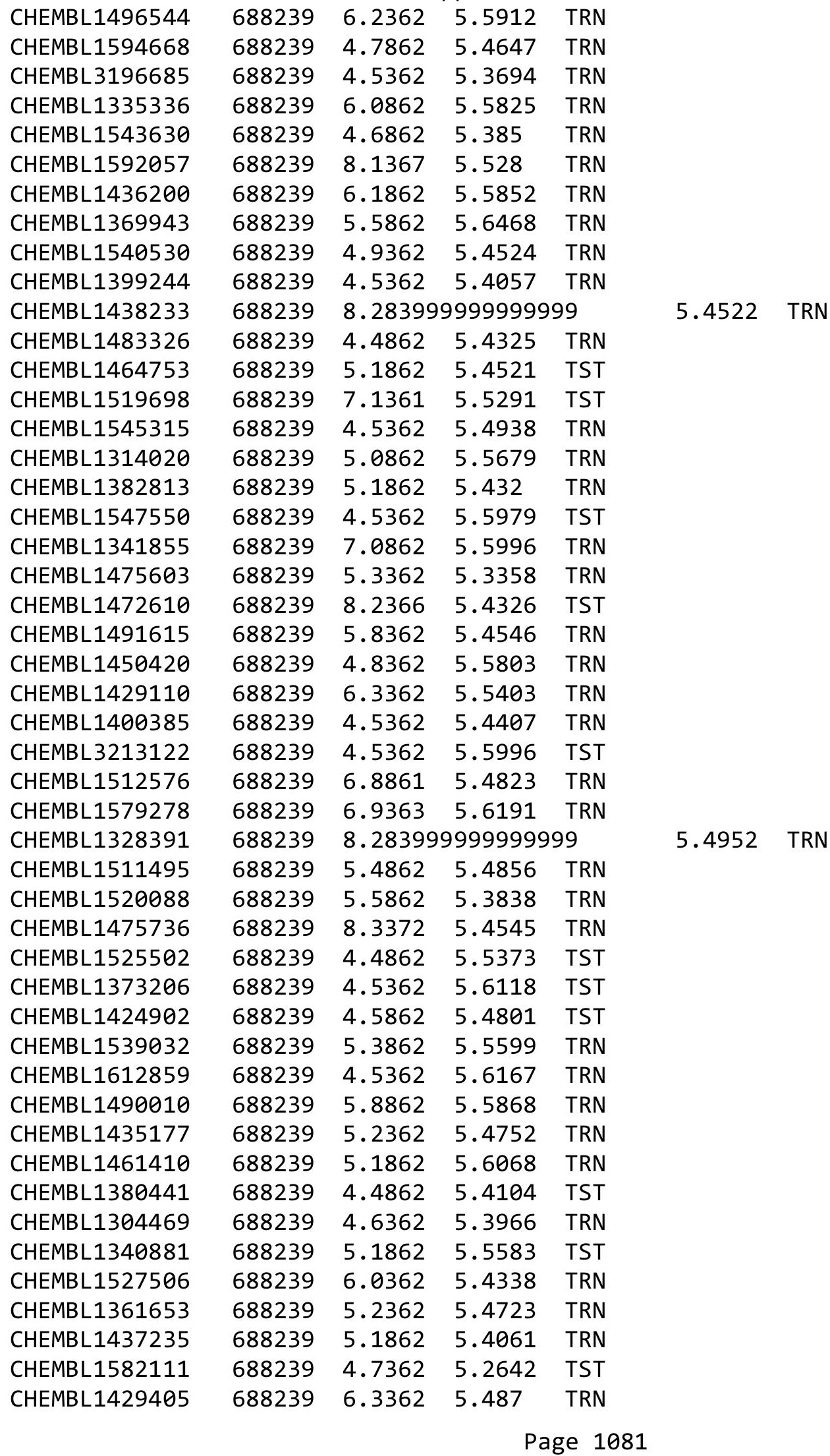


Supplemental Table S2.txt

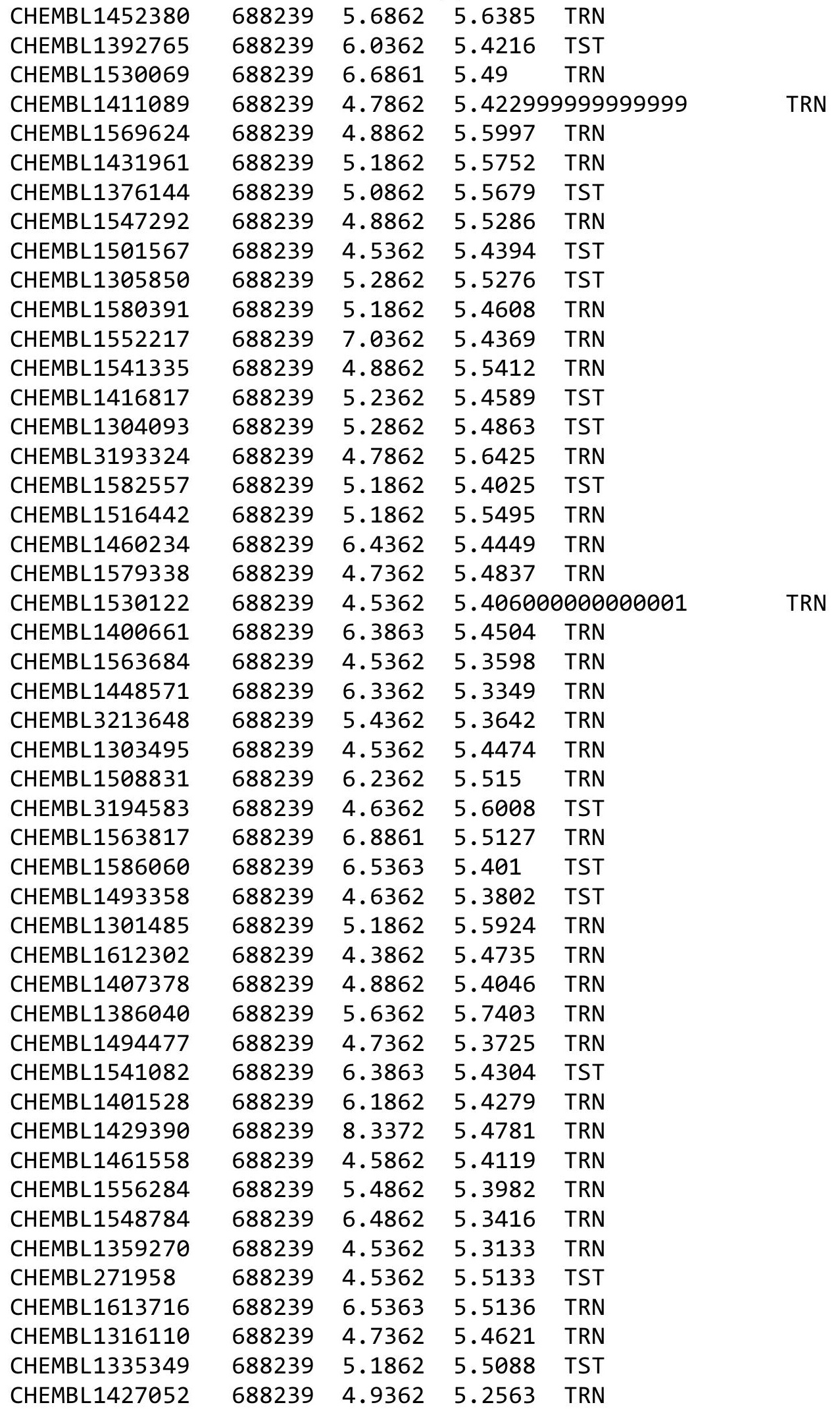

Page 1082 
Supplemental Table S2.txt

\begin{tabular}{|c|c|c|c|c|}
\hline CHEMBL1316168 & 688239 & 6.4862 & 5.5127 & TST \\
\hline CHEMBL1560367 & 688239 & 5.5862 & 5.4685 & TST \\
\hline CHEMBL1513322 & 688239 & 5.1862 & 5.5197 & TST \\
\hline CHEMBL1528862 & 688239 & 4.5362 & 5.4609 & TST \\
\hline CHEMBL1464795 & 688239 & 5.4862 & 5.6723 & TRN \\
\hline CHEMBL1580114 & 688239 & 5.1862 & 5.4114 & TRN \\
\hline CHEMBL1587081 & 688239 & 5.1862 & 5.5122 & TST \\
\hline CHEMBL1391087 & 688239 & 5.0362 & 5.3918 & TRN \\
\hline CHEMBL1329856 & 688239 & 5.3862 & 5.4718 & TRN \\
\hline CHEMBL1438078 & 688239 & 4.5362 & 5.4908 & TST \\
\hline CHEMBL1425070 & 688239 & 6.1862 & \multicolumn{2}{|c|}{5.513999999999999} \\
\hline CHEMBL1524275 & 688239 & 5.0362 & 5.6168 & TRN \\
\hline CHEMBL1503293 & 688239 & 5.7362 & 5.4754 & TST \\
\hline CHEMBL452337 & 688239 & 5.3862 & 5.5469 & TRN \\
\hline CHEMBL1450931 & 688239 & 6.3362 & 5.5606 & TST \\
\hline CHEMBL1605072 & 688239 & 4.5362 & 5.4749 & TRN \\
\hline CHEMBL1493822 & 688239 & 4.5362 & 5.6502 & TRN \\
\hline CHEMBL1507669 & 688239 & 6.5363 & 5.4952 & TRN \\
\hline CHEMBL1573948 & 688239 & 4.8862 & 5.3275 & TRN \\
\hline CHEMBL1381099 & 688239 & 6.8362 & 5.4275 & TRN \\
\hline CHEMBL1488281 & 688239 & 4.5362 & 5.4885 & TRN \\
\hline CHEMBL1449468 & 688239 & 5.7862 & 5.5216 & TST \\
\hline CHEMBL1321981 & 688239 & 8.3372 & 5.4526 & TRN \\
\hline CHEMBL1479878 & 688239 & 4.8362 & 5.6289 & TRN \\
\hline CHEMBL1382293 & 688239 & 4.5362 & 5.4305 & TRN \\
\hline CHEMBL1538693 & 688239 & 6.7862 & 5.4944 & TRN \\
\hline CHEMBL1415734 & 688239 & 4.4862 & 5.6249 & TRN \\
\hline CHEMBL1351257 & 688239 & 5.4862 & 5.6429 & TST \\
\hline CHEMBL1454128 & 688239 & 4.5362 & 5.5378 & TST \\
\hline CHEMBL1498603 & 688239 & 4.6862 & \multicolumn{2}{|c|}{5.412999999999999} \\
\hline CHEMBL1303803 & 688239 & 5.2362 & 5.5515 & TRN \\
\hline CHEMBL548615 & 688239 & 5.5862 & 5.4656 & TRN \\
\hline CHEMBL1397249 & 688239 & 6.2862 & 5.6214 & TRN \\
\hline CHEMBL1300116 & 688239 & 6.0862 & 5.4924 & TST \\
\hline CHEMBL1443828 & 688239 & 5.5862 & 5.6022 & TRN \\
\hline CHEMBL1518752 & 688239 & 6.9863 & 5.5485 & TST \\
\hline CHEMBL1372337 & 688239 & 4.5362 & 5.3642 & TRN \\
\hline CHEMBL1454446 & 688239 & 6.7361 & 5.5328 & TRN \\
\hline CHEMBL1557217 & 688239 & 4.6862 & 5.5208 & TRN \\
\hline CHEMBL1334070 & 688239 & 8.2366 & 5.5477 & TRN \\
\hline CHEMBL1601049 & 688239 & 5.1862 & 5.5038 & TRN \\
\hline CHEMBL1405477 & 688239 & 7.2366 & 5.5174 & TRN \\
\hline CHEMBL3195354 & 688239 & 6.1862 & 5.269 & TST \\
\hline CHEMBL1389300 & 688239 & 7.8861 & 5.4089 & TRN \\
\hline CHEMBL1571137 & 688239 & 4.6362 & 5.4125 & TRN \\
\hline CHEMBL1403696 & 688239 & 6.2862 & 5.6277 & TRN \\
\hline CHEMBL1321542 & 688239 & 6.1862 & 5.5557 & TRN \\
\hline CHEMBL1366552 & 688239 & 6.4362 & 5.5065 & TST \\
\hline
\end{tabular}

Page 1083 
Supplemental Table S2.txt

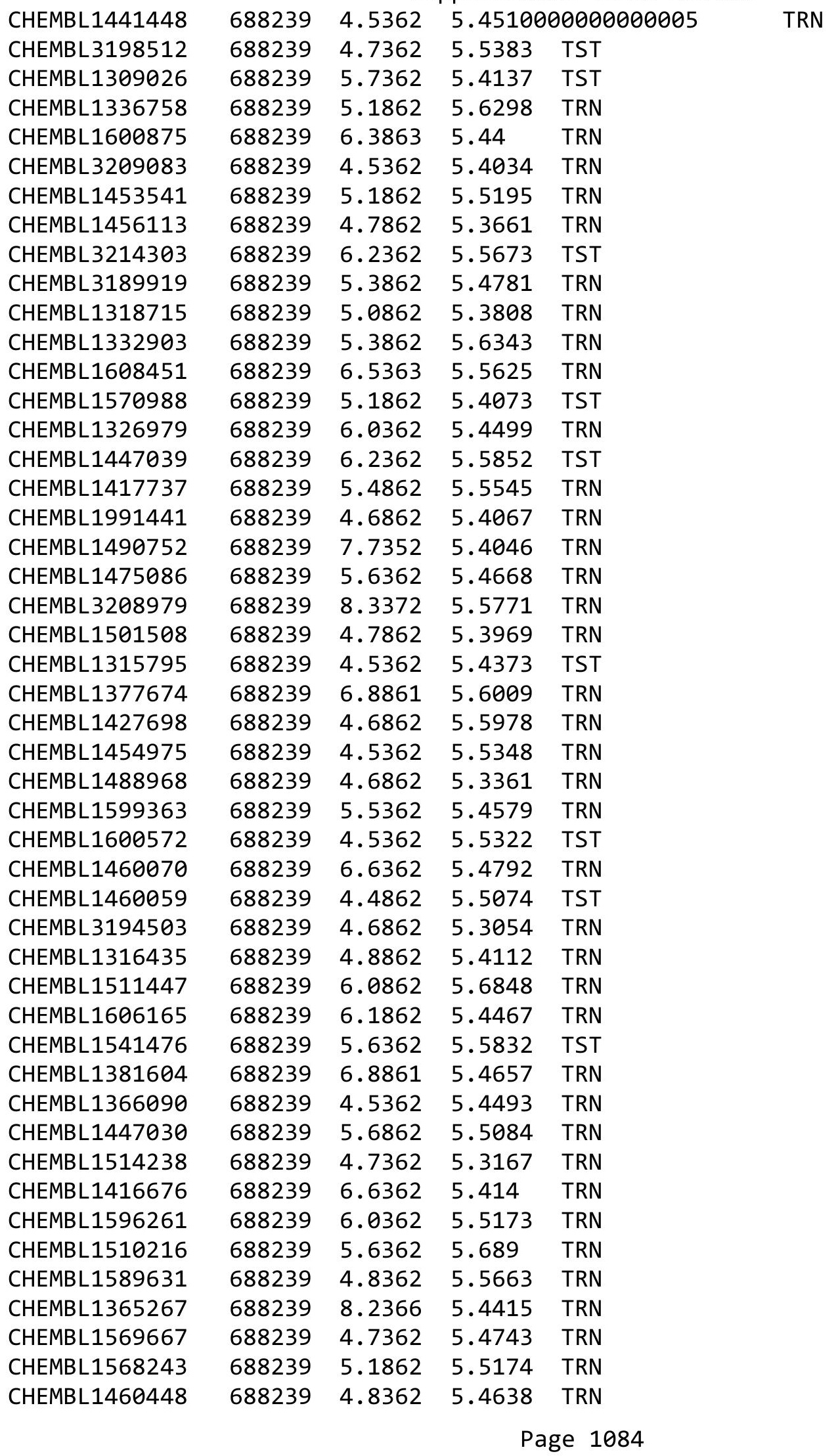


Supplemental Table S2.txt

\begin{tabular}{|c|c|c|c|c|c|}
\hline CHEMBL1581198 & 688239 & 5.6362 & 5.5325 & TST & \\
\hline CHEMBL1612255 & 688239 & 5.1862 & 5.5333 & TRN & \\
\hline CHEMBL1557148 & 688239 & 8.3872 & 5.6056 & TST & \\
\hline CHEMBL485012 & 688239 & 4.9862 & 5.46899 & 9999999999 & TRN \\
\hline CHEMBL1473837 & 688239 & 4.4862 & 5.4497 & TST & \\
\hline CHEMBL1563933 & 688239 & 4.5362 & 5.5118 & TRN & \\
\hline CHEMBL1300338 & 688239 & 6.3863 & 5.3743 & TST & \\
\hline CHEMBL1587672 & 688239 & 6.8861 & 5.3856 & TST & \\
\hline CHEMBL1436438 & 688239 & 4.6362 & 5.495 & TRN & \\
\hline CHEMBL1326357 & 688239 & 5.7862 & 5.6136 & TRN & \\
\hline CHEMBL1445219 & 688239 & 4.6862 & 5.4683 & TRN & \\
\hline CHEMBL1381382 & 688239 & 5.5362 & 5.5372 & TRN & \\
\hline CHEMBL1537310 & 688239 & 7.0862 & 5.6081 & TRN & \\
\hline CHEMBL1582805 & 688239 & 8.3372 & 5.48799 & 99999999995 & TRN \\
\hline CHEMBL1594535 & 688239 & 4.6362 & 5.3393 & TRN & \\
\hline CHEMBL1602021 & 688239 & 4.7362 & 5.4304 & TST & \\
\hline CHEMBL1355388 & 688239 & 5.2362 & 5.5381 & TRN & \\
\hline CHEMBL1438805 & 688239 & 5.3862 & 5.4807 & TRN & \\
\hline CHEMBL1421591 & 688239 & 5.7362 & 5.3285 & TST & \\
\hline CHEMBL1564498 & 688239 & 5.0862 & 5.5071 & TRN & \\
\hline CHEMBL1512815 & 688239 & 5.1362 & 5.4997 & TRN & \\
\hline CHEMBL1414017 & 688239 & 5.6862 & 5.49799 & 9999999999 & TRN \\
\hline CHEMBL1471240 & 688239 & 5.1862 & 5.5543 & TRN & \\
\hline CHEMBL1338126 & 688239 & 5.4862 & 5.5759 & TST & \\
\hline CHEMBL1375140 & 688239 & 5.8862 & 5.5495 & TRN & \\
\hline CHEMBL1345432 & 688239 & 5.1862 & 5.4712 & TRN & \\
\hline CHEMBL 3193110 & 688239 & 6.9863 & 5.4162 & TRN & \\
\hline CHEMBL469424 & 688239 & 4.9362 & 5.445 & TST & \\
\hline CHEMBL1537627 & 688239 & 5.7862 & 5.4385 & TRN & \\
\hline CHEMBL1340591 & 688239 & 4.6862 & 5.4741 & TST & \\
\hline CHEMBL1596625 & 688239 & 6.1862 & 5.6345 & TRN & \\
\hline CHEMBL 297304 & 688239 & 5.8862 & 5.4571 & TST & \\
\hline CHEMBL1607442 & 688239 & 5.4862 & 5.5651 & TRN & \\
\hline CHEMBL1587161 & 688239 & 4.7362 & 5.4832 & TRN & \\
\hline CHEMBL1358533 & 688239 & 6.3362 & 5.5182 & TST & \\
\hline CHEMBL1356140 & 688239 & 5.1862 & 5.4421 & TRN & \\
\hline CHEMBL1569172 & 688239 & 5.6862 & 5.6093 & TRN & \\
\hline CHEMBL1519887 & 688239 & 8.7447 & 5.5818 & TRN & \\
\hline CHEMBL1560663 & 688239 & 4.6362 & 5.4653 & TRN & \\
\hline CHEMBL1485079 & 688239 & 4.7362 & 5.4713 & TRN & \\
\hline CHEMBL1348040 & 688239 & 4.6362 & 5.5085 & TRN & \\
\hline CHEMBL1512108 & 688239 & 5.6362 & 5.3698 & TRN & \\
\hline CHEMBL1406875 & 688239 & 5.1862 & 5.598 & TRN & \\
\hline CHEMBL1348861 & 688239 & 7.7852 & 5.6073 & TRN & \\
\hline CHEMBL1497369 & 688239 & 5.6362 & 5.5227 & TST & \\
\hline CHEMBL1431282 & 688239 & 5.2362 & 5.4247 & TST & \\
\hline CHEMBL1569472 & 688239 & 5.1862 & 5.3714 & TST & \\
\hline CHEMBL1368616 & 688239 & 5.4362 & 5.6478 & TRN & \\
\hline
\end{tabular}


Supplemental Table S2.txt

\begin{tabular}{|c|c|c|c|c|c|}
\hline CHEMBL1493361 & 688239 & 6.9863 & 5.3599 & TST & \\
\hline CHEMBL3195473 & 688239 & 6.1862 & 5.4647 & TRN & \\
\hline CHEMBL1437684 & 688239 & 5.1862 & 5.5385 & TRN & \\
\hline CHEMBL1314654 & 688239 & 4.5362 & 5.5107 & TRN & \\
\hline CHEMBL1965444 & 688239 & 6.1362 & 5.5052 & TRN & \\
\hline CHEMBL1509711 & 688239 & 5.1862 & 5.3815 & TRN & \\
\hline CHEMBL1566720 & 688239 & 5.0362 & 5.2771 & TRN & \\
\hline CHEMBL1424560 & 688239 & 4.6862 & 5.427000 & 0000000005 & TRN \\
\hline CHEMBL1372103 & 688239 & 8.3372 & 5.4399 & TRN & \\
\hline CHEMBL1450470 & 688239 & 5.5362 & 5.5724 & TRN & \\
\hline CHEMBL1451566 & 688239 & 4.7862 & 5.4439 & TST & \\
\hline CHEMBL1386154 & 688239 & 8.283999 & 999999999 & 5.4979 & \\
\hline CHEMBL1323428 & 688239 & 4.7862 & 5.3525 & TRN & \\
\hline CHEMBL1398468 & 688239 & 5.1862 & 5.6361 & TRN & \\
\hline CHEMBL3210059 & 688239 & 6.1362 & 5.588999 & 9999999995 & TRN \\
\hline CHEMBL1436514 & 688239 & 4.8362 & 5.4528 & TRN & \\
\hline CHEMBL1396349 & 688239 & 4.5362 & 5.642 & TRN & \\
\hline CHEMBL1604157 & 688239 & 4.5862 & 5.6924 & TRN & \\
\hline CHEMBL1320101 & 688239 & 6.9863 & 5.5304 & TRN & \\
\hline CHEMBL1331418 & 688239 & 6.2862 & 5.7078 & TRN & \\
\hline CHEMBL1483241 & 688239 & 6.9363 & 5.5064 & TRN & \\
\hline CHEMBL1333480 & 688239 & 6.1862 & 5.6927 & TRN & \\
\hline CHEMBL1413670 & 688239 & 4.4862 & 5.6559 & TRN & \\
\hline CHEMBL1606317 & 688239 & 8.3872 & 5.5208 & TRN & \\
\hline CHEMBL1489131 & 688239 & 4.7362 & 5.4381 & TRN & \\
\hline CHEMBL1454502 & 688239 & 5.6862 & 5.6168 & TST & \\
\hline CHEMBL1435480 & 688239 & 7.0862 & 5.5524 & TRN & \\
\hline CHEMBL1445919 & 688239 & 5.4362 & 5.5317 & TRN & \\
\hline CHEMBL1303527 & 688239 & 8.28399 & 999999999 & 5.3893 & \\
\hline CHEMBL3210593 & 688239 & 4.9362 & 5.5087 & TRN & \\
\hline CHEMBL3210146 & 688239 & 4.5362 & 5.4313 & TRN & \\
\hline CHEMBL1346770 & 688239 & 4.4862 & 5.4393 & TRN & \\
\hline CHEMBL1526122 & 688239 & 6.2362 & 5.5911 & TRN & \\
\hline CHEMBL1438291 & 688239 & 6.7862 & 5.4864 & TRN & \\
\hline CHEMBL1606667 & 688239 & 4.7862 & 5.4419 & TRN & \\
\hline CHEMBL1330833 & 688239 & 4.5362 & 5.4289 & TRN & \\
\hline CHEMBL1557381 & 688239 & 4.5362 & 5.5353 & TST & \\
\hline CHEMBL1590764 & 688239 & 5.5862 & 5.3333 & TRN & \\
\hline CHEMBL1556099 & 688239 & 4.6362 & 5.4908 & TRN & \\
\hline CHEMBL1409234 & 688239 & 4.6362 & 5.5172 & TST & \\
\hline CHEMBL1442853 & 688239 & 5.3862 & 5.4571 & TRN & \\
\hline CHEMBL1454927 & 688239 & 4.6862 & 5.3677 & TRN & \\
\hline CHEMBL1562392 & 688239 & 5.5362 & 5.5354 & TST & \\
\hline CHEMBL1534762 & 688239 & 5.2362 & 5.5274 & TRN & \\
\hline CHEMBL1564862 & 688239 & 4.5362 & 5.548999 & 9999999995 & ST \\
\hline CHEMBL1365502 & 688239 & 5.6862 & 5.5808 & TRN & \\
\hline CHEMBL1561424 & 688239 & 8.3872 & 5.4126 & TST & \\
\hline CHEMBL1556163 & 688239 & 6.9363 & 5.4683 & TRN & \\
\hline
\end{tabular}


Supplemental Table S2.txt

\begin{tabular}{|c|c|c|c|c|}
\hline CHEMBL1505737 & 688239 & 6.2362 & 5.5072 & TRN \\
\hline CHEMBL1610215 & 688239 & 5.1862 & 5.4678 & TST \\
\hline CHEMBL1424929 & 688239 & 5.0862 & 5.4613 & TST \\
\hline CHEMBL1380019 & 688239 & 4.5362 & 5.4696 & TST \\
\hline CHEMBL1301898 & 688239 & 5.0362 & 5.5381 & TRN \\
\hline CHEMBL1401942 & 688239 & 8.3372 & 5.4457 & TRN \\
\hline CHEMBL1340732 & 688239 & 5.6862 & 5.5699 & TRN \\
\hline CHEMBL1490965 & 688239 & 7.3363 & 5.4898 & TRN \\
\hline CHEMBL3212554 & 688239 & 4.6862 & 5.45 & TRN \\
\hline CHEMBL1437997 & 688239 & 4.9862 & 5.4909 & TST \\
\hline CHEMBL1600797 & 688239 & 8.3372 & \multicolumn{2}{|c|}{5.502999999999999} \\
\hline CHEMBL1460844 & 688239 & 5.1862 & 5.6664 & TRN \\
\hline CHEMBL1606013 & 688239 & 4.5362 & 5.5328 & TRN \\
\hline CHEMBL1392083 & 688239 & 4.5362 & 5.4356 & TRN \\
\hline CHEMBL1325086 & 688239 & 4.45 & 5.5315 & TRN \\
\hline CHEMBL1364566 & 688239 & 6.8861 & 5.4177 & TRN \\
\hline CHEMBL1388714 & 688239 & 4.8862 & 5.5445 & TRN \\
\hline CHEMBL1472568 & 688239 & 6.5363 & 5.5565 & TRN \\
\hline CHEMBL1580010 & 688239 & 5.2362 & 5.4891 & TRN \\
\hline CHEMBL1491581 & 688239 & 6.2862 & 5.5208 & TRN \\
\hline CHEMBL1494623 & 688239 & 6.1362 & 5.5072 & TRN \\
\hline CHEMBL1559008 & 688239 & 4.7362 & 5.3844 & TST \\
\hline CHEMBL1327689 & 688239 & 4.6862 & 5.3678 & TRN \\
\hline CHEMBL1486020 & 688239 & 5.8362 & 5.7337 & TRN \\
\hline CHEMBL1509261 & 688239 & 5.4362 & 5.5847 & TST \\
\hline CHEMBL1530054 & 688239 & 4.4862 & 5.5048 & TST \\
\hline CHEMBL1580115 & 688239 & 4.5362 & 5.4326 & TST \\
\hline CHEMBL1571703 & 688239 & 5.8862 & 5.5916 & TRN \\
\hline CHEMBL1430796 & 688239 & 5.4862 & 5.7039 & TRN \\
\hline CHEMBL1522376 & 688239 & 5.6862 & 5.5433 & TRN \\
\hline CHEMBL1360529 & 688239 & 4.7362 & 5.5092 & TST \\
\hline CHEMBL1432372 & 688239 & 5.4862 & 5.5133 & TRN \\
\hline CHEMBL1568445 & 688239 & 4.6362 & 5.5332 & TRN \\
\hline CHEMBL1342832 & 688239 & 5.1862 & 5.3232 & TRN \\
\hline CHEMBL1372937 & 688239 & 4.7362 & 5.4008 & TRN \\
\hline CHEMBL1528100 & 688239 & 5.1862 & 5.4076 & TRN \\
\hline CHEMBL1331178 & 688239 & 8.3372 & 5.4284 & TRN \\
\hline CHEMBL1509752 & 688239 & 6.1862 & 5.5467 & TRN \\
\hline CHEMBL3208647 & 688239 & 5.1862 & 5.3798 & TST \\
\hline CHEMBL1590034 & 688239 & 4.6362 & 5.4318 & TRN \\
\hline CHEMBL1339675 & 688239 & 6.2362 & 5.3646 & TRN \\
\hline CHEMBL1575730 & 688239 & 5.6362 & 5.487 & TRN \\
\hline CHEMBL1327577 & 688239 & 6.8861 & 5.4433 & TRN \\
\hline CHEMBL1341877 & 688239 & 5.0862 & 5.5493 & TST \\
\hline CHEMBL1447484 & 688239 & 5.2862 & 5.4076 & TRN \\
\hline CHEMBL1540633 & 688239 & 6.2362 & 5.55200 & 00000000005 \\
\hline CHEMBL3208378 & 688239 & 5.9362 & 5.5799 & TRN \\
\hline CHEMBL1341105 & 688239 & 6.7862 & 5.5517 & TRN \\
\hline
\end{tabular}


Supplemental Table S2.txt

\begin{tabular}{|c|c|c|c|c|}
\hline CHEMBL1461997 & 688239 & 6.7862 & 5.5901 & TRN \\
\hline CHEMBL1311963 & 688239 & 6.7862 & 5.4598 & TRN \\
\hline CHEMBL1508395 & 688239 & 7.4365 & 5.5072 & TRN \\
\hline CHEMBL1417910 & 688239 & 7.2366 & 5.3844 & TRN \\
\hline CHEMBL1358031 & 688239 & 5.9862 & 5.4816 & TRN \\
\hline CHEMBL3197544 & 688239 & 6.2362 & 5.425 & TRN \\
\hline CHEMBL1543220 & 688239 & 4.5362 & 5.4838 & TRN \\
\hline CHEMBL1524137 & 688239 & 5.6862 & 5.5159 & TRN \\
\hline CHEMBL1432774 & 688239 & 4.5362 & 5.6275 & TRN \\
\hline CHEMBL1324131 & 688239 & 4.9362 & 5.5941 & TRN \\
\hline CHEMBL1602737 & 688239 & 5.3862 & 5.5154 & TRN \\
\hline CHEMBL1524594 & 688239 & 6.0362 & 5.4446 & TRN \\
\hline CHEMBL1517025 & 688239 & 4.55 & 5.4917 & TRN \\
\hline CHEMBL1569348 & 688239 & 4.6862 & 5.6465 & TRN \\
\hline CHEMBL1453807 & 688239 & 5.1862 & 5.4862 & TRN \\
\hline CHEMBL1538938 & 688239 & 5.5362 & 5.6579 & TST \\
\hline CHEMBL1588891 & 688239 & 5.7362 & 5.5873 & TRN \\
\hline CHEMBL1575523 & 688239 & 4.7362 & 5.4954 & TRN \\
\hline CHEMBL1369287 & 688239 & 4.5362 & 5.4085 & TST \\
\hline CHEMBL1410380 & 688239 & 6.9363 & 5.6685 & TRN \\
\hline CHEMBL3212650 & 688239 & 5.1862 & 5.507000 & 000000001 \\
\hline CHEMBL1339836 & 688239 & 4.5362 & 5.3337 & TST \\
\hline CHEMBL1438773 & 688239 & 5.8362 & 5.4728 & TRN \\
\hline CHEMBL1597250 & 688239 & 4.65 & 5.4491 & TRN \\
\hline CHEMBL1609132 & 688239 & 6.0862 & 5.6385 & TRN \\
\hline CHEMBL1505492 & 688239 & 4.7362 & 5.5107 & TRN \\
\hline CHEMBL1404458 & 688239 & 4.5362 & 5.5852 & TRN \\
\hline CHEMBL1305461 & 688239 & 4.5362 & 5.4915 & TRN \\
\hline CHEMBL1480058 & 688239 & 5.4362 & 5.4064 & TRN \\
\hline CHEMBL1537793 & 688239 & 6.8362 & 5.4977 & TST \\
\hline CHEMBL1550708 & 688239 & 4.5362 & 5.4531 & TST \\
\hline CHEMBL1460611 & 688239 & 5.3362 & 5.3906 & TRN \\
\hline CHEMBL1999475 & 688239 & 6.0 & 5.3092 & TRN \\
\hline CHEMBL1469647 & 688239 & 5.7862 & 5.6202 & TRN \\
\hline CHEMBL1493315 & 688239 & 5.9362 & 5.5206 & TRN \\
\hline CHEMBL1452058 & 688239 & 4.4862 & 5.6253 & TRN \\
\hline CHEMBL1420362 & 688239 & 5.0862 & 5.4792 & TST \\
\hline CHEMBL3194200 & 688239 & 4.8362 & 5.4398 & TRN \\
\hline CHEMBL1397387 & 688239 & 4.6362 & 5.4804 & TRN \\
\hline CHEMBL1313662 & 688239 & 4.5362 & 5.3502 & TRN \\
\hline CHEMBL1416498 & 688239 & 4.5362 & 5.6023 & TRN \\
\hline CHEMBL1324111 & 688239 & 4.5362 & 5.4999 & TST \\
\hline CHEMBL1335944 & 688239 & 5.0862 & 5.492999 & 999999999 \\
\hline CHEMBL1408840 & 688239 & 5.6862 & 5.5038 & TRN \\
\hline CHEMBL1431969 & 688239 & 4.5362 & 5.5401 & TRN \\
\hline CHEMBL1399735 & 688239 & 4.7862 & 5.4743 & TRN \\
\hline CHEMBL1492110 & 688239 & 5.2362 & 5.4432 & TRN \\
\hline CHEMBL1393264 & 688239 & 5.7362 & 5.4986 & TRN \\
\hline
\end{tabular}


Supplemental Table S2.txt

\begin{tabular}{|c|c|c|c|c|}
\hline 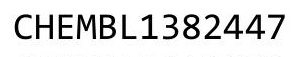 & & & & \\
\hline AEMBL1610333 & 38239 & 1862 & 95 & \\
\hline AEMBL1549615 & 39 & 862 & & \\
\hline & & 862 & & \\
\hline IEMBL13 & & 862 & & \\
\hline AEMBL1576798 & 88239 & 362 & & \\
\hline AEMBL1548769 & 88239 & 862 & 514 & \\
\hline AEMBL1422766 & & & & \\
\hline IEMBL13 & & 862 & & \\
\hline IEMBL13 & & 362 & & \\
\hline AEMBL1423636 & 39 & 362 & & \\
\hline AEMBL1329213 & & 372 & & \\
\hline AEMBL1400244 & & 862 & & \\
\hline AEMBL16 & & 72 & & \\
\hline AEMBL15 & & 362 & & \\
\hline AEMBL1359848 & & 862 & & \\
\hline AEMBL1438746 & & 864 & & \\
\hline AEMBL319 & & 62 & & \\
\hline AEMBL160 & & 62 & & \\
\hline JEMBL15 & & & & \\
\hline AEMBL1452475 & & 362 & & \\
\hline AEMBL3191705 & & 862 & & \\
\hline IEMBL144 & & 62 & & \\
\hline AFMRI 130 & & & & \\
\hline 19 & & 61 & & \\
\hline AEMBL1391209 & & 362 & & \\
\hline EMBL566 & & & & \\
\hline EMBL16 & & 62 & & \\
\hline$\theta$ & & 62 & & \\
\hline 72 & & 55 & & \\
\hline AEMBL1402800 & & & & \\
\hline IEMBL1502202 & & 362 & & \\
\hline & & & & \\
\hline 37 & & 51 & & \\
\hline & & & & \\
\hline AEMBL1596212 & & & & s \\
\hline AEMBL1456136 & & 362 & & F \\
\hline & & 62 & & \\
\hline 951 & & & & \\
\hline HEMBL1494130 & & & & $\mathrm{RI}$ \\
\hline AEMBL3210785 & & 62 & & $\mathrm{R}$ \\
\hline BL13 & & 62 & & \\
\hline & & & & \\
\hline HEMBL1501713 & & & & 1 \\
\hline AEMBL1345353 & & & & rs \\
\hline IEMBL1573 & & 362 & 89 & TS \\
\hline 150 & & & & \\
\hline HEMBL149555 & & & 5.6229 & \\
\hline
\end{tabular}

Page 1089 
Supplemental Table S2.txt

\begin{tabular}{|c|c|c|c|c|}
\hline CHEMBL1366936 & 688239 & 6.9363 & 5.5846 & TRN \\
\hline CHEMBL1389474 & 688239 & 6.0862 & 5.5265 & TRN \\
\hline CHEMBL1455290 & 688239 & 6.2362 & 5.4843 & TRN \\
\hline CHEMBL1465049 & 688239 & 4.5362 & 5.279 & TRN \\
\hline CHEMBL1591443 & 688239 & 5.3862 & 5.5401 & TRN \\
\hline CHEMBL1500987 & 688239 & 5.3362 & 5.5435 & TRN \\
\hline CHEMBL1468202 & 688239 & 5.4362 & 5.5472 & TRN \\
\hline CHEMBL1480165 & 688239 & 4.6362 & 5.4128 & TRN \\
\hline CHEMBL1554241 & 688239 & 7.1361 & 5.5203 & TRN \\
\hline CHEMBL1380312 & 688239 & 4.8362 & 5.2296 & TST \\
\hline CHEMBL1462585 & 688239 & 4.5362 & 5.4277 & TRN \\
\hline CHEMBL1308704 & 688239 & 5.1862 & 5.5022 & TST \\
\hline CHEMBL1606524 & 688239 & 5.1862 & 5.5473 & TRN \\
\hline CHEMBL1544082 & 688239 & 4.5362 & 5.4852 & TST \\
\hline CHEMBL1504982 & 688239 & 4.8862 & 5.4077 & TRN \\
\hline CHEMBL1512485 & 688239 & 5.0862 & 5.4461 & TRN \\
\hline CHEMBL1518847 & 688239 & 5.4362 & 5.4669 & TST \\
\hline CHEMBL1355511 & 688239 & 5.1862 & 5.4686 & TRN \\
\hline CHEMBL1509670 & 688239 & 5.1362 & 5.4004 & TRN \\
\hline CHEMBL1459084 & 688239 & 4.5362 & \multicolumn{2}{|c|}{5.662000000000001} \\
\hline CHEMBL1389698 & 688239 & 4.5362 & 5.5114 & TST \\
\hline CHEMBL1428886 & 688239 & 5.6862 & 5.4327 & TRN \\
\hline CHEMBL1389122 & 688239 & 6.1862 & 5.5947 & TRN \\
\hline CHEMBL1324680 & 688239 & 6.1862 & 5.4722 & TRN \\
\hline CHEMBL1968085 & 688239 & 4.5362 & 5.3336 & TST \\
\hline CHEMBL1391514 & 688239 & 5.1862 & 5.4612 & TRN \\
\hline CHEMBL1572591 & 688239 & 5.4862 & 5.5717 & TRN \\
\hline CHEMBL1362114 & 688239 & 6.5363 & \multicolumn{2}{|c|}{5.406000000000001} \\
\hline CHEMBL1527000 & 688239 & 5.7862 & 5.468 & TRN \\
\hline CHEMBL1563836 & 688239 & 5.4862 & 5.5052 & TRN \\
\hline CHEMBL1463346 & 688239 & 7.1864 & 5.4558 & TRN \\
\hline CHEMBL1349780 & 688239 & 5.6862 & 5.5186 & TRN \\
\hline CHEMBL1533940 & 688239 & 5.5862 & 5.5363 & TRN \\
\hline CHEMBL1374767 & 688239 & 4.8362 & 5.5093 & TRN \\
\hline CHEMBL1531069 & 688239 & 6.9363 & 5.3611 & TRN \\
\hline CHEMBL1547080 & 688239 & 5.1862 & 5.5209 & TRN \\
\hline CHEMBL1575853 & 688239 & 5.7862 & 5.4847 & TRN \\
\hline CHEMBL1323543 & 688239 & 4.5362 & 5.6186 & TRN \\
\hline CHEMBL1481068 & 688239 & 6.5862 & 5.4649 & TRN \\
\hline CHEMBL1400416 & 688239 & 4.5862 & 5.4488 & TRN \\
\hline CHEMBL581225 & 688239 & 5.0862 & 5.6135 & TST \\
\hline CHEMBL1395877 & 688239 & 4.7862 & 5.5913 & TST \\
\hline CHEMBL1337216 & 688239 & 4.6862 & 5.5809 & TRN \\
\hline CHEMBL1510981 & 688239 & 4.5362 & 5.4291 & TST \\
\hline CHEMBL1990527 & 688239 & 5.0862 & 5.4726 & TRN \\
\hline CHEMBL1307890 & 688239 & 6.1862 & 5.5807 & TRN \\
\hline CHEMBL1305455 & 688239 & 6.0 & 5.4662 & TRN \\
\hline CHEMBL1329977 & 688239 & 5.1362 & 5.5388 & TRN \\
\hline
\end{tabular}


Supplemental Table S2.txt

\begin{tabular}{|c|c|c|c|c|c|}
\hline CHEMBL1382236 & 688239 & 5.1862 & \multicolumn{2}{|c|}{5.4110000000000005} & TRN \\
\hline CHEMBL1591127 & 688239 & 4.5362 & 5.3909 & TRN & \\
\hline CHEMBL1472198 & 688239 & 5.4862 & 5.4303 & TRN & \\
\hline CHEMBL1441131 & 688239 & 6.1362 & 5.6255 & TRN & \\
\hline CHEMBL1329072 & 688239 & 4.7362 & 5.3968 & TRN & \\
\hline CHEMBL1446243 & 688239 & 5.2362 & 5.5019 & TRN & \\
\hline CHEMBL1488493 & 688239 & 5.2862 & 5.5468 & TST & \\
\hline CHEMBL1483983 & 688239 & 4.6362 & 5.5006 & TRN & \\
\hline CHEMBL1529374 & 688239 & 5.0362 & 5.5595 & TRN & \\
\hline CHEMBL1596202 & 688239 & 5.1362 & 5.6246 & TRN & \\
\hline CHEMBL1303268 & 688239 & 4.5362 & \multicolumn{2}{|c|}{5.577000000000001} & \\
\hline CHEMBL1338723 & 688239 & 5.5862 & 5.3718 & TRN & \\
\hline CHEMBL1550605 & 688239 & 6.0862 & 5.6085 & TST & \\
\hline CHEMBL1426756 & 688239 & 5.3362 & 5.4309 & TST & \\
\hline CHEMBL1527296 & 688239 & 6.7862 & 5.5613 & TST & \\
\hline CHEMBL1573904 & 688239 & 5.1862 & 5.6721 & TRN & \\
\hline CHEMBL1368071 & 688239 & 6.0862 & 5.5457 & TRN & \\
\hline CHEMBL1496780 & 688239 & 4.8862 & 5.2688 & TRN & \\
\hline CHEMBL3190597 & 688239 & 5.6362 & \multicolumn{2}{|c|}{5.497999999999999} & \\
\hline CHEMBL1577252 & 688239 & 5.6362 & 5.5015 & TRN & \\
\hline CHEMBL1398735 & 688239 & 5.3862 & 5.4324 & TRN & \\
\hline CHEMBL1482461 & 688239 & 5.1862 & 5.6681 & TRN & \\
\hline CHEMBL1383072 & 688239 & 4.5862 & 5.6529 & TRN & \\
\hline CHEMBL1490037 & 688239 & 5.5862 & 5.5909 & TST & \\
\hline CHEMBL1501883 & 688239 & 5.3862 & 5.5097 & TRN & \\
\hline CHEMBL1496147 & 688239 & 5.5362 & 5.4516 & TST & \\
\hline CHEMBL1585276 & 688239 & 4.5362 & 5.428 & TRN & \\
\hline CHEMBL1269809 & 688239 & 4.5362 & 5.5337 & TST & \\
\hline CHEMBL1446984 & 688239 & 8.28399 & \multicolumn{2}{|c|}{9999999999} & \\
\hline CHEMBL1341623 & 688239 & 4.8862 & 5.5387 & TRN & \\
\hline CHEMBL1429880 & 688239 & 6.2362 & 5.5512 & TST & \\
\hline CHEMBL576438 & 688239 & 7.0362 & 5.6706 & TRN & \\
\hline CHEMBL1409260 & 688239 & 5.4862 & 5.6795 & TRN & \\
\hline CHEMBL1322297 & 688239 & 4.7862 & 5.4525 & TRN & \\
\hline CHEMBL1381049 & 688239 & 5.6362 & 5.6387 & TRN & \\
\hline CHEMBL1575042 & 688239 & 4.7362 & 5.495 & TRN & \\
\hline CHEMBL1539894 & 688239 & 5.1862 & 5.5215 & TST & \\
\hline CHEMBL1608513 & 688239 & 4.7862 & \multicolumn{2}{|c|}{5.4479999999999995} & \\
\hline CHEMBL1326163 & 688239 & 5.9362 & 5.4797 & TRN & \\
\hline CHEMBL1087584 & 688239 & 5.2862 & 5.4846 & TST & \\
\hline CHEMBL1419737 & 688239 & 5.5862 & 5.5078 & TRN & \\
\hline CHEMBL1522535 & 688239 & 4.4862 & 5.5292 & TRN & \\
\hline CHEMBL1568921 & 688239 & 7.6861 & 5.4458 & TST & \\
\hline CHEMBL1308306 & 688239 & 6.9363 & 5.6355 & TST & \\
\hline CHEMBL1437271 & 688239 & 7.2366 & 5.4187 & TRN & \\
\hline CHEMBL 3213156 & 688239 & 4.5862 & 5.4734 & TST & \\
\hline CHEMBL1532958 & 688239 & 5.8862 & 5.4602 & TRN & \\
\hline CHEMBL1326556 & 688239 & 6.0362 & 5.5063 & TRN & \\
\hline
\end{tabular}

Page 1091 
Supplemental Table S2.txt

\begin{tabular}{|c|c|c|c|c|c|}
\hline CHEMBL1548157 & 688239 & 5.6862 & 5.5331 & TRN & \\
\hline CHEMBL1605879 & 688239 & 6.8362 & 5.4851 & TRN & \\
\hline CHEMBL1542090 & 688239 & 5.7362 & 5.3736 & TRN & \\
\hline CHEMBL1387446 & 688239 & 6.2362 & 5.4472 & TRN & \\
\hline CHEMBL1335713 & 688239 & 6.9863 & 5.46299 & 9999999999 & TRN \\
\hline CHEMBL1403666 & 688239 & 4.7862 & 5.5683 & TRN & \\
\hline CHEMBL1374898 & 688239 & 4.4862 & 5.53 & TRN & \\
\hline CHEMBL1388628 & 688239 & 4.6362 & 5.5119 & TRN & \\
\hline CHEMBL1368996 & 688239 & 4.6862 & 5.5278 & TRN & \\
\hline CHEMBL1317452 & 688239 & 6.2862 & 5.5122 & TRN & \\
\hline CHEMBL1424398 & 688239 & 5.0862 & 5.4495 & TRN & \\
\hline CHEMBL1582234 & 688239 & 4.7362 & 5.3348 & TRN & \\
\hline CHEMBL1313270 & 688239 & 4.8362 & 5.5677 & TRN & \\
\hline CHEMBL1316386 & 688239 & 4.8362 & 5.5396 & TRN & \\
\hline CHEMBL1521503 & 688239 & 8.2366 & 5.4753 & TST & \\
\hline CHEMBL1585677 & 688239 & 6.4862 & 5.4725 & TST & \\
\hline CHEMBL1304095 & 688239 & 5.1862 & 5.6081 & TRN & \\
\hline CHEMBL1334160 & 688239 & 8.3372 & 5.5885 & TRN & \\
\hline CHEMBL1340654 & 688239 & 5.1362 & 5.4126 & TRN & \\
\hline CHEMBL1545888 & 688239 & 4.5862 & 5.5795 & TRN & \\
\hline CHEMBL1498688 & 688239 & 5.3862 & 5.3592 & TRN & \\
\hline CHEMBL1419801 & 688239 & 6.2362 & 5.5031 & TRN & \\
\hline CHEMBL1532889 & 688239 & 6.2862 & 5.4234 & TRN & \\
\hline CHEMBL1429891 & 688239 & 4.5862 & 5.4805 & TST & \\
\hline CHEMBL1418639 & 688239 & 5.1862 & 5.5453 & TRN & \\
\hline CHEMBL1487174 & 688239 & 4.4862 & 5.551 & TRN & \\
\hline CHEMBL1606743 & 688239 & 4.5362 & 5.3974 & TRN & \\
\hline CHEMBL1535252 & 688239 & 4.5362 & 5.3416 & TST & \\
\hline CHEMBL1321840 & 688239 & 7.0362 & 5.5554 & TST & \\
\hline CHEMBL1531986 & 688239 & 4.7862 & 5.5068 & TRN & \\
\hline CHEMBL1534864 & 688239 & 5.6862 & 5.6856 & TRN & \\
\hline CHEMBL1411857 & 688239 & 6.1362 & 5.3932 & TRN & \\
\hline CHEMBL1353187 & 688239 & 6.2362 & 5.5033 & TST & \\
\hline CHEMBL1468117 & 688239 & 5.1362 & 5.5249 & TRN & \\
\hline CHEMBL1585086 & 688239 & 5.8362 & 5.4275 & TRN & \\
\hline CHEMBL1472707 & 688239 & 4.5362 & 5.4977 & TRN & \\
\hline CHEMBL1537908 & 688239 & 4.5362 & 5.4332 & TRN & \\
\hline CHEMBL1562650 & 688239 & 5.4362 & 5.6469 & TRN & \\
\hline CHEMBL1324769 & 688239 & 4.6862 & 5.4481 & TRN & \\
\hline CHEMBL1385833 & 688239 & 4.5862 & 5.3694 & TST & \\
\hline CHEMBL1329020 & 688239 & 5.1862 & \multicolumn{2}{|c|}{5.462999999999999} & TST \\
\hline CHEMBL1495766 & 688239 & 5.8362 & 5.4239 & TRN & \\
\hline CHEMBL1326333 & 688239 & 4.7862 & 5.4464 & TRN & \\
\hline CHEMBL1581354 & 688239 & 5.1862 & 5.5047 & TRN & \\
\hline CHEMBL1530509 & 688239 & 5.7362 & 5.4486 & TRN & \\
\hline CHEMBL1571529 & 688239 & 6.8861 & 5.4034 & TST & \\
\hline CHEMBL1392771 & 688239 & 4.6862 & 5.5811 & TST & \\
\hline CHEMBL1376061 & 688239 & 5.6862 & 5.4721 & TST & \\
\hline
\end{tabular}


Supplemental Table S2.txt

\begin{tabular}{|c|c|c|c|c|}
\hline The & & & & \\
\hline & & .8862 & 5.7517 & \\
\hline 36 & & & & \\
\hline AEMBL15 & & & & S \\
\hline AEMBL1523644 & 8239 & 361 & 1606 & \\
\hline HEMBL1448001 & 88239 & 2366 & 064 & \\
\hline HEMBL1C & 239 & 861 & 574 & \\
\hline 2012 & & & & RN \\
\hline AEMBL1504182 & & 862 & 5025 & \\
\hline HEMBL1359809 & 88239 & 361 & 098 & \\
\hline AEMBL2C & 239 & 862 & 899 & \\
\hline IEMBL14 & 39 & 362 & 812 & \\
\hline AEMBL1: & & & & \\
\hline AEMBL16 & & 862 & 5207 & \\
\hline AEMBL14 & & 862 & 807 & \\
\hline AEMBL13 & 39 & 362 & 5886 & \\
\hline AEMBL1 & & 62 & 737 & \\
\hline HEMBL1: & & & & \\
\hline AEMBL13 & & 863 & 1778 & \\
\hline IEMBL16 & & 62 & & \\
\hline AEMBL: & & 52 & 29 & KIV \\
\hline AEMBLI & & & & 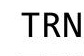 \\
\hline HEMBL5 & & 62 & & \\
\hline AEMBL1 & & & & \\
\hline AEMBL13 & & & & ( \\
\hline AEMBL1 & & 62 & & RIV \\
\hline AEMBL] & & & & ונס \\
\hline AFMBI 1 & & 62 & & \\
\hline HEMBL1 & & & & 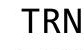 \\
\hline HEMBL 20 & & & & s \\
\hline HEMBL1 & & & 804 & RN \\
\hline HEMBLI & & & 37 & RN \\
\hline 337 & & & & RN \\
\hline HEMBL15 & & & & T \\
\hline HEMBL1339426 & & 362 & 5.4117 & TRN \\
\hline HEMBL1 & & 62 & 83 & RIN \\
\hline 1 & & & 95 & IRIN \\
\hline HEMBL1 & & & 777 & TRN \\
\hline HEMBL1508926 & 88239 & 862 & 727 & TST \\
\hline AEMBL14 & & 362 & 48 & $\Gamma \mathrm{RN}$ \\
\hline HEMBL1 & & 62 & 426 & \\
\hline HEMBL16 & & & 862 & TRN \\
\hline HEMBL16 & & 862 & 966 & RN \\
\hline AEMBL1359040 & 39 & 8662 & 5651 & TR \\
\hline MBL1 & & 62 & 5427 & $\mathrm{~N}$ \\
\hline HEMBL1: & & & .5383 & \\
\hline HEMBL 32 & & & 5.4273 & \\
\hline CHEMBL 2004956 & 688239 & 5.0862 & 5.4695 & RN \\
\hline
\end{tabular}

Page 1093 
Supplemental Table S2.txt

\begin{tabular}{|c|c|c|c|c|}
\hline CHEMBL1483350 & 688239 & 5.7862 & 5.5195 & TRN \\
\hline CHEMBL1503707 & 688239 & 4.5362 & 5.4528 & TRN \\
\hline CHEMBL1574750 & 688239 & 6.3362 & 5.7567 & TRN \\
\hline CHEMBL1530240 & 688239 & 7.1864 & 5.4315 & TRN \\
\hline CHEMBL1398994 & 688239 & 5.7362 & 5.4276 & TRN \\
\hline CHEMBL1359395 & 688239 & 4.9862 & 5.5464 & TST \\
\hline CHEMBL1471379 & 688239 & 5.4862 & 5.4888 & TST \\
\hline CHEMBL1466922 & 688239 & 5.1862 & 5.4038 & TRN \\
\hline CHEMBL1516505 & 688239 & 5.3362 & 5.6252 & TRN \\
\hline CHEMBL1371496 & 688239 & 5.6862 & 5.4831 & TRN \\
\hline CHEMBL1539293 & 688239 & 5.3362 & 5.6448 & TRN \\
\hline CHEMBL1442188 & 688239 & 4.5362 & 5.4414 & TRN \\
\hline CHEMBL1526969 & 688239 & 4.5362 & 5.4522 & TRN \\
\hline CHEMBL1474755 & 688239 & 5.6362 & 5.4982 & TRN \\
\hline CHEMBL3145282 & 688239 & 5.1362 & 5.3995 & TST \\
\hline CHEMBL1455093 & 688239 & 5.5862 & 5.5191 & TRN \\
\hline CHEMBL1511609 & 688239 & 5.1862 & 5.551 & TST \\
\hline CHEMBL1525657 & 688239 & 4.5362 & 5.3651 & TRN \\
\hline CHEMBL1363492 & 688239 & 5.8362 & 5.5691 & TRN \\
\hline CHEMBL1570952 & 688239 & 5.8362 & 5.5095 & TST \\
\hline CHEMBL1578967 & 688239 & 8.2366 & 5.4112 & TRN \\
\hline CHEMBL1324029 & 688239 & 6.2362 & 5.4436 & TRN \\
\hline CHEMBL1371367 & 688239 & 4.5362 & 5.5026 & TRN \\
\hline CHEMBL1370736 & 688239 & 5.9862 & 5.523 & TRN \\
\hline CHEMBL1493839 & 688239 & 4.6362 & 5.4997 & TST \\
\hline CHEMBL1414439 & 688239 & 4.9862 & 5.3518 & TRN \\
\hline CHEMBL1517849 & 688239 & 4.9862 & 5.5268 & TRN \\
\hline CHEMBL1578318 & 688239 & 5.1862 & 5.4038 & TRN \\
\hline CHEMBL1408398 & 688239 & 8.3872 & 5.5557 & TST \\
\hline CHEMBL1598573 & 688239 & 6.2862 & 5.5192 & TRN \\
\hline CHEMBL1568564 & 688239 & 6.2362 & 5.456 & TST \\
\hline CHEMBL1468181 & 688239 & 6.8861 & 5.5039 & TRN \\
\hline CHEMBL1309907 & 688239 & 4.5362 & 5.5219 & TRN \\
\hline CHEMBL1345347 & 688239 & 4.5362 & 5.4541 & TRN \\
\hline CHEMBL3194865 & 688239 & 5.0862 & 5.4951 & TST \\
\hline CHEMBL3213149 & 688239 & 5.1862 & 5.4984 & TRN \\
\hline CHEMBL1451642 & 688239 & 5.3862 & 5.4349 & TRN \\
\hline CHEMBL1530599 & 688239 & 4.5362 & 5.5585 & TST \\
\hline CHEMBL1453787 & 688239 & 5.1862 & 5.5558 & TRN \\
\hline CHEMBL1599540 & 688239 & 4.8862 & 5.3861 & TRN \\
\hline CHEMBL1499175 & 688239 & 5.1862 & 5.3049 & TST \\
\hline CHEMBL1495615 & 688239 & 5.3362 & 5.4607 & TRN \\
\hline CHEMBL1351068 & 688239 & 4.5362 & 5.452999 & 9999999999 \\
\hline CHEMBL1449992 & 688239 & 4.7862 & 5.5461 & TRN \\
\hline CHEMBL1406497 & 688239 & 5.0362 & 5.49 & TRN \\
\hline CHEMBL1598703 & 688239 & 5.6362 & 5.4658 & TRN \\
\hline CHEMBL1329280 & 688239 & 7.0362 & 5.4771 & TRN \\
\hline CHEMBL1605943 & 688239 & 4.5862 & 5.4904 & TRN \\
\hline
\end{tabular}


Supplemental Table S2.txt

\begin{tabular}{|c|c|c|c|c|c|}
\hline CHEMBL1475427 & 688239 & 5.1862 & 5.443 & TST & \\
\hline CHEMBL1543115 & 688239 & 6.1362 & 5.5302 & TST & \\
\hline CHEMBL1517652 & 688239 & 5.7862 & 5.4984 & TST & \\
\hline CHEMBL1321850 & 688239 & 4.5362 & 5.49 & TRN & \\
\hline CHEMBL1338510 & 688239 & 6.2362 & 5.447 & TRN & \\
\hline CHEMBL1407702 & 688239 & 5.5362 & 5.3623 & TST & \\
\hline CHEMBL1567256 & 688239 & 4.7862 & 5.4492 & TRN & \\
\hline CHEMBL1989158 & 688239 & 4.7362 & 5.449 & TRN & \\
\hline CHEMBL1349137 & 688239 & 5.6862 & 5.5528 & TRN & \\
\hline CHEMBL1351459 & 688239 & 4.6862 & 5.4189 & TRN & \\
\hline CHEMBL1404679 & 688239 & 4.5362 & 5.5484 & TRN & \\
\hline CHEMBL1323152 & 688239 & 8.2366 & 5.5514 & TRN & \\
\hline CHEMBL1981229 & 688239 & 6.1862 & 5.415 & TRN & \\
\hline CHEMBL525888 & 688239 & 6.3863 & 5.4355 & TRN & \\
\hline CHEMBL3191332 & 688239 & 5.5362 & 5.5756 & TRN & \\
\hline CHEMBL1510271 & 688239 & 4.6862 & 5.411000 & 0000000005 & TRN \\
\hline CHEMBL1463733 & 688239 & 4.5362 & 5.4025 & TST & \\
\hline CHEMBL1417171 & 688239 & 5.4862 & 5.5637 & TRN & \\
\hline CHEMBL1413117 & 688239 & 5.2362 & 5.6183 & TRN & \\
\hline CHEMBL1531439 & 688239 & 5.6862 & 5.4786 & TST & \\
\hline CHEMBL1354046 & 688239 & 6.1862 & 5.5238 & TRN & \\
\hline CHEMBL1309858 & 688239 & 4.5362 & 5.4607 & TST & \\
\hline CHEMBL1386504 & 688239 & 4.7862 & 5.598 & TRN & \\
\hline CHEMBL1556088 & 688239 & 4.6862 & 5.6538 & TRN & \\
\hline CHEMBL1409172 & 688239 & 4.5362 & 5.5552 & TRN & \\
\hline CHEMBL1469160 & 688239 & \multicolumn{3}{|c|}{8.283999999999999} & TST \\
\hline CHEMBL 1428615 & 688239 & 5.9362 & 5.5706 & TRN & \\
\hline CHEMBL1413816 & 688239 & 4.4862 & 5.3386 & TRN & \\
\hline CHEMBL1516716 & 688239 & 4.7362 & 5.4551 & TRN & \\
\hline CHEMBL1574708 & 688239 & 5.1862 & 5.5055 & TRN & \\
\hline CHEMBL1535134 & 688239 & 5.7362 & 5.4913 & TRN & \\
\hline CHEMBL1388927 & 688239 & 4.6862 & 5.4788 & TRN & \\
\hline CHEMBL1428599 & 688239 & 8.1871 & 5.3901 & TST & \\
\hline CHEMBL1420916 & 688239 & 4.7362 & 5.5027 & TRN & \\
\hline CHEMBL1332530 & 688239 & 6.8861 & 5.3861 & TRN & \\
\hline CHEMBL1333194 & 688239 & 6.1862 & 5.4063 & TRN & \\
\hline CHEMBL1594956 & 688239 & 8.28399 & 99999999 & 5.4818 & בי \\
\hline CHEMBL1349842 & 688239 & 4.6362 & 5.563 & TRN & \\
\hline CHEMBL1335421 & 688239 & 4.5362 & 5.4984 & TRN & \\
\hline CHEMBL1436960 & 688239 & 4.7862 & 5.6012 & TRN & \\
\hline CHEMBL1430102 & 688239 & 4.5362 & 5.6064 & TRN & \\
\hline CHEMBL3212498 & 688239 & 7.2865 & 5.4999 & TRN & \\
\hline CHEMBL1540003 & 688239 & 6.1862 & 5.6442 & TST & \\
\hline CHEMBL1363591 & 688239 & 7.9872 & 5.6563 & TRN & \\
\hline CHEMBL1548725 & 688239 & 8.3372 & 5.5782 & TST & \\
\hline CHEMBL1423702 & 688239 & 5.6362 & 5.5444 & TRN & \\
\hline CHEMBL1334764 & 688239 & 4.7862 & 5.3957 & TST & \\
\hline CHEMBL1449150 & 688239 & 4.7362 & 5.3651 & TST & \\
\hline
\end{tabular}


Supplemental Table S2.txt

\begin{tabular}{|c|c|c|c|c|}
\hline CHEMBL1491165 & 688239 & 4.5362 & 5.3988 & TST \\
\hline CHEMBL1566534 & 688239 & 4.7362 & 5.4992 & TST \\
\hline CHEMBL1555242 & 688239 & 4.6362 & 5.4286 & TRN \\
\hline CHEMBL1534944 & 688239 & 6.2362 & 5.3335 & TRN \\
\hline CHEMBL1417699 & 688239 & 5.2362 & 5.4847 & TRN \\
\hline CHEMBL1334113 & 688239 & 6.2862 & 5.6146 & TRN \\
\hline CHEMBL1342468 & 688239 & 6.2362 & 5.326006 & 00000000005 \\
\hline CHEMBL3194646 & 688239 & 5.1862 & 5.4865 & TST \\
\hline CHEMBL1332838 & 688239 & 5.1862 & 5.5072 & TST \\
\hline CHEMBL1304624 & 688239 & 4.6862 & 5.3712 & TRN \\
\hline CHEMBL1306422 & 688239 & 5.1362 & 5.5029 & TST \\
\hline CHEMBL1455067 & 688239 & 5.3362 & 5.4185 & TST \\
\hline CHEMBL2369175 & 688239 & 4.6362 & 5.436 & TST \\
\hline CHEMBL1584637 & 688239 & 5.6862 & 5.5991 & TRN \\
\hline CHEMBL3190167 & 688239 & 4.9862 & 5.5578 & TRN \\
\hline CHEMBL1592906 & 688239 & 6.9363 & 5.5143 & TRN \\
\hline CHEMBL1347497 & 688239 & 4.6362 & 5.3216 & TST \\
\hline CHEMBL1310725 & 688239 & 5.1862 & 5.5511 & TST \\
\hline CHEMBL1360951 & 688239 & 6.3362 & 5.6273 & TST \\
\hline CHEMBL1489709 & 688239 & 5.9362 & 5.3483 & TRN \\
\hline CHEMBL1511035 & 688239 & 6.6362 & 5.5512 & TRN \\
\hline CHEMBL1481754 & 688239 & 4.5362 & 5.4442 & TST \\
\hline CHEMBL1408136 & 688239 & 4.5362 & 5.3942 & TRN \\
\hline CHEMBL1341170 & 688239 & 6.7862 & 5.425 & TRN \\
\hline CHEMBL1415497 & 688239 & 4.5362 & 5.4972 & TRN \\
\hline CHEMBL1323527 & 688239 & 6.3362 & 5.7103 & TRN \\
\hline CHEMBL1392903 & 688239 & 6.2862 & 5.5195 & TRN \\
\hline CHEMBL1446421 & 688239 & 6.0362 & 5.5311 & TRN \\
\hline CHEMBL1300801 & 688239 & 8.3372 & 5.4797 & TRN \\
\hline CHEMBL1610328 & 688239 & 7.5867 & 5.5498 & TRN \\
\hline CHEMBL1306358 & 688239 & 4.5362 & 5.4244 & TRN \\
\hline CHEMBL1423412 & 688239 & 4.5362 & 5.2653 & TRN \\
\hline CHEMBL1299587 & 688239 & 4.5362 & 5.6244 & TRN \\
\hline CHEMBL1418870 & 688239 & 4.5362 & 5.2093 & TRN \\
\hline CHEMBL1391901 & 688239 & 5.6862 & 5.506 & TRN \\
\hline CHEMBL1391488 & 688239 & 4.5362 & 5.2884 & TRN \\
\hline CHEMBL1544779 & 688239 & 4.5362 & 5.5846 & TRN \\
\hline CHEMBL1367662 & 688239 & 4.6362 & 5.5019 & TRN \\
\hline CHEMBL1479623 & 688239 & 4.5362 & 5.6503 & TRN \\
\hline CHEMBL1417650 & 688239 & 4.5362 & 5.3472 & TRN \\
\hline CHEMBL1601759 & 688239 & 5.3362 & 5.3516 & TRN \\
\hline CHEMBL1354674 & 688239 & 6.1362 & 5.3767 & TST \\
\hline CHEMBL118595 & 688239 & 4.7862 & 5.4165 & TRN \\
\hline CHEMBL1481440 & 688239 & 6.9363 & 5.6061 & TRN \\
\hline CHEMBL1441811 & 688239 & 5.7862 & 5.4324 & TRN \\
\hline CHEMBL1542652 & 688239 & 7.0862 & 5.43 & TST \\
\hline CHEMBL1307195 & 688239 & 5.6862 & 5.6302 & TRN \\
\hline CHEMBL3199168 & 688239 & 4.6862 & 5.3308 & TRN \\
\hline
\end{tabular}


Supplemental Table S2.txt

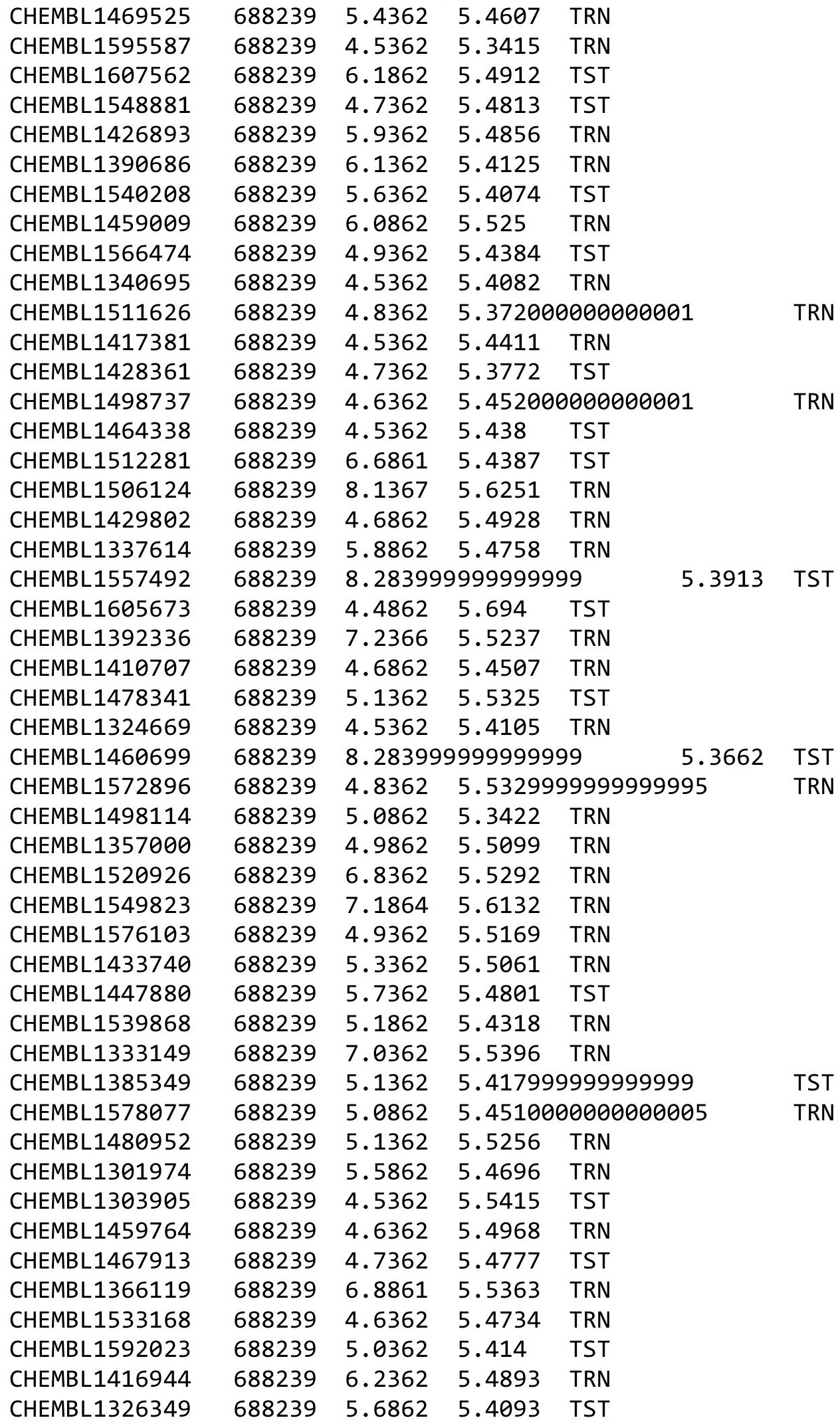

Page 1097 
Supplemental Table S2.txt

\begin{tabular}{|c|c|c|c|c|}
\hline CHEMBL1575299 & 688239 & 5.0362 & 5.5301 & TRN \\
\hline CHEMBL3194455 & 688239 & 4.5362 & 5.4315 & TRN \\
\hline CHEMBL1518757 & 688239 & 6.2362 & 5.4619 & TRN \\
\hline CHEMBL1383439 & 688239 & 5.1362 & 5.4501 & TRN \\
\hline CHEMBL1344822 & 688239 & 4.6362 & 5.6756 & TRN \\
\hline CHEMBL1495478 & 688239 & 4.5362 & 5.4406 & TRN \\
\hline CHEMBL1565444 & 688239 & 4.6362 & 5.4421 & TRN \\
\hline CHEMBL1370369 & 688239 & 6.7361 & 5.5333 & TST \\
\hline CHEMBL1460210 & 688239 & 5.1862 & 5.4226 & TRN \\
\hline CHEMBL3211050 & 688239 & 4.7862 & 5.4334 & TRN \\
\hline CHEMBL1337839 & 688239 & 4.7862 & 5.55 & TST \\
\hline CHEMBL1389040 & 688239 & 5.1862 & 5.2804 & TRN \\
\hline CHEMBL1338313 & 688239 & 4.5362 & 5.5239 & TRN \\
\hline CHEMBL3196378 & 688239 & 6.8861 & 5.4838 & TRN \\
\hline CHEMBL1548364 & 688239 & 4.7362 & 5.4756 & TST \\
\hline CHEMBL1543286 & 688239 & 5.1862 & 5.4767 & TRN \\
\hline CHEMBL1506301 & 688239 & 4.5362 & 5.2629 & TRN \\
\hline CHEMBL3212755 & 688239 & 5.8362 & 5.4818 & TRN \\
\hline CHEMBL1429921 & 688239 & 5.2862 & 5.4978 & TRN \\
\hline CHEMBL1349346 & 688239 & 4.5362 & 5.4831 & TST \\
\hline CHEMBL1325908 & 688239 & 4.5362 & 5.2534 & TRN \\
\hline CHEMBL1438779 & 688239 & 5.3862 & 5.5842 & TST \\
\hline CHEMBL3211279 & 688239 & 4.9362 & 5.416 & TST \\
\hline CHEMBL1328282 & 688239 & 6.1362 & 5.4757 & TST \\
\hline CHEMBL1311639 & 688239 & 5.3862 & 5.4802 & TRN \\
\hline CHEMBL1348259 & 688239 & 4.5362 & 5.5027 & TRN \\
\hline CHEMBL1508508 & 688239 & 5.1362 & 5.5946 & TRN \\
\hline CHEMBL3209336 & 688239 & 5.0362 & 5.4909 & TRN \\
\hline CHEMBL1526986 & 688239 & 5.6362 & 5.4548 & TRN \\
\hline CHEMBL1488191 & 688239 & 8.1367 & 5.4751 & TST \\
\hline CHEMBL1530018 & 688239 & 4.6862 & 5.3851 & TRN \\
\hline CHEMBL1363687 & 688239 & 4.7862 & 5.4716 & TRN \\
\hline CHEMBL1466754 & 688239 & 6.8861 & 5.4119 & TST \\
\hline CHEMBL1443770 & 688239 & 5.3362 & 5.3878 & TRN \\
\hline CHEMBL1443921 & 688239 & 4.6362 & 5.5111 & TRN \\
\hline CHEMBL1091933 & 688239 & 6.8861 & 5.3729 & TRN \\
\hline CHEMBL1547828 & 688239 & 8.3372 & 5.4841 & TST \\
\hline CHEMBL1577039 & 688239 & 5.6362 & 5.4585 & TRN \\
\hline CHEMBL1569081 & 688239 & 5.0862 & 5.547999 & 9999999999 \\
\hline CHEMBL1452829 & 688239 & 4.5362 & 5.4601 & TRN \\
\hline CHEMBL1484697 & 688239 & 5.2362 & 5.5598 & TRN \\
\hline CHEMBL1508223 & 688239 & 5.1862 & 5.4901 & TRN \\
\hline CHEMBL1586996 & 688239 & 4.7362 & 5.5825 & TRN \\
\hline CHEMBL1538304 & 688239 & 4.5362 & 5.5981 & TRN \\
\hline CHEMBL3198131 & 688239 & 4.4862 & 5.4942 & TRN \\
\hline CHEMBL1330667 & 688239 & 4.7862 & 5.5227 & TRN \\
\hline CHEMBL1389476 & 688239 & 5.6362 & 5.468 & TRN \\
\hline CHEMBL1394546 & 688239 & 5.5362 & 5.4206 & TRN \\
\hline
\end{tabular}


Supplemental Table S2.txt

\begin{tabular}{|c|c|c|c|c|c|}
\hline CHEMBL1308701 & 688239 & 4.8862 & 5.4413 & TST & \\
\hline CHEMBL1563677 & 688239 & 5.1362 & 5.4235 & TRN & \\
\hline CHEMBL1384456 & 688239 & 4.8862 & 5.6062 & TRN & \\
\hline CHEMBL1575681 & 688239 & 5.1862 & 5.5477 & TRN & \\
\hline CHEMBL1444791 & 688239 & 5.0362 & 5.3793 & TST & \\
\hline CHEMBL1487357 & 688239 & 5.1862 & 5.5096 & TRN & \\
\hline CHEMBL1444408 & 688239 & 5.0362 & 5.4264 & TST & \\
\hline CHEMBL1611514 & 688239 & 5.1862 & 5.5475 & TRN & \\
\hline CHEMBL1503588 & 688239 & 4.5362 & 5.5197 & TST & \\
\hline CHEMBL1350470 & 688239 & 5.5362 & 5.4649 & TRN & \\
\hline CHEMBL1459465 & 688239 & 4.7862 & 5.4329 & TST & \\
\hline CHEMBL1405281 & 688239 & 4.9862 & 5.3406 & TRN & \\
\hline CHEMBL1572983 & 688239 & 4.7362 & 5.4631 & TST & \\
\hline CHEMBL 2373579 & 688239 & 5.1862 & 5.5321 & TRN & \\
\hline CHEMBL1583327 & 688239 & 4.5362 & 5.3426 & TRN & \\
\hline CHEMBL3195402 & 688239 & 6.8362 & 5.484 & TST & \\
\hline CHEMBL1575939 & 688239 & 4.5362 & 5.63700 & 00000000005 & TRN \\
\hline CHEMBL1542229 & 688239 & 4.6362 & 5.4823 & TST & \\
\hline CHEMBL1612225 & 688239 & 5.4862 & 5.6175 & TRN & \\
\hline CHEMBL1313211 & 688239 & 4.5362 & 5.2811 & TRN & \\
\hline CHEMBL1311804 & 688239 & 4.7362 & 5.4232 & TRN & \\
\hline CHEMBL1401641 & 688239 & 6.6861 & 5.4309 & TRN & \\
\hline CHEMBL1604532 & 688239 & 4.7862 & 5.6027 & TST & \\
\hline CHEMBL1556580 & 688239 & 4.7862 & 5.45 & TRN & \\
\hline CHEMBL3191875 & 688239 & 4.9862 & 5.4237 & TRN & \\
\hline CHEMBL1455993 & 688239 & 4.5362 & 5.4864 & TRN & \\
\hline CHEMBL1333830 & 688239 & 6.1362 & 5.6255 & TST & \\
\hline CHEMBL1453368 & 688239 & 4.8862 & 5.5264 & TST & \\
\hline CHEMBL1492564 & 688239 & 4.9862 & 5.4613 & TRN & \\
\hline CHEMBL1324898 & 688239 & 4.5362 & 5.6372 & TRN & \\
\hline CHEMBL1465084 & 688239 & 4.4862 & 5.5388 & TRN & \\
\hline CHEMBL1446141 & 688239 & 4.8362 & 5.4219 & TRN & \\
\hline CHEMBL1382232 & 688239 & 4.6862 & 5.4746 & TRN & \\
\hline CHEMBL1605323 & 688239 & 6.9363 & 5.6286 & TRN & \\
\hline CHEMBL1551667 & 688239 & 5.2362 & 5.4906 & TRN & \\
\hline CHEMBL1401509 & 688239 & 6.5862 & 5.5988 & TRN & \\
\hline CHEMBL1412040 & 688239 & 4.5362 & 5.4448 & TRN & \\
\hline CHEMBL1437333 & 688239 & 4.5362 & 5.449 & TST & \\
\hline CHEMBL1360660 & 688239 & 5.3862 & 5.5292 & TRN & \\
\hline CHEMBL1317782 & 688239 & 6.7361 & 5.4778 & TRN & \\
\hline CHEMBL1459907 & 688239 & 5.5362 & 5.3278 & TRN & \\
\hline CHEMBL3195057 & 688239 & 4.7362 & 5.6135 & TRN & \\
\hline CHEMBL1539903 & 688239 & 5.6362 & 5.4818 & TRN & \\
\hline CHEMBL1999595 & 688239 & 4.6862 & 5.3959 & TRN & \\
\hline CHEMBL1308943 & 688239 & 6.1362 & 5.4619 & TST & \\
\hline CHEMBL1466554 & 688239 & 4.5362 & 5.5287 & TST & \\
\hline CHEMBL1380268 & 688239 & 6.2862 & 5.4392 & TRN & \\
\hline CHEMBL1462245 & 688239 & 5.6362 & 5.4382 & TST & \\
\hline
\end{tabular}


Supplemental Table S2.txt

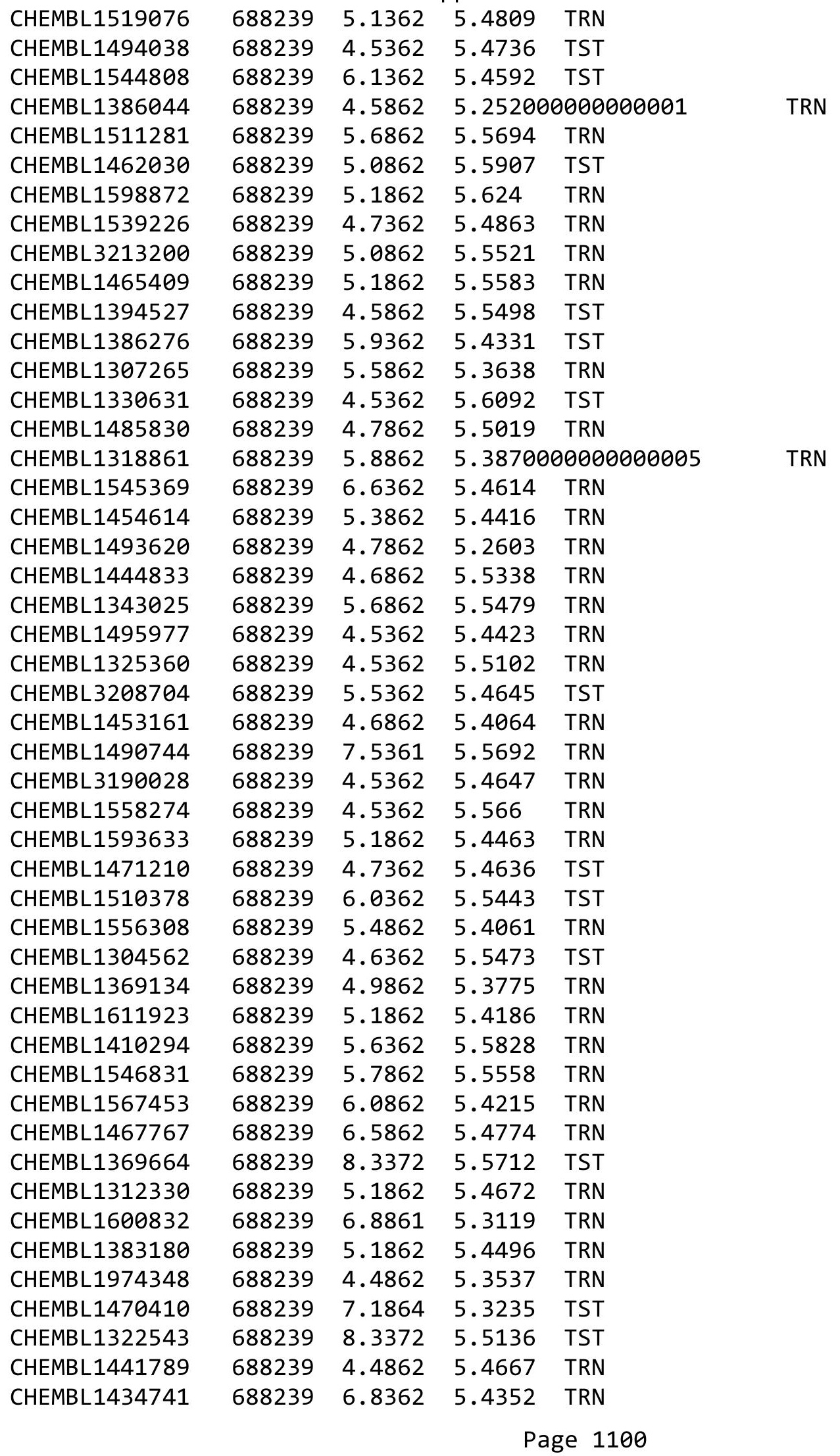




\begin{tabular}{|c|c|c|c|c|c|}
\hline & & & & & \\
\hline CHEMBL1532457 & 688239 & 7.3363 & 5.5498 & TST & \\
\hline CHEMBL1536540 & 688239 & 5.2362 & 5.5637 & TRN & \\
\hline CHEMBL1540699 & 688239 & 6.4362 & 5.637006 & 00000000005 & TRN \\
\hline CHEMBL1424053 & 688239 & 5.7862 & 5.4998 & TRN & \\
\hline CHEMBL3198188 & 688239 & 4.8362 & 5.5702 & TRN & \\
\hline CHEMBL1376493 & 688239 & 5.1862 & 5.524 & TRN & \\
\hline CHEMBL1495411 & 688239 & 4.5362 & 5.54899 & 99999999995 & TRN \\
\hline CHEMBL1374741 & 688239 & 4.7362 & 5.5925 & TRN & \\
\hline CHEMBL1345859 & 688239 & 5.3862 & 5.4354 & TRN & \\
\hline CHEMBL3213800 & 688239 & 5.6862 & 5.4647 & TRN & \\
\hline CHEMBL1432613 & 688239 & 4.6362 & 5.3703 & TRN & \\
\hline CHEMBL1574852 & 688239 & 4.6862 & 5.5035 & TRN & \\
\hline CHEMBL1505958 & 688239 & 4.8362 & 5.5494 & TST & \\
\hline CHEMBL3191813 & 688239 & 4.5362 & 5.611006 & 0000000001 & TRN \\
\hline CHEMBL1479130 & 688239 & 4.5862 & 5.5927 & TRN & \\
\hline CHEMBL1384034 & 688239 & 4.4862 & 5.5063 & TST & \\
\hline CHEMBL1489338 & 688239 & 4.6862 & 5.4807 & TST & \\
\hline CHEMBL1536486 & 688239 & 4.8362 & 5.5767 & TRN & \\
\hline CHEMBL1535181 & 688239 & 7.5361 & 5.5191 & TRN & \\
\hline CHEMBL1439330 & 688239 & 4.5362 & 5.3982 & TRN & \\
\hline CHEMBL1518003 & 688239 & 6.5862 & 5.5133 & TRN & \\
\hline CHEMBL1458307 & 688239 & 5.5862 & 5.3277 & TST & \\
\hline CHEMBL1525259 & 688239 & 4.5862 & 5.3938 & TST & \\
\hline CHEMBL3197447 & 688239 & 5.1362 & 5.4977 & TRN & \\
\hline CHEMBL3198869 & 688239 & 6.6861 & 5.3584 & TRN & \\
\hline CHEMBL1494295 & 688239 & 4.9362 & 5.3763 & TST & \\
\hline CHEMBL1316295 & 688239 & 5.1862 & 5.5335 & TST & \\
\hline CHEMBL1609640 & 688239 & 5.1362 & 5.2485 & TRN & \\
\hline CHEMBL1561304 & 688239 & 4.5362 & 5.3267 & TRN & \\
\hline CHEMBL1366478 & 688239 & 4.7862 & 5.6061 & TRN & \\
\hline CHEMBL1497960 & 688239 & 5.7862 & 5.5183 & TRN & \\
\hline CHEMBL1488716 & 688239 & 5.1862 & 5.5719 & TRN & \\
\hline CHEMBL1578763 & 688239 & 5.1362 & 5.4603 & TST & \\
\hline CHEMBL1396258 & 688239 & 4.7362 & 5.4174 & TRN & \\
\hline CHEMBL1526154 & 688239 & 4.9362 & 5.55399 & 9999999999 & TRN \\
\hline CHEMBL1497292 & 688239 & 4.9362 & 5.5328 & TRN & \\
\hline CHEMBL1300449 & 688239 & 5.1862 & 5.4857 & TRN & \\
\hline CHEMBL1613379 & 688239 & 6.6861 & 5.6062 & TRN & \\
\hline CHEMBL1306236 & 688239 & 5.6862 & 5.5097 & TST & \\
\hline CHEMBL1538305 & 688239 & 5.3362 & 5.4059 & TRN & \\
\hline CHEMBL1597254 & 688239 & 5.1362 & 5.5876 & TRN & \\
\hline CHEMBL1435673 & 688239 & 6.2362 & 5.5297 & TRN & \\
\hline CHEMBL512761 & 688239 & 4.7362 & 5.5615 & TST & \\
\hline CHEMBL 3207660 & 688239 & 6.1362 & 5.4384 & TRN & \\
\hline CHEMBL1454908 & 688239 & 6.9863 & 5.4759 & TRN & \\
\hline CHEMBL1367909 & 688239 & 6.8362 & 5.7203 & TRN & \\
\hline CHEMBL1567561 & 688239 & 5.2362 & 5.6654 & TRN & \\
\hline CHEMBL1494476 & 688239 & 6.1362 & 5.5377 & TST & \\
\hline
\end{tabular}


Supplemental Table S2.txt

\begin{tabular}{|c|c|c|c|c|}
\hline CHEMBL1441516 & 688239 & 5.3862 & 5.513 & TRN \\
\hline CHEMBL1583607 & 688239 & 5.9862 & 5.5652 & TRN \\
\hline CHEMBL1428556 & 688239 & 4.5362 & 5.6517 & TRN \\
\hline CHEMBL1391399 & 688239 & 4.5362 & 5.4153 & TRN \\
\hline CHEMBL1455120 & 688239 & 6.1362 & 5.4532 & TRN \\
\hline CHEMBL1375472 & 688239 & 4.5362 & 5.4461 & TRN \\
\hline CHEMBL1503472 & 688239 & 5.0362 & 5.5844 & TRN \\
\hline CHEMBL1380320 & 688239 & 4.5362 & 5.4692 & TST \\
\hline CHEMBL1607794 & 688239 & 8.28399 & 99999999 & 5.5851 \\
\hline CHEMBL1387967 & 688239 & 4.4862 & 5.4622 & TRN \\
\hline CHEMBL1428414 & 688239 & 4.5862 & 5.6333 & TRN \\
\hline CHEMBL1414104 & 688239 & 6.6861 & 5.4666 & TRN \\
\hline CHEMBL1533972 & 688239 & 4.7862 & 5.552006 & 0000000005 \\
\hline CHEMBL1440434 & 688239 & 5.1862 & 5.4656 & TST \\
\hline CHEMBL1484338 & 688239 & 4.5862 & 5.4997 & TRN \\
\hline CHEMBL1597917 & 688239 & 5.8362 & 5.4626 & TST \\
\hline CHEMBL1605145 & 688239 & 5.2362 & 5.3426 & TST \\
\hline CHEMBL 2385805 & 688239 & 5.2362 & 5.5337 & TRN \\
\hline CHEMBL1385339 & 688239 & 4.6362 & 5.4551 & TRN \\
\hline CHEMBL1371591 & 688239 & 5.4862 & 5.5214 & TST \\
\hline CHEMBL1608649 & 688239 & 6.1862 & 5.4424 & TST \\
\hline CHEMBL1329976 & 688239 & 4.5362 & 5.3142 & TRN \\
\hline CHEMBL1520654 & 688239 & 5.1862 & 5.5153 & TRN \\
\hline CHEMBL1314860 & 688239 & 6.2362 & 5.5118 & TRN \\
\hline CHEMBL1544485 & 688239 & 4.8862 & 5.5208 & TRN \\
\hline CHEMBL1604916 & 688239 & 6.8362 & 5.4965 & TRN \\
\hline CHEMBL1482378 & 688239 & 6.8362 & 5.6405 & TRN \\
\hline CHEMBL1358500 & 688239 & 5.4362 & 5.4205 & TRN \\
\hline CHEMBL1523395 & 688239 & 5.6862 & 5.5574 & TRN \\
\hline CHEMBL1359821 & 688239 & 6.8861 & 5.4356 & TRN \\
\hline CHEMBL1306052 & 688239 & 4.7862 & 5.5854 & TRN \\
\hline CHEMBL1435424 & 688239 & 6.1362 & 5.4431 & TST \\
\hline CHEMBL1545465 & 688239 & 4.5362 & 5.5556 & TRN \\
\hline CHEMBL1982945 & 688239 & 6.7862 & 5.3281 & TRN \\
\hline CHEMBL1366979 & 688239 & 4.6862 & 5.2996 & TRN \\
\hline CHEMBL1386000 & 688239 & 4.5362 & 5.5138 & TRN \\
\hline CHEMBL1984298 & 688239 & 4.5362 & 5.3242 & TRN \\
\hline CHEMBL1465626 & 688239 & 5.7862 & 5.4904 & TRN \\
\hline CHEMBL1537156 & 688239 & 4.45 & 5.465 & TRN \\
\hline CHEMBL1599304 & 688239 & 5.3362 & 5.4226 & TST \\
\hline CHEMBL1500404 & 688239 & 4.6362 & 5.4436 & TRN \\
\hline CHEMBL1310522 & 688239 & 4.5362 & 5.5111 & TRN \\
\hline CHEMBL1549819 & 688239 & 4.5362 & 5.4762 & TRN \\
\hline CHEMBL1529464 & 688239 & 4.4862 & 5.4733 & TST \\
\hline CHEMBL1416463 & 688239 & 4.7362 & 5.4346 & TRN \\
\hline CHEMBL1492482 & 688239 & 8.3372 & 5.6128 & TRN \\
\hline CHEMBL1468494 & 688239 & 4.5362 & 5.4547 & TRN \\
\hline CHEMBL1391542 & 688239 & 5.9362 & 5.3435 & TST \\
\hline
\end{tabular}

Page 1102 
Supplemental Table S2.txt

\begin{tabular}{|c|c|c|c|c|}
\hline CHEMBL1509598 & 688239 & 4.6862 & 5.5836 & TRN \\
\hline CHEMBL1452179 & 688239 & 5.3862 & 5.5009 & TRN \\
\hline CHEMBL1487304 & 688239 & 5.5362 & 5.4654 & TST \\
\hline CHEMBL1350670 & 688239 & 5.4862 & 5.4676 & TRN \\
\hline CHEMBL3210626 & 688239 & 6.9363 & 5.4389 & TST \\
\hline CHEMBL1507373 & 688239 & 5.9862 & 5.4728 & TRN \\
\hline CHEMBL1601369 & 688239 & 6.8362 & 5.465 & TRN \\
\hline CHEMBL1610957 & 688239 & 6.7862 & 5.6012 & TST \\
\hline CHEMBL1367267 & 688239 & 5.2362 & 5.4929 & TRN \\
\hline CHEMBL1431134 & 688239 & 4.6862 & 5.5221 & TRN \\
\hline CHEMBL1515749 & 688239 & 4.6862 & 5.4315 & TRN \\
\hline CHEMBL1345389 & 688239 & 5.1862 & 5.4368 & TST \\
\hline CHEMBL1480178 & 688239 & 4.5862 & 5.4608 & TST \\
\hline CHEMBL1331774 & 688239 & 4.6362 & 5.5135 & TRN \\
\hline CHEMBL1556369 & 688239 & 5.1862 & 5.4929 & TRN \\
\hline CHEMBL1408178 & 688239 & 4.5362 & 5.2538 & TRN \\
\hline CHEMBL1425806 & 688239 & 5.3862 & 5.3925 & TRN \\
\hline CHEMBL1556775 & 688239 & 6.0862 & 5.4218 & TRN \\
\hline CHEMBL1406290 & 688239 & 6.9363 & 5.556 & TRN \\
\hline CHEMBL1611158 & 688239 & 5.0862 & 5.4167 & TRN \\
\hline CHEMBL1586726 & 688239 & 8.3372 & 5.5831 & TST \\
\hline CHEMBL1354490 & 688239 & 5.1862 & 5.4717 & TRN \\
\hline CHEMBL1456943 & 688239 & 6.5 & 5.5974 & TRN \\
\hline CHEMBL1528687 & 688239 & 5.2862 & 5.5821 & TRN \\
\hline CHEMBL1322740 & 688239 & 4.8362 & 5.5133 & TRN \\
\hline CHEMBL1458181 & 688239 & 4.6362 & 5.4686 & TRN \\
\hline CHEMBL1440447 & 688239 & 6.0362 & 5.5111 & TST \\
\hline CHEMBL1504763 & 688239 & 5.1362 & 5.5372 & TRN \\
\hline CHEMBL1488569 & 688239 & 6.7862 & 5.4417 & TST \\
\hline CHEMBL1576537 & 688239 & 5.1862 & 5.6401 & TRN \\
\hline CHEMBL1587074 & 688239 & 4.6862 & 5.5737 & TRN \\
\hline CHEMBL1312039 & 688239 & 4.9862 & 5.4643 & TRN \\
\hline CHEMBL1446699 & 688239 & 5.4362 & 5.4031 & TRN \\
\hline CHEMBL1342916 & 688239 & 4.5362 & 5.428999 & 7999999999 \\
\hline CHEMBL1461992 & 688239 & 5.8362 & 5.3191 & TRN \\
\hline CHEMBL1460979 & 688239 & 5.5362 & 5.5293 & TRN \\
\hline CHEMBL1545255 & 688239 & 5.9862 & 5.6128 & TRN \\
\hline CHEMBL1556659 & 688239 & 8.28399 & 99999999 & 5.3446 \\
\hline CHEMBL1380277 & 688239 & 5.1862 & 5.4917 & TRN \\
\hline CHEMBL1367778 & 688239 & 4.4862 & 5.6349 & TRN \\
\hline CHEMBL1383472 & 688239 & 4.4862 & 5.5635 & TRN \\
\hline CHEMBL1334050 & 688239 & 4.8862 & 5.2883 & TST \\
\hline CHEMBL1451403 & 688239 & 6.2862 & 5.3819 & TRN \\
\hline CHEMBL1403604 & 688239 & 6.1362 & 5.526 & TRN \\
\hline CHEMBL1499032 & 688239 & 4.7862 & 5.5875 & TST \\
\hline CHEMBL1509036 & 688239 & 4.5362 & 5.3995 & TRN \\
\hline CHEMBL1400064 & 688239 & 5.5862 & 5.4962 & TST \\
\hline CHEMBL1303516 & 688239 & 6.2862 & 5.484 & TST \\
\hline
\end{tabular}


Supplemental Table S2.txt

\begin{tabular}{|c|c|c|c|c|c|}
\hline CHEMBL1598685 & 688239 & 4.5362 & \multicolumn{2}{|c|}{5.547999999999999} & TRN \\
\hline CHEMBL1471592 & 688239 & 4.7862 & 5.49299 & 9999999999 & TST \\
\hline CHEMBL1322981 & 688239 & 4.5362 & 5.5194 & TRN & \\
\hline CHEMBL1561899 & 688239 & 5.2362 & 5.4744 & TRN & \\
\hline CHEMBL1301510 & 688239 & 6.5363 & 5.4376 & TRN & \\
\hline CHEMBL1319455 & 688239 & 4.7862 & 5.5422 & TRN & \\
\hline CHEMBL1491500 & 688239 & 7.0362 & 5.4916 & TRN & \\
\hline CHEMBL1336020 & 688239 & 8.3372 & 5.4645 & TRN & \\
\hline CHEMBL1540905 & 688239 & 5.1362 & 5.4665 & TST & \\
\hline CHEMBL1420111 & 688239 & 4.5362 & 5.599 & TRN & \\
\hline CHEMBL1580006 & 688239 & 6.3362 & 5.3814 & TRN & \\
\hline CHEMBL1350199 & 688239 & 4.9862 & 5.4961 & TRN & \\
\hline CHEMBL1467309 & 688239 & 4.5362 & 5.5212 & TST & \\
\hline CHEMBL1488829 & 688239 & 6.6362 & 5.3965 & TRN & \\
\hline CHEMBL1501066 & 688239 & 5.1862 & 5.5043 & TRN & \\
\hline CHEMBL1311422 & 688239 & 5.4362 & 5.5018 & TRN & \\
\hline CHEMBL1443897 & 688239 & 4.6362 & 5.6915 & TRN & \\
\hline CHEMBL1350203 & 688239 & 4.8862 & 5.4621 & TST & \\
\hline CHEMBL1500741 & 688239 & 4.5362 & 5.4511 & TRN & \\
\hline CHEMBL1612048 & 688239 & 4.5362 & 5.5086 & TST & \\
\hline CHEMBL1514914 & 688239 & 5.1862 & 5.3955 & TRN & \\
\hline CHEMBL1457188 & 688239 & 6.7862 & 5.6853 & TRN & \\
\hline CHEMBL1381838 & 688239 & 4.5362 & 5.4358 & TRN & \\
\hline CHEMBL1456434 & 688239 & 5.9362 & 5.6367 & TST & \\
\hline CHEMBL1536373 & 688239 & 5.5862 & 5.4547 & TST & \\
\hline CHEMBL1470399 & 688239 & 5.4862 & 5.5803 & TRN & \\
\hline CHEMBL1412352 & 688239 & 8.3372 & 5.5236 & TRN & \\
\hline CHEMBL1446577 & 688239 & 5.3362 & 5.6136 & TRN & \\
\hline CHEMBL1589429 & 688239 & 5.4362 & 5.5073 & TRN & \\
\hline CHEMBL1570745 & 688239 & 7.0362 & 5.4202 & TRN & \\
\hline CHEMBL1368168 & 688239 & 4.8862 & 5.3973 & TRN & \\
\hline CHEMBL1481614 & 688239 & 5.4362 & 5.4878 & TRN & \\
\hline CHEMBL1428760 & 688239 & 5.4862 & 5.2792 & TRN & \\
\hline CHEMBL1364126 & 688239 & 5.3362 & 5.5627 & TRN & \\
\hline CHEMBL1423259 & 688239 & 4.6362 & 5.5895 & TST & \\
\hline CHEMBL1505056 & 688239 & 5.1862 & 5.4956 & TRN & \\
\hline CHEMBL1313122 & 688239 & 5.7862 & 5.4804 & TRN & \\
\hline CHEMBL1421588 & 688239 & 2.7862 & 5.5071 & TRN & \\
\hline CHEMBL1575244 & 688239 & 8.2366 & 5.4917 & TST & \\
\hline CHEMBL1583761 & 688239 & 4.7362 & 5.4571 & TRN & \\
\hline CHEMBL1571773 & 688239 & 4.6862 & 5.48 & TST & \\
\hline CHEMBL1467199 & 688239 & 4.5362 & 5.5669 & TRN & \\
\hline CHEMBL1510695 & 688239 & 7.0362 & 5.5271 & TRN & \\
\hline CHEMBL1610551 & 688239 & 6.3362 & 5.5068 & TRN & \\
\hline CHEMBL3213812 & 688239 & 5.3362 & 5.3767 & TRN & \\
\hline CHEMBL1563680 & 688239 & 4.9362 & 5.5484 & TRN & \\
\hline CHEMBL1501266 & 688239 & 4.5362 & 5.6449 & TST & \\
\hline CHEMBL1365372 & 688239 & 5.1862 & 5.5514 & TST & \\
\hline
\end{tabular}


Supplemental Table S2.txt

\begin{tabular}{|c|c|c|c|c|c|}
\hline CHEMBL1503541 & 688239 & 5.2362 & 5.5163 & TRN & \\
\hline CHEMBL1404557 & 688239 & 5.1862 & 5.6647 & TRN & \\
\hline CHEMBL1552477 & 688239 & 5.5862 & 5.55 & TRN & \\
\hline CHEMBL1537943 & 688239 & 4.5362 & 5.5207 & TRN & \\
\hline CHEMBL1536108 & 688239 & 5.1862 & 5.4125 & TRN & \\
\hline CHEMBL1483399 & 688239 & 4.5362 & 5.4556 & TST & \\
\hline CHEMBL1493964 & 688239 & 5.1862 & 5.4066 & TRN & \\
\hline CHEMBL1548220 & 688239 & 5.5862 & 5.5936 & TRN & \\
\hline CHEMBL1444620 & 688239 & 5.2862 & 5.4641 & TRN & \\
\hline CHEMBL11608 & 688239 & 4.7362 & 5.4694 & TST & \\
\hline CHEMBL1384990 & 688239 & 4.5362 & 5.4327 & TST & \\
\hline CHEMBL1543799 & 688239 & 6.1362 & 5.3879 & TRN & \\
\hline CHEMBL1596883 & 688239 & 6.1862 & 5.57700 & 0000000001 & TST \\
\hline CHEMBL1336720 & 688239 & 4.4862 & 5.4431 & TST & \\
\hline CHEMBL1423745 & 688239 & 5.4862 & 5.4847 & TST & \\
\hline CHEMBL1516849 & 688239 & 4.9362 & 5.4776 & TRN & \\
\hline CHEMBL1558882 & 688239 & 4.5362 & 5.5187 & TRN & \\
\hline CHEMBL1372452 & 688239 & 5.8362 & 5.4708 & TST & \\
\hline CHEMBL1352687 & 688239 & 6.7361 & 5.5262 & TRN & \\
\hline CHEMBL1605108 & 688239 & 6.8362 & 5.4926 & TRN & \\
\hline CHEMBL1311600 & 688239 & 5.5862 & 5.3784 & TST & \\
\hline CHEMBL1596589 & 688239 & 4.4862 & 5.4158 & TRN & \\
\hline CHEMBL1547829 & 688239 & 4.8362 & 5.4311 & TRN & \\
\hline CHEMBL1576417 & 688239 & 5.5862 & 5.3965 & TST & \\
\hline CHEMBL1580821 & 688239 & 6.8362 & 5.5781 & TST & \\
\hline CHEMBL1476464 & 688239 & 4.6862 & 5.4979 & TRN & \\
\hline CHEMBL1479713 & 688239 & 5.7862 & 5.5117 & TRN & \\
\hline CHEMBL1387100 & 688239 & 4.6862 & 5.5178 & TRN & \\
\hline CHEMBL486541 & 688239 & 4.6862 & 5.3067 & TRN & \\
\hline CHEMBL1404060 & 688239 & 4.7862 & 5.2363 & TRN & \\
\hline CHEMBL1371414 & 688239 & 4.5362 & 5.3836 & TRN & \\
\hline CHEMBL1459475 & 688239 & 5.4362 & 5.4148 & TST & \\
\hline CHEMBL1541227 & 688239 & 6.0362 & 5.4995 & TST & \\
\hline CHEMBL1376355 & 688239 & 4.6862 & 5.485 & TRN & \\
\hline CHEMBL1486551 & 688239 & 5.8862 & 5.5431 & TRN & \\
\hline CHEMBL1506846 & 688239 & 5.4862 & 5.5265 & TRN & \\
\hline CHEMBL1385555 & 688239 & 6.4862 & 5.6138 & TRN & \\
\hline CHEMBL1314208 & 688239 & 4.6862 & 5.4934 & TRN & \\
\hline CHEMBL1473258 & 688239 & 5.3862 & 5.6388 & TRN & \\
\hline CHEMBL3196216 & 688239 & 4.5362 & 5.3334 & TRN & \\
\hline CHEMBL1357480 & 688239 & 5.4362 & 5.6057 & TRN & \\
\hline CHEMBL1414763 & 688239 & 6.3362 & 5.4162 & TST & \\
\hline CHEMBL1563020 & 688239 & 4.9362 & 5.4381 & TRN & \\
\hline CHEMBL1564305 & 688239 & 5.1862 & 5.3992 & TRN & \\
\hline CHEMBL1429778 & 688239 & 5.1862 & 5.5135 & TRN & \\
\hline CHEMBL1343991 & 688239 & 4.6862 & 5.4619 & TRN & \\
\hline CHEMBL 3213485 & 688239 & 4.9362 & 5.3448 & TRN & \\
\hline CHEMBL1538632 & 688239 & 4.5362 & 5.3725 & TST & \\
\hline
\end{tabular}


Supplemental Table S2.txt

\begin{tabular}{|c|c|c|c|c|c|}
\hline CHEMBL3208187 & 688239 & 6.4862 & 5.5191 & TST & \\
\hline CHEMBL1504469 & 688239 & 4.5362 & 5.3459 & TRN & \\
\hline CHEMBL1596326 & 688239 & 4.6862 & 5.3299 & TRN & \\
\hline CHEMBL1430878 & 688239 & 5.2362 & 5.5403 & TRN & \\
\hline CHEMBL1357022 & 688239 & 4.5362 & 5.5925 & TRN & \\
\hline CHEMBL1333397 & 688239 & 6.1862 & 5.3866 & TRN & \\
\hline CHEMBL1346444 & 688239 & 5.4362 & 5.721 & TRN & \\
\hline CHEMBL1397894 & 688239 & 4.7362 & 5.3586 & TRN & \\
\hline CHEMBL1490350 & 688239 & 5.8862 & 5.4257 & TRN & \\
\hline CHEMBL1542144 & 688239 & 4.6862 & 5.4497 & TRN & \\
\hline CHEMBL1318098 & 688239 & 4.9362 & 5.4062 & TRN & \\
\hline CHEMBL1308948 & 688239 & 5.4362 & 5.4303 & TST & \\
\hline CHEMBL1610509 & 688239 & 8.28399 & 999999999 & 5.593 & TRN \\
\hline CHEMBL1607414 & 688239 & 6.3863 & 5.4942 & TRN & \\
\hline CHEMBL1409407 & 688239 & 4.5362 & 5.4906 & TRN & \\
\hline CHEMBL1389958 & 688239 & 4.5362 & 5.4611 & TRN & \\
\hline CHEMBL1504234 & 688239 & 5.3362 & 5.4932 & TRN & \\
\hline CHEMBL1547561 & 688239 & 5.8862 & 5.3693 & TST & \\
\hline CHEMBL1453761 & 688239 & 4.5362 & 5.4942 & TRN & \\
\hline CHEMBL3197332 & 688239 & 4.5362 & 5.3388 & TST & \\
\hline CHEMBL1536498 & 688239 & 5.7862 & 5.565 & TRN & \\
\hline CHEMBL1380343 & 688239 & 5.9362 & 5.4402 & TRN & \\
\hline CHEMBL1497593 & 688239 & 6.1862 & 5.3946 & TST & \\
\hline CHEMBL1508601 & 688239 & 4.9362 & 5.5476 & TRN & \\
\hline CHEMBL1545810 & 688239 & 6.3362 & 5.5281 & TRN & \\
\hline CHEMBL1550339 & 688239 & 6.0862 & 5.5454 & TRN & \\
\hline CHEMBL1376820 & 688239 & 6.7862 & 5.513 & TRN & \\
\hline CHEMBL1338628 & 688239 & 4.6362 & 5.5883 & TST & \\
\hline CHEMBL1409221 & 688239 & 5.5862 & 5.5378 & TRN & \\
\hline CHEMBL1392784 & 688239 & 4.8862 & 5.622000 & 0000000001 & TRN \\
\hline CHEMBL1599052 & 688239 & 4.7862 & 5.5993 & TRN & \\
\hline CHEMBL1561428 & 688239 & 8.28399 & 999999999 & 5.4688 & TRN \\
\hline CHEMBL1398953 & 688239 & 4.8862 & 5.5505 & TRN & \\
\hline CHEMBL1405151 & 688239 & 6.1362 & 5.516 & TRN & \\
\hline CHEMBL1397451 & 688239 & 4.8862 & 5.4492 & TRN & \\
\hline CHEMBL1367415 & 688239 & 4.5362 & 5.4899 & TST & \\
\hline CHEMBL1596063 & 688239 & 5.4362 & 5.297999 & 9999999999 & TRN \\
\hline CHEMBL1327579 & 688239 & 4.5362 & 5.5246 & TRN & \\
\hline CHEMBL1344506 & 688239 & 4.8862 & 5.4691 & TST & \\
\hline CHEMBL 3198056 & 688239 & 6.6861 & 5.5348 & TST & \\
\hline CHEMBL1305304 & 688239 & 5.1862 & 5.4201 & TRN & \\
\hline CHEMBL1475516 & 688239 & 5.4362 & 5.4203 & TRN & \\
\hline CHEMBL3191916 & 688239 & 6.3362 & 5.367000 & 0000000001 & TRN \\
\hline CHEMBL1580562 & 688239 & 4.5362 & 5.5451 & TRN & \\
\hline CHEMBL1439019 & 688239 & 4.5362 & 5.4012 & TST & \\
\hline CHEMBL1362016 & 688239 & 4.9362 & 5.527 & TRN & \\
\hline CHEMBL1558708 & 688239 & 5.2862 & 5.6395 & TST & \\
\hline CHEMBL1338602 & 688239 & 4.8362 & 5.5584 & TRN & \\
\hline
\end{tabular}


Supplemental Table S2.txt

\begin{tabular}{|c|c|c|c|c|}
\hline CHEMBL1484539 & 688239 & 6.3362 & 5.6938 & TST \\
\hline CHEMBL1479094 & 688239 & 4.7862 & 5.4577 & TST \\
\hline CHEMBL1466967 & 688239 & 6.9363 & 5.4917 & TST \\
\hline CHEMBL1551298 & 688239 & 5.0862 & 5.5365 & TRN \\
\hline CHEMBL1565240 & 688239 & 4.6362 & 5.4289 & TST \\
\hline CHEMBL1389135 & 688239 & 7.1864 & 5.6152 & TST \\
\hline CHEMBL1583138 & 688239 & 6.9863 & 5.5251 & TRN \\
\hline CHEMBL1447682 & 688239 & 5.1862 & 5.3484 & TRN \\
\hline CHEMBL1498999 & 688239 & 6.7862 & 5.5227 & TRN \\
\hline CHEMBL1497467 & 688239 & 7.9872 & 5.541 & TRN \\
\hline CHEMBL1357768 & 688239 & 4.7362 & 5.4657 & TRN \\
\hline CHEMBL1338487 & 688239 & 5.0862 & 5.4679 & TRN \\
\hline CHEMBL1437547 & 688239 & 4.4862 & 5.5815 & TRN \\
\hline CHEMBL1547034 & 688239 & 5.3862 & 5.6073 & TST \\
\hline CHEMBL1337414 & 688239 & 4.7362 & 5.4396 & TRN \\
\hline CHEMBL1479151 & 688239 & 5.4362 & 5.473 & TRN \\
\hline CHEMBL1306390 & 688239 & 4.5362 & 5.4715 & TST \\
\hline CHEMBL1316185 & 688239 & 5.1362 & 5.3291 & TRN \\
\hline CHEMBL1326415 & 688239 & 6.9363 & 5.4405 & TST \\
\hline CHEMBL1473428 & 688239 & 4.7862 & 5.5385 & TRN \\
\hline CHEMBL1542722 & 688239 & 5.1862 & 5.5848 & TRN \\
\hline CHEMBL1442616 & 688239 & 6.0 & 5.4051 & TRN \\
\hline CHEMBL1472447 & 688239 & 4.5362 & 5.5099 & TRN \\
\hline CHEMBL1336567 & 688239 & 5.0862 & 5.3403 & TRN \\
\hline CHEMBL1380039 & 688239 & 6.1862 & 5.5957 & TRN \\
\hline CHEMBL1379297 & 688239 & 7.0362 & 5.3958 & TRN \\
\hline CHEMBL1378210 & 688239 & 6.9363 & 5.5047 & TST \\
\hline CHEMBL1576907 & 688239 & 5.7862 & 5.4159 & TST \\
\hline CHEMBL1443048 & 688239 & 8.283999 & 999999999 & 5.56 \\
\hline CHEMBL1402342 & 688239 & 4.7362 & 5.6072 & TRN \\
\hline CHEMBL1329887 & 688239 & 6.3863 & 5.4857 & TRN \\
\hline CHEMBL1454876 & 688239 & 4.4862 & 5.5791 & TRN \\
\hline CHEMBL1514655 & 688239 & 4.9862 & 5.4775 & TRN \\
\hline CHEMBL1336506 & 688239 & 6.3362 & 5.6157 & TRN \\
\hline CHEMBL1338632 & 688239 & 5.1862 & 5.69 & TRN \\
\hline CHEMBL1603220 & 688239 & 5.4862 & 5.4593 & TRN \\
\hline CHEMBL1448520 & 688239 & 5.4362 & 5.6204 & TRN \\
\hline CHEMBL1445844 & 688239 & 5.2362 & 5.5331 & TRN \\
\hline CHEMBL1302192 & 688239 & 6.6362 & 5.5002 & TRN \\
\hline CHEMBL1373906 & 688239 & 5.1362 & 5.5079 & TST \\
\hline CHEMBL1322059 & 688239 & 5.5362 & 5.54200 & 0000000001 \\
\hline CHEMBL1517796 & 688239 & 4.8862 & 5.4255 & TRN \\
\hline CHEMBL1477875 & 688239 & 7.0862 & 5.5251 & TRN \\
\hline CHEMBL1485120 & 688239 & 4.5862 & 5.439 & TRN \\
\hline CHEMBL1519166 & 688239 & 5.2862 & 5.4492 & TRN \\
\hline CHEMBL1354909 & 688239 & 4.8362 & 5.4755 & TRN \\
\hline CHEMBL1537724 & 688239 & 8.1871 & 5.6668 & TST \\
\hline CHEMBL1544935 & 688239 & 5.4362 & 5.529 & TRN \\
\hline
\end{tabular}


Supplemental Table S2.txt

\begin{tabular}{|c|c|c|c|c|c|}
\hline CHEMBL1530355 & 688239 & 4.5362 & 5.5602 & TRN & \\
\hline CHEMBL1422425 & 688239 & 5.1862 & 5.46 & TRN & \\
\hline CHEMBL1519502 & 688239 & 5.1862 & 5.5102 & TRN & \\
\hline CHEMBL 3207442 & 688239 & 4.6862 & 5.5843 & TRN & \\
\hline CHEMBL1426402 & 688239 & 5.7362 & 5.3136 & TRN & \\
\hline CHEMBL1386457 & 688239 & 5.4862 & 5.5156 & TST & \\
\hline CHEMBL1368776 & 688239 & 4.8362 & 5.5706 & TST & \\
\hline CHEMBL1596118 & 688239 & 8.3372 & 5.38899 & 9999999999 & TRN \\
\hline CHEMBL1524784 & 688239 & 5.1362 & 5.6898 & TRN & \\
\hline CHEMBL1505908 & 688239 & 6.1362 & 5.676 & TST & \\
\hline CHEMBL1585940 & 688239 & 6.4362 & 5.45 & TRN & \\
\hline CHEMBL1317542 & 688239 & 6.1862 & 5.5345 & TRN & \\
\hline CHEMBL1432068 & 688239 & 4.5362 & 5.5936 & TST & \\
\hline CHEMBL1537545 & 688239 & 6.6861 & 5.5189 & TRN & \\
\hline CHEMBL1493543 & 688239 & 4.9362 & 5.4555 & TRN & \\
\hline CHEMBL1310490 & 688239 & 4.4862 & 5.5369 & TRN & \\
\hline CHEMBL1341349 & 688239 & 8.3372 & 5.3484 & TRN & \\
\hline CHEMBL1478072 & 688239 & 5.4362 & 5.3991 & TST & \\
\hline CHEMBL1551745 & 688239 & 5.1862 & 5.3873 & TRN & \\
\hline CHEMBL1600951 & 688239 & 4.5362 & 5.4521 & TRN & \\
\hline CHEMBL1319713 & 688239 & 6.9863 & 5.5991 & TST & \\
\hline CHEMBL1462190 & 688239 & 4.8362 & 5.4939 & TST & \\
\hline CHEMBL1599059 & 688239 & 6.2362 & 5.62700 & $\partial 000000001$ & TRN \\
\hline CHEMBL1356467 & 688239 & 6.1362 & 5.5184 & TST & \\
\hline CHEMBL1342671 & 688239 & 6.7862 & 5.5864 & TRN & \\
\hline CHEMBL1517078 & 688239 & 6.6861 & 5.6561 & TST & \\
\hline CHEMBL1423724 & 688239 & 4.6362 & 5.4831 & TRN & \\
\hline CHEMBL1320816 & 688239 & 4.7362 & 5.5791 & TRN & \\
\hline CHEMBL1604217 & 688239 & 4.6862 & 5.2982 & TRN & \\
\hline CHEMBL1462634 & 688239 & 5.8862 & 5.5403 & TRN & \\
\hline CHEMBL1599676 & 688239 & 6.2862 & 5.6943 & TRN & \\
\hline CHEMBL3192816 & 688239 & 4.7862 & 5.5454 & TST & \\
\hline CHEMBL1603005 & 688239 & 4.7362 & 5.55200 & 20000000005 & TST \\
\hline CHEMBL1527438 & 688239 & 5.8362 & 5.439 & TRN & \\
\hline CHEMBL1463494 & 688239 & 4.6862 & 5.446006 & 0000000001 & TRN \\
\hline CHEMBL1471692 & 688239 & 5.5862 & 5.5848 & TRN & \\
\hline CHEMBL1406941 & 688239 & 5.0362 & 5.579 & TST & \\
\hline CHEMBL1445415 & 688239 & 6.3362 & 5.4574 & TRN & \\
\hline CHEMBL1537325 & 688239 & 4.5362 & 5.4855 & TRN & \\
\hline CHEMBL1600121 & 688239 & 5.4362 & 5.7028 & TRN & \\
\hline CHEMBL1541339 & 688239 & 4.6362 & 5.4763 & TST & \\
\hline CHEMBL1563144 & 688239 & 6.0862 & 5.5344 & TRN & \\
\hline CHEMBL1401646 & 688239 & 4.7362 & 5.5199 & TRN & \\
\hline CHEMBL1389314 & 688239 & 4.7362 & 5.518 & TRN & \\
\hline CHEMBL1594613 & 688239 & 4.5862 & 5.4513 & TRN & \\
\hline CHEMBL1609689 & 688239 & 5.8362 & 5.49 & TRN & \\
\hline CHEMBL1527839 & 688239 & 4.6362 & 5.4775 & TRN & \\
\hline CHEMBL1421604 & 688239 & 6.8861 & 5.2473 & TST & \\
\hline
\end{tabular}


Supplemental Table S2.txt

\begin{tabular}{|c|c|c|c|c|c|}
\hline CHEMBL1529176 & 688239 & 5.0862 & 5.5872 & TRN & \\
\hline CHEMBL1468434 & 688239 & 4.8862 & 5.5365 & TRN & \\
\hline CHEMBL1558732 & 688239 & 6.1362 & 5.3312 & TRN & \\
\hline CHEMBL1446673 & 688239 & 4.6362 & 5.4343 & TRN & \\
\hline CHEMBL534047 & 688239 & 4.6862 & 5.4683 & TRN & \\
\hline CHEMBL1499507 & 688239 & 4.5362 & 5.4827 & TST & \\
\hline CHEMBL1524508 & 688239 & 4.7362 & 5.6533 & TRN & \\
\hline CHEMBL1573762 & 688239 & 5.4862 & 5.5207 & TRN & \\
\hline CHEMBL1338312 & 688239 & 4.8362 & 5.3995 & TRN & \\
\hline CHEMBL1573525 & 688239 & 4.9862 & 5.6447 & TRN & \\
\hline CHEMBL1991021 & 688239 & 4.6362 & 5.3785 & TRN & \\
\hline CHEMBL1483665 & 688239 & 4.6362 & 5.4837 & TRN & \\
\hline CHEMBL1530585 & 688239 & 5.1862 & 5.5532 & TRN & \\
\hline CHEMBL1603116 & 688239 & 4.5362 & 5.2243 & TRN & \\
\hline CHEMBL1490662 & 688239 & 7.8356 & 5.414 & TRN & \\
\hline CHEMBL1518336 & 688239 & 6.3362 & 5.5677 & TRN & \\
\hline CHEMBL1359167 & 688239 & 4.7362 & 5.5677 & TRN & \\
\hline CHEMBL1576577 & 688239 & 6.0362 & 5.4777 & TST & \\
\hline CHEMBL1578415 & 688239 & 4.9862 & 5.4671 & TST & \\
\hline CHEMBL1303508 & 688239 & 5.2362 & 5.3642 & TST & \\
\hline CHEMBL1596207 & 688239 & 6.2362 & 5.5517 & TRN & \\
\hline CHEMBL1594338 & 688239 & 6.2862 & 5.49799 & 9999999999 & TRN \\
\hline CHEMBL1311039 & 688239 & 4.6862 & 5.3763 & TRN & \\
\hline CHEMBL1478777 & 688239 & 5.0862 & 5.5317 & TRN & \\
\hline CHEMBL 3191165 & 688239 & 5.1362 & 5.5324 & TRN & \\
\hline CHEMBL1457327 & 688239 & 5.3862 & 5.5189 & TRN & \\
\hline CHEMBL1587414 & 688239 & 4.5362 & 5.7075 & TRN & \\
\hline CHEMBL1426028 & 688239 & 4.6362 & 5.3769 & TST & \\
\hline CHEMBL1549345 & 688239 & 4.9362 & 5.3718 & TRN & \\
\hline CHEMBL1431331 & 688239 & 4.7362 & 5.3556 & TRN & \\
\hline CHEMBL1369944 & 688239 & 5.1862 & 5.3888 & TST & \\
\hline CHEMBL1384430 & 688239 & 4.7862 & 5.5061 & TRN & \\
\hline CHEMBL1556924 & 688239 & 5.3362 & 5.5121 & TST & \\
\hline CHEMBL1600919 & 688239 & 5.1862 & 5.5733 & TRN & \\
\hline CHEMBL1552799 & 688239 & 7.0362 & 5.6731 & TRN & \\
\hline CHEMBL1456997 & 688239 & 6.9863 & 5.50700 & 0000000001 & TST \\
\hline CHEMBL 381077 & 688239 & 4.9362 & 5.4861 & TRN & \\
\hline CHEMBL3189396 & 688239 & 4.5862 & 5.5129 & TRN & \\
\hline CHEMBL1570740 & 688239 & 5.2362 & 5.5158 & TRN & \\
\hline CHEMBL1347988 & 688239 & 6.4362 & 5.4457 & TST & \\
\hline CHEMBL1519681 & 688239 & 6.1862 & 5.5402 & TST & \\
\hline CHEMBL1492553 & 688239 & 5.4862 & 5.4599 & TRN & \\
\hline CHEMBL1430649 & 688239 & 4.6862 & 5.593 & TRN & \\
\hline CHEMBL1358428 & 688239 & 4.6362 & 5.3827 & TRN & \\
\hline CHEMBL1443674 & 688239 & 4.6362 & 5.3934 & TST & \\
\hline CHEMBL1576916 & 688239 & 4.6362 & 5.4791 & TRN & \\
\hline CHEMBL1491781 & 688239 & 5.5362 & 5.5763 & TRN & \\
\hline CHEMBL260001 & 688239 & 4.5362 & 5.4633 & TRN & \\
\hline
\end{tabular}


Supplemental Table S2.txt

\begin{tabular}{|c|c|c|c|c|c|}
\hline CHEMBL3210589 & 688239 & 5.0362 & 5.4686 & TST & \\
\hline CHEMBL1303247 & 688239 & 6.1862 & 5.4982 & TRN & \\
\hline CHEMBL1334560 & 688239 & 7.5361 & 5.4925 & TRN & \\
\hline CHEMBL1368045 & 688239 & 4.6362 & 5.5421 & TRN & \\
\hline CHEMBL1573030 & 688239 & 4.6862 & 5.4221 & TST & \\
\hline CHEMBL1538364 & 688239 & 4.8362 & 5.5651 & TRN & \\
\hline CHEMBL1370322 & 688239 & 4.7862 & 5.4225 & TRN & \\
\hline CHEMBL 3199362 & 688239 & 4.4862 & 5.3303 & TRN & \\
\hline CHEMBL1362992 & 688239 & 4.5362 & $5.67700 e$ & 20000000005 & TRN \\
\hline CHEMBL1452317 & 688239 & 4.9362 & 5.4899 & TST & \\
\hline CHEMBL1707275 & 688239 & 6.5862 & 5.5791 & TRN & \\
\hline CHEMBL1555815 & 688239 & 5.0862 & 5.5518 & TST & \\
\hline CHEMBL1329915 & 688239 & 5.5862 & 5.5237 & TRN & \\
\hline CHEMBL1422628 & 688239 & 4.8362 & 5.4949 & TST & \\
\hline CHEMBL1383363 & 688239 & 5.1862 & 5.4963 & TST & \\
\hline CHEMBL1370905 & 688239 & 4.8362 & 5.4199 & TST & \\
\hline CHEMBL1534077 & 688239 & 6.2862 & 5.4907 & TRN & \\
\hline CHEMBL1300670 & 688239 & 6.9863 & 5.6748 & TRN & \\
\hline CHEMBL1426384 & 688239 & 7.0362 & 5.5549 & TRN & \\
\hline CHEMBL1333415 & 688239 & 6.2862 & 5.516 & TRN & \\
\hline CHEMBL 1462420 & 688239 & 6.2362 & 5.4236 & TRN & \\
\hline CHEMBL1520581 & 688239 & 4.8362 & 5.5839 & TRN & \\
\hline CHEMBL1388268 & 688239 & 5.4362 & 5.5233 & TRN & \\
\hline CHEMBL1485674 & 688239 & 6.1862 & 5.5103 & TRN & \\
\hline CHEMBL1390516 & 688239 & 5.3362 & 5.5002 & TRN & \\
\hline CHEMBL1509114 & 688239 & 5.1862 & 5.4956 & TRN & \\
\hline CHEMBL1427673 & 688239 & 4.5362 & 5.6425 & TRN & \\
\hline CHEMBL1424333 & 688239 & 4.6862 & 5.5486 & TST & \\
\hline CHEMBL1563404 & 688239 & 5.3862 & 5.3833 & TST & \\
\hline CHEMBL1386884 & 688239 & 4.5362 & 5.4226 & TRN & \\
\hline CHEMBL1491562 & 688239 & 6.6362 & 5.5002 & TRN & \\
\hline CHEMBL1380135 & 688239 & 5.7862 & 5.517 & TRN & \\
\hline CHEMBL 3192589 & 688239 & 7.0362 & 5.4105 & TRN & \\
\hline CHEMBL1442986 & 688239 & 4.5362 & 5.5146 & TRN & \\
\hline CHEMBL1532044 & 688239 & 8.3372 & 5.5493 & TRN & \\
\hline CHEMBL1484353 & 688239 & \multicolumn{3}{|c|}{8.283999999999999} & TST \\
\hline CHEMBL1391790 & 688239 & 4.5362 & 5.3701 & TST & \\
\hline CHEMBL1494487 & 688239 & 6.1362 & 5.5244 & TST & \\
\hline CHEMBL1346744 & 688239 & 6.9363 & 5.5501 & TRN & \\
\hline CHEMBL1497802 & 688239 & 4.6362 & 5.5139 & TRN & \\
\hline CHEMBL1393642 & 688239 & 5.4862 & 5.2745 & TRN & \\
\hline CHEMBL1363276 & 688239 & 6.9363 & 5.6262 & TRN & \\
\hline CHEMBL1459272 & 688239 & 4.7862 & 5.5809 & TRN & \\
\hline CHEMBL1324117 & 688239 & 5.4362 & 5.5215 & TRN & \\
\hline CHEMBL1531729 & 688239 & 4.6362 & 5.5697 & TRN & \\
\hline CHEMBL1430943 & 688239 & 5.5362 & 5.4032 & TRN & \\
\hline CHEMBL1454380 & 688239 & 5.8862 & 5.6405 & TRN & \\
\hline CHEMBL1429235 & 688239 & 4.5362 & 5.5162 & TRN & \\
\hline
\end{tabular}


Supplemental Table S2.txt

\begin{tabular}{|c|c|c|c|c|c|}
\hline CHEMBL1322036 & 688239 & 8.3372 & 5.559 & TST & \\
\hline CHEMBL1323359 & 688239 & 6.7862 & 5.5725 & TST & \\
\hline CHEMBL1334061 & 688239 & 6.8362 & 5.5119 & TST & \\
\hline CHEMBL1466968 & 688239 & 4.9862 & 5.4735 & TST & \\
\hline CHEMBL1345190 & 688239 & 4.5362 & 5.3967 & TRN & \\
\hline CHEMBL1402492 & 688239 & 6.8861 & 5.4461 & TRN & \\
\hline CHEMBL1305012 & 688239 & 7.2865 & 5.5649 & TRN & \\
\hline CHEMBL1586563 & 688239 & 5.5862 & 5.5625 & TRN & \\
\hline CHEMBL3209166 & 688239 & 5.6862 & 5.5015 & TRN & \\
\hline CHEMBL1306193 & 688239 & 4.6362 & 5.5449 & TRN & \\
\hline CHEMBL1316786 & 688239 & 4.6362 & 5.4532 & TRN & \\
\hline CHEMBL1528717 & 688239 & 6.5363 & 5.5635 & TST & \\
\hline CHEMBL1336298 & 688239 & 4.5362 & 5.5174 & TST & \\
\hline CHEMBL1538941 & 688239 & 8.3872 & 5.5002 & TST & \\
\hline CHEMBL1596606 & 688239 & 4.7362 & 5.5506 & TRN & \\
\hline CHEMBL1401897 & 688239 & 5.3362 & \multicolumn{2}{|c|}{5.5889999999999995} & TST \\
\hline CHEMBL1302621 & 688239 & 4.7362 & 5.6184 & TST & \\
\hline CHEMBL1612547 & 688239 & 8.2366 & 5.4749 & TRN & \\
\hline CHEMBL1321555 & 688239 & 4.6362 & 5.5259 & TST & \\
\hline CHEMBL1406185 & 688239 & 4.9862 & 5.5595 & TST & \\
\hline CHEMBL1330807 & 688239 & 8.3372 & 5.5256 & TST & \\
\hline CHEMBL1456491 & 688239 & 5.8362 & 5.5241 & TRN & \\
\hline CHEMBL1376508 & 688239 & 4.8862 & 5.5051 & TRN & \\
\hline CHEMBL1604067 & 688239 & 6.1362 & 5.3514 & TST & \\
\hline CHEMBL 3198424 & 688239 & 6.7862 & 5.4323 & TST & \\
\hline CHEMBL1597182 & 688239 & 5.2362 & 5.4507 & TRN & \\
\hline CHEMBL1393483 & 688239 & 5.7362 & 5.4434 & TRN & \\
\hline CHEMBL3199538 & 688239 & 4.8862 & 5.5888 & TRN & \\
\hline CHEMBL1377012 & 688239 & 5.5862 & 5.5296 & TRN & \\
\hline CHEMBL1516344 & 688239 & 6.4862 & 5.4913 & TRN & \\
\hline CHEMBL1345072 & 688239 & 4.5862 & 5.6347 & TRN & \\
\hline CHEMBL1337786 & 688239 & 6.8362 & 5.6372 & TRN & \\
\hline CHEMBL3196816 & 688239 & 5.7362 & 5.3324 & TRN & \\
\hline CHEMBL1493968 & 688239 & 5.5862 & 5.4708 & TRN & \\
\hline CHEMBL1425295 & 688239 & 4.45 & 5.5323 & TST & \\
\hline CHEMBL1303627 & 688239 & 5.5862 & 5.5101 & TRN & \\
\hline CHEMBL3213039 & 688239 & 6.1862 & 5.4341 & TRN & \\
\hline CHEMBL1545828 & 688239 & 5.1862 & 5.5819 & TRN & \\
\hline CHEMBL1574544 & 688239 & 6.1362 & 5.3741 & TST & \\
\hline CHEMBL1511384 & 688239 & 5.1362 & 5.6165 & TRN & \\
\hline CHEMBL1569206 & 688239 & 6.1362 & \multicolumn{2}{|c|}{5.593999999999999} & TST \\
\hline CHEMBL1356435 & 688239 & 4.8862 & 5.3905 & TRN & \\
\hline CHEMBL1301971 & 688239 & 5.1862 & 5.496 & TST & \\
\hline CHEMBL1505624 & 688239 & 5.0862 & 5.5347 & TRN & \\
\hline CHEMBL1333363 & 688239 & 5.7362 & 5.3673 & TRN & \\
\hline CHEMBL1450662 & 688239 & 5.1862 & 5.5525 & TRN & \\
\hline CHEMBL1477291 & 688239 & 4.9362 & 5.4926 & TRN & \\
\hline CHEMBL 74497 & 688239 & 4.5362 & 5.3891 & TRN & \\
\hline
\end{tabular}




\begin{tabular}{|c|c|c|c|c|c|}
\hline & & \multicolumn{4}{|c|}{ Supplemental Table S2.txt } \\
\hline CHEMBL1362634 & 688239 & 8.28399 & 79999999 & & TRN \\
\hline CHEMBL1582411 & 688239 & 4.5362 & 5.4884 & TST & \\
\hline CHEMBL1303092 & 688239 & 4.5362 & 5.6511 & TRN & \\
\hline CHEMBL1521172 & 688239 & 5.4862 & 5.4643 & TRN & \\
\hline CHEMBL1579644 & 688239 & 5.5362 & 5.4621 & TRN & \\
\hline CHEMBL1418859 & 688239 & 4.9862 & 5.57100 & 0000000001 & TRN \\
\hline CHEMBL1471782 & 688239 & 4.7862 & 5.4887 & TRN & \\
\hline CHEMBL3209059 & 688239 & 8.2366 & 5.3526 & TRN & \\
\hline CHEMBL1302921 & 688239 & 5.7362 & 5.5516 & TRN & \\
\hline CHEMBL1442928 & 688239 & 5.4862 & 5.5339 & TRN & \\
\hline CHEMBL1573092 & 688239 & 5.8362 & 5.4879 & TRN & \\
\hline CHEMBL1978364 & 688239 & 6.0362 & 5.53 & TRN & \\
\hline CHEMBL1580240 & 688239 & 5.7362 & 5.4926 & TRN & \\
\hline CHEMBL1363423 & 688239 & 6.9863 & 5.6106 & TRN & \\
\hline CHEMBL1535578 & 688239 & 4.5362 & 5.5967 & TRN & \\
\hline CHEMBL1348623 & 688239 & 4.4862 & 5.4712 & TST & \\
\hline CHEMBL1455209 & 688239 & 5.7862 & 5.7134 & TRN & \\
\hline CHEMBL1368818 & 688239 & 5.4362 & 5.42399 & 99999999995 & TST \\
\hline CHEMBL1538784 & 688239 & 4.5362 & 5.48799 & 99999999995 & TRN \\
\hline CHEMBL1411569 & 688239 & 4.5362 & 5.5054 & TRN & \\
\hline CHEMBL1994034 & 688239 & 7.5867 & 5.4449 & TST & \\
\hline CHEMBL1391906 & 688239 & 4.5362 & 5.49 & TRN & \\
\hline CHEMBL1400512 & 688239 & 4.5362 & 5.3658 & TST & \\
\hline CHEMBL1487152 & 688239 & 5.6862 & 5.4264 & TRN & \\
\hline CHEMBL1424443 & 688239 & 4.5362 & 5.3034 & TRN & \\
\hline CHEMBL1462075 & 688239 & 6.9363 & 5.4008 & TST & \\
\hline CHEMBL1331110 & 688239 & 4.7862 & 5.475 & TRN & \\
\hline CHEMBL1584087 & 688239 & 4.7362 & 5.5718 & TRN & \\
\hline CHEMBL1444768 & 688239 & 6.9363 & 5.4385 & TRN & \\
\hline CHEMBL1491788 & 688239 & 4.7362 & 5.5386 & TRN & \\
\hline CHEMBL1378788 & 688239 & 6.2362 & 5.5793 & TRN & \\
\hline CHEMBL1571377 & 688239 & 5.4362 & 5.4828 & TRN & \\
\hline CHEMBL1418893 & 688239 & 4.5362 & 5.4529 & TRN & \\
\hline CHEMBL3198935 & 688239 & 4.7362 & 5.3747 & TST & \\
\hline CHEMBL1506729 & 688239 & 5.8862 & 5.504 & TRN & \\
\hline CHEMBL1547307 & 688239 & 6.0862 & 5.4366 & TRN & \\
\hline CHEMBL1506103 & 688239 & 4.6862 & 5.5407 & TST & \\
\hline CHEMBL1537619 & 688239 & 5.5862 & 5.4311 & TST & \\
\hline CHEMBL1349175 & 688239 & 5.1862 & 5.4081 & TRN & \\
\hline CHEMBL1464723 & 688239 & 5.8362 & 5.4572 & TST & \\
\hline CHEMBL1509403 & 688239 & 5.0862 & 5.5302 & TST & \\
\hline CHEMBL1391064 & 688239 & 4.5362 & 5.3244 & TST & \\
\hline CHEMBL1454191 & 688239 & 5.1862 & 5.5991 & TST & \\
\hline CHEMBL1546518 & 688239 & 6.1362 & 5.57600 & 20000000005 & TRN \\
\hline CHEMBL1545132 & 688239 & 5.0362 & 5.5198 & TRN & \\
\hline CHEMBL1531607 & 688239 & 4.5362 & 5.6044 & TRN & \\
\hline CHEMBL1369400 & 688239 & 4.5362 & 5.5364 & TRN & \\
\hline CHEMBL1430936 & 688239 & 4.5862 & 5.5523 & TRN & \\
\hline
\end{tabular}


Supplemental Table S2.txt

\begin{tabular}{|c|c|c|c|c|c|}
\hline CHEMBL3214628 & 688239 & 5.8862 & 5.5541 & TRN & \\
\hline CHEMBL1455771 & 688239 & 4.5362 & \multicolumn{2}{|c|}{5.382999999999999} & TRN \\
\hline CHEMBL1321967 & 688239 & 6.6362 & 5.3247 & TRN & \\
\hline CHEMBL1452684 & 688239 & 6.0362 & 5.4027 & TST & \\
\hline CHEMBL1454228 & 688239 & 4.6862 & 5.4218 & TRN & \\
\hline CHEMBL1524407 & 688239 & 5.6362 & 5.5078 & TRN & \\
\hline CHEMBL1303633 & 688239 & 6.2862 & 5.4821 & TST & \\
\hline CHEMBL1578294 & 688239 & 7.1361 & 5.5461 & TRN & \\
\hline CHEMBL1332357 & 688239 & 4.5362 & 5.516 & TRN & \\
\hline CHEMBL3190904 & 688239 & 5.3362 & 5.4105 & TRN & \\
\hline CHEMBL1450086 & 688239 & 4.5362 & 5.4961 & TRN & \\
\hline CHEMBL1344148 & 688239 & 4.5362 & 5.4751 & TRN & \\
\hline CHEMBL3214155 & 688239 & 4.5362 & 5.5001 & TST & \\
\hline CHEMBL3198597 & 688239 & 4.5362 & 5.306 & TRN & \\
\hline CHEMBL1511011 & 688239 & 4.6362 & 5.6652 & TRN & \\
\hline CHEMBL1586437 & 688239 & 4.9862 & 5.4959 & TST & \\
\hline CHEMBL1556686 & 688239 & 6.5862 & 5.6053 & TST & \\
\hline CHEMBL1467809 & 688239 & 5.4862 & 5.3578 & TRN & \\
\hline CHEMBL1533827 & 688239 & 6.1362 & 5.5607 & TRN & \\
\hline CHEMBL1518156 & 688239 & 6.1362 & 5.5065 & TRN & \\
\hline CHEMBL1328975 & 688239 & 6.6861 & 5.4125 & TRN & \\
\hline CHEMBL1363859 & 688239 & 5.9862 & 5.4919 & TRN & \\
\hline CHEMBL1306238 & 688239 & 4.5362 & 5.4622 & TRN & \\
\hline CHEMBL1326274 & 688239 & 6.2362 & 5.5647 & TRN & \\
\hline CHEMBL1466031 & 688239 & 4.8862 & 5.4545 & TRN & \\
\hline CHEMBL1383868 & 688239 & 4.5362 & 5.6142 & TRN & \\
\hline CHEMBL1469132 & 688239 & 6.7862 & 5.6139 & TRN & \\
\hline CHEMBL1566450 & 688239 & 6.2862 & 5.3969 & TRN & \\
\hline CHEMBL1345582 & 688239 & 5.1862 & 5.5432 & TST & \\
\hline CHEMBL 3192432 & 688239 & 5.4862 & 5.4368 & TRN & \\
\hline CHEMBL1581146 & 688239 & 6.7361 & 5.4499 & TRN & \\
\hline CHEMBL1450558 & 688239 & 4.5362 & 5.3929 & TRN & \\
\hline CHEMBL1599495 & 688239 & 5.4362 & 5.4612 & TRN & \\
\hline CHEMBL1310330 & 688239 & 4.5362 & 5.4377 & TRN & \\
\hline CHEMBL1351813 & 688239 & 4.9362 & 5.5056 & TRN & \\
\hline CHEMBL1302173 & 688239 & 5.3862 & 5.56 & TST & \\
\hline CHEMBL1448157 & 688239 & 4.6362 & 5.51200 & 00000000005 & \\
\hline CHEMBL1406118 & 688239 & 5.1862 & 5.5613 & TST & \\
\hline CHEMBL1361306 & 688239 & 5.3362 & 5.5469 & TST & \\
\hline CHEMBL1359951 & 688239 & 4.9362 & 5.5782 & TRN & \\
\hline CHEMBL1347488 & 688239 & 4.5862 & 5.3335 & TRN & \\
\hline CHEMBL1362060 & 688239 & 7.2865 & 5.4664 & TRN & \\
\hline CHEMBL1390735 & 688239 & 6.8861 & 5.5935 & TRN & \\
\hline CHEMBL1542887 & 688239 & 4.5862 & 5.4926 & TRN & \\
\hline CHEMBL1496293 & 688239 & 4.6862 & 5.4712 & TRN & \\
\hline CHEMBL1990694 & 688239 & 4.7862 & 5.3232 & TRN & \\
\hline CHEMBL 3212253 & 688239 & 7.7352 & 5.3369 & TST & \\
\hline CHEMBL1359081 & 688239 & 4.5362 & 5.4385 & TST & \\
\hline
\end{tabular}

Page 1113 
Supplemental Table S2.txt

\begin{tabular}{|c|c|c|c|c|c|}
\hline CHEMBL1398986 & 688239 & 5.6362 & 5.6412 & TRN & \\
\hline CHEMBL1604200 & 688239 & 4.9862 & 5.5438 & TRN & \\
\hline CHEMBL1465591 & 688239 & 6.1862 & 5.5944 & TRN & \\
\hline CHEMBL1533654 & 688239 & 7.1864 & 5.419 & TRN & \\
\hline CHEMBL1980197 & 688239 & 4.5362 & 5.3664 & TRN & \\
\hline CHEMBL1507242 & 688239 & 4.8362 & 5.4987 & TRN & \\
\hline CHEMBL1313798 & 688239 & 6.4862 & 5.5421 & TST & \\
\hline CHEMBL1350542 & 688239 & 6.1362 & 5.7098 & TRN & \\
\hline CHEMBL1451724 & 688239 & 5.1862 & 5.5448 & TRN & \\
\hline CHEMBL1546584 & 688239 & 4.5362 & 5.3866 & TRN & \\
\hline CHEMBL1378294 & 688239 & 5.7362 & 5.3702 & TST & \\
\hline CHEMBL1438537 & 688239 & 4.8862 & 5.5469 & TST & \\
\hline CHEMBL1416155 & 688239 & 4.9862 & 5.4278 & TRN & \\
\hline CHEMBL1501778 & 688239 & 5.8362 & 5.5104 & TRN & \\
\hline CHEMBL1325576 & 688239 & 6.1362 & 5.624 & TRN & \\
\hline CHEMBL1522339 & 688239 & 6.3362 & 5.6333 & TRN & \\
\hline CHEMBL3191808 & 688239 & 4.5362 & 5.402 & TRN & \\
\hline CHEMBL1610679 & 688239 & 5.2862 & 5.4362 & TST & \\
\hline CHEMBL1486698 & 688239 & 6.3863 & 5.3907 & TRN & \\
\hline CHEMBL1302176 & 688239 & 4.7362 & 5.5146 & TRN & \\
\hline CHEMBL1502074 & 688239 & 5.6862 & 5.5057 & TRN & \\
\hline CHEMBL1564186 & 688239 & 5.1862 & 5.4952 & TRN & \\
\hline CHEMBL1370478 & 688239 & 6.8362 & 5.5699 & TRN & \\
\hline CHEMBL1350256 & 688239 & 4.8362 & 5.405 & TST & \\
\hline CHEMBL1585697 & 688239 & 5.7362 & 5.4059 & TRN & \\
\hline CHEMBL1568118 & 688239 & 6.9363 & 5.5087 & TRN & \\
\hline CHEMBL1328454 & 688239 & 5.7862 & 5.4289 & TRN & \\
\hline CHEMBL1373170 & 688239 & 5.0362 & 5.5065 & TRN & \\
\hline CHEMBL1473056 & 688239 & 4.7862 & 5.4656 & TST & \\
\hline CHEMBL1318564 & 688239 & 4.5362 & 5.4867 & TRN & \\
\hline CHEMBL1609362 & 688239 & 6.9863 & 5.5676 & TRN & \\
\hline CHEMBL3193978 & 688239 & 6.1862 & 5.447999 & 99999999995 & TST \\
\hline CHEMBL1374224 & 688239 & 4.6362 & 5.6051 & TRN & \\
\hline CHEMBL1438947 & 688239 & 4.5362 & 5.5796 & TRN & \\
\hline CHEMBL1557577 & 688239 & 5.1362 & 5.4101 & TRN & \\
\hline CHEMBL1466577 & 688239 & 8.28399 & 99999999 & 5.5053 & TRN \\
\hline CHEMBL3193881 & 688239 & 7.1361 & 5.4386 & TRN & \\
\hline CHEMBL1325571 & 688239 & 4.5362 & 5.5502 & TRN & \\
\hline CHEMBL1328745 & 688239 & 5.0862 & 5.5188 & TRN & \\
\hline CHEMBL1544406 & 688239 & 8.3372 & 5.3978 & TST & \\
\hline CHEMBL1587966 & 688239 & 4.5862 & 5.563 & TRN & \\
\hline CHEMBL1489561 & 688239 & 5.1862 & 5.3237 & TST & \\
\hline CHEMBL1377829 & 688239 & 5.1362 & 5.6051 & TRN & \\
\hline CHEMBL1499393 & 688239 & 5.1862 & 5.5579 & TRN & \\
\hline CHEMBL1581085 & 688239 & 5.1862 & 5.586 & TRN & \\
\hline CHEMBL1367753 & 688239 & 4.7362 & 5.449 & TRN & \\
\hline CHEMBL1565041 & 688239 & 4.5362 & 5.51 & TST & \\
\hline CHEMBL1543455 & 688239 & 4.45 & 5.3939 & TST & \\
\hline
\end{tabular}




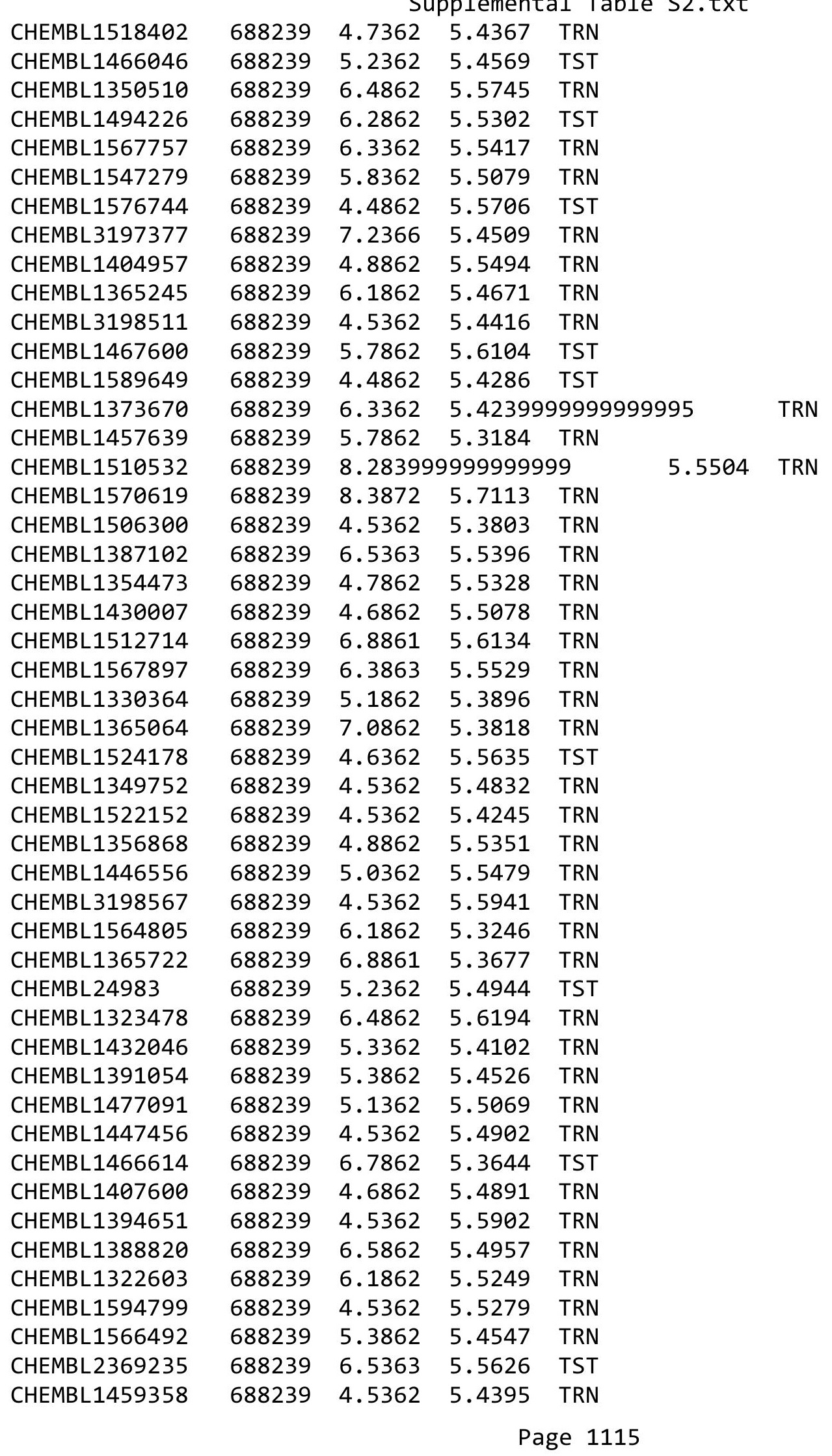


Supplemental Table S2.txt

\begin{tabular}{|c|c|c|c|c|c|}
\hline CHEMBL1380020 & 688239 & 4.5862 & 5.5694 & TRN & \\
\hline CHEMBL1352707 & 688239 & 5.7862 & 5.617999 & 999999999 & TST \\
\hline CHEMBL1599946 & 688239 & 5.3362 & 5.4433 & TRN & \\
\hline CHEMBL1365954 & 688239 & 5.1862 & 5.5353 & TRN & \\
\hline CHEMBL1999835 & 688239 & 4.8362 & 5.3423 & TRN & \\
\hline CHEMBL1463446 & 688239 & 5.4862 & 5.4206 & TRN & \\
\hline CHEMBL1598654 & 688239 & 4.6362 & 5.4982 & TRN & \\
\hline CHEMBL 3190483 & 688239 & 6.9363 & 5.5664 & TST & \\
\hline CHEMBL1527374 & 688239 & 4.5362 & 5.5217 & TRN & \\
\hline CHEMBL1413182 & 688239 & 5.5862 & 5.4137 & TRN & \\
\hline CHEMBL1563289 & 688239 & 4.5862 & 5.4012 & TRN & \\
\hline CHEMBL1424055 & 688239 & 5.1862 & 5.5689 & TST & \\
\hline CHEMBL1534367 & 688239 & 5.8362 & 5.4554 & TST & \\
\hline CHEMBL1433979 & 688239 & 4.5362 & 5.3098 & TRN & \\
\hline CHEMBL1409636 & 688239 & 4.6862 & 5.6435 & TRN & \\
\hline CHEMBL1569560 & 688239 & 4.9362 & 5.4107 & TRN & \\
\hline CHEMBL1563814 & 688239 & 5.6862 & 5.4599 & TRN & \\
\hline CHEMBL1448244 & 688239 & 5.1862 & 5.5317 & TRN & \\
\hline CHEMBL1388893 & 688239 & 4.7862 & 5.5682 & TST & \\
\hline CHEMBL1482739 & 688239 & 4.5862 & 5.5918 & TRN & \\
\hline CHEMBL1320932 & 688239 & 6.9863 & 5.4031 & TRN & \\
\hline CHEMBL3196215 & 688239 & 6.8362 & 5.6024 & TRN & \\
\hline CHEMBL1467187 & 688239 & 4.5362 & 5.393 & TRN & \\
\hline CHEMBL573627 & 688239 & 4.5362 & 5.3841 & TST & \\
\hline CHEMBL1511561 & 688239 & 4.4862 & 5.462000 & 000000001 & TST \\
\hline CHEMBL1543503 & 688239 & 4.5362 & 5.5317 & TRN & \\
\hline CHEMBL1509729 & 688239 & 4.4862 & 5.5472 & TRN & \\
\hline CHEMBL3193391 & 688239 & 4.4862 & 5.3287 & TST & \\
\hline CHEMBL1533961 & 688239 & 5.2862 & 5.5825 & TRN & \\
\hline CHEMBL1573475 & 688239 & 7.1361 & 5.4407 & TRN & \\
\hline CHEMBL1546998 & 688239 & 5.3862 & 5.3751 & TST & \\
\hline CHEMBL1600539 & 688239 & 8.28399 & 99999999 & 5.3254 & \\
\hline CHEMBL1571693 & 688239 & 4.7862 & 5.607 & TRN & \\
\hline CHEMBL1406889 & 688239 & 5.1862 & 5.4036 & TST & \\
\hline CHEMBL1405929 & 688239 & 4.8362 & 5.5116 & TST & \\
\hline CHEMBL1364334 & 688239 & 4.6362 & 5.5339 & TRN & \\
\hline CHEMBL1488172 & 688239 & 4.6862 & 5.3851 & TST & \\
\hline CHEMBL1391979 & 688239 & 4.6862 & 5.4454 & TRN & \\
\hline CHEMBL1587345 & 688239 & 5.7362 & 5.4865 & TST & \\
\hline CHEMBL1411398 & 688239 & 5.1362 & 5.6008 & TRN & \\
\hline CHEMBL1502409 & 688239 & 5.9362 & 5.5554 & TRN & \\
\hline CHEMBL1548679 & 688239 & 4.5862 & 5.5726 & TRN & \\
\hline CHEMBL1436365 & 688239 & 4.5862 & 5.2442 & TST & \\
\hline CHEMBL1334875 & 688239 & 4.8362 & 5.5835 & TRN & \\
\hline CHEMBL1348788 & 688239 & 4.6362 & 5.5359 & TST & \\
\hline CHEMBL1312515 & 688239 & 6.1862 & 5.5244 & TRN & \\
\hline CHEMBL1318363 & 688239 & 5.4362 & 5.5344 & TRN & \\
\hline CHEMBL1362148 & 688239 & 4.5362 & 5.5947 & TRN & \\
\hline
\end{tabular}




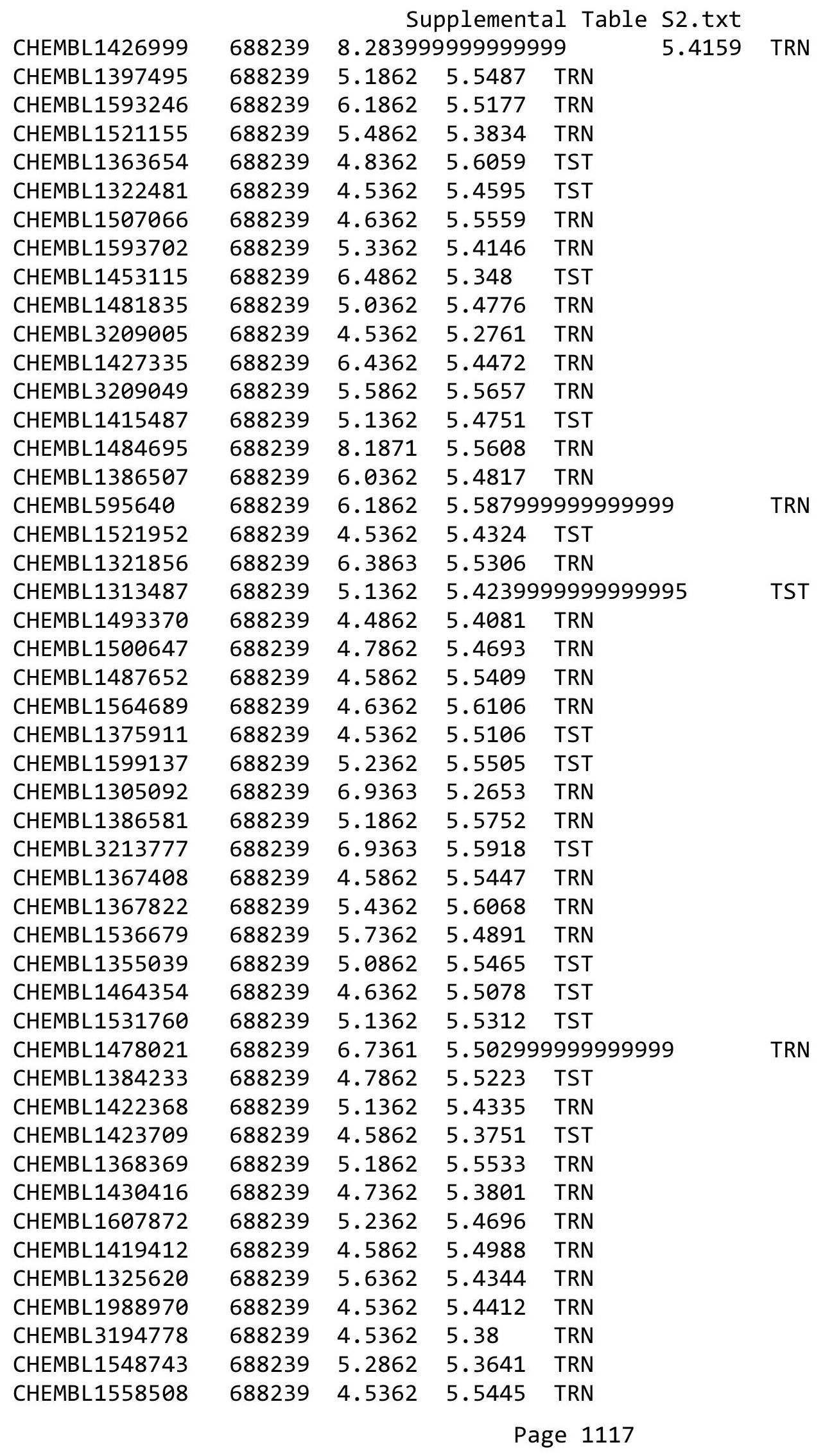


Supplemental Table S2.txt

\begin{tabular}{|c|c|c|c|c|}
\hline HEMBL1422195 & & 52 & & \\
\hline HEMPI 1550612 & & .4862 & 5.3524 & \\
\hline & & & & \\
\hline AEMBL1 & & & 87 & \\
\hline AEMBL198 & 8239 & 862 & & \\
\hline HEMBL1407394 & 88239 & 5862 & 4003 & \\
\hline HEMBL1 & 239 & 362 & 3797 & \\
\hline IEMBL1 & & & & \\
\hline HEMBL523 & 239 & 862 & 5448 & \\
\hline HEMBL142 & 88239 & 8662 & .4745 & \\
\hline AEMBL143 & 88239 & .1862 & .4 & \\
\hline IEMBL1 & 239 & 62 & & \\
\hline IEMBL1 & & & & \\
\hline HEMBL1 & & 362 & 3554 & \\
\hline AEMBL1 & & & & \\
\hline AEMBL1 & 39 & 362 & 99 & \\
\hline HEMBL1 & 39 & 61 & & \\
\hline HEMBL1 & & & & \\
\hline HEMBL1 & & 862 & & \\
\hline AEMBL3 & & & & \\
\hline AEMIBL & & 52 & 44 & 151 \\
\hline AEMBL & & & & \\
\hline HEMBL: & & & & \\
\hline 49 & & & & \\
\hline AEMBL1 & & & & ras \\
\hline HEMBLI & & & & RN \\
\hline HEMBL & & & & \\
\hline $\mathrm{AFMBI}$ & & & & ST \\
\hline HEMBL1 & & & & \\
\hline HEMBL14 & & & & SI \\
\hline HEMBL1 & & & & RIV \\
\hline $\mathrm{AFMB}$ & & & 44 & \\
\hline 47 & & & & RN \\
\hline HEMBL1 & & & & TRN \\
\hline HEMBL147 & & 862 & 341 & ГRN \\
\hline HEMBL1 & & & 14 & TRN \\
\hline HFMDI. & & & & RN \\
\hline JEMBL 14 & & & 729 & $\mathrm{RN}$ \\
\hline HEMBL1387130 & 88239 & 862 & 5.4445 & TST \\
\hline AEMBL1 & & 862 & 273 & RN \\
\hline HEMBL1 & & 362 & 223 & \\
\hline CHEMBL1 & & & & RN \\
\hline HEMBL1 & & 5862 & 5.5091 & IST \\
\hline AEMBL14 & 39 & 862 & 4921 & TST \\
\hline EBL1 & & & & TRN \\
\hline CHEMBL132 & & & & \\
\hline CHEMBL147 & & & 5.5563 & \\
\hline HEMBL1521768 & 688239 & 4.6862 & 5.5389 & ГRN \\
\hline
\end{tabular}

Page 1118 
Supplemental Table S2.txt

\begin{tabular}{|c|c|c|c|c|c|}
\hline CHEMBL1411544 & 688239 & 5.1862 & 5.5496 & TRN & \\
\hline CHEMBL1459234 & 688239 & 5.6862 & 5.6721 & TRN & \\
\hline CHEMBL1470815 & 688239 & 5.8862 & 5.511 & TRN & \\
\hline CHEMBL1368217 & 688239 & 5.8362 & 5.5819 & TRN & \\
\hline CHEMBL1573075 & 688239 & 4.5362 & 5.5861 & TRN & \\
\hline CHEMBL1552465 & 688239 & 4.7362 & 5.3466 & TRN & \\
\hline CHEMBL1349377 & 688239 & 5.1862 & 5.3453 & TST & \\
\hline CHEMBL1489602 & 688239 & 4.7362 & 5.4868 & TRN & \\
\hline CHEMBL1382073 & 688239 & 5.4362 & 5.4784 & TRN & \\
\hline CHEMBL1303786 & 688239 & 6.1862 & 5.587999 & 9999999999 & TST \\
\hline CHEMBL1575056 & 688239 & 6.2362 & 5.462999 & 9999999999 & TRN \\
\hline CHEMBL1566869 & 688239 & 6.4862 & 5.5378 & TST & \\
\hline CHEMBL1323334 & 688239 & 6.8362 & 5.4435 & TST & \\
\hline CHEMBL1384748 & 688239 & 4.5362 & 5.4337 & TRN & \\
\hline CHEMBL1397754 & 688239 & 6.5862 & 5.4817 & TRN & \\
\hline CHEMBL1588138 & 688239 & 5.6862 & 5.444 & TRN & \\
\hline CHEMBL1433394 & 688239 & 4.6862 & 5.4485 & TRN & \\
\hline CHEMBL1346423 & 688239 & 4.6862 & 5.4702 & TRN & \\
\hline CHEMBL1458822 & 688239 & 5.5362 & 5.5057 & TST & \\
\hline CHEMBL1491523 & 688239 & 5.2862 & 5.4501 & TRN & \\
\hline CHEMBL1525381 & 688239 & 5.4862 & 5.5973 & TRN & \\
\hline CHEMBL1306377 & 688239 & 4.5362 & 5.5867 & TRN & \\
\hline CHEMBL 3198309 & 688239 & 5.1362 & 5.3718 & TRN & \\
\hline CHEMBL1442742 & 688239 & 4.5362 & 5.2758 & TRN & \\
\hline CHEMBL1439906 & 688239 & 5.1862 & 5.502999 & 9999999999 & TRN \\
\hline CHEMBL 3193486 & 688239 & 6.0862 & 5.4101 & TRN & \\
\hline CHEMBL1369613 & 688239 & 5.3362 & 5.49 & TRN & \\
\hline CHEMBL1436276 & 688239 & 5.2862 & 5.4873 & TRN & \\
\hline CHEMBL3208795 & 688239 & 4.5362 & 5.5291 & TST & \\
\hline CHEMBL3196607 & 688239 & 4.9362 & 5.3264 & TST & \\
\hline CHEMBL 3193414 & 688239 & 6.4862 & 5.5059 & TRN & \\
\hline CHEMBL1471908 & 688239 & 4.9362 & 5.4864 & TRN & \\
\hline CHEMBL 3194910 & 688239 & 6.1862 & 5.4183 & TRN & \\
\hline CHEMBL1496517 & 688239 & 5.2862 & 5.5509 & TRN & \\
\hline CHEMBL 3191222 & 688239 & 5.1862 & 5.3533 & TRN & \\
\hline CHEMBL1315192 & 688239 & 4.5362 & 5.5547 & TRN & \\
\hline CHEMBL1302811 & 688239 & 5.4362 & 5.4751 & TRN & \\
\hline CHEMBL1486093 & 688239 & 5.3862 & 5.4128 & TRN & \\
\hline CHEMBL1410887 & 688239 & 5.4362 & 5.5535 & TRN & \\
\hline CHEMBL1318903 & 688239 & 4.5362 & 5.3541 & TRN & \\
\hline CHEMBL1483994 & 688239 & 5.1862 & 5.4493 & TRN & \\
\hline CHEMBL1357472 & 688239 & 4.5362 & 5.3841 & TST & \\
\hline CHEMBL1351579 & 688239 & 5.3862 & 5.4383 & TST & \\
\hline CHEMBL1525154 & 688239 & 4.5862 & 5.5724 & TRN & \\
\hline CHEMBL1355191 & 688239 & 4.6862 & 5.3734 & TRN & \\
\hline CHEMBL1572596 & 688239 & 5.8362 & 5.4876 & TRN & \\
\hline CHEMBL1333882 & 688239 & 5.7362 & 5.5762 & TRN & \\
\hline CHEMBL1450114 & 688239 & 8.3872 & 5.4027 & TRN & \\
\hline
\end{tabular}


Supplemental Table S2.txt

\begin{tabular}{|c|c|c|c|c|c|}
\hline CHEMBL1461469 & 688239 & 6.7862 & 5.558 & TRN & \\
\hline CHEMBL1494994 & 688239 & 4.5362 & 5.5242 & TST & \\
\hline CHEMBL1334051 & 688239 & 8.3372 & 5.4399 & TRN & \\
\hline CHEMBL1355527 & 688239 & 8.3372 & 5.5755 & TRN & \\
\hline CHEMBL1483328 & 688239 & 8.1871 & 5.4232 & TRN & \\
\hline CHEMBL1305932 & 688239 & 7.2366 & 5.5673 & TRN & \\
\hline CHEMBL1565420 & 688239 & 6.3362 & 5.4643 & TST & \\
\hline CHEMBL129261 & 688239 & 5.6362 & 5.3885 & TRN & \\
\hline CHEMBL1452481 & 688239 & 4.5362 & 5.4179 & TST & \\
\hline CHEMBL1441773 & 688239 & 5.4862 & 5.5237 & TST & \\
\hline CHEMBL 3196372 & 688239 & 6.5862 & 5.44 & TST & \\
\hline CHEMBL1526923 & 688239 & 4.8362 & 5.4382 & TRN & \\
\hline CHEMBL1595343 & 688239 & 6.4862 & 5.4693 & TRN & \\
\hline CHEMBL1411054 & 688239 & 5.0862 & 5.4757 & TRN & \\
\hline CHEMBL1404787 & 688239 & 7.1864 & 5.3665 & TST & \\
\hline CHEMBL1332486 & 688239 & 4.6362 & 5.6322 & TRN & \\
\hline CHEMBL1491664 & 688239 & 4.4862 & 5.70799 & 9999999999 & TST \\
\hline CHEMBL1383129 & 688239 & 4.5362 & 5.5133 & TRN & \\
\hline CHEMBL1305960 & 688239 & 4.5362 & 5.2293 & TRN & \\
\hline CHEMBL524222 & 688239 & 7.0862 & 5.5075 & TRN & \\
\hline CHEMBL1371365 & 688239 & 6.6861 & 5.54799 & 9999999999 & TRN \\
\hline CHEMBL 3207792 & 688239 & 4.5362 & 5.5161 & TRN & \\
\hline CHEMBL1443126 & 688239 & 6.8861 & 5.5725 & TST & \\
\hline CHEMBL1611364 & 688239 & 5.1862 & 5.4947 & TRN & \\
\hline CHEMBL1470239 & 688239 & 5.7362 & 5.37 & TRN & \\
\hline CHEMBL1495291 & 688239 & 6.0862 & 5.4852 & TST & \\
\hline CHEMBL1535794 & 688239 & 4.6862 & 5.4962 & TRN & \\
\hline CHEMBL1517511 & 688239 & 5.1862 & 5.4371 & TST & \\
\hline CHEMBL1358516 & 688239 & 5.6862 & 5.4634 & TRN & \\
\hline CHEMBL1429489 & 688239 & 4.5862 & 5.3899 & TRN & \\
\hline CHEMBL1469567 & 688239 & 4.5362 & 5.5807 & TRN & \\
\hline CHEMBL1322047 & 688239 & 6.0862 & 5.599 & TRN & \\
\hline CHEMBL1453296 & 688239 & 5.6362 & 5.4081 & TRN & \\
\hline CHEMBL1469841 & 688239 & 4.5362 & 5.4277 & TST & \\
\hline CHEMBL 3198682 & 688239 & 4.5362 & 5.5638 & TST & \\
\hline CHEMBL1349923 & 688239 & 5.4862 & 5.5432 & TRN & \\
\hline CHEMBL1441404 & 688239 & 6.1862 & 5.4981 & TST & \\
\hline CHEMBL1503755 & 688239 & 6.0362 & 5.4863 & TRN & \\
\hline CHEMBL601822 & 688239 & 4.5362 & 5.6039 & TST & \\
\hline CHEMBL1606912 & 688239 & 5.8862 & 5.5168 & TRN & \\
\hline CHEMBL1403481 & 688239 & 4.5362 & 5.5237 & TRN & \\
\hline CHEMBL1577881 & 688239 & 6.2862 & 5.5902 & TRN & \\
\hline CHEMBL1465116 & 688239 & 5.1862 & 5.4495 & TRN & \\
\hline CHEMBL1444174 & 688239 & 6.2862 & 5.345 & TRN & \\
\hline CHEMBL1558154 & 688239 & 4.7362 & 5.5966 & TRN & \\
\hline CHEMBL1612938 & 688239 & 5.1862 & 5.4412 & TRN & \\
\hline CHEMBL1336152 & 688239 & 6.8362 & 5.4893 & TRN & \\
\hline CHEMBL1362736 & 688239 & 4.5362 & 5.5227 & TRN & \\
\hline
\end{tabular}


Supplemental Table S2.txt

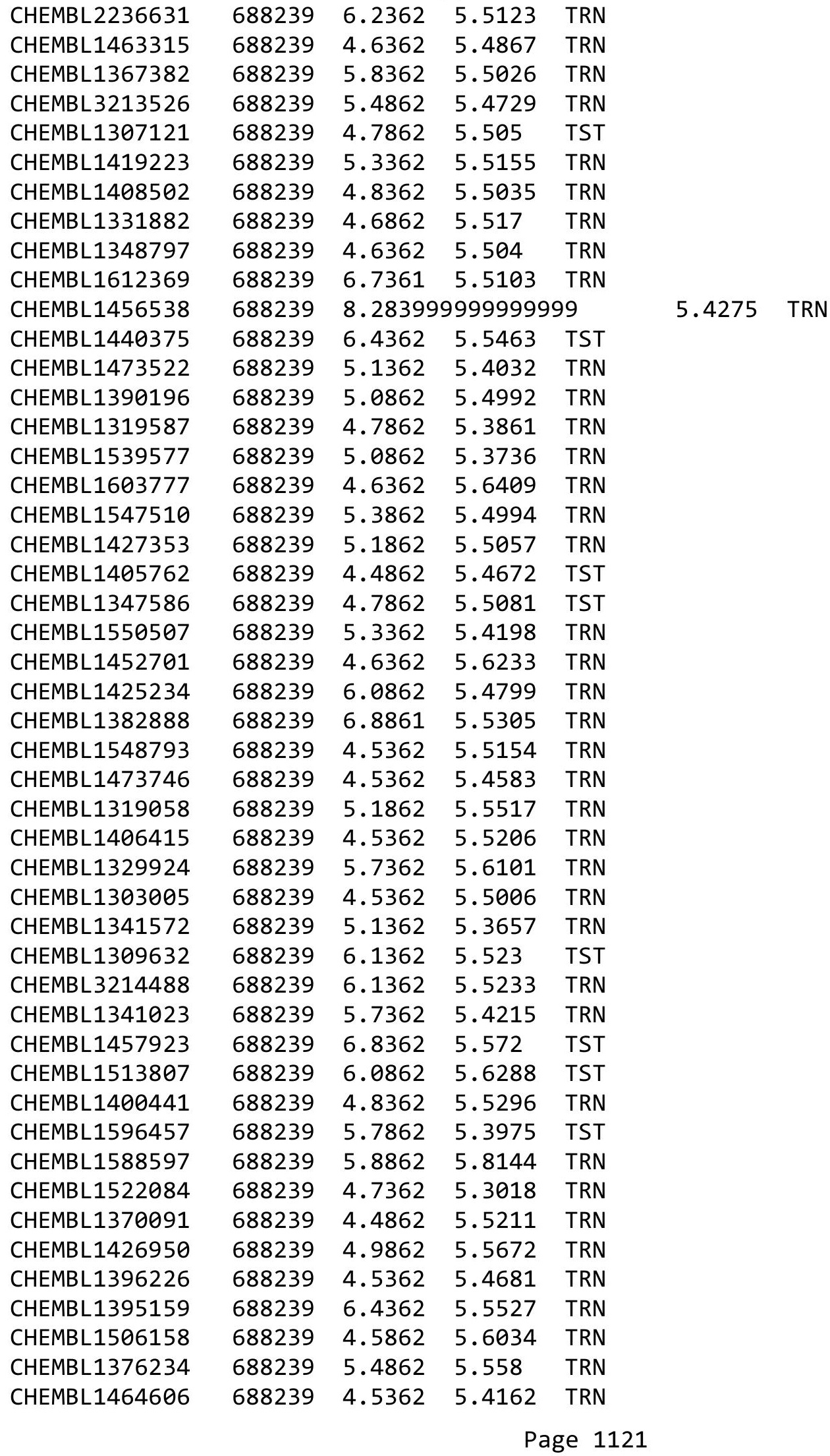


Supplemental Table S2.txt

\begin{tabular}{|c|c|c|c|c|}
\hline 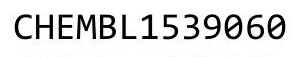 & & & & \\
\hline HEMBL1607669 & 38239 & 5362 & 5288 & \\
\hline AEMBL1522729 & 239 & 362 & & \\
\hline 805 & 39 & 862 & & \\
\hline AEMBL160 & 39 & 362 & & \\
\hline AEMBL1432553 & 88239 & 362 & 48 & \\
\hline AEMBL1344032 & 88239 & 862 & 3969 & \\
\hline AEMBL1500437 & & 862 & & \\
\hline EMBL 140 & 39 & 362 & & \\
\hline IEMBL1509467 & & 862 & & \\
\hline AEMBL1317180 & 239 & 362 & 76 & \\
\hline AEMBL1338206 & 39 & 862 & & \\
\hline HEMBL1465867 & & 62 & & \\
\hline HEMBL1530294 & & 62 & & \\
\hline HEMBL 142 & & & & \\
\hline AEMBL1454681 & & 362 & & \\
\hline AEMBL1609013 & & 862 & & \\
\hline IEMBL141; & & 62 & & \\
\hline JEMBL148 & & 62 & & \\
\hline AEMBL153 & & 62 & & \\
\hline HEMBL 321 & & 362 & & \\
\hline AEMBL1432 & & 861 & & \\
\hline HEMBL15 & & 63 & & \\
\hline HEMBL 17 & & & & \\
\hline 221 & & 62 & & \\
\hline (15MD 190 & & 362 & & \\
\hline IEMBL134C & & 62 & & \\
\hline AEMBL15 & & 361 & & \\
\hline$A F M B$ & & 52 & & \\
\hline IEMPI $15^{\circ}$ & & 362 & & \\
\hline AEMBL1309714 & & & & \\
\hline HEMBL1538981 & & 862 & & \\
\hline & & 62 & & \\
\hline 4 & & & & \\
\hline AEMBL31S & & & & RN \\
\hline AEMBL1303295 & & 362 & & \\
\hline AEMBL1453583 & & 862 & & \\
\hline & & 362 & & \\
\hline 9 & & & & \\
\hline HEMBL1972506 & & & & RN \\
\hline AEMBL1386988 & & 362 & & \\
\hline HEMBL 144 & & 362 & & \\
\hline & & & & \\
\hline HEMBL1333217 & & & & \\
\hline AEMBL1603946 & & 4.5362 & & RN \\
\hline IEMBL3209075 & & 372 & & \\
\hline .MOI 157141 & & & & \\
\hline HEMBL158905 & & & & \\
\hline
\end{tabular}

Page 1122 
Supplemental Table S2.txt

\begin{tabular}{|c|c|c|c|c|c|}
\hline CHEMBL1416948 & 688239 & 4.5362 & 5.4264 & TST & \\
\hline CHEMBL1604616 & 688239 & 6.8861 & \multicolumn{2}{|c|}{5.372999999999999} & TST \\
\hline CHEMBL1480625 & 688239 & 4.6362 & 5.4808 & TRN & \\
\hline CHEMBL1380492 & 688239 & 6.2862 & 5.4931 & TRN & \\
\hline CHEMBL1306640 & 688239 & 6.2862 & 5.5512 & TRN & \\
\hline CHEMBL1463838 & 688239 & 4.5362 & 5.4885 & TRN & \\
\hline CHEMBL1389284 & 688239 & 4.6862 & 5.5149 & TRN & \\
\hline CHEMBL1546607 & 688239 & 5.9362 & 5.3142 & TRN & \\
\hline CHEMBL1437383 & 688239 & 4.6862 & 5.4064 & TRN & \\
\hline CHEMBL1999538 & 688239 & 6.1362 & 5.5696 & TRN & \\
\hline CHEMBL1592968 & 688239 & 4.5362 & 5.615 & TRN & \\
\hline CHEMBL1603961 & 688239 & 5.6362 & 5.5421 & TST & \\
\hline CHEMBL1578267 & 688239 & 5.7862 & 5.5802 & TRN & \\
\hline CHEMBL1502937 & 688239 & 4.6362 & 5.2236 & TST & \\
\hline CHEMBL1374660 & 688239 & 4.45 & 5.5234 & TRN & \\
\hline CHEMBL1604684 & 688239 & 4.5362 & 5.5259 & TST & \\
\hline CHEMBL1484934 & 688239 & 4.6362 & 5.3928 & TST & \\
\hline CHEMBL1337483 & 688239 & 4.7362 & 5.5642 & TST & \\
\hline CHEMBL1353278 & 688239 & 6.0862 & 5.5113 & TRN & \\
\hline CHEMBL1416569 & 688239 & 6.2862 & 5.4078 & TRN & \\
\hline CHEMBL1421857 & 688239 & 4.8362 & 5.4767 & TST & \\
\hline CHEMBL1353671 & 688239 & 6.5862 & \multicolumn{2}{|c|}{5.4879999999999995} & TRN \\
\hline CHEMBL1411810 & 688239 & 4.7362 & 5.3475 & TRN & \\
\hline CHEMBL3189812 & 688239 & 6.0862 & 5.5642 & TST & \\
\hline CHEMBL1548931 & 688239 & 5.5862 & 5.4702 & TRN & \\
\hline CHEMBL1522317 & 688239 & 6.1362 & 5.4911 & TRN & \\
\hline CHEMBL1321199 & 688239 & 4.5362 & 5.5358 & TST & \\
\hline CHEMBL1397064 & 688239 & 4.5362 & 5.6469 & TRN & \\
\hline CHEMBL1571013 & 688239 & 6.2362 & 5.4725 & TST & \\
\hline CHEMBL1317064 & 688239 & 4.7362 & 5.5959 & TRN & \\
\hline CHEMBL1566594 & 688239 & 5.5862 & 5.4632 & TRN & \\
\hline CHEMBL1380937 & 688239 & 4.6862 & 5.4207 & TRN & \\
\hline CHEMBL1433237 & 688239 & 4.5362 & 5.4334 & TRN & \\
\hline CHEMBL1478804 & 688239 & 4.9362 & 5.5699 & TRN & \\
\hline CHEMBL578508 & 688239 & 5.1862 & 5.4196 & TST & \\
\hline CHEMBL1532794 & 688239 & 4.7362 & 5.4099 & TST & \\
\hline CHEMBL1500733 & 688239 & 8.2366 & 5.4486 & TST & \\
\hline CHEMBL1377849 & 688239 & 4.7 & 5.3916 & TRN & \\
\hline CHEMBL1566237 & 688239 & 4.6362 & 5.5375 & TRN & \\
\hline CHEMBL1525306 & 688239 & 5.1362 & 5.5801 & TRN & \\
\hline CHEMBL1450685 & 688239 & 7.2865 & 5.48 & TRN & \\
\hline CHEMBL1497692 & 688239 & 5.0862 & 5.5208 & TRN & \\
\hline CHEMBL1528853 & 688239 & 5.1862 & 5.5685 & TRN & \\
\hline CHEMBL1337038 & 688239 & 4.5362 & 5.3031 & TRN & \\
\hline CHEMBL1479992 & 688239 & 4.7862 & 5.556 & TRN & \\
\hline CHEMBL1557245 & 688239 & 6.3863 & 5.5519 & TST & \\
\hline CHEMBL1500071 & 688239 & 5.5362 & 5.5624 & TRN & \\
\hline CHEMBL1610038 & 688239 & 5.9362 & 5.5525 & TRN & \\
\hline
\end{tabular}


Supplemental Table S2.txt

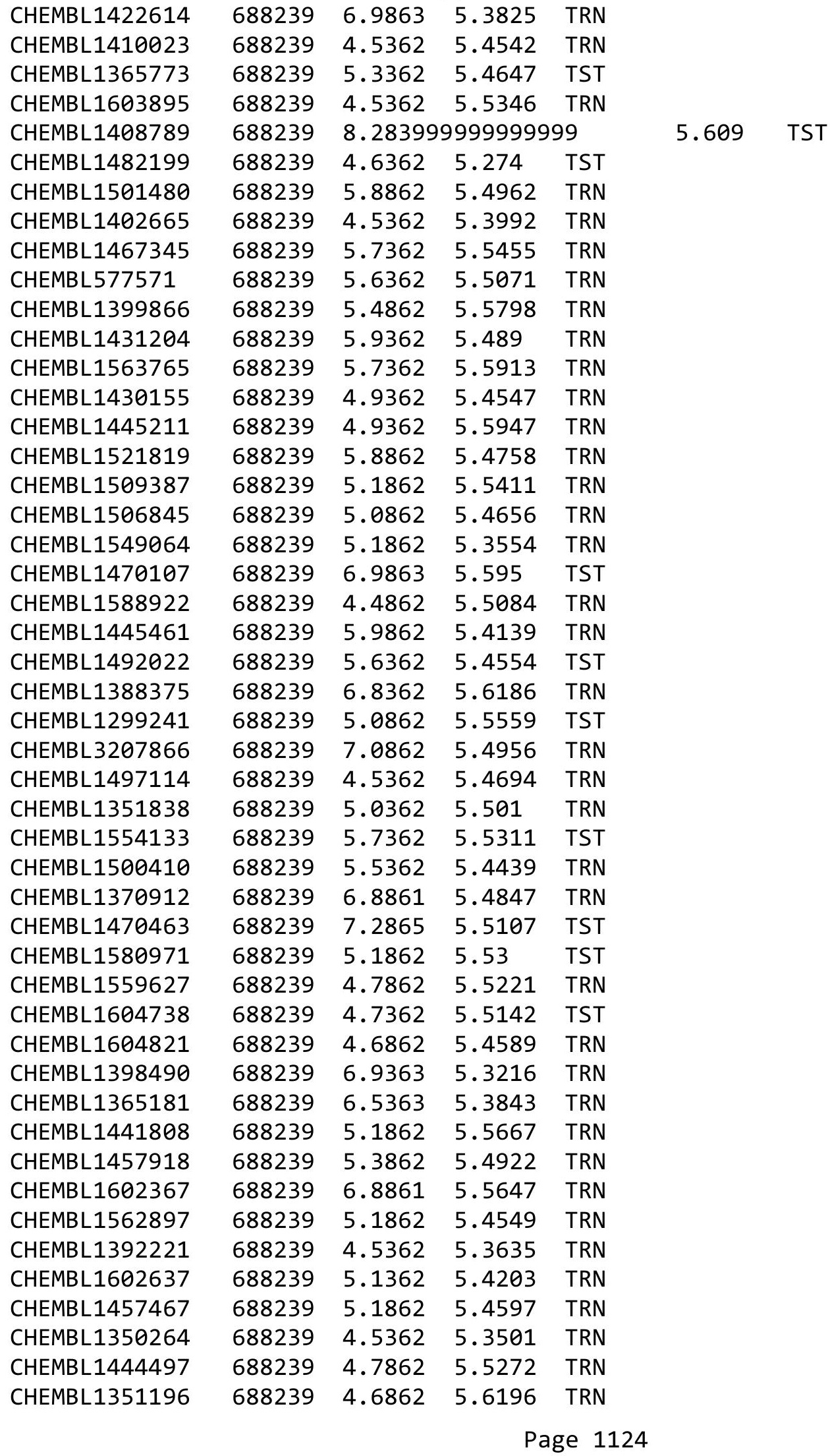




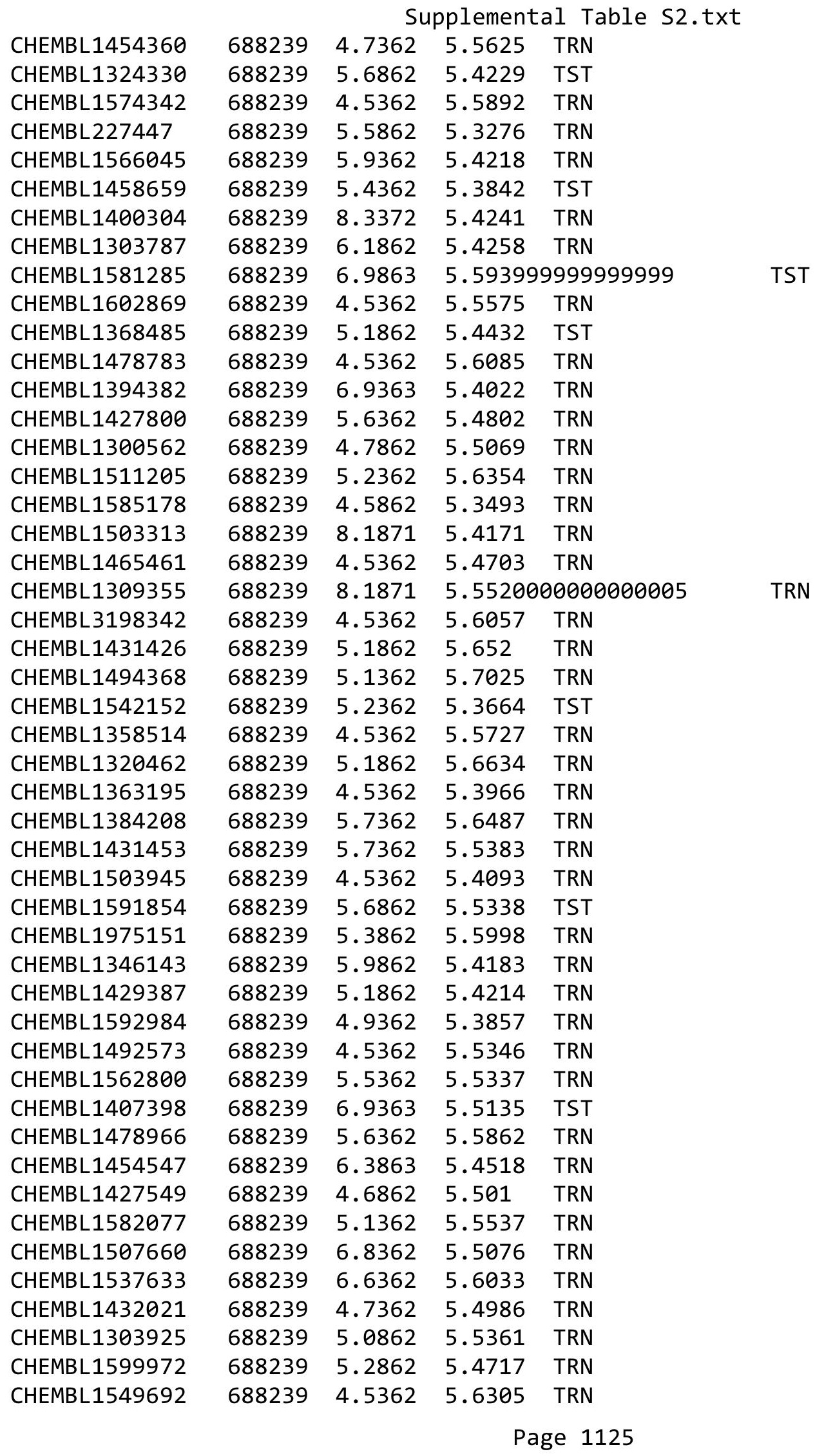


Supplemental Table S2.txt

\begin{tabular}{|c|c|c|c|c|}
\hline CHEMBL1573665 & 688239 & 4.6362 & 5.4035 & TRN \\
\hline CHEMBL1547010 & 688239 & 5.1862 & 5.5283 & TRN \\
\hline CHEMBL1501104 & 688239 & 4.8862 & 5.4411 & TRN \\
\hline CHEMBL1401459 & 688239 & 4.6362 & 5.5101 & TRN \\
\hline CHEMBL1562996 & 688239 & 4.7362 & 5.4026 & TRN \\
\hline CHEMBL1377483 & 688239 & 6.9863 & 5.4969 & TRN \\
\hline CHEMBL1381392 & 688239 & 5.6362 & 5.4159 & TRN \\
\hline CHEMBL1452213 & 688239 & 5.1862 & 5.4901 & TRN \\
\hline CHEMBL1521186 & 688239 & 4.5362 & 5.5713 & TRN \\
\hline CHEMBL1548184 & 688239 & 4.7362 & 5.6432 & TST \\
\hline CHEMBL1395848 & 688239 & 8.1367 & 5.4809 & TRN \\
\hline CHEMBL1322376 & 688239 & 4.6862 & 5.4713 & TST \\
\hline CHEMBL1479916 & 688239 & 5.7362 & 5.4597 & TRN \\
\hline CHEMBL1446492 & 688239 & 5.4362 & 5.4044 & TRN \\
\hline CHEMBL1478947 & 688239 & 5.8862 & 5.5659 & TRN \\
\hline CHEMBL1366570 & 688239 & 4.7362 & 5.4435 & TRN \\
\hline CHEMBL1538646 & 688239 & 5.1862 & 5.388 & TRN \\
\hline CHEMBL1520163 & 688239 & 5.6362 & 5.5186 & TRN \\
\hline CHEMBL1497901 & 688239 & 5.5362 & 5.5364 & TRN \\
\hline CHEMBL1544490 & 688239 & 5.6862 & 5.5178 & TRN \\
\hline CHEMBL1530873 & 688239 & 4.6862 & 5.5267 & TRN \\
\hline CHEMBL1426730 & 688239 & 4.7862 & 5.5124 & TRN \\
\hline CHEMBL1407193 & 688239 & 5.3862 & 5.5011 & TST \\
\hline CHEMBL1495761 & 688239 & 5.3362 & 5.4547 & TRN \\
\hline CHEMBL3191920 & 688239 & 4.5862 & 5.2723 & TRN \\
\hline CHEMBL1430480 & 688239 & 6.2362 & 5.4523 & TRN \\
\hline CHEMBL1502607 & 688239 & 4.7862 & 5.38700 & 30000000005 \\
\hline CHEMBL1408883 & 688239 & 4.5362 & 5.4152 & TRN \\
\hline CHEMBL1550833 & 688239 & 4.5362 & 5.5552 & TRN \\
\hline CHEMBL1462014 & 688239 & 5.4862 & 5.6308 & TRN \\
\hline CHEMBL1508909 & 688239 & 4.7362 & 5.3459 & TRN \\
\hline CHEMBL1583635 & 688239 & 5.1862 & 5.5246 & TRN \\
\hline CHEMBL1479675 & 688239 & 5.4862 & 5.442 & TRN \\
\hline CHEMBL1433037 & 688239 & 4.5862 & 5.3939 & TRN \\
\hline CHEMBL1334746 & 688239 & 4.6862 & 5.4876 & TRN \\
\hline CHEMBL1309267 & 688239 & 5.8862 & 5.7382 & TRN \\
\hline CHEMBL1374259 & 688239 & 5.1862 & 5.6222 & TRN \\
\hline CHEMBL1537732 & 688239 & 5.1862 & 5.4321 & TRN \\
\hline CHEMBL1579272 & 688239 & 5.4362 & 5.4577 & TRN \\
\hline CHEMBL1455198 & 688239 & 6.1862 & 5.5362 & TRN \\
\hline CHEMBL1579996 & 688239 & 6.1862 & 5.4402 & TRN \\
\hline CHEMBL1482088 & 688239 & 5.1862 & 5.3799 & TRN \\
\hline CHEMBL1419668 & 688239 & 4.6362 & 5.6022 & TST \\
\hline CHEMBL1583967 & 688239 & 4.5362 & 5.6155 & TRN \\
\hline CHEMBL1489611 & 688239 & 5.1862 & 5.607 & TRN \\
\hline CHEMBL 1452728 & 688239 & 4.5362 & 5.5653 & TST \\
\hline CHEMBL1580922 & 688239 & 4.65 & 5.4459 & TRN \\
\hline CHEMBL1373245 & 688239 & 5.1862 & 5.4405 & TRN \\
\hline
\end{tabular}


Supplemental Table S2.txt

\begin{tabular}{|c|c|c|c|c|c|}
\hline CHEMBL1439337 & 688239 & 4.5362 & 5.4942 & TRN & \\
\hline CHEMBL1382634 & 688239 & 4.5362 & 5.4173 & TRN & \\
\hline CHEMBL 3207328 & 688239 & 8.3372 & 5.477 & TRN & \\
\hline CHEMBL1480531 & 688239 & 6.1362 & 5.5563 & TRN & \\
\hline CHEMBL1573374 & 688239 & 4.7862 & 5.5281 & TRN & \\
\hline CHEMBL1417569 & 688239 & 4.7862 & 5.4356 & TRN & \\
\hline CHEMBL1437481 & 688239 & 5.4362 & 5.5113 & TRN & \\
\hline CHEMBL1577258 & 688239 & 6.0362 & 5.5114 & TST & \\
\hline CHEMBL1555482 & 688239 & 4.8362 & 5.445 & TRN & \\
\hline CHEMBL1449392 & 688239 & 6.7862 & 5.3601 & TRN & \\
\hline CHEMBL1492389 & 688239 & 6.9363 & 5.313 & TST & \\
\hline CHEMBL1492960 & 688239 & 5.5362 & 5.6304 & TRN & \\
\hline CHEMBL1575731 & 688239 & 7.1361 & 5.4665 & TRN & \\
\hline CHEMBL1328873 & 688239 & 4.7862 & 5.5958 & TRN & \\
\hline CHEMBL1535275 & 688239 & 4.5362 & 5.5959 & TRN & \\
\hline CHEMBL1371675 & 688239 & 5.0362 & 5.5303 & TRN & \\
\hline CHEMBL1496888 & 688239 & 5.4862 & 5.3923 & TRN & \\
\hline CHEMBL1499763 & 688239 & 5.1362 & 5.421 & TRN & \\
\hline CHEMBL1365317 & 688239 & 4.6362 & 5.5067 & TST & \\
\hline CHEMBL1381543 & 688239 & 7.0362 & 5.5526 & TRN & \\
\hline CHEMBL1402681 & 688239 & 7.5361 & 5.5663 & TRN & \\
\hline CHEMBL1423663 & 688239 & 5.2862 & 5.3945 & TRN & \\
\hline CHEMBL1427702 & 688239 & 4.7362 & 5.449 & TRN & \\
\hline CHEMBL405343 & 688239 & 4.5362 & 5.4784 & TRN & \\
\hline CHEMBL1605141 & 688239 & 4.7862 & 5.3931 & TRN & \\
\hline CHEMBL1547956 & 688239 & 5.4862 & 5.5463 & TRN & \\
\hline CHEMBL1429634 & 688239 & 4.5362 & 5.3507 & TRN & \\
\hline CHEMBL1320163 & 688239 & 5.6862 & 5.8 & TRN & \\
\hline CHEMBL1387516 & 688239 & 5.2362 & 5.4662 & TRN & \\
\hline CHEMBL1342531 & 688239 & 4.7862 & 5.3446 & TRN & \\
\hline CHEMBL1561259 & 688239 & 4.6862 & 5.49299 & 9999999999 & TRN \\
\hline CHEMBL1545316 & 688239 & 4.5362 & 5.5284 & TRN & \\
\hline CHEMBL1353382 & 688239 & 5.8362 & 5.5066 & TST & \\
\hline CHEMBL1357191 & 688239 & 4.5362 & 5.5542 & TST & \\
\hline CHEMBL1454865 & 688239 & 4.8862 & 5.4886 & TST & \\
\hline CHEMBL1363098 & 688239 & 7.1361 & 5.4639 & TST & \\
\hline CHEMBL1503659 & 688239 & 4.5362 & 5.42299 & 9999999999 & TRN \\
\hline CHEMBL1557966 & 688239 & 5.6362 & 5.5847 & TRN & \\
\hline CHEMBL1473315 & 688239 & 4.5362 & 5.4552 & TRN & \\
\hline CHEMBL1585440 & 688239 & 4.9862 & 5.4271 & TST & \\
\hline CHEMBL1460674 & 688239 & 5.4362 & 5.4937 & TST & \\
\hline CHEMBL1483262 & 688239 & 5.9362 & 5.5358 & TRN & \\
\hline CHEMBL1430665 & 688239 & 6.1362 & 5.4399 & TRN & \\
\hline CHEMBL 3192850 & 688239 & 5.1362 & 5.4339 & TST & \\
\hline CHEMBL1563374 & 688239 & 4.9362 & 5.4775 & TST & \\
\hline CHEMBL1578765 & 688239 & 4.5362 & 5.4945 & TRN & \\
\hline CHEMBL1306172 & 688239 & 5.3362 & 5.5661 & TRN & \\
\hline CHEMBL 3210254 & 688239 & 4.5362 & 5.54899 & 99999999995 & TRN \\
\hline
\end{tabular}


Supplemental Table S2.txt

\begin{tabular}{|c|c|c|c|c|}
\hline CHEMBL1397536 & 688239 & 5.1862 & 5.4912 & TRN \\
\hline CHEMBL1302257 & 688239 & 7.9872 & 5.5938 & TRN \\
\hline CHEMBL1581723 & 688239 & 4.6862 & 5.6173 & TRN \\
\hline CHEMBL1570592 & 688239 & 5.4362 & 5.4448 & TRN \\
\hline CHEMBL1334459 & 688239 & 4.8862 & 5.3724 & TRN \\
\hline CHEMBL 3191858 & 688239 & 5.6862 & 5.4221 & TRN \\
\hline CHEMBL1607796 & 688239 & 5.7862 & 5.4594 & TRN \\
\hline CHEMBL1348773 & 688239 & 6.1362 & 5.4703 & TST \\
\hline CHEMBL1499340 & 688239 & 4.6362 & 5.38 & TST \\
\hline CHEMBL1381245 & 688239 & 8.3372 & 5.5014 & TRN \\
\hline CHEMBL1508702 & 688239 & 5.1862 & 5.4263 & TRN \\
\hline CHEMBL1585071 & 688239 & 5.5362 & 5.4458 & TRN \\
\hline CHEMBL1610034 & 688239 & 5.1862 & 5.4022 & TRN \\
\hline CHEMBL1537024 & 688239 & 4.5362 & 5.4214 & TRN \\
\hline CHEMBL1587929 & 688239 & 4.7362 & 5.4351 & TRN \\
\hline CHEMBL1337233 & 688239 & 6.1362 & 5.4858 & TRN \\
\hline CHEMBL1440350 & 688239 & 5.2862 & 5.5183 & TRN \\
\hline CHEMBL1382675 & 688239 & 6.3863 & 5.5557 & TRN \\
\hline CHEMBL1544210 & 688239 & 4.5362 & 5.4081 & TRN \\
\hline CHEMBL1316224 & 688239 & 5.4362 & 5.4306 & TRN \\
\hline CHEMBL1318196 & 688239 & 7.2366 & 5.4339 & TRN \\
\hline CHEMBL1500536 & 688239 & 5.4362 & 5.6011 & TRN \\
\hline CHEMBL1304037 & 688239 & 5.0862 & 5.4615 & TRN \\
\hline CHEMBL1348502 & 688239 & 6.5862 & 5.4039 & TRN \\
\hline CHEMBL1462581 & 688239 & 6.0862 & 5.4728 & TRN \\
\hline CHEMBL1596635 & 688239 & 4.5362 & 5.3537 & TRN \\
\hline CHEMBL1609073 & 688239 & 4.6362 & 5.6032 & TST \\
\hline CHEMBL1608660 & 688239 & 6.9363 & 5.6337 & TRN \\
\hline CHEMBL1536467 & 688239 & 4.5362 & 5.5421 & TRN \\
\hline CHEMBL1346142 & 688239 & 4.6362 & 5.4261 & TRN \\
\hline CHEMBL1386080 & 688239 & 6.2862 & 5.5195 & TRN \\
\hline CHEMBL1415881 & 688239 & 4.9362 & 5.5646 & TST \\
\hline CHEMBL 3190641 & 688239 & 4.5362 & 5.381 & TRN \\
\hline CHEMBL1427013 & 688239 & 4.4862 & 5.5803 & TRN \\
\hline CHEMBL1464551 & 688239 & 5.7362 & 5.532999 & 99999999995 \\
\hline CHEMBL1577081 & 688239 & 6.0862 & 5.4267 & TST \\
\hline CHEMBL1597332 & 688239 & 4.4362 & 5.4007 & TRN \\
\hline CHEMBL1473345 & 688239 & 4.5362 & 5.4826 & TRN \\
\hline CHEMBL1441930 & 688239 & 5.1862 & 5.3416 & TST \\
\hline CHEMBL1305005 & 688239 & 4.4862 & 5.6301 & TRN \\
\hline CHEMBL1539639 & 688239 & 4.6362 & 5.5774 & TRN \\
\hline CHEMBL1580746 & 688239 & 4.5362 & 5.5629 & TRN \\
\hline CHEMBL1455152 & 688239 & 6.2362 & 5.5598 & TRN \\
\hline CHEMBL1487606 & 688239 & 5.1862 & 5.4643 & TRN \\
\hline CHEMBL1565006 & 688239 & 4.7362 & 5.6073 & TRN \\
\hline CHEMBL1371771 & 688239 & 5.3862 & 5.5345 & TST \\
\hline CHEMBL1483766 & 688239 & 8.2366 & 5.5491 & TRN \\
\hline CHEMBL1598628 & 688239 & 4.7862 & 5.4726 & TRN \\
\hline
\end{tabular}




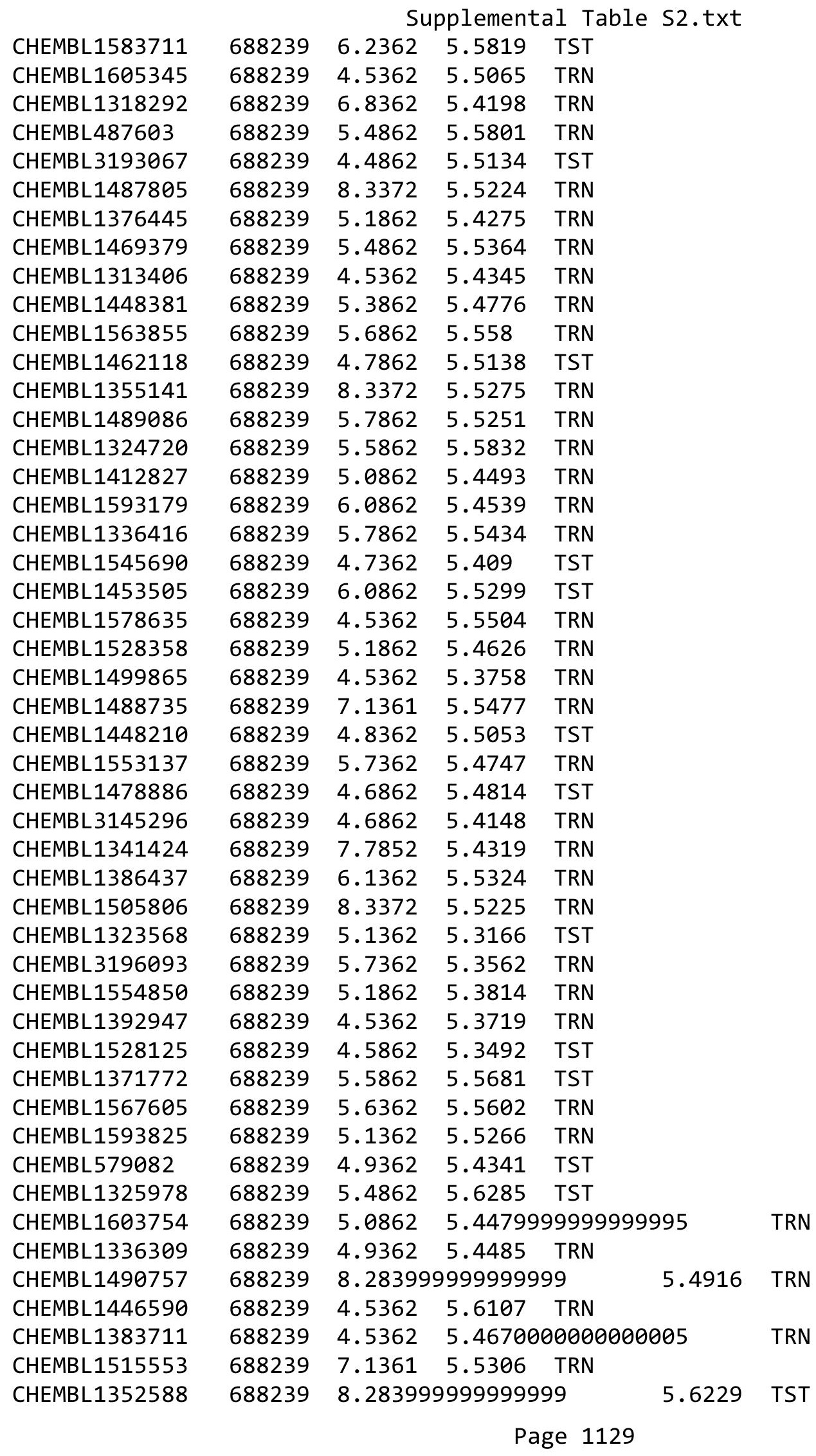


Supplemental Table S2.txt

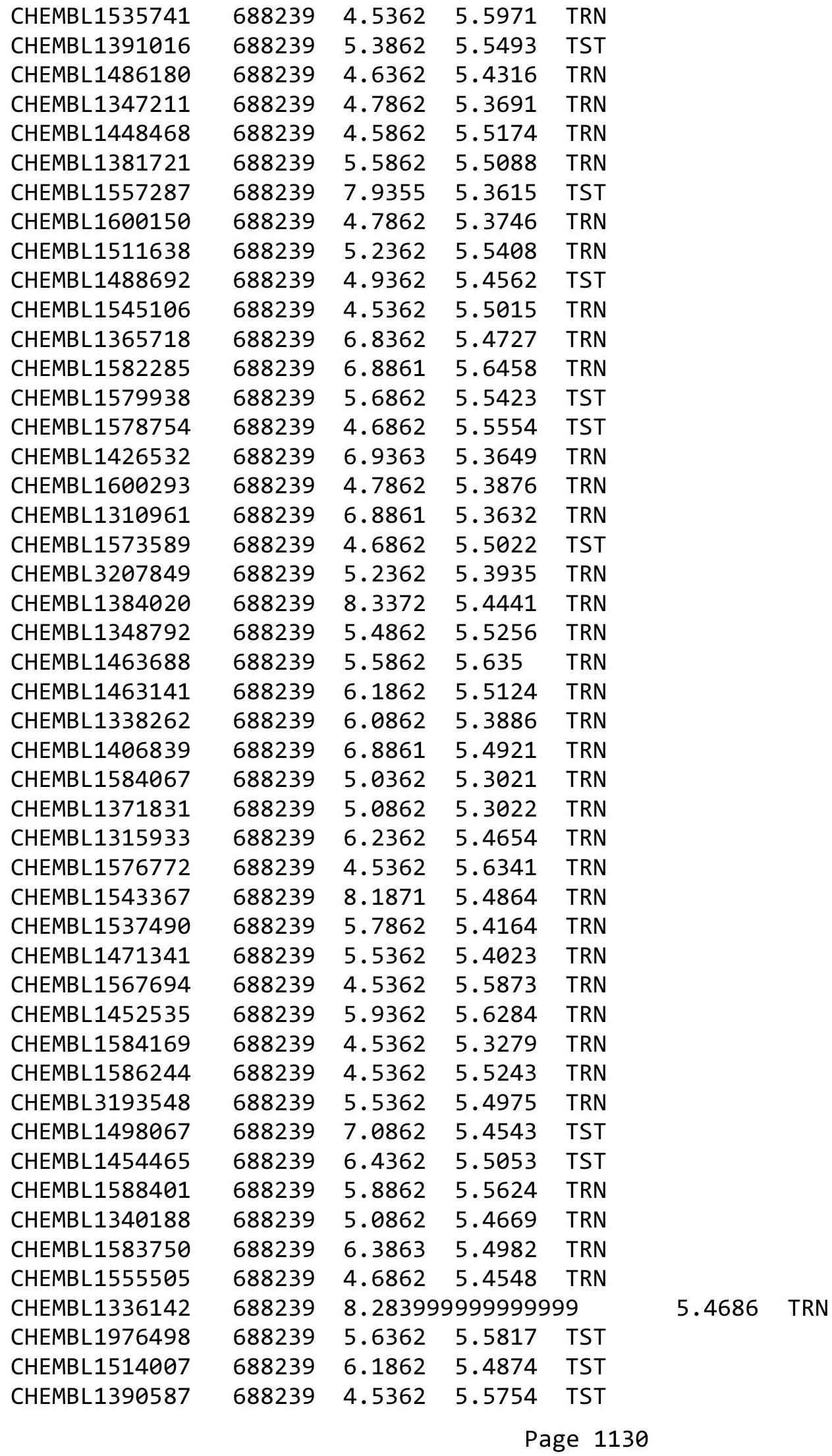




\begin{tabular}{|c|c|c|c|c|}
\hline \multicolumn{5}{|c|}{ Supplementa] } \\
\hline חILTIDLIJ4OJ & 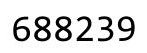 & 6.786 & & \\
\hline HEMBL1326030 & 88239 & .8861 & 5.4983 & \\
\hline HEMBL1319657 & 39 & 2 & & \\
\hline HEMBL15 & & & & \\
\hline HEMBL112 & 39 & & & \\
\hline HEMBL1493024 & 88239 & 1862 & 6 & \\
\hline HEMBL1525994 & 88239 & .2362 & 4654 & \\
\hline HEMBL1: & 9 & & & \\
\hline HEMBL3 & 39 & & 5.3887 & \\
\hline HEMBL] & 39 & & & \\
\hline HEMBL15 & 88239 & & 5.541 & \\
\hline HEMBL1 & 39 & & 5.5746 & \\
\hline HEMBL1 & 9 & & 5.3613 & \\
\hline AEMBL & 39 & & 5.5026 & \\
\hline HEMBL & & & & \\
\hline HEMBL] & 39 & & 5.4572 & \\
\hline HEMBL: & 39 & & & \\
\hline HEMBL & 58 & & 5.5026 & \\
\hline HEMBL & 9 & & 5. & \\
\hline HEMBL & & & 53 & \\
\hline לחוזות & & & & \\
\hline AEMBL & 9 & & & \\
\hline HEMBL: & 68 & & 5.5 & \\
\hline ABL & & & & \\
\hline 6 & & & & \\
\hline 37 & & & & \\
\hline HEMBL] & 9 & & & \\
\hline HEMBL1 & 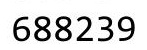 & & 5.5 & \\
\hline ABL & & & & \\
\hline ULMP & 39 & & 4 & \\
\hline 41 & & & & \\
\hline HEMBL: & 9 & & & \\
\hline$n_{0}$ & & & & \\
\hline 4 & & & 5. & \\
\hline 6 & & & 58 & \\
\hline HEMBL: & & & 5.6081 & \\
\hline HEMBL1 & 688 & & 5.6118 & \\
\hline & & & & \\
\hline - & & & 5. & \\
\hline 8 & & & 02 & - \\
\hline CHEMBL & $68 \varepsilon$ & 52 & 5.3775 & 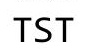 \\
\hline CHEMBL 1 & 9 & & 5.4 & 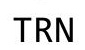 \\
\hline & & & & TR \\
\hline CHEMBL1 & & & 5.455 & $\cdots$ \\
\hline CHEMBL1 & & & 5.5 & TR \\
\hline CHEMBL & 39 & 3362 & 83 & $-e_{-1}+2$ \\
\hline CHEMBL & 688 & 6.6362 & 5.5242 & \\
\hline CHEMBL601768 & 688239 & 4.8362 & 5.3164 & $T R$ \\
\hline
\end{tabular}

Page 1131 
Supplemental Table S2.txt

\begin{tabular}{|c|c|c|c|c|c|}
\hline CHEMBL1555602 & 688239 & 5.6862 & 5.5812 & TRN & \\
\hline CHEMBL1366759 & 688239 & 4.5362 & 5.51399 & 9999999999 & TRN \\
\hline CHEMBL1534335 & 688239 & 5.0362 & 5.6614 & TRN & \\
\hline CHEMBL1325895 & 688239 & 8.3372 & 5.7542 & TRN & \\
\hline CHEMBL1381755 & 688239 & 6.9363 & 5.5027 & TRN & \\
\hline CHEMBL3211976 & 688239 & 5.1862 & 5.3601 & TST & \\
\hline CHEMBL1457440 & 688239 & 8.1367 & 5.4809 & TRN & \\
\hline CHEMBL1364928 & 688239 & 5.5862 & 5.3775 & TRN & \\
\hline CHEMBL1310782 & 688239 & 5.8862 & 5.291 & TRN & \\
\hline CHEMBL1546678 & 688239 & 4.5362 & 5.4168 & TRN & \\
\hline CHEMBL1589099 & 688239 & 4.5862 & 5.5839 & TRN & \\
\hline CHEMBL1341238 & 688239 & 6.1362 & 5.7011 & TRN & \\
\hline CHEMBL1513913 & 688239 & 4.7362 & 5.4902 & TRN & \\
\hline CHEMBL1445752 & 688239 & 4.5362 & 5.3578 & TRN & \\
\hline CHEMBL1456209 & 688239 & 5.8362 & 5.489 & TRN & \\
\hline CHEMBL3194642 & 688239 & 5.7362 & 5.5937 & TST & \\
\hline CHEMBL1300030 & 688239 & 4.5362 & 5.4269 & TRN & \\
\hline CHEMBL3194539 & 688239 & 6.0362 & 5.4331 & TST & \\
\hline CHEMBL1407507 & 688239 & 5.7862 & 5.4704 & TRN & \\
\hline CHEMBL1389732 & 688239 & 5.1862 & 5.4474 & TRN & \\
\hline CHEMBL1407737 & 688239 & 5.3862 & 5.541 & TRN & \\
\hline CHEMBL1405120 & 688239 & 4.5362 & 5.3691 & TRN & \\
\hline CHEMBL1402594 & 688239 & 5.9362 & 5.4225 & TRN & \\
\hline CHEMBL1557095 & 688239 & 6.0362 & 5.5396 & TST & \\
\hline CHEMBL1385406 & 688239 & 6.9363 & 5.4665 & TST & \\
\hline CHEMBL1546248 & 688239 & 8.3372 & 5.3895 & TRN & \\
\hline CHEMBL444096 & 688239 & 4.6862 & 5.4577 & TRN & \\
\hline CHEMBL1443319 & 688239 & 5.9862 & 5.5462 & TRN & \\
\hline CHEMBL1412469 & 688239 & 5.8862 & 5.4967 & TRN & \\
\hline CHEMBL1505523 & 688239 & 6.0362 & 5.5941 & TST & \\
\hline CHEMBL1483482 & 688239 & 8.3372 & 5.3277 & TRN & \\
\hline CHEMBL1574121 & 688239 & 4.5362 & 5.4578 & TRN & \\
\hline CHEMBL1559925 & 688239 & 6.9363 & 5.4536 & TRN & \\
\hline CHEMBL1401726 & 688239 & 8.3372 & 5.4943 & TRN & \\
\hline CHEMBL3207894 & 688239 & 5.4862 & 5.3832 & TST & \\
\hline CHEMBL3192065 & 688239 & 6.1862 & 5.3778 & TRN & \\
\hline CHEMBL1561471 & 688239 & 5.1862 & 5.4486 & TST & \\
\hline CHEMBL1609786 & 688239 & 5.3862 & 5.4358 & TRN & \\
\hline CHEMBL1477464 & 688239 & 5.3862 & 5.4147 & TST & \\
\hline CHEMBL1510824 & 688239 & 6.2362 & 5.4152 & TRN & \\
\hline CHEMBL1360996 & 688239 & 5.1862 & 5.3944 & TRN & \\
\hline CHEMBL1511180 & 688239 & 5.7362 & 5.5716 & TRN & \\
\hline CHEMBL1335528 & 688239 & 4.5362 & 5.5599 & TST & \\
\hline CHEMBL1410370 & 688239 & 4.5362 & 5.5146 & TRN & \\
\hline CHEMBL1360340 & 688239 & 5.6362 & 5.5536 & TRN & \\
\hline CHEMBL1481405 & 688239 & 4.6862 & 5.5792 & TST & \\
\hline CHEMBL3207303 & 688239 & 4.7862 & 5.4695 & TRN & \\
\hline CHEMBL1581749 & 688239 & 5.3362 & 5.5356 & TRN & \\
\hline
\end{tabular}


Supplemental Table S2.txt

\begin{tabular}{|c|c|c|c|c|c|}
\hline CHEMBL1373564 & 688239 & 6.6362 & 5.7725 & TRN & \\
\hline CHEMBL1542950 & 688239 & 5.3862 & 5.5173 & TRN & \\
\hline CHEMBL1315233 & 688239 & 6.7862 & 5.4095 & TRN & \\
\hline CHEMBL1350163 & 688239 & 4.8862 & 5.402 & TRN & \\
\hline CHEMBL1335323 & 688239 & 6.1362 & 5.3888 & TRN & \\
\hline CHEMBL1383372 & 688239 & 4.7862 & 5.5755 & TRN & \\
\hline CHEMBL1382184 & 688239 & 6.2862 & 5.4837 & TRN & \\
\hline CHEMBL1577399 & 688239 & 6.0862 & 5.4899 & TRN & \\
\hline CHEMBL1498325 & 688239 & 4.5362 & 5.6424 & TRN & \\
\hline CHEMBL1530058 & 688239 & 5.3862 & 5.5824 & TRN & \\
\hline CHEMBL1511678 & 688239 & 4.5862 & 5.4062 & TRN & \\
\hline CHEMBL1610245 & 688239 & 6.0862 & 5.5352 & TST & \\
\hline CHEMBL1422995 & 688239 & 5.9862 & 5.4753 & TRN & \\
\hline CHEMBL1406349 & 688239 & 6.5363 & 5.4057 & TRN & \\
\hline CHEMBL1550005 & 688239 & 6.2862 & 5.6736 & TRN & \\
\hline CHEMBL1536747 & 688239 & 5.4362 & 5.473 & TST & \\
\hline CHEMBL1369698 & 688239 & 4.5362 & 5.4131 & TRN & \\
\hline CHEMBL1596174 & 688239 & 5.8362 & 5.3778 & TST & \\
\hline CHEMBL1412990 & 688239 & 6.2862 & 5.358 & TRN & \\
\hline CHEMBL1574368 & 688239 & 5.1862 & 5.5172 & TRN & \\
\hline CHEMBL1536043 & 688239 & 5.7862 & 5.4893 & TST & \\
\hline CHEMBL1566419 & 688239 & 5.8862 & 5.4674 & TST & \\
\hline CHEMBL1552470 & 688239 & 4.5362 & 5.4918 & TRN & \\
\hline CHEMBL1601950 & 688239 & 4.6862 & 5.4821 & TRN & \\
\hline CHEMBL1328318 & 688239 & 6.0362 & 5.6838 & TRN & \\
\hline CHEMBL1304478 & 688239 & 5.1862 & 5.4572 & TST & \\
\hline CHEMBL1372356 & 688239 & 7.0862 & 5.5285 & TST & \\
\hline CHEMBL1408500 & 688239 & 6.3362 & 5.4824 & TRN & \\
\hline CHEMBL1514534 & 688239 & 5.6862 & 5.345 & TRN & \\
\hline CHEMBL1359762 & 688239 & 4.5362 & 5.3014 & TST & \\
\hline CHEMBL1495552 & 688239 & 6.8362 & 5.5632 & TRN & \\
\hline CHEMBL1408353 & 688239 & 4.7862 & 5.635 & TRN & \\
\hline CHEMBL1511273 & 688239 & 5.0362 & 5.3428 & TST & \\
\hline CHEMBL1464203 & 688239 & 8.283999 & 999999999 & 99 & 5.5363 \\
\hline CHEMBL1427207 & 688239 & 8.3872 & 5.484 & TRN & \\
\hline CHEMBL1550685 & 688239 & 4.9362 & 5.4472 & TST & \\
\hline CHEMBL1556490 & 688239 & 4.5362 & 5.3298 & TRN & \\
\hline CHEMBL1305996 & 688239 & 5.3862 & 5.3901 & TRN & \\
\hline CHEMBL1425388 & 688239 & 4.6362 & 5.4745 & TST & \\
\hline CHEMBL1536202 & 688239 & 5.8362 & 5.475 & TRN & \\
\hline CHEMBL1349657 & 688239 & 4.5362 & 5.447 & TST & \\
\hline CHEMBL1509201 & 688239 & 5.6862 & 5.5493 & TRN & \\
\hline CHEMBL1366944 & 688239 & 5.1862 & 5.477 & TRN & \\
\hline CHEMBL1497155 & 688239 & 6.5363 & 5.5634 & TRN & \\
\hline CHEMBL1538587 & 688239 & 4.9362 & 5.5896 & TST & \\
\hline CHEMBL1417418 & 688239 & 4.7362 & 5.5251 & TRN & \\
\hline CHEMBL1312175 & 688239 & 7.1864 & 5.3595 & TRN & \\
\hline CHEMBL1498896 & 688239 & 6.1362 & 5.4558 & TST & \\
\hline
\end{tabular}


Supplemental Table S2.txt

\begin{tabular}{|c|c|c|c|c|}
\hline CHEMBL1399073 & 688239 & 7.0362 & 5.4629 & TRN \\
\hline CHEMBL1444939 & 688239 & 6.1362 & 5.5196 & TRN \\
\hline CHEMBL1965911 & 688239 & 4.6862 & 5.4642 & TST \\
\hline CHEMBL1475355 & 688239 & 5.1862 & 5.4787 & TRN \\
\hline CHEMBL1300136 & 688239 & 4.5862 & 5.5352 & TRN \\
\hline CHEMBL1602188 & 688239 & 5.7862 & 5.4783 & TRN \\
\hline CHEMBL1601529 & 688239 & 4.8362 & 5.3721 & TST \\
\hline CHEMBL1390421 & 688239 & 6.2362 & 5.7032 & TRN \\
\hline CHEMBL1361088 & 688239 & 5.5862 & 5.4456 & TRN \\
\hline CHEMBL1374303 & 688239 & 5.1862 & 5.565 & TRN \\
\hline CHEMBL1470707 & 688239 & 4.4862 & 5.4385 & TRN \\
\hline CHEMBL1497472 & 688239 & 4.9362 & 5.5883 & TRN \\
\hline CHEMBL1347817 & 688239 & 5.1862 & 5.4162 & TST \\
\hline CHEMBL1483396 & 688239 & 4.5362 & 5.4687 & TRN \\
\hline CHEMBL1524223 & 688239 & 4.6362 & 5.6309 & TRN \\
\hline CHEMBL498436 & 688239 & 4.5362 & 5.3498 & TST \\
\hline CHEMBL1382474 & 688239 & 4.5362 & 5.4965 & TRN \\
\hline CHEMBL1300730 & 688239 & 5.1862 & 5.4473 & TRN \\
\hline CHEMBL1332581 & 688239 & 4.8362 & 5.7504 & TRN \\
\hline CHEMBL1328009 & 688239 & 6.1362 & 5.4763 & TRN \\
\hline CHEMBL1570837 & 688239 & 4.5362 & 5.5092 & TRN \\
\hline CHEMBL1388113 & 688239 & 5.0362 & 5.4968 & TST \\
\hline CHEMBL1317285 & 688239 & 4.5362 & 5.417999 & 9999999999 \\
\hline CHEMBL1378400 & 688239 & 4.6362 & 5.678 & TRN \\
\hline CHEMBL1493384 & 688239 & 4.5362 & 5.4756 & TRN \\
\hline CHEMBL1500962 & 688239 & 5.7362 & 5.7095 & TST \\
\hline CHEMBL1418939 & 688239 & 5.8362 & 5.4487 & TRN \\
\hline CHEMBL1593514 & 688239 & 5.1862 & 5.3787 & TRN \\
\hline CHEMBL1552199 & 688239 & 4.5362 & 5.5669 & TRN \\
\hline CHEMBL1451690 & 688239 & 5.4362 & 5.6093 & TRN \\
\hline CHEMBL1490732 & 688239 & 5.9862 & 5.4886 & TRN \\
\hline CHEMBL1417545 & 688239 & 4.5362 & 5.3578 & TRN \\
\hline CHEMBL1474943 & 688239 & 6.1362 & 5.6685 & TRN \\
\hline CHEMBL1491263 & 688239 & 7.0862 & 5.5301 & TRN \\
\hline CHEMBL1579573 & 688239 & 6.2362 & 5.4916 & TST \\
\hline CHEMBL1587260 & 688239 & 6.2862 & 5.6715 & TRN \\
\hline CHEMBL3199607 & 688239 & 5.4362 & 5.4969 & TRN \\
\hline CHEMBL3209204 & 688239 & 4.5862 & 5.4798 & TST \\
\hline CHEMBL1498398 & 688239 & 4.4862 & 5.5179 & TRN \\
\hline CHEMBL1536264 & 688239 & 5.6862 & 5.4687 & TRN \\
\hline CHEMBL1448175 & 688239 & 4.6362 & 5.5097 & TRN \\
\hline CHEMBL1329563 & 688239 & 5.9362 & 5.5855 & TRN \\
\hline CHEMBL1319700 & 688239 & 4.9862 & 5.6019 & TRN \\
\hline CHEMBL 275097 & 688239 & 6.2362 & 5.5702 & TST \\
\hline CHEMBL1347188 & 688239 & 4.5362 & 5.3897 & TST \\
\hline CHEMBL1581228 & 688239 & 5.6362 & 5.4542 & TRN \\
\hline CHEMBL1315918 & 688239 & 5.8862 & 5.407999 & 99999999995 \\
\hline CHEMBL1459429 & 688239 & 5.1862 & 5.5771 & TST \\
\hline
\end{tabular}


Supplemental Table S2.txt

\begin{tabular}{|c|c|c|c|c|c|}
\hline CHEMBL3210903 & 688239 & 6.1862 & 5.5195 & TRN & \\
\hline CHEMBL1544882 & 688239 & 5.6862 & 5.4857 & TST & \\
\hline CHEMBL1393326 & 688239 & 8.28399 & 99999999 & 99 & 5.4964 \\
\hline CHEMBL1607032 & 688239 & 6.1362 & 5.5139 & TRN & \\
\hline CHEMBL1513897 & 688239 & 5.3362 & 5.3866 & TRN & \\
\hline CHEMBL1572213 & 688239 & 5.1862 & 5.5512 & TRN & \\
\hline CHEMBL1577208 & 688239 & 5.1862 & 5.5008 & TRN & \\
\hline CHEMBL1366974 & 688239 & 6.1862 & 5.3563 & TRN & \\
\hline CHEMBL1971051 & 688239 & 4.7362 & 5.4113 & TRN & \\
\hline CHEMBL1345491 & 688239 & 6.1362 & 5.4961 & TST & \\
\hline CHEMBL1425765 & 688239 & 4.5362 & 5.6019 & TRN & \\
\hline CHEMBL1496561 & 688239 & 4.5362 & 5.612 & TRN & \\
\hline CHEMBL1607791 & 688239 & 6.0862 & 5.6567 & TST & \\
\hline CHEMBL1552593 & 688239 & 4.7862 & 5.3377 & TRN & \\
\hline CHEMBL1498855 & 688239 & 4.6862 & 5.5549 & TRN & \\
\hline CHEMBL1361617 & 688239 & 4.5362 & 5.4079 & TST & \\
\hline CHEMBL1373265 & 688239 & 5.3362 & 5.4316 & TRN & \\
\hline CHEMBL1343677 & 688239 & 4.5362 & 5.5525 & TST & \\
\hline CHEMBL1539110 & 688239 & 5.6862 & 5.4641 & TST & \\
\hline CHEMBL1321642 & 688239 & 5.1862 & 5.4085 & TST & \\
\hline CHEMBL1423327 & 688239 & 4.6 & 5.5092 & TRN & \\
\hline CHEMBL1388177 & 688239 & 5.7862 & 5.3929 & TRN & \\
\hline CHEMBL1366247 & 688239 & 5.1362 & 5.3565 & TRN & \\
\hline CHEMBL1393667 & 688239 & 4.6362 & 5.4402 & TRN & \\
\hline CHEMBL3193665 & 688239 & 6.3362 & 5.624 & TRN & \\
\hline CHEMBL1556452 & 688239 & 5.7362 & 5.5186 & TRN & \\
\hline CHEMBL1372469 & 688239 & 7.2865 & 5.5817 & TRN & \\
\hline CHEMBL120568 & 688239 & 6.9363 & 5.4597 & TRN & \\
\hline CHEMBL1556422 & 688239 & 5.8362 & 5.5073 & TRN & \\
\hline CHEMBL1497025 & 688239 & 8.3372 & 5.6146 & TRN & \\
\hline CHEMBL1319037 & 688239 & 5.4862 & 5.5159 & TST & \\
\hline CHEMBL1968355 & 688239 & 4.5862 & 5.3874 & TRN & \\
\hline CHEMBL 3193325 & 688239 & 8.3372 & 5.5768 & TRN & \\
\hline CHEMBL1449029 & 688239 & 4.7362 & 5.4295 & TRN & \\
\hline CHEMBL1340818 & 688239 & 5.6862 & 5.5111 & TST & \\
\hline CHEMBL1596512 & 688239 & 4.5362 & 5.3361 & TRN & \\
\hline CHEMBL1343623 & 688239 & 4.7862 & 5.3691 & TRN & \\
\hline CHEMBL1323615 & 688239 & 4.7362 & 5.5078 & TST & \\
\hline CHEMBL1573960 & 688239 & 4.5362 & 5.5356 & TRN & \\
\hline CHEMBL1371656 & 688239 & 4.5362 & 5.4593 & TST & \\
\hline CHEMBL1332829 & 688239 & 5.4862 & 5.4344 & TRN & \\
\hline CHEMBL3197101 & 688239 & 4.5362 & 5.4722 & TRN & \\
\hline CHEMBL1528483 & 688239 & 7.9355 & 5.3753 & TST & \\
\hline CHEMBL1444583 & 688239 & 4.6862 & 5.4312 & TRN & \\
\hline CHEMBL1471879 & 688239 & 6.9363 & 5.3222 & TRN & \\
\hline CHEMBL1299946 & 688239 & 4.7362 & 5.5985 & TRN & \\
\hline CHEMBL1345299 & 688239 & 4.4862 & 5.4455 & TST & \\
\hline CHEMBL1387520 & 688239 & 6.5363 & 5.4543 & TRN & \\
\hline
\end{tabular}


Supplemental Table S2.txt

\begin{tabular}{|c|c|c|c|c|}
\hline CHEMBL1406263 & 688239 & 6.2862 & 5.405 & TST \\
\hline CHEMBL1580440 & 688239 & 4.5362 & 5.4437 & TST \\
\hline CHEMBL1583351 & 688239 & 6.3863 & 5.5536 & TRN \\
\hline CHEMBL1306916 & 688239 & 5.6362 & 5.4563 & TST \\
\hline CHEMBL1463191 & 688239 & 4.7362 & 5.4152 & TST \\
\hline CHEMBL1404939 & 688239 & 4.5362 & 5.5702 & TRN \\
\hline CHEMBL1557806 & 688239 & 6.7862 & 5.579 & TRN \\
\hline CHEMBL1552867 & 688239 & 5.1362 & 5.4554 & TST \\
\hline CHEMBL1574360 & 688239 & 5.6362 & 5.3908 & TRN \\
\hline CHEMBL1442676 & 688239 & 6.0862 & 5.4729 & TRN \\
\hline CHEMBL1584482 & 688239 & 5.1862 & 5.4478 & TRN \\
\hline CHEMBL1506952 & 688239 & 5.1862 & 5.6247 & TRN \\
\hline CHEMBL1301547 & 688239 & 5.6862 & 5.5086 & TRN \\
\hline CHEMBL1419763 & 688239 & 6.3362 & 5.4709 & TRN \\
\hline CHEMBL 3211824 & 688239 & 5.0362 & 5.3787 & TRN \\
\hline CHEMBL1573111 & 688239 & 7.2366 & 5.4559 & TST \\
\hline CHEMBL1477159 & 688239 & 5.7362 & 5.5335 & TRN \\
\hline CHEMBL1407872 & 688239 & 5.1862 & 5.5557 & TST \\
\hline CHEMBL1483896 & 688239 & 4.6862 & 5.5336 & TRN \\
\hline CHEMBL1342522 & 688239 & 4.5362 & 5.3801 & TRN \\
\hline CHEMBL1610112 & 688239 & 5.4862 & 5.5397 & TST \\
\hline CHEMBL1459922 & 688239 & 4.7362 & 5.4935 & TRN \\
\hline CHEMBL1408013 & 688239 & 4.9362 & 5.3642 & TST \\
\hline CHEMBL1557897 & 688239 & 5.1862 & 5.4639 & TRN \\
\hline CHEMBL1605635 & 688239 & 4.5362 & 5.5639 & TRN \\
\hline CHEMBL1493994 & 688239 & 4.5362 & 5.6328 & TRN \\
\hline CHEMBL1376835 & 688239 & 5.1862 & 5.3644 & TST \\
\hline CHEMBL1573985 & 688239 & 4.5862 & 5.6183 & TRN \\
\hline CHEMBL1375232 & 688239 & 5.05 & 5.3293 & TRN \\
\hline CHEMBL1414568 & 688239 & 4.5362 & 5.5403 & TST \\
\hline CHEMBL1596592 & 688239 & 4.5362 & 5.4768 & TST \\
\hline CHEMBL1452110 & 688239 & 4.7362 & 5.4836 & TRN \\
\hline CHEMBL1505838 & 688239 & 7.0362 & 5.4675 & TRN \\
\hline CHEMBL1420743 & 688239 & 4.5362 & 5.4459 & TST \\
\hline CHEMBL1432255 & 688239 & 5.5362 & 5.5142 & TRN \\
\hline CHEMBL1370884 & 688239 & 4.8362 & 5.4371 & TST \\
\hline CHEMBL1512631 & 688239 & 5.6862 & 5.5613 & TRN \\
\hline CHEMBL1400905 & 688239 & 6.0 & 5.3789 & TRN \\
\hline CHEMBL1336838 & 688239 & 4.5362 & 5.5201 & TRN \\
\hline CHEMBL1514042 & 688239 & 4.4862 & 5.4974 & TRN \\
\hline CHEMBL1311015 & 688239 & 6.8861 & 5.54899 & 99999999995 \\
\hline CHEMBL1393283 & 688239 & 4.5862 & 5.4551 & TRN \\
\hline CHEMBL1348337 & 688239 & 5.3362 & 5.4301 & TST \\
\hline CHEMBL1317328 & 688239 & 6.1362 & 5.6089 & TRN \\
\hline CHEMBL1566508 & 688239 & 8.1871 & 5.4071 & TRN \\
\hline CHEMBL1502991 & 688239 & 4.7862 & 5.4728 & TST \\
\hline CHEMBL1508069 & 688239 & 5.3362 & 5.5112 & TRN \\
\hline CHEMBL1313526 & 688239 & 4.4862 & 5.3658 & TRN \\
\hline
\end{tabular}




\begin{tabular}{|c|c|c|c|c|}
\hline & & & oplement & al $\mathrm{T}$ \\
\hline CHEMBL1570912 & 688239 & 4.6362 & 5.5812 & TRN \\
\hline CHEMBL1369248 & 688239 & 6.0 & 5.3691 & TRN \\
\hline CHEMBL1437757 & 688239 & 4.6862 & 5.6105 & TRN \\
\hline CHEMBL1449353 & 688239 & 6.1862 & 5.5452 & TRN \\
\hline CHEMBL1301193 & 688239 & 7.0362 & 5.6912 & TRN \\
\hline CHEMBL1440006 & 688239 & 4.8862 & 5.3908 & TRN \\
\hline CHEMBL1484933 & 688239 & 6.5862 & 5.5549 & TST \\
\hline CHEMBL1509276 & 688239 & 5.2362 & 5.5236 & TRN \\
\hline CHEMBL1575569 & 688239 & 4.7362 & 5.5293 & TRN \\
\hline CHEMBL1402103 & 688239 & 4.9862 & 5.3447 & TRN \\
\hline CHEMBL1452437 & 688239 & 4.6862 & 5.3999 & TRN \\
\hline CHEMBL1479221 & 688239 & 5.4362 & 5.415 & TST \\
\hline CHEMBL1420942 & 688239 & 4.9862 & 5.308 & TRN \\
\hline CHEMBL1500372 & 688239 & 6.8362 & 5.3706 & TRN \\
\hline CHEMBL1573602 & 688239 & 4.5862 & 5.4178 & TRN \\
\hline CHEMBL1427946 & 688239 & 4.8362 & 5.5109 & TST \\
\hline CHEMBL1531330 & 688239 & 6.0362 & 5.5327 & TRN \\
\hline CHEMBL1441170 & 688239 & 5.4862 & 5.5147 & TST \\
\hline CHEMBL1453821 & 688239 & 5.8362 & 5.4026 & TRN \\
\hline CHEMBL1594378 & 688239 & 6.9363 & 5.4215 & TRN \\
\hline CHEMBL1419366 & 688239 & 6.1362 & 5.4997 & TST \\
\hline CHEMBL1503218 & 688239 & 4.7862 & 5.602 & TRN \\
\hline CHEMBL1569820 & 688239 & 4.5862 & 5.4481 & TRN \\
\hline CHEMBL1480238 & 688239 & 5.1862 & 5.4199 & TRN \\
\hline CHEMBL1501242 & 688239 & 6.0862 & 5.3963 & TST \\
\hline CHEMBL1502434 & 688239 & 4.9362 & 5.2933 & TRN \\
\hline CHEMBL1357732 & 688239 & 6.8861 & 5.5114 & TRN \\
\hline CHEMBL1301186 & 688239 & 4.5362 & 5.3558 & TRN \\
\hline CHEMBL1349809 & 688239 & 5.0862 & 5.4248 & TST \\
\hline CHEMBL1401513 & 688239 & 4.6862 & 5.5596 & TRN \\
\hline CHEMBL1424066 & 688239 & 5.0862 & 5.4099 & TRN \\
\hline CHEMBL1474058 & 688239 & 5.0362 & 5.4105 & TRN \\
\hline CHEMBL1575142 & 688239 & 7.1864 & 5.559 & TST \\
\hline CHEMBL1422306 & 688239 & 5.1862 & 5.4796 & TRN \\
\hline CHEMBL1438638 & 688239 & 4.9362 & 5.3378 & TRN \\
\hline CHEMBL1583068 & 688239 & 4.5362 & 5.3424 & TST \\
\hline CHEMBL3214296 & 688239 & 6.0362 & 5.4467 & TRN \\
\hline CHEMBL1587050 & 688239 & 7.2366 & 5.4457 & TRN \\
\hline CHEMBL1357102 & 688239 & 5.1862 & 5.4131 & TRN \\
\hline CHEMBL1348708 & 688239 & 5.1862 & 5.5052 & TRN \\
\hline CHEMBL1304410 & 688239 & 4.6862 & 5.4201 & TRN \\
\hline CHEMBL1318734 & 688239 & 5.9362 & 5.5361 & TRN \\
\hline CHEMBL1597922 & 688239 & 5.6362 & 5.4931 & TRN \\
\hline CHEMBL1326308 & 688239 & 8.3372 & 5.4873 & TRN \\
\hline CHEMBL1336336 & 688239 & 5.3362 & 5.4534 & TRN \\
\hline CHEMBL1461941 & 688239 & 6.2362 & 5.3523 & TST \\
\hline CHEMBL1465578 & 688239 & 6.8362 & 5.4841 & TRN \\
\hline CHEMBL1398266 & 688239 & 5.7362 & 5.3026 & TRN \\
\hline
\end{tabular}


Supplemental Table S2.txt

\begin{tabular}{|c|c|c|c|c|}
\hline & & & & \\
\hline AEMBL1547126 & 38239 & 362 & 4941 & \\
\hline AEMBL1315114 & 39 & 362 & & \\
\hline 217 & & & & \\
\hline EMBL1418372 & & & & \\
\hline AEMBL1508588 & 88239 & 862 & 5228 & \\
\hline AEMBL1324855 & 88239 & 862 & 4759 & \\
\hline HEMBL1598386 & & & & \\
\hline EMBL1486781 & 39 & 862 & & \\
\hline IEMBL1366729 & & & 15 & \\
\hline AEMBL3190375 & 39 & 862 & 3799 & \\
\hline AEMBL1603167 & & 362 & & \\
\hline AEMBL1509515 & & & & \\
\hline IEMBL1368099 & & & & \\
\hline AEMBL1427160 & & & & \\
\hline AEMBL1499045 & & 862 & & \\
\hline AEMBL1458283 & & 362 & & \\
\hline IEMBL1502 & & 52 & & \\
\hline IEMBL1407 & & & & \\
\hline JEMBL138 & & & & \\
\hline AEMBL1513651 & & 863 & & \\
\hline AEMBL1357726 & & 62 & & \\
\hline IEMBL1440 & & 62 & & \\
\hline IFMR 12 & & & & \\
\hline 59 & & & & \\
\hline AEMBL1306295 & & 62 & & \\
\hline IEMBL1319715 & & & & \\
\hline AEMBL1402 & & 52 & & \\
\hline$\theta$ & & & & \\
\hline 26 & & 62 & & \\
\hline חדרי 1יחניו & & & & \\
\hline IEMBL1425686 & & 362 & & \\
\hline & & & & \\
\hline 2 & & & & \\
\hline & & & & \\
\hline AEMBL1391573 & & & & F \\
\hline IEMBL1473799 & & 362 & 674 & \\
\hline 343 & & 62 & & \\
\hline 3 & & & & \\
\hline HEMBL1423448 & & & & RI \\
\hline AEMBL1356933 & & 362 & 21 & $\mathrm{R}$ \\
\hline MBL144 & & 62 & & 15 \\
\hline HEMBL1341569 & & & & \\
\hline & & & & TST \\
\hline AEMBL1466895 & & 6.0862 & 5468 & $\mathrm{R}$ \\
\hline MBL3212561 & & 362 & 819 & TS \\
\hline & & & & \\
\hline 7030 & & & & \\
\hline
\end{tabular}

Page 1138 
Supplemental Table S2.txt

\begin{tabular}{|c|c|c|c|c|}
\hline CHEMBL1484450 & 688239 & 4.4862 & 5.4926 & TST \\
\hline CHEMBL1536402 & 688239 & 5.2362 & 5.5783 & TRN \\
\hline CHEMBL1573349 & 688239 & 6.7862 & 5.4761 & TST \\
\hline CHEMBL1465249 & 688239 & 4.6362 & 5.4445 & TRN \\
\hline CHEMBL 3197534 & 688239 & 4.5362 & 5.5112 & TRN \\
\hline CHEMBL1443226 & 688239 & 5.1362 & 5.6188 & TRN \\
\hline CHEMBL 3212862 & 688239 & 5.1362 & 5.5104 & TRN \\
\hline CHEMBL1327375 & 688239 & 5.5862 & 5.6411 & TRN \\
\hline CHEMBL1536564 & 688239 & 5.0862 & 5.4348 & TRN \\
\hline CHEMBL1323773 & 688239 & 6.3362 & 5.585 & TRN \\
\hline CHEMBL1404552 & 688239 & 5.8362 & 5.5903 & TRN \\
\hline CHEMBL 3191427 & 688239 & 5.8862 & 5.5848 & TST \\
\hline CHEMBL1611892 & 688239 & 4.5362 & 5.4307 & TRN \\
\hline CHEMBL1343666 & 688239 & 5.1862 & 5.5654 & TRN \\
\hline CHEMBL1366057 & 688239 & 5.1862 & 5.5562 & TRN \\
\hline CHEMBL1435740 & 688239 & 5.1362 & 5.567 & TRN \\
\hline CHEMBL1491658 & 688239 & 5.6362 & 5.5175 & TRN \\
\hline CHEMBL1400595 & 688239 & 6.5862 & 5.5255 & TRN \\
\hline CHEMBL1455535 & 688239 & 5.1862 & 5.5584 & TRN \\
\hline CHEMBL1336909 & 688239 & 4.7862 & 5.4959 & TRN \\
\hline CHEMBL1585685 & 688239 & 6.1862 & 5.41 & TRN \\
\hline CHEMBL1606074 & 688239 & 7.2366 & 5.3552 & TRN \\
\hline CHEMBL1595778 & 688239 & 4.4862 & 5.5612 & TRN \\
\hline CHEMBL1599548 & 688239 & 6.6362 & 5.5658 & TST \\
\hline CHEMBL1592843 & 688239 & 5.0362 & 5.4823 & TST \\
\hline CHEMBL1443313 & 688239 & 4.5362 & 5.3772 & TRN \\
\hline CHEMBL1324021 & 688239 & 5.9362 & 5.4262 & TRN \\
\hline CHEMBL1399708 & 688239 & 7.0862 & 5.5559 & TRN \\
\hline CHEMBL1301822 & 688239 & 5.1862 & 5.4857 & TRN \\
\hline CHEMBL1307850 & 688239 & 4.9862 & 5.4396 & TRN \\
\hline CHEMBL1300077 & 688239 & 5.0362 & 5.565 & TRN \\
\hline CHEMBL1447252 & 688239 & 4.5362 & 5.5544 & TST \\
\hline CHEMBL1562355 & 688239 & 4.7362 & 5.4759 & TRN \\
\hline CHEMBL1531201 & 688239 & 4.7362 & 5.6089 & TRN \\
\hline CHEMBL1594682 & 688239 & 5.3362 & 5.541 & TST \\
\hline CHEMBL1373384 & 688239 & 5.7362 & 5.4033 & TRN \\
\hline CHEMBL1460384 & 688239 & 4.5362 & 5.5601 & TRN \\
\hline CHEMBL 3194740 & 688239 & 4.5362 & 5.4259 & TRN \\
\hline CHEMBL1585264 & 688239 & 6.0362 & 5.455 & TRN \\
\hline CHEMBL1549679 & 688239 & 5.1362 & 5.4869 & TRN \\
\hline CHEMBL1990598 & 688239 & 4.7862 & 5.5292 & TST \\
\hline CHEMBL1322176 & 688239 & 5.4362 & 5.5274 & TRN \\
\hline CHEMBL1477297 & 688239 & 5.9362 & 5.5989 & TRN \\
\hline CHEMBL1555245 & 688239 & 8.3372 & 5.4735 & TRN \\
\hline CHEMBL 3192602 & 688239 & 5.1862 & 5.50700 & 0000000001 \\
\hline CHEMBL1436122 & 688239 & 4.6862 & 5.477 & TRN \\
\hline CHEMBL1556759 & 688239 & 5.3362 & 5.4508 & TRN \\
\hline CHEMBL1515032 & 688239 & 4.6862 & 5.4289 & TRN \\
\hline
\end{tabular}


Supplemental Table S2.txt

\begin{tabular}{|c|c|c|c|c|}
\hline & & & & \\
\hline AEMBL1 & 8239 & 7362 & & \\
\hline IEMBL1432374 & 8239 & 3862 & 387 & \\
\hline HEMBL1499394 & 239 & 862 & 027 & \\
\hline 9090 & 239 & 862 & 792 & \\
\hline EMBL1337114 & 239 & 862 & 673 & \\
\hline AEMBL532641 & 239 & 862 & 2373 & \\
\hline AEMBL1481306 & 88239 & .3863 & 5523 & \\
\hline AEMBL1377809 & 239 & 862 & & \\
\hline IEMBL14 & 239 & 862 & 25 & \\
\hline IEMBL1599255 & & 362 & & \\
\hline AEMBL1467453 & 239 & 862 & 248 & \\
\hline AEMBL1340986 & 239 & 862 & 376 & $S$ \\
\hline IEMBL1576467 & & 362 & & \\
\hline IEMBL1571560 & & 362 & & \\
\hline AEMBL1485881 & & & & \\
\hline AEMBL1375531 & 39 & 372 & 352 & \\
\hline AEMBL1592252 & & 862 & & \\
\hline IEMBL14 & & 62 & & \\
\hline IEMBL15 & & & & \\
\hline AEMBL131 & & & & \\
\hline AEMBL1407235 & & 362 & & \\
\hline AEMBL156 & & 62 & & $\mathrm{RN}$ \\
\hline IEMBL18 & & 62 & & \\
\hline IEMBL13 & & & & ST \\
\hline AFMRI 15 & & 62 & & ST \\
\hline AEMBL589238 & & 362 & & ST \\
\hline AEMBL1609330 & & & & \\
\hline AEMBL3209511 & & 4. & & RI \\
\hline 001 & & 52 & & RN \\
\hline 945 & & 52 & & RN \\
\hline HEMBL1468462 & & & & $\mathrm{RN}$ \\
\hline AEMBL1502104 & & & & ST \\
\hline AEMBL 14 & & 62 & 39 & S1 1 \\
\hline 982 & & 52 & 69 & Tा \\
\hline 306 & & & & $\cdots$ \\
\hline AEMBL1401103 & & & & RN \\
\hline AEMBL1608702 & & & & $\Gamma S$ \\
\hline EMBL14 & & & & $\mathrm{RI}$ \\
\hline 593 & & & & 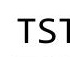 \\
\hline 395 & & & & $S 1$ \\
\hline AEMBL1395469 & & 862 & 745 & RN \\
\hline IEMBL31 & & & & $R$ \\
\hline EMBL14 & & & & \\
\hline CHEMBL1321322 & & & & \\
\hline CHEMBL1584187 & & 862 & 233 & S1 \\
\hline HEMBL1382630 & 88239 & 4.5362 & . 5999 & $\mathrm{TR}$ \\
\hline HFMRI 1514531 & 688239 & 6.0862 & 5.4182 & \\
\hline
\end{tabular}

Page 1140 
Supplemental Table S2.txt

\begin{tabular}{|c|c|c|c|c|}
\hline CHEMBL1530397 & 688239 & 6.1362 & 5.4219 & TRN \\
\hline CHEMBL1413954 & 688239 & 5.7362 & 5.5829 & TRN \\
\hline CHEMBL1301642 & 688239 & 4.5362 & 5.3689 & TST \\
\hline CHEMBL1093091 & 688239 & 5.1362 & 5.4201 & TRN \\
\hline CHEMBL59791 & 688239 & 5.1862 & 5.3591 & TRN \\
\hline CHEMBL1404754 & 688239 & 4.6362 & 5.3394 & TST \\
\hline CHEMBL1557089 & 688239 & 4.7362 & 5.3729 & TRN \\
\hline CHEMBL1402688 & 688239 & 4.5362 & 5.5877 & TST \\
\hline CHEMBL1595908 & 688239 & 6.0862 & 5.612999 & 99999999995 \\
\hline CHEMBL1363104 & 688239 & 4.5362 & 5.5341 & TST \\
\hline CHEMBL566283 & 688239 & 6.0 & 5.3876 & TRN \\
\hline CHEMBL3193682 & 688239 & 6.3863 & 5.6867 & TRN \\
\hline CHEMBL1559702 & 688239 & 5.5862 & 5.5718 & TRN \\
\hline CHEMBL1603552 & 688239 & 4.7362 & 5.4591 & TRN \\
\hline CHEMBL1302694 & 688239 & 5.2362 & 5.5279 & TRN \\
\hline CHEMBL1309139 & 688239 & 5.4362 & 5.6847 & TRN \\
\hline CHEMBL1573097 & 688239 & 6.1862 & 5.5449 & TRN \\
\hline CHEMBL1433201 & 688239 & 4.5362 & 5.4233 & TRN \\
\hline CHEMBL1336488 & 688239 & 8.3372 & 5.4286 & TRN \\
\hline CHEMBL1368207 & 688239 & 4.4862 & 5.4246 & TRN \\
\hline CHEMBL1299409 & 688239 & 5.1362 & 5.4997 & TRN \\
\hline CHEMBL1339872 & 688239 & 8.3372 & 5.4847 & TRN \\
\hline CHEMBL1402868 & 688239 & 6.3362 & 5.4189 & TRN \\
\hline CHEMBL1468772 & 688239 & 4.5362 & 5.35 & TRN \\
\hline CHEMBL1413125 & 688239 & 4.6862 & 5.4414 & TRN \\
\hline CHEMBL1487123 & 688239 & 6.1862 & 5.5049 & TRN \\
\hline CHEMBL1480562 & 688239 & 6.1362 & 5.6598 & TRN \\
\hline CHEMBL1404636 & 688239 & 4.6362 & 5.5217 & TRN \\
\hline CHEMBL1507704 & 688239 & 4.5362 & 5.4751 & TRN \\
\hline CHEMBL1591732 & 688239 & 4.7362 & 5.4045 & TRN \\
\hline CHEMBL1469960 & 688239 & 4.5362 & 5.4199 & TRN \\
\hline CHEMBL1531216 & 688239 & 5.6862 & 5.5074 & TRN \\
\hline CHEMBL1383270 & 688239 & 6.5363 & 5.6469 & TRN \\
\hline CHEMBL1449377 & 688239 & 4.5362 & 5.6437 & TRN \\
\hline CHEMBL1537931 & 688239 & 4.5862 & 5.6599 & TRN \\
\hline CHEMBL1409564 & 688239 & 5.1862 & 5.5366 & TRN \\
\hline CHEMBL1379927 & 688239 & 5.0862 & 5.6044 & TRN \\
\hline CHEMBL1310749 & 688239 & 4.9862 & 5.54 & TRN \\
\hline CHEMBL1303897 & 688239 & 4.4862 & 5.4391 & TST \\
\hline CHEMBL1526832 & 688239 & 4.5362 & 5.3984 & TRN \\
\hline CHEMBL1572746 & 688239 & 5.8362 & 5.4957 & TRN \\
\hline CHEMBL1384437 & 688239 & 4.5362 & 5.5704 & TRN \\
\hline CHEMBL599359 & 688239 & 4.8362 & 5.6391 & TRN \\
\hline CHEMBL 3211271 & 688239 & 6.1362 & 5.6411 & TST \\
\hline CHEMBL28449 & 688239 & 6.6861 & 5.6642 & TRN \\
\hline CHEMBL1609763 & 688239 & 5.6362 & 5.4051 & TST \\
\hline CHEMBL1483529 & 688239 & 4.7862 & 5.5806 & TRN \\
\hline CHEMBL1354181 & 688239 & 5.6362 & 5.3258 & TST \\
\hline
\end{tabular}


Supplemental Table S2.txt

\begin{tabular}{|c|c|c|c|c|}
\hline IE & & 52 & & \\
\hline UгMDI 1977 & & .1862 & 5.5838 & \\
\hline 87 & & & & \\
\hline AEMBL1 & & 52 & 579 & \\
\hline AEMBL1561280 & 38239 & 862 & & \\
\hline HEMBL1530534 & 88239 & 9862 & 5119 & \\
\hline HEMBL20e & 239 & 362 & 304 & \\
\hline IEMBL14 & & & & \\
\hline AEMBL14 & & 862 & .5242 & \\
\hline HEMBL156 & 88239 & 362 & 4632 & \\
\hline AEMBL153 & 239 & 862 & 5473 & \\
\hline IEMBL14 & 239 & 362 & .74 & \\
\hline IEMBL15 & & & & \\
\hline JEMBL15 & & 362 & 3942 & \\
\hline AEMBL 252 & & 366 & & \\
\hline AEMBL16e & 39 & 862 & 5166 & \\
\hline HEMBL15 & 39 & 62 & & \\
\hline HEMBL13 & & & & \\
\hline AEMBL15€ & & 362 & & \\
\hline AEMBL151 & & & & \\
\hline HEIMBLIt & & 62 & 01 & \\
\hline AEMBL13 & & & & \\
\hline HEMBL13 & & & & \\
\hline 73 & & 862 & & \\
\hline IEMBL 14 & & & & \\
\hline HEMBL1 & & 52 & 42 & \\
\hline HEMBL13 & & 61 & & \\
\hline HFMBI 31 & & 62 & & RN \\
\hline HEMBL16 & & & & $\mathrm{RN}$ \\
\hline HEMBL14€ & & & & RN \\
\hline HEMBL1: & & & & RN \\
\hline HFMBI 1 & & & & Niv \\
\hline 5 & & & & RN \\
\hline HEMBL 14 & & & 972 & $\mathrm{RN}$ \\
\hline HEMBL1496500 & & 362 & 5.5 & RN \\
\hline HEMBL15 & & 62 & & \\
\hline HᄃMPI 1 & & & & RN \\
\hline HEMBL1: & & & & RN \\
\hline HEMBL160 & 88239 & 55 & 5.6404 & RN \\
\hline EMBL1 & & 362 & 34 & RN \\
\hline HEMBL138 & & 362 & 88 & \\
\hline HEMBL31S & & & & ST \\
\hline HEMBL13S & & 7362 & 5.4678 & $\mathrm{RN}$ \\
\hline AEMBL136 & 39 & 363 & 3938 & TRN \\
\hline EMBL1 & & 362 & & \\
\hline CHEMBL154 & & .0362 & & \\
\hline CHEMBL151 & & & 5.4791 & \\
\hline THEMBL1598108 & 688239 & 4.6862 & 5.5802 & ГRN \\
\hline
\end{tabular}

Page 1142 
Supplemental Table S2.txt

\begin{tabular}{|c|c|c|c|c|}
\hline CHEMBL1392634 & 688239 & 4.9862 & 5.3433 & TRN \\
\hline CHEMBL1518302 & 688239 & 4.6362 & 5.4852 & TRN \\
\hline CHEMBL1605903 & 688239 & 6.2862 & 5.4582 & TRN \\
\hline CHEMBL1354825 & 688239 & 4.6362 & 5.5519 & TRN \\
\hline CHEMBL1338269 & 688239 & 4.7862 & 5.4633 & TRN \\
\hline CHEMBL1524899 & 688239 & 4.6362 & 5.5595 & TRN \\
\hline CHEMBL1339714 & 688239 & 5.1862 & 5.5273 & TRN \\
\hline CHEMBL1496501 & 688239 & 5.1862 & 5.5475 & TRN \\
\hline CHEMBL1588343 & 688239 & 5.0362 & 5.4824 & TST \\
\hline CHEMBL1553182 & 688239 & 5.1862 & 5.518 & TST \\
\hline CHEMBL1391738 & 688239 & 4.7362 & 5.3866 & TRN \\
\hline CHEMBL3195207 & 688239 & 4.5362 & 5.4201 & TRN \\
\hline CHEMBL1557157 & 688239 & 5.7862 & 5.461 & TST \\
\hline CHEMBL1324075 & 688239 & 6.8362 & 5.5129 & TRN \\
\hline CHEMBL1359293 & 688239 & 5.1862 & 5.4018 & TRN \\
\hline CHEMBL1427398 & 688239 & 7.3862 & 5.4463 & TST \\
\hline CHEMBL1533108 & 688239 & 6.2362 & 5.4673 & TRN \\
\hline CHEMBL1426346 & 688239 & 5.2362 & 5.48799 & 99999999995 \\
\hline CHEMBL1303769 & 688239 & 6.9363 & 5.5708 & TRN \\
\hline CHEMBL1583630 & 688239 & 5.2862 & 5.4301 & TRN \\
\hline CHEMBL1593920 & 688239 & 4.7862 & 5.4808 & TRN \\
\hline CHEMBL1330836 & 688239 & 4.5362 & 5.3834 & TRN \\
\hline CHEMBL1562401 & 688239 & 6.2362 & 5.2851 & TRN \\
\hline CHEMBL1342843 & 688239 & 4.4862 & 5.5617 & TRN \\
\hline CHEMBL1444121 & 688239 & 5.1862 & 5.5728 & TST \\
\hline CHEMBL1359523 & 688239 & 5.1862 & 5.3706 & TRN \\
\hline CHEMBL1464488 & 688239 & 5.3362 & 5.6632 & TRN \\
\hline CHEMBL1469468 & 688239 & 5.5862 & 5.4469 & TRN \\
\hline CHEMBL1965471 & 688239 & 4.8862 & 5.4725 & TRN \\
\hline CHEMBL1416011 & 688239 & 5.9862 & 5.4198 & TRN \\
\hline CHEMBL1424497 & 688239 & 5.8862 & 5.5886 & TST \\
\hline CHEMBL1524276 & 688239 & 4.5862 & 5.5072 & TRN \\
\hline CHEMBL1454120 & 688239 & 4.4862 & 5.5219 & TRN \\
\hline CHEMBL1412514 & 688239 & 4.5362 & 5.6812 & TRN \\
\hline CHEMBL1427987 & 688239 & 6.2862 & 5.666 & TRN \\
\hline CHEMBL1493473 & 688239 & 6.5363 & 5.5069 & TST \\
\hline CHEMBL1470778 & 688239 & 4.5862 & 5.4853 & TRN \\
\hline CHEMBL1441672 & 688239 & 6.5862 & 5.4437 & TRN \\
\hline CHEMBL1363033 & 688239 & 4.9362 & 5.3928 & TRN \\
\hline CHEMBL3198437 & 688239 & 5.4362 & 5.3791 & TST \\
\hline CHEMBL1500642 & 688239 & 5.2362 & 5.4238 & TRN \\
\hline CHEMBL1477589 & 688239 & 6.2362 & 5.4286 & TST \\
\hline CHEMBL1478290 & 688239 & 7.1864 & 5.5226 & TST \\
\hline CHEMBL1471783 & 688239 & 5.2362 & 5.4658 & TRN \\
\hline CHEMBL1520255 & 688239 & 6.2362 & 5.4535 & TST \\
\hline CHEMBL 1305769 & 688239 & 4.5862 & 5.6841 & TRN \\
\hline CHEMBL1351095 & 688239 & 4.4862 & 5.433 & TRN \\
\hline CHEMBL1457896 & 688239 & 4.5362 & 5.4006 & TST \\
\hline
\end{tabular}


Supplemental Table S2.txt

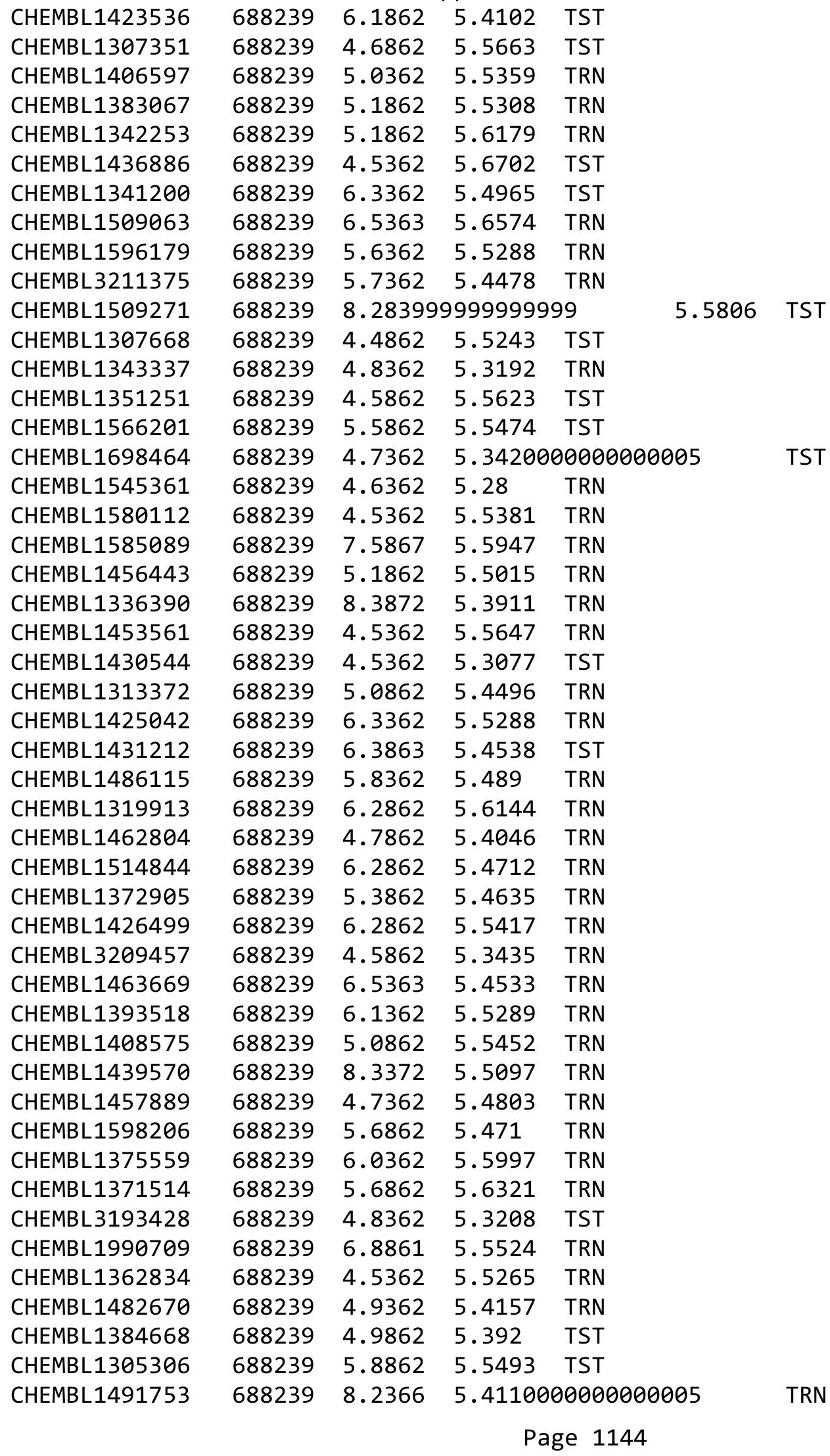


Supplemental Table S2.txt

\begin{tabular}{|c|c|c|c|c|c|}
\hline CHEMBL1325558 & 688239 & 4.8362 & 5.3838 & TRN & \\
\hline CHEMBL1523203 & 688239 & 6.3362 & 5.4918 & TST & \\
\hline CHEMBL1322422 & 688239 & 5.7362 & 5.4297 & TST & \\
\hline CHEMBL1333196 & 688239 & 5.3862 & 5.6294 & TRN & \\
\hline CHEMBL1300325 & 688239 & 6.9363 & 5.4745 & TRN & \\
\hline CHEMBL 260503 & 688239 & 7.0362 & 5.3927 & TRN & \\
\hline CHEMBL1554917 & 688239 & 6.0 & 5.419 & TRN & \\
\hline CHEMBL1346587 & 688239 & 4.7862 & 5.6288 & TRN & \\
\hline CHEMBL1595145 & 688239 & 7.5361 & 5.4946 & TST & \\
\hline CHEMBL 3197540 & 688239 & 6.3863 & 5.4848 & TRN & \\
\hline CHEMBL1303681 & 688239 & 5.7862 & 5.3961 & TRN & \\
\hline CHEMBL3192730 & 688239 & 4.6362 & 5.4866 & TRN & \\
\hline CHEMBL1323882 & 688239 & 8.3372 & 5.5507 & TRN & \\
\hline CHEMBL1310326 & 688239 & 4.9362 & 5.5379 & TRN & \\
\hline CHEMBL1342909 & 688239 & 4.5362 & 5.5293 & TRN & \\
\hline CHEMBL1304616 & 688239 & 4.5362 & 5.5011 & TRN & \\
\hline CHEMBL1400138 & 688239 & 5.9362 & 5.67200 & 0000000001 & TRN \\
\hline CHEMBL1570822 & 688239 & 6.7862 & 5.518 & TRN & \\
\hline CHEMBL1405302 & 688239 & 6.7862 & 5.3617 & TST & \\
\hline CHEMBL1567689 & 688239 & 4.7362 & 5.645 & TRN & \\
\hline CHEMBL1458827 & 688239 & 4.5362 & 5.4346 & TRN & \\
\hline CHEMBL1538809 & 688239 & 4.5362 & 5.4725 & TRN & \\
\hline CHEMBL1352117 & 688239 & 4.5362 & 5.4882 & TRN & \\
\hline CHEMBL1563874 & 688239 & 4.5362 & 5.4162 & TRN & \\
\hline CHEMBL1540597 & 688239 & 4.5362 & 5.4749 & TRN & \\
\hline CHEMBL1468842 & 688239 & 4.8862 & 5.4005 & TRN & \\
\hline CHEMBL1444271 & 688239 & 5.0362 & 5.5738 & TRN & \\
\hline CHEMBL1345029 & 688239 & 4.7362 & 5.4812 & TST & \\
\hline CHEMBL1518116 & 688239 & 5.1862 & 5.6337 & TRN & \\
\hline CHEMBL3193225 & 688239 & 4.7362 & 5.4403 & TST & \\
\hline CHEMBL1480823 & 688239 & 4.6862 & 5.3639 & TRN & \\
\hline CHEMBL1605025 & 688239 & 4.5362 & 5.5306 & TST & \\
\hline CHEMBL1475186 & 688239 & 6.0 & 5.4539 & TRN & \\
\hline CHEMBL1419310 & 688239 & 5.3362 & 5.5182 & TRN & \\
\hline CHEMBL1511284 & 688239 & 5.5862 & 5.4699 & TRN & \\
\hline CHEMBL1533060 & 688239 & 4.7862 & 5.4575 & TRN & \\
\hline CHEMBL1399583 & 688239 & 4.9862 & 5.4997 & TST & \\
\hline CHEMBL1520247 & 688239 & 5.0862 & 5.3924 & TRN & \\
\hline CHEMBL1478768 & 688239 & 4.5362 & 5.4969 & TRN & \\
\hline CHEMBL1471858 & 688239 & 5.1862 & 5.5906 & TRN & \\
\hline CHEMBL1405283 & 688239 & 4.5362 & 5.4279 & TST & \\
\hline CHEMBL1520800 & 688239 & 5.9362 & 5.535 & TRN & \\
\hline CHEMBL3190864 & 688239 & 5.1862 & 5.443 & TRN & \\
\hline CHEMBL1521373 & 688239 & 5.6362 & 5.5734 & TRN & \\
\hline CHEMBL1572659 & 688239 & 6.9363 & 5.4659 & TRN & \\
\hline CHEMBL1535397 & 688239 & 4.5362 & 5.5613 & TRN & \\
\hline CHEMBL1597564 & 688239 & 6.2362 & 5.5018 & TRN & \\
\hline CHEMBL1302915 & 688239 & 4.5362 & 5.5274 & TRN & \\
\hline
\end{tabular}


Supplemental Table S2.txt

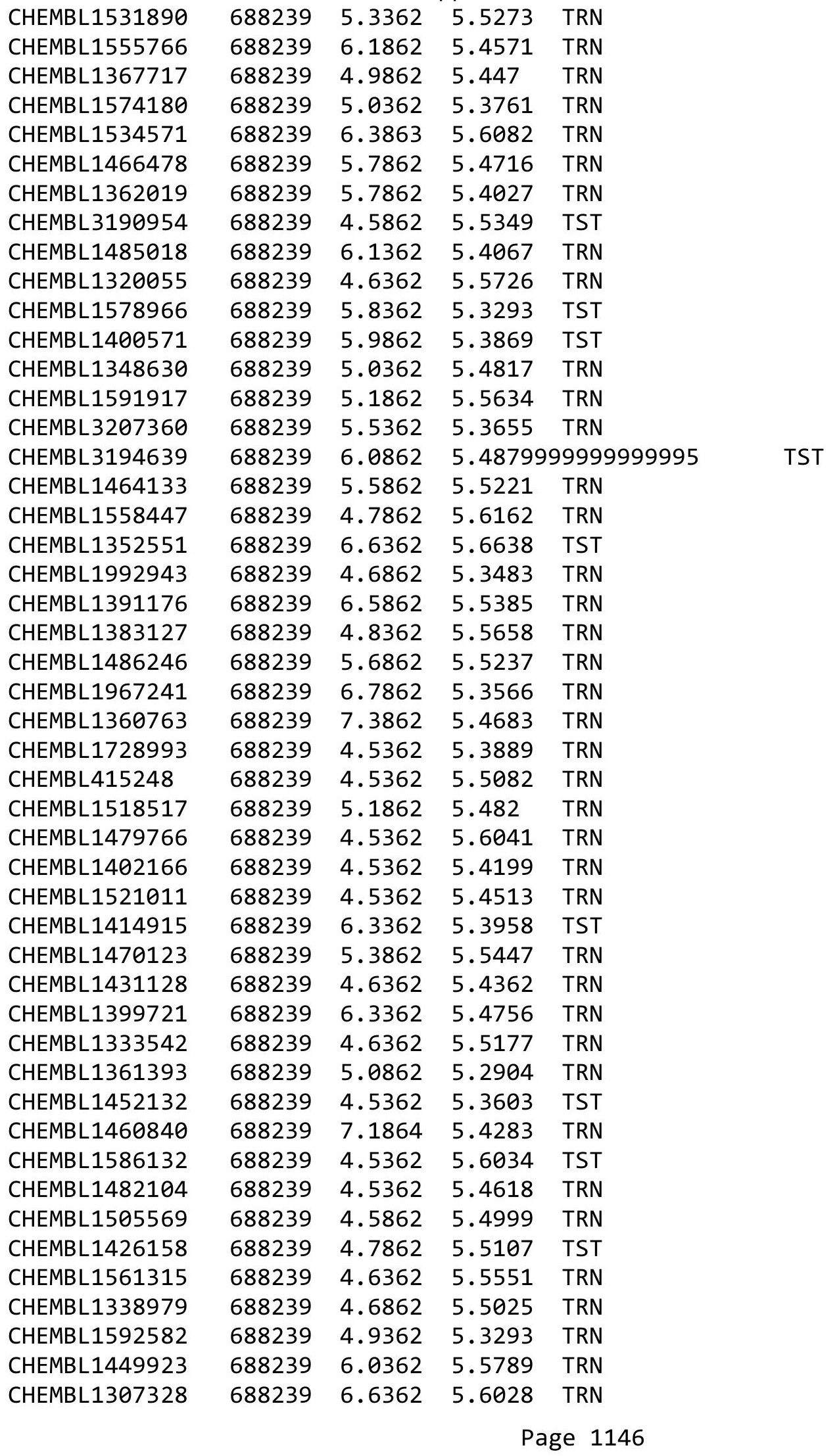


Supplemental Table S2.txt

\begin{tabular}{|c|c|c|c|c|c|}
\hline CHEMBL1321920 & 688239 & 4.5362 & 5.4923 & TRN & \\
\hline CHEMBL1536273 & 688239 & 5.7862 & 5.5639 & TRN & \\
\hline CHEMBL1414242 & 688239 & 5.7362 & 5.4173 & TRN & \\
\hline CHEMBL1501498 & 688239 & \multicolumn{2}{|c|}{8.283999999999999} & 5.5106 & TST \\
\hline CHEMBL 1374242 & 688239 & 6.3863 & 5.5 & TST & \\
\hline CHEMBL1577897 & 688239 & 6.0862 & 5.5438 & TRN & \\
\hline CHEMBL1359505 & 688239 & 5.5362 & 5.6194 & TRN & \\
\hline CHEMBL1390138 & 688239 & 6.0862 & 5.4488 & TST & \\
\hline CHEMBL1540242 & 688239 & 4.7362 & \multicolumn{2}{|c|}{5.452999999999999} & TRN \\
\hline CHEMBL1589239 & 688239 & 5.6362 & 5.665 & TRN & \\
\hline CHEMBL1569410 & 688239 & 4.6362 & 5.3895 & TRN & \\
\hline CHEMBL1504240 & 688239 & 4.7862 & 5.4216 & TRN & \\
\hline CHEMBL1380470 & 688239 & 4.7362 & 5.2999 & TRN & \\
\hline CHEMBL1432086 & 688239 & 4.6362 & 5.4653 & TRN & \\
\hline CHEMBL3212825 & 688239 & 5.8362 & 5.6776 & TST & \\
\hline CHEMBL1361943 & 688239 & 5.9862 & 5.5289 & TRN & \\
\hline CHEMBL1361747 & 688239 & 6.2362 & 5.5117 & TRN & \\
\hline CHEMBL1514248 & 688239 & 6.4862 & 5.5415 & TST & \\
\hline CHEMBL1447376 & 688239 & 6.9363 & 5.5396 & TRN & \\
\hline CHEMBL1535755 & 688239 & 4.7862 & \multicolumn{2}{|c|}{5.5089999999999995} & TST \\
\hline CHEMBL1458491 & 688239 & 6.0362 & 5.6196 & TRN & \\
\hline CHEMBL1434529 & 688239 & 8.3872 & 5.5155 & TRN & \\
\hline CHEMBL1584745 & 688239 & 5.1362 & 5.4905 & TRN & \\
\hline CHEMBL1559552 & 688239 & 5.2362 & 5.6408 & TRN & \\
\hline CHEMBL1304712 & 688239 & 5.1362 & \multicolumn{2}{|c|}{5.6370000000000005} & TRN \\
\hline CHEMBL1607700 & 688239 & 5.2362 & 5.6928 & TRN & \\
\hline CHEMBL1370323 & 688239 & 4.5362 & 5.6037 & TST & \\
\hline CHEMBL 2005653 & 688239 & 5.5362 & \multicolumn{2}{|c|}{5.4639999999999995} & TRN \\
\hline CHEMBL3191312 & 688239 & 7.1864 & 5.5049 & TRN & \\
\hline CHEMBL 1449743 & 688239 & 4.5362 & 5.5087 & TRN & \\
\hline CHEMBL1466567 & 688239 & 5.3362 & 5.665 & TRN & \\
\hline CHEMBL1422004 & 688239 & 6.2862 & 5.4998 & TRN & \\
\hline CHEMBL1996567 & 688239 & 6.1362 & 5.4033 & TRN & \\
\hline CHEMBL1515604 & 688239 & 5.1862 & 5.5049 & TRN & \\
\hline CHEMBL 1582440 & 688239 & 4.6362 & 5.4111 & TST & \\
\hline CHEMBL1564626 & 688239 & 4.6862 & 5.4121 & TRN & \\
\hline CHEMBL 1584370 & 688239 & 4.5362 & 5.5605 & TRN & \\
\hline CHEMBL1346225 & 688239 & 5.1862 & 5.3185 & TRN & \\
\hline CHEMBL3191855 & 688239 & 6.1862 & 5.2548 & TRN & \\
\hline CHEMBL 1357047 & 688239 & 4.5362 & 5.3232 & TST & \\
\hline CHEMBL1345115 & 688239 & 4.5362 & 5.4831 & TRN & \\
\hline CHEMBL1613089 & 688239 & 5.4862 & 5.4361 & TRN & \\
\hline CHEMBL1592121 & 688239 & 6.6362 & 5.5992 & TRN & \\
\hline CHEMBL1570797 & 688239 & 4.5362 & 5.4882 & TRN & \\
\hline CHEMBL1417092 & 688239 & 6.1362 & 5.5276 & TRN & \\
\hline CHEMBL1450714 & 688239 & 8.3372 & 5.5633 & TRN & \\
\hline CHEMBL1561924 & 688239 & 6.9363 & 5.5233 & TRN & \\
\hline CHEMBL1978067 & 688239 & 5.3862 & 5.4449 & TRN & \\
\hline
\end{tabular}


Supplemental Table S2.txt

\begin{tabular}{|c|c|c|c|c|c|}
\hline CHEMBL1377969 & 688239 & 7.1361 & 5.5552 & TRN & \\
\hline CHEMBL1573134 & 688239 & 8.3372 & 5.4865 & TST & \\
\hline CHEMBL1524339 & 688239 & 7.4868 & 5.5385 & TRN & \\
\hline CHEMBL1492133 & 688239 & 4.9862 & 5.5018 & TRN & \\
\hline CHEMBL1523823 & 688239 & 6.1862 & 5.4194 & TST & \\
\hline CHEMBL 3208584 & 688239 & 5.5862 & 5.5313 & TST & \\
\hline CHEMBL1314917 & 688239 & 6.6861 & 5.4347 & TRN & \\
\hline CHEMBL1374044 & 688239 & 6.2362 & 5.5155 & TRN & \\
\hline CHEMBL1299301 & 688239 & 4.5862 & 5.4835 & TRN & \\
\hline CHEMBL1309252 & 688239 & 4.45 & 5.3545 & TRN & \\
\hline CHEMBL1478088 & 688239 & 8.3372 & 5.5027 & TST & \\
\hline CHEMBL1600979 & 688239 & 6.1862 & 5.4344 & TST & \\
\hline CHEMBL1532125 & 688239 & 5.7362 & 5.394 & TRN & \\
\hline CHEMBL1439498 & 688239 & 5.5862 & 5.3652 & TRN & \\
\hline CHEMBL1406376 & 688239 & 4.5362 & 5.2738 & TRN & \\
\hline CHEMBL1402477 & 688239 & 5.9862 & 5.4359 & TRN & \\
\hline CHEMBL1468917 & 688239 & 5.6862 & 5.3373 & TRN & \\
\hline CHEMBL1611107 & 688239 & 5.3862 & 5.4356 & TRN & \\
\hline CHEMBL1374066 & 688239 & 6.7862 & 5.5644 & TRN & \\
\hline CHEMBL1559528 & 688239 & 4.6862 & 5.58200 & 0000000001 & TRN \\
\hline CHEMBL1415413 & 688239 & 4.7362 & 5.4262 & TRN & \\
\hline CHEMBL1574648 & 688239 & 4.7862 & 5.5953 & TRN & \\
\hline CHEMBL1592219 & 688239 & 5.0862 & 5.559 & TRN & \\
\hline CHEMBL1528179 & 688239 & 4.6862 & 5.6362 & TRN & \\
\hline CHEMBL1404772 & 688239 & 5.1862 & 5.5001 & TRN & \\
\hline CHEMBL1343696 & 688239 & 4.5362 & 5.3799 & TRN & \\
\hline CHEMBL1370435 & 688239 & 5.1362 & 5.4006 & TRN & \\
\hline CHEMBL1321355 & 688239 & 4.5362 & 5.5769 & TRN & \\
\hline CHEMBL1337607 & 688239 & 6.7862 & 5.5562 & TRN & \\
\hline CHEMBL1326441 & 688239 & 6.3362 & 5.5195 & TRN & \\
\hline CHEMBL1596799 & 688239 & 8.3372 & 5.5577 & TRN & \\
\hline CHEMBL1599318 & 688239 & 4.5362 & 5.5272 & TST & \\
\hline CHEMBL1408985 & 688239 & 6.5363 & 5.5295 & TRN & \\
\hline CHEMBL1449645 & 688239 & 5.7362 & 5.5696 & TRN & \\
\hline CHEMBL 3190016 & 688239 & 4.6862 & 5.4613 & TRN & \\
\hline CHEMBL1406943 & 688239 & 8.1871 & 5.4483 & TST & \\
\hline CHEMBL1409139 & 688239 & 4.5862 & 5.4674 & TRN & \\
\hline CHEMBL1580991 & 688239 & 6.0862 & 5.6284 & TRN & \\
\hline CHEMBL1382790 & 688239 & 5.4362 & 5.5914 & TRN & \\
\hline CHEMBL1321647 & 688239 & 5.5362 & 5.5776 & TRN & \\
\hline CHEMBL1397494 & 688239 & 5.8362 & 5.4642 & TST & \\
\hline CHEMBL1491596 & 688239 & 5.1862 & 5.6269 & TST & \\
\hline CHEMBL1400513 & 688239 & 5.5862 & 5.442 & TRN & \\
\hline CHEMBL1418834 & 688239 & 4.5862 & 5.5268 & TRN & \\
\hline CHEMBL1357502 & 688239 & 5.1862 & \multicolumn{2}{|c|}{5.412000000000001} & TRN \\
\hline CHEMBL1514620 & 688239 & 5.3362 & 5.6563 & TRN & \\
\hline CHEMBL1467578 & 688239 & 6.4862 & 5.5773 & TST & \\
\hline CHEMBL1401485 & 688239 & 6.8861 & 5.6631 & TRN & \\
\hline
\end{tabular}


Supplemental Table S2.txt

\begin{tabular}{|c|c|c|c|c|c|c|}
\hline CHEMBL1458129 & 688239 & 5.9862 & 5.5253 & TRN & & \\
\hline CHEMBL1425568 & 688239 & 5.4862 & 5.5099 & TRN & & \\
\hline CHEMBL1422904 & 688239 & 5.8862 & 5.4868 & TRN & & \\
\hline CHEMBL602969 & 688239 & 4.8862 & 5.4943 & TST & & \\
\hline CHEMBL1423027 & 688239 & 4.7362 & 5.6105 & TRN & & \\
\hline CHEMBL1538608 & 688239 & 4.6362 & 5.2844 & TST & & \\
\hline CHEMBL1382390 & 688239 & 6.9363 & 5.4244 & TRN & & \\
\hline CHEMBL1327665 & 688239 & 4.5862 & 5.4437 & TRN & & \\
\hline CHEMBL 3213028 & 688239 & \multicolumn{3}{|c|}{8.283999999999999} & 5.3846 & TST \\
\hline CHEMBL1326476 & 688239 & 5.1862 & 5.4301 & TST & & \\
\hline CHEMBL1608190 & 688239 & 6.5862 & 5.3714 & TRN & & \\
\hline CHEMBL1413971 & 688239 & 7.2366 & 5.4536 & TRN & & \\
\hline CHEMBL1475356 & 688239 & 4.5362 & 5.5469 & TRN & & \\
\hline CHEMBL1531053 & 688239 & 4.4862 & 5.5502 & TRN & & \\
\hline CHEMBL1572084 & 688239 & 6.1862 & 5.4315 & TST & & \\
\hline CHEMBL1528449 & 688239 & 8.1871 & 5.5544 & TST & & \\
\hline CHEMBL1482858 & 688239 & 5.0 & 5.5772 & TRN & & \\
\hline CHEMBL1325572 & 688239 & 6.8362 & 5.5652 & TRN & & \\
\hline CHEMBL1340480 & 688239 & 6.3863 & 5.4477 & TRN & & \\
\hline CHEMBL3210763 & 688239 & 4.8862 & 5.1998 & TRN & & \\
\hline CHEMBL1341113 & 688239 & 4.5362 & 5.4981 & TRN & & \\
\hline CHEMBL1551613 & 688239 & 4.5362 & 5.562 & TRN & & \\
\hline CHEMBL1502248 & 688239 & \multicolumn{3}{|c|}{8.283999999999999} & 5.6329 & TRN \\
\hline CHEMBL1580422 & 688239 & 4.5862 & 5.289 & TRN & & \\
\hline CHEMBL1399332 & 688239 & 4.5362 & 5.3063 & TST & & \\
\hline CHEMBL 3196868 & 688239 & 8.0362 & 5.4864 & TST & & \\
\hline CHEMBL1474032 & 688239 & 4.6362 & 5.6147 & TRN & & \\
\hline CHEMBL1578413 & 688239 & 4.5362 & 5.5831 & TRN & & \\
\hline CHEMBL1324666 & 688239 & \multicolumn{3}{|c|}{8.283999999999999} & 5.4078 & TRN \\
\hline CHEMBL1330506 & 688239 & 6.5862 & 5.5364 & TRN & & \\
\hline CHEMBL1434527 & 688239 & 4.5362 & 5.5578 & TRN & & \\
\hline CHEMBL1594157 & 688239 & 4.7862 & 5.6044 & TRN & & \\
\hline CHEMBL1300102 & 688239 & 4.8362 & 5.4623 & TST & & \\
\hline CHEMBL1509133 & 688239 & 4.7862 & 5.4709 & TRN & & \\
\hline CHEMBL1411157 & 688239 & 6.8362 & 5.4821 & TRN & & \\
\hline CHEMBL1450744 & 688239 & 4.9362 & 5.499 & TRN & & \\
\hline CHEMBL 1405005 & 688239 & 5.4862 & 5.4803 & TRN & & \\
\hline CHEMBL1424086 & 688239 & 4.5362 & 5.5871 & TRN & & \\
\hline CHEMBL1323387 & 688239 & 5.2862 & 5.5143 & TRN & & \\
\hline CHEMBL1472486 & 688239 & 4.9862 & 5.5246 & TRN & & \\
\hline CHEMBL1478917 & 688239 & 6.5862 & 5.602 & TST & & \\
\hline CHEMBL1312980 & 688239 & 4.8362 & 5.4312 & TRN & & \\
\hline CHEMBL1429834 & 688239 & 5.4362 & 5.4959 & TST & & \\
\hline CHEMBL1448041 & 688239 & 4.5362 & 5.4185 & TST & & \\
\hline CHEMBL1455322 & 688239 & 5.7362 & 5.5922 & TRN & & \\
\hline CHEMBL1518371 & 688239 & 5.5362 & 5.5824 & TST & & \\
\hline CHEMBL1377780 & 688239 & 4.6362 & 5.4961 & TST & & \\
\hline CHEMBL1571312 & 688239 & 6.1362 & 5.5176 & TRN & & \\
\hline
\end{tabular}


Supplemental Table S2.txt

\begin{tabular}{|c|c|c|c|c|}
\hline 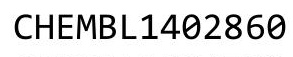 & & & & \\
\hline HEMBL1584722 & 38239 & 862 & 6 & \\
\hline AEMBL1478149 & 239 & 362 & & \\
\hline 737 & 39 & 366 & 928 & \\
\hline EMBL131 & 39 & 362 & & \\
\hline AEMBL1607668 & 88239 & 362 & 13 & \\
\hline AEMBL1458505 & 88239 & 372 & 5436 & \\
\hline HEMBL154 & & & & \\
\hline IEMBL13 & 39 & 862 & & \\
\hline IEMBL13 & & & & \\
\hline AEMBL1386875 & 239 & 862 & & \\
\hline AEMBL1305630 & & 362 & & \\
\hline HEMBL144 & & & & \\
\hline HEMBL133 & & & & \\
\hline HEMBL14C & & & & \\
\hline HEMBL137 & & 862 & & \\
\hline HEMBL155 & & 62 & & \\
\hline HEMBL159 & & & & \\
\hline AEMBL15 & & & & \\
\hline JEMBL15 & & & & \\
\hline HEMBL156 & & 62 & & \\
\hline HEMBL139 & & 62 & & \\
\hline HEMBL158 & & & & \\
\hline AFMRI $31 c$ & & & & \\
\hline 59 & & & & \\
\hline HEMBL130 & & 62 & & \\
\hline AEMBL159 & & & & \\
\hline JEMBL134 & & & & \\
\hline AFMR & & & & \\
\hline HEMBL13 & & & & \\
\hline HEMBL 141 & & & & \\
\hline HEMBL140 & & & & \\
\hline & & & & \\
\hline 7 & & & & \\
\hline HEMBL131 & & & & RN \\
\hline HEMBL1526 & & & & \\
\hline HEMBL154 & & 4 & & \\
\hline & & & & \\
\hline 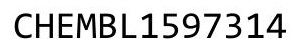 & & & & . \\
\hline HEMBL132 & & & & S \\
\hline HEMBL 321 & & 62 & & $\mathrm{R}$ \\
\hline AEMBL31 & & 61 & & \\
\hline & & & & \\
\hline HEMBL198 & & & & \\
\hline AEMBL1532 & & & & RN \\
\hline HEMBL 144 & 68 & 862 & & $\Gamma R$ \\
\hline 100 & & & & \\
\hline HEMBL 154829 & & & . 4901 & \\
\hline
\end{tabular}

Page 1150 
Supplemental Table S2.txt

\begin{tabular}{|c|c|c|c|c|c|}
\hline CHEMBL1359826 & 688239 & 6.1362 & 5.5303 & TRN & \\
\hline CHEMBL1424122 & 688239 & 4.5362 & 5.5211 & TRN & \\
\hline CHEMBL1537146 & 688239 & 6.2362 & 5.527 & TRN & \\
\hline CHEMBL1300915 & 688239 & 6.1862 & 5.4898 & TRN & \\
\hline CHEMBL1549835 & 688239 & 4.6862 & 5.4998 & TRN & \\
\hline CHEMBL1513561 & 688239 & 4.8362 & 5.6364 & TRN & \\
\hline CHEMBL1560141 & 688239 & 4.8862 & 5.3794 & TST & \\
\hline CHEMBL1409736 & 688239 & 4.5362 & 5.5475 & TRN & \\
\hline CHEMBL1433801 & 688239 & 5.4362 & 5.37 & TRN & \\
\hline CHEMBL1339286 & 688239 & 4.5362 & 5.5137 & TRN & \\
\hline CHEMBL1379642 & 688239 & 4.8862 & 5.6346 & TST & \\
\hline CHEMBL1430704 & 688239 & 5.2362 & 5.4626 & TRN & \\
\hline CHEMBL1406768 & 688239 & 6.8362 & 5.4764 & TRN & \\
\hline CHEMBL1377551 & 688239 & 6.1362 & 5.4682 & TST & \\
\hline CHEMBL1534258 & 688239 & 4.9862 & 5.4506 & TST & \\
\hline CHEMBL1365363 & 688239 & 5.7362 & 5.4774 & TRN & \\
\hline CHEMBL1975523 & 688239 & 4.5362 & 5.385 & TRN & \\
\hline CHEMBL1551269 & 688239 & 5.0862 & 5.6418 & TRN & \\
\hline CHEMBL1431346 & 688239 & 6.7361 & 5.3687 & TST & \\
\hline CHEMBL1577238 & 688239 & 5.5362 & 5.4904 & TST & \\
\hline CHEMBL1422519 & 688239 & 5.1862 & 5.3926 & TRN & \\
\hline CHEMBL1456459 & 688239 & 4.5862 & 5.635 & TRN & \\
\hline CHEMBL1613676 & 688239 & 6.5862 & 5.6498 & TRN & \\
\hline CHEMBL1397606 & 688239 & 6.2862 & 5.5947 & TRN & \\
\hline CHEMBL1374098 & 688239 & 4.5362 & 5.487999 & 99999999995 & \\
\hline CHEMBL 3213361 & 688239 & 4.6862 & 5.5719 & TST & \\
\hline CHEMBL1349310 & 688239 & 5.6362 & 5.4987 & TRN & \\
\hline CHEMBL1324801 & 688239 & 6.6861 & 5.6295 & TRN & \\
\hline CHEMBL1351544 & 688239 & 5.6362 & 5.4115 & TST & \\
\hline CHEMBL1495136 & 688239 & 4.5362 & 5.4113 & TRN & \\
\hline CHEMBL1597875 & 688239 & 8.28399 & 99999999 & 5.6304 & TST \\
\hline CHEMBL1414533 & 688239 & 4.8362 & 5.3785 & TRN & \\
\hline CHEMBL1327185 & 688239 & 5.6862 & 5.6681 & TRN & \\
\hline CHEMBL1521044 & 688239 & 8.28399 & 99999999 & 5.5731 & I Tा \\
\hline CHEMBL1511654 & 688239 & 4.5362 & 5.3843 & TST & \\
\hline CHEMBL1580334 & 688239 & 8.1367 & 5.5803 & TST & \\
\hline CHEMBL1405876 & 688239 & 4.6862 & 5.6612 & TRN & \\
\hline CHEMBL1563916 & 688239 & 6.5862 & 5.5523 & TST & \\
\hline CHEMBL1329798 & 688239 & 5.4362 & 5.3276 & TST & \\
\hline CHEMBL1513054 & 688239 & 5.0362 & 5.4354 & TRN & \\
\hline CHEMBL1441873 & 688239 & 4.9362 & 5.6424 & TRN & \\
\hline CHEMBL585071 & 688239 & 4.6362 & 5.6027 & TRN & \\
\hline CHEMBL1537718 & 688239 & 4.4862 & 5.5452 & TRN & \\
\hline CHEMBL1374724 & 688239 & 4.9362 & 5.4017 & TRN & \\
\hline CHEMBL1549277 & 688239 & 4.5362 & 5.3998 & TRN & \\
\hline CHEMBL1410838 & 688239 & 5.8362 & 5.6406 & TRN & \\
\hline CHEMBL1561119 & 688239 & 5.1862 & 5.5139 & TST & \\
\hline CHEMBL1414180 & 688239 & 6.8362 & 5.4446 & TST & \\
\hline
\end{tabular}


Supplemental Table S2.txt

\begin{tabular}{|c|c|c|c|c|}
\hline CHEMBL1520262 & 688239 & 6.2362 & 5.3879 & TRN \\
\hline CHEMBL1333685 & 688239 & 6.2362 & 5.6558 & TRN \\
\hline CHEMBL3209002 & 688239 & 4.6862 & 5.3278 & TST \\
\hline CHEMBL1506633 & 688239 & 5.7862 & 5.45200 & 0000000001 \\
\hline CHEMBL1546435 & 688239 & 6.1362 & 5.5695 & TST \\
\hline CHEMBL1361156 & 688239 & 6.2862 & 5.3984 & TRN \\
\hline CHEMBL1519596 & 688239 & 4.9862 & 5.4796 & TST \\
\hline CHEMBL1472782 & 688239 & 5.8862 & 5.3261 & TRN \\
\hline CHEMBL1413697 & 688239 & 5.5862 & 5.5334 & TRN \\
\hline CHEMBL1347283 & 688239 & 5.0862 & 5.3839 & TRN \\
\hline CHEMBL1428469 & 688239 & 4.7862 & 5.4324 & TRN \\
\hline CHEMBL1445062 & 688239 & 5.4862 & 5.5514 & TRN \\
\hline CHEMBL1300225 & 688239 & 4.6862 & 5.5161 & TRN \\
\hline CHEMBL1486033 & 688239 & 4.5862 & 5.3027 & TST \\
\hline CHEMBL1496854 & 688239 & 5.1862 & 5.4332 & TRN \\
\hline CHEMBL1304362 & 688239 & 6.0862 & 5.525 & TRN \\
\hline CHEMBL1313086 & 688239 & 7.5361 & 5.5581 & TRN \\
\hline CHEMBL1445073 & 688239 & 4.7862 & 5.2883 & TRN \\
\hline CHEMBL1569477 & 688239 & 5.6362 & 5.3681 & TRN \\
\hline CHEMBL1342447 & 688239 & 5.2862 & 5.4194 & TRN \\
\hline CHEMBL1353844 & 688239 & 4.5362 & 5.4911 & TRN \\
\hline CHEMBL1611138 & 688239 & 5.1862 & 5.4321 & TRN \\
\hline CHEMBL1606286 & 688239 & 4.8362 & 5.5537 & TRN \\
\hline CHEMBL1384221 & 688239 & 4.8362 & 5.4125 & TRN \\
\hline CHEMBL3192297 & 688239 & 4.8862 & 5.6117 & TRN \\
\hline CHEMBL1483823 & 688239 & 4.5862 & 5.4698 & TRN \\
\hline CHEMBL1490659 & 688239 & 4.8362 & 5.5409 & TST \\
\hline CHEMBL1512595 & 688239 & 4.5362 & 5.4422 & TRN \\
\hline CHEMBL1303356 & 688239 & 4.5362 & 5.5535 & TST \\
\hline CHEMBL1507759 & 688239 & 6.8861 & 5.2879 & TRN \\
\hline CHEMBL1414441 & 688239 & 5.4862 & 5.6541 & TRN \\
\hline CHEMBL1598950 & 688239 & 5.0862 & 5.3908 & TRN \\
\hline CHEMBL1339205 & 688239 & 6.8861 & 5.4999 & TRN \\
\hline CHEMBL1453557 & 688239 & 5.0862 & 5.4428 & TST \\
\hline CHEMBL1398363 & 688239 & 4.5362 & 5.5097 & TST \\
\hline CHEMBL1351453 & 688239 & 6.0362 & 5.5764 & TRN \\
\hline CHEMBL1332353 & 688239 & 4.6862 & 5.4342 & TRN \\
\hline CHEMBL1306285 & 688239 & 4.4862 & 5.4135 & TRN \\
\hline CHEMBL1612251 & 688239 & 6.5862 & 5.6986 & TRN \\
\hline CHEMBL1566286 & 688239 & 4.7862 & 5.4464 & TST \\
\hline CHEMBL3209651 & 688239 & 5.3362 & 5.5635 & TRN \\
\hline CHEMBL1424837 & 688239 & 4.5362 & 5.3231 & TRN \\
\hline CHEMBL3209531 & 688239 & 4.7862 & 5.4483 & TRN \\
\hline CHEMBL1418393 & 688239 & 5.1862 & 5.4734 & TST \\
\hline CHEMBL1594398 & 688239 & 4.8362 & 5.4357 & TRN \\
\hline CHEMBL1440254 & 688239 & 6.0362 & 5.5038 & TRN \\
\hline CHEMBL1595604 & 688239 & 5.1862 & 5.5789 & TRN \\
\hline CHEMBL1394395 & 688239 & 5.1362 & 5.3579 & TRN \\
\hline
\end{tabular}


Supplemental Table S2.txt

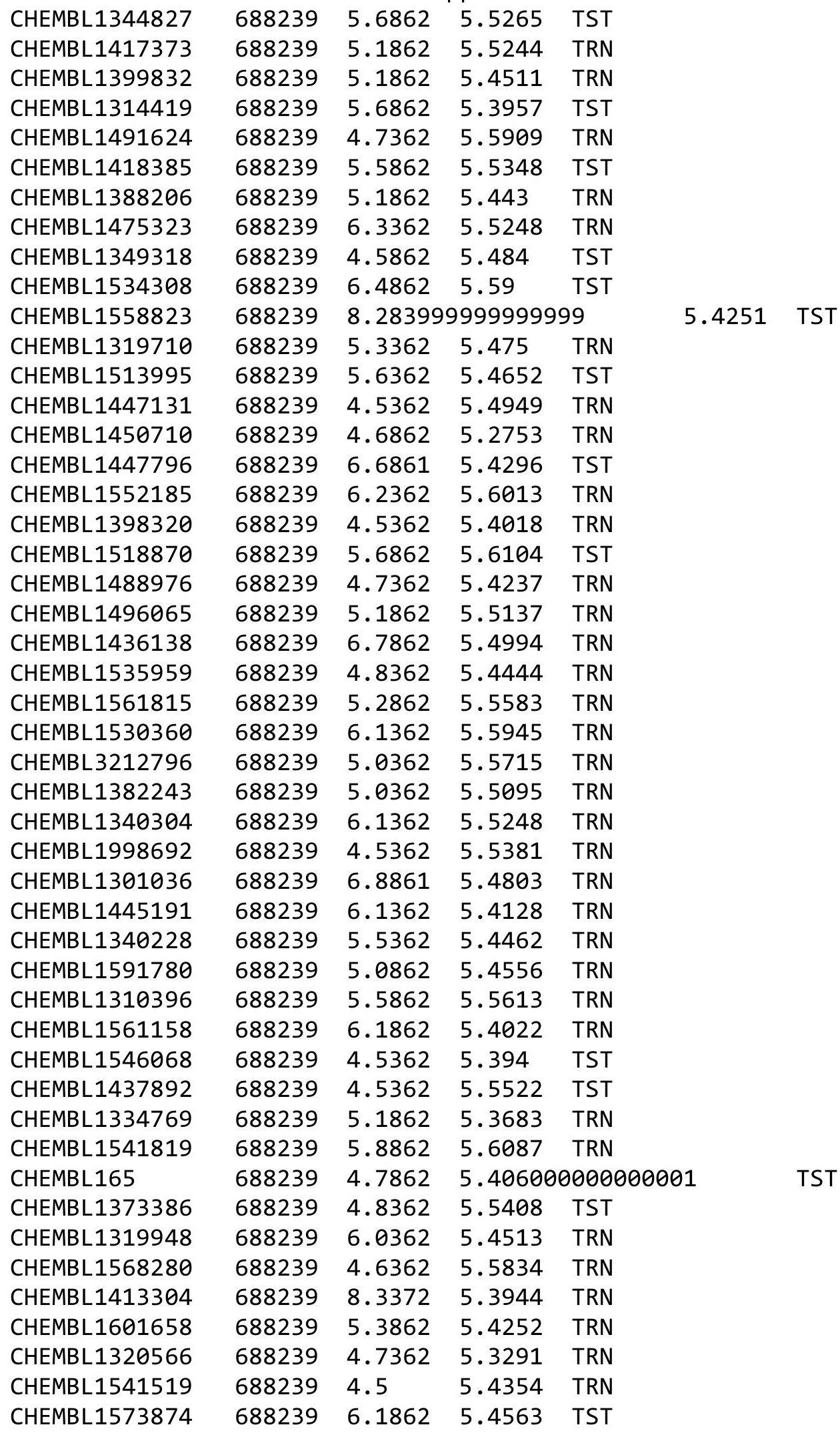

Page 1153 
Supplemental Table S2.txt

\begin{tabular}{|c|c|c|c|c|}
\hline & & & & \\
\hline IEMBL1 & 8239 & 362 & & \\
\hline IEMBL1411196 & 3239 & 862 & 4898 & \\
\hline HEMBL1394017 & 239 & 862 & 4358 & \\
\hline & 239 & 362 & & \\
\hline IFMRI 12 & 239 & 362 & 823 & \\
\hline AEMBL1590092 & 239 & 362 & 5085 & \\
\hline AEMBL1357345 & 88239 & 362 & 5488 & \\
\hline AEMBL1539345 & 239 & 862 & 937 & \\
\hline IEMBL1564378 & 239 & 862 & 203 & \\
\hline IEMBL1312360 & & & & \\
\hline AEMBL3198169 & 588239 & 862 & 5075 & \\
\hline AEMBL1533836 & 239 & 862 & 482 & \\
\hline IEMBL15 & & 363 & & \\
\hline IEMBL1460749 & & 62 & & \\
\hline AEMBL1307074 & & & & \\
\hline AEMBL1312565 & 239 & 862 & 872 & \\
\hline AEMBL1360776 & & 362 & & \\
\hline EMBL1502/35 & & 62 & & \\
\hline EMMBL1353648 & & & & \\
\hline AEMBL1495837 & & 62 & 33 & \\
\hline AEMBL1364342 & & 862 & 636 & \\
\hline IEMBL1429071 & & 62 & & RN \\
\hline IEMBL138 & & 62 & & \\
\hline IEMBL158 & & & & ST \\
\hline FMR 146 & & 68 & 66 & וכ \\
\hline HEMBL1379987 & & & & RN \\
\hline IEMBL1451147 & & & & \\
\hline AEMBL1584832 & & 62 & 87 & ST 1 \\
\hline HEMBL13] & & 62 & 15 & 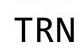 \\
\hline 501 & & 52 & & ST \\
\hline AEMBL1425358 & & & & RN \\
\hline AEMBL1440089 & & & & \\
\hline IEMBL1520400 & & 362 & & $\mathrm{RI}$ \\
\hline HEMBL1398234 & & 62 & 33 & $\cdots$ \\
\hline 386 & & & & $\cdots$ \\
\hline HEMBL1422986 & & & 1785 & $S$ \\
\hline AEMBL1387481 & & & & $R^{-}$ \\
\hline EMBL1533683 & & & & RI \\
\hline AEMBL1343356 & & & 46 & \\
\hline 157 & & & 12 & RN \\
\hline AEMBL1309639 & & 862 & 5909 & $\mathrm{R}$ \\
\hline IEMBL1369795 & & & 96 & TR \\
\hline MBL196 & & & & \\
\hline CHEMBL1448006 & & & 997 & \\
\hline CHEMBL1453689 & & 362 & 843 & IV \\
\hline AEMBL3194681 & 8239 & 5.3362 & .5386 & TS \\
\hline HFMRI 1179136 & 688239 & 5.1862 & 5.4505 & \\
\hline
\end{tabular}

Page 1154 
Supplemental Table S2.txt

\begin{tabular}{|c|c|c|c|c|}
\hline 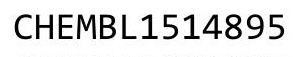 & & & & \\
\hline HEMBL1980827 & 38239 & 861 & 8 & \\
\hline AEMBL1456430 & 239 & & & \\
\hline & 39 & 362 & & \\
\hline IEMBL14 & & & & \\
\hline AEMBL1400869 & 88239 & 862 & 799 & \\
\hline AEMBL1430530 & 88239 & 362 & .4747 & \\
\hline HEMBL1304781 & & & & \\
\hline EMBL1356 & 39 & & & \\
\hline IEMBL1412 & & & & \\
\hline AEMBL1557545 & 239 & 362 & 5001 & \\
\hline HEMBL1382686 & & 362 & 4229 & \\
\hline AEMBL1416089 & & & 84 & \\
\hline AEMBL1556 & & & & \\
\hline HEMBL1534035 & & & & \\
\hline AEMBL1464437 & & 62 & 66 & \\
\hline AEMBL1322349 & & & & \\
\hline IEMBL1386 & & & & \\
\hline AEMBL3208 & & & & \\
\hline AEMBL1609 & & & & \\
\hline AEMBL1575953 & & & & \\
\hline AEMBL1477 & & & & \\
\hline EMBL 14623 & & & & \\
\hline JFMRI 125 & & & & \\
\hline 6 & & & & \\
\hline AEMBL1299444 & & & & \\
\hline IEMBL1589571 & & & & \\
\hline AEMBL13344 & & & & \\
\hline AFMRI 1562 & & & & \\
\hline 1 & & & & \\
\hline AEMBL14833 & & & & \\
\hline IEMBL1403393 & & & & \\
\hline & & & & \\
\hline 7 & & & & \\
\hline & & & & \\
\hline AEMBL1605916 & & & & S \\
\hline IEMBL1610739 & & & & \\
\hline & & & & \\
\hline $1455^{\circ}$ & & & & \\
\hline HEMBL1315286 & & & & RI \\
\hline AEMBL1571915 & & & & $\mathrm{F}$ \\
\hline L1434463 & & & & \\
\hline & & & & \\
\hline HEMBL 3198474 & & & & \\
\hline AEMBL1572137 & & & & RN \\
\hline IEMBL14994 & & & .77 & 11 \\
\hline 12 & & & & \\
\hline HEMBL150894 & & & & \\
\hline
\end{tabular}

Page 1155 
Supplemental Table S2.txt

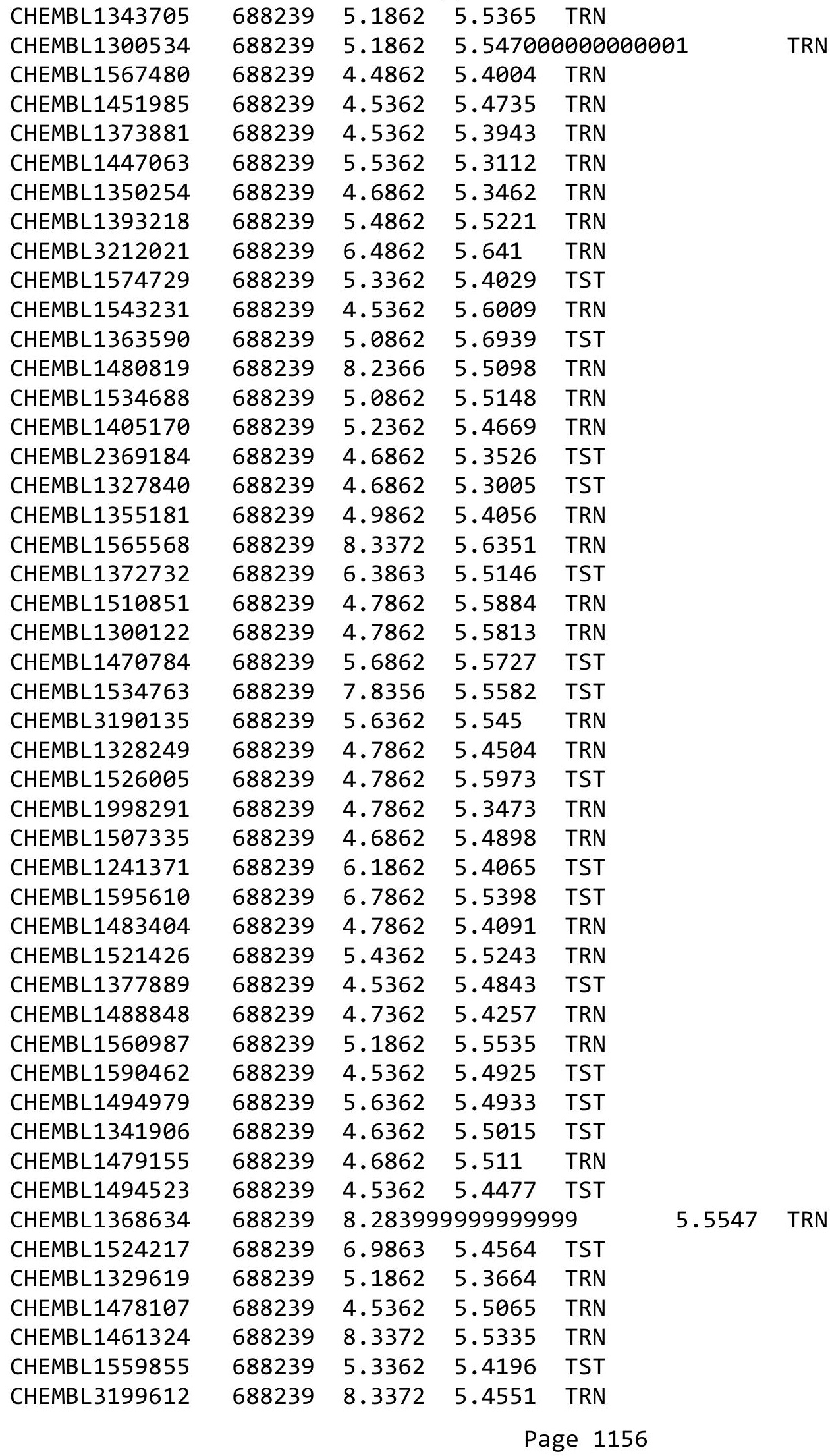


Supplemental Table S2.txt

\begin{tabular}{|c|c|c|c|c|}
\hline CHEMBL1382889 & 688239 & 6.2862 & 5.3847 & TRN \\
\hline CHEMBL1422240 & 688239 & 4.5362 & 5.4643 & TRN \\
\hline CHEMBL1361877 & 688239 & 7.4868 & 5.3615 & TRN \\
\hline CHEMBL3195433 & 688239 & 4.5362 & 5.4033 & TST \\
\hline CHEMBL605708 & 688239 & 4.5362 & 5.3945 & TRN \\
\hline CHEMBL1341549 & 688239 & 5.1362 & 5.3708 & TRN \\
\hline CHEMBL1304807 & 688239 & 5.5362 & \multicolumn{2}{|c|}{5.3870000000000005} \\
\hline CHEMBL1987563 & 688239 & 8.1871 & 5.4851 & TRN \\
\hline CHEMBL1315407 & 688239 & 4.4862 & 5.5043 & TRN \\
\hline CHEMBL1574603 & 688239 & 5.1362 & 5.3229 & TRN \\
\hline CHEMBL1373541 & 688239 & 4.9362 & 5.4305 & TST \\
\hline CHEMBL 3192347 & 688239 & 6.9863 & 5.3502 & TST \\
\hline CHEMBL1402145 & 688239 & 5.3362 & 5.4817 & TST \\
\hline CHEMBL1401304 & 688239 & 4.5862 & 5.6436 & TRN \\
\hline CHEMBL1542219 & 688239 & 5.1862 & 5.481 & TRN \\
\hline CHEMBL1305886 & 688239 & 5.7862 & 5.485 & TST \\
\hline CHEMBL1503615 & 688239 & 6.3362 & 5.5167 & TRN \\
\hline CHEMBL1524527 & 688239 & 4.4862 & 5.4816 & TST \\
\hline CHEMBL1598847 & 688239 & 5.1862 & 5.4745 & TRN \\
\hline CHEMBL1326798 & 688239 & 4.5362 & 5.556 & TRN \\
\hline CHEMBL1504557 & 688239 & 7.2366 & 5.4474 & TST \\
\hline CHEMBL1383041 & 688239 & 6.1362 & 5.415 & TST \\
\hline CHEMBL1525576 & 688239 & 6.0362 & 5.4382 & TRN \\
\hline CHEMBL1325936 & 688239 & 5.6362 & 5.5284 & TRN \\
\hline CHEMBL1465096 & 688239 & 4.6862 & 5.3258 & TST \\
\hline CHEMBL1386200 & 688239 & 5.4862 & 5.5058 & TRN \\
\hline CHEMBL1433656 & 688239 & 5.1862 & 5.4671 & TRN \\
\hline CHEMBL1544937 & 688239 & 6.7361 & 5.5085 & TRN \\
\hline CHEMBL1568144 & 688239 & 6.7361 & 5.3514 & TST \\
\hline CHEMBL 3194975 & 688239 & 7.0862 & 5.5348 & TRN \\
\hline CHEMBL1982078 & 688239 & 4.7862 & 5.4314 & TRN \\
\hline CHEMBL1393160 & 688239 & 5.1862 & 5.6098 & TRN \\
\hline CHEMBL1407125 & 688239 & 6.1862 & 5.6197 & TRN \\
\hline CHEMBL1483883 & 688239 & 4.8862 & 5.5229 & TRN \\
\hline CHEMBL1464156 & 688239 & 5.0862 & 5.3871 & TRN \\
\hline CHEMBL1526561 & 688239 & 4.5362 & 5.4046 & TRN \\
\hline CHEMBL1469624 & 688239 & 4.8362 & 5.3827 & TRN \\
\hline CHEMBL1586772 & 688239 & 5.2862 & 5.4324 & TRN \\
\hline CHEMBL1422534 & 688239 & 4.7862 & 5.5138 & TRN \\
\hline CHEMBL1463651 & 688239 & 5.1862 & 5.5171 & TRN \\
\hline CHEMBL1536891 & 688239 & 4.5362 & 5.4939 & TST \\
\hline CHEMBL1316518 & 688239 & 5.0862 & 5.5884 & TST \\
\hline CHEMBL1425484 & 688239 & 4.5362 & 5.4472 & TRN \\
\hline CHEMBL1309383 & 688239 & 4.5362 & 5.3939 & TRN \\
\hline CHEMBL1413516 & 688239 & 6.2362 & 5.402 & TRN \\
\hline CHEMBL3193922 & 688239 & 6.3863 & 5.4552 & TRN \\
\hline CHEMBL1386677 & 688239 & 6.0862 & 5.528 & TRN \\
\hline CHEMBL1432069 & 688239 & 8.2366 & 5.4371 & TST \\
\hline
\end{tabular}


Supplemental Table S2.txt

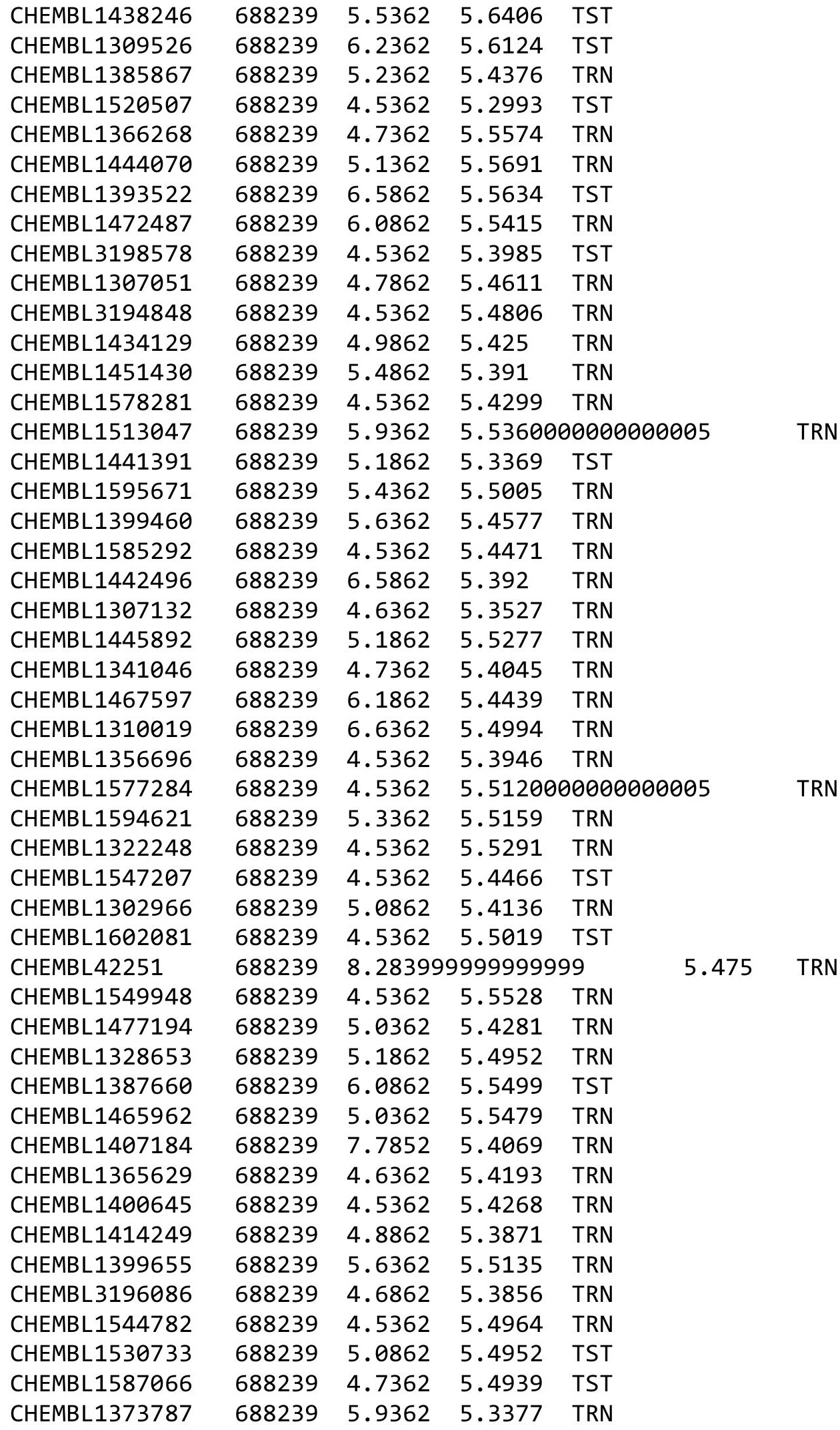

Page 1158 
Supplemental Table S2.txt

\begin{tabular}{|c|c|c|c|c|}
\hline CHEMBL1445079 & 688239 & 4.5362 & 5.5376 & TRN \\
\hline CHEMBL1446685 & 688239 & 6.1862 & 5.6633 & TRN \\
\hline CHEMBL1521764 & 688239 & 4.9862 & 5.4228 & TRN \\
\hline CHEMBL1568467 & 688239 & 5.1862 & 5.4318 & TST \\
\hline CHEMBL122360 & 688239 & 6.9363 & 5.5405 & TST \\
\hline CHEMBL1334392 & 688239 & 4.9862 & 5.5479 & TRN \\
\hline CHEMBL434915 & 688239 & 7.2366 & 5.5359 & TRN \\
\hline CHEMBL1483894 & 688239 & 5.2862 & 5.4841 & TRN \\
\hline CHEMBL1582139 & 688239 & 4.6362 & 5.4765 & TRN \\
\hline CHEMBL1464601 & 688239 & 5.1862 & 5.4962 & TST \\
\hline CHEMBL1597057 & 688239 & 4.5362 & 5.5599 & TRN \\
\hline CHEMBL1501018 & 688239 & 5.8862 & 5.3598 & TST \\
\hline CHEMBL1608254 & 688239 & 5.3862 & 5.5374 & TST \\
\hline CHEMBL1533299 & 688239 & 5.3862 & 5.2979 & TRN \\
\hline CHEMBL1458417 & 688239 & 6.9863 & 5.5858 & TRN \\
\hline CHEMBL1356827 & 688239 & 5.1862 & 5.5015 & TRN \\
\hline CHEMBL1483408 & 688239 & 4.5362 & 5.4891 & TST \\
\hline CHEMBL1306667 & 688239 & 6.9363 & 5.4349 & TRN \\
\hline CHEMBL1530842 & 688239 & 4.5362 & 5.4206 & TRN \\
\hline CHEMBL1585768 & 688239 & 5.3862 & 5.422006 & $\partial 000000001$ \\
\hline CHEMBL1557243 & 688239 & 4.5362 & 5.3533 & TRN \\
\hline CHEMBL1349943 & 688239 & 5.0362 & 5.5135 & TRN \\
\hline CHEMBL 3211555 & 688239 & 8.28399 & 99999999 & 5.4663 \\
\hline CHEMBL1377812 & 688239 & 5.5362 & 5.5248 & TRN \\
\hline CHEMBL 3144992 & 688239 & 4.5362 & 5.409 & TRN \\
\hline CHEMBL1383491 & 688239 & 5.7362 & 5.5082 & TRN \\
\hline CHEMBL1412980 & 688239 & 6.1362 & 5.4567 & TST \\
\hline CHEMBL1462557 & 688239 & 5.3862 & 5.5614 & TRN \\
\hline CHEMBL1339149 & 688239 & 4.8862 & 5.4806 & TRN \\
\hline CHEMBL1337249 & 688239 & 6.8362 & 5.5407 & TRN \\
\hline CHEMBL1346695 & 688239 & 4.7362 & 5.4849 & TST \\
\hline CHEMBL 3194765 & 688239 & 6.1362 & 5.3129 & TRN \\
\hline CHEMBL1349379 & 688239 & 5.7362 & 5.6805 & TRN \\
\hline CHEMBL1485410 & 688239 & 4.45 & 5.646 & TRN \\
\hline CHEMBL1562963 & 688239 & 5.5862 & 5.4382 & TRN \\
\hline CHEMBL1555864 & 688239 & 6.9863 & 5.6297 & TST \\
\hline CHEMBL1458403 & 688239 & 5.4362 & 5.3663 & TST \\
\hline CHEMBL1316153 & 688239 & 4.5362 & 5.5783 & TRN \\
\hline CHEMBL1566075 & 688239 & 4.7862 & 5.3436 & TRN \\
\hline CHEMBL1586019 & 688239 & 4.7862 & 5.3744 & TST \\
\hline CHEMBL1455001 & 688239 & 4.7862 & 5.3846 & TRN \\
\hline CHEMBL1324470 & 688239 & 5.4362 & 5.4367 & TRN \\
\hline CHEMBL1463996 & 688239 & 5.15 & 5.7607 & TRN \\
\hline CHEMBL 235891 & 688239 & 4.6862 & 5.3843 & TST \\
\hline CHEMBL1445082 & 688239 & 6.2362 & 5.5814 & TRN \\
\hline CHEMBL1465165 & 688239 & 4.6362 & 5.4191 & TST \\
\hline CHEMBL1300147 & 688239 & 6.4862 & 5.3934 & TRN \\
\hline CHEMBL1403201 & 688239 & 5.1862 & 5.5879 & TRN \\
\hline
\end{tabular}


Supplemental Table S2.txt

\begin{tabular}{|c|c|c|c|c|}
\hline CHEMBL1605188 & 688239 & 4.6362 & 5.545 & TRN \\
\hline CHEMBL1361249 & 688239 & 6.6362 & 5.499 & TRN \\
\hline CHEMBL1582535 & 688239 & 6.0362 & 5.5269 & TRN \\
\hline CHEMBL1492302 & 688239 & 4.5362 & 5.5938 & TRN \\
\hline CHEMBL1606437 & 688239 & 5.4362 & 5.5244 & TRN \\
\hline CHEMBL1448573 & 688239 & 4.6862 & 5.3335 & TST \\
\hline CHEMBL1451041 & 688239 & 5.1362 & 5.6032 & TST \\
\hline CHEMBL1325500 & 688239 & 5.1862 & 5.4878 & TRN \\
\hline CHEMBL1480947 & 688239 & 5.1862 & 5.5768 & TRN \\
\hline CHEMBL1383158 & 688239 & 5.5862 & 5.4576 & TST \\
\hline CHEMBL1423622 & 688239 & 6.4862 & 5.5119 & TRN \\
\hline CHEMBL1570257 & 688239 & 6.0862 & 5.3649 & TRN \\
\hline CHEMBL3194662 & 688239 & 6.0862 & 5.447 & TRN \\
\hline CHEMBL1550990 & 688239 & 7.1361 & 5.6019 & TRN \\
\hline CHEMBL1463679 & 688239 & 4.4862 & 5.5632 & TST \\
\hline CHEMBL1312898 & 688239 & 5.4862 & 5.5392 & TRN \\
\hline CHEMBL1497284 & 688239 & 5.7362 & 5.5699 & TRN \\
\hline CHEMBL1964317 & 688239 & 6.0362 & 5.5839 & TST \\
\hline CHEMBL1464693 & 688239 & 6.2362 & 5.6143 & TRN \\
\hline CHEMBL1451586 & 688239 & 4.8362 & 5.5142 & TRN \\
\hline CHEMBL1481313 & 688239 & 4.4862 & 5.4017 & TRN \\
\hline CHEMBL1475492 & 688239 & 4.9362 & 5.5597 & TRN \\
\hline CHEMBL1300342 & 688239 & 6.1862 & 5.6447 & TRN \\
\hline CHEMBL1425387 & 688239 & 5.1862 & 5.3494 & TST \\
\hline CHEMBL1561345 & 688239 & 4.4862 & 5.2174 & TRN \\
\hline CHEMBL3213382 & 688239 & 5.6862 & 5.365 & TST \\
\hline CHEMBL1589473 & 688239 & 8.28399 & 99999999 & 5.4541 \\
\hline CHEMBL1438636 & 688239 & 5.3362 & 5.6431 & TRN \\
\hline CHEMBL 3197487 & 688239 & 7.6861 & 5.6368 & TRN \\
\hline CHEMBL1538966 & 688239 & 4.5362 & 5.4753 & TST \\
\hline CHEMBL1503462 & 688239 & 4.7362 & 5.3984 & TST \\
\hline CHEMBL1426493 & 688239 & 6.5363 & 5.4116 & TRN \\
\hline CHEMBL1454579 & 688239 & 4.6362 & 5.5377 & TRN \\
\hline CHEMBL1391827 & 688239 & 5.5362 & 5.4237 & TST \\
\hline CHEMBL1517606 & 688239 & 4.5362 & 5.4678 & TST \\
\hline CHEMBL2005764 & 688239 & 4.7362 & 5.4372 & TRN \\
\hline CHEMBL1601499 & 688239 & 6.2362 & 5.5101 & TRN \\
\hline CHEMBL1374253 & 688239 & 5.3362 & 5.5911 & TRN \\
\hline CHEMBL1386810 & 688239 & 5.0862 & 5.4364 & TRN \\
\hline CHEMBL1328050 & 688239 & 5.3862 & 5.399 & TST \\
\hline CHEMBL1517696 & 688239 & 4.5862 & 5.4061 & TRN \\
\hline CHEMBL1334783 & 688239 & 4.7362 & 5.526 & TST \\
\hline CHEMBL1503867 & 688239 & 4.7362 & 5.4086 & TST \\
\hline CHEMBL1440831 & 688239 & 6.0862 & 5.6017 & TRN \\
\hline CHEMBL1588894 & 688239 & 5.5862 & 5.4822 & TRN \\
\hline CHEMBL1368538 & 688239 & 4.5362 & 5.44600 & 3000000001 \\
\hline CHEMBL1557558 & 688239 & 6.6362 & 5.4447 & TRN \\
\hline CHEMBL1546368 & 688239 & 8.3372 & 5.2576 & TRN \\
\hline
\end{tabular}


Supplemental Table S2.txt

\begin{tabular}{|c|c|c|c|c|c|}
\hline CHEMBL1341379 & 688239 & 4.5362 & 5.3878 & TRN & \\
\hline CHEMBL1579305 & 688239 & 6.2362 & 5.3696 & TRN & \\
\hline CHEMBL1442866 & 688239 & 5.2862 & 5.5175 & TRN & \\
\hline CHEMBL1304385 & 688239 & 5.0362 & 5.6863 & TRN & \\
\hline CHEMBL1541673 & 688239 & 5.1862 & 5.6143 & TRN & \\
\hline CHEMBL1321227 & 688239 & 5.7862 & 5.5509 & TRN & \\
\hline CHEMBL1545109 & 688239 & 5.5362 & 5.3598 & TST & \\
\hline CHEMBL1333606 & 688239 & 4.8862 & 5.4998 & TST & \\
\hline CHEMBL1318626 & 688239 & 5.0362 & 5.4669 & TST & \\
\hline CHEMBL1423201 & 688239 & 6.2362 & 5.5003 & TST & \\
\hline CHEMBL1539678 & 688239 & 5.7362 & 5.4128 & TRN & \\
\hline CHEMBL1608700 & 688239 & 6.1362 & 5.4766 & TRN & \\
\hline CHEMBL1388503 & 688239 & 4.7862 & 5.5627 & TST & \\
\hline CHEMBL1457707 & 688239 & 6.6362 & 5.5109 & TRN & \\
\hline CHEMBL3189708 & 688239 & 6.2362 & 5.5259 & TRN & \\
\hline CHEMBL1546760 & 688239 & 5.5862 & 5.4841 & TST & \\
\hline CHEMBL1349940 & 688239 & 5.1862 & 5.5924 & TRN & \\
\hline CHEMBL1487518 & 688239 & 5.1862 & 5.6238 & TRN & \\
\hline CHEMBL1577904 & 688239 & 5.0362 & 5.3907 & TRN & \\
\hline CHEMBL1524043 & 688239 & 4.4862 & 5.5765 & TST & \\
\hline CHEMBL1345583 & 688239 & 7.2366 & 5.5296 & TRN & \\
\hline CHEMBL1494805 & 688239 & 5.6862 & 5.6416 & TRN & \\
\hline CHEMBL1523191 & 688239 & 5.4862 & 5.3644 & TRN & \\
\hline CHEMBL1343051 & 688239 & 6.2862 & 5.314 & TRN & \\
\hline CHEMBL1420481 & 688239 & 6.5862 & 5.5162 & TST & \\
\hline CHEMBL1484580 & 688239 & 4.5362 & 5.4918 & TRN & \\
\hline CHEMBL1570221 & 688239 & 6.1362 & 5.5392 & TST & \\
\hline CHEMBL1578287 & 688239 & 6.7862 & 5.4945 & TRN & \\
\hline CHEMBL1468665 & 688239 & 5.5362 & 5.5295 & TST & \\
\hline CHEMBL1328688 & 688239 & 6.9363 & 5.4819 & TRN & \\
\hline CHEMBL1498086 & 688239 & 4.5862 & 5.5007 & TRN & \\
\hline CHEMBL1393176 & 688239 & 6.2362 & 5.5545 & TRN & \\
\hline CHEMBL1520061 & 688239 & 4.6862 & 5.6071 & TRN & \\
\hline CHEMBL1351881 & 688239 & 4.5362 & 5.4146 & TRN & \\
\hline CHEMBL3197274 & 688239 & 6.9863 & 5.3055 & TRN & \\
\hline CHEMBL1514012 & 688239 & 4.5862 & 5.3929 & TRN & \\
\hline CHEMBL1357337 & 688239 & 6.7862 & 5.46700 & 00000000005 & TRN \\
\hline CHEMBL1335496 & 688239 & 6.2362 & 5.5316 & TRN & \\
\hline CHEMBL1377063 & 688239 & 4.5362 & 5.5586 & TRN & \\
\hline CHEMBL1382230 & 688239 & 5.1862 & 5.402 & TST & \\
\hline CHEMBL1495896 & 688239 & 4.5362 & 5.5206 & TRN & \\
\hline CHEMBL1464681 & 688239 & 8.3372 & 5.6401 & TST & \\
\hline CHEMBL1541884 & 688239 & 6.9363 & 5.4716 & TRN & \\
\hline CHEMBL1467198 & 688239 & 4.5362 & 5.4694 & TRN & \\
\hline CHEMBL1535792 & 688239 & 6.8362 & 5.4203 & TRN & \\
\hline CHEMBL3214012 & 688239 & 5.1862 & 5.3944 & TST & \\
\hline CHEMBL1429396 & 688239 & 6.2362 & 5.5949 & TRN & \\
\hline CHEMBL1438874 & 688239 & 6.9863 & 5.6436 & TRN & \\
\hline
\end{tabular}


Supplemental Table S2.txt

\begin{tabular}{|c|c|c|c|c|c|}
\hline CHEMBL 2003356 & 688239 & 5.0362 & 5.2258 & TRN & \\
\hline CHEMBL1536530 & 688239 & 5.7362 & 5.5347 & TRN & \\
\hline CHEMBL3198546 & 688239 & 5.8362 & 5.3564 & TST & \\
\hline CHEMBL1381026 & 688239 & 4.7862 & 5.6061 & TST & \\
\hline CHEMBL1489879 & 688239 & 4.8362 & 5.5571 & TST & \\
\hline CHEMBL1461191 & 688239 & 6.2862 & 5.5403 & TRN & \\
\hline CHEMBL1310778 & 688239 & 6.2362 & 5.4061 & TRN & \\
\hline CHEMBL3194429 & 688239 & 5.1362 & 5.4808 & TRN & \\
\hline CHEMBL1480821 & 688239 & 6.2362 & 5.686 & TRN & \\
\hline CHEMBL1568159 & 688239 & 4.5362 & 5.3831 & TRN & \\
\hline CHEMBL1366571 & 688239 & 5.9862 & 5.5692 & TRN & \\
\hline CHEMBL3195555 & 688239 & 4.8862 & 5.5457 & TRN & \\
\hline CHEMBL1987417 & 688239 & 5.1862 & 5.4128 & TST & \\
\hline CHEMBL1564485 & 688239 & 4.6362 & 5.5737 & TRN & \\
\hline CHEMBL1440252 & 688239 & 4.5362 & 5.5069 & TST & \\
\hline CHEMBL1565708 & 688239 & 4.5362 & 5.4517 & TST & \\
\hline CHEMBL1438796 & 688239 & 6.1862 & 5.4254 & TST & \\
\hline CHEMBL1377180 & 688239 & 4.9862 & 5.4911 & TST & \\
\hline CHEMBL1380986 & 688239 & 5.1862 & 5.6273 & TST & \\
\hline CHEMBL1417701 & 688239 & 5.3862 & 5.3928 & TRN & \\
\hline CHEMBL1444450 & 688239 & 5.9862 & 5.4063 & TST & \\
\hline CHEMBL1390685 & 688239 & 5.0362 & 5.2406 & TRN & \\
\hline CHEMBL1529194 & 688239 & 4.8862 & 5.6322 & TRN & \\
\hline CHEMBL1300978 & 688239 & 5.1362 & 5.5636 & TRN & \\
\hline CHEMBL1430697 & 688239 & 4.4862 & 5.441 & TRN & \\
\hline CHEMBL1597934 & 688239 & 5.2362 & 5.3622 & TRN & \\
\hline CHEMBL1563724 & 688239 & 4.7862 & 5.3669 & TRN & \\
\hline CHEMBL1570234 & 688239 & 4.5362 & 5.4147 & TRN & \\
\hline CHEMBL1438953 & 688239 & 5.8362 & 5.4589 & TST & \\
\hline CHEMBL1345471 & 688239 & 8.3372 & 5.5293 & TRN & \\
\hline CHEMBL1496273 & 688239 & 6.1362 & 5.4669 & TRN & \\
\hline CHEMBL1448722 & 688239 & 5.1862 & 5.2831 & TRN & \\
\hline CHEMBL3207875 & 688239 & 6.3362 & 5.58200 & 0000000001 & TRN \\
\hline CHEMBL1402215 & 688239 & 6.6362 & 5.5573 & TRN & \\
\hline CHEMBL1340466 & 688239 & 5.7862 & 5.5943 & TRN & \\
\hline CHEMBL1445727 & 688239 & 6.0862 & 5.3868 & TST & \\
\hline CHEMBL1313112 & 688239 & 4.5362 & 5.4861 & TRN & \\
\hline CHEMBL1395759 & 688239 & 4.6862 & 5.4086 & TRN & \\
\hline CHEMBL1482369 & 688239 & 7.2366 & 5.442 & TST & \\
\hline CHEMBL3189202 & 688239 & 5.6862 & 5.3694 & TRN & \\
\hline CHEMBL1304631 & 688239 & 4.5362 & 5.4031 & TRN & \\
\hline CHEMBL1613498 & 688239 & 7.3862 & 5.5523 & TST & \\
\hline CHEMBL1579678 & 688239 & 6.8861 & 5.4498 & TST & \\
\hline CHEMBL1412127 & 688239 & 4.6862 & 5.4508 & TRN & \\
\hline CHEMBL1438210 & 688239 & 5.8362 & 5.4803 & TRN & \\
\hline CHEMBL518797 & 688239 & 4.7362 & 5.3463 & TRN & \\
\hline CHEMBL3194978 & 688239 & 6.0862 & 5.5289 & TRN & \\
\hline CHEMBL1407501 & 688239 & 6.1362 & 5.688 & TRN & \\
\hline
\end{tabular}


Supplemental Table S2.txt

\begin{tabular}{|c|c|c|c|c|c|}
\hline CHEMBL1381373 & 688239 & 4.5362 & 5.5617 & TRN & \\
\hline CHEMBL1589585 & 688239 & 4.6362 & 5.3791 & TRN & \\
\hline CHEMBL1411257 & 688239 & 5.4862 & 5.4873 & TRN & \\
\hline CHEMBL1432310 & 688239 & 4.5862 & 5.5571 & TRN & \\
\hline CHEMBL1570902 & 688239 & 5.2362 & 5.5651 & TRN & \\
\hline CHEMBL1418653 & 688239 & 4.8362 & 5.3463 & TST & \\
\hline CHEMBL1321343 & 688239 & 4.7362 & 5.5033 & TRN & \\
\hline CHEMBL1494681 & 688239 & 5.7862 & 5.5219 & TRN & \\
\hline CHEMBL1337389 & 688239 & 5.9862 & 5.5497 & TRN & \\
\hline CHEMBL1388372 & 688239 & 5.2362 & 5.5009 & TST & \\
\hline CHEMBL1475663 & 688239 & 6.4362 & 5.3905 & TRN & \\
\hline CHEMBL1358296 & 688239 & 4.5362 & 5.4976 & TRN & \\
\hline CHEMBL1534214 & 688239 & 4.6362 & 5.3185 & TST & \\
\hline CHEMBL1301769 & 688239 & 5.6362 & 5.3457 & TST & \\
\hline CHEMBL1414483 & 688239 & 5.0862 & 5.406006 & $\partial 000000001$ & TRN \\
\hline CHEMBL1349675 & 688239 & 4.6862 & 5.5914 & TRN & \\
\hline CHEMBL1548001 & 688239 & 5.4362 & 5.4712 & TRN & \\
\hline CHEMBL1301250 & 688239 & 6.6861 & 5.4649 & TST & \\
\hline CHEMBL1350245 & 688239 & 6.0 & 5.3065 & TRN & \\
\hline CHEMBL1456231 & 688239 & 4.5862 & 5.6579 & TRN & \\
\hline CHEMBL1605816 & 688239 & 4.5362 & 5.4779 & TST & \\
\hline CHEMBL 3210387 & 688239 & 5.1862 & 5.4446 & TRN & \\
\hline CHEMBL1445160 & 688239 & 4.7362 & 5.5555 & TRN & \\
\hline CHEMBL1586895 & 688239 & 4.7362 & 5.4637 & TST & \\
\hline CHEMBL1377422 & 688239 & 4.7862 & 5.4815 & TRN & \\
\hline CHEMBL1528689 & 688239 & 4.7362 & 5.6553 & TRN & \\
\hline CHEMBL1369300 & 688239 & 5.0362 & 5.5162 & TRN & \\
\hline CHEMBL1567557 & 688239 & 5.0362 & 5.705 & TST & \\
\hline CHEMBL1465931 & 688239 & 4.4862 & 5.5501 & TRN & \\
\hline CHEMBL1404074 & 688239 & 4.4862 & 5.4709 & TRN & \\
\hline CHEMBL1454633 & 688239 & 4.7862 & 5.4248 & TRN & \\
\hline CHEMBL1468367 & 688239 & 5.1862 & 5.4057 & TRN & \\
\hline CHEMBL1425269 & 688239 & 5.1862 & 5.3952 & TRN & \\
\hline CHEMBL1504749 & 688239 & 5.1862 & 5.5944 & TRN & \\
\hline CHEMBL 3197293 & 688239 & 5.2862 & 5.4573 & TRN & \\
\hline CHEMBL1426279 & 688239 & 5.5862 & 5.6099 & TRN & \\
\hline CHEMBL1459746 & 688239 & 6.3362 & 5.4435 & TRN & \\
\hline CHEMBL1359420 & 688239 & 5.7862 & 5.4598 & TRN & \\
\hline CHEMBL 3191355 & 688239 & 4.2862 & 5.3847 & TRN & \\
\hline CHEMBL1425863 & 688239 & 5.6362 & 5.5171 & TRN & \\
\hline CHEMBL1587108 & 688239 & 5.5862 & 5.4705 & TRN & \\
\hline CHEMBL3191378 & 688239 & 6.1362 & 5.5362 & TST & \\
\hline CHEMBL1348335 & 688239 & 5.1862 & 5.4097 & TRN & \\
\hline CHEMBL1431867 & 688239 & 5.3862 & 5.6221 & TRN & \\
\hline CHEMBL1334624 & 688239 & 6.8861 & 5.5015 & TST & \\
\hline CHEMBL1406259 & 688239 & 5.0362 & 5.4886 & TST & \\
\hline CHEMBL1368750 & 688239 & 5.0362 & 5.3954 & TST & \\
\hline CHEMBL1397920 & 688239 & 4.6362 & 5.4726 & TRN & \\
\hline
\end{tabular}


Supplemental Table S2.txt

\begin{tabular}{|c|c|c|c|c|}
\hline 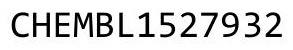 & & & & \\
\hline HEN & 38239 & 9863 & & \\
\hline AEMBL145005 & 38239 & 6362 & 5866 & \\
\hline HEMBL3190631 & 88239 & 5362 & 3732 & \\
\hline & 239 & 862 & 5518 & \\
\hline IEMBL1438845 & 3239 & 862 & 4629 & \\
\hline AEMBL1485287 & 88239 & 7362 & .442 & \\
\hline HEMBL1543402 & 88239 & .5862 & .5968 & \\
\hline HEMBL3196586 & 88239 & 3372 & .5836 & \\
\hline IEMBL15 & 38239 & 862 & 5706 & \\
\hline AEMBL1487189 & 239 & 362 & .3432 & \\
\hline HEMBL1519099 & 88239 & 7862 & 5.4793 & \\
\hline HEMBL1423572 & 88239 & 362 & 5.4883 & \\
\hline AEMBL1302288 & $8 \varepsilon$ & 62 & 34 & \\
\hline IEMBL1527151 & 88239 & 62 & & \\
\hline IEMBL1450374 & 88239 & 62 & 218 & \\
\hline AEMBL1588341 & 88239 & 362 & 5.664 & \\
\hline HEMBL1542176 & 88239 & 862 & 268 & \\
\hline L15 & 39 & 63 & 74 & \\
\hline L23150 & 39 & 62 & 98 & \\
\hline 9682 & 39 & 862 & & \\
\hline L1394667 & 88239 & 862 & 5.4916 & \\
\hline AEMBL1541152 & 39 & 862 & & \\
\hline AEMBL31 & 39 & 362 & 67 & \\
\hline 253 & & 62 & & \\
\hline 515 & 39 & 62 & 34 & $2 \mathrm{~N}$ \\
\hline L1526472 & 39 & 362 & & RN \\
\hline AEMBL1450972 & 39 & & & Iv \\
\hline AEMBL3197295 & 39 & 362 & 5.3513 & $5 T$ \\
\hline 228 & & 62 & 56 & ST \\
\hline 519 & 39 & 62 & 468 & RN \\
\hline AEMBL1565698 & & & 5.4801 & RN \\
\hline AEMBL1306293 & & & & RN \\
\hline AEMBL13 & 39 & 62 & 905 & $2 \mathrm{~N}$ \\
\hline 45 & & 62 & 49 & ST \\
\hline 51 & & & 22 & RN \\
\hline AEMBL1560041 & 88239 & 362 & 5.5771 & RN \\
\hline AEMBL 3194445 & & & & ST \\
\hline HEMBL14 & & 362 & 66 & RN \\
\hline 206 & & & 33 & RN \\
\hline 748 & 39 & 52 & 5.52 & RN \\
\hline AEMBL1420196 & 88239 & 7862 & 5.43 & RN \\
\hline AEMBL1580041 & 39 & 862 & 5.44 & TRN \\
\hline HEIMBLIS & & & 5 & \\
\hline HEMBL13 & & & 5.5521 & \\
\hline HEMBL1459736 & 39 & 862 & 5.3891 & $\mathrm{RN}$ \\
\hline L1370915 & 88239 & 5.2862 & 5.5244 & \\
\hline CHEMBL1479945 & 688239 & 6.3863 & 5.4189 & \\
\hline
\end{tabular}

Page 1164 
Supplemental Table S2.txt

\begin{tabular}{|c|c|c|c|c|c|}
\hline CHEMBL1579041 & 688239 & 4.6362 & 5.5294 & TRN & \\
\hline CHEMBL1414100 & 688239 & 7.5867 & 5.457999 & 999999999 & TST \\
\hline CHEMBL1999437 & 688239 & 5.6862 & 5.5124 & TRN & \\
\hline CHEMBL1565239 & 688239 & 4.9 & 5.6258 & TRN & \\
\hline CHEMBL1419472 & 688239 & 4.4862 & 5.4415 & TRN & \\
\hline CHEMBL1456785 & 688239 & 5.1862 & 5.4881 & TRN & \\
\hline CHEMBL1604422 & 688239 & 4.5362 & 5.5985 & TRN & \\
\hline CHEMBL1492403 & 688239 & 8.3372 & 5.5574 & TRN & \\
\hline CHEMBL1356612 & 688239 & 4.8362 & 5.512000 & 0000000005 & \\
\hline CHEMBL1305347 & 688239 & 5.1862 & 5.4177 & TRN & \\
\hline CHEMBL1530492 & 688239 & 4.5362 & 5.4265 & TST & \\
\hline CHEMBL1497527 & 688239 & 5.9862 & 5.4818 & TRN & \\
\hline CHEMBL1530569 & 688239 & 5.5362 & 5.4271 & TST & \\
\hline CHEMBL1387474 & 688239 & 4.5362 & 5.3602 & TRN & \\
\hline CHEMBL1387974 & 688239 & 4.4862 & 5.4544 & TRN & \\
\hline CHEMBL1461829 & 688239 & 4.5362 & 5.6916 & TRN & \\
\hline CHEMBL1525501 & 688239 & 4.8362 & 5.3746 & TRN & \\
\hline CHEMBL1505304 & 688239 & 5.3862 & 5.4468 & TRN & \\
\hline CHEMBL1513554 & 688239 & 6.7862 & 5.343999 & 999999999 & \\
\hline CHEMBL1514638 & 688239 & 6.2362 & 5.3909 & TRN & \\
\hline CHEMBL1309041 & 688239 & 6.5862 & 5.4483 & TRN & \\
\hline CHEMBL1555539 & 688239 & 6.0362 & 5.4824 & TRN & \\
\hline CHEMBL1570672 & 688239 & 5.9862 & 5.6479 & TRN & \\
\hline CHEMBL1393661 & 688239 & 4.5362 & 5.3496 & TRN & \\
\hline CHEMBL1388639 & 688239 & 6.1862 & 5.2797 & TRN & \\
\hline CHEMBL1558258 & 688239 & 5.4362 & 5.5348 & TRN & \\
\hline CHEMBL1588905 & 688239 & 4.6862 & 5.6437 & TST & \\
\hline CHEMBL1308191 & 688239 & 6.0862 & 5.4944 & TRN & \\
\hline CHEMBL1415442 & 688239 & 6.5862 & 5.426 & TRN & \\
\hline CHEMBL1521833 & 688239 & 5.5862 & 5.5939 & TRN & \\
\hline CHEMBL1359010 & 688239 & 8.3372 & 5.3851 & TRN & \\
\hline CHEMBL1363108 & 688239 & 4.6362 & 5.3568 & TRN & \\
\hline CHEMBL1574850 & 688239 & 6.4362 & 5.5557 & TRN & \\
\hline CHEMBL1418649 & 688239 & 4.9362 & 5.6015 & TRN & \\
\hline CHEMBL3209939 & 688239 & 6.1862 & 5.5583 & TRN & \\
\hline CHEMBL1304065 & 688239 & 8.3372 & 5.4838 & TRN & \\
\hline CHEMBL1408479 & 688239 & 6.2362 & 5.5376 & TST & \\
\hline CHEMBL1596142 & 688239 & 7.2865 & 5.4683 & TRN & \\
\hline CHEMBL1545992 & 688239 & 4.7862 & 5.3935 & TRN & \\
\hline CHEMBL1441145 & 688239 & 4.7362 & 5.3678 & TRN & \\
\hline CHEMBL1566183 & 688239 & 8.283999 & 999999999 & 5.4423 & \\
\hline CHEMBL1348725 & 688239 & 4.5362 & 5.4345 & TST & \\
\hline CHEMBL1348508 & 688239 & 5.1862 & 5.369 & TST & \\
\hline CHEMBL1519655 & 688239 & 4.7862 & 5.5128 & TRN & \\
\hline CHEMBL1549446 & 688239 & 5.0862 & 5.5275 & TRN & \\
\hline CHEMBL1481335 & 688239 & 4.4862 & 5.4938 & TST & \\
\hline CHEMBL1576104 & 688239 & 6.4362 & 5.3393 & TRN & \\
\hline CHEMBL1440409 & 688239 & 6.2362 & 5.527 & TRN & \\
\hline
\end{tabular}


Supplemental Table S2.txt

\begin{tabular}{|c|c|c|c|c|}
\hline . & & & & \\
\hline HEMBL1430165 & 38239 & 8861 & 4544 & \\
\hline AEMBL13 & 88239 & 5362 & 4908 & \\
\hline EMBL32 & & & 996 & \\
\hline EMBL31 & & 862 & 422 & \\
\hline AEMBL1376888 & 38239 & 362 & 5538 & \\
\hline HEMBL1589837 & 88239 & 3362 & .4029 & \\
\hline AEMBL1543540 & 39 & 362 & 1282 & \\
\hline EMBL1 & 39 & & 31 & \\
\hline EMBL16 & 39 & 362 & & \\
\hline AEMBL1505736 & 882 & 862 & 4268 & \\
\hline AEMBL1425735 & 39 & 3862 & 5246 & \\
\hline IEMBL1464512 & 39 & 862 & 114 & \\
\hline AEMBL3214277 & & & 34 & \\
\hline AEMBL13 & 9 & & 4935 & \\
\hline IEMBL1597681 & 39 & 862 & 5428 & \\
\hline HEMBL1425421 & 88 & 861 & .4541 & \\
\hline HEMBL 14 & 39 & 863 & 46 & \\
\hline AEMBL13 & & & & \\
\hline HEMB & 9 & & & $\mathrm{RN}$ \\
\hline AEMBL15 & 39 & & & \\
\hline IEMBL1597147 & 39 & 62 & 52 & \\
\hline HEMBL159 & 9 & 362 & 73 & \\
\hline JEMBL14 & & & & $\mathrm{RN}$ \\
\hline AEMBL152 & & & 254 & ST \\
\hline AEMBL158 & 9 & & & $\mathrm{~N}$ \\
\hline HEMBL1399586 & 39 & 62 & .5857 & | \\
\hline AEMBL1336547 & 9 & 62 & 464 & $\mathrm{RN}$ \\
\hline AEM & & & & ST \\
\hline AEM & & & & $\mathrm{RN}$ \\
\hline HEMBL150 & & & & ST \\
\hline AEMBL1404223 & 88 & 362 & .4932 & ST \\
\hline AEMBL1481119 & 39 & 62 & 58 & נד \\
\hline IF & & & & ST \\
\hline HEMBL147. & & & & RN \\
\hline AEMBL1411064 & 39 & & 59 & RN \\
\hline AEMBL1351421 & 39 & 362 & 116 & RN \\
\hline AEMBL1573845 & 9 & 62 & 93 & RIV \\
\hline 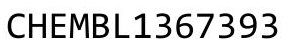 & & & & $\mathrm{RN}$ \\
\hline HEMBL136 & & & & RN \\
\hline AEMBL1341 & 39 & 62 & 82 & ST \\
\hline -IEMBL141 & 39 & 62 & 367 & RN \\
\hline HEMBL589458 & & & & \\
\hline & & & & $\mathrm{RN}$ \\
\hline HEMBL1359776 & & & 5737 & RN \\
\hline AEMBL13768 & 39 & 62 & .5577 & \\
\hline 14 & & & & \\
\hline & & & & \\
\hline
\end{tabular}

Page 1166 
Supplemental Table S2.txt

\begin{tabular}{|c|c|c|c|c|}
\hline th & & 862 & 5.3948 & \\
\hline & & .2862 & & \\
\hline 54 & & & & \\
\hline 7782 & & & & \\
\hline AEMBL1 & 8239 & 862 & & \\
\hline HEMBL1392315 & 88239 & .7362 & 4517 & \\
\hline 2211 & 239 & 3861 & & \\
\hline 38272 & & & & \\
\hline AEMBL15 & & 3862 & 5169 & \\
\hline HEMBL1341965 & 88239 & 362 & 3545 & \\
\hline HEMBL1418276 & 239 & 862 & & \\
\hline IEMBL15 & 39 & 862 & 323 & \\
\hline IEMBL1 & & & & \\
\hline AEMBL1 & & 862 & & \\
\hline AEMBL1: & & & & \\
\hline IEMBL45 & 39 & 62 & 16 & \\
\hline AEMBL1: & & 62 & & \\
\hline HEMBL1: & & & & \\
\hline AEMBL13 & & 372 & & \\
\hline IEMBL15 & & 62 & & \\
\hline HEMBLIC & & 62 & & Niv \\
\hline AEMBL] & & & & RIV \\
\hline AEMBL1 & & & & \\
\hline 316 & & & & \\
\hline IEMBL14 & & & & 151 \\
\hline AEMBL1 & & & & RN \\
\hline HEMBL1 & & & & 年 \\
\hline AFMBI 1 & & & & \\
\hline HEMBL15 & & & & RIV \\
\hline HEMBL1519720 & & & & I RN \\
\hline HEMBL1 & & & 167 & RN \\
\hline HEMBL & & & & ST \\
\hline AEMBL: & & & & 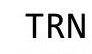 \\
\hline AEMBL1500758 & & & & is \\
\hline HEMBL1467493 & & 61 & 5096 & TRN \\
\hline HEMBL1 & & 62 & 346 & ST \\
\hline 1 & & & 29 & RN \\
\hline HEMBL1 & & & & ST \\
\hline HEMBL1554301 & & 362 & 705 & TRN \\
\hline IEMBL15 & & 362 & & 「RN \\
\hline HEMBL13 & & 362 & & \\
\hline HEMBL1 14 & & & & RIV \\
\hline HEMBL13 & & 362 & 5091 & TRN \\
\hline AEMBL1589511 & 39 & 362 & 742 & TR \\
\hline 12 & & 362 & 5.3996 & 13 \\
\hline HEMBL13 & & & & \\
\hline HEMBL 14 & & & 5.5624 & \\
\hline HEMBL1491717 & 688239 & 4.6862 & 5.4765 & ГST \\
\hline
\end{tabular}

Page 1167 
Supplemental Table S2.txt

\begin{tabular}{|c|c|c|c|c|}
\hline the & & 862 & 5.37 & \\
\hline & & .5862 & 50 & \\
\hline s & & & & \\
\hline AEMBL15 & & & & \\
\hline AEMBL155 & 8239 & 362 & & \\
\hline HEMBL1383644 & 88239 & 2865 & 5286 & \\
\hline & 239 & 362 & & \\
\hline IFMRI 14 & & & & \\
\hline HEMBL144 & 239 & 562 & & \\
\hline HEMBL158 & 88239 & 862 & .4042 & \\
\hline AEMBL133 & 239 & 862 & 5905 & \\
\hline IEMBL14 & 39 & 362 & 02 & \\
\hline IEMBL15 & & & & \\
\hline HEMBL15 & & 362 & & \\
\hline IEMBL15 & & 63 & 5233 & \\
\hline AEMBL15 & 39 & 362 & 43 & \\
\hline AEMBL13 & & 62 & & \\
\hline HEMBL 31 & & & & \\
\hline HEMBL31C & & 362 & & \\
\hline AEMBL136 & & & & \\
\hline AEMBLI4 & & 52 & 29 & Niv \\
\hline AEMBL15 & & & & 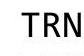 \\
\hline AEMBL13 & & & & \\
\hline AEMBL14 & & & & \\
\hline AEMBL15 & & & & \\
\hline AEMBL13 & & & 22 & RN \\
\hline HEMBL1: & & & 97 & RN \\
\hline HFMBI 15 & & 62 & & \\
\hline AEMBL13 & & & & TIV \\
\hline HEMBL142 & & & & וدד \\
\hline HEMBL13 & & & 35 & RN \\
\hline HEMBL1 & & & & RIV \\
\hline $15 M P$ & & & 58 & $\mathrm{~N}$ \\
\hline HEMBL13e & & & 361 & R \\
\hline HEMBL1372600 & & 362 & 999 & TRN \\
\hline HEMBL16 & & & 39 & TRN \\
\hline 1 & & & & RIN \\
\hline JEMBL 13 & & & & TRN \\
\hline HEMBL1386264 & 88239 & & 5.5767 & TRN \\
\hline AEMBL14ऽ & & & 854 & TST \\
\hline HEMBL13 & & & 5.5442 & \\
\hline HEMBL13 & & & & TRN \\
\hline HEMBL140 & & & 5.5087 & RN \\
\hline AEMBL143 & 39 & 862 & 4896 & TRN \\
\hline MRI 3 & & & & $\mathrm{~N}$ \\
\hline HEMBL15€ & & & & \\
\hline CHEMBL159 & & & 5.4811 & \\
\hline HEMBL319176 & 688239 & 6.1862 & 5.4611 & RN \\
\hline
\end{tabular}

Page 1168 


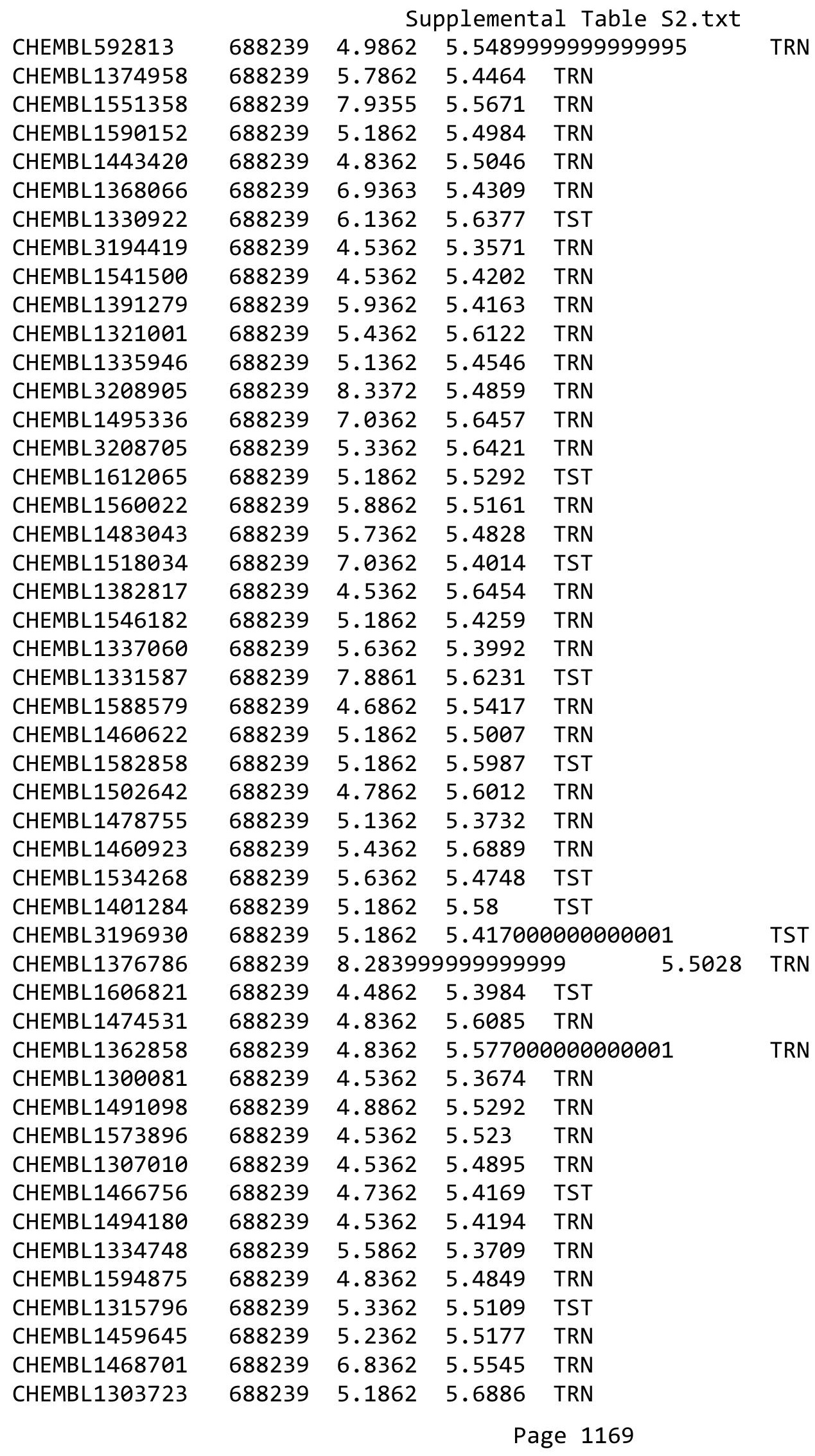


Supplemental Table S2.txt

\begin{tabular}{|c|c|c|c|c|c|}
\hline CHEMBL1461862 & 688239 & 6.1362 & 5.5783 & TRN & \\
\hline CHEMBL1313501 & 688239 & 5.4862 & 5.50700 & 0000000001 & TRN \\
\hline CHEMBL1378054 & 688239 & 6.2362 & 5.4606 & TRN & \\
\hline CHEMBL1561887 & 688239 & 4.6862 & 5.4652 & TST & \\
\hline CHEMBL1445180 & 688239 & 4.5362 & 5.4516 & TRN & \\
\hline CHEMBL1448642 & 688239 & 4.7862 & 5.4149 & TRN & \\
\hline CHEMBL1372101 & 688239 & 4.5362 & 5.386 & TRN & \\
\hline CHEMBL3210237 & 688239 & 5.5862 & 5.3257 & TRN & \\
\hline CHEMBL1510202 & 688239 & 4.5862 & 5.5639 & TRN & \\
\hline CHEMBL1343490 & 688239 & 5.4862 & 5.3368 & TST & \\
\hline CHEMBL1452496 & 688239 & 6.2862 & 5.6219 & TRN & \\
\hline CHEMBL1450296 & 688239 & 6.8861 & 5.4101 & TST & \\
\hline CHEMBL1544190 & 688239 & 5.3362 & 5.4648 & TST & \\
\hline CHEMBL1508364 & 688239 & 5.1362 & 5.4555 & TRN & \\
\hline CHEMBL1306262 & 688239 & 5.5362 & 5.4805 & TRN & \\
\hline CHEMBL1491504 & 688239 & 4.9862 & 5.5419 & TRN & \\
\hline CHEMBL1498652 & 688239 & 4.6362 & 5.4099 & TST & \\
\hline CHEMBL1337366 & 688239 & 4.5362 & 5.5679 & TRN & \\
\hline CHEMBL1607789 & 688239 & 5.3362 & 5.53 & TST & \\
\hline CHEMBL1422202 & 688239 & 4.9862 & 5.5025 & TRN & \\
\hline CHEMBL1387019 & 688239 & 6.0862 & 5.2945 & TRN & \\
\hline CHEMBL1340194 & 688239 & 4.6862 & 5.5114 & TRN & \\
\hline CHEMBL3189796 & 688239 & 4.4862 & 5.4208 & TRN & \\
\hline CHEMBL1351265 & 688239 & 5.0362 & 5.5717 & TRN & \\
\hline CHEMBL1329904 & 688239 & 5.8862 & 5.5833 & TRN & \\
\hline CHEMBL1326006 & 688239 & 4.5362 & 5.6277 & TST & \\
\hline CHEMBL 3213174 & 688239 & 4.5862 & 5.4193 & TRN & \\
\hline CHEMBL1467188 & 688239 & 5.1862 & 5.5352 & TRN & \\
\hline CHEMBL1448897 & 688239 & 4.5362 & 5.4775 & TRN & \\
\hline CHEMBL1379825 & 688239 & 6.2362 & 5.3275 & TST & \\
\hline CHEMBL1546438 & 688239 & 4.5362 & 5.4236 & TST & \\
\hline CHEMBL1579216 & 688239 & 5.6862 & 5.4189 & TST & \\
\hline CHEMBL1470375 & 688239 & 5.2862 & 5.5152 & TRN & \\
\hline CHEMBL1447699 & 688239 & 4.8862 & 5.4394 & TRN & \\
\hline CHEMBL 3214255 & 688239 & 5.0362 & 5.3854 & TST & \\
\hline CHEMBL1578511 & 688239 & 5.3362 & 5.4255 & TST & \\
\hline CHEMBL1394747 & 688239 & 5.9362 & 5.534 & TRN & \\
\hline CHEMBL1549258 & 688239 & 5.1862 & 5.4563 & TRN & \\
\hline CHEMBL1403913 & 688239 & 4.9362 & 5.4482 & TST & \\
\hline CHEMBL1339818 & 688239 & 5.7362 & 5.3313 & TST & \\
\hline CHEMBL1546496 & 688239 & 4.5362 & 5.4341 & TST & \\
\hline CHEMBL1504730 & 688239 & 4.7862 & 5.3948 & TRN & \\
\hline CHEMBL1523368 & 688239 & 6.8861 & 5.5298 & TRN & \\
\hline CHEMBL3209836 & 688239 & 5.3862 & 5.3753 & TST & \\
\hline CHEMBL1301408 & 688239 & 6.1362 & 5.5888 & TRN & \\
\hline CHEMBL1579266 & 688239 & 7.2865 & 5.7469 & TST & \\
\hline CHEMBL 3193823 & 688239 & 4.6862 & 5.4372 & TST & \\
\hline CHEMBL1609765 & 688239 & 4.5362 & 5.442 & TRN & \\
\hline
\end{tabular}


Supplemental Table S2.txt

\begin{tabular}{|c|c|c|c|c|c|c|}
\hline CHEMBL1395623 & 688239 & 7.0862 & 5.4181 & TRN & & \\
\hline CHEMBL1441483 & 688239 & 4.4862 & 5.5149 & TRN & & \\
\hline CHEMBL1384789 & 688239 & 4.9862 & 5.5805 & TRN & & \\
\hline CHEMBL1329408 & 688239 & 4.5362 & 5.4703 & TRN & & \\
\hline CHEMBL1340029 & 688239 & 5.0362 & 5.4418 & TRN & & \\
\hline CHEMBL1388607 & 688239 & 6.2862 & 5.4716 & TRN & & \\
\hline CHEMBL1495287 & 688239 & 5.2362 & 5.3234 & TRN & & \\
\hline CHEMBL1370612 & 688239 & 5.7362 & 5.6319 & TRN & & \\
\hline CHEMBL1449403 & 688239 & 5.1862 & 5.5378 & TRN & & \\
\hline CHEMBL 3196077 & 688239 & 4.5862 & 5.5168 & TRN & & \\
\hline CHEMBL1340359 & 688239 & 6.0 & 5.3872 & TRN & & \\
\hline CHEMBL1332681 & 688239 & 4.5362 & 5.456 & TST & & \\
\hline CHEMBL1495641 & 688239 & 5.3862 & 5.4542 & TST & & \\
\hline CHEMBL1536085 & 688239 & 6.9863 & 5.4232 & TRN & & \\
\hline CHEMBL1428002 & 688239 & 7.0362 & 5.5682 & TRN & & \\
\hline CHEMBL1497997 & 688239 & 4.5362 & 5.5002 & TRN & & \\
\hline CHEMBL1516987 & 688239 & 4.7862 & 5.4522 & TRN & & \\
\hline CHEMBL1434349 & 688239 & 4.8862 & 5.5291 & TRN & & \\
\hline CHEMBL1462618 & 688239 & 4.5862 & 5.5651 & TRN & & \\
\hline CHEMBL1532275 & 688239 & 8.28399 & 999999999 & 9 & 5.5025 & 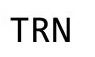 \\
\hline CHEMBL1352653 & 688239 & 4.5862 & 5.5335 & TST & & \\
\hline CHEMBL1493296 & 688239 & 7.2366 & 5.6501 & TRN & & \\
\hline CHEMBL156360 & 688239 & 4.5362 & 5.5264 & TRN & & \\
\hline CHEMBL1522118 & 688239 & 8.28399 & 99999999 & 9 & 5.5034 & ובו \\
\hline CHEMBL1444867 & 688239 & 7.8861 & 5.4924 & TRN & & \\
\hline CHEMBL1510114 & 688239 & 6.9863 & 5.3335 & TRN & & \\
\hline CHEMBL1595750 & 688239 & 8.28399 & 99999999 & 9 & 5.7122 & TRN \\
\hline CHEMBL1422976 & 688239 & 4.6862 & 5.4739 & TRN & & \\
\hline CHEMBL3195842 & 688239 & 4.6362 & 5.5973 & TRN & & \\
\hline CHEMBL1343934 & 688239 & 4.6862 & 5.4223 & TRN & & \\
\hline CHEMBL1574429 & 688239 & 4.8362 & 5.5027 & TST & & \\
\hline CHEMBL1346173 & 688239 & 5.1362 & 5.5905 & TRN & & \\
\hline CHEMBL1305017 & 688239 & 5.5862 & 5.4268 & TRN & & \\
\hline CHEMBL 3210481 & 688239 & 8.3372 & 5.4716 & TRN & & \\
\hline CHEMBL1598718 & 688239 & 6.7862 & 5.5997 & TRN & & \\
\hline CHEMBL1373693 & 688239 & 4.7362 & 5.7098 & TRN & & \\
\hline CHEMBL1391448 & 688239 & 6.5862 & 5.5838 & TRN & & \\
\hline CHEMBL 3213317 & 688239 & 5.4862 & 5.4954 & TRN & & \\
\hline CHEMBL1513067 & 688239 & 4.5362 & 5.4447 & TRN & & \\
\hline CHEMBL1373713 & 688239 & 5.1862 & 5.4119 & TRN & & \\
\hline CHEMBL1556607 & 688239 & 5.5862 & 5.4145 & TRN & & \\
\hline CHEMBL1387532 & 688239 & 8.3872 & 5.6126 & TRN & & \\
\hline CHEMBL1449087 & 688239 & 4.5862 & 5.4673 & TRN & & \\
\hline CHEMBL1317635 & 688239 & 5.2862 & 5.4744 & TST & & \\
\hline CHEMBL1608861 & 688239 & 5.5862 & 5.5277 & TRN & & \\
\hline CHEMBL1577583 & 688239 & 8.2366 & 5.3871 & TRN & & \\
\hline CHEMBL1341809 & 688239 & 4.7862 & 5.5165 & TST & & \\
\hline CHEMBL1460225 & 688239 & 6.0862 & 5.3671 & TRN & & \\
\hline
\end{tabular}


Supplemental Table S2.txt

\begin{tabular}{|c|c|c|c|c|c|}
\hline CHEMBL1501217 & 688239 & 4.6862 & 5.3205 & TST & \\
\hline CHEMBL3213912 & 688239 & 4.5362 & 5.3746 & TRN & \\
\hline CHEMBL1404430 & 688239 & 5.7862 & 5.4688 & TRN & \\
\hline CHEMBL1556391 & 688239 & 5.3862 & 5.5362 & TRN & \\
\hline CHEMBL1404253 & 688239 & 4.5362 & 5.4923 & TRN & \\
\hline CHEMBL42355 & 688239 & 5.4362 & 5.3804 & TST & \\
\hline CHEMBL1554867 & 688239 & 4.5362 & 5.4694 & TRN & \\
\hline CHEMBL1345518 & 688239 & 4.7862 & 5.3316 & TRN & \\
\hline CHEMBL1441893 & 688239 & 4.5862 & 5.3868 & TRN & \\
\hline CHEMBL1589915 & 688239 & 5.7862 & 5.4637 & TRN & \\
\hline CHEMBL1497282 & 688239 & 7.2366 & 5.3995 & TRN & \\
\hline CHEMBL1591354 & 688239 & 4.5362 & 5.5322 & TRN & \\
\hline CHEMBL1560605 & 688239 & 7.2366 & 5.4146 & TRN & \\
\hline CHEMBL1444699 & 688239 & 4.8362 & 5.4241 & TRN & \\
\hline CHEMBL1482134 & 688239 & 4.6362 & 5.579 & TST & \\
\hline CHEMBL1458304 & 688239 & 6.7361 & 5.5625 & TST & \\
\hline CHEMBL578504 & 688239 & 4.6862 & 5.4114 & TRN & \\
\hline CHEMBL1588275 & 688239 & 4.5362 & 5.2982 & TRN & \\
\hline CHEMBL1309945 & 688239 & 4.7862 & 5.5216 & TRN & \\
\hline CHEMBL1488001 & 688239 & 4.7362 & 5.30399 & 9999999999 & TRN \\
\hline CHEMBL1593382 & 688239 & 4.5362 & 5.2964 & TRN & \\
\hline CHEMBL1419011 & 688239 & 6.7862 & 5.5254 & TRN & \\
\hline CHEMBL1312038 & 688239 & 5.7862 & 5.4993 & TRN & \\
\hline CHEMBL1391230 & 688239 & 5.6862 & 5.5013 & TRN & \\
\hline CHEMBL1542570 & 688239 & 5.1862 & 5.3954 & TRN & \\
\hline CHEMBL1441142 & 688239 & 6.7862 & 5.4064 & TRN & \\
\hline CHEMBL1332658 & 688239 & 4.5362 & 5.436 & TRN & \\
\hline CHEMBL1313597 & 688239 & 8.3872 & 5.3948 & TRN & \\
\hline CHEMBL1320666 & 688239 & 5.1862 & 5.5079 & TRN & \\
\hline CHEMBL1977555 & 688239 & 5.7362 & 5.4192 & TRN & \\
\hline CHEMBL1532312 & 688239 & 4.5362 & 5.4527 & TRN & \\
\hline CHEMBL1545264 & 688239 & 4.6862 & 5.36299 & 99999999995 & TRN \\
\hline CHEMBL1544874 & 688239 & 4.5362 & 5.5692 & TRN & \\
\hline CHEMBL3190805 & 688239 & 4.5362 & 5.3921 & TRN & \\
\hline CHEMBL1536832 & 688239 & 5.6862 & 5.4621 & TRN & \\
\hline CHEMBL1349570 & 688239 & 4.7362 & 5.4399 & TRN & \\
\hline CHEMBL1556094 & 688239 & 8.2366 & 5.4085 & TRN & \\
\hline CHEMBL1432050 & 688239 & 5.2862 & 5.5678 & TRN & \\
\hline CHEMBL1356405 & 688239 & 5.1362 & 5.4368 & TRN & \\
\hline CHEMBL1390550 & 688239 & 6.4362 & 5.5113 & TRN & \\
\hline CHEMBL1456750 & 688239 & 4.7862 & 5.3691 & TRN & \\
\hline CHEMBL1411812 & 688239 & 4.5362 & 5.4566 & TRN & \\
\hline CHEMBL1603019 & 688239 & 8.2366 & 5.5183 & TRN & \\
\hline CHEMBL1301215 & 688239 & 5.1862 & 5.5152 & TRN & \\
\hline CHEMBL1300691 & 688239 & 5.5862 & 5.6233 & TRN & \\
\hline CHEMBL1471284 & 688239 & 5.8862 & 5.4114 & TRN & \\
\hline CHEMBL1322273 & 688239 & 4.5362 & 5.5036 & TRN & \\
\hline CHEMBL1423083 & 688239 & 4.5862 & 5.561 & TRN & \\
\hline
\end{tabular}


Supplemental Table S2.txt

\begin{tabular}{|c|c|c|c|c|}
\hline CHEMBL1557616 & 688239 & 6.5862 & 5.4586 & TRN \\
\hline CHEMBL1426788 & 688239 & 4.5362 & 5.2671 & TST \\
\hline CHEMBL1521093 & 688239 & 5.7362 & 5.5277 & TRN \\
\hline CHEMBL1597132 & 688239 & 4.6362 & 5.3251 & TRN \\
\hline CHEMBL1457993 & 688239 & 6.0862 & 5.5584 & TRN \\
\hline CHEMBL1586623 & 688239 & 5.1862 & 5.5759 & TRN \\
\hline CHEMBL1371429 & 688239 & 4.7862 & 5.6456 & TRN \\
\hline CHEMBL3208536 & 688239 & 8.3372 & 5.4207 & TST \\
\hline CHEMBL 3212190 & 688239 & 4.9362 & 5.4103 & TST \\
\hline CHEMBL1408506 & 688239 & 5.6862 & 5.5264 & TRN \\
\hline CHEMBL1453212 & 688239 & 5.4862 & 5.4914 & TST \\
\hline CHEMBL1563183 & 688239 & 6.6861 & 5.5542 & TRN \\
\hline CHEMBL 3190380 & 688239 & 7.0362 & 5.4971 & TRN \\
\hline CHEMBL1461130 & 688239 & 5.5362 & 5.6179 & TRN \\
\hline CHEMBL1350326 & 688239 & 4.6862 & 5.5127 & TST \\
\hline CHEMBL1517439 & 688239 & 4.9862 & 5.5518 & TRN \\
\hline CHEMBL1609286 & 688239 & 5.3862 & 5.422999 & 9999999999 \\
\hline CHEMBL1502482 & 688239 & 5.3862 & 5.3875 & TRN \\
\hline CHEMBL1310897 & 688239 & 4.6362 & 5.6718 & TRN \\
\hline CHEMBL1531987 & 688239 & 5.6862 & 5.465 & TST \\
\hline CHEMBL1524490 & 688239 & 4.8862 & 5.6666 & TRN \\
\hline CHEMBL1335060 & 688239 & 6.1362 & 5.581 & TRN \\
\hline CHEMBL1477694 & 688239 & 5.6362 & 5.4774 & TRN \\
\hline CHEMBL1461331 & 688239 & 6.8362 & 5.4921 & TRN \\
\hline CHEMBL1302039 & 688239 & 4.6862 & 5.5702 & TRN \\
\hline CHEMBL1335883 & 688239 & 6.3362 & 5.4981 & TRN \\
\hline CHEMBL3192439 & 688239 & 6.2862 & 5.5354 & TST \\
\hline CHEMBL1599799 & 688239 & 4.6362 & 5.5508 & TRN \\
\hline CHEMBL1334575 & 688239 & 6.2862 & 5.2848 & TRN \\
\hline CHEMBL1382543 & 688239 & 4.5362 & 5.5761 & TRN \\
\hline CHEMBL1433595 & 688239 & 5.8862 & 5.4452 & TRN \\
\hline CHEMBL 3213214 & 688239 & 5.4362 & 5.2982 & TST \\
\hline CHEMBL1487468 & 688239 & 4.6362 & 5.5771 & TRN \\
\hline CHEMBL1431574 & 688239 & 5.1862 & 5.3997 & TRN \\
\hline CHEMBL1593899 & 688239 & 5.6862 & 5.45 & TST \\
\hline CHEMBL1603520 & 688239 & 4.5362 & 5.5074 & TST \\
\hline CHEMBL1335858 & 688239 & 4.5362 & 5.5566 & TST \\
\hline CHEMBL1515637 & 688239 & 6.3362 & 5.6061 & TRN \\
\hline CHEMBL1978354 & 688239 & 4.9862 & 5.4062 & TRN \\
\hline CHEMBL1455687 & 688239 & 5.4862 & 5.537999 & 9999999999 \\
\hline CHEMBL1519733 & 688239 & 5.1862 & 5.5908 & TRN \\
\hline CHEMBL1328182 & 688239 & 4.5362 & 5.4339 & TST \\
\hline CHEMBL1568818 & 688239 & 6.1862 & 5.3812 & TRN \\
\hline CHEMBL1478380 & 688239 & 4.8862 & 5.4928 & TRN \\
\hline CHEMBL1372066 & 688239 & 6.2862 & 5.5196 & TRN \\
\hline CHEMBL1492195 & 688239 & 5.9362 & 5.515 & TRN \\
\hline CHEMBL1372617 & 688239 & 5.2862 & 5.6308 & TRN \\
\hline CHEMBL1583341 & 688239 & 4.5862 & 5.4807 & TRN \\
\hline
\end{tabular}




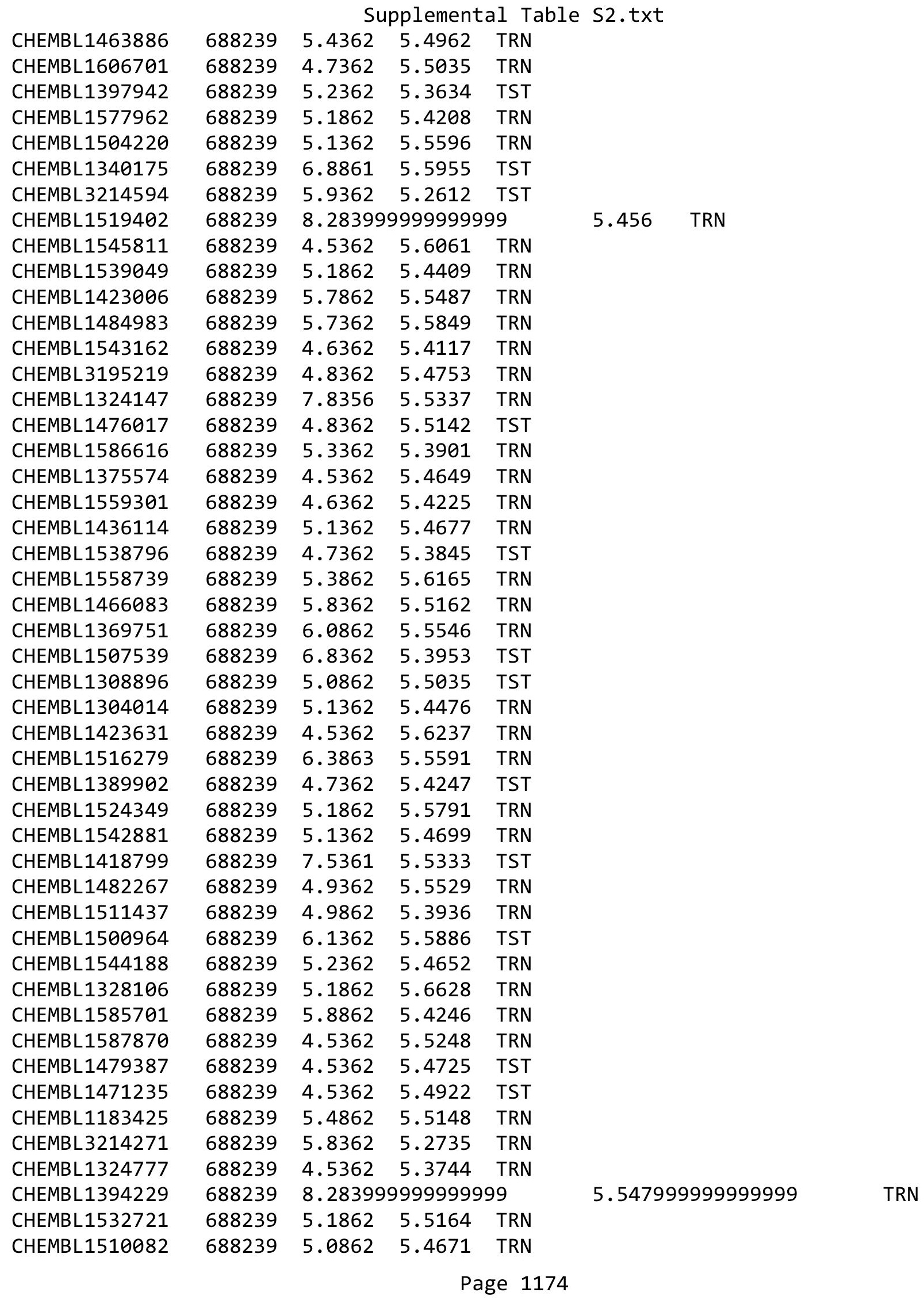


Supplemental Table S2.txt

\begin{tabular}{|c|c|c|c|c|c|}
\hline CHEMBL1572459 & 688239 & 5.3862 & 5.3984 & TRN & \\
\hline CHEMBL1982713 & 688239 & 6.8861 & 5.6096 & TRN & \\
\hline CHEMBL1473313 & 688239 & 5.1862 & 5.5093 & TRN & \\
\hline CHEMBL1344177 & 688239 & 4.5362 & 5.5279 & TST & \\
\hline CHEMBL1585894 & 688239 & 4.5362 & 5.3538 & TRN & \\
\hline CHEMBL 3199766 & 688239 & 5.6362 & 5.4929 & TRN & \\
\hline CHEMBL1548318 & 688239 & 4.8362 & 5.6914 & TST & \\
\hline CHEMBL1351636 & 688239 & 5.0862 & 5.4863 & TRN & \\
\hline CHEMBL1465284 & 688239 & 5.85 & 5.3242 & TRN & \\
\hline CHEMBL1551787 & 688239 & 5.4862 & 5.4245 & TRN & \\
\hline CHEMBL1256656 & 688239 & 4.5862 & 5.5175 & TST & \\
\hline CHEMBL1601864 & 688239 & 5.8862 & 5.4844 & TST & \\
\hline CHEMBL3212710 & 688239 & 4.7362 & 5.4524 & TRN & \\
\hline CHEMBL1583686 & 688239 & 4.4862 & 5.5436 & TST & \\
\hline CHEMBL 3193112 & 688239 & 4.5362 & 5.4891 & TRN & \\
\hline CHEMBL1365931 & 688239 & 5.4862 & 5.5722 & TRN & \\
\hline CHEMBL1457480 & 688239 & 5.3362 & 5.5561 & TST & \\
\hline CHEMBL1318102 & 688239 & 4.8362 & 5.48 & TST & \\
\hline CHEMBL3211987 & 688239 & 4.6362 & 5.4157 & TRN & \\
\hline CHEMBL1520825 & 688239 & 6.1862 & 5.4401 & TST & \\
\hline CHEMBL1489865 & 688239 & 4.7862 & 5.4831 & TRN & \\
\hline CHEMBL1556153 & 688239 & 5.4362 & 5.3722 & TST & \\
\hline CHEMBL1599772 & 688239 & 5.1862 & 5.4275 & TRN & \\
\hline CHEMBL1374277 & 688239 & 6.5862 & 5.4698 & TRN & \\
\hline CHEMBL1323374 & 688239 & 5.3862 & 5.4936 & TRN & \\
\hline CHEMBL1389184 & 688239 & 4.6862 & 5.3434 & TRN & \\
\hline CHEMBL1334605 & 688239 & 4.8362 & 5.5439 & TST & \\
\hline CHEMBL1607353 & 688239 & 4.5362 & 5.3599 & TST & \\
\hline CHEMBL1304481 & 688239 & 6.2862 & 5.528 & TST & \\
\hline CHEMBL 3193751 & 688239 & 6.5862 & 5.4895 & TRN & \\
\hline CHEMBL 3192367 & 688239 & 5.2362 & 5.6255 & TRN & \\
\hline CHEMBL588804 & 688239 & 6.8861 & 5.2911 & TRN & \\
\hline CHEMBL1549558 & 688239 & 8.28399 & 99999999 & 99 & 5.5772 \\
\hline CHEMBL1604631 & 688239 & 5.1862 & 5.574 & TRN & \\
\hline CHEMBL1448615 & 688239 & 6.5363 & 5.4049 & TST & \\
\hline CHEMBL 3208212 & 688239 & 6.7361 & 5.6062 & TRN & \\
\hline CHEMBL1328184 & 688239 & 4.5362 & 5.4033 & TRN & \\
\hline CHEMBL1526256 & 688239 & 6.1862 & 5.4471 & TST & \\
\hline CHEMBL1568056 & 688239 & 5.5862 & 5.4854 & TRN & \\
\hline CHEMBL1464584 & 688239 & 5.3862 & 5.3977 & TST & \\
\hline CHEMBL 3196041 & 688239 & 5.8862 & 5.4261 & TRN & \\
\hline CHEMBL1511369 & 688239 & 4.8862 & 5.4724 & TST & \\
\hline CHEMBL3192949 & 688239 & 7.0362 & 5.5808 & TRN & \\
\hline CHEMBL1359246 & 688239 & 6.1862 & 5.3495 & TST & \\
\hline CHEMBL1600270 & 688239 & 5.6862 & 5.4105 & TRN & \\
\hline CHEMBL1418937 & 688239 & 4.5362 & 5.3005 & TST & \\
\hline CHEMBL1537904 & 688239 & 5.1862 & 5.3406 & TST & \\
\hline CHEMBL1504714 & 688239 & 4.6862 & 5.3815 & TRN & \\
\hline
\end{tabular}


Supplemental Table S2.txt

\begin{tabular}{|c|c|c|c|c|c|}
\hline CHEMBL1559395 & 688239 & 4.6862 & 5.4772 & TRN & \\
\hline CHEMBL1477677 & 688239 & 6.1862 & 5.6094 & TRN & \\
\hline CHEMBL1484677 & 688239 & 5.8362 & 5.4706 & TRN & \\
\hline CHEMBL1535203 & 688239 & 4.7862 & 5.6287 & TRN & \\
\hline CHEMBL1430418 & 688239 & 6.7361 & 5.4348 & TST & \\
\hline CHEMBL1333186 & 688239 & 5.8862 & 5.6096 & TRN & \\
\hline CHEMBL1355358 & 688239 & 5.9862 & 5.5127 & TST & \\
\hline CHEMBL1485281 & 688239 & 5.4362 & 5.528 & TST & \\
\hline CHEMBL1501357 & 688239 & 6.1862 & 5.572 & TRN & \\
\hline CHEMBL1493855 & 688239 & 6.0862 & 5.6734 & TRN & \\
\hline CHEMBL1411388 & 688239 & 4.5362 & 5.4961 & TRN & \\
\hline CHEMBL1423484 & 688239 & 6.1862 & 5.5159 & TRN & \\
\hline CHEMBL1525273 & 688239 & 4.7362 & 5.5672 & TST & \\
\hline CHEMBL1389463 & 688239 & 5.4362 & 5.5853 & TST & \\
\hline CHEMBL1560781 & 688239 & 5.1862 & 5.4967 & TST & \\
\hline CHEMBL1364009 & 688239 & 6.2862 & 5.4426 & TRN & \\
\hline CHEMBL1353576 & 688239 & 4.5362 & 5.5913 & TRN & \\
\hline CHEMBL1352763 & 688239 & 5.6362 & 5.4781 & TRN & \\
\hline CHEMBL1340602 & 688239 & 4.4862 & 5.3394 & TRN & \\
\hline CHEMBL1564257 & 688239 & 5.4362 & 5.4315 & TST & \\
\hline CHEMBL1608482 & 688239 & 4.5362 & 5.5599 & TRN & \\
\hline CHEMBL1319308 & 688239 & 4.5362 & 5.4016 & TRN & \\
\hline CHEMBL1535122 & 688239 & 4.5362 & 5.4594 & TST & \\
\hline CHEMBL1601402 & 688239 & 5.2362 & 5.2988 & TRN & \\
\hline CHEMBL1422900 & 688239 & 5.1862 & 5.5006 & TRN & \\
\hline CHEMBL1371667 & 688239 & 6.5862 & 5.428 & TST & \\
\hline CHEMBL1499473 & 688239 & 5.1862 & 5.5104 & TRN & \\
\hline CHEMBL1377448 & 688239 & 4.5862 & 5.4595 & TRN & \\
\hline CHEMBL1496734 & 688239 & 6.9363 & 5.4813 & TRN & \\
\hline CHEMBL1606815 & 688239 & 6.9363 & 5.6401 & TST & \\
\hline CHEMBL1544072 & 688239 & 6.2362 & 5.4524 & TRN & \\
\hline CHEMBL1588768 & 688239 & 4.6862 & 5.66799 & 9999999999 & TRN \\
\hline CHEMBL1543881 & 688239 & 4.6362 & 5.4949 & TRN & \\
\hline CHEMBL1489567 & 688239 & 5.6862 & 5.4644 & TRN & \\
\hline CHEMBL1523788 & 688239 & 4.6362 & 5.4837 & TST & \\
\hline CHEMBL1415120 & 688239 & 4.9362 & 5.5309 & TRN & \\
\hline CHEMBL1571985 & 688239 & 4.7862 & 5.25799 & 9999999999 & TRN \\
\hline CHEMBL1613734 & 688239 & 4.8862 & 5.4652 & TRN & \\
\hline CHEMBL1312177 & 688239 & 4.5362 & 5.4463 & TRN & \\
\hline CHEMBL3193180 & 688239 & 8.4318 & 5.3126 & TST & \\
\hline CHEMBL 8165 & 688239 & 4.7362 & 5.4515 & TRN & \\
\hline CHEMBL1552090 & 688239 & 4.7862 & 5.3816 & TRN & \\
\hline CHEMBL1491198 & 688239 & 4.5362 & 5.5563 & TRN & \\
\hline CHEMBL1481078 & 688239 & 6.7361 & 5.62799 & э999999999 & TRN \\
\hline CHEMBL1583170 & 688239 & 5.2362 & 5.3695 & TST & \\
\hline CHEMBL1423578 & 688239 & 6.5862 & 5.4949 & TRN & \\
\hline CHEMBL1330806 & 688239 & 7.1864 & 5.313 & TRN & \\
\hline CHEMBL1340388 & 688239 & 4.6862 & 5.5354 & TRN & \\
\hline
\end{tabular}


Supplemental Table S2.txt

\begin{tabular}{|c|c|c|c|c|}
\hline CHEMBL1307566 & 688239 & 5.0862 & 5.4405 & TST \\
\hline CHEMBL1594102 & 688239 & 6.4362 & 5.4903 & TRN \\
\hline CHEMBL1505765 & 688239 & 4.6862 & 5.5458 & TRN \\
\hline CHEMBL1377554 & 688239 & 6.0362 & 5.5147 & TRN \\
\hline CHEMBL1424659 & 688239 & 5.9362 & 5.4695 & TRN \\
\hline CHEMBL1330867 & 688239 & 5.2362 & 5.4873 & TRN \\
\hline CHEMBL1551014 & 688239 & 8.1871 & 5.7002 & TRN \\
\hline CHEMBL1354011 & 688239 & 5.2862 & 5.5473 & TRN \\
\hline CHEMBL1461457 & 688239 & 6.2862 & 5.3831 & TST \\
\hline CHEMBL1482505 & 688239 & 4.8362 & 5.6559 & TRN \\
\hline CHEMBL1539406 & 688239 & 5.3362 & 5.3975 & TRN \\
\hline CHEMBL1592194 & 688239 & 5.7362 & 5.4372 & TRN \\
\hline CHEMBL1384229 & 688239 & 4.9362 & 5.6179 & TRN \\
\hline CHEMBL 3197594 & 688239 & 4.7362 & 5.4788 & TRN \\
\hline CHEMBL1352302 & 688239 & 6.8362 & 5.3823 & TRN \\
\hline CHEMBL1321594 & 688239 & 4.5362 & 5.447999 & 9999999995 \\
\hline CHEMBL1608795 & 688239 & 4.7862 & 5.5186 & TST \\
\hline CHEMBL1547849 & 688239 & 5.1862 & 5.3397 & TRN \\
\hline CHEMBL1571246 & 688239 & 6.8362 & 5.5333 & TRN \\
\hline CHEMBL1420520 & 688239 & 4.7862 & 5.4793 & TRN \\
\hline CHEMBL1610597 & 688239 & 8.28399 & 99999999 & 5.431 \\
\hline CHEMBL1518637 & 688239 & 5.1862 & 5.5049 & TRN \\
\hline CHEMBL1402579 & 688239 & 4.6862 & 5.4023 & TST \\
\hline CHEMBL1519579 & 688239 & 5.8362 & 5.5581 & TST \\
\hline CHEMBL1579667 & 688239 & 5.1862 & 5.452999 & 999999999 \\
\hline CHEMBL1529462 & 688239 & 5.1862 & 5.5858 & TRN \\
\hline CHEMBL1556905 & 688239 & 5.0362 & 5.5418 & TRN \\
\hline CHEMBL1490127 & 688239 & 6.9863 & 5.5648 & TRN \\
\hline CHEMBL1424767 & 688239 & 4.4862 & 5.457999 & 999999999 \\
\hline CHEMBL1359962 & 688239 & 5.1862 & 5.3818 & TRN \\
\hline CHEMBL1381962 & 688239 & 6.9363 & 5.4553 & TRN \\
\hline CHEMBL 3210897 & 688239 & 6.9863 & 5.6817 & TRN \\
\hline CHEMBL1366838 & 688239 & 6.6861 & 5.4173 & TST \\
\hline CHEMBL1578512 & 688239 & 7.8861 & 5.497000 & 000000001 \\
\hline CHEMBL1319519 & 688239 & 4.95 & 5.4362 & TRN \\
\hline CHEMBL1385858 & 688239 & 4.5362 & 5.4737 & TRN \\
\hline CHEMBL1558070 & 688239 & 4.9362 & 5.4237 & TRN \\
\hline CHEMBL1452106 & 688239 & 5.1862 & 5.4946 & TRN \\
\hline CHEMBL1303307 & 688239 & 5.2862 & 5.5446 & TRN \\
\hline CHEMBL1389485 & 688239 & 4.5862 & 5.4022 & TRN \\
\hline CHEMBL1431857 & 688239 & 4.5862 & 5.5475 & TRN \\
\hline CHEMBL1504148 & 688239 & 6.1362 & 5.5551 & TST \\
\hline CHEMBL1589927 & 688239 & 5.4362 & 5.5757 & TRN \\
\hline CHEMBL494083 & 688239 & 4.5362 & 5.3871 & TST \\
\hline CHEMBL1314012 & 688239 & 5.1862 & 5.5346 & TRN \\
\hline CHEMBL1565658 & 688239 & 5.2862 & 5.7022 & TRN \\
\hline CHEMBL1467846 & 688239 & 4.7362 & 5.7045 & TRN \\
\hline CHEMBL1408715 & 688239 & 4.8362 & 5.2579 & TRN \\
\hline
\end{tabular}


Supplemental Table S2.txt

\begin{tabular}{|c|c|c|c|c|c|}
\hline CHEMBL1317372 & 688239 & 4.5362 & 5.4711 & TRN & \\
\hline CHEMBL1565182 & 688239 & 5.8862 & 5.3813 & TRN & \\
\hline CHEMBL1399122 & 688239 & 4.7362 & 5.5126 & TRN & \\
\hline CHEMBL1609569 & 688239 & 5.6362 & 5.3379 & TST & \\
\hline CHEMBL1576342 & 688239 & 4.7862 & 5.3577 & TRN & \\
\hline CHEMBL1458159 & 688239 & 6.2362 & 5.5122 & TRN & \\
\hline CHEMBL1458910 & 688239 & 4.5362 & 5.4465 & TRN & \\
\hline CHEMBL1416274 & 688239 & 5.2362 & 5.4679 & TST & \\
\hline CHEMBL1351707 & 688239 & 7.5867 & 5.5933 & TRN & \\
\hline CHEMBL1600429 & 688239 & 4.7862 & 5.2928 & TRN & \\
\hline CHEMBL1329109 & 688239 & 4.4862 & 5.5889 & TRN & \\
\hline CHEMBL1373171 & 688239 & 4.8862 & 5.4729 & TST & \\
\hline CHEMBL1489342 & 688239 & 6.5363 & 5.5403 & TST & \\
\hline CHEMBL1491160 & 688239 & 4.5862 & 5.6423 & TRN & \\
\hline CHEMBL1533037 & 688239 & 5.6362 & 5.3836 & TRN & \\
\hline CHEMBL1384390 & 688239 & 5.1862 & 5.4807 & TST & \\
\hline CHEMBL1321030 & 688239 & 5.4362 & 5.4609 & TRN & \\
\hline CHEMBL1486471 & 688239 & 4.5362 & 5.5159 & TRN & \\
\hline CHEMBL1510041 & 688239 & 6.1862 & 5.4464 & TST & \\
\hline CHEMBL228862 & 688239 & 6.9363 & 5.4856 & TST & \\
\hline CHEMBL1351561 & 688239 & 4.5362 & 5.4535 & TRN & \\
\hline CHEMBL1449452 & 688239 & 5.0362 & 5.48799 & 99999999995 & TRN \\
\hline CHEMBL1565251 & 688239 & 4.5862 & 5.4795 & TRN & \\
\hline CHEMBL1524895 & 688239 & 4.6862 & 5.6384 & TRN & \\
\hline CHEMBL1439761 & 688239 & 4.6362 & 5.4365 & TRN & \\
\hline CHEMBL1344124 & 688239 & 6.3362 & 5.4655 & TRN & \\
\hline CHEMBL1527193 & 688239 & 4.8862 & 5.3722 & TST & \\
\hline CHEMBL1456085 & 688239 & 4.6862 & 5.2712 & TRN & \\
\hline CHEMBL1458203 & 688239 & 5.7362 & 5.4361 & TRN & \\
\hline CHEMBL1464667 & 688239 & 5.1862 & 5.4884 & TRN & \\
\hline CHEMBL1591060 & 688239 & 5.5862 & 5.5531 & TRN & \\
\hline CHEMBL1500585 & 688239 & 4.9862 & 5.4958 & TRN & \\
\hline CHEMBL1404229 & 688239 & 4.7862 & 5.3398 & TRN & \\
\hline CHEMBL1411184 & 688239 & 5.4362 & 5.5945 & TRN & \\
\hline CHEMBL1529236 & 688239 & 4.6862 & 5.2833 & TRN & \\
\hline CHEMBL1449632 & 688239 & 5.3362 & 5.3946 & TST & \\
\hline CHEMBL1488622 & 688239 & 5.1862 & 5.5253 & TST & \\
\hline CHEMBL1363388 & 688239 & 4.5362 & 5.4037 & TRN & \\
\hline CHEMBL1359388 & 688239 & 4.5362 & 5.6653 & TST & \\
\hline CHEMBL1499725 & 688239 & 4.9362 & 5.4053 & TRN & \\
\hline CHEMBL1428897 & 688239 & 4.7862 & 5.4639 & TST & \\
\hline CHEMBL1300876 & 688239 & 4.5362 & 5.3893 & TST & \\
\hline CHEMBL1301255 & 688239 & 5.0862 & 5.4635 & TRN & \\
\hline CHEMBL1399592 & 688239 & 6.7361 & 5.3776 & TRN & \\
\hline CHEMBL1481339 & 688239 & 4.5362 & 5.3943 & TRN & \\
\hline CHEMBL1319826 & 688239 & 5.6862 & 5.501 & TRN & \\
\hline CHEMBL1580796 & 688239 & 7.0362 & 5.5178 & TRN & \\
\hline CHEMBL1529923 & 688239 & 4.6862 & 5.5686 & TRN & \\
\hline
\end{tabular}


Supplemental Table S2.txt

\begin{tabular}{|c|c|c|c|c|c|c|}
\hline CHEMBL1403472 & 688239 & 5.3862 & 5.4651 & TST & & \\
\hline CHEMBL1319343 & 688239 & 5.4362 & 5.5619 & TRN & & \\
\hline CHEMBL1512940 & 688239 & 5.1362 & 5.4418 & TRN & & \\
\hline CHEMBL1463473 & 688239 & 6.0862 & 5.6106 & TRN & & \\
\hline CHEMBL1420686 & 688239 & 4.7862 & 5.5489 & TRN & & \\
\hline CHEMBL1450722 & 688239 & 4.4862 & 5.6625 & TRN & & \\
\hline CHEMBL1466009 & 688239 & 8.28399 & 99999999 & 9 & 5.4392 & TRN \\
\hline CHEMBL1489283 & 688239 & 5.1862 & 5.3093 & TRN & & \\
\hline CHEMBL1453512 & 688239 & 5.3862 & 5.3662 & TRN & & \\
\hline CHEMBL1434100 & 688239 & 5.2362 & 5.51 & TRN & & \\
\hline CHEMBL1351353 & 688239 & 4.6862 & 5.4804 & TST & & \\
\hline CHEMBL1986514 & 688239 & 6.2362 & 5.4435 & TST & & \\
\hline CHEMBL1418538 & 688239 & 4.5362 & 5.6299 & TRN & & \\
\hline CHEMBL1499631 & 688239 & 7.4365 & 5.5365 & TST & & \\
\hline CHEMBL1585657 & 688239 & 5.5862 & 5.4104 & TST & & \\
\hline CHEMBL1306463 & 688239 & 6.6362 & 5.5773 & TRN & & \\
\hline CHEMBL1314187 & 688239 & 4.5362 & 5.4594 & TRN & & \\
\hline CHEMBL1368367 & 688239 & 4.5362 & 5.5631 & TRN & & \\
\hline CHEMBL1448604 & 688239 & 6.0862 & 5.6266 & TRN & & \\
\hline CHEMBL1302819 & 688239 & 5.1862 & 5.6686 & TRN & & \\
\hline CHEMBL1304744 & 688239 & 6.1362 & 5.4665 & TST & & \\
\hline CHEMBL1343250 & 688239 & 5.0862 & 5.4484 & TRN & & \\
\hline CHEMBL1310069 & 688239 & 6.8861 & 5.4928 & TRN & & \\
\hline CHEMBL1443640 & 688239 & 4.6862 & 5.3321 & TRN & & \\
\hline CHEMBL1487824 & 688239 & 5.2862 & 5.5881 & TRN & & \\
\hline CHEMBL3193723 & 688239 & 4.5362 & 5.3063 & TRN & & \\
\hline CHEMBL1558229 & 688239 & 4.5362 & 5.7833 & TRN & & \\
\hline CHEMBL1330556 & 688239 & 4.5862 & 5.277 & TRN & & \\
\hline CHEMBL1528905 & 688239 & 5.7362 & 5.6531 & TRN & & \\
\hline CHEMBL1325893 & 688239 & 6.9363 & 5.4843 & TST & & \\
\hline CHEMBL1368707 & 688239 & 4.7362 & 5.5867 & TST & & \\
\hline CHEMBL1563073 & 688239 & 8.3372 & 5.5046 & TRN & & \\
\hline CHEMBL1363833 & 688239 & 5.7362 & 5.5022 & TRN & & \\
\hline CHEMBL1512262 & 688239 & 6.6362 & 5.5316 & TRN & & \\
\hline CHEMBL1345421 & 688239 & 4.7862 & 5.5276 & TRN & & \\
\hline CHEMBL1438704 & 688239 & 5.4362 & 5.5251 & TRN & & \\
\hline CHEMBL1466746 & 688239 & 5.1362 & 5.5137 & TRN & & \\
\hline CHEMBL1493646 & 688239 & 5.1862 & 5.4706 & TST & & \\
\hline CHEMBL 3198887 & 688239 & 4.9362 & 5.4589 & TST & & \\
\hline CHEMBL1428041 & 688239 & 5.6862 & 5.3997 & TRN & & \\
\hline CHEMBL1451022 & 688239 & 6.8861 & 5.6376 & TST & & \\
\hline CHEMBL1374839 & 688239 & 4.5362 & 5.4803 & TST & & \\
\hline CHEMBL1336565 & 688239 & 8.3372 & 5.4841 & TRN & & \\
\hline CHEMBL1441316 & 688239 & 4.5362 & 5.4407 & TRN & & \\
\hline CHEMBL1412626 & 688239 & 5.3362 & 5.5333 & TRN & & \\
\hline CHEMBL1489754 & 688239 & 5.0862 & 5.4897 & TRN & & \\
\hline CHEMBL1475123 & 688239 & 4.4862 & 5.6257 & TRN & & \\
\hline CHEMBL1562422 & 688239 & 5.1862 & 5.5509 & TRN & & \\
\hline
\end{tabular}

Page 1179 
Supplemental Table S2.txt

\begin{tabular}{|c|c|c|c|c|}
\hline CHEMBL1524354 & 688239 & 5.6862 & 5.4962 & TST \\
\hline CHEMBL1344786 & 688239 & 6.5363 & 5.6785 & TRN \\
\hline CHEMBL1447853 & 688239 & 4.6362 & 5.4128 & TRN \\
\hline CHEMBL1434293 & 688239 & 5.1862 & 5.495 & TRN \\
\hline CHEMBL1446198 & 688239 & 6.2862 & 5.5127 & TRN \\
\hline CHEMBL1588413 & 688239 & 5.1862 & \multicolumn{2}{|c|}{5.5089999999999995} \\
\hline CHEMBL1325724 & 688239 & 5.7862 & 5.5202 & TST \\
\hline CHEMBL1386659 & 688239 & 5.9362 & 5.5632 & TST \\
\hline CHEMBL1345104 & 688239 & 4.8362 & 5.4538 & TRN \\
\hline CHEMBL1358194 & 688239 & 4.5362 & 5.4772 & TRN \\
\hline CHEMBL1366834 & 688239 & 5.6362 & 5.5096 & TRN \\
\hline CHEMBL1393061 & 688239 & 7.5361 & 5.3457 & TRN \\
\hline CHEMBL580076 & 688239 & 4.8362 & 5.4344 & TRN \\
\hline CHEMBL1308853 & 688239 & 4.6362 & 5.4478 & TST \\
\hline CHEMBL1433125 & 688239 & 4.5362 & 5.5162 & TRN \\
\hline CHEMBL1414958 & 688239 & 4.6362 & 5.4296 & TRN \\
\hline CHEMBL1502606 & 688239 & 6.7361 & 5.5586 & TST \\
\hline CHEMBL1381896 & 688239 & 6.5363 & 5.4371 & TRN \\
\hline CHEMBL 3214380 & 688239 & 6.4862 & \multicolumn{2}{|c|}{5.327999999999999} \\
\hline CHEMBL1604096 & 688239 & 6.1362 & 5.5285 & TRN \\
\hline CHEMBL1444908 & 688239 & 5.4362 & 5.5049 & TRN \\
\hline CHEMBL1504289 & 688239 & 6.3362 & 5.4328 & TST \\
\hline CHEMBL1343729 & 688239 & 6.6362 & 5.6089 & TRN \\
\hline CHEMBL1589505 & 688239 & 8.3372 & 5.5606 & TRN \\
\hline CHEMBL1442722 & 688239 & 6.9863 & 5.5585 & TRN \\
\hline CHEMBL2003149 & 688239 & 6.1362 & 5.4122 & TST \\
\hline CHEMBL1302913 & 688239 & 5.6362 & 5.5841 & TST \\
\hline CHEMBL1306825 & 688239 & 5.9362 & 5.4945 & TRN \\
\hline CHEMBL1453108 & 688239 & 6.0 & 5.5371 & TRN \\
\hline CHEMBL1972015 & 688239 & 5.7862 & 5.4795 & TST \\
\hline CHEMBL1443962 & 688239 & 5.6862 & 5.5577 & TRN \\
\hline CHEMBL1509599 & 688239 & 5.2862 & 5.3131 & TRN \\
\hline CHEMBL1467816 & 688239 & 4.8862 & 5.3453 & TRN \\
\hline CHEMBL1392960 & 688239 & 5.0362 & 5.4883 & TRN \\
\hline CHEMBL1341663 & 688239 & 5.5862 & 5.5067 & TRN \\
\hline CHEMBL1519685 & 688239 & 4.6862 & 5.579 & TRN \\
\hline CHEMBL1545457 & 688239 & 4.6362 & 5.4951 & TRN \\
\hline CHEMBL1459936 & 688239 & 4.7862 & 5.5369 & TRN \\
\hline CHEMBL1441338 & 688239 & 4.5362 & 5.5757 & TRN \\
\hline CHEMBL1493185 & 688239 & 8.3372 & 5.4747 & TRN \\
\hline CHEMBL1573743 & 688239 & 6.2362 & 5.5426 & TRN \\
\hline CHEMBL1481907 & 688239 & 4.9362 & 5.5248 & TRN \\
\hline CHEMBL1472716 & 688239 & 4.5362 & 5.3714 & TRN \\
\hline CHEMBL1510738 & 688239 & 4.4862 & 5.587999 & 999999999 \\
\hline CHEMBL1404936 & 688239 & 6.9863 & 5.4615 & TRN \\
\hline CHEMBL1377541 & 688239 & 4.8862 & 5.5172 & TRN \\
\hline CHEMBL3211984 & 688239 & 5.2862 & 5.5245 & TST \\
\hline CHEMBL1460788 & 688239 & 5.1362 & 5.5344 & TRN \\
\hline
\end{tabular}


Supplemental Table S2.txt

\begin{tabular}{|c|c|c|c|c|c|}
\hline CHEMBL1580912 & 688239 & 5.5362 & 5.5708 & TRN & \\
\hline CHEMBL1488938 & 688239 & 5.7862 & 5.6001 & TRN & \\
\hline CHEMBL1395209 & 688239 & 5.2362 & 5.462999 & 999999999 & TRN \\
\hline CHEMBL1484098 & 688239 & 4.5362 & 5.5363 & TRN & \\
\hline CHEMBL1495965 & 688239 & 5.1862 & 5.4103 & TST & \\
\hline CHEMBL1482440 & 688239 & 6.0362 & 5.5601 & TRN & \\
\hline CHEMBL1975930 & 688239 & 4.5362 & 5.5385 & TRN & \\
\hline CHEMBL1443965 & 688239 & 5.1862 & 5.5098 & TRN & \\
\hline CHEMBL1521272 & 688239 & 5.3362 & 5.4274 & TST & \\
\hline CHEMBL1385698 & 688239 & 5.1862 & 5.4132 & TRN & \\
\hline CHEMBL1300406 & 688239 & 4.6362 & 5.6076 & TST & \\
\hline CHEMBL1420658 & 688239 & 4.7862 & 5.3939 & TRN & \\
\hline CHEMBL1419263 & 688239 & 5.6362 & 5.4148 & TRN & \\
\hline CHEMBL1585064 & 688239 & 6.5862 & 5.5615 & TRN & \\
\hline CHEMBL1585111 & 688239 & 6.1362 & 5.3701 & TRN & \\
\hline CHEMBL1379874 & 688239 & 6.6861 & 5.459 & TRN & \\
\hline CHEMBL3207768 & 688239 & 8.3872 & 5.3791 & TST & \\
\hline CHEMBL1349069 & 688239 & 7.7852 & 5.305 & TRN & \\
\hline CHEMBL1557067 & 688239 & 4.5362 & 5.626 & TRN & \\
\hline CHEMBL1357779 & 688239 & 4.6862 & 5.5201 & TRN & \\
\hline CHEMBL1361582 & 688239 & 8.3372 & 5.3254 & TRN & \\
\hline CHEMBL1380744 & 688239 & 5.0862 & 5.3694 & TRN & \\
\hline CHEMBL1601112 & 688239 & 5.1862 & 5.6256 & TRN & \\
\hline CHEMBL3197819 & 688239 & 4.5362 & 5.6694 & TST & \\
\hline CHEMBL1449675 & 688239 & 6.2862 & 5.5545 & TRN & \\
\hline CHEMBL1514095 & 688239 & 5.6862 & 5.5204 & TRN & \\
\hline CHEMBL1413205 & 688239 & 6.9363 & 5.2981 & TRN & \\
\hline CHEMBL1315866 & 688239 & 7.0862 & 5.4726 & TRN & \\
\hline CHEMBL1547109 & 688239 & 5.1862 & 5.4988 & TST & \\
\hline CHEMBL1537322 & 688239 & 4.5362 & 5.5946 & TRN & \\
\hline CHEMBL1543475 & 688239 & 5.0362 & \multicolumn{2}{|c|}{5.5120000000000005} & TRN \\
\hline CHEMBL1438869 & 688239 & 5.4362 & 5.3892 & TRN & \\
\hline CHEMBL1496800 & 688239 & 5.6862 & 5.5495 & TRN & \\
\hline CHEMBL1444740 & 688239 & 4.5862 & 5.4563 & TRN & \\
\hline CHEMBL1408690 & 688239 & 6.8362 & 5.4342 & TRN & \\
\hline CHEMBL1538233 & 688239 & 6.8861 & 5.7741 & TRN & \\
\hline CHEMBL1530333 & 688239 & 6.2362 & 5.5334 & TRN & \\
\hline CHEMBL1338174 & 688239 & 4.7862 & 5.4878 & TST & \\
\hline CHEMBL3209710 & 688239 & 5.0862 & 5.4598 & TRN & \\
\hline CHEMBL3191958 & 688239 & 4.5362 & 5.4412 & TRN & \\
\hline CHEMBL1411587 & 688239 & 5.4862 & 5.4185 & TRN & \\
\hline CHEMBL3199303 & 688239 & 4.6362 & 5.5123 & TRN & \\
\hline CHEMBL1596547 & 688239 & 4.5362 & 5.402 & TST & \\
\hline CHEMBL1410290 & 688239 & 5.8862 & 5.5096 & TRN & \\
\hline CHEMBL1339701 & 688239 & 5.4362 & 5.4231 & TRN & \\
\hline CHEMBL1370642 & 688239 & 5.7362 & 5.5454 & TRN & \\
\hline CHEMBL1337500 & 688239 & 5.5362 & 5.4775 & TST & \\
\hline CHEMBL1481877 & 688239 & 5.3362 & 5.5375 & TST & \\
\hline
\end{tabular}


Supplemental Table S2.txt

\begin{tabular}{|c|c|c|c|c|}
\hline CHEMBL1549471 & 688239 & 5.1862 & 5.4567 & TRN \\
\hline CHEMBL1358328 & 688239 & 4.9362 & 5.6261 & TRN \\
\hline CHEMBL1503756 & 688239 & 4.7362 & 5.5629 & TST \\
\hline CHEMBL521297 & 688239 & 6.2862 & 5.3748 & TST \\
\hline CHEMBL1374905 & 688239 & 5.1362 & 5.5271 & TRN \\
\hline CHEMBL1562918 & 688239 & 4.8362 & 5.4834 & TST \\
\hline CHEMBL1415455 & 688239 & 6.2862 & 5.4954 & TRN \\
\hline CHEMBL1345325 & 688239 & 4.5362 & 5.4668 & TST \\
\hline CHEMBL590949 & 688239 & 5.1862 & 5.3121 & TST \\
\hline CHEMBL1542619 & 688239 & 7.2865 & 5.4542 & TRN \\
\hline CHEMBL1455241 & 688239 & 4.5862 & 5.7427 & TST \\
\hline CHEMBL1549935 & 688239 & 5.1862 & 5.4302 & TRN \\
\hline CHEMBL3189398 & 688239 & 6.1862 & 5.431 & TRN \\
\hline CHEMBL1431666 & 688239 & 4.4862 & 5.212999 & 9999999999 \\
\hline CHEMBL1538665 & 688239 & 4.6362 & 5.4855 & TRN \\
\hline CHEMBL1567901 & 688239 & 5.1862 & 5.6176 & TST \\
\hline CHEMBL1402021 & 688239 & 6.8362 & 5.6063 & TRN \\
\hline CHEMBL1304400 & 688239 & 6.4362 & 5.4775 & TRN \\
\hline CHEMBL1448392 & 688239 & 6.8362 & 5.5399 & TRN \\
\hline CHEMBL1523369 & 688239 & 4.6362 & 5.5212 & TRN \\
\hline CHEMBL1482779 & 688239 & 5.3862 & 5.5706 & TRN \\
\hline CHEMBL1453404 & 688239 & 6.8861 & 5.6388 & TRN \\
\hline CHEMBL1975718 & 688239 & 5.2362 & 5.4527 & TRN \\
\hline CHEMBL237253 & 688239 & 6.0862 & 5.4992 & TRN \\
\hline CHEMBL1478235 & 688239 & 4.5362 & 5.5302 & TRN \\
\hline CHEMBL1395021 & 688239 & 6.7361 & 5.5103 & TRN \\
\hline CHEMBL3189403 & 688239 & 5.6362 & 5.4405 & TRN \\
\hline CHEMBL1362008 & 688239 & 5.3362 & 5.5714 & TST \\
\hline CHEMBL1569056 & 688239 & 4.7862 & 5.586 & TRN \\
\hline CHEMBL 2000992 & 688239 & 4.8362 & 5.455 & TST \\
\hline CHEMBL1442820 & 688239 & 4.5362 & 5.4783 & TRN \\
\hline CHEMBL1340514 & 688239 & 7.0362 & 5.4059 & TRN \\
\hline CHEMBL1581644 & 688239 & 5.1862 & 5.4248 & TRN \\
\hline CHEMBL1585269 & 688239 & 4.5362 & 5.4915 & TRN \\
\hline CHEMBL1420385 & 688239 & 4.9362 & 5.4247 & TRN \\
\hline CHEMBL1471117 & 688239 & 5.3362 & 5.5682 & TRN \\
\hline CHEMBL1575817 & 688239 & 4.7362 & 5.5199 & TRN \\
\hline CHEMBL1390169 & 688239 & 7.2865 & 5.6464 & TRN \\
\hline CHEMBL1357298 & 688239 & 6.0362 & 5.3878 & TRN \\
\hline CHEMBL1321302 & 688239 & 6.0362 & 5.4395 & TST \\
\hline CHEMBL1466854 & 688239 & 7.6861 & 5.6403 & TRN \\
\hline CHEMBL1373201 & 688239 & 4.6862 & 5.4237 & TST \\
\hline CHEMBL1475882 & 688239 & 5.6862 & 5.4297 & TRN \\
\hline CHEMBL1589255 & 688239 & 6.5862 & 5.4169 & TST \\
\hline CHEMBL1310129 & 688239 & 6.7361 & 5.5558 & TST \\
\hline CHEMBL1445036 & 688239 & 5.9862 & 5.4539 & TRN \\
\hline CHEMBL1482193 & 688239 & 4.7362 & \multicolumn{2}{|c|}{5.327999999999999} \\
\hline CHEMBL1477027 & 688239 & 8.3372 & 5.3401 & TST \\
\hline
\end{tabular}




\begin{tabular}{|c|c|c|c|c|c|}
\hline \multirow[b]{2}{*}{ CHEMBL1485073 } & & \multicolumn{4}{|c|}{ Supplemental Table S2.txt } \\
\hline & 688239 & 6.8861 & 5.49299 & 9999999999 & TRN \\
\hline CHEMBL1416390 & 688239 & 4.8362 & 5.4966 & TRN & \\
\hline CHEMBL1577331 & 688239 & 5.1862 & 5.542006 & 0000000001 & TRN \\
\hline CHEMBL1558653 & 688239 & 5.55 & 5.4705 & TRN & \\
\hline CHEMBL1468063 & 688239 & 6.4362 & 5.5738 & TRN & \\
\hline CHEMBL1554402 & 688239 & 4.8862 & 5.4603 & TRN & \\
\hline CHEMBL1308151 & 688239 & 5.1862 & 5.4963 & TRN & \\
\hline CHEMBL1389972 & 688239 & 5.1862 & 5.5576 & TRN & \\
\hline CHEMBL1503459 & 688239 & 5.1862 & 5.4782 & TST & \\
\hline CHEMBL1560929 & 688239 & 4.5362 & 5.4827 & TST & \\
\hline CHEMBL1610473 & 688239 & 4.7862 & 5.4075 & TRN & \\
\hline CHEMBL1536978 & 688239 & 6.7361 & 5.5928 & TRN & \\
\hline CHEMBL1610147 & 688239 & 4.7862 & 5.4602 & TRN & \\
\hline CHEMBL1536989 & 688239 & 5.8862 & 5.4799 & TRN & \\
\hline CHEMBL1308783 & 688239 & 4.7362 & 5.4855 & TRN & \\
\hline CHEMBL1300638 & 688239 & 5.0362 & 5.7419 & TRN & \\
\hline CHEMBL1320031 & 688239 & 8.3372 & 5.3692 & TRN & \\
\hline CHEMBL1574080 & 688239 & 5.7362 & 5.4491 & TRN & \\
\hline CHEMBL3194457 & 688239 & 5.1862 & 5.5384 & TRN & \\
\hline CHEMBL1540112 & 688239 & 4.6862 & 5.3971 & TRN & \\
\hline CHEMBL1328805 & 688239 & 6.6362 & 5.598 & TST & \\
\hline CHEMBL1365102 & 688239 & 4.5362 & 5.6193 & TRN & \\
\hline CHEMBL1322826 & 688239 & 6.6362 & 5.53299 & 99999999995 & TRN \\
\hline CHEMBL3189393 & 688239 & 4.4862 & 5.4455 & TST & \\
\hline CHEMBL1425817 & 688239 & 6.1362 & 5.5066 & TRN & \\
\hline CHEMBL1548761 & 688239 & 4.5362 & 5.313 & TRN & \\
\hline CHEMBL1568651 & 688239 & 5.6862 & 5.6036 & TST & \\
\hline CHEMBL1573007 & 688239 & 4.5362 & 5.3903 & TST & \\
\hline CHEMBL1539417 & 688239 & 4.5362 & 5.3745 & TST & \\
\hline CHEMBL1603395 & 688239 & 4.5362 & 5.4538 & TRN & \\
\hline CHEMBL1303193 & 688239 & 5.1862 & 5.4524 & TRN & \\
\hline CHEMBL1557682 & 688239 & 5.1862 & 5.4912 & TRN & \\
\hline CHEMBL1319054 & 688239 & 5.4362 & 5.4575 & TRN & \\
\hline CHEMBL162808 & 688239 & 4.5362 & 5.4667 & TRN & \\
\hline CHEMBL1607231 & 688239 & 6.5363 & 5.5475 & TRN & \\
\hline CHEMBL1967609 & 688239 & 6.8861 & 5.4375 & TRN & \\
\hline CHEMBL3194389 & 688239 & 5.2362 & 5.4366 & TRN & \\
\hline CHEMBL1590427 & 688239 & 7.1864 & 5.5627 & TRN & \\
\hline CHEMBL1342727 & 688239 & 7.2865 & 5.3981 & TRN & \\
\hline CHEMBL1328548 & 688239 & 4.8362 & 5.5065 & TRN & \\
\hline CHEMBL1464915 & 688239 & 5.6362 & 5.501 & TRN & \\
\hline CHEMBL1349207 & 688239 & 4.5362 & 5.3316 & TRN & \\
\hline CHEMBL1591461 & 688239 & 4.7362 & 5.3018 & TRN & \\
\hline CHEMBL1427994 & 688239 & 5.9362 & 5.3308 & TRN & \\
\hline CHEMBL1302845 & 688239 & 5.5362 & 5.6609 & TRN & \\
\hline CHEMBL1443509 & 688239 & 5.6862 & 5.44799 & 99999999995 & TST \\
\hline CHEMBL1408276 & 688239 & 4.6862 & 5.3362 & TRN & \\
\hline CHEMBL1525542 & 688239 & 5.5862 & 5.4287 & TRN & \\
\hline
\end{tabular}


Supplemental Table S2.txt

\begin{tabular}{|c|c|c|c|c|}
\hline CHEMBL1300798 & 688239 & 5.6362 & 5.5046 & TST \\
\hline CHEMBL1537327 & 688239 & 5.4862 & 5.4258 & TRN \\
\hline CHEMBL1433756 & 688239 & 5.7862 & 5.4909 & TST \\
\hline CHEMBL1446885 & 688239 & 4.5862 & 5.6041 & TRN \\
\hline CHEMBL1498074 & 688239 & 6.8362 & 5.4812 & TRN \\
\hline CHEMBL1347030 & 688239 & 4.6862 & 5.4127 & TST \\
\hline CHEMBL1604608 & 688239 & 4.5362 & 5.5318 & TST \\
\hline CHEMBL3196546 & 688239 & 4.4862 & 5.266 & TRN \\
\hline CHEMBL1513864 & 688239 & 7.2366 & 5.567 & TRN \\
\hline CHEMBL1321002 & 688239 & 5.6862 & 5.59399 & 9999999999 \\
\hline CHEMBL1435802 & 688239 & 5.4362 & 5.3522 & TRN \\
\hline CHEMBL1600009 & 688239 & 5.4862 & 5.6185 & TRN \\
\hline CHEMBL1467193 & 688239 & 6.3863 & 5.447 & TST \\
\hline CHEMBL1569677 & 688239 & 5.0862 & 5.5164 & TST \\
\hline CHEMBL1570665 & 688239 & 5.1862 & 5.5781 & TRN \\
\hline CHEMBL1484207 & 688239 & 5.5362 & 5.527 & TST \\
\hline CHEMBL1501333 & 688239 & 5.1862 & 5.3526 & TRN \\
\hline CHEMBL1415344 & 688239 & 5.3862 & 5.4402 & TRN \\
\hline CHEMBL1325864 & 688239 & 5.1862 & 5.5052 & TRN \\
\hline CHEMBL1597142 & 688239 & 6.4362 & 5.4149 & TST \\
\hline CHEMBL1592412 & 688239 & 4.8862 & 5.4592 & TST \\
\hline CHEMBL1317315 & 688239 & 5.6862 & 5.4285 & TST \\
\hline CHEMBL3191200 & 688239 & 4.6362 & 5.4223 & TRN \\
\hline CHEMBL1443997 & 688239 & 4.6862 & 5.5344 & TRN \\
\hline CHEMBL1591224 & 688239 & 5.9362 & 5.4594 & TST \\
\hline CHEMBL1431002 & 688239 & 4.7362 & 5.3604 & TRN \\
\hline CHEMBL1422114 & 688239 & 5.4862 & 5.4458 & TRN \\
\hline CHEMBL1299510 & 688239 & 4.5362 & 5.7102 & TST \\
\hline CHEMBL1571473 & 688239 & 6.0362 & 5.6092 & TRN \\
\hline CHEMBL1368990 & 688239 & 8.3372 & 5.4334 & TRN \\
\hline CHEMBL1484818 & 688239 & 4.6362 & 5.53600 & 30000000005 \\
\hline CHEMBL3211042 & 688239 & 6.6362 & 5.4562 & TRN \\
\hline CHEMBL1543973 & 688239 & 5.8362 & 5.54899 & 99999999995 \\
\hline CHEMBL1399260 & 688239 & 4.5362 & 5.4333 & TST \\
\hline CHEMBL1455923 & 688239 & 6.1862 & 5.6361 & TRN \\
\hline CHEMBL1540156 & 688239 & 5.0362 & 5.5806 & TRN \\
\hline CHEMBL1492297 & 688239 & 5.6862 & 5.4429 & TST \\
\hline CHEMBL1389716 & 688239 & 4.5362 & 5.4613 & TRN \\
\hline CHEMBL1441556 & 688239 & 4.5362 & 5.4303 & TRN \\
\hline CHEMBL1350905 & 688239 & 8.3372 & 5.4679 & TRN \\
\hline CHEMBL1425289 & 688239 & 4.8362 & 5.6367 & TRN \\
\hline CHEMBL1469576 & 688239 & 4.5362 & 5.5539 & TST \\
\hline CHEMBL 2000230 & 688239 & 5.2362 & 5.5505 & TRN \\
\hline CHEMBL1339905 & 688239 & 5.4362 & 5.5745 & TST \\
\hline CHEMBL1538113 & 688239 & 8.3372 & 5.4459 & TRN \\
\hline CHEMBL3190304 & 688239 & 5.1862 & 5.4674 & TRN \\
\hline CHEMBL1550622 & 688239 & 4.5362 & 5.4899 & TRN \\
\hline CHEMBL1547366 & 688239 & 7.0362 & 5.4554 & TRN \\
\hline
\end{tabular}


Supplemental Table S2.txt

\begin{tabular}{|c|c|c|c|c|c|}
\hline CHEMBL1572710 & 688239 & 4.6862 & 5.3139 & TST & \\
\hline CHEMBL1585823 & 688239 & 7.2366 & 5.4435 & TRN & \\
\hline CHEMBL1459528 & 688239 & 4.8362 & 5.4939 & TST & \\
\hline CHEMBL1347579 & 688239 & 8.3372 & 5.5444 & TRN & \\
\hline CHEMBL1421866 & 688239 & 6.3863 & 5.5538 & TST & \\
\hline CHEMBL1348601 & 688239 & 4.5362 & 5.5395 & TRN & \\
\hline CHEMBL1488216 & 688239 & 4.7862 & 5.6325 & TRN & \\
\hline CHEMBL1576549 & 688239 & 4.9362 & 5.4527 & TRN & \\
\hline CHEMBL1357200 & 688239 & 5.0862 & 5.4426 & TRN & \\
\hline CHEMBL1564501 & 688239 & 4.4862 & 5.475 & TST & \\
\hline CHEMBL3192188 & 688239 & 6.5862 & 5.3431 & TRN & \\
\hline CHEMBL1429406 & 688239 & 4.9862 & 5.4474 & TRN & \\
\hline CHEMBL1336503 & 688239 & 5.4362 & 5.5942 & TRN & \\
\hline CHEMBL1537649 & 688239 & 5.1362 & 5.5901 & TST & \\
\hline CHEMBL1394139 & 688239 & 4.5362 & 5.5193 & TST & \\
\hline CHEMBL1458879 & 688239 & 6.0 & 5.455 & TRN & \\
\hline CHEMBL1562326 & 688239 & 4.6362 & 5.4164 & TRN & \\
\hline CHEMBL1450615 & 688239 & 4.4862 & 5.3402 & TRN & \\
\hline CHEMBL1529188 & 688239 & 4.8362 & 5.4409 & TRN & \\
\hline CHEMBL1344707 & 688239 & 4.8362 & 5.7016 & TRN & \\
\hline CHEMBL1356635 & 688239 & 4.5362 & 5.5394 & TRN & \\
\hline CHEMBL1397100 & 688239 & 4.6362 & 5.3457 & TRN & \\
\hline CHEMBL1396347 & 688239 & 5.9862 & 5.4778 & TRN & \\
\hline CHEMBL1581213 & 688239 & 4.6362 & 5.3821 & TRN & \\
\hline CHEMBL1548365 & 688239 & 4.6862 & 5.459 & TRN & \\
\hline CHEMBL3213071 & 688239 & 5.7362 & 5.4789 & TST & \\
\hline CHEMBL1471023 & 688239 & 5.4362 & 5.5786 & TRN & \\
\hline CHEMBL1353243 & 688239 & 6.3863 & 5.6112 & TRN & \\
\hline CHEMBL1511663 & 688239 & 5.1362 & 5.353 & TST & \\
\hline CHEMBL1309165 & 688239 & 4.5362 & 5.3276 & TRN & \\
\hline CHEMBL1335098 & 688239 & 5.6362 & 5.4814 & TRN & \\
\hline CHEMBL602909 & 688239 & 5.1862 & 5.4323 & TRN & \\
\hline CHEMBL1311115 & 688239 & 6.1362 & 5.455 & TRN & \\
\hline CHEMBL1342066 & 688239 & 5.6362 & 5.4605 & TRN & \\
\hline CHEMBL1336879 & 688239 & 5.3362 & 5.4869 & TST & \\
\hline CHEMBL1342536 & 688239 & 4.5362 & 5.4685 & TRN & \\
\hline CHEMBL1397482 & 688239 & 8.28399 & 99999999 & 5.4215 & $\mathrm{TR}$ \\
\hline CHEMBL1438360 & 688239 & 6.0362 & 5.4723 & TRN & \\
\hline CHEMBL1459565 & 688239 & 6.1862 & 5.5843 & TRN & \\
\hline CHEMBL1538937 & 688239 & 5.5862 & 5.5242 & TST & \\
\hline CHEMBL1608887 & 688239 & 6.0862 & 5.4515 & TRN & \\
\hline CHEMBL1348569 & 688239 & 5.1862 & 5.5714 & TRN & \\
\hline CHEMBL1337200 & 688239 & 5.1862 & 5.4368 & TST & \\
\hline CHEMBL3198686 & 688239 & 5.1362 & 5.407999 & 99999999995 & TRN \\
\hline CHEMBL1546033 & 688239 & 6.5363 & 5.407999 & & TRN \\
\hline CHEMBL1446579 & 688239 & 4.7862 & 5.6077 & TST & \\
\hline CHEMBL1390206 & 688239 & 6.6861 & 5.3534 & TST & \\
\hline CHEMBL1445830 & 688239 & 5.3862 & 5.4991 & TRN & \\
\hline
\end{tabular}


Supplemental Table S2.txt

\begin{tabular}{|c|c|c|c|c|}
\hline CHEMBL1342141 & 688239 & 4.6862 & \multicolumn{2}{|c|}{5.457000000000001} \\
\hline CHEMBL1423173 & 688239 & 5.7362 & 5.4393 & TST \\
\hline CHEMBL1368571 & 688239 & 4.9862 & 5.5333 & TRN \\
\hline CHEMBL3213197 & 688239 & 6.4362 & 5.3784 & TST \\
\hline CHEMBL1304745 & 688239 & 5.2862 & 5.6463 & TRN \\
\hline CHEMBL3195633 & 688239 & 6.6362 & 5.4637 & TRN \\
\hline CHEMBL1383774 & 688239 & 4.5362 & 5.3292 & TRN \\
\hline CHEMBL1575342 & 688239 & 6.1362 & 5.4158 & TRN \\
\hline CHEMBL1455334 & 688239 & 4.5362 & 5.4849 & TST \\
\hline CHEMBL1365342 & 688239 & 4.5362 & 5.5959 & TST \\
\hline CHEMBL1516586 & 688239 & 7.0362 & 5.4004 & TRN \\
\hline CHEMBL1613705 & 688239 & 5.6862 & 5.4089 & TRN \\
\hline CHEMBL1324577 & 688239 & 5.3862 & 5.3557 & TST \\
\hline CHEMBL1529917 & 688239 & 4.4862 & 5.5076 & TRN \\
\hline CHEMBL1511337 & 688239 & 7.0862 & 5.5954 & TRN \\
\hline CHEMBL1492320 & 688239 & 5.2362 & 5.6736 & TRN \\
\hline CHEMBL1401904 & 688239 & 4.6362 & 5.4944 & TRN \\
\hline CHEMBL1574434 & 688239 & 5.2362 & 5.5 & TRN \\
\hline CHEMBL1533087 & 688239 & 5.2362 & 5.4287 & TRN \\
\hline CHEMBL1425143 & 688239 & 5.0862 & 5.6059 & TRN \\
\hline CHEMBL1561705 & 688239 & 6.8861 & 5.5507 & TST \\
\hline CHEMBL1351128 & 688239 & 5.8862 & 5.3638 & TRN \\
\hline CHEMBL1542766 & 688239 & 6.3863 & 5.412000 & 9000000001 \\
\hline CHEMBL1455305 & 688239 & 6.0362 & 5.5414 & TST \\
\hline CHEMBL1377204 & 688239 & 7.0862 & 5.4432 & TRN \\
\hline CHEMBL1434268 & 688239 & 8.1367 & 5.4922 & TST \\
\hline CHEMBL1495539 & 688239 & 5.3362 & 5.4392 & TRN \\
\hline CHEMBL1352862 & 688239 & 5.7362 & 5.4576 & TST \\
\hline CHEMBL1584040 & 688239 & 5.1862 & 5.4907 & TST \\
\hline CHEMBL1493016 & 688239 & 5.2362 & 5.3958 & TRN \\
\hline CHEMBL1310635 & 688239 & 5.4362 & 5.4537 & TRN \\
\hline CHEMBL1306312 & 688239 & 6.7862 & 5.5572 & TRN \\
\hline CHEMBL1469035 & 688239 & 5.0362 & 5.4625 & TST \\
\hline CHEMBL1578010 & 688239 & 4.9862 & 5.4835 & TST \\
\hline CHEMBL1510968 & 688239 & 5.9862 & 5.4872 & TRN \\
\hline CHEMBL1545222 & 688239 & 5.5862 & 5.5442 & TRN \\
\hline CHEMBL1462540 & 688239 & 5.6362 & 5.4094 & TRN \\
\hline CHEMBL1510235 & 688239 & 5.2362 & 5.4597 & TRN \\
\hline CHEMBL1345971 & 688239 & 4.5862 & 5.5248 & TRN \\
\hline CHEMBL1340316 & 688239 & 4.6862 & 5.3105 & TRN \\
\hline CHEMBL1447106 & 688239 & 4.7362 & 5.4867 & TRN \\
\hline CHEMBL1428388 & 688239 & 6.4362 & 5.5679 & TRN \\
\hline CHEMBL1356724 & 688239 & 4.6862 & 5.4508 & TST \\
\hline CHEMBL1419247 & 688239 & 5.5362 & 5.4922 & TST \\
\hline CHEMBL1308529 & 688239 & 5.15 & 5.6679 & TST \\
\hline CHEMBL1469394 & 688239 & 6.5363 & 5.5237 & TRN \\
\hline CHEMBL1346578 & 688239 & 5.1862 & 5.5819 & TRN \\
\hline CHEMBL1338848 & 688239 & 4.6362 & 5.4996 & TRN \\
\hline
\end{tabular}


Supplemental Table S2.txt

\begin{tabular}{|c|c|c|c|c|c|c|}
\hline CHEMBL1337513 & 688239 & 4.5362 & 5.504 & TST & & \\
\hline CHEMBL1533525 & 688239 & 5.6362 & 5.5888 & TRN & & \\
\hline CHEMBL1532796 & 688239 & 4.5362 & 5.608 & TRN & & \\
\hline CHEMBL1515722 & 688239 & 4.5862 & 5.58299 & 9999999999 & TRN & \\
\hline CHEMBL1427783 & 688239 & 4.7362 & 5.454 & TRN & & \\
\hline CHEMBL1441897 & 688239 & 4.6862 & 5.4338 & TRN & & \\
\hline CHEMBL1305812 & 688239 & 4.7862 & 5.381 & TRN & & \\
\hline CHEMBL1383089 & 688239 & 7.7852 & 5.4843 & TRN & & \\
\hline CHEMBL1400208 & 688239 & 8.3372 & 5.5939 & TRN & & \\
\hline CHEMBL1414068 & 688239 & 4.7362 & 5.5268 & TRN & & \\
\hline CHEMBL1444903 & 688239 & 5.2362 & 5.4138 & TRN & & \\
\hline CHEMBL1451660 & 688239 & 5.1862 & 5.4923 & TRN & & \\
\hline CHEMBL1971727 & 688239 & 4.7362 & 5.4006 & TST & & \\
\hline CHEMBL1481941 & 688239 & 5.2362 & 5.4955 & TRN & & \\
\hline CHEMBL1453344 & 688239 & 6.2862 & 5.4921 & TRN & & \\
\hline CHEMBL1589751 & 688239 & 6.2862 & 5.5495 & TRN & & \\
\hline CHEMBL1559784 & 688239 & 8.28399 & 99999999 & 99 & 5.4110000000000005 & TRN \\
\hline CHEMBL1405786 & 688239 & 6.9363 & 5.5824 & TRN & & \\
\hline CHEMBL1346801 & 688239 & 6.6362 & 5.4486 & TRN & & \\
\hline CHEMBL1380663 & 688239 & 5.8862 & 5.4838 & TRN & & \\
\hline CHEMBL3209221 & 688239 & 6.3362 & 5.6985 & TRN & & \\
\hline CHEMBL1432029 & 688239 & 6.2862 & 5.5878 & TRN & & \\
\hline CHEMBL1612241 & 688239 & 4.6862 & 5.5862 & TST & & \\
\hline CHEMBL1428308 & 688239 & 5.8862 & 5.518 & TRN & & \\
\hline CHEMBL1435933 & 688239 & 4.7862 & 5.5681 & TRN & & \\
\hline CHEMBL3197805 & 688239 & 4.7862 & 5.4792 & TST & & \\
\hline CHEMBL1334402 & 688239 & 4.4862 & 5.5724 & TRN & & \\
\hline CHEMBL3207698 & 688239 & 5.1362 & 5.5932 & TST & & \\
\hline CHEMBL1439439 & 688239 & 4.8862 & 5.4166 & TRN & & \\
\hline CHEMBL1304364 & 688239 & 5.0862 & 5.1769 & TRN & & \\
\hline CHEMBL1412594 & 688239 & 4.7362 & 5.5506 & TRN & & \\
\hline CHEMBL1328756 & 688239 & 4.7362 & 5.5793 & TRN & & \\
\hline CHEMBL1361848 & 688239 & 5.6862 & 5.4946 & TRN & & \\
\hline CHEMBL1607364 & 688239 & 5.4362 & 5.5608 & TRN & & \\
\hline CHEMBL3197104 & 688239 & 4.5362 & 5.2947 & TRN & & \\
\hline CHEMBL1517100 & 688239 & 4.5362 & 5.4889 & TRN & & \\
\hline CHEMBL1470470 & 688239 & 4.6862 & 5.5578 & TRN & & \\
\hline CHEMBL1589772 & 688239 & 6.8362 & 5.3891 & TRN & & \\
\hline CHEMBL163784 & 688239 & 4.5362 & 5.5394 & TST & & \\
\hline CHEMBL1312456 & 688239 & 4.6362 & 5.2856 & TRN & & \\
\hline CHEMBL1459702 & 688239 & 4.6862 & 5.5588 & TST & & \\
\hline CHEMBL1523189 & 688239 & 5.1862 & 5.5922 & TST & & \\
\hline CHEMBL1574281 & 688239 & 4.5362 & 5.3717 & TRN & & \\
\hline CHEMBL1394630 & 688239 & 6.1362 & 5.3888 & TST & & \\
\hline CHEMBL1569573 & 688239 & 5.1862 & 5.4551 & TRN & & \\
\hline CHEMBL1414062 & 688239 & 7.8356 & 5.6029 & TRN & & \\
\hline CHEMBL1323057 & 688239 & 4.4862 & 5.6551 & TRN & & \\
\hline CHEMBL1394790 & 688239 & 5.2862 & 5.4669 & TRN & & \\
\hline
\end{tabular}


Supplemental Table S2.txt

\begin{tabular}{|c|c|c|c|c|}
\hline 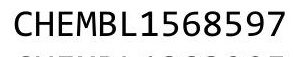 & & & & \\
\hline HEMBL1383295 & 8239 & 1862 & & \\
\hline AEMBL1453844 & 38239 & 362 & 503 & \\
\hline 485 & 88239 & 362 & & \\
\hline 75616 & 239 & 362 & & \\
\hline AEMBL1450712 & 239 & 5862 & 5291 & \\
\hline AEMBL1304658 & 88239 & 4.8362 & 4819 & \\
\hline HEMBL1472935 & 88239 & 862 & 061 & \\
\hline AEMBL1407186 & 239 & 362 & & \\
\hline IEMBL1426853 & 239 & 362 & & \\
\hline AEMBL1352199 & 239 & 362 & & \\
\hline AEMBL1507433 & 239 & 862 & & \\
\hline AEMBL1371802 & 239 & 363 & & \\
\hline IEMBL1608285 & 39 & 362 & & \\
\hline 373 & & & & \\
\hline AEMBL1398253 & & 362 & & \\
\hline IEMBL1353231 & 39 & 862 & & \\
\hline IEMBL1496019 & 39 & 5. & & \\
\hline 121 & & & & \\
\hline 508 & & & & \\
\hline L1378727 & & 362 & & \\
\hline L13 & & 62 & & \\
\hline IEMBL1334840 & & 362 & & \\
\hline 86 & & & & \\
\hline 78 & & & & \\
\hline 57 & & & & \\
\hline L133 & & & & \\
\hline 3L1463336 & & 62 & & \\
\hline 325 & & 62 & & \\
\hline 86 & & 62 & & \\
\hline & & & & \\
\hline L3213283 & & & & \\
\hline MBL1412408 & & 862 & & \\
\hline L1494726 & & 62 & & \\
\hline 1 & & & & \\
\hline AEMBL1362955 & & & & \\
\hline AEMBL1465142 & & & & \\
\hline 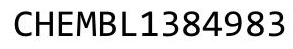 & & 362 & & \\
\hline IEMBL1554404 & & 4. & & \\
\hline מחת 190 & & & & \\
\hline AEMBL1411723 & & & & $\mathrm{RN}$ \\
\hline AEMBL1545171 & & & & \\
\hline 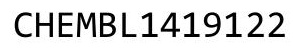 & & & & \\
\hline CHEMBL1540120 & & & & \\
\hline CHEMBL1481683 & & 8. & & RN \\
\hline AEMBL1229732 & 688239 & 4.5362 & 4772 & \\
\hline HEMBL1358763 & & 4.6862 & 62 & \\
\hline 1. & 600230 & 7.0362 & 5.3272 & \\
\hline
\end{tabular}

Page 1188 
Supplemental Table S2.txt

\begin{tabular}{|c|c|c|c|c|}
\hline CHEMBL1319483 & 688239 & 6.5363 & 5.6219 & TST \\
\hline CHEMBL1364320 & 688239 & 5.1362 & 5.4591 & TRN \\
\hline CHEMBL1377249 & 688239 & 5.7362 & 5.5544 & TRN \\
\hline CHEMBL1477180 & 688239 & 5.1362 & 5.5453 & TRN \\
\hline CHEMBL1313850 & 688239 & 6.7361 & 5.5942 & TRN \\
\hline CHEMBL1339877 & 688239 & 6.8861 & 5.7208 & TRN \\
\hline CHEMBL1378653 & 688239 & 6.1362 & 5.4346 & TST \\
\hline CHEMBL1444966 & 688239 & 4.7862 & 5.4979 & TST \\
\hline CHEMBL1407367 & 688239 & 5.1862 & 5.5376 & TRN \\
\hline CHEMBL1433153 & 688239 & 5.4862 & 5.4383 & TST \\
\hline CHEMBL1397708 & 688239 & 8.3372 & 5.5269 & TRN \\
\hline CHEMBL1442834 & 688239 & 5.1862 & 5.4604 & TST \\
\hline CHEMBL1433901 & 688239 & 4.8362 & 5.5616 & TRN \\
\hline CHEMBL1595563 & 688239 & 6.9863 & 5.4313 & TRN \\
\hline CHEMBL1401219 & 688239 & 5.9362 & 5.5932 & TST \\
\hline CHEMBL1340308 & 688239 & 6.0862 & 5.4301 & TRN \\
\hline CHEMBL1529080 & 688239 & 4.6862 & 5.4587 & TST \\
\hline CHEMBL1330903 & 688239 & 5.1862 & 5.4566 & TRN \\
\hline CHEMBL1589291 & 688239 & 5.3362 & 5.6216 & TRN \\
\hline CHEMBL1360824 & 688239 & 6.0862 & 5.5915 & TRN \\
\hline CHEMBL1431569 & 688239 & 5.1862 & 5.4359 & TRN \\
\hline CHEMBL1533265 & 688239 & 4.7362 & 5.4203 & TRN \\
\hline CHEMBL1430335 & 688239 & 4.7862 & 5.3825 & TRN \\
\hline CHEMBL1518602 & 688239 & 5.8862 & 5.4955 & TRN \\
\hline CHEMBL1602919 & 688239 & 6.1862 & 5.41100 & 00000000005 \\
\hline CHEMBL1512238 & 688239 & 6.2362 & 5.6435 & TST \\
\hline CHEMBL1556006 & 688239 & 5.3862 & 5.4925 & TST \\
\hline CHEMBL1340982 & 688239 & 6.1362 & 5.5942 & TRN \\
\hline CHEMBL1413469 & 688239 & 5.4362 & 5.4769 & TRN \\
\hline CHEMBL1376857 & 688239 & 6.8861 & 5.4975 & TRN \\
\hline CHEMBL1361428 & 688239 & 5.1362 & 5.5683 & TRN \\
\hline CHEMBL1361179 & 688239 & 4.4862 & 5.4019 & TRN \\
\hline CHEMBL1374090 & 688239 & 4.5362 & 5.4013 & TRN \\
\hline CHEMBL1476610 & 688239 & 5.3362 & 5.5587 & TRN \\
\hline CHEMBL 3207412 & 688239 & 4.5362 & 5.3749 & TRN \\
\hline CHEMBL1568256 & 688239 & 5.1862 & 5.4451 & TRN \\
\hline CHEMBL1399887 & 688239 & 5.5862 & 5.4367 & TRN \\
\hline CHEMBL1339942 & 688239 & 5.4862 & 5.6257 & TRN \\
\hline CHEMBL1596668 & 688239 & 6.2862 & 5.5077 & TST \\
\hline CHEMBL1407181 & 688239 & 4.8862 & 5.4364 & TST \\
\hline CHEMBL1598011 & 688239 & 4.9362 & 5.4253 & TRN \\
\hline CHEMBL1432126 & 688239 & 4.5362 & 5.5209 & TST \\
\hline CHEMBL1528460 & 688239 & 5.3862 & 5.5124 & TRN \\
\hline CHEMBL1438682 & 688239 & 4.5362 & 5.6684 & TRN \\
\hline CHEMBL1414347 & 688239 & 5.8862 & 5.4932 & TRN \\
\hline CHEMBL1324838 & 688239 & 7.0862 & 5.5114 & TST \\
\hline CHEMBL1310316 & 688239 & 6.7862 & 5.519 & TST \\
\hline CHEMBL1476421 & 688239 & 5.1862 & 5.3982 & TRN \\
\hline
\end{tabular}


Supplemental Table S2.txt

\begin{tabular}{|c|c|c|c|c|}
\hline CHEMBL1415343 & 688239 & 4.6862 & 5.3469 & TRN \\
\hline CHEMBL1589486 & 688239 & 5.6362 & 5.3564 & TRN \\
\hline CHEMBL1543480 & 688239 & 6.2362 & 5.6855 & TRN \\
\hline CHEMBL1610779 & 688239 & 5.0862 & 5.508999 & э99999999995 \\
\hline CHEMBL1329653 & 688239 & 4.5362 & 5.5748 & TST \\
\hline CHEMBL1608321 & 688239 & 6.2362 & 5.5837 & TRN \\
\hline CHEMBL1424488 & 688239 & 6.6362 & 5.5281 & TRN \\
\hline CHEMBL1597262 & 688239 & 5.8862 & 5.4977 & TRN \\
\hline CHEMBL1583644 & 688239 & 6.0862 & 5.4295 & TRN \\
\hline CHEMBL1366124 & 688239 & 4.6362 & 5.4009 & TRN \\
\hline CHEMBL1596420 & 688239 & 7.0862 & 5.4091 & TRN \\
\hline CHEMBL1460669 & 688239 & 4.8862 & 5.3927 & TST \\
\hline CHEMBL1466823 & 688239 & 4.6862 & 5.4402 & TST \\
\hline CHEMBL1411483 & 688239 & 5.6362 & 5.4935 & TRN \\
\hline CHEMBL1308692 & 688239 & 5.5862 & 5.4183 & TRN \\
\hline CHEMBL1328175 & 688239 & 5.3862 & 5.3777 & TRN \\
\hline CHEMBL1417907 & 688239 & 4.7862 & 5.5124 & TRN \\
\hline CHEMBL 3213896 & 688239 & 5.0862 & 5.4403 & TST \\
\hline CHEMBL1394021 & 688239 & 5.3362 & 5.3722 & TRN \\
\hline CHEMBL1597079 & 688239 & 6.0862 & 5.6699 & TRN \\
\hline CHEMBL1360807 & 688239 & 4.7362 & 5.4613 & TST \\
\hline CHEMBL1470083 & 688239 & 4.5362 & 5.372999 & 9999999999 \\
\hline CHEMBL1548656 & 688239 & 6.9363 & 5.6048 & TRN \\
\hline CHEMBL 2001476 & 688239 & 8.3372 & 5.5819 & TRN \\
\hline CHEMBL1346427 & 688239 & 4.5362 & 5.5893 & TRN \\
\hline CHEMBL1337065 & 688239 & 5.4362 & 5.6666 & TST \\
\hline CHEMBL1425037 & 688239 & 5.3862 & 5.6286 & TRN \\
\hline CHEMBL1458160 & 688239 & 6.4862 & 5.5321 & TST \\
\hline CHEMBL1401436 & 688239 & 8.3372 & 5.4853 & TST \\
\hline CHEMBL1979580 & 688239 & 4.5362 & 5.4578 & TRN \\
\hline CHEMBL1439444 & 688239 & 6.8362 & 5.5041 & TRN \\
\hline CHEMBL 3189163 & 688239 & 5.1862 & 5.3972 & TRN \\
\hline CHEMBL1455060 & 688239 & 5.1862 & $5.55200 e$ & 30000000005 \\
\hline CHEMBL1393262 & 688239 & 5.1862 & 5.398 & TRN \\
\hline CHEMBL1452857 & 688239 & 5.3362 & 5.364 & TST \\
\hline CHEMBL1498224 & 688239 & 6.7361 & 5.335 & TRN \\
\hline CHEMBL1511618 & 688239 & 5.6362 & 5.5304 & TRN \\
\hline CHEMBL1600701 & 688239 & 4.6862 & 5.3464 & TRN \\
\hline CHEMBL1348750 & 688239 & 4.5362 & 5.599 & TST \\
\hline CHEMBL 3197831 & 688239 & 5.6362 & 5.5353 & TRN \\
\hline CHEMBL 1485885 & 688239 & 4.5362 & 5.4816 & TRN \\
\hline CHEMBL1441568 & 688239 & 5.1862 & 5.4834 & TRN \\
\hline CHEMBL1340442 & 688239 & 5.1862 & 5.5407 & TST \\
\hline CHEMBL1540668 & 688239 & 6.1862 & 5.3371 & TRN \\
\hline CHEMBL1328281 & 688239 & 5.1862 & 5.5454 & TRN \\
\hline CHEMBL 1459803 & 688239 & 4.8362 & 5.3933 & TRN \\
\hline CHEMBL1431641 & 688239 & 5.6362 & 5.4824 & TRN \\
\hline CHEMBL 3190335 & 688239 & 4.5362 & 5.3335 & TRN \\
\hline
\end{tabular}


Supplemental Table S2.txt

\begin{tabular}{|c|c|c|c|c|}
\hline 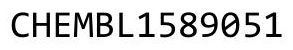 & & & & \\
\hline HEN & 8239 & 5362 & & \\
\hline IEMBL1441300 & 88239 & 362 & 4121 & \\
\hline HEMBL1566994 & 88239 & 1362 & 4198 & \\
\hline 352 & 39 & & 337 & \\
\hline IEMBL15 & 239 & 862 & 3886 & \\
\hline AEMBL1605931 & 88239 & 862 & 563 & \\
\hline HEMBL1440891 & 88239 & 1862 & .6712 & \\
\hline HEMBL15 & 88239 & & .4551 & \\
\hline EMBL13. & 239 & & & \\
\hline IEMBL153 & 239 & & & \\
\hline HEMBL1538267 & 88239 & 362 & 5.4221 & \\
\hline HEMBL1486465 & 88239 & & & ST \\
\hline AEMBL14 & 88 & 52 & & \\
\hline IEMBL142 & 38239 & & & \\
\hline IEMBL137 & 38239 & & & \\
\hline AEMBL1365356 & 88239 & & & RN \\
\hline AEMBL1306813 & 88239 & & & \\
\hline 850 & 39 & 52 & & \\
\hline 012 & 39 & & & \\
\hline 900 & 39 & & & RN \\
\hline L1354423 & 88239 & & & RN \\
\hline AEMBL15€ & 39 & & & $\ln$ \\
\hline HEMBL200 & 39 & & & \\
\hline L14 & & & & Iv \\
\hline 890 & 39 & & & RN \\
\hline L1600948 & 88239 & & & RN \\
\hline AEMBL1604176 & & & & RN \\
\hline IEMBL131 & 39 & & & RN \\
\hline 163 & & & & RN \\
\hline-14 & 39 & & & ST \\
\hline HEMBL138 & & & & RN \\
\hline AEMBL1332566 & & & & RN \\
\hline JEMBL16 & 39 & & & RN \\
\hline 39 & & & & ST \\
\hline 54 & & & & ST \\
\hline HEMBL1360484 & 88239 & & & RN \\
\hline AEMBL1340978 & & & & $\mathrm{RN}$ \\
\hline AEMBL13 & & & & RN \\
\hline 729 & & & & RIN \\
\hline 62 & & & & RN \\
\hline HEMBL1414641 & 88239 & 62 & 07 & TRN \\
\hline IEMBL15 & 39 & & & ST \\
\hline MEIMIDL & & & & TRN \\
\hline HEMBL15 & & & & \\
\hline HEMBL1524451 & & & 43 & ST \\
\hline L1335896 & 88239 & 4.8362 & 5.4323 & RN \\
\hline CHEMBL1401345 & 688239 & 5.1862 & 5.4474 & TST \\
\hline
\end{tabular}

Page 1191 
Supplemental Table S2.txt

\begin{tabular}{|c|c|c|c|c|c|}
\hline CHEMBL1513017 & 688239 & 6.5862 & 5.4849 & TRN & \\
\hline CHEMBL1337133 & 688239 & 5.1862 & 5.4877 & TRN & \\
\hline CHEMBL1503632 & 688239 & 6.15 & 5.3644 & TRN & \\
\hline CHEMBL1574303 & 688239 & 6.2362 & 5.4504 & TRN & \\
\hline CHEMBL1603571 & 688239 & 4.5362 & 5.4361 & TRN & \\
\hline CHEMBL1300701 & 688239 & 5.1862 & 5.4764 & TST & \\
\hline CHEMBL1404802 & 688239 & 5.6862 & 5.4241 & TST & \\
\hline CHEMBL3199606 & 688239 & 5.5862 & 5.4736 & TRN & \\
\hline CHEMBL 3198905 & 688239 & 8.3872 & 5.345 & TST & \\
\hline CHEMBL1397093 & 688239 & 6.5363 & 5.4038 & TRN & \\
\hline CHEMBL1388512 & 688239 & 5.4862 & 5.436 & TRN & \\
\hline CHEMBL1480309 & 688239 & 4.9362 & $5.49700 e$ & 0000000001 & TRN \\
\hline CHEMBL1530979 & 688239 & 6.0 & 5.5521 & TRN & \\
\hline CHEMBL1501982 & 688239 & 5.1862 & 5.5445 & TRN & \\
\hline CHEMBL1558527 & 688239 & 5.1362 & 5.4632 & TRN & \\
\hline CHEMBL1408665 & 688239 & 4.9362 & 5.4296 & TRN & \\
\hline CHEMBL1347696 & 688239 & 5.4862 & 5.6358 & TST & \\
\hline CHEMBL1319534 & 688239 & 6.2362 & 5.4037 & TRN & \\
\hline CHEMBL1420445 & 688239 & 4.7362 & 5.5074 & TRN & \\
\hline CHEMBL1498601 & 688239 & 7.1361 & 5.5337 & TRN & \\
\hline CHEMBL1314325 & 688239 & 5.1862 & 5.3526 & TRN & \\
\hline CHEMBL1581940 & 688239 & 4.5362 & 5.5427 & TRN & \\
\hline CHEMBL1369575 & 688239 & 4.4862 & 5.2662 & TRN & \\
\hline CHEMBL1516584 & 688239 & 4.7862 & 5.2948 & TRN & \\
\hline CHEMBL1350410 & 688239 & 4.6362 & 5.4704 & TRN & \\
\hline CHEMBL1396104 & 688239 & 6.7862 & 5.4802 & TRN & \\
\hline CHEMBL1458164 & 688239 & 5.4362 & 5.6343 & TRN & \\
\hline CHEMBL1531798 & 688239 & 7.5361 & 5.3848 & TRN & \\
\hline CHEMBL1572378 & 688239 & 6.9863 & 5.5213 & TRN & \\
\hline CHEMBL1348433 & 688239 & 4.5862 & 5.4217 & TST & \\
\hline CHEMBL1536075 & 688239 & 6.2362 & 5.4674 & TRN & \\
\hline CHEMBL1312945 & 688239 & 4.7862 & 5.5158 & TRN & \\
\hline CHEMBL1304662 & 688239 & 4.5362 & 5.5279 & TRN & \\
\hline CHEMBL1510826 & 688239 & 4.5362 & 5.4502 & TRN & \\
\hline CHEMBL1363538 & 688239 & 4.9862 & 5.5717 & TRN & \\
\hline CHEMBL1508733 & 688239 & 5.3862 & 5.4964 & TRN & \\
\hline CHEMBL1561150 & 688239 & 4.8362 & 5.2849 & TRN & \\
\hline CHEMBL1462513 & 688239 & 6.3362 & 5.4029 & TRN & \\
\hline CHEMBL1584320 & 688239 & 4.5362 & 5.4468 & TRN & \\
\hline CHEMBL1605002 & 688239 & 8.28399 & 99999999 & 5.4015 & TST \\
\hline CHEMBL1444584 & 688239 & 5.9362 & 5.6278 & TST & \\
\hline CHEMBL1358002 & 688239 & 5.0362 & 5.4351 & TRN & \\
\hline CHEMBL1484018 & 688239 & 4.9862 & 5.5574 & TST & \\
\hline CHEMBL1467648 & 688239 & 5.4362 & 5.3773 & TST & \\
\hline CHEMBL1505037 & 688239 & 4.5862 & 5.6034 & TRN & \\
\hline CHEMBL1368939 & 688239 & 6.9863 & 5.5195 & TRN & \\
\hline CHEMBL1606712 & 688239 & 6.4362 & 5.4535 & TST & \\
\hline CHEMBL1351856 & 688239 & 4.6362 & 5.6446 & TRN & \\
\hline
\end{tabular}


Supplemental Table S2.txt

\begin{tabular}{|c|c|c|c|c|}
\hline CHEMBL3197899 & 688239 & 7.0362 & 5.6427 & TRN \\
\hline CHEMBL1431012 & 688239 & 6.8861 & 5.5159 & TRN \\
\hline CHEMBL1344605 & 688239 & 6.6362 & 5.6535 & TRN \\
\hline CHEMBL1355084 & 688239 & 6.2362 & 5.4618 & TRN \\
\hline CHEMBL1609402 & 688239 & 7.2366 & 5.7061 & TRN \\
\hline CHEMBL1528433 & 688239 & 4.7362 & 5.4852 & TRN \\
\hline CHEMBL1430820 & 688239 & 4.5362 & 5.4273 & TRN \\
\hline CHEMBL1590869 & 688239 & 4.5862 & 5.4652 & TRN \\
\hline CHEMBL1304210 & 688239 & 4.5362 & 5.6178 & TST \\
\hline CHEMBL1421904 & 688239 & 5.1862 & 5.6028 & TRN \\
\hline CHEMBL1547013 & 688239 & 4.4862 & 5.5243 & TRN \\
\hline CHEMBL1530449 & 688239 & 6.0362 & 5.4261 & TRN \\
\hline CHEMBL3190633 & 688239 & 8.1871 & 5.7079 & TRN \\
\hline CHEMBL1385970 & 688239 & 5.3862 & 5.359 & TST \\
\hline CHEMBL1492024 & 688239 & 5.6862 & 5.5461 & TRN \\
\hline CHEMBL1399523 & 688239 & 4.5362 & 5.4561 & TRN \\
\hline CHEMBL1329907 & 688239 & 4.6362 & 5.4022 & TST \\
\hline CHEMBL1470918 & 688239 & 8.3372 & 5.5463 & TST \\
\hline CHEMBL3197912 & 688239 & 4.7362 & 5.4823 & TRN \\
\hline CHEMBL1460160 & 688239 & 5.4862 & 5.6411 & TRN \\
\hline CHEMBL1314965 & 688239 & 6.7862 & 5.5054 & TST \\
\hline CHEMBL3144967 & 688239 & 4.5362 & 5.4745 & TRN \\
\hline CHEMBL1497577 & 688239 & 4.7862 & 5.4851 & TST \\
\hline CHEMBL1600776 & 688239 & 4.5862 & 5.5252 & TST \\
\hline CHEMBL1416432 & 688239 & 5.7362 & 5.4185 & TST \\
\hline CHEMBL1485006 & 688239 & 5.1862 & 5.4248 & TRN \\
\hline CHEMBL1580243 & 688239 & 4.5362 & 5.5686 & TST \\
\hline CHEMBL1351840 & 688239 & 6.9363 & 5.5395 & TRN \\
\hline CHEMBL1582510 & 688239 & 5.0862 & 5.3804 & TRN \\
\hline CHEMBL1434585 & 688239 & 6.1862 & 5.3819 & TRN \\
\hline CHEMBL1508225 & 688239 & 4.7362 & 5.6342 & TRN \\
\hline CHEMBL1461739 & 688239 & 4.6362 & 5.5261 & TRN \\
\hline CHEMBL3194842 & 688239 & 4.6362 & 5.5392 & TST \\
\hline CHEMBL1589671 & 688239 & 5.6862 & 5.2482 & TST \\
\hline CHEMBL1504390 & 688239 & 5.6362 & 5.4169 & TST \\
\hline CHEMBL1383234 & 688239 & 4.8362 & 5.4528 & TRN \\
\hline CHEMBL1335353 & 688239 & 7.2865 & 5.4417 & TRN \\
\hline CHEMBL1610976 & 688239 & 6.0362 & 5.33700 & 000000001 \\
\hline CHEMBL1407091 & 688239 & 5.1862 & 5.4088 & TRN \\
\hline CHEMBL1525078 & 688239 & 5.8862 & 5.6296 & TRN \\
\hline CHEMBL252909 & 688239 & 4.5362 & 5.5617 & TST \\
\hline CHEMBL1330857 & 688239 & 5.0862 & 5.4378 & TRN \\
\hline CHEMBL1549960 & 688239 & 5.6862 & 5.5439 & TRN \\
\hline CHEMBL1550069 & 688239 & 5.9362 & 5.4031 & TRN \\
\hline CHEMBL3214513 & 688239 & 4.7862 & 5.3333 & TST \\
\hline CHEMBL1440260 & 688239 & 4.6862 & 5.4476 & TRN \\
\hline CHEMBL1474006 & 688239 & 5.0362 & 5.41100 & 00000000005 \\
\hline CHEMBL1309175 & 688239 & 5.5862 & 5.4234 & TRN \\
\hline
\end{tabular}


Supplemental Table S2.txt

\begin{tabular}{|c|c|c|c|c|}
\hline 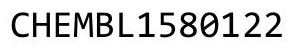 & & & & \\
\hline HEN & 38239 & 362 & & \\
\hline AEMBL1595921 & 88239 & 862 & 5192 & \\
\hline HEMBL1422821 & 88239 & 4362 & 5423 & \\
\hline & 239 & 862 & 5881 & \\
\hline AEMBL1336404 & 239 & 862 & 395 & \\
\hline AEMBL3213117 & 88239 & 862 & .4547 & \\
\hline HEMBL1604790 & 88239 & 3862 & 3902 & \\
\hline HEMBL1366678 & 88239 & 62 & 13 & \\
\hline AEMBL15 & 38239 & 862 & 5834 & \\
\hline AEMBL1549529 & 239 & 862 & .5635 & \\
\hline HEMBL1592092 & 88239 & 362 & 5.3683 & \\
\hline HEMBL1561708 & 88239 & & & \\
\hline AEMBL1586541 & 88 & & 44 & \\
\hline IEMBL1363173 & 38239 & & 57 & \\
\hline EMBL1519231 & 88239 & 362 & & \\
\hline AEMBL1565710 & 88239 & 862 & 5.4987 & \\
\hline AEMBL1315963 & 88239 & 62 & & \\
\hline L'319] & $8 \varepsilon$ & 72 & 39 & \\
\hline IEMBL1380442 & 39 & & & \\
\hline IEMBL1573198 & 239 & 62 & 36 & \\
\hline L1336851 & 88239 & 362 & 5.4917 & \\
\hline AEMBL1553622 & 39 & & & \\
\hline L1605 & 39 & & 85 & \\
\hline L3192 & & & & \\
\hline 1493 & 39 & & 86 & \\
\hline L1600468 & 88239 & & & RN \\
\hline AEMBL1488874 & 39 & & & \\
\hline AEMBL1497489 & 39 & & 342 & \\
\hline L15 & 39 & & 75 & \\
\hline 23 & 39 & & 148 & $\mathrm{RN}$ \\
\hline AEMBL1544212 & & & & RN \\
\hline AEMBL1416563 & & & & RN \\
\hline AEMBL13: & 39 & & 882 & RN \\
\hline-14 & 39 & & 967 & SI \\
\hline & & & 156 & $\mathrm{RN}$ \\
\hline AEMBL1347171 & 88239 & & 5.5795 & RN \\
\hline AEMBL1607026 & & & & $\mathrm{RN}$ \\
\hline HEMBL1361 & & & 742 & ST \\
\hline 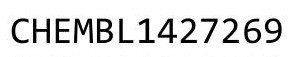 & & & & ST \\
\hline 2 & & & 603 & RN \\
\hline HEMBL1302752 & 88239 & & 5.5154 & RN \\
\hline AEMBL1305681 & 39 & & 197 & TST \\
\hline HEMBL155: & & & & \\
\hline HEMBL150 & & & 5.4521 & \\
\hline HEMBL3194184 & & & 5.4939 & ST \\
\hline L1495905 & 88239 & 4.8862 & 5.4479 & RN \\
\hline CHEMBL1400610 & 688239 & 4.5362 & 5.5092 & \\
\hline
\end{tabular}

Page 1194 
Supplemental Table S2.txt

\begin{tabular}{|c|c|c|c|c|c|}
\hline CHEMBL1388709 & 688239 & 4.5362 & 5.5868 & TRN & \\
\hline CHEMBL1425846 & 688239 & 4.5362 & 5.4401 & TRN & \\
\hline CHEMBL1334559 & 688239 & 8.28399 & 79999999 & 5.6122 & TRN \\
\hline CHEMBL1352491 & 688239 & 6.1862 & 5.4675 & TRN & \\
\hline CHEMBL1575004 & 688239 & 4.7362 & 5.4465 & TRN & \\
\hline CHEMBL1378543 & 688239 & 4.5362 & 5.5769 & TST & \\
\hline CHEMBL1407615 & 688239 & 4.8362 & 5.6431 & TRN & \\
\hline CHEMBL1354996 & 688239 & 7.0862 & 5.5907 & TRN & \\
\hline CHEMBL1320134 & 688239 & 4.4862 & 5.577999 & 9999999999 & TRN \\
\hline CHEMBL1425051 & 688239 & 5.2 & 5.5226 & TRN & \\
\hline CHEMBL1488544 & 688239 & 8.3872 & 5.6155 & TST & \\
\hline CHEMBL1457459 & 688239 & 5.9362 & 5.5962 & TRN & \\
\hline CHEMBL1426738 & 688239 & 6.7862 & 5.4222 & TST & \\
\hline CHEMBL1337529 & 688239 & 5.7862 & 5.4941 & TRN & \\
\hline CHEMBL1469229 & 688239 & 6.2862 & 5.5679 & TRN & \\
\hline CHEMBL1406165 & 688239 & 5.5362 & 5.3105 & TRN & \\
\hline CHEMBL3193317 & 688239 & 7.8356 & 5.4811 & TRN & \\
\hline CHEMBL1425566 & 688239 & 5.4862 & 5.5452 & TRN & \\
\hline CHEMBL1442388 & 688239 & 5.5362 & 5.4833 & TRN & \\
\hline CHEMBL1471036 & 688239 & 5.6362 & 5.6783 & TRN & \\
\hline CHEMBL1410706 & 688239 & 6.4362 & 5.5899 & TRN & \\
\hline CHEMBL1560751 & 688239 & 5.4362 & 5.3802 & TRN & \\
\hline CHEMBL1610812 & 688239 & 5.3362 & 5.4746 & TST & \\
\hline CHEMBL1496862 & 688239 & 5.7362 & 5.6878 & TRN & \\
\hline CHEMBL3196192 & 688239 & 7.6364 & 5.3617 & TRN & \\
\hline CHEMBL1308759 & 688239 & 4.7862 & 5.4602 & TST & \\
\hline CHEMBL1546499 & 688239 & 6.4362 & 5.5695 & TRN & \\
\hline CHEMBL1497694 & 688239 & 4.5362 & 5.4877 & TRN & \\
\hline CHEMBL1372567 & 688239 & 5.7362 & 5.6309 & TRN & \\
\hline CHEMBL1531071 & 688239 & 6.9363 & 5.6543 & TRN & \\
\hline CHEMBL1420213 & 688239 & 5.4362 & $5.54700 e$ & 0000000001 & TRN \\
\hline CHEMBL1483571 & 688239 & 6.0862 & 5.3967 & TRN & \\
\hline CHEMBL1359915 & 688239 & 4.5362 & 5.4682 & TST & \\
\hline CHEMBL1444851 & 688239 & 5.9862 & 5.6203 & TRN & \\
\hline CHEMBL1565017 & 688239 & 4.5362 & 5.4994 & TRN & \\
\hline CHEMBL1428381 & 688239 & 5.5862 & 5.5169 & TST & \\
\hline CHEMBL1331700 & 688239 & 4.5362 & 5.4882 & TST & \\
\hline CHEMBL1608842 & 688239 & 5.1862 & 5.6472 & TRN & \\
\hline CHEMBL1609748 & 688239 & 6.3362 & 5.4771 & TST & \\
\hline CHEMBL1351915 & 688239 & 5.0862 & 5.5657 & TRN & \\
\hline CHEMBL1350950 & 688239 & 4.5362 & 5.4667 & TRN & \\
\hline CHEMBL1398697 & 688239 & 4.9862 & 5.5072 & TRN & \\
\hline CHEMBL1462349 & 688239 & 4.5862 & 5.3692 & TRN & \\
\hline CHEMBL1604322 & 688239 & 5.1862 & 5.3498 & TRN & \\
\hline CHEMBL3198227 & 688239 & 8.3372 & 5.401 & TST & \\
\hline CHEMBL1586052 & 688239 & 7.1361 & 5.4201 & TST & \\
\hline CHEMBL1327937 & 688239 & 4.8362 & 5.5448 & TRN & \\
\hline CHEMBL1377597 & 688239 & 4.5862 & 5.5466 & TRN & \\
\hline
\end{tabular}


Supplemental Table S2.txt

\begin{tabular}{|c|c|c|c|c|}
\hline 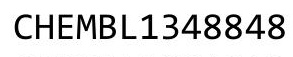 & & & & \\
\hline HEMBL1994913 & 38239 & 362 & 31 & \\
\hline AEMBL1496540 & 239 & 863 & 726 & \\
\hline 172 & 39 & 362 & & \\
\hline IEMBL14C & 39 & 362 & & \\
\hline AEMBL1311641 & 88239 & 362 & & \\
\hline AEMBL1524484 & 88239 & 4.9362 & 4848 & \\
\hline AEMBL1373780 & & & & \\
\hline EMBL1590362 & 39 & 862 & & \\
\hline IEMBL1381981 & & & & \\
\hline AEMBL1368226 & 39 & 362 & & \\
\hline AEMBL1368107 & & 862 & & \\
\hline AEMBL1520449 & & 862 & & \\
\hline AEMBL154 & & 62 & & \\
\hline HEMBL1305667 & & & & \\
\hline AEMBL1463163 & & 362 & & \\
\hline AEMBL1417351 & & 362 & & \\
\hline AEMBL146 & & 62 & & \\
\hline AEMBL137 & & & & \\
\hline IEMBL14 & & & & \\
\hline AEMBL1431245 & & 362 & & \\
\hline AEMBL1404126 & & & & \\
\hline IEMBL1323536 & & 62 & & \\
\hline AFMRI 158 & & & & \\
\hline 357 & & & & \\
\hline AEMBL1493140 & & 62 & & \\
\hline IEMBL1504168 & & & & \\
\hline IEMBL136 & & 62 & & \\
\hline 8 & & & & \\
\hline 76 & & 62 & & \\
\hline AEMBL3210455 & & & & \\
\hline AEMBL1548903 & & 362 & & \\
\hline & & & & \\
\hline 93 & & & & \\
\hline & & & & \\
\hline AEMBL1608179 & & & & RN \\
\hline AEMBL1533849 & & 862 & & $S$ \\
\hline & & 62 & & \\
\hline 712 & & & & \\
\hline HEMBL1422181 & & & & RN \\
\hline AEMBL1527654 & & 63 & & \\
\hline 294 & & 4. & & \\
\hline Fo & & & & \\
\hline HEMBL1498237 & & & & \\
\hline HEMBL1519898 & & & & ST \\
\hline AEMBL1442373 & & 362 & 29 & $\mathrm{R}$ \\
\hline & & & & \\
\hline г & & & & \\
\hline
\end{tabular}

Page 1196 
Supplemental Table S2.txt

\begin{tabular}{|c|c|c|c|c|}
\hline 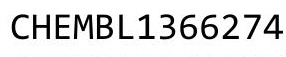 & & & & \\
\hline HEMBL1304536 & 88239 & 7862 & 01 & \\
\hline HEMBL1308105 & 88239 & 2362 & & \\
\hline 89 & & & & \\
\hline EMBL13 & & 62 & & \\
\hline HEMBL1547281 & 88239 & 3372 & 4248 & \\
\hline HEMBL1525206 & 88239 & .8362 & . 4191 & \\
\hline HEMBL147 & & & & \\
\hline EMBL14 & 39 & 352 & & \\
\hline IEMBL15 & 39 & & & \\
\hline HEMBL1567261 & 88239 & 863 & 6465 & \\
\hline HEMBL1591039 & 39 & 862 & & \\
\hline HEMBL160 & 39 & 862 & 35 & \\
\hline HEME & 39 & & & \\
\hline IEMBL131 & 39 & & & \\
\hline HEMBL13e & 39 & 362 & & \\
\hline HEMBL138 & 39 & & & \\
\hline HEMBL15e & 9 & & 12 & \\
\hline HEMBL13 & 9 & & & \\
\hline AEMBL15 & 39 & & & \\
\hline HEMBL13 & 39 & 62 & & \\
\hline HEMBL $32 e$ & 39 & & & \\
\hline HEMBL14 & 39 & 62 & & \\
\hline HEMBL15 & & & & Tro \\
\hline 40 & 39 & & & \\
\hline HEMBL 14 & 39 & & & 151 \\
\hline JEMBL13 & 39 & & & TST \\
\hline HEMBL13 & 39 & & & RN \\
\hline HEME & & & & RN \\
\hline HEME & & & & ST \\
\hline HEMBL133 & 9 & & & Ih \\
\hline HEMBL132 & 39 & & & TRN \\
\hline HEMBL1 & & & & \\
\hline HEM & 9 & & & \\
\hline HEMBL135 & & & & TRN \\
\hline HEMBL158 & 39 & & & TST \\
\hline HEMBL150 & 39 & & & TRN \\
\hline 4 & & & & RIV \\
\hline 1 & & & & \\
\hline HEMBL15 & & & & TST \\
\hline HEMBL157 & 88239 & & & TST \\
\hline HEMBL152 & 39 & & & TRN \\
\hline HEMBL133 & & & & \\
\hline HEMBL138 & & & & ГRN \\
\hline HEMBL1603572 & & & & IST \\
\hline HEMBL 149 & 39 & 62 & & ST \\
\hline HEM & 39 & & & \\
\hline . & & & & \\
\hline
\end{tabular}

Page 1197 
Supplemental Table S2.txt

\begin{tabular}{|c|c|c|c|c|}
\hline CHEMBL1423652 & 688239 & 6.6861 & 5.6036 & TRN \\
\hline CHEMBL3198141 & 688239 & 4.8362 & 5.3432 & TST \\
\hline CHEMBL1438515 & 688239 & 4.7862 & 5.5377 & TRN \\
\hline CHEMBL1451524 & 688239 & 5.4362 & 5.4608 & TRN \\
\hline CHEMBL1478690 & 688239 & 6.3863 & 5.3055 & TRN \\
\hline CHEMBL1426930 & 688239 & 5.6362 & 5.591 & TST \\
\hline CHEMBL1319326 & 688239 & 4.6362 & 5.6598 & TRN \\
\hline CHEMBL3194104 & 688239 & 5.0862 & 5.593999 & 9999999999 \\
\hline CHEMBL1550816 & 688239 & 6.1362 & 5.4198 & TRN \\
\hline CHEMBL1596551 & 688239 & 5.1862 & 5.5905 & TRN \\
\hline CHEMBL1311831 & 688239 & 4.4862 & 5.3399 & TRN \\
\hline CHEMBL1495895 & 688239 & 4.7362 & 5.5336 & TRN \\
\hline CHEMBL 3208988 & 688239 & 5.2862 & 5.4716 & TST \\
\hline CHEMBL1507377 & 688239 & 4.5362 & 5.5244 & TST \\
\hline CHEMBL3196914 & 688239 & 4.45 & 5.407 & TRN \\
\hline CHEMBL1580328 & 688239 & 5.4362 & 5.4446 & TST \\
\hline CHEMBL1320278 & 688239 & 4.5862 & 5.4131 & TRN \\
\hline CHEMBL1449516 & 688239 & 4.7862 & 5.4994 & TRN \\
\hline CHEMBL1564971 & 688239 & 5.4362 & 5.5713 & TST \\
\hline CHEMBL1430942 & 688239 & 4.5362 & 5.4339 & TRN \\
\hline CHEMBL1370192 & 688239 & 6.2362 & 5.5483 & TRN \\
\hline CHEMBL1413976 & 688239 & 5.3862 & 5.4506 & TRN \\
\hline CHEMBL1369329 & 688239 & 5.7862 & 5.4382 & TST \\
\hline CHEMBL1444283 & 688239 & 5.1862 & 5.3948 & TRN \\
\hline CHEMBL1310160 & 688239 & 4.8862 & 5.4915 & TRN \\
\hline CHEMBL1501143 & 688239 & 5.3362 & 5.4169 & TST \\
\hline CHEMBL1487242 & 688239 & 4.5362 & 5.447999 & 99999999995 \\
\hline CHEMBL1397055 & 688239 & 5.2862 & 5.457000 & 0000000001 \\
\hline CHEMBL1449104 & 688239 & 6.0862 & 5.5753 & TRN \\
\hline CHEMBL1506030 & 688239 & 6.0862 & 5.4405 & TRN \\
\hline CHEMBL1437852 & 688239 & 4.8362 & 5.6198 & TRN \\
\hline CHEMBL1583207 & 688239 & 4.5362 & 5.5392 & TRN \\
\hline CHEMBL1315009 & 688239 & 4.5362 & 5.4513 & TRN \\
\hline CHEMBL1399324 & 688239 & 5.1862 & 5.5791 & TRN \\
\hline CHEMBL1473685 & 688239 & 5.1362 & 5.6467 & TRN \\
\hline CHEMBL1558439 & 688239 & 4.5362 & 5.4989 & TST \\
\hline CHEMBL1304173 & 688239 & 8.3372 & 5.4964 & TST \\
\hline CHEMBL1600545 & 688239 & 8.3872 & 5.482 & TRN \\
\hline CHEMBL1427071 & 688239 & 6.2362 & 5.6015 & TST \\
\hline CHEMBL1331057 & 688239 & 5.1862 & 5.456 & TST \\
\hline CHEMBL1530416 & 688239 & 8.2366 & 5.5603 & TRN \\
\hline CHEMBL1300309 & 688239 & 4.7362 & 5.5106 & TST \\
\hline CHEMBL3196583 & 688239 & 5.7362 & 5.6457 & TRN \\
\hline CHEMBL1468444 & 688239 & 5.1362 & 5.5491 & TST \\
\hline CHEMBL1315333 & 688239 & 5.2862 & 5.4872 & TRN \\
\hline CHEMBL1421085 & 688239 & 6.2362 & 5.3667 & TRN \\
\hline CHEMBL1381593 & 688239 & 5.0362 & 5.4596 & TRN \\
\hline CHEMBL3199121 & 688239 & 6.9863 & 5.5131 & TST \\
\hline
\end{tabular}


Supplemental Table S2.txt

\begin{tabular}{|c|c|c|c|c|c|}
\hline CHEMBL1372098 & 688239 & 4.5362 & 5.5435 & TST & \\
\hline CHEMBL1337239 & 688239 & 5.6862 & 5.5131 & TRN & \\
\hline CHEMBL1555987 & 688239 & 6.2862 & 5.414 & TRN & \\
\hline CHEMBL1374389 & 688239 & 6.1362 & 5.6275 & TRN & \\
\hline CHEMBL1318202 & 688239 & 4.8862 & 5.535 & TRN & \\
\hline CHEMBL1594432 & 688239 & 5.3862 & 5.4021 & TRN & \\
\hline CHEMBL1504728 & 688239 & 5.0862 & 5.4551 & TRN & \\
\hline CHEMBL1341354 & 688239 & 4.6862 & 5.3514 & TST & \\
\hline CHEMBL1304805 & 688239 & 6.1362 & 5.4829 & TST & \\
\hline CHEMBL1531610 & 688239 & 7.4868 & 5.5834 & TST & \\
\hline CHEMBL1574009 & 688239 & 5.0362 & 5.53 & TRN & \\
\hline CHEMBL1481738 & 688239 & 4.5362 & 5.547000 & 0000000001 & TRN \\
\hline CHEMBL1468198 & 688239 & 4.4862 & 5.3948 & TRN & \\
\hline CHEMBL1423822 & 688239 & 4.5362 & 5.4132 & TRN & \\
\hline CHEMBL1512923 & 688239 & 4.8862 & 5.5576 & TRN & \\
\hline CHEMBL 3192084 & 688239 & 4.7862 & 5.4179 & TST & \\
\hline CHEMBL1312787 & 688239 & 4.4862 & 5.6329 & TST & \\
\hline CHEMBL1318845 & 688239 & 4.7362 & 5.4664 & TRN & \\
\hline CHEMBL1597544 & 688239 & 5.3362 & 5.4628 & TRN & \\
\hline CHEMBL1376186 & 688239 & 6.1862 & 5.4781 & TRN & \\
\hline CHEMBL1373118 & 688239 & 8.28399 & 99999999 & 5.4678 & TRN \\
\hline CHEMBL528919 & 688239 & 6.2362 & 5.3496 & TST & \\
\hline CHEMBL1374495 & 688239 & 4.9362 & 5.4535 & TST & \\
\hline CHEMBL1586832 & 688239 & 6.7361 & 5.5742 & TRN & \\
\hline CHEMBL1491867 & 688239 & 5.2362 & 5.2004 & TST & \\
\hline CHEMBL1309269 & 688239 & 5.1362 & 5.4975 & TRN & \\
\hline CHEMBL1535276 & 688239 & 4.6862 & 5.2644 & TST & \\
\hline CHEMBL1587145 & 688239 & 5.6362 & 5.5727 & TRN & \\
\hline CHEMBL1472108 & 688239 & 5.3362 & 5.5488 & TRN & \\
\hline CHEMBL1539462 & 688239 & 4.5362 & 5.6036 & TRN & \\
\hline CHEMBL1551115 & 688239 & 5.7362 & 5.6154 & TRN & \\
\hline CHEMBL1492317 & 688239 & 5.4362 & 5.4441 & TRN & \\
\hline CHEMBL1366651 & 688239 & 4.6362 & 5.1928 & TRN & \\
\hline CHEMBL1411249 & 688239 & 4.7862 & 5.5844 & TRN & \\
\hline CHEMBL1470222 & 688239 & 6.8362 & 5.5712 & TRN & \\
\hline CHEMBL1485372 & 688239 & 5.5362 & 5.4081 & TRN & \\
\hline CHEMBL1586928 & 688239 & 5.9362 & 5.547999 & 9999999999 & J \\
\hline CHEMBL1568197 & 688239 & 4.7362 & 5.5617 & TST & \\
\hline CHEMBL1417518 & 688239 & 4.8862 & 5.5011 & TRN & \\
\hline CHEMBL3209913 & 688239 & 5.6362 & 5.4721 & TST & \\
\hline CHEMBL3194784 & 688239 & 5.3362 & 5.4555 & TRN & \\
\hline CHEMBL1407102 & 688239 & 4.9862 & 5.4049 & TRN & \\
\hline CHEMBL1495504 & 688239 & 5.2362 & 5.3193 & TRN & \\
\hline CHEMBL1569107 & 688239 & 4.5362 & 5.4812 & TRN & \\
\hline CHEMBL1337685 & 688239 & 5.1862 & 5.4792 & TST & \\
\hline CHEMBL1414519 & 688239 & 6.0862 & 5.5016 & TST & \\
\hline CHEMBL 3197773 & 688239 & 4.6862 & 5.4648 & TRN & \\
\hline CHEMBL1320313 & 688239 & 4.6362 & 5.4154 & TRN & \\
\hline
\end{tabular}


Supplemental Table S2.txt

\begin{tabular}{|c|c|c|c|c|c|}
\hline CHEMBL1439527 & 688239 & 5.9362 & 5.6714 & TRN & \\
\hline CHEMBL1306251 & 688239 & 6.2362 & 5.4238 & TRN & \\
\hline CHEMBL1518495 & 688239 & 4.4862 & 5.7201 & TRN & \\
\hline CHEMBL1534643 & 688239 & 4.7362 & 5.5186 & TST & \\
\hline CHEMBL1417317 & 688239 & 4.8862 & 5.3641 & TRN & \\
\hline CHEMBL1496705 & 688239 & 5.3362 & 5.3254 & TST & \\
\hline CHEMBL1426484 & 688239 & 4.4862 & 5.4339 & TRN & \\
\hline CHEMBL1412624 & 688239 & 5.1862 & 5.5189 & TST & \\
\hline CHEMBL1597063 & 688239 & 4.9362 & 5.4422 & TRN & \\
\hline CHEMBL1434125 & 688239 & 4.5362 & 5.5414 & TRN & \\
\hline CHEMBL1973785 & 688239 & 4.5362 & 5.5424 & TRN & \\
\hline CHEMBL1378533 & 688239 & 5.5362 & 5.5616 & TRN & \\
\hline CHEMBL1586398 & 688239 & 7.2865 & 5.3923 & TRN & \\
\hline CHEMBL1458844 & 688239 & 4.7862 & 5.4481 & TRN & \\
\hline CHEMBL1789984 & 688239 & 4.6862 & 5.4949 & TST & \\
\hline CHEMBL1537069 & 688239 & 7.5867 & 5.188 & TRN & \\
\hline CHEMBL1505121 & 688239 & 4.6862 & 5.5535 & TST & \\
\hline CHEMBL1425578 & 688239 & 5.3362 & 5.4763 & TST & \\
\hline CHEMBL1486728 & 688239 & 4.7862 & 5.393 & TRN & \\
\hline CHEMBL1503835 & 688239 & 6.6861 & 5.553999 & 9999999999 & TRN \\
\hline CHEMBL1320397 & 688239 & 4.9362 & 5.4378 & TRN & \\
\hline CHEMBL1525530 & 688239 & 4.4862 & 5.2641 & TRN & \\
\hline CHEMBL1378429 & 688239 & 5.3862 & 5.6187 & TST & \\
\hline CHEMBL1320495 & 688239 & 4.7862 & 5.4335 & TRN & \\
\hline CHEMBL1367632 & 688239 & 4.9862 & 5.563 & TST & \\
\hline CHEMBL1608484 & 688239 & 4.6862 & 5.4946 & TRN & \\
\hline CHEMBL1570104 & 688239 & 5.7862 & 5.5354 & TST & \\
\hline CHEMBL1477825 & 688239 & 6.0862 & 5.5135 & TST & \\
\hline CHEMBL1560072 & 688239 & 4.6862 & 5.4655 & TST & \\
\hline CHEMBL1456206 & 688239 & 6.8861 & 5.3782 & TRN & \\
\hline CHEMBL1442236 & 688239 & 5.4862 & 5.6459 & TRN & \\
\hline CHEMBL1393290 & 688239 & 4.6862 & 5.6005 & TRN & \\
\hline CHEMBL1489258 & 688239 & 4.5362 & 5.4101 & TRN & \\
\hline CHEMBL1492400 & 688239 & 6.2862 & 5.4485 & TRN & \\
\hline CHEMBL1373761 & 688239 & 5.0362 & 5.5745 & TST & \\
\hline CHEMBL3195503 & 688239 & 4.5362 & 5.3554 & TRN & \\
\hline CHEMBL1499836 & 688239 & 4.6862 & 5.4613 & TRN & \\
\hline CHEMBL1420802 & 688239 & 4.7862 & 5.5188 & TRN & \\
\hline CHEMBL1572390 & 688239 & 5.5362 & 5.5893 & TRN & \\
\hline CHEMBL1325614 & 688239 & 5.0362 & 5.5675 & TST & \\
\hline CHEMBL1500555 & 688239 & 4.5362 & 5.5112 & TST & \\
\hline CHEMBL1415879 & 688239 & 4.7862 & 5.5683 & TST & \\
\hline CHEMBL1449799 & 688239 & 5.0862 & 5.2585 & TRN & \\
\hline CHEMBL1304228 & 688239 & 5.2862 & 5.5499 & TRN & \\
\hline CHEMBL1345409 & 688239 & 6.3863 & 5.6001 & TRN & \\
\hline CHEMBL1565277 & 688239 & 6.0862 & 5.5151 & TRN & \\
\hline CHEMBL1975547 & 688239 & 4.6862 & 5.5404 & TST & \\
\hline CHEMBL1987173 & 688239 & 4.5362 & 5.3741 & TST & \\
\hline
\end{tabular}


Supplemental Table S2.txt

\begin{tabular}{|c|c|c|c|c|c|}
\hline CHEMBL1407889 & 688239 & 5.0362 & 5.5028 & TRN & \\
\hline CHEMBL1532417 & 688239 & 5.1862 & 5.636 & TST & \\
\hline CHEMBL1408847 & 688239 & 5.2862 & 5.5363 & TST & \\
\hline CHEMBL3199377 & 688239 & 4.6862 & 5.3577 & TRN & \\
\hline CHEMBL1527457 & 688239 & 4.4862 & 5.4888 & TRN & \\
\hline CHEMBL1339976 & 688239 & 6.2362 & 5.4371 & TRN & \\
\hline CHEMBL1598984 & 688239 & 7.9872 & 5.5081 & TRN & \\
\hline CHEMBL3210675 & 688239 & 4.5362 & 5.7418 & TRN & \\
\hline CHEMBL1590125 & 688239 & 4.5862 & 5.5152 & TRN & \\
\hline CHEMBL1505198 & 688239 & 4.5362 & 5.504 & TST & \\
\hline CHEMBL1354008 & 688239 & 5.0362 & 5.3803 & TRN & \\
\hline CHEMBL1350302 & 688239 & 5.8362 & 5.5574 & TRN & \\
\hline CHEMBL1579286 & 688239 & 4.5362 & 5.4603 & TST & \\
\hline CHEMBL1585475 & 688239 & 5.0 & 5.655 & TRN & \\
\hline CHEMBL1584537 & 688239 & 4.9362 & 5.4834 & TRN & \\
\hline CHEMBL1518237 & 688239 & 5.8862 & 5.5265 & TRN & \\
\hline CHEMBL1536083 & 688239 & 4.9862 & 5.4737 & TRN & \\
\hline CHEMBL1491231 & 688239 & 4.6862 & 5.5483 & TRN & \\
\hline CHEMBL1414155 & 688239 & 4.7362 & 5.5312 & TST & \\
\hline CHEMBL1473797 & 688239 & 5.5362 & 5.5811 & TRN & \\
\hline CHEMBL1581077 & 688239 & 5.1362 & 5.482 & TRN & \\
\hline CHEMBL1499557 & 688239 & 5.1862 & 5.5047 & TRN & \\
\hline CHEMBL1431122 & 688239 & 5.7362 & 5.4293 & TRN & \\
\hline CHEMBL3211579 & 688239 & 5.2362 & 5.4218 & TRN & \\
\hline CHEMBL1320823 & 688239 & 4.8862 & 5.5111 & TRN & \\
\hline CHEMBL1571345 & 688239 & 4.5362 & 5.5007 & TRN & \\
\hline CHEMBL1438310 & 688239 & 5.7362 & 5.4846 & TRN & \\
\hline CHEMBL1456675 & 688239 & 4.8362 & 5.4327 & TRN & \\
\hline CHEMBL1385881 & 688239 & 5.4862 & 5.4351 & TST & \\
\hline CHEMBL3208001 & 688239 & 4.6862 & 5.374 & TRN & \\
\hline CHEMBL1411714 & 688239 & 6.5363 & 5.3729 & TRN & \\
\hline CHEMBL1390702 & 688239 & 5.4362 & 5.4089 & TRN & \\
\hline CHEMBL3194664 & 688239 & 4.4862 & 5.2681 & TST & \\
\hline CHEMBL1313641 & 688239 & 5.1862 & 5.5174 & TRN & \\
\hline CHEMBL1592777 & 688239 & 4.5862 & 5.4257 & TRN & \\
\hline CHEMBL1431490 & 688239 & 5.1862 & 5.66700 & 0000000001 & TRN \\
\hline CHEMBL1602059 & 688239 & 4.5862 & 5.4522 & TRN & \\
\hline CHEMBL1310266 & 688239 & 4.5362 & 5.6813 & TRN & \\
\hline CHEMBL1529264 & 688239 & 5.4862 & 5.5022 & TST & \\
\hline CHEMBL1328942 & 688239 & 6.4862 & 5.5746 & TRN & \\
\hline CHEMBL1493859 & 688239 & 5.1862 & 5.4957 & TRN & \\
\hline CHEMBL1524257 & 688239 & 4.7362 & 5.4704 & TRN & \\
\hline CHEMBL1482292 & 688239 & 6.0362 & 5.4107 & TST & \\
\hline CHEMBL1309268 & 688239 & 4.5362 & 5.4406 & TST & \\
\hline CHEMBL1474758 & 688239 & 4.5362 & 5.5023 & TRN & \\
\hline CHEMBL1421603 & 688239 & 6.1362 & 5.4135 & TST & \\
\hline CHEMBL1480497 & 688239 & 5.6862 & 5.3355 & TRN & \\
\hline CHEMBL1561463 & 688239 & 4.7862 & 5.5183 & TRN & \\
\hline
\end{tabular}

Page 1201 
Supplemental Table S2.txt

\begin{tabular}{|c|c|c|c|c|c|}
\hline CHEMBL1430583 & 688239 & 5.1362 & 5.5782 & TST & \\
\hline CHEMBL1350243 & 688239 & 5.1862 & 5.4525 & TRN & \\
\hline CHEMBL1520019 & 688239 & 5.2362 & 5.3962 & TRN & \\
\hline CHEMBL1396992 & 688239 & 6.1362 & 5.392 & TRN & \\
\hline CHEMBL1574556 & 688239 & 6.9863 & 5.4105 & TRN & \\
\hline CHEMBL1359387 & 688239 & 5.4362 & 5.4252 & TRN & \\
\hline CHEMBL1612992 & 688239 & 6.9363 & 5.6262 & TRN & \\
\hline CHEMBL1458524 & 688239 & 5.2862 & 5.3576 & TRN & \\
\hline CHEMBL1465511 & 688239 & 4.7362 & 5.4568 & TST & \\
\hline CHEMBL1373231 & 688239 & 5.5362 & 5.3944 & TST & \\
\hline CHEMBL1457978 & 688239 & 6.7862 & 5.45299 & 9999999999 & TRN \\
\hline CHEMBL1439376 & 688239 & 6.2362 & 5.4653 & TRN & \\
\hline CHEMBL1479466 & 688239 & 6.0362 & 5.5757 & TRN & \\
\hline CHEMBL1323654 & 688239 & 5.4862 & 5.6233 & TRN & \\
\hline CHEMBL3199152 & 688239 & 4.5362 & 5.5249 & TST & \\
\hline CHEMBL1495855 & 688239 & 5.0862 & 5.5227 & TRN & \\
\hline CHEMBL1487131 & 688239 & 7.0862 & 5.4521 & TST & \\
\hline CHEMBL1384623 & 688239 & 4.6862 & 5.5829 & TST & \\
\hline CHEMBL1527846 & 688239 & 4.8862 & 5.4421 & TST & \\
\hline CHEMBL1320241 & 688239 & 5.5362 & 5.5027 & TRN & \\
\hline CHEMBL1357730 & 688239 & 6.3362 & 5.5434 & TRN & \\
\hline CHEMBL1501712 & 688239 & 6.1862 & 5.6122 & TRN & \\
\hline CHEMBL1333478 & 688239 & 4.6862 & 5.5268 & TRN & \\
\hline CHEMBL1383860 & 688239 & 5.3862 & 5.4976 & TRN & \\
\hline CHEMBL1462744 & 688239 & 6.0862 & 5.5555 & TRN & \\
\hline CHEMBL1439989 & 688239 & 4.6362 & 5.6043 & TST & \\
\hline CHEMBL3191664 & 688239 & 4.5362 & 5.45700 & 0000000001 & TST \\
\hline CHEMBL1509861 & 688239 & 5.3862 & 5.6412 & TRN & \\
\hline CHEMBL1522937 & 688239 & 5.0362 & 5.5585 & TRN & \\
\hline CHEMBL1432738 & 688239 & 5.2862 & 5.5095 & TRN & \\
\hline CHEMBL1491560 & 688239 & 8.28399 & 99999999 & 5.4843 & TRN \\
\hline CHEMBL1348540 & 688239 & 4.4862 & 5.4479 & TRN & \\
\hline CHEMBL1391523 & 688239 & 4.5362 & 5.5527 & TRN & \\
\hline CHEMBL1591978 & 688239 & 4.5362 & 5.5645 & TRN & \\
\hline CHEMBL1547679 & 688239 & 7.1864 & 5.5514 & TRN & \\
\hline CHEMBL1329332 & 688239 & 4.5862 & 5.4491 & TRN & \\
\hline CHEMBL1366250 & 688239 & 5.9362 & 5.6037 & TRN & \\
\hline CHEMBL 270605 & 688239 & 4.75 & 5.4015 & TRN & \\
\hline CHEMBL1465067 & 688239 & 5.3862 & 5.5262 & TST & \\
\hline CHEMBL1536274 & 688239 & 4.5362 & 5.3856 & TRN & \\
\hline CHEMBL1358808 & 688239 & 4.5362 & 5.5083 & TRN & \\
\hline CHEMBL1369448 & 688239 & 5.5362 & 5.4346 & TRN & \\
\hline CHEMBL1533296 & 688239 & 5.6362 & 5.5895 & TRN & \\
\hline CHEMBL1333329 & 688239 & 4.5362 & 5.5738 & TRN & \\
\hline CHEMBL1394828 & 688239 & 4.7362 & \multicolumn{2}{|c|}{5.4479999999999995} & TRN \\
\hline CHEMBL1371453 & 688239 & 4.5362 & 5.4183 & TRN & \\
\hline CHEMBL1599607 & 688239 & 4.6862 & 5.4534 & TRN & \\
\hline CHEMBL1481084 & 688239 & 5.4862 & 5.6013 & TRN & \\
\hline
\end{tabular}


Supplemental Table S2.txt

\begin{tabular}{|c|c|c|c|c|}
\hline CHEMBL1610029 & 688239 & 5.0362 & 5.4566 & TRN \\
\hline CHEMBL1422701 & 688239 & 4.5362 & 5.4992 & TRN \\
\hline CHEMBL1324235 & 688239 & 5.2362 & \multicolumn{2}{|c|}{5.5760000000000005} \\
\hline CHEMBL1336226 & 688239 & 4.5362 & 5.3826 & TRN \\
\hline CHEMBL1408072 & 688239 & 5.4362 & 5.5238 & TRN \\
\hline CHEMBL1545751 & 688239 & 4.9862 & \multicolumn{2}{|c|}{5.502999999999999} \\
\hline CHEMBL1540545 & 688239 & 5.7862 & 5.6334 & TRN \\
\hline CHEMBL1322978 & 688239 & 4.5362 & 5.5498 & TRN \\
\hline CHEMBL 2006615 & 688239 & 6.8861 & 5.4906 & TRN \\
\hline CHEMBL1543972 & 688239 & 4.5362 & 5.5078 & TRN \\
\hline CHEMBL1368270 & 688239 & 5.4362 & 5.5733 & TRN \\
\hline CHEMBL3196221 & 688239 & 4.8362 & 5.3179 & TST \\
\hline CHEMBL1463683 & 688239 & 4.8362 & 5.4985 & TRN \\
\hline CHEMBL1606264 & 688239 & 4.5862 & 5.5094 & TRN \\
\hline CHEMBL1413269 & 688239 & 4.6862 & 5.6114 & TRN \\
\hline CHEMBL1335308 & 688239 & 5.3862 & 5.4137 & TRN \\
\hline CHEMBL1585485 & 688239 & 6.1362 & \multicolumn{2}{|c|}{5.627999999999999} \\
\hline CHEMBL3208142 & 688239 & 6.0362 & 5.5218 & TST \\
\hline CHEMBL1608698 & 688239 & 5.3362 & 5.468 & TRN \\
\hline CHEMBL1521470 & 688239 & 4.5362 & 5.409 & TRN \\
\hline CHEMBL1501615 & 688239 & 4.4862 & 5.5823 & TRN \\
\hline CHEMBL1335691 & 688239 & 6.95 & 5.3789 & TRN \\
\hline CHEMBL1406911 & 688239 & 4.5862 & 5.3504 & TRN \\
\hline CHEMBL1313689 & 688239 & 5.1862 & 5.6167 & TRN \\
\hline CHEMBL3194361 & 688239 & 6.6362 & 5.364 & TRN \\
\hline CHEMBL1556677 & 688239 & 4.5362 & 5.4845 & TRN \\
\hline CHEMBL1463048 & 688239 & 4.7362 & 5.4992 & TRN \\
\hline CHEMBL1549067 & 688239 & 6.8362 & 5.5553 & TRN \\
\hline CHEMBL1370423 & 688239 & 5.3362 & 5.5075 & TRN \\
\hline CHEMBL1550445 & 688239 & 4.5362 & 5.3723 & TRN \\
\hline CHEMBL1509045 & 688239 & 5.5362 & 5.4633 & TST \\
\hline CHEMBL1412410 & 688239 & 7.0862 & 5.4886 & TRN \\
\hline CHEMBL1440896 & 688239 & 6.2362 & 5.4152 & TRN \\
\hline CHEMBL3211110 & 688239 & 4.5362 & 5.5308 & TST \\
\hline CHEMBL1464797 & 688239 & 6.2362 & 5.4439 & TRN \\
\hline CHEMBL1572577 & 688239 & 4.7362 & 5.4431 & TST \\
\hline CHEMBL1966316 & 688239 & 6.0362 & 5.479 & TRN \\
\hline CHEMBL1313035 & 688239 & 4.4862 & 5.4325 & TRN \\
\hline CHEMBL1517575 & 688239 & 5.7862 & 5.5548 & TRN \\
\hline CHEMBL1517850 & 688239 & 4.7362 & 5.362 & TRN \\
\hline CHEMBL1411292 & 688239 & 4.7862 & 5.5395 & TRN \\
\hline CHEMBL1564591 & 688239 & 5.1362 & 5.5144 & TST \\
\hline CHEMBL1600013 & 688239 & 6.2862 & 5.5574 & TRN \\
\hline CHEMBL1375404 & 688239 & 5.6362 & 5.4346 & TRN \\
\hline CHEMBL1586145 & 688239 & 4.8362 & 5.3999 & TST \\
\hline CHEMBL1604432 & 688239 & 5.1862 & 5.4485 & TRN \\
\hline CHEMBL1537438 & 688239 & 4.6862 & 5.6072 & TRN \\
\hline CHEMBL1505964 & 688239 & 4.45 & 5.4276 & TRN \\
\hline
\end{tabular}


Supplemental Table S2.txt

\begin{tabular}{|c|c|c|c|c|}
\hline CHEMBL1524551 & 688239 & 4.5362 & 5.5726 & TRN \\
\hline CHEMBL1396435 & 688239 & 8.3372 & 5.3859 & TRN \\
\hline CHEMBL1456119 & 688239 & 6.2362 & 5.5342 & TRN \\
\hline CHEMBL1462715 & 688239 & 4.5362 & 5.5776 & TRN \\
\hline CHEMBL1513473 & 688239 & 5.1362 & 5.4745 & TRN \\
\hline CHEMBL1423959 & 688239 & 4.6362 & 5.6471 & TRN \\
\hline CHEMBL1515703 & 688239 & 4.5362 & 5.3976 & TRN \\
\hline CHEMBL1448545 & 688239 & 5.4862 & 5.5711 & TST \\
\hline CHEMBL1549369 & 688239 & 5.3362 & 5.5476 & TRN \\
\hline CHEMBL1599547 & 688239 & 5.6862 & 5.4751 & TST \\
\hline CHEMBL1456600 & 688239 & 5.4862 & 5.4881 & TRN \\
\hline CHEMBL1501226 & 688239 & 6.2862 & 5.5431 & TRN \\
\hline CHEMBL1597491 & 688239 & 6.2862 & 5.5383 & TRN \\
\hline CHEMBL1600590 & 688239 & 8.2366 & 5.4607 & TRN \\
\hline CHEMBL1386837 & 688239 & 4.6862 & 5.4689 & TRN \\
\hline CHEMBL1464197 & 688239 & 5.1862 & 5.3761 & TRN \\
\hline CHEMBL1585021 & 688239 & 5.1862 & 5.4754 & TRN \\
\hline CHEMBL1510681 & 688239 & 5.0362 & 5.5481 & TST \\
\hline CHEMBL1502797 & 688239 & 7.1864 & 5.6874 & TRN \\
\hline CHEMBL1612089 & 688239 & 4.5362 & 5.4705 & TRN \\
\hline CHEMBL1416418 & 688239 & 6.1362 & 5.6488 & TRN \\
\hline CHEMBL1483497 & 688239 & 4.7362 & 5.6119 & TRN \\
\hline CHEMBL1460429 & 688239 & 4.6862 & 5.6012 & TRN \\
\hline CHEMBL1563378 & 688239 & 4.7362 & 5.4806 & TST \\
\hline CHEMBL1307371 & 688239 & 6.1862 & 5.4181 & TRN \\
\hline CHEMBL1516512 & 688239 & 8.3372 & 5.5424 & TRN \\
\hline CHEMBL1494700 & 688239 & 4.6362 & 5.584 & TRN \\
\hline CHEMBL3208346 & 688239 & 4.5362 & 5.5749 & TRN \\
\hline CHEMBL591876 & 688239 & 4.7862 & 5.2777 & TRN \\
\hline CHEMBL1528464 & 688239 & 6.2362 & 5.44600 & 0000000001 \\
\hline CHEMBL1421427 & 688239 & 4.5362 & 5.4811 & TRN \\
\hline CHEMBL1472856 & 688239 & 6.8861 & 5.6459 & TRN \\
\hline CHEMBL1382851 & 688239 & 6.4862 & 5.4749 & TST \\
\hline CHEMBL1406749 & 688239 & 5.0362 & 5.6318 & TRN \\
\hline CHEMBL1368747 & 688239 & 4.9362 & 5.4653 & TRN \\
\hline CHEMBL1613413 & 688239 & 6.0362 & 5.4627 & TRN \\
\hline CHEMBL3213333 & 688239 & 4.8362 & 5.4726 & TST \\
\hline CHEMBL1595421 & 688239 & 5.2362 & 5.5214 & TRN \\
\hline CHEMBL1303665 & 688239 & 4.5362 & 5.4041 & TST \\
\hline CHEMBL1508545 & 688239 & 6.1362 & 5.518 & TRN \\
\hline CHEMBL1603698 & 688239 & 4.6862 & 5.4986 & TRN \\
\hline CHEMBL1497922 & 688239 & 4.9362 & 5.5496 & TRN \\
\hline CHEMBL1509254 & 688239 & 4.5362 & 5.296 & TRN \\
\hline CHEMBL1303494 & 688239 & 6.3362 & 5.4166 & TRN \\
\hline CHEMBL1604994 & 688239 & 4.5362 & 5.4436 & TRN \\
\hline CHEMBL1416609 & 688239 & 4.8362 & 5.6304 & TRN \\
\hline CHEMBL1578549 & 688239 & 5.6862 & 5.5888 & TRN \\
\hline CHEMBL1349492 & 688239 & 4.6362 & 5.5014 & TST \\
\hline
\end{tabular}




\begin{tabular}{|c|c|c|c|c|c|c|}
\hline \multicolumn{7}{|c|}{ Supplemental Table S2.txt } \\
\hline CHEMBL1456603 & 688239 & 4.4862 & 5.3941 & TST & & \\
\hline CHEMBL1511916 & 688239 & 5.8362 & 5.5315 & TRN & & \\
\hline CHEMBL1335113 & 688239 & 4.4862 & 5.5003 & TRN & & \\
\hline CHEMBL1313328 & 688239 & 6.2362 & 5.6489 & TRN & & \\
\hline CHEMBL1492439 & 688239 & 6.4362 & 5.5808 & TRN & & \\
\hline CHEMBL1346375 & 688239 & 5.4362 & 5.5078 & TRN & & \\
\hline CHEMBL3193435 & 688239 & 8.28399 & 99999999 & 99 & 5.2387 & TRN \\
\hline CHEMBL1348625 & 688239 & 5.7862 & 5.5202 & TRN & & \\
\hline CHEMBL1315710 & 688239 & 5.1862 & 5.5617 & TRN & & \\
\hline CHEMBL1366560 & 688239 & 6.0862 & 5.5627 & TRN & & \\
\hline CHEMBL1553762 & 688239 & 4.7862 & 5.4654 & TRN & & \\
\hline CHEMBL1524918 & 688239 & 4.8862 & 5.609 & TST & & \\
\hline CHEMBL1564218 & 688239 & 6.2362 & 5.4364 & TRN & & \\
\hline CHEMBL1314509 & 688239 & 4.6362 & 5.3457 & TRN & & \\
\hline CHEMBL1324272 & 688239 & 6.1362 & 5.5908 & TRN & & \\
\hline CHEMBL1421780 & 688239 & 5.0362 & 5.4614 & TRN & & \\
\hline CHEMBL1459189 & 688239 & 4.7362 & 5.4041 & TRN & & \\
\hline CHEMBL1543097 & 688239 & 5.4362 & 5.3813 & TST & & \\
\hline CHEMBL1336867 & 688239 & 4.6362 & 5.3569 & TRN & & \\
\hline CHEMBL1537102 & 688239 & 4.5362 & 5.4634 & TRN & & \\
\hline CHEMBL1602990 & 688239 & 6.2362 & 5.6064 & TRN & & \\
\hline CHEMBL1449092 & 688239 & 5.4862 & 5.5493 & TRN & & \\
\hline CHEMBL1462250 & 688239 & 4.5362 & 5.4435 & TRN & & \\
\hline CHEMBL1476237 & 688239 & 6.7862 & 5.5238 & TRN & & \\
\hline CHEMBL1491202 & 688239 & 6.8861 & 5.5368 & TRN & & \\
\hline CHEMBL1374244 & 688239 & 4.4862 & 5.5639 & TRN & & \\
\hline CHEMBL1310621 & 688239 & 5.1862 & 5.5525 & TST & & \\
\hline CHEMBL1420774 & 688239 & 4.5362 & 5.5376 & TRN & & \\
\hline CHEMBL3198378 & 688239 & 6.9363 & 5.6089 & TRN & & \\
\hline CHEMBL1421057 & 688239 & 6.1362 & 5.6361 & TRN & & \\
\hline CHEMBL1506837 & 688239 & 5.1862 & 5.3352 & TRN & & \\
\hline CHEMBL1302697 & 688239 & 5.1362 & 5.6198 & TRN & & \\
\hline CHEMBL1471674 & 688239 & 5.2862 & 5.6589 & TST & & \\
\hline CHEMBL1368802 & 688239 & 4.6862 & 5.4231 & TRN & & \\
\hline CHEMBL1394440 & 688239 & 5.3862 & 5.4311 & TRN & & \\
\hline CHEMBL1403425 & 688239 & 5.95 & 5.4673 & TRN & & \\
\hline CHEMBL1505132 & 688239 & 4.6362 & 5.4455 & TST & & \\
\hline CHEMBL1405645 & 688239 & 6.3863 & 5.4657 & TRN & & \\
\hline CHEMBL1396567 & 688239 & 5.0862 & 5.3709 & TRN & & \\
\hline CHEMBL1538465 & 688239 & 4.7362 & 5.4068 & TRN & & \\
\hline CHEMBL1379912 & 688239 & 5.1862 & 5.5146 & TRN & & \\
\hline CHEMBL1385953 & 688239 & 5.5862 & 5.5378 & TST & & \\
\hline CHEMBL227881 & 688239 & 6.0362 & 5.4043 & TRN & & \\
\hline CHEMBL1473180 & 688239 & 5.0862 & 5.4166 & TRN & & \\
\hline CHEMBL 3197587 & 688239 & 6.0362 & 5.4364 & TST & & \\
\hline CHEMBL1578560 & 688239 & 6.8861 & 5.2845 & TRN & & \\
\hline CHEMBL1557214 & 688239 & 5.8862 & 5.3324 & TRN & & \\
\hline CHEMBL1311786 & 688239 & 5.2362 & 5.4301 & TRN & & \\
\hline
\end{tabular}


Supplemental Table S2.txt

\begin{tabular}{|c|c|c|c|c|c|c|}
\hline CHEMBL1593042 & 688239 & 8.1871 & 5.4779 & TRN & & \\
\hline CHEMBL3196510 & 688239 & 8.28399 & 999999999 & 99 & 5.5132 & TRN \\
\hline CHEMBL1530466 & 688239 & 6.6362 & 5.4729 & TRN & & \\
\hline CHEMBL1308750 & 688239 & 4.7862 & 5.5251 & TST & & \\
\hline CHEMBL3197270 & 688239 & 5.3862 & 5.39 & TST & & \\
\hline CHEMBL3197463 & 688239 & 6.9363 & 5.4159 & TRN & & \\
\hline CHEMBL1561625 & 688239 & 5.6862 & 5.4908 & TRN & & \\
\hline CHEMBL1305638 & 688239 & 6.0862 & 5.504 & TRN & & \\
\hline CHEMBL1377031 & 688239 & 6.9863 & 5.3931 & TST & & \\
\hline CHEMBL1589904 & 688239 & 5.1862 & 5.5312 & TST & & \\
\hline CHEMBL1599254 & 688239 & 4.4362 & 5.585 & TRN & & \\
\hline CHEMBL1475580 & 688239 & 4.5362 & 5.4444 & TRN & & \\
\hline CHEMBL1343816 & 688239 & 5.3862 & 5.4946 & TRN & & \\
\hline CHEMBL1526996 & 688239 & 6.2862 & 5.3596 & TST & & \\
\hline CHEMBL1308080 & 688239 & 6.9363 & 5.5001 & TRN & & \\
\hline CHEMBL1387603 & 688239 & 6.6861 & 5.4447 & TST & & \\
\hline CHEMBL1546298 & 688239 & 4.5362 & 5.4904 & TRN & & \\
\hline CHEMBL1462256 & 688239 & 5.0362 & 5.6292 & TRN & & \\
\hline CHEMBL1378913 & 688239 & 5.2862 & 5.3217 & TRN & & \\
\hline CHEMBL1446696 & 688239 & 5.4862 & 5.3952 & TRN & & \\
\hline CHEMBL1421342 & 688239 & 4.7862 & 5.4394 & TST & & \\
\hline CHEMBL1383760 & 688239 & 4.5362 & 5.5707 & TST & & \\
\hline CHEMBL1325816 & 688239 & 5.5862 & 5.3845 & TST & & \\
\hline CHEMBL1447324 & 688239 & 5.2862 & 5.4662 & TST & & \\
\hline CHEMBL1391464 & 688239 & 5.3862 & 5.3123 & TRN & & \\
\hline CHEMBL1581685 & 688239 & 6.9863 & 5.4183 & TRN & & \\
\hline CHEMBL1318892 & 688239 & 4.6862 & 5.5271 & TRN & & \\
\hline CHEMBL1321443 & 688239 & 5.7862 & 5.525 & TRN & & \\
\hline CHEMBL1501925 & 688239 & 4.5362 & 5.5313 & TRN & & \\
\hline CHEMBL1319613 & 688239 & 6.7862 & 5.5891 & TRN & & \\
\hline CHEMBL1526447 & 688239 & 5.3362 & 5.5049 & TST & & \\
\hline CHEMBL1318467 & 688239 & 5.1362 & 5.3806 & TST & & \\
\hline CHEMBL1606885 & 688239 & \multicolumn{3}{|c|}{8.283999999999999} & 5.4437 & TRN \\
\hline CHEMBL1526962 & 688239 & 8.3872 & 5.2218 & TRN & & \\
\hline CHEMBL1304537 & 688239 & 6.8861 & 5.4893 & TRN & & \\
\hline CHEMBL1527387 & 688239 & 5.4362 & 5.5904 & TST & & \\
\hline CHEMBL1436258 & 688239 & 5.3862 & 5.5625 & TRN & & \\
\hline CHEMBL1509511 & 688239 & 6.2862 & 5.3793 & TRN & & \\
\hline CHEMBL1587717 & 688239 & 4.8362 & \multicolumn{3}{|c|}{5.5520000000000005} & TST \\
\hline CHEMBL1509323 & 688239 & 5.2862 & 5.5004 & TRN & & \\
\hline CHEMBL1360836 & 688239 & 4.5362 & 5.4892 & TRN & & \\
\hline CHEMBL1309191 & 688239 & 5.3862 & 5.4179 & TST & & \\
\hline CHEMBL1372009 & 688239 & 6.5862 & 5.6029 & TRN & & \\
\hline CHEMBL1422654 & 688239 & 6.1362 & 5.5537 & TRN & & \\
\hline CHEMBL1524130 & 688239 & 8.2366 & 5.5191 & TST & & \\
\hline CHEMBL1364019 & 688239 & 6.9863 & 5.508999 & 9999999995 & 95 & TRN \\
\hline CHEMBL3193107 & 688239 & 5.5362 & 5.3042 & TRN & & \\
\hline \multirow[t]{2}{*}{ CHEMBL1299832 } & 688239 & 5.5862 & 5.53700 & $\partial 000000 t$ & & נו \\
\hline & & \multicolumn{5}{|c|}{ Page 1206} \\
\hline
\end{tabular}


Supplemental Table S2.txt

\begin{tabular}{|c|c|c|c|c|c|}
\hline CHEMBL1599149 & 688239 & 6.0362 & 5.5158 & TRN & \\
\hline CHEMBL1381864 & 688239 & 5.7362 & 5.4617 & TST & \\
\hline CHEMBL1319268 & 688239 & 4.8362 & 5.4033 & TST & \\
\hline CHEMBL1301917 & 688239 & 4.5362 & 5.4855 & TRN & \\
\hline CHEMBL1561454 & 688239 & 5.2862 & 5.4443 & TRN & \\
\hline CHEMBL1596678 & 688239 & 4.6362 & 5.5515 & TRN & \\
\hline CHEMBL1472663 & 688239 & 4.5362 & 5.5728 & TRN & \\
\hline CHEMBL1454384 & 688239 & 4.5862 & 5.392 & TRN & \\
\hline CHEMBL1445240 & 688239 & 5.2362 & 5.4449 & TRN & \\
\hline CHEMBL1602380 & 688239 & 6.1362 & 5.3615 & TRN & \\
\hline CHEMBL1313752 & 688239 & 4.6862 & 5.4998 & TRN & \\
\hline CHEMBL1305030 & 688239 & 5.6362 & 5.4207 & TST & \\
\hline CHEMBL1320527 & 688239 & 4.9862 & 5.4149 & TST & \\
\hline CHEMBL1497402 & 688239 & 6.1862 & 5.4616 & TRN & \\
\hline CHEMBL1993145 & 688239 & 8.3372 & 5.4271 & TRN & \\
\hline CHEMBL1568069 & 688239 & 6.8861 & 5.4487 & TRN & \\
\hline CHEMBL1379619 & 688239 & 5.7362 & 5.58899 & 99999999995 & TRN \\
\hline CHEMBL1326553 & 688239 & 6.2862 & 5.4252 & TRN & \\
\hline CHEMBL1498157 & 688239 & 4.8862 & 5.4425 & TRN & \\
\hline CHEMBL1441818 & 688239 & 4.5362 & 5.5009 & TRN & \\
\hline CHEMBL1413931 & 688239 & 5.6862 & 5.3512 & TRN & \\
\hline CHEMBL1505496 & 688239 & 4.6362 & 5.3151 & TRN & \\
\hline CHEMBL1315788 & 688239 & 6.8861 & 5.5447 & TRN & \\
\hline CHEMBL1550665 & 688239 & 4.5362 & 5.5206 & TRN & \\
\hline CHEMBL1541808 & 688239 & 4.5862 & 5.3926 & TST & \\
\hline CHEMBL1396878 & 688239 & 5.6862 & 5.4172 & TRN & \\
\hline CHEMBL1595277 & 688239 & 5.6862 & 5.3911 & TRN & \\
\hline CHEMBL1968376 & 688239 & 6.1862 & 5.3619 & TRN & \\
\hline CHEMBL1408232 & 688239 & 4.5362 & 5.5038 & TRN & \\
\hline CHEMBL1369513 & 688239 & 6.0362 & 5.4346 & TRN & \\
\hline CHEMBL1503446 & 688239 & 5.0362 & 5.2753 & TRN & \\
\hline CHEMBL1598201 & 688239 & 4.7862 & 5.5308 & TRN & \\
\hline CHEMBL3208953 & 688239 & 5.1362 & 5.6021 & TRN & \\
\hline CHEMBL3210557 & 688239 & 5.0862 & 5.6108 & TRN & \\
\hline CHEMBL1608278 & 688239 & 5.1862 & 5.5703 & TRN & \\
\hline CHEMBL1462753 & 688239 & 5.8862 & 5.6106 & TRN & \\
\hline CHEMBL1408241 & 688239 & 5.2362 & 5.651 & TRN & \\
\hline CHEMBL1472888 & 688239 & 6.9863 & 5.3501 & TST & \\
\hline CHEMBL1534012 & 688239 & 4.7362 & 5.6752 & TRN & \\
\hline CHEMBL1478469 & 688239 & 5.5362 & 5.4557 & TST & \\
\hline CHEMBL45245 & 688239 & 4.7362 & 5.4497 & TST & \\
\hline CHEMBL1315631 & 688239 & 4.5362 & 5.5054 & TRN & \\
\hline CHEMBL1387943 & 688239 & 6.5862 & 5.5847 & TRN & \\
\hline CHEMBL1318392 & 688239 & 5.6862 & 5.517 & TRN & \\
\hline CHEMBL1505421 & 688239 & 4.8862 & 5.6081 & TST & \\
\hline CHEMBL561020 & 688239 & 6.1362 & 5.6184 & TST & \\
\hline CHEMBL1337854 & 688239 & 4.5362 & 5.4953 & TST & \\
\hline CHEMBL1414044 & 688239 & 5.2862 & 5.4748 & TRN & \\
\hline
\end{tabular}


Supplemental Table S2.txt

\begin{tabular}{|c|c|c|c|c|}
\hline HEMBL1. & & .7362 & & \\
\hline НГМDI 1210021 & & .8861 & & \\
\hline & & & & \\
\hline AEMBL152 & & 5862 & & \\
\hline AEMBL3213195 & 8239 & 362 & & \\
\hline HEMBL1488489 & 88239 & 5362 & 6838 & \\
\hline HEMBL15 & 239 & 362 & & \\
\hline IEMBL1 & & & & \\
\hline HEMBL1458517 & 239 & 362 & & \\
\hline HEMBL1416261 & 88239 & 362 & 3701 & \\
\hline HEMBL1576941 & 239 & 362 & & \\
\hline IEMBL13e & 39 & 62 & & \\
\hline AEMBL1 & & & & \\
\hline HEMBL146 & & 862 & & \\
\hline AEMBL1567071 & & 62 & & \\
\hline AEMBL1366934 & 39 & 62 & & \\
\hline HEMBL1 & 39 & & & \\
\hline HEMBL1 & & & & \\
\hline HEMBL1 & & 362 & & \\
\hline IEMBL1 & & & & \\
\hline AEMBL: & & 62 & & \\
\hline HEMBL1 & & & & הות \\
\hline HEMBL1 & & & & \\
\hline 873 & & & & \\
\hline JEMBL14 & & & & $\mathrm{niv}$ \\
\hline HEMBL1 & & 62 & & KIV \\
\hline HEMBL & & & & Niv \\
\hline HFMBI 1 & & & & \\
\hline HEMBL3 & & & & 15 \\
\hline HEMBL1434372 & & & & IK \\
\hline HEMBL1 & & & & SI \\
\hline HEMBL & & & 56 & RN \\
\hline AEMP & & 52 & & \\
\hline HEMBL1501575 & & & & $\mathrm{RN}$ \\
\hline HEMBL1373605 & & 62 & 5.4941 & $\mathrm{RN}$ \\
\hline HEMBL1 & & 362 & 798 & RN \\
\hline HᄃMPI 1 & & & 93 & RN \\
\hline HEMBL1 & & & & $\mathrm{RN}$ \\
\hline HEMBL1529438 & 88239 & 62 & 448 & rST \\
\hline AEMBL1 & & 362 & 527 & RN \\
\hline HEMBL14 & & & 5.4929 & \\
\hline CHEMBL14 & & & & RIV \\
\hline HEMBL153 & & & 189 & RN \\
\hline AEMBL1462487 & 39 & 862 & 5283 & $T R$ \\
\hline EMBL1 & & & & \\
\hline HEMBL136 & & & .5327 & \\
\hline CHEMBL1606362 & & & 5.4262 & \\
\hline HEMBL1322998 & 688239 & 6.6861 & 5.4641 & \\
\hline
\end{tabular}

Page 1208 
Supplemental Table S2.txt

\begin{tabular}{|c|c|c|c|c|c|c|}
\hline CHEMBL1421187 & 688239 & 5.9862 & \multicolumn{3}{|c|}{5.343999999999999} & 15 \\
\hline CHEMBL1507948 & 688239 & 5.6362 & 5.4176 & TRN & & \\
\hline CHEMBL1500787 & 688239 & 4.5362 & 5.5105 & TST & & \\
\hline CHEMBL1462900 & 688239 & 4.7862 & 5.3742 & TRN & & \\
\hline CHEMBL1545212 & 688239 & 6.1362 & 5.5482 & TRN & & \\
\hline CHEMBL1372590 & 688239 & 7.1864 & 5.6035 & TRN & & \\
\hline CHEMBL1306635 & 688239 & 5.4862 & 5.6022 & TRN & & \\
\hline CHEMBL1446847 & 688239 & 6.8861 & 5.6065 & TST & & \\
\hline CHEMBL1358430 & 688239 & 5.6362 & 5.347 & TRN & & \\
\hline CHEMBL1574470 & 688239 & 5.2862 & 5.52 & TRN & & \\
\hline CHEMBL1365638 & 688239 & 7.0362 & 5.4807 & TRN & & \\
\hline CHEMBL1460607 & 688239 & 5.1862 & 5.5056 & TRN & & \\
\hline CHEMBL1317736 & 688239 & 4.5362 & 5.4249 & TST & & \\
\hline CHEMBL1356776 & 688239 & 4.7862 & 5.5157 & TRN & & \\
\hline CHEMBL3196645 & 688239 & 4.6362 & 5.5692 & TRN & & \\
\hline CHEMBL1531345 & 688239 & 7.2865 & 5.5131 & TRN & & \\
\hline CHEMBL3195077 & 688239 & 5.4362 & 5.5147 & TRN & & \\
\hline CHEMBL1458842 & 688239 & 6.1362 & 5.3888 & TST & & \\
\hline CHEMBL1484980 & 688239 & 5.0362 & 5.4216 & TRN & & \\
\hline CHEMBL1464614 & 688239 & 6.4362 & 5.553999 & 9999999999 & & \\
\hline CHEMBL1448442 & 688239 & 5.3362 & 5.4497 & TRN & & \\
\hline CHEMBL1447010 & 688239 & 4.7862 & 5.422000 & 0000000001 & & \\
\hline CHEMBL1380514 & 688239 & 4.5362 & 5.3669 & TRN & & \\
\hline CHEMBL1407240 & 688239 & 8.2366 & 5.5071 & TRN & & \\
\hline CHEMBL3208218 & 688239 & 4.5362 & 5.3438 & TRN & & \\
\hline CHEMBL1468882 & 688239 & 4.5362 & 5.4145 & TRN & & \\
\hline CHEMBL1558807 & 688239 & 5.2862 & 5.5805 & TRN & & \\
\hline CHEMBL1387469 & 688239 & 4.7862 & 5.5201 & TRN & & \\
\hline CHEMBL1398573 & 688239 & 8.3372 & 5.734 & TRN & & \\
\hline CHEMBL1510659 & 688239 & 5.0862 & 5.4727 & TRN & & \\
\hline CHEMBL3199602 & 688239 & 5.1362 & 5.5681 & TRN & & \\
\hline CHEMBL1600076 & 688239 & 7.0362 & 5.598 & TRN & & \\
\hline CHEMBL1564515 & 688239 & 5.1862 & 5.4257 & TRN & & \\
\hline CHEMBL1380180 & 688239 & 5.1862 & 5.4664 & TST & & \\
\hline CHEMBL1325454 & 688239 & 5.1862 & 5.4703 & TRN & & \\
\hline CHEMBL1484597 & 688239 & 4.7362 & 5.4255 & TRN & & \\
\hline CHEMBL1430319 & 688239 & 4.6362 & 5.2853 & TRN & & \\
\hline CHEMBL1571918 & 688239 & 5.3362 & 5.5177 & TRN & & \\
\hline CHEMBL1320951 & 688239 & 4.5362 & 5.4553 & TRN & & \\
\hline CHEMBL1375682 & 688239 & 4.6862 & 5.4458 & TRN & & \\
\hline CHEMBL1385005 & 688239 & 5.0862 & 5.3925 & TRN & & \\
\hline CHEMBL1577671 & 688239 & 5.0862 & 5.4751 & TRN & & \\
\hline CHEMBL1299817 & 688239 & 5.5362 & 5.5158 & TRN & & \\
\hline CHEMBL1477847 & 688239 & 5.3862 & 5.6 & TRN & & \\
\hline CHEMBL1344746 & 688239 & 8.28399 & 999999999 & & .4347 & \\
\hline CHEMBL1557213 & 688239 & 4.5862 & 5.2674 & TST & & \\
\hline CHEMBL1588833 & 688239 & 5.6862 & 5.5609 & TRN & & \\
\hline CHEMBL1314889 & 688239 & 4.6362 & 5.4801 & TRN & & \\
\hline
\end{tabular}


Supplemental Table S2.txt

\begin{tabular}{|c|c|c|c|c|}
\hline HEM & & 362 & - & \\
\hline & & .1362 & & \\
\hline-1 & & & & \\
\hline IEMBL1 & & & & $\mathrm{MI}$ \\
\hline AEMBL1329428 & 8239 & & & \\
\hline HEMBL1443589 & 88239 & 362 & 2967 & \\
\hline 645 & 239 & 362 & & \\
\hline IFMRI 1 & & & & \\
\hline AEMBL15 & & & & \\
\hline HEMBL1505281 & 88239 & 862 & & \\
\hline HEMBL1589619 & 239 & 362 & & \\
\hline IEMBL1: & 39 & 362 & & \\
\hline IEMBL1 & & & & \\
\hline HEMBL1C & & & & \\
\hline AEMBL14 & & & & \\
\hline AEMBL1 & 39 & 362 & & \\
\hline HEMBL1C & & & & \\
\hline HEMBL13 & & & & \\
\hline HEMBL1C & & 862 & & \\
\hline IEMBL1: & & & & \\
\hline HEMBLI & & & & Niv \\
\hline AEMBL: & & & & וזנה \\
\hline HEMBLI & & & & \\
\hline 444 & & & & \\
\hline AEMBL15 & & & & I RIV \\
\hline AEMBL1 & & & & KIV \\
\hline HEMBLI & & & & Niv \\
\hline HFMRI 1 & & & & \\
\hline HEMBL1 & & & & in \\
\hline HEMBL13 & & & & 15 \\
\hline HEMBL1 & & & & ST \\
\hline HEMBL & & & & RN \\
\hline$\triangle 5 M P$ & & & & \\
\hline HEMBL15 & & & & $\mathrm{IR}$ \\
\hline HEMBL1493230 & & 362 & & TRN \\
\hline HEMBLI & & & & ST \\
\hline 1 & & & & RN \\
\hline HEMBL15 & & & & RN \\
\hline HEMBL1483368 & 88239 & & & TRN \\
\hline AEMBL1 & & & & TRN \\
\hline HEMBL1 & & 52 & & \\
\hline HEMBL15 & & & & ST \\
\hline HEMBL15 & & & & RN \\
\hline AEMBL14 & 39 & 362 & 387 & $\mathrm{R}$ \\
\hline MBL1 & & & & \\
\hline HEMBL3: & & & & \\
\hline HEMBL13 & & .1362 & 5.6144 & \\
\hline HEMBL1422029 & 688239 & 4.5362 & 5.4589 & \\
\hline
\end{tabular}

Page 1210 


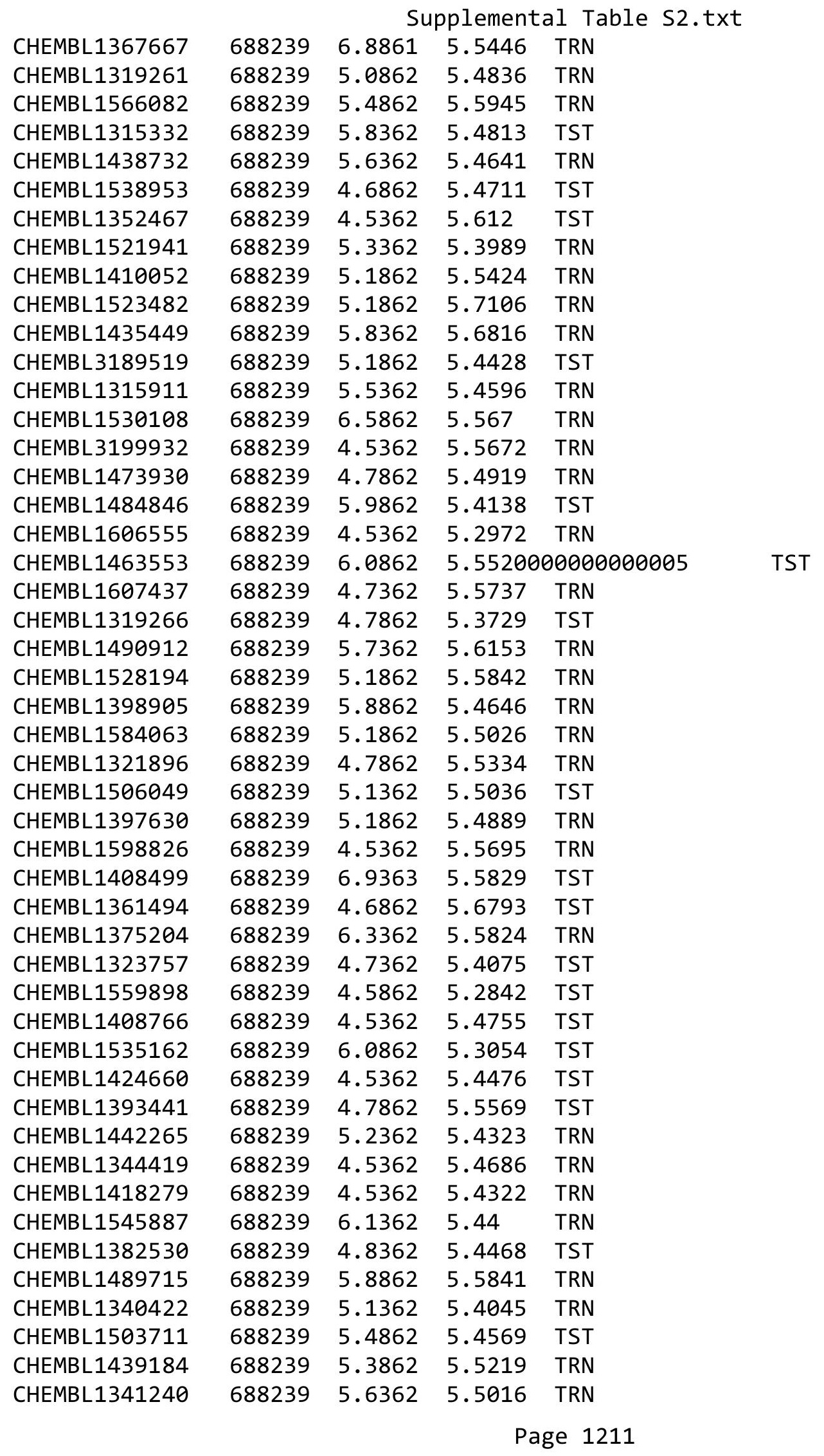


Supplemental Table S2.txt

\begin{tabular}{|c|c|c|c|c|c|}
\hline CHEMBL1387747 & 688239 & 6.2862 & 5.3866 & TST & \\
\hline CHEMBL1545726 & 688239 & 5.8362 & 5.4753 & TRN & \\
\hline CHEMBL1531455 & 688239 & 4.6862 & 5.5026 & TRN & \\
\hline CHEMBL1382876 & 688239 & 6.6362 & 5.5887 & TRN & \\
\hline CHEMBL1405889 & 688239 & 6.3362 & 5.6483 & TRN & \\
\hline CHEMBL1396655 & 688239 & 4.5362 & 5.4656 & TST & \\
\hline CHEMBL1491613 & 688239 & 4.6 & 5.5368 & TRN & \\
\hline CHEMBL1524078 & 688239 & 5.4362 & 5.6562 & TRN & \\
\hline CHEMBL1359923 & 688239 & 4.7362 & 5.4734 & TRN & \\
\hline CHEMBL1490799 & 688239 & 4.5862 & 5.3672 & TRN & \\
\hline CHEMBL3189654 & 688239 & 5.7362 & 5.3454 & TRN & \\
\hline CHEMBL1466958 & 688239 & 4.8362 & 5.6404 & TRN & \\
\hline CHEMBL1345247 & 688239 & 4.8362 & 5.5443 & TRN & \\
\hline CHEMBL1389275 & 688239 & 4.6862 & 5.4379 & TRN & \\
\hline CHEMBL1371719 & 688239 & 4.4862 & 5.4045 & TRN & \\
\hline CHEMBL1428822 & 688239 & 4.6362 & 5.4116 & TRN & \\
\hline CHEMBL1343861 & 688239 & 4.5362 & 5.4255 & TST & \\
\hline CHEMBL1429699 & 688239 & 4.5362 & 5.3655 & TRN & \\
\hline CHEMBL1432969 & 688239 & 4.6862 & 5.3356 & TST & \\
\hline CHEMBL1433138 & 688239 & 5.1862 & 5.4211 & TRN & \\
\hline CHEMBL1434443 & 688239 & 6.8362 & 5.4312 & TRN & \\
\hline CHEMBL1362267 & 688239 & 6.2862 & 5.5543 & TRN & \\
\hline CHEMBL1336881 & 688239 & 7.2865 & 5.5569 & TRN & \\
\hline CHEMBL1430225 & 688239 & 4.7862 & 5.4106 & TST & \\
\hline CHEMBL1357675 & 688239 & 5.1862 & 5.4749 & TRN & \\
\hline CHEMBL1568775 & 688239 & 4.8362 & 5.3894 & TRN & \\
\hline CHEMBL1360081 & 688239 & 6.8362 & 5.4525 & TRN & \\
\hline CHEMBL3193599 & 688239 & 5.6362 & 5.4086 & TRN & \\
\hline CHEMBL3213945 & 688239 & 5.1362 & $5.45100 t$ & 00000000005 & TST \\
\hline CHEMBL1543108 & 688239 & 5.0862 & 5.5474 & TST & \\
\hline CHEMBL1544693 & 688239 & 4.9862 & 5.3686 & TRN & \\
\hline CHEMBL1467797 & 688239 & 5.0862 & 5.5657 & TRN & \\
\hline CHEMBL1599105 & 688239 & 6.2862 & 5.4691 & TRN & \\
\hline CHEMBL1380826 & 688239 & 5.1362 & 5.479 & TRN & \\
\hline CHEMBL1519161 & 688239 & 4.7362 & 5.486006 & 0000000001 & TRN \\
\hline CHEMBL1557155 & 688239 & 5.5862 & 5.5662 & TRN & \\
\hline CHEMBL1470721 & 688239 & 6.3362 & 5.4522 & TST & \\
\hline CHEMBL 243314 & 688239 & 5.4862 & 5.5983 & TRN & \\
\hline CHEMBL1600265 & 688239 & 4.8862 & 5.3922 & TRN & \\
\hline CHEMBL1447457 & 688239 & 4.4862 & 5.315 & TST & \\
\hline CHEMBL1376022 & 688239 & 4.6862 & 5.4992 & TRN & \\
\hline CHEMBL1394451 & 688239 & 4.5362 & 5.4034 & TRN & \\
\hline CHEMBL1600587 & 688239 & 5.4362 & 5.4475 & TST & \\
\hline CHEMBL1381596 & 688239 & 4.6362 & 5.4953 & TST & \\
\hline CHEMBL1520156 & 688239 & 6.8861 & 5.4856 & TST & \\
\hline CHEMBL1599170 & 688239 & 6.3362 & 5.5197 & TRN & \\
\hline CHEMBL1536522 & 688239 & 4.7362 & 5.5158 & TRN & \\
\hline CHEMBL1599251 & 688239 & 6.2362 & 5.5923 & TST & \\
\hline
\end{tabular}


Supplemental Table S2.txt

\begin{tabular}{|c|c|c|c|c|}
\hline CHEMBL1346532 & 688239 & 5.5362 & 5.5257 & TRN \\
\hline CHEMBL1399340 & 688239 & 6.4862 & 5.4106 & TRN \\
\hline CHEMBL600906 & 688239 & 4.5362 & 5.4544 & TRN \\
\hline CHEMBL1403019 & 688239 & 4.5362 & 5.44799 & 99999999995 \\
\hline CHEMBL3195220 & 688239 & 4.8862 & 5.4467 & TRN \\
\hline CHEMBL1554409 & 688239 & 5.3862 & 5.4538 & TRN \\
\hline CHEMBL1594893 & 688239 & 5.7862 & 5.5816 & TRN \\
\hline CHEMBL1354295 & 688239 & 6.5862 & 5.5067 & TRN \\
\hline CHEMBL1476106 & 688239 & 6.8362 & 5.5541 & TST \\
\hline CHEMBL1433092 & 688239 & 7.2366 & 5.4682 & TRN \\
\hline CHEMBL1556562 & 688239 & 4.4862 & 5.5511 & TRN \\
\hline CHEMBL1546137 & 688239 & 4.4862 & 5.391 & TRN \\
\hline CHEMBL1467851 & 688239 & 6.7361 & 5.5753 & TST \\
\hline CHEMBL1571270 & 688239 & 5.1862 & 5.6088 & TST \\
\hline CHEMBL1523848 & 688239 & 4.4862 & 5.626 & TRN \\
\hline CHEMBL1451440 & 688239 & 5.3362 & 5.5151 & TRN \\
\hline CHEMBL1510767 & 688239 & 5.9362 & 5.4192 & TRN \\
\hline CHEMBL1321620 & 688239 & 4.5362 & 5.4773 & TST \\
\hline CHEMBL1468101 & 688239 & 4.8362 & 5.644 & TRN \\
\hline CHEMBL1431540 & 688239 & 5.6862 & 5.5165 & TST \\
\hline CHEMBL1448807 & 688239 & 4.5362 & 5.4263 & TRN \\
\hline CHEMBL1612459 & 688239 & 5.7362 & 5.5284 & TRN \\
\hline CHEMBL1368526 & 688239 & 5.1862 & 5.5043 & TRN \\
\hline CHEMBL1449653 & 688239 & 8.2366 & 5.6422 & TRN \\
\hline CHEMBL1483426 & 688239 & 5.5862 & 5.4842 & TRN \\
\hline CHEMBL1348328 & 688239 & 4.7862 & 5.5289 & TRN \\
\hline CHEMBL1408896 & 688239 & 5.2362 & 5.4007 & TRN \\
\hline CHEMBL1340868 & 688239 & 5.4362 & 5.2892 & TRN \\
\hline CHEMBL1426772 & 688239 & 8.3372 & 5.3946 & TST \\
\hline CHEMBL1510413 & 688239 & 5.1862 & 5.5216 & TST \\
\hline CHEMBL1322841 & 688239 & 4.4862 & 5.5238 & TRN \\
\hline CHEMBL1307101 & 688239 & 5.2862 & 5.4317 & TST \\
\hline CHEMBL1567014 & 688239 & 6.1862 & 5.5351 & TRN \\
\hline CHEMBL1541582 & 688239 & 4.5362 & 5.3511 & TRN \\
\hline CHEMBL1589465 & 688239 & 5.6862 & 5.4176 & TST \\
\hline CHEMBL1376465 & 688239 & 4.6862 & 5.4053 & TRN \\
\hline CHEMBL1562148 & 688239 & 6.2362 & 5.5486 & TRN \\
\hline CHEMBL1303994 & 688239 & 5.1862 & 5.5176 & TST \\
\hline CHEMBL1335450 & 688239 & 5.6362 & 5.3695 & TRN \\
\hline CHEMBL1328467 & 688239 & 4.5362 & 5.4342 & TRN \\
\hline CHEMBL1475071 & 688239 & 6.0862 & 5.4566 & TRN \\
\hline CHEMBL1554053 & 688239 & 6.7361 & 5.5665 & TRN \\
\hline CHEMBL1494959 & 688239 & 5.4362 & 5.4441 & TRN \\
\hline CHEMBL1531574 & 688239 & 5.0862 & 5.4009 & TRN \\
\hline CHEMBL1497709 & 688239 & 5.6862 & 5.3436 & TRN \\
\hline CHEMBL1513975 & 688239 & 6.0 & 5.4913 & TRN \\
\hline CHEMBL1534006 & 688239 & 5.2862 & 5.5112 & TRN \\
\hline CHEMBL1495238 & 688239 & 5.5862 & 5.3561 & TST \\
\hline
\end{tabular}


Supplemental Table S2.txt

\begin{tabular}{|c|c|c|c|c|}
\hline CHEMBL1411541 & 688239 & 5.3362 & 5.4884 & TRN \\
\hline CHEMBL1590167 & 688239 & 4.6862 & 5.4958 & TRN \\
\hline CHEMBL1313673 & 688239 & 4.8862 & 5.5808 & TRN \\
\hline CHEMBL 2005743 & 688239 & 4.8362 & 5.4866 & TRN \\
\hline CHEMBL1454682 & 688239 & 6.2362 & 5.5002 & TRN \\
\hline CHEMBL1392940 & 688239 & 4.7862 & 5.372006 & 000000001 \\
\hline CHEMBL1441412 & 688239 & 5.7362 & 5.6012 & TRN \\
\hline CHEMBL1415570 & 688239 & 6.3362 & 5.5574 & TST \\
\hline CHEMBL3214323 & 688239 & 6.9863 & 5.4349 & TRN \\
\hline CHEMBL259853 & 688239 & 5.7362 & 5.4914 & TRN \\
\hline CHEMBL1375460 & 688239 & 8.28399 & 99999999 & 5.5751 \\
\hline CHEMBL1437651 & 688239 & 4.4862 & 5.3477 & TRN \\
\hline CHEMBL 1471250 & 688239 & 5.1862 & 5.3927 & TRN \\
\hline CHEMBL 3195257 & 688239 & 6.1362 & 5.4398 & TRN \\
\hline CHEMBL1518470 & 688239 & 4.7362 & 5.5009 & TST \\
\hline CHEMBL1392544 & 688239 & 6.9363 & 5.5051 & TST \\
\hline CHEMBL1578927 & 688239 & 5.8362 & 5.4427 & TRN \\
\hline CHEMBL1515528 & 688239 & 5.4862 & 5.4989 & TST \\
\hline CHEMBL 3190145 & 688239 & 4.6862 & 5.2973 & TST \\
\hline CHEMBL1370151 & 688239 & 5.0862 & 5.524 & TRN \\
\hline CHEMBL1574821 & 688239 & 5.1862 & 5.4328 & TST \\
\hline CHEMBL1447594 & 688239 & 5.1862 & 5.5228 & TRN \\
\hline CHEMBL1435012 & 688239 & 4.5362 & 5.4551 & TRN \\
\hline CHEMBL1504614 & 688239 & 6.2862 & 5.4861 & TRN \\
\hline CHEMBL1376754 & 688239 & 6.1862 & 5.42 & TST \\
\hline CHEMBL1508761 & 688239 & 5.1862 & 5.4503 & TST \\
\hline CHEMBL1523714 & 688239 & 8.1871 & 5.5946 & TRN \\
\hline CHEMBL1391551 & 688239 & 4.6862 & 5.3452 & TST \\
\hline CHEMBL1445988 & 688239 & 4.5862 & 5.5303 & TRN \\
\hline CHEMBL1549562 & 688239 & 4.5362 & 5.3261 & TRN \\
\hline CHEMBL1404401 & 688239 & 5.2862 & 5.5113 & TRN \\
\hline CHEMBL1609878 & 688239 & 6.1362 & 5.5524 & TST \\
\hline CHEMBL1442466 & 688239 & 4.5362 & 5.5139 & TRN \\
\hline CHEMBL1552525 & 688239 & 5.3862 & 5.4 & TRN \\
\hline CHEMBL1472468 & 688239 & 4.5362 & 5.6339 & TST \\
\hline CHEMBL1606951 & 688239 & 6.2862 & 5.6146 & TRN \\
\hline CHEMBL1442063 & 688239 & 4.8362 & 5.4687 & TST \\
\hline CHEMBL591370 & 688239 & 4.9862 & 5.4144 & TRN \\
\hline CHEMBL1532006 & 688239 & 6.5363 & 5.439 & TRN \\
\hline CHEMBL1515547 & 688239 & 6.2362 & 5.5883 & TST \\
\hline CHEMBL1327051 & 688239 & 5.7362 & 5.4891 & TRN \\
\hline CHEMBL1415646 & 688239 & 5.5862 & 5.5088 & TST \\
\hline CHEMBL1353289 & 688239 & 6.9363 & 5.4856 & TRN \\
\hline CHEMBL1465573 & 688239 & 6.7862 & 5.3667 & TST \\
\hline CHEMBL1437965 & 688239 & 6.4862 & 5.3741 & TST \\
\hline CHEMBL1546210 & 688239 & 7.0362 & 5.4436 & TRN \\
\hline CHEMBL1455671 & 688239 & 4.5362 & 5.4812 & TRN \\
\hline CHEMBL1385784 & 688239 & 4.4862 & 5.4392 & TST \\
\hline
\end{tabular}




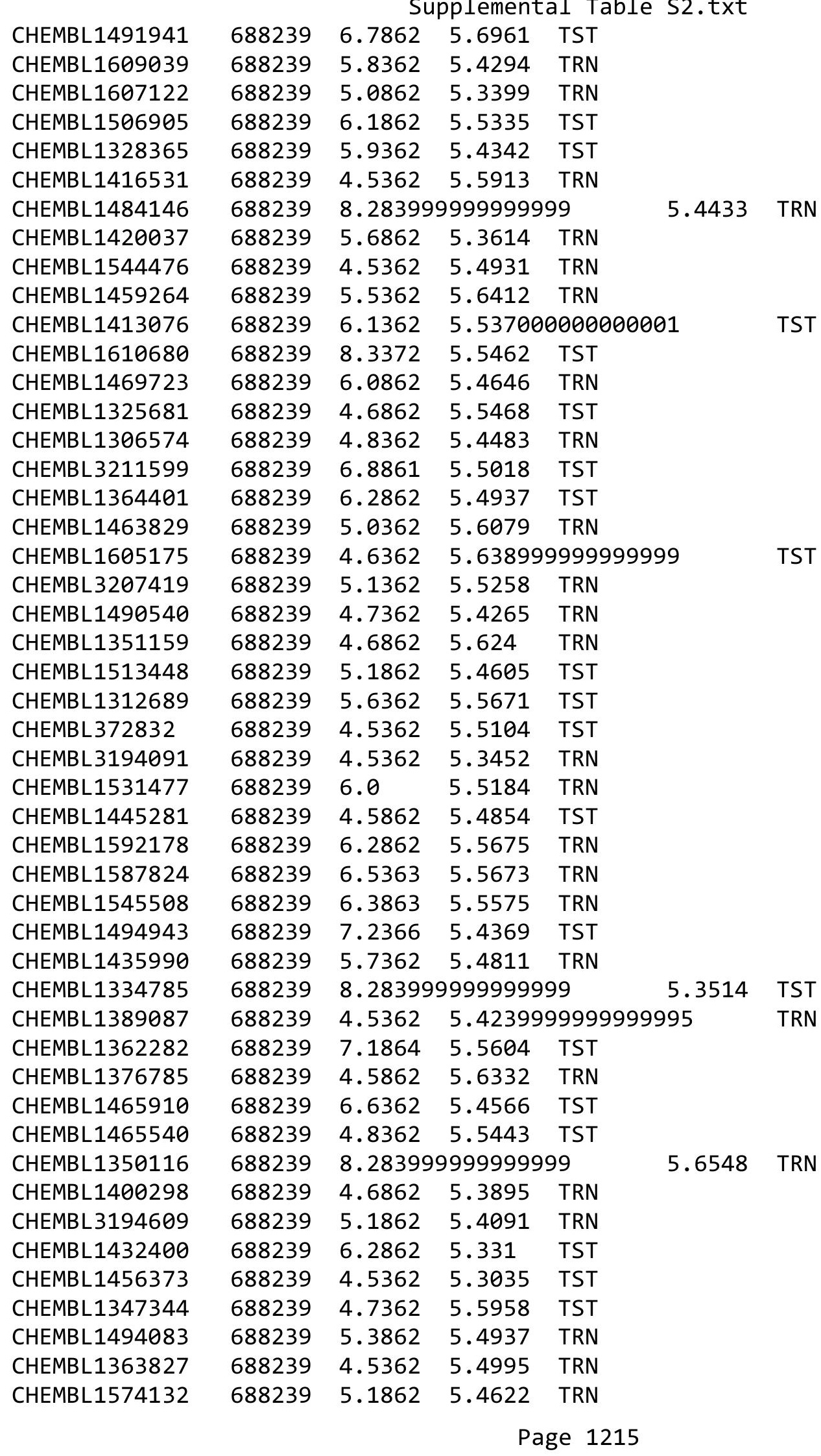




\begin{tabular}{|c|c|c|c|c|c|c|}
\hline \multicolumn{7}{|c|}{ Supplemental Table S2.txt } \\
\hline CHEMBL1565765 & 688239 & 5.4862 & 5.4233 & TRN & & \\
\hline CHEMBL1589136 & 688239 & 6.8362 & 5.334 & TRN & & \\
\hline CHEMBL1445559 & 688239 & 4.9362 & 5.4761 & TRN & & \\
\hline CHEMBL1353789 & 688239 & 6.7361 & 5.5779 & TRN & & \\
\hline CHEMBL140 & 688239 & 4.7362 & 5.4463 & TRN & & \\
\hline CHEMBL1505519 & 688239 & 5.1862 & 5.5366 & TST & & \\
\hline CHEMBL1443858 & 688239 & 5.1862 & 5.5994 & TRN & & \\
\hline CHEMBL1580350 & 688239 & 4.9362 & 5.7362 & TST & & \\
\hline CHEMBL1338102 & 688239 & 5.5862 & 5.3331 & TST & & \\
\hline CHEMBL1324241 & 688239 & 5.7362 & 5.4904 & TRN & & \\
\hline CHEMBL1302876 & 688239 & 8.3372 & 5.4854 & TST & & \\
\hline CHEMBL1381786 & 688239 & 7.2366 & 5.5193 & TRN & & \\
\hline CHEMBL1577861 & 688239 & 5.4862 & 5.5684 & TRN & & \\
\hline CHEMBL1568228 & 688239 & 8.2366 & 5.5076 & TRN & & \\
\hline CHEMBL1355248 & 688239 & 6.2362 & 5.4667 & TRN & & \\
\hline CHEMBL1330327 & 688239 & 5.0362 & 5.4316 & TST & & \\
\hline CHEMBL1420376 & 688239 & 8.28399 & 999999999 & 99 & 5.5588 & TRN \\
\hline CHEMBL1299766 & 688239 & 5.1362 & 5.562 & TRN & & \\
\hline CHEMBL1414769 & 688239 & 5.5862 & 5.6376 & TRN & & \\
\hline CHEMBL3195461 & 688239 & 4.6362 & 5.2563 & TRN & & \\
\hline CHEMBL1313222 & 688239 & 4.45 & 5.4588 & TRN & & \\
\hline CHEMBL1407557 & 688239 & 5.6362 & 5.5105 & TRN & & \\
\hline CHEMBL1322900 & 688239 & 4.7862 & 5.4219 & TRN & & \\
\hline CHEMBL1549488 & 688239 & 4.5362 & 5.4691 & TRN & & \\
\hline CHEMBL1496379 & 688239 & 5.1862 & 5.5027 & TRN & & \\
\hline CHEMBL1607568 & 688239 & 4.7862 & 5.5197 & TRN & & \\
\hline CHEMBL1397320 & 688239 & 5.1862 & 5.5342 & TRN & & \\
\hline CHEMBL1539827 & 688239 & 4.7362 & 5.4999 & TRN & & \\
\hline CHEMBL1421068 & 688239 & 7.2366 & 5.362999 & 999999999 & 95 & TRN \\
\hline CHEMBL1521389 & 688239 & 6.2362 & 5.6374 & TRN & & \\
\hline CHEMBL1533116 & 688239 & 5.1862 & 5.4939 & TRN & & \\
\hline CHEMBL1369387 & 688239 & 5.5362 & 5.5801 & TST & & \\
\hline CHEMBL3208268 & 688239 & 5.1862 & 5.475 & TRN & & \\
\hline CHEMBL1612044 & 688239 & 5.1862 & 5.5138 & TST & & \\
\hline CHEMBL1301263 & 688239 & 6.5862 & 5.5623 & TRN & & \\
\hline CHEMBL1431338 & 688239 & 6.0362 & 5.4511 & TRN & & \\
\hline CHEMBL1431987 & 688239 & 6.9863 & 5.6809 & TRN & & \\
\hline CHEMBL1399374 & 688239 & 6.0862 & 5.3561 & TST & & \\
\hline CHEMBL1498249 & 688239 & 4.5362 & 5.391 & TRN & & \\
\hline CHEMBL1608621 & 688239 & 5.1862 & 5.5417 & TRN & & \\
\hline CHEMBL1387031 & 688239 & 7.0362 & 5.3858 & TRN & & \\
\hline CHEMBL1430117 & 688239 & 5.5362 & 5.5377 & TST & & \\
\hline CHEMBL3208986 & 688239 & 4.5362 & 5.4594 & TRN & & \\
\hline CHEMBL1542156 & 688239 & 5.3362 & 5.5996 & TRN & & \\
\hline CHEMBL1583982 & 688239 & 5.0362 & 5.4486 & TRN & & \\
\hline CHEMBL1306094 & 688239 & 8.28399 & 999999999 & 99 & 5.5141 & TRN \\
\hline CHEMBL 1477687 & 688239 & 4.5862 & 5.4746 & TST & & \\
\hline CHEMBL1414055 & 688239 & 5.9362 & 5.5837 & TRN & & \\
\hline
\end{tabular}


Supplemental Table S2.txt

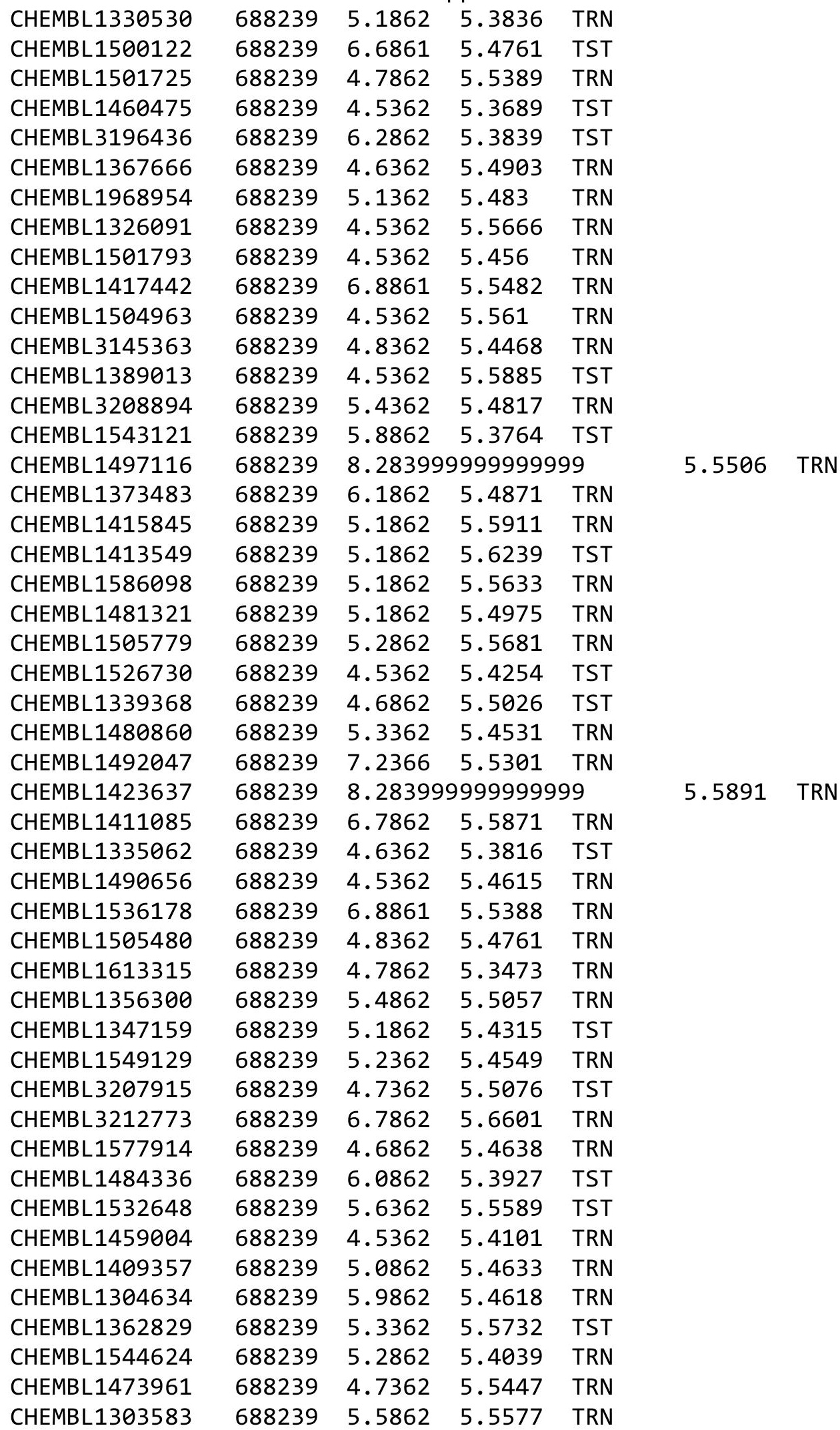

Page 1217 
Supplemental Table S2.txt

\begin{tabular}{|c|c|c|c|c|}
\hline CHEMBL1329726 & 688239 & 4.8362 & 5.3258 & TST \\
\hline CHEMBL1498163 & 688239 & 4.6862 & 5.3982 & TST \\
\hline CHEMBL1607674 & 688239 & 4.7862 & 5.3672 & TRN \\
\hline CHEMBL1377503 & 688239 & 5.9362 & 5.5791 & TRN \\
\hline CHEMBL1578758 & 688239 & 5.1862 & 5.7701 & TRN \\
\hline CHEMBL3214149 & 688239 & 7.2865 & 5.6428 & TRN \\
\hline CHEMBL1519892 & 688239 & 6.1862 & 5.5217 & TRN \\
\hline CHEMBL3210755 & 688239 & 6.2362 & 5.478 & TRN \\
\hline CHEMBL1343657 & 688239 & 5.1862 & 5.6096 & TRN \\
\hline CHEMBL1475977 & 688239 & 4.8862 & 5.49799 & 9999999999 \\
\hline CHEMBL1277809 & 688239 & 6.5363 & 5.5219 & TRN \\
\hline CHEMBL1496605 & 688239 & 6.1362 & 5.5712 & TRN \\
\hline CHEMBL3211112 & 688239 & 5.1862 & 5.5707 & TRN \\
\hline CHEMBL1309770 & 688239 & 4.6362 & 5.655 & TRN \\
\hline CHEMBL1551259 & 688239 & 4.7862 & 5.466 & TRN \\
\hline CHEMBL1384311 & 688239 & 6.1862 & 5.5292 & TST \\
\hline CHEMBL1413254 & 688239 & 5.3362 & 5.4446 & TST \\
\hline CHEMBL1304486 & 688239 & 4.6862 & 5.5255 & TRN \\
\hline CHEMBL1553248 & 688239 & 5.0862 & 5.6213 & TRN \\
\hline CHEMBL1517547 & 688239 & 4.9862 & 5.3065 & TRN \\
\hline CHEMBL3199618 & 688239 & 5.3362 & 5.4667 & TRN \\
\hline CHEMBL1565628 & 688239 & 4.8362 & 5.3632 & TRN \\
\hline CHEMBL1573320 & 688239 & 4.7362 & 5.5199 & TRN \\
\hline CHEMBL1459673 & 688239 & 6.4362 & 5.3617 & TRN \\
\hline CHEMBL1535744 & 688239 & 4.5362 & 5.499 & TRN \\
\hline CHEMBL1327661 & 688239 & 4.6362 & 5.5737 & TRN \\
\hline CHEMBL1470424 & 688239 & 4.6862 & 5.5341 & TRN \\
\hline CHEMBL1579555 & 688239 & 6.4362 & 5.5436 & TRN \\
\hline CHEMBL1492376 & 688239 & 4.7362 & 5.403 & TRN \\
\hline CHEMBL3211911 & 688239 & 5.4862 & 5.5163 & TST \\
\hline CHEMBL1519914 & 688239 & 6.0862 & 5.5185 & TRN \\
\hline CHEMBL1378358 & 688239 & 6.1862 & 5.3329 & TRN \\
\hline CHEMBL1590927 & 688239 & 4.6362 & 5.4531 & TRN \\
\hline CHEMBL1488383 & 688239 & 4.5862 & 5.3636 & TRN \\
\hline CHEMBL1545159 & 688239 & 5.0862 & 5.5501 & TRN \\
\hline CHEMBL260799 & 688239 & 4.6362 & 5.5944 & TRN \\
\hline CHEMBL451747 & 688239 & 4.8862 & 5.4291 & TST \\
\hline CHEMBL1589344 & 688239 & 5.2862 & 5.5626 & TRN \\
\hline CHEMBL1391247 & 688239 & 6.9363 & 5.504 & TRN \\
\hline CHEMBL1578122 & 688239 & 5.1362 & 5.5611 & TRN \\
\hline CHEMBL1505032 & 688239 & 6.2362 & 5.5658 & TRN \\
\hline CHEMBL1575133 & 688239 & 4.5362 & 5.5016 & TRN \\
\hline CHEMBL1392414 & 688239 & 4.8862 & 5.48 & TRN \\
\hline CHEMBL1507936 & 688239 & 4.5862 & 5.4793 & TST \\
\hline CHEMBL1375784 & 688239 & 4.8362 & 5.4302 & TRN \\
\hline CHEMBL1331562 & 688239 & 5.1362 & 5.5149 & TRN \\
\hline CHEMBL1464524 & 688239 & 5.1862 & 5.5065 & TST \\
\hline \multirow[t]{2}{*}{ CHEMBL1523914 } & 688239 & 4.7362 & 5.38200 & 0000000001 \\
\hline & & \multicolumn{3}{|c|}{ Page 1218} \\
\hline
\end{tabular}


Supplemental Table S2.txt

\begin{tabular}{|c|c|c|c|c|}
\hline CHEMBL1384392 & 688239 & 5.9362 & 5.6856 & TST \\
\hline CHEMBL1489105 & 688239 & 6.2862 & 5.3264 & TST \\
\hline CHEMBL1432524 & 688239 & 8.2366 & 5.4276 & TST \\
\hline CHEMBL 1477573 & 688239 & 6.1362 & 5.5337 & TRN \\
\hline CHEMBL1463674 & 688239 & 6.1362 & 5.5132 & TST \\
\hline CHEMBL1378714 & 688239 & 4.5862 & \multicolumn{2}{|c|}{5.5520000000000005} \\
\hline CHEMBL1383238 & 688239 & 5.4362 & 5.397 & TRN \\
\hline CHEMBL1533407 & 688239 & 4.7862 & 5.6165 & TRN \\
\hline CHEMBL1403311 & 688239 & 4.6862 & 5.5568 & TST \\
\hline CHEMBL1399604 & 688239 & 5.8362 & 5.4919 & TRN \\
\hline CHEMBL1416328 & 688239 & 4.5862 & 5.3954 & TRN \\
\hline CHEMBL1584077 & 688239 & 4.8362 & 5.6404 & TRN \\
\hline CHEMBL1301862 & 688239 & 5.0362 & 5.4038 & TRN \\
\hline CHEMBL1418554 & 688239 & 4.7862 & 5.3425 & TRN \\
\hline CHEMBL1313885 & 688239 & 4.6862 & 5.3776 & TRN \\
\hline CHEMBL1420482 & 688239 & 4.5362 & 5.4782 & TRN \\
\hline CHEMBL1573090 & 688239 & 4.7862 & 5.7057 & TRN \\
\hline CHEMBL31425 & 688239 & 6.3863 & 5.3887 & TST \\
\hline CHEMBL1563456 & 688239 & 5.7362 & 5.5747 & TRN \\
\hline CHEMBL1320624 & 688239 & 4.8362 & 5.4746 & TRN \\
\hline CHEMBL1567402 & 688239 & 4.8362 & 5.4117 & TST \\
\hline CHEMBL1352327 & 688239 & 6.2862 & 5.5088 & TST \\
\hline CHEMBL1428824 & 688239 & 5.1862 & 5.572 & TRN \\
\hline CHEMBL1401121 & 688239 & 4.5362 & 5.4 & TST \\
\hline CHEMBL1481973 & 688239 & 4.5362 & 5.4147 & TRN \\
\hline CHEMBL1488275 & 688239 & 6.3362 & 5.5091 & TRN \\
\hline CHEMBL1421029 & 688239 & 4.7862 & 5.4635 & TRN \\
\hline CHEMBL1488292 & 688239 & 4.5862 & \multicolumn{2}{|c|}{5.632000000000001} \\
\hline CHEMBL1342922 & 688239 & 6.7862 & 5.3858 & TRN \\
\hline CHEMBL1573604 & 688239 & 6.9363 & 5.4683 & TRN \\
\hline CHEMBL1374616 & 688239 & 8.3872 & \multicolumn{2}{|c|}{5.3660000000000005} \\
\hline CHEMBL1500248 & 688239 & 6.3863 & 5.3728 & TRN \\
\hline CHEMBL1502143 & 688239 & 5.5362 & 5.5687 & TST \\
\hline CHEMBL1589582 & 688239 & 4.9862 & 5.4479 & TRN \\
\hline CHEMBL1561864 & 688239 & 4.7362 & 5.6328 & TRN \\
\hline CHEMBL1370156 & 688239 & 4.5362 & 5.4571 & TRN \\
\hline CHEMBL1350787 & 688239 & 5.8862 & 5.3207 & TRN \\
\hline CHEMBL1426731 & 688239 & 5.4862 & 5.4595 & TRN \\
\hline CHEMBL1303487 & 688239 & 5.1862 & 5.4936 & TST \\
\hline CHEMBL 222759 & 688239 & 4.5862 & 5.4837 & TRN \\
\hline CHEMBL1300125 & 688239 & 6.8861 & 5.6493 & TST \\
\hline CHEMBL1560010 & 688239 & 4.7362 & 5.4114 & TRN \\
\hline CHEMBL1367242 & 688239 & 4.6862 & 5.5622 & TRN \\
\hline CHEMBL1360560 & 688239 & 4.4862 & 5.4811 & TRN \\
\hline CHEMBL1366727 & 688239 & 5.55 & 5.4837 & TRN \\
\hline CHEMBL1380699 & 688239 & 6.6861 & 5.4035 & TST \\
\hline CHEMBL1455728 & 688239 & 4.5362 & 5.5694 & TST \\
\hline CHEMBL1522070 & 688239 & 5.4362 & 5.6246 & TST \\
\hline
\end{tabular}


Supplemental Table S2.txt

\begin{tabular}{|c|c|c|c|c|}
\hline CHEMBL1423957 & 688239 & 6.4362 & 5.4235 & TRN \\
\hline CHEMBL1465697 & 688239 & 6.6861 & 5.4278 & TRN \\
\hline CHEMBL1517838 & 688239 & 5.6862 & 5.5195 & TRN \\
\hline CHEMBL1531741 & 688239 & 6.1862 & 5.3919 & TRN \\
\hline CHEMBL1342224 & 688239 & 6.9863 & 5.4993 & TRN \\
\hline CHEMBL1352252 & 688239 & 8.1871 & 5.511 & TRN \\
\hline CHEMBL1544639 & 688239 & 6.1362 & 5.5313 & TST \\
\hline CHEMBL1402766 & 688239 & 4.5362 & 5.643 & TRN \\
\hline CHEMBL1376386 & 688239 & 5.0362 & 5.4944 & TST \\
\hline CHEMBL1310298 & 688239 & 5.4362 & 5.6229 & TRN \\
\hline CHEMBL1539235 & 688239 & 4.5862 & 5.6301 & TRN \\
\hline CHEMBL1492732 & 688239 & 6.1862 & 5.5051 & TRN \\
\hline CHEMBL1492479 & 688239 & 6.9863 & 5.457000 & 0000000001 \\
\hline CHEMBL1406501 & 688239 & 5.0362 & 5.5831 & TRN \\
\hline CHEMBL1569987 & 688239 & 4.7362 & 5.3954 & TRN \\
\hline CHEMBL235036 & 688239 & 6.0362 & 5.5922 & TRN \\
\hline CHEMBL1420912 & 688239 & 4.7862 & 5.5195 & TRN \\
\hline CHEMBL1510523 & 688239 & 4.8362 & 5.4339 & TRN \\
\hline CHEMBL1594407 & 688239 & 5.1862 & 5.5631 & TRN \\
\hline CHEMBL1305832 & 688239 & 5.9362 & 5.3614 & TST \\
\hline CHEMBL1419796 & 688239 & 5.2862 & 5.532 & TRN \\
\hline CHEMBL1339824 & 688239 & 6.2362 & 5.4969 & TST \\
\hline CHEMBL2105246 & 688239 & 6.9363 & 5.4309 & TST \\
\hline CHEMBL1472730 & 688239 & 5.8862 & 5.5861 & TST \\
\hline CHEMBL1529173 & 688239 & 4.5862 & 5.4854 & TRN \\
\hline CHEMBL1440576 & 688239 & 4.4862 & 5.4608 & TST \\
\hline CHEMBL1338270 & 688239 & 6.5363 & 5.4034 & TST \\
\hline CHEMBL1447957 & 688239 & 4.6362 & 5.6427 & TRN \\
\hline CHEMBL1410593 & 688239 & 5.1862 & 5.4006 & TST \\
\hline CHEMBL1333743 & 688239 & 5.0862 & 5.4848 & TRN \\
\hline CHEMBL1468046 & 688239 & 4.5362 & $5.50200 e$ & 0000000001 \\
\hline CHEMBL1490020 & 688239 & 5.9362 & 5.4958 & TRN \\
\hline CHEMBL1489336 & 688239 & 5.1862 & 5.5732 & TRN \\
\hline CHEMBL1362463 & 688239 & 6.7361 & 5.4042 & TST \\
\hline CHEMBL1513231 & 688239 & 4.4862 & 5.442 & TRN \\
\hline CHEMBL1595577 & 688239 & 5.6362 & 5.5483 & TRN \\
\hline CHEMBL3212379 & 688239 & 6.5862 & 5.49 & TRN \\
\hline CHEMBL1431075 & 688239 & 5.1862 & 5.4056 & TRN \\
\hline CHEMBL1440770 & 688239 & 8.3872 & 5.3867 & TRN \\
\hline CHEMBL1378784 & 688239 & 6.7862 & 5.3846 & TST \\
\hline CHEMBL1596867 & 688239 & 5.4362 & 5.4247 & TST \\
\hline CHEMBL1490558 & 688239 & 4.9362 & 5.4302 & TRN \\
\hline CHEMBL1491517 & 688239 & 4.5362 & 5.4764 & TRN \\
\hline CHEMBL1395683 & 688239 & 5.3362 & 5.4414 & TRN \\
\hline CHEMBL1423309 & 688239 & 4.6862 & 5.4873 & TRN \\
\hline CHEMBL1316014 & 688239 & 4.4862 & 5.4187 & TST \\
\hline CHEMBL3199648 & 688239 & 6.9363 & 5.3664 & TRN \\
\hline CHEMBL1479734 & 688239 & 5.6362 & 5.6145 & TRN \\
\hline
\end{tabular}


Supplemental Table S2.txt

\begin{tabular}{|c|c|c|c|c|}
\hline CHEMBL1532459 & 688239 & 5.1862 & 5.4818 & TST \\
\hline CHEMBL1596184 & 688239 & 4.6862 & 5.55 & TST \\
\hline CHEMBL1300267 & 688239 & 5.1862 & 5.3386 & TRN \\
\hline CHEMBL1450865 & 688239 & 6.0362 & 5.4863 & TRN \\
\hline CHEMBL1445662 & 688239 & 4.5362 & 5.5607 & TRN \\
\hline CHEMBL1487194 & 688239 & 4.5362 & 5.5546 & TRN \\
\hline CHEMBL1533880 & 688239 & 4.5362 & 5.4305 & TRN \\
\hline CHEMBL1570124 & 688239 & 4.5362 & 5.5958 & TRN \\
\hline CHEMBL1497757 & 688239 & 5.8362 & 5.6652 & TRN \\
\hline CHEMBL1606166 & 688239 & 4.8862 & 5.3549 & TRN \\
\hline CHEMBL1526322 & 688239 & 4.5362 & 5.393 & TST \\
\hline CHEMBL1337809 & 688239 & 6.1862 & 5.3995 & TRN \\
\hline CHEMBL1366210 & 688239 & 8.28399 & 99999999 & 5.537000000000001 \\
\hline CHEMBL1613502 & 688239 & 5.8362 & 5.4455 & TRN \\
\hline CHEMBL1486492 & 688239 & 4.5362 & 5.4609 & TRN \\
\hline CHEMBL1377024 & 688239 & 5.7362 & 5.4628 & TRN \\
\hline CHEMBL1502717 & 688239 & 6.7361 & 5.3667 & TRN \\
\hline CHEMBL1613311 & 688239 & 4.5362 & 5.5554 & TRN \\
\hline CHEMBL1386513 & 688239 & 5.6362 & 5.3877 & TST \\
\hline CHEMBL1470038 & 688239 & 4.6362 & 5.4127 & TRN \\
\hline CHEMBL1389564 & 688239 & 5.5862 & 5.4987 & TRN \\
\hline CHEMBL1567915 & 688239 & 4.5362 & 5.5188 & TRN \\
\hline CHEMBL1313520 & 688239 & 8.3872 & 5.5637 & TRN \\
\hline CHEMBL1561439 & 688239 & 5.6362 & 5.4739 & TRN \\
\hline CHEMBL1571088 & 688239 & 4.6362 & 5.56 & TST \\
\hline CHEMBL3192348 & 688239 & 7.7852 & 5.3806 & TRN \\
\hline CHEMBL1473255 & 688239 & 4.6862 & 5.5246 & TRN \\
\hline CHEMBL1493492 & 688239 & 5.1862 & 5.54299 & 9999999999 \\
\hline CHEMBL1420552 & 688239 & 5.8862 & 5.4255 & TRN \\
\hline CHEMBL1438736 & 688239 & 6.2862 & 5.7215 & TST \\
\hline CHEMBL 2005001 & 688239 & 5.1862 & 5.4375 & TRN \\
\hline CHEMBL1471160 & 688239 & 5.3862 & 5.4716 & TST \\
\hline CHEMBL1321986 & 688239 & 4.4862 & 5.6596 & TRN \\
\hline CHEMBL3209201 & 688239 & 6.2862 & 5.4816 & TST \\
\hline CHEMBL1450511 & 688239 & 6.9363 & 5.5853 & TRN \\
\hline CHEMBL1428482 & 688239 & 5.1862 & 5.4479 & TST \\
\hline CHEMBL1321093 & 688239 & 4.5362 & 5.3727 & TRN \\
\hline CHEMBL1445153 & 688239 & 4.5362 & 5.4312 & TRN \\
\hline CHEMBL1429713 & 688239 & 5.4362 & 5.5583 & TRN \\
\hline CHEMBL1440672 & 688239 & 5.6862 & 5.5899 & TRN \\
\hline CHEMBL1365869 & 688239 & 4.9862 & 5.5492 & TRN \\
\hline CHEMBL1995409 & 688239 & 5.8862 & 5.4788 & TRN \\
\hline CHEMBL1458208 & 688239 & 4.8862 & 5.496 & TST \\
\hline CHEMBL1504499 & 688239 & 4.5362 & 5.3991 & TST \\
\hline CHEMBL3210096 & 688239 & 4.6862 & 5.4614 & TRN \\
\hline CHEMBL1338317 & 688239 & 5.1362 & 5.4396 & TST \\
\hline CHEMBL1309868 & 688239 & 5.8362 & 5.551 & TST \\
\hline CHEMBL1355605 & 688239 & 6.0362 & 5.6431 & TRN \\
\hline
\end{tabular}


Supplemental Table S2.txt

\begin{tabular}{|c|c|c|c|c|c|}
\hline CHEMBL1354948 & 688239 & 5.3362 & 5.4209 & TRN & \\
\hline CHEMBL1316743 & 688239 & 4.6362 & 5.4287 & TRN & \\
\hline CHEMBL1328326 & 688239 & 5.1862 & 5.4982 & TRN & \\
\hline CHEMBL1322769 & 688239 & 4.5362 & 5.4232 & TRN & \\
\hline CHEMBL1319860 & 688239 & 4.5862 & 5.4822 & TRN & \\
\hline CHEMBL1386389 & 688239 & 5.9362 & 5.6737 & TRN & \\
\hline CHEMBL1365999 & 688239 & 6.9363 & 5.4767 & TRN & \\
\hline CHEMBL1299589 & 688239 & 4.6362 & 5.4607 & TRN & \\
\hline CHEMBL1301659 & 688239 & 6.8861 & 5.5505 & TRN & \\
\hline CHEMBL1423135 & 688239 & 6.0862 & 5.4283 & TRN & \\
\hline CHEMBL1584168 & 688239 & 5.1862 & 5.5028 & TRN & \\
\hline CHEMBL1498476 & 688239 & 6.0862 & 5.4793 & TRN & \\
\hline CHEMBL1437512 & 688239 & 6.1862 & 5.54 & TRN & \\
\hline CHEMBL1501638 & 688239 & 4.7362 & 5.5979 & TRN & \\
\hline CHEMBL1531552 & 688239 & 5.7862 & 5.4737 & TRN & \\
\hline CHEMBL1368359 & 688239 & 5.9362 & \multicolumn{2}{|c|}{5.462000000000001} & TST \\
\hline CHEMBL1417555 & 688239 & 5.4862 & 5.4781 & TRN & \\
\hline CHEMBL1402020 & 688239 & 8.1871 & 5.5911 & TRN & \\
\hline CHEMBL1304113 & 688239 & 7.5361 & 5.6282 & TRN & \\
\hline CHEMBL1445725 & 688239 & 6.0862 & 5.3871 & TRN & \\
\hline CHEMBL1591760 & 688239 & 5.1862 & 5.4227 & TST & \\
\hline CHEMBL1344909 & 688239 & 4.5362 & \multicolumn{2}{|c|}{5.492000000000001} & TRN \\
\hline CHEMBL1388088 & 688239 & 5.1862 & 5.4827 & TRN & \\
\hline CHEMBL1372315 & 688239 & 4.6362 & 5.4812 & TST & \\
\hline CHEMBL1465501 & 688239 & 6.2362 & 5.4974 & TST & \\
\hline CHEMBL1406480 & 688239 & 4.7362 & 5.5777 & TRN & \\
\hline CHEMBL1451656 & 688239 & 6.0862 & 5.4522 & TRN & \\
\hline CHEMBL1533741 & 688239 & 6.7361 & 5.4767 & TST & \\
\hline CHEMBL3193910 & 688239 & 5.7362 & 5.5181 & TRN & \\
\hline CHEMBL1400672 & 688239 & 4.6862 & 5.4571 & TRN & \\
\hline CHEMBL1372561 & 688239 & 5.5862 & 5.2628 & TRN & \\
\hline CHEMBL1341501 & 688239 & 5.2862 & 5.4524 & TRN & \\
\hline CHEMBL532412 & 688239 & 5.6862 & 5.3498 & TST & \\
\hline CHEMBL3197962 & 688239 & 4.9362 & 5.5048 & TST & \\
\hline CHEMBL1594187 & 688239 & 4.6362 & 5.5581 & TRN & \\
\hline CHEMBL1348981 & 688239 & 6.5363 & 5.4567 & TST & \\
\hline CHEMBL1597204 & 688239 & 5.1862 & 5.5485 & TRN & \\
\hline CHEMBL3213419 & 688239 & 6.4862 & 5.5177 & TRN & \\
\hline CHEMBL1527040 & 688239 & 6.9363 & 5.4257 & TRN & \\
\hline CHEMBL1574887 & 688239 & 5.1862 & 5.4792 & TRN & \\
\hline CHEMBL1590445 & 688239 & 7.0362 & 5.4748 & TRN & \\
\hline CHEMBL1437868 & 688239 & 4.6862 & 5.4536 & TRN & \\
\hline CHEMBL1366409 & 688239 & 6.1362 & 5.4433 & TRN & \\
\hline CHEMBL1388235 & 688239 & 8.3372 & 5.4968 & TST & \\
\hline CHEMBL1613628 & 688239 & 5.7362 & 5.4622 & TRN & \\
\hline CHEMBL1521359 & 688239 & 8.3372 & 5.3193 & TRN & \\
\hline CHEMBL1363542 & 688239 & 4.5362 & 5.5194 & TRN & \\
\hline CHEMBL1457373 & 688239 & 5.1862 & 5.4621 & TST & \\
\hline
\end{tabular}


Supplemental Table S2.txt

\begin{tabular}{|c|c|c|c|c|c|}
\hline CHEMBL1557812 & 688239 & 4.5362 & 5.4561 & TRN & \\
\hline CHEMBL1583811 & 688239 & 4.5362 & 5.4102 & TST & \\
\hline CHEMBL1503078 & 688239 & 6.0362 & 5.3662 & TRN & \\
\hline CHEMBL1376947 & 688239 & 6.0362 & 5.5034 & TRN & \\
\hline CHEMBL3193647 & 688239 & 4.5362 & 5.5016 & TST & \\
\hline CHEMBL1494362 & 688239 & 5.2862 & 5.4646 & TRN & \\
\hline CHEMBL3190492 & 688239 & 4.6362 & 5.4703 & TST & \\
\hline CHEMBL1567730 & 688239 & 5.3862 & 5.5446 & TST & \\
\hline CHEMBL1533651 & 688239 & 4.5362 & 5.4717 & TST & \\
\hline CHEMBL1303738 & 688239 & 4.4862 & 5.4884 & TRN & \\
\hline CHEMBL1565820 & 688239 & 4.7862 & 5.5641 & TST & \\
\hline CHEMBL1385900 & 688239 & 5.1862 & 5.6225 & TST & \\
\hline CHEMBL1515768 & 688239 & 6.7862 & 5.4789 & TRN & \\
\hline CHEMBL1518227 & 688239 & 4.5362 & 5.4575 & TRN & \\
\hline CHEMBL1405784 & 688239 & 6.6861 & 5.4955 & TRN & \\
\hline CHEMBL1457985 & 688239 & 5.2862 & 5.4739 & TRN & \\
\hline CHEMBL1996281 & 688239 & 4.7362 & 5.3819 & TST & \\
\hline CHEMBL1430380 & 688239 & 4.6862 & 5.5707 & TRN & \\
\hline CHEMBL1335586 & 688239 & 4.6862 & 5.5878 & TRN & \\
\hline CHEMBL1346624 & 688239 & 6.0862 & 5.4882 & TRN & \\
\hline CHEMBL1549107 & 688239 & 5.1862 & 5.5754 & TRN & \\
\hline CHEMBL1611081 & 688239 & 6.0862 & 5.5912 & TRN & \\
\hline CHEMBL1334912 & 688239 & 7.0862 & 5.4863 & TRN & \\
\hline CHEMBL1307648 & 688239 & 5.0862 & 5.4918 & TRN & \\
\hline CHEMBL1497121 & 688239 & 8.3872 & 5.4137 & TRN & \\
\hline CHEMBL1309581 & 688239 & 4.5362 & 5.4797 & TRN & \\
\hline CHEMBL1584133 & 688239 & 4.7362 & 5.2837 & TRN & \\
\hline CHEMBL1568038 & 688239 & 5.2362 & 5.6695 & TRN & \\
\hline CHEMBL1312971 & 688239 & 6.8861 & 5.45799 & 9999999999 & TRN \\
\hline CHEMBL1516679 & 688239 & 4.5362 & 5.4845 & TRN & \\
\hline CHEMBL1536492 & 688239 & 5.1362 & 5.5173 & TRN & \\
\hline CHEMBL1505815 & 688239 & 5.1862 & 5.5828 & TST & \\
\hline CHEMBL1505542 & 688239 & 6.4862 & 5.3031 & TST & \\
\hline CHEMBL1379448 & 688239 & 4.6362 & 5.5232 & TRN & \\
\hline CHEMBL1410983 & 688239 & 5.1862 & 5.6139 & TRN & \\
\hline CHEMBL1328436 & 688239 & 5.9862 & 5.5653 & TRN & \\
\hline CHEMBL1454593 & 688239 & 5.5362 & 5.3988 & TRN & \\
\hline CHEMBL1544003 & 688239 & 6.4362 & 5.4814 & TRN & \\
\hline CHEMBL1536391 & 688239 & 4.6362 & 5.4887 & TRN & \\
\hline CHEMBL1602206 & 688239 & 4.4862 & 5.3705 & TST & \\
\hline CHEMBL1345132 & 688239 & 4.7862 & 5.5037 & TST & \\
\hline CHEMBL1409750 & 688239 & 4.7362 & 5.4138 & TST & \\
\hline CHEMBL1416771 & 688239 & 6.8362 & 5.6843 & TRN & \\
\hline CHEMBL1479995 & 688239 & 4.7362 & 5.461 & TRN & \\
\hline CHEMBL1557618 & 688239 & 4.6362 & 5.5357 & TRN & \\
\hline CHEMBL1490404 & 688239 & 6.6861 & 5.4691 & TRN & \\
\hline CHEMBL1519056 & 688239 & 5.3362 & 5.4403 & TRN & \\
\hline CHEMBL1602503 & 688239 & 5.3862 & 5.4608 & TRN & \\
\hline
\end{tabular}


Supplemental Table S2.txt

\begin{tabular}{|c|c|c|c|c|}
\hline CHEMBL1516390 & 688239 & 4.5862 & 5.4986 & TST \\
\hline CHEMBL1514332 & 688239 & 4.5362 & 5.4843 & TRN \\
\hline CHEMBL1594208 & 688239 & 4.5362 & 5.4027 & TST \\
\hline CHEMBL1314227 & 688239 & 4.9862 & 5.4293 & TRN \\
\hline CHEMBL1333829 & 688239 & 5.1862 & 5.5763 & TRN \\
\hline CHEMBL1377052 & 688239 & 5.2362 & 5.4948 & TRN \\
\hline CHEMBL1560728 & 688239 & 5.6362 & 5.4485 & TRN \\
\hline CHEMBL1469299 & 688239 & 5.3362 & 5.461 & TRN \\
\hline CHEMBL1340892 & 688239 & 5.1362 & 5.5118 & TRN \\
\hline CHEMBL1595177 & 688239 & 5.1862 & 5.5642 & TRN \\
\hline CHEMBL1400670 & 688239 & 4.4862 & 5.4768 & TST \\
\hline CHEMBL1342863 & 688239 & 5.8362 & 5.4089 & TRN \\
\hline CHEMBL1367453 & 688239 & 5.1862 & 5.6174 & TST \\
\hline CHEMBL1540935 & 688239 & 4.4862 & 5.4353 & TRN \\
\hline CHEMBL1481449 & 688239 & 5.0362 & 5.399 & TRN \\
\hline CHEMBL3196413 & 688239 & 4.5362 & 5.5473 & TRN \\
\hline CHEMBL1334268 & 688239 & 4.7362 & 5.4776 & TRN \\
\hline CHEMBL3194096 & 688239 & 7.5867 & 5.4263 & TRN \\
\hline CHEMBL1423887 & 688239 & 6.8861 & 5.3732 & TST \\
\hline CHEMBL3207354 & 688239 & 6.2362 & 5.5727 & TRN \\
\hline CHEMBL1323963 & 688239 & 5.5362 & 5.5194 & TRN \\
\hline CHEMBL1493170 & 688239 & 5.4362 & 5.6721 & TST \\
\hline CHEMBL1438116 & 688239 & 5.7862 & 5.4766 & TRN \\
\hline CHEMBL1335563 & 688239 & 4.4862 & 5.5295 & TST \\
\hline CHEMBL1518327 & 688239 & 4.5362 & 5.5257 & TRN \\
\hline CHEMBL1380285 & 688239 & 5.1862 & 5.4311 & TRN \\
\hline CHEMBL1391328 & 688239 & 4.7362 & $5.45100 e$ & 00000000005 \\
\hline CHEMBL1331629 & 688239 & 5.2362 & 5.5454 & TRN \\
\hline CHEMBL1381528 & 688239 & 6.7361 & 5.5698 & TRN \\
\hline CHEMBL1354900 & 688239 & 5.8862 & 5.5774 & TRN \\
\hline CHEMBL1395852 & 688239 & 6.1862 & 5.4552 & TRN \\
\hline CHEMBL1407230 & 688239 & 4.5362 & 5.4236 & TRN \\
\hline CHEMBL1406120 & 688239 & 6.5862 & 5.4757 & TRN \\
\hline CHEMBL1305254 & 688239 & 4.7362 & 5.4611 & TST \\
\hline CHEMBL3194414 & 688239 & 4.6362 & 5.4013 & TST \\
\hline CHEMBL1327610 & 688239 & 5.4362 & 5.3595 & TRN \\
\hline CHEMBL1437030 & 688239 & 5.6362 & 5.5086 & TRN \\
\hline CHEMBL1308866 & 688239 & 6.8861 & 5.5632 & TST \\
\hline CHEMBL1324583 & 688239 & 6.2362 & 5.3943 & TRN \\
\hline CHEMBL1400282 & 688239 & 5.4362 & 5.4433 & TST \\
\hline CHEMBL3214279 & 688239 & 6.0362 & 5.4445 & TRN \\
\hline CHEMBL1600817 & 688239 & 5.5862 & 5.5119 & TRN \\
\hline CHEMBL1386674 & 688239 & 4.9862 & 5.5144 & TST \\
\hline CHEMBL3213662 & 688239 & 5.3862 & 5.3834 & TRN \\
\hline CHEMBL1603986 & 688239 & 4.6362 & 5.3265 & TRN \\
\hline CHEMBL1524613 & 688239 & 5.1862 & 5.5329 & TST \\
\hline CHEMBL1351324 & 688239 & 4.5362 & 5.4468 & TRN \\
\hline \multirow[t]{2}{*}{ CHEMBL1364659 } & 688239 & 6.0362 & 5.45799 & 9999999 \\
\hline & & \multicolumn{3}{|c|}{ Page 1224} \\
\hline
\end{tabular}


Supplemental Table S2.txt

\begin{tabular}{|c|c|c|c|c|c|}
\hline CHEMBL1354787 & 688239 & 5.1862 & 5.4682 & TRN & \\
\hline CHEMBL1391212 & 688239 & 4.7362 & 5.5651 & TRN & \\
\hline CHEMBL1432272 & 688239 & 6.9363 & 5.4376 & TRN & \\
\hline CHEMBL1526140 & 688239 & 5.1862 & 5.5144 & TST & \\
\hline CHEMBL1373932 & 688239 & 5.3862 & 5.4716 & TRN & \\
\hline CHEMBL1545595 & 688239 & 6.2862 & 5.5875 & TRN & \\
\hline CHEMBL1406062 & 688239 & 4.7362 & 5.5219 & TRN & \\
\hline CHEMBL1418845 & 688239 & 4.9862 & 5.3761 & TST & \\
\hline CHEMBL1579021 & 688239 & 6.2362 & 5.4291 & TRN & \\
\hline CHEMBL1583583 & 688239 & 5.4362 & 5.4485 & TST & \\
\hline CHEMBL 3190837 & 688239 & 7.7352 & 5.4237 & TST & \\
\hline CHEMBL1533771 & 688239 & 5.1862 & 5.5225 & TRN & \\
\hline CHEMBL1304217 & 688239 & 4.5362 & 5.4333 & TRN & \\
\hline CHEMBL1576861 & 688239 & 4.7362 & 5.4724 & TRN & \\
\hline CHEMBL1562092 & 688239 & 5.1862 & 5.4176 & TRN & \\
\hline CHEMBL1543688 & 688239 & 8.3372 & 5.5578 & TRN & \\
\hline CHEMBL1367867 & 688239 & 4.5362 & 5.4858 & TRN & \\
\hline CHEMBL1467662 & 688239 & 5.0362 & 5.5895 & TRN & \\
\hline CHEMBL 3195547 & 688239 & 4.7 & 5.4112 & TRN & \\
\hline CHEMBL1323680 & 688239 & 4.6362 & 5.5095 & TRN & \\
\hline CHEMBL1483336 & 688239 & 5.4362 & 5.5154 & TST & \\
\hline CHEMBL1544103 & 688239 & 6.2362 & 5.4634 & TRN & \\
\hline CHEMBL3195793 & 688239 & 6.0862 & 5.4178 & TRN & \\
\hline CHEMBL1573098 & 688239 & 6.9363 & 5.596 & TST & \\
\hline CHEMBL1558049 & 688239 & 6.1362 & 5.4776 & TRN & \\
\hline CHEMBL1503213 & 688239 & 7.2366 & 5.5723 & TRN & \\
\hline CHEMBL1376069 & 688239 & 6.1362 & 5.4033 & TRN & \\
\hline CHEMBL1438936 & 688239 & 4.7362 & 5.4408 & TRN & \\
\hline CHEMBL1578590 & 688239 & 5.1862 & 5.6433 & TRN & \\
\hline CHEMBL1576576 & 688239 & 8.3372 & \multicolumn{2}{|c|}{5.502000000000001} & TST \\
\hline CHEMBL1354459 & 688239 & 4.5862 & 5.4771 & TRN & \\
\hline CHEMBL1490409 & 688239 & 4.8862 & 5.3287 & TRN & \\
\hline CHEMBL1432668 & 688239 & 4.6862 & 5.4627 & TRN & \\
\hline CHEMBL1543327 & 688239 & 4.9362 & 5.5267 & TRN & \\
\hline CHEMBL1462377 & 688239 & 6.6362 & 5.5986 & TRN & \\
\hline CHEMBL1602696 & 688239 & 4.5362 & \multicolumn{2}{|c|}{5.4110000000000005} & TRN \\
\hline CHEMBL1319905 & 688239 & 8.3372 & 5.4587 & TST & \\
\hline CHEMBL1578322 & 688239 & 5.4862 & 5.6767 & TRN & \\
\hline CHEMBL1579218 & 688239 & 6.1862 & 5.5428 & TST & \\
\hline CHEMBL1353336 & 688239 & 6.2862 & 5.4906 & TRN & \\
\hline CHEMBL1352893 & 688239 & 6.0862 & 5.4551 & TRN & \\
\hline CHEMBL1587920 & 688239 & 6.4862 & 5.5502 & TRN & \\
\hline CHEMBL1493131 & 688239 & 6.9363 & 5.4826 & TRN & \\
\hline CHEMBL1574482 & 688239 & 6.1362 & 5.4669 & TRN & \\
\hline CHEMBL1438401 & 688239 & 4.8362 & 5.5497 & TRN & \\
\hline CHEMBL1317268 & 688239 & 6.3362 & 5.4845 & TRN & \\
\hline CHEMBL1476160 & 688239 & 4.5862 & 5.4674 & TRN & \\
\hline CHEMBL1378309 & 688239 & 5.3862 & 5.4191 & TST & \\
\hline
\end{tabular}


Supplemental Table S2.txt

\begin{tabular}{|c|c|c|c|c|c|}
\hline CHEMBL1342406 & 688239 & 6.1362 & \multicolumn{2}{|c|}{5.502000000000001} & TRN \\
\hline CHEMBL1524486 & 688239 & 4.8362 & 5.4607 & TRN & \\
\hline CHEMBL1307154 & 688239 & 5.6362 & 5.5458 & TRN & \\
\hline CHEMBL1424526 & 688239 & 4.5362 & 5.4873 & TRN & \\
\hline CHEMBL1547387 & 688239 & 6.2362 & 5.4245 & TRN & \\
\hline CHEMBL1434592 & 688239 & 4.6862 & 5.4581 & TRN & \\
\hline CHEMBL1376376 & 688239 & 5.1862 & 5.4448 & TST & \\
\hline CHEMBL1452342 & 688239 & 4.5362 & 5.534 & TRN & \\
\hline CHEMBL1454889 & 688239 & 5.1862 & 5.475 & TST & \\
\hline CHEMBL1580284 & 688239 & 5.1862 & 5.4709 & TST & \\
\hline CHEMBL1534254 & 688239 & 4.6362 & 5.5223 & TRN & \\
\hline CHEMBL1543876 & 688239 & 4.6862 & 5.4991 & TRN & \\
\hline CHEMBL1608635 & 688239 & 5.1862 & 5.3375 & TRN & \\
\hline CHEMBL1504877 & 688239 & 6.4862 & 5.5252 & TRN & \\
\hline CHEMBL1593011 & 688239 & 4.7362 & 5.5078 & TST & \\
\hline CHEMBL1441849 & 688239 & 5.8362 & 5.521 & TRN & \\
\hline CHEMBL1415951 & 688239 & 6.9363 & 5.5266 & TRN & \\
\hline CHEMBL1307905 & 688239 & 4.5362 & 5.6415 & TRN & \\
\hline CHEMBL1445870 & 688239 & 4.6362 & \multicolumn{2}{|c|}{5.582999999999999} & TRN \\
\hline CHEMBL1598786 & 688239 & 4.7862 & 5.3869 & TRN & \\
\hline CHEMBL1366165 & 688239 & 4.7362 & 5.62799 & 9999999999 & TST \\
\hline CHEMBL1546379 & 688239 & 4.5362 & 5.4964 & TRN & \\
\hline CHEMBL1365822 & 688239 & 6.8362 & 5.6179 & TRN & \\
\hline CHEMBL1568853 & 688239 & 4.5362 & 5.4341 & TST & \\
\hline CHEMBL1468294 & 688239 & 6.1362 & 5.4803 & TST & \\
\hline CHEMBL1501777 & 688239 & 6.9863 & 5.5026 & TST & \\
\hline CHEMBL1566282 & 688239 & 7.2366 & 5.6517 & TRN & \\
\hline CHEMBL1486729 & 688239 & 6.1862 & \multicolumn{2}{|c|}{5.5729999999999995} & Tा \\
\hline CHEMBL1509636 & 688239 & 4.5362 & 5.3918 & TST & \\
\hline CHEMBL1546601 & 688239 & 5.8862 & 5.4491 & TRN & \\
\hline CHEMBL1467659 & 688239 & 4.7862 & 5.3981 & TRN & \\
\hline CHEMBL1547006 & 688239 & 5.3862 & 5.4559 & TRN & \\
\hline CHEMBL 3210358 & 688239 & 7.0 & 5.4998 & TST & \\
\hline CHEMBL1589380 & 688239 & 5.4862 & 5.3787 & TRN & \\
\hline CHEMBL1359973 & 688239 & 7.0862 & 5.61 & TST & \\
\hline CHEMBL1613258 & 688239 & 4.6862 & 5.5226 & TST & \\
\hline CHEMBL1452753 & 688239 & 6.0362 & 5.4479 & TRN & \\
\hline CHEMBL1327537 & 688239 & 4.7862 & 5.5452 & TRN & \\
\hline CHEMBL1407286 & 688239 & 4.7862 & 5.6354 & TRN & \\
\hline CHEMBL1512644 & 688239 & 5.3862 & 5.4706 & TRN & \\
\hline CHEMBL1327 & 688239 & 5.2862 & 5.4605 & TST & \\
\hline CHEMBL1503792 & 688239 & 4.6862 & 5.3893 & TRN & \\
\hline CHEMBL1403956 & 688239 & 6.5862 & 5.4556 & TST & \\
\hline CHEMBL1402563 & 688239 & 5.4362 & 5.5145 & TST & \\
\hline CHEMBL1344784 & 688239 & 5.4862 & 5.5422 & TRN & \\
\hline CHEMBL1361013 & 688239 & 5.1862 & 5.5288 & TRN & \\
\hline CHEMBL1502957 & 688239 & 4.5362 & 5.5482 & TRN & \\
\hline CHEMBL1425348 & 688239 & 6.9363 & 5.5434 & TRN & \\
\hline
\end{tabular}


Supplemental Table S2.txt

\begin{tabular}{|c|c|c|c|c|}
\hline CHEMBL1376183 & 688239 & 5.4862 & 5.4464 & TRN \\
\hline CHEMBL1526451 & 688239 & 4.6862 & 5.5781 & TST \\
\hline CHEMBL3211458 & 688239 & 5.4862 & 5.3528 & TST \\
\hline CHEMBL1429511 & 688239 & 5.9362 & 5.4865 & TRN \\
\hline CHEMBL1433660 & 688239 & 6.9863 & 5.3246 & TRN \\
\hline CHEMBL1433108 & 688239 & 5.6862 & 5.5402 & TRN \\
\hline CHEMBL1426632 & 688239 & 6.2362 & 5.541 & TRN \\
\hline CHEMBL1432392 & 688239 & 5.6862 & 5.5432 & TST \\
\hline CHEMBL1519045 & 688239 & 6.8861 & 5.5992 & TRN \\
\hline CHEMBL1504528 & 688239 & 6.8861 & 5.3473 & TRN \\
\hline CHEMBL1434920 & 688239 & 8.3372 & 5.5899 & TRN \\
\hline CHEMBL1611583 & 688239 & 6.6362 & 5.335 & TRN \\
\hline CHEMBL1502009 & 688239 & 6.3863 & 5.5519 & TST \\
\hline CHEMBL1443555 & 688239 & 4.8362 & 5.3667 & TRN \\
\hline CHEMBL1305285 & 688239 & 4.5862 & 5.5877 & TST \\
\hline CHEMBL1542012 & 688239 & 5.6862 & 5.4588 & TRN \\
\hline CHEMBL1542509 & 688239 & 8.2366 & 5.6676 & TRN \\
\hline CHEMBL1537596 & 688239 & 5.4862 & 5.409 & TST \\
\hline CHEMBL1508877 & 688239 & 5.2362 & 5.5409 & TRN \\
\hline CHEMBL1321686 & 688239 & 4.6862 & 5.6202 & TRN \\
\hline CHEMBL1581637 & 688239 & 4.5 & 5.4913 & TRN \\
\hline CHEMBL1553210 & 688239 & 4.5362 & 5.4981 & TRN \\
\hline CHEMBL1512765 & 688239 & 6.9363 & 5.5517 & TRN \\
\hline CHEMBL1579334 & 688239 & 5.3862 & 5.4958 & TRN \\
\hline CHEMBL1407759 & 688239 & 7.6861 & 5.5549 & TRN \\
\hline CHEMBL1552818 & 688239 & 5.7862 & 5.49 & TRN \\
\hline CHEMBL1496141 & 688239 & 5.1362 & 5.4002 & TRN \\
\hline CHEMBL1409443 & 688239 & 4.5362 & 5.4318 & TRN \\
\hline CHEMBL1469501 & 688239 & 5.3862 & 5.5254 & TST \\
\hline CHEMBL1563528 & 688239 & 4.7362 & 5.5522 & TRN \\
\hline CHEMBL1338882 & 688239 & 4.9362 & 5.4397 & TST \\
\hline CHEMBL1453201 & 688239 & 5.2362 & 5.54200 & 0000000001 \\
\hline CHEMBL1537308 & 688239 & 4.7862 & 5.6347 & TRN \\
\hline CHEMBL 1467324 & 688239 & 5.1362 & 5.4351 & TRN \\
\hline CHEMBL1418132 & 688239 & 4.5362 & 5.5436 & TRN \\
\hline CHEMBL233896 & 688239 & 4.5362 & 5.4723 & TST \\
\hline CHEMBL1430641 & 688239 & 4.7862 & 5.4654 & TRN \\
\hline CHEMBL1426136 & 688239 & 6.9863 & 5.6414 & TRN \\
\hline CHEMBL1608550 & 688239 & 5.3362 & 5.5694 & TRN \\
\hline CHEMBL1318058 & 688239 & 4.5362 & 5.3161 & TRN \\
\hline CHEMBL1390992 & 688239 & 6.2862 & 5.6063 & TRN \\
\hline CHEMBL1509490 & 688239 & 5.6862 & 5.5405 & TRN \\
\hline CHEMBL1306112 & 688239 & 5.7362 & 5.6125 & TRN \\
\hline CHEMBL1300727 & 688239 & 4.5362 & 5.4724 & TRN \\
\hline CHEMBL1565526 & 688239 & 5.2862 & 5.3988 & TRN \\
\hline CHEMBL1476088 & 688239 & 5.1362 & 5.5448 & TRN \\
\hline CHEMBL1313158 & 688239 & 5.4362 & 5.5524 & TST \\
\hline CHEMBL1325380 & 688239 & 5.4862 & 5.4299 & TRN \\
\hline
\end{tabular}


Supplemental Table S2.txt

\begin{tabular}{|c|c|c|c|c|c|}
\hline CHEMBL1494600 & 688239 & 4.5362 & 5.4353 & TRN & \\
\hline CHEMBL1581841 & 688239 & 5.1862 & 5.4132 & TRN & \\
\hline CHEMBL1500272 & 688239 & 7.0862 & 5.4857 & TRN & \\
\hline CHEMBL1495994 & 688239 & 5.0862 & 5.4896 & TRN & \\
\hline CHEMBL1463543 & 688239 & 4.8362 & 5.3004 & TRN & \\
\hline CHEMBL1448188 & 688239 & 4.5362 & 5.4491 & TRN & \\
\hline CHEMBL3195326 & 688239 & 5.2362 & 5.4212 & TST & \\
\hline CHEMBL1364130 & 688239 & 5.4862 & 5.5528 & TRN & \\
\hline CHEMBL1444327 & 688239 & 7.1361 & 5.5486 & TRN & \\
\hline CHEMBL1519098 & 688239 & 4.6862 & 5.3514 & TRN & \\
\hline CHEMBL1577086 & 688239 & 5.3862 & 5.4159 & TST & \\
\hline CHEMBL1971154 & 688239 & 5.4862 & 5.4323 & TRN & \\
\hline CHEMBL1342303 & 688239 & 5.1862 & 5.5005 & TRN & \\
\hline CHEMBL1546582 & 688239 & 4.5362 & 5.5211 & TST & \\
\hline CHEMBL1481227 & 688239 & 5.8862 & 5.4204 & TRN & \\
\hline CHEMBL1421784 & 688239 & 5.0362 & 5.425 & TRN & \\
\hline CHEMBL1976861 & 688239 & 4.5362 & 5.2989 & TST & \\
\hline CHEMBL1365442 & 688239 & 7.9872 & 5.4826 & TRN & \\
\hline CHEMBL608112 & 688239 & 5.1862 & 5.4705 & TRN & \\
\hline CHEMBL1549627 & 688239 & 4.5362 & 5.492000 & 000000001 & TRN \\
\hline CHEMBL1352040 & 688239 & 4.7362 & 5.3891 & TST & \\
\hline CHEMBL1594543 & 688239 & 5.1862 & 5.4953 & TRN & \\
\hline CHEMBL1495311 & 688239 & 5.4362 & 5.3131 & TRN & \\
\hline CHEMBL1435005 & 688239 & 8.3372 & 5.4564 & TRN & \\
\hline CHEMBL1526646 & 688239 & 4.85 & 5.5406 & TRN & \\
\hline CHEMBL1341107 & 688239 & 4.5362 & 5.5343 & TRN & \\
\hline CHEMBL1321452 & 688239 & 5.4362 & 5.5206 & TST & \\
\hline CHEMBL1420728 & 688239 & 4.6862 & 5.5083 & TRN & \\
\hline CHEMBL1559675 & 688239 & 5.6862 & 5.6052 & TRN & \\
\hline CHEMBL 223084 & 688239 & 4.5362 & 5.5308 & TST & \\
\hline CHEMBL1338092 & 688239 & 6.1362 & 5.4595 & TRN & \\
\hline CHEMBL1590894 & 688239 & 4.5362 & 5.4083 & TRN & \\
\hline CHEMBL1545890 & 688239 & 4.5362 & 5.6122 & TRN & \\
\hline CHEMBL1500846 & 688239 & 5.1862 & 5.4233 & TRN & \\
\hline CHEMBL1460375 & 688239 & 5.1862 & 5.3767 & TRN & \\
\hline CHEMBL1521371 & 688239 & 5.6862 & 5.5403 & TRN & \\
\hline CHEMBL1431372 & 688239 & 5.3862 & 5.6227 & TRN & \\
\hline CHEMBL1522389 & 688239 & 5.0862 & 5.5315 & TST & \\
\hline CHEMBL3193386 & 688239 & 4.5362 & 5.7423 & TRN & \\
\hline CHEMBL3197792 & 688239 & 4.7862 & 5.3928 & TRN & \\
\hline CHEMBL1569536 & 688239 & 5.2362 & 5.3893 & TRN & \\
\hline CHEMBL1466499 & 688239 & 8.28399 & 99999999 & 5.4937 & TST \\
\hline CHEMBL1312048 & 688239 & 5.7862 & 5.489 & TST & \\
\hline CHEMBL1596444 & 688239 & 6.3863 & 5.6144 & TRN & \\
\hline CHEMBL1516764 & 688239 & 5.6862 & 5.5809 & TRN & \\
\hline CHEMBL1386569 & 688239 & 6.3863 & 5.4561 & TRN & \\
\hline CHEMBL1489959 & 688239 & 4.9862 & 5.522 & TRN & \\
\hline CHEMBL1524338 & 688239 & 5.2862 & 5.4528 & TRN & \\
\hline
\end{tabular}


Supplemental Table S2.txt

\begin{tabular}{|c|c|c|c|c|}
\hline CHEMBL1508009 & 688239 & 5.0862 & 5.5502 & TRN \\
\hline CHEMBL1444471 & 688239 & 4.6862 & 5.484 & TRN \\
\hline CHEMBL1556989 & 688239 & 4.7862 & 5.4243 & TST \\
\hline CHEMBL1442451 & 688239 & 5.1362 & 5.4639 & TRN \\
\hline CHEMBL1462998 & 688239 & 6.0862 & 5.5813 & TRN \\
\hline CHEMBL3193204 & 688239 & 4.9862 & 5.2479 & TST \\
\hline CHEMBL1403808 & 688239 & 5.7862 & 5.5693 & TRN \\
\hline CHEMBL1380989 & 688239 & 5.5362 & 5.3447 & TRN \\
\hline CHEMBL3210615 & 688239 & 5.6362 & 5.4796 & TRN \\
\hline CHEMBL1311444 & 688239 & 4.5362 & 5.4972 & TRN \\
\hline CHEMBL1477968 & 688239 & 6.8362 & 5.5187 & TRN \\
\hline CHEMBL1528209 & 688239 & 5.5362 & 5.5548 & TRN \\
\hline CHEMBL1404390 & 688239 & 7.2366 & 5.4623 & TRN \\
\hline CHEMBL1557586 & 688239 & 5.3362 & 5.4867 & TRN \\
\hline CHEMBL1553906 & 688239 & 7.1361 & 5.518 & TRN \\
\hline CHEMBL1412592 & 688239 & 6.0362 & 5.3346 & TST \\
\hline CHEMBL1606072 & 688239 & 4.7362 & 5.4639 & TRN \\
\hline CHEMBL1507481 & 688239 & 4.6362 & 5.5769 & TRN \\
\hline CHEMBL1468464 & 688239 & 6.0362 & 5.4245 & TST \\
\hline CHEMBL1507045 & 688239 & 4.6362 & 5.4431 & TRN \\
\hline CHEMBL1307434 & 688239 & 6.2362 & 5.4316 & TRN \\
\hline CHEMBL1500794 & 688239 & 4.5362 & 5.4944 & TST \\
\hline CHEMBL1571065 & 688239 & 4.5362 & 5.4785 & TRN \\
\hline CHEMBL1305021 & 688239 & 5.1362 & 5.3716 & TRN \\
\hline CHEMBL1333992 & 688239 & 4.8862 & 5.5906 & TST \\
\hline CHEMBL1387238 & 688239 & 4.6862 & 5.6085 & TRN \\
\hline CHEMBL1299455 & 688239 & 8.3372 & 5.4603 & TRN \\
\hline CHEMBL1369264 & 688239 & 4.8862 & 5.5732 & TRN \\
\hline CHEMBL1395511 & 688239 & 5.0362 & 5.5332 & TRN \\
\hline CHEMBL1445462 & 688239 & 5.9362 & 5.6353 & TRN \\
\hline CHEMBL1602233 & 688239 & 5.1862 & 5.547999 & 9999999999 \\
\hline CHEMBL1498940 & 688239 & 4.6862 & 5.5918 & TRN \\
\hline CHEMBL1302358 & 688239 & 4.9362 & 5.5122 & TRN \\
\hline CHEMBL1426319 & 688239 & 6.2362 & 5.3627 & TRN \\
\hline CHEMBL1413504 & 688239 & 4.8862 & 5.28 & TRN \\
\hline CHEMBL1390345 & 688239 & 4.7362 & 5.5935 & TST \\
\hline CHEMBL1408027 & 688239 & 4.4862 & 5.6319 & TRN \\
\hline CHEMBL1331314 & 688239 & 6.2862 & 5.6609 & TRN \\
\hline CHEMBL324852 & 688239 & 6.0862 & 5.6812 & TST \\
\hline CHEMBL1309631 & 688239 & 6.0362 & 5.5746 & TRN \\
\hline CHEMBL1435497 & 688239 & 6.0862 & 5.4568 & TRN \\
\hline CHEMBL1495421 & 688239 & 6.8362 & 5.5073 & TRN \\
\hline CHEMBL1335844 & 688239 & 4.5362 & 5.3456 & TST \\
\hline CHEMBL1576504 & 688239 & 6.1362 & 5.476 & TST \\
\hline CHEMBL1466700 & 688239 & 4.7362 & 5.6692 & TRN \\
\hline CHEMBL1601858 & 688239 & 5.2362 & 5.6688 & TST \\
\hline CHEMBL1402628 & 688239 & 4.4862 & 5.3267 & TRN \\
\hline CHEMBL 3195222 & 688239 & 5.4862 & 5.3011 & TRN \\
\hline
\end{tabular}


Supplemental Table S2.txt

\begin{tabular}{|c|c|c|c|c|c|}
\hline CHEMBL1307185 & 688239 & 4.6362 & 5.4436 & TST & \\
\hline CHEMBL1989760 & 688239 & 5.3862 & 5.4783 & TRN & \\
\hline CHEMBL1558190 & 688239 & 7.1361 & 5.5584 & TRN & \\
\hline CHEMBL1605739 & 688239 & 6.5862 & 5.468 & TRN & \\
\hline CHEMBL1434385 & 688239 & 5.8862 & 5.2806 & TST & \\
\hline CHEMBL3189197 & 688239 & 4.4862 & 5.4994 & TST & \\
\hline CHEMBL1329299 & 688239 & 5.6862 & 5.5147 & TRN & \\
\hline CHEMBL1329296 & 688239 & 5.1362 & 5.4043 & TRN & \\
\hline CHEMBL 22966 & 688239 & 6.1362 & 5.4869 & TST & \\
\hline CHEMBL3198237 & 688239 & 4.9362 & 5.3316 & TRN & \\
\hline CHEMBL1344382 & 688239 & 7.1361 & 5.4602 & TST & \\
\hline CHEMBL1358020 & 688239 & 4.9862 & 5.4859 & TRN & \\
\hline CHEMBL1425111 & 688239 & 6.3362 & 5.7032 & TRN & \\
\hline CHEMBL 2133740 & 688239 & 6.9363 & 5.5917 & TRN & \\
\hline CHEMBL1608078 & 688239 & 4.6362 & 5.5267 & TRN & \\
\hline CHEMBL1540059 & 688239 & 4.5362 & 5.5531 & TST & \\
\hline CHEMBL3208918 & 688239 & 6.1862 & 5.4432 & TRN & \\
\hline CHEMBL1326680 & 688239 & 4.7362 & 5.5307 & TRN & \\
\hline CHEMBL1519500 & 688239 & 5.5862 & 5.6416 & TRN & \\
\hline CHEMBL1575497 & 688239 & 5.4362 & 5.5703 & TST & \\
\hline CHEMBL1587536 & 688239 & 7.0362 & 5.5135 & TST & \\
\hline CHEMBL1583769 & 688239 & 4.7862 & 5.57 & TRN & \\
\hline CHEMBL1332444 & 688239 & 5.4362 & 5.5551 & TRN & \\
\hline CHEMBL1571123 & 688239 & 6.8861 & 5.3461 & TRN & \\
\hline CHEMBL1320366 & 688239 & 5.5862 & 5.4197 & TRN & \\
\hline CHEMBL1417539 & 688239 & 5.4362 & 5.4609 & TRN & \\
\hline CHEMBL1522647 & 688239 & 5.0362 & 5.3295 & TST & \\
\hline CHEMBL1608454 & 688239 & 4.5362 & 5.5136 & TRN & \\
\hline CHEMBL1437204 & 688239 & 8.2366 & 5.6051 & TRN & \\
\hline CHEMBL1557584 & 688239 & 4.8862 & 5.6241 & TRN & \\
\hline CHEMBL1608931 & 688239 & 5.7362 & 5.5055 & TRN & \\
\hline CHEMBL1550025 & 688239 & 4.7862 & 5.5337 & TRN & \\
\hline CHEMBL1511097 & 688239 & 4.5862 & 5.3437 & TRN & \\
\hline CHEMBL1514279 & 688239 & 4.5862 & 5.4555 & TRN & \\
\hline CHEMBL1382622 & 688239 & 6.0362 & 5.5212 & TRN & \\
\hline CHEMBL1450426 & 688239 & 4.5362 & 5.4553 & TST & \\
\hline CHEMBL1606498 & 688239 & 4.5362 & 5.4354 & TRN & \\
\hline CHEMBL1556995 & 688239 & 8.283999 & 999999999 & 9 & 5.4986 \\
\hline CHEMBL1580288 & 688239 & 6.7862 & 5.3591 & TST & \\
\hline CHEMBL1489635 & 688239 & 4.7362 & 5.4676 & TRN & \\
\hline CHEMBL1601140 & 688239 & 4.5362 & 5.3959 & TRN & \\
\hline CHEMBL1310559 & 688239 & 5.0362 & 5.4975 & TRN & \\
\hline CHEMBL1567469 & 688239 & 5.1862 & 5.5746 & TST & \\
\hline CHEMBL1548226 & 688239 & 6.1362 & 5.4095 & TRN & \\
\hline CHEMBL1583275 & 688239 & 4.6862 & 5.6146 & TST & \\
\hline CHEMBL1537054 & 688239 & 8.2366 & 5.6022 & TST & \\
\hline CHEMBL1587638 & 688239 & 4.5862 & 5.4345 & TST & \\
\hline CHEMBL1311489 & 688239 & 5.0362 & 5.3528 & TRN & \\
\hline
\end{tabular}


Supplemental Table S2.txt

\begin{tabular}{|c|c|c|c|c|}
\hline CHEMBL1574995 & 688239 & 5.3862 & 5.5622 & TRN \\
\hline CHEMBL1451987 & 688239 & 5.3362 & 5.5042 & TST \\
\hline CHEMBL1460263 & 688239 & 4.5362 & 5.4974 & TRN \\
\hline CHEMBL1532752 & 688239 & 5.6362 & 5.3897 & TST \\
\hline CHEMBL1351894 & 688239 & 6.2862 & 5.5469 & TRN \\
\hline CHEMBL1454924 & 688239 & 5.1862 & 5.3925 & TST \\
\hline CHEMBL1558350 & 688239 & 4.6862 & 5.5943 & TRN \\
\hline CHEMBL3189904 & 688239 & 5.8862 & 5.4008 & TRN \\
\hline CHEMBL1351785 & 688239 & 5.7862 & 5.53100 & 0000000001 \\
\hline CHEMBL1381397 & 688239 & 5.1862 & 5.4734 & TRN \\
\hline CHEMBL1360341 & 688239 & 4.5362 & 5.3429 & TST \\
\hline CHEMBL3192095 & 688239 & 6.6861 & 5.3505 & TRN \\
\hline CHEMBL1326994 & 688239 & 5.2862 & 5.5145 & TRN \\
\hline CHEMBL1332156 & 688239 & 4.7362 & 5.5399 & TRN \\
\hline CHEMBL1973003 & 688239 & 4.5362 & 5.433 & TRN \\
\hline CHEMBL1604551 & 688239 & 5.5362 & 5.6272 & TST \\
\hline CHEMBL1392582 & 688239 & 7.2366 & 5.4244 & TRN \\
\hline CHEMBL1580364 & 688239 & 6.2862 & 5.4667 & TRN \\
\hline CHEMBL1439018 & 688239 & 6.9863 & 5.6046 & TRN \\
\hline CHEMBL1424499 & 688239 & 4.8362 & 5.6086 & TST \\
\hline CHEMBL1507901 & 688239 & 4.6862 & 5.6286 & TRN \\
\hline CHEMBL1385338 & 688239 & 7.5361 & 5.641 & TRN \\
\hline CHEMBL1494066 & 688239 & 4.7862 & 5.4419 & TST \\
\hline CHEMBL1487922 & 688239 & 5.2862 & 5.3857 & TRN \\
\hline CHEMBL1368191 & 688239 & 4.5362 & 5.572 & TST \\
\hline CHEMBL1338873 & 688239 & 4.8362 & 5.3954 & TRN \\
\hline CHEMBL1381821 & 688239 & 4.6362 & 5.3677 & TST \\
\hline CHEMBL1375947 & 688239 & 4.5362 & 5.4637 & TRN \\
\hline CHEMBL1442942 & 688239 & 7.0862 & 5.4615 & TRN \\
\hline CHEMBL1971115 & 688239 & 5.1862 & 5.447 & TST \\
\hline CHEMBL1371837 & 688239 & 6.2362 & 5.5332 & TST \\
\hline CHEMBL1526632 & 688239 & 4.5862 & 5.48 & TRN \\
\hline CHEMBL1395790 & 688239 & 5.1862 & 5.636 & TRN \\
\hline CHEMBL1450888 & 688239 & 6.0362 & 5.5025 & TRN \\
\hline CHEMBL1590592 & 688239 & 4.8862 & 5.3385 & TRN \\
\hline CHEMBL1455831 & 688239 & 4.5362 & 5.5144 & TRN \\
\hline CHEMBL1444895 & 688239 & 5.1862 & 5.4198 & TRN \\
\hline CHEMBL1392240 & 688239 & 8.4318 & 5.5204 & TRN \\
\hline CHEMBL1332326 & 688239 & 5.3362 & 5.5614 & TRN \\
\hline CHEMBL1608918 & 688239 & 4.5362 & 5.5044 & TRN \\
\hline CHEMBL1536835 & 688239 & 6.2862 & 5.5172 & TST \\
\hline CHEMBL3209365 & 688239 & 5.8862 & 5.4092 & TRN \\
\hline CHEMBL1549761 & 688239 & 8.2366 & 5.4074 & TRN \\
\hline CHEMBL1583723 & 688239 & 8.3872 & 5.5624 & TST \\
\hline CHEMBL3199876 & 688239 & 4.7362 & 5.5138 & TRN \\
\hline CHEMBL1322866 & 688239 & 4.7862 & 5.3509 & TST \\
\hline CHEMBL1511429 & 688239 & 6.2362 & 5.4425 & TST \\
\hline CHEMBL1377937 & 688239 & 5.4362 & 5.4719 & TST \\
\hline
\end{tabular}


Supplemental Table S2.txt

\begin{tabular}{|c|c|c|c|c|}
\hline CHEMBL1384394 & 688239 & 5.9362 & 5.4545 & TST \\
\hline CHEMBL1493555 & 688239 & 7.0362 & 5.5356 & TRN \\
\hline CHEMBL1396811 & 688239 & 4.7362 & 5.5171 & TRN \\
\hline CHEMBL1320243 & 688239 & 4.8362 & 5.4733 & TRN \\
\hline CHEMBL1512061 & 688239 & 4.5362 & 5.5823 & TRN \\
\hline CHEMBL1329519 & 688239 & 4.5362 & 5.5278 & TRN \\
\hline CHEMBL1334929 & 688239 & 4.5862 & 5.4671 & TST \\
\hline CHEMBL1539658 & 688239 & 6.9863 & 5.3644 & TRN \\
\hline CHEMBL1461299 & 688239 & 4.5362 & 5.5843 & TRN \\
\hline CHEMBL1429520 & 688239 & 8.2366 & 5.4902 & TRN \\
\hline CHEMBL1323414 & 688239 & 4.8862 & 5.4934 & TST \\
\hline CHEMBL1540940 & 688239 & 5.1862 & 5.4881 & TRN \\
\hline CHEMBL1572108 & 688239 & 4.9862 & 5.3521 & TRN \\
\hline CHEMBL3211298 & 688239 & 4.6362 & 5.3365 & TRN \\
\hline CHEMBL1408581 & 688239 & 4.7862 & 5.58 & TRN \\
\hline CHEMBL1600978 & 688239 & 5.7362 & 5.3424 & TST \\
\hline CHEMBL1445729 & 688239 & 4.6862 & 5.6427 & TRN \\
\hline CHEMBL1589084 & 688239 & 6.1362 & 5.569 & TRN \\
\hline CHEMBL1577617 & 688239 & 4.5362 & 5.4079 & TRN \\
\hline CHEMBL1497819 & 688239 & 5.7862 & 5.3334 & TRN \\
\hline CHEMBL1343184 & 688239 & 6.8362 & 5.4992 & TST \\
\hline CHEMBL1448654 & 688239 & 5.2862 & 5.5238 & TRN \\
\hline CHEMBL1505167 & 688239 & 4.5862 & 5.563 & TRN \\
\hline CHEMBL1590553 & 688239 & 4.6362 & 5.524 & TRN \\
\hline CHEMBL1430768 & 688239 & 5.8862 & 5.4608 & TRN \\
\hline CHEMBL1378182 & 688239 & 4.5362 & 5.4952 & TRN \\
\hline CHEMBL1413726 & 688239 & 4.6862 & 5.2936 & TST \\
\hline CHEMBL1343226 & 688239 & 4.6362 & 5.5538 & TRN \\
\hline CHEMBL 3194071 & 688239 & 4.5362 & 5.4544 & TRN \\
\hline CHEMBL558842 & 688239 & 6.4862 & 5.3918 & TST \\
\hline CHEMBL1350924 & 688239 & 6.3362 & 5.484 & TRN \\
\hline CHEMBL1417242 & 688239 & 4.4862 & 5.5152 & TST \\
\hline CHEMBL1367832 & 688239 & 5.9862 & 5.5516 & TRN \\
\hline CHEMBL1576934 & 688239 & 4.7862 & 5.6648 & TST \\
\hline CHEMBL1611028 & 688239 & 5.1862 & 5.4671 & TRN \\
\hline CHEMBL1338209 & 688239 & 6.1362 & 5.4419 & TST \\
\hline CHEMBL 3197197 & 688239 & 4.6862 & 5.3436 & TST \\
\hline CHEMBL1303560 & 688239 & 5.2862 & 5.5064 & TRN \\
\hline CHEMBL1496109 & 688239 & 8.3372 & 5.4771 & TST \\
\hline CHEMBL1439997 & 688239 & 4.5362 & 5.4747 & TRN \\
\hline CHEMBL1564942 & 688239 & 4.8862 & 5.3214 & TRN \\
\hline CHEMBL1356379 & 688239 & 8.2366 & 5.5752 & TRN \\
\hline CHEMBL1613079 & 688239 & 5.2862 & 5.4642 & TST \\
\hline CHEMBL1448358 & 688239 & 8.2366 & 5.6169 & TRN \\
\hline CHEMBL1397153 & 688239 & 6.1362 & 5.4452 & TRN \\
\hline CHEMBL1507986 & 688239 & 7.1361 & 5.6089 & TRN \\
\hline CHEMBL1399018 & 688239 & 5.1862 & 5.4679 & TST \\
\hline \multirow[t]{2}{*}{ CHEMBL1386979 } & 688239 & 4.7362 & 5.36100 & 0000000001 \\
\hline & & \multicolumn{3}{|c|}{ Page 1232} \\
\hline
\end{tabular}


Supplemental Table S2.txt

\begin{tabular}{|c|c|c|c|c|}
\hline 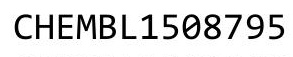 & & & & \\
\hline HEMBL1540166 & 38239 & 362 & 6146 & \\
\hline HEMBL1479208 & 239 & 862 & 3519 & \\
\hline IEMBL1310257 & 39 & 862 & & \\
\hline IEMBL16 & 39 & 362 & & \\
\hline AEMBL1371107 & 88239 & 362 & 373 & \\
\hline AEMBL1369014 & 88239 & 4.5362 & 4933 & \\
\hline HEMBL1549088 & & & & \\
\hline IEMBL157 & 39 & 362 & & \\
\hline IEMBL147 & & & & \\
\hline AEMBL1522301 & 239 & 362 & & \\
\hline HEMBL1609399 & & 362 & & \\
\hline HEMBL1482644 & & 862 & & \\
\hline AEMBL13 & & 362 & & \\
\hline HEMBL 14 & & & & \\
\hline AEMBL1482796 & & 362 & & \\
\hline AEMBL14C & & 362 & & \\
\hline HEMBL147 & & 61 & & \\
\hline HEMBL319 & & 62 & & \\
\hline AEMBL15 & & & & \\
\hline HEMBL472 & & 362 & & \\
\hline HEMBL130 & & 362 & & \\
\hline AEMBL148 & & 62 & & \\
\hline AFMRI 15 & & & & \\
\hline 84 & & & & \\
\hline & & 62 & & \\
\hline IEMBL1377973 & & & & \\
\hline AEMBL15 & & & & \\
\hline$A F M$ & & & & \\
\hline AEMBL15 & & 62 & & \\
\hline AEMBL 319 & & & & \\
\hline AEMBL1333696 & & & & \\
\hline & & & & \\
\hline 3 & & & & \\
\hline HEMBL158 & & & & \\
\hline AEMBL1420104 & & & & \\
\hline AEMBL1547326 & & 362 & & $\mathrm{~S}$ \\
\hline & & & & \\
\hline 2 & & & & \\
\hline HEMBL1434450 & & & & RN \\
\hline AEMBL1327702 & & 62 & & \\
\hline AEMBL1363233 & & 62 & & \\
\hline & & & & \\
\hline CHEMBL1429689 & & & & \\
\hline HEMBL1394216 & & & .5018 & ST \\
\hline MBL1448 & & 362 & 08 & \\
\hline & & & & \\
\hline 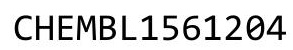 & & & & \\
\hline
\end{tabular}

Page 1233 
Supplemental Table S2.txt

\begin{tabular}{|c|c|c|c|c|c|}
\hline CHEMBL1552907 & 688239 & 5.1862 & 5.4528 & TRN & \\
\hline CHEMBL1412583 & 688239 & 6.3362 & 5.3982 & TST & \\
\hline CHEMBL1407755 & 688239 & 6.5363 & 5.5028 & TRN & \\
\hline CHEMBL607253 & 688239 & 4.5362 & 5.3873 & TST & \\
\hline CHEMBL1313860 & 688239 & 4.5362 & 5.425 & TRN & \\
\hline CHEMBL1400400 & 688239 & 7.1361 & 5.4905 & TRN & \\
\hline CHEMBL1534759 & 688239 & 6.3362 & 5.5859 & TRN & \\
\hline CHEMBL1564038 & 688239 & 4.6862 & 5.3206 & TRN & \\
\hline CHEMBL1428127 & 688239 & 5.1362 & 5.4345 & TRN & \\
\hline CHEMBL3211598 & 688239 & 6.0362 & 5.4047 & TRN & \\
\hline CHEMBL1461649 & 688239 & 5.5862 & 5.544 & TST & \\
\hline CHEMBL1461053 & 688239 & 5.7862 & 5.4667 & TRN & \\
\hline CHEMBL1351264 & 688239 & 7.8861 & 5.4716 & TRN & \\
\hline CHEMBL1489215 & 688239 & 5.4862 & 5.6642 & TST & \\
\hline CHEMBL1310057 & 688239 & 6.7361 & 5.5482 & TRN & \\
\hline CHEMBL1434438 & 688239 & 6.7862 & 5.5597 & TRN & \\
\hline CHEMBL1364975 & 688239 & 5.4362 & 5.59 & TRN & \\
\hline CHEMBL1405586 & 688239 & 6.7862 & 5.561 & TRN & \\
\hline CHEMBL1459118 & 688239 & 4.6362 & 5.6243 & TST & \\
\hline CHEMBL1548524 & 688239 & 5.0862 & 5.4978 & TRN & \\
\hline CHEMBL1595813 & 688239 & 5.5862 & 5.5423 & TRN & \\
\hline CHEMBL1411506 & 688239 & 4.5862 & 5.417999 & 999999999 & TRN \\
\hline CHEMBL1402803 & 688239 & 4.6862 & 5.4494 & TRN & \\
\hline CHEMBL1308665 & 688239 & 4.5362 & 5.4073 & TST & \\
\hline CHEMBL1581318 & 688239 & 4.5362 & 5.6115 & TRN & \\
\hline CHEMBL1366206 & 688239 & 4.7362 & 5.5069 & TST & \\
\hline CHEMBL1497205 & 688239 & 4.6362 & 5.626 & TRN & \\
\hline CHEMBL1967857 & 688239 & 4.9362 & 5.4312 & TRN & \\
\hline CHEMBL1503571 & 688239 & 5.4862 & 5.3619 & TRN & \\
\hline CHEMBL1402368 & 688239 & 4.6362 & 5.422000 & 000000001 & $1 \mathrm{KIV}$ \\
\hline CHEMBL1416899 & 688239 & 6.0362 & 5.4473 & TRN & \\
\hline CHEMBL1549677 & 688239 & 8.2366 & 5.4656 & TRN & \\
\hline CHEMBL1514177 & 688239 & 4.5362 & 5.4797 & TRN & \\
\hline CHEMBL1363338 & 688239 & 6.1862 & 5.5051 & TRN & \\
\hline CHEMBL1466699 & 688239 & 5.4862 & 5.4094 & TRN & \\
\hline CHEMBL1505630 & 688239 & 4.5862 & 5.7031 & TRN & \\
\hline CHEMBL1463211 & 688239 & 4.8362 & 5.4573 & TRN & \\
\hline CHEMBL 3211466 & 688239 & 4.6862 & 5.4843 & TRN & \\
\hline CHEMBL1597960 & 688239 & 8.283999 & 999999999 & 5.4911 & TC \\
\hline CHEMBL1412568 & 688239 & 4.6862 & 5.4162 & TST & \\
\hline CHEMBL1564542 & 688239 & 5.6862 & 5.369 & TRN & \\
\hline CHEMBL1309946 & 688239 & 5.4862 & 5.5047 & TRN & \\
\hline CHEMBL1313042 & 688239 & 6.2862 & 5.6692 & TST & \\
\hline CHEMBL1485298 & 688239 & 4.8862 & 5.5952 & TRN & \\
\hline CHEMBL1573107 & 688239 & 6.0362 & 5.6797 & TRN & \\
\hline CHEMBL1583144 & 688239 & 4.5862 & 5.5023 & TRN & \\
\hline CHEMBL1478820 & 688239 & 5.1862 & 5.5469 & TRN & \\
\hline CHEMBL1334634 & 688239 & 4.6862 & 5.5106 & TRN & \\
\hline
\end{tabular}




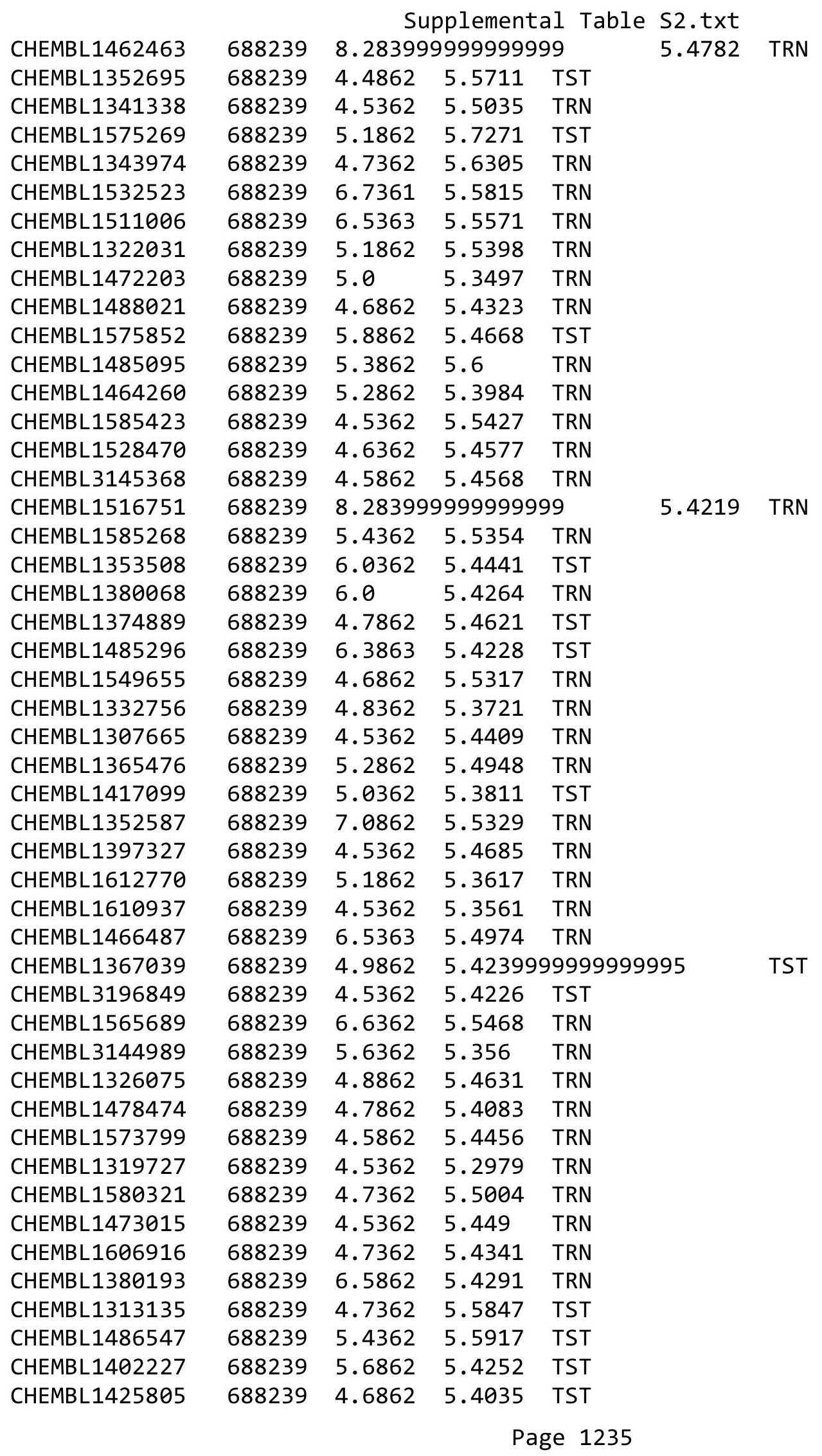


Supplemental Table S2.txt

\begin{tabular}{|c|c|c|c|c|c|c|}
\hline CHEMBL1602868 & 688239 & 4.5362 & 5.4222 & TST & & \\
\hline CHEMBL1377906 & 688239 & 4.8862 & 5.3316 & TRN & & \\
\hline CHEMBL1372343 & 688239 & 6.6362 & 5.7282 & TRN & & \\
\hline CHEMBL1419539 & 688239 & 5.0862 & 5.4913 & TRN & & \\
\hline CHEMBL1509277 & 688239 & 5.1362 & 5.5332 & TRN & & \\
\hline CHEMBL1488156 & 688239 & 5.3862 & 5.5096 & TRN & & \\
\hline CHEMBL597449 & 688239 & 5.5862 & 5.43 & TRN & & \\
\hline CHEMBL1563176 & 688239 & 4.5362 & 5.4034 & TRN & & \\
\hline CHEMBL1359565 & 688239 & 8.3372 & 5.4996 & TRN & & \\
\hline CHEMBL 3190757 & 688239 & 4.5362 & 5.266 & TST & & \\
\hline CHEMBL1512057 & 688239 & 4.7862 & 5.615 & TRN & & \\
\hline CHEMBL1362347 & 688239 & 4.5362 & 5.47 & TRN & & \\
\hline CHEMBL1389627 & 688239 & 4.6362 & 5.5463 & TRN & & \\
\hline CHEMBL3195862 & 688239 & 6.1862 & 5.5666 & TRN & & \\
\hline CHEMBL1577099 & 688239 & 6.1362 & 5.5709 & TRN & & \\
\hline CHEMBL1532635 & 688239 & 5.8362 & 5.4783 & TRN & & \\
\hline CHEMBL1542928 & 688239 & 5.6862 & 5.4886 & TRN & & \\
\hline CHEMBL1523752 & 688239 & 6.2862 & 5.5761 & TRN & & \\
\hline CHEMBL1419680 & 688239 & 5.2862 & 5.407 & TST & & \\
\hline CHEMBL1533375 & 688239 & 4.7862 & 5.4614 & TRN & & \\
\hline CHEMBL1568457 & 688239 & 5.1862 & 5.55 & TRN & & \\
\hline CHEMBL1463861 & 688239 & 5.1362 & 5.506 & TRN & & \\
\hline CHEMBL1300696 & 688239 & 5.7362 & 5.4885 & TRN & & \\
\hline CHEMBL1580566 & 688239 & 4.7362 & 5.6793 & TRN & & \\
\hline CHEMBL1478452 & 688239 & 6.8861 & 5.4072 & TRN & & \\
\hline CHEMBL1536631 & 688239 & 5.2862 & 5.5584 & TRN & & \\
\hline CHEMBL1570308 & 688239 & 8.28399 & 99999999 & 99 & 5.5899 & TR \\
\hline CHEMBL1448529 & 688239 & 4.6862 & 5.4145 & TRN & & \\
\hline CHEMBL1583514 & 688239 & 6.3362 & 5.6563 & TRN & & \\
\hline CHEMBL1493982 & 688239 & 4.5362 & 5.3275 & TRN & & \\
\hline CHEMBL1575447 & 688239 & 5.6862 & 5.3522 & TRN & & \\
\hline CHEMBL1299329 & 688239 & 5.9862 & 5.4278 & TRN & & \\
\hline CHEMBL1390771 & 688239 & 4.5362 & 5.5165 & TST & & \\
\hline CHEMBL1427158 & 688239 & 6.9363 & 5.4371 & TRN & & \\
\hline CHEMBL1571942 & 688239 & 5.0862 & 5.5733 & TRN & & \\
\hline CHEMBL1517646 & 688239 & 4.5362 & 5.3409 & TRN & & \\
\hline CHEMBL1524915 & 688239 & 6.0862 & 5.6638 & TRN & & \\
\hline CHEMBL1300819 & 688239 & 4.5362 & 5.4098 & TST & & \\
\hline CHEMBL1554205 & 688239 & \multicolumn{3}{|c|}{8.283999999999999} & 5.3974 & TRN \\
\hline CHEMBL1309938 & 688239 & 5.8862 & 5.6568 & TST & & \\
\hline CHEMBL1430277 & 688239 & 5.3862 & 5.6013 & TRN & & \\
\hline CHEMBL1608742 & 688239 & 5.1862 & 5.4291 & TRN & & \\
\hline CHEMBL1388505 & 688239 & 6.0362 & 5.55399 & 99999999999 & & \\
\hline CHEMBL1596798 & 688239 & 5.4862 & 5.4747 & TRN & & \\
\hline CHEMBL1590520 & 688239 & 6.7361 & 5.416 & TRN & & \\
\hline CHEMBL1312598 & 688239 & 4.7362 & 5.5947 & TRN & & \\
\hline CHEMBL1606486 & 688239 & 4.8862 & 5.4739 & TRN & & \\
\hline CHEMBL1462874 & 688239 & 5.3362 & 5.4537 & TRN & & \\
\hline
\end{tabular}

Page 1236 
Supplemental Table S2.txt

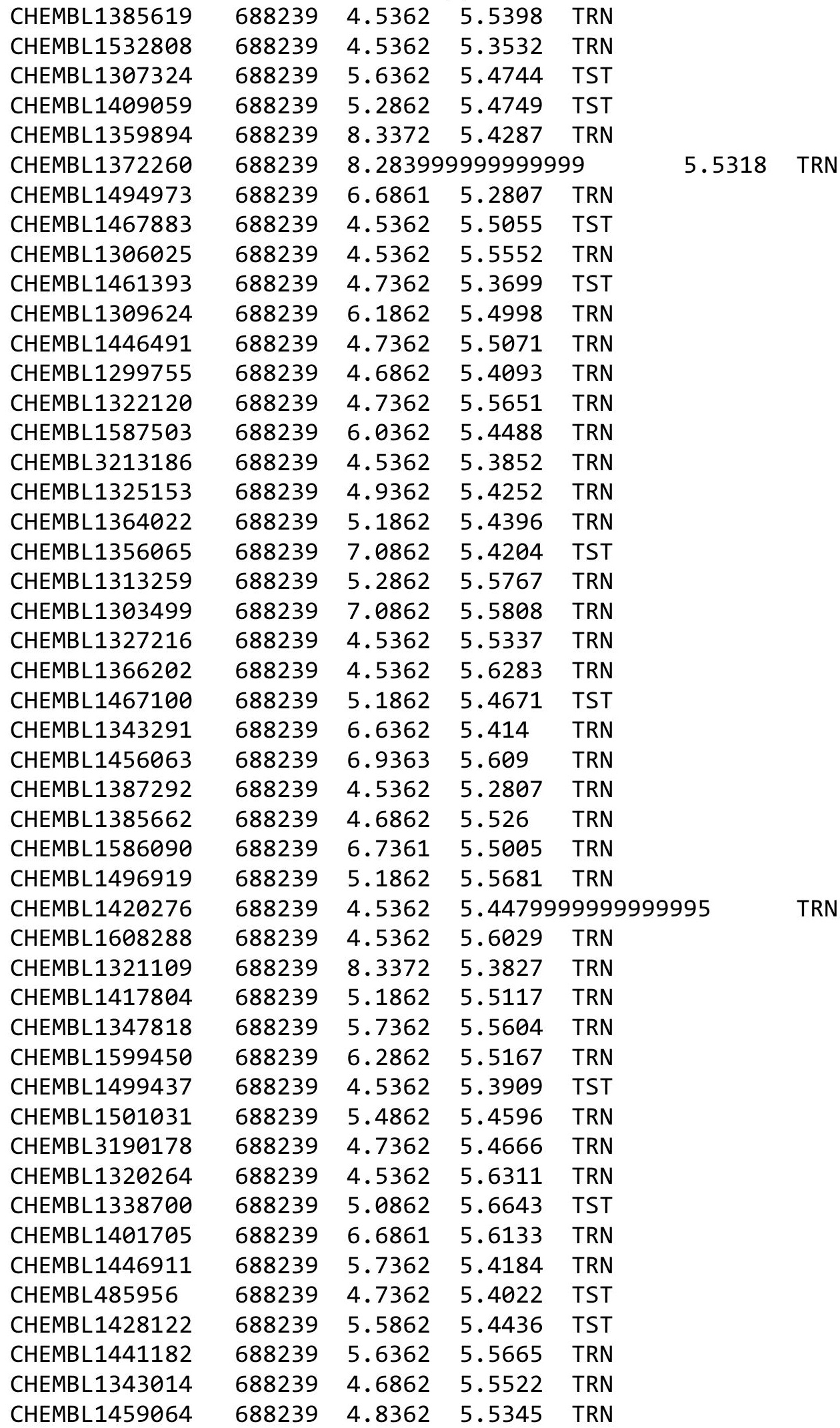


Supplemental Table S2.txt

\begin{tabular}{|c|c|c|c|c|c|}
\hline CHEMBL1533847 & 688239 & 5.8362 & 5.5009 & TRN & \\
\hline CHEMBL1313064 & 688239 & 5.6362 & 5.6452 & TRN & \\
\hline CHEMBL3209866 & 688239 & 5.4362 & 5.4394 & TRN & \\
\hline CHEMBL1517380 & 688239 & 4.5362 & 5.4168 & TST & \\
\hline CHEMBL1516900 & 688239 & 5.1862 & 5.422999 & 999999999 & TRN \\
\hline CHEMBL1509152 & 688239 & 4.5862 & 5.4655 & TRN & \\
\hline CHEMBL1463074 & 688239 & 7.0362 & 5.6244 & TRN & \\
\hline CHEMBL1537950 & 688239 & 4.6362 & 5.4244 & TRN & \\
\hline CHEMBL1381444 & 688239 & 4.5362 & 5.545 & TST & \\
\hline CHEMBL1423164 & 688239 & 5.1862 & 5.48 & TRN & \\
\hline CHEMBL1306385 & 688239 & 4.6362 & 5.3809 & TRN & \\
\hline CHEMBL1383044 & 688239 & 6.9863 & 5.3096 & TRN & \\
\hline CHEMBL1369059 & 688239 & 4.5862 & 5.5791 & TRN & \\
\hline CHEMBL1455758 & 688239 & 4.5862 & 5.49 & TRN & \\
\hline CHEMBL1452873 & 688239 & 4.5362 & 5.4487 & TRN & \\
\hline CHEMBL488140 & 688239 & 4.7862 & 5.3428 & TRN & \\
\hline CHEMBL1426049 & 688239 & 5.8362 & 5.5604 & TRN & \\
\hline CHEMBL1480902 & 688239 & 4.6862 & 5.486000 & 000000001 & \\
\hline CHEMBL1406783 & 688239 & 4.5362 & 5.5494 & TRN & \\
\hline CHEMBL1323050 & 688239 & 4.5362 & 5.5242 & TRN & \\
\hline CHEMBL1466750 & 688239 & 6.0862 & 5.457000 & 000000001 & \\
\hline CHEMBL1469079 & 688239 & 4.7862 & 5.5516 & TRN & \\
\hline CHEMBL1556290 & 688239 & 5.4362 & 5.5761 & TRN & \\
\hline CHEMBL1398568 & 688239 & 4.4862 & 5.3225 & TRN & \\
\hline CHEMBL1319584 & 688239 & 5.1362 & 5.4169 & TST & \\
\hline CHEMBL1350328 & 688239 & 4.6862 & 5.4595 & TRN & \\
\hline CHEMBL1478417 & 688239 & 7.4868 & 5.6181 & TRN & \\
\hline CHEMBL1336541 & 688239 & 5.3362 & 5.3598 & TST & \\
\hline CHEMBL1588611 & 688239 & 4.5362 & 5.59 & TRN & \\
\hline CHEMBL1536222 & 688239 & 6.1862 & 5.5708 & TST & \\
\hline CHEMBL1378382 & 688239 & 6.2862 & 5.6095 & TRN & \\
\hline CHEMBL1393429 & 688239 & 5.4862 & 5.5822 & TRN & \\
\hline CHEMBL1387462 & 688239 & 4.5362 & 5.3515 & TRN & \\
\hline CHEMBL1424056 & 688239 & 4.6862 & 5.5624 & TRN & \\
\hline CHEMBL1520861 & 688239 & 4.7362 & 5.702000 & 000000001 & \\
\hline CHEMBL1391140 & 688239 & 5.3362 & 5.4522 & TST & \\
\hline CHEMBL1324315 & 688239 & 6.6861 & 5.513 & TRN & \\
\hline CHEMBL1481549 & 688239 & 8.283999 & 999999999 & 5.5677 & \\
\hline CHEMBL3198300 & 688239 & 6.1362 & 5.3114 & TRN & \\
\hline CHEMBL3190093 & 688239 & 5.1362 & 5.5412 & TRN & \\
\hline CHEMBL1392488 & 688239 & 4.5362 & 5.5613 & TRN & \\
\hline CHEMBL1525926 & 688239 & 5.8362 & 5.4596 & TRN & \\
\hline CHEMBL1409913 & 688239 & 6.2362 & 5.4548 & TRN & \\
\hline CHEMBL1516175 & 688239 & 5.0362 & 5.4235 & TRN & \\
\hline CHEMBL1489666 & 688239 & 5.1862 & 5.5279 & TRN & \\
\hline CHEMBL1462825 & 688239 & 4.7362 & 5.5057 & TST & \\
\hline CHEMBL1391400 & 688239 & 5.7862 & 5.405 & TST & \\
\hline CHEMBL1316066 & 688239 & 4.6362 & 5.6428 & TRN & \\
\hline
\end{tabular}


Supplemental Table S2.txt

\begin{tabular}{|c|c|c|c|c|c|}
\hline CHEMBL1351380 & 688239 & 4.5862 & 5.4408 & TRN & \\
\hline CHEMBL1372721 & 688239 & 6.7862 & 5.5688 & TRN & \\
\hline CHEMBL1394127 & 688239 & 4.5362 & 5.4545 & TST & \\
\hline CHEMBL1307190 & 688239 & 7.2366 & 5.3648 & TRN & \\
\hline CHEMBL1302194 & 688239 & 6.2362 & 5.5847 & TRN & \\
\hline CHEMBL1595990 & 688239 & 5.3362 & 5.5606 & TRN & \\
\hline CHEMBL1560947 & 688239 & 4.6862 & 5.4944 & TRN & \\
\hline CHEMBL1380497 & 688239 & 4.5362 & 5.3005 & TRN & \\
\hline CHEMBL1563469 & 688239 & 6.0862 & 5.3051 & TRN & \\
\hline CHEMBL1406335 & 688239 & 5.0362 & 5.4719 & TRN & \\
\hline CHEMBL1591029 & 688239 & 6.2362 & 5.4518 & TST & \\
\hline CHEMBL1532143 & 688239 & 4.5362 & 5.4841 & TRN & \\
\hline CHEMBL1352810 & 688239 & 6.3362 & 5.5677 & TRN & \\
\hline CHEMBL1465298 & 688239 & 6.1862 & 5.5105 & TRN & \\
\hline CHEMBL1418803 & 688239 & 6.3362 & 5.4795 & TRN & \\
\hline CHEMBL1408478 & 688239 & 6.2862 & 5.5477 & TRN & \\
\hline CHEMBL1378701 & 688239 & 6.7862 & 5.5651 & TRN & \\
\hline CHEMBL1318007 & 688239 & 4.5362 & 5.5365 & TRN & \\
\hline CHEMBL1561396 & 688239 & 4.5362 & 5.5695 & TST & \\
\hline CHEMBL1384074 & 688239 & 4.5862 & 5.3186 & TRN & \\
\hline CHEMBL1489460 & 688239 & 6.6362 & 5.4056 & TRN & \\
\hline CHEMBL1426129 & 688239 & 4.5362 & 5.545 & TRN & \\
\hline CHEMBL1367900 & 688239 & 4.5362 & 5.5135 & TST & \\
\hline CHEMBL1586440 & 688239 & 8.3372 & 5.6619 & TRN & \\
\hline CHEMBL1460274 & 688239 & 4.5362 & 5.3466 & TRN & \\
\hline CHEMBL1611839 & 688239 & 5.3362 & 5.4224 & TRN & \\
\hline CHEMBL1576782 & 688239 & 6.8861 & 5.5889 & TRN & \\
\hline CHEMBL1510697 & 688239 & 4.7362 & 5.6405 & TRN & \\
\hline CHEMBL1597749 & 688239 & 5.1862 & 5.5355 & TRN & \\
\hline CHEMBL1483456 & 688239 & 4.7862 & 5.5076 & TRN & \\
\hline CHEMBL1441050 & 688239 & 6.1862 & 5.6417 & TST & \\
\hline CHEMBL1316060 & 688239 & 5.6862 & 5.4085 & TRN & \\
\hline CHEMBL1333989 & 688239 & 6.1862 & 5.4122 & TRN & \\
\hline CHEMBL1376505 & 688239 & 5.3362 & 5.4363 & TRN & \\
\hline CHEMBL1487478 & 688239 & 5.1862 & 5.5241 & TRN & \\
\hline CHEMBL1412159 & 688239 & 4.7862 & 5.42399 & 99999999995 & TRN \\
\hline CHEMBL1423693 & 688239 & 4.5362 & 5.539 & TST & \\
\hline CHEMBL1448176 & 688239 & 5.6362 & 5.6476 & TRN & \\
\hline CHEMBL1378742 & 688239 & 5.2862 & 5.4197 & TRN & \\
\hline CHEMBL1462560 & 688239 & 5.8862 & 5.5999 & TRN & \\
\hline CHEMBL1535889 & 688239 & 5.1362 & 5.4173 & TRN & \\
\hline CHEMBL1598539 & 688239 & 4.6862 & 5.5501 & TRN & \\
\hline CHEMBL1993788 & 688239 & 4.6862 & 5.3149 & TRN & \\
\hline CHEMBL1548271 & 688239 & 4.7362 & 5.4668 & TST & \\
\hline CHEMBL1476928 & 688239 & 6.3362 & 5.4899 & TRN & \\
\hline CHEMBL1605495 & 688239 & 4.8362 & 5.4864 & TST & \\
\hline CHEMBL1583354 & 688239 & 4.5362 & 5.5372 & TRN & \\
\hline CHEMBL1343167 & 688239 & 5.1862 & 5.6658 & TST & \\
\hline
\end{tabular}


Supplemental Table S2.txt

\begin{tabular}{|c|c|c|c|c|}
\hline CHEMBL1343234 & 688239 & 5.1862 & 5.4416 & TRN \\
\hline CHEMBL1387334 & 688239 & 5.2362 & 5.4188 & TST \\
\hline CHEMBL1512573 & 688239 & 5.1862 & 5.5361 & TRN \\
\hline CHEMBL1560483 & 688239 & 7.1864 & 5.3856 & TST \\
\hline CHEMBL1560043 & 688239 & 5.8862 & 5.37299 & 9999999999 \\
\hline CHEMBL1558464 & 688239 & 4.5362 & 5.2807 & TST \\
\hline CHEMBL1446505 & 688239 & 4.5862 & 5.5588 & TRN \\
\hline CHEMBL1602086 & 688239 & 5.1862 & 5.3718 & TST \\
\hline CHEMBL1332925 & 688239 & 4.5362 & 5.4061 & TRN \\
\hline CHEMBL1303381 & 688239 & 4.7862 & 5.4449 & TST \\
\hline CHEMBL1319089 & 688239 & 6.7361 & 5.5906 & TST \\
\hline CHEMBL1546216 & 688239 & 4.5362 & 5.5068 & TST \\
\hline CHEMBL1373696 & 688239 & 6.0362 & 5.6008 & TRN \\
\hline CHEMBL1306715 & 688239 & 6.7361 & 5.6042 & TST \\
\hline CHEMBL1468837 & 688239 & 6.1362 & 5.4759 & TRN \\
\hline CHEMBL1526789 & 688239 & 5.6862 & 5.4625 & TRN \\
\hline CHEMBL1468654 & 688239 & 4.5362 & 5.5669 & TST \\
\hline CHEMBL1507400 & 688239 & 6.1362 & 5.5353 & TRN \\
\hline CHEMBL1535609 & 688239 & 4.7862 & 5.7238 & TRN \\
\hline CHEMBL1470775 & 688239 & 5.3862 & 5.5004 & TST \\
\hline CHEMBL1580493 & 688239 & 4.5362 & 5.4403 & TRN \\
\hline CHEMBL1543984 & 688239 & 4.5362 & 5.6356 & TRN \\
\hline CHEMBL1517795 & 688239 & 4.7862 & 5.4845 & TRN \\
\hline CHEMBL1538677 & 688239 & 4.85 & 5.5424 & TRN \\
\hline CHEMBL1549889 & 688239 & 5.7862 & 5.6475 & TRN \\
\hline CHEMBL 2005923 & 688239 & 5.7862 & 5.4198 & TRN \\
\hline CHEMBL593305 & 688239 & 6.6362 & 5.5152 & TRN \\
\hline CHEMBL1488505 & 688239 & 5.0362 & 5.5319 & TRN \\
\hline CHEMBL1455237 & 688239 & 6.2362 & 5.5019 & TRN \\
\hline CHEMBL1547237 & 688239 & 5.7362 & 5.4232 & TRN \\
\hline CHEMBL114544 & 688239 & 6.9363 & 5.4927 & TST \\
\hline CHEMBL1372658 & 688239 & 4.9362 & 5.4917 & TST \\
\hline CHEMBL1342862 & 688239 & 6.1862 & 5.6175 & TRN \\
\hline CHEMBL1501503 & 688239 & 7.6861 & 5.6826 & TRN \\
\hline CHEMBL1396116 & 688239 & 5.3362 & 5.4785 & TST \\
\hline CHEMBL1587934 & 688239 & 4.5362 & 5.4956 & TRN \\
\hline CHEMBL1510127 & 688239 & 4.4862 & 5.5959 & TST \\
\hline CHEMBL1355439 & 688239 & 8.3872 & 5.5184 & TST \\
\hline CHEMBL1344597 & 688239 & 5.3862 & 5.3919 & TRN \\
\hline CHEMBL1346667 & 688239 & 6.7862 & 5.3581 & TST \\
\hline CHEMBL1605725 & 688239 & 4.6862 & 5.4955 & TRN \\
\hline CHEMBL1506214 & 688239 & 5.4362 & 5.5159 & TRN \\
\hline CHEMBL1462675 & 688239 & 5.9362 & 5.4678 & TRN \\
\hline CHEMBL1527488 & 688239 & 5.4362 & 5.5449 & TRN \\
\hline CHEMBL1321476 & 688239 & 5.1862 & 5.6799 & TRN \\
\hline CHEMBL1459434 & 688239 & 5.6362 & 5.6627 & TRN \\
\hline CHEMBL1435192 & 688239 & 5.4862 & 5.5381 & TRN \\
\hline CHEMBL1485798 & 688239 & 6.1362 & 5.4233 & TRN \\
\hline
\end{tabular}


Supplemental Table S2.txt

\begin{tabular}{|c|c|c|c|c|}
\hline & & & & \\
\hline HEMBL1529320 & 38239 & 863 & 14 & \\
\hline AEMBL1536005 & 239 & 362 & 887 & \\
\hline EMBL14 & 39 & & & \\
\hline IEMBL1313227 & & 362 & & \\
\hline AEMBL1482559 & 88239 & 362 & 1055 & \\
\hline AEMBL1489835 & 88239 & 4.8362 & 3362 & \\
\hline AEMBL14ع & & 362 & 044 & \\
\hline EMBL14 & 39 & 363 & 306 & \\
\hline EMBL15 & & & & \\
\hline AEMBL1565440 & 39 & 362 & 983 & \\
\hline AEMBL1522724 & & 862 & 879 & \\
\hline AEMBL3211218 & & 62 & & \\
\hline IEMBL1308858 & & & & \\
\hline AEMBL1311307 & & & 04 & \\
\hline AEMBL1497557 & & 362 & 187 & \\
\hline AEMBL1574481 & & 862 & & \\
\hline IEMBL136 & & 4 & & \\
\hline AEMBL146 & & & & \\
\hline JEMBL13. & & & & \\
\hline AEMBL1983234 & & 362 & & \\
\hline AEMBL1576572 & & 62 & & \\
\hline IEMBL1303 & & 62 & & \\
\hline AFMRI 153 & & & & \\
\hline 59 & & & & \\
\hline AEMBL1361098 & & 62 & & \\
\hline IEMBL1545174 & & & & \\
\hline IEMBL1593572 & & 62 & & \\
\hline 572 & & & & \\
\hline 00 & & 362 & 87 & \\
\hline AEMBL3194853 & & & & \\
\hline IEMBL1390226 & & 362 & 94 & \\
\hline & & & & \\
\hline 97 & & & & \\
\hline HEMBL1358925 & & & & \\
\hline AEMBL3210079 & & & 693 & \\
\hline AEMBL1328977 & & 66 & 334 & \\
\hline ter & & & 73 & \\
\hline 1393701 & & & & RN \\
\hline HEMBL1612772 & & & & RI \\
\hline AEMBL1409100 & & 62 & 171 & $\mathrm{R}$ \\
\hline IEMBL1594177 & & 62 & 216 & $\lceil\mathrm{~F}$ \\
\hline & & & & TS \\
\hline HEMBL1387000 & & & 807 & TST \\
\hline HEMBL1526070 & & & & is \\
\hline MBL1568456 & & 862 & 541 & TS \\
\hline MBL13666 & & & & \\
\hline HEMBL156029 & & & & \\
\hline
\end{tabular}

Page 1241 
Supplemental Table S2.txt

\begin{tabular}{|c|c|c|c|c|c|}
\hline CHEMBL1306875 & 688239 & 6.2862 & 5.4638 & TRN & \\
\hline CHEMBL1478672 & 688239 & 5.1862 & 5.4527 & TRN & \\
\hline CHEMBL1502186 & 688239 & 4.5362 & 5.6329 & TRN & \\
\hline CHEMBL1488657 & 688239 & 5.7862 & 5.5338 & TRN & \\
\hline CHEMBL1496619 & 688239 & 4.8362 & 5.4765 & TRN & \\
\hline CHEMBL3209620 & 688239 & 5.3362 & 5.5871 & TRN & \\
\hline CHEMBL1392855 & 688239 & 4.7362 & 5.5324 & TRN & \\
\hline CHEMBL1493380 & 688239 & 5.6362 & 5.5098 & TRN & \\
\hline CHEMBL1405439 & 688239 & 4.5362 & 5.405 & TRN & \\
\hline CHEMBL1343336 & 688239 & 4.9862 & 5.6103 & TRN & \\
\hline CHEMBL1482142 & 688239 & 5.1862 & 5.42399 & э99999999995 & TRN \\
\hline CHEMBL1509887 & 688239 & 5.1362 & 5.44799 & 99999999995 & TRN \\
\hline CHEMBL1358109 & 688239 & 4.5862 & 5.4686 & TRN & \\
\hline CHEMBL1343541 & 688239 & 4.6862 & 5.7526 & TRN & \\
\hline CHEMBL1553286 & 688239 & 4.6362 & 5.5622 & TRN & \\
\hline CHEMBL1496741 & 688239 & 6.2362 & 5.6598 & TRN & \\
\hline CHEMBL3189951 & 688239 & 6.4362 & 5.4067 & TRN & \\
\hline CHEMBL1495342 & 688239 & 4.5362 & 5.4985 & TRN & \\
\hline CHEMBL1392599 & 688239 & 4.6862 & 5.4003 & TST & \\
\hline CHEMBL3193737 & 688239 & 7.1864 & 5.4859 & TRN & \\
\hline CHEMBL1595224 & 688239 & 6.9863 & 5.6114 & TST & \\
\hline CHEMBL570376 & 688239 & 5.1862 & 5.5497 & TRN & \\
\hline CHEMBL1541169 & 688239 & 6.5862 & 5.6009 & TRN & \\
\hline CHEMBL1378301 & 688239 & 5.3862 & 5.7331 & TRN & \\
\hline CHEMBL1540679 & 688239 & 4.7862 & 5.6488 & TST & \\
\hline CHEMBL3194195 & 688239 & 4.4862 & 5.3457 & TST & \\
\hline CHEMBL3196985 & 688239 & 6.4862 & 5.4007 & TRN & \\
\hline CHEMBL1477708 & 688239 & 4.6362 & 5.4387 & TRN & \\
\hline CHEMBL1434064 & 688239 & 6.1862 & 5.432 & TRN & \\
\hline CHEMBL1581263 & 688239 & 6.7862 & 5.3425 & TRN & \\
\hline CHEMBL1456893 & 688239 & 4.6862 & 5.393 & TRN & \\
\hline CHEMBL1341796 & 688239 & 6.8861 & 5.6444 & TRN & \\
\hline CHEMBL1487185 & 688239 & 5.5362 & 5.5779 & TRN & \\
\hline CHEMBL3209622 & 688239 & 4.7362 & 5.42299 & 7999999999 & TRN \\
\hline CHEMBL1584764 & 688239 & 4.5362 & 5.2968 & TRN & \\
\hline CHEMBL1499388 & 688239 & 4.6362 & 5.5771 & TRN & \\
\hline CHEMBL1599072 & 688239 & 6.9863 & 5.3291 & TRN & \\
\hline CHEMBL1439095 & 688239 & 5.8862 & 5.5878 & TRN & \\
\hline CHEMBL1407624 & 688239 & 4.8862 & 5.5906 & TRN & \\
\hline CHEMBL1479455 & 688239 & 5.8862 & 5.4214 & TRN & \\
\hline CHEMBL1610069 & 688239 & 8.3872 & 5.4359 & TRN & \\
\hline CHEMBL1578865 & 688239 & 8.3372 & 5.54799 & 9999999999 & TRN \\
\hline CHEMBL1381306 & 688239 & 4.6862 & 5.4971 & TRN & \\
\hline CHEMBL1401858 & 688239 & 5.7862 & 5.4164 & TRN & \\
\hline CHEMBL1341091 & 688239 & 6.3863 & 5.7061 & TRN & \\
\hline CHEMBL1451475 & 688239 & 6.5363 & 5.4958 & TRN & \\
\hline CHEMBL1476459 & 688239 & 6.4362 & 5.4517 & TRN & \\
\hline CHEMBL1471666 & 688239 & 6.1862 & 5.5654 & TRN & \\
\hline
\end{tabular}


Supplemental Table S2.txt

\begin{tabular}{|c|c|c|c|c|}
\hline CHEMBL1465159 & 688239 & 5.1862 & 5.3772 & TRN \\
\hline CHEMBL1422456 & 688239 & 4.5362 & 5.2831 & TST \\
\hline CHEMBL1438179 & 688239 & 5.4 & 5.5343 & TRN \\
\hline CHEMBL1514598 & 688239 & 5.9862 & 5.5296 & TST \\
\hline CHEMBL1375150 & 688239 & 8.3372 & 5.4623 & TRN \\
\hline CHEMBL1543318 & 688239 & 5.1862 & 5.4951 & TRN \\
\hline CHEMBL1304272 & 688239 & 5.5362 & 5.6098 & TRN \\
\hline CHEMBL1338294 & 688239 & 5.4862 & 5.4914 & TRN \\
\hline CHEMBL1540121 & 688239 & 4.4862 & 5.4996 & TRN \\
\hline CHEMBL1466465 & 688239 & 5.8362 & 5.4719 & TRN \\
\hline CHEMBL1530721 & 688239 & 6.2862 & 5.5788 & TRN \\
\hline CHEMBL1423703 & 688239 & 4.8862 & 5.5225 & TRN \\
\hline CHEMBL1570223 & 688239 & 5.5862 & 5.4859 & TRN \\
\hline CHEMBL1528012 & 688239 & 4.5862 & 5.44600 & 0000000001 \\
\hline CHEMBL1476413 & 688239 & 4.7362 & 5.5696 & TRN \\
\hline CHEMBL1593160 & 688239 & 5.3862 & 5.4398 & TRN \\
\hline CHEMBL1310030 & 688239 & 4.7362 & 5.4556 & TST \\
\hline CHEMBL1431654 & 688239 & 5.0362 & 5.5196 & TRN \\
\hline CHEMBL1530366 & 688239 & 6.9363 & 5.5834 & TRN \\
\hline CHEMBL1550859 & 688239 & 6.0362 & 5.5129 & TRN \\
\hline CHEMBL1416798 & 688239 & 7.2366 & 5.6134 & TST \\
\hline CHEMBL1499046 & 688239 & 5.5862 & 5.5769 & TST \\
\hline CHEMBL1494441 & 688239 & 5.8362 & 5.3469 & TRN \\
\hline CHEMBL1495901 & 688239 & 5.4362 & 5.4509 & TRN \\
\hline CHEMBL1439245 & 688239 & 5.1862 & 5.4298 & TRN \\
\hline CHEMBL1442492 & 688239 & 5.1862 & 5.5045 & TST \\
\hline CHEMBL1503424 & 688239 & 4.9362 & 5.5207 & TST \\
\hline CHEMBL1439795 & 688239 & 5.3362 & 5.5351 & TRN \\
\hline CHEMBL1389449 & 688239 & 5.1862 & 5.6086 & TRN \\
\hline CHEMBL1459968 & 688239 & 6.8362 & 5.455 & TRN \\
\hline CHEMBL3196182 & 688239 & 6.5862 & 5.4747 & TST \\
\hline CHEMBL1347063 & 688239 & 5.3362 & 5.4731 & TST \\
\hline CHEMBL1359231 & 688239 & 5.9362 & 5.5632 & TRN \\
\hline CHEMBL1342248 & 688239 & 4.8362 & 5.2352 & TST \\
\hline CHEMBL1323370 & 688239 & 8.3872 & 5.4821 & TRN \\
\hline CHEMBL1448169 & 688239 & 4.7362 & 5.5104 & TRN \\
\hline CHEMBL1524995 & 688239 & 5.4862 & 5.5736 & TRN \\
\hline CHEMBL1423139 & 688239 & 4.6862 & 5.4967 & TRN \\
\hline CHEMBL1426277 & 688239 & 5.2362 & 5.5117 & TRN \\
\hline CHEMBL1432244 & 688239 & 4.5362 & 5.3984 & TRN \\
\hline CHEMBL1597041 & 688239 & 4.7362 & 5.4001 & TST \\
\hline CHEMBL1375811 & 688239 & 8.2366 & 5.5603 & TST \\
\hline CHEMBL1344375 & 688239 & 6.2362 & 5.513 & TRN \\
\hline CHEMBL1315901 & 688239 & 4.8362 & 5.4119 & TRN \\
\hline CHEMBL1588810 & 688239 & 4.5362 & 5.5231 & TRN \\
\hline CHEMBL1414543 & 688239 & 6.3362 & 5.4637 & TRN \\
\hline CHEMBL1432281 & 688239 & 5.2862 & 5.5598 & TRN \\
\hline CHEMBL1472147 & 688239 & 4.5362 & 5.485 & TRN \\
\hline
\end{tabular}




\begin{tabular}{|c|c|c|c|c|c|}
\hline \multicolumn{6}{|c|}{ Supplemental Table S2.txt } \\
\hline CHEMBL1382546 & 688239 & 6.6861 & 5.5782 & TRN & \\
\hline CHEMBL1550407 & 688239 & 7.0862 & 5.5583 & TRN & \\
\hline CHEMBL1324032 & 688239 & 5.0362 & 5.3152 & TST & \\
\hline CHEMBL1382882 & 688239 & 5.6862 & 5.5504 & TST & \\
\hline CHEMBL 1370390 & 688239 & 4.9362 & 5.4446 & TRN & \\
\hline CHEMBL1343192 & 688239 & 5.3862 & 5.5399 & TST & \\
\hline CHEMBL1520178 & 688239 & 4.6862 & 5.4207 & TRN & \\
\hline CHEMBL1438243 & 688239 & 4.5362 & 5.3837 & TRN & \\
\hline CHEMBL1519956 & 688239 & 5.1862 & 5.6569 & TST & \\
\hline CHEMBL1409916 & 688239 & 6.4862 & 5.4191 & TST & \\
\hline CHEMBL1610985 & 688239 & 4.5862 & 5.3938 & TRN & \\
\hline CHEMBL1374576 & 688239 & 6.9863 & 5.6373 & TRN & \\
\hline CHEMBL1302603 & 688239 & 6.1362 & 5.63299 & 9999999999 & TRN \\
\hline CHEMBL3210530 & 688239 & 5.8862 & 5.4438 & TRN & \\
\hline CHEMBL1527786 & 688239 & 6.6861 & 5.4772 & TRN & \\
\hline CHEMBL1427995 & 688239 & 6.2362 & 5.5775 & TRN & \\
\hline CHEMBL1369860 & 688239 & 4.8362 & 5.6373 & TST & \\
\hline CHEMBL1337904 & 688239 & 5.1862 & 5.5703 & TRN & \\
\hline CHEMBL1601054 & 688239 & 6.9363 & 5.5639 & TRN & \\
\hline CHEMBL1582737 & 688239 & 5.5862 & 5.5161 & TST & \\
\hline CHEMBL1536238 & 688239 & 4.9362 & 5.6869 & TRN & \\
\hline CHEMBL1440582 & 688239 & 4.7862 & 5.5382 & TST & \\
\hline CHEMBL1548439 & 688239 & 5.1362 & 5.4385 & TRN & \\
\hline CHEMBL1446566 & 688239 & 4.7362 & 5.4464 & TRN & \\
\hline CHEMBL1532097 & 688239 & 4.5362 & 5.4387 & TST & \\
\hline CHEMBL1398565 & 688239 & 4.5362 & 5.4488 & TST & \\
\hline CHEMBL1427919 & 688239 & 4.5362 & 5.524 & TRN & \\
\hline CHEMBL1310527 & 688239 & 5.0362 & 5.351 & TRN & \\
\hline CHEMBL1434356 & 688239 & 5.3862 & 5.3948 & TRN & \\
\hline CHEMBL1336068 & 688239 & 5.1862 & 5.426 & TRN & \\
\hline CHEMBL1350172 & 688239 & 6.4362 & 5.4375 & TST & \\
\hline CHEMBL1418940 & 688239 & 5.1362 & 5.5693 & TST & \\
\hline CHEMBL569227 & 688239 & 4.5862 & 5.5247 & TRN & \\
\hline CHEMBL1606280 & 688239 & 5.8362 & 5.4662 & TRN & \\
\hline CHEMBL1321931 & 688239 & 5.8862 & 5.6814 & TRN & \\
\hline CHEMBL1328690 & 688239 & 7.1361 & 5.5701 & TRN & \\
\hline CHEMBL1493262 & 688239 & 4.8862 & 5.6775 & TRN & \\
\hline CHEMBL1438198 & 688239 & 4.8362 & 5.5383 & TRN & \\
\hline CHEMBL1301939 & 688239 & 5.0862 & 5.4469 & TST & \\
\hline CHEMBL1538664 & 688239 & 5.7862 & 5.6107 & TRN & \\
\hline CHEMBL1304550 & 688239 & 5.1862 & 5.6805 & TRN & \\
\hline CHEMBL1588664 & 688239 & 4.4862 & 5.371 & TRN & \\
\hline CHEMBL1321076 & 688239 & 4.7362 & 5.5233 & TRN & \\
\hline CHEMBL1539146 & 688239 & 6.0862 & 5.5554 & TRN & \\
\hline CHEMBL1449076 & 688239 & 5.7862 & 5.4731 & TST & \\
\hline CHEMBL1322637 & 688239 & 5.1362 & 5.5904 & TRN & \\
\hline CHEMBL3189613 & 688239 & 5.5362 & 5.3977 & TRN & \\
\hline CHEMBL1379711 & 688239 & 4.4862 & 5.4581 & TRN & \\
\hline
\end{tabular}


Supplemental Table S2.txt

\begin{tabular}{|c|c|c|c|c|c|}
\hline CHEMBL1464972 & 688239 & 6.7862 & 5.6191 & TRN & \\
\hline CHEMBL1420246 & 688239 & 4.5362 & 5.38399 & 99999999995 & TRN \\
\hline CHEMBL1467754 & 688239 & 5.9362 & 5.3844 & TRN & \\
\hline CHEMBL1503902 & 688239 & 5.3862 & 5.6481 & TRN & \\
\hline CHEMBL1395739 & 688239 & 4.6362 & 5.5267 & TRN & \\
\hline CHEMBL1577145 & 688239 & 5.1362 & 5.4288 & TRN & \\
\hline CHEMBL1564576 & 688239 & 5.1862 & 5.6019 & TRN & \\
\hline CHEMBL1494276 & 688239 & 5.1862 & 5.4369 & TRN & \\
\hline CHEMBL1611369 & 688239 & 5.1862 & 5.5508 & TRN & \\
\hline CHEMBL1480194 & 688239 & 5.6862 & 5.4786 & TST & \\
\hline CHEMBL1418086 & 688239 & 5.3362 & 5.532 & TRN & \\
\hline CHEMBL1342477 & 688239 & 5.1362 & 5.4353 & TRN & \\
\hline CHEMBL1370909 & 688239 & 5.1862 & 5.5118 & TRN & \\
\hline CHEMBL1306534 & 688239 & 5.1362 & 5.5354 & TRN & \\
\hline CHEMBL1425513 & 688239 & 7.4365 & 5.4914 & TRN & \\
\hline CHEMBL1325517 & 688239 & 5.4862 & 5.5617 & TRN & \\
\hline CHEMBL1588370 & 688239 & 5.1862 & 5.5082 & TRN & \\
\hline CHEMBL1300886 & 688239 & 4.5362 & 5.4202 & TRN & \\
\hline CHEMBL1488516 & 688239 & 4.7362 & 5.5009 & TRN & \\
\hline CHEMBL1173823 & 688239 & 5.4362 & 5.5383 & TST & \\
\hline CHEMBL1390296 & 688239 & 5.2862 & 5.3824 & TRN & \\
\hline CHEMBL1405229 & 688239 & 5.2862 & 5.5944 & TRN & \\
\hline CHEMBL1485925 & 688239 & 4.6362 & 5.5884 & TRN & \\
\hline CHEMBL1506458 & 688239 & 5.5362 & 5.4988 & TRN & \\
\hline CHEMBL1382879 & 688239 & 4.5362 & 5.4275 & TST & \\
\hline CHEMBL1502880 & 688239 & 4.5362 & 5.6407 & TST & \\
\hline CHEMBL1406543 & 688239 & 4.5362 & 5.4943 & TRN & \\
\hline CHEMBL1439698 & 688239 & 4.5362 & 5.3489 & TRN & \\
\hline CHEMBL1320975 & 688239 & 5.6862 & 5.3967 & TST & \\
\hline CHEMBL1374097 & 688239 & 5.7362 & 5.5638 & TRN & \\
\hline CHEMBL1501375 & 688239 & 4.5362 & 5.3201 & TRN & \\
\hline CHEMBL1449147 & 688239 & 4.9862 & 5.4469 & TRN & \\
\hline CHEMBL1307247 & 688239 & 6.1362 & 5.4334 & TRN & \\
\hline CHEMBL1410002 & 688239 & 5.0362 & 5.527 & TRN & \\
\hline CHEMBL1454804 & 688239 & 5.1862 & 5.5747 & TRN & \\
\hline CHEMBL1545924 & 688239 & 8.3372 & 5.25799 & э999999999 & TST \\
\hline CHEMBL1392898 & 688239 & 5.2362 & 5.5722 & TRN & \\
\hline CHEMBL1353529 & 688239 & 5.0362 & 5.5274 & TRN & \\
\hline CHEMBL1425497 & 688239 & 5.2362 & 5.3763 & TRN & \\
\hline CHEMBL1369558 & 688239 & 6.4862 & 5.6303 & TRN & \\
\hline CHEMBL1456242 & 688239 & 5.4362 & 5.5204 & TRN & \\
\hline CHEMBL1446295 & 688239 & 4.7862 & 5.4759 & TST & \\
\hline CHEMBL1563988 & 688239 & 5.7362 & 5.5503 & TRN & \\
\hline CHEMBL405914 & 688239 & 5.3862 & 5.5685 & TRN & \\
\hline CHEMBL3195875 & 688239 & 6.1862 & 5.4406 & TST & \\
\hline CHEMBL1413422 & 688239 & 6.4862 & 5.4598 & TST & \\
\hline CHEMBL1329981 & 688239 & 5.0362 & 5.4709 & TST & \\
\hline CHEMBL1607203 & 688239 & 4.5362 & 5.4434 & TRN & \\
\hline
\end{tabular}


Supplemental Table S2.txt

\begin{tabular}{|c|c|c|c|c|}
\hline CHEMBL1529936 & 688239 & 5.5362 & 5.5019 & TRN \\
\hline CHEMBL1369435 & 688239 & 4.5862 & 5.5059 & TRN \\
\hline CHEMBL1314340 & 688239 & 7.3862 & 5.3891 & TRN \\
\hline CHEMBL1497875 & 688239 & 5.1862 & 5.4997 & TST \\
\hline CHEMBL 3193937 & 688239 & 4.8362 & 5.3113 & TRN \\
\hline CHEMBL1604104 & 688239 & 5.6362 & 5.6572 & TST \\
\hline CHEMBL1421629 & 688239 & 6.8861 & 5.5076 & TRN \\
\hline CHEMBL1375430 & 688239 & 6.9363 & 5.5787 & TRN \\
\hline CHEMBL1371494 & 688239 & 8.3372 & 5.4903 & TRN \\
\hline CHEMBL1493221 & 688239 & 4.6362 & 5.3283 & TST \\
\hline CHEMBL1331643 & 688239 & 5.4862 & 5.4881 & TST \\
\hline CHEMBL1415780 & 688239 & 6.2862 & 5.441 & TRN \\
\hline CHEMBL1458553 & 688239 & 7.2865 & 5.5014 & TRN \\
\hline CHEMBL1512655 & 688239 & 5.6862 & 5.5582 & TRN \\
\hline CHEMBL1587780 & 688239 & 5.1362 & 5.3188 & TST \\
\hline CHEMBL1559120 & 688239 & 5.1862 & 5.4092 & TRN \\
\hline CHEMBL1580093 & 688239 & 7.7852 & 5.6945 & TRN \\
\hline CHEMBL1538867 & 688239 & 4.5362 & 5.5476 & TRN \\
\hline CHEMBL1419251 & 688239 & 4.5362 & 5.5731 & TRN \\
\hline CHEMBL1426409 & 688239 & 7.1864 & 5.5558 & TRN \\
\hline CHEMBL1509578 & 688239 & 6.3863 & 5.5459 & TRN \\
\hline CHEMBL1380760 & 688239 & 4.5362 & 5.419 & TST \\
\hline CHEMBL1336478 & 688239 & 4.9362 & 5.5878 & TRN \\
\hline CHEMBL1313311 & 688239 & 4.5362 & 5.5609 & TRN \\
\hline CHEMBL1583199 & 688239 & 5.7862 & 5.5625 & TRN \\
\hline CHEMBL1590386 & 688239 & 5.1862 & 5.4884 & TRN \\
\hline CHEMBL1490373 & 688239 & 4.5362 & 5.49299 & 9999999999 \\
\hline CHEMBL1422465 & 688239 & 5.1362 & 5.4394 & TST \\
\hline CHEMBL1490849 & 688239 & 5.8862 & 5.5037 & TST \\
\hline CHEMBL3214299 & 688239 & 6.7361 & 5.5206 & TRN \\
\hline CHEMBL3193243 & 688239 & 6.9363 & 5.3843 & TRN \\
\hline CHEMBL1536469 & 688239 & 5.3362 & 5.3993 & TST \\
\hline CHEMBL1563948 & 688239 & 4.4862 & 5.4633 & TRN \\
\hline CHEMBL1349855 & 688239 & 4.5362 & 5.5075 & TRN \\
\hline CHEMBL1558952 & 688239 & 4.7862 & 5.2493 & TRN \\
\hline CHEMBL1508483 & 688239 & 4.6362 & 5.5698 & TRN \\
\hline CHEMBL1540641 & 688239 & 5.1362 & 5.5152 & TRN \\
\hline CHEMBL1609454 & 688239 & 4.6362 & 5.3542 & TRN \\
\hline CHEMBL1402150 & 688239 & 4.7862 & 5.5498 & TRN \\
\hline CHEMBL1527788 & 688239 & 5.1862 & 5.3453 & TST \\
\hline CHEMBL1547551 & 688239 & 4.4862 & 5.517 & TRN \\
\hline CHEMBL1548584 & 688239 & 5.1862 & 5.5273 & TRN \\
\hline CHEMBL1304171 & 688239 & 4.7862 & 5.4248 & TRN \\
\hline CHEMBL1579790 & 688239 & 5.4862 & 5.4858 & TST \\
\hline CHEMBL1451149 & 688239 & 5.1862 & 5.4752 & TRN \\
\hline CHEMBL1489997 & 688239 & 4.7362 & 5.4097 & TRN \\
\hline CHEMBL 2007120 & 688239 & 4.5362 & 5.475 & TST \\
\hline CHEMBL1883443 & 688239 & 5.3362 & 5.4143 & TRN \\
\hline
\end{tabular}




\begin{tabular}{|c|c|c|c|c|c|}
\hline \multirow[b]{2}{*}{ CHEMBL1360658 } & \multicolumn{5}{|c|}{ Supplemental Table S2.txt } \\
\hline & 688239 & 6.15 & 5.4136 & TRN & \\
\hline CHEMBL1370148 & 688239 & 6.5363 & 5.5162 & TRN & \\
\hline CHEMBL1501971 & 688239 & 7.0862 & 5.5865 & TRN & \\
\hline CHEMBL1339600 & 688239 & 8.28399 & 99999999 & 5.5342 & TRN \\
\hline CHEMBL1301076 & 688239 & 6.8362 & 5.7162 & TRN & \\
\hline CHEMBL1599051 & 688239 & 4.6362 & 5.5141 & TRN & \\
\hline CHEMBL1445909 & 688239 & 8.3372 & 5.41100 & 00000000005 & TST \\
\hline CHEMBL1547703 & 688239 & 5.7362 & 5.5247 & TRN & \\
\hline CHEMBL1408242 & 688239 & 6.2362 & 5.4365 & TRN & \\
\hline CHEMBL1611286 & 688239 & 6.1862 & 5.5067 & TST & \\
\hline CHEMBL1301593 & 688239 & 7.0362 & 5.5198 & TRN & \\
\hline CHEMBL1587831 & 688239 & 6.0362 & 5.5774 & TST & \\
\hline CHEMBL3207835 & 688239 & 4.6362 & 5.4042 & TST & \\
\hline CHEMBL1373886 & 688239 & 5.1862 & 5.3721 & TRN & \\
\hline CHEMBL1423428 & 688239 & 7.9355 & 5.5518 & TRN & \\
\hline CHEMBL1304198 & 688239 & 5.6362 & 5.5404 & TRN & \\
\hline CHEMBL1546493 & 688239 & 5.1862 & 5.3995 & TRN & \\
\hline CHEMBL1424666 & 688239 & 6.6362 & 5.4112 & TRN & \\
\hline CHEMBL3194413 & 688239 & 5.0362 & 5.4536 & TRN & \\
\hline CHEMBL1534074 & 688239 & 6.2362 & 5.4413 & TRN & \\
\hline CHEMBL1331586 & 688239 & 4.5362 & 5.4434 & TRN & \\
\hline CHEMBL1388439 & 688239 & 5.2862 & 5.5659 & TRN & \\
\hline CHEMBL1382428 & 688239 & 4.6862 & 5.4973 & TRN & \\
\hline CHEMBL 3211944 & 688239 & 4.5362 & 5.4943 & TRN & \\
\hline CHEMBL1299605 & 688239 & 6.1362 & 5.5581 & TRN & \\
\hline CHEMBL 78150 & 688239 & 5.2862 & 5.4113 & TST & \\
\hline CHEMBL1333862 & 688239 & 4.8862 & 5.6493 & TRN & \\
\hline CHEMBL1583836 & 688239 & 5.4862 & 5.6113 & TRN & \\
\hline CHEMBL1506093 & 688239 & 5.0 & 5.6645 & TRN & \\
\hline CHEMBL1333739 & 688239 & 6.2862 & 5.3516 & TRN & \\
\hline CHEMBL1527453 & 688239 & 4.5362 & 5.6439 & TST & \\
\hline CHEMBL1411358 & 688239 & 8.3372 & 5.5878 & TST & \\
\hline CHEMBL1510335 & 688239 & 5.1862 & 5.42 & TRN & \\
\hline CHEMBL3211485 & 688239 & 4.7362 & 5.41299 & 9999999999 & TRN \\
\hline CHEMBL1577016 & 688239 & 6.1862 & 5.4442 & TST & \\
\hline CHEMBL1357961 & 688239 & 4.9862 & 5.5568 & TRN & \\
\hline CHEMBL1337281 & 688239 & 6.1862 & 5.4855 & TRN & \\
\hline CHEMBL1550154 & 688239 & 4.5362 & 5.6366 & TRN & \\
\hline CHEMBL1524599 & 688239 & 4.7362 & 5.4544 & TRN & \\
\hline CHEMBL1539667 & 688239 & 6.7862 & 5.5176 & TST & \\
\hline CHEMBL1344189 & 688239 & 6.8861 & 5.5835 & TST & \\
\hline CHEMBL1607736 & 688239 & 4.6362 & 5.4274 & TRN & \\
\hline CHEMBL1598211 & 688239 & 6.8362 & 5.477 & TRN & \\
\hline CHEMBL1384398 & 688239 & 5.1862 & 5.5444 & TST & \\
\hline CHEMBL1534195 & 688239 & 6.0862 & 5.5698 & TRN & \\
\hline CHEMBL1564415 & 688239 & 6.1862 & 5.4216 & TRN & \\
\hline CHEMBL1588411 & 688239 & 4.5362 & 5.439 & TRN & \\
\hline CHEMBL1312145 & 688239 & 4.5362 & 5.6149 & TRN & \\
\hline
\end{tabular}


Supplemental Table S2.txt

\begin{tabular}{|c|c|c|c|c|c|}
\hline CHEMBL1560035 & 688239 & 5.6362 & 5.4466 & TRN & \\
\hline CHEMBL1554280 & 688239 & 4.5362 & 5.379 & TRN & \\
\hline CHEMBL1605567 & 688239 & 6.8861 & 5.6355 & TST & \\
\hline CHEMBL1466155 & 688239 & 5.3362 & 5.7521 & TRN & \\
\hline CHEMBL1346866 & 688239 & 5.1862 & 5.5287 & TST & \\
\hline CHEMBL1335152 & 688239 & 5.5362 & 5.6707 & TRN & \\
\hline CHEMBL1318641 & 688239 & 6.1362 & 5.4346 & TST & \\
\hline CHEMBL1412945 & 688239 & 4.5362 & 5.5562 & TRN & \\
\hline CHEMBL1344131 & 688239 & 4.5362 & 5.5084 & TST & \\
\hline CHEMBL3191471 & 688239 & 4.4862 & 5.4052 & TST & \\
\hline CHEMBL1334603 & 688239 & 5.5862 & 5.5271 & TST & \\
\hline CHEMBL1609512 & 688239 & 4.7862 & 5.3678 & TRN & \\
\hline CHEMBL1608972 & 688239 & 5.1862 & 5.6572 & TRN & \\
\hline CHEMBL1326826 & 688239 & 5.1862 & 5.4285 & TRN & \\
\hline CHEMBL1335047 & 688239 & 5.4362 & 5.5016 & TRN & \\
\hline CHEMBL1322408 & 688239 & 4.9362 & 5.4742 & TRN & \\
\hline CHEMBL1575294 & 688239 & 6.9863 & 5.5012 & TRN & \\
\hline CHEMBL 3213804 & 688239 & 4.6362 & 5.507000 & 000000001 & $\mathrm{TP}$ \\
\hline CHEMBL1578480 & 688239 & 5.1862 & 5.4994 & TRN & \\
\hline CHEMBL1505085 & 688239 & 6.0862 & 5.439 & TST & \\
\hline CHEMBL1461945 & 688239 & 4.5362 & 5.4351 & TST & \\
\hline CHEMBL1399114 & 688239 & 4.6362 & 5.5808 & TRN & \\
\hline CHEMBL1330282 & 688239 & 4.7362 & 5.3834 & TRN & \\
\hline CHEMBL1392499 & 688239 & 6.6362 & 5.4736 & TRN & \\
\hline CHEMBL1581602 & 688239 & 5.2362 & 5.3739 & TST & \\
\hline CHEMBL1549660 & 688239 & 5.1862 & 5.4082 & TRN & \\
\hline CHEMBL1493837 & 688239 & 5.3862 & 5.4062 & TST & \\
\hline CHEMBL1567528 & 688239 & 4.6862 & 5.5704 & TRN & \\
\hline CHEMBL1422217 & 688239 & 4.5362 & 5.3012 & TRN & \\
\hline CHEMBL1449509 & 688239 & 5.3862 & 5.6614 & TST & \\
\hline CHEMBL1472690 & 688239 & 8.2366 & 5.3523 & TRN & \\
\hline CHEMBL1428647 & 688239 & 4.5362 & 5.5654 & TRN & \\
\hline CHEMBL1609876 & 688239 & 5.6862 & 5.4438 & TRN & \\
\hline CHEMBL1424551 & 688239 & 5.6362 & 5.5515 & TRN & \\
\hline CHEMBL1479975 & 688239 & 5.3862 & 5.61 & TRN & \\
\hline CHEMBL1348339 & 688239 & 6.9363 & 5.4505 & TST & \\
\hline CHEMBL1565185 & 688239 & 4.5862 & 5.5152 & TRN & \\
\hline CHEMBL1520440 & 688239 & 5.6362 & 5.593 & TRN & \\
\hline CHEMBL1463896 & 688239 & 4.5362 & 5.5598 & TRN & \\
\hline CHEMBL1415172 & 688239 & 4.5362 & 5.5081 & TRN & \\
\hline CHEMBL1391323 & 688239 & 8.28399 & 99999999 & 5.5982 & TST \\
\hline CHEMBL1367356 & 688239 & 5.1862 & 5.4765 & TST & \\
\hline CHEMBL1542934 & 688239 & 5.6862 & 5.4806 & TST & \\
\hline CHEMBL1973951 & 688239 & 5.1862 & 5.5779 & TRN & \\
\hline CHEMBL1606752 & 688239 & 4.8362 & 5.3229 & TRN & \\
\hline CHEMBL1567387 & 688239 & 5.5862 & 5.5289 & TRN & \\
\hline CHEMBL1554835 & 688239 & 4.5362 & 5.3951 & TST & \\
\hline CHEMBL1319399 & 688239 & 4.5362 & 5.5007 & TST & \\
\hline
\end{tabular}


Supplemental Table S2.txt

\begin{tabular}{|c|c|c|c|c|}
\hline CHEMBL1466294 & 688239 & 5.2862 & 5.5008 & TRN \\
\hline CHEMBL1454097 & 688239 & 5.2862 & 5.5671 & TRN \\
\hline CHEMBL1597146 & 688239 & 4.7362 & 5.5294 & TRN \\
\hline CHEMBL1412144 & 688239 & 4.5362 & 5.5465 & TRN \\
\hline CHEMBL1594988 & 688239 & 5.2362 & 5.5448 & TRN \\
\hline CHEMBL 3192625 & 688239 & 4.7862 & 5.4269 & TRN \\
\hline CHEMBL1303121 & 688239 & 5.5862 & 5.5073 & TRN \\
\hline CHEMBL1314755 & 688239 & 5.5862 & 5.4983 & TRN \\
\hline CHEMBL1597770 & 688239 & 6.2362 & 5.5939 & TST \\
\hline CHEMBL1348169 & 688239 & 5.3862 & 5.5114 & TRN \\
\hline CHEMBL1559961 & 688239 & 5.7362 & 5.6505 & TRN \\
\hline CHEMBL3190789 & 688239 & 4.6362 & 5.6504 & TST \\
\hline CHEMBL1389514 & 688239 & 6.9863 & 5.4183 & TRN \\
\hline CHEMBL1492065 & 688239 & 5.1362 & 5.4779 & TRN \\
\hline CHEMBL1447164 & 688239 & 6.3863 & 5.5145 & TRN \\
\hline CHEMBL1471381 & 688239 & 6.0362 & 5.3898 & TRN \\
\hline CHEMBL1368114 & 688239 & 4.6862 & 5.3185 & TRN \\
\hline CHEMBL 3208224 & 688239 & 4.6362 & 5.5629 & TST \\
\hline CHEMBL1506619 & 688239 & 4.5862 & 5.5284 & TRN \\
\hline CHEMBL1434774 & 688239 & 4.9862 & 5.5214 & TRN \\
\hline CHEMBL1560590 & 688239 & 6.1362 & 5.5447 & TST \\
\hline CHEMBL1410789 & 688239 & 6.5862 & 5.3976 & TRN \\
\hline CHEMBL1329232 & 688239 & 4.5362 & 5.5909 & TRN \\
\hline CHEMBL 3196494 & 688239 & 7.2366 & 5.5561 & TRN \\
\hline CHEMBL1314071 & 688239 & 4.7362 & 5.4708 & TRN \\
\hline CHEMBL1348815 & 688239 & 5.1862 & 5.5766 & TRN \\
\hline CHEMBL1456335 & 688239 & 4.5862 & 5.6073 & TRN \\
\hline CHEMBL1538694 & 688239 & 7.1864 & 5.442 & TRN \\
\hline CHEMBL1504347 & 688239 & 5.4862 & 5.3131 & TRN \\
\hline CHEMBL1416793 & 688239 & 4.5362 & 5.61600 & 00000000005 \\
\hline CHEMBL578716 & 688239 & 4.5362 & 5.36799 & 9999999999 \\
\hline CHEMBL1460790 & 688239 & 6.1362 & 5.3612 & TRN \\
\hline CHEMBL1511773 & 688239 & 6.1362 & 5.5234 & TRN \\
\hline CHEMBL1579350 & 688239 & 5.3362 & 5.6026 & TRN \\
\hline CHEMBL1536175 & 688239 & 4.7362 & 5.3893 & TRN \\
\hline CHEMBL1475601 & 688239 & 4.7862 & 5.5206 & TRN \\
\hline CHEMBL1328657 & 688239 & 6.9863 & 5.4657 & TRN \\
\hline CHEMBL1499085 & 688239 & 4.6362 & 5.4086 & TRN \\
\hline CHEMBL1375309 & 688239 & 5.3362 & 5.455 & TRN \\
\hline CHEMBL1379751 & 688239 & 5.4862 & 5.4125 & TRN \\
\hline CHEMBL3210900 & 688239 & 5.4362 & 5.4339 & TRN \\
\hline CHEMBL1537585 & 688239 & 4.8362 & 5.82 & TRN \\
\hline CHEMBL1383844 & 688239 & 4.5362 & 5.4552 & TRN \\
\hline CHEMBL1336987 & 688239 & 5.9862 & 5.4873 & TRN \\
\hline CHEMBL1470727 & 688239 & 6.8861 & 5.3933 & TST \\
\hline CHEMBL1332568 & 688239 & 5.3362 & 5.4401 & TRN \\
\hline CHEMBL1311841 & 688239 & 8.3372 & 5.6445 & TRN \\
\hline CHEMBL1470413 & 688239 & 4.4862 & 5.4572 & TRN \\
\hline
\end{tabular}


Supplemental Table S2.txt

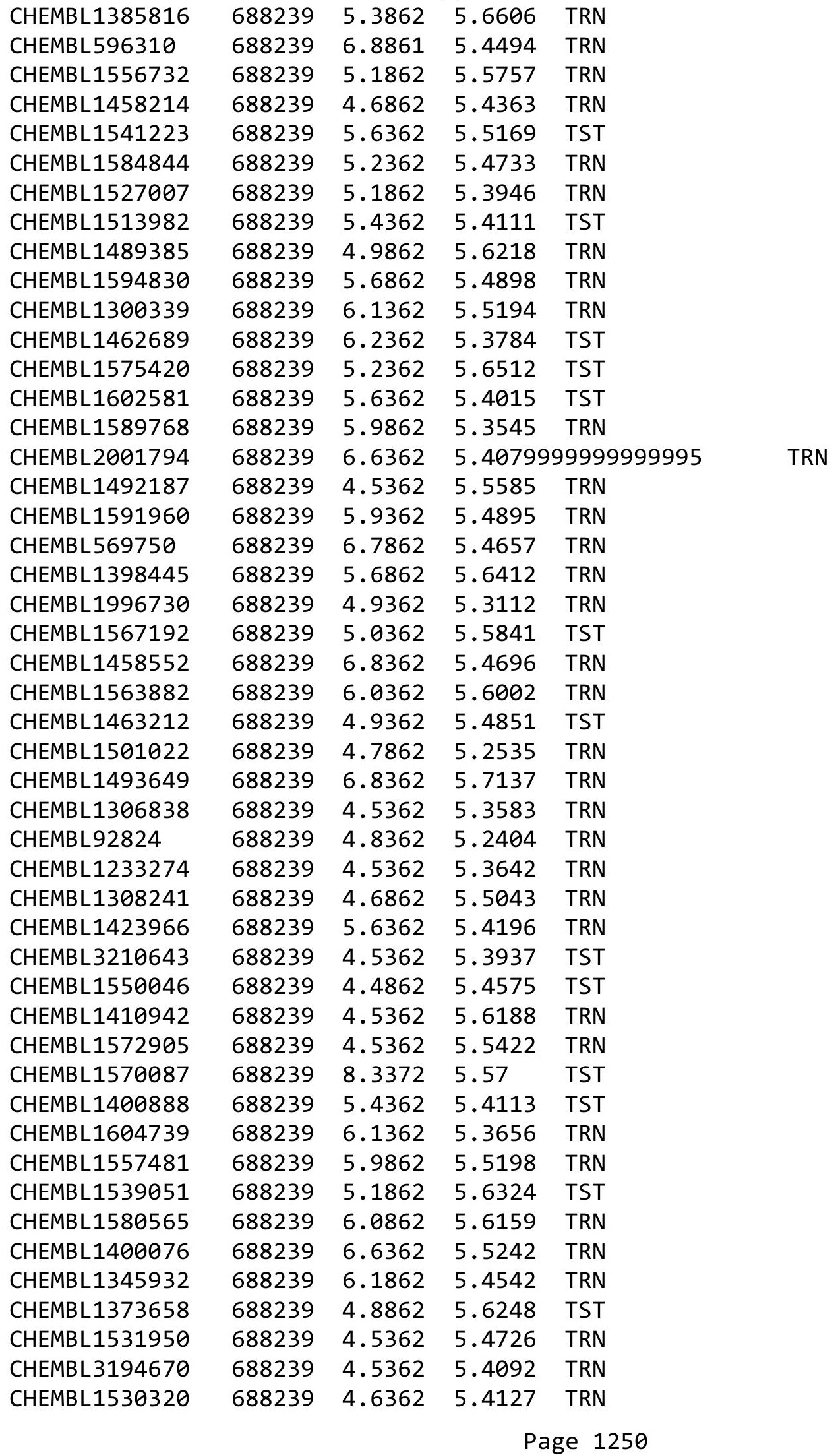


Supplemental Table S2.txt

\begin{tabular}{|c|c|c|c|c|c|}
\hline CHEMBL 3144940 & 688239 & 5.3862 & 5.4413 & TST & \\
\hline CHEMBL1393459 & 688239 & 5.2862 & 5.584 & TRN & \\
\hline CHEMBL1413149 & 688239 & 4.5862 & 5.5269 & TRN & \\
\hline CHEMBL1995177 & 688239 & 4.4862 & 5.491000 & 0000000005 & TST \\
\hline CHEMBL1300494 & 688239 & 4.8362 & 5.5375 & TST & \\
\hline CHEMBL1405102 & 688239 & 5.1362 & 5.4302 & TRN & \\
\hline CHEMBL1439349 & 688239 & 5.1862 & 5.5774 & TRN & \\
\hline CHEMBL1605302 & 688239 & 5.9362 & 5.4597 & TST & \\
\hline CHEMBL 3190901 & 688239 & 4.6862 & 5.4562 & TRN & \\
\hline CHEMBL1609285 & 688239 & 5.8362 & 5.326000 & 0000000005 & 5 \\
\hline CHEMBL1532104 & 688239 & 4.6862 & 5.4057 & TRN & \\
\hline CHEMBL1485561 & 688239 & 8.283999 & 99999999 & 5.3897 & \\
\hline CHEMBL1601820 & 688239 & 4.6362 & 5.422999 & (999999999 & \\
\hline CHEMBL1564165 & 688239 & 4.5362 & 5.3406 & TRN & \\
\hline CHEMBL1331593 & 688239 & 5.0862 & 5.3316 & TRN & \\
\hline CHEMBL1445655 & 688239 & 4.6862 & 5.4676 & TST & \\
\hline CHEMBL1490260 & 688239 & 4.9362 & 5.6685 & TST & \\
\hline CHEMBL1366118 & 688239 & 4.5362 & 5.4256 & TRN & \\
\hline CHEMBL1397416 & 688239 & 4.4862 & 5.5628 & TRN & \\
\hline CHEMBL1492935 & 688239 & 4.7862 & 5.4213 & TRN & \\
\hline CHEMBL1316785 & 688239 & 5.4362 & 5.5953 & TRN & \\
\hline CHEMBL1467061 & 688239 & 6.9863 & 5.3992 & TRN & \\
\hline CHEMBL1581968 & 688239 & 6.9363 & 5.4483 & TRN & \\
\hline CHEMBL1556335 & 688239 & 5.6862 & 5.5622 & TRN & \\
\hline CHEMBL1398264 & 688239 & 4.5362 & 5.5533 & TRN & \\
\hline CHEMBL1590772 & 688239 & 4.6862 & 5.5166 & TRN & \\
\hline CHEMBL1510785 & 688239 & 4.7362 & 5.5404 & TRN & \\
\hline CHEMBL1506455 & 688239 & 5.8362 & 5.611000 & 000000001 & \\
\hline CHEMBL 3195907 & 688239 & 5.8362 & 5.2851 & TRN & \\
\hline CHEMBL1323198 & 688239 & 5.6862 & 5.4954 & TRN & \\
\hline CHEMBL1369003 & 688239 & 5.5862 & 5.5154 & TRN & \\
\hline CHEMBL1564287 & 688239 & 4.7362 & 5.5622 & TRN & \\
\hline CHEMBL1341106 & 688239 & 5.0362 & 5.4577 & TST & \\
\hline CHEMBL1558069 & 688239 & 4.4862 & 5.4763 & TST & \\
\hline CHEMBL1384837 & 688239 & 6.1862 & 5.6202 & TST & \\
\hline CHEMBL1508871 & 688239 & 5.3862 & 5.3483 & TRN & \\
\hline CHEMBL1338348 & 688239 & 4.9362 & 5.5175 & TRN & \\
\hline CHEMBL1413937 & 688239 & 4.8362 & 5.4067 & TRN & \\
\hline CHEMBL1985343 & 688239 & 4.7362 & 5.279 & TST & \\
\hline CHEMBL1332642 & 688239 & 5.1862 & 5.4859 & TRN & \\
\hline CHEMBL1451974 & 688239 & 5.3862 & 5.5524 & TST & \\
\hline CHEMBL1462292 & 688239 & 6.1362 & 5.5131 & TRN & \\
\hline CHEMBL1568594 & 688239 & 5.8862 & 5.5425 & TST & \\
\hline CHEMBL1539449 & 688239 & 5.9362 & 5.5219 & TST & \\
\hline CHEMBL1588384 & 688239 & 6.5862 & 5.513 & TRN & \\
\hline CHEMBL1339770 & 688239 & 5.5362 & 5.6911 & TST & \\
\hline CHEMBL1372367 & 688239 & 4.5362 & 5.4711 & TST & \\
\hline CHEMBL1571360 & 688239 & 6.7862 & 5.4072 & TRN & \\
\hline
\end{tabular}


Supplemental Table S2.txt

\begin{tabular}{|c|c|c|c|c|c|}
\hline CHEMBL1301715 & 688239 & 6.2862 & 5.5847 & TRN & \\
\hline CHEMBL1418130 & 688239 & 4.8862 & 5.4039 & TRN & \\
\hline CHEMBL1351550 & 688239 & 5.6862 & 5.5338 & TRN & \\
\hline CHEMBL1583535 & 688239 & 4.6362 & $5.50700 e$ & 0000000001 & TST \\
\hline CHEMBL1548997 & 688239 & 5.7862 & 5.4506 & TRN & \\
\hline CHEMBL8950 & 688239 & 5.1862 & 5.4574 & TRN & \\
\hline CHEMBL1340292 & 688239 & 5.4362 & 5.5237 & TRN & \\
\hline CHEMBL1584288 & 688239 & 6.8362 & 5.4767 & TRN & \\
\hline CHEMBL1550064 & 688239 & 8.3372 & 5.4933 & TRN & \\
\hline CHEMBL1577268 & 688239 & 5.1862 & 5.6603 & TRN & \\
\hline CHEMBL1542517 & 688239 & 4.5362 & 5.5527 & TRN & \\
\hline CHEMBL1544969 & 688239 & 7.8861 & 5.5824 & TRN & \\
\hline CHEMBL1359559 & 688239 & 8.3372 & 5.6579 & TRN & \\
\hline CHEMBL1492098 & 688239 & 6.2862 & 5.5755 & TRN & \\
\hline CHEMBL1494120 & 688239 & 5.5362 & 5.3413 & TRN & \\
\hline CHEMBL1577948 & 688239 & 6.2362 & 5.4308 & TRN & \\
\hline CHEMBL1542445 & 688239 & 5.1362 & 5.4285 & TRN & \\
\hline CHEMBL1326077 & 688239 & 6.9363 & 5.4894 & TST & \\
\hline CHEMBL1539307 & 688239 & 4.9362 & 5.5279 & TRN & \\
\hline CHEMBL3190351 & 688239 & 5.8862 & 5.3379 & TRN & \\
\hline CHEMBL1366532 & 688239 & 4.5362 & 5.5142 & TST & \\
\hline CHEMBL1321472 & 688239 & 4.5362 & 5.4344 & TST & \\
\hline CHEMBL3193455 & 688239 & 4.5362 & 5.4226 & TRN & \\
\hline CHEMBL1575046 & 688239 & 4.7362 & 5.4745 & TRN & \\
\hline CHEMBL1355026 & 688239 & 6.1862 & 5.4277 & TST & \\
\hline CHEMBL1520640 & 688239 & 4.7362 & 5.5185 & TST & \\
\hline CHEMBL1376363 & 688239 & 6.5862 & 5.4247 & TST & \\
\hline CHEMBL1596379 & 688239 & 5.3862 & 5.5887 & TRN & \\
\hline CHEMBL1563350 & 688239 & 6.8362 & 5.6895 & TRN & \\
\hline CHEMBL1403149 & 688239 & 6.2362 & 5.5228 & TRN & \\
\hline CHEMBL1401086 & 688239 & 5.6862 & 5.6277 & TRN & \\
\hline CHEMBL1564739 & 688239 & 4.4862 & 5.6563 & TRN & \\
\hline CHEMBL1472194 & 688239 & 4.5362 & 5.5729 & TRN & \\
\hline CHEMBL1417465 & 688239 & 4.5362 & 5.4847 & TST & \\
\hline CHEMBL1543364 & 688239 & 7.0362 & 5.4322 & TST & \\
\hline CHEMBL1530444 & 688239 & 6.0862 & 5.6152 & TRN & \\
\hline CHEMBL 3209440 & 688239 & 4.5362 & 5.4812 & TRN & \\
\hline CHEMBL1310826 & 688239 & 5.5862 & 5.5153 & TRN & \\
\hline CHEMBL1516644 & 688239 & 5.0862 & 5.4778 & TRN & \\
\hline CHEMBL1561118 & 688239 & 6.0862 & 5.4707 & TRN & \\
\hline CHEMBL1335413 & 688239 & 4.8362 & 5.6343 & TRN & \\
\hline CHEMBL1393864 & 688239 & 5.1862 & 5.6794 & TRN & \\
\hline CHEMBL1388509 & 688239 & 4.7362 & 5.3699 & TST & \\
\hline CHEMBL1389045 & 688239 & 6.8362 & 5.3276 & TRN & \\
\hline CHEMBL1515206 & 688239 & 4.5362 & 5.5282 & TRN & \\
\hline CHEMBL1319881 & 688239 & 8.28399 & 999999999 & 5.5716 & TRN \\
\hline CHEMBL1513937 & 688239 & 6.0362 & 5.4225 & TRN & \\
\hline CHEMBL1595552 & 688239 & 6.9363 & 5.4929 & TRN & \\
\hline
\end{tabular}


Supplemental Table S2.txt

\begin{tabular}{|c|c|c|c|c|c|}
\hline CHEMBL 3208552 & 688239 & 4.5362 & 5.5808 & TST & \\
\hline CHEMBL1305865 & 688239 & 5.3862 & 5.3624 & TRN & \\
\hline CHEMBL1356983 & 688239 & 5.3862 & 5.3292 & TST & \\
\hline CHEMBL1420046 & 688239 & 4.5362 & 5.4726 & TST & \\
\hline CHEMBL1376929 & 688239 & 8.1871 & 5.5123 & TST & \\
\hline CHEMBL1461727 & 688239 & 6.8861 & 5.4865 & TRN & \\
\hline CHEMBL1469154 & 688239 & 5.0362 & 5.4526 & TRN & \\
\hline CHEMBL1352452 & 688239 & 4.8862 & 5.4318 & TRN & \\
\hline CHEMBL1559514 & 688239 & 4.5362 & 5.593999 & 9999999999 & TRN \\
\hline CHEMBL1486995 & 688239 & 6.0862 & 5.3827 & TST & \\
\hline CHEMBL1494390 & 688239 & 4.6862 & 5.291 & TRN & \\
\hline CHEMBL1306690 & 688239 & 8.28399 & 999999999 & 5.4401 & TS \\
\hline CHEMBL1524388 & 688239 & 4.5362 & 5.3179 & TRN & \\
\hline CHEMBL1406430 & 688239 & 5.3362 & 5.5055 & TRN & \\
\hline CHEMBL1495794 & 688239 & 5.6862 & 5.4471 & TRN & \\
\hline CHEMBL1527950 & 688239 & 6.0862 & 5.4495 & TST & \\
\hline CHEMBL1555077 & 688239 & 4.5362 & 5.396 & TRN & \\
\hline CHEMBL1525899 & 688239 & 5.7862 & 5.4 & TRN & \\
\hline CHEMBL1322225 & 688239 & 5.8362 & 5.4916 & TRN & \\
\hline CHEMBL1508699 & 688239 & 5.5362 & 5.5284 & TRN & \\
\hline CHEMBL1344214 & 688239 & 5.0362 & 5.4275 & TRN & \\
\hline CHEMBL1427906 & 688239 & 4.7362 & 5.3405 & TRN & \\
\hline CHEMBL1369501 & 688239 & 6.7361 & 5.4609 & TRN & \\
\hline CHEMBL1540191 & 688239 & 4.8862 & 5.5242 & TRN & \\
\hline CHEMBL1512378 & 688239 & 5.1862 & 5.6738 & TRN & \\
\hline CHEMBL1575594 & 688239 & 4.6362 & 5.4737 & TRN & \\
\hline CHEMBL1550650 & 688239 & 4.7362 & 5.5243 & TST & \\
\hline CHEMBL1612073 & 688239 & 4.5362 & 5.4139 & TRN & \\
\hline CHEMBL 3208568 & 688239 & 4.7362 & 5.4995 & TRN & \\
\hline CHEMBL1378386 & 688239 & 6.0862 & 5.5056 & TRN & \\
\hline CHEMBL1426229 & 688239 & 4.5362 & 5.5071 & TRN & \\
\hline CHEMBL 3212545 & 688239 & 4.5362 & 5.6047 & TST & \\
\hline CHEMBL 3194538 & 688239 & 4.5362 & 5.5198 & TRN & \\
\hline CHEMBL1524475 & 688239 & 5.1862 & 5.4591 & TRN & \\
\hline CHEMBL1364881 & 688239 & 4.5362 & 5.5808 & TRN & \\
\hline CHEMBL1504811 & 688239 & 4.7362 & 5.4961 & TRN & \\
\hline CHEMBL1513098 & 688239 & 4.5862 & 5.6644 & TRN & \\
\hline CHEMBL1415134 & 688239 & 4.5862 & 5.5197 & TST & \\
\hline CHEMBL1357893 & 688239 & 4.5362 & 5.5371 & TRN & \\
\hline CHEMBL1420801 & 688239 & 6.7862 & 5.532999 & 99999999995 & ה \\
\hline CHEMBL1555578 & 688239 & 4.7862 & 5.5296 & TRN & \\
\hline CHEMBL1428007 & 688239 & 5.5862 & 5.6382 & TRN & \\
\hline CHEMBL1461364 & 688239 & 4.5362 & 5.4634 & TRN & \\
\hline CHEMBL1550763 & 688239 & 5.6362 & 5.3949 & TRN & \\
\hline CHEMBL1436327 & 688239 & 5.2862 & 5.5057 & TRN & \\
\hline CHEMBL 3208044 & 688239 & 4.5362 & 5.5275 & TRN & \\
\hline CHEMBL1494532 & 688239 & 8.3372 & 5.4485 & TRN & \\
\hline CHEMBL1301801 & 688239 & 4.5362 & 5.5 & TRN & \\
\hline
\end{tabular}


Supplemental Table S2.txt

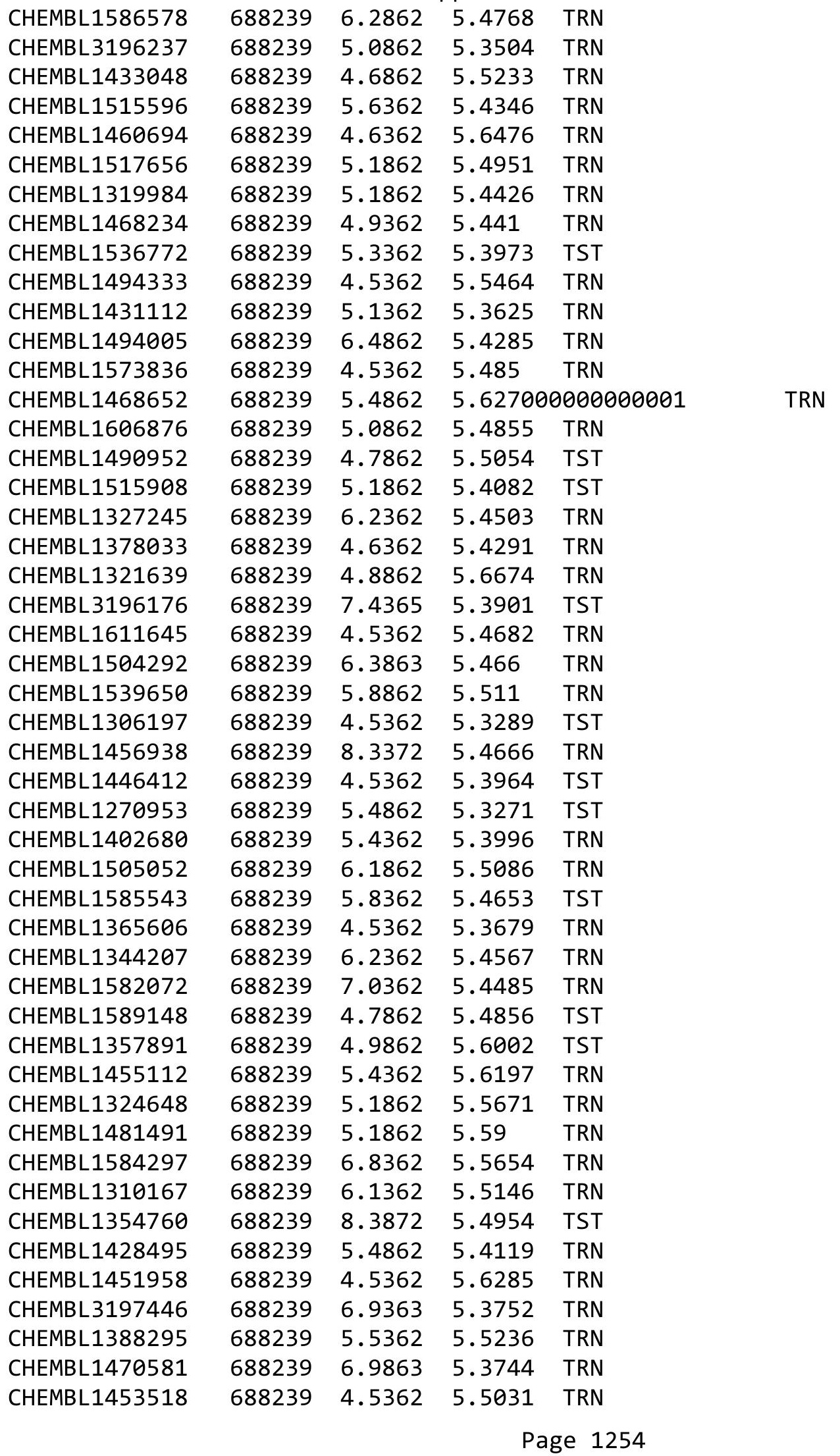


Supplemental Table S2.txt

\begin{tabular}{|c|c|c|c|c|}
\hline CHEMBL1497218 & 688239 & 7.1864 & 5.4888 & TRN \\
\hline CHEMBL1510927 & 688239 & 5.3362 & 5.4984 & TRN \\
\hline CHEMBL1465286 & 688239 & 4.5362 & 5.5873 & TRN \\
\hline CHEMBL1492048 & 688239 & 6.8362 & 5.5153 & TRN \\
\hline CHEMBL1535590 & 688239 & 4.5362 & 5.5588 & TRN \\
\hline CHEMBL1484634 & 688239 & 8.2366 & 5.3125 & TRN \\
\hline CHEMBL1456825 & 688239 & 7.2366 & 5.403 & TRN \\
\hline CHEMBL1502844 & 688239 & 4.6362 & 5.4331 & TRN \\
\hline CHEMBL1586567 & 688239 & 6.1862 & 5.5369 & TRN \\
\hline CHEMBL1472376 & 688239 & 5.5862 & 5.593999 & 999999999 \\
\hline CHEMBL1457354 & 688239 & 4.5362 & 5.4524 & TRN \\
\hline CHEMBL1321262 & 688239 & 4.5862 & 5.4455 & TRN \\
\hline CHEMBL1608197 & 688239 & 6.2862 & 5.4579 & TRN \\
\hline CHEMBL1383636 & 688239 & 4.5862 & 5.5129 & TRN \\
\hline CHEMBL1457359 & 688239 & 5.6362 & 5.4421 & TRN \\
\hline CHEMBL1562827 & 688239 & 5.0362 & 5.5457 & TST \\
\hline CHEMBL1471122 & 688239 & 4.7862 & 5.3987 & TST \\
\hline CHEMBL1474465 & 688239 & 5.3362 & 5.5973 & TRN \\
\hline CHEMBL1569900 & 688239 & 4.6862 & 5.3179 & TRN \\
\hline CHEMBL1604443 & 688239 & 4.5362 & 5.5074 & TRN \\
\hline CHEMBL1310689 & 688239 & 4.6862 & 5.6033 & TRN \\
\hline CHEMBL1976308 & 688239 & 4.5362 & 5.4179 & TRN \\
\hline CHEMBL1431996 & 688239 & 5.0862 & 5.6132 & TRN \\
\hline CHEMBL1536484 & 688239 & 5.7362 & 5.5167 & TRN \\
\hline CHEMBL1381652 & 688239 & 7.4365 & 5.6209 & TRN \\
\hline CHEMBL1492916 & 688239 & 4.6362 & 5.526 & TST \\
\hline CHEMBL1502363 & 688239 & 4.5862 & 5.5974 & TST \\
\hline CHEMBL1568998 & 688239 & 5.6862 & 5.5758 & TRN \\
\hline CHEMBL1343998 & 688239 & 6.0862 & 5.4259 & TRN \\
\hline CHEMBL1509903 & 688239 & 6.1862 & 5.5302 & TRN \\
\hline CHEMBL1307284 & 688239 & 7.0362 & 5.5516 & TST \\
\hline CHEMBL1431659 & 688239 & 4.5362 & 5.4499 & TRN \\
\hline CHEMBL1468819 & 688239 & 4.6362 & 5.3617 & TST \\
\hline CHEMBL1544400 & 688239 & 7.0362 & 5.681 & TRN \\
\hline CHEMBL1536366 & 688239 & 4.9362 & 5.5979 & TRN \\
\hline CHEMBL1502323 & 688239 & 4.6862 & 5.5172 & TRN \\
\hline CHEMBL3194894 & 688239 & 6.3362 & 5.612 & TRN \\
\hline CHEMBL1302518 & 688239 & 5.2862 & 5.4993 & TST \\
\hline CHEMBL1509377 & 688239 & 6.9363 & 5.407 & TRN \\
\hline CHEMBL1507920 & 688239 & 5.0862 & 5.61 & TRN \\
\hline CHEMBL1522787 & 688239 & 4.7362 & 5.6187 & TST \\
\hline CHEMBL1602718 & 688239 & 6.6362 & 5.4447 & TRN \\
\hline CHEMBL1301810 & 688239 & 8.3372 & \multicolumn{2}{|c|}{5.632000000000001} \\
\hline CHEMBL1598966 & 688239 & 5.4362 & 5.5874 & TST \\
\hline CHEMBL1375074 & 688239 & 5.3862 & 5.3527 & TST \\
\hline CHEMBL1466144 & 688239 & 6.5862 & 5.5441 & TRN \\
\hline CHEMBL1586829 & 688239 & 4.5362 & 5.572 & TRN \\
\hline CHEMBL579967 & 688239 & 5.5862 & 5.3853 & TRN \\
\hline
\end{tabular}


Supplemental Table S2.txt

\begin{tabular}{|c|c|c|c|c|c|}
\hline CHEMBL1501060 & 688239 & 4.6362 & 5.6722 & TRN & \\
\hline CHEMBL1305104 & 688239 & 4.7362 & 5.4337 & TST & \\
\hline CHEMBL1317392 & 688239 & 6.0862 & 5.5664 & TRN & \\
\hline CHEMBL1582957 & 688239 & 4.5362 & 5.5005 & TRN & \\
\hline CHEMBL1476163 & 688239 & 6.5363 & 5.5061 & TRN & \\
\hline CHEMBL235541 & 688239 & 4.5362 & 5.3639 & TST & \\
\hline CHEMBL1433911 & 688239 & 4.5362 & 5.4376 & TRN & \\
\hline CHEMBL1461388 & 688239 & 4.7862 & 5.5926 & TRN & \\
\hline CHEMBL1359528 & 688239 & 6.5363 & 5.4691 & TST & \\
\hline CHEMBL1389443 & 688239 & 5.6362 & 5.5128 & TRN & \\
\hline CHEMBL3214424 & 688239 & 5.1862 & 5.4169 & TRN & \\
\hline CHEMBL1558156 & 688239 & 7.0862 & 5.4039 & TRN & \\
\hline CHEMBL1301942 & 688239 & 6.9363 & 5.5793 & TRN & \\
\hline CHEMBL1559175 & 688239 & 4.4862 & 5.4543 & TRN & \\
\hline CHEMBL1394013 & 688239 & 5.0362 & 5.4788 & TRN & \\
\hline CHEMBL1602217 & 688239 & 6.1862 & 5.289 & TST & \\
\hline CHEMBL1359341 & 688239 & 6.0362 & 5.46299 & 9999999999 & TRN \\
\hline CHEMBL1531883 & 688239 & 4.4862 & 5.409 & TST & \\
\hline CHEMBL1394797 & 688239 & 6.2862 & 5.5104 & TRN & \\
\hline CHEMBL1400317 & 688239 & 4.6362 & 5.3778 & TRN & \\
\hline CHEMBL1518160 & 688239 & 4.6362 & 5.3935 & TRN & \\
\hline CHEMBL1483887 & 688239 & 5.1862 & 5.5185 & TRN & \\
\hline CHEMBL1416222 & 688239 & 5.1862 & 5.5062 & TRN & \\
\hline CHEMBL1494984 & 688239 & 4.8362 & 5.3849 & TRN & \\
\hline CHEMBL1400457 & 688239 & 5.1862 & 5.3249 & TRN & \\
\hline CHEMBL1328168 & 688239 & 4.6362 & 5.3473 & TST & \\
\hline CHEMBL1596638 & 688239 & 4.8362 & 5.4332 & TRN & \\
\hline CHEMBL1461348 & 688239 & 6.8362 & 5.5394 & TRN & \\
\hline CHEMBL1405384 & 688239 & 5.9362 & 5.4163 & TRN & \\
\hline CHEMBL1330353 & 688239 & 4.6862 & 5.4277 & TST & \\
\hline CHEMBL1441400 & 688239 & 5.4362 & 5.5978 & TRN & \\
\hline CHEMBL1518912 & 688239 & 4.5362 & 5.5447 & TST & \\
\hline CHEMBL1381833 & 688239 & 6.0862 & 5.4158 & TST & \\
\hline CHEMBL1400346 & 688239 & 4.7362 & 5.4158 & TST & \\
\hline CHEMBL3197978 & 688239 & 5.9362 & 5.4076 & TRN & \\
\hline CHEMBL1463086 & 688239 & 4.5862 & 5.5845 & TRN & \\
\hline CHEMBL 3196044 & 688239 & 4.4862 & 5.6649 & TRN & \\
\hline CHEMBL1580090 & 688239 & 6.1862 & 5.5809 & TRN & \\
\hline CHEMBL1556716 & 688239 & 5.3862 & 5.5888 & TRN & \\
\hline CHEMBL1561905 & 688239 & 4.5862 & 5.3612 & TRN & \\
\hline CHEMBL1317847 & 688239 & 4.4862 & 5.6968 & TRN & \\
\hline CHEMBL1531778 & 688239 & 6.0862 & 5.4949 & TRN & \\
\hline CHEMBL3208289 & 688239 & 5.1862 & 5.3549 & TRN & \\
\hline CHEMBL1399968 & 688239 & 4.7862 & 5.5546 & TST & \\
\hline CHEMBL1460380 & 688239 & 4.5862 & 5.5576 & TST & \\
\hline CHEMBL1517995 & 688239 & 4.6862 & 5.6027 & TRN & \\
\hline CHEMBL1549175 & 688239 & 4.6862 & 5.3146 & TRN & \\
\hline CHEMBL577862 & 688239 & 5.1862 & 5.4722 & TRN & \\
\hline
\end{tabular}


Supplemental Table S2.txt

\begin{tabular}{|c|c|c|c|c|}
\hline CHEMBL1583754 & 688239 & 4.5362 & 5.3974 & TRN \\
\hline CHEMBL1329140 & 688239 & 5.7362 & 5.3779 & TRN \\
\hline CHEMBL1335688 & 688239 & 6.0862 & 5.4197 & TRN \\
\hline CHEMBL1421507 & 688239 & 4.8862 & 5.4686 & TRN \\
\hline CHEMBL1383938 & 688239 & 8.3372 & 5.4624 & TRN \\
\hline CHEMBL1524710 & 688239 & 4.8362 & 5.4874 & TRN \\
\hline CHEMBL1370108 & 688239 & 6.1362 & 5.5649 & TRN \\
\hline CHEMBL1482125 & 688239 & 5.6362 & 5.5541 & TRN \\
\hline CHEMBL1405841 & 688239 & 4.7862 & 5.5459 & TRN \\
\hline CHEMBL1441399 & 688239 & 5.5862 & 5.4269 & TST \\
\hline CHEMBL1469075 & 688239 & 5.4862 & 5.4226 & TRN \\
\hline CHEMBL1434021 & 688239 & 5.7862 & 5.4221 & TRN \\
\hline CHEMBL1595420 & 688239 & 6.8861 & 5.5883 & TRN \\
\hline CHEMBL1541973 & 688239 & 6.3362 & 5.332999 & 9999999999 \\
\hline CHEMBL1402360 & 688239 & 4.6362 & 5.4449 & TRN \\
\hline CHEMBL1412993 & 688239 & 6.9363 & 5.4591 & TST \\
\hline CHEMBL1500262 & 688239 & 6.9363 & 5.4162 & TST \\
\hline CHEMBL1394640 & 688239 & 6.8362 & 5.3226 & TRN \\
\hline CHEMBL1364267 & 688239 & 6.4362 & 5.3966 & TST \\
\hline CHEMBL1497889 & 688239 & 4.9 & 5.3666 & TRN \\
\hline CHEMBL1338076 & 688239 & 6.3362 & 5.5556 & TRN \\
\hline CHEMBL3212642 & 688239 & 5.1862 & 5.4005 & TRN \\
\hline CHEMBL1427977 & 688239 & 5.0862 & 5.6302 & TRN \\
\hline CHEMBL1457471 & 688239 & 5.1862 & 5.5876 & TRN \\
\hline CHEMBL1551935 & 688239 & 4.6862 & 5.4749 & TRN \\
\hline CHEMBL1409510 & 688239 & 5.2362 & 5.5959 & TRN \\
\hline CHEMBL1453905 & 688239 & 4.7362 & 5.4819 & TRN \\
\hline CHEMBL1573406 & 688239 & 4.95 & 5.5327 & TRN \\
\hline CHEMBL1340319 & 688239 & 4.6362 & 5.6017 & TRN \\
\hline CHEMBL1413106 & 688239 & 4.6362 & 5.4441 & TST \\
\hline CHEMBL1538793 & 688239 & 6.1862 & 5.6371 & TRN \\
\hline CHEMBL1330391 & 688239 & 5.5862 & 5.6191 & TRN \\
\hline CHEMBL1492721 & 688239 & 4.7362 & 5.5523 & TRN \\
\hline CHEMBL1548149 & 688239 & 5.3362 & 5.4176 & TST \\
\hline CHEMBL1376400 & 688239 & 6.9863 & $5.48600 €$ & 0000000001 \\
\hline CHEMBL1439460 & 688239 & 6.4862 & 5.5814 & TRN \\
\hline CHEMBL1317990 & 688239 & 8.3372 & 5.3438 & TRN \\
\hline CHEMBL1368863 & 688239 & 4.7862 & 5.6 & TST \\
\hline CHEMBL567340 & 688239 & 5.5362 & 5.4132 & TST \\
\hline CHEMBL1336193 & 688239 & 4.5862 & 5.4935 & TST \\
\hline CHEMBL1304022 & 688239 & 4.6862 & 5.4704 & TRN \\
\hline CHEMBL1495045 & 688239 & 6.0862 & 5.3463 & TST \\
\hline CHEMBL1386498 & 688239 & 5.1862 & 5.5123 & TRN \\
\hline CHEMBL3210531 & 688239 & 5.4862 & 5.4425 & TST \\
\hline CHEMBL1428784 & 688239 & 5.8362 & 5.6107 & TST \\
\hline CHEMBL1439904 & 688239 & 5.1862 & 5.4872 & TST \\
\hline CHEMBL1507330 & 688239 & 5.4862 & 5.4116 & TRN \\
\hline CHEMBL1339648 & 688239 & 5.9862 & 5.4925 & TRN \\
\hline
\end{tabular}


Supplemental Table S2.txt

\begin{tabular}{|c|c|c|c|c|}
\hline CHEMBL1381495 & 688239 & 4.5362 & 5.3767 & TST \\
\hline CHEMBL1494788 & 688239 & 4.5362 & 5.6384 & TRN \\
\hline CHEMBL1543752 & 688239 & 4.5362 & 5.5361 & TST \\
\hline CHEMBL1339235 & 688239 & 5.5862 & 5.5044 & TST \\
\hline CHEMBL1511592 & 688239 & 4.9362 & 5.5105 & TRN \\
\hline CHEMBL1334539 & 688239 & 5.8362 & 5.51200 & 00000000005 \\
\hline CHEMBL1301314 & 688239 & 6.6362 & 5.5993 & TRN \\
\hline CHEMBL1468994 & 688239 & 6.0862 & 5.5086 & TRN \\
\hline CHEMBL1385128 & 688239 & 5.1862 & 5.2944 & TRN \\
\hline CHEMBL1414900 & 688239 & 5.2362 & 5.5918 & TRN \\
\hline CHEMBL1362290 & 688239 & 4.5362 & 5.5525 & TRN \\
\hline CHEMBL1334500 & 688239 & 4.6862 & 5.4349 & TRN \\
\hline CHEMBL1493745 & 688239 & 5.4362 & 5.5141 & TRN \\
\hline CHEMBL1572583 & 688239 & 4.6362 & 5.4999 & TRN \\
\hline CHEMBL1347934 & 688239 & 4.5362 & 5.5014 & TRN \\
\hline CHEMBL1538764 & 688239 & 6.1362 & 5.4985 & TRN \\
\hline CHEMBL1607120 & 688239 & 4.5362 & 5.3826 & TRN \\
\hline CHEMBL1313400 & 688239 & 4.7862 & 5.7018 & TRN \\
\hline CHEMBL1338389 & 688239 & 4.5362 & 5.5712 & TRN \\
\hline CHEMBL3190724 & 688239 & 7.0362 & 5.4379 & TST \\
\hline CHEMBL1589003 & 688239 & 5.1362 & 5.4803 & TRN \\
\hline CHEMBL1394228 & 688239 & 5.1862 & 5.518 & TST \\
\hline CHEMBL1458198 & 688239 & 4.8362 & 5.4856 & TRN \\
\hline CHEMBL 3211143 & 688239 & 7.1864 & 5.4201 & TRN \\
\hline CHEMBL1406520 & 688239 & 5.6362 & 5.261 & TST \\
\hline CHEMBL1419722 & 688239 & 6.9363 & 5.6359 & TRN \\
\hline CHEMBL1368948 & 688239 & 5.2862 & 5.5041 & TRN \\
\hline CHEMBL1490639 & 688239 & 7.1361 & 5.5201 & TRN \\
\hline CHEMBL3211964 & 688239 & 5.1862 & 5.4897 & TST \\
\hline CHEMBL1590874 & 688239 & 5.1862 & 5.4624 & TRN \\
\hline CHEMBL1494969 & 688239 & 6.9363 & 5.6383 & TRN \\
\hline CHEMBL1517895 & 688239 & 4.7362 & 5.4375 & TRN \\
\hline CHEMBL3191642 & 688239 & 6.7862 & 5.5296 & TRN \\
\hline CHEMBL1578226 & 688239 & 5.4862 & 5.6494 & TRN \\
\hline CHEMBL583584 & 688239 & 7.0362 & 5.3649 & TRN \\
\hline CHEMBL1299675 & 688239 & 4.5362 & 5.6469 & TRN \\
\hline CHEMBL1449235 & 688239 & 6.3863 & 5.5103 & TRN \\
\hline CHEMBL3195064 & 688239 & 5.1862 & 5.2538 & TRN \\
\hline CHEMBL1612956 & 688239 & 5.2362 & 5.4755 & TRN \\
\hline CHEMBL1431312 & 688239 & 5.0862 & 5.5508 & TRN \\
\hline CHEMBL1569626 & 688239 & 6.1362 & 5.4946 & TRN \\
\hline CHEMBL1512934 & 688239 & 6.3362 & 5.5488 & TRN \\
\hline CHEMBL1454787 & 688239 & 5.1862 & 5.3528 & TRN \\
\hline CHEMBL1455335 & 688239 & 4.5362 & 5.6017 & TRN \\
\hline CHEMBL1439475 & 688239 & 4.9862 & 5.4577 & TRN \\
\hline CHEMBL1464416 & 688239 & 5.7362 & 5.434 & TRN \\
\hline CHEMBL1303982 & 688239 & 5.6862 & 5.4118 & TRN \\
\hline CHEMBL1468615 & 688239 & 4.8362 & 5.5211 & TRN \\
\hline
\end{tabular}


Supplemental Table S2.txt

\begin{tabular}{|c|c|c|c|c|c|}
\hline CHEMBL1315092 & 688239 & 6.3362 & 5.6735 & TRN & \\
\hline CHEMBL1474285 & 688239 & 5.2862 & 5.4931 & TST & \\
\hline CHEMBL1392838 & 688239 & 4.5362 & 5.3006 & TRN & \\
\hline CHEMBL1421143 & 688239 & 5.2862 & 5.5486 & TST & \\
\hline CHEMBL1565038 & 688239 & 4.5362 & 5.48 & TRN & \\
\hline CHEMBL1531120 & 688239 & 5.7862 & 5.5162 & TRN & \\
\hline CHEMBL1482509 & 688239 & 5.6362 & 5.5175 & TRN & \\
\hline CHEMBL1326767 & 688239 & 4.8862 & 5.6139 & TST & \\
\hline CHEMBL1342745 & 688239 & 5.6862 & 5.4859 & TRN & \\
\hline CHEMBL1375829 & 688239 & 4.7862 & 5.5549 & TRN & \\
\hline CHEMBL1428756 & 688239 & 6.2362 & 5.5523 & TRN & \\
\hline CHEMBL1464386 & 688239 & 6.0362 & 5.426 & TST & \\
\hline CHEMBL1562642 & 688239 & 4.8362 & 5.6124 & TST & \\
\hline CHEMBL1520465 & 688239 & 4.5362 & 5.3057 & TRN & \\
\hline CHEMBL1609965 & 688239 & 5.5362 & 5.5515 & TST & \\
\hline CHEMBL 2001071 & 688239 & 6.8362 & 5.3565 & TST & \\
\hline CHEMBL1484216 & 688239 & 5.4862 & 5.5438 & TRN & \\
\hline CHEMBL1356092 & 688239 & 4.5362 & 5.3314 & TRN & \\
\hline CHEMBL1598955 & 688239 & 5.1862 & 5.4003 & TRN & \\
\hline CHEMBL1505538 & 688239 & 4.6362 & 5.4575 & TRN & \\
\hline CHEMBL1373694 & 688239 & 6.4362 & 5.4107 & TST & \\
\hline CHEMBL1315102 & 688239 & 7.8356 & 5.567 & TST & \\
\hline CHEMBL1454416 & 688239 & 4.7362 & 5.5062 & TRN & \\
\hline CHEMBL1300299 & 688239 & 5.4862 & 5.5941 & TRN & \\
\hline CHEMBL1597160 & 688239 & 5.2862 & 5.5218 & TRN & \\
\hline CHEMBL1603210 & 688239 & 4.9862 & 5.5442 & TST & \\
\hline CHEMBL1394671 & 688239 & 4.5362 & 5.4263 & TRN & \\
\hline CHEMBL1365821 & 688239 & 4.6862 & 5.6433 & TST & \\
\hline CHEMBL1311058 & 688239 & 4.5362 & 5.4675 & TRN & \\
\hline CHEMBL1416719 & 688239 & 5.4362 & 5.534 & TRN & \\
\hline CHEMBL3189505 & 688239 & 5.2362 & 5.5113 & TST & \\
\hline CHEMBL1536758 & 688239 & 4.5362 & 5.5094 & TRN & \\
\hline CHEMBL1555882 & 688239 & 4.5362 & 5.5619 & TRN & \\
\hline CHEMBL1300573 & 688239 & 6.2862 & 5.5482 & TRN & \\
\hline CHEMBL1576912 & 688239 & 7.1864 & 5.5278 & TRN & \\
\hline CHEMBL1470867 & 688239 & 5.2862 & 5.4485 & TRN & \\
\hline CHEMBL1415782 & 688239 & 4.6862 & 5.5317 & TRN & \\
\hline CHEMBL1502111 & 688239 & 4.5362 & 5.4014 & TRN & \\
\hline CHEMBL1415926 & 688239 & 4.5362 & 5.2894 & TST & \\
\hline CHEMBL1498329 & 688239 & 4.9862 & \multicolumn{2}{|c|}{5.452000000000001} & TRN \\
\hline CHEMBL1304359 & 688239 & 5.6362 & 5.6307 & TRN & \\
\hline CHEMBL1375348 & 688239 & 5.8862 & 5.4498 & TRN & \\
\hline CHEMBL1549327 & 688239 & 4.6862 & 5.4839 & TRN & \\
\hline CHEMBL1455665 & 688239 & 5.3362 & 5.5496 & TRN & \\
\hline CHEMBL1983220 & 688239 & 4.5362 & 5.3466 & TST & \\
\hline CHEMBL1377207 & 688239 & 5.2862 & 5.4621 & TST & \\
\hline CHEMBL1562980 & 688239 & 5.4362 & 5.5043 & TRN & \\
\hline CHEMBL1613666 & 688239 & 4.7862 & 5.3623 & TRN & \\
\hline
\end{tabular}

Page 1259 
Supplemental Table S2.txt

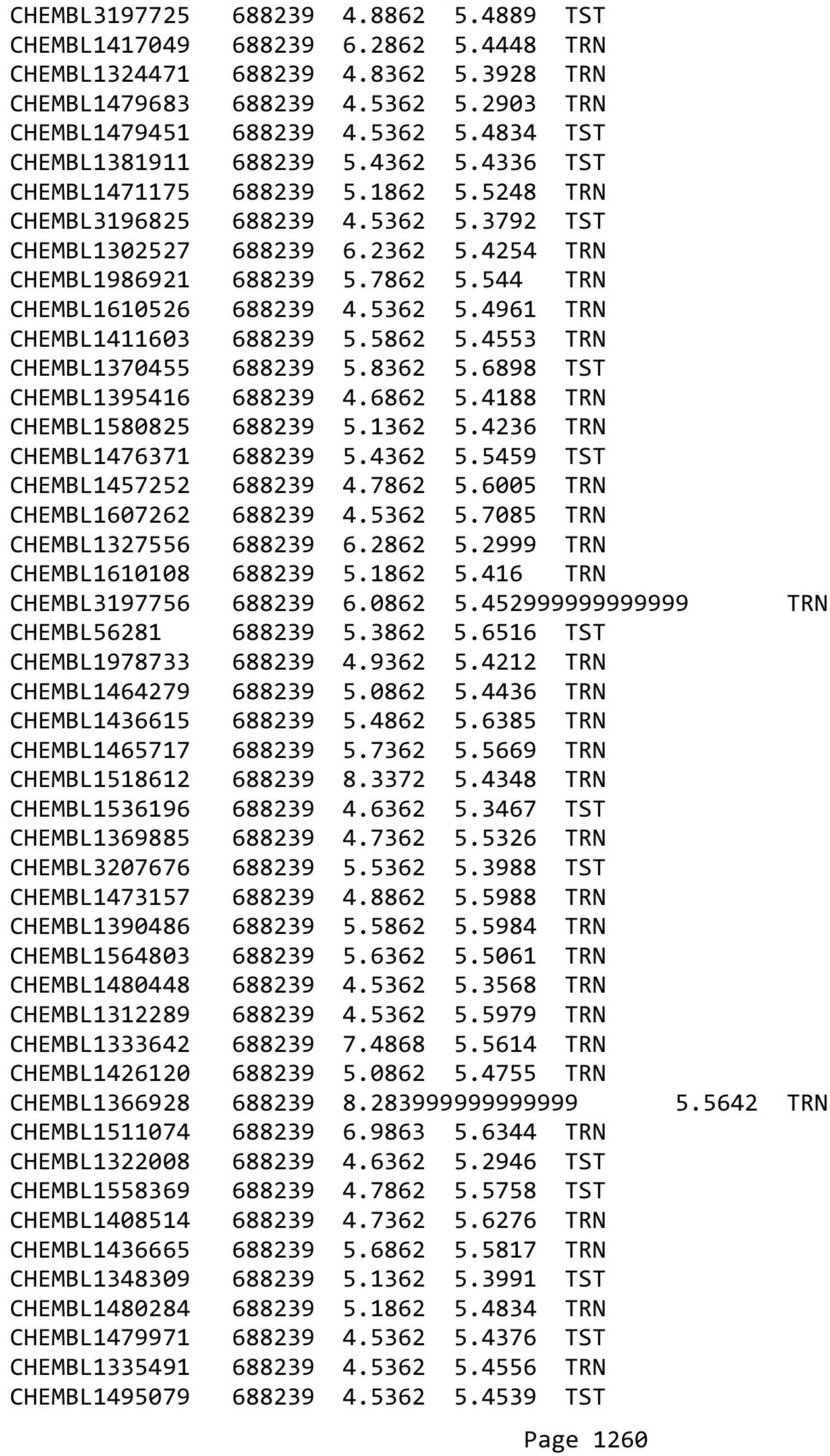


Supplemental Table S2.txt

\begin{tabular}{|c|c|c|c|c|c|}
\hline CHEMBL1328208 & 688239 & 5.3862 & 5.4548 & TRN & \\
\hline CHEMBL1457366 & 688239 & 6.6861 & 5.4757 & TRN & \\
\hline CHEMBL1528992 & 688239 & 6.7862 & 5.5467 & TST & \\
\hline CHEMBL1442135 & 688239 & 4.5362 & 5.4219 & TRN & \\
\hline CHEMBL1326250 & 688239 & 6.0862 & 5.3215 & TRN & \\
\hline CHEMBL1604798 & 688239 & 6.5862 & 5.4254 & TRN & \\
\hline CHEMBL1384570 & 688239 & 5.1862 & 5.4796 & TST & \\
\hline CHEMBL1603175 & 688239 & 6.9363 & 5.3898 & TST & \\
\hline CHEMBL1501640 & 688239 & 6.2362 & 5.4705 & TRN & \\
\hline CHEMBL1361140 & 688239 & 4.5362 & 5.4915 & TST & \\
\hline CHEMBL1482913 & 688239 & 6.1362 & 5.3922 & TRN & \\
\hline CHEMBL1329447 & 688239 & 4.5362 & 5.5871 & TRN & \\
\hline CHEMBL1319763 & 688239 & 4.6862 & 5.667006 & 0000000001 & TRN \\
\hline CHEMBL1609983 & 688239 & 4.7362 & 5.5976 & TRN & \\
\hline CHEMBL1500522 & 688239 & 5.2362 & 5.5767 & TRN & \\
\hline CHEMBL1381344 & 688239 & 5.7362 & 5.3469 & TRN & \\
\hline CHEMBL1573975 & 688239 & 4.6362 & 5.3845 & TRN & \\
\hline CHEMBL1470664 & 688239 & 5.0362 & 5.3985 & TST & \\
\hline CHEMBL1345768 & 688239 & 6.9863 & 5.5643 & TST & \\
\hline CHEMBL1597560 & 688239 & 5.7362 & 5.6281 & TRN & \\
\hline CHEMBL1305151 & 688239 & 6.2862 & 5.4787 & TRN & \\
\hline CHEMBL1496959 & 688239 & 5.1862 & 5.4159 & TRN & \\
\hline CHEMBL1325359 & 688239 & 4.6862 & 5.5493 & TRN & \\
\hline CHEMBL1587177 & 688239 & 4.7362 & 5.4488 & TRN & \\
\hline CHEMBL1495776 & 688239 & 5.1862 & 5.4932 & TST & \\
\hline CHEMBL1328563 & 688239 & 5.6362 & 5.522 & TRN & \\
\hline CHEMBL1581639 & 688239 & 6.0862 & 5.33299 & 9999999999 & TST \\
\hline CHEMBL1379979 & 688239 & 4.6862 & 5.6424 & TRN & \\
\hline CHEMBL1430436 & 688239 & 4.7362 & 5.2762 & TRN & \\
\hline CHEMBL1580178 & 688239 & 4.9862 & 5.4023 & TRN & \\
\hline CHEMBL1407635 & 688239 & 4.7862 & 5.3748 & TST & \\
\hline CHEMBL1494284 & 688239 & 6.7862 & 5.5057 & TRN & \\
\hline CHEMBL1360418 & 688239 & 6.3863 & 5.5345 & TRN & \\
\hline CHEMBL1366700 & 688239 & 4.5362 & 5.5218 & TRN & \\
\hline CHEMBL1348491 & 688239 & 5.6862 & 5.3794 & TST & \\
\hline CHEMBL1321034 & 688239 & 4.6362 & 5.4145 & TRN & \\
\hline CHEMBL1540488 & 688239 & 5.7362 & 5.4139 & TST & \\
\hline CHEMBL1479495 & 688239 & 4.7362 & 5.5022 & TRN & \\
\hline CHEMBL1417593 & 688239 & 4.5362 & 5.4202 & TRN & \\
\hline CHEMBL1578046 & 688239 & 4.5362 & 5.5295 & TRN & \\
\hline CHEMBL1437519 & 688239 & 5.8362 & 5.2422 & TRN & \\
\hline CHEMBL 3214473 & 688239 & 5.1862 & 5.4364 & TRN & \\
\hline CHEMBL1406630 & 688239 & 4.5362 & 5.4735 & TRN & \\
\hline CHEMBL1423522 & 688239 & 4.9362 & 5.4093 & TRN & \\
\hline CHEMBL1576528 & 688239 & 5.8362 & 5.4441 & TRN & \\
\hline CHEMBL1429538 & 688239 & 5.3862 & 5.4455 & TST & \\
\hline CHEMBL1582560 & 688239 & 4.5362 & 5.5256 & TRN & \\
\hline CHEMBL1530907 & 688239 & 6.1862 & 5.478 & TRN & \\
\hline
\end{tabular}


Supplemental Table S2.txt

\begin{tabular}{|c|c|c|c|c|}
\hline CHEMBL1603233 & 688239 & 5.2362 & 5.5923 & TRN \\
\hline CHEMBL1535600 & 688239 & 5.3862 & 5.4278 & TST \\
\hline CHEMBL1595493 & 688239 & 6.6362 & 5.4538 & TRN \\
\hline CHEMBL1479572 & 688239 & 6.2862 & 5.6473 & TRN \\
\hline CHEMBL 3198074 & 688239 & 4.8362 & \multicolumn{2}{|c|}{5.547000000000001} \\
\hline CHEMBL1411331 & 688239 & 4.6862 & 5.6731 & TST \\
\hline CHEMBL1487437 & 688239 & 7.0362 & 5.4009 & TRN \\
\hline CHEMBL1501751 & 688239 & 4.7362 & 5.4347 & TST \\
\hline CHEMBL1609232 & 688239 & 5.1862 & 5.4722 & TRN \\
\hline CHEMBL1402807 & 688239 & 4.5362 & 5.4835 & TRN \\
\hline CHEMBL1415233 & 688239 & 4.4862 & 5.416 & TRN \\
\hline CHEMBL1449340 & 688239 & 8.3372 & 5.4657 & TRN \\
\hline CHEMBL1523113 & 688239 & 4.6362 & 5.423999 & 99999999995 \\
\hline CHEMBL1579915 & 688239 & 4.8362 & 5.5658 & TRN \\
\hline CHEMBL1509799 & 688239 & 4.5862 & 5.4093 & TRN \\
\hline CHEMBL1308123 & 688239 & 8.1871 & 5.3519 & TRN \\
\hline CHEMBL1508751 & 688239 & 6.2862 & 5.5557 & TRN \\
\hline CHEMBL1541046 & 688239 & 6.3362 & 5.5476 & TRN \\
\hline CHEMBL1318519 & 688239 & 6.8861 & 5.5531 & TRN \\
\hline CHEMBL1566471 & 688239 & 4.5362 & 5.5618 & TRN \\
\hline CHEMBL1547717 & 688239 & 8.3372 & 5.3548 & TRN \\
\hline CHEMBL1609228 & 688239 & 4.8862 & 5.6157 & TRN \\
\hline CHEMBL1511802 & 688239 & 6.2862 & 5.7544 & TRN \\
\hline CHEMBL1612641 & 688239 & 5.4362 & 5.5229 & TRN \\
\hline CHEMBL1458747 & 688239 & 6.9363 & 5.4817 & TRN \\
\hline CHEMBL1504809 & 688239 & 4.5362 & 5.4611 & TRN \\
\hline CHEMBL1351491 & 688239 & 5.4362 & 5.4933 & TST \\
\hline CHEMBL1427486 & 688239 & 7.0362 & 5.5563 & TRN \\
\hline CHEMBL1409587 & 688239 & 5.6862 & 5.5029 & TRN \\
\hline CHEMBL1431580 & 688239 & 4.5362 & 5.4615 & TRN \\
\hline CHEMBL1590139 & 688239 & 4.4862 & 5.4617 & TRN \\
\hline CHEMBL1390860 & 688239 & 5.5362 & 5.5043 & TRN \\
\hline CHEMBL1349052 & 688239 & 4.5362 & 5.5242 & TRN \\
\hline CHEMBL1539216 & 688239 & 5.1862 & 5.5365 & TRN \\
\hline CHEMBL1402742 & 688239 & 5.5362 & 5.6184 & TST \\
\hline CHEMBL1487339 & 688239 & 5.7362 & 5.5518 & TRN \\
\hline CHEMBL3207977 & 688239 & 5.1862 & 5.487999 & 99999999995 \\
\hline CHEMBL1382849 & 688239 & 4.5362 & 5.5545 & TRN \\
\hline CHEMBL1435641 & 688239 & 4.5362 & 5.5467 & TRN \\
\hline CHEMBL1523858 & 688239 & 7.0362 & 5.4338 & TRN \\
\hline CHEMBL1320359 & 688239 & 4.8362 & 5.4716 & TRN \\
\hline CHEMBL1305060 & 688239 & 7.2366 & 5.648 & TRN \\
\hline CHEMBL1507094 & 688239 & 8.3872 & 5.5732 & TRN \\
\hline CHEMBL1481046 & 688239 & 6.5363 & 5.4167 & TRN \\
\hline CHEMBL1497576 & 688239 & 5.5362 & 5.5244 & TRN \\
\hline CHEMBL1313969 & 688239 & 4.5362 & 5.4171 & TRN \\
\hline CHEMBL1389060 & 688239 & 4.5362 & 5.4755 & TST \\
\hline CHEMBL1390834 & 688239 & 4.5362 & 5.4524 & TRN \\
\hline
\end{tabular}


Supplemental Table S2.txt

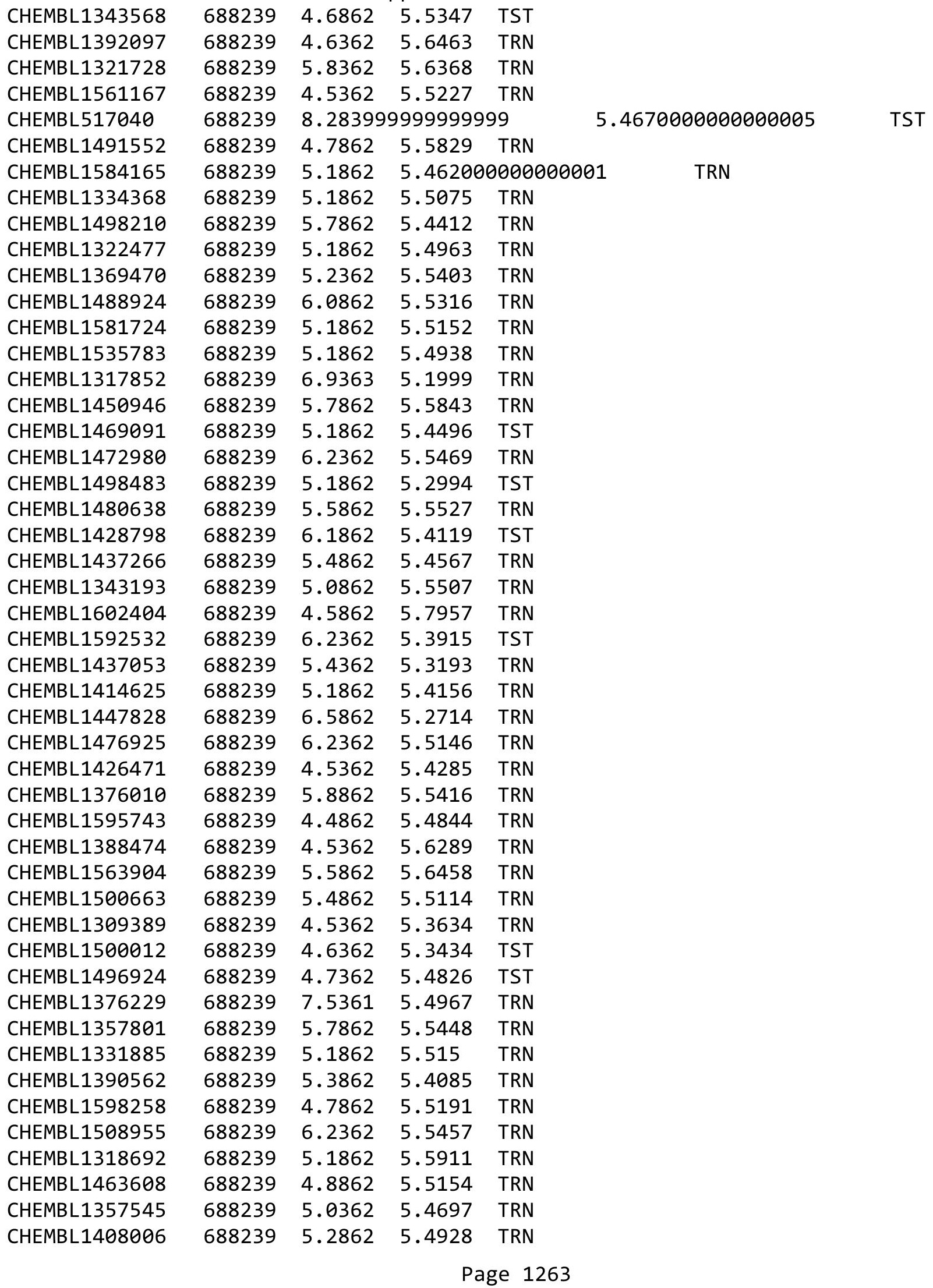


Supplemental Table S2.txt

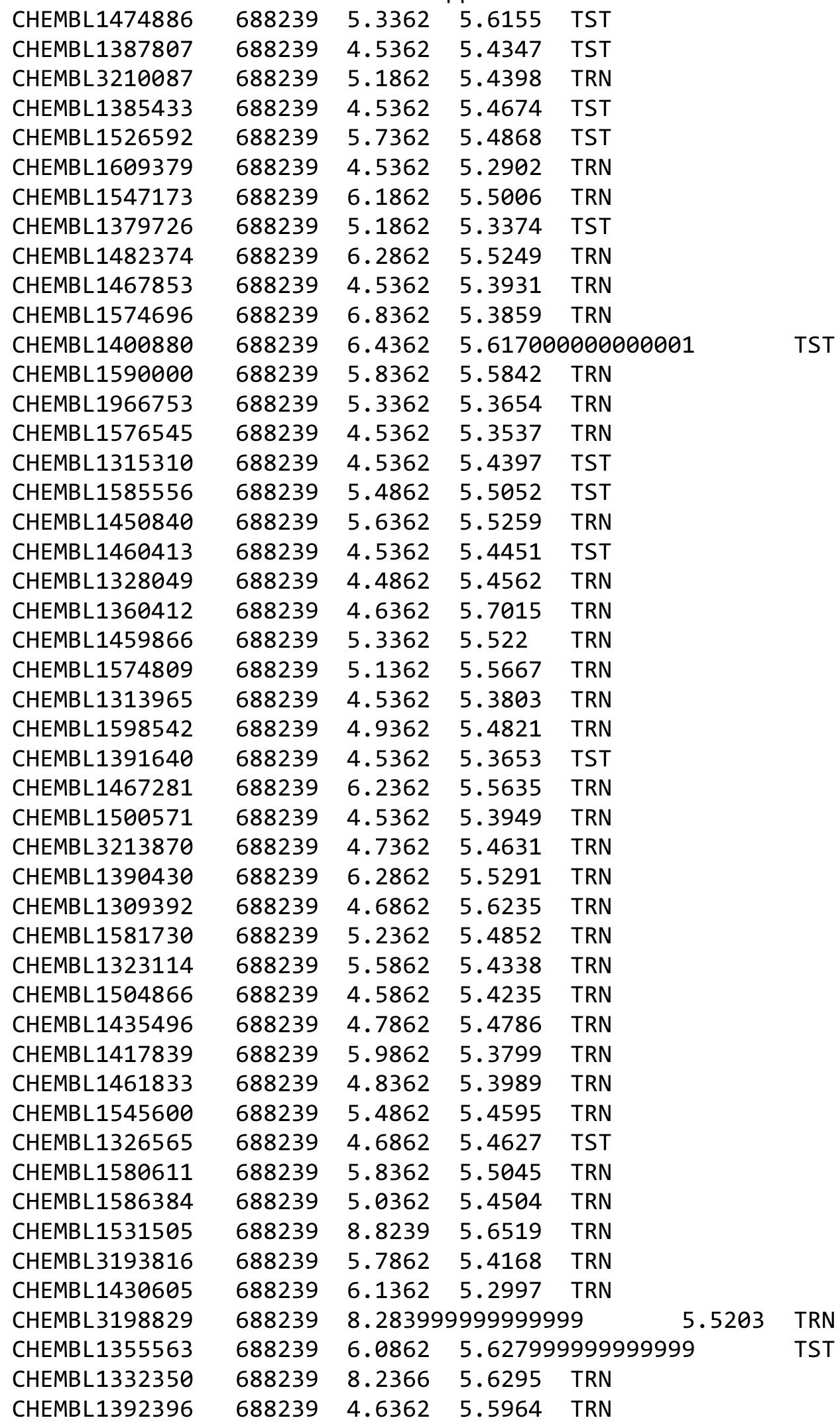


Supplemental Table S2.txt

\begin{tabular}{|c|c|c|c|c|}
\hline 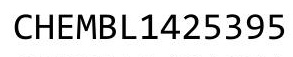 & & & & \\
\hline HEMBL1494934 & 38239 & 862 & & \\
\hline AEMBL1576691 & 239 & 862 & 892 & \\
\hline 8 & 39 & 862 & & \\
\hline IEMBL13 & 39 & 362 & & \\
\hline AEMBL1309887 & 88239 & 362 & & \\
\hline AEMBL1451538 & 88239 & 4.4862 & 591 & \\
\hline HEMBL1417291 & & & & \\
\hline EMBL14 & 39 & 862 & & \\
\hline IEMBL14 & & 362 & & \\
\hline AEMBL3391864 & 239 & 862 & & \\
\hline AEMBL1511542 & 39 & 862 & & \\
\hline AEMBL1359404 & & 362 & & \\
\hline HEMBL 318 & & 62 & & \\
\hline HEMBL16 & & & & \\
\hline AEMBL1323371 & & 362 & & \\
\hline HEMBL130 & & 362 & & \\
\hline AEMBL142 & & 62 & & \\
\hline AEMBL15 & & 62 & & \\
\hline HEMBL 15 & & & & \\
\hline HEMBL149 & & 362 & & \\
\hline HEMBL156 & & 862 & & \\
\hline HEMBL138 & & 62 & & \\
\hline AFMRI 156 & & & & \\
\hline 500 & & 363 & & \\
\hline HEMBL 147 & & 362 & & \\
\hline IEMBL1968273 & & & & \\
\hline JEMBL153 & & 72 & & \\
\hline AFMRI 14 & & 52 & & \\
\hline 505 & & 363 & & \\
\hline AEMBL1552140 & & & & \\
\hline AEMBL1311160 & & 362 & & \\
\hline & & & & \\
\hline 67 & & 52 & & \\
\hline HEMBL149 & & & & RN \\
\hline AEMBL1307167 & & & & \\
\hline AEMBL1562731 & & 362 & & \\
\hline & & 62 & & \\
\hline 0 & & & & \\
\hline HEMBL1476392 & & & & ST \\
\hline AEMBL3199886 & & 862 & & $\mathrm{~S}$ \\
\hline AEMBL13€ & & 362 & & \\
\hline HEIMGL 1403869 & & & & \\
\hline HEMBL374350 & & & & \\
\hline AEMBL1351038 & & 6.2862 & & RN \\
\hline IEMBL1390605 & & 372 & & \\
\hline $150-7>$ & & & & \\
\hline & & & & \\
\hline
\end{tabular}


Supplemental Table S2.txt

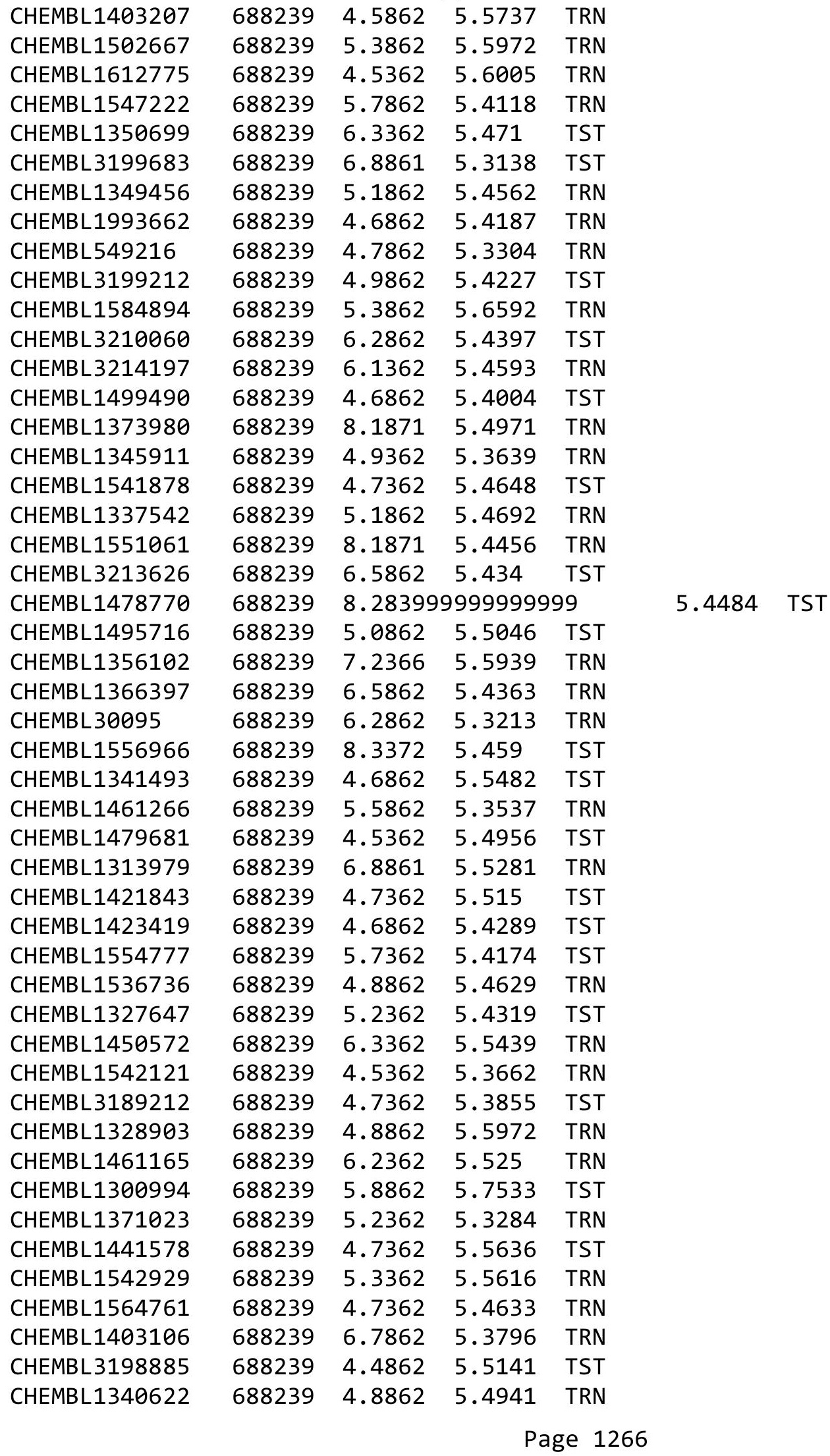


Supplemental Table S2.txt

\begin{tabular}{|c|c|c|c|c|c|}
\hline CHEMBL1423813 & 688239 & 5.6362 & 5.7537 & TRN & \\
\hline CHEMBL1445509 & 688239 & 5.1862 & 5.5017 & TRN & \\
\hline CHEMBL1519398 & 688239 & 5.0862 & 5.5653 & TRN & \\
\hline CHEMBL1398075 & 688239 & 4.5362 & 5.3642 & TRN & \\
\hline CHEMBL1334185 & 688239 & 4.5362 & 5.3714 & TRN & \\
\hline CHEMBL 3207774 & 688239 & 6.1862 & 5.4903 & TRN & \\
\hline CHEMBL1415540 & 688239 & 4.6362 & 5.2696 & TST & \\
\hline CHEMBL1515970 & 688239 & 4.9362 & 5.4331 & TRN & \\
\hline CHEMBL1470912 & 688239 & 6.1862 & 5.3989 & TRN & \\
\hline CHEMBL1520053 & 688239 & 4.6362 & 5.3875 & TRN & \\
\hline CHEMBL1586956 & 688239 & 4.95 & 5.5167 & TRN & \\
\hline CHEMBL1383622 & 688239 & 4.5362 & 5.3295 & TST & \\
\hline CHEMBL1384274 & 688239 & 4.7862 & 5.4593 & TRN & \\
\hline CHEMBL1431395 & 688239 & 5.0362 & 5.5223 & TRN & \\
\hline CHEMBL1318090 & 688239 & 4.5362 & 5.4313 & TRN & \\
\hline CHEMBL1520992 & 688239 & 4.5362 & 5.4908 & TRN & \\
\hline CHEMBL1351807 & 688239 & 6.1362 & 5.4941 & TST & \\
\hline CHEMBL1384866 & 688239 & 5.1862 & 5.4299 & TRN & \\
\hline CHEMBL1317723 & 688239 & 5.4862 & 5.6045 & TRN & \\
\hline CHEMBL1464460 & 688239 & 4.8862 & 5.5163 & TRN & \\
\hline CHEMBL1497665 & 688239 & 4.8362 & 5.6541 & TST & \\
\hline CHEMBL1513581 & 688239 & 5.2362 & 5.4108 & TRN & \\
\hline CHEMBL1329385 & 688239 & 4.9862 & 5.4608 & TRN & \\
\hline CHEMBL1375035 & 688239 & 5.1862 & 5.4625 & TRN & \\
\hline CHEMBL1517255 & 688239 & 5.3862 & 5.5989 & TST & \\
\hline CHEMBL1488768 & 688239 & \multicolumn{3}{|c|}{8.283999999999999} & TST \\
\hline CHEMBL1429388 & 688239 & 6.1362 & 5.4557 & TRN & \\
\hline CHEMBL1576253 & 688239 & 4.5362 & 5.4724 & TST & \\
\hline CHEMBL1329925 & 688239 & 5.2862 & 5.3982 & TRN & \\
\hline CHEMBL1320316 & 688239 & 6.0362 & 5.5097 & TRN & \\
\hline CHEMBL1349784 & 688239 & 6.9863 & 5.5362 & TRN & \\
\hline CHEMBL1378324 & 688239 & 5.1862 & 5.5358 & TRN & \\
\hline CHEMBL1452185 & 688239 & 5.4362 & 5.4094 & TST & \\
\hline CHEMBL1591987 & 688239 & 6.8362 & 5.4389 & TRN & \\
\hline CHEMBL1588669 & 688239 & 6.9363 & 5.5527 & TRN & \\
\hline CHEMBL1397989 & 688239 & 4.6362 & 5.5065 & TRN & \\
\hline CHEMBL1449238 & 688239 & 6.3362 & 5.4633 & TRN & \\
\hline CHEMBL1358572 & 688239 & 4.7362 & 5.449 & TRN & \\
\hline CHEMBL1320531 & 688239 & 4.4862 & 5.3983 & TRN & \\
\hline CHEMBL1432881 & 688239 & 4.5362 & 5.5027 & TRN & \\
\hline CHEMBL1402664 & 688239 & 5.5862 & 5.4869 & TRN & \\
\hline CHEMBL1596631 & 688239 & 6.8362 & 5.5281 & TRN & \\
\hline CHEMBL1607456 & 688239 & 5.5362 & 5.40600 & 0000000001 & $\mathrm{IRN}$ \\
\hline CHEMBL1573422 & 688239 & 6.1362 & 5.5484 & TRN & \\
\hline CHEMBL1534343 & 688239 & 4.7362 & 5.6565 & TST & \\
\hline CHEMBL1376285 & 688239 & 5.2362 & 5.5956 & TRN & \\
\hline CHEMBL1345921 & 688239 & 5.9362 & 5.4107 & TRN & \\
\hline CHEMBL1394121 & 688239 & 5.4362 & 5.3204 & TST & \\
\hline
\end{tabular}


Supplemental Table S2.txt

\begin{tabular}{|c|c|c|c|c|c|}
\hline CHEMBL1595153 & 688239 & 5.1862 & 5.5884 & TST & \\
\hline CHEMBL1312727 & 688239 & 7.0362 & 5.4439 & TRN & \\
\hline CHEMBL3197572 & 688239 & 5.0862 & 5.4408 & TST & \\
\hline CHEMBL1552036 & 688239 & 5.3362 & 5.604 & TRN & \\
\hline CHEMBL1600457 & 688239 & 8.3872 & 5.5385 & TRN & \\
\hline CHEMBL1521160 & 688239 & 6.0362 & 5.4598 & TRN & \\
\hline CHEMBL1587958 & 688239 & 6.2862 & 5.5069 & TRN & \\
\hline CHEMBL1396545 & 688239 & 6.0362 & 5.5079 & TRN & \\
\hline CHEMBL1428865 & 688239 & 6.1862 & 5.5108 & TST & \\
\hline CHEMBL1536427 & 688239 & 6.3362 & 5.5443 & TRN & \\
\hline CHEMBL1584502 & 688239 & 4.7862 & 5.513 & TST & \\
\hline CHEMBL1347041 & 688239 & 6.8861 & 5.645 & TRN & \\
\hline CHEMBL1541215 & 688239 & 8.3372 & 5.4394 & TRN & \\
\hline CHEMBL1323256 & 688239 & 5.1862 & 5.5572 & TRN & \\
\hline CHEMBL1596027 & 688239 & 5.3862 & 5.6009 & TST & \\
\hline CHEMBL1383820 & 688239 & 5.5362 & 5.3461 & TRN & \\
\hline CHEMBL1540553 & 688239 & 6.6861 & 5.5831 & TRN & \\
\hline CHEMBL146671 & 688239 & 5.1362 & 5.5365 & TRN & \\
\hline CHEMBL1390438 & 688239 & 5.2862 & 5.4971 & TRN & \\
\hline CHEMBL1312397 & 688239 & 5.6862 & 5.41 & TRN & \\
\hline CHEMBL1383152 & 688239 & 5.5862 & 5.6757 & TRN & \\
\hline CHEMBL1592705 & 688239 & 4.4862 & 5.4354 & TRN & \\
\hline CHEMBL1299596 & 688239 & 6.8362 & 5.6318 & TRN & \\
\hline CHEMBL1324511 & 688239 & 5.7862 & 5.6082 & TST & \\
\hline CHEMBL1382676 & 688239 & 5.1862 & 5.5345 & TRN & \\
\hline CHEMBL1311387 & 688239 & 5.1862 & 5.5074 & TST & \\
\hline CHEMBL1578401 & 688239 & 6.1862 & 5.4329 & TRN & \\
\hline CHEMBL1582249 & 688239 & 5.2362 & 5.5546 & TRN & \\
\hline CHEMBL1305083 & 688239 & 4.5862 & 5.4245 & TST & \\
\hline CHEMBL1457117 & 688239 & 8.3372 & 5.5618 & TRN & \\
\hline CHEMBL1464788 & 688239 & 4.4862 & 5.393 & TRN & \\
\hline CHEMBL1494109 & 688239 & 6.8861 & 5.4095 & TRN & \\
\hline CHEMBL1479262 & 688239 & 4.5862 & 5.551 & TRN & \\
\hline CHEMBL236615 & 688239 & 5.7862 & 5.4838 & TRN & \\
\hline CHEMBL1305438 & 688239 & 4.9862 & 5.4445 & TRN & \\
\hline CHEMBL1339177 & 688239 & 6.2362 & 5.4569 & TRN & \\
\hline CHEMBL1589052 & 688239 & 5.0862 & 5.4882 & TST & \\
\hline CHEMBL1410279 & 688239 & 5.7362 & 5.5408 & TRN & \\
\hline CHEMBL1307722 & 688239 & 4.9862 & 5.45200 & 2000000001 & TRN \\
\hline CHEMBL1471178 & 688239 & 4.5862 & 5.4199 & TRN & \\
\hline CHEMBL1311826 & 688239 & 4.5362 & 5.41299 & 9999999999 & TRN \\
\hline CHEMBL1598788 & 688239 & 6.2362 & 5.3848 & TRN & \\
\hline CHEMBL1561367 & 688239 & 4.6862 & 5.4128 & TST & \\
\hline CHEMBL1420326 & 688239 & 4.5362 & 5.5591 & TST & \\
\hline CHEMBL1577996 & 688239 & 5.6362 & 5.5454 & TST & \\
\hline CHEMBL1381790 & 688239 & 5.1862 & 5.3625 & TRN & \\
\hline CHEMBL566531 & 688239 & 4.6362 & 5.4865 & TRN & \\
\hline CHEMBL1540734 & 688239 & 4.5362 & 5.4113 & TRN & \\
\hline
\end{tabular}




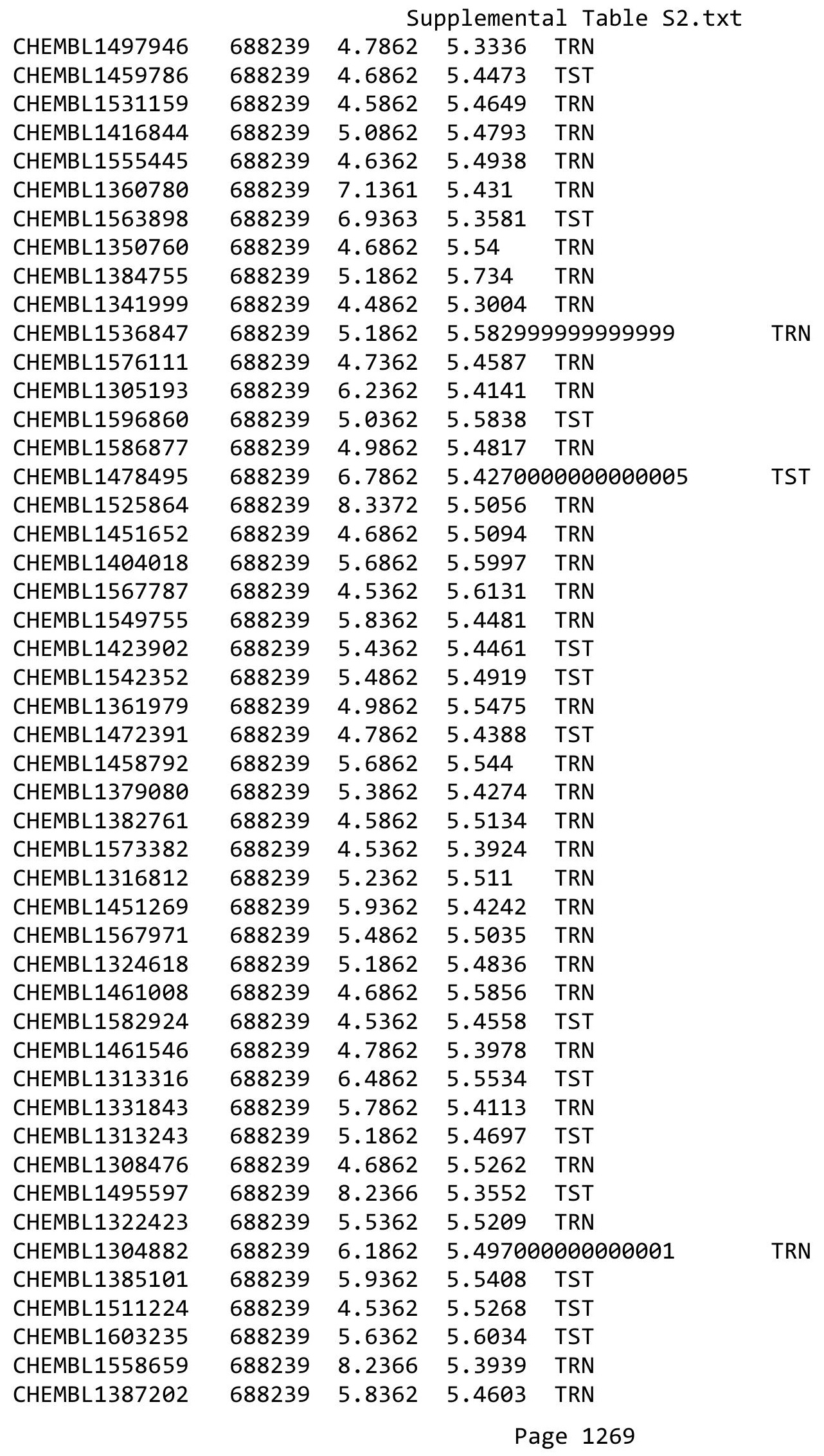


Supplemental Table S2.txt

\begin{tabular}{|c|c|c|c|c|c|c|}
\hline CHEMBL1312302 & 688239 & 8.3872 & 5.4436 & TRN & & \\
\hline CHEMBL1563623 & 688239 & 5.9362 & 5.4032 & TRN & & \\
\hline CHEMBL1577543 & 688239 & 5.0862 & 5.4447 & TRN & & \\
\hline CHEMBL1391368 & 688239 & 4.8862 & 5.6269 & TRN & & \\
\hline CHEMBL1524557 & 688239 & 4.7362 & 5.5204 & TRN & & \\
\hline CHEMBL1353327 & 688239 & 5.3862 & 5.5398 & TRN & & \\
\hline CHEMBL1317334 & 688239 & 4.9362 & 5.4926 & TRN & & \\
\hline CHEMBL1321926 & 688239 & 6.3362 & 5.3872 & TRN & & \\
\hline CHEMBL1469727 & 688239 & 4.4862 & 5.4565 & TRN & & \\
\hline CHEMBL1338977 & 688239 & 4.6362 & 5.5529 & TST & & \\
\hline CHEMBL1427085 & 688239 & \multicolumn{3}{|c|}{8.283999999999999} & 5.6868 & $\mathrm{TR}$ \\
\hline CHEMBL1470812 & 688239 & 4.8362 & 5.4724 & TRN & & \\
\hline CHEMBL1448871 & 688239 & 4.5362 & 5.5099 & TRN & & \\
\hline CHEMBL1523341 & 688239 & 7.2865 & 5.5438 & TRN & & \\
\hline CHEMBL1447768 & 688239 & 4.5362 & 5.5082 & TST & & \\
\hline CHEMBL1344489 & 688239 & 4.5362 & 5.5962 & TRN & & \\
\hline CHEMBL1318324 & 688239 & 4.5362 & 5.5617 & TRN & & \\
\hline CHEMBL1439361 & 688239 & 6.1362 & 5.5138 & TST & & \\
\hline CHEMBL1430454 & 688239 & 4.5362 & 5.4272 & TRN & & \\
\hline CHEMBL1381011 & 688239 & 6.7862 & 5.6094 & TRN & & \\
\hline CHEMBL1547324 & 688239 & 4.7862 & 5.4128 & TST & & \\
\hline CHEMBL1466661 & 688239 & 5.4362 & 5.5537 & TST & & \\
\hline CHEMBL1580723 & 688239 & 5.3362 & 5.5517 & TRN & & \\
\hline CHEMBL601176 & 688239 & 5.1362 & 5.419 & TRN & & \\
\hline CHEMBL1349634 & 688239 & 5.1862 & 5.3958 & TRN & & \\
\hline CHEMBL1327585 & 688239 & 8.3372 & 5.5508 & TRN & & \\
\hline CHEMBL1320734 & 688239 & 6.9363 & 5.6568 & TRN & & \\
\hline CHEMBL1605678 & 688239 & 5.4862 & 5.5591 & TRN & & \\
\hline CHEMBL1580861 & 688239 & 4.8862 & 5.5723 & TST & & \\
\hline CHEMBL1367305 & 688239 & 5.3362 & 5.6004 & TRN & & \\
\hline CHEMBL1323112 & 688239 & 6.9363 & 5.2832 & TRN & & \\
\hline CHEMBL1352723 & 688239 & 4.5362 & 5.5142 & TRN & & \\
\hline CHEMBL1471811 & 688239 & 5.6862 & 5.4446 & TRN & & \\
\hline CHEMBL1331749 & 688239 & 4.7862 & 5.6023 & TRN & & \\
\hline CHEMBL1453063 & 688239 & 4.9862 & 5.5117 & TRN & & \\
\hline CHEMBL1521050 & 688239 & 6.6362 & 5.6284 & TRN & & \\
\hline CHEMBL1587902 & 688239 & 4.7362 & 5.5504 & TRN & & \\
\hline CHEMBL1416935 & 688239 & 4.8362 & 5.4346 & TRN & & \\
\hline CHEMBL1319151 & 688239 & 8.3872 & 5.4357 & TRN & & \\
\hline CHEMBL1450210 & 688239 & 5.2362 & 5.5722 & TRN & & \\
\hline CHEMBL1489295 & 688239 & 4.7362 & 5.4128 & TST & & \\
\hline CHEMBL3193377 & 688239 & 4.7362 & 5.4678 & TRN & & \\
\hline CHEMBL1601489 & 688239 & 5.0862 & 5.5268 & TRN & & \\
\hline CHEMBL1367321 & 688239 & 4.6862 & 5.542006 & 2000000001 & & TST \\
\hline CHEMBL1468417 & 688239 & 4.9362 & $5.48600 €$ & 0000000001 & & TRN \\
\hline CHEMBL1609216 & 688239 & 7.0862 & 5.5967 & TST & & \\
\hline CHEMBL1493661 & 688239 & 5.3862 & 5.5533 & TRN & & \\
\hline CHEMBL1595483 & 688239 & 6.1862 & 5.6198 & TRN & & \\
\hline
\end{tabular}


Supplemental Table S2.txt

\begin{tabular}{|c|c|c|c|c|c|}
\hline CHEMBL1366902 & 688239 & 4.5362 & 5.5304 & TST & \\
\hline CHEMBL1489321 & 688239 & 5.0862 & 5.5217 & TST & \\
\hline CHEMBL1521537 & 688239 & 5.2362 & 5.2932 & TST & \\
\hline CHEMBL1441485 & 688239 & 4.7862 & 5.4083 & TST & \\
\hline CHEMBL1592074 & 688239 & 8.1871 & 5.5093 & TRN & \\
\hline CHEMBL1529121 & 688239 & 4.5362 & 5.633999 & э99999999995 & TRN \\
\hline CHEMBL1331989 & 688239 & 5.2362 & 5.5705 & TST & \\
\hline CHEMBL1383364 & 688239 & 4.8362 & 5.5382 & TRN & \\
\hline CHEMBL1567692 & 688239 & 5.7862 & 5.2959 & TRN & \\
\hline CHEMBL1380571 & 688239 & 4.5862 & 5.5765 & TST & \\
\hline CHEMBL536166 & 688239 & 5.3862 & 5.4159 & TRN & \\
\hline CHEMBL3212139 & 688239 & 4.6362 & 5.3379 & TST & \\
\hline CHEMBL1337066 & 688239 & 5.1862 & 5.3569 & TRN & \\
\hline CHEMBL1977018 & 688239 & 5.3362 & 5.3977 & TRN & \\
\hline CHEMBL3207892 & 688239 & 6.5363 & 5.7124 & TRN & \\
\hline CHEMBL1534739 & 688239 & 6.3 & 5.571000 & 3000000001 & IKIV \\
\hline CHEMBL3189252 & 688239 & 4.7362 & 5.3815 & TRN & \\
\hline CHEMBL1562687 & 688239 & 7.4868 & 5.4882 & TRN & \\
\hline CHEMBL1308315 & 688239 & 5.5862 & 5.4543 & TRN & \\
\hline CHEMBL1385926 & 688239 & 5.2362 & 5.4047 & TRN & \\
\hline CHEMBL1412383 & 688239 & 5.6862 & 5.6254 & TRN & \\
\hline CHEMBL1467697 & 688239 & 4.8362 & 5.3966 & TRN & \\
\hline CHEMBL1513713 & 688239 & 8.28399 & 999999999 & 5.3508 & \\
\hline CHEMBL1396449 & 688239 & 5.6362 & 5.3467 & TRN & \\
\hline CHEMBL1434244 & 688239 & 4.6862 & 5.273 & TRN & \\
\hline CHEMBL1483834 & 688239 & 4.6862 & 5.6226 & TRN & \\
\hline CHEMBL1584139 & 688239 & 6.2862 & 5.511 & TRN & \\
\hline CHEMBL1417003 & 688239 & 6.0862 & 5.5175 & TRN & \\
\hline CHEMBL1519909 & 688239 & 4.9362 & 5.4647 & TST & \\
\hline CHEMBL1389035 & 688239 & 6.5862 & 5.4981 & TST & \\
\hline CHEMBL1977858 & 688239 & 5.4862 & 5.3973 & TRN & \\
\hline CHEMBL1589979 & 688239 & 6.8861 & 5.5873 & TRN & \\
\hline CHEMBL1331406 & 688239 & 4.9362 & 5.3827 & TRN & \\
\hline CHEMBL1559423 & 688239 & 4.7362 & 5.5448 & TRN & \\
\hline CHEMBL1489129 & 688239 & 5.1862 & 5.5294 & TST & \\
\hline CHEMBL1493019 & 688239 & 5.0862 & 5.4845 & TRN & \\
\hline CHEMBL3208967 & 688239 & 8.1367 & 5.5461 & TRN & \\
\hline CHEMBL1516386 & 688239 & 4.4862 & 5.5383 & TRN & \\
\hline CHEMBL1427279 & 688239 & 6.2362 & 5.4767 & TRN & \\
\hline CHEMBL3211882 & 688239 & 5.6862 & 5.4489 & TST & \\
\hline CHEMBL3212382 & 688239 & 4.5362 & 5.5497 & TRN & \\
\hline CHEMBL1557581 & 688239 & 5.8362 & 5.4369 & TRN & \\
\hline CHEMBL1368639 & 688239 & 5.2362 & 5.329 & TST & \\
\hline CHEMBL1551875 & 688239 & 6.1362 & 5.4918 & TRN & \\
\hline CHEMBL1435451 & 688239 & 4.6862 & 5.5919 & TRN & \\
\hline CHEMBL1431239 & 688239 & \multicolumn{3}{|c|}{8.283999999999999} & $\mathrm{KI}$ \\
\hline CHEMBL1553448 & 688239 & 4.7862 & 5.4224 & TRN & \\
\hline CHEMBL1385598 & 688239 & 4.7362 & 5.2936 & TRN & \\
\hline
\end{tabular}


Supplemental Table S2.txt

\begin{tabular}{|c|c|c|c|c|c|}
\hline CHEMBL1394397 & 688239 & 4.9862 & 5.4669 & TRN & \\
\hline CHEMBL3198922 & 688239 & 5.4862 & 5.4818 & TRN & \\
\hline CHEMBL1558970 & 688239 & 5.9362 & 5.4283 & TRN & \\
\hline CHEMBL1485711 & 688239 & 4.5362 & 5.475 & TRN & \\
\hline CHEMBL1340679 & 688239 & 4.6862 & 5.6029 & TRN & \\
\hline CHEMBL1307682 & 688239 & 4.5362 & \multicolumn{2}{|c|}{5.327999999999999} & TST \\
\hline CHEMBL1597399 & 688239 & 5.4362 & \multicolumn{2}{|c|}{5.662999999999999} & TRN \\
\hline CHEMBL1526148 & 688239 & 4.9362 & 5.4696 & TRN & \\
\hline CHEMBL1464189 & 688239 & 5.3862 & 5.4616 & TRN & \\
\hline CHEMBL1415976 & 688239 & 5.3862 & 5.4733 & TST & \\
\hline CHEMBL1305801 & 688239 & 4.6862 & 5.5338 & TRN & \\
\hline CHEMBL1345565 & 688239 & 6.1862 & 5.5116 & TST & \\
\hline CHEMBL1357657 & 688239 & 5.9862 & 5.5326 & TRN & \\
\hline CHEMBL1351884 & 688239 & 4.5362 & 5.5212 & TRN & \\
\hline CHEMBL1551470 & 688239 & 6.0362 & 5.57 & TRN & \\
\hline CHEMBL1423669 & 688239 & 6.2362 & 5.5126 & TRN & \\
\hline CHEMBL1537601 & 688239 & 5.0362 & 5.4281 & TRN & \\
\hline CHEMBL1581233 & 688239 & 4.6362 & 5.391 & TRN & \\
\hline CHEMBL1326088 & 688239 & 4.5362 & 5.5498 & TRN & \\
\hline CHEMBL1466965 & 688239 & 5.0862 & 5.4487 & TRN & \\
\hline CHEMBL1317393 & 688239 & 6.9863 & 5.3501 & TST & \\
\hline CHEMBL1367747 & 688239 & 5.0362 & 5.5021 & TST & \\
\hline CHEMBL1599786 & 688239 & 5.4862 & 5.3824 & TRN & \\
\hline CHEMBL1339095 & 688239 & 7.2865 & 5.4369 & TST & \\
\hline CHEMBL1573221 & 688239 & 5.0862 & 5.6046 & TST & \\
\hline CHEMBL1375389 & 688239 & 5.1862 & 5.6577 & TRN & \\
\hline CHEMBL3193913 & 688239 & 4.5362 & 5.4555 & TST & \\
\hline CHEMBL1569816 & 688239 & 4.7362 & 5.3839 & TRN & \\
\hline CHEMBL1595612 & 688239 & 5.5362 & 5.5423 & TRN & \\
\hline CHEMBL1503204 & 688239 & 5.2362 & 5.6403 & TST & \\
\hline CHEMBL1460697 & 688239 & 4.5362 & 5.4599 & TRN & \\
\hline CHEMBL1483193 & 688239 & 5.1862 & 5.5239 & TRN & \\
\hline CHEMBL1525533 & 688239 & 4.7362 & 5.3749 & TRN & \\
\hline CHEMBL1356472 & 688239 & 5.1862 & 5.3045 & TRN & \\
\hline CHEMBL1471901 & 688239 & 4.7862 & 5.4194 & TRN & \\
\hline CHEMBL1581284 & 688239 & 5.1362 & 5.5657 & TRN & \\
\hline CHEMBL1481642 & 688239 & 6.7862 & 5.4856 & TRN & \\
\hline CHEMBL1338404 & 688239 & 4.9362 & 5.4712 & TRN & \\
\hline CHEMBL1490745 & 688239 & 4.8362 & 5.7319 & TRN & \\
\hline CHEMBL1488639 & 688239 & 5.1862 & 5.3325 & TRN & \\
\hline CHEMBL1488497 & 688239 & 8.3372 & 5.6026 & TRN & \\
\hline CHEMBL1537217 & 688239 & 6.0862 & 5.4734 & TRN & \\
\hline CHEMBL1421781 & 688239 & 5.8862 & 5.5307 & TRN & \\
\hline CHEMBL1565993 & 688239 & 4.6362 & 5.2926 & TRN & \\
\hline CHEMBL1311002 & 688239 & 4.5362 & 5.6044 & TRN & \\
\hline CHEMBL1476832 & 688239 & 5.0362 & 5.4093 & TST & \\
\hline CHEMBL1492522 & 688239 & 4.8362 & 5.4627 & TRN & \\
\hline CHEMBL1485469 & 688239 & 5.7862 & 5.6267 & TRN & \\
\hline
\end{tabular}

Page 1272 
Supplemental Table S2.txt

\begin{tabular}{|c|c|c|c|c|}
\hline 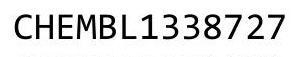 & & & & \\
\hline AEMBL1351321 & 38239 & 1862 & & \\
\hline AEMBL1512846 & 239 & 862 & 009 & \\
\hline & 39 & & & \\
\hline IEMBL1466121 & 39 & 362 & & \\
\hline AEMBL1608715 & 88239 & 362 & 573 & \\
\hline AEMBL1312648 & 88239 & 362 & 933 & \\
\hline HEMBL1359396 & & & & \\
\hline EMBL1570513 & 39 & 862 & & \\
\hline IEMBL1340242 & & & & \\
\hline AEMBL1377512 & 239 & 862 & & \\
\hline AEMBL1303115 & 39 & 362 & & \\
\hline AEMBL1309134 & & 62 & & \\
\hline AEMBL1471832 & & & & \\
\hline HEMBL1468983 & & & & \\
\hline AEMBL1505194 & & 862 & & \\
\hline AEMBL1401163 & & 362 & & \\
\hline IEMBL15384 & & 62 & & \\
\hline HEMBL15891 & & 62 & & \\
\hline AEMBL1603 & & & & \\
\hline AEMBL1557685 & & 862 & & \\
\hline AEMBL1379064 & & & & \\
\hline AEMBL15943 & & 62 & & \\
\hline AFMBI 32138 & & 62 & & \\
\hline HFM & & 61 & & \\
\hline AEMBL1578939 & & & & \\
\hline IEMBL1319976 & & & & \\
\hline EMBL14089 & & & & \\
\hline JEMP & & & & \\
\hline 1 & & 62 & & \\
\hline AEMBL15362 & & & & \\
\hline HEMBL1588649 & & 62 & & \\
\hline & & & & \\
\hline 4 & & 52 & & \\
\hline & & & & \\
\hline AEMBL1517805 & & & & F \\
\hline AEMBL1412747 & & 363 & & \\
\hline & & 72 & & \\
\hline 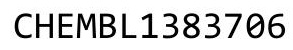 & & & & \\
\hline HEMBL1454407 & & & & $\mathrm{RI}$ \\
\hline AEMBL1351748 & & 62 & & TS \\
\hline AEMBL1482500 & & & & TP \\
\hline & & & & \\
\hline HEMBL1592690 & & & & rs \\
\hline AEMBL1458299 & & & & rs \\
\hline IEMBL1511370 & & 862 & 55 & TP \\
\hline & & & & \\
\hline HEMBL135421 & & & & \\
\hline
\end{tabular}

Page 1273 
Supplemental Table S2.txt

\begin{tabular}{|c|c|c|c|c|c|}
\hline CHEMBL1557387 & 688239 & 7.2366 & 5.5268 & TRN & \\
\hline CHEMBL1510429 & 688239 & 4.6362 & 5.4133 & TRN & \\
\hline CHEMBL1560381 & 688239 & 4.7362 & 5.4154 & TRN & \\
\hline CHEMBL1593328 & 688239 & 5.1862 & 5.4862 & TRN & \\
\hline CHEMBL1491120 & 688239 & 4.5362 & 5.4333 & TST & \\
\hline CHEMBL1483410 & 688239 & 4.5862 & 5.4605 & TRN & \\
\hline CHEMBL1988314 & 688239 & 6.6861 & 5.3395 & TRN & \\
\hline CHEMBL1325669 & 688239 & 4.6362 & 5.4873 & TST & \\
\hline CHEMBL1471993 & 688239 & 5.8362 & 5.4006 & TRN & \\
\hline CHEMBL1588732 & 688239 & 4.5362 & 5.4361 & TRN & \\
\hline CHEMBL1421290 & 688239 & 4.5362 & 5.4683 & TST & \\
\hline CHEMBL1440961 & 688239 & 4.5362 & 5.3775 & TST & \\
\hline CHEMBL1417348 & 688239 & 4.9862 & 5.4764 & TRN & \\
\hline CHEMBL1545914 & 688239 & 5.0362 & 5.5009 & TRN & \\
\hline CHEMBL1337635 & 688239 & 6.6362 & 5.7406 & TRN & \\
\hline CHEMBL1559507 & 688239 & 6.8362 & 5.4938 & TRN & \\
\hline CHEMBL1507763 & 688239 & 5.1862 & 5.5939 & TRN & \\
\hline CHEMBL1612643 & 688239 & 5.1362 & 5.5501 & TRN & \\
\hline CHEMBL1509641 & 688239 & 6.1862 & 5.5246 & TRN & \\
\hline CHEMBL1405513 & 688239 & 4.5362 & 5.3971 & TST & \\
\hline CHEMBL1509424 & 688239 & 6.5363 & 5.5713 & TRN & \\
\hline CHEMBL1350764 & 688239 & 6.5363 & 5.3754 & TRN & \\
\hline CHEMBL1596497 & 688239 & 5.6362 & 5.5521 & TRN & \\
\hline CHEMBL1321128 & 688239 & 4.5862 & 5.4213 & TRN & \\
\hline CHEMBL1310617 & 688239 & 5.2362 & 5.2632 & TST & \\
\hline CHEMBL1305405 & 688239 & 7.0362 & 5.6229 & TRN & \\
\hline CHEMBL1609509 & 688239 & 4.6862 & 5.6465 & TRN & \\
\hline CHEMBL1381807 & 688239 & 5.3862 & 5.5028 & TRN & \\
\hline CHEMBL1507201 & 688239 & 5.1862 & 5.5082 & TRN & \\
\hline CHEMBL1514369 & 688239 & 4.5362 & 5.4353 & TRN & \\
\hline CHEMBL1479768 & 688239 & 4.5362 & 5.557 & TRN & \\
\hline CHEMBL1379090 & 688239 & 4.5362 & 5.6015 & TRN & \\
\hline CHEMBL1359888 & 688239 & 5.5862 & 5.5701 & TRN & \\
\hline CHEMBL1555062 & 688239 & 5.2362 & 5.5116 & TRN & \\
\hline CHEMBL1489000 & 688239 & 4.6862 & 5.5072 & TRN & \\
\hline CHEMBL1420195 & 688239 & 7.2366 & 5.6015 & TRN & \\
\hline CHEMBL1307715 & 688239 & 5.2362 & 5.3398 & TST & \\
\hline CHEMBL1320770 & 688239 & 4.6362 & 5.2449 & TRN & \\
\hline CHEMBL1413672 & 688239 & 4.7362 & 5.5208 & TRN & \\
\hline CHEMBL1452033 & 688239 & 4.5362 & 5.3898 & TRN & \\
\hline CHEMBL1443806 & 688239 & 4.8362 & 5.4561 & TST & \\
\hline CHEMBL1995193 & 688239 & 6.1862 & 5.475 & TRN & \\
\hline CHEMBL1307513 & 688239 & 5.2362 & 5.4858 & TRN & \\
\hline CHEMBL1440631 & 688239 & 6.3362 & 5.6131 & TRN & \\
\hline CHEMBL1472221 & 688239 & 7.6861 & 5.5312 & TRN & \\
\hline CHEMBL1394211 & 688239 & 8.28399 & 99999999 & 99 & 5.4574 \\
\hline CHEMBL1589652 & 688239 & 4.8862 & 5.3963 & TST & \\
\hline CHEMBL1581226 & 688239 & 5.1862 & 5.6381 & TST & \\
\hline
\end{tabular}


Supplemental Table S2.txt

\begin{tabular}{|c|c|c|c|c|}
\hline CHEMBL1550209 & 688239 & 5.5862 & 5.5634 & TRN \\
\hline CHEMBL1357111 & 688239 & 8.3372 & 5.4006 & TRN \\
\hline CHEMBL1568583 & 688239 & 6.4862 & 5.2966 & TRN \\
\hline CHEMBL1520469 & 688239 & 8.283999 & 99999999 & 5.483 \\
\hline CHEMBL1417750 & 688239 & 5.3862 & 5.4153 & TST \\
\hline CHEMBL1312363 & 688239 & 4.5862 & 5.4396 & TRN \\
\hline CHEMBL1322560 & 688239 & 4.6862 & 5.3717 & TST \\
\hline CHEMBL1516819 & 688239 & 4.6362 & 5.4311 & TRN \\
\hline CHEMBL1536910 & 688239 & 4.6362 & 5.33299 & 9999999999 \\
\hline CHEMBL1510418 & 688239 & 5.5862 & 5.54200 & 0000000001 \\
\hline CHEMBL1326886 & 688239 & 5.6362 & 5.3918 & TRN \\
\hline CHEMBL1426657 & 688239 & 4.6362 & 5.4657 & TRN \\
\hline CHEMBL1299528 & 688239 & 4.4862 & 5.5731 & TRN \\
\hline CHEMBL1507167 & 688239 & 4.6362 & 5.3691 & TRN \\
\hline CHEMBL1493647 & 688239 & 5.3862 & 5.3919 & TRN \\
\hline CHEMBL1553590 & 688239 & 4.5362 & $5.34200 t$ & 00000000005 \\
\hline CHEMBL1402130 & 688239 & 6.9863 & 5.5487 & TRN \\
\hline CHEMBL1454765 & 688239 & 4.4862 & 5.3315 & TST \\
\hline CHEMBL1542380 & 688239 & 4.5362 & 5.584 & TRN \\
\hline CHEMBL1455600 & 688239 & 5.4362 & 5.3711 & TRN \\
\hline CHEMBL3190602 & 688239 & 4.6862 & 5.4309 & TRN \\
\hline CHEMBL1319241 & 688239 & 5.6862 & 5.3796 & TST \\
\hline CHEMBL 3195540 & 688239 & 6.1362 & 5.4666 & TST \\
\hline CHEMBL1300945 & 688239 & 4.5362 & 5.4621 & TRN \\
\hline CHEMBL3199061 & 688239 & 4.6862 & 5.6171 & TRN \\
\hline CHEMBL1334977 & 688239 & 4.5362 & 5.4959 & TRN \\
\hline CHEMBL1397232 & 688239 & 5.8862 & 5.4543 & TRN \\
\hline CHEMBL1585260 & 688239 & 6.0862 & 5.4716 & TRN \\
\hline CHEMBL1596611 & 688239 & 6.5363 & 5.3337 & TST \\
\hline CHEMBL1569766 & 688239 & 5.1362 & 5.4383 & TRN \\
\hline CHEMBL1320352 & 688239 & 4.9362 & 5.4192 & TRN \\
\hline CHEMBL1382837 & 688239 & 4.5362 & 5.6365 & TRN \\
\hline CHEMBL3190486 & 688239 & 6.4862 & 5.4465 & TRN \\
\hline CHEMBL1585376 & 688239 & 5.3362 & 5.4478 & TRN \\
\hline CHEMBL1572934 & 688239 & 4.7862 & 5.5492 & TRN \\
\hline CHEMBL1510098 & 688239 & 5.0362 & 5.4601 & TST \\
\hline CHEMBL1426754 & 688239 & 5.0362 & 5.5391 & TRN \\
\hline CHEMBL1486595 & 688239 & 4.7862 & 5.4892 & TRN \\
\hline CHEMBL1340027 & 688239 & 5.3362 & 5.5593 & TST \\
\hline CHEMBL1540099 & 688239 & 6.2362 & 5.4875 & TRN \\
\hline CHEMBL3191232 & 688239 & 7.1361 & 5.3022 & TRN \\
\hline CHEMBL1572642 & 688239 & 4.9362 & 5.426 & TRN \\
\hline CHEMBL1391451 & 688239 & 4.45 & 5.5452 & TRN \\
\hline CHEMBL1511479 & 688239 & 6.8861 & 5.41799 & 9999999999 \\
\hline CHEMBL1589079 & 688239 & 6.5363 & 5.3942 & TST \\
\hline CHEMBL1486454 & 688239 & 4.8362 & 5.5311 & TRN \\
\hline CHEMBL1311486 & 688239 & 5.4362 & 5.3897 & TRN \\
\hline CHEMBL1383253 & 688239 & 5.3862 & 5.47 & TRN \\
\hline
\end{tabular}


Supplemental Table S2.txt

\begin{tabular}{|c|c|c|c|c|c|}
\hline CHEMBL1322529 & 688239 & 6.9363 & 5.4983 & TRN & \\
\hline CHEMBL1514863 & 688239 & 4.5362 & 5.36 & TST & \\
\hline CHEMBL 3212725 & 688239 & 4.7362 & 5.3493 & TRN & \\
\hline CHEMBL1576431 & 688239 & 5.3 & 5.4908 & TRN & \\
\hline CHEMBL1345220 & 688239 & 7.2366 & 5.3962 & TRN & \\
\hline CHEMBL1540591 & 688239 & 5.8362 & 5.4973 & TRN & \\
\hline CHEMBL1582549 & 688239 & 5.5862 & 5.5682 & TST & \\
\hline CHEMBL1367574 & 688239 & 5.3862 & 5.2648 & TST & \\
\hline CHEMBL1346412 & 688239 & 5.1862 & 5.4279 & TRN & \\
\hline CHEMBL1304165 & 688239 & 5.1862 & 5.5203 & TRN & \\
\hline CHEMBL1528202 & 688239 & 5.1862 & 5.5719 & TRN & \\
\hline CHEMBL1505804 & 688239 & 4.7862 & 5.4582 & TRN & \\
\hline CHEMBL1479650 & 688239 & 5.2862 & 5.4583 & TRN & \\
\hline CHEMBL1333888 & 688239 & 4.7862 & 5.5482 & TRN & \\
\hline CHEMBL1367455 & 688239 & 4.7362 & 5.6667 & TRN & \\
\hline CHEMBL1596226 & 688239 & 4.6862 & 5.5256 & TST & \\
\hline CHEMBL1606733 & 688239 & 5.7862 & 5.5566 & TRN & \\
\hline CHEMBL1332787 & 688239 & 5.3862 & 5.6101 & TRN & \\
\hline CHEMBL1456225 & 688239 & 4.8362 & 5.4889 & TRN & \\
\hline CHEMBL577546 & 688239 & 5.1862 & 5.492000 & 000000001 & \\
\hline CHEMBL1424253 & 688239 & 5.1862 & 5.5271 & TRN & \\
\hline CHEMBL1523828 & 688239 & 4.4862 & 5.5134 & TST & \\
\hline CHEMBL 3207305 & 688239 & 6.9863 & 5.5759 & TST & \\
\hline CHEMBL1439747 & 688239 & 6.9363 & 5.5266 & TST & \\
\hline CHEMBL1411677 & 688239 & 4.6362 & 5.5034 & TST & \\
\hline CHEMBL1299364 & 688239 & 5.1862 & 5.3669 & TRN & \\
\hline CHEMBL1349438 & 688239 & 6.8861 & 5.5758 & TRN & \\
\hline CHEMBL1428873 & 688239 & 5.0362 & 5.5538 & TRN & \\
\hline CHEMBL1325020 & 688239 & 6.0862 & 5.5018 & TRN & \\
\hline CHEMBL1469361 & 688239 & 4.5362 & 5.6424 & TRN & \\
\hline CHEMBL1373902 & 688239 & 6.2362 & 5.3385 & TST & \\
\hline CHEMBL1507796 & 688239 & 4.8362 & 5.5626 & TRN & \\
\hline CHEMBL1596441 & 688239 & 6.3863 & 5.5436 & TRN & \\
\hline CHEMBL1551596 & 688239 & 8.2366 & 5.53 & TRN & \\
\hline CHEMBL1395191 & 688239 & 6.2362 & 5.5682 & TRN & \\
\hline CHEMBL1560459 & 688239 & 5.1862 & 5.492000 & 000000001 & TRN \\
\hline CHEMBL1564903 & 688239 & 6.1362 & 5.4152 & TRN & \\
\hline CHEMBL1571597 & 688239 & 5.4862 & 5.4924 & TRN & \\
\hline CHEMBL1567030 & 688239 & 5.6362 & 5.4766 & TRN & \\
\hline CHEMBL1534589 & 688239 & 6.3362 & 5.3582 & TRN & \\
\hline CHEMBL1584189 & 688239 & 4.5362 & 5.5657 & TRN & \\
\hline CHEMBL1495331 & 688239 & 4.6862 & 5.4331 & TRN & \\
\hline CHEMBL1458316 & 688239 & 6.2362 & 5.6831 & TRN & \\
\hline CHEMBL1451453 & 688239 & 8.283999 & 999999999 & 5.4039 & TRN \\
\hline CHEMBL1484423 & 688239 & 4.7362 & 5.5511 & TRN & \\
\hline CHEMBL1524864 & 688239 & 4.7862 & 5.4138 & TRN & \\
\hline CHEMBL1351402 & 688239 & 4.5362 & 5.515 & TRN & \\
\hline CHEMBL1481083 & 688239 & 6.1362 & 5.2251 & TRN & \\
\hline
\end{tabular}




\begin{tabular}{|c|c|c|c|c|c|}
\hline & & & oplement & al Table & \\
\hline CHEMBL1394804 & 688239 & 4.4862 & 5.4797 & TRN & \\
\hline CHEMBL1580998 & 688239 & 5.3862 & 5.48600 & 0000000001 & TRN \\
\hline CHEMBL1602805 & 688239 & 5.1862 & 5.5143 & TRN & \\
\hline CHEMBL1421988 & 688239 & 4.8862 & 5.5171 & TST & \\
\hline CHEMBL1516087 & 688239 & 8.3372 & 5.4911 & TRN & \\
\hline CHEMBL1442444 & 688239 & 6.3863 & 5.49700 & 0000000001 & TST \\
\hline CHEMBL1328166 & 688239 & 5.5862 & 5.441 & TST & \\
\hline CHEMBL1507707 & 688239 & 5.2362 & 5.5976 & TRN & \\
\hline CHEMBL1309293 & 688239 & 4.5362 & 5.4178 & TST & \\
\hline CHEMBL1398649 & 688239 & 4.6862 & 5.4732 & TST & \\
\hline CHEMBL3198593 & 688239 & 5.7862 & 5.5142 & TRN & \\
\hline CHEMBL1606856 & 688239 & 4.6362 & 5.5604 & TRN & \\
\hline CHEMBL1388918 & 688239 & 6.7862 & 5.4804 & TST & \\
\hline CHEMBL1375507 & 688239 & 5.4862 & 5.4096 & TRN & \\
\hline CHEMBL602363 & 688239 & 5.8362 & 5.3684 & TST & \\
\hline CHEMBL1453432 & 688239 & 5.6362 & 5.4661 & TRN & \\
\hline CHEMBL1340068 & 688239 & 4.5362 & 5.2798 & TRN & \\
\hline CHEMBL1304960 & 688239 & 6.2362 & 5.5928 & TRN & \\
\hline CHEMBL1357603 & 688239 & 6.2362 & 5.4115 & TST & \\
\hline CHEMBL1352603 & 688239 & 4.5362 & 5.5449 & TRN & \\
\hline CHEMBL1381256 & 688239 & 6.4362 & 5.4873 & TRN & \\
\hline CHEMBL1324526 & 688239 & 6.3362 & 5.4093 & TRN & \\
\hline CHEMBL1510611 & 688239 & 5.1862 & 5.6116 & TRN & \\
\hline CHEMBL1461663 & 688239 & 5.8362 & 5.5267 & TST & \\
\hline CHEMBL453974 & 688239 & 5.6362 & 5.3548 & TST & \\
\hline CHEMBL1565249 & 688239 & 6.1362 & 5.4776 & TST & \\
\hline CHEMBL1558783 & 688239 & 6.1862 & 5.4325 & TRN & \\
\hline CHEMBL1437705 & 688239 & 4.5862 & 5.5648 & TRN & \\
\hline CHEMBL1526600 & 688239 & 5.3862 & 5.4848 & TRN & \\
\hline CHEMBL3196651 & 688239 & 6.9863 & 5.5195 & TRN & \\
\hline CHEMBL1497586 & 688239 & 6.2362 & 5.5318 & TST & \\
\hline CHEMBL1558356 & 688239 & 5.7362 & 5.5449 & TRN & \\
\hline CHEMBL1305992 & 688239 & 4.8862 & 5.3615 & TRN & \\
\hline CHEMBL1458724 & 688239 & 4.5362 & 5.4809 & TST & \\
\hline CHEMBL1478422 & 688239 & 4.7862 & 5.5648 & TRN & \\
\hline CHEMBL1459618 & 688239 & 5.1862 & 5.466 & TRN & \\
\hline CHEMBL1571740 & 688239 & 4.5862 & 5.4954 & TST & \\
\hline CHEMBL1451790 & 688239 & 4.5362 & 5.5197 & TRN & \\
\hline CHEMBL3191831 & 688239 & 4.4862 & 5.3655 & TRN & \\
\hline CHEMBL1444795 & 688239 & 4.8362 & 5.3859 & TRN & \\
\hline CHEMBL1468597 & 688239 & 6.2862 & 5.6077 & TRN & \\
\hline CHEMBL1539835 & 688239 & 5.0362 & 5.5364 & TRN & \\
\hline CHEMBL1377051 & 688239 & 5.0862 & 5.5102 & TST & \\
\hline CHEMBL1372291 & 688239 & 5.0862 & 5.5424 & TRN & \\
\hline CHEMBL1597510 & 688239 & 6.0862 & 5.2413 & TRN & \\
\hline CHEMBL1459849 & 688239 & 5.1862 & 5.4152 & TST & \\
\hline CHEMBL1357798 & 688239 & 5.1862 & 5.5115 & TRN & \\
\hline CHEMBL1455747 & 688239 & 6.0862 & 5.3749 & TRN & \\
\hline
\end{tabular}


Supplemental Table S2.txt

\begin{tabular}{|c|c|c|c|c|}
\hline 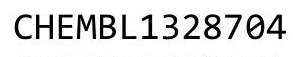 & & & & \\
\hline HEMBL1542074 & 38239 & 362 & 591 & \\
\hline AEMBL1357635 & 239 & 362 & & \\
\hline 76 & 39 & & & \\
\hline AEMBL151 & 39 & 362 & & \\
\hline AEMBL1348170 & 88239 & 362 & & \\
\hline AEMBL1508031 & 88239 & 362 & 4372 & \\
\hline HEMBL1299395 & & & & \\
\hline IEMBL13. & 39 & 862 & & \\
\hline IEMBL144 & & & & \\
\hline AEMBL1477787 & 39 & 862 & 5257 & \\
\hline AEMBL3208836 & & 362 & & \\
\hline AEMBL1417 & & 62 & & \\
\hline AEMBL 2006 & & 62 & & \\
\hline AEMBL1374 & & 62 & & \\
\hline AEMBL1531811 & & 862 & & \\
\hline AEMBL1492759 & & 362 & & \\
\hline IEMBL198 & & 62 & & \\
\hline HEMBL147 & & & & \\
\hline HEMBL137 & & & & \\
\hline AEMBL1482 & & 862 & & \\
\hline HEMBL1388 & & 62 & & \\
\hline AEMBL139 & & 62 & & \\
\hline AFMRI 142 & & & & \\
\hline 77 & & 62 & & \\
\hline ארי 12 & & 862 & & \\
\hline IEMBL1352 & & & & \\
\hline AEMBL146 & & 62 & & \\
\hline AFMRI 12 & & 52 & & \\
\hline 3 & & 62 & & \\
\hline AEMBL1466 & & & & \\
\hline HEMBL1498780 & & 62 & & \\
\hline & & & & \\
\hline 5 & & 52 & & \\
\hline & & & & \\
\hline AEMBL1424865 & & & & \\
\hline AEMBL3195548 & & 362 & 65 & \\
\hline & & & 46 & \\
\hline (2MO & & & & \\
\hline HEMBL1573851 & & & & RN \\
\hline AEMBL1578042 & & 62 & & \\
\hline HEMBL134 & & & & \\
\hline HEMBL1455893 & & & & \\
\hline & & & & \\
\hline AEMBL1344586 & & & & ST \\
\hline MBL131€ & & 862 & 198 & $\mathrm{R}$ \\
\hline & & & & \\
\hline $150-7$ & & & & \\
\hline
\end{tabular}


Supplemental Table S2.txt

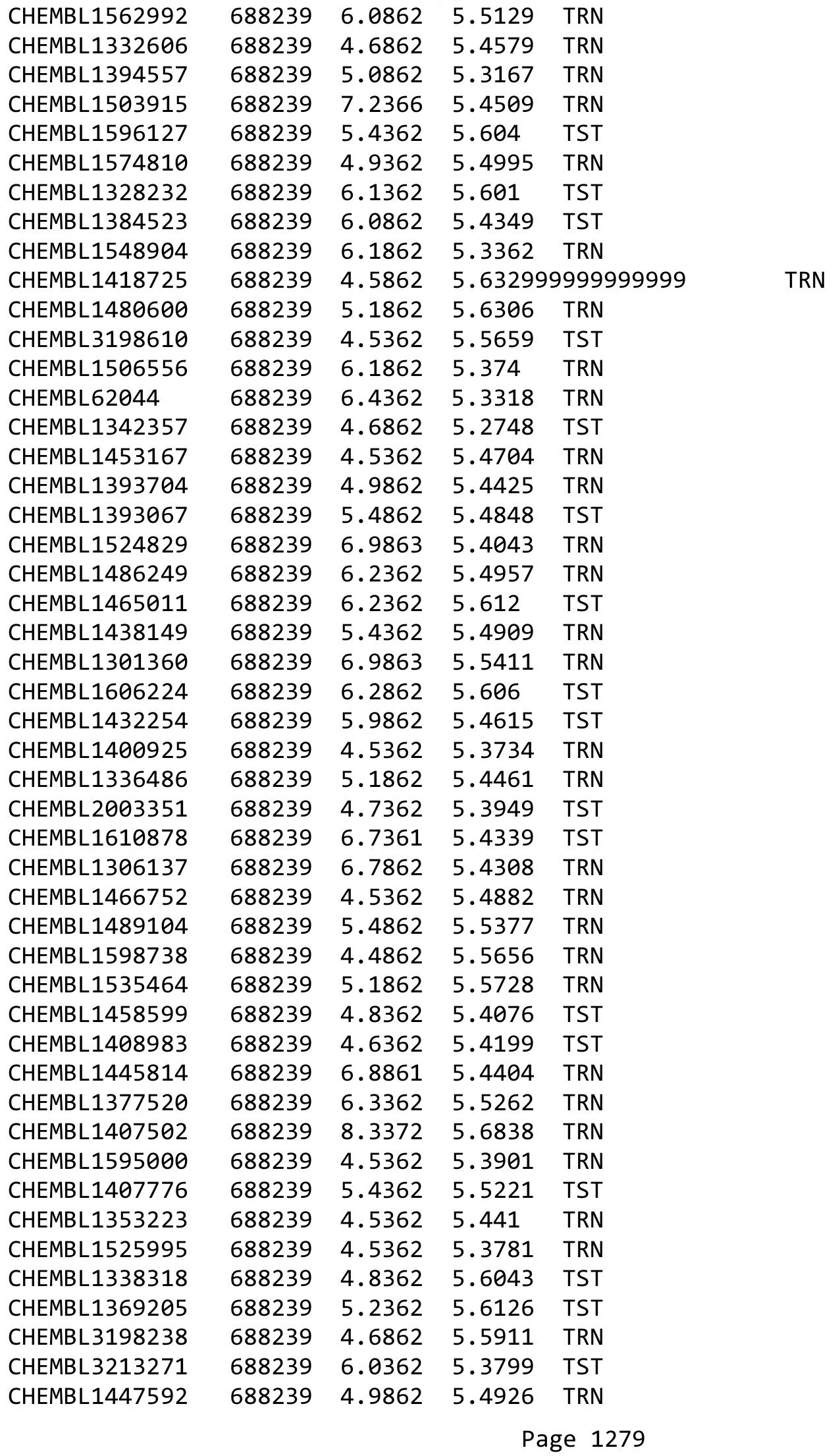


Supplemental Table S2.txt

\begin{tabular}{|c|c|c|c|c|}
\hline CHEMBL1612190 & 688239 & 4.5362 & 5.5682 & TRN \\
\hline CHEMBL1339897 & 688239 & 5.8862 & 5.4616 & TRN \\
\hline CHEMBL1361883 & 688239 & 4.5862 & 5.4868 & TST \\
\hline CHEMBL1463806 & 688239 & 6.8861 & 5.5163 & TRN \\
\hline CHEMBL1399898 & 688239 & 4.5362 & 5.4074 & TRN \\
\hline CHEMBL1328057 & 688239 & 6.1862 & 5.5229 & TRN \\
\hline CHEMBL1543670 & 688239 & 5.7362 & 5.4409 & TRN \\
\hline CHEMBL1502557 & 688239 & 4.5362 & 5.4323 & TRN \\
\hline CHEMBL1332781 & 688239 & 5.1862 & 5.4941 & TRN \\
\hline CHEMBL1391046 & 688239 & 5.1362 & 5.3732 & TRN \\
\hline CHEMBL1395955 & 688239 & 4.7362 & 5.4953 & TRN \\
\hline CHEMBL1467263 & 688239 & 5.1862 & 5.4803 & TRN \\
\hline CHEMBL 3211503 & 688239 & 6.2862 & 5.387006 & 0000000005 \\
\hline CHEMBL 3198530 & 688239 & 4.7862 & 5.5194 & TST \\
\hline CHEMBL1360202 & 688239 & 4.5362 & 5.377999 & 999999999 \\
\hline CHEMBL1329093 & 688239 & 4.6862 & 5.4587 & TRN \\
\hline CHEMBL1585658 & 688239 & 4.5362 & 5.3826 & TRN \\
\hline CHEMBL 3209060 & 688239 & 5.9862 & 5.5705 & TRN \\
\hline CHEMBL1308867 & 688239 & 5.4362 & 5.7267 & TST \\
\hline CHEMBL1596126 & 688239 & 4.5362 & 5.4281 & TRN \\
\hline CHEMBL1303773 & 688239 & 6.7862 & 5.6049 & TRN \\
\hline CHEMBL1455451 & 688239 & 5.0362 & 5.5063 & TRN \\
\hline CHEMBL1496827 & 688239 & 5.1862 & 5.4489 & TRN \\
\hline CHEMBL1544513 & 688239 & 5.2862 & 5.4753 & TRN \\
\hline CHEMBL1585364 & 688239 & 4.5362 & 5.3743 & TST \\
\hline CHEMBL1412218 & 688239 & 7.1864 & 5.4757 & TST \\
\hline CHEMBL1567611 & 688239 & 4.5862 & 5.608 & TRN \\
\hline CHEMBL1323843 & 688239 & 5.4362 & 5.5142 & TRN \\
\hline CHEMBL1326743 & 688239 & 4.6362 & 5.5038 & TRN \\
\hline CHEMBL1546953 & 688239 & 6.8362 & 5.6593 & TRN \\
\hline CHEMBL1605848 & 688239 & 5.4862 & 5.4362 & TRN \\
\hline CHEMBL1376029 & 688239 & 4.5362 & 5.6366 & TRN \\
\hline CHEMBL1601868 & 688239 & 6.0862 & 5.4742 & TRN \\
\hline CHEMBL1461689 & 688239 & 5.3362 & 5.673999 & 9999999995 \\
\hline CHEMBL1498084 & 688239 & 5.3862 & 5.4682 & TRN \\
\hline CHEMBL1587715 & 688239 & 4.5362 & 5.2087 & TRN \\
\hline CHEMBL1440916 & 688239 & 5.1862 & 5.5237 & TRN \\
\hline CHEMBL1584563 & 688239 & 6.0362 & 5.5686 & TRN \\
\hline CHEMBL1577319 & 688239 & 4.7862 & 5.5239 & TRN \\
\hline CHEMBL1457787 & 688239 & 6.1862 & 5.3605 & TST \\
\hline CHEMBL1386342 & 688239 & 4.6362 & 5.5484 & TRN \\
\hline CHEMBL1448410 & 688239 & 4.5362 & 5.3864 & TRN \\
\hline CHEMBL1403431 & 688239 & 4.6862 & 5.5056 & TST \\
\hline CHEMBL 3208578 & 688239 & 4.5862 & 5.4439 & TST \\
\hline CHEMBL1572720 & 688239 & 4.6362 & 5.6019 & TRN \\
\hline CHEMBL1484975 & 688239 & 6.9363 & 5.5645 & TRN \\
\hline CHEMBL1570542 & 688239 & 4.9362 & 5.5118 & TRN \\
\hline CHEMBL1335733 & 688239 & 5.7862 & 5.5141 & TRN \\
\hline
\end{tabular}




\begin{tabular}{|c|c|c|c|c|c|}
\hline & & & & & \\
\hline CHEMBL1370282 & 688239 & 4.4862 & 5.65 & TST & \\
\hline CHEMBL1326981 & 688239 & 4.7862 & 5.3685 & TRN & \\
\hline CHEMBL1511950 & 688239 & 6.2862 & 5.3502 & TRN & \\
\hline CHEMBL1322186 & 688239 & 5.2862 & 5.5306 & TST & \\
\hline CHEMBL1541146 & 688239 & 4.7362 & 5.5413 & TST & \\
\hline CHEMBL1603201 & 688239 & 5.2362 & 5.5652 & TST & \\
\hline CHEMBL1553044 & 688239 & 4.7862 & 5.5156 & TRN & \\
\hline CHEMBL1387428 & 688239 & 4.9362 & 5.4642 & TST & \\
\hline CHEMBL1393719 & 688239 & 4.8862 & 5.6075 & TRN & \\
\hline CHEMBL1430512 & 688239 & 4.5362 & 5.4829 & TRN & \\
\hline CHEMBL1395989 & 688239 & 4.5362 & 5.6198 & TRN & \\
\hline CHEMBL1368953 & 688239 & 4.6362 & 5.21200 & $\partial 000000001$ & TRN \\
\hline CHEMBL1521466 & 688239 & 5.2862 & 5.3399 & TST & \\
\hline CHEMBL1303799 & 688239 & 5.3362 & 5.3678 & TRN & \\
\hline CHEMBL1478676 & 688239 & 4.7362 & 5.6448 & TST & \\
\hline CHEMBL1452075 & 688239 & 4.6862 & 5.5168 & TST & \\
\hline CHEMBL1579240 & 688239 & 5.9362 & 5.637006 & 00000000005 & TRN \\
\hline CHEMBL1553459 & 688239 & 4.7362 & 5.5882 & TRN & \\
\hline CHEMBL1586713 & 688239 & 5.3362 & 5.5433 & TST & \\
\hline CHEMBL1300750 & 688239 & 4.8362 & 5.6061 & TST & \\
\hline CHEMBL1498979 & 688239 & 4.5362 & 5.4813 & TRN & \\
\hline CHEMBL1506061 & 688239 & 4.5862 & 5.5322 & TST & \\
\hline CHEMBL1417142 & 688239 & 6.0 & 5.3441 & TRN & \\
\hline CHEMBL1416308 & 688239 & 4.5362 & 5.581 & TRN & \\
\hline CHEMBL1315659 & 688239 & 6.1362 & 5.4604 & TRN & \\
\hline CHEMBL1573608 & 688239 & 4.4862 & 5.5973 & TRN & \\
\hline CHEMBL1384967 & 688239 & 5.1362 & 5.4074 & TRN & \\
\hline CHEMBL1586027 & 688239 & 4.5862 & 5.5552 & TRN & \\
\hline CHEMBL3210568 & 688239 & 5.2862 & 5.5081 & TRN & \\
\hline CHEMBL1340159 & 688239 & 6.5363 & 5.5705 & TRN & \\
\hline CHEMBL3213614 & 688239 & 5.1862 & 5.4276 & TST & \\
\hline CHEMBL1475173 & 688239 & 4.6362 & 5.5042 & TRN & \\
\hline CHEMBL1602529 & 688239 & 6.1362 & 5.4892 & TRN & \\
\hline CHEMBL1608860 & 688239 & 4.5362 & 5.5197 & TST & \\
\hline CHEMBL1391324 & 688239 & 5.2362 & 5.5016 & TRN & \\
\hline CHEMBL1582753 & 688239 & 6.0862 & 5.5095 & TRN & \\
\hline CHEMBL1389148 & 688239 & 5.5362 & 5.5684 & TRN & \\
\hline CHEMBL1557636 & 688239 & 8.28399 & 99999999 & 5.5229 & TRN \\
\hline CHEMBL181939 & 688239 & 6.1862 & 5.3718 & TRN & \\
\hline CHEMBL1311374 & 688239 & 4.9862 & 5.5078 & TST & \\
\hline CHEMBL1356606 & 688239 & 6.2862 & 5.562 & TRN & \\
\hline CHEMBL1475024 & 688239 & 5.1362 & 5.5515 & TRN & \\
\hline CHEMBL1561549 & 688239 & 6.8362 & 5.5031 & TST & \\
\hline CHEMBL1519408 & 688239 & 4.6862 & 5.617006 & 0000000001 & TRN \\
\hline CHEMBL1552163 & 688239 & 4.8362 & 5.5846 & TRN & \\
\hline CHEMBL1494582 & 688239 & 5.7362 & 5.4995 & TRN & \\
\hline CHEMBL1596492 & 688239 & 4.5362 & 5.4589 & TST & \\
\hline CHEMBL1369131 & 688239 & 5.3862 & 5.4806 & TST & \\
\hline
\end{tabular}


Supplemental Table S2.txt

\begin{tabular}{|c|c|c|c|c|}
\hline CHEMBL326801 & 688239 & 5.3862 & 5.4576 & TRN \\
\hline CHEMBL1464029 & 688239 & 5.8362 & 5.5176 & TRN \\
\hline CHEMBL1507437 & 688239 & 4.5362 & 5.3788 & TRN \\
\hline CHEMBL1329242 & 688239 & 5.8362 & 5.5859 & TST \\
\hline CHEMBL1363610 & 688239 & 5.5362 & 5.5388 & TST \\
\hline CHEMBL1437904 & 688239 & 4.8362 & 5.4988 & TST \\
\hline CHEMBL1332713 & 688239 & 4.5362 & 5.4638 & TRN \\
\hline CHEMBL1368792 & 688239 & 4.5362 & 5.4018 & TRN \\
\hline CHEMBL3190924 & 688239 & 4.6862 & 5.3061 & TRN \\
\hline CHEMBL1443995 & 688239 & 4.9862 & 5.4624 & TRN \\
\hline CHEMBL1545410 & 688239 & 5.4862 & 5.6424 & TRN \\
\hline CHEMBL1378625 & 688239 & 6.3362 & 5.3654 & TRN \\
\hline CHEMBL1506824 & 688239 & 4.6862 & 5.5338 & TRN \\
\hline CHEMBL3196325 & 688239 & 5.0362 & 5.4494 & TRN \\
\hline CHEMBL1391178 & 688239 & 5.9362 & 5.4882 & TRN \\
\hline CHEMBL1461574 & 688239 & 4.8362 & 5.4016 & TST \\
\hline CHEMBL1608469 & 688239 & 4.5362 & 5.4124 & TRN \\
\hline CHEMBL1491637 & 688239 & 4.5362 & 5.4899 & TRN \\
\hline CHEMBL1428516 & 688239 & 6.9863 & 5.3668 & TRN \\
\hline CHEMBL1321129 & 688239 & 5.2362 & 5.3721 & TRN \\
\hline CHEMBL1305940 & 688239 & 5.7362 & 5.5536 & TRN \\
\hline CHEMBL3191782 & 688239 & 4.5362 & 5.4295 & TST \\
\hline CHEMBL1574223 & 688239 & 6.8362 & 5.5447 & TRN \\
\hline CHEMBL1331670 & 688239 & 7.2865 & 5.5265 & TRN \\
\hline CHEMBL1540655 & 688239 & 4.5362 & 5.4271 & TST \\
\hline CHEMBL1351825 & 688239 & 6.0 & 5.5726 & TST \\
\hline CHEMBL1520002 & 688239 & 4.5362 & 5.5933 & TRN \\
\hline CHEMBL1558145 & 688239 & 4.45 & 5.6449 & TRN \\
\hline CHEMBL1308711 & 688239 & 6.2362 & 5.5996 & TRN \\
\hline CHEMBL1419538 & 688239 & 4.6362 & 5.4928 & TRN \\
\hline CHEMBL1388545 & 688239 & 6.1862 & 5.4475 & TRN \\
\hline CHEMBL1479816 & 688239 & 4.5362 & 5.4725 & TRN \\
\hline CHEMBL3214122 & 688239 & 5.1862 & 5.4808 & TST \\
\hline CHEMBL1364432 & 688239 & 4.7362 & 5.3245 & TRN \\
\hline CHEMBL1333469 & 688239 & 4.8862 & 5.5521 & TRN \\
\hline CHEMBL411236 & 688239 & 4.8362 & 5.4548 & TRN \\
\hline CHEMBL1320151 & 688239 & 5.1862 & 5.4992 & TRN \\
\hline CHEMBL1478002 & 688239 & 6.3362 & 5.5181 & TRN \\
\hline CHEMBL1990701 & 688239 & 6.8861 & 5.5396 & TST \\
\hline CHEMBL1408032 & 688239 & 6.2862 & 5.3788 & TRN \\
\hline CHEMBL1540885 & 688239 & 4.5362 & 5.4346 & TRN \\
\hline CHEMBL1473233 & 688239 & 5.7862 & 5.2542 & TRN \\
\hline CHEMBL1569243 & 688239 & 4.9362 & 5.5703 & TST \\
\hline CHEMBL1413524 & 688239 & 4.5362 & 5.3405 & TRN \\
\hline CHEMBL1307429 & 688239 & 5.6362 & 5.4433 & TRN \\
\hline CHEMBL1375001 & 688239 & 5.6362 & 5.4889 & TRN \\
\hline CHEMBL1384699 & 688239 & 5.9362 & \multicolumn{2}{|c|}{5.537000000000001} \\
\hline CHEMBL1408685 & 688239 & 4.7362 & 5.5621 & TRN \\
\hline
\end{tabular}


Supplemental Table S2.txt

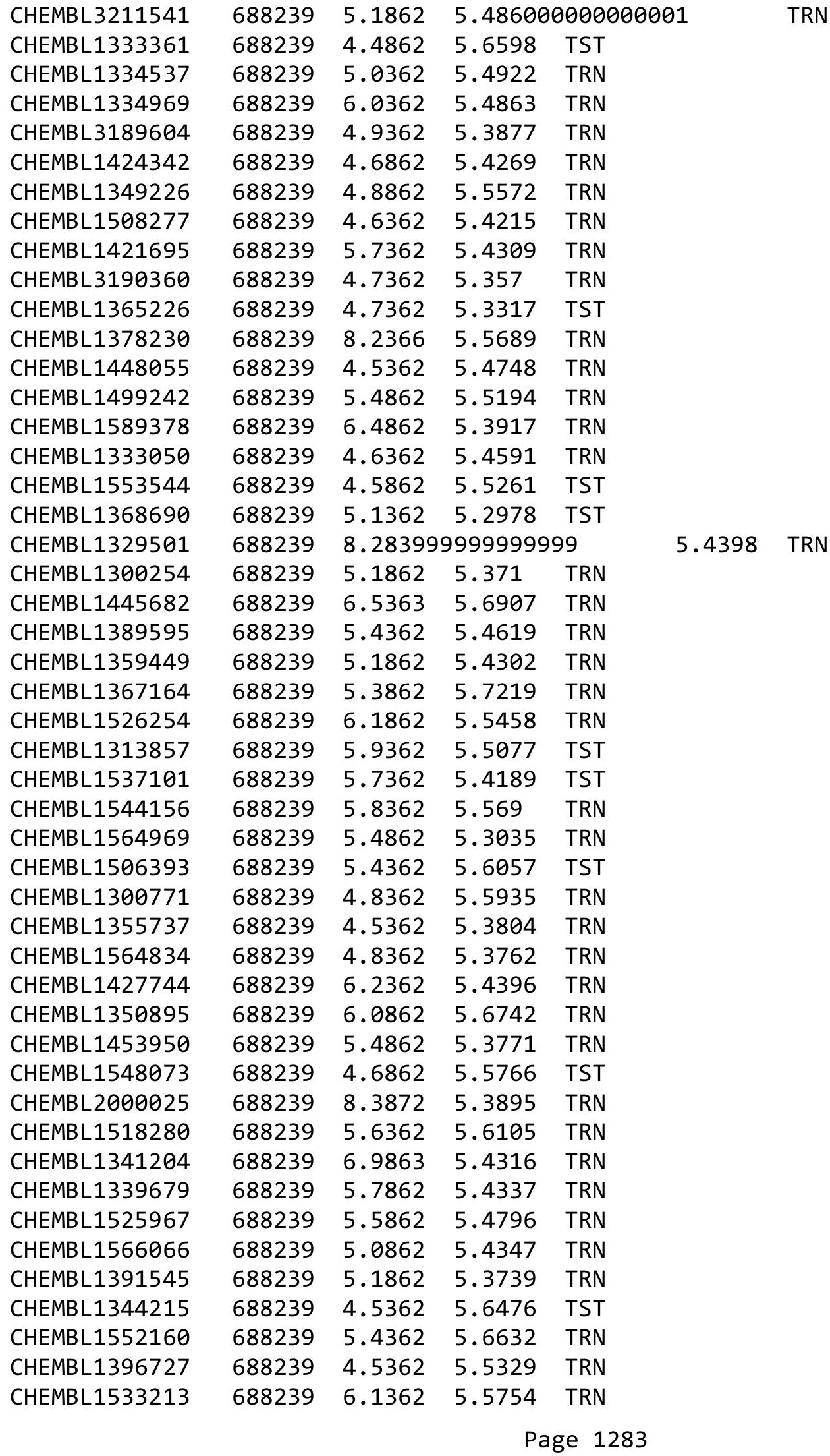


Supplemental Table S2.txt

\begin{tabular}{|c|c|c|c|c|}
\hline CHEMBL1322744 & 688239 & 4.5362 & 5.4679 & TRN \\
\hline CHEMBL1558203 & 688239 & 5.4362 & 5.4532 & TRN \\
\hline CHEMBL1469429 & 688239 & 5.4862 & 5.3802 & TST \\
\hline CHEMBL1401907 & 688239 & 6.2362 & 5.6363 & TRN \\
\hline CHEMBL1329512 & 688239 & 4.5362 & 5.5505 & TRN \\
\hline CHEMBL1502154 & 688239 & 5.2362 & 5.5015 & TRN \\
\hline CHEMBL1353603 & 688239 & 7.5867 & 5.4852 & TRN \\
\hline CHEMBL1370651 & 688239 & 6.8362 & 5.5616 & TRN \\
\hline CHEMBL1484600 & 688239 & 5.0862 & 5.4399 & TST \\
\hline CHEMBL585654 & 688239 & 5.5362 & 5.4535 & TRN \\
\hline CHEMBL1562892 & 688239 & 6.1362 & 5.4393 & TRN \\
\hline CHEMBL1300742 & 688239 & 5.1862 & 5.4536 & TRN \\
\hline CHEMBL1452233 & 688239 & 4.9862 & 5.4878 & TRN \\
\hline CHEMBL1424231 & 688239 & 4.7362 & 5.4267 & TRN \\
\hline CHEMBL1531004 & 688239 & 6.6362 & 5.7645 & TRN \\
\hline CHEMBL1411668 & 688239 & 5.4862 & 5.5172 & TST \\
\hline CHEMBL1490041 & 688239 & 4.5862 & 5.45200 & 3000000001 \\
\hline CHEMBL1351487 & 688239 & 8.2366 & 5.386 & TST \\
\hline CHEMBL1322926 & 688239 & 6.8362 & 5.3769 & TST \\
\hline CHEMBL1541340 & 688239 & 5.5862 & 5.3484 & TRN \\
\hline CHEMBL574779 & 688239 & 5.8862 & 5.5687 & TRN \\
\hline CHEMBL1589394 & 688239 & 5.1862 & 5.6131 & TRN \\
\hline CHEMBL1498298 & 688239 & 4.5362 & 5.579 & TRN \\
\hline CHEMBL1402055 & 688239 & 7.0362 & 5.4594 & TST \\
\hline CHEMBL1531572 & 688239 & 4.6362 & 5.5869 & TRN \\
\hline CHEMBL1477985 & 688239 & 8.2366 & 5.4746 & TRN \\
\hline CHEMBL1499299 & 688239 & 5.7362 & 5.5052 & TRN \\
\hline CHEMBL1396714 & 688239 & 5.4362 & 5.6159 & TRN \\
\hline CHEMBL1456497 & 688239 & 6.2362 & 5.5553 & TST \\
\hline CHEMBL1581038 & 688239 & 4.5862 & 5.4865 & TRN \\
\hline CHEMBL1455829 & 688239 & 4.9362 & 5.6144 & TRN \\
\hline CHEMBL1520917 & 688239 & 5.9862 & 5.4446 & TST \\
\hline CHEMBL1355232 & 688239 & 6.1862 & 5.4308 & TRN \\
\hline CHEMBL1308839 & 688239 & 5.5362 & 5.4784 & TRN \\
\hline CHEMBL1591875 & 688239 & 4.7362 & 5.3274 & TRN \\
\hline CHEMBL528564 & 688239 & 5.8862 & 5.4884 & TRN \\
\hline CHEMBL1530061 & 688239 & 5.8862 & 5.4504 & TST \\
\hline CHEMBL1471212 & 688239 & 5.6862 & 5.5151 & TRN \\
\hline CHEMBL1332410 & 688239 & 4.5362 & 5.3006 & TRN \\
\hline CHEMBL1508921 & 688239 & 4.5362 & 5.5288 & TRN \\
\hline CHEMBL1477101 & 688239 & 6.1862 & 5.4663 & TRN \\
\hline CHEMBL1332990 & 688239 & 8.2366 & 5.4079 & TRN \\
\hline CHEMBL1509233 & 688239 & 6.5862 & 5.4623 & TRN \\
\hline CHEMBL1495881 & 688239 & 6.5363 & 5.545 & TRN \\
\hline CHEMBL1496951 & 688239 & 4.7362 & 5.6201 & TST \\
\hline CHEMBL1589042 & 688239 & 5.1362 & 5.4855 & TRN \\
\hline CHEMBL1394915 & 688239 & 4.7862 & 5.5693 & TRN \\
\hline CHEMBL1367199 & 688239 & 5.0362 & 5.4056 & TRN \\
\hline
\end{tabular}


Supplemental Table S2.txt

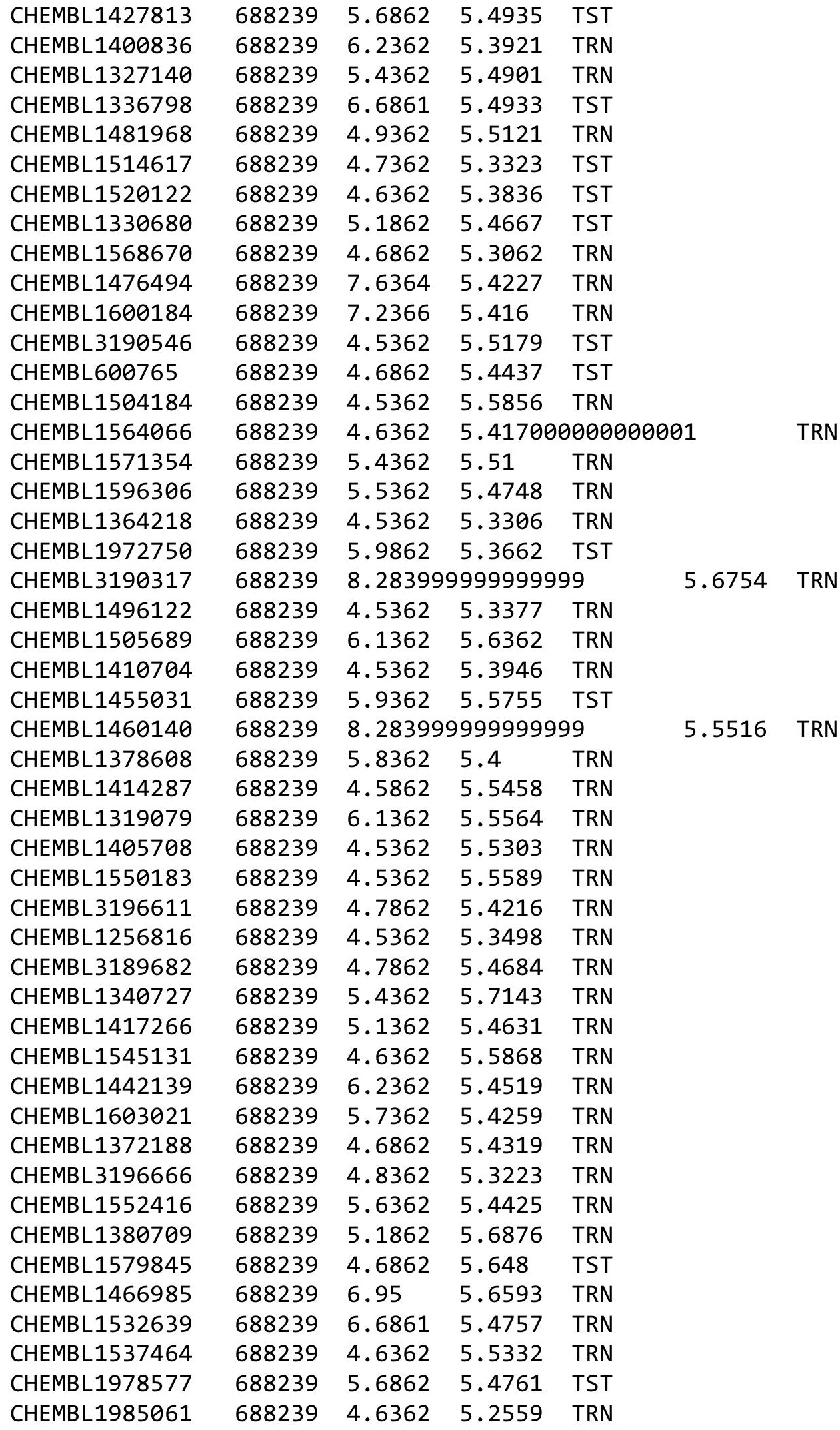


Supplemental Table S2.txt

\begin{tabular}{|c|c|c|c|c|}
\hline CHEMBL1590768 & 688239 & 6.9363 & 5.5312 & TRN \\
\hline CHEMBL1541537 & 688239 & 6.7361 & 5.6229 & TRN \\
\hline CHEMBL1321257 & 688239 & 4.7862 & 5.4443 & TRN \\
\hline CHEMBL3208820 & 688239 & 5.2862 & 5.4169 & TRN \\
\hline CHEMBL1485531 & 688239 & 5.1862 & 5.5188 & TRN \\
\hline CHEMBL1319986 & 688239 & 6.6362 & 5.4505 & TRN \\
\hline CHEMBL1579326 & 688239 & 6.0362 & 5.4746 & TRN \\
\hline CHEMBL1538961 & 688239 & 6.1862 & 5.6428 & TRN \\
\hline CHEMBL1354076 & 688239 & 5.5362 & 5.4932 & TRN \\
\hline CHEMBL1462713 & 688239 & 5.0862 & 5.7526 & TRN \\
\hline CHEMBL1530110 & 688239 & 6.8861 & 5.7187 & TRN \\
\hline CHEMBL1450809 & 688239 & 6.0862 & 5.3971 & TRN \\
\hline CHEMBL1344574 & 688239 & 6.9363 & 5.4456 & TST \\
\hline CHEMBL 3208279 & 688239 & 4.5362 & 5.572 & TRN \\
\hline CHEMBL1586526 & 688239 & 4.6362 & 5.6088 & TST \\
\hline CHEMBL1603328 & 688239 & 4.5362 & 5.4828 & TRN \\
\hline CHEMBL1318916 & 688239 & 5.4862 & 5.3412 & TRN \\
\hline CHEMBL1505710 & 688239 & 7.4365 & 5.6924 & TRN \\
\hline CHEMBL1421381 & 688239 & 6.8362 & 5.459 & TRN \\
\hline CHEMBL1596089 & 688239 & 4.6862 & 5.3183 & TRN \\
\hline CHEMBL1393880 & 688239 & 6.7862 & 5.6037 & TRN \\
\hline CHEMBL1541449 & 688239 & 6.9363 & 5.4443 & TRN \\
\hline CHEMBL1556072 & 688239 & 4.6362 & 5.3803 & TRN \\
\hline CHEMBL1399225 & 688239 & 6.0862 & 5.37700 & 000000001 \\
\hline CHEMBL3197585 & 688239 & 5.1862 & 5.3113 & TRN \\
\hline CHEMBL1446341 & 688239 & 7.6364 & 5.3987 & TRN \\
\hline CHEMBL1531247 & 688239 & 4.5362 & 5.5092 & TST \\
\hline CHEMBL1563731 & 688239 & 5.7362 & 5.5102 & TRN \\
\hline CHEMBL1458450 & 688239 & 4.5362 & 5.3936 & TRN \\
\hline CHEMBL505670 & 688239 & 5.4362 & 5.4321 & TRN \\
\hline CHEMBL1531541 & 688239 & 5.4362 & 5.4912 & TRN \\
\hline CHEMBL1541684 & 688239 & 4.6362 & 5.4785 & TRN \\
\hline CHEMBL1327117 & 688239 & 4.6862 & 5.5285 & TRN \\
\hline CHEMBL1524835 & 688239 & 7.0362 & 5.6105 & TRN \\
\hline CHEMBL3193601 & 688239 & 5.1862 & 5.4232 & TRN \\
\hline CHEMBL1544912 & 688239 & 5.4362 & 5.5265 & TRN \\
\hline CHEMBL1585835 & 688239 & 5.4862 & 5.5199 & TRN \\
\hline CHEMBL1405104 & 688239 & 4.5862 & 5.4482 & TRN \\
\hline CHEMBL1530116 & 688239 & 6.1862 & 5.5346 & TRN \\
\hline CHEMBL1336966 & 688239 & 7.0362 & 5.6105 & TRN \\
\hline CHEMBL1547092 & 688239 & 4.5362 & 5.3929 & TST \\
\hline CHEMBL1409238 & 688239 & 4.8362 & 5.4072 & TRN \\
\hline CHEMBL1482436 & 688239 & 6.2362 & 5.5234 & TST \\
\hline CHEMBL1465662 & 688239 & 5.0362 & 5.402 & TRN \\
\hline CHEMBL1570776 & 688239 & 4.4862 & 5.5367 & TRN \\
\hline CHEMBL1462755 & 688239 & 4.8362 & 5.5218 & TST \\
\hline CHEMBL1452868 & 688239 & 5.0862 & 5.5196 & TST \\
\hline CHEMBL1311362 & 688239 & 4.8362 & 5.5077 & TRN \\
\hline
\end{tabular}

Page 1286 
Supplemental Table S2.txt

\begin{tabular}{|c|c|c|c|c|}
\hline CHEMBL1448430 & 688239 & 8.3872 & 5.3845 & TRN \\
\hline CHEMBL1429941 & 688239 & 5.5362 & 5.4688 & TRN \\
\hline CHEMBL1539268 & 688239 & 6.5862 & 5.4322 & TRN \\
\hline CHEMBL1308888 & 688239 & 4.7 & 5.3869 & TRN \\
\hline CHEMBL1356357 & 688239 & 4.8362 & 5.4629 & TRN \\
\hline CHEMBL1353102 & 688239 & 5.8362 & 5.5353 & TRN \\
\hline CHEMBL1588946 & 688239 & 8.3872 & 5.4091 & TRN \\
\hline CHEMBL1379105 & 688239 & 5.2862 & \multicolumn{2}{|c|}{5.452999999999999} \\
\hline CHEMBL1537763 & 688239 & 5.2362 & 5.4153 & TST \\
\hline CHEMBL1500672 & 688239 & 6.0362 & 5.5233 & TRN \\
\hline CHEMBL1389028 & 688239 & 5.2362 & 5.5953 & TRN \\
\hline CHEMBL1536338 & 688239 & 6.1362 & 5.4236 & TST \\
\hline CHEMBL1358569 & 688239 & 4.4862 & 5.5425 & TRN \\
\hline CHEMBL1498035 & 688239 & 4.5362 & 5.5168 & TRN \\
\hline CHEMBL1368190 & 688239 & 5.4362 & \multicolumn{2}{|c|}{5.542999999999999} \\
\hline CHEMBL1438914 & 688239 & 7.1864 & 5.5653 & TRN \\
\hline CHEMBL1391299 & 688239 & 4.5362 & 5.5165 & TRN \\
\hline CHEMBL1413163 & 688239 & 5.1862 & 5.4871 & TST \\
\hline CHEMBL1517113 & 688239 & 6.3362 & 5.534 & TRN \\
\hline CHEMBL1448832 & 688239 & 5.1862 & 5.5088 & TST \\
\hline CHEMBL1547627 & 688239 & 4.5362 & 5.6168 & TST \\
\hline CHEMBL1420060 & 688239 & 4.5362 & \multicolumn{2}{|c|}{5.412000000000001} \\
\hline CHEMBL1592676 & 688239 & 4.5362 & 5.4097 & TRN \\
\hline CHEMBL1531317 & 688239 & 5.5862 & 5.5351 & TRN \\
\hline CHEMBL1611404 & 688239 & 6.9363 & 5.4865 & TRN \\
\hline CHEMBL1325284 & 688239 & 6.7862 & 5.5356 & TRN \\
\hline CHEMBL1346130 & 688239 & 5.6362 & 5.4412 & TRN \\
\hline CHEMBL1436205 & 688239 & 4.5362 & 5.3953 & TST \\
\hline CHEMBL1975679 & 688239 & 4.7362 & 5.4286 & TST \\
\hline CHEMBL1528865 & 688239 & 5.4362 & 5.3814 & TRN \\
\hline CHEMBL3209698 & 688239 & 5.1862 & 5.4677 & TST \\
\hline CHEMBL1496536 & 688239 & 5.1862 & 5.4648 & TST \\
\hline CHEMBL 2028186 & 688239 & 5.1862 & 5.2942 & TST \\
\hline CHEMBL1309559 & 688239 & 4.5362 & 5.3743 & TRN \\
\hline CHEMBL1378602 & 688239 & 5.3362 & 5.4988 & TRN \\
\hline CHEMBL1605883 & 688239 & 5.4862 & 5.461 & TRN \\
\hline CHEMBL1468461 & 688239 & 6.0862 & 5.5639 & TRN \\
\hline CHEMBL467382 & 688239 & 4.5862 & 5.5623 & TST \\
\hline CHEMBL1385608 & 688239 & 4.6362 & 5.4418 & TRN \\
\hline CHEMBL1593554 & 688239 & 4.8862 & 5.4379 & TRN \\
\hline CHEMBL1415324 & 688239 & 4.6362 & 5.4623 & TST \\
\hline CHEMBL1483931 & 688239 & 6.1362 & 5.4509 & TRN \\
\hline CHEMBL1443946 & 688239 & 5.4362 & 5.41 & TRN \\
\hline CHEMBL1323520 & 688239 & 5.8862 & 5.6312 & TRN \\
\hline CHEMBL1299218 & 688239 & 6.9363 & 5.6546 & TRN \\
\hline CHEMBL1576646 & 688239 & 6.3863 & \multicolumn{2}{|c|}{5.422000000000001} \\
\hline CHEMBL577494 & 688239 & 5.4362 & 5.5047 & TST \\
\hline CHEMBL1551176 & 688239 & 5.1862 & 5.4832 & TRN \\
\hline
\end{tabular}

Page 1287 
Supplemental Table S2.txt

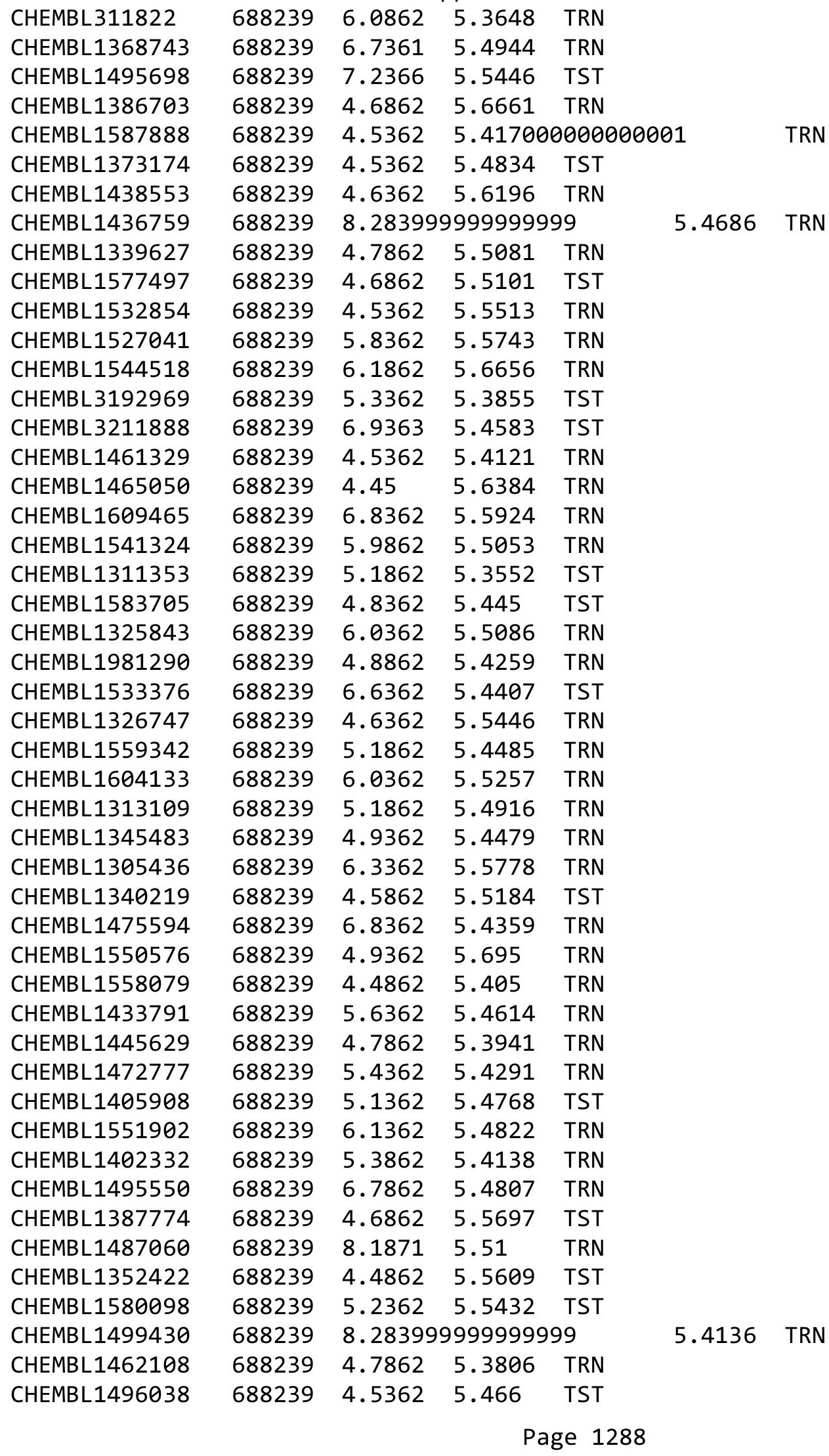


Supplemental Table S2.txt

\begin{tabular}{|c|c|c|c|c|}
\hline CHEMBL1594426 & 688239 & 4.6862 & 5.4857 & TRN \\
\hline CHEMBL1319789 & 688239 & 5.2362 & 5.3238 & TST \\
\hline CHEMBL1540797 & 688239 & 6.5363 & 5.5729 & TRN \\
\hline CHEMBL1546143 & 688239 & 4.5362 & 5.4255 & TST \\
\hline CHEMBL1319501 & 688239 & 5.3862 & 5.4303 & TRN \\
\hline CHEMBL3199469 & 688239 & 5.0362 & 5.4594 & TRN \\
\hline CHEMBL1443298 & 688239 & 4.7862 & 5.4479 & TST \\
\hline CHEMBL1562596 & 688239 & 4.7862 & 5.4717 & TRN \\
\hline CHEMBL1386179 & 688239 & 6.2362 & 5.4187 & TRN \\
\hline CHEMBL1407449 & 688239 & 8.1367 & 5.4564 & TRN \\
\hline CHEMBL3196919 & 688239 & 4.5362 & 5.4521 & TRN \\
\hline CHEMBL1519195 & 688239 & 5.7862 & 5.3567 & TRN \\
\hline CHEMBL1483312 & 688239 & 5.8862 & 5.4149 & TST \\
\hline CHEMBL1313092 & 688239 & 7.0362 & 5.5574 & TRN \\
\hline CHEMBL1319548 & 688239 & 4.5362 & 5.6753 & TRN \\
\hline CHEMBL1451460 & 688239 & 4.5362 & 5.4905 & TRN \\
\hline CHEMBL1456445 & 688239 & 4.4862 & 5.4851 & TST \\
\hline CHEMBL1363510 & 688239 & 6.0862 & 5.5284 & TRN \\
\hline CHEMBL 3208985 & 688239 & 4.7362 & 5.4829 & TRN \\
\hline CHEMBL1535940 & 688239 & 5.0362 & 5.4557 & TRN \\
\hline CHEMBL1329473 & 688239 & 5.2362 & 5.404 & TST \\
\hline CHEMBL1560529 & 688239 & 4.5362 & 5.4304 & TST \\
\hline CHEMBL1362362 & 688239 & 7.0362 & 5.4634 & TRN \\
\hline CHEMBL3211983 & 688239 & 4.5362 & 5.4295 & TRN \\
\hline CHEMBL3193338 & 688239 & 6.1862 & 5.2943 & TST \\
\hline CHEMBL1406659 & 688239 & 5.3862 & 5.6201 & TRN \\
\hline CHEMBL1379287 & 688239 & 4.7362 & 5.6396 & TRN \\
\hline CHEMBL1553550 & 688239 & 5.4862 & 5.4888 & TRN \\
\hline CHEMBL1510353 & 688239 & 5.4862 & 5.4283 & TRN \\
\hline CHEMBL1355166 & 688239 & 4.7862 & $5.45700 €$ & 000000001 \\
\hline CHEMBL1440902 & 688239 & 4.5362 & 5.5455 & TRN \\
\hline CHEMBL1367498 & 688239 & 4.4862 & 5.6749 & TRN \\
\hline CHEMBL1430595 & 688239 & 4.4862 & 5.4897 & TST \\
\hline CHEMBL1341971 & 688239 & 5.1862 & 5.4952 & TST \\
\hline CHEMBL1305868 & 688239 & 4.4862 & 5.4898 & TRN \\
\hline CHEMBL1504275 & 688239 & 6.0362 & 5.5139 & TRN \\
\hline CHEMBL1503276 & 688239 & 4.5362 & 5.3933 & TRN \\
\hline CHEMBL1497239 & 688239 & 4.5362 & 5.4319 & TST \\
\hline CHEMBL1306078 & 688239 & 4.5362 & 5.6654 & TRN \\
\hline CHEMBL1445279 & 688239 & 5.3862 & 5.3399 & TRN \\
\hline CHEMBL1430329 & 688239 & 5.4362 & 5.6877 & TRN \\
\hline CHEMBL1608668 & 688239 & 4.4862 & 5.5009 & TRN \\
\hline CHEMBL1569767 & 688239 & 6.2862 & 5.5881 & TRN \\
\hline CHEMBL1423052 & 688239 & 6.9363 & 5.3491 & TRN \\
\hline CHEMBL1469629 & 688239 & 6.8861 & 5.6049 & TRN \\
\hline CHEMBL1324310 & 688239 & 4.5362 & 5.527 & TST \\
\hline CHEMBL1440431 & 688239 & 6.6861 & 5.441 & TRN \\
\hline CHEMBL1502108 & 688239 & 6.1362 & 5.3218 & TRN \\
\hline
\end{tabular}


Supplemental Table S2.txt

\begin{tabular}{|c|c|c|c|c|}
\hline 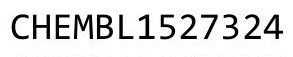 & & 362 & & \\
\hline HEMBL1385795 & 88239 & 7862 & & \\
\hline HEMBL15 & 39 & 62 & 364 & \\
\hline 28 & & & & \\
\hline AEMBL15 & & & & \\
\hline AEMBL1422692 & 88239 & 8862 & 4853 & \\
\hline HEMBL1438168 & 88239 & .9862 & .5151 & \\
\hline HEMBL1540976 & & 362 & 5365 & \\
\hline AEMBL13 & & & 935 & \\
\hline AEMBL13e & & & & \\
\hline HEMBL1571318 & 88239 & 362 & . 3764 & \\
\hline HEMBL1592190 & 88239 & 66 & .4697 & \\
\hline HEMBL131 & 39 & 62 & 4841 & \\
\hline HEMBL13 & & & 351 & \\
\hline HEMBL13 & & & & \\
\hline HEMBL1601620 & 88239 & 5861 & 4047 & \\
\hline AEMBL3195297 & & & & \\
\hline HEMBL143 & 39 & 52 & 19 & \\
\hline L16 & & & & \\
\hline 51 & & & & \\
\hline HEMBL1501748 & & 872 & 3609 & \\
\hline AEMBL155 & & & & \\
\hline HEMBL 14 & & & 5.6726 & \\
\hline L13 & & & 601 & \\
\hline HEM & & & 335 & \\
\hline L134 & & & 843 & \\
\hline AEMBL1522377 & & & 392 & r \\
\hline HEMBL14 & & & 276 & \\
\hline HEN & & & & \\
\hline AFMRI 14 & & & 556 & \\
\hline AEMBL1319836 & & & & ST \\
\hline HEMBL1355165 & & & 31 & RN \\
\hline HEMBL1C & & & & \\
\hline 13 & & & & RN \\
\hline 36 & & & 768 & $\mathrm{RN}$ \\
\hline AEMBL1346459 & & & & RN \\
\hline AEMBL1505054 & & & 396 & RN \\
\hline 1 & & & & KIV \\
\hline ה19 וסמזו & & & 64 & RIV \\
\hline HEMBL15 & & & 869 & RN \\
\hline AEMBL1454461 & & & 5.3624 & RN \\
\hline AEMBL1328961 & & & 5.4791 & ST \\
\hline & & & & \\
\hline HEMBL $32 \ell$ & & & .3913 & \\
\hline HEMBL1489764 & & & 5.6342 & $\mathrm{RN}$ \\
\hline IEMBL 3191766 & 39 & 62 & 5.4457 & \\
\hline ה 12 & & & & \\
\hline $10-\pi-5$ & & 5.6862 & & \\
\hline
\end{tabular}

Page 1290 
Supplemental Table S2.txt

\begin{tabular}{|c|c|c|c|c|c|}
\hline CHEMBL1596773 & 688239 & 6.1862 & 5.5119 & TRN & \\
\hline CHEMBL1338479 & 688239 & 5.9362 & 5.5978 & TST & \\
\hline CHEMBL1473469 & 688239 & 5.6362 & 5.5262 & TRN & \\
\hline CHEMBL1394784 & 688239 & 4.6362 & 5.4436 & TRN & \\
\hline CHEMBL1534093 & 688239 & 4.9862 & 5.4259 & TST & \\
\hline CHEMBL1577601 & 688239 & 6.5363 & 5.5739 & TRN & \\
\hline CHEMBL1437785 & 688239 & 4.8862 & 5.4077 & TRN & \\
\hline CHEMBL1413509 & 688239 & 5.1862 & 5.3607 & TRN & \\
\hline CHEMBL1524488 & 688239 & 5.5862 & 5.527 & TRN & \\
\hline CHEMBL1320036 & 688239 & 4.7362 & 5.5278 & TRN & \\
\hline CHEMBL1472411 & 688239 & 4.5862 & 5.4288 & TST & \\
\hline CHEMBL3195428 & 688239 & 5.1862 & 5.32799 & 9999999999 & TST \\
\hline CHEMBL1562863 & 688239 & 5.3862 & 5.4313 & TRN & \\
\hline CHEMBL1551759 & 688239 & 5.1862 & 5.4751 & TST & \\
\hline CHEMBL1446420 & 688239 & 4.5362 & 5.4245 & TST & \\
\hline CHEMBL1607877 & 688239 & 4.65 & 5.3631 & TRN & \\
\hline CHEMBL1613252 & 688239 & 5.1862 & 5.6695 & TRN & \\
\hline CHEMBL1413357 & 688239 & 6.9363 & 5.5064 & TST & \\
\hline CHEMBL1325089 & 688239 & 6.1362 & 5.4643 & TRN & \\
\hline CHEMBL1568934 & 688239 & 4.8862 & 5.4507 & TRN & \\
\hline CHEMBL1511398 & 688239 & 4.7362 & 5.4563 & TRN & \\
\hline CHEMBL1361919 & 688239 & 4.5362 & 5.4794 & TST & \\
\hline CHEMBL1489892 & 688239 & 4.6862 & 5.4504 & TRN & \\
\hline CHEMBL1530839 & 688239 & 4.6862 & 5.4661 & TRN & \\
\hline CHEMBL1990055 & 688239 & 4.5362 & 5.49 & TRN & \\
\hline CHEMBL1529025 & 688239 & 4.5862 & 5.4335 & TRN & \\
\hline CHEMBL1440258 & 688239 & 4.9862 & 5.5088 & TRN & \\
\hline CHEMBL1348924 & 688239 & 4.7362 & 5.4186 & TRN & \\
\hline CHEMBL1472185 & 688239 & 4.5362 & 5.4959 & TRN & \\
\hline CHEMBL1555129 & 688239 & 6.2862 & 5.3545 & TRN & \\
\hline CHEMBL1404633 & 688239 & 4.6362 & 5.4522 & TST & \\
\hline CHEMBL1311679 & 688239 & 6.8861 & 5.437 & TRN & \\
\hline CHEMBL1431797 & 688239 & 4.7862 & 5.4044 & TRN & \\
\hline CHEMBL1343050 & 688239 & 5.8362 & 5.4315 & TRN & \\
\hline CHEMBL1539957 & 688239 & 4.5362 & 5.3909 & TRN & \\
\hline CHEMBL1467956 & 688239 & 5.1862 & 5.3873 & TRN & \\
\hline CHEMBL1448340 & 688239 & 5.7362 & 5.4714 & TRN & \\
\hline CHEMBL 3212815 & 688239 & 6.8362 & 5.4325 & TST & \\
\hline CHEMBL1413397 & 688239 & 5.8862 & 5.5243 & TST & \\
\hline CHEMBL1401469 & 688239 & 5.0362 & 5.5064 & TRN & \\
\hline CHEMBL1326607 & 688239 & 7.5361 & 5.5304 & TST & \\
\hline CHEMBL1545989 & 688239 & 6.3863 & 5.6363 & TRN & \\
\hline CHEMBL1319310 & 688239 & 5.8362 & 5.3607 & TRN & \\
\hline CHEMBL1517370 & 688239 & 6.3362 & 5.5206 & TRN & \\
\hline CHEMBL1444335 & 688239 & 4.5362 & 5.5573 & TST & \\
\hline CHEMBL1463499 & 688239 & 7.1864 & 5.6027 & TST & \\
\hline CHEMBL1329789 & 688239 & 5.3862 & 5.4041 & TRN & \\
\hline CHEMBL1418115 & 688239 & 4.9362 & 5.4254 & TST & \\
\hline
\end{tabular}


Supplemental Table S2.txt

\begin{tabular}{|c|c|c|c|c|}
\hline CHEMBL1577937 & 688239 & 6.2862 & 5.4222 & TRN \\
\hline CHEMBL1603849 & 688239 & 6.0862 & 5.4957 & TRN \\
\hline CHEMBL1604290 & 688239 & 5.1862 & 5.4794 & TRN \\
\hline CHEMBL1440303 & 688239 & 4.5362 & 5.5161 & TST \\
\hline CHEMBL1340632 & 688239 & 6.9363 & 5.6125 & TRN \\
\hline CHEMBL1461932 & 688239 & 5.3362 & 5.4395 & TST \\
\hline CHEMBL3194668 & 688239 & 5.3862 & 5.3752 & TRN \\
\hline CHEMBL3199900 & 688239 & 5.8362 & 5.5362 & TRN \\
\hline CHEMBL1546818 & 688239 & 5.4862 & 5.3836 & TST \\
\hline CHEMBL1546793 & 688239 & 5.6362 & 5.3986 & TRN \\
\hline CHEMBL1396472 & 688239 & 5.2362 & 5.4721 & TST \\
\hline CHEMBL1558004 & 688239 & 5.1862 & 5.4582 & TST \\
\hline CHEMBL1367754 & 688239 & 5.4362 & 5.548999 & 99999999995 \\
\hline CHEMBL3210516 & 688239 & 6.2862 & 5.3933 & TRN \\
\hline CHEMBL1594778 & 688239 & 4.6862 & 5.5399 & TRN \\
\hline CHEMBL1318352 & 688239 & 6.3362 & 5.6051 & TRN \\
\hline CHEMBL1338616 & 688239 & 5.8862 & 5.4179 & TST \\
\hline CHEMBL1333253 & 688239 & 4.7362 & 5.5002 & TRN \\
\hline CHEMBL1518044 & 688239 & 4.5862 & 5.5607 & TRN \\
\hline CHEMBL1535013 & 688239 & 4.8362 & 5.4338 & TRN \\
\hline CHEMBL1574761 & 688239 & 5.3362 & 5.4744 & TRN \\
\hline CHEMBL1301858 & 688239 & 4.5362 & 5.5687 & TST \\
\hline CHEMBL1511702 & 688239 & 5.7362 & 5.3878 & TRN \\
\hline CHEMBL1465617 & 688239 & 5.2862 & 5.3953 & TRN \\
\hline CHEMBL1356058 & 688239 & 6.2362 & 5.4148 & TRN \\
\hline CHEMBL1591676 & 688239 & 5.7862 & 5.4434 & TST \\
\hline CHEMBL1481288 & 688239 & 5.1862 & 5.4585 & TRN \\
\hline CHEMBL1308585 & 688239 & 5.4862 & 5.3953 & TST \\
\hline CHEMBL1482877 & 688239 & 4.5362 & 5.2704 & TST \\
\hline CHEMBL1613135 & 688239 & 5.4362 & 5.4642 & TRN \\
\hline CHEMBL1386463 & 688239 & 4.5362 & 5.4618 & TRN \\
\hline CHEMBL1320534 & 688239 & 4.5362 & 5.4105 & TRN \\
\hline CHEMBL1587539 & 688239 & 4.5362 & 5.421 & TRN \\
\hline CHEMBL1454742 & 688239 & 4.7362 & 5.4087 & TST \\
\hline CHEMBL580609 & 688239 & 4.6862 & 5.3107 & TRN \\
\hline CHEMBL1528070 & 688239 & 4.6862 & 5.5286 & TRN \\
\hline CHEMBL1609815 & 688239 & 4.7362 & 5.4517 & TRN \\
\hline CHEMBL1445000 & 688239 & 4.8862 & 5.5514 & TRN \\
\hline CHEMBL1526081 & 688239 & 4.6862 & 5.3692 & TRN \\
\hline CHEMBL1448954 & 688239 & 6.8362 & 5.5374 & TRN \\
\hline CHEMBL1405862 & 688239 & 7.0362 & 5.5927 & TST \\
\hline CHEMBL1309422 & 688239 & 4.9862 & 5.5056 & TRN \\
\hline CHEMBL1389870 & 688239 & 5.7862 & 5.43 & TST \\
\hline CHEMBL1451902 & 688239 & 5.3862 & 5.3325 & TRN \\
\hline CHEMBL1464656 & 688239 & 4.8862 & 5.4362 & TRN \\
\hline CHEMBL1387162 & 688239 & 5.5362 & 5.3804 & TRN \\
\hline CHEMBL1327953 & 688239 & 5.1862 & 5.5526 & TST \\
\hline CHEMBL1543176 & 688239 & 6.8861 & 5.6034 & TST \\
\hline
\end{tabular}


Supplemental Table S2.txt

\begin{tabular}{|c|c|c|c|c|c|}
\hline CHEMBL1377729 & 688239 & 5.7862 & 5.5552 & TST & \\
\hline CHEMBL1600622 & 688239 & 5.0862 & 5.5547 & TST & \\
\hline CHEMBL 2003086 & 688239 & 4.5362 & 5.5281 & TRN & \\
\hline CHEMBL1386673 & 688239 & 6.1862 & 5.3568 & TRN & \\
\hline CHEMBL1448598 & 688239 & 5.8862 & 5.4214 & TST & \\
\hline CHEMBL1482395 & 688239 & 4.7362 & 5.5133 & TRN & \\
\hline CHEMBL 3213144 & 688239 & 6.6861 & 5.3962 & TRN & \\
\hline CHEMBL1479354 & 688239 & 4.5362 & 5.5028 & TRN & \\
\hline CHEMBL1411785 & 688239 & 4.6362 & 5.4655 & TRN & \\
\hline CHEMBL1484047 & 688239 & 4.7362 & 5.518 & TRN & \\
\hline CHEMBL1349702 & 688239 & 6.0362 & 5.4929 & TST & \\
\hline CHEMBL1548648 & 688239 & 4.7362 & 5.4581 & TRN & \\
\hline CHEMBL1581343 & 688239 & 6.9363 & 5.3959 & TST & \\
\hline CHEMBL1504394 & 688239 & 5.2362 & 5.6429 & TST & \\
\hline CHEMBL1601395 & 688239 & 6.6362 & 5.3895 & TRN & \\
\hline CHEMBL1506514 & 688239 & 5.9362 & 5.5169 & TST & \\
\hline CHEMBL1373760 & 688239 & 5.1862 & 5.5446 & TRN & \\
\hline CHEMBL1483268 & 688239 & 4.5362 & 5.5455 & TST & \\
\hline CHEMBL1339584 & 688239 & 6.1862 & 5.457999 & 9999999999 & TRN \\
\hline CHEMBL 3189251 & 688239 & 4.8862 & 5.5388 & TST & \\
\hline CHEMBL1583460 & 688239 & 5.1862 & 5.5644 & TRN & \\
\hline CHEMBL1437839 & 688239 & 7.4365 & 5.6596 & TRN & \\
\hline CHEMBL1598936 & 688239 & 4.6362 & 5.6986 & TRN & \\
\hline CHEMBL1372312 & 688239 & 5.1862 & 5.5202 & TRN & \\
\hline CHEMBL1588697 & 688239 & 4.4862 & 5.3663 & TST & \\
\hline CHEMBL1555070 & 688239 & 5.2362 & 5.5553 & TRN & \\
\hline CHEMBL1304677 & 688239 & 5.6862 & 5.557 & TRN & \\
\hline CHEMBL1341738 & 688239 & 6.1362 & 5.5191 & TRN & \\
\hline CHEMBL1349860 & 688239 & 4.5862 & 5.5585 & TRN & \\
\hline CHEMBL1303349 & 688239 & 6.8861 & 5.5154 & TRN & \\
\hline CHEMBL3207586 & 688239 & 5.2862 & 5.4451 & TRN & \\
\hline CHEMBL1578879 & 688239 & 5.3862 & 5.4117 & TRN & \\
\hline CHEMBL1559013 & 688239 & 6.5363 & 5.5273 & TRN & \\
\hline CHEMBL1421429 & 688239 & 6.4362 & 5.4893 & TRN & \\
\hline CHEMBL1350201 & 688239 & 4.7862 & 5.4405 & TRN & \\
\hline CHEMBL1507278 & 688239 & 4.7362 & 5.5416 & TRN & \\
\hline CHEMBL1453380 & 688239 & 4.7362 & 5.4471 & TRN & \\
\hline CHEMBL1483686 & 688239 & 4.4862 & 5.4218 & TRN & \\
\hline CHEMBL1454576 & 688239 & 4.9362 & 5.3521 & TRN & \\
\hline CHEMBL1366527 & 688239 & 5.7862 & 5.4323 & TRN & \\
\hline CHEMBL1504124 & 688239 & 5.8862 & 5.532999 & 99999999995 & TST \\
\hline CHEMBL1362053 & 688239 & 4.5362 & 5.4996 & TRN & \\
\hline CHEMBL1407448 & 688239 & 4.5362 & 5.4909 & TRN & \\
\hline CHEMBL1353834 & 688239 & 4.5362 & 5.5232 & TRN & \\
\hline CHEMBL1326895 & 688239 & 5.6862 & 5.5954 & TST & \\
\hline CHEMBL1552912 & 688239 & 5.7362 & 5.4195 & TRN & \\
\hline CHEMBL1599557 & 688239 & 4.5362 & 5.5476 & TST & \\
\hline CHEMBL 2006503 & 688239 & 4.4862 & 5.2568 & TRN & \\
\hline
\end{tabular}


Supplemental Table S2.txt

\begin{tabular}{|c|c|c|c|c|}
\hline & & & & \\
\hline AEMBL1 & 8239 & 7862 & & \\
\hline IEMBL1353476 & 8239 & 862 & 5339 & \\
\hline AEMBL1335241 & 239 & 862 & 64 & \\
\hline & 239 & 862 & & \\
\hline IFMBI 16 & 239 & 862 & 58 & \\
\hline AEMBL3213442 & 88239 & 362 & 5067 & \\
\hline AEMBL1315550 & 88239 & 862 & 5099 & \\
\hline AEMBL1388790 & 239 & 862 & & \\
\hline IEMBL136 & 239 & 362 & & \\
\hline AEMBL1462829 & & & & \\
\hline AEMBL1390488 & 588239 & 862 & 732 & \\
\hline AEMBL1525066 & 239 & 362 & & \\
\hline IEMBL14 & & 862 & & \\
\hline IEMBL14 & & 62 & & \\
\hline AEMBL 321 & & & & \\
\hline AEMBL1354653 & 239 & 362 & 629 & \\
\hline AEMBL1460126 & & 362 & & \\
\hline IEMBL16 & & 62 & & \\
\hline IEMBL15€ & & & & \\
\hline AEMBL 158 & & 62 & 25 & $\sigma_{-1}$ \\
\hline HEMBL2000592 & & 362 & 839 & ST \\
\hline IEMBL1352034 & & & & ST \\
\hline EMBL4C & & & & SI \\
\hline EMBL16 & & & & $\mathrm{RN}$ \\
\hline IFMRI 16 & & 62 & & RN \\
\hline AEMBL132 & & & & ST \\
\hline HEMBL 148 & & & & ST \\
\hline AEMBL13835 & & & & ST \\
\hline HEMBL13 & & & & ST \\
\hline$L 5$ & & 62 & & $\mathrm{RN}$ \\
\hline HEMBL145 & & & & RN \\
\hline AEMBL1416504 & & & & RI \\
\hline AEMBL158 & & & & RI \\
\hline 395 & & & & $\cdots$ \\
\hline 39 & & & & W. \\
\hline AEMBL1307323 & & & & RN \\
\hline AEMBL1571157 & & & & $\mathrm{R}$ \\
\hline IEMBL 321 & & & & RI \\
\hline HEMBL146 & & & 74 & \\
\hline & & & & RN \\
\hline AEMBL1380545 & & 362 & 914 & $\mathrm{R}$ \\
\hline IEMBL1543440 & & & & $T R$ \\
\hline EMBL133 & & & & TS \\
\hline CHEMBL1531044 & & & & \\
\hline CHEMBL1375968 & & & 709 & RN \\
\hline AEMBL1603402 & 8239 & 5.5862 & 5.6557 & $\mathrm{TR}$ \\
\hline HFMRI 1578263 & 688239 & 6.2362 & 5.4826 & \\
\hline
\end{tabular}

Page 1294 
Supplemental Table S2.txt

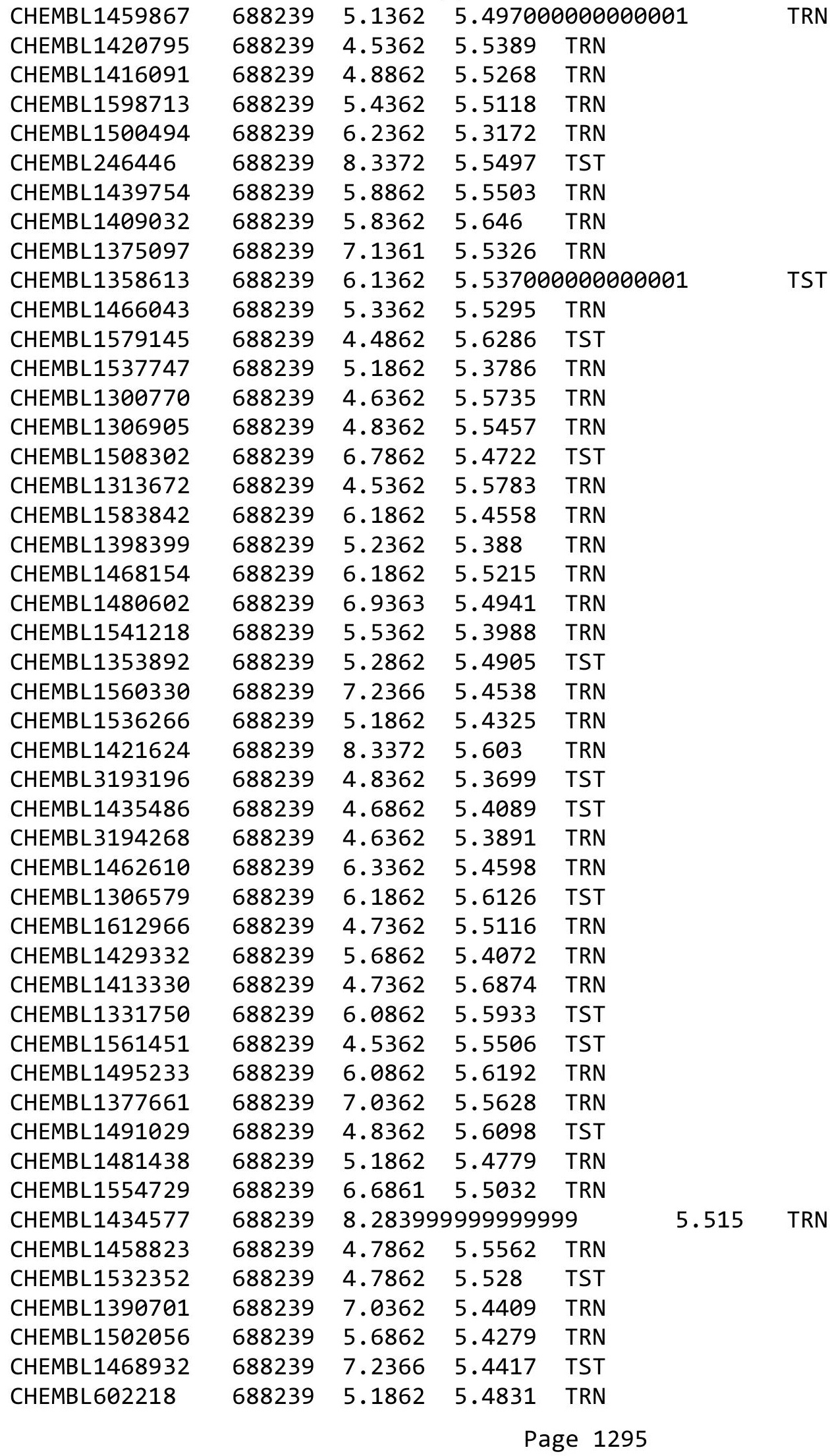


Supplemental Table S2.txt

\begin{tabular}{|c|c|c|c|c|}
\hline CHEMBL1366992 & 688239 & 4.7362 & 5.3025 & TST \\
\hline CHEMBL1978901 & 688239 & 4.5362 & 5.3748 & TRN \\
\hline CHEMBL1577158 & 688239 & 5.0862 & 5.4814 & TST \\
\hline CHEMBL1524465 & 688239 & 4.5362 & 5.3887 & TRN \\
\hline CHEMBL1517452 & 688239 & 7.1864 & 5.4677 & TST \\
\hline CHEMBL1300519 & 688239 & 4.5362 & 5.5523 & TRN \\
\hline CHEMBL1310050 & 688239 & 6.9363 & 5.4521 & TST \\
\hline CHEMBL3210490 & 688239 & 6.2862 & 5.5241 & TRN \\
\hline CHEMBL1376735 & 688239 & 4.5362 & 5.5704 & TRN \\
\hline CHEMBL1437116 & 688239 & 6.1862 & 5.5167 & TRN \\
\hline CHEMBL1321661 & 688239 & 6.3863 & 5.3649 & TRN \\
\hline CHEMBL1369708 & 688239 & 4.5862 & 5.4328 & TRN \\
\hline CHEMBL1515561 & 688239 & 6.0862 & 5.3837 & TRN \\
\hline CHEMBL1586769 & 688239 & 5.4362 & 5.4932 & TRN \\
\hline CHEMBL1354927 & 688239 & 4.5362 & 5.3261 & TST \\
\hline CHEMBL1354712 & 688239 & 4.6362 & 5.3023 & TST \\
\hline CHEMBL1580961 & 688239 & 4.5362 & 5.5585 & TRN \\
\hline CHEMBL1078441 & 688239 & 4.5362 & 5.3869 & TST \\
\hline CHEMBL1607853 & 688239 & 4.5362 & 5.6125 & TRN \\
\hline CHEMBL1396871 & 688239 & 5.7862 & 5.4889 & TRN \\
\hline CHEMBL1405134 & 688239 & 5.1862 & 5.4869 & TRN \\
\hline CHEMBL1584306 & 688239 & 6.9863 & 5.5744 & TST \\
\hline CHEMBL1335266 & 688239 & 5.9362 & 5.4579 & TRN \\
\hline CHEMBL1608141 & 688239 & 6.2862 & 5.6483 & TRN \\
\hline CHEMBL1549606 & 688239 & 5.3862 & 5.3582 & TRN \\
\hline CHEMBL1345626 & 688239 & 4.7862 & 5.4028 & TRN \\
\hline CHEMBL1376639 & 688239 & 5.3862 & 5.3585 & TST \\
\hline CHEMBL1420584 & 688239 & 6.0362 & 5.6384 & TRN \\
\hline CHEMBL1530705 & 688239 & 5.1862 & 5.4524 & TRN \\
\hline CHEMBL1543165 & 688239 & 4.5362 & 5.6651 & TRN \\
\hline CHEMBL1374330 & 688239 & 4.9862 & 5.535 & TRN \\
\hline CHEMBL1466751 & 688239 & 4.9862 & 5.4026 & TRN \\
\hline CHEMBL1518795 & 688239 & 5.7862 & 5.4955 & TRN \\
\hline CHEMBL1299557 & 688239 & 4.5362 & 5.4589 & TRN \\
\hline CHEMBL1313003 & 688239 & 4.5362 & 5.4593 & TRN \\
\hline CHEMBL1474083 & 688239 & 4.5362 & 5.5003 & TRN \\
\hline CHEMBL1586748 & 688239 & 5.4862 & 5.5416 & TRN \\
\hline CHEMBL1582911 & 688239 & 5.1862 & 5.4905 & TST \\
\hline CHEMBL1413929 & 688239 & 5.1862 & 5.46299 & 9999999999 \\
\hline CHEMBL3195279 & 688239 & 6.9363 & 5.6073 & TRN \\
\hline CHEMBL1602291 & 688239 & 4.7862 & 5.5217 & TRN \\
\hline CHEMBL1501093 & 688239 & 6.1362 & 5.4338 & TST \\
\hline CHEMBL1546100 & 688239 & 4.4862 & 5.6294 & TRN \\
\hline CHEMBL1536811 & 688239 & 4.7862 & 5.6573 & TST \\
\hline CHEMBL1303615 & 688239 & 6.2362 & 5.5831 & TST \\
\hline CHEMBL1444303 & 688239 & 6.8362 & 5.5033 & TST \\
\hline CHEMBL1520013 & 688239 & 8.3372 & 5.50899 & 99999999995 \\
\hline CHEMBL1538762 & 688239 & 8.2366 & 5.4489 & TRN \\
\hline
\end{tabular}


Supplemental Table S2.txt

\begin{tabular}{|c|c|c|c|c|c|}
\hline CHEMBL1441077 & 688239 & 5.4862 & 5.5748 & TRN & \\
\hline CHEMBL1490771 & 688239 & 5.5862 & 5.7169 & TRN & \\
\hline CHEMBL1583575 & 688239 & 5.9362 & 5.5585 & TST & \\
\hline CHEMBL1431493 & 688239 & 4.4862 & 5.4521 & TRN & \\
\hline CHEMBL1482945 & 688239 & 5.1862 & 5.6014 & TST & \\
\hline CHEMBL1508760 & 688239 & 4.7862 & 5.5272 & TST & \\
\hline CHEMBL1612911 & 688239 & 6.0362 & 5.391 & TST & \\
\hline CHEMBL3189853 & 688239 & 4.5362 & 5.3789 & TRN & \\
\hline CHEMBL1520350 & 688239 & 4.7862 & 5.4949 & TRN & \\
\hline CHEMBL1447988 & 688239 & 6.7361 & 5.3523 & TRN & \\
\hline CHEMBL1389517 & 688239 & 5.8862 & 5.4789 & TRN & \\
\hline CHEMBL1399987 & 688239 & 6.1362 & 5.449 & TRN & \\
\hline CHEMBL3209013 & 688239 & 6.9863 & 5.3829 & TRN & \\
\hline CHEMBL1530804 & 688239 & 4.9862 & 5.4478 & TRN & \\
\hline CHEMBL1453455 & 688239 & 4.5362 & 5.3047 & TRN & \\
\hline CHEMBL1479285 & 688239 & 4.7362 & 5.4994 & TRN & \\
\hline CHEMBL1409815 & 688239 & 4.6362 & 5.4803 & TRN & \\
\hline CHEMBL1448798 & 688239 & 6.4862 & 5.3981 & TST & \\
\hline CHEMBL1493561 & 688239 & 4.5362 & 5.4914 & TST & \\
\hline CHEMBL1518546 & 688239 & 5.5862 & 5.4684 & TST & \\
\hline CHEMBL1554949 & 688239 & 6.3362 & 5.4375 & TST & \\
\hline CHEMBL1476363 & 688239 & 5.1862 & 5.58700 & 2000000001 & TRN \\
\hline CHEMBL1610528 & 688239 & 6.8861 & 5.5317 & TRN & \\
\hline CHEMBL1598323 & 688239 & 5.0362 & 5.4518 & TST & \\
\hline CHEMBL1559764 & 688239 & 4.4862 & 5.4068 & TST & \\
\hline CHEMBL1467657 & 688239 & 6.5862 & 5.6407 & TST & \\
\hline CHEMBL1316990 & 688239 & 4.8862 & 5.5059 & TRN & \\
\hline CHEMBL1337100 & 688239 & 5.7362 & 5.5411 & TST & \\
\hline CHEMBL1457466 & 688239 & 7.0362 & 5.5225 & TRN & \\
\hline CHEMBL1546181 & 688239 & 4.4862 & 5.5448 & TRN & \\
\hline CHEMBL1431172 & 688239 & 5.3862 & 5.5156 & TRN & \\
\hline CHEMBL1429007 & 688239 & 5.2362 & 5.3122 & TRN & \\
\hline CHEMBL1390128 & 688239 & 4.4862 & 5.5648 & TRN & \\
\hline CHEMBL1612645 & 688239 & 4.6362 & 5.4462 & TRN & \\
\hline CHEMBL1452832 & 688239 & 5.7862 & 5.5169 & TRN & \\
\hline CHEMBL1526338 & 688239 & 5.1862 & 5.5507 & TRN & \\
\hline CHEMBL1590068 & 688239 & 6.6362 & 5.4478 & TRN & \\
\hline CHEMBL1495498 & 688239 & 8.3372 & 5.4859 & TST & \\
\hline CHEMBL3210051 & 688239 & 4.5362 & 5.2635 & TRN & \\
\hline CHEMBL1326435 & 688239 & 6.4362 & 5.4279 & TST & \\
\hline CHEMBL1589467 & 688239 & 4.5362 & 5.5101 & TRN & \\
\hline CHEMBL1458138 & 688239 & 5.5362 & 5.5489 & TRN & \\
\hline CHEMBL1376484 & 688239 & 4.5362 & 5.5052 & TST & \\
\hline CHEMBL1397812 & 688239 & 4.5362 & 5.4604 & TRN & \\
\hline CHEMBL1402441 & 688239 & 5.2862 & 5.5212 & TRN & \\
\hline CHEMBL 1500739 & 688239 & 4.6862 & 5.598 & TRN & \\
\hline CHEMBL1414094 & 688239 & 8.3372 & 5.325 & TRN & \\
\hline CHEMBL1525050 & 688239 & 4.7862 & 5.5415 & TST & \\
\hline
\end{tabular}


Supplemental Table S2.txt

\begin{tabular}{|c|c|c|c|c|c|}
\hline CHEMBL1346293 & 688239 & 6.1362 & 5.6 & TRN & \\
\hline CHEMBL1490864 & 688239 & 5.0362 & 5.496 & TRN & \\
\hline CHEMBL1477126 & 688239 & 6.9363 & 5.492999 & 999999999 & TRN \\
\hline CHEMBL3195919 & 688239 & 4.7362 & 5.3721 & TRN & \\
\hline CHEMBL1330994 & 688239 & 6.2362 & 5.4638 & TRN & \\
\hline CHEMBL1607479 & 688239 & 4.7362 & 5.6149 & TRN & \\
\hline CHEMBL1589246 & 688239 & 6.9863 & 5.6229 & TRN & \\
\hline CHEMBL1520600 & 688239 & 5.7862 & 5.5321 & TST & \\
\hline CHEMBL1421795 & 688239 & 4.5362 & 5.4256 & TRN & \\
\hline CHEMBL1591509 & 688239 & 4.8362 & 5.4571 & TRN & \\
\hline CHEMBL3213933 & 688239 & 6.1862 & 5.4239 & TRN & \\
\hline CHEMBL1550829 & 688239 & 6.2362 & 5.5516 & TRN & \\
\hline CHEMBL1347377 & 688239 & 5.1362 & 5.5393 & TST & \\
\hline CHEMBL3195266 & 688239 & 5.6362 & 5.5955 & TST & \\
\hline CHEMBL1386403 & 688239 & 4.9362 & 5.4886 & TRN & \\
\hline CHEMBL1459805 & 688239 & 5.5362 & 5.4965 & TST & \\
\hline CHEMBL1511913 & 688239 & 4.7862 & 5.5198 & TST & \\
\hline CHEMBL1503717 & 688239 & 8.2366 & 5.4958 & TRN & \\
\hline CHEMBL1390048 & 688239 & 4.6862 & 5.5271 & TRN & \\
\hline CHEMBL1601295 & 688239 & 5.8862 & 5.5494 & TRN & \\
\hline CHEMBL1345596 & 688239 & 6.2362 & 5.4166 & TRN & \\
\hline CHEMBL1449719 & 688239 & 5.1862 & 5.4174 & TST & \\
\hline CHEMBL1994211 & 688239 & 4.6862 & 5.404 & TRN & \\
\hline CHEMBL1536780 & 688239 & 5.0362 & 5.3689 & TRN & \\
\hline CHEMBL1590180 & 688239 & 5.1862 & 5.5365 & TRN & \\
\hline CHEMBL1538783 & 688239 & 5.2862 & 5.5177 & TST & \\
\hline CHEMBL1405434 & 688239 & 4.7362 & 5.4838 & TRN & \\
\hline CHEMBL1348905 & 688239 & 7.1361 & 5.605 & TRN & \\
\hline CHEMBL1477560 & 688239 & 8.3872 & 5.6193 & TRN & \\
\hline CHEMBL1347277 & 688239 & 4.6362 & 5.539 & TRN & \\
\hline CHEMBL1519569 & 688239 & 8.3372 & 5.51 & TRN & \\
\hline CHEMBL1461291 & 688239 & 4.5362 & 5.6248 & TST & \\
\hline CHEMBL1387710 & 688239 & 4.7862 & 5.3108 & TST & \\
\hline CHEMBL3189869 & 688239 & 6.7361 & 5.4078 & TST & \\
\hline CHEMBL1343977 & 688239 & 5.1862 & 5.4087 & TST & \\
\hline CHEMBL1611092 & 688239 & 4.5362 & 5.4113 & TST & \\
\hline CHEMBL1481854 & 688239 & 5.7862 & 5.345 & TRN & \\
\hline CHEMBL1526236 & 688239 & 4.7362 & 5.4845 & TRN & \\
\hline CHEMBL1558712 & 688239 & 4.9362 & 5.6292 & TRN & \\
\hline CHEMBL1372645 & 688239 & 4.5362 & 5.4418 & TRN & \\
\hline CHEMBL1540909 & 688239 & 5.8362 & 5.547999 & 999999999 & TRN \\
\hline CHEMBL1604990 & 688239 & 4.8362 & 5.4094 & TRN & \\
\hline CHEMBL3194635 & 688239 & 4.5362 & 5.3929 & TRN & \\
\hline CHEMBL1603023 & 688239 & 4.5362 & 5.4686 & TRN & \\
\hline CHEMBL1357772 & 688239 & 6.0862 & 5.5227 & TST & \\
\hline CHEMBL1458434 & 688239 & 4.7362 & 5.3873 & TRN & \\
\hline CHEMBL1542582 & 688239 & 6.1362 & 5.2872 & TST & \\
\hline CHEMBL1548442 & 688239 & 6.8861 & 5.4971 & TRN & \\
\hline
\end{tabular}


Supplemental Table S2.txt

\begin{tabular}{|c|c|c|c|c|c|}
\hline CHEMBL1430000 & 688239 & 5.7862 & 5.5906 & TRN & \\
\hline CHEMBL3208725 & 688239 & 4.5362 & 5.4866 & TRN & \\
\hline CHEMBL1492628 & 688239 & 6.2862 & 5.3077 & TST & \\
\hline CHEMBL1506014 & 688239 & 5.1862 & 5.5932 & TRN & \\
\hline CHEMBL1578779 & 688239 & 4.5362 & 5.4971 & TRN & \\
\hline CHEMBL1612917 & 688239 & 4.5362 & 5.5193 & TRN & \\
\hline CHEMBL1371599 & 688239 & 6.7361 & 5.5786 & TRN & \\
\hline CHEMBL197131 & 688239 & 4.7362 & 5.3938 & TRN & \\
\hline CHEMBL1432316 & 688239 & 5.3362 & 5.5426 & TRN & \\
\hline CHEMBL1558183 & 688239 & 4.5362 & 5.4294 & TRN & \\
\hline CHEMBL1335679 & 688239 & 6.4362 & 5.5114 & TRN & \\
\hline CHEMBL1371992 & 688239 & 5.0862 & 5.5566 & TRN & \\
\hline CHEMBL1387852 & 688239 & 6.1862 & 5.5473 & TRN & \\
\hline CHEMBL1491777 & 688239 & 4.5362 & 5.4321 & TST & \\
\hline CHEMBL1373469 & 688239 & 4.5362 & 5.4557 & TRN & \\
\hline CHEMBL1576778 & 688239 & 6.9863 & 5.5781 & TRN & \\
\hline CHEMBL1537084 & 688239 & 4.8362 & 5.5329 & TRN & \\
\hline CHEMBL1551441 & 688239 & 6.7862 & 5.4726 & TRN & \\
\hline CHEMBL1584516 & 688239 & 5.9362 & 5.6079 & TRN & \\
\hline CHEMBL1376012 & 688239 & 6.1362 & 5.4127 & TRN & \\
\hline CHEMBL1345708 & 688239 & 4.5362 & 5.4671 & TRN & \\
\hline CHEMBL1365274 & 688239 & 6.1862 & 5.5783 & TRN & \\
\hline CHEMBL1521406 & 688239 & 6.8362 & 5.512000 & 30000000005 & TST \\
\hline CHEMBL1564799 & 688239 & 5.6862 & 5.4871 & TRN & \\
\hline CHEMBL1469985 & 688239 & 6.0862 & 5.5036 & TRN & \\
\hline CHEMBL1517566 & 688239 & 4.5362 & 5.5824 & TST & \\
\hline CHEMBL1357028 & 688239 & 4.7862 & 5.5108 & TRN & \\
\hline CHEMBL3208533 & 688239 & 4.5362 & 5.3638 & TST & \\
\hline CHEMBL1541195 & 688239 & 5.4862 & 5.4286 & TST & \\
\hline CHEMBL1331482 & 688239 & 7.1361 & 5.6027 & TST & \\
\hline CHEMBL1311055 & 688239 & 5.2362 & 5.5192 & TRN & \\
\hline CHEMBL1313617 & 688239 & 4.5362 & 5.4528 & TST & \\
\hline CHEMBL1599228 & 688239 & 4.5362 & 5.4763 & TRN & \\
\hline CHEMBL1550473 & 688239 & 6.0862 & 5.657 & TRN & \\
\hline CHEMBL1479476 & 688239 & 6.0862 & 5.6619 & TRN & \\
\hline CHEMBL1508416 & 688239 & 4.4862 & 5.364 & TRN & \\
\hline CHEMBL1541958 & 688239 & 8.28399 & 99999999 & 5.4471 & TST \\
\hline CHEMBL1309388 & 688239 & 5.0362 & 5.5673 & TRN & \\
\hline CHEMBL1514342 & 688239 & 6.1362 & 5.4394 & TST & \\
\hline CHEMBL1325003 & 688239 & 4.5362 & 5.2732 & TRN & \\
\hline CHEMBL1538413 & 688239 & 4.6362 & 5.4671 & TRN & \\
\hline CHEMBL1422943 & 688239 & 6.1862 & 5.5154 & TST & \\
\hline CHEMBL1313000 & 688239 & 6.5363 & 5.463999 & 99999999995 & TST \\
\hline CHEMBL1582982 & 688239 & 4.5862 & 5.6026 & TST & \\
\hline CHEMBL1594286 & 688239 & 5.5362 & 5.5922 & TRN & \\
\hline CHEMBL1401510 & 688239 & 5.8362 & 5.5663 & TST & \\
\hline CHEMBL1523263 & 688239 & 6.1362 & 5.6027 & TST & \\
\hline CHEMBL1429756 & 688239 & 6.0862 & 5.6326 & TRN & \\
\hline
\end{tabular}


Supplemental Table S2.txt

\begin{tabular}{|c|c|c|c|c|}
\hline CHEMBL1457794 & 688239 & 4.5362 & 5.4424 & TST \\
\hline CHEMBL1367963 & 688239 & 5.0862 & 5.5628 & TST \\
\hline CHEMBL1534839 & 688239 & 4.5362 & 5.5392 & TST \\
\hline CHEMBL1407320 & 688239 & 4.5862 & 5.4825 & TRN \\
\hline CHEMBL1475372 & 688239 & 4.6862 & 5.3671 & TRN \\
\hline CHEMBL1445677 & 688239 & 4.7362 & 5.3637 & TRN \\
\hline CHEMBL1375785 & 688239 & 5.7362 & 5.4994 & TRN \\
\hline CHEMBL1373873 & 688239 & 5.3862 & 5.5295 & TST \\
\hline CHEMBL1406465 & 688239 & 4.7862 & 5.507006 & 0000000001 \\
\hline CHEMBL1335164 & 688239 & 4.5862 & 5.3976 & TRN \\
\hline CHEMBL1334730 & 688239 & 6.7862 & 5.4079 & TST \\
\hline CHEMBL1599330 & 688239 & 4.5362 & 5.5029 & TST \\
\hline CHEMBL1507097 & 688239 & 4.7362 & 5.5087 & TRN \\
\hline CHEMBL1480487 & 688239 & 5.4862 & 5.5156 & TRN \\
\hline CHEMBL1469835 & 688239 & 6.4362 & 5.5522 & TST \\
\hline CHEMBL1475335 & 688239 & 4.5362 & 5.5386 & TST \\
\hline CHEMBL1524454 & 688239 & 4.5362 & 5.4545 & TST \\
\hline CHEMBL1536150 & 688239 & 6.9363 & 5.3939 & TST \\
\hline CHEMBL1449746 & 688239 & 8.3372 & 5.6197 & TST \\
\hline CHEMBL1372611 & 688239 & 4.7362 & 5.4578 & TRN \\
\hline CHEMBL1553097 & 688239 & 4.4862 & 5.3833 & TRN \\
\hline CHEMBL1467401 & 688239 & 5.7362 & 5.3864 & TRN \\
\hline CHEMBL1447254 & 688239 & 4.4862 & 5.5207 & TRN \\
\hline CHEMBL1460315 & 688239 & 4.4862 & 5.3908 & TRN \\
\hline CHEMBL1437951 & 688239 & 4.6862 & 5.4149 & TRN \\
\hline CHEMBL1539381 & 688239 & 4.5362 & 5.5312 & TRN \\
\hline CHEMBL1445581 & 688239 & 6.9863 & 5.4986 & TRN \\
\hline CHEMBL1359069 & 688239 & 4.7362 & 5.4545 & TRN \\
\hline CHEMBL1582431 & 688239 & 4.7362 & 5.472 & TRN \\
\hline CHEMBL1363249 & 688239 & 4.8362 & 5.414 & TRN \\
\hline CHEMBL1582347 & 688239 & 6.8861 & 5.5489 & TRN \\
\hline CHEMBL1309619 & 688239 & 5.0362 & 5.5038 & TRN \\
\hline CHEMBL1380679 & 688239 & 6.4362 & 5.5884 & TRN \\
\hline CHEMBL1415583 & 688239 & 4.6362 & 5.5945 & TRN \\
\hline CHEMBL1534199 & 688239 & 5.3862 & 5.5211 & TRN \\
\hline CHEMBL1415839 & 688239 & 4.6362 & 5.4489 & TRN \\
\hline CHEMBL1542281 & 688239 & 4.8362 & 5.5116 & TST \\
\hline CHEMBL1467775 & 688239 & 6.1362 & 5.4932 & TRN \\
\hline CHEMBL1327749 & 688239 & 4.6362 & 5.5183 & TST \\
\hline CHEMBL1606440 & 688239 & 5.3362 & 5.4576 & TRN \\
\hline CHEMBL1533983 & 688239 & 8.3372 & 5.4332 & TST \\
\hline CHEMBL1426822 & 688239 & 4.5362 & \multicolumn{2}{|c|}{5.5120000000000005} \\
\hline CHEMBL1410225 & 688239 & 5.2862 & 5.4661 & TRN \\
\hline CHEMBL1549388 & 688239 & 4.6862 & 5.4785 & TRN \\
\hline CHEMBL 3193172 & 688239 & 4.6362 & 5.5753 & TST \\
\hline CHEMBL 3194017 & 688239 & 5.6362 & 5.4988 & TRN \\
\hline CHEMBL1459835 & 688239 & 6.8861 & 5.4387 & TST \\
\hline CHEMBL1336243 & 688239 & 7.2366 & 5.5772 & TRN \\
\hline
\end{tabular}


Supplemental Table S2.txt

\begin{tabular}{|c|c|c|c|c|}
\hline CHEMBL1403958 & 688239 & 5.9362 & 5.6566 & TRN \\
\hline CHEMBL1444619 & 688239 & 4.5362 & 5.4828 & TRN \\
\hline CHEMBL1418537 & 688239 & 4.8862 & 5.5719 & TST \\
\hline CHEMBL1426078 & 688239 & 5.1862 & 5.556 & TRN \\
\hline CHEMBL1439443 & 688239 & 5.3862 & 5.4016 & TRN \\
\hline CHEMBL1323750 & 688239 & 5.2862 & 5.7287 & TRN \\
\hline CHEMBL1415160 & 688239 & 4.5362 & 5.5559 & TRN \\
\hline CHEMBL1465836 & 688239 & 6.4862 & 5.5961 & TRN \\
\hline CHEMBL467786 & 688239 & 6.05 & 5.7501 & TRN \\
\hline CHEMBL1444293 & 688239 & 5.5862 & 5.4694 & TST \\
\hline CHEMBL1981150 & 688239 & 4.6862 & 5.3947 & TST \\
\hline CHEMBL1461806 & 688239 & 4.6362 & 5.422999 & 999999999 \\
\hline CHEMBL1577610 & 688239 & 4.7362 & 5.5597 & TRN \\
\hline CHEMBL1546067 & 688239 & 4.8862 & 5.3711 & TST \\
\hline CHEMBL1381517 & 688239 & 5.4362 & 5.4333 & TRN \\
\hline CHEMBL1531708 & 688239 & 6.8861 & 5.3489 & TRN \\
\hline CHEMBL1366644 & 688239 & 4.8862 & 5.4757 & TRN \\
\hline CHEMBL1590872 & 688239 & 4.5362 & 5.4535 & TRN \\
\hline CHEMBL1570110 & 688239 & 7.6364 & 5.4371 & TST \\
\hline CHEMBL1319729 & 688239 & 6.9863 & 5.4832 & TRN \\
\hline CHEMBL1415429 & 688239 & 5.3862 & 5.5339 & TRN \\
\hline CHEMBL1497426 & 688239 & 5.5362 & 5.371 & TRN \\
\hline CHEMBL1524972 & 688239 & 5.6362 & 5.4672 & TRN \\
\hline CHEMBL1594169 & 688239 & 6.2862 & 5.3745 & TRN \\
\hline CHEMBL1300391 & 688239 & 4.5362 & 5.2865 & TRN \\
\hline CHEMBL1299315 & 688239 & 5.3862 & 5.4418 & TST \\
\hline CHEMBL1559967 & 688239 & 4.5862 & 5.3825 & TST \\
\hline CHEMBL1461076 & 688239 & 4.6362 & $5.57100 e$ & 0000000001 \\
\hline CHEMBL1551673 & 688239 & 4.9362 & 5.5559 & TRN \\
\hline CHEMBL1531546 & 688239 & 8.2366 & 5.39 & TRN \\
\hline CHEMBL1482347 & 688239 & 7.2366 & 5.6165 & TRN \\
\hline CHEMBL95508 & 688239 & 6.7862 & 5.4755 & TRN \\
\hline CHEMBL1092472 & 688239 & 5.1862 & 5.4337 & TRN \\
\hline CHEMBL1449624 & 688239 & 4.5862 & 5.5432 & TST \\
\hline CHEMBL539027 & 688239 & 4.7362 & 5.2829 & TST \\
\hline CHEMBL1332797 & 688239 & 4.5362 & 5.53 & TRN \\
\hline CHEMBL1305097 & 688239 & 5.0362 & 5.4202 & TRN \\
\hline CHEMBL1411046 & 688239 & 4.5862 & 5.6182 & TRN \\
\hline CHEMBL1405629 & 688239 & 5.4362 & 5.5071 & TRN \\
\hline CHEMBL1347523 & 688239 & 6.8861 & 5.5103 & TRN \\
\hline CHEMBL1481099 & 688239 & 4.5362 & 5.4564 & TRN \\
\hline CHEMBL1506998 & 688239 & 4.7362 & 5.5754 & TRN \\
\hline CHEMBL1561674 & 688239 & 5.8862 & 5.4904 & TRN \\
\hline CHEMBL3192965 & 688239 & 6.2362 & 5.5196 & TRN \\
\hline CHEMBL1594639 & 688239 & 5.1862 & 5.6824 & TRN \\
\hline CHEMBL1416346 & 688239 & 4.8362 & 5.4267 & TRN \\
\hline CHEMBL1598986 & 688239 & 4.6862 & 5.4447 & TRN \\
\hline CHEMBL1359885 & 688239 & 6.8362 & 5.4979 & TRN \\
\hline
\end{tabular}


Supplemental Table S2.txt

\begin{tabular}{|c|c|c|c|c|c|}
\hline CHEMBL1453481 & 688239 & 8.1871 & 5.5243 & TRN & \\
\hline CHEMBL1385523 & 688239 & 5.1862 & 5.4541 & TRN & \\
\hline CHEMBL1568626 & 688239 & 4.7862 & 5.3886 & TRN & \\
\hline CHEMBL 2007057 & 688239 & 6.0862 & 5.4541 & TRN & \\
\hline CHEMBL3189217 & 688239 & 5.6862 & 5.4122 & TRN & \\
\hline CHEMBL1393612 & 688239 & 5.4362 & 5.4959 & TRN & \\
\hline CHEMBL1453495 & 688239 & 4.4862 & 5.5732 & TST & \\
\hline CHEMBL1414585 & 688239 & 6.2362 & 5.641 & TRN & \\
\hline CHEMBL1536065 & 688239 & 5.4362 & 5.5557 & TRN & \\
\hline CHEMBL1554393 & 688239 & 4.5362 & 5.4898 & TRN & \\
\hline CHEMBL1315694 & 688239 & 5.5362 & 5.45799 & 9999999999 & TRN \\
\hline CHEMBL1445381 & 688239 & 5.7362 & 5.49700 & 0000000001 & TRN \\
\hline CHEMBL1525884 & 688239 & 6.1362 & 5.4335 & TST & \\
\hline CHEMBL1600738 & 688239 & 6.0862 & 5.5976 & TRN & \\
\hline CHEMBL1408837 & 688239 & 5.1362 & 5.3476 & TRN & \\
\hline CHEMBL1506576 & 688239 & 4.7362 & 5.5541 & TRN & \\
\hline CHEMBL1376864 & 688239 & 6.0862 & 5.4043 & TRN & \\
\hline CHEMBL1382728 & 688239 & 6.0862 & 5.49299 & 9999999999 & TST \\
\hline CHEMBL1570172 & 688239 & 5.8862 & 5.5815 & TRN & \\
\hline CHEMBL1436863 & 688239 & 5.2862 & 5.3939 & TST & \\
\hline CHEMBL1523970 & 688239 & 4.7862 & 5.5577 & TRN & \\
\hline CHEMBL1583340 & 688239 & 5.8862 & 5.5699 & TRN & \\
\hline CHEMBL1479283 & 688239 & 5.6862 & 5.3378 & TST & \\
\hline CHEMBL1338461 & 688239 & 5.0862 & 5.5472 & TRN & \\
\hline CHEMBL1560049 & 688239 & 4.7362 & 5.5438 & TRN & \\
\hline CHEMBL1572627 & 688239 & 7.0362 & 5.4006 & TRN & \\
\hline CHEMBL1344485 & 688239 & 5.1862 & 5.4829 & TRN & \\
\hline CHEMBL1328635 & 688239 & 5.4862 & 5.5077 & TRN & \\
\hline CHEMBL1376396 & 688239 & 6.7862 & 5.4457 & TRN & \\
\hline CHEMBL1589134 & 688239 & 6.3863 & 5.3821 & TRN & \\
\hline CHEMBL3214253 & 688239 & 5.1862 & 5.3627 & TST & \\
\hline CHEMBL1554995 & 688239 & 5.3362 & 5.4226 & TRN & \\
\hline CHEMBL1475724 & 688239 & 4.5862 & 5.5274 & TRN & \\
\hline CHEMBL1534833 & 688239 & 5.9862 & 5.6388 & TRN & \\
\hline CHEMBL1435680 & 688239 & 4.6362 & 5.5894 & TRN & \\
\hline CHEMBL1528783 & 688239 & 4.5362 & 5.3069 & TRN & \\
\hline CHEMBL1538392 & 688239 & 6.1362 & 5.4247 & TRN & \\
\hline CHEMBL1480381 & 688239 & 5.6362 & 5.6661 & TRN & \\
\hline CHEMBL1369056 & 688239 & 4.7362 & 5.6232 & TRN & \\
\hline CHEMBL1523643 & 688239 & 4.5362 & 5.5557 & TRN & \\
\hline CHEMBL600940 & 688239 & 5.9362 & 5.4289 & TRN & \\
\hline CHEMBL1471052 & 688239 & 6.2362 & 5.4817 & TST & \\
\hline CHEMBL1375433 & 688239 & 4.7862 & 5.4873 & TRN & \\
\hline CHEMBL3212805 & 688239 & 4.5362 & 5.4383 & TRN & \\
\hline CHEMBL1302674 & 688239 & 6.8362 & 5.4605 & TRN & \\
\hline CHEMBL1974269 & 688239 & 5.6362 & 5.4234 & TRN & \\
\hline CHEMBL1390612 & 688239 & 5.1862 & 5.5761 & TST & \\
\hline CHEMBL3190685 & 688239 & 5.2862 & 5.5094 & TRN & \\
\hline
\end{tabular}


Supplemental Table S2.txt

\begin{tabular}{|c|c|c|c|c|}
\hline CHEMBL1525424 & 688239 & 4.6862 & 5.4412 & TRN \\
\hline CHEMBL1535126 & 688239 & 5.4362 & 5.5315 & TRN \\
\hline CHEMBL1460665 & 688239 & 5.3862 & 5.3548 & TST \\
\hline CHEMBL1527156 & 688239 & 4.5362 & 5.4688 & TRN \\
\hline CHEMBL1332795 & 688239 & 6.3362 & 5.4262 & TRN \\
\hline CHEMBL1386613 & 688239 & 4.7862 & 5.3256 & TST \\
\hline CHEMBL1308677 & 688239 & 5.5862 & 5.5595 & TST \\
\hline CHEMBL1376791 & 688239 & 5.7362 & 5.3558 & TRN \\
\hline CHEMBL1573502 & 688239 & 4.9362 & 5.5718 & TST \\
\hline CHEMBL1438683 & 688239 & 6.4362 & 5.5525 & TST \\
\hline CHEMBL1477498 & 688239 & 4.5362 & 5.4057 & TRN \\
\hline CHEMBL541974 & 688239 & 5.1862 & 5.4485 & TST \\
\hline CHEMBL1315032 & 688239 & 5.6862 & 5.5187 & TRN \\
\hline CHEMBL1544568 & 688239 & 6.1862 & 5.4322 & TRN \\
\hline CHEMBL1335227 & 688239 & 5.7862 & 5.4984 & TST \\
\hline CHEMBL1358702 & 688239 & 4.5362 & 5.4591 & TRN \\
\hline CHEMBL1580954 & 688239 & 6.1862 & 5.5485 & TRN \\
\hline CHEMBL1521023 & 688239 & 5.3362 & 5.4052 & TRN \\
\hline CHEMBL1363553 & 688239 & 5.4862 & 5.4639 & TRN \\
\hline CHEMBL1566628 & 688239 & 4.5362 & 5.5424 & TRN \\
\hline CHEMBL1475934 & 688239 & 5.6362 & 5.4919 & TRN \\
\hline CHEMBL1390719 & 688239 & 7.1864 & 5.4197 & TRN \\
\hline CHEMBL1334204 & 688239 & 6.1362 & 5.478 & TRN \\
\hline CHEMBL1554856 & 688239 & 4.9862 & 5.5146 & TRN \\
\hline CHEMBL1485116 & 688239 & 4.6862 & 5.5243 & TRN \\
\hline CHEMBL1525003 & 688239 & 5.1362 & 5.3922 & TST \\
\hline CHEMBL1438429 & 688239 & 5.1862 & 5.686 & TRN \\
\hline CHEMBL1449932 & 688239 & 4.6862 & 5.4863 & TST \\
\hline CHEMBL3196559 & 688239 & 4.9362 & 5.4408 & TRN \\
\hline CHEMBL1456146 & 688239 & 4.5362 & 5.4749 & TRN \\
\hline CHEMBL229185 & 688239 & 5.1862 & 5.4678 & TRN \\
\hline CHEMBL1481592 & 688239 & 5.1362 & 5.4602 & TRN \\
\hline CHEMBL1380831 & 688239 & 6.3362 & 5.4742 & TRN \\
\hline CHEMBL1335628 & 688239 & 5.3862 & 5.4619 & TRN \\
\hline CHEMBL1558285 & 688239 & 4.5862 & 5.4305 & TST \\
\hline CHEMBL1569672 & 688239 & 5.0362 & 5.5211 & TRN \\
\hline CHEMBL1402149 & 688239 & 5.8862 & 5.5021 & TRN \\
\hline CHEMBL1385093 & 688239 & 4.5362 & 5.4704 & TST \\
\hline CHEMBL1534490 & 688239 & 5.0362 & 5.5014 & TST \\
\hline CHEMBL1594408 & 688239 & 4.9862 & 5.5565 & TRN \\
\hline CHEMBL1609989 & 688239 & 4.8862 & 5.6823 & TRN \\
\hline CHEMBL1459388 & 688239 & 5.5862 & 5.6419 & TRN \\
\hline CHEMBL1409932 & 688239 & 5.5862 & 5.486006 & 0000000001 \\
\hline CHEMBL1454684 & 688239 & 6.6861 & 5.565 & TRN \\
\hline CHEMBL1372304 & 688239 & 4.4862 & 5.455 & TST \\
\hline CHEMBL1353643 & 688239 & 4.5362 & 5.3766 & TRN \\
\hline CHEMBL1488812 & 688239 & 4.9862 & 5.4249 & TST \\
\hline CHEMBL1323243 & 688239 & 5.0362 & 5.3572 & TRN \\
\hline
\end{tabular}


Supplemental Table S2.txt

\begin{tabular}{|c|c|c|c|c|}
\hline CHEMBL1386877 & 688239 & 4.8362 & 5.6459 & TRN \\
\hline CHEMBL1506137 & 688239 & 5.2362 & 5.574 & TST \\
\hline CHEMBL1558697 & 688239 & 5.4862 & 5.3673 & TRN \\
\hline CHEMBL1472506 & 688239 & 5.1862 & 5.4597 & TRN \\
\hline CHEMBL1372080 & 688239 & 6.3362 & 5.5225 & TRN \\
\hline CHEMBL1536258 & 688239 & 4.7862 & 5.3284 & TRN \\
\hline CHEMBL1375807 & 688239 & 5.9862 & 5.4607 & TRN \\
\hline CHEMBL1564857 & 688239 & 6.4362 & 5.5207 & TRN \\
\hline CHEMBL1458504 & 688239 & 8.3872 & 5.4651 & TRN \\
\hline CHEMBL1348256 & 688239 & 4.9362 & 5.4249 & TRN \\
\hline CHEMBL1470777 & 688239 & 5.1862 & 5.3584 & TRN \\
\hline CHEMBL1442152 & 688239 & 4.6862 & 5.5296 & TRN \\
\hline CHEMBL1363057 & 688239 & 5.3362 & 5.4408 & TRN \\
\hline CHEMBL1516592 & 688239 & 6.9863 & 5.4438 & TRN \\
\hline CHEMBL1302057 & 688239 & 6.9363 & 5.4629 & TRN \\
\hline CHEMBL 3193389 & 688239 & 5.1862 & 5.2932 & TST \\
\hline CHEMBL1438546 & 688239 & 4.9362 & 5.6115 & TRN \\
\hline CHEMBL1594734 & 688239 & 4.4862 & 5.4842 & TST \\
\hline CHEMBL1542142 & 688239 & 4.6862 & 5.4136 & TST \\
\hline CHEMBL1367661 & 688239 & 6.9363 & 5.4032 & TRN \\
\hline CHEMBL1505399 & 688239 & 6.1862 & 5.6085 & TRN \\
\hline CHEMBL1372180 & 688239 & 4.8862 & 5.5328 & TRN \\
\hline CHEMBL1299799 & 688239 & 6.5862 & 5.5144 & TST \\
\hline CHEMBL 3207865 & 688239 & 4.8362 & 5.5302 & TRN \\
\hline CHEMBL1232076 & 688239 & 4.5362 & 5.6857 & TST \\
\hline CHEMBL1487210 & 688239 & 4.7362 & 5.4966 & TRN \\
\hline CHEMBL1527863 & 688239 & 4.7862 & 5.3851 & TRN \\
\hline CHEMBL1564504 & 688239 & 6.6362 & 5.6492 & TRN \\
\hline CHEMBL1456608 & 688239 & 6.1862 & 5.5012 & TRN \\
\hline CHEMBL1516720 & 688239 & 8.3372 & 5.5253 & TRN \\
\hline CHEMBL1348867 & 688239 & 4.7362 & 5.5087 & TRN \\
\hline CHEMBL 3198091 & 688239 & 5.2362 & 5.5463 & TRN \\
\hline CHEMBL1411129 & 688239 & 5.1862 & 5.5248 & TRN \\
\hline CHEMBL1419636 & 688239 & 4.5362 & 5.5446 & TRN \\
\hline CHEMBL1539530 & 688239 & 5.1862 & 5.6942 & TRN \\
\hline CHEMBL1964735 & 688239 & 4.7362 & 5.3442 & TST \\
\hline CHEMBL1363742 & 688239 & 8.3372 & 5.598 & TRN \\
\hline CHEMBL1323091 & 688239 & 5.8362 & 5.5204 & TRN \\
\hline CHEMBL1460587 & 688239 & 4.5362 & 5.45799 & э999999999 \\
\hline CHEMBL1589640 & 688239 & 6.1862 & 5.5174 & TRN \\
\hline CHEMBL1401863 & 688239 & 5.3862 & 5.5544 & TST \\
\hline CHEMBL1440358 & 688239 & 6.5363 & 5.3853 & TRN \\
\hline CHEMBL1475906 & 688239 & 7.7352 & 5.4478 & TRN \\
\hline CHEMBL1511700 & 688239 & 5.7862 & 5.5114 & TRN \\
\hline CHEMBL1414524 & 688239 & 4.4862 & 5.459 & TRN \\
\hline CHEMBL1310133 & 688239 & 4.4862 & 5.3938 & TST \\
\hline CHEMBL1494829 & 688239 & 4.7362 & 5.5905 & TST \\
\hline CHEMBL1384427 & 688239 & 4.5362 & 5.5502 & TRN \\
\hline
\end{tabular}




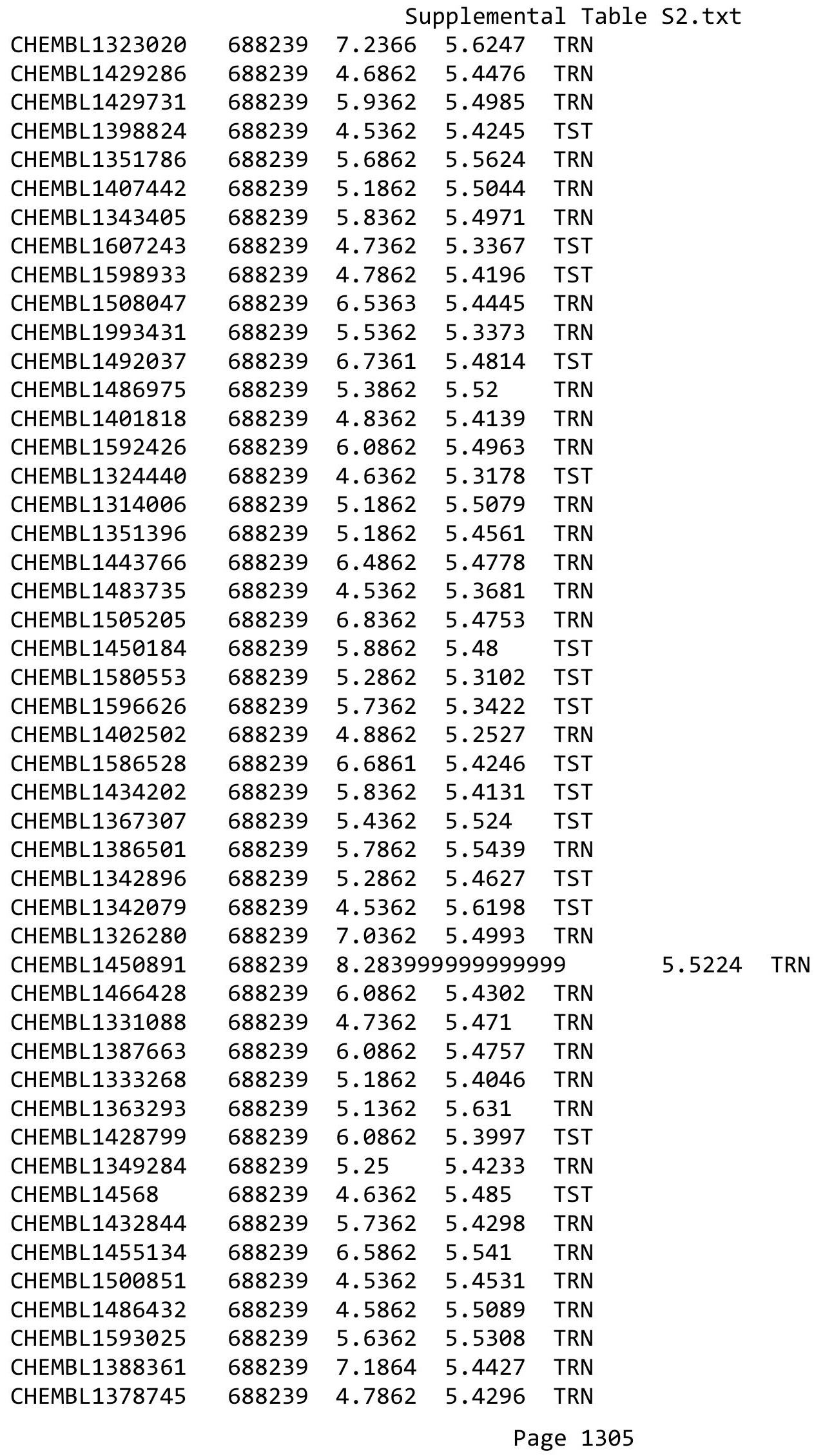


Supplemental Table S2.txt

\begin{tabular}{|c|c|c|c|c|}
\hline CHEMBL1595543 & 688239 & 4.4862 & 5.5768 & TRN \\
\hline CHEMBL1490569 & 688239 & 6.2362 & 5.3081 & TST \\
\hline CHEMBL1353121 & 688239 & 5.6862 & 5.4596 & TRN \\
\hline CHEMBL1335422 & 688239 & 8.1871 & 5.4462 & TRN \\
\hline CHEMBL1549645 & 688239 & 5.7862 & 5.4529 & TST \\
\hline CHEMBL1383200 & 688239 & 6.7361 & 5.3732 & TST \\
\hline CHEMBL1333422 & 688239 & 4.5862 & 5.4734 & TST \\
\hline CHEMBL1340716 & 688239 & 6.7361 & 5.4629 & TRN \\
\hline CHEMBL1383015 & 688239 & 5.0362 & 5.4203 & TRN \\
\hline CHEMBL1576350 & 688239 & 6.7862 & 5.5741 & TRN \\
\hline CHEMBL1326859 & 688239 & 4.7862 & 5.4841 & TRN \\
\hline CHEMBL1480865 & 688239 & 5.2362 & 5.7087 & TRN \\
\hline CHEMBL1351630 & 688239 & 6.1362 & 5.6623 & TRN \\
\hline CHEMBL1583916 & 688239 & 4.5362 & 5.5055 & TRN \\
\hline CHEMBL1508397 & 688239 & 5.1862 & 5.5048 & TRN \\
\hline CHEMBL1369042 & 688239 & 4.5362 & 5.5917 & TRN \\
\hline CHEMBL1566406 & 688239 & 5.1862 & 5.5324 & TRN \\
\hline CHEMBL1352024 & 688239 & 6.9363 & 5.4379 & TST \\
\hline CHEMBL1567616 & 688239 & 4.6362 & 5.6242 & TRN \\
\hline CHEMBL1329134 & 688239 & 4.5362 & 5.6842 & TRN \\
\hline CHEMBL1317651 & 688239 & 4.8362 & 5.5153 & TRN \\
\hline CHEMBL1576217 & 688239 & 5.6362 & 5.4317 & TST \\
\hline CHEMBL1441171 & 688239 & 5.1862 & 5.5112 & TST \\
\hline CHEMBL1334350 & 688239 & 7.0362 & 5.3809 & TRN \\
\hline CHEMBL1429951 & 688239 & 4.8862 & 5.4715 & TST \\
\hline CHEMBL1316421 & 688239 & 5.7862 & 5.402 & TRN \\
\hline CHEMBL1466190 & 688239 & 6.6861 & 5.5398 & TRN \\
\hline CHEMBL1478411 & 688239 & 4.5862 & 5.44600 & 0000000001 \\
\hline CHEMBL1309059 & 688239 & 5.2362 & 5.3062 & TRN \\
\hline CHEMBL1340337 & 688239 & 6.9363 & 5.4981 & TRN \\
\hline CHEMBL1367723 & 688239 & 6.1862 & 5.6208 & TRN \\
\hline CHEMBL 3208557 & 688239 & 4.6862 & 5.4742 & TST \\
\hline CHEMBL1575534 & 688239 & 5.0362 & 5.6502 & TRN \\
\hline CHEMBL1469691 & 688239 & 4.4862 & 5.4784 & TRN \\
\hline CHEMBL1562586 & 688239 & 7.0362 & 5.4179 & TST \\
\hline CHEMBL1434524 & 688239 & 6.2362 & 5.5177 & TRN \\
\hline CHEMBL1310545 & 688239 & 6.6861 & 5.4818 & TRN \\
\hline CHEMBL3211365 & 688239 & 5.8862 & 5.6317 & TRN \\
\hline CHEMBL1301945 & 688239 & 5.4362 & 5.4218 & TRN \\
\hline CHEMBL1574198 & 688239 & 6.4362 & 5.5484 & TRN \\
\hline CHEMBL1430594 & 688239 & 6.2362 & 5.5172 & TST \\
\hline CHEMBL1345419 & 688239 & 8.1871 & 5.5106 & TRN \\
\hline CHEMBL3197729 & 688239 & 6.2362 & 5.4787 & TRN \\
\hline CHEMBL1532433 & 688239 & 6.9863 & 5.4664 & TST \\
\hline CHEMBL1364703 & 688239 & 5.9362 & 5.4403 & TRN \\
\hline CHEMBL1501501 & 688239 & 8.3372 & 5.5327 & TST \\
\hline CHEMBL1358204 & 688239 & 7.0362 & 5.5335 & TRN \\
\hline CHEMBL1486402 & 688239 & 4.6862 & 5.5975 & TRN \\
\hline
\end{tabular}

Page 1306 
Supplemental Table S2.txt

\begin{tabular}{|c|c|c|c|c|}
\hline 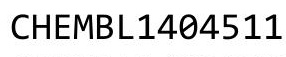 & & & & \\
\hline HEMBL1499036 & 88239 & 862 & & \\
\hline HEMBL1453524 & 88239 & 362 & & \\
\hline 08 & & & & \\
\hline EMBL14 & & & 571 & \\
\hline HEMBL1373096 & 88239 & 5862 & 3826 & \\
\hline HEMBL1361352 & 88239 & .0362 & 4605 & \\
\hline HEMBL1304924 & & & & \\
\hline IEMBL1508400 & 39 & & & \\
\hline IEMBL400374 & 39 & & & \\
\hline HEMBL1539724 & 88239 & 362 & 182 & \\
\hline HEMBL1552592 & 39 & 62 & 4245 & \\
\hline HEMBL1568241 & 39 & & 52 & \\
\hline 389212 & 39 & & & \\
\hline HEMBL1394556 & 39 & & & \\
\hline AEMBL1173694 & 39 & & 36 & \\
\hline HEMBL1450970 & 39 & & & \\
\hline HEMBL1468617 & 9 & & 336 & \\
\hline HEMBL1387215 & 9 & & & \\
\hline HEMBL591006 & 39 & & & \\
\hline HEMBL3195790 & 39 & & & \\
\hline HEMBL1300645 & 39 & & & \\
\hline HEMBL1483836 & 39 & & 68 & ו \\
\hline HEMBL1472798 & & & & RN \\
\hline 600540 & 39 & & & RN \\
\hline AEMBL1451145 & 39 & & & 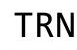 \\
\hline AEMBL1412759 & 39 & & & I RN \\
\hline HEMBL3199246 & 9 & & & RN \\
\hline 1334816 & & & & RN \\
\hline 721 & & 52 & 81 & ST \\
\hline HEMBL1413834 & 9 & & & RN \\
\hline HEMBL1567462 & 39 & & 27 & TRN \\
\hline HEMBL15 & & & & \\
\hline HEM & 9 & & & \\
\hline HEMBL1311190 & & & & RN \\
\hline HEMBL1409402 & 39 & & & IST \\
\hline HEMBL1398710 & 39 & & 235 & ГRN \\
\hline 1326262 & 39 & 52 & 51 & \\
\hline HEMBL1608140 & 9 & & & \\
\hline HEMBL1375116 & & & & $\mathrm{RN}$ \\
\hline HEMBL1379264 & 39 & 62 & 105 & TRN \\
\hline HEMBL1563259 & 39 & & 355 & RN \\
\hline 1442 & 39 & & 5.3893 & \\
\hline HEMBL1320480 & 39 & & & RIN \\
\hline HEMBL1417009 & & & .5732 & $\mathrm{RN}$ \\
\hline HEMBL1431482 & 88 & 62 & 5.6567 & \\
\hline L15558 & & & & \\
\hline HFMRI 135958 & & & & \\
\hline
\end{tabular}

Page 1307 
Supplemental Table S2.txt

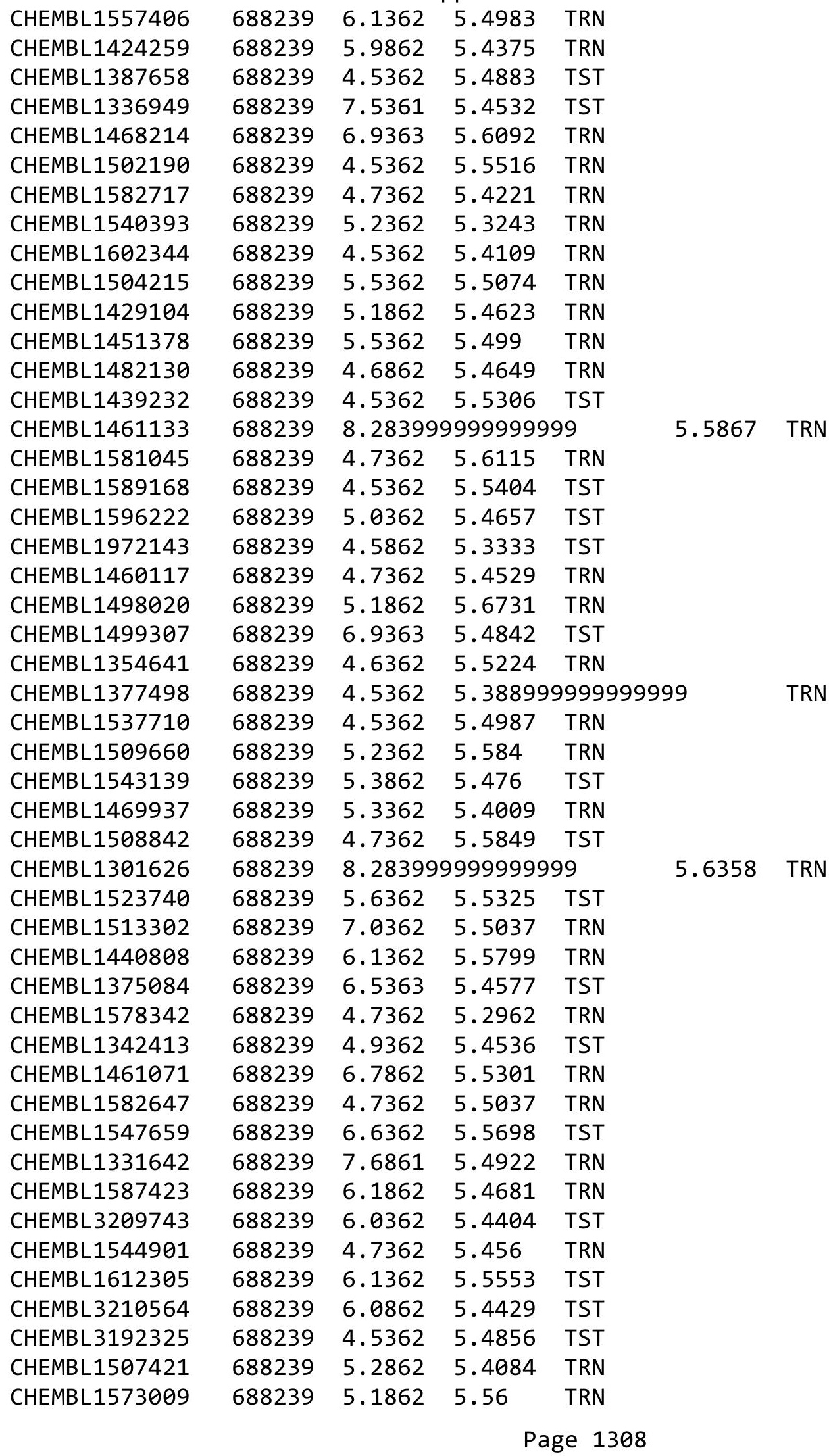


Supplemental Table S2.txt

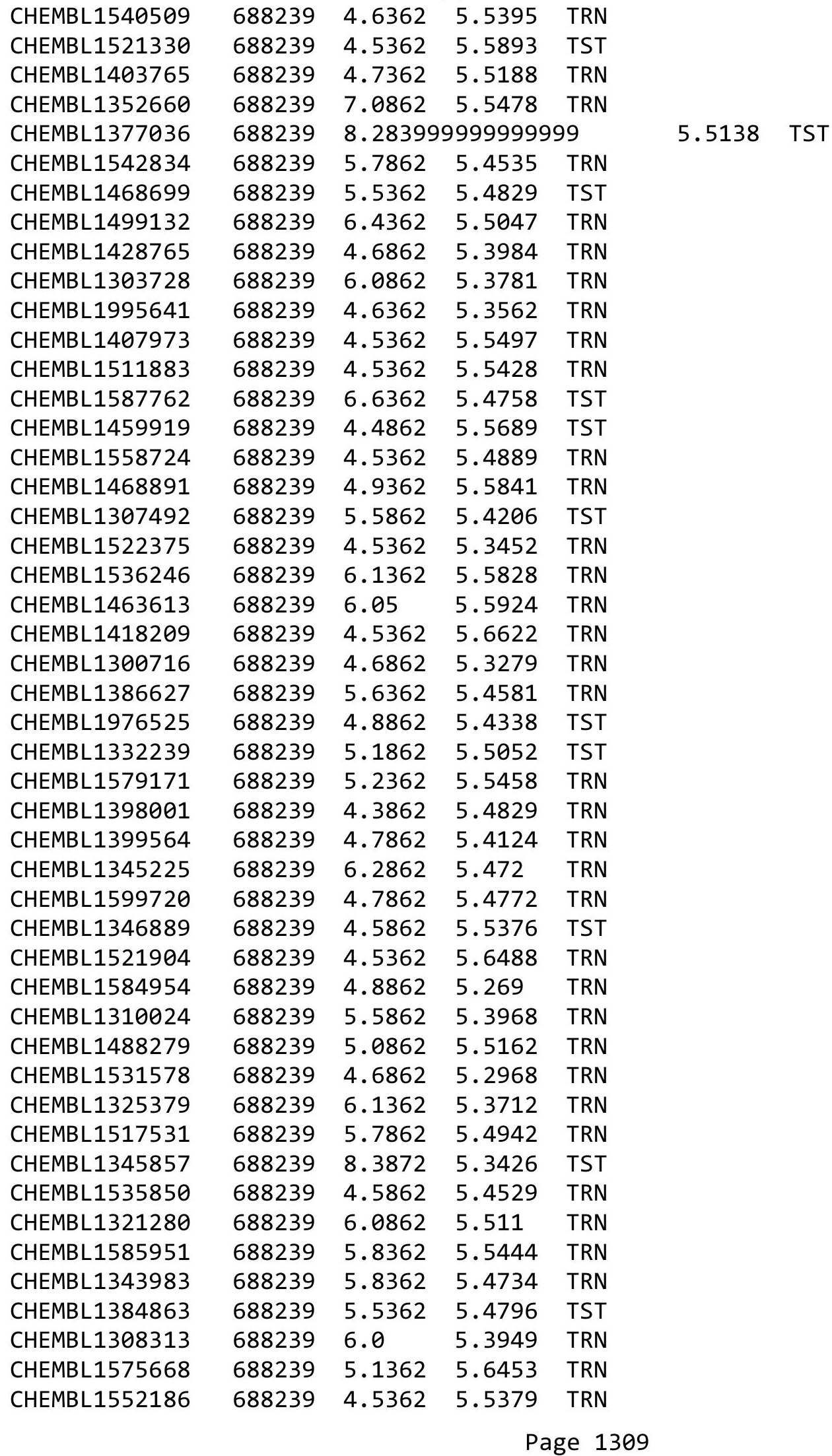


Supplemental Table S2.txt

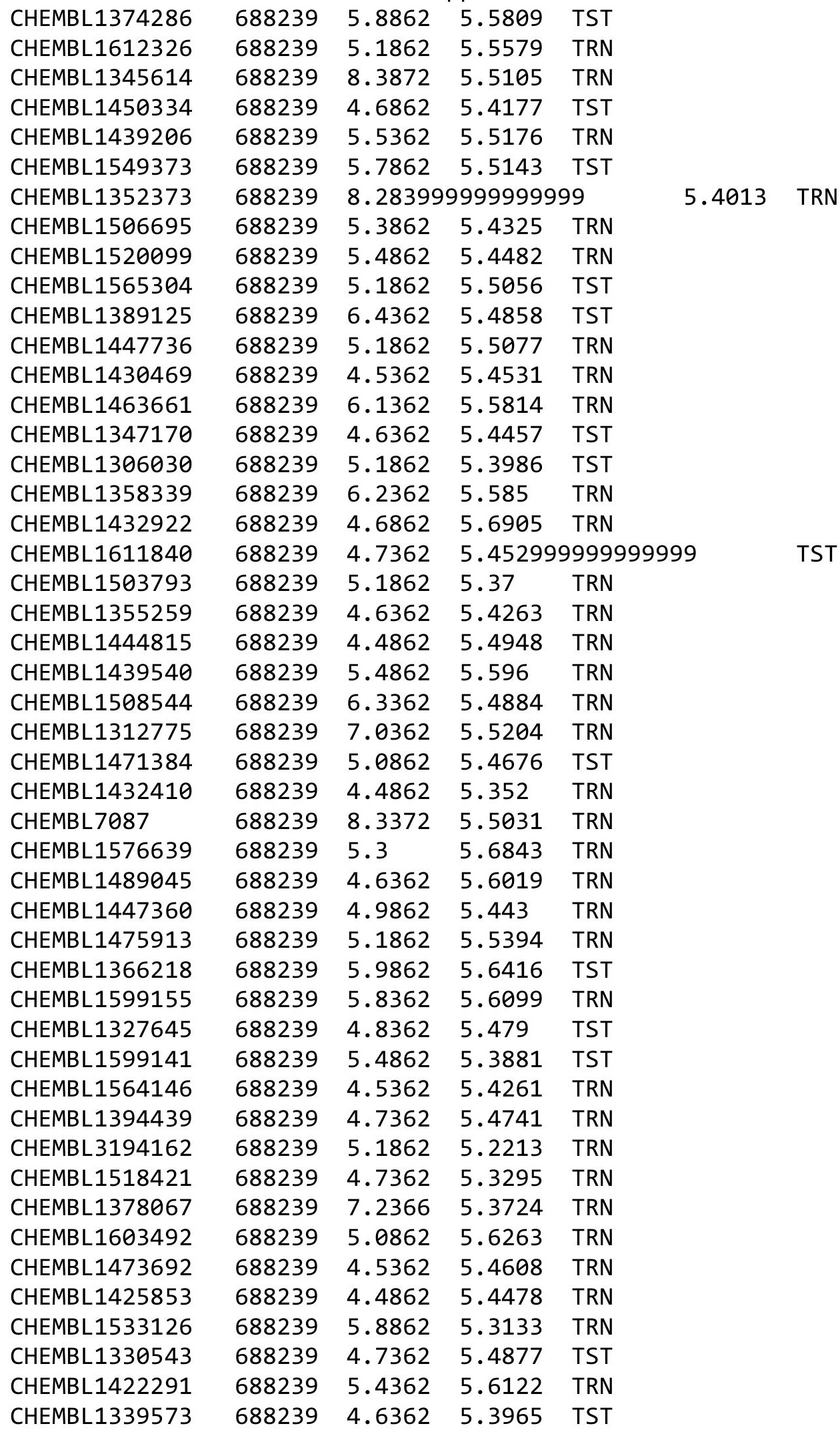

Page 1310 
Supplemental Table S2.txt

\begin{tabular}{|c|c|c|c|c|}
\hline CHEMBL1520594 & 688239 & 4.5362 & 5.4946 & TRN \\
\hline CHEMBL1370186 & 688239 & 4.6862 & 5.5529 & TRN \\
\hline CHEMBL1524857 & 688239 & 4.5362 & 5.5078 & TST \\
\hline CHEMBL1329673 & 688239 & 4.8862 & 5.6509 & TST \\
\hline CHEMBL1509292 & 688239 & 4.5862 & 5.5292 & TRN \\
\hline CHEMBL1539282 & 688239 & 4.5362 & 5.5764 & TRN \\
\hline CHEMBL1538223 & 688239 & 4.7362 & 5.3621 & TRN \\
\hline CHEMBL1424963 & 688239 & 4.7362 & 5.5803 & TRN \\
\hline CHEMBL1455110 & 688239 & 4.5362 & 5.4002 & TST \\
\hline CHEMBL1469405 & 688239 & 4.6862 & 5.5054 & TRN \\
\hline CHEMBL1610445 & 688239 & 5.5862 & 5.5748 & TST \\
\hline CHEMBL586029 & 688239 & 4.6362 & 5.4542 & TRN \\
\hline CHEMBL1352585 & 688239 & 4.5362 & 5.4676 & TRN \\
\hline CHEMBL1399966 & 688239 & 4.6862 & 5.5118 & TRN \\
\hline CHEMBL1389629 & 688239 & 6.5862 & 5.4617 & TST \\
\hline CHEMBL1365204 & 688239 & 6.1362 & 5.6689 & TST \\
\hline CHEMBL1358897 & 688239 & 5.7862 & 5.5637 & TRN \\
\hline CHEMBL1530814 & 688239 & 4.5362 & 5.3688 & TRN \\
\hline CHEMBL1453823 & 688239 & 8.2366 & 5.5832 & TST \\
\hline CHEMBL1299211 & 688239 & 5.6362 & 5.4325 & TRN \\
\hline CHEMBL3196411 & 688239 & 5.1362 & 5.4793 & TRN \\
\hline CHEMBL1455733 & 688239 & 4.9362 & 5.4721 & TST \\
\hline CHEMBL1449342 & 688239 & 5.1862 & 5.4359 & TST \\
\hline CHEMBL1355688 & 688239 & 4.6862 & 5.4365 & TRN \\
\hline CHEMBL1580027 & 688239 & 4.7362 & 5.3732 & TRN \\
\hline CHEMBL1403649 & 688239 & 4.5362 & 5.431 & TRN \\
\hline CHEMBL1524102 & 688239 & 6.8362 & 5.5776 & TRN \\
\hline CHEMBL1430245 & 688239 & 6.9363 & 5.391 & TRN \\
\hline CHEMBL1581158 & 688239 & 5.3362 & 5.445 & TST \\
\hline CHEMBL1530910 & 688239 & 5.9862 & 5.4224 & TRN \\
\hline CHEMBL1574067 & 688239 & 4.5362 & 5.478 & TST \\
\hline CHEMBL1461886 & 688239 & 5.8362 & 5.527 & TRN \\
\hline CHEMBL1604963 & 688239 & 5.1862 & 5.3755 & TST \\
\hline CHEMBL1329361 & 688239 & 6.3362 & 5.416 & TST \\
\hline CHEMBL1485942 & 688239 & 4.5362 & 5.577999 & 9999999999 \\
\hline CHEMBL1467912 & 688239 & 4.5362 & 5.2453 & TRN \\
\hline CHEMBL1568173 & 688239 & 4.5862 & 5.6235 & TRN \\
\hline CHEMBL1571546 & 688239 & 6.1362 & 5.5538 & TRN \\
\hline CHEMBL1450834 & 688239 & 5.4862 & 5.5576 & TST \\
\hline CHEMBL1518703 & 688239 & 7.3862 & 5.4127 & TRN \\
\hline CHEMBL1429289 & 688239 & 6.0362 & 5.4692 & TRN \\
\hline CHEMBL1611429 & 688239 & 5.6362 & 5.4105 & TST \\
\hline CHEMBL1333912 & 688239 & 5.3362 & 5.6325 & TRN \\
\hline CHEMBL1517119 & 688239 & 5.3362 & 5.4376 & TST \\
\hline CHEMBL1547885 & 688239 & 6.7361 & 5.4758 & TRN \\
\hline CHEMBL1318194 & 688239 & 5.6862 & 5.5893 & TRN \\
\hline CHEMBL1589060 & 688239 & 4.6362 & 5.6903 & TST \\
\hline CHEMBL1484332 & 688239 & 5.4862 & 5.454 & TST \\
\hline
\end{tabular}


Supplemental Table S2.txt

\begin{tabular}{|c|c|c|c|c|c|}
\hline CHEMBL1349497 & 688239 & 4.7862 & 5.5507 & TRN & \\
\hline CHEMBL1311879 & 688239 & 5.2862 & 5.4276 & TST & \\
\hline CHEMBL1461737 & 688239 & 4.5362 & 5.4764 & TRN & \\
\hline CHEMBL1327523 & 688239 & 5.3862 & 5.5272 & TRN & \\
\hline CHEMBL1309751 & 688239 & 5.8362 & 5.5716 & TST & \\
\hline CHEMBL1354074 & 688239 & 6.9863 & 5.4783 & TST & \\
\hline CHEMBL3194530 & 688239 & 5.5362 & 5.5288 & TRN & \\
\hline CHEMBL3210178 & 688239 & 5.1862 & 5.5416 & TRN & \\
\hline CHEMBL1538344 & 688239 & 4.5362 & 5.5328 & TST & \\
\hline CHEMBL1593652 & 688239 & 6.1362 & 5.4607 & TRN & \\
\hline CHEMBL1309723 & 688239 & 4.5362 & 5.5661 & TRN & \\
\hline CHEMBL1490498 & 688239 & 4.8862 & 5.5612 & TRN & \\
\hline CHEMBL1347877 & 688239 & 4.6362 & 5.5825 & TRN & \\
\hline CHEMBL1610152 & 688239 & 5.1862 & 5.4601 & TST & \\
\hline CHEMBL1483710 & 688239 & 4.8862 & 5.4507 & TST & \\
\hline CHEMBL1609725 & 688239 & 4.7362 & 5.6027 & TRN & \\
\hline CHEMBL1387979 & 688239 & 5.1362 & 5.5838 & TRN & \\
\hline CHEMBL1455381 & 688239 & 5.3362 & 5.3513 & TRN & \\
\hline CHEMBL1414067 & 688239 & 4.5362 & 5.4309 & TST & \\
\hline CHEMBL1326652 & 688239 & 6.2362 & 5.4204 & TRN & \\
\hline CHEMBL1360694 & 688239 & 8.3372 & 5.5719 & TRN & \\
\hline CHEMBL1382566 & 688239 & 5.8862 & 5.5328 & TRN & \\
\hline CHEMBL1508317 & 688239 & 6.2362 & \multicolumn{2}{|c|}{5.462000000000001} & TRN \\
\hline CHEMBL1390682 & 688239 & 4.5362 & 5.426 & TRN & \\
\hline CHEMBL1311729 & 688239 & 5.6862 & 5.5324 & TRN & \\
\hline CHEMBL1367461 & 688239 & 6.8861 & 5.4968 & TRN & \\
\hline CHEMBL1440320 & 688239 & 4.4862 & 5.5416 & TRN & \\
\hline CHEMBL1423118 & 688239 & 4.5362 & 5.2882 & TRN & \\
\hline CHEMBL1447038 & 688239 & 6.5862 & 5.58 & TRN & \\
\hline CHEMBL1536409 & 688239 & 5.6362 & \multicolumn{2}{|c|}{5.468999999999999} & TRN \\
\hline CHEMBL1369690 & 688239 & 4.4862 & 5.4368 & TRN & \\
\hline CHEMBL1507690 & 688239 & 6.1362 & 5.3179 & TRN & \\
\hline CHEMBL1591897 & 688239 & 5.2862 & 5.3965 & TRN & \\
\hline CHEMBL3195691 & 688239 & 5.7862 & 5.3465 & TRN & \\
\hline CHEMBL1338771 & 688239 & 4.5362 & 5.466 & TRN & \\
\hline CHEMBL1530400 & 688239 & 6.1362 & 5.5832 & TRN & \\
\hline CHEMBL1459375 & 688239 & 5.8862 & 5.5658 & TRN & \\
\hline CHEMBL1304204 & 688239 & 6.0362 & 5.504 & TRN & \\
\hline CHEMBL1313169 & 688239 & 5.9362 & 5.6418 & TRN & \\
\hline CHEMBL1447822 & 688239 & 6.1862 & 5.4086 & TRN & \\
\hline CHEMBL1316302 & 688239 & 5.0362 & 5.4192 & TRN & \\
\hline CHEMBL1533756 & 688239 & 5.0862 & 5.4901 & TRN & \\
\hline CHEMBL1352897 & 688239 & 6.1862 & 5.3826 & TRN & \\
\hline CHEMBL1481130 & 688239 & 4.5362 & \multicolumn{2}{|c|}{5.452000000000001} & TST \\
\hline CHEMBL1347764 & 688239 & 6.0362 & 5.7295 & TST & \\
\hline CHEMBL1382482 & 688239 & 6.0862 & 5.4478 & TRN & \\
\hline CHEMBL1601252 & 688239 & 5.6862 & 5.4201 & TRN & \\
\hline CHEMBL1562424 & 688239 & 7.0862 & 5.4957 & TST & \\
\hline
\end{tabular}




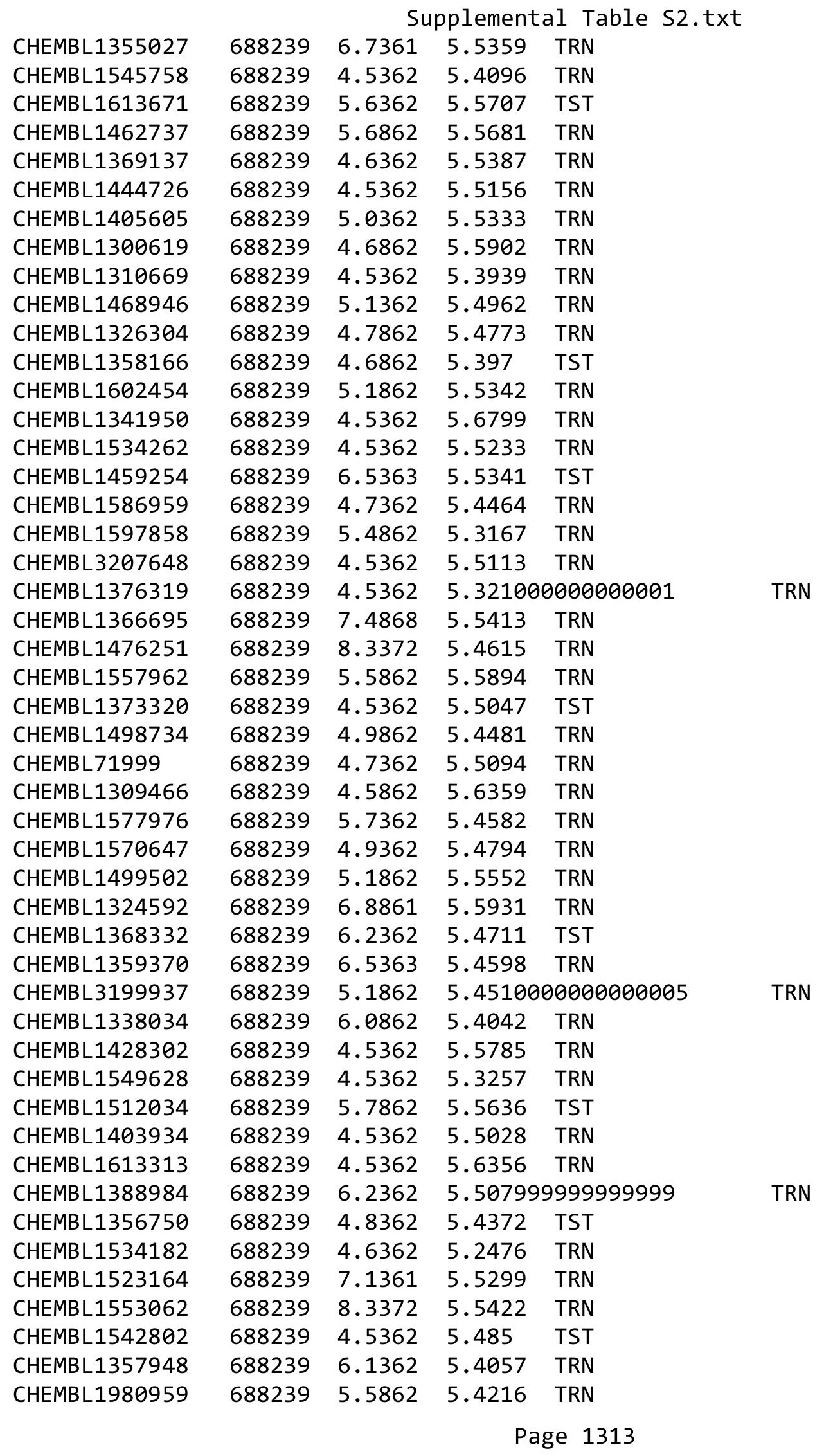


Supplemental Table S2.txt

\begin{tabular}{|c|c|c|c|c|}
\hline CHEMBL1361888 & 688239 & 4.5362 & 5.4921 & TST \\
\hline CHEMBL1426535 & 688239 & 5.1862 & 5.3964 & TST \\
\hline CHEMBL1492125 & 688239 & 4.5862 & 5.62 & TRN \\
\hline CHEMBL 3195299 & 688239 & 4.5362 & 5.4287 & TRN \\
\hline CHEMBL 3213222 & 688239 & 7.2366 & 5.5689 & TRN \\
\hline CHEMBL1366813 & 688239 & 5.1362 & 5.5302 & TRN \\
\hline CHEMBL1602965 & 688239 & 5.1862 & 5.6304 & TRN \\
\hline CHEMBL1492514 & 688239 & 8.3372 & 5.3197 & TRN \\
\hline CHEMBL1478123 & 688239 & 4.5362 & 5.4448 & TST \\
\hline CHEMBL1450136 & 688239 & 5.7362 & 5.6386 & TRN \\
\hline CHEMBL1601347 & 688239 & 4.5362 & 5.4602 & TST \\
\hline CHEMBL1384497 & 688239 & 5.7362 & 5.3573 & TRN \\
\hline CHEMBL1363271 & 688239 & 4.95 & 5.5111 & TRN \\
\hline CHEMBL1508431 & 688239 & 4.5862 & 5.4349 & TST \\
\hline CHEMBL1589513 & 688239 & 5.7362 & 5.7042 & TRN \\
\hline CHEMBL1522890 & 688239 & 4.4862 & 5.53 & TRN \\
\hline CHEMBL1369065 & 688239 & 6.2362 & 5.4711 & TRN \\
\hline CHEMBL1549821 & 688239 & 4.5362 & 5.4456 & TRN \\
\hline CHEMBL1488147 & 688239 & 6.1862 & 5.5795 & TRN \\
\hline CHEMBL1411471 & 688239 & 4.9862 & 5.5093 & TRN \\
\hline CHEMBL1560773 & 688239 & 4.6362 & 5.58200 & 0000000001 \\
\hline CHEMBL1310688 & 688239 & 4.6362 & 5.3952 & TST \\
\hline CHEMBL1505033 & 688239 & 5.1862 & 5.621 & TRN \\
\hline CHEMBL1395079 & 688239 & 4.7362 & 5.4397 & TRN \\
\hline CHEMBL1444843 & 688239 & 5.5362 & 5.5867 & TRN \\
\hline CHEMBL1544100 & 688239 & 5.4862 & 5.6551 & TRN \\
\hline CHEMBL1350258 & 688239 & 4.5362 & 5.5253 & TST \\
\hline CHEMBL1592692 & 688239 & 7.7852 & 5.5235 & TRN \\
\hline CHEMBL1381915 & 688239 & 4.8862 & 5.5207 & TST \\
\hline CHEMBL1595073 & 688239 & 4.5362 & 5.4954 & TST \\
\hline CHEMBL1409791 & 688239 & 5.8362 & 5.6207 & TRN \\
\hline CHEMBL1433258 & 688239 & 4.6862 & 5.58700 & 0000000001 \\
\hline CHEMBL1609784 & 688239 & 4.7362 & 5.3446 & TRN \\
\hline CHEMBL1445272 & 688239 & 5.3862 & 5.4609 & TST \\
\hline CHEMBL1561031 & 688239 & 5.6862 & 5.647 & TRN \\
\hline CHEMBL1570606 & 688239 & 7.2366 & 5.5915 & TRN \\
\hline CHEMBL1462318 & 688239 & 4.8862 & 5.479 & TST \\
\hline CHEMBL 2003178 & 688239 & 4.5362 & 5.319 & TST \\
\hline CHEMBL1305434 & 688239 & 5.3862 & 5.5504 & TRN \\
\hline CHEMBL1483975 & 688239 & 4.8362 & 5.3067 & TRN \\
\hline CHEMBL1568433 & 688239 & 6.8861 & 5.6213 & TST \\
\hline CHEMBL1522329 & 688239 & 6.2862 & 5.5191 & TRN \\
\hline CHEMBL1497844 & 688239 & 4.5362 & 5.3573 & TRN \\
\hline CHEMBL1576150 & 688239 & 4.5362 & 5.4755 & TST \\
\hline CHEMBL1494629 & 688239 & 5.0362 & 5.4444 & TST \\
\hline CHEMBL1349326 & 688239 & 4.6862 & 5.4698 & TRN \\
\hline CHEMBL1569035 & 688239 & 5.6362 & 5.4271 & TRN \\
\hline CHEMBL1610893 & 688239 & 4.5862 & 5.5459 & TRN \\
\hline
\end{tabular}


Supplemental Table S2.txt

\begin{tabular}{|c|c|c|c|c|}
\hline The & & 862 & & \\
\hline & & .8362 & 5.5304 & \\
\hline$-\sigma_{2}$ & & & & \\
\hline AEMBL1 & & & & \\
\hline AEMBL3195373 & 8239 & 862 & & \\
\hline HEMBL1499424 & 88239 & 4362 & 22 & \\
\hline AEMBL1501732 & 239 & 362 & & \\
\hline 580823 & & & & \\
\hline AEMBL1534647 & & 362 & & \\
\hline HEMBL1483509 & 38239 & 862 & 612 & \\
\hline HEMBL1487031 & 239 & 363 & 075 & \\
\hline IEMBL14 & 239 & 63 & 921 & \\
\hline IEMBL32 & & & & \\
\hline AEMBL1ك & & 362 & 3422 & \\
\hline IEMBL157 & & & 992 & \\
\hline AEMBL1 & 39 & 862 & 09 & \\
\hline AEMBL13 & & 62 & 01 & \\
\hline HEMBL15 & & 362 & & \\
\hline JEMBL14. & & 862 & 5753 & \\
\hline AEMBL13 & & & & \\
\hline 化MBLI & & 62 & & \\
\hline AEMBL13 & & & 18 & 2 \\
\hline AEMBL16 & & 62 & & \\
\hline AEMBL14 & & & & \\
\hline AEMBL13 & & & & I NIV \\
\hline AEMBL1 & & 62 & & RIV \\
\hline HEMBL: & & & & (1) \\
\hline AFMRI 1 & & 62 & 52 & \\
\hline AEMBL16 & & & & I RIV \\
\hline HEMBL1340988 & & & & I RIV \\
\hline HEMBL1C & & & 369 & RIV \\
\hline HEMBL & & & & 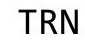 \\
\hline 7 & & & & \\
\hline HEMBL1506774 & & & 64 & T \\
\hline HEMBL1420517 & & & 151 & TRN \\
\hline HEMBLI & & 52 & & |SI \\
\hline HFMRI 3 & & & & TRN \\
\hline HEMBL 13579 & & & 857 & IST \\
\hline HEMBL1546834 & 88239 & & 5.3711 & TRN \\
\hline AEMBL14 & & & 536 & TRN \\
\hline HEMBL158. & & & 805 & \\
\hline HEMBL1392 & & & & TIrv \\
\hline HEMBL1491821 & & & 5284 & TST \\
\hline AEMBL1374957 & & 362 & 453 & TRN \\
\hline MBL13 & & & 5.4321 & ב \\
\hline HEMBL1 & & & & \\
\hline CHEMBL1984523 & & & 5.3755 & \\
\hline HEMBL130524 & 688239 & 4.6362 & 5.3355 & ГRN \\
\hline
\end{tabular}

Page 1315 
Supplemental Table S2.txt

\begin{tabular}{|c|c|c|c|c|}
\hline 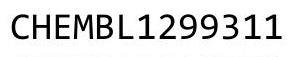 & & & & \\
\hline HEMBL1319773 & 88239 & 5362 & 5.4872 & \\
\hline HEMBL1603178 & 88239 & 1862 & 52 & \\
\hline IEMBL1 & & 872 & 728 & \\
\hline EMBL13 & & 362 & 152 & \\
\hline HEMBL1452963 & 88239 & 362 & 499 & \\
\hline HEMBL1602373 & 88239 & .8861 & .6762 & \\
\hline HEMBL1458337 & & & & \\
\hline IEMBL13 & 39 & 862 & .5809 & \\
\hline IEMBL144 & 39 & 862 & & \\
\hline HEMBL1581474 & 88239 & 5862 & .4981 & \\
\hline HEMBL1367444 & 39 & .5362 & .7116 & \\
\hline HEMBL1401343 & 39 & 862 & .4734 & \\
\hline HEMBL131S & 39 & 62 & 505 & \\
\hline AEMBL1585 & 39 & 862 & 733 & \\
\hline HEMBL1554055 & 39 & 861 & 3797 & \\
\hline HEMBL1313612 & 39 & 362 & & \\
\hline HEMBL142 & 9 & 62 & 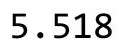 & \\
\hline HEME & 9 & 62 & & \\
\hline HEME & 39 & 62 & & \\
\hline HEMBL1458 & 39 & 862 & & \\
\hline HEMBL1330722 & 39 & 62 & & \\
\hline HEMBL155 & 39 & 56 & & \\
\hline HEMBL 32 & & 72 & & NIV \\
\hline 42 & 39 & 62 & 55 & \\
\hline HEMBL196 & 39 & 862 & & ( \\
\hline AEMBL136 & 39 & 872 & & I RIV \\
\hline HEMBL137 & 39 & 62 & & RIV \\
\hline HEME & & & & \\
\hline HEM & & 62 & 5 & 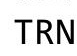 \\
\hline HEMBL134 & 9 & & & RN \\
\hline HEMBL319 & 39 & 362 & & TRN \\
\hline HEMBL1: & & 52 & & \\
\hline$A F M$ & 9 & & & ST \\
\hline HEMBL 153 & & & & ST \\
\hline HEMBL1548974 & 39 & & & RN \\
\hline HEMBL1347753 & 88 & 862 & & ST \\
\hline 政 & 39 & 362 & & ST \\
\hline תו 19 & 39 & & 71 & RN \\
\hline HEMBL1317134 & & & & RN \\
\hline HEMBL1438 & 39 & 362 & 5 . & RN \\
\hline HEMBL15 & 39 & 362 & & $\mathrm{RN}$ \\
\hline LI & & & & \\
\hline HEMBL1597767 & & 862 & & RN \\
\hline HEMBL 142 & & 5362 & & $\mathrm{RN}$ \\
\hline HEMBL135 & 39 & 362 & 83 & \\
\hline SHEMBL1585 & & 362 & & \\
\hline . & & & 5.5716 & \\
\hline
\end{tabular}

Page 1316 
Supplemental Table S2.txt

\begin{tabular}{|c|c|c|c|c|}
\hline CHEMBL1306395 & 688239 & 6.6362 & 5.6989 & TRN \\
\hline CHEMBL1487975 & 688239 & 6.4862 & 5.3761 & TRN \\
\hline CHEMBL609027 & 688239 & 4.8862 & 5.4691 & TST \\
\hline CHEMBL1345809 & 688239 & 4.6362 & 5.506 & TST \\
\hline CHEMBL1335298 & 688239 & 6.1362 & 5.3465 & TST \\
\hline CHEMBL1379572 & 688239 & 4.5362 & 5.50299 & 9999999999 \\
\hline CHEMBL1445431 & 688239 & 5.1862 & 5.4648 & TST \\
\hline CHEMBL1610587 & 688239 & 4.7362 & 5.4498 & TST \\
\hline CHEMBL1347648 & 688239 & 6.7361 & 5.5061 & TST \\
\hline CHEMBL1458419 & 688239 & 5.3862 & \multicolumn{2}{|c|}{5.5089999999999995} \\
\hline CHEMBL1572734 & 688239 & 5.8862 & 5.3094 & TRN \\
\hline CHEMBL1417204 & 688239 & 6.8861 & 5.3962 & TRN \\
\hline CHEMBL1584400 & 688239 & 6.1862 & \multicolumn{2}{|c|}{5.672000000000001} \\
\hline CHEMBL1510092 & 688239 & 6.8362 & 5.5019 & TRN \\
\hline CHEMBL1383345 & 688239 & 4.7362 & 5.6069 & TRN \\
\hline CHEMBL3196796 & 688239 & 5.0362 & 5.3429 & TRN \\
\hline CHEMBL1434526 & 688239 & 4.5862 & 5.4657 & TST \\
\hline CHEMBL1520131 & 688239 & 4.5362 & 5.3965 & TRN \\
\hline CHEMBL1528004 & 688239 & 6.8362 & 5.5066 & TRN \\
\hline CHEMBL1448878 & 688239 & 5.3862 & 5.4368 & TRN \\
\hline CHEMBL1423273 & 688239 & 4.6362 & 5.5482 & TST \\
\hline CHEMBL3210251 & 688239 & 7.5867 & 5.4358 & TRN \\
\hline CHEMBL1356769 & 688239 & 8.3372 & 5.535 & TST \\
\hline CHEMBL1435191 & 688239 & 4.5862 & 5.5272 & TRN \\
\hline CHEMBL 2001685 & 688239 & 6.3863 & 5.6032 & TST \\
\hline CHEMBL3196983 & 688239 & 5.7362 & 5.404 & TRN \\
\hline CHEMBL1347028 & 688239 & 5.0362 & 5.5648 & TRN \\
\hline CHEMBL1399653 & 688239 & 5.6862 & 5.3917 & TRN \\
\hline CHEMBL1606376 & 688239 & 6.7361 & 5.5549 & TRN \\
\hline CHEMBL1308291 & 688239 & 5.6862 & 5.6018 & TRN \\
\hline CHEMBL1491448 & 688239 & 5.3862 & 5.4951 & TRN \\
\hline CHEMBL1529219 & 688239 & 6.8861 & 5.4788 & TRN \\
\hline CHEMBL1480985 & 688239 & 6.1362 & 5.6447 & TRN \\
\hline CHEMBL609604 & 688239 & 5.0862 & 5.5484 & TRN \\
\hline CHEMBL1569453 & 688239 & 8.2366 & 5.4789 & TRN \\
\hline CHEMBL3193293 & 688239 & 4.4862 & 5.4739 & TST \\
\hline CHEMBL1556432 & 688239 & 4.5362 & 5.5318 & TST \\
\hline CHEMBL1523633 & 688239 & 4.7362 & 5.6078 & TRN \\
\hline CHEMBL1316645 & 688239 & 4.5362 & 5.3648 & TST \\
\hline CHEMBL1595469 & 688239 & 4.5362 & 5.4517 & TRN \\
\hline CHEMBL1460039 & 688239 & 4.4862 & 5.3228 & TST \\
\hline CHEMBL1392387 & 688239 & 5.8362 & 5.4772 & TRN \\
\hline CHEMBL1517015 & 688239 & 5.1862 & 5.4809 & TRN \\
\hline CHEMBL1300887 & 688239 & 5.4862 & 5.4096 & TST \\
\hline CHEMBL1309341 & 688239 & 4.4862 & 5.4161 & TRN \\
\hline CHEMBL1589796 & 688239 & 5.1862 & 5.32 & TRN \\
\hline CHEMBL1477311 & 688239 & 4.7362 & 5.4328 & TRN \\
\hline CHEMBL1605897 & 688239 & 5.0862 & 5.4309 & TST \\
\hline
\end{tabular}


Supplemental Table S2.txt

\begin{tabular}{|c|c|c|c|c|c|}
\hline CHEMBL1355619 & 688239 & 6.2862 & 5.5069 & TRN & \\
\hline CHEMBL567341 & 688239 & 6.1862 & 5.5093 & TST & \\
\hline CHEMBL1327593 & 688239 & 5.5862 & 5.4075 & TRN & \\
\hline CHEMBL3210075 & 688239 & 6.2362 & 5.5129 & TRN & \\
\hline CHEMBL1436660 & 688239 & 5.4862 & 5.5175 & TRN & \\
\hline CHEMBL1502078 & 688239 & 6.3863 & 5.3927 & TRN & \\
\hline CHEMBL1485056 & 688239 & 5.2862 & 5.5573 & TRN & \\
\hline CHEMBL1516177 & 688239 & 5.0862 & 5.4852 & TRN & \\
\hline CHEMBL1336605 & 688239 & 5.7862 & 5.5655 & TRN & \\
\hline CHEMBL1462991 & 688239 & 6.8861 & 5.4888 & TRN & \\
\hline CHEMBL1507012 & 688239 & 6.2862 & 5.5755 & TRN & \\
\hline CHEMBL598885 & 688239 & 5.0362 & 5.511 & TRN & \\
\hline CHEMBL1585652 & 688239 & 4.5362 & 5.3628 & TRN & \\
\hline CHEMBL1601102 & 688239 & 4.6362 & 5.3758 & TRN & \\
\hline CHEMBL1511787 & 688239 & 4.9862 & 5.5443 & TRN & \\
\hline CHEMBL1417466 & 688239 & 5.3362 & 5.6297 & TRN & \\
\hline CHEMBL1401900 & 688239 & 4.5362 & 5.4145 & TST & \\
\hline CHEMBL1330773 & 688239 & 4.5362 & 5.4144 & TRN & \\
\hline CHEMBL1423771 & 688239 & 4.4862 & 5.5749 & TRN & \\
\hline CHEMBL3145369 & 688239 & 4.5862 & 5.5963 & TRN & \\
\hline CHEMBL1559291 & 688239 & 5.4862 & 5.5948 & TRN & \\
\hline CHEMBL1434521 & 688239 & 4.8862 & 5.3917 & TST & \\
\hline CHEMBL1380401 & 688239 & 5.0862 & 5.4304 & TRN & \\
\hline CHEMBL1528536 & 688239 & 4.5362 & 5.3245 & TST & \\
\hline CHEMBL1612137 & 688239 & 4.5362 & 5.4902 & TRN & \\
\hline CHEMBL1482489 & 688239 & 6.0362 & 5.4468 & TRN & \\
\hline CHEMBL1587253 & 688239 & 4.6862 & 5.4544 & TRN & \\
\hline CHEMBL1486743 & 688239 & 6.3863 & 5.3433 & TST & \\
\hline CHEMBL1361683 & 688239 & 7.5867 & 5.4976 & TRN & \\
\hline CHEMBL1326535 & 688239 & 6.2862 & 5.4128 & TRN & \\
\hline CHEMBL1360088 & 688239 & 4.5362 & 5.5428 & TRN & \\
\hline CHEMBL1399960 & 688239 & 4.6862 & 5.3189 & TRN & \\
\hline CHEMBL3189976 & 688239 & 7.0362 & 5.555 & TRN & \\
\hline CHEMBL1472627 & 688239 & 5.4862 & 5.5681 & TRN & \\
\hline CHEMBL1579961 & 688239 & 4.5362 & 5.4829 & TRN & \\
\hline CHEMBL1527638 & 688239 & 6.8861 & 5.432 & TRN & \\
\hline CHEMBL1537999 & 688239 & 6.2862 & 5.4819 & TST & \\
\hline CHEMBL1390664 & 688239 & 5.1862 & 5.5287 & TRN & \\
\hline CHEMBL1352499 & 688239 & 4.7362 & 5.3854 & TRN & \\
\hline CHEMBL1310433 & 688239 & 5.1862 & 5.4371 & TRN & \\
\hline CHEMBL1342205 & 688239 & 4.7362 & 5.5569 & TRN & \\
\hline CHEMBL1319454 & 688239 & 5.7862 & 5.4994 & TRN & \\
\hline CHEMBL1387227 & 688239 & 4.5362 & 5.4478 & TRN & \\
\hline CHEMBL1300154 & 688239 & 4.8362 & 5.313 & TRN & \\
\hline CHEMBL3661373 & 688239 & 4.5362 & 5.4275 & TRN & \\
\hline CHEMBL1317432 & 688239 & 5.4862 & 5.3669 & TRN & \\
\hline CHEMBL1479167 & 688239 & 8.28399 & 9999999 & 99 & 5.3755 \\
\hline CHEMBL1347840 & 688239 & 8.3372 & 5.556 & TST & \\
\hline
\end{tabular}


Supplemental Table S2.txt

\begin{tabular}{|c|c|c|c|c|}
\hline 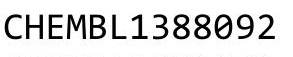 & & & & \\
\hline CHEMBL1521301 & 38239 & 5.6862 & 5189 & \\
\hline HEMBL19 & 3239 & 5862 & & \\
\hline EMBL1 & 239 & & & \\
\hline EMBL1: & 8239 & 362 & & \\
\hline AEMBL1508611 & 88239 & 3372 & 724 & \\
\hline HEMBL1396391 & 88239 & .3362 & 966 & \\
\hline HEMBL1 & & & 34 & \\
\hline 910 & 38239 & 62 & & \\
\hline IEMBL: & 239 & 362 & & \\
\hline AEMBL1: & 88239 & 3372 & 527 & \\
\hline AEMBL1 & 88239 & .5362 & & \\
\hline HEMBL: & 39 & 362 & & \\
\hline 5844 & 239 & 362 & & \\
\hline 417 & 239 & 862 & & \\
\hline 3666 & 239 & 362 & & \\
\hline AEMBL: & & 862 & & \\
\hline AEMBL & & 52 & & \\
\hline 320 & & & & \\
\hline 917 & 39 & 6. & & \\
\hline IEMBL & & 62 & & \\
\hline AEMBL & & & & \\
\hline HEMBL & 9 & 52 & & \\
\hline AEMBL & & & & \\
\hline 268 & & 62 & & 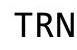 \\
\hline 404 & & & & \\
\hline AEMBL: & & & & \\
\hline AEMBL & & & & \\
\hline 92 & & & & \\
\hline 58 & & 363 & & RN \\
\hline EMBL & & & & \\
\hline AEMBL: & & 362 & & RI \\
\hline 75 & & & & $\mathrm{R \Lambda}$ \\
\hline 55 & & & & \\
\hline 946 & & & & 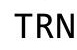 \\
\hline IEMBL: & & & & $R$ \\
\hline HEMBL: & 39 & 862 & & \\
\hline & & & & S \\
\hline 598 & & & & RN \\
\hline HEMBL & & & & RI \\
\hline EMBL & & 362 & & $\mathrm{RI}$ \\
\hline AEMBL & 39 & 62 & & RI \\
\hline & & & & \\
\hline CHEMBL: & & & & \\
\hline CHEMBLI & & & & $\mathrm{ST}$ \\
\hline AEMBL & 39 & 862 & 106 & $\mathrm{R}$ \\
\hline 005 & & & & \\
\hline CHEMBL1 & & & & \\
\hline
\end{tabular}

Page 1319 
Supplemental Table S2.txt

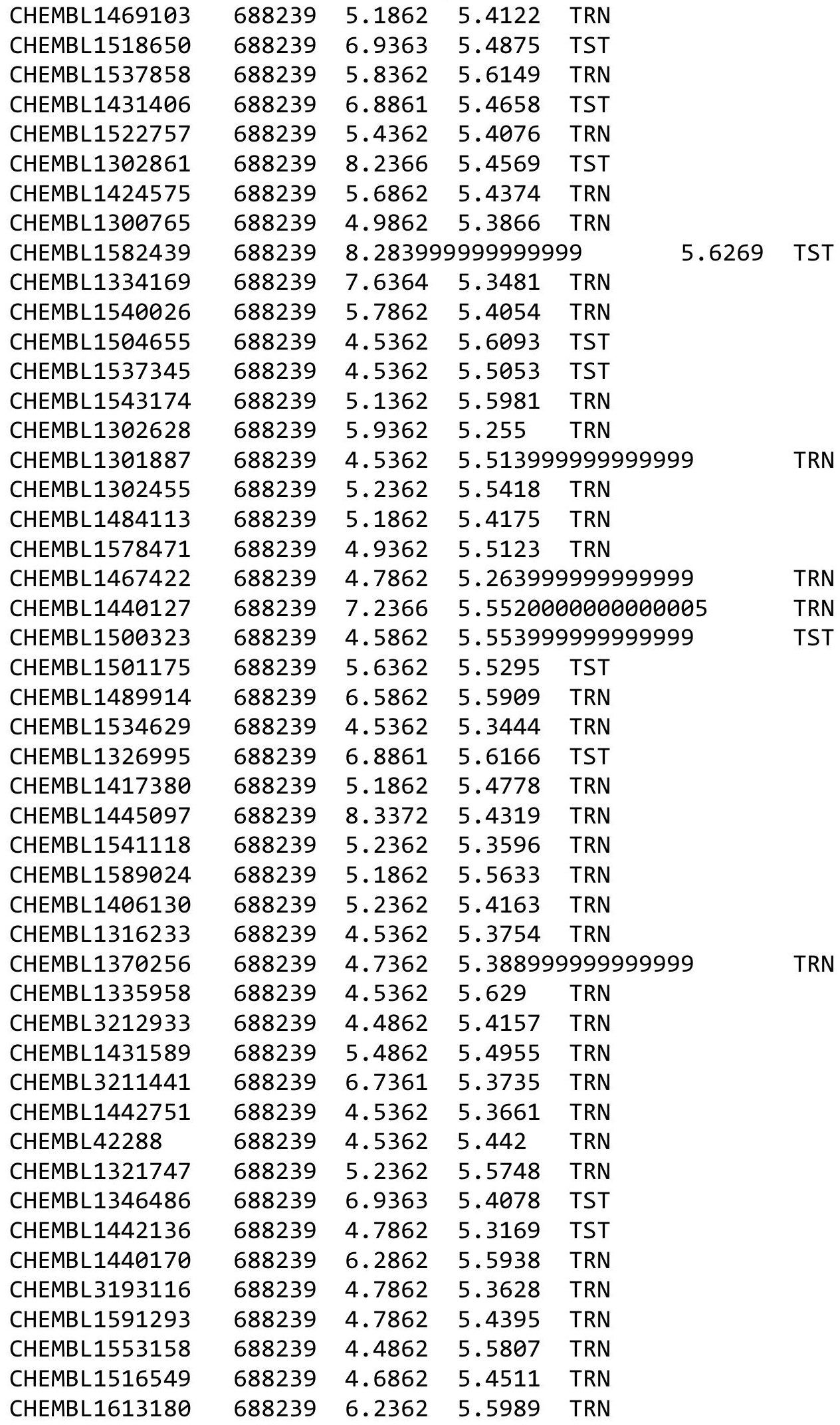

Page 1320 
Supplemental Table S2.txt

\begin{tabular}{|c|c|c|c|c|c|}
\hline CHEMBL1429358 & 688239 & 6.2862 & 5.5803 & TST & \\
\hline CHEMBL1426480 & 688239 & 8.3372 & 5.4689 & TRN & \\
\hline CHEMBL1602588 & 688239 & 5.0362 & 5.4044 & TRN & \\
\hline CHEMBL1320045 & 688239 & 5.9362 & 5.4777 & TRN & \\
\hline CHEMBL1477381 & 688239 & 5.5362 & 5.367999 & 9999999999 & TRN \\
\hline CHEMBL1345904 & 688239 & 6.1362 & 5.6003 & TRN & \\
\hline CHEMBL1305737 & 688239 & 4.7362 & 5.3637 & TRN & \\
\hline CHEMBL1455738 & 688239 & 4.9862 & 5.4302 & TRN & \\
\hline CHEMBL1366725 & 688239 & 5.1862 & 5.3743 & TRN & \\
\hline CHEMBL1581036 & 688239 & 7.7352 & 5.561 & TST & \\
\hline CHEMBL1429818 & 688239 & 6.0 & 5.5356 & TST & \\
\hline CHEMBL1342098 & 688239 & 6.4862 & 5.5364 & TRN & \\
\hline CHEMBL1467507 & 688239 & 4.8362 & 5.6152 & TRN & \\
\hline CHEMBL1378562 & 688239 & 6.8362 & 5.4457 & TST & \\
\hline CHEMBL1511605 & 688239 & 7.6364 & 5.542999 & 9999999999 & TST \\
\hline CHEMBL1378469 & 688239 & 4.4362 & 5.5997 & TRN & \\
\hline CHEMBL1536825 & 688239 & 4.5362 & 5.3688 & TRN & \\
\hline CHEMBL1551507 & 688239 & 6.8362 & 5.364 & TRN & \\
\hline CHEMBL1404613 & 688239 & 6.0362 & 5.501 & TRN & \\
\hline CHEMBL1369662 & 688239 & 6.5862 & 5.5704 & TRN & \\
\hline CHEMBL1309428 & 688239 & 5.3362 & 5.4457 & TRN & \\
\hline CHEMBL1479654 & 688239 & 6.1362 & 5.3309 & TST & \\
\hline CHEMBL1496622 & 688239 & 6.1862 & 5.4563 & TRN & \\
\hline CHEMBL1549964 & 688239 & 5.6362 & 5.4475 & TRN & \\
\hline CHEMBL1454070 & 688239 & 4.6362 & 5.4822 & TRN & \\
\hline CHEMBL1417630 & 688239 & 4.8362 & 5.3909 & TST & \\
\hline CHEMBL1576993 & 688239 & 4.7862 & 5.5426 & TRN & \\
\hline CHEMBL1502651 & 688239 & 5.3862 & 5.4992 & TRN & \\
\hline CHEMBL1379145 & 688239 & 7.2865 & 5.5487 & TST & \\
\hline CHEMBL1431219 & 688239 & 4.7862 & 5.5444 & TRN & \\
\hline CHEMBL1966168 & 688239 & 4.7862 & 5.3841 & TRN & \\
\hline CHEMBL1549017 & 688239 & 4.9362 & 5.499 & TRN & \\
\hline CHEMBL1468981 & 688239 & 4.6862 & 5.4583 & TRN & \\
\hline CHEMBL1428151 & 688239 & 6.3863 & 5.479 & TST & \\
\hline CHEMBL1402865 & 688239 & 5.1862 & 5.4022 & TRN & \\
\hline CHEMBL1523712 & 688239 & 5.3862 & 5.4855 & TRN & \\
\hline CHEMBL1561261 & 688239 & 5.3362 & 5.3494 & TRN & \\
\hline CHEMBL1395331 & 688239 & 4.5362 & 5.4235 & TRN & \\
\hline CHEMBL1336837 & 688239 & 5.1362 & 5.4593 & TST & \\
\hline CHEMBL1548767 & 688239 & 6.0362 & 5.5449 & TRN & \\
\hline CHEMBL1439910 & 688239 & 5.0862 & 5.4062 & TRN & \\
\hline CHEMBL1358752 & 688239 & 6.6362 & 5.465 & TRN & \\
\hline CHEMBL1468395 & 688239 & 5.2862 & 5.4885 & TST & \\
\hline CHEMBL1531124 & 688239 & 7.0362 & 5.461 & TRN & \\
\hline CHEMBL1487806 & 688239 & 5.0362 & 5.4823 & TST & \\
\hline CHEMBL3209872 & 688239 & 4.4862 & 5.4577 & TRN & \\
\hline CHEMBL1513376 & 688239 & 6.1362 & 5.4463 & TRN & \\
\hline CHEMBL1385453 & 688239 & 4.5362 & 5.5812 & TRN & \\
\hline
\end{tabular}


Supplemental Table S2.txt

\begin{tabular}{|c|c|c|c|c|}
\hline CHEMBL1606959 & 688239 & 4.9362 & 5.6203 & TRN \\
\hline CHEMBL3211805 & 688239 & 4.6362 & 5.5055 & TST \\
\hline CHEMBL1419180 & 688239 & 5.1862 & 5.4935 & TRN \\
\hline CHEMBL1423948 & 688239 & 6.9863 & 5.4365 & TRN \\
\hline CHEMBL1502956 & 688239 & 4.5362 & 5.4234 & TRN \\
\hline CHEMBL1364672 & 688239 & 4.7862 & 5.5633 & TRN \\
\hline CHEMBL1964862 & 688239 & 4.6862 & 5.4739 & TRN \\
\hline CHEMBL1583725 & 688239 & 5.1862 & 5.475 & TRN \\
\hline CHEMBL1429686 & 688239 & 5.4862 & 5.6144 & TRN \\
\hline CHEMBL1503796 & 688239 & 5.0862 & 5.4172 & TST \\
\hline CHEMBL1607212 & 688239 & 6.5363 & 5.507006 & 000000001 \\
\hline CHEMBL1371068 & 688239 & 4.5862 & 5.5422 & TRN \\
\hline CHEMBL1413273 & 688239 & 5.1862 & 5.4102 & TRN \\
\hline CHEMBL1376629 & 688239 & 4.5362 & 5.4863 & TRN \\
\hline CHEMBL1419958 & 688239 & 5.1862 & 5.5135 & TRN \\
\hline CHEMBL1356458 & 688239 & 4.4862 & 5.4037 & TRN \\
\hline CHEMBL1399975 & 688239 & 4.8362 & 5.4862 & TRN \\
\hline CHEMBL1502840 & 688239 & 5.0362 & 5.3897 & TRN \\
\hline CHEMBL1422936 & 688239 & 4.5362 & 5.4861 & TRN \\
\hline CHEMBL1458795 & 688239 & 4.5862 & 5.4962 & TRN \\
\hline CHEMBL1359266 & 688239 & 6.3362 & 5.5182 & TRN \\
\hline CHEMBL1310549 & 688239 & 6.8861 & 5.6586 & TRN \\
\hline CHEMBL1475009 & 688239 & 5.9362 & 5.4556 & TRN \\
\hline CHEMBL503763 & 688239 & 5.5862 & 5.5955 & TST \\
\hline CHEMBL1513528 & 688239 & 6.3362 & 5.4793 & TRN \\
\hline CHEMBL1458779 & 688239 & 5.5362 & 5.5231 & TRN \\
\hline CHEMBL1498860 & 688239 & 6.2862 & 5.5742 & TRN \\
\hline CHEMBL1373925 & 688239 & 4.5862 & 5.593 & TRN \\
\hline CHEMBL1558669 & 688239 & 4.5362 & 5.4266 & TST \\
\hline CHEMBL1466809 & 688239 & 4.4862 & 5.3477 & TST \\
\hline CHEMBL1405849 & 688239 & 6.1862 & 5.6059 & TST \\
\hline CHEMBL1562999 & 688239 & 4.5362 & 5.4396 & TRN \\
\hline CHEMBL1502655 & 688239 & 4.7362 & 5.6515 & TRN \\
\hline CHEMBL1400396 & 688239 & 6.2362 & 5.427006 & 0000000005 \\
\hline CHEMBL1575154 & 688239 & 5.1362 & 5.4505 & TRN \\
\hline CHEMBL1333188 & 688239 & 4.7862 & 5.5001 & TRN \\
\hline CHEMBL1592707 & 688239 & 5.7362 & 5.5301 & TST \\
\hline CHEMBL1574527 & 688239 & 4.6862 & 5.459 & TST \\
\hline CHEMBL1325578 & 688239 & 5.2862 & 5.3562 & TRN \\
\hline CHEMBL3209713 & 688239 & 4.6862 & 5.5023 & TRN \\
\hline CHEMBL 3208301 & 688239 & 6.0362 & 5.526 & TRN \\
\hline CHEMBL3198376 & 688239 & 7.6364 & 5.5315 & TRN \\
\hline CHEMBL1499941 & 688239 & 6.1362 & 5.5098 & TRN \\
\hline CHEMBL3192953 & 688239 & 5.6362 & 5.5867 & TRN \\
\hline CHEMBL1384223 & 688239 & 6.2362 & 5.4778 & TRN \\
\hline CHEMBL1531205 & 688239 & 4.8862 & 5.6873 & TRN \\
\hline CHEMBL1547176 & 688239 & 4.5362 & 5.365 & TRN \\
\hline CHEMBL1964338 & 688239 & 4.5362 & 5.3105 & TST \\
\hline
\end{tabular}


Supplemental Table S2.txt

\begin{tabular}{|c|c|c|c|c|}
\hline . & & & & \\
\hline HEMBL 395709 & 38239 & 362 & 8 & \\
\hline HEMBL1480981 & 239 & & & \\
\hline 63 & 39 & & & \\
\hline IEMBL13 & 39 & & & \\
\hline AEMBL1512254 & 88239 & 362 & 525 & \\
\hline AEMBL1404493 & 88239 & 362 & 4 & \\
\hline AEMBL1339502 & & & & \\
\hline EMBL1 & 39 & 862 & & \\
\hline IEMBL1505195 & & 861 & & \\
\hline AEMBL1394988 & 39 & 362 & & \\
\hline AEMBL1332892 & & 362 & & \\
\hline AEMBL1494641 & & & & \\
\hline AEMBL13 & & & & \\
\hline HEMBL138 & & & & \\
\hline AEMBL1567318 & & 362 & 61 & \\
\hline AEMBL1464493 & & 362 & & \\
\hline AEMBL199 & & & & \\
\hline AEMBL14 & & & & \\
\hline JEMBL15 & & & & \\
\hline AEMBL1526253 & & 862 & & \\
\hline AEMBL1469739 & & 62 & & \\
\hline JEMBL339 & & & & \\
\hline 005 & & & & \\
\hline 473 & & & & \\
\hline AEMBL1530080 & & 62 & & \\
\hline IEMBL548294 & & & & \\
\hline AEMBL1331329 & & & & \\
\hline 516 & & & & \\
\hline 168 & & & & \\
\hline AEMBL1575306 & & & & \\
\hline HEMBL1422027 & & 362 & & \\
\hline & & 62 & & \\
\hline 9 & & & & \\
\hline & & & & \\
\hline AEMBL1511899 & & & 696 & \\
\hline AEMBL1486983 & & 62 & & \\
\hline & & & & \\
\hline 827 & & & & \\
\hline HEMBL1485210 & & & & $\mathrm{RI}$ \\
\hline AEMBL1349283 & & & & \\
\hline 3254 & & & & \\
\hline HEMBL1411576 & & & & \\
\hline HEMBL1474562 & & & & \\
\hline AEMBL1410078 & & & .4213 & ST \\
\hline AEMBL1394498 & 68 & 862 & 582 & $\mathrm{~F}$ \\
\hline & & & & \\
\hline & & & .3222 & \\
\hline
\end{tabular}

Page 1323 
Supplemental Table S2.txt

\begin{tabular}{|c|c|c|c|c|}
\hline ( & & & & \\
\hline HEMBL1597545 & 38239 & 362 & 738 & \\
\hline AEMBL1384718 & 239 & 362 & 169 & \\
\hline 390 & 39 & & & \\
\hline AEMBL152 & 39 & & & \\
\hline AEMBL1452670 & 88239 & 862 & 5702 & \\
\hline AEMBL1390798 & 88239 & 362 & 333 & \\
\hline HEMBL1426936 & & & & \\
\hline EMBL1300292 & 39 & 362 & & \\
\hline IEMBL3207633 & & 362 & & \\
\hline AEMBL1585912 & 239 & 862 & & \\
\hline AEMBL1424341 & 39 & 862 & & \\
\hline AEMBL1544487 & & 62 & & \\
\hline AEMBL15 & & 62 & & \\
\hline HEMBL13€ & & 62 & & \\
\hline AEMBL1571568 & & 362 & & \\
\hline AEMBL1585336 & & 362 & & \\
\hline IEMBL 142 & & 62 & & \\
\hline AEMBL1374811 & & & & \\
\hline AEMBL15 & & & & \\
\hline AEMBL1530016 & & 862 & & \\
\hline AEMBL1366037 & & 362 & & \\
\hline IEMBL1586547 & & 67 & & \\
\hline AFMRI 156 & & & & \\
\hline 994 & & 66 & & \\
\hline AEMBL1361703 & & 362 & & \\
\hline IEMBL 3197230 & & 62 & & \\
\hline EMBL156 & & 62 & & \\
\hline 590 & & & & \\
\hline IFMPI 150 & & 62 & & \\
\hline AEMBL1607963 & & & & \\
\hline IEMBL1355325 & & 362 & & \\
\hline & & & & \\
\hline 9 & & & & \\
\hline & & & & \\
\hline AEMBL1555299 & & & & \\
\hline AEMBL1557196 & & 862 & & \\
\hline 83233 & & 62 & & \\
\hline ل & & & & \\
\hline AEMBL1310172 & & & & $\mathrm{RI}$ \\
\hline AEMBL1322440 & & 362 & & s \\
\hline IEMBL1565785 & & 362 & & \\
\hline & & & & \\
\hline HEMBL1324224 & & & & \\
\hline AEMBL1302321 & & 4.5362 & .3747 & RN \\
\hline IEMBL3211638 & & 362 & 62 & \\
\hline 1 & & & & \\
\hline 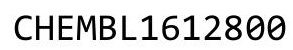 & & & & \\
\hline
\end{tabular}

Page 1324 
Supplemental Table S2.txt

\begin{tabular}{|c|c|c|c|c|}
\hline CHEMBL1475376 & 688239 & 5.5862 & 5.4732 & TRN \\
\hline CHEMBL1589590 & 688239 & 5.1862 & 5.4576 & TRN \\
\hline CHEMBL1526424 & 688239 & 5.1862 & 5.4771 & TST \\
\hline CHEMBL1398593 & 688239 & 5.1862 & 5.3874 & TRN \\
\hline CHEMBL1424587 & 688239 & 7.2865 & 5.5914 & TRN \\
\hline CHEMBL1595013 & 688239 & 4.7362 & 5.4946 & TST \\
\hline CHEMBL1486464 & 688239 & 5.8862 & 5.5436 & TRN \\
\hline CHEMBL1487870 & 688239 & 4.6862 & 5.3898 & TRN \\
\hline CHEMBL1535432 & 688239 & 8.3872 & 5.6236 & TRN \\
\hline CHEMBL1484813 & 688239 & 4.6862 & 5.6043 & TST \\
\hline CHEMBL1445027 & 688239 & 4.8362 & 5.3592 & TRN \\
\hline CHEMBL1491167 & 688239 & 4.6362 & 5.4701 & TRN \\
\hline CHEMBL3211914 & 688239 & 6.6861 & 5.4276 & TRN \\
\hline CHEMBL1318535 & 688239 & 4.5862 & 5.585 & TRN \\
\hline CHEMBL1370026 & 688239 & 6.7862 & 5.3947 & TRN \\
\hline CHEMBL1473466 & 688239 & 5.0362 & 5.5023 & TRN \\
\hline CHEMBL1476861 & 688239 & 4.5362 & 5.4353 & TRN \\
\hline CHEMBL1528808 & 688239 & 6.2862 & 5.4821 & TRN \\
\hline CHEMBL1421669 & 688239 & 6.1362 & 5.5168 & TST \\
\hline CHEMBL1333191 & 688239 & 4.5862 & 5.3553 & TRN \\
\hline CHEMBL1585487 & 688239 & 4.6862 & 5.38200 & 2000000001 \\
\hline CHEMBL1362536 & 688239 & 5.1862 & 5.393 & TST \\
\hline CHEMBL1369647 & 688239 & 5.1862 & 5.4362 & TRN \\
\hline CHEMBL1462518 & 688239 & 5.6862 & 5.3706 & TST \\
\hline CHEMBL1584386 & 688239 & 4.5362 & 5.5921 & TRN \\
\hline CHEMBL 3197281 & 688239 & 6.3362 & 5.46200 & 3000000001 \\
\hline CHEMBL1384300 & 688239 & 6.2362 & 5.4889 & TRN \\
\hline CHEMBL1593023 & 688239 & 4.6362 & 5.4634 & TST \\
\hline CHEMBL1304408 & 688239 & 4.7362 & 5.6187 & TRN \\
\hline CHEMBL1340766 & 688239 & 5.0862 & 5.5136 & TRN \\
\hline CHEMBL1404756 & 688239 & 5.3362 & 5.5255 & TST \\
\hline CHEMBL1387893 & 688239 & 5.1862 & 5.6139 & TRN \\
\hline CHEMBL1396232 & 688239 & 4.5362 & 5.4546 & TST \\
\hline CHEMBL1458459 & 688239 & 4.6362 & 5.5746 & TRN \\
\hline CHEMBL1475228 & 688239 & 4.5362 & 5.5512 & TRN \\
\hline CHEMBL1525846 & 688239 & 4.5362 & 5.5508 & TRN \\
\hline CHEMBL1594700 & 688239 & 5.7362 & 5.4648 & TRN \\
\hline CHEMBL1331926 & 688239 & 5.3862 & 5.3785 & TRN \\
\hline CHEMBL1561449 & 688239 & 5.1362 & 5.5211 & TRN \\
\hline CHEMBL1497547 & 688239 & 6.0862 & 5.3988 & TST \\
\hline CHEMBL1527450 & 688239 & 4.5362 & 5.67899 & 9999999999 \\
\hline CHEMBL1458187 & 688239 & 4.5362 & 5.3455 & TRN \\
\hline CHEMBL1581544 & 688239 & 6.3863 & 5.5665 & TST \\
\hline CHEMBL1530856 & 688239 & 4.8862 & 5.3954 & TRN \\
\hline CHEMBL1414020 & 688239 & 5.1862 & 5.3571 & TRN \\
\hline CHEMBL1540872 & 688239 & 6.8362 & 5.5888 & TRN \\
\hline CHEMBL1559203 & 688239 & 5.3362 & 5.4155 & TRN \\
\hline CHEMBL1301351 & 688239 & 5.3862 & 5.4876 & TRN \\
\hline
\end{tabular}


Supplemental Table S2.txt

\begin{tabular}{|c|c|c|c|c|c|}
\hline CHEMBL 2005655 & 688239 & 5.8862 & 5.2784 & TRN & \\
\hline CHEMBL1468695 & 688239 & 5.6362 & 5.4409 & TRN & \\
\hline CHEMBL3195652 & 688239 & 4.8362 & 5.41299 & 99999999999 & TRN \\
\hline CHEMBL1539986 & 688239 & 5.5362 & 5.5223 & TST & \\
\hline CHEMBL3214105 & 688239 & 6.4862 & 5.467006 & 00000000005 & TST \\
\hline CHEMBL1326102 & 688239 & 5.1862 & 5.5483 & TRN & \\
\hline CHEMBL1593400 & 688239 & 4.8362 & 5.5288 & TST & \\
\hline CHEMBL416657 & 688239 & 5.1862 & 5.2719 & TST & \\
\hline CHEMBL1574312 & 688239 & 5.4362 & 5.4127 & TST & \\
\hline CHEMBL3196684 & 688239 & 7.8861 & 5.3737 & TRN & \\
\hline CHEMBL1410443 & 688239 & 6.2862 & 5.4433 & TRN & \\
\hline CHEMBL1377725 & 688239 & 4.5362 & 5.5119 & TST & \\
\hline CHEMBL1442242 & 688239 & 5.8362 & 5.4794 & TST & \\
\hline CHEMBL1559435 & 688239 & 5.2362 & 5.3514 & TST & \\
\hline CHEMBL1413639 & 688239 & 5.0862 & 5.3537 & TRN & \\
\hline CHEMBL1545645 & 688239 & 5.4362 & 5.6132 & TRN & \\
\hline CHEMBL53268 & 688239 & 5.4362 & 5.5763 & TST & \\
\hline CHEMBL1338172 & 688239 & 4.8362 & 5.5907 & TRN & \\
\hline CHEMBL1505851 & 688239 & 4.5362 & 5.4789 & TST & \\
\hline CHEMBL1476390 & 688239 & 6.1362 & 5.4955 & TRN & \\
\hline CHEMBL1447900 & 688239 & 5.2362 & 5.5456 & TRN & \\
\hline CHEMBL1438926 & 688239 & 4.5362 & 5.3748 & TRN & \\
\hline CHEMBL1428658 & 688239 & 4.5362 & 5.5047 & TRN & \\
\hline CHEMBL1531100 & 688239 & 4.5362 & 5.4468 & TRN & \\
\hline CHEMBL1426918 & 688239 & 7.2366 & 5.6215 & TST & \\
\hline CHEMBL1560831 & 688239 & 5.2862 & 5.6007 & TST & \\
\hline CHEMBL1605771 & 688239 & 6.1862 & \multicolumn{2}{|c|}{5.417000000000001} & TRN \\
\hline CHEMBL1522906 & 688239 & 7.1864 & 5.475 & TRN & \\
\hline CHEMBL3211406 & 688239 & 4.4862 & 5.5498 & TST & \\
\hline CHEMBL1593154 & 688239 & 8.3372 & 5.3121 & TRN & \\
\hline CHEMBL279335 & 688239 & 4.6862 & 5.4776 & TRN & \\
\hline CHEMBL1584182 & 688239 & 4.8862 & 5.3329 & TST & \\
\hline CHEMBL1416557 & 688239 & 4.6362 & 5.5625 & TRN & \\
\hline CHEMBL1323504 & 688239 & 6.0362 & 5.3217 & TRN & \\
\hline CHEMBL1527739 & 688239 & 4.6862 & 5.4199 & TRN & \\
\hline CHEMBL1542948 & 688239 & 4.5862 & 5.5579 & TST & \\
\hline CHEMBL1447608 & 688239 & 6.8861 & 5.4641 & TRN & \\
\hline CHEMBL1442895 & 688239 & 4.5362 & 5.4535 & TRN & \\
\hline CHEMBL1464186 & 688239 & 5.9362 & 5.5382 & TST & \\
\hline CHEMBL1592687 & 688239 & 4.5362 & \multicolumn{2}{|c|}{5.4079999999999995} & TRN \\
\hline CHEMBL1306164 & 688239 & 4.5362 & 5.4473 & TST & \\
\hline CHEMBL1589442 & 688239 & 5.1362 & 5.4072 & TRN & \\
\hline CHEMBL1499558 & 688239 & 5.3862 & 5.3678 & TRN & \\
\hline CHEMBL1597022 & 688239 & 5.8862 & 5.5516 & TRN & \\
\hline CHEMBL1321559 & 688239 & 4.5862 & 5.4905 & TST & \\
\hline CHEMBL1321241 & 688239 & 7.0862 & 5.4435 & TRN & \\
\hline CHEMBL1513519 & 688239 & 4.5362 & 5.3382 & TRN & \\
\hline CHEMBL1386397 & 688239 & 5.1862 & 5.4506 & TRN & \\
\hline
\end{tabular}


Supplemental Table S2.txt

\begin{tabular}{|c|c|c|c|c|}
\hline CHEMBL1344491 & 688239 & 5.1862 & 5.3677 & TRN \\
\hline CHEMBL1407016 & 688239 & 5.9362 & 5.4226 & TRN \\
\hline CHEMBL1520519 & 688239 & 6.5363 & 5.4242 & TRN \\
\hline CHEMBL1420264 & 688239 & 5.9862 & 5.5043 & TST \\
\hline CHEMBL3193765 & 688239 & 5.0862 & 5.2887 & TRN \\
\hline CHEMBL1461980 & 688239 & 6.0362 & 5.5913 & TRN \\
\hline CHEMBL1335869 & 688239 & 5.7862 & 5.4062 & TRN \\
\hline CHEMBL 2005729 & 688239 & 6.5363 & \multicolumn{2}{|c|}{5.547999999999999} \\
\hline CHEMBL1370428 & 688239 & 4.7362 & 5.4298 & TRN \\
\hline CHEMBL1347006 & 688239 & 6.0862 & 5.5468 & TRN \\
\hline CHEMBL1329784 & 688239 & 5.8362 & 5.5026 & TRN \\
\hline CHEMBL1366147 & 688239 & 7.7352 & 5.5639 & TRN \\
\hline CHEMBL1582651 & 688239 & 5.1862 & 5.581 & TRN \\
\hline CHEMBL1337627 & 688239 & 4.7362 & 5.5069 & TRN \\
\hline CHEMBL1379480 & 688239 & 6.0362 & 5.2887 & TRN \\
\hline CHEMBL3199285 & 688239 & 5.9362 & 5.3717 & TRN \\
\hline CHEMBL1585220 & 688239 & 4.8362 & 5.4173 & TRN \\
\hline CHEMBL1426177 & 688239 & 6.8362 & 5.2795 & TRN \\
\hline CHEMBL1593847 & 688239 & 4.6362 & 5.4069 & TST \\
\hline CHEMBL1447770 & 688239 & 4.7362 & 5.5195 & TRN \\
\hline CHEMBL1343719 & 688239 & 4.5362 & 5.47 & TST \\
\hline CHEMBL1355355 & 688239 & 5.5362 & 5.5632 & TRN \\
\hline CHEMBL1374305 & 688239 & 4.5862 & 5.4198 & TRN \\
\hline CHEMBL1326718 & 688239 & 4.9862 & 5.5583 & TRN \\
\hline CHEMBL1507208 & 688239 & 4.7362 & 5.3275 & TRN \\
\hline CHEMBL1462806 & 688239 & 4.5362 & 5.473 & TST \\
\hline CHEMBL1346994 & 688239 & 6.1862 & 5.5221 & TRN \\
\hline CHEMBL1609781 & 688239 & 5.6362 & 5.4699 & TRN \\
\hline CHEMBL1451362 & 688239 & 5.6862 & 5.4492 & TRN \\
\hline CHEMBL1521589 & 688239 & 6.1362 & 5.4625 & TRN \\
\hline CHEMBL1527668 & 688239 & 5.1362 & \multicolumn{2}{|c|}{5.3660000000000005} \\
\hline CHEMBL1461426 & 688239 & 4.9362 & 5.5349 & TRN \\
\hline CHEMBL1512095 & 688239 & 4.5362 & 5.5413 & TRN \\
\hline CHEMBL1411518 & 688239 & 4.7862 & 5.3513 & TRN \\
\hline CHEMBL1556733 & 688239 & 4.8362 & 5.5023 & TRN \\
\hline CHEMBL1378092 & 688239 & 6.7862 & 5.5034 & TRN \\
\hline CHEMBL1327746 & 688239 & 5.0362 & 5.6363 & TRN \\
\hline CHEMBL1333892 & 688239 & 4.5362 & 5.3486 & TRN \\
\hline CHEMBL1321704 & 688239 & 4.5362 & 5.5172 & TRN \\
\hline CHEMBL1526065 & 688239 & 5.5862 & \multicolumn{2}{|c|}{5.547000000000001} \\
\hline CHEMBL1302892 & 688239 & 5.4862 & 5.5121 & TRN \\
\hline CHEMBL1454477 & 688239 & 4.5862 & 5.3771 & TRN \\
\hline CHEMBL1558015 & 688239 & 4.4862 & 5.4952 & TRN \\
\hline CHEMBL1389477 & 688239 & 5.7362 & 5.4647 & TRN \\
\hline CHEMBL1305779 & 688239 & 4.8362 & 5.52 & TRN \\
\hline CHEMBL1594965 & 688239 & 4.5362 & 5.5135 & TST \\
\hline CHEMBL1326243 & 688239 & 6.3362 & 5.4534 & TST \\
\hline CHEMBL1538089 & 688239 & 5.6862 & 5.5045 & TRN \\
\hline
\end{tabular}


Supplemental Table S2.txt

\begin{tabular}{|c|c|c|c|c|c|}
\hline CHEMBL1532856 & 688239 & 4.6362 & 5.5247 & TRN & \\
\hline CHEMBL1380390 & 688239 & 5.1862 & 5.6125 & TRN & \\
\hline CHEMBL1499016 & 688239 & 4.8362 & 5.4502 & TRN & \\
\hline CHEMBL1365224 & 688239 & 8.28399 & 99999999 & 5.6487 & $\mathrm{TI}$ \\
\hline CHEMBL 3213263 & 688239 & 5.2862 & 5.4487 & TST & \\
\hline CHEMBL1548138 & 688239 & 4.8362 & 5.3856 & TRN & \\
\hline CHEMBL1319869 & 688239 & 5.4862 & 5.6062 & TST & \\
\hline CHEMBL1475823 & 688239 & 6.8861 & 5.5319 & TRN & \\
\hline CHEMBL1445192 & 688239 & 5.7362 & 5.5128 & TRN & \\
\hline CHEMBL3196426 & 688239 & 4.7362 & 5.3644 & TST & \\
\hline CHEMBL1543965 & 688239 & 5.4862 & 5.4626 & TRN & \\
\hline CHEMBL1465656 & 688239 & 5.3862 & 5.4669 & TRN & \\
\hline CHEMBL 3144922 & 688239 & 5.1862 & 5.4899 & TST & \\
\hline CHEMBL1494509 & 688239 & 4.5362 & 5.447 & TRN & \\
\hline CHEMBL1546816 & 688239 & 8.3372 & 5.6278 & TST & \\
\hline CHEMBL1473018 & 688239 & 5.5362 & 5.6283 & TRN & \\
\hline CHEMBL1356883 & 688239 & 4.7862 & 5.4929 & TRN & \\
\hline CHEMBL1323463 & 688239 & 4.4862 & 5.4271 & TRN & \\
\hline CHEMBL1576029 & 688239 & 5.6362 & 5.5289 & TRN & \\
\hline CHEMBL1523651 & 688239 & 5.3362 & 5.5859 & TRN & \\
\hline CHEMBL1472479 & 688239 & 5.1862 & 5.5014 & TST & \\
\hline CHEMBL1608063 & 688239 & 6.1362 & 5.5891 & TRN & \\
\hline CHEMBL1527160 & 688239 & 4.9862 & 5.465 & TST & \\
\hline CHEMBL1591116 & 688239 & 6.6861 & 5.445 & TRN & \\
\hline CHEMBL 3192621 & 688239 & 4.8362 & 5.3832 & TRN & \\
\hline CHEMBL1542487 & 688239 & 5.1862 & 5.4403 & TRN & \\
\hline CHEMBL1527978 & 688239 & 6.1862 & 5.4133 & TRN & \\
\hline CHEMBL1381452 & 688239 & 5.8362 & \multicolumn{2}{|c|}{5.4479999999999995} & \\
\hline CHEMBL1464353 & 688239 & 8.28399 & 99999999 & 5.4823 & \\
\hline CHEMBL1485588 & 688239 & 5.9362 & 5.544 & TRN & \\
\hline CHEMBL1613414 & 688239 & 6.2362 & 5.5577 & TRN & \\
\hline CHEMBL339587 & 688239 & 4.4862 & 5.2971 & TST & \\
\hline CHEMBL1335921 & 688239 & 4.7362 & 5.4579 & TST & \\
\hline CHEMBL1600031 & 688239 & 5.0362 & 5.3783 & TST & \\
\hline CHEMBL1516602 & 688239 & 5.2362 & 5.4966 & TRN & \\
\hline CHEMBL1353617 & 688239 & 7.2366 & 5.5403 & TRN & \\
\hline CHEMBL200238 & 688239 & 6.1862 & 5.4321 & TRN & \\
\hline CHEMBL1449125 & 688239 & 5.1862 & 5.5026 & TRN & \\
\hline CHEMBL1327783 & 688239 & 6.3863 & 5.5659 & TST & \\
\hline CHEMBL1359213 & 688239 & 5.9362 & 5.2447 & TRN & \\
\hline CHEMBL1603929 & 688239 & 4.6362 & 5.4977 & TST & \\
\hline CHEMBL1545893 & 688239 & 6.4862 & 5.5249 & TRN & \\
\hline CHEMBL1419683 & 688239 & 5.1862 & 5.5367 & TRN & \\
\hline CHEMBL1343064 & 688239 & 5.3862 & 5.6148 & TST & \\
\hline CHEMBL1413678 & 688239 & 5.2362 & 5.5704 & TRN & \\
\hline CHEMBL1330729 & 688239 & 5.8362 & 5.4075 & TST & \\
\hline CHEMBL1596968 & 688239 & 5.3862 & 5.5353 & TST & \\
\hline CHEMBL1592775 & 688239 & 4.8862 & 5.4833 & TRN & \\
\hline
\end{tabular}

Page 1328 
Supplemental Table S2.txt

\begin{tabular}{|c|c|c|c|c|}
\hline 3 & & 52 & & \\
\hline HEMBL1450084 & & .1862 & & \\
\hline ICMPI & & & & \\
\hline AEMBL3: & & & & \\
\hline AEMBL1358361 & 38239 & 862 & & \\
\hline HEMBL1414515 & 88239 & 1362 & 305 & \\
\hline HEMBL146 & 239 & 362 & & \\
\hline IFMBI 13 & & & & \\
\hline AEMBL1403432 & 239 & & & \\
\hline HEMBL1542798 & 38239 & 864 & & \\
\hline HEMBL1503024 & 239 & 362 & & \\
\hline IEMBL13 & 39 & 62 & & \\
\hline AEMBL14 & & & & \\
\hline HEMBL15 & & & & \\
\hline AEMBL132 & & & & \\
\hline AEMBL137 & 39 & 62 & & \\
\hline HEMBL14 & & & & \\
\hline HEMBL15 & & & & \\
\hline AEMBL15: & & 362 & & \\
\hline AEMBL15 & & & & \\
\hline AEMBLI6 & & & & \\
\hline AEMBL11 & & & & \\
\hline HEMBL13 & & & & \\
\hline HEMBL134 & & & & \\
\hline HEMBL15e & & & & RN \\
\hline HEMBL135 & & 2 & & \\
\hline AEMBL14 & & & & RN \\
\hline HFMBI 16 & & & & ST \\
\hline HEMBL136 & & & & TST \\
\hline HEMBL3210 & & & 22 & ISI \\
\hline HEMBL14 & & 52 & & TRN \\
\hline HFMBI 13 & & & & Nov \\
\hline 1 & & & & ST \\
\hline HEMBL1566529 & & & & RN \\
\hline HEMBL1575247 & & 62 & & RN \\
\hline HEMBL15 & & & & \\
\hline HЕMP 1 & & & & RN \\
\hline HEMBL16 & & & & RN \\
\hline HEMBL1433319 & & 4.6862 & & TRN \\
\hline EMBL14 & & 362 & & RN \\
\hline HEMBL140 & & 53 & & \\
\hline CHEMBL1493 & & & & RN \\
\hline HEMBL1585099 & & & & RN \\
\hline AEMBL1465984 & 39 & 862 & 902 & RN \\
\hline MBL14 & & & & \\
\hline CHEMBL1495098 & & 5.3862 & & \\
\hline CHEMBL1568873 & & 4.7862 & 5.5309 & \\
\hline SHEMBL1443900 & 688239 & 4.8362 & 5.289 & ГRN \\
\hline
\end{tabular}

Page 1329 
Supplemental Table S2.txt

\begin{tabular}{|c|c|c|c|c|c|}
\hline CHEMBL1498529 & 688239 & 5.1862 & 5.4524 & TST & \\
\hline CHEMBL1541936 & 688239 & 5.2362 & 5.5707 & TRN & \\
\hline CHEMBL1601006 & 688239 & 4.8362 & 5.4274 & TRN & \\
\hline CHEMBL1360287 & 688239 & 4.7362 & 5.4934 & TRN & \\
\hline CHEMBL1595699 & 688239 & 4.5362 & 5.4818 & TRN & \\
\hline CHEMBL1415943 & 688239 & 6.2362 & 5.5159 & TRN & \\
\hline CHEMBL1302315 & 688239 & 4.5862 & 5.4187 & TRN & \\
\hline CHEMBL1583638 & 688239 & 4.5362 & 5.4351 & TRN & \\
\hline CHEMBL97643 & 688239 & 4.5362 & 5.42399 & 99999999995 & TRN \\
\hline CHEMBL1572600 & 688239 & 5.1862 & 5.2846 & TST & \\
\hline CHEMBL1439786 & 688239 & 5.0362 & 5.50200 & 0000000001 & TRN \\
\hline CHEMBL1467242 & 688239 & 6.7862 & 5.4158 & TST & \\
\hline CHEMBL1971965 & 688239 & 4.7362 & 5.5751 & TRN & \\
\hline CHEMBL1509091 & 688239 & 5.3862 & 5.42700 & 00000000005 & TST \\
\hline CHEMBL1373729 & 688239 & 6.1362 & 5.4376 & TRN & \\
\hline CHEMBL1360235 & 688239 & 5.6362 & 5.5039 & TST & \\
\hline CHEMBL1327600 & 688239 & 5.8362 & 5.4442 & TST & \\
\hline CHEMBL1592233 & 688239 & 4.7862 & 5.48799 & 99999999995 & TRN \\
\hline CHEMBL1538348 & 688239 & 8.3372 & 5.5173 & TRN & \\
\hline CHEMBL1373987 & 688239 & 4.7362 & 5.3381 & TRN & \\
\hline CHEMBL1352658 & 688239 & 5.4362 & 5.5659 & TST & \\
\hline CHEMBL1413835 & 688239 & 5.3362 & 5.42299 & 9999999999 & TRN \\
\hline CHEMBL1457107 & 688239 & 6.5363 & 5.5893 & TRN & \\
\hline CHEMBL1989603 & 688239 & 4.8862 & 5.4287 & TST & \\
\hline CHEMBL1304584 & 688239 & 4.4862 & 5.4376 & TRN & \\
\hline CHEMBL1583876 & 688239 & 4.4862 & 5.4415 & TRN & \\
\hline CHEMBL1435929 & 688239 & 6.4862 & 5.4805 & TRN & \\
\hline CHEMBL1494562 & 688239 & 5.6862 & 5.445 & TRN & \\
\hline CHEMBL1581648 & 688239 & 5.1862 & 5.5581 & TRN & \\
\hline CHEMBL3212126 & 688239 & 5.6362 & 5.4095 & TST & \\
\hline CHEMBL552134 & 688239 & 4.5362 & 5.6204 & TRN & \\
\hline CHEMBL1438412 & 688239 & 6.6861 & 5.4871 & TRN & \\
\hline CHEMBL1320953 & 688239 & 5.8362 & 5.519 & TRN & \\
\hline CHEMBL1344467 & 688239 & 5.4362 & 5.5952 & TRN & \\
\hline CHEMBL1353915 & 688239 & 4.6362 & 5.4847 & TRN & \\
\hline CHEMBL1528580 & 688239 & 4.6362 & 5.4442 & TRN & \\
\hline CHEMBL1362137 & 688239 & 4.7362 & 5.6301 & TRN & \\
\hline CHEMBL1564085 & 688239 & 5.1862 & 5.5017 & TRN & \\
\hline CHEMBL1546566 & 688239 & 4.5862 & 5.6613 & TRN & \\
\hline CHEMBL1320857 & 688239 & 4.5362 & 5.3791 & TST & \\
\hline CHEMBL1567895 & 688239 & 4.5862 & 5.4697 & TRN & \\
\hline CHEMBL1538346 & 688239 & 6.2362 & 5.473 & TRN & \\
\hline CHEMBL1357319 & 688239 & 7.0362 & 5.65 & TRN & \\
\hline CHEMBL1457782 & 688239 & 4.5362 & 5.5993 & TRN & \\
\hline CHEMBL1592415 & 688239 & 5.2862 & 5.4374 & TRN & \\
\hline CHEMBL1449156 & 688239 & 4.6362 & 5.5197 & TRN & \\
\hline CHEMBL1603489 & 688239 & 6.5862 & 5.5141 & TRN & \\
\hline CHEMBL1525630 & 688239 & 4.9362 & 5.5062 & TRN & \\
\hline
\end{tabular}


Supplemental Table S2.txt

\begin{tabular}{|c|c|c|c|c|}
\hline CHEMBL1519642 & 688239 & 4.6362 & 5.4632 & TRN \\
\hline CHEMBL1369397 & 688239 & 4.7862 & 5.4603 & TST \\
\hline CHEMBL3197634 & 688239 & 4.7862 & 5.4573 & TRN \\
\hline CHEMBL 2003939 & 688239 & 5.1862 & 5.5864 & TST \\
\hline CHEMBL1562783 & 688239 & 5.3362 & 5.55399 & 9999999999 \\
\hline CHEMBL1461549 & 688239 & 4.5362 & 5.5388 & TRN \\
\hline CHEMBL1367477 & 688239 & 4.7362 & 5.6771 & TRN \\
\hline CHEMBL1382654 & 688239 & 4.5862 & 5.566 & TRN \\
\hline CHEMBL1386573 & 688239 & 6.7862 & 5.4834 & TST \\
\hline CHEMBL1441921 & 688239 & 6.9863 & 5.5164 & TST \\
\hline CHEMBL1370219 & 688239 & 5.1862 & 5.4804 & TRN \\
\hline CHEMBL 81316 & 688239 & 6.0362 & 5.4819 & TRN \\
\hline CHEMBL1360234 & 688239 & 6.2362 & 5.4148 & TRN \\
\hline CHEMBL1439511 & 688239 & 4.5362 & 5.5236 & TRN \\
\hline CHEMBL1518058 & 688239 & 6.1362 & 5.4321 & TRN \\
\hline CHEMBL1596428 & 688239 & 7.1864 & 5.3889 & TRN \\
\hline CHEMBL1601910 & 688239 & 5.0362 & 5.4647 & TRN \\
\hline CHEMBL1465779 & 688239 & 5.2862 & 5.4452 & TST \\
\hline CHEMBL1478026 & 688239 & 4.8862 & 5.5091 & TRN \\
\hline CHEMBL1508918 & 688239 & 4.7362 & 5.5177 & TRN \\
\hline CHEMBL1505306 & 688239 & 5.2362 & 5.5818 & TRN \\
\hline CHEMBL1470159 & 688239 & 4.7862 & 5.4484 & TRN \\
\hline CHEMBL1585138 & 688239 & 4.9362 & 5.3157 & TRN \\
\hline CHEMBL1312316 & 688239 & 6.5363 & 5.5081 & TRN \\
\hline CHEMBL1307380 & 688239 & 6.5363 & 5.6614 & TRN \\
\hline CHEMBL1435795 & 688239 & 5.8862 & 5.4798 & TRN \\
\hline CHEMBL1573785 & 688239 & 6.2362 & 5.5383 & TRN \\
\hline CHEMBL1311534 & 688239 & 6.6362 & 5.4964 & TRN \\
\hline CHEMBL1536748 & 688239 & 7.2366 & 5.4639 & TRN \\
\hline CHEMBL1334731 & 688239 & 8.3372 & 5.5947 & TRN \\
\hline CHEMBL1386556 & 688239 & 5.9862 & 5.4806 & TRN \\
\hline CHEMBL1412616 & 688239 & 5.8862 & 5.3783 & TRN \\
\hline CHEMBL3145195 & 688239 & 5.1362 & 5.4953 & TST \\
\hline CHEMBL3197345 & 688239 & 4.95 & 5.3449 & TRN \\
\hline CHEMBL1565981 & 688239 & 4.8362 & 5.5069 & TRN \\
\hline CHEMBL1529986 & 688239 & 6.9863 & 5.4918 & TRN \\
\hline CHEMBL1399352 & 688239 & 5.8362 & 5.4352 & TRN \\
\hline CHEMBL3145085 & 688239 & 5.1862 & 5.5636 & TST \\
\hline CHEMBL1566503 & 688239 & 4.5362 & 5.4259 & TRN \\
\hline CHEMBL1585574 & 688239 & 4.8362 & 5.6803 & TRN \\
\hline CHEMBL1392219 & 688239 & 4.5362 & 5.4066 & TST \\
\hline CHEMBL1610941 & 688239 & 4.7862 & 5.4384 & TRN \\
\hline CHEMBL1429712 & 688239 & 4.7862 & 5.369 & TRN \\
\hline CHEMBL1554795 & 688239 & 4.5362 & 5.4085 & TRN \\
\hline CHEMBL1486158 & 688239 & 4.8362 & 5.3315 & TRN \\
\hline CHEMBL1570997 & 688239 & 5.3362 & 5.6344 & TST \\
\hline CHEMBL1545274 & 688239 & 7.3363 & 5.518 & TRN \\
\hline CHEMBL1343955 & 688239 & 6.3362 & 5.4387 & TST \\
\hline
\end{tabular}




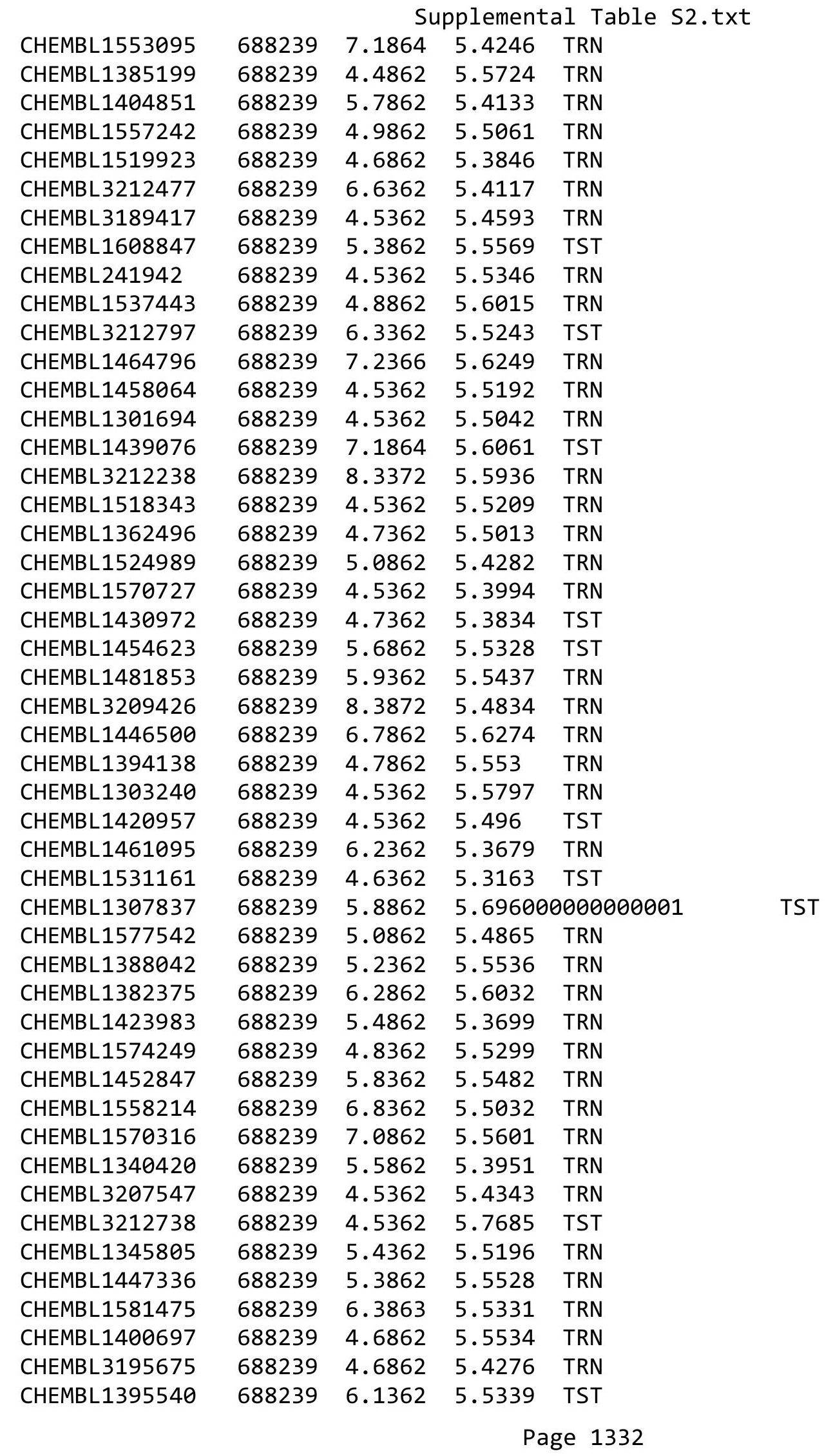


Supplemental Table S2.txt

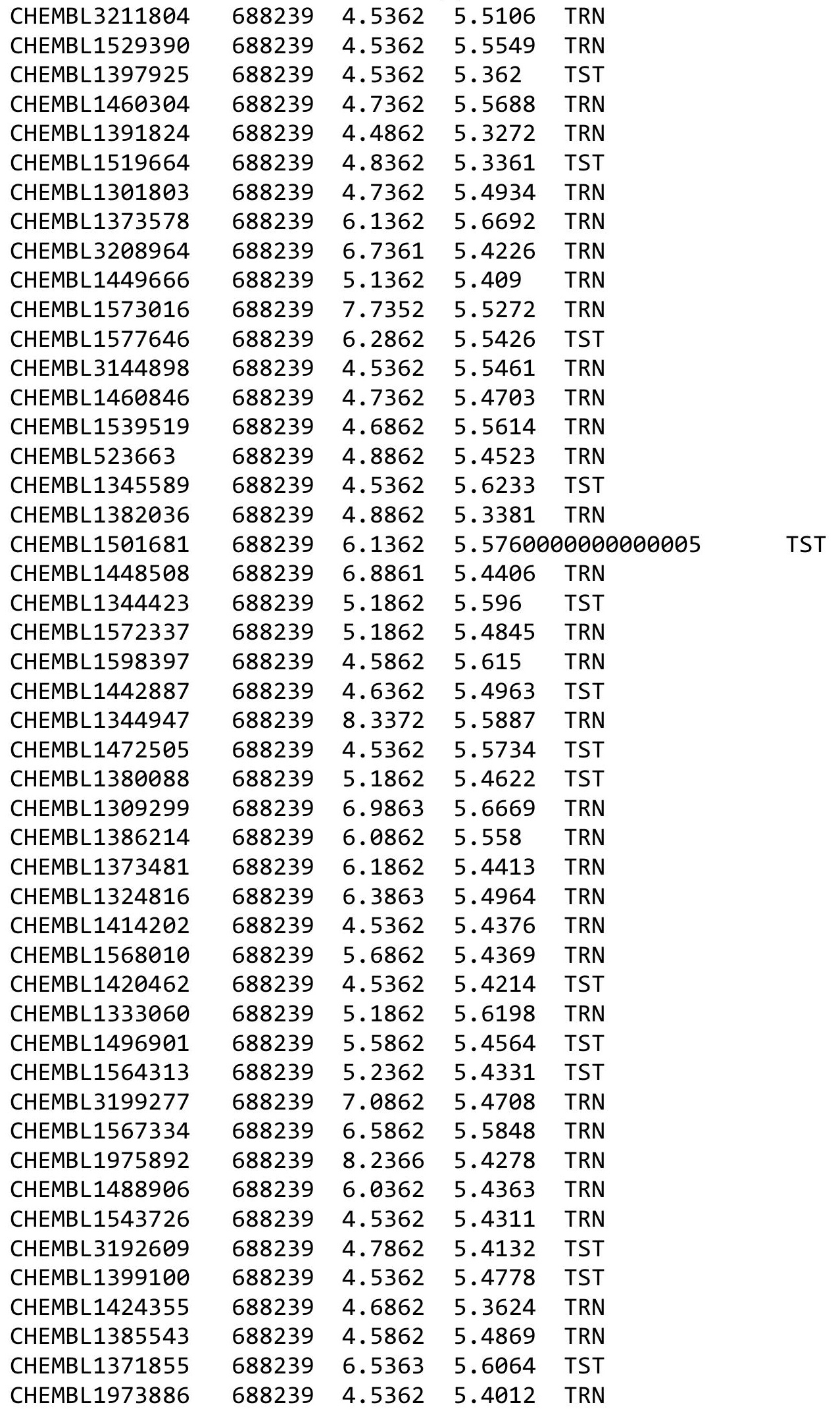

Page 1333 
Supplemental Table S2.txt

\begin{tabular}{|c|c|c|c|c|}
\hline CHEMBL1489810 & 688239 & 6.1362 & 5.544 & TRN \\
\hline CHEMBL1335910 & 688239 & 4.5362 & 5.5545 & TRN \\
\hline CHEMBL1404842 & 688239 & 4.5362 & 5.4126 & TRN \\
\hline CHEMBL1481179 & 688239 & 4.5362 & 5.3414 & TST \\
\hline CHEMBL1518312 & 688239 & 5.1862 & 5.3318 & TST \\
\hline CHEMBL1301527 & 688239 & 6.1862 & 5.6308 & TST \\
\hline CHEMBL1602989 & 688239 & 4.5362 & 5.4922 & TST \\
\hline CHEMBL1510517 & 688239 & 5.6862 & 5.6925 & TRN \\
\hline CHEMBL1506954 & 688239 & 5.0362 & 5.4591 & TRN \\
\hline CHEMBL1321450 & 688239 & 4.6862 & 5.4943 & TST \\
\hline CHEMBL1477640 & 688239 & 4.6362 & 5.4712 & TST \\
\hline CHEMBL1302840 & 688239 & 6.2362 & 5.6344 & TRN \\
\hline CHEMBL1576825 & 688239 & 7.0362 & 5.6088 & TRN \\
\hline CHEMBL1369954 & 688239 & 8.3372 & 5.5687 & TRN \\
\hline CHEMBL1424002 & 688239 & 5.1862 & 5.4766 & TRN \\
\hline CHEMBL1396617 & 688239 & 5.1862 & 5.5025 & TRN \\
\hline CHEMBL3190201 & 688239 & 5.5362 & 5.4941 & TST \\
\hline CHEMBL1501605 & 688239 & 4.8862 & 5.4664 & TRN \\
\hline CHEMBL1337481 & 688239 & 5.5862 & 5.4703 & TRN \\
\hline CHEMBL1385190 & 688239 & 4.5362 & 5.4384 & TRN \\
\hline CHEMBL1344428 & 688239 & 5.4362 & 5.4552 & TRN \\
\hline CHEMBL1612180 & 688239 & 5.6862 & 5.5972 & TRN \\
\hline CHEMBL1507537 & 688239 & 5.3862 & 5.5598 & TRN \\
\hline CHEMBL1416897 & 688239 & 5.5862 & 5.5175 & TRN \\
\hline CHEMBL1463413 & 688239 & 5.8862 & 5.4379 & TRN \\
\hline CHEMBL1505499 & 688239 & 5.8862 & 5.4443 & TRN \\
\hline CHEMBL1464373 & 688239 & 6.0862 & 5.5913 & TRN \\
\hline CHEMBL1566098 & 688239 & 5.0862 & 5.4443 & TRN \\
\hline CHEMBL1085705 & 688239 & 5.7362 & 5.596 & TRN \\
\hline CHEMBL1435780 & 688239 & 4.8862 & 5.5427 & TRN \\
\hline CHEMBL1598177 & 688239 & 6.6362 & 5.41799 & 9999999999 \\
\hline CHEMBL1322901 & 688239 & 8.3372 & 5.4608 & TST \\
\hline CHEMBL1309245 & 688239 & 6.0862 & 5.4526 & TRN \\
\hline CHEMBL1554175 & 688239 & 4.6362 & 5.481 & TST \\
\hline CHEMBL1372894 & 688239 & 4.5362 & 5.5019 & TRN \\
\hline CHEMBL1586106 & 688239 & 5.8862 & 5.7441 & TRN \\
\hline CHEMBL1526785 & 688239 & 5.2362 & 5.4983 & TST \\
\hline CHEMBL1584585 & 688239 & 6.0862 & 5.5007 & TRN \\
\hline CHEMBL1439177 & 688239 & 4.5362 & 5.4283 & TRN \\
\hline CHEMBL1442047 & 688239 & 6.5363 & 5.4481 & TRN \\
\hline CHEMBL1326534 & 688239 & 5.6862 & 5.5923 & TRN \\
\hline CHEMBL 3214589 & 688239 & 5.0862 & 5.4907 & TST \\
\hline CHEMBL1447466 & 688239 & 6.0362 & 5.4823 & TRN \\
\hline CHEMBL1340147 & 688239 & 6.1362 & 5.5029 & TRN \\
\hline CHEMBL1474080 & 688239 & 4.5862 & 5.4355 & TRN \\
\hline CHEMBL1347670 & 688239 & 6.9863 & 5.4696 & TRN \\
\hline CHEMBL1331483 & 688239 & 4.6362 & 5.4357 & TRN \\
\hline CHEMBL1539668 & 688239 & 4.5862 & 5.5033 & TRN \\
\hline
\end{tabular}


Supplemental Table S2.txt

\begin{tabular}{|c|c|c|c|c|c|}
\hline CHEMBL1379833 & 688239 & 4.8862 & 5.5518 & TRN & \\
\hline CHEMBL1480594 & 688239 & 4.4862 & 5.5989 & TRN & \\
\hline CHEMBL1518062 & 688239 & 4.5362 & 5.4971 & TRN & \\
\hline CHEMBL1358780 & 688239 & 4.7862 & 5.5758 & TST & \\
\hline CHEMBL1570511 & 688239 & 4.7362 & 5.5435 & TRN & \\
\hline CHEMBL1557173 & 688239 & 6.8362 & 5.4287 & TRN & \\
\hline CHEMBL1436313 & 688239 & 5.5862 & 5.4384 & TRN & \\
\hline CHEMBL1418948 & 688239 & 5.1862 & 5.4195 & TRN & \\
\hline CHEMBL1321765 & 688239 & 4.7362 & 5.4664 & TRN & \\
\hline CHEMBL1392400 & 688239 & 5.1862 & 5.5055 & TRN & \\
\hline CHEMBL1462010 & 688239 & 6.0862 & 5.4075 & TRN & \\
\hline CHEMBL1380513 & 688239 & 7.2366 & 5.6484 & TRN & \\
\hline CHEMBL1541433 & 688239 & 7.2865 & 5.5039 & TST & \\
\hline CHEMBL1360534 & 688239 & 4.5362 & 5.4716 & TRN & \\
\hline CHEMBL1569862 & 688239 & 6.9863 & 5.4869 & TRN & \\
\hline CHEMBL1465114 & 688239 & 4.6362 & 5.3979 & TRN & \\
\hline CHEMBL1301374 & 688239 & 4.4862 & 5.3175 & TRN & \\
\hline CHEMBL1339930 & 688239 & 4.6362 & 5.5759 & TRN & \\
\hline CHEMBL1470926 & 688239 & 5.3862 & 5.5434 & TST & \\
\hline CHEMBL1340942 & 688239 & 5.6862 & 5.482 & TRN & \\
\hline CHEMBL 3208878 & 688239 & \multicolumn{3}{|c|}{ 8. 283999999999999} & TRN \\
\hline CHEMBL1402366 & 688239 & 6.8861 & 5.7139 & TRN & \\
\hline CHEMBL1446839 & 688239 & 5.6862 & 5.5091 & TRN & \\
\hline CHEMBL1379092 & 688239 & 4.8862 & 5.5741 & TRN & \\
\hline CHEMBL1540648 & 688239 & 4.8862 & \multicolumn{2}{|c|}{5.486000000000001} & \\
\hline CHEMBL1338480 & 688239 & 5.1362 & 5.5956 & TRN & \\
\hline CHEMBL1346683 & 688239 & 7.0362 & 5.5594 & TRN & \\
\hline CHEMBL 3190482 & 688239 & 4.7362 & 5.4068 & TST & \\
\hline CHEMBL1459397 & 688239 & 6.2362 & \multicolumn{2}{|c|}{5.492000000000001} & TRN \\
\hline CHEMBL1513092 & 688239 & 4.7862 & 5.4586 & TST & \\
\hline CHEMBL1344487 & 688239 & 5.5362 & 5.4914 & TST & \\
\hline CHEMBL1539805 & 688239 & 8.3372 & 5.5746 & TRN & \\
\hline CHEMBL1397361 & 688239 & 5.3362 & 5.5074 & TRN & \\
\hline CHEMBL1489605 & 688239 & 5.4362 & 5.4485 & TRN & \\
\hline CHEMBL1376344 & 688239 & 6.7862 & 5.3107 & TRN & \\
\hline CHEMBL1605940 & 688239 & 4.4862 & 5.3868 & TST & \\
\hline CHEMBL1501468 & 688239 & 6.8362 & 5.4579 & TRN & \\
\hline CHEMBL1541886 & 688239 & 4.6862 & 5.3838 & TST & \\
\hline CHEMBL1389950 & 688239 & 6.6861 & 5.3717 & TRN & \\
\hline CHEMBL1429636 & 688239 & 4.8362 & 5.3702 & TRN & \\
\hline CHEMBL1461178 & 688239 & 7.0362 & 5.4421 & TRN & \\
\hline CHEMBL1559980 & 688239 & 6.1362 & \multicolumn{2}{|c|}{5.486000000000001} & זעי \\
\hline CHEMBL1329168 & 688239 & 4.6862 & 5.4656 & TRN & \\
\hline CHEMBL1355425 & 688239 & 5.1862 & 5.5199 & TRN & \\
\hline CHEMBL1549667 & 688239 & 4.8362 & 5.4953 & TRN & \\
\hline CHEMBL1413832 & 688239 & 6.8861 & 5.6543 & TRN & \\
\hline CHEMBL1605335 & 688239 & 5.8362 & 5.5665 & TRN & \\
\hline CHEMBL3213980 & 688239 & 4.8362 & 5.3896 & TRN & \\
\hline
\end{tabular}


Supplemental Table S2.txt

\begin{tabular}{|c|c|c|c|c|}
\hline CHEMBL1315456 & 688239 & 5.1862 & 5.5516 & TRN \\
\hline CHEMBL1490590 & 688239 & 6.2362 & 5.6636 & TRN \\
\hline CHEMBL1568163 & 688239 & 4.8362 & 5.4936 & TRN \\
\hline CHEMBL1477632 & 688239 & 4.8362 & 5.5442 & TRN \\
\hline CHEMBL1314963 & 688239 & 6.6362 & 5.4818 & TRN \\
\hline CHEMBL1607366 & 688239 & 5.5362 & 5.5972 & TST \\
\hline CHEMBL1473150 & 688239 & 4.9362 & 5.5078 & TRN \\
\hline CHEMBL1449316 & 688239 & 7.0862 & 5.707999 & (999999999 \\
\hline CHEMBL1380630 & 688239 & 8.3372 & 5.6295 & TRN \\
\hline CHEMBL1548731 & 688239 & 5.0862 & 5.4075 & TRN \\
\hline CHEMBL1460432 & 688239 & 4.8862 & 5.6547 & TRN \\
\hline CHEMBL1466774 & 688239 & 4.7862 & 5.3444 & TRN \\
\hline CHEMBL1458982 & 688239 & 4.4862 & 5.4207 & TST \\
\hline CHEMBL1602411 & 688239 & 8.28399 & 99999999 & 5.5433 \\
\hline CHEMBL1389002 & 688239 & 5.8862 & 5.5419 & TRN \\
\hline CHEMBL1524186 & 688239 & 6.2362 & 5.4198 & TRN \\
\hline CHEMBL1601210 & 688239 & 5.6862 & 5.3364 & TRN \\
\hline CHEMBL1417239 & 688239 & 6.5862 & 5.5599 & TRN \\
\hline CHEMBL1496886 & 688239 & 4.5362 & 5.4589 & TRN \\
\hline CHEMBL1545895 & 688239 & 5.7862 & 5.5513 & TRN \\
\hline CHEMBL1305842 & 688239 & 5.6862 & 5.3841 & TRN \\
\hline CHEMBL1560429 & 688239 & 6.0362 & 5.4458 & TRN \\
\hline CHEMBL1600240 & 688239 & 5.2362 & 5.3996 & TRN \\
\hline CHEMBL1500293 & 688239 & 4.7362 & 5.3883 & TRN \\
\hline CHEMBL1470683 & 688239 & 5.6362 & 5.6553 & TRN \\
\hline CHEMBL1490529 & 688239 & 5.1862 & 5.3525 & TRN \\
\hline CHEMBL1580604 & 688239 & 4.7862 & 5.3759 & TRN \\
\hline CHEMBL1311380 & 688239 & 5.2362 & 5.5152 & TRN \\
\hline CHEMBL1358997 & 688239 & 5.9362 & 5.6293 & TST \\
\hline CHEMBL1502201 & 688239 & 4.5362 & 5.3985 & TST \\
\hline CHEMBL1556896 & 688239 & 6.5363 & 5.5493 & TRN \\
\hline CHEMBL1530932 & 688239 & 4.5362 & 5.356 & TRN \\
\hline CHEMBL1464447 & 688239 & 5.5862 & 5.3922 & TRN \\
\hline CHEMBL1442816 & 688239 & 6.9863 & 5.3529 & TRN \\
\hline CHEMBL1610791 & 688239 & 7.7352 & 5.4186 & TRN \\
\hline CHEMBL1584309 & 688239 & 5.2362 & 5.4496 & TST \\
\hline CHEMBL1576875 & 688239 & 4.6862 & 5.4361 & TRN \\
\hline CHEMBL1389937 & 688239 & 4.8862 & 5.501 & TRN \\
\hline CHEMBL1453529 & 688239 & 5.7362 & 5.6071 & TRN \\
\hline CHEMBL1550788 & 688239 & 4.6362 & 5.5808 & TRN \\
\hline CHEMBL3191069 & 688239 & 6.2862 & 5.4777 & TRN \\
\hline CHEMBL1541473 & 688239 & 5.4362 & 5.4071 & TRN \\
\hline CHEMBL1589529 & 688239 & 6.8861 & 5.4694 & TRN \\
\hline CHEMBL1524636 & 688239 & 4.6362 & 5.4874 & TRN \\
\hline CHEMBL1500114 & 688239 & 6.2862 & 5.496 & TST \\
\hline CHEMBL1447221 & 688239 & 5.1862 & 5.3476 & TRN \\
\hline CHEMBL1417246 & 688239 & 6.7862 & 5.6697 & TRN \\
\hline CHEMBL1538019 & 688239 & 6.6861 & 5.5945 & TRN \\
\hline
\end{tabular}

Page 1336 
Supplemental Table S2.txt

\begin{tabular}{|c|c|c|c|c|c|}
\hline CHEMBL1382834 & 688239 & 5.1862 & 5.4303 & TST & \\
\hline CHEMBL1323647 & 688239 & 5.3362 & 5.3658 & TRN & \\
\hline CHEMBL1306995 & 688239 & 4.5362 & 5.5113 & TRN & \\
\hline CHEMBL1583308 & 688239 & 5.1362 & 5.5287 & TRN & \\
\hline CHEMBL1451175 & 688239 & 5.8362 & 5.5091 & TRN & \\
\hline CHEMBL3208661 & 688239 & 7.0862 & 5.3476 & TRN & \\
\hline CHEMBL1564276 & 688239 & 4.6362 & 5.4378 & TRN & \\
\hline CHEMBL1480968 & 688239 & 5.0362 & 5.643 & TRN & \\
\hline CHEMBL1608638 & 688239 & 5.6362 & 5.4583 & TRN & \\
\hline CHEMBL1437237 & 688239 & 6.3863 & 5.4675 & TRN & \\
\hline CHEMBL1488888 & 688239 & 5.3862 & 5.5368 & TST & \\
\hline CHEMBL3197098 & 688239 & 8.3372 & 5.4471 & TRN & \\
\hline CHEMBL1308727 & 688239 & 5.1862 & 5.5093 & TRN & \\
\hline CHEMBL1502338 & 688239 & 4.7362 & 5.4832 & TRN & \\
\hline CHEMBL1512529 & 688239 & 5.5862 & 5.5072 & TRN & \\
\hline CHEMBL1593606 & 688239 & 4.7862 & 5.4027 & TRN & \\
\hline CHEMBL374632 & 688239 & 4.7362 & 5.4405 & TRN & \\
\hline CHEMBL3198822 & 688239 & 5.8362 & 5.2631 & TRN & \\
\hline CHEMBL1582238 & 688239 & 5.1862 & 5.3386 & TRN & \\
\hline CHEMBL1535818 & 688239 & 4.5362 & 5.5506 & TRN & \\
\hline CHEMBL1596265 & 688239 & 4.5362 & 5.5902 & TRN & \\
\hline CHEMBL3190800 & 688239 & 8.3372 & 5.2877 & TRN & \\
\hline CHEMBL1460653 & 688239 & 6.0362 & 5.4557 & TRN & \\
\hline CHEMBL1564632 & 688239 & 4.6862 & 5.3043 & TRN & \\
\hline CHEMBL1365006 & 688239 & 4.5362 & 5.482 & TRN & \\
\hline CHEMBL1379943 & 688239 & 6.8362 & 5.529 & TRN & \\
\hline CHEMBL1370425 & 688239 & 6.2362 & 5.4085 & TRN & \\
\hline CHEMBL1439453 & 688239 & 5.4862 & 5.4654 & TRN & \\
\hline CHEMBL1586040 & 688239 & 5.5862 & 5.4657 & TRN & \\
\hline CHEMBL1420987 & 688239 & 5.4862 & 5.5841 & TRN & \\
\hline CHEMBL1452354 & 688239 & 4.4862 & 5.4879 & TRN & \\
\hline CHEMBL1500711 & 688239 & 6.1862 & 5.5009 & TRN & \\
\hline CHEMBL1337058 & 688239 & 8.2366 & 5.6328 & TRN & \\
\hline CHEMBL1540370 & 688239 & 4.9362 & 5.4413 & TST & \\
\hline CHEMBL1468774 & 688239 & 4.5862 & 5.5997 & TST & \\
\hline CHEMBL1557724 & 688239 & 5.1862 & 5.5194 & TST & \\
\hline CHEMBL1310384 & 688239 & 4.7362 & 5.4617 & TRN & \\
\hline CHEMBL1469341 & 688239 & 5.2362 & 5.6432 & TRN & \\
\hline CHEMBL1567084 & 688239 & 5.1362 & 5.3781 & TRN & \\
\hline CHEMBL1982658 & 688239 & 5.6862 & 5.472 & TRN & \\
\hline CHEMBL1606776 & 688239 & 5.1862 & 5.5278 & TST & \\
\hline CHEMBL1368269 & 688239 & 4.5362 & 5.4494 & TRN & \\
\hline CHEMBL1474620 & 688239 & 6.9863 & 5.6276 & TST & \\
\hline CHEMBL1441768 & 688239 & 5.8862 & 5.5768 & TRN & \\
\hline CHEMBL1586462 & 688239 & 4.9362 & 5.2956 & TRN & \\
\hline CHEMBL1332241 & 688239 & 5.4862 & 5.3539 & TRN & \\
\hline CHEMBL1415014 & 688239 & 5.1862 & 5.4979 & TRN & \\
\hline CHEMBL1574011 & 688239 & 8.28399 & 79999999 & & 5.4196 \\
\hline
\end{tabular}


Supplemental Table S2.txt

\begin{tabular}{|c|c|c|c|c|c|}
\hline CHEMBL1407105 & 688239 & 5.3862 & 5.5603 & TST & \\
\hline CHEMBL1546629 & 688239 & 4.5862 & 5.5536 & TRN & \\
\hline CHEMBL3211277 & 688239 & 5.1862 & 5.4743 & TST & \\
\hline CHEMBL1455593 & 688239 & 5.7362 & 5.4333 & TRN & \\
\hline CHEMBL1379087 & 688239 & 4.7362 & 5.4521 & TST & \\
\hline CHEMBL1483788 & 688239 & 4.6362 & 5.374 & TST & \\
\hline CHEMBL1334581 & 688239 & 4.5362 & 5.4665 & TRN & \\
\hline CHEMBL1579877 & 688239 & 4.9362 & 5.5309 & TST & \\
\hline CHEMBL1451828 & 688239 & 4.5362 & 5.4711 & TRN & \\
\hline CHEMBL1515207 & 688239 & 4.6862 & 5.3925 & TRN & \\
\hline CHEMBL1467023 & 688239 & 4.6862 & 5.5225 & TRN & \\
\hline CHEMBL1555273 & 688239 & 5.1862 & 5.5503 & TRN & \\
\hline CHEMBL3213803 & 688239 & 5.1862 & 5.4218 & TRN & \\
\hline CHEMBL1463310 & 688239 & 6.0862 & 5.5219 & TRN & \\
\hline CHEMBL1488017 & 688239 & 4.8362 & 5.56 & TRN & \\
\hline CHEMBL1572624 & 688239 & 4.5362 & 5.4607 & TRN & \\
\hline CHEMBL1593205 & 688239 & 6.8861 & 5.5292 & TRN & \\
\hline CHEMBL1584806 & 688239 & 5.1862 & 5.4575 & TST & \\
\hline CHEMBL1547285 & 688239 & 5.3362 & 5.4447 & TRN & \\
\hline CHEMBL 2007598 & 688239 & 4.6362 & 5.371 & TRN & \\
\hline CHEMBL1370694 & 688239 & 4.5362 & 5.3169 & TST & \\
\hline CHEMBL1333929 & 688239 & 6.0 & 5.3846 & TRN & \\
\hline CHEMBL1514206 & 688239 & 5.2362 & 5.6477 & TRN & \\
\hline CHEMBL1387358 & 688239 & 5.0362 & 5.3898 & TRN & \\
\hline CHEMBL1522650 & 688239 & 4.5362 & 5.6939 & TRN & \\
\hline CHEMBL1336413 & 688239 & 6.2862 & 5.445 & TRN & \\
\hline CHEMBL1439442 & 688239 & 4.5362 & 5.5514 & TRN & \\
\hline CHEMBL1340856 & 688239 & 6.2362 & 5.4658 & TST & \\
\hline CHEMBL1592359 & 688239 & 6.6861 & 5.6085 & TRN & \\
\hline CHEMBL3192087 & 688239 & 5.8862 & 5.4873 & TRN & \\
\hline CHEMBL1441614 & 688239 & 5.1862 & 5.559 & TST & \\
\hline CHEMBL1565226 & 688239 & 5.1862 & 5.4791 & TST & \\
\hline CHEMBL1572185 & 688239 & 8.28399 & 99999999 & 5.5042 & TST \\
\hline CHEMBL3211822 & 688239 & 6.0862 & 5.4404 & TRN & \\
\hline CHEMBL1340375 & 688239 & 6.1862 & 5.3692 & TST & \\
\hline CHEMBL1455267 & 688239 & 4.6362 & 5.4666 & TRN & \\
\hline CHEMBL1410182 & 688239 & 5.2362 & 5.468999 & 9999999999 & TRI \\
\hline CHEMBL1543404 & 688239 & 4.7362 & 5.5154 & TST & \\
\hline CHEMBL3192009 & 688239 & 4.7362 & 5.4405 & TRN & \\
\hline CHEMBL1385874 & 688239 & 6.1362 & 5.4766 & TRN & \\
\hline CHEMBL1526013 & 688239 & 5.3862 & 5.6264 & TRN & \\
\hline CHEMBL1336046 & 688239 & 4.7862 & 5.4602 & TRN & \\
\hline CHEMBL1552860 & 688239 & 5.0362 & 5.4151 & TRN & \\
\hline CHEMBL1400278 & 688239 & 4.4862 & 5.4605 & TST & \\
\hline CHEMBL1313918 & 688239 & 5.6362 & 5.502999 & 9999999999 & TRN \\
\hline CHEMBL1326200 & 688239 & 8.3372 & 5.4393 & TRN & \\
\hline CHEMBL1443454 & 688239 & 4.5862 & 5.4448 & TRN & \\
\hline CHEMBL1416962 & 688239 & 4.6862 & 5.4064 & TRN & \\
\hline
\end{tabular}


Supplemental Table S2.txt

\begin{tabular}{|c|c|c|c|c|}
\hline CHEMBL 3189954 & 688239 & 4.5362 & 5.305 & TST \\
\hline CHEMBL1402272 & 688239 & 5.6862 & 5.4408 & TRN \\
\hline CHEMBL1314123 & 688239 & 8.2366 & 5.3785 & TRN \\
\hline CHEMBL1612247 & 688239 & 4.5362 & 5.3784 & TRN \\
\hline CHEMBL1460090 & 688239 & 4.5362 & 5.6186 & TRN \\
\hline CHEMBL329836 & 688239 & 4.5362 & 5.4587 & TST \\
\hline CHEMBL1335956 & 688239 & 6.2862 & 5.4254 & TRN \\
\hline CHEMBL1609727 & 688239 & 4.8362 & 5.4322 & TRN \\
\hline CHEMBL1364639 & 688239 & 4.8362 & 5.3094 & TRN \\
\hline CHEMBL1458630 & 688239 & 5.9362 & 5.519 & TST \\
\hline CHEMBL1328414 & 688239 & 4.9862 & 5.5014 & TRN \\
\hline CHEMBL1311782 & 688239 & 5.1862 & 5.4732 & TRN \\
\hline CHEMBL1534867 & 688239 & 4.5362 & 5.414 & TRN \\
\hline CHEMBL1578591 & 688239 & 4.6862 & 5.3055 & TST \\
\hline CHEMBL1572836 & 688239 & 4.6862 & 5.6001 & TRN \\
\hline CHEMBL1379841 & 688239 & 6.9863 & 5.4655 & TRN \\
\hline CHEMBL1375255 & 688239 & 6.2862 & 5.532 & TRN \\
\hline CHEMBL 2001024 & 688239 & 4.5362 & 5.4174 & TRN \\
\hline CHEMBL1485953 & 688239 & 5.1862 & 5.4392 & TRN \\
\hline CHEMBL1405935 & 688239 & 4.5362 & 5.5254 & TRN \\
\hline CHEMBL1498716 & 688239 & 5.8862 & 5.4361 & TRN \\
\hline CHEMBL1498001 & 688239 & 4.7862 & 5.5095 & TRN \\
\hline CHEMBL1393133 & 688239 & 6.8362 & 5.4866 & TRN \\
\hline CHEMBL1601739 & 688239 & 4.4862 & 5.6673 & TRN \\
\hline CHEMBL1489593 & 688239 & 8.3372 & 5.4016 & TST \\
\hline CHEMBL1586286 & 688239 & 4.5862 & 5.5903 & TRN \\
\hline CHEMBL1352323 & 688239 & 4.5362 & 5.6302 & TRN \\
\hline CHEMBL1581518 & 688239 & 5.8862 & 5.6519 & TST \\
\hline CHEMBL1490904 & 688239 & 4.6362 & 5.3884 & TRN \\
\hline CHEMBL1608228 & 688239 & 5.2862 & 5.5136 & TST \\
\hline CHEMBL1446369 & 688239 & 5.1862 & 5.4851 & TRN \\
\hline CHEMBL1567788 & 688239 & 5.2362 & 5.5071 & TRN \\
\hline CHEMBL3193692 & 688239 & 6.7862 & 5.4999 & TRN \\
\hline CHEMBL1459976 & 688239 & 5.1862 & 5.3925 & TRN \\
\hline CHEMBL1978549 & 688239 & 6.7361 & 5.4872 & TRN \\
\hline CHEMBL1422693 & 688239 & 5.5862 & 5.4762 & TRN \\
\hline CHEMBL1370459 & 688239 & 4.6362 & 5.3409 & TRN \\
\hline CHEMBL1319714 & 688239 & 5.2362 & 5.4842 & TRN \\
\hline CHEMBL1410990 & 688239 & 4.5362 & 5.5023 & TRN \\
\hline CHEMBL1987145 & 688239 & 4.4862 & 5.4261 & TRN \\
\hline CHEMBL1612110 & 688239 & 4.7362 & 5.5139 & TRN \\
\hline CHEMBL1361227 & 688239 & 4.7862 & 5.2762 & TRN \\
\hline CHEMBL1524840 & 688239 & 4.8862 & 5.5069 & TRN \\
\hline CHEMBL1515931 & 688239 & 4.8862 & 5.45299 & 9999999999 \\
\hline CHEMBL1533459 & 688239 & 4.6862 & 5.4005 & TRN \\
\hline CHEMBL1531995 & 688239 & 8.3372 & 5.5905 & TRN \\
\hline CHEMBL1406753 & 688239 & 5.4862 & 5.5554 & TRN \\
\hline CHEMBL3198926 & 688239 & 4.5362 & 5.7167 & TRN \\
\hline
\end{tabular}

Page 1339 
Supplemental Table S2.txt

\begin{tabular}{|c|c|c|c|c|}
\hline 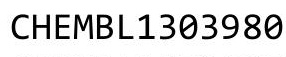 & & & 6772 & \\
\hline HEMBL1552085 & 88239 & 4362 & 4963 & \\
\hline HEMBL1308994 & 88239 & 5362 & & \\
\hline 94 & & & & \\
\hline EMBL1463282 & & & 1729 & \\
\hline HEMBL1546196 & 88239 & 362 & 5171 & \\
\hline HEMBL1424751 & 88239 & .8362 & .6142 & \\
\hline HEMBL14 & & & & \\
\hline IEMBL15 & 39 & & 4242 & \\
\hline EMBL15 & 39 & & .484 & \\
\hline HEMBL1525634 & 88239 & 362 & .4521 & \\
\hline HEMBL1522648 & 39 & & .4723 & \\
\hline HEMBL1311042 & 39 & & 3728 & \\
\hline AEME & 39 & & .6097 & \\
\hline AEMBL16 & 39 & & .4759 & \\
\hline AEMBL14ع & 39 & & 4804 & \\
\hline HEMBL1530662 & 39 & & & \\
\hline HEMBL 148 & 9 & & 554 & \\
\hline HEM & 39 & & & \\
\hline HEME & 39 & & 507 & \\
\hline HEMBL 14 & 39 & & 737 & \\
\hline HEMBL152 & 39 & & & \\
\hline HEMBL13 & 39 & & & \\
\hline HEMBL14 & & & & \\
\hline HEM & 39 & & 209 & \\
\hline HEMBL136 & 39 & & & \\
\hline HEMBL1468950 & 39 & & & ГRN \\
\hline HEMBL10 & 9 & & & \\
\hline HEME & & & 91 & \\
\hline HEM & & & 452 & RN \\
\hline HEMBL16013 & 9 & & & IRN \\
\hline HEMBL1545548 & 39 & & 887 & ГRN \\
\hline HEMBL32 & & & & וד \\
\hline HEM & 9 & & 32 & RN \\
\hline HEMBL13 & & & 5.3344 & RN \\
\hline HEMBL1596502 & 39 & & 5.4512 & IST \\
\hline HEMBL1484070 & 88 & & 3576 & RN \\
\hline 政T & 39 & & 804 & | \\
\hline ר 19 & 39 & & 033 & TRN \\
\hline HEMBL157 & & & & RN \\
\hline HEMBL1462741 & 88239 & 363 & 5.5806 & RN \\
\hline HEMBL13 & 39 & & 5.5977 & ГRN \\
\hline LI & & & & \\
\hline HEMBL1503749 & 39 & & .2851 & IRIN \\
\hline HEMBL1469292 & & & 5.4421 & ST \\
\hline HEMBL1583585 & 39 & 62 & .3729 & $N$ \\
\hline & & & & \\
\hline . & & & & \\
\hline
\end{tabular}

Page 1340 
Supplemental Table S2.txt

\begin{tabular}{|c|c|c|c|c|c|}
\hline CHEMBL3194285 & 688239 & 5.5362 & 5.3862 & TST & \\
\hline CHEMBL1391528 & 688239 & 5.2862 & 5.4899 & TST & \\
\hline CHEMBL1522850 & 688239 & 4.5362 & \multicolumn{2}{|c|}{5.5360000000000005} & TRN \\
\hline CHEMBL1466712 & 688239 & 5.9862 & 5.4957 & TRN & \\
\hline CHEMBL1429748 & 688239 & 6.3362 & 5.5235 & TRN & \\
\hline CHEMBL1561597 & 688239 & 4.5362 & 5.5386 & TRN & \\
\hline CHEMBL1479116 & 688239 & 5.6862 & 5.5208 & TRN & \\
\hline CHEMBL1543574 & 688239 & 4.6362 & 5.3408 & TST & \\
\hline CHEMBL1335448 & 688239 & 4.5862 & 5.6248 & TRN & \\
\hline CHEMBL1482272 & 688239 & 5.8362 & 5.5443 & TRN & \\
\hline CHEMBL 2369306 & 688239 & 4.7362 & 5.5105 & TST & \\
\hline CHEMBL1337117 & 688239 & 6.0862 & 5.5162 & TRN & \\
\hline CHEMBL1382267 & 688239 & 5.4362 & 5.5047 & TST & \\
\hline CHEMBL1485709 & 688239 & 5.3362 & 5.5451 & TRN & \\
\hline CHEMBL1458846 & 688239 & 6.8362 & 5.5255 & TRN & \\
\hline CHEMBL1606505 & 688239 & 6.6861 & 5.4544 & TRN & \\
\hline CHEMBL1430315 & 688239 & 4.6362 & 5.5853 & TRN & \\
\hline CHEMBL1347728 & 688239 & 7.6861 & 5.6017 & TRN & \\
\hline CHEMBL1502215 & 688239 & 5.1362 & 5.6031 & TRN & \\
\hline CHEMBL1466114 & 688239 & 5.8362 & 5.4816 & TRN & \\
\hline CHEMBL1352228 & 688239 & 4.5362 & 5.4095 & TRN & \\
\hline CHEMBL1601593 & 688239 & 6.4862 & 5.5687 & TRN & \\
\hline CHEMBL1345527 & 688239 & 5.7362 & 5.4904 & TRN & \\
\hline CHEMBL1365294 & 688239 & 5.1862 & 5.4965 & TRN & \\
\hline CHEMBL1380138 & 688239 & 5.1362 & \multicolumn{2}{|c|}{5.417000000000001} & TRN \\
\hline CHEMBL1333951 & 688239 & 5.8362 & 5.3534 & TRN & \\
\hline CHEMBL1327111 & 688239 & 5.1862 & 5.5976 & TRN & \\
\hline CHEMBL1595404 & 688239 & 4.5362 & 5.414 & TRN & \\
\hline CHEMBL3193786 & 688239 & 4.5362 & 5.4882 & TRN & \\
\hline CHEMBL1494350 & 688239 & 5.1362 & 5.4736 & TRN & \\
\hline CHEMBL1467935 & 688239 & 4.6362 & 5.4745 & TRN & \\
\hline CHEMBL1403787 & 688239 & 4.7362 & 5.4762 & TRN & \\
\hline CHEMBL1373531 & 688239 & 6.2362 & 5.6063 & TST & \\
\hline CHEMBL1318026 & 688239 & 6.9363 & 5.6414 & TRN & \\
\hline CHEMBL1440858 & 688239 & 6.9363 & 5.4834 & TRN & \\
\hline CHEMBL1337211 & 688239 & 5.2862 & 5.4711 & TRN & \\
\hline CHEMBL1347634 & 688239 & 4.5862 & 5.5154 & TST & \\
\hline CHEMBL 338743 & 688239 & 6.8362 & 5.6547 & TST & \\
\hline CHEMBL3193106 & 688239 & 5.7862 & 5.4775 & TRN & \\
\hline CHEMBL1488665 & 688239 & 5.0862 & 5.381 & TRN & \\
\hline CHEMBL1401936 & 688239 & 4.6362 & 5.6443 & TRN & \\
\hline CHEMBL1349472 & 688239 & 4.6362 & 5.426 & TST & \\
\hline CHEMBL1542661 & 688239 & 5.5862 & 5.485 & TRN & \\
\hline CHEMBL1399595 & 688239 & 4.5862 & 5.4196 & TRN & \\
\hline CHEMBL1311524 & 688239 & 6.4862 & 5.4235 & TST & \\
\hline CHEMBL3197557 & 688239 & 4.5362 & 5.397 & TRN & \\
\hline CHEMBL1398595 & 688239 & 4.5362 & 5.3732 & TRN & \\
\hline CHEMBL1412090 & 688239 & 4.9362 & 5.6162 & TRN & \\
\hline
\end{tabular}


Supplemental Table S2.txt

\begin{tabular}{|c|c|c|c|c|}
\hline CHEMBL1521376 & 688239 & 4.8362 & 5.4053 & TRN \\
\hline CHEMBL1352791 & 688239 & 5.1862 & 5.3971 & TRN \\
\hline CHEMBL1489674 & 688239 & 6.8362 & 5.4883 & TRN \\
\hline CHEMBL1503136 & 688239 & 5.8862 & 5.5937 & TRN \\
\hline CHEMBL1512400 & 688239 & 8.3372 & 5.5139 & TRN \\
\hline CHEMBL1573625 & 688239 & 4.6862 & 5.662006 & 0000000001 \\
\hline CHEMBL1576575 & 688239 & 5.2 & 5.4324 & TRN \\
\hline CHEMBL1533185 & 688239 & 4.5362 & 5.6755 & TRN \\
\hline CHEMBL1405400 & 688239 & 7.2366 & 5.3917 & TRN \\
\hline CHEMBL1473213 & 688239 & 5.2362 & 5.335 & TST \\
\hline CHEMBL1338846 & 688239 & 6.5862 & 5.5935 & TRN \\
\hline CHEMBL1526656 & 688239 & 4.9362 & 5.5448 & TRN \\
\hline CHEMBL1598935 & 688239 & 5.4362 & 5.2002 & TST \\
\hline CHEMBL1337289 & 688239 & 4.4862 & 5.4807 & TRN \\
\hline CHEMBL1399606 & 688239 & 7.0362 & 5.4835 & TRN \\
\hline CHEMBL3209044 & 688239 & 4.5362 & 5.3551 & TST \\
\hline CHEMBL1467300 & 688239 & 4.5362 & 5.5033 & TRN \\
\hline CHEMBL1548910 & 688239 & 4.7362 & 5.403 & TRN \\
\hline CHEMBL1397928 & 688239 & 4.7362 & 5.4155 & TRN \\
\hline CHEMBL1577355 & 688239 & 8.3372 & 5.308 & TRN \\
\hline CHEMBL1398343 & 688239 & 8.28399 & 99999999 & 5.5423 \\
\hline CHEMBL1610402 & 688239 & 4.5362 & 5.4995 & TRN \\
\hline CHEMBL1380289 & 688239 & 8.1871 & 5.3832 & TRN \\
\hline CHEMBL1502265 & 688239 & 6.8362 & 5.5625 & TST \\
\hline CHEMBL1549505 & 688239 & 5.1862 & 5.5162 & TRN \\
\hline CHEMBL1423993 & 688239 & 4.5362 & 5.4873 & TRN \\
\hline CHEMBL1402768 & 688239 & 4.7862 & 5.4218 & TRN \\
\hline CHEMBL1347162 & 688239 & 7.0362 & 5.6721 & TRN \\
\hline CHEMBL3208810 & 688239 & 4.9362 & 5.2768 & TST \\
\hline CHEMBL1488195 & 688239 & 5.1862 & 5.4969 & TRN \\
\hline CHEMBL1312194 & 688239 & 5.6362 & 5.3581 & TRN \\
\hline CHEMBL1324548 & 688239 & 4.8362 & 5.5434 & TRN \\
\hline CHEMBL1577196 & 688239 & 5.4862 & 5.4176 & TRN \\
\hline CHEMBL1414722 & 688239 & 4.5862 & 5.6249 & TST \\
\hline CHEMBL1544453 & 688239 & 5.4862 & 5.5508 & TRN \\
\hline CHEMBL1565742 & 688239 & 4.6862 & 5.6558 & TRN \\
\hline CHEMBL1473031 & 688239 & 6.9863 & 5.5373 & TRN \\
\hline CHEMBL3191637 & 688239 & 6.3362 & 5.568 & TRN \\
\hline CHEMBL1444221 & 688239 & 5.0862 & 5.3575 & TRN \\
\hline CHEMBL1370208 & 688239 & 7.3862 & 5.5911 & TST \\
\hline CHEMBL1505458 & 688239 & 6.7862 & 5.4389 & TRN \\
\hline CHEMBL1476661 & 688239 & 4.9862 & 5.3303 & TRN \\
\hline CHEMBL1600286 & 688239 & 6.4862 & 5.6485 & TRN \\
\hline CHEMBL1605895 & 688239 & 4.6362 & 5.5159 & TRN \\
\hline CHEMBL1303930 & 688239 & 6.0862 & 5.5974 & TRN \\
\hline CHEMBL3191282 & 688239 & 5.9862 & 5.4112 & TST \\
\hline CHEMBL1331968 & 688239 & 4.8362 & 5.5913 & TRN \\
\hline CHEMBL1351374 & 688239 & 5.8362 & 5.5301 & TRN \\
\hline
\end{tabular}


Supplemental Table S2.txt

\begin{tabular}{|c|c|c|c|c|c|c|}
\hline CHEMBL1347265 & 688239 & 6.5862 & 5.4368 & TRN & & \\
\hline CHEMBL1451825 & 688239 & 8.28399 & 99999999 & 99 & 5.551 & TRN \\
\hline CHEMBL1426741 & 688239 & 4.5362 & 5.445 & TRN & & \\
\hline CHEMBL1409039 & 688239 & 5.5362 & 5.3248 & TRN & & \\
\hline CHEMBL 3213746 & 688239 & 4.8862 & 5.4559 & TST & & \\
\hline CHEMBL1467243 & 688239 & 4.7862 & 5.4 & TRN & & \\
\hline CHEMBL1407233 & 688239 & 5.4362 & 5.4096 & TRN & & \\
\hline CHEMBL3212878 & 688239 & 6.1362 & 5.5874 & TST & & \\
\hline CHEMBL 1443072 & 688239 & 4.7862 & 5.4643 & TRN & & \\
\hline CHEMBL1408342 & 688239 & 5.2862 & 5.4724 & TRN & & \\
\hline CHEMBL1362804 & 688239 & 5.4362 & 5.4745 & TRN & & \\
\hline CHEMBL1449839 & 688239 & 5.8362 & 5.4767 & TRN & & \\
\hline CHEMBL1402642 & 688239 & 4.6362 & 5.5157 & TST & & \\
\hline CHEMBL1576542 & 688239 & 5.7362 & 5.61799 & 9999999999 & & \\
\hline CHEMBL1576510 & 688239 & 4.7862 & 5.5411 & TRN & & \\
\hline CHEMBL1341593 & 688239 & 5.4862 & 5.3877 & TRN & & \\
\hline CHEMBL1579012 & 688239 & 6.2362 & 5.5729 & TRN & & \\
\hline CHEMBL1323739 & 688239 & 6.6362 & 5.5841 & TRN & & \\
\hline CHEMBL1579821 & 688239 & 6.2862 & 5.4719 & TST & & \\
\hline CHEMBL1457331 & 688239 & 4.7362 & 5.4497 & TRN & & \\
\hline CHEMBL1365018 & 688239 & 8.3372 & 5.4215 & TRN & & \\
\hline CHEMBL1600319 & 688239 & 5.1862 & 5.5375 & TST & & \\
\hline CHEMBL1344490 & 688239 & 5.0862 & 5.6194 & TST & & \\
\hline CHEMBL1507192 & 688239 & 4.7362 & 5.3507 & TST & & \\
\hline CHEMBL 3190928 & 688239 & 5.1362 & 5.3846 & TRN & & \\
\hline CHEMBL1494810 & 688239 & 5.4362 & 5.5309 & TRN & & \\
\hline CHEMBL1609370 & 688239 & 6.0362 & 5.4796 & TRN & & \\
\hline CHEMBL1521196 & 688239 & 5.1862 & 5.3999 & TST & & \\
\hline CHEMBL1414764 & 688239 & 8.28399 & 9999999 & 99 & 5.3119 & \\
\hline CHEMBL1430658 & 688239 & 5.7862 & 5.3743 & TRN & & \\
\hline CHEMBL1370471 & 688239 & 5.1362 & 5.3772 & TST & & \\
\hline CHEMBL600770 & 688239 & 8.3872 & 5.3977 & TRN & & \\
\hline CHEMBL1346615 & 688239 & 5.1862 & 5.5433 & TRN & & \\
\hline CHEMBL1568988 & 688239 & 5.1862 & 5.46200 & 0000000001 & & \\
\hline CHEMBL1370419 & 688239 & 4.7362 & 5.2987 & TST & & \\
\hline CHEMBL1558592 & 688239 & 6.8362 & 5.3415 & TST & & \\
\hline CHEMBL1348642 & 688239 & 4.6862 & 5.6052 & TST & & \\
\hline CHEMBL1333714 & 688239 & 6.6362 & 5.4537 & TRN & & \\
\hline CHEMBL1463949 & 688239 & 4.5862 & 5.4078 & TRN & & \\
\hline CHEMBL1441115 & 688239 & 5.0862 & 5.5184 & TRN & & \\
\hline CHEMBL1471364 & 688239 & 6.8861 & 5.593 & TST & & \\
\hline CHEMBL1556503 & 688239 & 8.3372 & 5.5414 & TST & & \\
\hline CHEMBL1448078 & 688239 & 4.5362 & 5.3494 & TST & & \\
\hline CHEMBL1464024 & 688239 & 6.8362 & 5.3864 & TRN & & \\
\hline CHEMBL1386983 & 688239 & 5.4362 & 5.2837 & TRN & & \\
\hline CHEMBL1456141 & 688239 & 6.6362 & 5.4186 & TST & & \\
\hline CHEMBL1611685 & 688239 & 4.5362 & 5.4261 & TRN & & \\
\hline CHEMBL1364253 & 688239 & 4.6862 & 5.3409 & TRN & & \\
\hline
\end{tabular}

Page 1343 
Supplemental Table S2.txt

\begin{tabular}{|c|c|c|c|c|}
\hline CHEMBL1433291 & 688239 & 4.9862 & 5.3532 & TRN \\
\hline CHEMBL1316525 & 688239 & 4.7362 & 5.4172 & TRN \\
\hline CHEMBL3194076 & 688239 & 5.2362 & 5.4288 & TRN \\
\hline CHEMBL1596588 & 688239 & 6.6362 & 5.4952 & TRN \\
\hline CHEMBL1554386 & 688239 & 5.3862 & 5.5424 & TRN \\
\hline CHEMBL1369637 & 688239 & 5.3862 & 5.4633 & TST \\
\hline CHEMBL1380908 & 688239 & 5.2362 & 5.4606 & TRN \\
\hline CHEMBL1487028 & 688239 & 6.2862 & 5.6038 & TRN \\
\hline CHEMBL1460731 & 688239 & 4.5362 & 5.5629 & TRN \\
\hline CHEMBL1324747 & 688239 & 4.5362 & 5.3881 & TRN \\
\hline CHEMBL1429833 & 688239 & 8.28399 & 99999999 & 5.3217 \\
\hline CHEMBL1523948 & 688239 & 6.9863 & 5.4609 & TRN \\
\hline CHEMBL1464839 & 688239 & 4.8362 & 5.5193 & TST \\
\hline CHEMBL1465479 & 688239 & 6.1862 & 5.402 & TRN \\
\hline CHEMBL1563491 & 688239 & 5.1862 & 5.4945 & TRN \\
\hline CHEMBL1578369 & 688239 & 4.8362 & 5.454 & TRN \\
\hline CHEMBL1586755 & 688239 & 4.5362 & 5.5356 & TRN \\
\hline CHEMBL 3211469 & 688239 & 4.5362 & 5.3657 & TST \\
\hline CHEMBL1555003 & 688239 & 5.6862 & 5.3946 & TRN \\
\hline CHEMBL1397990 & 688239 & 5.4362 & 5.5227 & TRN \\
\hline CHEMBL1571630 & 688239 & 5.6862 & 5.6062 & TRN \\
\hline CHEMBL1317942 & 688239 & 5.9362 & 5.4703 & TRN \\
\hline CHEMBL1599027 & 688239 & 5.3862 & 5.4609 & TRN \\
\hline CHEMBL1514108 & 688239 & 5.1862 & 5.4542 & TRN \\
\hline CHEMBL1353759 & 688239 & 5.1362 & 5.4032 & TRN \\
\hline CHEMBL1331251 & 688239 & 4.5862 & 5.5756 & TRN \\
\hline CHEMBL1340454 & 688239 & 4.9362 & 5.4181 & TRN \\
\hline CHEMBL1370337 & 688239 & 4.9862 & 5.6066 & TST \\
\hline CHEMBL1443279 & 688239 & 5.4362 & 5.5104 & TRN \\
\hline CHEMBL1510243 & 688239 & 5.5862 & 5.652 & TRN \\
\hline CHEMBL1517631 & 688239 & 4.5362 & 5.501 & TST \\
\hline CHEMBL1309602 & 688239 & 6.2362 & 5.5277 & TRN \\
\hline CHEMBL1398113 & 688239 & 4.5362 & 5.3942 & TRN \\
\hline CHEMBL1400176 & 688239 & 5.1362 & 5.452999 & 9999999999 \\
\hline CHEMBL1310376 & 688239 & 4.5862 & 5.4401 & TRN \\
\hline CHEMBL1359064 & 688239 & 5.7862 & 5.36 & TRN \\
\hline CHEMBL1352166 & 688239 & 4.5362 & 5.4363 & TRN \\
\hline CHEMBL1501687 & 688239 & 5.8362 & 5.4662 & TST \\
\hline CHEMBL1522438 & 688239 & 5.8362 & 5.3413 & TST \\
\hline CHEMBL1523556 & 688239 & 5.8362 & 5.5231 & TST \\
\hline CHEMBL1365760 & 688239 & 5.4862 & 5.5743 & TRN \\
\hline CHEMBL1482400 & 688239 & 6.0362 & 5.4966 & TRN \\
\hline CHEMBL1577378 & 688239 & 5.3362 & 5.5615 & TRN \\
\hline CHEMBL1378709 & 688239 & 6.4862 & 5.5409 & TST \\
\hline CHEMBL1347980 & 688239 & 5.9362 & 5.5057 & TRN \\
\hline CHEMBL1374521 & 688239 & 4.5362 & 5.5745 & TRN \\
\hline CHEMBL1302320 & 688239 & 7.9872 & 5.4069 & TRN \\
\hline CHEMBL1415443 & 688239 & 6.7862 & 5.6123 & TST \\
\hline
\end{tabular}


Supplemental Table S2.txt

\begin{tabular}{|c|c|c|c|c|c|}
\hline CHEMBL1611867 & 688239 & 6.5862 & 5.3863 & TRN & \\
\hline CHEMBL1317808 & 688239 & 5.1862 & 5.4692 & TRN & \\
\hline CHEMBL1544387 & 688239 & 4.5362 & 5.5361 & TRN & \\
\hline CHEMBL1406032 & 688239 & 6.0862 & 5.5317 & TRN & \\
\hline CHEMBL1361743 & 688239 & 4.9362 & 5.4727 & TRN & \\
\hline CHEMBL1526932 & 688239 & 4.5362 & 5.4663 & TRN & \\
\hline CHEMBL1581813 & 688239 & 4.9362 & 5.2802 & TRN & \\
\hline CHEMBL1591501 & 688239 & 5.4362 & 5.4954 & TRN & \\
\hline CHEMBL1508518 & 688239 & 4.7362 & 5.5878 & TRN & \\
\hline CHEMBL1527139 & 688239 & 5.1862 & 5.4561 & TRN & \\
\hline CHEMBL1475845 & 688239 & 4.5362 & 5.4242 & TRN & \\
\hline CHEMBL3189684 & 688239 & 4.5362 & 5.4548 & TRN & \\
\hline CHEMBL1322261 & 688239 & 6.6362 & 5.395 & TST & \\
\hline CHEMBL1469182 & 688239 & 5.0362 & 5.4891 & TRN & \\
\hline CHEMBL1383989 & 688239 & 5.2362 & 5.4021 & TRN & \\
\hline CHEMBL1604213 & 688239 & 5.3362 & 5.5896 & TRN & \\
\hline CHEMBL1404467 & 688239 & 4.5362 & 5.556 & TRN & \\
\hline CHEMBL1548353 & 688239 & 4.5362 & 5.5229 & TRN & \\
\hline CHEMBL1607998 & 688239 & 4.4862 & 5.4251 & TRN & \\
\hline CHEMBL1333709 & 688239 & 4.5862 & 5.3062 & TRN & \\
\hline CHEMBL1375170 & 688239 & 4.4862 & 5.5015 & TRN & \\
\hline CHEMBL1494555 & 688239 & 6.6861 & 5.3984 & TRN & \\
\hline CHEMBL1534401 & 688239 & 5.7862 & 5.427000 & 30000000005 & TR \\
\hline CHEMBL1527924 & 688239 & 4.6862 & 5.4497 & TRN & \\
\hline CHEMBL1458045 & 688239 & 6.8362 & 5.4781 & TST & \\
\hline CHEMBL1587082 & 688239 & 6.7862 & 5.6731 & TST & \\
\hline CHEMBL1597726 & 688239 & 4.6862 & 5.4742 & TRN & \\
\hline CHEMBL 2002420 & 688239 & 5.1362 & 5.5821 & TRN & \\
\hline CHEMBL1500869 & 688239 & 6.8362 & 5.3976 & TRN & \\
\hline CHEMBL1447963 & 688239 & 5.1862 & 5.4363 & TRN & \\
\hline CHEMBL1581259 & 688239 & 4.8862 & 5.5027 & TRN & \\
\hline CHEMBL1603540 & 688239 & 6.8362 & 5.5538 & TST & \\
\hline CHEMBL1436044 & 688239 & 5.8362 & 5.4959 & TRN & \\
\hline CHEMBL1463676 & 688239 & 5.1862 & 5.5632 & TRN & \\
\hline CHEMBL1387248 & 688239 & 5.1362 & 5.4913 & TST & \\
\hline CHEMBL1483811 & 688239 & 6.7361 & 5.6277 & TRN & \\
\hline CHEMBL1476843 & 688239 & 5.6862 & 5.5615 & TRN & \\
\hline CHEMBL1401341 & 688239 & 6.2362 & 5.451000 & 00000000005 & $\mathrm{~T} \mathrm{RI}$ \\
\hline CHEMBL1382347 & 688239 & 5.3362 & 5.4845 & TST & \\
\hline CHEMBL1558813 & 688239 & 4.6862 & 5.3984 & TRN & \\
\hline CHEMBL1306308 & 688239 & 4.5362 & 5.5019 & TRN & \\
\hline CHEMBL1536339 & 688239 & 4.5362 & 5.5051 & TRN & \\
\hline CHEMBL1498402 & 688239 & 4.6362 & 5.5439 & TST & \\
\hline CHEMBL1597850 & 688239 & 4.5362 & 5.4487 & TRN & \\
\hline CHEMBL1561607 & 688239 & \multicolumn{3}{|c|}{8.283999999999999} & ובו \\
\hline CHEMBL1372071 & 688239 & 5.2862 & 5.4892 & TST & \\
\hline CHEMBL1461619 & 688239 & 5.0862 & 5.532 & TRN & \\
\hline CHEMBL1408848 & 688239 & 4.5362 & 5.4542 & TRN & \\
\hline
\end{tabular}


Supplemental Table S2.txt

\begin{tabular}{|c|c|c|c|c|c|}
\hline CHEMBL1562702 & 688239 & 5.8862 & 5.4077 & TRN & \\
\hline CHEMBL1540433 & 688239 & 4.5362 & 5.3662 & TST & \\
\hline CHEMBL1421237 & 688239 & 5.8862 & 5.6561 & TRN & \\
\hline CHEMBL1451786 & 688239 & 7.0362 & 5.5405 & TRN & \\
\hline CHEMBL1439520 & 688239 & 6.6362 & 5.5695 & TRN & \\
\hline CHEMBL1300181 & 688239 & 4.5362 & 5.4363 & TRN & \\
\hline CHEMBL1594389 & 688239 & 4.7362 & 5.4635 & TRN & \\
\hline CHEMBL1512990 & 688239 & 4.6362 & 5.5592 & TRN & \\
\hline CHEMBL1376399 & 688239 & 6.2362 & 5.6671 & TRN & \\
\hline CHEMBL1339708 & 688239 & 5.2362 & 5.5201 & TRN & \\
\hline CHEMBL1477793 & 688239 & 6.1362 & 5.5109 & TRN & \\
\hline CHEMBL1463156 & 688239 & 5.9862 & 5.5815 & TST & \\
\hline CHEMBL1453609 & 688239 & 4.7362 & 5.465 & TRN & \\
\hline CHEMBL1466720 & 688239 & 6.8861 & 5.4256 & TRN & \\
\hline CHEMBL1336001 & 688239 & 6.6362 & 5.433 & TRN & \\
\hline CHEMBL1404481 & 688239 & 5.1362 & 5.5751 & TST & \\
\hline CHEMBL1534363 & 688239 & 5.7862 & 5.3772 & TRN & \\
\hline CHEMBL1485353 & 688239 & 5.1862 & 5.3654 & TRN & \\
\hline CHEMBL1457747 & 688239 & 6.2862 & 5.5782 & TRN & \\
\hline CHEMBL1391850 & 688239 & 4.5362 & 5.6374 & TST & \\
\hline CHEMBL 1454734 & 688239 & 4.5362 & 5.3938 & TST & \\
\hline CHEMBL1591693 & 688239 & 8.3372 & 5.6309 & TRN & \\
\hline CHEMBL607309 & 688239 & 4.6862 & 5.3571 & TRN & \\
\hline CHEMBL1390753 & 688239 & 4.5362 & 5.6069 & TRN & \\
\hline CHEMBL1406758 & 688239 & 4.7862 & 5.4892 & TRN & \\
\hline CHEMBL1426866 & 688239 & 7.1361 & 5.5417 & TRN & \\
\hline CHEMBL1490009 & 688239 & 4.6362 & 5.5063 & TRN & \\
\hline CHEMBL1351966 & 688239 & 6.7862 & 5.6833 & TRN & \\
\hline CHEMBL1357352 & 688239 & 6.7862 & 5.5823 & TST & \\
\hline CHEMBL1398510 & 688239 & 5.7862 & 5.4773 & TST & \\
\hline CHEMBL1592960 & 688239 & 5.1862 & 5.3347 & TRN & \\
\hline CHEMBL1496510 & 688239 & 5.1862 & 5.4427 & TRN & \\
\hline CHEMBL1533789 & 688239 & 5.6862 & 5.3968 & TRN & \\
\hline CHEMBL1342771 & 688239 & 5.0862 & 5.4453 & TRN & \\
\hline CHEMBL1613500 & 688239 & 5.1862 & 5.4401 & TRN & \\
\hline CHEMBL1430036 & 688239 & 6.3863 & 5.4339 & TRN & \\
\hline CHEMBL1423641 & 688239 & 4.6862 & 5.4653 & TST & \\
\hline CHEMBL1429218 & 688239 & 4.4862 & 5.4848 & TRN & \\
\hline CHEMBL1569174 & 688239 & 4.7362 & 5.41200 & 0000000001 & TRN \\
\hline CHEMBL1444081 & 688239 & 6.7862 & 5.5177 & TRN & \\
\hline CHEMBL1443560 & 688239 & 4.6862 & 5.4932 & TRN & \\
\hline CHEMBL1313249 & 688239 & 4.5362 & 5.5149 & TRN & \\
\hline CHEMBL1380065 & 688239 & 4.4862 & 5.4852 & TRN & \\
\hline CHEMBL1359640 & 688239 & 4.6362 & 5.3397 & TRN & \\
\hline CHEMBL1542376 & 688239 & 7.6364 & 5.3557 & TRN & \\
\hline CHEMBL1474292 & 688239 & 4.7862 & 5.5065 & TRN & \\
\hline CHEMBL 3213600 & 688239 & 5.1362 & 5.4472 & TRN & \\
\hline CHEMBL1569499 & 688239 & 4.5362 & 5.4659 & TRN & \\
\hline
\end{tabular}


Supplemental Table S2.txt

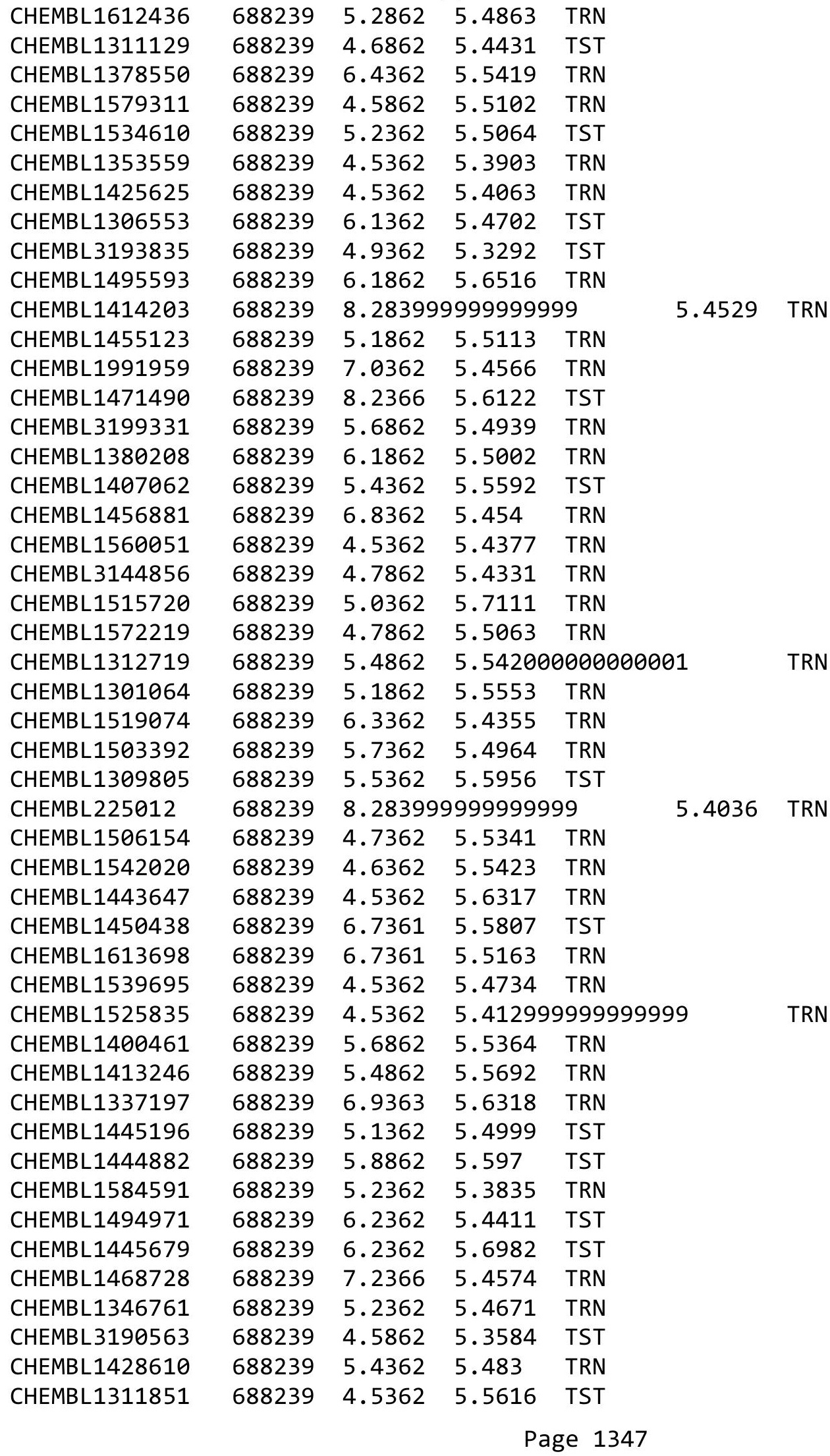


Supplemental Table S2.txt

\begin{tabular}{|c|c|c|c|c|}
\hline 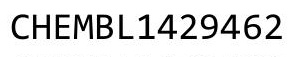 & & 862 & - & \\
\hline HEMBL1609490 & 88239 & 7362 & 3599 & TCT \\
\hline HEMBL1499893 & 39 & 62 & & \\
\hline HEMBL14 & & & & \\
\hline IEMBL1479474 & & 862 & & \\
\hline AEMBL1351470 & 88239 & .3362 & .4038 & \\
\hline HEMBL1350434 & 88239 & .8362 & .6209 & \\
\hline HEMBL1338475 & 39 & & & \\
\hline AEMBL1324015 & & & & \\
\hline AEMBL1570804 & & & & \\
\hline HEMBL1580845 & 88239 & 6.0 & .3841 & \\
\hline HEMBL1499290 & 88239 & 72 & 5.4563 & \\
\hline HEMBL1363872 & 39 & & .5452 & \\
\hline HEMBL 14 & & & & \\
\hline AEMBL15 & & & & \\
\hline HEMBL1606919 & 88239 & 2362 & .5044 & \\
\hline AEMBL1549185 & & & & \\
\hline HEMBL1551934 & 39 & 52 & 44 & \\
\hline L155 & & & & \\
\hline L158 & & & & \\
\hline HEMBL1604372 & 39 & 862 & & \\
\hline AEMBL1419681 & & & & \\
\hline HEMBL133 & 39 & 62 & 5 . & \\
\hline L13 & & & & \\
\hline 54 & & & & \\
\hline L1610316 & & & & \\
\hline AEMBL1383728 & & & & \\
\hline HEMBL132 & & & & \\
\hline L13 & & & & \\
\hline 13 & & 51 & & \\
\hline AEMBL1345007 & & & & \\
\hline HEMBL1582819 & & & & RN \\
\hline AEMBL13 & & & & \\
\hline 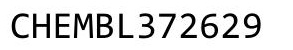 & & & & \\
\hline 19 & & & & ST \\
\hline AEMBL1476398 & & & & RN \\
\hline HEMBL1399544 & & & & \\
\hline$\theta$ & & & & \\
\hline רב ובחזו & & & & RIV \\
\hline HEMBL 14 & & & & RN \\
\hline AEMBL1574702 & & 62 & 232 & RN \\
\hline HEMBL136e & & & & RN \\
\hline 86 & & & & \\
\hline HEMBL 146 & & & & \\
\hline HEMBL1537894 & & & 5.5495 & ST \\
\hline IEMBL1492289 & & 62 & 196 & RN \\
\hline HEMBL133 & & & & \\
\hline נרתיתו & & 6.8362 & 5.4317 & \\
\hline
\end{tabular}

Page 1348 
Supplemental Table S2.txt

\begin{tabular}{|c|c|c|c|c|c|}
\hline CHEMBL1342174 & 688239 & 6.2362 & 5.3768 & TRN & \\
\hline CHEMBL1566955 & 688239 & 7.0862 & 5.4479 & TST & \\
\hline CHEMBL 3209325 & 688239 & 6.7361 & 5.5313 & TRN & \\
\hline CHEMBL1456981 & 688239 & 5.7362 & 5.4105 & TRN & \\
\hline CHEMBL1306328 & 688239 & 4.6362 & 5.4261 & TRN & \\
\hline CHEMBL1377086 & 688239 & 6.7862 & 5.3852 & TRN & \\
\hline CHEMBL1472656 & 688239 & 5.3862 & 5.6149 & TST & \\
\hline CHEMBL1558784 & 688239 & 5.6862 & 5.5705 & TST & \\
\hline CHEMBL1389445 & 688239 & 4.5362 & 5.4795 & TRN & \\
\hline CHEMBL1428337 & 688239 & 4.7862 & 5.587999 & 999999999 & TRN \\
\hline CHEMBL1600696 & 688239 & 4.9362 & 5.419 & TRN & \\
\hline CHEMBL1588009 & 688239 & 6.2362 & 5.3949 & TRN & \\
\hline CHEMBL1398450 & 688239 & 4.8862 & 5.6746 & TRN & \\
\hline CHEMBL1584723 & 688239 & 4.5862 & 5.416 & TRN & \\
\hline CHEMBL1550004 & 688239 & 5.1862 & 5.4686 & TRN & \\
\hline CHEMBL1492085 & 688239 & 7.7852 & 5.5218 & TST & \\
\hline CHEMBL1541791 & 688239 & 4.6862 & 5.4818 & TRN & \\
\hline CHEMBL1351940 & 688239 & 4.5362 & 5.4021 & TST & \\
\hline CHEMBL1467335 & 688239 & 4.8862 & 5.4694 & TRN & \\
\hline CHEMBL1415195 & 688239 & 5.9862 & 5.4457 & TRN & \\
\hline CHEMBL1510932 & 688239 & 4.5362 & 5.3706 & TRN & \\
\hline CHEMBL1449994 & 688239 & 7.1361 & 5.6136 & TRN & \\
\hline CHEMBL1413223 & 688239 & 4.6862 & 5.4193 & TRN & \\
\hline CHEMBL1423770 & 688239 & 5.1862 & 5.5561 & TRN & \\
\hline CHEMBL1391141 & 688239 & 6.2362 & 5.5267 & TRN & \\
\hline CHEMBL1468982 & 688239 & 4.5362 & 5.4007 & TRN & \\
\hline CHEMBL1486386 & 688239 & 5.1862 & 5.5089 & TST & \\
\hline CHEMBL1573607 & 688239 & 6.0862 & 5.4883 & TRN & \\
\hline CHEMBL1539763 & 688239 & 6.8861 & 5.61 & TRN & \\
\hline CHEMBL1562564 & 688239 & 4.7862 & 5.4934 & TRN & \\
\hline CHEMBL1593350 & 688239 & 4.8362 & 5.4985 & TRN & \\
\hline CHEMBL1443675 & 688239 & 4.5362 & 5.5112 & TRN & \\
\hline CHEMBL1470892 & 688239 & 6.9863 & 5.3998 & TRN & \\
\hline CHEMBL1546340 & 688239 & 4.5362 & 5.5039 & TST & \\
\hline CHEMBL1303724 & 688239 & 4.8362 & 5.4964 & TRN & \\
\hline CHEMBL1427867 & 688239 & 5.1862 & 5.5256 & TRN & \\
\hline CHEMBL1346716 & 688239 & 5.1862 & 5.4411 & TRN & \\
\hline CHEMBL1389472 & 688239 & 6.8362 & 5.6247 & TRN & \\
\hline CHEMBL1522516 & 688239 & 4.5362 & 5.4489 & TST & \\
\hline CHEMBL3211958 & 688239 & 4.5362 & 5.6159 & TRN & \\
\hline CHEMBL1595441 & 688239 & 5.1862 & 5.481 & TRN & \\
\hline CHEMBL1519239 & 688239 & 5.45 & 5.3506 & TST & \\
\hline CHEMBL1610711 & 688239 & 5.3362 & 5.5781 & TRN & \\
\hline CHEMBL1509973 & 688239 & 4.6362 & 5.4702 & TRN & \\
\hline CHEMBL1345876 & 688239 & 8.28399 & 99999999 & 5.5366 & ונמו \\
\hline CHEMBL1306908 & 688239 & 5.5362 & 5.5813 & TST & \\
\hline CHEMBL1598591 & 688239 & 6.1362 & 5.5188 & TST & \\
\hline CHEMBL489941 & 688239 & 5.3862 & 5.5149 & TRN & \\
\hline
\end{tabular}


Supplemental Table S2.txt

\begin{tabular}{|c|c|c|c|c|c|}
\hline CHEMBL1333318 & 688239 & 4.5362 & 5.4375 & TST & \\
\hline CHEMBL1406515 & 688239 & 5.1862 & 5.3525 & TST & \\
\hline CHEMBL1399416 & 688239 & 5.6362 & 5.4628 & TRN & \\
\hline CHEMBL1311121 & 688239 & 4.9362 & 5.4924 & TST & \\
\hline CHEMBL1590574 & 688239 & 4.7362 & 5.455 & TRN & \\
\hline CHEMBL1488241 & 688239 & 4.7862 & 5.3673 & TRN & \\
\hline CHEMBL3209416 & 688239 & 5.2362 & 5.4746 & TST & \\
\hline CHEMBL1511386 & 688239 & 7.2366 & 5.3867 & TRN & \\
\hline CHEMBL1425451 & 688239 & 5.7862 & 5.6221 & TRN & \\
\hline CHEMBL1383405 & 688239 & 5.9362 & 5.4427 & TRN & \\
\hline CHEMBL1338224 & 688239 & 4.8862 & 5.5472 & TRN & \\
\hline CHEMBL1445718 & 688239 & 6.4862 & 5.4217 & TRN & \\
\hline CHEMBL1531498 & 688239 & 6.8861 & 5.5814 & TRN & \\
\hline CHEMBL1434062 & 688239 & 4.6862 & 5.4696 & TRN & \\
\hline CHEMBL1460892 & 688239 & 4.6362 & 5.3645 & TST & \\
\hline CHEMBL1564214 & 688239 & 6.9863 & 5.4309 & TRN & \\
\hline CHEMBL1596751 & 688239 & 5.1862 & 5.6338 & TRN & \\
\hline CHEMBL1417145 & 688239 & 4.5362 & 5.4102 & TRN & \\
\hline CHEMBL1591642 & 688239 & 6.0362 & 5.5904 & TRN & \\
\hline CHEMBL1561608 & 688239 & 6.1862 & 5.4837 & TRN & \\
\hline CHEMBL1466512 & 688239 & 5.4862 & 5.4329 & TRN & \\
\hline CHEMBL1465322 & 688239 & 5.1362 & 5.4841 & TRN & \\
\hline CHEMBL1541415 & 688239 & 5.6362 & 5.5509 & TRN & \\
\hline CHEMBL1559839 & 688239 & 4.5362 & 5.5679 & TST & \\
\hline CHEMBL489696 & 688239 & 4.5362 & 5.4907 & TRN & \\
\hline CHEMBL1499443 & 688239 & 6.1362 & 5.664 & TRN & \\
\hline CHEMBL1561895 & 688239 & 6.4362 & 5.5506 & TRN & \\
\hline CHEMBL1330279 & 688239 & 4.7362 & 5.3248 & TRN & \\
\hline CHEMBL1486720 & 688239 & 4.8862 & 5.4719 & TRN & \\
\hline CHEMBL1318963 & 688239 & 4.7362 & 5.6436 & TRN & \\
\hline CHEMBL1611221 & 688239 & 5.7862 & 5.545 & TRN & \\
\hline CHEMBL3209650 & 688239 & 5.6362 & 5.3475 & TST & \\
\hline CHEMBL1367918 & 688239 & 6.1862 & 5.4587 & TST & \\
\hline CHEMBL1438135 & 688239 & 5.4362 & 5.466 & TST & \\
\hline CHEMBL1596319 & 688239 & 4.8362 & 5.4714 & TST & \\
\hline CHEMBL1525769 & 688239 & 5.6362 & 5.4748 & TST & \\
\hline CHEMBL1572265 & 688239 & 5.1362 & 5.5122 & TRN & \\
\hline CHEMBL1557502 & 688239 & 4.6362 & 5.462006 & 0000000001 & TRN \\
\hline CHEMBL1200921 & 688239 & 5.7862 & 5.5281 & TST & \\
\hline CHEMBL1464674 & 688239 & 5.1362 & 5.508999 & 99999999995 & TRN \\
\hline CHEMBL1969597 & 688239 & 4.7862 & 5.4756 & TRN & \\
\hline CHEMBL1459757 & 688239 & 4.5362 & 5.5457 & TRN & \\
\hline CHEMBL1528171 & 688239 & 6.0862 & 5.5534 & TRN & \\
\hline CHEMBL1580101 & 688239 & 4.5362 & 5.6133 & TST & \\
\hline CHEMBL1577096 & 688239 & 4.5362 & 5.5132 & TRN & \\
\hline CHEMBL1299474 & 688239 & 6.0862 & 5.4835 & TRN & \\
\hline CHEMBL1370933 & 688239 & 5.7862 & 5.4622 & TRN & \\
\hline CHEMBL1976764 & 688239 & 5.1862 & 5.4463 & TST & \\
\hline
\end{tabular}


Supplemental Table S2.txt

\begin{tabular}{|c|c|c|c|c|c|}
\hline CHEMBL1468679 & 688239 & 4.5362 & \multicolumn{2}{|c|}{5.428999999999999} & TR \\
\hline CHEMBL1488995 & 688239 & 4.6862 & 5.5313 & TRN & \\
\hline CHEMBL1350071 & 688239 & 5.9862 & 5.5006 & TRN & \\
\hline CHEMBL1577886 & 688239 & 5.1862 & 5.32 & TRN & \\
\hline CHEMBL1416096 & 688239 & 5.4362 & 5.3547 & TRN & \\
\hline CHEMBL1589282 & 688239 & 5.0862 & 5.5315 & TST & \\
\hline CHEMBL1599121 & 688239 & 5.9362 & 5.5373 & TST & \\
\hline CHEMBL1520848 & 688239 & 4.5362 & 5.4717 & TRN & \\
\hline CHEMBL1393397 & 688239 & 4.7862 & 5.3948 & TRN & \\
\hline CHEMBL584868 & 688239 & 4.5362 & 5.3076 & TRN & \\
\hline CHEMBL1332986 & 688239 & 5.1862 & 5.5322 & TRN & \\
\hline CHEMBL1525749 & 688239 & 4.7362 & 5.516 & TRN & \\
\hline CHEMBL1484178 & 688239 & 4.6362 & 5.5508 & TRN & \\
\hline CHEMBL1483002 & 688239 & 4.5362 & 5.4857 & TRN & \\
\hline CHEMBL1573173 & 688239 & 4.5362 & 5.4909 & TRN & \\
\hline CHEMBL1589525 & 688239 & 4.5362 & 5.5809 & TRN & \\
\hline CHEMBL1344982 & 688239 & 6.2862 & 5.485 & TRN & \\
\hline CHEMBL1470810 & 688239 & 6.9863 & 5.4428 & TRN & \\
\hline CHEMBL1581252 & 688239 & 4.8362 & 5.6492 & TRN & \\
\hline CHEMBL1324158 & 688239 & 6.1362 & 5.4804 & TRN & \\
\hline CHEMBL1323651 & 688239 & 5.1862 & 5.5535 & TRN & \\
\hline CHEMBL1306433 & 688239 & 4.5362 & 5.4234 & TRN & \\
\hline CHEMBL1520354 & 688239 & 6.1362 & 5.5644 & TST & \\
\hline CHEMBL1499689 & 688239 & 4.7862 & 5.45100 & 00000000005 & \\
\hline CHEMBL1503649 & 688239 & 4.5362 & 5.3257 & TST & \\
\hline CHEMBL1303186 & 688239 & 4.6362 & 5.51200 & 00000000005 & \\
\hline CHEMBL3208586 & 688239 & 7.2366 & 5.1983 & TRN & \\
\hline CHEMBL1579379 & 688239 & 6.1362 & 5.5416 & TRN & \\
\hline CHEMBL1531101 & 688239 & 5.1862 & 5.444 & TST & \\
\hline CHEMBL1605731 & 688239 & 5.3362 & 5.5744 & TRN & \\
\hline CHEMBL1422342 & 688239 & 5.8862 & 5.5148 & TRN & \\
\hline CHEMBL1575529 & 688239 & 6.1862 & 5.5724 & TST & \\
\hline CHEMBL1556926 & 688239 & 5.1862 & 5.4474 & TRN & \\
\hline CHEMBL1603128 & 688239 & 4.5362 & 5.5693 & TRN & \\
\hline CHEMBL1574286 & 688239 & 8.3372 & 5.6112 & TRN & \\
\hline CHEMBL1299368 & 688239 & 5.4362 & 5.44799 & 99999999995 & \\
\hline CHEMBL1327407 & 688239 & 4.7362 & 5.3419 & TRN & \\
\hline CHEMBL1456194 & 688239 & 6.8861 & 5.5165 & TRN & \\
\hline CHEMBL1327725 & 688239 & 5.1362 & 5.6386 & TRN & \\
\hline CHEMBL1352798 & 688239 & 4.5362 & 5.4346 & TRN & \\
\hline CHEMBL1573891 & 688239 & 4.8362 & 5.4021 & TRN & \\
\hline CHEMBL1506806 & 688239 & 5.1862 & 5.416 & TRN & \\
\hline CHEMBL1439310 & 688239 & 5.2362 & 5.4822 & TRN & \\
\hline CHEMBL1331225 & 688239 & 4.5362 & 5.5235 & TRN & \\
\hline CHEMBL1490091 & 688239 & 5.1862 & 5.5494 & TRN & \\
\hline CHEMBL1605791 & 688239 & 5.5862 & 5.4405 & TST & \\
\hline CHEMBL1349678 & 688239 & 6.7862 & 5.4978 & TRN & \\
\hline CHEMBL1541544 & 688239 & 5.1862 & 5.6393 & TRN & \\
\hline
\end{tabular}

Page 1351 
Supplemental Table S2.txt

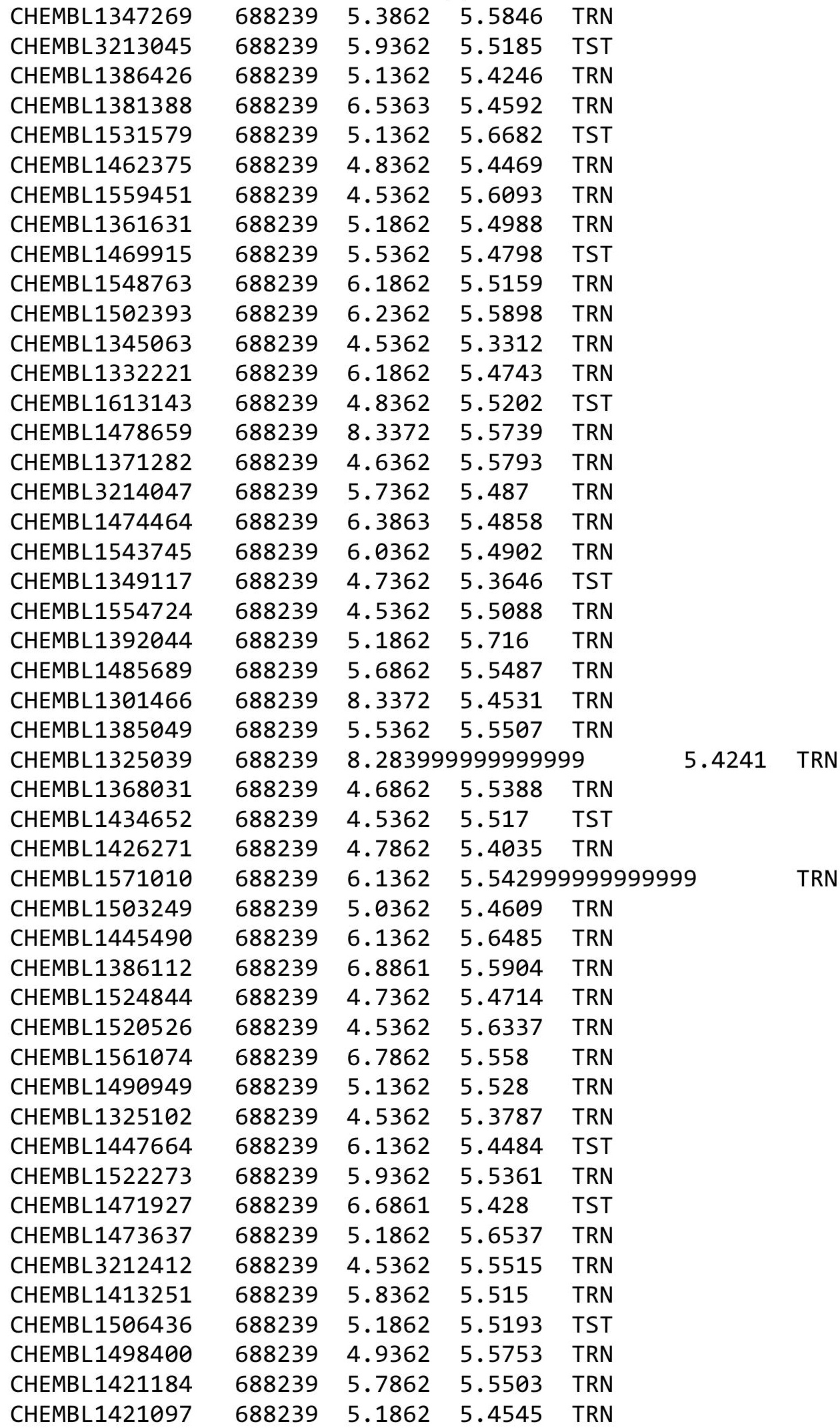

Page 1352 
Supplemental Table S2.txt

\begin{tabular}{|c|c|c|c|c|}
\hline CHEMBL1341701 & 688239 & 5.4362 & 5.3771 & TRN \\
\hline CHEMBL1489024 & 688239 & 6.8362 & 5.4026 & TRN \\
\hline CHEMBL1299360 & 688239 & 5.2362 & 5.3413 & TST \\
\hline CHEMBL1449131 & 688239 & 4.7362 & 5.6718 & TRN \\
\hline CHEMBL1442429 & 688239 & 4.5362 & 5.5401 & TRN \\
\hline CHEMBL1611106 & 688239 & 4.6362 & 5.5903 & TRN \\
\hline CHEMBL1386163 & 688239 & 5.1862 & 5.5019 & TST \\
\hline CHEMBL1561079 & 688239 & 4.7862 & 5.551 & TRN \\
\hline CHEMBL1445353 & 688239 & 4.7862 & 5.548999 & 9999999995 \\
\hline CHEMBL1538904 & 688239 & 6.3362 & 5.5773 & TST \\
\hline CHEMBL1382874 & 688239 & 4.5362 & 5.5555 & TRN \\
\hline CHEMBL1583653 & 688239 & 4.6862 & 5.544 & TST \\
\hline CHEMBL1465707 & 688239 & 4.6862 & 5.5256 & TRN \\
\hline CHEMBL1488926 & 688239 & 6.4362 & 5.5284 & TRN \\
\hline CHEMBL1416536 & 688239 & 4.5362 & 5.3674 & TRN \\
\hline CHEMBL1341833 & 688239 & 6.5363 & 5.7067 & TST \\
\hline CHEMBL1313622 & 688239 & 4.7862 & 5.3391 & TRN \\
\hline CHEMBL1378431 & 688239 & 6.1862 & 5.5903 & TRN \\
\hline CHEMBL1375412 & 688239 & 5.3862 & 5.4647 & TRN \\
\hline CHEMBL1490515 & 688239 & 6.1862 & 5.6633 & TRN \\
\hline CHEMBL1362025 & 688239 & 5.8362 & 5.3769 & TRN \\
\hline CHEMBL1383714 & 688239 & 4.8362 & 5.4042 & TRN \\
\hline CHEMBL1440573 & 688239 & 6.5363 & 5.6202 & TRN \\
\hline CHEMBL1545234 & 688239 & 5.0362 & 5.3204 & TRN \\
\hline CHEMBL1383406 & 688239 & 4.5362 & 5.4984 & TRN \\
\hline CHEMBL1422318 & 688239 & 4.8362 & 5.3631 & TRN \\
\hline CHEMBL3194786 & 688239 & 5.1862 & 5.4835 & TRN \\
\hline CHEMBL1508746 & 688239 & 5.1362 & 5.5418 & TRN \\
\hline CHEMBL1386322 & 688239 & 4.7862 & 5.3773 & TRN \\
\hline CHEMBL1464531 & 688239 & 8.2366 & 5.5057 & TST \\
\hline CHEMBL1301697 & 688239 & 5.0362 & 5.388 & TRN \\
\hline CHEMBL1325350 & 688239 & 6.8362 & 5.5444 & TST \\
\hline CHEMBL1547708 & 688239 & 8.1871 & 5.5611 & TRN \\
\hline CHEMBL1489310 & 688239 & 6.8861 & 5.4738 & TRN \\
\hline CHEMBL1597899 & 688239 & 5.1862 & 5.7431 & TST \\
\hline CHEMBL1531844 & 688239 & 4.5362 & 5.5335 & TRN \\
\hline CHEMBL1574475 & 688239 & 4.6362 & 5.5539 & TST \\
\hline CHEMBL 375781 & 688239 & 5.1862 & 5.5805 & TST \\
\hline CHEMBL1353129 & 688239 & 6.3362 & 5.467006 & 0000000005 \\
\hline CHEMBL1584836 & 688239 & 5.1862 & 5.5716 & TRN \\
\hline CHEMBL1610763 & 688239 & 5.4362 & 5.4399 & TRN \\
\hline CHEMBL1543033 & 688239 & 6.2862 & 5.5264 & TRN \\
\hline CHEMBL3207965 & 688239 & 5.1362 & 5.5067 & TRN \\
\hline CHEMBL1491910 & 688239 & 5.7862 & 5.5828 & TRN \\
\hline CHEMBL1368980 & 688239 & 5.2862 & 5.4202 & TRN \\
\hline CHEMBL1477202 & 688239 & 5.1862 & 5.6682 & TRN \\
\hline CHEMBL1586905 & 688239 & 5.7862 & 5.5793 & TRN \\
\hline CHEMBL1502725 & 688239 & 5.1862 & 5.513 & TST \\
\hline
\end{tabular}


Supplemental Table S2.txt

\begin{tabular}{|c|c|c|c|c|c|}
\hline CHEMBL1577085 & 688239 & 5.8862 & 5.5036 & TST & \\
\hline CHEMBL1475112 & 688239 & 4.6862 & 5.4369 & TRN & \\
\hline CHEMBL1394265 & 688239 & 6.1862 & 5.4968 & TRN & \\
\hline CHEMBL1312100 & 688239 & 7.0862 & 5.5432 & TRN & \\
\hline CHEMBL1513203 & 688239 & 5.1862 & 5.4986 & TST & \\
\hline CHEMBL1491993 & 688239 & 7.0362 & 5.5555 & TST & \\
\hline CHEMBL1523330 & 688239 & 6.3863 & 5.5221 & TRN & \\
\hline CHEMBL1546757 & 688239 & 5.4362 & 5.5073 & TRN & \\
\hline CHEMBL1490834 & 688239 & 4.6862 & 5.5661 & TST & \\
\hline CHEMBL1613522 & 688239 & 6.7361 & 5.479 & TRN & \\
\hline CHEMBL1412842 & 688239 & 5.4362 & 5.5597 & TRN & \\
\hline CHEMBL1554828 & 688239 & 4.6862 & 5.4123 & TRN & \\
\hline CHEMBL1426791 & 688239 & 6.0862 & 5.462006 & 0000000001 & $\mathrm{TR}$ \\
\hline CHEMBL1306759 & 688239 & 4.6362 & 5.5553 & TRN & \\
\hline CHEMBL1311667 & 688239 & 5.1862 & 5.6343 & TRN & \\
\hline CHEMBL1325854 & 688239 & 8.1871 & 5.6309 & TRN & \\
\hline CHEMBL1468683 & 688239 & 5.7362 & 5.4284 & TRN & \\
\hline CHEMBL 3192756 & 688239 & 4.7862 & 5.4916 & TST & \\
\hline CHEMBL1440216 & 688239 & 5.1862 & 5.4226 & TST & \\
\hline CHEMBL1336273 & 688239 & 4.5362 & 5.5094 & TRN & \\
\hline CHEMBL 3192476 & 688239 & 6.7862 & 5.5418 & TRN & \\
\hline CHEMBL1313926 & 688239 & 6.1362 & 5.3741 & TRN & \\
\hline CHEMBL 3192907 & 688239 & 6.1862 & 5.246 & TRN & \\
\hline CHEMBL1526305 & 688239 & 5.9862 & 5.4809 & TRN & \\
\hline CHEMBL1524701 & 688239 & 5.6362 & 5.4901 & TRN & \\
\hline CHEMBL1333468 & 688239 & 6.7862 & 5.5025 & TRN & \\
\hline CHEMBL1461330 & 688239 & 4.7362 & 5.502999 & 9999999999 & TST \\
\hline CHEMBL1494975 & 688239 & 5.6862 & 5.4752 & TST & \\
\hline CHEMBL1342321 & 688239 & 4.6362 & 5.4432 & TRN & \\
\hline CHEMBL1537107 & 688239 & 5.1862 & 5.5361 & TST & \\
\hline CHEMBL1397665 & 688239 & 5.2862 & 5.5001 & TRN & \\
\hline CHEMBL1356150 & 688239 & 4.4862 & 5.4854 & TRN & \\
\hline CHEMBL1303427 & 688239 & 5.4862 & 5.5367 & TRN & \\
\hline CHEMBL 3198656 & 688239 & 4.7362 & 5.3141 & TRN & \\
\hline CHEMBL1387126 & 688239 & 8.28399 & 99999999 & 5.4814 & TRN \\
\hline CHEMBL1390728 & 688239 & 4.5362 & 5.4404 & TST & \\
\hline CHEMBL 3189143 & 688239 & 6.4362 & 5.561 & TST & \\
\hline CHEMBL1429150 & 688239 & 5.1862 & 5.5045 & TRN & \\
\hline CHEMBL1577554 & 688239 & 6.6362 & 5.5644 & TRN & \\
\hline CHEMBL1564318 & 688239 & 6.8861 & 5.5871 & TRN & \\
\hline CHEMBL1346673 & 688239 & 6.2362 & 5.3998 & TRN & \\
\hline CHEMBL1993610 & 688239 & 7.2865 & 5.4852 & TRN & \\
\hline CHEMBL1531657 & 688239 & 8.3372 & 5.4188 & TRN & \\
\hline CHEMBL1509838 & 688239 & 4.5862 & 5.5055 & TST & \\
\hline CHEMBL1457420 & 688239 & 4.8362 & 5.4154 & TRN & \\
\hline CHEMBL1423662 & 688239 & 5.1862 & 5.4031 & TRN & \\
\hline CHEMBL1469141 & 688239 & 4.5362 & 5.4884 & TRN & \\
\hline CHEMBL1302981 & 688239 & 5.2862 & 5.4205 & TST & \\
\hline
\end{tabular}


Supplemental Table S2.txt

\begin{tabular}{|c|c|c|c|c|c|}
\hline CHEMBL1421202 & 688239 & 4.6362 & 5.5234 & TST & \\
\hline CHEMBL1460303 & 688239 & 5.0862 & 5.4937 & TRN & \\
\hline CHEMBL1423120 & 688239 & 6.6362 & 5.4418 & TRN & \\
\hline CHEMBL1344677 & 688239 & 6.2362 & 5.4875 & TST & \\
\hline CHEMBL1336743 & 688239 & 5.7862 & 5.562 & TRN & \\
\hline CHEMBL1477848 & 688239 & 5.3862 & 5.416 & TRN & \\
\hline CHEMBL1481778 & 688239 & 4.7362 & 5.4925 & TRN & \\
\hline CHEMBL1496317 & 688239 & 6.8861 & 5.4805 & TRN & \\
\hline CHEMBL1538111 & 688239 & 5.7862 & 5.5433 & TRN & \\
\hline CHEMBL1424695 & 688239 & 4.6362 & 5.5361 & TRN & \\
\hline CHEMBL1543754 & 688239 & 4.5362 & 5.5832 & TRN & \\
\hline CHEMBL1460391 & 688239 & 6.4862 & 5.5038 & TRN & \\
\hline CHEMBL1455854 & 688239 & 6.2862 & 5.4996 & TRN & \\
\hline CHEMBL1312443 & 688239 & 6.9863 & 5.5613 & TST & \\
\hline CHEMBL1572973 & 688239 & 6.7361 & 5.6389 & TRN & \\
\hline CHEMBL1425926 & 688239 & 5.1862 & 5.5096 & TRN & \\
\hline CHEMBL1560875 & 688239 & 6.1362 & 5.4395 & TRN & \\
\hline CHEMBL1355001 & 688239 & 5.7362 & 5.5647 & TRN & \\
\hline CHEMBL1575372 & 688239 & 5.3862 & 5.3278 & TRN & \\
\hline CHEMBL3210392 & 688239 & 5.1862 & 5.4499 & TRN & \\
\hline CHEMBL1312643 & 688239 & 5.1862 & 5.5496 & TST & \\
\hline CHEMBL1485381 & 688239 & 4.6862 & 5.7009 & TRN & \\
\hline CHEMBL1531060 & 688239 & 7.2865 & 5.4806 & TRN & \\
\hline CHEMBL1532716 & 688239 & 5.6362 & 5.4519 & TRN & \\
\hline CHEMBL 1446000 & 688239 & 6.8861 & 5.4805 & TRN & \\
\hline CHEMBL3192593 & 688239 & 8.1871 & 5.4696 & TRN & \\
\hline CHEMBL1327964 & 688239 & 4.5362 & 5.5211 & TRN & \\
\hline CHEMBL1331667 & 688239 & 5.3362 & 5.5163 & TRN & \\
\hline CHEMBL3193871 & 688239 & 4.6862 & 5.5186 & TRN & \\
\hline CHEMBL1474234 & 688239 & 6.1862 & 5.5793 & TRN & \\
\hline CHEMBL1319098 & 688239 & 4.5862 & 5.5647 & TST & \\
\hline CHEMBL1503706 & 688239 & 6.8861 & 5.4284 & TRN & \\
\hline CHEMBL3191419 & 688239 & 8.28399 & 99999999 & 99 & 5.4296 \\
\hline CHEMBL1605295 & 688239 & 4.7362 & 5.2887 & TST & \\
\hline CHEMBL1606736 & 688239 & 6.5363 & 5.5716 & TST & \\
\hline CHEMBL1497458 & 688239 & 8.3372 & 5.6525 & TRN & \\
\hline CHEMBL1448109 & 688239 & 6.1362 & 5.6089 & TST & \\
\hline CHEMBL1543493 & 688239 & 6.5862 & 5.4883 & TRN & \\
\hline CHEMBL1464637 & 688239 & 4.8862 & 5.6442 & TRN & \\
\hline CHEMBL1491491 & 688239 & 4.5362 & 5.5786 & TST & \\
\hline CHEMBL1423051 & 688239 & 6.8362 & 5.4688 & TRN & \\
\hline CHEMBL1300051 & 688239 & 5.7362 & 5.3232 & TRN & \\
\hline CHEMBL1314489 & 688239 & 4.6362 & 5.4674 & TRN & \\
\hline CHEMBL1345998 & 688239 & 4.7862 & 5.4894 & TRN & \\
\hline CHEMBL3192129 & 688239 & 4.5362 & 5.3865 & TST & \\
\hline CHEMBL 1548950 & 688239 & 4.6862 & 5.5169 & TRN & \\
\hline CHEMBL1471237 & 688239 & 4.5362 & 5.4682 & TRN & \\
\hline CHEMBL1488531 & 688239 & 4.5362 & 5.5808 & TRN & \\
\hline
\end{tabular}


Supplemental Table S2.txt

\begin{tabular}{|c|c|c|c|c|}
\hline 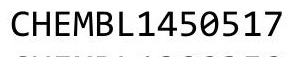 & & 362 & & \\
\hline HEMBL1388358 & 88239 & 362 & 4639 & \\
\hline HEMBL1557005 & 88239 & 3872 & 6388 & \\
\hline 212 & 38239 & 362 & 3443 & \\
\hline AEMBL3195030 & 38239 & & & \\
\hline AEMBL152 & 88239 & 362 & .4854 & \\
\hline HEMBL3209191 & 88239 & 4862 & .5006 & \\
\hline HEMBL1388307 & 88239 & 366 & 4457 & \\
\hline AEMBL13S & 88239 & 862 & .4427 & \\
\hline IEMBL137 & 88239 & & & \\
\hline AEMBL1503124 & 88239 & 362 & .5105 & \\
\hline AEMBL1376125 & 88239 & 362 & 4636 & \\
\hline HEMBL1540961 & 88239 & 362 & .6113 & \\
\hline IEMBL15 & 239 & 62 & 5154 & \\
\hline 185 & & & & \\
\hline JEMBL14 & 88239 & & 5.4974 & \\
\hline IEMBL 14 & 39 & & 5224 & \\
\hline HEMBL1308217 & 39 & 62 & 5.61 & \\
\hline L13 & 39 & & 62 & \\
\hline 58 & & & & \\
\hline 10 & & & & \\
\hline L32 & 39 & & & RN \\
\hline HEMLISE & 39 & 62 & 31 & \\
\hline L13 & & & 16 & \\
\hline 2 & 39 & & & \\
\hline 575 & & & & PM \\
\hline IEMBL14 & & & & RN \\
\hline IEMBL16 & 39 & & 5857 & RN \\
\hline IEM & 39 & & 364 & 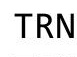 \\
\hline 70 & 39 & 62 & 826 & RN \\
\hline & & & & RN \\
\hline AEMBL14 & & & & RN \\
\hline IEMBL14 & 39 & & 277 & RN \\
\hline IEMBL15 & 39 & & 66 & KIV \\
\hline 58 & 39 & & 341 & RN \\
\hline AEMBL148 & & & 242 & RN \\
\hline IEMBL159 & & & 356 & IST \\
\hline IEMBL14 & & & & RN \\
\hline IFMRI 14 & 39 & & 13 & \\
\hline & & & & RN \\
\hline HEMBL1566389 & 88239 & & 5.4837 & ST \\
\hline IEMBL 14 & 39 & & 48 & ST \\
\hline 50 & & & & \\
\hline HEMBL 319 & & & & \\
\hline HEMBL1540173 & 88239 & 862 & 5.4832 & ST \\
\hline IEMBL1337438 & 588239 & 7.2366 & 5.629 & RN \\
\hline HEMBL145 & 88239 & 4.6862 & 5.4346 & \\
\hline -HEMPI 221259 & 588239 & & & \\
\hline
\end{tabular}

Page 1356 
Supplemental Table S2.txt

\begin{tabular}{|c|c|c|c|c|c|}
\hline CHEMBL1488455 & 688239 & 5.1862 & 5.3273 & TRN & \\
\hline CHEMBL1346684 & 688239 & 5.2862 & 5.682 & TRN & \\
\hline CHEMBL1484881 & 688239 & 5.4362 & 5.5391 & TST & \\
\hline CHEMBL1390752 & 688239 & 6.2362 & 5.5798 & TRN & \\
\hline CHEMBL1514326 & 688239 & 5.1862 & 5.534 & TRN & \\
\hline CHEMBL1324675 & 688239 & 4.5362 & 5.5896 & TRN & \\
\hline CHEMBL1472348 & 688239 & 4.7362 & 5.5568 & TST & \\
\hline CHEMBL1479187 & 688239 & 5.9862 & 5.3922 & TRN & \\
\hline CHEMBL1516165 & 688239 & 4.5362 & 5.4821 & TST & \\
\hline CHEMBL1474945 & 688239 & 4.5362 & 5.3718 & TRN & \\
\hline CHEMBL1514823 & 688239 & \multicolumn{3}{|c|}{8.283999999999999} & TRN \\
\hline CHEMBL1313010 & 688239 & 5.3362 & 5.5004 & TRN & \\
\hline CHEMBL1393625 & 688239 & 4.5362 & 5.3796 & TST & \\
\hline CHEMBL1450694 & 688239 & 6.3863 & 5.5927 & TST & \\
\hline CHEMBL1527270 & 688239 & 5.3862 & 5.7113 & TRN & \\
\hline CHEMBL1535891 & 688239 & 5.7362 & 5.3954 & TRN & \\
\hline CHEMBL1543000 & 688239 & 5.0862 & 5.5622 & TST & \\
\hline CHEMBL1509924 & 688239 & 6.3362 & 5.4588 & TRN & \\
\hline CHEMBL1358060 & 688239 & 6.8362 & 5.3185 & TRN & \\
\hline CHEMBL1305154 & 688239 & 5.1862 & 5.454 & TRN & \\
\hline CHEMBL1312668 & 688239 & 4.6862 & \multicolumn{2}{|c|}{5.617999999999999} & TST \\
\hline CHEMBL1599478 & 688239 & 5.0362 & 5.5563 & TRN & \\
\hline CHEMBL1573738 & 688239 & 4.5862 & 5.5658 & TRN & \\
\hline CHEMBL1441685 & 688239 & 6.6362 & 5.3972 & TRN & \\
\hline CHEMBL1537179 & 688239 & 4.5362 & 5.3917 & TST & \\
\hline CHEMBL3195874 & 688239 & 4.5362 & 5.3959 & TRN & \\
\hline CHEMBL1572234 & 688239 & 4.7362 & 5.3308 & TST & \\
\hline CHEMBL1585375 & 688239 & 4.6862 & 5.3861 & TRN & \\
\hline CHEMBL1499777 & 688239 & 4.7362 & 5.4673 & TRN & \\
\hline CHEMBL1330617 & 688239 & 8.2366 & 5.4559 & TST & \\
\hline CHEMBL1466980 & 688239 & 6.7862 & 5.4989 & TRN & \\
\hline CHEMBL1313117 & 688239 & 4.5862 & 5.5569 & TST & \\
\hline CHEMBL1419973 & 688239 & 4.8862 & 5.4634 & TRN & \\
\hline CHEMBL1555562 & 688239 & 6.0362 & 5.3687 & TRN & \\
\hline CHEMBL1562943 & 688239 & 5.2362 & 5.4502 & TRN & \\
\hline CHEMBL1444830 & 688239 & 5.7362 & 5.3916 & TRN & \\
\hline CHEMBL1359013 & 688239 & 4.8862 & 5.4392 & TRN & \\
\hline CHEMBL1474988 & 688239 & 4.6362 & 5.4851 & TST & \\
\hline CHEMBL1481635 & 688239 & 5.4862 & 5.7395 & TRN & \\
\hline CHEMBL1518916 & 688239 & 5.0362 & 5.3852 & TRN & \\
\hline CHEMBL1518393 & 688239 & 4.5862 & 5.5332 & TRN & \\
\hline CHEMBL1601975 & 688239 & 4.6362 & 5.2757 & TST & \\
\hline CHEMBL1332943 & 688239 & 6.1862 & 5.4117 & TRN & \\
\hline CHEMBL1453654 & 688239 & 4.7862 & 5.3567 & TST & \\
\hline CHEMBL1344904 & 688239 & 5.5862 & 5.3927 & TRN & \\
\hline CHEMBL1444736 & 688239 & 7.5867 & 5.5843 & TST & \\
\hline CHEMBL1541199 & 688239 & 4.5362 & 5.4912 & TRN & \\
\hline \multirow[t]{2}{*}{ CHEMBL1402904 } & 688239 & 5.5362 & \multicolumn{2}{|c|}{5.417000000000001} & \\
\hline & & & & ge 1357 & \\
\hline
\end{tabular}


Supplemental Table S2.txt

\begin{tabular}{|c|c|c|c|c|}
\hline CHEMBL1443574 & 688239 & 5.1362 & 5.4415 & TRN \\
\hline CHEMBL1373452 & 688239 & 5.4862 & 5.4857 & TRN \\
\hline CHEMBL1335520 & 688239 & 5.6862 & 5.4365 & TST \\
\hline CHEMBL1509982 & 688239 & 5.6862 & 5.4411 & TRN \\
\hline CHEMBL1558017 & 688239 & 6.6362 & 5.6207 & TRN \\
\hline CHEMBL1603789 & 688239 & 4.7862 & 5.5676 & TRN \\
\hline CHEMBL1601279 & 688239 & 6.9363 & 5.4893 & TRN \\
\hline CHEMBL1336475 & 688239 & 4.5362 & 5.4285 & TRN \\
\hline CHEMBL1973773 & 688239 & 6.0862 & 5.4951 & TST \\
\hline CHEMBL1431030 & 688239 & 6.8861 & 5.5915 & TRN \\
\hline CHEMBL1519778 & 688239 & 4.5862 & 5.6171 & TRN \\
\hline CHEMBL1418842 & 688239 & 5.2362 & 5.3432 & TRN \\
\hline CHEMBL1540712 & 688239 & 5.0362 & 5.5205 & TRN \\
\hline CHEMBL1430390 & 688239 & 4.5362 & 5.4876 & TRN \\
\hline CHEMBL1325982 & 688239 & 4.5362 & 5.6105 & TRN \\
\hline CHEMBL1521231 & 688239 & 5.8362 & 5.38299 & 99999999999 \\
\hline CHEMBL1431821 & 688239 & 6.1362 & 5.46200 & 0000000001 \\
\hline CHEMBL1374796 & 688239 & 4.6362 & 5.4744 & TRN \\
\hline CHEMBL1536834 & 688239 & 5.4362 & 5.431 & TRN \\
\hline CHEMBL1359637 & 688239 & 6.8362 & 5.3879 & TRN \\
\hline CHEMBL1388672 & 688239 & 4.7862 & 5.5878 & TRN \\
\hline CHEMBL1374934 & 688239 & 7.6364 & 5.6522 & TRN \\
\hline CHEMBL1309231 & 688239 & 6.5363 & 5.4286 & TRN \\
\hline CHEMBL1412538 & 688239 & 4.6362 & 5.5256 & TST \\
\hline CHEMBL1489375 & 688239 & 4.7362 & 5.4286 & TRN \\
\hline CHEMBL1575512 & 688239 & 7.2865 & 5.4657 & TST \\
\hline CHEMBL1553007 & 688239 & 5.6362 & 5.4875 & TRN \\
\hline CHEMBL1314350 & 688239 & 7.5361 & 5.6161 & TRN \\
\hline CHEMBL1476321 & 688239 & 6.7862 & 5.5197 & TRN \\
\hline CHEMBL1391950 & 688239 & 5.2862 & 5.3742 & TRN \\
\hline CHEMBL1325129 & 688239 & 7.0362 & 5.3464 & TRN \\
\hline CHEMBL1505095 & 688239 & 4.7862 & 5.5973 & TRN \\
\hline CHEMBL1586104 & 688239 & 6.8362 & 5.5853 & TRN \\
\hline CHEMBL1401662 & 688239 & 5.6862 & 5.3849 & TRN \\
\hline CHEMBL1379868 & 688239 & 6.2862 & 5.6421 & TST \\
\hline CHEMBL1504767 & 688239 & 4.5362 & 5.6489 & TRN \\
\hline CHEMBL1497565 & 688239 & 4.7362 & 5.4886 & TST \\
\hline CHEMBL1498753 & 688239 & 6.0362 & 5.3983 & TRN \\
\hline CHEMBL1567035 & 688239 & 4.5362 & 5.4435 & TST \\
\hline CHEMBL1433804 & 688239 & 5.4362 & 5.4516 & TRN \\
\hline CHEMBL1430425 & 688239 & 4.7862 & 5.4424 & TST \\
\hline CHEMBL1535490 & 688239 & 5.3362 & 5.5349 & TRN \\
\hline CHEMBL1381391 & 688239 & 7.0362 & 5.4365 & TRN \\
\hline CHEMBL1386412 & 688239 & 8.3372 & 5.4794 & TST \\
\hline CHEMBL1571417 & 688239 & 5.9362 & 5.4637 & TRN \\
\hline CHEMBL1440404 & 688239 & 5.4362 & 5.4073 & TRN \\
\hline CHEMBL1467024 & 688239 & 4.9862 & 5.2991 & TRN \\
\hline CHEMBL1495717 & 688239 & 5.1862 & 5.5559 & TRN \\
\hline
\end{tabular}

Page 1358 


\begin{tabular}{|c|c|c|c|c|c|c|}
\hline & & & & & & \\
\hline CHEMBL1521596 & 688239 & 5.2362 & 5.5038 & TRN & & \\
\hline CHEMBL1457479 & 688239 & 5.1862 & 5.4498 & TST & & \\
\hline CHEMBL1579747 & 688239 & 4.7362 & 5.4824 & TST & & \\
\hline CHEMBL1305821 & 688239 & 4.5362 & 5.3998 & TRN & & \\
\hline CHEMBL1607960 & 688239 & 7.2366 & 5.3565 & TRN & & \\
\hline CHEMBL1402305 & 688239 & 6.1362 & 5.5571 & TRN & & \\
\hline CHEMBL1386288 & 688239 & 6.5363 & 5.5133 & TST & & \\
\hline CHEMBL1566829 & 688239 & 4.5362 & 5.3112 & TST & & \\
\hline CHEMBL1976304 & 688239 & 4.9362 & 5.3485 & TST & & \\
\hline CHEMBL1438378 & 688239 & 8.28399 & 99999999 & 99 & 5.5285 & TRN \\
\hline CHEMBL1398183 & 688239 & 4.7362 & 5.4415 & TRN & & \\
\hline CHEMBL1469921 & 688239 & 5.6862 & 5.4128 & TRN & & \\
\hline CHEMBL1573385 & 688239 & 8.28399 & 99999999 & 99 & 5.455 & TST \\
\hline CHEMBL1317391 & 688239 & 4.5362 & 5.4707 & TRN & & \\
\hline CHEMBL1456108 & 688239 & 6.5363 & 5.5208 & TRN & & \\
\hline CHEMBL1580601 & 688239 & 5.1862 & 5.3869 & TRN & & \\
\hline CHEMBL1605599 & 688239 & 6.8861 & 5.4681 & TRN & & \\
\hline CHEMBL1491221 & 688239 & 5.1862 & 5.5576 & TRN & & \\
\hline CHEMBL1463673 & 688239 & 4.4862 & 5.5785 & TRN & & \\
\hline CHEMBL1353118 & 688239 & 5.1862 & 5.5016 & TST & & \\
\hline CHEMBL1486225 & 688239 & 5.1862 & 5.5314 & TRN & & \\
\hline CHEMBL1417932 & 688239 & 5.1862 & 5.3413 & TST & & \\
\hline CHEMBL1559069 & 688239 & 5.6862 & 5.54799 & 9999999999 & & TRN \\
\hline CHEMBL1313824 & 688239 & 6.7862 & 5.5503 & TRN & & \\
\hline CHEMBL1313771 & 688239 & 4.6862 & 5.6725 & TRN & & \\
\hline CHEMBL1359506 & 688239 & 4.5362 & 5.3473 & TRN & & \\
\hline CHEMBL1528244 & 688239 & 5.1862 & 5.5954 & TRN & & \\
\hline CHEMBL1523568 & 688239 & 4.5362 & 5.3638 & TRN & & \\
\hline CHEMBL1375734 & 688239 & 5.4362 & 5.4464 & TRN & & \\
\hline CHEMBL1552410 & 688239 & 5.2862 & 5.6169 & TRN & & \\
\hline CHEMBL1479589 & 688239 & 8.28399 & 99999999 & & 5.6513 & TRN \\
\hline CHEMBL1518594 & 688239 & 5.3362 & 5.3329 & TRN & & \\
\hline CHEMBL1372140 & 688239 & 8.0362 & 5.5003 & TST & & \\
\hline CHEMBL1385959 & 688239 & 4.5362 & 5.5335 & TRN & & \\
\hline CHEMBL1552340 & 688239 & 4.7362 & 5.517 & TST & & \\
\hline CHEMBL1413329 & 688239 & 4.5362 & 5.4589 & TRN & & \\
\hline CHEMBL1600663 & 688239 & 5.1862 & 5.6177 & TRN & & \\
\hline CHEMBL1581369 & 688239 & 5.4362 & 5.5979 & TST & & \\
\hline CHEMBL1464141 & 688239 & 4.6362 & 5.4414 & TRN & & \\
\hline CHEMBL1601142 & 688239 & 5.1862 & 5.4608 & TRN & & \\
\hline CHEMBL1414252 & 688239 & 5.6362 & 5.3307 & TST & & \\
\hline CHEMBL1436297 & 688239 & 5.7362 & 5.4387 & TRN & & \\
\hline CHEMBL1527026 & 688239 & 4.9362 & 5.3919 & TRN & & \\
\hline CHEMBL1405168 & 688239 & 4.6862 & 5.5605 & TRN & & \\
\hline CHEMBL1435909 & 688239 & 7.1864 & 5.2922 & TRN & & \\
\hline CHEMBL1506283 & 688239 & 6.4362 & $5.54200 t$ & 0000000001 & & TRN \\
\hline CHEMBL1587194 & 688239 & 4.5362 & 5.6479 & TRN & & \\
\hline CHEMBL1549778 & 688239 & 7.0362 & 5.6391 & TST & & \\
\hline
\end{tabular}


Supplemental Table S2.txt

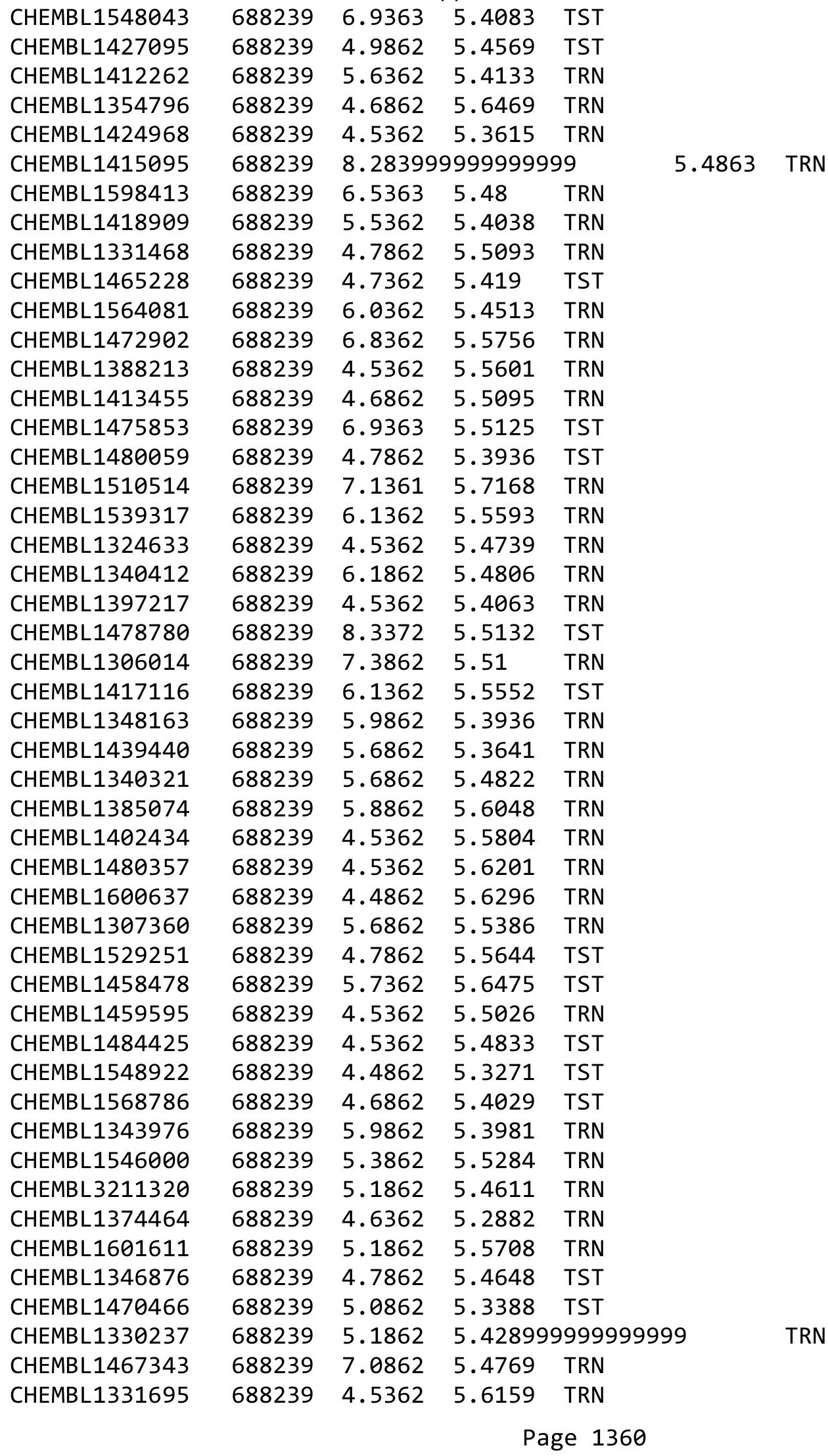


Supplemental Table S2.txt

\begin{tabular}{|c|c|c|c|c|c|}
\hline CHEMBL1352524 & 688239 & 6.9363 & 5.5304 & TRN & \\
\hline CHEMBL1514511 & 688239 & 5.1862 & 5.3789 & TRN & \\
\hline CHEMBL1375134 & 688239 & 5.8862 & 5.5466 & TRN & \\
\hline CHEMBL1305974 & 688239 & 5.5362 & 5.5562 & TRN & \\
\hline CHEMBL1528755 & 688239 & 5.2862 & 5.4923 & TRN & \\
\hline CHEMBL1385842 & 688239 & 5.6362 & 5.529 & TRN & \\
\hline CHEMBL1608425 & 688239 & 4.9362 & 5.476 & TRN & \\
\hline CHEMBL1390955 & 688239 & 4.5362 & 5.447 & TRN & \\
\hline CHEMBL1509891 & 688239 & 6.2362 & 5.3863 & TRN & \\
\hline CHEMBL1455191 & 688239 & 4.8362 & 5.5208 & TRN & \\
\hline CHEMBL1395448 & 688239 & 4.6362 & 5.4369 & TRN & \\
\hline CHEMBL1508627 & 688239 & 5.4362 & 5.4311 & TST & \\
\hline CHEMBL1540168 & 688239 & 6.8861 & 5.4632 & TRN & \\
\hline CHEMBL1420803 & 688239 & 6.4362 & 5.5013 & TST & \\
\hline CHEMBL1517762 & 688239 & 5.4362 & 5.4554 & TST & \\
\hline CHEMBL1510142 & 688239 & 4.6362 & 5.5193 & TRN & \\
\hline CHEMBL1398939 & 688239 & 6.1362 & 5.4937 & TST & \\
\hline CHEMBL1613708 & 688239 & 4.9362 & 5.6259 & TRN & \\
\hline CHEMBL1382559 & 688239 & 5.3862 & 5.372999 & э999999999 & TRN \\
\hline CHEMBL1335788 & 688239 & 5.7362 & 5.5989 & TRN & \\
\hline CHEMBL1474357 & 688239 & 4.9362 & 5.4513 & TRN & \\
\hline CHEMBL1586256 & 688239 & 4.5362 & 5.5797 & TRN & \\
\hline CHEMBL1593632 & 688239 & 4.5862 & 5.3723 & TRN & \\
\hline CHEMBL1423343 & 688239 & 6.1362 & 5.519 & TRN & \\
\hline CHEMBL1449059 & 688239 & 4.6362 & 5.4255 & TRN & \\
\hline CHEMBL1595201 & 688239 & 5.0862 & 5.3607 & TRN & \\
\hline CHEMBL1438694 & 688239 & 4.5862 & 5.5514 & TRN & \\
\hline CHEMBL1458280 & 688239 & 5.7362 & 5.3675 & TRN & \\
\hline CHEMBL1339187 & 688239 & 6.3863 & 5.4839 & TRN & \\
\hline CHEMBL1323916 & 688239 & 5.1862 & 5.5561 & TRN & \\
\hline CHEMBL3189892 & 688239 & 6.1862 & 5.4471 & TRN & \\
\hline CHEMBL1354592 & 688239 & 6.1862 & 5.4523 & TRN & \\
\hline CHEMBL1428188 & 688239 & 5.1862 & 5.6241 & TRN & \\
\hline CHEMBL1306701 & 688239 & 4.5362 & 5.5476 & TRN & \\
\hline CHEMBL1460446 & 688239 & 4.7362 & 5.4407 & TST & \\
\hline CHEMBL1335273 & 688239 & 5.7362 & 5.3738 & TRN & \\
\hline CHEMBL1424009 & 688239 & 4.7862 & 5.5008 & TST & \\
\hline CHEMBL1394968 & 688239 & 5.0362 & 5.4863 & TRN & \\
\hline CHEMBL1593512 & 688239 & 6.8362 & 5.3908 & TST & \\
\hline CHEMBL3213019 & 688239 & 5.4862 & 5.3819 & TRN & \\
\hline CHEMBL1458083 & 688239 & 5.5862 & 5.3265 & TST & \\
\hline CHEMBL1524364 & 688239 & 6.8362 & 5.6962 & TRN & \\
\hline CHEMBL1561378 & 688239 & 5.7862 & 5.4938 & TRN & \\
\hline CHEMBL 3213238 & 688239 & 5.7362 & 5.487999 & 99999999995 & TRN \\
\hline CHEMBL1390774 & 688239 & 5.4862 & 5.4831 & TRN & \\
\hline CHEMBL1570587 & 688239 & 5.6362 & 5.454 & TST & \\
\hline CHEMBL1420308 & 688239 & 6.2362 & 5.5362 & TRN & \\
\hline CHEMBL1565632 & 688239 & 5.8862 & 5.4593 & TRN & \\
\hline
\end{tabular}

Page 1361 
Supplemental Table S2.txt

\begin{tabular}{|c|c|c|c|c|c|}
\hline CHEMBL1538402 & 688239 & 5.8862 & 5.3193 & TST & \\
\hline CHEMBL1361781 & 688239 & 4.5862 & 5.5131 & TRN & \\
\hline CHEMBL1409416 & 688239 & 6.1362 & 5.6167 & TRN & \\
\hline CHEMBL1622371 & 688239 & 4.8362 & 5.5642 & TST & \\
\hline CHEMBL1303259 & 688239 & 4.7862 & 5.5497 & TST & \\
\hline CHEMBL1422564 & 688239 & 8.3372 & 5.5445 & TST & \\
\hline CHEMBL1453312 & 688239 & 4.6862 & 5.6194 & TRN & \\
\hline CHEMBL1602755 & 688239 & 5.2862 & 5.5291 & TRN & \\
\hline CHEMBL1413252 & 688239 & 4.6362 & 5.5073 & TST & \\
\hline CHEMBL1430320 & 688239 & 4.8362 & 5.482 & TRN & \\
\hline CHEMBL 3194854 & 688239 & 4.6862 & 5.3598 & TRN & \\
\hline CHEMBL1406767 & 688239 & 5.0862 & 5.4348 & TST & \\
\hline CHEMBL1530105 & 688239 & 4.8862 & 5.6775 & TRN & \\
\hline CHEMBL1314523 & 688239 & 5.4862 & 5.6191 & TST & \\
\hline CHEMBL1335013 & 688239 & 4.5862 & 5.3845 & TRN & \\
\hline CHEMBL1469702 & 688239 & 4.9362 & 5.5975 & TRN & \\
\hline CHEMBL1559059 & 688239 & 4.7862 & 5.4782 & TRN & \\
\hline CHEMBL1543478 & 688239 & 5.0862 & 5.282 & TRN & \\
\hline CHEMBL1475158 & 688239 & 4.5362 & 5.6116 & TRN & \\
\hline CHEMBL1381241 & 688239 & 7.0362 & 5.5706 & TST & \\
\hline CHEMBL1605906 & 688239 & 4.7362 & 5.5582 & TST & \\
\hline CHEMBL1384068 & 688239 & 4.7862 & 5.3723 & TRN & \\
\hline CHEMBL1472180 & 688239 & 5.0362 & 5.37299 & 9999999999 & TRN \\
\hline CHEMBL1449197 & 688239 & 4.8362 & 5.596 & TRN & \\
\hline CHEMBL1588585 & 688239 & 4.4862 & 5.5227 & TRN & \\
\hline CHEMBL1305298 & 688239 & 4.9362 & 5.6221 & TST & \\
\hline CHEMBL1455076 & 688239 & 5.0362 & 5.4333 & TST & \\
\hline CHEMBL 3190349 & 688239 & 4.8362 & 5.5548 & TST & \\
\hline CHEMBL1496835 & 688239 & 5.6862 & 5.3928 & TRN & \\
\hline CHEMBL1469668 & 688239 & 8.1871 & 5.5316 & TST & \\
\hline CHEMBL1422836 & 688239 & 5.1862 & 5.6323 & TRN & \\
\hline CHEMBL1522057 & 688239 & 4.4862 & 5.6204 & TRN & \\
\hline CHEMBL1465342 & 688239 & 4.5362 & 5.2865 & TST & \\
\hline CHEMBL1582358 & 688239 & 5.6862 & 5.6078 & TST & \\
\hline CHEMBL1375394 & 688239 & 6.1362 & 5.4201 & TST & \\
\hline CHEMBL1411657 & 688239 & 5.1862 & \multicolumn{2}{|c|}{5.3870000000000005} & TRN \\
\hline CHEMBL1600928 & 688239 & 5.8362 & 5.5158 & TST & \\
\hline CHEMBL 3195172 & 688239 & 6.6362 & 5.6171 & TRN & \\
\hline CHEMBL1455885 & 688239 & 4.5362 & 5.3414 & TRN & \\
\hline CHEMBL1424505 & 688239 & 4.5362 & 5.3759 & TST & \\
\hline CHEMBL1488064 & 688239 & 5.1862 & \multicolumn{2}{|c|}{5.507000000000001} & TST \\
\hline CHEMBL1459246 & 688239 & 4.7362 & 5.3867 & TST & \\
\hline CHEMBL1593544 & 688239 & 6.0362 & 5.5491 & TRN & \\
\hline CHEMBL1487959 & 688239 & 4.4862 & 5.2812 & TRN & \\
\hline CHEMBL1591631 & 688239 & 4.7862 & 5.5055 & TRN & \\
\hline CHEMBL1479468 & 688239 & 4.8862 & 5.2776 & TRN & \\
\hline CHEMBL1343483 & 688239 & 4.9362 & 5.615 & TRN & \\
\hline CHEMBL1599269 & 688239 & 6.2862 & 5.4132 & TRN & \\
\hline
\end{tabular}


Supplemental Table S2.txt

\begin{tabular}{|c|c|c|c|c|c|c|}
\hline CHEMBL1569828 & 688239 & 5.8862 & 5.5129 & TRN & & \\
\hline CHEMBL1497113 & 688239 & 4.5362 & 5.5147 & TRN & & \\
\hline CHEMBL1570423 & 688239 & 7.0362 & 5.3904 & TST & & \\
\hline CHEMBL1979849 & 688239 & 4.6362 & 5.3683 & TRN & & \\
\hline CHEMBL1497838 & 688239 & 4.5362 & 5.4173 & TST & & \\
\hline CHEMBL1500958 & 688239 & 4.5862 & 5.4723 & TST & & \\
\hline CHEMBL1418927 & 688239 & 5.0362 & 5.3367 & TST & & \\
\hline CHEMBL1424950 & 688239 & 5.8362 & 5.6228 & TST & & \\
\hline CHEMBL1527720 & 688239 & 4.9862 & 5.3075 & TST & & \\
\hline CHEMBL1583888 & 688239 & 6.0362 & 5.5242 & TST & & \\
\hline CHEMBL567551 & 688239 & 6.6362 & 5.5391 & TRN & & \\
\hline CHEMBL1594089 & 688239 & 5.8862 & 5.3743 & TRN & & \\
\hline CHEMBL1581530 & 688239 & 4.8362 & 5.4264 & TRN & & \\
\hline CHEMBL1453657 & 688239 & 5.3362 & 5.4018 & TRN & & \\
\hline CHEMBL1523252 & 688239 & 6.2862 & 5.4663 & TRN & & \\
\hline CHEMBL1575159 & 688239 & 5.7362 & 5.449 & TST & & \\
\hline CHEMBL1522483 & 688239 & 4.5362 & 5.5953 & TST & & \\
\hline CHEMBL1403522 & 688239 & 4.8362 & 5.4428 & TRN & & \\
\hline CHEMBL1425826 & 688239 & 4.5362 & 5.5542 & TRN & & \\
\hline CHEMBL1546675 & 688239 & 5.5862 & 5.5613 & TST & & \\
\hline CHEMBL1536500 & 688239 & 6.1362 & 5.4705 & TRN & & \\
\hline CHEMBL1525209 & 688239 & 4.6362 & 5.5585 & TST & & \\
\hline CHEMBL1565294 & 688239 & 4.7862 & 5.579 & TRN & & \\
\hline CHEMBL1549230 & 688239 & 5.0362 & 5.4624 & TRN & & \\
\hline CHEMBL1400408 & 688239 & 6.8861 & 5.4215 & TRN & & \\
\hline CHEMBL1302282 & 688239 & 4.4862 & 5.4321 & TRN & & \\
\hline CHEMBL1562730 & 688239 & 5.1862 & 5.6842 & TRN & & \\
\hline CHEMBL1444858 & 688239 & 4.4862 & 5.3934 & TRN & & \\
\hline CHEMBL1394787 & 688239 & 6.2362 & 5.4693 & TRN & & \\
\hline CHEMBL1344077 & 688239 & 4.7362 & 5.5427 & TST & & \\
\hline CHEMBL1585675 & 688239 & 4.4862 & 5.5494 & TST & & \\
\hline CHEMBL1562043 & 688239 & 5.8362 & 5.4954 & TRN & & \\
\hline CHEMBL1550140 & 688239 & 5.3862 & 5.5589 & TRN & & \\
\hline CHEMBL1368592 & 688239 & 6.8362 & 5.4449 & TRN & & \\
\hline CHEMBL1576060 & 688239 & 5.4362 & 5.5384 & TST & & \\
\hline CHEMBL1467890 & 688239 & 8.3372 & 5.6084 & TRN & & \\
\hline CHEMBL1323611 & 688239 & 6.8861 & 5.601 & TST & & \\
\hline CHEMBL1373163 & 688239 & 8.28399 & 99999999 & 99 & 5.5439 & TST \\
\hline CHEMBL1487609 & 688239 & 5.3862 & 5.3517 & TRN & & \\
\hline CHEMBL1589544 & 688239 & 4.5362 & 5.4712 & TST & & \\
\hline CHEMBL1599428 & 688239 & 4.7362 & 5.4436 & TRN & & \\
\hline CHEMBL1484928 & 688239 & 8.2366 & 5.5111 & TRN & & \\
\hline CHEMBL1327805 & 688239 & 4.6362 & 5.396 & TRN & & \\
\hline CHEMBL1479993 & 688239 & 7.1361 & 5.5212 & TRN & & \\
\hline CHEMBL1368550 & 688239 & 4.9362 & 5.4444 & TRN & & \\
\hline CHEMBL1478581 & 688239 & 4.9862 & 5.6142 & TRN & & \\
\hline CHEMBL1399974 & 688239 & 7.3363 & 5.5319 & TRN & & \\
\hline CHEMBL1571420 & 688239 & 4.5862 & 5.5454 & TRN & & \\
\hline
\end{tabular}


Supplemental Table S2.txt

\begin{tabular}{|c|c|c|c|c|c|}
\hline CHEMBL1527142 & 688239 & 5.1862 & 5.4934 & TRN & \\
\hline CHEMBL1503197 & 688239 & 7.5867 & 5.5007 & TRN & \\
\hline CHEMBL1523353 & 688239 & 4.5362 & 5.3912 & TRN & \\
\hline CHEMBL1405714 & 688239 & 7.5867 & 5.6006 & TRN & \\
\hline CHEMBL1385241 & 688239 & 5.2362 & 5.4795 & TRN & \\
\hline CHEMBL1432156 & 688239 & 5.8862 & 5.4625 & TST & \\
\hline CHEMBL1376135 & 688239 & 4.7862 & 5.5299 & TRN & \\
\hline CHEMBL1446077 & 688239 & 5.1862 & 5.6319 & TRN & \\
\hline CHEMBL1601998 & 688239 & 5.6362 & 5.4574 & TST & \\
\hline CHEMBL1313041 & 688239 & 5.4362 & 5.4687 & TRN & \\
\hline CHEMBL3194549 & 688239 & 5.3362 & 5.5384 & TRN & \\
\hline CHEMBL1541317 & 688239 & 5.1862 & 5.6278 & TST & \\
\hline CHEMBL1563126 & 688239 & 5.0362 & 5.5796 & TRN & \\
\hline CHEMBL3191053 & 688239 & 6.5862 & 5.4472 & TST & \\
\hline CHEMBL1451096 & 688239 & 4.6362 & 5.5795 & TRN & \\
\hline CHEMBL1381054 & 688239 & 5.9362 & 5.516 & TRN & \\
\hline CHEMBL1603416 & 688239 & 4.4862 & 5.3264 & TST & \\
\hline CHEMBL1424408 & 688239 & 4.7362 & 5.3915 & TRN & \\
\hline CHEMBL1422315 & 688239 & 5.6362 & 5.4617 & TRN & \\
\hline CHEMBL1504421 & 688239 & 4.5362 & 5.49299 & 9999999999 & TRN \\
\hline CHEMBL1552384 & 688239 & 4.7862 & 5.3927 & TST & \\
\hline CHEMBL1997177 & 688239 & 6.6861 & 5.2504 & TST & \\
\hline CHEMBL1406210 & 688239 & 5.8362 & 5.6528 & TRN & \\
\hline CHEMBL1402271 & 688239 & 4.6862 & 5.5094 & TRN & \\
\hline CHEMBL1419597 & 688239 & 7.1864 & 5.489 & TRN & \\
\hline CHEMBL1584449 & 688239 & 6.2362 & 5.5064 & TRN & \\
\hline CHEMBL1597887 & 688239 & 6.1362 & 5.447 & TRN & \\
\hline CHEMBL1517743 & 688239 & 6.0862 & 5.4015 & TRN & \\
\hline CHEMBL1603721 & 688239 & 6.9363 & 5.5007 & TST & \\
\hline CHEMBL1516213 & 688239 & 4.5362 & 5.5792 & TRN & \\
\hline CHEMBL1595152 & 688239 & 4.7862 & 5.364 & TST & \\
\hline CHEMBL1344770 & 688239 & 4.7362 & 5.4646 & TRN & \\
\hline CHEMBL1444615 & 688239 & 5.8862 & 5.5844 & TRN & \\
\hline CHEMBL1566298 & 688239 & 6.9863 & 5.6949 & TRN & \\
\hline CHEMBL1459518 & 688239 & 4.8862 & 5.4579 & TRN & \\
\hline CHEMBL1535355 & 688239 & 4.7862 & 5.3496 & TST & \\
\hline CHEMBL1384980 & 688239 & 5.2362 & 5.4813 & TRN & \\
\hline CHEMBL1366258 & 688239 & 5.7862 & 5.4905 & TRN & \\
\hline CHEMBL1485846 & 688239 & 4.8362 & 5.4846 & TST & \\
\hline CHEMBL1566259 & 688239 & 6.5363 & 5.5363 & TRN & \\
\hline CHEMBL1345776 & 688239 & 5.9362 & 5.3824 & TRN & \\
\hline CHEMBL1307020 & 688239 & 6.0362 & 5.5355 & TRN & \\
\hline CHEMBL1385666 & 688239 & 5.1862 & 5.3276 & TST & \\
\hline CHEMBL1510954 & 688239 & 6.1362 & 5.3483 & TRN & \\
\hline CHEMBL1478716 & 688239 & 5.7362 & 5.3752 & TST & \\
\hline CHEMBL1483522 & 688239 & 6.2862 & 5.4954 & TRN & \\
\hline CHEMBL1469724 & 688239 & 4.6362 & 5.5538 & TRN & \\
\hline CHEMBL1510129 & 688239 & 6.2362 & 5.5251 & TRN & \\
\hline
\end{tabular}


Supplemental Table S2.txt

\begin{tabular}{|c|c|c|c|c|c|}
\hline CHEMBL1323617 & 688239 & 8.2366 & 5.5445 & TRN & \\
\hline CHEMBL1346800 & 688239 & 4.4862 & 5.5509 & TRN & \\
\hline CHEMBL1424958 & 688239 & 6.6861 & 5.5347 & TST & \\
\hline CHEMBL1510953 & 688239 & 4.7362 & 5.5507 & TRN & \\
\hline CHEMBL1457818 & 688239 & 5.7362 & 5.5297 & TRN & \\
\hline CHEMBL1390313 & 688239 & 6.2862 & 5.6552 & TRN & \\
\hline CHEMBL3196159 & 688239 & 8.3372 & 5.5584 & TST & \\
\hline CHEMBL1309927 & 688239 & 5.1362 & 5.4946 & TRN & \\
\hline CHEMBL1600804 & 688239 & 5.5862 & 5.3265 & TRN & \\
\hline CHEMBL1329777 & 688239 & 4.5362 & 5.5477 & TST & \\
\hline CHEMBL1549574 & 688239 & 4.7362 & 5.2947 & TRN & \\
\hline CHEMBL1471441 & 688239 & 6.2862 & 5.5037 & TRN & \\
\hline CHEMBL1571641 & 688239 & 4.6862 & 5.5191 & TRN & \\
\hline CHEMBL1536577 & 688239 & 6.5862 & 5.5759 & TRN & \\
\hline CHEMBL1464042 & 688239 & 6.0862 & 5.3427 & TST & \\
\hline CHEMBL1468955 & 688239 & 5.95 & 5.5575 & TST & \\
\hline CHEMBL1448000 & 688239 & 5.8862 & 5.5471 & TRN & \\
\hline CHEMBL1587138 & 688239 & 6.9863 & 5.5277 & TRN & \\
\hline CHEMBL1407221 & 688239 & 6.6362 & 5.4761 & TRN & \\
\hline CHEMBL1441890 & 688239 & 4.4862 & 5.626 & TST & \\
\hline CHEMBL1602069 & 688239 & 5.1862 & 5.3002 & TST & \\
\hline CHEMBL 291558 & 688239 & 8.28399 & 99999999 & 99 & 5.3777 \\
\hline CHEMBL1503312 & 688239 & 4.6862 & 5.599 & TRN & \\
\hline CHEMBL1442784 & 688239 & 4.5362 & 5.4858 & TRN & \\
\hline CHEMBL1534095 & 688239 & 4.6362 & 5.5237 & TRN & \\
\hline CHEMBL1382636 & 688239 & 5.1862 & 5.5913 & TST & \\
\hline CHEMBL1606097 & 688239 & 5.1362 & 5.3257 & TST & \\
\hline CHEMBL1571329 & 688239 & 6.2362 & 5.6812 & TRN & \\
\hline CHEMBL1579408 & 688239 & 6.2862 & 5.4415 & TRN & \\
\hline CHEMBL1603068 & 688239 & 6.9363 & 5.3182 & TRN & \\
\hline CHEMBL1438641 & 688239 & 6.1362 & 5.4363 & TRN & \\
\hline CHEMBL1305513 & 688239 & 4.5862 & 5.5121 & TRN & \\
\hline CHEMBL1587181 & 688239 & 4.6862 & 5.4153 & TST & \\
\hline CHEMBL1516580 & 688239 & 5.7362 & 5.5773 & TRN & \\
\hline CHEMBL3192395 & 688239 & 5.0362 & 5.4889 & TRN & \\
\hline CHEMBL1612940 & 688239 & 5.1862 & 5.4809 & TRN & \\
\hline CHEMBL1591703 & 688239 & 6.8861 & 5.4175 & TRN & \\
\hline CHEMBL1419743 & 688239 & 5.6862 & 5.5142 & TRN & \\
\hline CHEMBL1551706 & 688239 & 7.0862 & 5.5339 & TRN & \\
\hline CHEMBL1377026 & 688239 & 5.9862 & 5.3134 & TST & \\
\hline CHEMBL 3192140 & 688239 & 5.7862 & 5.4928 & TST & \\
\hline CHEMBL1559187 & 688239 & 6.1862 & 5.3222 & TRN & \\
\hline CHEMBL1447596 & 688239 & 4.5362 & 5.5265 & TRN & \\
\hline CHEMBL1307669 & 688239 & 5.1862 & 5.6149 & TRN & \\
\hline CHEMBL3191300 & 688239 & 7.7852 & 5.6643 & TRN & \\
\hline CHEMBL1439691 & 688239 & 6.2362 & 5.4032 & TST & \\
\hline CHEMBL1476814 & 688239 & 7.2865 & 5.4417 & TRN & \\
\hline CHEMBL1373409 & 688239 & 4.6362 & 5.5182 & TST & \\
\hline
\end{tabular}


Supplemental Table S2.txt

\begin{tabular}{|c|c|c|c|c|c|}
\hline CHEMBL1301888 & 688239 & 4.5362 & 5.4175 & TST & \\
\hline CHEMBL 3198451 & 688239 & 6.5862 & 5.4278 & TRN & \\
\hline CHEMBL1604577 & 688239 & 6.8362 & 5.5466 & TRN & \\
\hline CHEMBL 3214400 & 688239 & 5.7862 & 5.4271 & TST & \\
\hline CHEMBL1304503 & 688239 & 4.6862 & 5.6303 & TRN & \\
\hline CHEMBL1442711 & 688239 & 4.7862 & 5.6102 & TST & \\
\hline CHEMBL1443805 & 688239 & 5.2362 & 5.3877 & TRN & \\
\hline CHEMBL1541376 & 688239 & 6.5363 & 5.3681 & TRN & \\
\hline CHEMBL1519744 & 688239 & 5.1862 & 5.5216 & TST & \\
\hline CHEMBL1444730 & 688239 & 5.3862 & 5.5617 & TRN & \\
\hline CHEMBL1341247 & 688239 & 5.1362 & 5.6447 & TRN & \\
\hline CHEMBL 3192543 & 688239 & 8.1871 & 5.4538 & TST & \\
\hline CHEMBL1589037 & 688239 & 5.1862 & 5.5935 & TRN & \\
\hline CHEMBL1475659 & 688239 & 5.1862 & 5.5626 & TRN & \\
\hline CHEMBL1393820 & 688239 & 5.1862 & 5.5798 & TRN & \\
\hline CHEMBL1336991 & 688239 & 4.7862 & 5.4454 & TRN & \\
\hline CHEMBL1388236 & 688239 & 4.6862 & 5.2955 & TST & \\
\hline CHEMBL1545526 & 688239 & 5.1362 & 5.2917 & TRN & \\
\hline CHEMBL1362684 & 688239 & 6.2362 & 5.3767 & TST & \\
\hline CHEMBL1346237 & 688239 & 4.6862 & 5.4438 & TRN & \\
\hline CHEMBL1341528 & 688239 & 6.0 & 5.5028 & TRN & \\
\hline CHEMBL1459704 & 688239 & 4.8362 & 5.4794 & TRN & \\
\hline CHEMBL1325019 & 688239 & 5.1862 & 5.5636 & TST & \\
\hline CHEMBL1304770 & 688239 & 5.6362 & 5.4096 & TRN & \\
\hline CHEMBL1530817 & 688239 & 4.7362 & 5.4556 & TRN & \\
\hline CHEMBL1412904 & 688239 & 5.8362 & 5.4627 & TRN & \\
\hline CHEMBL1423426 & 688239 & 5.1862 & 5.3935 & TST & \\
\hline CHEMBL1398458 & 688239 & 5.5362 & 5.7065 & TRN & \\
\hline CHEMBL1580343 & 688239 & 4.6362 & 5.4733 & TRN & \\
\hline CHEMBL1426383 & 688239 & 4.5362 & 5.3665 & TST & \\
\hline CHEMBL1352145 & 688239 & 4.7362 & 5.4663 & TST & \\
\hline CHEMBL1389285 & 688239 & 4.7362 & 5.39 & TRN & \\
\hline CHEMBL1578341 & 688239 & 5.1362 & 5.4598 & TRN & \\
\hline CHEMBL1605718 & 688239 & 4.45 & 5.3873 & TRN & \\
\hline CHEMBL1345965 & 688239 & 5.4362 & \multicolumn{2}{|c|}{5.5760000000000005} & TRN \\
\hline CHEMBL1301164 & 688239 & 4.6362 & 5.4036 & TST & \\
\hline CHEMBL1360732 & 688239 & 4.5362 & 5.3156 & TRN & \\
\hline CHEMBL1418754 & 688239 & 4.5362 & 5.3608 & TST & \\
\hline CHEMBL1406427 & 688239 & 5.7362 & 5.5643 & TRN & \\
\hline CHEMBL1502842 & 688239 & 8.3372 & 5.5481 & TRN & \\
\hline CHEMBL1507264 & 688239 & 4.6362 & 5.4467 & TRN & \\
\hline CHEMBL1429107 & 688239 & 5.3362 & 5.4442 & TRN & \\
\hline CHEMBL1471094 & 688239 & 5.1862 & 5.5233 & TST & \\
\hline CHEMBL1581611 & 688239 & 4.9862 & 5.4089 & TST & \\
\hline CHEMBL1392721 & 688239 & 4.5362 & 5.5368 & TRN & \\
\hline CHEMBL1416724 & 688239 & 4.5362 & 5.5516 & TRN & \\
\hline CHEMBL1444609 & 688239 & 5.1362 & 5.5368 & TRN & \\
\hline CHEMBL1478816 & 688239 & 5.0362 & 5.5698 & TRN & \\
\hline
\end{tabular}

Page 1366 
Supplemental Table S2.txt

\begin{tabular}{|c|c|c|c|c|}
\hline 7 & & 52 & & \\
\hline HEMBL1408292 & & .7362 & 5.3859 & \\
\hline 75 & & & & \\
\hline IEMBL1 & & 52 & & \\
\hline AEMBL1995152 & 8239 & 362 & & \\
\hline HEMBL1542288 & 88239 & 8362 & 5836 & \\
\hline 586 & 239 & 862 & & \\
\hline 956 & & & & \\
\hline AEMBL1 & 239 & 362 & & \\
\hline HEMBL13 & 88239 & 862 & & \\
\hline AEMBL1 & 239 & 862 & 64 & \\
\hline AEMBL1 & 39 & 62 & 18 & \\
\hline AEMBL1 & & & & \\
\hline HEMBL1 & & & & \\
\hline AEMBL1 & & & & \\
\hline AEMBL1 & 39 & 362 & 88 & \\
\hline HEMBL1 & 39 & 861 & & \\
\hline HEMBL1 & & & & \\
\hline AEMBL1 & & 862 & & \\
\hline AEMBL1 & & & & וد \\
\hline AEMIBL & & 52 & & \\
\hline HEMBL & & & & \\
\hline HEMBL & & 62 & & \\
\hline 79 & & & & \\
\hline AEMBL1 & & & & ( \\
\hline HEMBL & & & & RN \\
\hline HEMBL & & & & \\
\hline HFMRI & & 52 & & RN \\
\hline HEMBL1 & & & & ונדו \\
\hline HEMBL1 & & & & ISI \\
\hline HEMBL: & & & & ST \\
\hline HEMBL & & & & RN \\
\hline HEMP & & 52 & & RN \\
\hline HEMBL1 & & & 086 & TRN \\
\hline HEMBL1672291 & & 362 & 5.3321 & ГRN \\
\hline HEMBL1 & & 361 & 774 & \\
\hline - & & & & ST \\
\hline HEMBL1 & & & & $\mathrm{RN}$ \\
\hline HEMBL1: & 88239 & 862 & 5.5167 & TRN \\
\hline AEMBL1 & & 62 & 19 & ST \\
\hline HEMBL1 & & 362 & 5.3871 & \\
\hline HEMBL1 & & & & ST \\
\hline HEMBL1 & & & 5.6274 & TRN \\
\hline AEMBL1 & 39 & 362 & 3183 & ГST \\
\hline MBL1 & & & & \\
\hline CHEMBL1 & & & & \\
\hline CHEMBL1 & & .5362 & 5.5783 & \\
\hline HEMBL1540928 & 688239 & 4.5362 & 5.5944 & 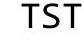 \\
\hline
\end{tabular}

Page 1367 


\begin{tabular}{|c|c|c|c|c|c|}
\hline \multicolumn{6}{|c|}{ Supplemental Table S2.txt } \\
\hline CHEMBL1495966 & 688239 & 4.7362 & 5.4787 & TRN & \\
\hline CHEMBL1538598 & 688239 & 6.0362 & 5.3953 & TST & \\
\hline CHEMBL1317671 & 688239 & 5.2862 & 5.5278 & TRN & \\
\hline CHEMBL1573085 & 688239 & 4.7862 & 5.4543 & TRN & \\
\hline CHEMBL1389882 & 688239 & 6.0362 & 5.3243 & TST & \\
\hline CHEMBL1391750 & 688239 & 4.5362 & 5.5745 & TRN & \\
\hline CHEMBL1507967 & 688239 & 5.8862 & 5.459 & TRN & \\
\hline CHEMBL1570357 & 688239 & 5.1862 & 5.473 & TRN & \\
\hline CHEMBL1322736 & 688239 & 8.3872 & 5.4213 & TRN & \\
\hline CHEMBL1566576 & 688239 & 5.8862 & 5.4126 & TRN & \\
\hline CHEMBL1567307 & 688239 & 5.1862 & 5.4852 & TRN & \\
\hline CHEMBL1487930 & 688239 & 5.1862 & 5.6234 & TRN & \\
\hline CHEMBL1314397 & 688239 & 5.4862 & 5.4852 & TRN & \\
\hline CHEMBL1492936 & 688239 & 5.0362 & 5.4339 & TRN & \\
\hline CHEMBL1466682 & 688239 & 5.5862 & 5.3817 & TRN & \\
\hline CHEMBL1584154 & 688239 & 7.0362 & 5.5043 & TRN & \\
\hline CHEMBL1438110 & 688239 & 5.2862 & 5.5669 & TST & \\
\hline CHEMBL1352797 & 688239 & 6.1362 & 5.4273 & TRN & \\
\hline CHEMBL1370094 & 688239 & 7.1361 & 5.513 & TRN & \\
\hline CHEMBL1608515 & 688239 & 4.4862 & 5.5199 & TRN & \\
\hline CHEMBL3208046 & 688239 & 8.3872 & 5.3031 & TST & \\
\hline CHEMBL565893 & 688239 & 4.7862 & 5.5521 & TRN & \\
\hline CHEMBL1386951 & 688239 & 5.3362 & 5.6601 & TRN & \\
\hline CHEMBL1380627 & 688239 & 6.0362 & 5.307 & TST & \\
\hline CHEMBL1342668 & 688239 & 8.2366 & 5.5646 & TRN & \\
\hline CHEMBL1531994 & 688239 & 4.5362 & 5.5091 & TST & \\
\hline CHEMBL1363979 & 688239 & 4.7362 & 5.3945 & TRN & \\
\hline CHEMBL1417005 & 688239 & 6.1862 & 5.6165 & TRN & \\
\hline CHEMBL1348056 & 688239 & 4.5362 & 5.3687 & TRN & \\
\hline CHEMBL1394222 & 688239 & 4.8362 & 5.4778 & TRN & \\
\hline CHEMBL1491920 & 688239 & 6.8861 & 5.5089 & TST & \\
\hline CHEMBL1356655 & 688239 & 5.1862 & 5.5736 & TRN & \\
\hline CHEMBL1471503 & 688239 & 4.7862 & 5.3845 & TRN & \\
\hline CHEMBL1568858 & 688239 & 4.7862 & 5.4381 & TRN & \\
\hline CHEMBL1458209 & 688239 & 6.2862 & 5.4285 & TRN & \\
\hline CHEMBL1318323 & 688239 & 5.5362 & 5.4391 & TRN & \\
\hline CHEMBL1470210 & 688239 & 5.4362 & 5.4078 & TST & \\
\hline CHEMBL1452207 & 688239 & 6.6362 & 5.5482 & TRN & \\
\hline CHEMBL 2005484 & 688239 & 6.2862 & 5.2301 & TST & \\
\hline CHEMBL1541129 & 688239 & 5.1362 & 5.5296 & TST & \\
\hline CHEMBL1496883 & 688239 & 4.5862 & 5.5076 & TRN & \\
\hline CHEMBL1528834 & 688239 & 5.7862 & 5.37299 & 9999999999 & TRN \\
\hline CHEMBL1329288 & 688239 & 4.5362 & 5.5178 & TST & \\
\hline CHEMBL597670 & 688239 & 5.1862 & 5.5807 & TRN & \\
\hline CHEMBL1383819 & 688239 & 5.1862 & 5.4237 & TST & \\
\hline CHEMBL1472785 & 688239 & 5.7862 & 5.5388 & TRN & \\
\hline CHEMBL1328079 & 688239 & 4.7862 & 5.2965 & TRN & \\
\hline CHEMBL1370035 & 688239 & 7.0362 & 5.345 & TST & \\
\hline
\end{tabular}


Supplemental Table S2.txt

\begin{tabular}{|c|c|c|c|c|}
\hline HEMBL & & & & \\
\hline HEMBL1378361 & & 6.9863 & & \\
\hline & & & & \\
\hline IEMBL1 & & & & S \\
\hline HEMBL140 & 8239 & & & \\
\hline HEMBL3199192 & 88239 & 4.6362 & 358 & \\
\hline 25 & 239 & 862 & & \\
\hline IFMRI 14 & & & & \\
\hline HEMBL154 & & 862 & & \\
\hline HEMBL140 & 38239 & 862 & & \\
\hline AEMBL159 & 239 & 362 & & \\
\hline IEMBL14 & 39 & 362 & & \\
\hline IEMBL16 & & & & \\
\hline HEMBL19 & & 862 & & \\
\hline IEMBL13 & & 362 & & \\
\hline AEMBL134 & 39 & 865 & & \\
\hline AEMBL13 & & 62 & & \\
\hline HEMBL 14 & & 362 & & \\
\hline AEMBL13. & & 362 & & \\
\hline AEMBL132 & & & & \\
\hline AEMBLIS & & 62 & & ונד \\
\hline HEMBL14 & & & & \\
\hline HEMBL13 & & 61 & & \\
\hline IEMBL14 & & 862 & & \\
\hline AEMBL13 & & & & 151 \\
\hline HEMBL1 & & 62 & & RN \\
\hline HEMBL15 & & 52 & & 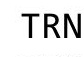 \\
\hline HFMBI 14 & & 62 & & \\
\hline AEMBL13 & & & & r \\
\hline HEMBL15\& & & & & s \\
\hline HEMBL14 & & & & RN \\
\hline HEMBL1. & & & & RIV \\
\hline AEMBL3 & & 52 & & \\
\hline HEMBL133 & & & & IRN \\
\hline HEMBL1582417 & & & & ГRN \\
\hline HEMBL13 & & 62 & & DN \\
\hline HᄃMP I 1 & & & & RIV \\
\hline & & & & $\mathrm{RN}$ \\
\hline HEMBL152: & & 862 & & TRN \\
\hline AEMBL31 & & 362 & & ГRN \\
\hline HEMBL15 & & 862 & & \\
\hline HEMBL 15 & & & & IST \\
\hline HEMBL155 & & & & RN \\
\hline AEMBL152 & 39 & 862 & & RN \\
\hline MRI 1 & & & & \\
\hline HEMBL155 & & 361 & & \\
\hline CHEMBL153 & & .5862 & & \\
\hline HEMBL131354 & 688239 & 5.0362 & 5.4983 & \\
\hline
\end{tabular}

Page 1369 
Supplemental Table S2.txt

\begin{tabular}{|c|c|c|c|c|}
\hline CHEMBL1544916 & 688239 & 4.7862 & 5.4423 & TRN \\
\hline CHEMBL1533746 & 688239 & 6.4862 & 5.4765 & TST \\
\hline CHEMBL1474081 & 688239 & 4.5362 & 5.5116 & TRN \\
\hline CHEMBL1302868 & 688239 & 4.8362 & 5.3651 & TRN \\
\hline CHEMBL1594638 & 688239 & 5.0362 & 5.4761 & TRN \\
\hline CHEMBL1538174 & 688239 & 5.4362 & 5.5189 & TST \\
\hline CHEMBL1505907 & 688239 & 6.9863 & 5.4908 & TST \\
\hline CHEMBL1395556 & 688239 & 5.6362 & 5.5475 & TRN \\
\hline CHEMBL1338488 & 688239 & 4.8362 & \multicolumn{2}{|c|}{5.6370000000000005} \\
\hline CHEMBL1581116 & 688239 & 4.7862 & 5.5626 & TRN \\
\hline CHEMBL1392977 & 688239 & 5.5862 & 5.4305 & TST \\
\hline CHEMBL1523221 & 688239 & 4.5362 & 5.3797 & TRN \\
\hline CHEMBL1333737 & 688239 & 5.3862 & 5.4075 & TRN \\
\hline CHEMBL1465586 & 688239 & 5.1862 & 5.3615 & TRN \\
\hline CHEMBL1542847 & 688239 & 4.5362 & 5.5087 & TRN \\
\hline CHEMBL1306478 & 688239 & 5.8362 & 5.4825 & TRN \\
\hline CHEMBL1487580 & 688239 & 4.5362 & 5.4451 & TRN \\
\hline CHEMBL1519374 & 688239 & 5.2362 & 5.27 & TRN \\
\hline CHEMBL1599220 & 688239 & 6.6861 & 5.4792 & TRN \\
\hline CHEMBL1511227 & 688239 & 4.7362 & 5.5112 & TRN \\
\hline CHEMBL1377160 & 688239 & 5.2362 & 5.4997 & TST \\
\hline CHEMBL1369430 & 688239 & 4.6862 & 5.4757 & TRN \\
\hline CHEMBL1444682 & 688239 & 5.4862 & 5.3921 & TRN \\
\hline CHEMBL1471794 & 688239 & 6.8861 & 5.5322 & TRN \\
\hline CHEMBL1553695 & 688239 & 5.1362 & 5.4781 & TRN \\
\hline CHEMBL1568648 & 688239 & 5.0362 & 5.3763 & TRN \\
\hline CHEMBL1596956 & 688239 & 4.6862 & 5.3329 & TST \\
\hline CHEMBL1360862 & 688239 & 4.5362 & 5.3998 & TRN \\
\hline CHEMBL3190565 & 688239 & 4.5862 & \multicolumn{2}{|c|}{5.5520000000000005} \\
\hline CHEMBL1455378 & 688239 & 5.3862 & 5.4596 & TRN \\
\hline CHEMBL1479143 & 688239 & 4.5362 & 5.4523 & TRN \\
\hline CHEMBL1345913 & 688239 & 5.9862 & 5.4622 & TRN \\
\hline CHEMBL1513299 & 688239 & 5.3862 & 5.5057 & TRN \\
\hline CHEMBL1584202 & 688239 & 5.5362 & 5.4543 & TRN \\
\hline CHEMBL1314928 & 688239 & 8.3372 & 5.6199 & TST \\
\hline CHEMBL1593773 & 688239 & 4.7862 & 5.6107 & TST \\
\hline CHEMBL1513450 & 688239 & 6.0362 & 5.3832 & TST \\
\hline CHEMBL1561472 & 688239 & 5.0362 & 5.6099 & TRN \\
\hline CHEMBL1300370 & 688239 & 4.6362 & 5.3804 & TST \\
\hline CHEMBL1523805 & 688239 & 5.6362 & 5.4388 & TRN \\
\hline CHEMBL3207335 & 688239 & 4.5362 & 5.5849 & TRN \\
\hline CHEMBL1571234 & 688239 & 6.2362 & 5.3949 & TRN \\
\hline CHEMBL1501919 & 688239 & 4.5862 & 5.5797 & TRN \\
\hline CHEMBL1329681 & 688239 & 6.2862 & 5.5342 & TRN \\
\hline CHEMBL1604007 & 688239 & 4.9862 & 5.526 & TST \\
\hline CHEMBL1426717 & 688239 & 4.7862 & 5.5584 & TRN \\
\hline CHEMBL1442362 & 688239 & 4.7362 & 5.4693 & TST \\
\hline CHEMBL1325644 & 688239 & 6.9363 & 5.5193 & TRN \\
\hline
\end{tabular}

Page 1370 
Supplemental Table S2.txt

\begin{tabular}{|c|c|c|c|c|c|}
\hline CHEMBL1324576 & 688239 & 5.1362 & 5.5426 & TRN & \\
\hline CHEMBL1612041 & 688239 & 4.9362 & 5.649 & TST & \\
\hline CHEMBL1508667 & 688239 & 4.9362 & 5.4219 & TRN & \\
\hline CHEMBL1560935 & 688239 & 4.5362 & 5.6414 & TRN & \\
\hline CHEMBL1504715 & 688239 & 4.8362 & 5.5297 & TRN & \\
\hline CHEMBL1313571 & 688239 & 6.1862 & 5.4827 & TRN & \\
\hline CHEMBL1538398 & 688239 & 4.5362 & 5.4974 & TRN & \\
\hline CHEMBL1398877 & 688239 & 4.5362 & 5.3844 & TRN & \\
\hline CHEMBL1366443 & 688239 & 4.9862 & 5.5542 & TRN & \\
\hline CHEMBL1578725 & 688239 & 8.3372 & 5.4575 & TRN & \\
\hline CHEMBL1315230 & 688239 & 5.9862 & 5.4115 & TRN & \\
\hline CHEMBL1360719 & 688239 & 4.8362 & 5.4533 & TRN & \\
\hline CHEMBL1345171 & 688239 & 5.5862 & 5.5239 & TRN & \\
\hline CHEMBL1483809 & 688239 & 4.9862 & 5.4938 & TST & \\
\hline CHEMBL1489727 & 688239 & 5.6362 & 5.4572 & TRN & \\
\hline CHEMBL3197031 & 688239 & 4.5362 & 5.4269 & TRN & \\
\hline CHEMBL1347572 & 688239 & 4.9362 & 5.4755 & TST & \\
\hline CHEMBL1598876 & 688239 & 6.4362 & 5.5007 & TRN & \\
\hline CHEMBL1471436 & 688239 & 4.6862 & 5.4793 & TRN & \\
\hline CHEMBL1472133 & 688239 & 6.6861 & 5.5141 & TST & \\
\hline CHEMBL3207677 & 688239 & 4.6862 & 5.3809 & TRN & \\
\hline CHEMBL1493265 & 688239 & 8.3372 & 5.5262 & TRN & \\
\hline CHEMBL1613166 & 688239 & 6.1862 & 5.4873 & TRN & \\
\hline CHEMBL1382628 & 688239 & 5.7362 & 5.5511 & TRN & \\
\hline CHEMBL1312890 & 688239 & 4.5362 & 5.5503 & TRN & \\
\hline CHEMBL1327663 & 688239 & 4.5362 & 5.6341 & TRN & \\
\hline CHEMBL1374635 & 688239 & 5.2362 & 5.7089 & TRN & \\
\hline CHEMBL1435464 & 688239 & 5.8362 & 5.5033 & TRN & \\
\hline CHEMBL1397250 & 688239 & 6.6362 & 5.6266 & TRN & \\
\hline CHEMBL1551801 & 688239 & 5.1862 & 5.5283 & TST & \\
\hline CHEMBL1465340 & 688239 & 4.7362 & 5.3585 & TRN & \\
\hline CHEMBL1521130 & 688239 & 4.8362 & 5.5157 & TRN & \\
\hline CHEMBL1451795 & 688239 & 6.2862 & 5.5299 & TRN & \\
\hline CHEMBL1511674 & 688239 & 4.5362 & 5.4208 & TRN & \\
\hline CHEMBL1584679 & 688239 & 6.9363 & 5.3613 & TRN & \\
\hline CHEMBL1474339 & 688239 & 5.1362 & 5.4466 & TRN & \\
\hline CHEMBL 362919 & 688239 & 5.9362 & 5.426 & TST & \\
\hline CHEMBL1331675 & 688239 & 5.3862 & 5.5867 & TRN & \\
\hline CHEMBL1506967 & 688239 & 4.7862 & 5.367006 & 0000000001 & TST \\
\hline CHEMBL3197096 & 688239 & 7.0362 & 5.5335 & TRN & \\
\hline CHEMBL1479190 & 688239 & 6.0862 & 5.5397 & TST & \\
\hline CHEMBL1462465 & 688239 & 6.8861 & 5.587999 & 9999999999 & TST \\
\hline CHEMBL1547165 & 688239 & 5.6362 & 5.5814 & TRN & \\
\hline CHEMBL1311016 & 688239 & 4.5362 & 5.5202 & TRN & \\
\hline CHEMBL40439 & 688239 & 5.1862 & 5.6349 & TRN & \\
\hline CHEMBL1481061 & 688239 & 4.7362 & 5.438 & TST & \\
\hline CHEMBL 3194227 & 688239 & 4.6862 & 5.3347 & TRN & \\
\hline CHEMBL1517829 & 688239 & 4.6362 & 5.4127 & TRN & \\
\hline
\end{tabular}


Supplemental Table S2.txt

\begin{tabular}{|c|c|c|c|c|c|}
\hline CHEMBL1461187 & 688239 & 8.3372 & 5.5668 & TRN & \\
\hline CHEMBL1563333 & 688239 & 5.5862 & 5.5738 & TST & \\
\hline CHEMBL1980308 & 688239 & 4.9362 & 5.4292 & TST & \\
\hline CHEMBL1411686 & 688239 & 4.6362 & 5.3379 & TRN & \\
\hline CHEMBL1341611 & 688239 & 6.2362 & 5.5425 & TRN & \\
\hline CHEMBL1982845 & 688239 & 5.1862 & 5.5851 & TST & \\
\hline CHEMBL1391893 & 688239 & 4.8362 & 5.5788 & TRN & \\
\hline CHEMBL1550202 & 688239 & 4.5362 & 5.5154 & TRN & \\
\hline CHEMBL1579474 & 688239 & 4.9362 & 5.5762 & TRN & \\
\hline CHEMBL1387114 & 688239 & 7.7852 & 5.4846 & TRN & \\
\hline CHEMBL1568814 & 688239 & 6.1362 & 5.6518 & TRN & \\
\hline CHEMBL1438042 & 688239 & 5.4862 & 5.5405 & TRN & \\
\hline CHEMBL1426109 & 688239 & 6.1362 & 5.4106 & TRN & \\
\hline CHEMBL1612737 & 688239 & 4.5362 & 5.4189 & TRN & \\
\hline CHEMBL1524026 & 688239 & 5.6862 & 5.42899 & 9999999999 & TRN \\
\hline CHEMBL1462494 & 688239 & 5.3862 & 5.6274 & TRN & \\
\hline CHEMBL1349865 & 688239 & 7.0862 & 5.4405 & TRN & \\
\hline CHEMBL3207785 & 688239 & 4.5362 & 5.444 & TST & \\
\hline CHEMBL1393038 & 688239 & 4.6862 & 5.34200 & 00000000005 & TST \\
\hline CHEMBL1594960 & 688239 & 4.5362 & 5.6229 & TRN & \\
\hline CHEMBL1256739 & 688239 & 4.6362 & 5.5125 & TST & \\
\hline CHEMBL1582183 & 688239 & 6.3863 & 5.5341 & TRN & \\
\hline CHEMBL1600607 & 688239 & 5.1862 & 5.4923 & TRN & \\
\hline CHEMBL226876 & 688239 & 5.6862 & 5.2926 & TRN & \\
\hline CHEMBL1557296 & 688239 & 6.1862 & 5.4962 & TRN & \\
\hline CHEMBL1368683 & 688239 & 6.8362 & 5.6776 & TST & \\
\hline CHEMBL1573464 & 688239 & 5.0362 & 5.4067 & TRN & \\
\hline CHEMBL1558228 & 688239 & 4.5362 & 5.5443 & TST & \\
\hline CHEMBL1450664 & 688239 & 5.5362 & 5.3808 & TST & \\
\hline CHEMBL1556084 & 688239 & 4.5362 & 5.6604 & TRN & \\
\hline CHEMBL1609317 & 688239 & 4.5862 & 5.4926 & TST & \\
\hline CHEMBL1595026 & 688239 & 6.1362 & 5.3628 & TRN & \\
\hline CHEMBL1570047 & 688239 & 7.2366 & 5.4596 & TRN & \\
\hline CHEMBL1341045 & 688239 & 4.5362 & 5.6069 & TRN & \\
\hline CHEMBL1304785 & 688239 & 4.5362 & 5.5978 & TST & \\
\hline CHEMBL1503437 & 688239 & 5.1862 & 5.3872 & TST & \\
\hline CHEMBL1976631 & 688239 & 4.9362 & 5.3203 & TST & \\
\hline CHEMBL1342161 & 688239 & 4.5362 & 5.4525 & TRN & \\
\hline CHEMBL1603221 & 688239 & 5.3362 & 5.4495 & TST & \\
\hline CHEMBL1405947 & 688239 & 5.7362 & 5.2679 & TRN & \\
\hline CHEMBL1303194 & 688239 & 7.4868 & 5.6371 & TRN & \\
\hline CHEMBL1490693 & 688239 & 5.1862 & 5.5346 & TRN & \\
\hline CHEMBL1425172 & 688239 & 4.7862 & 5.4551 & TST & \\
\hline CHEMBL1433468 & 688239 & 7.6861 & 5.4637 & TRN & \\
\hline CHEMBL1303376 & 688239 & 4.6862 & 5.4903 & TRN & \\
\hline CHEMBL1387883 & 688239 & 4.5362 & 5.4774 & TRN & \\
\hline CHEMBL3191792 & 688239 & 4.7862 & 5.441 & TST & \\
\hline CHEMBL1309412 & 688239 & 5.9362 & 5.6053 & TRN & \\
\hline
\end{tabular}


Supplemental Table S2.txt

\begin{tabular}{|c|c|c|c|c|c|}
\hline CHEMBL1581626 & 688239 & 8.3372 & 5.4414 & TRN & \\
\hline CHEMBL1466555 & 688239 & 5.2862 & 5.4075 & TRN & \\
\hline CHEMBL1499398 & 688239 & 6.0862 & 5.5158 & TRN & \\
\hline CHEMBL1559957 & 688239 & 5.1862 & 5.4324 & TST & \\
\hline CHEMBL1368530 & 688239 & 8.28399 & 99999999 & 5.4022 & TRN \\
\hline CHEMBL1543828 & 688239 & 4.5362 & 5.4736 & TRN & \\
\hline CHEMBL1470840 & 688239 & 4.4862 & 5.5566 & TRN & \\
\hline CHEMBL1564005 & 688239 & 4.9362 & 5.4787 & TRN & \\
\hline CHEMBL1573046 & 688239 & 5.2362 & 5.4204 & TRN & \\
\hline CHEMBL3209827 & 688239 & 4.5362 & 5.407999 & 99999999995 & TST \\
\hline CHEMBL1361961 & 688239 & 6.0862 & 5.5981 & TST & \\
\hline CHEMBL1437866 & 688239 & 6.1862 & 5.5889 & TRN & \\
\hline CHEMBL1519170 & 688239 & 7.0862 & 5.4744 & TRN & \\
\hline CHEMBL1535481 & 688239 & 4.6862 & 5.5546 & TRN & \\
\hline CHEMBL1445033 & 688239 & 5.5362 & 5.5934 & TRN & \\
\hline CHEMBL1598694 & 688239 & 5.1362 & 5.298999 & 99999999995 & TST \\
\hline CHEMBL1560140 & 688239 & 5.1862 & 5.5919 & TRN & \\
\hline CHEMBL1434559 & 688239 & 5.9362 & 5.3302 & TRN & \\
\hline CHEMBL1493432 & 688239 & 5.4862 & 5.4757 & TST & \\
\hline CHEMBL1609231 & 688239 & 4.7362 & 5.6029 & TRN & \\
\hline CHEMBL1554419 & 688239 & 5.8862 & 5.6561 & TRN & \\
\hline CHEMBL1432853 & 688239 & 4.5362 & 5.4099 & TRN & \\
\hline CHEMBL1530521 & 688239 & 4.7362 & 5.3462 & TRN & \\
\hline CHEMBL1597684 & 688239 & 5.2362 & 5.4442 & TRN & \\
\hline CHEMBL1470844 & 688239 & 5.3862 & 5.3806 & TRN & \\
\hline CHEMBL1462565 & 688239 & 8.3372 & 5.495 & TRN & \\
\hline CHEMBL1436768 & 688239 & 7.6364 & 5.5322 & TRN & \\
\hline CHEMBL1522335 & 688239 & 4.6862 & 5.5438 & TRN & \\
\hline CHEMBL3191115 & 688239 & 6.3863 & 5.4388 & TRN & \\
\hline CHEMBL1612581 & 688239 & 6.2362 & 5.5377 & TRN & \\
\hline CHEMBL1555527 & 688239 & 5.9362 & 5.5813 & TRN & \\
\hline CHEMBL1609504 & 688239 & 4.8362 & 5.3954 & TRN & \\
\hline CHEMBL1454192 & 688239 & 6.3863 & 5.5611 & TRN & \\
\hline CHEMBL1439351 & 688239 & 4.7862 & 5.5935 & TRN & \\
\hline CHEMBL1525375 & 688239 & 5.1362 & 5.6064 & TRN & \\
\hline CHEMBL1561812 & 688239 & 6.0862 & 5.6429 & TST & \\
\hline CHEMBL1479127 & 688239 & 5.5862 & 5.5148 & TRN & \\
\hline CHEMBL1504090 & 688239 & 5.7862 & 5.51 & TRN & \\
\hline CHEMBL1350250 & 688239 & 5.6862 & 5.5389 & TRN & \\
\hline CHEMBL1587837 & 688239 & 4.5362 & 5.3612 & TST & \\
\hline CHEMBL1582222 & 688239 & 4.7862 & 5.4579 & TRN & \\
\hline CHEMBL1333756 & 688239 & 4.7362 & 5.3872 & TRN & \\
\hline CHEMBL1388969 & 688239 & 4.9862 & 5.4424 & TRN & \\
\hline CHEMBL1422039 & 688239 & 4.6362 & 5.6056 & TRN & \\
\hline CHEMBL1462809 & 688239 & 5.3862 & 5.4802 & TRN & \\
\hline CHEMBL1443882 & 688239 & 6.0862 & 5.4654 & TRN & \\
\hline CHEMBL1605815 & 688239 & 5.4362 & 5.4303 & TRN & \\
\hline CHEMBL1584712 & 688239 & 4.6362 & 5.3542 & TRN & \\
\hline
\end{tabular}


Supplemental Table S2.txt

\begin{tabular}{|c|c|c|c|c|c|}
\hline CHEMBL1306729 & 688239 & 5.6862 & 5.5047 & TST & \\
\hline CHEMBL1610633 & 688239 & 5.1862 & 5.5453 & TRN & \\
\hline CHEMBL1446484 & 688239 & 5.4862 & 5.4508 & TST & \\
\hline CHEMBL1421372 & 688239 & 4.5862 & 5.461 & TRN & \\
\hline CHEMBL1344625 & 688239 & 4.5362 & 5.4845 & TRN & \\
\hline CHEMBL1406674 & 688239 & 6.1862 & 5.5808 & TRN & \\
\hline CHEMBL1577686 & 688239 & 5.7862 & 5.4469 & TRN & \\
\hline CHEMBL1469620 & 688239 & 4.7862 & 5.5564 & TRN & \\
\hline CHEMBL1396187 & 688239 & 5.1862 & 5.6217 & TRN & \\
\hline CHEMBL1363917 & 688239 & 4.6362 & 5.5567 & TRN & \\
\hline CHEMBL1437609 & 688239 & 4.5862 & 5.4372 & TRN & \\
\hline CHEMBL1416352 & 688239 & 4.5362 & 5.5302 & TRN & \\
\hline CHEMBL1536098 & 688239 & 5.3862 & 5.4732 & TRN & \\
\hline CHEMBL1299776 & 688239 & 5.2362 & 5.5616 & TRN & \\
\hline CHEMBL1393543 & 688239 & 4.7362 & 5.4532 & TRN & \\
\hline CHEMBL1506585 & 688239 & 6.8362 & 5.5209 & TRN & \\
\hline CHEMBL3190057 & 688239 & 6.6362 & 5.4505 & TST & \\
\hline CHEMBL1463353 & 688239 & 5.7862 & 5.3895 & TRN & \\
\hline CHEMBL1580675 & 688239 & 4.5362 & 5.50899 & 99999999995 & TRN \\
\hline CHEMBL1488864 & 688239 & 6.7862 & 5.5412 & TRN & \\
\hline CHEMBL1438003 & 688239 & 5.3862 & 5.5191 & TST & \\
\hline CHEMBL1555680 & 688239 & 4.8862 & 5.46 & TRN & \\
\hline CHEMBL1468162 & 688239 & 7.2366 & 5.5237 & TRN & \\
\hline CHEMBL1546533 & 688239 & 6.3362 & 5.6833 & TRN & \\
\hline CHEMBL 3210360 & 688239 & 6.8362 & 5.5544 & TRN & \\
\hline CHEMBL3213605 & 688239 & 4.8362 & 5.4527 & TST & \\
\hline CHEMBL1610351 & 688239 & 4.5362 & 5.4341 & TST & \\
\hline CHEMBL1425183 & 688239 & 4.5362 & 5.3158 & TRN & \\
\hline CHEMBL1395553 & 688239 & 4.4862 & 5.4421 & TRN & \\
\hline CHEMBL1571633 & 688239 & 4.7362 & 5.4946 & TRN & \\
\hline CHEMBL1580490 & 688239 & 6.1862 & 5.5772 & TRN & \\
\hline CHEMBL1347298 & 688239 & 5.6362 & 5.49299 & 9999999999 & TRN \\
\hline CHEMBL1339507 & 688239 & 4.6362 & 5.3577 & TRN & \\
\hline CHEMBL1394124 & 688239 & 4.6862 & 5.4621 & TRN & \\
\hline CHEMBL1477879 & 688239 & 4.5862 & 5.3379 & TST & \\
\hline CHEMBL1574706 & 688239 & 6.5862 & 5.5115 & TRN & \\
\hline CHEMBL1325260 & 688239 & 8.3372 & 5.4052 & TRN & \\
\hline CHEMBL1611655 & 688239 & 4.7362 & 5.4837 & TRN & \\
\hline CHEMBL1521013 & 688239 & 4.5362 & 5.4469 & TST & \\
\hline CHEMBL1488782 & 688239 & 5.3862 & 5.6415 & TRN & \\
\hline CHEMBL1603413 & 688239 & 6.0862 & 5.3753 & TST & \\
\hline CHEMBL1577254 & 688239 & 6.1362 & 5.3442 & TRN & \\
\hline CHEMBL1439259 & 688239 & 6.9863 & 5.5086 & TRN & \\
\hline CHEMBL1453255 & 688239 & 5.0862 & 5.4957 & TST & \\
\hline CHEMBL1366790 & 688239 & 6.2 & 5.586 & TRN & \\
\hline CHEMBL1508195 & 688239 & 5.4362 & 5.4105 & TRN & \\
\hline CHEMBL1519634 & 688239 & 6.9363 & 5.7018 & TRN & \\
\hline CHEMBL1612525 & 688239 & 5.1862 & 5.4445 & TST & \\
\hline
\end{tabular}


Supplemental Table S2.txt

\begin{tabular}{|c|c|c|c|c|}
\hline CHEMBL1358781 & 688239 & 5.1862 & 5.5112 & TRN \\
\hline CHEMBL1467430 & 688239 & 5.2862 & 5.4283 & TRN \\
\hline CHEMBL1533298 & 688239 & 6.5363 & 5.5618 & TRN \\
\hline CHEMBL1416616 & 688239 & 4.7362 & 5.5396 & TRN \\
\hline CHEMBL1474484 & 688239 & 4.7862 & 5.5376 & TRN \\
\hline CHEMBL1532621 & 688239 & 5.6362 & 5.6698 & TRN \\
\hline CHEMBL580918 & 688239 & 5.5862 & 5.4159 & TRN \\
\hline CHEMBL1556879 & 688239 & 5.1862 & 5.5484 & TRN \\
\hline CHEMBL1336234 & 688239 & 4.5362 & 5.5703 & TRN \\
\hline CHEMBL3207535 & 688239 & 4.5362 & 5.4698 & TRN \\
\hline CHEMBL1405960 & 688239 & 5.7862 & 5.5559 & TRN \\
\hline CHEMBL1471134 & 688239 & 4.7862 & 5.5489 & TST \\
\hline CHEMBL1492609 & 688239 & 5.2862 & 5.5179 & TST \\
\hline CHEMBL1457403 & 688239 & 5.0362 & 5.5112 & TST \\
\hline CHEMBL1329115 & 688239 & 4.9862 & 5.421 & TST \\
\hline CHEMBL1503606 & 688239 & 4.5362 & 5.5454 & TRN \\
\hline CHEMBL1563142 & 688239 & 5.1862 & 5.4294 & TST \\
\hline CHEMBL1545576 & 688239 & 4.7362 & 5.6471 & TRN \\
\hline CHEMBL1341726 & 688239 & 4.5362 & 5.4066 & TRN \\
\hline CHEMBL1304840 & 688239 & 6.5862 & 5.5093 & TST \\
\hline CHEMBL1386391 & 688239 & 6.2862 & 5.4062 & TRN \\
\hline CHEMBL1383515 & 688239 & 5.1862 & 5.605 & TRN \\
\hline CHEMBL1490991 & 688239 & 6.2362 & 5.4245 & TRN \\
\hline CHEMBL1479156 & 688239 & 6.9863 & 5.5041 & TRN \\
\hline CHEMBL 3189442 & 688239 & 6.0862 & 5.6241 & TRN \\
\hline CHEMBL1458340 & 688239 & 7.0 & 5.5331 & TRN \\
\hline CHEMBL1336337 & 688239 & 4.5362 & 5.4704 & TST \\
\hline CHEMBL1598782 & 688239 & 5.1362 & 5.5907 & TRN \\
\hline CHEMBL1430003 & 688239 & 6.8861 & 5.4759 & TRN \\
\hline CHEMBL1406425 & 688239 & 6.3362 & 5.4805 & TST \\
\hline CHEMBL1475014 & 688239 & 5.3862 & 5.42899 & 9999999999 \\
\hline CHEMBL1579096 & 688239 & 4.7862 & 5.5034 & TST \\
\hline CHEMBL1553425 & 688239 & 4.5362 & 5.3868 & TRN \\
\hline CHEMBL1502846 & 688239 & 4.7862 & 5.5278 & TST \\
\hline CHEMBL1517821 & 688239 & 4.7862 & 5.4575 & TRN \\
\hline CHEMBL486078 & 688239 & 4.6862 & 5.4255 & TRN \\
\hline CHEMBL1560538 & 688239 & 4.4862 & 5.5821 & TRN \\
\hline CHEMBL1396659 & 688239 & 4.5862 & 5.5307 & TRN \\
\hline CHEMBL1450635 & 688239 & 4.6862 & 5.5005 & TRN \\
\hline CHEMBL1507107 & 688239 & 6.4862 & 5.5874 & TST \\
\hline CHEMBL1478856 & 688239 & 5.7362 & 5.3979 & TST \\
\hline CHEMBL1543393 & 688239 & 5.6862 & 5.5084 & TRN \\
\hline CHEMBL1457756 & 688239 & 6.5363 & 5.5473 & TRN \\
\hline CHEMBL1513907 & 688239 & 4.8362 & 5.4822 & TRN \\
\hline CHEMBL1594381 & 688239 & 5.3862 & 5.4681 & TRN \\
\hline CHEMBL1596903 & 688239 & 5.4862 & 5.3839 & TST \\
\hline CHEMBL1400860 & 688239 & 6.9363 & 5.4305 & TRN \\
\hline CHEMBL1476708 & 688239 & 4.7862 & 5.71200 & 0000000001 \\
\hline
\end{tabular}


Supplemental Table S2.txt

\begin{tabular}{|c|c|c|c|c|c|}
\hline CHEMBL3198187 & 688239 & 5.1862 & 5.3765 & TRN & \\
\hline CHEMBL1385550 & 688239 & 6.7862 & 5.5726 & TRN & \\
\hline CHEMBL1533176 & 688239 & 4.8862 & \multicolumn{2}{|c|}{5.462999999999999} & TRN \\
\hline CHEMBL1597009 & 688239 & 6.8362 & 5.5225 & TRN & \\
\hline CHEMBL1329266 & 688239 & 8.3372 & 5.4829 & TRN & \\
\hline CHEMBL1550174 & 688239 & 4.5362 & 5.3935 & TRN & \\
\hline CHEMBL1567515 & 688239 & 7.6861 & 5.5491 & TRN & \\
\hline CHEMBL1456009 & 688239 & 4.5362 & 5.4605 & TRN & \\
\hline CHEMBL1604585 & 688239 & 4.5362 & 5.581 & TRN & \\
\hline CHEMBL1586685 & 688239 & 4.7862 & 5.472 & TST & \\
\hline CHEMBL1613651 & 688239 & 5.8862 & 5.6318 & TRN & \\
\hline CHEMBL1306057 & 688239 & 5.1362 & 5.579 & TRN & \\
\hline CHEMBL1430396 & 688239 & 4.5362 & 5.5855 & TRN & \\
\hline CHEMBL1472169 & 688239 & 4.5362 & 5.3806 & TRN & \\
\hline CHEMBL1538003 & 688239 & 4.4862 & 5.5404 & TRN & \\
\hline CHEMBL1358271 & 688239 & 4.6362 & 5.369 & TRN & \\
\hline CHEMBL1564625 & 688239 & 4.7362 & 5.5425 & TRN & \\
\hline CHEMBL3194368 & 688239 & 4.5362 & 5.2671 & TRN & \\
\hline CHEMBL1385353 & 688239 & 6.9863 & 5.5657 & TRN & \\
\hline CHEMBL1339825 & 688239 & 4.5362 & 5.6184 & TRN & \\
\hline CHEMBL1400254 & 688239 & 4.7862 & 5.4946 & TRN & \\
\hline CHEMBL1413514 & 688239 & 5.3862 & \multicolumn{2}{|c|}{5.542999999999999} & TRN \\
\hline CHEMBL1599409 & 688239 & 6.3362 & 5.4533 & TRN & \\
\hline CHEMBL1301009 & 688239 & 4.5362 & 5.4652 & TRN & \\
\hline CHEMBL1553118 & 688239 & 6.9363 & 5.5819 & TRN & \\
\hline CHEMBL1590558 & 688239 & 6.2362 & 5.5032 & TRN & \\
\hline CHEMBL1312878 & 688239 & 7.4365 & \multicolumn{2}{|c|}{5.611000000000001} & TST \\
\hline CHEMBL1318756 & 688239 & 5.7362 & 5.5884 & TRN & \\
\hline CHEMBL1324203 & 688239 & 5.6862 & 5.3922 & TRN & \\
\hline CHEMBL1388985 & 688239 & 4.9362 & 5.5473 & TRN & \\
\hline CHEMBL1585570 & 688239 & 5.1862 & 5.472 & TRN & \\
\hline CHEMBL1359427 & 688239 & 4.7862 & 5.4611 & TRN & \\
\hline CHEMBL1421330 & 688239 & 4.6862 & 5.4342 & TST & \\
\hline CHEMBL 3190727 & 688239 & 4.5362 & 5.5254 & TRN & \\
\hline CHEMBL1534397 & 688239 & 6.2362 & 5.435 & TRN & \\
\hline CHEMBL1390375 & 688239 & 4.9362 & 5.3312 & TRN & \\
\hline CHEMBL1405214 & 688239 & 4.5362 & 5.5696 & TST & \\
\hline CHEMBL1362795 & 688239 & 4.6362 & 5.5141 & TRN & \\
\hline CHEMBL1438785 & 688239 & 5.2862 & 5.4149 & TRN & \\
\hline CHEMBL 1378220 & 688239 & 4.5362 & \multicolumn{2}{|c|}{5.537000000000001} & TRN \\
\hline CHEMBL1595572 & 688239 & 4.5362 & 5.4697 & TST & \\
\hline CHEMBL1333857 & 688239 & 6.9363 & 5.5191 & TST & \\
\hline CHEMBL1444825 & 688239 & 4.7862 & 5.5408 & TRN & \\
\hline CHEMBL3212374 & 688239 & 5.0362 & 5.5019 & TRN & \\
\hline CHEMBL1336389 & 688239 & 6.2862 & 5.5479 & TRN & \\
\hline CHEMBL1405797 & 688239 & 6.8861 & 5.5152 & TRN & \\
\hline CHEMBL1324784 & 688239 & 4.5362 & 5.5776 & TST & \\
\hline CHEMBL1489485 & 688239 & 4.8362 & 5.4852 & TST & \\
\hline
\end{tabular}


Supplemental Table S2.txt

\begin{tabular}{|c|c|c|c|c|}
\hline - & & & & \\
\hline HEMBL1451163 & 88239 & 7862 & 5.4834 & \\
\hline & & & & \\
\hline 1 & 39 & 352 & 375 & \\
\hline IEMBL1998853 & 38239 & 364 & & \\
\hline AEMBL1459909 & 88239 & 1862 & 4632 & \\
\hline HEMBL13 & 88239 & 362 & .5682 & \\
\hline AFMR 15 & & 366 & & \\
\hline IEMBL 395092 & 88239 & 3362 & & \\
\hline AEMBL1348793 & 88239 & 362 & 5262 & \\
\hline AEMBL1596741 & 88239 & 362 & 448 & \\
\hline IEMBL1481546 & 88239 & 862 & 765 & \\
\hline IEMBL13 & 239 & & & \\
\hline AEMBL16 & 88239 & 862 & & \\
\hline AEMBL1352962 & 88239 & 362 & 3866 & \\
\hline IEMBL1334395 & 88239 & 872 & 5287 & \\
\hline AEMBL1385990 & 88239 & 862 & & \\
\hline HEMBL1582525 & 38239 & 862 & & \\
\hline 84 & 88239 & 362 & & \\
\hline AEMBL141 & 38239 & 362 & & \\
\hline IEMBL1307742 & 239 & 862 & 56 & וد \\
\hline AEMBL1450237 & 38239 & 361 & & \\
\hline HEMBL1426576 & 38239 & 62 & & \\
\hline 535 & & 362 & & \\
\hline IEMBL13 & 39 & 52 & & RI \\
\hline 394 & 8239 & 52 & & $5 \mathrm{~T}$ \\
\hline AEMBL14 & 38239 & 362 & 02 & RN \\
\hline 11 & 39 & 62 & & \\
\hline 99 & & & & 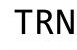 \\
\hline AEMBL1571 & 39 & 62 & 16 & RN \\
\hline IEMBL13 & 39 & 362 & 305 & $\mathrm{RN}$ \\
\hline 993 & 39 & 362 & 46 & וכ \\
\hline & & & & $2 \mathrm{~N}$ \\
\hline HEMBL1351789 & & & & I RIV \\
\hline AEMBL1472341 & 88239 & 63 & 88 & IST \\
\hline AEMBL15 & 39 & 62 & 93 & ST \\
\hline 1 & & & & RN \\
\hline & & & & $\mathrm{RN}$ \\
\hline HEMBL1427212 & 88239 & 862 & & IST \\
\hline IEMBL159816 & 39 & 361 & & IST \\
\hline AEMBL1449628 & 39 & 72 & 98 & ח \\
\hline & & & & RN \\
\hline HEMBL13 & 8239 & & 4208 & $\mathrm{RN}$ \\
\hline IEMBL1464413 & 88239 & 362 & 636 & RN \\
\hline MBL14 & 39 & & . 4977 & \\
\hline HEMBL3210138 & & & .5902 & \\
\hline (1) & 88239 & .0862 & 5.5054 & \\
\hline HEMBL138114 & 688239 & 5.1862 & 5.6039 & ГST \\
\hline
\end{tabular}

Page 1377 
Supplemental Table S2.txt

\begin{tabular}{|c|c|c|c|c|c|}
\hline CHEMBL1474021 & 688239 & 5.1362 & 5.441 & TST & \\
\hline CHEMBL1390126 & 688239 & 4.7362 & 5.4725 & TST & \\
\hline CHEMBL1470583 & 688239 & 4.5362 & 5.5741 & TRN & \\
\hline CHEMBL1330187 & 688239 & 5.1862 & 5.4933 & TRN & \\
\hline CHEMBL1357638 & 688239 & 5.1862 & 5.608 & TRN & \\
\hline CHEMBL 3211815 & 688239 & 4.5362 & 5.3494 & TST & \\
\hline CHEMBL 3207731 & 688239 & 5.2362 & 5.4752 & TST & \\
\hline CHEMBL1391210 & 688239 & 4.8362 & 5.4358 & TRN & \\
\hline CHEMBL1404256 & 688239 & 6.3863 & 5.6035 & TRN & \\
\hline CHEMBL1373370 & 688239 & 4.6362 & 5.3302 & TST & \\
\hline CHEMBL1451527 & 688239 & 5.1862 & 5.5249 & TRN & \\
\hline CHEMBL1472543 & 688239 & 4.5362 & 5.432 & TST & \\
\hline CHEMBL1376897 & 688239 & 4.5362 & 5.6518 & TRN & \\
\hline CHEMBL1594539 & 688239 & 7.3862 & 5.5739 & TST & \\
\hline CHEMBL3211743 & 688239 & 5.9362 & 5.4692 & TST & \\
\hline CHEMBL1406862 & 688239 & 4.9862 & 5.5401 & TRN & \\
\hline CHEMBL1315270 & 688239 & 6.1362 & 5.6041 & TRN & \\
\hline CHEMBL1567858 & 688239 & 8.3372 & 5.3661 & TRN & \\
\hline CHEMBL1382000 & 688239 & 5.3862 & 5.6943 & TRN & \\
\hline CHEMBL1568485 & 688239 & 4.7362 & 5.5294 & TST & \\
\hline CHEMBL1606909 & 688239 & 5.1862 & 5.4575 & TST & \\
\hline CHEMBL1382361 & 688239 & 6.2362 & 5.485 & TRN & \\
\hline CHEMBL1299724 & 688239 & 6.9863 & 5.325 & TST & \\
\hline CHEMBL1532182 & 688239 & 7.5361 & 5.4164 & TRN & \\
\hline CHEMBL1481525 & 688239 & 5.0862 & 5.3848 & TRN & \\
\hline CHEMBL1387194 & 688239 & 4.6862 & 5.361000 & 000000001 & TRN \\
\hline CHEMBL1503824 & 688239 & 4.9 & 5.4299 & TST & \\
\hline CHEMBL1498357 & 688239 & 4.6362 & 5.4244 & TRN & \\
\hline CHEMBL1514940 & 688239 & 4.6362 & 5.601 & TRN & \\
\hline CHEMBL1339445 & 688239 & 5.6362 & 5.4051 & TRN & \\
\hline CHEMBL1417649 & 688239 & 4.8362 & 5.4331 & TRN & \\
\hline CHEMBL1407504 & 688239 & 5.0362 & 5.4498 & TST & \\
\hline CHEMBL1399327 & 688239 & 5.4862 & 5.5355 & TRN & \\
\hline CHEMBL1506940 & 688239 & 4.8362 & 5.5333 & TRN & \\
\hline CHEMBL1317267 & 688239 & 4.8362 & 5.4622 & TST & \\
\hline CHEMBL1459855 & 688239 & 4.7362 & 5.3807 & TRN & \\
\hline CHEMBL1332565 & 688239 & 5.7862 & 5.4167 & TRN & \\
\hline CHEMBL1341243 & 688239 & 4.7862 & 5.4781 & TRN & \\
\hline CHEMBL1344171 & 688239 & 6.1862 & 5.425 & TRN & \\
\hline CHEMBL1608662 & 688239 & 8.1871 & 5.5557 & TRN & \\
\hline CHEMBL1309058 & 688239 & 6.0862 & 5.6418 & TST & \\
\hline CHEMBL1325933 & 688239 & 6.1862 & 5.6105 & TRN & \\
\hline CHEMBL1488863 & 688239 & 6.8861 & 5.4535 & TRN & \\
\hline CHEMBL1333822 & 688239 & 5.1862 & 5.4926 & TRN & \\
\hline CHEMBL1320019 & 688239 & 7.2865 & 5.2801 & TRN & \\
\hline CHEMBL1401369 & 688239 & 4.4862 & 5.526 & TRN & \\
\hline CHEMBL1587590 & 688239 & 8.283999 & 99999999 & 5.4521 & $\mathrm{~T} \mathrm{KN}$ \\
\hline CHEMBL1344294 & 688239 & 6.2362 & 5.3912 & TST & \\
\hline
\end{tabular}


Supplemental Table S2.txt

\begin{tabular}{|c|c|c|c|c|}
\hline 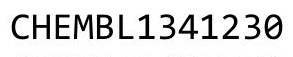 & & & & \\
\hline HEMBL1425770 & 88239 & 1362 & 5.4662 & \\
\hline HEMBL1468029 & 88239 & 2862 & 4324 & \\
\hline AEMBL13 & & & 551 & \\
\hline EMBL31 & & 362 & & \\
\hline HEMBL3195012 & 88239 & 3862 & 3077 & \\
\hline HEMBL1372427 & 88239 & .5362 & .4856 & \\
\hline HEMBL1333810 & 88239 & 362 & .5009 & \\
\hline IEMBL] & 39 & 862 & .5181 & \\
\hline IEMBL16 & 39 & 862 & .3812 & \\
\hline HEMBL1303612 & 39 & 362 & 5195 & \\
\hline HEMBL1569069 & 39 & 862 & .5423 & \\
\hline HEMBL1479070 & 39 & 362 & 774 & \\
\hline HEMBL 145 & & & 89 & \\
\hline HEMBL14 & 39 & 62 & & \\
\hline HEMBL132 & 39 & 862 & 4296 & \\
\hline HEMBL1545577 & 39 & 862 & .5844 & \\
\hline HEMBL137 & 39 & 362 & 14 & \\
\hline HEMBL13 & & & & \\
\hline HEMBL14 & 9 & & & \\
\hline HEMBL13 & 39 & & & \\
\hline HEMBL1346538 & 39 & 61 & 47 & RN \\
\hline HEMBL135e & 39 & 62 & 55 & \\
\hline HEMBL158 & & & & \\
\hline HEMBL1352 & 39 & & & RN \\
\hline HEMBL 147 & 39 & & & RN \\
\hline HEMBL592363 & 39 & 62 & 15 & I \\
\hline HEMBL141 & 39 & 61 & 23 & $\mathrm{RN}$ \\
\hline HEM & & & & RN \\
\hline HEME & & & & RN \\
\hline HEMBL153 & & & & RN \\
\hline HEMBL1593281 & 39 & 362 & 5104 & ST \\
\hline HEMBL1608009 & 39 & 362 & 225 & RN \\
\hline 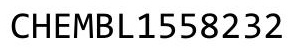 & & & & ST \\
\hline HEMBL 200 & & & & RN \\
\hline HEMBL13101 & 39 & & & RN \\
\hline HEMBL596674 & 39 & 862 & 3653 & ST \\
\hline HEMBL 1575537 & 39 & 62 & 857 & NIV \\
\hline 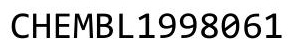 & & & & ST \\
\hline HEMBL1510777 & & & 4782 & RN \\
\hline HEMBL 260021 & 39 & 362 & 527 & RN \\
\hline HEMBL136 & 39 & 362 & 5.5072 & ST \\
\hline HEMBL136 & & & & \\
\hline & & & & ST \\
\hline HEMBL13 & & & .4806 & RN \\
\hline HEMBL1483510 & 39 & 862 & 5.4936 & $N$ \\
\hline HEN & & & & \\
\hline & & & & \\
\hline
\end{tabular}

Page 1379 
Supplemental Table S2.txt

\begin{tabular}{|c|c|c|c|c|c|c|}
\hline CHEMBL1507459 & 688239 & 5.1862 & 5.4317 & TRN & & \\
\hline CHEMBL1484498 & 688239 & 5.8862 & 5.5167 & TRN & & \\
\hline CHEMBL1490288 & 688239 & 5.8362 & 5.53700 & 0000000001 & & TRN \\
\hline CHEMBL1466617 & 688239 & 4.4862 & 5.4388 & TRN & & \\
\hline CHEMBL1535970 & 688239 & 7.0862 & 5.5219 & TST & & \\
\hline CHEMBL1523527 & 688239 & 5.2862 & 5.5512 & TRN & & \\
\hline CHEMBL1501717 & 688239 & 5.1862 & 5.3573 & TRN & & \\
\hline CHEMBL1343543 & 688239 & 4.5362 & 5.4009 & TST & & \\
\hline CHEMBL582050 & 688239 & 6.1362 & 5.5363 & TST & & \\
\hline CHEMBL1436126 & 688239 & 5.1862 & 5.4211 & TRN & & \\
\hline CHEMBL1370697 & 688239 & 6.1862 & 5.4505 & TRN & & \\
\hline CHEMBL1529515 & 688239 & 4.5362 & 5.5244 & TST & & \\
\hline CHEMBL1465509 & 688239 & 4.5362 & 5.4863 & TRN & & \\
\hline CHEMBL1553802 & 688239 & 6.0862 & 5.4568 & TRN & & \\
\hline CHEMBL1533770 & 688239 & 5.4362 & 5.4769 & TST & & \\
\hline CHEMBL1477290 & 688239 & 8.1367 & 5.6689 & TRN & & \\
\hline CHEMBL1364235 & 688239 & 6.1362 & 5.5299 & TRN & & \\
\hline CHEMBL1441832 & 688239 & 4.7862 & 5.419 & TRN & & \\
\hline CHEMBL1537681 & 688239 & 6.6861 & 5.5661 & TRN & & \\
\hline CHEMBL1313964 & 688239 & 8.28399 & و9999999 & 99 & 5.6852 & TRN \\
\hline CHEMBL1342053 & 688239 & 5.1862 & 5.3952 & TRN & & \\
\hline CHEMBL1404059 & 688239 & 5.7862 & 5.4762 & TRN & & \\
\hline CHEMBL1549395 & 688239 & 4.5362 & 5.5356 & TRN & & \\
\hline CHEMBL1587373 & 688239 & 5.1862 & 5.3502 & TRN & & \\
\hline CHEMBL1461485 & 688239 & 5.3862 & 5.4692 & TRN & & \\
\hline CHEMBL3197610 & 688239 & \multicolumn{3}{|c|}{8.283999999999999} & 5.5724 & TRN \\
\hline CHEMBL1529346 & 688239 & 5.5862 & 5.5615 & TRN & & \\
\hline CHEMBL1605767 & 688239 & 4.5362 & 5.5323 & TRN & & \\
\hline CHEMBL1523413 & 688239 & 6.2862 & 5.5142 & TRN & & \\
\hline CHEMBL1424133 & 688239 & 4.5362 & 5.5981 & TRN & & \\
\hline CHEMBL1594698 & 688239 & 5.1862 & 5.5171 & TRN & & \\
\hline CHEMBL1587981 & 688239 & 4.5362 & 5.3364 & TST & & \\
\hline CHEMBL1514092 & 688239 & 6.7361 & 5.4134 & TRN & & \\
\hline CHEMBL1422899 & 688239 & \multicolumn{3}{|c|}{8.283999999999999} & 5.4725 & \\
\hline CHEMBL1420099 & 688239 & 4.5362 & 5.5364 & TRN & & \\
\hline CHEMBL1392801 & 688239 & 5.6362 & 5.49 & TRN & & \\
\hline CHEMBL1521034 & 688239 & 5.7362 & 5.5457 & TST & & \\
\hline CHEMBL1605351 & 688239 & 5.0862 & 5.6617 & TST & & \\
\hline CHEMBL1512748 & 688239 & 4.5362 & 5.5649 & TRN & & \\
\hline CHEMBL1361248 & 688239 & 4.9362 & 5.4796 & TST & & \\
\hline CHEMBL1489478 & 688239 & 5.4862 & 5.5405 & TST & & \\
\hline CHEMBL3212003 & 688239 & 5.3362 & 5.45299 & 9999999999 & & J \\
\hline CHEMBL1304946 & 688239 & 4.6362 & 5.5737 & TST & & \\
\hline CHEMBL1348877 & 688239 & 6.1362 & 5.7209 & TRN & & \\
\hline CHEMBL1544067 & 688239 & 5.3362 & 5.4352 & TST & & \\
\hline CHEMBL3197999 & 688239 & 6.8861 & 5.3562 & TRN & & \\
\hline CHEMBL1301177 & 688239 & 4.8862 & 5.4268 & TRN & & \\
\hline CHEMBL3198985 & 688239 & 5.3862 & 5.42899 & 99999 & & \\
\hline
\end{tabular}


Supplemental Table S2.txt

\begin{tabular}{|c|c|c|c|c|}
\hline CHEMBL1429577 & 688239 & 5.1362 & 5.6091 & TRN \\
\hline CHEMBL1352748 & 688239 & 4.5362 & 5.4598 & TRN \\
\hline CHEMBL1475082 & 688239 & 5.3862 & 5.5302 & TRN \\
\hline CHEMBL284742 & 688239 & 4.6362 & 5.483 & TRN \\
\hline CHEMBL1395386 & 688239 & 5.2362 & 5.2653 & TRN \\
\hline CHEMBL1521368 & 688239 & 6.0862 & 5.3507 & TST \\
\hline CHEMBL1384078 & 688239 & 5.1862 & 5.766 & TRN \\
\hline CHEMBL1465266 & 688239 & 4.6362 & 5.5144 & TRN \\
\hline CHEMBL 1504530 & 688239 & 6.2362 & 5.5815 & TST \\
\hline CHEMBL1366841 & 688239 & 5.9862 & 5.5313 & TRN \\
\hline CHEMBL483633 & 688239 & 6.3362 & 5.5285 & TRN \\
\hline CHEMBL1527208 & 688239 & 6.2862 & 5.4871 & TRN \\
\hline CHEMBL1520089 & 688239 & 4.8362 & 5.5084 & TRN \\
\hline CHEMBL1413605 & 688239 & 4.6362 & 5.4681 & TRN \\
\hline CHEMBL1368991 & 688239 & 6.8362 & 5.4943 & TRN \\
\hline CHEMBL1372505 & 688239 & 5.5862 & 5.4922 & TRN \\
\hline CHEMBL1420608 & 688239 & 6.8861 & 5.5252 & TST \\
\hline CHEMBL1581095 & 688239 & 4.7862 & 5.4905 & TRN \\
\hline CHEMBL1526985 & 688239 & 6.9863 & 5.5195 & TRN \\
\hline CHEMBL 3190610 & 688239 & 5.6362 & 5.4742 & TRN \\
\hline CHEMBL1438086 & 688239 & 8.3372 & 5.3925 & TRN \\
\hline CHEMBL1535017 & 688239 & 5.5362 & 5.45200 & 0000000001 \\
\hline CHEMBL1611445 & 688239 & 5.1362 & 5.4566 & TRN \\
\hline CHEMBL1564611 & 688239 & 5.1862 & 5.4671 & TRN \\
\hline CHEMBL1369369 & 688239 & 8.3372 & 5.5274 & TRN \\
\hline CHEMBL1413717 & 688239 & 5.6862 & 5.3735 & TRN \\
\hline CHEMBL1550324 & 688239 & 5.3862 & 5.5548 & TST \\
\hline CHEMBL1304012 & 688239 & 5.0862 & 5.3689 & TRN \\
\hline CHEMBL1495757 & 688239 & 4.9362 & 5.4284 & TRN \\
\hline CHEMBL1554138 & 688239 & 4.5362 & 5.3892 & TRN \\
\hline CHEMBL1333370 & 688239 & 5.1362 & 5.4639 & TRN \\
\hline CHEMBL1521322 & 688239 & 8.3372 & 5.49100 & 00000000005 \\
\hline CHEMBL1368189 & 688239 & 6.2362 & 5.3644 & TRN \\
\hline CHEMBL1484238 & 688239 & 4.6862 & 5.3248 & TRN \\
\hline CHEMBL1530281 & 688239 & 4.9362 & 5.524 & TRN \\
\hline CHEMBL1396931 & 688239 & 5.1862 & 5.4632 & TRN \\
\hline CHEMBL1543321 & 688239 & 5.1862 & 5.4566 & TRN \\
\hline CHEMBL1389009 & 688239 & 6.2862 & 5.5243 & TRN \\
\hline CHEMBL1477894 & 688239 & 5.1862 & 5.5266 & TST \\
\hline CHEMBL1336690 & 688239 & 5.2862 & 5.5141 & TRN \\
\hline CHEMBL1533584 & 688239 & 6.8861 & 5.5386 & TRN \\
\hline CHEMBL1527086 & 688239 & 4.5362 & 5.5557 & TST \\
\hline CHEMBL1420610 & 688239 & 4.5362 & 5.4027 & TST \\
\hline CHEMBL1437660 & 688239 & 4.8862 & 5.4469 & TRN \\
\hline CHEMBL1557239 & 688239 & 6.8861 & 5.5226 & TRN \\
\hline CHEMBL1565164 & 688239 & 4.6362 & 5.3991 & TST \\
\hline CHEMBL1411798 & 688239 & 5.8862 & 5.4625 & TRN \\
\hline CHEMBL 3196951 & 688239 & 4.7862 & 5.4137 & TRN \\
\hline
\end{tabular}

Page 1381 
Supplemental Table S2.txt

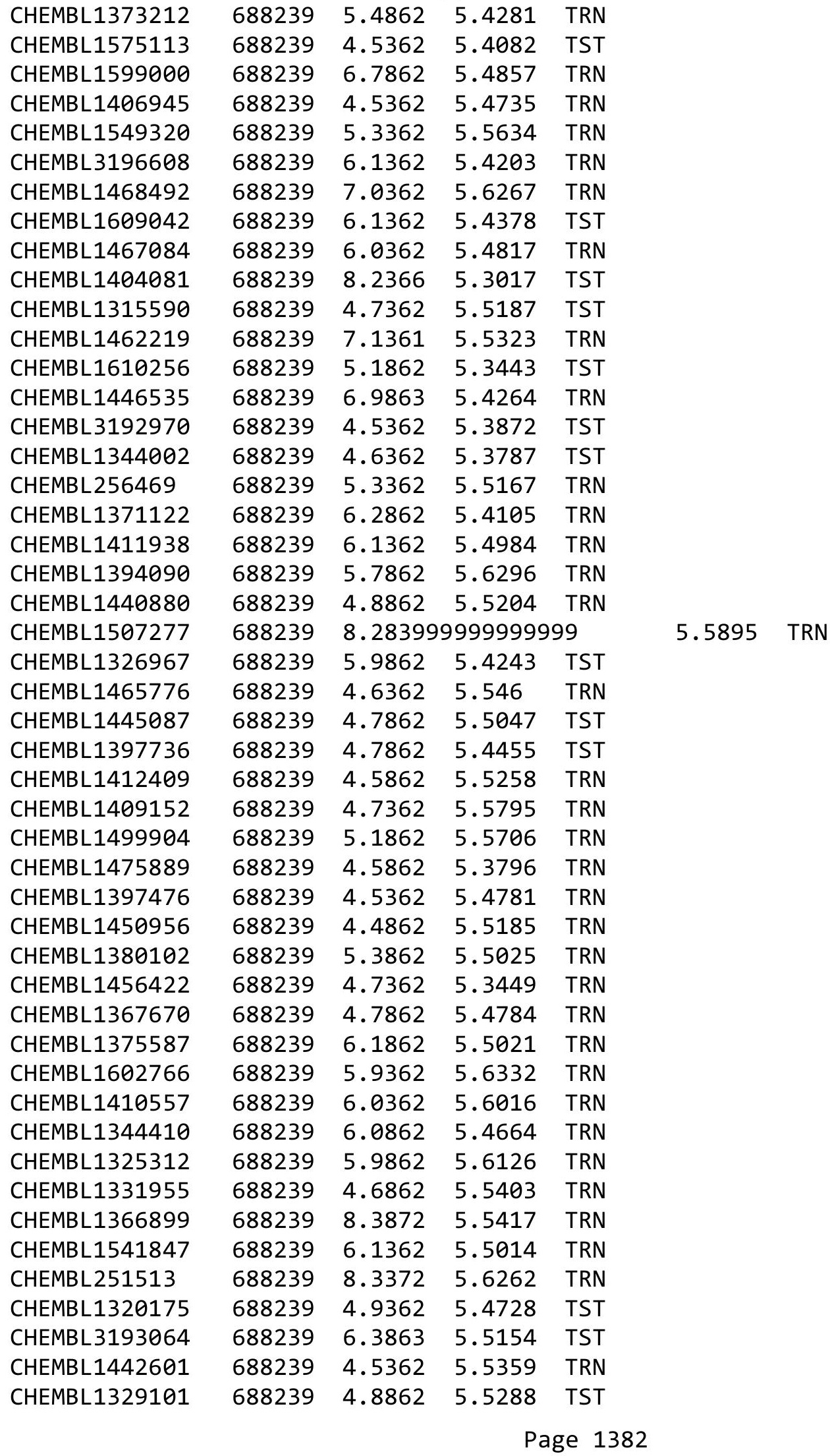


Supplemental Table S2.txt

\begin{tabular}{|c|c|c|c|c|}
\hline CHEMBL1441058 & 688239 & 5.8362 & 5.6224 & TRN \\
\hline CHEMBL1584872 & 688239 & 4.5362 & 5.6019 & TRN \\
\hline CHEMBL1443852 & 688239 & 6.0362 & 5.4223 & TRN \\
\hline CHEMBL1462718 & 688239 & 5.2 & 5.4659 & TST \\
\hline CHEMBL1339305 & 688239 & 6.7361 & 5.5889 & TRN \\
\hline CHEMBL1383463 & 688239 & 5.4362 & 5.5386 & TRN \\
\hline CHEMBL1518985 & 688239 & 4.5362 & 5.477 & TRN \\
\hline CHEMBL1474769 & 688239 & 6.1862 & 5.6475 & TST \\
\hline CHEMBL1416220 & 688239 & 6.8362 & 5.5193 & TRN \\
\hline CHEMBL1486779 & 688239 & 5.4362 & 5.4807 & TRN \\
\hline CHEMBL1372674 & 688239 & 5.7362 & 5.4613 & TRN \\
\hline CHEMBL1352926 & 688239 & 5.7362 & 5.5659 & TRN \\
\hline CHEMBL1599485 & 688239 & 5.9362 & 5.6616 & TRN \\
\hline CHEMBL1339635 & 688239 & 4.4862 & 5.4504 & TRN \\
\hline CHEMBL1510662 & 688239 & 4.5862 & 5.395 & TRN \\
\hline CHEMBL1339980 & 688239 & 6.6861 & 5.3582 & TRN \\
\hline CHEMBL1338736 & 688239 & 4.5362 & 5.4109 & TST \\
\hline CHEMBL1564994 & 688239 & 4.5362 & 5.4752 & TST \\
\hline CHEMBL577102 & 688239 & 4.5362 & 5.2936 & TRN \\
\hline CHEMBL1427466 & 688239 & 4.8362 & 5.4334 & TRN \\
\hline CHEMBL1330103 & 688239 & 4.5362 & 5.5434 & TST \\
\hline CHEMBL1395268 & 688239 & 7.2366 & 5.5293 & TRN \\
\hline CHEMBL1361457 & 688239 & 4.5362 & 5.3963 & TRN \\
\hline CHEMBL1471900 & 688239 & 4.5362 & 5.4108 & TRN \\
\hline CHEMBL1355414 & 688239 & 6.7361 & 5.5485 & TRN \\
\hline CHEMBL1586191 & 688239 & 5.0362 & 5.59399 & 9999999999 \\
\hline CHEMBL1433877 & 688239 & 5.0362 & 5.4396 & TST \\
\hline CHEMBL1587185 & 688239 & 6.1362 & 5.4276 & TRN \\
\hline CHEMBL1416036 & 688239 & 6.9363 & 5.4592 & TST \\
\hline CHEMBL1442284 & 688239 & 4.5362 & 5.4284 & TST \\
\hline CHEMBL1386570 & 688239 & 4.6362 & 5.5333 & TRN \\
\hline CHEMBL1304954 & 688239 & 7.4868 & 5.5385 & TST \\
\hline CHEMBL1402945 & 688239 & 6.5363 & 5.6259 & TRN \\
\hline CHEMBL 3194912 & 688239 & 6.2862 & 5.4983 & TRN \\
\hline CHEMBL1545024 & 688239 & 7.1864 & 5.4836 & TRN \\
\hline CHEMBL1299599 & 688239 & 5.6362 & 5.5287 & TRN \\
\hline CHEMBL1398661 & 688239 & 4.7862 & 5.599 & TRN \\
\hline CHEMBL1430910 & 688239 & 6.2362 & 5.4724 & TST \\
\hline CHEMBL1414771 & 688239 & 7.6364 & 5.5169 & TRN \\
\hline CHEMBL1386929 & 688239 & 5.7362 & 5.5505 & TRN \\
\hline CHEMBL1568224 & 688239 & 6.0862 & 5.5038 & TRN \\
\hline CHEMBL1604378 & 688239 & 5.6362 & 5.3516 & TRN \\
\hline CHEMBL1578931 & 688239 & 4.6862 & 5.4799 & TRN \\
\hline CHEMBL1498314 & 688239 & 6.3362 & 5.4245 & TRN \\
\hline CHEMBL1573214 & 688239 & 4.4862 & 5.5906 & TRN \\
\hline CHEMBL1417420 & 688239 & 5.3862 & 5.4192 & TRN \\
\hline CHEMBL1570214 & 688239 & 5.1862 & 5.5727 & TRN \\
\hline CHEMBL1393805 & 688239 & 4.5362 & 5.5083 & TRN \\
\hline
\end{tabular}


Supplemental Table S2.txt

\begin{tabular}{|c|c|c|c|c|c|}
\hline CHEMBL1361974 & 688239 & 5.0862 & 5.5234 & TRN & \\
\hline CHEMBL1532294 & 688239 & 6.1362 & \multicolumn{2}{|c|}{5.446000000000001} & TRN \\
\hline CHEMBL1399876 & 688239 & 5.1362 & 5.4435 & TRN & \\
\hline CHEMBL1461994 & 688239 & 4.5362 & \multicolumn{2}{|c|}{5.417000000000001} & TRN \\
\hline CHEMBL 3212453 & 688239 & 6.5862 & 5.3297 & TRN & \\
\hline CHEMBL1383283 & 688239 & 6.5862 & 5.3112 & TRN & \\
\hline CHEMBL1530533 & 688239 & 4.9862 & 5.5087 & TRN & \\
\hline CHEMBL1414956 & 688239 & 5.1862 & 5.4489 & TRN & \\
\hline CHEMBL1482487 & 688239 & 5.6862 & 5.5268 & TST & \\
\hline CHEMBL523238 & 688239 & 4.5362 & 5.4123 & TRN & \\
\hline CHEMBL1493485 & 688239 & 4.4862 & 5.5599 & TST & \\
\hline CHEMBL1557965 & 688239 & 6.5363 & 5.4785 & TRN & \\
\hline CHEMBL1458560 & 688239 & 4.5362 & 5.4481 & TRN & \\
\hline CHEMBL1388941 & 688239 & 7.5361 & 5.3841 & TRN & \\
\hline CHEMBL1458519 & 688239 & 6.8861 & 5.3964 & TST & \\
\hline CHEMBL1502996 & 688239 & 5.0362 & 5.5826 & TST & \\
\hline CHEMBL1586222 & 688239 & 4.5362 & 5.4848 & TST & \\
\hline CHEMBL1329805 & 688239 & 4.6862 & 5.6837 & TST & \\
\hline CHEMBL1477579 & 688239 & 6.8861 & 5.5636 & TRN & \\
\hline CHEMBL1388974 & 688239 & 6.1862 & 5.5625 & TRN & \\
\hline CHEMBL1347499 & 688239 & 4.6862 & 5.5148 & TST & \\
\hline CHEMBL1388539 & 688239 & 4.4862 & 5.5259 & TST & \\
\hline CHEMBL1407985 & 688239 & 6.6861 & 5.6209 & TRN & \\
\hline CHEMBL1573293 & 688239 & 7.0362 & 5.449 & TRN & \\
\hline CHEMBL1476997 & 688239 & 5.4362 & 5.5486 & TRN & \\
\hline CHEMBL1342362 & 688239 & 7.5361 & 5.405 & TRN & \\
\hline CHEMBL259840 & 688239 & 6.7361 & 5.5326 & TRN & \\
\hline CHEMBL3189331 & 688239 & 5.2362 & 5.4739 & TRN & \\
\hline CHEMBL 2003606 & 688239 & 6.6861 & 5.4436 & TRN & \\
\hline CHEMBL1304740 & 688239 & 5.6362 & 5.3802 & TRN & \\
\hline CHEMBL1381483 & 688239 & 5.1862 & \multicolumn{2}{|c|}{5.667999999999999} & TRN \\
\hline CHEMBL1418549 & 688239 & 4.7362 & 5.5919 & TRN & \\
\hline CHEMBL1514578 & 688239 & 4.7862 & 5.46 & TRN & \\
\hline CHEMBL1466326 & 688239 & 6.3863 & 5.7228 & TST & \\
\hline CHEMBL1359080 & 688239 & 6.9363 & 5.4327 & TST & \\
\hline CHEMBL1396930 & 688239 & 5.1862 & 5.5873 & TRN & \\
\hline CHEMBL1540943 & 688239 & 6.0862 & 5.468 & TRN & \\
\hline CHEMBL1454335 & 688239 & 6.7862 & 5.5728 & TRN & \\
\hline CHEMBL1389594 & 688239 & 5.0862 & 5.3887 & TRN & \\
\hline CHEMBL1539505 & 688239 & 4.5362 & 5.4087 & TRN & \\
\hline CHEMBL1405624 & 688239 & 6.8861 & 5.6102 & TRN & \\
\hline CHEMBL1996749 & 688239 & 4.6862 & 5.6096 & TRN & \\
\hline CHEMBL1471217 & 688239 & 5.7862 & 5.651 & TRN & \\
\hline CHEMBL1487442 & 688239 & 8.3372 & 5.4485 & TRN & \\
\hline CHEMBL1384101 & 688239 & 6.0862 & 5.5854 & TRN & \\
\hline CHEMBL1382271 & 688239 & 5.4862 & 5.5779 & TST & \\
\hline CHEMBL1310089 & 688239 & 6.0862 & \multicolumn{2}{|c|}{5.6160000000000005} & TST \\
\hline CHEMBL1466030 & 688239 & 6.5363 & 5.4874 & TRN & \\
\hline
\end{tabular}


Supplemental Table S2.txt

\begin{tabular}{|c|c|c|c|c|c|}
\hline CHEMBL1557731 & 688239 & 4.6362 & 5.641 & TRN & \\
\hline CHEMBL1389311 & 688239 & 4.8362 & 5.5883 & TRN & \\
\hline CHEMBL 3199800 & 688239 & 6.1362 & 5.3599 & TST & \\
\hline CHEMBL1449768 & 688239 & 5.0862 & 5.5299 & TRN & \\
\hline CHEMBL1569376 & 688239 & 5.2862 & 5.3469 & TRN & \\
\hline CHEMBL 3214207 & 688239 & 4.9862 & 5.5784 & TRN & \\
\hline CHEMBL1430113 & 688239 & 6.1862 & 5.6429 & TRN & \\
\hline CHEMBL1520173 & 688239 & 6.5363 & 5.4125 & TST & \\
\hline CHEMBL1608313 & 688239 & 5.1862 & 5.5279 & TST & \\
\hline CHEMBL1399295 & 688239 & 7.4868 & 5.4249 & TRN & \\
\hline CHEMBL1591771 & 688239 & 4.7862 & 5.449 & TRN & \\
\hline CHEMBL1400146 & 688239 & 4.5362 & 5.5515 & TRN & \\
\hline CHEMBL1300353 & 688239 & 8.3872 & 5.4747 & TST & \\
\hline CHEMBL1339757 & 688239 & 5.2362 & 5.5044 & TRN & \\
\hline CHEMBL1510713 & 688239 & 4.5362 & 5.5743 & TRN & \\
\hline CHEMBL1330303 & 688239 & 4.5362 & 5.4945 & TRN & \\
\hline CHEMBL1387894 & 688239 & 5.5362 & 5.492999 & 999999999 & TRN \\
\hline CHEMBL1607363 & 688239 & 6.0862 & 5.6707 & TRN & \\
\hline CHEMBL1464654 & 688239 & 5.1862 & 5.3196 & TRN & \\
\hline CHEMBL1531050 & 688239 & 4.6862 & 5.386 & TST & \\
\hline CHEMBL1588100 & 688239 & 5.4362 & 5.6619 & TRN & \\
\hline CHEMBL1492007 & 688239 & 6.8861 & 5.485 & TRN & \\
\hline CHEMBL1302030 & 688239 & 4.8862 & 5.4516 & TRN & \\
\hline CHEMBL1427997 & 688239 & 4.5862 & 5.5702 & TRN & \\
\hline CHEMBL 1407788 & 688239 & 5.1362 & 5.4046 & TRN & \\
\hline CHEMBL1399749 & 688239 & 5.6362 & 5.5468 & TRN & \\
\hline CHEMBL1381572 & 688239 & 8.1871 & 5.6411 & TST & \\
\hline CHEMBL1350296 & 688239 & 4.4862 & 5.5337 & TRN & \\
\hline CHEMBL1433041 & 688239 & 5.1862 & 5.4989 & TRN & \\
\hline CHEMBL1304354 & 688239 & 5.4862 & 5.432 & TRN & \\
\hline CHEMBL1328086 & 688239 & 6.4362 & 5.392 & TST & \\
\hline CHEMBL1341414 & 688239 & 4.8362 & 5.5098 & TRN & \\
\hline CHEMBL1336535 & 688239 & 4.5362 & 5.5479 & TRN & \\
\hline CHEMBL1326824 & 688239 & 4.5362 & 5.502999 & 999999999 & TST \\
\hline CHEMBL1433127 & 688239 & 4.5362 & 5.4021 & TRN & \\
\hline CHEMBL1379326 & 688239 & 6.1862 & 5.6158 & TST & \\
\hline CHEMBL1374475 & 688239 & 4.6362 & 5.5649 & TRN & \\
\hline CHEMBL1521900 & 688239 & 4.5362 & 5.4722 & TRN & \\
\hline CHEMBL1425610 & 688239 & 5.1862 & 5.4239 & TRN & \\
\hline CHEMBL1543871 & 688239 & 4.5362 & 5.6119 & TRN & \\
\hline CHEMBL1378759 & 688239 & 4.5362 & 5.472 & TRN & \\
\hline CHEMBL1548264 & 688239 & 6.0862 & 5.3891 & TRN & \\
\hline CHEMBL1390044 & 688239 & 6.0862 & 5.4373 & TRN & \\
\hline CHEMBL1595188 & 688239 & 4.8862 & 5.4763 & TRN & \\
\hline CHEMBL1445459 & 688239 & 5.5862 & 5.439 & TRN & \\
\hline CHEMBL1334659 & 688239 & 4.6362 & 5.3933 & TRN & \\
\hline CHEMBL1587380 & 688239 & 8.28399 & 99999999 & 5.4916 & $\mathrm{~K} / \mathrm{N}$ \\
\hline CHEMBL1300936 & 688239 & 5.6362 & 5.5056 & TRN & \\
\hline
\end{tabular}


Supplemental Table S2.txt

\begin{tabular}{|c|c|c|c|c|c|}
\hline CHEMBL1347687 & 688239 & 4.7862 & 5.5206 & TRN & \\
\hline CHEMBL1426340 & 688239 & 4.6362 & 5.3425 & TST & \\
\hline CHEMBL1613075 & 688239 & 5.2862 & 5.5829 & TRN & \\
\hline CHEMBL1329243 & 688239 & 6.2362 & \multicolumn{2}{|c|}{5.361000000000001} & TRN \\
\hline CHEMBL1335425 & 688239 & 6.1862 & 5.4385 & TRN & \\
\hline CHEMBL1414583 & 688239 & 6.2362 & 5.5164 & TRN & \\
\hline CHEMBL1444592 & 688239 & 6.1362 & 5.4797 & TRN & \\
\hline CHEMBL1563270 & 688239 & 5.1362 & 5.5426 & TRN & \\
\hline CHEMBL1588378 & 688239 & 4.8862 & 5.5278 & TRN & \\
\hline CHEMBL1454021 & 688239 & 4.7362 & 5.4325 & TST & \\
\hline CHEMBL1531973 & 688239 & 7.2366 & 5.608 & TRN & \\
\hline CHEMBL1574914 & 688239 & 6.1862 & 5.3995 & TRN & \\
\hline CHEMBL1488860 & 688239 & 5.1362 & 5.6366 & TRN & \\
\hline CHEMBL1580185 & 688239 & 4.5362 & 5.525 & TRN & \\
\hline CHEMBL1317348 & 688239 & 4.9862 & 5.4555 & TRN & \\
\hline CHEMBL1496784 & 688239 & 4.7862 & 5.4924 & TRN & \\
\hline CHEMBL1470837 & 688239 & 6.9863 & 5.4438 & TRN & \\
\hline CHEMBL1518437 & 688239 & 5.9862 & 5.5025 & TRN & \\
\hline CHEMBL1456788 & 688239 & 5.2862 & 5.4944 & TST & \\
\hline CHEMBL1541298 & 688239 & 4.6362 & 5.4694 & TRN & \\
\hline CHEMBL1300029 & 688239 & 4.7862 & 5.4342 & TRN & \\
\hline CHEMBL1531666 & 688239 & 5.1362 & 5.5955 & TRN & \\
\hline CHEMBL1339513 & 688239 & 4.8362 & 5.4985 & TRN & \\
\hline CHEMBL1301205 & 688239 & 6.2362 & 5.5586 & TRN & \\
\hline CHEMBL1352726 & 688239 & 4.5362 & 5.3926 & TRN & \\
\hline CHEMBL1463004 & 688239 & 6.7361 & 5.5975 & TRN & \\
\hline CHEMBL1310197 & 688239 & 6.1862 & 5.6163 & TST & \\
\hline CHEMBL1352079 & 688239 & 5.9362 & 5.5093 & TRN & \\
\hline CHEMBL1499935 & 688239 & 5.1862 & 5.3714 & TRN & \\
\hline CHEMBL1982108 & 688239 & 6.8861 & 5.4347 & TRN & \\
\hline CHEMBL1369150 & 688239 & 6.9363 & 5.5249 & TST & \\
\hline CHEMBL1585082 & 688239 & 4.7362 & 5.4896 & TST & \\
\hline CHEMBL1462803 & 688239 & 6.0 & 5.5135 & TRN & \\
\hline CHEMBL1419349 & 688239 & 5.4362 & 5.5166 & TST & \\
\hline CHEMBL1451336 & 688239 & 6.3863 & 5.4024 & TST & \\
\hline CHEMBL1317137 & 688239 & 6.1862 & 5.6025 & TRN & \\
\hline CHEMBL1413154 & 688239 & 8.3372 & 5.50799 & 9999999999 & TRN \\
\hline CHEMBL1477840 & 688239 & 5.2862 & 5.6331 & TRN & \\
\hline CHEMBL1376577 & 688239 & 4.6862 & 5.5482 & TRN & \\
\hline CHEMBL1458769 & 688239 & 5.1862 & 5.4974 & TRN & \\
\hline CHEMBL1607972 & 688239 & 4.5362 & 5.4838 & TRN & \\
\hline CHEMBL1367343 & 688239 & 5.2862 & 5.4058 & TRN & \\
\hline CHEMBL1409027 & 688239 & 6.0862 & 5.4499 & TRN & \\
\hline CHEMBL1384455 & 688239 & 5.1862 & 5.5393 & TRN & \\
\hline CHEMBL1612869 & 688239 & 5.1862 & 5.3278 & TST & \\
\hline CHEMBL1980684 & 688239 & 5.5362 & 5.4388 & TRN & \\
\hline CHEMBL1465166 & 688239 & 4.6362 & 5.6327 & TRN & \\
\hline CHEMBL1330920 & 688239 & 4.5362 & 5.4686 & TST & \\
\hline
\end{tabular}


Supplemental Table S2.txt

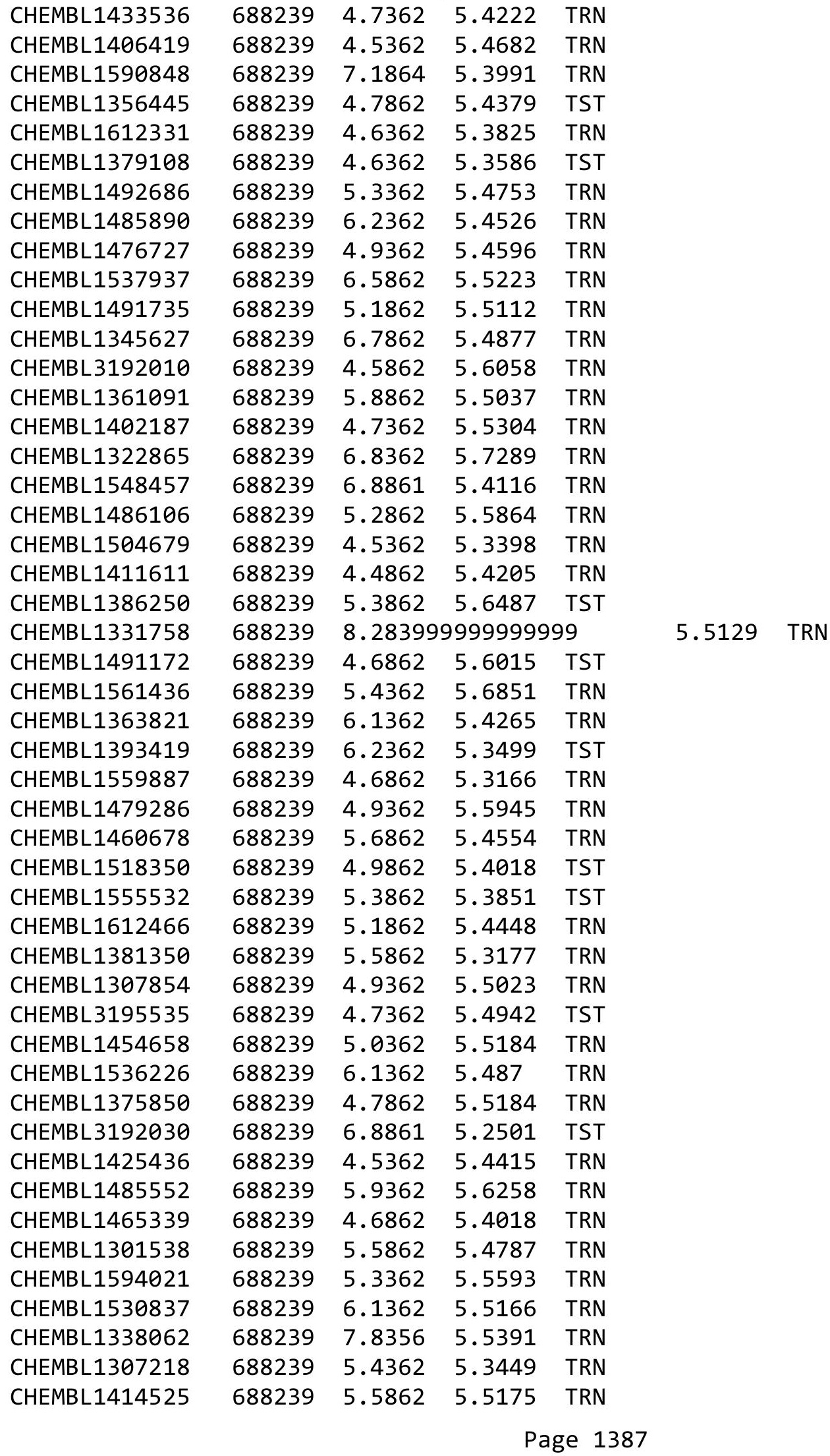


Supplemental Table S2.txt

\begin{tabular}{|c|c|c|c|c|c|c|}
\hline CHEMBL1331767 & 688239 & 6.9363 & 5.3888 & TRN & & \\
\hline CHEMBL1545886 & 688239 & 6.0862 & 5.4515 & TST & & \\
\hline CHEMBL1380178 & 688239 & 6.6362 & 5.4983 & TRN & & \\
\hline CHEMBL1333165 & 688239 & 8.3872 & 5.4837 & TRN & & \\
\hline CHEMBL1313265 & 688239 & 4.7862 & 5.4782 & TRN & & \\
\hline CHEMBL1317590 & 688239 & 6.1362 & 5.3157 & TRN & & \\
\hline CHEMBL1524548 & 688239 & 4.5362 & 5.621 & TRN & & \\
\hline CHEMBL1557151 & 688239 & 5.1862 & 5.544 & TST & & \\
\hline CHEMBL1370203 & 688239 & 5.5362 & 5.5025 & TRN & & \\
\hline CHEMBL1313043 & 688239 & 4.5362 & 5.3716 & TST & & \\
\hline CHEMBL478501 & 688239 & 5.7362 & 5.5158 & TRN & & \\
\hline CHEMBL1501007 & 688239 & 4.6362 & 5.4656 & TRN & & \\
\hline CHEMBL1451532 & 688239 & 8.28399 & 99999999 & & 5.4231 & TRN \\
\hline CHEMBL1468577 & 688239 & 4.8362 & 5.3331 & TRN & & \\
\hline CHEMBL1300041 & 688239 & 5.7362 & 5.5603 & TST & & \\
\hline CHEMBL1350734 & 688239 & 6.2362 & 5.5477 & TST & & \\
\hline CHEMBL1569640 & 688239 & 6.2862 & 5.585 & TRN & & \\
\hline CHEMBL1600498 & 688239 & 5.2862 & 5.4169 & TST & & \\
\hline CHEMBL1384545 & 688239 & 4.7862 & 5.4781 & TST & & \\
\hline CHEMBL1308855 & 688239 & 6.7361 & 5.3548 & TRN & & \\
\hline CHEMBL1574048 & 688239 & 4.5362 & 5.4136 & TST & & \\
\hline CHEMBL1319842 & 688239 & 4.5862 & 5.5104 & TST & & \\
\hline CHEMBL1314495 & 688239 & 5.8862 & 5.4438 & TRN & & \\
\hline CHEMBL1362430 & 688239 & 8.28399 & 99999999 & 99 & 5.6129 & тाт \\
\hline CHEMBL1309385 & 688239 & 5.3862 & 5.4139 & TRN & & \\
\hline CHEMBL1360449 & 688239 & 7.6861 & 5.3434 & TRN & & \\
\hline CHEMBL1430020 & 688239 & 6.8362 & 5.5527 & TST & & \\
\hline CHEMBL1607219 & 688239 & 6.2862 & 5.5954 & TRN & & \\
\hline CHEMBL1612919 & 688239 & 4.5862 & 5.4642 & TST & & \\
\hline CHEMBL1366221 & 688239 & 6.0 & 5.359 & TST & & \\
\hline CHEMBL1519654 & 688239 & 4.6362 & 5.4861 & TRN & & \\
\hline CHEMBL1543099 & 688239 & 4.5362 & 5.4049 & TRN & & \\
\hline CHEMBL1339798 & 688239 & 6.5862 & 5.4366 & TRN & & \\
\hline CHEMBL1389036 & 688239 & 8.28399 & 99999999 & 99 & 5.4301 & ובנו \\
\hline CHEMBL1432839 & 688239 & 6.0362 & 5.4125 & TRN & & \\
\hline CHEMBL1599080 & 688239 & 4.6362 & 5.3865 & TST & & \\
\hline CHEMBL1415447 & 688239 & 5.0362 & 5.4381 & TST & & \\
\hline CHEMBL1336935 & 688239 & 5.1362 & 5.5137 & TRN & & \\
\hline CHEMBL1577622 & 688239 & 7.2366 & 5.4321 & TRN & & \\
\hline CHEMBL1517219 & 688239 & 8.3372 & 5.6479 & TRN & & \\
\hline CHEMBL1527341 & 688239 & 5.6862 & 5.4142 & TST & & \\
\hline CHEMBL1487645 & 688239 & 5.6362 & 5.5252 & TRN & & \\
\hline CHEMBL1384970 & 688239 & 7.0362 & 5.6034 & TRN & & \\
\hline CHEMBL1478338 & 688239 & 4.9362 & 5.4797 & TRN & & \\
\hline CHEMBL1576765 & 688239 & 4.7862 & 5.5022 & TRN & & \\
\hline CHEMBL1486017 & 688239 & 5.7862 & 5.5577 & TST & & \\
\hline CHEMBL1311175 & 688239 & 6.8861 & 5.357 & TST & & \\
\hline CHEMBL1299673 & 688239 & 4.4862 & 5.6125 & TRN & & \\
\hline
\end{tabular}


Supplemental Table S2.txt

\begin{tabular}{|c|c|c|c|c|}
\hline CHEMBL1556558 & 688239 & 4.4862 & 5.5175 & TRN \\
\hline CHEMBL1503777 & 688239 & 6.8362 & 5.4572 & TRN \\
\hline CHEMBL1586000 & 688239 & 5.6362 & 5.2739 & TRN \\
\hline CHEMBL1439708 & 688239 & 4.6862 & 5.5399 & TST \\
\hline CHEMBL1473772 & 688239 & 5.6862 & 5.4719 & TRN \\
\hline CHEMBL1335507 & 688239 & 5.6362 & 5.4061 & TRN \\
\hline CHEMBL1562771 & 688239 & 6.1362 & 5.4519 & TRN \\
\hline CHEMBL1541824 & 688239 & 6.9363 & 5.59399 & 9999999999 \\
\hline CHEMBL1348377 & 688239 & 6.2362 & 5.7023 & TRN \\
\hline CHEMBL1444540 & 688239 & 6.3362 & 5.4252 & TST \\
\hline CHEMBL1517755 & 688239 & 4.7362 & 5.2951 & TST \\
\hline CHEMBL1446121 & 688239 & 4.5362 & 5.5261 & TRN \\
\hline CHEMBL1588442 & 688239 & 7.2366 & 5.5749 & TRN \\
\hline CHEMBL1406535 & 688239 & 5.0362 & 5.5408 & TRN \\
\hline CHEMBL1584173 & 688239 & 5.1362 & 5.5218 & TRN \\
\hline CHEMBL3194245 & 688239 & 4.5362 & 5.3404 & TST \\
\hline CHEMBL1339303 & 688239 & 5.1862 & 5.3771 & TST \\
\hline CHEMBL1469609 & 688239 & 5.1862 & 5.3694 & TRN \\
\hline CHEMBL1486331 & 688239 & 5.1862 & 5.4805 & TRN \\
\hline CHEMBL1584335 & 688239 & 4.6862 & 5.7611 & TRN \\
\hline CHEMBL1586581 & 688239 & 6.0862 & 5.4043 & TST \\
\hline CHEMBL1988376 & 688239 & 5.2362 & 5.4049 & TRN \\
\hline CHEMBL1347747 & 688239 & 4.7862 & 5.6187 & TRN \\
\hline CHEMBL1550392 & 688239 & 6.2862 & 5.6503 & TRN \\
\hline CHEMBL3198766 & 688239 & 5.3362 & 5.4352 & TRN \\
\hline CHEMBL1421977 & 688239 & 4.6862 & 5.3899 & TRN \\
\hline CHEMBL1540634 & 688239 & 6.5363 & 5.6102 & TRN \\
\hline CHEMBL1466913 & 688239 & 4.8362 & 5.4337 & TST \\
\hline CHEMBL1603990 & 688239 & 5.6362 & 5.5899 & TRN \\
\hline CHEMBL1391610 & 688239 & 6.0362 & 5.3956 & TRN \\
\hline CHEMBL1555469 & 688239 & 7.2865 & 5.6694 & TRN \\
\hline CHEMBL1549056 & 688239 & 4.4862 & 5.5645 & TST \\
\hline CHEMBL1313329 & 688239 & 5.4862 & 5.4947 & TST \\
\hline CHEMBL1522235 & 688239 & 5.8862 & 5.5584 & TRN \\
\hline CHEMBL1423765 & 688239 & 5.1862 & 5.5743 & TRN \\
\hline CHEMBL1544375 & 688239 & 4.5362 & 5.5086 & TST \\
\hline CHEMBL1424562 & 688239 & 4.6362 & 5.3992 & TRN \\
\hline CHEMBL1429691 & 688239 & 4.5362 & 5.3717 & TRN \\
\hline CHEMBL1314257 & 688239 & 4.4862 & 5.3572 & TRN \\
\hline CHEMBL1965571 & 688239 & 4.5362 & 5.5197 & TRN \\
\hline CHEMBL1453636 & 688239 & 5.4862 & 5.5789 & TST \\
\hline CHEMBL1402993 & 688239 & 5.1862 & 5.6194 & TRN \\
\hline CHEMBL1481965 & 688239 & 5.2862 & 5.3645 & TST \\
\hline CHEMBL1300736 & 688239 & 5.3862 & 5.3638 & TST \\
\hline CHEMBL1459680 & 688239 & 4.8862 & 5.4001 & TRN \\
\hline CHEMBL579919 & 688239 & 4.4862 & 5.3267 & TRN \\
\hline CHEMBL1405943 & 688239 & 5.2362 & 5.4999 & TRN \\
\hline CHEMBL1393151 & 688239 & 6.2862 & 5.3867 & TST \\
\hline
\end{tabular}


Supplemental Table S2.txt

\begin{tabular}{|c|c|c|c|c|}
\hline CHEMBL1505972 & 688239 & 4.9362 & 5.5509 & TRN \\
\hline CHEMBL1533452 & 688239 & 5.1862 & 5.6174 & TST \\
\hline CHEMBL1579471 & 688239 & 4.5362 & 5.4551 & TRN \\
\hline CHEMBL1392720 & 688239 & 4.9862 & 5.5517 & TRN \\
\hline CHEMBL1590512 & 688239 & 7.1864 & 5.6641 & TRN \\
\hline CHEMBL1541398 & 688239 & 4.5362 & 5.4782 & TRN \\
\hline CHEMBL578257 & 688239 & 4.9862 & 5.2463 & TRN \\
\hline CHEMBL1374099 & 688239 & 4.5362 & 5.409 & TRN \\
\hline CHEMBL1313422 & 688239 & 5.1862 & 5.5978 & TRN \\
\hline CHEMBL1559051 & 688239 & 5.3862 & 5.4282 & TRN \\
\hline CHEMBL1460440 & 688239 & 5.2862 & 5.5038 & TRN \\
\hline CHEMBL1570192 & 688239 & 6.0362 & 5.5089 & TRN \\
\hline CHEMBL1498563 & 688239 & 4.6862 & 5.5488 & TRN \\
\hline CHEMBL1302117 & 688239 & 4.6362 & 5.5331 & TST \\
\hline CHEMBL1390266 & 688239 & 4.6362 & 5.5419 & TRN \\
\hline CHEMBL1477642 & 688239 & 5.4362 & 5.4724 & TRN \\
\hline CHEMBL1561245 & 688239 & 4.8362 & 5.5515 & TRN \\
\hline CHEMBL1540652 & 688239 & 6.4862 & 5.5826 & TRN \\
\hline CHEMBL1413355 & 688239 & 4.8362 & 5.4752 & TRN \\
\hline CHEMBL1451294 & 688239 & 4.9862 & 5.3821 & TRN \\
\hline CHEMBL1511800 & 688239 & 8.3372 & 5.4444 & TST \\
\hline CHEMBL1322322 & 688239 & 7.9355 & 5.4769 & TST \\
\hline CHEMBL1527144 & 688239 & 4.7862 & 5.4374 & TRN \\
\hline CHEMBL1435097 & 688239 & 5.1862 & 5.4841 & TRN \\
\hline CHEMBL1562059 & 688239 & 4.6862 & 5.4858 & TRN \\
\hline CHEMBL1585250 & 688239 & 5.4862 & 5.5852 & TST \\
\hline CHEMBL1322343 & 688239 & 5.5362 & 5.4028 & TRN \\
\hline CHEMBL1461402 & 688239 & 4.5362 & 5.5493 & TRN \\
\hline CHEMBL1320522 & 688239 & 4.5362 & 5.3131 & TRN \\
\hline CHEMBL1369174 & 688239 & 5.1862 & 5.4857 & TRN \\
\hline CHEMBL1493921 & 688239 & 4.5362 & 5.3939 & TST \\
\hline CHEMBL1419026 & 688239 & 4.5362 & 5.4672 & TRN \\
\hline CHEMBL1554614 & 688239 & 6.2362 & 5.5573 & TRN \\
\hline CHEMBL1418506 & 688239 & 6.8861 & 5.5417 & TRN \\
\hline CHEMBL1583227 & 688239 & 5.4862 & 5.386 & TST \\
\hline CHEMBL1307156 & 688239 & 4.7862 & 5.3235 & TST \\
\hline CHEMBL1487597 & 688239 & 4.7862 & 5.478 & TRN \\
\hline CHEMBL1380148 & 688239 & 5.4362 & 5.6067 & TRN \\
\hline CHEMBL1443511 & 688239 & 4.5362 & 5.3724 & TST \\
\hline CHEMBL1559808 & 688239 & 4.5362 & 5.4138 & TRN \\
\hline CHEMBL1457056 & 688239 & 4.6862 & 5.4755 & TST \\
\hline CHEMBL1474504 & 688239 & 4.5362 & 5.4965 & TRN \\
\hline CHEMBL1372515 & 688239 & 4.6362 & 5.4151 & TST \\
\hline CHEMBL1424899 & 688239 & 5.2862 & 5.3946 & TRN \\
\hline CHEMBL1341196 & 688239 & 5.6862 & 5.3286 & TRN \\
\hline CHEMBL1401972 & 688239 & 4.8862 & 5.54899 & 99999999995 \\
\hline CHEMBL1402797 & 688239 & 4.5362 & 5.5683 & TRN \\
\hline CHEMBL1335042 & 688239 & 4.7362 & 5.4255 & TRN \\
\hline
\end{tabular}




\begin{tabular}{|c|c|c|c|c|c|}
\hline \multicolumn{6}{|c|}{ Supplemental Table S2.txt } \\
\hline CHEMBL1383126 & 688239 & 7.2366 & 5.4846 & TST & \\
\hline CHEMBL1672292 & 688239 & 4.4862 & 5.4058 & TRN & \\
\hline CHEMBL3191294 & 688239 & 5.1862 & 5.4932 & TST & \\
\hline CHEMBL1302101 & 688239 & 4.9862 & 5.5661 & TRN & \\
\hline CHEMBL1561510 & 688239 & 6.2362 & 5.5809 & TRN & \\
\hline CHEMBL1582120 & 688239 & 4.6362 & 5.5882 & TST & \\
\hline CHEMBL1350636 & 688239 & 5.6362 & 5.4486 & TST & \\
\hline CHEMBL1351674 & 688239 & 5.8362 & 5.5013 & TST & \\
\hline CHEMBL3194058 & 688239 & 6.1362 & 5.2807 & TST & \\
\hline CHEMBL1599781 & 688239 & 5.7862 & 5.4161 & TRN & \\
\hline CHEMBL1458992 & 688239 & 4.5862 & 5.5733 & TRN & \\
\hline CHEMBL1450988 & 688239 & 4.5362 & 5.4171 & TST & \\
\hline CHEMBL1593868 & 688239 & 4.7862 & 5.5362 & TRN & \\
\hline CHEMBL1344377 & 688239 & 6.0862 & 5.6571 & TRN & \\
\hline CHEMBL1435517 & 688239 & 4.8862 & 5.3444 & TST & \\
\hline CHEMBL3211194 & 688239 & 6.1362 & 5.4689 & TST & \\
\hline CHEMBL1539220 & 688239 & 6.2362 & 5.4935 & TST & \\
\hline CHEMBL1352488 & 688239 & 8.3372 & 5.602 & TST & \\
\hline CHEMBL1409597 & 688239 & 5.1862 & 5.529 & TRN & \\
\hline CHEMBL3145081 & 688239 & 5.2362 & 5.4992 & TRN & \\
\hline CHEMBL1557351 & 688239 & 4.5862 & 5.5043 & TST & \\
\hline CHEMBL1572133 & 688239 & 5.2362 & 5.5138 & TRN & \\
\hline CHEMBL1562664 & 688239 & 5.8362 & 5.4796 & TRN & \\
\hline CHEMBL1463840 & 688239 & 5.1862 & 5.4058 & TRN & \\
\hline CHEMBL1389655 & 688239 & 4.5362 & 5.4175 & TRN & \\
\hline CHEMBL1606238 & 688239 & 7.0362 & 5.5256 & TST & \\
\hline CHEMBL1393509 & 688239 & 4.5362 & 5.4357 & TRN & \\
\hline CHEMBL1332912 & 688239 & 5.7362 & 5.457999 & 9999999999 & TRN \\
\hline CHEMBL1538853 & 688239 & 5.6862 & 5.5624 & TST & \\
\hline CHEMBL3198439 & 688239 & 8.28399 & 999999999 & 5.3039 & TST \\
\hline CHEMBL1547098 & 688239 & 6.7862 & 5.451000 & 00000000005 & TRN \\
\hline CHEMBL1417297 & 688239 & 4.6362 & 5.3951 & TRN & \\
\hline CHEMBL1369023 & 688239 & 4.7862 & 5.5098 & TRN & \\
\hline CHEMBL1450422 & 688239 & 4.5862 & 5.2846 & TRN & \\
\hline CHEMBL1544543 & 688239 & 6.0362 & 5.4711 & TRN & \\
\hline CHEMBL1415611 & 688239 & 5.1862 & 5.4482 & TRN & \\
\hline CHEMBL1531851 & 688239 & 5.3362 & 5.5831 & TRN & \\
\hline CHEMBL1546625 & 688239 & 4.8362 & 5.492000 & $\partial 000000001$ & TRN \\
\hline CHEMBL1328711 & 688239 & 5.8362 & 5.4932 & TRN & \\
\hline CHEMBL1598277 & 688239 & 4.5362 & 5.3758 & TRN & \\
\hline CHEMBL1413488 & 688239 & 4.5362 & 5.3978 & TST & \\
\hline CHEMBL1402873 & 688239 & 5.7862 & 5.4946 & TRN & \\
\hline CHEMBL1457508 & 688239 & 4.5362 & 5.4659 & TRN & \\
\hline CHEMBL1300206 & 688239 & 5.1862 & 5.4129 & TST & \\
\hline CHEMBL1459661 & 688239 & 6.4362 & 5.4801 & TRN & \\
\hline CHEMBL1316780 & 688239 & 4.5362 & 5.4866 & TRN & \\
\hline CHEMBL3197091 & 688239 & 6.0362 & 5.2548 & TRN & \\
\hline CHEMBL1540588 & 688239 & 4.6862 & 5.5333 & TRN & \\
\hline
\end{tabular}




\begin{tabular}{|c|c|c|c|c|c|}
\hline \multirow{3}{*}{$\begin{array}{l}\text { CHEMBL } 2374022 \\
\text { CHFMRI } 154993\end{array}$} & \multicolumn{5}{|c|}{ Supplemental Table S2.txt } \\
\hline & 688239 & 7.475 & 5.40799 & 99999999995 & TST \\
\hline & 688239 & 5.1862 & 5.4573 & TRN & \\
\hline CHEMBL1406777 & 688239 & 4.7362 & 5.5217 & TRN & \\
\hline CHEMBL1323471 & 688239 & 6.1862 & 5.504 & TRN & \\
\hline CHEMBL580183 & 688239 & 5.9362 & 5.4251 & TST & \\
\hline CHEMBL1324732 & 688239 & 4.5362 & 5.4706 & TRN & \\
\hline CHEMBL1343700 & 688239 & 4.4862 & 5.4564 & TST & \\
\hline CHEMBL1379462 & 688239 & 7.0362 & 5.3887 & TRN & \\
\hline CHEMBL1549609 & 688239 & 4.7862 & 5.4907 & TRN & \\
\hline CHEMBL1373018 & 688239 & 5.9862 & 5.5234 & TRN & \\
\hline CHEMBL1404792 & 688239 & 4.5862 & 5.3254 & TRN & \\
\hline CHEMBL 3213094 & 688239 & 5.1862 & 5.4876 & TST & \\
\hline CHEMBL1315111 & 688239 & 5.0862 & 5.487 & TRN & \\
\hline CHEMBL1404859 & 688239 & 5.1362 & 5.5097 & TRN & \\
\hline CHEMBL1522988 & 688239 & 5.1362 & 5.527 & TST & \\
\hline CHEMBL1469539 & 688239 & 4.6862 & 5.2849 & TST & \\
\hline CHEMBL1355391 & 688239 & 5.1862 & 5.4654 & TRN & \\
\hline CHEMBL1478667 & 688239 & 4.7362 & 5.47 & TRN & \\
\hline CHEMBL1341536 & 688239 & 4.7862 & 5.415 & TST & \\
\hline CHEMBL1485768 & 688239 & 7.0362 & 5.4435 & TRN & \\
\hline CHEMBL1331093 & 688239 & 4.8362 & 5.3646 & TRN & \\
\hline CHEMBL1407971 & 688239 & 6.3362 & 5.4537 & TRN & \\
\hline CHEMBL1986183 & 688239 & 5.5362 & 5.40799 & 99999999995 & TRN \\
\hline CHEMBL1330984 & 688239 & 7.0862 & 5.54899 & 99999999995 & TRN \\
\hline CHEMBL1381516 & 688239 & 5.5862 & 5.6033 & TRN & \\
\hline CHEMBL1444633 & 688239 & 6.0862 & 5.416 & TST & \\
\hline CHEMBL1415898 & 688239 & 5.6362 & 5.4657 & TRN & \\
\hline CHEMBL1381781 & 688239 & 5.2862 & 5.4777 & TST & \\
\hline CHEMBL1477627 & 688239 & 6.8362 & 5.6352 & TRN & \\
\hline CHEMBL1564934 & 688239 & 6.6861 & 5.6569 & TRN & \\
\hline CHEMBL1605770 & 688239 & 5.2362 & 5.3845 & TRN & \\
\hline CHEMBL1352466 & 688239 & 5.7362 & 5.5334 & TRN & \\
\hline CHEMBL1554343 & 688239 & 5.1862 & 5.461 & TRN & \\
\hline CHEMBL1442009 & 688239 & 5.6362 & 5.4293 & TST & \\
\hline CHEMBL1462439 & 688239 & 4.5362 & 5.2815 & TRN & \\
\hline CHEMBL3192858 & 688239 & 7.5361 & 5.5171 & TRN & \\
\hline CHEMBL1568392 & 688239 & 8.3372 & 5.5439 & TST & \\
\hline CHEMBL1540439 & 688239 & 5.8862 & 5.5727 & TRN & \\
\hline CHEMBL1559706 & 688239 & 5.1862 & 5.391 & TRN & \\
\hline CHEMBL1515231 & 688239 & 4.6862 & 5.5262 & TRN & \\
\hline CHEMBL1478187 & 688239 & 4.5362 & 5.5155 & TRN & \\
\hline CHEMBL1601574 & 688239 & 6.1862 & 5.4902 & TST & \\
\hline CHEMBL1409872 & 688239 & 5.1862 & 5.522 & TRN & \\
\hline CHEMBL1375702 & 688239 & 5.6362 & 5.4161 & TST & \\
\hline CHEMBL1400219 & 688239 & 4.5362 & 5.5206 & TRN & \\
\hline CHEMBL1572444 & 688239 & 5.0362 & 5.5085 & TRN & \\
\hline CHEMBL1609901 & 688239 & 5.1862 & 5.4724 & TRN & \\
\hline CHEMBL1383632 & 688239 & 4.6862 & 5.3142 & TRN & \\
\hline
\end{tabular}


Supplemental Table S2.txt

\begin{tabular}{|c|c|c|c|c|c|}
\hline CHEMBL1506414 & 688239 & 5.0362 & \multicolumn{2}{|c|}{5.61299999999999995} & \multirow[t]{2}{*}{ TR } \\
\hline CHEMBL1372546 & 688239 & 7.1361 & 5.4123 & TST & \\
\hline CHEMBL1495286 & 688239 & 5.7362 & 5.6131 & TST & \\
\hline CHEMBL1406311 & 688239 & 6.0362 & 5.6004 & TRN & \\
\hline CHEMBL1582495 & 688239 & 4.7362 & 5.322 & TRN & \\
\hline CHEMBL1536616 & 688239 & 5.1862 & 5.6137 & TRN & \\
\hline CHEMBL1330848 & 688239 & 5.4862 & 5.4084 & TRN & \\
\hline CHEMBL1599583 & 688239 & 4.5862 & 5.5449 & TRN & \\
\hline CHEMBL3799844 & 688239 & 6.2862 & 5.4921 & TST & \\
\hline CHEMBL1364361 & 688239 & 4.5362 & 5.3445 & TRN & \\
\hline CHEMBL1583130 & 688239 & 5.1862 & 5.5828 & TST & \\
\hline CHEMBL1514723 & 688239 & 4.7862 & 5.5257 & TRN & \\
\hline CHEMBL1359880 & 688239 & 4.9862 & 5.6357 & TRN & \\
\hline CHEMBL1524757 & 688239 & 6.8362 & 5.5782 & TRN & \\
\hline CHEMBL1582704 & 688239 & 5.1862 & \multicolumn{2}{|c|}{5.547000000000001} & $\mathrm{~T}$ \\
\hline CHEMBL1390689 & 688239 & 4.4862 & 5.3509 & TRN & \\
\hline CHEMBL1501402 & 688239 & 8.1871 & 5.5217 & TRN & \\
\hline CHEMBL1306810 & 688239 & 5.2362 & \multicolumn{2}{|c|}{5.742999999999999} & TS \\
\hline CHEMBL1385345 & 688239 & 4.5362 & \multicolumn{2}{|c|}{5.38399999999999995} & TRI \\
\hline CHEMBL1332349 & 688239 & 5.3362 & 5.4851 & TST & \\
\hline CHEMBL1393296 & 688239 & 5.7362 & 5.4902 & TST & \\
\hline CHEMBL3212201 & 688239 & 5.0362 & 5.4511 & TST & \\
\hline CHEMBL1463060 & 688239 & 4.9362 & 5.5235 & TRN & \\
\hline CHEMBL1442260 & 688239 & 5.1362 & 5.51 & TRN & \\
\hline CHEMBL1307202 & 688239 & 5.1862 & 5.4036 & TRN & \\
\hline CHEMBL1525559 & 688239 & 4.4862 & 5.4023 & TST & \\
\hline CHEMBL1583558 & 688239 & 4.9862 & 5.4969 & TRN & \\
\hline CHEMBL1522447 & 688239 & 5.2862 & 5.6084 & TRN & \\
\hline CHEMBL1570703 & 688239 & 4.5362 & 5.3954 & TRN & \\
\hline CHEMBL3199638 & 688239 & 4.5362 & 5.4613 & TST & \\
\hline CHEMBL1422104 & 688239 & 5.1862 & 5.3973 & TST & \\
\hline CHEMBL1435194 & 688239 & 5.8862 & 5.5482 & TRN & \\
\hline CHEMBL1488334 & 688239 & 4.5862 & 5.4512 & TRN & \\
\hline CHEMBL1523359 & 688239 & 4.7862 & 5.4925 & TST & \\
\hline CHEMBL1327397 & 688239 & 4.5362 & 5.5422 & TRN & \\
\hline CHEMBL1595618 & 688239 & 6.1862 & 5.5643 & TRN & \\
\hline CHEMBL1524209 & 688239 & 6.2362 & 5.4369 & TRN & \\
\hline CHEMBL1474035 & 688239 & 5.2362 & 5.4684 & TRN & \\
\hline CHEMBL529675 & 688239 & 4.5362 & 5.3684 & TST & \\
\hline CHEMBL1540051 & 688239 & 4.7362 & 5.4787 & TRN & \\
\hline CHEMBL1335611 & 688239 & 5.6862 & 5.5816 & TRN & \\
\hline CHEMBL1414047 & 688239 & 6.8861 & 5.4583 & TRN & \\
\hline CHEMBL1326129 & 688239 & 4.7862 & 5.3051 & TST & \\
\hline CHEMBL1559402 & 688239 & 6.1362 & 5.6049 & TST & \\
\hline CHEMBL1443208 & 688239 & 6.2362 & 5.6116 & TRN & \\
\hline CHEMBL1486001 & 688239 & 5.6862 & 5.6505 & TRN & \\
\hline CHEMBL1592210 & 688239 & 6.8861 & 5.4247 & TRN & \\
\hline \multirow[t]{2}{*}{ CHEMBL1398968 } & 688239 & 4.6862 & \multicolumn{2}{|c|}{5.627999999999999} & 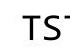 \\
\hline & & & & 1393 & \\
\hline
\end{tabular}


Supplemental Table S2.txt

\begin{tabular}{|c|c|c|c|c|}
\hline CHEMBL1341130 & 688239 & 5.1862 & 5.4937 & TST \\
\hline CHEMBL1523513 & 688239 & 5.6862 & 5.2776 & TRN \\
\hline CHEMBL1441731 & 688239 & 5.5362 & 5.6353 & TST \\
\hline CHEMBL1456413 & 688239 & 4.6362 & 5.5927 & TST \\
\hline CHEMBL1578749 & 688239 & 5.5862 & 5.5801 & TRN \\
\hline CHEMBL1348572 & 688239 & 5.6362 & 5.39 & TRN \\
\hline CHEMBL1506016 & 688239 & 5.8362 & 5.5046 & TRN \\
\hline CHEMBL 3212317 & 688239 & 5.0862 & 5.5385 & TRN \\
\hline CHEMBL1481700 & 688239 & 5.0362 & 5.41 & TRN \\
\hline CHEMBL1574201 & 688239 & 5.6862 & 5.50700 & 0000000001 \\
\hline CHEMBL1502360 & 688239 & 6.0862 & 5.3307 & TRN \\
\hline CHEMBL1465015 & 688239 & 8.3872 & 5.4288 & TST \\
\hline CHEMBL1495212 & 688239 & 5.9362 & 5.4126 & TST \\
\hline CHEMBL1463183 & 688239 & 5.8362 & 5.4109 & TST \\
\hline CHEMBL 3196999 & 688239 & 5.1862 & 5.5742 & TRN \\
\hline CHEMBL410063 & 688239 & 5.1862 & 5.3692 & TST \\
\hline CHEMBL1369091 & 688239 & 4.8362 & 5.4758 & TRN \\
\hline CHEMBL1436866 & 688239 & 5.0362 & 5.57700 & 0000000001 \\
\hline CHEMBL1322505 & 688239 & 7.1361 & 5.38200 & 000000001 \\
\hline CHEMBL1549399 & 688239 & 6.1862 & 5.5493 & TRN \\
\hline CHEMBL1456014 & 688239 & 6.0862 & 5.3998 & TST \\
\hline CHEMBL1304004 & 688239 & 4.5362 & 5.6268 & TRN \\
\hline CHEMBL1602534 & 688239 & 4.7362 & 5.5396 & TST \\
\hline CHEMBL1502758 & 688239 & 5.1862 & 5.5695 & TST \\
\hline CHEMBL1566202 & 688239 & 6.1862 & 5.6301 & TRN \\
\hline CHEMBL1452713 & 688239 & 5.1862 & 5.6453 & TRN \\
\hline CHEMBL1361085 & 688239 & 4.7362 & 5.6293 & TRN \\
\hline CHEMBL1439573 & 688239 & 5.3362 & 5.3687 & TST \\
\hline CHEMBL1300243 & 688239 & 4.7362 & 5.6032 & TST \\
\hline CHEMBL 3196269 & 688239 & 8.1871 & 5.511 & TST \\
\hline CHEMBL1446088 & 688239 & 6.3863 & 5.5682 & TRN \\
\hline CHEMBL1613574 & 688239 & 6.4362 & 5.5078 & TRN \\
\hline CHEMBL 3196486 & 688239 & 4.7862 & 5.4487 & TRN \\
\hline CHEMBL1333842 & 688239 & 5.4362 & 5.4982 & TRN \\
\hline CHEMBL1498082 & 688239 & 6.6362 & 5.5423 & TST \\
\hline CHEMBL1538266 & 688239 & 4.5362 & 5.4188 & TRN \\
\hline CHEMBL582491 & 688239 & 4.8862 & 5.3542 & TST \\
\hline CHEMBL1461028 & 688239 & 6.8861 & 5.4966 & TRN \\
\hline CHEMBL1586760 & 688239 & 4.7362 & 5.6211 & TRN \\
\hline CHEMBL1365581 & 688239 & 8.3372 & 5.3472 & TRN \\
\hline CHEMBL1335543 & 688239 & 5.9862 & 5.4914 & TRN \\
\hline CHEMBL1415456 & 688239 & 5.1862 & 5.5654 & TRN \\
\hline CHEMBL1541523 & 688239 & 6.2362 & 5.358 & TRN \\
\hline CHEMBL1306648 & 688239 & 4.5362 & 5.5996 & TRN \\
\hline CHEMBL1485328 & 688239 & 6.0862 & 5.5138 & TRN \\
\hline CHEMBL1352761 & 688239 & 5.2362 & 5.4472 & TRN \\
\hline CHEMBL 3196414 & 688239 & 4.7862 & 5.5014 & TRN \\
\hline CHEMBL1484700 & 688239 & 6.8362 & 5.4738 & TRN \\
\hline
\end{tabular}


Supplemental Table S2.txt

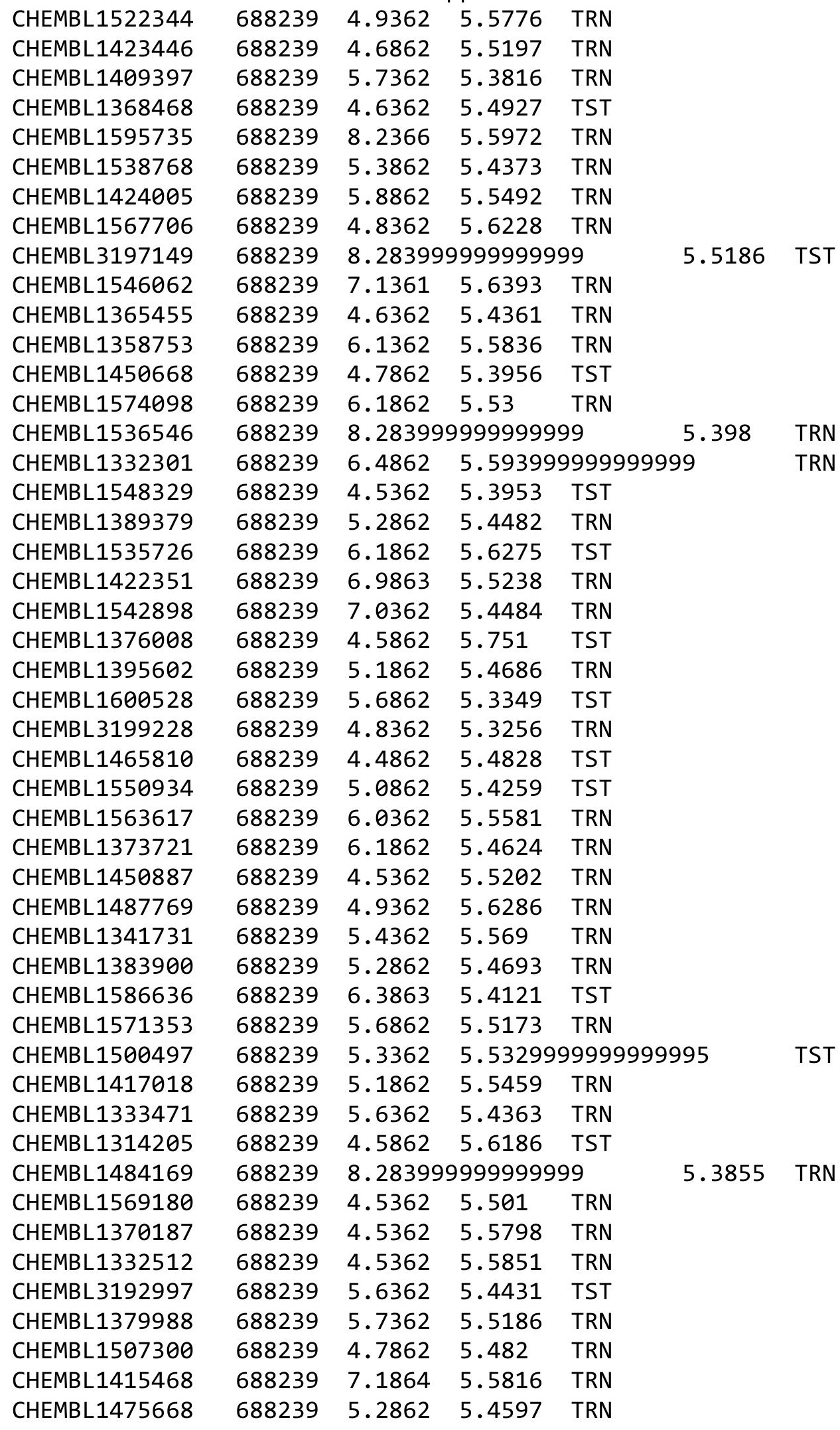


Supplemental Table S2.txt

\begin{tabular}{|c|c|c|c|c|c|}
\hline CHEMBL1451016 & 688239 & 4.6862 & 5.5327 & TRN & \\
\hline CHEMBL1487377 & 688239 & 4.7862 & 5.42399 & 99999999995 & TRN \\
\hline CHEMBL1414424 & 688239 & 6.7862 & 5.6911 & TRN & \\
\hline CHEMBL1332351 & 688239 & 5.1862 & 5.55 & TRN & \\
\hline CHEMBL1530012 & 688239 & 5.6862 & 5.5529 & TST & \\
\hline CHEMBL1320546 & 688239 & 6.8861 & 5.3657 & TRN & \\
\hline CHEMBL1336522 & 688239 & 5.6362 & 5.4453 & TRN & \\
\hline CHEMBL1521668 & 688239 & 5.1862 & 5.5045 & TRN & \\
\hline CHEMBL1460516 & 688239 & 6.9863 & 5.5827 & TST & \\
\hline CHEMBL1574446 & 688239 & 4.5362 & 5.5219 & TST & \\
\hline CHEMBL1456210 & 688239 & 6.1862 & 5.4492 & TST & \\
\hline CHEMBL1553896 & 688239 & 4.4862 & 5.5079 & TST & \\
\hline CHEMBL1463485 & 688239 & 4.5362 & 5.6662 & TRN & \\
\hline CHEMBL1563213 & 688239 & 4.4862 & 5.3686 & TRN & \\
\hline CHEMBL1440315 & 688239 & 4.5862 & 5.3498 & TRN & \\
\hline CHEMBL1507477 & 688239 & 6.4862 & 5.4761 & TRN & \\
\hline CHEMBL1450542 & 688239 & 6.1862 & 5.5523 & TRN & \\
\hline CHEMBL1598301 & 688239 & 5.1862 & 5.6529 & TRN & \\
\hline CHEMBL1563276 & 688239 & 5.1862 & 5.4297 & TRN & \\
\hline CHEMBL1435245 & 688239 & 6.8362 & 5.5536 & TRN & \\
\hline CHEMBL1364582 & 688239 & 4.5362 & 5.5825 & TST & \\
\hline CHEMBL1445019 & 688239 & 4.5362 & 5.4478 & TST & \\
\hline CHEMBL1333790 & 688239 & 4.7862 & 5.6931 & TRN & \\
\hline CHEMBL1449333 & 688239 & 5.5862 & 5.3302 & TRN & \\
\hline CHEMBL1577132 & 688239 & 6.2862 & 5.4497 & TRN & \\
\hline CHEMBL1613616 & 688239 & 4.6362 & 5.4292 & TST & \\
\hline CHEMBL1483905 & 688239 & 5.3862 & 5.5801 & TRN & \\
\hline CHEMBL1474694 & 688239 & 5.5862 & 5.4545 & TRN & \\
\hline CHEMBL1517661 & 688239 & 5.9862 & 5.5319 & TRN & \\
\hline CHEMBL1351239 & 688239 & 4.5362 & \multicolumn{2}{|c|}{5.4910000000000005} & TRN \\
\hline CHEMBL1513795 & 688239 & 6.7361 & 5.4153 & TRN & \\
\hline CHEMBL3194574 & 688239 & 4.6862 & 5.5144 & TST & \\
\hline CHEMBL1531200 & 688239 & 5.6362 & 5.4536 & TRN & \\
\hline CHEMBL1353152 & 688239 & 5.7862 & 5.4423 & TRN & \\
\hline CHEMBL1409494 & 688239 & 4.5362 & 5.5528 & TRN & \\
\hline CHEMBL3209909 & 688239 & 4.5362 & 5.4093 & TST & \\
\hline CHEMBL1423235 & 688239 & 4.9362 & 5.5354 & TRN & \\
\hline CHEMBL1439015 & 688239 & 7.1361 & 5.4598 & TRN & \\
\hline CHEMBL 3199588 & 688239 & 5.4862 & 5.4166 & TRN & \\
\hline CHEMBL1410258 & 688239 & 5.8862 & 5.5379 & TRN & \\
\hline CHEMBL1522173 & 688239 & 5.1862 & 5.5798 & TRN & \\
\hline CHEMBL1581142 & 688239 & 7.5867 & 5.4013 & TST & \\
\hline CHEMBL1474146 & 688239 & 4.5862 & 5.4825 & TRN & \\
\hline CHEMBL1474762 & 688239 & 4.7862 & 5.5178 & TRN & \\
\hline CHEMBL1607992 & 688239 & 6.0362 & 5.4959 & TST & \\
\hline CHEMBL1470092 & 688239 & 7.6364 & 5.5158 & TRN & \\
\hline CHEMBL1358499 & 688239 & 5.1862 & 5.4251 & TRN & \\
\hline CHEMBL1399759 & 688239 & 4.8362 & 5.4074 & TRN & \\
\hline
\end{tabular}


Supplemental Table S2.txt

\begin{tabular}{|c|c|c|c|c|}
\hline CHEMBL1999480 & 688239 & 4.5362 & 5.4113 & TST \\
\hline CHEMBL1474505 & 688239 & 5.6362 & 5.359 & TRN \\
\hline CHEMBL1324331 & 688239 & 6.7862 & 5.5563 & TST \\
\hline CHEMBL1348912 & 688239 & 6.0862 & 5.4339 & TST \\
\hline CHEMBL1590248 & 688239 & 4.5862 & 5.3948 & TRN \\
\hline CHEMBL1483332 & 688239 & 4.7362 & 5.4494 & TRN \\
\hline CHEMBL1539599 & 688239 & 4.5362 & 5.4843 & TRN \\
\hline CHEMBL3190337 & 688239 & 5.4362 & 5.2552 & TRN \\
\hline CHEMBL1471073 & 688239 & 6.8362 & 5.5377 & TRN \\
\hline CHEMBL1521949 & 688239 & 5.2362 & 5.6694 & TRN \\
\hline CHEMBL1538984 & 688239 & 4.9862 & 5.4344 & TST \\
\hline CHEMBL1342432 & 688239 & 5.1862 & 5.4388 & TRN \\
\hline CHEMBL1343915 & 688239 & 5.8362 & 5.5643 & TST \\
\hline CHEMBL3196529 & 688239 & 4.5362 & 5.3899 & TRN \\
\hline CHEMBL 3194040 & 688239 & 6.2362 & 5.434 & TRN \\
\hline CHEMBL1339673 & 688239 & 5.7862 & 5.5396 & TST \\
\hline CHEMBL1506709 & 688239 & 6.5363 & 5.5289 & TRN \\
\hline CHEMBL1541250 & 688239 & 5.7862 & 5.5815 & TRN \\
\hline CHEMBL1605525 & 688239 & 6.9363 & 5.5258 & TRN \\
\hline CHEMBL1467614 & 688239 & 7.0862 & 5.4121 & TST \\
\hline CHEMBL1468326 & 688239 & 4.7362 & 5.523 & TST \\
\hline CHEMBL1488434 & 688239 & 6.6362 & 5.5681 & TRN \\
\hline CHEMBL1514907 & 688239 & 5.0862 & 5.6232 & TRN \\
\hline CHEMBL1342872 & 688239 & 7.0862 & 5.4997 & TRN \\
\hline CHEMBL1393654 & 688239 & 4.5362 & 5.5784 & TRN \\
\hline CHEMBL1546813 & 688239 & 5.1862 & 5.4433 & TRN \\
\hline CHEMBL1442022 & 688239 & 5.4862 & 5.4056 & TST \\
\hline CHEMBL1596538 & 688239 & 5.4362 & 5.5938 & TRN \\
\hline CHEMBL1341938 & 688239 & 4.7862 & 5.4388 & TRN \\
\hline CHEMBL1449472 & 688239 & 8.3372 & 5.3588 & TRN \\
\hline CHEMBL1534314 & 688239 & 4.75 & 5.5794 & TRN \\
\hline CHEMBL1404367 & 688239 & 5.1862 & 5.4419 & TRN \\
\hline CHEMBL1552052 & 688239 & 6.4362 & 5.4224 & TRN \\
\hline CHEMBL1361561 & 688239 & 6.2362 & 5.3866 & TRN \\
\hline CHEMBL1603362 & 688239 & 4.8862 & 5.598 & TRN \\
\hline CHEMBL3191299 & 688239 & 5.5362 & \multicolumn{2}{|c|}{5.382000000000001} \\
\hline CHEMBL1581693 & 688239 & 4.4862 & 5.3951 & TST \\
\hline CHEMBL1350979 & 688239 & 6.1362 & 5.3711 & TST \\
\hline CHEMBL1531816 & 688239 & 5.8862 & 5.4627 & TST \\
\hline CHEMBL1306712 & 688239 & 5.2862 & 5.4225 & TRN \\
\hline CHEMBL1428299 & 688239 & 4.6362 & 5.6533 & TRN \\
\hline CHEMBL1436530 & 688239 & 6.1362 & \multicolumn{2}{|c|}{5.5329999999999995} \\
\hline CHEMBL1357417 & 688239 & 5.1862 & 5.5954 & TRN \\
\hline CHEMBL1352404 & 688239 & 4.7362 & 5.5857 & TRN \\
\hline CHEMBL1334299 & 688239 & 5.9862 & 5.5255 & TRN \\
\hline CHEMBL1492459 & 688239 & 5.9362 & 5.3113 & TST \\
\hline CHEMBL1549250 & 688239 & 4.9362 & 5.4727 & TRN \\
\hline CHEMBL1355079 & 688239 & 5.1862 & 5.5925 & TRN \\
\hline
\end{tabular}

Page 1397 
Supplemental Table S2.txt

\begin{tabular}{|c|c|c|c|c|}
\hline CHEMBL1561769 & 688239 & 6.5862 & 5.556 & TRN \\
\hline CHEMBL1441833 & 688239 & 4.7362 & 5.4773 & TRN \\
\hline CHEMBL1609580 & 688239 & 4.6862 & 5.4138 & TRN \\
\hline CHEMBL1478685 & 688239 & 5.8362 & 5.4622 & TRN \\
\hline CHEMBL1396974 & 688239 & 6.9363 & 5.5998 & TRN \\
\hline CHEMBL1398944 & 688239 & 4.5362 & 5.3888 & TRN \\
\hline CHEMBL1370711 & 688239 & 5.1862 & 5.5136 & TST \\
\hline CHEMBL1318781 & 688239 & 6.7862 & 5.5346 & TRN \\
\hline CHEMBL1331887 & 688239 & 5.1362 & 5.4386 & TRN \\
\hline CHEMBL1449380 & 688239 & 5.3362 & 5.5341 & TRN \\
\hline CHEMBL1300121 & 688239 & 5.5362 & 5.4942 & TRN \\
\hline CHEMBL1326617 & 688239 & 5.4862 & 5.3857 & TST \\
\hline CHEMBL1371759 & 688239 & 5.7862 & 5.5926 & TST \\
\hline CHEMBL1389886 & 688239 & 4.4862 & 5.5355 & TRN \\
\hline CHEMBL1383806 & 688239 & 5.5362 & 5.3691 & TRN \\
\hline CHEMBL3197423 & 688239 & 5.1362 & 5.5735 & TST \\
\hline CHEMBL1547979 & 688239 & 4.6862 & 5.3266 & TST \\
\hline CHEMBL1612849 & 688239 & 4.5362 & 5.3742 & TRN \\
\hline CHEMBL1519492 & 688239 & 4.9362 & 5.6074 & TRN \\
\hline CHEMBL1451391 & 688239 & 5.7862 & 5.3849 & TRN \\
\hline CHEMBL1416167 & 688239 & 5.9862 & 5.5162 & TST \\
\hline CHEMBL 3197245 & 688239 & 5.8362 & 5.3997 & TRN \\
\hline CHEMBL1371945 & 688239 & 8.3872 & 5.5432 & TRN \\
\hline CHEMBL1372569 & 688239 & 4.5362 & 5.5966 & TRN \\
\hline CHEMBL1591647 & 688239 & 4.4862 & 5.3388 & TST \\
\hline CHEMBL1530980 & 688239 & 8.1871 & 5.5016 & TRN \\
\hline CHEMBL1552567 & 688239 & 5.1862 & 5.4599 & TST \\
\hline CHEMBL1478381 & 688239 & 6.4362 & 5.5563 & TST \\
\hline CHEMBL 3190079 & 688239 & 4.9862 & 5.4682 & TRN \\
\hline CHEMBL1441450 & 688239 & 4.5362 & 5.59200 & 30000000005 \\
\hline CHEMBL1323665 & 688239 & 6.5862 & 5.5245 & TST \\
\hline CHEMBL1368727 & 688239 & 4.5362 & 5.3846 & TST \\
\hline CHEMBL1495472 & 688239 & 4.5362 & 5.4753 & TST \\
\hline CHEMBL1474098 & 688239 & 6.2862 & 5.142 & TRN \\
\hline CHEMBL1612201 & 688239 & 5.6862 & 5.5253 & TRN \\
\hline CHEMBL1514699 & 688239 & 5.5862 & 5.3335 & TRN \\
\hline CHEMBL3212753 & 688239 & 6.2862 & 5.4904 & TRN \\
\hline CHEMBL1343215 & 688239 & 4.9362 & 5.5484 & TRN \\
\hline CHEMBL1529951 & 688239 & 5.3362 & 5.4101 & TRN \\
\hline CHEMBL1400209 & 688239 & 4.7362 & 5.4111 & TRN \\
\hline CHEMBL1418535 & 688239 & 5.2 & 5.559 & TRN \\
\hline CHEMBL1344644 & 688239 & 5.4862 & 5.3575 & TRN \\
\hline CHEMBL1490072 & 688239 & 4.6862 & 5.5233 & TRN \\
\hline CHEMBL1611256 & 688239 & 6.0862 & 5.5548 & TRN \\
\hline CHEMBL1471803 & 688239 & 5.8862 & 5.3258 & TST \\
\hline CHEMBL 260370 & 688239 & 4.7362 & 5.3991 & TRN \\
\hline CHEMBL1507679 & 688239 & 4.8862 & 5.4152 & TRN \\
\hline CHEMBL1574817 & 688239 & 4.5362 & 5.4274 & TRN \\
\hline
\end{tabular}


Supplemental Table S2.txt

\begin{tabular}{|c|c|c|c|c|}
\hline 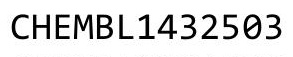 & & 362 & 然 & \\
\hline HEMBL3194436 & 88239 & 9863 & & TCT \\
\hline HEMBL1321569 & 239 & 62 & & \\
\hline 57 & & & & \\
\hline AEMBL1473115 & & & & \\
\hline AEMBL1377431 & 88239 & 1862 & 4362 & \\
\hline HEMBL1474885 & 88239 & .1362 & .4105 & \\
\hline HEMBL134C & 39 & 7862 & & \\
\hline HEMBL14 & & 862 & 391 & \\
\hline AEMBL152 & & & & \\
\hline HEMBL3190578 & 88239 & 5.1862 & .3622 & \\
\hline HEMBL1506424 & 88239 & 6.6362 & .6183 & \\
\hline HEMBL156 & 39 & 62 & 16 & \\
\hline HEMBL14 & & & & \\
\hline HEMBL13 & & & & \\
\hline HEMBL1551013 & 88239 & 362 & & \\
\hline HEMBL151 & & & & \\
\hline HEMBL154 & 39 & & 52 & \\
\hline L15 & & & & \\
\hline HEM & & & & \\
\hline HEMBL131 & & 62 & & \\
\hline HEMBL142 & & & & \\
\hline HEMBL 32 & 39 & & 5 . & SI \\
\hline L15 & & & & \\
\hline HEM & & & & \\
\hline L131 & & & & \\
\hline HEMBL151 & & & & \\
\hline HEMBL14 & & & & SI \\
\hline HEN & & & & RN \\
\hline 23 & & 72 & & ST \\
\hline AEMBL145 & & & & IST \\
\hline AEMBL157 & & & & TRN \\
\hline HEMBL15 & & & & \\
\hline 5 & & & & I I \\
\hline 77 & & & & $\mathrm{RN}$ \\
\hline AEMBL1324703 & & & & $\mathrm{RN}$ \\
\hline AEMBL1348795 & & & & RN \\
\hline 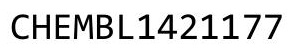 & & & & \\
\hline 1 & & & & KIV \\
\hline & & & & RN \\
\hline AEMBL1530903 & & 62 & & s \\
\hline HEMBL13 & & & & s \\
\hline & & & & \\
\hline HEMBL15 & & & & RN \\
\hline HEMBL13 & & & & RN \\
\hline IEMBL14e & & 362 & 49 & \\
\hline 19 & & & & \\
\hline CHEI & 688239 & 6.0862 & 5.428 & \\
\hline
\end{tabular}

Page 1399 
Supplemental Table S2.txt

\begin{tabular}{|c|c|c|c|c|c|c|}
\hline CHEMBL1497036 & 688239 & 7.0362 & 5.6629 & TRN & & \\
\hline CHEMBL1421786 & 688239 & 4.7362 & 5.3989 & TRN & & \\
\hline CHEMBL1425394 & 688239 & 5.6862 & 5.557 & TRN & & \\
\hline CHEMBL1461169 & 688239 & 6.1362 & 5.6318 & TRN & & \\
\hline CHEMBL1481951 & 688239 & 4.4862 & 5.3267 & TST & & \\
\hline CHEMBL1340069 & 688239 & 4.5362 & 5.4831 & TRN & & \\
\hline CHEMBL1499372 & 688239 & 5.5362 & 5.6717 & TRN & & \\
\hline CHEMBL1554319 & 688239 & 4.7862 & 5.4229 & TRN & & \\
\hline CHEMBL1611186 & 688239 & 6.5363 & 5.4303 & TST & & \\
\hline CHEMBL1403119 & 688239 & 4.6862 & 5.4051 & TST & & \\
\hline CHEMBL1556586 & 688239 & 6.1362 & 5.4653 & TRN & & \\
\hline CHEMBL1472966 & 688239 & 8.2366 & 5.4096 & TRN & & \\
\hline CHEMBL1369730 & 688239 & 5.1862 & 5.4087 & TST & & \\
\hline CHEMBL3210795 & 688239 & 4.8362 & 5.3473 & TRN & & \\
\hline CHEMBL1573970 & 688239 & 4.6362 & 5.4933 & TRN & & \\
\hline CHEMBL1442757 & 688239 & 6.2362 & 5.6646 & TRN & & \\
\hline CHEMBL3211535 & 688239 & 6.3362 & 5.5712 & TRN & & \\
\hline CHEMBL1394340 & 688239 & 8.2366 & 5.4635 & TRN & & \\
\hline CHEMBL1606060 & 688239 & 4.5362 & 5.5898 & TRN & & \\
\hline CHEMBL3196629 & 688239 & 5.1362 & 5.3246 & TRN & & \\
\hline CHEMBL1374925 & 688239 & 5.9362 & 5.4013 & TRN & & \\
\hline CHEMBL1590736 & 688239 & 5.1862 & 5.5345 & TRN & & \\
\hline CHEMBL1540348 & 688239 & 6.3362 & 5.4915 & TRN & & \\
\hline CHEMBL1334870 & 688239 & 4.5362 & 5.3669 & TRN & & \\
\hline CHEMBL1542605 & 688239 & 6.7862 & 5.4579 & TRN & & \\
\hline CHEMBL1437066 & 688239 & 5.1862 & 5.5259 & TRN & & \\
\hline CHEMBL3197064 & 688239 & 4.8862 & 5.5362 & TRN & & \\
\hline CHEMBL1583201 & 688239 & 5.1862 & 5.6105 & TRN & & \\
\hline CHEMBL1549031 & 688239 & 6.2362 & 5.5742 & TRN & & \\
\hline CHEMBL1533602 & 688239 & 4.6862 & 5.5511 & TRN & & \\
\hline CHEMBL1493929 & 688239 & 4.5362 & 5.5412 & TRN & & \\
\hline CHEMBL1502558 & 688239 & 4.7362 & 5.2705 & TRN & & \\
\hline CHEMBL1337947 & 688239 & 6.1362 & 5.4308 & TST & & \\
\hline CHEMBL1489687 & 688239 & 5.1862 & 5.4202 & TRN & & \\
\hline CHEMBL1390171 & 688239 & 6.1362 & 5.472 & TRN & & \\
\hline CHEMBL1565980 & 688239 & 4.5362 & 5.5135 & TST & & \\
\hline CHEMBL127023 & 688239 & 5.1862 & 5.5309 & TST & & \\
\hline CHEMBL1545874 & 688239 & 5.2362 & 5.541 & TRN & & \\
\hline CHEMBL1349749 & 688239 & 4.5362 & 5.4311 & TST & & \\
\hline CHEMBL1498958 & 688239 & 6.1362 & 5.5112 & TRN & & \\
\hline CHEMBL1455676 & 688239 & 5.0362 & 5.473 & TRN & & \\
\hline CHEMBL1388289 & 688239 & 8.2366 & 5.6102 & TRN & & \\
\hline CHEMBL1468311 & 688239 & 8.28399 & 99999999 & 9 & 5.4696 & TST \\
\hline CHEMBL3190501 & 688239 & 4.5362 & 5.2658 & TRN & & \\
\hline CHEMBL1541167 & 688239 & 5.2362 & 5.3833 & TRN & & \\
\hline CHEMBL1362339 & 688239 & 4.7862 & 5.5811 & TRN & & \\
\hline CHEMBL1323590 & 688239 & 4.5862 & 5.3977 & TRN & & \\
\hline CHEMBL3190391 & 688239 & 6.0362 & 5.3238 & TST & & \\
\hline
\end{tabular}


Supplemental Table S2.txt

\begin{tabular}{|c|c|c|c|c|c|}
\hline CHEMBL1551344 & 688239 & 5.1862 & 5.3973 & TRN & \\
\hline CHEMBL1598889 & 688239 & 7.5867 & 5.5969 & TRN & \\
\hline CHEMBL1417876 & 688239 & 5.8862 & 5.5569 & TRN & \\
\hline CHEMBL1438249 & 688239 & 5.5862 & 5.6461 & TRN & \\
\hline CHEMBL1574640 & 688239 & 5.6862 & 5.5162 & TRN & \\
\hline CHEMBL1468459 & 688239 & 5.5362 & 5.6619 & TRN & \\
\hline CHEMBL1432362 & 688239 & 4.9362 & 5.523 & TRN & \\
\hline CHEMBL1319535 & 688239 & 8.283999 & 99999999 & 99 & 5.4303 \\
\hline CHEMBL1590715 & 688239 & 4.5862 & 5.4918 & TST & \\
\hline CHEMBL1379590 & 688239 & 4.5362 & 5.4857 & TST & \\
\hline CHEMBL1556546 & 688239 & 4.5362 & 5.5435 & TRN & \\
\hline CHEMBL1524036 & 688239 & 4.6862 & 5.5179 & TRN & \\
\hline CHEMBL1543397 & 688239 & 7.7852 & 5.761 & TRN & \\
\hline CHEMBL 2004075 & 688239 & 4.9362 & 5.4594 & TRN & \\
\hline CHEMBL1352125 & 688239 & 4.6362 & 5.4211 & TRN & \\
\hline CHEMBL1611747 & 688239 & 5.3362 & 5.5397 & TRN & \\
\hline CHEMBL 3196032 & 688239 & 4.5362 & 5.4447 & TST & \\
\hline CHEMBL1432295 & 688239 & 4.8362 & 5.6057 & TST & \\
\hline CHEMBL1299400 & 688239 & 5.3362 & 5.5815 & TRN & \\
\hline CHEMBL1482131 & 688239 & 8.3372 & 5.5456 & TRN & \\
\hline CHEMBL1457504 & 688239 & 4.5362 & 5.5586 & TRN & \\
\hline CHEMBL1465533 & 688239 & 4.6862 & 5.5351 & TRN & \\
\hline CHEMBL1523795 & 688239 & 5.7862 & 5.3474 & TST & \\
\hline CHEMBL1387360 & 688239 & 7.7852 & 5.4287 & TST & \\
\hline CHEMBL1371997 & 688239 & 4.7862 & 5.4669 & TRN & \\
\hline CHEMBL1550624 & 688239 & 5.4862 & 5.5991 & TRN & \\
\hline CHEMBL1608692 & 688239 & 4.5862 & 5.6439 & TRN & \\
\hline CHEMBL1555497 & 688239 & 4.7862 & 5.4387 & TRN & \\
\hline CHEMBL1522028 & 688239 & 5.3862 & 5.4836 & TST & \\
\hline CHEMBL1483148 & 688239 & 6.9863 & 5.5135 & TRN & \\
\hline CHEMBL1583930 & 688239 & 5.4862 & 5.4609 & TST & \\
\hline CHEMBL1450025 & 688239 & 4.7862 & 5.5001 & TRN & \\
\hline CHEMBL1387329 & 688239 & 4.6862 & 5.5249 & TST & \\
\hline CHEMBL1375825 & 688239 & 6.9363 & 5.4994 & TRN & \\
\hline CHEMBL1468096 & 688239 & 5.8862 & 5.7389 & TRN & \\
\hline CHEMBL1466468 & 688239 & 6.2362 & 5.3889 & TRN & \\
\hline CHEMBL1518494 & 688239 & 6.8362 & 5.4373 & TRN & \\
\hline CHEMBL1613309 & 688239 & 6.0862 & 5.5098 & TRN & \\
\hline CHEMBL1534206 & 688239 & 5.1362 & 5.4757 & TRN & \\
\hline CHEMBL1376332 & 688239 & 6.1862 & 5.5018 & TST & \\
\hline CHEMBL1584429 & 688239 & 5.1862 & 5.581 & TRN & \\
\hline CHEMBL1457129 & 688239 & 5.4362 & 5.3565 & TST & \\
\hline CHEMBL1552264 & 688239 & 4.9362 & 5.5643 & TRN & \\
\hline CHEMBL1594511 & 688239 & 4.5362 & 5.6323 & TST & \\
\hline CHEMBL1510411 & 688239 & 6.7361 & 5.7336 & TRN & \\
\hline CHEMBL1595278 & 688239 & 6.9363 & 5.4656 & TRN & \\
\hline CHEMBL1474648 & 688239 & 7.0362 & 5.5492 & TST & \\
\hline CHEMBL1323406 & 688239 & 5.9362 & 5.5491 & TST & \\
\hline
\end{tabular}


Supplemental Table S2.txt

\begin{tabular}{|c|c|c|c|c|}
\hline CHEMBL1510504 & 688239 & 5.0862 & 5.3946 & TRN \\
\hline CHEMBL1375533 & 688239 & 4.9362 & 5.4332 & TST \\
\hline CHEMBL1481720 & 688239 & 4.4862 & 5.5739 & TRN \\
\hline CHEMBL1462882 & 688239 & 4.5362 & 5.2817 & TRN \\
\hline CHEMBL1390178 & 688239 & 5.1362 & 5.5362 & TRN \\
\hline CHEMBL1569575 & 688239 & 5.0362 & 5.4783 & TRN \\
\hline CHEMBL1457733 & 688239 & 5.1862 & 5.5367 & TST \\
\hline CHEMBL1311188 & 688239 & 5.7862 & 5.4617 & TRN \\
\hline CHEMBL1582427 & 688239 & 4.5362 & 5.4357 & TRN \\
\hline CHEMBL1529741 & 688239 & 7.2865 & 5.6086 & TRN \\
\hline CHEMBL1387568 & 688239 & 5.2362 & 5.5939 & TRN \\
\hline CHEMBL3193211 & 688239 & 6.0862 & 5.4746 & TRN \\
\hline CHEMBL1508927 & 688239 & 5.1862 & 5.473 & TST \\
\hline CHEMBL1517991 & 688239 & 4.7362 & 5.6188 & TRN \\
\hline CHEMBL1510313 & 688239 & 6.0862 & 5.5108 & TST \\
\hline CHEMBL1430772 & 688239 & 4.7362 & 5.354 & TRN \\
\hline CHEMBL1427268 & 688239 & 5.1862 & 5.5912 & TRN \\
\hline CHEMBL1480693 & 688239 & 5.2862 & 5.3777 & TRN \\
\hline CHEMBL1589817 & 688239 & 4.7362 & 5.5676 & TST \\
\hline CHEMBL1604592 & 688239 & 4.5362 & 5.4258 & TRN \\
\hline CHEMBL1357548 & 688239 & 4.6862 & 5.3767 & TRN \\
\hline CHEMBL1454899 & 688239 & 5.1362 & 5.5345 & TST \\
\hline CHEMBL1602689 & 688239 & 6.2362 & 5.4232 & TRN \\
\hline CHEMBL1473616 & 688239 & 4.7362 & 5.5438 & TRN \\
\hline CHEMBL1449646 & 688239 & 6.5363 & 5.5105 & TST \\
\hline CHEMBL1500299 & 688239 & 6.1362 & 5.4589 & TST \\
\hline CHEMBL1392487 & 688239 & 5.9862 & 5.4784 & TRN \\
\hline CHEMBL1569692 & 688239 & 4.7362 & 5.4116 & TRN \\
\hline CHEMBL1371054 & 688239 & 6.7862 & 5.526 & TRN \\
\hline CHEMBL1555227 & 688239 & 6.8362 & 5.5179 & TRN \\
\hline CHEMBL1501617 & 688239 & 7.0362 & 5.6014 & TST \\
\hline CHEMBL1427981 & 688239 & 6.2362 & 5.5824 & TRN \\
\hline CHEMBL1376530 & 688239 & 5.1862 & 5.4146 & TRN \\
\hline CHEMBL 3214267 & 688239 & 7.0362 & 5.3703 & TRN \\
\hline CHEMBL1336938 & 688239 & 4.6862 & 5.4793 & TST \\
\hline CHEMBL563294 & 688239 & 4.5362 & 5.4338 & TRN \\
\hline CHEMBL1338156 & 688239 & 7.0862 & 5.5757 & TST \\
\hline CHEMBL1362821 & 688239 & 6.3863 & 5.5826 & TRN \\
\hline CHEMBL1592715 & 688239 & 5.1362 & 5.4424 & TRN \\
\hline CHEMBL1386628 & 688239 & 4.7862 & 5.3699 & TRN \\
\hline CHEMBL1414873 & 688239 & 4.7362 & 5.303999 & 9999999999 \\
\hline CHEMBL1467704 & 688239 & 5.7862 & 5.4567 & TRN \\
\hline CHEMBL1433231 & 688239 & 5.7862 & 5.5431 & TRN \\
\hline CHEMBL1360934 & 688239 & 8.3372 & 5.4397 & TRN \\
\hline CHEMBL1367188 & 688239 & 4.7362 & 5.532 & TRN \\
\hline CHEMBL1492033 & 688239 & 5.1862 & 5.5017 & TRN \\
\hline CHEMBL1589417 & 688239 & 6.9863 & 5.4197 & TRN \\
\hline CHEMBL1560387 & 688239 & 4.5362 & 5.3997 & TRN \\
\hline
\end{tabular}

Page 1402 


\begin{tabular}{|c|c|c|c|c|}
\hline & & & pplement & al $\mathrm{Ta}$ \\
\hline CHEMBL1424220 & 688239 & 7.4868 & 5.5974 & TRN \\
\hline CHEMBL1600881 & 688239 & 4.5362 & 5.5236 & TRN \\
\hline CHEMBL1543289 & 688239 & 4.6862 & 5.425 & TRN \\
\hline CHEMBL1481296 & 688239 & 4.6362 & 5.4291 & TRN \\
\hline CHEMBL1604282 & 688239 & 4.6362 & 5.2875 & TRN \\
\hline CHEMBL1299647 & 688239 & 6.6362 & 5.4933 & TST \\
\hline CHEMBL1537977 & 688239 & 6.1362 & 5.3666 & TRN \\
\hline CHEMBL3199392 & 688239 & 6.9863 & 5.3805 & TST \\
\hline CHEMBL3194927 & 688239 & 6.0862 & 5.314 & TST \\
\hline CHEMBL1533978 & 688239 & 5.2362 & 5.5826 & TRN \\
\hline CHEMBL1352319 & 688239 & 5.7362 & 5.5403 & TST \\
\hline CHEMBL1501837 & 688239 & 5.5362 & 5.6095 & TRN \\
\hline CHEMBL1492201 & 688239 & 4.9362 & 5.5866 & TRN \\
\hline CHEMBL1302825 & 688239 & 5.1862 & 5.5247 & TRN \\
\hline CHEMBL1300674 & 688239 & 5.3362 & 5.4546 & TST \\
\hline CHEMBL1563687 & 688239 & 6.3863 & 5.4602 & TRN \\
\hline CHEMBL1459864 & 688239 & 5.1862 & 5.4583 & TRN \\
\hline CHEMBL 3213828 & 688239 & 4.7362 & 5.6483 & TRN \\
\hline CHEMBL1576463 & 688239 & 4.9362 & 5.5424 & TRN \\
\hline CHEMBL1526112 & 688239 & 4.6862 & 5.5471 & TST \\
\hline CHEMBL1454247 & 688239 & 5.2362 & 5.4023 & TRN \\
\hline CHEMBL1516928 & 688239 & 5.0362 & 5.5233 & TRN \\
\hline CHEMBL1339238 & 688239 & 5.5862 & 5.4929 & TRN \\
\hline CHEMBL1350579 & 688239 & 5.1862 & 5.3931 & TRN \\
\hline CHEMBL1597454 & 688239 & 4.7362 & 5.4483 & TRN \\
\hline CHEMBL1563393 & 688239 & 5.2862 & 5.4821 & TST \\
\hline CHEMBL1378638 & 688239 & 4.5362 & 5.5424 & TRN \\
\hline CHEMBL1584407 & 688239 & 5.1862 & 5.3722 & TRN \\
\hline CHEMBL1474857 & 688239 & 5.7362 & 5.5294 & TRN \\
\hline CHEMBL1512153 & 688239 & 4.7362 & 5.4826 & TRN \\
\hline CHEMBL1517939 & 688239 & 4.5362 & 5.4831 & TRN \\
\hline CHEMBL1423790 & 688239 & 5.1862 & 5.4851 & TRN \\
\hline CHEMBL1523432 & 688239 & 4.7362 & 5.461 & TRN \\
\hline CHEMBL3192611 & 688239 & 6.1362 & 5.5882 & TRN \\
\hline CHEMBL1320633 & 688239 & 5.4362 & 5.6326 & TST \\
\hline CHEMBL1401084 & 688239 & 6.0862 & 5.4322 & TRN \\
\hline CHEMBL1315262 & 688239 & 4.5862 & 5.3558 & TRN \\
\hline CHEMBL1971144 & 688239 & 5.1862 & 5.4022 & TRN \\
\hline CHEMBL1302653 & 688239 & 6.0362 & 5.569 & TRN \\
\hline CHEMBL1569125 & 688239 & 6.1862 & 5.478 & TRN \\
\hline CHEMBL1505971 & 688239 & 4.5362 & 5.4008 & TRN \\
\hline CHEMBL1430756 & 688239 & 5.2362 & 5.6112 & TST \\
\hline CHEMBL1304462 & 688239 & 5.3362 & 5.4422 & TRN \\
\hline CHEMBL1465435 & 688239 & 4.6862 & 5.3956 & TRN \\
\hline CHEMBL1422950 & 688239 & 5.3362 & 5.6722 & TRN \\
\hline CHEMBL1555849 & 688239 & 4.5362 & 5.2779 & TRN \\
\hline CHEMBL1309980 & 688239 & 4.8862 & 5.3155 & TRN \\
\hline CHEMBL1588319 & 688239 & 4.5362 & 5.4653 & TRN \\
\hline
\end{tabular}


Supplemental Table S2.txt

\begin{tabular}{|c|c|c|c|c|}
\hline CHEMBL1344958 & 688239 & 6.5862 & 5.3861 & TRN \\
\hline CHEMBL1469401 & 688239 & 5.5362 & 5.4784 & TST \\
\hline CHEMBL581868 & 688239 & 4.7862 & 5.2843 & TRN \\
\hline CHEMBL1489019 & 688239 & 6.3362 & 5.2807 & TRN \\
\hline CHEMBL1555071 & 688239 & 4.5362 & 5.4602 & TST \\
\hline CHEMBL1422894 & 688239 & 4.4862 & 5.4012 & TRN \\
\hline CHEMBL 3194323 & 688239 & 6.2862 & 5.4327 & TST \\
\hline CHEMBL1611573 & 688239 & 4.9862 & 5.4925 & TST \\
\hline CHEMBL1403591 & 688239 & 4.5362 & 5.6753 & TRN \\
\hline CHEMBL1444259 & 688239 & 4.5362 & 5.6104 & TRN \\
\hline CHEMBL1378765 & 688239 & 6.3362 & 5.5216 & TRN \\
\hline CHEMBL1454662 & 688239 & 5.5862 & 5.4988 & TRN \\
\hline CHEMBL1574392 & 688239 & 6.4862 & 5.5041 & TRN \\
\hline CHEMBL1566136 & 688239 & 5.5862 & 5.3863 & TRN \\
\hline CHEMBL1485737 & 688239 & 4.5862 & 5.4349 & TRN \\
\hline CHEMBL1467443 & 688239 & 6.3362 & 5.5267 & TRN \\
\hline CHEMBL1320939 & 688239 & 7.0862 & 5.3355 & TRN \\
\hline CHEMBL1304969 & 688239 & 5.1362 & 5.5078 & TRN \\
\hline CHEMBL1571533 & 688239 & 5.4862 & 5.6026 & TRN \\
\hline CHEMBL1554179 & 688239 & 5.4362 & 5.4204 & TST \\
\hline CHEMBL1331195 & 688239 & 4.6362 & 5.4835 & TST \\
\hline CHEMBL1434404 & 688239 & 5.1862 & 5.6267 & TRN \\
\hline CHEMBL1574933 & 688239 & 5.4362 & 5.5651 & TRN \\
\hline CHEMBL1301690 & 688239 & 4.6362 & 5.4312 & TRN \\
\hline CHEMBL1582024 & 688239 & 6.3362 & 5.4459 & TRN \\
\hline CHEMBL1597373 & 688239 & 5.3362 & 5.5485 & TRN \\
\hline CHEMBL1476079 & 688239 & 4.7862 & 5.4006 & TRN \\
\hline CHEMBL 3195041 & 688239 & 4.5862 & 5.5042 & TRN \\
\hline CHEMBL1595886 & 688239 & 8.28399 & 99999999 & 5.7167 \\
\hline CHEMBL1392473 & 688239 & 4.8362 & 5.4114 & TRN \\
\hline CHEMBL1556061 & 688239 & 5.1362 & 5.5876 & TRN \\
\hline CHEMBL1425932 & 688239 & 4.7362 & 5.537006 & 0000000001 \\
\hline CHEMBL1342544 & 688239 & 5.4362 & 5.5085 & TST \\
\hline CHEMBL1347417 & 688239 & 4.5862 & 5.3293 & TST \\
\hline CHEMBL1351102 & 688239 & 4.4862 & 5.5348 & TRN \\
\hline CHEMBL1983549 & 688239 & 6.5862 & 5.4978 & TST \\
\hline CHEMBL1488140 & 688239 & 4.6862 & 5.6274 & TRN \\
\hline CHEMBL1535546 & 688239 & 4.8362 & 5.4646 & TRN \\
\hline CHEMBL1441587 & 688239 & 5.3862 & 5.4208 & TRN \\
\hline CHEMBL 3194542 & 688239 & 5.1862 & 5.528 & TRN \\
\hline CHEMBL1304234 & 688239 & 5.8362 & 5.6212 & TRN \\
\hline CHEMBL 3210824 & 688239 & 6.8362 & 5.5971 & TRN \\
\hline CHEMBL 282489 & 688239 & 4.6862 & 5.3821 & TST \\
\hline CHEMBL 3193003 & 688239 & 6.1862 & 5.4477 & TRN \\
\hline CHEMBL1424007 & 688239 & 5.8862 & 5.4744 & TST \\
\hline CHEMBL1376582 & 688239 & 5.1862 & 5.6222 & TRN \\
\hline CHEMBL1467436 & 688239 & 4.5362 & 5.4209 & TRN \\
\hline CHEMBL1590934 & 688239 & 4.7362 & 5.3425 & TST \\
\hline
\end{tabular}


Supplemental Table S2.txt

\begin{tabular}{|c|c|c|c|c|}
\hline CHEMBL1582044 & 688239 & 5.7862 & 5.4806 & TRN \\
\hline CHEMBL1495055 & 688239 & 5.1862 & 5.4743 & TRN \\
\hline CHEMBL1322559 & 688239 & 7.2366 & 5.5866 & TST \\
\hline CHEMBL1466972 & 688239 & 4.5362 & 5.5815 & TRN \\
\hline CHEMBL1557359 & 688239 & 6.2862 & 5.5374 & TST \\
\hline CHEMBL600490 & 688239 & 6.8362 & 5.2741 & TRN \\
\hline CHEMBL1544107 & 688239 & 4.5362 & 5.407 & TST \\
\hline CHEMBL1380408 & 688239 & 4.7362 & 5.536000 & 0000000005 \\
\hline CHEMBL1609505 & 688239 & 4.7862 & 5.4937 & TRN \\
\hline CHEMBL1309709 & 688239 & 4.9862 & 5.5005 & TRN \\
\hline CHEMBL 3189685 & 688239 & 6.5862 & 5.5414 & TRN \\
\hline CHEMBL 3209575 & 688239 & 4.5362 & 5.4568 & TRN \\
\hline CHEMBL 3209851 & 688239 & 5.9862 & 5.52 & TRN \\
\hline CHEMBL1429623 & 688239 & 4.5362 & 5.6058 & TRN \\
\hline CHEMBL 3210767 & 688239 & 4.5362 & 5.721 & TRN \\
\hline CHEMBL1518845 & 688239 & 6.0862 & 5.4969 & TRN \\
\hline CHEMBL1538287 & 688239 & 8.3372 & 5.4695 & TRN \\
\hline CHEMBL1578746 & 688239 & 5.2362 & 5.5104 & TRN \\
\hline CHEMBL1554705 & 688239 & 4.6862 & 5.5394 & TRN \\
\hline CHEMBL1559058 & 688239 & 4.5362 & 5.5514 & TRN \\
\hline CHEMBL1441569 & 688239 & 4.5362 & 5.4332 & TRN \\
\hline CHEMBL1319088 & 688239 & 5.4362 & 5.5847 & TRN \\
\hline CHEMBL1349885 & 688239 & 6.3863 & 5.4358 & TRN \\
\hline CHEMBL1583663 & 688239 & 4.5362 & 5.4498 & TST \\
\hline CHEMBL1591303 & 688239 & 7.9355 & 5.3667 & TRN \\
\hline CHEMBL1526892 & 688239 & 4.7362 & 5.4622 & TRN \\
\hline CHEMBL1429381 & 688239 & 5.0862 & 5.734 & TRN \\
\hline CHEMBL1582442 & 688239 & 6.2862 & 5.3745 & TST \\
\hline CHEMBL548458 & 688239 & 4.5362 & 5.447999 & 9999999995 \\
\hline CHEMBL1606315 & 688239 & 6.0862 & 5.4093 & TRN \\
\hline CHEMBL1421121 & 688239 & 5.5362 & 5.5035 & TST \\
\hline CHEMBL1511013 & 688239 & 4.5362 & 5.4831 & TRN \\
\hline CHEMBL1329801 & 688239 & 5.2362 & 5.7176 & TRN \\
\hline CHEMBL1565627 & 688239 & 5.2862 & 5.5003 & TRN \\
\hline CHEMBL1438901 & 688239 & 4.9862 & 5.4753 & TRN \\
\hline CHEMBL1347521 & 688239 & 4.6862 & 5.3471 & TRN \\
\hline CHEMBL1428071 & 688239 & 4.5362 & 5.2401 & TST \\
\hline CHEMBL1419670 & 688239 & 6.2862 & 5.4353 & TRN \\
\hline CHEMBL1569486 & 688239 & 4.5362 & 5.6209 & TRN \\
\hline CHEMBL1497544 & 688239 & 6.1362 & 5.4517 & TRN \\
\hline CHEMBL1461620 & 688239 & 5.0362 & 5.5001 & TRN \\
\hline CHEMBL1599301 & 688239 & 5.2362 & 5.4193 & TRN \\
\hline CHEMBL1527177 & 688239 & 5.1362 & 5.4888 & TRN \\
\hline CHEMBL1602016 & 688239 & 7.1361 & 5.5109 & TRN \\
\hline CHEMBL1400468 & 688239 & 4.5362 & 5.5325 & TST \\
\hline CHEMBL1454199 & 688239 & 5.5862 & 5.4897 & TST \\
\hline CHEMBL1528662 & 688239 & 4.5362 & 5.551 & TRN \\
\hline CHEMBL1473762 & 688239 & 4.5362 & 5.5112 & TST \\
\hline
\end{tabular}


Supplemental Table S2.txt

\begin{tabular}{|c|c|c|c|c|}
\hline HEN & & .0862 & & \\
\hline & & .3872 & 5.3668 & \\
\hline & & & & \\
\hline IEMBL1 & & 362 & & 2N \\
\hline AEMBL1530957 & 8239 & 362 & 501 & \\
\hline HEMBL1359842 & 88239 & .6862 & 572 & \\
\hline HEMBL13 & 239 & 362 & 5163 & \\
\hline IFMBI 32 & & & & \\
\hline AEMBL1499042 & 88239 & 362 & & \\
\hline HEMBL1384033 & 38239 & 862 & 4411 & \\
\hline HEMBL1417147 & 239 & 862 & 58 & \\
\hline IEMBL14 & 39 & & 318 & \\
\hline IEMBL1 & & & & \\
\hline HEMBL16 & & 362 & .5993 & \\
\hline AEMBL13 & & & & \\
\hline AEMBL1 & 39 & 64 & 16 & \\
\hline AEMBL14 & & & & \\
\hline HEMBL13 & & & & \\
\hline JEMBL15 & & & & \\
\hline AEMBL13 & & & & \\
\hline FEBLI & & & & \\
\hline AEMBL1: & & & & . \\
\hline AEMBL1: & & & & \\
\hline AFMBI 71851 & & & & \\
\hline JEMBL14 & & & & I RIV \\
\hline AEMBL1 & & & & KIV \\
\hline HEMBL1 & & & & RN \\
\hline HFMBI 1 & & & & \\
\hline HEMBL13\& & & & & I RIN \\
\hline HEMBL 333889 & & & & $\cdots$ \\
\hline HEMBL1 & & & & SI \\
\hline HEMBL & & & & RN \\
\hline IFMPI - & & & & 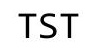 \\
\hline HEMBL1546523 & & & & R \\
\hline HEMBL1584349 & & & & TRN \\
\hline HEMBL1 & & & & TRN \\
\hline 1 & & & & \\
\hline HEMBL1 & & & & IST \\
\hline HEMBL 215479 & & & & TST \\
\hline AEMBL13 & & & & TST \\
\hline HEMBL13 & & 62 & & TRN \\
\hline HEMBL13 & & & & TRN \\
\hline HEMBL1514401 & & & 773 & $\Gamma R$ \\
\hline AEMBL1362891 & 39 & 862 & 114 & TR \\
\hline MPI 1 & & & & 13 \\
\hline HEMBL13 & & & 5.3904 & \\
\hline CHEMBL1587 & & & 5.476 & \\
\hline HEMBL1364374 & 688239 & 4.5862 & 5.4006 & \\
\hline
\end{tabular}

Page 1406 


\begin{tabular}{|c|c|c|c|c|c|}
\hline \multirow[b]{2}{*}{ CHEMBL1980614 } & & \multicolumn{4}{|c|}{ Supplemental Table S2.txt } \\
\hline & 688239 & 4.5362 & 5.41200 & 0000000001 & TST \\
\hline CHEMBL1309695 & 688239 & 4.6362 & 5.4268 & TRN & \\
\hline CHEMBL1511471 & 688239 & 4.5362 & 5.4796 & TRN & \\
\hline CHEMBL1593302 & 688239 & 5.4862 & 5.3653 & TRN & \\
\hline CHEMBL1444674 & 688239 & 4.4862 & 5.54299 & 9999999999 & TRN \\
\hline CHEMBL1567672 & 688239 & 5.5362 & 5.535 & TRN & \\
\hline CHEMBL1464813 & 688239 & 4.2862 & 5.4718 & TRN & \\
\hline CHEMBL1509851 & 688239 & 4.8362 & 5.3542 & TRN & \\
\hline CHEMBL1604711 & 688239 & 4.7862 & 5.6702 & TRN & \\
\hline CHEMBL1476550 & 688239 & 4.7362 & 5.3952 & TRN & \\
\hline CHEMBL1583413 & 688239 & 4.5362 & 5.50899 & 99999999995 & TRN \\
\hline CHEMBL1330370 & 688239 & 4.5362 & 5.3951 & TRN & \\
\hline CHEMBL3214465 & 688239 & 4.7862 & 5.4999 & TST & \\
\hline CHEMBL1591691 & 688239 & 4.6862 & 5.5366 & TRN & \\
\hline CHEMBL1497744 & 688239 & 8.1871 & 5.5372 & TRN & \\
\hline CHEMBL1313871 & 688239 & 4.8862 & 5.5919 & TRN & \\
\hline CHEMBL1341613 & 688239 & 5.9362 & 5.4636 & TRN & \\
\hline CHEMBL1382989 & 688239 & 4.7862 & 5.3618 & TRN & \\
\hline CHEMBL3194663 & 688239 & 4.5362 & 5.2908 & TST & \\
\hline CHEMBL1342647 & 688239 & 4.7862 & 5.5692 & TST & \\
\hline CHEMBL1389371 & 688239 & 6.4362 & 5.5561 & TRN & \\
\hline CHEMBL1602995 & 688239 & 4.6362 & 5.4214 & TRN & \\
\hline CHEMBL1493082 & 688239 & 5.1862 & 5.638 & TRN & \\
\hline CHEMBL1379930 & 688239 & 6.2362 & 5.45 & TRN & \\
\hline CHEMBL1533164 & 688239 & 6.2362 & 5.6052 & TST & \\
\hline CHEMBL425065 & 688239 & 6.3362 & 5.3522 & TST & \\
\hline CHEMBL1377707 & 688239 & 5.2362 & 5.4619 & TRN & \\
\hline CHEMBL1561026 & 688239 & 4.5362 & 5.5792 & TRN & \\
\hline CHEMBL1351519 & 688239 & 4.6362 & 5.4957 & TST & \\
\hline CHEMBL1573303 & 688239 & 4.5362 & 5.407 & TST & \\
\hline CHEMBL1524329 & 688239 & 5.7862 & 5.6378 & TRN & \\
\hline CHEMBL1342532 & 688239 & 4.5362 & 5.5579 & TRN & \\
\hline CHEMBL 278939 & 688239 & 6.3863 & 5.5666 & TST & \\
\hline CHEMBL3194360 & 688239 & 4.7362 & 5.3187 & TST & \\
\hline CHEMBL1450683 & 688239 & 6.9863 & 5.5852 & TRN & \\
\hline CHEMBL1334374 & 688239 & 8.3372 & 5.4414 & TRN & \\
\hline CHEMBL1382455 & 688239 & 4.5362 & 5.6125 & TRN & \\
\hline CHEMBL1422128 & 688239 & 4.6362 & 5.3175 & TRN & \\
\hline CHEMBL1438581 & 688239 & 4.6862 & 5.5365 & TST & \\
\hline CHEMBL1515275 & 688239 & 5.7862 & 5.6119 & TRN & \\
\hline CHEMBL1555898 & 688239 & 5.5862 & 5.3475 & TRN & \\
\hline CHEMBL1487601 & 688239 & 4.5362 & 5.5018 & TRN & \\
\hline CHEMBL1494359 & 688239 & 4.8362 & 5.3488 & TRN & \\
\hline CHEMBL1409646 & 688239 & 4.8362 & 5.567 & TRN & \\
\hline CHEMBL1582656 & 688239 & 6.9363 & 5.5644 & TST & \\
\hline CHEMBL1478801 & 688239 & 6.1362 & 5.5117 & TRN & \\
\hline CHEMBL1584210 & 688239 & 4.6362 & 5.6982 & TRN & \\
\hline CHEMBL1387003 & 688239 & 5.5862 & 5.5025 & TRN & \\
\hline
\end{tabular}


Supplemental Table S2.txt

\begin{tabular}{|c|c|c|c|c|c|}
\hline CHEMBL3194196 & 688239 & 4.5362 & 5.5142 & TRN & \\
\hline CHEMBL1353227 & 688239 & 5.4362 & 5.5678 & TRN & \\
\hline CHEMBL1511114 & 688239 & 4.7862 & 5.5625 & TRN & \\
\hline CHEMBL1376415 & 688239 & 5.1862 & 5.5356 & TRN & \\
\hline CHEMBL1509788 & 688239 & 4.7862 & 5.2855 & TRN & \\
\hline CHEMBL1416658 & 688239 & 5.3362 & 5.4352 & TRN & \\
\hline CHEMBL1491020 & 688239 & 4.5862 & 5.6222 & TRN & \\
\hline CHEMBL1441364 & 688239 & 8.28399 & 99999999 & 99 & 5.5541 \\
\hline CHEMBL1557314 & 688239 & 4.5362 & 5.5828 & TST & \\
\hline CHEMBL1432160 & 688239 & 7.1864 & 5.331 & TST & \\
\hline CHEMBL1408200 & 688239 & 5.4862 & 5.5215 & TRN & \\
\hline CHEMBL1538767 & 688239 & 5.7862 & 5.4475 & TST & \\
\hline CHEMBL1996630 & 688239 & 4.6362 & 5.4262 & TST & \\
\hline CHEMBL1487097 & 688239 & 4.7862 & 5.3571 & TRN & \\
\hline CHEMBL1462205 & 688239 & 4.6862 & 5.4848 & TRN & \\
\hline CHEMBL1343066 & 688239 & 5.3862 & 5.5589 & TRN & \\
\hline CHEMBL3196594 & 688239 & 5.9362 & 5.3834 & TRN & \\
\hline CHEMBL1533642 & 688239 & 6.8362 & 5.5509 & TST & \\
\hline CHEMBL1382120 & 688239 & 5.7362 & 5.5427 & TRN & \\
\hline CHEMBL1451161 & 688239 & 5.1862 & 5.5321 & TRN & \\
\hline CHEMBL1337409 & 688239 & 5.0862 & 5.4694 & TRN & \\
\hline CHEMBL1556036 & 688239 & 5.1862 & 5.4975 & TRN & \\
\hline CHEMBL1549025 & 688239 & 6.9363 & 5.5194 & TRN & \\
\hline CHEMBL1438525 & 688239 & 4.5362 & 5.4812 & TRN & \\
\hline CHEMBL1334074 & 688239 & 4.7362 & 5.4192 & TRN & \\
\hline CHEMBL1425713 & 688239 & 5.1862 & 5.4613 & TST & \\
\hline CHEMBL1309453 & 688239 & 6.1862 & 5.6171 & TRN & \\
\hline CHEMBL1311513 & 688239 & 4.5362 & 5.4059 & TRN & \\
\hline CHEMBL1444411 & 688239 & 4.7862 & 5.4852 & TRN & \\
\hline CHEMBL1567197 & 688239 & 4.6362 & 5.6039 & TRN & \\
\hline CHEMBL1304120 & 688239 & 4.6362 & 5.5473 & TRN & \\
\hline CHEMBL1336911 & 688239 & 5.3862 & 5.345 & TRN & \\
\hline CHEMBL1484992 & 688239 & 4.7862 & 5.4401 & TRN & \\
\hline CHEMBL1583020 & 688239 & 5.4862 & 5.49 & TRN & \\
\hline CHEMBL1557670 & 688239 & 6.3863 & 5.402 & TRN & \\
\hline CHEMBL1606689 & 688239 & 5.3862 & 5.4304 & TRN & \\
\hline CHEMBL579322 & 688239 & 5.1862 & 5.4209 & TRN & \\
\hline CHEMBL1355163 & 688239 & 4.7862 & 5.5536 & TST & \\
\hline CHEMBL3902037 & 688239 & 6.4362 & 5.4957 & TRN & \\
\hline CHEMBL1418266 & 688239 & 5.4862 & 5.4517 & TST & \\
\hline CHEMBL 2028173 & 688239 & 6.0862 & 5.3977 & TST & \\
\hline CHEMBL1519183 & 688239 & 5.5362 & 5.5373 & TST & \\
\hline CHEMBL1531780 & 688239 & 4.5362 & 5.5105 & TST & \\
\hline CHEMBL1989852 & 688239 & 4.5362 & 5.5346 & TRN & \\
\hline CHEMBL1433295 & 688239 & 5.7862 & 5.4716 & TRN & \\
\hline CHEMBL1414311 & 688239 & 4.9362 & 5.5487 & TRN & \\
\hline CHEMBL3211846 & 688239 & 6.1362 & 5.3751 & TRN & \\
\hline CHEMBL1330101 & 688239 & 4.5362 & 5.4475 & TRN & \\
\hline
\end{tabular}


Supplemental Table S2.txt

\begin{tabular}{|c|c|c|c|c|}
\hline IE & & 52 & & \\
\hline & & 4.8362 & 5.4087 & \\
\hline 11 & & & & \\
\hline AEMBL1462 & & & 3879 & \\
\hline AEMBL1510055 & 8239 & 862 & & \\
\hline HEMBL1516582 & 88239 & 9363 & 5848 & \\
\hline HEMBL 320 & 239 & 361 & & \\
\hline IFMRI 14 & & & & \\
\hline AEMBL1520451 & & 362 & .468 & \\
\hline HEMBL1427794 & 38239 & 862 & 5365 & \\
\hline HEMBL1383343 & 39 & 363 & 294 & \\
\hline IEMBL14 & 239 & 362 & 964 & \\
\hline IEMBL13 & & & & \\
\hline HEMBL151 & & 862 & .4982 & \\
\hline AEMBL152 & & 62 & & \\
\hline AEMBL318 & 39 & 362 & 5622 & \\
\hline AEMBL15 & & 53 & 873 & \\
\hline HEMBL13ऽ & & & 78 & \\
\hline AEMBL15€ & & 863 & 6256 & \\
\hline IEMBL14 & & & & \\
\hline AEMBL14 & & 52 & 35 & \\
\hline HEMBL13 & & & 37 & \\
\hline HEMBL14 & & & & \\
\hline AEMBL15. & & & & \\
\hline HEMBL157 & & & & \\
\hline AEMBL14 & & & 95 & \\
\hline AEMBL13 & & & 99 & \\
\hline HFMBI 32 & & 52 & & RN \\
\hline JEMBL14 & & & 5.56 & \\
\hline HEMBL152 & & & & ISI \\
\hline HEMBL14 & & 52 & & RN \\
\hline HEMBL1S & & & & 年 \\
\hline AEMBL15 & & 52 & & RN \\
\hline HEMBL1418931 & & & & \\
\hline HEMBL1416560 & & & & $\Gamma \mathrm{RN}$ \\
\hline HEMBL13 & & & 426 & \\
\hline HEMDI 15 & & & & ST \\
\hline HEMBL13 & & & 566 & RN \\
\hline HEMBL3196276 & 88239 & & 5.4231 & $\mathrm{RI}$ \\
\hline EMBL14 & & & 582 & RI \\
\hline HEMBL1383942 & & 362 & 195 & \\
\hline CHEMBL154 & & & & \\
\hline HEMBL134 & & & 5.4532 & IST \\
\hline AEMBL1325227 & 39 & 8662 & 5.3997 & ГST \\
\hline MBL13 & & 862 & 5.4013 & 1 \\
\hline CHEMBL1399951 & & & 5.5681 & \\
\hline CHEMBL1428378 & & .5862 & 5.5834 & \\
\hline HEMBL1331691 & 688239 & 5.0362 & 5.4795 & ГRN \\
\hline
\end{tabular}


Supplemental Table S2.txt

\begin{tabular}{|c|c|c|c|c|c|}
\hline CHEMBL1375866 & 688239 & 5.1862 & 5.5281 & TRN & \\
\hline CHEMBL1588987 & 688239 & 5.1362 & 5.4574 & TST & \\
\hline CHEMBL3199347 & 688239 & 5.9362 & 5.4631 & TRN & \\
\hline CHEMBL1604624 & 688239 & 5.8362 & 5.6192 & TST & \\
\hline CHEMBL1503622 & 688239 & 4.5362 & 5.5632 & TRN & \\
\hline CHEMBL1399886 & 688239 & 5.9362 & 5.4157 & TRN & \\
\hline CHEMBL 3193884 & 688239 & 5.2362 & 5.4241 & TRN & \\
\hline CHEMBL1559543 & 688239 & 5.3862 & 5.4068 & TRN & \\
\hline CHEMBL1540659 & 688239 & 6.5363 & 5.3975 & TRN & \\
\hline CHEMBL1608737 & 688239 & 4.5362 & 5.5795 & TRN & \\
\hline CHEMBL1536081 & 688239 & 6.1362 & 5.5195 & TRN & \\
\hline CHEMBL1610014 & 688239 & 5.1862 & 5.3792 & TST & \\
\hline CHEMBL1369612 & 688239 & 5.6362 & 5.3874 & TRN & \\
\hline CHEMBL1527538 & 688239 & 4.5362 & 5.5867 & TRN & \\
\hline CHEMBL1539139 & 688239 & 4.7362 & 5.5056 & TRN & \\
\hline CHEMBL1611686 & 688239 & 5.1362 & 5.3789 & TRN & \\
\hline CHEMBL1377682 & 688239 & 5.4362 & 5.5671 & TRN & \\
\hline CHEMBL1599200 & 688239 & 4.9362 & 5.5011 & TRN & \\
\hline CHEMBL1425207 & 688239 & 6.1862 & 5.5311 & TRN & \\
\hline CHEMBL1384331 & 688239 & 5.4362 & 5.7203 & TRN & \\
\hline CHEMBL1546932 & 688239 & 4.6862 & 5.41299 & 9999999999 & TRN \\
\hline CHEMBL1313181 & 688239 & 5.1862 & 5.6055 & TRN & \\
\hline CHEMBL1549385 & 688239 & 6.1362 & 5.4137 & TST & \\
\hline CHEMBL1556617 & 688239 & 7.2366 & 5.4335 & TRN & \\
\hline CHEMBL 3192808 & 688239 & 5.4362 & 5.5259 & TRN & \\
\hline CHEMBL1570153 & 688239 & 5.0862 & 5.3773 & TST & \\
\hline CHEMBL1461946 & 688239 & 4.5362 & 5.5536 & TRN & \\
\hline CHEMBL1583419 & 688239 & 4.5362 & 5.3516 & TRN & \\
\hline CHEMBL1371616 & 688239 & 6.2862 & 5.6281 & TRN & \\
\hline CHEMBL1587342 & 688239 & 5.0362 & 5.5583 & TRN & \\
\hline CHEMBL1349597 & 688239 & 6.3362 & 5.4573 & TRN & \\
\hline CHEMBL1319422 & 688239 & 5.1862 & 5.4642 & TRN & \\
\hline CHEMBL1488415 & 688239 & 5.5362 & 5.536006 & 00000000005 & TRN \\
\hline CHEMBL1601242 & 688239 & 6.0862 & 5.4417 & TRN & \\
\hline CHEMBL1612619 & 688239 & 6.2362 & 5.4947 & TRN & \\
\hline CHEMBL1504185 & 688239 & 5.1862 & 5.55200 & 00000000005 & TRN \\
\hline CHEMBL3199419 & 688239 & 4.5362 & 5.4298 & TRN & \\
\hline CHEMBL1333387 & 688239 & 4.5362 & 5.5025 & TRN & \\
\hline CHEMBL1417982 & 688239 & 5.8362 & 5.6021 & TRN & \\
\hline CHEMBL1313297 & 688239 & 8.2366 & 5.4811 & TRN & \\
\hline CHEMBL1525157 & 688239 & 4.8862 & 5.5052 & TRN & \\
\hline CHEMBL1502405 & 688239 & 4.5362 & 5.4366 & TRN & \\
\hline CHEMBL527585 & 688239 & 4.6862 & 5.516 & TRN & \\
\hline CHEMBL1486414 & 688239 & 5.1862 & 5.4983 & TRN & \\
\hline CHEMBL1512443 & 688239 & 5.3362 & 5.5261 & TRN & \\
\hline CHEMBL1313483 & 688239 & 5.3362 & 5.4704 & TRN & \\
\hline CHEMBL1532663 & 688239 & 5.1862 & 5.4588 & TRN & \\
\hline CHEMBL1303720 & 688239 & 5.4862 & 5.4925 & TST & \\
\hline
\end{tabular}


Supplemental Table S2.txt

\begin{tabular}{|c|c|c|c|c|c|}
\hline CHEMBL1438361 & 688239 & 8.1871 & 5.4065 & TRN & \\
\hline CHEMBL1513690 & 688239 & 6.7862 & 5.5795 & TRN & \\
\hline CHEMBL1402750 & 688239 & 4.5362 & 5.3738 & TST & \\
\hline CHEMBL1438540 & 688239 & 5.3862 & 5.3641 & TST & \\
\hline CHEMBL1363926 & 688239 & 5.1862 & 5.3071 & TST & \\
\hline CHEMBL1456044 & 688239 & 8.3372 & 5.6064 & TRN & \\
\hline CHEMBL1582109 & 688239 & 4.6362 & 5.4448 & TST & \\
\hline CHEMBL1422876 & 688239 & 4.5362 & 5.3982 & TRN & \\
\hline CHEMBL1579226 & 688239 & 6.3362 & 5.5184 & TST & \\
\hline CHEMBL1552042 & 688239 & 4.7362 & 5.353 & TRN & \\
\hline CHEMBL1363774 & 688239 & 5.6362 & 5.4314 & TRN & \\
\hline CHEMBL1354881 & 688239 & 4.7362 & 5.3572 & TRN & \\
\hline CHEMBL1600606 & 688239 & 5.1862 & 5.5691 & TRN & \\
\hline CHEMBL1491265 & 688239 & 4.5362 & 5.6065 & TRN & \\
\hline CHEMBL1497931 & 688239 & 5.4862 & 5.3248 & TRN & \\
\hline CHEMBL1341120 & 688239 & 4.6362 & 5.3426 & TRN & \\
\hline CHEMBL1344291 & 688239 & 5.0362 & 5.4054 & TRN & \\
\hline CHEMBL1559165 & 688239 & 5.4362 & 5.5213 & TST & \\
\hline CHEMBL1337377 & 688239 & 6.3362 & 5.5315 & TST & \\
\hline CHEMBL1536318 & 688239 & 5.1362 & 5.48799 & 99999999995 & TRN \\
\hline CHEMBL1613189 & 688239 & 8.3872 & 5.3011 & TRN & \\
\hline CHEMBL1575911 & 688239 & 4.5362 & 5.5772 & TRN & \\
\hline CHEMBL1423462 & 688239 & 5.3362 & 5.4892 & TRN & \\
\hline CHEMBL1550977 & 688239 & 5.2362 & 5.5298 & TRN & \\
\hline CHEMBL1569764 & 688239 & 4.7862 & 5.5443 & TRN & \\
\hline CHEMBL1379115 & 688239 & 5.3362 & 5.2965 & TST & \\
\hline CHEMBL2001294 & 688239 & 4.4862 & 5.396 & TRN & \\
\hline CHEMBL1495788 & 688239 & 4.7862 & 5.4871 & TRN & \\
\hline CHEMBL1560229 & 688239 & 5.6362 & 5.5445 & TRN & \\
\hline CHEMBL1477336 & 688239 & 5.4862 & 5.5793 & TRN & \\
\hline CHEMBL1502261 & 688239 & 6.0862 & 5.5461 & TRN & \\
\hline CHEMBL1540417 & 688239 & 6.6861 & 5.54799 & 9999999999 & TST \\
\hline CHEMBL1449445 & 688239 & 5.6362 & 5.5766 & TRN & \\
\hline CHEMBL1609525 & 688239 & 6.7862 & 5.3734 & TRN & \\
\hline CHEMBL1544527 & 688239 & 6.0862 & 5.4592 & TST & \\
\hline CHEMBL1312437 & 688239 & 5.1362 & 5.5589 & TRN & \\
\hline CHEMBL1604271 & 688239 & 5.4362 & 5.6359 & TST & \\
\hline CHEMBL3210611 & 688239 & 4.5362 & 5.3476 & TRN & \\
\hline CHEMBL 2000222 & 688239 & 6.7361 & 5.3262 & TST & \\
\hline CHEMBL1348216 & 688239 & 4.5362 & 5.4387 & TRN & \\
\hline CHEMBL1553750 & 688239 & 4.6862 & 5.4741 & TRN & \\
\hline CHEMBL1434856 & 688239 & 5.1362 & 5.5106 & TRN & \\
\hline CHEMBL1597847 & 688239 & 4.9862 & 5.6362 & TRN & \\
\hline CHEMBL1320388 & 688239 & 4.5862 & 5.3944 & TRN & \\
\hline CHEMBL1456553 & 688239 & 5.0362 & 5.3922 & TRN & \\
\hline CHEMBL1371798 & 688239 & 4.4862 & 5.5181 & TRN & \\
\hline CHEMBL1410803 & 688239 & 5.1862 & 5.4463 & TRN & \\
\hline CHEMBL1579189 & 688239 & 6.7361 & 5.4843 & TST & \\
\hline
\end{tabular}


Supplemental Table S2.txt

\begin{tabular}{|c|c|c|c|c|}
\hline CHEMBL1416232 & 688239 & 4.7362 & 5.5324 & TRN \\
\hline CHEMBL3199367 & 688239 & 4.6362 & 5.3909 & TRN \\
\hline CHEMBL1420563 & 688239 & 4.7362 & 5.4285 & TRN \\
\hline CHEMBL1320447 & 688239 & 7.1864 & 5.4502 & TRN \\
\hline CHEMBL1525704 & 688239 & 6.0862 & 5.51200 & 20000000005 \\
\hline CHEMBL1301386 & 688239 & 4.5362 & 5.4763 & TST \\
\hline CHEMBL1364651 & 688239 & 4.7362 & 5.50799 & 9999999999 \\
\hline CHEMBL1582975 & 688239 & 6.2362 & 5.353 & TRN \\
\hline CHEMBL1512174 & 688239 & 5.3862 & 5.5162 & TST \\
\hline CHEMBL1345828 & 688239 & 6.2862 & 5.4874 & TRN \\
\hline CHEMBL1322354 & 688239 & 4.6362 & 5.5745 & TRN \\
\hline CHEMBL1401172 & 688239 & 5.4362 & 5.55399 & 9999999999 \\
\hline CHEMBL1431063 & 688239 & 4.6362 & 5.6528 & TRN \\
\hline CHEMBL1342190 & 688239 & 5.3862 & 5.4218 & TRN \\
\hline CHEMBL1366091 & 688239 & 4.7362 & 5.4775 & TRN \\
\hline CHEMBL1454498 & 688239 & 6.7862 & 5.5608 & TRN \\
\hline CHEMBL1370386 & 688239 & 4.8362 & 5.4275 & TRN \\
\hline CHEMBL1610118 & 688239 & 4.5862 & 5.416 & TRN \\
\hline CHEMBL1308405 & 688239 & 5.2362 & 5.7099 & TST \\
\hline CHEMBL1606273 & 688239 & 4.7362 & 5.5568 & TST \\
\hline CHEMBL1583090 & 688239 & 5.7362 & 5.3998 & TST \\
\hline CHEMBL1604094 & 688239 & 5.7362 & 5.416 & TRN \\
\hline CHEMBL1455677 & 688239 & 5.4362 & 5.4901 & TRN \\
\hline CHEMBL1575423 & 688239 & 5.8862 & 5.6448 & TRN \\
\hline CHEMBL1542043 & 688239 & 4.5362 & 5.3515 & TRN \\
\hline CHEMBL1489274 & 688239 & 4.5362 & 5.4323 & TRN \\
\hline CHEMBL1611580 & 688239 & 4.6862 & 5.4315 & TRN \\
\hline CHEMBL1483198 & 688239 & 4.7862 & 5.4335 & TRN \\
\hline CHEMBL3209358 & 688239 & 5.8862 & 5.5593 & TRN \\
\hline CHEMBL1305208 & 688239 & 5.0862 & 5.4375 & TST \\
\hline CHEMBL1455114 & 688239 & 4.5362 & 5.5324 & TST \\
\hline CHEMBL1543684 & 688239 & 4.7362 & 5.5248 & TRN \\
\hline CHEMBL1502249 & 688239 & 5.1862 & 5.5911 & TST \\
\hline CHEMBL1310656 & 688239 & 6.0862 & 5.33 & TRN \\
\hline CHEMBL1507111 & 688239 & 6.8362 & 5.4133 & TST \\
\hline CHEMBL1319571 & 688239 & 4.5362 & 5.6594 & TRN \\
\hline CHEMBL1434698 & 688239 & 5.2362 & 5.4981 & TRN \\
\hline CHEMBL1411174 & 688239 & 4.5362 & 5.6407 & TST \\
\hline CHEMBL1512546 & 688239 & 4.5362 & 5.4418 & TRN \\
\hline CHEMBL322535 & 688239 & 4.5362 & 5.4021 & TST \\
\hline CHEMBL1569508 & 688239 & 5.7362 & 5.6855 & TST \\
\hline CHEMBL1364747 & 688239 & 5.5362 & 5.4536 & TST \\
\hline CHEMBL3207841 & 688239 & 5.8362 & 5.4507 & TRN \\
\hline CHEMBL1355930 & 688239 & 5.3862 & 5.3994 & TRN \\
\hline CHEMBL1483530 & 688239 & 6.8362 & 5.6523 & TRN \\
\hline CHEMBL1529519 & 688239 & 8.3372 & 5.6505 & TRN \\
\hline CHEMBL1506282 & 688239 & 4.6862 & 5.4369 & TRN \\
\hline CHEMBL1588248 & 688239 & 5.2362 & 5.5549 & TST \\
\hline
\end{tabular}


Supplemental Table S2.txt

\begin{tabular}{|c|c|c|c|c|}
\hline CHEMBL1320532 & 688239 & 4.5362 & 5.3849 & TST \\
\hline CHEMBL1347581 & 688239 & 5.7362 & 5.4854 & TRN \\
\hline CHEMBL1611653 & 688239 & 5.1862 & 5.4599 & TRN \\
\hline CHEMBL1464291 & 688239 & 4.6362 & 5.5448 & TST \\
\hline CHEMBL1497903 & 688239 & 6.1362 & 5.7264 & TRN \\
\hline CHEMBL 3211206 & 688239 & 6.0862 & 5.3816 & TRN \\
\hline CHEMBL1466788 & 688239 & 6.7862 & 5.3616 & TRN \\
\hline CHEMBL1322535 & 688239 & 4.5362 & 5.4629 & TRN \\
\hline CHEMBL1533067 & 688239 & 6.4862 & 5.4796 & TST \\
\hline CHEMBL1300042 & 688239 & 4.5362 & 5.474 & TRN \\
\hline CHEMBL1530855 & 688239 & 5.5862 & 5.5196 & TST \\
\hline CHEMBL1498042 & 688239 & 5.7362 & 5.48799 & 99999999995 \\
\hline CHEMBL1387891 & 688239 & 6.8861 & 5.5112 & TRN \\
\hline CHEMBL1431538 & 688239 & 4.6862 & 5.3416 & TRN \\
\hline CHEMBL1490934 & 688239 & 6.1362 & 5.6779 & TRN \\
\hline CHEMBL1396254 & 688239 & 5.1862 & 5.4852 & TRN \\
\hline CHEMBL1492990 & 688239 & 5.9862 & 5.3839 & TRN \\
\hline CHEMBL1299956 & 688239 & 4.9862 & 5.4268 & TST \\
\hline CHEMBL1340813 & 688239 & 4.5862 & 5.473 & TST \\
\hline CHEMBL1998118 & 688239 & 4.6862 & 5.3642 & TRN \\
\hline CHEMBL1423935 & 688239 & 5.2862 & 5.36799 & 9999999999 \\
\hline CHEMBL1604128 & 688239 & 5.3862 & 5.5755 & TRN \\
\hline CHEMBL1456280 & 688239 & 5.8862 & 5.5179 & TRN \\
\hline CHEMBL1418559 & 688239 & 5.7862 & 5.4976 & TRN \\
\hline CHEMBL1332654 & 688239 & 5.4362 & 5.4524 & TRN \\
\hline CHEMBL1534567 & 688239 & 6.6861 & 5.3926 & TST \\
\hline CHEMBL1338250 & 688239 & 6.8861 & 5.6707 & TST \\
\hline CHEMBL1991431 & 688239 & 4.8862 & 5.4465 & TRN \\
\hline CHEMBL1423734 & 688239 & 4.5362 & 5.513 & TRN \\
\hline CHEMBL1450959 & 688239 & 5.6362 & 5.49100 & 00000000005 \\
\hline CHEMBL1581796 & 688239 & 4.5 & 5.5792 & TRN \\
\hline CHEMBL1336009 & 688239 & 4.8362 & 5.5674 & TRN \\
\hline CHEMBL1507916 & 688239 & 4.8862 & 5.3584 & TRN \\
\hline CHEMBL1444863 & 688239 & 4.5862 & 5.4775 & TRN \\
\hline CHEMBL1336086 & 688239 & 5.5362 & 5.47 & TRN \\
\hline CHEMBL1375971 & 688239 & 7.0362 & 5.3448 & TST \\
\hline CHEMBL1478125 & 688239 & 5.8362 & 5.6145 & TRN \\
\hline CHEMBL1565546 & 688239 & 6.7862 & 5.5618 & TRN \\
\hline CHEMBL1346300 & 688239 & 6.6362 & 5.5709 & TRN \\
\hline CHEMBL1469163 & 688239 & 6.6362 & 5.4175 & TRN \\
\hline CHEMBL1321534 & 688239 & 4.5362 & 5.4851 & TRN \\
\hline CHEMBL1412979 & 688239 & 5.1862 & 5.4346 & TRN \\
\hline CHEMBL1398228 & 688239 & 5.1362 & 5.3947 & TRN \\
\hline CHEMBL1306997 & 688239 & 6.1362 & \multicolumn{2}{|c|}{5.531000000000001} \\
\hline CHEMBL3191609 & 688239 & 4.5362 & 5.52 & TRN \\
\hline CHEMBL1413005 & 688239 & 4.5362 & 5.33 & TST \\
\hline CHEMBL1378957 & 688239 & 4.6362 & \multicolumn{2}{|c|}{5.492000000000001} \\
\hline CHEMBL1366088 & 688239 & 5.3862 & 5.4828 & TRN \\
\hline
\end{tabular}


Supplemental Table S2.txt

\begin{tabular}{|c|c|c|c|c|c|}
\hline CHEMBL1609295 & 688239 & 6.1862 & \multicolumn{2}{|c|}{5.327000000000001} & TRN \\
\hline CHEMBL1532668 & 688239 & 5.1862 & 5.4698 & TRN & \\
\hline CHEMBL1571201 & 688239 & 5.8862 & 5.5486 & TRN & \\
\hline CHEMBL1533337 & 688239 & 5.1862 & 5.5429 & TST & \\
\hline CHEMBL1571371 & 688239 & 6.3863 & 5.5883 & TST & \\
\hline CHEMBL1585271 & 688239 & 6.2862 & 5.4739 & TRN & \\
\hline CHEMBL1389657 & 688239 & 5.6862 & 5.5787 & TRN & \\
\hline CHEMBL1421112 & 688239 & 6.8362 & 5.5776 & TRN & \\
\hline CHEMBL1560944 & 688239 & 4.5362 & 5.5291 & TST & \\
\hline CHEMBL1467766 & 688239 & 4.7862 & 5.3391 & TRN & \\
\hline CHEMBL1460585 & 688239 & 4.9362 & 5.4885 & TST & \\
\hline CHEMBL1511049 & 688239 & 5.2362 & 5.6066 & TRN & \\
\hline CHEMBL1566521 & 688239 & 4.7862 & 5.4339 & TST & \\
\hline CHEMBL1532904 & 688239 & 5.2862 & 5.347 & TRN & \\
\hline CHEMBL3199269 & 688239 & 5.7862 & 5.6033 & TRN & \\
\hline CHEMBL1540793 & 688239 & 6.2862 & \multicolumn{2}{|c|}{5.507000000000001} & TRN \\
\hline CHEMBL1567372 & 688239 & 4.6362 & 5.6058 & TRN & \\
\hline CHEMBL1411887 & 688239 & 4.7362 & 5.4124 & TRN & \\
\hline CHEMBL1612632 & 688239 & 4.6862 & 5.4714 & TST & \\
\hline CHEMBL1357034 & 688239 & 4.7862 & 5.5235 & TRN & \\
\hline CHEMBL1603046 & 688239 & 5.5362 & 5.5052 & TRN & \\
\hline CHEMBL1420440 & 688239 & 5.3862 & 5.5049 & TRN & \\
\hline CHEMBL1600800 & 688239 & 5.1862 & 5.5302 & TRN & \\
\hline CHEMBL1499100 & 688239 & 5.1862 & 5.3785 & TRN & \\
\hline CHEMBL1478794 & 688239 & 7.0862 & 5.4859 & TRN & \\
\hline CHEMBL1347736 & 688239 & 4.5362 & 5.6075 & TRN & \\
\hline CHEMBL1301106 & 688239 & 5.7362 & 5.4564 & TRN & \\
\hline CHEMBL1373828 & 688239 & 5.1862 & 5.6216 & TST & \\
\hline CHEMBL463175 & 688239 & 4.7362 & 5.4243 & TST & \\
\hline CHEMBL1603289 & 688239 & 6.1362 & 5.5691 & TST & \\
\hline CHEMBL3192298 & 688239 & 4.4862 & \multicolumn{2}{|c|}{5.332000000000001} & TST \\
\hline CHEMBL1410119 & 688239 & 4.4862 & 5.3678 & TRN & \\
\hline CHEMBL1534639 & 688239 & 5.5362 & 5.5996 & TRN & \\
\hline CHEMBL1347407 & 688239 & 5.2862 & 5.5223 & TRN & \\
\hline CHEMBL1498970 & 688239 & 4.7862 & 5.5819 & TST & \\
\hline CHEMBL1371273 & 688239 & 4.9862 & 5.4919 & TRN & \\
\hline CHEMBL1343628 & 688239 & 5.1862 & 5.5947 & TRN & \\
\hline CHEMBL1610356 & 688239 & 4.7362 & 5.4519 & TST & \\
\hline CHEMBL1350397 & 688239 & 4.6862 & 5.4705 & TRN & \\
\hline CHEMBL1482371 & 688239 & 4.5362 & 5.5102 & TRN & \\
\hline CHEMBL1372403 & 688239 & 6.2362 & 5.7449 & TST & \\
\hline CHEMBL1535605 & 688239 & 5.6362 & 5.4871 & TRN & \\
\hline CHEMBL1407642 & 688239 & 8.3372 & 5.3286 & TST & \\
\hline CHEMBL1529816 & 688239 & 5.9862 & 5.4911 & TRN & \\
\hline CHEMBL 236897 & 688239 & 4.6362 & 5.4289 & TRN & \\
\hline CHEMBL1395520 & 688239 & 4.7862 & 5.5069 & TRN & \\
\hline CHEMBL1423096 & 688239 & 6.0862 & \multicolumn{2}{|c|}{5.3660000000000005} & 151 \\
\hline CHEMBL1559830 & 688239 & 4.5362 & 5.3771 & TST & \\
\hline
\end{tabular}




\begin{tabular}{|c|c|c|c|c|c|}
\hline & & \multicolumn{4}{|c|}{ Supplemental Table s2.txt } \\
\hline CHEMBL1455141 & 688239 & 4.85 & 5.4841 & TRN & \\
\hline CHEMBL1466124 & 688239 & 4.5362 & 5.4859 & TST & \\
\hline CHEMBL1479720 & 688239 & 6.9863 & 5.4096 & TRN & \\
\hline CHEMBL1564568 & 688239 & 6.1862 & 5.3408 & TRN & \\
\hline CHEMBL1592807 & 688239 & 5.1862 & 5.3573 & TRN & \\
\hline CHEMBL1535085 & 688239 & 4.6362 & 5.4928 & TRN & \\
\hline CHEMBL1504701 & 688239 & 5.2362 & 5.3392 & TRN & \\
\hline CHEMBL1534136 & 688239 & 4.7862 & 5.4706 & TRN & \\
\hline CHEMBL1355418 & 688239 & 4.9862 & 5.4502 & TRN & \\
\hline CHEMBL1307045 & 688239 & 6.5363 & 5.5105 & TRN & \\
\hline CHEMBL1424478 & 688239 & 4.7362 & 5.4079 & TRN & \\
\hline CHEMBL 1421410 & 688239 & 4.7362 & 5.5312 & TRN & \\
\hline CHEMBL1387018 & 688239 & 6.5363 & 5.5983 & TST & \\
\hline CHEMBL1323446 & 688239 & 5.4362 & 5.5654 & TRN & \\
\hline CHEMBL1413656 & 688239 & 6.1862 & 5.4211 & TRN & \\
\hline CHEMBL1382202 & 688239 & 5.3862 & 5.5899 & TRN & \\
\hline CHEMBL1509558 & 688239 & 5.5362 & 5.5964 & TRN & \\
\hline CHEMBL1530137 & 688239 & 4.6862 & 5.3595 & TRN & \\
\hline CHEMBL1442403 & 688239 & 6.5363 & 5.3525 & TST & \\
\hline CHEMBL1604767 & 688239 & 4.5362 & 5.654 & TRN & \\
\hline CHEMBL1398177 & 688239 & 5.1862 & 5.5166 & TRN & \\
\hline CHEMBL1349772 & 688239 & 4.5362 & 5.3293 & TST & \\
\hline CHEMBL1424967 & 688239 & 5.1862 & 5.5043 & TRN & \\
\hline CHEMBL1526582 & 688239 & 6.9863 & 5.2714 & TST & \\
\hline CHEMBL1400042 & 688239 & 5.0362 & 5.5953 & TRN & \\
\hline CHEMBL1558668 & 688239 & 5.9362 & 5.5929 & TRN & \\
\hline CHEMBL1415766 & 688239 & 6.4862 & 5.4682 & TST & \\
\hline CHEMBL1322663 & 688239 & 5.8862 & 5.3614 & TRN & \\
\hline CHEMBL1432035 & 688239 & 6.1362 & 5.7046 & TST & \\
\hline CHEMBL1440527 & 688239 & 6.8861 & 5.3494 & TST & \\
\hline CHEMBL1405482 & 688239 & 5.7862 & 5.6001 & TST & \\
\hline CHEMBL1319368 & 688239 & 5.1862 & 5.4226 & TRN & \\
\hline CHEMBL1445922 & 688239 & 5.6862 & 5.5129 & TRN & \\
\hline CHEMBL3193460 & 688239 & 4.5362 & 5.318 & TRN & \\
\hline CHEMBL1508350 & 688239 & 5.6862 & 5.5557 & TST & \\
\hline CHEMBL1543457 & 688239 & 5.1862 & 5.5893 & TRN & \\
\hline CHEMBL1487729 & 688239 & 4.5362 & 5.5206 & TRN & \\
\hline CHEMBL1304039 & 688239 & 4.6362 & 5.5037 & TRN & \\
\hline CHEMBL1405523 & 688239 & 8.28399 & 99999999 & 5.4235 & TRN \\
\hline CHEMBL41920 & 688239 & 5.4362 & 5.5393 & TRN & \\
\hline CHEMBL1453417 & 688239 & 8.3372 & 5.6511 & TRN & \\
\hline CHEMBL1426865 & 688239 & 4.5362 & 5.5258 & TRN & \\
\hline CHEMBL1412260 & 688239 & 4.7362 & 5.48799 & 99999999995 & TRN \\
\hline CHEMBL1315923 & 688239 & 6.1862 & 5.5273 & TST & \\
\hline CHEMBL1550565 & 688239 & 5.1862 & 5.5011 & TRN & \\
\hline CHEMBL1468840 & 688239 & 4.7862 & 5.7029 & TST & \\
\hline CHEMBL212504 & 688239 & 5.1862 & 5.45700 & 0000000001 & TST \\
\hline CHEMBL 1442370 & 688239 & 5.8862 & 5.4453 & TRN & \\
\hline
\end{tabular}


Supplemental Table S2.txt

\begin{tabular}{|c|c|c|c|c|c|}
\hline CHEMBL1522113 & 688239 & 5.1862 & 5.4464 & TRN & \\
\hline CHEMBL1613318 & 688239 & 5.5362 & \multicolumn{2}{|c|}{5.4639999999999995} & TRN \\
\hline CHEMBL1505844 & 688239 & 6.9363 & 5.5745 & TRN & \\
\hline CHEMBL1331496 & 688239 & 6.2862 & 5.5288 & TST & \\
\hline CHEMBL1343034 & 688239 & 4.5362 & 5.465 & TRN & \\
\hline CHEMBL3191492 & 688239 & 6.2362 & 5.525 & TST & \\
\hline CHEMBL1409337 & 688239 & 4.5362 & 5.5155 & TRN & \\
\hline CHEMBL1483430 & 688239 & 5.5362 & 5.5339 & TRN & \\
\hline CHEMBL1351900 & 688239 & 4.7362 & 5.5505 & TRN & \\
\hline CHEMBL1484930 & 688239 & 4.6362 & 5.6578 & TRN & \\
\hline CHEMBL1417205 & 688239 & 4.5362 & 5.4685 & TST & \\
\hline CHEMBL1424152 & 688239 & 5.2362 & 5.5123 & TRN & \\
\hline CHEMBL1416493 & 688239 & 4.5362 & 5.2705 & TRN & \\
\hline CHEMBL1523008 & 688239 & 5.0862 & 5.4105 & TST & \\
\hline CHEMBL 217864 & 688239 & 5.3862 & 5.4863 & TRN & \\
\hline CHEMBL1407214 & 688239 & 5.0362 & 5.4072 & TRN & \\
\hline CHEMBL1570900 & 688239 & 6.4862 & 5.5979 & TST & \\
\hline CHEMBL1306748 & 688239 & 5.2362 & 5.6582 & TRN & \\
\hline CHEMBL1608364 & 688239 & 5.8862 & 5.3994 & TRN & \\
\hline CHEMBL1425157 & 688239 & 4.5362 & 5.3975 & TRN & \\
\hline CHEMBL1324458 & 688239 & 5.1862 & \multicolumn{2}{|c|}{5.4270000000000005} & TRN \\
\hline CHEMBL1315479 & 688239 & 5.6362 & 5.3583 & TST & \\
\hline CHEMBL1300349 & 688239 & 4.5362 & 5.5443 & TRN & \\
\hline CHEMBL1517288 & 688239 & 6.0862 & 5.5041 & TST & \\
\hline CHEMBL1497605 & 688239 & 6.9363 & 5.5871 & TRN & \\
\hline CHEMBL1602679 & 688239 & 4.5362 & 5.3709 & TST & \\
\hline CHEMBL1503134 & 688239 & 4.5362 & 5.4498 & TST & \\
\hline CHEMBL1380170 & 688239 & 5.0362 & 5.5763 & TST & \\
\hline CHEMBL1503742 & 688239 & 4.5862 & 5.4529 & TRN & \\
\hline CHEMBL1425707 & 688239 & 4.5362 & 5.3912 & TRN & \\
\hline CHEMBL1525014 & 688239 & 5.7362 & 5.5605 & TRN & \\
\hline CHEMBL1332727 & 688239 & 5.4362 & 5.5031 & TRN & \\
\hline CHEMBL1461440 & 688239 & 4.5362 & 5.5635 & TRN & \\
\hline CHEMBL1374735 & 688239 & 4.9862 & 5.4276 & TRN & \\
\hline CHEMBL1560052 & 688239 & 4.5362 & 5.6108 & TRN & \\
\hline CHEMBL1339860 & 688239 & 5.6862 & 5.5455 & TRN & \\
\hline CHEMBL1385333 & 688239 & 5.6362 & 5.4682 & TRN & \\
\hline CHEMBL1439137 & 688239 & 5.0362 & 5.5022 & TST & \\
\hline CHEMBL1574499 & 688239 & 5.3362 & 5.5091 & TRN & \\
\hline CHEMBL3209405 & 688239 & 4.5362 & 5.5163 & TST & \\
\hline CHEMBL1465146 & 688239 & 8.3372 & 5.6683 & TRN & \\
\hline CHEMBL1354997 & 688239 & 5.2362 & 5.4744 & TRN & \\
\hline CHEMBL1543678 & 688239 & 6.8861 & 5.4445 & TST & \\
\hline CHEMBL1405107 & 688239 & 4.85 & 5.5058 & TST & \\
\hline CHEMBL1524005 & 688239 & 5.4362 & 5.5294 & TRN & \\
\hline CHEMBL 74689 & 688239 & 5.3862 & 5.5481 & TST & \\
\hline CHEMBL1594655 & 688239 & 4.5362 & 5.4709 & TRN & \\
\hline CHEMBL 236353 & 688239 & 7.1361 & 5.5904 & TRN & \\
\hline
\end{tabular}


Supplemental Table S2.txt

\begin{tabular}{|c|c|c|c|c|}
\hline CHEMBL1450368 & 688239 & 5.7862 & 5.6254 & TRN \\
\hline CHEMBL1499947 & 688239 & 4.5362 & 5.4594 & TST \\
\hline CHEMBL3198564 & 688239 & 4.4862 & 5.4353 & TRN \\
\hline CHEMBL1355086 & 688239 & 5.0862 & 5.5369 & TRN \\
\hline CHEMBL1603082 & 688239 & 8.3372 & 5.5657 & TRN \\
\hline CHEMBL46881 & 688239 & 4.5362 & 5.4435 & TRN \\
\hline CHEMBL1423904 & 688239 & 5.7362 & 5.5293 & TRN \\
\hline CHEMBL 3209735 & 688239 & 6.1362 & \multicolumn{2}{|c|}{5.4879999999999995} \\
\hline CHEMBL1349559 & 688239 & 8.28399 & 999999999 & 5.4884 \\
\hline CHEMBL1558816 & 688239 & 5.4862 & 5.5439 & TST \\
\hline CHEMBL1446179 & 688239 & 6.0862 & \multicolumn{2}{|c|}{5.452000000000001} \\
\hline CHEMBL1556911 & 688239 & 6.1362 & 5.6115 & TST \\
\hline CHEMBL1455992 & 688239 & 4.7862 & 5.4053 & TST \\
\hline CHEMBL 3192059 & 688239 & 5.5862 & 5.4216 & TST \\
\hline CHEMBL1367446 & 688239 & 5.8362 & 5.5622 & TST \\
\hline CHEMBL1504049 & 688239 & 5.2362 & 5.4538 & TRN \\
\hline CHEMBL1576781 & 688239 & 5.1862 & 5.3906 & TRN \\
\hline CHEMBL1578911 & 688239 & 6.1862 & 5.419 & TST \\
\hline CHEMBL1547261 & 688239 & 4.7862 & 5.3505 & TRN \\
\hline CHEMBL1307714 & 688239 & 4.5362 & 5.5541 & TRN \\
\hline CHEMBL1492059 & 688239 & 5.2362 & 5.5726 & TRN \\
\hline CHEMBL1375577 & 688239 & 4.7862 & 5.2524 & TRN \\
\hline CHEMBL1606937 & 688239 & 6.3362 & 5.4765 & TRN \\
\hline CHEMBL1496673 & 688239 & 5.1862 & 5.4001 & TST \\
\hline CHEMBL 3189751 & 688239 & 5.7862 & 5.4069 & TST \\
\hline CHEMBL1377656 & 688239 & 5.0362 & 5.3667 & TRN \\
\hline CHEMBL1572340 & 688239 & 6.8362 & 5.44 & TRN \\
\hline CHEMBL1482015 & 688239 & 4.8862 & 5.4827 & TRN \\
\hline CHEMBL1351231 & 688239 & 4.4862 & 5.4259 & TST \\
\hline CHEMBL1499604 & 688239 & 6.8861 & 5.4228 & TST \\
\hline CHEMBL1347594 & 688239 & 5.5362 & 5.5144 & TRN \\
\hline CHEMBL1354059 & 688239 & 4.4862 & 5.5924 & TRN \\
\hline CHEMBL1303936 & 688239 & 4.6362 & 5.4777 & TST \\
\hline CHEMBL1519049 & 688239 & 5.1862 & 5.5351 & TST \\
\hline CHEMBL1496234 & 688239 & 6.4862 & 5.4509 & TRN \\
\hline CHEMBL383918 & 688239 & 4.4862 & 5.5243 & TST \\
\hline CHEMBL1494972 & 688239 & 5.4362 & 5.4847 & TRN \\
\hline CHEMBL1517507 & 688239 & 4.5362 & 5.3611 & TRN \\
\hline CHEMBL1582385 & 688239 & 5.4362 & 5.5861 & TST \\
\hline CHEMBL1558477 & 688239 & 7.7852 & 5.3705 & TRN \\
\hline CHEMBL1554589 & 688239 & 5.5862 & 5.5309 & TRN \\
\hline CHEMBL1471997 & 688239 & 5.7362 & 5.3918 & TRN \\
\hline CHEMBL1458563 & 688239 & 6.7862 & 5.4297 & TST \\
\hline CHEMBL1608401 & 688239 & 5.5862 & 5.6321 & TRN \\
\hline CHEMBL1401361 & 688239 & 4.6862 & 5.5064 & TST \\
\hline CHEMBL1567539 & 688239 & 4.5362 & 5.6038 & TRN \\
\hline CHEMBL1525524 & 688239 & 4.5362 & 5.4765 & TRN \\
\hline CHEMBL1306559 & 688239 & 4.7362 & 5.4048 & TRN \\
\hline
\end{tabular}




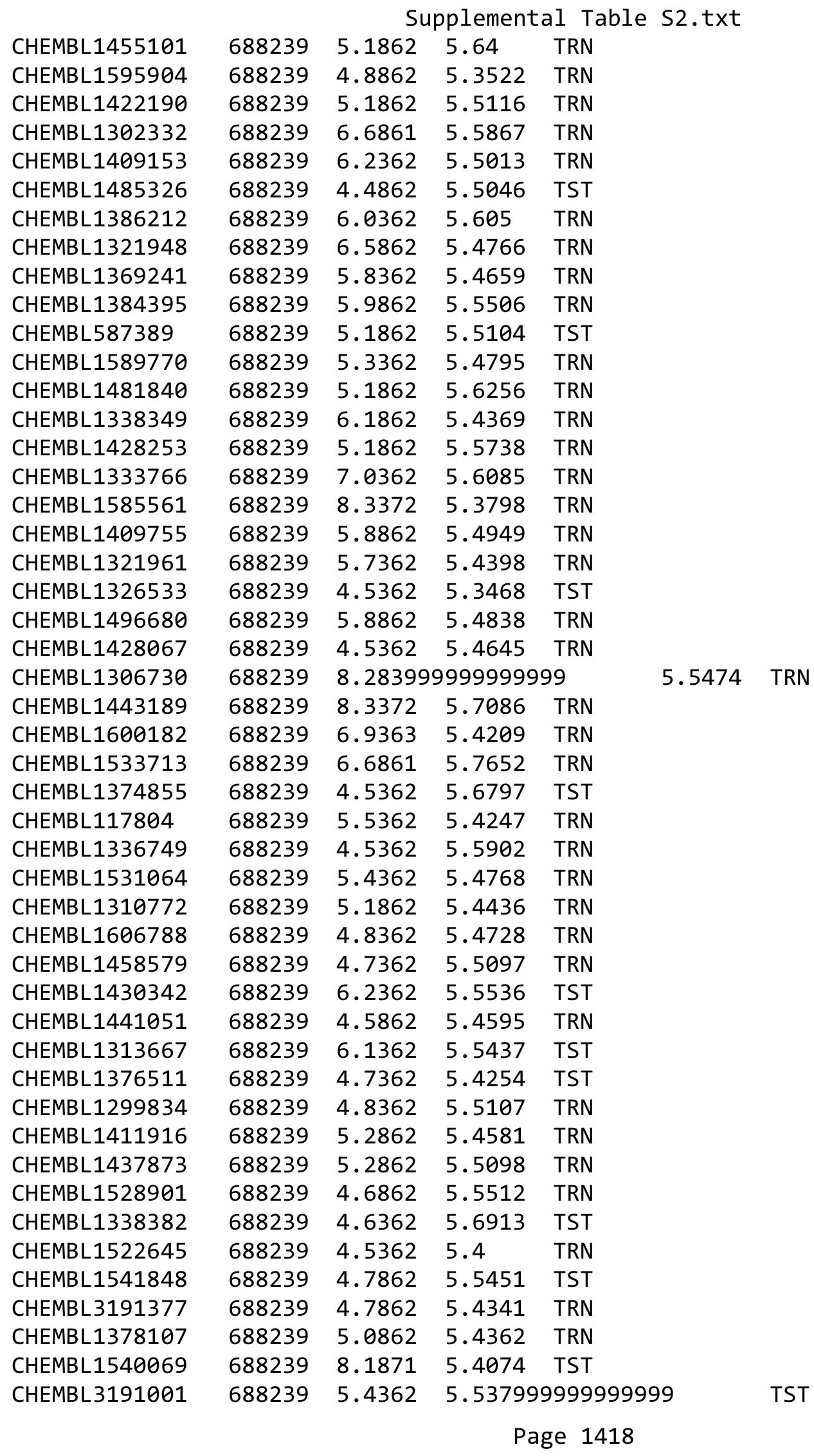


Supplemental Table S2.txt

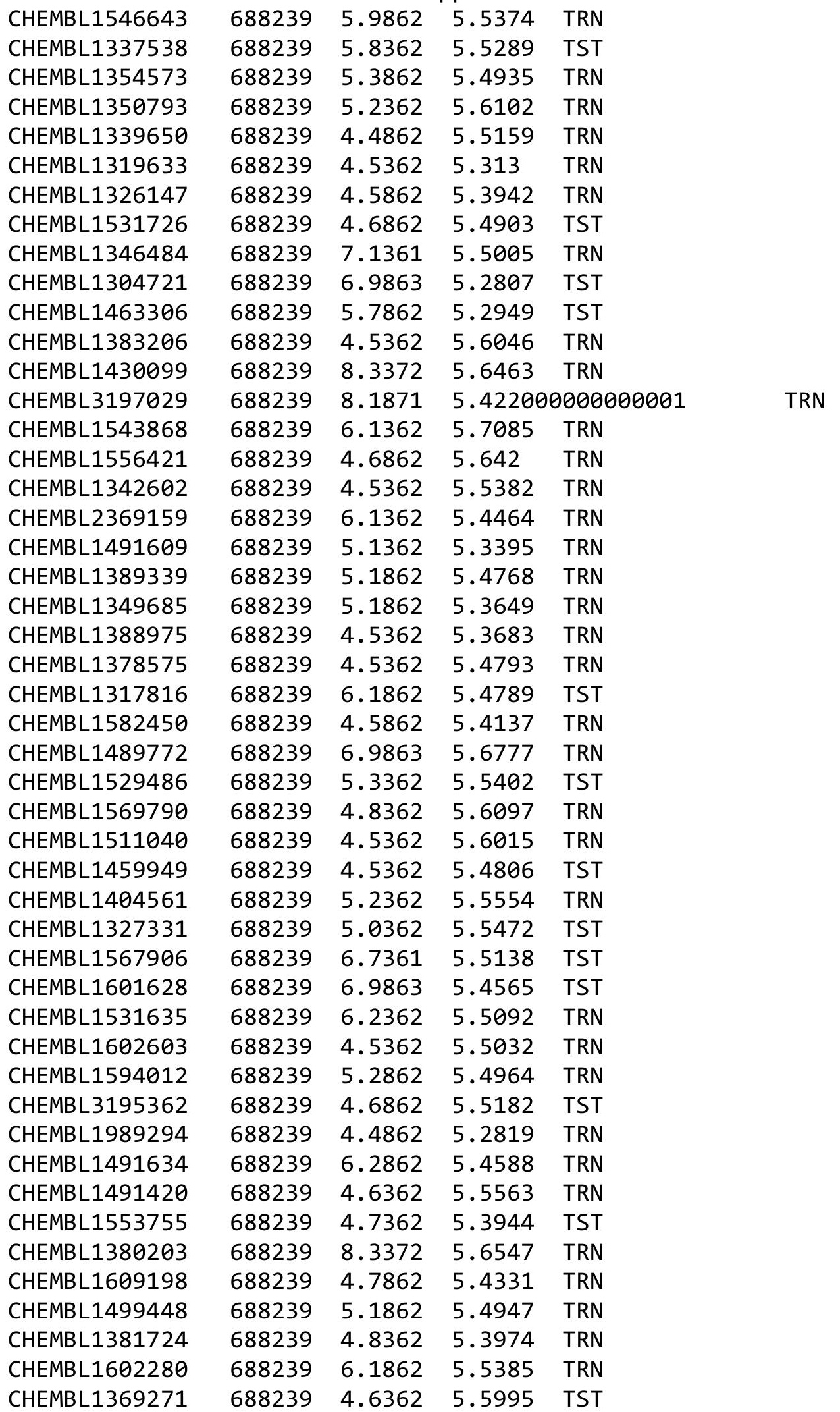

Page 1419 


\begin{tabular}{|c|c|c|c|c|c|c|}
\hline & & \multicolumn{5}{|c|}{ Supplemental Table S2.txt } \\
\hline CHEMBL1524383 & 688239 & 4.7362 & 5.5358 & TRN & & \\
\hline CHEMBL1458820 & 688239 & 4.6362 & 5.4337 & TST & & \\
\hline CHEMBL1317367 & 688239 & 4.7362 & 5.6159 & TRN & & \\
\hline CHEMBL1608297 & 688239 & 4.9862 & 5.4555 & TRN & & \\
\hline CHEMBL1393368 & 688239 & 4.7862 & 5.5474 & TRN & & \\
\hline CHEMBL1541190 & 688239 & 5.2862 & 5.572 & TRN & & \\
\hline CHEMBL1534798 & 688239 & 4.5362 & 5.4856 & TRN & & \\
\hline CHEMBL1400255 & 688239 & 5.1862 & 5.476 & TRN & & \\
\hline CHEMBL1551586 & 688239 & 5.3362 & 5.3415 & TRN & & \\
\hline CHEMBL1359674 & 688239 & 6.6362 & 5.5362 & TRN & & \\
\hline CHEMBL1312441 & 688239 & 4.6362 & 5.3295 & TRN & & \\
\hline CHEMBL1393697 & 688239 & 4.7362 & 5.461 & TRN & & \\
\hline CHEMBL1440747 & 688239 & 5.6862 & 5.4349 & TRN & & \\
\hline CHEMBL1408979 & 688239 & 8.3872 & 5.4394 & TST & & \\
\hline CHEMBL1308492 & 688239 & 4.5362 & 5.4772 & TRN & & \\
\hline CHEMBL1299656 & 688239 & 7.2366 & 5.6013 & TST & & \\
\hline CHEMBL1343449 & 688239 & 4.7362 & 5.5421 & TST & & \\
\hline CHEMBL1314923 & 688239 & 4.8862 & 5.438 & TRN & & \\
\hline CHEMBL1463950 & 688239 & 5.1862 & 5.4144 & TST & & \\
\hline CHEMBL1403896 & 688239 & 6.8861 & 5.5132 & TRN & & \\
\hline CHEMBL1606893 & 688239 & 5.7362 & 5.5384 & TRN & & \\
\hline CHEMBL1300634 & 688239 & 5.6362 & 5.4917 & TRN & & \\
\hline CHEMBL1544033 & 688239 & 6.1862 & 5.5674 & TRN & & \\
\hline CHEMBL1303164 & 688239 & 4.6862 & 5.447 & TRN & & \\
\hline CHEMBL1510246 & 688239 & 4.5362 & 5.3817 & TRN & & \\
\hline CHEMBL1506423 & 688239 & 5.1862 & 5.6242 & TST & & \\
\hline CHEMBL1389899 & 688239 & 4.9862 & 5.6498 & TRN & & \\
\hline CHEMBL1572962 & 688239 & 5.3362 & 5.5314 & TRN & & \\
\hline CHEMBL3212706 & 688239 & 5.2862 & 5.4157 & TRN & & \\
\hline CHEMBL1543613 & 688239 & 8.28399 & (9999999 & 99 & 5.6193 & TRN \\
\hline CHEMBL1344180 & 688239 & 5.0362 & 5.2471 & TRN & & \\
\hline CHEMBL1450898 & 688239 & 4.5362 & 5.5075 & TRN & & \\
\hline CHEMBL1425121 & 688239 & 5.5862 & 5.5277 & TRN & & \\
\hline CHEMBL1397493 & 688239 & 4.7362 & 5.4778 & TRN & & \\
\hline CHEMBL1494584 & 688239 & 5.1862 & 5.3099 & TRN & & \\
\hline CHEMBL1410312 & 688239 & 6.1362 & 5.566 & TRN & & \\
\hline CHEMBL1571320 & 688239 & 5.1862 & 5.6074 & TRN & & \\
\hline CHEMBL1488662 & 688239 & 5.1862 & 5.5347 & TST & & \\
\hline CHEMBL1591681 & 688239 & 4.7362 & 5.3724 & TRN & & \\
\hline CHEMBL1597104 & 688239 & 5.1862 & 5.4847 & TRN & & \\
\hline CHEMBL1361928 & 688239 & 6.9363 & 5.4811 & TRN & & \\
\hline CHEMBL3210154 & 688239 & 7.3363 & 5.4254 & TRN & & \\
\hline CHEMBL1599116 & 688239 & 4.5862 & 5.6388 & TRN & & \\
\hline CHEMBL1388341 & 688239 & 8.3372 & 5.6493 & TST & & \\
\hline CHEMBL1438753 & 688239 & 6.8861 & 5.5802 & TRN & & \\
\hline CHEMBL1340340 & 688239 & 6.2362 & 5.5249 & TRN & & \\
\hline CHEMBL1549030 & 688239 & 4.7362 & 5.3902 & TRN & & \\
\hline CHEMBL1395222 & 688239 & 5.1862 & 5.4879 & TRN & & \\
\hline
\end{tabular}


Supplemental Table S2.txt

\begin{tabular}{|c|c|c|c|c|}
\hline 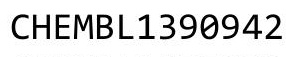 & & & & \\
\hline HEMBL1557933 & 88239 & 8362 & 6221 & \\
\hline HEMBL1317203 & 88239 & 862 & 4317 & \\
\hline 3230 & & & & \\
\hline EMBL13 & & 62 & .42 & \\
\hline HEMBL1608295 & 88239 & 362 & 5339 & \\
\hline HEMBL1504491 & 88239 & .0362 & .5279 & \\
\hline HEMBL1374155 & & & & \\
\hline IEMBL145 & 39 & 862 & 38 & \\
\hline IEMBL130 & 39 & 362 & . 4995 & \\
\hline HEMBL1579518 & 88239 & 362 & .4485 & \\
\hline HEMBL1444912 & 39 & 2366 & .5629 & \\
\hline HEMBL1378226 & 39 & 62 & 4789 & \\
\hline HEMBL198 & 39 & & .2928 & \\
\hline HEMBL137 & 39 & & .4229 & \\
\hline HEMBL1596032 & 39 & 62 & .4682 & \\
\hline HEMBL1428003 & 39 & & & \\
\hline HEMBL157 & 9 & & 96 & \\
\hline HEMBL133 & 9 & & & \\
\hline HEMBL319 & 39 & & 05 & RN \\
\hline HEMBL 319 & 39 & & & RN \\
\hline HEMBL1586 & $8 \varepsilon$ & & & \\
\hline HEMBL145 & 39 & & 19 & RIV \\
\hline HEMBL15 & & & & \\
\hline HEM & 39 & & & ST \\
\hline HEMBL138 & 39 & & & 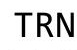 \\
\hline HEMBL 145 & 39 & & & $R / N$ \\
\hline HEMBL 15 & 9 & & & RN \\
\hline HEMBL 14 & 9 & & & RN \\
\hline HEMBL13 & 39 & & 73 & RN \\
\hline HEMBL146 & 9 & & & $R N$ \\
\hline HEMBL3189346 & 39 & & 77 & RN \\
\hline HEMBL14 & & & & $\mathrm{RN}$ \\
\hline HEM & 9 & & & \\
\hline HEMBL 145 & & & & RN \\
\hline HEMBL1554218 & 39 & & & RN \\
\hline HEMBL1504310 & 39 & & & TRN \\
\hline HEMBL143 & 39 & & & RN \\
\hline רז1 נחמזו & 9 & & & RN \\
\hline HEMBL3193536 & & & & RN \\
\hline HEMBL1403530 & 88239 & 62 & & RN \\
\hline HEMBL14 & 39 & 62 & & $\mathrm{RN}$ \\
\hline HEMBL141 & 88 & & & \\
\hline CHEMBL1545762 & 88239 & & 5.3171 & RN \\
\hline HEMBL 140 & & & 5.4764 & RN \\
\hline HEMBL3211107 & 39 & 362 & 5.4812 & \\
\hline LHEMBL 14 & & & & \\
\hline م & & & & \\
\hline
\end{tabular}

Page 1421 
Supplemental Table S2.txt

\begin{tabular}{|c|c|c|c|c|c|c|}
\hline CHEMBL1400115 & 688239 & 5.6362 & 5.6558 & TST & & \\
\hline CHEMBL1329543 & 688239 & 5.3362 & 5.3889 & TRN & & \\
\hline CHEMBL1366316 & 688239 & 5.7862 & 5.5428 & TST & & \\
\hline CHEMBL1346317 & 688239 & 4.4862 & 5.4993 & TRN & & \\
\hline CHEMBL1394722 & 688239 & 6.7862 & 5.4053 & TRN & & \\
\hline CHEMBL1553087 & 688239 & 4.6862 & 5.4472 & TRN & & \\
\hline CHEMBL1513632 & 688239 & 5.1862 & 5.4095 & TRN & & \\
\hline CHEMBL1386812 & 688239 & 4.7862 & 5.5189 & TST & & \\
\hline CHEMBL 3214055 & 688239 & 4.5362 & 5.5077 & TRN & & \\
\hline CHEMBL1305303 & 688239 & 5.7862 & 5.3235 & TRN & & \\
\hline CHEMBL1436662 & 688239 & 4.9862 & 5.3739 & TRN & & \\
\hline CHEMBL1545084 & 688239 & 5.9362 & 5.5356 & TRN & & \\
\hline CHEMBL1329943 & 688239 & 4.5362 & 5.4096 & TRN & & \\
\hline CHEMBL1567596 & 688239 & 6.0862 & 5.5574 & TST & & \\
\hline CHEMBL1323104 & 688239 & 6.1862 & 5.5171 & TRN & & \\
\hline CHEMBL1325931 & 688239 & 6.0362 & 5.4742 & TST & & \\
\hline CHEMBL1315960 & 688239 & 4.7862 & 5.3689 & TST & & \\
\hline CHEMBL1491936 & 688239 & 6.9363 & 5.6281 & TRN & & \\
\hline CHEMBL1322081 & 688239 & 4.5362 & 5.5431 & TRN & & \\
\hline CHEMBL1460938 & 688239 & 4.5362 & 5.388 & TRN & & \\
\hline CHEMBL1382369 & 688239 & 5.3862 & 5.4855 & TRN & & \\
\hline CHEMBL1489696 & 688239 & 8.28399 & 99999999 & 9 & 5.492000000000001 & TRN \\
\hline CHEMBL1318112 & 688239 & 5.8862 & 5.6584 & TST & & \\
\hline CHEMBL1590075 & 688239 & 4.7862 & 5.4739 & TRN & & \\
\hline CHEMBL1545554 & 688239 & 4.5362 & 5.6364 & TST & & \\
\hline CHEMBL1548319 & 688239 & 5.1862 & 5.6276 & TRN & & \\
\hline CHEMBL3193609 & 688239 & 6.1862 & 5.558 & TRN & & \\
\hline CHEMBL1340874 & 688239 & 5.1862 & 5.3779 & TRN & & \\
\hline CHEMBL3211507 & 688239 & 6.9363 & 5.4878 & TRN & & \\
\hline CHEMBL1313050 & 688239 & 4.5362 & 5.5648 & TST & & \\
\hline CHEMBL1597515 & 688239 & 5.1362 & 5.4929 & TST & & \\
\hline CHEMBL1319150 & 688239 & 4.5362 & 5.5872 & TRN & & \\
\hline CHEMBL1506612 & 688239 & 4.5362 & 5.5531 & TRN & & \\
\hline CHEMBL1334887 & 688239 & 4.6862 & 5.1649 & TRN & & \\
\hline CHEMBL1398852 & 688239 & 5.5862 & 5.6054 & TRN & & \\
\hline CHEMBL1464296 & 688239 & 5.2862 & 5.6588 & TRN & & \\
\hline CHEMBL1352023 & 688239 & 5.3362 & 5.7101 & TRN & & \\
\hline CHEMBL1415525 & 688239 & 4.5362 & 5.4594 & TST & & \\
\hline CHEMBL1418841 & 688239 & 6.1362 & 5.5884 & TRN & & \\
\hline CHEMBL490095 & 688239 & 6.8861 & 5.4426 & TRN & & \\
\hline CHEMBL1568335 & 688239 & 5.1862 & 5.527 & TRN & & \\
\hline CHEMBL1370303 & 688239 & 5.2362 & 5.4786 & TRN & & \\
\hline CHEMBL1612830 & 688239 & 5.1862 & 5.6226 & TRN & & \\
\hline CHEMBL1537958 & 688239 & 6.1362 & 5.5575 & TRN & & \\
\hline CHEMBL1466198 & 688239 & 4.6862 & 5.5092 & TRN & & \\
\hline CHEMBL1499895 & 688239 & 5.9362 & 5.4949 & TRN & & \\
\hline CHEMBL370109 & 688239 & 4.7862 & 5.5555 & TST & & \\
\hline CHEMBL1537303 & 688239 & 4.6362 & 5.4619 & TRN & & \\
\hline
\end{tabular}


Supplemental Table S2.txt

\begin{tabular}{|c|c|c|c|c|}
\hline CHEMBL1465764 & 688239 & 4.6362 & 5.5499 & TRN \\
\hline CHEMBL1416198 & 688239 & 5.6362 & 5.5495 & TRN \\
\hline CHEMBL1323777 & 688239 & 5.6862 & 5.5492 & TRN \\
\hline CHEMBL1436452 & 688239 & 6.2862 & 5.5465 & TRN \\
\hline CHEMBL1386883 & 688239 & 5.5862 & 5.5156 & TRN \\
\hline CHEMBL1382111 & 688239 & 5.1362 & 5.4875 & TRN \\
\hline CHEMBL1315195 & 688239 & 8.1871 & 5.482 & TST \\
\hline CHEMBL1508097 & 688239 & 6.8362 & 5.4126 & TRN \\
\hline CHEMBL1544338 & 688239 & 6.0862 & 5.4391 & TRN \\
\hline CHEMBL1404661 & 688239 & 4.4862 & 5.4586 & TRN \\
\hline CHEMBL1358405 & 688239 & 5.2362 & 5.4659 & TRN \\
\hline CHEMBL1532522 & 688239 & 6.8861 & 5.3885 & TRN \\
\hline CHEMBL1555448 & 688239 & 5.4362 & 5.5416 & TRN \\
\hline CHEMBL1393511 & 688239 & 5.5362 & 5.5627 & TST \\
\hline CHEMBL1367812 & 688239 & 5.3862 & 5.5369 & TRN \\
\hline CHEMBL1569528 & 688239 & 5.7862 & 5.4503 & TRN \\
\hline CHEMBL1404301 & 688239 & 4.5362 & 5.5384 & TRN \\
\hline CHEMBL1507877 & 688239 & 6.0862 & 5.4905 & TRN \\
\hline CHEMBL1493122 & 688239 & 4.5362 & 5.5211 & TRN \\
\hline CHEMBL1586185 & 688239 & 5.6362 & 5.5879 & TRN \\
\hline CHEMBL3211682 & 688239 & 5.1862 & 5.6455 & TST \\
\hline CHEMBL1560985 & 688239 & 4.6362 & 5.5174 & TRN \\
\hline CHEMBL1398512 & 688239 & 5.2362 & 5.3853 & TRN \\
\hline CHEMBL1568387 & 688239 & 5.5362 & 5.4946 & TRN \\
\hline CHEMBL1528508 & 688239 & 5.0862 & 5.5572 & TST \\
\hline CHEMBL3207679 & 688239 & 5.7862 & 5.4992 & TRN \\
\hline CHEMBL1305460 & 688239 & 4.7862 & 5.4761 & TST \\
\hline CHEMBL1541338 & 688239 & 4.8362 & 5.4308 & TST \\
\hline CHEMBL1349546 & 688239 & 5.8862 & 5.2863 & TST \\
\hline CHEMBL1271971 & 688239 & 4.4862 & 5.423999 & 9999999995 \\
\hline CHEMBL1308296 & 688239 & 8.3372 & 5.4222 & TRN \\
\hline CHEMBL1324214 & 688239 & 8.3372 & 5.5736 & TRN \\
\hline CHEMBL1459325 & 688239 & 4.5862 & 5.5007 & TRN \\
\hline CHEMBL1371381 & 688239 & 4.5362 & 5.3952 & TST \\
\hline CHEMBL1309229 & 688239 & 6.5862 & 5.3592 & TST \\
\hline CHEMBL1524812 & 688239 & 4.6862 & 5.5044 & TRN \\
\hline CHEMBL1459546 & 688239 & 5.1362 & 5.6562 & TRN \\
\hline CHEMBL1610155 & 688239 & 6.7862 & 5.4919 & TRN \\
\hline CHEMBL1419880 & 688239 & 4.5362 & 5.5 & TRN \\
\hline CHEMBL1498317 & 688239 & 5.1862 & 5.4597 & TRN \\
\hline CHEMBL1597139 & 688239 & 5.3862 & 5.553999 & 999999999 \\
\hline CHEMBL1445802 & 688239 & 5.4862 & 5.4906 & TRN \\
\hline CHEMBL1467859 & 688239 & 4.5362 & 5.5111 & TRN \\
\hline CHEMBL1981840 & 688239 & 4.9362 & 5.3525 & TST \\
\hline CHEMBL3212261 & 688239 & 5.4862 & 5.4781 & TST \\
\hline CHEMBL1414223 & 688239 & 5.1862 & 5.4311 & TST \\
\hline CHEMBL1610867 & 688239 & 4.6862 & 5.5035 & TRN \\
\hline CHEMBL1462109 & 688239 & 5.6862 & 5.398 & TST \\
\hline
\end{tabular}




\begin{tabular}{|c|c|c|c|c|}
\hline & & & pplement & al Table S \\
\hline CHEMBL1524140 & 688239 & 4.4862 & 5.5138 & TST \\
\hline CHEMBL1383779 & 688239 & 4.9362 & 5.5658 & TST \\
\hline CHEMBL1344281 & 688239 & 5.0862 & 5.5385 & TRN \\
\hline CHEMBL1473928 & 688239 & 4.6862 & 5.4383 & TST \\
\hline CHEMBL1316517 & 688239 & 5.0362 & 5.6423 & TST \\
\hline CHEMBL1300100 & 688239 & 6.2862 & 5.5932 & TST \\
\hline CHEMBL1415110 & 688239 & 4.5362 & 5.50700 & 0000000001 \\
\hline CHEMBL1439469 & 688239 & 6.1362 & 5.4953 & TRN \\
\hline CHEMBL1308935 & 688239 & 8.2366 & 5.5947 & TST \\
\hline CHEMBL1397077 & 688239 & 4.6862 & 5.4096 & TRN \\
\hline CHEMBL209398 & 688239 & 5.2362 & 5.6452 & TRN \\
\hline CHEMBL1306491 & 688239 & 4.6362 & 5.4959 & TRN \\
\hline CHEMBL1510394 & 688239 & 4.6362 & 5.6072 & TRN \\
\hline CHEMBL1344663 & 688239 & 5.4862 & 5.4837 & TST \\
\hline CHEMBL1539175 & 688239 & 5.9362 & 5.4904 & TRN \\
\hline CHEMBL1489239 & 688239 & 5.6362 & 5.3868 & TRN \\
\hline CHEMBL1507941 & 688239 & 4.6862 & 5.5808 & TRN \\
\hline CHEMBL1409457 & 688239 & 4.8862 & 5.4093 & TST \\
\hline CHEMBL1426585 & 688239 & 6.2362 & 5.641 & TRN \\
\hline CHEMBL1439284 & 688239 & 6.0862 & 5.5664 & TRN \\
\hline CHEMBL1320645 & 688239 & 7.1361 & 5.4083 & TRN \\
\hline CHEMBL1364948 & 688239 & 4.6362 & 5.5495 & TRN \\
\hline CHEMBL1383251 & 688239 & 4.7362 & 5.5527 & TRN \\
\hline CHEMBL1342028 & 688239 & 4.9862 & 5.5085 & TRN \\
\hline CHEMBL1473784 & 688239 & 5.1362 & 5.4931 & TRN \\
\hline CHEMBL1542566 & 688239 & 4.45 & 5.4855 & TRN \\
\hline CHEMBL1507426 & 688239 & 6.3362 & 5.6289 & TRN \\
\hline CHEMBL1365623 & 688239 & 5.9362 & 5.5408 & TRN \\
\hline CHEMBL1500845 & 688239 & 4.9362 & 5.5375 & TRN \\
\hline CHEMBL1613632 & 688239 & 7.1864 & 5.5788 & TRN \\
\hline CHEMBL 1488089 & 688239 & 4.7362 & 5.3709 & TST \\
\hline CHEMBL1373831 & 688239 & 8.2366 & 5.4934 & TST \\
\hline CHEMBL1430626 & 688239 & 4.7862 & 5.5647 & TRN \\
\hline CHEMBL1331334 & 688239 & 4.7862 & 5.4442 & TRN \\
\hline CHEMBL530361 & 688239 & 4.6362 & 5.3627 & TRN \\
\hline CHEMBL3214329 & 688239 & 6.4362 & 5.402 & TRN \\
\hline CHEMBL1425475 & 688239 & 5.1862 & 5.5683 & TRN \\
\hline CHEMBL1411001 & 688239 & 4.5362 & 5.5348 & TRN \\
\hline CHEMBL1573731 & 688239 & 4.5362 & 5.4721 & TST \\
\hline CHEMBL1545524 & 688239 & 5.3362 & 5.5337 & TRN \\
\hline CHEMBL1521223 & 688239 & 4.5362 & 5.4636 & TST \\
\hline CHEMBL1409516 & 688239 & 5.8862 & 5.4403 & TST \\
\hline CHEMBL 2005671 & 688239 & 6.8362 & 5.381 & TRN \\
\hline CHEMBL1321485 & 688239 & 5.1862 & 5.5428 & TST \\
\hline CHEMBL1490946 & 688239 & 6.4862 & 5.3699 & TRN \\
\hline CHEMBL1492032 & 688239 & 5.4862 & 5.5346 & TRN \\
\hline CHEMBL1523620 & 688239 & 4.5362 & 5.2721 & TRN \\
\hline CHEMBL1334916 & 688239 & 4.7862 & 5.5627 & TRN \\
\hline
\end{tabular}


Supplemental Table S2.txt

\begin{tabular}{|c|c|c|c|c|c|}
\hline CHEMBL1506263 & 688239 & 4.5362 & 5.3966 & TST & \\
\hline CHEMBL1374511 & 688239 & 6.1362 & 5.2215 & TST & \\
\hline CHEMBL1541130 & 688239 & 5.6362 & 5.5113 & TRN & \\
\hline CHEMBL1589061 & 688239 & 4.5862 & 5.5047 & TRN & \\
\hline CHEMBL1359257 & 688239 & 4.7862 & 5.4549 & TRN & \\
\hline CHEMBL1348977 & 688239 & 6.6861 & 5.3573 & TST & \\
\hline CHEMBL1348490 & 688239 & 5.1362 & 5.4656 & TRN & \\
\hline CHEMBL1580056 & 688239 & 6.2362 & 5.6272 & TRN & \\
\hline CHEMBL1477044 & 688239 & 4.5362 & 5.5773 & TRN & \\
\hline CHEMBL1528237 & 688239 & 4.6362 & 5.4305 & TST & \\
\hline CHEMBL1542699 & 688239 & 5.0 & 5.4693 & TRN & \\
\hline CHEMBL1339351 & 688239 & 5.1862 & 5.6107 & TRN & \\
\hline CHEMBL1489356 & 688239 & 4.7362 & 5.4804 & TRN & \\
\hline CHEMBL1584355 & 688239 & 6.2362 & 5.38 & TRN & \\
\hline CHEMBL1431884 & 688239 & 6.4362 & 5.30399 & 9999999999 & TRN \\
\hline CHEMBL3198248 & 688239 & 6.0862 & 5.3165 & TST & \\
\hline CHEMBL1527554 & 688239 & 5.1862 & 5.5056 & TST & \\
\hline CHEMBL594957 & 688239 & 6.9863 & 5.5395 & TST & \\
\hline CHEMBL1512368 & 688239 & 5.1862 & 5.5294 & TST & \\
\hline CHEMBL1551895 & 688239 & 6.7862 & 5.4333 & TRN & \\
\hline CHEMBL1345833 & 688239 & 5.5862 & 5.4414 & TRN & \\
\hline CHEMBL1378933 & 688239 & 8.3872 & 5.3935 & TRN & \\
\hline CHEMBL1583512 & 688239 & 4.8362 & 5.5156 & TRN & \\
\hline CHEMBL1495315 & 688239 & 4.8362 & 5.4888 & TST & \\
\hline CHEMBL1477230 & 688239 & 4.5362 & 5.6696 & TRN & \\
\hline CHEMBL1515541 & 688239 & 5.4362 & 5.5392 & TRN & \\
\hline CHEMBL1564254 & 688239 & 4.5362 & 5.6286 & TST & \\
\hline CHEMBL1409585 & 688239 & 4.5362 & 5.5117 & TRN & \\
\hline CHEMBL1346875 & 688239 & 4.7862 & 5.5624 & TST & \\
\hline CHEMBL1428540 & 688239 & 5.6862 & 5.5552 & TRN & \\
\hline CHEMBL1426295 & 688239 & 4.7862 & 5.3399 & TRN & \\
\hline CHEMBL1578626 & 688239 & 5.5362 & 5.4299 & TRN & \\
\hline CHEMBL1565131 & 688239 & 5.6362 & 5.2694 & TRN & \\
\hline CHEMBL3197239 & 688239 & 5.6862 & 5.5676 & TRN & \\
\hline CHEMBL1568266 & 688239 & 5.0862 & 5.599 & TST & \\
\hline CHEMBL1414410 & 688239 & 6.1862 & 5.4924 & TST & \\
\hline CHEMBL1400634 & 688239 & 6.0362 & 5.5555 & TRN & \\
\hline CHEMBL1397303 & 688239 & 5.7862 & 5.4735 & TRN & \\
\hline CHEMBL1587280 & 688239 & 4.5362 & 5.6224 & TRN & \\
\hline CHEMBL1332977 & 688239 & 5.9362 & 5.3905 & TRN & \\
\hline CHEMBL1357925 & 688239 & 5.0362 & 5.4278 & TRN & \\
\hline CHEMBL1515800 & 688239 & 5.4862 & 5.50899 & 99999999995 & TRN \\
\hline CHEMBL1580698 & 688239 & 4.5362 & 5.5221 & TST & \\
\hline CHEMBL1401597 & 688239 & 5.3862 & 5.4221 & TRN & \\
\hline CHEMBL1382852 & 688239 & 6.1362 & 5.5296 & TRN & \\
\hline CHEMBL3191815 & 688239 & 4.8362 & 5.4384 & TST & \\
\hline CHEMBL1334835 & 688239 & 4.8862 & 5.4888 & TRN & \\
\hline CHEMBL1444409 & 688239 & 6.1862 & 5.6337 & TRN & \\
\hline
\end{tabular}


Supplemental Table S2.txt

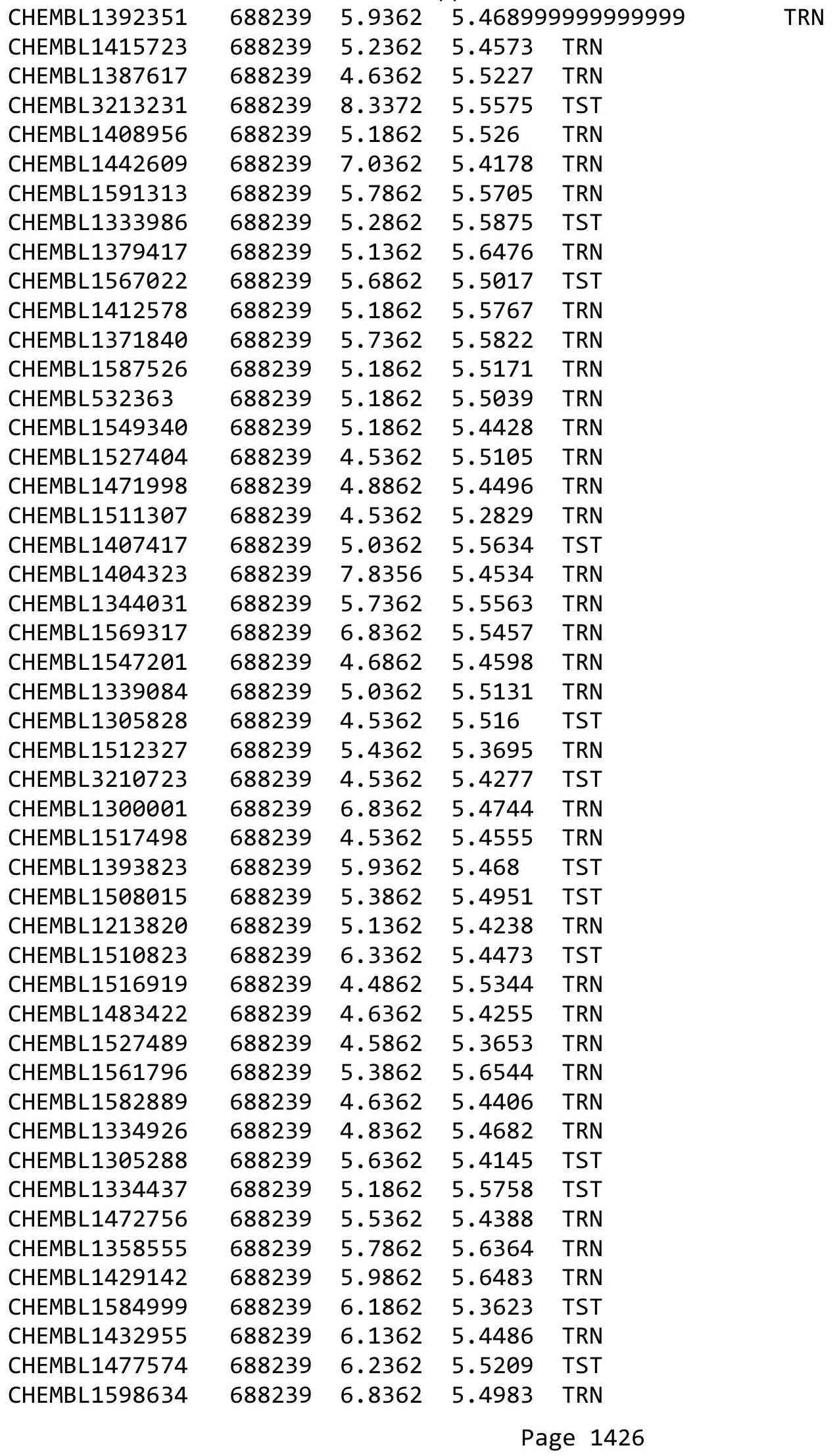


Supplemental Table S2.txt

\begin{tabular}{|c|c|c|c|c|c|c|}
\hline CHEMBL1362698 & 688239 & 8.3872 & 5.5617 & TRN & & \\
\hline CHEMBL1584170 & 688239 & 4.6362 & 5.32 & TST & & \\
\hline CHEMBL1452419 & 688239 & 5.8862 & 5.5689 & TRN & & \\
\hline CHEMBL1441868 & 688239 & 5.1362 & 5.2404 & TST & & \\
\hline CHEMBL1541442 & 688239 & 5.0862 & 5.3835 & TRN & & \\
\hline CHEMBL1532131 & 688239 & 4.6862 & 5.4987 & TRN & & \\
\hline CHEMBL1395376 & 688239 & 4.6862 & 5.5058 & TRN & & \\
\hline CHEMBL1483941 & 688239 & 5.0862 & 5.3283 & TST & & \\
\hline CHEMBL1371579 & 688239 & 5.6862 & 5.5568 & TRN & & \\
\hline CHEMBL1586330 & 688239 & 4.5362 & 5.5434 & TST & & \\
\hline CHEMBL1366390 & 688239 & 5.4362 & 5.4391 & TST & & \\
\hline CHEMBL1592771 & 688239 & 7.0362 & 5.2763 & TRN & & \\
\hline CHEMBL1407311 & 688239 & 6.2362 & 5.4724 & TST & & \\
\hline CHEMBL1410720 & 688239 & 6.5363 & 5.3807 & TRN & & \\
\hline CHEMBL1364729 & 688239 & 6.0862 & 5.4771 & TST & & \\
\hline CHEMBL1424855 & 688239 & 5.1862 & 5.4703 & TRN & & \\
\hline CHEMBL1581336 & 688239 & 4.4862 & 5.4812 & TRN & & \\
\hline CHEMBL1568936 & 688239 & 6.1862 & 5.5874 & TRN & & \\
\hline CHEMBL1425841 & 688239 & 6.8362 & 5.5886 & TRN & & \\
\hline CHEMBL444357 & 688239 & 5.9862 & 5.4434 & TRN & & \\
\hline CHEMBL1367710 & 688239 & 5.2362 & 5.5789 & TRN & & \\
\hline CHEMBL1452833 & 688239 & 5.4362 & 5.6327 & TST & & \\
\hline CHEMBL1432407 & 688239 & 4.5362 & 5.4676 & TRN & & \\
\hline CHEMBL1500156 & 688239 & 7.2865 & 5.6158 & TRN & & \\
\hline CHEMBL1437979 & 688239 & 4.7862 & 5.4767 & TRN & & \\
\hline CHEMBL1513765 & 688239 & 4.5362 & 5.4773 & TRN & & \\
\hline CHEMBL1569171 & 688239 & 5.2862 & 5.5919 & TST & & \\
\hline CHEMBL1463404 & 688239 & 5.1862 & 5.5321 & TRN & & \\
\hline CHEMBL1311509 & 688239 & 6.2362 & 5.3457 & TRN & & \\
\hline CHEMBL1350669 & 688239 & 5.4362 & 5.5446 & TST & & \\
\hline CHEMBL1393708 & 688239 & 4.5362 & 5.5818 & TRN & & \\
\hline CHEMBL1452336 & 688239 & 6.1862 & 5.4388 & TRN & & \\
\hline CHEMBL1353248 & 688239 & 4.7862 & 5.4619 & TRN & & \\
\hline CHEMBL1997635 & 688239 & 4.5862 & 5.3944 & TRN & & \\
\hline CHEMBL3210930 & 688239 & 4.5362 & 5.5191 & TRN & & \\
\hline CHEMBL1590859 & 688239 & 5.1362 & 5.4338 & TST & & \\
\hline CHEMBL1507355 & 688239 & 4.6362 & 5.5424 & TRN & & \\
\hline CHEMBL1559624 & 688239 & 8.28399 & 999999999 & 99 & 5.2314 & TRN \\
\hline CHEMBL1539111 & 688239 & 8.3372 & 5.5088 & TRN & & \\
\hline CHEMBL1604014 & 688239 & 6.3362 & 5.5744 & TRN & & \\
\hline CHEMBL1488374 & 688239 & 5.5862 & 5.55 & TRN & & \\
\hline CHEMBL1563574 & 688239 & 6.9363 & 5.3932 & TRN & & \\
\hline CHEMBL1495661 & 688239 & 6.0362 & 5.6305 & TRN & & \\
\hline CHEMBL1418543 & 688239 & 6.1862 & 5.4644 & TRN & & \\
\hline CHEMBL1301445 & 688239 & 5.5862 & 5.3547 & TRN & & \\
\hline CHEMBL1436016 & 688239 & 4.9362 & 5.4961 & TRN & & \\
\hline CHEMBL1596135 & 688239 & 8.28399 & 999999999 & 99 & 5.6838 & TRN \\
\hline CHEMBL1362806 & 688239 & 4.5362 & 5.4869 & TRN & & \\
\hline
\end{tabular}


Supplemental Table S2.txt

\begin{tabular}{|c|c|c|c|c|}
\hline CHEMBL1510038 & 688239 & 5.6862 & 5.2879 & TRN \\
\hline CHEMBL1506943 & 688239 & 4.7362 & 5.4818 & TST \\
\hline CHEMBL1569391 & 688239 & 4.7862 & 5.5707 & TST \\
\hline CHEMBL1355356 & 688239 & 4.5862 & 5.3235 & TST \\
\hline CHEMBL3195702 & 688239 & 4.5362 & 5.3483 & TST \\
\hline CHEMBL1403973 & 688239 & 4.4862 & 5.4554 & TRN \\
\hline CHEMBL1577285 & 688239 & 5.2362 & 5.5467 & TRN \\
\hline CHEMBL1488141 & 688239 & 5.7362 & 5.4203 & TRN \\
\hline CHEMBL1502816 & 688239 & 5.4862 & 5.5806 & TRN \\
\hline CHEMBL1471907 & 688239 & 4.5362 & 5.3869 & TRN \\
\hline CHEMBL1451546 & 688239 & 5.1862 & 5.4584 & TST \\
\hline CHEMBL1489168 & 688239 & 4.5362 & 5.4716 & TRN \\
\hline CHEMBL1447620 & 688239 & 6.8861 & 5.6193 & TRN \\
\hline CHEMBL1341044 & 688239 & 5.7362 & 5.697 & TRN \\
\hline CHEMBL1601622 & 688239 & 5.0862 & 5.4812 & TRN \\
\hline CHEMBL1592667 & 688239 & 5.1362 & 5.6087 & TST \\
\hline CHEMBL1581154 & 688239 & 8.0862 & 5.5364 & TST \\
\hline CHEMBL1546944 & 688239 & 6.5862 & 5.454 & TRN \\
\hline CHEMBL1423519 & 688239 & 4.6362 & 5.5556 & TRN \\
\hline CHEMBL1426562 & 688239 & 4.7862 & $5.45200 e$ & 0000 \\
\hline CHEMBL1495739 & 688239 & 5.6362 & 5.4527 & TST \\
\hline CHEMBL1534157 & 688239 & 4.7862 & 5.3442 & TRN \\
\hline CHEMBL1343493 & 688239 & 6.5862 & 5.4746 & TST \\
\hline CHEMBL1349361 & 688239 & 5.3862 & 5.5288 & TRN \\
\hline CHEMBL1509148 & 688239 & 6.6362 & 5.3268 & TST \\
\hline CHEMBL1388805 & 688239 & 6.1862 & 5.4204 & TRN \\
\hline CHEMBL1488014 & 688239 & 4.6362 & 5.5306 & TRN \\
\hline CHEMBL1321831 & 688239 & 5.3862 & 5.4107 & TRN \\
\hline CHEMBL1568286 & 688239 & 6.7862 & 5.6399 & TST \\
\hline CHEMBL1392186 & 688239 & 5.8862 & 5.5151 & TST \\
\hline CHEMBL1322796 & 688239 & 4.5362 & 5.5868 & TST \\
\hline CHEMBL1542793 & 688239 & 5.4362 & 5.5141 & TRN \\
\hline CHEMBL1402978 & 688239 & 5.4362 & 5.5443 & TRN \\
\hline CHEMBL1456839 & 688239 & 5.3362 & 5.5354 & TRN \\
\hline CHEMBL1502519 & 688239 & 5.6362 & 5.5863 & TRN \\
\hline CHEMBL 2369218 & 688239 & 4.6362 & 5.2663 & TST \\
\hline CHEMBL1583997 & 688239 & 6.1362 & 5.4644 & TRN \\
\hline CHEMBL1419653 & 688239 & 4.5362 & 5.5915 & TRN \\
\hline CHEMBL1348826 & 688239 & 5.9862 & 5.407 & TRN \\
\hline CHEMBL1558322 & 688239 & 6.9363 & 5.5901 & TRN \\
\hline CHEMBL1426206 & 688239 & 4.5362 & 5.4839 & TRN \\
\hline CHEMBL1587562 & 688239 & 4.6862 & 5.5252 & TRN \\
\hline CHEMBL1354277 & 688239 & 5.5862 & 5.4589 & TST \\
\hline CHEMBL1379808 & 688239 & 4.5862 & 5.5221 & TST \\
\hline CHEMBL1333517 & 688239 & 6.0862 & 5.4977 & TRN \\
\hline CHEMBL1425219 & 688239 & 4.5362 & 5.5287 & TRN \\
\hline CHEMBL1547494 & 688239 & 5.3362 & 5.5747 & TRN \\
\hline CHEMBL1333835 & 688239 & 4.8862 & 5.3859 & TRN \\
\hline
\end{tabular}


Supplemental Table S2.txt

\begin{tabular}{|c|c|c|c|c|}
\hline 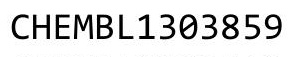 & & & & \\
\hline HEMBL3189412 & 88239 & 5862 & 838 & \\
\hline HEMBL131 & 88239 & 8362 & & \\
\hline IEMBL1 & & & & \\
\hline EMBL13 & & & & \\
\hline HEMBL1551665 & 88239 & 362 & 132 & \\
\hline HEMBL1531230 & 88239 & .0862 & .4253 & \\
\hline HEMBL1493574 & 239 & 862 & & \\
\hline IEMBL14 & 39 & 862 & & \\
\hline IEMBL15] & 39 & 867 & & \\
\hline HEMBL1392264 & 88239 & 362 & & \\
\hline HEMBL1310740 & 39 & 362 & & \\
\hline HEMBL159 & 39 & 862 & 21 & \\
\hline HEMBL154 & & & & \\
\hline HEMBL16 & 39 & 862 & & \\
\hline HEMBL 319 & 39 & 372 & & \\
\hline HEMBL1306309 & 88 & 362 & 22 & \\
\hline HEMBL141 & 39 & 872 & 59 & \\
\hline HEMBL158 & & & & \\
\hline HEME & 39 & & & DN \\
\hline HEMBL139 & 39 & & & ST \\
\hline HEMBL145€ & 39 & 62 & 58 & RN \\
\hline HEMBL152 & 39 & 362 & 25 & \\
\hline HEMBL14 & & & & \\
\hline HEM & & & & RN \\
\hline AEMBL156 & 39 & & & ST \\
\hline HEMBL134 & 39 & 362 & 94 & $R / N$ \\
\hline HEMBL138 & 39 & 66 & & \\
\hline HFM & & & & ST \\
\hline HEM & & & & RN \\
\hline HEMBL159 & 9 & & & RN \\
\hline HEMBL133: & 39 & 362 & & ST \\
\hline JEMBL147 & 39 & 362 & & RN \\
\hline 1 & & & & RN \\
\hline HEMBL137 & & & & ST \\
\hline HEMBL157 & 39 & & & RN \\
\hline HEMBL130 & 39 & 362 & & RN \\
\hline JEMBL133 & 39 & 62 & & I \\
\hline 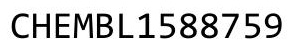 & & & & RN \\
\hline HEMBL159 & & & & RN \\
\hline HEMBL147: & 39 & 362 & & $\mathrm{RN}$ \\
\hline HEMBL15 & 39 & 62 & & RN \\
\hline HEMBL159 & & & & \\
\hline & & & & RN \\
\hline HEMBL152 & & .5361 & . 4515 & ST \\
\hline HEMBL142 & 88 & 362 & 29 & RN \\
\hline 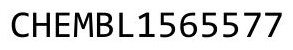 & & & & \\
\hline & & & & \\
\hline
\end{tabular}

Page 1429 
Supplemental Table S2.txt

\begin{tabular}{|c|c|c|c|c|}
\hline CHEMBL1310555 & 688239 & 4.5362 & 5.4466 & TRN \\
\hline CHEMBL1560181 & 688239 & 6.5363 & 5.4533 & TRN \\
\hline CHEMBL1429046 & 688239 & 4.7862 & 5.3194 & TRN \\
\hline CHEMBL1374352 & 688239 & 6.7361 & 5.5743 & TRN \\
\hline CHEMBL 3193829 & 688239 & 6.5363 & 5.5518 & TRN \\
\hline CHEMBL1561898 & 688239 & 4.6362 & 5.5532 & TST \\
\hline CHEMBL1311609 & 688239 & 4.4862 & 5.3785 & TST \\
\hline CHEMBL1463755 & 688239 & 4.5362 & 5.4587 & TRN \\
\hline CHEMBL1572702 & 688239 & 5.1862 & 5.4742 & TRN \\
\hline CHEMBL1582567 & 688239 & 6.9363 & 5.3731 & TRN \\
\hline CHEMBL1406841 & 688239 & 8.3372 & 5.4702 & TST \\
\hline CHEMBL1540830 & 688239 & 4.4862 & 5.4109 & TRN \\
\hline CHEMBL1334095 & 688239 & 4.6362 & 5.4501 & TRN \\
\hline CHEMBL1341790 & 688239 & 5.0862 & 5.3644 & TRN \\
\hline CHEMBL1558298 & 688239 & 4.5362 & 5.49 & TRN \\
\hline CHEMBL1453479 & 688239 & 4.7362 & 5.4476 & TRN \\
\hline CHEMBL1465190 & 688239 & 5.1862 & 5.4053 & TST \\
\hline CHEMBL1534717 & 688239 & 5.3862 & 5.4112 & TST \\
\hline CHEMBL3213286 & 688239 & 4.6862 & 5.4452 & TST \\
\hline CHEMBL1559827 & 688239 & 6.9363 & 5.5734 & TRN \\
\hline CHEMBL1456376 & 688239 & 7.7352 & 5.4524 & TRN \\
\hline CHEMBL1461341 & 688239 & 4.7862 & 5.3997 & TRN \\
\hline CHEMBL1301380 & 688239 & 5.1862 & 5.5573 & TRN \\
\hline CHEMBL1308404 & 688239 & 5.4362 & 5.3226 & TRN \\
\hline CHEMBL1599975 & 688239 & 8.3372 & 5.5175 & TRN \\
\hline CHEMBL1587597 & 688239 & 8.1367 & 5.58299 & э9999999999 \\
\hline CHEMBL1464973 & 688239 & 5.3362 & 5.4336 & TRN \\
\hline CHEMBL1381335 & 688239 & 5.5362 & 5.4395 & TRN \\
\hline CHEMBL1544707 & 688239 & 5.6862 & 5.6505 & TRN \\
\hline CHEMBL1555421 & 688239 & 5.6362 & 5.4881 & TRN \\
\hline CHEMBL1512135 & 688239 & 4.5862 & 5.3702 & TRN \\
\hline CHEMBL1475172 & 688239 & 7.2366 & 5.49799 & 9999999999 \\
\hline CHEMBL1367503 & 688239 & 4.4862 & 5.6168 & TRN \\
\hline CHEMBL1363682 & 688239 & 5.1862 & 5.409 & TRN \\
\hline CHEMBL1528893 & 688239 & 4.6362 & 5.4409 & TRN \\
\hline CHEMBL1467893 & 688239 & 6.2362 & 5.4459 & TRN \\
\hline CHEMBL1538193 & 688239 & 4.5362 & 5.5456 & TRN \\
\hline CHEMBL1580146 & 688239 & 5.7862 & 5.4822 & TRN \\
\hline CHEMBL1556070 & 688239 & 4.8362 & 5.4689 & TRN \\
\hline CHEMBL1506966 & 688239 & 5.3862 & 5.4922 & TST \\
\hline CHEMBL1432187 & 688239 & 4.4862 & 5.3908 & TRN \\
\hline CHEMBL1467203 & 688239 & 6.4362 & 5.5633 & TST \\
\hline CHEMBL1525057 & 688239 & 5.6362 & 5.5596 & TRN \\
\hline CHEMBL1607871 & 688239 & 5.5862 & 5.5505 & TRN \\
\hline CHEMBL1329725 & 688239 & 5.4362 & 5.4256 & TRN \\
\hline CHEMBL1571496 & 688239 & 6.7361 & 5.5629 & TRN \\
\hline CHEMBL1392463 & 688239 & 5.5862 & 5.5759 & TST \\
\hline CHEMBL1441798 & 688239 & 5.2862 & 5.4486 & TRN \\
\hline
\end{tabular}


Supplemental Table S2.txt

\begin{tabular}{|c|c|c|c|c|}
\hline CHEMBL1605549 & 688239 & 4.5362 & 5.6261 & TST \\
\hline CHEMBL1994266 & 688239 & 5.2362 & 5.4407 & TST \\
\hline CHEMBL1333301 & 688239 & 6.8861 & 5.4985 & TRN \\
\hline CHEMBL1313573 & 688239 & 4.5362 & 5.4995 & TRN \\
\hline CHEMBL1402524 & 688239 & 4.5362 & 5.5503 & TRN \\
\hline CHEMBL1449900 & 688239 & 4.6862 & 5.5933 & TST \\
\hline CHEMBL1578147 & 688239 & 5.0862 & 5.4506 & TRN \\
\hline CHEMBL1310679 & 688239 & 4.5362 & 5.4714 & TRN \\
\hline CHEMBL1526389 & 688239 & 4.5362 & 5.5775 & TST \\
\hline CHEMBL1495014 & 688239 & 5.6362 & 5.4811 & TRN \\
\hline CHEMBL1993316 & 688239 & 6.8861 & 5.4544 & TRN \\
\hline CHEMBL1420288 & 688239 & 8.2366 & 5.4417 & TRN \\
\hline CHEMBL 2005139 & 688239 & 4.6362 & 5.3826 & TST \\
\hline CHEMBL1370221 & 688239 & 4.6362 & 5.6442 & TRN \\
\hline CHEMBL1528023 & 688239 & 4.5362 & 5.4479 & TRN \\
\hline CHEMBL1529235 & 688239 & 7.1864 & 5.4476 & TRN \\
\hline CHEMBL1421950 & 688239 & 8.28399 & 99999999 & 5.6311 \\
\hline CHEMBL1500251 & 688239 & 4.5362 & 5.5011 & TRN \\
\hline CHEMBL1604919 & 688239 & 4.6362 & 5.3239 & TRN \\
\hline CHEMBL1505633 & 688239 & 5.2862 & 5.4769 & TRN \\
\hline CHEMBL1529375 & 688239 & 6.9363 & 5.4142 & TRN \\
\hline CHEMBL1547901 & 688239 & 5.1862 & 5.5578 & TRN \\
\hline CHEMBL1537181 & 688239 & 5.7862 & 5.4598 & TRN \\
\hline CHEMBL 3214176 & 688239 & 6.5363 & 5.5164 & TRN \\
\hline CHEMBL1425991 & 688239 & 5.7862 & 5.4651 & TRN \\
\hline CHEMBL1486679 & 688239 & 4.5362 & 5.5687 & TRN \\
\hline CHEMBL1319882 & 688239 & 4.7862 & 5.4391 & TRN \\
\hline CHEMBL1492382 & 688239 & 6.5363 & 5.4264 & TRN \\
\hline CHEMBL1494173 & 688239 & 6.1362 & 5.4672 & TRN \\
\hline CHEMBL1609863 & 688239 & 5.0 & 5.5392 & TRN \\
\hline CHEMBL1315573 & 688239 & 5.1862 & 5.4364 & TRN \\
\hline CHEMBL1550299 & 688239 & 6.2362 & 5.5438 & TRN \\
\hline CHEMBL1425860 & 688239 & 6.0862 & 5.5808 & TST \\
\hline CHEMBL1592626 & 688239 & 5.1362 & 5.4436 & TRN \\
\hline CHEMBL1522051 & 688239 & 5.4862 & 5.4574 & TRN \\
\hline CHEMBL1511060 & 688239 & 6.2362 & 5.5104 & TRN \\
\hline CHEMBL1565317 & 688239 & 5.4362 & 5.4517 & TRN \\
\hline CHEMBL1583069 & 688239 & 4.6862 & 5.4501 & TST \\
\hline CHEMBL1589679 & 688239 & 6.9363 & 5.537000 & 000000001 \\
\hline CHEMBL1391383 & 688239 & 5.5862 & 5.4023 & TRN \\
\hline CHEMBL1538083 & 688239 & 5.1862 & 5.4173 & TRN \\
\hline CHEMBL1429549 & 688239 & 4.5362 & 5.4206 & TST \\
\hline CHEMBL1482710 & 688239 & 5.1362 & 5.4538 & TRN \\
\hline CHEMBL1470662 & 688239 & 5.6862 & 5.7162 & TST \\
\hline CHEMBL1348239 & 688239 & 5.0362 & 5.5383 & TST \\
\hline CHEMBL1468509 & 688239 & 6.1362 & 5.6034 & TRN \\
\hline CHEMBL3199351 & 688239 & 6.8861 & 5.4693 & TRN \\
\hline CHEMBL1482438 & 688239 & 4.4862 & 5.2347 & TRN \\
\hline
\end{tabular}


Supplemental Table S2.txt

\begin{tabular}{|c|c|c|c|c|}
\hline HEMBL & & 2362 & & \\
\hline HГMDI 146719 & & .7862 & & \\
\hline 19 & & & & \\
\hline AEMBL1 & & 862 & & \\
\hline AEMBL1581541 & 8239 & 362 & & \\
\hline HEMBL1375173 & 88239 & 5862 & 5408 & \\
\hline HEMBL1 & 239 & 363 & & \\
\hline 860 & & & & \\
\hline IEMBL13 & & & & \\
\hline HEMBL13 & 38239 & 862 & & \\
\hline HEMBL14 & 239 & 362 & & \\
\hline IEMBL1; & 39 & & & \\
\hline IEMBL1 & & & & \\
\hline HEMBL15 & & 362 & & \\
\hline AEMBL15 & & & & \\
\hline AEMBL1: & 39 & 62 & & \\
\hline HEMBL15 & 39 & & & \\
\hline HEMBL16 & & & & \\
\hline AEMBL13 & & 62 & & \\
\hline AEMBL13 & & & & \\
\hline HEMBLI & & 52 & 63 & ו \\
\hline AEMBL1: & & & & \\
\hline AEMBL3: & & & & \\
\hline AEMBL1C & & & & \\
\hline AEMBL14 & & & & I NIV \\
\hline HEMBL1 & & & & RN \\
\hline HEMBL1 & & & & 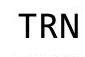 \\
\hline HFMBI 12 & & & & \\
\hline HEMBL14 & & & & $T_{2}$ \\
\hline HEMBL13 & & & & 15 \\
\hline HEMBL1: & & & & RN \\
\hline HEMBL & & & & ST \\
\hline HEMBL: & & & & ST \\
\hline HEMBL13 & & & & is \\
\hline HEMBL1328775 & & & 5 . & TRN \\
\hline HEMBL1 & & & & ST \\
\hline HᄃMP 1 & & & & RN \\
\hline & & & & ГRN \\
\hline HEMBL 15 & & & & $\Gamma R$ \\
\hline JEMBL14 & & & & $\mathrm{RN}$ \\
\hline HEMBL13 & & & 21 & ГRN \\
\hline HEMBL15 & & & & ГST \\
\hline HEMBL16 & & & & $\Gamma R$ \\
\hline AEMBL14 & 39 & 862 & & TR \\
\hline MBL13 & & & & 3 \\
\hline HEMBL14 & & & & \\
\hline HEMBL13 & & & & \\
\hline HEMBL1526313 & 688239 & 6.7361 & 5.4305 & \\
\hline
\end{tabular}

Page 1432 
Supplemental Table S2.txt

\begin{tabular}{|c|c|c|c|c|}
\hline- & & & & \\
\hline HЕMP 1566151 & 88239 & 6862 & $5.438 \varepsilon$ & \\
\hline & & & & \\
\hline$M D 1$. & 39 & & 18 & \\
\hline IEMBL14 & 38239 & 862 & & \\
\hline AEMBL1448308 & 88239 & 2362 & 5204 & \\
\hline JEMBL13 & 88239 & 362 & 5165 & \\
\hline 373 & 8239 & 361 & & \\
\hline EMBL13 & 88239 & 372 & & \\
\hline AEMBL1548048 & 88239 & 5862 & & \\
\hline AEMBL1547409 & 88239 & 4862 & & \\
\hline IEMBL15 & 38239 & 363 & 64 & \\
\hline IEMBL15 & & & & \\
\hline AEMBL1 & 88239 & & & \\
\hline JEMBL3210018 & 88239 & 362 & & \\
\hline IEMBL1526731 & 88239 & 7362 & 08 & \\
\hline AEMBL1611086 & 38239 & 862 & 69 & \\
\hline HEMBL15 & 38239 & 862 & & \\
\hline 51 & 88239 & 362 & & \\
\hline IEMBL14 & 39 & 362 & & \\
\hline IEMBL1443987 & 38239 & 362 & & \\
\hline HEMBL15 & 38239 & 362 & 489 & \\
\hline AEMBL14 & 8239 & & & \\
\hline 22 & 39 & 862 & & RN \\
\hline AEMBL16 & 39 & 52 & & ГST \\
\hline L14 & 39 & 56 & 69 & RI \\
\hline 133 & 8239 & 62 & 82 & $\mathrm{RN}$ \\
\hline 6 & 39 & 62 & & RN \\
\hline 84 & & & & RN \\
\hline HEMBL138 & 39 & 62 & +3 & RN \\
\hline IEMBL144€ & 39 & 362 & 292 & \\
\hline 79 & 39 & 52 & 775 & \\
\hline & & & & ST \\
\hline AEMBL1377494 & & & & RN \\
\hline AEMBL1369914 & 88239 & 62 & 909 & RN \\
\hline AEMBL1 & 39 & 62 & 68 & \\
\hline IFMDI 1 - & & & & RN \\
\hline HEMBL1502604 & & & & RN \\
\hline HEMBL1326419 & 88239 & 872 & 053 & TRN \\
\hline IEMBL145 & 39 & 362 & .5584 & RN \\
\hline HEMBL13 & 39 & 362 & 308 & \\
\hline & & & & \\
\hline HEMBL1506399 & 8239 & 362 & 558 & TST \\
\hline IEMBL1535251 & 88239 & 862 & 082 & $\Gamma R$ \\
\hline FMPI 12 & 88239 & & & \\
\hline HEMBL14 & & 862 & & \\
\hline (4) & 88239 & 4.5362 & 5.4976 & \\
\hline CHEMBL1339465 & 688239 & 5.0362 & 5.5493 & ГRN \\
\hline
\end{tabular}

Page 1433 
Supplemental Table S2.txt

\begin{tabular}{|c|c|c|c|c|}
\hline CHEMBL1304538 & 688239 & 4.5362 & 5.6104 & TRN \\
\hline CHEMBL130596 & 688239 & 6.0362 & 5.5683 & TST \\
\hline CHEMBL1541807 & 688239 & 4.5362 & 5.5046 & TRN \\
\hline CHEMBL1451579 & 688239 & 7.5867 & 5.5483 & TRN \\
\hline CHEMBL1431727 & 688239 & 5.4862 & 5.4717 & TRN \\
\hline CHEMBL1372798 & 688239 & 5.6862 & 5.5183 & TST \\
\hline CHEMBL1447641 & 688239 & 5.2862 & 5.5966 & TRN \\
\hline CHEMBL1402997 & 688239 & 5.4362 & 5.4696 & TST \\
\hline CHEMBL1359642 & 688239 & 4.5362 & 5.5284 & TRN \\
\hline CHEMBL1326240 & 688239 & 6.1362 & 5.5566 & TST \\
\hline CHEMBL1390661 & 688239 & 5.0362 & 5.5844 & TRN \\
\hline CHEMBL1582872 & 688239 & 4.5362 & 5.33200 & 0000000001 \\
\hline CHEMBL1308187 & 688239 & 6.1362 & 5.4658 & TST \\
\hline CHEMBL1493477 & 688239 & 4.4862 & 5.4448 & TRN \\
\hline CHEMBL1517640 & 688239 & 5.0362 & 5.49700 & 0000000001 \\
\hline CHEMBL1351392 & 688239 & 4.7862 & 5.5524 & TRN \\
\hline CHEMBL3195559 & 688239 & 5.8862 & 5.4715 & TRN \\
\hline CHEMBL1587443 & 688239 & 4.8362 & 5.579 & TRN \\
\hline CHEMBL1439036 & 688239 & 4.9362 & 5.4385 & TST \\
\hline CHEMBL3196453 & 688239 & 5.5362 & 5.45299 & 9999999999 \\
\hline CHEMBL1531126 & 688239 & 4.5362 & 5.4539 & TRN \\
\hline CHEMBL1482530 & 688239 & 4.5362 & 5.5455 & TRN \\
\hline CHEMBL1525570 & 688239 & 5.6362 & 5.4617 & TRN \\
\hline CHEMBL1534861 & 688239 & 4.8362 & 5.6065 & TST \\
\hline CHEMBL1353062 & 688239 & 5.6862 & 5.4136 & TRN \\
\hline CHEMBL1351559 & 688239 & 6.1362 & 5.5279 & TRN \\
\hline CHEMBL1392171 & 688239 & 4.9362 & 5.4635 & TRN \\
\hline CHEMBL1545489 & 688239 & 4.5362 & 5.3459 & TST \\
\hline CHEMBL1344876 & 688239 & 5.1862 & 5.4997 & TRN \\
\hline CHEMBL1420837 & 688239 & 4.8362 & 5.5176 & TRN \\
\hline CHEMBL1501389 & 688239 & 5.2362 & 5.5793 & TRN \\
\hline CHEMBL1345331 & 688239 & 4.5362 & 5.3695 & TRN \\
\hline CHEMBL1575887 & 688239 & 5.4362 & 5.40799 & \\
\hline CHEMBL1436869 & 688239 & 4.5362 & 5.4356 & TRN \\
\hline CHEMBL1413818 & 688239 & 5.1862 & 5.495 & TRN \\
\hline CHEMBL1361001 & 688239 & 5.9362 & 5.4706 & TST \\
\hline CHEMBL1561134 & 688239 & 8.2366 & 5.5118 & TRN \\
\hline CHEMBL1494339 & 688239 & 4.5362 & 5.5541 & TRN \\
\hline CHEMBL1477751 & 688239 & 8.1367 & 5.5526 & TRN \\
\hline CHEMBL1540821 & 688239 & 4.7362 & 5.432 & TST \\
\hline CHEMBL1593305 & 688239 & 6.9863 & 5.3533 & TRN \\
\hline CHEMBL1544384 & 688239 & 4.6862 & 5.5484 & TST \\
\hline CHEMBL1379375 & 688239 & 5.3862 & 5.4511 & TRN \\
\hline CHEMBL1383497 & 688239 & 4.5362 & 5.4593 & TRN \\
\hline CHEMBL1380481 & 688239 & 6.0362 & 5.5586 & TRN \\
\hline CHEMBL1994523 & 688239 & 4.6862 & 5.4389 & TRN \\
\hline CHEMBL1572098 & 688239 & 4.9862 & 5.5282 & TRN \\
\hline CHEMBL1359296 & 688239 & 4.5362 & 5.37 & TST \\
\hline
\end{tabular}


Supplemental Table S2.txt

\begin{tabular}{|c|c|c|c|c|c|}
\hline CHEMBL1427761 & 688239 & 5.1862 & 5.4189 & TRN & \\
\hline CHEMBL1418122 & 688239 & 4.7362 & 5.4383 & TRN & \\
\hline CHEMBL1455428 & 688239 & 4.4862 & 5.5476 & TRN & \\
\hline CHEMBL1570726 & 688239 & 5.6862 & 5.619 & TST & \\
\hline CHEMBL1456916 & 688239 & 4.6362 & 5.6013 & TRN & \\
\hline CHEMBL1582755 & 688239 & 5.6862 & 5.5924 & TST & \\
\hline CHEMBL 1467745 & 688239 & 5.6862 & 5.4529 & TST & \\
\hline CHEMBL1330359 & 688239 & 6.5862 & 5.5268 & TRN & \\
\hline CHEMBL1591227 & 688239 & 6.1862 & 5.5253 & TRN & \\
\hline CHEMBL1503040 & 688239 & 4.7862 & 5.5442 & TST & \\
\hline CHEMBL1400707 & 688239 & 4.7362 & 5.6979 & TRN & \\
\hline CHEMBL1471570 & 688239 & 4.5362 & 5.6481 & TST & \\
\hline CHEMBL1486228 & 688239 & 6.4862 & 5.5765 & TRN & \\
\hline CHEMBL1346785 & 688239 & 5.1862 & 5.4984 & TST & \\
\hline CHEMBL1987798 & 688239 & 4.6362 & 5.3487 & TRN & \\
\hline CHEMBL1577147 & 688239 & 4.7862 & 5.4423 & TRN & \\
\hline CHEMBL1317437 & 688239 & 4.7362 & 5.3222 & TRN & \\
\hline CHEMBL1612503 & 688239 & 5.1362 & 5.3144 & TRN & \\
\hline CHEMBL1341972 & 688239 & 4.7862 & 5.5548 & TRN & \\
\hline CHEMBL1465362 & 688239 & 4.5362 & 5.5072 & TRN & \\
\hline CHEMBL1488719 & 688239 & 5.3862 & 5.4874 & TRN & \\
\hline CHEMBL1596842 & 688239 & 5.3362 & 5.4324 & TRN & \\
\hline CHEMBL1589665 & 688239 & 5.9362 & 5.6231 & TRN & \\
\hline CHEMBL1571448 & 688239 & 5.1362 & 5.3863 & TRN & \\
\hline CHEMBL1305570 & 688239 & 6.0862 & 5.4225 & TRN & \\
\hline CHEMBL1306068 & 688239 & 6.6362 & 5.5599 & TRN & \\
\hline CHEMBL1390629 & 688239 & 6.8861 & 5.3904 & TRN & \\
\hline CHEMBL1483926 & 688239 & 4.9362 & 5.4626 & TRN & \\
\hline CHEMBL1451423 & 688239 & 8.283999 & 999999999 & 9 & 5.385 \\
\hline CHEMBL 3209980 & 688239 & 4.5362 & 5.3985 & TRN & \\
\hline CHEMBL1385518 & 688239 & 5.0362 & 5.5527 & TST & \\
\hline CHEMBL1566158 & 688239 & 5.2362 & 5.4521 & TRN & \\
\hline CHEMBL1322913 & 688239 & 5.1862 & 5.6374 & TRN & \\
\hline CHEMBL1365857 & 688239 & 4.7362 & 5.485 & TRN & \\
\hline CHEMBL1343002 & 688239 & 4.8362 & 5.4917 & TRN & \\
\hline CHEMBL1480398 & 688239 & 4.5362 & 5.4183 & TST & \\
\hline CHEMBL1376350 & 688239 & 4.8362 & 5.2966 & TRN & \\
\hline CHEMBL 3192275 & 688239 & 4.4862 & 5.6189 & TST & \\
\hline CHEMBL1310780 & 688239 & 5.6362 & 5.3578 & TST & \\
\hline CHEMBL1580600 & 688239 & 5.1862 & 5.5121 & TRN & \\
\hline CHEMBL1600976 & 688239 & 4.6362 & 5.5087 & TST & \\
\hline CHEMBL1336052 & 688239 & 4.7862 & 5.3635 & TRN & \\
\hline CHEMBL3209604 & 688239 & 5.8362 & 5.3776 & TST & \\
\hline CHEMBL1512617 & 688239 & 5.6362 & 5.4293 & TRN & \\
\hline CHEMBL1453028 & 688239 & 5.4362 & 5.3893 & TRN & \\
\hline CHEMBL1509908 & 688239 & 4.5362 & 5.428 & TRN & \\
\hline CHEMBL1569780 & 688239 & 6.3362 & 5.5063 & TRN & \\
\hline CHEMBL1305625 & 688239 & 4.7362 & 5.6984 & TRN & \\
\hline
\end{tabular}


Supplemental Table S2.txt

\begin{tabular}{|c|c|c|c|c|}
\hline CHEMBL1413981 & 688239 & 4.7862 & 5.5386 & TRN \\
\hline CHEMBL1546512 & 688239 & 4.5362 & 5.4781 & TST \\
\hline CHEMBL1271014 & 688239 & 4.5362 & 5.5147 & TRN \\
\hline CHEMBL1414508 & 688239 & 4.7862 & 5.3278 & TRN \\
\hline CHEMBL1395119 & 688239 & 5.0862 & 5.5153 & TST \\
\hline CHEMBL1580617 & 688239 & 5.1862 & 5.5009 & TRN \\
\hline CHEMBL1496357 & 688239 & 5.6362 & 5.4928 & TRN \\
\hline CHEMBL1555542 & 688239 & 4.7362 & 5.6032 & TRN \\
\hline CHEMBL1488365 & 688239 & 4.5362 & 5.5081 & TRN \\
\hline CHEMBL1363996 & 688239 & 5.5362 & 5.3593 & TRN \\
\hline CHEMBL1339702 & 688239 & 5.6362 & 5.4668 & TRN \\
\hline CHEMBL1515299 & 688239 & 5.6362 & 5.4196 & TRN \\
\hline CHEMBL1372001 & 688239 & 6.9363 & 5.5228 & TRN \\
\hline CHEMBL1475400 & 688239 & 4.7862 & 5.3987 & TRN \\
\hline CHEMBL1587292 & 688239 & 5.0362 & 5.5291 & TST \\
\hline CHEMBL1578790 & 688239 & 6.2362 & 5.5521 & TST \\
\hline CHEMBL1526075 & 688239 & 6.4362 & 5.5663 & TST \\
\hline CHEMBL1493557 & 688239 & 6.3863 & 5.6515 & TRN \\
\hline CHEMBL1528407 & 688239 & 5.6362 & 5.4334 & TRN \\
\hline CHEMBL1536056 & 688239 & 4.5362 & 5.4369 & TRN \\
\hline CHEMBL1421337 & 688239 & 8.28399 & 99999999 & 5.4957 \\
\hline CHEMBL1399767 & 688239 & 5.0362 & 5.3992 & TRN \\
\hline CHEMBL1482208 & 688239 & 4.5362 & 5.5614 & TST \\
\hline CHEMBL1390416 & 688239 & 4.5362 & 5.5038 & TST \\
\hline CHEMBL1536147 & 688239 & 6.3863 & 5.6309 & TRN \\
\hline CHEMBL1491700 & 688239 & 5.5362 & 5.5569 & TRN \\
\hline CHEMBL1299302 & 688239 & 6.0862 & 5.5241 & TRN \\
\hline CHEMBL1338235 & 688239 & 6.1362 & 5.5155 & TRN \\
\hline CHEMBL1400451 & 688239 & 4.5362 & 5.5292 & TRN \\
\hline CHEMBL1301965 & 688239 & 5.1862 & 5.5114 & TRN \\
\hline CHEMBL1342923 & 688239 & 5.2862 & 5.4716 & TRN \\
\hline CHEMBL1448706 & 688239 & 5.1862 & 5.5331 & TRN \\
\hline CHEMBL1364335 & 688239 & 7.0862 & 5.5062 & TRN \\
\hline CHEMBL1405440 & 688239 & 4.7362 & 5.5554 & TST \\
\hline CHEMBL1322175 & 688239 & 4.5362 & 5.6115 & TRN \\
\hline CHEMBL1594231 & 688239 & 8.2366 & 5.4877 & TST \\
\hline CHEMBL1499559 & 688239 & 4.9362 & 5.4352 & TRN \\
\hline CHEMBL1506959 & 688239 & 5.2362 & 5.5152 & TRN \\
\hline CHEMBL1317033 & 688239 & 6.3362 & 5.4097 & TST \\
\hline CHEMBL1567998 & 688239 & 6.1862 & 5.5871 & TST \\
\hline CHEMBL1568646 & 688239 & 5.5862 & 5.4308 & TRN \\
\hline CHEMBL1349033 & 688239 & 5.4362 & 5.5434 & TRN \\
\hline CHEMBL1529898 & 688239 & 5.7862 & 5.547999 & 9999999999 \\
\hline CHEMBL1421346 & 688239 & 5.5362 & 5.5139 & TRN \\
\hline CHEMBL1532333 & 688239 & 4.5362 & 5.4816 & TRN \\
\hline CHEMBL1602605 & 688239 & 5.4862 & 5.4884 & TRN \\
\hline CHEMBL1414789 & 688239 & 5.8862 & 5.3829 & TRN \\
\hline CHEMBL 3207383 & 688239 & 5.5362 & 5.4985 & TRN \\
\hline
\end{tabular}

Page 1436 
Supplemental Table S2.txt

\begin{tabular}{|c|c|c|c|c|}
\hline CHEMBL 3210812 & 688239 & 4.7362 & 5.4306 & TRN \\
\hline CHEMBL1317295 & 688239 & 5.5862 & 5.5106 & TRN \\
\hline CHEMBL1476341 & 688239 & 6.5363 & 5.6103 & TRN \\
\hline CHEMBL1344147 & 688239 & 6.0862 & 5.4283 & TST \\
\hline CHEMBL1612145 & 688239 & 6.5363 & 5.5951 & TRN \\
\hline CHEMBL1485389 & 688239 & 6.9363 & 5.4377 & TRN \\
\hline CHEMBL1441443 & 688239 & 5.1862 & 5.3172 & TRN \\
\hline CHEMBL1562592 & 688239 & 5.6862 & 5.6152 & TRN \\
\hline CHEMBL1335395 & 688239 & 4.7862 & 5.4856 & TRN \\
\hline CHEMBL1472023 & 688239 & 5.2862 & 5.3607 & TRN \\
\hline CHEMBL1547235 & 688239 & 8.3372 & 5.5042 & TRN \\
\hline CHEMBL3196134 & 688239 & 4.4862 & 5.3967 & TST \\
\hline CHEMBL1541133 & 688239 & 5.7362 & 5.5856 & TRN \\
\hline CHEMBL1458295 & 688239 & 4.4862 & 5.5231 & TST \\
\hline CHEMBL1542411 & 688239 & 6.9363 & 5.4062 & TRN \\
\hline CHEMBL1476579 & 688239 & 5.1862 & 5.4223 & TRN \\
\hline CHEMBL1335482 & 688239 & 8.3372 & 5.6658 & TST \\
\hline CHEMBL1335385 & 688239 & 4.6362 & 5.4842 & TRN \\
\hline CHEMBL1552476 & 688239 & 5.9362 & 5.3578 & TRN \\
\hline CHEMBL1396832 & 688239 & 8.3372 & 5.6146 & TRN \\
\hline CHEMBL1328549 & 688239 & 7.2366 & 5.4956 & TRN \\
\hline CHEMBL1505856 & 688239 & 5.3362 & 5.4266 & TRN \\
\hline CHEMBL1453875 & 688239 & 5.1862 & 5.5698 & TRN \\
\hline CHEMBL1340226 & 688239 & 4.5362 & 5.3672 & TRN \\
\hline CHEMBL1484167 & 688239 & 5.2362 & 5.2831 & TST \\
\hline CHEMBL1362776 & 688239 & 5.2862 & 5.5117 & TRN \\
\hline CHEMBL1544620 & 688239 & 6.3362 & 5.3927 & TRN \\
\hline CHEMBL1527397 & 688239 & 4.6862 & 5.4853 & TRN \\
\hline CHEMBL1610993 & 688239 & 4.5362 & 5.6664 & TRN \\
\hline CHEMBL3191426 & 688239 & 6.0362 & 5.627999 & \\
\hline CHEMBL1413650 & 688239 & 5.1362 & 5.5307 & TRN \\
\hline CHEMBL1371029 & 688239 & 4.8362 & 5.3667 & TST \\
\hline CHEMBL1425249 & 688239 & 4.4862 & 5.4805 & TRN \\
\hline CHEMBL1606618 & 688239 & 5.0362 & 5.4821 & TST \\
\hline CHEMBL1512039 & 688239 & 5.1862 & 5.5365 & TST \\
\hline CHEMBL1360313 & 688239 & 5.4362 & 5.4422 & TST \\
\hline CHEMBL1311751 & 688239 & 4.45 & 5.5066 & TRN \\
\hline CHEMBL1425762 & 688239 & 5.9362 & 5.5466 & TRN \\
\hline CHEMBL1320809 & 688239 & 8.3372 & 5.3953 & TRN \\
\hline CHEMBL1313066 & 688239 & 5.8362 & 5.375 & TRN \\
\hline CHEMBL1473968 & 688239 & 6.5862 & 5.6816 & TRN \\
\hline CHEMBL1569776 & 688239 & 5.1862 & 5.3805 & TRN \\
\hline CHEMBL1427491 & 688239 & 4.9362 & 5.4825 & TRN \\
\hline CHEMBL1416497 & 688239 & 5.1862 & 5.2405 & TRN \\
\hline CHEMBL1465913 & 688239 & 4.5362 & 5.4486 & TST \\
\hline CHEMBL1546583 & 688239 & 4.7862 & 5.4262 & TRN \\
\hline CHEMBL1498843 & 688239 & 4.5362 & 5.5906 & TRN \\
\hline CHEMBL3214429 & 688239 & 4.5362 & 5.3439 & TST \\
\hline
\end{tabular}


Supplemental Table S2.txt

\begin{tabular}{|c|c|c|c|c|}
\hline CHEMBL1499987 & 688239 & 6.9363 & 5.4588 & TRN \\
\hline CHEMBL1454027 & 688239 & 4.6862 & 5.4676 & TRN \\
\hline CHEMBL1500549 & 688239 & 4.7862 & 5.4771 & TRN \\
\hline CHEMBL1505089 & 688239 & 4.7862 & 5.3511 & TRN \\
\hline CHEMBL1340020 & 688239 & 5.1362 & 5.6226 & TRN \\
\hline CHEMBL1482971 & 688239 & 6.0862 & \multicolumn{2}{|c|}{5.5089999999999995} \\
\hline CHEMBL1457201 & 688239 & 4.5362 & 5.4754 & TRN \\
\hline CHEMBL1608271 & 688239 & 4.6362 & 5.4193 & TRN \\
\hline CHEMBL1523007 & 688239 & 5.9362 & 5.5745 & TRN \\
\hline CHEMBL1479166 & 688239 & 5.3362 & 5.4505 & TRN \\
\hline CHEMBL1519072 & 688239 & 4.6362 & 5.51 & TRN \\
\hline CHEMBL1562763 & 688239 & 5.1862 & 5.4218 & TRN \\
\hline CHEMBL1420642 & 688239 & 5.5362 & 5.2679 & TST \\
\hline CHEMBL1488160 & 688239 & 4.7362 & 5.4677 & TST \\
\hline CHEMBL1465969 & 688239 & 6.7862 & 5.6134 & TRN \\
\hline CHEMBL1452143 & 688239 & 6.1362 & 5.5094 & TRN \\
\hline CHEMBL1597337 & 688239 & 4.5362 & 5.5389 & TRN \\
\hline CHEMBL1446584 & 688239 & 4.5362 & 5.4727 & TRN \\
\hline CHEMBL1373456 & 688239 & 5.8862 & 5.4374 & TRN \\
\hline CHEMBL1540523 & 688239 & 5.3862 & 5.5811 & TRN \\
\hline CHEMBL1612732 & 688239 & 5.2362 & 5.4273 & TST \\
\hline CHEMBL1581278 & 688239 & 4.8862 & 5.5895 & TRN \\
\hline CHEMBL1350947 & 688239 & 5.6362 & 5.5415 & TRN \\
\hline CHEMBL1518095 & 688239 & 5.4862 & 5.5905 & TRN \\
\hline CHEMBL1365196 & 688239 & 6.4862 & 5.5499 & TRN \\
\hline CHEMBL1347022 & 688239 & 5.8862 & 5.5145 & TST \\
\hline CHEMBL 3213631 & 688239 & 6.1362 & 5.4938 & TRN \\
\hline CHEMBL1389094 & 688239 & 6.2362 & 5.6271 & TRN \\
\hline CHEMBL1605668 & 688239 & 4.8862 & 5.4739 & TRN \\
\hline CHEMBL1597369 & 688239 & 5.1362 & 5.4079 & TRN \\
\hline CHEMBL1526854 & 688239 & 5.7362 & 5.5348 & TRN \\
\hline CHEMBL1468712 & 688239 & 6.3362 & 5.3794 & TST \\
\hline CHEMBL 3210801 & 688239 & 6.1362 & 5.701006 & 00000000005 \\
\hline CHEMBL1599597 & 688239 & 4.5362 & 5.502999 & 999999999 \\
\hline CHEMBL1416816 & 688239 & 4.5362 & 5.5061 & TST \\
\hline CHEMBL1568622 & 688239 & 5.5862 & 5.5071 & TRN \\
\hline CHEMBL1575517 & 688239 & 5.6862 & 5.4951 & TRN \\
\hline CHEMBL1347595 & 688239 & 4.5362 & 5.4999 & TRN \\
\hline CHEMBL1588509 & 688239 & 4.7362 & 5.4003 & TRN \\
\hline CHEMBL1457789 & 688239 & 4.7862 & 5.412999 & 999999999 \\
\hline CHEMBL1492630 & 688239 & 6.7862 & 5.6253 & TRN \\
\hline CHEMBL1557637 & 688239 & 4.6862 & 5.5636 & TRN \\
\hline CHEMBL1306694 & 688239 & 4.9362 & 5.3225 & TRN \\
\hline CHEMBL1532101 & 688239 & 4.5362 & 5.4459 & TRN \\
\hline CHEMBL1447647 & 688239 & 5.2862 & 5.5469 & TRN \\
\hline CHEMBL1525911 & 688239 & 5.4362 & 5.6482 & TRN \\
\hline CHEMBL1504729 & 688239 & 5.2862 & 5.5886 & TRN \\
\hline CHEMBL1470684 & 688239 & 4.9862 & 5.4356 & TRN \\
\hline
\end{tabular}


Supplemental Table S2.txt

\begin{tabular}{|c|c|c|c|c|}
\hline CHEMBL1409672 & 688239 & 6.9863 & 5.5084 & TRN \\
\hline CHEMBL1508182 & 688239 & 4.5362 & 5.4321 & TRN \\
\hline CHEMBL1588214 & 688239 & 6.8861 & 5.4571 & TRN \\
\hline CHEMBL1324090 & 688239 & 6.9863 & 5.4022 & TST \\
\hline CHEMBL1355767 & 688239 & 6.0862 & 5.574 & TRN \\
\hline CHEMBL1367772 & 688239 & 4.4862 & 5.5383 & TRN \\
\hline CHEMBL1598383 & 688239 & 4.5362 & 5.489 & TRN \\
\hline CHEMBL1421400 & 688239 & 5.3362 & 5.4958 & TRN \\
\hline CHEMBL1554035 & 688239 & 4.9862 & 5.483 & TRN \\
\hline CHEMBL1474450 & 688239 & 6.0362 & 5.5329 & TRN \\
\hline CHEMBL1383621 & 688239 & 6.9363 & 5.4255 & TRN \\
\hline CHEMBL1322627 & 688239 & 6.1362 & 5.5753 & TST \\
\hline CHEMBL1544232 & 688239 & 5.8862 & 5.3991 & TST \\
\hline CHEMBL1584848 & 688239 & 4.5362 & 5.3363 & TRN \\
\hline CHEMBL1390826 & 688239 & 8.28399 & 99999999 & 5.5967 \\
\hline CHEMBL1461177 & 688239 & 4.5362 & 5.5176 & TST \\
\hline CHEMBL1548432 & 688239 & 4.5362 & 5.5785 & TRN \\
\hline CHEMBL1546074 & 688239 & 5.0862 & 5.494 & TRN \\
\hline CHEMBL1510522 & 688239 & 4.6862 & 5.4971 & TST \\
\hline CHEMBL1528642 & 688239 & 5.2362 & 5.3646 & TRN \\
\hline CHEMBL1529911 & 688239 & 5.1862 & 5.6233 & TRN \\
\hline CHEMBL1438212 & 688239 & 4.5362 & 5.5 & TRN \\
\hline CHEMBL1598139 & 688239 & 5.3862 & 5.4248 & TRN \\
\hline CHEMBL1468039 & 688239 & 6.2862 & 5.7482 & TRN \\
\hline CHEMBL1567167 & 688239 & 6.1862 & 5.4487 & TST \\
\hline CHEMBL1301666 & 688239 & 6.8362 & 5.4214 & TRN \\
\hline CHEMBL1316883 & 688239 & 4.7862 & 5.5662 & TRN \\
\hline CHEMBL1468254 & 688239 & 5.1862 & 5.3034 & TRN \\
\hline CHEMBL1305414 & 688239 & 6.8362 & 5.461 & TRN \\
\hline CHEMBL1489933 & 688239 & 5.3862 & 5.4485 & TRN \\
\hline CHEMBL1547742 & 688239 & 4.5362 & 5.5835 & TRN \\
\hline CHEMBL1406096 & 688239 & 4.7362 & 5.4218 & TST \\
\hline CHEMBL1485986 & 688239 & 4.5862 & 5.4647 & TRN \\
\hline CHEMBL1556602 & 688239 & 4.7862 & 5.5062 & TST \\
\hline CHEMBL1502417 & 688239 & 4.6362 & 5.3621 & TST \\
\hline CHEMBL1401258 & 688239 & 4.5362 & 5.4769 & TRN \\
\hline CHEMBL3193925 & 688239 & 4.6862 & 5.433 & TRN \\
\hline CHEMBL1485515 & 688239 & 5.1862 & 5.377000 & 0000000001 \\
\hline CHEMBL1574079 & 688239 & 5.5862 & 5.5435 & TRN \\
\hline CHEMBL1577352 & 688239 & 4.8362 & 5.4851 & TRN \\
\hline CHEMBL1544876 & 688239 & 5.4862 & 5.3308 & TRN \\
\hline CHEMBL1544504 & 688239 & 5.1862 & 5.5178 & TRN \\
\hline CHEMBL1456971 & 688239 & 6.7361 & 5.4537 & TRN \\
\hline CHEMBL1521852 & 688239 & 4.5362 & 5.5852 & TRN \\
\hline CHEMBL1492492 & 688239 & 5.1862 & 5.5162 & TRN \\
\hline CHEMBL1470751 & 688239 & 4.5862 & 5.3804 & TRN \\
\hline CHEMBL1373492 & 688239 & 5.5362 & 5.5656 & TRN \\
\hline CHEMBL1536015 & 688239 & 5.2862 & 5.4828 & TRN \\
\hline
\end{tabular}


Supplemental Table S2.txt

\begin{tabular}{|c|c|c|c|c|c|}
\hline CHEMBL1314865 & 688239 & 5.1862 & 5.3821 & TRN & \\
\hline CHEMBL1411515 & 688239 & 6.6362 & 5.5946 & TRN & \\
\hline CHEMBL1499003 & 688239 & 6.1862 & 5.5962 & TRN & \\
\hline CHEMBL1607435 & 688239 & 6.8861 & 5.5075 & TRN & \\
\hline CHEMBL1595453 & 688239 & 4.7362 & 5.4913 & TRN & \\
\hline CHEMBL1354298 & 688239 & 5.4362 & 5.3887 & TRN & \\
\hline CHEMBL1537540 & 688239 & 4.6862 & 5.5832 & TRN & \\
\hline CHEMBL1438620 & 688239 & 5.1862 & 5.3739 & TRN & \\
\hline CHEMBL1588239 & 688239 & 5.6362 & 5.6038 & TRN & \\
\hline CHEMBL1494268 & 688239 & 5.8362 & 5.6224 & TRN & \\
\hline CHEMBL1384821 & 688239 & 6.8362 & 5.53100 & $\partial 000000001$ & TRN \\
\hline CHEMBL1460623 & 688239 & 5.3862 & 5.36799 & 9999999999 & TST \\
\hline CHEMBL1425798 & 688239 & 4.4862 & 5.4979 & TRN & \\
\hline CHEMBL1469370 & 688239 & 5.0862 & 5.57600 & 00000000005 & TRN \\
\hline CHEMBL1468791 & 688239 & 6.5363 & 5.6513 & TST & \\
\hline CHEMBL1989234 & 688239 & 5.5362 & 5.356 & TRN & \\
\hline CHEMBL1420878 & 688239 & 4.5362 & 5.5883 & TST & \\
\hline CHEMBL1581985 & 688239 & 5.7362 & 5.4019 & TST & \\
\hline CHEMBL1454233 & 688239 & 4.5862 & 5.5587 & TST & \\
\hline CHEMBL1563660 & 688239 & 4.7362 & 5.4024 & TST & \\
\hline CHEMBL1377949 & 688239 & 4.6862 & 5.5439 & TRN & \\
\hline CHEMBL1371733 & 688239 & 5.7362 & 5.5691 & TRN & \\
\hline CHEMBL1337111 & 688239 & 4.7862 & 5.3607 & TRN & \\
\hline CHEMBL1570239 & 688239 & 4.4862 & 5.3984 & TST & \\
\hline CHEMBL1331479 & 688239 & 6.4862 & 5.45799 & 9999999999 & TRN \\
\hline CHEMBL1419280 & 688239 & 5.5362 & 5.5135 & TRN & \\
\hline CHEMBL1421163 & 688239 & 5.6362 & 5.5159 & TRN & \\
\hline CHEMBL1609378 & 688239 & 6.4862 & 5.4629 & TST & \\
\hline CHEMBL1356447 & 688239 & 5.2362 & 5.5694 & TRN & \\
\hline CHEMBL1545594 & 688239 & 5.0362 & 5.4589 & TRN & \\
\hline CHEMBL1381240 & 688239 & 4.5362 & 5.5778 & TRN & \\
\hline CHEMBL1362129 & 688239 & 4.7362 & 5.2936 & TRN & \\
\hline CHEMBL1403944 & 688239 & 8.3372 & 5.6236 & TRN & \\
\hline CHEMBL1429306 & 688239 & 4.4862 & 5.4691 & TRN & \\
\hline CHEMBL3193980 & 688239 & 6.0362 & 5.4619 & TST & \\
\hline CHEMBL1580552 & 688239 & 5.5862 & 5.3995 & TRN & \\
\hline CHEMBL1525361 & 688239 & 7.4868 & 5.4843 & TRN & \\
\hline CHEMBL1303398 & 688239 & 4.9362 & 5.4751 & TRN & \\
\hline CHEMBL3197696 & 688239 & 5.5862 & 5.6478 & TRN & \\
\hline CHEMBL1576803 & 688239 & 4.5362 & 5.456 & TRN & \\
\hline CHEMBL1308694 & 688239 & 5.1862 & 5.5915 & TRN & \\
\hline CHEMBL1345963 & 688239 & 6.0862 & 5.6101 & TRN & \\
\hline CHEMBL3214187 & 688239 & 5.1862 & 5.5513 & TST & \\
\hline CHEMBL3211186 & 688239 & 4.5862 & 5.3649 & TRN & \\
\hline CHEMBL3190639 & 688239 & 4.5362 & 5.4365 & TRN & \\
\hline CHEMBL1519336 & 688239 & 5.5362 & 5.4941 & TRN & \\
\hline CHEMBL42210 & 688239 & 6.0 & 5.4295 & TRN & \\
\hline CHEMBL1378880 & 688239 & 4.6362 & 5.655 & TRN & \\
\hline
\end{tabular}


Supplemental Table S2.txt

\begin{tabular}{|c|c|c|c|c|c|}
\hline CHEMBL1563579 & 688239 & 6.1362 & 5.5114 & TRN & \\
\hline CHEMBL1583923 & 688239 & 5.1862 & 5.5493 & TRN & \\
\hline CHEMBL1360954 & 688239 & 7.1361 & 5.5689 & TRN & \\
\hline CHEMBL1510831 & 688239 & 8.3372 & 5.3333 & TRN & \\
\hline CHEMBL1445128 & 688239 & 6.1362 & 5.5531 & TRN & \\
\hline CHEMBL1424836 & 688239 & 4.9862 & 5.3773 & TST & \\
\hline CHEMBL1605659 & 688239 & 5.4862 & 5.4599 & TST & \\
\hline CHEMBL1334615 & 688239 & 4.5362 & 5.4958 & TRN & \\
\hline CHEMBL1602366 & 688239 & 5.3862 & 5.3967 & TST & \\
\hline CHEMBL1339198 & 688239 & 5.6362 & 5.4813 & TST & \\
\hline CHEMBL1416296 & 688239 & 4.6862 & 5.5849 & TRN & \\
\hline CHEMBL1430207 & 688239 & 4.7362 & 5.5675 & TRN & \\
\hline CHEMBL1377711 & 688239 & 4.5362 & 5.6936 & TRN & \\
\hline CHEMBL1355864 & 688239 & 8.3372 & 5.3474 & TRN & \\
\hline CHEMBL1332956 & 688239 & 5.1362 & 5.3622 & TRN & \\
\hline CHEMBL1532436 & 688239 & 4.5362 & 5.5603 & TRN & \\
\hline CHEMBL1311795 & 688239 & 7.1361 & 5.4598 & TST & \\
\hline CHEMBL1494571 & 688239 & 5.0862 & 5.3437 & TRN & \\
\hline CHEMBL1444308 & 688239 & 7.8861 & 5.5851 & TRN & \\
\hline CHEMBL1536451 & 688239 & 6.2862 & 5.4566 & TST & \\
\hline CHEMBL1343766 & 688239 & 4.5362 & 5.5608 & TRN & \\
\hline CHEMBL1482472 & 688239 & 4.9362 & 5.4179 & TRN & \\
\hline CHEMBL1491883 & 688239 & 5.2362 & 5.4372 & TRN & \\
\hline CHEMBL1374191 & 688239 & 6.2362 & 5.536006 & 00000000005 & TRN \\
\hline CHEMBL1468540 & 688239 & 4.7362 & 5.4781 & TST & \\
\hline CHEMBL1465841 & 688239 & 6.8362 & 5.3468 & TRN & \\
\hline CHEMBL1527239 & 688239 & 5.3362 & 5.4603 & TRN & \\
\hline CHEMBL1410979 & 688239 & 4.7862 & 5.4097 & TRN & \\
\hline CHEMBL1449455 & 688239 & 8.3372 & 5.5183 & TRN & \\
\hline CHEMBL 3197357 & 688239 & 5.1862 & 5.4885 & TRN & \\
\hline CHEMBL1470349 & 688239 & 4.7362 & 5.5468 & TRN & \\
\hline CHEMBL1412422 & 688239 & 4.7862 & 5.4021 & TRN & \\
\hline CHEMBL1418042 & 688239 & 5.6862 & 5.5883 & TRN & \\
\hline CHEMBL1412168 & 688239 & 5.8862 & 5.6308 & TRN & \\
\hline CHEMBL1377987 & 688239 & 4.5362 & 5.5459 & TRN & \\
\hline CHEMBL1455145 & 688239 & 4.5362 & 5.4311 & TRN & \\
\hline CHEMBL1366896 & 688239 & 6.9363 & 5.4914 & TST & \\
\hline CHEMBL1594967 & 688239 & 5.2862 & 5.483 & TRN & \\
\hline CHEMBL 3214103 & 688239 & 5.9862 & 5.4147 & TRN & \\
\hline CHEMBL1393462 & 688239 & 6.2362 & 5.6619 & TRN & \\
\hline CHEMBL1566717 & 688239 & 6.2362 & 5.4148 & TRN & \\
\hline CHEMBL1500904 & 688239 & 4.6862 & 5.4719 & TST & \\
\hline CHEMBL1419473 & 688239 & 6.1362 & 5.6327 & TRN & \\
\hline CHEMBL1531096 & 688239 & 5.2362 & 5.4973 & TRN & \\
\hline CHEMBL1611322 & 688239 & 6.8362 & 5.4822 & TRN & \\
\hline CHEMBL1502848 & 688239 & 5.9362 & 5.5322 & TST & \\
\hline CHEMBL1445900 & 688239 & 6.2362 & 5.5454 & TRN & \\
\hline CHEMBL1303361 & 688239 & 4.6862 & 5.3334 & TST & \\
\hline
\end{tabular}


Supplemental Table S2.txt

\begin{tabular}{|c|c|c|c|c|c|c|}
\hline CHEMBL1399252 & 688239 & 4.6862 & 5.3468 & TST & & \\
\hline CHEMBL1535209 & 688239 & 4.5862 & 5.6061 & TRN & & \\
\hline CHEMBL1517084 & 688239 & 4.6862 & 5.5271 & TRN & & \\
\hline CHEMBL1382058 & 688239 & 6.8861 & 5.5759 & TRN & & \\
\hline CHEMBL1583816 & 688239 & 8.28399 & 9999999 & 99 & 5.3221 & TST \\
\hline CHEMBL1443027 & 688239 & 4.4862 & 5.4989 & TRN & & \\
\hline CHEMBL1362716 & 688239 & 7.1361 & 5.5471 & TRN & & \\
\hline CHEMBL1603485 & 688239 & 4.5362 & 5.3477 & TST & & \\
\hline CHEMBL1385958 & 688239 & 5.3362 & 5.5317 & TRN & & \\
\hline CHEMBL1601148 & 688239 & 5.2362 & 5.3387 & TST & & \\
\hline CHEMBL1337942 & 688239 & 5.9862 & 5.5371 & TRN & & \\
\hline CHEMBL1420012 & 688239 & 4.6862 & 5.5228 & TST & & \\
\hline CHEMBL1456706 & 688239 & 4.8862 & 5.4222 & TRN & & \\
\hline CHEMBL1590415 & 688239 & 5.1362 & 5.3662 & TRN & & \\
\hline CHEMBL1369583 & 688239 & 5.1862 & 5.6045 & TRN & & \\
\hline CHEMBL1547446 & 688239 & 5.2362 & 5.4509 & TRN & & \\
\hline CHEMBL1430872 & 688239 & 4.8862 & 5.2867 & TST & & \\
\hline CHEMBL1493465 & 688239 & 4.5362 & 5.3773 & TRN & & \\
\hline CHEMBL1511157 & 688239 & 6.7862 & 5.5656 & TST & & \\
\hline CHEMBL1523530 & 688239 & 5.5862 & 5.517 & TRN & & \\
\hline CHEMBL1357584 & 688239 & 4.6362 & 5.5385 & TRN & & \\
\hline CHEMBL1348217 & 688239 & 4.7362 & 5.3717 & TRN & & \\
\hline CHEMBL 3211523 & 688239 & 6.5363 & 5.4602 & TST & & \\
\hline CHEMBL1301024 & 688239 & 4.6862 & 5.5225 & TRN & & \\
\hline CHEMBL1537770 & 688239 & 5.4862 & 5.6161 & TRN & & \\
\hline CHEMBL1400192 & 688239 & 5.0362 & 5.4594 & TRN & & \\
\hline CHEMBL1405426 & 688239 & 5.5362 & 5.5426 & TRN & & \\
\hline CHEMBL1360176 & 688239 & 4.5362 & 5.6277 & TST & & \\
\hline CHEMBL1548191 & 688239 & 4.9862 & 5.4256 & TRN & & \\
\hline CHEMBL1447582 & 688239 & 5.3862 & 5.4717 & TRN & & \\
\hline CHEMBL 3211533 & 688239 & 4.5362 & 5.534 & TST & & \\
\hline CHEMBL1358604 & 688239 & 4.6362 & 5.4712 & TST & & \\
\hline CHEMBL1521647 & 688239 & 4.5362 & 5.5036 & TRN & & \\
\hline CHEMBL1581062 & 688239 & 5.2862 & 5.5014 & TRN & & \\
\hline CHEMBL1443666 & 688239 & 4.6862 & 5.4356 & TRN & & \\
\hline CHEMBL1593256 & 688239 & 4.5362 & 5.4478 & TRN & & \\
\hline CHEMBL1361319 & 688239 & 5.5862 & 5.4009 & TRN & & \\
\hline CHEMBL1351826 & 688239 & 4.6362 & 5.4068 & TRN & & \\
\hline CHEMBL533954 & 688239 & 5.1862 & 5.3851 & TRN & & \\
\hline CHEMBL 1422548 & 688239 & 4.4862 & 5.5247 & TST & & \\
\hline CHEMBL1453545 & 688239 & 4.6862 & 5.5285 & TST & & \\
\hline CHEMBL1437741 & 688239 & 4.6862 & 5.6495 & TST & & \\
\hline CHEMBL1317475 & 688239 & 5.1862 & 5.563 & TST & & \\
\hline CHEMBL1524827 & 688239 & 4.6362 & 5.1962 & TRN & & \\
\hline CHEMBL1543203 & 688239 & 4.6362 & 5.3903 & TRN & & \\
\hline CHEMBL1456594 & 688239 & 6.9363 & 5.6816 & TRN & & \\
\hline CHEMBL1403438 & 688239 & 5.1862 & 5.3752 & TST & & \\
\hline CHEMBL1332732 & 688239 & 5.3862 & 5.5052 & TRN & & \\
\hline
\end{tabular}


Supplemental Table S2.txt

\begin{tabular}{|c|c|c|c|c|c|}
\hline CHEMBL1465790 & 688239 & 6.9863 & 5.5497 & TST & \\
\hline CHEMBL1977376 & 688239 & 8.3372 & 5.4441 & TRN & \\
\hline CHEMBL1596210 & 688239 & 6.0362 & 5.4549 & TRN & \\
\hline CHEMBL1592523 & 688239 & 5.5862 & 5.3692 & TRN & \\
\hline CHEMBL1552063 & 688239 & 8.28399 & 99999999 & 5.5691 & TRN \\
\hline CHEMBL1345414 & 688239 & 5.3862 & 5.3559 & TRN & \\
\hline CHEMBL1349723 & 688239 & 6.1862 & 5.4026 & TST & \\
\hline CHEMBL3214383 & 688239 & 5.8362 & 5.3116 & TRN & \\
\hline CHEMBL1430434 & 688239 & 5.9862 & 5.4266 & TRN & \\
\hline CHEMBL1384226 & 688239 & 5.9862 & 5.5636 & TST & \\
\hline CHEMBL1558913 & 688239 & 6.0862 & 5.6342 & TST & \\
\hline CHEMBL1586571 & 688239 & 5.6362 & 5.6133 & TRN & \\
\hline CHEMBL1549938 & 688239 & 4.7362 & 5.54799 & 9999999999 & TRN \\
\hline CHEMBL1432998 & 688239 & 6.2862 & 5.4123 & TST & \\
\hline CHEMBL1476624 & 688239 & 6.5363 & 5.4582 & TST & \\
\hline CHEMBL1303169 & 688239 & 4.5362 & 5.5561 & TRN & \\
\hline CHEMBL1418051 & 688239 & 4.5362 & 5.4609 & TRN & \\
\hline CHEMBL1453177 & 688239 & 4.5362 & 5.5607 & TRN & \\
\hline CHEMBL1402173 & 688239 & 5.1862 & 5.5436 & TRN & \\
\hline CHEMBL1502906 & 688239 & 4.5362 & 5.567 & TRN & \\
\hline CHEMBL1544593 & 688239 & 4.7862 & 5.6212 & TRN & \\
\hline CHEMBL1367322 & 688239 & 5.1862 & 5.4053 & TRN & \\
\hline CHEMBL1457432 & 688239 & 4.6362 & 5.4588 & TRN & \\
\hline CHEMBL3208060 & 688239 & 5.7362 & 5.4114 & TRN & \\
\hline CHEMBL1560088 & 688239 & 6.2362 & 5.5066 & TST & \\
\hline CHEMBL1455573 & 688239 & 5.5362 & 5.5244 & TRN & \\
\hline CHEMBL1436185 & 688239 & 6.2862 & 5.6384 & TST & \\
\hline CHEMBL1580752 & 688239 & 4.5362 & 5.5566 & TRN & \\
\hline CHEMBL1423317 & 688239 & 6.7361 & 5.5181 & TRN & \\
\hline CHEMBL1597190 & 688239 & 5.1362 & 5.3244 & TRN & \\
\hline CHEMBL1551096 & 688239 & 5.4362 & 5.524 & TRN & \\
\hline CHEMBL1332786 & 688239 & 5.4862 & 5.7108 & TRN & \\
\hline CHEMBL1500525 & 688239 & 6.1862 & 5.4657 & TRN & \\
\hline CHEMBL1521573 & 688239 & 4.5362 & 5.45299 & 9999999999 & \\
\hline CHEMBL59507 & 688239 & 5.0362 & 5.3168 & TST & \\
\hline CHEMBL1573560 & 688239 & 6.3362 & 5.5058 & TRN & \\
\hline CHEMBL1595647 & 688239 & 5.1862 & 5.5049 & TRN & \\
\hline CHEMBL1446240 & 688239 & 6.1362 & 5.6781 & TRN & \\
\hline CHEMBL1350242 & 688239 & 5.5862 & 5.3998 & TRN & \\
\hline CHEMBL1483880 & 688239 & 4.5362 & 5.7517 & TRN & \\
\hline CHEMBL1560801 & 688239 & 4.5362 & 5.5314 & TST & \\
\hline CHEMBL1558814 & 688239 & 4.7862 & 5.4876 & TRN & \\
\hline CHEMBL1394325 & 688239 & 5.9362 & 5.4005 & TST & \\
\hline CHEMBL1313384 & 688239 & 8.3372 & 5.545 & TRN & \\
\hline CHEMBL1372615 & 688239 & 5.6862 & 5.4324 & TRN & \\
\hline CHEMBL1546042 & 688239 & 6.4362 & 5.6019 & TRN & \\
\hline CHEMBL1417625 & 688239 & 6.3863 & 5.54 & TRN & \\
\hline \multirow[t]{2}{*}{ CHEMBL1535652 } & 688239 & 4.7862 & 5.5310 & $\partial 000000001$ & \\
\hline & & \multicolumn{3}{|c|}{ Page 1443} & \\
\hline
\end{tabular}


Supplemental Table S2.txt

\begin{tabular}{|c|c|c|c|c|}
\hline CHEMBL1986444 & 688239 & 6.5862 & 5.4617 & TST \\
\hline CHEMBL1601919 & 688239 & 4.5362 & 5.6006 & TRN \\
\hline CHEMBL3195648 & 688239 & 4.7362 & 5.2611 & TRN \\
\hline CHEMBL1362027 & 688239 & 8.3372 & 5.4547 & TRN \\
\hline CHEMBL1343900 & 688239 & 4.6862 & 5.3534 & TRN \\
\hline CHEMBL1469463 & 688239 & 4.5862 & 5.518 & TST \\
\hline CHEMBL1431712 & 688239 & 4.6862 & 5.4685 & TRN \\
\hline CHEMBL1583268 & 688239 & 5.4862 & 5.625 & TRN \\
\hline CHEMBL1402118 & 688239 & 5.0862 & 5.4939 & TRN \\
\hline CHEMBL1444719 & 688239 & 4.5362 & 5.5415 & TRN \\
\hline CHEMBL1551462 & 688239 & 5.6362 & 5.5258 & TRN \\
\hline CHEMBL1303094 & 688239 & 4.5862 & 5.5252 & TRN \\
\hline CHEMBL1543517 & 688239 & 4.8862 & 5.427006 & 30000000005 \\
\hline CHEMBL1554939 & 688239 & 6.7862 & 5.4547 & TRN \\
\hline CHEMBL3212235 & 688239 & 4.5362 & 5.6837 & TRN \\
\hline CHEMBL1467154 & 688239 & 5.3362 & 5.5505 & TRN \\
\hline CHEMBL1453825 & 688239 & 8.2366 & 5.5243 & TRN \\
\hline CHEMBL1497625 & 688239 & 5.4362 & 5.407999 & 99999999995 \\
\hline CHEMBL1352796 & 688239 & 4.9362 & 5.478 & TRN \\
\hline CHEMBL1367119 & 688239 & 5.7362 & $5.62700 €$ & 0000000001 \\
\hline CHEMBL1437344 & 688239 & 4.9862 & 5.5622 & TRN \\
\hline CHEMBL1513106 & 688239 & 4.5362 & 5.6457 & TRN \\
\hline CHEMBL1325024 & 688239 & 4.8362 & 5.6878 & TRN \\
\hline CHEMBL1412031 & 688239 & 4.7362 & 5.2862 & TRN \\
\hline CHEMBL1537840 & 688239 & 6.0362 & 5.6064 & TRN \\
\hline CHEMBL3195192 & 688239 & 4.7862 & 5.4773 & TRN \\
\hline CHEMBL1416170 & 688239 & 5.9862 & 5.5252 & TRN \\
\hline CHEMBL1349518 & 688239 & 6.7361 & 5.5135 & TRN \\
\hline CHEMBL1498064 & 688239 & 5.1362 & 5.5074 & TRN \\
\hline CHEMBL1303408 & 688239 & 4.5862 & 5.4865 & TRN \\
\hline CHEMBL1558081 & 688239 & 4.7862 & 5.3859 & TRN \\
\hline CHEMBL1361745 & 688239 & 6.6861 & 5.6077 & TRN \\
\hline CHEMBL1606424 & 688239 & 8.2366 & 5.6381 & TRN \\
\hline CHEMBL607524 & 688239 & 6.9863 & 5.3858 & TRN \\
\hline CHEMBL1491016 & 688239 & 4.5362 & 5.3174 & TRN \\
\hline CHEMBL1977763 & 688239 & 6.3362 & 5.3026 & TRN \\
\hline CHEMBL1321749 & 688239 & 4.5362 & 5.5594 & TRN \\
\hline CHEMBL1546308 & 688239 & 5.1862 & 5.4992 & TRN \\
\hline CHEMBL1557814 & 688239 & 6.2862 & 5.5372 & TRN \\
\hline CHEMBL1452045 & 688239 & 4.5362 & 5.4232 & TST \\
\hline CHEMBL1411188 & 688239 & 6.1862 & 5.4941 & TRN \\
\hline CHEMBL1308000 & 688239 & 4.5362 & 5.4627 & TRN \\
\hline CHEMBL1569933 & 688239 & 4.6362 & 5.5016 & TRN \\
\hline CHEMBL1510603 & 688239 & 6.1362 & 5.5803 & TRN \\
\hline CHEMBL1418354 & 688239 & 5.1862 & 5.522 & TRN \\
\hline CHEMBL591834 & 688239 & 6.2362 & 5.5221 & TST \\
\hline CHEMBL1481967 & 688239 & 4.9862 & 5.5112 & TRN \\
\hline CHEMBL3211529 & 688239 & 4.7362 & 5.4134 & TRN \\
\hline
\end{tabular}


Supplemental Table S2.txt

\begin{tabular}{|c|c|c|c|c|}
\hline CHEMBL578944 & 688239 & 5.5362 & 5.3184 & TRN \\
\hline CHEMBL3213033 & 688239 & 4.5362 & 5.3841 & TRN \\
\hline CHEMBL1374575 & 688239 & 4.8862 & 5.399 & TST \\
\hline CHEMBL1441914 & 688239 & 4.9362 & 5.4892 & TRN \\
\hline CHEMBL1563135 & 688239 & 4.5362 & 5.5216 & TRN \\
\hline CHEMBL1378168 & 688239 & 5.3862 & 5.6538 & TRN \\
\hline CHEMBL1448296 & 688239 & 5.7862 & 5.5283 & TRN \\
\hline CHEMBL1344720 & 688239 & 6.8362 & 5.5553 & TRN \\
\hline CHEMBL1424460 & 688239 & 6.9363 & 5.5218 & TRN \\
\hline CHEMBL 2005198 & 688239 & 4.5362 & 5.3575 & TRN \\
\hline CHEMBL1394621 & 688239 & 4.6862 & 5.6389 & TRN \\
\hline CHEMBL1523635 & 688239 & 6.3362 & 5.3204 & TRN \\
\hline CHEMBL1375198 & 688239 & 4.5362 & 5.5448 & TRN \\
\hline CHEMBL1301125 & 688239 & 5.7362 & 5.3789 & TST \\
\hline CHEMBL1508996 & 688239 & 4.5362 & 5.6359 & TRN \\
\hline CHEMBL1601842 & 688239 & 4.5362 & 5.4488 & TRN \\
\hline CHEMBL1496283 & 688239 & 6.0362 & 5.4143 & TRN \\
\hline CHEMBL 3209335 & 688239 & 4.7362 & 5.26 & TST \\
\hline CHEMBL1390842 & 688239 & 4.5362 & 5.4212 & TRN \\
\hline CHEMBL1452476 & 688239 & 4.5362 & 5.3913 & TST \\
\hline CHEMBL3211572 & 688239 & 5.5862 & 5.3698 & TRN \\
\hline CHEMBL1412194 & 688239 & 6.4862 & 5.5757 & TST \\
\hline CHEMBL1474017 & 688239 & 5.6862 & 5.4668 & TRN \\
\hline CHEMBL1488492 & 688239 & 4.9362 & 5.6475 & TRN \\
\hline CHEMBL1580685 & 688239 & 6.8362 & 5.5391 & TST \\
\hline CHEMBL1346320 & 688239 & 5.1362 & 5.5878 & TRN \\
\hline CHEMBL3192561 & 688239 & 6.5862 & 5.581 & TRN \\
\hline CHEMBL3210583 & 688239 & 4.7362 & 5.38399 & 99999999995 \\
\hline CHEMBL1309828 & 688239 & 6.1862 & 5.52 & TST \\
\hline CHEMBL1330928 & 688239 & 4.9362 & 5.3826 & TST \\
\hline CHEMBL1466940 & 688239 & 4.7362 & 5.5699 & TRN \\
\hline CHEMBL1348671 & 688239 & 4.5362 & 5.3671 & TRN \\
\hline CHEMBL1584274 & 688239 & 5.3362 & 5.5794 & TST \\
\hline CHEMBL1464544 & 688239 & 5.0362 & 5.4392 & TST \\
\hline CHEMBL1443472 & 688239 & 5.3362 & 5.5567 & TST \\
\hline CHEMBL3145205 & 688239 & 5.0362 & 5.532 & TRN \\
\hline CHEMBL1404109 & 688239 & 4.8362 & 5.5546 & TRN \\
\hline CHEMBL1434011 & 688239 & 5.8362 & 5.4216 & TRN \\
\hline CHEMBL1475623 & 688239 & 6.8861 & 5.4957 & TRN \\
\hline CHEMBL2140539 & 688239 & 5.6862 & 5.3961 & TST \\
\hline CHEMBL1490039 & 688239 & 4.5362 & 5.5921 & TRN \\
\hline CHEMBL1317939 & 688239 & 5.8362 & 5.3995 & TRN \\
\hline CHEMBL1577129 & 688239 & 6.2362 & 5.4295 & TRN \\
\hline CHEMBL1311663 & 688239 & 5.4362 & 5.3922 & TRN \\
\hline CHEMBL1606982 & 688239 & 4.5362 & 5.4496 & TRN \\
\hline CHEMBL1391908 & 688239 & 5.1862 & 5.4141 & TRN \\
\hline CHEMBL1313453 & 688239 & 6.6362 & 5.38299 & 9999999999 \\
\hline CHEMBL1443838 & 688239 & 5.0862 & 5.5107 & TRN \\
\hline
\end{tabular}


Supplemental Table S2.txt

\begin{tabular}{|c|c|c|c|c|c|}
\hline CHEMBL1484897 & 688239 & 7.1361 & 5.4798 & TRN & \\
\hline CHEMBL1591640 & 688239 & 5.2862 & 5.5901 & TRN & \\
\hline CHEMBL1462399 & 688239 & 4.5362 & 5.5188 & TRN & \\
\hline CHEMBL1547468 & 688239 & 4.5362 & 5.4005 & TRN & \\
\hline CHEMBL1328367 & 688239 & 4.7862 & 5.2504 & TRN & \\
\hline CHEMBL1299268 & 688239 & 4.4862 & 5.5647 & TRN & \\
\hline CHEMBL1504125 & 688239 & 4.9862 & 5.5089 & TRN & \\
\hline CHEMBL1349066 & 688239 & 4.7862 & 5.6076 & TRN & \\
\hline CHEMBL1359767 & 688239 & 4.5362 & 5.4828 & TRN & \\
\hline CHEMBL1438676 & 688239 & 4.9362 & 5.4988 & TRN & \\
\hline CHEMBL1579149 & 688239 & 4.5362 & 5.6749 & TRN & \\
\hline CHEMBL 3210404 & 688239 & 6.2362 & 5.5499 & TRN & \\
\hline CHEMBL1484335 & 688239 & 6.7361 & 5.5381 & TRN & \\
\hline CHEMBL1333080 & 688239 & 4.6362 & 5.5691 & TRN & \\
\hline CHEMBL1517000 & 688239 & 5.4862 & 5.5353 & TRN & \\
\hline CHEMBL1450047 & 688239 & 4.5362 & 5.4555 & TRN & \\
\hline CHEMBL1579804 & 688239 & 5.1862 & 5.423999 & 9999999995 & TST \\
\hline CHEMBL1495252 & 688239 & 5.9362 & 5.4818 & TRN & \\
\hline CHEMBL600968 & 688239 & 5.7362 & 5.4627 & TRN & \\
\hline CHEMBL1346975 & 688239 & 6.9863 & 5.3816 & TRN & \\
\hline CHEMBL1408095 & 688239 & 4.6862 & 5.4479 & TRN & \\
\hline CHEMBL1414589 & 688239 & 5.6862 & 5.5219 & TRN & \\
\hline CHEMBL1540280 & 688239 & 5.8862 & 5.5037 & TRN & \\
\hline CHEMBL1313295 & 688239 & 6.5862 & 5.5662 & TRN & \\
\hline CHEMBL1352727 & 688239 & 6.1362 & 5.3927 & TRN & \\
\hline CHEMBL1308246 & 688239 & 5.1862 & 5.4146 & TRN & \\
\hline CHEMBL1562924 & 688239 & 6.6861 & 5.468 & TRN & \\
\hline CHEMBL 3209055 & 688239 & 5.0362 & 5.3682 & TRN & \\
\hline CHEMBL1586327 & 688239 & 4.6862 & 5.2796 & TST & \\
\hline CHEMBL1337112 & 688239 & 6.2862 & 5.5028 & TRN & \\
\hline CHEMBL1969610 & 688239 & 4.5362 & 5.4536 & TST & \\
\hline CHEMBL1527163 & 688239 & 6.2862 & 5.3612 & TST & \\
\hline CHEMBL1458768 & 688239 & 5.1862 & 5.3411 & TRN & \\
\hline CHEMBL1404091 & 688239 & 4.5362 & 5.5141 & TRN & \\
\hline CHEMBL1380271 & 688239 & 5.5362 & 5.4994 & TRN & \\
\hline CHEMBL1382212 & 688239 & 4.7862 & 5.4761 & TST & \\
\hline CHEMBL586000 & 688239 & 4.5362 & 5.3198 & TST & \\
\hline CHEMBL1604537 & 688239 & 8.283999 & 999999999 & 5.6733 & TRN \\
\hline CHEMBL1474307 & 688239 & 4.5362 & 5.4631 & TRN & \\
\hline CHEMBL1575920 & 688239 & 5.7362 & 5.4122 & TRN & \\
\hline CHEMBL1565877 & 688239 & 5.1862 & 5.5392 & TRN & \\
\hline CHEMBL1588616 & 688239 & 6.2862 & 5.6049 & TRN & \\
\hline CHEMBL3212093 & 688239 & 6.2362 & 5.3904 & TRN & \\
\hline CHEMBL 3213319 & 688239 & 5.4362 & 5.3974 & TST & \\
\hline CHEMBL1578248 & 688239 & 6.7361 & 5.4453 & TRN & \\
\hline CHEMBL1365587 & 688239 & 4.5362 & 5.5095 & TST & \\
\hline CHEMBL1585152 & 688239 & 5.1862 & 5.5237 & TST & \\
\hline CHEMBL1485844 & 688239 & 6.8362 & 5.4176 & TRN & \\
\hline
\end{tabular}


Supplemental Table S2.txt

\begin{tabular}{|c|c|c|c|c|}
\hline CHEMBL1506859 & 688239 & 5.9362 & 5.4712 & TRN \\
\hline CHEMBL1578155 & 688239 & 4.6862 & 5.4547 & TST \\
\hline CHEMBL1390367 & 688239 & 4.9862 & 5.5829 & TST \\
\hline CHEMBL1339933 & 688239 & 5.5862 & \multicolumn{2}{|c|}{5.4910000000000005} \\
\hline CHEMBL1379992 & 688239 & 4.8362 & 5.5358 & TRN \\
\hline CHEMBL1584159 & 688239 & 4.5362 & 5.4211 & TRN \\
\hline CHEMBL1436202 & 688239 & 4.7862 & 5.5165 & TRN \\
\hline CHEMBL1399697 & 688239 & 4.5362 & 5.5474 & TRN \\
\hline CHEMBL1543733 & 688239 & 5.7862 & 5.4514 & TRN \\
\hline CHEMBL1569223 & 688239 & 6.1862 & 5.5886 & TRN \\
\hline CHEMBL1486542 & 688239 & 6.9863 & 5.4661 & TRN \\
\hline CHEMBL1487777 & 688239 & 4.5362 & 5.4471 & TRN \\
\hline CHEMBL1300101 & 688239 & 4.4862 & 5.4779 & TST \\
\hline CHEMBL1363861 & 688239 & 4.8362 & 5.2463 & TRN \\
\hline CHEMBL1445991 & 688239 & 4.5362 & 5.635 & TRN \\
\hline CHEMBL1611750 & 688239 & 5.4862 & 5.6407 & TRN \\
\hline CHEMBL1581219 & 688239 & 4.8862 & 5.4563 & TRN \\
\hline CHEMBL1574285 & 688239 & 5.4862 & 5.5086 & TRN \\
\hline CHEMBL1503968 & 688239 & 5.3862 & 5.5925 & TST \\
\hline CHEMBL1324625 & 688239 & 6.5862 & 5.6268 & TRN \\
\hline CHEMBL1557565 & 688239 & 4.6362 & 5.4472 & TRN \\
\hline CHEMBL1306947 & 688239 & 4.9362 & 5.4439 & TRN \\
\hline CHEMBL1377009 & 688239 & 7.0862 & 5.6593 & TRN \\
\hline CHEMBL1518193 & 688239 & 5.7362 & 5.4768 & TRN \\
\hline CHEMBL1426198 & 688239 & 4.7362 & 5.4797 & TRN \\
\hline CHEMBL1409549 & 688239 & 4.7862 & 5.5781 & TRN \\
\hline CHEMBL1441256 & 688239 & 6.9363 & 5.4402 & TRN \\
\hline CHEMBL1478481 & 688239 & 6.9863 & 5.6371 & TRN \\
\hline CHEMBL1446214 & 688239 & 4.9362 & 5.4847 & TRN \\
\hline CHEMBL1553533 & 688239 & 4.5362 & 5.4851 & TST \\
\hline CHEMBL427692 & 688239 & 4.5362 & 5.5769 & TRN \\
\hline CHEMBL1430526 & 688239 & 4.4862 & 5.5298 & TST \\
\hline CHEMBL1536190 & 688239 & 6.3863 & 5.4197 & TRN \\
\hline CHEMBL1310803 & 688239 & 4.5362 & 5.4703 & TRN \\
\hline CHEMBL1306075 & 688239 & 4.5362 & 5.4699 & TST \\
\hline CHEMBL1490464 & 688239 & 6.4362 & 5.4879 & TRN \\
\hline CHEMBL1978037 & 688239 & 5.0362 & 5.32799 & 9999999999 \\
\hline CHEMBL1600475 & 688239 & 4.5862 & 5.5122 & TRN \\
\hline CHEMBL1326887 & 688239 & 4.5362 & 5.5856 & TST \\
\hline CHEMBL1473706 & 688239 & 4.4862 & 5.3807 & TRN \\
\hline CHEMBL1497070 & 688239 & 4.7862 & 5.494 & TST \\
\hline CHEMBL1335474 & 688239 & 7.0362 & 5.5227 & TRN \\
\hline CHEMBL1354264 & 688239 & 4.5362 & 5.5787 & TRN \\
\hline CHEMBL1383532 & 688239 & 4.6362 & 5.6241 & TST \\
\hline CHEMBL1465179 & 688239 & 5.4362 & 5.6028 & TRN \\
\hline CHEMBL1549027 & 688239 & 8.3372 & 5.3915 & TRN \\
\hline CHEMBL1451371 & 688239 & 4.5862 & 5.51399 & 9999999999 \\
\hline CHEMBL1509991 & 688239 & 4.7362 & 5.4902 & TST \\
\hline
\end{tabular}


Supplemental Table S2.txt

\begin{tabular}{|c|c|c|c|}
\hline HEMBL3212279 & 688239 & 5.1862 & כל לדים \\
\hline CHEMBL1331211 & 688239 & 4.5362 & 5.3392 \\
\hline CHEMBL1570139 & 8239 & 4.5362 & 5057 \\
\hline HEMBL1452752 & 8239 & 6.1862 & 5.6681 \\
\hline HEMBL1318190 & 88239 & 6.7361 & 441 \\
\hline HEMBL1383863 & 588239 & 4.5362 & 5.4089 \\
\hline HEMBL1351307 & 588239 & 6.0862 & 5.4583 \\
\hline CHEMBL56970 & 588239 & 8.2366 & 5.3918 \\
\hline HEMBL3208955 & 688239 & 4.5362 & 5.3424 \\
\hline CHEMBL1431185 & 688239 & 5.8362 & 5.4622 \\
\hline CHEMBL1489389 & 688239 & 5.2362 & 5.5037 \\
\hline CHEMBL 3213302 & 688239 & 5.1862 & 5.4121 \\
\hline CHEMBL1314485 & 688239 & 6.0862 & 5.4603 \\
\hline HEMBL1550099 & 88239 & 5.9362 & 5.4454 \\
\hline HEMBL1419152 & 688239 & $5 . \ell$ & 5.4826 \\
\hline CHEMBL1586236 & 688239 & 6.8861 & 5.471 \\
\hline CHEMBL1530022 & 688239 & 5.9362 & 5.4597 \\
\hline CHEMBL1324892 & 688239 & 5.8 & 5.4583 \\
\hline HEMBL199 & 688239 & 4.6 & 5.474 \\
\hline CHEMBL149 & 688239 & 5.1 & 5.6938 \\
\hline HEMBL1485352 & 688239 & 7.4868 & 5.4905 \\
\hline CHEMBL1418583 & 688239 & 5.7 & 5.7028 \\
\hline CHEMBL157 & 688239 & 4.5362 & 5.4948 \\
\hline CHEMBL139 & 688239 & 6. & 5.5418 \\
\hline CHEMBL319 & 88239 & 4 & 5.5199 \\
\hline HEMBL1595588 & 688239 & 4.7362 & 5.5238 \\
\hline CHEMBL1324292 & 688239 & 6.3863 & 5.4126 \\
\hline CHEMBL1426323 & 688239 & 6 & 5.5333 \\
\hline AEMBL1 & 39 & 6. & 865 \\
\hline HEMBL1484396 & 688239 & 5. & 5.4355 \\
\hline CHEMBL1392275 & 688239 & 5.5362 & 5.4317 \\
\hline CHEMBL1529964 & 688239 & 5.7862 & 5.6138 \\
\hline CHEMBL151 & 688239 & 4. & 752 \\
\hline HEMBL & 39 & 4. & 806 \\
\hline HEMBL 148 & 688 & 4. & 5.4798 \\
\hline CHEMBL1383856 & 688239 & 4.6862 & 5.5078 \\
\hline CHEMBL1088018 & 688239 & 8.3372 & 5.4689 \\
\hline CHEMBL & 39 & & \\
\hline CHEMBL159 & 39 & 5 & 5.3745 \\
\hline CHEMBL1505267 & 688239 & 4.5362 & 5.4427 \\
\hline CHEMBL1496555 & 688239 & 6.1362 & 5.4969 \\
\hline CHEMBL1452410 & 688239 & 6.8861 & 5.4355 \\
\hline CHEMBL & & & \\
\hline CHEMBL1412505 & 688239 & 5.5362 & 5.439 \\
\hline CHEMBL1327215 & 688239 & 5.8362 & 5.534 \\
\hline CHEMBL1388934 & 688239 & 6.6861 & 5.5118 \\
\hline CHEMBL1562171 & 688239 & 5.4862 & 5.5128 \\
\hline CHEMBL1301691 & & 5.9862 & 5.399 \\
\hline
\end{tabular}


Supplemental Table S2.txt

\begin{tabular}{|c|c|c|c|c|c|}
\hline CHEMBL1503411 & 688239 & 4.8362 & 5.3587 & TRN & \\
\hline CHEMBL1409659 & 688239 & 5.4862 & 5.5327 & TRN & \\
\hline CHEMBL512090 & 688239 & 5.4362 & 5.5216 & TRN & \\
\hline CHEMBL1440301 & 688239 & 6.3362 & 5.5225 & TRN & \\
\hline CHEMBL1352063 & 688239 & 6.1862 & 5.6459 & TRN & \\
\hline CHEMBL1454597 & 688239 & 5.2362 & 5.4476 & TRN & \\
\hline CHEMBL1448305 & 688239 & 4.5362 & 5.3496 & TRN & \\
\hline CHEMBL1539721 & 688239 & 6.7862 & 5.4137 & TST & \\
\hline CHEMBL1392451 & 688239 & 4.7862 & 5.428 & TRN & \\
\hline CHEMBL3192532 & 688239 & 5.1862 & 5.4301 & TST & \\
\hline CHEMBL1392318 & 688239 & 4.9362 & 5.4189 & TRN & \\
\hline CHEMBL1512488 & 688239 & 7.8861 & 5.4985 & TRN & \\
\hline CHEMBL1477276 & 688239 & 4.5362 & 5.4462 & TRN & \\
\hline CHEMBL1402960 & 688239 & 4.9862 & 5.5176 & TRN & \\
\hline CHEMBL1545909 & 688239 & 4.7862 & 5.6088 & TST & \\
\hline CHEMBL1313507 & 688239 & 4.5362 & 5.3344 & TST & \\
\hline CHEMBL1486565 & 688239 & 5.8862 & 5.5895 & TRN & \\
\hline CHEMBL1464653 & 688239 & 5.1862 & 5.5634 & TRN & \\
\hline CHEMBL1509654 & 688239 & 5.6362 & 5.5894 & TRN & \\
\hline CHEMBL1409274 & 688239 & 5.7362 & 5.5443 & TRN & \\
\hline CHEMBL1365145 & 688239 & 4.6862 & 5.6066 & TRN & \\
\hline CHEMBL1392167 & 688239 & 5.9862 & 5.5426 & TRN & \\
\hline CHEMBL1540084 & 688239 & 7.2366 & 5.5065 & TRN & \\
\hline CHEMBL1373675 & 688239 & 5.1862 & 5.3983 & TRN & \\
\hline CHEMBL1457685 & 688239 & 5.7362 & 5.5412 & TST & \\
\hline CHEMBL 1358887 & 688239 & 4.5362 & 5.3416 & TRN & \\
\hline CHEMBL1302574 & 688239 & 4.5362 & 5.5044 & TRN & \\
\hline CHEMBL3209030 & 688239 & 5.0362 & 5.6574 & TRN & \\
\hline CHEMBL1386261 & 688239 & 5.1862 & 5.5765 & TRN & \\
\hline CHEMBL1381802 & 688239 & 4.7862 & 5.4713 & TST & \\
\hline CHEMBL1433482 & 688239 & 5.9362 & 5.3778 & TRN & \\
\hline CHEMBL1514060 & 688239 & 7.2366 & 5.4329 & TRN & \\
\hline CHEMBL1609247 & 688239 & 4.9862 & 5.4776 & TRN & \\
\hline CHEMBL1421018 & 688239 & 5.5862 & 5.3846 & TRN & \\
\hline CHEMBL1412124 & 688239 & 6.4862 & 5.63299 & 9999999999 & TRN \\
\hline CHEMBL1529086 & 688239 & 5.7362 & 5.5418 & TST & \\
\hline CHEMBL1497207 & 688239 & 6.5862 & 5.5264 & TRN & \\
\hline CHEMBL1572194 & 688239 & 6.5363 & 5.4877 & TST & \\
\hline CHEMBL1526597 & 688239 & 6.2362 & 5.5016 & TRN & \\
\hline CHEMBL1494962 & 688239 & 4.7362 & 5.5407 & TST & \\
\hline CHEMBL1496003 & 688239 & 5.5362 & 5.4115 & TRN & \\
\hline CHEMBL1466148 & 688239 & 4.4862 & 5.3515 & TRN & \\
\hline CHEMBL1465123 & 688239 & 5.1862 & 5.5406 & TRN & \\
\hline CHEMBL1355766 & 688239 & 5.6362 & 5.567 & TRN & \\
\hline CHEMBL1470799 & 688239 & 5.8362 & 5.6471 & TRN & \\
\hline CHEMBL1308431 & 688239 & 6.2362 & 5.4977 & TRN & \\
\hline CHEMBL1525192 & 688239 & 4.8862 & 5.4792 & TRN & \\
\hline CHEMBL1534627 & 688239 & 4.5362 & 5.4707 & TRN & \\
\hline
\end{tabular}




\begin{tabular}{|c|c|c|c|c|c|c|}
\hline & & \multicolumn{5}{|c|}{ Supplemental Table s2.txt } \\
\hline CHEMBL1329628 & 688239 & 4.7862 & 5.5781 & TRN & & \\
\hline CHEMBL1611147 & 688239 & 4.8862 & 5.6734 & TRN & & \\
\hline CHEMBL1414235 & 688239 & 6.2362 & 5.4713 & TST & & \\
\hline CHEMBL1350381 & 688239 & 6.6362 & 5.4495 & TST & & \\
\hline CHEMBL1347380 & 688239 & \multicolumn{3}{|c|}{8.283999999999999} & 5.3749 & TRN \\
\hline CHEMBL1408613 & 688239 & 4.4862 & 5.5871 & TRN & & \\
\hline CHEMBL1381647 & 688239 & 5.1862 & 5.6244 & TRN & & \\
\hline CHEMBL1418794 & 688239 & 5.0862 & 5.3837 & TRN & & \\
\hline CHEMBL1323218 & 688239 & 4.8862 & 5.6052 & TRN & & \\
\hline CHEMBL1504651 & 688239 & 4.7862 & 5.4704 & TRN & & \\
\hline CHEMBL1349027 & 688239 & 4.6362 & 5.4706 & TRN & & \\
\hline CHEMBL1579231 & 688239 & 6.6861 & 5.3805 & TRN & & \\
\hline CHEMBL3196293 & 688239 & 4.5362 & 5.4167 & TRN & & \\
\hline CHEMBL1415421 & 688239 & 4.5362 & 5.5314 & TRN & & \\
\hline CHEMBL1566152 & 688239 & 6.3863 & 5.3474 & TRN & & \\
\hline CHEMBL1373526 & 688239 & 6.2862 & 5.4638 & TRN & & \\
\hline CHEMBL1306743 & 688239 & 5.5362 & 5.4127 & TRN & & \\
\hline CHEMBL1397282 & 688239 & 4.6862 & 5.3358 & TRN & & \\
\hline CHEMBL1394333 & 688239 & 5.1862 & 5.5249 & TST & & \\
\hline CHEMBL1345615 & 688239 & 4.9862 & 5.4531 & TRN & & \\
\hline CHEMBL3198055 & 688239 & 6.7361 & 5.5243 & TRN & & \\
\hline CHEMBL1515806 & 688239 & 5.2862 & 5.5173 & TST & & \\
\hline CHEMBL1575637 & 688239 & 5.0362 & 5.5669 & TST & & \\
\hline CHEMBL1525345 & 688239 & 5.225 & 5.3769 & TST & & \\
\hline CHEMBL1493534 & 688239 & 5.0362 & 5.4128 & TST & & \\
\hline CHEMBL1429650 & 688239 & 6.1362 & 5.6486 & TRN & & \\
\hline CHEMBL1307314 & 688239 & 5.0362 & 5.4465 & TRN & & \\
\hline CHEMBL1453266 & 688239 & 6.8861 & 5.4634 & TRN & & \\
\hline CHEMBL1612989 & 688239 & 6.1862 & 5.6254 & TST & & \\
\hline CHEMBL1556410 & 688239 & 6.8362 & 5.4249 & TRN & & \\
\hline CHEMBL1979837 & 688239 & 5.5362 & 5.4115 & TRN & & \\
\hline CHEMBL1567367 & 688239 & 6.3863 & 5.6054 & TRN & & \\
\hline CHEMBL1440804 & 688239 & 5.4862 & 5.5342 & TRN & & \\
\hline CHEMBL1580673 & 688239 & 4.5362 & 5.6383 & TRN & & \\
\hline CHEMBL1564487 & 688239 & 8.1871 & 5.4694 & TRN & & \\
\hline CHEMBL1493261 & 688239 & 7.0362 & 5.5486 & TRN & & \\
\hline CHEMBL3196709 & 688239 & 5.3862 & 5.5711 & TST & & \\
\hline CHEMBL1349245 & 688239 & 6.1362 & 5.4525 & TRN & & \\
\hline CHEMBL1562635 & 688239 & 8.3372 & 5.4914 & TST & & \\
\hline CHEMBL1477068 & 688239 & 6.8861 & 5.4508 & TST & & \\
\hline CHEMBL1460015 & 688239 & 8.1871 & 5.5306 & TRN & & \\
\hline CHEMBL1384493 & 688239 & 5.7862 & 5.4379 & TRN & & \\
\hline CHEMBL1308510 & 688239 & 4.5362 & 5.5068 & TRN & & \\
\hline CHEMBL1432336 & 688239 & 4.5362 & 5.5841 & TST & & \\
\hline CHEMBL1308728 & 688239 & 5.1862 & 5.3381 & TRN & & \\
\hline CHEMBL1499578 & 688239 & 6.4862 & 5.395 & TRN & & \\
\hline CHEMBL1607331 & 688239 & 8.3872 & 5.7823 & TRN & & \\
\hline CHEMBL1362564 & 688239 & 4.7362 & 5.24700 & jo00000e & & TRN \\
\hline & & & & 1450 & & \\
\hline
\end{tabular}


Supplemental Table S2.txt

\begin{tabular}{|c|c|c|c|c|}
\hline CHEMBL1363119 & 688239 & 4.5362 & 5.5581 & TST \\
\hline CHEMBL1455223 & 688239 & 6.4862 & 5.5507 & TST \\
\hline CHEMBL1452640 & 688239 & 5.4362 & 5.5326 & TRN \\
\hline CHEMBL1613134 & 688239 & 8.2366 & 5.6027 & TST \\
\hline CHEMBL3145147 & 688239 & 6.8362 & 5.4946 & TST \\
\hline CHEMBL1338886 & 688239 & 5.4362 & 5.3851 & TST \\
\hline CHEMBL1486354 & 688239 & 4.5362 & 5.49700 & 0000000001 \\
\hline CHEMBL1577262 & 688239 & 4.7362 & 5.4915 & TST \\
\hline CHEMBL1375041 & 688239 & 8.1871 & 5.5249 & TRN \\
\hline CHEMBL1486978 & 688239 & 4.4862 & 5.3708 & TRN \\
\hline CHEMBL1457662 & 688239 & 5.1862 & 5.5931 & TST \\
\hline CHEMBL1494538 & 688239 & 5.6862 & 5.5253 & TRN \\
\hline CHEMBL1600763 & 688239 & 5.0862 & 5.3944 & TST \\
\hline CHEMBL1468413 & 688239 & 6.4362 & 5.2875 & TRN \\
\hline CHEMBL1443543 & 688239 & 5.0362 & 5.4794 & TRN \\
\hline CHEMBL1342491 & 688239 & 5.0862 & 5.4856 & TRN \\
\hline CHEMBL1447508 & 688239 & 5.4862 & 5.4864 & TRN \\
\hline CHEMBL1545501 & 688239 & 5.1862 & 5.5251 & TST \\
\hline CHEMBL1333348 & 688239 & 4.5362 & 5.3566 & TRN \\
\hline CHEMBL1368600 & 688239 & 5.1362 & 5.6821 & TRN \\
\hline CHEMBL1427333 & 688239 & 6.0862 & 5.4256 & TRN \\
\hline CHEMBL1462624 & 688239 & 5.5862 & 5.6141 & TRN \\
\hline CHEMBL1539754 & 688239 & 6.1362 & 5.5561 & TRN \\
\hline CHEMBL1324997 & 688239 & 4.5362 & 5.3969 & TRN \\
\hline CHEMBL1306836 & 688239 & 4.7862 & 5.3184 & TRN \\
\hline CHEMBL1484449 & 688239 & 4.75 & 5.4862 & TRN \\
\hline CHEMBL1359361 & 688239 & 4.6862 & 5.3604 & TRN \\
\hline CHEMBL1416698 & 688239 & 5.1862 & 5.4586 & TRN \\
\hline CHEMBL1421791 & 688239 & 6.4862 & 5.44799 & 79999999995 \\
\hline CHEMBL1535479 & 688239 & 5.7862 & 5.4854 & TRN \\
\hline CHEMBL1393274 & 688239 & 8.3372 & 5.5036 & TRN \\
\hline CHEMBL1576994 & 688239 & 5.3862 & 5.4646 & TRN \\
\hline CHEMBL1547310 & 688239 & 6.8861 & 5.5315 & TRN \\
\hline CHEMBL1378116 & 688239 & 4.9362 & 5.4122 & TRN \\
\hline CHEMBL1446435 & 688239 & 4.5362 & 5.4462 & TRN \\
\hline CHEMBL1307253 & 688239 & 6.1862 & 5.345 & TRN \\
\hline CHEMBL1360537 & 688239 & 4.5362 & 5.5734 & TRN \\
\hline CHEMBL1485456 & 688239 & 5.9862 & 5.6689 & TST \\
\hline CHEMBL1537477 & 688239 & 6.1862 & 5.5665 & TRN \\
\hline CHEMBL1385946 & 688239 & 8.3372 & 5.5684 & TRN \\
\hline CHEMBL1548083 & 688239 & 4.6862 & 5.25899 & 99999999995 \\
\hline CHEMBL1322761 & 688239 & 5.8862 & 5.7087 & TRN \\
\hline CHEMBL1391899 & 688239 & 4.5362 & 5.45100 & 00000000005 \\
\hline CHEMBL1320623 & 688239 & 6.1862 & 5.6358 & TRN \\
\hline CHEMBL1437260 & 688239 & 5.1862 & 5.5602 & TRN \\
\hline CHEMBL1441635 & 688239 & 7.2366 & 5.4419 & TRN \\
\hline CHEMBL1408518 & 688239 & 5.1862 & 5.5048 & TRN \\
\hline CHEMBL1492946 & 688239 & 4.8362 & 5.4953 & TST \\
\hline
\end{tabular}


Supplemental Table S2.txt

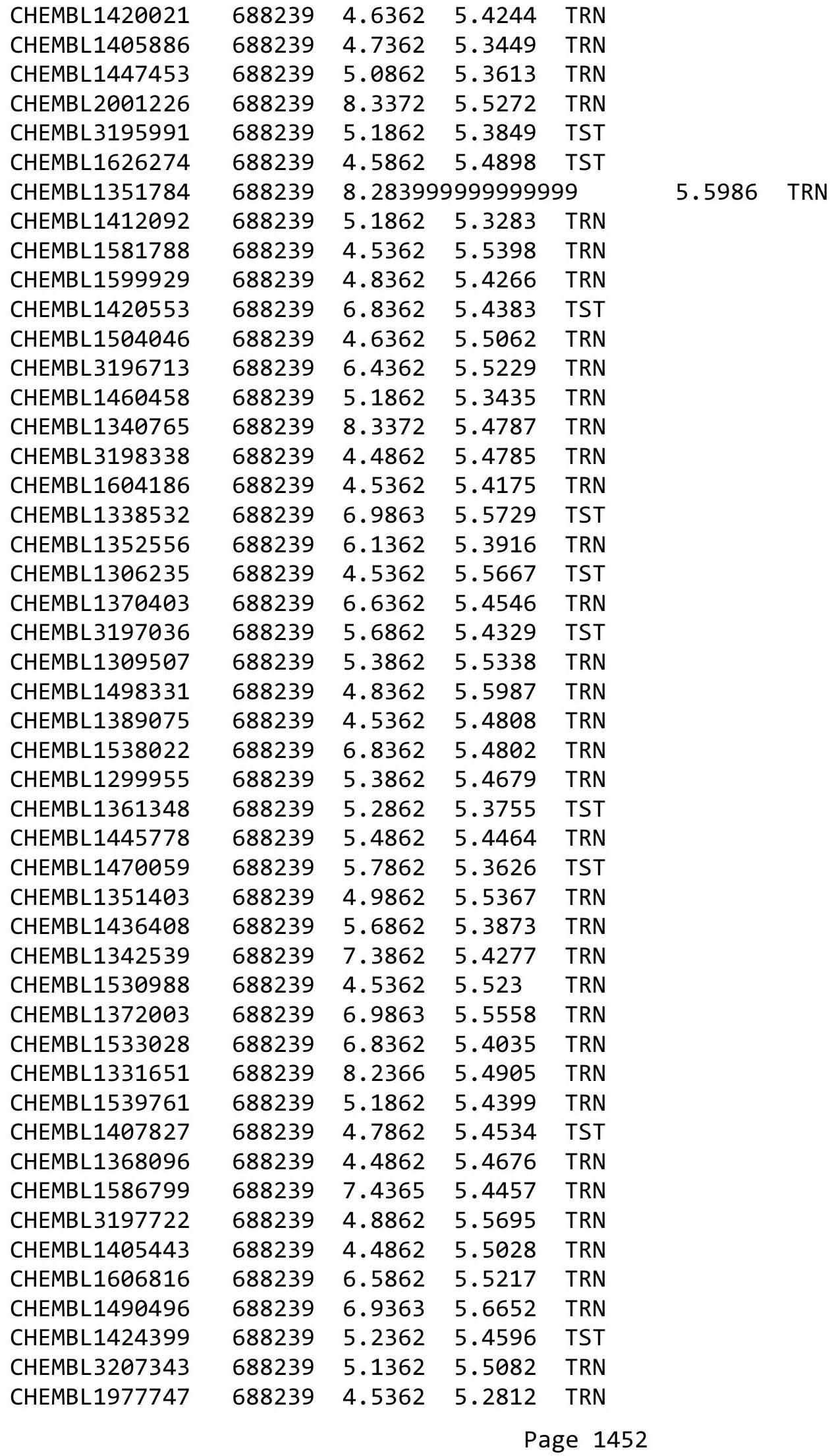


Supplemental Table S2.txt

\begin{tabular}{|c|c|c|c|c|}
\hline CHEMBL1525419 & 688239 & 6.5363 & 5.5166 & TRN \\
\hline CHEMBL1413497 & 688239 & 5.1862 & 5.4638 & TRN \\
\hline CHEMBL1381023 & 688239 & 5.2862 & 5.317 & TST \\
\hline CHEMBL1523281 & 688239 & 4.6862 & 5.3587 & TRN \\
\hline CHEMBL1456705 & 688239 & 5.1862 & 5.5977 & TRN \\
\hline CHEMBL1546367 & 688239 & 6.8861 & 5.5021 & TRN \\
\hline CHEMBL1558256 & 688239 & 4.4862 & 5.3499 & TST \\
\hline CHEMBL1454602 & 688239 & 6.1362 & 5.439 & TRN \\
\hline CHEMBL1478782 & 688239 & 4.5362 & 5.4854 & TRN \\
\hline CHEMBL1430747 & 688239 & 5.3862 & 5.2328 & TRN \\
\hline CHEMBL1566800 & 688239 & 5.3362 & 5.5062 & TRN \\
\hline CHEMBL1544165 & 688239 & 4.5862 & 5.6158 & TST \\
\hline CHEMBL1577321 & 688239 & 6.3362 & 5.4266 & TRN \\
\hline CHEMBL1447265 & 688239 & 4.7862 & 5.5282 & TST \\
\hline CHEMBL1610733 & 688239 & 6.0362 & 5.6069 & TRN \\
\hline CHEMBL1333832 & 688239 & 5.6862 & 5.4223 & TRN \\
\hline CHEMBL1402395 & 688239 & 8.283999 & 99999999 & 5.4586 \\
\hline CHEMBL1491459 & 688239 & 6.1862 & 5.3811 & TRN \\
\hline CHEMBL1553198 & 688239 & 5.1862 & 5.4576 & TRN \\
\hline CHEMBL1338023 & 688239 & 6.8861 & 5.5562 & TRN \\
\hline CHEMBL 1407372 & 688239 & 4.7362 & 5.5713 & TRN \\
\hline CHEMBL1368129 & 688239 & 4.5362 & 5.4091 & TRN \\
\hline CHEMBL1447566 & 688239 & 5.0862 & 5.517 & TRN \\
\hline CHEMBL1482627 & 688239 & 4.8862 & 5.3937 & TST \\
\hline CHEMBL1611280 & 688239 & 6.8861 & 5.5912 & TST \\
\hline CHEMBL1420914 & 688239 & 5.3862 & 5.622000 & 000000001 \\
\hline CHEMBL1360060 & 688239 & 5.8362 & 5.5012 & TST \\
\hline CHEMBL1557118 & 688239 & 4.5362 & 5.5538 & TRN \\
\hline CHEMBL1494386 & 688239 & 8.3372 & 5.6006 & TRN \\
\hline CHEMBL1464643 & 688239 & 5.6362 & 5.2981 & TST \\
\hline CHEMBL1324285 & 688239 & 6.0862 & 5.362999 & 9999999995 \\
\hline CHEMBL 3190037 & 688239 & 6.1862 & 5.5685 & TRN \\
\hline CHEMBL1341992 & 688239 & 6.9363 & 5.3589 & TST \\
\hline CHEMBL1334426 & 688239 & 8.3872 & 5.3706 & TRN \\
\hline CHEMBL1578897 & 688239 & 4.5362 & 5.5742 & TRN \\
\hline CHEMBL3193782 & 688239 & 5.2362 & 5.4192 & TST \\
\hline CHEMBL1565972 & 688239 & 6.7862 & 5.6385 & TRN \\
\hline CHEMBL3195276 & 688239 & 5.7362 & 5.3179 & TST \\
\hline CHEMBL1473874 & 688239 & 4.5362 & 5.4213 & TST \\
\hline CHEMBL1340624 & 688239 & 6.1862 & 5.6208 & TRN \\
\hline CHEMBL1370044 & 688239 & 4.5362 & 5.4802 & TRN \\
\hline CHEMBL1387784 & 688239 & 4.5362 & 5.5225 & TRN \\
\hline CHEMBL1423681 & 688239 & 4.8362 & 5.4705 & TRN \\
\hline CHEMBL1402203 & 688239 & 5.6862 & 5.358 & TST \\
\hline CHEMBL1407170 & 688239 & 5.6862 & 5.4151 & TST \\
\hline CHEMBL1364892 & 688239 & 4.8362 & 5.3621 & TRN \\
\hline CHEMBL1522327 & 688239 & 5.0362 & 5.5398 & TRN \\
\hline CHEMBL1345379 & 688239 & 4.5362 & 5.5388 & TRN \\
\hline
\end{tabular}


Supplemental Table S2.txt

\begin{tabular}{|c|c|c|c|c|c|}
\hline CHEMBL1406319 & 688239 & 6.0862 & 5.443 & TRN & \\
\hline CHEMBL1547624 & 688239 & 6.2862 & 5.4649 & TRN & \\
\hline CHEMBL1409120 & 688239 & 5.1862 & 5.4353 & TRN & \\
\hline CHEMBL1447958 & 688239 & 4.7362 & 5.4435 & TRN & \\
\hline CHEMBL1496958 & 688239 & 6.2362 & 5.5332 & TST & \\
\hline CHEMBL1412362 & 688239 & 4.95 & 5.4003 & TRN & \\
\hline CHEMBL1400657 & 688239 & 4.6862 & 5.489 & TRN & \\
\hline CHEMBL1591843 & 688239 & 5.1862 & 5.41799 & 9999999999 & TRN \\
\hline CHEMBL1442679 & 688239 & 4.5362 & 5.4456 & TRN & \\
\hline CHEMBL1385599 & 688239 & 4.8862 & 5.6316 & TST & \\
\hline CHEMBL1601114 & 688239 & 5.2362 & 5.5964 & TRN & \\
\hline CHEMBL1458402 & 688239 & 6.9363 & 5.4366 & TST & \\
\hline CHEMBL1503154 & 688239 & 4.6862 & 5.4867 & TRN & \\
\hline CHEMBL1362052 & 688239 & 5.1362 & 5.5348 & TRN & \\
\hline CHEMBL1547105 & 688239 & 5.4862 & 5.3643 & TST & \\
\hline CHEMBL1308782 & 688239 & 5.0362 & 5.7133 & TRN & \\
\hline CHEMBL1440443 & 688239 & 4.4862 & 5.4999 & TRN & \\
\hline CHEMBL1427851 & 688239 & 4.6862 & 5.5362 & TRN & \\
\hline CHEMBL1459997 & 688239 & 5.0362 & 5.5567 & TST & \\
\hline CHEMBL1587961 & 688239 & 6.8861 & 5.46899 & 9999999999 & TRN \\
\hline CHEMBL1434238 & 688239 & 4.5362 & 5.5253 & TRN & \\
\hline CHEMBL1589678 & 688239 & 4.6862 & 5.51399 & 9999999999 & TRN \\
\hline CHEMBL1365414 & 688239 & 4.5862 & 5.4944 & TST & \\
\hline CHEMBL1305329 & 688239 & 4.4862 & 5.3845 & TRN & \\
\hline CHEMBL232148 & 688239 & 5.3362 & 5.4652 & TRN & \\
\hline CHEMBL1377610 & 688239 & 6.1362 & 5.4659 & TRN & \\
\hline CHEMBL1554345 & 688239 & 4.7362 & 5.3873 & TRN & \\
\hline CHEMBL1342605 & 688239 & 7.1361 & 5.5421 & TRN & \\
\hline CHEMBL1350215 & 688239 & 6.9363 & 5.4037 & TRN & \\
\hline CHEMBL1441016 & 688239 & 5.1862 & 5.5487 & TRN & \\
\hline CHEMBL1430631 & 688239 & 6.0862 & 5.4269 & TST & \\
\hline CHEMBL1544018 & 688239 & 6.7862 & 5.482 & TRN & \\
\hline CHEMBL1461045 & 688239 & 5.4362 & 5.447 & TST & \\
\hline CHEMBL1505950 & 688239 & 5.4362 & 5.4629 & TST & \\
\hline CHEMBL1470733 & 688239 & 4.8362 & 5.3998 & TST & \\
\hline CHEMBL1385876 & 688239 & 4.5362 & 5.567 & TRN & \\
\hline CHEMBL1465613 & 688239 & 5.4862 & 5.5759 & TST & \\
\hline CHEMBL1410608 & 688239 & 5.1862 & 5.3759 & TST & \\
\hline CHEMBL1550245 & 688239 & 4.5362 & 5.3763 & TST & \\
\hline CHEMBL1310158 & 688239 & 6.9363 & 5.4125 & TRN & \\
\hline CHEMBL1436032 & 688239 & 4.5362 & 5.3869 & TST & \\
\hline CHEMBL1340389 & 688239 & 4.6862 & 5.4628 & TRN & \\
\hline CHEMBL1600477 & 688239 & 6.0862 & 5.5289 & TST & \\
\hline CHEMBL1554978 & 688239 & 5.9362 & 5.4712 & TRN & \\
\hline CHEMBL1468682 & 688239 & 4.5362 & 5.4318 & TRN & \\
\hline CHEMBL1460888 & 688239 & 4.9862 & 5.5046 & TRN & \\
\hline CHEMBL1300628 & 688239 & 4.5362 & 5.4745 & TRN & \\
\hline CHEMBL1394045 & 688239 & 6.9363 & 5.5226 & TRN & \\
\hline
\end{tabular}


Supplemental Table S2.txt

\begin{tabular}{|c|c|c|c|c|c|}
\hline CHEMBL1459626 & 688239 & 5.3862 & 5.5126 & TST & \\
\hline CHEMBL1506092 & 688239 & 5.8862 & 5.4895 & TRN & \\
\hline CHEMBL1437715 & 688239 & 4.6362 & 5.4554 & TRN & \\
\hline CHEMBL1362436 & 688239 & 6.9863 & 5.4495 & TRN & \\
\hline CHEMBL1330245 & 688239 & 4.5862 & 5.5018 & TRN & \\
\hline CHEMBL442964 & 688239 & 4.6362 & 5.5155 & TRN & \\
\hline CHEMBL1352411 & 688239 & 5.2862 & 5.4728 & TST & \\
\hline CHEMBL1537335 & 688239 & 5.2362 & 5.6704 & TST & \\
\hline CHEMBL1492101 & 688239 & 4.7862 & 5.48600 & 0000000001 & TRN \\
\hline CHEMBL3199891 & 688239 & 5.6862 & 5.32100 & 0000000001 & TST \\
\hline CHEMBL3196686 & 688239 & 4.5362 & 5.2945 & TST & \\
\hline CHEMBL1480530 & 688239 & 5.0362 & 5.4966 & TST & \\
\hline CHEMBL1444458 & 688239 & 4.8862 & 5.5357 & TRN & \\
\hline CHEMBL1474113 & 688239 & 4.5362 & 5.5676 & TRN & \\
\hline CHEMBL1413089 & 688239 & 4.5362 & 5.3741 & TST & \\
\hline CHEMBL1461568 & 688239 & 6.7862 & 5.5284 & TRN & \\
\hline CHEMBL1473023 & 688239 & 4.5362 & 5.5066 & TST & \\
\hline CHEMBL1331241 & 688239 & 4.4862 & 5.5818 & TRN & \\
\hline CHEMBL1569793 & 688239 & 6.7862 & 5.6245 & TRN & \\
\hline CHEMBL1393834 & 688239 & 4.5362 & 5.4618 & TRN & \\
\hline CHEMBL1605649 & 688239 & 4.5362 & 5.4266 & TRN & \\
\hline CHEMBL1585135 & 688239 & 4.5362 & 5.5508 & TST & \\
\hline CHEMBL1591496 & 688239 & 5.3862 & 5.3609 & TST & \\
\hline CHEMBL1428821 & 688239 & 5.1862 & 5.5239 & TRN & \\
\hline CHEMBL1496671 & 688239 & 6.9363 & 5.4775 & TRN & \\
\hline CHEMBL1307003 & 688239 & 4.5862 & 5.5839 & TRN & \\
\hline CHEMBL1561851 & 688239 & 8.3372 & 5.4314 & TST & \\
\hline CHEMBL1337280 & 688239 & 5.8362 & 5.5298 & TST & \\
\hline CHEMBL1477760 & 688239 & 4.7862 & 5.3621 & TST & \\
\hline CHEMBL1455244 & 688239 & 5.1862 & 5.4413 & TRN & \\
\hline CHEMBL1384782 & 688239 & 6.5363 & 5.4385 & TRN & \\
\hline CHEMBL1584801 & 688239 & 4.5362 & 5.5438 & TRN & \\
\hline CHEMBL1349579 & 688239 & 4.5362 & 5.5619 & TRN & \\
\hline CHEMBL1415401 & 688239 & 4.6362 & 5.4119 & TRN & \\
\hline CHEMBL1311572 & 688239 & 4.5362 & 5.2287 & TST & \\
\hline CHEMBL1462285 & 688239 & 6.1862 & 5.5835 & TRN & \\
\hline CHEMBL1461842 & 688239 & 7.1864 & 5.4497 & TST & \\
\hline CHEMBL1388705 & 688239 & 6.0862 & 5.5488 & TRN & \\
\hline CHEMBL1304316 & 688239 & 5.1862 & 5.5598 & TST & \\
\hline CHEMBL1492160 & 688239 & 4.5362 & 5.4805 & TRN & \\
\hline CHEMBL1404735 & 688239 & 4.9862 & 5.4839 & TRN & \\
\hline CHEMBL1597106 & 688239 & 4.5862 & 5.4606 & TRN & \\
\hline CHEMBL1497966 & 688239 & 4.7362 & 5.4437 & TRN & \\
\hline CHEMBL1517912 & 688239 & 4.8362 & 5.4127 & TRN & \\
\hline CHEMBL1399485 & 688239 & 4.5862 & 5.2879 & TRN & \\
\hline CHEMBL3207934 & 688239 & 4.5362 & 5.5818 & TRN & \\
\hline CHEMBL1496457 & 688239 & 5.1862 & 5.4449 & TST & \\
\hline CHEMBL1996625 & 688239 & 5.4862 & 5.5215 & TRN & \\
\hline
\end{tabular}


Supplemental Table S2.txt

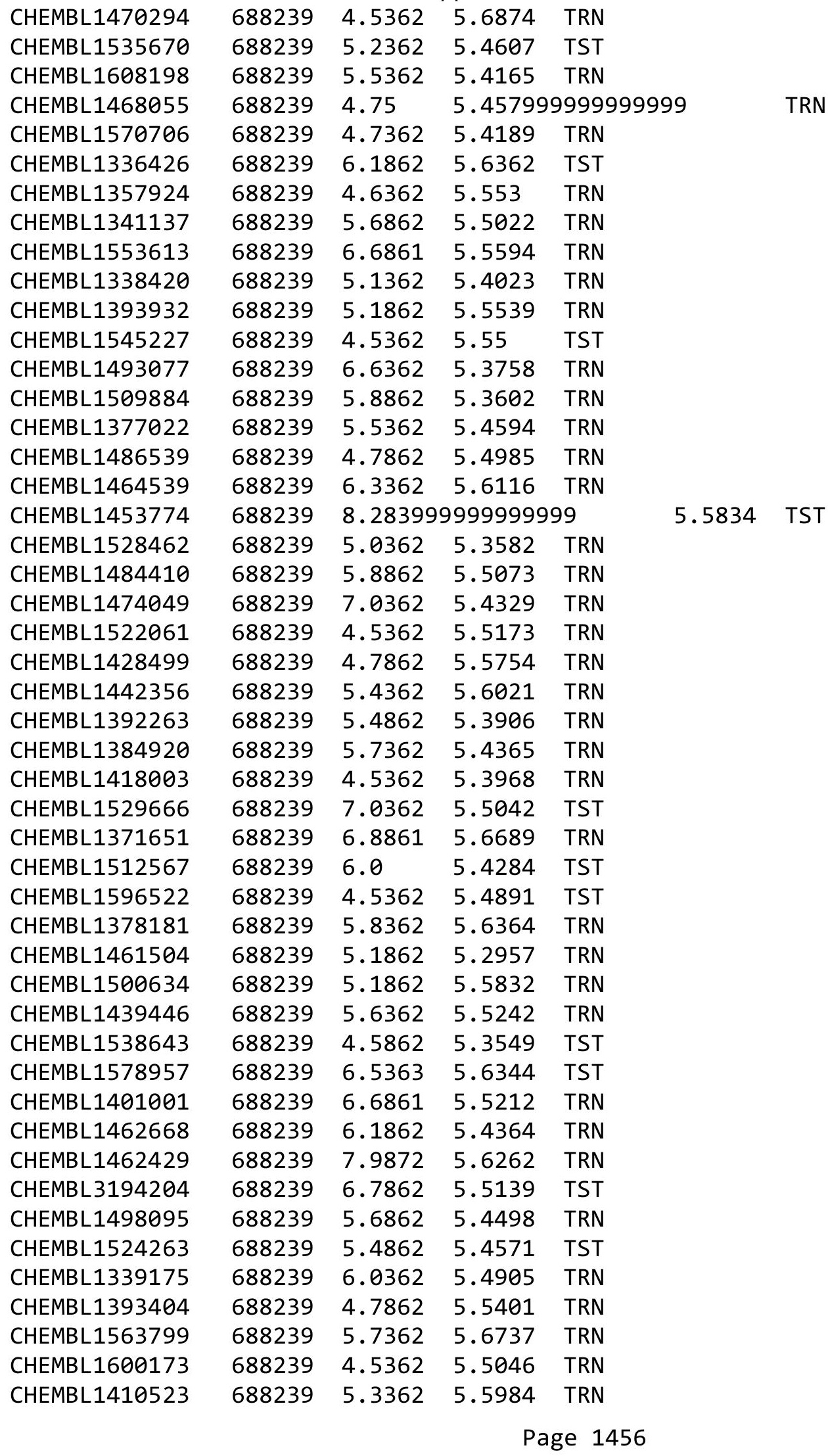


Supplemental Table S2.txt

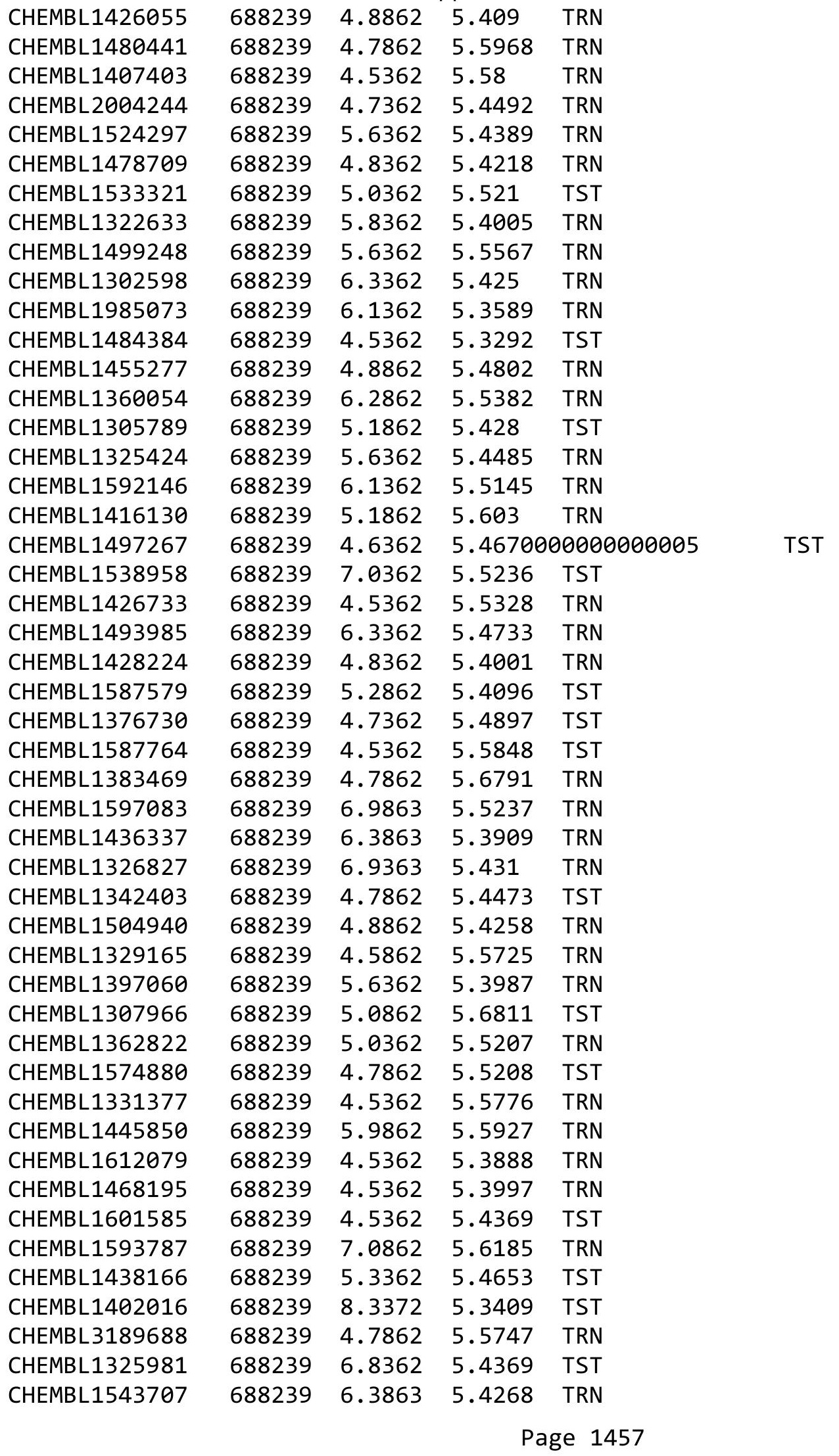


Supplemental Table S2.txt

\begin{tabular}{|c|c|c|c|c|}
\hline CHEMBL1594507 & 688239 & 6.0862 & 5.4691 & TST \\
\hline CHEMBL1501990 & 688239 & 6.3362 & 5.4967 & TST \\
\hline CHEMBL1497962 & 688239 & 5.1862 & 5.4723 & TST \\
\hline CHEMBL1309050 & 688239 & 5.3362 & 5.5357 & TST \\
\hline CHEMBL1531965 & 688239 & 6.2862 & 5.5758 & TRN \\
\hline CHEMBL1366830 & 688239 & 5.8862 & 5.601 & TST \\
\hline CHEMBL1374988 & 688239 & 5.8362 & 5.3559 & TST \\
\hline CHEMBL1468940 & 688239 & 4.5362 & 5.4495 & TRN \\
\hline CHEMBL1606415 & 688239 & 5.6862 & 5.4512 & TRN \\
\hline CHEMBL1408191 & 688239 & 5.1862 & 5.3182 & TRN \\
\hline CHEMBL1412290 & 688239 & 4.6862 & 5.4509 & TST \\
\hline CHEMBL1561418 & 688239 & 4.5862 & 5.5439 & TST \\
\hline CHEMBL1370277 & 688239 & 6.1862 & 5.3926 & TRN \\
\hline CHEMBL1571737 & 688239 & 4.5862 & 5.4335 & TRN \\
\hline CHEMBL1540375 & 688239 & 5.4362 & 5.4956 & TRN \\
\hline CHEMBL1403167 & 688239 & 4.5362 & 5.4618 & TRN \\
\hline CHEMBL1602357 & 688239 & 5.4362 & 5.5171 & TRN \\
\hline CHEMBL1315564 & 688239 & 5.7862 & 5.3137 & TRN \\
\hline CHEMBL1487979 & 688239 & 5.1862 & 5.3537 & TRN \\
\hline CHEMBL1525172 & 688239 & 4.7362 & 5.3731 & TRN \\
\hline CHEMBL1612431 & 688239 & 6.0362 & 5.6442 & TRN \\
\hline CHEMBL1437758 & 688239 & 4.5362 & 5.6918 & TST \\
\hline CHEMBL1537050 & 688239 & 5.6862 & 5.5447 & TRN \\
\hline CHEMBL1308365 & 688239 & 6.0862 & 5.6189 & TRN \\
\hline CHEMBL1538399 & 688239 & 4.6862 & 5.3961 & TRN \\
\hline CHEMBL1550691 & 688239 & 4.8362 & 5.6307 & TRN \\
\hline CHEMBL3191910 & 688239 & 4.6862 & 5.4666 & TST \\
\hline CHEMBL1436985 & 688239 & 5.8862 & 5.4736 & TRN \\
\hline CHEMBL1479051 & 688239 & 6.3362 & 5.433 & TRN \\
\hline CHEMBL1544724 & 688239 & 6.2362 & 5.4645 & TRN \\
\hline CHEMBL407501 & 688239 & 6.4362 & 5.4118 & TRN \\
\hline CHEMBL3211676 & 688239 & 5.0362 & 5.3658 & TST \\
\hline CHEMBL3194219 & 688239 & 8.3372 & 5.3492 & TST \\
\hline CHEMBL1544486 & 688239 & 4.6862 & 5.4715 & TRN \\
\hline CHEMBL1383098 & 688239 & 4.8862 & 5.4237 & TRN \\
\hline CHEMBL1587620 & 688239 & 5.2862 & 5.6031 & TRN \\
\hline CHEMBL1425362 & 688239 & 5.6362 & 5.4641 & TRN \\
\hline CHEMBL1305839 & 688239 & 4.5362 & 5.5347 & TRN \\
\hline CHEMBL1361009 & 688239 & 5.7362 & 5.4819 & TRN \\
\hline CHEMBL1545598 & 688239 & 4.8862 & 5.4406 & TRN \\
\hline CHEMBL1440654 & 688239 & 4.6862 & 5.49700 & 0000000001 \\
\hline CHEMBL1324813 & 688239 & 7.6364 & 5.5044 & TST \\
\hline CHEMBL1427146 & 688239 & 6.2862 & 5.3956 & TST \\
\hline CHEMBL3199111 & 688239 & 6.9863 & 5.5365 & TST \\
\hline CHEMBL1404824 & 688239 & 6.2362 & 5.4707 & TRN \\
\hline CHEMBL1404413 & 688239 & 6.2362 & 5.6937 & TRN \\
\hline CHEMBL1459010 & 688239 & 4.6862 & 5.4583 & TRN \\
\hline CHEMBL1603731 & 688239 & 4.4862 & 5.3889 & TRN \\
\hline
\end{tabular}


Supplemental Table S2.txt

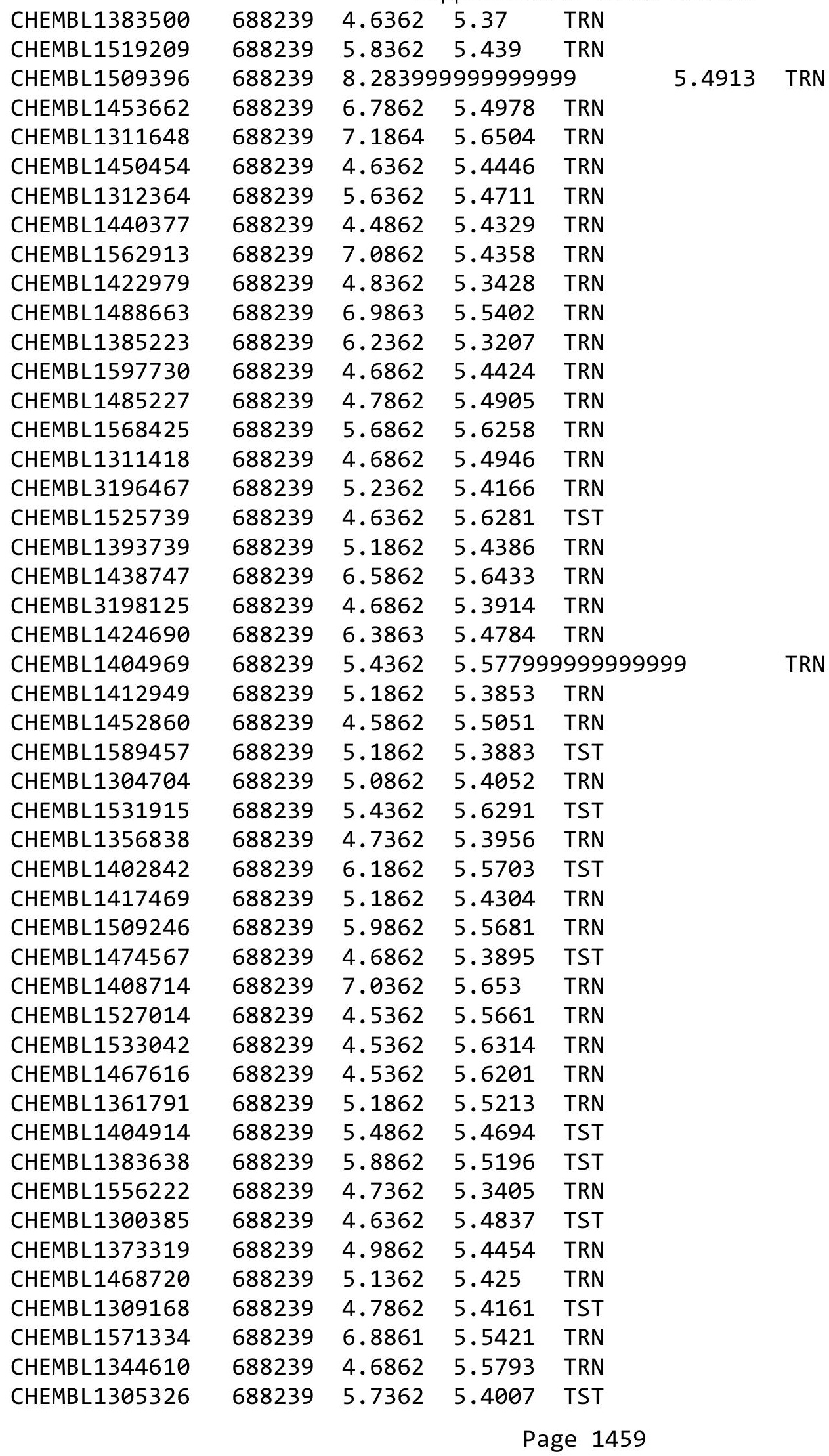


Supplemental Table S2.txt

\begin{tabular}{|c|c|c|c|c|c|}
\hline CHEMBL1458441 & 688239 & 8.3372 & 5.3078 & TST & \\
\hline CHEMBL1344272 & 688239 & 5.8362 & 5.4817 & TRN & \\
\hline CHEMBL1453103 & 688239 & 6.5862 & 5.4772 & TST & \\
\hline CHEMBL1474973 & 688239 & 5.0362 & 5.46899 & 9999999999 & TRN \\
\hline CHEMBL1542987 & 688239 & 4.5362 & 5.2897 & TRN & \\
\hline CHEMBL1455806 & 688239 & 4.9862 & 5.4717 & TST & \\
\hline CHEMBL1551172 & 688239 & 7.2366 & 5.4714 & TRN & \\
\hline CHEMBL1407859 & 688239 & 6.1862 & 5.4166 & TRN & \\
\hline CHEMBL1489657 & 688239 & 8.3372 & 5.46899 & 9999999999 & TRN \\
\hline CHEMBL1545556 & 688239 & 5.0362 & 5.4854 & TRN & \\
\hline CHEMBL1422297 & 688239 & 4.5362 & 5.5663 & TST & \\
\hline CHEMBL1421165 & 688239 & 4.9862 & 5.3814 & TRN & \\
\hline CHEMBL1535152 & 688239 & 4.6862 & 5.3411 & TRN & \\
\hline CHEMBL1559081 & 688239 & 6.9863 & 5.511 & TRN & \\
\hline CHEMBL1554017 & 688239 & 6.7361 & 5.3452 & TRN & \\
\hline CHEMBL1330100 & 688239 & 5.6862 & 5.6904 & TST & \\
\hline CHEMBL3191099 & 688239 & 6.8362 & 5.4985 & TRN & \\
\hline CHEMBL1443680 & 688239 & 5.7362 & 5.4063 & TRN & \\
\hline CHEMBL1549882 & 688239 & 6.8362 & 5.3808 & TRN & \\
\hline CHEMBL1395563 & 688239 & 5.7862 & 5.4338 & TRN & \\
\hline CHEMBL1488806 & 688239 & 6.8861 & 5.444 & TRN & \\
\hline CHEMBL1585732 & 688239 & 7.0362 & 5.4432 & TRN & \\
\hline CHEMBL1524766 & 688239 & 6.9363 & 5.3997 & TST & \\
\hline CHEMBL1348482 & 688239 & 5.8862 & 5.5363 & TRN & \\
\hline CHEMBL1530277 & 688239 & 5.8362 & 5.4829 & TRN & \\
\hline CHEMBL1445722 & 688239 & 6.1862 & \multicolumn{2}{|c|}{5.507000000000001} & TRN \\
\hline CHEMBL1426894 & 688239 & 5.7862 & 5.4976 & TRN & \\
\hline CHEMBL1490413 & 688239 & 5.1862 & 5.6053 & TRN & \\
\hline CHEMBL1416970 & 688239 & 5.1862 & 5.4711 & TST & \\
\hline CHEMBL1441995 & 688239 & 6.2862 & 5.5348 & TRN & \\
\hline CHEMBL1428971 & 688239 & 5.1862 & 5.4854 & TRN & \\
\hline CHEMBL1572723 & 688239 & 5.1862 & 5.5408 & TRN & \\
\hline CHEMBL1311301 & 688239 & 4.9362 & 5.5903 & TRN & \\
\hline CHEMBL1481901 & 688239 & 6.4862 & 5.6097 & TRN & \\
\hline CHEMBL1437516 & 688239 & 5.2362 & 5.2348 & TST & \\
\hline CHEMBL1580558 & 688239 & 5.4862 & 5.4878 & TST & \\
\hline CHEMBL1341995 & 688239 & 6.2362 & 5.5014 & TRN & \\
\hline CHEMBL1341393 & 688239 & 5.3862 & 5.3948 & TRN & \\
\hline CHEMBL1418046 & 688239 & 4.85 & 5.3492 & TRN & \\
\hline CHEMBL1574826 & 688239 & 5.6362 & 5.4267 & TST & \\
\hline CHEMBL1530527 & 688239 & 8.1871 & 5.5127 & TST & \\
\hline CHEMBL1571458 & 688239 & 6.8362 & 5.4058 & TRN & \\
\hline CHEMBL1496207 & 688239 & 5.9862 & 5.5795 & TRN & \\
\hline CHEMBL1351695 & 688239 & 4.5362 & 5.2859 & TRN & \\
\hline CHEMBL1549169 & 688239 & 8.3872 & 5.5393 & TRN & \\
\hline CHEMBL1311375 & 688239 & 8.3372 & 5.3976 & TST & \\
\hline CHEMBL1335915 & 688239 & 4.5362 & 5.2526 & TST & \\
\hline CHEMBL1340365 & 688239 & 4.7862 & 5.5041 & TST & \\
\hline
\end{tabular}


Supplemental Table S2.txt

\begin{tabular}{|c|c|c|c|c|}
\hline CHEMBL1524849 & 688239 & 4.4862 & 5.4574 & TRN \\
\hline CHEMBL1422600 & 688239 & 4.5362 & 5.4379 & TST \\
\hline CHEMBL581860 & 688239 & 4.7362 & 5.2132 & TRN \\
\hline CHEMBL1329751 & 688239 & 7.7352 & 5.3967 & TRN \\
\hline CHEMBL1326303 & 688239 & 6.7862 & 5.6537 & TRN \\
\hline CHEMBL1503492 & 688239 & 5.7362 & 5.4546 & TRN \\
\hline CHEMBL1345129 & 688239 & 4.7362 & 5.4945 & TRN \\
\hline CHEMBL1365295 & 688239 & 5.5362 & 5.3645 & TRN \\
\hline CHEMBL1516724 & 688239 & 7.0362 & 5.5809 & TRN \\
\hline CHEMBL1409479 & 688239 & 6.5501 & 5.3423 & TRN \\
\hline CHEMBL1569366 & 688239 & 4.6362 & 5.5742 & TST \\
\hline CHEMBL1371636 & 688239 & 7.8356 & 5.5376 & TST \\
\hline CHEMBL1905194 & 688239 & 5.7362 & 5.6599 & TRN \\
\hline CHEMBL1315805 & 688239 & 6.1862 & 5.5036 & TST \\
\hline CHEMBL1571351 & 688239 & 4.5362 & 5.6699 & TRN \\
\hline CHEMBL1531259 & 688239 & 5.1862 & 5.4919 & TRN \\
\hline CHEMBL1403254 & 688239 & 4.7362 & 5.54799 & 9999999999 \\
\hline CHEMBL1579697 & 688239 & 5.2362 & 5.4823 & TST \\
\hline CHEMBL1304276 & 688239 & 4.6362 & 5.4721 & TRN \\
\hline CHEMBL1346277 & 688239 & 5.4362 & 5.3865 & TRN \\
\hline CHEMBL1517426 & 688239 & 6.8362 & 5.4974 & TST \\
\hline CHEMBL1557037 & 688239 & 5.4862 & 5.5705 & TRN \\
\hline CHEMBL3192181 & 688239 & 4.5362 & 5.3095 & TRN \\
\hline CHEMBL1355207 & 688239 & 5.6362 & 5.4537 & TRN \\
\hline CHEMBL1408344 & 688239 & 5.1862 & 5.5568 & TST \\
\hline CHEMBL1574651 & 688239 & 6.8861 & 5.4857 & TRN \\
\hline CHEMBL1539746 & 688239 & 4.5362 & 5.6063 & TST \\
\hline CHEMBL1363153 & 688239 & 4.7862 & 5.7227 & TRN \\
\hline CHEMBL1463795 & 688239 & 5.7362 & 5.4943 & TRN \\
\hline CHEMBL1569209 & 688239 & 5.1362 & 5.4525 & TRN \\
\hline CHEMBL1457301 & 688239 & 5.2362 & 5.3521 & TRN \\
\hline CHEMBL1424652 & 688239 & 5.9362 & 5.3534 & TRN \\
\hline CHEMBL1605062 & 688239 & 5.7862 & 5.5779 & TRN \\
\hline CHEMBL1468333 & 688239 & 8.3372 & 5.4108 & TRN \\
\hline CHEMBL1332951 & 688239 & 7.2865 & 5.5592 & TRN \\
\hline CHEMBL1381550 & 688239 & 5.3862 & 5.4668 & TRN \\
\hline CHEMBL1417754 & 688239 & 4.5362 & 5.5177 & TRN \\
\hline CHEMBL1604481 & 688239 & 5.6862 & 5.4255 & TRN \\
\hline CHEMBL1403918 & 688239 & 6.1362 & 5.4826 & TRN \\
\hline CHEMBL1410747 & 688239 & 5.4362 & 5.5483 & TRN \\
\hline CHEMBL1322240 & 688239 & 5.1862 & 5.4969 & TRN \\
\hline CHEMBL1331236 & 688239 & 4.6862 & 5.4989 & TRN \\
\hline CHEMBL1521037 & 688239 & 6.5862 & 5.6321 & TRN \\
\hline CHEMBL 3145382 & 688239 & 5.6362 & 5.4893 & TRN \\
\hline CHEMBL1577387 & 688239 & 5.9362 & 5.5198 & TRN \\
\hline CHEMBL1440025 & 688239 & 4.5362 & 5.5552 & TST \\
\hline CHEMBL1575574 & 688239 & 5.1862 & 5.4781 & TST \\
\hline CHEMBL1599123 & 688239 & 6.1362 & 5.43 & TRN \\
\hline
\end{tabular}


Supplemental Table S2.txt

\begin{tabular}{|c|c|c|c|c|}
\hline 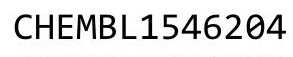 & & & & \\
\hline AEMBL1550629 & 38239 & 5362 & 7 & \\
\hline AEMBL1433717 & 239 & 362 & 115 & \\
\hline EMBL14 & 39 & & & \\
\hline IEMBL1409280 & 39 & 862 & & \\
\hline AEMBL1566659 & 88239 & 862 & & \\
\hline AEMBL1370133 & 88239 & 5.4362 & 4797 & \\
\hline AEMBL3197923 & & & & \\
\hline IEMBL14 & 39 & 362 & & \\
\hline IEMBL160 & & & & \\
\hline AEMBL1462052 & 239 & 362 & 672 & \\
\hline AEMBL1344583 & 39 & 362 & & \\
\hline AEMBL1353024 & & & & \\
\hline AEMBL1505922 & & & & \\
\hline HEMBL1412912 & & & & \\
\hline AEMBL1386430 & & 862 & & \\
\hline AEMBL1419951 & & 862 & & \\
\hline HEMBL137. & & 62 & & \\
\hline AEMBL 14 & & & & \\
\hline AEMBL15 & & & & \\
\hline AEMBL133 & & 862 & & \\
\hline AEMBL1447732 & & 62 & & \\
\hline IEMBL19ऽ & & 4 & & \\
\hline AEMBL 326 & & & & \\
\hline JFMRI 324 & & & & \\
\hline AEMBL3211616 & & 62 & & \\
\hline IEMBL1377965 & & & & \\
\hline IEMBL1519] & & 62 & & \\
\hline$A F M$ & & & & \\
\hline JEMPI 1110 & & 62 & & \\
\hline AEMBL1586978 & & & & \\
\hline HEMBL1588898 & & 63 & & \\
\hline & & & & \\
\hline 4 & & & & \\
\hline & & & & \\
\hline AEMBL1506279 & & & & \\
\hline AEMBL1542542 & & 62 & & \\
\hline & & & & \\
\hline 12 & & & & \\
\hline HEMBL1454563 & & & & RN \\
\hline AEMBL1542328 & & 62 & & \\
\hline AEMBL1528 & & 62 & & \\
\hline & & & & \\
\hline CHEMBL1474437 & & & & \\
\hline AEMBL1499017 & & & & RN \\
\hline AEMBL1320 & & 862 & & \\
\hline & & & & \\
\hline 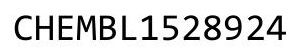 & & & & \\
\hline
\end{tabular}

Page 1462 
Supplemental Table S2.txt

\begin{tabular}{|c|c|c|c|c|c|}
\hline CHEMBL1494172 & 688239 & 6.2362 & 5.3787 & TST & \\
\hline CHEMBL1306460 & 688239 & 6.2362 & \multicolumn{2}{|c|}{5.4110000000000005} & TRN \\
\hline CHEMBL1547410 & 688239 & 5.8862 & 5.6029 & TRN & \\
\hline CHEMBL1450612 & 688239 & 6.6362 & 5.478 & TRN & \\
\hline CHEMBL1421909 & 688239 & 6.1862 & 5.6618 & TRN & \\
\hline CHEMBL1556488 & 688239 & 4.7362 & 5.4822 & TRN & \\
\hline CHEMBL1360339 & 688239 & 8.3872 & 5.5946 & TRN & \\
\hline CHEMBL1091786 & 688239 & 5.2862 & 5.5448 & TST & \\
\hline CHEMBL1558136 & 688239 & 5.1862 & 5.4851 & TRN & \\
\hline CHEMBL117966 & 688239 & 5.3862 & 5.4383 & TRN & \\
\hline CHEMBL1392379 & 688239 & 6.0862 & 5.6391 & TRN & \\
\hline CHEMBL460601 & 688239 & 4.6862 & 5.5256 & TST & \\
\hline CHEMBL1331601 & 688239 & 4.8362 & 5.2814 & TST & \\
\hline CHEMBL1579359 & 688239 & 4.6362 & 5.4641 & TRN & \\
\hline CHEMBL1333365 & 688239 & 4.5362 & 5.4629 & TRN & \\
\hline CHEMBL1566972 & 688239 & 4.5362 & 5.3925 & TRN & \\
\hline CHEMBL1375397 & 688239 & 5.4362 & 5.4346 & TRN & \\
\hline CHEMBL1576722 & 688239 & 6.1362 & 5.5693 & TST & \\
\hline CHEMBL 3197476 & 688239 & 5.1862 & 5.3875 & TRN & \\
\hline CHEMBL1374161 & 688239 & 4.5362 & 5.6612 & TRN & \\
\hline CHEMBL1577700 & 688239 & 5.3862 & 5.4741 & TRN & \\
\hline CHEMBL1443057 & 688239 & 5.1862 & 5.4002 & TRN & \\
\hline CHEMBL1537821 & 688239 & 5.1362 & 5.7679 & TRN & \\
\hline CHEMBL1494150 & 688239 & 5.6862 & 5.3118 & TST & \\
\hline CHEMBL1540672 & 688239 & 4.6862 & 5.4532 & TRN & \\
\hline CHEMBL1595093 & 688239 & 6.1362 & 5.4572 & TRN & \\
\hline CHEMBL1405932 & 688239 & 5.1862 & 5.4047 & TST & \\
\hline CHEMBL1333759 & 688239 & 4.5862 & 5.5633 & TST & \\
\hline CHEMBL1339720 & 688239 & 4.6862 & 5.6323 & TST & \\
\hline CHEMBL1471434 & 688239 & 7.2366 & 5.5974 & TRN & \\
\hline CHEMBL1460036 & 688239 & 5.0862 & 5.4629 & TRN & \\
\hline CHEMBL1424449 & 688239 & 4.5362 & 5.4859 & TRN & \\
\hline CHEMBL1468687 & 688239 & 4.8362 & 5.6766 & TRN & \\
\hline CHEMBL1411992 & 688239 & 4.9362 & 5.5215 & TRN & \\
\hline CHEMBL1575370 & 688239 & 4.8862 & 5.5837 & TRN & \\
\hline CHEMBL1599957 & 688239 & 5.1362 & 5.4589 & TST & \\
\hline CHEMBL1377362 & 688239 & 5.1862 & 5.4158 & TRN & \\
\hline CHEMBL 3210808 & 688239 & 5.0862 & 5.4681 & TRN & \\
\hline CHEMBL1434077 & 688239 & 5.6862 & 5.3733 & TRN & \\
\hline CHEMBL1545491 & 688239 & 7.2366 & 5.4694 & TST & \\
\hline CHEMBL1306964 & 688239 & 4.7862 & 5.4406 & TRN & \\
\hline CHEMBL1418887 & 688239 & 4.6862 & 5.5277 & TRN & \\
\hline CHEMBL1461439 & 688239 & 5.7362 & 5.4649 & TRN & \\
\hline CHEMBL1533226 & 688239 & 5.3362 & 5.5014 & TST & \\
\hline CHEMBL1359379 & 688239 & 4.5362 & 5.5835 & TRN & \\
\hline CHEMBL1487240 & 688239 & 4.9362 & 5.4818 & TRN & \\
\hline CHEMBL1383384 & 688239 & 6.8861 & 5.4939 & TRN & \\
\hline CHEMBL1539557 & 688239 & 4.7862 & 5.3953 & TRN & \\
\hline
\end{tabular}

Page 1463 


\begin{tabular}{|c|c|c|c|c|c|}
\hline \multicolumn{6}{|c|}{ Supplemental Table S2.txt } \\
\hline CHEMBL1314125 & 688239 & 4.6862 & 5.518 & TRN & \\
\hline CHEMBL1551577 & 688239 & 5.1862 & 5.50299 & 9999999999 & TRN \\
\hline CHEMBL1608514 & 688239 & 5.0862 & 5.5605 & TRN & \\
\hline CHEMBL1342371 & 688239 & 8.3372 & 5.4605 & TRN & \\
\hline CHEMBL1495797 & 688239 & 8.3372 & 5.4547 & TRN & \\
\hline CHEMBL1320381 & 688239 & 5.7862 & 5.6232 & TRN & \\
\hline CHEMBL1304333 & 688239 & 4.6862 & 5.5319 & TRN & \\
\hline CHEMBL1392794 & 688239 & 4.5362 & 5.4597 & TRN & \\
\hline CHEMBL1365550 & 688239 & 6.7361 & 5.4861 & TRN & \\
\hline CHEMBL1349340 & 688239 & 5.4362 & 5.4696 & TRN & \\
\hline CHEMBL1341129 & 688239 & 4.5362 & 5.336 & TRN & \\
\hline CHEMBL1498425 & 688239 & 4.9362 & 5.5372 & TST & \\
\hline CHEMBL1485061 & 688239 & 7.6364 & 5.4101 & TRN & \\
\hline CHEMBL1344750 & 688239 & 4.6862 & 5.41200 & 0000000001 & TST \\
\hline CHEMBL1599956 & 688239 & 4.5362 & 5.5277 & TRN & \\
\hline CHEMBL1371081 & 688239 & 4.5362 & 5.57799 & 9999999999 & TRN \\
\hline CHEMBL1554571 & 688239 & 4.7362 & 5.4417 & TRN & \\
\hline CHEMBL1572609 & 688239 & 7.1361 & 5.4819 & TST & \\
\hline CHEMBL1306272 & 688239 & 6.8362 & 5.5102 & TRN & \\
\hline CHEMBL1540639 & 688239 & 6.2362 & 5.6876 & TST & \\
\hline CHEMBL1370536 & 688239 & 4.5362 & 5.416 & TRN & \\
\hline CHEMBL1374557 & 688239 & 5.1862 & 5.5337 & TRN & \\
\hline CHEMBL1552613 & 688239 & 7.4868 & 5.471 & TRN & \\
\hline CHEMBL1439960 & 688239 & 4.7362 & 5.445 & TRN & \\
\hline CHEMBL1508101 & 688239 & 5.2862 & 5.3982 & TRN & \\
\hline CHEMBL1308604 & 688239 & 5.2362 & 5.5439 & TRN & \\
\hline CHEMBL1361562 & 688239 & 6.0862 & 5.5137 & TRN & \\
\hline CHEMBL1300858 & 688239 & 5.1862 & 5.5067 & TST & \\
\hline CHEMBL1537616 & 688239 & 4.5362 & 5.4907 & TRN & \\
\hline CHEMBL1577441 & 688239 & 4.7362 & 5.3152 & TST & \\
\hline CHEMBL1384196 & 688239 & 5.7862 & 5.4699 & TST & \\
\hline CHEMBL1355008 & 688239 & 4.5362 & 5.4156 & TRN & \\
\hline CHEMBL1384894 & 688239 & 4.7362 & 5.4448 & TRN & \\
\hline CHEMBL1548849 & 688239 & 4.5362 & 5.5615 & TST & \\
\hline CHEMBL1348975 & 688239 & 6.3863 & 5.6248 & TRN & \\
\hline CHEMBL1421518 & 688239 & 4.6362 & 5.3857 & TST & \\
\hline CHEMBL1524525 & 688239 & 5.2362 & 5.6061 & TRN & \\
\hline CHEMBL1443544 & 688239 & 5.3862 & 5.4647 & TRN & \\
\hline CHEMBL1333041 & 688239 & 5.0362 & 5.5487 & TRN & \\
\hline CHEMBL1528928 & 688239 & 5.1862 & 5.3911 & TST & \\
\hline CHEMBL1522346 & 688239 & 6.2362 & 5.5254 & TRN & \\
\hline CHEMBL1390939 & 688239 & 4.5362 & 5.4325 & TRN & \\
\hline CHEMBL1469706 & 688239 & 4.9862 & 5.4628 & TRN & \\
\hline CHEMBL1446315 & 688239 & 4.7862 & 5.5524 & TRN & \\
\hline CHEMBL1361645 & 688239 & 6.9863 & 5.3512 & TRN & \\
\hline CHEMBL1575751 & 688239 & 4.6862 & 5.4027 & TST & \\
\hline CHEMBL1363785 & 688239 & 5.0362 & 5.5058 & TRN & \\
\hline CHEMBL1301705 & 688239 & 5.7862 & 5.404 & TRN & \\
\hline
\end{tabular}


Supplemental Table S2.txt

\begin{tabular}{|c|c|c|c|c|}
\hline & & & & \\
\hline HEMBL1534650 & 88239 & 1362 & & \\
\hline AEMBL136 & 39 & 52 & & \\
\hline & & & & \\
\hline AFMRI 16 & & & & \\
\hline AEMBL1526297 & 88239 & 372 & 54 & \\
\hline AEMBL1465471 & 88239 & 5.1862 & 5756 & \\
\hline HEMBL1548338 & & & & \\
\hline AEMBL152 & & & & \\
\hline IEMBL1528064 & & & & \\
\hline AEMBL1603391 & 39 & & & \\
\hline AEMBL1448855 & 39 & 4. & & \\
\hline HEMBL136: & & & & \\
\hline AEMBL13 & & & & \\
\hline AEMBL138 & & & & \\
\hline AEMBL1534419 & & & & \\
\hline AEMBL1313012 & & & & \\
\hline HEMBL160 & & & & \\
\hline HEMBL13 & & & & \\
\hline AEMBL15 & & & & \\
\hline AEMBL1415855 & & & & \\
\hline AEMBL157€ & & & & \\
\hline JEMBL49 & & & & \\
\hline AEMBL13 & & & & \\
\hline AFMBI 15 & & & & \\
\hline AEMBL1612788 & & & & \\
\hline AEMBL1358253 & & & & \\
\hline HEMBL152 & & & & \\
\hline AEM & & & & \\
\hline HFMRI 138 & & & & \\
\hline AEMBL1502694 & & & & \\
\hline AEMBL1600324 & & & & \\
\hline 1 & & & & \\
\hline 5 & & & & \\
\hline 9 & & & & \\
\hline AEMBL1425546 & & & & \\
\hline AEMBL1348927 & & & & \\
\hline & & & & \\
\hline 4 & & & & \\
\hline 9 & & & & RN \\
\hline AEMBL1467845 & & & & $\mathrm{S}$ \\
\hline HEMBL141 & & & & \\
\hline & & & & \\
\hline HEMBL356061 & & & & \\
\hline HEMBL321255 & & & & RN \\
\hline EMBL1327480 & & & 23 & \\
\hline 120 & & & & \\
\hline & & & 5.4327 & \\
\hline
\end{tabular}

Page 1465 
Supplemental Table S2.txt

\begin{tabular}{|c|c|c|c|c|c|}
\hline CHEMBL1320745 & 688239 & 4.6362 & 5.5801 & TRN & \\
\hline CHEMBL1560310 & 688239 & 5.8862 & 5.4364 & TST & \\
\hline CHEMBL1485661 & 688239 & 5.3862 & 5.4283 & TST & \\
\hline CHEMBL1384007 & 688239 & 5.5362 & 5.4359 & TRN & \\
\hline CHEMBL1461757 & 688239 & 6.2362 & 5.5664 & TRN & \\
\hline CHEMBL1596765 & 688239 & 5.1862 & 5.4565 & TST & \\
\hline CHEMBL1300704 & 688239 & 4.8362 & 5.4934 & TRN & \\
\hline CHEMBL1314913 & 688239 & 4.6362 & 5.3665 & TST & \\
\hline CHEMBL1308429 & 688239 & 4.7362 & 5.5733 & TST & \\
\hline CHEMBL1311569 & 688239 & 5.7862 & 5.5452 & TST & \\
\hline CHEMBL1494988 & 688239 & 7.1361 & 5.5088 & TRN & \\
\hline CHEMBL1583063 & 688239 & 4.9362 & 5.5804 & TRN & \\
\hline CHEMBL1709970 & 688239 & 4.8362 & 5.3131 & TST & \\
\hline CHEMBL1313150 & 688239 & 4.6362 & 5.3496 & TRN & \\
\hline CHEMBL1490811 & 688239 & 6.1862 & 5.6161 & TRN & \\
\hline CHEMBL1574402 & 688239 & 4.5362 & 5.4217 & TRN & \\
\hline CHEMBL1555484 & 688239 & 4.5362 & 5.3747 & TRN & \\
\hline CHEMBL1515480 & 688239 & 6.9363 & 5.44799 & 99999999995 & TST \\
\hline CHEMBL1569612 & 688239 & 5.0862 & 5.4891 & TRN & \\
\hline CHEMBL1341004 & 688239 & 4.7362 & 5.4978 & TRN & \\
\hline CHEMBL 3199073 & 688239 & 8.3372 & 5.3395 & TRN & \\
\hline CHEMBL1985601 & 688239 & 4.5362 & 5.5164 & TRN & \\
\hline CHEMBL1370003 & 688239 & 4.5362 & 5.5642 & TRN & \\
\hline CHEMBL1456011 & 688239 & 4.7362 & 5.4539 & TRN & \\
\hline CHEMBL1303556 & 688239 & 4.6862 & 5.2503 & TRN & \\
\hline CHEMBL1420004 & 688239 & 4.5362 & 5.556 & TST & \\
\hline CHEMBL1368504 & 688239 & 5.1862 & 5.4408 & TST & \\
\hline CHEMBL1577294 & 688239 & 4.9862 & 5.5703 & TRN & \\
\hline CHEMBL1521956 & 688239 & 4.8362 & 5.4581 & TRN & \\
\hline CHEMBL1585191 & 688239 & 6.8362 & 5.4165 & TST & \\
\hline CHEMBL1349006 & 688239 & 4.6862 & 5.6617 & TRN & \\
\hline CHEMBL1399012 & 688239 & 6.2362 & 5.5435 & TRN & \\
\hline CHEMBL1506825 & 688239 & 5.5862 & 5.3925 & TRN & \\
\hline CHEMBL1446154 & 688239 & 5.7862 & 5.329 & TRN & \\
\hline CHEMBL1338183 & 688239 & 5.3862 & 5.4299 & TRN & \\
\hline CHEMBL1366160 & 688239 & 7.8356 & 5.4302 & TRN & \\
\hline CHEMBL1353207 & 688239 & 4.8862 & 5.5351 & TRN & \\
\hline CHEMBL1369533 & 688239 & 4.9862 & 5.4936 & TRN & \\
\hline CHEMBL1447236 & 688239 & 5.1362 & 5.5157 & TRN & \\
\hline CHEMBL1463124 & 688239 & 5.5862 & 5.6195 & TRN & \\
\hline CHEMBL1399463 & 688239 & 5.4862 & 5.5421 & TRN & \\
\hline CHEMBL3196945 & 688239 & 5.2862 & 5.5079 & TRN & \\
\hline CHEMBL1607924 & 688239 & 7.2865 & 5.3922 & TRN & \\
\hline CHEMBL1323702 & 688239 & 6.6362 & 5.4957 & TRN & \\
\hline CHEMBL1605317 & 688239 & 5.4362 & 5.6029 & TST & \\
\hline CHEMBL3197865 & 688239 & 5.7862 & 5.3894 & TST & \\
\hline CHEMBL1334388 & 688239 & 4.5862 & 5.459 & TST & \\
\hline CHEMBL1343035 & 688239 & 5.7862 & 5.4778 & TRN & \\
\hline
\end{tabular}


Supplemental Table S2.txt

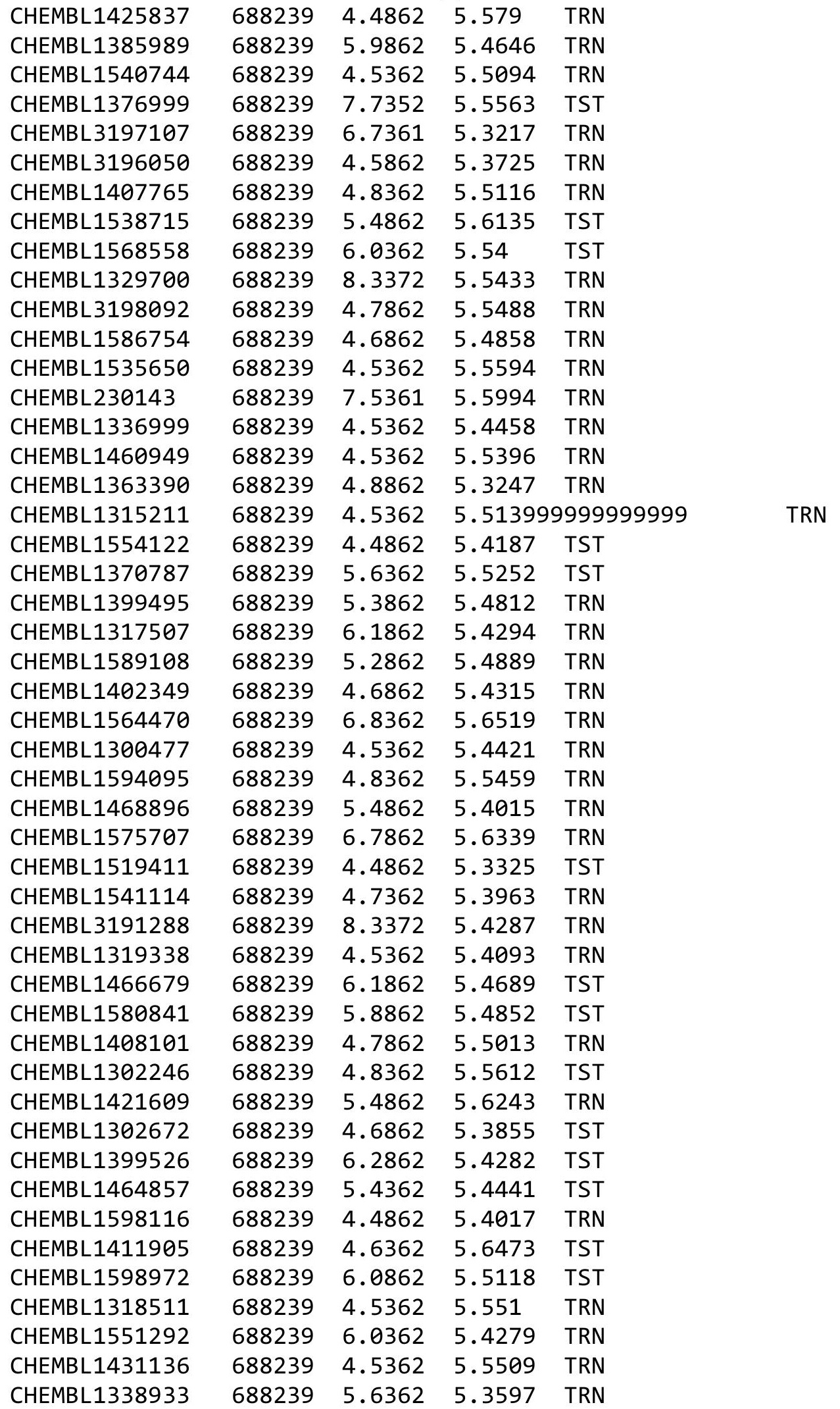


Supplemental Table S2.txt

\begin{tabular}{|c|c|c|c|c|}
\hline CHEMBL1555155 & 688239 & 5.6862 & 5.5184 & TRN \\
\hline CHEMBL1308971 & 688239 & 5.6862 & 5.4644 & TRN \\
\hline CHEMBL1581686 & 688239 & 4.5362 & 5.3986 & TRN \\
\hline CHEMBL1324133 & 688239 & 4.7862 & 5.5939 & TRN \\
\hline CHEMBL1451615 & 688239 & 4.9362 & 5.5538 & TRN \\
\hline CHEMBL1340749 & 688239 & 6.3362 & 5.6695 & TRN \\
\hline CHEMBL1556151 & 688239 & 4.5362 & 5.3803 & TST \\
\hline CHEMBL1213831 & 688239 & 6.3863 & 5.4697 & TRN \\
\hline CHEMBL1465129 & 688239 & 5.3362 & 5.5236 & TST \\
\hline CHEMBL1432203 & 688239 & 4.9362 & $5.45200 e$ & 000000001 \\
\hline CHEMBL1413352 & 688239 & 5.1362 & $5.45100 e$ & 00000000005 \\
\hline CHEMBL1365812 & 688239 & 6.4862 & 5.5826 & TRN \\
\hline CHEMBL 382602 & 688239 & 7.0362 & 5.6602 & TRN \\
\hline CHEMBL1582993 & 688239 & 6.0362 & 5.5626 & TST \\
\hline CHEMBL1299741 & 688239 & 7.1361 & 5.5403 & TST \\
\hline CHEMBL1409958 & 688239 & 4.9362 & 5.3748 & TRN \\
\hline CHEMBL1496696 & 688239 & 4.5362 & 5.4526 & TST \\
\hline CHEMBL1419375 & 688239 & 6.9863 & 5.61 & TRN \\
\hline CHEMBL1457272 & 688239 & 5.7862 & 5.4187 & TRN \\
\hline CHEMBL1547821 & 688239 & 4.8362 & 5.3968 & TRN \\
\hline CHEMBL1575906 & 688239 & 5.6862 & 5.5031 & TRN \\
\hline CHEMBL1390257 & 688239 & 5.1862 & 5.4328 & TRN \\
\hline CHEMBL1602013 & 688239 & 5.1862 & 5.5505 & TRN \\
\hline CHEMBL1344632 & 688239 & 5.4862 & 5.4653 & TRN \\
\hline CHEMBL1399175 & 688239 & 4.5862 & 5.4244 & TST \\
\hline CHEMBL1541761 & 688239 & 5.8862 & 5.4718 & TRN \\
\hline CHEMBL1467509 & 688239 & 4.5862 & 5.4465 & TST \\
\hline CHEMBL1592668 & 688239 & 4.8862 & 5.4505 & TRN \\
\hline CHEMBL1380779 & 688239 & 5.1862 & 5.4538 & TRN \\
\hline CHEMBL1431979 & 688239 & 5.1862 & 5.6 & TST \\
\hline CHEMBL1326164 & 688239 & 5.9362 & 5.4927 & TRN \\
\hline CHEMBL1458940 & 688239 & 4.7362 & 5.4263 & TRN \\
\hline CHEMBL1459686 & 688239 & 5.6862 & 5.4704 & TRN \\
\hline CHEMBL1571058 & 688239 & 6.3863 & 5.5711 & TRN \\
\hline CHEMBL1463110 & 688239 & 6.4362 & 5.3997 & TST \\
\hline CHEMBL1319084 & 688239 & 4.7362 & 5.4558 & TRN \\
\hline CHEMBL1534804 & 688239 & 7.0862 & 5.4949 & TRN \\
\hline CHEMBL 2004141 & 688239 & 4.4862 & 5.4307 & TRN \\
\hline CHEMBL1352717 & 688239 & 5.2362 & 5.4471 & TRN \\
\hline CHEMBL1564980 & 688239 & 6.9863 & 5.5288 & TRN \\
\hline CHEMBL1436191 & 688239 & 4.7362 & 5.3657 & TRN \\
\hline CHEMBL1546959 & 688239 & 5.1862 & 5.3486 & TRN \\
\hline CHEMBL1576716 & 688239 & 5.4862 & 5.4133 & TRN \\
\hline CHEMBL1576284 & 688239 & 4.6362 & 5.2348 & TRN \\
\hline CHEMBL1539665 & 688239 & 5.2362 & 5.4766 & TRN \\
\hline CHEMBL1573223 & 688239 & 7.1361 & 5.4414 & TRN \\
\hline CHEMBL1607929 & 688239 & 4.5362 & 5.4424 & TRN \\
\hline CHEMBL1301247 & 688239 & 4.5362 & 5.4557 & TRN \\
\hline
\end{tabular}


Supplemental Table S2.txt

\begin{tabular}{|c|c|c|c|c|c|}
\hline CHEMBL1363034 & 688239 & 4.7862 & 5.4329 & TRN & \\
\hline CHEMBL1314103 & 688239 & 5.5362 & 5.4346 & TRN & \\
\hline CHEMBL1324718 & 688239 & 5.4862 & 5.5671 & TRN & \\
\hline CHEMBL1542584 & 688239 & 4.8362 & 5.5222 & TRN & \\
\hline CHEMBL1368713 & 688239 & 6.5862 & 5.3795 & TRN & \\
\hline CHEMBL1316692 & 688239 & 8.3872 & 5.5178 & TST & \\
\hline CHEMBL1405009 & 688239 & 4.6862 & \multicolumn{2}{|c|}{5.492999999999999} & TRN \\
\hline CHEMBL1582591 & 688239 & 6.5862 & 5.6158 & TRN & \\
\hline CHEMBL1562563 & 688239 & 4.5362 & 5.4527 & TRN & \\
\hline CHEMBL1369193 & 688239 & 7.4868 & 5.3787 & TRN & \\
\hline CHEMBL1451141 & 688239 & 5.9862 & 5.5016 & TRN & \\
\hline CHEMBL1453658 & 688239 & 5.5862 & 5.4113 & TRN & \\
\hline CHEMBL3195808 & 688239 & 5.1862 & 5.3699 & TRN & \\
\hline CHEMBL1559136 & 688239 & 6.3863 & 5.4326 & TRN & \\
\hline CHEMBL1580156 & 688239 & 8.3372 & \multicolumn{2}{|c|}{5.457999999999999} & TRN \\
\hline CHEMBL1511473 & 688239 & 4.4862 & 5.4892 & TRN & \\
\hline CHEMBL1308497 & 688239 & 4.7362 & 5.3346 & TRN & \\
\hline CHEMBL1500335 & 688239 & 5.9362 & 5.5389 & TRN & \\
\hline CHEMBL1402777 & 688239 & 6.1362 & 5.4173 & TST & \\
\hline CHEMBL1387551 & 688239 & 6.3362 & 5.6056 & TRN & \\
\hline CHEMBL1368583 & 688239 & 8.3372 & 5.5033 & TRN & \\
\hline CHEMBL1338692 & 688239 & 6.0862 & \multicolumn{2}{|c|}{5.492000000000001} & TRN \\
\hline CHEMBL1452941 & 688239 & 5.7862 & 5.6168 & TRN & \\
\hline CHEMBL1579044 & 688239 & 4.6862 & \multicolumn{2}{|c|}{5.5489999999999995} & TST \\
\hline CHEMBL1311285 & 688239 & 5.7362 & 5.4854 & TRN & \\
\hline CHEMBL1506934 & 688239 & 4.4862 & 5.546 & TRN & \\
\hline CHEMBL1424828 & 688239 & 5.5862 & 5.4134 & TST & \\
\hline CHEMBL3194181 & 688239 & 4.5362 & 5.5553 & TRN & \\
\hline CHEMBL1299567 & 688239 & 5.1862 & 5.6152 & TRN & \\
\hline CHEMBL1408945 & 688239 & 6.9363 & 5.5858 & TST & \\
\hline CHEMBL1610324 & 688239 & 5.5862 & 5.5158 & TST & \\
\hline CHEMBL3199464 & 688239 & 6.3863 & 5.4598 & TRN & \\
\hline CHEMBL1384167 & 688239 & 5.1362 & 5.4386 & TRN & \\
\hline CHEMBL1581435 & 688239 & 6.1862 & 5.5472 & TST & \\
\hline CHEMBL1586492 & 688239 & 4.5362 & 5.4369 & TRN & \\
\hline CHEMBL1369010 & 688239 & 4.9362 & 5.6368 & TRN & \\
\hline CHEMBL1364719 & 688239 & 6.1362 & 5.5776 & TRN & \\
\hline CHEMBL1417609 & 688239 & 6.0862 & 5.5052 & TRN & \\
\hline CHEMBL1550008 & 688239 & 5.3362 & 5.5384 & TST & \\
\hline CHEMBL1318385 & 688239 & 4.5362 & 5.6544 & TRN & \\
\hline CHEMBL1332754 & 688239 & 4.8862 & 5.481 & TRN & \\
\hline CHEMBL1549750 & 688239 & 5.5862 & \multicolumn{2}{|c|}{5.452999999999999} & TST \\
\hline CHEMBL1573010 & 688239 & 5.3362 & 5.4557 & TRN & \\
\hline CHEMBL1544345 & 688239 & 6.2862 & 5.4399 & TST & \\
\hline CHEMBL1598205 & 688239 & 5.9862 & 5.6414 & TRN & \\
\hline CHEMBL3190196 & 688239 & 4.9862 & 5.5623 & TRN & \\
\hline CHEMBL1538923 & 688239 & 4.7362 & 5.4339 & TST & \\
\hline CHEMBL1572116 & 688239 & 4.8362 & 5.5238 & TST & \\
\hline
\end{tabular}


Supplemental Table S2.txt

\begin{tabular}{|c|c|c|c|c|c|}
\hline CHEMBL1383818 & 688239 & 5.4362 & 5.4368 & TST & \\
\hline CHEMBL1571803 & 688239 & 4.7362 & 5.6357 & TRN & \\
\hline CHEMBL1391980 & 688239 & 6.0362 & 5.4286 & TST & \\
\hline CHEMBL1423893 & 688239 & 4.6362 & 5.383999 & 9999999995 & TRN \\
\hline CHEMBL1470042 & 688239 & 8.3372 & 5.5897 & TRN & \\
\hline CHEMBL1507304 & 688239 & 5.6862 & 5.4558 & TRN & \\
\hline CHEMBL1458810 & 688239 & 5.4362 & 5.5628 & TRN & \\
\hline CHEMBL1303531 & 688239 & 5.4362 & 5.5033 & TRN & \\
\hline CHEMBL3199131 & 688239 & 5.4362 & 5.4473 & TST & \\
\hline CHEMBL1399106 & 688239 & 4.5362 & 5.4623 & TST & \\
\hline CHEMBL1313338 & 688239 & 4.5362 & 5.3867 & TRN & \\
\hline CHEMBL1360296 & 688239 & 4.5362 & 5.3727 & TST & \\
\hline CHEMBL1605568 & 688239 & 4.7862 & 5.5093 & TRN & \\
\hline CHEMBL1447710 & 688239 & 4.6862 & 5.4802 & TRN & \\
\hline CHEMBL1308047 & 688239 & 4.6862 & 5.5317 & TST & \\
\hline CHEMBL1381301 & 688239 & 4.5362 & 5.4386 & TST & \\
\hline CHEMBL1430227 & 688239 & 5.9362 & $5.36600 e$ & 0000000005 & TST \\
\hline CHEMBL362863 & 688239 & 6.8362 & 5.3942 & TST & \\
\hline CHEMBL1572147 & 688239 & 5.7862 & 5.5307 & TRN & \\
\hline CHEMBL1528843 & 688239 & 5.4362 & 5.4734 & TRN & \\
\hline CHEMBL1541811 & 688239 & 5.4862 & 5.4775 & TRN & \\
\hline CHEMBL3189962 & 688239 & 6.5363 & 5.3918 & TRN & \\
\hline CHEMBL1466434 & 688239 & 7.1864 & 5.5722 & TRN & \\
\hline CHEMBL1468561 & 688239 & 5.1862 & 5.4096 & TST & \\
\hline CHEMBL1407393 & 688239 & 5.1862 & 5.4237 & TRN & \\
\hline CHEMBL1564610 & 688239 & 5.6862 & 5.4723 & TRN & \\
\hline CHEMBL1385612 & 688239 & 5.3362 & 5.5117 & TRN & \\
\hline CHEMBL1544843 & 688239 & 4.5362 & 5.4071 & TRN & \\
\hline CHEMBL1502358 & 688239 & 6.8861 & 5.4268 & TST & \\
\hline CHEMBL3213576 & 688239 & 5.6862 & 5.4324 & TST & \\
\hline CHEMBL3190943 & 688239 & 6.8861 & 5.4418 & TRN & \\
\hline CHEMBL1988896 & 688239 & 4.8862 & 5.2683 & TRN & \\
\hline CHEMBL1421358 & 688239 & 6.1362 & 5.5214 & TRN & \\
\hline CHEMBL1466539 & 688239 & 5.6862 & 5.3654 & TRN & \\
\hline CHEMBL579640 & 688239 & 4.5362 & 5.4413 & TRN & \\
\hline CHEMBL1488178 & 688239 & 6.8362 & 5.4972 & TRN & \\
\hline CHEMBL1564493 & 688239 & 7.1864 & 5.5893 & TRN & \\
\hline CHEMBL1358494 & 688239 & 7.4868 & 5.5835 & TRN & \\
\hline CHEMBL1496395 & 688239 & 4.7362 & 5.3904 & TRN & \\
\hline CHEMBL1391642 & 688239 & 5.0362 & 5.4964 & TRN & \\
\hline CHEMBL1543640 & 688239 & 4.7362 & 5.4393 & TST & \\
\hline CHEMBL1502709 & 688239 & 4.5362 & 5.357 & TRN & \\
\hline CHEMBL1385508 & 688239 & 5.4862 & 5.5961 & TRN & \\
\hline CHEMBL1594715 & 688239 & 8.1871 & 5.6428 & TST & \\
\hline CHEMBL1369582 & 688239 & 5.0862 & 5.3963 & TRN & \\
\hline CHEMBL1311733 & 688239 & 4.8362 & 5.5745 & TRN & \\
\hline CHEMBL1390030 & 688239 & 4.8862 & 5.4506 & TST & \\
\hline CHEMBL1416490 & 688239 & 4.6862 & 5.477 & TST & \\
\hline
\end{tabular}


Supplemental Table S2.txt

\begin{tabular}{|c|c|c|c|c|}
\hline CHEMBL1537524 & 688239 & 7.3363 & 5.5963 & TRN \\
\hline CHEMBL1586014 & 688239 & 4.5362 & 5.4666 & TRN \\
\hline CHEMBL1509374 & 688239 & 5.7862 & 5.4838 & TST \\
\hline CHEMBL1492981 & 688239 & 5.1862 & 5.6185 & TRN \\
\hline CHEMBL1480648 & 688239 & 6.0862 & 5.6389 & TRN \\
\hline CHEMBL 3210403 & 688239 & 4.5362 & 5.4961 & TRN \\
\hline CHEMBL1328732 & 688239 & 6.2862 & 5.4524 & TRN \\
\hline CHEMBL1469998 & 688239 & 5.1862 & 5.4562 & TRN \\
\hline CHEMBL1579112 & 688239 & 4.7362 & 5.4977 & TRN \\
\hline CHEMBL1599893 & 688239 & 4.4862 & 5.5496 & TRN \\
\hline CHEMBL1405703 & 688239 & 5.3362 & 5.5806 & TRN \\
\hline CHEMBL1561034 & 688239 & 6.9363 & 5.3322 & TRN \\
\hline CHEMBL1994221 & 688239 & 6.3362 & 5.4249 & TRN \\
\hline CHEMBL1441120 & 688239 & 4.5362 & 5.5313 & TRN \\
\hline CHEMBL1441181 & 688239 & 6.0862 & 5.4241 & TRN \\
\hline CHEMBL1515048 & 688239 & 5.1862 & 5.5351 & TRN \\
\hline CHEMBL1360697 & 688239 & 4.7362 & 5.6121 & TRN \\
\hline CHEMBL3199436 & 688239 & 4.5362 & 5.3694 & TRN \\
\hline CHEMBL1412796 & 688239 & 4.5362 & 5.5763 & TRN \\
\hline CHEMBL3194753 & 688239 & 6.5363 & 5.504 & TRN \\
\hline CHEMBL1405021 & 688239 & 6.9363 & 5.4599 & TST \\
\hline CHEMBL1572924 & 688239 & 4.7362 & 5.2659 & TRN \\
\hline CHEMBL1473528 & 688239 & 6.0862 & 5.6217 & TRN \\
\hline CHEMBL1530571 & 688239 & 6.8861 & 5.4829 & TST \\
\hline CHEMBL1413826 & 688239 & 4.6362 & 5.3873 & TRN \\
\hline CHEMBL1612409 & 688239 & 6.1862 & 5.5825 & TST \\
\hline CHEMBL1517500 & 688239 & 5.1862 & 5.6287 & TRN \\
\hline CHEMBL1435536 & 688239 & 6.3362 & 5.5686 & TRN \\
\hline CHEMBL1468123 & 688239 & 4.7862 & 5.4418 & TST \\
\hline CHEMBL1324848 & 688239 & 6.4362 & 5.3909 & TRN \\
\hline CHEMBL1396682 & 688239 & 6.6861 & 5.57299 & 99999999995 \\
\hline CHEMBL1471996 & 688239 & 5.1862 & 5.3228 & TRN \\
\hline CHEMBL1408155 & 688239 & 7.0862 & 5.5603 & TRN \\
\hline CHEMBL1448651 & 688239 & 5.3862 & 5.5849 & TRN \\
\hline CHEMBL1496722 & 688239 & 4.6862 & 5.5814 & TRN \\
\hline CHEMBL1430476 & 688239 & 4.5362 & 5.5134 & TRN \\
\hline CHEMBL1354394 & 688239 & 5.2362 & 5.3787 & TRN \\
\hline CHEMBL1594806 & 688239 & 6.2362 & 5.28299 & 99999999995 \\
\hline CHEMBL1555826 & 688239 & 4.6862 & 5.4475 & TRN \\
\hline CHEMBL1528960 & 688239 & 6.3863 & 5.395 & TRN \\
\hline CHEMBL1335043 & 688239 & 5.1362 & 5.5614 & TRN \\
\hline CHEMBL1378518 & 688239 & 5.4362 & 5.6753 & TRN \\
\hline CHEMBL1519094 & 688239 & 4.7362 & 5.4639 & TRN \\
\hline CHEMBL1300990 & 688239 & 5.8862 & 5.4255 & TRN \\
\hline CHEMBL1504095 & 688239 & 4.5862 & 5.5326 & TRN \\
\hline CHEMBL1389502 & 688239 & 4.5362 & 5.3741 & TST \\
\hline CHEMBL1332790 & 688239 & 6.6362 & 5.3753 & TRN \\
\hline CHEMBL1459155 & 688239 & 4.5362 & 5.4377 & TRN \\
\hline
\end{tabular}

Page 1471 


\begin{tabular}{|c|c|c|c|c|c|}
\hline \multirow{3}{*}{$\begin{array}{l}\text { CHEMBL1499760 } \\
\text { CHEMBL1328575 }\end{array}$} & \multirow{3}{*}{$\begin{array}{l}688239 \\
688239\end{array}$} & \multicolumn{4}{|c|}{ Supplemental Table S2.txt } \\
\hline & & 4.5362 & \multicolumn{2}{|c|}{5.6579999999999995} & \multirow[t]{3}{*}{ TRN } \\
\hline & & 4.5362 & 5.5412 & TRN & \\
\hline CHEMBL1309878 & 688239 & 6.2862 & 5.4732 & TST & \\
\hline CHEMBL1425036 & 688239 & 5.9862 & \multicolumn{2}{|c|}{5.747000000000001} & TRN \\
\hline CHEMBL1409137 & 688239 & 4.7862 & 5.6144 & TRN & \\
\hline CHEMBL1497976 & 688239 & 8.1367 & 5.539 & TRN & \\
\hline CHEMBL1537719 & 688239 & 6.1362 & 5.6317 & TST & \\
\hline CHEMBL1433480 & 688239 & 5.8862 & 5.4186 & TRN & \\
\hline CHEMBL1479519 & 688239 & 4.5362 & 5.4834 & TRN & \\
\hline CHEMBL1455199 & 688239 & 5.7362 & 5.5149 & TRN & \\
\hline CHEMBL1551062 & 688239 & 4.5362 & 5.4742 & TRN & \\
\hline CHEMBL1409667 & 688239 & 4.5862 & 5.5492 & TRN & \\
\hline CHEMBL1457624 & 688239 & 4.5362 & 5.5343 & TRN & \\
\hline CHEMBL1458566 & 688239 & 5.4362 & 5.597 & TRN & \\
\hline CHEMBL1311650 & 688239 & 4.7862 & 5.7161 & TRN & \\
\hline CHEMBL3193129 & 688239 & 4.8362 & 5.518 & TST & \\
\hline CHEMBL1465968 & 688239 & 6.7862 & 5.5137 & TRN & \\
\hline CHEMBL1581598 & 688239 & 4.5362 & 5.4327 & TST & \\
\hline CHEMBL1453615 & 688239 & 5.1862 & 5.4674 & TST & \\
\hline CHEMBL1509168 & 688239 & 4.5362 & 5.4936 & TRN & \\
\hline CHEMBL1400166 & 688239 & 4.5362 & 5.4899 & TRN & \\
\hline CHEMBL1548486 & 688239 & 6.2362 & 5.5828 & TST & \\
\hline CHEMBL1419463 & 688239 & 5.3362 & 5.4655 & TST & \\
\hline CHEMBL1465039 & 688239 & 6.0862 & 5.4449 & TRN & \\
\hline CHEMBL1437493 & 688239 & 6.2362 & 5.5644 & TRN & \\
\hline CHEMBL1380658 & 688239 & 6.8362 & 5.551 & TRN & \\
\hline CHEMBL1525716 & 688239 & 4.4862 & 5.3855 & TRN & \\
\hline CHEMBL1300063 & 688239 & 5.4362 & 5.5316 & TRN & \\
\hline CHEMBL1496841 & 688239 & 5.1862 & 5.4664 & TRN & \\
\hline CHEMBL1562573 & 688239 & 5.2862 & 5.3857 & TRN & \\
\hline CHEMBL1471229 & 688239 & 4.7862 & 5.5018 & TRN & \\
\hline CHEMBL1477226 & 688239 & 7.9872 & 5.6132 & TRN & \\
\hline CHEMBL1513094 & 688239 & 6.3362 & 5.4223 & TRN & \\
\hline CHEMBL1587276 & 688239 & 5.1862 & 5.3273 & TRN & \\
\hline CHEMBL1519626 & 688239 & 4.5362 & 5.2871 & TST & \\
\hline CHEMBL1391964 & 688239 & 6.7361 & 5.5014 & TST & \\
\hline CHEMBL1448919 & 688239 & 6.2362 & 5.5867 & TRN & \\
\hline CHEMBL1198307 & 688239 & 4.7862 & 5.3274 & TRN & \\
\hline CHEMBL1449428 & 688239 & 4.9362 & 5.4057 & TRN & \\
\hline CHEMBL1602587 & 688239 & 6.9363 & 5.4857 & TST & \\
\hline CHEMBL1498574 & 688239 & 5.1862 & 5.2856 & TRN & \\
\hline CHEMBL1545057 & 688239 & 6.0362 & 5.522 & TRN & \\
\hline CHEMBL1433415 & 688239 & 4.7862 & 5.5365 & TRN & \\
\hline CHEMBL1321717 & 688239 & 5.6862 & 5.6122 & TRN & \\
\hline CHEMBL1561191 & 688239 & 5.1862 & 5.3475 & TRN & \\
\hline CHEMBL1557931 & 688239 & 4.5362 & 5.70799 & 9999999999 & TST \\
\hline CHEMBL1312122 & 688239 & 4.5362 & 5.3441 & TST & \\
\hline CHEMBL1406551 & 688239 & 6.3362 & 5.6693 & TRN & \\
\hline
\end{tabular}


Supplemental Table S2.txt

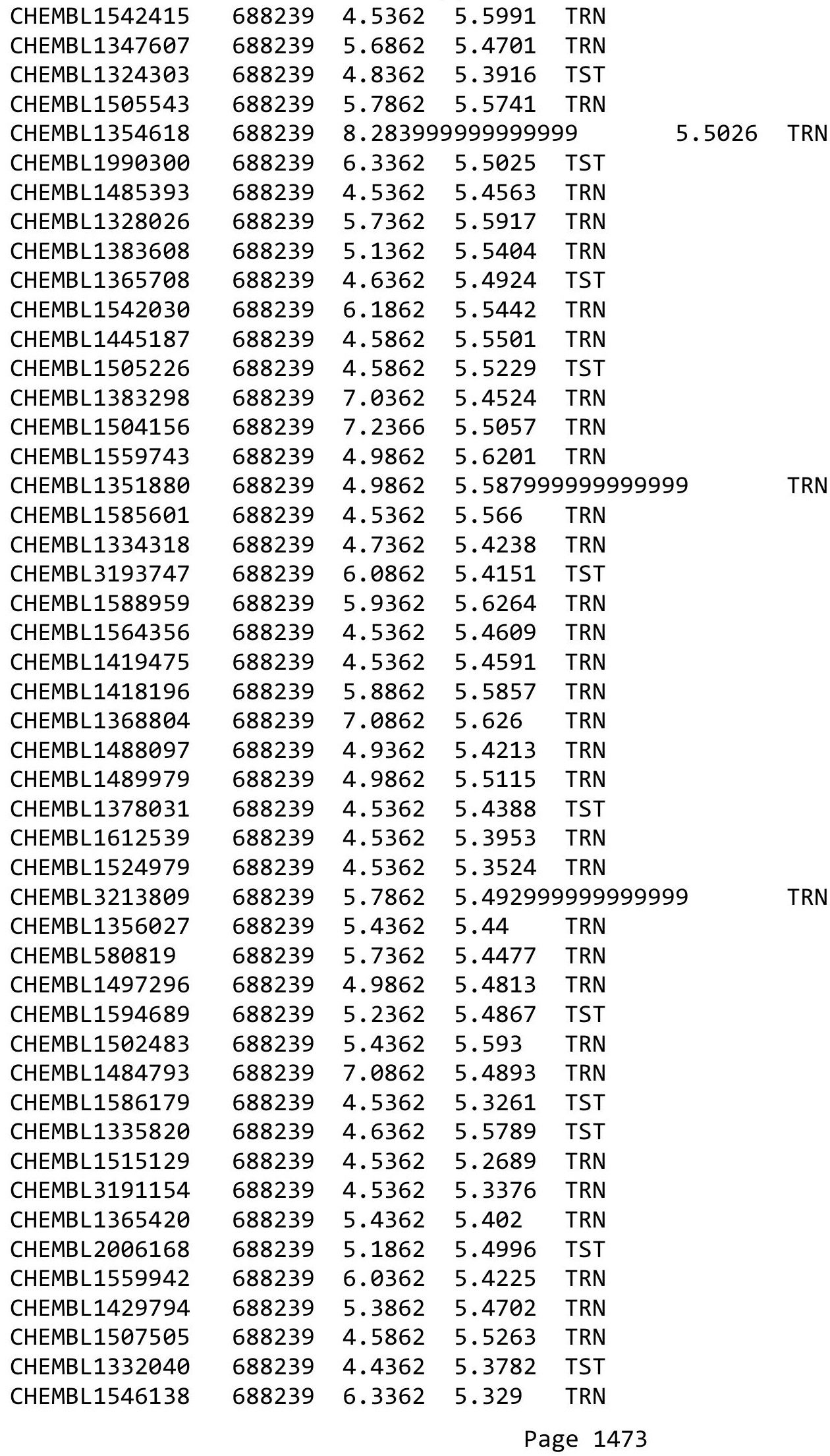




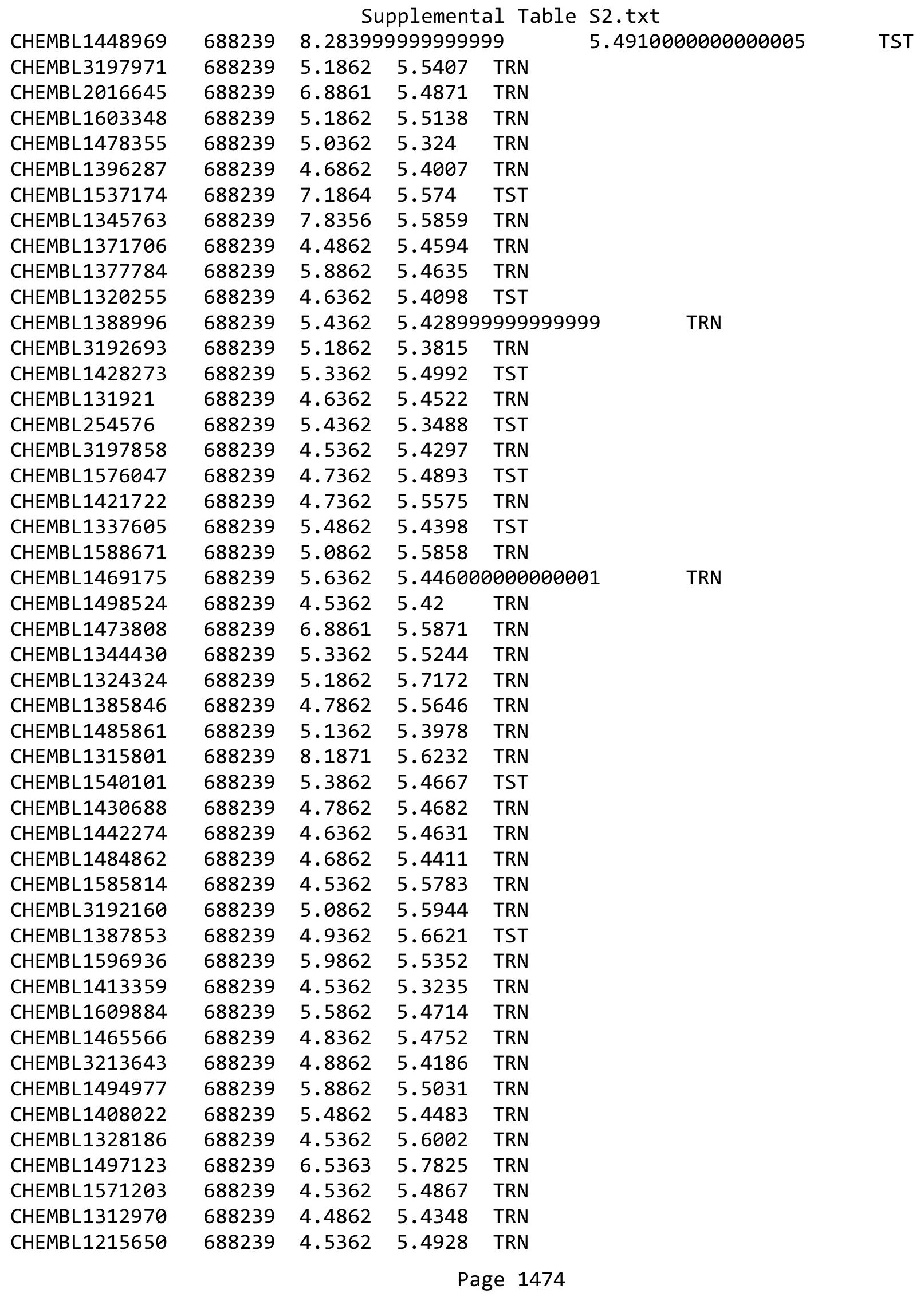




\begin{tabular}{|c|c|c|c|c|c|c|}
\hline & & \multicolumn{5}{|c|}{ Supplemental Table S2.txt } \\
\hline CHEMBL1607001 & 688239 & 4.4862 & 5.6516 & TRN & & \\
\hline CHEMBL1928491 & 688239 & 5.1862 & 5.346 & TRN & & \\
\hline CHEMBL1543010 & 688239 & 5.1862 & 5.5717 & TRN & & \\
\hline CHEMBL1310787 & 688239 & 4.6362 & 5.6998 & TRN & & \\
\hline CHEMBL1353935 & 688239 & 4.4862 & 5.6945 & TRN & & \\
\hline CHEMBL1454475 & 688239 & 8.2366 & 5.7489 & TRN & & \\
\hline CHEMBL1535356 & 688239 & 5.1862 & 5.4829 & TRN & & \\
\hline CHEMBL1350571 & 688239 & 5.8862 & 5.5192 & TRN & & \\
\hline CHEMBL1605173 & 688239 & 4.6362 & 5.4113 & TRN & & \\
\hline CHEMBL1552538 & 688239 & 5.4862 & 5.5094 & TRN & & \\
\hline CHEMBL1463678 & 688239 & 5.6862 & 5.5656 & TRN & & \\
\hline CHEMBL1446736 & 688239 & 5.2862 & 5.4995 & TRN & & \\
\hline CHEMBL1344411 & 688239 & 4.5362 & 5.5124 & TRN & & \\
\hline CHEMBL1561503 & 688239 & 6.1862 & 5.3956 & TRN & & \\
\hline CHEMBL1408207 & 688239 & 8.3872 & 5.5387 & TST & & \\
\hline CHEMBL1371979 & 688239 & 4.5362 & 5.4804 & TRN & & \\
\hline CHEMBL1521182 & 688239 & 8.28399 & 99999999 & 99 & 5.7264 & TRN \\
\hline CHEMBL1424986 & 688239 & 5.1862 & 5.4322 & TRN & & \\
\hline CHEMBL1573803 & 688239 & 5.9862 & 5.4411 & TST & & \\
\hline CHEMBL1509777 & 688239 & 6.1862 & 5.4258 & TRN & & \\
\hline CHEMBL1399797 & 688239 & 4.5362 & 5.6415 & TRN & & \\
\hline CHEMBL1480666 & 688239 & 4.7362 & 5.4488 & TRN & & \\
\hline CHEMBL1354699 & 688239 & 7.2366 & 5.5799 & TRN & & \\
\hline CHEMBL1454298 & 688239 & 5.0362 & 5.3529 & TRN & & \\
\hline CHEMBL1347833 & 688239 & 4.4862 & 5.3419 & TRN & & \\
\hline CHEMBL1474319 & 688239 & 4.5362 & 5.4714 & TRN & & \\
\hline CHEMBL1392991 & 688239 & 5.7362 & 5.4071 & TRN & & \\
\hline CHEMBL1513441 & 688239 & 4.8862 & 5.4282 & TRN & & \\
\hline CHEMBL1325077 & 688239 & 5.3362 & 5.4698 & TRN & & \\
\hline CHEMBL1498872 & 688239 & 4.9862 & 5.5976 & TRN & & \\
\hline CHEMBL1303655 & 688239 & 5.9362 & 5.5833 & TRN & & \\
\hline CHEMBL1371955 & 688239 & 4.5362 & 5.4328 & TRN & & \\
\hline CHEMBL1320219 & 688239 & 4.5362 & 5.6706 & TRN & & \\
\hline CHEMBL1489946 & 688239 & 5.7362 & 5.5682 & TRN & & \\
\hline CHEMBL1383737 & 688239 & 6.9863 & 5.4531 & TRN & & \\
\hline CHEMBL1349725 & 688239 & 4.8362 & 5.4581 & TRN & & \\
\hline CHEMBL1401664 & 688239 & 5.1862 & 5.3728 & TST & & \\
\hline CHEMBL1517609 & 688239 & 5.7362 & 5.3354 & TRN & & \\
\hline CHEMBL1608824 & 688239 & 6.1362 & 5.5256 & TRN & & \\
\hline CHEMBL1560524 & 688239 & 7.2865 & 5.6033 & TRN & & \\
\hline CHEMBL3144869 & 688239 & 6.1362 & 5.5376 & TRN & & \\
\hline CHEMBL1398524 & 688239 & 4.6862 & 5.4534 & TRN & & \\
\hline CHEMBL1423779 & 688239 & 4.6362 & 5.4058 & TRN & & \\
\hline CHEMBL1340522 & 688239 & 7.2865 & 5.5049 & TRN & & \\
\hline CHEMBL1304886 & 688239 & 4.7362 & 5.4772 & TRN & & \\
\hline CHEMBL1459572 & 688239 & 4.6862 & 5.3926 & TRN & & \\
\hline CHEMBL1598917 & 688239 & 6.3362 & 5.4245 & TRN & & \\
\hline CHEMBL1299846 & 688239 & 6.0362 & 5.6033 & TRN & & \\
\hline
\end{tabular}


Supplemental Table S2.txt

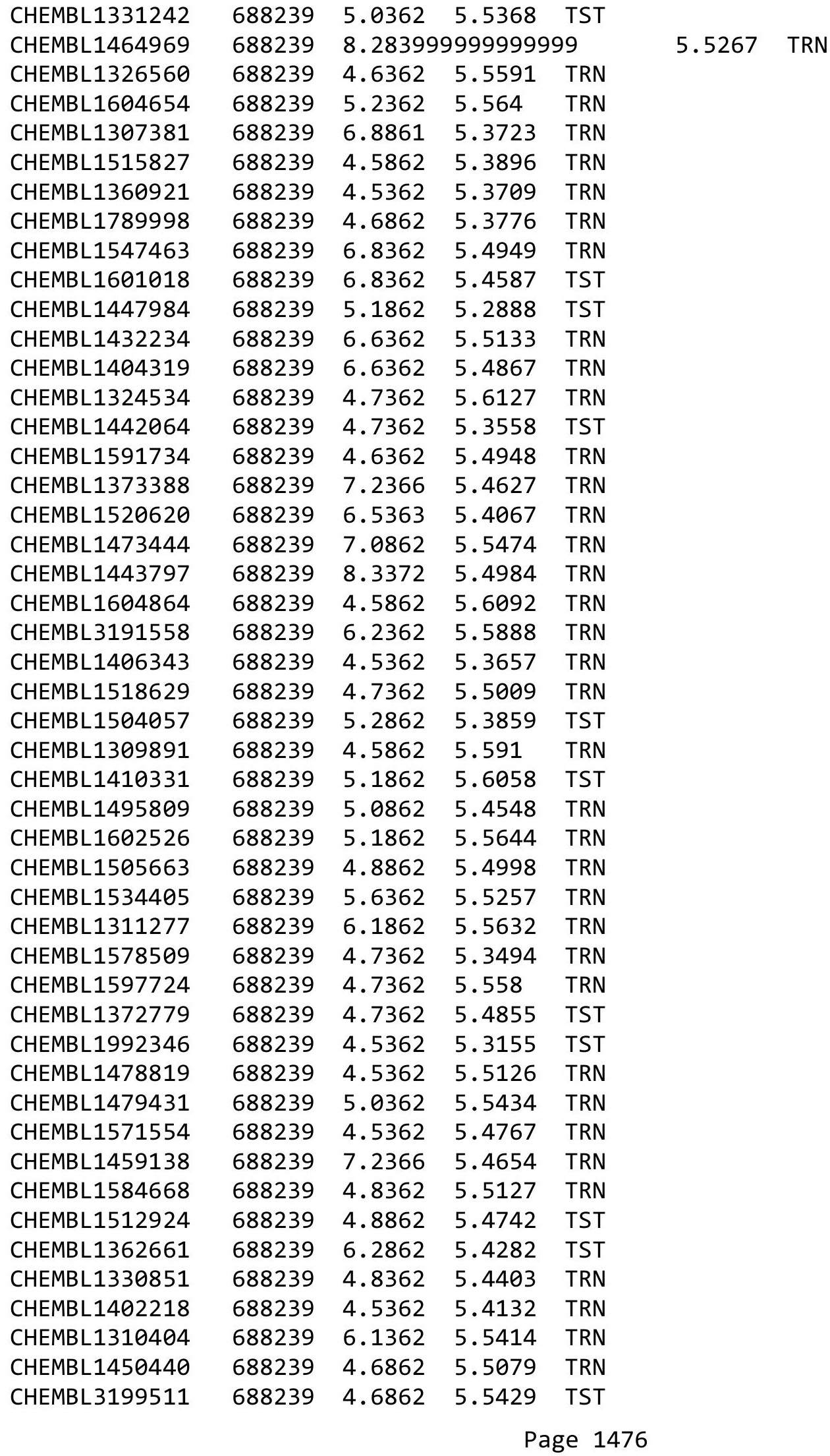


Supplemental Table S2.txt

\begin{tabular}{|c|c|c|c|c|}
\hline CHEMBL1313339 & 688239 & 5.9362 & 5.4552 & TRN \\
\hline CHEMBL1594394 & 688239 & 6.2862 & 5.5289 & TRN \\
\hline CHEMBL1577564 & 688239 & 5.6862 & 5.6125 & TST \\
\hline CHEMBL1385358 & 688239 & 5.6862 & 5.4013 & TRN \\
\hline CHEMBL1489671 & 688239 & 5.6362 & 5.4536 & TRN \\
\hline CHEMBL1558195 & 688239 & 5.1862 & 5.4769 & TRN \\
\hline CHEMBL1597980 & 688239 & 4.5362 & 5.5526 & TRN \\
\hline CHEMBL1605927 & 688239 & 4.5362 & 5.4461 & TST \\
\hline CHEMBL1490760 & 688239 & 7.6364 & 5.5372 & TRN \\
\hline CHEMBL1555966 & 688239 & 5.7862 & 5.5516 & TRN \\
\hline CHEMBL579956 & 688239 & 4.7862 & 5.4224 & TRN \\
\hline CHEMBL1532483 & 688239 & 4.5362 & 5.3866 & TRN \\
\hline CHEMBL1444853 & 688239 & 4.7862 & 5.4504 & TRN \\
\hline CHEMBL1432727 & 688239 & 5.3362 & 5.4583 & TST \\
\hline CHEMBL1605773 & 688239 & 5.0362 & 5.4681 & TRN \\
\hline CHEMBL1542833 & 688239 & 6.3863 & 5.5913 & TRN \\
\hline CHEMBL3209316 & 688239 & 6.6362 & 5.5842 & TRN \\
\hline CHEMBL1325290 & 688239 & 5.2862 & 5.3869 & TRN \\
\hline CHEMBL1578604 & 688239 & 4.5862 & 5.4539 & TRN \\
\hline CHEMBL1342382 & 688239 & 7.0362 & 5.51200 & 00000000005 \\
\hline CHEMBL1340792 & 688239 & 4.8362 & 5.4262 & TST \\
\hline CHEMBL1483654 & 688239 & 6.1362 & 5.5142 & TST \\
\hline CHEMBL1538753 & 688239 & 4.6362 & 5.553 & TRN \\
\hline CHEMBL1595406 & 688239 & 5.3362 & 5.3833 & TST \\
\hline CHEMBL1403939 & 688239 & 5.4862 & 5.4612 & TRN \\
\hline CHEMBL1600863 & 688239 & 4.8862 & 5.341 & TRN \\
\hline CHEMBL573290 & 688239 & 4.7362 & 5.5756 & TRN \\
\hline CHEMBL1395153 & 688239 & 8.3372 & 5.4072 & TRN \\
\hline CHEMBL591404 & 688239 & 4.7362 & 5.3368 & TRN \\
\hline CHEMBL1473476 & 688239 & 5.1862 & 5.4431 & TRN \\
\hline CHEMBL1708334 & 688239 & 4.6362 & 5.3496 & TRN \\
\hline CHEMBL1316431 & 688239 & 4.7362 & 5.5932 & TRN \\
\hline CHEMBL1530489 & 688239 & 5.7362 & 5.6173 & TRN \\
\hline CHEMBL3190606 & 688239 & 5.5362 & 5.481 & TRN \\
\hline CHEMBL1612717 & 688239 & 5.1862 & 5.4247 & TST \\
\hline CHEMBL3189968 & 688239 & 5.3862 & 5.4602 & TRN \\
\hline CHEMBL1462619 & 688239 & 6.1362 & 5.5478 & TRN \\
\hline CHEMBL1483651 & 688239 & 5.7362 & 5.4036 & TRN \\
\hline CHEMBL1404896 & 688239 & 6.1362 & 5.3953 & TST \\
\hline CHEMBL1389692 & 688239 & 5.5362 & 5.4912 & TRN \\
\hline CHEMBL 1446778 & 688239 & 4.9862 & 5.5033 & TRN \\
\hline CHEMBL1511414 & 688239 & 6.7862 & 5.5481 & TRN \\
\hline CHEMBL1519304 & 688239 & 4.6862 & 5.4601 & TRN \\
\hline CHEMBL1343125 & 688239 & 5.5862 & 5.5051 & TST \\
\hline CHEMBL1529118 & 688239 & 6.8861 & 5.5243 & TRN \\
\hline CHEMBL 3194785 & 688239 & 4.8862 & 5.349 & TRN \\
\hline CHEMBL3196624 & 688239 & 4.6862 & 5.46299 & 9999999999 \\
\hline CHEMBL1326160 & 688239 & 4.5362 & 5.4858 & TRN \\
\hline
\end{tabular}




\begin{tabular}{|c|c|c|c|c|c|}
\hline & & & & & \\
\hline CHEMBL1517978 & 688239 & 5.7362 & 5.5265 & TRN & \\
\hline CHEMBL1506081 & 688239 & 5.5362 & 5.4833 & TST & \\
\hline CHEMBL1324796 & 688239 & 6.2862 & 5.4597 & TRN & \\
\hline CHEMBL1547308 & 688239 & 5.5862 & 5.3952 & TST & \\
\hline CHEMBL1398844 & 688239 & 5.7362 & 5.4885 & TRN & \\
\hline CHEMBL1572817 & 688239 & 7.0362 & 5.5384 & TRN & \\
\hline CHEMBL3199461 & 688239 & 4.5362 & 5.40799 & 99999999995 & TRN \\
\hline CHEMBL1422293 & 688239 & 7.0362 & 5.5136 & TRN & \\
\hline CHEMBL1444033 & 688239 & 4.6362 & 5.5567 & TRN & \\
\hline CHEMBL1359780 & 688239 & 4.5362 & 5.4257 & TST & \\
\hline CHEMBL1608598 & 688239 & 4.6362 & 5.5226 & TST & \\
\hline CHEMBL1302200 & 688239 & 5.8862 & 5.5481 & TRN & \\
\hline CHEMBL3196994 & 688239 & 5.4862 & 5.4602 & TRN & \\
\hline CHEMBL1299732 & 688239 & 4.7862 & 5.57600 & 00000000005 & TRN \\
\hline CHEMBL1547337 & 688239 & 6.8861 & 5.7038 & TRN & \\
\hline CHEMBL1588581 & 688239 & 4.5362 & 5.4401 & TRN & \\
\hline CHEMBL1509643 & 688239 & 4.4862 & 5.5181 & TRN & \\
\hline CHEMBL1598438 & 688239 & 6.0862 & 5.4748 & TRN & \\
\hline CHEMBL1515099 & 688239 & 4.5362 & 5.4576 & TRN & \\
\hline CHEMBL1521487 & 688239 & 4.7862 & 5.4521 & TRN & \\
\hline CHEMBL1518921 & 688239 & 4.7862 & 5.4862 & TST & \\
\hline CHEMBL1329053 & 688239 & 5.1362 & 5.4788 & TRN & \\
\hline CHEMBL1337957 & 688239 & 6.7862 & 5.5387 & TRN & \\
\hline CHEMBL1540854 & 688239 & 5.7862 & 5.439 & TST & \\
\hline CHEMBL1334673 & 688239 & 6.6362 & 5.4004 & TRN & \\
\hline CHEMBL1579958 & 688239 & 7.2865 & 5.4187 & TST & \\
\hline CHEMBL1546383 & 688239 & 6.7862 & 5.4392 & TRN & \\
\hline CHEMBL1567448 & 688239 & 6.0 & 5.5023 & TRN & \\
\hline CHEMBL3212818 & 688239 & 4.6362 & 5.4054 & TRN & \\
\hline CHEMBL1495876 & 688239 & 4.5362 & 5.5062 & TRN & \\
\hline CHEMBL1256885 & 688239 & 5.0862 & 5.2998 & TST & \\
\hline CHEMBL1450401 & 688239 & 6.8861 & 5.4489 & TST & \\
\hline CHEMBL1506812 & 688239 & 4.6862 & 5.42899 & 9999999999 & TRN \\
\hline CHEMBL19954 & 688239 & 4.8362 & 5.53799 & 9999999999 & TST \\
\hline CHEMBL1543911 & 688239 & 4.5362 & 5.3874 & TRN & \\
\hline CHEMBL1527691 & 688239 & 5.0862 & 5.3884 & TRN & \\
\hline CHEMBL1542884 & 688239 & 4.6862 & 5.4906 & TST & \\
\hline CHEMBL1515911 & 688239 & 5.4362 & 5.4748 & TRN & \\
\hline CHEMBL1353388 & 688239 & 6.9863 & 5.5148 & TRN & \\
\hline CHEMBL1272150 & 688239 & 6.0862 & 5.69799 & 99999999995 & TRN \\
\hline CHEMBL1515590 & 688239 & 6.8362 & 5.5418 & TRN & \\
\hline CHEMBL1306475 & 688239 & 7.2366 & 5.4305 & TST & \\
\hline CHEMBL1387273 & 688239 & 6.1362 & 5.5581 & TRN & \\
\hline CHEMBL60907 & 688239 & 4.8362 & 5.3463 & TRN & \\
\hline CHEMBL1608110 & 688239 & 4.6362 & 5.4447 & TST & \\
\hline CHEMBL1323154 & 688239 & 5.4362 & 5.5268 & TRN & \\
\hline CHEMBL1312523 & 688239 & 5.7862 & 5.3585 & TRN & \\
\hline CHEMBL102714 & 688239 & 4.5362 & 5.3674 & TST & \\
\hline
\end{tabular}


Supplemental Table S2.txt

\begin{tabular}{|c|c|c|c|c|c|}
\hline CHEMBL1451989 & 688239 & 6.9863 & 5.5504 & TRN & \\
\hline CHEMBL1986259 & 688239 & 4.7862 & 5.4609 & TRN & \\
\hline CHEMBL1384758 & 688239 & 4.5362 & 5.5236 & TRN & \\
\hline CHEMBL1451381 & 688239 & 4.4862 & 5.4182 & TRN & \\
\hline CHEMBL1504323 & 688239 & 5.9862 & 5.4207 & TRN & \\
\hline CHEMBL1601160 & 688239 & 5.6362 & 5.513999 & 999999999 & TRN \\
\hline CHEMBL1346640 & 688239 & 4.5362 & 5.1618 & TRN & \\
\hline CHEMBL1403612 & 688239 & 7.4365 & 5.4647 & TRN & \\
\hline CHEMBL1474433 & 688239 & 4.7362 & 5.3318 & TRN & \\
\hline CHEMBL1370704 & 688239 & 4.4862 & 5.5069 & TRN & \\
\hline CHEMBL1526396 & 688239 & 4.5362 & 5.4807 & TRN & \\
\hline CHEMBL1528563 & 688239 & 5.1862 & 5.4001 & TRN & \\
\hline CHEMBL1417805 & 688239 & 4.6862 & 5.4234 & TRN & \\
\hline CHEMBL1514482 & 688239 & 5.6362 & 5.5048 & TRN & \\
\hline CHEMBL1547143 & 688239 & 6.9363 & 5.6093 & TRN & \\
\hline CHEMBL1439993 & 688239 & 6.1862 & 5.4633 & TRN & \\
\hline CHEMBL1570855 & 688239 & 4.7862 & 5.5643 & TRN & \\
\hline CHEMBL1368346 & 688239 & 5.1862 & 5.5271 & TRN & \\
\hline CHEMBL1494464 & 688239 & 6.1362 & 5.5654 & TRN & \\
\hline CHEMBL1386806 & 688239 & 4.5862 & 5.4625 & TRN & \\
\hline CHEMBL1584946 & 688239 & 4.5862 & 5.5935 & TRN & \\
\hline CHEMBL1559312 & 688239 & 8.3372 & 5.455 & TRN & \\
\hline CHEMBL1324642 & 688239 & 4.5362 & 5.4009 & TST & \\
\hline CHEMBL1409024 & 688239 & 4.7362 & 5.5046 & TRN & \\
\hline CHEMBL1451772 & 688239 & 4.4862 & 5.2878 & TRN & \\
\hline CHEMBL1597028 & 688239 & 5.9862 & 5.5483 & TRN & \\
\hline CHEMBL1490431 & 688239 & 6.0862 & 5.4153 & TRN & \\
\hline CHEMBL1462837 & 688239 & 5.0862 & 5.4515 & TRN & \\
\hline CHEMBL1372935 & 688239 & 6.0362 & 5.5049 & TST & \\
\hline CHEMBL1507878 & 688239 & 5.1862 & 5.5017 & TRN & \\
\hline CHEMBL1606720 & 688239 & 4.8362 & 5.6024 & TRN & \\
\hline CHEMBL3189568 & 688239 & 4.5362 & 5.3923 & TST & \\
\hline CHEMBL1505469 & 688239 & 4.5362 & 5.3542 & TRN & \\
\hline CHEMBL1523339 & 688239 & 4.6362 & 5.473 & TRN & \\
\hline CHEMBL1553634 & 688239 & 5.9362 & 5.6129 & TRN & \\
\hline CHEMBL1382967 & 688239 & 5.2362 & 5.5727 & TST & \\
\hline CHEMBL1557323 & 688239 & 4.8862 & 5.3316 & TRN & \\
\hline CHEMBL1374933 & 688239 & 5.3362 & 5.3872 & TRN & \\
\hline CHEMBL1586241 & 688239 & 4.6862 & 5.3948 & TRN & \\
\hline CHEMBL1501216 & 688239 & 5.5362 & 5.5193 & TRN & \\
\hline CHEMBL1575954 & 688239 & 5.4362 & 5.6215 & TRN & \\
\hline CHEMBL1440999 & 688239 & 6.1362 & 5.4471 & TRN & \\
\hline CHEMBL1474076 & 688239 & 6.2862 & 5.5375 & TST & \\
\hline CHEMBL1299549 & 688239 & 4.5362 & 5.5554 & TRN & \\
\hline CHEMBL1331464 & 688239 & 5.5862 & 5.5155 & TRN & \\
\hline CHEMBL1361167 & 688239 & 5.1862 & 5.491000 & 0000000005 & KIV \\
\hline CHEMBL1593059 & 688239 & 8.28399 & 99999999 & 5.5092 & \\
\hline CHEMBL1448849 & 688239 & 6.9363 & 5.3511 & TST & \\
\hline
\end{tabular}


Supplemental Table S2.txt

\begin{tabular}{|c|c|c|c|c|c|}
\hline CHEMBL1562311 & 688239 & 6.5363 & 5.4972 & TRN & \\
\hline CHEMBL1375395 & 688239 & 5.1862 & 5.4513 & TRN & \\
\hline CHEMBL1518536 & 688239 & 5.1862 & 5.5171 & TRN & \\
\hline CHEMBL1595118 & 688239 & 4.5862 & 5.524 & TRN & \\
\hline CHEMBL1563730 & 688239 & 5.2862 & 5.4605 & TRN & \\
\hline CHEMBL1460905 & 688239 & 5.4362 & 5.4568 & TRN & \\
\hline CHEMBL3194933 & 688239 & 5.5362 & 5.4483 & TST & \\
\hline CHEMBL1350672 & 688239 & 5.6362 & 5.4522 & TRN & \\
\hline CHEMBL1395585 & 688239 & 5.4362 & 5.4698 & TRN & \\
\hline CHEMBL1550751 & 688239 & 4.9362 & 5.565 & TST & \\
\hline CHEMBL1507569 & 688239 & 4.7362 & 5.4995 & TRN & \\
\hline CHEMBL1474237 & 688239 & 5.4362 & 5.31 & TST & \\
\hline CHEMBL1563291 & 688239 & 4.7362 & 5.4409 & TRN & \\
\hline CHEMBL1567944 & 688239 & 6.0 & 5.4157 & TST & \\
\hline CHEMBL1412772 & 688239 & 4.6362 & 5.5679 & TRN & \\
\hline CHEMBL1468247 & 688239 & 4.7362 & 5.5433 & TST & \\
\hline CHEMBL1580947 & 688239 & 4.7862 & 5.5447 & TRN & \\
\hline CHEMBL 3212526 & 688239 & 7.0362 & 5.38899 & 9999999999 & TRN \\
\hline CHEMBL1323056 & 688239 & 4.4862 & 5.6568 & TRN & \\
\hline CHEMBL1315813 & 688239 & 5.4362 & 5.5976 & TRN & \\
\hline CHEMBL1550357 & 688239 & 4.5362 & 5.2891 & TST & \\
\hline CHEMBL1584925 & 688239 & 4.6862 & 5.4635 & TST & \\
\hline CHEMBL1572898 & 688239 & 6.2362 & 5.4094 & TRN & \\
\hline CHEMBL3214156 & 688239 & 6.0362 & 5.3639 & TRN & \\
\hline CHEMBL1318918 & 688239 & 4.5362 & 5.5642 & TRN & \\
\hline CHEMBL1530558 & 688239 & 6.6861 & 5.3663 & TRN & \\
\hline CHEMBL1559091 & 688239 & 5.8362 & 5.5129 & TST & \\
\hline CHEMBL1509740 & 688239 & 5.2362 & 5.5021 & TRN & \\
\hline CHEMBL1464259 & 688239 & 4.4862 & 5.5656 & TRN & \\
\hline CHEMBL1548204 & 688239 & 4.7862 & 5.4729 & TRN & \\
\hline CHEMBL1488965 & 688239 & 4.9362 & 5.5587 & TST & \\
\hline CHEMBL1319412 & 688239 & 5.2862 & 5.5954 & TRN & \\
\hline CHEMBL1307962 & 688239 & 6.1362 & 5.3546 & TRN & \\
\hline CHEMBL1311123 & 688239 & 5.1862 & 5.454 & TRN & \\
\hline CHEMBL1312472 & 688239 & 4.6862 & 5.6236 & TST & \\
\hline CHEMBL1450456 & 688239 & 5.4862 & 5.4745 & TRN & \\
\hline CHEMBL3192101 & 688239 & 5.1862 & 5.3268 & TST & \\
\hline CHEMBL1558999 & 688239 & 7.1361 & 5.4319 & TST & \\
\hline CHEMBL1361521 & 688239 & 4.5362 & 5.41100 & 00000000005 & TRN \\
\hline CHEMBL1409060 & 688239 & 5.6862 & 5.5381 & TST & \\
\hline CHEMBL1315658 & 688239 & 4.8862 & 5.4221 & TRN & \\
\hline CHEMBL1604423 & 688239 & 5.7362 & 5.4422 & TRN & \\
\hline CHEMBL1498223 & 688239 & 4.6862 & 5.4849 & TRN & \\
\hline CHEMBL1484865 & 688239 & 5.1862 & 5.3642 & TST & \\
\hline CHEMBL1442286 & 688239 & 4.5362 & 5.4131 & TRN & \\
\hline CHEMBL1410745 & 688239 & 6.3362 & 5.3233 & TST & \\
\hline CHEMBL1345065 & 688239 & 5.7862 & 5.5519 & TRN & \\
\hline CHEMBL1357137 & 688239 & 6.1362 & 5.4476 & TRN & \\
\hline
\end{tabular}




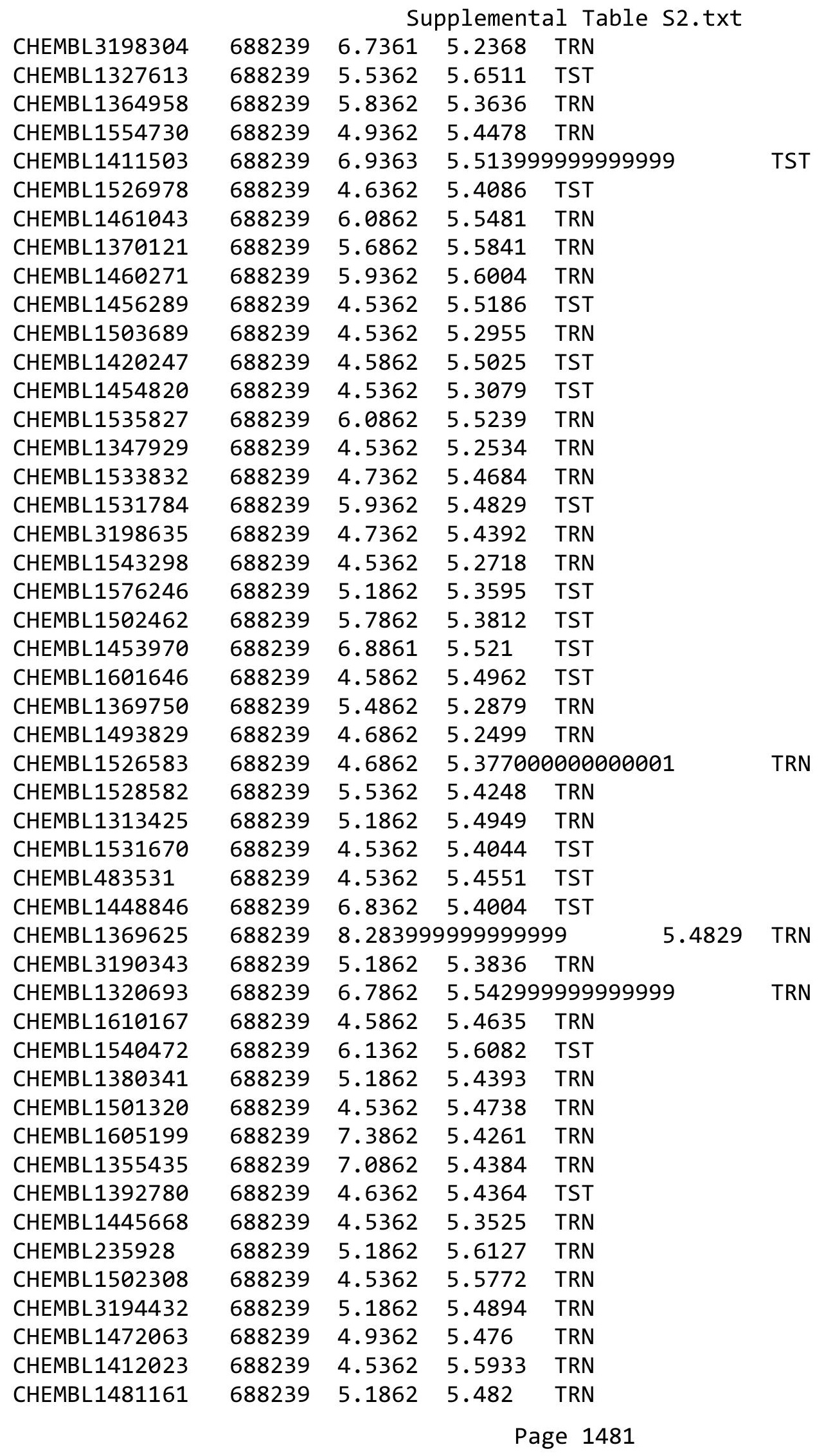


Supplemental Table S2.txt

\begin{tabular}{|c|c|c|c|c|}
\hline CHEMBL3192651 & 688239 & 4.6362 & 5.4406 & TRN \\
\hline CHEMBL1342761 & 688239 & 5.6362 & 5.3464 & TRN \\
\hline CHEMBL1559017 & 688239 & 4.6862 & 5.5713 & TRN \\
\hline CHEMBL1457698 & 688239 & 6.6861 & 5.7138 & TRN \\
\hline CHEMBL1488078 & 688239 & 5.6362 & 5.4317 & TRN \\
\hline CHEMBL 3208609 & 688239 & 5.6362 & 5.4974 & TRN \\
\hline CHEMBL 3207624 & 688239 & 6.7862 & 5.5678 & TRN \\
\hline CHEMBL1371999 & 688239 & 6.8861 & 5.5261 & TRN \\
\hline CHEMBL1421377 & 688239 & 6.8861 & 5.3292 & TST \\
\hline CHEMBL1371820 & 688239 & 4.8362 & 5.4297 & TRN \\
\hline CHEMBL1333633 & 688239 & 5.1862 & 5.4642 & TST \\
\hline CHEMBL1456718 & 688239 & 5.2862 & 5.4103 & TST \\
\hline CHEMBL1557301 & 688239 & 5.8362 & 5.4476 & TST \\
\hline CHEMBL 2028184 & 688239 & 6.6861 & 5.449 & TRN \\
\hline CHEMBL1309320 & 688239 & 4.5362 & 5.5801 & TRN \\
\hline CHEMBL1455867 & 688239 & 6.0862 & 5.6342 & TRN \\
\hline CHEMBL1336407 & 688239 & 5.7362 & 5.4018 & TRN \\
\hline CHEMBL1303213 & 688239 & 4.5362 & 5.4931 & TST \\
\hline CHEMBL1572492 & 688239 & 4.6362 & 5.4567 & TST \\
\hline CHEMBL1391847 & 688239 & 6.0862 & 5.5043 & TRN \\
\hline CHEMBL1546128 & 688239 & 6.5862 & 5.6114 & TRN \\
\hline CHEMBL1327842 & 688239 & 5.1862 & 5.4708 & TRN \\
\hline CHEMBL1307997 & 688239 & 6.7862 & 5.3618 & TRN \\
\hline CHEMBL 3213720 & 688239 & 5.1862 & 5.4422 & TRN \\
\hline CHEMBL1427426 & 688239 & 5.3862 & 5.5245 & TRN \\
\hline CHEMBL1537866 & 688239 & 4.4862 & 5.7306 & TRN \\
\hline CHEMBL1337878 & 688239 & 4.4862 & 5.3753 & TRN \\
\hline CHEMBL1594306 & 688239 & 4.8862 & 5.4279 & TRN \\
\hline CHEMBL1395656 & 688239 & 4.5362 & 5.4809 & TRN \\
\hline CHEMBL1991888 & 688239 & 4.5362 & 5.2753 & TST \\
\hline CHEMBL1406164 & 688239 & 6.8362 & 5.5635 & TRN \\
\hline CHEMBL1478454 & 688239 & 4.8362 & 5.5164 & TRN \\
\hline CHEMBL1547317 & 688239 & 4.9362 & 5.5002 & TST \\
\hline CHEMBL1392438 & 688239 & 6.5862 & 5.4132 & TRN \\
\hline CHEMBL1314608 & 688239 & 4.5362 & 5.508999 & 99999999995 \\
\hline CHEMBL245820 & 688239 & 6.5363 & 5.5436 & TRN \\
\hline CHEMBL1519041 & 688239 & 6.7361 & 5.4801 & TRN \\
\hline CHEMBL 3214238 & 688239 & 4.5362 & 5.3811 & TRN \\
\hline CHEMBL1510874 & 688239 & 6.9863 & 5.4963 & TRN \\
\hline CHEMBL3196953 & 688239 & 4.4862 & 5.4388 & TRN \\
\hline CHEMBL1339297 & 688239 & 5.8362 & 5.5619 & TRN \\
\hline CHEMBL1575147 & 688239 & 5.1862 & 5.5579 & TRN \\
\hline CHEMBL1466731 & 688239 & 5.1862 & 5.4501 & TRN \\
\hline CHEMBL1450398 & 688239 & 5.3862 & 5.4824 & TST \\
\hline CHEMBL1425729 & 688239 & 4.5362 & 5.4996 & TRN \\
\hline CHEMBL1535639 & 688239 & 6.8861 & 5.5345 & TRN \\
\hline CHEMBL1495520 & 688239 & 5.3862 & 5.4376 & TRN \\
\hline CHEMBL1385129 & 688239 & 5.7862 & 5.4422 & TRN \\
\hline
\end{tabular}


Supplemental Table S2.txt

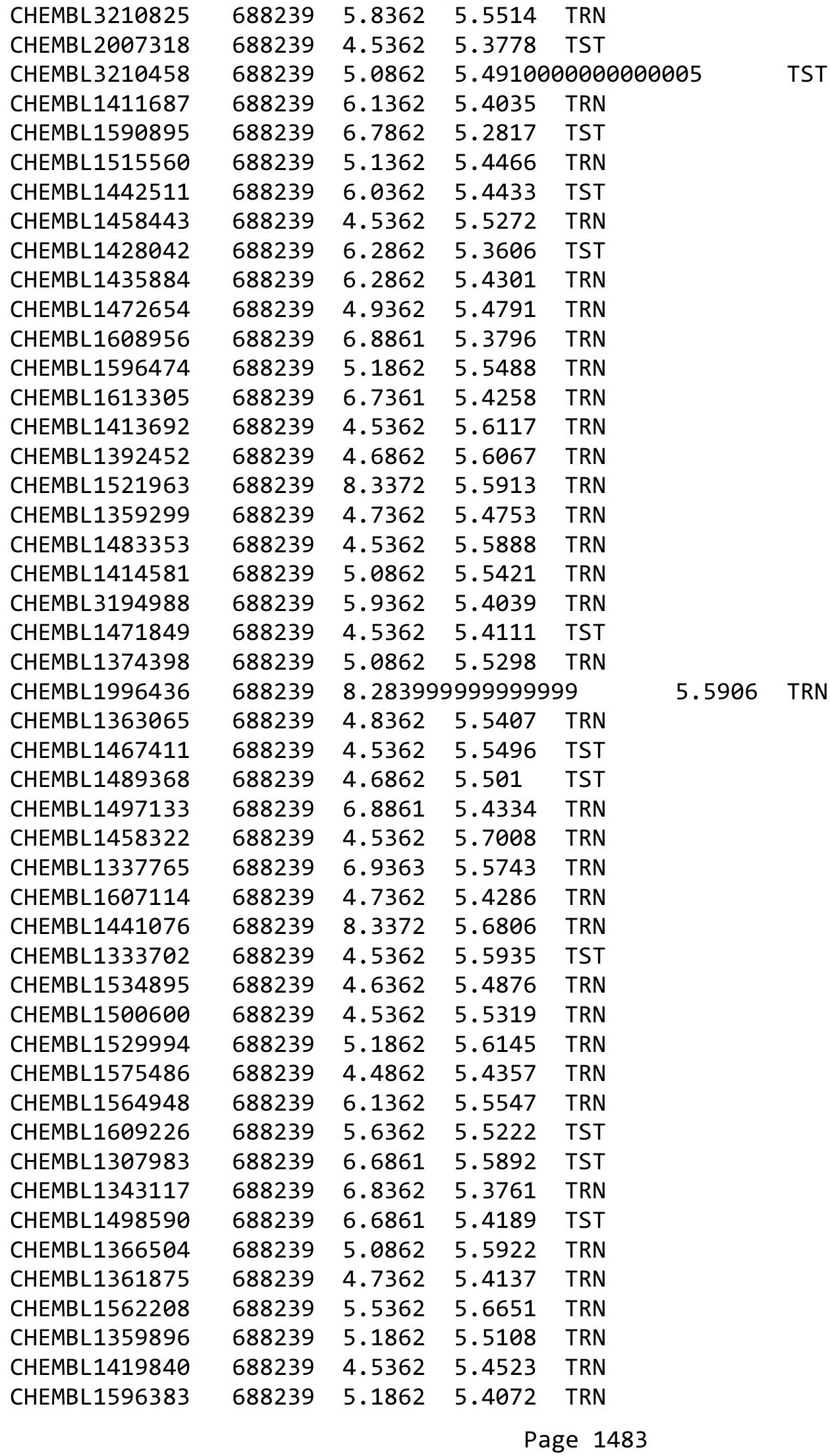


Supplemental Table S2.txt

\begin{tabular}{|c|c|c|c|c|c|}
\hline CHEMBL1605328 & 688239 & 4.9362 & 5.5002 & TRN & \\
\hline CHEMBL1455304 & 688239 & 7.0862 & 5.642 & TST & \\
\hline CHEMBL1375272 & 688239 & 5.6362 & 5.5531 & TRN & \\
\hline CHEMBL1313543 & 688239 & 4.7862 & 5.5151 & TRN & \\
\hline CHEMBL1525628 & 688239 & 4.7362 & 5.5302 & TST & \\
\hline CHEMBL 2001792 & 688239 & 4.9362 & \multicolumn{2}{|c|}{5.377999999999999} & TST \\
\hline CHEMBL1396638 & 688239 & 5.1862 & 5.4934 & TST & \\
\hline CHEMBL1493060 & 688239 & 5.2 & 5.6913 & TRN & \\
\hline CHEMBL1498338 & 688239 & 5.3862 & 5.4802 & TST & \\
\hline CHEMBL1312841 & 688239 & 5.8862 & 5.5589 & TRN & \\
\hline CHEMBL1301804 & 688239 & 6.0362 & 5.5575 & TRN & \\
\hline CHEMBL1363965 & 688239 & 4.7362 & 5.4023 & TST & \\
\hline CHEMBL3214048 & 688239 & 4.5362 & 5.5255 & TRN & \\
\hline CHEMBL1592509 & 688239 & 4.9362 & 5.4911 & TRN & \\
\hline CHEMBL1393659 & 688239 & 5.9362 & 5.6109 & TRN & \\
\hline CHEMBL1375659 & 688239 & 4.5362 & 5.4134 & TST & \\
\hline CHEMBL1472073 & 688239 & 4.9362 & 5.5191 & TRN & \\
\hline CHEMBL1466694 & 688239 & 4.5362 & 5.4089 & TRN & \\
\hline CHEMBL1528794 & 688239 & 5.2362 & 5.454 & TST & \\
\hline CHEMBL1584909 & 688239 & 5.6862 & 5.6374 & TST & \\
\hline CHEMBL1500376 & 688239 & 4.4862 & 5.4495 & TST & \\
\hline CHEMBL1334085 & 688239 & 6.1862 & 5.6838 & TRN & \\
\hline CHEMBL1315469 & 688239 & 4.6862 & 5.5399 & TRN & \\
\hline CHEMBL1538161 & 688239 & 5.2862 & 5.6042 & TRN & \\
\hline CHEMBL1453490 & 688239 & 5.1862 & 5.5289 & TRN & \\
\hline CHEMBL1584082 & 688239 & 6.6861 & 5.5646 & TRN & \\
\hline CHEMBL1462041 & 688239 & 4.5862 & 5.4151 & TRN & \\
\hline CHEMBL1401581 & 688239 & 6.0862 & 5.4163 & TST & \\
\hline CHEMBL1314365 & 688239 & 4.5362 & 5.4224 & TRN & \\
\hline CHEMBL1418747 & 688239 & 5.0362 & 5.4845 & TRN & \\
\hline CHEMBL1490826 & 688239 & 5.9862 & 5.5135 & TRN & \\
\hline CHEMBL1593409 & 688239 & 4.5362 & 5.4111 & TRN & \\
\hline CHEMBL1530672 & 688239 & 4.9362 & 5.4726 & TRN & \\
\hline CHEMBL1580021 & 688239 & 5.9362 & 5.6611 & TST & \\
\hline CHEMBL1572811 & 688239 & 4.8862 & 5.49799 & 9999999999 & TRN \\
\hline CHEMBL1498953 & 688239 & 5.7362 & 5.4407 & TRN & \\
\hline CHEMBL1516974 & 688239 & 6.8861 & 5.3839 & TRN & \\
\hline CHEMBL1404355 & 688239 & 4.7862 & 5.4363 & TRN & \\
\hline CHEMBL1380932 & 688239 & 5.8862 & 5.4622 & TRN & \\
\hline CHEMBL1516907 & 688239 & 6.9363 & 5.6294 & TRN & \\
\hline CHEMBL1569858 & 688239 & 4.8362 & 5.4348 & TRN & \\
\hline CHEMBL1398127 & 688239 & 4.6362 & 5.3909 & TST & \\
\hline CHEMBL153101 & 688239 & 4.9862 & 5.5249 & TST & \\
\hline CHEMBL1508206 & 688239 & 5.9362 & 5.4932 & TRN & \\
\hline CHEMBL1563608 & 688239 & 4.6362 & 5.3816 & TRN & \\
\hline CHEMBL1424243 & 688239 & 6.2362 & 5.2849 & TST & \\
\hline CHEMBL1542665 & 688239 & 6.0862 & 5.4202 & TRN & \\
\hline CHEMBL1444143 & 688239 & 5.2362 & 5.506 & TRN & \\
\hline
\end{tabular}


Supplemental Table S2.txt

\begin{tabular}{|c|c|c|c|c|c|}
\hline CHEMBL3192962 & 688239 & 5.8862 & 5.5749 & TRN & \\
\hline CHEMBL1467247 & 688239 & 8.3372 & 5.3547 & TRN & \\
\hline CHEMBL1327879 & 688239 & 5.1362 & 5.5487 & TRN & \\
\hline CHEMBL1485478 & 688239 & 8.2366 & 5.4266 & TST & \\
\hline CHEMBL1513831 & 688239 & 5.3362 & 5.4502 & TRN & \\
\hline CHEMBL1405874 & 688239 & 6.7862 & 5.6628 & TST & \\
\hline CHEMBL1548753 & 688239 & 4.7862 & 5.5288 & TRN & \\
\hline CHEMBL3211240 & 688239 & 4.5362 & 5.4251 & TRN & \\
\hline CHEMBL1434805 & 688239 & 4.5362 & 5.4384 & TRN & \\
\hline CHEMBL1581215 & 688239 & 4.5362 & 5.5329 & TRN & \\
\hline CHEMBL1548597 & 688239 & 5.3362 & 5.5649 & TRN & \\
\hline CHEMBL1380662 & 688239 & 4.4862 & 5.5021 & TRN & \\
\hline CHEMBL1319935 & 688239 & 4.6862 & 5.5309 & TRN & \\
\hline CHEMBL1579447 & 688239 & 4.7362 & 5.3381 & TRN & \\
\hline CHEMBL1494472 & 688239 & 4.6362 & 5.5957 & TRN & \\
\hline CHEMBL1435915 & 688239 & 4.5362 & 5.6153 & TRN & \\
\hline CHEMBL1457394 & 688239 & 5.4362 & 5.6033 & TRN & \\
\hline CHEMBL1529992 & 688239 & 6.8861 & 5.4557 & TRN & \\
\hline CHEMBL1527583 & 688239 & 6.2862 & 5.4845 & TRN & \\
\hline CHEMBL1607084 & 688239 & 5.8862 & 5.4341 & TRN & \\
\hline CHEMBL1479833 & 688239 & 5.8362 & 5.5932 & TRN & \\
\hline CHEMBL1407537 & 688239 & 4.8362 & 5.4984 & TRN & \\
\hline CHEMBL1457754 & 688239 & 6.4862 & 5.4181 & TST & \\
\hline CHEMBL1563290 & 688239 & 6.3863 & 5.5379 & TST & \\
\hline CHEMBL1501628 & 688239 & 6.0362 & 5.6898 & TRN & \\
\hline CHEMBL 3193844 & 688239 & 4.6862 & 5.3909 & TST & \\
\hline CHEMBL1384568 & 688239 & 5.1862 & 5.6443 & TRN & \\
\hline CHEMBL1568654 & 688239 & 5.5862 & 5.4633 & TRN & \\
\hline CHEMBL1326364 & 688239 & 5.7862 & 5.4185 & TRN & \\
\hline CHEMBL1584239 & 688239 & 5.1862 & 5.5641 & TRN & \\
\hline CHEMBL1536813 & 688239 & 6.1862 & 5.3997 & TRN & \\
\hline CHEMBL1478377 & 688239 & 5.2362 & 5.6379 & TRN & \\
\hline CHEMBL1378270 & 688239 & 5.7862 & 5.707999 & 9999999999 & TRN \\
\hline CHEMBL1587320 & 688239 & 4.5362 & 5.4489 & TRN & \\
\hline CHEMBL1341462 & 688239 & 7.0362 & 5.4487 & TRN & \\
\hline CHEMBL1537929 & 688239 & 4.5362 & 5.3144 & TRN & \\
\hline CHEMBL1473289 & 688239 & 6.4862 & 5.4248 & TST & \\
\hline CHEMBL1299897 & 688239 & 4.5362 & 5.5278 & TRN & \\
\hline CHEMBL1439211 & 688239 & 4.5362 & 5.5253 & TST & \\
\hline CHEMBL1505394 & 688239 & 4.7362 & 5.4869 & TRN & \\
\hline CHEMBL1449797 & 688239 & 6.3362 & 5.4762 & TRN & \\
\hline CHEMBL1451261 & 688239 & 4.5362 & 5.4393 & TRN & \\
\hline CHEMBL1413710 & 688239 & 6.0362 & 5.5893 & TRN & \\
\hline CHEMBL1407563 & 688239 & 4.7362 & 5.4369 & TRN & \\
\hline CHEMBL1568992 & 688239 & 5.6362 & 5.4779 & TST & \\
\hline CHEMBL1359233 & 688239 & 5.1862 & 5.5136 & TST & \\
\hline CHEMBL1512350 & 688239 & 5.0862 & 5.5023 & TRN & \\
\hline CHEMBL1557455 & 688239 & 6.6362 & 5.5353 & TRN & \\
\hline
\end{tabular}

Page 1485 
Supplemental Table S2.txt

\begin{tabular}{|c|c|c|c|c|c|}
\hline CHEMBL1333346 & 688239 & 5.5362 & 5.5224 & TRN & \\
\hline CHEMBL1469047 & 688239 & 6.3362 & 5.3977 & TST & \\
\hline CHEMBL1570026 & 688239 & 5.6362 & 5.6202 & TRN & \\
\hline CHEMBL 3193311 & 688239 & 5.5362 & 5.4032 & TRN & \\
\hline CHEMBL1529545 & 688239 & 4.5362 & 5.6029 & TST & \\
\hline CHEMBL1464814 & 688239 & 6.4862 & 5.3965 & TRN & \\
\hline CHEMBL1542416 & 688239 & 6.1362 & 5.5303 & TRN & \\
\hline CHEMBL1527360 & 688239 & 6.5862 & 5.5628 & TRN & \\
\hline CHEMBL1988782 & 688239 & 4.8862 & 5.3631 & TST & \\
\hline CHEMBL1452568 & 688239 & 6.8362 & 5.5028 & TRN & \\
\hline CHEMBL1311256 & 688239 & 6.1362 & 5.3034 & TRN & \\
\hline CHEMBL1407374 & 688239 & 5.0862 & 5.5045 & TST & \\
\hline CHEMBL578512 & 688239 & 4.8862 & 5.6348 & TRN & \\
\hline CHEMBL1599876 & 688239 & 4.8362 & 5.5778 & TST & \\
\hline CHEMBL1612210 & 688239 & 4.5362 & 5.5136 & TRN & \\
\hline CHEMBL 3207939 & 688239 & 6.8362 & 5.5718 & TRN & \\
\hline CHEMBL1501907 & 688239 & 7.1361 & 5.41 & TRN & \\
\hline CHEMBL1601783 & 688239 & 4.5362 & 5.5768 & TRN & \\
\hline CHEMBL1554134 & 688239 & 6.5363 & 5.6145 & TRN & \\
\hline CHEMBL1305357 & 688239 & 5.5362 & 5.4341 & TST & \\
\hline CHEMBL1606054 & 688239 & 4.8362 & 5.4192 & TST & \\
\hline CHEMBL1592730 & 688239 & 5.8862 & 5.5285 & TRN & \\
\hline CHEMBL1483019 & 688239 & 8.1367 & 5.4078 & TRN & \\
\hline CHEMBL1410333 & 688239 & 5.7862 & 5.5718 & TRN & \\
\hline CHEMBL1466715 & 688239 & 4.5362 & 5.4071 & TRN & \\
\hline CHEMBL1545829 & 688239 & 4.9862 & 5.5631 & TRN & \\
\hline CHEMBL1096706 & 688239 & 4.5362 & 5.4398 & TRN & \\
\hline CHEMBL1611395 & 688239 & 5.2862 & 5.6198 & TRN & \\
\hline CHEMBL1400922 & 688239 & 4.6362 & 5.5769 & TRN & \\
\hline CHEMBL1571486 & 688239 & 8.1367 & 5.4166 & TST & \\
\hline CHEMBL1367419 & 688239 & 5.8862 & 5.4438 & TRN & \\
\hline CHEMBL1301750 & 688239 & 5.6862 & 5.7108 & TRN & \\
\hline CHEMBL 3189435 & 688239 & 6.1862 & 5.6309 & TST & \\
\hline CHEMBL 3198347 & 688239 & 5.1862 & 5.5281 & TRN & \\
\hline CHEMBL1330450 & 688239 & 7.0362 & 5.5648 & TST & \\
\hline CHEMBL1574669 & 688239 & 6.1362 & 5.3795 & TRN & \\
\hline CHEMBL1301213 & 688239 & 6.0862 & 5.5276 & TRN & \\
\hline CHEMBL1540251 & 688239 & 5.4862 & 5.6925 & TST & \\
\hline CHEMBL1558060 & 688239 & 6.2862 & 5.4867 & TRN & \\
\hline CHEMBL1529697 & 688239 & 6.0 & 5.57700 & 0000000001 & TRN \\
\hline CHEMBL1350565 & 688239 & 7.6364 & 5.5242 & TRN & \\
\hline CHEMBL1481808 & 688239 & 5.7362 & 5.5348 & TRN & \\
\hline CHEMBL 3194172 & 688239 & 8.3372 & 5.5583 & TRN & \\
\hline CHEMBL1378281 & 688239 & 8.283999 & 99999999 & 5.4386 & TRN \\
\hline CHEMBL1421001 & 688239 & 6.1362 & 5.4996 & TRN & \\
\hline CHEMBL 3194826 & 688239 & 6.8861 & 5.4951 & TST & \\
\hline CHEMBL1471312 & 688239 & 5.3362 & 5.6295 & TRN & \\
\hline CHEMBL1383726 & 688239 & 4.5862 & 5.6106 & TRN & \\
\hline
\end{tabular}


Supplemental Table S2.txt

\begin{tabular}{|c|c|c|c|c|c|}
\hline CHEMBL1387163 & 688239 & 5.3362 & 5.365 & TRN & \\
\hline CHEMBL1594575 & 688239 & 8.3372 & 5.5016 & TRN & \\
\hline CHEMBL1309390 & 688239 & 4.5862 & 5.444 & TST & \\
\hline CHEMBL1418211 & 688239 & 6.0362 & 5.5209 & TRN & \\
\hline CHEMBL1506374 & 688239 & 4.5362 & 5.641 & TRN & \\
\hline CHEMBL1471245 & 688239 & 6.8362 & 5.7876 & TRN & \\
\hline CHEMBL1483400 & 688239 & 5.1862 & 5.5203 & TRN & \\
\hline CHEMBL3189372 & 688239 & 4.8862 & 5.5897 & TRN & \\
\hline CHEMBL1409920 & 688239 & 5.7362 & 5.3762 & TRN & \\
\hline CHEMBL1582739 & 688239 & 6.1862 & 5.3999 & TRN & \\
\hline CHEMBL1569439 & 688239 & 6.5862 & 5.6446 & TST & \\
\hline CHEMBL1554109 & 688239 & 5.1862 & 5.5021 & TRN & \\
\hline CHEMBL1370327 & 688239 & 4.9862 & 5.4089 & TRN & \\
\hline CHEMBL1382491 & 688239 & 4.6362 & 5.5703 & TST & \\
\hline CHEMBL1323599 & 688239 & 6.1362 & 5.4929 & TRN & \\
\hline CHEMBL1498127 & 688239 & 5.7362 & 5.4009 & TRN & \\
\hline CHEMBL1300781 & 688239 & 5.7362 & 5.5786 & TRN & \\
\hline CHEMBL1446530 & 688239 & 6.6362 & 5.4495 & TRN & \\
\hline CHEMBL1385133 & 688239 & 5.1862 & 5.4967 & TRN & \\
\hline CHEMBL1415988 & 688239 & 5.1362 & 5.7212 & TRN & \\
\hline CHEMBL1334573 & 688239 & 6.0862 & 5.4345 & TRN & \\
\hline CHEMBL1536426 & 688239 & 4.8362 & 5.5948 & TRN & \\
\hline CHEMBL1373764 & 688239 & 8.28399 & 79999999 & 5.4653 & TRN \\
\hline CHEMBL1613167 & 688239 & 5.6362 & 5.7139 & TRN & \\
\hline CHEMBL1388884 & 688239 & 6.6362 & 5.4499 & TRN & \\
\hline CHEMBL1497408 & 688239 & 4.8362 & 5.5202 & TRN & \\
\hline CHEMBL1526087 & 688239 & 4.7362 & 5.4437 & TST & \\
\hline CHEMBL1568009 & 688239 & 6.3362 & 5.5367 & TST & \\
\hline CHEMBL1493272 & 688239 & 5.1862 & 5.6319 & TST & \\
\hline CHEMBL1435832 & 688239 & 5.6362 & 5.654 & TRN & \\
\hline CHEMBL1310682 & 688239 & 4.4862 & 5.4207 & TRN & \\
\hline CHEMBL1577023 & 688239 & 5.6862 & 5.5463 & TRN & \\
\hline CHEMBL1385828 & 688239 & 6.6861 & 5.3372 & TRN & \\
\hline CHEMBL1326394 & 688239 & 6.0862 & 5.4221 & TRN & \\
\hline CHEMBL565118 & 688239 & 5.6862 & 5.4707 & TRN & \\
\hline CHEMBL1348050 & 688239 & 6.8861 & 5.5031 & TST & \\
\hline CHEMBL1366726 & 688239 & 4.9362 & 5.4032 & TRN & \\
\hline CHEMBL1591701 & 688239 & 5.2362 & 5.5126 & TRN & \\
\hline CHEMBL1506951 & 688239 & 4.5362 & 5.401 & TRN & \\
\hline CHEMBL1382081 & 688239 & 6.4862 & 5.4548 & TRN & \\
\hline CHEMBL1559495 & 688239 & 6.2362 & 5.49700 & 0000000001 & ומנו \\
\hline CHEMBL1508728 & 688239 & 6.9863 & 5.4656 & TRN & \\
\hline CHEMBL1463647 & 688239 & 5.1862 & 5.6763 & TST & \\
\hline CHEMBL1531961 & 688239 & 5.7362 & 5.4743 & TRN & \\
\hline CHEMBL1378258 & 688239 & 4.7862 & 5.55200 & 30000000005 & TRN \\
\hline CHEMBL1331680 & 688239 & 5.7362 & 5.4779 & TST & \\
\hline CHEMBL1552129 & 688239 & 4.6862 & 5.5291 & TRN & \\
\hline CHEMBL1428731 & 688239 & 4.6862 & 5.2546 & TRN & \\
\hline
\end{tabular}




\begin{tabular}{|c|c|c|c|c|c|}
\hline & & \\
\hline CHEMBL1486777 & 688239 & 6.7361 & 5.5085 & TRN & \\
\hline CHEMBL1441308 & 688239 & 5.1362 & 5.4452 & TRN & \\
\hline CHEMBL1303526 & 688239 & 5.9362 & 5.556 & TRN & \\
\hline CHEMBL1339791 & 688239 & 6.2862 & 5.3468 & TRN & \\
\hline CHEMBL1588230 & 688239 & 6.1362 & 5.4222 & TRN & \\
\hline CHEMBL1421421 & 688239 & 5.5862 & 5.4674 & TRN & \\
\hline CHEMBL1524682 & 688239 & 4.7862 & 5.598 & TRN & \\
\hline CHEMBL1328694 & 688239 & 6.8362 & 5.4768 & TRN & \\
\hline CHEMBL1485146 & 688239 & 4.6362 & 5.5196 & TST & \\
\hline CHEMBL1606590 & 688239 & 4.8362 & 5.4545 & TST & \\
\hline CHEMBL1299659 & 688239 & 4.5362 & 5.3033 & TRN & \\
\hline CHEMBL1480004 & 688239 & 5.1862 & 5.5078 & TRN & \\
\hline CHEMBL1476056 & 688239 & 6.4862 & 5.5052 & TRN & \\
\hline CHEMBL1512649 & 688239 & 5.1862 & 5.4551 & TST & \\
\hline CHEMBL1343920 & 688239 & 4.4862 & 5.3937 & TRN & \\
\hline CHEMBL1416372 & 688239 & 4.5362 & 5.4098 & TRN & \\
\hline CHEMBL1348901 & 688239 & 5.1862 & 5.5298 & TRN & \\
\hline CHEMBL1384798 & 688239 & 5.3862 & 5.5208 & TST & \\
\hline CHEMBL1464961 & 688239 & 6.6861 & 5.6456 & TRN & \\
\hline CHEMBL1601483 & 688239 & 5.2862 & 5.4796 & TST & \\
\hline CHEMBL1331768 & 688239 & 5.9862 & 5.6139 & TST & \\
\hline CHEMBL1538803 & 688239 & 4.5362 & 5.5013 & TRN & \\
\hline CHEMBL1581767 & 688239 & 5.2862 & 5.50799 & 9999999999 & TRN \\
\hline CHEMBL1332630 & 688239 & 7.2366 & 5.4441 & TRN & \\
\hline CHEMBL1380544 & 688239 & 5.5362 & 5.5442 & TST & \\
\hline CHEMBL1380295 & 688239 & 5.5862 & 5.6038 & TST & \\
\hline CHEMBL3193920 & 688239 & 4.5362 & 5.4366 & TRN & \\
\hline CHEMBL1378282 & 688239 & 5.8862 & 5.4491 & TRN & \\
\hline CHEMBL1585868 & 688239 & 5.1862 & 5.3877 & TRN & \\
\hline CHEMBL1332126 & 688239 & 5.1862 & 5.3298 & TST & \\
\hline CHEMBL1531500 & 688239 & 5.4362 & 5.3712 & TRN & \\
\hline CHEMBL 3214188 & 688239 & 5.3862 & 5.4937 & TST & \\
\hline CHEMBL1448499 & 688239 & 5.1862 & 5.5088 & TRN & \\
\hline CHEMBL1305658 & 688239 & 6.1362 & 5.5696 & TRN & \\
\hline CHEMBL1450917 & 688239 & 6.1862 & 5.4973 & TRN & \\
\hline CHEMBL1494762 & 688239 & 5.3862 & 5.5714 & TRN & \\
\hline CHEMBL1468792 & 688239 & 5.6862 & 5.5529 & TRN & \\
\hline CHEMBL3197361 & 688239 & 6.9363 & 5.3984 & TST & \\
\hline CHEMBL1542861 & 688239 & 5.0862 & 5.5713 & TRN & \\
\hline CHEMBL1588742 & 688239 & 4.5362 & 5.4079 & TST & \\
\hline CHEMBL3208056 & 688239 & 4.5362 & 5.4973 & TRN & \\
\hline CHEMBL3213138 & 688239 & 6.8362 & 5.4777 & TRN & \\
\hline CHEMBL1573569 & 688239 & 4.6362 & 5.3474 & TRN & \\
\hline CHEMBL1478913 & 688239 & 4.5362 & 5.5239 & TRN & \\
\hline CHEMBL1441747 & 688239 & 4.5362 & 5.42299 & 9999999999 & TST \\
\hline CHEMBL1402212 & 688239 & 4.5362 & 5.7019 & TRN & \\
\hline CHEMBL1413764 & 688239 & 5.6862 & 5.685 & TRN & \\
\hline CHEMBL1594573 & 688239 & 5.5362 & 5.63299 & 9999999999 & TRN \\
\hline & & & & $148 \varepsilon$ & \\
\hline
\end{tabular}


Supplemental Table S2.txt

\begin{tabular}{|c|c|c|c|c|}
\hline 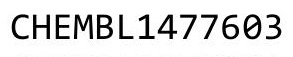 & & & 5682 & \\
\hline HEMBL1376894 & 88239 & 1862 & & \\
\hline HEMBL1558139 & 8239 & 9863 & & \\
\hline & & & & \\
\hline HEMBL1389303 & & 862 & & \\
\hline AEMBL1404445 & 88239 & 5862 & & \\
\hline HEMBL1398853 & 88239 & 4.5862 & .4111 & \\
\hline HEMBL14 & 39 & 2362 & & \\
\hline AEMBL13 & & 362 & & \\
\hline AEMBL1401746 & & 362 & & \\
\hline HEMBL1407743 & 88239 & .3863 & .5861 & \\
\hline HEMBL1531176 & 88239 & 1362 & 5.4058 & \\
\hline HEMBL1315607 & 39 & 62 & 83 & \\
\hline HEMBL 14 & & 862 & & \\
\hline AEMBL1418793 & & 362 & & \\
\hline HEMBL3191810 & 88239 & 862 & & \\
\hline AEMBL3199352 & & 362 & & \\
\hline HEMBL 319 & 39 & 362 & 95 & \\
\hline L16 & & 62 & & \\
\hline AEMBL14 & & 863 & & \\
\hline HEMBL1388755 & & 362 & & \\
\hline AEMBL1578606 & & 62 & & \\
\hline HEMBL1448645 & 39 & 362 & 5 . & \\
\hline L15 & & 361 & & \\
\hline 70 & & 62 & & $2 \mathrm{~N}$ \\
\hline L1301152 & & 372 & & RN \\
\hline HEMBL1529639 & & & & iv \\
\hline HEMBL 14 & & 862 & & \\
\hline HEN & & 52 & & RIV \\
\hline JEMBL15€ & & 865 & & RN \\
\hline AEMBL1375980 & & & 5.38 & ST \\
\hline HEMBL1583064 & & 362 & & RN \\
\hline AEMBL13 & & & & RN \\
\hline 9 & & & & RN \\
\hline 1 & & & & $\mathrm{RN}$ \\
\hline AEMBL1381502 & & 52 & & ST \\
\hline AEMBL1528111 & & & & TST \\
\hline 514 & & & & RN \\
\hline 10 & & & & RN \\
\hline AEMBL1313352 & & & & RN \\
\hline AEMBL1396477 & & 362 & & RN \\
\hline HEMBL15 & & 362 & & RN \\
\hline-258089 & & & & \\
\hline HEMBL1413828 & & & & \\
\hline HEMBL1596156 & & 3862 & & RN \\
\hline AEMBL1611275 & 39 & 6.9863 & 882 & RN \\
\hline$a_{1}$ & & & & \\
\hline CHEMBL1497 & 688239 & & 5.4088 & \\
\hline
\end{tabular}

Page 1489 
Supplemental Table S2.txt

\begin{tabular}{|c|c|c|c|c|}
\hline CHEMBL1404580 & 688239 & 5.1862 & 5.4297 & TRN \\
\hline CHEMBL1348248 & 688239 & 4.5362 & 5.434 & TST \\
\hline CHEMBL1600786 & 688239 & 5.1862 & 5.4302 & TST \\
\hline CHEMBL1314500 & 688239 & 6.9363 & 5.4308 & TRN \\
\hline CHEMBL1539964 & 688239 & 5.2862 & 5.4608 & TRN \\
\hline CHEMBL1470195 & 688239 & 5.0362 & 5.4823 & TST \\
\hline CHEMBL3196921 & 688239 & 5.1862 & 5.4186 & TRN \\
\hline CHEMBL1386862 & 688239 & 4.8362 & 5.4018 & TRN \\
\hline CHEMBL1413946 & 688239 & 5.3362 & 5.4938 & TRN \\
\hline CHEMBL1586507 & 688239 & 4.5862 & 5.355 & TRN \\
\hline CHEMBL1334286 & 688239 & 4.8362 & 5.4952 & TST \\
\hline CHEMBL1350235 & 688239 & 4.5362 & 5.4778 & TRN \\
\hline CHEMBL1416495 & 688239 & 6.9863 & 5.4973 & TST \\
\hline CHEMBL1473696 & 688239 & 4.5362 & 5.5699 & TRN \\
\hline CHEMBL1515419 & 688239 & 5.1862 & 5.4529 & TRN \\
\hline CHEMBL1490197 & 688239 & 5.1862 & 5.48799 & 99999999995 \\
\hline CHEMBL1340754 & 688239 & 4.8362 & 5.2832 & TST \\
\hline CHEMBL1376830 & 688239 & 5.7862 & 5.4005 & TRN \\
\hline CHEMBL1587569 & 688239 & 5.1862 & 5.4394 & TRN \\
\hline CHEMBL1392096 & 688239 & 6.0862 & 5.5605 & TRN \\
\hline CHEMBL1378599 & 688239 & 4.6862 & 5.49700 & 0000000001 \\
\hline CHEMBL1478015 & 688239 & 5.3862 & 5.5516 & TRN \\
\hline CHEMBL3212566 & 688239 & 4.8362 & 5.3077 & TRN \\
\hline CHEMBL1310972 & 688239 & 5.1862 & 5.4783 & TRN \\
\hline CHEMBL1466239 & 688239 & 5.9362 & 5.6253 & TRN \\
\hline CHEMBL1439483 & 688239 & 4.7362 & 5.6247 & TRN \\
\hline CHEMBL1563928 & 688239 & 6.9363 & 5.3375 & TRN \\
\hline CHEMBL1513035 & 688239 & 4.6862 & 5.4174 & TRN \\
\hline CHEMBL1422566 & 688239 & 7.4365 & 5.6621 & TRN \\
\hline CHEMBL1322000 & 688239 & 6.3362 & 5.6926 & TRN \\
\hline CHEMBL1381681 & 688239 & 5.3362 & 5.53600 & 30000000005 \\
\hline CHEMBL1578302 & 688239 & 5.0362 & 5.5504 & TRN \\
\hline CHEMBL1322457 & 688239 & 8.0862 & 5.4384 & TRN \\
\hline CHEMBL1321110 & 688239 & 4.8362 & 5.3778 & TST \\
\hline CHEMBL1436975 & 688239 & 5.3862 & 5.3962 & TRN \\
\hline CHEMBL1586817 & 688239 & 4.9862 & 5.3919 & TST \\
\hline CHEMBL1496866 & 688239 & 5.5362 & 5.6141 & TRN \\
\hline CHEMBL1379465 & 688239 & 6.8861 & 5.6855 & TRN \\
\hline CHEMBL1409442 & 688239 & 5.5362 & 5.4473 & TRN \\
\hline CHEMBL1465565 & 688239 & 5.1862 & 5.5155 & TRN \\
\hline CHEMBL1451216 & 688239 & 4.5362 & 5.4847 & TST \\
\hline CHEMBL1524759 & 688239 & 4.8862 & 5.5373 & TRN \\
\hline CHEMBL1596915 & 688239 & 6.1862 & 5.5499 & TRN \\
\hline CHEMBL3208828 & 688239 & 6.4362 & 5.4581 & TRN \\
\hline CHEMBL1535241 & 688239 & 4.5362 & 5.3869 & TRN \\
\hline CHEMBL1607935 & 688239 & 4.7362 & 5.4422 & TRN \\
\hline CHEMBL1362342 & 688239 & 5.2862 & 5.535 & TST \\
\hline \multirow[t]{2}{*}{ CHEMBL1539418 } & 688239 & 4.5362 & 5.6179 & 9999999999 \\
\hline & & \multicolumn{3}{|c|}{ Page 1490} \\
\hline
\end{tabular}


Supplemental Table S2.txt

\begin{tabular}{|c|c|c|c|c|}
\hline CHEMBL1352111 & 688239 & 4.5362 & 5.4874 & TRN \\
\hline CHEMBL1572306 & 688239 & 6.8362 & 5.5701 & TRN \\
\hline CHEMBL1413645 & 688239 & 4.5362 & 5.4956 & TRN \\
\hline CHEMBL1313876 & 688239 & 5.9362 & 5.5604 & TRN \\
\hline CHEMBL1432754 & 688239 & 4.5862 & 5.4493 & TRN \\
\hline CHEMBL1332455 & 688239 & 6.1362 & 5.3715 & TST \\
\hline CHEMBL1456466 & 688239 & 5.5362 & 5.371 & TRN \\
\hline CHEMBL1463145 & 688239 & 5.1862 & 5.5907 & TRN \\
\hline CHEMBL1373562 & 688239 & 6.2362 & 5.5435 & TRN \\
\hline CHEMBL1523763 & 688239 & 5.3362 & 5.5255 & TRN \\
\hline CHEMBL1574557 & 688239 & 5.9362 & 5.4737 & TST \\
\hline CHEMBL1429312 & 688239 & 4.6362 & 5.3297 & TRN \\
\hline CHEMBL1606288 & 688239 & 5.3862 & 5.4305 & TST \\
\hline CHEMBL1382571 & 688239 & 6.8861 & 5.4898 & TRN \\
\hline CHEMBL1349083 & 688239 & 4.9862 & 5.4316 & TRN \\
\hline CHEMBL1611711 & 688239 & 5.0862 & 5.5133 & TRN \\
\hline CHEMBL1567848 & 688239 & 5.1862 & 5.5239 & TRN \\
\hline CHEMBL1305204 & 688239 & 5.9362 & 5.426 & TST \\
\hline CHEMBL1400778 & 688239 & 6.0862 & 5.2933 & TST \\
\hline CHEMBL1368669 & 688239 & 7.0362 & 5.5074 & TRN \\
\hline CHEMBL1590292 & 688239 & 5.3862 & 5.3706 & TRN \\
\hline CHEMBL1613308 & 688239 & 4.6862 & 5.65799 & 9999999995 \\
\hline CHEMBL1556216 & 688239 & 6.3362 & 5.5912 & TRN \\
\hline CHEMBL1589382 & 688239 & 4.5362 & 5.5085 & TST \\
\hline CHEMBL1606352 & 688239 & 5.3862 & 5.6171 & TST \\
\hline CHEMBL1427009 & 688239 & 6.1362 & 5.4753 & TRN \\
\hline CHEMBL1423780 & 688239 & 4.45 & 5.5375 & TRN \\
\hline CHEMBL1521935 & 688239 & 4.8362 & 5.5313 & TRN \\
\hline CHEMBL1317604 & 688239 & 5.6362 & 5.6003 & TRN \\
\hline CHEMBL1432779 & 688239 & 5.1862 & 5.4876 & TRN \\
\hline CHEMBL1572978 & 688239 & 5.7862 & 5.3715 & TRN \\
\hline CHEMBL1371287 & 688239 & 5.1862 & 5.5437 & TRN \\
\hline CHEMBL1418203 & 688239 & 5.9362 & 5.3875 & TRN \\
\hline CHEMBL1564060 & 688239 & 6.3863 & 5.4325 & TST \\
\hline CHEMBL1436449 & 688239 & 5.1862 & 5.4453 & TRN \\
\hline CHEMBL1568160 & 688239 & 5.1862 & 5.4187 & TST \\
\hline CHEMBL1378096 & 688239 & 5.5862 & 5.3544 & TRN \\
\hline CHEMBL1339408 & 688239 & 4.9862 & 5.4847 & TRN \\
\hline CHEMBL1516502 & 688239 & 6.4362 & 5.4872 & TST \\
\hline CHEMBL1529618 & 688239 & 6.0862 & 5.5607 & TST \\
\hline CHEMBL1321815 & 688239 & 4.7362 & 5.5382 & TRN \\
\hline CHEMBL1319979 & 688239 & 4.4862 & 5.5578 & TRN \\
\hline CHEMBL1509089 & 688239 & 4.5362 & 5.4357 & TRN \\
\hline CHEMBL1454107 & 688239 & 4.7362 & 5.4836 & TRN \\
\hline CHEMBL1560199 & 688239 & 4.6862 & 5.5394 & TRN \\
\hline CHEMBL1365945 & 688239 & 4.5862 & 5.5533 & TRN \\
\hline CHEMBL1474676 & 688239 & 4.5362 & 5.6607 & TRN \\
\hline CHEMBL1341666 & 688239 & 5.1862 & 5.5795 & TRN \\
\hline
\end{tabular}


Supplemental Table S2.txt

\begin{tabular}{|c|c|c|c|c|}
\hline CHEMBL1486955 & 688239 & 4.5362 & 5.4349 & TRN \\
\hline CHEMBL1523223 & 688239 & 5.9862 & 5.5166 & TST \\
\hline CHEMBL1549065 & 688239 & 5.2862 & 5.515 & TST \\
\hline CHEMBL1561088 & 688239 & 5.3862 & 5.5603 & TST \\
\hline CHEMBL1328337 & 688239 & 4.7362 & 5.4289 & TRN \\
\hline CHEMBL1410445 & 688239 & 5.9362 & 5.4072 & TRN \\
\hline CHEMBL1537735 & 688239 & 5.4362 & 5.5678 & TRN \\
\hline CHEMBL1321774 & 688239 & 5.8862 & 5.6177 & TST \\
\hline CHEMBL1385652 & 688239 & 4.5362 & 5.4255 & TRN \\
\hline CHEMBL1332941 & 688239 & 4.7362 & 5.50299 & 9999999999 \\
\hline CHEMBL1589746 & 688239 & 4.6362 & 5.3502 & TST \\
\hline CHEMBL1353407 & 688239 & 6.1362 & 5.5102 & TRN \\
\hline CHEMBL591458 & 688239 & 4.5862 & 5.4567 & TST \\
\hline CHEMBL1403036 & 688239 & 4.5362 & 5.5964 & TRN \\
\hline CHEMBL1428207 & 688239 & 4.8362 & 5.4369 & TST \\
\hline CHEMBL1419673 & 688239 & 4.4862 & 5.4324 & TST \\
\hline CHEMBL1503811 & 688239 & 4.4862 & 5.4022 & TRN \\
\hline CHEMBL1514142 & 688239 & 5.7362 & 5.5582 & TRN \\
\hline CHEMBL1520646 & 688239 & 7.2865 & 5.4238 & TST \\
\hline CHEMBL1460904 & 688239 & 5.0862 & 5.3436 & TRN \\
\hline CHEMBL1306148 & 688239 & 7.0862 & 5.6453 & TST \\
\hline CHEMBL1532108 & 688239 & 6.1362 & 5.44 & TRN \\
\hline CHEMBL 2000196 & 688239 & 4.6862 & 5.4982 & TST \\
\hline CHEMBL1605612 & 688239 & 5.4362 & 5.4868 & TST \\
\hline CHEMBL1328054 & 688239 & 4.6362 & 5.4016 & TRN \\
\hline CHEMBL1442240 & 688239 & 7.5361 & 5.5771 & TRN \\
\hline CHEMBL3191413 & 688239 & 4.5362 & 5.5086 & TST \\
\hline CHEMBL1536657 & 688239 & 5.1862 & 5.4736 & TRN \\
\hline CHEMBL1337945 & 688239 & 6.9363 & 5.537006 & 0000000001 \\
\hline CHEMBL1389047 & 688239 & 5.0362 & 5.3192 & TST \\
\hline CHEMBL 208914 & 688239 & 4.4862 & 5.4026 & TRN \\
\hline CHEMBL1454340 & 688239 & 6.3362 & 5.5779 & TRN \\
\hline CHEMBL1477285 & 688239 & 4.8862 & 5.3842 & TRN \\
\hline CHEMBL1327396 & 688239 & 8.3372 & 5.4263 & TST \\
\hline CHEMBL1584242 & 688239 & 4.6362 & 5.3466 & TRN \\
\hline CHEMBL1310286 & 688239 & 4.6862 & 5.6082 & TRN \\
\hline CHEMBL1603977 & 688239 & 7.0862 & 5.4968 & TST \\
\hline CHEMBL1517599 & 688239 & 4.7862 & 5.7081 & TRN \\
\hline CHEMBL1595522 & 688239 & 5.1862 & 5.5469 & TRN \\
\hline CHEMBL1593316 & 688239 & 5.5362 & 5.5578 & TST \\
\hline CHEMBL1430121 & 688239 & 4.5362 & 5.4936 & TRN \\
\hline CHEMBL1608816 & 688239 & 4.6862 & 5.435 & TRN \\
\hline CHEMBL1398745 & 688239 & 5.8362 & 5.6442 & TRN \\
\hline CHEMBL1565815 & 688239 & 5.6362 & 5.4752 & TRN \\
\hline CHEMBL3212646 & 688239 & 7.0862 & 5.3614 & TST \\
\hline CHEMBL1547479 & 688239 & 6.9863 & 5.5723 & TST \\
\hline CHEMBL1572073 & 688239 & 4.7362 & 5.6855 & TST \\
\hline CHEMBL1467218 & 688239 & 6.1862 & 5.55 & TST \\
\hline
\end{tabular}


Supplemental Table S2.txt

\begin{tabular}{|c|c|c|c|c|c|}
\hline CHEMBL1558536 & 688239 & 4.5362 & 5.3877 & TST & \\
\hline CHEMBL1492559 & 688239 & 4.7862 & 5.5567 & TST & \\
\hline CHEMBL1483685 & 688239 & 4.5362 & 5.6488 & TRN & \\
\hline CHEMBL1170485 & 688239 & 4.5862 & 5.397 & TST & \\
\hline CHEMBL1577676 & 688239 & 4.6862 & \multicolumn{2}{|c|}{5.412999999999999} & TRN \\
\hline CHEMBL1468740 & 688239 & 4.6862 & 5.4784 & TRN & \\
\hline CHEMBL1570956 & 688239 & 4.5362 & 5.5097 & TRN & \\
\hline CHEMBL1519930 & 688239 & 4.5862 & 5.5022 & TRN & \\
\hline CHEMBL1507260 & 688239 & 5.8862 & 5.4419 & TRN & \\
\hline CHEMBL1372808 & 688239 & 6.1362 & 5.431 & TRN & \\
\hline CHEMBL1500284 & 688239 & 5.3362 & 5.5274 & TST & \\
\hline CHEMBL1433223 & 688239 & 4.9362 & 5.4697 & TRN & \\
\hline CHEMBL3199332 & 688239 & 5.1862 & 5.3015 & TRN & \\
\hline CHEMBL1491525 & 688239 & 6.2862 & 5.4907 & TRN & \\
\hline CHEMBL1420053 & 688239 & 4.5362 & 5.4367 & TRN & \\
\hline CHEMBL1552884 & 688239 & 6.0862 & 5.5191 & TRN & \\
\hline CHEMBL1465464 & 688239 & 4.8362 & 5.3817 & TRN & \\
\hline CHEMBL1398065 & 688239 & 5.0362 & 5.5059 & TRN & \\
\hline CHEMBL 3196342 & 688239 & 4.7362 & 5.4589 & TST & \\
\hline CHEMBL1371727 & 688239 & 6.1862 & 5.4242 & TST & \\
\hline CHEMBL1493779 & 688239 & 6.3863 & 5.4008 & TRN & \\
\hline CHEMBL1370599 & 688239 & 4.4862 & 5.5746 & TST & \\
\hline CHEMBL1346858 & 688239 & 4.4862 & 5.4366 & TRN & \\
\hline CHEMBL1313743 & 688239 & 4.5362 & 5.3948 & TRN & \\
\hline CHEMBL1509024 & 688239 & 6.2362 & 5.6647 & TRN & \\
\hline CHEMBL1504569 & 688239 & 6.6861 & 5.3706 & TST & \\
\hline CHEMBL1440231 & 688239 & 6.1362 & 5.388999 & 9999999999 & TRN \\
\hline CHEMBL1373556 & 688239 & 5.1862 & 5.3612 & TRN & \\
\hline CHEMBL1348865 & 688239 & 6.7862 & 5.6002 & TRN & \\
\hline CHEMBL1306950 & 688239 & 6.3362 & 5.6675 & TRN & \\
\hline CHEMBL1426148 & 688239 & 8.0362 & 5.5521 & TRN & \\
\hline CHEMBL1496305 & 688239 & 5.0862 & 5.5881 & TST & \\
\hline CHEMBL1567983 & 688239 & 4.5362 & 5.4623 & TRN & \\
\hline CHEMBL1607211 & 688239 & 6.3362 & 5.5766 & TRN & \\
\hline CHEMBL1392332 & 688239 & 4.7862 & 5.3801 & TST & \\
\hline CHEMBL417727 & 688239 & 5.1362 & 5.4378 & TRN & \\
\hline CHEMBL1549722 & 688239 & 4.5362 & 5.4427 & TRN & \\
\hline CHEMBL1556719 & 688239 & 5.9862 & 5.6245 & TRN & \\
\hline CHEMBL1430806 & 688239 & 5.3362 & 5.5765 & TST & \\
\hline CHEMBL1495939 & 688239 & 4.7362 & 5.4031 & TRN & \\
\hline CHEMBL1429553 & 688239 & 5.1862 & 5.6596 & TRN & \\
\hline CHEMBL1399536 & 688239 & 5.7862 & 5.3922 & TST & \\
\hline CHEMBL1448133 & 688239 & 5.7362 & 5.4132 & TST & \\
\hline CHEMBL1439140 & 688239 & 4.8362 & 5.4778 & TRN & \\
\hline CHEMBL1320753 & 688239 & 4.7862 & 5.6119 & TRN & \\
\hline CHEMBL1302037 & 688239 & 7.6364 & 5.5599 & TRN & \\
\hline CHEMBL1299907 & 688239 & 4.8862 & 5.432 & TRN & \\
\hline CHEMBL1321860 & 688239 & 6.0862 & 5.436 & TRN & \\
\hline
\end{tabular}




\begin{tabular}{|c|c|c|c|c|c|}
\hline \multirow[b]{2}{*}{ CHEMBL1313171 } & \multicolumn{5}{|c|}{ Supplemental Table S2.txt } \\
\hline & 688239 & 4.7862 & 5.5711 & TST & \\
\hline CHEMBL1347662 & 688239 & 7.8861 & 5.42299 & 9999999999 & TST \\
\hline CHEMBL1571817 & 688239 & 4.5362 & 5.4279 & TRN & \\
\hline CHEMBL1574090 & 688239 & 4.5362 & 5.5292 & TRN & \\
\hline CHEMBL1334804 & 688239 & 4.5362 & 5.4759 & TST & \\
\hline CHEMBL1397570 & 688239 & 4.6862 & 5.5085 & TRN & \\
\hline CHEMBL1480476 & 688239 & 5.6362 & 5.61600 & 00000000005 & TRN \\
\hline CHEMBL1399071 & 688239 & 5.0362 & 5.4882 & TRN & \\
\hline CHEMBL 2003806 & 688239 & 4.5862 & 5.3363 & TRN & \\
\hline CHEMBL1461560 & 688239 & 6.5363 & 5.5986 & TRN & \\
\hline CHEMBL 3211522 & 688239 & 5.0362 & 5.3833 & TRN & \\
\hline CHEMBL1533027 & 688239 & 4.5362 & 5.4096 & TRN & \\
\hline CHEMBL1303911 & 688239 & 5.3862 & 5.6595 & TRN & \\
\hline CHEMBL1438318 & 688239 & 4.8362 & 5.4777 & TRN & \\
\hline CHEMBL3198153 & 688239 & 4.5362 & 5.4802 & TST & \\
\hline CHEMBL1438001 & 688239 & 4.7862 & 5.49 & TRN & \\
\hline CHEMBL1983104 & 688239 & 5.0862 & 5.3106 & TST & \\
\hline CHEMBL1578643 & 688239 & 4.7862 & 5.318 & TRN & \\
\hline CHEMBL1716992 & 688239 & 7.8861 & 5.6531 & TRN & \\
\hline CHEMBL1421589 & 688239 & 5.1862 & 5.2803 & TRN & \\
\hline CHEMBL3195101 & 688239 & 5.3862 & 5.4671 & TRN & \\
\hline CHEMBL1459489 & 688239 & 5.5362 & 5.4967 & TRN & \\
\hline CHEMBL1412822 & 688239 & 4.5362 & 5.5393 & TRN & \\
\hline CHEMBL1582630 & 688239 & 5.8862 & 5.3095 & TST & \\
\hline CHEMBL1408033 & 688239 & 4.7362 & 5.4556 & TRN & \\
\hline CHEMBL1337609 & 688239 & 8.1367 & 5.4139 & TST & \\
\hline CHEMBL1457098 & 688239 & 5.6862 & 5.3444 & TST & \\
\hline CHEMBL1487259 & 688239 & 5.8862 & 5.4763 & TRN & \\
\hline CHEMBL1605119 & 688239 & 5.4862 & 5.5644 & TRN & \\
\hline CHEMBL1559529 & 688239 & 4.5362 & 5.4939 & TRN & \\
\hline CHEMBL1306924 & 688239 & 4.6362 & 5.41100 & 00000000005 & TRN \\
\hline CHEMBL1534810 & 688239 & 5.1862 & 5.5354 & TRN & \\
\hline CHEMBL1473383 & 688239 & 5.1862 & 5.3457 & TRN & \\
\hline CHEMBL1563359 & 688239 & 5.7862 & 5.3965 & TST & \\
\hline CHEMBL1349315 & 688239 & 5.5862 & 5.3676 & TST & \\
\hline CHEMBL1489676 & 688239 & 6.4862 & 5.5633 & TRN & \\
\hline CHEMBL1537825 & 688239 & 5.1862 & 5.5763 & TST & \\
\hline CHEMBL3189847 & 688239 & 6.7862 & 5.3474 & TST & \\
\hline CHEMBL1607647 & 688239 & 5.7362 & 5.46700 & 00000000005 & TST \\
\hline CHEMBL1585113 & 688239 & 4.8362 & 5.3729 & TRN & \\
\hline CHEMBL1594963 & 688239 & 6.3863 & 5.563 & TRN & \\
\hline CHEMBL1510493 & 688239 & 4.7862 & 5.6946 & TRN & \\
\hline CHEMBL3195334 & 688239 & 6.9363 & 5.5415 & TRN & \\
\hline CHEMBL1504635 & 688239 & 6.1862 & 5.6866 & TRN & \\
\hline CHEMBL1417923 & 688239 & 7.5361 & 5.3803 & TRN & \\
\hline CHEMBL1410287 & 688239 & 6.1862 & 5.4732 & TRN & \\
\hline CHEMBL1579319 & 688239 & 4.5862 & 5.4661 & TRN & \\
\hline CHEMBL1435532 & 688239 & 5.9862 & 5.4892 & TRN & \\
\hline
\end{tabular}


Supplemental Table S2.txt

\begin{tabular}{|c|c|c|c|c|c|}
\hline CHEMBL1601990 & 688239 & 5.1362 & 5.4396 & TRN & \\
\hline CHEMBL1441644 & 688239 & 4.7862 & 5.399 & TST & \\
\hline CHEMBL1550097 & 688239 & 6.0862 & 5.388999 & 9999999999 & TST \\
\hline CHEMBL1434614 & 688239 & 4.5362 & 5.3656 & TRN & \\
\hline CHEMBL1613617 & 688239 & 4.5362 & 5.587999 & 9999999999 & \\
\hline CHEMBL1467710 & 688239 & 6.1862 & 5.5902 & TRN & \\
\hline CHEMBL1571550 & 688239 & 5.8862 & 5.5677 & TRN & \\
\hline CHEMBL1533749 & 688239 & 7.2865 & 5.5827 & TST & \\
\hline CHEMBL1588347 & 688239 & 5.1862 & 5.4858 & TRN & \\
\hline CHEMBL1310354 & 688239 & 6.8362 & 5.4599 & TRN & \\
\hline CHEMBL1307873 & 688239 & 8.3872 & 5.5233 & TRN & \\
\hline CHEMBL1370168 & 688239 & 6.1362 & 5.5779 & TST & \\
\hline CHEMBL1503402 & 688239 & 4.7862 & 5.5986 & TRN & \\
\hline CHEMBL1560760 & 688239 & 4.7362 & 5.5694 & TRN & \\
\hline CHEMBL1300917 & 688239 & 4.7362 & 5.5701 & TRN & \\
\hline CHEMBL1353758 & 688239 & 8.28399 & 9999999 & 5.5782 & \\
\hline CHEMBL1537371 & 688239 & 6.2362 & 5.2789 & TST & \\
\hline CHEMBL1343701 & 688239 & 5.3362 & 5.5622 & TRN & \\
\hline CHEMBL1507360 & 688239 & 5.5362 & 5.5678 & TRN & \\
\hline CHEMBL1497056 & 688239 & 4.6362 & 5.5305 & TRN & \\
\hline CHEMBL1363503 & 688239 & 5.4862 & 5.4759 & TRN & \\
\hline CHEMBL3191096 & 688239 & 4.5362 & 5.5294 & TRN & \\
\hline CHEMBL1496347 & 688239 & 4.5362 & 5.362999 & 99999999995 & \\
\hline CHEMBL1360193 & 688239 & 5.8862 & 5.3971 & TRN & \\
\hline CHEMBL1454336 & 688239 & 5.9362 & 5.5519 & TRN & \\
\hline CHEMBL1418605 & 688239 & 4.9362 & 5.3873 & TRN & \\
\hline CHEMBL1986773 & 688239 & 5.1862 & 5.5062 & TRN & \\
\hline CHEMBL1571674 & 688239 & 6.4862 & 5.4976 & TRN & \\
\hline CHEMBL 1508750 & 688239 & 4.5362 & 5.5234 & TRN & \\
\hline CHEMBL1410859 & 688239 & 4.6862 & 5.4705 & TRN & \\
\hline CHEMBL1570920 & 688239 & 4.5362 & 5.3782 & TST & \\
\hline CHEMBL3193509 & 688239 & 4.5362 & 5.421 & TRN & \\
\hline CHEMBL1397119 & 688239 & 6.8362 & 5.4665 & TRN & \\
\hline CHEMBL1477959 & 688239 & 5.5862 & 5.3845 & TRN & \\
\hline CHEMBL1420289 & 688239 & 4.5362 & 5.6796 & TRN & \\
\hline CHEMBL1372687 & 688239 & 6.7361 & 5.5725 & TST & \\
\hline CHEMBL1454292 & 688239 & 5.1362 & 5.4546 & TRN & \\
\hline CHEMBL1601624 & 688239 & 4.6862 & 5.544 & TRN & \\
\hline CHEMBL1398951 & 688239 & 5.1862 & 5.5829 & TRN & \\
\hline CHEMBL1316720 & 688239 & 6.8362 & 5.3862 & TRN & \\
\hline CHEMBL1340694 & 688239 & 5.0362 & 5.4113 & TRN & \\
\hline CHEMBL1560983 & 688239 & 4.5362 & 5.3803 & TRN & \\
\hline CHEMBL1441572 & 688239 & 4.5362 & 5.4681 & TRN & \\
\hline CHEMBL1431196 & 688239 & 4.8862 & 5.4576 & TRN & \\
\hline CHEMBL1388588 & 688239 & 4.5862 & 5.4759 & TRN & \\
\hline CHEMBL601135 & 688239 & 4.5362 & 5.4082 & TRN & \\
\hline CHEMBL1588368 & 688239 & 4.5362 & 5.4451 & TRN & \\
\hline CHEMBL1388806 & 688239 & 5.2862 & 5.5083 & TRN & \\
\hline
\end{tabular}




\begin{tabular}{|c|c|c|c|c|c|}
\hline \multicolumn{6}{|c|}{ Supplemental Table S2.txt } \\
\hline CHEMBL1479896 & 688239 & 8.2366 & 5.4699 & TRN & \\
\hline CHEMBL1368988 & 688239 & 5.0362 & 5.4168 & TRN & \\
\hline CHEMBL1324977 & 688239 & 7.1361 & 5.5108 & TST & \\
\hline CHEMBL1447872 & 688239 & 4.4862 & 5.3593 & TST & \\
\hline CHEMBL1471861 & 688239 & 4.9862 & 5.4602 & TRN & \\
\hline CHEMBL1309786 & 688239 & 4.5362 & 5.5091 & TRN & \\
\hline CHEMBL3195682 & 688239 & 4.5362 & 5.6761 & TRN & \\
\hline CHEMBL1354103 & 688239 & 6.7862 & 5.5726 & TRN & \\
\hline CHEMBL1428961 & 688239 & 5.9362 & 5.4617 & TST & \\
\hline CHEMBL1567053 & 688239 & 5.1862 & 5.5279 & TRN & \\
\hline CHEMBL1519081 & 688239 & 8.3372 & 5.5127 & TRN & \\
\hline CHEMBL1505143 & 688239 & 5.8362 & 5.59200 & 00000000005 & TRN \\
\hline CHEMBL3192131 & 688239 & 5.5862 & 5.4 & TRN & \\
\hline CHEMBL1600959 & 688239 & 7.6364 & 5.6232 & TRN & \\
\hline CHEMBL1340928 & 688239 & 4.5362 & 5.5327 & TRN & \\
\hline CHEMBL1516981 & 688239 & 4.6862 & 5.3865 & TRN & \\
\hline CHEMBL3199318 & 688239 & 4.4862 & 5.4934 & TST & \\
\hline CHEMBL1569531 & 688239 & 5.2362 & 5.5485 & TRN & \\
\hline CHEMBL1402038 & 688239 & 5.3362 & 5.4116 & TST & \\
\hline CHEMBL1364676 & 688239 & 5.1862 & 5.5047 & TRN & \\
\hline CHEMBL1577476 & 688239 & 5.2862 & 5.4582 & TST & \\
\hline CHEMBL1314145 & 688239 & 4.5362 & 5.6786 & TRN & \\
\hline CHEMBL1352942 & 688239 & 6.1862 & 5.5133 & TST & \\
\hline CHEMBL1307039 & 688239 & 6.5363 & 5.5078 & TRN & \\
\hline CHEMBL1307346 & 688239 & 5.4362 & 5.4142 & TRN & \\
\hline CHEMBL1481649 & 688239 & 5.0862 & 5.4908 & TRN & \\
\hline CHEMBL1550278 & 688239 & 5.4862 & 5.4554 & TRN & \\
\hline CHEMBL1492783 & 688239 & 4.8862 & 5.6456 & TRN & \\
\hline CHEMBL1363520 & 688239 & 4.4862 & 5.4905 & TRN & \\
\hline CHEMBL1338515 & 688239 & 4.5362 & 5.4402 & TRN & \\
\hline CHEMBL1344444 & 688239 & 6.5363 & 5.6499 & TRN & \\
\hline CHEMBL1532725 & 688239 & 5.6862 & 5.5746 & TRN & \\
\hline CHEMBL1308681 & 688239 & 6.5862 & 5.4389 & TRN & \\
\hline CHEMBL1512191 & 688239 & 4.5362 & 5.2843 & TRN & \\
\hline CHEMBL1542419 & 688239 & 5.2862 & 5.5208 & TRN & \\
\hline CHEMBL1353825 & 688239 & 5.5862 & 5.5188 & TRN & \\
\hline CHEMBL1482281 & 688239 & 5.1862 & 5.4242 & TRN & \\
\hline CHEMBL1575864 & 688239 & 5.1362 & 5.4059 & TRN & \\
\hline CHEMBL1313599 & 688239 & 4.5362 & 5.4501 & TST & \\
\hline CHEMBL1493645 & 688239 & 4.6862 & 5.596 & TRN & \\
\hline CHEMBL1332572 & 688239 & 5.4362 & 5.4827 & TRN & \\
\hline CHEMBL1389160 & 688239 & 6.9363 & 5.4885 & TRN & \\
\hline CHEMBL1352589 & 688239 & 5.1862 & 5.3965 & TST & \\
\hline CHEMBL1575588 & 688239 & 4.9862 & 5.312 & TST & \\
\hline CHEMBL1439324 & 688239 & 5.1862 & 5.4929 & TRN & \\
\hline CHEMBL1485310 & 688239 & 5.8362 & 5.4264 & TRN & \\
\hline CHEMBL1453465 & 688239 & 5.6362 & 5.465 & TRN & \\
\hline CHEMBL1565219 & 688239 & 5.1862 & 5.3807 & TRN & \\
\hline
\end{tabular}


Supplemental Table S2.txt

\begin{tabular}{|c|c|c|c|c|c|}
\hline CHEMBL1546504 & 688239 & 5.7362 & \multicolumn{2}{|c|}{5.507999999999999} & TRN \\
\hline CHEMBL1300467 & 688239 & 4.5362 & 5.4355 & TRN & \\
\hline CHEMBL1606765 & 688239 & 7.8356 & 5.5266 & TST & \\
\hline CHEMBL1325392 & 688239 & 6.0362 & 5.4902 & TRN & \\
\hline CHEMBL1328336 & 688239 & 6.9363 & 5.6302 & TRN & \\
\hline CHEMBL1528495 & 688239 & 5.0362 & 5.4148 & TRN & \\
\hline CHEMBL585628 & 688239 & 4.9362 & 5.4317 & TRN & \\
\hline CHEMBL1495731 & 688239 & 5.9362 & 5.5917 & TRN & \\
\hline CHEMBL1414872 & 688239 & 5.4862 & 5.5386 & TST & \\
\hline CHEMBL1369971 & 688239 & 5.6862 & 5.4303 & TST & \\
\hline CHEMBL1408820 & 688239 & 5.2362 & 5.5218 & TRN & \\
\hline CHEMBL1491102 & 688239 & 5.2362 & 5.6127 & TRN & \\
\hline CHEMBL1438238 & 688239 & 4.5862 & 5.6619 & TRN & \\
\hline CHEMBL1558307 & 688239 & 5.9862 & 5.515 & TRN & \\
\hline CHEMBL1483632 & 688239 & 5.7862 & 5.4878 & TST & \\
\hline CHEMBL 1578382 & 688239 & 5.0362 & 5.3707 & TRN & \\
\hline CHEMBL1389253 & 688239 & 5.4362 & 5.4535 & TRN & \\
\hline CHEMBL1578366 & 688239 & 5.1862 & 5.5435 & TST & \\
\hline CHEMBL1461908 & 688239 & 4.6862 & 5.4124 & TRN & \\
\hline CHEMBL1330738 & 688239 & 6.0862 & 5.4958 & TRN & \\
\hline CHEMBL1504115 & 688239 & 6.9363 & 5.4503 & TRN & \\
\hline CHEMBL1556458 & 688239 & 5.7862 & 5.5009 & TST & \\
\hline CHEMBL1383065 & 688239 & 8.3372 & 5.5079 & TST & \\
\hline CHEMBL1518089 & 688239 & 5.6862 & 5.4056 & TST & \\
\hline CHEMBL1408827 & 688239 & 5.1862 & 5.5729 & TRN & \\
\hline CHEMBL1609755 & 688239 & 4.5362 & 5.4971 & TRN & \\
\hline CHEMBL1391903 & 688239 & 5.3862 & 5.511 & TRN & \\
\hline CHEMBL1430599 & 688239 & 4.8362 & 5.4964 & TRN & \\
\hline CHEMBL1443283 & 688239 & 6.0862 & 5.3927 & TRN & \\
\hline CHEMBL1543042 & 688239 & 4.7 & 5.3466 & TRN & \\
\hline CHEMBL1356035 & 688239 & 5.1862 & 5.556 & TRN & \\
\hline CHEMBL1314780 & 688239 & 6.1362 & 5.6321 & TST & \\
\hline CHEMBL1612731 & 688239 & 4.6862 & 5.4789 & TRN & \\
\hline CHEMBL 1339003 & 688239 & 4.9862 & 5.4394 & TRN & \\
\hline CHEMBL1508301 & 688239 & 5.4862 & 5.4348 & TRN & \\
\hline CHEMBL1501028 & 688239 & 4.8862 & 5.4025 & TRN & \\
\hline CHEMBL1363889 & 688239 & 5.2362 & 5.5179 & TRN & \\
\hline CHEMBL1356486 & 688239 & 5.5862 & 5.5167 & TST & \\
\hline CHEMBL1347109 & 688239 & 4.9862 & 5.3934 & TRN & \\
\hline CHEMBL1391277 & 688239 & 4.5362 & 5.4557 & TRN & \\
\hline CHEMBL1415058 & 688239 & 8.2366 & 5.4852 & TRN & \\
\hline CHEMBL1344621 & 688239 & 8.3372 & 5.54200 & 0000000001 & \\
\hline CHEMBL1522509 & 688239 & 4.5362 & 5.4248 & TRN & \\
\hline CHEMBL 1555833 & 688239 & 4.5362 & 5.2613 & TRN & \\
\hline CHEMBL 3209069 & 688239 & 5.7362 & 5.2967 & TRN & \\
\hline CHEMBL 3187257 & 688239 & 5.0362 & 5.5679 & TRN & \\
\hline CHEMBL1399486 & 688239 & 4.7362 & 5.391 & TST & \\
\hline CHEMBL1395812 & 688239 & 4.5362 & 5.5047 & TRN & \\
\hline
\end{tabular}


Supplemental Table S2.txt

\begin{tabular}{|c|c|c|c|c|}
\hline CHEMBL1437884 & 688239 & 6.1862 & 5.7573 & TRN \\
\hline CHEMBL1408129 & 688239 & 5.1862 & 5.5865 & TRN \\
\hline CHEMBL1317765 & 688239 & 6.1362 & 5.5833 & TRN \\
\hline CHEMBL1437309 & 688239 & 4.5362 & 5.5592 & TRN \\
\hline CHEMBL1584854 & 688239 & 5.4862 & 5.5213 & TRN \\
\hline CHEMBL1420001 & 688239 & 4.5362 & 5.4895 & TRN \\
\hline CHEMBL1589276 & 688239 & 6.8861 & 5.4934 & TRN \\
\hline CHEMBL1330516 & 688239 & 4.6862 & 5.4423 & TRN \\
\hline CHEMBL1429203 & 688239 & 4.5362 & 5.4756 & TRN \\
\hline CHEMBL1399121 & 688239 & 4.7862 & 5.4035 & TRN \\
\hline CHEMBL1422221 & 688239 & 6.4362 & 5.3419 & TST \\
\hline CHEMBL1588030 & 688239 & 6.2362 & 5.5697 & TRN \\
\hline CHEMBL1544799 & 688239 & 5.9862 & 5.5516 & TST \\
\hline CHEMBL1573204 & 688239 & 7.2366 & 5.5795 & TST \\
\hline CHEMBL1318874 & 688239 & 7.4365 & 5.5219 & TRN \\
\hline CHEMBL1565263 & 688239 & 5.6362 & 5.4926 & TRN \\
\hline CHEMBL1530969 & 688239 & 7.0362 & 5.5104 & TRN \\
\hline CHEMBL1588180 & 688239 & 4.6362 & 5.5966 & TRN \\
\hline CHEMBL1505332 & 688239 & 5.1362 & 5.4196 & TRN \\
\hline CHEMBL1515506 & 688239 & 4.7862 & 5.3911 & TRN \\
\hline CHEMBL1607017 & 688239 & 6.1862 & 5.5183 & TRN \\
\hline CHEMBL1560342 & 688239 & 8.3372 & 5.5537 & TRN \\
\hline CHEMBL3192384 & 688239 & 5.7862 & 5.4572 & TRN \\
\hline CHEMBL1438028 & 688239 & 5.1862 & 5.5892 & TRN \\
\hline CHEMBL1302726 & 688239 & 8.3372 & 5.4933 & TRN \\
\hline CHEMBL1373120 & 688239 & 6.1362 & 5.6305 & TRN \\
\hline CHEMBL1368955 & 688239 & 6.9863 & 5.3921 & TST \\
\hline CHEMBL1423517 & 688239 & 6.9363 & 5.5192 & TRN \\
\hline CHEMBL1380838 & 688239 & 6.8861 & 5.5482 & TRN \\
\hline CHEMBL1543822 & 688239 & 5.2862 & 5.5021 & TST \\
\hline CHEMBL1504717 & 688239 & 6.1362 & 5.6939 & TST \\
\hline CHEMBL1423097 & 688239 & 6.6362 & 5.4877 & TST \\
\hline CHEMBL3209423 & 688239 & 4.5362 & 5.4814 & TST \\
\hline CHEMBL1510116 & 688239 & 4.7862 & 5.3577 & TRN \\
\hline CHEMBL1585509 & 688239 & 5.1362 & 5.6426 & TRN \\
\hline CHEMBL1541341 & 688239 & 6.0862 & 5.3777 & TRN \\
\hline CHEMBL1562341 & 688239 & 5.6862 & 5.4936 & TRN \\
\hline CHEMBL1450531 & 688239 & 8.3372 & 5.50700 & 0000000001 \\
\hline CHEMBL1333634 & 688239 & 7.0862 & 5.3655 & TST \\
\hline CHEMBL1328115 & 688239 & 4.7862 & 5.5773 & TRN \\
\hline CHEMBL1410645 & 688239 & 4.5362 & 5.6053 & TST \\
\hline CHEMBL1520055 & 688239 & 4.7862 & 5.6025 & TRN \\
\hline CHEMBL1995800 & 688239 & 4.6362 & 5.4431 & TRN \\
\hline CHEMBL1424656 & 688239 & 5.0862 & 5.7294 & TRN \\
\hline CHEMBL1402053 & 688239 & 6.0862 & 5.5986 & TST \\
\hline CHEMBL1462743 & 688239 & 6.3362 & 5.612 & TRN \\
\hline CHEMBL1508560 & 688239 & 5.7362 & 5.4908 & TRN \\
\hline CHEMBL1434273 & 688239 & 6.1362 & 5.3946 & TRN \\
\hline
\end{tabular}


Supplemental Table S2.txt

\begin{tabular}{|c|c|c|c|c|}
\hline CHEMBL1346630 & 688239 & 4.5362 & 5.5396 & TRN \\
\hline CHEMBL1425253 & 688239 & 7.2865 & 5.5983 & TRN \\
\hline CHEMBL1478337 & 688239 & 6.8362 & 5.5057 & TRN \\
\hline CHEMBL1494947 & 688239 & 5.1862 & 5.6941 & TST \\
\hline CHEMBL1495110 & 688239 & 4.5362 & 5.4929 & TST \\
\hline CHEMBL1436559 & 688239 & 4.7862 & 5.4569 & TRN \\
\hline CHEMBL1496868 & 688239 & 4.5362 & 5.2896 & TRN \\
\hline CHEMBL1450921 & 688239 & 4.6862 & 5.5378 & TRN \\
\hline CHEMBL1453037 & 688239 & 5.3362 & 5.5627 & TST \\
\hline CHEMBL1332107 & 688239 & 4.5362 & 5.4678 & TRN \\
\hline CHEMBL1369173 & 688239 & 4.6362 & 5.4577 & TRN \\
\hline CHEMBL1579261 & 688239 & 5.7862 & 5.5393 & TRN \\
\hline CHEMBL 3145071 & 688239 & 5.8862 & 5.3878 & TRN \\
\hline CHEMBL1481823 & 688239 & 6.5363 & 5.5781 & TST \\
\hline CHEMBL1440500 & 688239 & 5.8862 & 5.5595 & TST \\
\hline CHEMBL1398275 & 688239 & 6.7862 & 5.5458 & TRN \\
\hline CHEMBL3192122 & 688239 & 4.7362 & 5.3353 & TST \\
\hline CHEMBL2369174 & 688239 & 5.8362 & 5.4159 & TRN \\
\hline CHEMBL3199112 & 688239 & 4.5362 & 5.4663 & TST \\
\hline CHEMBL3196976 & 688239 & 5.4862 & 5.4408 & TRN \\
\hline CHEMBL1451392 & 688239 & 6.4862 & 5.5994 & TRN \\
\hline CHEMBL1319053 & 688239 & 4.8362 & 5.5583 & TRN \\
\hline CHEMBL1489907 & 688239 & 4.7362 & 5.4213 & TRN \\
\hline CHEMBL1492858 & 688239 & 6.9363 & 5.5034 & TST \\
\hline CHEMBL1527225 & 688239 & 5.0362 & 5.5229 & TRN \\
\hline CHEMBL1382982 & 688239 & 6.6861 & 5.5387 & TRN \\
\hline CHEMBL1407875 & 688239 & 6.8362 & 5.6224 & TRN \\
\hline CHEMBL1326996 & 688239 & 4.6362 & 5.4436 & TRN \\
\hline CHEMBL1496635 & 688239 & 4.7362 & 5.4665 & TST \\
\hline CHEMBL1349619 & 688239 & 6.1862 & 5.7143 & TST \\
\hline CHEMBL1482053 & 688239 & 5.1862 & 5.3886 & TRN \\
\hline CHEMBL1538495 & 688239 & 6.8861 & 5.3957 & TRN \\
\hline CHEMBL1396351 & 688239 & 5.1862 & 5.4562 & TRN \\
\hline CHEMBL1491018 & 688239 & 4.5362 & 5.5687 & TRN \\
\hline CHEMBL1503309 & 688239 & 4.7862 & 5.4959 & TRN \\
\hline CHEMBL1431555 & 688239 & 5.1862 & 5.4692 & TRN \\
\hline CHEMBL1340948 & 688239 & 5.4862 & 5.6012 & TRN \\
\hline CHEMBL1400618 & 688239 & 4.6362 & 5.5993 & TRN \\
\hline CHEMBL1568039 & 688239 & 5.5362 & 5.5201 & TRN \\
\hline CHEMBL1572335 & 688239 & 4.7362 & 5.6077 & TST \\
\hline CHEMBL1420978 & 688239 & 4.4862 & 5.3228 & TRN \\
\hline CHEMBL1488959 & 688239 & 4.5362 & 5.4161 & TRN \\
\hline CHEMBL1427003 & 688239 & 5.5362 & 5.6207 & TST \\
\hline CHEMBL1440981 & 688239 & 6.0862 & 5.5922 & TST \\
\hline CHEMBL1341308 & 688239 & 4.8362 & 5.3212 & TST \\
\hline CHEMBL1308114 & 688239 & 6.9363 & 5.6168 & TRN \\
\hline CHEMBL1329045 & 688239 & 5.8862 & 5.5357 & TRN \\
\hline \multirow[t]{2}{*}{ CHEMBL1443615 } & 688239 & 5.1862 & 5.42399 & 99999999995 \\
\hline & & \multicolumn{3}{|c|}{ Page 1499} \\
\hline
\end{tabular}


Supplemental Table S2.txt

\begin{tabular}{|c|c|c|c|c|}
\hline- & & & & \\
\hline HEMBL 3207510 & 38239 & 863 & 679 & \\
\hline HEMBL1457884 & 239 & 861 & 255 & \\
\hline & 39 & 361 & & \\
\hline IEMBL319 & 39 & & & \\
\hline AEMBL3195185 & 88239 & 362 & 367 & \\
\hline AEMBL1386765 & 88239 & 863 & 5622 & \\
\hline AEMBL1507637 & & & & \\
\hline EMBL: & 39 & 862 & & \\
\hline IEMBL1518 & & 861 & & \\
\hline AEMBL1448906 & 39 & 862 & & \\
\hline AEMBL1465590 & & 362 & & \\
\hline HEMBL1392588 & & 62 & & \\
\hline HEMBL1464985 & & 362 & & \\
\hline AEMBL1721226 & & 863 & & \\
\hline AEMBL1425983 & & 362 & & \\
\hline AEMBL1488655 & & 863 & & \\
\hline IEMBL1388 & & 72 & & \\
\hline AEMBL3192 & & 62 & & \\
\hline IEMBL140 & & 62 & & \\
\hline HEMBL135 & & 862 & & \\
\hline AEMBL1415023 & & & & \\
\hline AEMBL136 & & 72 & & \\
\hline AFMRI 15 & & & & \\
\hline 88 & & & & \\
\hline 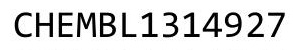 & & 62 & & \\
\hline IEMBL1531 & & 62 & & \\
\hline EMBL141 & & & & \\
\hline AFME & & & & \\
\hline 15 & & 62 & & \\
\hline AEMBL3192732 & & & & \\
\hline HEMBL1399785 & & 362 & & \\
\hline & & & & \\
\hline 9 & & & & \\
\hline AEMBL1542480 & & & & \\
\hline AEMBL1381856 & & & & \\
\hline AEMBL1485003 & & 362 & & \\
\hline & & & & \\
\hline 7 & & & & \\
\hline AEMBL3212853 & & & & RN \\
\hline AEMBL1367055 & & 62 & & -9 \\
\hline AEMBL1466932 & & 4. & & \\
\hline & & & & \\
\hline HEMBL1495133 & & & & \\
\hline AEMBL3192786 & & & 863 & $\Gamma \mathrm{R}$ \\
\hline IEMBL3190813 & & 362 & & \\
\hline 290 & & & & \\
\hline HEMBL144777 & & & & \\
\hline
\end{tabular}

Page 1500 
Supplemental Table S2.txt

\begin{tabular}{|c|c|c|c|c|}
\hline CHEMBL1488855 & 688239 & 4.6362 & 5.5628 & TRN \\
\hline CHEMBL1464955 & 688239 & 4.5362 & 5.5553 & TRN \\
\hline CHEMBL1408333 & 688239 & 5.4862 & 5.4682 & TRN \\
\hline CHEMBL1418766 & 688239 & 5.4362 & 5.3697 & TST \\
\hline CHEMBL1612399 & 688239 & 5.1862 & 5.5741 & TRN \\
\hline CHEMBL1415087 & 688239 & 7.1864 & 5.5368 & TRN \\
\hline CHEMBL1447441 & 688239 & 4.8862 & 5.4174 & TRN \\
\hline CHEMBL1585127 & 688239 & 4.9862 & 5.507999 & 9999999999 \\
\hline CHEMBL1450227 & 688239 & 5.7362 & 5.5393 & TRN \\
\hline CHEMBL1551279 & 688239 & 5.1862 & 5.485 & TRN \\
\hline CHEMBL1508564 & 688239 & 5.5362 & 5.5687 & TRN \\
\hline CHEMBL3211057 & 688239 & 5.8362 & 5.4196 & TST \\
\hline CHEMBL1567847 & 688239 & 5.0862 & 5.4564 & TRN \\
\hline CHEMBL3191827 & 688239 & 5.4862 & 5.6316 & TRN \\
\hline CHEMBL1463545 & 688239 & 5.0862 & 5.4004 & TRN \\
\hline CHEMBL1512203 & 688239 & 4.5862 & 5.3967 & TST \\
\hline CHEMBL1506783 & 688239 & 7.0362 & 5.5157 & TRN \\
\hline CHEMBL3196717 & 688239 & 8.28399 & 99999999 & 5.4792 \\
\hline CHEMBL1574954 & 688239 & 4.8862 & 5.4926 & TRN \\
\hline CHEMBL1473725 & 688239 & 6.5363 & 5.5358 & TRN \\
\hline CHEMBL1438091 & 688239 & 4.5362 & 5.5645 & TRN \\
\hline CHEMBL1404736 & 688239 & 4.6862 & 5.5637 & TRN \\
\hline CHEMBL1460142 & 688239 & 4.5862 & 5.3925 & TST \\
\hline CHEMBL1351562 & 688239 & 4.7862 & 5.3084 & TRN \\
\hline CHEMBL1418456 & 688239 & 5.6362 & 5.3699 & TRN \\
\hline CHEMBL1443944 & 688239 & 4.6362 & 5.6029 & TRN \\
\hline CHEMBL1609069 & 688239 & 6.0862 & 5.4091 & TRN \\
\hline CHEMBL1453808 & 688239 & 5.1862 & 5.5393 & TRN \\
\hline CHEMBL 29097 & 688239 & 4.8362 & 5.2833 & TST \\
\hline CHEMBL1370451 & 688239 & 4.4862 & 5.3135 & TST \\
\hline CHEMBL1591082 & 688239 & 4.6362 & 5.3271 & TRN \\
\hline CHEMBL1554041 & 688239 & 6.8861 & 5.4951 & TRN \\
\hline CHEMBL1373766 & 688239 & 5.6862 & 5.5829 & TRN \\
\hline CHEMBL1595337 & 688239 & 4.7862 & 5.5383 & TST \\
\hline CHEMBL1997108 & 688239 & 5.4862 & 5.5366 & TST \\
\hline CHEMBL1379157 & 688239 & 5.4862 & 5.5201 & TRN \\
\hline CHEMBL1483079 & 688239 & 4.5362 & 5.5489 & TRN \\
\hline CHEMBL1575516 & 688239 & 5.1862 & 5.5317 & TST \\
\hline CHEMBL1439834 & 688239 & 4.6362 & 5.5512 & TST \\
\hline CHEMBL1461540 & 688239 & 5.4862 & 5.4653 & TRN \\
\hline CHEMBL1363585 & 688239 & 6.9363 & 5.4534 & TRN \\
\hline CHEMBL1557655 & 688239 & 7.0862 & 5.505 & TRN \\
\hline CHEMBL1543892 & 688239 & 5.1362 & 5.5384 & TRN \\
\hline CHEMBL1486934 & 688239 & 4.5362 & 5.529 & TRN \\
\hline CHEMBL1460385 & 688239 & 4.6862 & 5.3846 & TRN \\
\hline CHEMBL1568655 & 688239 & 4.5362 & 5.5784 & TRN \\
\hline CHEMBL1392792 & 688239 & 5.3362 & 5.5179 & TST \\
\hline CHEMBL1301913 & 688239 & 4.5362 & 5.4613 & TRN \\
\hline
\end{tabular}

Page 1501 
Supplemental Table S2.txt

\begin{tabular}{|c|c|c|c|c|c|}
\hline CHEMBL3191364 & 688239 & 4.9862 & 5.4386 & TRN & \\
\hline CHEMBL 3198977 & 688239 & 5.4362 & 5.5357 & TRN & \\
\hline CHEMBL1450482 & 688239 & 7.4868 & 5.5446 & TST & \\
\hline CHEMBL1398162 & 688239 & 4.5362 & 5.5418 & TRN & \\
\hline CHEMBL1325131 & 688239 & 5.3862 & 5.5068 & TRN & \\
\hline CHEMBL 3197132 & 688239 & 4.7862 & 5.4218 & TST & \\
\hline CHEMBL1472051 & 688239 & 5.1862 & 5.6072 & TRN & \\
\hline CHEMBL1306630 & 688239 & 6.3362 & 5.4669 & TRN & \\
\hline CHEMBL1462339 & 688239 & 6.1362 & 5.5228 & TRN & \\
\hline CHEMBL1446096 & 688239 & 4.6362 & 5.6212 & TRN & \\
\hline CHEMBL1549500 & 688239 & 4.6862 & 5.572999 & 79999999995 & TRN \\
\hline CHEMBL1394952 & 688239 & 4.5862 & 5.502999 & 9999999999 & TRN \\
\hline CHEMBL1371720 & 688239 & 5.5362 & 5.5169 & TRN & \\
\hline CHEMBL1459898 & 688239 & 5.5362 & 5.3788 & TRN & \\
\hline CHEMBL1553358 & 688239 & 6.2362 & 5.4745 & TRN & \\
\hline CHEMBL1313728 & 688239 & 4.5362 & 5.5767 & TRN & \\
\hline CHEMBL1438523 & 688239 & 4.4862 & 5.4095 & TRN & \\
\hline CHEMBL1522088 & 688239 & 4.7362 & 5.562 & TRN & \\
\hline CHEMBL1307290 & 688239 & 5.0862 & 5.5569 & TRN & \\
\hline CHEMBL1351877 & 688239 & 6.0362 & 5.3716 & TRN & \\
\hline CHEMBL1441691 & 688239 & 5.9362 & 5.4926 & TST & \\
\hline CHEMBL1454078 & 688239 & 4.6862 & 5.5521 & TRN & \\
\hline CHEMBL1576378 & 688239 & 4.8862 & 5.3994 & TRN & \\
\hline CHEMBL1502578 & 688239 & 4.5362 & 5.3711 & TRN & \\
\hline CHEMBL1370073 & 688239 & 5.3362 & 5.593 & TST & \\
\hline CHEMBL1576968 & 688239 & 4.5862 & 5.5522 & TRN & \\
\hline CHEMBL1537717 & 688239 & 5.8362 & 5.4847 & TST & \\
\hline CHEMBL1413139 & 688239 & 6.0862 & 5.445 & TRN & \\
\hline CHEMBL1496614 & 688239 & 4.5362 & 5.504 & TRN & \\
\hline CHEMBL1465033 & 688239 & 5.6862 & 5.4866 & TRN & \\
\hline CHEMBL1463384 & 688239 & 6.9363 & 5.5151 & TRN & \\
\hline CHEMBL1545437 & 688239 & 6.0862 & 5.5226 & TRN & \\
\hline CHEMBL1363753 & 688239 & 4.7862 & 5.3891 & TRN & \\
\hline CHEMBL1939687 & 688239 & 5.1862 & 5.2233 & TRN & \\
\hline CHEMBL1472109 & 688239 & 5.3862 & 5.5664 & TRN & \\
\hline CHEMBL1319868 & 688239 & 5.8862 & 5.5331 & TRN & \\
\hline CHEMBL1339662 & 688239 & 4.5362 & 5.5494 & TRN & \\
\hline CHEMBL1352039 & 688239 & \multicolumn{3}{|c|}{8.283999999999999} & I KIV \\
\hline CHEMBL1434611 & 688239 & 4.9862 & 5.4047 & TRN & \\
\hline CHEMBL1613051 & 688239 & 5.7862 & 5.5192 & TST & \\
\hline CHEMBL1471144 & 688239 & 4.6862 & 5.4482 & TRN & \\
\hline CHEMBL 3189959 & 688239 & 4.5362 & 5.2416 & TST & \\
\hline CHEMBL1469461 & 688239 & 5.1862 & 5.4621 & TRN & \\
\hline CHEMBL1509795 & 688239 & 6.6362 & 5.4815 & TST & \\
\hline CHEMBL1363698 & 688239 & 5.6362 & 5.3433 & TST & \\
\hline CHEMBL1541532 & 688239 & 4.7862 & 5.5011 & TRN & \\
\hline CHEMBL 3214458 & 688239 & 6.3362 & 5.48 & TST & \\
\hline CHEMBL1554062 & 688239 & 8.28399 & 999999 & 5.7527 & RN \\
\hline
\end{tabular}


Supplemental Table S2.txt

\begin{tabular}{|c|c|c|c|c|c|}
\hline CHEMBL1418929 & 688239 & 4.4862 & 5.5556 & TRN & \\
\hline CHEMBL1581147 & 688239 & 4.6862 & 5.5057 & TST & \\
\hline CHEMBL1502782 & 688239 & 6.7862 & 5.4421 & TRN & \\
\hline CHEMBL1492737 & 688239 & 7.0862 & 5.3642 & TST & \\
\hline CHEMBL1579198 & 688239 & 5.0362 & 5.5064 & TST & \\
\hline CHEMBL1549858 & 688239 & 6.2362 & 5.5159 & TST & \\
\hline CHEMBL1242180 & 688239 & 5.6362 & 5.3648 & TRN & \\
\hline CHEMBL1882125 & 688239 & 4.9862 & 5.3382 & TRN & \\
\hline CHEMBL1399646 & 688239 & 4.6362 & 5.397 & TRN & \\
\hline CHEMBL1368495 & 688239 & 6.2362 & 5.7443 & TRN & \\
\hline CHEMBL1590102 & 688239 & 4.5362 & 5.3429 & TRN & \\
\hline CHEMBL1592746 & 688239 & 5.9362 & 5.5207 & TRN & \\
\hline CHEMBL1504214 & 688239 & 5.1862 & 5.51399 & & TST \\
\hline CHEMBL1604088 & 688239 & 4.5362 & 5.5603 & TRN & \\
\hline CHEMBL 3209174 & 688239 & 4.5362 & 5.3091 & TST & \\
\hline CHEMBL1538535 & 688239 & 4.8362 & 5.3507 & TRN & \\
\hline CHEMBL1964407 & 688239 & 4.6362 & 5.4125 & TST & \\
\hline CHEMBL1317553 & 688239 & 5.7362 & 5.4965 & TST & \\
\hline CHEMBL1529614 & 688239 & 7.2366 & 5.71899 & э999999999 & $T$ \\
\hline CHEMBL1471576 & 688239 & 5.5862 & 5.5178 & TRN & \\
\hline CHEMBL1471681 & 688239 & 4.6362 & 5.4082 & TRN & \\
\hline CHEMBL1439966 & 688239 & 4.5362 & 5.4568 & TRN & \\
\hline CHEMBL3198711 & 688239 & 6.8362 & 5.3932 & TST & \\
\hline CHEMBL1470534 & 688239 & 6.2362 & 5.564 & TRN & \\
\hline CHEMBL1586997 & 688239 & 6.9863 & 5.5087 & TST & \\
\hline CHEMBL1608760 & 688239 & 4.5362 & 5.4286 & TRN & \\
\hline CHEMBL1330001 & 688239 & 6.7862 & 5.4493 & TRN & \\
\hline CHEMBL1595409 & 688239 & 5.0862 & 5.4708 & TRN & \\
\hline CHEMBL1322348 & 688239 & 5.8362 & 5.364 & TST & \\
\hline CHEMBL1320916 & 688239 & 4.5362 & 5.3821 & TRN & \\
\hline CHEMBL1512917 & 688239 & 5.1862 & 5.5369 & TRN & \\
\hline CHEMBL1562448 & 688239 & 6.3362 & 5.5099 & TRN & \\
\hline CHEMBL1404799 & 688239 & 6.0862 & 5.5208 & TRN & \\
\hline CHEMBL1465893 & 688239 & 5.4362 & 5.4908 & TRN & \\
\hline CHEMBL1333823 & 688239 & 6.1862 & 5.5888 & TST & \\
\hline CHEMBL1564847 & 688239 & 4.5362 & 5.5711 & TRN & \\
\hline CHEMBL1545182 & 688239 & 5.6862 & 5.7425 & TRN & \\
\hline CHEMBL1442525 & 688239 & 4.5362 & 5.4944 & TST & \\
\hline CHEMBL1969593 & 688239 & 4.5362 & 5.3582 & TRN & \\
\hline CHEMBL1576529 & 688239 & 4.5362 & 5.5352 & TRN & \\
\hline CHEMBL3193473 & 688239 & 4.5362 & 5.4348 & TRN & \\
\hline CHEMBL1313256 & 688239 & 4.6862 & 5.5971 & TST & \\
\hline CHEMBL1581717 & 688239 & 5.1862 & 5.5772 & TRN & \\
\hline CHEMBL1971875 & 688239 & 5.0362 & 5.4351 & TRN & \\
\hline CHEMBL1364996 & 688239 & 5.7862 & 5.5052 & TRN & \\
\hline CHEMBL1386543 & 688239 & 6.9363 & 5.5082 & TRN & \\
\hline CHEMBL1356547 & 688239 & 4.5362 & 5.4423 & TST & \\
\hline CHEMBL1601951 & 688239 & 8.28399 & 79999999 & 5.3747 & \\
\hline
\end{tabular}


Supplemental Table S2.txt

\begin{tabular}{|c|c|c|c|c|c|}
\hline CHEMBL1311697 & 688239 & 4.7362 & 5.5138 & TRN & \\
\hline CHEMBL1415639 & 688239 & 5.4862 & 5.5839 & TST & \\
\hline CHEMBL1523694 & 688239 & 7.0862 & 5.5002 & TRN & \\
\hline CHEMBL1473859 & 688239 & 6.7361 & 5.4312 & TRN & \\
\hline CHEMBL1560338 & 688239 & 5.0862 & 5.5597 & TRN & \\
\hline CHEMBL1415508 & 688239 & 5.7862 & 5.2929 & TRN & \\
\hline CHEMBL1377062 & 688239 & 5.9862 & 5.4843 & TRN & \\
\hline CHEMBL1398328 & 688239 & 6.2362 & 5.546 & TRN & \\
\hline CHEMBL1392282 & 688239 & 5.5362 & 5.4258 & TRN & \\
\hline CHEMBL1586634 & 688239 & 4.7862 & 5.4845 & TRN & \\
\hline CHEMBL3195238 & 688239 & 6.8362 & 5.3667 & TRN & \\
\hline CHEMBL1470299 & 688239 & 4.5362 & 5.5666 & TRN & \\
\hline CHEMBL1442486 & 688239 & 6.9363 & 5.5016 & TRN & \\
\hline CHEMBL1523554 & 688239 & 4.5362 & 5.5123 & TRN & \\
\hline CHEMBL1356959 & 688239 & 4.6362 & 5.4832 & TRN & \\
\hline CHEMBL1535328 & 688239 & 6.1362 & 5.5344 & TRN & \\
\hline CHEMBL1396336 & 688239 & 5.4862 & 5.4483 & TRN & \\
\hline CHEMBL3211706 & 688239 & 6.1362 & 5.6302 & TST & \\
\hline CHEMBL1497672 & 688239 & 8.2366 & 5.4196 & TST & \\
\hline CHEMBL1576486 & 688239 & 5.1862 & 5.3352 & TRN & \\
\hline CHEMBL1553069 & 688239 & 5.1862 & 5.42700 & 00000000005 & TRN \\
\hline CHEMBL1462335 & 688239 & 6.7862 & 5.46700 & 20000000005 & TRN \\
\hline CHEMBL1610798 & 688239 & 6.1862 & 5.5102 & TRN & \\
\hline CHEMBL1344723 & 688239 & 6.3362 & 5.58899 & 99999999995 & TRN \\
\hline CHEMBL1413043 & 688239 & 5.1862 & 5.4087 & TRN & \\
\hline CHEMBL1543858 & 688239 & 5.3362 & 5.4701 & TRN & \\
\hline CHEMBL1563031 & 688239 & 4.6862 & 5.4879 & TRN & \\
\hline CHEMBL1325832 & 688239 & 4.5362 & 5.4786 & TST & \\
\hline CHEMBL1601086 & 688239 & 5.9362 & 5.6048 & TRN & \\
\hline CHEMBL1549469 & 688239 & 4.7862 & 5.3982 & TRN & \\
\hline CHEMBL1586761 & 688239 & 5.1362 & 5.5968 & TST & \\
\hline CHEMBL1600568 & 688239 & 5.1862 & 5.6602 & TRN & \\
\hline CHEMBL1589252 & 688239 & 5.4362 & 5.3558 & TST & \\
\hline CHEMBL1539244 & 688239 & 4.5362 & 5.6076 & TST & \\
\hline CHEMBL1537590 & 688239 & 5.3862 & 5.4676 & TRN & \\
\hline CHEMBL1451396 & 688239 & 6.3362 & 5.5616 & TST & \\
\hline CHEMBL1478931 & 688239 & 5.9362 & 5.5118 & TRN & \\
\hline CHEMBL1500535 & 688239 & 6.9363 & 5.6125 & TST & \\
\hline CHEMBL1467762 & 688239 & 5.3362 & 5.5826 & TST & \\
\hline CHEMBL1341387 & 688239 & 4.8862 & 5.397 & TRN & \\
\hline CHEMBL1312251 & 688239 & 4.5362 & 5.5258 & TRN & \\
\hline CHEMBL1347093 & 688239 & 4.5362 & 5.4747 & TST & \\
\hline CHEMBL1351438 & 688239 & 4.5362 & 5.545 & TST & \\
\hline CHEMBL1382352 & 688239 & 5.1862 & 5.426 & TST & \\
\hline CHEMBL1350247 & 688239 & 5.0362 & 5.5508 & TST & \\
\hline CHEMBL1338940 & 688239 & 6.9363 & 5.4552 & TST & \\
\hline CHEMBL1422861 & 688239 & 6.9363 & 5.5312 & TRN & \\
\hline CHEMBL1591310 & 688239 & 4.7362 & 5.4608 & TRN & \\
\hline
\end{tabular}


Supplemental Table S2.txt

\begin{tabular}{|c|c|c|c|c|}
\hline CHEMBL1326910 & 688239 & 5.1862 & 5.4537 & TRN \\
\hline CHEMBL1565391 & 688239 & 5.3862 & 5.5456 & TRN \\
\hline CHEMBL1480962 & 688239 & 6.7361 & 5.5818 & TRN \\
\hline CHEMBL1553280 & 688239 & 4.9362 & 5.4923 & TRN \\
\hline CHEMBL1585946 & 688239 & 4.7862 & 5.3721 & TRN \\
\hline CHEMBL1457230 & 688239 & 4.9362 & 5.3959 & TRN \\
\hline CHEMBL1349247 & 688239 & 4.7862 & 5.4705 & TST \\
\hline CHEMBL3191679 & 688239 & 6.5363 & 5.4381 & TRN \\
\hline CHEMBL1353842 & 688239 & 6.3362 & 5.5238 & TRN \\
\hline CHEMBL1522713 & 688239 & 4.6862 & 5.4138 & TRN \\
\hline CHEMBL1324776 & 688239 & 7.0862 & 5.5657 & TRN \\
\hline CHEMBL1600668 & 688239 & 8.3372 & 5.6399 & TRN \\
\hline CHEMBL1459171 & 688239 & 8.3372 & 5.468999 & 9999999999 \\
\hline CHEMBL1374938 & 688239 & 6.5363 & 5.6308 & TRN \\
\hline CHEMBL1612224 & 688239 & 6.9363 & 5.4738 & TRN \\
\hline CHEMBL1551313 & 688239 & 6.8362 & 5.3687 & TRN \\
\hline CHEMBL1413963 & 688239 & 4.6862 & 5.2484 & TRN \\
\hline CHEMBL1609208 & 688239 & 5.4362 & 5.3951 & TRN \\
\hline CHEMBL1361086 & 688239 & 5.6362 & 5.5387 & TRN \\
\hline CHEMBL1327104 & 688239 & 7.2366 & 5.7053 & TRN \\
\hline CHEMBL1605086 & 688239 & 4.5362 & 5.4946 & TRN \\
\hline CHEMBL1559499 & 688239 & 6.7361 & 5.5052 & TRN \\
\hline CHEMBL1453286 & 688239 & 4.5362 & 5.3571 & TRN \\
\hline CHEMBL1318819 & 688239 & 7.3862 & 5.4153 & TST \\
\hline CHEMBL1465240 & 688239 & 4.8862 & 5.3972 & TRN \\
\hline CHEMBL1303611 & 688239 & 5.4362 & 5.4557 & TRN \\
\hline CHEMBL1500392 & 688239 & 5.1862 & 5.4614 & TRN \\
\hline CHEMBL1456230 & 688239 & 6.8362 & 5.6406 & TST \\
\hline CHEMBL1600937 & 688239 & 5.6862 & 5.3837 & TRN \\
\hline CHEMBL1335048 & 688239 & 6.2862 & 5.5642 & TST \\
\hline CHEMBL1381281 & 688239 & 4.5362 & 5.3719 & TRN \\
\hline CHEMBL1493020 & 688239 & 5.0362 & 5.5212 & TRN \\
\hline CHEMBL1578573 & 688239 & 7.2865 & 5.434 & TRN \\
\hline CHEMBL1307150 & 688239 & 5.1862 & 5.4803 & TRN \\
\hline CHEMBL1407458 & 688239 & 5.0362 & 5.4565 & TRN \\
\hline CHEMBL1333864 & 688239 & 4.5362 & 5.4993 & TRN \\
\hline CHEMBL1480946 & 688239 & 7.2865 & 5.5521 & TRN \\
\hline CHEMBL1568145 & 688239 & 6.3863 & 5.5289 & TST \\
\hline CHEMBL1594358 & 688239 & 4.7362 & 5.3677 & TST \\
\hline CHEMBL1340360 & 688239 & 5.2362 & 5.6592 & TRN \\
\hline CHEMBL1577819 & 688239 & 5.1862 & 5.4473 & TRN \\
\hline CHEMBL1588188 & 688239 & 4.5362 & 5.3622 & TST \\
\hline CHEMBL1395875 & 688239 & 4.5362 & 5.5148 & TRN \\
\hline CHEMBL1535860 & 688239 & 5.4862 & 5.4796 & TRN \\
\hline CHEMBL1479708 & 688239 & 5.6362 & 5.5544 & TST \\
\hline CHEMBL1379444 & 688239 & 4.9362 & 5.4937 & TST \\
\hline CHEMBL 3211147 & 688239 & 8.3372 & 5.4643 & TST \\
\hline CHEMBL1448748 & 688239 & 5.3362 & 5.4984 & TRN \\
\hline
\end{tabular}


Supplemental Table S2.txt

\begin{tabular}{|c|c|c|c|c|c|}
\hline CHEMBL1386196 & 688239 & 6.0862 & 5.3151 & TRN & \\
\hline CHEMBL1445942 & 688239 & 4.7362 & 5.6968 & TRN & \\
\hline CHEMBL1521259 & 688239 & 4.5362 & 5.2721 & TST & \\
\hline CHEMBL1584977 & 688239 & 4.9362 & 5.4471 & TST & \\
\hline CHEMBL3196080 & 688239 & 5.0862 & 5.3746 & TRN & \\
\hline CHEMBL1304357 & 688239 & 4.8362 & 5.5614 & TST & \\
\hline CHEMBL1309884 & 688239 & 5.7862 & 5.439 & TRN & \\
\hline CHEMBL1365288 & 688239 & 5.9362 & 5.5479 & TRN & \\
\hline CHEMBL1546356 & 688239 & 4.5362 & 5.5993 & TRN & \\
\hline CHEMBL1517664 & 688239 & 6.2862 & 5.4298 & TRN & \\
\hline CHEMBL1585505 & 688239 & 5.6362 & 5.4216 & TRN & \\
\hline CHEMBL1431336 & 688239 & 6.2362 & 5.6725 & TRN & \\
\hline CHEMBL1368290 & 688239 & 5.7362 & 5.4219 & TST & \\
\hline CHEMBL1545849 & 688239 & 8.3372 & 5.5311 & TRN & \\
\hline CHEMBL1557974 & 688239 & 6.7361 & 5.595 & TRN & \\
\hline CHEMBL1535574 & 688239 & 6.6362 & 5.37299 & э9999999999 & TRN \\
\hline CHEMBL1337041 & 688239 & 4.7362 & 5.3863 & TST & \\
\hline CHEMBL1591698 & 688239 & 4.5362 & 5.3961 & TRN & \\
\hline CHEMBL1434481 & 688239 & 6.3362 & 5.6495 & TRN & \\
\hline CHEMBL1569009 & 688239 & 7.1361 & 5.4204 & TRN & \\
\hline CHEMBL1463600 & 688239 & 8.28399 & 99999999 & 5.472 & TRN \\
\hline CHEMBL1562954 & 688239 & 6.5363 & 5.5614 & TST & \\
\hline CHEMBL1371903 & 688239 & 5.0362 & 5.4951 & TRN & \\
\hline CHEMBL1446867 & 688239 & 5.1862 & 5.442 & TRN & \\
\hline CHEMBL1379285 & 688239 & 5.1862 & 5.4265 & TRN & \\
\hline CHEMBL1523998 & 688239 & 5.3362 & 5.6005 & TRN & \\
\hline CHEMBL1329736 & 688239 & 4.6862 & 5.4347 & TST & \\
\hline CHEMBL1303717 & 688239 & 5.1362 & 5.4536 & TRN & \\
\hline CHEMBL1562655 & 688239 & 6.1862 & 5.568 & TST & \\
\hline CHEMBL1418945 & 688239 & 6.7862 & 5.5848 & TRN & \\
\hline CHEMBL1430744 & 688239 & 4.6362 & 5.4633 & TRN & \\
\hline CHEMBL1359369 & 688239 & 7.2865 & 5.5329 & TRN & \\
\hline CHEMBL1378424 & 688239 & 4.7362 & 5.4623 & TRN & \\
\hline CHEMBL1545043 & 688239 & 4.8862 & 5.4774 & TRN & \\
\hline CHEMBL1328460 & 688239 & \multicolumn{2}{|c|}{8.283999999999999} & 5.5238 & . \\
\hline CHEMBL1343866 & 688239 & 4.5362 & 5.6052 & TRN & \\
\hline CHEMBL1464146 & 688239 & 4.5362 & 5.3419 & TST & \\
\hline CHEMBL1578503 & 688239 & 4.5362 & 5.3902 & TRN & \\
\hline CHEMBL1369220 & 688239 & 4.6862 & 5.4058 & TRN & \\
\hline CHEMBL1579677 & 688239 & 4.5362 & 5.37299 & 999999999 & TRN \\
\hline CHEMBL1400913 & 688239 & 6.1862 & 5.5306 & TRN & \\
\hline CHEMBL1595924 & 688239 & 5.1362 & 5.4815 & TST & \\
\hline CHEMBL1322723 & 688239 & 4.5362 & 5.3524 & TRN & \\
\hline CHEMBL3194365 & 688239 & 6.8362 & 5.5011 & TRN & \\
\hline CHEMBL1545350 & 688239 & 4.5362 & 5.4632 & TRN & \\
\hline CHEMBL1351564 & 688239 & 6.1862 & 5.7091 & TRN & \\
\hline CHEMBL1469197 & 688239 & 4.9362 & 5.4634 & TRN & \\
\hline CHEMBL1402418 & 688239 & 5.6862 & 5.4208 & TRN & \\
\hline
\end{tabular}


Supplemental Table S2.txt

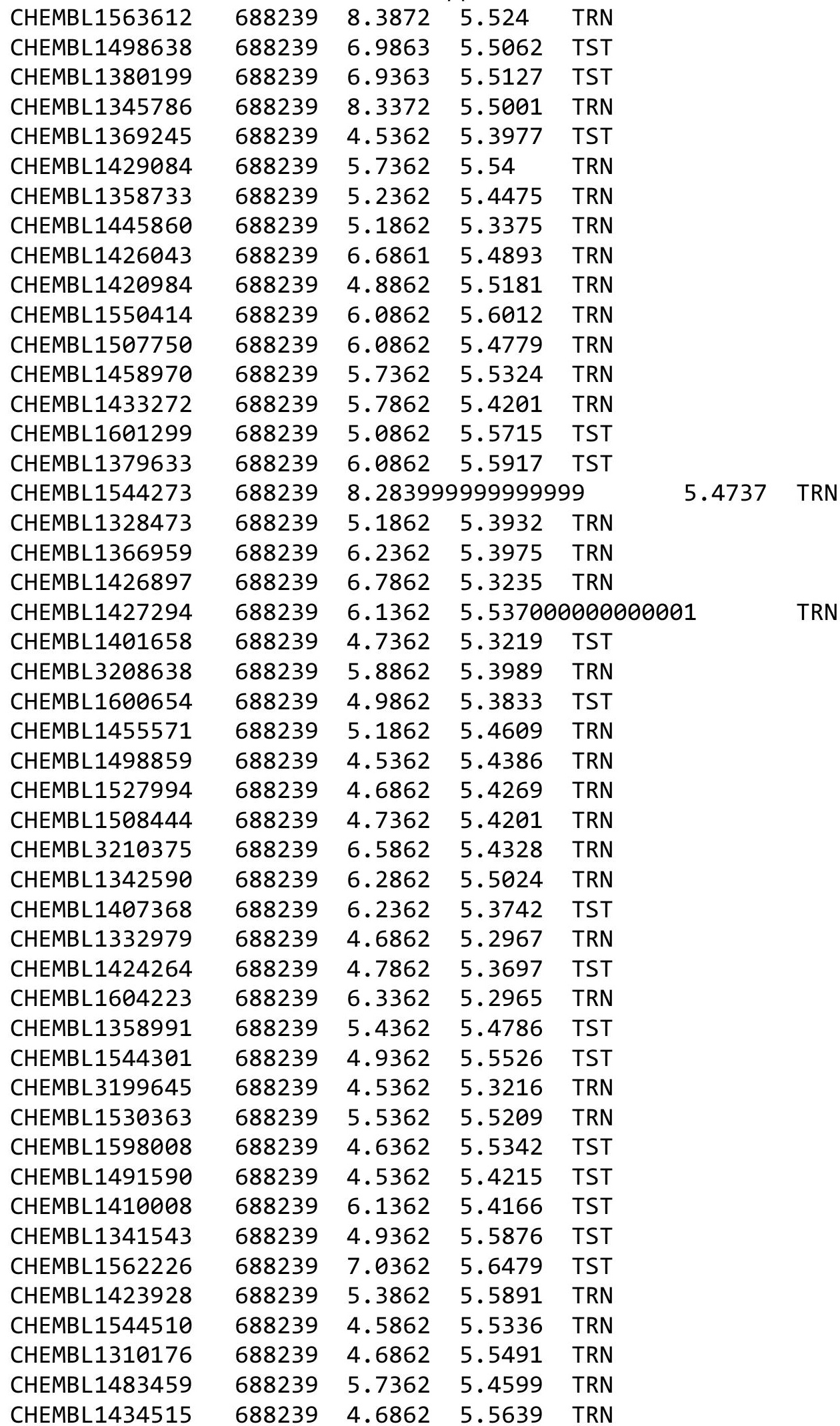

Page 1507 


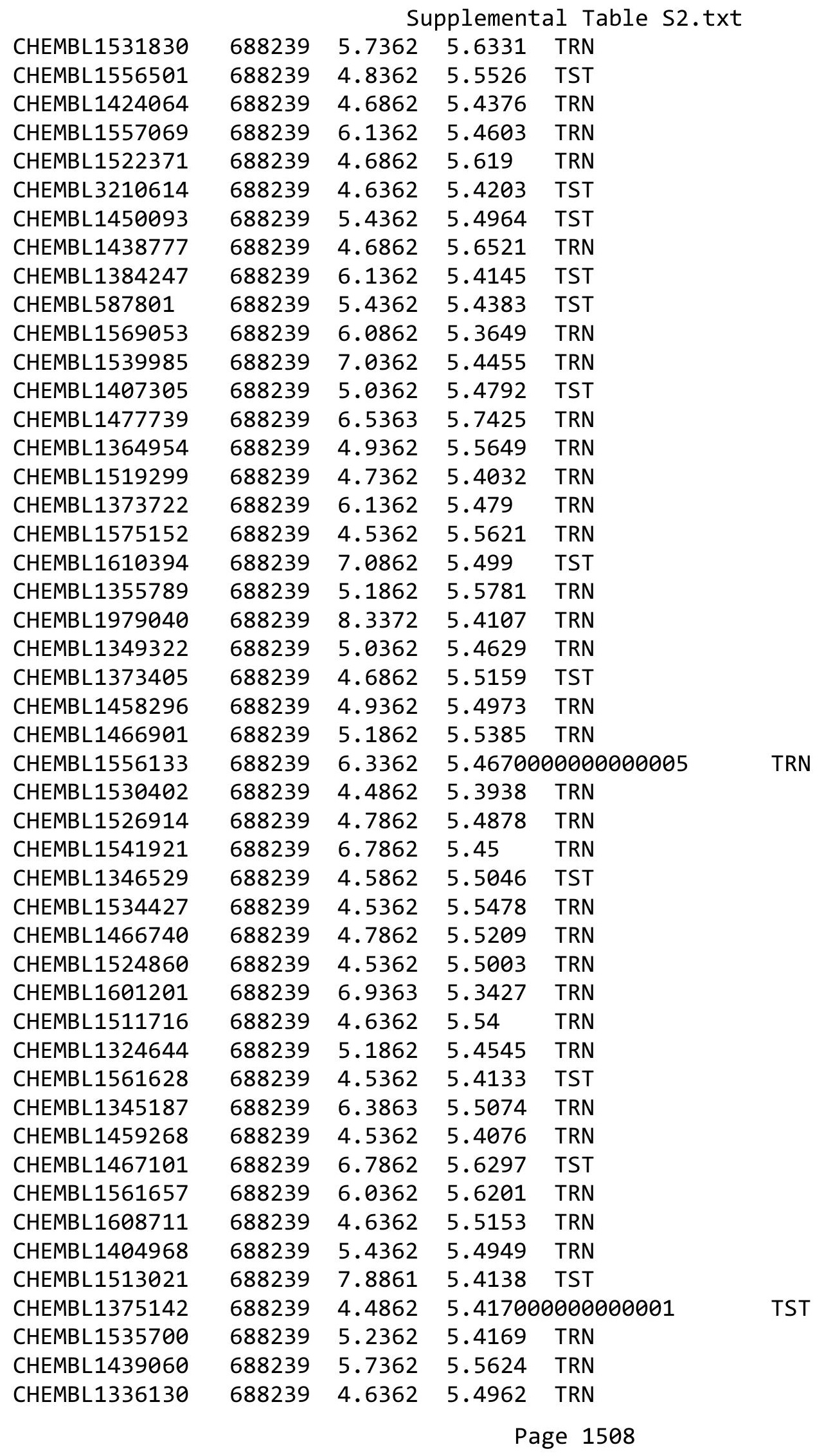


Supplemental Table S2.txt

\begin{tabular}{|c|c|c|c|c|}
\hline CHEMBL1307748 & 688239 & 5.1862 & 5.5213 & TRN \\
\hline CHEMBL1379245 & 688239 & 4.5362 & 5.41 & TST \\
\hline CHEMBL1361371 & 688239 & 5.4362 & 5.5132 & TRN \\
\hline CHEMBL1415871 & 688239 & 6.9363 & 5.4413 & TRN \\
\hline CHEMBL1585865 & 688239 & 5.1862 & 5.6188 & TRN \\
\hline CHEMBL1301829 & 688239 & 5.1862 & 5.4849 & TST \\
\hline CHEMBL584211 & 688239 & 8.3372 & 5.3968 & TST \\
\hline CHEMBL1520302 & 688239 & 4.5362 & 5.6565 & TRN \\
\hline CHEMBL1425733 & 688239 & 6.9863 & 5.438 & TST \\
\hline CHEMBL1459067 & 688239 & 4.5362 & 5.5812 & TRN \\
\hline CHEMBL1360527 & 688239 & 4.4862 & 5.4884 & TRN \\
\hline CHEMBL1491784 & 688239 & 8.3372 & 5.5485 & TRN \\
\hline CHEMBL1449259 & 688239 & 5.5362 & 5.605 & TRN \\
\hline CHEMBL1341614 & 688239 & 4.5362 & 5.677006 & 0000000005 \\
\hline CHEMBL1597012 & 688239 & 6.2362 & 5.4516 & TRN \\
\hline CHEMBL454893 & 688239 & 6.8861 & 5.3852 & TST \\
\hline CHEMBL1447102 & 688239 & 5.1862 & 5.4815 & TST \\
\hline CHEMBL1418822 & 688239 & 8.3872 & 5.4436 & TRN \\
\hline CHEMBL1350411 & 688239 & 4.5362 & 5.3806 & TRN \\
\hline CHEMBL1406045 & 688239 & 4.9362 & 5.4233 & TST \\
\hline CHEMBL1333135 & 688239 & 4.5362 & 5.5226 & TRN \\
\hline CHEMBL1365380 & 688239 & 4.4862 & 5.4237 & TRN \\
\hline CHEMBL1323668 & 688239 & 5.3862 & 5.4972 & TRN \\
\hline CHEMBL1597321 & 688239 & 6.1862 & 5.6197 & TRN \\
\hline CHEMBL1605336 & 688239 & 5.1862 & 5.4596 & TRN \\
\hline CHEMBL 3209374 & 688239 & 5.1862 & 5.5154 & TRN \\
\hline CHEMBL1487899 & 688239 & 5.1862 & 5.5455 & TST \\
\hline CHEMBL1491259 & 688239 & 6.5363 & 5.7526 & TRN \\
\hline CHEMBL1337129 & 688239 & 6.9863 & 5.4908 & TRN \\
\hline CHEMBL1341643 & 688239 & 5.1862 & 5.6678 & TRN \\
\hline CHEMBL1504880 & 688239 & 6.1362 & 5.4303 & TRN \\
\hline CHEMBL1510886 & 688239 & 5.4362 & 5.5568 & TRN \\
\hline CHEMBL1476473 & 688239 & 5.0362 & 5.4317 & TRN \\
\hline CHEMBL1340677 & 688239 & 5.3862 & 5.4952 & TST \\
\hline CHEMBL1506894 & 688239 & 4.6862 & 5.3406 & TRN \\
\hline CHEMBL1334985 & 688239 & 5.5362 & 5.4657 & TRN \\
\hline CHEMBL1578741 & 688239 & 4.8362 & 5.5166 & TRN \\
\hline CHEMBL1594916 & 688239 & 5.7362 & 5.3166 & TRN \\
\hline CHEMBL1388492 & 688239 & 4.6862 & 5.5744 & TRN \\
\hline CHEMBL1487336 & 688239 & 4.6362 & 5.6531 & TST \\
\hline CHEMBL1342309 & 688239 & 5.1862 & 5.5407 & TST \\
\hline CHEMBL1555474 & 688239 & 5.2362 & 5.4399 & TRN \\
\hline CHEMBL3209500 & 688239 & 4.5362 & 5.696006 & 000000001 \\
\hline CHEMBL1587796 & 688239 & 4.4862 & 5.349 & TRN \\
\hline CHEMBL1343102 & 688239 & 6.8861 & 5.3601 & TST \\
\hline CHEMBL1542574 & 688239 & 4.5362 & 5.4196 & TRN \\
\hline CHEMBL1555669 & 688239 & 4.7362 & 5.4134 & TRN \\
\hline CHEMBL1300980 & 688239 & 4.8862 & 5.4755 & TRN \\
\hline
\end{tabular}




\begin{tabular}{|c|c|c|c|c|c|}
\hline \multirow[b]{2}{*}{ CHEMBL1438396 } & \multirow{2}{*}{688239} & \\
\hline & & 5.0862 & 5.5051 & TRN & \\
\hline CHEMBL1352901 & 688239 & 6.1862 & 5.5138 & TRN & \\
\hline CHEMBL1511026 & 688239 & 4.8362 & 5.5399 & TRN & \\
\hline CHEMBL1591974 & 688239 & 5.4362 & 5.5294 & TRN & \\
\hline CHEMBL1529889 & 688239 & 5.0362 & 5.5065 & TRN & \\
\hline CHEMBL1413565 & 688239 & 5.4362 & 5.4609 & TRN & \\
\hline CHEMBL1460259 & 688239 & 5.4862 & 5.5013 & TRN & \\
\hline CHEMBL1609249 & 688239 & 5.4362 & 5.4496 & TST & \\
\hline CHEMBL1477827 & 688239 & 6.0362 & 5.5454 & TST & \\
\hline CHEMBL1347115 & 688239 & 5.0862 & 5.4873 & TRN & \\
\hline CHEMBL3190168 & 688239 & 5.3862 & \multicolumn{2}{|c|}{5.457999999999999} & TRN \\
\hline CHEMBL1414207 & 688239 & 6.8362 & 5.4428 & TRN & \\
\hline CHEMBL1490474 & 688239 & 4.5362 & 5.4692 & TRN & \\
\hline CHEMBL1583499 & 688239 & 4.9862 & 5.3568 & TRN & \\
\hline CHEMBL1341188 & 688239 & 5.1862 & \multicolumn{2}{|c|}{5.6160000000000005} & TRN \\
\hline CHEMBL1506131 & 688239 & \multicolumn{3}{|c|}{8.283999999999999} & TRN \\
\hline CHEMBL1532713 & 688239 & 6.8362 & 5.3938 & TRN & \\
\hline CHEMBL1352270 & 688239 & 4.5362 & 5.4961 & TRN & \\
\hline CHEMBL1576522 & 688239 & 5.0362 & 5.5282 & TRN & \\
\hline CHEMBL1374422 & 688239 & 5.1862 & 5.4208 & TRN & \\
\hline CHEMBL1351891 & 688239 & 5.6862 & 5.4812 & TRN & \\
\hline CHEMBL 2002262 & 688239 & 4.5362 & 5.4025 & TST & \\
\hline CHEMBL1502229 & 688239 & 4.6862 & 5.49 & TST & \\
\hline CHEMBL1428680 & 688239 & 5.4362 & 5.5935 & TST & \\
\hline CHEMBL1608855 & 688239 & 5.9362 & 5.692 & TRN & \\
\hline CHEMBL1597717 & 688239 & 5.3362 & 5.5383 & TRN & \\
\hline CHEMBL1613084 & 688239 & 5.1862 & 5.461 & TRN & \\
\hline CHEMBL1544407 & 688239 & 5.1862 & 5.5663 & TRN & \\
\hline CHEMBL1507728 & 688239 & 6.7862 & 5.5413 & TRN & \\
\hline CHEMBL1375196 & 688239 & 4.6862 & 5.3209 & TST & \\
\hline CHEMBL1413169 & 688239 & 4.6862 & 5.6061 & TRN & \\
\hline CHEMBL1335119 & 688239 & 6.0862 & 5.5406 & TRN & \\
\hline CHEMBL1587353 & 688239 & 5.3862 & 5.6254 & TRN & \\
\hline CHEMBL1505605 & 688239 & 8.3372 & 5.5318 & TRN & \\
\hline CHEMBL1355941 & 688239 & 4.9362 & 5.41299 & 9999999999 & TRN \\
\hline CHEMBL1509946 & 688239 & 8.3372 & 5.4019 & TRN & \\
\hline CHEMBL1570946 & 688239 & 4.5362 & 5.5759 & TRN & \\
\hline CHEMBL1335819 & 688239 & 4.7362 & 5.4592 & TST & \\
\hline CHEMBL1425222 & 688239 & 8.28399 & 99999999 & 5.4379 & TRN \\
\hline CHEMBL1577892 & 688239 & 4.5362 & 5.4662 & TRN & \\
\hline CHEMBL184450 & 688239 & 6.7862 & 5.3544 & TST & \\
\hline CHEMBL1361709 & 688239 & 4.4862 & 5.4105 & TST & \\
\hline CHEMBL1986274 & 688239 & 4.7862 & $5.54200 t$ & 0000000001 & TRN \\
\hline CHEMBL1464238 & 688239 & 6.0362 & 5.6297 & TRN & \\
\hline CHEMBL1456587 & 688239 & 5.3862 & 5.5486 & TRN & \\
\hline CHEMBL1473357 & 688239 & 5.4362 & 5.4689 & TST & \\
\hline CHEMBL1334316 & 688239 & 8.3372 & 5.3829 & TRN & \\
\hline CHEMBL1563827 & 688239 & 6.8362 & 5.446006 & $\partial 000000001$ & TST \\
\hline & & & & 1510 & \\
\hline
\end{tabular}


Page 1511 
Supplemental Table S2.txt

\begin{tabular}{|c|c|c|c|c|}
\hline CHEMBL1596784 & 688239 & 5.6362 & 5.5705 & TST \\
\hline CHEMBL1430883 & 688239 & 7.2366 & 5.5257 & TRN \\
\hline CHEMBL1407123 & 688239 & 6.8362 & 5.653 & TRN \\
\hline CHEMBL1395345 & 688239 & 6.6362 & 5.6312 & TRN \\
\hline CHEMBL1584260 & 688239 & 5.3862 & 5.5405 & TRN \\
\hline CHEMBL1334090 & 688239 & 4.5862 & 5.4228 & TRN \\
\hline CHEMBL1391716 & 688239 & 8.3372 & 5.3826 & TST \\
\hline CHEMBL1509181 & 688239 & 6.7862 & 5.5494 & TRN \\
\hline CHEMBL1530792 & 688239 & 4.8362 & 5.4152 & TST \\
\hline CHEMBL3213918 & 688239 & 5.1862 & 5.4115 & TRN \\
\hline CHEMBL1400051 & 688239 & 6.1862 & 5.6236 & TRN \\
\hline CHEMBL1300822 & 688239 & 5.6862 & 5.5926 & TRN \\
\hline CHEMBL1409191 & 688239 & 4.6362 & 5.4519 & TRN \\
\hline CHEMBL3191290 & 688239 & 4.8362 & \multicolumn{2}{|c|}{5.468999999999999} \\
\hline CHEMBL 3191142 & 688239 & 5.7362 & 5.6544 & TRN \\
\hline CHEMBL1530786 & 688239 & 4.5362 & 5.3351 & TRN \\
\hline CHEMBL1320927 & 688239 & 4.5362 & \multicolumn{2}{|c|}{5.3660000000000005} \\
\hline CHEMBL1583513 & 688239 & 5.6362 & 5.3975 & TRN \\
\hline CHEMBL1305618 & 688239 & 5.0862 & 5.5804 & TST \\
\hline CHEMBL1549805 & 688239 & 6.9863 & 5.516 & TRN \\
\hline CHEMBL1485292 & 688239 & 4.5362 & \multicolumn{2}{|c|}{5.452000000000001} \\
\hline CHEMBL1504267 & 688239 & 4.4862 & 5.5525 & TRN \\
\hline CHEMBL1407633 & 688239 & 4.6362 & 5.5168 & TRN \\
\hline CHEMBL1438484 & 688239 & 6.0362 & 5.5824 & TRN \\
\hline CHEMBL1476429 & 688239 & 4.7362 & 5.5771 & TRN \\
\hline CHEMBL1454775 & 688239 & 5.7862 & 5.5751 & TST \\
\hline CHEMBL1324364 & 688239 & 6.1862 & 5.3776 & TRN \\
\hline CHEMBL1407354 & 688239 & 5.4362 & 5.5819 & TRN \\
\hline CHEMBL528492 & 688239 & 4.5362 & 5.5254 & TST \\
\hline CHEMBL1476541 & 688239 & 5.1862 & \multicolumn{2}{|c|}{5.537999999999999} \\
\hline CHEMBL1531598 & 688239 & 6.1862 & 5.5911 & TRN \\
\hline CHEMBL1374292 & 688239 & 6.9863 & 5.5437 & TST \\
\hline CHEMBL1560676 & 688239 & 5.2362 & 5.3735 & TRN \\
\hline CHEMBL3199452 & 688239 & 4.5862 & 5.4355 & TRN \\
\hline CHEMBL1603438 & 688239 & 5.1862 & 5.5413 & TRN \\
\hline CHEMBL1393302 & 688239 & 5.8362 & 5.4073 & TRN \\
\hline CHEMBL1611149 & 688239 & 4.5362 & 5.3805 & TRN \\
\hline CHEMBL1601093 & 688239 & 6.5363 & 5.4697 & TST \\
\hline CHEMBL1333679 & 688239 & 5.4862 & 5.4054 & TRN \\
\hline CHEMBL1359507 & 688239 & 4.6862 & 5.6347 & TRN \\
\hline CHEMBL1425462 & 688239 & 4.9862 & 5.4764 & TRN \\
\hline CHEMBL1579429 & 688239 & 5.0862 & 5.3998 & TRN \\
\hline CHEMBL1319974 & 688239 & 4.8362 & 5.4319 & TST \\
\hline CHEMBL1387117 & 688239 & 4.5362 & 5.5012 & TST \\
\hline CHEMBL1576508 & 688239 & 4.5362 & 5.513 & TRN \\
\hline CHEMBL1411500 & 688239 & 6.8861 & 5.5623 & TRN \\
\hline CHEMBL1576589 & 688239 & 4.6362 & 5.5381 & TRN \\
\hline CHEMBL1587841 & 688239 & 5.2362 & 5.5227 & TRN \\
\hline
\end{tabular}

Page 1512 
Supplemental Table S2.txt

\begin{tabular}{|c|c|c|c|c|c|c|}
\hline CHEMBL1327382 & 688239 & 8.3372 & \multicolumn{3}{|c|}{5.4479999999999995} & TST \\
\hline CHEMBL1455742 & 688239 & 6.3863 & 5.5995 & TRN & & \\
\hline CHEMBL1322995 & 688239 & 5.6862 & 5.4514 & TRN & & \\
\hline CHEMBL1574582 & 688239 & 5.6862 & 5.5383 & TRN & & \\
\hline CHEMBL1381399 & 688239 & 8.2366 & 5.5786 & TRN & & \\
\hline CHEMBL1518317 & 688239 & 5.1862 & 5.5358 & TRN & & \\
\hline CHEMBL3212557 & 688239 & 8.3372 & 5.479 & TRN & & \\
\hline CHEMBL3208137 & 688239 & 5.4862 & 5.4998 & TRN & & \\
\hline CHEMBL1456115 & 688239 & 5.1862 & 5.4851 & TST & & \\
\hline CHEMBL1523272 & 688239 & 4.4862 & 5.3099 & TST & & \\
\hline CHEMBL1449495 & 688239 & 6.1362 & 5.375 & TRN & & \\
\hline CHEMBL1990742 & 688239 & 4.9362 & 5.4626 & TRN & & \\
\hline CHEMBL1376726 & 688239 & 4.7362 & 5.5484 & TRN & & \\
\hline CHEMBL1380801 & 688239 & 7.8356 & 5.3695 & TRN & & \\
\hline CHEMBL1311620 & 688239 & 5.1862 & 5.4978 & TRN & & \\
\hline CHEMBL1324030 & 688239 & 4.5862 & 5.6241 & TRN & & \\
\hline CHEMBL1471110 & 688239 & 4.8362 & 5.359 & TRN & & \\
\hline CHEMBL1426958 & 688239 & 4.7862 & 5.4712 & TRN & & \\
\hline CHEMBL1451515 & 688239 & 6.8861 & 5.5299 & TRN & & \\
\hline CHEMBL521035 & 688239 & 6.4362 & 5.5149 & TST & & \\
\hline CHEMBL1304936 & 688239 & 8.28399 & 99999999 & 99 & 5.4844 & \\
\hline CHEMBL1429539 & 688239 & 5.8362 & 5.4408 & TRN & & \\
\hline CHEMBL1464132 & 688239 & 4.6862 & 5.4983 & TST & & \\
\hline CHEMBL1368195 & 688239 & 4.8862 & 5.6203 & TRN & & \\
\hline CHEMBL3192939 & 688239 & 4.6362 & 5.2989 & TST & & \\
\hline CHEMBL1422752 & 688239 & 5.7862 & 5.5339 & TST & & \\
\hline CHEMBL1306297 & 688239 & 5.9362 & 5.574 & TRN & & \\
\hline CHEMBL3213889 & 688239 & 8.2366 & 5.5215 & TRN & & \\
\hline CHEMBL1613538 & 688239 & 4.5362 & 5.3569 & TST & & \\
\hline CHEMBL1577246 & 688239 & 5.9862 & 5.5282 & TRN & & \\
\hline CHEMBL1579087 & 688239 & 6.2862 & 5.5259 & TRN & & \\
\hline CHEMBL1560744 & 688239 & 6.9863 & 5.609 & TRN & & \\
\hline CHEMBL1539862 & 688239 & 5.3362 & 5.5035 & TRN & & \\
\hline CHEMBL1581411 & 688239 & 6.3362 & 5.4837 & TRN & & \\
\hline CHEMBL1972249 & 688239 & 4.4862 & 5.3537 & TRN & & \\
\hline CHEMBL1451596 & 688239 & 4.5362 & 5.5926 & TRN & & \\
\hline CHEMBL1302762 & 688239 & 5.3362 & 5.5345 & TRN & & \\
\hline CHEMBL1436275 & 688239 & 5.2362 & 5.6284 & TRN & & \\
\hline CHEMBL1500021 & 688239 & 5.1862 & 5.5232 & TRN & & \\
\hline CHEMBL1501262 & 688239 & 5.2862 & 5.4742 & TRN & & \\
\hline CHEMBL1391877 & 688239 & 4.9362 & 5.4256 & TRN & & \\
\hline CHEMBL1516141 & 688239 & 6.3863 & 5.4374 & TRN & & \\
\hline CHEMBL3208119 & 688239 & 4.5862 & 5.4688 & TST & & \\
\hline CHEMBL1516951 & 688239 & 4.6362 & 5.6008 & TRN & & \\
\hline CHEMBL1338820 & 688239 & 4.5362 & 5.5128 & TRN & & \\
\hline CHEMBL1498113 & 688239 & 6.6861 & 5.5902 & TRN & & \\
\hline CHEMBL1526487 & 688239 & 5.1862 & 5.4632 & TRN & & \\
\hline CHEMBL1458016 & 688239 & 4.5362 & 5.5393 & TRN & & \\
\hline
\end{tabular}

Page 1513 
Supplemental Table S2.txt

\begin{tabular}{|c|c|c|c|c|c|}
\hline CHEMBL1404174 & 688239 & 6.1362 & \multicolumn{2}{|c|}{5.622000000000001} & TRN \\
\hline CHEMBL1418480 & 688239 & 4.5862 & 5.4602 & TRN & \\
\hline CHEMBL1428029 & 688239 & 4.7362 & 5.3956 & TRN & \\
\hline CHEMBL1591755 & 688239 & 5.9362 & 5.4368 & TRN & \\
\hline CHEMBL1596970 & 688239 & 5.6362 & 5.4249 & TRN & \\
\hline CHEMBL1571822 & 688239 & 5.1362 & 5.3916 & TRN & \\
\hline CHEMBL1345855 & 688239 & 6.2862 & 5.4608 & TRN & \\
\hline CHEMBL1591134 & 688239 & 5.6862 & 5.44 & TRN & \\
\hline CHEMBL1383104 & 688239 & 6.5862 & 5.5257 & TST & \\
\hline CHEMBL1599361 & 688239 & 4.6862 & 5.5755 & TRN & \\
\hline CHEMBL 2000577 & 688239 & 6.7361 & 5.5103 & TRN & \\
\hline CHEMBL1593815 & 688239 & 8.3372 & 5.5656 & TST & \\
\hline CHEMBL1436689 & 688239 & 6.3863 & 5.5816 & TST & \\
\hline CHEMBL1426806 & 688239 & 5.1862 & 5.46399 & 99999999995 & TST \\
\hline CHEMBL1591386 & 688239 & 4.4862 & 5.489 & TST & \\
\hline CHEMBL3211793 & 688239 & 5.4862 & 5.3808 & TRN & \\
\hline CHEMBL 3194202 & 688239 & 5.1862 & 5.2879 & TRN & \\
\hline CHEMBL1597528 & 688239 & 6.0862 & 5.5672 & TRN & \\
\hline CHEMBL 3193713 & 688239 & 4.5362 & 5.4142 & TRN & \\
\hline CHEMBL1568002 & 688239 & 6.6861 & 5.4909 & TST & \\
\hline CHEMBL1417401 & 688239 & 4.7862 & 5.4962 & TST & \\
\hline CHEMBL1569868 & 688239 & 4.7862 & 5.4733 & TST & \\
\hline CHEMBL1523280 & 688239 & 5.3862 & 5.426 & TRN & \\
\hline CHEMBL1592832 & 688239 & 4.5362 & 5.2815 & TRN & \\
\hline CHEMBL1496202 & 688239 & 6.7862 & 5.3501 & TRN & \\
\hline CHEMBL1505050 & 688239 & 4.5362 & 5.5909 & TRN & \\
\hline CHEMBL1456562 & 688239 & 6.7862 & 5.5952 & TRN & \\
\hline CHEMBL1569676 & 688239 & 5.1862 & 5.5061 & TRN & \\
\hline CHEMBL1337998 & 688239 & 6.7862 & 5.4689 & TST & \\
\hline CHEMBL1479393 & 688239 & 4.6862 & 5.3573 & TST & \\
\hline CHEMBL1514855 & 688239 & 5.1362 & 5.5968 & TRN & \\
\hline CHEMBL1605139 & 688239 & 5.1862 & 5.37 & TST & \\
\hline CHEMBL3192746 & 688239 & 6.8861 & 5.5024 & TRN & \\
\hline CHEMBL1429590 & 688239 & 6.3863 & 5.4791 & TST & \\
\hline CHEMBL1409559 & 688239 & 8.3372 & 5.5165 & TRN & \\
\hline CHEMBL1503064 & 688239 & 5.2362 & 5.4321 & TRN & \\
\hline CHEMBL1534850 & 688239 & 4.5362 & 5.6698 & TRN & \\
\hline CHEMBL1587093 & 688239 & 6.0862 & 5.4554 & TST & \\
\hline CHEMBL1596085 & 688239 & 5.1862 & 5.3351 & TST & \\
\hline CHEMBL1982477 & 688239 & 4.6362 & 5.3607 & TST & \\
\hline CHEMBL1399473 & 688239 & 5.6862 & 5.6595 & TRN & \\
\hline CHEMBL 3213761 & 688239 & 6.1862 & 5.5565 & TRN & \\
\hline CHEMBL1611837 & 688239 & 4.5362 & 5.5042 & TRN & \\
\hline CHEMBL1426661 & 688239 & 4.5862 & 5.609 & TRN & \\
\hline CHEMBL1582587 & 688239 & 5.1862 & 5.5358 & TRN & \\
\hline CHEMBL1303327 & 688239 & 6.8362 & 5.4921 & TST & \\
\hline CHEMBL1573859 & 688239 & 4.6862 & 5.3506 & TST & \\
\hline CHEMBL1533132 & 688239 & 4.7362 & 5.4108 & TRN & \\
\hline
\end{tabular}


Supplemental Table S2.txt

\begin{tabular}{|c|c|c|c|c|c|}
\hline CHEMBL1467510 & 688239 & 4.7862 & 5.5765 & TRN & \\
\hline CHEMBL1573955 & 688239 & 4.5362 & 5.4334 & TRN & \\
\hline CHEMBL1601988 & 688239 & 5.2862 & 5.3968 & TRN & \\
\hline CHEMBL1539554 & 688239 & 6.1862 & 5.6492 & TRN & \\
\hline CHEMBL1990796 & 688239 & 4.7862 & 5.4682 & TRN & \\
\hline CHEMBL1584790 & 688239 & 7.0362 & 5.5925 & TRN & \\
\hline CHEMBL1453411 & 688239 & 5.6862 & 5.4807 & TRN & \\
\hline CHEMBL1591931 & 688239 & 5.9862 & 5.4205 & TST & \\
\hline CHEMBL1444728 & 688239 & 4.5362 & 5.4383 & TRN & \\
\hline CHEMBL1401778 & 688239 & 6.2362 & 5.3165 & TST & \\
\hline CHEMBL1417457 & 688239 & 4.7862 & 5.4955 & TRN & \\
\hline CHEMBL1571409 & 688239 & 4.9862 & 5.5014 & TRN & \\
\hline CHEMBL3198843 & 688239 & 4.5362 & 5.3348 & TST & \\
\hline CHEMBL1388619 & 688239 & 7.6364 & 5.3683 & TRN & \\
\hline CHEMBL1557650 & 688239 & 5.6862 & 5.5215 & TST & \\
\hline CHEMBL1601082 & 688239 & 6.3362 & 5.5233 & TST & \\
\hline CHEMBL1452206 & 688239 & 5.1862 & 5.5119 & TRN & \\
\hline CHEMBL1448506 & 688239 & 5.1862 & 5.6934 & TRN & \\
\hline CHEMBL1542983 & 688239 & 5.1862 & 5.5045 & TST & \\
\hline CHEMBL1395231 & 688239 & 5.1862 & 5.6261 & TRN & \\
\hline CHEMBL1419655 & 688239 & 5.9362 & 5.49799 & 9999999999 & TRN \\
\hline CHEMBL1333636 & 688239 & 4.7362 & 5.437 & TRN & \\
\hline CHEMBL1348622 & 688239 & 5.0362 & 5.5598 & TRN & \\
\hline CHEMBL1320844 & 688239 & 5.5862 & 5.5183 & TST & \\
\hline CHEMBL1526882 & 688239 & 5.3862 & 5.5289 & TST & \\
\hline CHEMBL1613387 & 688239 & 4.5362 & 5.4546 & TRN & \\
\hline CHEMBL1610731 & 688239 & 4.5362 & 5.443 & TRN & \\
\hline CHEMBL1323880 & 688239 & 4.6862 & 5.6135 & TST & \\
\hline CHEMBL1402853 & 688239 & 7.7852 & 5.5192 & TRN & \\
\hline CHEMBL1423424 & 688239 & 5.1862 & 5.6514 & TST & \\
\hline CHEMBL1460028 & 688239 & 4.5362 & 5.5938 & TRN & \\
\hline CHEMBL551004 & 688239 & 4.8362 & 5.4746 & TRN & \\
\hline CHEMBL3212826 & 688239 & 4.6862 & 5.3924 & TRN & \\
\hline CHEMBL1309899 & 688239 & 5.7362 & 5.5748 & TST & \\
\hline CHEMBL1468601 & 688239 & 6.7361 & 5.5451 & TRN & \\
\hline CHEMBL1306440 & 688239 & 5.1862 & 5.5088 & TRN & \\
\hline CHEMBL1319112 & 688239 & 5.6862 & 5.6045 & TRN & \\
\hline CHEMBL1402411 & 688239 & 5.7362 & 5.4485 & TRN & \\
\hline CHEMBL1428999 & 688239 & 5.4362 & 5.5356 & TRN & \\
\hline CHEMBL1609163 & 688239 & 6.0362 & 5.4421 & TRN & \\
\hline CHEMBL1507995 & 688239 & 4.7362 & 5.4633 & TRN & \\
\hline CHEMBL1410444 & 688239 & 6.8362 & 5.5372 & TRN & \\
\hline CHEMBL1541601 & 688239 & 5.0362 & 5.4933 & TRN & \\
\hline CHEMBL1429755 & 688239 & 4.5362 & 5.5948 & TRN & \\
\hline CHEMBL1577757 & 688239 & 8.3372 & 5.5665 & TRN & \\
\hline CHEMBL1369234 & 688239 & 4.5362 & 5.4847 & TRN & \\
\hline CHEMBL1352805 & 688239 & 7.3862 & 5.3949 & TRN & \\
\hline CHEMBL1580627 & 688239 & 8.2366 & 5.6023 & TRN & \\
\hline
\end{tabular}


Supplemental Table S2.txt

\begin{tabular}{|c|c|c|c|c|}
\hline CHEMBL1319479 & 688239 & 6.7862 & 5.6386 & TST \\
\hline CHEMBL1486136 & 688239 & 7.2366 & 5.5175 & TST \\
\hline CHEMBL3209031 & 688239 & 4.5362 & 5.3527 & TST \\
\hline CHEMBL 3189260 & 688239 & 6.1362 & 5.4884 & TRN \\
\hline CHEMBL1583567 & 688239 & 4.5362 & 5.47 & TRN \\
\hline CHEMBL1420694 & 688239 & 4.9362 & 5.5464 & TRN \\
\hline CHEMBL1299246 & 688239 & 6.6861 & 5.3699 & TRN \\
\hline CHEMBL1521452 & 688239 & 5.1362 & \multicolumn{2}{|c|}{5.5760000000000005} \\
\hline CHEMBL1505572 & 688239 & 4.4862 & 5.3705 & TST \\
\hline CHEMBL1542603 & 688239 & 4.6362 & 5.3907 & TST \\
\hline CHEMBL1369304 & 688239 & 6.6861 & 5.4955 & TRN \\
\hline CHEMBL1346357 & 688239 & 8.3372 & 5.5735 & TRN \\
\hline CHEMBL1516153 & 688239 & 6.4362 & 5.4599 & TRN \\
\hline CHEMBL3211898 & 688239 & 6.0362 & 5.5515 & TST \\
\hline CHEMBL1583423 & 688239 & 5.1362 & 5.5357 & TST \\
\hline CHEMBL1523015 & 688239 & 5.4862 & 5.5281 & TRN \\
\hline CHEMBL3210707 & 688239 & 4.5862 & 5.4926 & TST \\
\hline CHEMBL1546061 & 688239 & 6.1362 & 5.5679 & TST \\
\hline CHEMBL1327924 & 688239 & 4.5862 & 5.5774 & TRN \\
\hline CHEMBL1566510 & 688239 & 6.1862 & 5.6162 & TRN \\
\hline CHEMBL1324378 & 688239 & 5.1862 & 5.5081 & TRN \\
\hline CHEMBL1392047 & 688239 & 6.2362 & 5.4557 & TRN \\
\hline CHEMBL1327636 & 688239 & 5.2862 & 5.3749 & TRN \\
\hline CHEMBL1483616 & 688239 & 4.5362 & 5.3779 & TRN \\
\hline CHEMBL1558222 & 688239 & 4.5362 & 5.3228 & TST \\
\hline CHEMBL1449592 & 688239 & 6.7862 & 5.4468 & TRN \\
\hline CHEMBL1532583 & 688239 & 4.5362 & \multicolumn{2}{|c|}{5.497000000000001} \\
\hline CHEMBL1367641 & 688239 & 6.0862 & 5.4973 & TST \\
\hline CHEMBL1343465 & 688239 & 5.0862 & 5.3718 & TRN \\
\hline CHEMBL1469340 & 688239 & 5.3862 & 5.4603 & TRN \\
\hline CHEMBL1381010 & 688239 & 4.5862 & 5.6184 & TRN \\
\hline CHEMBL1542702 & 688239 & 5.7362 & 5.6531 & TST \\
\hline CHEMBL1602074 & 688239 & 4.7862 & 5.3845 & TRN \\
\hline CHEMBL1575327 & 688239 & 4.8362 & 5.5367 & TRN \\
\hline CHEMBL1345974 & 688239 & 5.1862 & 5.6023 & TST \\
\hline CHEMBL1526230 & 688239 & 6.2362 & \multicolumn{2}{|c|}{5.6129999999999995} \\
\hline CHEMBL1555020 & 688239 & 4.5362 & 5.5472 & TRN \\
\hline CHEMBL1612126 & 688239 & 5.6362 & 5.4596 & TST \\
\hline CHEMBL1316723 & 688239 & 6.8861 & 5.3703 & TRN \\
\hline CHEMBL1590233 & 688239 & 5.4362 & 5.4515 & TST \\
\hline CHEMBL1346815 & 688239 & 6.1362 & 5.4209 & TRN \\
\hline CHEMBL1534574 & 688239 & 4.7362 & 5.4807 & TRN \\
\hline CHEMBL1596562 & 688239 & 4.7862 & 5.5998 & TRN \\
\hline CHEMBL1309552 & 688239 & 6.0362 & 5.4505 & TST \\
\hline CHEMBL1433862 & 688239 & 4.7362 & 5.4695 & TRN \\
\hline CHEMBL3193572 & 688239 & 6.0862 & 5.4299 & TRN \\
\hline CHEMBL1342829 & 688239 & 5.4862 & 5.5898 & TRN \\
\hline CHEMBL1445145 & 688239 & 4.7862 & 5.5177 & TRN \\
\hline
\end{tabular}


Supplemental Table S2.txt

\begin{tabular}{|c|c|c|c|c|c|c|}
\hline CHEMBL1553332 & 688239 & 5.1862 & 5.5088 & TRN & & \\
\hline CHEMBL1565616 & 688239 & 5.1862 & 5.4739 & TRN & & \\
\hline CHEMBL1477407 & 688239 & 6.0862 & 5.5117 & TST & & \\
\hline CHEMBL1512824 & 688239 & 8.283999 & 79999999 & & 5.5643 & 11 \\
\hline CHEMBL1303637 & 688239 & 4.7362 & 5.5072 & TRN & & \\
\hline CHEMBL1530191 & 688239 & 6.2362 & 5.4611 & TRN & & \\
\hline CHEMBL1452428 & 688239 & 5.0362 & 5.484 & TRN & & \\
\hline CHEMBL1447100 & 688239 & 5.1862 & 5.4002 & TST & & \\
\hline CHEMBL561589 & 688239 & 6.7862 & 5.4989 & TRN & & \\
\hline CHEMBL1332870 & 688239 & 5.7362 & 5.5431 & TRN & & \\
\hline CHEMBL1606159 & 688239 & 5.5862 & 5.4307 & TRN & & \\
\hline CHEMBL1332942 & 688239 & 6.9863 & 5.3945 & TST & & \\
\hline CHEMBL1510133 & 688239 & 4.5362 & 5.5328 & TRN & & \\
\hline CHEMBL1335555 & 688239 & 4.4862 & 5.4919 & TRN & & \\
\hline CHEMBL1453624 & 688239 & 5.6862 & 5.5709 & TRN & & \\
\hline CHEMBL1420109 & 688239 & 4.8362 & 5.614 & TRN & & \\
\hline CHEMBL584841 & 688239 & 4.6862 & 5.2796 & TRN & & \\
\hline CHEMBL1574616 & 688239 & 5.4362 & 5.3057 & TRN & & \\
\hline CHEMBL1503269 & 688239 & 6.2362 & 5.5251 & TRN & & \\
\hline CHEMBL1567505 & 688239 & 4.5362 & 5.4036 & TRN & & \\
\hline CHEMBL1409466 & 688239 & 4.5362 & 5.3169 & TRN & & \\
\hline CHEMBL1486217 & 688239 & 4.7362 & 5.6099 & TRN & & \\
\hline CHEMBL3197334 & 688239 & 4.8862 & 5.5035 & TST & & \\
\hline CHEMBL1604779 & 688239 & 5.8862 & 5.4343 & TRN & & \\
\hline CHEMBL1304366 & 688239 & 5.2362 & 5.4897 & TST & & \\
\hline CHEMBL1498661 & 688239 & 5.6362 & 5.4495 & TST & & \\
\hline CHEMBL3198513 & 688239 & 4.8862 & 5.3734 & TST & & \\
\hline CHEMBL1365801 & 688239 & 4.5362 & 5.4549 & TRN & & \\
\hline CHEMBL1381544 & 688239 & 4.8362 & 5.5618 & TRN & & \\
\hline CHEMBL1391045 & 688239 & 4.6862 & 5.4109 & TST & & \\
\hline CHEMBL1503205 & 688239 & 6.3362 & 5.4529 & TRN & & \\
\hline CHEMBL1380591 & 688239 & 5.4862 & 5.6605 & TRN & & \\
\hline CHEMBL1602068 & 688239 & 6.0862 & 5.5634 & TST & & \\
\hline CHEMBL1612440 & 688239 & 4.9862 & 5.5959 & TRN & & \\
\hline CHEMBL1320909 & 688239 & 4.8362 & 5.3634 & TRN & & \\
\hline CHEMBL1559328 & 688239 & \multicolumn{3}{|c|}{8.283999999999999} & 5.4728 & TRN \\
\hline CHEMBL1432361 & 688239 & 6.0862 & 5.4411 & TST & & \\
\hline CHEMBL1478893 & 688239 & 6.4362 & 5.6523 & TRN & & \\
\hline CHEMBL1327722 & 688239 & 6.4362 & 5.3896 & TRN & & \\
\hline CHEMBL1583665 & 688239 & 4.6362 & 5.3735 & TRN & & \\
\hline CHEMBL1330938 & 688239 & 5.1862 & 5.7149 & TRN & & \\
\hline CHEMBL1361998 & 688239 & 4.6362 & 5.7297 & TRN & & \\
\hline CHEMBL1317833 & 688239 & 8.3372 & 5.5778 & TRN & & \\
\hline CHEMBL1559297 & 688239 & 6.1862 & 5.5149 & TRN & & \\
\hline CHEMBL3196318 & 688239 & 4.7862 & 5.5266 & TST & & \\
\hline CHEMBL1603723 & 688239 & 6.5862 & 5.5832 & TRN & & \\
\hline CHEMBL1562162 & 688239 & 5.5362 & 5.5265 & TST & & \\
\hline CHEMBL1424302 & 688239 & 5.7862 & 5.6362 & TRN & & \\
\hline
\end{tabular}


Supplemental Table S2.txt

\begin{tabular}{|c|c|c|c|c|c|}
\hline CHEMBL 3189347 & 688239 & 5.0862 & 5.4047 & TST & \\
\hline CHEMBL1325354 & 688239 & 4.5862 & 5.3309 & TST & \\
\hline CHEMBL1586083 & 688239 & 4.5362 & 5.5175 & TRN & \\
\hline CHEMBL1362815 & 688239 & 5.5862 & 5.4263 & TST & \\
\hline CHEMBL1405581 & 688239 & 4.5362 & 5.6517 & TST & \\
\hline CHEMBL1393150 & 688239 & 6.0362 & 5.5285 & TST & \\
\hline CHEMBL3198480 & 688239 & 8.3372 & 5.3416 & TRN & \\
\hline CHEMBL1443686 & 688239 & 6.3362 & 5.2459 & TRN & \\
\hline CHEMBL455399 & 688239 & 5.1362 & 5.4973 & TRN & \\
\hline CHEMBL1345273 & 688239 & 5.6862 & 5.5595 & TRN & \\
\hline CHEMBL3208598 & 688239 & 5.6362 & 5.5105 & TRN & \\
\hline CHEMBL1517831 & 688239 & 4.5362 & 5.4822 & TST & \\
\hline CHEMBL1375964 & 688239 & 4.9862 & 5.4425 & TST & \\
\hline CHEMBL1574725 & 688239 & 8.3372 & 5.6089 & TRN & \\
\hline CHEMBL3198524 & 688239 & 4.5362 & 5.4916 & TRN & \\
\hline CHEMBL1559153 & 688239 & 5.6362 & 5.4513 & TRN & \\
\hline CHEMBL1478307 & 688239 & 5.0862 & 5.3963 & TRN & \\
\hline CHEMBL1534891 & 688239 & 5.4362 & 5.6076 & TST & \\
\hline CHEMBL1470661 & 688239 & 5.1362 & 5.4584 & TRN & \\
\hline CHEMBL1569549 & 688239 & 5.6362 & 5.568 & TRN & \\
\hline CHEMBL1303437 & 688239 & 4.6862 & $5.45200 e$ & 0000000001 & TST \\
\hline CHEMBL1373861 & 688239 & 4.4862 & 5.4953 & TRN & \\
\hline CHEMBL465843 & 688239 & 4.6862 & 5.5364 & TRN & \\
\hline CHEMBL1332836 & 688239 & 5.3862 & 5.6059 & TST & \\
\hline CHEMBL1470293 & 688239 & 6.1862 & 5.4634 & TRN & \\
\hline CHEMBL1503043 & 688239 & 6.5363 & 5.6287 & TRN & \\
\hline CHEMBL1484107 & 688239 & 5.6362 & 5.4091 & TRN & \\
\hline CHEMBL1603107 & 688239 & 5.4862 & 5.4882 & TRN & \\
\hline CHEMBL3213009 & 688239 & 4.4862 & 5.5102 & TRN & \\
\hline CHEMBL1607948 & 688239 & 4.6362 & 5.4224 & TRN & \\
\hline CHEMBL1492588 & 688239 & 5.1862 & 5.5331 & TRN & \\
\hline CHEMBL1355035 & 688239 & 4.6362 & 5.5838 & TRN & \\
\hline CHEMBL1575531 & 688239 & 4.5362 & 5.4931 & TST & \\
\hline CHEMBL1468945 & 688239 & 7.7352 & 5.4769 & TST & \\
\hline CHEMBL1397800 & 688239 & 6.7361 & 5.4919 & TRN & \\
\hline CHEMBL1401638 & 688239 & 7.0362 & 5.3712 & TST & \\
\hline CHEMBL3190124 & 688239 & 6.2362 & 5.6308 & TST & \\
\hline CHEMBL1348097 & 688239 & 4.8362 & 5.3026 & TRN & \\
\hline CHEMBL1355913 & 688239 & 4.5362 & 5.3798 & TRN & \\
\hline CHEMBL1382919 & 688239 & 5.3862 & 5.5231 & TRN & \\
\hline CHEMBL1390202 & 688239 & 6.1862 & 5.442 & TST & \\
\hline CHEMBL1391017 & 688239 & 5.3862 & 5.5056 & TRN & \\
\hline CHEMBL1497217 & 688239 & 5.1862 & 5.5558 & TRN & \\
\hline CHEMBL1430179 & 688239 & 6.1362 & 5.3276 & TRN & \\
\hline CHEMBL1467761 & 688239 & 4.7362 & 5.4407 & TST & \\
\hline CHEMBL1512911 & 688239 & 5.3362 & 5.4136 & TRN & \\
\hline CHEMBL1312631 & 688239 & 6.8362 & 5.5286 & TRN & \\
\hline CHEMBL1428310 & 688239 & 5.1862 & 5.567 & TRN & \\
\hline
\end{tabular}




\begin{tabular}{|c|c|c|c|c|c|c|}
\hline & & \multicolumn{5}{|c|}{ Supplemental Table s2.txt } \\
\hline CHEMBL1351735 & 688239 & 8.2839 & 99999999 & & 5.6427 & TST \\
\hline CHEMBL1349345 & 688239 & 6.3863 & 5.3311 & TST & & \\
\hline CHEMBL1499282 & 688239 & 6.9863 & 5.3747 & TST & & \\
\hline CHEMBL1530180 & 688239 & 5.1862 & 5.4609 & TST & & \\
\hline CHEMBL1464367 & 688239 & 5.0362 & 5.5846 & TRN & & \\
\hline CHEMBL1530515 & 688239 & 7.2366 & 5.4259 & TRN & & \\
\hline CHEMBL1346832 & 688239 & 4.6362 & 5.5383 & TRN & & \\
\hline CHEMBL1381253 & 688239 & 4.6362 & 5.5673 & TRN & & \\
\hline CHEMBL1509745 & 688239 & 5.9862 & 5.6283 & TRN & & \\
\hline CHEMBL1585190 & 688239 & 5.1862 & 5.4896 & TRN & & \\
\hline CHEMBL1607680 & 688239 & 4.5362 & 5.5619 & TRN & & \\
\hline CHEMBL1489767 & 688239 & 4.8862 & 5.3517 & TRN & & \\
\hline CHEMBL3194256 & 688239 & 4.4862 & 5.4079 & TRN & & \\
\hline CHEMBL1473995 & 688239 & 5.1862 & 5.4861 & TRN & & \\
\hline CHEMBL1493256 & 688239 & 5.1362 & 5.5196 & TST & & \\
\hline CHEMBL1488624 & 688239 & 6.9863 & 5.6427 & TRN & & \\
\hline CHEMBL1541244 & 688239 & 8.1367 & 5.4899 & TRN & & \\
\hline CHEMBL1368487 & 688239 & 4.5362 & 5.4404 & TRN & & \\
\hline CHEMBL1564351 & 688239 & 6.9863 & 5.5687 & TRN & & \\
\hline CHEMBL1344305 & 688239 & 4.6862 & 5.4081 & TST & & \\
\hline CHEMBL1529629 & 688239 & 6.6362 & 5.4752 & TRN & & \\
\hline CHEMBL1540081 & 688239 & 4.9862 & 5.3825 & TRN & & \\
\hline CHEMBL1309437 & 688239 & 5.1862 & 5.4723 & TST & & \\
\hline CHEMBL1326482 & 688239 & 4.8862 & 5.5498 & TST & & \\
\hline CHEMBL1509918 & 688239 & 5.4862 & 5.6097 & TRN & & \\
\hline CHEMBL 3198780 & 688239 & 5.4862 & 5.3931 & TRN & & \\
\hline CHEMBL1437290 & 688239 & 6.8362 & 5.5031 & TRN & & \\
\hline CHEMBL1393399 & 688239 & 4.5362 & 5.5541 & TST & & \\
\hline CHEMBL1430105 & 688239 & 4.6862 & 5.2417 & TST & & \\
\hline CHEMBL1320254 & 688239 & 6.3362 & 5.521 & TST & & \\
\hline CHEMBL1403497 & 688239 & 6.6362 & 5.6187 & TRN & & \\
\hline CHEMBL1591585 & 688239 & 4.6862 & 5.6147 & TRN & & \\
\hline CHEMBL1426798 & 688239 & 6.1362 & 5.6104 & TRN & & \\
\hline CHEMBL1558867 & 688239 & 4.5362 & 5.5451 & TST & & \\
\hline CHEMBL1589607 & 688239 & 6.2362 & 5.5804 & TRN & & \\
\hline CHEMBL1476744 & 688239 & 4.5362 & 5.4596 & TRN & & \\
\hline CHEMBL1404962 & 688239 & 8.3372 & 5.4717 & TRN & & \\
\hline CHEMBL1603770 & 688239 & 5.9862 & 5.5253 & TRN & & \\
\hline CHEMBL1355168 & 688239 & 4.7862 & 5.392 & TRN & & \\
\hline CHEMBL3195229 & 688239 & 5.5362 & 5.3349 & TRN & & \\
\hline CHEMBL1585933 & 688239 & 6.0362 & 5.5949 & TRN & & \\
\hline CHEMBL1304587 & 688239 & 5.9362 & 5.4772 & TRN & & \\
\hline CHEMBL1511338 & 688239 & 5.5862 & 5.54 & TRN & & \\
\hline CHEMBL3197934 & 688239 & 4.5362 & 5.4877 & TRN & & \\
\hline CHEMBL1582962 & 688239 & 6.3362 & 5.4589 & TST & & \\
\hline CHEMBL1374527 & 688239 & 4.5362 & 5.4501 & TRN & & \\
\hline CHEMBL1610814 & 688239 & 6.5363 & 5.5647 & TST & & \\
\hline CHEMBL1490454 & 688239 & 4.7862 & 5.4411 & TRN & & \\
\hline
\end{tabular}


Supplemental Table S2.txt

\begin{tabular}{|c|c|c|c|c|}
\hline CHEMBL1371430 & 688239 & 6.6362 & 5.4329 & TRN \\
\hline CHEMBL1541229 & 688239 & 5.0362 & 5.6279 & TRN \\
\hline CHEMBL1308614 & 688239 & 4.4862 & 5.5289 & TRN \\
\hline CHEMBL1585686 & 688239 & 6.7361 & 5.5097 & TRN \\
\hline CHEMBL 3145193 & 688239 & 4.7362 & 5.5257 & TRN \\
\hline CHEMBL1349947 & 688239 & 5.2362 & 5.3104 & TRN \\
\hline CHEMBL1489396 & 688239 & 6.0362 & 5.6028 & TRN \\
\hline CHEMBL1491441 & 688239 & 4.5362 & 5.5187 & TRN \\
\hline CHEMBL1327056 & 688239 & 4.5362 & 5.5457 & TRN \\
\hline CHEMBL1453885 & 688239 & 6.9863 & 5.5166 & TRN \\
\hline CHEMBL1601698 & 688239 & 5.9362 & 5.5726 & TST \\
\hline CHEMBL1451899 & 688239 & 4.7862 & 5.5926 & TRN \\
\hline CHEMBL1610344 & 688239 & 5.3862 & 5.4703 & TRN \\
\hline CHEMBL1987106 & 688239 & 6.1862 & 5.5509 & TRN \\
\hline CHEMBL1363434 & 688239 & 6.2362 & 5.6076 & TRN \\
\hline CHEMBL1375906 & 688239 & 4.6362 & 5.5902 & TRN \\
\hline CHEMBL1405190 & 688239 & 6.9363 & 5.5281 & TRN \\
\hline CHEMBL1576655 & 688239 & 5.1362 & 5.4326 & TRN \\
\hline CHEMBL1416217 & 688239 & 4.6862 & 5.5798 & TRN \\
\hline CHEMBL1299830 & 688239 & 4.4862 & 5.5966 & TRN \\
\hline CHEMBL1434667 & 688239 & 4.4862 & 5.4897 & TRN \\
\hline CHEMBL1333102 & 688239 & 5.1362 & 5.5097 & TRN \\
\hline CHEMBL1538284 & 688239 & 4.7362 & 5.4859 & TRN \\
\hline CHEMBL1301341 & 688239 & 5.1862 & 5.4977 & TRN \\
\hline CHEMBL1568170 & 688239 & 5.2862 & 5.4168 & TRN \\
\hline CHEMBL3197234 & 688239 & 6.4362 & 5.5125 & TRN \\
\hline CHEMBL1605952 & 688239 & 5.4862 & 5.6104 & TRN \\
\hline CHEMBL3192481 & 688239 & 4.8362 & 5.4122 & TRN \\
\hline CHEMBL1332321 & 688239 & 6.8362 & 5.473 & TRN \\
\hline CHEMBL1330293 & 688239 & 4.7362 & 5.5147 & TRN \\
\hline CHEMBL1323872 & 688239 & 7.0862 & 5.3958 & TRN \\
\hline CHEMBL1331412 & 688239 & 4.5862 & 5.4839 & TRN \\
\hline CHEMBL1459732 & 688239 & 5.5862 & 5.4674 & TRN \\
\hline CHEMBL1513901 & 688239 & 5.2362 & 5.4471 & TST \\
\hline CHEMBL1375929 & 688239 & 4.6362 & 5.4298 & TRN \\
\hline CHEMBL1312875 & 688239 & 5.1862 & 5.5557 & TRN \\
\hline CHEMBL1504652 & 688239 & 6.0362 & 5.6273 & TRN \\
\hline CHEMBL1610087 & 688239 & 5.6862 & 5.3687 & TST \\
\hline CHEMBL1482622 & 688239 & 4.7362 & 5.567 & TRN \\
\hline CHEMBL1341520 & 688239 & 6.0862 & 5.4982 & TRN \\
\hline CHEMBL1373805 & 688239 & 5.6862 & 5.602 & TRN \\
\hline CHEMBL1526851 & 688239 & 7.9355 & 5.3388 & TST \\
\hline CHEMBL1571856 & 688239 & 5.6862 & 5.3844 & TRN \\
\hline CHEMBL1491791 & 688239 & 4.5362 & 5.5357 & TRN \\
\hline CHEMBL1307221 & 688239 & 5.9362 & 5.5549 & TRN \\
\hline CHEMBL1413300 & 688239 & 4.7862 & 5.381 & TRN \\
\hline CHEMBL1510368 & 688239 & 5.4862 & 5.36299 & 99999999995 \\
\hline CHEMBL1432339 & 688239 & 4.5862 & 5.6491 & TRN \\
\hline
\end{tabular}


Supplemental Table S2.txt

\begin{tabular}{|c|c|c|c|c|}
\hline (1) & & & & \\
\hline IEM & 38239 & 864 & & \\
\hline IEMBL146 & 88239 & 7862 & & \\
\hline HEMBL1492532 & 88239 & 9862 & .4952 & \\
\hline & 239 & 362 & & \\
\hline AEMBL15 & 239 & 362 & 39 & \\
\hline AEMBL1406591 & 88239 & 7362 & .4637 & \\
\hline HEMBL1464274 & 88239 & .1862 & .4784 & \\
\hline HEMBL1567335 & 88239 & 862 & 53 & \\
\hline IEMBL14 & 38239 & 862 & & \\
\hline IEMBL14 & 239 & 362 & & \\
\hline HEMBL1306647 & 88239 & 5.8862 & .5836 & \\
\hline HEMBL1410144 & 88239 & 862 & & \\
\hline AEMBL13 & 88 & & & \\
\hline IEMBL14 & 38239 & 862 & & \\
\hline AEMBL13 & 38239 & 362 & & \\
\hline HEMBL1338238 & 88239 & 362 & & \\
\hline JEMBL13 & 88239 & 362 & & \\
\hline 105 & $8 \varepsilon$ & 362 & 1 & \\
\hline IEMBL13 & 39 & 62 & & \\
\hline AEMBL14 & 39 & 362 & & \\
\hline L14 & 88239 & 861 & & \\
\hline AEMBL15 & 39 & 862 & & \\
\hline EMBL 32 & 39 & 61 & & \\
\hline L1: & & & & \\
\hline 11 & 39 & 862 & & RN \\
\hline $3 L 31$ & 88239 & 362 & & RN \\
\hline AEMBL13 & 39 & & & \\
\hline AEMBL14 & 39 & 62 & 91 & $\mathrm{R}$ \\
\hline L12 & & 62 & & RN \\
\hline 62 & 39 & 62 & & ST \\
\hline AEMBL13: & & & & RN \\
\hline HEMBL1318226 & & & & $\mathrm{R}$ \\
\hline AEMBL14 & 39 & 362 & 83 & $\mathrm{RN}$ \\
\hline L1: & 39 & 62 & & RN \\
\hline & & & & ST \\
\hline HEMBL1488046 & 88239 & 362 & & RN \\
\hline AEMBL1407668 & & & & $\mathrm{RN}$ \\
\hline HEMBL13 & & 361 & & RN \\
\hline 6 & & 62 & & \\
\hline 22 & & 62 & & ST \\
\hline HEMBL1532811 & 88239 & 363 & 5 . & RN \\
\hline AEMBL13 & 39 & 362 & & RN \\
\hline HEMBL1 14 & & & & \\
\hline & & & & \\
\hline HEMBL 15 & 39 & 862 & & RN \\
\hline 3L1504019 & 88239 & 4.9362 & 5.5233 & \\
\hline CHEMBL1448816 & 688239 & 5.3862 & 5.5629 & \\
\hline
\end{tabular}

Page 1521 
Supplemental Table S2.txt

\begin{tabular}{|c|c|c|c|c|c|}
\hline CHEMBL1517669 & 688239 & 5.1362 & 5.4416 & TRN & \\
\hline CHEMBL1449815 & 688239 & 6.7361 & 5.5005 & TST & \\
\hline CHEMBL1584153 & 688239 & 6.0 & 5.5137 & TRN & \\
\hline CHEMBL1356366 & 688239 & 6.8362 & 5.562 & TRN & \\
\hline CHEMBL1606228 & 688239 & 6.8362 & 5.6072 & TRN & \\
\hline CHEMBL1341050 & 688239 & 4.6362 & 5.5451 & TRN & \\
\hline CHEMBL1533758 & 688239 & 5.1362 & 5.6404 & TRN & \\
\hline CHEMBL1561145 & 688239 & 5.4862 & 5.6018 & TRN & \\
\hline CHEMBL3199472 & 688239 & 4.6362 & 5.3766 & TST & \\
\hline CHEMBL1434417 & 688239 & 6.0362 & 5.6489 & TRN & \\
\hline CHEMBL1302707 & 688239 & 6.7361 & 5.4722 & TST & \\
\hline CHEMBL1449486 & 688239 & 4.7862 & 5.5905 & TRN & \\
\hline CHEMBL1560214 & 688239 & 4.5362 & 5.2101 & TST & \\
\hline CHEMBL1330308 & 688239 & 6.9863 & 5.4539 & TRN & \\
\hline CHEMBL1493708 & 688239 & 5.7362 & 5.4452 & TRN & \\
\hline CHEMBL1611956 & 688239 & 5.4862 & 5.4603 & TRN & \\
\hline CHEMBL1341786 & 688239 & 5.1362 & 5.4283 & TST & \\
\hline CHEMBL1303938 & 688239 & 5.7362 & 5.6207 & TRN & \\
\hline CHEMBL1603355 & 688239 & 5.3862 & 5.5792 & TRN & \\
\hline CHEMBL1547646 & 688239 & 8.3872 & 5.4523 & TRN & \\
\hline CHEMBL1556364 & 688239 & 5.1862 & 5.3337 & TRN & \\
\hline CHEMBL1414564 & 688239 & 7.1864 & 5.5139 & TRN & \\
\hline CHEMBL1572134 & 688239 & 4.4862 & 5.2541 & TRN & \\
\hline CHEMBL1315825 & 688239 & 4.5862 & 5.485 & TST & \\
\hline CHEMBL1530692 & 688239 & 4.5362 & 5.5829 & TRN & \\
\hline CHEMBL1526265 & 688239 & 4.8362 & 5.5069 & TRN & \\
\hline CHEMBL1585478 & 688239 & 5.8362 & 5.6333 & TRN & \\
\hline CHEMBL1610060 & 688239 & 5.1362 & 5.5806 & TRN & \\
\hline CHEMBL1554906 & 688239 & 4.5362 & 5.54 & TRN & \\
\hline CHEMBL3214184 & 688239 & 6.0862 & 5.5609 & TST & \\
\hline CHEMBL1466394 & 688239 & 4.5362 & 5.4537 & TRN & \\
\hline CHEMBL1411367 & 688239 & 4.8362 & 5.2968 & TST & \\
\hline CHEMBL1441524 & 688239 & 5.3362 & 5.4127 & TRN & \\
\hline CHEMBL1488993 & 688239 & 4.8862 & 5.4017 & TRN & \\
\hline CHEMBL1581645 & 688239 & 4.7362 & 5.4797 & TRN & \\
\hline CHEMBL1505855 & 688239 & 8.28399 & 99999999 & 9 & 5.5633 \\
\hline CHEMBL1457028 & 688239 & 4.7862 & 5.5163 & TRN & \\
\hline CHEMBL1450934 & 688239 & 4.7862 & 5.4923 & TST & \\
\hline CHEMBL1307372 & 688239 & 4.5362 & 5.5083 & TRN & \\
\hline CHEMBL1306228 & 688239 & 5.6362 & 5.4213 & TST & \\
\hline CHEMBL1532772 & 688239 & 4.6862 & 5.5608 & TRN & \\
\hline CHEMBL1492000 & 688239 & 4.8862 & 5.3904 & TST & \\
\hline CHEMBL1489758 & 688239 & 5.0862 & 5.5254 & TST & \\
\hline CHEMBL1386110 & 688239 & 4.6862 & 5.2934 & TRN & \\
\hline CHEMBL1300695 & 688239 & 5.4362 & 5.5469 & TST & \\
\hline CHEMBL1372788 & 688239 & 4.5362 & 5.4676 & TST & \\
\hline CHEMBL1538880 & 688239 & 4.5362 & 5.5822 & TRN & \\
\hline CHEMBL1495170 & 688239 & 4.5362 & 5.426 & TST & \\
\hline
\end{tabular}


Supplemental Table S2.txt

\begin{tabular}{|c|c|c|c|c|c|c|}
\hline CHEMBL1385714 & 688239 & 4.7862 & 5.4198 & TST & & \\
\hline CHEMBL1454712 & 688239 & 4.6362 & 5.4287 & TST & & \\
\hline CHEMBL1571489 & 688239 & 5.4862 & 5.4013 & TRN & & \\
\hline CHEMBL3210299 & 688239 & 6.8362 & 5.507000 & 0000000 & & $2 \mathrm{~N}$ \\
\hline CHEMBL1540114 & 688239 & 5.2862 & 5.5374 & TRN & & \\
\hline CHEMBL1581350 & 688239 & 4.5862 & 5.4241 & TRN & & \\
\hline CHEMBL1517572 & 688239 & 4.9362 & 5.5942 & TRN & & \\
\hline CHEMBL 1476860 & 688239 & 5.3362 & 5.5166 & TRN & & \\
\hline CHEMBL1508427 & 688239 & 4.5362 & 5.5522 & TST & & \\
\hline CHEMBL3199201 & 688239 & 4.5362 & 5.5771 & TRN & & \\
\hline CHEMBL1421575 & 688239 & 5.9362 & 5.4306 & TRN & & \\
\hline CHEMBL1499219 & 688239 & 4.6862 & 5.5214 & TST & & \\
\hline CHEMBL1435629 & 688239 & 4.5862 & 5.6383 & TST & & \\
\hline CHEMBL1483417 & 688239 & 4.5362 & 5.4687 & TRN & & \\
\hline CHEMBL1491335 & 688239 & 5.1862 & 5.5385 & TRN & & \\
\hline CHEMBL1990685 & 688239 & 5.2362 & 5.3799 & TRN & & \\
\hline CHEMBL1304775 & 688239 & 7.8861 & 5.4503 & TST & & \\
\hline CHEMBL1593879 & 688239 & 5.6862 & 5.5506 & TRN & & \\
\hline CHEMBL1381020 & 688239 & 5.0862 & 5.5209 & TRN & & \\
\hline CHEMBL1405304 & 688239 & 4.5362 & 5.6879 & TST & & \\
\hline CHEMBL1567297 & 688239 & 5.2362 & 5.4544 & TST & & \\
\hline CHEMBL1572652 & 688239 & 8.28399 & 99999999 & 99 & 5.5795 & \\
\hline CHEMBL 3213212 & 688239 & 5.9862 & 5.4989 & TRN & & \\
\hline CHEMBL1515313 & 688239 & 6.0862 & 5.5659 & TRN & & \\
\hline CHEMBL1522073 & 688239 & 5.1862 & 5.4776 & TRN & & \\
\hline CHEMBL1536349 & 688239 & 5.1862 & 5.5973 & TRN & & \\
\hline CHEMBL 3208641 & 688239 & 8.28399 & 99999999 & 99 & 5.393 & \\
\hline CHEMBL1512724 & 688239 & 5.1862 & 5.45 & TRN & & \\
\hline CHEMBL1488273 & 688239 & 7.0862 & 5.4495 & TRN & & \\
\hline CHEMBL1553837 & 688239 & 4.7862 & 5.4254 & TST & & \\
\hline CHEMBL 2000218 & 688239 & 5.6862 & 5.3557 & TST & & \\
\hline CHEMBL1576560 & 688239 & 6.1362 & 5.4575 & TST & & \\
\hline CHEMBL1457360 & 688239 & 5.6862 & 5.4383 & TRN & & \\
\hline CHEMBL1520385 & 688239 & 5.0862 & 5.5952 & TST & & \\
\hline CHEMBL1395743 & 688239 & 5.0862 & 5.5332 & TRN & & \\
\hline CHEMBL1485614 & 688239 & 4.5362 & 5.5776 & TRN & & \\
\hline CHEMBL1477261 & 688239 & 4.5362 & 5.5506 & TRN & & \\
\hline CHEMBL1590413 & 688239 & 5.2862 & 5.5044 & TRN & & \\
\hline CHEMBL1423110 & 688239 & 5.4862 & 5.5205 & TRN & & \\
\hline CHEMBL1339324 & 688239 & 5.9862 & 5.3832 & TRN & & \\
\hline CHEMBL1613216 & 688239 & 4.5362 & 5.3478 & TRN & & \\
\hline CHEMBL1310835 & 688239 & 4.7362 & 5.5454 & TRN & & \\
\hline CHEMBL1388923 & 688239 & 6.2362 & 5.5872 & TRN & & \\
\hline CHEMBL1530738 & 688239 & 6.7862 & 5.4946 & TST & & \\
\hline CHEMBL1565303 & 688239 & 5.3862 & 5.4503 & TRN & & \\
\hline CHEMBL1599756 & 688239 & 4.7362 & 5.5301 & TRN & & \\
\hline CHEMBL1323632 & 688239 & 5.1862 & 5.6448 & TRN & & \\
\hline CHEMBL 3191797 & 688239 & 5.2362 & 5.4977 & TRN & & \\
\hline
\end{tabular}

Page 1523 
Supplemental Table S2.txt

\begin{tabular}{|c|c|c|c|c|}
\hline CHEMBL1530273 & 688239 & 4.5362 & 5.4794 & TRN \\
\hline CHEMBL1459374 & 688239 & 4.5362 & 5.5526 & TST \\
\hline CHEMBL1495955 & 688239 & 6.0862 & 5.5216 & TRN \\
\hline CHEMBL1495592 & 688239 & 4.5362 & 5.4558 & TRN \\
\hline CHEMBL1503720 & 688239 & 4.4862 & 5.3403 & TRN \\
\hline CHEMBL1556984 & 688239 & 5.9362 & 5.4164 & TST \\
\hline CHEMBL1612317 & 688239 & 4.7862 & 5.5495 & TRN \\
\hline CHEMBL1427985 & 688239 & 5.1862 & 5.3921 & TST \\
\hline CHEMBL1476647 & 688239 & 4.5862 & 5.4568 & TRN \\
\hline CHEMBL1558953 & 688239 & 4.6362 & 5.5028 & TRN \\
\hline CHEMBL1423575 & 688239 & 4.5362 & 5.3135 & TST \\
\hline CHEMBL1441860 & 688239 & 6.5862 & 5.5899 & TRN \\
\hline CHEMBL1605129 & 688239 & 4.5362 & 5.5907 & TRN \\
\hline CHEMBL1579957 & 688239 & 6.1862 & 5.4768 & TRN \\
\hline CHEMBL1511759 & 688239 & 6.6362 & 5.584 & TST \\
\hline CHEMBL1333407 & 688239 & 4.5362 & 5.4053 & TRN \\
\hline CHEMBL1427701 & 688239 & 6.6861 & 5.4813 & TRN \\
\hline CHEMBL1364506 & 688239 & 5.4362 & 5.6037 & TRN \\
\hline CHEMBL1375651 & 688239 & 4.5362 & 5.478 & TST \\
\hline CHEMBL1999738 & 688239 & 4.6362 & 5.5003 & TST \\
\hline CHEMBL1369724 & 688239 & 4.7862 & 5.4123 & TRN \\
\hline CHEMBL1579217 & 688239 & 4.7362 & 5.39 & TRN \\
\hline CHEMBL1441096 & 688239 & 5.6362 & 5.4528 & TRN \\
\hline CHEMBL1350139 & 688239 & 6.7862 & 5.4843 & TST \\
\hline CHEMBL1504972 & 688239 & 4.5862 & 5.3591 & TRN \\
\hline CHEMBL1571738 & 688239 & 6.0862 & 5.4583 & TRN \\
\hline CHEMBL1502893 & 688239 & 6.4362 & 5.6289 & TST \\
\hline CHEMBL1504952 & 688239 & 5.5362 & 5.4911 & TRN \\
\hline CHEMBL1578515 & 688239 & 4.5362 & 5.4778 & TRN \\
\hline CHEMBL1391884 & 688239 & 6.0 & 5.439 & TRN \\
\hline CHEMBL1376998 & 688239 & 6.2862 & 5.4564 & TRN \\
\hline CHEMBL1485160 & 688239 & 4.6862 & 5.4523 & TRN \\
\hline CHEMBL1601953 & 688239 & 6.8362 & 5.4206 & TST \\
\hline CHEMBL1369204 & 688239 & 4.5362 & 5.4093 & TRN \\
\hline CHEMBL1382039 & 688239 & 6.2862 & 5.3701 & TRN \\
\hline CHEMBL1549583 & 688239 & 6.8861 & 5.7712 & TRN \\
\hline CHEMBL1570253 & 688239 & 8.3372 & 5.5458 & TRN \\
\hline CHEMBL1410642 & 688239 & 4.6362 & 5.2919 & TRN \\
\hline CHEMBL1580649 & 688239 & 4.7362 & 5.5338 & TRN \\
\hline CHEMBL1309506 & 688239 & 4.5362 & 5.6451 & TRN \\
\hline CHEMBL1558140 & 688239 & 5.5862 & 5.4352 & TRN \\
\hline CHEMBL1470500 & 688239 & 5.7362 & 5.3227 & TRN \\
\hline CHEMBL1310686 & 688239 & 6.2362 & 5.4963 & TST \\
\hline CHEMBL1389077 & 688239 & 7.5361 & 5.3561 & TRN \\
\hline CHEMBL1466204 & 688239 & 5.1862 & 5.541 & TST \\
\hline CHEMBL1349958 & 688239 & 6.1862 & 5.50799 & 9999999999 \\
\hline CHEMBL1345839 & 688239 & 5.1862 & 5.3948 & TRN \\
\hline CHEMBL1440913 & 688239 & 4.7362 & 5.5877 & TRN \\
\hline
\end{tabular}

Page 1524 
Supplemental Table S2.txt

\begin{tabular}{|c|c|c|c|c|}
\hline CHEMBL1510037 & 688239 & 4.5862 & 5.5675 & TST \\
\hline CHEMBL1480281 & 688239 & 4.5362 & 5.6298 & TRN \\
\hline CHEMBL1341937 & 688239 & 4.9362 & 5.5329 & TST \\
\hline CHEMBL1331862 & 688239 & 4.5362 & 5.4684 & TRN \\
\hline CHEMBL1572356 & 688239 & 6.2862 & 5.4828 & TRN \\
\hline CHEMBL1412896 & 688239 & 4.9362 & 5.4428 & TRN \\
\hline CHEMBL 2007273 & 688239 & 4.7862 & 5.4389 & TRN \\
\hline CHEMBL3191125 & 688239 & 6.0862 & 5.3892 & TRN \\
\hline CHEMBL1414639 & 688239 & 4.8362 & 5.3532 & TRN \\
\hline CHEMBL1343759 & 688239 & 4.6862 & 5.4257 & TST \\
\hline CHEMBL1539372 & 688239 & 5.5362 & 5.3744 & TRN \\
\hline CHEMBL1435380 & 688239 & 5.4862 & 5.49799 & 9999999999 \\
\hline CHEMBL1335206 & 688239 & 4.7862 & 5.4887 & TST \\
\hline CHEMBL1424732 & 688239 & 4.5362 & 5.3896 & TST \\
\hline CHEMBL1469029 & 688239 & 4.7362 & 5.4801 & TST \\
\hline CHEMBL1310786 & 688239 & 6.1862 & 5.4937 & TRN \\
\hline CHEMBL1336140 & 688239 & 4.6862 & 5.4525 & TRN \\
\hline CHEMBL1607418 & 688239 & 4.6362 & 5.4011 & TRN \\
\hline CHEMBL1613578 & 688239 & 5.2862 & 5.4239 & TST \\
\hline CHEMBL1550078 & 688239 & 6.3362 & 5.5808 & TRN \\
\hline CHEMBL1562580 & 688239 & 4.7362 & 5.4071 & TRN \\
\hline CHEMBL1597505 & 688239 & 5.1862 & 5.475 & TRN \\
\hline CHEMBL1551756 & 688239 & 4.5362 & 5.4413 & TRN \\
\hline CHEMBL1355810 & 688239 & 6.7862 & 5.2888 & TST \\
\hline CHEMBL1494648 & 688239 & 4.5362 & 5.5071 & TRN \\
\hline CHEMBL1413606 & 688239 & 4.6362 & 5.4125 & TST \\
\hline CHEMBL1334328 & 688239 & 4.5362 & 5.4338 & TRN \\
\hline CHEMBL 2003998 & 688239 & 4.5362 & 5.461 & TRN \\
\hline CHEMBL497568 & 688239 & 5.3362 & 5.454 & TRN \\
\hline CHEMBL1509964 & 688239 & 4.5362 & 5.5803 & TRN \\
\hline CHEMBL1383930 & 688239 & 4.7862 & 5.4535 & TRN \\
\hline CHEMBL1332553 & 688239 & 5.6362 & 5.4047 & TST \\
\hline CHEMBL 3145098 & 688239 & 6.1862 & 5.5268 & TRN \\
\hline CHEMBL1451124 & 688239 & 5.7862 & 5.5284 & TST \\
\hline CHEMBL1526364 & 688239 & 4.5862 & 5.5814 & TRN \\
\hline CHEMBL1417770 & 688239 & 6.2862 & 5.3134 & TRN \\
\hline CHEMBL1424973 & 688239 & 5.1862 & 5.3266 & TST \\
\hline CHEMBL1480198 & 688239 & 5.4862 & 5.3745 & TRN \\
\hline CHEMBL1392460 & 688239 & 4.5362 & 5.5293 & TST \\
\hline CHEMBL1490684 & 688239 & 5.6862 & 5.4002 & TRN \\
\hline CHEMBL1581364 & 688239 & 4.6362 & 5.2999 & TRN \\
\hline CHEMBL1303369 & 688239 & 5.3862 & 5.6239 & TST \\
\hline CHEMBL1560405 & 688239 & 6.0862 & 5.58 & TST \\
\hline CHEMBL1535721 & 688239 & 4.5362 & 5.5319 & TRN \\
\hline CHEMBL1576592 & 688239 & 5.6362 & 5.5538 & TRN \\
\hline CHEMBL1607266 & 688239 & 6.9863 & 5.5218 & TRN \\
\hline CHEMBL1499335 & 688239 & 5.3862 & 5.6492 & TRN \\
\hline CHEMBL1400084 & 688239 & 5.4862 & 5.3914 & TST \\
\hline
\end{tabular}


Supplemental Table S2.txt

\begin{tabular}{|c|c|c|c|c|}
\hline HEN & & 6862 & 5.5524 & \\
\hline & & .1862 & 5.5667 & \\
\hline-2 & & & & \\
\hline IEMBL1 & & & & \\
\hline AEMBL 14 & 8239 & & 3602 & \\
\hline HEMBL1342764 & 88239 & 1862 & 3925 & \\
\hline HEMBL] & 239 & 862 & & \\
\hline 2635 & & & & \\
\hline AEMBL1313288 & 239 & 362 & & \\
\hline HEMBL1503118 & 88239 & 362 & & \\
\hline HEMBL1344224 & 239 & 862 & & \\
\hline IEMBL1 & 239 & 362 & & \\
\hline IEMBL: & & & & \\
\hline HEMBL1 & & 862 & & \\
\hline IEMBL1446932 & & & & \\
\hline AEMBL1 & 39 & 63 & 69 & \\
\hline AEMBL1 & & & & \\
\hline HEMBL1 & & & & \\
\hline 8885 & & 62 & & \\
\hline IEMBL1 & & & & \\
\hline HEMBL: & & 52 & & Niv \\
\hline AEMBL & & & & RN \\
\hline HEMBL: & & 62 & & \\
\hline 7975 & & & & \\
\hline IEMBL1 & & & & $\Gamma \mathrm{RN}$ \\
\hline AEMBL: & & & & RN \\
\hline 351 & & & & 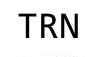 \\
\hline 605 & & & & \\
\hline AEMBL1 & & & & in \\
\hline HEMBL1421581 & & & & I RN \\
\hline HEMBL1 & & & & RIV \\
\hline HEMBL & & & & ST \\
\hline 10 & & & & (ng) \\
\hline HEMBL1 & & & & R \\
\hline HEMBL1424179 & & & & TRN \\
\hline HEMBL & & & & Niv \\
\hline HCMDI & & & & \\
\hline HEMBL: & & & & ГRN \\
\hline HEMBL3196238 & 88239 & 362 & & TRN \\
\hline IEMBL1 & & & & TST \\
\hline HEMBL1 & & 52 & & \\
\hline HEMBL1 & & & & TRN \\
\hline HEMBL1 & & 362 & & RN \\
\hline AEMBL1346960 & 39 & 362 & 3608 & TR \\
\hline MBL1 & & & & $\mathrm{N}$ \\
\hline HEMBL1 & & & & \\
\hline HEMBL1 & & & & \\
\hline HEMBL158723 & 688239 & 5.1362 & 5.6473 & \\
\hline
\end{tabular}

Page 1526 
Supplemental Table S2.txt

\begin{tabular}{|c|c|c|c|c|}
\hline CHEMBL1439058 & 688239 & 5.0362 & 5.2869 & TST \\
\hline CHEMBL1574219 & 688239 & 4.7862 & 5.4899 & TST \\
\hline CHEMBL1329392 & 688239 & 4.4862 & 5.4222 & TRN \\
\hline CHEMBL1508222 & 688239 & 5.1862 & 5.4281 & TST \\
\hline CHEMBL1449809 & 688239 & 6.4362 & 5.5606 & TST \\
\hline CHEMBL1574874 & 688239 & 4.4862 & 5.4513 & TST \\
\hline CHEMBL1427916 & 688239 & 5.9862 & 5.5122 & TRN \\
\hline CHEMBL1610250 & 688239 & 5.1362 & 5.5212 & TRN \\
\hline CHEMBL1537862 & 688239 & 4.7862 & 5.4916 & TRN \\
\hline CHEMBL1382612 & 688239 & 5.9862 & 5.5048 & TST \\
\hline CHEMBL1602730 & 688239 & 4.5862 & 5.2716 & TRN \\
\hline CHEMBL1389173 & 688239 & 5.1362 & 5.403 & TRN \\
\hline CHEMBL1498145 & 688239 & 4.6362 & 5.5793 & TRN \\
\hline CHEMBL1381299 & 688239 & 4.7862 & 5.5907 & TST \\
\hline CHEMBL1442507 & 688239 & 4.7362 & 5.4713 & TRN \\
\hline CHEMBL1452927 & 688239 & 5.9362 & 5.5029 & TRN \\
\hline CHEMBL1437129 & 688239 & 5.3862 & 5.477 & TRN \\
\hline CHEMBL1498023 & 688239 & 4.7862 & 5.4683 & TRN \\
\hline CHEMBL1426156 & 688239 & 5.4362 & 5.3465 & TRN \\
\hline CHEMBL1586738 & 688239 & 5.4362 & 5.4981 & TRN \\
\hline CHEMBL1612325 & 688239 & 4.5862 & 5.5835 & TST \\
\hline CHEMBL1452031 & 688239 & 6.9863 & 5.4546 & TST \\
\hline CHEMBL1466548 & 688239 & 5.4362 & 5.46700 & 00000000005 \\
\hline CHEMBL1333476 & 688239 & 5.2362 & 5.5662 & TST \\
\hline CHEMBL1406558 & 688239 & 8.3372 & 5.5485 & TRN \\
\hline CHEMBL1471949 & 688239 & 6.4362 & 5.5529 & TRN \\
\hline CHEMBL1418496 & 688239 & 5.2362 & 5.3828 & TST \\
\hline CHEMBL1446679 & 688239 & 4.5362 & 5.5185 & TRN \\
\hline CHEMBL1526276 & 688239 & 6.1862 & 5.5701 & TST \\
\hline CHEMBL1499077 & 688239 & 5.1862 & 5.5807 & TST \\
\hline CHEMBL1368132 & 688239 & 4.6362 & 5.5193 & TRN \\
\hline CHEMBL1427564 & 688239 & 4.8862 & 5.4618 & TST \\
\hline CHEMBL1556894 & 688239 & 4.5362 & 5.6099 & TRN \\
\hline CHEMBL1305951 & 688239 & 5.4362 & 5.3685 & TST \\
\hline CHEMBL1305259 & 688239 & 4.5362 & 5.4984 & TRN \\
\hline CHEMBL1517476 & 688239 & 6.8362 & 5.5636 & TRN \\
\hline CHEMBL1476205 & 688239 & 7.2865 & 5.6097 & TRN \\
\hline CHEMBL1574932 & 688239 & 5.7362 & 5.5494 & TST \\
\hline CHEMBL1470788 & 688239 & 5.9362 & 5.4632 & TRN \\
\hline CHEMBL1395461 & 688239 & 5.8862 & 5.5477 & TRN \\
\hline CHEMBL1304299 & 688239 & 6.1362 & 5.6399 & TRN \\
\hline CHEMBL1597501 & 688239 & 4.5362 & 5.5114 & TRN \\
\hline CHEMBL1358884 & 688239 & 4.5362 & 5.817 & TRN \\
\hline CHEMBL1447009 & 688239 & 5.9862 & 5.5182 & TRN \\
\hline CHEMBL1330122 & 688239 & 5.1862 & 5.55399 & э999999999 \\
\hline CHEMBL1441188 & 688239 & 5.6862 & 5.5457 & TRN \\
\hline CHEMBL1466591 & 688239 & 5.0862 & 5.5263 & TRN \\
\hline CHEMBL1973139 & 688239 & 4.6862 & 5.3984 & TRN \\
\hline
\end{tabular}


Supplemental Table S2.txt

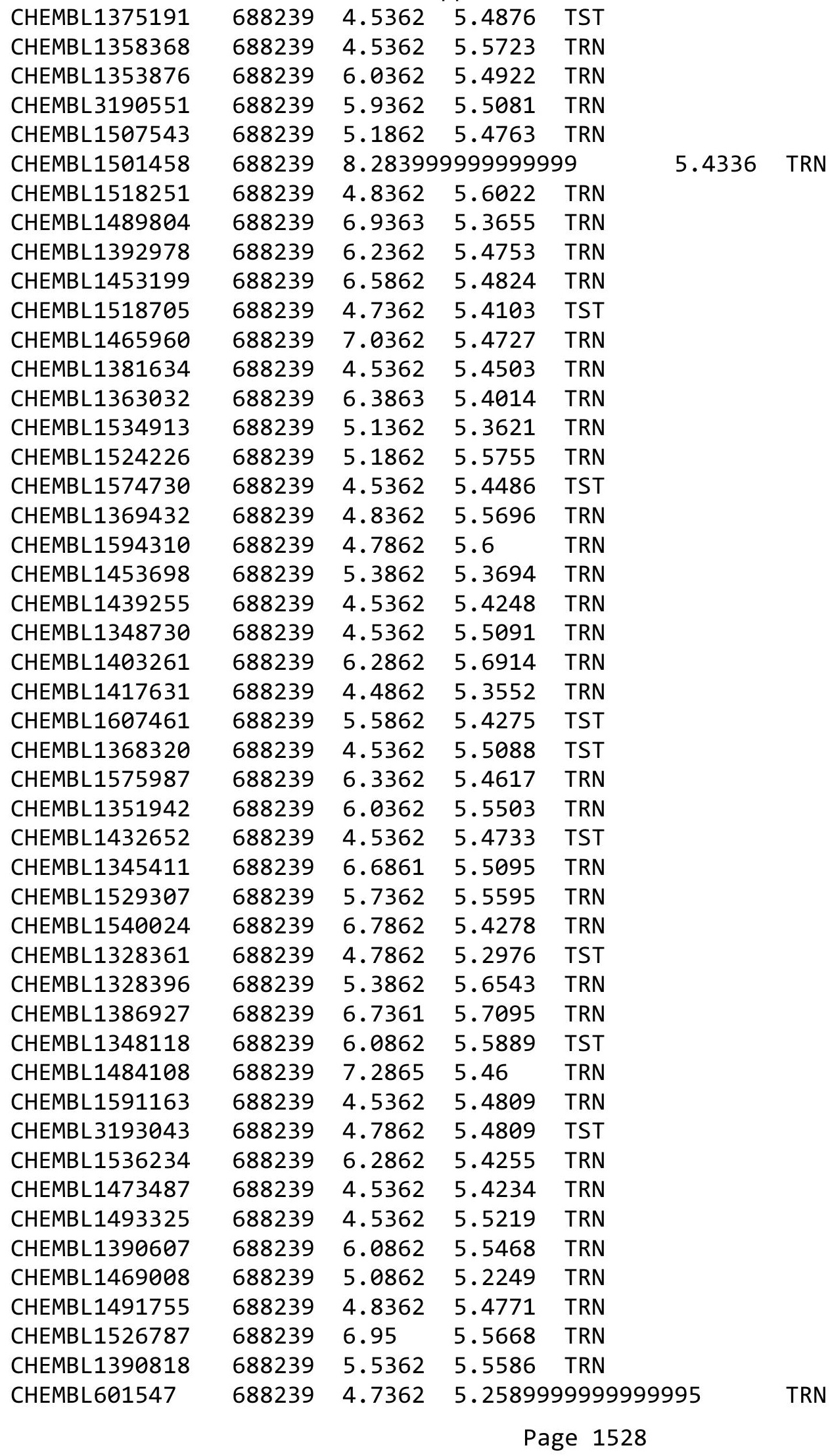


Supplemental Table S2.txt

\begin{tabular}{|c|c|c|c|c|}
\hline CHEMBL182490 & 688239 & 4.5862 & 5.568 & TST \\
\hline CHEMBL1540068 & 688239 & 4.7362 & 5.5431 & TRN \\
\hline CHEMBL1422006 & 688239 & 5.4362 & 5.5601 & TRN \\
\hline CHEMBL1476140 & 688239 & 5.4362 & 5.615 & TRN \\
\hline CHEMBL1328118 & 688239 & 5.0862 & 5.263 & TRN \\
\hline CHEMBL1413533 & 688239 & 5.3862 & 5.4465 & TST \\
\hline CHEMBL1542992 & 688239 & 8.3372 & 5.5969 & TST \\
\hline CHEMBL1341239 & 688239 & 4.6862 & 5.4845 & TRN \\
\hline CHEMBL1380103 & 688239 & 4.8862 & 5.4674 & TRN \\
\hline CHEMBL1337741 & 688239 & 6.1362 & \multicolumn{2}{|c|}{5.377999999999999} \\
\hline CHEMBL1432099 & 688239 & 4.7362 & 5.4774 & TRN \\
\hline CHEMBL1441759 & 688239 & 4.8862 & 5.5852 & TRN \\
\hline CHEMBL1369838 & 688239 & 5.6362 & 5.4642 & TRN \\
\hline CHEMBL1428124 & 688239 & 4.6862 & 5.4013 & TRN \\
\hline CHEMBL1548089 & 688239 & 5.1862 & 5.4786 & TRN \\
\hline CHEMBL1592669 & 688239 & 5.8362 & 5.5929 & TRN \\
\hline CHEMBL1469586 & 688239 & 6.4862 & 5.6029 & TST \\
\hline CHEMBL1437865 & 688239 & 5.4362 & 5.4834 & TRN \\
\hline CHEMBL1512790 & 688239 & 5.1362 & 5.2597 & TRN \\
\hline CHEMBL1419074 & 688239 & 5.35 & 5.5913 & TRN \\
\hline CHEMBL1343625 & 688239 & 5.2362 & 5.619 & TRN \\
\hline CHEMBL1424760 & 688239 & 4.7362 & 5.6134 & TRN \\
\hline CHEMBL1403272 & 688239 & 5.6862 & 5.6552 & TRN \\
\hline CHEMBL1415689 & 688239 & 6.4862 & 5.4211 & TRN \\
\hline CHEMBL1442898 & 688239 & 5.6862 & 5.3878 & TRN \\
\hline CHEMBL1509418 & 688239 & 4.7362 & 5.6082 & TRN \\
\hline CHEMBL1364307 & 688239 & 4.8862 & 5.4701 & TRN \\
\hline CHEMBL1483365 & 688239 & 5.8862 & 5.652 & TRN \\
\hline CHEMBL1433154 & 688239 & 7.2865 & 5.7441 & TRN \\
\hline CHEMBL1519770 & 688239 & 5.7362 & 5.4894 & TST \\
\hline CHEMBL1448233 & 688239 & 4.5362 & 5.4833 & TRN \\
\hline CHEMBL1568089 & 688239 & 5.5362 & 5.3708 & TRN \\
\hline CHEMBL1588357 & 688239 & 5.3862 & 5.5748 & TRN \\
\hline CHEMBL1587940 & 688239 & 5.2362 & 5.6848 & TRN \\
\hline CHEMBL1561636 & 688239 & 8.2366 & 5.5331 & TST \\
\hline CHEMBL1412115 & 688239 & 6.8362 & 5.4789 & TST \\
\hline CHEMBL1613573 & 688239 & 4.5362 & 5.4819 & TRN \\
\hline CHEMBL1574614 & 688239 & 4.9362 & 5.4896 & TRN \\
\hline CHEMBL1334772 & 688239 & 5.5362 & 5.4391 & TST \\
\hline CHEMBL1381408 & 688239 & 5.6362 & 5.38200 & 0000000001 \\
\hline CHEMBL1375495 & 688239 & 4.5362 & 5.6144 & TRN \\
\hline CHEMBL1585118 & 688239 & 6.7361 & 5.6164 & TRN \\
\hline CHEMBL1594921 & 688239 & 4.4862 & 5.5884 & TRN \\
\hline CHEMBL1433403 & 688239 & 5.7362 & 5.4364 & TRN \\
\hline CHEMBL1605163 & 688239 & 5.6862 & 5.636 & TST \\
\hline CHEMBL1313045 & 688239 & 5.4362 & 5.6415 & TRN \\
\hline CHEMBL1540673 & 688239 & 4.7362 & 5.5041 & TRN \\
\hline CHEMBL1307622 & 688239 & 4.6862 & 5.6045 & TRN \\
\hline
\end{tabular}

Page 1529 


\begin{tabular}{|c|c|c|c|c|c|}
\hline \multicolumn{6}{|c|}{ Supplemental Table s2.txt } \\
\hline CHEMBL1489840 & 688239 & 5.2862 & 5.5399 & TRN & \\
\hline CHEMBL1553500 & 688239 & 6.6861 & 5.471 & TRN & \\
\hline CHEMBL1450391 & 688239 & 4.6362 & 5.4604 & TRN & \\
\hline CHEMBL1557290 & 688239 & 5.5362 & 5.4424 & TRN & \\
\hline CHEMBL1313459 & 688239 & 6.1862 & 5.2788 & TRN & \\
\hline CHEMBL8739 & 688239 & 4.5362 & 5.5072 & TST & \\
\hline CHEMBL1583106 & 688239 & 5.1362 & 5.6076 & TRN & \\
\hline CHEMBL1519862 & 688239 & 5.3362 & 5.3559 & TRN & \\
\hline CHEMBL 3198395 & 688239 & 6.8362 & 5.3155 & TST & \\
\hline CHEMBL1344120 & 688239 & 4.6862 & 5.6033 & TST & \\
\hline CHEMBL1469916 & 688239 & 5.4362 & 5.398 & TRN & \\
\hline CHEMBL1363856 & 688239 & 5.1862 & 5.4842 & TRN & \\
\hline CHEMBL 3196261 & 688239 & 5.6862 & 5.5336 & TRN & \\
\hline CHEMBL1385826 & 688239 & 5.4862 & 5.4851 & TRN & \\
\hline CHEMBL1506075 & 688239 & 5.1862 & 5.4563 & TRN & \\
\hline CHEMBL1995365 & 688239 & 5.4862 & 5.5949 & TRN & \\
\hline CHEMBL1600941 & 688239 & 5.6862 & 5.5103 & TRN & \\
\hline CHEMBL1362792 & 688239 & 5.7362 & 5.6098 & TRN & \\
\hline CHEMBL1499996 & 688239 & 4.5362 & 5.6167 & TRN & \\
\hline CHEMBL1552866 & 688239 & 4.5362 & 5.4146 & TRN & \\
\hline CHEMBL1362371 & 688239 & 5.2362 & 5.4379 & TST & \\
\hline CHEMBL1549135 & 688239 & 5.7862 & 5.5249 & TRN & \\
\hline CHEMBL585462 & 688239 & 4.8862 & 5.4797 & TRN & \\
\hline CHEMBL1323203 & 688239 & 4.6862 & 5.4873 & TRN & \\
\hline CHEMBL1460014 & 688239 & 5.4362 & 5.5068 & TST & \\
\hline CHEMBL1594909 & 688239 & 5.1862 & 5.5306 & TRN & \\
\hline CHEMBL1477839 & 688239 & 5.9862 & 5.53100 & 0000000001 & TST \\
\hline CHEMBL1463286 & 688239 & 4.4862 & 5.726 & TRN & \\
\hline CHEMBL1577512 & 688239 & 4.6862 & 5.477 & TRN & \\
\hline CHEMBL1506067 & 688239 & 4.8362 & 5.5104 & TRN & \\
\hline CHEMBL1584197 & 688239 & 6.4862 & 5.4796 & TRN & \\
\hline CHEMBL1370172 & 688239 & 6.7361 & 5.3942 & TRN & \\
\hline CHEMBL1550521 & 688239 & 5.1362 & 5.32 & TST & \\
\hline CHEMBL1441792 & 688239 & 6.3362 & 5.3761 & TRN & \\
\hline CHEMBL1344187 & 688239 & 6.95 & 5.5734 & TRN & \\
\hline CHEMBL1994963 & 688239 & 6.0862 & 5.3179 & TRN & \\
\hline CHEMBL1599967 & 688239 & 6.4862 & 5.3848 & TRN & \\
\hline CHEMBL3208547 & 688239 & 5.6362 & 5.5151 & TST & \\
\hline CHEMBL1528292 & 688239 & 4.6862 & 5.5191 & TRN & \\
\hline CHEMBL1343422 & 688239 & 5.1362 & 5.2817 & TRN & \\
\hline CHEMBL1337862 & 688239 & 5.0862 & 5.5951 & TRN & \\
\hline CHEMBL1440412 & 688239 & 4.7362 & 5.402 & TST & \\
\hline CHEMBL1568915 & 688239 & 4.5362 & 5.3733 & TST & \\
\hline CHEMBL1419438 & 688239 & 4.6862 & 5.4363 & TRN & \\
\hline CHEMBL1404165 & 688239 & 6.7361 & 5.5829 & TRN & \\
\hline CHEMBL1559327 & 688239 & 4.5362 & 5.5581 & TRN & \\
\hline CHEMBL1346997 & 688239 & 4.6362 & 5.5378 & TRN & \\
\hline CHEMBL1474066 & 688239 & 5.5862 & 5.431 & TRN & \\
\hline
\end{tabular}


Supplemental Table S2.txt

\begin{tabular}{|c|c|c|c|c|c|c|}
\hline CHEMBL1419393 & 688239 & 6.2362 & 5.4501 & TRN & & \\
\hline CHEMBL1430074 & 688239 & 4.4862 & 5.41299 & 9999999999 & & נו \\
\hline CHEMBL1494658 & 688239 & 5.7362 & 5.4164 & TST & & \\
\hline CHEMBL1419767 & 688239 & 5.3862 & 5.5055 & TRN & & \\
\hline CHEMBL3192950 & 688239 & 6.8861 & 5.4825 & TRN & & \\
\hline CHEMBL1418934 & 688239 & 7.2366 & 5.5853 & TST & & \\
\hline CHEMBL1547395 & 688239 & 4.7362 & 5.3795 & TRN & & \\
\hline CHEMBL1519405 & 688239 & 4.4862 & 5.4881 & TRN & & \\
\hline CHEMBL1601991 & 688239 & 6.5862 & 5.655 & TRN & & \\
\hline CHEMBL1397934 & 688239 & 8.28399 & 99999999 & 99 & 5.3833 & $\mathrm{TR}$ \\
\hline CHEMBL1587212 & 688239 & 4.4862 & 5.5747 & TRN & & \\
\hline CHEMBL1585404 & 688239 & 4.7862 & 5.5313 & TRN & & \\
\hline CHEMBL1384794 & 688239 & 5.1862 & 5.5517 & TST & & \\
\hline CHEMBL1455430 & 688239 & 4.5362 & 5.5313 & TST & & \\
\hline CHEMBL1594995 & 688239 & 4.5362 & 5.5285 & TRN & & \\
\hline CHEMBL3192996 & 688239 & 6.1862 & 5.4686 & TRN & & \\
\hline CHEMBL1377158 & 688239 & 6.8861 & 5.5659 & TRN & & \\
\hline CHEMBL1492242 & 688239 & 7.1361 & 5.4249 & TRN & & \\
\hline CHEMBL1480578 & 688239 & 6.2862 & 5.6297 & TST & & \\
\hline CHEMBL1514872 & 688239 & 4.5362 & 5.5408 & TST & & \\
\hline CHEMBL270362 & 688239 & 4.7362 & 5.4425 & TST & & \\
\hline CHEMBL1583401 & 688239 & 4.5362 & 5.5696 & TRN & & \\
\hline CHEMBL1470402 & 688239 & 6.7862 & 5.6708 & TRN & & \\
\hline CHEMBL1407992 & 688239 & 6.7862 & 5.4941 & TRN & & \\
\hline CHEMBL1583718 & 688239 & 6.2362 & 5.6416 & TRN & & \\
\hline CHEMBL1579560 & 688239 & 4.7862 & 5.5662 & TRN & & \\
\hline CHEMBL1360570 & 688239 & 6.0862 & 5.6247 & TRN & & \\
\hline CHEMBL1515763 & 688239 & 4.5862 & \multicolumn{3}{|c|}{5.492000000000001} & \\
\hline CHEMBL1586635 & 688239 & 5.3362 & 5.4567 & TRN & & \\
\hline CHEMBL1358281 & 688239 & 5.4362 & 5.5208 & TRN & & \\
\hline CHEMBL1352557 & 688239 & 4.6362 & 5.3025 & TRN & & \\
\hline CHEMBL1428367 & 688239 & 6.2362 & 5.4165 & TST & & \\
\hline CHEMBL1422972 & 688239 & 6.3362 & 5.6624 & TRN & & \\
\hline CHEMBL1534677 & 688239 & 6.3362 & 5.6229 & TRN & & \\
\hline CHEMBL1503359 & 688239 & 4.9862 & 5.4436 & TST & & \\
\hline CHEMBL1557540 & 688239 & 6.9863 & 5.3791 & TST & & \\
\hline CHEMBL1603384 & 688239 & 6.1362 & 5.4955 & TRN & & \\
\hline CHEMBL1438887 & 688239 & 6.7361 & 5.5527 & TRN & & \\
\hline CHEMBL1546046 & 688239 & 5.5862 & 5.5869 & TST & & \\
\hline CHEMBL1555237 & 688239 & 6.9363 & 5.6166 & TRN & & \\
\hline CHEMBL1516491 & 688239 & 5.3862 & 5.5041 & TRN & & \\
\hline CHEMBL1534309 & 688239 & 4.5362 & 5.5404 & TRN & & \\
\hline CHEMBL1518502 & 688239 & 6.5363 & 5.4193 & TRN & & \\
\hline CHEMBL1534350 & 688239 & 5.7362 & 5.5026 & TRN & & \\
\hline CHEMBL1402701 & 688239 & 7.1361 & 5.6055 & TRN & & \\
\hline CHEMBL1404637 & 688239 & 5.1862 & 5.4721 & TRN & & \\
\hline CHEMBL1470952 & 688239 & 5.6862 & 5.3692 & TRN & & \\
\hline CHEMBL1399417 & 688239 & 4.9362 & 5.5392 & TRN & & \\
\hline
\end{tabular}

Page 1531 
Supplemental Table S2.txt

\begin{tabular}{|c|c|c|c|c|c|}
\hline CHEMBL1427059 & 688239 & 4.9862 & 5.4074 & TRN & \\
\hline CHEMBL1577650 & 688239 & 4.5362 & 5.54 & TRN & \\
\hline CHEMBL1456918 & 688239 & 5.6862 & 5.5072 & TST & \\
\hline CHEMBL1348672 & 688239 & 4.9362 & 5.3605 & TST & \\
\hline CHEMBL1567588 & 688239 & 4.6862 & 5.4485 & TRN & \\
\hline CHEMBL1588769 & 688239 & 5.1362 & 5.3954 & TRN & \\
\hline CHEMBL1563759 & 688239 & 4.7362 & 5.4647 & TST & \\
\hline CHEMBL1484533 & 688239 & 5.4862 & 5.4117 & TRN & \\
\hline CHEMBL1376810 & 688239 & 6.1862 & 5.4775 & TRN & \\
\hline CHEMBL1537652 & 688239 & 5.2362 & 5.6143 & TST & \\
\hline CHEMBL1494402 & 688239 & 4.5362 & 5.5496 & TRN & \\
\hline CHEMBL1481208 & 688239 & 5.5362 & 5.622999 & 9999999999 & TRN \\
\hline CHEMBL1364771 & 688239 & 4.4862 & 5.3438 & TRN & \\
\hline CHEMBL1586780 & 688239 & 5.6362 & 5.4742 & TST & \\
\hline CHEMBL1539625 & 688239 & 4.7362 & 5.3748 & TST & \\
\hline CHEMBL1410952 & 688239 & 5.1862 & 5.4844 & TRN & \\
\hline CHEMBL1409622 & 688239 & 4.9862 & 5.5049 & TRN & \\
\hline CHEMBL1376340 & 688239 & 5.6362 & 5.4086 & TRN & \\
\hline CHEMBL1605457 & 688239 & 4.9362 & 5.4507 & TRN & \\
\hline CHEMBL1472320 & 688239 & 4.5362 & 5.6634 & TRN & \\
\hline CHEMBL1430808 & 688239 & 5.4362 & 5.4225 & TRN & \\
\hline CHEMBL1478296 & 688239 & 4.4862 & 5.3644 & TST & \\
\hline CHEMBL1471230 & 688239 & 5.9362 & 5.5133 & TRN & \\
\hline CHEMBL1440815 & 688239 & 5.6362 & 5.4596 & TRN & \\
\hline CHEMBL1437566 & 688239 & 4.6362 & 5.5594 & TRN & \\
\hline CHEMBL1543131 & 688239 & 4.5362 & 5.4412 & TRN & \\
\hline CHEMBL3198420 & 688239 & 4.6362 & 5.3557 & TRN & \\
\hline CHEMBL1483922 & 688239 & 4.7362 & 5.5527 & TRN & \\
\hline CHEMBL1548886 & 688239 & 5.6362 & 5.4191 & TRN & \\
\hline CHEMBL1455723 & 688239 & 6.9363 & 5.5692 & TRN & \\
\hline CHEMBL1584415 & 688239 & 4.6862 & 5.4586 & TRN & \\
\hline CHEMBL1496565 & 688239 & 4.5362 & 5.4304 & TST & \\
\hline CHEMBL1477103 & 688239 & 5.7862 & 5.3969 & TRN & \\
\hline CHEMBL1305864 & 688239 & 8.283999 & 999999999 & 5.4726 & 151 \\
\hline CHEMBL1516499 & 688239 & 4.7862 & 5.5477 & TRN & \\
\hline CHEMBL1558383 & 688239 & 6.9363 & 5.4166 & TST & \\
\hline CHEMBL1395871 & 688239 & 6.2362 & 5.5401 & TRN & \\
\hline CHEMBL1527043 & 688239 & 4.5862 & 5.4848 & TRN & \\
\hline CHEMBL1442811 & 688239 & 6.7361 & 5.6672 & TRN & \\
\hline CHEMBL1572649 & 688239 & 5.3362 & 5.5534 & TRN & \\
\hline CHEMBL1565158 & 688239 & 5.4362 & 5.4753 & TRN & \\
\hline CHEMBL1570101 & 688239 & 5.3862 & 5.4527 & TRN & \\
\hline CHEMBL1424512 & 688239 & 4.5362 & 5.4485 & TRN & \\
\hline CHEMBL1435209 & 688239 & 6.8362 & 5.5692 & TRN & \\
\hline CHEMBL3191391 & 688239 & 4.7862 & 5.3718 & TST & \\
\hline CHEMBL1300137 & 688239 & 4.7362 & 5.5039 & TRN & \\
\hline CHEMBL3210574 & 688239 & 6.1862 & 5.591 & TST & \\
\hline CHEMBL1507944 & 688239 & 6.0362 & 5.385 & TST & \\
\hline
\end{tabular}


Supplemental Table S2.txt

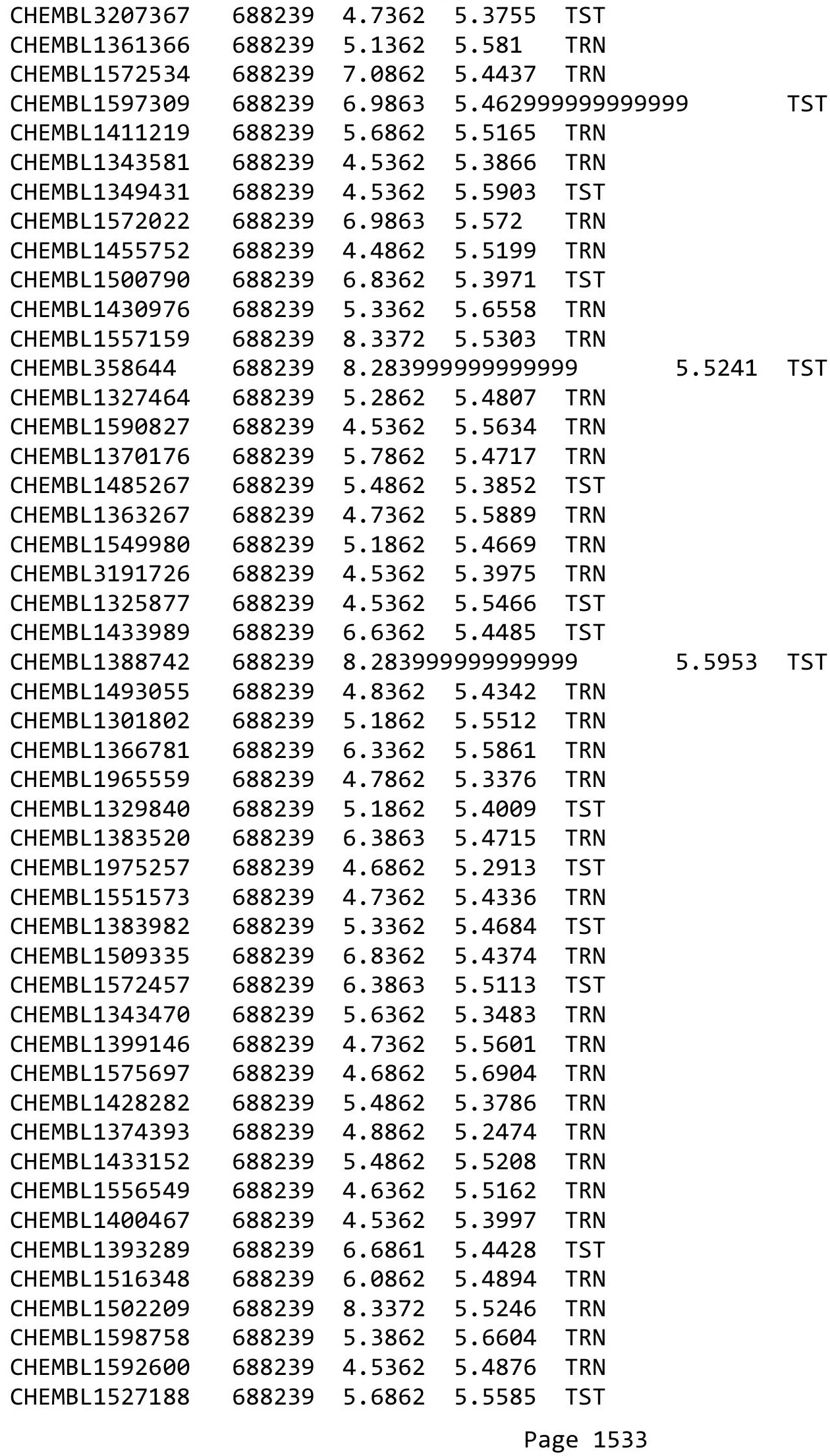


Supplemental Table S2.txt

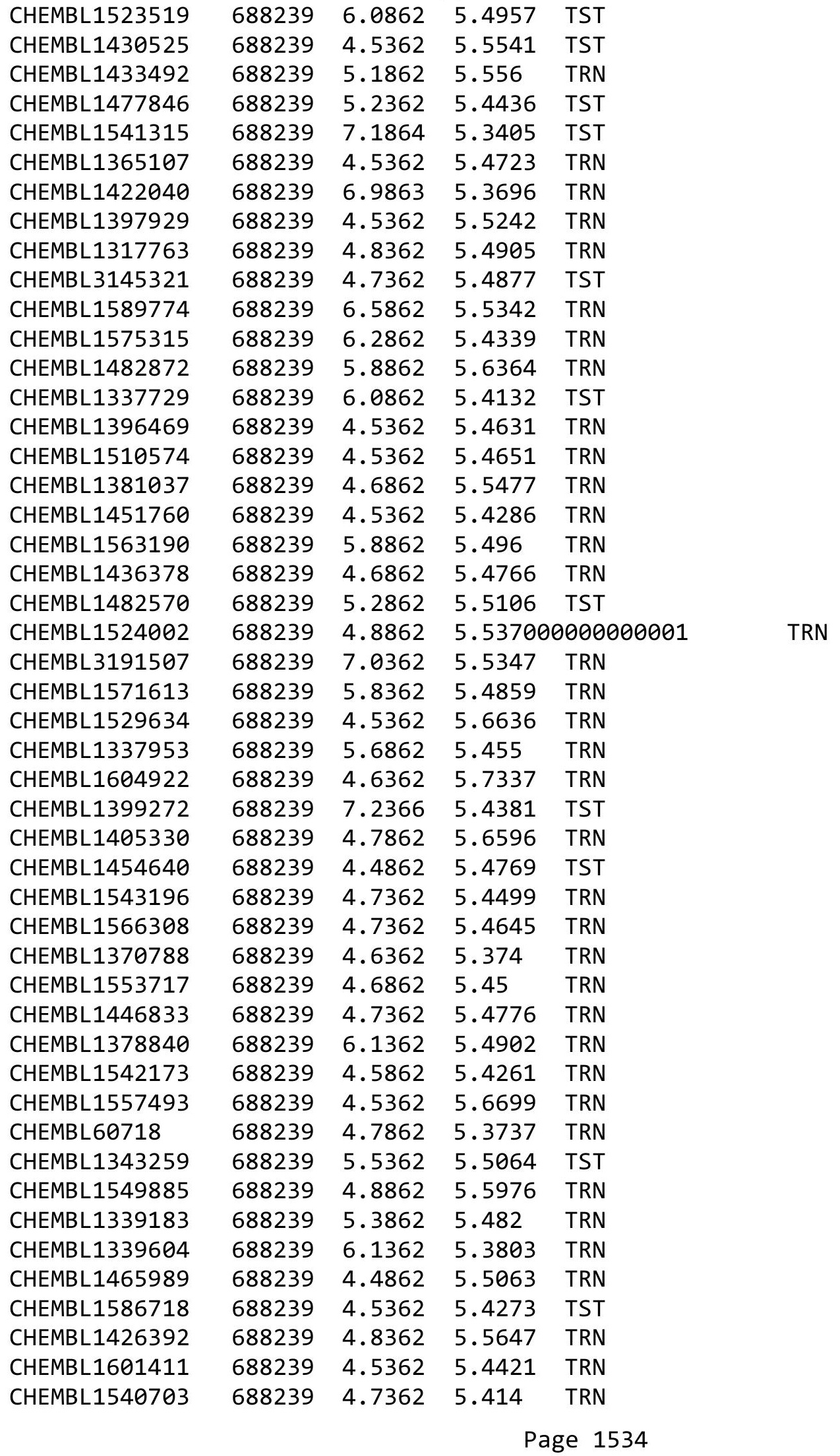


Supplemental Table S2.txt

\begin{tabular}{|c|c|c|c|c|c|}
\hline CHEMBL1398652 & 688239 & 5.1362 & 5.4958 & TST & \\
\hline CHEMBL1351088 & 688239 & 6.7361 & 5.5288 & TRN & \\
\hline CHEMBL1562415 & 688239 & 4.5362 & 5.435 & TST & \\
\hline CHEMBL1511271 & 688239 & 4.5862 & 5.5354 & TRN & \\
\hline CHEMBL1520941 & 688239 & 4.7862 & 5.478 & TST & \\
\hline CHEMBL1389243 & 688239 & 4.8362 & 5.4558 & TST & \\
\hline CHEMBL1420138 & 688239 & 5.4362 & 5.5222 & TRN & \\
\hline CHEMBL1354122 & 688239 & 4.5362 & 5.3578 & TST & \\
\hline CHEMBL1513854 & 688239 & 8.3372 & 5.4876 & TRN & \\
\hline CHEMBL1472149 & 688239 & 4.5362 & 5.4875 & TST & \\
\hline CHEMBL1555388 & 688239 & 5.3362 & 5.4364 & TRN & \\
\hline CHEMBL1402019 & 688239 & 4.6362 & 5.4183 & TRN & \\
\hline CHEMBL1439892 & 688239 & 6.1362 & 5.5164 & TRN & \\
\hline CHEMBL1523855 & 688239 & 5.1862 & 5.5049 & TRN & \\
\hline CHEMBL1419416 & 688239 & 7.0862 & 5.6189 & TRN & \\
\hline CHEMBL1304099 & 688239 & 5.2362 & 5.4593 & TRN & \\
\hline CHEMBL1423071 & 688239 & 5.1862 & 5.3941 & TRN & \\
\hline CHEMBL3193084 & 688239 & 4.45 & 5.5495 & TST & \\
\hline CHEMBL1484409 & 688239 & 6.3863 & 5.54700 & 0000000001 & TRN \\
\hline CHEMBL1451047 & 688239 & 4.6362 & 5.5056 & TRN & \\
\hline CHEMBL1338031 & 688239 & 5.7862 & 5.63 & TRN & \\
\hline CHEMBL1566089 & 688239 & 6.1362 & 5.4351 & TRN & \\
\hline CHEMBL1468805 & 688239 & 4.5362 & 5.36799 & 9999999999 & TRN \\
\hline CHEMBL1495922 & 688239 & 6.4862 & 5.4986 & TRN & \\
\hline CHEMBL1523024 & 688239 & 4.4862 & 5.5541 & TST & \\
\hline CHEMBL1361966 & 688239 & 7.0362 & 5.4048 & TRN & \\
\hline CHEMBL1311395 & 688239 & 4.5362 & 5.4049 & TST & \\
\hline CHEMBL1490316 & 688239 & 6.7361 & 5.6416 & TRN & \\
\hline CHEMBL1081819 & 688239 & 6.2362 & 5.6892 & TST & \\
\hline CHEMBL1507405 & 688239 & 4.6362 & 5.4456 & TRN & \\
\hline CHEMBL1487545 & 688239 & 5.1862 & 5.461 & TST & \\
\hline CHEMBL1341793 & 688239 & 5.9862 & 5.5137 & TRN & \\
\hline CHEMBL1448624 & 688239 & 5.7362 & 5.314 & TST & \\
\hline CHEMBL1505699 & 688239 & 5.1862 & 5.3497 & TST & \\
\hline CHEMBL3198133 & 688239 & 5.2362 & 5.4543 & TRN & \\
\hline CHEMBL1342598 & 688239 & 6.7862 & 5.4181 & TRN & \\
\hline CHEMBL1330504 & 688239 & 5.5862 & 5.4771 & TRN & \\
\hline CHEMBL1498252 & 688239 & 6.2862 & 5.5066 & TST & \\
\hline CHEMBL1324659 & 688239 & 4.5362 & 5.4364 & TRN & \\
\hline CHEMBL1338643 & 688239 & 4.5362 & 5.3515 & TRN & \\
\hline CHEMBL1612269 & 688239 & 4.4862 & 5.4924 & TRN & \\
\hline CHEMBL1547776 & 688239 & 4.6362 & 5.5126 & TRN & \\
\hline CHEMBL1521580 & 688239 & 5.1862 & 5.2889 & TRN & \\
\hline CHEMBL1375884 & 688239 & 5.1862 & 5.2711 & TRN & \\
\hline CHEMBL1318815 & 688239 & 8.3872 & 5.4604 & TRN & \\
\hline CHEMBL 238188 & 688239 & 4.7862 & 5.3878 & TST & \\
\hline CHEMBL3196120 & 688239 & 4.5362 & 5.4625 & TST & \\
\hline CHEMBL1566605 & 688239 & 5.3362 & 5.4157 & TRN & \\
\hline
\end{tabular}


Supplemental Table S2.txt

\begin{tabular}{|c|c|c|c|c|c|}
\hline CHEMBL1463487 & 688239 & 5.0362 & 5.471 & TRN & \\
\hline CHEMBL3213908 & 688239 & 6.8861 & 5.5556 & TRN & \\
\hline CHEMBL3144890 & 688239 & 5.1862 & 5.4578 & TRN & \\
\hline CHEMBL1579684 & 688239 & 5.1862 & 5.4789 & TRN & \\
\hline CHEMBL1581616 & 688239 & 4.5362 & 5.5427 & TRN & \\
\hline CHEMBL1431620 & 688239 & 6.2862 & 5.4555 & TST & \\
\hline CHEMBL602127 & 688239 & 4.7862 & 5.5621 & TST & \\
\hline CHEMBL1426596 & 688239 & 6.1362 & 5.4853 & TRN & \\
\hline CHEMBL1322446 & 688239 & 5.0862 & 5.5211 & TRN & \\
\hline CHEMBL1444048 & 688239 & 4.5362 & 5.5397 & TRN & \\
\hline CHEMBL1469223 & 688239 & 4.9862 & 5.5638 & TRN & \\
\hline CHEMBL1592531 & 688239 & 7.0362 & 5.5659 & TRN & \\
\hline CHEMBL1402000 & 688239 & 8.2366 & 5.4724 & TST & \\
\hline CHEMBL1517559 & 688239 & 5.1362 & 5.4294 & TRN & \\
\hline CHEMBL1431865 & 688239 & 6.0862 & 5.502006 & 000000001 & TRN \\
\hline CHEMBL1358594 & 688239 & 5.4362 & 5.4184 & TRN & \\
\hline CHEMBL1337259 & 688239 & 8.1871 & 5.5377 & TRN & \\
\hline CHEMBL1577301 & 688239 & 7.2366 & 5.3946 & TST & \\
\hline CHEMBL1303261 & 688239 & 5.9362 & 5.5179 & TRN & \\
\hline CHEMBL1349928 & 688239 & 5.2862 & 5.4871 & TRN & \\
\hline CHEMBL1423962 & 688239 & 4.5362 & 5.4772 & TST & \\
\hline CHEMBL1602124 & 688239 & 4.6862 & 5.349 & TST & \\
\hline CHEMBL1302405 & 688239 & 6.1862 & 5.6119 & TRN & \\
\hline CHEMBL1460087 & 688239 & 4.9862 & 5.5079 & TRN & \\
\hline CHEMBL1530292 & 688239 & 4.4862 & 5.506 & TRN & \\
\hline CHEMBL1450513 & 688239 & 6.8861 & 5.3824 & TRN & \\
\hline CHEMBL1571105 & 688239 & 6.1862 & 5.3108 & TST & \\
\hline CHEMBL1558982 & 688239 & 6.7862 & 5.5451 & TRN & \\
\hline CHEMBL1611804 & 688239 & 5.0362 & 5.4009 & TRN & \\
\hline CHEMBL1327703 & 688239 & 4.5362 & 5.4171 & TRN & \\
\hline CHEMBL1370675 & 688239 & 4.5362 & 5.2412 & TRN & \\
\hline CHEMBL1413094 & 688239 & 4.7862 & 5.4271 & TST & \\
\hline CHEMBL1357271 & 688239 & 5.6862 & 5.5575 & TRN & \\
\hline CHEMBL1380763 & 688239 & 5.6362 & 5.5731 & TRN & \\
\hline CHEMBL1327517 & 688239 & 5.1862 & 5.4936 & TRN & \\
\hline CHEMBL1335696 & 688239 & 5.1862 & 5.4555 & TST & \\
\hline CHEMBL1327412 & 688239 & 5.0862 & 5.3951 & TRN & \\
\hline CHEMBL1482223 & 688239 & 4.5362 & 5.557 & TRN & \\
\hline CHEMBL1394972 & 688239 & 5.3862 & 5.5433 & TST & \\
\hline CHEMBL1572890 & 688239 & 4.7362 & \multicolumn{2}{|c|}{5.5120000000000005} & TRN \\
\hline CHEMBL1399222 & 688239 & 7.2366 & 5.6944 & TRN & \\
\hline CHEMBL1333398 & 688239 & 8.3372 & 5.6387 & TST & \\
\hline CHEMBL1373190 & 688239 & 5.6362 & 5.5756 & TRN & \\
\hline CHEMBL1438485 & 688239 & 6.2362 & 5.6474 & TRN & \\
\hline CHEMBL3194341 & 688239 & 5.3362 & 5.3176 & TRN & \\
\hline CHEMBL1365416 & 688239 & 6.7862 & 5.4886 & TRN & \\
\hline CHEMBL1323423 & 688239 & 6.0362 & 5.5712 & TRN & \\
\hline CHEMBL1447306 & 688239 & 6.5862 & 5.4842 & TST & \\
\hline
\end{tabular}


Supplemental Table S2.txt

\begin{tabular}{|c|c|c|c|c|c|c|}
\hline CHEMBL1545532 & 688239 & 6.2862 & 5.5617 & TRN & & \\
\hline CHEMBL1498399 & 688239 & 4.6362 & 5.3574 & TRN & & \\
\hline CHEMBL1413064 & 688239 & 4.5362 & 5.544 & TRN & & \\
\hline CHEMBL1368987 & 688239 & 5.1862 & 5.307 & TRN & & \\
\hline CHEMBL1540052 & 688239 & 4.5362 & 5.6307 & TRN & & \\
\hline CHEMBL1504139 & 688239 & 4.5362 & 5.3452 & TST & & \\
\hline CHEMBL1440787 & 688239 & 4.5362 & 5.5116 & TRN & & \\
\hline CHEMBL1403117 & 688239 & 6.1862 & 5.4241 & TRN & & \\
\hline CHEMBL1306885 & 688239 & 4.5362 & 5.5396 & TST & & \\
\hline CHEMBL1407051 & 688239 & 4.7362 & 5.3644 & TRN & & \\
\hline CHEMBL1464083 & 688239 & 5.3362 & 5.3922 & TRN & & \\
\hline CHEMBL1607024 & 688239 & 4.7362 & 5.5135 & TRN & & \\
\hline CHEMBL1339270 & 688239 & 4.5362 & 5.3989 & TRN & & \\
\hline CHEMBL1437310 & 688239 & 4.7362 & 5.6003 & TRN & & \\
\hline CHEMBL 3199455 & 688239 & 8.28399 & 999999999 & 9 & 5.5944 & TRN \\
\hline CHEMBL1564859 & 688239 & 5.1862 & 5.5453 & TRN & & \\
\hline CHEMBL1390248 & 688239 & 7.6364 & 5.4587 & TRN & & \\
\hline CHEMBL1513705 & 688239 & 4.7362 & 5.4764 & TRN & & \\
\hline CHEMBL1377746 & 688239 & 5.4862 & 5.5954 & TST & & \\
\hline CHEMBL1543387 & 688239 & 4.8362 & 5.5014 & TRN & & \\
\hline CHEMBL1371059 & 688239 & 7.6861 & 5.6233 & TRN & & \\
\hline CHEMBL1477210 & 688239 & 4.6862 & 5.4728 & TRN & & \\
\hline CHEMBL1303750 & 688239 & 5.4862 & 5.4325 & TRN & & \\
\hline CHEMBL1336231 & 688239 & 4.5362 & 5.5388 & TRN & & \\
\hline CHEMBL1347962 & 688239 & 4.5362 & 5.3235 & TST & & \\
\hline CHEMBL 2007601 & 688239 & 5.1862 & 5.3679 & TST & & \\
\hline CHEMBL1468631 & 688239 & 4.5362 & 5.4726 & TRN & & \\
\hline CHEMBL1463081 & 688239 & 5.3862 & 5.5242 & TRN & & \\
\hline CHEMBL1607445 & 688239 & 4.8362 & 5.5404 & TRN & & \\
\hline CHEMBL1461629 & 688239 & 8.2366 & 5.4641 & TRN & & \\
\hline CHEMBL1300777 & 688239 & 5.1862 & 5.5321 & TST & & \\
\hline CHEMBL1326345 & 688239 & 4.5862 & 5.51 & TRN & & \\
\hline CHEMBL1468625 & 688239 & 5.7362 & 5.4422 & TRN & & \\
\hline CHEMBL1346372 & 688239 & 5.2362 & 5.4861 & TST & & \\
\hline CHEMBL3199065 & 688239 & 4.7362 & 5.4948 & TST & & \\
\hline CHEMBL1309335 & 688239 & 4.5862 & 5.5657 & TRN & & \\
\hline CHEMBL1346976 & 688239 & 5.1862 & 5.3883 & TRN & & \\
\hline CHEMBL1600348 & 688239 & 4.4862 & 5.6241 & TST & & \\
\hline CHEMBL1398819 & 688239 & 8.3372 & 5.4442 & TRN & & \\
\hline CHEMBL1322881 & 688239 & 4.5362 & 5.4746 & TRN & & \\
\hline CHEMBL1350372 & 688239 & 5.1862 & 5.4458 & TRN & & \\
\hline CHEMBL3193812 & 688239 & 5.4362 & 5.3791 & TRN & & \\
\hline CHEMBL1366947 & 688239 & 8.283999 & 999999999 & 9 & 5.7397 & I RIV \\
\hline CHEMBL1517882 & 688239 & 6.6362 & 5.433 & TRN & & \\
\hline CHEMBL 3189703 & 688239 & 5.3362 & 5.4208 & TRN & & \\
\hline CHEMBL3199136 & 688239 & 4.7362 & 5.3832 & TRN & & \\
\hline CHEMBL1585706 & 688239 & 4.7862 & 5.4503 & TRN & & \\
\hline CHEMBL1593373 & 688239 & 6.2362 & 5.4592 & TRN & & \\
\hline
\end{tabular}


Supplemental Table S2.txt

\begin{tabular}{|c|c|c|c|c|c|}
\hline CHEMBL 3208832 & 688239 & 4.6862 & 5.4558 & TRN & \\
\hline CHEMBL1426618 & 688239 & 6.1862 & 5.548999 & 99999999995 & TRN \\
\hline CHEMBL1990571 & 688239 & 5.2362 & 5.3768 & TRN & \\
\hline CHEMBL 3194623 & 688239 & 4.5362 & 5.3657 & TRN & \\
\hline CHEMBL1418409 & 688239 & 5.3362 & 5.504 & TST & \\
\hline CHEMBL1587573 & 688239 & 4.7862 & 5.4259 & TRN & \\
\hline CHEMBL1377032 & 688239 & 6.3863 & 5.4131 & TRN & \\
\hline CHEMBL1359550 & 688239 & 5.6862 & 5.5059 & TST & \\
\hline CHEMBL1461530 & 688239 & 4.5362 & 5.4963 & TRN & \\
\hline CHEMBL1329779 & 688239 & 5.1362 & 5.6085 & TRN & \\
\hline CHEMBL1333700 & 688239 & 6.0362 & 5.5559 & TRN & \\
\hline CHEMBL 3145381 & 688239 & 6.1862 & 5.52 & TRN & \\
\hline CHEMBL1381056 & 688239 & 6.2362 & 5.4799 & TRN & \\
\hline CHEMBL1608722 & 688239 & 4.8862 & 5.4074 & TST & \\
\hline CHEMBL1525141 & 688239 & 5.3862 & 5.4209 & TRN & \\
\hline CHEMBL1370688 & 688239 & 5.0362 & 5.4862 & TRN & \\
\hline CHEMBL1530177 & 688239 & 4.5862 & 5.4411 & TRN & \\
\hline CHEMBL1596269 & 688239 & 5.1862 & 5.5355 & TRN & \\
\hline CHEMBL1575400 & 688239 & 5.1862 & 5.5477 & TRN & \\
\hline CHEMBL1456452 & 688239 & 8.28399 & 99999999 & 5.5398 & TST \\
\hline CHEMBL1389965 & 688239 & 4.5362 & \multicolumn{3}{|c|}{$5.4879999999999995 \quad$ TRN } \\
\hline CHEMBL1547707 & 688239 & 4.6862 & 5.435 & TST & \\
\hline CHEMBL 3198277 & 688239 & 6.2362 & 5.3903 & TST & \\
\hline CHEMBL1559353 & 688239 & 5.1862 & 5.4642 & TRN & \\
\hline CHEMBL1579173 & 688239 & 5.3862 & 5.3964 & TST & \\
\hline CHEMBL1421596 & 688239 & 6.6861 & 5.4609 & TST & \\
\hline CHEMBL1500959 & 688239 & 5.6862 & 5.5438 & TRN & \\
\hline CHEMBL1360962 & 688239 & 5.6362 & 5.5053 & TRN & \\
\hline CHEMBL 8747 & 688239 & 5.8862 & 5.2712 & TST & \\
\hline CHEMBL1374787 & 688239 & 4.7362 & 5.5417 & TRN & \\
\hline CHEMBL1335952 & 688239 & 5.1862 & 5.522 & TRN & \\
\hline CHEMBL1420318 & 688239 & 5.0862 & 5.5529 & TRN & \\
\hline CHEMBL1600005 & 688239 & 5.4862 & 5.4012 & TRN & \\
\hline CHEMBL3189518 & 688239 & \multicolumn{3}{|c|}{8.283999999999999} & TST \\
\hline CHEMBL1472901 & 688239 & 5.2862 & 5.545 & TRN & \\
\hline CHEMBL1470065 & 688239 & 5.6862 & 5.481 & TST & \\
\hline CHEMBL1548590 & 688239 & 4.7862 & 5.5521 & TRN & \\
\hline CHEMBL 3198762 & 688239 & 4.5362 & 5.4662 & TRN & \\
\hline CHEMBL1393224 & 688239 & 4.7362 & 5.5648 & TRN & \\
\hline CHEMBL1531094 & 688239 & 5.7862 & 5.4232 & TRN & \\
\hline CHEMBL1573497 & 688239 & 4.8362 & 5.5507 & TRN & \\
\hline CHEMBL1308952 & 688239 & 4.4862 & 5.5017 & TRN & \\
\hline CHEMBL1471989 & 688239 & 6.9363 & 5.4943 & TRN & \\
\hline CHEMBL1478238 & 688239 & 4.8362 & 5.5863 & TST & \\
\hline CHEMBL1474882 & 688239 & 5.3862 & 5.4365 & TRN & \\
\hline CHEMBL 3212487 & 688239 & 6.9363 & 5.4778 & TRN & \\
\hline CHEMBL1348841 & 688239 & 6.8362 & 5.4563 & TRN & \\
\hline CHEMBL1524040 & 688239 & 5.4862 & 5.5888 & TRN & \\
\hline
\end{tabular}


Supplemental Table S2.txt

\begin{tabular}{|c|c|c|c|c|}
\hline CHEMBL1302511 & 688239 & 4.5362 & 5.5661 & TRN \\
\hline CHEMBL1459140 & 688239 & 6.0 & 5.4588 & TST \\
\hline CHEMBL3392060 & 688239 & 5.5862 & 5.5772 & TST \\
\hline CHEMBL1384638 & 688239 & 5.7862 & 5.6443 & TRN \\
\hline CHEMBL1587692 & 688239 & 5.1362 & 5.3455 & TRN \\
\hline CHEMBL1609804 & 688239 & 4.5362 & 5.6325 & TRN \\
\hline CHEMBL1379591 & 688239 & 4.5362 & 5.5394 & TRN \\
\hline CHEMBL1498866 & 688239 & 5.0362 & 5.6445 & TRN \\
\hline CHEMBL1579069 & 688239 & 4.4862 & 5.4109 & TRN \\
\hline CHEMBL1471665 & 688239 & 5.4362 & 5.4927 & TST \\
\hline CHEMBL1558179 & 688239 & 5.1862 & 5.5219 & TRN \\
\hline CHEMBL1565214 & 688239 & 5.0862 & 5.5141 & TRN \\
\hline CHEMBL1492792 & 688239 & 7.5867 & 5.3623 & TRN \\
\hline CHEMBL1334480 & 688239 & 6.8362 & 5.4753 & TRN \\
\hline CHEMBL1403070 & 688239 & 4.7362 & 5.5138 & TRN \\
\hline CHEMBL1596434 & 688239 & 5.9362 & 5.4279 & TRN \\
\hline CHEMBL1407625 & 688239 & 5.1862 & 5.6495 & TST \\
\hline CHEMBL1539534 & 688239 & 5.3862 & 5.5554 & TST \\
\hline CHEMBL1381001 & 688239 & 5.1862 & 5.4815 & TRN \\
\hline CHEMBL1486416 & 688239 & 4.7862 & 5.4648 & TRN \\
\hline CHEMBL1507087 & 688239 & 4.5362 & 5.568 & TRN \\
\hline CHEMBL1535612 & 688239 & 5.3362 & 5.5477 & TRN \\
\hline CHEMBL 3212420 & 688239 & 5.2862 & 5.4256 & TRN \\
\hline CHEMBL1381100 & 688239 & 6.6861 & 5.4468 & TRN \\
\hline CHEMBL1323531 & 688239 & 5.1862 & 5.5706 & TST \\
\hline CHEMBL1416591 & 688239 & 5.8362 & 5.4736 & TRN \\
\hline CHEMBL237615 & 688239 & 4.5362 & 5.5701 & TRN \\
\hline CHEMBL1447489 & 688239 & 5.8862 & 5.6197 & TRN \\
\hline CHEMBL 239483 & 688239 & 4.7862 & 5.4659 & TRN \\
\hline CHEMBL1492171 & 688239 & 5.7862 & 5.4109 & TST \\
\hline CHEMBL1573395 & 688239 & 4.5362 & 5.4042 & TRN \\
\hline CHEMBL1379151 & 688239 & 5.2362 & 5.5704 & TRN \\
\hline CHEMBL1327335 & 688239 & 5.1862 & 5.41799 & \\
\hline CHEMBL1348195 & 688239 & 4.5862 & 5.581 & TST \\
\hline CHEMBL1320640 & 688239 & 7.5361 & 5.4285 & TRN \\
\hline CHEMBL1543599 & 688239 & 4.7862 & 5.4232 & TRN \\
\hline CHEMBL1557008 & 688239 & 6.0862 & 5.7157 & TRN \\
\hline CHEMBL1465113 & 688239 & 4.5362 & 5.4647 & TST \\
\hline CHEMBL1329964 & 688239 & 5.8862 & 5.5821 & TRN \\
\hline CHEMBL 3212188 & 688239 & 5.0862 & 5.4605 & TST \\
\hline CHEMBL1469639 & 688239 & 5.1862 & 5.4864 & TRN \\
\hline CHEMBL1427689 & 688239 & 4.5362 & 5.4309 & TRN \\
\hline CHEMBL1514963 & 688239 & 7.1361 & 5.5185 & TST \\
\hline CHEMBL1367464 & 688239 & 5.1862 & 5.5002 & TRN \\
\hline CHEMBL1388680 & 688239 & 5.1862 & 5.4704 & TRN \\
\hline CHEMBL1319017 & 688239 & 6.5862 & 5.545 & TRN \\
\hline CHEMBL1336752 & 688239 & 6.6362 & 5.6555 & TRN \\
\hline CHEMBL1324337 & 688239 & 5.1862 & 5.4241 & TRN \\
\hline
\end{tabular}


Supplemental Table S2.txt

\begin{tabular}{|c|c|c|c|c|c|}
\hline CHEMBL1355756 & 688239 & 4.6362 & 5.4054 & TRN & \\
\hline CHEMBL1362694 & 688239 & 5.1862 & 5.551 & TST & \\
\hline CHEMBL1493252 & 688239 & 5.1862 & 5.5308 & TRN & \\
\hline CHEMBL1594586 & 688239 & 4.6362 & 5.5421 & TRN & \\
\hline CHEMBL1501009 & 688239 & 8.3372 & 5.5249 & TRN & \\
\hline CHEMBL1373947 & 688239 & 4.8862 & 5.4818 & TRN & \\
\hline CHEMBL1478317 & 688239 & 4.8862 & 5.4998 & TRN & \\
\hline CHEMBL1542427 & 688239 & 4.7362 & 5.5488 & TRN & \\
\hline CHEMBL1471610 & 688239 & 5.4362 & 5.4665 & TST & \\
\hline CHEMBL1470007 & 688239 & 5.6362 & 5.5065 & TST & \\
\hline CHEMBL1349364 & 688239 & 5.1862 & 5.3976 & TRN & \\
\hline CHEMBL1390236 & 688239 & 4.8862 & 5.4401 & TST & \\
\hline CHEMBL1579920 & 688239 & 6.0362 & 5.6835 & TST & \\
\hline CHEMBL1311044 & 688239 & 4.5362 & 5.3299 & TRN & \\
\hline CHEMBL1345075 & 688239 & 4.9362 & 5.4921 & TRN & \\
\hline CHEMBL1420119 & 688239 & 4.9362 & 5.6621 & TRN & \\
\hline CHEMBL1483235 & 688239 & 5.0362 & 5.2738 & TST & \\
\hline CHEMBL1390357 & 688239 & 5.1862 & 5.6576 & TST & \\
\hline CHEMBL1499179 & 688239 & 4.7862 & 5.5932 & TRN & \\
\hline CHEMBL3192342 & 688239 & 5.1862 & 5.4157 & TRN & \\
\hline CHEMBL1555930 & 688239 & 5.1362 & 5.4831 & TRN & \\
\hline CHEMBL1506653 & 688239 & 6.0362 & 5.4715 & TST & \\
\hline CHEMBL1466132 & 688239 & 5.7862 & 5.5482 & TRN & \\
\hline CHEMBL1609981 & 688239 & 5.7862 & 5.5819 & TRN & \\
\hline CHEMBL1468143 & 688239 & 5.0362 & 5.4474 & TRN & \\
\hline CHEMBL1304799 & 688239 & 4.4862 & 5.4426 & TST & \\
\hline CHEMBL1386770 & 688239 & 6.8861 & 5.7278 & TRN & \\
\hline CHEMBL1607115 & 688239 & 4.5362 & 5.6389 & TRN & \\
\hline CHEMBL1343996 & 688239 & 4.8362 & 5.5046 & TRN & \\
\hline CHEMBL1428297 & 688239 & 5.5862 & 5.6143 & TRN & \\
\hline CHEMBL302753 & 688239 & 4.5362 & 5.4838 & TRN & \\
\hline CHEMBL1506420 & 688239 & 4.6862 & 5.3088 & TRN & \\
\hline CHEMBL1546828 & 688239 & 5.1362 & 5.5483 & TRN & \\
\hline CHEMBL1589526 & 688239 & 4.8862 & 5.3515 & TRN & \\
\hline CHEMBL1412357 & 688239 & 5.0362 & 5.5278 & TRN & \\
\hline CHEMBL1577629 & 688239 & 4.7862 & 5.42399 & 99999999995 & TRN \\
\hline CHEMBL1576975 & 688239 & 7.1361 & 5.5295 & TRN & \\
\hline CHEMBL1405880 & 688239 & 5.7362 & 5.5872 & TST & \\
\hline CHEMBL1492010 & 688239 & 4.5362 & 5.3141 & TRN & \\
\hline CHEMBL3210489 & 688239 & 4.6862 & 5.4144 & TST & \\
\hline CHEMBL1411197 & 688239 & 5.1862 & 5.5939 & TST & \\
\hline CHEMBL1538051 & 688239 & 5.4362 & 5.526 & TRN & \\
\hline CHEMBL1463431 & 688239 & 4.5362 & 5.5757 & TST & \\
\hline CHEMBL1608180 & 688239 & 4.6862 & 5.388 & TRN & \\
\hline CHEMBL1515782 & 688239 & 5.6862 & 5.3204 & TRN & \\
\hline CHEMBL1504076 & 688239 & 6.1362 & 5.5193 & TRN & \\
\hline CHEMBL1603192 & 688239 & 4.4862 & 5.44 & TRN & \\
\hline CHEMBL3198579 & 688239 & 4.5362 & 5.3343 & TST & \\
\hline
\end{tabular}


Supplemental Table S2.txt

\begin{tabular}{|c|c|c|c|c|}
\hline CHEMBL1377627 & 688239 & 6.2862 & 5.5038 & TRN \\
\hline CHEMBL1405959 & 688239 & 4.5362 & 5.4968 & TST \\
\hline CHEMBL1565504 & 688239 & 4.7862 & 5.5817 & TRN \\
\hline CHEMBL1590369 & 688239 & 5.4362 & 5.4745 & TST \\
\hline CHEMBL 3213046 & 688239 & 5.6362 & 5.3921 & TRN \\
\hline CHEMBL1432474 & 688239 & 5.0862 & 5.5869 & TRN \\
\hline CHEMBL1368272 & 688239 & 4.5362 & 5.3723 & TST \\
\hline CHEMBL1530147 & 688239 & 4.5362 & 5.508999 & 99999999995 \\
\hline CHEMBL1319169 & 688239 & 4.4862 & 5.5515 & TRN \\
\hline CHEMBL1972348 & 688239 & 6.5862 & 5.3178 & TRN \\
\hline CHEMBL1513487 & 688239 & 6.7862 & 5.4572 & TST \\
\hline CHEMBL1524749 & 688239 & 6.1862 & 5.3349 & TST \\
\hline CHEMBL1442376 & 688239 & 4.4862 & 5.4567 & TRN \\
\hline CHEMBL1392925 & 688239 & 6.7862 & 5.575 & TRN \\
\hline CHEMBL1374197 & 688239 & 4.5362 & 5.5835 & TST \\
\hline CHEMBL1590119 & 688239 & 4.5362 & 5.5021 & TST \\
\hline CHEMBL1382573 & 688239 & 4.7362 & 5.4359 & TRN \\
\hline CHEMBL1321822 & 688239 & 5.1362 & 5.4692 & TST \\
\hline CHEMBL1556715 & 688239 & 4.9862 & 5.5215 & TST \\
\hline CHEMBL1607000 & 688239 & 6.6362 & 5.6424 & TST \\
\hline CHEMBL1398414 & 688239 & 5.0862 & 5.6938 & TRN \\
\hline CHEMBL3212758 & 688239 & 5.3362 & 5.3826 & TRN \\
\hline CHEMBL1438701 & 688239 & 6.2362 & 5.5515 & TRN \\
\hline CHEMBL1396338 & 688239 & 5.1862 & 5.4311 & TRN \\
\hline CHEMBL1446557 & 688239 & 5.6362 & 5.4832 & TST \\
\hline CHEMBL1536393 & 688239 & 8.1367 & 5.6196 & TRN \\
\hline CHEMBL1585469 & 688239 & 4.5362 & 5.468999 & 9999999999 \\
\hline CHEMBL1360892 & 688239 & 5.9362 & 5.4637 & TRN \\
\hline CHEMBL 3198278 & 688239 & 4.5362 & 5.468 & TST \\
\hline CHEMBL1346855 & 688239 & 5.6862 & 5.5171 & TRN \\
\hline CHEMBL1335069 & 688239 & 5.1862 & 5.4661 & TST \\
\hline CHEMBL1428311 & 688239 & 4.6362 & 5.6142 & TRN \\
\hline CHEMBL1305271 & 688239 & 5.1362 & 5.495 & TST \\
\hline CHEMBL1526684 & 688239 & 7.1864 & 5.612 & TST \\
\hline CHEMBL 3212366 & 688239 & 5.3862 & 5.4836 & TST \\
\hline CHEMBL1592365 & 688239 & 8.3872 & 5.4064 & TRN \\
\hline CHEMBL1576144 & 688239 & 4.5862 & 5.4138 & TRN \\
\hline CHEMBL1577241 & 688239 & 5.6862 & 5.4885 & TRN \\
\hline CHEMBL1444849 & 688239 & 4.5362 & 5.4463 & TST \\
\hline CHEMBL3209910 & 688239 & 5.4862 & 5.4667 & TST \\
\hline CHEMBL1480000 & 688239 & 5.0362 & 5.4401 & TST \\
\hline CHEMBL1356747 & 688239 & 5.3862 & 5.4776 & TRN \\
\hline CHEMBL1408313 & 688239 & 4.5362 & 5.6341 & TRN \\
\hline CHEMBL1436249 & 688239 & 4.8862 & 5.6357 & TRN \\
\hline CHEMBL1577484 & 688239 & 4.5862 & 5.5127 & TST \\
\hline CHEMBL1537264 & 688239 & 7.2366 & 5.6421 & TRN \\
\hline CHEMBL1408451 & 688239 & 5.6362 & 5.4411 & TRN \\
\hline CHEMBL1589420 & 688239 & 6.8861 & 5.6162 & TRN \\
\hline
\end{tabular}


Supplemental Table S2.txt

\begin{tabular}{|c|c|c|c|c|c|c|}
\hline CHEMBL1344581 & 688239 & 4.8362 & 5.5137 & TRN & & \\
\hline CHEMBL1568613 & 688239 & 4.9862 & 5.3647 & TRN & & \\
\hline CHEMBL1313853 & 688239 & 5.7362 & 5.5252 & TRN & & \\
\hline CHEMBL1380515 & 688239 & 6.0862 & 5.5361 & TST & & \\
\hline CHEMBL 3190885 & 688239 & 6.0862 & 5.4383 & TST & & \\
\hline CHEMBL1562793 & 688239 & 6.5363 & 5.461 & TRN & & \\
\hline CHEMBL1485544 & 688239 & 4.5362 & 5.5699 & TST & & \\
\hline CHEMBL1336108 & 688239 & 5.3862 & 5.5437 & TRN & & \\
\hline CHEMBL1471776 & 688239 & 5.4362 & 5.4118 & TRN & & \\
\hline CHEMBL1532755 & 688239 & 4.7862 & 5.4037 & TRN & & \\
\hline CHEMBL1327649 & 688239 & 5.7862 & 5.5119 & TRN & & \\
\hline CHEMBL1422289 & 688239 & 4.9362 & 5.5752 & TRN & & \\
\hline CHEMBL1395140 & 688239 & 5.5362 & 5.2747 & TRN & & \\
\hline CHEMBL1467311 & 688239 & 5.2362 & 5.4441 & TRN & & \\
\hline CHEMBL1561915 & 688239 & 5.1362 & 5.6596 & TRN & & \\
\hline CHEMBL1393089 & 688239 & 4.4862 & 5.4733 & TST & & \\
\hline CHEMBL1544931 & 688239 & 6.9863 & 5.5449 & TST & & \\
\hline CHEMBL1313101 & 688239 & 4.5362 & 5.4252 & TRN & & \\
\hline CHEMBL1535002 & 688239 & 4.5362 & 5.4686 & TRN & & \\
\hline CHEMBL1466378 & 688239 & 8.3372 & 5.575 & TST & & \\
\hline CHEMBL1595161 & 688239 & 5.7362 & 5.608 & TST & & \\
\hline CHEMBL1485010 & 688239 & 4.7362 & 5.5774 & TRN & & \\
\hline CHEMBL1366758 & 688239 & 4.7362 & 5.5826 & TST & & \\
\hline CHEMBL1542387 & 688239 & 5.4362 & 5.5238 & TRN & & \\
\hline CHEMBL 1429340 & 688239 & 4.5362 & 5.4849 & TRN & & \\
\hline CHEMBL1431753 & 688239 & 5.4362 & 5.5242 & TRN & & \\
\hline CHEMBL1410576 & 688239 & 4.5362 & 5.4227 & TRN & & \\
\hline CHEMBL1299852 & 688239 & 4.6862 & 5.4777 & TRN & & \\
\hline CHEMBL1531553 & 688239 & 5.4362 & 5.4748 & TRN & & \\
\hline CHEMBL1474981 & 688239 & 8.28399 & 99999999 & 99 & 5.4638 & TST \\
\hline CHEMBL1475460 & 688239 & 5.5862 & 5.4785 & TRN & & \\
\hline CHEMBL1562785 & 688239 & 5.9862 & 5.6896 & TST & & \\
\hline CHEMBL1526485 & 688239 & 5.3362 & 5.5607 & TRN & & \\
\hline CHEMBL1310308 & 688239 & 6.2362 & 5.4378 & TRN & & \\
\hline CHEMBL1445294 & 688239 & 5.3362 & 5.5632 & TRN & & \\
\hline CHEMBL1478294 & 688239 & 4.5362 & 5.4912 & TRN & & \\
\hline CHEMBL1425392 & 688239 & 5.1862 & 5.5214 & TRN & & \\
\hline CHEMBL1303737 & 688239 & 4.5362 & 5.3768 & TST & & \\
\hline CHEMBL1352414 & 688239 & 5.4362 & 5.4578 & TRN & & \\
\hline CHEMBL1348333 & 688239 & 5.1862 & 5.604 & TRN & & \\
\hline CHEMBL1322002 & 688239 & 6.2862 & 5.3542 & TRN & & \\
\hline CHEMBL1485811 & 688239 & 5.7862 & 5.4573 & TRN & & \\
\hline CHEMBL1407663 & 688239 & 5.4362 & 5.4857 & TRN & & \\
\hline CHEMBL1566740 & 688239 & 4.6362 & 5.4815 & TST & & \\
\hline CHEMBL1466452 & 688239 & 6.1862 & 5.5141 & TST & & \\
\hline CHEMBL1576427 & 688239 & 6.0362 & 5.504 & TRN & & \\
\hline CHEMBL1554340 & 688239 & 5.1862 & 5.6532 & TRN & & \\
\hline CHEMBL1387172 & 688239 & 4.9362 & 5.4582 & TRN & & \\
\hline
\end{tabular}


Supplemental Table S2.txt

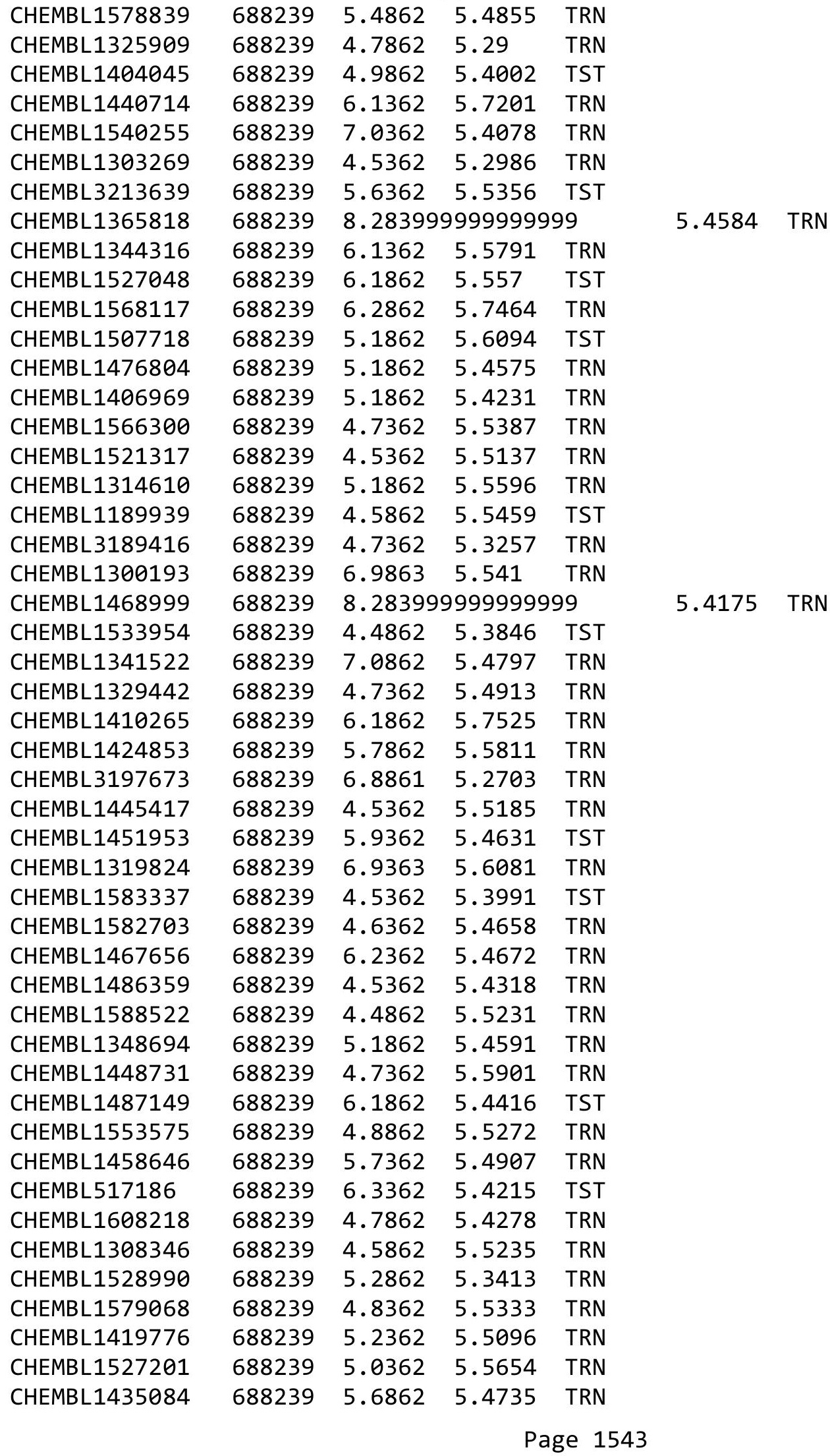


Supplemental Table S2.txt

\begin{tabular}{|c|c|c|c|c|}
\hline CHEMBL1510526 & 688239 & 5.0362 & 5.5307 & TRN \\
\hline CHEMBL1310444 & 688239 & 5.8362 & 5.4404 & TRN \\
\hline CHEMBL1425666 & 688239 & 6.7361 & 5.4617 & TRN \\
\hline CHEMBL3191344 & 688239 & 5.2862 & 5.3317 & TST \\
\hline CHEMBL1339290 & 688239 & 6.8861 & 5.7095 & TRN \\
\hline CHEMBL365939 & 688239 & 6.3863 & 5.4017 & TRN \\
\hline CHEMBL1426700 & 688239 & 5.0362 & 5.4307 & TRN \\
\hline CHEMBL1977499 & 688239 & 4.9362 & 5.412999 & 9999999999 \\
\hline CHEMBL1402371 & 688239 & 4.7862 & 5.4816 & TRN \\
\hline CHEMBL1378417 & 688239 & 5.2862 & 5.5453 & TRN \\
\hline CHEMBL1530117 & 688239 & 5.9362 & 5.4929 & TST \\
\hline CHEMBL1389335 & 688239 & 4.9362 & 5.5468 & TRN \\
\hline CHEMBL1488540 & 688239 & 6.5363 & 5.565 & TST \\
\hline CHEMBL1609473 & 688239 & 6.5363 & 5.5708 & TRN \\
\hline CHEMBL1487237 & 688239 & 6.1362 & 5.6415 & TRN \\
\hline CHEMBL1360779 & 688239 & 6.0862 & 5.5659 & TST \\
\hline CHEMBL1460389 & 688239 & 6.5363 & 5.3814 & TRN \\
\hline CHEMBL1537429 & 688239 & 8.3872 & 5.678 & TRN \\
\hline CHEMBL1369967 & 688239 & 5.1862 & 5.3965 & TST \\
\hline CHEMBL1525490 & 688239 & 5.0362 & 5.529 & TST \\
\hline CHEMBL1569095 & 688239 & 4.7862 & 5.5167 & TRN \\
\hline CHEMBL1558337 & 688239 & 4.5362 & 5.3844 & TRN \\
\hline CHEMBL1549253 & 688239 & 6.3863 & 5.4356 & TRN \\
\hline CHEMBL1566693 & 688239 & 5.5862 & 5.3857 & TST \\
\hline CHEMBL1976810 & 688239 & 4.5862 & 5.3587 & TRN \\
\hline CHEMBL1544897 & 688239 & 4.7362 & 5.376 & TRN \\
\hline CHEMBL3194235 & 688239 & 5.2862 & 5.4988 & TRN \\
\hline CHEMBL551294 & 688239 & 4.5362 & 5.4442 & TST \\
\hline CHEMBL3210064 & 688239 & 7.1361 & 5.4677 & TRN \\
\hline CHEMBL 3209297 & 688239 & 4.5362 & 5.4258 & TST \\
\hline CHEMBL1305539 & 688239 & 4.4862 & 5.3443 & TRN \\
\hline CHEMBL1613343 & 688239 & 6.8362 & 5.43 & TST \\
\hline CHEMBL1464838 & 688239 & 5.7362 & 5.5883 & TRN \\
\hline CHEMBL1499696 & 688239 & 4.6862 & 5.506 & TST \\
\hline CHEMBL1539180 & 688239 & 4.5362 & 5.2595 & TRN \\
\hline CHEMBL1547938 & 688239 & 4.5862 & 5.4536 & TRN \\
\hline CHEMBL1480940 & 688239 & 4.5362 & 5.5566 & TST \\
\hline CHEMBL1607513 & 688239 & 7.1864 & 5.5869 & TRN \\
\hline CHEMBL1479758 & 688239 & 6.8861 & 5.6206 & TRN \\
\hline CHEMBL1451560 & 688239 & 8.2366 & 5.5376 & TRN \\
\hline CHEMBL1562910 & 688239 & 6.9863 & 5.6384 & TRN \\
\hline CHEMBL1440762 & 688239 & 6.2362 & 5.4375 & TRN \\
\hline CHEMBL3212838 & 688239 & 5.1862 & 5.4387 & TRN \\
\hline CHEMBL1538902 & 688239 & 5.8362 & 5.5345 & TST \\
\hline CHEMBL1373172 & 688239 & 4.7362 & 5.3748 & TST \\
\hline CHEMBL1601323 & 688239 & 6.9863 & 5.4907 & TRN \\
\hline CHEMBL1449494 & 688239 & 6.3362 & 5.4032 & TST \\
\hline CHEMBL1255966 & 688239 & 4.5362 & 5.3714 & TST \\
\hline
\end{tabular}


Supplemental Table S2.txt

\begin{tabular}{|c|c|c|c|c|}
\hline 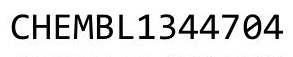 & & 362 & & \\
\hline HEMBL1420528 & 88239 & 9363 & 5034 & 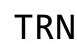 \\
\hline HEMBL 391877 & 39 & 61 & & \\
\hline 014 & & & & \\
\hline AEMBL15 & & & & \\
\hline AEMBL1367206 & 88239 & 6862 & .414 & \\
\hline HEMBL1457323 & 88239 & 4.5362 & .5776 & \\
\hline HEMBL1475175 & 39 & & 4351 & \\
\hline HEMBL14 & & & & \\
\hline AEMBL13e & & & & \\
\hline HEMBL1342196 & 88239 & 0862 & 5421 & \\
\hline HEMBL1415371 & 88239 & .6362 & 63 & \\
\hline HEMBL132 & 39 & 62 & 4764 & \\
\hline HEMBL 15 & & & & \\
\hline HEMBL 142 & & & & \\
\hline HEMBL1544650 & 88239 & 3862 & 5084 & \\
\hline AEMBL1353 & & 362 & & \\
\hline HEMBL153 & 39 & & 26 & \\
\hline L13 & & & & \\
\hline HEMBL 31 & & & & \\
\hline HEMBL1476306 & & 862 & & \\
\hline AEMBL1301499 & & & & \\
\hline HEMBL14 & 39 & 52 & 47 & \\
\hline L15 & & & & \\
\hline 54 & & & & \\
\hline L139 & & & & \\
\hline AEMBL155 & & & & RN \\
\hline HEMBL15 & & & & \\
\hline HEN & & & & \\
\hline 85 & & & & \\
\hline HEMBL 143 & & & & RN \\
\hline HEMBL1381326 & & & & $\mathrm{RN}$ \\
\hline HEMBL2C & & & & RN \\
\hline 5 & & & & RN \\
\hline L13 & & & & $\mathrm{RN}$ \\
\hline HEMBL132 & & & & TRN \\
\hline HEMBL1347516 & & & & ST \\
\hline & & & & ST \\
\hline 1 & & & & RN \\
\hline HEMBL 15 & & & & $\mathrm{RN}$ \\
\hline HEMBL1312556 & 39 & 62 & 889 & $\mathrm{RN}$ \\
\hline HEMBL 14 & & & & IST \\
\hline & & & & \\
\hline HEMBL 15 & & & & \\
\hline HEMBL144 & & & & $\mathrm{RN}$ \\
\hline IEMBL1965162 & & 62 & 991 & \\
\hline HEMBL 14 & & & & \\
\hline 150זים & & 4.5362 & & \\
\hline
\end{tabular}

Page 1545 
Supplemental Table S2.txt

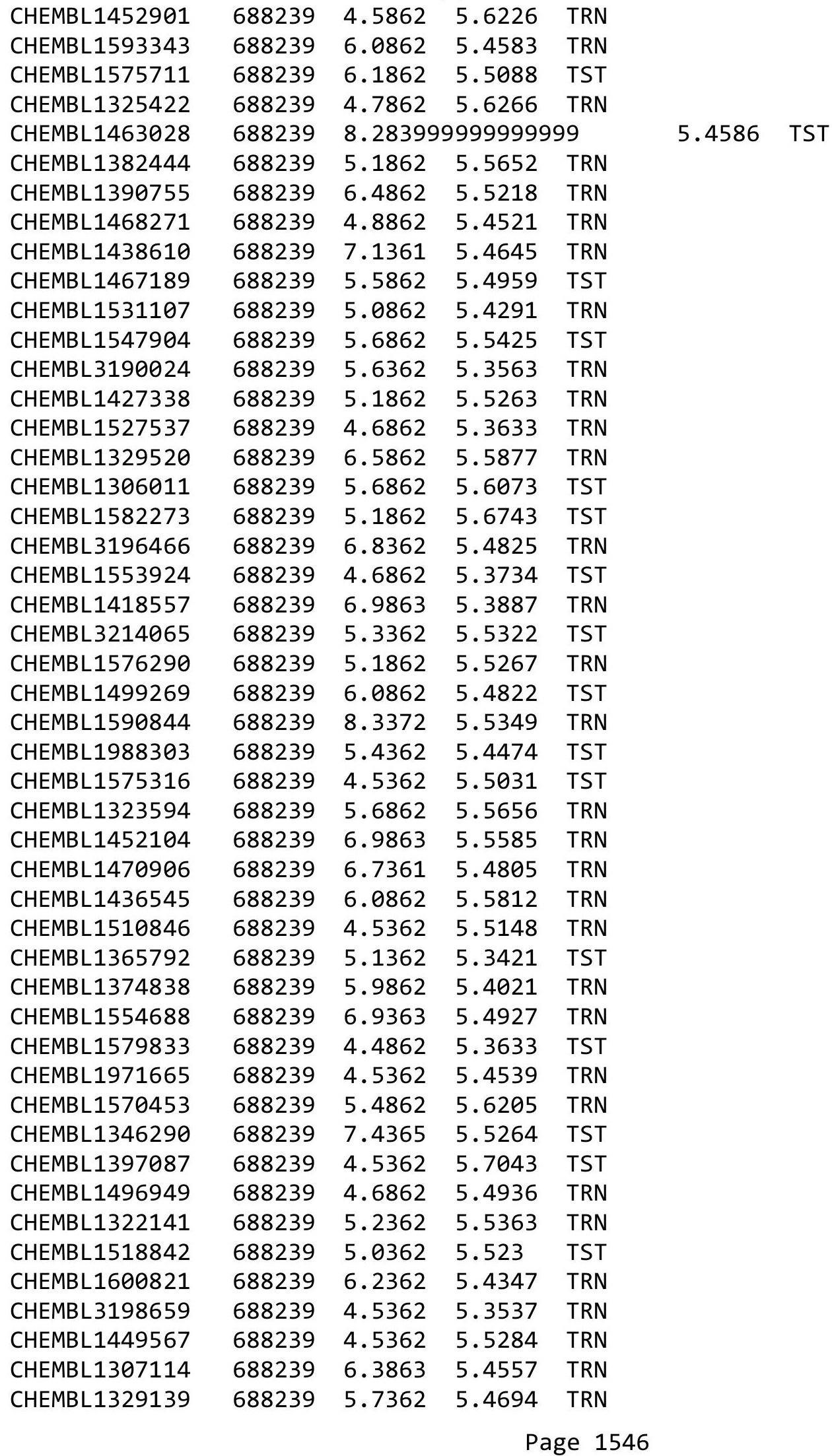


Supplemental Table S2.txt

\begin{tabular}{|c|c|c|c|c|c|}
\hline CHEMBL1597893 & 688239 & 6.9863 & 5.4313 & TRN & \\
\hline CHEMBL1439230 & 688239 & 6.1362 & 5.4675 & TRN & \\
\hline CHEMBL1498761 & 688239 & 4.5362 & 5.49200 & 0000000001 & TRN \\
\hline CHEMBL1382171 & 688239 & 5.1862 & 5.4778 & TRN & \\
\hline CHEMBL1511710 & 688239 & 5.1862 & 5.4437 & TST & \\
\hline CHEMBL1612371 & 688239 & 4.5362 & 5.6069 & TRN & \\
\hline CHEMBL1456621 & 688239 & 4.5862 & 5.54700 & 0000000001 & TRN \\
\hline CHEMBL1351298 & 688239 & 4.6362 & 5.4675 & TRN & \\
\hline CHEMBL1411990 & 688239 & 5.3862 & 5.57100 & 0000000001 & TRN \\
\hline CHEMBL1514934 & 688239 & 4.7362 & 5.4847 & TRN & \\
\hline CHEMBL1441714 & 688239 & 6.2862 & 5.557 & TRN & \\
\hline CHEMBL1571229 & 688239 & 6.0862 & 5.5491 & TRN & \\
\hline CHEMBL1427297 & 688239 & 8.28399 & 99999999 & 5.4038 & ות \\
\hline CHEMBL1364880 & 688239 & 5.6362 & 5.5154 & TRN & \\
\hline CHEMBL3195176 & 688239 & 7.0362 & 5.4565 & TRN & \\
\hline CHEMBL1528832 & 688239 & 6.1862 & 5.3975 & TST & \\
\hline CHEMBL1570808 & 688239 & 5.4362 & 5.5052 & TRN & \\
\hline CHEMBL1563577 & 688239 & 5.5862 & 5.4108 & TRN & \\
\hline CHEMBL 3144948 & 688239 & 4.5362 & 5.586 & TRN & \\
\hline CHEMBL1453673 & 688239 & 5.7362 & 5.5411 & TRN & \\
\hline CHEMBL1604161 & 688239 & 6.2362 & 5.3563 & TRN & \\
\hline CHEMBL1566675 & 688239 & 6.4862 & 5.4506 & TRN & \\
\hline CHEMBL1299327 & 688239 & 4.8362 & 5.4769 & TST & \\
\hline CHEMBL1302175 & 688239 & 4.5362 & 5.3556 & TST & \\
\hline CHEMBL1359733 & 688239 & 4.6362 & 5.3758 & TRN & \\
\hline CHEMBL1304076 & 688239 & 5.6862 & 5.6196 & TRN & \\
\hline CHEMBL1469896 & 688239 & 4.8362 & 5.6536 & TRN & \\
\hline CHEMBL1561064 & 688239 & 5.1862 & 5.5613 & TRN & \\
\hline CHEMBL1543579 & 688239 & 5.8862 & 5.5357 & TRN & \\
\hline CHEMBL1378902 & 688239 & 6.6362 & 5.5787 & TRN & \\
\hline CHEMBL1328622 & 688239 & 5.1862 & 5.4829 & TRN & \\
\hline CHEMBL1423701 & 688239 & 4.5362 & 5.4601 & TRN & \\
\hline CHEMBL1362227 & 688239 & 4.5362 & 5.3611 & TRN & \\
\hline CHEMBL1486503 & 688239 & 4.8362 & 5.4855 & TST & \\
\hline CHEMBL1555809 & 688239 & 5.3362 & 5.3952 & TST & \\
\hline CHEMBL1444008 & 688239 & 5.5862 & 5.5471 & TRN & \\
\hline CHEMBL1489091 & 688239 & 5.05 & 5.4848 & TRN & \\
\hline CHEMBL1383558 & 688239 & 4.6862 & 5.5142 & TRN & \\
\hline CHEMBL1445369 & 688239 & 6.8861 & 5.4872 & TRN & \\
\hline CHEMBL3191638 & 688239 & 5.7362 & 5.3463 & TST & \\
\hline CHEMBL1300103 & 688239 & 4.7362 & 5.4265 & TRN & \\
\hline CHEMBL1306985 & 688239 & 4.6862 & 5.3871 & TRN & \\
\hline CHEMBL1467410 & 688239 & 5.1862 & 5.5031 & TRN & \\
\hline CHEMBL1319100 & 688239 & 8.3372 & 5.5194 & TST & \\
\hline CHEMBL1422980 & 688239 & 4.4862 & 5.51399 & э999999999 & TRN \\
\hline CHEMBL1413850 & 688239 & 4.7862 & 5.3756 & TRN & \\
\hline CHEMBL1526566 & 688239 & 4.5362 & 5.5792 & TRN & \\
\hline CHEMBL1467075 & 688239 & 5.5862 & 5.5582 & TRN & \\
\hline
\end{tabular}


Supplemental Table S2.txt

\begin{tabular}{|c|c|c|c|c|}
\hline CHEMBL1602656 & 688239 & 5.4862 & 5.57 & TRN \\
\hline CHEMBL1325656 & 688239 & 5.0862 & 5.4333 & TST \\
\hline CHEMBL1508825 & 688239 & 5.4362 & 5.5448 & TRN \\
\hline CHEMBL1335433 & 688239 & 4.6362 & 5.4006 & TRN \\
\hline CHEMBL1349561 & 688239 & 6.0862 & 5.342006 & $\partial 0000000005$ \\
\hline CHEMBL1442187 & 688239 & 4.5362 & 5.5159 & TRN \\
\hline CHEMBL1404929 & 688239 & 5.0862 & 5.4509 & TRN \\
\hline CHEMBL1424706 & 688239 & 4.5362 & 5.3861 & TRN \\
\hline CHEMBL3145053 & 688239 & 5.5362 & 5.4415 & TRN \\
\hline CHEMBL1497490 & 688239 & 4.5362 & 5.4745 & TRN \\
\hline CHEMBL1368543 & 688239 & 5.3862 & 5.5841 & TRN \\
\hline CHEMBL1348321 & 688239 & 4.4862 & 5.4866 & TRN \\
\hline CHEMBL1347274 & 688239 & 4.9862 & 5.3785 & TRN \\
\hline CHEMBL1313588 & 688239 & 4.5362 & 5.4 & TST \\
\hline CHEMBL1524012 & 688239 & 6.0362 & 5.5512 & TRN \\
\hline CHEMBL1560346 & 688239 & 4.7862 & 5.5791 & TRN \\
\hline CHEMBL1399552 & 688239 & 5.1862 & 5.5276 & TRN \\
\hline CHEMBL1327737 & 688239 & 4.6862 & 5.3693 & TRN \\
\hline CHEMBL1500644 & 688239 & 4.6862 & 5.5537 & TRN \\
\hline CHEMBL3211803 & 688239 & 4.5362 & 5.5416 & TST \\
\hline CHEMBL1541496 & 688239 & 5.1862 & 5.5084 & TST \\
\hline CHEMBL1576808 & 688239 & 4.5362 & 5.5457 & TRN \\
\hline CHEMBL1356459 & 688239 & 5.1862 & 5.3762 & TRN \\
\hline CHEMBL1346436 & 688239 & 6.9363 & 5.612 & TRN \\
\hline CHEMBL1353968 & 688239 & 4.8362 & 5.4461 & TRN \\
\hline CHEMBL1589443 & 688239 & 4.7362 & 5.5301 & TRN \\
\hline CHEMBL1587017 & 688239 & 4.5362 & 5.4848 & TRN \\
\hline CHEMBL1412957 & 688239 & 5.7362 & 5.5592 & TRN \\
\hline CHEMBL1428525 & 688239 & 5.1362 & 5.5608 & TRN \\
\hline CHEMBL1370036 & 688239 & 4.5362 & 5.495 & TST \\
\hline CHEMBL1497957 & 688239 & 4.5362 & 5.6288 & TST \\
\hline CHEMBL1405144 & 688239 & 4.5362 & 5.4357 & TRN \\
\hline CHEMBL1491152 & 688239 & 4.9862 & 5.4993 & TRN \\
\hline CHEMBL1604364 & 688239 & 5.3362 & 5.4382 & TST \\
\hline CHEMBL1423306 & 688239 & 4.8862 & 5.5262 & TRN \\
\hline CHEMBL1559111 & 688239 & 4.5862 & 5.4407 & TRN \\
\hline CHEMBL1485911 & 688239 & 4.5362 & 5.5998 & TST \\
\hline CHEMBL1461520 & 688239 & 6.3362 & 5.7008 & TRN \\
\hline CHEMBL1321632 & 688239 & 8.1367 & 5.4774 & TRN \\
\hline CHEMBL3194944 & 688239 & 4.4862 & 5.4977 & TST \\
\hline CHEMBL1586302 & 688239 & 5.3862 & 5.4663 & TST \\
\hline CHEMBL1388115 & 688239 & 7.2366 & 5.6479 & TRN \\
\hline CHEMBL549208 & 688239 & 5.6362 & 5.4736 & TRN \\
\hline CHEMBL1303452 & 688239 & 4.7862 & 5.4899 & TRN \\
\hline CHEMBL1367805 & 688239 & 5.1862 & 5.4406 & TRN \\
\hline CHEMBL1590854 & 688239 & 4.5862 & 5.359 & TRN \\
\hline CHEMBL1508521 & 688239 & 4.8862 & 5.3894 & TRN \\
\hline CHEMBL3189169 & 688239 & 5.4862 & 5.415 & TRN \\
\hline
\end{tabular}


Supplemental Table S2.txt

\begin{tabular}{|c|c|c|c|c|c|}
\hline CHEMBL1450836 & 688239 & 5.5862 & 5.5135 & TRN & \\
\hline CHEMBL1569540 & 688239 & 5.9362 & 5.466 & TRN & \\
\hline CHEMBL1544759 & 688239 & 4.6362 & 5.4684 & TST & \\
\hline CHEMBL1567065 & 688239 & 6.0862 & 5.6273 & TST & \\
\hline CHEMBL1344730 & 688239 & 5.0362 & 5.5982 & TRN & \\
\hline CHEMBL1532348 & 688239 & 6.2362 & 5.6219 & TRN & \\
\hline CHEMBL1525297 & 688239 & 4.4862 & 5.3852 & TRN & \\
\hline CHEMBL1342680 & 688239 & 4.6862 & 5.404 & TRN & \\
\hline CHEMBL1487935 & 688239 & 7.5867 & 5.4162 & TRN & \\
\hline CHEMBL1362268 & 688239 & 5.1862 & 5.4807 & TRN & \\
\hline CHEMBL1520753 & 688239 & 5.1862 & 5.4682 & TRN & \\
\hline CHEMBL1531651 & 688239 & 5.1362 & 5.5111 & TST & \\
\hline CHEMBL1525850 & 688239 & 7.7852 & 5.5045 & TRN & \\
\hline CHEMBL1534345 & 688239 & 5.8862 & 5.4671 & TRN & \\
\hline CHEMBL1301879 & 688239 & 6.8861 & 5.3756 & TST & \\
\hline CHEMBL1445334 & 688239 & 8.2366 & 5.3761 & TRN & \\
\hline CHEMBL1451869 & 688239 & 5.3362 & 5.468 & TRN & \\
\hline CHEMBL1365287 & 688239 & 4.5362 & 5.3546 & TRN & \\
\hline CHEMBL1351704 & 688239 & 4.5362 & 5.5375 & TRN & \\
\hline CHEMBL1560928 & 688239 & 5.4362 & 5.6362 & TRN & \\
\hline CHEMBL1477008 & 688239 & 4.9862 & 5.4506 & TST & \\
\hline CHEMBL1525421 & 688239 & 4.4862 & 5.5816 & TRN & \\
\hline CHEMBL1302373 & 688239 & 6.6861 & 5.4445 & TRN & \\
\hline CHEMBL1392116 & 688239 & 5.4362 & 5.3706 & TRN & \\
\hline CHEMBL1403710 & 688239 & 6.8861 & 5.3832 & TRN & \\
\hline CHEMBL1516455 & 688239 & 4.7362 & 5.4758 & TRN & \\
\hline CHEMBL1966289 & 688239 & 6.1862 & 5.5015 & TRN & \\
\hline CHEMBL1574830 & 688239 & 5.4862 & 5.4092 & TST & \\
\hline CHEMBL1438604 & 688239 & 6.7361 & 5.3817 & TST & \\
\hline CHEMBL1605518 & 688239 & 6.6861 & 5.4598 & TRN & \\
\hline CHEMBL1402165 & 688239 & 4.6862 & 5.4989 & TRN & \\
\hline CHEMBL1610780 & 688239 & 5.2862 & 5.4831 & TRN & \\
\hline CHEMBL1371757 & 688239 & 8.28399 & 99999999 & 9 & 5.5152 \\
\hline CHEMBL1501850 & 688239 & 4.5362 & 5.369 & TRN & \\
\hline CHEMBL1417937 & 688239 & 6.1862 & 5.5776 & TST & \\
\hline CHEMBL1385877 & 688239 & 4.5362 & 5.4796 & TRN & \\
\hline CHEMBL1480514 & 688239 & 4.5362 & 5.4006 & TRN & \\
\hline CHEMBL1392074 & 688239 & 5.8862 & 5.5036 & TRN & \\
\hline CHEMBL1533587 & 688239 & 4.6362 & 5.6065 & TRN & \\
\hline CHEMBL1459139 & 688239 & 4.5862 & 5.471 & TST & \\
\hline CHEMBL1465394 & 688239 & 7.4365 & 5.4888 & TST & \\
\hline CHEMBL1502123 & 688239 & 6.1362 & 5.4752 & TST & \\
\hline CHEMBL1537987 & 688239 & 6.1862 & 5.5038 & TRN & \\
\hline CHEMBL1442634 & 688239 & 4.6862 & 5.4955 & TRN & \\
\hline CHEMBL1558798 & 688239 & 5.8362 & 5.4065 & TRN & \\
\hline CHEMBL1502530 & 688239 & 6.2362 & 5.5194 & TRN & \\
\hline CHEMBL1458392 & 688239 & 4.6862 & 5.3388 & TRN & \\
\hline CHEMBL1427965 & 688239 & 5.4362 & 5.4143 & TST & \\
\hline
\end{tabular}


Supplemental Table S2.txt

\begin{tabular}{|c|c|c|c|c|c|}
\hline CHEMBL1335138 & 688239 & 7.0362 & 5.5141 & TRN & \\
\hline CHEMBL1564603 & 688239 & 5.4362 & 5.5515 & TST & \\
\hline CHEMBL1467530 & 688239 & 5.1362 & 5.5771 & TRN & \\
\hline CHEMBL1303568 & 688239 & 5.2362 & 5.5243 & TRN & \\
\hline CHEMBL1562483 & 688239 & 4.6862 & 5.5366 & TRN & \\
\hline CHEMBL1422401 & 688239 & 5.1862 & 5.4089 & TST & \\
\hline CHEMBL1530677 & 688239 & 5.0362 & 5.6095 & TRN & \\
\hline CHEMBL1445593 & 688239 & 6.3362 & 5.5776 & TRN & \\
\hline CHEMBL1408073 & 688239 & 4.5362 & 5.5568 & TRN & \\
\hline CHEMBL1443508 & 688239 & 5.4362 & 5.4714 & TST & \\
\hline CHEMBL1364463 & 688239 & 4.6362 & 5.3861 & TRN & \\
\hline CHEMBL1355523 & 688239 & 7.3363 & 5.6225 & TRN & \\
\hline CHEMBL1337335 & 688239 & 5.9362 & 5.5342 & TRN & \\
\hline CHEMBL1470478 & 688239 & 4.6362 & 5.6112 & TRN & \\
\hline CHEMBL1441999 & 688239 & 6.0362 & 5.5119 & TRN & \\
\hline CHEMBL1343480 & 688239 & 5.4862 & 5.621 & TRN & \\
\hline CHEMBL1315843 & 688239 & 5.6362 & 5.3581 & TST & \\
\hline CHEMBL1486572 & 688239 & 5.7362 & 5.4058 & TRN & \\
\hline CHEMBL1394247 & 688239 & 8.3872 & 5.6402 & TRN & \\
\hline CHEMBL1435937 & 688239 & 6.0362 & 5.5424 & TRN & \\
\hline CHEMBL1330146 & 688239 & 4.5362 & 5.4747 & TST & \\
\hline CHEMBL1429728 & 688239 & 5.1862 & 5.487 & TST & \\
\hline CHEMBL1606358 & 688239 & 4.9362 & 5.5516 & TRN & \\
\hline CHEMBL1564773 & 688239 & 4.6862 & 5.5399 & TRN & \\
\hline CHEMBL1439867 & 688239 & 5.6362 & 5.4851 & TRN & \\
\hline CHEMBL 1305780 & 688239 & 4.6862 & 5.3448 & TST & \\
\hline CHEMBL1607360 & 688239 & 5.7862 & 5.5868 & TRN & \\
\hline CHEMBL 2359072 & 688239 & 6.0862 & 5.325 & TRN & \\
\hline CHEMBL1572712 & 688239 & 4.6362 & 5.4883 & TRN & \\
\hline CHEMBL1532267 & 688239 & 4.5362 & 5.5554 & TRN & \\
\hline CHEMBL 1384703 & 688239 & 6.1362 & 5.6751 & TRN & \\
\hline CHEMBL1336694 & 688239 & 4.5362 & 5.5598 & TRN & \\
\hline CHEMBL1412716 & 688239 & 4.7362 & 5.6747 & TRN & \\
\hline CHEMBL1381685 & 688239 & 4.5362 & 5.5932 & TST & \\
\hline CHEMBL1310157 & 688239 & 6.3362 & 5.4633 & TRN & \\
\hline CHEMBL1431143 & 688239 & 5.7862 & 5.4852 & TRN & \\
\hline CHEMBL1384592 & 688239 & 6.0362 & 5.5114 & TRN & \\
\hline CHEMBL407491 & 688239 & 5.4362 & 5.4749 & TRN & \\
\hline CHEMBL1402722 & 688239 & 6.6362 & 5.41700 & 0000000001 & TRN \\
\hline CHEMBL1301597 & 688239 & 7.0362 & 5.6574 & TRN & \\
\hline CHEMBL1364868 & 688239 & 4.5362 & 5.6111 & TRN & \\
\hline CHEMBL1498451 & 688239 & 4.9862 & 5.5941 & TRN & \\
\hline CHEMBL1557163 & 688239 & 6.1362 & 5.3449 & TRN & \\
\hline CHEMBL1485584 & 688239 & 6.6861 & 5.5329 & TRN & \\
\hline CHEMBL1489040 & 688239 & 4.5362 & 5.5555 & TRN & \\
\hline CHEMBL3207742 & 688239 & 4.5362 & 5.4552 & TST & \\
\hline CHEMBL1376120 & 688239 & 5.1362 & 5.5178 & TRN & \\
\hline CHEMBL1327053 & 688239 & 5.2362 & 5.5159 & TRN & \\
\hline
\end{tabular}


Supplemental Table S2.txt

\begin{tabular}{|c|c|c|c|c|c|}
\hline CHEMBL1509943 & 688239 & 4.5862 & 5.33 & TRN & \\
\hline CHEMBL1344418 & 688239 & 5.8362 & 5.5158 & TRN & \\
\hline CHEMBL1538986 & 688239 & 4.7362 & 5.3236 & TRN & \\
\hline CHEMBL1349201 & 688239 & 5.0362 & 5.4095 & TRN & \\
\hline CHEMBL199194 & 688239 & 5.8362 & 5.4493 & TST & \\
\hline CHEMBL1358902 & 688239 & 5.1862 & 5.4676 & TRN & \\
\hline CHEMBL1370701 & 688239 & 5.1862 & 5.5139 & TST & \\
\hline CHEMBL1319709 & 688239 & 5.8862 & 5.4201 & TRN & \\
\hline CHEMBL1445947 & 688239 & 4.5362 & 5.6305 & TRN & \\
\hline CHEMBL1420429 & 688239 & 6.8861 & 5.5205 & TRN & \\
\hline CHEMBL1601525 & 688239 & 5.1862 & 5.5434 & TRN & \\
\hline CHEMBL1346803 & 688239 & 5.3862 & 5.4524 & TST & \\
\hline CHEMBL1362117 & 688239 & 6.1862 & 5.5702 & TRN & \\
\hline CHEMBL1573232 & 688239 & 5.6862 & 5.5166 & TRN & \\
\hline CHEMBL1390133 & 688239 & 4.4862 & 5.2902 & TRN & \\
\hline CHEMBL1375950 & 688239 & 4.5362 & 5.5238 & TST & \\
\hline CHEMBL1431475 & 688239 & 4.5362 & 5.4556 & TRN & \\
\hline CHEMBL1417662 & 688239 & 5.1862 & 5.4737 & TST & \\
\hline CHEMBL1486027 & 688239 & 4.6862 & 5.4606 & TRN & \\
\hline CHEMBL1338045 & 688239 & 5.0862 & 5.4198 & TRN & \\
\hline CHEMBL1419932 & 688239 & 4.5862 & 5.3971 & TST & \\
\hline CHEMBL1512986 & 688239 & 5.6862 & 5.3847 & TRN & \\
\hline CHEMBL1604984 & 688239 & 4.5362 & 5.3887 & TRN & \\
\hline CHEMBL1342736 & 688239 & 5.7862 & 5.5053 & TST & \\
\hline CHEMBL1610201 & 688239 & 5.8362 & 5.5887 & TRN & \\
\hline CHEMBL1391910 & 688239 & 4.7362 & 5.5689 & TST & \\
\hline CHEMBL1401061 & 688239 & 4.5362 & 5.5133 & TRN & \\
\hline CHEMBL1547007 & 688239 & 5.1862 & 5.392 & TRN & \\
\hline CHEMBL1577365 & 688239 & 4.6862 & 5.5032 & TST & \\
\hline CHEMBL1512268 & 688239 & 6.4862 & 5.6562 & TRN & \\
\hline CHEMBL3196731 & 688239 & 4.6862 & 5.3075 & TST & \\
\hline CHEMBL1403023 & 688239 & 6.1862 & 5.5821 & TRN & \\
\hline CHEMBL1419646 & 688239 & 5.8862 & 5.4476 & TST & \\
\hline CHEMBL1424393 & 688239 & 5.3862 & 5.5019 & TRN & \\
\hline CHEMBL1516660 & 688239 & 7.2366 & 5.5768 & TRN & \\
\hline CHEMBL1491782 & 688239 & 4.6362 & 5.4632 & TST & \\
\hline CHEMBL1338451 & 688239 & 5.2362 & 5.4731 & TST & \\
\hline CHEMBL1420533 & 688239 & 5.1862 & 5.4601 & TRN & \\
\hline CHEMBL1524870 & 688239 & 6.9363 & 5.7268 & TRN & \\
\hline CHEMBL1568923 & 688239 & 6.5862 & 5.3333 & TRN & \\
\hline CHEMBL1578183 & 688239 & 7.1361 & 5.6426 & TRN & \\
\hline CHEMBL1449954 & 688239 & 7.8356 & 5.6576 & TRN & \\
\hline CHEMBL1341324 & 688239 & 5.9362 & 5.5785 & TRN & \\
\hline CHEMBL1460186 & 688239 & 5.3362 & 5.4907 & TST & \\
\hline CHEMBL1529376 & 688239 & 4.5362 & 5.4183 & TRN & \\
\hline CHEMBL1396943 & 688239 & 4.5362 & 5.5738 & TRN & \\
\hline CHEMBL1579494 & 688239 & 8.28399 & 9999999 & 99 & 5.4405 \\
\hline CHEMBL1482182 & 688239 & 5.7862 & 5.4632 & TST & \\
\hline
\end{tabular}




\begin{tabular}{|c|c|c|c|c|c|}
\hline \multicolumn{6}{|c|}{ Supplemental Table S2.txt } \\
\hline CHEMBL1399147 & 688239 & 5.4862 & 5.5097 & TRN & \\
\hline CHEMBL1320957 & 688239 & 7.9355 & 5.4432 & TRN & \\
\hline CHEMBL3190511 & 688239 & 5.4862 & 5.4451 & TST & \\
\hline CHEMBL1405751 & 688239 & 5.5862 & 5.6471 & TRN & \\
\hline CHEMBL1543904 & 688239 & 4.5362 & 5.4043 & TST & \\
\hline CHEMBL1363278 & 688239 & 4.7862 & 5.3235 & TRN & \\
\hline CHEMBL1500604 & 688239 & 4.9862 & 5.3973 & TST & \\
\hline CHEMBL1504146 & 688239 & 6.5363 & 5.4622 & TST & \\
\hline CHEMBL1387999 & 688239 & 6.1362 & 5.4998 & TRN & \\
\hline CHEMBL1465637 & 688239 & 4.6862 & 5.38700 & 00000000005 & TRN \\
\hline CHEMBL1607939 & 688239 & 4.9862 & 5.4725 & TRN & \\
\hline CHEMBL1513657 & 688239 & 5.3862 & 5.3984 & TST & \\
\hline CHEMBL1576571 & 688239 & 4.5362 & 5.3347 & TST & \\
\hline CHEMBL1341119 & 688239 & 5.1862 & 5.4649 & TRN & \\
\hline CHEMBL1586326 & 688239 & 4.6862 & 5.5957 & TST & \\
\hline CHEMBL1475928 & 688239 & 5.1862 & 5.6288 & TRN & \\
\hline CHEMBL1531533 & 688239 & 4.5362 & 5.3655 & TST & \\
\hline CHEMBL1610079 & 688239 & 6.8362 & 5.5326 & TRN & \\
\hline CHEMBL1510907 & 688239 & 5.6362 & 5.4625 & TRN & \\
\hline CHEMBL3199047 & 688239 & 4.8862 & 5.5858 & TRN & \\
\hline CHEMBL1608310 & 688239 & 4.6862 & 5.5257 & TRN & \\
\hline CHEMBL1301394 & 688239 & 6.0362 & 5.5179 & TST & \\
\hline CHEMBL1338508 & 688239 & 5.2862 & 5.3486 & TST & \\
\hline CHEMBL1440067 & 688239 & 4.5362 & 5.5212 & TRN & \\
\hline CHEMBL3198433 & 688239 & 6.3863 & 5.6567 & TRN & \\
\hline CHEMBL1512280 & 688239 & 4.5362 & 5.4994 & TRN & \\
\hline CHEMBL1341830 & 688239 & 6.8861 & 5.3802 & TRN & \\
\hline CHEMBL1442046 & 688239 & 4.7862 & 5.5949 & TRN & \\
\hline CHEMBL1432320 & 688239 & 4.4362 & 5.3727 & TRN & \\
\hline CHEMBL1512100 & 688239 & 6.1362 & 5.4746 & TRN & \\
\hline CHEMBL1466301 & 688239 & 5.1862 & 5.3967 & TST & \\
\hline CHEMBL1524562 & 688239 & 4.9862 & 5.4781 & TST & \\
\hline CHEMBL1582039 & 688239 & 5.2862 & 5.3584 & TRN & \\
\hline CHEMBL1371700 & 688239 & 4.7862 & 5.4175 & TRN & \\
\hline CHEMBL1469275 & 688239 & 6.0862 & 5.5678 & TRN & \\
\hline CHEMBL3189828 & 688239 & 5.1862 & 5.355 & TST & \\
\hline CHEMBL1581709 & 688239 & 7.0362 & 5.4374 & TRN & \\
\hline CHEMBL1599923 & 688239 & 5.1862 & 5.5686 & TRN & \\
\hline CHEMBL1599467 & 688239 & 4.5362 & 5.4912 & TRN & \\
\hline CHEMBL1437255 & 688239 & 4.5862 & 5.3321 & TRN & \\
\hline CHEMBL1331826 & 688239 & 5.2362 & 5.4079 & TRN & \\
\hline CHEMBL1324788 & 688239 & 5.4362 & 5.6258 & TRN & \\
\hline CHEMBL1488970 & 688239 & 4.9362 & 5.7902 & TRN & \\
\hline CHEMBL1463963 & 688239 & 6.3863 & 5.4879 & TRN & \\
\hline CHEMBL1525070 & 688239 & 6.1862 & 5.6089 & TRN & \\
\hline CHEMBL1456185 & 688239 & 6.7361 & 5.3827 & TST & \\
\hline CHEMBL1459991 & 688239 & 5.1362 & 5.4689 & TRN & \\
\hline CHEMBL1532389 & 688239 & 4.5362 & 5.5665 & TST & \\
\hline
\end{tabular}


Supplemental Table S2.txt

\begin{tabular}{|c|c|c|c|c|c|}
\hline CHEMBL1510554 & 688239 & 5.1862 & 5.4111 & TST & \\
\hline CHEMBL1599310 & 688239 & 4.5362 & 5.733 & TRN & \\
\hline CHEMBL1604664 & 688239 & 5.9362 & 5.3225 & TRN & \\
\hline CHEMBL1591868 & 688239 & 5.5862 & 5.4759 & TRN & \\
\hline CHEMBL1546716 & 688239 & 5.4362 & 5.4306 & TST & \\
\hline CHEMBL1470527 & 688239 & 4.9862 & 5.5525 & TRN & \\
\hline CHEMBL1328716 & 688239 & 5.7362 & 5.5295 & TRN & \\
\hline CHEMBL1557097 & 688239 & 5.1862 & 5.56 & TRN & \\
\hline CHEMBL1352070 & 688239 & 4.6862 & 5.4965 & TRN & \\
\hline CHEMBL1400760 & 688239 & 6.5862 & 5.6116 & TRN & \\
\hline CHEMBL1325536 & 688239 & 4.9862 & 5.5264 & TST & \\
\hline CHEMBL1375908 & 688239 & 6.2362 & 5.39 & TRN & \\
\hline CHEMBL1302606 & 688239 & 4.8362 & 5.4226 & TRN & \\
\hline CHEMBL1330289 & 688239 & 4.5362 & 5.4001 & TRN & \\
\hline CHEMBL1578932 & 688239 & 5.2362 & 5.3347 & TRN & \\
\hline CHEMBL1471062 & 688239 & 4.5362 & 5.616000 & 00000000005 & TRN \\
\hline CHEMBL1301368 & 688239 & 6.7862 & 5.3541 & TRN & \\
\hline CHEMBL1568146 & 688239 & 5.1362 & 5.4793 & TRN & \\
\hline CHEMBL1497339 & 688239 & 8.28399 & 999999999 & 5.5067 & \\
\hline CHEMBL1548131 & 688239 & 5.4362 & 5.5568 & TST & \\
\hline CHEMBL1444201 & 688239 & 6.2362 & 5.5591 & TRN & \\
\hline CHEMBL1538107 & 688239 & 5.8362 & 5.4891 & TRN & \\
\hline CHEMBL1398535 & 688239 & 5.5362 & 5.612 & TST & \\
\hline CHEMBL1410171 & 688239 & 6.7862 & 5.4085 & TST & \\
\hline CHEMBL1429684 & 688239 & 5.6862 & 5.457000 & 0000000001 & \\
\hline CHEMBL1511748 & 688239 & 5.9362 & 5.4872 & TRN & \\
\hline CHEMBL1603582 & 688239 & 7.1864 & 5.3687 & TST & \\
\hline CHEMBL1393529 & 688239 & 5.2362 & 5.4117 & TRN & \\
\hline CHEMBL 3213813 & 688239 & 5.8862 & 5.497999 & 9999999999 & זעו \\
\hline CHEMBL1381857 & 688239 & 4.7362 & 5.4256 & TST & \\
\hline CHEMBL1429885 & 688239 & 4.7862 & 5.5363 & TRN & \\
\hline CHEMBL1496588 & 688239 & 8.3372 & 5.3572 & TRN & \\
\hline CHEMBL1392476 & 688239 & 5.3862 & 5.5568 & TRN & \\
\hline CHEMBL1464662 & 688239 & 4.7362 & 5.4595 & TRN & \\
\hline CHEMBL1481786 & 688239 & 6.3863 & 5.4008 & TST & \\
\hline CHEMBL1329287 & 688239 & 6.2362 & 5.4739 & TST & \\
\hline CHEMBL1360505 & 688239 & 6.2862 & 5.4784 & TRN & \\
\hline CHEMBL1495865 & 688239 & 4.5362 & 5.463999 & 99999999995 & \\
\hline CHEMBL1338004 & 688239 & 4.9362 & 5.314 & TRN & \\
\hline CHEMBL1370807 & 688239 & 5.3862 & 5.4254 & TRN & \\
\hline CHEMBL1531245 & 688239 & 5.0362 & 5.5018 & TST & \\
\hline CHEMBL1561092 & 688239 & 4.6862 & 5.5109 & TST & \\
\hline CHEMBL1520081 & 688239 & 5.7362 & 5.6904 & TST & \\
\hline CHEMBL1598759 & 688239 & 5.3362 & 5.471 & TRN & \\
\hline CHEMBL1612228 & 688239 & 4.5362 & 5.4805 & TRN & \\
\hline CHEMBL1498414 & 688239 & 5.7862 & 5.5606 & TRN & \\
\hline CHEMBL 1453378 & 688239 & 6.8861 & 5.5662 & TRN & \\
\hline CHEMBL1399562 & 688239 & 5.7362 & 5.4804 & TRN & \\
\hline
\end{tabular}


Supplemental Table S2.txt

\begin{tabular}{|c|c|c|c|c|}
\hline CHEMBL1483659 & 688239 & 5.8862 & 5.4235 & TRN \\
\hline CHEMBL1578878 & 688239 & 5.1862 & 5.7354 & TRN \\
\hline CHEMBL1544576 & 688239 & 4.5862 & 5.5578 & TRN \\
\hline CHEMBL1566392 & 688239 & 4.5362 & 5.4869 & TRN \\
\hline CHEMBL164290 & 688239 & 5.7862 & 5.6074 & TST \\
\hline CHEMBL1603550 & 688239 & 4.5862 & 5.7077 & TRN \\
\hline CHEMBL1472729 & 688239 & 5.1862 & 5.5411 & TRN \\
\hline CHEMBL1599931 & 688239 & 4.5362 & 5.3901 & TRN \\
\hline CHEMBL1354160 & 688239 & 6.9363 & 5.4782 & TST \\
\hline CHEMBL1465031 & 688239 & 6.5363 & 5.5699 & TRN \\
\hline CHEMBL1336711 & 688239 & 4.5362 & 5.6198 & TST \\
\hline CHEMBL1497366 & 688239 & 6.7862 & 5.50700 & 0000000001 \\
\hline CHEMBL1356190 & 688239 & 4.6362 & 5.3664 & TRN \\
\hline CHEMBL1393684 & 688239 & 8.2366 & 5.4108 & TST \\
\hline CHEMBL3198979 & 688239 & 4.5362 & 5.6264 & TRN \\
\hline CHEMBL1533190 & 688239 & 5.3362 & 5.50700 & 2000000001 \\
\hline CHEMBL1455036 & 688239 & 6.6362 & 5.5958 & TRN \\
\hline CHEMBL1391068 & 688239 & 4.6862 & 5.3114 & TRN \\
\hline CHEMBL1533170 & 688239 & 6.5363 & 5.5451 & TST \\
\hline CHEMBL1541232 & 688239 & 4.5362 & 5.4526 & TST \\
\hline CHEMBL1452606 & 688239 & 6.9863 & 5.4729 & TRN \\
\hline CHEMBL1580435 & 688239 & 5.9862 & 5.6569 & TRN \\
\hline CHEMBL1429089 & 688239 & 6.8861 & 5.3938 & TRN \\
\hline CHEMBL1421203 & 688239 & 4.5862 & 5.4731 & TRN \\
\hline CHEMBL1577890 & 688239 & 5.1862 & 5.4406 & TRN \\
\hline CHEMBL1481155 & 688239 & 7.0362 & 5.5255 & TRN \\
\hline CHEMBL547483 & 688239 & 5.9862 & 5.4067 & TRN \\
\hline CHEMBL1367843 & 688239 & 6.9363 & 5.4354 & TRN \\
\hline CHEMBL1466794 & 688239 & 5.4362 & 5.4498 & TRN \\
\hline CHEMBL1305690 & 688239 & 6.8861 & 5.4179 & TRN \\
\hline CHEMBL1461881 & 688239 & 4.7862 & 5.5012 & TRN \\
\hline CHEMBL566501 & 688239 & 6.1862 & 5.3354 & TRN \\
\hline CHEMBL3213835 & 688239 & 4.6362 & 5.4523 & TRN \\
\hline CHEMBL1395244 & 688239 & 5.4862 & 5.5757 & TRN \\
\hline CHEMBL3189493 & 688239 & 5.1862 & 5.532 & TRN \\
\hline CHEMBL1332207 & 688239 & 5.1862 & 5.5287 & TST \\
\hline CHEMBL1373574 & 688239 & 4.5362 & 5.4259 & TRN \\
\hline CHEMBL1421056 & 688239 & 5.4862 & 5.4586 & TRN \\
\hline CHEMBL1435921 & 688239 & 4.7862 & 5.5867 & TRN \\
\hline CHEMBL 3145060 & 688239 & 4.5362 & 5.5204 & TRN \\
\hline CHEMBL1455606 & 688239 & 4.5362 & 5.5561 & TRN \\
\hline CHEMBL1380391 & 688239 & 4.5362 & 5.3003 & TST \\
\hline CHEMBL1582373 & 688239 & 8.3872 & 5.5147 & TRN \\
\hline CHEMBL1348012 & 688239 & 5.1862 & 5.6206 & TST \\
\hline CHEMBL1525745 & 688239 & 4.8362 & 5.3138 & TRN \\
\hline CHEMBL1417877 & 688239 & 6.4862 & 5.5628 & TRN \\
\hline CHEMBL1516796 & 688239 & 5.1862 & 5.5887 & TST \\
\hline \multirow[t]{2}{*}{ CHEMBL1308212 } & 688239 & 4.5362 & 5.42299 & 9999999999 \\
\hline & & \multicolumn{3}{|c|}{ Page 1554} \\
\hline
\end{tabular}


Supplemental Table S2.txt

\begin{tabular}{|c|c|c|c|c|}
\hline The & & & - & \\
\hline & & .7362 & & \\
\hline-1 & & & & \\
\hline AEMBL1500268 & & & & $\mathrm{MI}$ \\
\hline AEMBL1541101 & 8239 & 362 & 271 & \\
\hline HEMBL1450450 & 88239 & 862 & .4433 & \\
\hline 782 & 239 & 362 & 681 & \\
\hline 577 & & & & \\
\hline AEMBL1398696 & & 862 & 343 & \\
\hline HEMBL1344108 & 38239 & 862 & 4177 & \\
\hline AEMBL1506357 & 39 & 362 & 3205 & \\
\hline IEMBL1 & 39 & 362 & 323 & \\
\hline EMBL & & & & RN \\
\hline HEMBL1 & & 362 & & \\
\hline AEMBL1511291 & & & & \\
\hline AEMBL1 & 39 & 62 & 57 & \\
\hline AEMBL5 & & 52 & 97 & \\
\hline HEMBL1 & & & & \\
\hline AEMBLI & & 362 & 884 & \\
\hline AEMBLI & & & & \\
\hline AEIMBL. & & & 652 & 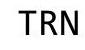 \\
\hline AEMBL & & & 852 & KIV \\
\hline AEMBL & & 51 & 305 & \\
\hline 013 & & 862 & & \\
\hline AEMBL1 & & & & . \\
\hline AEMBL & & & 201 & KIV \\
\hline HEMBL & & & 14 & Niv \\
\hline AFMR & & 52 & 723 & \\
\hline AEMBL & & & & $T_{2}$ \\
\hline HEMBL14 & & & 374 & IRN \\
\hline HEMBL1 & & & 81 & RIN \\
\hline HEMBL & & & & RN \\
\hline 99 & & 52 & & \\
\hline HEMBL1300192 & & & 792 & in \\
\hline HEMBL1508938 & & & 5.7525 & 「RN \\
\hline HEMBL: & & & 4144 & RN \\
\hline - & & & 97 & \\
\hline HEMBL1 & & & 766 & RN \\
\hline HEMBL1461061 & 88239 & & 5.4224 & TST \\
\hline IEMBL1 & & 362 & 738 & TRN \\
\hline HEMBL1 & & 51 & .5468 & \\
\hline HEMBL1. & & & 5.5745 & RIV \\
\hline HEMBL1580953 & & & 5.4831 & RN \\
\hline AEMBL1372507 & 39 & 862 & 4615 & TR \\
\hline+2 & & & 5.4185 & $\mathrm{RN}$ \\
\hline HEMBL1 & & & 3988 & \\
\hline CHEMBL1539905 & & & 5.5264 & \\
\hline HEMBL1340032 & 688239 & 5.8862 & 5.4527 & \\
\hline
\end{tabular}

Page 1555 
Supplemental Table S2.txt

\begin{tabular}{|c|c|c|c|c|}
\hline & & & & \\
\hline AEMBL13 & 8239 & 362 & 4011 & \\
\hline IEMBL1458139 & 8239 & 362 & 5262 & \\
\hline AEMBL1492173 & 239 & 372 & 738 & \\
\hline 6655 & 239 & 862 & & \\
\hline IEMBL1308062 & 239 & 362 & 704 & \\
\hline AEMBL1306716 & 88239 & 1862 & 1434 & \\
\hline AEMBL1601220 & 88239 & 372 & 4649 & \\
\hline AEMBL3207580 & 239 & 862 & 6 & \\
\hline IEMBL1303454 & 239 & 62 & 98 & \\
\hline IEMBL1562482 & & & & \\
\hline AEMBL1578760 & 688239 & 362 & 5696 & \\
\hline AEMBL1441839 & 239 & & 23 & - \\
\hline IEMBL1324 & & & & \\
\hline IEMBL1522772 & & & & \\
\hline AEMBL1456748 & & & & \\
\hline AEMBL1557781 & 239 & 862 & 692 & RN \\
\hline AEMBL1506069 & & 62 & & \\
\hline EMBL136s & & & 21 & \\
\hline AEMBL1555727 & & & 23 & \\
\hline AEMBL1510105 & & & & RN \\
\hline AEMBL1234781 & & & 823 & RN \\
\hline IEMBL1587985 & & & & ST \\
\hline AEMBL147 & & & & \\
\hline HEMBL13 & & & & RN \\
\hline AFMRI 148 & & & & וכ \\
\hline HEMBL1497 & & & & RN \\
\hline AEMBL1430292 & & & & \\
\hline AEMBL1393 & & & 27 & RI \\
\hline L152 & & & 12 & 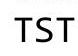 \\
\hline 26 & & & & 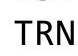 \\
\hline HEMBL1350228 & & & & RN \\
\hline AEMBL1371936 & & & & RI \\
\hline IEMBL3189319 & & & 686 & ST \\
\hline HEMBL144 & & & & . \\
\hline 13 & & & & se \\
\hline AEMBL1343761 & & & & $\mathrm{R}$ \\
\hline AEMBL1491478 & & & & \\
\hline EMBL1603 & & & & RI \\
\hline משר יחוזו & & & 79 & 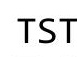 \\
\hline & & & 47 & RN \\
\hline AEMBL1467604 & & & 5531 & $\mathrm{R}$ \\
\hline IEMBL1547 & & & & $\mathrm{R}$ \\
\hline JEMBL13 & & & & \\
\hline CHEMBL1435 & & & & \\
\hline CHEMBL1516575 & & & 837 & ST \\
\hline HEMBL159148 & 88239 & 6.1862 & 5.5406 & $\mathrm{TR}$ \\
\hline HFMBI 1594998 & 688239 & 6.1862 & 5.6477 & \\
\hline
\end{tabular}

Page 1556 
Supplemental Table S2.txt

\begin{tabular}{|c|c|c|c|c|}
\hline CHEMBL1535189 & 688239 & 5.9862 & 5.4482 & TST \\
\hline CHEMBL1497277 & 688239 & 6.4862 & 5.5265 & TRN \\
\hline CHEMBL584879 & 688239 & 4.5362 & 5.4943 & TRN \\
\hline CHEMBL1310252 & 688239 & 5.2862 & 5.4476 & TRN \\
\hline CHEMBL1462061 & 688239 & 5.4362 & 5.685 & TRN \\
\hline CHEMBL1563803 & 688239 & 5.2362 & \multicolumn{2}{|c|}{5.593999999999999} \\
\hline CHEMBL1420262 & 688239 & 6.9363 & 5.4438 & TRN \\
\hline CHEMBL1380245 & 688239 & 5.1862 & 5.4622 & TST \\
\hline CHEMBL1432446 & 688239 & 5.4862 & 5.4549 & TRN \\
\hline CHEMBL1379872 & 688239 & 4.5362 & 5.4619 & TRN \\
\hline CHEMBL1586717 & 688239 & 6.3362 & 5.5287 & TST \\
\hline CHEMBL1299939 & 688239 & 4.5362 & 5.562 & TST \\
\hline CHEMBL1518738 & 688239 & 6.9863 & 5.5747 & TRN \\
\hline CHEMBL1429883 & 688239 & 6.4362 & 5.4056 & TST \\
\hline CHEMBL1584906 & 688239 & 4.5362 & 5.4075 & TST \\
\hline CHEMBL1364629 & 688239 & 5.1862 & 5.5083 & TRN \\
\hline CHEMBL1510588 & 688239 & 6.2362 & 5.4674 & TST \\
\hline CHEMBL1544249 & 688239 & 5.8862 & 5.5731 & TRN \\
\hline CHEMBL1350299 & 688239 & 6.8362 & 5.5493 & TST \\
\hline CHEMBL1499479 & 688239 & 5.4862 & 5.5587 & TRN \\
\hline CHEMBL1502631 & 688239 & 4.7362 & 5.5138 & TRN \\
\hline CHEMBL1352349 & 688239 & 4.5362 & 5.528 & TRN \\
\hline CHEMBL1376248 & 688239 & 6.8861 & 5.4565 & TRN \\
\hline CHEMBL1442086 & 688239 & 4.5862 & 5.4537 & TST \\
\hline CHEMBL1612218 & 688239 & 6.9863 & 5.5054 & TST \\
\hline CHEMBL1322009 & 688239 & 4.9362 & 5.5019 & TRN \\
\hline CHEMBL1568681 & 688239 & 4.6862 & 5.4741 & TST \\
\hline CHEMBL1354683 & 688239 & 8.3372 & 5.4427 & TRN \\
\hline CHEMBL1426365 & 688239 & 4.9362 & 5.5354 & TST \\
\hline CHEMBL1418396 & 688239 & 6.0862 & 5.4011 & TRN \\
\hline CHEMBL1351586 & 688239 & 6.9863 & 5.4804 & TRN \\
\hline CHEMBL1446095 & 688239 & 4.7362 & 5.3407 & TST \\
\hline CHEMBL1457593 & 688239 & 5.1862 & 5.5051 & TRN \\
\hline CHEMBL1526871 & 688239 & 4.4862 & 5.4424 & TST \\
\hline CHEMBL1374150 & 688239 & 5.1862 & 5.4953 & TRN \\
\hline CHEMBL1362788 & 688239 & 8.3872 & 5.4707 & TRN \\
\hline CHEMBL 585997 & 688239 & 6.1862 & 5.4886 & TST \\
\hline CHEMBL1485284 & 688239 & 5.3362 & 5.54 & TST \\
\hline CHEMBL1611928 & 688239 & 8.3372 & 5.5701 & TRN \\
\hline CHEMBL1468440 & 688239 & 5.4362 & 5.6414 & TRN \\
\hline CHEMBL1574014 & 688239 & 5.1862 & 5.445 & TST \\
\hline CHEMBL1519630 & 688239 & 5.0362 & 5.3403 & TRN \\
\hline CHEMBL1481477 & 688239 & 4.5862 & 5.3996 & TRN \\
\hline CHEMBL1593562 & 688239 & 4.6362 & 5.4084 & TRN \\
\hline CHEMBL1310347 & 688239 & 4.5362 & 5.534 & TRN \\
\hline CHEMBL1454959 & 688239 & 5.1862 & 5.6157 & TRN \\
\hline CHEMBL1553659 & 688239 & 4.5362 & 5.4327 & TRN \\
\hline CHEMBL1538888 & 688239 & 5.1862 & 5.5866 & TRN \\
\hline
\end{tabular}


Supplemental Table S2.txt

\begin{tabular}{|c|c|c|c|c|c|}
\hline CHEMBL1491703 & 688239 & 5.2362 & 5.4697 & TRN & \\
\hline CHEMBL595700 & 688239 & 5.0862 & 5.36799 & 9999999999 & TRN \\
\hline CHEMBL1564624 & 688239 & 5.2862 & 5.5689 & TRN & \\
\hline CHEMBL1459327 & 688239 & 6.2362 & 5.3386 & TRN & \\
\hline CHEMBL1558075 & 688239 & 4.7362 & 5.4872 & TST & \\
\hline CHEMBL3207449 & 688239 & 5.3362 & 5.4841 & TRN & \\
\hline CHEMBL1419036 & 688239 & 4.5362 & 5.4634 & TRN & \\
\hline CHEMBL1455564 & 688239 & 4.8362 & 5.4759 & TST & \\
\hline CHEMBL1339137 & 688239 & 6.1362 & 5.441 & TRN & \\
\hline CHEMBL1334058 & 688239 & 5.5862 & 5.3333 & TRN & \\
\hline CHEMBL1977480 & 688239 & 4.4862 & 5.4185 & TRN & \\
\hline CHEMBL1473225 & 688239 & 4.5862 & 5.5157 & TRN & \\
\hline CHEMBL1385897 & 688239 & 4.5362 & 5.687 & TRN & \\
\hline CHEMBL1562581 & 688239 & 5.3862 & 5.5635 & TRN & \\
\hline CHEMBL1340530 & 688239 & 4.5362 & 5.4723 & TRN & \\
\hline CHEMBL1501860 & 688239 & 5.2862 & 5.4291 & TRN & \\
\hline CHEMBL1500232 & 688239 & 4.6862 & 5.2772 & TST & \\
\hline CHEMBL1457010 & 688239 & 4.5362 & 5.4088 & TRN & \\
\hline CHEMBL1419509 & 688239 & 4.9362 & 5.6596 & TST & \\
\hline CHEMBL1331727 & 688239 & 5.1862 & 5.5182 & TRN & \\
\hline CHEMBL208926 & 688239 & 4.6862 & 5.3593 & TST & \\
\hline CHEMBL1427017 & 688239 & 6.7862 & 5.6275 & TRN & \\
\hline CHEMBL1532573 & 688239 & 6.2862 & 5.3212 & TRN & \\
\hline CHEMBL1361715 & 688239 & 4.7862 & 5.6622 & TRN & \\
\hline CHEMBL 7747 & 688239 & 5.0362 & 5.3768 & TRN & \\
\hline CHEMBL1570054 & 688239 & 4.7362 & 5.6385 & TRN & \\
\hline CHEMBL1575160 & 688239 & 5.3362 & 5.5128 & TRN & \\
\hline CHEMBL1307271 & 688239 & 6.0862 & 5.4291 & TRN & \\
\hline CHEMBL1333962 & 688239 & 4.5362 & 5.513 & TRN & \\
\hline CHEMBL1574262 & 688239 & 4.6862 & 5.5417 & TRN & \\
\hline CHEMBL1475045 & 688239 & 5.1362 & 5.5282 & TRN & \\
\hline CHEMBL1335632 & 688239 & 6.0362 & 5.3887 & TRN & \\
\hline CHEMBL1362961 & 688239 & 4.6362 & 5.3105 & TRN & \\
\hline CHEMBL1703256 & 688239 & 6.8861 & 5.4567 & TST & \\
\hline CHEMBL1302274 & 688239 & 4.4862 & 5.4556 & TRN & \\
\hline CHEMBL3193429 & 688239 & 6.9363 & 5.5969 & TRN & \\
\hline CHEMBL1362120 & 688239 & 5.3362 & 5.4702 & TST & \\
\hline CHEMBL31293 & 688239 & 5.1362 & 5.4958 & TRN & \\
\hline CHEMBL1300612 & 688239 & 4.5362 & 5.4746 & TST & \\
\hline CHEMBL1383387 & 688239 & 4.7862 & 5.5907 & TRN & \\
\hline CHEMBL1299745 & 688239 & 4.6862 & 5.3269 & TRN & \\
\hline CHEMBL1439539 & 688239 & 6.8861 & 5.644 & TRN & \\
\hline CHEMBL1477934 & 688239 & 5.5362 & 5.6014 & TRN & \\
\hline CHEMBL1431481 & 688239 & 4.4862 & 5.3387 & TRN & \\
\hline CHEMBL1307263 & 688239 & 6.8861 & 5.4817 & TST & \\
\hline CHEMBL1300540 & 688239 & 4.6862 & 5.5736 & TRN & \\
\hline CHEMBL1469763 & 688239 & 5.0362 & 5.4726 & TRN & \\
\hline CHEMBL1529018 & 688239 & 4.5862 & 5.4607 & TRN & \\
\hline
\end{tabular}


Supplemental Table S2.txt

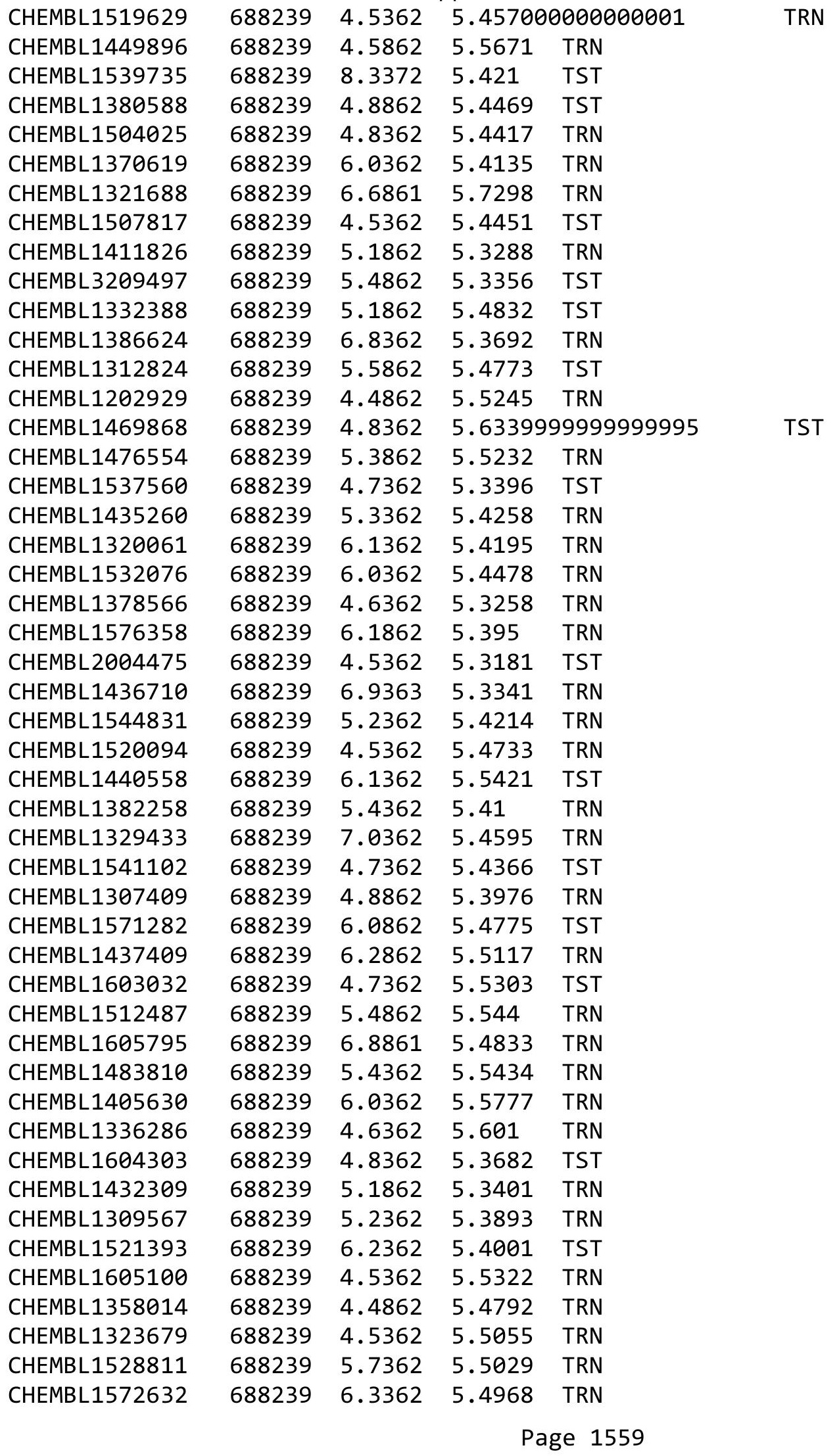


Supplemental Table S2.txt

\begin{tabular}{|c|c|c|c|c|}
\hline CHEMBL1356220 & 688239 & 5.6862 & 5.3645 & TRN \\
\hline CHEMBL1401999 & 688239 & 6.7361 & 5.4872 & TRN \\
\hline CHEMBL1598101 & 688239 & 4.6862 & 5.4603 & TST \\
\hline CHEMBL1477861 & 688239 & 5.1862 & 5.3445 & TRN \\
\hline CHEMBL1544985 & 688239 & 5.5862 & 5.5726 & TRN \\
\hline CHEMBL1463847 & 688239 & 4.6362 & 5.4335 & TRN \\
\hline CHEMBL1449230 & 688239 & 5.6362 & 5.4606 & TST \\
\hline CHEMBL1593676 & 688239 & 4.9362 & 5.5041 & TRN \\
\hline CHEMBL1390349 & 688239 & 5.1862 & 5.3661 & TST \\
\hline CHEMBL1392893 & 688239 & 5.2362 & 5.50700 & 0000000001 \\
\hline CHEMBL1499705 & 688239 & 4.6362 & 5.6036 & TST \\
\hline CHEMBL1519368 & 688239 & 8.3372 & 5.4512 & TRN \\
\hline CHEMBL1395715 & 688239 & 5.4862 & 5.3683 & TRN \\
\hline CHEMBL1592899 & 688239 & 4.5362 & 5.3989 & TRN \\
\hline CHEMBL1299518 & 688239 & 5.9862 & 5.3861 & TRN \\
\hline CHEMBL1391553 & 688239 & 5.3862 & 5.5296 & TST \\
\hline CHEMBL1439715 & 688239 & 4.5362 & 5.5014 & TRN \\
\hline CHEMBL1403277 & 688239 & 5.4862 & 5.5986 & TST \\
\hline CHEMBL1502824 & 688239 & 6.5862 & 5.4023 & TRN \\
\hline CHEMBL1431162 & 688239 & 4.5362 & 5.4951 & TRN \\
\hline CHEMBL1561835 & 688239 & 7.0862 & 5.4375 & TRN \\
\hline CHEMBL1412054 & 688239 & 4.5362 & 5.5491 & TRN \\
\hline CHEMBL1425081 & 688239 & 4.5362 & 5.5855 & TRN \\
\hline CHEMBL1310759 & 688239 & 5.4862 & 5.45 & TST \\
\hline CHEMBL1443714 & 688239 & 5.8862 & 5.5632 & TRN \\
\hline CHEMBL1518456 & 688239 & 4.6862 & 5.4239 & TST \\
\hline CHEMBL1481677 & 688239 & 4.7362 & 5.3957 & TRN \\
\hline CHEMBL1435941 & 688239 & 4.5862 & 5.5587 & TRN \\
\hline CHEMBL299853 & 688239 & 4.7362 & 5.3241 & TRN \\
\hline CHEMBL1367353 & 688239 & 5.4362 & 5.5243 & TRN \\
\hline CHEMBL1435737 & 688239 & 6.2362 & 5.5262 & TRN \\
\hline CHEMBL1415602 & 688239 & 5.1862 & 5.5426 & TRN \\
\hline CHEMBL1534952 & 688239 & 5.1862 & 5.4904 & TRN \\
\hline CHEMBL1332033 & 688239 & 4.8362 & 5.5359 & TRN \\
\hline CHEMBL1331428 & 688239 & 6.1362 & 5.4989 & TRN \\
\hline CHEMBL1326948 & 688239 & 5.6362 & 5.44 & TRN \\
\hline CHEMBL 2449003 & 688239 & 6.1362 & 5.5427 & TRN \\
\hline CHEMBL 3192706 & 688239 & 7.0362 & 5.4156 & TRN \\
\hline CHEMBL1385252 & 688239 & 5.9362 & 5.3936 & TST \\
\hline CHEMBL1315900 & 688239 & 4.5362 & 5.5265 & TRN \\
\hline CHEMBL1309502 & 688239 & 5.2862 & 5.398 & TRN \\
\hline CHEMBL1567750 & 688239 & 5.6862 & 5.5055 & TRN \\
\hline CHEMBL124006 & 688239 & 4.7362 & 5.4276 & TST \\
\hline CHEMBL1342614 & 688239 & 6.8362 & 5.4831 & TRN \\
\hline CHEMBL3196788 & 688239 & 5.6362 & 5.4431 & TRN \\
\hline CHEMBL1326791 & 688239 & 4.8862 & 5.5009 & TST \\
\hline CHEMBL1330562 & 688239 & 4.5362 & 5.8057 & TRN \\
\hline CHEMBL1986504 & 688239 & 5.6362 & 5.4453 & TST \\
\hline
\end{tabular}


Supplemental Table S2.txt

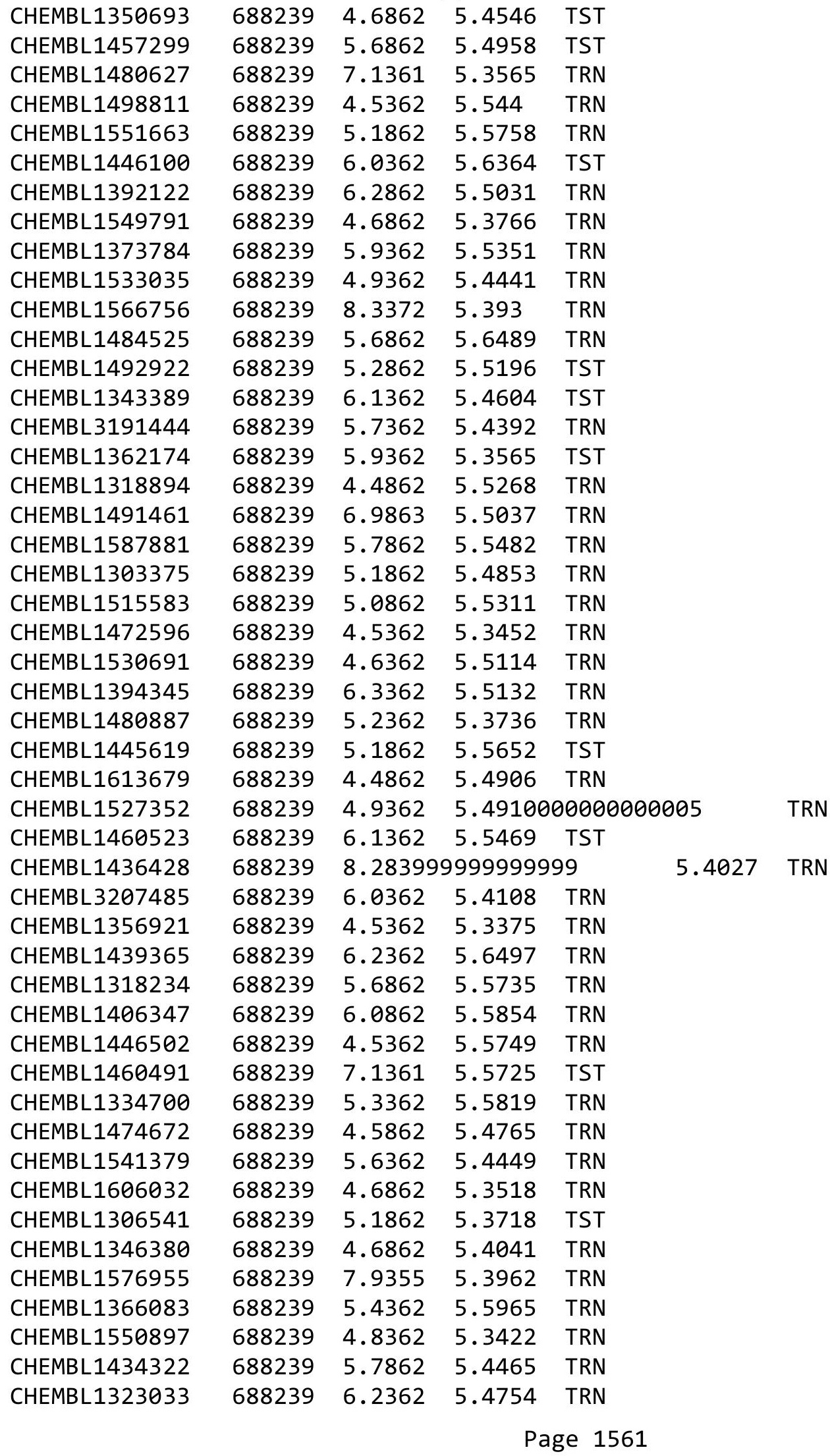


Supplemental Table S2.txt

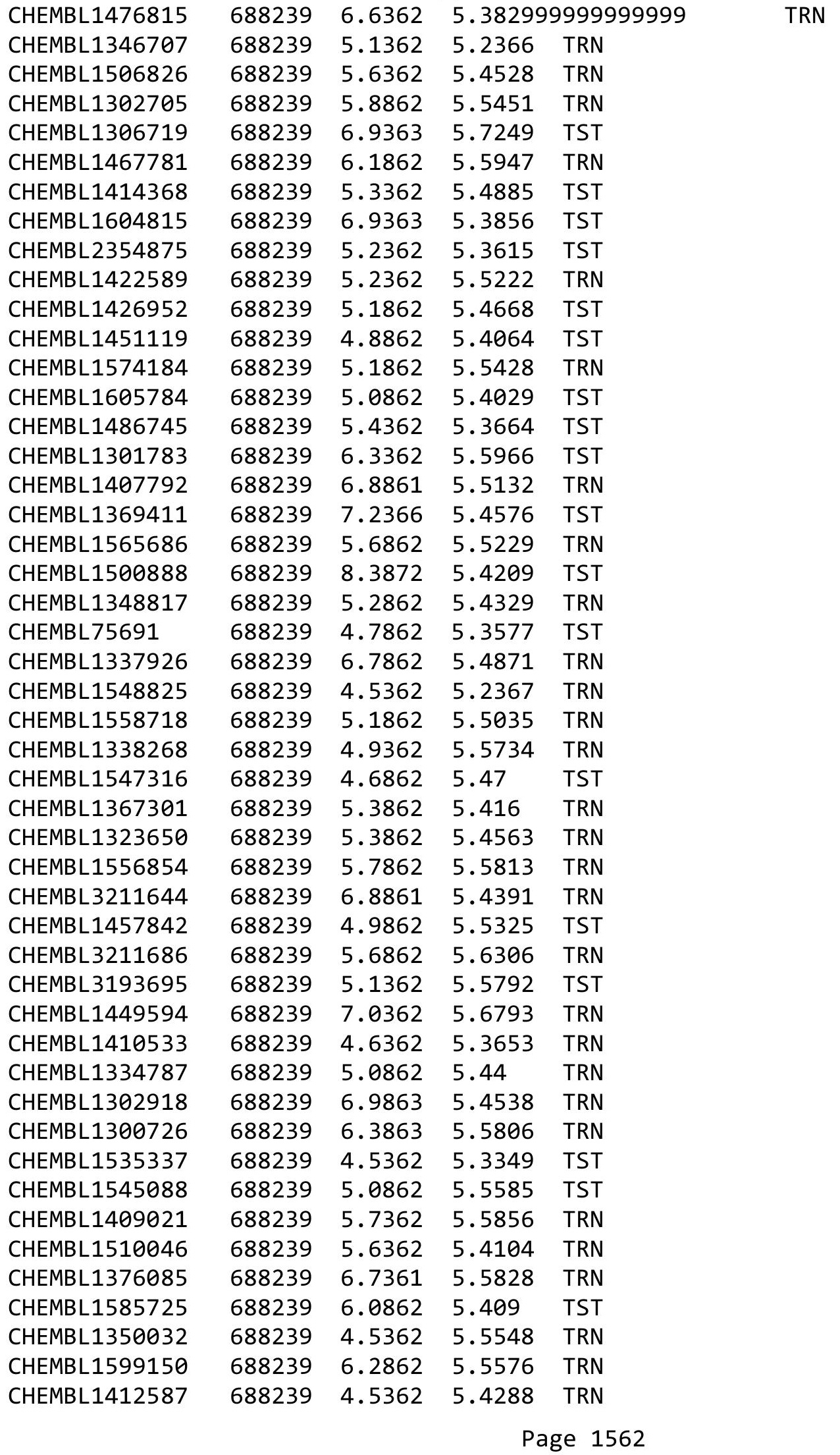


Supplemental Table S2.txt

\begin{tabular}{|c|c|c|c|c|c|}
\hline CHEMBL1443347 & 688239 & 4.8862 & 5.4141 & TRN & \\
\hline CHEMBL1992081 & 688239 & 5.8862 & 5.3241 & TRN & \\
\hline CHEMBL1576583 & 688239 & 4.5362 & 5.4314 & TRN & \\
\hline CHEMBL1420187 & 688239 & 4.7362 & 5.513999 & э999999999 & TRN \\
\hline CHEMBL1320643 & 688239 & 5.1862 & 5.6332 & TRN & \\
\hline CHEMBL1360535 & 688239 & 4.8362 & 5.3423 & TST & \\
\hline CHEMBL1588738 & 688239 & 5.2362 & 5.4025 & TST & \\
\hline CHEMBL1387400 & 688239 & 8.3872 & 5.6143 & TRN & \\
\hline CHEMBL1601199 & 688239 & 4.7862 & 5.4782 & TRN & \\
\hline CHEMBL1449061 & 688239 & 4.8862 & 5.5058 & TRN & \\
\hline CHEMBL1562643 & 688239 & 8.3372 & 5.4968 & TRN & \\
\hline CHEMBL1322426 & 688239 & 5.8862 & 5.4878 & TRN & \\
\hline CHEMBL1448708 & 688239 & 5.1862 & 5.4913 & TST & \\
\hline CHEMBL1555338 & 688239 & 4.4862 & 5.427000 & 00000000005 & TRN \\
\hline CHEMBL 3196498 & 688239 & 5.3362 & 5.4875 & TST & \\
\hline CHEMBL1482111 & 688239 & 5.4362 & 5.3638 & TST & \\
\hline CHEMBL1444199 & 688239 & 6.2862 & 5.4933 & TST & \\
\hline CHEMBL1354125 & 688239 & 6.6362 & 5.5785 & TRN & \\
\hline CHEMBL1342375 & 688239 & 4.5362 & 5.5668 & TRN & \\
\hline CHEMBL1445667 & 688239 & 4.5862 & 5.466 & TST & \\
\hline CHEMBL1445882 & 688239 & 4.6362 & 5.4135 & TST & \\
\hline CHEMBL1305085 & 688239 & 5.1362 & 5.678999 & 9999999999 & TRN \\
\hline CHEMBL1486335 & 688239 & 4.4862 & 5.4369 & TRN & \\
\hline CHEMBL1575869 & 688239 & 4.6862 & 5.4996 & TST & \\
\hline CHEMBL1501197 & 688239 & 5.1862 & 5.5037 & TRN & \\
\hline CHEMBL1393164 & 688239 & 4.5862 & 5.4739 & TRN & \\
\hline CHEMBL1391999 & 688239 & 5.1862 & 5.5153 & TRN & \\
\hline CHEMBL1563800 & 688239 & 5.1362 & 5.4519 & TRN & \\
\hline CHEMBL1316581 & 688239 & 5.6862 & 5.4124 & TST & \\
\hline CHEMBL1537892 & 688239 & 4.5362 & 5.6367 & TRN & \\
\hline CHEMBL1486749 & 688239 & 4.5362 & 5.4454 & TST & \\
\hline CHEMBL1348799 & 688239 & 5.5362 & 5.4084 & TRN & \\
\hline CHEMBL1422041 & 688239 & 5.6362 & 5.4915 & TST & \\
\hline CHEMBL1593274 & 688239 & 4.5362 & 5.5779 & TRN & \\
\hline CHEMBL1424132 & 688239 & 4.6362 & 5.5096 & TST & \\
\hline CHEMBL1465183 & 688239 & 6.0862 & 5.5285 & TRN & \\
\hline CHEMBL1414733 & 688239 & 4.9862 & 5.5413 & TRN & \\
\hline CHEMBL1499127 & 688239 & 5.2862 & 5.5398 & TRN & \\
\hline CHEMBL1594885 & 688239 & 4.5862 & 5.4106 & TRN & \\
\hline CHEMBL1400786 & 688239 & 5.1862 & 5.5642 & TRN & \\
\hline CHEMBL1425499 & 688239 & 6.0862 & 5.5456 & TRN & \\
\hline CHEMBL1490608 & 688239 & 4.5362 & 5.6059 & TRN & \\
\hline CHEMBL1405749 & 688239 & 4.5362 & \multicolumn{2}{|c|}{5.462999999999999} & TRN \\
\hline CHEMBL1540620 & 688239 & 4.4862 & 5.3376 & TRN & \\
\hline CHEMBL1386667 & 688239 & 6.2362 & 5.4617 & TRN & \\
\hline CHEMBL1512775 & 688239 & 6.5363 & 5.3933 & TRN & \\
\hline CHEMBL1343672 & 688239 & 4.6362 & 5.4714 & TST & \\
\hline CHEMBL1579080 & 688239 & 4.5362 & 5.4358 & TRN & \\
\hline
\end{tabular}


Supplemental Table S2.txt

\begin{tabular}{|c|c|c|c|c|}
\hline CHEMBL1567308 & 688239 & 4.5862 & 5.6003 & TRN \\
\hline CHEMBL1386293 & 688239 & 4.6862 & 5.6386 & TRN \\
\hline CHEMBL1325250 & 688239 & 6.0362 & 5.4011 & TRN \\
\hline CHEMBL1559824 & 688239 & 6.0862 & 5.478 & TRN \\
\hline CHEMBL321747 & 688239 & 8.3372 & 5.4178 & TRN \\
\hline CHEMBL1578724 & 688239 & 7.4868 & 5.6807 & TRN \\
\hline CHEMBL1537614 & 688239 & 5.3362 & 5.546 & TRN \\
\hline CHEMBL1541406 & 688239 & 4.5362 & 5.4706 & TRN \\
\hline CHEMBL1546071 & 688239 & 6.1362 & 5.3354 & TRN \\
\hline CHEMBL1403757 & 688239 & 4.5362 & 5.5519 & TRN \\
\hline CHEMBL1459512 & 688239 & 5.6362 & 5.4386 & TST \\
\hline CHEMBL3213430 & 688239 & 5.3362 & 5.5098 & TRN \\
\hline CHEMBL1311317 & 688239 & 6.7862 & 5.6145 & TRN \\
\hline CHEMBL1332174 & 688239 & 4.7862 & 5.4692 & TRN \\
\hline CHEMBL1346276 & 688239 & 5.5362 & 5.3653 & TST \\
\hline CHEMBL1590184 & 688239 & 5.1862 & 5.3683 & TST \\
\hline CHEMBL1478003 & 688239 & 4.7362 & 5.489 & TST \\
\hline CHEMBL1542782 & 688239 & 6.1362 & 5.4699 & TRN \\
\hline CHEMBL1548029 & 688239 & 5.5362 & 5.4783 & TRN \\
\hline CHEMBL1513702 & 688239 & 4.5362 & $5.44600 €$ & 000000001 \\
\hline CHEMBL1522441 & 688239 & 5.1862 & 5.6867 & TRN \\
\hline CHEMBL303252 & 688239 & 4.7362 & 5.4635 & TST \\
\hline CHEMBL55145 & 688239 & 6.9363 & 5.3652 & TST \\
\hline CHEMBL3213907 & 688239 & 5.0362 & 5.5254 & TRN \\
\hline CHEMBL3196770 & 688239 & 5.0362 & 5.3859 & TRN \\
\hline CHEMBL1515222 & 688239 & 6.0862 & 5.5632 & TRN \\
\hline CHEMBL1600741 & 688239 & 4.5362 & 5.5198 & TST \\
\hline CHEMBL1391783 & 688239 & 6.0362 & 5.5184 & TST \\
\hline CHEMBL1519989 & 688239 & 5.8362 & 5.4015 & TRN \\
\hline CHEMBL1485596 & 688239 & 4.6862 & 5.6424 & TRN \\
\hline CHEMBL1383385 & 688239 & 4.8862 & 5.4973 & TRN \\
\hline CHEMBL 3144987 & 688239 & 4.6862 & 5.4204 & TST \\
\hline CHEMBL1430378 & 688239 & 6.1862 & 5.4745 & TRN \\
\hline CHEMBL1487451 & 688239 & 6.3362 & 5.4955 & TST \\
\hline CHEMBL1330838 & 688239 & 5.3362 & 5.5229 & TRN \\
\hline CHEMBL1449339 & 688239 & 4.5362 & 5.5779 & TRN \\
\hline CHEMBL1320097 & 688239 & 4.8862 & 5.4373 & TRN \\
\hline CHEMBL1611567 & 688239 & 5.1862 & 5.4109 & TRN \\
\hline CHEMBL1994490 & 688239 & 8.3372 & 5.3359 & TST \\
\hline CHEMBL1467150 & 688239 & 5.5362 & 5.4489 & TRN \\
\hline CHEMBL1453853 & 688239 & 4.6362 & 5.4815 & TST \\
\hline CHEMBL3210113 & 688239 & 5.1862 & 5.4855 & TRN \\
\hline CHEMBL1415702 & 688239 & 5.0862 & 5.287000 & 000000001 \\
\hline CHEMBL1595683 & 688239 & 4.6362 & 5.5874 & TRN \\
\hline CHEMBL3197702 & 688239 & 4.5862 & 5.2996 & TST \\
\hline CHEMBL1560813 & 688239 & 4.5362 & 5.5654 & TRN \\
\hline CHEMBL1516501 & 688239 & 6.3362 & 5.524 & TRN \\
\hline CHEMBL1438178 & 688239 & 5.5362 & 5.5319 & TRN \\
\hline
\end{tabular}

Page 1564 
Supplemental Table S2.txt

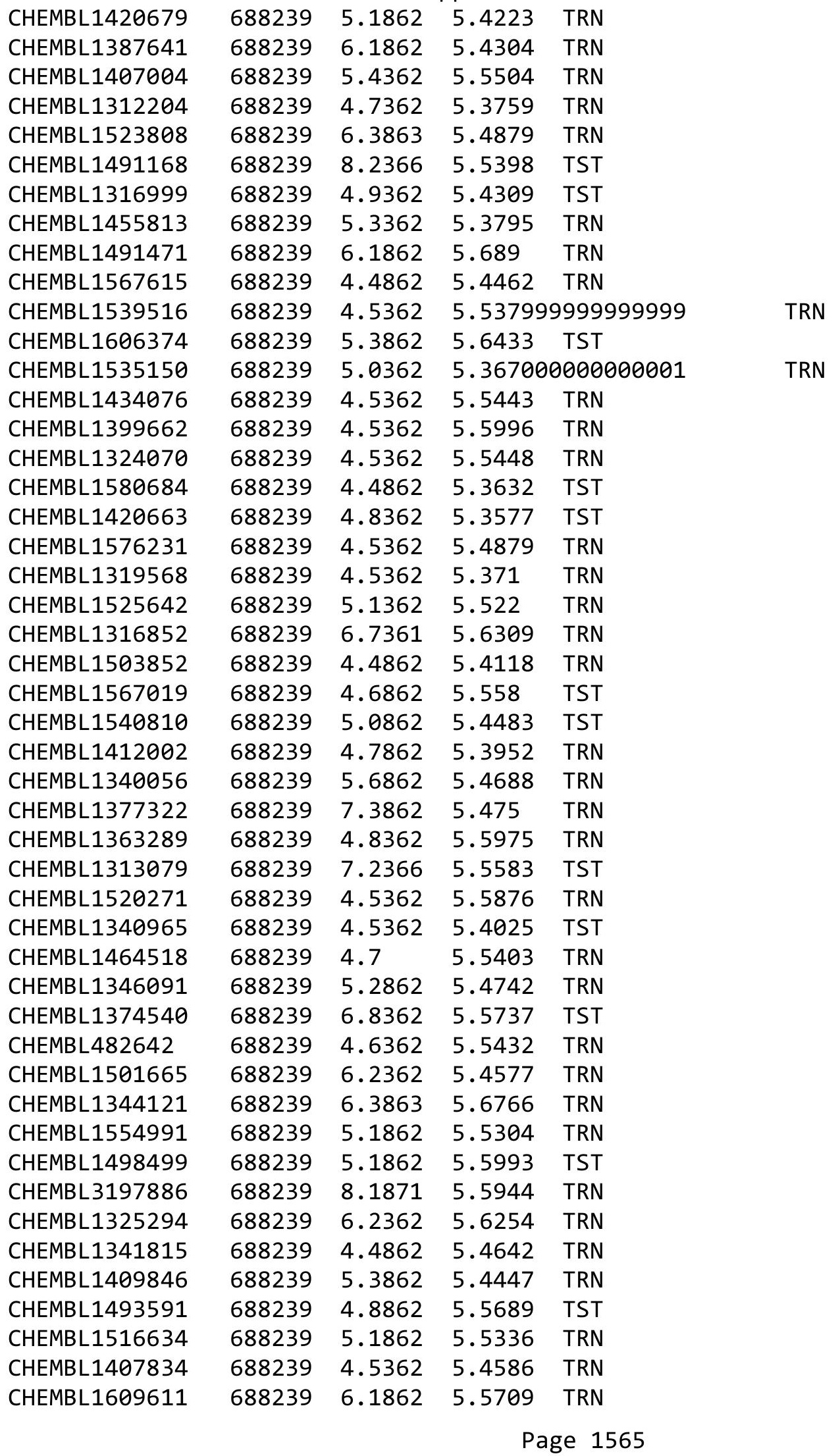


Supplemental Table S2.txt

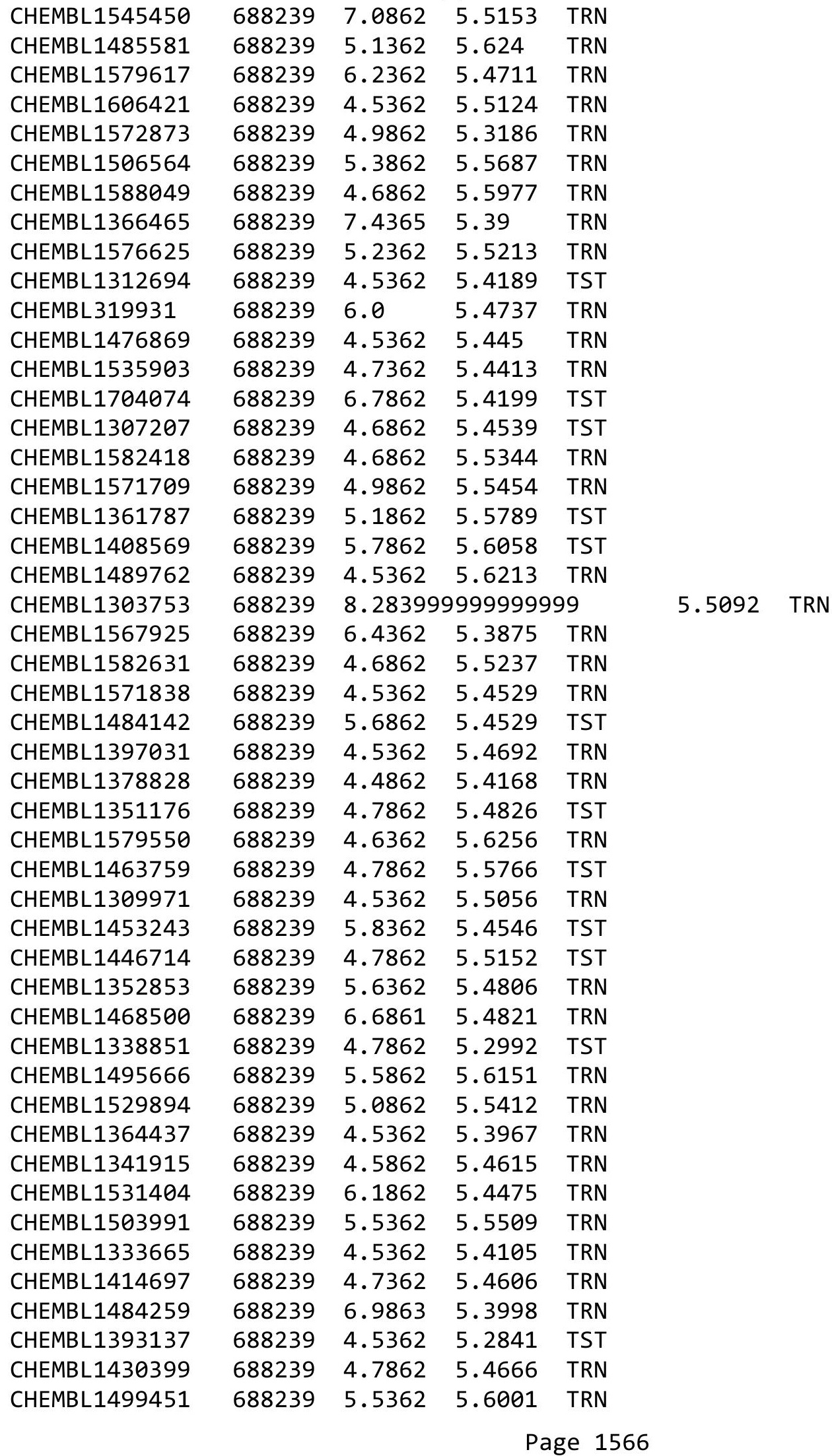




\begin{tabular}{|c|c|c|c|c|c|}
\hline CHEMBL1437881 & 688239 & \multicolumn{3}{|c|}{ Supplemental Table S2.txt } & TRN \\
\hline CHEMBL1455507 & 688239 & 4.5362 & 5.4004 & TRN & \\
\hline CHEMBL1380069 & 688239 & 4.6862 & 5.3571 & TRN & \\
\hline CHEMBL1462816 & 688239 & 5.1862 & 5.4791 & TRN & \\
\hline CHEMBL1408090 & 688239 & 5.4362 & 5.447 & TRN & \\
\hline CHEMBL1570022 & 688239 & 5.1862 & 5.4549 & TRN & \\
\hline CHEMBL1305297 & 688239 & 4.5362 & 5.5502 & TRN & \\
\hline CHEMBL1331696 & 688239 & 4.6362 & 5.5867 & TRN & \\
\hline CHEMBL1512104 & 688239 & 6.9363 & 5.6361 & TRN & \\
\hline CHEMBL1503354 & 688239 & 8.3372 & 5.5706 & TST & \\
\hline CHEMBL1587941 & 688239 & 6.0862 & 5.4529 & TRN & \\
\hline CHEMBL1496571 & 688239 & 6.6861 & 5.5266 & TRN & \\
\hline CHEMBL1313604 & 688239 & 4.5362 & 5.6008 & TRN & \\
\hline CHEMBL1486355 & 688239 & 4.7862 & 5.5292 & TRN & \\
\hline CHEMBL1443853 & 688239 & 8.3872 & 5.5277 & TRN & \\
\hline CHEMBL1299662 & 688239 & 4.4862 & 5.4572 & TRN & \\
\hline CHEMBL1585776 & 688239 & 5.8862 & 5.5827 & TRN & \\
\hline CHEMBL1444889 & 688239 & 4.7362 & 5.3316 & TRN & \\
\hline CHEMBL1453285 & 688239 & 6.5363 & 5.4669 & TRN & \\
\hline CHEMBL1348548 & 688239 & 6.0862 & 5.6895 & TRN & \\
\hline CHEMBL1384368 & 688239 & 5.8362 & 5.4188 & TRN & \\
\hline CHEMBL1356632 & 688239 & 8.3372 & 5.5915 & TRN & \\
\hline CHEMBL1494181 & 688239 & 5.0362 & 5.5408 & TRN & \\
\hline CHEMBL1608950 & 688239 & 4.6862 & 5.49100 & 00000000005 & TRN \\
\hline CHEMBL1560544 & 688239 & 6.7361 & 5.563 & TRN & \\
\hline CHEMBL1420739 & 688239 & 5.4862 & 5.4104 & TRN & \\
\hline CHEMBL1443716 & 688239 & 5.2362 & 5.5223 & TRN & \\
\hline CHEMBL1596543 & 688239 & 4.85 & 5.5884 & TRN & \\
\hline CHEMBL1580352 & 688239 & 5.8362 & 5.5155 & TRN & \\
\hline CHEMBL1388817 & 688239 & 5.4362 & 5.4472 & TST & \\
\hline CHEMBL1475939 & 688239 & 5.1862 & 5.40600 & 2000000001 & TRN \\
\hline CHEMBL1419051 & 688239 & 4.8862 & 5.4211 & TRN & \\
\hline CHEMBL1475797 & 688239 & 4.6862 & 5.6145 & TRN & \\
\hline CHEMBL1323587 & 688239 & 5.6862 & 5.4622 & TRN & \\
\hline CHEMBL1561543 & 688239 & 4.7362 & 5.4033 & TRN & \\
\hline CHEMBL1427724 & 688239 & 5.1862 & 5.50299 & 9999999999 & TRN \\
\hline CHEMBL1471024 & 688239 & 5.8862 & 5.3584 & TRN & \\
\hline CHEMBL1509621 & 688239 & 5.6362 & 5.3014 & TRN & \\
\hline CHEMBL1481762 & 688239 & 4.5362 & 5.3095 & TRN & \\
\hline CHEMBL1360395 & 688239 & 5.0362 & 5.4834 & TRN & \\
\hline CHEMBL1466942 & 688239 & 4.5362 & 5.5212 & TST & \\
\hline CHEMBL1524076 & 688239 & 7.2366 & 5.5022 & TRN & \\
\hline CHEMBL1302503 & 688239 & 4.8862 & 5.6005 & TST & \\
\hline CHEMBL1574442 & 688239 & 4.5362 & 5.5594 & TRN & \\
\hline CHEMBL 3189872 & 688239 & 5.7362 & 5.4071 & TRN & \\
\hline CHEMBL1468862 & 688239 & 6.1362 & 5.6463 & TRN & \\
\hline CHEMBL1545553 & 688239 & 6.2362 & 5.4867 & TRN & \\
\hline CHEMBL1561344 & 688239 & 4.6862 & 5.4138 & TST & \\
\hline
\end{tabular}


Supplemental Table S2.txt

\begin{tabular}{|c|c|c|c|c|}
\hline CHEMBL1606357 & 688239 & 4.7362 & 5.5907 & TRN \\
\hline CHEMBL1560507 & 688239 & 4.7862 & 5.4422 & TRN \\
\hline CHEMBL1428802 & 688239 & 6.1362 & 5.6088 & TRN \\
\hline CHEMBL1331140 & 688239 & 4.5362 & 5.3636 & TRN \\
\hline CHEMBL1555836 & 688239 & 4.5362 & 5.5541 & TRN \\
\hline CHEMBL1529440 & 688239 & 4.5362 & 5.5231 & TRN \\
\hline CHEMBL1519964 & 688239 & 4.7862 & 5.40799 & 99999999995 \\
\hline CHEMBL1608535 & 688239 & 5.7862 & 5.6471 & TST \\
\hline CHEMBL1459091 & 688239 & 4.8362 & 5.4493 & TRN \\
\hline CHEMBL1736377 & 688239 & 6.9863 & 5.5916 & TRN \\
\hline CHEMBL1471965 & 688239 & 4.5862 & 5.42700 & 00000000005 \\
\hline CHEMBL1512113 & 688239 & 5.6362 & 5.359 & TRN \\
\hline CHEMBL1439017 & 688239 & 4.5362 & 5.5192 & TRN \\
\hline CHEMBL1587055 & 688239 & 5.3862 & 5.5198 & TRN \\
\hline CHEMBL1454491 & 688239 & 5.1862 & 5.3568 & TRN \\
\hline CHEMBL1417388 & 688239 & 4.5362 & 5.4591 & TRN \\
\hline CHEMBL1501753 & 688239 & 5.6862 & 5.4153 & TRN \\
\hline CHEMBL1572955 & 688239 & 4.5362 & 5.4841 & TRN \\
\hline CHEMBL1575685 & 688239 & 5.3362 & 5.473 & TST \\
\hline CHEMBL1382983 & 688239 & 4.6362 & 5.4592 & TRN \\
\hline CHEMBL1473815 & 688239 & 5.0362 & 5.5329 & TRN \\
\hline CHEMBL1451055 & 688239 & 6.2362 & 5.4611 & TRN \\
\hline CHEMBL1612555 & 688239 & 6.8861 & 5.5129 & TST \\
\hline CHEMBL1470118 & 688239 & 6.1862 & 5.4862 & TRN \\
\hline CHEMBL1460313 & 688239 & 5.5362 & 5.4117 & TST \\
\hline CHEMBL 3212263 & 688239 & 7.1864 & 5.5702 & TRN \\
\hline CHEMBL1372563 & 688239 & 4.7862 & 5.4664 & TRN \\
\hline CHEMBL1547898 & 688239 & 4.6862 & 5.5777 & TRN \\
\hline CHEMBL1479627 & 688239 & 5.4362 & 5.4687 & TRN \\
\hline CHEMBL1485920 & 688239 & 4.5362 & 5.4485 & TST \\
\hline CHEMBL1345878 & 688239 & 5.1862 & 5.3747 & TRN \\
\hline CHEMBL1317256 & 688239 & 5.7862 & 5.4017 & TRN \\
\hline CHEMBL1581527 & 688239 & 4.6862 & 5.4795 & TST \\
\hline CHEMBL1317382 & 688239 & 5.6862 & 5.5707 & TRN \\
\hline CHEMBL1457942 & 688239 & 4.7862 & 5.5079 & TRN \\
\hline CHEMBL1309855 & 688239 & 4.6362 & 5.6541 & TRN \\
\hline CHEMBL1545985 & 688239 & 4.5362 & 5.3834 & TRN \\
\hline CHEMBL1501476 & 688239 & 6.2362 & 5.6803 & TRN \\
\hline CHEMBL1388713 & 688239 & 5.4362 & 5.4997 & TRN \\
\hline CHEMBL1440029 & 688239 & 5.1862 & 5.4653 & TRN \\
\hline CHEMBL1372207 & 688239 & 4.5362 & 5.5178 & TRN \\
\hline CHEMBL1578230 & 688239 & 4.7362 & 5.3909 & TST \\
\hline CHEMBL1353184 & 688239 & 5.7362 & 5.3724 & TRN \\
\hline CHEMBL1303281 & 688239 & 5.1862 & 5.4296 & TRN \\
\hline CHEMBL1307909 & 688239 & 4.7362 & \multicolumn{2}{|c|}{5.332000000000001} \\
\hline CHEMBL1583471 & 688239 & 4.9862 & 5.4736 & TRN \\
\hline CHEMBL1513228 & 688239 & 8.3872 & 5.2797 & TRN \\
\hline CHEMBL1386978 & 688239 & 4.7362 & 5.5836 & TST \\
\hline
\end{tabular}


Supplemental Table S2.txt

\begin{tabular}{|c|c|c|c|c|}
\hline 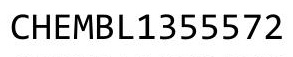 & & & - & \\
\hline HEMBL1333536 & 88239 & 6362 & 4714 & \\
\hline HEMBL1342275 & 88239 & 2862 & & \\
\hline 13 & & & & \\
\hline EMBL1 & & 862 & & \\
\hline HEMBL1532269 & 88239 & 862 & 5947 & \\
\hline HEMBL1359912 & 88239 & 5362 & .4604 & \\
\hline HEMBL14 & 39 & 362 & & \\
\hline IEMBL13 & 39 & 862 & 5815 & \\
\hline AEMBL152 & 39 & 862 & & \\
\hline HEMBL3189911 & 88 & 362 & .564 & \\
\hline HEMBL1344153 & 39 & 362 & .4585 & \\
\hline HEMBL1528044 & 39 & 366 & .5507 & \\
\hline HEMBL1555902 & & & 04 & \\
\hline HEMBL14 & 9 & 862 & .3544 & \\
\hline HEMBL14 & 39 & & .5275 & \\
\hline HEMBL1421880 & 39 & 362 & .4515 & \\
\hline HEMBL14 & 39 & 862 & 5207 & \\
\hline HEMBL 14 & & & & \\
\hline HEMBL15 & 9 & & & \\
\hline HEMBL133 & 39 & 62 & & RN \\
\hline AEMBL1532372 & 39 & 62 & 56 & IST \\
\hline HEMBL 14 & 39 & 862 & 17 & RN \\
\hline HEMBL14 & & & & \\
\hline HEMBL135 & & & & RN \\
\hline AEMBL136 & 39 & & & RN \\
\hline HEMBL1525719 & 39 & 62 & .5056 & RN \\
\hline HEMBL1479624 & 39 & 62 & 514 & $\mathrm{RN}$ \\
\hline HEM & & & & RN \\
\hline HEM & & & & RN \\
\hline HEMBL15459 & & & & $\mathrm{R}$ \\
\hline HEMBL1497597 & 39 & 862 & .2506 & RN \\
\hline HEMBL14 & 39 & 362 & 774 & \\
\hline 5 & & & & RN \\
\hline HEMBL148 & & & & RN \\
\hline HEMBL1501872 & 39 & & .4641 & RN \\
\hline HEMBL1337644 & 39 & 362 & .5374 & ST \\
\hline HEMBL1496670 & 39 & 62 & .5432 & RN \\
\hline 2 & & & & RN \\
\hline HEMBL1547180 & & & & RN \\
\hline HEMBL1342 & 39 & 362 & & RN \\
\hline HEMBL160 & 39 & 63 & 273 & RN \\
\hline HEMBL15\& & & & & \\
\hline & & & & RN \\
\hline HEMBL153 & & & .4263 & ST \\
\hline HEMBL1405687 & 39 & 362 & & RN \\
\hline or & & & 52 & \\
\hline & & & & \\
\hline
\end{tabular}

Page 1569 
Supplemental Table S2.txt

\begin{tabular}{|c|c|c|c|c|}
\hline CHEMBL1381836 & 688239 & 5.1862 & 5.6296 & TRN \\
\hline CHEMBL1540195 & 688239 & 4.5362 & 5.4458 & TRN \\
\hline CHEMBL1400127 & 688239 & 6.6861 & 5.3916 & TST \\
\hline CHEMBL1394159 & 688239 & 4.6862 & 5.4418 & TRN \\
\hline CHEMBL1420731 & 688239 & 6.2862 & 5.4328 & TST \\
\hline CHEMBL1442559 & 688239 & 5.4862 & 5.5551 & TRN \\
\hline CHEMBL1379866 & 688239 & 4.5362 & 5.4772 & TST \\
\hline CHEMBL1610520 & 688239 & 5.4362 & 5.5129 & TRN \\
\hline CHEMBL 3214046 & 688239 & 4.5362 & 5.4235 & TST \\
\hline CHEMBL1506499 & 688239 & 5.7862 & 5.5395 & TRN \\
\hline CHEMBL 1457882 & 688239 & 4.6362 & 5.5573 & TRN \\
\hline CHEMBL1361360 & 688239 & 4.6862 & 5.5006 & TRN \\
\hline CHEMBL1487651 & 688239 & 8.1871 & 5.4224 & TST \\
\hline CHEMBL1483677 & 688239 & 6.2862 & 5.412999 & 999999999 \\
\hline CHEMBL1457223 & 688239 & 4.5362 & 5.5702 & TST \\
\hline CHEMBL1597498 & 688239 & 5.9362 & 5.4584 & TST \\
\hline CHEMBL1420644 & 688239 & 5.5362 & 5.6167 & TRN \\
\hline CHEMBL1395608 & 688239 & 6.7862 & 5.6109 & TRN \\
\hline CHEMBL1404175 & 688239 & 6.8362 & 5.5415 & TRN \\
\hline CHEMBL1307829 & 688239 & 6.8362 & 5.4636 & TST \\
\hline CHEMBL1579702 & 688239 & 6.0362 & 5.4746 & TRN \\
\hline CHEMBL1449916 & 688239 & 4.5862 & 5.4035 & TST \\
\hline CHEMBL1526724 & 688239 & 5.1362 & 5.5481 & TRN \\
\hline CHEMBL1579443 & 688239 & 6.2362 & 5.4773 & TRN \\
\hline CHEMBL1561926 & 688239 & 5.7362 & 5.5091 & TRN \\
\hline CHEMBL1370702 & 688239 & 8.1871 & 5.4948 & TRN \\
\hline CHEMBL1358932 & 688239 & 7.1864 & 5.4938 & TRN \\
\hline CHEMBL1480697 & 688239 & 5.4862 & 5.6519 & TRN \\
\hline CHEMBL1605554 & 688239 & 6.9863 & 5.4205 & TRN \\
\hline CHEMBL1344152 & 688239 & 5.1862 & 5.5678 & TRN \\
\hline CHEMBL1598708 & 688239 & 6.7862 & 5.5173 & TRN \\
\hline CHEMBL1332665 & 688239 & 4.5362 & 5.4526 & TRN \\
\hline CHEMBL1470225 & 688239 & 4.7362 & 5.362 & TRN \\
\hline CHEMBL1385003 & 688239 & 5.2862 & 5.5419 & TRN \\
\hline CHEMBL1604962 & 688239 & 5.0362 & 5.4946 & TRN \\
\hline CHEMBL3194409 & 688239 & 5.6862 & 5.165 & TST \\
\hline CHEMBL1517481 & 688239 & 6.2362 & 5.4327 & TRN \\
\hline CHEMBL1426636 & 688239 & 4.8862 & 5.5033 & TRN \\
\hline CHEMBL1510436 & 688239 & 4.5362 & 5.57 & TRN \\
\hline CHEMBL1325425 & 688239 & 5.1862 & 5.5435 & TRN \\
\hline CHEMBL1354022 & 688239 & 5.6362 & 5.4719 & TRN \\
\hline CHEMBL1586165 & 688239 & 5.4862 & 5.5678 & TRN \\
\hline CHEMBL1461756 & 688239 & 4.5362 & 5.3952 & TST \\
\hline CHEMBL1415838 & 688239 & 5.3862 & \multicolumn{2}{|c|}{5.3260000000000005} \\
\hline CHEMBL1300788 & 688239 & 8.3372 & 5.5652 & TRN \\
\hline CHEMBL1340295 & 688239 & 6.5363 & 5.5637 & TRN \\
\hline CHEMBL1488386 & 688239 & 5.3362 & 5.3769 & TRN \\
\hline CHEMBL1436188 & 688239 & 5.2862 & 5.4238 & TRN \\
\hline
\end{tabular}


Supplemental Table S2.txt

\begin{tabular}{|c|c|c|c|c|}
\hline CHEMBL1359444 & 688239 & 6.0862 & 5.4456 & TRN \\
\hline CHEMBL3208838 & 688239 & 6.8362 & 5.5751 & TRN \\
\hline CHEMBL1447085 & 688239 & 5.0362 & 5.4429 & TRN \\
\hline CHEMBL1555197 & 688239 & 4.5362 & 5.5601 & TRN \\
\hline CHEMBL1301114 & 688239 & 5.5862 & 5.466 & TST \\
\hline CHEMBL1415318 & 688239 & 6.0862 & 5.5683 & TRN \\
\hline CHEMBL1419471 & 688239 & 4.6862 & 5.391 & TRN \\
\hline CHEMBL1566629 & 688239 & 7.1361 & 5.4324 & TRN \\
\hline CHEMBL1467161 & 688239 & 4.9362 & 5.5366 & TRN \\
\hline CHEMBL1448600 & 688239 & 5.4862 & 5.518 & TRN \\
\hline CHEMBL1368374 & 688239 & 5.1862 & 5.615 & TRN \\
\hline CHEMBL1601452 & 688239 & 4.5862 & 5.4673 & TRN \\
\hline CHEMBL1459651 & 688239 & 5.2362 & 5.431 & TRN \\
\hline CHEMBL1491890 & 688239 & 4.9862 & 5.5065 & TRN \\
\hline CHEMBL1464856 & 688239 & 7.0862 & 5.52 & TRN \\
\hline CHEMBL1461468 & 688239 & 6.3863 & 5.5749 & TRN \\
\hline CHEMBL1437856 & 688239 & 5.2862 & 5.476 & TRN \\
\hline CHEMBL1315617 & 688239 & 4.5362 & 5.6093 & TRN \\
\hline CHEMBL1712181 & 688239 & 5.2362 & 5.4762 & TST \\
\hline CHEMBL1508535 & 688239 & 8.3372 & 5.5193 & TRN \\
\hline CHEMBL577660 & 688239 & 5.1862 & 5.4239 & TRN \\
\hline CHEMBL3209835 & 688239 & 6.9863 & 5.4773 & TST \\
\hline CHEMBL1386432 & 688239 & 5.2362 & 5.4399 & TRN \\
\hline CHEMBL1540050 & 688239 & 4.4862 & 5.566 & TRN \\
\hline CHEMBL1383961 & 688239 & 7.0362 & 5.5536 & TRN \\
\hline CHEMBL1506790 & 688239 & 5.6362 & 5.4916 & TRN \\
\hline CHEMBL1451348 & 688239 & 4.6862 & 5.3543 & TST \\
\hline CHEMBL1491767 & 688239 & 4.4862 & 5.697999 & 99999999995 \\
\hline CHEMBL1574762 & 688239 & 5.9862 & 5.5521 & TRN \\
\hline CHEMBL1492394 & 688239 & 5.3362 & 5.5629 & TRN \\
\hline CHEMBL1351393 & 688239 & 5.1862 & 5.5633 & TRN \\
\hline CHEMBL1495111 & 688239 & 6.4862 & 5.5629 & TRN \\
\hline CHEMBL1316450 & 688239 & 5.6362 & 5.3984 & TST \\
\hline CHEMBL1340112 & 688239 & 5.0362 & 5.5143 & TRN \\
\hline CHEMBL1593364 & 688239 & 5.3362 & 5.4293 & TRN \\
\hline CHEMBL1376882 & 688239 & 5.6862 & 5.4538 & TRN \\
\hline CHEMBL1417551 & 688239 & 5.0362 & 5.4823 & TRN \\
\hline CHEMBL1320181 & 688239 & 5.7362 & 5.2429 & TRN \\
\hline CHEMBL1419465 & 688239 & 5.4862 & 5.5373 & TST \\
\hline CHEMBL3207877 & 688239 & 4.5862 & 5.3947 & TRN \\
\hline CHEMBL1373504 & 688239 & 5.3362 & 5.4366 & TRN \\
\hline CHEMBL1472113 & 688239 & 4.5362 & 5.4662 & TRN \\
\hline CHEMBL1456492 & 688239 & 5.1862 & 5.5996 & TRN \\
\hline CHEMBL1540113 & 688239 & 5.1862 & 5.5406 & TRN \\
\hline CHEMBL1415412 & 688239 & 5.0862 & 5.5269 & TST \\
\hline CHEMBL1611063 & 688239 & 4.7 & 5.4983 & TRN \\
\hline CHEMBL1543989 & 688239 & 4.5362 & 5.4263 & TST \\
\hline CHEMBL1498428 & 688239 & 4.8362 & 5.4148 & TST \\
\hline
\end{tabular}




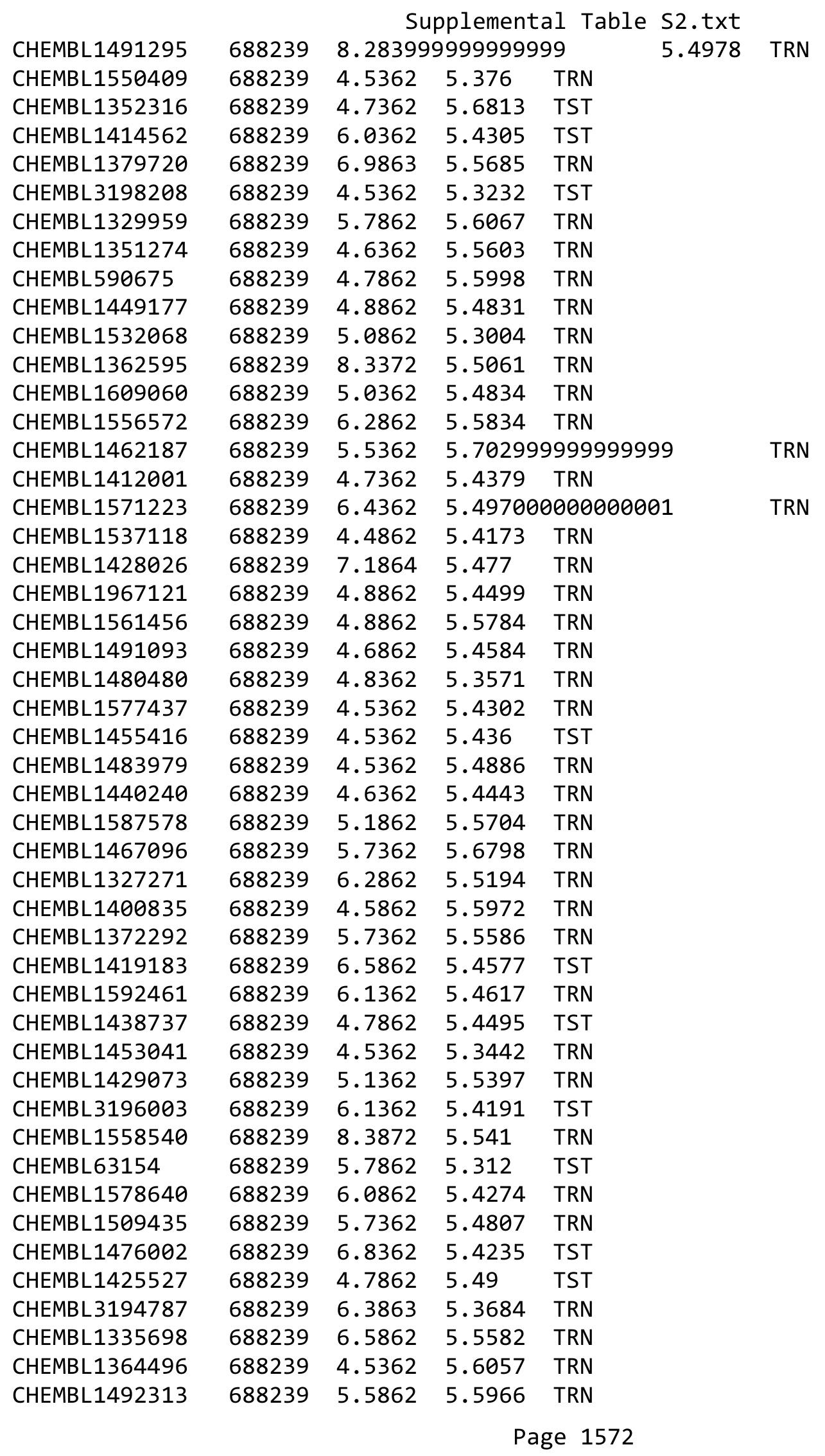


Supplemental Table S2.txt

\begin{tabular}{|c|c|c|c|c|}
\hline CHEMBL1328553 & 688239 & 5.2362 & 5.3987 & TST \\
\hline CHEMBL1308015 & 688239 & 4.5362 & 5.436 & TRN \\
\hline CHEMBL1307352 & 688239 & 5.3862 & 5.5293 & TRN \\
\hline CHEMBL1552466 & 688239 & 4.4862 & 5.4869 & TRN \\
\hline CHEMBL1492490 & 688239 & 5.1862 & 5.3515 & TRN \\
\hline CHEMBL1579672 & 688239 & 5.8862 & 5.4 & TST \\
\hline CHEMBL1354240 & 688239 & 6.5363 & 5.4699 & TRN \\
\hline CHEMBL1527731 & 688239 & 4.4862 & 5.3392 & TRN \\
\hline CHEMBL1345203 & 688239 & 4.7362 & 5.4645 & TRN \\
\hline CHEMBL1356453 & 688239 & 5.6862 & 5.5351 & TRN \\
\hline CHEMBL1429240 & 688239 & 5.6362 & 5.4853 & TST \\
\hline CHEMBL1469687 & 688239 & 4.5362 & 5.4577 & TST \\
\hline CHEMBL1585350 & 688239 & 6.9863 & 5.5158 & TRN \\
\hline CHEMBL1599701 & 688239 & 6.6362 & 5.5162 & TRN \\
\hline CHEMBL1608316 & 688239 & 5.1362 & 5.6274 & TRN \\
\hline CHEMBL1488706 & 688239 & 5.6862 & 5.4445 & TRN \\
\hline CHEMBL1353355 & 688239 & 6.6362 & 5.7159 & TRN \\
\hline CHEMBL1321503 & 688239 & 6.5363 & 5.5192 & TST \\
\hline CHEMBL1413552 & 688239 & 5.1362 & 5.5688 & TRN \\
\hline CHEMBL1521706 & 688239 & 5.1862 & 5.7066 & TRN \\
\hline CHEMBL1570575 & 688239 & 7.0362 & 5.5143 & TRN \\
\hline CHEMBL1328519 & 688239 & 4.8862 & 5.4733 & TRN \\
\hline CHEMBL1383487 & 688239 & 6.1362 & 5.4023 & TST \\
\hline CHEMBL1356587 & 688239 & 4.5362 & 5.5064 & TRN \\
\hline CHEMBL1303976 & 688239 & 4.5362 & 5.3907 & TST \\
\hline CHEMBL1500252 & 688239 & 5.8362 & 5.6098 & TRN \\
\hline CHEMBL1575861 & 688239 & 5.1362 & 5.5004 & TRN \\
\hline CHEMBL1531141 & 688239 & 5.6362 & 5.5257 & TRN \\
\hline CHEMBL1400324 & 688239 & 4.5362 & 5.5145 & TRN \\
\hline CHEMBL1588973 & 688239 & 5.5862 & 5.5198 & TRN \\
\hline CHEMBL1580354 & 688239 & 5.0362 & 5.5199 & TST \\
\hline CHEMBL 3214487 & 688239 & 5.1862 & 5.4297 & TST \\
\hline CHEMBL1605535 & 688239 & 5.3862 & 5.6765 & TST \\
\hline CHEMBL1436592 & 688239 & 4.5362 & 5.4073 & TRN \\
\hline CHEMBL1412853 & 688239 & 6.2362 & 5.553999 & 9999999999 \\
\hline CHEMBL1536189 & 688239 & 4.4862 & 5.6374 & TRN \\
\hline CHEMBL1472136 & 688239 & 5.0862 & 5.5687 & TRN \\
\hline CHEMBL1610143 & 688239 & 4.7862 & 5.4181 & TST \\
\hline CHEMBL1483371 & 688239 & 5.3362 & 5.6209 & TRN \\
\hline CHEMBL1599171 & 688239 & 5.0362 & 5.7027 & TRN \\
\hline CHEMBL1568018 & 688239 & 4.9362 & 5.4602 & TRN \\
\hline CHEMBL1327549 & 688239 & 5.1862 & 5.5979 & TST \\
\hline CHEMBL1416245 & 688239 & 5.1862 & 5.5841 & TST \\
\hline CHEMBL1481274 & 688239 & 5.1862 & 5.5305 & TRN \\
\hline CHEMBL1560921 & 688239 & 5.7862 & 5.296 & TST \\
\hline CHEMBL1561077 & 688239 & 6.9863 & 5.3756 & TRN \\
\hline CHEMBL1444941 & 688239 & 5.0362 & 5.4615 & TRN \\
\hline CHEMBL1517960 & 688239 & 6.7361 & 5.3828 & TRN \\
\hline
\end{tabular}


Supplemental Table S2.txt

\begin{tabular}{|c|c|c|c|c|c|}
\hline CHEMBL1304041 & 688239 & 5.5862 & 5.4156 & TRN & \\
\hline CHEMBL1423981 & 688239 & 6.5363 & 5.501 & TRN & \\
\hline CHEMBL1598870 & 688239 & 5.9362 & 5.3661 & TRN & \\
\hline CHEMBL1534050 & 688239 & 4.5362 & 5.5958 & TRN & \\
\hline CHEMBL1528271 & 688239 & 5.4362 & 5.5306 & TST & \\
\hline CHEMBL1529686 & 688239 & 5.3362 & \multicolumn{2}{|c|}{5.5760000000000005} & TRN \\
\hline CHEMBL1555579 & 688239 & 5.45 & 5.5022 & TRN & \\
\hline CHEMBL1509594 & 688239 & 6.9363 & 5.4895 & TRN & \\
\hline CHEMBL1307482 & 688239 & 5.2862 & 5.4807 & TRN & \\
\hline CHEMBL1325774 & 688239 & 5.4362 & 5.5722 & TRN & \\
\hline CHEMBL1535564 & 688239 & 4.8362 & 5.449 & TRN & \\
\hline CHEMBL1358191 & 688239 & 5.8862 & 5.3984 & TRN & \\
\hline CHEMBL1512068 & 688239 & 5.9362 & 5.4469 & TRN & \\
\hline CHEMBL1529112 & 688239 & 5.8362 & 5.4492 & TST & \\
\hline CHEMBL1319102 & 688239 & 5.1862 & \multicolumn{2}{|c|}{5.712999999999999} & TRN \\
\hline CHEMBL1446858 & 688239 & 4.7362 & 5.4483 & TRN & \\
\hline CHEMBL1401207 & 688239 & 5.1862 & 5.58299 & 9999999999 & TRN \\
\hline CHEMBL1573334 & 688239 & 4.6362 & 5.3542 & TRN & \\
\hline CHEMBL1387391 & 688239 & 5.2362 & 5.5543 & TST & \\
\hline CHEMBL1422924 & 688239 & 5.6362 & 5.4413 & TRN & \\
\hline CHEMBL1387320 & 688239 & 4.7862 & \multicolumn{2}{|c|}{5.4910000000000005} & TRN \\
\hline CHEMBL1405882 & 688239 & 5.3362 & 5.5149 & TRN & \\
\hline CHEMBL1474679 & 688239 & 4.7862 & 5.5816 & TST & \\
\hline CHEMBL 3199652 & 688239 & 7.7852 & 5.3696 & TRN & \\
\hline CHEMBL1492819 & 688239 & 6.1862 & 5.5455 & TRN & \\
\hline CHEMBL1402209 & 688239 & 4.9362 & 5.3844 & TST & \\
\hline CHEMBL1336378 & 688239 & 4.9362 & 5.4384 & TRN & \\
\hline CHEMBL1447580 & 688239 & 4.5362 & 5.4597 & TRN & \\
\hline CHEMBL1448443 & 688239 & 4.7862 & 5.5964 & TRN & \\
\hline CHEMBL 3198198 & 688239 & 5.1362 & 5.5867 & TRN & \\
\hline CHEMBL1548896 & 688239 & 4.5362 & 5.4199 & TRN & \\
\hline CHEMBL1467056 & 688239 & 5.1862 & 5.4902 & TRN & \\
\hline CHEMBL1546689 & 688239 & 8.2366 & 5.5639 & TRN & \\
\hline CHEMBL1606518 & 688239 & 5.5362 & 5.495 & TST & \\
\hline CHEMBL1419094 & 688239 & 4.6862 & 5.5647 & TRN & \\
\hline CHEMBL1421017 & 688239 & 4.5362 & 5.4854 & TRN & \\
\hline CHEMBL1493071 & 688239 & 4.6862 & 5.3235 & TRN & \\
\hline CHEMBL1551314 & 688239 & 5.7362 & 5.5197 & TRN & \\
\hline CHEMBL1335431 & 688239 & 6.1362 & 5.525 & TRN & \\
\hline CHEMBL1358776 & 688239 & 5.0862 & 5.4664 & TST & \\
\hline CHEMBL1314778 & 688239 & 6.0 & 5.4112 & TRN & \\
\hline CHEMBL1529991 & 688239 & 4.5362 & 5.4868 & TRN & \\
\hline CHEMBL1439164 & 688239 & 4.6862 & 5.3281 & TRN & \\
\hline CHEMBL1471455 & 688239 & 5.8862 & 5.4117 & TRN & \\
\hline CHEMBL1403069 & 688239 & 4.7862 & 5.4964 & TST & \\
\hline CHEMBL3209004 & 688239 & 6.7862 & 5.4391 & TRN & \\
\hline CHEMBL1479307 & 688239 & 5.6362 & 5.5183 & TST & \\
\hline CHEMBL1566963 & 688239 & 4.5362 & 5.3764 & TRN & \\
\hline
\end{tabular}


Supplemental Table S2.txt

\begin{tabular}{|c|c|c|c|c|c|}
\hline CHEMBL1353704 & 688239 & 5.0362 & \multicolumn{2}{|c|}{5.5089999999999995} & TRN \\
\hline CHEMBL1527308 & 688239 & 5.4862 & 5.7319 & TRN & \\
\hline CHEMBL1470887 & 688239 & 4.6862 & 5.4338 & TRN & \\
\hline CHEMBL1398344 & 688239 & 6.0862 & 5.5793 & TRN & \\
\hline CHEMBL1378882 & 688239 & 4.4862 & 5.4399 & TRN & \\
\hline CHEMBL1324423 & 688239 & 5.2862 & 5.5018 & TRN & \\
\hline CHEMBL1971185 & 688239 & 5.2362 & 5.6706 & TRN & \\
\hline CHEMBL1381107 & 688239 & 6.1862 & 5.4976 & TRN & \\
\hline CHEMBL1461378 & 688239 & 4.9362 & 5.4419 & TRN & \\
\hline CHEMBL1582507 & 688239 & 4.7362 & 5.4556 & TST & \\
\hline CHEMBL3213968 & 688239 & 4.7362 & 5.4746 & TRN & \\
\hline CHEMBL1391341 & 688239 & 7.4365 & 5.5009 & TRN & \\
\hline CHEMBL1558795 & 688239 & 4.5362 & 5.5446 & TRN & \\
\hline CHEMBL1379871 & 688239 & 4.7362 & 5.5341 & TRN & \\
\hline CHEMBL1470966 & 688239 & 4.8862 & 5.5488 & TRN & \\
\hline CHEMBL1599866 & 688239 & 6.7862 & 5.4346 & TRN & \\
\hline CHEMBL1555597 & 688239 & 6.9863 & 5.4979 & TST & \\
\hline CHEMBL1571783 & 688239 & 6.8861 & 5.4616 & TST & \\
\hline CHEMBL1576014 & 688239 & 6.2362 & 5.5703 & TRN & \\
\hline CHEMBL1440179 & 688239 & 4.5362 & 5.5454 & TRN & \\
\hline CHEMBL1307280 & 688239 & 5.9362 & 5.4899 & TST & \\
\hline CHEMBL1310950 & 688239 & 6.3362 & 5.4675 & TST & \\
\hline CHEMBL1330098 & 688239 & 6.4862 & \multicolumn{2}{|c|}{5.4110000000000005} & TRN \\
\hline CHEMBL1454175 & 688239 & 5.9862 & 5.6291 & TRN & \\
\hline CHEMBL1509402 & 688239 & 4.9362 & 5.5024 & TRN & \\
\hline CHEMBL1502794 & 688239 & 6.1362 & 5.4544 & TRN & \\
\hline CHEMBL1565394 & 688239 & 4.5362 & 5.5101 & TRN & \\
\hline CHEMBL1316764 & 688239 & 6.5862 & 5.4784 & TRN & \\
\hline CHEMBL1393881 & 688239 & 4.4862 & \multicolumn{2}{|c|}{5.422999999999999} & TRN \\
\hline CHEMBL1506389 & 688239 & 5.1862 & 5.4838 & TST & \\
\hline CHEMBL1327193 & 688239 & 6.4862 & 5.3995 & TRN & \\
\hline CHEMBL1527692 & 688239 & 5.1862 & 5.3359 & TST & \\
\hline CHEMBL1340576 & 688239 & 6.3362 & 5.5925 & TST & \\
\hline CHEMBL1520804 & 688239 & 6.1362 & 5.466 & TRN & \\
\hline CHEMBL1407109 & 688239 & 4.8862 & 5.3852 & TST & \\
\hline CHEMBL1391334 & 688239 & 5.5862 & 5.6826 & TRN & \\
\hline CHEMBL1506957 & 688239 & 5.9362 & 5.5901 & TST & \\
\hline CHEMBL1599183 & 688239 & 5.3862 & 5.5903 & TRN & \\
\hline CHEMBL1494462 & 688239 & 7.5361 & 5.5107 & TRN & \\
\hline CHEMBL3213716 & 688239 & 4.7362 & 5.388 & TRN & \\
\hline CHEMBL1524319 & 688239 & 4.4862 & \multicolumn{2}{|c|}{5.537000000000001} & RN \\
\hline CHEMBL567337 & 688239 & 6.2862 & 5.5323 & TRN & \\
\hline CHEMBL1307946 & 688239 & 4.5862 & 5.5816 & TRN & \\
\hline CHEMBL1427275 & 688239 & 6.1362 & 5.5187 & TRN & \\
\hline CHEMBL1413037 & 688239 & 5.1362 & 5.3949 & TRN & \\
\hline CHEMBL1446155 & 688239 & 4.8862 & 5.5331 & TRN & \\
\hline CHEMBL1579300 & 688239 & 4.9362 & 5.4937 & TST & \\
\hline CHEMBL3214114 & 688239 & 4.5362 & 5.4311 & TRN & \\
\hline
\end{tabular}


Supplemental Table S2.txt

\begin{tabular}{|c|c|c|c|c|}
\hline & & & & \\
\hline AEMBL1599134 & 8239 & 6862 & & \\
\hline IEMBL1506025 & 8239 & 862 & 4062 & \\
\hline AEMBL1343653 & 239 & 4862 & 5567 & \\
\hline 592866 & 239 & 362 & & \\
\hline IEMBL1410924 & 239 & 862 & & \\
\hline AEMBL3210636 & 239 & 362 & 3261 & \\
\hline AEMBL1583133 & 88239 & 862 & 5258 & \\
\hline AEMBL1369236 & 239 & 862 & & \\
\hline IEMBL1539374 & 239 & 62 & & \\
\hline IEMBL1504876 & & & & \\
\hline AEMBL1583137 & 688239 & 362 & & \\
\hline AEMBL1431742 & 239 & 861 & & \\
\hline IEMBL1522938 & & 62 & & \\
\hline IEMBL150 & & & & \\
\hline AEMBL1334708 & & & & \\
\hline AEMBL1458056 & 239 & & & \\
\hline AEMBL1391189 & & 62 & & \\
\hline IEMBL143 & & & & \\
\hline IEMBL14 & & & & \\
\hline EMBL 14 & & & 44 & \\
\hline HEMBL1539112 & & & 133 & \\
\hline IEMBL1490087 & & & & \\
\hline IEMBL1386602 & & & & \\
\hline EMBL13 & & & & ST \\
\hline IEMBL 3212450 & & & & 15 \\
\hline AEMBL1449276 & & & & RN \\
\hline AEMBL1512105 & & & & \\
\hline AEMBL1584113 & & & 294 & ST \\
\hline EMMBL1498824 & & & 99 & . \\
\hline 154 & & & & - \\
\hline HEMBL1549235 & & & & RN \\
\hline AEMBL1572975 & & & & RI \\
\hline IEMBL1449767 & & & & S \\
\hline 5030 & & & & $\cdots$ \\
\hline 36 & & & & ST \\
\hline AEMBL1493588 & & & & RN \\
\hline AEMBL1596036 & & & & \\
\hline IEMBL1551246 & & & & RI \\
\hline HEMBL1592967 & & & 93 & \\
\hline HEMBL1594454 & & & & RN \\
\hline AEMBL3213103 & & & 5489 & ST \\
\hline IEMBL1547368 & & & & 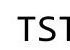 \\
\hline EMBL1529810 & & & & \\
\hline CHEMBL1584251 & & & & \\
\hline CHEMBL1378887 & & & & RN \\
\hline HEMBL158087 & 8239 & 5.0862 & 5.7275 & $\mathrm{TR}$ \\
\hline HFMRI 1591398 & 688239 & 4.4862 & 5.3349 & \\
\hline
\end{tabular}

Page 1576 
Supplemental Table S2.txt

\begin{tabular}{|c|c|c|c|c|}
\hline CHEMBL1345936 & 688239 & 5.6862 & 5.4192 & TRN \\
\hline CHEMBL1493791 & 688239 & 6.3362 & 5.5572 & TST \\
\hline CHEMBL3197241 & 688239 & 4.6862 & 5.3665 & TST \\
\hline CHEMBL1355108 & 688239 & 4.5862 & 5.3064 & TRN \\
\hline CHEMBL1328929 & 688239 & 4.6862 & 5.4933 & TST \\
\hline CHEMBL1562104 & 688239 & 6.8861 & 5.4939 & TST \\
\hline CHEMBL1486818 & 688239 & 5.2862 & 5.4361 & TRN \\
\hline CHEMBL1466340 & 688239 & 4.7862 & 5.4552 & TRN \\
\hline CHEMBL1541040 & 688239 & 5.9862 & 5.5927 & TRN \\
\hline CHEMBL1539885 & 688239 & 5.3862 & 5.5392 & TRN \\
\hline CHEMBL1380615 & 688239 & 4.7862 & 5.6441 & TRN \\
\hline CHEMBL1426103 & 688239 & 5.4862 & 5.4669 & TRN \\
\hline CHEMBL1548712 & 688239 & 5.4362 & 5.3556 & TST \\
\hline CHEMBL1312551 & 688239 & 5.1862 & 5.5084 & TRN \\
\hline CHEMBL1369720 & 688239 & 5.1862 & 5.5111 & TRN \\
\hline CHEMBL1341236 & 688239 & 4.5362 & 5.5309 & TST \\
\hline CHEMBL1513164 & 688239 & 5.1862 & 5.5475 & TRN \\
\hline CHEMBL1343425 & 688239 & 4.7362 & 5.5014 & TST \\
\hline CHEMBL1433030 & 688239 & 4.6862 & 5.4091 & TST \\
\hline CHEMBL1386894 & 688239 & 4.8362 & 5.499 & TST \\
\hline CHEMBL1594927 & 688239 & 4.5362 & 5.3813 & TST \\
\hline CHEMBL1376458 & 688239 & 4.5862 & 5.5585 & TRN \\
\hline CHEMBL1558363 & 688239 & 6.3863 & 5.5161 & TST \\
\hline CHEMBL1426818 & 688239 & 6.8861 & 5.4932 & TRN \\
\hline CHEMBL1404837 & 688239 & 5.6862 & 5.6607 & TST \\
\hline CHEMBL1353983 & 688239 & 5.7862 & 5.4577 & TRN \\
\hline CHEMBL3191504 & 688239 & 8.1871 & 5.3412 & TRN \\
\hline CHEMBL1508209 & 688239 & 5.9362 & 5.5357 & TRN \\
\hline CHEMBL1384992 & 688239 & 5.8862 & 5.4905 & TRN \\
\hline CHEMBL1444585 & 688239 & 4.7362 & 5.5185 & TST \\
\hline CHEMBL1307165 & 688239 & 5.8862 & 5.3918 & TRN \\
\hline CHEMBL1346878 & 688239 & 6.4362 & 5.4932 & TRN \\
\hline CHEMBL1309662 & 688239 & 5.4362 & 5.443 & TST \\
\hline CHEMBL69612 & 688239 & 5.1862 & 5.382006 & 0000000001 \\
\hline CHEMBL1520965 & 688239 & 6.0862 & 5.6075 & TRN \\
\hline CHEMBL1453197 & 688239 & 5.1862 & 5.5579 & TRN \\
\hline CHEMBL1359417 & 688239 & 5.1362 & 5.4669 & TST \\
\hline CHEMBL1517147 & 688239 & 4.7862 & 5.5602 & TRN \\
\hline CHEMBL1517227 & 688239 & 5.0862 & 5.4575 & TRN \\
\hline CHEMBL1510181 & 688239 & 4.7362 & 5.485 & TST \\
\hline CHEMBL1304024 & 688239 & 4.5362 & 5.3203 & TST \\
\hline CHEMBL1336904 & 688239 & 5.4362 & 5.6258 & TST \\
\hline CHEMBL1354411 & 688239 & 5.4362 & 5.3989 & TRN \\
\hline CHEMBL1494735 & 688239 & 8.3872 & 5.5197 & TRN \\
\hline CHEMBL1525520 & 688239 & 5.4362 & 5.5121 & TRN \\
\hline CHEMBL1313711 & 688239 & 4.5362 & 5.4211 & TRN \\
\hline CHEMBL1372736 & 688239 & 5.5862 & 5.3996 & TRN \\
\hline CHEMBL1431837 & 688239 & 5.3362 & 5.5023 & TRN \\
\hline
\end{tabular}




\begin{tabular}{|c|c|c|c|c|c|}
\hline \multicolumn{6}{|c|}{ Supplemental Table S2.txt } \\
\hline CHEMBL1595843 & 688239 & 4.75 & 5.4555 & TRN & \\
\hline CHEMBL1567962 & 688239 & 4.5362 & 5.5405 & TST & \\
\hline CHEMBL1301514 & 688239 & 4.8362 & 5.3966 & TRN & \\
\hline CHEMBL3207851 & 688239 & 4.5862 & 5.3958 & TST & \\
\hline CHEMBL1537689 & 688239 & 4.9862 & 5.5785 & TRN & \\
\hline CHEMBL1313212 & 688239 & 5.2362 & 5.3516 & TRN & \\
\hline CHEMBL1446203 & 688239 & 6.1362 & 5.3184 & TRN & \\
\hline CHEMBL1346359 & 688239 & 4.7862 & 5.2973 & TRN & \\
\hline CHEMBL1325018 & 688239 & 4.5362 & 5.3531 & TRN & \\
\hline CHEMBL1402093 & 688239 & 6.1862 & 5.5641 & TST & \\
\hline CHEMBL1301637 & 688239 & 4.7362 & 5.6221 & TRN & \\
\hline CHEMBL1569557 & 688239 & 6.9363 & 5.5123 & TRN & \\
\hline CHEMBL1608933 & 688239 & 4.9862 & 5.4909 & TRN & \\
\hline CHEMBL1453539 & 688239 & 6.8861 & 5.4366 & TRN & \\
\hline CHEMBL1532525 & 688239 & 4.7362 & 5.4443 & TRN & \\
\hline CHEMBL1308574 & 688239 & 4.7862 & 5.5336 & TRN & \\
\hline CHEMBL1341419 & 688239 & 5.2362 & 5.3411 & TST & \\
\hline CHEMBL1343109 & 688239 & 5.6862 & 5.6006 & TRN & \\
\hline CHEMBL1420030 & 688239 & 4.4862 & 5.5356 & TRN & \\
\hline CHEMBL1496541 & 688239 & 4.5362 & 5.4668 & TRN & \\
\hline CHEMBL1464348 & 688239 & 6.2362 & 5.4041 & TRN & \\
\hline CHEMBL1472593 & 688239 & 4.4862 & 5.471 & TRN & \\
\hline CHEMBL1381968 & 688239 & 5.1862 & 5.4951 & TRN & \\
\hline CHEMBL1403593 & 688239 & 4.7362 & 5.5808 & TRN & \\
\hline CHEMBL1464691 & 688239 & 5.5862 & 5.2502 & TRN & \\
\hline CHEMBL1484715 & 688239 & 5.6362 & 5.6863 & TRN & \\
\hline CHEMBL1319850 & 688239 & 4.6862 & 5.7576 & TRN & \\
\hline CHEMBL1513552 & 688239 & 8.3372 & 5.4296 & TRN & \\
\hline CHEMBL1412661 & 688239 & 5.2862 & 5.6202 & TRN & \\
\hline CHEMBL1517368 & 688239 & 4.7362 & 5.291 & TRN & \\
\hline CHEMBL1491181 & 688239 & 6.1862 & 5.441 & TRN & \\
\hline CHEMBL1464616 & 688239 & 4.9862 & 5.4269 & TRN & \\
\hline CHEMBL3195014 & 688239 & 6.0362 & 5.357 & TRN & \\
\hline CHEMBL1613540 & 688239 & 5.1362 & 5.476 & TRN & \\
\hline CHEMBL1304193 & 688239 & 4.6862 & 5.6313 & TRN & \\
\hline CHEMBL1557289 & 688239 & 6.7862 & 5.5293 & TST & \\
\hline CHEMBL1333141 & 688239 & 5.8862 & 5.6069 & TST & \\
\hline CHEMBL1597091 & 688239 & 6.1362 & 5.46299 & 9999999999 & TST \\
\hline CHEMBL1332927 & 688239 & 5.2862 & 5.3783 & TST & \\
\hline CHEMBL1434586 & 688239 & 5.6362 & 5.5029 & TRN & \\
\hline CHEMBL1491841 & 688239 & 4.8862 & 5.5262 & TRN & \\
\hline CHEMBL1308999 & 688239 & 5.6362 & 5.4296 & TRN & \\
\hline CHEMBL1458987 & 688239 & 5.5362 & 5.6238 & TRN & \\
\hline CHEMBL1526350 & 688239 & 6.1862 & 5.5602 & TRN & \\
\hline CHEMBL1377697 & 688239 & 4.9862 & 5.4485 & TRN & \\
\hline CHEMBL1439650 & 688239 & 6.1862 & 5.6726 & TRN & \\
\hline CHEMBL1381235 & 688239 & 8.1871 & 5.4911 & TRN & \\
\hline CHEMBL1541016 & 688239 & 6.0862 & 5.5614 & TRN & \\
\hline
\end{tabular}


Supplemental Table S2.txt

\begin{tabular}{|c|c|c|c|c|c|c|c|}
\hline CHEMBL1448271 & 688239 & 5.1862 & 5.6612 & TRN & & & \\
\hline CHEMBL1402074 & 688239 & 4.6362 & 5.5244 & TRN & & & \\
\hline CHEMBL1408800 & 688239 & 6.9363 & 5.5769 & TRN & & & \\
\hline CHEMBL1504277 & 688239 & 5.5862 & 5.5072 & TST & & & \\
\hline CHEMBL1527981 & 688239 & 4.7362 & 5.3603 & TST & & & \\
\hline CHEMBL 3199398 & 688239 & 6.0862 & 5.4316 & TRN & & & \\
\hline CHEMBL1423188 & 688239 & 4.4862 & 5.4865 & TRN & & & \\
\hline CHEMBL1518113 & 688239 & 8.3872 & \multicolumn{3}{|c|}{5.457000000000001} & TRN & \\
\hline CHEMBL1304025 & 688239 & \multicolumn{3}{|c|}{8.283999999999999} & 5.4495 & TRN & \\
\hline CHEMBL1470009 & 688239 & 4.6362 & 5.4593 & TST & & & \\
\hline CHEMBL1313146 & 688239 & 4.9862 & 5.5488 & TST & & & \\
\hline CHEMBL1299653 & 688239 & 4.5362 & 5.4615 & TRN & & & \\
\hline CHEMBL1602310 & 688239 & 5.5862 & 5.4806 & TRN & & & \\
\hline CHEMBL1341656 & 688239 & 5.1862 & 5.4262 & TRN & & & \\
\hline CHEMBL1477567 & 688239 & 4.7362 & 5.4581 & TRN & & & \\
\hline CHEMBL1584571 & 688239 & 4.6862 & 5.4577 & TRN & & & \\
\hline CHEMBL1360994 & 688239 & 4.6362 & \multicolumn{3}{|c|}{5.367000000000001} & TRN & \\
\hline CHEMBL500812 & 688239 & 4.6862 & 5.401 & TST & & & \\
\hline CHEMBL1375119 & 688239 & 6.0862 & 5.4424 & TST & & & \\
\hline CHEMBL1454183 & 688239 & 4.8362 & 5.4594 & TST & & & \\
\hline CHEMBL1605698 & 688239 & 4.6862 & 5.3212 & TRN & & & \\
\hline CHEMBL1580654 & 688239 & 6.9863 & 5.5664 & TRN & & & \\
\hline CHEMBL1523130 & 688239 & 5.1862 & 5.4935 & TRN & & & \\
\hline CHEMBL1332770 & 688239 & 5.1862 & 5.5401 & TRN & & & \\
\hline CHEMBL1473163 & 688239 & 5.8362 & 5.3797 & TRN & & & \\
\hline CHEMBL1310451 & 688239 & 6.9863 & 5.7238 & TRN & & & \\
\hline CHEMBL1313535 & 688239 & 4.5362 & 5.4552 & TRN & & & \\
\hline CHEMBL1336032 & 688239 & 5.4862 & 5.5217 & TRN & & & \\
\hline CHEMBL1319026 & 688239 & 5.4862 & 5.62 & TST & & & \\
\hline CHEMBL1588605 & 688239 & 6.6362 & 5.4713 & TST & & & \\
\hline CHEMBL1557201 & 688239 & 5.3362 & 5.3775 & TRN & & & \\
\hline CHEMBL528065 & 688239 & 4.6862 & 5.6218 & TRN & & & \\
\hline CHEMBL1426404 & 688239 & 4.5362 & 5.5539 & TST & & & \\
\hline CHEMBL1403004 & 688239 & 6.1862 & 5.655 & TRN & & & \\
\hline CHEMBL3209522 & 688239 & 5.1862 & 5.3568 & TST & & & \\
\hline CHEMBL1444896 & 688239 & 4.4862 & 5.4297 & TRN & & & \\
\hline CHEMBL1576892 & 688239 & 4.5362 & 5.2926 & TRN & & & \\
\hline CHEMBL1449761 & 688239 & 5.8362 & 5.5049 & TRN & & & \\
\hline CHEMBL1322499 & 688239 & 5.1862 & 5.5947 & TRN & & & \\
\hline CHEMBL1431679 & 688239 & 4.5862 & 5.5161 & TRN & & & \\
\hline CHEMBL1523655 & 688239 & 4.9362 & 5.5914 & TRN & & & \\
\hline CHEMBL1300820 & 688239 & 6.4862 & 5.5377 & TRN & & & \\
\hline CHEMBL1391218 & 688239 & 4.5362 & 5.4451 & TRN & & & \\
\hline CHEMBL1302086 & 688239 & 8.28399 & 999999999 & 99 & 5.5370 & 0000000001 & TST \\
\hline CHEMBL1308141 & 688239 & 5.1862 & 5.4233 & TRN & & & \\
\hline CHEMBL1519839 & 688239 & 4.7862 & 5.6791 & TRN & & & \\
\hline CHEMBL1330996 & 688239 & 4.7362 & 5.605 & TRN & & & \\
\hline CHEMBL1501662 & 688239 & 4.4862 & 5.3011 & TRN & & & \\
\hline
\end{tabular}


Supplemental Table S2.txt

\begin{tabular}{|c|c|c|c|c|c|}
\hline CHEMBL1336456 & 688239 & 4.8362 & 5.4235 & TRN & \\
\hline CHEMBL1314560 & 688239 & 4.5362 & 5.4239 & TRN & \\
\hline CHEMBL1434850 & 688239 & 5.4362 & 5.4955 & TRN & \\
\hline CHEMBL1591244 & 688239 & 4.5362 & 5.3868 & TRN & \\
\hline CHEMBL1406842 & 688239 & 4.7362 & 5.5409 & TRN & \\
\hline CHEMBL1377673 & 688239 & 4.5362 & 5.6193 & TRN & \\
\hline CHEMBL1495621 & 688239 & 6.2362 & 5.5548 & TST & \\
\hline CHEMBL1428403 & 688239 & 5.1862 & 5.4624 & TST & \\
\hline CHEMBL1562262 & 688239 & 5.9862 & 5.5074 & TRN & \\
\hline CHEMBL1427577 & 688239 & 5.6362 & 5.5159 & TRN & \\
\hline CHEMBL1558329 & 688239 & 5.4362 & 5.5376 & TST & \\
\hline CHEMBL1338342 & 688239 & 5.4862 & 5.5358 & TRN & \\
\hline CHEMBL1350530 & 688239 & 5.3862 & 5.6428 & TST & \\
\hline CHEMBL3210112 & 688239 & 4.7362 & 5.5179 & TST & \\
\hline CHEMBL1431745 & 688239 & 5.3862 & 5.4926 & TRN & \\
\hline CHEMBL1359301 & 688239 & 5.7362 & 5.5636 & TRN & \\
\hline CHEMBL1585316 & 688239 & 6.7862 & 5.3715 & TRN & \\
\hline CHEMBL1578501 & 688239 & 5.1862 & 5.3132 & TRN & \\
\hline CHEMBL1460579 & 688239 & 6.3362 & 5.4199 & TRN & \\
\hline CHEMBL1538737 & 688239 & 4.6862 & 5.4774 & TST & \\
\hline CHEMBL1508593 & 688239 & 4.8362 & 5.3082 & TST & \\
\hline CHEMBL1377432 & 688239 & 5.1862 & 5.3747 & TRN & \\
\hline CHEMBL1490563 & 688239 & 6.9863 & 5.6978 & TRN & \\
\hline CHEMBL1446302 & 688239 & 7.1864 & 5.5875 & TST & \\
\hline CHEMBL1459539 & 688239 & 5.1862 & 5.2794 & TST & \\
\hline CHEMBL1585389 & 688239 & 5.2362 & 5.421 & TRN & \\
\hline CHEMBL1579796 & 688239 & 5.4362 & 5.4563 & TRN & \\
\hline CHEMBL1525062 & 688239 & 4.5362 & 5.5311 & TRN & \\
\hline CHEMBL1439157 & 688239 & 7.2366 & 5.5033 & TST & \\
\hline CHEMBL1484137 & 688239 & 5.7362 & 5.5747 & TRN & \\
\hline CHEMBL1572081 & 688239 & 4.5362 & 5.4419 & TRN & \\
\hline CHEMBL1455318 & 688239 & 5.4362 & 5.4069 & TRN & \\
\hline CHEMBL1326812 & 688239 & 6.5862 & 5.4777 & TRN & \\
\hline CHEMBL1409197 & 688239 & 4.7362 & 5.5972 & TRN & \\
\hline CHEMBL 271620 & 688239 & 8.2366 & 5.5074 & TRN & \\
\hline CHEMBL1360020 & 688239 & 5.6362 & 5.2817 & TRN & \\
\hline CHEMBL1545805 & 688239 & 7.0862 & 5.5534 & TRN & \\
\hline CHEMBL1323318 & 688239 & 5.7862 & 5.4728 & TRN & \\
\hline CHEMBL1525692 & 688239 & 5.1862 & 5.5469 & TRN & \\
\hline CHEMBL1499794 & 688239 & 8.28399 & 99999999 & 9 & 5.4924 \\
\hline CHEMBL1386733 & 688239 & 5.1862 & 5.5744 & TST & \\
\hline CHEMBL1466900 & 688239 & 5.7362 & 5.6574 & TRN & \\
\hline CHEMBL1544695 & 688239 & 5.0862 & 5.5303 & TST & \\
\hline CHEMBL1507109 & 688239 & 4.8362 & 5.4756 & TST & \\
\hline CHEMBL 3209025 & 688239 & 4.5362 & 5.5942 & TST & \\
\hline CHEMBL1606795 & 688239 & 4.9362 & 5.4927 & TRN & \\
\hline CHEMBL1392735 & 688239 & 5.0362 & 5.5933 & TRN & \\
\hline CHEMBL1495775 & 688239 & 5.1862 & 5.4056 & TST & \\
\hline
\end{tabular}


Supplemental Table S2.txt

\begin{tabular}{|c|c|c|c|c|}
\hline CHEMBL1479980 & 688239 & 4.7362 & 5.5055 & TST \\
\hline CHEMBL1600170 & 688239 & 4.5362 & 5.517 & TRN \\
\hline CHEMBL1333338 & 688239 & 4.7862 & 5.3326 & TST \\
\hline CHEMBL 3197259 & 688239 & 4.7862 & 5.2625 & TST \\
\hline CHEMBL1590896 & 688239 & 4.9362 & 5.5456 & TRN \\
\hline CHEMBL1399320 & 688239 & 4.9862 & 5.5252 & TRN \\
\hline CHEMBL1511341 & 688239 & 6.4362 & 5.4978 & TRN \\
\hline CHEMBL1503746 & 688239 & 6.2862 & 5.5592 & TRN \\
\hline CHEMBL1480040 & 688239 & 4.5362 & 5.558 & TRN \\
\hline CHEMBL1586532 & 688239 & 4.5362 & 5.3661 & TRN \\
\hline CHEMBL 3212377 & 688239 & 4.5362 & 5.4282 & TST \\
\hline CHEMBL1553259 & 688239 & 4.7862 & 5.5016 & TST \\
\hline CHEMBL1549822 & 688239 & 4.9362 & 5.4993 & TST \\
\hline CHEMBL1508000 & 688239 & 4.8362 & 5.5018 & TRN \\
\hline CHEMBL1583397 & 688239 & 4.9862 & 5.601 & TRN \\
\hline CHEMBL1399916 & 688239 & 8.2366 & 5.5204 & TRN \\
\hline CHEMBL1536439 & 688239 & 6.5363 & 5.4664 & TRN \\
\hline CHEMBL1341304 & 688239 & 8.3372 & 5.5846 & TRN \\
\hline CHEMBL1579354 & 688239 & 6.0862 & 5.4243 & TST \\
\hline CHEMBL1447315 & 688239 & 5.2362 & 5.5438 & TST \\
\hline CHEMBL1388070 & 688239 & 5.8862 & 5.4866 & TRN \\
\hline CHEMBL3196808 & 688239 & 4.8862 & 5.3585 & TRN \\
\hline CHEMBL1498013 & 688239 & 5.5362 & 5.6024 & TRN \\
\hline CHEMBL1405404 & 688239 & 5.8862 & 5.5889 & TRN \\
\hline CHEMBL1524105 & 688239 & 4.7362 & 5.481 & TRN \\
\hline CHEMBL1436146 & 688239 & 4.5362 & 5.65799 & 99999999995 \\
\hline CHEMBL1576381 & 688239 & 7.2366 & 5.5122 & TRN \\
\hline CHEMBL1477600 & 688239 & 4.5362 & 5.4837 & TRN \\
\hline CHEMBL1498987 & 688239 & 4.6862 & 5.5687 & TRN \\
\hline CHEMBL1543446 & 688239 & 5.5362 & 5.6085 & TRN \\
\hline CHEMBL1485014 & 688239 & 4.7862 & 5.4259 & TST \\
\hline CHEMBL1605788 & 688239 & 6.9863 & 5.4802 & TRN \\
\hline CHEMBL1579227 & 688239 & 4.6862 & 5.3715 & TRN \\
\hline CHEMBL1465309 & 688239 & 6.7361 & 5.4314 & TRN \\
\hline CHEMBL1395886 & 688239 & 4.5862 & 5.2056 & TRN \\
\hline CHEMBL1478292 & 688239 & 4.5362 & 5.586 & TRN \\
\hline CHEMBL1302327 & 688239 & 6.1362 & 5.5249 & TST \\
\hline CHEMBL1385956 & 688239 & 5.7862 & 5.6835 & TST \\
\hline CHEMBL1523715 & 688239 & 5.6362 & 5.4852 & TRN \\
\hline CHEMBL1410700 & 688239 & 8.6778 & 5.4401 & TRN \\
\hline CHEMBL1536673 & 688239 & 6.4862 & 5.4039 & TRN \\
\hline CHEMBL1583599 & 688239 & 4.8362 & 5.4873 & TRN \\
\hline CHEMBL1473113 & 688239 & 5.1862 & 5.4281 & TRN \\
\hline CHEMBL1458760 & 688239 & 4.5862 & 5.5241 & TST \\
\hline CHEMBL1443182 & 688239 & 4.6362 & 5.5343 & TRN \\
\hline CHEMBL1299993 & 688239 & 5.8362 & 5.5205 & TRN \\
\hline CHEMBL1558966 & 688239 & 4.6862 & 5.6252 & TRN \\
\hline CHEMBL1489756 & 688239 & 4.7362 & 5.7239 & TST \\
\hline
\end{tabular}

Page 1581 
Supplemental Table S2.txt

\begin{tabular}{|c|c|c|c|c|}
\hline CHEMBL1550089 & 688239 & 4.5362 & 5.3867 & TST \\
\hline CHEMBL1368329 & 688239 & 5.4862 & 5.575 & TRN \\
\hline CHEMBL578883 & 688239 & 4.7862 & 5.5581 & TRN \\
\hline CHEMBL1425612 & 688239 & 5.6862 & 5.5902 & TRN \\
\hline CHEMBL1326622 & 688239 & 6.7361 & 5.4977 & TRN \\
\hline CHEMBL1433010 & 688239 & 5.0862 & 5.49 & TRN \\
\hline CHEMBL1500341 & 688239 & 4.7862 & 5.5106 & TST \\
\hline CHEMBL1330896 & 688239 & 6.5862 & 5.3586 & TST \\
\hline CHEMBL1374081 & 688239 & 4.4862 & 5.6534 & TRN \\
\hline CHEMBL1507391 & 688239 & 5.6362 & 5.4333 & TRN \\
\hline CHEMBL1537165 & 688239 & 5.9362 & 5.5431 & TRN \\
\hline CHEMBL1583097 & 688239 & 5.1362 & 5.286006 & 00000000005 \\
\hline CHEMBL1471992 & 688239 & 8.2366 & 5.5353 & TRN \\
\hline CHEMBL1599032 & 688239 & 5.2862 & 5.4443 & TRN \\
\hline CHEMBL1462876 & 688239 & 5.7862 & 5.3339 & TRN \\
\hline CHEMBL1387529 & 688239 & 5.5362 & 5.4375 & TRN \\
\hline CHEMBL1426817 & 688239 & 6.8362 & 5.415 & TST \\
\hline CHEMBL1468240 & 688239 & 5.5362 & 5.5316 & TRN \\
\hline CHEMBL1333030 & 688239 & 6.2362 & 5.3569 & TST \\
\hline CHEMBL1539528 & 688239 & 6.6362 & 5.3724 & TRN \\
\hline CHEMBL 262083 & 688239 & 4.5362 & 5.4609 & TST \\
\hline CHEMBL1425626 & 688239 & 4.4862 & 5.5697 & TST \\
\hline CHEMBL1553547 & 688239 & 6.2862 & 5.5098 & TRN \\
\hline CHEMBL1446091 & 688239 & 6.8362 & 5.4589 & TRN \\
\hline CHEMBL1601247 & 688239 & 6.6362 & 5.5155 & TRN \\
\hline CHEMBL1402659 & 688239 & 4.8862 & 5.3675 & TST \\
\hline CHEMBL1456606 & 688239 & 5.3362 & 5.4037 & TST \\
\hline CHEMBL1543952 & 688239 & 4.7862 & 5.5614 & TRN \\
\hline CHEMBL1403998 & 688239 & 5.0362 & 5.4354 & TST \\
\hline CHEMBL1470142 & 688239 & 6.3863 & 5.5355 & TRN \\
\hline CHEMBL 3190149 & 688239 & 5.6862 & 5.4039 & TRN \\
\hline CHEMBL1387366 & 688239 & 5.0862 & 5.5201 & TST \\
\hline CHEMBL1348059 & 688239 & 5.5862 & 5.4277 & TRN \\
\hline CHEMBL1306180 & 688239 & 4.8862 & 5.4652 & TRN \\
\hline CHEMBL1520293 & 688239 & 4.5362 & 5.4071 & TRN \\
\hline CHEMBL3192106 & 688239 & 6.2362 & 5.3388 & TST \\
\hline CHEMBL1326953 & 688239 & 4.5362 & 5.5906 & TRN \\
\hline CHEMBL1371639 & 688239 & 5.1862 & 5.4482 & TRN \\
\hline CHEMBL1582686 & 688239 & 6.1862 & 5.4398 & TRN \\
\hline CHEMBL1390540 & 688239 & 5.4362 & 5.2759 & TST \\
\hline CHEMBL1339193 & 688239 & 5.1862 & 5.3562 & TRN \\
\hline CHEMBL1354063 & 688239 & 5.4862 & 5.4903 & TST \\
\hline CHEMBL1375781 & 688239 & 5.5862 & 5.4065 & TST \\
\hline CHEMBL1346559 & 688239 & 5.1362 & 5.5026 & TRN \\
\hline CHEMBL1350852 & 688239 & 6.1862 & 5.4756 & TRN \\
\hline CHEMBL1569096 & 688239 & 4.7862 & 5.5036 & TRN \\
\hline CHEMBL1474034 & 688239 & 6.1362 & 5.66 & TRN \\
\hline CHEMBL1309213 & 688239 & 4.5362 & 5.5517 & TRN \\
\hline
\end{tabular}




\begin{tabular}{|c|c|c|c|c|c|}
\hline & & & & & \\
\hline CHEMBL1605785 & 688239 & 7.2366 & 5.6118 & TRN & \\
\hline CHEMBL1453444 & 688239 & 5.5862 & 5.4005 & TRN & \\
\hline CHEMBL1410842 & 688239 & 4.5362 & 5.4801 & TRN & \\
\hline CHEMBL1334611 & 688239 & 5.0862 & 5.5364 & TRN & \\
\hline CHEMBL 3210764 & 688239 & 5.2862 & 5.5579 & TRN & \\
\hline CHEMBL1407015 & 688239 & 6.6861 & 5.5517 & TRN & \\
\hline CHEMBL1378614 & 688239 & 4.8862 & 5.4961 & TST & \\
\hline CHEMBL1350329 & 688239 & 4.6362 & 5.5601 & TRN & \\
\hline CHEMBL1610952 & 688239 & 4.7862 & 5.519 & TRN & \\
\hline CHEMBL1490306 & 688239 & 5.6362 & 5.6017 & TRN & \\
\hline CHEMBL1423951 & 688239 & 4.5362 & 5.42899 & 9999999999 & TRN \\
\hline CHEMBL1534045 & 688239 & 6.0362 & 5.4531 & TRN & \\
\hline CHEMBL1545629 & 688239 & 8.1367 & 5.5375 & TRN & \\
\hline CHEMBL1367112 & 688239 & 4.8862 & 5.5405 & TRN & \\
\hline CHEMBL1316462 & 688239 & 6.0 & 5.3265 & TRN & \\
\hline CHEMBL1326110 & 688239 & 4.5362 & 5.5102 & TRN & \\
\hline CHEMBL1381513 & 688239 & 4.5362 & 5.5154 & TRN & \\
\hline CHEMBL1558416 & 688239 & 5.2862 & 5.517 & TRN & \\
\hline CHEMBL1557718 & 688239 & 6.0362 & 5.4936 & TRN & \\
\hline CHEMBL1603452 & 688239 & 5.6362 & 5.5844 & TRN & \\
\hline CHEMBL1379071 & 688239 & 4.6362 & 5.4683 & TRN & \\
\hline CHEMBL1365153 & 688239 & 6.9863 & 5.4346 & TRN & \\
\hline CHEMBL1391260 & 688239 & 5.2862 & 5.665 & TRN & \\
\hline CHEMBL1367691 & 688239 & 4.5362 & 5.3861 & TRN & \\
\hline CHEMBL1491712 & 688239 & 4.5862 & 5.4129 & TRN & \\
\hline CHEMBL1984336 & 688239 & 6.2362 & 5.4308 & TRN & \\
\hline CHEMBL1503017 & 688239 & 5.5862 & 5.5747 & TRN & \\
\hline CHEMBL1391437 & 688239 & 4.7362 & 5.4374 & TRN & \\
\hline CHEMBL1493455 & 688239 & 4.8362 & 5.4842 & TRN & \\
\hline CHEMBL3189850 & 688239 & 6.5363 & 5.5371 & TRN & \\
\hline CHEMBL3195013 & 688239 & 4.5362 & 5.38200 & 0000000001 & TRN \\
\hline CHEMBL1302958 & 688239 & 5.1862 & 5.3858 & TST & \\
\hline CHEMBL1559391 & 688239 & 4.5362 & 5.499 & TST & \\
\hline CHEMBL1365404 & 688239 & 4.5362 & 5.4977 & TRN & \\
\hline CHEMBL1406505 & 688239 & 6.1862 & 5.5172 & TST & \\
\hline CHEMBL1584709 & 688239 & 4.4862 & 5.44600 & 0000000001 & TRN \\
\hline CHEMBL1369424 & 688239 & 5.2862 & 5.4455 & TST & \\
\hline CHEMBL1449009 & 688239 & 4.7862 & 5.4554 & TRN & \\
\hline CHEMBL3208072 & 688239 & 4.7362 & 5.4489 & TST & \\
\hline CHEMBL1483361 & 688239 & 4.4862 & 5.5282 & TST & \\
\hline CHEMBL1998946 & 688239 & 5.1862 & 5.289 & TRN & \\
\hline CHEMBL1432956 & 688239 & 5.1862 & 5.5688 & TRN & \\
\hline CHEMBL3194636 & 688239 & 4.5362 & 5.4371 & TRN & \\
\hline CHEMBL1385532 & 688239 & 7.1864 & 5.4672 & TRN & \\
\hline CHEMBL1969707 & 688239 & 4.7362 & 5.4115 & TRN & \\
\hline CHEMBL1453263 & 688239 & 6.7361 & 5.5295 & TST & \\
\hline CHEMBL1394237 & 688239 & 4.6862 & 5.3101 & TRN & \\
\hline CHEMBL1607303 & 688239 & 5.1362 & 5.4049 & TRN & \\
\hline
\end{tabular}


Supplemental Table S2.txt

\begin{tabular}{|c|c|c|c|c|}
\hline CHEMBL1525290 & 688239 & 6.6362 & 5.43 & TRN \\
\hline CHEMBL1502883 & 688239 & 4.7862 & 5.2768 & TRN \\
\hline CHEMBL1507926 & 688239 & 5.1862 & 5.644 & TRN \\
\hline CHEMBL1400013 & 688239 & 4.5362 & 5.5365 & TRN \\
\hline CHEMBL1549034 & 688239 & 6.5363 & 5.4235 & TRN \\
\hline CHEMBL1348804 & 688239 & 8.1871 & 5.5082 & TST \\
\hline CHEMBL1500766 & 688239 & 4.5362 & 5.3523 & TRN \\
\hline CHEMBL1410792 & 688239 & 4.5362 & 5.4214 & TRN \\
\hline CHEMBL1520114 & 688239 & 6.7862 & 5.4685 & TRN \\
\hline CHEMBL1394063 & 688239 & 4.5362 & 5.4974 & TRN \\
\hline CHEMBL3208258 & 688239 & 5.4862 & 5.4728 & TRN \\
\hline CHEMBL1338960 & 688239 & 4.5362 & 5.3634 & TST \\
\hline CHEMBL1479550 & 688239 & 4.5362 & 5.5086 & TRN \\
\hline CHEMBL1572297 & 688239 & 4.5362 & 5.5856 & TST \\
\hline CHEMBL1372854 & 688239 & 6.0862 & 5.5712 & TRN \\
\hline CHEMBL1472776 & 688239 & 5.1862 & 5.4929 & TRN \\
\hline CHEMBL1569027 & 688239 & 4.5362 & 5.4782 & TRN \\
\hline CHEMBL1349169 & 688239 & 6.6362 & 5.5559 & TRN \\
\hline CHEMBL3192060 & 688239 & 6.7862 & 5.5182 & TRN \\
\hline CHEMBL1381872 & 688239 & 4.5862 & 5.3464 & TST \\
\hline CHEMBL1469168 & 688239 & 4.5362 & 5.6186 & TRN \\
\hline CHEMBL1487991 & 688239 & 4.7362 & 5.5129 & TRN \\
\hline CHEMBL3196206 & 688239 & 5.1862 & 5.544 & TRN \\
\hline CHEMBL1577529 & 688239 & 6.1862 & 5.4418 & TRN \\
\hline CHEMBL3190614 & 688239 & 4.5862 & 5.5839 & TST \\
\hline CHEMBL1991215 & 688239 & 4.5362 & 5.4454 & TRN \\
\hline CHEMBL1530627 & 688239 & 5.2362 & 5.4239 & TRN \\
\hline CHEMBL486706 & 688239 & 4.6862 & 5.4124 & TST \\
\hline CHEMBL1422397 & 688239 & 6.0 & 5.3834 & TRN \\
\hline CHEMBL1473838 & 688239 & 4.5362 & 5.4311 & TRN \\
\hline CHEMBL1357907 & 688239 & 4.5362 & 5.5029 & TRN \\
\hline CHEMBL1404933 & 688239 & 4.6862 & 5.5957 & TRN \\
\hline CHEMBL1550723 & 688239 & 4.7362 & 5.4937 & TRN \\
\hline CHEMBL1590307 & 688239 & 6.1862 & 5.4458 & TRN \\
\hline CHEMBL1314752 & 688239 & 5.1862 & 5.4675 & TRN \\
\hline CHEMBL1521444 & 688239 & 5.6862 & 5.7182 & TRN \\
\hline CHEMBL1561665 & 688239 & 4.5862 & 5.4813 & TRN \\
\hline CHEMBL1406896 & 688239 & 5.1862 & 5.428999 & 9999999999 \\
\hline CHEMBL1403108 & 688239 & 6.0362 & 5.4462 & TRN \\
\hline CHEMBL1589232 & 688239 & 5.4362 & 5.3655 & TST \\
\hline CHEMBL1510497 & 688239 & 4.5362 & 5.3673 & TRN \\
\hline CHEMBL1343191 & 688239 & 4.6362 & 5.6034 & TRN \\
\hline CHEMBL1479014 & 688239 & 5.1862 & 5.4514 & TRN \\
\hline CHEMBL1486682 & 688239 & 4.6362 & 5.3644 & TRN \\
\hline CHEMBL1564582 & 688239 & 4.8862 & 5.4121 & TST \\
\hline CHEMBL1380625 & 688239 & 5.1362 & 5.4799 & TRN \\
\hline CHEMBL1336346 & 688239 & 4.9362 & 5.5135 & TRN \\
\hline CHEMBL1307766 & 688239 & 5.5362 & 5.5066 & TRN \\
\hline
\end{tabular}




\begin{tabular}{|c|c|c|c|c|c|c|}
\hline \multirow{3}{*}{$\begin{array}{l}\text { CHEMBL1595650 } \\
\text { CHFMBI } 1519843\end{array}$} & & \multicolumn{5}{|c|}{ Supplemental Table S2.txt } \\
\hline & 688239 & 5.3862 & \multicolumn{3}{|c|}{5.672999999999999} & TRN \\
\hline & 688239 & 4.5362 & 5.4292 & TRN & & \\
\hline CHEMBL1498517 & 688239 & 4.7862 & 5.4821 & TRN & & \\
\hline CHEMBL1442165 & 688239 & 8.1871 & 5.3733 & TST & & \\
\hline CHEMBL1384377 & 688239 & 4.7362 & 5.419 & TRN & & \\
\hline CHEMBL1333466 & 688239 & 4.5362 & 5.5802 & TRN & & \\
\hline CHEMBL1448493 & 688239 & 4.8862 & 5.5501 & TRN & & \\
\hline CHEMBL1448256 & 688239 & 6.8362 & 5.5099 & TRN & & \\
\hline CHEMBL1472321 & 688239 & 4.5862 & 5.341 & TRN & & \\
\hline CHEMBL1391645 & 688239 & 4.8362 & 5.4097 & TRN & & \\
\hline CHEMBL1507357 & 688239 & 5.2862 & 5.5022 & TRN & & \\
\hline CHEMBL1237007 & 688239 & 6.3362 & 5.4312 & TRN & & \\
\hline CHEMBL1572639 & 688239 & 4.5362 & 5.5897 & TRN & & \\
\hline CHEMBL1586678 & 688239 & 5.3862 & 5.5251 & TRN & & \\
\hline CHEMBL1515928 & 688239 & 6.7361 & 5.61799 & 9999999999 & & TRN \\
\hline CHEMBL1517316 & 688239 & 4.5362 & 5.4403 & TRN & & \\
\hline CHEMBL1317132 & 688239 & 6.9363 & 5.4298 & TRN & & \\
\hline CHEMBL1438919 & 688239 & 5.1862 & 5.4184 & TRN & & \\
\hline CHEMBL1565045 & 688239 & 5.1862 & 5.5324 & TRN & & \\
\hline CHEMBL1397126 & 688239 & 4.6362 & 5.4194 & TRN & & \\
\hline CHEMBL1418741 & 688239 & 4.9862 & 5.5069 & TRN & & \\
\hline CHEMBL1334092 & 688239 & 4.4862 & 5.3151 & TRN & & \\
\hline CHEMBL1387459 & 688239 & 6.9863 & 5.3162 & TRN & & \\
\hline CHEMBL1381682 & 688239 & 8.28399 & 99999999 & & 5.4531 & TRN \\
\hline CHEMBL1586942 & 688239 & 5.4362 & 5.4867 & TRN & & \\
\hline CHEMBL1361711 & 688239 & 5.8362 & 5.4984 & TRN & & \\
\hline CHEMBL1551304 & 688239 & 6.2862 & 5.4429 & TRN & & \\
\hline CHEMBL1485471 & 688239 & 7.0362 & 5.5288 & TRN & & \\
\hline CHEMBL1602446 & 688239 & 4.7362 & 5.4117 & TRN & & \\
\hline CHEMBL3210269 & 688239 & 4.5362 & 5.4384 & TRN & & \\
\hline CHEMBL1522275 & 688239 & 5.1362 & 5.4852 & TST & & \\
\hline CHEMBL1599243 & 688239 & 4.8362 & 5.3971 & TRN & & \\
\hline CHEMBL3192376 & 688239 & 5.6362 & 5.5703 & TRN & & \\
\hline CHEMBL1531348 & 688239 & 6.4362 & 5.4776 & TST & & \\
\hline CHEMBL1596852 & 688239 & 5.6862 & 5.4603 & TRN & & \\
\hline CHEMBL1413291 & 688239 & 4.5362 & 5.4166 & TRN & & \\
\hline CHEMBL1447246 & 688239 & 4.5362 & 5.3548 & TRN & & \\
\hline CHEMBL1425429 & 688239 & 6.9363 & 5.6869 & TRN & & \\
\hline CHEMBL1496066 & 688239 & 5.3862 & 5.4515 & TRN & & \\
\hline CHEMBL 259515 & 688239 & 6.5363 & 5.584 & TRN & & \\
\hline CHEMBL1363804 & 688239 & 5.9362 & 5.3887 & TRN & & \\
\hline CHEMBL1329224 & 688239 & 6.2362 & 5.6953 & TST & & \\
\hline CHEMBL1537777 & 688239 & 5.1862 & 5.6315 & TRN & & \\
\hline CHEMBL1522551 & 688239 & 5.1862 & 5.6177 & TRN & & \\
\hline CHEMBL1421282 & 688239 & 5.2362 & 5.4071 & TRN & & \\
\hline CHEMBL1342208 & 688239 & 5.1362 & 5.46899 & 9999999999 & & TRN \\
\hline CHEMBL1599974 & 688239 & 4.7362 & 5.4657 & TRN & & \\
\hline CHEMBL1534166 & 688239 & 5.1 & 5.5618 & TRN & & \\
\hline
\end{tabular}


Supplemental Table S2.txt

\begin{tabular}{|c|c|c|c|c|}
\hline CHEMBL1366860 & 688239 & 5.8362 & 5.6111 & TRN \\
\hline CHEMBL1535878 & 688239 & 6.8362 & 5.5652 & TRN \\
\hline CHEMBL1499746 & 688239 & 4.5362 & 5.5446 & TRN \\
\hline CHEMBL1506639 & 688239 & 4.5362 & 5.473 & TRN \\
\hline CHEMBL1588838 & 688239 & 4.7362 & 5.5984 & TRN \\
\hline CHEMBL1521304 & 688239 & 5.3362 & 5.4616 & TRN \\
\hline CHEMBL1439534 & 688239 & 6.9863 & 5.4259 & TRN \\
\hline CHEMBL1568737 & 688239 & 4.7362 & 5.4648 & TRN \\
\hline CHEMBL1570582 & 688239 & 4.5362 & 5.4743 & TRN \\
\hline CHEMBL1421864 & 688239 & 5.3362 & 5.5936 & TST \\
\hline CHEMBL1525358 & 688239 & 5.2862 & 5.5336 & TRN \\
\hline CHEMBL1464247 & 688239 & 4.6362 & 5.3809 & TRN \\
\hline CHEMBL1419916 & 688239 & 4.5362 & 5.5766 & TRN \\
\hline CHEMBL1493120 & 688239 & 4.5362 & 5.4743 & TRN \\
\hline CHEMBL1554275 & 688239 & 5.5862 & 5.4942 & TST \\
\hline CHEMBL1590401 & 688239 & 5.5862 & 5.4845 & TRN \\
\hline CHEMBL1334907 & 688239 & 4.4862 & 5.5096 & TRN \\
\hline CHEMBL1453262 & 688239 & 6.1362 & 5.4039 & TRN \\
\hline CHEMBL1410129 & 688239 & 5.1362 & 5.4821 & TRN \\
\hline CHEMBL3194385 & 688239 & 4.4862 & 5.4476 & TRN \\
\hline CHEMBL1420789 & 688239 & 6.3362 & 5.5308 & TRN \\
\hline CHEMBL1401825 & 688239 & 6.8861 & 5.6605 & TRN \\
\hline CHEMBL1324935 & 688239 & 5.3862 & 5.4848 & TRN \\
\hline CHEMBL1370087 & 688239 & 5.1362 & 5.4873 & TRN \\
\hline CHEMBL1384209 & 688239 & 4.5362 & 5.3014 & TRN \\
\hline CHEMBL1316670 & 688239 & 5.1362 & 5.4035 & TST \\
\hline CHEMBL1363976 & 688239 & 5.3862 & 5.4887 & TRN \\
\hline CHEMBL3207683 & 688239 & 5.1862 & 5.4729 & TRN \\
\hline CHEMBL1583220 & 688239 & 5.8362 & 5.4653 & TRN \\
\hline CHEMBL1541813 & 688239 & 4.6362 & 5.5023 & TST \\
\hline CHEMBL1478206 & 688239 & 5.1862 & 5.4628 & TRN \\
\hline CHEMBL1355812 & 688239 & 6.8362 & 5.4913 & TRN \\
\hline CHEMBL1485466 & 688239 & 5.6862 & 5.5482 & TRN \\
\hline CHEMBL1461163 & 688239 & 6.3863 & 5.5501 & TRN \\
\hline CHEMBL1592786 & 688239 & 6.1362 & 5.4252 & TST \\
\hline CHEMBL1299920 & 688239 & 4.5362 & 5.6346 & TST \\
\hline CHEMBL1559722 & 688239 & 5.2862 & 5.4718 & TRN \\
\hline CHEMBL1346932 & 688239 & 4.7362 & 5.5326 & TST \\
\hline CHEMBL1423915 & 688239 & 4.7362 & 5.3664 & TRN \\
\hline CHEMBL1422838 & 688239 & 5.8862 & 5.4751 & TRN \\
\hline CHEMBL1583694 & 688239 & 4.8862 & 5.6268 & TRN \\
\hline CHEMBL1580548 & 688239 & 5.2862 & 5.3874 & TRN \\
\hline CHEMBL1366845 & 688239 & 4.8362 & 5.3246 & TRN \\
\hline CHEMBL1586703 & 688239 & 4.7362 & 5.5876 & TRN \\
\hline CHEMBL1349877 & 688239 & 5.6362 & \multicolumn{2}{|c|}{5.5360000000000005} \\
\hline CHEMBL1517807 & 688239 & 4.5362 & 5.4062 & TRN \\
\hline CHEMBL1600059 & 688239 & 6.3362 & 5.3545 & TRN \\
\hline CHEMBL1314703 & 688239 & 8.3372 & 5.3705 & TRN \\
\hline
\end{tabular}


Supplemental Table S2.txt

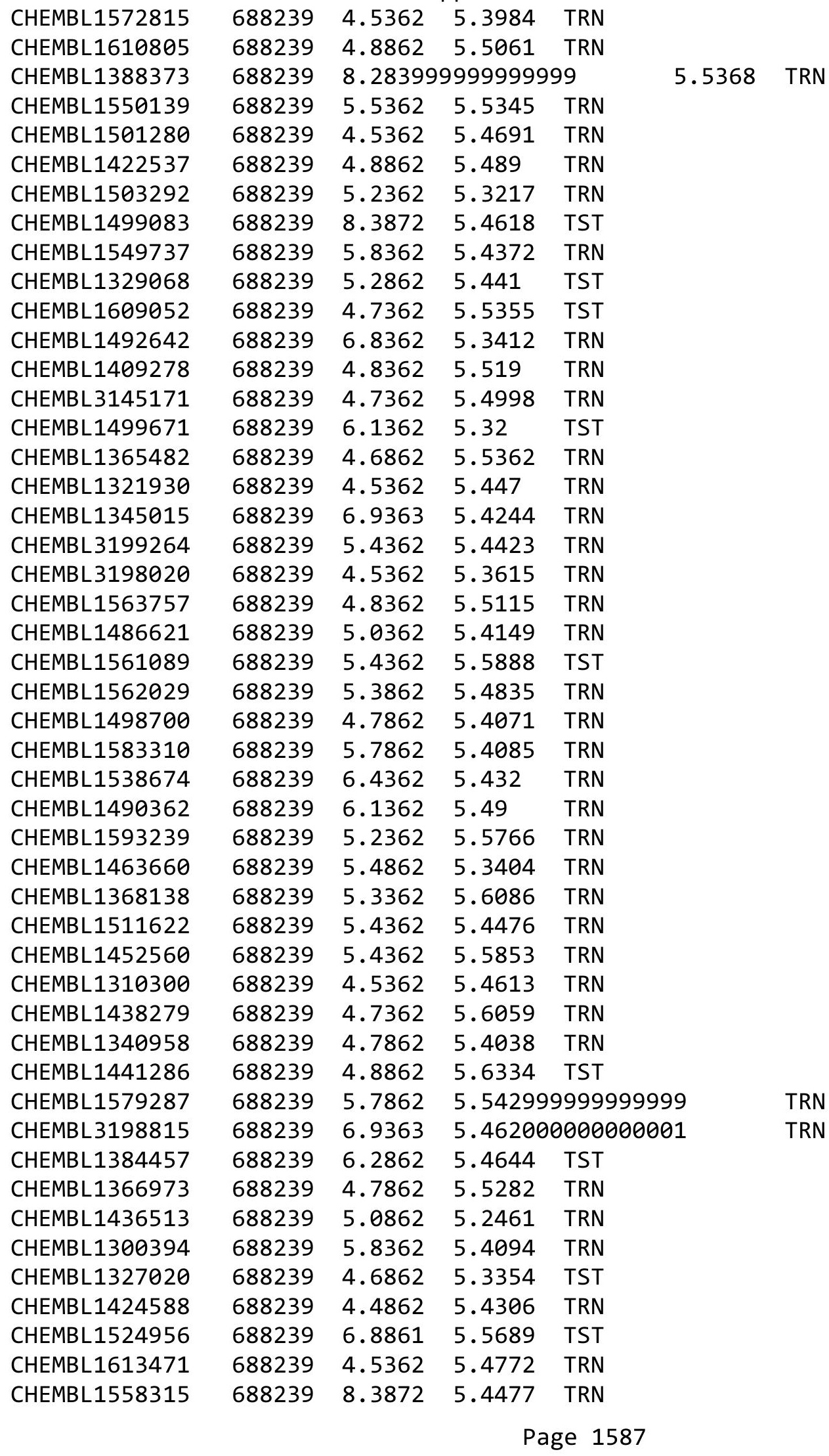


Supplemental Table S2.txt

\begin{tabular}{|c|c|c|c|c|}
\hline CHEMBL1448628 & 688239 & 4.7362 & 5.5934 & TRN \\
\hline CHEMBL1410970 & 688239 & 4.5362 & 5.4891 & TRN \\
\hline CHEMBL1354386 & 688239 & 5.3862 & 5.4256 & TRN \\
\hline CHEMBL1582592 & 688239 & 6.6362 & 5.542999 & 999999999 \\
\hline CHEMBL1329221 & 688239 & 5.8362 & 5.5313 & TRN \\
\hline CHEMBL1414177 & 688239 & 5.2862 & 5.4568 & TST \\
\hline CHEMBL1489373 & 688239 & 6.2362 & 5.5754 & TRN \\
\hline CHEMBL1349293 & 688239 & 4.5362 & 5.3714 & TST \\
\hline CHEMBL1426189 & 688239 & 5.0862 & 5.4098 & TRN \\
\hline CHEMBL1390359 & 688239 & 5.5362 & 5.5455 & TST \\
\hline CHEMBL1406587 & 688239 & 5.4362 & 5.4422 & TRN \\
\hline CHEMBL1546029 & 688239 & 5.2862 & 5.3718 & TRN \\
\hline CHEMBL1365575 & 688239 & 6.1862 & 5.4011 & TRN \\
\hline CHEMBL1610553 & 688239 & 4.5362 & 5.7262 & TRN \\
\hline CHEMBL1588500 & 688239 & 4.8362 & 5.343 & TRN \\
\hline CHEMBL1391517 & 688239 & 5.1862 & 5.5779 & TRN \\
\hline CHEMBL1577261 & 688239 & 5.0362 & 5.39 & TST \\
\hline CHEMBL1597561 & 688239 & 5.0362 & 5.4664 & TRN \\
\hline CHEMBL1414181 & 688239 & 7.1864 & 5.5362 & TRN \\
\hline CHEMBL1572005 & 688239 & 4.5862 & 5.5573 & TRN \\
\hline CHEMBL1417832 & 688239 & 4.5362 & 5.4341 & TRN \\
\hline CHEMBL1397953 & 688239 & 4.5362 & 5.4714 & TRN \\
\hline CHEMBL1378213 & 688239 & 6.0862 & 5.5975 & TRN \\
\hline CHEMBL1532786 & 688239 & 4.5862 & 5.5304 & TRN \\
\hline CHEMBL 3214205 & 688239 & 5.9862 & 5.3761 & TRN \\
\hline CHEMBL1517940 & 688239 & 4.6362 & 5.4399 & TRN \\
\hline CHEMBL1545149 & 688239 & 4.5362 & 5.4617 & TRN \\
\hline CHEMBL3199926 & 688239 & 4.5862 & 5.4268 & TRN \\
\hline CHEMBL1609302 & 688239 & 5.3862 & 5.3664 & TRN \\
\hline CHEMBL1503870 & 688239 & 6.1862 & 5.4126 & TST \\
\hline CHEMBL1045 & 688239 & 7.1864 & 5.5827 & TRN \\
\hline CHEMBL1557088 & 688239 & 5.3862 & 5.4846 & TRN \\
\hline CHEMBL1327325 & 688239 & 5.1862 & 5.5074 & TRN \\
\hline CHEMBL1589298 & 688239 & 6.9363 & 5.582000 & 000000001 \\
\hline CHEMBL1527310 & 688239 & 5.3362 & 5.4151 & TST \\
\hline CHEMBL1474842 & 688239 & 5.1862 & 5.5088 & TRN \\
\hline CHEMBL1589547 & 688239 & 6.5862 & 5.4283 & TRN \\
\hline CHEMBL1580851 & 688239 & 7.0362 & 5.5818 & TRN \\
\hline CHEMBL1552330 & 688239 & 4.5362 & 5.2569 & TRN \\
\hline CHEMBL1559459 & 688239 & 4.5862 & 5.3502 & TST \\
\hline CHEMBL1467225 & 688239 & 4.4862 & 5.6481 & TST \\
\hline CHEMBL1422508 & 688239 & 6.2362 & 5.4709 & TST \\
\hline CHEMBL1598400 & 688239 & 6.6362 & 5.3336 & TRN \\
\hline CHEMBL1367217 & 688239 & 5.9362 & 5.4657 & TRN \\
\hline CHEMBL1478702 & 688239 & 4.9362 & 5.5374 & TRN \\
\hline CHEMBL1412022 & 688239 & 5.2862 & 5.409 & TRN \\
\hline CHEMBL1553685 & 688239 & 4.5362 & 5.61 & TRN \\
\hline CHEMBL1361982 & 688239 & 5.8862 & 5.4094 & TST \\
\hline
\end{tabular}


Supplemental Table S2.txt

\begin{tabular}{|c|c|c|c|c|c|}
\hline CHEMBL1460985 & 688239 & 4.5362 & 5.5774 & TRN & \\
\hline CHEMBL1525410 & 688239 & 5.1862 & 5.5112 & TRN & \\
\hline CHEMBL1612604 & 688239 & 5.7362 & 5.432 & TRN & \\
\hline CHEMBL1414173 & 688239 & 4.9862 & 5.6075 & TRN & \\
\hline CHEMBL1559555 & 688239 & 4.6862 & 5.3709 & TRN & \\
\hline CHEMBL1517699 & 688239 & 4.6362 & 5.441 & TST & \\
\hline CHEMBL 1417878 & 688239 & 4.5362 & 5.6394 & TRN & \\
\hline CHEMBL1418810 & 688239 & 5.4362 & 5.5082 & TRN & \\
\hline CHEMBL1319546 & 688239 & 6.3362 & 5.4723 & TRN & \\
\hline CHEMBL1548294 & 688239 & 5.2362 & 5.3334 & TRN & \\
\hline CHEMBL 1608092 & 688239 & 4.7862 & 5.3726 & TST & \\
\hline CHEMBL1481300 & 688239 & 4.7362 & 5.4335 & TRN & \\
\hline CHEMBL1496071 & 688239 & 6.2362 & 5.5097 & TRN & \\
\hline CHEMBL 3197748 & 688239 & 5.8862 & 5.5103 & TRN & \\
\hline CHEMBL1432389 & 688239 & 4.5362 & 5.632999 & 9999999999 & TRN \\
\hline CHEMBL1508130 & 688239 & 4.6862 & 5.523 & TST & \\
\hline CHEMBL1520979 & 688239 & 5.1862 & 5.4992 & TRN & \\
\hline CHEMBL 3193947 & 688239 & 6.4362 & 5.365 & TRN & \\
\hline CHEMBL1536272 & 688239 & 4.5362 & 5.591 & TRN & \\
\hline CHEMBL1466808 & 688239 & 7.3363 & 5.5342 & TRN & \\
\hline CHEMBL1357927 & 688239 & 6.1862 & 5.4319 & TRN & \\
\hline CHEMBL1463270 & 688239 & 4.6862 & 5.5966 & TRN & \\
\hline CHEMBL1313436 & 688239 & 5.1862 & 5.4798 & TRN & \\
\hline CHEMBL1563604 & 688239 & 5.8362 & 5.3687 & TRN & \\
\hline CHEMBL1577439 & 688239 & 4.8362 & 5.5859 & TRN & \\
\hline CHEMBL 3189785 & 688239 & 4.6862 & 5.5521 & TRN & \\
\hline CHEMBL1456355 & 688239 & 5.5362 & 5.3925 & TST & \\
\hline CHEMBL1498502 & 688239 & 5.1362 & 5.3908 & TRN & \\
\hline CHEMBL1507256 & 688239 & 6.9863 & 5.461 & TRN & \\
\hline CHEMBL1389124 & 688239 & 5.1862 & 5.4217 & TRN & \\
\hline CHEMBL1417817 & 688239 & 4.9862 & 5.4027 & TRN & \\
\hline CHEMBL1594793 & 688239 & 5.2362 & 5.5579 & TRN & \\
\hline CHEMBL1467073 & 688239 & 6.8362 & 5.3924 & TST & \\
\hline CHEMBL1576310 & 688239 & 4.7862 & 5.3599 & TST & \\
\hline CHEMBL1585278 & 688239 & 5.7362 & 5.4287 & TST & \\
\hline CHEMBL1453005 & 688239 & 6.3362 & 5.5456 & TRN & \\
\hline CHEMBL1313765 & 688239 & 5.6862 & 5.422000 & 0000000001 & TST \\
\hline CHEMBL1534977 & 688239 & 8.28399 & 99999999 & & 5029999999999 . \\
\hline CHEMBL1422503 & 688239 & 4.8362 & 5.4637 & TRN & \\
\hline CHEMBL1326723 & 688239 & 4.8862 & 5.5521 & TRN & \\
\hline CHEMBL1372112 & 688239 & 4.7362 & 5.4197 & TRN & \\
\hline CHEMBL1567732 & 688239 & 4.5362 & 5.5422 & TST & \\
\hline CHEMBL1446329 & 688239 & 4.8362 & 5.407999 & 99999999995 & TRN \\
\hline CHEMBL1333413 & 688239 & 5.2862 & 5.5852 & TRN & \\
\hline CHEMBL1509734 & 688239 & 4.5362 & 5.4608 & TST & \\
\hline CHEMBL1350141 & 688239 & 6.7862 & 5.5174 & TRN & \\
\hline CHEMBL1317536 & 688239 & 4.4862 & 5.5001 & TRN & \\
\hline CHEMBL1345655 & 688239 & 7.7352 & 5.6928 & TRN & \\
\hline
\end{tabular}

TST 
Supplemental Table S2.txt

\begin{tabular}{|c|c|c|c|c|c|}
\hline CHEMBL1423025 & 688239 & 4.6862 & 5.5841 & TRN & \\
\hline CHEMBL1582494 & 688239 & 6.6362 & 5.4646 & TRN & \\
\hline CHEMBL1342279 & 688239 & 4.6862 & 5.4928 & TRN & \\
\hline CHEMBL1440699 & 688239 & 5.5862 & 5.6248 & TRN & \\
\hline CHEMBL1377183 & 688239 & 6.1362 & 5.4989 & TRN & \\
\hline CHEMBL1608103 & 688239 & 4.5362 & 5.5471 & TRN & \\
\hline CHEMBL 201152 & 688239 & 6.8861 & 5.4791 & TRN & \\
\hline CHEMBL1350541 & 688239 & 4.5862 & 5.494 & TST & \\
\hline CHEMBL1484662 & 688239 & 5.1862 & 5.4674 & TST & \\
\hline CHEMBL1300130 & 688239 & 4.7862 & 5.5934 & TST & \\
\hline CHEMBL1581477 & 688239 & 4.5362 & 5.4806 & TRN & \\
\hline CHEMBL1309483 & 688239 & 7.0862 & 5.4747 & TRN & \\
\hline CHEMBL1479694 & 688239 & 4.7362 & 5.619 & TRN & \\
\hline CHEMBL1577133 & 688239 & 5.5862 & 5.5509 & TST & \\
\hline CHEMBL1322094 & 688239 & 5.6862 & 5.4583 & TRN & \\
\hline CHEMBL1413673 & 688239 & 4.6362 & 5.4679 & TRN & \\
\hline CHEMBL1422993 & 688239 & 6.2362 & 5.4775 & TST & \\
\hline CHEMBL1379501 & 688239 & 5.4362 & 5.4745 & TRN & \\
\hline CHEMBL1331998 & 688239 & 5.3862 & 5.4271 & TRN & \\
\hline CHEMBL1409116 & 688239 & 5.1862 & 5.5701 & TRN & \\
\hline CHEMBL1448938 & 688239 & 6.2362 & 5.4253 & TRN & \\
\hline CHEMBL1367991 & 688239 & 5.9862 & 5.4294 & TST & \\
\hline CHEMBL1372234 & 688239 & 7.4868 & 5.4142 & TRN & \\
\hline CHEMBL1517413 & 688239 & 8.3372 & 5.5757 & TRN & \\
\hline CHEMBL1499487 & 688239 & 4.5362 & 5.3838 & TRN & \\
\hline CHEMBL1371888 & 688239 & 4.9862 & 5.5123 & TRN & \\
\hline CHEMBL1467078 & 688239 & 8.3872 & 5.357 & TST & \\
\hline CHEMBL1417310 & 688239 & 8.2366 & 5.5714 & TRN & \\
\hline CHEMBL1511375 & 688239 & 4.5362 & 5.4995 & TRN & \\
\hline CHEMBL1591549 & 688239 & 4.5362 & 5.5829 & TST & \\
\hline CHEMBL1609903 & 688239 & 7.0862 & 5.4296 & TST & \\
\hline CHEMBL1322326 & 688239 & 5.7862 & 5.5955 & TRN & \\
\hline CHEMBL1497076 & 688239 & 8.28399 & 99999999 & 99 & 5.5827 \\
\hline CHEMBL1429647 & 688239 & 6.2362 & 5.4923 & TRN & \\
\hline CHEMBL 287509 & 688239 & 6.5363 & 5.5306 & TST & \\
\hline CHEMBL1522801 & 688239 & 4.7862 & 5.375 & TRN & \\
\hline CHEMBL1565997 & 688239 & 5.5862 & 5.5228 & TRN & \\
\hline CHEMBL1496338 & 688239 & 4.6862 & 5.4083 & TRN & \\
\hline CHEMBL3199899 & 688239 & 4.6362 & 5.1805 & TST & \\
\hline CHEMBL1487042 & 688239 & 4.5362 & 5.6559 & TRN & \\
\hline CHEMBL1499230 & 688239 & 4.5362 & 5.4848 & TRN & \\
\hline CHEMBL1502763 & 688239 & 4.5362 & 5.5155 & TRN & \\
\hline CHEMBL1417128 & 688239 & 5.7362 & 5.5188 & TRN & \\
\hline CHEMBL1572869 & 688239 & 5.5862 & 5.4359 & TRN & \\
\hline CHEMBL3212368 & 688239 & 8.3372 & 5.4099 & TRN & \\
\hline CHEMBL1533639 & 688239 & 6.8362 & 5.5454 & TRN & \\
\hline CHEMBL1300222 & 688239 & 5.3362 & 5.3303 & TRN & \\
\hline CHEMBL1428461 & 688239 & 5.3362 & 5.6522 & TRN & \\
\hline
\end{tabular}


Supplemental Table S2.txt

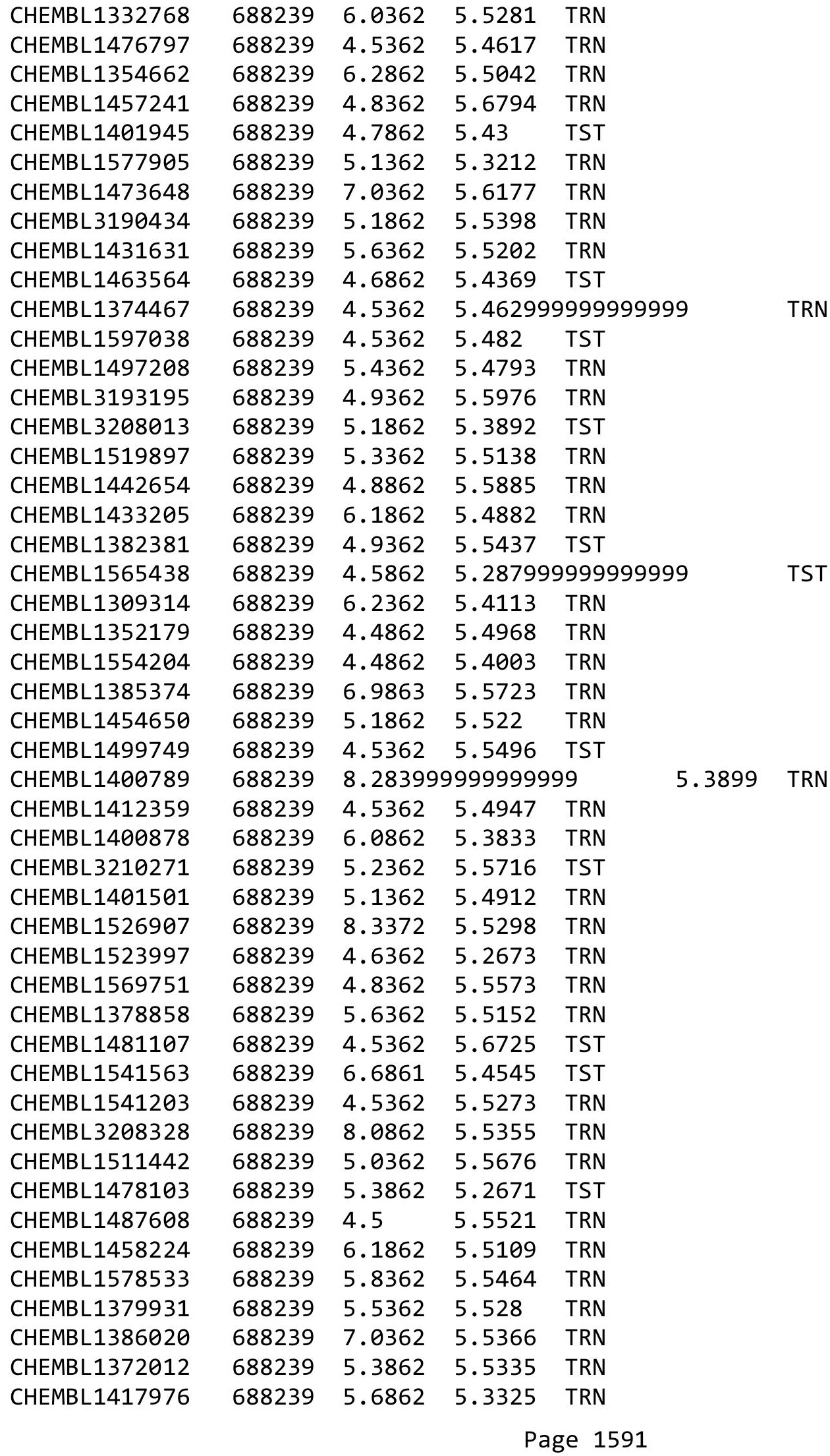


Supplemental Table S2.txt

\begin{tabular}{|c|c|c|c|c|c|}
\hline CHEMBL3194735 & 688239 & 4.7862 & 5.3599 & TST & \\
\hline CHEMBL1482029 & 688239 & 4.6862 & 5.4584 & TST & \\
\hline CHEMBL1480684 & 688239 & \multicolumn{3}{|c|}{8.283999999999999} & TRN \\
\hline CHEMBL1504554 & 688239 & 4.7362 & 5.3478 & TRN & \\
\hline CHEMBL1468056 & 688239 & 6.2362 & 5.6169 & TRN & \\
\hline CHEMBL1474071 & 688239 & 6.2362 & 5.4634 & TRN & \\
\hline CHEMBL1442490 & 688239 & 5.2862 & 5.5377 & TRN & \\
\hline CHEMBL1516308 & 688239 & 4.5362 & 5.2217 & TRN & \\
\hline CHEMBL1423881 & 688239 & 4.8362 & 5.5343 & TRN & \\
\hline CHEMBL1330430 & 688239 & 7.1864 & 5.5023 & TRN & \\
\hline CHEMBL1581948 & 688239 & 5.1362 & 5.5039 & TST & \\
\hline CHEMBL1333077 & 688239 & 5.8862 & 5.3271 & TST & \\
\hline CHEMBL1528619 & 688239 & 4.5862 & 5.3482 & TRN & \\
\hline CHEMBL1319510 & 688239 & 4.6362 & 5.5611 & TRN & \\
\hline CHEMBL1523058 & 688239 & 4.8362 & \multicolumn{2}{|c|}{5.537000000000001} & TRN \\
\hline CHEMBL1476438 & 688239 & 4.7362 & 5.5469 & TRN & \\
\hline CHEMBL1390259 & 688239 & 4.5362 & 5.5213 & TRN & \\
\hline CHEMBL1364979 & 688239 & 4.6362 & 5.3699 & TST & \\
\hline CHEMBL1422337 & 688239 & 5.5862 & 5.4512 & TRN & \\
\hline CHEMBL1478560 & 688239 & 4.5362 & 5.4877 & TST & \\
\hline CHEMBL1341474 & 688239 & 5.9862 & 5.6599 & TRN & \\
\hline CHEMBL1301537 & 688239 & 4.5362 & 5.5709 & TST & \\
\hline CHEMBL1539277 & 688239 & 4.5362 & 5.5642 & TRN & \\
\hline CHEMBL1405834 & 688239 & 5.9362 & 5.461 & TST & \\
\hline CHEMBL1591767 & 688239 & 4.9362 & 5.5119 & TRN & \\
\hline CHEMBL 1404500 & 688239 & 6.0862 & 5.5422 & TRN & \\
\hline CHEMBL1534390 & 688239 & 4.5362 & 5.42 & TST & \\
\hline CHEMBL1997659 & 688239 & 4.7862 & 5.4131 & TRN & \\
\hline CHEMBL1402279 & 688239 & 6.1862 & 5.5562 & TRN & \\
\hline CHEMBL1333288 & 688239 & 4.5362 & 5.829 & TRN & \\
\hline CHEMBL1597378 & 688239 & 4.5862 & 5.5181 & TRN & \\
\hline CHEMBL1464218 & 688239 & 4.8362 & 5.4798 & TST & \\
\hline CHEMBL1458688 & 688239 & 5.8862 & 5.5319 & TRN & \\
\hline CHEMBL1562656 & 688239 & 5.9862 & 5.4857 & TRN & \\
\hline CHEMBL1571635 & 688239 & 6.0 & 5.4453 & TRN & \\
\hline CHEMBL1561399 & 688239 & 6.8362 & 5.6032 & TRN & \\
\hline CHEMBL1469164 & 688239 & 5.8862 & 5.4823 & TRN & \\
\hline CHEMBL1576526 & 688239 & 4.5362 & 5.5287 & TST & \\
\hline CHEMBL1599793 & 688239 & 8.3372 & 5.5098 & TRN & \\
\hline CHEMBL1349228 & 688239 & 4.8362 & 5.5428 & TRN & \\
\hline CHEMBL1535514 & 688239 & 6.8861 & 5.7141 & TRN & \\
\hline CHEMBL3198986 & 688239 & 4.5362 & 5.3598 & TST & \\
\hline CHEMBL1437499 & 688239 & 5.2362 & 5.63299 & 9999999999 & TRN \\
\hline CHEMBL1386025 & 688239 & 5.1862 & 5.6652 & TRN & \\
\hline CHEMBL1596279 & 688239 & 4.5362 & 5.5256 & TRN & \\
\hline CHEMBL1386999 & 688239 & 5.1862 & 5.6951 & TRN & \\
\hline CHEMBL1567460 & 688239 & 5.1862 & 5.5548 & TST & \\
\hline \multirow[t]{2}{*}{ CHEMBL1595495 } & 688239 & 5.0362 & \multicolumn{2}{|c|}{5.492000000000001} & TRN \\
\hline & & & & ge 1592 & \\
\hline
\end{tabular}


Supplemental Table S2.txt

\begin{tabular}{|c|c|c|c|c|c|}
\hline CHEMBL1568331 & 688239 & 4.6862 & 5.5364 & TRN & \\
\hline CHEMBL1613107 & 688239 & 4.7362 & 5.4218 & TRN & \\
\hline CHEMBL1447734 & 688239 & 4.5362 & 5.5533 & TRN & \\
\hline CHEMBL1495919 & 688239 & 4.7862 & 5.4364 & TRN & \\
\hline CHEMBL1569360 & 688239 & 5.4862 & 5.5827 & TRN & \\
\hline CHEMBL1301262 & 688239 & 5.8862 & 5.5271 & TRN & \\
\hline CHEMBL1315077 & 688239 & 5.1862 & 5.4031 & TRN & \\
\hline CHEMBL1307172 & 688239 & 4.7862 & 5.4762 & TRN & \\
\hline CHEMBL1350006 & 688239 & 5.2862 & 5.6134 & TRN & \\
\hline CHEMBL1303418 & 688239 & 5.6862 & 5.5734 & TST & \\
\hline CHEMBL1387054 & 688239 & 5.4362 & 5.485 & TRN & \\
\hline CHEMBL1349655 & 688239 & 5.1862 & 5.4422 & TST & \\
\hline CHEMBL1562772 & 688239 & 4.6862 & 5.6169 & TRN & \\
\hline CHEMBL1563906 & 688239 & 6.7862 & 5.5301 & TRN & \\
\hline CHEMBL1515828 & 688239 & 4.9862 & 5.4796 & TRN & \\
\hline CHEMBL1551725 & 688239 & 7.6861 & 5.5373 & TRN & \\
\hline CHEMBL1301468 & 688239 & 4.8862 & 5.4595 & TST & \\
\hline CHEMBL1535912 & 688239 & 5.4362 & 5.5068 & TRN & \\
\hline CHEMBL1405327 & 688239 & 5.6862 & 5.5415 & TRN & \\
\hline CHEMBL1563415 & 688239 & 5.5362 & 5.3148 & TRN & \\
\hline CHEMBL1309193 & 688239 & 4.4862 & 5.4874 & TRN & \\
\hline CHEMBL3191693 & 688239 & 6.9863 & 5.5504 & TRN & \\
\hline CHEMBL1584174 & 688239 & 5.6862 & 5.2659 & TRN & \\
\hline CHEMBL 2004756 & 688239 & 4.7862 & 5.29799 & 9999999999 & TRN \\
\hline CHEMBL1330117 & 688239 & 5.9362 & 5.4134 & TRN & \\
\hline CHEMBL1522416 & 688239 & 5.1862 & 5.4492 & TRN & \\
\hline CHEMBL1424856 & 688239 & 4.5862 & 5.3834 & TRN & \\
\hline CHEMBL3210356 & 688239 & 5.6362 & 5.4717 & TST & \\
\hline CHEMBL1349416 & 688239 & 5.8862 & 5.5424 & TRN & \\
\hline CHEMBL1390098 & 688239 & 5.0862 & 5.6844 & TRN & \\
\hline CHEMBL1589654 & 688239 & 5.0862 & 5.5193 & TRN & \\
\hline CHEMBL1523379 & 688239 & 6.6861 & 5.468 & TRN & \\
\hline CHEMBL1442879 & 688239 & 4.5362 & 5.474 & TRN & \\
\hline CHEMBL1507726 & 688239 & 6.9363 & 5.4634 & TRN & \\
\hline CHEMBL1413033 & 688239 & 4.7862 & 5.3983 & TRN & \\
\hline CHEMBL1548051 & 688239 & 5.4362 & 5.4177 & TRN & \\
\hline CHEMBL1533281 & 688239 & 4.7362 & 5.5402 & TST & \\
\hline CHEMBL1459728 & 688239 & 4.5362 & 5.5317 & TRN & \\
\hline CHEMBL1574948 & 688239 & 4.8862 & 5.5148 & TRN & \\
\hline CHEMBL3214297 & 688239 & 5.1862 & 5.5884 & TRN & \\
\hline CHEMBL1303355 & 688239 & 6.0 & 5.5953 & TRN & \\
\hline CHEMBL1581305 & 688239 & 5.8362 & 5.5763 & TRN & \\
\hline CHEMBL1602323 & 688239 & 5.6862 & 5.532 & TRN & \\
\hline CHEMBL1362881 & 688239 & 4.5362 & 5.4258 & TRN & \\
\hline CHEMBL1579551 & 688239 & 5.5362 & 5.5253 & TRN & \\
\hline CHEMBL1546039 & 688239 & 6.8362 & 5.4539 & TST & \\
\hline CHEMBL1405577 & 688239 & 4.5362 & 5.3653 & TRN & \\
\hline CHEMBL1583720 & 688239 & 4.7362 & 5.5844 & TRN & \\
\hline
\end{tabular}


Supplemental Table S2.txt

\begin{tabular}{|c|c|c|c|c|}
\hline CHEMBL1474877 & 688239 & 5.5362 & 5.3979 & TRN \\
\hline CHEMBL1465234 & 688239 & 4.6862 & 5.6232 & TRN \\
\hline CHEMBL1510960 & 688239 & 4.8362 & 5.6294 & TRN \\
\hline CHEMBL1322522 & 688239 & 5.1362 & 5.4557 & TRN \\
\hline CHEMBL1428039 & 688239 & 4.6862 & 5.5713 & TRN \\
\hline CHEMBL1424019 & 688239 & 4.5862 & 5.5722 & TRN \\
\hline CHEMBL1366516 & 688239 & 4.7362 & 5.5764 & TST \\
\hline CHEMBL 3207578 & 688239 & 4.7862 & 5.4181 & TRN \\
\hline CHEMBL1598989 & 688239 & 6.9863 & 5.3216 & TST \\
\hline CHEMBL1608877 & 688239 & 4.5862 & 5.5926 & TRN \\
\hline CHEMBL1547552 & 688239 & 5.8862 & 5.4289 & TRN \\
\hline CHEMBL1559313 & 688239 & 5.6862 & 5.5378 & TRN \\
\hline CHEMBL1404743 & 688239 & 6.8362 & 5.566 & TST \\
\hline CHEMBL1459953 & 688239 & 8.283999 & 999999999 & 5.5815 \\
\hline CHEMBL1467906 & 688239 & 5.1862 & 5.4886 & TRN \\
\hline CHEMBL3196582 & 688239 & 5.7362 & 5.2911 & TRN \\
\hline CHEMBL578896 & 688239 & 5.4862 & 5.4733 & TRN \\
\hline CHEMBL1514191 & 688239 & 5.8862 & 5.675 & TRN \\
\hline CHEMBL1578539 & 688239 & 5.7862 & 5.5638 & TST \\
\hline CHEMBL1546326 & 688239 & 5.5362 & 5.5637 & TST \\
\hline CHEMBL1592062 & 688239 & 5.6362 & 5.4461 & TRN \\
\hline CHEMBL3208175 & 688239 & 6.3863 & 5.3614 & TRN \\
\hline CHEMBL1448023 & 688239 & 4.4862 & 5.5334 & TRN \\
\hline CHEMBL1527708 & 688239 & 7.2865 & 5.508999 & 9999999995 \\
\hline CHEMBL1564868 & 688239 & 4.7 & 5.5731 & TRN \\
\hline CHEMBL1418933 & 688239 & 6.1862 & 5.5639 & TRN \\
\hline CHEMBL1419367 & 688239 & 4.6862 & 5.5755 & TST \\
\hline CHEMBL1322115 & 688239 & 5.7362 & 5.6635 & TRN \\
\hline CHEMBL1310243 & 688239 & 4.5362 & 5.5747 & TST \\
\hline CHEMBL1564723 & 688239 & 6.0862 & 5.5578 & TRN \\
\hline CHEMBL1518806 & 688239 & 4.7362 & 5.6078 & TRN \\
\hline CHEMBL1313632 & 688239 & 6.1362 & 5.388999 & 999999999 \\
\hline CHEMBL1576066 & 688239 & 6.9363 & 5.582999 & 999999999 \\
\hline CHEMBL1513743 & 688239 & 5.8362 & 5.4635 & TRN \\
\hline CHEMBL1383795 & 688239 & 8.3372 & 5.297999 & 999999999 \\
\hline CHEMBL1380420 & 688239 & 4.9362 & 5.4197 & TRN \\
\hline CHEMBL1532366 & 688239 & 5.6362 & 5.5448 & TRN \\
\hline CHEMBL1472559 & 688239 & 5.5862 & 5.3456 & TRN \\
\hline CHEMBL3212347 & 688239 & 4.5362 & 5.6178 & TRN \\
\hline CHEMBL1488617 & 688239 & 4.7362 & 5.6281 & TRN \\
\hline CHEMBL1320050 & 688239 & 4.8862 & 5.4959 & TST \\
\hline CHEMBL1302759 & 688239 & 4.5362 & 5.4438 & TST \\
\hline CHEMBL1303572 & 688239 & 5.1862 & 5.476 & TRN \\
\hline CHEMBL1464834 & 688239 & 4.5362 & 5.2655 & TRN \\
\hline CHEMBL1557150 & 688239 & 4.7362 & 5.5529 & TRN \\
\hline CHEMBL1374340 & 688239 & 5.3362 & 5.3296 & TST \\
\hline CHEMBL1391081 & 688239 & 6.1862 & 5.5786 & TST \\
\hline CHEMBL1500610 & 688239 & 4.5362 & 5.4501 & TRN \\
\hline
\end{tabular}


Supplemental Table S2.txt

\begin{tabular}{|c|c|c|c|c|}
\hline 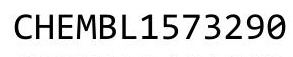 & & & & \\
\hline HEMBL1444949 & 38239 & 1862 & 4787 & \\
\hline AEMBL1332761 & 239 & 362 & 305 & \\
\hline EMBL1605520 & 39 & 362 & & \\
\hline EMBL483965 & 39 & 862 & & \\
\hline AEMBL1595311 & 88239 & 862 & & \\
\hline AEMBL3194217 & 88239 & 4.7862 & 546 & \\
\hline HEMBL1594847 & & 862 & & \\
\hline AEMBL1424063 & 39 & 362 & & \\
\hline IEMBL14C & & 362 & & \\
\hline AEMBL1525612 & 39 & 362 & 06 & \\
\hline HEMBL1496817 & & 362 & 992 & \\
\hline AEMBL1509018 & & 62 & & \\
\hline AEMBL15 & & 62 & & \\
\hline HEMBL15 & & & & \\
\hline AEMBL1608281 & & 362 & & \\
\hline AEMBL1410053 & & 363 & & \\
\hline AEMBL153 & & 62 & & \\
\hline AEMBL13. & & & & \\
\hline HEMBL 14 & & 362 & & \\
\hline AEMBL3194540 & & 862 & & \\
\hline AEMBL1523467 & & 862 & & \\
\hline AEMBL152 & & 62 & & \\
\hline AEMBL 131 & & 62 & & \\
\hline 914 & & 362 & & \\
\hline AEMBL1364179 & & 362 & & \\
\hline IEMBL1513655 & & & & \\
\hline EMBL14C & & 62 & & \\
\hline AEME & & & & \\
\hline (15M 1 & & 62 & & \\
\hline AEMBL3194703 & & & & \\
\hline HEMBL1368930 & & 62 & & \\
\hline & & & & \\
\hline 8 & & 52 & & \\
\hline & & & & \\
\hline AEMBL1568449 & & 362 & & \\
\hline AEMBL1308038 & & 362 & & \\
\hline 363305 & & 62 & & \\
\hline 5 & & & & \\
\hline HEMBL1352766 & & & & RN \\
\hline AEMBL1399624 & & 362 & & \\
\hline AEMBL130 & & 62 & & \\
\hline HEMBL1392375 & & & & \\
\hline HEMBL1371895 & & & & \\
\hline AEMBL1305901 & & & & ST \\
\hline MBL1502430 & & 862 & & TR \\
\hline 2 & & & & \\
\hline ס & & & & \\
\hline
\end{tabular}

Page 1595 
Supplemental Table S2.txt

\begin{tabular}{|c|c|c|c|c|}
\hline 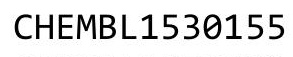 & & & & \\
\hline HEMBL1576422 & 38239 & 362 & 6 & \\
\hline AEMBL1415899 & 239 & 362 & 791 & \\
\hline & 39 & 362 & & \\
\hline IEMBL1330737 & 39 & 862 & & \\
\hline AEMBL1370296 & 88239 & 362 & 61 & \\
\hline AEMBL1318814 & 88239 & 6.1862 & 1005 & \\
\hline AEMBL1508059 & & 862 & & \\
\hline IEMBL1453622 & 39 & 362 & & \\
\hline IEMBL1586549 & & 862 & & \\
\hline AEMBL1365680 & 39 & 362 & 6 & \\
\hline AEMBL1458548 & 39 & 862 & & \\
\hline AEMBL1516201 & & 362 & & \\
\hline AEMBL141C & & 62 & & \\
\hline AEMBL1524 & & & & \\
\hline AEMBL1424917 & & 362 & & \\
\hline AEMBL3208233 & & 862 & & \\
\hline AEMBL13551 & & 52 & & \\
\hline AEMBL15773 & & & & \\
\hline AEMBL1422 & & & & \\
\hline AEMBL1321734 & & 862 & & \\
\hline AEMBL1478582 & & 362 & & \\
\hline IEMBL1469] & & & & \\
\hline AEMBL 136 & & & & \\
\hline 57 & & & & \\
\hline AEMBL1531576 & & 362 & & \\
\hline IEMBL1386014 & & 62 & & \\
\hline EMBL15821 & & 61 & & \\
\hline AFMRI 153 & & 52 & & \\
\hline F $15 M$ & & 62 & & \\
\hline AEMBL14998 & & & & \\
\hline HEMBL1487481 & & 362 & & \\
\hline & & 62 & & \\
\hline 9 & & 52 & & \\
\hline & & & & \\
\hline AEMBL1501241 & & 362 & & \\
\hline AEMBL1303153 & & 862 & & \\
\hline$\theta$ & & & & \\
\hline קת & & & & \\
\hline HEMBL1390366 & & & & RN \\
\hline AEMBL1581261 & & 362 & & \\
\hline AEMBL1361956 & & 362 & & \\
\hline S & & & & \\
\hline HEMBL1478319 & & & & \\
\hline AEMBL1509293 & & & & RN \\
\hline IEMBL1420e & & 362 & 09 & \\
\hline 1 & & & & \\
\hline HEMBL130953 & & & & \\
\hline
\end{tabular}

Page 1596 
Supplemental Table S2.txt

\begin{tabular}{|c|c|c|c|c|}
\hline CHEMBL1458672 & 688239 & 4.7862 & 5.4593 & TST \\
\hline CHEMBL1302258 & 688239 & 4.8362 & 5.5479 & TRN \\
\hline CHEMBL1420034 & 688239 & 4.5362 & 5.4486 & TRN \\
\hline CHEMBL1403707 & 688239 & 6.1862 & 5.3805 & TST \\
\hline CHEMBL1486192 & 688239 & 5.1862 & 5.5169 & TRN \\
\hline CHEMBL1583578 & 688239 & 5.5862 & 5.7348 & TRN \\
\hline CHEMBL1517360 & 688239 & 5.0862 & 5.4316 & TRN \\
\hline CHEMBL1583081 & 688239 & 6.8861 & 5.5494 & TRN \\
\hline CHEMBL1504815 & 688239 & 6.9863 & 5.4577 & TRN \\
\hline CHEMBL1395867 & 688239 & 5.9362 & 5.4267 & TRN \\
\hline CHEMBL1469503 & 688239 & 6.3863 & 5.3331 & TRN \\
\hline CHEMBL1457243 & 688239 & 6.2862 & 5.4918 & TST \\
\hline CHEMBL1379298 & 688239 & 4.6362 & 5.5971 & TRN \\
\hline CHEMBL1336197 & 688239 & 5.0362 & 5.3512 & TST \\
\hline CHEMBL1477441 & 688239 & 4.6862 & 5.4285 & TRN \\
\hline CHEMBL1336691 & 688239 & 5.6862 & 5.5422 & TRN \\
\hline CHEMBL547974 & 688239 & 6.9363 & 5.3332 & TST \\
\hline CHEMBL1325506 & 688239 & 5.2362 & 5.5138 & TST \\
\hline CHEMBL1337818 & 688239 & 5.1862 & 5.5192 & TRN \\
\hline CHEMBL392680 & 688239 & 4.5362 & 5.4558 & TST \\
\hline CHEMBL1385148 & 688239 & 6.0362 & 5.5918 & TST \\
\hline CHEMBL1339125 & 688239 & 4.5362 & 5.4145 & TRN \\
\hline CHEMBL399506 & 688239 & 5.0862 & 5.6542 & TRN \\
\hline CHEMBL1324890 & 688239 & 5.8862 & 5.5789 & TRN \\
\hline CHEMBL1307917 & 688239 & 5.5362 & 5.4869 & TRN \\
\hline CHEMBL1391938 & 688239 & 7.0362 & 5.4739 & TRN \\
\hline CHEMBL1430237 & 688239 & 7.6861 & 5.4219 & TRN \\
\hline CHEMBL1582032 & 688239 & 5.3862 & 5.4051 & TST \\
\hline CHEMBL1596038 & 688239 & 4.7862 & 5.4661 & TRN \\
\hline CHEMBL1551207 & 688239 & 5.9362 & 5.3077 & TRN \\
\hline CHEMBL1463799 & 688239 & 4.9362 & 5.4195 & TRN \\
\hline CHEMBL1387817 & 688239 & 4.4862 & 5.4702 & TST \\
\hline CHEMBL1347482 & 688239 & 6.1862 & 5.5869 & TRN \\
\hline CHEMBL1999548 & 688239 & 6.3362 & 5.3436 & TRN \\
\hline CHEMBL1472907 & 688239 & 5.6362 & 5.505 & TRN \\
\hline CHEMBL1318019 & 688239 & 5.4362 & 5.5625 & TRN \\
\hline CHEMBL1430247 & 688239 & 6.1362 & 5.65799 & 9999999995 \\
\hline CHEMBL1304287 & 688239 & 6.1362 & 5.4169 & TST \\
\hline CHEMBL1506978 & 688239 & 4.5362 & 5.4963 & TRN \\
\hline CHEMBL1394050 & 688239 & 6.9863 & 5.5026 & TRN \\
\hline CHEMBL1490215 & 688239 & 4.5362 & 5.4945 & TST \\
\hline CHEMBL1574982 & 688239 & 4.6862 & 5.4327 & TRN \\
\hline CHEMBL1313497 & 688239 & 5.0362 & 5.6141 & TST \\
\hline CHEMBL1607767 & 688239 & 4.8362 & 5.4164 & TST \\
\hline CHEMBL1608453 & 688239 & 6.7862 & 5.3655 & TRN \\
\hline CHEMBL 2369290 & 688239 & 5.1362 & 5.4033 & TRN \\
\hline CHEMBL1309427 & 688239 & 4.5362 & 5.5893 & TRN \\
\hline CHEMBL1433065 & 688239 & 6.8861 & 5.4085 & TRN \\
\hline
\end{tabular}

Page 1597 
Supplemental Table S2.txt

\begin{tabular}{|c|c|c|c|c|}
\hline CHEMBL1454434 & 688239 & 5.4862 & 5.4166 & TRN \\
\hline CHEMBL1971282 & 688239 & 5.4862 & 5.4018 & TRN \\
\hline CHEMBL1497404 & 688239 & 6.7361 & 5.4423 & TRN \\
\hline CHEMBL1507522 & 688239 & 4.6862 & 5.551 & TST \\
\hline CHEMBL1398194 & 688239 & 4.7362 & 5.4541 & TRN \\
\hline CHEMBL1385386 & 688239 & 4.5362 & 5.4327 & TRN \\
\hline CHEMBL1343797 & 688239 & 6.9863 & 5.4089 & TRN \\
\hline CHEMBL1584075 & 688239 & 6.9363 & 5.5467 & TRN \\
\hline CHEMBL1323685 & 688239 & 4.5362 & 5.6982 & TRN \\
\hline CHEMBL1363200 & 688239 & 4.7362 & $5.45100 €$ & 0000000005 \\
\hline CHEMBL1613255 & 688239 & 5.4362 & 5.5164 & TRN \\
\hline CHEMBL1524303 & 688239 & 4.5362 & 5.3762 & TST \\
\hline CHEMBL1377825 & 688239 & 4.7862 & 5.5819 & TRN \\
\hline CHEMBL1511245 & 688239 & 5.6862 & 5.7014 & TRN \\
\hline CHEMBL1516952 & 688239 & 4.7862 & 5.586 & TRN \\
\hline CHEMBL1344567 & 688239 & 4.7362 & 5.4469 & TST \\
\hline CHEMBL3212617 & 688239 & 4.9362 & 5.5022 & TRN \\
\hline CHEMBL1421010 & 688239 & 4.7362 & 5.3871 & TRN \\
\hline CHEMBL1561292 & 688239 & 5.8862 & 5.5409 & TRN \\
\hline CHEMBL1527582 & 688239 & 5.1862 & 5.5149 & TRN \\
\hline CHEMBL1565446 & 688239 & 4.7362 & 5.3983 & TRN \\
\hline CHEMBL1358418 & 688239 & 4.4862 & 5.4859 & TRN \\
\hline CHEMBL1442059 & 688239 & 5.0862 & 5.4536 & TRN \\
\hline CHEMBL1548701 & 688239 & 4.5862 & 5.5445 & TST \\
\hline CHEMBL1433483 & 688239 & 7.6861 & 5.4082 & TRN \\
\hline CHEMBL 244328 & 688239 & 4.5362 & 5.4498 & TRN \\
\hline CHEMBL1507322 & 688239 & 6.4862 & 5.4342 & TRN \\
\hline CHEMBL1591774 & 688239 & 5.9362 & 5.4995 & TRN \\
\hline CHEMBL1305945 & 688239 & 6.7862 & 5.4486 & TRN \\
\hline CHEMBL1504960 & 688239 & 8.3872 & 5.4634 & TST \\
\hline CHEMBL1426603 & 688239 & 5.1862 & 5.4812 & TST \\
\hline CHEMBL1335522 & 688239 & 5.2362 & 5.5205 & TST \\
\hline CHEMBL1442344 & 688239 & 5.1862 & 5.572 & TRN \\
\hline CHEMBL1530870 & 688239 & 6.4862 & 5.5775 & TST \\
\hline CHEMBL1382650 & 688239 & 5.1862 & 5.5955 & TST \\
\hline CHEMBL1366439 & 688239 & 5.1862 & 5.6498 & TST \\
\hline CHEMBL1481354 & 688239 & 5.1862 & 5.3819 & TST \\
\hline CHEMBL1573909 & 688239 & 6.2362 & 5.4967 & TRN \\
\hline CHEMBL1350749 & 688239 & 4.9362 & 5.3316 & TRN \\
\hline CHEMBL1309357 & 688239 & 6.8861 & 5.5811 & TRN \\
\hline CHEMBL1323854 & 688239 & 4.5362 & 5.4643 & TRN \\
\hline CHEMBL1490797 & 688239 & 5.6862 & 5.2728 & TST \\
\hline CHEMBL1437647 & 688239 & 5.1862 & 5.4405 & TRN \\
\hline CHEMBL1330140 & 688239 & 4.5362 & 5.3865 & TRN \\
\hline CHEMBL389130 & 688239 & 4.7362 & 5.5848 & TRN \\
\hline CHEMBL1546429 & 688239 & 5.7862 & 5.7011 & TRN \\
\hline CHEMBL1538271 & 688239 & 5.1862 & 5.4929 & TRN \\
\hline CHEMBL1515940 & 688239 & 4.4862 & 5.4091 & TRN \\
\hline
\end{tabular}


Supplemental Table S2.txt

\begin{tabular}{|c|c|c|c|c|}
\hline CHEMBL1466861 & 688239 & 5.1862 & 5.5007 & TRN \\
\hline CHEMBL1585043 & 688239 & 8.3372 & 5.2658 & TRN \\
\hline CHEMBL1553104 & 688239 & 6.2862 & 5.4938 & TRN \\
\hline CHEMBL1588798 & 688239 & 5.7362 & 5.4539 & TRN \\
\hline CHEMBL1602077 & 688239 & 5.1862 & 5.3512 & TST \\
\hline CHEMBL1361713 & 688239 & 5.1862 & 5.5859 & TRN \\
\hline CHEMBL1554792 & 688239 & 4.5862 & 5.66799 & 9999999999 \\
\hline CHEMBL1413643 & 688239 & 4.8862 & 5.4463 & TRN \\
\hline CHEMBL1439141 & 688239 & 7.9872 & 5.3748 & TST \\
\hline CHEMBL1447172 & 688239 & 6.1862 & 5.4517 & TRN \\
\hline CHEMBL251172 & 688239 & 4.7362 & 5.6065 & TRN \\
\hline CHEMBL1349898 & 688239 & 4.5362 & 5.4026 & TRN \\
\hline CHEMBL1304595 & 688239 & 5.1862 & 5.4959 & TRN \\
\hline CHEMBL1487016 & 688239 & 6.3362 & 5.5755 & TRN \\
\hline CHEMBL492116 & 688239 & 4.5362 & 5.5345 & TRN \\
\hline CHEMBL1345616 & 688239 & 4.5362 & 5.4079 & TRN \\
\hline CHEMBL1473177 & 688239 & 5.3862 & 5.596 & TRN \\
\hline CHEMBL1970371 & 688239 & 5.8362 & 5.1907 & TST \\
\hline CHEMBL1511893 & 688239 & 5.0362 & 5.43 & TRN \\
\hline CHEMBL1566466 & 688239 & 4.5362 & 5.5855 & TRN \\
\hline CHEMBL1440413 & 688239 & 5.3362 & 5.4478 & TRN \\
\hline CHEMBL1609898 & 688239 & 6.2862 & 5.4639 & TST \\
\hline CHEMBL 2000655 & 688239 & 4.7362 & 5.4716 & TRN \\
\hline CHEMBL1423980 & 688239 & 4.5362 & 5.5276 & TRN \\
\hline CHEMBL1445594 & 688239 & 5.4862 & 5.4993 & TST \\
\hline CHEMBL1517929 & 688239 & 4.5362 & 5.3606 & TRN \\
\hline CHEMBL1424129 & 688239 & 4.5862 & 5.5885 & TST \\
\hline CHEMBL1389962 & 688239 & 4.5362 & 5.5394 & TST \\
\hline CHEMBL1312377 & 688239 & 4.6862 & 5.5157 & TST \\
\hline CHEMBL1415972 & 688239 & 6.2362 & 5.5617 & TRN \\
\hline CHEMBL174487 & 688239 & 6.2862 & 5.5561 & TRN \\
\hline CHEMBL1305720 & 688239 & 5.0362 & 5.5333 & TRN \\
\hline CHEMBL1405673 & 688239 & 5.1862 & 5.4488 & TRN \\
\hline CHEMBL1570319 & 688239 & 5.0362 & 5.3784 & TRN \\
\hline CHEMBL3197134 & 688239 & 4.4862 & 5.4264 & TST \\
\hline CHEMBL1307086 & 688239 & 4.7362 & 5.3737 & TST \\
\hline CHEMBL3192934 & 688239 & 6.1362 & 5.3308 & TRN \\
\hline CHEMBL1474550 & 688239 & 6.2362 & 5.3327 & TRN \\
\hline CHEMBL1349028 & 688239 & 4.8862 & 5.5867 & TRN \\
\hline CHEMBL1383494 & 688239 & 4.4862 & 5.4699 & TRN \\
\hline CHEMBL1483627 & 688239 & 4.5362 & 5.4795 & TRN \\
\hline CHEMBL1364768 & 688239 & 5.7862 & 5.5578 & TRN \\
\hline CHEMBL1425757 & 688239 & 5.5362 & 5.4556 & TST \\
\hline CHEMBL1547269 & 688239 & 5.1862 & 5.3337 & TRN \\
\hline CHEMBL1514128 & 688239 & 4.8862 & 5.3873 & TRN \\
\hline CHEMBL1455818 & 688239 & 4.8362 & \multicolumn{2}{|c|}{5.513999999999999} \\
\hline CHEMBL1606934 & 688239 & 5.0362 & 5.4896 & TRN \\
\hline CHEMBL1362393 & 688239 & 4.5362 & 5.4827 & TRN \\
\hline
\end{tabular}


Supplemental Table S2.txt

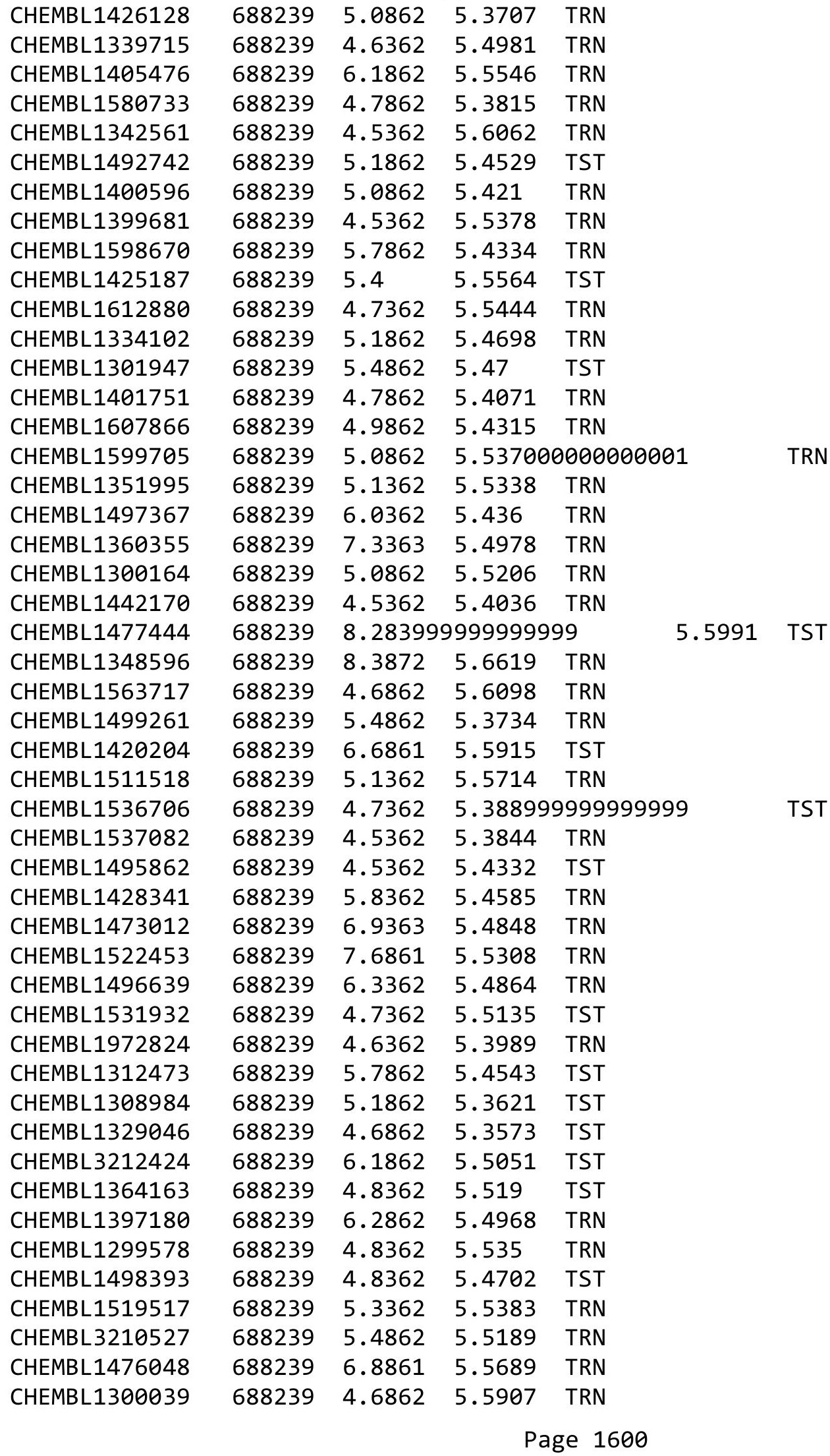


Supplemental Table S2.txt

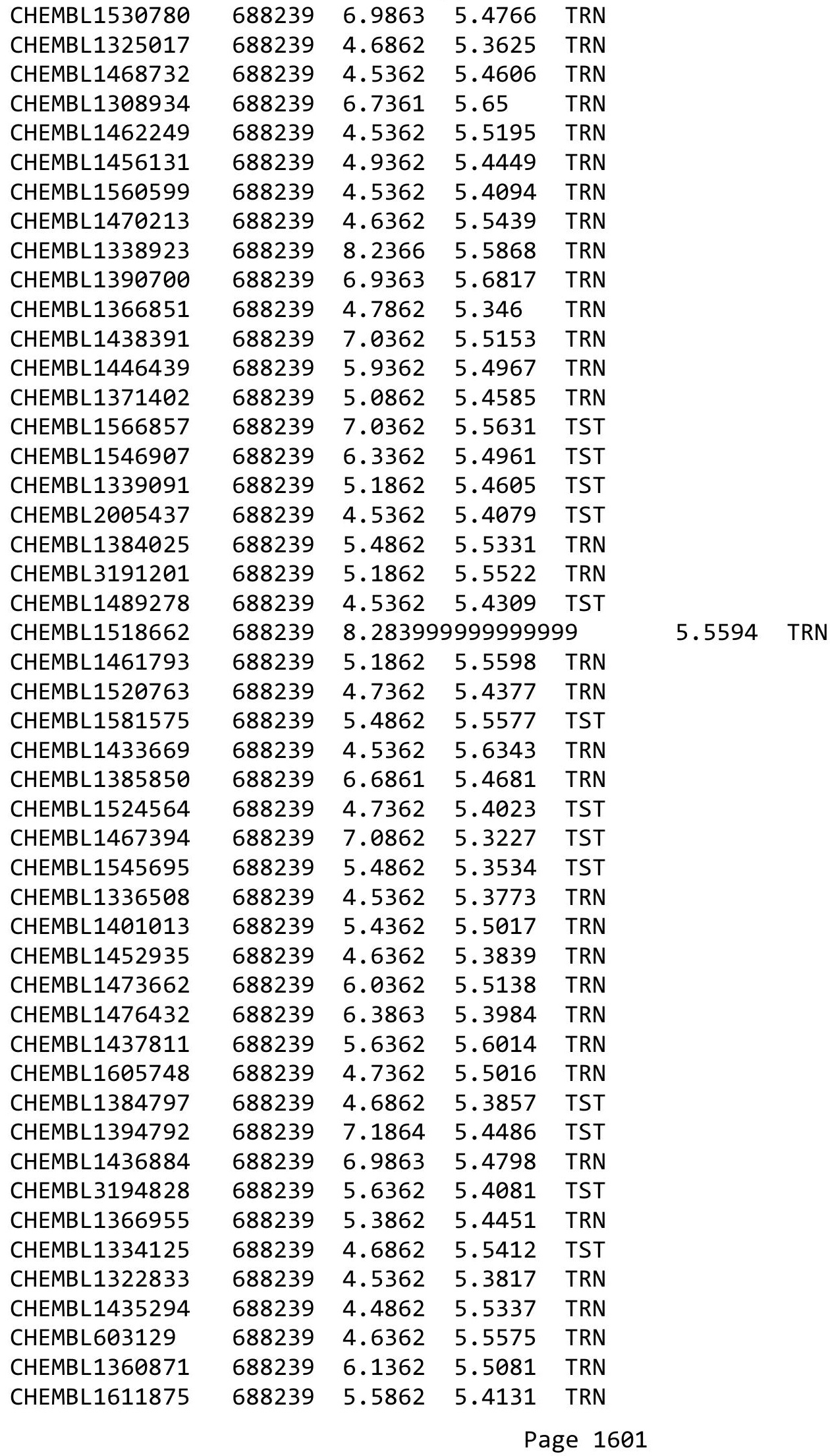


Supplemental Table S2.txt

\begin{tabular}{|c|c|c|c|c|}
\hline IE & & 52 & 79 & TR \\
\hline ר 1 & 88239 & .7862 & 5.6083 & \\
\hline$I F M$ & & & & \\
\hline AEMBL13186 & & 62 & 75 & \\
\hline AEMBL3195626 & 38239 & 362 & 411 & \\
\hline HEMBL1583901 & 88239 & 0362 & 3928 & \\
\hline HEMBL1359187 & 239 & 362 & & \\
\hline IEMBL1370 & & & & \\
\hline AEMBL14656 & 239 & 862 & & \\
\hline HEMBL3212666 & 88239 & 362 & & \\
\hline HEMBL1389016 & 239 & 362 & & \\
\hline IEMBL1 & 239 & 62 & & \\
\hline IEMBL3 & & & & \\
\hline AEMBL1559588 & & 363 & & \\
\hline AEMBL1547229 & & & & \\
\hline AEMBL1505 & 39 & 62 & & \\
\hline HEMBL1315 & & & & \\
\hline HEMBL144e & & & & \\
\hline AEMBL1473359 & & & & \\
\hline AEMBL158 & & & & RN \\
\hline AEMBL1608 & & & & \\
\hline HEMBL134 & & & & \\
\hline HEMBL140 & & & & \\
\hline AFMP 1515 & & & & \\
\hline AEMBL13687 & & & & KIV \\
\hline HEMBLI & & & & \\
\hline HEMBL1 & & & & 然 \\
\hline HFMBI 132 & & & & ST \\
\hline HEMBL1608 & & & & $\mathrm{RN}$ \\
\hline HEMBL1602905 & & & & RIN \\
\hline HEMBL15708 & & & & RN \\
\hline AFMBI 1 & & & & RIV \\
\hline 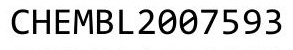 & & & & RN \\
\hline HEMBL1499182 & & & & RN \\
\hline HEMBL135177 & & & & RN \\
\hline HEMBL152782 & & & & \\
\hline HFMRI 1 & & & & RN \\
\hline HEMBL1 & & & & RN \\
\hline HEMBL1426075 & 88239 & & & $\mathrm{RN}$ \\
\hline AEMBL1421 & & & & ST \\
\hline HEMBL13270 & & & & \\
\hline CHEMBL14 & & & & RN \\
\hline HEMBL1497549 & & & 784 & RN \\
\hline AEMBL1428623 & 39 & 63 & 862 & RN \\
\hline EMBL1 & & & & \\
\hline HEMBL1542 & & & & \\
\hline LHEMBL1538436 & & & 5.4983 & \\
\hline HEMBL136167 & 688239 & 8.1871 & 5.4266 & \\
\hline
\end{tabular}

Page 1602 
Supplemental Table S2.txt

\begin{tabular}{|c|c|c|c|c|}
\hline 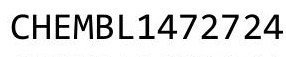 & & & & \\
\hline HEMBL1520004 & 88239 & 2362 & 027 & \\
\hline HEMBL1544715 & 88239 & 1862 & & \\
\hline 246 & & & & \\
\hline EMBL32 & & 862 & & \\
\hline HEMBL1532067 & 88239 & 362 & 4985 & \\
\hline HEMBL1546739 & 88239 & .5362 & .3706 & \\
\hline HEMBL3199870 & 39 & 861 & & \\
\hline IEMBL: & 39 & 862 & & \\
\hline IEMBL: & 39 & 362 & & \\
\hline HEMBL1520829 & 88239 & .5862 & & \\
\hline HEMBL1441160 & 39 & .2362 & & \\
\hline HEMBL1421207 & 39 & 862 & 45 & \\
\hline HEMBL13 & 39 & 862 & & \\
\hline HEMBL3] & 39 & 362 & & \\
\hline HEMBL1573362 & 39 & 862 & & \\
\hline HEMBL1491693 & 88 & 3362 & 23 & \\
\hline HEMBL15 & 39 & 363 & 96 & \\
\hline HEMBL15 & & & & \\
\hline HEMBL1 & 39 & 862 & & \\
\hline HEMBL1C & 39 & 862 & & \\
\hline HEMBL14 & 39 & 362 & 59 & RN \\
\hline HEMBL1C & 39 & 862 & & \\
\hline HEMBL1 & & 362 & & \\
\hline HEM & 39 & 362 & & ST \\
\hline HEMBL15 & 39 & 362 & & RN \\
\hline AEMBL15 & 39 & 362 & & SI \\
\hline HEMBL15 & 39 & 361 & & \\
\hline HEM & & & & ST \\
\hline HEME & & 61 & & RN \\
\hline HEMBL138 & 9 & & & RN \\
\hline HEMBL1572689 & 88 & 362 & & RN \\
\hline HEMBL13 & 39 & 362 & & . \\
\hline 1 & 9 & & & RN \\
\hline HEMBL13 & & & & RN \\
\hline HEMBL1412329 & 39 & 862 & & RN \\
\hline HEMBL1518221 & 39 & 862 & & RN \\
\hline HEMBL13 & 39 & 362 & & RIV \\
\hline 2 & & & & RN \\
\hline HEMBL13 & & & & RN \\
\hline HEMBL1300347 & 39 & 362 & & RN \\
\hline HEMBL13 & 39 & 362 & & RI \\
\hline HEMBL13 & & & & \\
\hline & & & & RN \\
\hline HEMBL1323913 & & 4.6862 & 5.7043 & RN \\
\hline HEMBL1304298 & 39 & 862 & & N \\
\hline 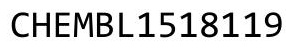 & & & & \\
\hline & & & & \\
\hline
\end{tabular}

Page 1603 
Supplemental Table S2.txt

\begin{tabular}{|c|c|c|c|c|c|c|}
\hline CHEMBL1443312 & 688239 & 4.6362 & 5.2353 & TST & & \\
\hline CHEMBL1449924 & 688239 & 7.8861 & 5.5639 & TRN & & \\
\hline CHEMBL1472107 & 688239 & 5.5362 & 5.4136 & TST & & \\
\hline CHEMBL1392294 & 688239 & 4.9862 & 5.4916 & TRN & & \\
\hline CHEMBL1364378 & 688239 & 8.28399 & 79999999 & & 5.553999999999999 & TRN \\
\hline CHEMBL1560993 & 688239 & 7.7852 & 5.5287 & TRN & & \\
\hline CHEMBL1532249 & 688239 & 6.2362 & 5.4589 & TRN & & \\
\hline CHEMBL1499938 & 688239 & 5.6362 & 5.3177 & TRN & & \\
\hline CHEMBL1361889 & 688239 & 4.7362 & 5.4624 & TST & & \\
\hline CHEMBL1516715 & 688239 & 5.4362 & 5.3156 & TST & & \\
\hline CHEMBL1549842 & 688239 & 4.6862 & 5.6096 & TRN & & \\
\hline CHEMBL1380037 & 688239 & 5.8362 & 5.5306 & TRN & & \\
\hline CHEMBL1396137 & 688239 & 6.1362 & 5.3896 & TRN & & \\
\hline CHEMBL1445928 & 688239 & 5.4362 & 5.4956 & TST & & \\
\hline CHEMBL1559864 & 688239 & 6.1862 & 5.5162 & TRN & & \\
\hline CHEMBL1351112 & 688239 & 8.28399 & 79999999 & & 5.2667 TST & \\
\hline CHEMBL1469999 & 688239 & 6.1362 & 5.6929 & TRN & & \\
\hline CHEMBL1401060 & 688239 & 6.2862 & 5.5079 & TRN & & \\
\hline CHEMBL1522958 & 688239 & 4.5362 & 5.4896 & TRN & & \\
\hline CHEMBL1464136 & 688239 & 5.5862 & 5.4552 & TRN & & \\
\hline CHEMBL1550926 & 688239 & 4.6862 & 5.2948 & TRN & & \\
\hline CHEMBL1383160 & 688239 & 5.7862 & 5.4778 & TST & & \\
\hline CHEMBL1316804 & 688239 & 5.1862 & 5.529 & TRN & & \\
\hline CHEMBL1444258 & 688239 & 4.9362 & 5.4959 & TRN & & \\
\hline CHEMBL3209039 & 688239 & 6.8362 & 5.4643 & TRN & & \\
\hline CHEMBL3194510 & 688239 & 4.7862 & 5.3852 & TRN & & \\
\hline CHEMBL1446924 & 688239 & 8.2366 & 5.3855 & TRN & & \\
\hline CHEMBL1303052 & 688239 & 5.3862 & 5.505 & TRN & & \\
\hline CHEMBL1521425 & 688239 & 4.6862 & 5.4315 & TRN & & \\
\hline CHEMBL1555593 & 688239 & 5.0862 & 5.3241 & TRN & & \\
\hline CHEMBL1409863 & 688239 & 4.6862 & 5.6071 & TRN & & \\
\hline CHEMBL1367866 & 688239 & 4.5862 & 5.401 & TRN & & \\
\hline CHEMBL1357462 & 688239 & 4.6862 & 5.5211 & TRN & & \\
\hline CHEMBL1452004 & 688239 & 4.5362 & 5.5281 & TRN & & \\
\hline CHEMBL1527569 & 688239 & 6.2362 & 5.4254 & TRN & & \\
\hline CHEMBL1572312 & 688239 & 4.8862 & 5.4915 & TRN & & \\
\hline CHEMBL1361556 & 688239 & 5.3862 & 5.5187 & TRN & & \\
\hline CHEMBL1558466 & 688239 & 6.1862 & 5.5179 & TST & & \\
\hline CHEMBL1393197 & 688239 & 4.4862 & 5.5238 & TRN & & \\
\hline CHEMBL1352133 & 688239 & 4.5362 & 5.6214 & TRN & & \\
\hline CHEMBL1460548 & 688239 & 5.3862 & 5.5554 & TST & & \\
\hline CHEMBL1456241 & 688239 & 5.0362 & 5.4758 & TST & & \\
\hline CHEMBL1361050 & 688239 & 4.5362 & 5.3719 & TST & & \\
\hline CHEMBL1417094 & 688239 & 5.1862 & 5.4299 & TRN & & \\
\hline CHEMBL1519496 & 688239 & 5.7862 & 5.6437 & TRN & & \\
\hline CHEMBL1573431 & 688239 & 6.9363 & 5.4324 & TRN & & \\
\hline CHEMBL1547119 & 688239 & 5.3362 & 5.4216 & TRN & & \\
\hline CHEMBL1504190 & 688239 & 5.3362 & 5.4718 & TST & & \\
\hline
\end{tabular}




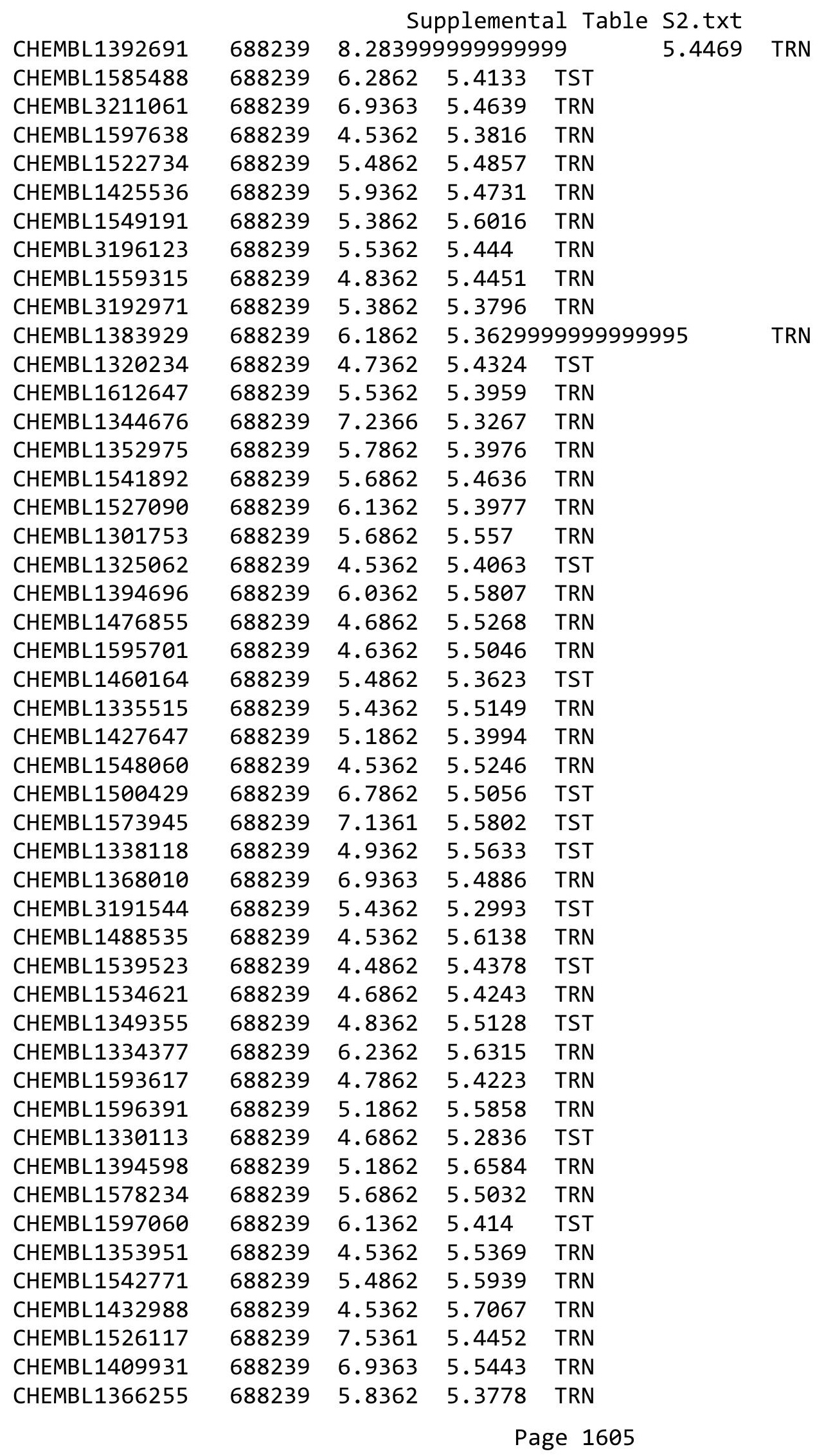


Supplemental Table S2.txt

\begin{tabular}{|c|c|c|c|c|c|}
\hline CHEMBL1340289 & 688239 & 5.7362 & 5.5016 & TRN & \\
\hline CHEMBL1976549 & 688239 & 5.0362 & 5.5453 & TRN & \\
\hline CHEMBL1487036 & 688239 & 5.7862 & 5.441 & TRN & \\
\hline CHEMBL1514932 & 688239 & 8.3372 & 5.6225 & TRN & \\
\hline CHEMBL1336332 & 688239 & 4.5362 & 5.463999 & 9999999995 & RN \\
\hline CHEMBL1505279 & 688239 & 6.1362 & 5.4106 & TRN & \\
\hline CHEMBL1417962 & 688239 & 5.6862 & 5.5503 & TRN & \\
\hline CHEMBL1563280 & 688239 & 6.3362 & 5.5314 & TRN & \\
\hline CHEMBL1551026 & 688239 & 5.2862 & 5.6234 & TRN & \\
\hline CHEMBL1597301 & 688239 & 4.5862 & 5.5283 & TRN & \\
\hline CHEMBL1480199 & 688239 & 6.9863 & 5.444 & TRN & \\
\hline CHEMBL1395442 & 688239 & 4.5362 & 5.5124 & TRN & \\
\hline CHEMBL1510091 & 688239 & 4.5362 & 5.5624 & TRN & \\
\hline CHEMBL1603772 & 688239 & 4.6862 & 5.6648 & TRN & \\
\hline CHEMBL1537703 & 688239 & 5.1862 & 5.6324 & TRN & \\
\hline CHEMBL1435388 & 688239 & 4.8362 & 5.4327 & TRN & \\
\hline CHEMBL1310203 & 688239 & 5.6862 & 5.5356 & TRN & \\
\hline CHEMBL1448198 & 688239 & 6.0 & 5.396 & TRN & \\
\hline CHEMBL1479899 & 688239 & 6.0362 & 5.5333 & TST & \\
\hline CHEMBL1507802 & 688239 & 6.8861 & 5.6458 & TST & \\
\hline CHEMBL1476029 & 688239 & 4.8362 & 5.3527 & TRN & \\
\hline CHEMBL1563457 & 688239 & 4.5362 & 5.4684 & TRN & \\
\hline CHEMBL1493174 & 688239 & 5.1862 & 5.4488 & TRN & \\
\hline CHEMBL1504313 & 688239 & 7.2366 & 5.4227 & TST & \\
\hline CHEMBL1427247 & 688239 & 5.1862 & 5.5634 & TRN & \\
\hline CHEMBL1364790 & 688239 & 4.5362 & 5.5054 & TST & \\
\hline CHEMBL1376190 & 688239 & 4.5862 & 5.4736 & TRN & \\
\hline CHEMBL1419909 & 688239 & 4.7362 & 5.4536 & TRN & \\
\hline CHEMBL1538110 & 688239 & 5.8862 & 5.48 & TRN & \\
\hline CHEMBL1364152 & 688239 & 4.9362 & 5.4744 & TRN & \\
\hline CHEMBL1332835 & 688239 & 5.4862 & 5.5794 & TRN & \\
\hline CHEMBL1391048 & 688239 & 4.6862 & 5.3786 & TST & \\
\hline CHEMBL1587116 & 688239 & 5.4862 & 5.4061 & TST & \\
\hline CHEMBL1336246 & 688239 & 8.3372 & 5.3655 & TRN & \\
\hline CHEMBL1480773 & 688239 & 4.9862 & 5.4656 & TRN & \\
\hline CHEMBL1566886 & 688239 & 5.7862 & 5.5701 & TST & \\
\hline CHEMBL1361628 & 688239 & 4.7362 & 5.3934 & TRN & \\
\hline CHEMBL1547187 & 688239 & 5.9362 & 5.4721 & TRN & \\
\hline CHEMBL1391297 & 688239 & 6.9363 & 5.4181 & TRN & \\
\hline CHEMBL1517717 & 688239 & 6.2862 & 5.4398 & TRN & \\
\hline CHEMBL1376173 & 688239 & \multicolumn{3}{|c|}{8.283999999999999} & $1 \mathrm{~m}$ \\
\hline CHEMBL1544550 & 688239 & 5.1862 & 5.444 & TRN & \\
\hline CHEMBL3209338 & 688239 & 4.6362 & 5.3808 & TST & \\
\hline CHEMBL1445020 & 688239 & 4.5362 & 5.5112 & TRN & \\
\hline CHEMBL1526269 & 688239 & 5.4362 & 5.5024 & TRN & \\
\hline CHEMBL1511160 & 688239 & 5.1862 & 5.6158 & TRN & \\
\hline CHEMBL1560321 & 688239 & 4.5362 & 5.6948 & TST & \\
\hline CHEMBL1413178 & 688239 & 5.2862 & 5.4213 & TST & \\
\hline
\end{tabular}


Supplemental Table S2.txt

\begin{tabular}{|c|c|c|c|c|}
\hline 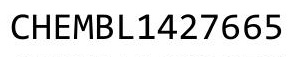 & & & & \\
\hline HEMBL1299978 & 88239 & 5862 & 468 & \\
\hline HEMBL1533092 & 88239 & 1862 & 5179 & \\
\hline IEMBL1 & & & 794 & \\
\hline EMBL13 & & 62 & 5183 & \\
\hline HEMBL1348687 & 88239 & 862 & 4207 & \\
\hline HEMBL 313163 & 88239 & .1361 & .4804 & \\
\hline HEMBL198 & 39 & 362 & 4863 & \\
\hline IEMBL196 & 39 & 362 & & \\
\hline IEMBL146 & 39 & 362 & 903 & \\
\hline HEMBL1593713 & 88239 & 362 & 5533 & \\
\hline HEMBL3196135 & 39 & 7862 & 39 & \\
\hline HEMBL1312300 & 39 & 862 & 4315 & \\
\hline HEMBL151 & 39 & & .5644 & \\
\hline HEMBL158 & 39 & & .5359 & \\
\hline HEMBL139 & 39 & 366 & 4634 & \\
\hline HEMBL149 & 39 & & & \\
\hline HEMBL157 & 9 & & 41 & \\
\hline HEMBL14 & 9 & & & \\
\hline HEMBL15 & 9 & & & \\
\hline HEMBL156 & 39 & 62 & & \\
\hline HEMBL395 & 39 & 65 & & \\
\hline HEMBL 14 & 39 & 862 & & \\
\hline HEMBL14 & & 63 & & \\
\hline HEM & 39 & 362 & & RN \\
\hline HEMBL13 & 39 & & & RN \\
\hline HEMBL154 & 39 & 362 & 15 & ГST \\
\hline HEMBL15 & 9 & 362 & 86 & RN \\
\hline HEM & & & & ST \\
\hline HEME & & 62 & & RN \\
\hline HEMBL 149 & 9 & & & ST \\
\hline HEMBL136 & 88 & 362 & 365 & ST \\
\hline HEMBL13 & 39 & 862 & 04 & RN \\
\hline 9 & 9 & & & RN \\
\hline HEMBL 14 & & & & RN \\
\hline HEMBL157 & 39 & & & RN \\
\hline HEMBL 315 & 39 & 862 & 031 & RN \\
\hline HEMBL 13 & 39 & 62 & 95 & RN \\
\hline IIM & & & & RN \\
\hline HEMBL14e & & & & RN \\
\hline HEMBL157€ & 88239 & 862 & & ST \\
\hline HEMBL31C & 39 & 362 & & RN \\
\hline HEMBL159 & & 4.7862 & & \\
\hline CHEMBL 138 & & & & RN \\
\hline HEMBL1439905 & & 5.1862 & 5.3924 & ST \\
\hline HEMBL16e & 39 & 362 & 931 & RN \\
\hline 13 & & & & \\
\hline ב 1 & & & & \\
\hline
\end{tabular}

Page 1607 
Supplemental Table S2.txt

\begin{tabular}{|c|c|c|c|c|}
\hline CHEMBL1566352 & 688239 & 5.7362 & 5.5302 & TST \\
\hline CHEMBL1512963 & 688239 & 5.1862 & 5.4593 & TST \\
\hline CHEMBL1467881 & 688239 & 4.6862 & 5.5296 & TST \\
\hline CHEMBL1364724 & 688239 & 6.0862 & 5.5228 & TRN \\
\hline CHEMBL1424942 & 688239 & 4.9362 & 5.2876 & TRN \\
\hline CHEMBL1499139 & 688239 & 6.8362 & 5.6021 & TST \\
\hline CHEMBL3194477 & 688239 & 5.0862 & 5.3816 & TRN \\
\hline CHEMBL1419522 & 688239 & 5.7862 & 5.5642 & TST \\
\hline CHEMBL1344640 & 688239 & 5.4862 & 5.4605 & TRN \\
\hline CHEMBL1382374 & 688239 & 6.1862 & 5.4741 & TRN \\
\hline CHEMBL1518145 & 688239 & 5.5862 & 5.482 & TRN \\
\hline CHEMBL1532207 & 688239 & 5.4862 & 5.4703 & TRN \\
\hline CHEMBL1315789 & 688239 & 6.9863 & 5.4754 & TRN \\
\hline CHEMBL1403138 & 688239 & 4.5362 & 5.3567 & TRN \\
\hline CHEMBL3213026 & 688239 & 6.8861 & 5.4154 & TST \\
\hline CHEMBL1385883 & 688239 & 5.1862 & 5.506 & TRN \\
\hline CHEMBL1403960 & 688239 & 5.4362 & 5.5258 & TRN \\
\hline CHEMBL1410950 & 688239 & 6.1362 & 5.5187 & TRN \\
\hline CHEMBL1548893 & 688239 & 5.0362 & 5.3371 & TST \\
\hline CHEMBL1308069 & 688239 & 6.3863 & 5.4685 & TRN \\
\hline CHEMBL1556637 & 688239 & 5.6362 & 5.5747 & TRN \\
\hline CHEMBL1561991 & 688239 & 6.6362 & 5.5174 & TRN \\
\hline CHEMBL1598962 & 688239 & 4.5862 & 5.4399 & TRN \\
\hline CHEMBL1448439 & 688239 & 5.7362 & 5.3877 & TST \\
\hline CHEMBL3209768 & 688239 & 4.5862 & 5.4908 & TST \\
\hline CHEMBL1597973 & 688239 & 6.7862 & 5.50299 & 9999999999 \\
\hline CHEMBL1446160 & 688239 & 5.1362 & 5.5809 & TRN \\
\hline CHEMBL1513332 & 688239 & 6.0862 & 5.6046 & TRN \\
\hline CHEMBL1508805 & 688239 & 4.5362 & 5.6406 & TRN \\
\hline CHEMBL1599066 & 688239 & 4.7862 & 5.5216 & TRN \\
\hline CHEMBL1522430 & 688239 & 5.2362 & 5.7581 & TRN \\
\hline CHEMBL1454164 & 688239 & 4.7862 & 5.5378 & TRN \\
\hline CHEMBL1605986 & 688239 & 5.1362 & 5.4975 & TST \\
\hline CHEMBL1446368 & 688239 & 6.8861 & 5.3907 & TST \\
\hline CHEMBL1573515 & 688239 & 6.7862 & 5.4923 & TST \\
\hline CHEMBL1489450 & 688239 & 4.4862 & 5.603 & TRN \\
\hline CHEMBL1347310 & 688239 & 4.7862 & 5.3735 & TRN \\
\hline CHEMBL3209481 & 688239 & 6.1362 & 5.3975 & TRN \\
\hline CHEMBL1598460 & 688239 & 4.6362 & 5.4443 & TRN \\
\hline CHEMBL1379577 & 688239 & 5.1862 & 5.6816 & TRN \\
\hline CHEMBL573373 & 688239 & 5.1862 & 5.6216 & TST \\
\hline CHEMBL3198757 & 688239 & 5.2862 & 5.4887 & TRN \\
\hline CHEMBL1583141 & 688239 & 4.5362 & 5.2686 & TRN \\
\hline CHEMBL1332212 & 688239 & 4.5362 & 5.5119 & TRN \\
\hline CHEMBL1463971 & 688239 & 4.5362 & 5.34399 & 9999999999 \\
\hline CHEMBL1533409 & 688239 & 4.7362 & 5.5931 & TRN \\
\hline CHEMBL1569377 & 688239 & 5.4362 & 5.471 & TRN \\
\hline CHEMBL1370972 & 688239 & 6.7862 & 5.3685 & TRN \\
\hline
\end{tabular}

Page 1608 
Supplemental Table S2.txt

\begin{tabular}{|c|c|c|c|c|}
\hline CHEMBL3199594 & 688239 & 4.6362 & 5.4587 & TRN \\
\hline CHEMBL1515090 & 688239 & 5.1362 & 5.3918 & TRN \\
\hline CHEMBL1579362 & 688239 & 4.7862 & 5.5031 & TRN \\
\hline CHEMBL1427525 & 688239 & 4.8862 & 5.5064 & TRN \\
\hline CHEMBL1518424 & 688239 & 5.1862 & 5.4299 & TRN \\
\hline CHEMBL1608611 & 688239 & 4.5862 & 5.4645 & TST \\
\hline CHEMBL1472355 & 688239 & 7.1361 & 5.4389 & TST \\
\hline CHEMBL1505188 & 688239 & 4.5362 & 5.4675 & TRN \\
\hline CHEMBL1603357 & 688239 & 6.1862 & 5.4849 & TRN \\
\hline CHEMBL1435411 & 688239 & 5.1862 & 5.4529 & TRN \\
\hline CHEMBL1529716 & 688239 & 6.2362 & 5.5749 & TRN \\
\hline CHEMBL1329273 & 688239 & 6.0862 & 5.6523 & TRN \\
\hline CHEMBL1424742 & 688239 & 5.4862 & 5.4435 & TRN \\
\hline CHEMBL1494830 & 688239 & 4.7362 & 5.4715 & TRN \\
\hline CHEMBL1483483 & 688239 & 5.5362 & 5.5257 & TRN \\
\hline CHEMBL1498307 & 688239 & 4.9862 & 5.4462 & TST \\
\hline CHEMBL1362279 & 688239 & 4.7362 & 5.5737 & TRN \\
\hline CHEMBL1459761 & 688239 & 4.6862 & 5.6311 & TRN \\
\hline CHEMBL1365563 & 688239 & 4.5362 & 5.359 & TRN \\
\hline CHEMBL1426988 & 688239 & 5.1862 & 5.5427 & TRN \\
\hline CHEMBL1529372 & 688239 & 4.7862 & 5.4342 & TST \\
\hline CHEMBL1335285 & 688239 & 5.4362 & 5.4748 & TRN \\
\hline CHEMBL1341694 & 688239 & 6.2362 & 5.5716 & TRN \\
\hline CHEMBL1422842 & 688239 & 4.5362 & 5.6319 & TRN \\
\hline CHEMBL1510428 & 688239 & 5.0362 & 5.473 & TRN \\
\hline CHEMBL1483660 & 688239 & 4.6862 & 5.4086 & TRN \\
\hline CHEMBL1501088 & 688239 & 4.7362 & 5.5352 & TRN \\
\hline CHEMBL1349899 & 688239 & 5.0862 & 5.5755 & TRN \\
\hline CHEMBL1493239 & 688239 & 5.1862 & 5.4524 & TRN \\
\hline CHEMBL1312602 & 688239 & 5.1862 & 5.3382 & TST \\
\hline CHEMBL1345901 & 688239 & 6.8861 & 5.2545 & TST \\
\hline CHEMBL1553739 & 688239 & 5.1862 & 5.4777 & TRN \\
\hline CHEMBL443831 & 688239 & 6.8362 & 5.4573 & TRN \\
\hline CHEMBL1560100 & 688239 & 4.5362 & 5.4309 & TRN \\
\hline CHEMBL1390154 & 688239 & 4.5362 & 5.4651 & TRN \\
\hline CHEMBL1456737 & 688239 & 4.6862 & 5.36 & TRN \\
\hline CHEMBL1587699 & 688239 & 4.5362 & 5.485 & TST \\
\hline CHEMBL1356187 & 688239 & 5.1362 & 5.4045 & TRN \\
\hline CHEMBL1500984 & 688239 & 4.5362 & 5.5913 & TRN \\
\hline CHEMBL1311481 & 688239 & 4.5362 & 5.5912 & TRN \\
\hline CHEMBL1528285 & 688239 & 4.7362 & 5.41200 & 0000000001 \\
\hline CHEMBL1504303 & 688239 & 6.3863 & 5.4421 & TRN \\
\hline CHEMBL1325376 & 688239 & 5.6362 & 5.4246 & TRN \\
\hline CHEMBL1405512 & 688239 & 5.0362 & 5.5027 & TRN \\
\hline CHEMBL1530751 & 688239 & 5.4862 & 5.5791 & TST \\
\hline CHEMBL 71189 & 688239 & 6.1362 & 5.6415 & TRN \\
\hline CHEMBL1490266 & 688239 & 6.8362 & 5.4946 & TRN \\
\hline CHEMBL1602629 & 688239 & 6.1862 & 5.57600 & 00000000005 \\
\hline
\end{tabular}




\begin{tabular}{|c|c|c|c|c|c|c|}
\hline \\
\hline CHEMBL1507590 & 688239 & 5.7862 & 5.7034 & TRN & & \\
\hline CHEMBL1490614 & 688239 & 5.3362 & 5.446000 & 000000000 & & TST \\
\hline CHEMBL1489783 & 688239 & 8.283999 & 799999999 & 99 & 5.4945 & TRN \\
\hline CHEMBL1430898 & 688239 & 6.8362 & 5.6002 & TRN & & \\
\hline CHEMBL1340605 & 688239 & 5.2362 & 5.3273 & TRN & & \\
\hline CHEMBL1364518 & 688239 & 5.3862 & 5.4636 & TST & & \\
\hline CHEMBL1499065 & 688239 & 5.6362 & 5.617999 & 999999999 & & Tा \\
\hline CHEMBL1550857 & 688239 & 5.6862 & 5.3419 & TRN & & \\
\hline CHEMBL1526751 & 688239 & 8.3872 & 5.3696 & TRN & & \\
\hline CHEMBL1534197 & 688239 & 7.0862 & 5.4695 & TRN & & \\
\hline CHEMBL1480011 & 688239 & 5.4862 & 5.5008 & TRN & & \\
\hline CHEMBL1313516 & 688239 & 5.2362 & 5.4599 & TRN & & \\
\hline CHEMBL1564045 & 688239 & 5.1862 & 5.5014 & TRN & & \\
\hline CHEMBL1406031 & 688239 & 6.1862 & 5.4317 & TRN & & \\
\hline CHEMBL1346601 & 688239 & 8.283999 & 799999999 & 99 & 5.6053 & N \\
\hline CHEMBL1483825 & 688239 & 4.5862 & 5.6177 & TRN & & \\
\hline CHEMBL1452854 & 688239 & 4.5362 & 5.5464 & TRN & & \\
\hline CHEMBL1453525 & 688239 & 6.3863 & 5.5222 & TRN & & \\
\hline CHEMBL1463416 & 688239 & 4.4362 & 5.4926 & TRN & & \\
\hline CHEMBL1322394 & 688239 & 4.9362 & 5.4381 & TRN & & \\
\hline CHEMBL1315587 & 688239 & 8.283999 & 799999999 & 99 & 5.476 & ST \\
\hline CHEMBL1422773 & 688239 & 4.5362 & 5.4752 & TRN & & \\
\hline CHEMBL1543073 & 688239 & 4.6362 & 5.4318 & TST & & \\
\hline CHEMBL1508898 & 688239 & 5.5862 & 5.3392 & TRN & & \\
\hline CHEMBL1481517 & 688239 & 6.0862 & 5.5137 & TST & & \\
\hline CHEMBL3192856 & 688239 & 5.1862 & 5.4225 & TRN & & \\
\hline CHEMBL1309477 & 688239 & 6.4862 & 5.5022 & TST & & \\
\hline CHEMBL1547826 & 688239 & 6.2362 & 5.3533 & TRN & & \\
\hline CHEMBL1978925 & 688239 & 4.5362 & 5.2617 & TRN & & \\
\hline CHEMBL1305805 & 688239 & 4.4862 & 5.5644 & TRN & & \\
\hline CHEMBL1310653 & 688239 & 5.8862 & 5.5016 & TRN & & \\
\hline CHEMBL1610734 & 688239 & 6.2362 & 5.6215 & TRN & & \\
\hline CHEMBL3196400 & 688239 & 5.6362 & 5.537000 & 000000000 & & \\
\hline CHEMBL1305435 & 688239 & 4.9362 & 5.305 & TRN & & \\
\hline CHEMBL 3212073 & 688239 & 5.4362 & 5.4901 & TRN & & \\
\hline CHEMBL1378847 & 688239 & 4.6862 & 5.4682 & TRN & & \\
\hline CHEMBL1445918 & 688239 & 4.5362 & 5.4383 & TRN & & \\
\hline CHEMBL1354890 & 688239 & 4.5362 & 5.4245 & TRN & & \\
\hline CHEMBL1300358 & 688239 & 6.1862 & 5.3994 & TRN & & \\
\hline CHEMBL1588559 & 688239 & 5.5862 & 5.6349 & TRN & & \\
\hline CHEMBL1521599 & 688239 & 5.1862 & 5.4172 & TRN & & \\
\hline CHEMBL1311111 & 688239 & 4.5362 & 5.4812 & TRN & & \\
\hline CHEMBL1601686 & 688239 & 5.4862 & 5.3641 & TST & & \\
\hline CHEMBL1479965 & 688239 & 5.1862 & 5.4822 & TST & & \\
\hline CHEMBL1596369 & 688239 & 5.7862 & 5.5083 & TRN & & \\
\hline CHEMBL1502352 & 688239 & 5.6862 & 5.6498 & TRN & & \\
\hline CHEMBL1599744 & 688239 & 4.6862 & 5.3475 & TRN & & \\
\hline CHEMBL1505000 & 688239 & 8.3872 & 5.4859 & TRN & & \\
\hline
\end{tabular}


Supplemental Table S2.txt

\begin{tabular}{|c|c|c|c|c|c|}
\hline CHEMBL1573327 & 688239 & 4.7362 & 5.6546 & TRN & \\
\hline CHEMBL1571040 & 688239 & 6.0 & 5.6068 & TRN & \\
\hline CHEMBL1360224 & 688239 & 4.9362 & 5.3389 & TRN & \\
\hline CHEMBL1480814 & 688239 & 5.7362 & 5.4435 & TRN & \\
\hline CHEMBL1398727 & 688239 & 4.5362 & 5.512000 & 0000000005 & TRN \\
\hline CHEMBL1422309 & 688239 & 6.9363 & 5.5397 & TRN & \\
\hline CHEMBL1506648 & 688239 & 5.1862 & 5.5028 & TRN & \\
\hline CHEMBL1311457 & 688239 & 5.1362 & 5.5978 & TRN & \\
\hline CHEMBL1570880 & 688239 & 5.6362 & 5.3936 & TRN & \\
\hline CHEMBL1532013 & 688239 & 6.2862 & 5.6876 & TST & \\
\hline CHEMBL1390903 & 688239 & 4.8862 & 5.5637 & TRN & \\
\hline CHEMBL 2006568 & 688239 & 4.8862 & 5.3293 & TST & \\
\hline CHEMBL1603522 & 688239 & 4.8862 & 5.4162 & TRN & \\
\hline CHEMBL1412563 & 688239 & 5.1862 & 5.5281 & TST & \\
\hline CHEMBL1498787 & 688239 & 4.7862 & 5.531000 & 000000001 & \\
\hline CHEMBL1380595 & 688239 & 7.1361 & 5.6487 & TRN & \\
\hline CHEMBL1541629 & 688239 & 7.5361 & 5.5681 & TRN & \\
\hline CHEMBL1424059 & 688239 & 4.8362 & 5.5242 & TRN & \\
\hline CHEMBL1577139 & 688239 & 4.6862 & 5.3161 & TST & \\
\hline CHEMBL1542150 & 688239 & 5.5362 & 5.484 & TRN & \\
\hline CHEMBL1565157 & 688239 & 4.55 & 5.3948 & TRN & \\
\hline CHEMBL1378333 & 688239 & 5.1362 & 5.5835 & TRN & \\
\hline CHEMBL1518477 & 688239 & 5.4362 & 5.5588 & TRN & \\
\hline CHEMBL155122 & 688239 & 5.7862 & 5.5407 & TST & \\
\hline CHEMBL1481137 & 688239 & 5.1862 & 5.4826 & TRN & \\
\hline CHEMBL1393463 & 688239 & 5.0362 & 5.5667 & TRN & \\
\hline CHEMBL 3209893 & 688239 & 6.6362 & 5.3911 & TRN & \\
\hline CHEMBL1499011 & 688239 & 5.5862 & 5.631 & TRN & \\
\hline CHEMBL 3195403 & 688239 & 5.0862 & 5.4967 & TST & \\
\hline CHEMBL1534392 & 688239 & 4.5362 & 5.4375 & TRN & \\
\hline CHEMBL1473805 & 688239 & 5.1862 & 5.6462 & TRN & \\
\hline CHEMBL1536244 & 688239 & 4.7362 & 5.4333 & TRN & \\
\hline CHEMBL1320143 & 688239 & 4.5362 & 5.5123 & TRN & \\
\hline CHEMBL1567247 & 688239 & 6.8861 & 5.4063 & TRN & \\
\hline CHEMBL1534020 & 688239 & 5.5862 & 5.6809 & TRN & \\
\hline CHEMBL1544806 & 688239 & 5.4862 & 5.3403 & TRN & \\
\hline CHEMBL1561420 & 688239 & 4.7362 & 5.2769 & TRN & \\
\hline CHEMBL1406821 & 688239 & 5.4862 & 5.5638 & TRN & \\
\hline CHEMBL1340463 & 688239 & 4.5362 & 5.4822 & TRN & \\
\hline CHEMBL1375501 & 688239 & 6.7862 & 5.3911 & TRN & \\
\hline CHEMBL1482402 & 688239 & 5.7862 & 5.4778 & TRN & \\
\hline CHEMBL1322164 & 688239 & 8.283999 & 99999999 & 5.4836 & J \\
\hline CHEMBL1402527 & 688239 & 5.5862 & 5.3904 & TRN & \\
\hline CHEMBL3190564 & 688239 & 4.6862 & 5.4544 & TST & \\
\hline CHEMBL1573398 & 688239 & 6.9363 & 5.5889 & TRN & \\
\hline CHEMBL1479189 & 688239 & 4.9362 & 5.4478 & TRN & \\
\hline CHEMBL1329301 & 688239 & 6.3362 & 5.6121 & TRN & \\
\hline CHEMBL1504883 & 688239 & 4.7362 & 5.5623 & TST & \\
\hline
\end{tabular}


Supplemental Table S2.txt

\begin{tabular}{|c|c|c|c|c|c|}
\hline CHEMBL1594281 & 688239 & 4.6862 & 5.5718 & TRN & \\
\hline CHEMBL1431929 & 688239 & 4.5362 & 5.4338 & TRN & \\
\hline CHEMBL1319572 & 688239 & 4.5362 & 5.379 & TRN & \\
\hline CHEMBL 3208762 & 688239 & 5.1862 & 5.5297 & TRN & \\
\hline CHEMBL1299640 & 688239 & 4.5362 & 5.4135 & TST & \\
\hline CHEMBL1452365 & 688239 & 5.2362 & 5.5552 & TRN & \\
\hline CHEMBL1310745 & 688239 & 5.6362 & 5.4679 & TRN & \\
\hline CHEMBL1384708 & 688239 & 6.9363 & 5.4685 & TST & \\
\hline CHEMBL1363985 & 688239 & 8.3372 & 5.5458 & TST & \\
\hline CHEMBL1430777 & 688239 & 5.4362 & 5.5552 & TRN & \\
\hline CHEMBL1505376 & 688239 & 4.8362 & 5.4405 & TST & \\
\hline CHEMBL1308409 & 688239 & 6.8861 & 5.4744 & TRN & \\
\hline CHEMBL1332703 & 688239 & 5.3362 & 5.428999 & 9999999999 & TRN \\
\hline CHEMBL1318602 & 688239 & 4.7862 & 5.5469 & TRN & \\
\hline CHEMBL1370348 & 688239 & 5.7362 & 5.4957 & TST & \\
\hline CHEMBL1522280 & 688239 & 5.9362 & 5.457999 & 9999999999 & TRN \\
\hline CHEMBL1522404 & 688239 & 5.2362 & 5.4176 & TST & \\
\hline CHEMBL1361833 & 688239 & 5.5862 & 5.5265 & TRN & \\
\hline CHEMBL1428503 & 688239 & 5.3862 & 5.406006 & 0000000001 & TRN \\
\hline CHEMBL1547172 & 688239 & 6.5862 & 5.4596 & TRN & \\
\hline CHEMBL1596646 & 688239 & 5.5862 & 5.4753 & TST & \\
\hline CHEMBL1318033 & 688239 & 4.5362 & 5.3356 & TST & \\
\hline CHEMBL1311949 & 688239 & 5.3862 & 5.5849 & TRN & \\
\hline CHEMBL1494839 & 688239 & 4.8862 & 5.4349 & TRN & \\
\hline CHEMBL1428197 & 688239 & 5.8362 & 5.4343 & TRN & \\
\hline CHEMBL1523487 & 688239 & 4.7362 & 5.447 & TRN & \\
\hline CHEMBL1325550 & 688239 & 5.1862 & 5.5284 & TRN & \\
\hline CHEMBL1311216 & 688239 & 5.1862 & 5.4789 & TRN & \\
\hline CHEMBL1313908 & 688239 & 5.9362 & 5.5754 & TRN & \\
\hline CHEMBL1550054 & 688239 & 6.5363 & 5.4871 & TRN & \\
\hline CHEMBL1518905 & 688239 & 6.1362 & 5.3287 & TST & \\
\hline CHEMBL1352366 & 688239 & 4.5362 & 5.5847 & TRN & \\
\hline CHEMBL1372771 & 688239 & 4.5362 & 5.476 & TRN & \\
\hline CHEMBL1310096 & 688239 & 6.9863 & 5.511 & TRN & \\
\hline CHEMBL1405922 & 688239 & 4.6862 & 5.4828 & TRN & \\
\hline CHEMBL1468998 & 688239 & 4.4862 & 5.4014 & TST & \\
\hline CHEMBL1328587 & 688239 & 5.4362 & 5.5653 & TRN & \\
\hline CHEMBL1588311 & 688239 & 4.6862 & 5.4915 & TRN & \\
\hline CHEMBL1431300 & 688239 & 6.1362 & 5.6791 & TST & \\
\hline CHEMBL1551031 & 688239 & 6.2862 & 5.4175 & TRN & \\
\hline CHEMBL1533217 & 688239 & 4.5362 & 5.5409 & TRN & \\
\hline CHEMBL1577018 & 688239 & 6.0362 & 5.38 & TRN & \\
\hline CHEMBL1408807 & 688239 & 5.2362 & 5.3012 & TRN & \\
\hline CHEMBL3144968 & 688239 & 5.2862 & 5.5142 & TRN & \\
\hline CHEMBL1530924 & 688239 & 4.5362 & 5.5535 & TRN & \\
\hline CHEMBL1521794 & 688239 & 4.8362 & 5.4412 & TRN & \\
\hline CHEMBL1346764 & 688239 & 6.0362 & 5.4534 & TRN & \\
\hline CHEMBL3191296 & 688239 & 5.7362 & 5.5212 & TST & \\
\hline
\end{tabular}


Supplemental Table S2.txt

\begin{tabular}{|c|c|c|c|c|}
\hline CHEMBL1352296 & 688239 & 5.1362 & 5.4116 & TST \\
\hline CHEMBL1580028 & 688239 & 4.6362 & 5.3685 & TRN \\
\hline CHEMBL3207307 & 688239 & 7.9355 & 5.3681 & TST \\
\hline CHEMBL1496362 & 688239 & 5.6862 & 5.4606 & TST \\
\hline CHEMBL1360945 & 688239 & 7.0362 & 5.4581 & TRN \\
\hline CHEMBL1345268 & 688239 & 6.8362 & 5.6589 & TRN \\
\hline CHEMBL1421659 & 688239 & 6.8861 & 5.3646 & TRN \\
\hline CHEMBL600100 & 688239 & 4.6362 & 5.4154 & TRN \\
\hline CHEMBL1352030 & 688239 & 5.45 & 5.3832 & TST \\
\hline CHEMBL1553060 & 688239 & 5.3362 & 5.5379 & TRN \\
\hline CHEMBL1347112 & 688239 & 4.6862 & 5.4507 & TRN \\
\hline CHEMBL1352234 & 688239 & 4.4862 & 5.4372 & TST \\
\hline CHEMBL1380604 & 688239 & 5.1862 & 5.421 & TRN \\
\hline CHEMBL1534899 & 688239 & 4.6862 & 5.3027 & TRN \\
\hline CHEMBL1354843 & 688239 & 5.4862 & 5.5029 & TRN \\
\hline CHEMBL1584224 & 688239 & 6.1862 & 5.4309 & TRN \\
\hline CHEMBL1352586 & 688239 & 4.6362 & 5.3875 & TRN \\
\hline CHEMBL1589750 & 688239 & 4.5362 & 5.526 & TRN \\
\hline CHEMBL1599410 & 688239 & 4.9 & 5.4997 & TRN \\
\hline CHEMBL1390525 & 688239 & 4.7362 & 5.5986 & TRN \\
\hline CHEMBL1519724 & 688239 & 6.0862 & 5.5776 & TRN \\
\hline CHEMBL1551375 & 688239 & 4.5362 & 5.4605 & TRN \\
\hline CHEMBL1393130 & 688239 & 5.1362 & 5.4148 & TRN \\
\hline CHEMBL 3207963 & 688239 & 6.2362 & 5.6108 & TRN \\
\hline CHEMBL1441853 & 688239 & 5.5362 & 5.6262 & TRN \\
\hline CHEMBL1525619 & 688239 & 6.8362 & 5.5323 & TRN \\
\hline CHEMBL1420268 & 688239 & 4.7362 & 5.4232 & TST \\
\hline CHEMBL1348391 & 688239 & 6.1862 & 5.5498 & TRN \\
\hline CHEMBL1548167 & 688239 & 5.7362 & 5.4435 & TRN \\
\hline CHEMBL1352015 & 688239 & 4.5362 & 5.6263 & TRN \\
\hline CHEMBL1600467 & 688239 & 6.0862 & 5.597 & TRN \\
\hline CHEMBL1372526 & 688239 & 5.1862 & 5.564 & TRN \\
\hline CHEMBL1398848 & 688239 & 5.1862 & 5.5391 & TRN \\
\hline CHEMBL1539021 & 688239 & 6.3863 & 5.5583 & TRN \\
\hline CHEMBL1418932 & 688239 & 4.6862 & 5.4502 & TRN \\
\hline CHEMBL1414077 & 688239 & 5.7862 & 5.6141 & TRN \\
\hline CHEMBL1382462 & 688239 & 4.7862 & 5.5772 & TST \\
\hline CHEMBL1391127 & 688239 & 4.5362 & 5.3475 & TRN \\
\hline CHEMBL1457614 & 688239 & 6.9863 & 5.548999 & 99999999995 \\
\hline CHEMBL1553832 & 688239 & 4.5362 & 5.4182 & TRN \\
\hline CHEMBL1421348 & 688239 & 6.0862 & 5.4985 & TRN \\
\hline CHEMBL1469504 & 688239 & 4.5362 & 5.622999 & 9999999999 \\
\hline CHEMBL1312146 & 688239 & 5.5862 & 5.4915 & TRN \\
\hline CHEMBL1318835 & 688239 & 6.0862 & 5.603 & TRN \\
\hline CHEMBL1413183 & 688239 & 6.0362 & 5.5337 & TRN \\
\hline CHEMBL1449966 & 688239 & 5.1862 & 5.4313 & TRN \\
\hline CHEMBL1311062 & 688239 & 4.5862 & 5.4869 & TRN \\
\hline CHEMBL1459871 & 688239 & 5.1862 & 5.5114 & TRN \\
\hline
\end{tabular}


Supplemental Table S2.txt

\begin{tabular}{|c|c|c|c|c|}
\hline 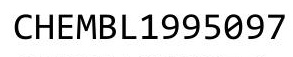 & & & & \\
\hline HEMBL 262870 & 3239 & 362 & 367 & \\
\hline AEMBL1462925 & 239 & 362 & 851 & \\
\hline & 39 & 862 & & \\
\hline IEMBL1479112 & & 862 & 866 & \\
\hline AEMBL1545458 & 88239 & 362 & 1132 & \\
\hline AEMBL1401079 & 88239 & 372 & 4724 & \\
\hline AEMBL1334052 & & & & \\
\hline EMBL3209 & 39 & 362 & 308 & \\
\hline IEMBL1422636 & & & & \\
\hline AEMBL1490163 & 39 & 863 & 504 & \\
\hline AEMBL1418271 & & 862 & 414 & \\
\hline AEMBL1330069 & & 62 & & \\
\hline IEMBL1486817 & & 62 & & \\
\hline IEMBL1333317 & & & 39 & \\
\hline AEMBL1452486 & & 863 & 13 & \\
\hline HEMBL2003436 & & 362 & & \\
\hline IEMBL1606 & & 4 & & \\
\hline IEMBL133 & & & & \\
\hline JEMBL142 & & & & \\
\hline AEMPI 1150 & & 862 & & \\
\hline AEMBL1587077 & & 62 & & \\
\hline AEMBL 154 & & 62 & & \\
\hline AFMBI 149 & & & & \\
\hline 82 & & 62 & & \\
\hline AEMBL1485922 & & 362 & & \\
\hline IEMBL1476395 & & 62 & & \\
\hline 3L13596 & & 62 & & \\
\hline 7 & & 62 & & \\
\hline 11911 & & 62 & & \\
\hline AEMBL1528 & & & & \\
\hline HEMBL1498645 & & 362 & & \\
\hline & & & & \\
\hline 200 & & & & \\
\hline HEMBL1338304 & & & & \\
\hline AEMBL1341318 & & 862 & & \\
\hline AEMBL1592106 & & 362 & & \\
\hline & & 62 & & \\
\hline 9 & & & & \\
\hline HEMBL1469460 & & & & \\
\hline AEMBL1568249 & & 861 & & \\
\hline BL1519297 & & 362 & & \\
\hline HEMBL1342343 & & & & \\
\hline HEMBL1463005 & & & & \\
\hline AEMBL1321132 & & & 5279 & RN \\
\hline IEMBL1502302 & & 862 & 3849 & \\
\hline $15 \varepsilon$ & & & & \\
\hline HEMBL319649 & & & & \\
\hline
\end{tabular}

Page 1614 
Supplemental Table S2.txt

\begin{tabular}{|c|c|c|c|c|c|}
\hline CHEMBL1401178 & 688239 & 5.3862 & 5.4239 & TRN & \\
\hline CHEMBL1325873 & 688239 & 7.7352 & 5.555 & TRN & \\
\hline CHEMBL1304184 & 688239 & 5.2862 & 5.6701 & TRN & \\
\hline CHEMBL1320545 & 688239 & 5.1862 & 5.5238 & TRN & \\
\hline CHEMBL1336368 & 688239 & 4.5362 & 5.5597 & TRN & \\
\hline CHEMBL1495363 & 688239 & 4.5362 & 5.4111 & TRN & \\
\hline CHEMBL1387609 & 688239 & 5.7862 & 5.6373 & TRN & \\
\hline CHEMBL1414349 & 688239 & 6.1362 & 5.4897 & TRN & \\
\hline CHEMBL1492371 & 688239 & 4.5362 & 5.4984 & TST & \\
\hline CHEMBL1348242 & 688239 & 6.9363 & 5.5391 & TRN & \\
\hline CHEMBL1504159 & 688239 & 5.1362 & 5.2692 & TST & \\
\hline CHEMBL1601040 & 688239 & 5.5862 & 5.5323 & TST & \\
\hline CHEMBL1476035 & 688239 & 4.7362 & 5.3079 & TRN & \\
\hline CHEMBL1497717 & 688239 & 7.1361 & 5.5828 & TST & \\
\hline CHEMBL1975583 & 688239 & 5.9862 & 5.433 & TRN & \\
\hline CHEMBL1388730 & 688239 & 4.9362 & 5.5728 & TRN & \\
\hline CHEMBL1358238 & 688239 & 6.9363 & 5.4577 & TRN & \\
\hline CHEMBL1382422 & 688239 & 6.3863 & 5.3689 & TRN & \\
\hline CHEMBL1491319 & 688239 & 6.6861 & 5.5334 & TRN & \\
\hline CHEMBL1546796 & 688239 & 7.2366 & 5.351 & TRN & \\
\hline CHEMBL1545831 & 688239 & 4.4862 & 5.4017 & TST & \\
\hline CHEMBL1305195 & 688239 & 5.6862 & 5.5044 & TRN & \\
\hline CHEMBL1428123 & 688239 & 6.8362 & 5.4689 & TRN & \\
\hline CHEMBL1586657 & 688239 & 6.1362 & 5.4378 & TRN & \\
\hline CHEMBL1519805 & 688239 & 5.8362 & 5.379 & TRN & \\
\hline CHEMBL1451388 & 688239 & 5.1862 & 5.3384 & TRN & \\
\hline CHEMBL1332682 & 688239 & 5.2862 & 5.4711 & TST & \\
\hline CHEMBL1523303 & 688239 & 4.5362 & 5.5428 & TRN & \\
\hline CHEMBL1575392 & 688239 & 4.5362 & 5.3656 & TRN & \\
\hline CHEMBL1305756 & 688239 & 5.0862 & 5.6917 & TRN & \\
\hline CHEMBL1439927 & 688239 & 4.6362 & 5.5304 & TRN & \\
\hline CHEMBL1563781 & 688239 & 5.3362 & 5.5168 & TRN & \\
\hline CHEMBL1517671 & 688239 & 6.1862 & 5.7128 & TRN & \\
\hline CHEMBL1380598 & 688239 & 4.5862 & 5.5661 & TRN & \\
\hline CHEMBL3199050 & 688239 & 5.7862 & 5.4492 & TRN & \\
\hline CHEMBL1399565 & 688239 & 4.7862 & 5.4234 & TRN & \\
\hline CHEMBL1320690 & 688239 & 4.6862 & 5.5527 & TRN & \\
\hline CHEMBL3195314 & 688239 & 6.1362 & 5.5073 & TST & \\
\hline CHEMBL1482100 & 688239 & 4.9362 & 5.4748 & TRN & \\
\hline CHEMBL 1256776 & 688239 & 4.5362 & 5.4801 & TRN & \\
\hline CHEMBL1457974 & 688239 & 5.3862 & 5.5771 & TST & \\
\hline CHEMBL1475266 & 688239 & 5.3362 & 5.4854 & TRN & \\
\hline CHEMBL1463763 & 688239 & 7.2366 & 5.3894 & TRN & \\
\hline CHEMBL1376811 & 688239 & 5.7362 & 5.7258 & TRN & \\
\hline CHEMBL1535193 & 688239 & 5.1862 & \multicolumn{2}{|c|}{5.672000000000001} & TRN \\
\hline CHEMBL1522014 & 688239 & 4.5362 & 5.4861 & TRN & \\
\hline CHEMBL1572463 & 688239 & 4.5362 & 5.5258 & TRN & \\
\hline CHEMBL1301885 & 688239 & 6.4862 & 5.5559 & TRN & \\
\hline
\end{tabular}


Supplemental Table S2.txt

\begin{tabular}{|c|c|c|c|c|}
\hline CHEMBL1300623 & 688239 & 4.6862 & 5.3348 & TRN \\
\hline CHEMBL1326551 & 688239 & 4.5362 & 5.5167 & TRN \\
\hline CHEMBL1382992 & 688239 & 5.3362 & 5.5406 & TRN \\
\hline CHEMBL3213256 & 688239 & 5.0362 & 5.426 & TRN \\
\hline CHEMBL1517918 & 688239 & 8.2366 & 5.4056 & TRN \\
\hline CHEMBL1434201 & 688239 & 6.9363 & 5.5786 & TST \\
\hline CHEMBL1427080 & 688239 & 5.2862 & 5.4199 & TRN \\
\hline CHEMBL1393672 & 688239 & 5.8362 & 5.443 & TRN \\
\hline CHEMBL1399737 & 688239 & 4.5362 & 5.5236 & TRN \\
\hline CHEMBL1428477 & 688239 & 5.1362 & 5.6247 & TRN \\
\hline CHEMBL1360208 & 688239 & 5.1862 & 5.3178 & TST \\
\hline CHEMBL1518021 & 688239 & 5.1362 & 5.4671 & TRN \\
\hline CHEMBL1405640 & 688239 & 6.0862 & 5.4579 & TRN \\
\hline CHEMBL1462382 & 688239 & 4.5362 & 5.6236 & TRN \\
\hline CHEMBL1592379 & 688239 & 6.0 & 5.4383 & TRN \\
\hline CHEMBL1579387 & 688239 & 5.4862 & 5.5024 & TRN \\
\hline CHEMBL1988657 & 688239 & 4.9362 & 5.3232 & TRN \\
\hline CHEMBL1315647 & 688239 & 5.4862 & 5.4727 & TRN \\
\hline CHEMBL1458574 & 688239 & 5.8362 & 5.3431 & TST \\
\hline CHEMBL1462309 & 688239 & 6.8861 & 5.4537 & TST \\
\hline CHEMBL1585465 & 688239 & 5.0862 & 5.6101 & TRN \\
\hline CHEMBL1368832 & 688239 & 4.5362 & 5.2327 & TST \\
\hline CHEMBL1300784 & 688239 & 8.1871 & 5.5881 & TRN \\
\hline CHEMBL1308267 & 688239 & 5.1862 & 5.4149 & TST \\
\hline CHEMBL 3189343 & 688239 & 6.1862 & 5.4354 & TRN \\
\hline CHEMBL1361970 & 688239 & 4.8362 & 5.6151 & TRN \\
\hline CHEMBL3212068 & 688239 & 5.1862 & 5.4442 & TRN \\
\hline CHEMBL1580260 & 688239 & 5.1862 & 5.5666 & TST \\
\hline CHEMBL1353567 & 688239 & 5.1362 & 5.407 & TST \\
\hline CHEMBL1340976 & 688239 & 4.6362 & 5.3711 & TRN \\
\hline CHEMBL1446456 & 688239 & 4.9362 & 5.496 & TRN \\
\hline CHEMBL1386815 & 688239 & 6.0862 & 5.4782 & TRN \\
\hline CHEMBL1418594 & 688239 & 4.5362 & 5.4202 & TRN \\
\hline CHEMBL1607818 & 688239 & 5.4862 & 5.6086 & TRN \\
\hline CHEMBL1580695 & 688239 & 4.5362 & 5.4374 & TRN \\
\hline CHEMBL1462911 & 688239 & 4.6362 & 5.5797 & TRN \\
\hline CHEMBL1501079 & 688239 & 6.6861 & $5.61700 e$ & 0000000001 \\
\hline CHEMBL1484041 & 688239 & 5.1362 & 5.2304 & TRN \\
\hline CHEMBL1436552 & 688239 & 5.1862 & 5.5562 & TRN \\
\hline CHEMBL1426151 & 688239 & 8.3372 & 5.4422 & TRN \\
\hline CHEMBL1587014 & 688239 & 4.8362 & 5.553 & TRN \\
\hline CHEMBL1591493 & 688239 & 4.8862 & 5.4845 & TRN \\
\hline CHEMBL1536354 & 688239 & 4.6862 & 5.626 & TRN \\
\hline CHEMBL1506032 & 688239 & 5.8862 & 5.5693 & TRN \\
\hline CHEMBL1452698 & 688239 & 4.6362 & 5.6058 & TRN \\
\hline CHEMBL1542650 & 688239 & 4.7862 & 5.457999 & 9999999999 \\
\hline CHEMBL1570734 & 688239 & 4.6862 & 5.5384 & TRN \\
\hline CHEMBL1597493 & 688239 & 5.0862 & 5.4794 & TRN \\
\hline
\end{tabular}


Supplemental Table S2.txt

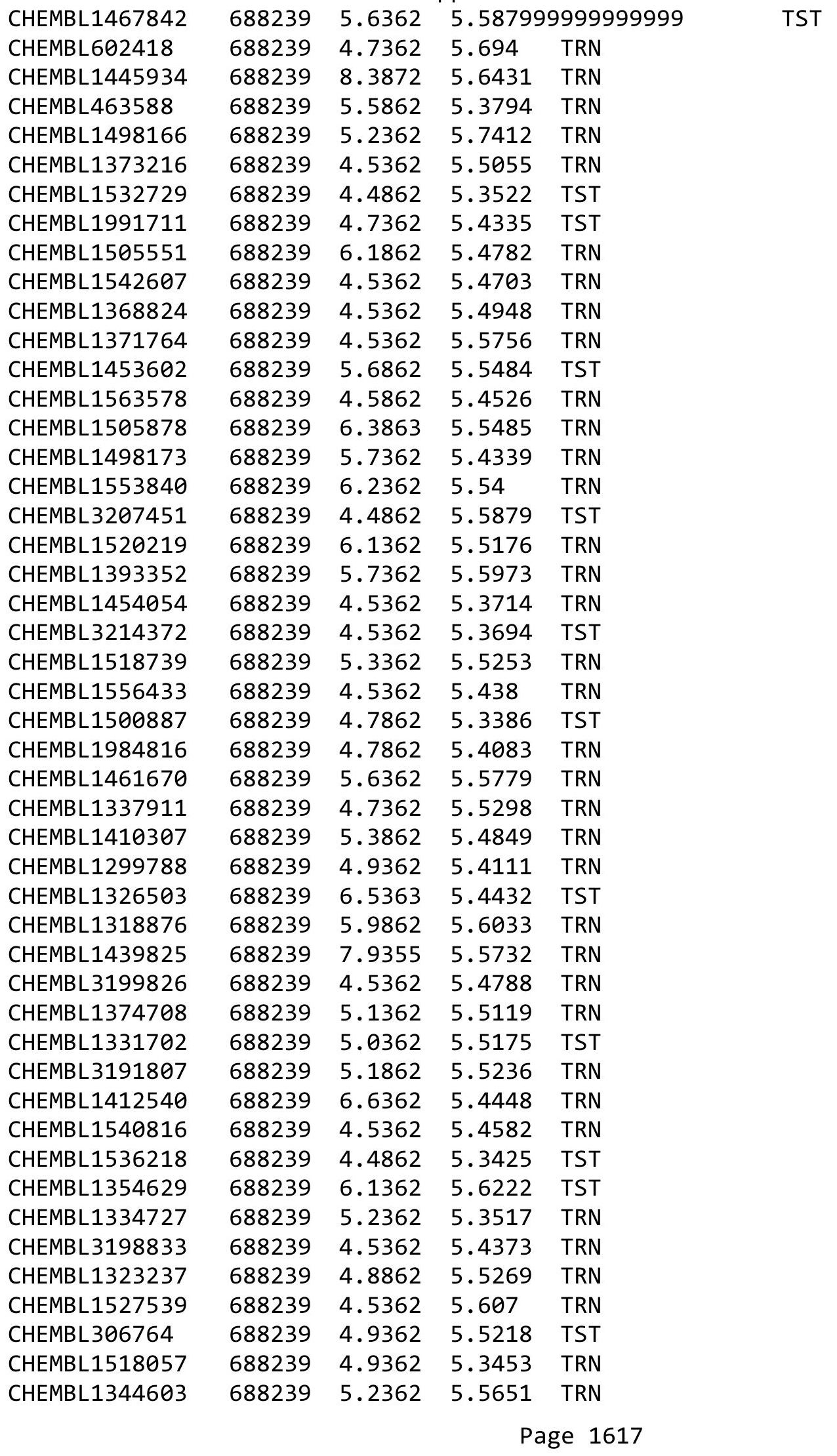


Supplemental Table S2.txt

\begin{tabular}{|c|c|c|c|c|}
\hline 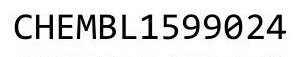 & & & & \\
\hline HEMBL1499472 & 38239 & 362 & & \\
\hline AEMBL1358622 & 239 & 7862 & & \\
\hline 然 & 39 & 362 & & \\
\hline IEMBL134872 & 39 & 362 & & \\
\hline AEMBL1412520 & 88239 & 362 & & \\
\hline AEMBL1545416 & 88239 & 361 & 5742 & \\
\hline AEMBL3213695 & & & & \\
\hline EMBL13 & 39 & 362 & & \\
\hline IEMBL14 & & & & \\
\hline AEMBL1451397 & 39 & 362 & 31 & \\
\hline AEMBL1377440 & 39 & 862 & & \\
\hline AEMBL1364722 & & & & \\
\hline AEMBL1579444 & & & & \\
\hline HEMBL1342949 & & & & \\
\hline AEMBL1580785 & & 862 & & \\
\hline AEMBL1598620 & & 72 & & \\
\hline IEMBL1507 & & & & \\
\hline AEMBL1343 & & & & \\
\hline AEMBL3196534 & & & & \\
\hline AEMBL1376028 & & 363 & & \\
\hline AEMBL3191581 & & & & \\
\hline EMBL14520 & & & & \\
\hline AFMBI 1692 & & & & \\
\hline 69 & & & & \\
\hline AEMBL1322027 & & & & \\
\hline IEMBL1452153 & & & & \\
\hline IEMBL13534 & & & & \\
\hline AFMR & & & & \\
\hline AEMBL1390 & & & & \\
\hline AEMBL1612730 & & & & \\
\hline HEMBL1387537 & & 62 & & \\
\hline & & 62 & & \\
\hline 2 & & & & \\
\hline AEMBL1522130 & & & & RN \\
\hline AEMBL1509527 & & & & \\
\hline AEMBL1322863 & & & & \\
\hline$\partial 86$ & & & & \\
\hline 3 & & & & \\
\hline HEMBL1501979 & & & & ST \\
\hline AEMBL1468021 & & & & \\
\hline IEMBL1320 & & & & \\
\hline HEMBL1450773 & & & & \\
\hline HEMBL1323643 & & & & \\
\hline AEMBL1457418 & & 4.7862 & & RN \\
\hline IEMBL1364018 & & 362 & & \\
\hline 13 & & & & \\
\hline 1 & & & & \\
\hline
\end{tabular}

Page 1618 
Supplemental Table S2.txt

\begin{tabular}{|c|c|c|c|c|c|c|}
\hline CHEMBL1452392 & 688239 & 6.2362 & 5.439 & TST & & \\
\hline CHEMBL1354684 & 688239 & 6.1362 & 5.4799 & TRN & & \\
\hline CHEMBL1519549 & 688239 & 6.0862 & 5.45799 & 99999999 & & TRN \\
\hline CHEMBL1306893 & 688239 & 5.7362 & 5.3802 & TRN & & \\
\hline CHEMBL1323201 & 688239 & 5.1862 & 5.5514 & TST & & \\
\hline CHEMBL1385058 & 688239 & 4.7862 & 5.2422 & TRN & & \\
\hline CHEMBL1580855 & 688239 & 5.9362 & 5.6414 & TST & & \\
\hline CHEMBL1510622 & 688239 & 5.0862 & 5.3997 & TRN & & \\
\hline CHEMBL1332122 & 688239 & 7.0362 & 5.4472 & TST & & \\
\hline CHEMBL1547246 & 688239 & 5.4862 & 5.4053 & TST & & \\
\hline CHEMBL1335784 & 688239 & 6.0362 & 5.5211 & TRN & & \\
\hline CHEMBL1378821 & 688239 & 7.8861 & 5.4298 & TRN & & \\
\hline CHEMBL1410329 & 688239 & 6.2862 & 5.4598 & TRN & & \\
\hline CHEMBL1329691 & 688239 & 5.6362 & 5.5695 & TRN & & \\
\hline CHEMBL1574745 & 688239 & 4.5862 & 5.4881 & TRN & & \\
\hline CHEMBL1420867 & 688239 & 5.6862 & 5.5452 & TRN & & \\
\hline CHEMBL1459015 & 688239 & 4.9862 & 5.5583 & TRN & & \\
\hline CHEMBL1477718 & 688239 & 5.5862 & 5.5104 & TRN & & \\
\hline CHEMBL1603160 & 688239 & 5.4362 & 5.4108 & TRN & & \\
\hline CHEMBL1613434 & 688239 & 4.7862 & 5.5346 & TRN & & \\
\hline CHEMBL1388380 & 688239 & 4.7362 & 5.3586 & TST & & \\
\hline CHEMBL 256042 & 688239 & 4.9362 & 5.3901 & TST & & \\
\hline CHEMBL1356349 & 688239 & 5.1862 & 5.311 & TRN & & \\
\hline CHEMBL1340598 & 688239 & 5.1862 & 5.6784 & TRN & & \\
\hline CHEMBL1413116 & 688239 & 4.5362 & 5.4766 & TRN & & \\
\hline CHEMBL1359122 & 688239 & 8.3372 & 5.4091 & TRN & & \\
\hline CHEMBL1359657 & 688239 & 5.3362 & 5.4479 & TRN & & \\
\hline CHEMBL1341444 & 688239 & 5.1362 & 5.3666 & TST & & \\
\hline CHEMBL1365138 & 688239 & 7.5361 & 5.5172 & TRN & & \\
\hline CHEMBL1602386 & 688239 & \multicolumn{3}{|c|}{8.283999999999999} & 5.5938 & $\mathrm{Kl}$ \\
\hline CHEMBL1362116 & 688239 & 4.5362 & 5.3768 & TST & & \\
\hline CHEMBL1319294 & 688239 & 4.5862 & 5.4518 & TRN & & \\
\hline CHEMBL1389864 & 688239 & 6.5363 & 5.5198 & TST & & \\
\hline CHEMBL3194914 & 688239 & 4.5362 & 5.3248 & TST & & \\
\hline CHEMBL1446624 & 688239 & 4.8862 & 5.4877 & TST & & \\
\hline CHEMBL1574307 & 688239 & 5.3862 & 5.5039 & TRN & & \\
\hline CHEMBL1452344 & 688239 & 7.6364 & 5.6716 & TRN & & \\
\hline CHEMBL1578330 & 688239 & 4.5362 & 5.4332 & TRN & & \\
\hline CHEMBL1299735 & 688239 & 5.1362 & 5.3674 & TRN & & \\
\hline CHEMBL1596623 & 688239 & 6.8362 & 5.5522 & TRN & & \\
\hline CHEMBL1570753 & 688239 & 4.5862 & 5.3184 & TRN & & \\
\hline CHEMBL1321239 & 688239 & 4.5362 & 5.4431 & TST & & \\
\hline CHEMBL1383772 & 688239 & 4.5362 & 5.5712 & TRN & & \\
\hline CHEMBL1536139 & 688239 & 8.3372 & 5.4198 & TRN & & \\
\hline CHEMBL1524649 & 688239 & 5.7862 & 5.4495 & TRN & & \\
\hline CHEMBL1499574 & 688239 & 6.6861 & 5.4425 & TST & & \\
\hline CHEMBL1410625 & 688239 & 5.9862 & 5.3587 & TST & & \\
\hline CHEMBL1511557 & 688239 & 6.4362 & 5.4792 & TRN & & \\
\hline
\end{tabular}


Supplemental Table S2.txt

\begin{tabular}{|c|c|c|c|c|c|}
\hline CHEMBL 3207694 & 688239 & 5.6362 & 5.4466 & TRN & \\
\hline CHEMBL1600249 & 688239 & 4.5362 & 5.7021 & TRN & \\
\hline CHEMBL1602709 & 688239 & 5.4362 & 5.2976 & TRN & \\
\hline CHEMBL1441085 & 688239 & 4.7862 & 5.4259 & TRN & \\
\hline CHEMBL1597679 & 688239 & 5.1862 & 5.5609 & TST & \\
\hline CHEMBL1520513 & 688239 & 5.3362 & 5.5459 & TRN & \\
\hline CHEMBL1443668 & 688239 & 4.5362 & 5.5032 & TRN & \\
\hline CHEMBL1531408 & 688239 & 5.1862 & 5.6204 & TRN & \\
\hline CHEMBL1498907 & 688239 & 4.5862 & 5.5306 & TRN & \\
\hline CHEMBL1330575 & 688239 & 8.3872 & 5.5292 & TRN & \\
\hline CHEMBL1550753 & 688239 & 4.5362 & 5.2878 & TRN & \\
\hline CHEMBL1574203 & 688239 & 5.1862 & 5.3165 & TRN & \\
\hline CHEMBL1611894 & 688239 & 6.3362 & 5.5685 & TRN & \\
\hline CHEMBL3191542 & 688239 & 5.4362 & 5.2958 & TST & \\
\hline CHEMBL1588859 & 688239 & 4.6862 & 5.4267 & TRN & \\
\hline CHEMBL1411512 & 688239 & 4.5862 & 5.3713 & TRN & \\
\hline CHEMBL1480302 & 688239 & 6.4862 & 5.5602 & TRN & \\
\hline CHEMBL3210412 & 688239 & 6.5363 & 5.5525 & TRN & \\
\hline CHEMBL1495173 & 688239 & 5.1862 & 5.4425 & TST & \\
\hline CHEMBL1562504 & 688239 & 6.1362 & 5.4072 & TRN & \\
\hline CHEMBL1561821 & 688239 & 5.5862 & 5.5191 & TRN & \\
\hline CHEMBL1608648 & 688239 & 5.1362 & 5.43 & TRN & \\
\hline CHEMBL1572587 & 688239 & 4.6862 & 5.3272 & TRN & \\
\hline CHEMBL1572526 & 688239 & 6.0862 & 5.3913 & TRN & \\
\hline CHEMBL1542690 & 688239 & 6.2362 & 5.4738 & TRN & \\
\hline CHEMBL1501999 & 688239 & 5.8862 & 5.5552 & TRN & \\
\hline CHEMBL1339178 & 688239 & 6.8362 & 5.6101 & TST & \\
\hline CHEMBL1503052 & 688239 & 4.4862 & $5.41100 e$ & 00000000005 & TRN \\
\hline CHEMBL1546612 & 688239 & 4.5362 & 5.5456 & TRN & \\
\hline CHEMBL1379392 & 688239 & 4.5862 & 5.5112 & TRN & \\
\hline CHEMBL1359336 & 688239 & 4.5362 & 5.3868 & TST & \\
\hline CHEMBL1344083 & 688239 & 5.3362 & 5.507999 & 9999999999 & TRN \\
\hline CHEMBL12327 & 688239 & 4.6862 & 5.4882 & TRN & \\
\hline CHEMBL1351793 & 688239 & 5.7362 & 5.5924 & TRN & \\
\hline CHEMBL1322541 & 688239 & 5.0362 & 5.3452 & TRN & \\
\hline CHEMBL1465064 & 688239 & 4.7362 & 5.3956 & TRN & \\
\hline CHEMBL1312734 & 688239 & 4.6362 & 5.5381 & TRN & \\
\hline CHEMBL1364388 & 688239 & 5.0862 & 5.4655 & TRN & \\
\hline CHEMBL562192 & 688239 & 7.2366 & 5.6248 & TRN & \\
\hline CHEMBL1418065 & 688239 & 5.1862 & 5.5269 & TRN & \\
\hline CHEMBL1571035 & 688239 & 4.5362 & 5.6425 & TRN & \\
\hline CHEMBL1377688 & 688239 & 4.8362 & 5.4577 & TST & \\
\hline CHEMBL1457664 & 688239 & 5.9862 & 5.4532 & TST & \\
\hline CHEMBL1480830 & 688239 & 4.7862 & 5.3553 & TST & \\
\hline CHEMBL1534902 & 688239 & \multicolumn{3}{|c|}{8.283999999999999} & TST \\
\hline CHEMBL1398858 & 688239 & 5.9362 & 5.6358 & TRN & \\
\hline CHEMBL1398670 & 688239 & 5.2362 & 5.5675 & TRN & \\
\hline CHEMBL1522443 & 688239 & 5.2862 & 5.4785 & TRN & \\
\hline
\end{tabular}


Supplemental Table S2.txt

\begin{tabular}{|c|c|c|c|c|}
\hline IE & & & & \\
\hline HEMBL3191924 & & .9862 & & \\
\hline 42 & & & & \\
\hline AEMBL1 & & 51 & & \\
\hline AEMBL1360903 & 8239 & 862 & & \\
\hline HEMBL1539147 & 88239 & 7362 & 4621 & \\
\hline 731 & 239 & 862 & & \\
\hline 111 & & & & \\
\hline AEMBL1562445 & & 362 & 638 & \\
\hline HEMBL1506797 & 38239 & 362 & & \\
\hline AEMBL1573451 & 39 & 362 & 44 & \\
\hline IEMBL1337 & 39 & & 923 & \\
\hline HEMBL134 & & & & \\
\hline HEMBL1337375 & & 62 & & \\
\hline AEMBL1393265 & & & & \\
\hline AEMBL1486277 & 39 & 62 & 12 & \\
\hline IEMBL149 & & 52 & & \\
\hline HEMBL152S & & & & \\
\hline AEMBL1377 & & 862 & & \\
\hline AEMBL156 & & & & \\
\hline HEMBLISL. & & & & NIV \\
\hline AEMBL13 & & & & \\
\hline AEMBL14 & & & & \\
\hline 6429 & & & & \\
\hline HEMBL146S & & & & KIV \\
\hline AEMBL153. & & & & RI \\
\hline AEMBL: & & & & \\
\hline AFMRI 1 & & 62 & & \\
\hline HEMBL1612 & & & & r \\
\hline HEMBL1315238 & & & 76 & IRN \\
\hline HEMBL1363 & & 52 & 82 & ST \\
\hline AFMBI 1 & & & & RN \\
\hline 5 & & & & ST \\
\hline AEMBL1567166 & & & & is \\
\hline HEMBL3194729 & & 62 & 394 & ГRN \\
\hline HEMBL1 & & & & \\
\hline 1 & & & & RN \\
\hline HEMBL1 & & & & RN \\
\hline HEMBL1597891 & 88239 & 62 & & $\Gamma \mathrm{RN}$ \\
\hline EMBL1 & & & & IST \\
\hline HEMBL1395925 & & 52 & & \\
\hline HEMBL411307 & & & & RN \\
\hline HEMBL1492392 & & 362 & & RN \\
\hline AEMBL1530396 & 39 & 372 & 29 & TR \\
\hline EMBL1 & & & 332 & RN \\
\hline CHEMBL1322264 & & & 5.3862 & \\
\hline CHEMBL1598370 & & & $\partial 14$ & \\
\hline HEMBL134825 & 688239 & 5.1862 & 5.4709 & ГRN \\
\hline
\end{tabular}

Page 1621 


\begin{tabular}{|c|c|c|c|c|c|}
\hline \multicolumn{6}{|c|}{ Supplemental Table s2.txt } \\
\hline CHEMBL1536768 & 688239 & 5.4362 & 5.4124 & TRN & \\
\hline CHEMBL1596707 & 688239 & 7.1361 & 5.5628 & TST & \\
\hline CHEMBL1527719 & 688239 & 4.5862 & 5.5331 & TRN & \\
\hline CHEMBL1567620 & 688239 & 4.8862 & 5.4271 & TRN & \\
\hline CHEMBL1549422 & 688239 & 5.1362 & 5.441 & TRN & \\
\hline CHEMBL1306454 & 688239 & 4.8862 & 5.6557 & TRN & \\
\hline CHEMBL1361660 & 688239 & 4.5362 & 5.5101 & TRN & \\
\hline CHEMBL1522893 & 688239 & 6.0862 & 5.4926 & TST & \\
\hline CHEMBL1545745 & 688239 & 5.2362 & 5.5306 & TRN & \\
\hline CHEMBL1512665 & 688239 & 6.0862 & 5.4817 & TRN & \\
\hline CHEMBL1341384 & 688239 & 4.5362 & 5.4063 & TRN & \\
\hline CHEMBL1603845 & 688239 & 5.3362 & 5.5184 & TRN & \\
\hline CHEMBL3198024 & 688239 & 8.1367 & \multicolumn{2}{|c|}{5.587999999999999} & TRN \\
\hline CHEMBL1492851 & 688239 & 5.6862 & 5.4645 & TRN & \\
\hline CHEMBL1304360 & 688239 & 5.8862 & 5.4557 & TRN & \\
\hline CHEMBL1366078 & 688239 & 6.7862 & 5.7273 & TRN & \\
\hline CHEMBL1364889 & 688239 & 4.6862 & 5.5003 & TRN & \\
\hline CHEMBL1389742 & 688239 & 4.5862 & 5.3056 & TST & \\
\hline CHEMBL1611908 & 688239 & 6.2362 & 5.3751 & TRN & \\
\hline CHEMBL1482982 & 688239 & 4.6862 & \multicolumn{2}{|c|}{5.531000000000001} & TRN \\
\hline CHEMBL1462726 & 688239 & 4.5362 & \multicolumn{2}{|c|}{5.417999999999999} & TRN \\
\hline CHEMBL1441662 & 688239 & 6.6861 & 5.4625 & TRN & \\
\hline CHEMBL1584270 & 688239 & 4.5362 & 5.3736 & TRN & \\
\hline CHEMBL1324748 & 688239 & 4.5862 & 5.3104 & TRN & \\
\hline CHEMBL1584713 & 688239 & 6.2362 & 5.5384 & TRN & \\
\hline CHEMBL1507077 & 688239 & 6.2862 & 5.4851 & TRN & \\
\hline CHEMBL1444520 & 688239 & 6.9863 & 5.4769 & TRN & \\
\hline CHEMBL1517925 & 688239 & 4.7862 & 5.5093 & TRN & \\
\hline CHEMBL1536988 & 688239 & 4.5362 & 5.396 & TRN & \\
\hline CHEMBL1444455 & 688239 & 6.3362 & 5.4823 & TRN & \\
\hline CHEMBL1348605 & 688239 & 5.4362 & 5.4487 & TRN & \\
\hline CHEMBL1531698 & 688239 & 4.5362 & 5.3817 & TST & \\
\hline CHEMBL1312745 & 688239 & 4.6862 & 5.4827 & TRN & \\
\hline CHEMBL1344792 & 688239 & 5.5862 & 5.4387 & TST & \\
\hline CHEMBL1419030 & 688239 & 6.5862 & 5.4056 & TRN & \\
\hline CHEMBL1428118 & 688239 & 5.0862 & 5.3989 & TRN & \\
\hline CHEMBL1305292 & 688239 & 4.9862 & 5.44 & TRN & \\
\hline CHEMBL1421959 & 688239 & 4.9362 & 5.4172 & TRN & \\
\hline CHEMBL1453976 & 688239 & 6.1362 & 5.6625 & TRN & \\
\hline CHEMBL1528969 & 688239 & 4.5862 & 5.5059 & TRN & \\
\hline CHEMBL1582666 & 688239 & 4.5362 & 5.407 & TRN & \\
\hline CHEMBL1372559 & 688239 & 4.7362 & 5.4933 & TST & \\
\hline CHEMBL1318180 & 688239 & 7.8356 & 5.3716 & TST & \\
\hline CHEMBL1326975 & 688239 & 4.5362 & 5.5541 & TST & \\
\hline CHEMBL1484769 & 688239 & 5.9362 & 5.4239 & TST & \\
\hline CHEMBL1504231 & 688239 & 5.4362 & 5.5289 & TRN & \\
\hline CHEMBL1593585 & 688239 & 5.4362 & 5.3911 & TRN & \\
\hline \multirow[t]{2}{*}{ CHEMBL3199822 } & 688239 & 5.6862 & \multicolumn{2}{|c|}{5.332999999999999} & TRN \\
\hline & & & & 162 & \\
\hline
\end{tabular}


Supplemental Table S2.txt

\begin{tabular}{|c|c|c|c|c|}
\hline & & & & \\
\hline AEMBL1590905 & 38239 & 4362 & & \\
\hline IEMBL1474355 & 8239 & 1862 & 4211 & \\
\hline HEMBL1583949 & 239 & 1362 & 327 & \\
\hline 981 & 239 & 362 & & \\
\hline IEMBL 3196897 & 239 & 362 & & \\
\hline AEMBL1425957 & 88239 & 1862 & & \\
\hline AEMBL1438866 & 88239 & 4.7362 & 3458 & \\
\hline AEMBL1433693 & 239 & 362 & & \\
\hline IEMBL13 & 239 & 362 & 986 & \\
\hline HEMBL132 & & & & \\
\hline AEMBL1371605 & 688239 & 362 & 541 & \\
\hline AEMBL1606041 & 239 & 862 & 09 & \\
\hline IEMBL1393565 & & 61 & & \\
\hline IEMBL134 & & & & \\
\hline AEMBL1423944 & & & & \\
\hline AEMBL1359934 & 239 & 862 & & \\
\hline AEMBL1563110 & & 362 & & \\
\hline IEMBL1348128 & & 62 & & \\
\hline AEMBL1444169 & & & & \\
\hline AEMBL1411284 & & 62 & & \\
\hline AEMBL1468115 & & & & \\
\hline AEMBL1419822 & & 62 & & \\
\hline IEMBL15 & & 62 & & \\
\hline AEMBL14 & & 52 & & \\
\hline AFMRI 15 & & 62 & & \\
\hline AEMBL1327076 & & 362 & & \\
\hline AEMBL1390005 & & & & \\
\hline AEMBL1477488 & & 362 & & \\
\hline HEMBL135 & & 62 & & \\
\hline 152 & & 62 & & \\
\hline HEMBL1349948 & & & & \\
\hline AEMBL1338484 & & & & \\
\hline IEMBL1391175 & & 862 & & \\
\hline HEMBL1430978 & & 62 & & \\
\hline & & 62 & & \\
\hline AEMBL1394144 & & & & \\
\hline AEMBL1592423 & & & & \\
\hline IEMBL131C & & 62 & & \\
\hline HEMBL1359939 & & 4. & & \\
\hline 1431384 & & 8. & & \\
\hline HEMBL1388237 & & 862 & & \\
\hline IEMBL1551436 & & 62 & & \\
\hline EMBL1553 & & & & \\
\hline CHEMBL1339591 & & & & \\
\hline CHEMBL 1452492 & & 362 & & \\
\hline AEMBL1471926 & 38239 & 4.7862 & 5.4717 & \\
\hline HFMRI 1413915 & 688239 & 6.8861 & 5.5934 & \\
\hline
\end{tabular}

Page 1623 
Supplemental Table S2.txt

\begin{tabular}{|c|c|c|c|c|}
\hline CHEMBL1392821 & 688239 & 4.5362 & 5.5136 & TRN \\
\hline CHEMBL1383483 & 688239 & 4.5362 & 5.5144 & TRN \\
\hline CHEMBL1386826 & 688239 & 5.0862 & 5.4452 & TRN \\
\hline CHEMBL1303284 & 688239 & 4.4862 & 5.5144 & TST \\
\hline CHEMBL1593380 & 688239 & 6.3362 & 5.4873 & TRN \\
\hline CHEMBL1382525 & 688239 & 4.6862 & 5.4235 & TRN \\
\hline CHEMBL1417537 & 688239 & 5.7362 & 5.5667 & TRN \\
\hline CHEMBL1384228 & 688239 & 4.5362 & 5.4447 & TRN \\
\hline CHEMBL1365604 & 688239 & 4.5362 & 5.7681 & TST \\
\hline CHEMBL1468544 & 688239 & 5.1862 & 5.5965 & TST \\
\hline CHEMBL1395857 & 688239 & 4.9862 & 5.4993 & TRN \\
\hline CHEMBL1480146 & 688239 & 6.1362 & 5.4493 & TRN \\
\hline CHEMBL1558040 & 688239 & 4.6862 & 5.3865 & TST \\
\hline CHEMBL1343381 & 688239 & 5.0862 & 5.416 & TRN \\
\hline CHEMBL1300941 & 688239 & 4.6362 & 5.6175 & TRN \\
\hline CHEMBL1432896 & 688239 & 6.3362 & 5.4527 & TRN \\
\hline CHEMBL1413438 & 688239 & 6.9863 & 5.5052 & TRN \\
\hline CHEMBL1302367 & 688239 & 6.1362 & 5.506 & TRN \\
\hline CHEMBL1428720 & 688239 & 4.7362 & 5.4771 & TRN \\
\hline CHEMBL1331417 & 688239 & 5.1862 & 5.5652 & TRN \\
\hline CHEMBL1471771 & 688239 & 6.9863 & 5.5738 & TRN \\
\hline CHEMBL1577038 & 688239 & 6.9863 & 5.519 & TRN \\
\hline CHEMBL1494939 & 688239 & 5.3362 & 5.3827 & TST \\
\hline CHEMBL1522239 & 688239 & 4.6862 & 5.4085 & TRN \\
\hline CHEMBL1550049 & 688239 & 6.1362 & 5.2926 & TST \\
\hline CHEMBL1583473 & 688239 & 5.1862 & 5.5565 & TRN \\
\hline CHEMBL1457415 & 688239 & 4.5362 & 5.57799 & э999999999 \\
\hline CHEMBL1393475 & 688239 & 5.4862 & 5.3948 & TST \\
\hline CHEMBL1534023 & 688239 & 8.1871 & 5.5892 & TRN \\
\hline CHEMBL1885024 & 688239 & 4.8862 & 5.414 & TRN \\
\hline CHEMBL1359019 & 688239 & 5.8362 & 5.4465 & TRN \\
\hline CHEMBL1598724 & 688239 & 6.2862 & 5.652 & TRN \\
\hline CHEMBL1433849 & 688239 & 5.1862 & 5.5157 & TRN \\
\hline CHEMBL1318822 & 688239 & 6.1862 & 5.3668 & TRN \\
\hline CHEMBL1530047 & 688239 & 4.7362 & 5.3707 & TST \\
\hline CHEMBL1488057 & 688239 & 4.5362 & 5.4884 & TRN \\
\hline CHEMBL1471080 & 688239 & 5.6862 & 5.4279 & TRN \\
\hline CHEMBL1564114 & 688239 & 5.6862 & 5.5338 & TST \\
\hline CHEMBL1312990 & 688239 & 5.5362 & 5.6783 & TRN \\
\hline CHEMBL1548861 & 688239 & 4.5362 & 5.3776 & TST \\
\hline CHEMBL1483330 & 688239 & 5.7362 & 5.5339 & TST \\
\hline CHEMBL 3207976 & 688239 & 5.4862 & 5.4775 & TST \\
\hline CHEMBL3209046 & 688239 & 4.4862 & 5.5837 & TRN \\
\hline CHEMBL1416994 & 688239 & 4.5362 & 5.4599 & TST \\
\hline CHEMBL1496767 & 688239 & 6.1862 & 5.6022 & TRN \\
\hline CHEMBL1583794 & 688239 & 5.1862 & 5.4861 & TRN \\
\hline CHEMBL1574746 & 688239 & 4.7362 & 5.4864 & TRN \\
\hline CHEMBL1414879 & 688239 & 5.3362 & 5.7809 & TRN \\
\hline
\end{tabular}


Supplemental Table S2.txt

\begin{tabular}{|c|c|c|c|c|}
\hline CHEMBL1480001 & 688239 & 4.5362 & 5.3306 & TST \\
\hline CHEMBL1484918 & 688239 & 4.5362 & 5.5666 & TRN \\
\hline CHEMBL1380694 & 688239 & 4.4862 & 5.4791 & TRN \\
\hline CHEMBL1391021 & 688239 & 4.9362 & 5.4216 & TRN \\
\hline CHEMBL1538642 & 688239 & 5.6862 & 5.2735 & TRN \\
\hline CHEMBL3213545 & 688239 & 4.6862 & 5.5086 & TRN \\
\hline CHEMBL1604025 & 688239 & 4.5362 & 5.5419 & TRN \\
\hline CHEMBL1583569 & 688239 & 4.4862 & 5.4433 & TRN \\
\hline CHEMBL1337785 & 688239 & 5.0362 & 5.5196 & TRN \\
\hline CHEMBL1417048 & 688239 & 6.0362 & 5.4885 & TRN \\
\hline CHEMBL1424721 & 688239 & 6.7862 & 5.4986 & TRN \\
\hline CHEMBL1557294 & 688239 & 4.8862 & 5.4252 & TRN \\
\hline CHEMBL1512671 & 688239 & 8.3372 & 5.6004 & TRN \\
\hline CHEMBL1432526 & 688239 & 4.5862 & 5.4325 & TRN \\
\hline CHEMBL1450820 & 688239 & 4.6862 & 5.46899 & 9999999999 \\
\hline CHEMBL1327442 & 688239 & 5.8862 & 5.5397 & TRN \\
\hline CHEMBL1515119 & 688239 & 5.0862 & 5.51 & TST \\
\hline CHEMBL1465815 & 688239 & 4.5362 & 5.3762 & TRN \\
\hline CHEMBL1498576 & 688239 & 4.7362 & 5.5509 & TST \\
\hline CHEMBL1579436 & 688239 & 5.0862 & 5.4874 & TRN \\
\hline CHEMBL1385549 & 688239 & 5.8362 & 5.4642 & TRN \\
\hline CHEMBL1323160 & 688239 & 6.3863 & 5.4076 & TST \\
\hline CHEMBL1301934 & 688239 & 6.6861 & 5.4696 & TRN \\
\hline CHEMBL1419564 & 688239 & 5.6362 & 5.5139 & TRN \\
\hline CHEMBL1592015 & 688239 & 4.7362 & 5.6312 & TRN \\
\hline CHEMBL1413856 & 688239 & 5.4862 & 5.49 & TRN \\
\hline CHEMBL1326634 & 688239 & 4.6862 & 5.359 & TST \\
\hline CHEMBL1435056 & 688239 & 6.3362 & 5.4478 & TST \\
\hline CHEMBL1496418 & 688239 & 4.5362 & 5.4277 & TRN \\
\hline CHEMBL1342867 & 688239 & 4.7862 & 5.4229 & TRN \\
\hline CHEMBL1323644 & 688239 & 5.7362 & 5.4619 & TRN \\
\hline CHEMBL1603760 & 688239 & 4.6362 & 5.46299 & 9999999999 \\
\hline CHEMBL1311386 & 688239 & 6.1362 & 5.48600 & 0000000001 \\
\hline CHEMBL1339052 & 688239 & 4.4862 & 5.5061 & TRN \\
\hline CHEMBL1508538 & 688239 & 5.6862 & 5.5269 & TRN \\
\hline CHEMBL1495714 & 688239 & 4.5362 & 5.4448 & TST \\
\hline CHEMBL1435155 & 688239 & 8.3372 & 5.5373 & TRN \\
\hline CHEMBL1535144 & 688239 & 7.1864 & 5.5541 & TRN \\
\hline CHEMBL1391895 & 688239 & 5.1862 & 5.5406 & TRN \\
\hline CHEMBL1381288 & 688239 & 6.1862 & 5.4271 & TRN \\
\hline CHEMBL1373205 & 688239 & 7.7852 & 5.4751 & TRN \\
\hline CHEMBL1548908 & 688239 & 4.5362 & 5.3991 & TRN \\
\hline CHEMBL1463406 & 688239 & 5.7862 & 5.4163 & TRN \\
\hline CHEMBL1450270 & 688239 & 4.6362 & 5.5912 & TRN \\
\hline CHEMBL3212934 & 688239 & 4.6362 & 5.3117 & TST \\
\hline CHEMBL1586442 & 688239 & 5.4362 & 5.6004 & TRN \\
\hline CHEMBL1553438 & 688239 & 4.5362 & 5.5773 & TRN \\
\hline CHEMBL1588133 & 688239 & 4.9 & 5.3824 & TRN \\
\hline
\end{tabular}




\begin{tabular}{|c|c|c|c|c|c|}
\hline & & & 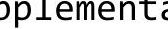 & & \\
\hline CHEMBL1377898 & 688239 & 7.2366 & 5.5251 & TRN & \\
\hline CHEMBL1399779 & 688239 & 4.5362 & 5.4902 & TRN & \\
\hline CHEMBL1564232 & 688239 & 7.1864 & 5.55399 & 9999999999 & TRN \\
\hline CHEMBL1313568 & 688239 & 5.1862 & 5.5229 & TRN & \\
\hline CHEMBL1324284 & 688239 & 5.8862 & 5.6204 & TST & \\
\hline CHEMBL1344325 & 688239 & 6.9863 & 5.5344 & TRN & \\
\hline CHEMBL1328726 & 688239 & 4.5362 & 5.5685 & TRN & \\
\hline CHEMBL1450480 & 688239 & 4.7362 & 5.6774 & TRN & \\
\hline CHEMBL1612787 & 688239 & 6.3863 & 5.4822 & TRN & \\
\hline CHEMBL1608952 & 688239 & 4.7362 & 5.5934 & TRN & \\
\hline CHEMBL1470879 & 688239 & 6.3362 & 5.5987 & TRN & \\
\hline CHEMBL1465102 & 688239 & 6.2362 & 5.5666 & TRN & \\
\hline CHEMBL1421411 & 688239 & 5.1362 & 5.5604 & TRN & \\
\hline CHEMBL1463144 & 688239 & 4.7362 & 5.45299 & 9999999999 & TRN \\
\hline CHEMBL1493533 & 688239 & 6.8362 & 5.6063 & TST & \\
\hline CHEMBL1491992 & 688239 & 4.6362 & 5.4382 & TRN & \\
\hline CHEMBL3391890 & 688239 & 6.8362 & 5.646 & TRN & \\
\hline CHEMBL1312646 & 688239 & 5.5362 & 5.4659 & TRN & \\
\hline CHEMBL1578495 & 688239 & 6.2862 & 5.5364 & TRN & \\
\hline CHEMBL1464213 & 688239 & 7.2366 & 5.3912 & TST & \\
\hline CHEMBL1385368 & 688239 & 4.9362 & 5.5884 & TRN & \\
\hline CHEMBL1406114 & 688239 & 4.5362 & 5.4373 & TRN & \\
\hline CHEMBL1569239 & 688239 & 4.8362 & 5.4607 & TRN & \\
\hline CHEMBL1468922 & 688239 & 5.1862 & 5.3691 & TRN & \\
\hline CHEMBL1410163 & 688239 & 4.5862 & 5.4678 & TST & \\
\hline CHEMBL1462144 & 688239 & 4.5362 & 5.5176 & TST & \\
\hline CHEMBL1340139 & 688239 & 6.7361 & 5.7279 & TRN & \\
\hline CHEMBL1489795 & 688239 & 4.9862 & 5.4374 & TRN & \\
\hline CHEMBL1979018 & 688239 & 5.5362 & 5.4139 & TRN & \\
\hline CHEMBL1580472 & 688239 & 5.5862 & 5.4456 & TST & \\
\hline CHEMBL1439371 & 688239 & 5.2362 & 5.6103 & TRN & \\
\hline CHEMBL1570686 & 688239 & 5.1862 & 5.5551 & TRN & \\
\hline CHEMBL1480300 & 688239 & 5.3862 & 5.5412 & TST & \\
\hline CHEMBL1555215 & 688239 & 4.5362 & 5.402 & TRN & \\
\hline CHEMBL3197566 & 688239 & 4.7362 & 5.4369 & TST & \\
\hline CHEMBL1431081 & 688239 & 4.6362 & 5.4612 & TRN & \\
\hline CHEMBL1343324 & 688239 & 5.0362 & 5.499 & TRN & \\
\hline CHEMBL1504631 & 688239 & 5.9862 & 5.5296 & TST & \\
\hline CHEMBL3197744 & 688239 & 5.7362 & 5.3942 & TRN & \\
\hline CHEMBL1336631 & 688239 & 4.6862 & 5.4658 & TRN & \\
\hline CHEMBL1326592 & 688239 & 4.5362 & 5.5453 & TRN & \\
\hline CHEMBL1328730 & 688239 & 4.5362 & 5.4579 & TRN & \\
\hline CHEMBL1420950 & 688239 & 5.6362 & 5.4116 & TRN & \\
\hline CHEMBL1569850 & 688239 & 5.1362 & 5.3803 & TRN & \\
\hline CHEMBL1588729 & 688239 & 5.6862 & 5.6343 & TST & \\
\hline CHEMBL1611437 & 688239 & 4.5362 & 5.6485 & TRN & \\
\hline CHEMBL1569929 & 688239 & 7.1361 & 5.4734 & TRN & \\
\hline CHEMBL1486661 & 688239 & 4.6362 & 5.4267 & TRN & \\
\hline
\end{tabular}




\begin{tabular}{|c|c|c|c|c|c|}
\hline \multicolumn{6}{|c|}{ Supplemental Table S2.txt } \\
\hline CHEMBL3189553 & 688239 & 6.0 & 5.5498 & TRN & \\
\hline CHEMBL1549803 & 688239 & 5.7362 & 5.5457 & TRN & \\
\hline CHEMBL1351116 & 688239 & 4.5362 & 5.5181 & TRN & \\
\hline CHEMBL1407837 & 688239 & 6.3362 & 5.4751 & TRN & \\
\hline CHEMBL1426294 & 688239 & 5.1862 & 5.5681 & TRN & \\
\hline CHEMBL1582674 & 688239 & 5.0862 & 5.3673 & TRN & \\
\hline CHEMBL1451521 & 688239 & 4.5362 & 5.5357 & TRN & \\
\hline CHEMBL1578072 & 688239 & 4.5362 & 5.6888 & TRN & \\
\hline CHEMBL1582915 & 688239 & 4.5362 & 5.4874 & TST & \\
\hline CHEMBL1554863 & 688239 & 4.5362 & 5.5118 & TRN & \\
\hline CHEMBL1330009 & 688239 & 4.5362 & 5.6187 & TRN & \\
\hline CHEMBL1584411 & 688239 & 5.3362 & 5.4715 & TRN & \\
\hline CHEMBL1466474 & 688239 & 6.1862 & 5.6338 & TRN & \\
\hline CHEMBL1329079 & 688239 & 4.6362 & 5.5373 & TRN & \\
\hline CHEMBL1446257 & 688239 & 5.1862 & 5.5113 & TRN & \\
\hline CHEMBL1603931 & 688239 & 4.5362 & 5.5757 & TST & \\
\hline CHEMBL1571441 & 688239 & 6.1362 & 5.5444 & TRN & \\
\hline CHEMBL1581043 & 688239 & 5.4362 & 5.4532 & TST & \\
\hline CHEMBL1548092 & 688239 & 4.5862 & 5.4631 & TRN & \\
\hline CHEMBL1474793 & 688239 & 5.0862 & 5.4817 & TRN & \\
\hline CHEMBL1483870 & 688239 & 4.8362 & 5.5459 & TST & \\
\hline CHEMBL1611000 & 688239 & 5.1862 & 5.5499 & TRN & \\
\hline CHEMBL1359086 & 688239 & 5.2362 & 5.523 & TRN & \\
\hline CHEMBL1526507 & 688239 & 5.6362 & 5.4069 & TRN & \\
\hline CHEMBL1444297 & 688239 & 6.2862 & 5.5138 & TRN & \\
\hline CHEMBL2005119 & 688239 & 4.9362 & 5.4991 & TRN & \\
\hline CHEMBL1409112 & 688239 & 4.5362 & 5.5936 & TST & \\
\hline CHEMBL1506005 & 688239 & 5.3862 & 5.5617 & TRN & \\
\hline CHEMBL1319953 & 688239 & 5.5362 & 5.5575 & TRN & \\
\hline CHEMBL1495198 & 688239 & 6.6861 & 5.4116 & TST & \\
\hline CHEMBL1318944 & 688239 & 4.5362 & 5.472 & TRN & \\
\hline CHEMBL3213672 & 688239 & 5.4362 & 5.40799 & 99999999995 & TRN \\
\hline CHEMBL1425175 & 688239 & 5.3362 & 5.48600 & 0000000001 & TRN \\
\hline CHEMBL1389614 & 688239 & 5.6862 & 5.4703 & TRN & \\
\hline CHEMBL1335129 & 688239 & 4.7862 & 5.4561 & TRN & \\
\hline CHEMBL1475138 & 688239 & 4.5862 & 5.29299 & 9999999999 & TRN \\
\hline CHEMBL1432873 & 688239 & 4.8862 & 5.5611 & TRN & \\
\hline CHEMBL1405356 & 688239 & 4.6362 & 5.5475 & TST & \\
\hline CHEMBL1368938 & 688239 & 4.5362 & 5.364 & TST & \\
\hline CHEMBL1305806 & 688239 & 4.7362 & 5.55200 & 00000000005 & TRN \\
\hline CHEMBL1489855 & 688239 & 4.8362 & 5.472 & TRN & \\
\hline CHEMBL1522032 & 688239 & 5.3362 & 5.4459 & TRN & \\
\hline CHEMBL1306261 & 688239 & 5.8362 & 5.4639 & TST & \\
\hline CHEMBL1368940 & 688239 & 8.3372 & 5.496 & TRN & \\
\hline CHEMBL1361729 & 688239 & 4.4862 & 5.53700 & 0000000001 & TRN \\
\hline CHEMBL1517254 & 688239 & 7.1864 & 5.3366 & TRN & \\
\hline CHEMBL1575451 & 688239 & 4.9862 & 5.5217 & TRN & \\
\hline CHEMBL1400641 & 688239 & 4.5362 & 5.6189 & TRN & \\
\hline
\end{tabular}


Supplemental Table S2.txt

\begin{tabular}{|c|c|c|c|c|}
\hline CHEMBL1502177 & 688239 & 6.7862 & 5.5438 & TRN \\
\hline CHEMBL1464848 & 688239 & 4.5362 & 5.4279 & TRN \\
\hline CHEMBL1525972 & 688239 & 5.1862 & 5.4307 & TRN \\
\hline CHEMBL1305467 & 688239 & 4.7362 & 5.5559 & TRN \\
\hline CHEMBL1329901 & 688239 & 6.5363 & 5.6066 & TRN \\
\hline CHEMBL1463933 & 688239 & 5.3862 & 5.4203 & TST \\
\hline CHEMBL 3195741 & 688239 & 4.9362 & \multicolumn{2}{|c|}{5.388999999999999} \\
\hline CHEMBL1519784 & 688239 & 5.7862 & 5.426 & TRN \\
\hline CHEMBL1305004 & 688239 & 4.6362 & 5.4776 & TRN \\
\hline CHEMBL1477430 & 688239 & 5.3362 & 5.4287 & TRN \\
\hline CHEMBL1422648 & 688239 & 5.1862 & 5.4517 & TST \\
\hline CHEMBL1477193 & 688239 & 7.5867 & 5.4468 & TRN \\
\hline CHEMBL1546152 & 688239 & 5.6862 & 5.5982 & TRN \\
\hline CHEMBL1496476 & 688239 & 6.1362 & 5.4495 & TRN \\
\hline CHEMBL1610205 & 688239 & 5.8862 & 5.4567 & TST \\
\hline CHEMBL1462951 & 688239 & 4.7362 & 5.4284 & TRN \\
\hline CHEMBL1305216 & 688239 & 5.2362 & 5.4667 & TRN \\
\hline CHEMBL1359756 & 688239 & 5.7362 & 5.4626 & TRN \\
\hline CHEMBL1432790 & 688239 & 4.4862 & 5.3835 & TRN \\
\hline CHEMBL1552849 & 688239 & 6.9863 & 5.5385 & TRN \\
\hline CHEMBL1583796 & 688239 & 5.2362 & 5.5114 & TRN \\
\hline CHEMBL1453907 & 688239 & 5.2862 & 5.4687 & TRN \\
\hline CHEMBL1422570 & 688239 & 6.4862 & 5.4923 & TRN \\
\hline CHEMBL1340556 & 688239 & 4.9862 & 5.5654 & TRN \\
\hline CHEMBL 3182281 & 688239 & 5.1862 & 5.4345 & TRN \\
\hline CHEMBL1393165 & 688239 & 5.3862 & 5.4215 & TST \\
\hline CHEMBL1316993 & 688239 & 6.7361 & 5.4729 & TRN \\
\hline CHEMBL1484139 & 688239 & 4.4862 & 5.5129 & TST \\
\hline CHEMBL1386358 & 688239 & 5.4362 & 5.5082 & TRN \\
\hline CHEMBL1372949 & 688239 & 4.7362 & 5.5218 & TRN \\
\hline CHEMBL1471878 & 688239 & 5.1362 & 5.5898 & TRN \\
\hline CHEMBL1385448 & 688239 & 7.1361 & 5.4886 & TRN \\
\hline CHEMBL1520175 & 688239 & 5.5862 & 5.537006 & 000000001 \\
\hline CHEMBL1579764 & 688239 & 5.2362 & 5.4119 & TRN \\
\hline CHEMBL1390035 & 688239 & 4.5362 & 5.4385 & TRN \\
\hline CHEMBL1398949 & 688239 & 5.0362 & 5.4102 & TST \\
\hline CHEMBL1465750 & 688239 & 5.1862 & 5.4645 & TST \\
\hline CHEMBL1599099 & 688239 & 5.1362 & 5.606 & TST \\
\hline CHEMBL1359146 & 688239 & 4.5362 & 5.4929 & TST \\
\hline CHEMBL1409239 & 688239 & 6.2362 & 5.6437 & TST \\
\hline CHEMBL1304097 & 688239 & 6.4862 & 5.5472 & TST \\
\hline CHEMBL1473174 & 688239 & 5.4862 & 5.4762 & TRN \\
\hline CHEMBL1387557 & 688239 & 4.5862 & 5.5394 & TST \\
\hline CHEMBL1383263 & 688239 & 5.7862 & 5.4841 & TRN \\
\hline CHEMBL1364476 & 688239 & 6.1862 & 5.6254 & TRN \\
\hline CHEMBL1492677 & 688239 & 4.6862 & 5.3615 & TRN \\
\hline CHEMBL1566828 & 688239 & 5.7362 & 5.5866 & TRN \\
\hline CHEMBL1536711 & 688239 & 5.2362 & 5.5076 & TST \\
\hline
\end{tabular}


Supplemental Table S2.txt

\begin{tabular}{|c|c|c|c|c|c|}
\hline CHEMBL1331979 & 688239 & 5.4862 & 5.4856 & TRN & \\
\hline CHEMBL1610971 & 688239 & 6.2862 & 5.5982 & TRN & \\
\hline CHEMBL1562685 & 688239 & 5.3362 & 5.5409 & TRN & \\
\hline CHEMBL1562744 & 688239 & 4.5362 & 5.3993 & TRN & \\
\hline CHEMBL1507206 & 688239 & 5.0862 & 5.4333 & TRN & \\
\hline CHEMBL1561006 & 688239 & 7.0362 & 5.4864 & TRN & \\
\hline CHEMBL1366966 & 688239 & 6.4862 & 5.4686 & TRN & \\
\hline CHEMBL1460766 & 688239 & 5.3362 & 5.5225 & TRN & \\
\hline CHEMBL1513640 & 688239 & 6.5862 & 5.4865 & TRN & \\
\hline CHEMBL3195898 & 688239 & 4.4862 & 5.3809 & TRN & \\
\hline CHEMBL1548122 & 688239 & 4.5362 & 5.3208 & TST & \\
\hline CHEMBL1401414 & 688239 & 5.3862 & 5.5601 & TRN & \\
\hline CHEMBL1540056 & 688239 & 6.0862 & 5.5892 & TRN & \\
\hline CHEMBL1569149 & 688239 & 4.5362 & 5.4708 & TRN & \\
\hline CHEMBL1587995 & 688239 & 6.2362 & 5.5313 & TRN & \\
\hline CHEMBL1430014 & 688239 & 5.9362 & 5.6257 & TST & \\
\hline CHEMBL1460460 & 688239 & 5.4362 & 5.5495 & TRN & \\
\hline CHEMBL1406196 & 688239 & 8.3372 & 5.4926 & TST & \\
\hline CHEMBL1577969 & 688239 & 5.1862 & 5.3246 & TRN & \\
\hline CHEMBL1576580 & 688239 & 4.5862 & 5.4123 & TRN & \\
\hline CHEMBL1864040 & 688239 & 4.6862 & 5.2211 & TRN & \\
\hline CHEMBL1556219 & 688239 & 7.0862 & 5.4455 & TRN & \\
\hline CHEMBL1488861 & 688239 & 6.2862 & 5.68 & TRN & \\
\hline CHEMBL1571648 & 688239 & 4.8862 & 5.5427 & TST & \\
\hline CHEMBL1368164 & 688239 & 4.5362 & 5.6096 & TRN & \\
\hline CHEMBL1569036 & 688239 & 5.2862 & 5.5498 & TRN & \\
\hline CHEMBL1500409 & 688239 & 5.1362 & 5.5589 & TST & \\
\hline CHEMBL3210792 & 688239 & 6.1862 & 5.4018 & TRN & \\
\hline CHEMBL1449047 & 688239 & 4.5362 & 5.4483 & TRN & \\
\hline CHEMBL1406729 & 688239 & 4.6862 & 5.5931 & TRN & \\
\hline CHEMBL1320295 & 688239 & 5.6862 & 5.4134 & TRN & \\
\hline CHEMBL 3194054 & 688239 & 5.8362 & 5.4738 & TRN & \\
\hline CHEMBL1408772 & 688239 & 4.7362 & 5.4293 & TRN & \\
\hline CHEMBL1570001 & 688239 & 5.9362 & 5.3828 & TRN & \\
\hline CHEMBL1443482 & 688239 & 4.8862 & \multicolumn{2}{|c|}{5.712999999999999} & TRN \\
\hline CHEMBL1578744 & 688239 & 5.1362 & 5.5041 & TRN & \\
\hline CHEMBL1324394 & 688239 & 5.3862 & 5.4237 & TRN & \\
\hline CHEMBL1326074 & 688239 & 4.7362 & 5.4794 & TRN & \\
\hline CHEMBL1322070 & 688239 & 4.7362 & 5.4582 & TRN & \\
\hline CHEMBL1328314 & 688239 & 5.9862 & 5.4342 & TRN & \\
\hline CHEMBL1513224 & 688239 & 5.1362 & 5.6007 & TRN & \\
\hline CHEMBL1470483 & 688239 & 5.2862 & 5.2186 & TRN & \\
\hline CHEMBL1583947 & 688239 & 5.3862 & 5.4557 & TRN & \\
\hline CHEMBL1420862 & 688239 & 6.1362 & 5.541 & TRN & \\
\hline CHEMBL1588387 & 688239 & 5.9862 & 5.4604 & TRN & \\
\hline CHEMBL1506135 & 688239 & 6.9363 & 5.5658 & TRN & \\
\hline CHEMBL161254 & 688239 & 4.5362 & 5.4239 & TRN & \\
\hline CHEMBL1432045 & 688239 & 7.1864 & 5.6323 & TRN & \\
\hline
\end{tabular}

Page 1629 
Supplemental Table S2.txt

\begin{tabular}{|c|c|c|c|c|c|}
\hline CHEMBL3208840 & 688239 & 5.3362 & 5.3644 & TRN & \\
\hline CHEMBL1466446 & 688239 & 4.5362 & 5.4985 & TRN & \\
\hline CHEMBL1470599 & 688239 & 4.5362 & 5.5883 & TRN & \\
\hline CHEMBL1569016 & 688239 & 5.4362 & 5.5358 & TST & \\
\hline CHEMBL1441912 & 688239 & 4.7862 & 5.5194 & TRN & \\
\hline CHEMBL1432447 & 688239 & 4.5362 & 5.3958 & TRN & \\
\hline CHEMBL1370767 & 688239 & 4.5362 & 5.6977 & TRN & \\
\hline CHEMBL1407111 & 688239 & 5.7362 & 5.534 & TRN & \\
\hline CHEMBL1529272 & 688239 & 5.1862 & 5.3988 & TST & \\
\hline CHEMBL1428942 & 688239 & 8.3372 & 5.5112 & TRN & \\
\hline CHEMBL1306386 & 688239 & 8.3372 & 5.5352 & TRN & \\
\hline CHEMBL1436641 & 688239 & 4.5362 & 5.4956 & TST & \\
\hline CHEMBL1530736 & 688239 & 6.8861 & 5.5851 & TRN & \\
\hline CHEMBL1424209 & 688239 & 4.6362 & 5.5217 & TRN & \\
\hline CHEMBL1582989 & 688239 & 5.7362 & 5.4711 & TRN & \\
\hline CHEMBL3193361 & 688239 & 4.6362 & 5.4341 & TST & \\
\hline CHEMBL1426651 & 688239 & 4.8362 & 5.5135 & TRN & \\
\hline CHEMBL1456727 & 688239 & 4.5362 & 5.4532 & TRN & \\
\hline CHEMBL1411432 & 688239 & 6.2362 & 5.5407 & TRN & \\
\hline CHEMBL1463570 & 688239 & 6.1362 & 5.4534 & TRN & \\
\hline CHEMBL3195358 & 688239 & 4.5862 & 5.4159 & TRN & \\
\hline CHEMBL1539351 & 688239 & 6.3362 & 5.4669 & TRN & \\
\hline CHEMBL1321300 & 688239 & 4.5362 & 5.5584 & TRN & \\
\hline CHEMBL1436893 & 688239 & 4.5362 & 5.4048 & TRN & \\
\hline CHEMBL1445372 & 688239 & 5.1862 & 5.3577 & TRN & \\
\hline CHEMBL1497679 & 688239 & 5.1862 & 5.4922 & TRN & \\
\hline CHEMBL1330094 & 688239 & 5.2862 & 5.605 & TRN & \\
\hline CHEMBL1326134 & 688239 & 4.5862 & 5.3744 & TST & \\
\hline CHEMBL1447974 & 688239 & 4.5362 & 5.2715 & TST & \\
\hline CHEMBL3193275 & 688239 & 4.5362 & 5.4241 & TRN & \\
\hline CHEMBL1353155 & 688239 & 5.8362 & 5.4572 & TRN & \\
\hline CHEMBL1456862 & 688239 & 6.1862 & 5.4835 & TRN & \\
\hline CHEMBL1473670 & 688239 & 4.5862 & 5.5533 & TRN & \\
\hline CHEMBL1354236 & 688239 & 5.5362 & 5.5581 & TRN & \\
\hline CHEMBL1564589 & 688239 & 5.0862 & 5.4945 & TRN & \\
\hline CHEMBL3189206 & 688239 & 5.3362 & 5.5086 & TRN & \\
\hline CHEMBL1496980 & 688239 & 4.5362 & 5.4697 & TRN & \\
\hline CHEMBL1593917 & 688239 & 4.5362 & 5.5803 & TRN & \\
\hline CHEMBL3211192 & 688239 & 6.8861 & 5.5511 & TRN & \\
\hline CHEMBL1549210 & 688239 & 5.0362 & 5.388 & TRN & \\
\hline CHEMBL1446651 & 688239 & 8.28399 & 99999999 & 99 & 5.4284 \\
\hline CHEMBL1336815 & 688239 & 4.5362 & 5.5296 & TRN & \\
\hline CHEMBL16223 & 688239 & 4.8362 & 5.3823 & TRN & \\
\hline CHEMBL1308672 & 688239 & 4.8362 & 5.5828 & TST & \\
\hline CHEMBL1592125 & 688239 & 6.8861 & 5.6033 & TRN & \\
\hline CHEMBL1594930 & 688239 & 6.8861 & 5.4534 & TRN & \\
\hline CHEMBL1488113 & 688239 & 5.6862 & 5.4091 & TRN & \\
\hline CHEMBL1558196 & 688239 & 6.1362 & 5.5485 & TRN & \\
\hline
\end{tabular}


Supplemental Table S2.txt

\begin{tabular}{|c|c|c|c|c|}
\hline CHEMBL1583887 & 688239 & 5.8862 & 5.4892 & TRN \\
\hline CHEMBL1378221 & 688239 & 7.4868 & 5.4912 & TST \\
\hline CHEMBL1489640 & 688239 & 4.7862 & 5.5791 & TRN \\
\hline CHEMBL1480662 & 688239 & 4.5862 & 5.4895 & TRN \\
\hline CHEMBL3208173 & 688239 & 4.7862 & 5.4537 & TRN \\
\hline CHEMBL1601004 & 688239 & 4.7362 & 5.4509 & TST \\
\hline CHEMBL1444002 & 688239 & 6.3362 & 5.5159 & TRN \\
\hline CHEMBL1396201 & 688239 & 4.8862 & 5.3996 & TRN \\
\hline CHEMBL1379855 & 688239 & 5.1362 & 5.5518 & TRN \\
\hline CHEMBL1427292 & 688239 & 5.6862 & 5.6366 & TST \\
\hline CHEMBL1331994 & 688239 & 5.3862 & 5.4997 & TRN \\
\hline CHEMBL1334162 & 688239 & 4.7362 & 5.4488 & TRN \\
\hline CHEMBL1449886 & 688239 & 5.7362 & 5.282 & TRN \\
\hline CHEMBL1447199 & 688239 & 7.3363 & 5.5391 & TRN \\
\hline CHEMBL1547058 & 688239 & 4.5362 & 5.4375 & TRN \\
\hline CHEMBL1342737 & 688239 & 5.3362 & 5.4978 & TRN \\
\hline CHEMBL1735961 & 688239 & 4.5362 & 5.4979 & TST \\
\hline CHEMBL1510853 & 688239 & 5.0362 & 5.4619 & TST \\
\hline CHEMBL1539920 & 688239 & 6.2862 & 5.4394 & TRN \\
\hline CHEMBL1388795 & 688239 & 7.2366 & 5.5064 & TRN \\
\hline CHEMBL1387310 & 688239 & 6.2362 & 5.5468 & TRN \\
\hline CHEMBL 2004241 & 688239 & 5.0362 & 5.6213 & TST \\
\hline CHEMBL1395679 & 688239 & 5.0862 & 5.468 & TRN \\
\hline CHEMBL1604030 & 688239 & 4.6862 & 5.5065 & TRN \\
\hline CHEMBL1478767 & 688239 & 5.1862 & 5.5535 & TRN \\
\hline CHEMBL1375752 & 688239 & 4.5362 & 5.4493 & TRN \\
\hline CHEMBL1592862 & 688239 & 4.6362 & 5.5151 & TRN \\
\hline CHEMBL1552101 & 688239 & 5.1862 & 5.4964 & TRN \\
\hline CHEMBL1367123 & 688239 & 6.1362 & 5.4925 & TRN \\
\hline CHEMBL1311392 & 688239 & 4.6862 & 5.4991 & TRN \\
\hline CHEMBL1405338 & 688239 & 4.8362 & 5.4899 & TRN \\
\hline CHEMBL1347751 & 688239 & 4.5362 & 5.3759 & TRN \\
\hline CHEMBL1394454 & 688239 & 5.1862 & 5.5536 & TRN \\
\hline CHEMBL1320249 & 688239 & 5.4362 & 5.5186 & TRN \\
\hline CHEMBL1483012 & 688239 & 5.0362 & 5.4975 & TRN \\
\hline CHEMBL1603807 & 688239 & 6.8861 & 5.5982 & TRN \\
\hline CHEMBL1490556 & 688239 & 5.8362 & 5.5823 & TRN \\
\hline CHEMBL1466550 & 688239 & 5.7362 & 5.5562 & TRN \\
\hline CHEMBL1370096 & 688239 & 4.5862 & 5.32700 & 0000000001 \\
\hline CHEMBL3191839 & 688239 & 4.7862 & 5.3973 & TST \\
\hline CHEMBL1370306 & 688239 & 5.0862 & 5.4892 & TRN \\
\hline CHEMBL3191983 & 688239 & 5.1862 & 5.3421 & TRN \\
\hline CHEMBL1355531 & 688239 & 4.6862 & 5.2509 & TRN \\
\hline CHEMBL1301479 & 688239 & 5.3862 & 5.5656 & TST \\
\hline CHEMBL1416440 & 688239 & 6.2862 & 5.5093 & TST \\
\hline CHEMBL1442301 & 688239 & 6.7862 & 5.4179 & TRN \\
\hline CHEMBL1330880 & 688239 & 5.2362 & 5.4472 & TST \\
\hline CHEMBL1301826 & 688239 & 5.0362 & 5.4196 & TRN \\
\hline
\end{tabular}


Supplemental Table S2.txt

\begin{tabular}{|c|c|c|c|c|c|}
\hline CHEMBL1589766 & 688239 & 4.6862 & 5.4614 & TRN & \\
\hline CHEMBL1499250 & 688239 & 4.5362 & 5.4668 & TST & \\
\hline CHEMBL1548301 & 688239 & 4.7362 & 5.4323 & TRN & \\
\hline CHEMBL1595536 & 688239 & 7.0862 & 5.6218 & TRN & \\
\hline CHEMBL1332615 & 688239 & 4.5362 & 5.3632 & TST & \\
\hline CHEMBL119769 & 688239 & 5.1862 & 5.3875 & TRN & \\
\hline CHEMBL1422179 & 688239 & 5.1862 & 5.5599 & TRN & \\
\hline CHEMBL1556446 & 688239 & 6.5862 & 5.4655 & TRN & \\
\hline CHEMBL1442042 & 688239 & 4.7362 & 5.4871 & TRN & \\
\hline CHEMBL1369908 & 688239 & 5.2362 & 5.5356 & TST & \\
\hline CHEMBL1375130 & 688239 & 6.0862 & 5.4744 & TRN & \\
\hline CHEMBL1474612 & 688239 & 5.1862 & 5.4829 & TRN & \\
\hline CHEMBL1542019 & 688239 & 5.1862 & 5.6187 & TRN & \\
\hline CHEMBL1398090 & 688239 & 6.1362 & 5.3189 & TRN & \\
\hline CHEMBL3189899 & 688239 & 5.6362 & 5.463999 & 9999999995 & TR \\
\hline CHEMBL1488553 & 688239 & 6.2862 & 5.4125 & TRN & \\
\hline CHEMBL1352545 & 688239 & 5.7362 & 5.2522 & TST & \\
\hline CHEMBL1350503 & 688239 & 4.5362 & 5.5366 & TRN & \\
\hline CHEMBL1479436 & 688239 & 4.4362 & 5.3744 & TRN & \\
\hline CHEMBL1475887 & 688239 & 5.1862 & 5.2873 & TST & \\
\hline CHEMBL 3212846 & 688239 & 4.5862 & 5.5847 & TRN & \\
\hline CHEMBL1440061 & 688239 & 5.3862 & 5.4919 & TRN & \\
\hline CHEMBL1501842 & 688239 & 6.3362 & 5.5512 & TRN & \\
\hline CHEMBL535277 & 688239 & 4.5862 & 5.3711 & TST & \\
\hline CHEMBL1382228 & 688239 & 5.5362 & 5.4073 & TRN & \\
\hline CHEMBL1564104 & 688239 & 4.5362 & 5.5283 & TRN & \\
\hline CHEMBL1610410 & 688239 & 4.5362 & 5.4975 & TRN & \\
\hline CHEMBL1409001 & 688239 & 5.7362 & 5.4356 & TST & \\
\hline CHEMBL1452204 & 688239 & 4.5362 & 5.355 & TRN & \\
\hline CHEMBL1579356 & 688239 & 6.6861 & 5.4283 & TST & \\
\hline CHEMBL1455871 & 688239 & 6.2362 & 5.4228 & TRN & \\
\hline CHEMBL1471183 & 688239 & 8.3372 & 5.401 & TST & \\
\hline CHEMBL1315547 & 688239 & 8.28399 & 99999999 & 5.4657 & $1 \mathrm{~N}$ \\
\hline CHEMBL1366987 & 688239 & 4.9362 & 5.3451 & TST & \\
\hline CHEMBL535315 & 688239 & 4.5362 & 5.5131 & TRN & \\
\hline CHEMBL1427383 & 688239 & 7.1864 & 5.5273 & TRN & \\
\hline CHEMBL1338665 & 688239 & 6.2862 & 5.3644 & TRN & \\
\hline CHEMBL 3199914 & 688239 & 5.3862 & 5.5633 & TRN & \\
\hline CHEMBL1531801 & 688239 & 6.2862 & 5.4629 & TRN & \\
\hline CHEMBL1566337 & 688239 & 4.7362 & 5.5058 & TRN & \\
\hline CHEMBL1444323 & 688239 & 5.0862 & 5.4434 & TRN & \\
\hline CHEMBL1521617 & 688239 & 4.5362 & 5.2377 & TRN & \\
\hline CHEMBL 3189497 & 688239 & 5.0362 & 5.3299 & TST & \\
\hline CHEMBL1508543 & 688239 & 5.1862 & 5.37299 & 9999999 & \\
\hline CHEMBL 3189752 & 688239 & 4.4862 & 5.3057 & TST & \\
\hline CHEMBL1401109 & 688239 & 5.5862 & 5.4959 & TRN & \\
\hline CHEMBL1309874 & 688239 & 4.6362 & 5.3478 & TST & \\
\hline CHEMBL1506773 & 688239 & 5.2362 & 5.5763 & TRN & \\
\hline
\end{tabular}

Page 1632 
Supplemental Table S2.txt

\begin{tabular}{|c|c|c|c|c|}
\hline CHEMBL1332560 & 688239 & 8.1871 & 5.5523 & TRN \\
\hline CHEMBL1301472 & 688239 & 6.2862 & 5.6115 & TRN \\
\hline CHEMBL1969470 & 688239 & 4.4862 & 5.4331 & TRN \\
\hline CHEMBL3196635 & 688239 & 6.4362 & 5.46 & TRN \\
\hline CHEMBL1537808 & 688239 & 4.5362 & 5.4829 & TRN \\
\hline CHEMBL1560136 & 688239 & 4.8862 & 5.4674 & TRN \\
\hline CHEMBL1371703 & 688239 & 5.1862 & 5.6093 & TRN \\
\hline CHEMBL1374587 & 688239 & 6.9863 & 5.4065 & TST \\
\hline CHEMBL3212409 & 688239 & 5.5362 & 5.4869 & TST \\
\hline CHEMBL1557049 & 688239 & 4.8362 & 5.4026 & TST \\
\hline CHEMBL1324023 & 688239 & 4.5362 & 5.7084 & TRN \\
\hline CHEMBL1486156 & 688239 & 4.6862 & 5.4725 & TRN \\
\hline CHEMBL1376611 & 688239 & 5.6862 & 5.4687 & TRN \\
\hline CHEMBL1420815 & 688239 & 6.4362 & 5.4104 & TRN \\
\hline CHEMBL1350524 & 688239 & 5.1862 & 5.5276 & TRN \\
\hline CHEMBL1420325 & 688239 & 4.9362 & 5.4106 & TST \\
\hline CHEMBL1602951 & 688239 & 5.1862 & 5.4505 & TRN \\
\hline CHEMBL3211386 & 688239 & 5.9362 & 5.5783 & TRN \\
\hline CHEMBL1319091 & 688239 & 6.6861 & 5.5911 & TRN \\
\hline CHEMBL1532198 & 688239 & 5.1862 & 5.3167 & TST \\
\hline CHEMBL1374919 & 688239 & 4.9862 & 5.4035 & TRN \\
\hline CHEMBL1591782 & 688239 & 6.1362 & 5.4863 & TRN \\
\hline CHEMBL1402073 & 688239 & 8.3372 & 5.4214 & TST \\
\hline CHEMBL3211946 & 688239 & 4.7362 & 5.3372 & TRN \\
\hline CHEMBL1570846 & 688239 & 5.1862 & 5.4689 & TRN \\
\hline CHEMBL1360814 & 688239 & 6.1362 & 5.5413 & TRN \\
\hline CHEMBL1371612 & 688239 & 5.1362 & 5.5949 & TRN \\
\hline CHEMBL1419629 & 688239 & 4.5362 & 5.4868 & TST \\
\hline CHEMBL1566998 & 688239 & 7.1361 & 5.3983 & TRN \\
\hline CHEMBL1464954 & 688239 & 4.8362 & 5.45299 & 99999999999 \\
\hline CHEMBL1302432 & 688239 & 5.2362 & 5.4443 & TRN \\
\hline CHEMBL1513681 & 688239 & 5.1862 & 5.4454 & TRN \\
\hline CHEMBL1487065 & 688239 & 4.4862 & 5.3931 & TST \\
\hline CHEMBL1611853 & 688239 & 6.1362 & 5.4644 & TRN \\
\hline CHEMBL1582453 & 688239 & 4.5362 & 5.4776 & TST \\
\hline CHEMBL1495290 & 688239 & 4.5362 & 5.5119 & TST \\
\hline CHEMBL1420171 & 688239 & 5.4862 & 5.5229 & TST \\
\hline CHEMBL1312799 & 688239 & 6.2362 & 5.3993 & TRN \\
\hline CHEMBL1433831 & 688239 & 5.4862 & 5.4368 & TRN \\
\hline CHEMBL1584879 & 688239 & 5.2362 & 5.3213 & TRN \\
\hline CHEMBL1300500 & 688239 & 6.7862 & 5.4463 & TRN \\
\hline CHEMBL3189245 & 688239 & 7.2366 & 5.50700 & 0000000001 \\
\hline CHEMBL1570332 & 688239 & 5.3362 & 5.4587 & TRN \\
\hline CHEMBL3197151 & 688239 & 4.6862 & 5.5758 & TRN \\
\hline CHEMBL1485664 & 688239 & 6.2362 & 5.5019 & TRN \\
\hline CHEMBL1527210 & 688239 & 5.2862 & 5.6252 & TST \\
\hline CHEMBL1460895 & 688239 & 6.0862 & 5.5695 & TRN \\
\hline CHEMBL3189696 & 688239 & 6.5363 & 5.3919 & TRN \\
\hline
\end{tabular}

Page 1633 


\begin{tabular}{|c|c|c|c|c|c|}
\hline & & & premertice & & \\
\hline CHEMBL1459145 & 688239 & 5.4362 & 5.4522 & TST & \\
\hline CHEMBL1416075 & 688239 & 4.4862 & 5.3235 & TRN & \\
\hline CHEMBL1428528 & 688239 & 5.3362 & 5.38299 & 9999999999 & TRN \\
\hline CHEMBL1462836 & 688239 & 4.5362 & 5.6037 & TRN & \\
\hline CHEMBL1458544 & 688239 & 5.0362 & 5.4235 & TRN & \\
\hline CHEMBL1355536 & 688239 & 4.5362 & 5.5019 & TRN & \\
\hline CHEMBL1324311 & 688239 & 5.1862 & 5.5143 & TRN & \\
\hline CHEMBL1405821 & 688239 & 4.4862 & 5.5524 & TST & \\
\hline CHEMBL3189647 & 688239 & 4.7862 & 5.33899 & 99999999995 & TRN \\
\hline CHEMBL1537895 & 688239 & 5.9862 & 5.4755 & TRN & \\
\hline CHEMBL1581313 & 688239 & 6.2862 & 5.4239 & TRN & \\
\hline CHEMBL1504042 & 688239 & 4.5362 & 5.4997 & TRN & \\
\hline CHEMBL1968217 & 688239 & 6.6362 & 5.4754 & TRN & \\
\hline CHEMBL1547141 & 688239 & 4.5362 & 5.4963 & TRN & \\
\hline CHEMBL1341436 & 688239 & 5.1862 & 5.5829 & TRN & \\
\hline CHEMBL1341245 & 688239 & 5.0362 & 5.5613 & TRN & \\
\hline CHEMBL1359179 & 688239 & 4.4862 & 5.632006 & 0000000001 & TRN \\
\hline CHEMBL1355440 & 688239 & 4.7862 & 5.5825 & TRN & \\
\hline CHEMBL1300233 & 688239 & 6.0862 & 5.5437 & TRN & \\
\hline CHEMBL1529927 & 688239 & 6.7361 & 5.5615 & TRN & \\
\hline CHEMBL1390386 & 688239 & 4.7362 & 5.3444 & TRN & \\
\hline CHEMBL1497263 & 688239 & 5.8362 & 5.4906 & TST & \\
\hline CHEMBL1342814 & 688239 & 5.1862 & 5.4119 & TRN & \\
\hline CHEMBL1553594 & 688239 & 4.6362 & 5.4614 & TRN & \\
\hline CHEMBL1559197 & 688239 & 4.4862 & 5.5053 & TST & \\
\hline CHEMBL1359890 & 688239 & 4.5362 & 5.5084 & TRN & \\
\hline CHEMBL1468191 & 688239 & 6.3362 & 5.6414 & TST & \\
\hline CHEMBL1563927 & 688239 & 7.7852 & 5.4505 & TRN & \\
\hline CHEMBL1328663 & 688239 & 4.5362 & 5.5344 & TRN & \\
\hline CHEMBL587620 & 688239 & 6.9863 & 5.4791 & TRN & \\
\hline CHEMBL600778 & 688239 & 4.7362 & 5.281006 & 0000000001 & TRN \\
\hline CHEMBL1588283 & 688239 & 6.9363 & 5.4465 & TST & \\
\hline CHEMBL1335767 & 688239 & 6.0362 & 5.4632 & TRN & \\
\hline CHEMBL1302532 & 688239 & 4.5362 & 5.5938 & TRN & \\
\hline CHEMBL1375158 & 688239 & 5.0362 & 5.4327 & TRN & \\
\hline CHEMBL1371791 & 688239 & 5.0362 & 5.3694 & TRN & \\
\hline CHEMBL1464289 & 688239 & 5.1862 & 5.4649 & TRN & \\
\hline CHEMBL1380527 & 688239 & 6.2862 & 5.4525 & TST & \\
\hline CHEMBL1574190 & 688239 & 7.4868 & 5.5069 & TRN & \\
\hline CHEMBL1368905 & 688239 & 8.28399 & 99999999 & 5.6566 & TRN \\
\hline CHEMBL1441769 & 688239 & 5.1862 & 5.4728 & TST & \\
\hline CHEMBL3212580 & 688239 & 5.7862 & 5.5946 & TRN & \\
\hline CHEMBL1398293 & 688239 & 5.2862 & 5.367006 & 0000000001 & TST \\
\hline CHEMBL1543545 & 688239 & 6.9363 & 5.6159 & TRN & \\
\hline CHEMBL1395633 & 688239 & 4.5362 & 5.5013 & TRN & \\
\hline CHEMBL1488044 & 688239 & 5.1862 & 5.5565 & TRN & \\
\hline CHEMBL1565432 & 688239 & 5.0362 & 5.5604 & TRN & \\
\hline CHEMBL1599904 & 688239 & 4.5362 & 5.7146 & TST & \\
\hline
\end{tabular}


Supplemental Table S2.txt

\begin{tabular}{|c|c|c|c|c|c|}
\hline CHEMBL1308718 & 688239 & 6.6362 & 5.6368 & TRN & \\
\hline CHEMBL1394281 & 688239 & 5.1362 & 5.456 & TRN & \\
\hline CHEMBL1385465 & 688239 & 6.2362 & 5.6302 & TRN & \\
\hline CHEMBL1407816 & 688239 & 6.9363 & 5.4713 & TST & \\
\hline CHEMBL1602194 & 688239 & 6.0862 & 5.5898 & TRN & \\
\hline CHEMBL1484551 & 688239 & 5.0862 & 5.4801 & TRN & \\
\hline CHEMBL1405275 & 688239 & 5.3862 & 5.5832 & TRN & \\
\hline CHEMBL1421048 & 688239 & 5.3862 & 5.2233 & TST & \\
\hline CHEMBL1311330 & 688239 & 5.1862 & 5.4935 & TRN & \\
\hline CHEMBL1467817 & 688239 & 5.2362 & 5.5922 & TRN & \\
\hline CHEMBL597683 & 688239 & 5.5862 & 5.5104 & TRN & \\
\hline CHEMBL1515213 & 688239 & 4.5362 & 5.5403 & TRN & \\
\hline CHEMBL1439922 & 688239 & 5.7362 & 5.5683 & TRN & \\
\hline CHEMBL1585003 & 688239 & 5.8362 & 5.3035 & TST & \\
\hline CHEMBL1578256 & 688239 & 6.3362 & 5.4929 & TRN & \\
\hline CHEMBL1333791 & 688239 & 5.1862 & 5.4966 & TRN & \\
\hline CHEMBL1610668 & 688239 & 5.7862 & 5.433 & TRN & \\
\hline CHEMBL1609650 & 688239 & 5.7362 & 5.6707 & TRN & \\
\hline CHEMBL1346101 & 688239 & 4.5862 & 5.5947 & TRN & \\
\hline CHEMBL1561423 & 688239 & 4.4862 & 5.4579 & TST & \\
\hline CHEMBL1998944 & 688239 & 4.7862 & 5.5349 & TRN & \\
\hline CHEMBL1340987 & 688239 & 6.8362 & 5.4705 & TST & \\
\hline CHEMBL1356249 & 688239 & 5.4862 & 5.2799 & TRN & \\
\hline CHEMBL1390003 & 688239 & 5.0862 & 5.4787 & TST & \\
\hline CHEMBL1547030 & 688239 & 4.6862 & 5.5175 & TRN & \\
\hline CHEMBL1392790 & 688239 & 5.8862 & 5.4795 & TRN & \\
\hline CHEMBL1588222 & 688239 & 5.6862 & 5.4518 & TRN & \\
\hline CHEMBL1386198 & 688239 & 6.6861 & 5.4607 & TRN & \\
\hline CHEMBL1543875 & 688239 & 4.5362 & 5.2645 & TRN & \\
\hline CHEMBL 3213472 & 688239 & 5.6862 & 5.4746 & TST & \\
\hline CHEMBL1538471 & 688239 & 5.2362 & 5.5173 & TRN & \\
\hline CHEMBL1368103 & 688239 & 4.7862 & 5.3911 & TRN & \\
\hline CHEMBL1337003 & 688239 & 4.8362 & 5.5784 & TRN & \\
\hline CHEMBL1338476 & 688239 & 5.1862 & 5.3055 & TRN & \\
\hline CHEMBL1380394 & 688239 & 5.0362 & 5.4905 & TST & \\
\hline CHEMBL1597661 & 688239 & 5.6362 & 5.5653 & TST & \\
\hline CHEMBL1442774 & 688239 & 4.8362 & 5.4704 & TRN & \\
\hline CHEMBL1565414 & 688239 & 6.4362 & 5.5392 & TRN & \\
\hline CHEMBL1440003 & 688239 & 6.1362 & 5.5747 & TRN & \\
\hline CHEMBL1604055 & 688239 & 6.4362 & 5.5074 & TRN & \\
\hline CHEMBL1518699 & 688239 & 4.8362 & 5.5316 & TRN & \\
\hline CHEMBL1423832 & 688239 & 8.28399 & 99999999 & 9 & 5.4587 \\
\hline CHEMBL1302459 & 688239 & 5.2862 & 5.4741 & TST & \\
\hline CHEMBL1522342 & 688239 & 4.5362 & 5.3644 & TST & \\
\hline CHEMBL 3145300 & 688239 & 5.7362 & 5.5397 & TRN & \\
\hline CHEMBL1450546 & 688239 & 5.5862 & 5.4782 & TRN & \\
\hline CHEMBL1556186 & 688239 & 4.6862 & 5.5233 & TST & \\
\hline CHEMBL1540953 & 688239 & 4.4862 & 5.4979 & TRN & \\
\hline
\end{tabular}


Supplemental Table S2.txt

\begin{tabular}{|c|c|c|c|c|}
\hline CHEMBL3192726 & 688239 & 4.8362 & 5.3866 & TRN \\
\hline CHEMBL1437556 & 688239 & 5.8362 & 5.4344 & TRN \\
\hline CHEMBL1533556 & 688239 & 4.6362 & 5.4334 & TRN \\
\hline CHEMBL1608807 & 688239 & 5.3362 & 5.4925 & TRN \\
\hline CHEMBL1438851 & 688239 & 4.9362 & 5.32100 & 0000000001 \\
\hline CHEMBL1427161 & 688239 & 6.2362 & 5.4484 & TRN \\
\hline CHEMBL1328955 & 688239 & 7.2865 & 5.4991 & TRN \\
\hline CHEMBL1353287 & 688239 & 5.1862 & 5.36100 & 0000000001 \\
\hline CHEMBL1570782 & 688239 & 5.5362 & 5.5192 & TRN \\
\hline CHEMBL1309547 & 688239 & 4.5362 & 5.4828 & TST \\
\hline CHEMBL1429268 & 688239 & 4.6362 & 5.5323 & TRN \\
\hline CHEMBL1424396 & 688239 & 8.3372 & 5.5222 & TRN \\
\hline CHEMBL1307019 & 688239 & 5.7362 & 5.3753 & TST \\
\hline CHEMBL1426621 & 688239 & 4.7362 & 5.3965 & TRN \\
\hline CHEMBL1304337 & 688239 & 5.9362 & 5.601 & TRN \\
\hline CHEMBL1566643 & 688239 & 4.6862 & 5.5461 & TRN \\
\hline CHEMBL1485291 & 688239 & 6.2362 & 5.5471 & TRN \\
\hline CHEMBL1528009 & 688239 & 5.7862 & 5.6721 & TRN \\
\hline CHEMBL1525954 & 688239 & 5.1362 & 5.5221 & TRN \\
\hline CHEMBL1321888 & 688239 & 5.0862 & 5.4121 & TST \\
\hline CHEMBL1450365 & 688239 & 5.6362 & 5.7179 & TST \\
\hline CHEMBL1409595 & 688239 & 4.7362 & 5.5576 & TRN \\
\hline CHEMBL1425227 & 688239 & 4.9362 & 5.4733 & TRN \\
\hline CHEMBL1505849 & 688239 & 5.9862 & 5.5001 & TRN \\
\hline CHEMBL1339861 & 688239 & 5.1862 & 5.4138 & TST \\
\hline CHEMBL1388312 & 688239 & 6.0862 & 5.3496 & TRN \\
\hline CHEMBL1468761 & 688239 & 4.6862 & 5.3412 & TRN \\
\hline CHEMBL1601126 & 688239 & 4.6862 & 5.4637 & TRN \\
\hline CHEMBL1491222 & 688239 & 4.4862 & 5.319 & TRN \\
\hline CHEMBL1348871 & 688239 & 4.5362 & 5.4915 & TRN \\
\hline CHEMBL1496666 & 688239 & 5.8862 & 5.5296 & TRN \\
\hline CHEMBL1427432 & 688239 & 4.5362 & 5.5887 & TRN \\
\hline CHEMBL1402034 & 688239 & 4.7362 & 5.4606 & TST \\
\hline CHEMBL1391552 & 688239 & 4.4862 & 5.5304 & TRN \\
\hline CHEMBL1536574 & 688239 & 5.9362 & 5.3615 & TRN \\
\hline CHEMBL1315131 & 688239 & 4.7362 & 5.4934 & TRN \\
\hline CHEMBL1564850 & 688239 & 5.8862 & 5.4602 & TRN \\
\hline CHEMBL1459253 & 688239 & 4.5362 & 5.3918 & TRN \\
\hline CHEMBL1452168 & 688239 & 4.5362 & 5.4313 & TRN \\
\hline CHEMBL1367021 & 688239 & 5.1862 & 5.3847 & TRN \\
\hline CHEMBL1502300 & 688239 & 6.3863 & 5.5023 & TRN \\
\hline CHEMBL1306769 & 688239 & 4.5362 & 5.3751 & TST \\
\hline CHEMBL1487001 & 688239 & 4.5362 & 5.4694 & TRN \\
\hline CHEMBL1323384 & 688239 & 4.6362 & 5.3669 & TST \\
\hline CHEMBL1556938 & 688239 & 5.1862 & 5.597 & TRN \\
\hline CHEMBL1343076 & 688239 & 5.1362 & 5.6295 & TRN \\
\hline CHEMBL1350695 & 688239 & 6.2862 & 5.3933 & TRN \\
\hline CHEMBL1363940 & 688239 & 5.2362 & 5.6633 & TRN \\
\hline
\end{tabular}


Supplemental Table S2.txt

\begin{tabular}{|c|c|c|c|c|c|}
\hline CHEMBL1600749 & 688239 & 5.2862 & 5.459 & TRN & \\
\hline CHEMBL1565465 & 688239 & 5.1362 & 5.4665 & TRN & \\
\hline CHEMBL1349848 & 688239 & 4.7362 & 5.4356 & TRN & \\
\hline CHEMBL1327067 & 688239 & 4.7862 & 5.4155 & TST & \\
\hline CHEMBL1498710 & 688239 & 4.6862 & 5.3665 & TRN & \\
\hline CHEMBL1444302 & 688239 & 4.8362 & 5.5733 & TRN & \\
\hline CHEMBL1586899 & 688239 & 5.1862 & 5.4133 & TST & \\
\hline CHEMBL1454541 & 688239 & 4.4862 & 5.3786 & TST & \\
\hline CHEMBL 3197584 & 688239 & 6.2862 & 5.5548 & TRN & \\
\hline CHEMBL1413598 & 688239 & 4.7862 & 5.3912 & TST & \\
\hline CHEMBL1385292 & 688239 & 5.1862 & 5.4116 & TRN & \\
\hline CHEMBL1562844 & 688239 & 8.2366 & 5.785 & TRN & \\
\hline CHEMBL1461351 & 688239 & 5.7862 & 5.4429 & TRN & \\
\hline CHEMBL1531888 & 688239 & 8.2366 & 5.5221 & TRN & \\
\hline CHEMBL 3210193 & 688239 & 5.3362 & 5.41100 & 00000000005 & TST \\
\hline CHEMBL1467008 & 688239 & 5.9362 & 5.55399 & 9999999999 & TRN \\
\hline CHEMBL1407935 & 688239 & 5.7862 & 5.5021 & TRN & \\
\hline CHEMBL1407697 & 688239 & 5.1862 & 5.5201 & TST & \\
\hline CHEMBL1310592 & 688239 & 6.1362 & 5.4511 & TST & \\
\hline CHEMBL1406528 & 688239 & 6.1862 & 5.53799 & 9999999999 & TRN \\
\hline CHEMBL1601883 & 688239 & 4.5862 & 5.5873 & TRN & \\
\hline CHEMBL1331056 & 688239 & 5.2362 & 5.7175 & TRN & \\
\hline CHEMBL1495644 & 688239 & 8.1871 & 5.4595 & TRN & \\
\hline CHEMBL1384384 & 688239 & 4.8862 & 5.4497 & TRN & \\
\hline CHEMBL1494166 & 688239 & 4.9862 & 5.3533 & TRN & \\
\hline CHEMBL1379505 & 688239 & 6.5363 & 5.4924 & TRN & \\
\hline CHEMBL1469459 & 688239 & 5.6862 & 5.4548 & TRN & \\
\hline CHEMBL1491584 & 688239 & 4.4862 & 5.5886 & TRN & \\
\hline CHEMBL1407981 & 688239 & 5.3362 & 5.606 & TRN & \\
\hline CHEMBL1521279 & 688239 & 4.7362 & 5.5654 & TRN & \\
\hline CHEMBL1972938 & 688239 & 6.1362 & 5.5431 & TST & \\
\hline CHEMBL1436417 & 688239 & 5.6362 & 5.5292 & TRN & \\
\hline CHEMBL1481704 & 688239 & 6.7862 & 5.5915 & TRN & \\
\hline CHEMBL1461392 & 688239 & 4.7862 & 5.385 & TST & \\
\hline CHEMBL1504118 & 688239 & 5.3362 & 5.4942 & TRN & \\
\hline CHEMBL1421272 & 688239 & 8.3372 & 5.5504 & TRN & \\
\hline CHEMBL1357795 & 688239 & 5.5862 & 5.2969 & TST & \\
\hline CHEMBL1426721 & 688239 & 6.2362 & 5.4073 & TRN & \\
\hline CHEMBL1336712 & 688239 & 6.8861 & 5.5405 & TRN & \\
\hline CHEMBL1312500 & 688239 & 5.1862 & 5.641 & TST & \\
\hline CHEMBL1580592 & 688239 & 5.0362 & 5.4555 & TST & \\
\hline CHEMBL1441980 & 688239 & 4.6862 & 5.6131 & TRN & \\
\hline CHEMBL1533104 & 688239 & 4.7862 & 5.3779 & TRN & \\
\hline CHEMBL1579949 & 688239 & 5.3862 & 5.4741 & TST & \\
\hline CHEMBL1444336 & 688239 & 6.3362 & 5.3583 & TRN & \\
\hline CHEMBL1600719 & 688239 & 4.6362 & 5.3927 & TRN & \\
\hline CHEMBL1328496 & 688239 & 6.2362 & 5.4723 & TST & \\
\hline CHEMBL1349627 & 688239 & 4.8362 & 5.5014 & TRN & \\
\hline
\end{tabular}




\begin{tabular}{|c|c|c|c|c|c|}
\hline & & \multicolumn{4}{|c|}{ Supplemental Table s2.txt } \\
\hline CHEMBL1439735 & 688239 & 6.8861 & 5.5878 & TRN & \\
\hline CHEMBL1314297 & 688239 & 4.5862 & 5.5239 & TRN & \\
\hline CHEMBL1570496 & 688239 & 4.5862 & 5.5295 & TRN & \\
\hline CHEMBL1303648 & 688239 & 4.5362 & 5.5087 & TRN & \\
\hline CHEMBL1584720 & 688239 & 4.8362 & 5.2994 & TRN & \\
\hline CHEMBL1606818 & 688239 & 4.7862 & 5.6717 & TRN & \\
\hline CHEMBL1415127 & 688239 & 4.6862 & 5.3764 & TRN & \\
\hline CHEMBL3189244 & 688239 & 6.8362 & 5.5264 & TST & \\
\hline CHEMBL3198101 & 688239 & 5.3362 & 5.4156 & TRN & \\
\hline CHEMBL1549880 & 688239 & 4.5362 & 5.4126 & TRN & \\
\hline CHEMBL1555566 & 688239 & 6.6362 & 5.4742 & TRN & \\
\hline CHEMBL1429637 & 688239 & 4.5362 & 5.5457 & TRN & \\
\hline CHEMBL1497002 & 688239 & 5.1862 & 5.4187 & TRN & \\
\hline CHEMBL1375697 & 688239 & 6.1362 & 5.5487 & TRN & \\
\hline CHEMBL1353025 & 688239 & 4.5362 & 5.4721 & TRN & \\
\hline CHEMBL1597983 & 688239 & 7.0862 & 5.4186 & TRN & \\
\hline CHEMBL1604397 & 688239 & 5.0362 & 5.5709 & TRN & \\
\hline CHEMBL1348749 & 688239 & 4.6862 & 5.4182 & TRN & \\
\hline CHEMBL1438404 & 688239 & 6.7862 & 5.5912 & TRN & \\
\hline CHEMBL1576130 & 688239 & 4.7362 & 5.5586 & TST & \\
\hline CHEMBL1540328 & 688239 & 5.7362 & 5.3746 & TRN & \\
\hline CHEMBL1460734 & 688239 & 4.5362 & 5.4937 & TRN & \\
\hline CHEMBL1331743 & 688239 & 6.8861 & 5.4879 & TST & \\
\hline CHEMBL1384808 & 688239 & 6.1862 & 5.4546 & TRN & \\
\hline CHEMBL1402540 & 688239 & 5.8362 & 5.4375 & TST & \\
\hline CHEMBL1575877 & 688239 & 4.5362 & 5.4409 & TRN & \\
\hline CHEMBL1434500 & 688239 & 4.8362 & 5.5138 & TRN & \\
\hline CHEMBL1496005 & 688239 & 4.5362 & 5.5356 & TRN & \\
\hline CHEMBL1492263 & 688239 & 4.7362 & 5.5662 & TRN & \\
\hline CHEMBL1362136 & 688239 & 7.0862 & 5.5035 & TRN & \\
\hline CHEMBL1486199 & 688239 & 6.0862 & 5.4384 & TST & \\
\hline CHEMBL1416650 & 688239 & 4.5362 & 5.6106 & TRN & \\
\hline CHEMBL1343529 & 688239 & 4.6862 & 5.4807 & TST & \\
\hline CHEMBL1386954 & 688239 & 4.6362 & 5.415 & TRN & \\
\hline CHEMBL1299935 & 688239 & 6.9863 & 5.55399 & 9999999999 & TRN \\
\hline CHEMBL1466819 & 688239 & 5.1862 & 5.6112 & TRN & \\
\hline CHEMBL1531881 & 688239 & 6.5363 & 5.4551 & TST & \\
\hline CHEMBL1507519 & 688239 & 5.2362 & 5.5764 & TRN & \\
\hline CHEMBL1348325 & 688239 & 5.1862 & 5.4355 & TST & \\
\hline CHEMBL1352283 & 688239 & 4.7362 & 5.5158 & TST & \\
\hline CHEMBL1609340 & 688239 & 6.8861 & 5.3685 & TRN & \\
\hline CHEMBL1431141 & 688239 & 4.8362 & 5.4425 & TRN & \\
\hline CHEMBL1332894 & 688239 & 5.1862 & 5.4382 & TRN & \\
\hline CHEMBL523200 & 688239 & 4.6362 & 5.4061 & TRN & \\
\hline CHEMBL1411920 & 688239 & 6.9363 & 5.6498 & TRN & \\
\hline CHEMBL1522770 & 688239 & 8.28399 & 99999999 & 5.5066 & TST \\
\hline CHEMBL1582146 & 688239 & 4.6362 & 5.5254 & TRN & \\
\hline CHEMBL1535487 & 688239 & 4.5362 & 5.4142 & TRN & \\
\hline
\end{tabular}


Supplemental Table S2.txt

\begin{tabular}{|c|c|c|c|c|c|}
\hline CHEMBL1533474 & 688239 & 6.3863 & 5.4684 & TRN & \\
\hline CHEMBL1605557 & 688239 & 6.9863 & 5.6341 & TRN & \\
\hline CHEMBL1370452 & 688239 & 4.7362 & 5.5839 & TST & \\
\hline CHEMBL1486806 & 688239 & 7.0362 & 5.6474 & TRN & \\
\hline CHEMBL1387992 & 688239 & 4.5862 & 5.5329 & TST & \\
\hline CHEMBL1442544 & 688239 & 6.1862 & 5.5875 & TRN & \\
\hline CHEMBL1437190 & 688239 & 5.6362 & 5.4866 & TRN & \\
\hline CHEMBL1580332 & 688239 & 4.8362 & 5.6185 & TRN & \\
\hline CHEMBL1518162 & 688239 & 5.1862 & 5.6563 & TRN & \\
\hline CHEMBL1486517 & 688239 & 4.7362 & 5.5809 & TRN & \\
\hline CHEMBL1508373 & 688239 & 8.3372 & 5.5156 & TRN & \\
\hline CHEMBL1388073 & 688239 & 5.1862 & 5.5875 & TRN & \\
\hline CHEMBL1522379 & 688239 & 4.4862 & 5.425 & TRN & \\
\hline CHEMBL1351050 & 688239 & 5.1362 & 5.4711 & TRN & \\
\hline CHEMBL1475897 & 688239 & 4.5862 & 5.3626 & TRN & \\
\hline CHEMBL1500997 & 688239 & 5.5862 & 5.4382 & TRN & \\
\hline CHEMBL1545123 & 688239 & 6.9363 & 5.5792 & TRN & \\
\hline CHEMBL1612245 & 688239 & 4.4862 & 5.4678 & TRN & \\
\hline CHEMBL1612840 & 688239 & 5.1862 & 5.3632 & TRN & \\
\hline CHEMBL1324749 & 688239 & 5.7862 & 5.4579 & TRN & \\
\hline CHEMBL1411006 & 688239 & 4.5362 & 5.351 & TST & \\
\hline CHEMBL1591242 & 688239 & 5.2862 & 5.5314 & TST & \\
\hline CHEMBL1574671 & 688239 & 4.7862 & 5.3828 & TST & \\
\hline CHEMBL1544370 & 688239 & 8.3372 & 5.4388 & TRN & \\
\hline CHEMBL1526025 & 688239 & 5.5862 & 5.4786 & TST & \\
\hline CHEMBL1304030 & 688239 & 5.4862 & 5.5865 & TRN & \\
\hline CHEMBL1315057 & 688239 & 6.7361 & 5.3803 & TRN & \\
\hline CHEMBL1345319 & 688239 & 4.8362 & 5.5679 & TRN & \\
\hline CHEMBL1419376 & 688239 & 6.3863 & 5.6149 & TRN & \\
\hline CHEMBL1588451 & 688239 & 4.5362 & 5.3449 & TST & \\
\hline CHEMBL1475030 & 688239 & 6.9363 & 5.3484 & TRN & \\
\hline CHEMBL1525637 & 688239 & 7.4868 & 5.6659 & TST & \\
\hline CHEMBL1552855 & 688239 & 7.0862 & 5.5328 & TST & \\
\hline CHEMBL1319346 & 688239 & 5.7362 & 5.4649 & TST & \\
\hline CHEMBL1460793 & 688239 & 6.1862 & 5.4894 & TRN & \\
\hline CHEMBL1344158 & 688239 & 5.1862 & 5.5425 & TRN & \\
\hline CHEMBL1592451 & 688239 & 6.2362 & 5.4417 & TRN & \\
\hline CHEMBL1595106 & 688239 & 8.283999 & 999999999 & 9 & 5.5864 \\
\hline CHEMBL1480471 & 688239 & 4.5362 & 5.6127 & TRN & \\
\hline CHEMBL1500413 & 688239 & 4.4862 & 5.4251 & TRN & \\
\hline CHEMBL1404477 & 688239 & 6.2362 & 5.6699 & TRN & \\
\hline CHEMBL1333871 & 688239 & 7.2366 & 5.3911 & TRN & \\
\hline CHEMBL1558900 & 688239 & 6.2362 & 5.5442 & TRN & \\
\hline CHEMBL1503862 & 688239 & 4.5362 & 5.6694 & TRN & \\
\hline CHEMBL1572163 & 688239 & 4.7862 & 5.6943 & TRN & \\
\hline CHEMBL1528784 & 688239 & 6.2362 & 5.4342 & TRN & \\
\hline CHEMBL1462647 & 688239 & 5.4862 & 5.5856 & TRN & \\
\hline CHEMBL 2003973 & 688239 & 8.3372 & 5.394 & TST & \\
\hline
\end{tabular}


Supplemental Table S2.txt

\begin{tabular}{|c|c|c|c|c|c|}
\hline CHEMBL1319484 & 688239 & 6.6362 & 5.5177 & TRN & \\
\hline CHEMBL1352420 & 688239 & 5.1862 & 5.5859 & TRN & \\
\hline CHEMBL1568857 & 688239 & 6.2362 & 5.5464 & TRN & \\
\hline CHEMBL227496 & 688239 & 5.3862 & 5.4602 & TRN & \\
\hline CHEMBL1486888 & 688239 & 5.1862 & 5.5813 & TRN & \\
\hline CHEMBL1593517 & 688239 & 5.6362 & 5.5545 & TRN & \\
\hline CHEMBL3193269 & 688239 & 5.1862 & 5.4896 & TST & \\
\hline CHEMBL1304902 & 688239 & 4.6362 & 5.3264 & TST & \\
\hline CHEMBL1342293 & 688239 & 5.1862 & 5.4775 & TRN & \\
\hline CHEMBL1396608 & 688239 & 4.6362 & 5.4883 & TRN & \\
\hline CHEMBL3209700 & 688239 & 6.0862 & 5.3953 & TRN & \\
\hline CHEMBL1984876 & 688239 & 5.6862 & 5.4383 & TRN & \\
\hline CHEMBL1590591 & 688239 & 5.5862 & 5.4558 & TRN & \\
\hline CHEMBL1531884 & 688239 & 4.8362 & 5.5491 & TST & \\
\hline CHEMBL1381135 & 688239 & 5.6362 & 5.6009 & TRN & \\
\hline CHEMBL1524420 & 688239 & 4.5362 & 5.5206 & TST & \\
\hline CHEMBL1348649 & 688239 & 5.5862 & 5.4773 & TRN & \\
\hline CHEMBL1531898 & 688239 & 4.5362 & 5.4935 & TRN & \\
\hline CHEMBL1351347 & 688239 & 5.3362 & 5.3647 & TRN & \\
\hline CHEMBL1389916 & 688239 & 5.5862 & 5.4763 & TRN & \\
\hline CHEMBL3196128 & 688239 & 4.8362 & 5.4017 & TST & \\
\hline CHEMBL1496723 & 688239 & 5.1862 & 5.5066 & TRN & \\
\hline CHEMBL1461156 & 688239 & 5.1862 & 5.3746 & TST & \\
\hline CHEMBL1310712 & 688239 & 5.2862 & 5.4484 & TST & \\
\hline CHEMBL1353540 & 688239 & 5.7362 & 5.3941 & TST & \\
\hline CHEMBL 1558790 & 688239 & 4.7862 & 5.5021 & TRN & \\
\hline CHEMBL1328251 & 688239 & 4.5362 & 5.5921 & TRN & \\
\hline CHEMBL1604597 & 688239 & 6.7862 & 5.5866 & TST & \\
\hline CHEMBL1356066 & 688239 & 4.7362 & 5.4766 & TST & \\
\hline CHEMBL1377428 & 688239 & 5.1862 & 5.5099 & TRN & \\
\hline CHEMBL1429023 & 688239 & 4.5362 & 5.4789 & TRN & \\
\hline CHEMBL1568766 & 688239 & 4.9862 & 5.41200 & 2000000001 & TRN \\
\hline CHEMBL1435617 & 688239 & 4.9362 & 5.5117 & TRN & \\
\hline CHEMBL1544802 & 688239 & 5.8362 & 5.416 & TST & \\
\hline CHEMBL1471370 & 688239 & 6.0362 & 5.5411 & TRN & \\
\hline CHEMBL1533134 & 688239 & 5.7362 & 5.5509 & TRN & \\
\hline CHEMBL1501905 & 688239 & 7.1864 & 5.6163 & TRN & \\
\hline CHEMBL1306587 & 688239 & 5.4362 & 5.4775 & TRN & \\
\hline CHEMBL1480761 & 688239 & 4.9362 & 5.5317 & TRN & \\
\hline CHEMBL600841 & 688239 & 5.0862 & 5.4999 & TRN & \\
\hline CHEMBL1391044 & 688239 & 5.1862 & 5.4781 & TRN & \\
\hline CHEMBL1359606 & 688239 & 5.4362 & 5.3529 & TRN & \\
\hline CHEMBL1490175 & 688239 & 4.7862 & 5.45 & TRN & \\
\hline CHEMBL1401954 & 688239 & 6.9863 & 5.5705 & TRN & \\
\hline CHEMBL1441472 & 688239 & 6.9363 & 5.4245 & TRN & \\
\hline CHEMBL1497431 & 688239 & 4.7362 & 5.4868 & TRN & \\
\hline CHEMBL1367284 & 688239 & 6.1362 & 5.4117 & TST & \\
\hline CHEMBL1365998 & 688239 & 5.1862 & 5.5573 & TST & \\
\hline
\end{tabular}


Supplemental Table S2.txt

\begin{tabular}{|c|c|c|c|c|}
\hline CHEMBL1571911 & 688239 & 4.8362 & 5.4007 & TRN \\
\hline CHEMBL1416769 & 688239 & 5.1362 & 5.2074 & TRN \\
\hline CHEMBL1309206 & 688239 & 6.4862 & 5.5839 & TRN \\
\hline CHEMBL1474799 & 688239 & 4.7862 & 5.4528 & TRN \\
\hline CHEMBL1593072 & 688239 & 6.2362 & 5.6196 & TRN \\
\hline CHEMBL1494566 & 688239 & 6.8861 & 5.4631 & TRN \\
\hline CHEMBL1408481 & 688239 & 4.7362 & 5.4297 & TST \\
\hline CHEMBL1469227 & 688239 & 6.2862 & 5.4181 & TST \\
\hline CHEMBL1387872 & 688239 & 4.5362 & 5.3808 & TRN \\
\hline CHEMBL1346176 & 688239 & 6.1362 & 5.5362 & TRN \\
\hline CHEMBL1361200 & 688239 & 5.2362 & 5.4863 & TRN \\
\hline CHEMBL1595909 & 688239 & 5.1862 & 5.4427 & TRN \\
\hline CHEMBL1570707 & 688239 & 4.6362 & 5.3249 & TST \\
\hline CHEMBL1319281 & 688239 & 5.1862 & 5.5827 & TRN \\
\hline CHEMBL1472127 & 688239 & 4.6362 & 5.5209 & TRN \\
\hline CHEMBL 3207512 & 688239 & 5.1862 & 5.416 & TST \\
\hline CHEMBL1439681 & 688239 & 5.0862 & 5.4621 & TST \\
\hline CHEMBL1575266 & 688239 & 5.1862 & 5.5609 & TRN \\
\hline CHEMBL1348847 & 688239 & 4.8362 & 5.4735 & TST \\
\hline CHEMBL1419700 & 688239 & 5.8362 & 5.5137 & TRN \\
\hline CHEMBL1608323 & 688239 & 7.0362 & 5.5129 & TRN \\
\hline CHEMBL1372547 & 688239 & 5.4862 & 5.5086 & TST \\
\hline CHEMBL1385574 & 688239 & 5.6862 & 5.5604 & TST \\
\hline CHEMBL1599111 & 688239 & 5.0362 & 5.3424 & TST \\
\hline CHEMBL1598850 & 688239 & 5.2362 & 5.4573 & TRN \\
\hline CHEMBL1594600 & 688239 & 4.7362 & \multicolumn{2}{|c|}{5.617000000000001} \\
\hline CHEMBL1491238 & 688239 & 5.3362 & 5.3669 & TRN \\
\hline CHEMBL1375683 & 688239 & 6.1362 & 5.5081 & TRN \\
\hline CHEMBL1393015 & 688239 & 5.6362 & 5.3203 & TRN \\
\hline CHEMBL1346574 & 688239 & 4.6862 & 5.3813 & TRN \\
\hline CHEMBL1587566 & 688239 & 5.1862 & 5.4357 & TRN \\
\hline CHEMBL1560591 & 688239 & 4.5862 & 5.5073 & TST \\
\hline CHEMBL1337884 & 688239 & 4.9862 & 5.4061 & TRN \\
\hline CHEMBL1506665 & 688239 & 4.5362 & 5.3739 & TST \\
\hline CHEMBL1431319 & 688239 & 5.1862 & 5.4483 & TRN \\
\hline CHEMBL1474824 & 688239 & 6.9363 & 5.6611 & TRN \\
\hline CHEMBL1363806 & 688239 & 5.1862 & 5.435 & TRN \\
\hline CHEMBL1483173 & 688239 & 4.7362 & 5.4821 & TRN \\
\hline CHEMBL3213340 & 688239 & 4.5362 & 5.4494 & TRN \\
\hline CHEMBL1602458 & 688239 & 5.7862 & 5.4557 & TRN \\
\hline CHEMBL1332058 & 688239 & 5.4862 & 5.5284 & TRN \\
\hline CHEMBL3193323 & 688239 & 4.5362 & 5.4742 & TRN \\
\hline CHEMBL1321293 & 688239 & 6.1862 & 5.6576 & TRN \\
\hline CHEMBL1553987 & 688239 & 6.8362 & 5.5598 & TRN \\
\hline CHEMBL1371410 & 688239 & 5.8862 & 5.4679 & TRN \\
\hline CHEMBL1384619 & 688239 & 7.0362 & 5.5158 & TRN \\
\hline CHEMBL1576320 & 688239 & 5.5362 & 5.4319 & TRN \\
\hline CHEMBL1321669 & 688239 & 6.7361 & 5.477 & TRN \\
\hline
\end{tabular}


Supplemental Table S2.txt

\begin{tabular}{|c|c|c|c|c|c|c|}
\hline CHEMBL1462524 & 688239 & 5.5362 & \multicolumn{3}{|c|}{5.3020000000000005} & TRN \\
\hline CHEMBL1305339 & 688239 & 5.6862 & 5.4332 & TST & & \\
\hline CHEMBL1460147 & 688239 & 5.2362 & 5.4619 & TST & & \\
\hline CHEMBL1383626 & 688239 & 5.8362 & 5.61799 & 9999999999 & & TST \\
\hline CHEMBL1406161 & 688239 & 4.8862 & 5.4901 & TRN & & \\
\hline CHEMBL1611672 & 688239 & 6.8861 & 5.6015 & TRN & & \\
\hline CHEMBL1555341 & 688239 & 4.5362 & 5.4623 & TRN & & \\
\hline CHEMBL1484913 & 688239 & 6.2862 & 5.6338 & TRN & & \\
\hline CHEMBL1431636 & 688239 & 5.1862 & 5.4747 & TRN & & \\
\hline CHEMBL1544828 & 688239 & 6.9363 & 5.5287 & TRN & & \\
\hline CHEMBL1346141 & 688239 & 5.5862 & 5.4993 & TRN & & \\
\hline CHEMBL1501739 & 688239 & 4.7862 & 5.4535 & TRN & & \\
\hline CHEMBL1569326 & 688239 & 5.6862 & 5.602 & TRN & & \\
\hline CHEMBL1352694 & 688239 & 8.1871 & 5.3466 & TRN & & \\
\hline CHEMBL1578431 & 688239 & 4.5362 & 5.3582 & TRN & & \\
\hline CHEMBL1568081 & 688239 & 6.1362 & 5.6116 & TRN & & \\
\hline CHEMBL1584103 & 688239 & 5.1362 & 5.5041 & TRN & & \\
\hline CHEMBL1461319 & 688239 & 5.5362 & 5.3844 & TST & & \\
\hline CHEMBL1331326 & 688239 & 4.7362 & 5.4479 & TRN & & \\
\hline CHEMBL1503566 & 688239 & 7.1864 & 5.5841 & TRN & & \\
\hline CHEMBL3190844 & 688239 & 4.8362 & 5.3739 & TRN & & \\
\hline CHEMBL1438627 & 688239 & 5.1862 & 5.4397 & TST & & \\
\hline CHEMBL1378119 & 688239 & 6.3863 & 5.5989 & TST & & \\
\hline CHEMBL1480970 & 688239 & 5.5362 & 5.5922 & TRN & & \\
\hline CHEMBL1605261 & 688239 & 5.5362 & 5.3486 & TRN & & \\
\hline CHEMBL1374430 & 688239 & 5.6362 & 5.3513 & TRN & & \\
\hline CHEMBL1416594 & 688239 & 4.5362 & 5.4337 & TRN & & \\
\hline CHEMBL1538817 & 688239 & 4.9862 & 5.4586 & TST & & \\
\hline CHEMBL1501583 & 688239 & 5.2862 & 5.4449 & TRN & & \\
\hline CHEMBL1502723 & 688239 & 4.5362 & 5.3931 & TRN & & \\
\hline CHEMBL1549963 & 688239 & 5.2362 & 5.6539 & TRN & & \\
\hline CHEMBL1567331 & 688239 & 4.7362 & 5.4988 & TRN & & \\
\hline CHEMBL1463445 & 688239 & 4.5362 & 5.4652 & TRN & & \\
\hline CHEMBL1368178 & 688239 & 5.5862 & 5.5732 & TRN & & \\
\hline CHEMBL1547748 & 688239 & 4.5362 & 5.531006 & 0000000001 & & TKIV \\
\hline CHEMBL1383501 & 688239 & 4.7362 & 5.5641 & TRN & & \\
\hline CHEMBL3211959 & 688239 & 5.2362 & 5.5855 & TRN & & \\
\hline CHEMBL1613341 & 688239 & 5.7362 & 5.4328 & TST & & \\
\hline CHEMBL1546278 & 688239 & 4.7862 & 5.5426 & TRN & & \\
\hline CHEMBL1543384 & 688239 & 4.5362 & 5.468 & TRN & & \\
\hline CHEMBL1338915 & 688239 & 8.3372 & 5.4609 & TRN & & \\
\hline CHEMBL1607280 & 688239 & 6.9363 & 5.4503 & TRN & & \\
\hline CHEMBL1429086 & 688239 & 4.6862 & 5.4344 & TRN & & \\
\hline CHEMBL1396143 & 688239 & 8.28399 & 99999999 & 99 & 5.4551 & TRN \\
\hline CHEMBL3198508 & 688239 & 5.0362 & 5.4053 & TST & & \\
\hline CHEMBL3213688 & 688239 & 5.1862 & 5.5353 & TRN & & \\
\hline CHEMBL1543915 & 688239 & 4.5362 & 5.5461 & TRN & & \\
\hline CHEMBL1380590 & 688239 & 5.1862 & 5.5354 & TRN & & \\
\hline
\end{tabular}


Supplemental Table S2.txt

\begin{tabular}{|c|c|c|c|c|}
\hline CHEMBL1503307 & 688239 & 4.6362 & 5.4701 & TRN \\
\hline CHEMBL1333337 & 688239 & 4.5362 & 5.2993 & TRN \\
\hline CHEMBL1503590 & 688239 & 5.0362 & 5.4989 & TRN \\
\hline CHEMBL1585879 & 688239 & 5.4862 & 5.6225 & TRN \\
\hline CHEMBL1555700 & 688239 & 4.5362 & 5.55 & TRN \\
\hline CHEMBL3214233 & 688239 & 5.0362 & 5.3137 & TRN \\
\hline CHEMBL1306046 & 688239 & 5.4362 & 5.6584 & TRN \\
\hline CHEMBL1314001 & 688239 & 5.9862 & 5.5187 & TST \\
\hline CHEMBL1604057 & 688239 & 5.1862 & 5.4574 & TST \\
\hline CHEMBL3199785 & 688239 & 4.5362 & 5.4507 & TRN \\
\hline CHEMBL1311607 & 688239 & 5.1362 & 5.4686 & TRN \\
\hline CHEMBL1403587 & 688239 & 4.7862 & 5.4755 & TRN \\
\hline CHEMBL 3209883 & 688239 & 4.5362 & 5.4527 & TST \\
\hline CHEMBL1498925 & 688239 & 6.9863 & 5.3516 & TST \\
\hline CHEMBL1399437 & 688239 & 4.7862 & 5.4416 & TST \\
\hline CHEMBL1475824 & 688239 & 5.6362 & 5.5444 & TRN \\
\hline CHEMBL1393783 & 688239 & 4.5362 & 5.3757 & TRN \\
\hline CHEMBL1562625 & 688239 & 4.5362 & 5.4336 & TST \\
\hline CHEMBL1559053 & 688239 & 5.9362 & 5.4678 & TST \\
\hline CHEMBL1374461 & 688239 & 6.9363 & 5.4834 & TRN \\
\hline CHEMBL1365580 & 688239 & 7.0362 & 5.4995 & TRN \\
\hline CHEMBL1601992 & 688239 & 5.1862 & 5.6225 & TRN \\
\hline CHEMBL1420344 & 688239 & 7.1864 & 5.6301 & TST \\
\hline CHEMBL1563490 & 688239 & 5.1862 & 5.428999 & 999999999 \\
\hline CHEMBL1336497 & 688239 & 4.7362 & 5.4441 & TRN \\
\hline CHEMBL1972450 & 688239 & 5.1862 & 5.2901 & TST \\
\hline CHEMBL1412667 & 688239 & 5.5862 & 5.5732 & TST \\
\hline CHEMBL1350915 & 688239 & 5.6362 & 5.5173 & TRN \\
\hline CHEMBL1421219 & 688239 & 5.1862 & 5.4799 & TST \\
\hline CHEMBL1337115 & 688239 & 4.8362 & 5.5761 & TST \\
\hline CHEMBL1608158 & 688239 & 4.5362 & 5.5821 & TRN \\
\hline CHEMBL1349305 & 688239 & 5.6862 & 5.5573 & TRN \\
\hline CHEMBL1421106 & 688239 & 4.5362 & 5.4004 & TRN \\
\hline CHEMBL1327514 & 688239 & 4.6362 & 5.5648 & TRN \\
\hline CHEMBL1992800 & 688239 & 4.5362 & 5.3879 & TRN \\
\hline CHEMBL1974537 & 688239 & 4.5362 & 5.4572 & TRN \\
\hline CHEMBL1411270 & 688239 & 4.6862 & 5.403 & TST \\
\hline CHEMBL1453858 & 688239 & 4.7862 & 5.3077 & TRN \\
\hline CHEMBL1548351 & 688239 & 6.2362 & 5.5869 & TRN \\
\hline CHEMBL1452861 & 688239 & 5.7862 & 5.4183 & TRN \\
\hline CHEMBL1407505 & 688239 & 4.6862 & 5.3733 & TRN \\
\hline CHEMBL1483729 & 688239 & 4.6862 & 5.5396 & TRN \\
\hline CHEMBL1500058 & 688239 & 8.3872 & 5.5168 & TST \\
\hline CHEMBL1426054 & 688239 & 5.4362 & 5.3792 & TRN \\
\hline CHEMBL1410667 & 688239 & 4.9862 & 5.4437 & TRN \\
\hline CHEMBL1422627 & 688239 & 6.1862 & 5.5545 & TST \\
\hline CHEMBL1499918 & 688239 & 6.2362 & 5.364 & TRN \\
\hline CHEMBL1423967 & 688239 & 5.5862 & 5.4137 & TRN \\
\hline
\end{tabular}

Page 1643 


\begin{tabular}{|c|c|c|c|c|c|c|}
\hline & & \multicolumn{5}{|c|}{ Supplemental Table S2.txt } \\
\hline CHEMBL1411524 & 688239 & 4.5362 & 5.459 & TRN & & \\
\hline CHEMBL1424898 & 688239 & 4.7362 & \multicolumn{3}{|c|}{5.4670000000000005} & TRN \\
\hline CHEMBL1575264 & 688239 & 4.5362 & 5.6336 & TRN & & \\
\hline CHEMBL1315308 & 688239 & \multicolumn{3}{|c|}{8.283999999999999} & 5.4138 & TRN \\
\hline CHEMBL1331024 & 688239 & 8.3372 & 5.5927 & TRN & & \\
\hline CHEMBL1339006 & 688239 & 6.1362 & 5.5682 & TRN & & \\
\hline CHEMBL1593217 & 688239 & 5.4362 & 5.5298 & TRN & & \\
\hline CHEMBL1367150 & 688239 & 4.4862 & 5.4661 & TST & & \\
\hline CHEMBL1406129 & 688239 & 4.7362 & 5.4431 & TRN & & \\
\hline CHEMBL1398760 & 688239 & 4.8362 & 5.5284 & TRN & & \\
\hline CHEMBL1364690 & 688239 & 6.6861 & 5.5255 & TRN & & \\
\hline CHEMBL1570252 & 688239 & 4.5862 & 5.5924 & TST & & \\
\hline CHEMBL3199468 & 688239 & 4.9862 & 5.4162 & TRN & & \\
\hline CHEMBL1322525 & 688239 & 8.2366 & 5.513 & TST & & \\
\hline CHEMBL1606099 & 688239 & 5.5862 & \multicolumn{3}{|c|}{5.571000000000001} & TRN \\
\hline CHEMBL1610978 & 688239 & 6.7862 & 5.6272 & TST & & \\
\hline CHEMBL1355068 & 688239 & 6.1862 & 5.4435 & TRN & & \\
\hline CHEMBL1406552 & 688239 & 4.8862 & 5.4555 & TRN & & \\
\hline CHEMBL1329205 & 688239 & 4.8362 & 5.4948 & TRN & & \\
\hline CHEMBL1608436 & 688239 & 4.5362 & 5.5065 & TRN & & \\
\hline CHEMBL1481132 & 688239 & 5.2862 & 5.5366 & TRN & & \\
\hline CHEMBL1305262 & 688239 & 5.7362 & 5.5085 & TST & & \\
\hline CHEMBL1339880 & 688239 & 4.5362 & 5.4389 & TST & & \\
\hline CHEMBL1505070 & 688239 & 4.5362 & 5.5893 & TRN & & \\
\hline CHEMBL1559124 & 688239 & 4.6862 & 5.4371 & TRN & & \\
\hline CHEMBL1332223 & 688239 & 7.5361 & 5.48799 & 9999999999 & 95 & TRN \\
\hline CHEMBL1595514 & 688239 & 5.1862 & 5.521 & TRN & & \\
\hline CHEMBL 3212783 & 688239 & 4.5362 & 5.3621 & TST & & \\
\hline CHEMBL1420724 & 688239 & 4.7362 & 5.5875 & TST & & \\
\hline CHEMBL1566340 & 688239 & 5.1862 & 5.5645 & TRN & & \\
\hline CHEMBL1520682 & 688239 & 5.3862 & 5.4822 & TRN & & \\
\hline CHEMBL1578005 & 688239 & 5.1862 & 5.4173 & TST & & \\
\hline CHEMBL1412846 & 688239 & 7.2366 & 5.5688 & TRN & & \\
\hline CHEMBL1557702 & 688239 & \multicolumn{3}{|c|}{8.283999999999999} & 5.3602 & TRN \\
\hline CHEMBL1306595 & 688239 & 4.5362 & 5.4785 & TRN & & \\
\hline CHEMBL1327334 & 688239 & 6.3362 & 5.584 & TRN & & \\
\hline CHEMBL1543674 & 688239 & 5.9862 & 5.4786 & TRN & & \\
\hline CHEMBL1328934 & 688239 & 4.7862 & 5.5744 & TRN & & \\
\hline CHEMBL1519168 & 688239 & 4.5362 & 5.2899 & TRN & & \\
\hline CHEMBL3210926 & 688239 & 8.3372 & 5.4365 & TRN & & \\
\hline CHEMBL527307 & 688239 & 6.2362 & 5.4778 & TST & & \\
\hline CHEMBL1600503 & 688239 & 5.0362 & 5.3978 & TRN & & \\
\hline CHEMBL1996858 & 688239 & 4.6862 & 5.4293 & TRN & & \\
\hline CHEMBL1301631 & 688239 & 4.5362 & 5.5252 & TRN & & \\
\hline CHEMBL1348710 & 688239 & 5.4862 & 5.4496 & TRN & & \\
\hline CHEMBL1533893 & 688239 & 5.0362 & 5.5035 & TRN & & \\
\hline CHEMBL1417212 & 688239 & 7.0362 & 5.5399 & TRN & & \\
\hline CHEMBL1442000 & 688239 & 4.7362 & 5.5168 & TRN & & \\
\hline
\end{tabular}




\begin{tabular}{|c|c|c|c|c|c|c|}
\hline & & & & & & \\
\hline CHEMBL1312860 & 688239 & 4.7362 & 5.4322 & TST & & \\
\hline CHEMBL1461700 & 688239 & 5.5862 & 5.5792 & TRN & & \\
\hline CHEMBL1575429 & 688239 & 4.7862 & 5.5852 & TST & & \\
\hline CHEMBL1324413 & 688239 & 5.6362 & 5.5237 & TST & & \\
\hline CHEMBL1555592 & 688239 & 4.7362 & 5.545 & TST & & \\
\hline CHEMBL1398911 & 688239 & 5.8362 & 5.4969 & TRN & & \\
\hline CHEMBL1444465 & 688239 & 5.6862 & 5.6159 & TST & & \\
\hline CHEMBL1597258 & 688239 & 4.7362 & 5.5232 & TRN & & \\
\hline CHEMBL3207705 & 688239 & 5.3362 & 5.3903 & TST & & \\
\hline CHEMBL1357317 & 688239 & 5.1862 & 5.61100 & 0000000001 & & TRN \\
\hline CHEMBL1518911 & 688239 & 4.4862 & 5.5304 & TRN & & \\
\hline CHEMBL1380275 & 688239 & 4.6862 & 5.4553 & TRN & & \\
\hline CHEMBL1571999 & 688239 & 5.1862 & 5.5797 & TRN & & \\
\hline CHEMBL1408739 & 688239 & 4.7 & 5.5197 & TRN & & \\
\hline CHEMBL1451318 & 688239 & 4.5862 & 5.4388 & TST & & \\
\hline CHEMBL1587616 & 688239 & 6.1362 & 5.5419 & TRN & & \\
\hline CHEMBL1338847 & 688239 & 4.6362 & 5.3514 & TRN & & \\
\hline CHEMBL1424846 & 688239 & 4.6862 & 5.4354 & TST & & \\
\hline CHEMBL1590582 & 688239 & 4.8862 & 5.6862 & TST & & \\
\hline CHEMBL1484593 & 688239 & 5.3862 & 5.6132 & TRN & & \\
\hline CHEMBL3207468 & 688239 & 6.2362 & 5.2899 & TST & & \\
\hline CHEMBL1418678 & 688239 & 6.8861 & 5.4867 & TST & & \\
\hline CHEMBL1442319 & 688239 & 4.6862 & 5.41299 & 9999999999 & & TRN \\
\hline CHEMBL1364735 & 688239 & 6.3362 & 5.6145 & TRN & & \\
\hline CHEMBL1576216 & 688239 & 7.6364 & 5.5188 & TRN & & \\
\hline CHEMBL1506017 & 688239 & 4.5362 & 5.5294 & TRN & & \\
\hline CHEMBL1474559 & 688239 & 5.6862 & 5.485 & TRN & & \\
\hline CHEMBL1545715 & 688239 & 5.6862 & 5.3815 & TRN & & \\
\hline CHEMBL1546092 & 688239 & 5.1362 & 5.2996 & TST & & \\
\hline CHEMBL1434999 & 688239 & 4.5362 & 5.3824 & TRN & & \\
\hline CHEMBL1368945 & 688239 & 8.28399 & 79999999 & 99 & 5.3864 & TRN \\
\hline CHEMBL1399883 & 688239 & 4.4862 & 5.6506 & TRN & & \\
\hline CHEMBL1441118 & 688239 & 4.9862 & 5.3702 & TRN & & \\
\hline CHEMBL1491330 & 688239 & 4.7862 & 5.5193 & TRN & & \\
\hline CHEMBL1406097 & 688239 & 4.5362 & 5.5792 & TST & & \\
\hline CHEMBL1558761 & 688239 & 5.2862 & 5.4555 & TST & & \\
\hline CHEMBL1480651 & 688239 & 4.5362 & 5.3724 & TRN & & \\
\hline CHEMBL1257078 & 688239 & 4.7362 & 5.3783 & TST & & \\
\hline CHEMBL1382311 & 688239 & 5.1862 & 5.5295 & TRN & & \\
\hline CHEMBL1510332 & 688239 & 4.6362 & 5.4212 & TST & & \\
\hline CHEMBL1375313 & 688239 & 5.4362 & 5.4118 & TST & & \\
\hline CHEMBL1571701 & 688239 & 5.7362 & 5.5936 & TRN & & \\
\hline CHEMBL1321833 & 688239 & 6.3362 & 5.345 & TRN & & \\
\hline CHEMBL1431597 & 688239 & 4.5362 & 5.4767 & TRN & & \\
\hline CHEMBL1463218 & 688239 & 5.4862 & 5.5187 & TRN & & \\
\hline CHEMBL1504009 & 688239 & 5.0862 & 5.4648 & TRN & & \\
\hline CHEMBL1400136 & 688239 & 5.1862 & 5.3853 & TST & & \\
\hline CHEMBL1349184 & 688239 & 4.7362 & 5.5158 & TRN & & \\
\hline
\end{tabular}


Supplemental Table S2.txt

\begin{tabular}{|c|c|c|c|c|}
\hline CHEMBL1393553 & 688239 & 6.8861 & 5.5395 & TRN \\
\hline CHEMBL1392724 & 688239 & 4.4862 & 5.5453 & TRN \\
\hline CHEMBL1377461 & 688239 & 5.0362 & 5.4342 & TRN \\
\hline CHEMBL1543694 & 688239 & 4.5362 & 5.6366 & TRN \\
\hline CHEMBL1524875 & 688239 & 5.2362 & 5.5313 & TRN \\
\hline CHEMBL1551658 & 688239 & 4.8362 & 5.55 & TRN \\
\hline CHEMBL1403084 & 688239 & 5.1862 & 5.524 & TRN \\
\hline CHEMBL1569251 & 688239 & 8.3372 & 5.4357 & TST \\
\hline CHEMBL1448184 & 688239 & 4.7362 & 5.646 & TRN \\
\hline CHEMBL1585532 & 688239 & 4.5362 & 5.6164 & TRN \\
\hline CHEMBL1393427 & 688239 & 5.4362 & 5.5674 & TRN \\
\hline CHEMBL1383833 & 688239 & 5.0862 & 5.4605 & TRN \\
\hline CHEMBL1402480 & 688239 & 5.0862 & 5.502006 & 000000001 \\
\hline CHEMBL1494256 & 688239 & 5.1862 & 5.5267 & TRN \\
\hline CHEMBL1341524 & 688239 & 6.0862 & 5.6328 & TST \\
\hline CHEMBL1418162 & 688239 & 4.8362 & 5.4565 & TRN \\
\hline CHEMBL1419015 & 688239 & 8.28399 & 99999999 & 5.4329 \\
\hline CHEMBL1486524 & 688239 & 4.4862 & 5.568 & TST \\
\hline CHEMBL1397089 & 688239 & 6.5363 & 5.4642 & TST \\
\hline CHEMBL1301998 & 688239 & 6.7862 & 5.3588 & TRN \\
\hline CHEMBL1446999 & 688239 & 4.6862 & 5.5881 & TRN \\
\hline CHEMBL1422928 & 688239 & 4.6362 & 5.4903 & TRN \\
\hline CHEMBL1505521 & 688239 & 4.9862 & 5.5184 & TRN \\
\hline CHEMBL1586535 & 688239 & 4.5362 & 5.5432 & TRN \\
\hline CHEMBL1326038 & 688239 & 5.6862 & 5.5543 & TRN \\
\hline CHEMBL 3213370 & 688239 & 5.4362 & 5.4793 & TRN \\
\hline CHEMBL1326840 & 688239 & 6.1862 & 5.3242 & TRN \\
\hline CHEMBL1503959 & 688239 & 8.3872 & 5.6265 & TRN \\
\hline CHEMBL1537860 & 688239 & 4.9362 & 5.3949 & TRN \\
\hline CHEMBL1340181 & 688239 & 4.7862 & 5.476 & TST \\
\hline CHEMBL1595175 & 688239 & 4.7862 & 5.5927 & TRN \\
\hline CHEMBL1355017 & 688239 & 4.5362 & 5.4616 & TRN \\
\hline CHEMBL1505996 & 688239 & 8.3372 & 5.4916 & TST \\
\hline CHEMBL3192091 & 688239 & 4.7362 & 5.3729 & TST \\
\hline CHEMBL3211585 & 688239 & 5.4362 & 5.3688 & TRN \\
\hline CHEMBL1348197 & 688239 & 6.2362 & 5.4408 & TRN \\
\hline CHEMBL1384586 & 688239 & 4.6862 & 5.3595 & TRN \\
\hline CHEMBL1323333 & 688239 & 7.1361 & 5.5176 & TST \\
\hline CHEMBL 1437370 & 688239 & 5.4862 & 5.5062 & TRN \\
\hline CHEMBL1303973 & 688239 & 6.2362 & 5.5239 & TST \\
\hline CHEMBL1387923 & 688239 & 5.4362 & 5.4195 & TRN \\
\hline CHEMBL1411125 & 688239 & 4.6862 & 5.4451 & TRN \\
\hline CHEMBL1339503 & 688239 & 5.4362 & 5.5781 & TRN \\
\hline CHEMBL1546835 & 688239 & 5.2362 & 5.4606 & TRN \\
\hline CHEMBL1308103 & 688239 & 5.9362 & 5.4107 & TRN \\
\hline CHEMBL1346215 & 688239 & 7.2865 & 5.3881 & TRN \\
\hline CHEMBL1517739 & 688239 & 4.5362 & 5.5511 & TRN \\
\hline CHEMBL 3209274 & 688239 & 4.8862 & 5.5483 & TST \\
\hline
\end{tabular}

Page 1646 
Supplemental Table S2.txt

\begin{tabular}{|c|c|c|c|c|}
\hline 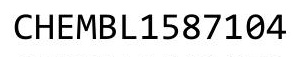 & & & & \\
\hline HEMBL1541373 & 38239 & 362 & 3563 & \\
\hline HEMBL1523817 & 239 & 863 & 275 & \\
\hline & 39 & & 804 & \\
\hline IEMBL1390436 & & 862 & & \\
\hline AEMBL1423541 & 88239 & 362 & 5535 & \\
\hline AEMBL1328928 & 88239 & 862 & 62 & \\
\hline AEMBL145 & & & & \\
\hline EMBL16 & 39 & 362 & & \\
\hline IEMBL15 & & & & \\
\hline AEMBL1402429 & 39 & 862 & 478 & \\
\hline AEMBL1367529 & 39 & 862 & & \\
\hline AEMBL1416850 & & & & \\
\hline AEMBL15 & & & & \\
\hline HEMBL13 & & & & \\
\hline AEMBL1527530 & & 362 & & \\
\hline AEMBL1423107 & & 362 & & \\
\hline IEMBL13 & & 52 & & \\
\hline AEMBL15 & & & & \\
\hline IEMBL14 & & & & \\
\hline AEMBL 14 & & 862 & & \\
\hline AEMBL13 & & 362 & & \\
\hline IEMBL15 & & 62 & & \\
\hline 205 & & & & \\
\hline 704 & & & & \\
\hline 811 & & 362 & & \\
\hline IEMBL1538752 & & 62 & & \\
\hline AEMBL15 & & 62 & & \\
\hline 84 & & & & \\
\hline 566 & & 62 & & \\
\hline AEMBL1307709 & & & & \\
\hline AEMBL1359271 & & 62 & & \\
\hline & & & & \\
\hline 47 & & & & \\
\hline AEMBL146 & & & & \\
\hline AEMBL1380080 & & & & \\
\hline AEMBL1610555 & & 862 & 81 & \\
\hline & & 62 & & \\
\hline 50 & & & & \\
\hline HEMBL1340010 & & & & ST \\
\hline IEMBL1600916 & & & 383 & $\mathrm{R}$ \\
\hline AEMBL1496330 & & 62 & & \\
\hline HEMBL160 & & & & \\
\hline HEMBL1331566 & & & & \\
\hline AEMBL1517604 & & & & RN \\
\hline IEMBL1551674 & 68 & 362 & 857 & is \\
\hline 1911 & & & & \\
\hline מברת 19 & & & & \\
\hline
\end{tabular}




\begin{tabular}{|c|c|c|c|c|c|c|}
\hline \multirow[b]{2}{*}{ CHEMBL 3198569} & & \multicolumn{5}{|c|}{ Supplemental Table S2.txt } \\
\hline & 688239 & 4.5362 & 5.53100 & 0000000001 & & TST \\
\hline CHEMBL1533148 & 688239 & 6.4862 & 5.4914 & TRN & & \\
\hline CHEMBL1518831 & 688239 & 8.3372 & 5.5448 & TRN & & \\
\hline CHEMBL 3212407 & 688239 & 5.4362 & 5.3468 & TST & & \\
\hline CHEMBL1502285 & 688239 & 5.4362 & 5.2694 & TST & & \\
\hline CHEMBL1310083 & 688239 & 5.6362 & 5.5551 & TST & & \\
\hline CHEMBL1487983 & 688239 & 8.28399 & 99999999 & 99 & 5.4678 & TRN \\
\hline CHEMBL1331153 & 688239 & 4.5362 & 5.3755 & TST & & \\
\hline CHEMBL3198243 & 688239 & 5.8862 & 5.5272 & TRN & & \\
\hline CHEMBL1445182 & 688239 & 5.9862 & 5.4586 & TRN & & \\
\hline CHEMBL1339827 & 688239 & 5.4862 & 5.3675 & TRN & & \\
\hline CHEMBL1479162 & 688239 & 6.9363 & 5.4492 & TRN & & \\
\hline CHEMBL1577599 & 688239 & 4.5362 & 5.3675 & TRN & & \\
\hline CHEMBL1322589 & 688239 & 4.7862 & 5.5186 & TRN & & \\
\hline CHEMBL1407599 & 688239 & 5.1862 & 5.4828 & TRN & & \\
\hline CHEMBL1401127 & 688239 & 4.9362 & 5.3956 & TRN & & \\
\hline CHEMBL1383688 & 688239 & 5.6862 & 5.4129 & TRN & & \\
\hline CHEMBL1370062 & 688239 & 5.1862 & 5.3879 & TRN & & \\
\hline CHEMBL1439193 & 688239 & 7.2366 & 5.4237 & TRN & & \\
\hline CHEMBL1529362 & 688239 & 6.8861 & 5.5555 & TRN & & \\
\hline CHEMBL1570767 & 688239 & 4.5362 & 5.5337 & TRN & & \\
\hline CHEMBL1322097 & 688239 & 7.1864 & 5.4093 & TRN & & \\
\hline CHEMBL1397435 & 688239 & 5.5862 & 5.4113 & TRN & & \\
\hline CHEMBL1579541 & 688239 & 4.7362 & 5.4699 & TRN & & \\
\hline CHEMBL1365590 & 688239 & 4.5362 & 5.5326 & TRN & & \\
\hline CHEMBL1392006 & 688239 & 6.2362 & 5.5422 & TRN & & \\
\hline CHEMBL1568184 & 688239 & 4.5362 & 5.3383 & TRN & & \\
\hline CHEMBL1504644 & 688239 & 8.2366 & 5.4242 & TST & & \\
\hline CHEMBL1491145 & 688239 & 4.7362 & 5.4164 & TRN & & \\
\hline CHEMBL1374785 & 688239 & 6.2362 & 5.4939 & TRN & & \\
\hline CHEMBL244920 & 688239 & 5.2862 & 5.5675 & TRN & & \\
\hline CHEMBL1506646 & 688239 & 4.5362 & 5.4974 & TRN & & \\
\hline CHEMBL3208012 & 688239 & 5.8362 & 5.3866 & TRN & & \\
\hline CHEMBL1303626 & 688239 & 4.5362 & 5.3402 & TST & & \\
\hline CHEMBL1558665 & 688239 & 5.5862 & 5.5217 & TRN & & \\
\hline CHEMBL1564981 & 688239 & 6.1362 & 5.5738 & TRN & & \\
\hline CHEMBL1530030 & 688239 & 4.8362 & 5.5317 & TRN & & \\
\hline CHEMBL1432697 & 688239 & 5.9862 & 5.4978 & TRN & & \\
\hline CHEMBL1501597 & 688239 & 6.8861 & 5.3549 & TRN & & \\
\hline CHEMBL1402403 & 688239 & 5.9362 & 5.37 & TRN & & \\
\hline CHEMBL1543749 & 688239 & 8.3372 & 5.5915 & TRN & & \\
\hline CHEMBL1609541 & 688239 & 5.1862 & 5.5009 & TRN & & \\
\hline CHEMBL1457501 & 688239 & 4.6862 & 5.2712 & TRN & & \\
\hline CHEMBL1566582 & 688239 & 5.4862 & 5.5936 & TST & & \\
\hline CHEMBL1340300 & 688239 & 4.4862 & 5.3651 & TRN & & \\
\hline CHEMBL1488361 & 688239 & 5.2362 & 5.5257 & TST & & \\
\hline CHEMBL 3212442 & 688239 & 5.3862 & 5.3644 & TST & & \\
\hline CHEMBL1339620 & 688239 & 4.5362 & 5.3177 & TRN & & \\
\hline
\end{tabular}


Supplemental Table S2.txt

\begin{tabular}{|c|c|c|c|c|c|}
\hline CHEMBL1372628 & 688239 & 8.3872 & 5.5266 & TRN & \\
\hline CHEMBL1510088 & 688239 & 4.5362 & 5.6379 & TRN & \\
\hline CHEMBL1315667 & 688239 & 5.6862 & 5.5114 & TRN & \\
\hline CHEMBL1377740 & 688239 & 5.7362 & 5.428 & TRN & \\
\hline CHEMBL1482898 & 688239 & 6.2362 & 5.3868 & TRN & \\
\hline CHEMBL1548409 & 688239 & 6.5862 & 5.4811 & TST & \\
\hline CHEMBL1386167 & 688239 & 6.2362 & 5.5522 & TRN & \\
\hline CHEMBL1545107 & 688239 & 4.5362 & 5.4985 & TRN & \\
\hline CHEMBL1353769 & 688239 & 5.4362 & 5.6221 & TRN & \\
\hline CHEMBL1576658 & 688239 & 4.7362 & 5.4375 & TST & \\
\hline CHEMBL1503936 & 688239 & 4.6862 & 5.3411 & TST & \\
\hline CHEMBL1357685 & 688239 & 4.6362 & 5.4354 & TRN & \\
\hline CHEMBL1424705 & 688239 & 4.4862 & 5.3636 & TRN & \\
\hline CHEMBL3199323 & 688239 & 6.1362 & 5.4336 & TRN & \\
\hline CHEMBL1540649 & 688239 & 4.5362 & 5.5055 & TRN & \\
\hline CHEMBL1457673 & 688239 & 5.1862 & 5.5578 & TRN & \\
\hline CHEMBL1302679 & 688239 & 5.9362 & 5.5689 & TRN & \\
\hline CHEMBL1605190 & 688239 & 5.1862 & 5.54899 & 99999999995 & TRN \\
\hline CHEMBL1577829 & 688239 & 4.7362 & 5.3889 & TST & \\
\hline CHEMBL1440418 & 688239 & 5.5862 & 5.483 & TRN & \\
\hline CHEMBL1418541 & 688239 & 4.5362 & 5.409 & TST & \\
\hline CHEMBL1479308 & 688239 & 8.3872 & 5.3869 & TRN & \\
\hline CHEMBL1316343 & 688239 & 4.8862 & 5.3615 & TRN & \\
\hline CHEMBL1587935 & 688239 & 5.3862 & 5.4549 & TRN & \\
\hline CHEMBL1344127 & 688239 & 4.4862 & 5.5804 & TRN & \\
\hline CHEMBL1612142 & 688239 & 8.3872 & 5.4552 & TRN & \\
\hline CHEMBL1386918 & 688239 & 5.1362 & 5.2666 & TRN & \\
\hline CHEMBL1537765 & 688239 & 4.6362 & 5.5367 & TRN & \\
\hline CHEMBL1548880 & 688239 & 5.9862 & 5.4227 & TRN & \\
\hline CHEMBL1347600 & 688239 & 5.8862 & 5.2859 & TRN & \\
\hline CHEMBL1321324 & 688239 & 4.9362 & 5.5207 & TRN & \\
\hline CHEMBL1384354 & 688239 & 5.0862 & 5.4875 & TRN & \\
\hline CHEMBL1609967 & 688239 & 5.7362 & 5.5153 & TRN & \\
\hline CHEMBL1310107 & 688239 & 6.1362 & 5.6695 & TST & \\
\hline CHEMBL1441657 & 688239 & 6.1862 & 5.4195 & TRN & \\
\hline CHEMBL1597772 & 688239 & 5.5862 & 5.6298 & TRN & \\
\hline CHEMBL1569552 & 688239 & 5.2362 & 5.6383 & TRN & \\
\hline CHEMBL1573875 & 688239 & 5.3362 & 5.5244 & TRN & \\
\hline CHEMBL3192846 & 688239 & 5.2862 & 5.3989 & TRN & \\
\hline CHEMBL1567200 & 688239 & 5.6362 & 5.6625 & TRN & \\
\hline CHEMBL1314198 & 688239 & 4.4862 & 5.5212 & TRN & \\
\hline CHEMBL1430317 & 688239 & 5.2362 & 5.5429 & TRN & \\
\hline CHEMBL1571280 & 688239 & 5.5862 & 5.3791 & TRN & \\
\hline CHEMBL1375059 & 688239 & 5.4862 & 5.4446 & TRN & \\
\hline CHEMBL1431213 & 688239 & 6.6362 & 5.5078 & TRN & \\
\hline CHEMBL1589826 & 688239 & 5.4362 & 5.5894 & TRN & \\
\hline CHEMBL1572198 & 688239 & 5.8362 & 5.4737 & TRN & \\
\hline CHEMBL1572953 & 688239 & 4.8362 & 5.4871 & TST & \\
\hline
\end{tabular}


Supplemental Table S2.txt

\begin{tabular}{|c|c|c|c|c|}
\hline . & & & & \\
\hline HEMBL1386267 & 38239 & 362 & 54 & \\
\hline HEMBL1309454 & 239 & 862 & & \\
\hline 995 & 39 & 362 & & \\
\hline IEMBL14 & & 862 & & \\
\hline AEMBL3209261 & 88239 & 863 & 84 & \\
\hline AEMBL1391503 & 88239 & 362 & 3747 & \\
\hline AEMBL607140 & & 362 & & \\
\hline EMBL1365125 & 39 & 867 & 87 & \\
\hline IEMBL 3214147 & & 862 & & \\
\hline AEMBL1384051 & 39 & 862 & & \\
\hline AEMBL3212137 & & 362 & & \\
\hline HEMBL1439833 & & 862 & & \\
\hline 418795 & & 362 & & \\
\hline IEMBL3392052 & & 862 & & \\
\hline AEMBL1302129 & & 862 & & \\
\hline AEMBL1504589 & & 362 & & \\
\hline IEMBL1605 & & 62 & & \\
\hline HEMBL1531 & & 62 & & \\
\hline JEMBL156 & & & & \\
\hline AEMBL1364655 & & 362 & & \\
\hline AEMBL1474822 & & 62 & & \\
\hline AEMBL138: & & 62 & & \\
\hline AFMRI 138 & & & & \\
\hline 68 & & 62 & & \\
\hline AEMBL1586912 & & 362 & & \\
\hline IEMBL1309556 & & & & \\
\hline IEMBL1415859 & & 62 & & \\
\hline 2 & & 62 & & \\
\hline 22 & & 72 & & \\
\hline AEMBL1300431 & & & & \\
\hline AEMBL1537209 & & 362 & & \\
\hline & & 62 & & \\
\hline 7 & & 52 & & \\
\hline & & & & \\
\hline AEMBL1515994 & & 861 & & \\
\hline AEMBL1316524 & & 362 & & \\
\hline & & & & \\
\hline 1308923 & & & & \\
\hline HEMBL1311467 & & & & RN \\
\hline AEMBL1322379 & & 362 & & $\mathrm{r}$ \\
\hline IEMBL1595925 & & 66 & & \\
\hline & & & & \\
\hline HEMBL1420932 & & & & RN \\
\hline AEMBL1455614 & & & & s \\
\hline IEMBL1607624 & 68 & 362 & & TP \\
\hline MBL1351193 & & & & \\
\hline HEMBL1370878 & & & & \\
\hline
\end{tabular}

Page 1650 
Supplemental Table S2.txt

\begin{tabular}{|c|c|c|c|c|}
\hline CHEMBL1461367 & 688239 & 5.1862 & \multicolumn{2}{|c|}{5.4639999999999995} \\
\hline CHEMBL1442421 & 688239 & 7.0362 & 5.3138 & TRN \\
\hline CHEMBL1517778 & 688239 & 4.5362 & 5.4931 & TST \\
\hline CHEMBL1549575 & 688239 & 6.6362 & 5.4362 & TST \\
\hline CHEMBL1585843 & 688239 & 4.6362 & 5.4998 & TRN \\
\hline CHEMBL1587076 & 688239 & 6.9863 & 5.4458 & TRN \\
\hline CHEMBL1562995 & 688239 & 5.5862 & 5.3811 & TST \\
\hline CHEMBL1379137 & 688239 & 4.5362 & 5.6013 & TST \\
\hline CHEMBL1452961 & 688239 & 6.3863 & 5.6209 & TRN \\
\hline CHEMBL3195449 & 688239 & 4.4862 & 5.4967 & TRN \\
\hline CHEMBL1412036 & 688239 & 4.5862 & 5.5431 & TRN \\
\hline CHEMBL1420007 & 688239 & 4.4862 & 5.3195 & TST \\
\hline CHEMBL3192616 & 688239 & 5.0362 & 5.2505 & TRN \\
\hline CHEMBL1459999 & 688239 & 6.7862 & 5.5476 & TRN \\
\hline CHEMBL1471378 & 688239 & 4.5362 & 5.5905 & TRN \\
\hline CHEMBL1389147 & 688239 & 5.1862 & 5.5797 & TST \\
\hline CHEMBL1424834 & 688239 & 4.8362 & 5.6533 & TRN \\
\hline CHEMBL1313927 & 688239 & 4.5362 & 5.4784 & TRN \\
\hline CHEMBL1585668 & 688239 & 4.6862 & 5.4577 & TRN \\
\hline CHEMBL3199782 & 688239 & 5.1362 & 5.4475 & TRN \\
\hline CHEMBL1443616 & 688239 & 4.5362 & 5.4728 & TST \\
\hline CHEMBL1329017 & 688239 & 5.3862 & 5.4572 & TRN \\
\hline CHEMBL1432150 & 688239 & 5.5362 & 5.5995 & TRN \\
\hline CHEMBL1303552 & 688239 & 4.8362 & 5.5164 & TRN \\
\hline CHEMBL1528371 & 688239 & 4.9362 & 5.4834 & TRN \\
\hline CHEMBL1571024 & 688239 & 6.1362 & 5.4756 & TST \\
\hline CHEMBL1346463 & 688239 & 4.5362 & 5.5969 & TRN \\
\hline CHEMBL1505644 & 688239 & 5.5362 & 5.5324 & TRN \\
\hline CHEMBL1540154 & 688239 & 4.8362 & 5.6034 & TST \\
\hline CHEMBL1447709 & 688239 & 5.3362 & 5.4376 & TRN \\
\hline CHEMBL1481266 & 688239 & 5.7862 & 5.682 & TRN \\
\hline CHEMBL1399815 & 688239 & 5.3862 & 5.4262 & TRN \\
\hline CHEMBL1450985 & 688239 & 5.1862 & 5.7347 & TRN \\
\hline CHEMBL1445286 & 688239 & 4.6862 & 5.5759 & TRN \\
\hline CHEMBL1531623 & 688239 & 6.1862 & 5.544 & TST \\
\hline CHEMBL3214405 & 688239 & 6.6362 & 5.4921 & TRN \\
\hline CHEMBL1607982 & 688239 & 4.2362 & 5.3523 & TRN \\
\hline CHEMBL1382047 & 688239 & 4.5362 & 5.4482 & TRN \\
\hline CHEMBL1542969 & 688239 & 5.6362 & 5.5696 & TST \\
\hline CHEMBL1383742 & 688239 & 5.0362 & 5.4676 & TRN \\
\hline CHEMBL1588022 & 688239 & 4.7362 & 5.5294 & TRN \\
\hline CHEMBL1560379 & 688239 & 4.8362 & 5.4219 & TRN \\
\hline CHEMBL1473535 & 688239 & 5.1362 & 5.5471 & TRN \\
\hline CHEMBL1464781 & 688239 & 4.5362 & 5.4419 & TST \\
\hline CHEMBL1440212 & 688239 & 6.2362 & 5.4351 & TST \\
\hline CHEMBL1319145 & 688239 & 6.7361 & 5.4546 & TRN \\
\hline CHEMBL1572235 & 688239 & 7.2366 & 5.4469 & TRN \\
\hline CHEMBL1373367 & 688239 & 4.9862 & 5.4183 & TRN \\
\hline
\end{tabular}


Supplemental Table S2.txt

\begin{tabular}{|c|c|c|c|c|c|}
\hline CHEMBL1313362 & 688239 & 5.6362 & 5.4428 & TST & \\
\hline CHEMBL1407951 & 688239 & 6.2862 & 5.4393 & TST & \\
\hline CHEMBL1477320 & 688239 & 5.2862 & 5.5376 & TRN & \\
\hline CHEMBL1584504 & 688239 & 4.7362 & 5.575 & TRN & \\
\hline CHEMBL1545069 & 688239 & 4.5362 & 5.5166 & TST & \\
\hline CHEMBL585329 & 688239 & 5.9362 & 5.5485 & TRN & \\
\hline CHEMBL1401849 & 688239 & 7.1361 & 5.4838 & TST & \\
\hline CHEMBL1374769 & 688239 & 8.3372 & 5.515 & TRN & \\
\hline CHEMBL1605158 & 688239 & 4.6862 & 5.3505 & TRN & \\
\hline CHEMBL1544776 & 688239 & 4.6862 & 5.401 & TRN & \\
\hline CHEMBL1550219 & 688239 & 4.5362 & 5.4117 & TRN & \\
\hline CHEMBL 3194487 & 688239 & 4.5362 & 5.4287 & TRN & \\
\hline CHEMBL1567819 & 688239 & 5.1862 & 5.4033 & TRN & \\
\hline CHEMBL1420823 & 688239 & 4.6862 & 5.3292 & TRN & \\
\hline CHEMBL1593726 & 688239 & 4.5362 & 5.5555 & TRN & \\
\hline CHEMBL1394676 & 688239 & 5.0862 & 5.5735 & TRN & \\
\hline CHEMBL1505984 & 688239 & 4.5362 & 5.4859 & TRN & \\
\hline CHEMBL1505872 & 688239 & 5.8862 & 5.507000 & 000000001 & $\mathrm{TH}$ \\
\hline CHEMBL1517768 & 688239 & 6.2362 & 5.4111 & TST & \\
\hline CHEMBL1563120 & 688239 & 5.1862 & 5.4727 & TRN & \\
\hline CHEMBL1366917 & 688239 & 5.0362 & 5.2807 & TRN & \\
\hline CHEMBL1333602 & 688239 & 5.3862 & 5.4649 & TRN & \\
\hline CHEMBL1998141 & 688239 & 4.5362 & 5.7481 & TST & \\
\hline CHEMBL1447787 & 688239 & 4.5362 & 5.4332 & TRN & \\
\hline CHEMBL1574521 & 688239 & 5.35 & 5.4666 & TST & \\
\hline CHEMBL1452673 & 688239 & 5.0362 & 5.4301 & TST & \\
\hline CHEMBL1498356 & 688239 & 4.5362 & 5.564 & TST & \\
\hline CHEMBL1382486 & 688239 & 6.1362 & 5.5085 & TST & \\
\hline CHEMBL1363208 & 688239 & 5.9862 & 5.553 & TRN & \\
\hline CHEMBL3190333 & 688239 & 6.1362 & 5.5179 & TST & \\
\hline CHEMBL1308720 & 688239 & 6.5862 & 5.53 & TRN & \\
\hline CHEMBL1411700 & 688239 & 5.4862 & 5.3793 & TRN & \\
\hline CHEMBL1492895 & 688239 & 6.1862 & 5.3338 & TRN & \\
\hline CHEMBL1596824 & 688239 & 5.3862 & 5.6234 & TRN & \\
\hline CHEMBL1302713 & 688239 & 4.9362 & 5.4872 & TRN & \\
\hline CHEMBL1445258 & 688239 & 6.7361 & 5.4772 & TRN & \\
\hline CHEMBL1523295 & 688239 & 4.4862 & 5.5792 & TRN & \\
\hline CHEMBL1305301 & 688239 & 5.1862 & 5.4784 & TRN & \\
\hline CHEMBL1447555 & 688239 & 5.2862 & 5.5941 & TST & \\
\hline CHEMBL1587433 & 688239 & 4.7362 & 5.4761 & TRN & \\
\hline CHEMBL1378015 & 688239 & 5.1862 & 5.5323 & TRN & \\
\hline CHEMBL1458360 & 688239 & 4.7862 & 5.4114 & TST & \\
\hline CHEMBL1567508 & 688239 & 6.3863 & 5.3668 & TST & \\
\hline CHEMBL1538965 & 688239 & 6.4362 & 5.555 & TRN & \\
\hline CHEMBL1438089 & 688239 & 4.7362 & 5.5075 & TRN & \\
\hline CHEMBL1388668 & 688239 & \multicolumn{3}{|c|}{8.283999999999999} & $\mathrm{TKT}$ \\
\hline CHEMBL1555549 & 688239 & 6.1362 & 5.4664 & TRN & \\
\hline CHEMBL1322735 & 688239 & 5.4862 & 5.5489 & TRN & \\
\hline
\end{tabular}


Supplemental Table S2.txt

\begin{tabular}{|c|c|c|c|c|}
\hline CHEMBL1540621 & 688239 & 5.5862 & 5.3784 & TRN \\
\hline CHEMBL1450371 & 688239 & 5.2362 & 5.3918 & TRN \\
\hline CHEMBL1549603 & 688239 & 8.3372 & 5.4993 & TRN \\
\hline CHEMBL1469714 & 688239 & 5.7362 & 5.5252 & TST \\
\hline CHEMBL1332072 & 688239 & 4.8362 & 5.4972 & TRN \\
\hline CHEMBL3208808 & 688239 & 4.5862 & 5.3682 & TRN \\
\hline CHEMBL1511236 & 688239 & 8.3372 & 5.1939 & TRN \\
\hline CHEMBL1531271 & 688239 & 7.0362 & 5.6748 & TST \\
\hline CHEMBL1453740 & 688239 & 8.28399 & 99999999 & 5.7869 \\
\hline CHEMBL1334231 & 688239 & 4.5362 & 5.5385 & TRN \\
\hline CHEMBL3199216 & 688239 & 5.4862 & 5.5562 & TRN \\
\hline CHEMBL1411379 & 688239 & 5.6862 & 5.577999 & 999999999 \\
\hline CHEMBL1386777 & 688239 & 6.1862 & 5.465 & TRN \\
\hline CHEMBL1337692 & 688239 & 5.1862 & 5.5628 & TST \\
\hline CHEMBL1428846 & 688239 & 5.8362 & 5.6376 & TST \\
\hline CHEMBL1383083 & 688239 & 4.7362 & 5.4172 & TST \\
\hline CHEMBL1385208 & 688239 & 4.5362 & 5.4885 & TRN \\
\hline CHEMBL1498056 & 688239 & 5.7862 & 5.5344 & TRN \\
\hline CHEMBL1394811 & 688239 & 4.7362 & 5.4367 & TRN \\
\hline CHEMBL1549839 & 688239 & 4.9362 & 5.4694 & TST \\
\hline CHEMBL1612986 & 688239 & 5.4362 & 5.2976 & TRN \\
\hline CHEMBL1454171 & 688239 & 4.6862 & 5.5135 & TST \\
\hline CHEMBL1582401 & 688239 & 4.5362 & 5.5223 & TRN \\
\hline CHEMBL1329982 & 688239 & 5.1862 & 5.5147 & TRN \\
\hline CHEMBL1527912 & 688239 & 5.3362 & 5.5279 & TRN \\
\hline CHEMBL1317365 & 688239 & 4.7362 & 5.507000 & 000000001 \\
\hline CHEMBL579420 & 688239 & 4.5362 & 5.4091 & TRN \\
\hline CHEMBL1571103 & 688239 & 7.2366 & 5.5303 & TST \\
\hline CHEMBL1420231 & 688239 & 4.5362 & 5.4774 & TRN \\
\hline CHEMBL1508418 & 688239 & 4.5362 & 5.3737 & TRN \\
\hline CHEMBL389723 & 688239 & 5.1362 & 5.6661 & TRN \\
\hline CHEMBL1350869 & 688239 & 4.4862 & 5.55 & TST \\
\hline CHEMBL1374935 & 688239 & 8.3872 & 5.4057 & TRN \\
\hline CHEMBL1448449 & 688239 & 6.9863 & 5.569 & TRN \\
\hline CHEMBL1577957 & 688239 & 8.3372 & 5.5448 & TST \\
\hline CHEMBL464176 & 688239 & 4.7862 & 5.3622 & TST \\
\hline CHEMBL1338925 & 688239 & 5.1862 & 5.3692 & TRN \\
\hline CHEMBL1311922 & 688239 & 5.4362 & 5.4462 & TRN \\
\hline CHEMBL1497673 & 688239 & 6.0862 & 5.5001 & TST \\
\hline CHEMBL1446622 & 688239 & 7.6861 & 5.5706 & TRN \\
\hline CHEMBL 3212467 & 688239 & 4.6362 & 5.4432 & TRN \\
\hline CHEMBL1454573 & 688239 & 4.5362 & 5.4686 & TRN \\
\hline CHEMBL1341392 & 688239 & 4.7862 & 5.4997 & TRN \\
\hline CHEMBL1327013 & 688239 & 4.9362 & 5.4118 & TRN \\
\hline CHEMBL1300839 & 688239 & 5.4862 & 5.5163 & TRN \\
\hline CHEMBL1539867 & 688239 & 8.3372 & 5.4455 & TRN \\
\hline CHEMBL1308495 & 688239 & 6.9363 & 5.584 & TRN \\
\hline CHEMBL1323510 & 688239 & 6.1362 & 5.4055 & TRN \\
\hline
\end{tabular}

Page 1653 
Supplemental Table S2.txt

\begin{tabular}{|c|c|c|c|c|c|}
\hline CHEMBL1375329 & 688239 & 4.6362 & 5.3779 & TRN & \\
\hline CHEMBL1457407 & 688239 & 5.0862 & 5.3732 & TST & \\
\hline CHEMBL1311342 & 688239 & 4.5362 & 5.4842 & TRN & \\
\hline CHEMBL1393035 & 688239 & 5.2362 & 5.4434 & TRN & \\
\hline CHEMBL1553651 & 688239 & 4.7862 & 5.2943 & TST & \\
\hline CHEMBL1328109 & 688239 & 4.4862 & 5.44 & TST & \\
\hline CHEMBL1360635 & 688239 & 6.2362 & 5.4669 & TRN & \\
\hline CHEMBL1451249 & 688239 & 6.7862 & 5.5292 & TRN & \\
\hline CHEMBL1406027 & 688239 & 6.9863 & 5.4322 & TRN & \\
\hline CHEMBL1299804 & 688239 & 4.5862 & 5.5709 & TRN & \\
\hline CHEMBL1529968 & 688239 & 4.7362 & 5.3852 & TRN & \\
\hline CHEMBL1481734 & 688239 & 4.7 & 5.4506 & TST & \\
\hline CHEMBL1480555 & 688239 & 5.4862 & 5.5247 & TRN & \\
\hline CHEMBL1538996 & 688239 & 4.7362 & 5.5793 & TRN & \\
\hline CHEMBL1500629 & 688239 & 5.6862 & 5.4534 & TRN & \\
\hline CHEMBL1540064 & 688239 & 4.8362 & 5.4912 & TRN & \\
\hline CHEMBL1388012 & 688239 & 5.1362 & 5.5125 & TST & \\
\hline CHEMBL1400460 & 688239 & 5.7362 & 5.4938 & TRN & \\
\hline CHEMBL1600789 & 688239 & 8.3372 & 5.62299 & 9999999999 & TRN \\
\hline CHEMBL1975809 & 688239 & 4.5362 & 5.3699 & TRN & \\
\hline CHEMBL1405413 & 688239 & 5.1862 & 5.5717 & TRN & \\
\hline CHEMBL1565970 & 688239 & 4.6862 & 5.5974 & TRN & \\
\hline CHEMBL1460718 & 688239 & 4.6362 & 5.3766 & TST & \\
\hline CHEMBL1303770 & 688239 & 5.5862 & 5.4855 & TST & \\
\hline CHEMBL1971935 & 688239 & 5.3862 & 5.4201 & TRN & \\
\hline CHEMBL1335808 & 688239 & 4.6362 & 5.5004 & TRN & \\
\hline CHEMBL1605727 & 688239 & 4.5362 & 5.3906 & TRN & \\
\hline CHEMBL1504839 & 688239 & 5.6862 & 5.564 & TST & \\
\hline CHEMBL1525550 & 688239 & 6.1862 & 5.5002 & TST & \\
\hline CHEMBL1380093 & 688239 & 6.1362 & 5.4756 & TRN & \\
\hline CHEMBL1598046 & 688239 & 6.8362 & 5.5149 & TRN & \\
\hline CHEMBL1361355 & 688239 & 6.4862 & 5.5063 & TRN & \\
\hline CHEMBL1603864 & 688239 & 6.7862 & 5.4272 & TRN & \\
\hline CHEMBL1574586 & 688239 & 6.2862 & 5.4594 & TRN & \\
\hline CHEMBL1510472 & 688239 & 7.8861 & 5.4263 & TRN & \\
\hline CHEMBL1316308 & 688239 & 4.5862 & 5.5473 & TRN & \\
\hline CHEMBL1520141 & 688239 & 4.4862 & 5.5503 & TRN & \\
\hline CHEMBL1480153 & 688239 & 4.7862 & 5.4193 & TRN & \\
\hline CHEMBL1467464 & 688239 & 5.3362 & 5.49100 & 00000000005 & TRN \\
\hline CHEMBL1329752 & 688239 & 6.8362 & 5.3544 & TRN & \\
\hline CHEMBL1577008 & 688239 & 4.7362 & 5.5511 & TRN & \\
\hline CHEMBL1414081 & 688239 & 5.1862 & 5.5688 & TRN & \\
\hline CHEMBL1965786 & 688239 & 6.0362 & 5.4693 & TRN & \\
\hline CHEMBL1342341 & 688239 & 4.5362 & 5.6141 & TST & \\
\hline CHEMBL1551998 & 688239 & 5.7362 & 5.5696 & TRN & \\
\hline CHEMBL1421941 & 688239 & 6.1362 & 5.558 & TST & \\
\hline CHEMBL1533279 & 688239 & 4.9862 & 5.2978 & TRN & \\
\hline CHEMBL1464728 & 688239 & 4.7362 & 5.4996 & TST & \\
\hline
\end{tabular}


Supplemental Table S2.txt

\begin{tabular}{|c|c|c|c|c|}
\hline CHEMBL1447965 & 688239 & 4.5362 & 5.5402 & TRN \\
\hline CHEMBL1570165 & 688239 & 5.5362 & 5.5452 & TRN \\
\hline CHEMBL1544038 & 688239 & 6.3863 & 5.7112 & TRN \\
\hline CHEMBL1469305 & 688239 & 5.4862 & 5.3346 & TST \\
\hline CHEMBL1575389 & 688239 & 5.1862 & 5.4595 & TST \\
\hline CHEMBL1317807 & 688239 & 5.5362 & 5.5001 & TRN \\
\hline CHEMBL1525816 & 688239 & 5.1362 & 5.5733 & TRN \\
\hline CHEMBL1531955 & 688239 & 6.1862 & 5.3127 & TRN \\
\hline CHEMBL1333243 & 688239 & 5.6862 & 5.5844 & TRN \\
\hline CHEMBL1561917 & 688239 & 6.1362 & 5.5542 & TRN \\
\hline CHEMBL1528954 & 688239 & 6.1362 & 5.4758 & TST \\
\hline CHEMBL1404647 & 688239 & 5.1862 & 5.3979 & TRN \\
\hline CHEMBL1539694 & 688239 & 5.0862 & \multicolumn{2}{|c|}{5.5760000000000005} \\
\hline CHEMBL1513138 & 688239 & 5.2862 & 5.4357 & TRN \\
\hline CHEMBL1555594 & 688239 & 5.6362 & 5.5141 & TRN \\
\hline CHEMBL1561333 & 688239 & 4.4862 & 5.4118 & TRN \\
\hline CHEMBL1415732 & 688239 & 4.6362 & 5.591 & TRN \\
\hline CHEMBL1588045 & 688239 & 4.9862 & 5.5575 & TRN \\
\hline CHEMBL1418407 & 688239 & 5.5862 & 5.3952 & TST \\
\hline CHEMBL1602143 & 688239 & 5.8862 & 5.4523 & TRN \\
\hline CHEMBL1603129 & 688239 & 5.6362 & 5.4816 & TRN \\
\hline CHEMBL1353135 & 688239 & 4.7862 & 5.4463 & TRN \\
\hline CHEMBL1548499 & 688239 & 4.6862 & \multicolumn{2}{|c|}{5.492999999999999} \\
\hline CHEMBL1486275 & 688239 & 5.3362 & 5.5763 & TRN \\
\hline CHEMBL1467383 & 688239 & 4.5362 & 5.2934 & TRN \\
\hline CHEMBL1602470 & 688239 & 5.6362 & 5.3972 & TRN \\
\hline CHEMBL1544172 & 688239 & 5.9362 & 5.4349 & TST \\
\hline CHEMBL1357816 & 688239 & 4.5362 & 5.3598 & TRN \\
\hline CHEMBL1551863 & 688239 & 4.6362 & 5.5168 & TRN \\
\hline CHEMBL1410787 & 688239 & 4.6862 & 5.2953 & TRN \\
\hline CHEMBL1303566 & 688239 & 6.3863 & 5.5447 & TRN \\
\hline CHEMBL1470453 & 688239 & 5.8362 & 5.4527 & TRN \\
\hline CHEMBL1467519 & 688239 & 4.5362 & 5.4623 & TRN \\
\hline CHEMBL1455950 & 688239 & 5.0862 & \multicolumn{2}{|c|}{5.4510000000000005} \\
\hline CHEMBL1470969 & 688239 & 6.1362 & 5.6126 & TRN \\
\hline CHEMBL1569152 & 688239 & 4.8362 & 5.5177 & TRN \\
\hline CHEMBL1426518 & 688239 & 6.2362 & 5.6049 & TRN \\
\hline CHEMBL1536331 & 688239 & 5.3862 & 5.5007 & TRN \\
\hline CHEMBL1465270 & 688239 & 5.8362 & 5.7733 & TRN \\
\hline CHEMBL1602369 & 688239 & 7.4868 & 5.3554 & TRN \\
\hline CHEMBL1591726 & 688239 & 7.0362 & 5.5383 & TRN \\
\hline CHEMBL1507068 & 688239 & 5.3362 & 5.5381 & TRN \\
\hline CHEMBL1362451 & 688239 & 6.7361 & 5.6756 & TRN \\
\hline CHEMBL1369865 & 688239 & 4.6862 & 5.4302 & TST \\
\hline CHEMBL1525317 & 688239 & 5.1362 & 5.4077 & TRN \\
\hline CHEMBL1321945 & 688239 & 5.1862 & 5.3067 & TRN \\
\hline CHEMBL3211924 & 688239 & 4.5362 & 5.5749 & TST \\
\hline CHEMBL1424976 & 688239 & 4.7862 & 5.5462 & TRN \\
\hline
\end{tabular}

Page 1655 
Supplemental Table S2.txt

\begin{tabular}{|c|c|c|c|c|c|}
\hline CHEMBL1429295 & 688239 & 5.6362 & 5.5449 & TRN & \\
\hline CHEMBL1519520 & 688239 & 5.9862 & 5.5685 & TRN & \\
\hline CHEMBL3191803 & 688239 & 5.6362 & 5.4589 & TRN & \\
\hline CHEMBL1430150 & 688239 & 6.9863 & 5.3628 & TRN & \\
\hline CHEMBL1981797 & 688239 & 7.2366 & 5.4196 & TRN & \\
\hline CHEMBL1376804 & 688239 & 5.0362 & 5.477 & TRN & \\
\hline CHEMBL1348803 & 688239 & 4.5362 & 5.516 & TRN & \\
\hline CHEMBL1475441 & 688239 & 4.6862 & 5.4263 & TRN & \\
\hline CHEMBL1579903 & 688239 & 6.6861 & 5.4866 & TRN & \\
\hline CHEMBL1422956 & 688239 & 5.1362 & 5.566 & TRN & \\
\hline CHEMBL1524184 & 688239 & 4.6862 & 5.4068 & TRN & \\
\hline CHEMBL1530237 & 688239 & 6.3863 & 5.4609 & TST & \\
\hline CHEMBL 3211645 & 688239 & 5.2362 & 5.6027 & TRN & \\
\hline CHEMBL1463859 & 688239 & 5.1862 & 5.5085 & TRN & \\
\hline CHEMBL1552263 & 688239 & 4.5362 & 5.5671 & TRN & \\
\hline CHEMBL1342176 & 688239 & 5.6362 & 5.5133 & TST & \\
\hline CHEMBL1510647 & 688239 & 4.9862 & 5.5241 & TST & \\
\hline CHEMBL1492855 & 688239 & 4.7862 & 5.55 & TRN & \\
\hline CHEMBL1359115 & 688239 & 5.0362 & 5.4429 & TRN & \\
\hline CHEMBL340416 & 688239 & 7.7852 & 5.6045 & TRN & \\
\hline CHEMBL1489170 & 688239 & 5.8362 & 5.5098 & TRN & \\
\hline CHEMBL1429690 & 688239 & 5.1362 & 5.4707 & TRN & \\
\hline CHEMBL1418164 & 688239 & 5.8862 & 5.585 & TRN & \\
\hline CHEMBL1564338 & 688239 & 8.3372 & 5.5867 & TRN & \\
\hline CHEMBL1612056 & 688239 & 8.283999 & 99999999 & 99 & 5.4811 \\
\hline CHEMBL1447098 & 688239 & 4.5362 & 5.4516 & TRN & \\
\hline CHEMBL1339555 & 688239 & 5.1862 & 5.5306 & TRN & \\
\hline CHEMBL1451330 & 688239 & 6.1862 & 5.4954 & TRN & \\
\hline CHEMBL1467294 & 688239 & 4.5362 & 5.3974 & TRN & \\
\hline CHEMBL1409198 & 688239 & 4.5862 & 5.504 & TRN & \\
\hline CHEMBL1377053 & 688239 & 6.5363 & 5.6009 & TRN & \\
\hline CHEMBL1412560 & 688239 & 4.5862 & 5.5052 & TRN & \\
\hline CHEMBL1420063 & 688239 & 5.5362 & 5.5841 & TST & \\
\hline CHEMBL1464585 & 688239 & 5.1862 & 5.5014 & TST & \\
\hline CHEMBL1460352 & 688239 & 5.2362 & 5.3687 & TST & \\
\hline CHEMBL 3197625 & 688239 & 5.1362 & 5.3033 & TRN & \\
\hline CHEMBL1990336 & 688239 & 4.4862 & 5.3805 & TRN & \\
\hline CHEMBL1463649 & 688239 & 6.5862 & 5.3751 & TRN & \\
\hline CHEMBL1558382 & 688239 & 5.1362 & 5.5249 & TRN & \\
\hline CHEMBL1423460 & 688239 & 5.4362 & 5.5978 & TST & \\
\hline CHEMBL1399011 & 688239 & 5.1362 & 5.4568 & TRN & \\
\hline CHEMBL1302199 & 688239 & 5.4362 & 5.6214 & TRN & \\
\hline CHEMBL534288 & 688239 & 5.0362 & 5.3494 & TRN & \\
\hline CHEMBL1595720 & 688239 & 5.6362 & 5.476 & TST & \\
\hline CHEMBL1369945 & 688239 & 4.5362 & 5.3893 & TRN & \\
\hline CHEMBL1301886 & 688239 & 5.1862 & 5.4893 & TRN & \\
\hline CHEMBL1326295 & 688239 & 6.3362 & 5.5862 & TRN & \\
\hline CHEMBL1458977 & 688239 & 7.1361 & 5.5121 & TRN & \\
\hline
\end{tabular}


Supplemental Table S2.txt

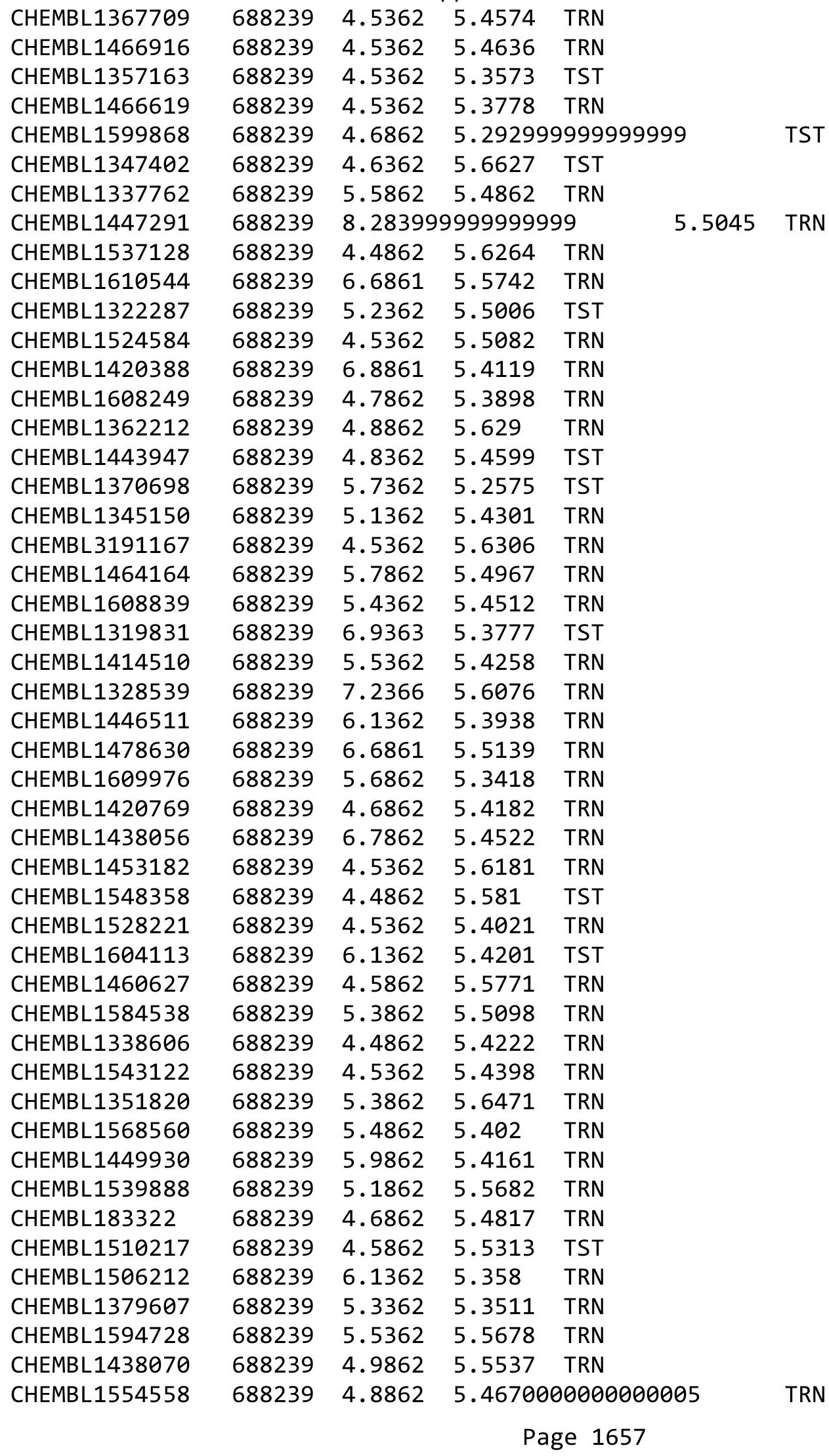


Supplemental Table S2.txt

\begin{tabular}{|c|c|c|c|c|c|}
\hline CHEMBL1585627 & 688239 & 4.5362 & \multicolumn{2}{|c|}{5.382000000000001} & \multirow[t]{2}{*}{ TST } \\
\hline CHEMBL1432800 & 688239 & 4.5362 & 5.6386 & TST & \\
\hline CHEMBL1542184 & 688239 & 6.7862 & 5.3993 & TST & \\
\hline CHEMBL1600942 & 688239 & 4.7862 & 5.6232 & TRN & \\
\hline CHEMBL1460728 & 688239 & 5.1862 & 5.49799 & 9999999999 & TST \\
\hline CHEMBL1524291 & 688239 & 4.9362 & 5.4153 & TST & \\
\hline CHEMBL3196909 & 688239 & 8.1871 & 5.3265 & TRN & \\
\hline CHEMBL1427854 & 688239 & 4.9362 & 5.5894 & TRN & \\
\hline CHEMBL1357965 & 688239 & 4.5362 & 5.5417 & TRN & \\
\hline CHEMBL1445885 & 688239 & 6.5363 & 5.2905 & TST & \\
\hline CHEMBL1379198 & 688239 & 5.1862 & 5.4698 & TRN & \\
\hline CHEMBL1309998 & 688239 & 6.9863 & 5.598 & TRN & \\
\hline CHEMBL1426173 & 688239 & 4.5362 & 5.4874 & TRN & \\
\hline CHEMBL1334675 & 688239 & 4.5862 & 5.3566 & TST & \\
\hline CHEMBL1464127 & 688239 & 4.5362 & 5.4552 & TST & \\
\hline CHEMBL3199054 & 688239 & 5.9362 & 5.5549 & TRN & \\
\hline CHEMBL1382008 & 688239 & 5.8862 & 5.6115 & TRN & \\
\hline CHEMBL1449524 & 688239 & 7.0362 & 5.5123 & TRN & \\
\hline CHEMBL550826 & 688239 & 4.7862 & 5.5401 & TRN & \\
\hline CHEMBL1435769 & 688239 & 4.7362 & 5.3367 & TRN & \\
\hline CHEMBL1385808 & 688239 & 4.7362 & 5.4253 & TST & \\
\hline CHEMBL1426503 & 688239 & 5.1362 & 5.602 & TRN & \\
\hline CHEMBL1567490 & 688239 & 4.5362 & 5.5682 & TRN & \\
\hline CHEMBL1430339 & 688239 & 6.9363 & 5.5294 & TRN & \\
\hline CHEMBL1380837 & 688239 & 5.4362 & 5.4513 & TRN & \\
\hline CHEMBL1422155 & 688239 & 5.3862 & 5.3054 & TRN & \\
\hline CHEMBL1567125 & 688239 & 5.1862 & 5.5375 & TRN & \\
\hline CHEMBL1494076 & 688239 & 5.1862 & 5.4955 & TRN & \\
\hline CHEMBL1343028 & 688239 & 4.8862 & 5.5758 & TST & \\
\hline CHEMBL1481047 & 688239 & 4.5862 & 5.5004 & TST & \\
\hline CHEMBL1527547 & 688239 & 4.8862 & 5.7049 & TRN & \\
\hline CHEMBL1561978 & 688239 & 4.6862 & 5.4225 & TRN & \\
\hline CHEMBL1318001 & 688239 & 4.5362 & 5.4275 & TRN & \\
\hline CHEMBL1351964 & 688239 & 4.7362 & 5.4088 & TRN & \\
\hline CHEMBL1549527 & 688239 & 5.7862 & 5.4646 & TRN & \\
\hline CHEMBL1342750 & 688239 & 7.7852 & 5.5224 & TRN & \\
\hline CHEMBL1337270 & 688239 & 6.8861 & 5.6903 & TRN & \\
\hline CHEMBL1403217 & 688239 & 5.4362 & 5.5086 & TST & \\
\hline CHEMBL1306049 & 688239 & 4.5362 & 5.6091 & TRN & \\
\hline CHEMBL1419526 & 688239 & 4.7862 & 5.2849 & TRN & \\
\hline CHEMBL1530299 & 688239 & 6.2862 & 5.5706 & TRN & \\
\hline CHEMBL1547542 & 688239 & 5.6362 & 5.3727 & TST & \\
\hline CHEMBL1547350 & 688239 & 4.7862 & 5.2336 & TRN & \\
\hline CHEMBL1365952 & 688239 & 4.6862 & 5.5662 & TRN & \\
\hline CHEMBL1423882 & 688239 & 5.5862 & 5.5108 & TRN & \\
\hline CHEMBL1984924 & 688239 & 4.6362 & 5.3285 & TST & \\
\hline CHEMBL1540586 & 688239 & 4.9362 & 5.4969 & TRN & \\
\hline CHEMBL1564964 & 688239 & 5.3862 & 5.4897 & TST & \\
\hline
\end{tabular}


Supplemental Table S2.txt

\begin{tabular}{|c|c|c|c|c|}
\hline CHEMBL1499088 & 688239 & 8.3372 & 5.4751 & TRN \\
\hline CHEMBL1310470 & 688239 & 4.4862 & 5.4804 & TST \\
\hline CHEMBL1434435 & 688239 & 5.1362 & 5.5315 & TRN \\
\hline CHEMBL1412315 & 688239 & 6.1862 & 5.5758 & TRN \\
\hline CHEMBL1482602 & 688239 & 4.5362 & 5.4962 & TRN \\
\hline CHEMBL1415620 & 688239 & 4.6862 & 5.4817 & TRN \\
\hline CHEMBL1457667 & 688239 & 5.8862 & \multicolumn{2}{|c|}{5.622999999999999} \\
\hline CHEMBL1578064 & 688239 & 4.7862 & 5.4615 & TST \\
\hline CHEMBL 3190080 & 688239 & 6.6362 & 5.4396 & TRN \\
\hline CHEMBL1348810 & 688239 & 5.7862 & 5.6265 & TST \\
\hline CHEMBL1363429 & 688239 & 6.8861 & 5.4861 & TRN \\
\hline CHEMBL1359127 & 688239 & 4.5362 & 5.3922 & TRN \\
\hline CHEMBL1472375 & 688239 & 4.4862 & 5.4275 & TRN \\
\hline CHEMBL1579435 & 688239 & 4.4862 & 5.4262 & TRN \\
\hline CHEMBL1393629 & 688239 & 6.2362 & 5.5117 & TRN \\
\hline CHEMBL3199381 & 688239 & 4.5362 & 5.5452 & TRN \\
\hline CHEMBL1583477 & 688239 & 4.6862 & 5.4063 & TRN \\
\hline CHEMBL1413470 & 688239 & 5.1862 & 5.4198 & TRN \\
\hline CHEMBL1425452 & 688239 & 8.3372 & 5.5282 & TRN \\
\hline CHEMBL 3208721 & 688239 & 5.7862 & 5.4455 & TRN \\
\hline CHEMBL1449204 & 688239 & 4.6862 & 5.4549 & TRN \\
\hline CHEMBL1386265 & 688239 & 5.8862 & 5.5474 & TRN \\
\hline CHEMBL1496367 & 688239 & 4.5362 & 5.5141 & TRN \\
\hline CHEMBL1340532 & 688239 & 4.5362 & 5.5308 & TRN \\
\hline CHEMBL1404696 & 688239 & 4.7862 & 5.4482 & TRN \\
\hline CHEMBL1586995 & 688239 & 4.6862 & 5.4299 & TRN \\
\hline CHEMBL1446436 & 688239 & 4.5362 & 5.4516 & TRN \\
\hline CHEMBL1513451 & 688239 & 5.1862 & 5.4577 & TRN \\
\hline CHEMBL1571366 & 688239 & 6.8362 & 5.4376 & TST \\
\hline CHEMBL1334118 & 688239 & 5.6362 & 5.6539 & TRN \\
\hline CHEMBL1399142 & 688239 & 5.9862 & 5.5245 & TST \\
\hline CHEMBL1415422 & 688239 & 4.5362 & 5.5563 & TRN \\
\hline CHEMBL1443791 & 688239 & 4.7362 & 5.4548 & TST \\
\hline CHEMBL1306362 & 688239 & 6.7862 & 5.6186 & TRN \\
\hline CHEMBL1501549 & 688239 & 4.6862 & 5.3929 & TST \\
\hline CHEMBL1404155 & 688239 & 6.8362 & 5.7049 & TRN \\
\hline CHEMBL1556945 & 688239 & 5.1862 & 5.5301 & TRN \\
\hline CHEMBL1510997 & 688239 & 7.5361 & 5.5124 & TRN \\
\hline CHEMBL1341884 & 688239 & 4.7362 & 5.5512 & TRN \\
\hline CHEMBL1338572 & 688239 & 5.3862 & 5.5223 & TRN \\
\hline CHEMBL1492254 & 688239 & 4.5362 & 5.5223 & TST \\
\hline CHEMBL1562959 & 688239 & 5.6862 & 5.4094 & TRN \\
\hline CHEMBL1342186 & 688239 & 5.4862 & 5.5938 & TRN \\
\hline CHEMBL1313500 & 688239 & 4.5362 & 5.4288 & TST \\
\hline CHEMBL3208179 & 688239 & 4.6862 & 5.3389 & TRN \\
\hline CHEMBL1546906 & 688239 & 4.7362 & 5.3932 & TRN \\
\hline CHEMBL1576617 & 688239 & 5.1862 & 5.4974 & TRN \\
\hline CHEMBL1568223 & 688239 & 7.0362 & 5.4865 & TRN \\
\hline
\end{tabular}


Supplemental Table S2.txt

\begin{tabular}{|c|c|c|c|c|}
\hline CHEMBL1977473 & 688239 & 5.1862 & 5.4466 & TRN \\
\hline CHEMBL1567782 & 688239 & 5.0362 & 5.5503 & TST \\
\hline CHEMBL1433007 & 688239 & 5.1862 & 5.4429 & TST \\
\hline CHEMBL1301716 & 688239 & 4.5362 & 5.5156 & TRN \\
\hline CHEMBL1404001 & 688239 & 4.8362 & 5.3735 & TRN \\
\hline CHEMBL1321265 & 688239 & 4.6862 & 5.5436 & TRN \\
\hline CHEMBL1412950 & 688239 & 6.7862 & 5.4476 & TRN \\
\hline CHEMBL1565837 & 688239 & 5.2362 & 5.5311 & TRN \\
\hline CHEMBL1306006 & 688239 & 7.0362 & 5.6452 & TST \\
\hline CHEMBL1437038 & 688239 & 4.8862 & 5.4053 & TRN \\
\hline CHEMBL1566834 & 688239 & 5.8862 & 5.5266 & TRN \\
\hline CHEMBL1473259 & 688239 & 4.5362 & 5.3719 & TRN \\
\hline CHEMBL1492782 & 688239 & 5.1862 & 5.37 & TRN \\
\hline CHEMBL1366617 & 688239 & 4.6862 & 5.5749 & TST \\
\hline CHEMBL1606478 & 688239 & 5.1862 & 5.4564 & TRN \\
\hline CHEMBL 3195897 & 688239 & 4.5362 & 5.4945 & TST \\
\hline CHEMBL1464086 & 688239 & 4.4862 & 5.5141 & TRN \\
\hline CHEMBL601970 & 688239 & 5.1862 & 5.4242 & TRN \\
\hline CHEMBL1604878 & 688239 & 5.1862 & 5.6309 & TRN \\
\hline CHEMBL1599339 & 688239 & 4.5362 & 5.4606 & TRN \\
\hline CHEMBL1499522 & 688239 & 5.1862 & 5.6027 & TST \\
\hline CHEMBL1313977 & 688239 & 5.1862 & 5.4018 & TRN \\
\hline CHEMBL1323722 & 688239 & 5.0862 & 5.2999 & TRN \\
\hline CHEMBL1604698 & 688239 & 6.1862 & 5.5546 & TRN \\
\hline CHEMBL1571795 & 688239 & 4.5362 & 5.5732 & TST \\
\hline CHEMBL1608238 & 688239 & 6.2362 & 5.4884 & TRN \\
\hline CHEMBL1343012 & 688239 & 5.1862 & 5.4457 & TRN \\
\hline CHEMBL1576867 & 688239 & 6.1862 & 5.6673 & TRN \\
\hline CHEMBL1446294 & 688239 & 6.0362 & 5.587006 & 000000001 \\
\hline CHEMBL1612038 & 688239 & 5.2862 & 5.5067 & TRN \\
\hline CHEMBL1476380 & 688239 & 5.4862 & 5.4638 & TRN \\
\hline CHEMBL1460802 & 688239 & 5.3862 & 5.4247 & TRN \\
\hline CHEMBL1602798 & 688239 & 5.6362 & 5.4654 & TRN \\
\hline CHEMBL1302426 & 688239 & 5.3362 & 5.3274 & TST \\
\hline CHEMBL1397408 & 688239 & 6.8861 & 5.5401 & TRN \\
\hline CHEMBL1600828 & 688239 & 7.2366 & 5.5269 & TRN \\
\hline CHEMBL1353301 & 688239 & 6.9363 & 5.4952 & TRN \\
\hline CHEMBL1353133 & 688239 & 6.1362 & 5.5611 & TRN \\
\hline CHEMBL1390812 & 688239 & 5.1362 & 5.4622 & TRN \\
\hline CHEMBL1425013 & 688239 & 4.6362 & 5.5027 & TRN \\
\hline CHEMBL1343436 & 688239 & 4.5362 & 5.5503 & TRN \\
\hline CHEMBL1488457 & 688239 & 5.6862 & 5.5462 & TST \\
\hline CHEMBL1593801 & 688239 & 4.7362 & 5.5448 & TRN \\
\hline CHEMBL1419540 & 688239 & 6.2362 & 5.4282 & TRN \\
\hline CHEMBL1365603 & 688239 & 5.3862 & 5.5379 & TRN \\
\hline CHEMBL1425360 & 688239 & 4.5362 & 5.2868 & TRN \\
\hline CHEMBL1528948 & 688239 & 5.7362 & 5.4653 & TRN \\
\hline CHEMBL1493523 & 688239 & 6.8861 & 5.559 & TRN \\
\hline
\end{tabular}




\begin{tabular}{|c|c|c|c|c|c|}
\hline \multicolumn{6}{|c|}{ Supplemental Table s2.txt } \\
\hline CHEMBL1367022 & 688239 & 6.8861 & 5.5106 & TRN & \\
\hline CHEMBL1524049 & 688239 & 4.6862 & 5.5179 & TST & \\
\hline CHEMBL1434329 & 688239 & 5.9362 & 5.5289 & TST & \\
\hline CHEMBL1595159 & 688239 & 6.8861 & 5.4161 & TRN & \\
\hline CHEMBL1535802 & 688239 & 8.0862 & 5.5523 & TRN & \\
\hline CHEMBL1308550 & 688239 & 5.7862 & 5.6181 & TRN & \\
\hline CHEMBL1432974 & 688239 & 6.8861 & \multicolumn{2}{|c|}{5.492000000000001} & TRN \\
\hline CHEMBL1564396 & 688239 & 6.2362 & 5.4621 & TRN & \\
\hline CHEMBL1394457 & 688239 & 4.6862 & 5.4469 & TRN & \\
\hline CHEMBL1606687 & 688239 & 7.0862 & 5.6421 & TST & \\
\hline CHEMBL1551570 & 688239 & 5.3362 & 5.4746 & TRN & \\
\hline CHEMBL1331442 & 688239 & 5.6362 & 5.4627 & TST & \\
\hline CHEMBL1454375 & 688239 & 4.6362 & 5.558 & TRN & \\
\hline CHEMBL1589425 & 688239 & 4.9362 & 5.1359 & TST & \\
\hline CHEMBL1506489 & 688239 & 5.9862 & 5.3973 & TRN & \\
\hline CHEMBL1608804 & 688239 & 5.5362 & 5.4915 & TRN & \\
\hline CHEMBL1520856 & 688239 & 6.2862 & 5.4273 & TST & \\
\hline CHEMBL1435072 & 688239 & 4.5362 & 5.3848 & TRN & \\
\hline CHEMBL1597205 & 688239 & 4.5862 & 5.5606 & TRN & \\
\hline CHEMBL1987891 & 688239 & 5.1862 & 5.3786 & TRN & \\
\hline CHEMBL1392492 & 688239 & 5.4362 & 5.5329 & TRN & \\
\hline CHEMBL1501221 & 688239 & 5.8362 & 5.4747 & TRN & \\
\hline CHEMBL1562140 & 688239 & 5.0862 & 5.454 & TST & \\
\hline CHEMBL1456019 & 688239 & 4.9362 & 5.4612 & TRN & \\
\hline CHEMBL1516451 & 688239 & 5.0862 & 5.5494 & TRN & \\
\hline CHEMBL1431440 & 688239 & 4.5362 & 5.4121 & TRN & \\
\hline CHEMBL3195110 & 688239 & 6.7862 & 5.4383 & TRN & \\
\hline CHEMBL1382277 & 688239 & 4.8862 & 5.3388 & TRN & \\
\hline CHEMBL1473536 & 688239 & 5.1362 & 5.4596 & TRN & \\
\hline CHEMBL3195502 & 688239 & 4.5362 & 5.3221 & TST & \\
\hline CHEMBL1445423 & 688239 & 5.1862 & 5.7053 & TRN & \\
\hline CHEMBL1310217 & 688239 & 5.1862 & 5.5067 & TRN & \\
\hline CHEMBL1327994 & 688239 & 4.5362 & 5.4433 & TRN & \\
\hline CHEMBL1556107 & 688239 & 5.1862 & \multicolumn{2}{|c|}{5.537999999999999} & TRN \\
\hline CHEMBL1460416 & 688239 & 4.5362 & 5.4567 & TRN & \\
\hline CHEMBL1484459 & 688239 & 5.0362 & 5.5046 & TRN & \\
\hline CHEMBL1387888 & 688239 & 6.2862 & 5.3816 & TRN & \\
\hline CHEMBL1584757 & 688239 & 4.5362 & 5.4731 & TST & \\
\hline CHEMBL1429651 & 688239 & 6.1862 & \multicolumn{2}{|c|}{5.6160000000000005} & TRN \\
\hline CHEMBL1605395 & 688239 & 4.7362 & 5.4714 & TRN & \\
\hline CHEMBL1601081 & 688239 & 5.6862 & 5.5254 & TRN & \\
\hline CHEMBL1498666 & 688239 & 6.1862 & 5.6724 & TRN & \\
\hline CHEMBL1345903 & 688239 & 5.4862 & 5.5431 & TRN & \\
\hline CHEMBL1393449 & 688239 & 4.6862 & 5.6727 & TRN & \\
\hline CHEMBL1538678 & 688239 & 5.0862 & 5.4048 & TRN & \\
\hline CHEMBL1368428 & 688239 & 5.4862 & 5.4454 & TRN & \\
\hline CHEMBL1573162 & 688239 & 4.5362 & 5.534 & TST & \\
\hline \multirow[t]{2}{*}{ CHEMBL1486707 } & 688239 & 5.1862 & \multicolumn{2}{|c|}{5.513999999999999} & TRN \\
\hline & & & & 166 & \\
\hline
\end{tabular}


Supplemental Table S2.txt

\begin{tabular}{|c|c|c|c|c|}
\hline AEMBL1360765 & & 6.2362 & 5.6351 & \\
\hline & 88239 & 5.3862 & & \\
\hline$=M D / 1$ & 3239 & & & \\
\hline EMBL] & 239 & 862 & & \\
\hline AEMBL1372213 & 38239 & 362 & & \\
\hline HEMBL1 & 8239 & 362 & .3528 & \\
\hline AEMBLI & 239 & 862 & & \\
\hline IEMBL: & & 362 & & \\
\hline 61883 & 38239 & 862 & & \\
\hline HEMBL1516560 & 38239 & 862 & & \\
\hline HEMBL: & & 4.5362 & & \\
\hline IEMBL & & 362 & & \\
\hline AEMBL & & 362 & & \\
\hline AEMBL & 38239 & 8862 & & \\
\hline HEMBL: & & 862 & & \\
\hline AEMBL: & & & & \\
\hline IEMBL & & 362 & & \\
\hline AEMBL & & 862 & & \\
\hline IEMBL & & 862 & & \\
\hline AEMBL: & & & & \\
\hline AEMB & & & & \\
\hline EMB & & 62 & & 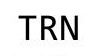 \\
\hline EMB & & 362 & & \\
\hline IEMBL & & 862 & & \\
\hline EMBL: & & & & \\
\hline AEMBL: & & & & ות \\
\hline IEMB & & 02 & & $\cdots$ \\
\hline 28 & & 362 & & \\
\hline $5 \mathrm{MO}$ & & & & रा \\
\hline EMBL: & & 862 & & \\
\hline & & 52 & & ות \\
\hline 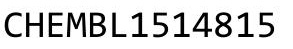 & & 65 & & 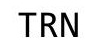 \\
\hline & & 62 & & \\
\hline IEMBL & & 62 & & $\mathrm{R}$ \\
\hline AEMBL: & & 362 & & TRI \\
\hline & & & & $T R$ \\
\hline 7 & & 52 & & $\Gamma \mathrm{R}$ \\
\hline AEMBL & & & & $\mathrm{RI}$ \\
\hline IEMBL & & 362 & & R \\
\hline IEMBL & & 62 & & S \\
\hline ME & & & & ב \\
\hline HEMBL & & 362 & & $\Gamma \mathrm{R}$ \\
\hline HEMBL & & 5.6362 & & S \\
\hline AEMBL & & 362 & & $R$ \\
\hline UГM & & & & $\mathrm{R}$ \\
\hline CHEMBL & & & & $\Gamma R$ \\
\hline CHEMBLI & & 362 & 5.6255 & \\
\hline CHEMBL1570282 & 688239 & 4.5862 & 5.6731 & TS \\
\hline
\end{tabular}

Page 1662 
Supplemental Table S2.txt

\begin{tabular}{|c|c|c|c|c|}
\hline CHEMBL1425251 & 688239 & 4.5362 & 5.4632 & TRN \\
\hline CHEMBL1488758 & 688239 & 5.2362 & 5.4508 & TRN \\
\hline CHEMBL1299752 & 688239 & 5.6362 & 5.4128 & TRN \\
\hline CHEMBL1445626 & 688239 & 8.3372 & 5.4101 & TST \\
\hline CHEMBL1515481 & 688239 & 5.7862 & 5.3813 & TRN \\
\hline CHEMBL1428679 & 688239 & 5.1862 & 5.6491 & TRN \\
\hline CHEMBL1385609 & 688239 & 4.6362 & 5.4968 & TST \\
\hline CHEMBL1595837 & 688239 & 5.4862 & 5.5722 & TRN \\
\hline CHEMBL1536478 & 688239 & 6.2862 & 5.5766 & TRN \\
\hline CHEMBL1384984 & 688239 & 5.6862 & 5.5387 & TRN \\
\hline CHEMBL1412319 & 688239 & 5.7862 & 5.4855 & TRN \\
\hline CHEMBL1302974 & 688239 & 4.5362 & 5.5524 & TRN \\
\hline CHEMBL1483313 & 688239 & 5.1862 & 5.5366 & TST \\
\hline CHEMBL1591687 & 688239 & 4.5362 & 5.3429 & TRN \\
\hline CHEMBL1504204 & 688239 & 5.4862 & 5.5645 & TST \\
\hline CHEMBL1589738 & 688239 & 4.5362 & 5.3056 & TRN \\
\hline CHEMBL1525539 & 688239 & 4.5362 & 5.4642 & TRN \\
\hline CHEMBL1331694 & 688239 & 5.1862 & 5.51 & TRN \\
\hline CHEMBL1353015 & 688239 & 4.6862 & 5.5341 & TRN \\
\hline CHEMBL1479366 & 688239 & 6.8861 & 5.4134 & TRN \\
\hline CHEMBL1510745 & 688239 & 6.0362 & 5.5972 & TRN \\
\hline CHEMBL1390805 & 688239 & 8.3372 & 5.3378 & TST \\
\hline CHEMBL1421811 & 688239 & 6.1362 & 5.4637 & TRN \\
\hline CHEMBL1348746 & 688239 & 7.1864 & 5.4724 & TST \\
\hline CHEMBL1369127 & 688239 & 6.1862 & 5.5797 & TRN \\
\hline CHEMBL1410395 & 688239 & 5.4362 & 5.5646 & TRN \\
\hline CHEMBL1473704 & 688239 & 5.4362 & 5.5474 & TRN \\
\hline CHEMBL1523373 & 688239 & 4.6862 & 5.4869 & TRN \\
\hline CHEMBL1383537 & 688239 & 4.8362 & 5.5494 & TRN \\
\hline CHEMBL1462918 & 688239 & 5.1862 & 5.4764 & TRN \\
\hline CHEMBL1489191 & 688239 & 4.5362 & 5.415 & TRN \\
\hline CHEMBL1517830 & 688239 & 5.1862 & 5.5929 & TRN \\
\hline CHEMBL1319446 & 688239 & 4.7862 & 5.6153 & TRN \\
\hline CHEMBL1579776 & 688239 & 4.5362 & 5.5464 & TRN \\
\hline CHEMBL1568631 & 688239 & 4.4862 & 5.4953 & TRN \\
\hline CHEMBL1382672 & 688239 & 4.7362 & 5.4202 & TST \\
\hline CHEMBL1410048 & 688239 & 7.5867 & 5.4346 & TRN \\
\hline CHEMBL1349598 & 688239 & 5.1862 & 5.3735 & TRN \\
\hline CHEMBL1524216 & 688239 & 4.8862 & 5.5831 & TRN \\
\hline CHEMBL1581453 & 688239 & 5.9862 & 5.6036 & TRN \\
\hline CHEMBL1498922 & 688239 & 4.6362 & 5.4779 & TST \\
\hline CHEMBL1544837 & 688239 & 4.6362 & 5.5447 & TRN \\
\hline CHEMBL1461979 & 688239 & 5.4862 & 5.4499 & TRN \\
\hline CHEMBL1540404 & 688239 & 4.8362 & 5.6447 & TST \\
\hline CHEMBL1548011 & 688239 & 6.8861 & 5.4407 & TRN \\
\hline CHEMBL1589492 & 688239 & 4.8362 & 5.48600 & 0000000001 \\
\hline CHEMBL1996441 & 688239 & 6.2362 & 5.3335 & TST \\
\hline CHEMBL1609408 & 688239 & 4.5362 & 5.466 & TRN \\
\hline
\end{tabular}


Supplemental Table S2.txt

\begin{tabular}{|c|c|c|c|c|c|}
\hline CHEMBL1576473 & 688239 & 5.1862 & 5.4148 & TRN & \\
\hline CHEMBL1337235 & 688239 & 4.5362 & 5.4989 & TRN & \\
\hline CHEMBL1333635 & 688239 & 5.4362 & 5.4415 & TRN & \\
\hline CHEMBL1465701 & 688239 & 4.6862 & 5.325 & TST & \\
\hline CHEMBL1350427 & 688239 & 6.3863 & 5.4945 & TRN & \\
\hline CHEMBL1509540 & 688239 & 6.7361 & 5.4118 & TST & \\
\hline CHEMBL1337206 & 688239 & 8.3372 & 5.4796 & TST & \\
\hline CHEMBL1446337 & 688239 & 4.7862 & 5.5643 & TRN & \\
\hline CHEMBL1508757 & 688239 & 5.3362 & 5.5431 & TRN & \\
\hline CHEMBL1421939 & 688239 & 4.5362 & 5.5018 & TRN & \\
\hline CHEMBL1427439 & 688239 & 4.5362 & 5.355 & TRN & \\
\hline CHEMBL1545982 & 688239 & 4.7862 & 5.4026 & TRN & \\
\hline CHEMBL1452541 & 688239 & 5.6362 & 5.5839 & TST & \\
\hline CHEMBL1441981 & 688239 & 6.3863 & 5.347 & TRN & \\
\hline CHEMBL1398423 & 688239 & 6.8861 & 5.5445 & TRN & \\
\hline CHEMBL1525182 & 688239 & 5.1862 & 5.6151 & TRN & \\
\hline CHEMBL1308809 & 688239 & 6.4862 & 5.5222 & TRN & \\
\hline CHEMBL1572688 & 688239 & 5.6862 & 5.572 & TRN & \\
\hline CHEMBL1482524 & 688239 & 5.0862 & 5.447999 & 9999999995 & \\
\hline CHEMBL1332881 & 688239 & 4.5362 & 5.412000 & 000000001 & \\
\hline CHEMBL1503560 & 688239 & 8.2366 & 5.5068 & TRN & \\
\hline CHEMBL1571405 & 688239 & 5.5862 & 5.4 & TRN & \\
\hline CHEMBL1521071 & 688239 & 5.8362 & 5.49 & TST & \\
\hline CHEMBL1550334 & 688239 & 5.8862 & 5.5187 & TRN & \\
\hline CHEMBL1424508 & 688239 & 5.3862 & 5.4097 & TRN & \\
\hline CHEMBL1452899 & 688239 & 5.4362 & 5.4218 & TRN & \\
\hline CHEMBL1453565 & 688239 & 5.4862 & 5.4903 & TRN & \\
\hline CHEMBL1511220 & 688239 & 4.6862 & 5.5133 & TRN & \\
\hline CHEMBL1305874 & 688239 & 4.4862 & 5.417000 & 000000001 & \\
\hline CHEMBL1452029 & 688239 & 5.5362 & 5.5276 & TRN & \\
\hline CHEMBL1482532 & 688239 & 5.0862 & 5.5717 & TRN & \\
\hline CHEMBL 3208824 & 688239 & 4.4862 & 5.4342 & TRN & \\
\hline CHEMBL1468762 & 688239 & 5.2362 & 5.5416 & TRN & \\
\hline CHEMBL1307095 & 688239 & 7.0862 & 5.4496 & TRN & \\
\hline CHEMBL1587804 & 688239 & 6.3362 & 5.4045 & TRN & \\
\hline CHEMBL1547895 & 688239 & 5.0862 & 5.4156 & TRN & \\
\hline CHEMBL1484091 & 688239 & 8.28399 & 99999999 & 5.4879 & \\
\hline CHEMBL1471082 & 688239 & 4.5862 & 5.5503 & TST & \\
\hline CHEMBL1441095 & 688239 & 4.5362 & 5.5231 & TST & \\
\hline CHEMBL1496314 & 688239 & 4.5362 & 5.4611 & TRN & \\
\hline CHEMBL1417134 & 688239 & 8.2366 & 5.4403 & TST & \\
\hline CHEMBL1425375 & 688239 & 5.3862 & 5.3978 & TRN & \\
\hline CHEMBL1374775 & 688239 & 4.6862 & 5.4607 & TRN & \\
\hline CHEMBL1308932 & 688239 & 6.5862 & 5.5203 & TRN & \\
\hline CHEMBL1582151 & 688239 & 6.1862 & 5.5262 & TRN & \\
\hline CHEMBL1371743 & 688239 & 5.4362 & 5.4572 & TST & \\
\hline CHEMBL1310073 & 688239 & 5.0862 & 5.4159 & TST & \\
\hline CHEMBL1396706 & 688239 & 5.2362 & 5.5446 & TRN & \\
\hline
\end{tabular}


Supplemental Table S2.txt

\begin{tabular}{|c|c|c|c|c|c|c|}
\hline CHEMBL1412327 & 688239 & 4.9862 & \multicolumn{3}{|c|}{5.542999999999999} & \\
\hline CHEMBL1579699 & 688239 & 5.2362 & 5.6282 & TRN & & \\
\hline CHEMBL1613682 & 688239 & 6.1862 & 5.6672 & TST & & \\
\hline CHEMBL1342434 & 688239 & 5.5862 & 5.6613 & TRN & & \\
\hline CHEMBL1565753 & 688239 & 5.1862 & 5.5193 & TRN & & \\
\hline CHEMBL1593459 & 688239 & 4.7362 & 5.557 & TRN & & \\
\hline CHEMBL1377994 & 688239 & 6.9863 & 5.6367 & TRN & & \\
\hline CHEMBL1549155 & 688239 & 4.4862 & 5.4119 & TRN & & \\
\hline CHEMBL1383459 & 688239 & 5.1862 & 5.6085 & TRN & & \\
\hline CHEMBL1362746 & 688239 & 6.3362 & 5.4788 & TRN & & \\
\hline CHEMBL1576920 & 688239 & 6.1362 & 5.4932 & TST & & \\
\hline CHEMBL1600343 & 688239 & 4.5862 & 5.4203 & TST & & \\
\hline CHEMBL1445405 & 688239 & 5.4862 & 5.4084 & TRN & & \\
\hline CHEMBL1322956 & 688239 & 8.28399 & 99999999 & 99 & 5.4494 & \\
\hline CHEMBL1409757 & 688239 & 6.8362 & 5.4871 & TRN & & \\
\hline CHEMBL1366466 & 688239 & 4.7362 & 5.5499 & TST & & \\
\hline CHEMBL1313579 & 688239 & 5.3362 & 5.4839 & TRN & & \\
\hline CHEMBL1412046 & 688239 & 5.2862 & 5.6991 & TRN & & \\
\hline CHEMBL1479892 & 688239 & 5.1862 & 5.4929 & TRN & & \\
\hline CHEMBL1439012 & 688239 & 4.7362 & 5.752999 & 9999999999 & & \\
\hline CHEMBL1311908 & 688239 & 5.1862 & 5.4848 & TRN & & \\
\hline CHEMBL1471446 & 688239 & 5.1862 & 5.4694 & TRN & & \\
\hline CHEMBL1391627 & 688239 & 6.9363 & 5.6781 & TST & & \\
\hline CHEMBL1408186 & 688239 & 6.8362 & 5.7212 & TRN & & \\
\hline CHEMBL1480475 & 688239 & 5.6862 & 5.3947 & TRN & & \\
\hline CHEMBL1425676 & 688239 & 7.2865 & 5.6145 & TRN & & \\
\hline CHEMBL1370015 & 688239 & 5.1362 & 5.5255 & TRN & & \\
\hline CHEMBL1420518 & 688239 & 7.2366 & 5.5313 & TRN & & \\
\hline CHEMBL1579273 & 688239 & 5.0362 & 5.5519 & TRN & & \\
\hline CHEMBL1350843 & 688239 & 5.1362 & 5.5076 & TRN & & \\
\hline CHEMBL1395083 & 688239 & 6.2362 & 5.4178 & TRN & & \\
\hline CHEMBL1305957 & 688239 & 5.7362 & 5.3957 & TST & & \\
\hline CHEMBL1549917 & 688239 & 5.1862 & 5.6289 & TRN & & \\
\hline CHEMBL3191864 & 688239 & 5.7862 & 5.3885 & TRN & & \\
\hline CHEMBL 3197615 & 688239 & 4.6362 & 5.5561 & TRN & & \\
\hline CHEMBL16068 & 688239 & 7.1361 & 5.4208 & TST & & \\
\hline CHEMBL1461067 & 688239 & 6.6362 & 5.5872 & TRN & & \\
\hline CHEMBL1602371 & 688239 & 4.8862 & 5.3177 & TRN & & \\
\hline CHEMBL1323842 & 688239 & 5.2862 & 5.4314 & TRN & & \\
\hline CHEMBL3209339 & 688239 & 8.3372 & 5.5324 & TRN & & \\
\hline CHEMBL3209063 & 688239 & 5.5862 & 5.4369 & TST & & \\
\hline CHEMBL1338627 & 688239 & 4.8362 & 5.4699 & TST & & \\
\hline CHEMBL1343924 & 688239 & 5.2862 & 5.4948 & TRN & & \\
\hline CHEMBL1560451 & 688239 & 6.0862 & 5.5562 & TRN & & \\
\hline CHEMBL1584534 & 688239 & 5.3862 & 5.5106 & TST & & \\
\hline CHEMBL1990774 & 688239 & 4.5862 & 5.3931 & TRN & & \\
\hline CHEMBL1316724 & 688239 & 4.6862 & 5.5642 & TRN & & \\
\hline CHEMBL1343261 & 688239 & 5.6862 & 5.5292 & TRN & & \\
\hline
\end{tabular}


Supplemental Table S2.txt

\begin{tabular}{|c|c|c|c|c|}
\hline CHEMBL1453222 & 688239 & 4.6862 & 5.4132 & TRN \\
\hline CHEMBL1456713 & 688239 & 6.1862 & 5.6057 & TRN \\
\hline CHEMBL582694 & 688239 & 4.6862 & 5.4951 & TRN \\
\hline CHEMBL3193277 & 688239 & 4.5362 & 5.3697 & TRN \\
\hline CHEMBL1376096 & 688239 & 5.1862 & 5.4172 & TRN \\
\hline CHEMBL1376615 & 688239 & 4.6862 & 5.4468 & TRN \\
\hline CHEMBL1329342 & 688239 & 4.5362 & 5.5535 & TRN \\
\hline CHEMBL1425638 & 688239 & 4.5362 & 5.7267 & TRN \\
\hline CHEMBL1518080 & 688239 & 4.5862 & 5.5243 & TST \\
\hline CHEMBL1418314 & 688239 & 4.4862 & 5.4584 & TRN \\
\hline CHEMBL1536801 & 688239 & 4.7862 & 5.4679 & TRN \\
\hline CHEMBL1328564 & 688239 & 5.2362 & 5.5621 & TRN \\
\hline CHEMBL1512383 & 688239 & 5.7362 & 5.5206 & TRN \\
\hline CHEMBL1498009 & 688239 & 6.3362 & 5.6707 & TST \\
\hline CHEMBL3196435 & 688239 & 4.7862 & 5.6406 & TST \\
\hline CHEMBL1337583 & 688239 & 5.7362 & 5.5019 & TST \\
\hline CHEMBL1508296 & 688239 & 6.2362 & 5.4636 & TST \\
\hline CHEMBL1387254 & 688239 & 4.5862 & 5.4989 & TRN \\
\hline CHEMBL1486819 & 688239 & 5.6362 & 5.5467 & TRN \\
\hline CHEMBL1548659 & 688239 & 5.4862 & 5.5433 & TRN \\
\hline CHEMBL1575387 & 688239 & 6.0862 & 5.5087 & TRN \\
\hline CHEMBL3198573 & 688239 & 6.8362 & 5.4272 & TRN \\
\hline CHEMBL1359409 & 688239 & 6.3362 & 5.43 & TST \\
\hline CHEMBL1488451 & 688239 & 5.1862 & 5.4408 & TRN \\
\hline CHEMBL1330142 & 688239 & 5.4362 & 5.5225 & TST \\
\hline CHEMBL1385739 & 688239 & 6.1862 & 5.5532 & TRN \\
\hline CHEMBL86104 & 688239 & 5.3362 & 5.2561 & TRN \\
\hline CHEMBL1476532 & 688239 & 8.3372 & 5.65600 & 0000000001 \\
\hline CHEMBL3192539 & 688239 & 4.5362 & 5.4187 & TST \\
\hline CHEMBL1532797 & 688239 & 6.8362 & 5.4251 & TRN \\
\hline CHEMBL1470376 & 688239 & 5.3362 & 5.5103 & TRN \\
\hline CHEMBL1353521 & 688239 & 5.7862 & 5.54 & TST \\
\hline CHEMBL1507841 & 688239 & 5.7862 & 5.4002 & TST \\
\hline CHEMBL1570792 & 688239 & 4.8362 & 5.5865 & TRN \\
\hline CHEMBL1414684 & 688239 & 4.4862 & 5.4708 & TRN \\
\hline CHEMBL1423737 & 688239 & 6.3362 & 5.5716 & TRN \\
\hline CHEMBL 3212013 & 688239 & 6.0862 & 5.4274 & TST \\
\hline CHEMBL1450679 & 688239 & 4.7862 & 5.3832 & TRN \\
\hline CHEMBL1388585 & 688239 & 5.2362 & 5.4964 & TRN \\
\hline CHEMBL1559398 & 688239 & 5.3862 & 5.392 & TST \\
\hline CHEMBL1372007 & 688239 & 6.8861 & 5.593 & TRN \\
\hline CHEMBL1458363 & 688239 & 4.8862 & 5.5104 & TRN \\
\hline CHEMBL1583906 & 688239 & 5.1862 & 5.2413 & TRN \\
\hline CHEMBL 3212267 & 688239 & 8.3372 & 5.3058 & TST \\
\hline CHEMBL1519082 & 688239 & 5.5862 & 5.5424 & TRN \\
\hline CHEMBL1478243 & 688239 & 4.7862 & 5.5794 & TRN \\
\hline CHEMBL1587441 & 688239 & 5.1862 & 5.54 & TST \\
\hline CHEMBL1469871 & 688239 & 6.8861 & 5.5091 & TRN \\
\hline
\end{tabular}

Page 1666 
Supplemental Table S2.txt

\begin{tabular}{|c|c|c|c|c|}
\hline CHEMBL1581768 & 688239 & 4.5362 & 5.5761 & TRN \\
\hline CHEMBL1313442 & 688239 & 5.5362 & 5.5175 & TRN \\
\hline CHEMBL1353739 & 688239 & 7.4365 & 5.5583 & TST \\
\hline CHEMBL1545739 & 688239 & 5.1362 & 5.5013 & TRN \\
\hline CHEMBL1311020 & 688239 & 5.4362 & 5.5873 & TST \\
\hline CHEMBL1351700 & 688239 & 5.9362 & 5.5476 & TST \\
\hline CHEMBL1437544 & 688239 & 7.1361 & 5.4827 & TRN \\
\hline CHEMBL1603026 & 688239 & 5.7362 & 5.5985 & TRN \\
\hline CHEMBL1404426 & 688239 & 4.4862 & 5.4873 & TRN \\
\hline CHEMBL1370943 & 688239 & 5.0362 & 5.4536 & TST \\
\hline CHEMBL1467715 & 688239 & 5.0862 & 5.343 & TST \\
\hline CHEMBL1309459 & 688239 & 6.1862 & 5.5852 & TRN \\
\hline CHEMBL1574420 & 688239 & 4.5362 & 5.4307 & TRN \\
\hline CHEMBL1596835 & 688239 & 7.9355 & 5.6567 & TRN \\
\hline CHEMBL3192731 & 688239 & 5.4362 & 5.3423 & TRN \\
\hline CHEMBL3190454 & 688239 & 6.0862 & 5.4322 & TRN \\
\hline CHEMBL1519979 & 688239 & 4.5862 & 5.5263 & TRN \\
\hline CHEMBL1470609 & 688239 & 5.1862 & 5.5016 & TST \\
\hline CHEMBL1551946 & 688239 & 4.8362 & 5.5735 & TRN \\
\hline CHEMBL1519251 & 688239 & 4.6362 & 5.6182 & TRN \\
\hline CHEMBL1611185 & 688239 & 5.8862 & 5.4322 & TST \\
\hline CHEMBL1610013 & 688239 & 6.2862 & 5.3875 & TRN \\
\hline CHEMBL1469211 & 688239 & 5.1862 & 5.5642 & TST \\
\hline CHEMBL1409632 & 688239 & 5.6862 & 5.4469 & TST \\
\hline CHEMBL1424494 & 688239 & 5.5362 & 5.5113 & TRN \\
\hline CHEMBL1527268 & 688239 & 4.5362 & 5.4435 & TRN \\
\hline CHEMBL1385371 & 688239 & 4.5862 & 5.5546 & TRN \\
\hline CHEMBL1582092 & 688239 & 7.7352 & 5.5595 & TRN \\
\hline CHEMBL1500030 & 688239 & 5.3362 & 5.6089 & TRN \\
\hline CHEMBL1495176 & 688239 & 5.1862 & 5.4899 & TRN \\
\hline CHEMBL1514510 & 688239 & 4.4862 & 5.4481 & TRN \\
\hline CHEMBL1523242 & 688239 & 6.3863 & 5.3526 & TRN \\
\hline CHEMBL1414296 & 688239 & 5.0362 & 5.4502 & TRN \\
\hline CHEMBL1536653 & 688239 & 4.6862 & 5.347 & TST \\
\hline CHEMBL1312803 & 688239 & 4.5862 & 5.4379 & TRN \\
\hline CHEMBL1412268 & 688239 & 5.7862 & 5.4832 & TRN \\
\hline CHEMBL1581238 & 688239 & 6.5363 & 5.5352 & TST \\
\hline CHEMBL1557744 & 688239 & 6.4862 & 5.428 & TRN \\
\hline CHEMBL1557389 & 688239 & 4.4862 & 5.3622 & TRN \\
\hline CHEMBL1541183 & 688239 & 7.2366 & 5.643 & TRN \\
\hline CHEMBL1458468 & 688239 & 4.7362 & 5.4535 & TST \\
\hline CHEMBL1355719 & 688239 & 6.7862 & 5.541 & TRN \\
\hline CHEMBL1523112 & 688239 & 4.5362 & \multicolumn{2}{|c|}{5.497000000000001} \\
\hline CHEMBL1433642 & 688239 & 4.5362 & 5.4749 & TRN \\
\hline CHEMBL1563483 & 688239 & 4.4862 & 5.4454 & TST \\
\hline CHEMBL1511705 & 688239 & 8.3872 & 5.5648 & TRN \\
\hline CHEMBL1456626 & 688239 & 4.5362 & 5.4635 & TRN \\
\hline CHEMBL1559243 & 688239 & 8.3372 & 5.44600 & 0000000001 \\
\hline
\end{tabular}


Supplemental Table S2.txt

\begin{tabular}{|c|c|c|c|c|}
\hline CHEMBL1385915 & 688239 & 6.2862 & 5.4306 & TRN \\
\hline CHEMBL1427951 & 688239 & 6.2362 & 5.5496 & TRN \\
\hline CHEMBL1611392 & 688239 & 5.1362 & 5.4311 & TST \\
\hline CHEMBL1332445 & 688239 & 4.5362 & 5.5327 & TST \\
\hline CHEMBL1556208 & 688239 & 6.0862 & \multicolumn{2}{|c|}{5.4510000000000005} \\
\hline CHEMBL1515277 & 688239 & 4.9862 & 5.5931 & TRN \\
\hline CHEMBL1569703 & 688239 & 6.9863 & 5.4239 & TST \\
\hline CHEMBL1397229 & 688239 & 4.5362 & 5.5371 & TRN \\
\hline CHEMBL1361174 & 688239 & 4.5362 & 5.5371 & TRN \\
\hline CHEMBL1411907 & 688239 & 5.0362 & 5.5417 & TRN \\
\hline CHEMBL1584644 & 688239 & 6.7862 & 5.6151 & TRN \\
\hline CHEMBL1505214 & 688239 & 5.4362 & 5.3903 & TRN \\
\hline CHEMBL1460362 & 688239 & 4.6362 & 5.4748 & TRN \\
\hline CHEMBL1304416 & 688239 & 5.2362 & 5.7028 & TRN \\
\hline CHEMBL1581308 & 688239 & 6.8861 & 5.4926 & TRN \\
\hline CHEMBL1339411 & 688239 & 5.9362 & 5.4854 & TRN \\
\hline CHEMBL1578174 & 688239 & 4.4862 & 5.3893 & TRN \\
\hline CHEMBL1471613 & 688239 & 7.2366 & 5.4083 & TRN \\
\hline CHEMBL1411335 & 688239 & 4.7862 & 5.4984 & TRN \\
\hline CHEMBL1537556 & 688239 & 4.9362 & 5.496 & TRN \\
\hline CHEMBL1540377 & 688239 & 4.8362 & 5.4293 & TST \\
\hline CHEMBL1425445 & 688239 & 4.7362 & 5.6139 & TRN \\
\hline CHEMBL3196057 & 688239 & 4.7862 & 5.4248 & TRN \\
\hline CHEMBL1539448 & 688239 & 7.0862 & 5.4193 & TRN \\
\hline CHEMBL1451201 & 688239 & 8.1871 & 5.6418 & TST \\
\hline CHEMBL1376398 & 688239 & 7.2366 & 5.4893 & TRN \\
\hline CHEMBL1406935 & 688239 & 5.9862 & 5.461 & TRN \\
\hline CHEMBL1497095 & 688239 & 5.4862 & 5.5351 & TRN \\
\hline CHEMBL1322946 & 688239 & 5.5362 & 5.61100 & 0000000001 \\
\hline CHEMBL1381418 & 688239 & 6.5363 & 5.631 & TRN \\
\hline CHEMBL1405061 & 688239 & 4.5862 & 5.3992 & TRN \\
\hline CHEMBL1485528 & 688239 & 4.5362 & 5.4403 & TST \\
\hline CHEMBL1431603 & 688239 & 5.5362 & 5.6539 & TRN \\
\hline CHEMBL1565991 & 688239 & 5.2862 & 5.5295 & TRN \\
\hline CHEMBL1314941 & 688239 & 5.3362 & 5.4567 & TRN \\
\hline CHEMBL1603242 & 688239 & 6.4862 & 5.4777 & TRN \\
\hline CHEMBL1536882 & 688239 & 5.1862 & 5.4048 & TRN \\
\hline CHEMBL1309244 & 688239 & 4.5362 & 5.4483 & TRN \\
\hline CHEMBL1512630 & 688239 & 6.1862 & 5.4565 & TRN \\
\hline CHEMBL1345195 & 688239 & 4.9362 & 5.2754 & TRN \\
\hline CHEMBL1480330 & 688239 & 6.3863 & 5.5242 & TST \\
\hline CHEMBL1359680 & 688239 & 4.5362 & 5.595 & TRN \\
\hline CHEMBL428495 & 688239 & 5.8862 & 5.501 & TRN \\
\hline CHEMBL1485241 & 688239 & 4.6862 & 5.5214 & TST \\
\hline CHEMBL1374400 & 688239 & 4.5362 & 5.4541 & TRN \\
\hline CHEMBL1573380 & 688239 & 5.3862 & 5.3837 & TRN \\
\hline CHEMBL1567399 & 688239 & 4.5362 & 5.6041 & TRN \\
\hline CHEMBL1392281 & 688239 & 6.3362 & 5.5339 & TRN \\
\hline
\end{tabular}

Page 1668 
Supplemental Table S2.txt

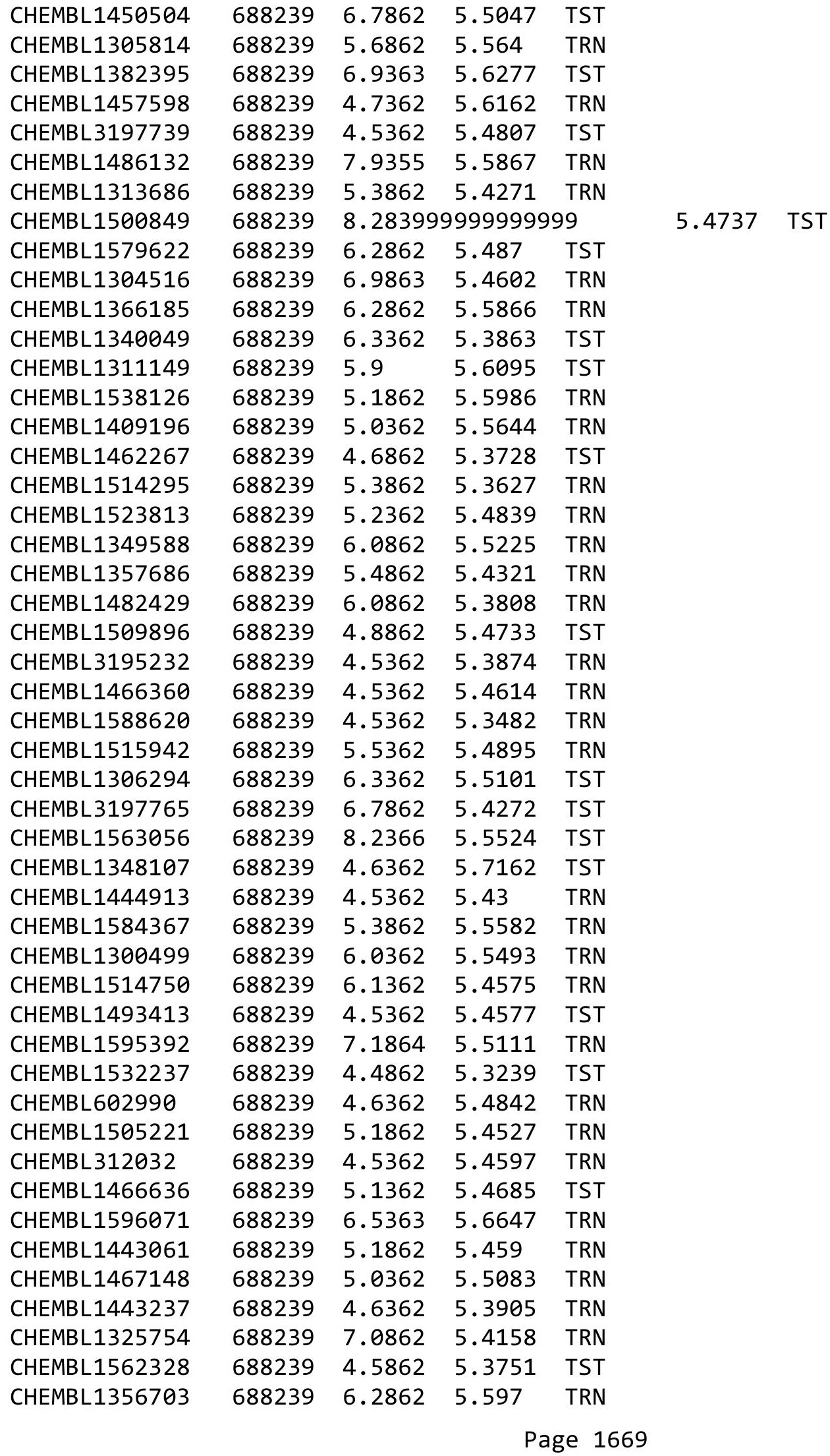


Supplemental Table S2.txt

\begin{tabular}{|c|c|c|c|c|c|c|}
\hline CHEMBL1315767 & 688239 & 5.9862 & 5.3589 & TRN & & \\
\hline CHEMBL1429991 & 688239 & 5.2362 & 5.5258 & TRN & & \\
\hline CHEMBL1419295 & 688239 & 8.28399 & 999999999 & & 5.6202 & TST \\
\hline CHEMBL1438240 & 688239 & 4.5362 & 5.3124 & TRN & & \\
\hline CHEMBL1602251 & 688239 & 4.6862 & 5.4892 & TRN & & \\
\hline CHEMBL1523250 & 688239 & 5.7362 & 5.531000 & 00000000 & & \\
\hline CHEMBL1574959 & 688239 & 4.8862 & 5.2885 & TRN & & \\
\hline CHEMBL1432512 & 688239 & 5.8862 & 5.4852 & TRN & & \\
\hline CHEMBL1569362 & 688239 & 4.7862 & 5.4861 & TRN & & \\
\hline CHEMBL1460636 & 688239 & 4.5362 & 5.5286 & TRN & & \\
\hline CHEMBL3198063 & 688239 & 5.4862 & 5.4886 & TST & & \\
\hline CHEMBL1571698 & 688239 & 6.7862 & 5.4746 & TRN & & \\
\hline CHEMBL1579884 & 688239 & 5.5362 & 5.4651 & TST & & \\
\hline CHEMBL1503944 & 688239 & 6.3362 & 5.5731 & TRN & & \\
\hline CHEMBL1363223 & 688239 & 5.7362 & 5.3829 & TST & & \\
\hline CHEMBL1453148 & 688239 & 5.4362 & 5.5487 & TRN & & \\
\hline CHEMBL1355397 & 688239 & 7.0362 & 5.5471 & TRN & & \\
\hline CHEMBL1357845 & 688239 & 6.8861 & 5.5563 & TRN & & \\
\hline CHEMBL1439596 & 688239 & 5.9362 & 5.4916 & TRN & & \\
\hline CHEMBL1482785 & 688239 & 4.4862 & 5.4804 & TRN & & \\
\hline CHEMBL1480308 & 688239 & 5.3862 & 5.5468 & TRN & & \\
\hline CHEMBL1303719 & 688239 & 4.5362 & 5.3763 & TST & & \\
\hline CHEMBL1331256 & 688239 & 4.5862 & 5.5912 & TRN & & \\
\hline CHEMBL1477221 & 688239 & 4.5362 & 5.4226 & TRN & & \\
\hline CHEMBL1559504 & 688239 & 5.1362 & 5.6185 & TRN & & \\
\hline CHEMBL1589196 & 688239 & 4.5362 & 5.6991 & TRN & & \\
\hline CHEMBL1978479 & 688239 & 5.5362 & 5.4215 & TST & & \\
\hline CHEMBL1984190 & 688239 & 5.5862 & 5.3781 & TST & & \\
\hline CHEMBL3199311 & 688239 & 5.2862 & 5.5375 & TRN & & \\
\hline CHEMBL1379474 & 688239 & 6.9363 & 5.4703 & TST & & \\
\hline CHEMBL1359188 & 688239 & 4.7862 & 5.3116 & TRN & & \\
\hline CHEMBL1426332 & 688239 & 4.5362 & 5.4138 & TRN & & \\
\hline CHEMBL3191779 & 688239 & 4.5362 & 5.5416 & TST & & \\
\hline CHEMBL1550953 & 688239 & 8.28399 & 999999999 & 99 & 5.4831 & \\
\hline CHEMBL1463659 & 688239 & 6.4862 & 5.6137 & TRN & & \\
\hline CHEMBL1312195 & 688239 & 5.1862 & 5.5899 & TRN & & \\
\hline CHEMBL1323144 & 688239 & 5.1862 & 5.5044 & TRN & & \\
\hline CHEMBL1593237 & 688239 & 5.6862 & 5.376 & TST & & \\
\hline CHEMBL1599530 & 688239 & 4.9862 & 5.5308 & TRN & & \\
\hline CHEMBL1475113 & 688239 & 5.5862 & 5.4049 & TRN & & \\
\hline CHEMBL1589347 & 688239 & 6.9363 & 5.3559 & TRN & & \\
\hline CHEMBL1387183 & 688239 & 5.6862 & 5.5504 & TRN & & \\
\hline CHEMBL3211127 & 688239 & 6.2862 & 5.4398 & TRN & & \\
\hline CHEMBL1547614 & 688239 & 5.1862 & 5.4865 & TRN & & \\
\hline CHEMBL1539604 & 688239 & 4.6362 & 5.4848 & TST & & \\
\hline CHEMBL1512605 & 688239 & 4.5362 & 5.4264 & TST & & \\
\hline CHEMBL1495179 & 688239 & 6.1362 & 5.455 & TST & & \\
\hline CHEMBL1564978 & 688239 & 4.6862 & 5.5196 & TRN & & \\
\hline
\end{tabular}


Supplemental Table S2.txt

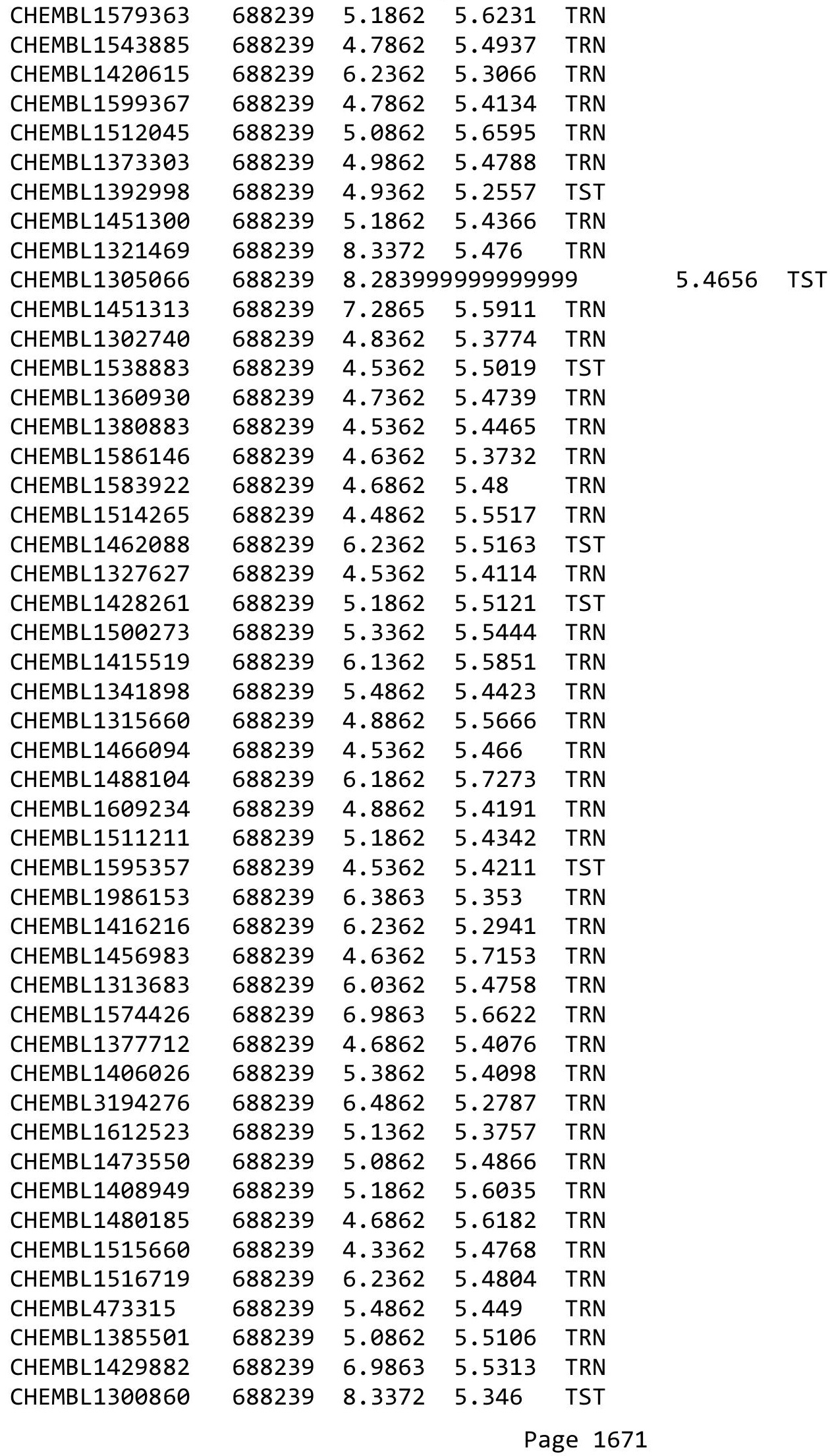


Supplemental Table S2.txt

\begin{tabular}{|c|c|c|c|c|}
\hline 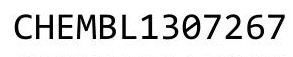 & & & & \\
\hline AEMBL1315246 & 38239 & 7362 & & \\
\hline AEMBL1328051 & 239 & 362 & & \\
\hline AEMBL1459529 & 239 & 362 & & \\
\hline EMBL156 & 239 & 362 & & \\
\hline AEMBL1344615 & 88239 & 4862 & & \\
\hline AEMBL1538243 & 88239 & 362 & 5218 & \\
\hline HEMBL1372920 & & 862 & & \\
\hline AEMBL1981667 & 39 & 362 & 01 & \\
\hline IEMBL1407722 & & 362 & & \\
\hline AEMBL1608435 & 39 & 362 & & \\
\hline AEMBL1554283 & 39 & 362 & & \\
\hline AEMBL1303046 & & & & \\
\hline HEMBL139 & & 62 & & \\
\hline AEMBL142 & & 62 & & \\
\hline AEMBL1522777 & & 862 & & \\
\hline AEMBL1424436 & & 362 & & \\
\hline IEMBL1579316 & & 62 & & \\
\hline AEMBL1506738 & & & & \\
\hline IEMBL14 & & & & \\
\hline JEMBL13. & & 862 & & \\
\hline JEMBL14 & & 862 & & \\
\hline IEMBL15 & & 62 & & \\
\hline AFMRI 15 & & & & \\
\hline 230 & & 362 & & \\
\hline 5996 & & 862 & & \\
\hline IEMBL1512942 & & 362 & & \\
\hline EMBL1440821 & & 62 & & \\
\hline IEMPI & & & & \\
\hline 117 & & 362 & & \\
\hline AEMBL3189830 & & & & \\
\hline AEMBL1518161 & & 362 & & \\
\hline 42 & & 62 & & \\
\hline 31 & & 52 & & \\
\hline AEMBL1365965 & & & & RN \\
\hline AEMBL1480426 & & 362 & & \\
\hline AEMBL1301148 & & 362 & & \\
\hline & & & & \\
\hline 705 & & & & \\
\hline HEMBL1350514 & & & & $\mathrm{RI}$ \\
\hline AEMBL1359343 & & 362 & & $\mathrm{~s}$ \\
\hline HEMBL135 & & 62 & & \\
\hline & & & & \\
\hline HEMBL1455761 & & & & \\
\hline AEMBL1310180 & & 4.5362 & & RN \\
\hline IEMBL1303643 & & 362 & & TS \\
\hline & & & & \\
\hline HEMBL133727 & & & 5.5538 & \\
\hline
\end{tabular}

Page 1672 
Supplemental Table S2.txt

\begin{tabular}{|c|c|c|c|c|}
\hline CHEMBL1465805 & 688239 & 5.2862 & 5.5471 & TRN \\
\hline CHEMBL3199174 & 688239 & 4.6862 & 5.527 & TRN \\
\hline CHEMBL1350202 & 688239 & 6.2362 & 5.5714 & TRN \\
\hline CHEMBL1326302 & 688239 & 4.6862 & 5.3154 & TRN \\
\hline CHEMBL1566836 & 688239 & 6.2362 & 5.5487 & TST \\
\hline CHEMBL1545782 & 688239 & 7.5867 & 5.6098 & TST \\
\hline CHEMBL1585651 & 688239 & 4.8362 & 5.4444 & TRN \\
\hline CHEMBL1462405 & 688239 & 5.3862 & 5.4766 & TRN \\
\hline CHEMBL1317704 & 688239 & 4.5362 & 5.5558 & TRN \\
\hline CHEMBL1304999 & 688239 & 4.6362 & 5.3524 & TST \\
\hline CHEMBL3196925 & 688239 & 5.1362 & 5.4593 & TST \\
\hline CHEMBL1372122 & 688239 & 4.6862 & 5.4775 & TRN \\
\hline CHEMBL1581633 & 688239 & 6.1362 & 5.5718 & TRN \\
\hline CHEMBL3211796 & 688239 & 4.4862 & 5.4176 & TRN \\
\hline CHEMBL 3199368 & 688239 & 5.0362 & 5.4165 & TST \\
\hline CHEMBL1408487 & 688239 & 6.8362 & 5.4553 & TRN \\
\hline CHEMBL1441741 & 688239 & 5.0362 & 5.638 & TRN \\
\hline CHEMBL1582133 & 688239 & 5.8862 & 5.5421 & TRN \\
\hline CHEMBL1303703 & 688239 & 4.7862 & 5.2406 & TRN \\
\hline CHEMBL1444097 & 688239 & 5.3362 & 5.4933 & TRN \\
\hline CHEMBL1586182 & 688239 & 6.7862 & 5.6767 & TRN \\
\hline CHEMBL1458126 & 688239 & 4.4862 & 5.6209 & TRN \\
\hline CHEMBL1552873 & 688239 & 5.3362 & 5.4867 & TRN \\
\hline CHEMBL1320510 & 688239 & 4.5362 & 5.2636 & TRN \\
\hline CHEMBL1398579 & 688239 & 5.7862 & 5.5624 & TRN \\
\hline CHEMBL1416368 & 688239 & 5.5362 & 5.5023 & TRN \\
\hline CHEMBL1613342 & 688239 & 6.1362 & 5.5611 & TRN \\
\hline CHEMBL1541883 & 688239 & 5.5862 & 5.4551 & TRN \\
\hline CHEMBL1601271 & 688239 & 5.5862 & 5.58299 & 9999999999 \\
\hline CHEMBL1363523 & 688239 & 4.9362 & 5.5028 & TST \\
\hline CHEMBL1417470 & 688239 & 5.1362 & 5.3295 & TRN \\
\hline CHEMBL 3195603 & 688239 & 6.1362 & 5.4015 & TRN \\
\hline CHEMBL1342319 & 688239 & 5.3862 & 5.4842 & TRN \\
\hline CHEMBL1441479 & 688239 & 4.5362 & 5.5761 & TRN \\
\hline CHEMBL 3198453 & 688239 & 4.9862 & 5.4493 & TRN \\
\hline CHEMBL1592798 & 688239 & 5.3862 & 5.41200 & 0000000001 \\
\hline CHEMBL1538248 & 688239 & 5.4862 & 5.4431 & TST \\
\hline CHEMBL1970780 & 688239 & 4.5362 & 5.3467 & TST \\
\hline CHEMBL1449408 & 688239 & 5.1862 & 5.391 & TRN \\
\hline CHEMBL1503846 & 688239 & 5.4362 & 5.6166 & TRN \\
\hline CHEMBL1299579 & 688239 & 4.7362 & 5.4056 & TRN \\
\hline CHEMBL1392576 & 688239 & 5.3862 & 5.5442 & TST \\
\hline CHEMBL1574462 & 688239 & 4.4862 & 5.6074 & TRN \\
\hline CHEMBL 3190466 & 688239 & 4.6862 & 5.5889 & TRN \\
\hline CHEMBL1401410 & 688239 & 4.8862 & 5.5702 & TRN \\
\hline CHEMBL1559902 & 688239 & 6.45 & 5.5184 & TRN \\
\hline CHEMBL1416182 & 688239 & 5.8362 & 5.624 & TST \\
\hline CHEMBL1534394 & 688239 & 6.9863 & 5.5206 & TRN \\
\hline
\end{tabular}

Page 1673 
Supplemental Table S2.txt

\begin{tabular}{|c|c|c|c|c|}
\hline CHEMBL1581574 & 688239 & 4.6362 & 5.431 & TRN \\
\hline CHEMBL1337245 & 688239 & 5.7862 & 5.614 & TRN \\
\hline CHEMBL1346833 & 688239 & 5.5862 & 5.6051 & TRN \\
\hline CHEMBL1577103 & 688239 & 5.9362 & 5.5048 & TRN \\
\hline CHEMBL1384618 & 688239 & 5.1862 & 5.4754 & TRN \\
\hline CHEMBL1521730 & 688239 & 5.2862 & 5.557 & TRN \\
\hline CHEMBL1482047 & 688239 & 6.3362 & 5.4932 & TST \\
\hline CHEMBL1360708 & 688239 & 4.8862 & 5.4536 & TRN \\
\hline CHEMBL1554701 & 688239 & 4.6862 & 5.4405 & TST \\
\hline CHEMBL1997747 & 688239 & 4.7362 & 5.482 & TRN \\
\hline CHEMBL1595619 & 688239 & 4.8362 & 5.4334 & TRN \\
\hline CHEMBL1597700 & 688239 & 6.1862 & 5.5063 & TRN \\
\hline CHEMBL1501922 & 688239 & 4.5362 & 5.5126 & TRN \\
\hline CHEMBL1469231 & 688239 & 5.1862 & 5.5039 & TRN \\
\hline CHEMBL1324524 & 688239 & 6.7361 & 5.5166 & TRN \\
\hline CHEMBL1491196 & 688239 & 7.0362 & 5.5603 & TST \\
\hline CHEMBL1360550 & 688239 & 5.1362 & 5.4931 & TRN \\
\hline CHEMBL1528337 & 688239 & 6.7862 & 5.7073 & TRN \\
\hline CHEMBL1350970 & 688239 & 4.9362 & 5.5841 & TRN \\
\hline CHEMBL1332469 & 688239 & 6.2862 & 5.5421 & TRN \\
\hline CHEMBL3196282 & 688239 & 4.6362 & 5.2692 & TRN \\
\hline CHEMBL3192359 & 688239 & 6.2862 & 5.4462 & TRN \\
\hline CHEMBL1327120 & 688239 & 8.3372 & 5.5329 & TRN \\
\hline CHEMBL1394820 & 688239 & 5.4862 & 5.3571 & TRN \\
\hline CHEMBL1406810 & 688239 & 5.9862 & 5.4773 & TRN \\
\hline CHEMBL3190973 & 688239 & 4.5362 & 5.3966 & TRN \\
\hline CHEMBL1526741 & 688239 & 6.9363 & 5.3819 & TRN \\
\hline CHEMBL1477800 & 688239 & 5.2362 & 5.5319 & TRN \\
\hline CHEMBL1327332 & 688239 & 6.9363 & 5.4715 & TST \\
\hline CHEMBL1517868 & 688239 & 5.1362 & 5.4784 & TRN \\
\hline CHEMBL1428772 & 688239 & 5.6862 & 5.6109 & TST \\
\hline CHEMBL1523031 & 688239 & 6.0862 & 5.5373 & TST \\
\hline CHEMBL3194106 & 688239 & 4.7362 & 5.3906 & TST \\
\hline CHEMBL1518194 & 688239 & 4.5362 & 5.4143 & TRN \\
\hline CHEMBL1343100 & 688239 & 4.6362 & 5.6328 & TST \\
\hline CHEMBL1376156 & 688239 & 6.9363 & 5.4808 & TRN \\
\hline CHEMBL1328771 & 688239 & 4.5362 & 5.4811 & TRN \\
\hline CHEMBL1367679 & 688239 & 4.5362 & 5.4441 & TRN \\
\hline CHEMBL1983302 & 688239 & 5.1862 & \multicolumn{2}{|c|}{5.5520000000000005} \\
\hline CHEMBL1335245 & 688239 & 4.6862 & 5.5229 & TRN \\
\hline CHEMBL1417696 & 688239 & 6.1862 & 5.5441 & TST \\
\hline CHEMBL1581622 & 688239 & 6.8362 & 5.5149 & TST \\
\hline CHEMBL1485981 & 688239 & 4.7362 & \multicolumn{2}{|c|}{5.5889999999999995} \\
\hline CHEMBL1545036 & 688239 & 4.5362 & 5.3905 & TRN \\
\hline CHEMBL1511534 & 688239 & 6.1862 & 5.5235 & TRN \\
\hline CHEMBL1613340 & 688239 & 5.8362 & 5.5235 & TRN \\
\hline CHEMBL1413724 & 688239 & 6.1362 & 5.3424 & TST \\
\hline CHEMBL1337254 & 688239 & 6.0362 & 5.4021 & TST \\
\hline
\end{tabular}


Supplemental Table S2.txt

\begin{tabular}{|c|c|c|c|c|}
\hline CHEMBL1546685 & 688239 & 5.1862 & 5.6006 & TST \\
\hline CHEMBL1981446 & 688239 & 4.5362 & 5.2689 & TRN \\
\hline CHEMBL1427635 & 688239 & 6.2862 & 5.4667 & TST \\
\hline CHEMBL1593896 & 688239 & 4.9362 & 5.3765 & TRN \\
\hline CHEMBL1469170 & 688239 & 6.7862 & 5.602 & TST \\
\hline CHEMBL1428170 & 688239 & 5.7862 & 5.3636 & TST \\
\hline CHEMBL1497828 & 688239 & 6.1862 & 5.3377 & TRN \\
\hline CHEMBL1455466 & 688239 & 5.0362 & 5.3089 & TRN \\
\hline CHEMBL451748 & 688239 & 4.5362 & 5.5741 & TST \\
\hline CHEMBL1379159 & 688239 & 4.6362 & 5.548999 & \\
\hline CHEMBL1573969 & 688239 & 5.3862 & 5.3729 & TRN \\
\hline CHEMBL3189409 & 688239 & 4.5362 & 5.3691 & TRN \\
\hline CHEMBL1427976 & 688239 & 7.0362 & 5.581 & TRN \\
\hline CHEMBL1325417 & 688239 & 4.5862 & 5.6467 & TST \\
\hline CHEMBL1550630 & 688239 & 4.5362 & 5.5076 & TRN \\
\hline CHEMBL1495028 & 688239 & 5.4362 & 5.4306 & TRN \\
\hline CHEMBL1467298 & 688239 & 6.6362 & 5.4718 & TST \\
\hline CHEMBL1337049 & 688239 & 5.8362 & 5.4881 & TRN \\
\hline CHEMBL1529748 & 688239 & 4.5362 & 5.5086 & TRN \\
\hline CHEMBL1463055 & 688239 & 5.5862 & 5.4985 & TST \\
\hline CHEMBL1586311 & 688239 & 5.3862 & 5.4532 & TRN \\
\hline CHEMBL1492652 & 688239 & 6.6362 & 5.403 & TRN \\
\hline CHEMBL1545153 & 688239 & 4.7362 & 5.3846 & TRN \\
\hline CHEMBL1598225 & 688239 & 6.7862 & 5.6148 & TRN \\
\hline CHEMBL1463225 & 688239 & 5.4362 & 5.4612 & TRN \\
\hline CHEMBL3213829 & 688239 & 7.0362 & 5.3296 & TRN \\
\hline CHEMBL1531919 & 688239 & 6.3362 & 5.588999 & 99999999995 \\
\hline CHEMBL1439647 & 688239 & 5.6862 & 5.6161 & TRN \\
\hline CHEMBL1306622 & 688239 & 5.2362 & 5.7443 & TST \\
\hline CHEMBL1534231 & 688239 & 4.9362 & 5.5527 & TRN \\
\hline CHEMBL1439847 & 688239 & 4.8362 & 5.492999 & 7999999999 \\
\hline CHEMBL1490802 & 688239 & 4.7862 & 5.5395 & TST \\
\hline CHEMBL1507950 & 688239 & 4.6862 & 5.4027 & TRN \\
\hline CHEMBL1341712 & 688239 & 4.5362 & 5.6544 & TRN \\
\hline CHEMBL1481019 & 688239 & 4.45 & 5.392 & TRN \\
\hline CHEMBL1550335 & 688239 & 5.0362 & 5.5349 & TRN \\
\hline CHEMBL1536887 & 688239 & 4.5362 & 5.4542 & TRN \\
\hline CHEMBL1323635 & 688239 & 4.5362 & 5.3921 & TRN \\
\hline CHEMBL1549591 & 688239 & 6.0862 & 5.5584 & TRN \\
\hline CHEMBL1582930 & 688239 & 6.7862 & 5.5384 & TRN \\
\hline CHEMBL1337853 & 688239 & 5.1862 & 5.5684 & TRN \\
\hline CHEMBL1526765 & 688239 & 6.3362 & 5.4701 & TRN \\
\hline CHEMBL3192702 & 688239 & 6.7862 & 5.3444 & TRN \\
\hline CHEMBL1331854 & 688239 & 5.1862 & 5.4057 & TST \\
\hline CHEMBL518292 & 688239 & 5.2362 & 5.4254 & TST \\
\hline CHEMBL1470502 & 688239 & 5.6862 & 5.4623 & TST \\
\hline CHEMBL1428768 & 688239 & 4.5362 & 5.2874 & TST \\
\hline CHEMBL1330547 & 688239 & 5.1862 & 5.5773 & TRN \\
\hline
\end{tabular}


Supplemental Table S2.txt

\begin{tabular}{|c|c|c|c|c|}
\hline CHEMBL1605358 & 688239 & 5.0862 & 5.6771 & TRN \\
\hline CHEMBL1564021 & 688239 & 4.8362 & 5.5816 & TRN \\
\hline CHEMBL1374261 & 688239 & 4.5362 & 5.5409 & TRN \\
\hline CHEMBL1535390 & 688239 & 4.8362 & 5.4416 & TRN \\
\hline CHEMBL1601289 & 688239 & 4.7862 & 5.295 & TRN \\
\hline CHEMBL1501473 & 688239 & 6.2362 & 5.6097 & TRN \\
\hline CHEMBL1304780 & 688239 & 5.8362 & 5.4069 & TRN \\
\hline CHEMBL1524258 & 688239 & 4.9862 & 5.5011 & TRN \\
\hline CHEMBL1391881 & 688239 & 4.8362 & 5.4912 & TRN \\
\hline CHEMBL1312370 & 688239 & 5.5862 & 5.5877 & TRN \\
\hline CHEMBL1408624 & 688239 & 6.1362 & 5.4219 & TRN \\
\hline CHEMBL1433029 & 688239 & 5.2862 & 5.4502 & TRN \\
\hline CHEMBL1345743 & 688239 & 6.0862 & 5.536006 & 30000000005 \\
\hline CHEMBL1375025 & 688239 & 5.1862 & 5.5186 & TST \\
\hline CHEMBL151797 & 688239 & 6.2362 & 5.5706 & TST \\
\hline CHEMBL1409826 & 688239 & 5.1862 & 5.5018 & TRN \\
\hline CHEMBL1887153 & 688239 & 4.7862 & 5.2153 & TST \\
\hline CHEMBL1391845 & 688239 & 5.5862 & 5.5457 & TRN \\
\hline CHEMBL1403178 & 688239 & 6.3362 & 5.5135 & TRN \\
\hline CHEMBL1579789 & 688239 & 6.0 & 5.3889 & TRN \\
\hline CHEMBL1310698 & 688239 & 5.1362 & 5.4816 & TRN \\
\hline CHEMBL1508017 & 688239 & 6.0862 & 5.4584 & TST \\
\hline CHEMBL1300700 & 688239 & 5.1862 & 5.3563 & TST \\
\hline CHEMBL1315764 & 688239 & 6.2862 & 5.6428 & TRN \\
\hline CHEMBL1536067 & 688239 & 5.5862 & 5.495 & TST \\
\hline CHEMBL1603040 & 688239 & 4.8862 & 5.402 & TRN \\
\hline CHEMBL1572555 & 688239 & 4.6862 & 5.4673 & TRN \\
\hline CHEMBL1356006 & 688239 & 5.2362 & 5.3273 & TRN \\
\hline CHEMBL1451584 & 688239 & 4.5362 & 5.558 & TRN \\
\hline CHEMBL3197567 & 688239 & 6.3362 & 5.4141 & TRN \\
\hline CHEMBL491747 & 688239 & 5.9862 & 5.367006 & 0000000001 \\
\hline CHEMBL1570867 & 688239 & 6.2362 & 5.4389 & TRN \\
\hline CHEMBL1393888 & 688239 & 4.5862 & 5.4936 & TRN \\
\hline CHEMBL1424945 & 688239 & 4.7862 & 5.3239 & TRN \\
\hline CHEMBL3196469 & 688239 & 4.5362 & 5.4599 & TRN \\
\hline CHEMBL1337596 & 688239 & 7.9355 & 5.5381 & TRN \\
\hline CHEMBL1731995 & 688239 & 5.1362 & 5.4817 & TRN \\
\hline CHEMBL1573978 & 688239 & 4.6362 & 5.5077 & TST \\
\hline CHEMBL1973429 & 688239 & 4.4862 & 5.3897 & TST \\
\hline CHEMBL1594912 & 688239 & 4.6362 & 5.4843 & TRN \\
\hline CHEMBL1488638 & 688239 & 7.5361 & 5.4202 & TRN \\
\hline CHEMBL1497481 & 688239 & 4.7862 & 5.3738 & TST \\
\hline CHEMBL1440535 & 688239 & 6.1862 & 5.386 & TRN \\
\hline CHEMBL1470597 & 688239 & 4.4862 & 5.6624 & TRN \\
\hline CHEMBL1374415 & 688239 & 4.7862 & 5.4003 & TRN \\
\hline CHEMBL3208963 & 688239 & 4.5362 & 5.3831 & TRN \\
\hline CHEMBL1549481 & 688239 & 4.7362 & 5.3327 & TRN \\
\hline CHEMBL1527930 & 688239 & 5.4362 & 5.5281 & TRN \\
\hline
\end{tabular}


Supplemental Table S2.txt

\begin{tabular}{|c|c|c|c|c|c|}
\hline CHEMBL1405220 & 688239 & 4.5362 & 5.3335 & TRN & \\
\hline CHEMBL1539571 & 688239 & 4.5362 & 5.4303 & TST & \\
\hline CHEMBL1388083 & 688239 & 4.5362 & 5.4683 & TST & \\
\hline CHEMBL1458860 & 688239 & 5.3862 & 5.4685 & TRN & \\
\hline CHEMBL1379810 & 688239 & 4.7362 & 5.5765 & TRN & \\
\hline CHEMBL1340588 & 688239 & 4.9362 & 5.3677 & TST & \\
\hline CHEMBL1556988 & 688239 & 5.7362 & 5.6566 & TRN & \\
\hline CHEMBL1477651 & 688239 & 4.7362 & 5.4604 & TRN & \\
\hline CHEMBL1341974 & 688239 & 4.5362 & 5.6499 & TRN & \\
\hline CHEMBL1347445 & 688239 & 5.1862 & 5.5953 & TRN & \\
\hline CHEMBL1359162 & 688239 & 5.1862 & 5.3694 & TST & \\
\hline CHEMBL1564192 & 688239 & 5.4362 & 5.6066 & TRN & \\
\hline CHEMBL3211693 & 688239 & 4.7862 & 5.4296 & TRN & \\
\hline CHEMBL1311725 & 688239 & 5.5362 & 5.5479 & TST & \\
\hline CHEMBL1334550 & 688239 & 5.5362 & 5.3368 & TRN & \\
\hline CHEMBL1472231 & 688239 & 5.1862 & 5.5633 & TRN & \\
\hline CHEMBL1438710 & 688239 & 8.3872 & 5.444 & TRN & \\
\hline CHEMBL1395438 & 688239 & 5.1862 & 5.4734 & TRN & \\
\hline CHEMBL1370385 & 688239 & 4.7362 & 5.4572 & TST & \\
\hline CHEMBL1446084 & 688239 & 6.2862 & 5.574 & TRN & \\
\hline CHEMBL1530192 & 688239 & 7.9355 & 5.5519 & TST & \\
\hline CHEMBL1544313 & 688239 & 4.9862 & 5.5077 & TST & \\
\hline CHEMBL1517114 & 688239 & 5.1862 & 5.4328 & TST & \\
\hline CHEMBL1567886 & 688239 & 4.8362 & 5.6303 & TST & \\
\hline CHEMBL1305139 & 688239 & 6.2862 & 5.5452 & TRN & \\
\hline CHEMBL1553834 & 688239 & 4.5362 & 5.5721 & TRN & \\
\hline CHEMBL 2007403 & 688239 & 4.7862 & 5.4341 & TRN & \\
\hline CHEMBL1300805 & 688239 & 5.8362 & 5.4271 & TST & \\
\hline CHEMBL1386012 & 688239 & 4.8362 & 5.5019 & TRN & \\
\hline CHEMBL1602525 & 688239 & 7.0362 & 5.4309 & TRN & \\
\hline CHEMBL1303147 & 688239 & 5.0862 & 5.3605 & TRN & \\
\hline CHEMBL1386939 & 688239 & 6.2362 & 5.3685 & TRN & \\
\hline CHEMBL1492107 & 688239 & 6.2862 & 5.5166 & TRN & \\
\hline CHEMBL1416559 & 688239 & 6.5862 & 5.4393 & TST & \\
\hline CHEMBL582081 & 688239 & 6.1862 & 5.3797 & TST & \\
\hline CHEMBL1538462 & 688239 & 5.9362 & 5.4199 & TST & \\
\hline CHEMBL1554647 & 688239 & 5.5862 & 5.45700 & 0000000001 & TRN \\
\hline CHEMBL1568530 & 688239 & 4.6362 & 5.5712 & TRN & \\
\hline CHEMBL1401546 & 688239 & 4.9362 & 5.5101 & TRN & \\
\hline CHEMBL1327366 & 688239 & 5.0362 & 5.2914 & TRN & \\
\hline CHEMBL1496633 & 688239 & 5.6862 & 5.3051 & TRN & \\
\hline CHEMBL1548027 & 688239 & 5.7362 & 5.58700 & 0000000001 & TRN \\
\hline CHEMBL1465400 & 688239 & 7.0362 & 5.4691 & TST & \\
\hline CHEMBL1420592 & 688239 & 6.9863 & 5.5584 & TRN & \\
\hline CHEMBL1532210 & 688239 & 6.4362 & 5.3881 & TRN & \\
\hline CHEMBL1301817 & 688239 & 4.5362 & 5.4435 & TRN & \\
\hline CHEMBL1609936 & 688239 & 6.1362 & 5.4888 & TRN & \\
\hline CHEMBL1516627 & 688239 & 5.1862 & 5.2389 & TRN & \\
\hline
\end{tabular}


Supplemental Table S2.txt

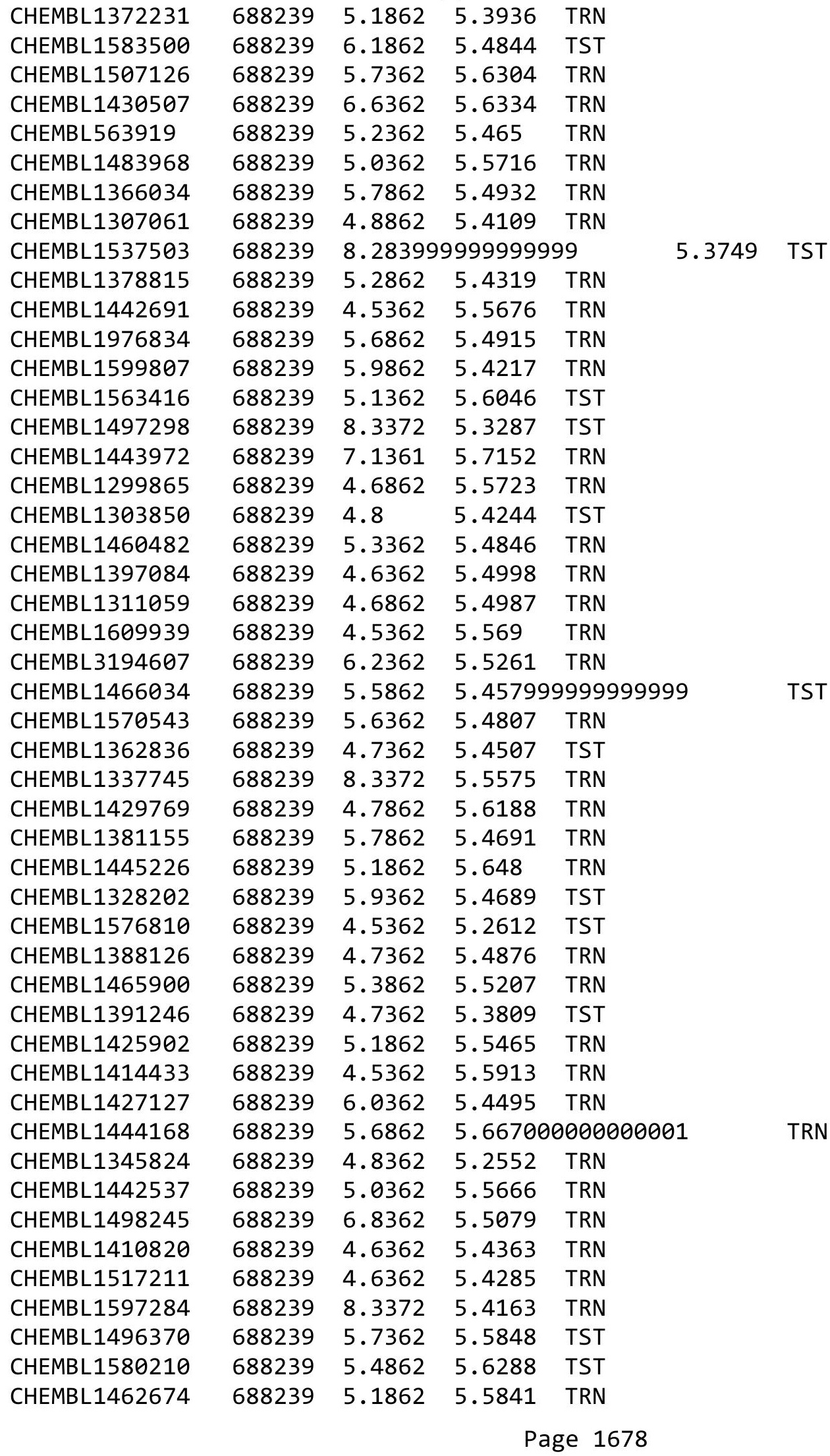


Supplemental Table S2.txt

\begin{tabular}{|c|c|c|c|c|c|}
\hline CHEMBL1531750 & 688239 & 4.5362 & 5.4562 & TST & \\
\hline CHEMBL1452376 & 688239 & 8.3372 & 5.4939 & TRN & \\
\hline CHEMBL1532421 & 688239 & 6.0862 & 5.4627 & TRN & \\
\hline CHEMBL1583697 & 688239 & 8.3372 & 5.5766 & TRN & \\
\hline CHEMBL1429025 & 688239 & 6.1362 & 5.4307 & TRN & \\
\hline CHEMBL1464887 & 688239 & 4.7862 & 5.6537 & TRN & \\
\hline CHEMBL1377034 & 688239 & 4.6362 & 5.5035 & TST & \\
\hline CHEMBL1427390 & 688239 & 4.5362 & 5.5049 & TRN & \\
\hline CHEMBL1534936 & 688239 & 7.9872 & \multicolumn{2}{|c|}{5.388999999999999} & TRN \\
\hline CHEMBL1535354 & 688239 & 6.1362 & 5.4367 & TST & \\
\hline CHEMBL1460529 & 688239 & 4.7862 & 5.3999 & TRN & \\
\hline CHEMBL1373225 & 688239 & 4.5362 & 5.4475 & TRN & \\
\hline CHEMBL1300359 & 688239 & 4.7362 & 5.6837 & TRN & \\
\hline CHEMBL1407667 & 688239 & 4.8362 & 5.4179 & TST & \\
\hline CHEMBL1579256 & 688239 & 4.8862 & \multicolumn{2}{|c|}{5.468999999999999} & TST \\
\hline CHEMBL1541743 & 688239 & 4.5362 & 5.4291 & TST & \\
\hline CHEMBL1511005 & 688239 & 6.0862 & 5.591 & TRN & \\
\hline CHEMBL1560964 & 688239 & 4.9862 & 5.532 & TST & \\
\hline CHEMBL1394775 & 688239 & 4.5362 & 5.4468 & TRN & \\
\hline CHEMBL1548867 & 688239 & 5.9362 & 5.5761 & TRN & \\
\hline CHEMBL1394492 & 688239 & 4.6362 & 5.3733 & TST & \\
\hline CHEMBL1317530 & 688239 & 6.0 & 5.4328 & TRN & \\
\hline CHEMBL1404275 & 688239 & 7.1864 & 5.5204 & TRN & \\
\hline CHEMBL1582082 & 688239 & 5.8362 & 5.4088 & TRN & \\
\hline CHEMBL1366337 & 688239 & 8.3372 & 5.4773 & TRN & \\
\hline CHEMBL1531744 & 688239 & 4.8862 & 5.4596 & TRN & \\
\hline CHEMBL1574325 & 688239 & 6.4362 & 5.5381 & TRN & \\
\hline CHEMBL1306673 & 688239 & 6.3362 & \multicolumn{2}{|c|}{5.377000000000001} & TRN \\
\hline CHEMBL1509864 & 688239 & 5.4862 & 5.5331 & TST & \\
\hline CHEMBL1361857 & 688239 & 6.3863 & 5.4145 & TST & \\
\hline CHEMBL1406998 & 688239 & 4.8362 & 5.3833 & TRN & \\
\hline CHEMBL1397625 & 688239 & 6.0862 & 5.4594 & TST & \\
\hline CHEMBL1319787 & 688239 & 6.2362 & 5.4565 & TRN & \\
\hline CHEMBL1438095 & 688239 & 6.2362 & 5.5425 & TRN & \\
\hline CHEMBL1562195 & 688239 & 5.6862 & 5.495 & TRN & \\
\hline CHEMBL1304415 & 688239 & 7.5361 & 5.4256 & TRN & \\
\hline CHEMBL1388587 & 688239 & 5.6862 & 5.2861 & TRN & \\
\hline CHEMBL1310403 & 688239 & 6.7862 & 5.5997 & TRN & \\
\hline CHEMBL1332985 & 688239 & 5.0362 & 5.615 & TRN & \\
\hline CHEMBL1507283 & 688239 & 5.3862 & 5.3947 & TRN & \\
\hline CHEMBL1417688 & 688239 & 5.1362 & 5.4281 & TRN & \\
\hline CHEMBL1543518 & 688239 & 4.5862 & 5.4283 & TRN & \\
\hline CHEMBL1331356 & 688239 & 6.2862 & 5.6132 & TRN & \\
\hline CHEMBL1331257 & 688239 & 6.1862 & \multicolumn{2}{|c|}{5.5329999999999995} & TRN \\
\hline CHEMBL1408188 & 688239 & 5.5862 & 5.4902 & TRN & \\
\hline CHEMBL1612213 & 688239 & 8.3372 & 5.3659 & TRN & \\
\hline CHEMBL1536086 & 688239 & 4.8362 & 5.3687 & TRN & \\
\hline CHEMBL1479977 & 688239 & 5.4362 & 5.3887 & TRN & \\
\hline
\end{tabular}




\begin{tabular}{|c|c|c|c|c|c|}
\hline \multirow{3}{*}{$\begin{array}{l}\text { CHEMBL1313125 } \\
\text { CHEMBL1386138 }\end{array}$} & \multirow{2}{*}{688239} & \multicolumn{4}{|c|}{ Supplemental Table S2.txt } \\
\hline & & 4.7862 & \multicolumn{2}{|c|}{5.446000000000001} & TST \\
\hline & 688239 & 4.8362 & 5.6268 & TST & \\
\hline CHEMBL1535894 & 688239 & 4.5362 & 5.5244 & TRN & \\
\hline CHEMBL1506849 & 688239 & 5.5862 & 5.5635 & TRN & \\
\hline CHEMBL1535846 & 688239 & 5.5362 & 5.4536 & TST & \\
\hline CHEMBL1410790 & 688239 & 4.5362 & 5.5156 & TST & \\
\hline CHEMBL1333383 & 688239 & 5.1862 & 5.5218 & TRN & \\
\hline CHEMBL1367237 & 688239 & 8.3872 & 5.4925 & TRN & \\
\hline CHEMBL1407823 & 688239 & 6.8861 & 5.4813 & TRN & \\
\hline CHEMBL3193964 & 688239 & 4.7862 & 5.3052 & TST & \\
\hline CHEMBL1498106 & 688239 & 5.2362 & 5.5284 & TRN & \\
\hline CHEMBL1596896 & 688239 & 7.2865 & 5.3795 & TRN & \\
\hline CHEMBL1479149 & 688239 & 4.7362 & 5.4833 & TRN & \\
\hline CHEMBL1522245 & 688239 & 4.4862 & 5.4683 & TRN & \\
\hline CHEMBL1428354 & 688239 & 5.2362 & 5.5627 & TRN & \\
\hline CHEMBL1532780 & 688239 & 6.6362 & 5.5233 & TRN & \\
\hline CHEMBL1601280 & 688239 & 4.5362 & 5.3647 & TST & \\
\hline CHEMBL1369907 & 688239 & 6.1862 & 5.563 & TRN & \\
\hline CHEMBL1526144 & 688239 & 4.9862 & 5.5707 & TRN & \\
\hline CHEMBL1990214 & 688239 & 5.0362 & 5.38 & TST & \\
\hline CHEMBL1524173 & 688239 & 4.6362 & 5.4493 & TST & \\
\hline CHEMBL1405103 & 688239 & 5.1862 & 5.4277 & TRN & \\
\hline CHEMBL1602747 & 688239 & 5.2362 & 5.5393 & TST & \\
\hline CHEMBL1338526 & 688239 & 6.3863 & 5.5147 & TRN & \\
\hline CHEMBL1351537 & 688239 & 6.2862 & 5.33299 & 9999999999 & TRN \\
\hline CHEMBL1452188 & 688239 & 4.5362 & 5.4326 & TRN & \\
\hline CHEMBL1371218 & 688239 & 6.1862 & 5.5305 & TRN & \\
\hline CHEMBL1577749 & 688239 & 5.7362 & 5.6039 & TRN & \\
\hline CHEMBL1425604 & 688239 & 7.9872 & 5.4769 & TRN & \\
\hline CHEMBL1508450 & 688239 & 5.1862 & 5.3551 & TRN & \\
\hline CHEMBL580955 & 688239 & 4.7362 & 5.367006 & 0000000001 & TRN \\
\hline CHEMBL1428567 & 688239 & 4.5362 & 5.4344 & TRN & \\
\hline CHEMBL1385224 & 688239 & 4.5362 & 5.5187 & TST & \\
\hline CHEMBL1474444 & 688239 & 4.4862 & 5.5622 & TRN & \\
\hline CHEMBL1485165 & 688239 & 5.7362 & 5.5471 & TRN & \\
\hline CHEMBL1414749 & 688239 & 4.5862 & 5.5382 & TST & \\
\hline CHEMBL1359910 & 688239 & 5.6862 & 5.4148 & TST & \\
\hline CHEMBL1428575 & 688239 & 5.6862 & 5.4282 & TRN & \\
\hline CHEMBL1410906 & 688239 & 4.5362 & 5.2993 & TRN & \\
\hline CHEMBL1446760 & 688239 & 6.5363 & 5.4581 & TRN & \\
\hline CHEMBL1561159 & 688239 & 7.1864 & 5.5773 & TRN & \\
\hline CHEMBL1376766 & 688239 & 4.5362 & 5.5807 & TRN & \\
\hline CHEMBL1582117 & 688239 & 4.9362 & 5.4251 & TRN & \\
\hline CHEMBL1335693 & 688239 & 4.4862 & 5.42399 & 99999999995 & TRN \\
\hline CHEMBL1580769 & 688239 & 4.5362 & 5.5563 & TST & \\
\hline CHEMBL1568975 & 688239 & 5.4362 & 5.5188 & TRN & \\
\hline CHEMBL1464468 & 688239 & 6.4862 & 5.4344 & TRN & \\
\hline CHEMBL1352008 & 688239 & 5.0362 & 5.518 & TRN & \\
\hline
\end{tabular}


Supplemental Table S2.txt

\begin{tabular}{|c|c|c|c|c|}
\hline CHEMBL1410344 & 688239 & 6.8362 & 5.5484 & TRN \\
\hline CHEMBL1364649 & 688239 & 6.3863 & 5.5691 & TST \\
\hline CHEMBL1522363 & 688239 & 4.7862 & 5.5711 & TRN \\
\hline CHEMBL1575153 & 688239 & 6.9363 & 5.6022 & TRN \\
\hline CHEMBL1430683 & 688239 & 4.4862 & 5.3964 & TRN \\
\hline CHEMBL1578490 & 688239 & 4.4862 & 5.5173 & TRN \\
\hline CHEMBL1567458 & 688239 & 6.3362 & 5.449 & TRN \\
\hline CHEMBL1335678 & 688239 & 6.0362 & 5.5303 & TRN \\
\hline CHEMBL1344588 & 688239 & 5.1862 & 5.431 & TRN \\
\hline CHEMBL1519827 & 688239 & 4.7362 & 5.4532 & TST \\
\hline CHEMBL1577545 & 688239 & 5.6362 & 5.4197 & TRN \\
\hline CHEMBL1577462 & 688239 & 6.1862 & 5.5926 & TRN \\
\hline CHEMBL1464195 & 688239 & 4.5362 & 5.6159 & TRN \\
\hline CHEMBL1599261 & 688239 & 4.5362 & 5.5653 & TST \\
\hline CHEMBL1463153 & 688239 & 6.7862 & 5.3085 & TST \\
\hline CHEMBL1562613 & 688239 & 5.4862 & 5.5384 & TRN \\
\hline CHEMBL1501996 & 688239 & 5.1862 & 5.474 & TST \\
\hline CHEMBL 3211967 & 688239 & 6.3362 & 5.5063 & TRN \\
\hline CHEMBL1547306 & 688239 & 5.1362 & 5.4858 & TRN \\
\hline CHEMBL1434186 & 688239 & 6.3362 & 5.6193 & TRN \\
\hline CHEMBL1970117 & 688239 & 7.6364 & 5.6347 & TRN \\
\hline CHEMBL1445803 & 688239 & 5.4362 & 5.4423 & TRN \\
\hline CHEMBL1389155 & 688239 & 5.1862 & 5.5031 & TRN \\
\hline CHEMBL1335325 & 688239 & 4.5362 & 5.5129 & TRN \\
\hline CHEMBL1521583 & 688239 & 5.9362 & 5.4554 & TRN \\
\hline CHEMBL1308902 & 688239 & 4.5862 & 5.5536 & TRN \\
\hline CHEMBL1336745 & 688239 & 4.7862 & 5.4898 & TRN \\
\hline CHEMBL1459095 & 688239 & 6.1362 & 5.6088 & TRN \\
\hline CHEMBL1471153 & 688239 & 5.1862 & 5.6305 & TRN \\
\hline CHEMBL1594166 & 688239 & 5.3862 & 5.6038 & TRN \\
\hline CHEMBL1332490 & 688239 & 6.9863 & 5.5303 & TST \\
\hline CHEMBL1570178 & 688239 & 7.5867 & 5.6096 & TRN \\
\hline CHEMBL1420227 & 688239 & 4.5362 & 5.4661 & TRN \\
\hline CHEMBL1306163 & 688239 & 5.6862 & 5.4608 & TRN \\
\hline CHEMBL 2001518 & 688239 & 6.7862 & 5.4121 & TRN \\
\hline CHEMBL1562768 & 688239 & 5.0862 & 5.4896 & TST \\
\hline CHEMBL1530342 & 688239 & 5.5362 & 5.4798 & TRN \\
\hline CHEMBL1503721 & 688239 & 5.7362 & 5.4698 & TRN \\
\hline CHEMBL1383122 & 688239 & 4.5362 & 5.4258 & TST \\
\hline CHEMBL1314542 & 688239 & 5.1862 & 5.5381 & TRN \\
\hline CHEMBL1547297 & 688239 & 5.9862 & 5.5291 & TRN \\
\hline CHEMBL1373485 & 688239 & 4.5862 & 5.3904 & TRN \\
\hline CHEMBL1979597 & 688239 & 6.9363 & 5.5907 & TRN \\
\hline CHEMBL1543514 & 688239 & 4.5362 & 5.547999 & 7999999999 \\
\hline CHEMBL1993020 & 688239 & 5.3362 & 5.4474 & TRN \\
\hline CHEMBL1452625 & 688239 & 6.2862 & 5.4451 & TRN \\
\hline CHEMBL1399547 & 688239 & 5.5862 & 5.3962 & TRN \\
\hline CHEMBL1596104 & 688239 & 5.8862 & 5.4957 & TRN \\
\hline
\end{tabular}


Supplemental Table S2.txt

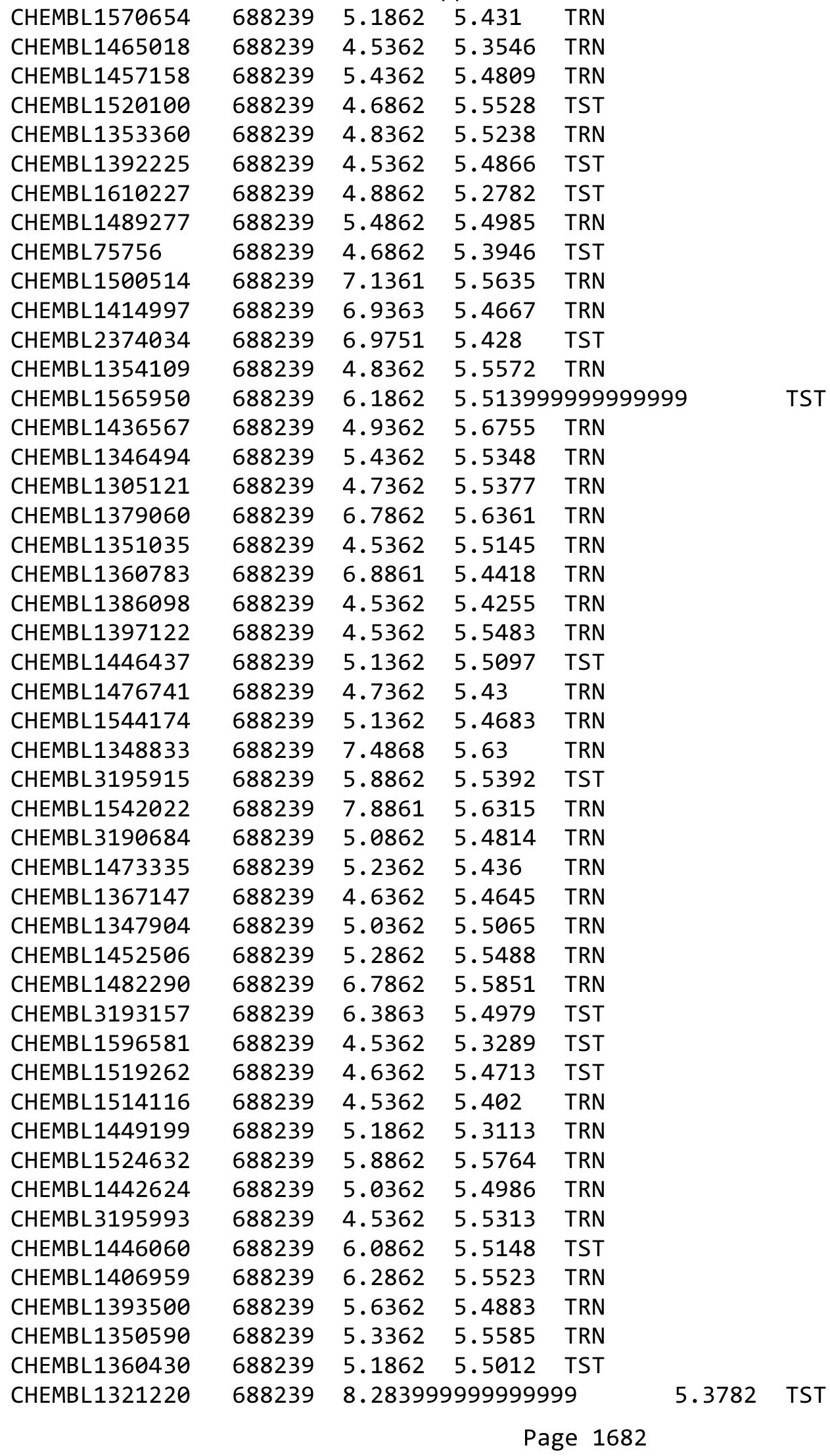


Supplemental Table S2.txt

\begin{tabular}{|c|c|c|c|c|}
\hline CHEMBL1586568 & 688239 & 4.8362 & 5.51 & TRN \\
\hline CHEMBL1353829 & 688239 & 6.8861 & 5.404 & TST \\
\hline CHEMBL1542206 & 688239 & 5.2362 & 5.6426 & TRN \\
\hline CHEMBL3196500 & 688239 & 6.2362 & \multicolumn{2}{|c|}{5.457999999999999} \\
\hline CHEMBL1389069 & 688239 & 5.1862 & 5.5356 & TRN \\
\hline CHEMBL1427588 & 688239 & 8.3372 & 5.5705 & TRN \\
\hline CHEMBL1436375 & 688239 & 4.6862 & 5.5009 & TRN \\
\hline CHEMBL1610969 & 688239 & 5.4862 & 5.6646 & TRN \\
\hline CHEMBL1473290 & 688239 & 5.7862 & 5.5272 & TST \\
\hline CHEMBL1349059 & 688239 & 4.7362 & 5.5069 & TRN \\
\hline CHEMBL1519547 & 688239 & 4.6362 & 5.4963 & TRN \\
\hline CHEMBL1459726 & 688239 & 4.7362 & 5.4087 & TRN \\
\hline CHEMBL1348413 & 688239 & 4.5362 & 5.415 & TRN \\
\hline CHEMBL1428857 & 688239 & 8.1367 & 5.4949 & TRN \\
\hline CHEMBL1358067 & 688239 & 4.5362 & 5.5416 & TRN \\
\hline CHEMBL1310479 & 688239 & 4.7862 & \multicolumn{2}{|c|}{5.428999999999999} \\
\hline CHEMBL1604609 & 688239 & 5.8862 & 5.6687 & TRN \\
\hline CHEMBL1501953 & 688239 & 4.6862 & 5.5357 & TST \\
\hline CHEMBL1475935 & 688239 & 5.7362 & 5.4734 & TST \\
\hline CHEMBL1389739 & 688239 & 4.9362 & 5.4384 & TST \\
\hline CHEMBL1302824 & 688239 & 4.7362 & 5.4535 & TRN \\
\hline CHEMBL1344458 & 688239 & 5.5362 & 5.4447 & TRN \\
\hline CHEMBL1495137 & 688239 & 4.9362 & 5.6492 & TRN \\
\hline CHEMBL3212540 & 688239 & 5.4862 & 5.4822 & TRN \\
\hline CHEMBL1321513 & 688239 & 4.7362 & 5.665 & TST \\
\hline CHEMBL3194840 & 688239 & 5.6362 & 5.5939 & TST \\
\hline CHEMBL1310126 & 688239 & 4.5362 & 5.6803 & TRN \\
\hline CHEMBL1352180 & 688239 & 5.9362 & 5.4876 & TRN \\
\hline CHEMBL1597322 & 688239 & 6.5862 & 5.4925 & TRN \\
\hline CHEMBL1536107 & 688239 & 4.4862 & 5.3084 & TRN \\
\hline CHEMBL194594 & 688239 & 4.7862 & 5.4738 & TST \\
\hline CHEMBL1497021 & 688239 & 5.6862 & 5.5333 & TRN \\
\hline CHEMBL1418911 & 688239 & 7.7352 & 5.5776 & TRN \\
\hline CHEMBL1390059 & 688239 & 5.7362 & 5.5952 & TRN \\
\hline CHEMBL1434287 & 688239 & 6.8362 & 5.4888 & TRN \\
\hline CHEMBL1536841 & 688239 & 6.1862 & 5.6071 & TRN \\
\hline CHEMBL1563293 & 688239 & 5.9362 & 5.4848 & TST \\
\hline CHEMBL1436028 & 688239 & 5.375 & 5.3924 & TST \\
\hline CHEMBL1341131 & 688239 & 6.1362 & 5.4552 & TRN \\
\hline CHEMBL1479776 & 688239 & 4.8862 & 5.5377 & TRN \\
\hline CHEMBL1500688 & 688239 & 5.1862 & 5.5883 & TST \\
\hline CHEMBL3198406 & 688239 & 5.6362 & 5.4624 & TST \\
\hline CHEMBL1352340 & 688239 & 4.6362 & 5.3519 & TST \\
\hline CHEMBL1607531 & 688239 & 6.8362 & 5.4874 & TRN \\
\hline CHEMBL1404668 & 688239 & 4.5362 & 5.5154 & TRN \\
\hline CHEMBL1356574 & 688239 & 6.3362 & 5.29200 & 3000000001 \\
\hline CHEMBL1579586 & 688239 & 4.7862 & 5.4688 & TRN \\
\hline CHEMBL1381783 & 688239 & 4.7362 & 5.3413 & TST \\
\hline
\end{tabular}


Supplemental Table S2.txt

\begin{tabular}{|c|c|c|c|c|c|}
\hline CHEMBL1512466 & 688239 & 5.1362 & 5.4925 & TRN & \\
\hline CHEMBL1395721 & 688239 & 5.6362 & 5.6244 & TRN & \\
\hline CHEMBL1394465 & 688239 & 4.9862 & 5.4344 & TRN & \\
\hline CHEMBL1370266 & 688239 & 4.5362 & 5.5074 & TRN & \\
\hline CHEMBL1463555 & 688239 & 4.5362 & 5.5066 & TRN & \\
\hline CHEMBL1419086 & 688239 & 8.3372 & 5.4886 & TST & \\
\hline CHEMBL1447650 & 688239 & 6.8362 & 5.5595 & TRN & \\
\hline CHEMBL1537923 & 688239 & 6.8861 & 5.4019 & TRN & \\
\hline CHEMBL1534378 & 688239 & 6.8362 & 5.5574 & TRN & \\
\hline CHEMBL1391880 & 688239 & 5.6862 & 5.6004 & TRN & \\
\hline CHEMBL1428389 & 688239 & 4.5362 & 5.5842 & TST & \\
\hline CHEMBL1312930 & 688239 & 7.2865 & 5.5678 & TRN & \\
\hline CHEMBL1380705 & 688239 & 5.7862 & 5.4544 & TST & \\
\hline CHEMBL1551814 & 688239 & 8.3372 & 5.4304 & TRN & \\
\hline CHEMBL1556249 & 688239 & 4.5362 & 5.39 & TRN & \\
\hline CHEMBL1581195 & 688239 & 4.4862 & 5.4744 & TST & \\
\hline CHEMBL1560475 & 688239 & 4.9862 & 5.4091 & TRN & \\
\hline CHEMBL1413548 & 688239 & 5.2862 & 5.4488 & TRN & \\
\hline CHEMBL1538549 & 688239 & 8.3372 & 5.6093 & TRN & \\
\hline CHEMBL1453246 & 688239 & 5.8862 & 5.4842 & TRN & \\
\hline CHEMBL1433875 & 688239 & 7.0362 & 5.4803 & TRN & \\
\hline CHEMBL1440191 & 688239 & 5.4862 & 5.47 & TRN & \\
\hline CHEMBL1412581 & 688239 & 8.3372 & 5.4743 & TRN & \\
\hline CHEMBL3145371 & 688239 & 5.3362 & 5.5707 & TRN & \\
\hline CHEMBL 3190702 & 688239 & 4.6362 & 5.4068 & TRN & \\
\hline CHEMBL1590319 & 688239 & 4.5362 & 5.3644 & TRN & \\
\hline CHEMBL1363203 & 688239 & 5.2362 & 5.3642 & TST & \\
\hline CHEMBL188734 & 688239 & 4.6862 & 5.5071 & TRN & \\
\hline CHEMBL1564343 & 688239 & 4.8362 & 5.2887 & TRN & \\
\hline CHEMBL1438528 & 688239 & 6.0362 & 5.5673 & TST & \\
\hline CHEMBL1547059 & 688239 & 4.6862 & 5.4406 & TRN & \\
\hline CHEMBL1385615 & 688239 & 7.6861 & 5.5628 & TRN & \\
\hline CHEMBL1466891 & 688239 & 4.5862 & 5.4963 & TST & \\
\hline CHEMBL1531375 & 688239 & 4.5362 & 5.5223 & TRN & \\
\hline CHEMBL1559343 & 688239 & 4.5362 & 5.4771 & TST & \\
\hline CHEMBL1320717 & 688239 & 6.2362 & 5.6901 & TRN & \\
\hline CHEMBL1418193 & 688239 & 4.5362 & 5.4981 & TRN & \\
\hline CHEMBL1451963 & 688239 & 5.1362 & 5.5554 & TST & \\
\hline CHEMBL1511734 & 688239 & 6.9863 & 5.4669 & TRN & \\
\hline CHEMBL 237442 & 688239 & 5.2362 & 5.6506 & TRN & \\
\hline CHEMBL1355748 & 688239 & 7.1864 & 5.4253 & TRN & \\
\hline CHEMBL1331942 & 688239 & 5.2362 & 5.575 & TRN & \\
\hline CHEMBL1412454 & 688239 & 7.1864 & 5.617999 & 9999999999 & TRN \\
\hline CHEMBL1541708 & 688239 & 6.1362 & 5.5462 & TRN & \\
\hline CHEMBL1322199 & 688239 & 4.6862 & 5.5851 & TRN & \\
\hline CHEMBL1319590 & 688239 & 8.28399 & 999999999 & 5.3696 & TRN \\
\hline CHEMBL1311118 & 688239 & 4.7362 & 5.4126 & TRN & \\
\hline CHEMBL1493868 & 688239 & 4.5362 & 5.3737 & TRN & \\
\hline
\end{tabular}


Supplemental Table S2.txt

\begin{tabular}{|c|c|c|c|c|}
\hline 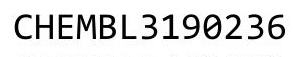 & & & & \\
\hline AEMBL1462692 & 38239 & 862 & 265 & \\
\hline AEMBL1517870 & 239 & 362 & 735 & \\
\hline 1455037 & 39 & & & \\
\hline IEMBL1590615 & 39 & & & \\
\hline AEMBL1572209 & 88239 & 862 & 5026 & \\
\hline AEMBL1341199 & 88239 & 362 & 311 & \\
\hline AEMBL1575735 & & & & \\
\hline AEMBL140 & 39 & 362 & & \\
\hline IEMBL1327016 & & & & \\
\hline AEMBL1501123 & 239 & 362 & 19 & \\
\hline AEMBL1476757 & 39 & 372 & & \\
\hline AEMBL1322463 & & & & \\
\hline HEMBL1579820 & & & & \\
\hline HEMBL1459676 & & & & \\
\hline AEMBL3197055 & & 862 & & \\
\hline AEMBL1357078 & & & & \\
\hline IEMBL1589 & & & & \\
\hline AEMBL1534 & & & & \\
\hline AEMBL1417516 & & & & \\
\hline AEMBL1379520 & & 62 & & \\
\hline AEMBL1369543 & & & & \\
\hline AEMBL3211 & & & & \\
\hline AEMBL 1515 & & & & \\
\hline 15 & & & & \\
\hline AEMBL1417391 & & & & \\
\hline IEMBL1354479 & & & & \\
\hline EMBL152 & & & & \\
\hline AFME $-2-P A$ & & & & \\
\hline AEMBL1299219 & & & & \\
\hline AEMBL1535828 & & & & \\
\hline AEMBL1443632 & & & & \\
\hline 144 & & & & \\
\hline 4 & & & & \\
\hline HEMBL1377923 & & & & \\
\hline AEMBL1359437 & & & & \\
\hline AEMBL1380629 & & & & \\
\hline & & & & \\
\hline 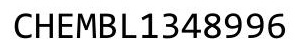 & & & & \\
\hline AEMBL1551458 & & & & RN \\
\hline AEMBL1448930 & & & & $\mathrm{R}$ \\
\hline AEMBL1609767 & & & & \\
\hline & & & & \\
\hline & & & & \\
\hline AEMBL1477652 & & & 4989 & RN \\
\hline IEMBL1596153 & & 5 . & 221 & \\
\hline 136 & & & & \\
\hline HEMBL153248 & & & & \\
\hline
\end{tabular}

Page 1685 
Supplemental Table S2.txt

\begin{tabular}{|c|c|c|c|c|c|}
\hline CHEMBL1479147 & 688239 & 5.1862 & 5.4226 & TRN & \\
\hline CHEMBL1348691 & 688239 & 4.5362 & \multicolumn{2}{|c|}{5.486000000000001} & TRN \\
\hline CHEMBL3194088 & 688239 & 4.7862 & 5.5331 & TRN & \\
\hline CHEMBL1611870 & 688239 & 4.7862 & 5.5341 & TRN & \\
\hline CHEMBL1313525 & 688239 & 4.8362 & 5.5405 & TRN & \\
\hline CHEMBL1541187 & 688239 & 5.9362 & 5.4687 & TRN & \\
\hline CHEMBL1345450 & 688239 & 5.1862 & 5.5003 & TRN & \\
\hline CHEMBL1499389 & 688239 & 6.1362 & 5.5561 & TRN & \\
\hline CHEMBL3211814 & 688239 & 5.3862 & 5.4156 & TRN & \\
\hline CHEMBL1438560 & 688239 & 6.0 & 5.4057 & TRN & \\
\hline CHEMBL1509147 & 688239 & 7.1361 & 5.3735 & TRN & \\
\hline CHEMBL3207399 & 688239 & 6.1862 & 5.4003 & TST & \\
\hline CHEMBL1348221 & 688239 & 6.2362 & 5.399 & TRN & \\
\hline CHEMBL1310864 & 688239 & 7.0362 & 5.4103 & TRN & \\
\hline CHEMBL1500856 & 688239 & 4.5862 & 5.4518 & TRN & \\
\hline CHEMBL1563580 & 688239 & 6.9363 & 5.3038 & TRN & \\
\hline CHEMBL1380265 & 688239 & 5.4362 & 5.3036 & TRN & \\
\hline CHEMBL1313174 & 688239 & 4.6362 & 5.3023 & TRN & \\
\hline CHEMBL1577430 & 688239 & 6.1362 & 5.4875 & TRN & \\
\hline CHEMBL3213249 & 688239 & 4.7362 & 5.4752 & TST & \\
\hline CHEMBL 3196001 & 688239 & 8.2366 & 5.4197 & TRN & \\
\hline CHEMBL1579357 & 688239 & 7.1361 & 5.5557 & TST & \\
\hline CHEMBL1415579 & 688239 & 5.4362 & 5.4791 & TRN & \\
\hline CHEMBL1475410 & 688239 & 4.5362 & 5.5022 & TRN & \\
\hline CHEMBL1495459 & 688239 & 4.5362 & 5.4537 & TRN & \\
\hline CHEMBL1544740 & 688239 & 5.9362 & 5.6337 & TST & \\
\hline CHEMBL1401155 & 688239 & 4.4862 & 5.4268 & TST & \\
\hline CHEMBL1342610 & 688239 & 6.8861 & 5.6118 & TRN & \\
\hline CHEMBL1471521 & 688239 & 6.1362 & 5.6611 & TRN & \\
\hline CHEMBL1383998 & 688239 & 4.5862 & 5.3029 & TRN & \\
\hline CHEMBL1377365 & 688239 & 5.1862 & 5.4999 & TRN & \\
\hline CHEMBL1417983 & 688239 & 5.7362 & 5.4674 & TRN & \\
\hline CHEMBL1400357 & 688239 & 5.7362 & 5.5855 & TRN & \\
\hline CHEMBL1441395 & 688239 & 5.8362 & 5.4578 & TRN & \\
\hline CHEMBL1504117 & 688239 & 6.9363 & 5.3966 & TRN & \\
\hline CHEMBL1411263 & 688239 & 4.8862 & 5.42299 & 9999999999 & TRN \\
\hline CHEMBL3214526 & 688239 & 6.0862 & 5.4995 & TST & \\
\hline CHEMBL1588531 & 688239 & 5.7862 & 5.4986 & TST & \\
\hline CHEMBL1538844 & 688239 & 4.7362 & 5.2781 & TRN & \\
\hline CHEMBL1445430 & 688239 & 6.5862 & 5.5024 & TRN & \\
\hline CHEMBL1413512 & 688239 & 5.0862 & 5.6307 & TRN & \\
\hline CHEMBL1406227 & 688239 & 6.0862 & 5.5843 & TRN & \\
\hline CHEMBL1458218 & 688239 & 4.4862 & 5.5837 & TRN & \\
\hline CHEMBL1299658 & 688239 & 7.2865 & 5.5388 & TRN & \\
\hline CHEMBL1376764 & 688239 & 5.0362 & 5.6092 & TRN & \\
\hline CHEMBL1465596 & 688239 & 6.4362 & 5.4752 & TRN & \\
\hline CHEMBL1449975 & 688239 & 5.9862 & 5.369 & TRN & \\
\hline CHEMBL1433069 & 688239 & 4.5862 & 5.4263 & TST & \\
\hline
\end{tabular}


Supplemental Table S2.txt

\begin{tabular}{|c|c|c|c|c|}
\hline CHEMBL1315689 & 688239 & 4.5862 & 5.4339 & TRN \\
\hline CHEMBL1367476 & 688239 & 4.5362 & 5.4878 & TRN \\
\hline CHEMBL1405013 & 688239 & 4.8362 & 5.6094 & TST \\
\hline CHEMBL1312337 & 688239 & 5.5362 & 5.5016 & TST \\
\hline CHEMBL1304324 & 688239 & 4.7362 & 5.4243 & TRN \\
\hline CHEMBL1473579 & 688239 & 5.8862 & 5.4904 & TRN \\
\hline CHEMBL1521560 & 688239 & 5.1862 & 5.5067 & TST \\
\hline CHEMBL1601113 & 688239 & 5.1862 & 5.7379 & TST \\
\hline CHEMBL1371521 & 688239 & 4.5362 & 5.7602 & TST \\
\hline CHEMBL1304585 & 688239 & 4.8862 & 5.5869 & TRN \\
\hline CHEMBL1364911 & 688239 & 6.3362 & 5.5106 & TRN \\
\hline CHEMBL1503375 & 688239 & 5.5362 & 5.3885 & TST \\
\hline CHEMBL1312409 & 688239 & 7.1864 & 5.5611 & TRN \\
\hline CHEMBL1483828 & 688239 & 4.8362 & 5.6176 & TRN \\
\hline CHEMBL1358372 & 688239 & 4.7362 & 5.4943 & TRN \\
\hline CHEMBL1510339 & 688239 & 4.5862 & 5.308 & TRN \\
\hline CHEMBL1521414 & 688239 & 4.7862 & 5.5778 & TRN \\
\hline CHEMBL1578007 & 688239 & 5.5862 & 5.3538 & TRN \\
\hline CHEMBL1400839 & 688239 & 4.5362 & 5.3758 & TRN \\
\hline CHEMBL 3192327 & 688239 & 4.6362 & 5.4481 & TRN \\
\hline CHEMBL1452171 & 688239 & 5.0862 & 5.4284 & TRN \\
\hline CHEMBL1492156 & 688239 & 5.3862 & 5.4264 & TRN \\
\hline CHEMBL1489078 & 688239 & 7.0862 & 5.3133 & TRN \\
\hline CHEMBL1366704 & 688239 & 8.28399 & 99999999 & 5.6829 \\
\hline CHEMBL1365143 & 688239 & 6.5862 & 5.5536 & TRN \\
\hline CHEMBL1578323 & 688239 & 5.6362 & 5.5982 & TRN \\
\hline CHEMBL1569656 & 688239 & 5.3362 & 5.3998 & TRN \\
\hline CHEMBL1470526 & 688239 & 4.6862 & 5.452999 & 9999999999 \\
\hline CHEMBL1399286 & 688239 & 4.5862 & 5.5696 & TST \\
\hline CHEMBL1497614 & 688239 & 5.3862 & 5.5516 & TRN \\
\hline CHEMBL1610856 & 688239 & 7.2865 & 5.582000 & 0000000001 \\
\hline CHEMBL1384154 & 688239 & 4.6862 & 5.3336 & TRN \\
\hline CHEMBL1226 & 688239 & 5.1862 & 5.5774 & TST \\
\hline CHEMBL1604009 & 688239 & 5.3362 & 5.4417 & TST \\
\hline CHEMBL1392803 & 688239 & 4.4862 & 5.5373 & TRN \\
\hline CHEMBL1442281 & 688239 & 4.7362 & 5.4113 & TST \\
\hline CHEMBL1499702 & 688239 & 4.9362 & 5.5478 & TRN \\
\hline CHEMBL1402454 & 688239 & 5.1362 & 5.6343 & TST \\
\hline CHEMBL1400971 & 688239 & 5.8362 & 5.5282 & TRN \\
\hline CHEMBL1509495 & 688239 & 5.1862 & 5.6731 & TST \\
\hline CHEMBL1529640 & 688239 & 8.3372 & 5.5399 & TRN \\
\hline CHEMBL1505647 & 688239 & 8.3872 & 5.4784 & TRN \\
\hline CHEMBL1453089 & 688239 & 4.9362 & 5.3536 & TST \\
\hline CHEMBL1536803 & 688239 & 6.8861 & 5.4539 & TRN \\
\hline CHEMBL1718423 & 688239 & 4.6862 & 5.2359 & TST \\
\hline CHEMBL1449481 & 688239 & 5.7362 & 5.6349 & TST \\
\hline CHEMBL1316570 & 688239 & 4.9862 & 5.3794 & TRN \\
\hline CHEMBL1563673 & 688239 & 6.1862 & 5.449 & TRN \\
\hline
\end{tabular}


Supplemental Table S2.txt

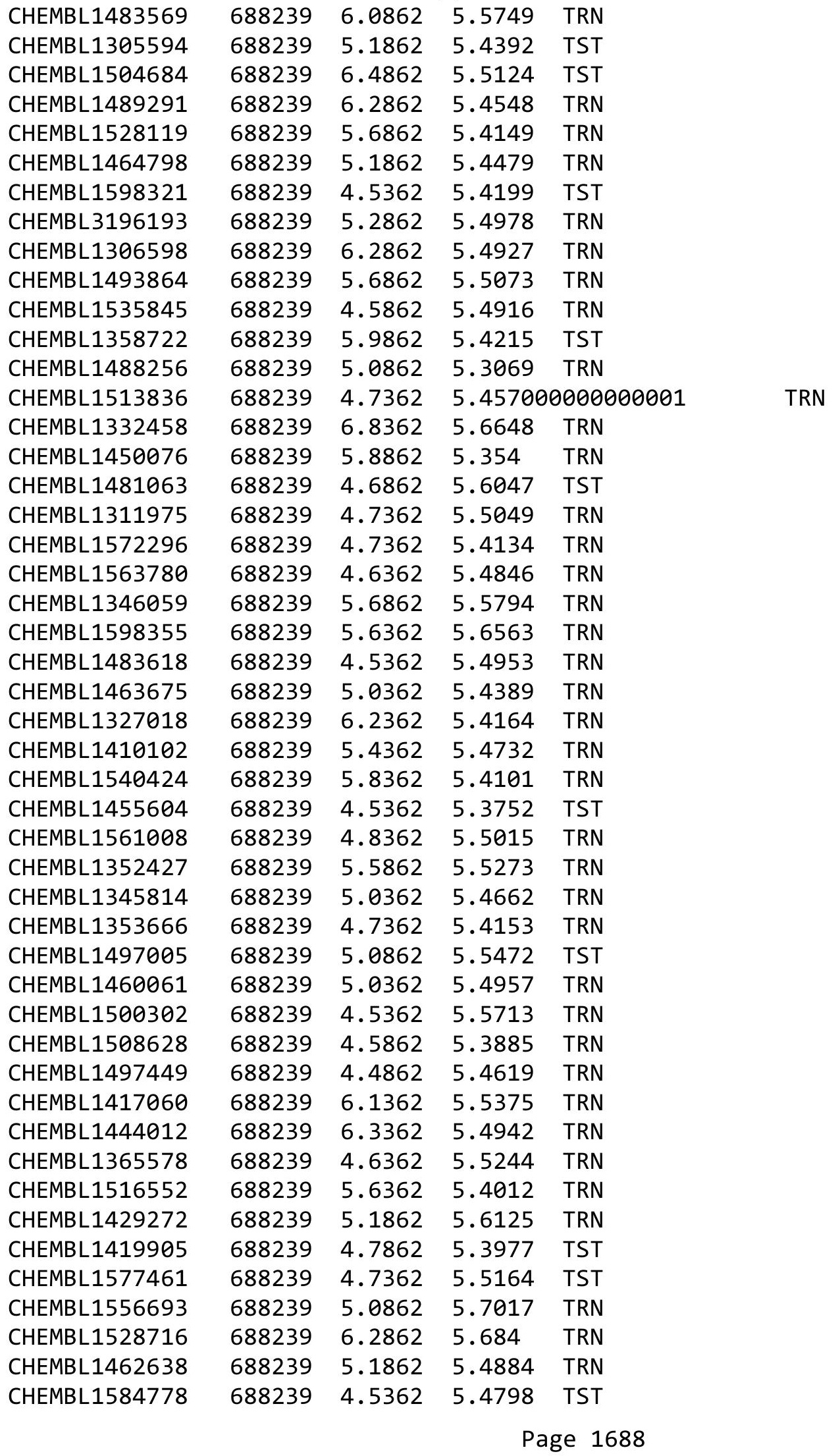


Supplemental Table S2.txt

\begin{tabular}{|c|c|c|c|c|c|}
\hline CHEMBL1479060 & 688239 & 4.6862 & 5.392 & TRN & \\
\hline CHEMBL1388308 & 688239 & 6.5862 & 5.4358 & TRN & \\
\hline CHEMBL1388087 & 688239 & 4.7362 & 5.4906 & TRN & \\
\hline CHEMBL1319050 & 688239 & 5.5362 & \multicolumn{2}{|c|}{5.486000000000001} & TRN \\
\hline CHEMBL1356380 & 688239 & 4.7862 & 5.5319 & TRN & \\
\hline CHEMBL1526221 & 688239 & 6.4862 & 5.3906 & TRN & \\
\hline CHEMBL496378 & 688239 & 5.3862 & 5.3991 & TST & \\
\hline CHEMBL1373754 & 688239 & 5.7362 & \multicolumn{2}{|c|}{5.5889999999999995} & TRN \\
\hline CHEMBL1322600 & 688239 & 5.8362 & \multicolumn{2}{|c|}{5.5729999999999995} & TRN \\
\hline CHEMBL1383858 & 688239 & 4.6862 & 5.434 & TRN & \\
\hline CHEMBL1366953 & 688239 & 4.5362 & 5.2194 & TRN & \\
\hline CHEMBL1501963 & 688239 & 4.5362 & 5.5035 & TRN & \\
\hline CHEMBL1488148 & 688239 & 4.8362 & 5.5251 & TRN & \\
\hline CHEMBL1335738 & 688239 & 5.8362 & 5.3013 & TRN & \\
\hline CHEMBL1541403 & 688239 & 6.1862 & 5.7018 & TRN & \\
\hline CHEMBL1478485 & 688239 & 5.1862 & 5.4738 & TRN & \\
\hline CHEMBL1326112 & 688239 & 4.5862 & 5.5581 & TST & \\
\hline CHEMBL1608491 & 688239 & 5.9862 & 5.4623 & TRN & \\
\hline CHEMBL1312736 & 688239 & 4.6362 & 5.4137 & TRN & \\
\hline CHEMBL1564764 & 688239 & 6.7862 & 5.5868 & TRN & \\
\hline CHEMBL1387689 & 688239 & 5.2362 & 5.4263 & TRN & \\
\hline CHEMBL1373937 & 688239 & 5.1862 & 5.3617 & TST & \\
\hline CHEMBL1328126 & 688239 & 5.8362 & 5.3588 & TRN & \\
\hline CHEMBL1493656 & 688239 & 5.2362 & 5.3925 & TRN & \\
\hline CHEMBL 1412485 & 688239 & 4.5362 & 5.6222 & TRN & \\
\hline CHEMBL1503939 & 688239 & 5.6862 & 5.4756 & TRN & \\
\hline CHEMBL1587407 & 688239 & 6.9363 & 5.5317 & TST & \\
\hline CHEMBL1460277 & 688239 & 5.1862 & 5.557 & TRN & \\
\hline CHEMBL1366671 & 688239 & 6.6362 & 5.6556 & TRN & \\
\hline CHEMBL1588746 & 688239 & 8.1367 & 5.585 & TRN & \\
\hline CHEMBL1566248 & 688239 & 4.6862 & 5.4932 & TRN & \\
\hline CHEMBL1500423 & 688239 & 4.9862 & 5.4701 & TST & \\
\hline CHEMBL1400429 & 688239 & 5.1862 & 5.4746 & TRN & \\
\hline CHEMBL1415613 & 688239 & 6.8861 & 5.3979 & TRN & \\
\hline CHEMBL1461871 & 688239 & 5.4862 & 5.4966 & TRN & \\
\hline CHEMBL1382938 & 688239 & 6.3863 & 5.6543 & TRN & \\
\hline CHEMBL1531195 & 688239 & 4.6362 & 5.50200 & 0000000001 & TRN \\
\hline CHEMBL1313945 & 688239 & 4.5362 & 5.3013 & TRN & \\
\hline CHEMBL1402458 & 688239 & 6.3362 & 5.4344 & TRN & \\
\hline CHEMBL 1452563 & 688239 & 6.4362 & 5.3785 & TRN & \\
\hline CHEMBL1478217 & 688239 & 6.1862 & 5.4496 & TRN & \\
\hline CHEMBL1367673 & 688239 & 6.3362 & 5.3209 & TRN & \\
\hline CHEMBL1420011 & 688239 & 5.1862 & 5.5425 & TST & \\
\hline CHEMBL1375700 & 688239 & 4.6862 & 5.45799 & 9999999999 & TRN \\
\hline CHEMBL1419604 & 688239 & 5.0862 & 5.6415 & TRN & \\
\hline CHEMBL1494137 & 688239 & 5.4862 & 5.595 & TST & \\
\hline CHEMBL1586986 & 688239 & 6.5363 & 5.5705 & TRN & \\
\hline CHEMBL1587092 & 688239 & 8.1871 & 5.6244 & TRN & \\
\hline
\end{tabular}


Supplemental Table S2.txt

\begin{tabular}{|c|c|c|c|c|}
\hline CHEMBL1466093 & 688239 & 6.1362 & 5.45 & TRN \\
\hline CHEMBL1467839 & 688239 & 4.7362 & 5.513 & TRN \\
\hline CHEMBL1526237 & 688239 & 5.1862 & 5.521 & TST \\
\hline CHEMBL183 & 688239 & 5.3862 & 5.5172 & TST \\
\hline CHEMBL1570588 & 688239 & 5.1362 & 5.4468 & TRN \\
\hline CHEMBL 3196395 & 688239 & 5.1862 & 5.4937 & TST \\
\hline CHEMBL1351399 & 688239 & 4.7362 & 5.4713 & TRN \\
\hline CHEMBL3192599 & 688239 & 5.1862 & 5.6498 & TRN \\
\hline CHEMBL1613205 & 688239 & 6.0362 & 5.5369 & TRN \\
\hline CHEMBL1441083 & 688239 & 6.8362 & 5.4122 & TST \\
\hline CHEMBL1579725 & 688239 & 5.1862 & 5.5274 & TST \\
\hline CHEMBL1346258 & 688239 & 4.9362 & 5.5908 & TRN \\
\hline CHEMBL1478959 & 688239 & 5.3362 & 5.5698 & TRN \\
\hline CHEMBL1348306 & 688239 & 4.5362 & 5.492999 & 9999999999 \\
\hline CHEMBL1417566 & 688239 & 5.2362 & 5.4768 & TRN \\
\hline CHEMBL1538736 & 688239 & 6.0862 & 5.5307 & TRN \\
\hline CHEMBL1331239 & 688239 & 4.8362 & 5.5137 & TST \\
\hline CHEMBL1469122 & 688239 & 5.6862 & 5.5384 & TRN \\
\hline CHEMBL1342156 & 688239 & 5.5362 & 5.3846 & TRN \\
\hline CHEMBL1472419 & 688239 & 6.2862 & 5.6896 & TRN \\
\hline CHEMBL1447316 & 688239 & 6.1362 & 5.5407 & TRN \\
\hline CHEMBL1511267 & 688239 & 6.8861 & 5.6149 & TST \\
\hline CHEMBL1466003 & 688239 & 4.5362 & 5.4012 & TST \\
\hline CHEMBL1479749 & 688239 & 6.9863 & 5.375 & TST \\
\hline CHEMBL1444117 & 688239 & 5.8362 & 5.5408 & TRN \\
\hline CHEMBL1490337 & 688239 & 6.0862 & 5.7099 & TRN \\
\hline CHEMBL1582041 & 688239 & 5.7362 & 5.4854 & TRN \\
\hline CHEMBL1454486 & 688239 & 8.3372 & 5.4528 & TST \\
\hline CHEMBL1377276 & 688239 & 5.3862 & 5.5152 & TRN \\
\hline CHEMBL1373128 & 688239 & 6.8861 & 5.6116 & TRN \\
\hline CHEMBL1450030 & 688239 & 6.0862 & 5.3666 & TST \\
\hline CHEMBL1382664 & 688239 & 4.5362 & 5.468999 & 9999999999 \\
\hline CHEMBL1377348 & 688239 & 6.1362 & 5.5121 & TRN \\
\hline CHEMBL1405320 & 688239 & 4.45 & 5.4368 & TST \\
\hline CHEMBL1573118 & 688239 & 4.8362 & 5.2994 & TST \\
\hline CHEMBL1589438 & 688239 & 4.6362 & 5.5701 & TRN \\
\hline CHEMBL1516812 & 688239 & 5.8862 & 5.4771 & TRN \\
\hline CHEMBL1605877 & 688239 & 4.5362 & 5.4103 & TRN \\
\hline CHEMBL1443216 & 688239 & 5.1862 & 5.6594 & TRN \\
\hline CHEMBL1487429 & 688239 & 4.7862 & 5.5721 & TST \\
\hline CHEMBL1364210 & 688239 & 4.6362 & 5.3397 & TRN \\
\hline CHEMBL1494108 & 688239 & 7.4868 & 5.5836 & TRN \\
\hline CHEMBL1366353 & 688239 & 4.8862 & 5.4598 & TRN \\
\hline CHEMBL1458671 & 688239 & 4.5362 & 5.5872 & TRN \\
\hline CHEMBL1316144 & 688239 & 4.5362 & 5.4756 & TRN \\
\hline CHEMBL1491176 & 688239 & 6.1862 & 5.5421 & TRN \\
\hline CHEMBL1387750 & 688239 & 4.6862 & 5.4128 & TRN \\
\hline CHEMBL1445410 & 688239 & 6.4362 & 5.4887 & TRN \\
\hline
\end{tabular}


Supplemental Table S2.txt

\begin{tabular}{|c|c|c|c|c|c|}
\hline CHEMBL1407860 & 688239 & 5.1862 & 5.5051 & TST & \\
\hline CHEMBL1369157 & 688239 & 5.3862 & 5.601 & TRN & \\
\hline CHEMBL1335827 & 688239 & 4.6862 & 5.3929 & TST & \\
\hline CHEMBL1432490 & 688239 & 5.9862 & \multicolumn{2}{|c|}{5.6370000000000005} & TRN \\
\hline CHEMBL3198566 & 688239 & 4.5362 & 5.5451 & TRN & \\
\hline CHEMBL1535643 & 688239 & 6.1362 & 5.4237 & TRN & \\
\hline CHEMBL1411044 & 688239 & 6.8861 & 5.3588 & TRN & \\
\hline CHEMBL1556256 & 688239 & 4.5362 & 5.385 & TRN & \\
\hline CHEMBL1344591 & 688239 & 4.5362 & 5.4964 & TRN & \\
\hline CHEMBL1601085 & 688239 & 5.1862 & 5.5274 & TRN & \\
\hline CHEMBL1522109 & 688239 & 5.6862 & 5.4604 & TRN & \\
\hline CHEMBL1502230 & 688239 & 4.6862 & 5.4177 & TRN & \\
\hline CHEMBL1418756 & 688239 & 5.9362 & 5.4593 & TRN & \\
\hline CHEMBL1326513 & 688239 & 7.4365 & 5.5522 & TRN & \\
\hline CHEMBL1323437 & 688239 & 7.0362 & 5.4644 & TRN & \\
\hline CHEMBL1379820 & 688239 & 6.1862 & 5.5426 & TST & \\
\hline CHEMBL1386779 & 688239 & 4.7862 & 5.4761 & TRN & \\
\hline CHEMBL1520334 & 688239 & 6.1362 & \multicolumn{2}{|c|}{5.406000000000001} & TST \\
\hline CHEMBL1358367 & 688239 & 6.7862 & 5.4611 & TRN & \\
\hline CHEMBL1582934 & 688239 & 4.6862 & 5.2465 & TRN & \\
\hline CHEMBL1323526 & 688239 & 5.7862 & 5.5147 & TRN & \\
\hline CHEMBL1552269 & 688239 & 5.1862 & 5.5195 & TRN & \\
\hline CHEMBL1302652 & 688239 & 4.5362 & 5.5183 & TRN & \\
\hline CHEMBL3190326 & 688239 & 4.8862 & 5.4086 & TST & \\
\hline CHEMBL1315267 & 688239 & 4.8362 & 5.4072 & TRN & \\
\hline CHEMBL1601181 & 688239 & 6.1362 & 5.5497 & TRN & \\
\hline CHEMBL1443025 & 688239 & 5.3362 & 5.665 & TST & \\
\hline CHEMBL1425384 & 688239 & 4.6862 & 5.4759 & TST & \\
\hline CHEMBL1325225 & 688239 & 5.0862 & 5.4973 & TRN & \\
\hline CHEMBL1405309 & 688239 & 4.5362 & 5.6042 & TRN & \\
\hline CHEMBL1591095 & 688239 & 5.6362 & 5.4546 & TRN & \\
\hline CHEMBL1329066 & 688239 & 7.0362 & 5.4979 & TRN & \\
\hline CHEMBL1591089 & 688239 & 5.2862 & 5.6446 & TST & \\
\hline CHEMBL1547078 & 688239 & 4.5362 & 5.3709 & TRN & \\
\hline CHEMBL1492484 & 688239 & 5.6362 & 5.593 & TRN & \\
\hline CHEMBL1464414 & 688239 & 4.7362 & 5.416 & TST & \\
\hline CHEMBL1454740 & 688239 & 4.7362 & 5.5196 & TRN & \\
\hline CHEMBL1570530 & 688239 & 5.7362 & 5.5738 & TRN & \\
\hline CHEMBL1308461 & 688239 & 4.6862 & 5.4476 & TRN & \\
\hline CHEMBL1514675 & 688239 & 4.6862 & 5.3214 & TRN & \\
\hline CHEMBL1435731 & 688239 & 4.8862 & 5.5413 & TRN & \\
\hline CHEMBL1332928 & 688239 & 5.0862 & 5.4347 & TST & \\
\hline CHEMBL1992286 & 688239 & 4.5362 & 5.4142 & TRN & \\
\hline CHEMBL1575053 & 688239 & 8.2366 & 5.6329 & TST & \\
\hline CHEMBL1354738 & 688239 & 4.5362 & 5.3317 & TRN & \\
\hline CHEMBL1592740 & 688239 & 5.5362 & 5.5558 & TST & \\
\hline CHEMBL1584066 & 688239 & 7.1361 & 5.4536 & TST & \\
\hline CHEMBL1471649 & 688239 & 6.3863 & 5.4699 & TRN & \\
\hline
\end{tabular}


Supplemental Table S2.txt

\begin{tabular}{|c|c|c|c|c|c|}
\hline CHEMBL1533078 & 688239 & 5.3862 & 5.5516 & TRN & \\
\hline CHEMBL1580645 & 688239 & 5.5862 & 5.5199 & TST & \\
\hline CHEMBL1572121 & 688239 & 4.7362 & 5.5066 & TST & \\
\hline CHEMBL1595544 & 688239 & 5.3862 & 5.4816 & TST & \\
\hline CHEMBL1305641 & 688239 & 5.4362 & 5.3166 & TRN & \\
\hline CHEMBL1350719 & 688239 & 4.6862 & 5.4363 & TRN & \\
\hline CHEMBL1332694 & 688239 & 5.2362 & 5.4966 & TRN & \\
\hline CHEMBL1547793 & 688239 & 6.0862 & 5.5579 & TRN & \\
\hline CHEMBL1384214 & 688239 & 5.1862 & 5.4543 & TRN & \\
\hline CHEMBL1463605 & 688239 & 4.5362 & 5.3819 & TST & \\
\hline CHEMBL1517958 & 688239 & 6.6362 & 5.3612 & TRN & \\
\hline CHEMBL1518467 & 688239 & 6.7862 & 5.6309 & TRN & \\
\hline CHEMBL1467905 & 688239 & 5.8862 & 5.4034 & TRN & \\
\hline CHEMBL1389478 & 688239 & 5.2362 & 5.5681 & TRN & \\
\hline CHEMBL1605221 & 688239 & 5.1862 & 5.5843 & TST & \\
\hline CHEMBL1447355 & 688239 & 5.9862 & 5.3722 & TRN & \\
\hline CHEMBL1401744 & 688239 & 6.0862 & 5.2025 & TRN & \\
\hline CHEMBL1307701 & 688239 & 5.3362 & 5.6134 & TRN & \\
\hline CHEMBL1986972 & 688239 & 4.7362 & 5.3068 & TRN & \\
\hline CHEMBL1383954 & 688239 & 5.1362 & 5.2872 & TRN & \\
\hline CHEMBL1417964 & 688239 & 4.6362 & 5.5606 & TRN & \\
\hline CHEMBL1403154 & 688239 & 4.7362 & 5.4298 & TST & \\
\hline CHEMBL1590706 & 688239 & 6.2362 & 5.4252 & TRN & \\
\hline CHEMBL1545145 & 688239 & 5.7862 & 5.4743 & TRN & \\
\hline CHEMBL1588004 & 688239 & 4.5362 & 5.5158 & TST & \\
\hline CHEMBL1554606 & 688239 & 6.8861 & 5.4018 & TRN & \\
\hline CHEMBL1315463 & 688239 & 4.7362 & 5.3137 & TRN & \\
\hline CHEMBL1305372 & 688239 & 5.1362 & 5.4527 & TST & \\
\hline CHEMBL1561398 & 688239 & 4.7862 & 5.3453 & TRN & \\
\hline CHEMBL1417450 & 688239 & 6.1362 & 5.6949 & TST & \\
\hline CHEMBL1526282 & 688239 & 4.9862 & 5.4513 & TRN & \\
\hline CHEMBL1456106 & 688239 & 4.5362 & 5.5834 & TRN & \\
\hline CHEMBL1388258 & 688239 & 6.0862 & 5.4802 & TRN & \\
\hline CHEMBL1368104 & 688239 & 4.7362 & 5.4071 & TST & \\
\hline CHEMBL1345987 & 688239 & 4.9362 & 5.5293 & TST & \\
\hline CHEMBL1560712 & 688239 & 6.4362 & 5.5916 & TRN & \\
\hline CHEMBL1411828 & 688239 & 6.5862 & 5.6409 & TRN & \\
\hline CHEMBL1544013 & 688239 & 5.6862 & 5.4282 & TST & \\
\hline CHEMBL1519973 & 688239 & 6.2862 & 5.42899 & 9999999999 & TRN \\
\hline CHEMBL 3210800 & 688239 & 4.5362 & 5.4088 & TRN & \\
\hline CHEMBL1377716 & 688239 & 5.4862 & 5.5055 & TRN & \\
\hline CHEMBL1996068 & 688239 & 4.6362 & 5.3723 & TRN & \\
\hline CHEMBL1964583 & 688239 & 5.1862 & 5.4282 & TST & \\
\hline CHEMBL1306462 & 688239 & 6.2362 & 5.4392 & TRN & \\
\hline CHEMBL1592236 & 688239 & 4.8862 & 5.416 & TRN & \\
\hline CHEMBL1376883 & 688239 & 5.1862 & 5.3433 & TRN & \\
\hline CHEMBL1447934 & 688239 & 6.2362 & 5.4749 & TRN & \\
\hline CHEMBL1310615 & 688239 & 6.8861 & 5.6591 & TST & \\
\hline
\end{tabular}


Supplemental Table S2.txt

\begin{tabular}{|c|c|c|c|c|c|}
\hline CHEMBL1524443 & 688239 & 5.1862 & 5.474 & TST & \\
\hline CHEMBL112597 & 688239 & 4.4862 & 5.5514 & TST & \\
\hline CHEMBL1389359 & 688239 & 4.5362 & 5.4554 & TRN & \\
\hline CHEMBL1500977 & 688239 & 4.5362 & 5.3583 & TST & \\
\hline CHEMBL1308160 & 688239 & 4.5362 & 5.6378 & TST & \\
\hline CHEMBL1410873 & 688239 & 4.9362 & 5.522 & TRN & \\
\hline CHEMBL1576713 & 688239 & 6.1362 & 5.4117 & TST & \\
\hline CHEMBL1475649 & 688239 & 5.3362 & 5.5346 & TRN & \\
\hline CHEMBL1546715 & 688239 & 6.5363 & 5.5062 & TRN & \\
\hline CHEMBL3196710 & 688239 & 5.6362 & 5.5044 & TST & \\
\hline CHEMBL1987087 & 688239 & 5.3862 & 5.4366 & TRN & \\
\hline CHEMBL3198236 & 688239 & 5.8362 & 5.6338 & TRN & \\
\hline CHEMBL1397390 & 688239 & 6.9863 & \multicolumn{2}{|c|}{5.6160000000000005} & TRN \\
\hline CHEMBL1604598 & 688239 & 4.5362 & 5.575 & TRN & \\
\hline CHEMBL1384481 & 688239 & 6.8362 & 5.5113 & TST & \\
\hline CHEMBL1312081 & 688239 & 5.3362 & 5.5163 & TST & \\
\hline CHEMBL1304761 & 688239 & 6.1362 & 5.8185 & TRN & \\
\hline CHEMBL1568140 & 688239 & 6.8362 & 5.2773 & TST & \\
\hline CHEMBL1416767 & 688239 & 7.2366 & 5.505 & TRN & \\
\hline CHEMBL1305549 & 688239 & 6.0862 & 5.4596 & TRN & \\
\hline CHEMBL1495510 & 688239 & 4.5362 & 5.5798 & TRN & \\
\hline CHEMBL1422118 & 688239 & 4.6862 & 5.4843 & TRN & \\
\hline CHEMBL1565648 & 688239 & 5.1362 & 5.4681 & TRN & \\
\hline CHEMBL1405497 & 688239 & 6.05 & 5.5847 & TST & \\
\hline CHEMBL1500171 & 688239 & 4.8862 & 5.517 & TRN & \\
\hline CHEMBL1313019 & 688239 & 4.9862 & 5.4542 & TST & \\
\hline CHEMBL1310975 & 688239 & 6.1362 & 5.5138 & TRN & \\
\hline CHEMBL1461733 & 688239 & 6.1862 & 5.4423 & TRN & \\
\hline CHEMBL1395108 & 688239 & 5.7862 & 5.4892 & TRN & \\
\hline CHEMBL1314518 & 688239 & 4.7862 & 5.3362 & TRN & \\
\hline CHEMBL1422207 & 688239 & 5.5362 & 5.6476 & TRN & \\
\hline CHEMBL1352815 & 688239 & 5.1862 & 5.4663 & TRN & \\
\hline CHEMBL1321719 & 688239 & 4.5362 & 5.4083 & TRN & \\
\hline CHEMBL1306886 & 688239 & 5.7362 & \multicolumn{2}{|c|}{5.587000000000001} & TRN \\
\hline CHEMBL1540510 & 688239 & 5.3862 & 5.4632 & TRN & \\
\hline CHEMBL1390361 & 688239 & 5.0862 & 5.4096 & TRN & \\
\hline CHEMBL1464314 & 688239 & 4.6362 & 5.5459 & TRN & \\
\hline CHEMBL3198176 & 688239 & 4.6362 & 5.3666 & TRN & \\
\hline CHEMBL1312635 & 688239 & 4.5362 & 5.6121 & TRN & \\
\hline CHEMBL1399663 & 688239 & 5.3862 & \multicolumn{2}{|c|}{5.428999999999999} & TST \\
\hline CHEMBL1480851 & 688239 & 4.6862 & 5.3968 & TRN & \\
\hline CHEMBL1401346 & 688239 & 5.9362 & 5.39 & TRN & \\
\hline CHEMBL1607286 & 688239 & 4.6362 & 5.3688 & TST & \\
\hline CHEMBL1424054 & 688239 & 6.1362 & \multicolumn{2}{|c|}{5.422999999999999} & TRN \\
\hline CHEMBL1504395 & 688239 & 4.5362 & 5.6143 & TRN & \\
\hline CHEMBL1552662 & 688239 & 6.6362 & 5.6008 & TRN & \\
\hline CHEMBL1605902 & 688239 & 5.4362 & 5.5155 & TRN & \\
\hline \multirow[t]{2}{*}{ CHEMBL1394109 } & 688239 & 6.2362 & \multicolumn{2}{|c|}{5.4910000000000005} & TST \\
\hline & & & & 1693 & \\
\hline
\end{tabular}


Supplemental Table S2.txt

\begin{tabular}{|c|c|c|c|c|c|}
\hline CHEMBL1306670 & 688239 & 5.1862 & 5.4525 & TST & \\
\hline CHEMBL1357954 & 688239 & 4.6362 & 5.4647 & TST & \\
\hline CHEMBL1390533 & 688239 & 8.3372 & 5.6905 & TRN & \\
\hline CHEMBL1602224 & 688239 & 5.4862 & 5.3659 & TRN & \\
\hline CHEMBL1448474 & 688239 & 4.7362 & 5.3478 & TRN & \\
\hline CHEMBL1344861 & 688239 & 5.0862 & 5.6494 & TRN & \\
\hline CHEMBL1445603 & 688239 & 4.5362 & 5.3309 & TRN & \\
\hline CHEMBL3196073 & 688239 & 4.5362 & 5.4199 & TST & \\
\hline CHEMBL1491516 & 688239 & 4.6362 & 5.4474 & TRN & \\
\hline CHEMBL1300334 & 688239 & 4.5362 & 5.5091 & TRN & \\
\hline CHEMBL3194406 & 688239 & 4.5362 & 5.4449 & TRN & \\
\hline CHEMBL1565256 & 688239 & 5.8862 & 5.5122 & TST & \\
\hline CHEMBL1505206 & 688239 & 4.8362 & 5.4886 & TRN & \\
\hline CHEMBL1504399 & 688239 & 6.4362 & 5.3425 & TRN & \\
\hline CHEMBL1338414 & 688239 & 4.6862 & 5.5636 & TRN & \\
\hline CHEMBL1367536 & 688239 & 6.3362 & 5.622000 & 000000001 & TRN \\
\hline CHEMBL1483690 & 688239 & 6.2362 & 5.4261 & TRN & \\
\hline CHEMBL1503314 & 688239 & 4.6862 & 5.5509 & TRN & \\
\hline CHEMBL1421435 & 688239 & 6.3863 & 5.5874 & TRN & \\
\hline CHEMBL1415789 & 688239 & 6.0362 & 5.5355 & TRN & \\
\hline CHEMBL1394793 & 688239 & 4.6362 & 5.4708 & TRN & \\
\hline CHEMBL1365354 & 688239 & 5.1862 & 5.5044 & TRN & \\
\hline CHEMBL1527511 & 688239 & 5.9362 & 5.6073 & TRN & \\
\hline CHEMBL1999137 & 688239 & 5.7862 & 5.4809 & TRN & \\
\hline CHEMBL1418643 & 688239 & 5.3862 & 5.3913 & TRN & \\
\hline CHEMBL1353805 & 688239 & 5.6862 & 5.502000 & 000000001 & TST \\
\hline CHEMBL1511545 & 688239 & 4.6862 & 5.4788 & TST & \\
\hline CHEMBL1602569 & 688239 & 5.9362 & 5.5157 & TRN & \\
\hline CHEMBL1473791 & 688239 & 5.8862 & 5.457999 & 999999999 & \\
\hline CHEMBL1500289 & 688239 & 5.1862 & 5.5203 & TRN & \\
\hline CHEMBL3195488 & 688239 & 4.8362 & 5.3571 & TST & \\
\hline CHEMBL1368716 & 688239 & 6.2362 & 5.3353 & TRN & \\
\hline CHEMBL1393546 & 688239 & 4.5362 & 5.5459 & TRN & \\
\hline CHEMBL1527118 & 688239 & 4.8862 & 5.5447 & TRN & \\
\hline CHEMBL 1449580 & 688239 & 4.7862 & 5.5317 & TRN & \\
\hline CHEMBL1597506 & 688239 & 4.5362 & 5.3141 & TRN & \\
\hline CHEMBL1300717 & 688239 & 4.5362 & 5.3796 & TRN & \\
\hline CHEMBL1404186 & 688239 & 5.1862 & 5.4285 & TRN & \\
\hline CHEMBL1406183 & 688239 & 4.9362 & 5.421 & TRN & \\
\hline CHEMBL1371358 & 688239 & 5.6362 & 5.4344 & TRN & \\
\hline CHEMBL1304229 & 688239 & 4.5362 & 5.466 & TRN & \\
\hline CHEMBL1338186 & 688239 & 5.6362 & 5.4986 & TRN & \\
\hline CHEMBL1380600 & 688239 & 8.28399 & 99999999 & 5.4326 & IS \\
\hline CHEMBL1311809 & 688239 & 4.7362 & 5.5059 & TST & \\
\hline CHEMBL1439379 & 688239 & 5.6362 & 5.4678 & TRN & \\
\hline CHEMBL1477621 & 688239 & 5.1862 & 5.4785 & TST & \\
\hline CHEMBL1387455 & 688239 & 6.1862 & 5.3937 & TRN & \\
\hline CHEMBL1377799 & 688239 & 4.6862 & 5.3559 & TRN & \\
\hline
\end{tabular}


Supplemental Table S2.txt

\begin{tabular}{|c|c|c|c|c|}
\hline CHEMBL1593765 & 688239 & 5.3862 & 5.3511 & TRN \\
\hline CHEMBL1461383 & 688239 & 6.2362 & 5.431 & TRN \\
\hline CHEMBL1320386 & 688239 & 4.7862 & 5.5063 & TST \\
\hline CHEMBL1543548 & 688239 & 4.5362 & 5.5191 & TRN \\
\hline CHEMBL1404786 & 688239 & 5.3362 & 5.6606 & TRN \\
\hline CHEMBL1526503 & 688239 & 4.6362 & 5.5792 & TRN \\
\hline CHEMBL1527664 & 688239 & 4.6862 & 5.3146 & TRN \\
\hline CHEMBL1443992 & 688239 & 6.3362 & 5.5937 & TRN \\
\hline CHEMBL3192769 & 688239 & 4.8362 & 5.4352 & TST \\
\hline CHEMBL1547262 & 688239 & 8.3872 & 5.4229 & TST \\
\hline CHEMBL1328712 & 688239 & 4.7862 & 5.3907 & TST \\
\hline CHEMBL1476822 & 688239 & 7.9355 & 5.3418 & TRN \\
\hline CHEMBL1306069 & 688239 & 4.5862 & 5.4361 & TRN \\
\hline CHEMBL1426008 & 688239 & 5.7362 & 5.5146 & TST \\
\hline CHEMBL1596597 & 688239 & 5.1862 & 5.4672 & TRN \\
\hline CHEMBL3209679 & 688239 & 5.2862 & 5.6332 & TRN \\
\hline CHEMBL1490325 & 688239 & 4.9362 & 5.6119 & TST \\
\hline CHEMBL1406068 & 688239 & 5.1862 & 5.5485 & TRN \\
\hline CHEMBL1426399 & 688239 & 4.5362 & 5.4945 & TRN \\
\hline CHEMBL1506284 & 688239 & 5.1862 & 5.5072 & TRN \\
\hline CHEMBL1339291 & 688239 & 4.7362 & 5.6094 & TRN \\
\hline CHEMBL1372475 & 688239 & 6.6861 & 5.4739 & TRN \\
\hline CHEMBL1380457 & 688239 & 5.1862 & 5.47 & TST \\
\hline CHEMBL1317484 & 688239 & 8.3872 & 5.5592 & TRN \\
\hline CHEMBL1464713 & 688239 & 5.1862 & 5.3966 & TST \\
\hline CHEMBL 1450175 & 688239 & 4.5362 & 5.5376 & TST \\
\hline CHEMBL1371589 & 688239 & 6.6362 & 5.5319 & TRN \\
\hline CHEMBL1309952 & 688239 & 5.4862 & 5.4285 & TRN \\
\hline CHEMBL1556067 & 688239 & 4.9362 & 5.4919 & TST \\
\hline CHEMBL1407588 & 688239 & 4.4862 & 5.4067 & TRN \\
\hline CHEMBL 2385797 & 688239 & 5.1862 & 5.4934 & TRN \\
\hline CHEMBL1319593 & 688239 & 5.5862 & 5.5379 & TST \\
\hline CHEMBL1606772 & 688239 & 6.7361 & 5.6099 & TST \\
\hline CHEMBL1525964 & 688239 & 4.6862 & 5.5239 & TRN \\
\hline CHEMBL1580838 & 688239 & 6.7862 & 5.4505 & TRN \\
\hline CHEMBL1486788 & 688239 & 6.4362 & 5.5053 & TRN \\
\hline CHEMBL1555005 & 688239 & 4.5362 & 5.4834 & TRN \\
\hline CHEMBL1332851 & 688239 & 5.3362 & 5.6108 & TRN \\
\hline CHEMBL1352713 & 688239 & 6.2862 & 5.4543 & TRN \\
\hline CHEMBL3198038 & 688239 & 4.4862 & 5.3093 & TST \\
\hline CHEMBL1522596 & 688239 & 4.6362 & 5.6653 & TRN \\
\hline CHEMBL1530040 & 688239 & 7.5361 & 5.5926 & TRN \\
\hline CHEMBL1579782 & 688239 & 5.1862 & 5.5807 & TRN \\
\hline CHEMBL1612931 & 688239 & 4.9362 & 5.3516 & TST \\
\hline CHEMBL1578618 & 688239 & 4.5362 & 5.5793 & TRN \\
\hline CHEMBL1536210 & 688239 & 7.2366 & 5.54200 & 0000000001 \\
\hline CHEMBL1338204 & 688239 & 4.6862 & 5.5597 & TST \\
\hline CHEMBL1524787 & 688239 & 4.5362 & 5.5448 & TRN \\
\hline
\end{tabular}


Supplemental Table S2.txt

\begin{tabular}{|c|c|c|c|c|}
\hline & & & & \\
\hline HEMBL1307052 & 38239 & 362 & $\partial 8$ & \\
\hline AEMBL1449264 & 239 & 362 & & \\
\hline 978 & 39 & 362 & & \\
\hline IEMBL1435854 & & 862 & & \\
\hline AEMBL1567149 & 88239 & 3861 & 272 & \\
\hline AEMBL1469112 & 88239 & 363 & 543 & \\
\hline HEMBL1388154 & & & & \\
\hline IEMBL1592940 & 39 & 867 & & \\
\hline IEMBL1304083 & & 362 & & \\
\hline AEMBL1454264 & 39 & 372 & 24 & \\
\hline AEMBL1331875 & & 861 & & \\
\hline AEMBL3190774 & & & & \\
\hline HEMBL155 & & 62 & & \\
\hline HEMBL150 & & & & \\
\hline AEMBL1360050 & & 862 & 68 & \\
\hline AEMBL1444925 & & 862 & & \\
\hline AEMBL160 & & 62 & & \\
\hline HEMBL144 & & & & \\
\hline JEMBL13 & & & & \\
\hline AFMRI 156 & & 862 & & \\
\hline AEMBL1386656 & & 62 & & \\
\hline JEMBL133 & & 62 & & \\
\hline AFMRI 148 & & & & \\
\hline 334 & & & & \\
\hline 944 & & 862 & & \\
\hline AEMBL150 & & 62 & & \\
\hline EMBL132 & & 62 & & \\
\hline 7 & & & & \\
\hline 45 & & 62 & & \\
\hline AEMBL1534651 & & & & \\
\hline AEMBL1353720 & & 362 & & \\
\hline & & & & \\
\hline 196 & & & & \\
\hline 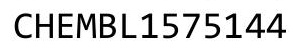 & & & & \\
\hline AEMBL1487903 & & 362 & & \\
\hline AEMBL1519501 & & 362 & & \\
\hline & & & & \\
\hline 322 & & & & \\
\hline & & & & RI \\
\hline AEMBL3195916 & & 362 & 06 & $\mathrm{~F}$ \\
\hline AEMBL1502527 & & 62 & & \\
\hline & & & & \\
\hline HEMBL1610158 & & & 5514 & rs \\
\hline AEMBL1433955 & & 5.2862 & 5324 & $\mathrm{R}$ \\
\hline MBL1348554 & & 362 & 232 & TR \\
\hline (20 & & & & \\
\hline HEMBL138572 & & & .5669 & \\
\hline
\end{tabular}

Page 1696 
Supplemental Table S2.txt

\begin{tabular}{|c|c|c|c|c|}
\hline CHEMBL1560465 & 688239 & 4.5862 & 5.3451 & TRN \\
\hline CHEMBL1305990 & 688239 & 4.7862 & 5.6055 & TST \\
\hline CHEMBL1546631 & 688239 & 8.3372 & 5.3738 & TRN \\
\hline CHEMBL1392125 & 688239 & 4.8362 & 5.5144 & TRN \\
\hline CHEMBL1320877 & 688239 & 5.5862 & 5.6625 & TRN \\
\hline CHEMBL1607860 & 688239 & 4.8862 & 5.4991 & TST \\
\hline CHEMBL1386691 & 688239 & 6.0362 & 5.5157 & TRN \\
\hline CHEMBL1462262 & 688239 & 5.3362 & 5.5182 & TRN \\
\hline CHEMBL1519345 & 688239 & 8.28399 & 99999999 & 5.5159 \\
\hline CHEMBL1322140 & 688239 & 5.5862 & 5.5477 & TRN \\
\hline CHEMBL1516758 & 688239 & 4.9862 & 5.4131 & TST \\
\hline CHEMBL1318667 & 688239 & 4.7362 & 5.4906 & TRN \\
\hline CHEMBL571380 & 688239 & 6.2362 & 5.4 & TRN \\
\hline CHEMBL1503942 & 688239 & 6.5862 & 5.7989 & TRN \\
\hline CHEMBL1399557 & 688239 & 4.8362 & 5.3982 & TRN \\
\hline CHEMBL1524680 & 688239 & 6.2862 & 5.5854 & TST \\
\hline CHEMBL1507711 & 688239 & 6.4862 & 5.3008 & TRN \\
\hline CHEMBL1368422 & 688239 & 4.5362 & 5.4998 & TRN \\
\hline CHEMBL 8612 & 688239 & 5.8862 & 5.4117 & TST \\
\hline CHEMBL1590702 & 688239 & 6.8861 & 5.5698 & TRN \\
\hline CHEMBL1562344 & 688239 & 4.9362 & 5.5925 & TRN \\
\hline CHEMBL1393644 & 688239 & 4.5362 & 5.4651 & TRN \\
\hline CHEMBL1323258 & 688239 & 4.5862 & 5.4397 & TRN \\
\hline CHEMBL1419990 & 688239 & 4.5862 & 5.3792 & TRN \\
\hline CHEMBL165447 & 688239 & 5.2362 & 5.512000 & 0000000005 \\
\hline CHEMBL1515977 & 688239 & 6.1362 & 5.4781 & TRN \\
\hline CHEMBL1563563 & 688239 & 4.4362 & 5.5677 & TRN \\
\hline CHEMBL1609279 & 688239 & 5.7362 & 5.4616 & TRN \\
\hline CHEMBL1324502 & 688239 & 5.0362 & 5.5057 & TST \\
\hline CHEMBL1445939 & 688239 & 5.5862 & 5.4143 & TRN \\
\hline CHEMBL1393996 & 688239 & 4.7862 & 5.3906 & TST \\
\hline CHEMBL1351971 & 688239 & 4.5362 & 5.5116 & TRN \\
\hline CHEMBL1394965 & 688239 & 4.5362 & 5.4428 & TRN \\
\hline CHEMBL1483848 & 688239 & 5.5862 & 5.5448 & TRN \\
\hline CHEMBL1349529 & 688239 & 4.5362 & 5.5811 & TRN \\
\hline CHEMBL1452137 & 688239 & 5.1862 & 5.5707 & TST \\
\hline CHEMBL1396828 & 688239 & 5.1862 & 5.4472 & TST \\
\hline CHEMBL1386243 & 688239 & 5.1862 & 5.5315 & TRN \\
\hline CHEMBL1517741 & 688239 & 4.7362 & 5.2985 & TRN \\
\hline CHEMBL1380205 & 688239 & 4.5362 & 5.5008 & TRN \\
\hline CHEMBL1431465 & 688239 & 7.2865 & 5.4817 & TRN \\
\hline CHEMBL1457634 & 688239 & 5.0862 & 5.5446 & TRN \\
\hline CHEMBL1487842 & 688239 & 5.4362 & 5.4939 & TRN \\
\hline CHEMBL1465747 & 688239 & 4.4862 & 5.6828 & TRN \\
\hline CHEMBL1554662 & 688239 & 5.4862 & 5.4718 & TRN \\
\hline CHEMBL3189932 & 688239 & 5.3362 & 5.4347 & TRN \\
\hline CHEMBL1585187 & 688239 & 5.1862 & 5.4892 & TST \\
\hline CHEMBL1544731 & 688239 & 4.5862 & 5.5722 & TRN \\
\hline
\end{tabular}


Supplemental Table S2.txt

\begin{tabular}{|c|c|c|c|c|c|}
\hline CHEMBL1477884 & 688239 & 5.3862 & 5.4647 & TRN & \\
\hline CHEMBL1570555 & 688239 & 5.6362 & 5.3999 & TRN & \\
\hline CHEMBL1419773 & 688239 & 5.1862 & 5.4096 & TST & \\
\hline CHEMBL1299339 & 688239 & 5.6362 & 5.6628 & TST & \\
\hline CHEMBL581049 & 688239 & 8.3372 & 5.4888 & TRN & \\
\hline CHEMBL1377603 & 688239 & 5.4362 & 5.5623 & TST & \\
\hline CHEMBL1446619 & 688239 & 5.8362 & 5.5186 & TST & \\
\hline CHEMBL 3208420 & 688239 & 6.3362 & 5.4144 & TRN & \\
\hline CHEMBL1612782 & 688239 & 4.5362 & 5.6418 & TST & \\
\hline CHEMBL1472188 & 688239 & 7.2366 & 5.4512 & TRN & \\
\hline CHEMBL1422720 & 688239 & 4.6362 & 5.5834 & TRN & \\
\hline CHEMBL1461839 & 688239 & 5.4362 & 5.5436 & TST & \\
\hline CHEMBL1337260 & 688239 & 4.4862 & 5.4698 & TRN & \\
\hline CHEMBL1401555 & 688239 & 6.6362 & 5.5047 & TRN & \\
\hline CHEMBL1446862 & 688239 & 5.0362 & 5.53 & TRN & \\
\hline CHEMBL1368744 & 688239 & 5.2862 & 5.3225 & TST & \\
\hline CHEMBL1579517 & 688239 & 5.5862 & 5.4123 & TRN & \\
\hline CHEMBL1573999 & 688239 & 5.4862 & 5.5921 & TRN & \\
\hline CHEMBL1532712 & 688239 & 8.3372 & \multicolumn{2}{|c|}{5.462000000000001} & TST \\
\hline CHEMBL1339262 & 688239 & 6.8362 & 5.59 & TRN & \\
\hline CHEMBL1456411 & 688239 & 4.6862 & \multicolumn{2}{|c|}{5.5729999999999995} & TRN \\
\hline CHEMBL1343260 & 688239 & 8.1871 & 5.5537 & TRN & \\
\hline CHEMBL1399846 & 688239 & 5.4362 & 5.5229 & TRN & \\
\hline CHEMBL1465996 & 688239 & 6.3863 & 5.4989 & TRN & \\
\hline CHEMBL1306870 & 688239 & 5.0362 & 5.3448 & TRN & \\
\hline CHEMBL 3196096 & 688239 & 8.2366 & 5.595 & TST & \\
\hline CHEMBL1310613 & 688239 & 6.2362 & 5.4899 & TST & \\
\hline CHEMBL1545693 & 688239 & 4.6862 & 5.4677 & TST & \\
\hline CHEMBL1449703 & 688239 & 5.7862 & 5.4419 & TRN & \\
\hline CHEMBL1580213 & 688239 & 4.6362 & 5.5921 & TST & \\
\hline CHEMBL1340643 & 688239 & 5.1862 & 5.4319 & TRN & \\
\hline CHEMBL1386514 & 688239 & 4.5362 & 5.5078 & TST & \\
\hline CHEMBL1447339 & 688239 & 4.5362 & 5.5418 & TRN & \\
\hline CHEMBL1434872 & 688239 & 7.7747 & 5.3636 & TST & \\
\hline CHEMBL1464341 & 688239 & 5.6362 & 5.4516 & TRN & \\
\hline CHEMBL1603314 & 688239 & 6.5363 & 5.4445 & TRN & \\
\hline CHEMBL1465022 & 688239 & 5.1862 & 5.6329 & TST & \\
\hline CHEMBL1446259 & 688239 & 5.5862 & 5.4479 & TST & \\
\hline CHEMBL1487709 & 688239 & 5.9862 & 5.5245 & TRN & \\
\hline CHEMBL3195621 & 688239 & 4.8362 & 5.5909 & TRN & \\
\hline CHEMBL1604900 & 688239 & 5.4362 & \multicolumn{2}{|c|}{5.497000000000001} & TRN \\
\hline CHEMBL1533058 & 688239 & 6.7361 & 5.425 & TRN & \\
\hline CHEMBL1359094 & 688239 & 6.8861 & 5.5885 & TRN & \\
\hline CHEMBL1320934 & 688239 & 5.0862 & 5.5528 & TRN & \\
\hline CHEMBL1504524 & 688239 & 4.4862 & 5.428 & TRN & \\
\hline CHEMBL 3189314 & 688239 & 5.1862 & 5.4328 & TRN & \\
\hline CHEMBL1308767 & 688239 & 6.6 & 5.3679 & TST & \\
\hline CHEMBL586602 & 688239 & 5.6862 & 5.4159 & TRN & \\
\hline
\end{tabular}




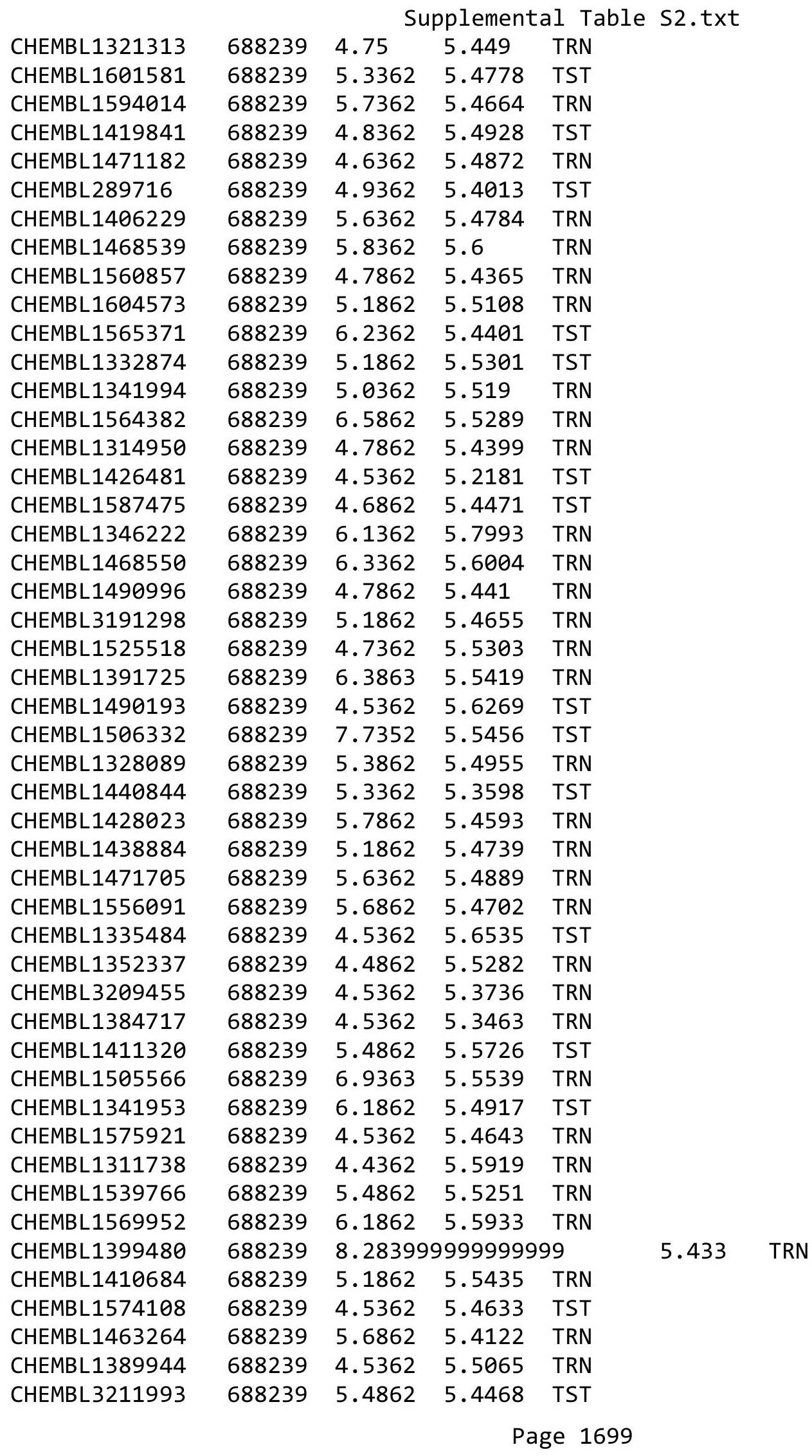


Supplemental Table S2.txt

\begin{tabular}{|c|c|c|c|c|c|c|}
\hline CHEMBL1500240 & 688239 & 4.5362 & 5.3604 & TST & & \\
\hline CHEMBL1505345 & 688239 & 6.0862 & 5.4011 & TRN & & \\
\hline CHEMBL1559949 & 688239 & 6.4862 & 5.5538 & TST & & \\
\hline CHEMBL1391879 & 688239 & 6.2362 & 5.6192 & TST & & \\
\hline CHEMBL1448860 & 688239 & 4.5362 & 5.3383 & TRN & & \\
\hline CHEMBL1468487 & 688239 & 6.4362 & 5.499 & TRN & & \\
\hline CHEMBL1343473 & 688239 & 5.0862 & 5.4986 & TRN & & \\
\hline CHEMBL3193930 & 688239 & 4.5362 & 5.4409 & TST & & \\
\hline CHEMBL3208003 & 688239 & 4.7862 & 5.3562 & TRN & & \\
\hline CHEMBL1499240 & 688239 & 4.5362 & 5.4804 & TRN & & \\
\hline CHEMBL1376195 & 688239 & 5.0862 & 5.4837 & TRN & & \\
\hline CHEMBL1588067 & 688239 & 8.28399 & 99999999 & 9 & 5.5388 & TRN \\
\hline CHEMBL1393128 & 688239 & 5.0862 & 5.4001 & TRN & & \\
\hline CHEMBL1310977 & 688239 & 4.7362 & 5.5478 & TRN & & \\
\hline CHEMBL1290699 & 688239 & 4.6362 & 5.5143 & TRN & & \\
\hline CHEMBL1464859 & 688239 & 5.2362 & 5.5168 & TRN & & \\
\hline CHEMBL3208529 & 688239 & 4.6362 & 5.4822 & TRN & & \\
\hline CHEMBL1526034 & 688239 & 4.6862 & 5.5193 & TRN & & \\
\hline CHEMBL3196952 & 688239 & 7.2366 & 5.4585 & TRN & & \\
\hline CHEMBL1383444 & 688239 & 4.5362 & 5.5915 & TST & & \\
\hline CHEMBL1518782 & 688239 & 4.7362 & 5.4853 & TRN & & \\
\hline CHEMBL1442229 & 688239 & 4.7862 & 5.3564 & TRN & & \\
\hline CHEMBL1580800 & 688239 & 5.2862 & 5.5258 & TRN & & \\
\hline CHEMBL1529542 & 688239 & 5.7362 & 5.5095 & TRN & & \\
\hline CHEMBL1368555 & 688239 & 5.8362 & 5.4902 & TST & & \\
\hline CHEMBL1512022 & 688239 & 4.5362 & 5.4785 & TRN & & \\
\hline CHEMBL1480918 & 688239 & 6.2362 & 5.566 & TRN & & \\
\hline CHEMBL1575434 & 688239 & 4.5362 & 5.414 & TST & & \\
\hline CHEMBL1402109 & 688239 & 4.9362 & 5.504 & TRN & & \\
\hline CHEMBL1579995 & 688239 & 4.5362 & 5.5665 & TRN & & \\
\hline CHEMBL3198006 & 688239 & 4.5862 & 5.4749 & TRN & & \\
\hline CHEMBL1322829 & 688239 & 5.1862 & 5.5069 & TRN & & \\
\hline CHEMBL1589307 & 688239 & 4.5362 & 5.4481 & TRN & & \\
\hline CHEMBL1553453 & 688239 & 6.3362 & 5.4044 & TST & & \\
\hline CHEMBL1449351 & 688239 & 4.5362 & 5.4606 & TRN & & \\
\hline CHEMBL1573705 & 688239 & 5.6862 & 5.4603 & TRN & & \\
\hline CHEMBL1391703 & 688239 & 4.6362 & 5.4317 & TRN & & \\
\hline CHEMBL1595923 & 688239 & 5.1862 & 5.4743 & TRN & & \\
\hline CHEMBL1331822 & 688239 & 4.9862 & 5.3813 & TST & & \\
\hline CHEMBL1525725 & 688239 & 6.0362 & 5.3647 & TRN & & \\
\hline CHEMBL1319477 & 688239 & 4.5362 & 5.3725 & TST & & \\
\hline CHEMBL1509681 & 688239 & 6.8861 & 5.5231 & TRN & & \\
\hline CHEMBL3207509 & 688239 & 4.5362 & 5.5353 & TST & & \\
\hline CHEMBL1385277 & 688239 & 6.8362 & 5.584 & TRN & & \\
\hline CHEMBL1411647 & 688239 & 4.6862 & 5.5416 & TRN & & \\
\hline CHEMBL1547582 & 688239 & 4.5362 & 5.5379 & TRN & & \\
\hline CHEMBL1364166 & 688239 & 7.1864 & 5.436 & TRN & & \\
\hline CHEMBL1330226 & 688239 & 4.8862 & 5.4646 & TRN & & \\
\hline
\end{tabular}


Supplemental Table S2.txt

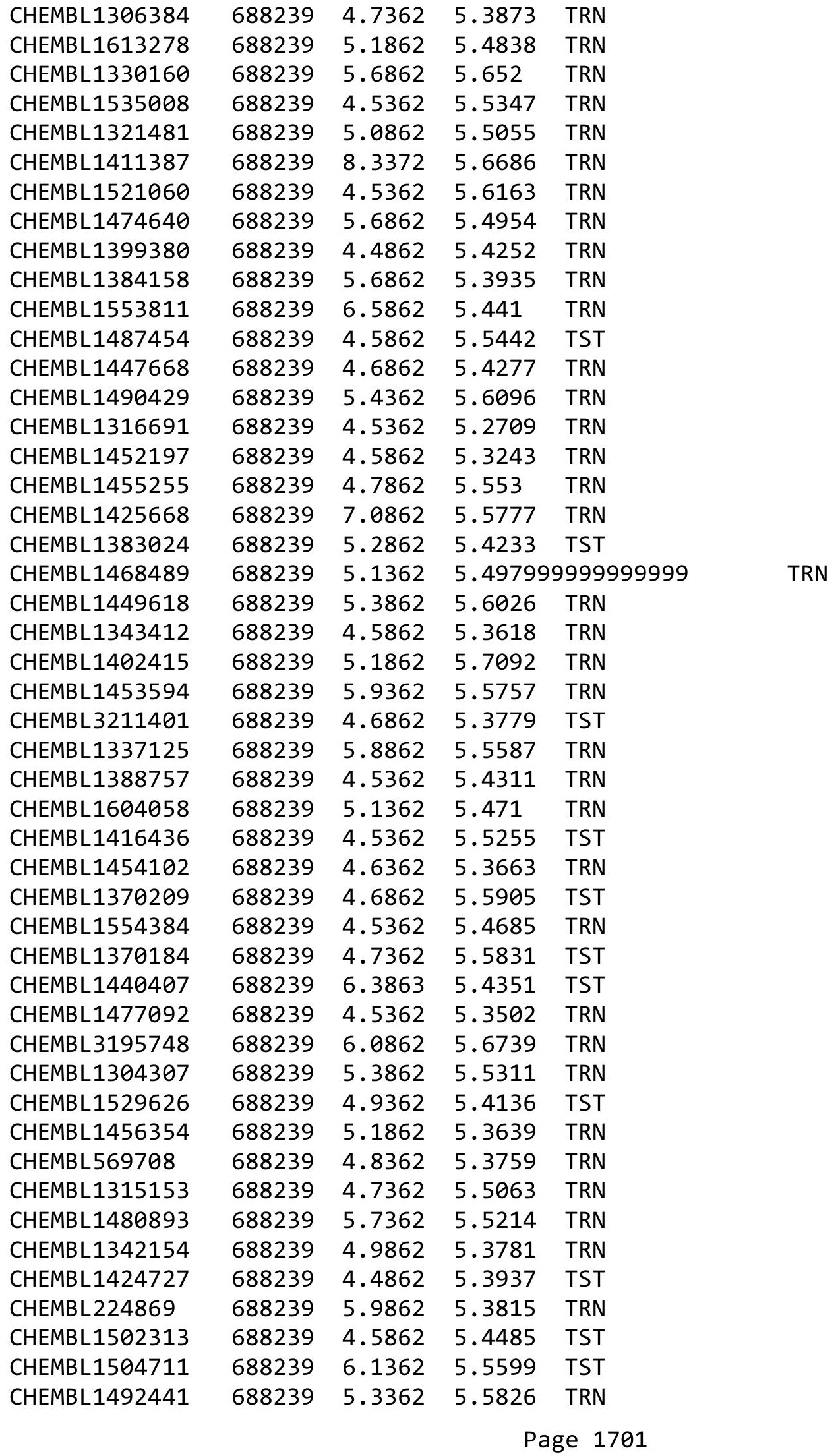


Supplemental Table S2.txt

\begin{tabular}{|c|c|c|c|c|}
\hline 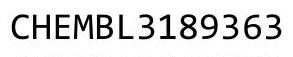 & & 1362 & 1664 & \\
\hline HEMBL1546679 & 88239 & 3372 & 3972 & \\
\hline HEMBL1391359 & 88239 & 5362 & & \\
\hline IEMBL1 & & & & \\
\hline IEMBL13 & & 362 & & \\
\hline HEMBL1485903 & 88239 & 7862 & 5729 & \\
\hline HEMBL1402762 & 88239 & 5.9863 & .4529 & \\
\hline HEMBL14 & 88239 & & & \\
\hline IEMBL16 & 39 & 862 & & \\
\hline IEMBL15 & 39 & 862 & & \\
\hline HEMBL3193358 & 88239 & 362 & .4049 & \\
\hline HEMBL1485062 & 39 & 362 & & \\
\hline HEMBL14 & 39 & 362 & .4449 & \\
\hline HEMBL15 & & & .5989 & \\
\hline HEMBL13 & 39 & & & \\
\hline HEMBL157 & 39 & & & \\
\hline HEMBL1490133 & 88 & 52 & & \\
\hline HEMBL 14 & 39 & 62 & 05 & \\
\hline HEMBL13 & 9 & & & \\
\hline HEMBL13 & 39 & & & RN \\
\hline HEMBL14 & 39 & & & - \\
\hline HEMBL1346347 & 39 & 52 & 74 & RN \\
\hline HEMBL14 & 39 & 52 & & \\
\hline HEMBL14 & & & & \\
\hline HEMBL15 & & & & RN \\
\hline HEMBL 14 & 39 & & & RN \\
\hline HEMBL60e & 39 & 52 & 43 & ST \\
\hline HEMBL 15 & 39 & 52 & & RN \\
\hline HEM & & & & RN \\
\hline 69 & & & & ST \\
\hline HEMBL13 & 9 & & & RN \\
\hline HEMBL1467866 & 88 & 61 & 58 & ST \\
\hline HEMBL15 & 39 & 62 & 41 & RN \\
\hline 7 & & & & RN \\
\hline HEMBL131 & & & & RN \\
\hline HEMBL1469698 & 39 & & & RN \\
\hline HEMBL1303852 & 39 & 362 & & RN \\
\hline HEMBL1474088 & 39 & 62 & & RIV \\
\hline 66 & & & & RN \\
\hline HEMBL 14 & & & & RN \\
\hline HEMBL1562193 & 39 & 362 & & RN \\
\hline HEMBL13 & 39 & & & RN \\
\hline HEMBL14 & & & & \\
\hline & & & & ST \\
\hline HEMBL13 & & .7362 & & RN \\
\hline HEMBL15 & 88 & 4.5362 & .5049 & RN \\
\hline 14 & & & & \\
\hline & & & & \\
\hline
\end{tabular}

Page 1702 


\begin{tabular}{|c|c|c|c|c|c|}
\hline \multicolumn{6}{|c|}{ lementa } \\
\hline CHEMBL604587 & 688239 & 4.4862 & 5.4559 & TST & \\
\hline CHEMBL1366348 & 688239 & 4.5362 & 5.3811 & TRN & \\
\hline CHEMBL1313735 & 688239 & 4.7362 & 5.4724 & TST & \\
\hline CHEMBL1303219 & 688239 & 4.8862 & 5.6349 & TST & \\
\hline CHEMBL3195335 & 688239 & 5.6862 & 5.5976 & TRN & \\
\hline CHEMBL1528798 & 688239 & 5.6862 & 5.4944 & TRN & \\
\hline CHEMBL1394942 & 688239 & 5.1862 & 5.4025 & TRN & \\
\hline CHEMBL1316689 & 688239 & 5.4862 & 5.4642 & TRN & \\
\hline CHEMBL1544401 & 688239 & 4.5362 & 5.3935 & TRN & \\
\hline CHEMBL3192884 & 688239 & 4.4862 & 5.5141 & TRN & \\
\hline CHEMBL1407858 & 688239 & 5.3362 & 5.4795 & TRN & \\
\hline CHEMBL1385375 & 688239 & 6.4862 & 5.5648 & TST & \\
\hline CHEMBL1382337 & 688239 & 4.7862 & 5.4342 & TRN & \\
\hline CHEMBL1420585 & 688239 & 4.7362 & 5.53700 & 0000000001 & TRN \\
\hline CHEMBL1339932 & 688239 & 6.8362 & 5.456 & TRN & \\
\hline CHEMBL1392053 & 688239 & 4.4862 & 5.4266 & TRN & \\
\hline CHEMBL3196555 & 688239 & 5.3862 & 5.3971 & TRN & \\
\hline CHEMBL3199873 & 688239 & 5.5362 & 5.4946 & TST & \\
\hline CHEMBL1347616 & 688239 & 5.9362 & 5.5946 & TRN & \\
\hline CHEMBL1508857 & 688239 & 5.1862 & 5.5914 & TST & \\
\hline CHEMBL 2140526 & 688239 & 7.0362 & 5.4256 & TST & \\
\hline CHEMBL1465472 & 688239 & 4.7362 & 5.3085 & TRN & \\
\hline CHEMBL1598787 & 688239 & 5.7862 & 5.4341 & TST & \\
\hline CHEMBL1327304 & 688239 & 6.6362 & 5.3683 & TRN & \\
\hline CHEMBL1594703 & 688239 & 6.9863 & 5.6651 & TRN & \\
\hline CHEMBL1589934 & 688239 & 8.0862 & 5.5783 & TRN & \\
\hline CHEMBL1604267 & 688239 & 5.1862 & 5.58200 & 0000000001 & TST \\
\hline CHEMBL1356979 & 688239 & 6.1362 & 5.5443 & TRN & \\
\hline CHEMBL1324556 & 688239 & 4.7362 & 5.5212 & TRN & \\
\hline CHEMBL1311767 & 688239 & 5.2862 & 5.5011 & TRN & \\
\hline CHEMBL1518516 & 688239 & 5.1862 & 5.59 & TRN & \\
\hline CHEMBL1587914 & 688239 & 8.2366 & 5.32 & TRN & \\
\hline CHEMBL1565410 & 688239 & 6.0862 & 5.468 & TRN & \\
\hline CHEMBL1438635 & 688239 & 5.5862 & 5.66100 & 00000000005 & TRN \\
\hline CHEMBL1383817 & 688239 & 8.3372 & 5.5786 & TRN & \\
\hline CHEMBL1541953 & 688239 & 4.5362 & 5.3509 & TRN & \\
\hline CHEMBL1486400 & 688239 & 4.5862 & 5.7018 & TRN & \\
\hline CHEMBL1414726 & 688239 & 5.2862 & 5.468 & TRN & \\
\hline CHEMBL1350656 & 688239 & 4.7862 & 5.3432 & TRN & \\
\hline CHEMBL1613223 & 688239 & 4.5862 & 5.4756 & TRN & \\
\hline CHEMBL1378774 & 688239 & 6.1862 & 5.4403 & TRN & \\
\hline CHEMBL1535954 & 688239 & 4.5362 & 5.5242 & TRN & \\
\hline CHEMBL1607756 & 688239 & 4.5362 & 5.4848 & TRN & \\
\hline CHEMBL1396157 & 688239 & 5.1862 & 5.4285 & TST & \\
\hline CHEMBL1428245 & 688239 & 4.5362 & 5.3487 & TRN & \\
\hline CHEMBL3209732 & 688239 & 6.4862 & 5.5033 & TRN & \\
\hline CHEMBL1307886 & 688239 & 7.1864 & 5.4135 & TST & \\
\hline CHEMBL1383682 & 688239 & 4.6862 & 5.6206 & TST & \\
\hline
\end{tabular}


Supplemental Table S2.txt

\begin{tabular}{|c|c|c|c|c|c|}
\hline CHEMBL1500342 & 688239 & 6.2862 & \multicolumn{2}{|c|}{5.4479999999999995} & TRN \\
\hline CHEMBL1508018 & 688239 & 5.2862 & 5.5907 & TRN & \\
\hline CHEMBL1378017 & 688239 & 6.5363 & 5.4931 & TRN & \\
\hline CHEMBL1408428 & 688239 & 5.3862 & 5.3589 & TST & \\
\hline CHEMBL1329864 & 688239 & 6.0862 & 5.5409 & TRN & \\
\hline CHEMBL1450792 & 688239 & 6.1862 & 5.6961 & TRN & \\
\hline CHEMBL1309690 & 688239 & 4.5362 & 5.4156 & TST & \\
\hline CHEMBL1412114 & 688239 & 4.7362 & 5.2964 & TRN & \\
\hline CHEMBL1314666 & 688239 & 4.5362 & 5.6088 & TRN & \\
\hline CHEMBL1561231 & 688239 & 4.7862 & 5.5456 & TRN & \\
\hline CHEMBL1381034 & 688239 & 4.5362 & 5.4063 & TRN & \\
\hline CHEMBL1533189 & 688239 & 4.9862 & 5.4567 & TST & \\
\hline CHEMBL1326786 & 688239 & 5.1862 & 5.5183 & TRN & \\
\hline CHEMBL1541677 & 688239 & 7.5867 & 5.6033 & TRN & \\
\hline CHEMBL1569331 & 688239 & 4.7862 & 5.4007 & TRN & \\
\hline CHEMBL1443383 & 688239 & 4.6362 & 5.3624 & TST & \\
\hline CHEMBL1308769 & 688239 & 4.6862 & 5.5958 & TRN & \\
\hline CHEMBL1565072 & 688239 & 5.3862 & 5.5423 & TRN & \\
\hline CHEMBL1346671 & 688239 & 6.0362 & 5.5292 & TRN & \\
\hline CHEMBL1590337 & 688239 & 4.7862 & 5.5104 & TRN & \\
\hline CHEMBL1524993 & 688239 & 5.1862 & 5.5297 & TRN & \\
\hline CHEMBL1457063 & 688239 & 6.3863 & 5.4457 & TST & \\
\hline CHEMBL1503111 & 688239 & 6.9863 & 5.6145 & TRN & \\
\hline CHEMBL1548848 & 688239 & 4.6862 & 5.4566 & TRN & \\
\hline CHEMBL1381045 & 688239 & 4.6862 & 5.3307 & TST & \\
\hline CHEMBL1300657 & 688239 & 6.4862 & 5.5111 & TRN & \\
\hline CHEMBL1576322 & 688239 & 5.4862 & 5.5165 & TRN & \\
\hline CHEMBL1483187 & 688239 & 4.6362 & 5.4008 & TRN & \\
\hline CHEMBL1316303 & 688239 & 5.7362 & 5.5961 & TRN & \\
\hline CHEMBL1524050 & 688239 & 4.7362 & 5.4559 & TRN & \\
\hline CHEMBL1536288 & 688239 & 6.1862 & 5.5158 & TRN & \\
\hline CHEMBL1334617 & 688239 & 5.4362 & 5.4878 & TRN & \\
\hline CHEMBL1480889 & 688239 & 4.5362 & 5.5498 & TRN & \\
\hline CHEMBL1383195 & 688239 & 4.9862 & 5.4115 & TRN & \\
\hline CHEMBL1984554 & 688239 & 6.4862 & 5.3599 & TRN & \\
\hline CHEMBL1559638 & 688239 & 6.3863 & 5.3838 & TRN & \\
\hline CHEMBL1399614 & 688239 & 5.1362 & 5.5608 & TRN & \\
\hline CHEMBL1574687 & 688239 & 5.8362 & 5.5146 & TST & \\
\hline CHEMBL1607488 & 688239 & 5.1862 & 5.5726 & TRN & \\
\hline CHEMBL1602507 & 688239 & 4.5362 & 5.6824 & TRN & \\
\hline CHEMBL1347413 & 688239 & 4.45 & 5.4746 & TST & \\
\hline CHEMBL1455741 & 688239 & 5.1862 & 5.5716 & TRN & \\
\hline CHEMBL1336784 & 688239 & 6.0 & 5.4789 & TST & \\
\hline CHEMBL1379948 & 688239 & 5.1862 & 5.3645 & TRN & \\
\hline CHEMBL1432815 & 688239 & 5.6862 & 5.4733 & TRN & \\
\hline CHEMBL1469529 & 688239 & 4.8862 & 5.4026 & TST & \\
\hline CHEMBL1405636 & 688239 & 5.0362 & 5.4834 & TRN & \\
\hline CHEMBL1327276 & 688239 & 4.9362 & 5.4996 & TRN & \\
\hline
\end{tabular}




\begin{tabular}{|c|c|c|c|c|c|c|c|}
\hline \multicolumn{7}{|c|}{ Supplemental Table S2.txt } & \\
\hline CHEMBL1601547 & 688239 & 6.6861 & 5.4746 & TRN & & & \\
\hline CHEMBL1465373 & 688239 & 5.0862 & 5.6338 & TST & & & \\
\hline CHEMBL1551967 & 688239 & 4.5362 & 5.6307 & TRN & & & \\
\hline CHEMBL 3192214 & 688239 & 4.4862 & 5.3643 & TRN & & & \\
\hline CHEMBL1401373 & 688239 & 5.2862 & 5.4929 & TST & & & \\
\hline CHEMBL1414214 & 688239 & 7.1864 & 5.5853 & TST & & & \\
\hline CHEMBL1418347 & 688239 & 4.9862 & 5.5769 & TRN & & & \\
\hline CHEMBL 3195583 & 688239 & 5.1862 & 5.522 & TST & & & \\
\hline CHEMBL1357295 & 688239 & 6.6861 & 5.5282 & TRN & & & \\
\hline CHEMBL1575535 & 688239 & 4.5362 & 5.5406 & TRN & & & \\
\hline CHEMBL1607098 & 688239 & 5.6862 & 5.3773 & TRN & & & \\
\hline CHEMBL1504038 & 688239 & 4.5862 & 5.4566 & TRN & & & \\
\hline CHEMBL1330804 & 688239 & 4.4862 & 5.372999 & 999999999 & & TRN & \\
\hline CHEMBL 3198535 & 688239 & 6.1362 & 5.5346 & TRN & & & \\
\hline CHEMBL1554809 & 688239 & 5.5362 & 5.3604 & TRN & & & \\
\hline CHEMBL1087646 & 688239 & 6.7862 & 5.5442 & TRN & & & \\
\hline CHEMBL1375713 & 688239 & 4.9362 & 5.396 & TRN & & & \\
\hline CHEMBL1375391 & 688239 & 4.7862 & 5.5658 & TST & & & \\
\hline CHEMBL1386676 & 688239 & 4.6862 & 5.669 & TRN & & & \\
\hline CHEMBL1974538 & 688239 & 5.3862 & 5.4674 & TRN & & & \\
\hline CHEMBL1427355 & 688239 & 6.2362 & 5.5787 & TRN & & & \\
\hline CHEMBL1415632 & 688239 & 6.8861 & 5.4974 & TRN & & & \\
\hline CHEMBL1429026 & 688239 & 4.5362 & 5.3058 & TST & & & \\
\hline CHEMBL1591684 & 688239 & 4.7862 & 5.3232 & TRN & & & \\
\hline CHEMBL1450294 & 688239 & 8.1871 & 5.4828 & TRN & & & \\
\hline CHEMBL3144988 & 688239 & 6.3863 & 5.6072 & TST & & & \\
\hline CHEMBL1540500 & 688239 & 5.1362 & 5.4232 & TRN & & & \\
\hline CHEMBL1362490 & 688239 & 4.5362 & 5.4131 & TST & & & \\
\hline CHEMBL1528913 & 688239 & 4.9862 & 5.556 & TRN & & & \\
\hline CHEMBL1327064 & 688239 & 8.28399 & 999999999 & 99 & 5.4669 & TST & \\
\hline CHEMBL1585828 & 688239 & 4.9362 & 5.4785 & TRN & & & \\
\hline CHEMBL1523020 & 688239 & 4.6862 & 5.3551 & TRN & & & \\
\hline CHEMBL3199654 & 688239 & 5.2362 & 5.4116 & TRN & & & \\
\hline CHEMBL1334428 & 688239 & 8.3372 & 5.5097 & TRN & & & \\
\hline CHEMBL1584783 & 688239 & 4.9862 & 5.3883 & TST & & & \\
\hline CHEMBL1505786 & 688239 & 4.5362 & 5.5845 & TRN & & & \\
\hline CHEMBL1412374 & 688239 & 6.2362 & 5.5349 & TRN & & & \\
\hline CHEMBL1548322 & 688239 & 5.8362 & 5.6416 & TRN & & & \\
\hline CHEMBL1390814 & 688239 & 5.1862 & 5.3523 & TST & & & \\
\hline CHEMBL1340883 & 688239 & 5.1362 & 5.4553 & TRN & & & \\
\hline CHEMBL1388983 & 688239 & 5.8362 & 5.4013 & TRN & & & \\
\hline CHEMBL1500745 & 688239 & 8.28399 & 999999999 & 99 & 5.53299 & 99999999995 & TRN \\
\hline CHEMBL3199767 & 688239 & 4.5362 & 5.5176 & TRN & & & \\
\hline CHEMBL1431611 & 688239 & 5.6362 & 5.4003 & TST & & & \\
\hline CHEMBL1345910 & 688239 & 5.1862 & 5.4999 & TST & & & \\
\hline CHEMBL1382618 & 688239 & 5.1862 & 5.5838 & TRN & & & \\
\hline CHEMBL1352482 & 688239 & 5.1362 & 5.5268 & TRN & & & \\
\hline CHEMBL1527369 & 688239 & 5.2862 & 5.4776 & TRN & & & \\
\hline
\end{tabular}




\begin{tabular}{|c|c|c|c|c|c|c|}
\hline \multirow[b]{2}{*}{ CHEMBL1323185 } & \multicolumn{6}{|c|}{ Supplemental Table S2.txt } \\
\hline & 688239 & 7.2865 & 5.6303 & TRN & & \\
\hline CHEMBL1317397 & 688239 & 5.3862 & 5.4747 & TRN & & \\
\hline CHEMBL1597492 & 688239 & 7.3862 & 5.4807 & TRN & & \\
\hline CHEMBL1400035 & 688239 & 4.6362 & 5.44 & TRN & & \\
\hline CHEMBL1490351 & 688239 & 4.6362 & 5.3687 & TRN & & \\
\hline CHEMBL1506567 & 688239 & 5.5362 & 5.5823 & TRN & & \\
\hline CHEMBL1608376 & 688239 & 6.1862 & 5.4267 & TRN & & \\
\hline CHEMBL234378 & 688239 & 4.5862 & 5.5877 & TRN & & \\
\hline CHEMBL1333656 & 688239 & 5.1862 & 5.4219 & TRN & & \\
\hline CHEMBL1585075 & 688239 & 6.8362 & 5.5052 & TRN & & \\
\hline CHEMBL1368714 & 688239 & 6.5862 & 5.5428 & TRN & & \\
\hline CHEMBL1381175 & 688239 & 6.6362 & 5.5155 & TRN & & \\
\hline CHEMBL1421647 & 688239 & 6.8362 & 5.4431 & TRN & & \\
\hline CHEMBL1489306 & 688239 & 4.5362 & 5.5245 & TRN & & \\
\hline CHEMBL1371179 & 688239 & 6.0362 & 5.3467 & TRN & & \\
\hline CHEMBL1522058 & 688239 & 4.5362 & 5.442 & TRN & & \\
\hline CHEMBL1314899 & 688239 & 4.5862 & 5.5139 & TRN & & \\
\hline CHEMBL1580774 & 688239 & 4.5362 & 5.4202 & TST & & \\
\hline CHEMBL1421643 & 688239 & 4.5362 & 5.5202 & TRN & & \\
\hline CHEMBL1337288 & 688239 & 4.6362 & 5.3747 & TRN & & \\
\hline CHEMBL1462940 & 688239 & 8.3372 & 5.4936 & TST & & \\
\hline CHEMBL1510157 & 688239 & 8.28399 & 99999999 & 99 & 5.4712 & TRN \\
\hline CHEMBL1306560 & 688239 & 6.3362 & 5.4528 & TRN & & \\
\hline CHEMBL565674 & 688239 & 4.5362 & 5.5263 & TRN & & \\
\hline CHEMBL1508945 & 688239 & 4.5362 & 5.4724 & TRN & & \\
\hline CHEMBL1413531 & 688239 & 6.6861 & 5.5781 & TRN & & \\
\hline CHEMBL1416074 & 688239 & 4.8362 & 5.4617 & TRN & & \\
\hline CHEMBL1433755 & 688239 & 4.4862 & 5.485 & TRN & & \\
\hline CHEMBL1385045 & 688239 & 6.1362 & 5.7024 & TRN & & \\
\hline CHEMBL1409104 & 688239 & 5.4362 & 5.3015 & TST & & \\
\hline CHEMBL1578343 & 688239 & 6.1862 & 5.4131 & TST & & \\
\hline CHEMBL1529977 & 688239 & 6.5862 & 5.51 & TRN & & \\
\hline CHEMBL1342967 & 688239 & 6.4862 & 5.3599 & TRN & & \\
\hline CHEMBL1427227 & 688239 & 8.3372 & 5.4356 & TRN & & \\
\hline CHEMBL1486441 & 688239 & 5.6862 & 5.5883 & TRN & & \\
\hline CHEMBL1525579 & 688239 & 5.1862 & 5.442 & TRN & & \\
\hline CHEMBL1497181 & 688239 & 6.1362 & 5.4029 & TST & & \\
\hline CHEMBL1429013 & 688239 & 6.1862 & 5.4247 & TRN & & \\
\hline CHEMBL1400510 & 688239 & 5.1862 & 5.4932 & TRN & & \\
\hline CHEMBL1365225 & 688239 & 5.4362 & 5.7444 & TRN & & \\
\hline CHEMBL1404805 & 688239 & 4.5362 & 5.6215 & TRN & & \\
\hline CHEMBL3209056 & 688239 & 5.5362 & 5.5219 & TRN & & \\
\hline CHEMBL1336827 & 688239 & 6.1862 & 5.4564 & TRN & & \\
\hline CHEMBL1355160 & 688239 & 6.0862 & 5.3493 & TRN & & \\
\hline CHEMBL1498642 & 688239 & 4.5862 & 5.50200 & 0000000001 & & TRN \\
\hline CHEMBL1374030 & 688239 & 4.6862 & 5.5924 & TRN & & \\
\hline CHEMBL3209938 & 688239 & 4.6362 & 5.2809 & TST & & \\
\hline CHEMBL1537909 & 688239 & 8.28399 & 79999999 & 99 & 5.5308 & TRN \\
\hline
\end{tabular}


Supplemental Table S2.txt

\begin{tabular}{|c|c|c|c|c|}
\hline CHEMBL1349556 & 688239 & 6.8362 & 5.4456 & TRN \\
\hline CHEMBL1507526 & 688239 & 6.7862 & 5.6548 & TRN \\
\hline CHEMBL454843 & 688239 & 4.4862 & 5.4419 & TST \\
\hline CHEMBL1377272 & 688239 & 7.6364 & 5.4274 & TRN \\
\hline CHEMBL1549305 & 688239 & 4.7862 & 5.4307 & TRN \\
\hline CHEMBL1554450 & 688239 & 4.5362 & \multicolumn{2}{|c|}{5.547999999999999} \\
\hline CHEMBL1523796 & 688239 & 4.4862 & 5.369 & TRN \\
\hline CHEMBL1373377 & 688239 & 5.9362 & \multirow{2}{*}{\multicolumn{2}{|c|}{$\begin{array}{l}5.452999999999999 \\
5.4079999999999995\end{array}$}} \\
\hline CHEMBL1349155 & 688239 & 5.3862 & & \\
\hline CHEMBL1484452 & 688239 & 5.8362 & 5.5858 & TRN \\
\hline CHEMBL1489641 & 688239 & 5.9862 & 5.4803 & TRN \\
\hline CHEMBL1401269 & 688239 & 6.0862 & 5.4161 & TRN \\
\hline CHEMBL1547123 & 688239 & 4.5362 & 5.4135 & TST \\
\hline CHEMBL1347236 & 688239 & 6.8362 & 5.347 & TST \\
\hline CHEMBL1518098 & 688239 & 4.8362 & 5.3972 & TST \\
\hline CHEMBL3191909 & 688239 & 5.5362 & 5.4344 & TRN \\
\hline CHEMBL1428677 & 688239 & 4.5362 & 5.3897 & TST \\
\hline CHEMBL1398268 & 688239 & 4.7362 & 5.5303 & TRN \\
\hline CHEMBL1387877 & 688239 & 4.6862 & 5.4258 & TRN \\
\hline CHEMBL1323433 & 688239 & 6.8362 & 5.5088 & TRN \\
\hline CHEMBL1388327 & 688239 & 6.9863 & 5.5692 & TRN \\
\hline CHEMBL3211078 & 688239 & 6.2362 & 5.4091 & TST \\
\hline CHEMBL1420839 & 688239 & 8.3372 & 5.5043 & TRN \\
\hline CHEMBL1447677 & 688239 & 4.5862 & 5.6035 & TRN \\
\hline CHEMBL1581764 & 688239 & 5.6862 & 5.5405 & TRN \\
\hline CHEMBL1360349 & 688239 & 5.9362 & 5.5628 & TRN \\
\hline CHEMBL1578718 & 688239 & 4.5362 & 5.2882 & TRN \\
\hline CHEMBL1352879 & 688239 & 6.9863 & 5.4186 & TRN \\
\hline CHEMBL1392791 & 688239 & 5.6862 & 5.3484 & TST \\
\hline CHEMBL1341936 & 688239 & 5.8862 & 5.4274 & TRN \\
\hline CHEMBL1504363 & 688239 & 6.2362 & 5.6158 & TRN \\
\hline CHEMBL1451855 & 688239 & 4.5362 & 5.5978 & TRN \\
\hline CHEMBL1468066 & 688239 & 6.3362 & 5.3586 & TRN \\
\hline CHEMBL1365411 & 688239 & 4.5362 & 5.4826 & TRN \\
\hline CHEMBL1602987 & 688239 & 5.1862 & 5.5776 & TRN \\
\hline CHEMBL1417597 & 688239 & 5.6862 & 5.5536 & TRN \\
\hline CHEMBL1391581 & 688239 & 4.5862 & 5.44 & TRN \\
\hline CHEMBL1533268 & 688239 & 5.5862 & 5.4571 & TRN \\
\hline CHEMBL1423274 & 688239 & 4.4862 & 5.4791 & TRN \\
\hline CHEMBL1301685 & 688239 & 4.5362 & 5.5587 & TRN \\
\hline CHEMBL1524553 & 688239 & 6.2862 & 5.4781 & TRN \\
\hline CHEMBL1547739 & 688239 & 4.7362 & 5.4359 & TRN \\
\hline CHEMBL1441314 & 688239 & 5.9362 & 5.6288 & TRN \\
\hline CHEMBL1473591 & 688239 & 4.6862 & 5.4981 & TST \\
\hline CHEMBL1307055 & 688239 & 5.5362 & 5.5416 & TRN \\
\hline CHEMBL1353224 & 688239 & 6.1862 & 5.50799 & 9999999999 \\
\hline CHEMBL1304231 & 688239 & 4.6862 & 5.5629 & TRN \\
\hline CHEMBL1485921 & 688239 & 6.0362 & 5.6711 & TRN \\
\hline
\end{tabular}


Supplemental Table S2.txt

\begin{tabular}{|c|c|c|c|c|c|}
\hline CHEMBL1524967 & 688239 & 5.4362 & 5.5117 & TRN & \\
\hline CHEMBL1479250 & 688239 & 4.7362 & 5.4419 & TRN & \\
\hline CHEMBL1494591 & 688239 & 4.6362 & 5.4649 & TRN & \\
\hline CHEMBL1965415 & 688239 & 6.0862 & 5.4068 & TRN & \\
\hline CHEMBL1377146 & 688239 & 4.8862 & 5.5208 & TST & \\
\hline CHEMBL1534828 & 688239 & 6.5363 & 5.4757 & TST & \\
\hline CHEMBL1406350 & 688239 & 5.1862 & 5.3325 & TRN & \\
\hline CHEMBL1391022 & 688239 & 5.6862 & 5.4179 & TST & \\
\hline CHEMBL1445262 & 688239 & 6.5862 & 5.4297 & TST & \\
\hline CHEMBL1545150 & 688239 & 5.4362 & 5.4492 & TRN & \\
\hline CHEMBL1500097 & 688239 & 5.2862 & 5.4695 & TRN & \\
\hline CHEMBL1556197 & 688239 & 5.9862 & 5.4783 & TRN & \\
\hline CHEMBL1529055 & 688239 & 5.4862 & 5.3164 & TRN & \\
\hline CHEMBL1576371 & 688239 & 4.6862 & 5.4268 & TRN & \\
\hline CHEMBL3196706 & 688239 & 5.3362 & 5.4834 & TST & \\
\hline CHEMBL1546089 & 688239 & 5.4362 & 5.5345 & TRN & \\
\hline CHEMBL1399873 & 688239 & 4.5362 & 5.5904 & TST & \\
\hline CHEMBL1411864 & 688239 & 4.9362 & 5.5607 & TST & \\
\hline CHEMBL1350022 & 688239 & 4.5362 & 5.5257 & TRN & \\
\hline CHEMBL1443017 & 688239 & 6.1362 & 5.6757 & TRN & \\
\hline CHEMBL1471759 & 688239 & 6.2362 & 5.5078 & TRN & \\
\hline CHEMBL3210163 & 688239 & 4.5362 & 5.3564 & TST & \\
\hline CHEMBL1404085 & 688239 & 6.7862 & 5.5031 & TST & \\
\hline CHEMBL1317160 & 688239 & 5.2362 & 5.4358 & TRN & \\
\hline CHEMBL3189292 & 688239 & 6.1862 & 5.4078 & TRN & \\
\hline CHEMBL1606901 & 688239 & 4.7362 & 5.4457 & TRN & \\
\hline CHEMBL1351588 & 688239 & 5.0362 & 5.6112 & TRN & \\
\hline CHEMBL1546223 & 688239 & 4.8362 & 5.473 & TST & \\
\hline CHEMBL1410659 & 688239 & 5.2862 & 5.4101 & TRN & \\
\hline CHEMBL3207662 & 688239 & 6.9363 & 5.4433 & TST & \\
\hline CHEMBL1568749 & 688239 & 4.5862 & 5.4984 & TRN & \\
\hline CHEMBL1489922 & 688239 & 5.2362 & 5.6505 & TRN & \\
\hline CHEMBL1597776 & 688239 & 6.6861 & 5.4838 & TRN & \\
\hline CHEMBL1366556 & 688239 & 4.6862 & 5.534 & TRN & \\
\hline CHEMBL1443613 & 688239 & 4.5362 & 5.4742 & TRN & \\
\hline CHEMBL1471978 & 688239 & 4.7862 & 5.4959 & TRN & \\
\hline CHEMBL1538798 & 688239 & 5.1862 & 5.51399 & 9999999999 & TRN \\
\hline CHEMBL1536490 & 688239 & 4.7862 & 5.4453 & TRN & \\
\hline CHEMBL1584024 & 688239 & 4.7862 & 5.567 & TRN & \\
\hline CHEMBL1512854 & 688239 & 7.6364 & 5.5447 & TRN & \\
\hline CHEMBL1473683 & 688239 & 4.5362 & 5.4423 & TRN & \\
\hline CHEMBL1338081 & 688239 & 5.1862 & 5.4844 & TRN & \\
\hline CHEMBL1990383 & 688239 & 4.4862 & 5.4326 & TRN & \\
\hline CHEMBL1498390 & 688239 & 6.9363 & 5.5858 & TST & \\
\hline CHEMBL1613673 & 688239 & 6.8861 & 5.5418 & TRN & \\
\hline CHEMBL1325767 & 688239 & 4.7362 & 5.4517 & TRN & \\
\hline CHEMBL1494269 & 688239 & 4.4362 & 5.6818 & TRN & \\
\hline CHEMBL1576182 & 688239 & 5.3862 & 5.5441 & TRN & \\
\hline
\end{tabular}




\begin{tabular}{|c|c|c|c|c|}
\hline \multicolumn{5}{|c|}{ Supplemental Table S2.txt } \\
\hline CHEMBL1489685 & 688239 & 6.0 & 5.3744 & TRN \\
\hline CHEMBL1489436 & 688239 & 4.5362 & 5.4958 & TRN \\
\hline CHEMBL1594540 & 688239 & 4.5362 & 5.5114 & TRN \\
\hline CHEMBL1514006 & 688239 & 4.7862 & 5.3232 & TRN \\
\hline CHEMBL1441570 & 688239 & 5.2862 & 5.4672 & TRN \\
\hline CHEMBL1422764 & 688239 & 5.1862 & 5.3805 & TRN \\
\hline CHEMBL1496682 & 688239 & 6.9363 & 5.4698 & TRN \\
\hline CHEMBL1459328 & 688239 & 4.7362 & 5.4431 & TRN \\
\hline CHEMBL3195337 & 688239 & 4.8362 & 5.5975 & TRN \\
\hline CHEMBL1513954 & 688239 & 4.9862 & 5.6204 & TRN \\
\hline CHEMBL1444733 & 688239 & 5.1862 & 5.5102 & TRN \\
\hline CHEMBL1348586 & 688239 & 4.5362 & 5.4366 & TRN \\
\hline CHEMBL1498643 & 688239 & 5.8862 & 5.3375 & TST \\
\hline CHEMBL1377857 & 688239 & 6.1862 & 5.5026 & TRN \\
\hline CHEMBL1550532 & 688239 & 7.2366 & 5.521 & TRN \\
\hline CHEMBL1537996 & 688239 & 5.0862 & 5.443 & TRN \\
\hline CHEMBL1606786 & 688239 & 4.5362 & 5.4407 & TRN \\
\hline CHEMBL1352562 & 688239 & 5.0362 & 5.6923 & TST \\
\hline CHEMBL1338150 & 688239 & 5.2862 & 5.5778 & TRN \\
\hline CHEMBL1346150 & 688239 & 4.7362 & 5.4241 & TRN \\
\hline CHEMBL1458052 & 688239 & 7.0362 & 5.5461 & TRN \\
\hline CHEMBL1496522 & 688239 & 5.2862 & 5.6312 & TRN \\
\hline CHEMBL1576844 & 688239 & 4.7862 & 5.6304 & TRN \\
\hline CHEMBL1443263 & 688239 & 5.6862 & 5.5468 & TRN \\
\hline CHEMBL1401281 & 688239 & 5.8362 & 5.4724 & TRN \\
\hline CHEMBL1396078 & 688239 & 6.0862 & 5.4812 & TRN \\
\hline CHEMBL1411368 & 688239 & 5.1362 & 5.5226 & TRN \\
\hline CHEMBL1467978 & 688239 & 5.5862 & 5.5336 & TST \\
\hline CHEMBL1546475 & 688239 & 4.7362 & 5.5688 & TRN \\
\hline CHEMBL1469974 & 688239 & 4.7862 & 5.5578 & TRN \\
\hline CHEMBL1397289 & 688239 & 5.2362 & 5.414 & TRN \\
\hline CHEMBL1368606 & 688239 & 6.9863 & 5.5186 & TST \\
\hline CHEMBL1309553 & 688239 & 5.2862 & 5.3179 & TRN \\
\hline CHEMBL1510004 & 688239 & 4.5362 & 5.4552 & TST \\
\hline CHEMBL1449835 & 688239 & 7.6861 & 5.5313 & TRN \\
\hline CHEMBL1594992 & 688239 & 5.0362 & 5.4579 & TRN \\
\hline CHEMBL1437397 & 688239 & 7.0862 & 5.584 & TRN \\
\hline CHEMBL1322847 & 688239 & 4.5362 & 5.4773 & TST \\
\hline CHEMBL1489217 & 688239 & 4.5862 & 5.6096 & TRN \\
\hline CHEMBL1340573 & 688239 & 4.7362 & 5.3842 & TST \\
\hline CHEMBL1426005 & 688239 & 5.7862 & 5.2844 & TRN \\
\hline CHEMBL1516593 & 688239 & 5.1862 & 5.2944 & TRN \\
\hline CHEMBL1348459 & 688239 & 5.7362 & 5.5992 & TRN \\
\hline CHEMBL1407329 & 688239 & 4.5362 & 5.4314 & TRN \\
\hline CHEMBL1466526 & 688239 & 4.7362 & 5.5568 & TST \\
\hline CHEMBL1448705 & 688239 & 4.4862 & 5.3375 & TRN \\
\hline CHEMBL1610180 & 688239 & 4.5362 & 5.5826 & TRN \\
\hline CHEMBL1441258 & 688239 & 6.8861 & 5.5168 & TST \\
\hline
\end{tabular}


Supplemental Table S2.txt

\begin{tabular}{|c|c|c|c|c|}
\hline CHEMBL1608925 & 688239 & 6.9863 & 5.5277 & TRN \\
\hline CHEMBL1412660 & 688239 & 4.9862 & 5.6006 & TRN \\
\hline CHEMBL1404386 & 688239 & 5.1362 & 5.6988 & TRN \\
\hline CHEMBL1564842 & 688239 & 4.7862 & \multicolumn{2}{|c|}{5.367999999999999} \\
\hline CHEMBL1370939 & 688239 & 4.9362 & 5.3808 & TRN \\
\hline CHEMBL3190732 & 688239 & 5.2862 & 5.3571 & TRN \\
\hline CHEMBL1386515 & 688239 & 8.3372 & 5.4943 & TRN \\
\hline CHEMBL1364384 & 688239 & 4.5362 & 5.4572 & TRN \\
\hline CHEMBL1338445 & 688239 & 6.8362 & 5.5428 & TRN \\
\hline CHEMBL1500488 & 688239 & 4.5362 & 5.5092 & TRN \\
\hline CHEMBL1382995 & 688239 & 4.6862 & \multicolumn{2}{|c|}{5.497000000000001} \\
\hline CHEMBL1582856 & 688239 & 4.5362 & 5.3592 & TST \\
\hline CHEMBL1607902 & 688239 & 6.9863 & 5.4687 & TRN \\
\hline CHEMBL1377778 & 688239 & 8.3872 & 5.4257 & TRN \\
\hline CHEMBL3207466 & 688239 & 4.5362 & 5.4463 & TST \\
\hline CHEMBL1454339 & 688239 & 5.6862 & 5.4 & TRN \\
\hline CHEMBL1322732 & 688239 & 6.9863 & 5.5223 & TRN \\
\hline CHEMBL1306710 & 688239 & 4.5362 & 5.5345 & TRN \\
\hline CHEMBL1541912 & 688239 & 5.3862 & 5.4393 & TRN \\
\hline CHEMBL1600947 & 688239 & 4.8362 & \multicolumn{2}{|c|}{5.5920000000000005} \\
\hline CHEMBL1337587 & 688239 & 4.5362 & 5.404 & TRN \\
\hline CHEMBL3191595 & 688239 & 4.7362 & 5.4501 & TRN \\
\hline CHEMBL1507174 & 688239 & 5.2862 & 5.5188 & TRN \\
\hline CHEMBL1326103 & 688239 & 6.9363 & 5.5494 & TRN \\
\hline CHEMBL1433157 & 688239 & 4.5362 & \multicolumn{2}{|c|}{5.377999999999999} \\
\hline CHEMBL1379717 & 688239 & 7.0862 & 5.5377 & TRN \\
\hline CHEMBL3195313 & 688239 & 5.5862 & 5.5057 & TST \\
\hline CHEMBL1499843 & 688239 & 4.5362 & 5.5185 & TRN \\
\hline CHEMBL1463388 & 688239 & 5.1862 & 5.4833 & TRN \\
\hline CHEMBL1999700 & 688239 & 4.5862 & 5.3454 & TRN \\
\hline CHEMBL1362532 & 688239 & 4.7862 & 5.5005 & TRN \\
\hline CHEMBL1409691 & 688239 & 5.2362 & 5.4769 & TRN \\
\hline CHEMBL1574512 & 688239 & 6.2362 & 5.4788 & TST \\
\hline CHEMBL1515297 & 688239 & 4.6862 & 5.5488 & TRN \\
\hline CHEMBL1507792 & 688239 & 5.3362 & 5.3975 & TST \\
\hline CHEMBL1304914 & 688239 & 4.6362 & 5.5413 & TRN \\
\hline CHEMBL1532453 & 688239 & 5.2862 & 5.4406 & TRN \\
\hline CHEMBL1493243 & 688239 & 5.9862 & 5.369 & TST \\
\hline CHEMBL1548269 & 688239 & 4.5362 & 5.2697 & TRN \\
\hline CHEMBL1441675 & 688239 & 4.8862 & 5.4938 & TST \\
\hline CHEMBL1477880 & 688239 & 6.1862 & 5.5405 & TRN \\
\hline CHEMBL1306672 & 688239 & 5.6362 & 5.5276 & TRN \\
\hline CHEMBL1496204 & 688239 & 7.0862 & 5.5167 & TST \\
\hline CHEMBL1447116 & 688239 & 5.6862 & 5.5526 & TRN \\
\hline CHEMBL1429057 & 688239 & 4.4862 & 5.4726 & TRN \\
\hline CHEMBL1571547 & 688239 & 4.7862 & 5.5564 & TRN \\
\hline CHEMBL1310578 & 688239 & 6.7361 & 5.6628 & TRN \\
\hline CHEMBL1370882 & 688239 & 5.1862 & 5.4837 & TST \\
\hline
\end{tabular}

Page 1710 
Supplemental Table S2.txt

\begin{tabular}{|c|c|c|c|c|}
\hline CHEMBL1352121 & 688239 & 5.0362 & 5.5721 & TRN \\
\hline CHEMBL1482787 & 688239 & 5.0862 & 5.4571 & TRN \\
\hline CHEMBL1443064 & 688239 & 4.5362 & 5.4615 & TRN \\
\hline CHEMBL1444057 & 688239 & 5.0362 & 5.5143 & TRN \\
\hline CHEMBL1445297 & 688239 & 5.3862 & 5.4637 & TRN \\
\hline CHEMBL3213166 & 688239 & 5.1862 & 5.5815 & TST \\
\hline CHEMBL1456305 & 688239 & 4.4862 & 5.4741 & TST \\
\hline CHEMBL 3194760 & 688239 & 4.7362 & 5.4376 & TRN \\
\hline CHEMBL1605078 & 688239 & 6.3863 & 5.5651 & TRN \\
\hline CHEMBL1317220 & 688239 & 5.2862 & 5.4773 & TRN \\
\hline CHEMBL1424083 & 688239 & 4.5362 & 5.4396 & TRN \\
\hline CHEMBL1515296 & 688239 & 4.5362 & 5.4891 & TRN \\
\hline CHEMBL1542317 & 688239 & 4.7862 & 5.4594 & TST \\
\hline CHEMBL1444179 & 688239 & 5.1862 & 5.687 & TRN \\
\hline CHEMBL1342119 & 688239 & 5.7862 & 5.3959 & TRN \\
\hline CHEMBL1557467 & 688239 & 4.5362 & 5.4911 & TRN \\
\hline CHEMBL1344115 & 688239 & 4.8862 & 5.4292 & TST \\
\hline CHEMBL1508914 & 688239 & 4.5862 & 5.3549 & TRN \\
\hline CHEMBL3194686 & 688239 & 4.8862 & 5.4567 & TST \\
\hline CHEMBL1344078 & 688239 & 4.4862 & 5.477 & TRN \\
\hline CHEMBL1442571 & 688239 & 5.1862 & 5.4728 & TST \\
\hline CHEMBL1473306 & 688239 & 6.7862 & 5.5152 & TRN \\
\hline CHEMBL1364596 & 688239 & 4.7862 & 5.5175 & TRN \\
\hline CHEMBL3193156 & 688239 & 4.7862 & 5.4621 & TST \\
\hline CHEMBL1360545 & 688239 & 4.7362 & 5.517 & TRN \\
\hline CHEMBL1308107 & 688239 & 4.5362 & 5.5258 & TRN \\
\hline CHEMBL1590651 & 688239 & 4.5362 & 5.5771 & TRN \\
\hline CHEMBL1373542 & 688239 & 6.7862 & 5.6462 & TST \\
\hline CHEMBL1459316 & 688239 & 5.0362 & 5.4992 & TST \\
\hline CHEMBL1571526 & 688239 & 5.6362 & 5.4977 & TRN \\
\hline CHEMBL1564097 & 688239 & 5.6862 & 5.5636 & TRN \\
\hline CHEMBL1601334 & 688239 & 4.6862 & 5.5233 & TST \\
\hline CHEMBL1343006 & 688239 & 5.6362 & 5.3861 & TRN \\
\hline CHEMBL1425780 & 688239 & 4.5362 & 5.6389 & TST \\
\hline CHEMBL1549669 & 688239 & 4.7362 & 5.4396 & TRN \\
\hline CHEMBL1451960 & 688239 & 4.5362 & 5.7089 & TST \\
\hline CHEMBL1472586 & 688239 & 5.6362 & 5.4291 & TRN \\
\hline CHEMBL1396367 & 688239 & 6.0862 & 5.4544 & TRN \\
\hline CHEMBL1998302 & 688239 & 6.7862 & 5.314 & TRN \\
\hline CHEMBL1570574 & 688239 & 5.3362 & 5.5311 & TRN \\
\hline CHEMBL1506271 & 688239 & 6.4862 & 5.50299 & 9999999999 \\
\hline CHEMBL1451026 & 688239 & 4.7862 & 5.4368 & TRN \\
\hline CHEMBL1477684 & 688239 & 6.5862 & 5.6024 & TRN \\
\hline CHEMBL1984107 & 688239 & 4.5362 & 5.5425 & TST \\
\hline CHEMBL1488752 & 688239 & 4.6362 & 5.4992 & TST \\
\hline CHEMBL1340810 & 688239 & 5.3862 & 5.4831 & TRN \\
\hline CHEMBL1446301 & 688239 & 5.5862 & 5.5632 & TRN \\
\hline CHEMBL1544562 & 688239 & 4.9862 & 5.4369 & TRN \\
\hline
\end{tabular}

Page 1711 
Supplemental Table S2.txt

\begin{tabular}{|c|c|c|c|c|c|}
\hline CHEMBL1311291 & 688239 & 8.1871 & 5.5628 & TST & \\
\hline CHEMBL1439931 & 688239 & 4.7862 & 5.5521 & TRN & \\
\hline CHEMBL1387093 & 688239 & 6.7862 & 5.5762 & TRN & \\
\hline CHEMBL1515114 & 688239 & 5.6862 & 5.4895 & TRN & \\
\hline CHEMBL1530464 & 688239 & 5.1362 & 5.3068 & TRN & \\
\hline CHEMBL1580579 & 688239 & 5.8362 & 5.4859 & TRN & \\
\hline CHEMBL1509454 & 688239 & 5.6362 & 5.50299 & 9999999999 & TRN \\
\hline CHEMBL1504522 & 688239 & 4.9862 & 5.4563 & TRN & \\
\hline CHEMBL1407174 & 688239 & 5.6862 & 5.6245 & TRN & \\
\hline CHEMBL1314995 & 688239 & 5.1862 & 5.4187 & TST & \\
\hline CHEMBL1440222 & 688239 & 4.8362 & 5.4285 & TST & \\
\hline CHEMBL1361273 & 688239 & 4.7362 & 5.5365 & TST & \\
\hline CHEMBL1587829 & 688239 & 4.5362 & 5.4707 & TRN & \\
\hline CHEMBL1333047 & 688239 & 5.0862 & 5.6416 & TRN & \\
\hline CHEMBL1535801 & 688239 & 5.4362 & 5.4121 & TST & \\
\hline CHEMBL1596750 & 688239 & 5.7362 & 5.4545 & TRN & \\
\hline CHEMBL1323443 & 688239 & 7.0362 & 5.4836 & TRN & \\
\hline CHEMBL1500431 & 688239 & 6.3362 & 5.4072 & TST & \\
\hline CHEMBL1505554 & 688239 & 5.3862 & 5.5076 & TRN & \\
\hline CHEMBL1559474 & 688239 & 6.7862 & 5.6992 & TRN & \\
\hline CHEMBL1300806 & 688239 & 5.2862 & 5.5021 & TRN & \\
\hline CHEMBL1490507 & 688239 & 8.3372 & 5.6137 & TRN & \\
\hline CHEMBL1482788 & 688239 & 4.5362 & 5.53700 & 0000000001 & TRN \\
\hline CHEMBL1451078 & 688239 & 4.7862 & 5.3446 & TRN & \\
\hline CHEMBL1544227 & 688239 & 5.1862 & 5.4877 & TRN & \\
\hline CHEMBL1596871 & 688239 & 4.8362 & 5.3535 & TST & \\
\hline CHEMBL1436965 & 688239 & 4.7862 & 5.4861 & TRN & \\
\hline CHEMBL1544203 & 688239 & 4.6862 & 5.4777 & TRN & \\
\hline CHEMBL1342833 & 688239 & 5.4862 & 5.392 & TRN & \\
\hline CHEMBL1306218 & 688239 & 4.5362 & 5.4002 & TRN & \\
\hline CHEMBL1490780 & 688239 & 4.5362 & 5.4126 & TST & \\
\hline CHEMBL1456480 & 688239 & 4.8362 & 5.66799 & 9999999999 & TRN \\
\hline CHEMBL1488579 & 688239 & 6.0362 & 5.6935 & TRN & \\
\hline CHEMBL1598831 & 688239 & 4.9862 & 5.4313 & TST & \\
\hline CHEMBL1498990 & 688239 & 5.8362 & 5.5114 & TRN & \\
\hline CHEMBL3194581 & 688239 & 4.5362 & 5.276 & TST & \\
\hline CHEMBL1595012 & 688239 & 4.7362 & 5.4491 & TRN & \\
\hline CHEMBL1544005 & 688239 & 5.7362 & 5.4872 & TRN & \\
\hline CHEMBL1529247 & 688239 & 4.5362 & 5.5942 & TRN & \\
\hline CHEMBL1471093 & 688239 & 6.2362 & 5.58 & TST & \\
\hline CHEMBL1390795 & 688239 & 5.4362 & 5.5811 & TRN & \\
\hline CHEMBL1484376 & 688239 & 4.5362 & 5.5833 & TRN & \\
\hline CHEMBL1450031 & 688239 & 5.2862 & 5.4541 & TST & \\
\hline CHEMBL1449522 & 688239 & 4.8362 & 5.5001 & TRN & \\
\hline CHEMBL1481008 & 688239 & 4.8362 & 5.5449 & TRN & \\
\hline CHEMBL1429324 & 688239 & 4.5362 & 5.4789 & TRN & \\
\hline CHEMBL1445048 & 688239 & 4.7362 & 5.4982 & TRN & \\
\hline CHEMBL1582936 & 688239 & 6.9863 & 5.6004 & TST & \\
\hline
\end{tabular}


Supplemental Table S2.txt

\begin{tabular}{|c|c|c|c|c|}
\hline CHEMBL1466041 & 688239 & 6.9863 & 5.5223 & TRN \\
\hline CHEMBL1464140 & 688239 & 6.2362 & 5.3755 & TRN \\
\hline CHEMBL3189878 & 688239 & 4.5862 & 5.3091 & TRN \\
\hline CHEMBL1341133 & 688239 & 5.1862 & 5.5848 & TRN \\
\hline CHEMBL1370128 & 688239 & 4.4862 & 5.2841 & TRN \\
\hline CHEMBL1311498 & 688239 & 4.8862 & 5.6235 & TRN \\
\hline CHEMBL1445320 & 688239 & 6.1362 & 5.3044 & TRN \\
\hline CHEMBL1484453 & 688239 & 5.3362 & 5.5031 & TRN \\
\hline CHEMBL1369531 & 688239 & 5.2862 & 5.5447 & TRN \\
\hline CHEMBL1545673 & 688239 & 8.3372 & 5.5294 & TST \\
\hline CHEMBL1450844 & 688239 & 8.3372 & \multicolumn{2}{|c|}{5.452000000000001} \\
\hline CHEMBL1409977 & 688239 & 4.9362 & 5.3384 & TRN \\
\hline CHEMBL1371370 & 688239 & 7.0362 & 5.4979 & TST \\
\hline CHEMBL1540859 & 688239 & 6.6362 & 5.4586 & TRN \\
\hline CHEMBL1397830 & 688239 & 5.5862 & 5.4617 & TRN \\
\hline CHEMBL1506924 & 688239 & 5.2362 & 5.5965 & TRN \\
\hline CHEMBL1469505 & 688239 & 4.7362 & 5.4626 & TRN \\
\hline CHEMBL1600950 & 688239 & 5.9362 & 5.5829 & TRN \\
\hline CHEMBL1384516 & 688239 & 6.9363 & 5.6281 & TRN \\
\hline CHEMBL 2369305 & 688239 & 5.3862 & 5.4905 & TST \\
\hline CHEMBL1299342 & 688239 & 5.0862 & 5.3404 & TST \\
\hline CHEMBL1529093 & 688239 & 6.5363 & 5.3652 & TST \\
\hline CHEMBL1525766 & 688239 & 4.5362 & 5.4213 & TRN \\
\hline CHEMBL1439424 & 688239 & 4.5862 & 5.4137 & TST \\
\hline CHEMBL1352886 & 688239 & 5.1862 & 5.6134 & TRN \\
\hline CHEMBL1431394 & 688239 & 6.1362 & 5.4605 & TRN \\
\hline CHEMBL1456800 & 688239 & 5.1862 & 5.3532 & TST \\
\hline CHEMBL1358243 & 688239 & 4.5862 & 5.4361 & TRN \\
\hline CHEMBL3208417 & 688239 & 6.6362 & 5.4508 & TRN \\
\hline CHEMBL1410772 & 688239 & 6.9863 & 5.4607 & TRN \\
\hline CHEMBL1602898 & 688239 & 4.4362 & 5.54 & TRN \\
\hline CHEMBL1607476 & 688239 & 5.6862 & 5.471 & TRN \\
\hline CHEMBL3191208 & 688239 & 4.5362 & 5.474 & TRN \\
\hline CHEMBL1430195 & 688239 & 5.7362 & 5.45200 & 000000001 \\
\hline CHEMBL1376146 & 688239 & 4.5362 & 5.6079 & TST \\
\hline CHEMBL1420659 & 688239 & 4.8862 & 5.4788 & TRN \\
\hline CHEMBL1588299 & 688239 & 4.65 & 5.6377 & TRN \\
\hline CHEMBL1338792 & 688239 & 4.7862 & 5.5189 & TRN \\
\hline CHEMBL1343121 & 688239 & 5.2362 & 5.5352 & TST \\
\hline CHEMBL1564342 & 688239 & 5.7862 & 5.5223 & TST \\
\hline CHEMBL1519009 & 688239 & 4.8862 & 5.6266 & TRN \\
\hline CHEMBL1435182 & 688239 & 4.8862 & 5.5128 & TRN \\
\hline CHEMBL1608353 & 688239 & 4.5362 & 5.4477 & TRN \\
\hline CHEMBL1468613 & 688239 & 4.5362 & 5.5042 & TRN \\
\hline CHEMBL1433335 & 688239 & 4.9362 & 5.4535 & TRN \\
\hline CHEMBL1332516 & 688239 & 4.7862 & 5.5079 & TRN \\
\hline CHEMBL1578566 & 688239 & 8.3872 & 5.4482 & TRN \\
\hline CHEMBL1598168 & 688239 & 8.3372 & 5.5057 & TRN \\
\hline
\end{tabular}


Supplemental Table S2.txt

\begin{tabular}{|c|c|c|c|c|}
\hline & & 862 & & \\
\hline CHEMBL1506250 & 88239 & .6362 & 5.4655 & \\
\hline HEMBL1490942 & 239 & 5362 & & \\
\hline 73 & 239 & & 994 & \\
\hline EMBL: & 3239 & 862 & 445 & \\
\hline IEMBL1361161 & 88239 & 4365 & 3503 & \\
\hline HEMBL3211764 & 88239 & 4.5362 & 4785 & \\
\hline HEMBL1 & & & 326 & \\
\hline EMBL & 239 & .5362 & 257 & \\
\hline IEMBL & 239 & .5362 & 144 & \\
\hline AEMBL1587619 & 88239 & .5362 & 314 & \\
\hline AEMBL1441874 & 8239 & .1862 & & \\
\hline HEMBL 1 & 39 & & & \\
\hline AEMBL & 239 & 362 & & \\
\hline AEMBL & 239 & 362 & & \\
\hline 41389 & 239 & 8.1871 & 217 & \\
\hline HEMBL: & & 4.5862 & & \\
\hline AEMBL & & 51 & & \\
\hline HEMBL & & & & \\
\hline IEMB & & & & \\
\hline IEMBL & & 62 & & \\
\hline AEMBL & & & & \\
\hline AEMBL & 9 & 52 & & \\
\hline AEMBL & & & & \\
\hline IEMB & & & & \\
\hline IEMBL & & 862 & & \\
\hline AEMBL: & & & & \\
\hline AEMBL & & & & \\
\hline IEMB & & & & \\
\hline 89 & & 62 & & \\
\hline 08462 & & & & \\
\hline 82568 & & 362 & & \\
\hline 73 & & & & \\
\hline 0 & & & & \\
\hline 920 & & & & RN \\
\hline 07652 & & & & \\
\hline AEMBL] & & & & \\
\hline 7 & & & & \\
\hline 1 & & & & \\
\hline 273 & & & & \\
\hline 02716 & & 862 & & \\
\hline AEMBL & & 51 & & \\
\hline & & & & \\
\hline CHEMBL: & & & & \\
\hline CHEMBL & & 4.4862 & & $\mathrm{RI}$ \\
\hline 92314 & 39 & 362 & 64 & \\
\hline ו & & & & \\
\hline CHEMBL1499831 & & & & \\
\hline
\end{tabular}

Page 1714 
Supplemental Table S2.txt

\begin{tabular}{|c|c|c|c|c|c|}
\hline CHEMBL1588266 & 688239 & 4.5362 & 5.3368 & TRN & \\
\hline CHEMBL1334760 & 688239 & 7.0362 & 5.5157 & TRN & \\
\hline CHEMBL1330842 & 688239 & 4.8362 & 5.6359 & TRN & \\
\hline CHEMBL1430800 & 688239 & 6.1362 & 5.4036 & TST & \\
\hline CHEMBL1512972 & 688239 & 6.4362 & 5.5322 & TRN & \\
\hline CHEMBL1404731 & 688239 & 5.7362 & 5.4879 & TRN & \\
\hline CHEMBL1556146 & 688239 & 5.8362 & 5.3981 & TST & \\
\hline CHEMBL1375357 & 688239 & 4.75 & 5.4242 & TRN & \\
\hline CHEMBL1468708 & 688239 & 5.5362 & 5.5185 & TRN & \\
\hline CHEMBL1517157 & 688239 & 5.1362 & 5.5712 & TRN & \\
\hline CHEMBL1456783 & 688239 & 4.5362 & 5.3255 & TRN & \\
\hline CHEMBL1966166 & 688239 & 4.6362 & 5.2546 & TRN & \\
\hline CHEMBL1466943 & 688239 & 5.3362 & 5.5474 & TRN & \\
\hline CHEMBL1366647 & 688239 & 6.0862 & 5.4137 & TRN & \\
\hline CHEMBL1305713 & 688239 & 5.7362 & 5.6335 & TRN & \\
\hline CHEMBL1492445 & 688239 & 6.1862 & 5.4384 & TRN & \\
\hline CHEMBL1299671 & 688239 & 4.5362 & 5.4575 & TST & \\
\hline CHEMBL1426551 & 688239 & 4.7362 & 5.4862 & TRN & \\
\hline CHEMBL1585529 & 688239 & 5.6862 & 5.539 & TST & \\
\hline CHEMBL1601711 & 688239 & 4.7862 & 5.44600 & 0000000001 & TRN \\
\hline CHEMBL1500844 & 688239 & 5.2862 & 5.362 & TST & \\
\hline CHEMBL1533529 & 688239 & 4.7862 & 5.5656 & TST & \\
\hline CHEMBL1600344 & 688239 & 4.5362 & 5.4718 & TRN & \\
\hline CHEMBL1374348 & 688239 & 5.5362 & 5.4633 & TST & \\
\hline CHEMBL1467870 & 688239 & 4.5362 & 5.4477 & TST & \\
\hline CHEMBL1318514 & 688239 & 6.8861 & 5.3902 & TRN & \\
\hline CHEMBL1307988 & 688239 & 4.5362 & 5.4544 & TRN & \\
\hline CHEMBL1613208 & 688239 & 6.3362 & 5.5514 & TRN & \\
\hline CHEMBL1507561 & 688239 & 4.5362 & 5.4687 & TRN & \\
\hline CHEMBL1439200 & 688239 & 4.5362 & 5.4699 & TST & \\
\hline CHEMBL1415580 & 688239 & 4.7362 & 5.3847 & TST & \\
\hline CHEMBL1321790 & 688239 & 6.6861 & 5.3211 & TRN & \\
\hline CHEMBL1507869 & 688239 & 5.2862 & 5.4763 & TRN & \\
\hline CHEMBL1530718 & 688239 & 5.2862 & 5.5047 & TST & \\
\hline CHEMBL1399302 & 688239 & 5.7362 & 5.6176 & TST & \\
\hline CHEMBL1582659 & 688239 & 5.5362 & 5.3996 & TST & \\
\hline CHEMBL1515422 & 688239 & 5.7362 & 5.4615 & TRN & \\
\hline CHEMBL3194302 & 688239 & 4.5362 & 5.6238 & TST & \\
\hline CHEMBL1378229 & 688239 & 6.3863 & 5.5993 & TRN & \\
\hline CHEMBL1305100 & 688239 & 6.7862 & 5.6842 & TRN & \\
\hline CHEMBL1520586 & 688239 & 4.5362 & 5.4675 & TRN & \\
\hline CHEMBL1420008 & 688239 & 6.0862 & 5.3322 & TST & \\
\hline CHEMBL1374365 & 688239 & 6.9863 & 5.416 & TST & \\
\hline CHEMBL1577359 & 688239 & 4.6862 & 5.5278 & TRN & \\
\hline CHEMBL1351592 & 688239 & 6.2362 & 5.3755 & TRN & \\
\hline CHEMBL139935 & 688239 & 4.5362 & 5.4101 & TRN & \\
\hline CHEMBL1605664 & 688239 & 5.6362 & 5.3142 & TRN & \\
\hline CHEMBL1414927 & 688239 & 5.0862 & 5.5698 & TRN & \\
\hline
\end{tabular}


Supplemental Table S2.txt

\begin{tabular}{|c|c|c|c|c|}
\hline CHEMBL1387133 & 688239 & 5.5362 & 5.5266 & TRN \\
\hline CHEMBL1301347 & 688239 & 4.5862 & 5.4867 & TST \\
\hline CHEMBL1321453 & 688239 & 4.6862 & 5.566 & TRN \\
\hline CHEMBL1331452 & 688239 & 5.1862 & 5.5617 & TRN \\
\hline CHEMBL1608509 & 688239 & 4.5362 & 5.5092 & TRN \\
\hline CHEMBL1214270 & 688239 & 5.1862 & 5.596 & TRN \\
\hline CHEMBL1989897 & 688239 & 4.6862 & 5.3168 & TST \\
\hline CHEMBL1597779 & 688239 & 5.8362 & 5.604 & TRN \\
\hline CHEMBL1477946 & 688239 & 4.7362 & 5.577999 & 9999999999 \\
\hline CHEMBL1440200 & 688239 & 4.4862 & 5.4345 & TRN \\
\hline CHEMBL1366804 & 688239 & 5.3362 & 5.5101 & TRN \\
\hline CHEMBL1541163 & 688239 & 8.3372 & 5.4917 & TRN \\
\hline CHEMBL1371602 & 688239 & 5.1862 & 5.5346 & TRN \\
\hline CHEMBL1378422 & 688239 & 4.5862 & 5.3054 & TRN \\
\hline CHEMBL1302728 & 688239 & 5.6862 & 5.419 & TRN \\
\hline CHEMBL1335110 & 688239 & 4.8862 & 5.4271 & TST \\
\hline CHEMBL1598478 & 688239 & 6.8861 & 5.4532 & TST \\
\hline CHEMBL1571074 & 688239 & 4.8362 & 5.5215 & TRN \\
\hline CHEMBL1303673 & 688239 & 6.0362 & 5.5187 & TRN \\
\hline CHEMBL1314107 & 688239 & 4.8362 & 5.5816 & TRN \\
\hline CHEMBL1564620 & 688239 & 6.9363 & 5.553 & TST \\
\hline CHEMBL3193759 & 688239 & 4.6362 & 5.2946 & TST \\
\hline CHEMBL1562156 & 688239 & 4.5362 & 5.4882 & TRN \\
\hline CHEMBL1328762 & 688239 & 6.1362 & 5.4807 & TRN \\
\hline CHEMBL1330778 & 688239 & 4.4862 & 5.4123 & TRN \\
\hline CHEMBL1516409 & 688239 & 4.4862 & 5.3636 & TRN \\
\hline CHEMBL1353992 & 688239 & 5.4862 & 5.517 & TRN \\
\hline CHEMBL1382997 & 688239 & 5.0862 & 5.5971 & TST \\
\hline CHEMBL1355782 & 688239 & 4.5362 & 5.4621 & TST \\
\hline CHEMBL1589706 & 688239 & 5.8362 & 5.5692 & TRN \\
\hline CHEMBL1462446 & 688239 & 5.8862 & 5.6151 & TRN \\
\hline CHEMBL1540238 & 688239 & 4.6362 & 5.5973 & TRN \\
\hline CHEMBL1486952 & 688239 & 4.9362 & 5.4412 & TRN \\
\hline CHEMBL1485216 & 688239 & 5.2862 & 5.4365 & TRN \\
\hline CHEMBL1417532 & 688239 & 4.7862 & 5.5253 & TRN \\
\hline CHEMBL 3193271 & 688239 & 4.5362 & 5.517 & TRN \\
\hline CHEMBL1421446 & 688239 & 6.6362 & 5.3014 & TRN \\
\hline CHEMBL1505252 & 688239 & 5.3 & 5.5212 & TRN \\
\hline CHEMBL1511968 & 688239 & 8.3372 & 5.3555 & TRN \\
\hline CHEMBL1410661 & 688239 & 6.4862 & 5.5095 & TRN \\
\hline CHEMBL1483204 & 688239 & 7.8861 & 5.4785 & TST \\
\hline CHEMBL1464639 & 688239 & 5.8362 & \multicolumn{2}{|c|}{5.542999999999999} \\
\hline CHEMBL1445330 & 688239 & 5.5862 & 5.3716 & TST \\
\hline CHEMBL1391776 & 688239 & 6.5363 & 5.4655 & TRN \\
\hline CHEMBL1301435 & 688239 & 4.7362 & 5.3723 & TRN \\
\hline CHEMBL1548291 & 688239 & 4.5362 & 5.3917 & TST \\
\hline CHEMBL1375057 & 688239 & 4.7362 & 5.5597 & TRN \\
\hline CHEMBL1388424 & 688239 & 4.5362 & 5.4028 & TRN \\
\hline
\end{tabular}


Supplemental Table S2.txt

\begin{tabular}{|c|c|c|c|c|}
\hline CHEMBL1319544 & 688239 & 5.2362 & 5.3002 & TRN \\
\hline CHEMBL3207930 & 688239 & 4.8862 & 5.3537 & TST \\
\hline CHEMBL3189297 & 688239 & 6.8362 & 5.2904 & TST \\
\hline CHEMBL1584227 & 688239 & 4.6362 & 5.5201 & TST \\
\hline CHEMBL1385692 & 688239 & 4.5862 & 5.5038 & TRN \\
\hline CHEMBL1536445 & 688239 & 4.5362 & 5.4422 & TRN \\
\hline CHEMBL1416642 & 688239 & 5.2862 & 5.4696 & TRN \\
\hline CHEMBL1440401 & 688239 & 4.5862 & 5.3573 & TST \\
\hline CHEMBL1346249 & 688239 & 5.1862 & 5.5341 & TST \\
\hline CHEMBL1438363 & 688239 & 6.3863 & 5.3767 & TRN \\
\hline CHEMBL1466935 & 688239 & 4.7862 & 5.5027 & TRN \\
\hline CHEMBL1337210 & 688239 & 4.7862 & 5.4979 & TRN \\
\hline CHEMBL1397985 & 688239 & 5.3862 & 5.4934 & TRN \\
\hline CHEMBL1562127 & 688239 & 6.1862 & 5.4498 & TRN \\
\hline CHEMBL1395972 & 688239 & 4.5362 & 5.3785 & TST \\
\hline CHEMBL1586698 & 688239 & 4.6862 & 5.5509 & TRN \\
\hline CHEMBL1352196 & 688239 & 6.1862 & 5.4351 & TST \\
\hline CHEMBL1459312 & 688239 & 5.7362 & 5.4509 & TRN \\
\hline CHEMBL1312974 & 688239 & 4.5362 & 5.5774 & TST \\
\hline CHEMBL1582115 & 688239 & 5.3862 & 5.6252 & TRN \\
\hline CHEMBL1275727 & 688239 & 6.9863 & 5.4481 & TRN \\
\hline CHEMBL1538044 & 688239 & 6.0362 & 5.2985 & TRN \\
\hline CHEMBL1610590 & 688239 & 6.2362 & 5.5238 & TRN \\
\hline CHEMBL1601964 & 688239 & 4.5362 & 5.5441 & TRN \\
\hline CHEMBL1422885 & 688239 & 8.3372 & 5.4577 & TST \\
\hline CHEMBL1359950 & 688239 & 4.5362 & 5.5147 & TST \\
\hline CHEMBL1482722 & 688239 & 7.5361 & 5.5218 & TRN \\
\hline CHEMBL1513575 & 688239 & 4.9362 & 5.5272 & TRN \\
\hline CHEMBL1403382 & 688239 & 4.7862 & 5.2895 & TRN \\
\hline CHEMBL1583898 & 688239 & 5.0862 & 5.4653 & TRN \\
\hline CHEMBL1404663 & 688239 & 6.1362 & 5.4352 & TST \\
\hline CHEMBL1598924 & 688239 & 7.0862 & 5.42700 & 30000000005 \\
\hline CHEMBL1324399 & 688239 & 5.0362 & 5.5333 & TST \\
\hline CHEMBL1342392 & 688239 & 6.5363 & 5.37299 & 9999999999 \\
\hline CHEMBL1402531 & 688239 & 5.1862 & 5.3714 & TRN \\
\hline CHEMBL3195034 & 688239 & 4.9362 & 5.5016 & TRN \\
\hline CHEMBL1497716 & 688239 & 5.5862 & 5.4544 & TRN \\
\hline CHEMBL1425880 & 688239 & 5.1862 & 5.5428 & TRN \\
\hline CHEMBL1362665 & 688239 & 5.1362 & 5.3916 & TRN \\
\hline CHEMBL1371983 & 688239 & 5.2862 & 5.4521 & TST \\
\hline CHEMBL1608594 & 688239 & 5.1862 & 5.4224 & TRN \\
\hline CHEMBL1578651 & 688239 & 5.5862 & 5.4723 & TST \\
\hline CHEMBL1407612 & 688239 & 5.1862 & 5.4363 & TST \\
\hline CHEMBL1390418 & 688239 & 5.7362 & 5.4203 & TRN \\
\hline CHEMBL1588760 & 688239 & 4.4862 & 5.3149 & TRN \\
\hline CHEMBL1597900 & 688239 & 5.0362 & 5.6016 & TRN \\
\hline CHEMBL1365719 & 688239 & 6.8861 & 5.3709 & TRN \\
\hline CHEMBL 3210742 & 688239 & 4.5362 & 5.5967 & TRN \\
\hline
\end{tabular}


Supplemental Table S2.txt

\begin{tabular}{|c|c|c|c|c|}
\hline 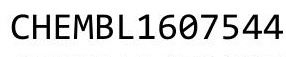 & & & & \\
\hline HEMBL1473325 & 88239 & 9362 & 4366 & \\
\hline HEMBL1466401 & 88239 & 862 & & \\
\hline 762 & & & 987 & \\
\hline EMBL13 & & & 241 & \\
\hline HEMBL1550941 & 88239 & 862 & 5372 & \\
\hline HEMBL1561499 & 88239 & .8861 & 5124 & \\
\hline HEMBL1419537 & & & & \\
\hline IEMBL1 & 39 & 499 & 4981 & \\
\hline IEMBL15 & 39 & 362 & 4853 & \\
\hline HEMBL1478204 & 88239 & 362 & 4063 & \\
\hline HEMBL1592448 & 39 & 362 & .4829 & \\
\hline HEMBL1517683 & 39 & 362 & 4826 & \\
\hline AEMBL13 & 39 & & & \\
\hline AEMBL14 & 39 & & & \\
\hline HEMBL1586957 & 39 & 867 & 173 & \\
\hline HEMBL1498195 & 39 & & & \\
\hline HEMBL1583113 & 9 & 62 & 21 & \\
\hline 005 & 39 & & & \\
\hline 012 & 39 & 62 & & \\
\hline HEMBL1598915 & 39 & 62 & 58 & \\
\hline HEMBL1303834 & 39 & & & \\
\hline HEMBL15 & 9 & 62 & & \\
\hline HEMBL 14 & & & & \\
\hline 555 & & & & RN \\
\hline HEMBL15 & 39 & & & \\
\hline HEMBL1609137 & 39 & & & RN \\
\hline HEMBL14 & 9 & 62 & 82 & \\
\hline HEM & & & 81 & \\
\hline 558 & & 52 & 64 & $\mathrm{RN}$ \\
\hline HEMBL1427881 & 9 & & & RN \\
\hline HEMBL1492870 & 39 & 362 & & IST \\
\hline HEMBL1: & & & & RN \\
\hline HEM & 9 & & & \\
\hline HEM & & & 21 & $\mathrm{RN}$ \\
\hline HEMBL1544467 & 39 & & & RN \\
\hline HEMBL1455749 & 39 & 62 & 404 & RN \\
\hline 0 & & & 511 & KIV \\
\hline 4 & 39 & & & RN \\
\hline HEMBL1485699 & & & & RN \\
\hline HEMBL1551916 & 39 & 362 & 138 & ST \\
\hline HEMBL15 & 39 & 62 & & RN \\
\hline 12 & & & & \\
\hline CHEMBL1598294 & & & 5.5525 & RN \\
\hline HEMBL1474057 & & & .5398 & RN \\
\hline HEMBL3208134 & 39 & 862 & 5.3472 & \\
\hline HEMBL 14 & & & & \\
\hline . & & & & \\
\hline
\end{tabular}

Page 1718 
Supplemental Table S2.txt

\begin{tabular}{|c|c|c|c|c|c|}
\hline CHEMBL1497073 & 688239 & 7.5361 & 5.476 & TST & \\
\hline CHEMBL1595052 & 688239 & 5.3862 & 5.2673 & TRN & \\
\hline CHEMBL1415153 & 688239 & 4.6862 & 5.4943 & TST & \\
\hline CHEMBL3207989 & 688239 & 7.0362 & 5.6783 & TRN & \\
\hline CHEMBL1463158 & 688239 & 5.4362 & 5.6242 & TRN & \\
\hline CHEMBL1350185 & 688239 & 4.6362 & 5.4275 & TST & \\
\hline CHEMBL1428076 & 688239 & 4.5362 & 5.6599 & TRN & \\
\hline CHEMBL1495085 & 688239 & 8.3372 & 5.56 & TST & \\
\hline CHEMBL1361517 & 688239 & 4.5862 & 5.5558 & TRN & \\
\hline CHEMBL1548866 & 688239 & 5.4362 & 5.54 & TRN & \\
\hline CHEMBL1485924 & 688239 & 6.0362 & 5.5735 & TRN & \\
\hline CHEMBL1513726 & 688239 & 5.5862 & 5.4583 & TST & \\
\hline CHEMBL1580418 & 688239 & 4.6862 & 5.5836 & TRN & \\
\hline CHEMBL1516490 & 688239 & 4.7362 & 5.6533 & TRN & \\
\hline CHEMBL1541778 & 688239 & 6.1862 & 5.5947 & TST & \\
\hline CHEMBL1451862 & 688239 & 4.6862 & 5.5281 & TRN & \\
\hline CHEMBL1323875 & 688239 & 4.5362 & 5.4386 & TST & \\
\hline CHEMBL1353970 & 688239 & 5.1362 & 5.5565 & TRN & \\
\hline CHEMBL1337567 & 688239 & 5.5362 & 5.5643 & TST & \\
\hline CHEMBL3211126 & 688239 & 6.9363 & 5.405 & TRN & \\
\hline CHEMBL1340751 & 688239 & 4.7362 & 5.4747 & TRN & \\
\hline CHEMBL1394755 & 688239 & 5.6362 & 5.3144 & TRN & \\
\hline CHEMBL1463266 & 688239 & 4.4862 & 5.6359 & TRN & \\
\hline CHEMBL1356529 & 688239 & 4.7362 & 5.5566 & TRN & \\
\hline CHEMBL1308918 & 688239 & 5.5362 & 5.5478 & TRN & \\
\hline CHEMBL1421554 & 688239 & 5.9362 & 5.5825 & TST & \\
\hline CHEMBL1345364 & 688239 & 4.5862 & 5.5724 & TRN & \\
\hline CHEMBL1391331 & 688239 & 5.7362 & 5.648 & TST & \\
\hline CHEMBL1528575 & 688239 & 5.1862 & 5.4582 & TRN & \\
\hline CHEMBL1334923 & 688239 & 6.0862 & 5.4403 & TST & \\
\hline CHEMBL1481299 & 688239 & 5.6362 & 5.5968 & TRN & \\
\hline CHEMBL3196738 & 688239 & 4.5362 & 5.6514 & TRN & \\
\hline CHEMBL 3207781 & 688239 & 4.5362 & 5.6842 & TRN & \\
\hline CHEMBL1334017 & 688239 & 4.4862 & 5.4959 & TRN & \\
\hline CHEMBL1982290 & 688239 & 4.9862 & 5.4012 & TRN & \\
\hline CHEMBL1537025 & 688239 & 5.0862 & 5.4165 & TST & \\
\hline CHEMBL1569634 & 688239 & 5.2862 & 5.6309 & TST & \\
\hline CHEMBL1585232 & 688239 & 6.3362 & 5.6073 & TRN & \\
\hline CHEMBL1356660 & 688239 & 5.7362 & 5.4963 & TRN & \\
\hline CHEMBL1300688 & 688239 & 6.3863 & 5.5366 & TRN & \\
\hline CHEMBL1609605 & 688239 & 6.4862 & 5.5596 & TRN & \\
\hline CHEMBL1585830 & 688239 & 5.4362 & 5.513999 & 9999999999 & TST \\
\hline CHEMBL1581434 & 688239 & 6.0362 & 5.5243 & TRN & \\
\hline CHEMBL1445104 & 688239 & 5.0862 & 5.6173 & TRN & \\
\hline CHEMBL1500934 & 688239 & 4.4862 & 5.4013 & TRN & \\
\hline CHEMBL1304476 & 688239 & 4.5362 & 5.5359 & TST & \\
\hline CHEMBL1595670 & 688239 & 7.9355 & 5.452000 & 0000000001 & TST \\
\hline CHEMBL1406953 & 688239 & 8.28399 & 99999999 & $99 \quad 5.4116$ & TST \\
\hline
\end{tabular}




\begin{tabular}{|c|c|c|c|c|c|}
\hline \multicolumn{6}{|c|}{ supplementa } \\
\hline CHEMBL1504660 & 688239 & 5.7862 & 5.4791 & TRN & \\
\hline CHEMBL1479786 & 688239 & 4.5362 & 5.4776 & TST & \\
\hline CHEMBL1323501 & 688239 & 6.2362 & 5.4219 & TST & \\
\hline CHEMBL1410537 & 688239 & 4.5362 & 5.5414 & TRN & \\
\hline CHEMBL85826 & 688239 & 6.1362 & 5.4629 & TST & \\
\hline CHEMBL1344986 & 688239 & 7.1361 & 5.5689 & TRN & \\
\hline CHEMBL1595283 & 688239 & 5.1362 & 5.5216 & TRN & \\
\hline CHEMBL1469212 & 688239 & 4.5362 & 5.54 & TRN & \\
\hline CHEMBL1408012 & 688239 & 5.1862 & 5.6318 & TRN & \\
\hline CHEMBL1525563 & 688239 & 5.0862 & 5.4434 & TRN & \\
\hline CHEMBL1594842 & 688239 & 5.4362 & 5.6173 & TRN & \\
\hline CHEMBL1423342 & 688239 & 5.3862 & 5.38299 & 9999999999 & TST \\
\hline CHEMBL1338828 & 688239 & 4.5362 & 5.4695 & TST & \\
\hline CHEMBL3195193 & 688239 & 5.1862 & 5.4246 & TRN & \\
\hline CHEMBL1465524 & 688239 & 4.8362 & 5.3947 & TST & \\
\hline CHEMBL3195596 & 688239 & 8.3372 & 5.4876 & TST & \\
\hline CHEMBL1399559 & 688239 & 4.4862 & 5.4989 & TRN & \\
\hline CHEMBL1400048 & 688239 & 6.1362 & 5.4115 & TRN & \\
\hline CHEMBL 3214150 & 688239 & 5.5362 & 5.4581 & TRN & \\
\hline CHEMBL1312457 & 688239 & 6.1362 & 5.4898 & TRN & \\
\hline CHEMBL1320012 & 688239 & 5.8362 & 5.5289 & TRN & \\
\hline CHEMBL1603474 & 688239 & 5.9862 & 5.5282 & TRN & \\
\hline CHEMBL3211349 & 688239 & 4.6862 & 5.3879 & TRN & \\
\hline CHEMBL1459632 & 688239 & 5.2862 & 5.4302 & TRN & \\
\hline CHEMBL1312849 & 688239 & 5.9862 & 5.4835 & TST & \\
\hline CHEMBL3212549 & 688239 & 5.2362 & 5.562 & TST & \\
\hline CHEMBL1502348 & 688239 & 4.7862 & 5.3535 & TST & \\
\hline CHEMBL1589645 & 688239 & 5.4362 & 5.4242 & TRN & \\
\hline CHEMBL1361157 & 688239 & 5.3862 & 5.4763 & TRN & \\
\hline CHEMBL1335075 & 688239 & 4.7862 & 5.3943 & TRN & \\
\hline CHEMBL1329747 & 688239 & 6.8362 & 5.4929 & TRN & \\
\hline CHEMBL1610217 & 688239 & 8.1871 & 5.526 & TRN & \\
\hline CHEMBL1306519 & 688239 & 4.9862 & 5.44600 & 0000000001 & TRN \\
\hline CHEMBL1583940 & 688239 & 4.7362 & 5.5864 & TRN & \\
\hline CHEMBL1373499 & 688239 & 4.7862 & 5.4537 & TRN & \\
\hline CHEMBL1442972 & 688239 & 5.1862 & 5.5115 & TRN & \\
\hline CHEMBL1445458 & 688239 & 5.1362 & 5.5087 & TST & \\
\hline CHEMBL1381636 & 688239 & 5.2362 & 5.4713 & TRN & \\
\hline CHEMBL1377518 & 688239 & 4.5362 & 5.5136 & TRN & \\
\hline CHEMBL1403376 & 688239 & 5.9862 & 5.5704 & TRN & \\
\hline CHEMBL1432594 & 688239 & 7.0862 & 5.4934 & TST & \\
\hline CHEMBL1432855 & 688239 & 5.3362 & 5.53299 & 99999999995 & TRN \\
\hline CHEMBL1337744 & 688239 & 6.5862 & 5.5521 & TRN & \\
\hline CHEMBL1327727 & 688239 & 4.5362 & 5.3559 & TRN & \\
\hline CHEMBL1340546 & 688239 & 5.0862 & 5.4197 & TRN & \\
\hline CHEMBL1536079 & 688239 & 4.8862 & 5.4681 & TRN & \\
\hline CHEMBL1372489 & 688239 & 5.4362 & 5.4493 & TST & \\
\hline CHEMBL1373426 & 688239 & 4.7362 & 5.4996 & TRN & \\
\hline
\end{tabular}


Supplemental Table S2.txt

\begin{tabular}{|c|c|c|c|c|}
\hline CHEMBL1351574 & 688239 & 5.8862 & 5.4017 & TRN \\
\hline CHEMBL1569661 & 688239 & 5.5362 & 5.4467 & TRN \\
\hline CHEMBL1438624 & 688239 & 5.8862 & 5.4706 & TRN \\
\hline CHEMBL1607271 & 688239 & 4.7362 & 5.4645 & TRN \\
\hline CHEMBL1574879 & 688239 & 5.2362 & 5.4028 & TRN \\
\hline CHEMBL1367528 & 688239 & 6.0862 & 5.3594 & TST \\
\hline CHEMBL1433073 & 688239 & 5.0862 & 5.4179 & TST \\
\hline CHEMBL1349594 & 688239 & 6.1362 & 5.3631 & TRN \\
\hline CHEMBL3209593 & 688239 & 5.7862 & 5.3711 & TRN \\
\hline CHEMBL1364924 & 688239 & 5.3862 & 5.4065 & TRN \\
\hline CHEMBL1586041 & 688239 & 7.7352 & 5.5889 & TRN \\
\hline CHEMBL1454838 & 688239 & 8.3372 & 5.3809 & TRN \\
\hline CHEMBL357625 & 688239 & 4.5362 & 5.3136 & TRN \\
\hline CHEMBL1538933 & 688239 & 5.3862 & 5.4942 & TRN \\
\hline CHEMBL1501890 & 688239 & 4.4862 & 5.4524 & TRN \\
\hline CHEMBL1587227 & 688239 & 6.7361 & 5.4805 & TRN \\
\hline CHEMBL1406678 & 688239 & 4.6362 & 5.4674 & TRN \\
\hline CHEMBL1493281 & 688239 & 5.1362 & 5.3262 & TST \\
\hline CHEMBL1453917 & 688239 & 4.5362 & 5.5291 & TST \\
\hline CHEMBL1489177 & 688239 & 5.7862 & 5.5002 & TST \\
\hline CHEMBL1423145 & 688239 & 5.8362 & 5.5493 & TRN \\
\hline CHEMBL1486266 & 688239 & 4.5362 & 5.32 & TST \\
\hline CHEMBL1375962 & 688239 & 4.7 & 5.4474 & TRN \\
\hline CHEMBL1485407 & 688239 & 4.5362 & 5.4347 & TRN \\
\hline CHEMBL1408296 & 688239 & 4.5362 & 5.4713 & TRN \\
\hline CHEMBL1422920 & 688239 & 4.6862 & 5.4368 & TRN \\
\hline CHEMBL1438600 & 688239 & 5.6362 & 5.5964 & TST \\
\hline CHEMBL1499471 & 688239 & 5.9862 & 5.4544 & TST \\
\hline CHEMBL1478371 & 688239 & 5.1362 & 5.6635 & TST \\
\hline CHEMBL1523325 & 688239 & 4.6362 & 5.3987 & TRN \\
\hline CHEMBL1415409 & 688239 & 5.8862 & 5.5835 & TRN \\
\hline CHEMBL1535058 & 688239 & 5.1862 & 5.5059 & TST \\
\hline CHEMBL1304196 & 688239 & 4.8862 & 5.4787 & TRN \\
\hline CHEMBL1597071 & 688239 & 7.0862 & 5.4472 & TRN \\
\hline CHEMBL1412535 & 688239 & 6.4362 & 5.6365 & TST \\
\hline CHEMBL1435226 & 688239 & 5.3362 & 5.5479 & TRN \\
\hline CHEMBL1607118 & 688239 & 4.6362 & 5.4727 & TRN \\
\hline CHEMBL1330802 & 688239 & 4.9862 & 5.6215 & TST \\
\hline CHEMBL1313978 & 688239 & 4.7862 & 5.3059 & TRN \\
\hline CHEMBL1433229 & 688239 & 7.0862 & 5.5939 & TRN \\
\hline CHEMBL1562139 & 688239 & 5.2362 & 5.5052 & TRN \\
\hline CHEMBL1410749 & 688239 & 5.1862 & 5.5031 & TRN \\
\hline CHEMBL1406592 & 688239 & 4.5362 & 5.4556 & TRN \\
\hline CHEMBL1490759 & 688239 & 7.2366 & 5.5407 & TRN \\
\hline CHEMBL1535682 & 688239 & 4.5362 & 5.4798 & TRN \\
\hline CHEMBL3209796 & 688239 & 5.1862 & 5.5873 & TST \\
\hline CHEMBL1505897 & 688239 & 4.8 & \multicolumn{2}{|c|}{5.582000000000001} \\
\hline CHEMBL1463911 & 688239 & 6.8362 & 5.5915 & TST \\
\hline
\end{tabular}


Supplemental Table S2.txt

\begin{tabular}{|c|c|c|c|c|c|c|}
\hline CHEMBL1574456 & 688239 & 6.2862 & 5.3686 & TRN & & \\
\hline CHEMBL1405525 & 688239 & 6.1362 & 5.6813 & TST & & \\
\hline CHEMBL1520553 & 688239 & 5.4362 & 5.4897 & TRN & & \\
\hline CHEMBL3191961 & 688239 & 4.9862 & 5.4703 & TST & & \\
\hline CHEMBL1497570 & 688239 & 6.7361 & 5.5906 & TST & & \\
\hline CHEMBL1507604 & 688239 & 4.5362 & 5.4251 & TST & & \\
\hline CHEMBL1420532 & 688239 & 5.1862 & 5.4528 & TST & & \\
\hline CHEMBL1508299 & 688239 & 5.9362 & 5.4838 & TRN & & \\
\hline CHEMBL1439639 & 688239 & 4.6362 & 5.4577 & TST & & \\
\hline CHEMBL1319670 & 688239 & 5.3862 & 5.4846 & TRN & & \\
\hline CHEMBL1344645 & 688239 & 4.5362 & 5.5305 & TRN & & \\
\hline CHEMBL1329462 & 688239 & 5.8862 & 5.5933 & TRN & & \\
\hline CHEMBL1521793 & 688239 & 4.4862 & 5.5103 & TRN & & \\
\hline CHEMBL1575986 & 688239 & 5.1862 & 5.3777 & TRN & & \\
\hline CHEMBL1402464 & 688239 & 4.5362 & 5.5833 & TRN & & \\
\hline CHEMBL1324464 & 688239 & 6.3863 & 5.4948 & TRN & & \\
\hline CHEMBL1444313 & 688239 & 5.8862 & 5.4488 & TRN & & \\
\hline CHEMBL1309521 & 688239 & 5.5862 & 5.6735 & TRN & & \\
\hline CHEMBL1445364 & 688239 & 4.8362 & 5.5442 & TRN & & \\
\hline CHEMBL1303959 & 688239 & 4.5362 & 5.5828 & TRN & & \\
\hline CHEMBL1346788 & 688239 & 7.1361 & 5.481 & TRN & & \\
\hline CHEMBL1381555 & 688239 & 6.9363 & 5.5804 & TRN & & \\
\hline CHEMBL1590622 & 688239 & 6.0 & 5.4914 & TRN & & \\
\hline CHEMBL1331775 & 688239 & 5.2862 & 5.6027 & TRN & & \\
\hline CHEMBL1601980 & 688239 & 5.2362 & 5.5737 & TRN & & \\
\hline CHEMBL1303367 & 688239 & 5.3862 & 5.4998 & TRN & & \\
\hline CHEMBL 2003063 & 688239 & 4.5362 & 5.3409 & TRN & & \\
\hline CHEMBL1596535 & 688239 & 6.3863 & 5.5693 & TRN & & \\
\hline CHEMBL1311133 & 688239 & 6.9863 & 5.6463 & TRN & & \\
\hline CHEMBL1348591 & 688239 & 5.6862 & 5.5873 & TRN & & \\
\hline CHEMBL1389856 & 688239 & 5.1362 & 5.3565 & TRN & & \\
\hline CHEMBL1472159 & 688239 & 4.6362 & 5.4975 & TRN & & \\
\hline CHEMBL1324146 & 688239 & 8.28399 & 99999999 & 99 & 5.5544 & TST \\
\hline CHEMBL1577550 & 688239 & 4.6862 & 5.404 & TST & & \\
\hline CHEMBL1545332 & 688239 & 5.1862 & 5.4982 & TRN & & \\
\hline CHEMBL1275611 & 688239 & 4.7362 & 5.6558 & TRN & & \\
\hline CHEMBL1564474 & 688239 & 8.3372 & 5.555 & TRN & & \\
\hline CHEMBL1491248 & 688239 & 7.0862 & 5.4856 & TRN & & \\
\hline CHEMBL1467279 & 688239 & 5.4362 & 5.4708 & TRN & & \\
\hline CHEMBL1393863 & 688239 & 5.5862 & 5.5238 & TRN & & \\
\hline CHEMBL1544283 & 688239 & 4.5362 & 5.3525 & TRN & & \\
\hline CHEMBL1438430 & 688239 & 4.5362 & 5.5225 & TRN & & \\
\hline CHEMBL1389453 & 688239 & 6.1862 & 5.403 & TRN & & \\
\hline CHEMBL1400256 & 688239 & 4.5362 & 5.3716 & TRN & & \\
\hline CHEMBL1491942 & 688239 & 5.5862 & 5.5005 & TRN & & \\
\hline CHEMBL1573224 & 688239 & 8.2366 & 5.6225 & TRN & & \\
\hline CHEMBL1422268 & 688239 & 4.5362 & 5.5259 & TRN & & \\
\hline CHEMBL1465746 & 688239 & 5.1862 & 5.529 & TRN & & \\
\hline
\end{tabular}


Supplemental Table S2.txt

\begin{tabular}{|c|c|c|c|c|c|}
\hline CHEMBL 3193630 & 688239 & 4.8362 & 5.4332 & TRN & \\
\hline CHEMBL1388517 & 688239 & 6.2862 & 5.4451 & TST & \\
\hline CHEMBL142816 & 688239 & 5.1862 & 5.3735 & TST & \\
\hline CHEMBL1451399 & 688239 & 6.8362 & 5.5584 & TRN & \\
\hline CHEMBL1415331 & 688239 & \multicolumn{2}{|c|}{8.283999999999999} & 5.4223 & TRN \\
\hline CHEMBL1303180 & 688239 & 5.6862 & 5.494 & TRN & \\
\hline CHEMBL1453172 & 688239 & 5.6362 & 5.5633 & TRN & \\
\hline CHEMBL1579115 & 688239 & 6.8861 & 5.5478 & TRN & \\
\hline CHEMBL1426916 & 688239 & 4.6362 & 5.5025 & TRN & \\
\hline CHEMBL1326846 & 688239 & 6.8861 & 5.6206 & TRN & \\
\hline CHEMBL1517988 & 688239 & 4.8362 & 5.4929 & TRN & \\
\hline CHEMBL1442897 & 688239 & 4.5362 & 5.5436 & TRN & \\
\hline CHEMBL1323901 & 688239 & 4.5362 & 5.3631 & TRN & \\
\hline CHEMBL1550207 & 688239 & 6.0362 & 5.5442 & TST & \\
\hline CHEMBL1459833 & 688239 & 4.6362 & 5.4721 & TST & \\
\hline CHEMBL1384704 & 688239 & 5.1862 & 5.4849 & TST & \\
\hline CHEMBL1532586 & 688239 & 6.2362 & 5.588999 & 79999999 & \\
\hline CHEMBL1316554 & 688239 & 5.3862 & 5.4626 & TST & \\
\hline CHEMBL1420526 & 688239 & 5.7362 & 5.6148 & TRN & \\
\hline CHEMBL1519238 & 688239 & 4.8362 & 5.5382 & TRN & \\
\hline CHEMBL1406182 & 688239 & 5.1362 & 5.4095 & TRN & \\
\hline CHEMBL1556154 & 688239 & 4.7362 & 5.4054 & TST & \\
\hline CHEMBL1424534 & 688239 & 5.4362 & 5.5434 & TRN & \\
\hline CHEMBL1585072 & 688239 & 6.9363 & 5.3899 & TRN & \\
\hline CHEMBL1608002 & 688239 & 4.5862 & 5.4945 & TRN & \\
\hline CHEMBL1399083 & 688239 & 5.1862 & 5.3831 & TST & \\
\hline CHEMBL3197479 & 688239 & 4.5362 & 5.3748 & TRN & \\
\hline CHEMBL1462975 & 688239 & 6.2862 & 5.4856 & TRN & \\
\hline CHEMBL1307212 & 688239 & 5.5362 & 5.5728 & TRN & \\
\hline CHEMBL1422496 & 688239 & 5.1862 & 5.4792 & TRN & \\
\hline CHEMBL1367596 & 688239 & 4.7862 & 5.3491 & TST & \\
\hline CHEMBL1389712 & 688239 & 4.9862 & 5.322 & TST & \\
\hline CHEMBL1374166 & 688239 & 5.3862 & 5.3911 & TRN & \\
\hline CHEMBL1537953 & 688239 & 4.6862 & 5.5453 & TST & \\
\hline CHEMBL1599167 & 688239 & 5.5362 & 5.4894 & TST & \\
\hline CHEMBL1563977 & 688239 & 6.1362 & 5.487999 & 99999999995 & \\
\hline CHEMBL1350013 & 688239 & 6.9863 & 5.5332 & TRN & \\
\hline CHEMBL585425 & 688239 & 5.5362 & 5.4361 & TRN & \\
\hline CHEMBL1351642 & 688239 & 5.1862 & 5.3997 & TRN & \\
\hline CHEMBL1363898 & 688239 & 6.1362 & 5.4554 & TST & \\
\hline CHEMBL 3194192 & 688239 & 6.2862 & 5.4769 & TST & \\
\hline CHEMBL1989467 & 688239 & 5.7362 & 5.444 & TRN & \\
\hline CHEMBL1562238 & 688239 & 5.7362 & 5.4736 & TRN & \\
\hline CHEMBL1509603 & 688239 & 5.8862 & 5.3951 & TST & \\
\hline CHEMBL1575866 & 688239 & 6.1862 & 5.4543 & TST & \\
\hline CHEMBL1580362 & 688239 & 5.0362 & 5.5468 & TRN & \\
\hline CHEMBL1366313 & 688239 & 5.7362 & 5.4731 & TST & \\
\hline CHEMBL1487913 & 688239 & 5.4862 & 5.5951 & TRN & \\
\hline
\end{tabular}

Page 1723 
Supplemental Table S2.txt

\begin{tabular}{|c|c|c|c|c|c|}
\hline CHEMBL1530351 & 688239 & 4.5362 & 5.4033 & TST & \\
\hline CHEMBL1370088 & 688239 & 5.5362 & 5.4637 & TRN & \\
\hline CHEMBL1461524 & 688239 & 4.7862 & 5.3709 & TRN & \\
\hline CHEMBL1421550 & 688239 & 5.0862 & \multicolumn{2}{|c|}{5.3629999999999995} & TRN \\
\hline CHEMBL1391293 & 688239 & 5.1862 & 5.4416 & TRN & \\
\hline CHEMBL1399676 & 688239 & 6.1862 & 5.6039 & TST & \\
\hline CHEMBL1503882 & 688239 & 4.7362 & 5.4556 & TRN & \\
\hline CHEMBL1608759 & 688239 & 4.6862 & 5.5741 & TST & \\
\hline CHEMBL3191430 & 688239 & 4.6362 & 5.3858 & TRN & \\
\hline CHEMBL1607187 & 688239 & 4.7362 & 5.3339 & TRN & \\
\hline CHEMBL1534474 & 688239 & 5.5362 & 5.5795 & TRN & \\
\hline CHEMBL1532365 & 688239 & 6.1862 & 5.5065 & TRN & \\
\hline CHEMBL1425861 & 688239 & 7.3363 & 5.5725 & TRN & \\
\hline CHEMBL1331161 & 688239 & 4.5362 & 5.4046 & TST & \\
\hline CHEMBL1399453 & 688239 & 6.5363 & 5.6837 & TRN & \\
\hline CHEMBL1302609 & 688239 & 6.9363 & 5.516 & TST & \\
\hline CHEMBL1385436 & 688239 & 5.4862 & 5.4278 & TRN & \\
\hline CHEMBL1595819 & 688239 & 6.8861 & 5.5737 & TST & \\
\hline CHEMBL1548267 & 688239 & 6.6861 & 5.5696 & TST & \\
\hline CHEMBL1579613 & 688239 & 4.5362 & \multicolumn{2}{|c|}{5.4270000000000005} & TST \\
\hline CHEMBL1523207 & 688239 & 6.2362 & \multicolumn{2}{|c|}{5.4639999999999995} & TRN \\
\hline CHEMBL1504801 & 688239 & 5.8362 & 5.4735 & TRN & \\
\hline CHEMBL1575923 & 688239 & 5.4862 & 5.5534 & TST & \\
\hline CHEMBL1608679 & 688239 & 4.4862 & 5.6384 & TRN & \\
\hline CHEMBL1314584 & 688239 & 4.5362 & 5.479 & TRN & \\
\hline CHEMBL1598927 & 688239 & 4.6862 & 5.4914 & TRN & \\
\hline CHEMBL1437242 & 688239 & 5.1862 & 5.3552 & TRN & \\
\hline CHEMBL1390066 & 688239 & 5.4362 & 5.5062 & TRN & \\
\hline CHEMBL1598580 & 688239 & 6.1362 & 5.4952 & TST & \\
\hline CHEMBL1364962 & 688239 & 5.2362 & 5.5248 & TST & \\
\hline CHEMBL 3199806 & 688239 & 4.5362 & 5.348 & TRN & \\
\hline CHEMBL3194085 & 688239 & 4.9862 & 5.4442 & TRN & \\
\hline CHEMBL1517070 & 688239 & 4.7362 & 5.5006 & TRN & \\
\hline CHEMBL1387488 & 688239 & 5.1862 & 5.5738 & TST & \\
\hline CHEMBL1484476 & 688239 & 5.0862 & 5.4891 & TRN & \\
\hline CHEMBL 3208042 & 688239 & 4.7862 & 5.371 & TRN & \\
\hline CHEMBL1540497 & 688239 & 5.3862 & 5.5041 & TRN & \\
\hline CHEMBL1441021 & 688239 & 6.2362 & 5.5605 & TST & \\
\hline CHEMBL1510479 & 688239 & 4.7862 & 5.3171 & TST & \\
\hline CHEMBL1611152 & 688239 & 5.1362 & 5.4805 & TRN & \\
\hline CHEMBL1428140 & 688239 & 5.6362 & 5.4977 & TRN & \\
\hline CHEMBL 2006012 & 688239 & 5.1862 & 5.4348 & TST & \\
\hline CHEMBL1336984 & 688239 & 5.4862 & 5.4228 & TRN & \\
\hline CHEMBL1377583 & 688239 & 7.5867 & 5.31 & TRN & \\
\hline CHEMBL1363402 & 688239 & 4.5862 & 5.3197 & TRN & \\
\hline CHEMBL1484411 & 688239 & 4.8362 & 5.5441 & TRN & \\
\hline CHEMBL 1584710 & 688239 & 5.2362 & 5.5282 & TRN & \\
\hline \multirow[t]{2}{*}{ CHEMBL1574907 } & 688239 & 4.5362 & \multicolumn{2}{|c|}{5.382999999999999} & TRN \\
\hline & & & & 1724 & \\
\hline
\end{tabular}


Supplemental Table S2.txt

\begin{tabular}{|c|c|c|c|c|c|}
\hline CHEMBL1507849 & 688239 & 4.5362 & 5.5375 & TRN & \\
\hline CHEMBL3198781 & 688239 & 5.7862 & 5.5192 & TRN & \\
\hline CHEMBL1373195 & 688239 & 5.1362 & 5.5433 & TRN & \\
\hline CHEMBL1526767 & 688239 & 5.4362 & 5.4773 & TST & \\
\hline CHEMBL1584262 & 688239 & 4.6362 & 5.6251 & TRN & \\
\hline CHEMBL1433412 & 688239 & 5.2362 & 5.5554 & TRN & \\
\hline CHEMBL1435606 & 688239 & 4.5362 & 5.5423 & TST & \\
\hline CHEMBL1381559 & 688239 & 4.8362 & 5.5292 & TST & \\
\hline CHEMBL1581128 & 688239 & 4.6862 & 5.6321 & TRN & \\
\hline CHEMBL1414336 & 688239 & 4.7362 & 5.5203 & TRN & \\
\hline CHEMBL1370592 & 688239 & 5.7862 & 5.4053 & TST & \\
\hline CHEMBL1570812 & 688239 & 5.4362 & 5.6253 & TST & \\
\hline CHEMBL3193372 & 688239 & 4.5362 & 5.4669 & TRN & \\
\hline CHEMBL1467570 & 688239 & 5.3862 & 5.4582 & TRN & \\
\hline CHEMBL1349459 & 688239 & 5.6862 & 5.553 & TRN & \\
\hline CHEMBL1600658 & 688239 & 6.6861 & 5.5705 & TRN & \\
\hline CHEMBL3189153 & 688239 & 6.5862 & 5.4853 & TRN & \\
\hline CHEMBL1351412 & 688239 & 5.7362 & 5.479 & TST & \\
\hline CHEMBL1552841 & 688239 & 6.1362 & 5.5123 & TRN & \\
\hline CHEMBL3198373 & 688239 & 4.6862 & 5.4493 & TST & \\
\hline CHEMBL1403773 & 688239 & 4.5362 & 5.49799 & 9999999999 & TRN \\
\hline CHEMBL1315086 & 688239 & 5.9362 & 5.5363 & TRN & \\
\hline CHEMBL1332872 & 688239 & 6.2362 & 5.676 & TRN & \\
\hline CHEMBL1567686 & 688239 & 5.0862 & 5.6218 & TRN & \\
\hline CHEMBL1336341 & 688239 & 5.0362 & 5.2774 & TRN & \\
\hline CHEMBL1495012 & 688239 & 5.8362 & 5.5055 & TST & \\
\hline CHEMBL1408170 & 688239 & 5.1862 & 5.6421 & TRN & \\
\hline CHEMBL1351181 & 688239 & 4.6862 & 5.3965 & TST & \\
\hline CHEMBL1550189 & 688239 & 5.2862 & 5.6089 & TRN & \\
\hline CHEMBL1502603 & 688239 & 6.0862 & 5.5872 & TRN & \\
\hline CHEMBL1374975 & 688239 & 4.4862 & 5.4877 & TRN & \\
\hline CHEMBL1393605 & 688239 & 4.5362 & 5.5069 & TST & \\
\hline CHEMBL1607351 & 688239 & 5.1362 & 5.4213 & TRN & \\
\hline CHEMBL1398751 & 688239 & 6.1362 & 5.4646 & TRN & \\
\hline CHEMBL1407716 & 688239 & 6.3362 & 5.5505 & TRN & \\
\hline CHEMBL 267233 & 688239 & 5.8362 & 5.4337 & TST & \\
\hline CHEMBL1478765 & 688239 & 5.1862 & 5.3822 & TRN & \\
\hline CHEMBL1311904 & 688239 & 4.9862 & 5.3545 & TST & \\
\hline CHEMBL1506348 & 688239 & 4.5362 & 5.4821 & TRN & \\
\hline CHEMBL1341577 & 688239 & 5.2362 & 5.3641 & TRN & \\
\hline CHEMBL1549355 & 688239 & 5.9862 & 5.6177 & TRN & \\
\hline CHEMBL3211835 & 688239 & 6.1362 & 5.47 & TRN & \\
\hline CHEMBL1387673 & 688239 & 5.7862 & 5.5021 & TRN & \\
\hline CHEMBL1444557 & 688239 & 5.5362 & 5.414 & TRN & \\
\hline CHEMBL1452620 & 688239 & 5.2362 & 5.3459 & TRN & \\
\hline CHEMBL1497630 & 688239 & 6.1862 & 5.5676 & TRN & \\
\hline CHEMBL1300607 & 688239 & 7.2366 & 5.4982 & TRN & \\
\hline CHEMBL1348013 & 688239 & 4.7362 & 5.5421 & TRN & \\
\hline
\end{tabular}


Supplemental Table S2.txt

\begin{tabular}{|c|c|c|c|c|}
\hline CHEMBL1581165 & 688239 & 6.1862 & 5.5472 & TST \\
\hline CHEMBL1579409 & 688239 & 4.5362 & 5.4626 & TRN \\
\hline CHEMBL1386164 & 688239 & 5.0862 & 5.354 & TRN \\
\hline CHEMBL1588173 & 688239 & 4.5362 & 5.3742 & TST \\
\hline CHEMBL1511536 & 688239 & 4.7862 & 5.4662 & TRN \\
\hline CHEMBL1467605 & 688239 & 5.1862 & 5.3647 & TRN \\
\hline CHEMBL1392743 & 688239 & 5.2362 & 5.4215 & TRN \\
\hline CHEMBL1431320 & 688239 & 5.1862 & 5.3819 & TRN \\
\hline CHEMBL1321237 & 688239 & 5.5362 & 5.4974 & TRN \\
\hline CHEMBL1571090 & 688239 & 5.1362 & 5.4484 & TRN \\
\hline CHEMBL1442164 & 688239 & 5.7362 & \multicolumn{2}{|c|}{5.4670000000000005} \\
\hline CHEMBL1412370 & 688239 & 4.5362 & 5.3785 & TRN \\
\hline CHEMBL1611917 & 688239 & 4.5362 & 5.44 & TRN \\
\hline CHEMBL1420460 & 688239 & 4.6362 & 5.4573 & TRN \\
\hline CHEMBL1352220 & 688239 & 6.6861 & 5.5483 & TRN \\
\hline CHEMBL1596450 & 688239 & 5.1862 & 5.5056 & TST \\
\hline CHEMBL1349906 & 688239 & 5.1862 & 5.5638 & TRN \\
\hline CHEMBL1523781 & 688239 & 5.5862 & 5.4601 & TRN \\
\hline CHEMBL1597777 & 688239 & 4.9862 & 5.5632 & TRN \\
\hline CHEMBL1602680 & 688239 & 4.5362 & 5.5365 & TRN \\
\hline CHEMBL1313814 & 688239 & 5.6862 & 5.4869 & TST \\
\hline CHEMBL1588805 & 688239 & 4.6362 & 5.4934 & TRN \\
\hline CHEMBL1594206 & 688239 & 4.5362 & 5.4197 & TRN \\
\hline CHEMBL1309982 & 688239 & 6.1362 & 5.5175 & TRN \\
\hline CHEMBL1426185 & 688239 & 5.4362 & 5.3425 & TRN \\
\hline CHEMBL1534146 & 688239 & 5.7862 & 5.4618 & TRN \\
\hline CHEMBL1526220 & 688239 & 5.8862 & 5.5176 & TRN \\
\hline CHEMBL1447501 & 688239 & 4.8862 & \multicolumn{2}{|c|}{5.406000000000001} \\
\hline CHEMBL1299420 & 688239 & 4.5362 & 5.3468 & TRN \\
\hline CHEMBL1525735 & 688239 & 4.5362 & 5.3738 & TRN \\
\hline CHEMBL1311837 & 688239 & 5.2362 & 5.4877 & TRN \\
\hline CHEMBL1440359 & 688239 & 5.4362 & 5.5383 & TRN \\
\hline CHEMBL1583414 & 688239 & 6.1362 & 5.5609 & TRN \\
\hline CHEMBL1344415 & 688239 & 7.0362 & 5.601 & TRN \\
\hline CHEMBL1386215 & 688239 & 5.1862 & 5.3959 & TST \\
\hline CHEMBL1407821 & 688239 & 4.6862 & 5.5967 & TRN \\
\hline CHEMBL1442594 & 688239 & 5.4862 & 5.5899 & TRN \\
\hline CHEMBL1526763 & 688239 & 5.2362 & 5.3136 & TRN \\
\hline CHEMBL1538951 & 688239 & 4.7862 & 5.6028 & TRN \\
\hline CHEMBL1416421 & 688239 & 4.7862 & 5.4869 & TRN \\
\hline CHEMBL1574188 & 688239 & 4.7362 & 5.4994 & TRN \\
\hline CHEMBL1340858 & 688239 & 5.4362 & 5.6426 & TRN \\
\hline CHEMBL1424367 & 688239 & 7.0862 & 5.4205 & TST \\
\hline CHEMBL1455560 & 688239 & 6.9363 & 5.5594 & TRN \\
\hline CHEMBL1303536 & 688239 & 6.2862 & 5.4267 & TRN \\
\hline CHEMBL1566802 & 688239 & 4.8862 & 5.4816 & TRN \\
\hline CHEMBL1369033 & 688239 & 4.9362 & 5.4614 & TRN \\
\hline CHEMBL1306824 & 688239 & 5.9862 & 5.3997 & TST \\
\hline
\end{tabular}

Page 1726 
Supplemental Table S2.txt

\begin{tabular}{|c|c|c|c|c|c|}
\hline CHEMBL1523967 & 688239 & 4.7362 & 5.4034 & TRN & \\
\hline CHEMBL1470162 & 688239 & 4.7362 & 5.4416 & TRN & \\
\hline CHEMBL1319466 & 688239 & 5.6362 & 5.2624 & TRN & \\
\hline CHEMBL1430795 & 688239 & 4.5362 & 5.4322 & TST & \\
\hline CHEMBL1327999 & 688239 & 5.7362 & 5.3976 & TRN & \\
\hline CHEMBL1564585 & 688239 & 4.5362 & 5.5129 & TRN & \\
\hline CHEMBL1350126 & 688239 & 5.9362 & 5.5464 & TST & \\
\hline CHEMBL1312897 & 688239 & 4.7362 & 5.5041 & TRN & \\
\hline CHEMBL1562056 & 688239 & 5.1862 & 5.4179 & TRN & \\
\hline CHEMBL1329684 & 688239 & 4.5362 & 5.6067 & TRN & \\
\hline CHEMBL1514868 & 688239 & 5.7362 & 5.3854 & TRN & \\
\hline CHEMBL1341876 & 688239 & 4.4862 & 5.4127 & TRN & \\
\hline CHEMBL1519904 & 688239 & 4.8862 & 5.5288 & TRN & \\
\hline CHEMBL1576131 & 688239 & 6.9363 & 5.2888 & TRN & \\
\hline CHEMBL1482090 & 688239 & 4.6862 & 5.4939 & TRN & \\
\hline CHEMBL1348251 & 688239 & 5.4862 & 5.5942 & TRN & \\
\hline CHEMBL 3207340 & 688239 & 6.8362 & 5.54200 & 0000000001 & TRN \\
\hline CHEMBL1590455 & 688239 & 5.9862 & 5.55399 & 9999999999 & TRN \\
\hline CHEMBL1377019 & 688239 & 6.2362 & 5.5293 & TST & \\
\hline CHEMBL1539232 & 688239 & 5.7862 & 5.5923 & TRN & \\
\hline CHEMBL1392245 & 688239 & 4.5862 & 5.3561 & TRN & \\
\hline CHEMBL1562560 & 688239 & 4.7362 & 5.4221 & TRN & \\
\hline CHEMBL1469242 & 688239 & 5.1862 & 5.5841 & TRN & \\
\hline CHEMBL1439136 & 688239 & 4.5862 & 5.271 & TST & \\
\hline CHEMBL1405035 & 688239 & 4.5362 & 5.4399 & TRN & \\
\hline CHEMBL1534731 & 688239 & 6.1862 & 5.5131 & TST & \\
\hline CHEMBL1471662 & 688239 & 4.5362 & 5.5105 & TRN & \\
\hline CHEMBL1584912 & 688239 & 4.5362 & 5.5265 & TRN & \\
\hline CHEMBL1504382 & 688239 & 6.2362 & 5.6038 & TRN & \\
\hline CHEMBL1560814 & 688239 & 4.6862 & 5.5525 & TST & \\
\hline CHEMBL1343540 & 688239 & 4.7862 & 5.5405 & TST & \\
\hline CHEMBL1436434 & 688239 & 4.6862 & 5.6641 & TRN & \\
\hline CHEMBL1375852 & 688239 & 5.4362 & 5.3908 & TST & \\
\hline CHEMBL 3212283 & 688239 & 8.28399 & 79999999 & 5.5548 & TST \\
\hline CHEMBL1401791 & 688239 & 4.4362 & 5.4821 & TST & \\
\hline CHEMBL1367216 & 688239 & 4.7862 & 5.3345 & TRN & \\
\hline CHEMBL1533091 & 688239 & 4.5362 & 5.5028 & TRN & \\
\hline CHEMBL1477954 & 688239 & 4.4862 & 5.504 & TRN & \\
\hline CHEMBL1532328 & 688239 & 5.2862 & 5.3346 & TRN & \\
\hline CHEMBL1589905 & 688239 & 4.5362 & 5.5062 & TRN & \\
\hline CHEMBL1478545 & 688239 & 4.6862 & 5.3682 & TRN & \\
\hline CHEMBL1375882 & 688239 & 5.1862 & 5.6033 & TRN & \\
\hline CHEMBL1457314 & 688239 & 4.6362 & 5.4742 & TRN & \\
\hline CHEMBL1364398 & 688239 & 4.5362 & 5.6673 & TRN & \\
\hline CHEMBL 3208144 & 688239 & 5.1862 & 5.5301 & TST & \\
\hline CHEMBL1301779 & 688239 & 4.5362 & 5.5688 & TRN & \\
\hline CHEMBL 3189325 & 688239 & 5.8362 & 5.2736 & TRN & \\
\hline CHEMBL1332035 & 688239 & 5.1862 & 5.47 & TRN & \\
\hline
\end{tabular}


Supplemental Table S2.txt

\begin{tabular}{|c|c|c|c|c|c|}
\hline CHEMBL1315966 & 688239 & 5.1862 & 5.5415 & TRN & \\
\hline CHEMBL1538781 & 688239 & 5.2862 & 5.485 & TRN & \\
\hline CHEMBL1335030 & 688239 & 4.7362 & 5.4314 & TRN & \\
\hline CHEMBL1304620 & 688239 & 6.1362 & 5.6178 & TRN & \\
\hline CHEMBL1537309 & 688239 & 4.5362 & 5.3742 & TRN & \\
\hline CHEMBL1563232 & 688239 & 8.2366 & 5.439 & TRN & \\
\hline CHEMBL1492547 & 688239 & 4.5362 & 5.6145 & TST & \\
\hline CHEMBL1510576 & 688239 & 4.5362 & 5.482 & TRN & \\
\hline CHEMBL1322418 & 688239 & 6.1862 & 5.3795 & TRN & \\
\hline CHEMBL1508071 & 688239 & 5.0862 & 5.5837 & TRN & \\
\hline CHEMBL584444 & 688239 & 4.6362 & 5.4337 & TST & \\
\hline CHEMBL1310644 & 688239 & 4.9362 & 5.4716 & TRN & \\
\hline CHEMBL1364284 & 688239 & 8.28399 & 999999999 & 5.4821 & TRN \\
\hline CHEMBL1446551 & 688239 & 5.0362 & 5.5877 & TRN & \\
\hline CHEMBL1304090 & 688239 & 5.3362 & 5.5418 & TRN & \\
\hline CHEMBL 3195623 & 688239 & 5.1862 & 5.4102 & TST & \\
\hline CHEMBL1529280 & 688239 & 5.8362 & 5.4235 & TRN & \\
\hline CHEMBL1339353 & 688239 & 4.6862 & 5.4862 & TST & \\
\hline CHEMBL1427897 & 688239 & 5.1862 & 5.3878 & TRN & \\
\hline CHEMBL1600788 & 688239 & 5.1362 & 5.4428 & TRN & \\
\hline CHEMBL1489098 & 688239 & 5.6862 & 5.5173 & TST & \\
\hline CHEMBL1367899 & 688239 & 4.5362 & 5.5135 & TRN & \\
\hline CHEMBL1613116 & 688239 & 6.9363 & 5.4475 & TRN & \\
\hline CHEMBL1481930 & 688239 & 4.7362 & 5.5118 & TST & \\
\hline CHEMBL1584820 & 688239 & 5.6862 & 5.4549 & TRN & \\
\hline CHEMBL1588599 & 688239 & 5.2362 & 5.6666 & TRN & \\
\hline CHEMBL1541224 & 688239 & 5.7862 & 5.5412 & TST & \\
\hline CHEMBL1527120 & 688239 & 4.8862 & 5.3644 & TRN & \\
\hline CHEMBL2369155 & 688239 & 4.7862 & 5.4933 & TST & \\
\hline CHEMBL1571387 & 688239 & 4.8362 & 5.5089 & TRN & \\
\hline CHEMBL1454115 & 688239 & 4.7362 & 5.4397 & TRN & \\
\hline CHEMBL1441026 & 688239 & 5.1862 & 5.3884 & TRN & \\
\hline CHEMBL1562060 & 688239 & 4.5362 & 5.4935 & TRN & \\
\hline CHEMBL1448091 & 688239 & 5.7362 & 5.502000 & 0000000001 & $\mathrm{TR}$ \\
\hline CHEMBL1439268 & 688239 & 5.5362 & 5.3689 & TST & \\
\hline CHEMBL1460134 & 688239 & 4.5862 & 5.241000 & 00000000005 & TS \\
\hline CHEMBL1430521 & 688239 & 4.7362 & 5.4291 & TRN & \\
\hline CHEMBL1413148 & 688239 & 4.5362 & 5.2983 & TRN & \\
\hline CHEMBL1520437 & 688239 & 6.1362 & 5.6273 & TST & \\
\hline CHEMBL1530899 & 688239 & 4.5362 & 5.4266 & TRN & \\
\hline CHEMBL1473794 & 688239 & 6.1362 & 5.5645 & TST & \\
\hline CHEMBL1535060 & 688239 & 4.7362 & 5.3751 & TST & \\
\hline CHEMBL1505088 & 688239 & 4.7862 & 5.5647 & TRN & \\
\hline CHEMBL1522215 & 688239 & 6.7862 & 5.6107 & TRN & \\
\hline CHEMBL1489811 & 688239 & 4.4862 & 5.4569 & TRN & \\
\hline CHEMBL1322150 & 688239 & 6.4862 & 5.7117 & TRN & \\
\hline CHEMBL1351146 & 688239 & 4.6862 & 5.362999 & 99999999995 & RT \\
\hline CHEMBL1525467 & 688239 & 5.6862 & 5.4641 & TRN & \\
\hline
\end{tabular}




\begin{tabular}{|c|c|c|c|c|c|}
\hline & & \multicolumn{4}{|c|}{ Supplemental Table S2.txt } \\
\hline CHEMBL1319885 & 688239 & 4.5362 & 5.2508 & TRN & \\
\hline CHEMBL1610736 & 688239 & 5.7362 & 5.4652 & TRN & \\
\hline CHEMBL1384459 & 688239 & 4.45 & 5.4945 & TST & \\
\hline CHEMBL1612884 & 688239 & 5.1862 & 5.6294 & TST & \\
\hline CHEMBL1301289 & 688239 & 4.5362 & 5.4622 & TRN & \\
\hline CHEMBL1337365 & 688239 & 5.3362 & 5.5912 & TRN & \\
\hline CHEMBL1452554 & 688239 & 4.8362 & 5.5169 & TRN & \\
\hline CHEMBL1569433 & 688239 & 4.7862 & 5.3271 & TRN & \\
\hline CHEMBL1473860 & 688239 & 6.0362 & 5.6868 & TRN & \\
\hline CHEMBL1456761 & 688239 & 4.7362 & 5.4819 & TRN & \\
\hline CHEMBL1431789 & 688239 & 4.5362 & 5.4505 & TRN & \\
\hline CHEMBL3208309 & 688239 & 4.7362 & 5.5858 & TRN & \\
\hline CHEMBL1500693 & 688239 & 5.6862 & 5.4257 & TRN & \\
\hline CHEMBL1567734 & 688239 & 6.2362 & 5.3431 & TST & \\
\hline CHEMBL1478415 & 688239 & 4.7862 & 5.6669 & TST & \\
\hline CHEMBL1388750 & 688239 & 6.4862 & 5.4114 & TRN & \\
\hline CHEMBL1349424 & 688239 & 4.7862 & 5.4757 & TRN & \\
\hline CHEMBL1382942 & 688239 & 4.6862 & 5.5167 & TST & \\
\hline CHEMBL1305079 & 688239 & 4.6362 & 5.4479 & TST & \\
\hline CHEMBL1376315 & 688239 & 5.5862 & 5.5597 & TRN & \\
\hline CHEMBL1357094 & 688239 & 4.5862 & 5.4256 & TST & \\
\hline CHEMBL1538619 & 688239 & 4.9862 & 5.4871 & TST & \\
\hline CHEMBL1499264 & 688239 & 5.8862 & 5.4762 & TRN & \\
\hline CHEMBL1406459 & 688239 & 5.7362 & 5.5296 & TRN & \\
\hline CHEMBL1991388 & 688239 & 5.8362 & 5.3507 & TRN & \\
\hline CHEMBL1501745 & 688239 & 4.6362 & 5.5645 & TRN & \\
\hline CHEMBL3210647 & 688239 & 5.7362 & 5.3958 & TRN & \\
\hline CHEMBL3193983 & 688239 & 5.1862 & 5.3387 & TRN & \\
\hline CHEMBL1320795 & 688239 & 4.5362 & 5.4452 & TRN & \\
\hline CHEMBL1418663 & 688239 & 7.4868 & 5.6163 & TRN & \\
\hline CHEMBL1397437 & 688239 & 6.0862 & 5.5211 & TRN & \\
\hline CHEMBL1438963 & 688239 & 6.0362 & 5.5276 & TRN & \\
\hline CHEMBL1417850 & 688239 & 5.5862 & 5.3887 & TRN & \\
\hline CHEMBL1537369 & 688239 & 6.2362 & 5.6547 & TST & \\
\hline CHEMBL1342460 & 688239 & 5.1862 & 5.4518 & TST & \\
\hline CHEMBL1406243 & 688239 & 5.5862 & 5.53299 & 99999999995 & TRN \\
\hline CHEMBL1499890 & 688239 & 4.4862 & 5.3087 & TST & \\
\hline CHEMBL1346328 & 688239 & 5.1862 & 5.5454 & TRN & \\
\hline CHEMBL3199283 & 688239 & 6.9363 & 5.4597 & TRN & \\
\hline CHEMBL1376417 & 688239 & 4.5362 & 5.3897 & TRN & \\
\hline CHEMBL1428015 & 688239 & 6.2862 & 5.4984 & TRN & \\
\hline CHEMBL1519825 & 688239 & 5.5362 & 5.5139 & TRN & \\
\hline CHEMBL1458737 & 688239 & 5.3862 & 5.285 & TRN & \\
\hline CHEMBL1436629 & 688239 & 4.9362 & 5.4413 & TRN & \\
\hline CHEMBL1316231 & 688239 & 4.8362 & 5.49100 & 00000000005 & TRN \\
\hline CHEMBL1508128 & 688239 & 7.5361 & 5.2787 & TRN & \\
\hline CHEMBL1379038 & 688239 & 8.3372 & 5.5074 & TRN & \\
\hline CHEMBL1563997 & 688239 & 5.6862 & 5.4656 & TST & \\
\hline
\end{tabular}




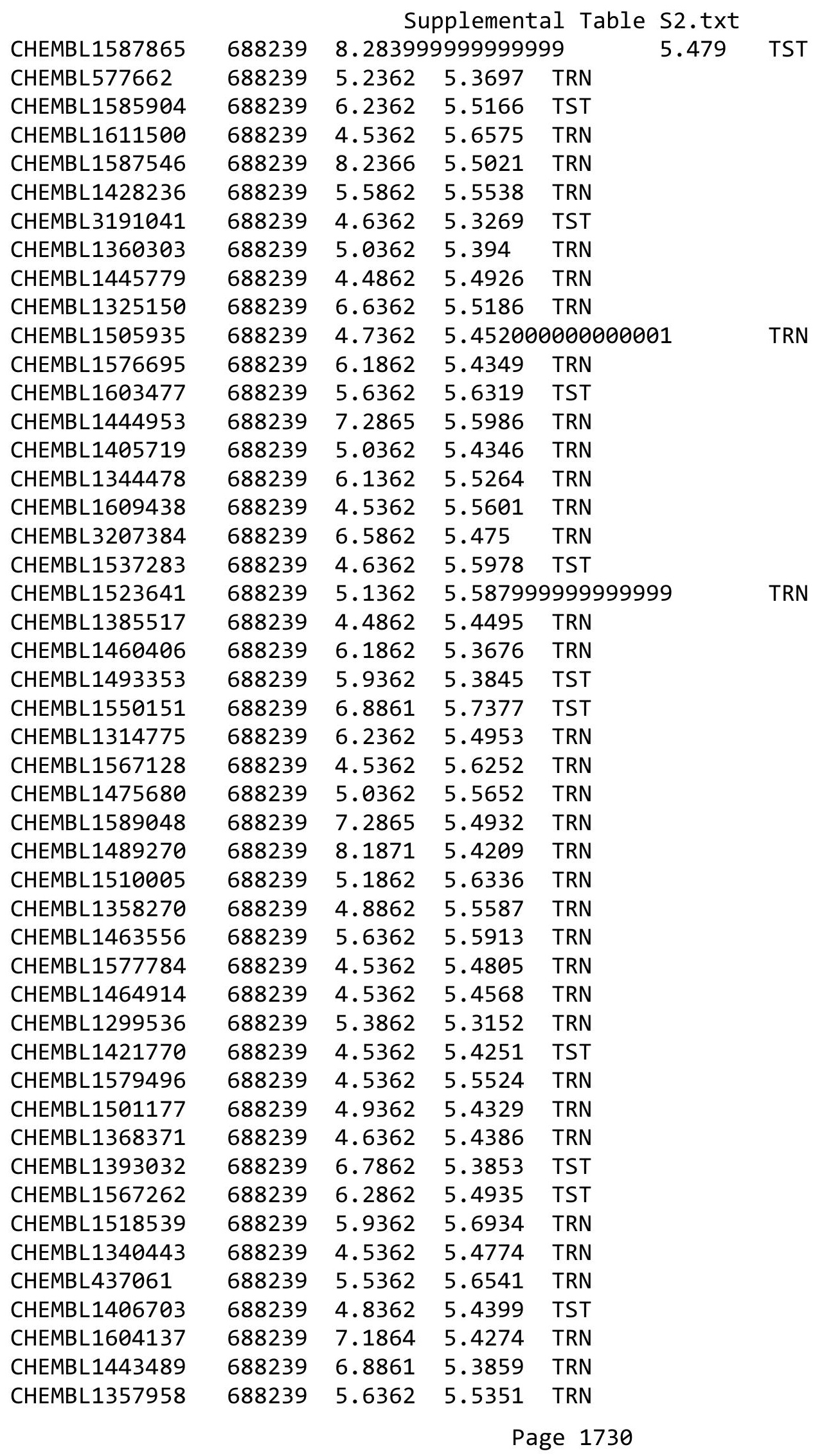


Supplemental Table S2.txt

\begin{tabular}{|c|c|c|c|c|}
\hline & & & & \\
\hline AEMBL15 & 38239 & $\partial 862$ & & \\
\hline IEMBL1494214 & 8239 & 862 & 4114 & \\
\hline HEMBL1399862 & 239 & 362 & 139 & \\
\hline & 239 & 362 & & \\
\hline IFMRI 14 & 239 & 862 & & \\
\hline AEMBL1415640 & 88239 & 862 & 586 & \\
\hline AEMBL3211866 & 88239 & 362 & 681 & \\
\hline AEMBL1595858 & 239 & 362 & & \\
\hline EMBL1538016 & 239 & 862 & & \\
\hline AEMBL1363992 & & 362 & & \\
\hline AEMBL1474102 & 688239 & 862 & 397 & \\
\hline AEMBL1388301 & 239 & 862 & 42 & \\
\hline IEMBL 319 & & 362 & & \\
\hline IEMBL1497513 & & 62 & & \\
\hline AEMBL1352489 & & & & \\
\hline AEMBL1594491 & 239 & 861 & 754 & \\
\hline AEMBL1532325 & 39 & 372 & & \\
\hline EMBL1606 & & 62 & & \\
\hline EMBL147 & & & & \\
\hline AEMBL135 & & 62 & & \\
\hline AEMBL1564931 & & 863 & & \\
\hline AEMBL 2003027 & & & & \\
\hline AEMBL155 & & 62 & & \\
\hline IEMBL152 & & & & \\
\hline AFMRI 156 & & 62 & & \\
\hline HEMBL1585 & & & & \\
\hline AEMBL1541472 & & & & \\
\hline AEMBL1304406 & & 62 & & RI \\
\hline AEMBL1340374 & & 61 & & \\
\hline 79 & & 62 & & \\
\hline HEMBL1898721 & & & & RN \\
\hline AEMBL1306175 & & & & ST \\
\hline AEMBL1311828 & & 62 & & RI \\
\hline HEMBL156 & & 63 & & \\
\hline 127 & & & & $\mathrm{RN}$ \\
\hline AEMBL1435813 & & & & RN \\
\hline AEMBL1418043 & & & & \\
\hline IEMBL32€ & & 61 & 964 & $S$ \\
\hline HEMBL1608898 & & & & \\
\hline HEMBL321. & & & & $\mathrm{RN}$ \\
\hline HEMBL1335554 & & 863 & & RI \\
\hline AEMBL142 & & & & \\
\hline EMBL14 & & & & \\
\hline HEMBL 146 & & & & \\
\hline CHEMBL1353642 & & 362 & .5872 & \\
\hline AEMBL1430542 & 88239 & 6.3362 & 5.6485 & \\
\hline HEMBL1498828 & 688239 & 5.1362 & 5.5095 & \\
\hline
\end{tabular}

Page 1731 
Supplemental Table S2.txt

\begin{tabular}{|c|c|c|c|c|c|}
\hline CHEMBL1566968 & 688239 & 4.5362 & 5.5459 & TST & \\
\hline CHEMBL1419563 & 688239 & 4.6362 & 5.4236 & TRN & \\
\hline CHEMBL1543581 & 688239 & 4.7362 & 5.5585 & TST & \\
\hline CHEMBL1556833 & 688239 & 5.4862 & 5.5892 & TRN & \\
\hline CHEMBL1462663 & 688239 & 4.7862 & 5.5912 & TST & \\
\hline CHEMBL1304604 & 688239 & 5.7862 & 5.5075 & TST & \\
\hline CHEMBL1327373 & 688239 & 5.4362 & 5.55399 & 9999999999 & TRN \\
\hline CHEMBL1368401 & 688239 & 6.1862 & 5.5146 & TST & \\
\hline CHEMBL1353067 & 688239 & 5.3362 & 5.5499 & TRN & \\
\hline CHEMBL1340626 & 688239 & 5.2362 & 5.5497 & TRN & \\
\hline CHEMBL1435506 & 688239 & 5.0862 & 5.4119 & TRN & \\
\hline CHEMBL1407999 & 688239 & 5.1362 & 5.4199 & TST & \\
\hline CHEMBL1363497 & 688239 & 6.5363 & 5.5291 & TST & \\
\hline CHEMBL1405700 & 688239 & 4.9862 & 5.3614 & TST & \\
\hline CHEMBL1547647 & 688239 & 4.6862 & 5.3548 & TRN & \\
\hline CHEMBL1451611 & 688239 & 4.5362 & 5.4719 & TRN & \\
\hline CHEMBL1492323 & 688239 & 5.2862 & 5.5286 & TRN & \\
\hline CHEMBL1480815 & 688239 & 6.9363 & 5.3723 & TST & \\
\hline CHEMBL1447327 & 688239 & 6.5363 & 5.4562 & TRN & \\
\hline CHEMBL1312215 & 688239 & 4.6862 & 5.4189 & TST & \\
\hline CHEMBL3212690 & 688239 & 6.1362 & 5.4427 & TST & \\
\hline CHEMBL1374916 & 688239 & 5.8862 & 5.5064 & TRN & \\
\hline CHEMBL1563048 & 688239 & 5.8862 & 5.4417 & TST & \\
\hline CHEMBL1335454 & 688239 & 5.7362 & 5.65799 & 99999999995 & 11 \\
\hline CHEMBL1491000 & 688239 & 5.5862 & 5.5568 & TRN & \\
\hline CHEMBL1571819 & 688239 & 5.3362 & 5.5606 & TRN & \\
\hline CHEMBL1349854 & 688239 & 4.5362 & 5.46899 & 9999999999 & II \\
\hline CHEMBL1607687 & 688239 & 4.7362 & 5.4488 & TRN & \\
\hline CHEMBL1557911 & 688239 & 6.2362 & 5.3999 & TRN & \\
\hline CHEMBL3190797 & 688239 & 6.1362 & 5.5637 & TRN & \\
\hline CHEMBL1456527 & 688239 & 4.5362 & 5.4765 & TRN & \\
\hline CHEMBL1509052 & 688239 & 6.9863 & 5.494 & TRN & \\
\hline CHEMBL1520973 & 688239 & 5.3862 & 5.5871 & TST & \\
\hline CHEMBL1432344 & 688239 & 4.6362 & 5.584 & TST & \\
\hline CHEMBL1590112 & 688239 & 5.1862 & 5.6521 & TRN & \\
\hline CHEMBL3195899 & 688239 & 5.3362 & 5.2618 & TRN & \\
\hline CHEMBL1398302 & 688239 & 5.8862 & 5.5461 & TST & \\
\hline CHEMBL1355487 & 688239 & 5.3362 & 5.3083 & TRN & \\
\hline CHEMBL1317733 & 688239 & 4.6362 & 5.3941 & TRN & \\
\hline CHEMBL1330568 & 688239 & 4.7362 & 5.5283 & TST & \\
\hline CHEMBL1502611 & 688239 & 4.7862 & 5.3633 & TST & \\
\hline CHEMBL1347957 & 688239 & 4.4862 & 5.5167 & TRN & \\
\hline CHEMBL1312326 & 688239 & 4.5362 & 5.5285 & TRN & \\
\hline CHEMBL1396468 & 688239 & 5.7362 & 5.4183 & TST & \\
\hline CHEMBL1346618 & 688239 & 4.5362 & 5.4962 & TST & \\
\hline CHEMBL1499563 & 688239 & 5.8362 & 5.6325 & TST & \\
\hline CHEMBL1493527 & 688239 & 8.2366 & 5.6199 & TRN & \\
\hline CHEMBL1607164 & 688239 & 8.28399 & 9999999 & 5.4161 & \\
\hline
\end{tabular}




\begin{tabular}{|c|c|c|c|c|}
\hline \multicolumn{5}{|c|}{ Supplemental Tab. } \\
\hline CHEMBL1518624 & 688239 & 4.4862 & 5.5555 & TRN \\
\hline CHEMBL1605147 & 688239 & 6.0862 & 5.55 & TST \\
\hline CHEMBL1476598 & 688239 & 5.6362 & 5.5194 & TRN \\
\hline CHEMBL1999551 & 688239 & 5.1362 & 5.3401 & TRN \\
\hline CHEMBL1609082 & 688239 & 4.5862 & 5.4521 & TST \\
\hline CHEMBL1597318 & 688239 & 6.25 & 5.5029 & TRN \\
\hline CHEMBL1517890 & 688239 & 7.1361 & 5.5919 & TST \\
\hline CHEMBL1470994 & 688239 & 4.4862 & 5.3887 & TRN \\
\hline CHEMBL1551339 & 688239 & 4.5362 & 5.5028 & TRN \\
\hline CHEMBL1574466 & 688239 & 5.5862 & 5.4716 & TRN \\
\hline CHEMBL1314813 & 688239 & 4.7362 & 5.3905 & TRN \\
\hline CHEMBL1465739 & 688239 & 4.6862 & 5.596 & TRN \\
\hline CHEMBL1378649 & 688239 & 6.6362 & 5.4819 & TST \\
\hline CHEMBL1594867 & 688239 & 4.7362 & 5.5204 & TST \\
\hline CHEMBL1589573 & 688239 & 6.1862 & 5.528 & TRN \\
\hline CHEMBL1601720 & 688239 & 5.4362 & 5.4429 & TST \\
\hline CHEMBL1331253 & 688239 & 5.6362 & 5.4433 & TRN \\
\hline CHEMBL1587666 & 688239 & 5.8862 & 5.5658 & TRN \\
\hline CHEMBL1488677 & 688239 & 5.3862 & 5.4597 & TRN \\
\hline CHEMBL1600813 & 688239 & 6.6861 & 5.5832 & TRN \\
\hline CHEMBL1433960 & 688239 & 4.9862 & 5.3893 & TRN \\
\hline CHEMBL1313106 & 688239 & 5.6362 & 5.4612 & TRN \\
\hline CHEMBL3209257 & 688239 & 4.7362 & 5.4219 & TRN \\
\hline CHEMBL1457053 & 688239 & 4.6862 & 5.2848 & TRN \\
\hline CHEMBL1600168 & 688239 & 4.5362 & 5.5679 & TST \\
\hline CHEMBL1472038 & 688239 & 4.7362 & 5.5075 & TST \\
\hline CHEMBL1605822 & 688239 & 4.5862 & 5.4465 & TRN \\
\hline CHEMBL1607080 & 688239 & 5.6862 & 5.5452 & TRN \\
\hline CHEMBL1600933 & 688239 & 4.5362 & 5.608 & TST \\
\hline CHEMBL1606761 & 688239 & 4.5362 & 5.5579 & TRN \\
\hline CHEMBL1381263 & 688239 & 4.4862 & 5.4875 & TRN \\
\hline CHEMBL3194684 & 688239 & 6.8362 & 5.4526 & TST \\
\hline CHEMBL1524655 & 688239 & 5.1862 & 5.4811 & TST \\
\hline CHEMBL1306837 & 688239 & 5.2862 & 5.465 & TRN \\
\hline CHEMBL1334839 & 688239 & 6.0862 & 5.6085 & TRN \\
\hline CHEMBL1448277 & 688239 & 4.9362 & 5.5027 & TRN \\
\hline CHEMBL1389770 & 688239 & 8.3372 & 5.4432 & TST \\
\hline CHEMBL1420477 & 688239 & 4.5362 & 5.4592 & TST \\
\hline CHEMBL1307740 & 688239 & 5.0862 & 5.4693 & TRN \\
\hline CHEMBL1376099 & 688239 & 6.6362 & 5.6031 & TRN \\
\hline CHEMBL1609532 & 688239 & 5.6862 & 5.5858 & TRN \\
\hline CHEMBL1504790 & 688239 & 4.5362 & 5.3828 & TRN \\
\hline CHEMBL1584993 & 688239 & 6.1862 & 5.4742 & TRN \\
\hline CHEMBL1326033 & 688239 & 7.2366 & 5.6264 & TST \\
\hline CHEMBL1402961 & 688239 & 6.8861 & 5.5197 & TRN \\
\hline CHEMBL1414811 & 688239 & 5.0862 & 5.5365 & TRN \\
\hline CHEMBL1447284 & 688239 & 4.8362 & 5.4412 & TRN \\
\hline CHEMBL1444977 & 688239 & 5.3862 & 5.5478 & TRN \\
\hline
\end{tabular}


Supplemental Table S2.txt

\begin{tabular}{|c|c|c|c|c|}
\hline CHEMBL1344094 & 688239 & 5.1862 & 5.454 & TRN \\
\hline CHEMBL1466535 & 688239 & 4.9862 & 5.4669 & TRN \\
\hline CHEMBL1369493 & 688239 & 4.6362 & 5.4382 & TST \\
\hline CHEMBL1510187 & 688239 & 6.5363 & 5.4716 & TST \\
\hline CHEMBL1469814 & 688239 & 5.3862 & 5.5876 & TST \\
\hline CHEMBL1453770 & 688239 & 4.7862 & 5.4817 & TRN \\
\hline CHEMBL1563366 & 688239 & 5.1862 & 5.5078 & TRN \\
\hline CHEMBL1418760 & 688239 & 6.1362 & 5.559 & TST \\
\hline CHEMBL1499196 & 688239 & 4.8362 & 5.5877 & TRN \\
\hline CHEMBL1312754 & 688239 & 6.8362 & 5.5293 & TRN \\
\hline CHEMBL1468138 & 688239 & 5.7362 & \multicolumn{2}{|c|}{5.502000000000001} \\
\hline CHEMBL1473194 & 688239 & 5.7362 & 5.3411 & TST \\
\hline CHEMBL1578026 & 688239 & 6.4862 & 5.4731 & TRN \\
\hline CHEMBL1572169 & 688239 & 4.7862 & 5.5765 & TRN \\
\hline CHEMBL1507737 & 688239 & 7.8356 & 5.4416 & TRN \\
\hline CHEMBL1338275 & 688239 & 5.1862 & 5.3409 & TRN \\
\hline CHEMBL1603734 & 688239 & 4.6862 & 5.6055 & TST \\
\hline CHEMBL1394488 & 688239 & 5.7362 & 5.4974 & TRN \\
\hline CHEMBL1318868 & 688239 & 6.2862 & 5.4531 & TST \\
\hline CHEMBL1385992 & 688239 & 4.5862 & 5.4363 & TST \\
\hline CHEMBL1300218 & 688239 & 5.1862 & 5.5636 & TRN \\
\hline CHEMBL1357477 & 688239 & 4.5362 & 5.4308 & TRN \\
\hline CHEMBL1588574 & 688239 & 6.9863 & 5.5522 & TST \\
\hline CHEMBL1354364 & 688239 & 5.1862 & 5.5222 & TST \\
\hline CHEMBL1551015 & 688239 & 6.1362 & \multicolumn{2}{|c|}{5.4479999999999995} \\
\hline CHEMBL1573647 & 688239 & 4.8362 & 5.3802 & TRN \\
\hline CHEMBL1559569 & 688239 & 4.5362 & 5.5147 & TRN \\
\hline CHEMBL 3193784 & 688239 & 4.5362 & 5.4442 & TST \\
\hline CHEMBL1387062 & 688239 & 5.2362 & 5.6296 & TST \\
\hline CHEMBL1325101 & 688239 & 5.1862 & 5.3873 & TST \\
\hline CHEMBL1433859 & 688239 & 4.7862 & 5.3709 & TST \\
\hline CHEMBL1400118 & 688239 & 6.5363 & 5.5722 & TRN \\
\hline CHEMBL1380108 & 688239 & 6.2362 & 5.4996 & TRN \\
\hline CHEMBL1405491 & 688239 & 4.6362 & 5.4663 & TRN \\
\hline CHEMBL1351418 & 688239 & 4.7362 & 5.6503 & TST \\
\hline CHEMBL1364499 & 688239 & 6.1862 & 5.5802 & TST \\
\hline CHEMBL1423479 & 688239 & 5.9862 & 5.4781 & TRN \\
\hline CHEMBL1438802 & 688239 & 5.1862 & 5.5552 & TRN \\
\hline CHEMBL 2005518 & 688239 & 4.5362 & 5.3539 & TST \\
\hline CHEMBL1532936 & 688239 & 5.6862 & 5.5379 & TRN \\
\hline CHEMBL1507254 & 688239 & 4.5362 & 5.4545 & TST \\
\hline CHEMBL1402700 & 688239 & 5.2862 & 5.6615 & TRN \\
\hline CHEMBL1305621 & 688239 & 5.1862 & 5.4181 & TRN \\
\hline CHEMBL1324450 & 688239 & 6.6861 & 5.5124 & TRN \\
\hline CHEMBL1399410 & 688239 & 4.9362 & 5.5391 & TRN \\
\hline CHEMBL1488738 & 688239 & 4.7362 & 5.5652 & TRN \\
\hline CHEMBL1575245 & 688239 & 4.6362 & 5.53100 & 0000000001 \\
\hline CHEMBL1460323 & 688239 & 4.5862 & 5.5608 & TRN \\
\hline
\end{tabular}


Supplemental Table S2.txt

\begin{tabular}{|c|c|c|c|c|}
\hline CHEMBL1484213 & 688239 & 6.1862 & 5.5602 & TRN \\
\hline CHEMBL1382320 & 688239 & 4.5362 & 5.5518 & TRN \\
\hline CHEMBL1572350 & 688239 & 5.6362 & 5.481 & TRN \\
\hline CHEMBL1381019 & 688239 & 4.5362 & 5.3946 & TRN \\
\hline CHEMBL1489005 & 688239 & 4.6862 & 5.3854 & TST \\
\hline CHEMBL1458882 & 688239 & 4.7862 & 5.4988 & TST \\
\hline CHEMBL1508398 & 688239 & 4.6362 & 5.4373 & TRN \\
\hline CHEMBL1318542 & 688239 & 6.9863 & 5.3923 & TRN \\
\hline CHEMBL1361634 & 688239 & 8.3372 & 5.5151 & TRN \\
\hline CHEMBL1415768 & 688239 & 4.9362 & 5.4766 & TRN \\
\hline CHEMBL1545670 & 688239 & 4.5862 & 5.391 & TRN \\
\hline CHEMBL1454849 & 688239 & 5.6862 & 5.4365 & TRN \\
\hline CHEMBL1321968 & 688239 & 4.5362 & 5.5953 & TRN \\
\hline CHEMBL3392023 & 688239 & 6.7862 & 5.4342 & TRN \\
\hline CHEMBL1569732 & 688239 & 4.5362 & 5.4205 & TST \\
\hline CHEMBL1401984 & 688239 & 5.1862 & 5.4629 & TRN \\
\hline CHEMBL1610984 & 688239 & 4.6862 & 5.5757 & TRN \\
\hline CHEMBL1335605 & 688239 & 4.5362 & 5.4133 & TRN \\
\hline CHEMBL1528484 & 688239 & 4.6862 & 5.3861 & TRN \\
\hline CHEMBL1364640 & 688239 & 6.7862 & 5.2979 & TRN \\
\hline CHEMBL1332175 & 688239 & 6.1362 & 5.6015 & TRN \\
\hline CHEMBL1385536 & 688239 & 7.2366 & 5.6381 & TRN \\
\hline CHEMBL1563041 & 688239 & 5.1862 & 5.6014 & TST \\
\hline CHEMBL1519924 & 688239 & 6.0362 & 5.6876 & TRN \\
\hline CHEMBL1579470 & 688239 & 4.5362 & 5.4095 & TRN \\
\hline CHEMBL1569824 & 688239 & 5.2362 & 5.402 & TST \\
\hline CHEMBL3196659 & 688239 & 8.3372 & 5.4099 & TST \\
\hline CHEMBL3189598 & 688239 & 6.2862 & 5.4023 & TRN \\
\hline CHEMBL1552357 & 688239 & 4.5362 & 5.5255 & TRN \\
\hline CHEMBL1563595 & 688239 & 5.8862 & 5.6744 & TRN \\
\hline CHEMBL1418935 & 688239 & 5.3862 & 5.6436 & TRN \\
\hline CHEMBL1419895 & 688239 & 5.1362 & 5.4784 & TST \\
\hline CHEMBL1544265 & 688239 & 5.4362 & 5.5728 & TST \\
\hline CHEMBL1431215 & 688239 & 5.3862 & 5.5649 & TRN \\
\hline CHEMBL1367506 & 688239 & 4.7362 & 5.4717 & TRN \\
\hline CHEMBL1605259 & 688239 & 4.5862 & 5.4745 & TRN \\
\hline CHEMBL1455615 & 688239 & 6.8362 & 5.4635 & TRN \\
\hline CHEMBL1452325 & 688239 & 7.0362 & 5.3451 & TRN \\
\hline CHEMBL1531017 & 688239 & 4.7862 & 5.4197 & TRN \\
\hline CHEMBL1444894 & 688239 & 5.2362 & 5.6359 & TRN \\
\hline CHEMBL1426954 & 688239 & 5.1862 & 5.4623 & TRN \\
\hline CHEMBL1423421 & 688239 & 4.7362 & 5.414 & TST \\
\hline CHEMBL1429665 & 688239 & 4.6862 & 5.4892 & TST \\
\hline CHEMBL1438109 & 688239 & 4.4862 & 5.343999 & 7999999999 \\
\hline CHEMBL1329394 & 688239 & 5.5362 & 5.4992 & TRN \\
\hline CHEMBL1597647 & 688239 & 6.5862 & 5.5742 & TRN \\
\hline CHEMBL3191176 & 688239 & 5.3862 & 5.4132 & TST \\
\hline CHEMBL1416365 & 688239 & 5.6362 & 5.4116 & TRN \\
\hline
\end{tabular}


Supplemental Table S2.txt

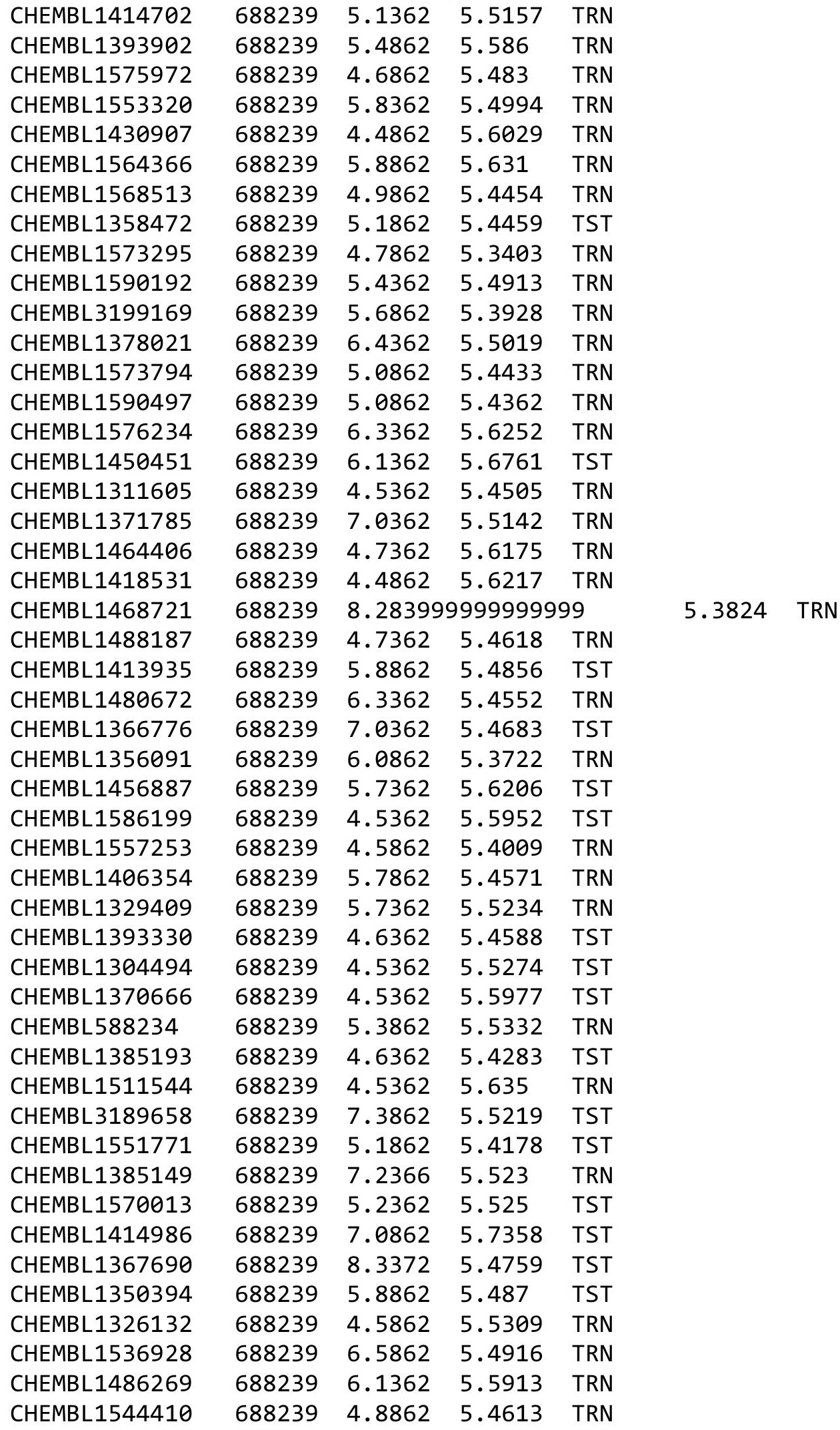

Page 1736 


\begin{tabular}{|c|c|c|c|c|}
\hline & & & & \\
\hline EMBL1475088 & בנד<0 & 362 & 3561 & $\cdot$ \\
\hline CHEMBL1583820 & 688239 & 5.7862 & 5631 & \\
\hline HEMBL3192036 & 88239 & 1862 & & \\
\hline HEMBL1594657 & 88239 & 6.4862 & 4392 & \\
\hline CHEMBL3192303 & 88239 & 6.0862 & 776 & \\
\hline HEMBL1544222 & 88239 & 5.5862 & $\lfloor 72$ & \\
\hline CHEMBL448060 & 88239 & 5.3362 & & \\
\hline CHEMBL1349455 & 588239 & 4362 & & \\
\hline CHEMBL1500754 & 588239 & 6.5363 & 5.3625 & \\
\hline CHEMBL1371191 & 239 & 4.5362 & & \\
\hline HEMBL14 & 39 & 5.3862 & & \\
\hline CHEMBL15 & 39 & 5363 & & \\
\hline CHEMBL1 & 688239 & 3362 & & \\
\hline CHEMBL1444111 & 39 & 5.0362 & & \\
\hline CHEMBL1 & 68 & 8.3372 & 05 & \\
\hline HEMBL & 39 & 862 & 25 & \\
\hline CHEMBL 1 & 39 & 862 & & \\
\hline CHEMBL1580179 & 688239 & 3862 & & \\
\hline CHEMBL15 & 68 & 862 & & \\
\hline CHEMBL1 & 68 & 862 & & \\
\hline HEMBL: & 39 & 362 & & \\
\hline CHEMBL 1 & 39 & 362 & & \\
\hline CHEMBL 1 & 39 & 362 & & \\
\hline HEMBL1 & 68 & 362 & & \\
\hline CHEMBL1 & 68 & 362 & & \\
\hline CHEMBL & 39 & 862 & & \\
\hline CHEMBL: & 39 & 362 & & \\
\hline HEMBL: & 68 & 362 & & \\
\hline CHEMBL1584716 & 688239 & 5.6362 & 62 & \\
\hline CHEMBL1318723 & 6882 & 5.6862 & & \\
\hline CHEMBL: & 39 & 862 & & \\
\hline CHEMBL: & 39 & 362 & & \\
\hline CHEMBL1 & $68 \varepsilon$ & 362 & & \\
\hline CHEMBL1313368 & 688239 & 361 & 274 & \\
\hline CHEMBL 1 & & 862 & & \\
\hline CHEMBL 1 & 39 & 862 & 53 & \\
\hline CHEMBL: & & 361 & 272 & \\
\hline CHEMBL1349173 & 688239 & 6.2362 & 932 & TR \\
\hline CHEMBL1542560 & 688239 & 5.6862 & & \\
\hline CHEMBL: & & & & $\mathrm{R}$ \\
\hline CHEMBL 1 & $68 \varepsilon$ & 6.0862 & 82 & \\
\hline CHEMBL1518861 & 688239 & 6.0362 & 5.5146 & $\mathrm{TR}$ \\
\hline CHEMBL3191047 & 688239 & 5.1362 & 26 & \\
\hline CHEMBL1364020 & 688239 & 5.4362 & & TS \\
\hline CHEMBL & & 362 & & $S$ \\
\hline CHEMBL1501490 & 688239 & 6.7862 & 5.4049 & \\
\hline CHEMBL1386786 & 688239 & 4.5362 & 5.5071 & $\mathrm{R}$ \\
\hline CHEMBL1394129 & 688239 & 6.1862 & 5.5542 & $\mathrm{R}$ \\
\hline
\end{tabular}


Supplemental Table S2.txt

\begin{tabular}{|c|c|c|c|c|}
\hline CHEMBL1467217 & 688239 & 5.6362 & 5.4025 & TRN \\
\hline CHEMBL1372902 & 688239 & 4.6862 & 5.4714 & TRN \\
\hline CHEMBL1355599 & 688239 & 6.2362 & 5.4479 & TRN \\
\hline CHEMBL1607639 & 688239 & 7.9355 & 5.551 & TRN \\
\hline CHEMBL1368718 & 688239 & 6.1362 & 5.6068 & TRN \\
\hline CHEMBL1572542 & 688239 & 7.6364 & \multicolumn{2}{|c|}{5.571000000000001} \\
\hline CHEMBL 3192279 & 688239 & 5.5862 & 5.3079 & TRN \\
\hline CHEMBL3195728 & 688239 & 5.6862 & 5.4926 & TST \\
\hline CHEMBL1449948 & 688239 & 5.1862 & 5.5852 & TRN \\
\hline CHEMBL1389421 & 688239 & 4.5362 & 5.2736 & TST \\
\hline CHEMBL1565392 & 688239 & 6.1862 & 5.5273 & TST \\
\hline CHEMBL1448422 & 688239 & 5.8362 & 5.4942 & TRN \\
\hline CHEMBL 3193783 & 688239 & 5.1362 & 5.2293 & TST \\
\hline CHEMBL1303054 & 688239 & 4.6862 & 5.5489 & TRN \\
\hline CHEMBL1340933 & 688239 & 4.7862 & 5.5303 & TRN \\
\hline CHEMBL1489793 & 688239 & 4.6362 & 5.3803 & TRN \\
\hline CHEMBL1379475 & 688239 & 5.1862 & 5.4465 & TRN \\
\hline CHEMBL1357903 & 688239 & 5.8862 & 5.619 & TRN \\
\hline CHEMBL1505650 & 688239 & 8.2366 & 5.5052 & TST \\
\hline CHEMBL1428330 & 688239 & 5.3862 & 5.4827 & TRN \\
\hline CHEMBL1402586 & 688239 & 4.7862 & 5.4482 & TRN \\
\hline CHEMBL1414333 & 688239 & 5.8362 & 5.4501 & TRN \\
\hline CHEMBL1498230 & 688239 & 4.6862 & 5.5701 & TRN \\
\hline CHEMBL1530072 & 688239 & 4.5362 & 5.5721 & TRN \\
\hline CHEMBL1601091 & 688239 & 4.7362 & \multicolumn{2}{|c|}{5.502000000000001} \\
\hline CHEMBL1599151 & 688239 & 4.5362 & 5.6066 & TST \\
\hline CHEMBL 3210272 & 688239 & 7.0362 & 5.4076 & TRN \\
\hline CHEMBL1548086 & 688239 & 4.6362 & 5.1359 & TST \\
\hline CHEMBL1365788 & 688239 & 4.6862 & 5.4331 & TST \\
\hline CHEMBL1602774 & 688239 & 4.6862 & 5.5223 & TST \\
\hline CHEMBL1465219 & 688239 & 5.6362 & 5.3815 & TRN \\
\hline CHEMBL1488825 & 688239 & 6.0362 & 5.4225 & TRN \\
\hline CHEMBL1361152 & 688239 & 4.8362 & 5.5919 & TRN \\
\hline CHEMBL1602622 & 688239 & 4.5362 & 5.521 & TRN \\
\hline CHEMBL1416282 & 688239 & 6.6362 & 5.5328 & TRN \\
\hline CHEMBL1428795 & 688239 & 4.5362 & 5.4714 & TST \\
\hline CHEMBL1514711 & 688239 & 4.5362 & 5.4838 & TST \\
\hline CHEMBL1995707 & 688239 & 4.5362 & 5.4254 & TRN \\
\hline CHEMBL1445083 & 688239 & 5.3362 & \multicolumn{2}{|c|}{5.497999999999999} \\
\hline CHEMBL1349024 & 688239 & 4.6362 & 5.4858 & TRN \\
\hline CHEMBL2004511 & 688239 & 4.8862 & 5.4179 & TRN \\
\hline CHEMBL1602590 & 688239 & 4.5362 & 5.3454 & TRN \\
\hline CHEMBL1478808 & 688239 & 5.1862 & 5.6003 & TRN \\
\hline CHEMBL 3208200 & 688239 & 5.4862 & 5.4939 & TRN \\
\hline CHEMBL1604970 & 688239 & 5.6862 & 5.4024 & TRN \\
\hline CHEMBL1378514 & 688239 & 5.1862 & 5.5646 & TST \\
\hline CHEMBL1375299 & 688239 & 5.7862 & 5.5365 & TRN \\
\hline CHEMBL1385030 & 688239 & 4.7362 & 5.4057 & TRN \\
\hline
\end{tabular}




\begin{tabular}{|c|c|c|c|c|c|}
\hline \multirow[b]{2}{*}{ CHEMBL1579492 } & & \multicolumn{4}{|c|}{ Supplemental Table S2.txt } \\
\hline & 688239 & 4.8362 & 5.53600 & 00000000005 & TST \\
\hline CHEMBL1498821 & 688239 & 4.4862 & 5.4592 & TRN & \\
\hline CHEMBL1319907 & 688239 & 6.0862 & 5.6004 & TRN & \\
\hline CHEMBL 3209940 & 688239 & 6.0362 & 5.3065 & TST & \\
\hline CHEMBL1439610 & 688239 & 6.9363 & 5.4622 & TRN & \\
\hline CHEMBL1382322 & 688239 & 6.6362 & 5.7111 & TRN & \\
\hline CHEMBL1548559 & 688239 & 4.6362 & 5.5981 & TRN & \\
\hline CHEMBL1507881 & 688239 & 4.4862 & 5.5 & TST & \\
\hline CHEMBL1537417 & 688239 & 4.7362 & 5.5963 & TST & \\
\hline CHEMBL1315585 & 688239 & 4.5862 & 5.5112 & TRN & \\
\hline CHEMBL1526067 & 688239 & 5.4862 & 5.3689 & TRN & \\
\hline CHEMBL1539128 & 688239 & 4.5862 & 5.5669 & TRN & \\
\hline CHEMBL1520206 & 688239 & 5.1862 & 5.4081 & TST & \\
\hline CHEMBL1612723 & 688239 & 4.5362 & 5.6035 & TST & \\
\hline CHEMBL1414563 & 688239 & 4.5862 & 5.4045 & TRN & \\
\hline CHEMBL1420244 & 688239 & 5.1862 & 5.4034 & TRN & \\
\hline CHEMBL1319094 & 688239 & 5.8362 & 5.5933 & TRN & \\
\hline CHEMBL1552514 & 688239 & 6.1862 & 5.5739 & TST & \\
\hline CHEMBL1416184 & 688239 & 4.8862 & 5.3338 & TRN & \\
\hline CHEMBL1352912 & 688239 & 6.9863 & 5.6784 & TRN & \\
\hline CHEMBL1366868 & 688239 & 6.8362 & 5.5118 & TST & \\
\hline CHEMBL1358278 & 688239 & 4.5362 & 5.4517 & TRN & \\
\hline CHEMBL3208835 & 688239 & 5.3862 & 5.4487 & TRN & \\
\hline CHEMBL1496054 & 688239 & 7.3862 & 5.4108 & TRN & \\
\hline CHEMBL1587005 & 688239 & 6.9863 & 5.5236 & TRN & \\
\hline CHEMBL1545560 & 688239 & 4.8362 & 5.3807 & TRN & \\
\hline CHEMBL1613678 & 688239 & 4.5362 & 5.3824 & TRN & \\
\hline CHEMBL1494247 & 688239 & 6.7862 & 5.4415 & TRN & \\
\hline CHEMBL1333115 & 688239 & 7.1361 & 5.4661 & TRN & \\
\hline CHEMBL1320646 & 688239 & 6.7361 & 5.4831 & TST & \\
\hline CHEMBL1327431 & 688239 & 5.5362 & 5.4579 & TST & \\
\hline CHEMBL1433825 & 688239 & 4.5362 & 5.3626 & TRN & \\
\hline CHEMBL3198317 & 688239 & 6.1862 & 5.4444 & TRN & \\
\hline CHEMBL1498355 & 688239 & 5.5362 & 5.4749 & TRN & \\
\hline CHEMBL1482651 & 688239 & 4.5362 & 5.4124 & TST & \\
\hline CHEMBL1515696 & 688239 & 4.6862 & 5.4001 & TRN & \\
\hline CHEMBL1579771 & 688239 & 4.5862 & 5.3883 & TRN & \\
\hline CHEMBL1520846 & 688239 & 5.4862 & 5.4863 & TRN & \\
\hline CHEMBL1986284 & 688239 & 8.3872 & 5.3979 & TRN & \\
\hline CHEMBL1505042 & 688239 & 5.4362 & 5.5198 & TRN & \\
\hline CHEMBL1353105 & 688239 & 5.0862 & 5.6126 & TRN & \\
\hline CHEMBL1299810 & 688239 & 4.7362 & 5.374 & TST & \\
\hline CHEMBL1549585 & 688239 & 6.9363 & 5.3897 & TST & \\
\hline CHEMBL1545094 & 688239 & 4.4862 & 5.6184 & TRN & \\
\hline CHEMBL1373457 & 688239 & 4.7362 & 5.5044 & TRN & \\
\hline CHEMBL1530057 & 688239 & 5.3862 & 5.49799 & 9999999999 & IRI \\
\hline CHEMBL1353853 & 688239 & 4.8362 & 5.5117 & TST & \\
\hline CHEMBL1414060 & 688239 & 4.7362 & 5.5255 & TST & \\
\hline
\end{tabular}




\begin{tabular}{|c|c|c|c|c|c|}
\hline \multirow[b]{2}{*}{ CHEMBL1350405 } & & \multicolumn{4}{|c|}{ Supplemental Table S2.txt } \\
\hline & 688239 & 5.3862 & 5.57100 & 3000000001 & TRN \\
\hline CHEMBL1490182 & 688239 & 4.6362 & 5.5578 & TRN & \\
\hline CHEMBL1423095 & 688239 & 4.6362 & 5.4582 & TRN & \\
\hline CHEMBL1554772 & 688239 & 8.8239 & 5.5099 & TRN & \\
\hline CHEMBL 1447078 & 688239 & 4.7362 & 5.4032 & TST & \\
\hline CHEMBL1445317 & 688239 & 6.5363 & 5.428 & TRN & \\
\hline CHEMBL1579104 & 688239 & 6.8861 & 5.4585 & TST & \\
\hline CHEMBL1486230 & 688239 & 6.1862 & 5.3515 & TST & \\
\hline CHEMBL1478335 & 688239 & 6.8861 & 5.4034 & TRN & \\
\hline CHEMBL1330268 & 688239 & 6.1362 & 5.5164 & TRN & \\
\hline CHEMBL1412804 & 688239 & 4.8862 & 5.4228 & TST & \\
\hline CHEMBL1522518 & 688239 & 6.7862 & 5.7475 & TRN & \\
\hline CHEMBL1568641 & 688239 & 6.8861 & 5.369 & TST & \\
\hline CHEMBL1360724 & 688239 & 5.2862 & 5.5977 & TRN & \\
\hline CHEMBL1427566 & 688239 & 4.5862 & 5.5221 & TRN & \\
\hline CHEMBL1585329 & 688239 & 5.2362 & 5.5038 & TRN & \\
\hline CHEMBL1543164 & 688239 & 6.5363 & 5.6488 & TRN & \\
\hline CHEMBL1408802 & 688239 & 4.5862 & 5.4003 & TRN & \\
\hline CHEMBL1326837 & 688239 & 6.6362 & 5.4477 & TST & \\
\hline CHEMBL1442037 & 688239 & 6.0362 & 5.4633 & TRN & \\
\hline CHEMBL1370515 & 688239 & 5.1862 & 5.6377 & TRN & \\
\hline CHEMBL1334228 & 688239 & 4.5362 & 5.4501 & TST & \\
\hline CHEMBL1545327 & 688239 & 6.0862 & 5.4749 & TRN & \\
\hline CHEMBL1558114 & 688239 & 4.6862 & 5.4033 & TST & \\
\hline CHEMBL1424938 & 688239 & 5.9362 & 5.3758 & TRN & \\
\hline CHEMBL1569892 & 688239 & 6.1862 & 5.347 & TST & \\
\hline CHEMBL1482421 & 688239 & 4.5362 & 5.4131 & TRN & \\
\hline CHEMBL1611486 & 688239 & 4.6862 & 5.4397 & TRN & \\
\hline CHEMBL1382101 & 688239 & 5.2362 & 5.4198 & TRN & \\
\hline CHEMBL1367781 & 688239 & 4.5362 & 5.3194 & TRN & \\
\hline CHEMBL1489187 & 688239 & 5.4362 & 5.6574 & TST & \\
\hline CHEMBL1580903 & 688239 & 6.9863 & 5.6388 & TRN & \\
\hline CHEMBL1327326 & 688239 & 6.2862 & 5.545 & TRN & \\
\hline CHEMBL1410731 & 688239 & 6.5363 & 5.5092 & TRN & \\
\hline CHEMBL1373664 & 688239 & 4.5362 & 5.4608 & TRN & \\
\hline CHEMBL1440852 & 688239 & 6.8362 & 5.5671 & TRN & \\
\hline CHEMBL1521969 & 688239 & 4.6862 & 5.5209 & TRN & \\
\hline CHEMBL 2088269 & 688239 & 5.7362 & 5.3473 & TRN & \\
\hline CHEMBL3198740 & 688239 & 6.1862 & 5.4332 & TST & \\
\hline CHEMBL1375453 & 688239 & 5.1862 & 5.5317 & TRN & \\
\hline CHEMBL1310680 & 688239 & 4.7862 & 5.4758 & TST & \\
\hline CHEMBL1445573 & 688239 & 5.4362 & 5.5817 & TST & \\
\hline CHEMBL1397287 & 688239 & 6.3863 & 5.4788 & TRN & \\
\hline CHEMBL1419408 & 688239 & 5.2862 & 5.6088 & TRN & \\
\hline CHEMBL1510865 & 688239 & 6.5363 & 5.5728 & TST & \\
\hline CHEMBL1319267 & 688239 & 6.6362 & 5.5375 & TRN & \\
\hline CHEMBL1580481 & 688239 & 4.5362 & 5.4314 & TRN & \\
\hline CHEMBL1555088 & 688239 & 7.3363 & 5.4488 & TRN & \\
\hline
\end{tabular}




\begin{tabular}{|c|c|c|c|c|c|c|}
\hline & & \multicolumn{5}{|c|}{ Supplemental Table S2.txt } \\
\hline CHEMBL1301758 & 688239 & 5.4862 & 5.5919 & TRN & & \\
\hline CHEMBL1602138 & 688239 & 5.3862 & 5.3613 & TRN & & \\
\hline CHEMBL1322441 & 688239 & 6.1862 & 5.3939 & TRN & & \\
\hline CHEMBL1336189 & 688239 & 6.8362 & 5.3673 & TRN & & \\
\hline CHEMBL1425137 & 688239 & 4.5362 & 5.3834 & TRN & & \\
\hline CHEMBL1535334 & 688239 & 6.1362 & 5.5478 & TRN & & \\
\hline CHEMBL1507007 & 688239 & 4.7862 & 5.5138 & TRN & & \\
\hline CHEMBL1536992 & 688239 & 4.45 & 5.3477 & TST & & \\
\hline CHEMBL1415552 & 688239 & 4.5362 & 5.4057 & TST & & \\
\hline CHEMBL1469115 & 688239 & 5.2362 & 5.4627 & TST & & \\
\hline CHEMBL1495937 & 688239 & 4.5362 & 5.3835 & TRN & & \\
\hline CHEMBL1450035 & 688239 & 5.7862 & 5.4315 & TRN & & \\
\hline CHEMBL1316170 & 688239 & 5.9362 & 5.4504 & TRN & & \\
\hline CHEMBL1526956 & 688239 & 4.5362 & 5.5768 & TRN & & \\
\hline CHEMBL1546159 & 688239 & 5.4862 & 5.5372 & TRN & & \\
\hline CHEMBL1345481 & 688239 & 4.6862 & 5.4374 & TRN & & \\
\hline CHEMBL1541097 & 688239 & 6.9863 & 5.5327 & TRN & & \\
\hline CHEMBL1405776 & 688239 & 4.5362 & 5.5685 & TST & & \\
\hline CHEMBL1477634 & 688239 & 4.9362 & 5.5337 & TRN & & \\
\hline CHEMBL1337394 & 688239 & 4.6362 & 5.5341 & TRN & & \\
\hline CHEMBL1334703 & 688239 & 4.5362 & 5.4672 & TST & & \\
\hline CHEMBL1571891 & 688239 & 4.5862 & 5.4131 & TST & & \\
\hline CHEMBL1506887 & 688239 & 6.0862 & 5.5311 & TRN & & \\
\hline CHEMBL1307125 & 688239 & 4.4862 & 5.3746 & TST & & \\
\hline CHEMBL1599019 & 688239 & 8.28399 & 99999999 & 99 & 5.4658 & TRN \\
\hline CHEMBL1531172 & 688239 & 4.45 & 5.4149 & TRN & & \\
\hline CHEMBL1353212 & 688239 & 5.4862 & 5.4647 & TRN & & \\
\hline CHEMBL1399037 & 688239 & 5.2362 & 5.4196 & TRN & & \\
\hline CHEMBL3209211 & 688239 & 5.2362 & 5.5658 & TRN & & \\
\hline CHEMBL1532997 & 688239 & 4.5362 & 5.4064 & TST & & \\
\hline CHEMBL1547964 & 688239 & 5.3362 & 5.4778 & TRN & & \\
\hline CHEMBL1562631 & 688239 & 5.3362 & 5.5962 & TRN & & \\
\hline CHEMBL3189806 & 688239 & 6.8861 & 5.5582 & TST & & \\
\hline CHEMBL1573323 & 688239 & 8.3872 & 5.434 & TST & & \\
\hline CHEMBL1540325 & 688239 & 7.6861 & 5.5467 & TRN & & \\
\hline CHEMBL1586263 & 688239 & 4.7362 & 5.5671 & TRN & & \\
\hline CHEMBL1574991 & 688239 & 5.3862 & 5.5403 & TST & & \\
\hline CHEMBL1541507 & 688239 & 5.6862 & 5.3845 & TRN & & \\
\hline CHEMBL1306822 & 688239 & 5.4862 & 5.5161 & TRN & & \\
\hline CHEMBL1493575 & 688239 & 5.1862 & 5.2803 & TST & & \\
\hline CHEMBL1605315 & 688239 & 4.5862 & 5.4706 & TRN & & \\
\hline CHEMBL1562802 & 688239 & 8.2366 & 5.473 & TRN & & \\
\hline CHEMBL1467373 & 688239 & 4.7362 & 5.5747 & TST & & \\
\hline CHEMBL1494661 & 688239 & 5.5862 & 5.5456 & TRN & & \\
\hline CHEMBL1556830 & 688239 & 4.5362 & 5.4985 & TRN & & \\
\hline CHEMBL1478268 & 688239 & 4.9362 & 5.3804 & TRN & & \\
\hline CHEMBL1426275 & 688239 & 6.0 & 5.5289 & TST & & \\
\hline CHEMBL1589634 & 688239 & 5.6862 & 5.5136 & TST & & \\
\hline
\end{tabular}


Supplemental Table S2.txt

\begin{tabular}{|c|c|c|c|c|}
\hline CHEMBL1350986 & 688239 & 4.5362 & 5.3627 & TRN \\
\hline CHEMBL1562380 & 688239 & 4.9362 & 5.434 & TRN \\
\hline CHEMBL1559493 & 688239 & 5.4362 & 5.5671 & TRN \\
\hline CHEMBL1544202 & 688239 & 4.8362 & 5.4895 & TRN \\
\hline CHEMBL 3214463 & 688239 & 4.8362 & 5.5028 & TST \\
\hline CHEMBL1515912 & 688239 & 4.5362 & 5.4815 & TRN \\
\hline CHEMBL1474396 & 688239 & 6.2862 & 5.5041 & TRN \\
\hline CHEMBL1982547 & 688239 & 5.6862 & 5.5344 & TST \\
\hline CHEMBL1436551 & 688239 & 4.7862 & 5.4333 & TRN \\
\hline CHEMBL1608146 & 688239 & 7.2366 & 5.4645 & TRN \\
\hline CHEMBL1428811 & 688239 & 4.5362 & 5.447 & TRN \\
\hline CHEMBL1574530 & 688239 & 5.0362 & 5.4172 & TRN \\
\hline CHEMBL1428729 & 688239 & 5.1862 & 5.5616 & TRN \\
\hline CHEMBL1494369 & 688239 & 6.3362 & 5.4959 & TRN \\
\hline CHEMBL1459330 & 688239 & 4.4862 & 5.2579 & TRN \\
\hline CHEMBL1590739 & 688239 & 7.1864 & 5.4679 & TRN \\
\hline CHEMBL1332328 & 688239 & 4.6862 & 5.6714 & TST \\
\hline CHEMBL1425031 & 688239 & 4.9362 & 5.3828 & TRN \\
\hline CHEMBL1433187 & 688239 & 8.2366 & 5.4779 & TRN \\
\hline CHEMBL1548445 & 688239 & 5.6862 & 5.4914 & TRN \\
\hline CHEMBL1335922 & 688239 & 4.8862 & 5.3999 & TRN \\
\hline CHEMBL1398792 & 688239 & 6.1362 & 5.4791 & TRN \\
\hline CHEMBL1502911 & 688239 & 4.5362 & 5.5173 & TRN \\
\hline CHEMBL 3210421 & 688239 & 7.9872 & 5.5165 & TRN \\
\hline CHEMBL1599172 & 688239 & 4.5362 & 5.371 & TST \\
\hline CHEMBL1587368 & 688239 & 4.7362 & 5.6117 & TRN \\
\hline CHEMBL1467801 & 688239 & 4.7362 & 5.4352 & TRN \\
\hline CHEMBL1342788 & 688239 & 4.6862 & 5.4655 & TRN \\
\hline CHEMBL1534130 & 688239 & 4.8362 & 5.3264 & TRN \\
\hline CHEMBL1430357 & 688239 & 5.8362 & 5.6835 & TRN \\
\hline CHEMBL1407559 & 688239 & 6.3863 & 5.4723 & TRN \\
\hline CHEMBL1435645 & 688239 & 4.5362 & 5.59200 & 0000000005 \\
\hline CHEMBL1348199 & 688239 & 4.7362 & 5.5068 & TRN \\
\hline CHEMBL1435469 & 688239 & 4.8862 & 5.47 & TRN \\
\hline CHEMBL1403267 & 688239 & 8.3372 & 5.3944 & TST \\
\hline CHEMBL1373317 & 688239 & 5.0362 & 5.4284 & TRN \\
\hline CHEMBL1463424 & 688239 & 7.6364 & 5.5776 & TRN \\
\hline CHEMBL1576109 & 688239 & 6.1362 & 5.5374 & TRN \\
\hline CHEMBL1305095 & 688239 & 5.1862 & 5.3578 & TRN \\
\hline CHEMBL 3212543 & 688239 & 5.4362 & 5.2747 & TST \\
\hline CHEMBL1379089 & 688239 & 5.1862 & 5.4282 & TRN \\
\hline CHEMBL1347564 & 688239 & 5.2362 & 5.4779 & TRN \\
\hline CHEMBL1453141 & 688239 & 6.7361 & 5.6955 & TRN \\
\hline CHEMBL1373999 & 688239 & 5.1862 & 5.4562 & TRN \\
\hline CHEMBL1510672 & 688239 & 6.1362 & 5.5204 & TRN \\
\hline CHEMBL1310877 & 688239 & 6.0862 & 5.5618 & TRN \\
\hline CHEMBL288998 & 688239 & 6.7862 & 5.5067 & TST \\
\hline CHEMBL1300239 & 688239 & 4.7862 & 5.4563 & TRN \\
\hline
\end{tabular}

Page 1742 
Supplemental Table S2.txt

\begin{tabular}{|c|c|c|c|c|c|}
\hline CHEMBL1523910 & 688239 & 5.3862 & 5.7842 & TRN & \\
\hline CHEMBL1377647 & 688239 & 4.4862 & 5.5892 & TST & \\
\hline CHEMBL1329847 & 688239 & 5.8862 & 5.5373 & TRN & \\
\hline CHEMBL1377920 & 688239 & 4.4862 & 5.5231 & TST & \\
\hline CHEMBL1549784 & 688239 & 5.6862 & 5.5023 & TRN & \\
\hline CHEMBL1498312 & 688239 & 4.8862 & 5.4533 & TRN & \\
\hline CHEMBL1395183 & 688239 & 5.1862 & 5.4563 & TRN & \\
\hline CHEMBL1509886 & 688239 & 5.7362 & 5.3821 & TST & \\
\hline CHEMBL1495956 & 688239 & 6.7862 & 5.4172 & TRN & \\
\hline CHEMBL1610701 & 688239 & 7.0862 & 5.5148 & TRN & \\
\hline CHEMBL1345850 & 688239 & 5.4362 & 5.5444 & TST & \\
\hline CHEMBL1595227 & 688239 & 5.0362 & 5.5878 & TRN & \\
\hline CHEMBL1361963 & 688239 & 6.1862 & 5.5313 & TRN & \\
\hline CHEMBL1442912 & 688239 & 5.7362 & 5.5411 & TRN & \\
\hline CHEMBL1383908 & 688239 & 6.1862 & 5.5631 & TRN & \\
\hline CHEMBL1571064 & 688239 & 7.0362 & 5.4248 & TRN & \\
\hline CHEMBL1315414 & 688239 & 4.7362 & 5.4815 & TRN & \\
\hline CHEMBL1594824 & 688239 & 4.7362 & 5.5139 & TRN & \\
\hline CHEMBL1450155 & 688239 & 5.7362 & 5.6471 & TRN & \\
\hline CHEMBL1602024 & 688239 & 5.0862 & 5.5029 & TRN & \\
\hline CHEMBL1379170 & 688239 & 4.5362 & 5.5057 & TRN & \\
\hline CHEMBL1345388 & 688239 & 5.7862 & 5.4667 & TST & \\
\hline CHEMBL1569881 & 688239 & 4.5362 & 5.4517 & TRN & \\
\hline CHEMBL1426411 & 688239 & 5.6862 & 5.4918 & TST & \\
\hline CHEMBL1441748 & 688239 & 4.9862 & 5.6174 & TRN & \\
\hline CHEMBL1549271 & 688239 & 7.0362 & 5.4764 & TRN & \\
\hline CHEMBL1570639 & 688239 & 6.6362 & 5.5525 & TRN & \\
\hline CHEMBL1471837 & 688239 & 8.3372 & 5.3125 & TST & \\
\hline CHEMBL1559407 & 688239 & 4.9362 & 5.4427 & TRN & \\
\hline CHEMBL1347271 & 688239 & 4.5362 & 5.4317 & TRN & \\
\hline CHEMBL1979599 & 688239 & 5.1862 & 5.301 & TRN & \\
\hline CHEMBL1512176 & 688239 & 5.1862 & 5.4226 & TRN & \\
\hline CHEMBL1439348 & 688239 & 7.0362 & 5.4083 & TRN & \\
\hline CHEMBL1586306 & 688239 & 4.4862 & 5.521 & TRN & \\
\hline CHEMBL1560300 & 688239 & 4.7362 & 5.631 & TRN & \\
\hline CHEMBL1496107 & 688239 & 5.4862 & 5.3531 & TST & \\
\hline CHEMBL3193400 & 688239 & 4.6862 & 5.3769 & TRN & \\
\hline CHEMBL1440906 & 688239 & 4.9862 & 5.4715 & TST & \\
\hline CHEMBL1347076 & 688239 & 4.6862 & 5.6241 & TRN & \\
\hline CHEMBL1469191 & 688239 & 6.6362 & 5.632006 & 0000000001 & TRN \\
\hline CHEMBL1415827 & 688239 & 8.2366 & 5.5122 & TST & \\
\hline CHEMBL1430742 & 688239 & 5.4862 & 5.4908 & TRN & \\
\hline CHEMBL1299457 & 688239 & 5.5362 & 5.3823 & TST & \\
\hline CHEMBL1495829 & 688239 & 4.5362 & 5.3583 & TST & \\
\hline CHEMBL1450418 & 688239 & 6.8362 & 5.4733 & TRN & \\
\hline CHEMBL1405963 & 688239 & 6.0862 & 5.5511 & TRN & \\
\hline CHEMBL1569983 & 688239 & 4.5362 & 5.6003 & TRN & \\
\hline CHEMBL1537526 & 688239 & 5.1862 & 5.3918 & TRN & \\
\hline
\end{tabular}


Supplemental Table S2.txt

CHEMBL3211202
CHEMBL1312205
CHEMBL1501835
CHEMBL1534748
CHEMBL3211621
CHEMBL1500296
CHEMBL1561797
CHEMBL1409968
688239
$\begin{array}{lll}6.6861 & 5.4099 & \text { TRN }\end{array}$

$\begin{array}{llll}688239 & 5.3862 & 5.5042 & \text { TST }\end{array}$

$\begin{array}{llll}688239 & 5.5862 & 5.4037 & \text { TRN }\end{array}$

$\begin{array}{lllll}688239 & 4.7362 & 5.4533 & \text { TRN }\end{array}$

$\begin{array}{llll}688239 & 4.6862 & 5.4373 & \text { TST }\end{array}$

$\begin{array}{llll}688239 & 5.8862 & 5.4083 & \text { TST }\end{array}$

$\begin{array}{llll}688239 & 6.2862 & 5.4844 & \text { TRN }\end{array}$

$\begin{array}{llll}688239 & 4.5362 & 5.585 & \text { TRN }\end{array}$

CHEMBL1558973

688239

5.6362

5.5429 TRN

CHEMBL1514826

CHEMBL 3190252

CHEMBL1458137

CHEMBL1602160

CHEMBL1496229

CHEMBL1572308

CHEMBL1509106

CHEMBL3209379

CHEMBL1431930

CHEMBL1365304

CHEMBL1489197

CHEMBL1389606

CHEMBL 3212403

CHEMBL1460748

CHEMBL3193406

688239

5.9862

5.6121 TRN

688239

5.7362

5.4314 TRN

688239

688239

688239

4.8362

5.6619 TRN

$\begin{array}{lll}6.0 & 5.4708 \text { TST }\end{array}$

688239

5.2862

5.5313 TRN

688239

4.7362

5.4855 TRN

688239

5.1862

5.619 TRN

688239

5.3362

5.3893 TRN

688239

6.2362

5.386

4.5362

5.5722 TST

688239

6.4362

5.5722 TST

688239

5.0862

5.4545 TST

688239

4.7862

5.4846 TRN

688239

4.5362

5.4152 TST

688239

5.5362

5.497000000000001

TST

688239

6.9863

5.3558 TRN

688239

6.1362

5.5892 TRN

CHEMBL1301562

688239

5.4362

5.6328

TRN

688239

7.0362

5.3401 TST

CHEMBL1364176

CHEMBL1348487

CHEMBL1341087

CHEMBL1369391

CHEMBL1417713

CHEMBL1600778

CHEMBL1309338

CHEMBL1364225

CHEMBL1354523

CHEMBL1512282

CHEMBL1388756

CHEMBL3208409

CHEMBL1493623

CHEMBL1442798

688239

5.6862

5.4682 TRN

688239

688239

5.8862

5.5765 TRN

688239

6.2362

5.5303 TST

688239

5.3862

5.3993 TRN

688239

6.5862

5.5637 TRN

688239

4.5362

5.5394 TRN

688239

6.9863

5.5304 TRN

688239

4.9862

5.5544 TRN

688239

5.7362

5.4911 TRN

688239

7.8861

5.5761 TRN

688239

6.3863

5.5672 TRN

688239

4.4862

5.4424 TRN

CHEMBL1507706

688239

5.3862

5.48

TST

688239

6.7361

5.3838 TST

CHEMBL1350978

4.4862

5.6991 TRN

688239

4.7862

5.5719 TST

688239

6.5862

5.3517 TRN

CHEMBL1423333

CHEMBL1442056

CHEMBL1602528

688239

4.8362

5.5146 TRN

688239

4.5362

5.35 TST

688239

5.2862

5.4777 TRN

5.5971 TRN

Page 1744 


\begin{tabular}{|c|c|c|c|c|c|}
\hline \multicolumn{6}{|c|}{ Supplemental Table s2.txt } \\
\hline CHEMBL1541306 & 688239 & 5.7362 & 5.5811 & TRN & \\
\hline CHEMBL1407167 & 688239 & 6.3863 & 5.5796 & TRN & \\
\hline CHEMBL1489071 & 688239 & 8.1871 & 5.5247 & TST & \\
\hline CHEMBL1482823 & 688239 & 6.2362 & 5.4762 & TST & \\
\hline CHEMBL1528305 & 688239 & 4.8362 & 5.4812 & TST & \\
\hline CHEMBL1480809 & 688239 & 4.5362 & 5.3971 & TRN & \\
\hline CHEMBL1516532 & 688239 & 6.7361 & 5.5277 & TST & \\
\hline CHEMBL3211382 & 688239 & 5.2362 & 5.3932 & TRN & \\
\hline CHEMBL1563429 & 688239 & 4.6362 & 5.3471 & TRN & \\
\hline CHEMBL1486897 & 688239 & 5.1862 & 5.4413 & TRN & \\
\hline CHEMBL1388877 & 688239 & 4.8362 & 5.3788 & TRN & \\
\hline CHEMBL1378687 & 688239 & 5.5362 & 5.4005 & TST & \\
\hline CHEMBL3197897 & 688239 & 4.5362 & 5.4961 & TRN & \\
\hline CHEMBL1463507 & 688239 & 6.9863 & 5.6627 & TST & \\
\hline CHEMBL1516127 & 688239 & 4.8862 & 5.5283 & TRN & \\
\hline CHEMBL1321515 & 688239 & 5.0362 & 5.3368 & TRN & \\
\hline CHEMBL1470717 & 688239 & 4.5362 & 5.4757 & TST & \\
\hline CHEMBL1302045 & 688239 & 6.0362 & 5.5151 & TRN & \\
\hline CHEMBL1345950 & 688239 & 5.7862 & 5.5285 & TRN & \\
\hline CHEMBL 244693 & 688239 & 6.1862 & 5.5822 & TST & \\
\hline CHEMBL1555393 & 688239 & 5.3862 & 5.3694 & TRN & \\
\hline CHEMBL1386966 & 688239 & 8.28399 & 99999999 & 5.4511 & TRN \\
\hline CHEMBL1967821 & 688239 & 4.5362 & 5.3797 & TRN & \\
\hline CHEMBL1565109 & 688239 & 5.7862 & 5.4176 & TRN & \\
\hline CHEMBL1528085 & 688239 & 4.5362 & 5.5559 & TRN & \\
\hline CHEMBL1371150 & 688239 & 5.0862 & 5.6202 & TST & \\
\hline CHEMBL1338998 & 688239 & 4.5362 & 5.5626 & TRN & \\
\hline CHEMBL1596815 & 688239 & 4.5362 & 5.4564 & TRN & \\
\hline CHEMBL1353343 & 688239 & 5.7862 & 5.46 & TST & \\
\hline CHEMBL1369665 & 688239 & 5.3362 & 5.5395 & TRN & \\
\hline CHEMBL1532477 & 688239 & 5.2362 & 5.682 & TRN & \\
\hline CHEMBL1579862 & 688239 & 5.4362 & 5.4695 & TRN & \\
\hline CHEMBL1411598 & 688239 & 5.1362 & 5.55399 & 9999999999 & TRN \\
\hline CHEMBL1371441 & 688239 & 8.2366 & 5.494 & TST & \\
\hline CHEMBL1519210 & 688239 & 8.28399 & 79999999 & 5.4433 & TRN \\
\hline CHEMBL1558563 & 688239 & 4.5862 & 5.3685 & TST & \\
\hline CHEMBL1515396 & 688239 & 6.1362 & 5.61799 & 9999999999 & TRN \\
\hline CHEMBL1580085 & 688239 & 4.5362 & 5.5332 & TRN & \\
\hline CHEMBL1506496 & 688239 & 5.6362 & 5.401 & TRN & \\
\hline CHEMBL1324112 & 688239 & 4.5362 & 5.5881 & TST & \\
\hline CHEMBL1362356 & 688239 & 8.3372 & 5.5247 & TRN & \\
\hline CHEMBL1408919 & 688239 & 6.1362 & 5.3913 & TRN & \\
\hline CHEMBL587728 & 688239 & 6.2862 & 5.409 & TRN & \\
\hline CHEMBL1426743 & 688239 & 5.3862 & 5.5207 & TRN & \\
\hline CHEMBL1531270 & 688239 & 6.2362 & 5.504 & TRN & \\
\hline CHEMBL1415174 & 688239 & 4.7362 & 5.4021 & TRN & \\
\hline CHEMBL1361962 & 688239 & 5.6862 & 5.5109 & TRN & \\
\hline CHEMBL1309593 & 688239 & 6.8362 & 5.5312 & TRN & \\
\hline
\end{tabular}


Supplemental Table S2.txt

\begin{tabular}{|c|c|c|c|c|}
\hline CHEMBL1398669 & 688239 & 5.1362 & 5.3689 & TRN \\
\hline CHEMBL1410183 & 688239 & 7.5867 & 5.5555 & TRN \\
\hline CHEMBL3190021 & 688239 & 6.0362 & 5.3674 & TRN \\
\hline CHEMBL1326398 & 688239 & 8.3372 & 5.4958 & TST \\
\hline CHEMBL1342828 & 688239 & 6.7361 & 5.5909 & TST \\
\hline CHEMBL1474240 & 688239 & 5.4362 & 5.5218 & TRN \\
\hline CHEMBL1359466 & 688239 & 5.4362 & 5.65799 & 99999999995 \\
\hline CHEMBL3195385 & 688239 & 5.3862 & 5.5635 & TST \\
\hline CHEMBL1532228 & 688239 & 5.7862 & 5.4966 & TRN \\
\hline CHEMBL1371406 & 688239 & 5.5862 & 5.3894 & TRN \\
\hline CHEMBL169143 & 688239 & 6.2362 & 5.6198 & TRN \\
\hline CHEMBL1331855 & 688239 & 5.5862 & 5.5227 & TST \\
\hline CHEMBL1519574 & 688239 & 4.7862 & 5.5226 & TRN \\
\hline CHEMBL1387533 & 688239 & 4.4862 & 5.54 & TRN \\
\hline CHEMBL1423876 & 688239 & 5.9362 & 5.6067 & TRN \\
\hline CHEMBL1469077 & 688239 & 6.9363 & 5.5359 & TRN \\
\hline CHEMBL1338330 & 688239 & 5.0862 & 5.4835 & TST \\
\hline CHEMBL1572370 & 688239 & 4.8862 & 5.4777 & TRN \\
\hline CHEMBL3208386 & 688239 & 4.5362 & 5.3778 & TRN \\
\hline CHEMBL1991234 & 688239 & 5.1862 & 5.3498 & TRN \\
\hline CHEMBL1320509 & 688239 & 7.1361 & 5.3562 & TRN \\
\hline CHEMBL1569399 & 688239 & 4.7862 & 5.4114 & TRN \\
\hline CHEMBL1364131 & 688239 & 6.2362 & 5.3377 & TST \\
\hline CHEMBL3195005 & 688239 & 5.8362 & 5.4719 & TRN \\
\hline CHEMBL 2006634 & 688239 & 4.5362 & 5.3214 & TRN \\
\hline CHEMBL3198637 & 688239 & 7.0362 & 5.44 & TST \\
\hline CHEMBL1388291 & 688239 & 5.6362 & 5.4728 & TRN \\
\hline CHEMBL1505138 & 688239 & 4.5362 & 5.4928 & TRN \\
\hline CHEMBL1595016 & 688239 & 6.5363 & 5.523 & TRN \\
\hline CHEMBL 1309674 & 688239 & 4.7862 & 5.5638 & TRN \\
\hline CHEMBL1318492 & 688239 & 4.9862 & 5.5101 & TRN \\
\hline CHEMBL1587769 & 688239 & 4.9362 & 5.6161 & TRN \\
\hline CHEMBL1327440 & 688239 & 5.8862 & 5.4412 & TRN \\
\hline CHEMBL1369152 & 688239 & 4.7862 & 5.6133 & TST \\
\hline CHEMBL 76144 & 688239 & 5.4362 & 5.4557 & TRN \\
\hline CHEMBL1429157 & 688239 & 4.5862 & 5.4084 & TRN \\
\hline CHEMBL1365374 & 688239 & 4.6362 & 5.5665 & TST \\
\hline CHEMBL1416385 & 688239 & 4.5362 & 5.4358 & TRN \\
\hline CHEMBL1613195 & 688239 & 6.1362 & 5.2541 & TRN \\
\hline CHEMBL1417225 & 688239 & 5.1362 & 5.4704 & TRN \\
\hline CHEMBL1369618 & 688239 & 5.3862 & 5.3216 & TRN \\
\hline CHEMBL1360609 & 688239 & 4.6362 & 5.6157 & TRN \\
\hline CHEMBL1535739 & 688239 & 4.6862 & 5.4483 & TRN \\
\hline CHEMBL1516597 & 688239 & 4.7862 & 5.4913 & TST \\
\hline CHEMBL1576264 & 688239 & 4.6362 & 5.4474 & TST \\
\hline CHEMBL1469025 & 688239 & 6.2362 & 5.5121 & TRN \\
\hline CHEMBL1388059 & 688239 & 6.7862 & 5.6403 & TST \\
\hline CHEMBL1308903 & 688239 & 5.1862 & 5.4553 & TRN \\
\hline
\end{tabular}


Supplemental Table S2.txt

\begin{tabular}{|c|c|c|c|c|c|}
\hline CHEMBL1977978 & 688239 & 5.1862 & 5.2692 & TRN & \\
\hline CHEMBL1486601 & 688239 & 6.2362 & 5.5192 & TRN & \\
\hline CHEMBL1448205 & 688239 & 5.8362 & 5.3444 & TST & \\
\hline CHEMBL 3214119 & 688239 & 5.5362 & 5.4501 & TRN & \\
\hline CHEMBL1325046 & 688239 & 4.6862 & 5.5418 & TST & \\
\hline CHEMBL1305925 & 688239 & 5.1862 & 5.441 & TRN & \\
\hline CHEMBL1419446 & 688239 & 6.1862 & 5.5285 & TRN & \\
\hline CHEMBL1438871 & 688239 & 8.283999 & 99999999 & 5.4825 & \\
\hline CHEMBL1544967 & 688239 & 5.2862 & 5.5634 & TRN & \\
\hline CHEMBL1313554 & 688239 & 4.6862 & 5.5599 & TRN & \\
\hline CHEMBL1346980 & 688239 & 7.1864 & 5.6771 & TRN & \\
\hline CHEMBL1581953 & 688239 & 6.8861 & 5.6117 & TRN & \\
\hline CHEMBL1508178 & 688239 & 5.2862 & 5.4041 & TRN & \\
\hline CHEMBL1421284 & 688239 & 4.8362 & 5.5809 & TRN & \\
\hline CHEMBL1526842 & 688239 & 4.6362 & 5.4253 & TRN & \\
\hline CHEMBL1390845 & 688239 & 7.1864 & 5.5762 & TST & \\
\hline CHEMBL1557562 & 688239 & 5.6862 & 5.6277 & TRN & \\
\hline CHEMBL1608765 & 688239 & 5.3862 & 5.465 & TST & \\
\hline CHEMBL1510503 & 688239 & 6.1362 & 5.5552 & TRN & \\
\hline CHEMBL1455181 & 688239 & 4.5362 & 5.5146 & TRN & \\
\hline CHEMBL1302388 & 688239 & 5.1862 & 5.3342 & TST & \\
\hline CHEMBL1355859 & 688239 & 5.3862 & 5.6115 & TRN & \\
\hline CHEMBL1486191 & 688239 & 6.2862 & 5.3186 & TST & \\
\hline CHEMBL1410893 & 688239 & 6.2862 & 5.4843 & TST & \\
\hline CHEMBL1511419 & 688239 & 4.7862 & 5.5658 & TRN & \\
\hline CHEMBL1592248 & 688239 & 6.9863 & 5.481 & TRN & \\
\hline CHEMBL1581684 & 688239 & 6.2362 & 5.487999 & 9999999995 & \\
\hline CHEMBL1559928 & 688239 & 4.6362 & 5.2787 & TRN & \\
\hline CHEMBL1360080 & 688239 & 6.2362 & 5.5669 & TRN & \\
\hline CHEMBL1515390 & 688239 & 7.0862 & 5.6599 & TRN & \\
\hline CHEMBL1460472 & 688239 & 4.6362 & 5.4434 & TRN & \\
\hline CHEMBL1312601 & 688239 & 5.7362 & 5.55 & TST & \\
\hline CHEMBL1488445 & 688239 & 4.6362 & 5.5217 & TRN & \\
\hline CHEMBL1575999 & 688239 & 4.8362 & 5.4937 & TRN & \\
\hline CHEMBL 3190077 & 688239 & 4.5362 & 5.5272 & TST & \\
\hline CHEMBL1556127 & 688239 & 5.8362 & 5.3624 & TRN & \\
\hline CHEMBL1574564 & 688239 & 8.3372 & 5.5916 & TRN & \\
\hline CHEMBL1490530 & 688239 & 5.6362 & 5.3962 & TRN & \\
\hline CHEMBL1560949 & 688239 & 5.1862 & 5.4742 & TRN & \\
\hline CHEMBL1328882 & 688239 & 4.6862 & 5.3817 & TST & \\
\hline CHEMBL1357792 & 688239 & 4.5362 & 5.5537 & TST & \\
\hline CHEMBL1536127 & 688239 & 4.5362 & 5.4747 & TRN & \\
\hline CHEMBL1424404 & 688239 & 8.28399 & 99999999 & 5.3182 & TIV \\
\hline CHEMBL1436550 & 688239 & 6.3362 & 5.4775 & TRN & \\
\hline CHEMBL1425367 & 688239 & 4.6362 & 5.3769 & TRN & \\
\hline CHEMBL3195999 & 688239 & 4.5362 & 5.4044 & TRN & \\
\hline CHEMBL1496118 & 688239 & 5.6362 & 5.5834 & TRN & \\
\hline CHEMBL1335147 & 688239 & 4.5362 & 5.3959 & TRN & \\
\hline
\end{tabular}


Supplemental Table S2.txt

\begin{tabular}{|c|c|c|c|c|}
\hline CHEMBL3209064 & 688239 & 5.3362 & 5.5529 & TRN \\
\hline CHEMBL3212234 & 688239 & 5.6362 & 5.593 & TRN \\
\hline CHEMBL1347958 & 688239 & 5.4862 & 5.4423 & TST \\
\hline CHEMBL3190604 & 688239 & 5.4362 & \multicolumn{2}{|c|}{5.696000000000001} \\
\hline CHEMBL1408054 & 688239 & 4.5862 & 5.6045 & TRN \\
\hline CHEMBL1973300 & 688239 & 4.4862 & 5.4188 & TRN \\
\hline CHEMBL1304244 & 688239 & 4.6862 & 5.4628 & TRN \\
\hline CHEMBL1470861 & 688239 & 4.95 & 5.5233 & TRN \\
\hline CHEMBL1380584 & 688239 & 6.2862 & 5.4775 & TRN \\
\hline CHEMBL1497179 & 688239 & 4.5362 & 5.5253 & TST \\
\hline CHEMBL1327547 & 688239 & 4.5862 & 5.4923 & TST \\
\hline CHEMBL1329411 & 688239 & 6.8362 & 5.6295 & TRN \\
\hline CHEMBL1313081 & 688239 & 4.4862 & 5.4984 & TST \\
\hline CHEMBL1974319 & 688239 & 5.5862 & 5.3166 & TRN \\
\hline CHEMBL1337132 & 688239 & 5.1362 & \multicolumn{2}{|c|}{5.4510000000000005} \\
\hline CHEMBL1560238 & 688239 & 5.5862 & 5.5456 & TRN \\
\hline CHEMBL1563700 & 688239 & 5.6362 & 5.5182 & TST \\
\hline CHEMBL1588494 & 688239 & 5.0862 & 5.4508 & TRN \\
\hline CHEMBL1308521 & 688239 & 6.2362 & \multicolumn{2}{|c|}{5.542000000000001} \\
\hline CHEMBL3197015 & 688239 & 5.0362 & 5.4048 & TST \\
\hline CHEMBL1474082 & 688239 & 6.3362 & 5.6144 & TRN \\
\hline CHEMBL3196026 & 688239 & 4.6862 & 5.4442 & TST \\
\hline CHEMBL1381126 & 688239 & 4.5362 & 5.4041 & TRN \\
\hline CHEMBL1450874 & 688239 & 4.4862 & 5.6099 & TRN \\
\hline CHEMBL 2358514 & 688239 & 4.4862 & 5.3953 & TST \\
\hline CHEMBL1423686 & 688239 & 7.1361 & 5.6364 & TRN \\
\hline CHEMBL1324619 & 688239 & 5.1862 & 5.5317 & TST \\
\hline CHEMBL1339787 & 688239 & 5.7362 & 5.3694 & TRN \\
\hline CHEMBL1380430 & 688239 & 5.4362 & 5.6224 & TRN \\
\hline CHEMBL1421483 & 688239 & 6.5363 & 5.4939 & TST \\
\hline CHEMBL1456331 & 688239 & 5.2862 & 5.444 & TST \\
\hline CHEMBL1497465 & 688239 & 4.5362 & 5.3623 & TRN \\
\hline CHEMBL1540200 & 688239 & 5.1862 & 5.4567 & TRN \\
\hline CHEMBL1458166 & 688239 & 4.5862 & 5.4519 & TRN \\
\hline CHEMBL1529978 & 688239 & 4.7362 & 5.4498 & TRN \\
\hline CHEMBL1366044 & 688239 & 7.2366 & 5.4615 & TRN \\
\hline CHEMBL1555194 & 688239 & 5.1362 & 5.6187 & TRN \\
\hline CHEMBL1325167 & 688239 & 6.1362 & 5.5475 & TST \\
\hline CHEMBL1607206 & 688239 & 6.0862 & 5.6777 & TRN \\
\hline CHEMBL1583158 & 688239 & 8.3372 & 5.6291 & TRN \\
\hline CHEMBL1325801 & 688239 & 4.5362 & 5.3031 & TRN \\
\hline CHEMBL1353481 & 688239 & 6.8861 & 5.3676 & TST \\
\hline CHEMBL1594815 & 688239 & 5.5362 & \multicolumn{2}{|c|}{5.571000000000001} \\
\hline CHEMBL1303035 & 688239 & 6.7862 & 5.3405 & TST \\
\hline CHEMBL1335123 & 688239 & 4.6362 & 5.3862 & TRN \\
\hline CHEMBL1545020 & 688239 & 6.2862 & 5.5184 & TRN \\
\hline CHEMBL1543282 & 688239 & 5.4862 & 5.5581 & TRN \\
\hline CHEMBL1401516 & 688239 & 4.5362 & 5.5786 & TRN \\
\hline
\end{tabular}




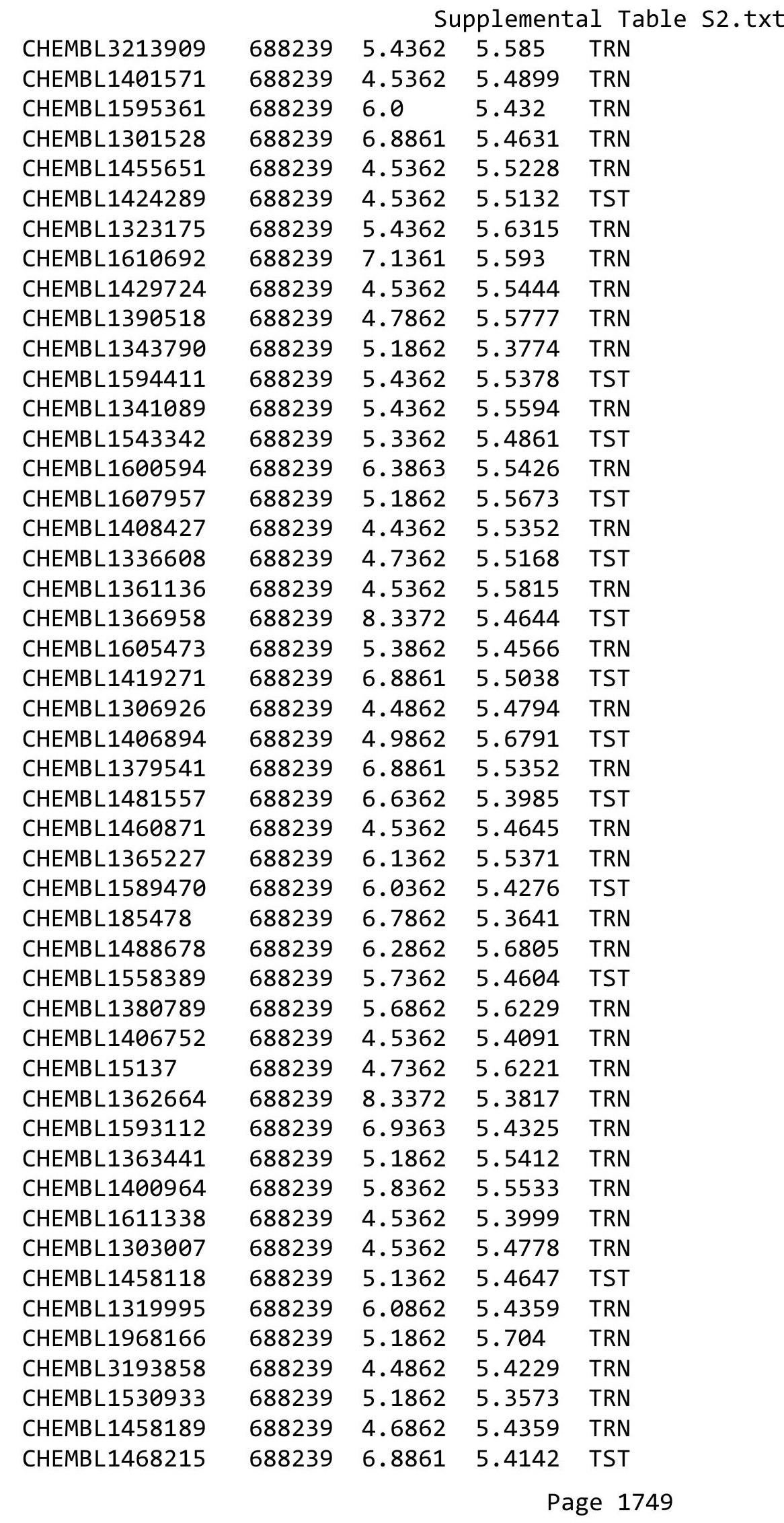


Supplemental Table S2.txt

\begin{tabular}{|c|c|c|c|c|}
\hline CHEMBL1568625 & 688239 & 8.3872 & 5.5626 & TRN \\
\hline CHEMBL1609339 & 688239 & 5.6862 & 5.5413 & TRN \\
\hline CHEMBL3199101 & 688239 & 4.5362 & 5.3955 & TRN \\
\hline CHEMBL1558928 & 688239 & 5.7362 & 5.5165 & TRN \\
\hline CHEMBL1477337 & 688239 & 5.0862 & 5.6224 & TRN \\
\hline CHEMBL1522351 & 688239 & 6.0862 & 5.5232 & TST \\
\hline CHEMBL1374376 & 688239 & 4.5362 & 5.5211 & TRN \\
\hline CHEMBL1490572 & 688239 & 5.1862 & 5.5149 & TST \\
\hline CHEMBL1370224 & 688239 & 4.5362 & 5.5687 & TRN \\
\hline CHEMBL1468963 & 688239 & 6.1862 & 5.4193 & TST \\
\hline CHEMBL 3194428 & 688239 & 5.3862 & 5.5181 & TST \\
\hline CHEMBL602424 & 688239 & 5.6362 & 5.5545 & TRN \\
\hline CHEMBL1606144 & 688239 & 4.5362 & 5.2762 & TST \\
\hline CHEMBL3190320 & 688239 & 6.2362 & 5.5332 & TRN \\
\hline CHEMBL1489544 & 688239 & 6.1862 & 5.4498 & TRN \\
\hline CHEMBL1308768 & 688239 & 5.7362 & 5.4154 & TST \\
\hline CHEMBL1335400 & 688239 & 8.3372 & 5.5491 & TRN \\
\hline CHEMBL1510256 & 688239 & 8.3372 & 5.5248 & TRN \\
\hline CHEMBL1324798 & 688239 & 5.5362 & 5.4647 & TRN \\
\hline CHEMBL1491061 & 688239 & 4.7862 & 5.4384 & TRN \\
\hline CHEMBL1549958 & 688239 & 4.7362 & 5.4117 & TRN \\
\hline CHEMBL1411560 & 688239 & 5.7862 & 5.6526 & TRN \\
\hline CHEMBL1460730 & 688239 & 4.6362 & 5.4412 & TRN \\
\hline CHEMBL1449040 & 688239 & 6.8362 & 5.3911 & TST \\
\hline CHEMBL1428405 & 688239 & 6.2862 & 5.387006 & 0000000005 \\
\hline CHEMBL1412285 & 688239 & 4.7862 & 5.5087 & TST \\
\hline CHEMBL1452885 & 688239 & 4.5362 & 5.4015 & TRN \\
\hline CHEMBL1477638 & 688239 & 5.3862 & 5.5415 & TRN \\
\hline CHEMBL1343736 & 688239 & 5.9862 & 5.6533 & TRN \\
\hline CHEMBL1571059 & 688239 & 4.5362 & 5.617006 & 000000001 \\
\hline CHEMBL1573254 & 688239 & 5.3362 & 5.4145 & TST \\
\hline CHEMBL1511309 & 688239 & 6.3863 & 5.5889 & TRN \\
\hline CHEMBL1579110 & 688239 & 6.2362 & 5.5684 & TRN \\
\hline CHEMBL1450124 & 688239 & 4.5362 & 5.4146 & TRN \\
\hline CHEMBL1518619 & 688239 & 6.2862 & 5.4797 & TRN \\
\hline CHEMBL1584962 & 688239 & 4.4862 & 5.425 & TRN \\
\hline CHEMBL1516623 & 688239 & 7.1361 & 5.3695 & TRN \\
\hline CHEMBL1982521 & 688239 & 4.8862 & 5.5427 & TRN \\
\hline CHEMBL1573089 & 688239 & 4.7362 & 5.481 & TRN \\
\hline CHEMBL1508930 & 688239 & 4.5362 & 5.3619 & TST \\
\hline CHEMBL1422059 & 688239 & 5.1862 & 5.467006 & 0000000005 \\
\hline CHEMBL1491764 & 688239 & 8.0362 & 5.4574 & TRN \\
\hline CHEMBL1411756 & 688239 & 6.9363 & 5.4774 & TST \\
\hline CHEMBL1426910 & 688239 & 4.9362 & 5.4417 & TRN \\
\hline CHEMBL1465857 & 688239 & 4.9362 & 5.3411 & TRN \\
\hline CHEMBL1496419 & 688239 & 4.7362 & 5.4802 & TST \\
\hline CHEMBL1380985 & 688239 & 5.4362 & 5.4772 & TRN \\
\hline CHEMBL1504602 & 688239 & 5.3362 & 5.6285 & TST \\
\hline
\end{tabular}


Supplemental Table S2.txt

\begin{tabular}{|c|c|c|c|c|c|}
\hline CHEMBL1403358 & 688239 & 4.8862 & 5.5396 & TRN & \\
\hline CHEMBL1412579 & 688239 & 4.5862 & 5.57 & TST & \\
\hline CHEMBL1299529 & 688239 & 4.9362 & 5.5454 & TST & \\
\hline CHEMBL1447634 & 688239 & 5.1862 & 5.4335 & TRN & \\
\hline CHEMBL1434195 & 688239 & 6.2862 & 5.5436 & TRN & \\
\hline CHEMBL1594068 & 688239 & 4.5362 & 5.4805 & TST & \\
\hline CHEMBL3198917 & 688239 & 4.5362 & 5.3956 & TRN & \\
\hline CHEMBL1471619 & 688239 & 5.6862 & 5.6007 & TRN & \\
\hline CHEMBL1446042 & 688239 & 4.6862 & 5.3574 & TST & \\
\hline CHEMBL1339598 & 688239 & 4.5862 & 5.5159 & TRN & \\
\hline CHEMBL1584032 & 688239 & 5.1862 & 5.4902 & TRN & \\
\hline CHEMBL1528581 & 688239 & 4.5362 & 5.3782 & TRN & \\
\hline CHEMBL1447479 & 688239 & 4.5362 & 5.55200 & 00000000005 & TRN \\
\hline CHEMBL3190122 & 688239 & 5.2862 & 5.4986 & TRN & \\
\hline CHEMBL1302035 & 688239 & 4.5362 & 5.4704 & TST & \\
\hline CHEMBL1320713 & 688239 & 5.1862 & 5.4568 & TRN & \\
\hline CHEMBL1439251 & 688239 & 6.9363 & 5.5996 & TRN & \\
\hline CHEMBL1611182 & 688239 & 5.3362 & 5.274 & TRN & \\
\hline CHEMBL1588423 & 688239 & 4.5362 & 5.395 & TRN & \\
\hline CHEMBL1559414 & 688239 & 5.6862 & 5.5881 & TST & \\
\hline CHEMBL1520672 & 688239 & 4.7862 & 5.4757 & TRN & \\
\hline CHEMBL1582031 & 688239 & 4.5862 & 5.6496 & TRN & \\
\hline CHEMBL1594557 & 688239 & 5.2362 & 5.5636 & TRN & \\
\hline CHEMBL1446392 & 688239 & 4.7862 & 5.4505 & TRN & \\
\hline CHEMBL1344731 & 688239 & 5.5362 & 5.4723 & TRN & \\
\hline CHEMBL1422843 & 688239 & 4.9862 & 5.4029 & TRN & \\
\hline CHEMBL1502367 & 688239 & 4.5362 & 5.4444 & TST & \\
\hline CHEMBL213896 & 688239 & 6.1862 & 5.3716 & TRN & \\
\hline CHEMBL1483279 & 688239 & 5.5362 & 5.5776 & TRN & \\
\hline CHEMBL1596045 & 688239 & 5.1862 & 5.5299 & TRN & \\
\hline CHEMBL1426299 & 688239 & 4.5362 & 5.4481 & TRN & \\
\hline CHEMBL1477405 & 688239 & 4.7362 & 5.4365 & TRN & \\
\hline CHEMBL1579738 & 688239 & 5.9362 & 5.5314 & TRN & \\
\hline CHEMBL1544085 & 688239 & 4.6862 & 5.5327 & TRN & \\
\hline CHEMBL1385039 & 688239 & 5.3362 & 5.6229 & TST & \\
\hline CHEMBL1386630 & 688239 & 4.6862 & 5.4589 & TST & \\
\hline CHEMBL1597680 & 688239 & 5.3362 & 5.4655 & TST & \\
\hline CHEMBL1313738 & 688239 & 4.5362 & 5.5773 & TRN & \\
\hline CHEMBL1391872 & 688239 & 5.0862 & 5.5669 & TRN & \\
\hline CHEMBL1470791 & 688239 & 5.3862 & 5.4266 & TRN & \\
\hline CHEMBL1510336 & 688239 & 4.5362 & 5.4114 & TRN & \\
\hline CHEMBL1524907 & 688239 & 4.7362 & 5.596 & TRN & \\
\hline CHEMBL3210038 & 688239 & 4.7362 & 5.4279 & TRN & \\
\hline CHEMBL3192483 & 688239 & 5.4362 & 5.347 & TRN & \\
\hline CHEMBL1344959 & 688239 & 4.8362 & 5.4688 & TRN & \\
\hline CHEMBL1443464 & 688239 & 6.3362 & 5.3623 & TST & \\
\hline CHEMBL1305136 & 688239 & 5.0862 & 5.7298 & TRN & \\
\hline CHEMBL1353887 & 688239 & 6.8362 & 5.5968 & TRN & \\
\hline
\end{tabular}




\begin{tabular}{|c|c|c|c|c|c|}
\hline \multicolumn{6}{|c|}{ Supplemental Table S2.txt } \\
\hline CHEMBL1386478 & 688239 & 6.6861 & 5.4428 & TST & \\
\hline CHEMBL1369466 & 688239 & 5.4362 & 5.351 & TRN & \\
\hline CHEMBL1394536 & 688239 & 4.6862 & 5.5507 & TST & \\
\hline CHEMBL463763 & 688239 & 6.0862 & 5.41799 & 7999999999 & TST \\
\hline CHEMBL1555907 & 688239 & 6.1862 & 5.4903 & TRN & \\
\hline CHEMBL1589081 & 688239 & 4.5362 & 5.44 & TRN & \\
\hline CHEMBL1435429 & 688239 & 4.5362 & 5.4877 & TST & \\
\hline CHEMBL1497725 & 688239 & 7.2865 & 5.4608 & TRN & \\
\hline CHEMBL1427586 & 688239 & 5.4862 & 5.5553 & TRN & \\
\hline CHEMBL3192271 & 688239 & 5.2862 & 5.3961 & TRN & \\
\hline CHEMBL1542705 & 688239 & 6.2362 & 5.55399 & 9999999999 & TRN \\
\hline CHEMBL1427263 & 688239 & 5.4362 & 5.5863 & TRN & \\
\hline CHEMBL1486889 & 688239 & 4.5362 & 5.5968 & TRN & \\
\hline CHEMBL1581210 & 688239 & 4.5362 & 5.4894 & TRN & \\
\hline CHEMBL1538675 & 688239 & 6.2362 & 5.5044 & TST & \\
\hline CHEMBL1449103 & 688239 & 5.2862 & 5.3534 & TRN & \\
\hline CHEMBL1367592 & 688239 & 4.5862 & 5.6469 & TST & \\
\hline CHEMBL1397076 & 688239 & 4.5362 & 5.4116 & TRN & \\
\hline CHEMBL1485036 & 688239 & 5.1862 & 5.62299 & 7999999999 & TRN \\
\hline CHEMBL1553434 & 688239 & 4.6862 & 5.4936 & TRN & \\
\hline CHEMBL1462131 & 688239 & 4.7862 & 5.7407 & TRN & \\
\hline CHEMBL1435030 & 688239 & 5.6362 & 5.2671 & TST & \\
\hline CHEMBL1583258 & 688239 & 6.0862 & 5.545 & TST & \\
\hline CHEMBL1491977 & 688239 & 5.5362 & 5.4651 & TRN & \\
\hline CHEMBL1458584 & 688239 & 5.3862 & 5.5303 & TRN & \\
\hline CHEMBL1353773 & 688239 & 4.6862 & 5.5443 & TST & \\
\hline CHEMBL1536878 & 688239 & 4.5362 & 5.5652 & TST & \\
\hline CHEMBL1575483 & 688239 & 6.9363 & 5.4889 & TRN & \\
\hline CHEMBL1494459 & 688239 & 4.5362 & 5.5438 & TRN & \\
\hline CHEMBL1320817 & 688239 & 5.1862 & 5.4514 & TRN & \\
\hline CHEMBL1437560 & 688239 & 4.7362 & 5.2002 & TRN & \\
\hline CHEMBL1562028 & 688239 & 5.1862 & 5.5822 & TST & \\
\hline CHEMBL1475938 & 688239 & 5.3362 & 5.4793 & TRN & \\
\hline CHEMBL1403523 & 688239 & 4.7362 & 5.3015 & TST & \\
\hline CHEMBL1506897 & 688239 & 4.5362 & 5.6138 & TRN & \\
\hline CHEMBL1392050 & 688239 & 4.6362 & 5.5155 & TRN & \\
\hline CHEMBL 1346314 & 688239 & 5.4362 & 5.6045 & TST & \\
\hline CHEMBL1574337 & 688239 & 4.7362 & 5.5139 & TRN & \\
\hline CHEMBL1517283 & 688239 & 6.1862 & 5.3873 & TRN & \\
\hline CHEMBL1481897 & 688239 & 4.6362 & 5.4881 & TRN & \\
\hline CHEMBL3196222 & 688239 & 4.8862 & 5.4318 & TRN & \\
\hline CHEMBL1314522 & 688239 & 5.5862 & 5.3526 & TST & \\
\hline CHEMBL3210968 & 688239 & 8.3372 & 5.4021 & TRN & \\
\hline CHEMBL1482153 & 688239 & 5.6362 & 5.4979 & TST & \\
\hline CHEMBL1512999 & 688239 & 4.6862 & 5.4654 & TRN & \\
\hline CHEMBL1496238 & 688239 & 6.3362 & 5.5476 & TRN & \\
\hline CHEMBL1444479 & 688239 & 4.5362 & 5.3831 & TRN & \\
\hline CHEMBL1564442 & 688239 & 6.3362 & 5.4557 & TRN & \\
\hline
\end{tabular}


Supplemental Table S2.txt

\begin{tabular}{|c|c|c|c|c|}
\hline CHEMBL1397955 & 688239 & 5.3862 & 5.3518 & TRN \\
\hline CHEMBL1524064 & 688239 & 4.7362 & 5.6555 & TST \\
\hline CHEMBL1563083 & 688239 & 6.9363 & 5.6284 & TRN \\
\hline CHEMBL1306119 & 688239 & 4.4862 & 5.3092 & TRN \\
\hline CHEMBL1568877 & 688239 & 4.6862 & 5.3321 & TRN \\
\hline CHEMBL1346963 & 688239 & 6.9363 & 5.5986 & TRN \\
\hline CHEMBL1428533 & 688239 & 6.7862 & \multicolumn{2}{|c|}{5.406000000000001} \\
\hline CHEMBL1328586 & 688239 & 5.4362 & 5.5978 & TRN \\
\hline CHEMBL3197177 & 688239 & 5.2862 & 5.3321 & TRN \\
\hline CHEMBL1572573 & 688239 & 4.4862 & 5.5135 & TST \\
\hline CHEMBL1402155 & 688239 & 4.5362 & 5.5079 & TRN \\
\hline CHEMBL1373996 & 688239 & 4.5362 & 5.3444 & TST \\
\hline CHEMBL1462869 & 688239 & 5.1862 & 5.6337 & TRN \\
\hline CHEMBL1415275 & 688239 & 4.4862 & 5.6133 & TRN \\
\hline CHEMBL1336307 & 688239 & 6.2362 & 5.5145 & TST \\
\hline CHEMBL1351187 & 688239 & 4.5862 & 5.4065 & TRN \\
\hline CHEMBL1308139 & 688239 & 4.5862 & 5.5794 & TST \\
\hline CHEMBL1485435 & 688239 & 5.1862 & 5.4977 & TRN \\
\hline CHEMBL1539947 & 688239 & 6.1862 & 5.4979 & TRN \\
\hline CHEMBL1316052 & 688239 & 5.0362 & 5.4464 & TRN \\
\hline CHEMBL1322356 & 688239 & 4.4862 & 5.6087 & TRN \\
\hline CHEMBL1982808 & 688239 & 5.1862 & 5.4461 & TST \\
\hline CHEMBL1338862 & 688239 & 6.2362 & 5.5044 & TRN \\
\hline CHEMBL1438868 & 688239 & 4.7862 & 5.5857 & TRN \\
\hline CHEMBL1417399 & 688239 & 5.3362 & \multicolumn{2}{|c|}{5.617000000000001} \\
\hline CHEMBL1596537 & 688239 & 5.4862 & 5.5418 & TST \\
\hline CHEMBL1495481 & 688239 & 5.0362 & 5.4667 & TST \\
\hline CHEMBL1314705 & 688239 & 5.0362 & 5.4961 & TRN \\
\hline CHEMBL1312888 & 688239 & 4.8362 & 5.3687 & TRN \\
\hline CHEMBL1547570 & 688239 & 6.5862 & 5.6435 & TRN \\
\hline CHEMBL1341837 & 688239 & 5.4862 & 5.4311 & TRN \\
\hline CHEMBL1592239 & 688239 & 4.8862 & 5.2376 & TRN \\
\hline CHEMBL1394412 & 688239 & 5.1362 & 5.4738 & TRN \\
\hline CHEMBL1479963 & 688239 & 4.5362 & 5.4265 & TRN \\
\hline CHEMBL1382529 & 688239 & 4.7362 & 5.5065 & TRN \\
\hline CHEMBL1586125 & 688239 & 4.5362 & 5.6727 & TRN \\
\hline CHEMBL1312381 & 688239 & 5.4362 & 5.5491 & TRN \\
\hline CHEMBL1523786 & 688239 & 8.3372 & 5.5314 & TRN \\
\hline CHEMBL1391666 & 688239 & 4.7862 & 5.4003 & TRN \\
\hline CHEMBL1311169 & 688239 & 4.4862 & 5.5569 & TRN \\
\hline CHEMBL1305551 & 688239 & 4.5362 & 5.5848 & TST \\
\hline CHEMBL531451 & 688239 & 6.4362 & 5.5231 & TRN \\
\hline CHEMBL1422765 & 688239 & 4.5362 & 5.3761 & TRN \\
\hline CHEMBL1404655 & 688239 & 6.4862 & 5.5004 & TRN \\
\hline CHEMBL1572799 & 688239 & 6.0362 & 5.6291 & TRN \\
\hline CHEMBL1332048 & 688239 & 6.0862 & 5.4374 & TRN \\
\hline CHEMBL1588329 & 688239 & 4.5362 & 5.4288 & TST \\
\hline CHEMBL1612036 & 688239 & 5.0362 & 5.6399 & TRN \\
\hline
\end{tabular}

Page 1753 
Supplemental Table S2.txt

\begin{tabular}{|c|c|c|c|c|c|}
\hline CHEMBL3192463 & 688239 & 4.7362 & 5.3247 & TRN & \\
\hline CHEMBL1373961 & 688239 & 4.5362 & 5.53799 & 7999999999 & TRN \\
\hline CHEMBL1529874 & 688239 & 6.1862 & 5.4919 & TRN & \\
\hline CHEMBL1387261 & 688239 & 6.6861 & 5.5699 & TRN & \\
\hline CHEMBL1360237 & 688239 & 8.3372 & 5.477 & TRN & \\
\hline CHEMBL1482094 & 688239 & 6.8861 & 5.5602 & TRN & \\
\hline CHEMBL1578700 & 688239 & 4.6862 & 5.3039 & TRN & \\
\hline CHEMBL1569093 & 688239 & 6.5862 & 5.3773 & TRN & \\
\hline CHEMBL1456398 & 688239 & 4.7862 & 5.5033 & TRN & \\
\hline CHEMBL1335851 & 688239 & 5.1862 & 5.5361 & TRN & \\
\hline CHEMBL1492626 & 688239 & 6.5363 & 5.4575 & TRN & \\
\hline CHEMBL 3214133 & 688239 & 5.4862 & 5.3414 & TRN & \\
\hline CHEMBL1525393 & 688239 & 8.3372 & 5.5972 & TRN & \\
\hline CHEMBL1374932 & 688239 & 4.5362 & 5.5326 & TRN & \\
\hline CHEMBL1509306 & 688239 & 4.5362 & 5.2561 & TST & \\
\hline CHEMBL1536392 & 688239 & 5.6362 & 5.4303 & TRN & \\
\hline CHEMBL1467551 & 688239 & 6.3362 & 5.4917 & TRN & \\
\hline CHEMBL1567142 & 688239 & 5.6362 & 5.4186 & TRN & \\
\hline CHEMBL1581361 & 688239 & 5.3362 & 5.5387 & TST & \\
\hline CHEMBL1537702 & 688239 & 7.9872 & 5.5413 & TRN & \\
\hline CHEMBL1299851 & 688239 & 8.3372 & 5.4665 & TRN & \\
\hline CHEMBL1304997 & 688239 & 4.5362 & 5.5124 & TST & \\
\hline CHEMBL1478724 & 688239 & 5.0862 & 5.5207 & TRN & \\
\hline CHEMBL1548967 & 688239 & 4.6362 & 5.4405 & TST & \\
\hline CHEMBL1301848 & 688239 & 4.6862 & 5.4619 & TRN & \\
\hline CHEMBL1594163 & 688239 & 7.0862 & 5.5012 & TRN & \\
\hline CHEMBL1471118 & 688239 & 4.5362 & 5.5118 & TRN & \\
\hline CHEMBL1563925 & 688239 & 5.5362 & 5.5452 & TRN & \\
\hline CHEMBL1531759 & 688239 & 4.4862 & 5.4823 & TST & \\
\hline CHEMBL1557839 & 688239 & 5.3362 & 5.4981 & TRN & \\
\hline CHEMBL1591835 & 688239 & 5.3862 & 5.4509 & TST & \\
\hline CHEMBL1563835 & 688239 & 4.5362 & 5.3785 & TST & \\
\hline CHEMBL1587998 & 688239 & 6.9363 & \multicolumn{2}{|c|}{5.5360000000000005} & TRN \\
\hline CHEMBL1535752 & 688239 & 5.7862 & 5.3848 & TRN & \\
\hline CHEMBL1330646 & 688239 & 4.7862 & 5.5871 & TRN & \\
\hline CHEMBL1587432 & 688239 & 4.5362 & 5.3911 & TST & \\
\hline CHEMBL1415201 & 688239 & 4.8362 & 5.6253 & TST & \\
\hline CHEMBL1331649 & 688239 & 4.8362 & 5.5063 & TRN & \\
\hline CHEMBL1560420 & 688239 & 4.5362 & 5.517 & TRN & \\
\hline CHEMBL1331380 & 688239 & 4.5362 & 5.3506 & TRN & \\
\hline CHEMBL1425824 & 688239 & 6.0362 & 5.6105 & TST & \\
\hline CHEMBL1460004 & 688239 & 5.0862 & 5.3397 & TRN & \\
\hline CHEMBL1565337 & 688239 & 4.5362 & 5.3219 & TST & \\
\hline CHEMBL1446692 & 688239 & 7.4365 & 5.4544 & TRN & \\
\hline CHEMBL1494128 & 688239 & 6.8861 & 5.5543 & TRN & \\
\hline CHEMBL1420808 & 688239 & 5.5862 & 5.4694 & TRN & \\
\hline CHEMBL1429617 & 688239 & 6.3362 & 5.3432 & TRN & \\
\hline CHEMBL1454848 & 688239 & 5.1862 & 5.3684 & TRN & \\
\hline
\end{tabular}


Supplemental Table S2.txt

\begin{tabular}{|c|c|c|c|c|}
\hline - & & & 4 & \\
\hline HEMBL1374703 & 88239 & .1862 & 5.5755 & \\
\hline 86 & & & & \\
\hline 58 & 39 & & 329 & \\
\hline IEMBL148 & 38239 & 862 & 4286 & \\
\hline AEMBL1604660 & 88239 & 362 & 4799 & \\
\hline HEMBL14 & 88239 & 362 & .49 & \\
\hline IFMRI 1 & & & 255 & \\
\hline IEMBL15 & 88239 & 362 & 5 & \\
\hline AEMBL1505629 & 88239 & 362 & 4467 & \\
\hline HEMBL1317979 & 88239 & 362 & .18 & \\
\hline IEMBL15 & 88239 & 362 & 4615 & \\
\hline IEMBL31 & 239 & & & \\
\hline AEMBL15 & 88239 & 62 & .4719 & \\
\hline AEMBL15e & 88239 & 362 & 4735 & \\
\hline IEMBL1355021 & 88239 & 362 & 45 & \\
\hline HEMBL14 & 88239 & 71 & 28 & \\
\hline HEMBL15 & 38239 & & & \\
\hline EEMBL14 & 88239 & & & \\
\hline IEMBL31 & 39 & & & \\
\hline IEIMIBL 132 & 88239 & & .4074 & וכ \\
\hline HEMBL14 & 38239 & & 32 & \\
\hline HEMBL 14 & 38239 & & & \\
\hline 9 & & & & \\
\hline IEMBL15 & 39 & & 73 & RI \\
\hline L2 & 39 & & 23 & ГRN \\
\hline IEMBL14 & 8239 & & 45 & \\
\hline 1 & 39 & & & \\
\hline AEN & & & & RN \\
\hline AEMBL13e & 39 & & 23 & RIN \\
\hline IEMBL15 & 39 & & & RN \\
\hline AFMB $1:$ & 39 & & & \\
\hline & & & & RN \\
\hline HEMBL131 & & & & $1 \mathrm{k}$ \\
\hline AEMBL153 & 39 & & 023 & IST \\
\hline AEMBL15 & 39 & & 751 & \\
\hline 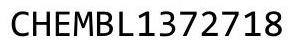 & & & & \\
\hline 80 & & & 334 & $\mathrm{RN}$ \\
\hline HEMBL1891759 & 88239 & & 5.3026 & TRN \\
\hline IEMBL150 & 39 & & 319 & IST \\
\hline HEMBL158 & 39 & & 824 & \\
\hline & & & & RN \\
\hline HEMBL1497699 & 8239 & & 5032 & TRN \\
\hline AEMBL1351225 & 88239 & & 96 & TRN \\
\hline L16 & & & 426 & \\
\hline HEMBL14 & & & & \\
\hline 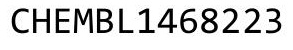 & 688239 & & 5.5465 & \\
\hline HEMBL3210017 & 688239 & 6.3362 & 5.4562 & ГRN \\
\hline
\end{tabular}

Page 1755 
Supplemental Table S2.txt

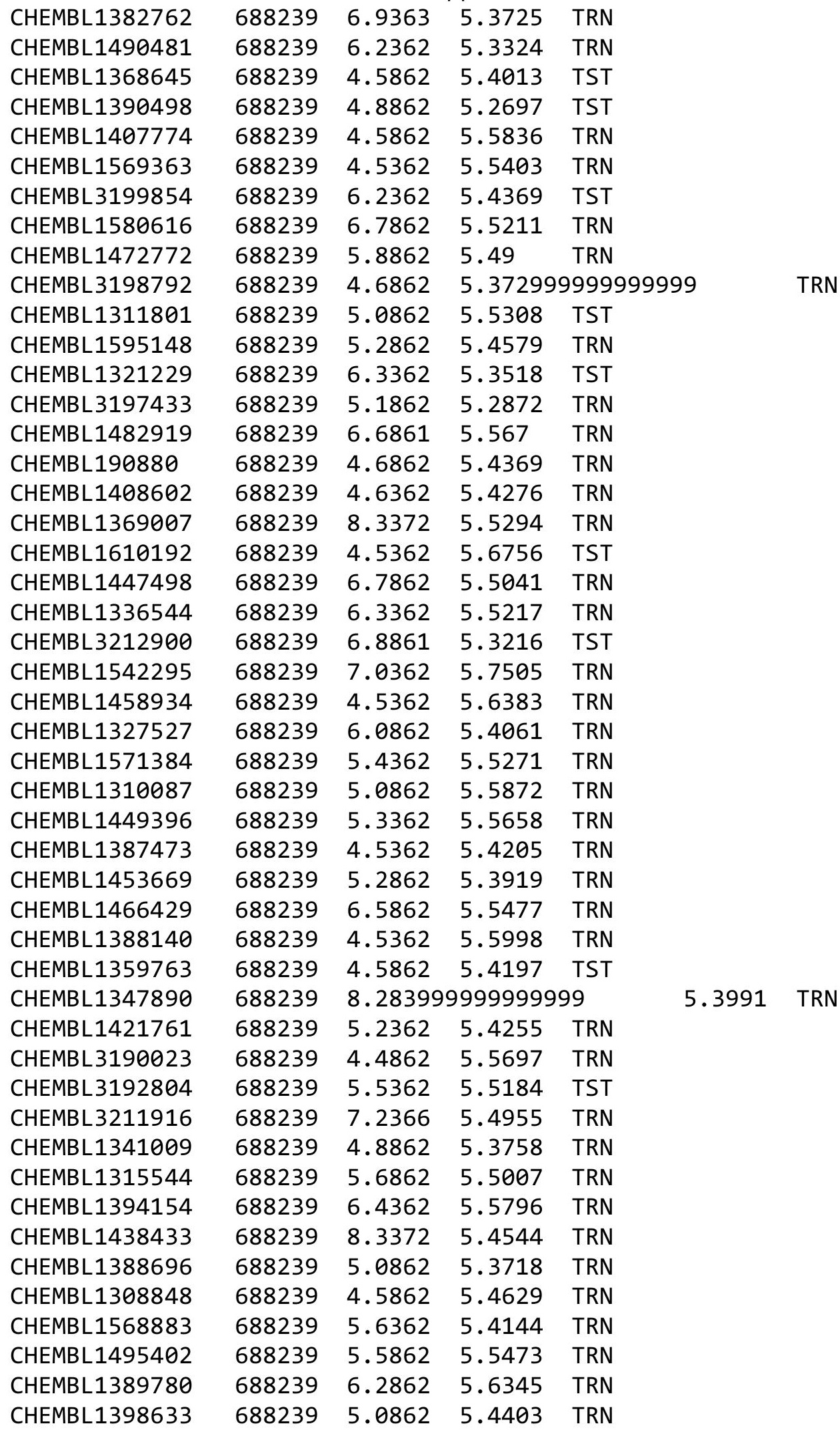


Supplemental Table S2.txt

\begin{tabular}{|c|c|c|c|c|}
\hline IE & & 2 & & TR \\
\hline & & .1862 & & \\
\hline (2) & & & & \\
\hline AEMBL: & & & & \\
\hline AEMBL1529069 & 8239 & 362 & & \\
\hline HEMBL3211315 & 88239 & 862 & 5 & \\
\hline HEMBL1494542 & 239 & 362 & & \\
\hline 03957 & & & & \\
\hline 01429 & & 862 & & \\
\hline HEMBL1321752 & 88239 & 362 & & \\
\hline AEMBL1552197 & 239 & 862 & 85 & \\
\hline IEMBL1 & 239 & 362 & & \\
\hline HEMBL 1 & & & & \\
\hline AEMBL1343565 & & 862 & & \\
\hline AEMBL1 & & 62 & & \\
\hline AEMBL1 & 39 & 362 & 56 & \\
\hline HEMBL1 & & 62 & & \\
\hline HEMBL1 & & & & \\
\hline HEMBLI & & 362 & & \\
\hline AEMBL1 & & & & \\
\hline HEMBL: & & & $L 2$ & \\
\hline AEMBL & & & & \\
\hline HEMBL & & 52 & & \\
\hline 56 & & & & \\
\hline HEMBL1 & & & & $\Gamma \mathrm{RN}$ \\
\hline HEMBL & & & & \\
\hline AEMBL & & & & \\
\hline HFMRI & & 62 & & RN \\
\hline HEMBL1518293 & & & & TRN \\
\hline HEMBL1383242 & & 52 & & ISI \\
\hline HEMBL: & & 52 & & RN \\
\hline HFMBI & & & & Niv \\
\hline 2 & & 52 & & RN \\
\hline HEMBL3209218 & & & & TRN \\
\hline HEMBL3189940 & & & 5 . & TRN \\
\hline HEMBL1 & & & & \\
\hline HCMDI & & & & RN \\
\hline HEMBL1375066 & & & & $\mathrm{RN}$ \\
\hline HEMBL1382119 & 88239 & 862 & 206 & TST \\
\hline AEMBL1 & & 362 & 307 & IST \\
\hline HEMBL1 & & 862 & 572 & \\
\hline HEMBL1431553 & & & & RN \\
\hline HEMBL1381963 & & 862 & & $\mathrm{RN}$ \\
\hline AEMBL1350773 & 39 & 362 & 38 & TRN \\
\hline $\mathrm{MBL}$ & & & & RN \\
\hline CHEMBL1385124 & & & & \\
\hline LHEMBL1470838 & & 7.1361 & & \\
\hline HEMBL159042 & 688239 & 4.5362 & 5.6145 & ГRN \\
\hline
\end{tabular}

Page 1757 
Supplemental Table S2.txt

\begin{tabular}{|c|c|c|c|c|c|}
\hline CHEMBL1438329 & 688239 & 5.1862 & 5.415 & TST & \\
\hline CHEMBL1575766 & 688239 & 4.5362 & 5.5895 & TRN & \\
\hline CHEMBL1578792 & 688239 & 4.5862 & 5.49299 & 9999999999 & TRN \\
\hline CHEMBL1468872 & 688239 & 6.1362 & 5.49100 & 00000000005 & TRN \\
\hline CHEMBL1419262 & 688239 & 4.6862 & 5.6089 & TST & \\
\hline CHEMBL1372843 & 688239 & 5.0862 & 5.5695 & TRN & \\
\hline CHEMBL1470850 & 688239 & 5.7362 & 5.485 & TST & \\
\hline CHEMBL1393324 & 688239 & 6.0862 & 5.4946 & TRN & \\
\hline CHEMBL1410442 & 688239 & 4.5862 & 5.5189 & TST & \\
\hline CHEMBL1532728 & 688239 & 5.9862 & 5.4176 & TRN & \\
\hline CHEMBL1432510 & 688239 & 5.0362 & 5.7061 & TRN & \\
\hline CHEMBL1548996 & 688239 & 5.0862 & 5.404 & TST & \\
\hline CHEMBL1466079 & 688239 & 8.3872 & 5.5077 & TRN & \\
\hline CHEMBL1608156 & 688239 & 4.5362 & 5.4949 & TRN & \\
\hline CHEMBL1340577 & 688239 & 4.5362 & 5.6108 & TST & \\
\hline CHEMBL1550277 & 688239 & 4.5362 & 5.6371 & TRN & \\
\hline CHEMBL1332589 & 688239 & 5.1862 & \multicolumn{2}{|c|}{5.417000000000001} & TRN \\
\hline CHEMBL1426944 & 688239 & 4.7362 & 5.4342 & TST & \\
\hline CHEMBL1446353 & 688239 & 4.5862 & 5.3784 & TRN & \\
\hline CHEMBL1472972 & 688239 & 6.1362 & 5.5407 & TRN & \\
\hline CHEMBL1406681 & 688239 & 5.7362 & 5.585 & TRN & \\
\hline CHEMBL1379787 & 688239 & 4.6362 & 5.4719 & TRN & \\
\hline CHEMBL1501328 & 688239 & 6.8362 & 5.4828 & TRN & \\
\hline CHEMBL1427185 & 688239 & 5.5362 & 5.4056 & TRN & \\
\hline CHEMBL1509975 & 688239 & 4.5862 & 5.4402 & TRN & \\
\hline CHEMBL1555483 & 688239 & 4.5362 & 5.4366 & TRN & \\
\hline CHEMBL1610357 & 688239 & 5.8362 & 5.4435 & TRN & \\
\hline CHEMBL1985606 & 688239 & 4.5362 & 5.3738 & TST & \\
\hline CHEMBL1407851 & 688239 & 5.1862 & 5.3756 & TRN & \\
\hline CHEMBL1407416 & 688239 & 5.4862 & 5.3661 & TRN & \\
\hline CHEMBL1423105 & 688239 & 4.5362 & 5.5094 & TRN & \\
\hline CHEMBL1548173 & 688239 & 4.7862 & 5.4686 & TST & \\
\hline CHEMBL1474424 & 688239 & 4.5362 & 5.6065 & TRN & \\
\hline CHEMBL1305033 & 688239 & 5.1362 & 5.3516 & TST & \\
\hline CHEMBL1213910 & 688239 & 4.7362 & 5.5773 & TRN & \\
\hline CHEMBL1451928 & 688239 & 4.5362 & 5.4326 & TRN & \\
\hline CHEMBL1446648 & 688239 & 6.6362 & 5.3985 & TRN & \\
\hline CHEMBL1353253 & 688239 & 5.4362 & 5.4839 & TRN & \\
\hline CHEMBL1306786 & 688239 & 5.6862 & 5.5053 & TRN & \\
\hline CHEMBL1307186 & 688239 & 5.9362 & 5.4534 & TRN & \\
\hline CHEMBL81782 & 688239 & 5.2862 & 5.2839 & TRN & \\
\hline CHEMBL1307957 & 688239 & 4.6862 & 5.4437 & TST & \\
\hline CHEMBL1434601 & 688239 & 5.5362 & 5.4107 & TRN & \\
\hline CHEMBL1564830 & 688239 & 6.2862 & 5.6054 & TRN & \\
\hline CHEMBL1303086 & 688239 & 6.1362 & 5.5437 & TRN & \\
\hline CHEMBL3208957 & 688239 & 5.1362 & 5.4772 & TST & \\
\hline CHEMBL1324835 & 688239 & 5.6862 & 5.3891 & TRN & \\
\hline CHEMBL1373333 & 688239 & 5.7362 & 5.459 & TRN & \\
\hline
\end{tabular}


Supplemental Table S2.txt

\begin{tabular}{|c|c|c|c|c|}
\hline CHEMBL3198996 & 688239 & 5.2862 & 5.5108 & TRN \\
\hline CHEMBL1612277 & 688239 & 4.7362 & 5.4988 & TRN \\
\hline CHEMBL1539389 & 688239 & 5.1862 & 5.5804 & TST \\
\hline CHEMBL1378944 & 688239 & 5.2862 & 5.4734 & TRN \\
\hline CHEMBL1438606 & 688239 & 5.7862 & 5.5753 & TRN \\
\hline CHEMBL1486244 & 688239 & 6.1362 & 5.4728 & TRN \\
\hline CHEMBL1605672 & 688239 & 5.1862 & 5.5505 & TRN \\
\hline CHEMBL1559930 & 688239 & 5.6862 & 5.3959 & TRN \\
\hline CHEMBL1335146 & 688239 & 4.9362 & 5.5921 & TRN \\
\hline CHEMBL1528514 & 688239 & 6.1362 & 5.454 & TST \\
\hline CHEMBL1481213 & 688239 & 5.3862 & 5.5251 & TRN \\
\hline CHEMBL1510929 & 688239 & 4.7362 & 5.5446 & TST \\
\hline CHEMBL1566137 & 688239 & 8.2366 & 5.645 & TRN \\
\hline CHEMBL1522660 & 688239 & 4.7362 & 5.532999 & 9999999995 \\
\hline CHEMBL1401697 & 688239 & 4.5362 & 5.4965 & TST \\
\hline CHEMBL1583491 & 688239 & 4.5362 & 5.6123 & TRN \\
\hline CHEMBL1393791 & 688239 & 5.1862 & 5.4559 & TRN \\
\hline CHEMBL1456450 & 688239 & 4.5362 & 5.5619 & TRN \\
\hline CHEMBL1373242 & 688239 & 6.1862 & 5.5464 & TRN \\
\hline CHEMBL1574738 & 688239 & 8.3372 & 5.5206 & TRN \\
\hline CHEMBL1528558 & 688239 & 5.4862 & 5.4357 & TST \\
\hline CHEMBL1558635 & 688239 & 6.4362 & 5.2604 & TRN \\
\hline CHEMBL1565935 & 688239 & 6.4862 & 5.3844 & TST \\
\hline CHEMBL1306527 & 688239 & 6.9363 & 5.5705 & TRN \\
\hline CHEMBL1310014 & 688239 & 4.7362 & 5.563 & TST \\
\hline CHEMBL1609731 & 688239 & 4.9362 & 5.604 & TRN \\
\hline CHEMBL1469266 & 688239 & 4.6362 & 5.4525 & TRN \\
\hline CHEMBL1509202 & 688239 & 4.5362 & 5.5077 & TRN \\
\hline CHEMBL3192911 & 688239 & 5.4362 & 5.4638 & TST \\
\hline CHEMBL1508407 & 688239 & 7.8356 & 5.5158 & TRN \\
\hline CHEMBL1569949 & 688239 & 5.0862 & 5.4846 & TST \\
\hline CHEMBL1580063 & 688239 & 6.2862 & 5.4154 & TRN \\
\hline CHEMBL1530796 & 688239 & 4.5362 & 5.4725 & TRN \\
\hline CHEMBL 1384028 & 688239 & 4.6862 & 5.4341 & TRN \\
\hline CHEMBL3199423 & 688239 & 4.6862 & 5.3553 & TST \\
\hline CHEMBL1473483 & 688239 & 6.1862 & 5.4117 & TRN \\
\hline CHEMBL1454256 & 688239 & 5.1362 & 5.4952 & TRN \\
\hline CHEMBL1350079 & 688239 & 4.6862 & 5.426 & TRN \\
\hline CHEMBL1503611 & 688239 & 4.6862 & 5.5362 & TST \\
\hline CHEMBL1415247 & 688239 & 6.4362 & 5.6222 & TRN \\
\hline CHEMBL1601296 & 688239 & 4.8862 & 5.4011 & TRN \\
\hline CHEMBL1582384 & 688239 & 6.0862 & 5.4876 & TST \\
\hline CHEMBL1429226 & 688239 & 6.1862 & 5.4824 & TRN \\
\hline CHEMBL1509650 & 688239 & 4.5362 & 5.5313 & TST \\
\hline CHEMBL1587767 & 688239 & 5.1862 & 5.4622 & TRN \\
\hline CHEMBL1334639 & 688239 & 5.3362 & 5.4876 & TST \\
\hline CHEMBL1312474 & 688239 & 5.0862 & 5.3253 & TST \\
\hline CHEMBL1570719 & 688239 & 4.5362 & 5.5283 & TST \\
\hline
\end{tabular}

Page 1759 
Supplemental Table S2.txt

\begin{tabular}{|c|c|c|c|c|}
\hline CHEMBL1559311 & 688239 & 6.6362 & 5.6899 & TST \\
\hline CHEMBL1536755 & 688239 & 5.4362 & 5.5093 & TRN \\
\hline CHEMBL1346092 & 688239 & 6.3362 & 5.4418 & TST \\
\hline CHEMBL1413105 & 688239 & 5.8862 & 5.4389 & TRN \\
\hline CHEMBL1497667 & 688239 & 4.7362 & 5.4336 & TST \\
\hline CHEMBL3197493 & 688239 & 5.1862 & 5.5933 & TRN \\
\hline CHEMBL1489792 & 688239 & 4.5362 & 5.5023 & TRN \\
\hline CHEMBL1348150 & 688239 & 5.4362 & 5.5403 & TST \\
\hline CHEMBL1500757 & 688239 & 6.0362 & 5.4508 & TRN \\
\hline CHEMBL1443874 & 688239 & 4.7862 & 5.523 & TRN \\
\hline CHEMBL1367780 & 688239 & 6.0862 & 5.553 & TST \\
\hline CHEMBL1303677 & 688239 & 5.1862 & 5.5499 & TST \\
\hline CHEMBL1405748 & 688239 & 4.5362 & 5.3926 & TST \\
\hline CHEMBL1449245 & 688239 & 4.5362 & 5.3953 & TST \\
\hline CHEMBL1337037 & 688239 & 5.8362 & 5.4308 & TRN \\
\hline CHEMBL1428150 & 688239 & 6.5862 & 5.3495 & TRN \\
\hline CHEMBL1453584 & 688239 & 4.5362 & 5.3202 & TRN \\
\hline CHEMBL1539259 & 688239 & 5.1862 & 5.4906 & TST \\
\hline CHEMBL1570297 & 688239 & 5.1862 & 5.6004 & TRN \\
\hline CHEMBL1322989 & 688239 & 7.2366 & 5.4181 & TRN \\
\hline CHEMBL1551143 & 688239 & 6.0862 & 5.4915 & TRN \\
\hline CHEMBL1522942 & 688239 & 5.1862 & 5.5873 & TRN \\
\hline CHEMBL1505545 & 688239 & 4.5362 & 5.6401 & TRN \\
\hline CHEMBL3199719 & 688239 & 4.9862 & 5.3979 & TRN \\
\hline CHEMBL1410497 & 688239 & 5.1862 & 5.4736 & TST \\
\hline CHEMBL1340349 & 688239 & 5.5862 & 5.6054 & TRN \\
\hline CHEMBL1525957 & 688239 & 4.5362 & 5.5048 & TST \\
\hline CHEMBL1328482 & 688239 & 6.2362 & 5.5553 & TST \\
\hline CHEMBL1451481 & 688239 & 4.5362 & 5.5936 & TRN \\
\hline CHEMBL1607850 & 688239 & 4.6862 & 5.3815 & TRN \\
\hline CHEMBL1607337 & 688239 & 4.7362 & 5.5776 & TST \\
\hline CHEMBL1405500 & 688239 & 4.5362 & 5.4256 & TRN \\
\hline CHEMBL1401802 & 688239 & 5.9862 & 5.3288 & TRN \\
\hline CHEMBL1410762 & 688239 & 4.7362 & 5.5553 & TRN \\
\hline CHEMBL1503507 & 688239 & 5.7862 & 5.4276 & TRN \\
\hline CHEMBL1430686 & 688239 & 4.7362 & 5.3011 & TRN \\
\hline CHEMBL1471488 & 688239 & 5.2362 & 5.3978 & TST \\
\hline CHEMBL1455195 & 688239 & 5.8862 & 5.2943 & TRN \\
\hline CHEMBL1586093 & 688239 & 8.2366 & 5.5197 & TST \\
\hline CHEMBL1593421 & 688239 & 5.4862 & 5.4284 & TRN \\
\hline CHEMBL1512423 & 688239 & 4.6362 & 5.5973 & TRN \\
\hline CHEMBL1468201 & 688239 & 6.5862 & 5.3519 & TST \\
\hline CHEMBL1477586 & 688239 & 4.8362 & 5.352 & TRN \\
\hline CHEMBL1302549 & 688239 & 5.2862 & 5.48 & TRN \\
\hline CHEMBL1386547 & 688239 & 4.6362 & 5.4624 & TRN \\
\hline CHEMBL1607123 & 688239 & 6.8861 & 5.55200 & 00000000005 \\
\hline CHEMBL1360564 & 688239 & 5.6862 & 5.4757 & TRN \\
\hline CHEMBL3145039 & 688239 & 5.0862 & 5.4811 & TRN \\
\hline
\end{tabular}


Supplemental Table S2.txt

\begin{tabular}{|c|c|c|c|c|c|}
\hline CHEMBL1435328 & 688239 & 8.3872 & 5.4017 & TRN & \\
\hline CHEMBL1348175 & 688239 & 5.3862 & 5.4009 & TRN & \\
\hline CHEMBL1516480 & 688239 & 5.4862 & 5.6768 & TRN & \\
\hline CHEMBL1378676 & 688239 & 5.1862 & 5.5634 & TRN & \\
\hline CHEMBL1371224 & 688239 & 6.0362 & 5.5363 & TST & \\
\hline CHEMBL1479831 & 688239 & 4.9862 & 5.4912 & TRN & \\
\hline CHEMBL1503240 & 688239 & 5.1362 & 5.5828 & TRN & \\
\hline CHEMBL3194544 & 688239 & 6.1862 & 5.5836 & TRN & \\
\hline CHEMBL1548247 & 688239 & 4.6862 & 5.6356 & TRN & \\
\hline CHEMBL1482680 & 688239 & 6.3863 & 5.4945 & TRN & \\
\hline CHEMBL1492374 & 688239 & 6.7862 & 5.5196 & TRN & \\
\hline CHEMBL1582802 & 688239 & 5.0862 & 5.5635 & TRN & \\
\hline CHEMBL1525028 & 688239 & 6.8362 & 5.5383 & TRN & \\
\hline CHEMBL1450789 & 688239 & 5.1862 & 5.4316 & TRN & \\
\hline CHEMBL1532449 & 688239 & 6.1862 & 5.6644 & TST & \\
\hline CHEMBL1531728 & 688239 & 5.0362 & 5.5561 & TRN & \\
\hline CHEMBL1341346 & 688239 & 4.5362 & 5.4906 & TRN & \\
\hline CHEMBL1530469 & 688239 & 5.1862 & 5.5435 & TRN & \\
\hline CHEMBL1335083 & 688239 & 6.2362 & 5.5715 & TRN & \\
\hline CHEMBL1586587 & 688239 & 4.6862 & 5.5878 & TST & \\
\hline CHEMBL1344814 & 688239 & 4.5362 & 5.38899 & 9999999999 & TRN \\
\hline CHEMBL3210929 & 688239 & 4.6862 & 5.428 & TST & \\
\hline CHEMBL1360149 & 688239 & 6.4362 & 5.4015 & TRN & \\
\hline CHEMBL1503366 & 688239 & 5.6362 & 5.6467 & TRN & \\
\hline CHEMBL1603827 & 688239 & 4.7862 & 5.5201 & TRN & \\
\hline CHEMBL1482789 & 688239 & 4.5362 & 5.5294 & TST & \\
\hline CHEMBL1502719 & 688239 & 4.6362 & 5.5288 & TRN & \\
\hline CHEMBL1406819 & 688239 & 4.7362 & 5.484 & TRN & \\
\hline CHEMBL3213141 & 688239 & 5.1862 & 5.5138 & TST & \\
\hline CHEMBL1502787 & 688239 & 4.9862 & 5.5528 & TRN & \\
\hline CHEMBL1573866 & 688239 & 4.7362 & 5.4791 & TST & \\
\hline CHEMBL1459980 & 688239 & 5.1362 & 5.4554 & TRN & \\
\hline CHEMBL1467702 & 688239 & 4.5362 & 5.5366 & TRN & \\
\hline CHEMBL1348537 & 688239 & 4.6362 & 5.43 & TST & \\
\hline CHEMBL1353942 & 688239 & 5.5362 & 5.4654 & TRN & \\
\hline CHEMBL1404248 & 688239 & 5.5362 & 5.4711 & TRN & \\
\hline CHEMBL1318830 & 688239 & 4.5362 & 5.461 & TRN & \\
\hline CHEMBL1361391 & 688239 & 4.5362 & 5.4416 & TRN & \\
\hline CHEMBL1584455 & 688239 & 6.5862 & 5.4283 & TRN & \\
\hline CHEMBL356828 & 688239 & 6.2362 & 5.4412 & TST & \\
\hline CHEMBL1598555 & 688239 & 4.6362 & 5.5255 & TRN & \\
\hline CHEMBL1581410 & 688239 & 4.5362 & 5.506 & TRN & \\
\hline CHEMBL1486348 & 688239 & 4.9362 & 5.4788 & TRN & \\
\hline CHEMBL1498567 & 688239 & 4.9362 & 5.5964 & TRN & \\
\hline CHEMBL1482418 & 688239 & 4.5362 & 5.5468 & TRN & \\
\hline CHEMBL1504688 & 688239 & 4.6862 & 5.3672 & TRN & \\
\hline CHEMBL1554703 & 688239 & 4.7862 & 5.4246 & TRN & \\
\hline CHEMBL1485624 & 688239 & 5.7362 & 5.5428 & TRN & \\
\hline
\end{tabular}


Supplemental Table S2.txt

\begin{tabular}{|c|c|c|c|c|}
\hline CHEMBL1504878 & 688239 & 5.1862 & 5.5497 & TRN \\
\hline CHEMBL1557499 & 688239 & 5.0362 & 5.6226 & TRN \\
\hline CHEMBL1565480 & 688239 & 4.5362 & 5.5455 & TRN \\
\hline CHEMBL1385766 & 688239 & 6.1862 & 5.4854 & TST \\
\hline CHEMBL1379864 & 688239 & 5.3362 & 5.4214 & TRN \\
\hline CHEMBL3199241 & 688239 & 4.5362 & 5.3783 & TRN \\
\hline CHEMBL1533417 & 688239 & 6.5862 & 5.4134 & TRN \\
\hline CHEMBL1364758 & 688239 & 4.5362 & 5.5919 & TST \\
\hline CHEMBL1581269 & 688239 & 6.9863 & 5.3851 & TRN \\
\hline CHEMBL1349830 & 688239 & 4.6362 & 5.5947 & TST \\
\hline CHEMBL1410488 & 688239 & 6.7862 & 5.5401 & TRN \\
\hline CHEMBL1326109 & 688239 & 5.5362 & 5.5149 & TST \\
\hline CHEMBL1506733 & 688239 & 5.3862 & 5.3777 & TRN \\
\hline CHEMBL1508208 & 688239 & 5.4862 & 5.5586 & TRN \\
\hline CHEMBL 3207534 & 688239 & 5.5862 & 5.3723 & TRN \\
\hline CHEMBL1462123 & 688239 & 4.5362 & 5.4358 & TRN \\
\hline CHEMBL230431 & 688239 & 4.6862 & 5.7152 & TRN \\
\hline CHEMBL1304384 & 688239 & 4.9362 & 5.5185 & TST \\
\hline CHEMBL1563594 & 688239 & 4.8862 & 5.5545 & TRN \\
\hline CHEMBL1416567 & 688239 & 6.3863 & 5.5972 & TRN \\
\hline CHEMBL1369505 & 688239 & 5.0862 & 5.534 & TRN \\
\hline CHEMBL1328723 & 688239 & 5.8362 & 5.5403 & TRN \\
\hline CHEMBL1576078 & 688239 & 5.1362 & 5.5168 & TST \\
\hline CHEMBL3199284 & 688239 & 5.9362 & 5.4241 & TRN \\
\hline CHEMBL91844 & 688239 & 6.0862 & 5.41200 & 0000000001 \\
\hline CHEMBL1549489 & 688239 & 5.0862 & 5.4808 & TRN \\
\hline CHEMBL1525720 & 688239 & 4.5362 & 5.49200 & 0000000001 \\
\hline CHEMBL1595168 & 688239 & 4.5362 & 5.5335 & TRN \\
\hline CHEMBL1585517 & 688239 & 5.1862 & 5.5462 & TRN \\
\hline CHEMBL1378706 & 688239 & 5.7862 & 5.5051 & TST \\
\hline CHEMBL1595138 & 688239 & 5.2862 & 5.4446 & TRN \\
\hline CHEMBL1339380 & 688239 & 4.7362 & 5.4235 & TRN \\
\hline CHEMBL1608868 & 688239 & 6.1362 & 5.5057 & TRN \\
\hline CHEMBL1300802 & 688239 & 6.8861 & 5.5422 & TRN \\
\hline CHEMBL1544983 & 688239 & 5.6862 & 5.5515 & TRN \\
\hline CHEMBL1483953 & 688239 & 6.2362 & 5.4571 & TRN \\
\hline CHEMBL1495053 & 688239 & 5.7362 & 5.3281 & TST \\
\hline CHEMBL1385865 & 688239 & 4.4862 & 5.49799 & 9999999999 \\
\hline CHEMBL1580014 & 688239 & 5.3862 & 5.6068 & TRN \\
\hline CHEMBL1330038 & 688239 & 4.5362 & 5.4948 & TRN \\
\hline CHEMBL1322290 & 688239 & 6.3863 & 5.5443 & TST \\
\hline CHEMBL1540937 & 688239 & 7.1864 & 5.5475 & TRN \\
\hline CHEMBL1604867 & 688239 & 6.2362 & 5.5354 & TRN \\
\hline CHEMBL1522790 & 688239 & 4.4862 & 5.6017 & TRN \\
\hline CHEMBL1534059 & 688239 & 6.4862 & 5.5467 & TRN \\
\hline CHEMBL1419182 & 688239 & 6.1362 & 5.6152 & TST \\
\hline CHEMBL1370395 & 688239 & 5.2362 & 5.5512 & TST \\
\hline CHEMBL1313299 & 688239 & 6.2362 & 5.4369 & TRN \\
\hline
\end{tabular}

Page 1762 
Supplemental Table S2.txt

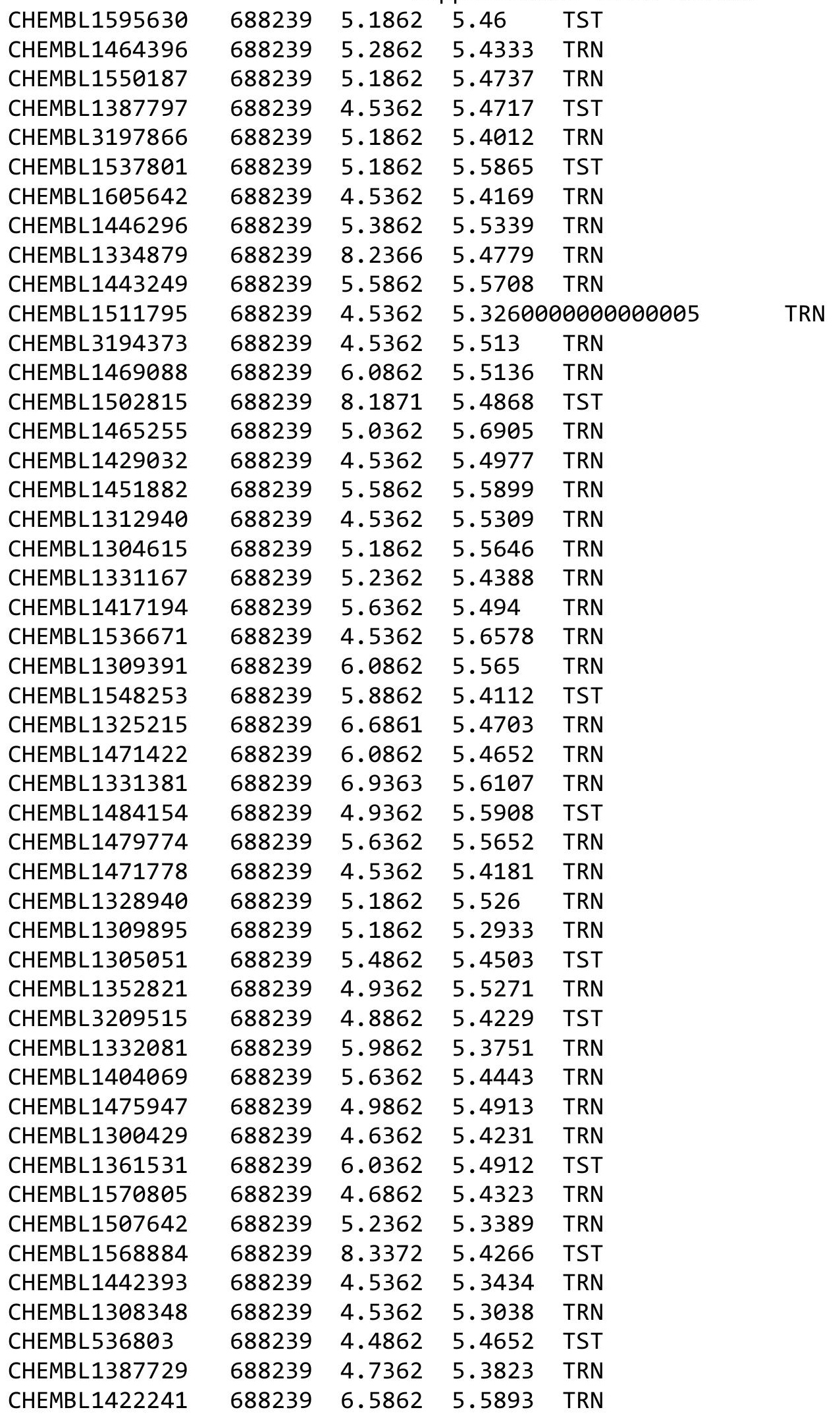

Page 1763 
Supplemental Table S2.txt

\begin{tabular}{|c|c|c|c|c|}
\hline CHEMBL1594637 & 688239 & 4.6362 & 5.3649 & TST \\
\hline CHEMBL1453366 & 688239 & 4.5862 & 5.5641 & TST \\
\hline CHEMBL1357918 & 688239 & 4.5362 & 5.5679 & TST \\
\hline CHEMBL1416631 & 688239 & 8.2366 & 5.7342 & TRN \\
\hline CHEMBL1469660 & 688239 & 4.5362 & 5.5294 & TRN \\
\hline CHEMBL1426427 & 688239 & 4.6862 & 5.5921 & TRN \\
\hline CHEMBL1345303 & 688239 & 6.1362 & 5.6273 & TRN \\
\hline CHEMBL1579928 & 688239 & 4.7362 & 5.5461 & TST \\
\hline CHEMBL1444377 & 688239 & 6.9863 & 5.3679 & TST \\
\hline CHEMBL1403443 & 688239 & 5.1862 & 5.4751 & TRN \\
\hline CHEMBL1416396 & 688239 & 4.5362 & 5.6305 & TST \\
\hline CHEMBL1308577 & 688239 & 5.6362 & 5.4904 & TRN \\
\hline CHEMBL1491151 & 688239 & 5.1862 & 5.5889 & TRN \\
\hline CHEMBL1489415 & 688239 & 4.5362 & 5.3842 & TRN \\
\hline CHEMBL1405030 & 688239 & 5.0362 & 5.617006 & 0000000001 \\
\hline CHEMBL1359277 & 688239 & 6.1362 & 5.459 & TRN \\
\hline CHEMBL1447683 & 688239 & 6.4362 & 5.3856 & TRN \\
\hline CHEMBL1467487 & 688239 & 4.5362 & 5.6304 & TRN \\
\hline CHEMBL1405164 & 688239 & 5.1862 & 5.4806 & TRN \\
\hline CHEMBL1560170 & 688239 & 5.0862 & 5.5216 & TRN \\
\hline CHEMBL1322331 & 688239 & 6.8362 & 5.4723 & TRN \\
\hline CHEMBL1404638 & 688239 & 6.5862 & 5.5898 & TRN \\
\hline CHEMBL119247 & 688239 & 5.9862 & 5.5059 & TRN \\
\hline CHEMBL1420397 & 688239 & 4.5362 & 5.3863 & TRN \\
\hline CHEMBL1542649 & 688239 & 5.6362 & 5.4008 & TST \\
\hline CHEMBL1455620 & 688239 & 5.2862 & 5.5323 & TRN \\
\hline CHEMBL1550323 & 688239 & 5.7362 & 5.6025 & TRN \\
\hline CHEMBL1371353 & 688239 & 4.5362 & 5.3825 & TRN \\
\hline CHEMBL3190992 & 688239 & 5.1362 & 5.3369 & TRN \\
\hline CHEMBL1524513 & 688239 & 5.3862 & 5.4695 & TRN \\
\hline CHEMBL1383579 & 688239 & 5.8862 & 5.5953 & TRN \\
\hline CHEMBL1402509 & 688239 & 4.5362 & 5.4937 & TRN \\
\hline CHEMBL1444532 & 688239 & 5.1862 & 5.6067 & TRN \\
\hline CHEMBL1559945 & 688239 & 4.6362 & 5.3119 & TRN \\
\hline CHEMBL1556076 & 688239 & 6.9363 & 5.4643 & TRN \\
\hline CHEMBL3193381 & 688239 & 4.7862 & 5.4656 & TRN \\
\hline CHEMBL1381751 & 688239 & 7.0362 & 5.6738 & TRN \\
\hline CHEMBL1595878 & 688239 & 6.7862 & 5.4157 & TRN \\
\hline CHEMBL1410316 & 688239 & 4.6362 & 5.4161 & TRN \\
\hline CHEMBL1324856 & 688239 & 5.1862 & 5.4399 & TRN \\
\hline CHEMBL1313099 & 688239 & 4.7862 & 5.5173 & TST \\
\hline CHEMBL1564680 & 688239 & 6.5862 & 5.553999 & 9999999999 \\
\hline CHEMBL1426133 & 688239 & 4.7362 & 5.4478 & TST \\
\hline CHEMBL1365209 & 688239 & 4.7362 & 5.3689 & TRN \\
\hline CHEMBL1391911 & 688239 & 4.5362 & 5.4229 & TRN \\
\hline CHEMBL1556970 & 688239 & 4.4362 & 5.6076 & TRN \\
\hline CHEMBL1383902 & 688239 & 6.7862 & 5.4821 & TRN \\
\hline CHEMBL1597110 & 688239 & 6.8861 & 5.343 & TRN \\
\hline
\end{tabular}


Supplemental Table S2.txt

\begin{tabular}{|c|c|c|c|c|}
\hline CHEMBL1431653 & 688239 & 6.2362 & 5.3703 & TRN \\
\hline CHEMBL1442014 & 688239 & 4.6362 & 5.5435 & TRN \\
\hline CHEMBL1372423 & 688239 & 4.5862 & 5.5909 & TRN \\
\hline CHEMBL1337144 & 688239 & 6.1362 & 5.3942 & TRN \\
\hline CHEMBL1439537 & 688239 & 5.4862 & 5.5234 & TRN \\
\hline CHEMBL1433845 & 688239 & 4.5362 & 5.4391 & TRN \\
\hline CHEMBL1486014 & 688239 & 6.2862 & 5.4495 & TRN \\
\hline CHEMBL1503996 & 688239 & 4.9862 & 5.598 & TRN \\
\hline CHEMBL1325600 & 688239 & 4.4862 & \multicolumn{2}{|c|}{5.672000000000001} \\
\hline CHEMBL1528159 & 688239 & 4.5362 & 5.4616 & TRN \\
\hline CHEMBL1402911 & 688239 & 4.4862 & 5.5332 & TRN \\
\hline CHEMBL1327607 & 688239 & 4.5862 & 5.4723 & TRN \\
\hline CHEMBL3213612 & 688239 & 5.8862 & 5.5655 & TST \\
\hline CHEMBL1346481 & 688239 & 5.1862 & 5.5307 & TRN \\
\hline CHEMBL1462863 & 688239 & 4.5362 & \multicolumn{2}{|c|}{5.582000000000001} \\
\hline CHEMBL 235713 & 688239 & 4.6362 & 5.6064 & TRN \\
\hline CHEMBL1364208 & 688239 & 8.2366 & 5.5961 & TRN \\
\hline CHEMBL1306706 & 688239 & 8.3872 & 5.5232 & TRN \\
\hline CHEMBL1473673 & 688239 & 5.5362 & 5.6159 & TRN \\
\hline CHEMBL3211413 & 688239 & 4.9862 & \multicolumn{2}{|c|}{5.513999999999999} \\
\hline CHEMBL1362152 & 688239 & 4.9862 & 5.5493 & TRN \\
\hline CHEMBL1504675 & 688239 & 8.3372 & 5.43 & TST \\
\hline CHEMBL1995862 & 688239 & 4.6862 & 5.4718 & TRN \\
\hline CHEMBL1325890 & 688239 & 4.4862 & 5.4963 & TRN \\
\hline CHEMBL1517220 & 688239 & 7.2366 & 5.4576 & TST \\
\hline CHEMBL1535025 & 688239 & 4.5362 & 5.5082 & TRN \\
\hline CHEMBL1545838 & 688239 & 4.5362 & 5.4429 & TST \\
\hline CHEMBL1417694 & 688239 & 5.1862 & 5.4325 & TRN \\
\hline CHEMBL1339713 & 688239 & 4.5362 & 5.5343 & TST \\
\hline CHEMBL3209434 & 688239 & 4.4862 & 5.4578 & TST \\
\hline CHEMBL3199639 & 688239 & 4.5362 & 5.2834 & TRN \\
\hline CHEMBL1549140 & 688239 & 4.8862 & 5.5874 & TST \\
\hline CHEMBL1483463 & 688239 & 5.8362 & 5.6167 & TRN \\
\hline CHEMBL1443251 & 688239 & 4.5362 & 5.4157 & TST \\
\hline CHEMBL1360561 & 688239 & 4.8362 & 5.5465 & TRN \\
\hline CHEMBL1599827 & 688239 & 6.0362 & 5.4322 & TRN \\
\hline CHEMBL1987622 & 688239 & 4.5362 & 5.3663 & TST \\
\hline CHEMBL1316390 & 688239 & 7.1361 & 5.5661 & TRN \\
\hline CHEMBL1422345 & 688239 & 5.5862 & 5.4636 & TRN \\
\hline CHEMBL1554962 & 688239 & 6.3362 & 5.5284 & TRN \\
\hline CHEMBL1561341 & 688239 & 5.1862 & 5.442 & TRN \\
\hline CHEMBL1427221 & 688239 & 4.5362 & 5.4438 & TRN \\
\hline CHEMBL1464786 & 688239 & 4.6862 & 5.4006 & TRN \\
\hline CHEMBL1359171 & 688239 & 5.3362 & 5.6326 & TST \\
\hline CHEMBL1398451 & 688239 & 6.5363 & 5.5193 & TRN \\
\hline CHEMBL1424407 & 688239 & 4.5862 & 5.5011 & TRN \\
\hline CHEMBL1551588 & 688239 & 4.5362 & 5.53799 & 9999999999 \\
\hline CHEMBL1385096 & 688239 & 5.1862 & 5.4025 & TRN \\
\hline
\end{tabular}




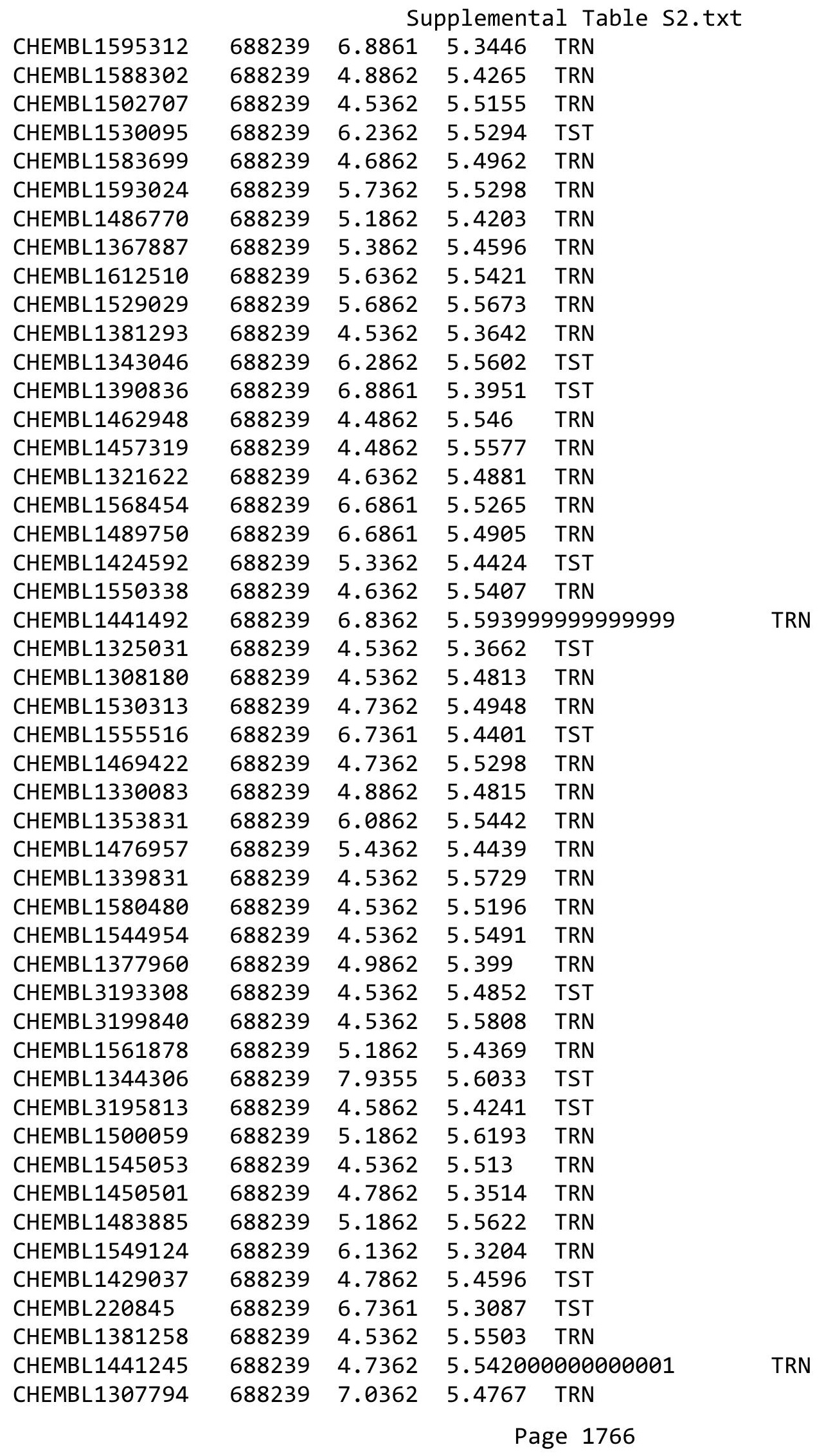


Supplemental Table S2.txt

\begin{tabular}{|c|c|c|c|c|}
\hline CHEMBL1377902 & 688239 & 4.6862 & 5.3331 & TRN \\
\hline CHEMBL1610802 & 688239 & 4.5362 & 5.5149 & TST \\
\hline CHEMBL1492779 & 688239 & 6.2362 & 5.4614 & TRN \\
\hline CHEMBL1481582 & 688239 & 5.1862 & 5.3709 & TST \\
\hline CHEMBL1450518 & 688239 & 5.7862 & 5.5096 & TST \\
\hline CHEMBL1539368 & 688239 & 5.1362 & 5.4929 & TRN \\
\hline CHEMBL1425515 & 688239 & 4.4862 & 5.4446 & TRN \\
\hline CHEMBL1611419 & 688239 & 4.4862 & 5.444 & TRN \\
\hline CHEMBL1538000 & 688239 & 4.8862 & 5.4681 & TRN \\
\hline CHEMBL1312953 & 688239 & 4.5362 & 5.1901 & TRN \\
\hline CHEMBL1310893 & 688239 & 4.6862 & 5.3693 & TST \\
\hline CHEMBL1535841 & 688239 & 6.1862 & 5.5124 & TST \\
\hline CHEMBL1514462 & 688239 & 4.6862 & 5.5164 & TRN \\
\hline CHEMBL1326567 & 688239 & 5.3362 & 5.4477 & TRN \\
\hline CHEMBL1464482 & 688239 & 5.0362 & 5.5972 & TST \\
\hline CHEMBL1440528 & 688239 & 6.1862 & 5.5289 & TST \\
\hline CHEMBL1426393 & 688239 & 6.6362 & 5.527 & TST \\
\hline CHEMBL1313615 & 688239 & 5.0862 & 5.5664 & TRN \\
\hline CHEMBL1304527 & 688239 & 6.5862 & 5.4416 & TST \\
\hline CHEMBL1594541 & 688239 & 6.2862 & 5.3824 & TRN \\
\hline CHEMBL1508605 & 688239 & 6.0862 & 5.5383 & TRN \\
\hline CHEMBL3195029 & 688239 & 4.5362 & 5.4256 & TST \\
\hline CHEMBL1412171 & 688239 & 6.0362 & 5.4144 & TRN \\
\hline CHEMBL1613144 & 688239 & 4.5362 & 5.5245 & TST \\
\hline CHEMBL1329217 & 688239 & 6.1862 & 5.4403 & TRN \\
\hline CHEMBL1386262 & 688239 & 7.0862 & 5.41799 & 9999999999 \\
\hline CHEMBL3211394 & 688239 & 6.5363 & 5.4706 & TST \\
\hline CHEMBL1431858 & 688239 & 5.3862 & 5.3556 & TST \\
\hline CHEMBL1605801 & 688239 & 4.5362 & 5.63299 & 9999999999 \\
\hline CHEMBL3190922 & 688239 & 7.3363 & 5.4868 & TST \\
\hline CHEMBL1318883 & 688239 & 4.6362 & 5.3739 & TST \\
\hline CHEMBL1414934 & 688239 & 4.6862 & 5.4069 & TRN \\
\hline CHEMBL1303183 & 688239 & 7.7852 & 5.5459 & TRN \\
\hline CHEMBL1344990 & 688239 & 5.4862 & 5.4702 & TRN \\
\hline CHEMBL1340274 & 688239 & 5.4862 & 5.3656 & TST \\
\hline CHEMBL1607438 & 688239 & 6.6362 & 5.5681 & TRN \\
\hline CHEMBL1468757 & 688239 & 4.5862 & 5.4746 & TRN \\
\hline CHEMBL1460752 & 688239 & 6.6362 & 5.5374 & TRN \\
\hline CHEMBL1312336 & 688239 & 5.7362 & 5.4969 & TRN \\
\hline CHEMBL1521612 & 688239 & 5.0862 & 5.5664 & TST \\
\hline CHEMBL1498214 & 688239 & 5.7362 & 5.5161 & TST \\
\hline CHEMBL1483830 & 688239 & 4.6862 & 5.3703 & TST \\
\hline CHEMBL3197398 & 688239 & 5.1362 & 5.3962 & TRN \\
\hline CHEMBL1420889 & 688239 & 5.4362 & 5.5073 & TRN \\
\hline CHEMBL1512322 & 688239 & 4.5362 & 5.4601 & TRN \\
\hline CHEMBL1542466 & 688239 & 5.1862 & 5.49100 & 20000000005 \\
\hline CHEMBL1375284 & 688239 & 5.1862 & 5.4711 & TRN \\
\hline CHEMBL1304011 & 688239 & 5.6862 & 5.51399 & 9999999999 \\
\hline
\end{tabular}


Supplemental Table S2.txt

\begin{tabular}{|c|c|c|c|c|}
\hline CHEMBL1536550 & 688239 & 4.5362 & 5.5655 & TRN \\
\hline CHEMBL1385769 & 688239 & 4.5362 & 5.4258 & TST \\
\hline CHEMBL1466181 & 688239 & 4.5862 & 5.4734 & TST \\
\hline CHEMBL1539069 & 688239 & 4.5362 & 5.5259 & TRN \\
\hline CHEMBL1521776 & 688239 & 4.6862 & 5.4146 & TRN \\
\hline CHEMBL1452115 & 688239 & 4.5362 & 5.2136 & TRN \\
\hline CHEMBL1966792 & 688239 & 4.6362 & 5.5339 & TST \\
\hline CHEMBL1313371 & 688239 & 4.6862 & 5.6423 & TRN \\
\hline CHEMBL1519844 & 688239 & 5.5362 & 5.5655 & TRN \\
\hline CHEMBL1550354 & 688239 & 6.1862 & 5.4845 & TRN \\
\hline CHEMBL1468756 & 688239 & 4.5362 & 5.5037 & TRN \\
\hline CHEMBL1400274 & 688239 & 5.5862 & 5.443 & TRN \\
\hline CHEMBL1446059 & 688239 & 4.7862 & 5.629 & TRN \\
\hline CHEMBL1316378 & 688239 & 6.7862 & 5.5882 & TRN \\
\hline CHEMBL1577324 & 688239 & 6.2362 & 5.5027 & TST \\
\hline CHEMBL1551388 & 688239 & 4.7362 & 5.2673 & TRN \\
\hline CHEMBL1303159 & 688239 & 6.0862 & 5.5057 & TRN \\
\hline CHEMBL1465304 & 688239 & 6.0862 & 5.4377 & TST \\
\hline CHEMBL1444281 & 688239 & 5.4862 & 5.3897 & TRN \\
\hline CHEMBL1560266 & 688239 & 4.5362 & 5.5013 & TRN \\
\hline CHEMBL1564439 & 688239 & 5.4362 & 5.5723 & TST \\
\hline CHEMBL1562985 & 688239 & 6.6362 & 5.5091 & TRN \\
\hline CHEMBL1433757 & 688239 & 5.7362 & 5.6335 & TRN \\
\hline CHEMBL1495814 & 688239 & 5.6362 & 5.4651 & TRN \\
\hline CHEMBL1427924 & 688239 & 5.4362 & 5.4888 & TRN \\
\hline CHEMBL1601269 & 688239 & 4.5362 & 5.5752 & TRN \\
\hline CHEMBL1419489 & 688239 & 6.1362 & 5.6142 & TRN \\
\hline CHEMBL1606674 & 688239 & 5.1862 & 5.6249 & TRN \\
\hline CHEMBL1318494 & 688239 & 4.5362 & 5.3989 & TRN \\
\hline CHEMBL1452200 & 688239 & 5.1862 & 5.4814 & TRN \\
\hline CHEMBL1477896 & 688239 & 4.6862 & 5.53799 & 9999999999 \\
\hline CHEMBL1414548 & 688239 & 5.4362 & 5.4066 & TRN \\
\hline CHEMBL1368482 & 688239 & 5.3862 & 5.5427 & TST \\
\hline CHEMBL 3214423 & 688239 & 4.5362 & 5.6062 & TST \\
\hline CHEMBL1381173 & 688239 & 5.9362 & 5.5077 & TST \\
\hline CHEMBL1443654 & 688239 & 5.4862 & 5.5988 & TST \\
\hline CHEMBL1501611 & 688239 & 6.1362 & 5.5226 & TRN \\
\hline CHEMBL1350398 & 688239 & 4.5362 & 5.4895 & TST \\
\hline CHEMBL1576001 & 688239 & 8.3372 & 5.5384 & TRN \\
\hline CHEMBL1604409 & 688239 & 6.8362 & 5.5083 & TRN \\
\hline CHEMBL1391765 & 688239 & 5.9862 & 5.63899 & 9999999999 \\
\hline CHEMBL1413654 & 688239 & 6.3863 & 5.4784 & TRN \\
\hline CHEMBL1489361 & 688239 & 5.8862 & 5.5097 & TST \\
\hline CHEMBL1443906 & 688239 & 4.6862 & 5.5798 & TRN \\
\hline CHEMBL1449890 & 688239 & 7.0362 & 5.4493 & TRN \\
\hline CHEMBL1548653 & 688239 & 4.5362 & 5.4929 & TRN \\
\hline CHEMBL1531168 & 688239 & 4.7862 & 5.3099 & TRN \\
\hline CHEMBL1455071 & 688239 & 4.8362 & 5.3829 & TRN \\
\hline
\end{tabular}


Supplemental Table S2.txt

\begin{tabular}{|c|c|c|c|c|c|}
\hline CHEMBL1589448 & 688239 & 5.6362 & 5.4504 & TRN & \\
\hline CHEMBL1612946 & 688239 & 5.0862 & 5.3462 & TRN & \\
\hline CHEMBL1469438 & 688239 & 7.2366 & \multicolumn{2}{|c|}{5.417000000000001} & TRN \\
\hline CHEMBL1579634 & 688239 & 5.0862 & 5.3487 & TRN & \\
\hline CHEMBL1301161 & 688239 & 5.2362 & 5.5308 & TRN & \\
\hline CHEMBL1387635 & 688239 & 4.6862 & 5.5758 & TRN & \\
\hline CHEMBL1351232 & 688239 & 4.5362 & 5.4525 & TRN & \\
\hline CHEMBL1543643 & 688239 & 4.9862 & 5.3995 & TRN & \\
\hline CHEMBL1363072 & 688239 & 5.4362 & 5.4148 & TRN & \\
\hline CHEMBL406845 & 688239 & 4.6362 & 5.4704 & TST & \\
\hline CHEMBL1317675 & 688239 & 4.5362 & 5.6217 & TRN & \\
\hline CHEMBL1399439 & 688239 & 4.5362 & 5.6256 & TRN & \\
\hline CHEMBL1327137 & 688239 & 4.6362 & 5.2585 & TST & \\
\hline CHEMBL1425839 & 688239 & 5.4362 & \multicolumn{2}{|c|}{5.452000000000001} & TRN \\
\hline CHEMBL1426344 & 688239 & 4.5862 & 5.3915 & TRN & \\
\hline CHEMBL1415705 & 688239 & 4.6862 & 5.246 & TST & \\
\hline CHEMBL1366945 & 688239 & 5.3362 & 5.6471 & TRN & \\
\hline CHEMBL1587057 & 688239 & 4.5362 & 5.6001 & TRN & \\
\hline CHEMBL1398081 & 688239 & 4.5362 & 5.5332 & TRN & \\
\hline CHEMBL 3189537 & 688239 & 4.7362 & 5.3067 & TRN & \\
\hline CHEMBL1395726 & 688239 & 6.0362 & 5.635 & TST & \\
\hline CHEMBL1444859 & 688239 & 4.7862 & 5.5442 & TST & \\
\hline CHEMBL1586643 & 688239 & 4.9362 & 5.6025 & TRN & \\
\hline CHEMBL1503010 & 688239 & 5.0862 & 5.4269 & TRN & \\
\hline CHEMBL1454381 & 688239 & 4.5362 & 5.3906 & TRN & \\
\hline CHEMBL1341863 & 688239 & 4.8862 & 5.5257 & TRN & \\
\hline CHEMBL 3213228 & 688239 & 4.5362 & 5.3972 & TRN & \\
\hline CHEMBL1598663 & 688239 & 4.8862 & \multicolumn{2}{|c|}{5.5520000000000005} & TRN \\
\hline CHEMBL1369755 & 688239 & 5.4362 & 5.6011 & TRN & \\
\hline CHEMBL1610037 & 688239 & 5.3362 & \multicolumn{2}{|c|}{5.4270000000000005} & TRN \\
\hline CHEMBL1448522 & 688239 & 4.5362 & 5.6776 & TRN & \\
\hline CHEMBL1486556 & 688239 & 4.7362 & 5.64 & TRN & \\
\hline CHEMBL1496770 & 688239 & 5.5362 & 5.4429 & TST & \\
\hline CHEMBL1539889 & 688239 & 6.0362 & 5.402 & TRN & \\
\hline CHEMBL1396991 & 688239 & 7.0862 & 5.3429 & TRN & \\
\hline CHEMBL1530362 & 688239 & 5.1862 & 5.5277 & TST & \\
\hline CHEMBL1425858 & 688239 & 4.9862 & 5.4693 & TST & \\
\hline CHEMBL1416462 & 688239 & 5.3362 & 5.601 & TRN & \\
\hline CHEMBL 2000334 & 688239 & 4.5362 & 5.4345 & TRN & \\
\hline CHEMBL1390601 & 688239 & 8.3372 & 5.5116 & TRN & \\
\hline CHEMBL1570655 & 688239 & 7.5361 & 5.425 & TRN & \\
\hline CHEMBL1588793 & 688239 & 4.4862 & 5.3593 & TRN & \\
\hline CHEMBL1552948 & 688239 & 5.1362 & 5.4937 & TRN & \\
\hline CHEMBL1578481 & 688239 & 5.0862 & 5.4582 & TRN & \\
\hline CHEMBL1601632 & 688239 & 6.2862 & 5.5002 & TST & \\
\hline CHEMBL1340593 & 688239 & 4.8362 & 5.5577 & TST & \\
\hline CHEMBL1589977 & 688239 & 5.5362 & 5.4534 & TRN & \\
\hline CHEMBL1587015 & 688239 & 5.5862 & 5.6376 & TST & \\
\hline
\end{tabular}


Supplemental Table S2.txt

\begin{tabular}{|c|c|c|c|c|}
\hline CHEMBL1548872 & 688239 & 4.5362 & 5.565 & TRN \\
\hline CHEMBL1437595 & 688239 & 6.0362 & 5.559 & TRN \\
\hline CHEMBL1374801 & 688239 & 6.1862 & 5.6465 & TRN \\
\hline CHEMBL3197847 & 688239 & 4.7362 & 5.3182 & TRN \\
\hline CHEMBL3198681 & 688239 & 5.1862 & 5.65 & TST \\
\hline CHEMBL1425920 & 688239 & 4.9862 & 5.5466 & TRN \\
\hline CHEMBL1335989 & 688239 & 8.3872 & 5.5295 & TRN \\
\hline CHEMBL1330405 & 688239 & 6.7361 & 5.4697 & TST \\
\hline CHEMBL3197393 & 688239 & 5.0362 & 5.336 & TRN \\
\hline CHEMBL1519772 & 688239 & 6.7361 & 5.3083 & TST \\
\hline CHEMBL1533652 & 688239 & 4.6862 & 5.2874 & TRN \\
\hline CHEMBL1510124 & 688239 & 5.1362 & 5.5688 & TRN \\
\hline CHEMBL1613238 & 688239 & 4.6362 & 5.3684 & TRN \\
\hline CHEMBL3209811 & 688239 & 5.4362 & 5.4194 & TST \\
\hline CHEMBL1411475 & 688239 & 4.5362 & 5.6053 & TRN \\
\hline CHEMBL1610191 & 688239 & 4.7862 & 5.3415 & TRN \\
\hline CHEMBL1343479 & 688239 & 6.9363 & 5.5406 & TRN \\
\hline CHEMBL1545736 & 688239 & 5.2362 & 5.4164 & TRN \\
\hline CHEMBL1518036 & 688239 & 5.7862 & 5.2873 & TRN \\
\hline CHEMBL1544036 & 688239 & 4.5362 & 5.492999 & 9999999999 \\
\hline CHEMBL95910 & 688239 & 4.5862 & 5.3963 & TRN \\
\hline CHEMBL3192337 & 688239 & 5.4362 & 5.2748 & TRN \\
\hline CHEMBL1436758 & 688239 & 6.1362 & 5.5232 & TST \\
\hline CHEMBL3193452 & 688239 & 5.1862 & 5.4513 & TRN \\
\hline CHEMBL1581217 & 688239 & 6.6362 & 5.4663 & TRN \\
\hline CHEMBL1531357 & 688239 & 5.0362 & 5.303 & TRN \\
\hline CHEMBL1305710 & 688239 & 4.5362 & 5.5592 & TRN \\
\hline CHEMBL1503383 & 688239 & 4.6362 & 5.5413 & TRN \\
\hline CHEMBL1978903 & 688239 & 4.8862 & 5.4286 & TST \\
\hline CHEMBL1558326 & 688239 & 5.0862 & 5.5648 & TRN \\
\hline CHEMBL3196873 & 688239 & 4.5362 & 5.3687 & TST \\
\hline CHEMBL1564692 & 688239 & 6.0862 & 5.4942 & TRN \\
\hline CHEMBL1462056 & 688239 & 8.28399 & 99999999 & 5.5915 \\
\hline CHEMBL1513912 & 688239 & 7.1361 & 5.4722 & TRN \\
\hline CHEMBL1347492 & 688239 & 4.7362 & 5.6258 & TRN \\
\hline CHEMBL1420647 & 688239 & 6.9863 & 5.4791 & TRN \\
\hline CHEMBL3193228 & 688239 & 4.5362 & 5.2907 & TRN \\
\hline CHEMBL1483374 & 688239 & 4.9862 & 5.3994 & TRN \\
\hline CHEMBL1372400 & 688239 & 5.0862 & 5.4484 & TST \\
\hline CHEMBL1373545 & 688239 & 6.9863 & 5.5497 & TRN \\
\hline CHEMBL1340736 & 688239 & 4.5362 & 5.4676 & TST \\
\hline CHEMBL1609572 & 688239 & 6.1862 & 5.5378 & TRN \\
\hline CHEMBL1531293 & 688239 & 6.7361 & 5.5638 & TRN \\
\hline CHEMBL1594726 & 688239 & 5.5862 & 5.4828 & TRN \\
\hline CHEMBL1446311 & 688239 & 4.5362 & 5.4213 & TRN \\
\hline CHEMBL1587430 & 688239 & 5.5362 & 5.4449 & TRN \\
\hline CHEMBL1428898 & 688239 & 5.1862 & 5.5816 & TRN \\
\hline CHEMBL1307243 & 688239 & 7.1361 & 5.6892 & TRN \\
\hline
\end{tabular}


Supplemental Table S2.txt

CHEMBL1409978
CHEMBL1325228
CHEMBL3192475
CHEMBL1567884
CHEMBL1506775
CHEMBL1535341
CHEMBL1446070

$\begin{array}{llll}688239 & 4.5362 & 5.3869 & \text { TST }\end{array}$

$\begin{array}{llll}688239 & 5.7362 & 5.3401 & \text { TST }\end{array}$

$\begin{array}{llll}688239 & 4.6362 & 5.5468 & \text { TST }\end{array}$

$\begin{array}{llll}688239 & 5.2862 & 5.3891 & \text { TRN }\end{array}$

$\begin{array}{llll}688239 & 5.1362 & 5.456 & \text { TST }\end{array}$

$\begin{array}{llll}688239 & 5.1862 & 5.4046 & \text { TRN }\end{array}$

$\begin{array}{llll}688239 & 6.7862 & 5.4992 & \text { TST }\end{array}$

CHEMBL1523719

688239

688239

688239

688239

688239

688239

688239

688239

688239

688239

688239

688239

688239

688239

688239

688239

5.1362

5.5371 TRN

$\begin{array}{lll}6.2362 & 5.487 & \text { TST }\end{array}$

$\begin{array}{lll}6.2362 & 5.4807 & \text { TST }\end{array}$

$\begin{array}{lll}4.7362 & 5.4347 & \text { TRN }\end{array}$

$\begin{array}{lll}5.0862 & 5.4377 & \text { TST }\end{array}$

$4.6862 \quad 5.4945$ TST

$\begin{array}{lll}4.5362 & 5.5374 & \text { TRN }\end{array}$

$\begin{array}{lll}5.1862 & 5.5858 & \text { TRN }\end{array}$

CHEMBL1571882

4.9362

5.5507 TRN

4.88625 .6326 TRN

CHEMBL1375122

5.1862

5.6173

4.5362

TRN

CHEMBL1537807

4.5362

5.4467

TRN

CHEMBL1569859

4.5362

5.4348

TRN

CHEMBL1970554

6.1862

5.4867

TRN

CHEMBL1517472

4.5862

5.6033

TST

688239

4.7362

5.4733

TRN

CHEMBL1558105

CHEMBL1450995

688239

4.5862

5.7053

TST

688239

5.7862

5.5215

TRN

688239

4.5362

5.4105

TRN

CHEMBL3196205

688239

4.7362

5.4403

TST

688239

4.7362

5.4538 TRN

CHEMBL1322397

CHEMBL1481297

688239

6.0362

5.3238 TRN

CHEMBL1526803

688239

6.1862

5.3696 TRN

CHEMBL1415026

CHEMBL1305912

688239

5.1362

5.5137 TRN

688239

5.3862

5.4936 TST

CHEMBL1493901

688239

4.5362

5.4566 TST

CHEMBL1454294

688239

4.8362

5.6102 TRN

CHEMBL1604506

688239

5.3862

5.7065 TST

688239

5.2862

5.5199

TRN

688239

4.5862

5.4142

CHEMBL1494133

CHEMBL1481094

688239

5.1362

5.4479

TRN

688239

5.1362

5.4758

TRN

CHEMBL1400531

CHEMBL1320992

688239

4.7362

5.4048

TRN

688239

6.6861

5.4221 TRN

CHEMBL 3195591

CHEMBL1303022

688239

6.0862

5.5076 TRN

688239

5.0862

5.5041 TST

CHEMBL1567664

688239

5.8862

5.4756 TRN

CHEMBL1454043

CHEMBL1466063

CHEMBL1331305

688239

6.1862

5.486000000000001

TST

688239

5.2362

5.6571 TRN

688239

4.5362

5.6434 TRN

5.5038 TST

Page 1771 


\begin{tabular}{|c|c|c|c|c|c|}
\hline \multicolumn{6}{|c|}{ Supplemental Table S2.txt } \\
\hline CHEMBL1554376 & 688239 & 5.2362 & 5.5139 & TRN & \\
\hline CHEMBL1350226 & 688239 & 4.9862 & 5.5627 & TST & \\
\hline CHEMBL1374041 & 688239 & 5.3862 & 5.6244 & TRN & \\
\hline CHEMBL1414551 & 688239 & 4.8362 & 5.4487 & TRN & \\
\hline CHEMBL1348342 & 688239 & 5.1862 & 5.559 & TRN & \\
\hline CHEMBL1320274 & 688239 & 4.7362 & 5.461 & TST & \\
\hline CHEMBL1438593 & 688239 & 7.7852 & 5.5731 & TST & \\
\hline CHEMBL1424225 & 688239 & 5.6362 & 5.52 & TRN & \\
\hline CHEMBL1535541 & 688239 & 6.4862 & 5.67899 & 9999999999 & TRN \\
\hline CHEMBL1329605 & 688239 & 5.4862 & 5.4775 & TRN & \\
\hline CHEMBL1468912 & 688239 & 6.9363 & 5.5025 & TRN & \\
\hline CHEMBL1472868 & 688239 & 4.5362 & 5.5773 & TRN & \\
\hline CHEMBL3208229 & 688239 & 6.2862 & 5.5814 & TRN & \\
\hline CHEMBL1375189 & 688239 & 5.2862 & 5.4606 & TST & \\
\hline CHEMBL1522481 & 688239 & 4.5362 & 5.3811 & TST & \\
\hline CHEMBL3198677 & 688239 & 6.0362 & 5.4713 & TRN & \\
\hline CHEMBL1500366 & 688239 & 4.6362 & 5.5507 & TRN & \\
\hline CHEMBL1596725 & 688239 & 5.4362 & 5.4226 & TRN & \\
\hline CHEMBL1452504 & 688239 & 6.3362 & 5.5005 & TST & \\
\hline CHEMBL1577590 & 688239 & 4.6862 & 5.2872 & TST & \\
\hline CHEMBL1535477 & 688239 & 6.9363 & 5.6704 & TRN & \\
\hline CHEMBL1405012 & 688239 & 6.0362 & 5.5156 & TRN & \\
\hline CHEMBL1527684 & 688239 & 6.9863 & 5.5096 & TST & \\
\hline CHEMBL1483014 & 688239 & 4.5362 & 5.7272 & TRN & \\
\hline CHEMBL1543343 & 688239 & 5.0362 & 5.5154 & TRN & \\
\hline CHEMBL1600107 & 688239 & 5.4862 & 5.5486 & TRN & \\
\hline CHEMBL1490022 & 688239 & 6.0862 & 5.4187 & TST & \\
\hline CHEMBL1550090 & 688239 & 4.4362 & 5.455 & TRN & \\
\hline CHEMBL1484099 & 688239 & 4.5362 & 5.3805 & TST & \\
\hline CHEMBL1591215 & 688239 & 6.0362 & 5.3578 & TRN & \\
\hline CHEMBL1506870 & 688239 & 5.4362 & 5.5424 & TRN & \\
\hline CHEMBL1540598 & 688239 & 4.9362 & 5.5419 & TRN & \\
\hline CHEMBL3199387 & 688239 & 5.2862 & 5.3818 & TRN & \\
\hline CHEMBL1577209 & 688239 & 5.1862 & 5.4369 & TRN & \\
\hline CHEMBL1338149 & 688239 & 5.8362 & 5.4601 & TST & \\
\hline CHEMBL1394835 & 688239 & 6.7862 & 5.4951 & TRN & \\
\hline CHEMBL1372923 & 688239 & 5.8862 & 5.5347 & TRN & \\
\hline CHEMBL1993532 & 688239 & 5.0362 & 5.5512 & TST & \\
\hline CHEMBL1585360 & 688239 & 6.0362 & 5.5117 & TRN & \\
\hline CHEMBL1470346 & 688239 & 6.3362 & 5.4656 & TST & \\
\hline CHEMBL1575656 & 688239 & 4.5362 & 5.5868 & TRN & \\
\hline CHEMBL1542211 & 688239 & 6.2362 & 5.4604 & TRN & \\
\hline CHEMBL1559098 & 688239 & 4.7862 & 5.5008 & TRN & \\
\hline CHEMBL1586686 & 688239 & 5.6862 & 5.4756 & TST & \\
\hline CHEMBL1371202 & 688239 & 5.5362 & 5.4798 & TRN & \\
\hline CHEMBL1582460 & 688239 & 4.5362 & 5.4271 & TRN & \\
\hline CHEMBL1359788 & 688239 & 5.1862 & 5.3402 & TRN & \\
\hline CHEMBL1343618 & 688239 & 5.2362 & 5.3595 & TRN & \\
\hline
\end{tabular}


Supplemental Table S2.txt

\begin{tabular}{|c|c|c|c|c|c|}
\hline CHEMBL1389254 & 688239 & 5.4362 & 5.4899 & TRN & \\
\hline CHEMBL1549732 & 688239 & 5.1862 & 5.4881 & TRN & \\
\hline CHEMBL1305798 & 688239 & 7.0862 & 5.5906 & TST & \\
\hline CHEMBL1434295 & 688239 & 4.5362 & 5.3186 & TRN & \\
\hline CHEMBL1595696 & 688239 & 6.9363 & 5.4261 & TRN & \\
\hline CHEMBL1549105 & 688239 & 5.3862 & 5.5544 & TST & \\
\hline CHEMBL1422781 & 688239 & 5.6362 & 5.4307 & TST & \\
\hline CHEMBL1325977 & 688239 & 6.0862 & 5.494 & TRN & \\
\hline CHEMBL1586024 & 688239 & 5.4362 & 5.5697 & TRN & \\
\hline CHEMBL1427553 & 688239 & 6.3863 & 5.5272 & TST & \\
\hline CHEMBL1371041 & 688239 & 6.1362 & 5.5092 & TRN & \\
\hline CHEMBL1334008 & 688239 & 4.5362 & 5.5428 & TRN & \\
\hline CHEMBL1385315 & 688239 & 4.5362 & 5.4437 & TST & \\
\hline CHEMBL1375674 & 688239 & 5.2362 & 5.4853 & TRN & \\
\hline CHEMBL1382970 & 688239 & 4.5362 & 5.4976 & TRN & \\
\hline CHEMBL1585914 & 688239 & 4.7362 & 5.4643 & TRN & \\
\hline CHEMBL1478774 & 688239 & 4.4862 & 5.33700 & 2000000001 & TRN \\
\hline CHEMBL1301567 & 688239 & 5.7362 & 5.4548 & TRN & \\
\hline CHEMBL1406921 & 688239 & 4.8362 & 5.53700 & 0000000001 & TRN \\
\hline CHEMBL1343366 & 688239 & 4.5362 & 5.3381 & TST & \\
\hline CHEMBL1379902 & 688239 & 4.7862 & 5.62700 & 0000000001 & TRN \\
\hline CHEMBL1313224 & 688239 & 4.9362 & 5.4107 & TRN & \\
\hline CHEMBL1313991 & 688239 & 4.6862 & 5.4339 & TST & \\
\hline CHEMBL1529662 & 688239 & 4.5362 & 5.4845 & TST & \\
\hline CHEMBL1541357 & 688239 & 5.2862 & 5.4762 & TRN & \\
\hline CHEMBL1372855 & 688239 & 5.2862 & 5.4638 & TRN & \\
\hline CHEMBL1488220 & 688239 & 5.4362 & 5.371 & TST & \\
\hline CHEMBL1464513 & 688239 & 6.0362 & 5.4811 & TRN & \\
\hline CHEMBL3194346 & 688239 & 7.6861 & 5.5614 & TRN & \\
\hline CHEMBL1533282 & 688239 & 4.5362 & 5.4324 & TST & \\
\hline CHEMBL1328067 & 688239 & 5.0862 & 5.4704 & TST & \\
\hline CHEMBL1364329 & 688239 & 7.0362 & 5.5767 & TRN & \\
\hline CHEMBL1544091 & 688239 & 5.7362 & 5.5645 & TRN & \\
\hline CHEMBL1353458 & 688239 & 6.9363 & 5.5189 & TST & \\
\hline CHEMBL1420964 & 688239 & 4.8862 & 5.4897 & TST & \\
\hline CHEMBL1559738 & 688239 & 4.5362 & 5.4801 & TRN & \\
\hline CHEMBL3145367 & 688239 & 5.0862 & 5.5758 & TRN & \\
\hline CHEMBL1467261 & 688239 & 5.5862 & 5.5597 & TRN & \\
\hline CHEMBL1500147 & 688239 & 5.5862 & 5.6169 & TST & \\
\hline CHEMBL1509703 & 688239 & 5.5362 & 5.3912 & TST & \\
\hline CHEMBL1480879 & 688239 & 4.5362 & \multicolumn{2}{|c|}{5.587999999999999} & TRN \\
\hline CHEMBL1410157 & 688239 & 4.6862 & 5.519 & TRN & \\
\hline CHEMBL1590557 & 688239 & 6.5862 & 5.4146 & TRN & \\
\hline CHEMBL1425737 & 688239 & 5.6362 & 5.5086 & TRN & \\
\hline CHEMBL1322151 & 688239 & 4.7362 & 5.2617 & TST & \\
\hline CHEMBL1365079 & 688239 & 4.5862 & 5.5995 & TRN & \\
\hline CHEMBL1407920 & 688239 & 5.1862 & 5.5551 & TRN & \\
\hline CHEMBL1338142 & 688239 & 4.5362 & 5.539 & TRN & \\
\hline
\end{tabular}


Supplemental Table S2.txt

\begin{tabular}{|c|c|c|c|c|c|}
\hline CHEMBL1360615 & 688239 & 5.0362 & 5.456 & TST & \\
\hline CHEMBL1529003 & 688239 & 4.6862 & 5.4638 & TRN & \\
\hline CHEMBL1363236 & 688239 & 4.5362 & 5.6173 & TRN & \\
\hline CHEMBL1314101 & 688239 & 4.6362 & 5.5355 & TST & \\
\hline CHEMBL1548796 & 688239 & 5.1862 & 5.5496 & TST & \\
\hline CHEMBL1595961 & 688239 & 7.8861 & 5.4637 & TRN & \\
\hline CHEMBL1496157 & 688239 & 6.4862 & 5.5356 & TRN & \\
\hline CHEMBL1331219 & 688239 & 5.1862 & 5.7319 & TRN & \\
\hline CHEMBL1535409 & 688239 & 4.7862 & 5.5576 & TRN & \\
\hline CHEMBL1379583 & 688239 & 6.2862 & 5.5846 & TST & \\
\hline CHEMBL 3209283 & 688239 & 4.9862 & 5.4463 & TST & \\
\hline CHEMBL1605516 & 688239 & 5.8362 & 5.4383 & TST & \\
\hline CHEMBL1406534 & 688239 & 7.6861 & 5.3708 & TRN & \\
\hline CHEMBL1378779 & 688239 & 5.6862 & 5.4739 & TRN & \\
\hline CHEMBL1562776 & 688239 & 6.1362 & 5.5803 & TRN & \\
\hline CHEMBL1602256 & 688239 & 4.6862 & 5.6761 & TST & \\
\hline CHEMBL1589872 & 688239 & 5.3862 & 5.4722 & TRN & \\
\hline CHEMBL1346913 & 688239 & 6.8861 & 5.6248 & TRN & \\
\hline CHEMBL1527067 & 688239 & 4.5362 & 5.4764 & TRN & \\
\hline CHEMBL1498978 & 688239 & 5.1862 & 5.3797 & TRN & \\
\hline CHEMBL1497982 & 688239 & 5.8862 & 5.3732 & TST & \\
\hline CHEMBL1451630 & 688239 & 7.8356 & 5.529 & TRN & \\
\hline CHEMBL3199720 & 688239 & 4.7862 & 5.5311 & TRN & \\
\hline CHEMBL1535608 & 688239 & 5.2362 & 5.4059 & TST & \\
\hline CHEMBL3198475 & 688239 & 4.6862 & 5.5816 & TRN & \\
\hline CHEMBL1477794 & 688239 & 4.5362 & 5.4673 & TRN & \\
\hline CHEMBL 31840 & 688239 & 5.3862 & 5.3774 & TST & \\
\hline CHEMBL1462906 & 688239 & 4.6862 & 5.32299 & 99999999995 & TST \\
\hline CHEMBL1447867 & 688239 & 5.8862 & 5.6238 & TRN & \\
\hline CHEMBL1567152 & 688239 & 5.5862 & 5.6815 & TRN & \\
\hline CHEMBL1497395 & 688239 & 5.5362 & 5.3889 & TST & \\
\hline CHEMBL1479843 & 688239 & 4.5862 & 5.4561 & TRN & \\
\hline CHEMBL243651 & 688239 & 5.4862 & 5.4126 & TRN & \\
\hline CHEMBL1485865 & 688239 & 4.7362 & 5.4478 & TST & \\
\hline CHEMBL1568231 & 688239 & 6.9363 & 5.5187 & TRN & \\
\hline CHEMBL1477795 & 688239 & 6.8861 & 5.54299 & 9999999999 & TRN \\
\hline CHEMBL1400093 & 688239 & 5.4362 & 5.5217 & TRN & \\
\hline CHEMBL1420519 & 688239 & 4.5362 & 5.5075 & TST & \\
\hline CHEMBL1613545 & 688239 & 5.9862 & 5.5343 & TRN & \\
\hline CHEMBL1311334 & 688239 & 5.4862 & 5.3817 & TRN & \\
\hline CHEMBL1439730 & 688239 & 5.0862 & 5.407 & TRN & \\
\hline CHEMBL1331803 & 688239 & 5.4862 & 5.6448 & TST & \\
\hline CHEMBL520275 & 688239 & 5.6862 & 5.4216 & TST & \\
\hline CHEMBL1300146 & 688239 & 4.5362 & 5.2994 & TRN & \\
\hline CHEMBL1609215 & 688239 & 6.9863 & 5.5722 & TRN & \\
\hline CHEMBL1471652 & 688239 & 5.5862 & 5.2973 & TST & \\
\hline CHEMBL1520242 & 688239 & 4.5362 & 5.3939 & TST & \\
\hline CHEMBL1553984 & 688239 & 8.28399 & 79999999 & 5.5759 & T \\
\hline
\end{tabular}


Supplemental Table S2.txt

\begin{tabular}{|c|c|c|c|c|c|}
\hline CHEMBL1417846 & 688239 & 5.3362 & 5.5018 & TRN & \\
\hline CHEMBL1312547 & 688239 & 6.9363 & 5.5957 & TST & \\
\hline CHEMBL1489056 & 688239 & 6.9863 & 5.4383 & TRN & \\
\hline CHEMBL1587355 & 688239 & 5.2862 & 5.4789 & TST & \\
\hline CHEMBL1537589 & 688239 & 5.0362 & 5.5213 & TRN & \\
\hline CHEMBL1568694 & 688239 & 4.6362 & 5.5765 & TST & \\
\hline CHEMBL1517618 & 688239 & 5.7362 & 5.5086 & TRN & \\
\hline CHEMBL1538532 & 688239 & 6.7361 & 5.4601 & TRN & \\
\hline CHEMBL1528081 & 688239 & 6.1362 & 5.4914 & TRN & \\
\hline CHEMBL1369431 & 688239 & 4.7862 & 5.3697 & TRN & \\
\hline CHEMBL1412223 & 688239 & 5.1862 & 5.4433 & TRN & \\
\hline CHEMBL1491623 & 688239 & 4.7362 & 5.4073 & TRN & \\
\hline CHEMBL1302916 & 688239 & 5.6862 & 5.5479 & TST & \\
\hline CHEMBL1352322 & 688239 & 4.5362 & 5.4898 & TST & \\
\hline CHEMBL1519840 & 688239 & 8.3372 & 5.5755 & TRN & \\
\hline CHEMBL1508109 & 688239 & 5.3362 & 5.5568 & TRN & \\
\hline CHEMBL1474735 & 688239 & 5.6862 & 5.728 & TRN & \\
\hline CHEMBL1508864 & 688239 & 4.5362 & 5.5493 & TRN & \\
\hline CHEMBL3214406 & 688239 & 5.7862 & 5.3902 & TST & \\
\hline CHEMBL1411139 & 688239 & 5.5362 & 5.487 & TRN & \\
\hline CHEMBL1540283 & 688239 & 6.4362 & 5.5925 & TRN & \\
\hline CHEMBL1332656 & 688239 & 5.8362 & 5.3675 & TST & \\
\hline CHEMBL1434343 & 688239 & 4.5362 & 5.5194 & TRN & \\
\hline CHEMBL1465515 & 688239 & 4.5362 & 5.5558 & TRN & \\
\hline CHEMBL1471826 & 688239 & 8.3372 & 5.4376 & TRN & \\
\hline CHEMBL1346664 & 688239 & 4.5362 & 5.3156 & TRN & \\
\hline CHEMBL1435952 & 688239 & 6.1862 & 5.4329 & TRN & \\
\hline CHEMBL1357398 & 688239 & 5.0862 & 5.6234 & TRN & \\
\hline CHEMBL1386195 & 688239 & 5.1862 & 5.4426 & TRN & \\
\hline CHEMBL1385416 & 688239 & 4.6862 & 5.4526 & TRN & \\
\hline CHEMBL1544397 & 688239 & 4.6362 & 5.4307 & TST & \\
\hline CHEMBL1602959 & 688239 & 6.7361 & 5.4038 & TST & \\
\hline CHEMBL1389574 & 688239 & 6.0862 & 5.3669 & TRN & \\
\hline CHEMBL1415063 & 688239 & 4.5362 & 5.5168 & TRN & \\
\hline CHEMBL1420252 & 688239 & 4.8362 & 5.6068 & TRN & \\
\hline CHEMBL1372215 & 688239 & 4.5862 & 5.55200 & 00000000005 & TRN \\
\hline CHEMBL1587140 & 688239 & 4.4862 & 5.3008 & TRN & \\
\hline CHEMBL1410518 & 688239 & 6.1362 & 5.5809 & TST & \\
\hline CHEMBL1495914 & 688239 & 5.1862 & 5.5377 & TRN & \\
\hline CHEMBL1312288 & 688239 & 6.9363 & 5.5033 & TRN & \\
\hline CHEMBL1580106 & 688239 & 7.8356 & 5.4005 & TRN & \\
\hline CHEMBL1486798 & 688239 & 5.1362 & 5.3918 & TRN & \\
\hline CHEMBL1457533 & 688239 & 6.7862 & 5.2892 & TRN & \\
\hline CHEMBL1964628 & 688239 & 8.3372 & 5.3872 & TRN & \\
\hline CHEMBL1589180 & 688239 & 4.5362 & 5.4263 & TRN & \\
\hline CHEMBL1486478 & 688239 & 6.6362 & 5.4954 & TRN & \\
\hline CHEMBL1322919 & 688239 & 6.3863 & 5.3585 & TRN & \\
\hline CHEMBL1376949 & 688239 & 5.1862 & 5.5146 & TRN & \\
\hline
\end{tabular}


Supplemental Table S2.txt

\begin{tabular}{|c|c|c|c|c|}
\hline CHEMBL1395934 & 688239 & 6.8362 & 5.5731 & TRN \\
\hline CHEMBL1553163 & 688239 & 4.9862 & 5.4678 & TRN \\
\hline CHEMBL1567413 & 688239 & 6.7862 & 5.5054 & TRN \\
\hline CHEMBL1480930 & 688239 & 6.25 & 5.3768 & TRN \\
\hline CHEMBL1484954 & 688239 & 4.6362 & 5.5229 & TRN \\
\hline CHEMBL1583852 & 688239 & 4.5362 & 5.5908 & TRN \\
\hline CHEMBL1498775 & 688239 & 5.3362 & 5.5243 & TST \\
\hline CHEMBL3192925 & 688239 & 5.7862 & 5.5525 & TRN \\
\hline CHEMBL1461640 & 688239 & 5.3862 & 5.5177 & TRN \\
\hline CHEMBL1604715 & 688239 & 6.9863 & 5.5211 & TRN \\
\hline CHEMBL572806 & 688239 & 5.1862 & 5.4056 & TST \\
\hline CHEMBL1333649 & 688239 & 4.5362 & 5.5029 & TRN \\
\hline CHEMBL1606341 & 688239 & 4.5362 & 5.4222 & TRN \\
\hline CHEMBL1341279 & 688239 & 5.2362 & 5.5616 & TRN \\
\hline CHEMBL1565154 & 688239 & 6.8861 & 5.5148 & TRN \\
\hline CHEMBL1462637 & 688239 & 5.4862 & 5.4797 & TRN \\
\hline CHEMBL1582104 & 688239 & 5.2362 & 5.4457 & TRN \\
\hline CHEMBL1442472 & 688239 & 4.5362 & 5.4269 & TRN \\
\hline CHEMBL1367733 & 688239 & 4.9362 & 5.3543 & TRN \\
\hline CHEMBL1391954 & 688239 & 5.0862 & 5.5715 & TRN \\
\hline CHEMBL1483523 & 688239 & 4.9862 & 5.5902 & TRN \\
\hline CHEMBL1379524 & 688239 & 4.7862 & 5.4513 & TRN \\
\hline CHEMBL1392413 & 688239 & 4.5362 & 5.3911 & TRN \\
\hline CHEMBL1411874 & 688239 & 5.1862 & 5.5962 & TRN \\
\hline CHEMBL1368873 & 688239 & 4.8362 & 5.5726 & TRN \\
\hline CHEMBL1507327 & 688239 & 4.4862 & 5.4045 & TRN \\
\hline CHEMBL1312926 & 688239 & 8.3372 & 5.5567 & TRN \\
\hline CHEMBL1359747 & 688239 & 6.1362 & 5.5192 & TRN \\
\hline CHEMBL1541809 & 688239 & 6.8362 & 5.5415 & TST \\
\hline CHEMBL1349230 & 688239 & 4.6362 & 5.4715 & TRN \\
\hline CHEMBL1587647 & 688239 & 5.3862 & 5.5275 & TRN \\
\hline CHEMBL1395491 & 688239 & 4.5362 & 5.5371 & TRN \\
\hline CHEMBL1600159 & 688239 & 5.1862 & 5.7054 & TST \\
\hline CHEMBL1458229 & 688239 & 4.5362 & 5.4902 & TRN \\
\hline CHEMBL90146 & 688239 & 4.9362 & 5.4466 & TST \\
\hline CHEMBL1553497 & 688239 & 4.5362 & 5.4709 & TST \\
\hline CHEMBL1547430 & 688239 & 4.9362 & 5.4253 & TRN \\
\hline CHEMBL1539830 & 688239 & 4.8862 & 5.49 & TRN \\
\hline CHEMBL1321881 & 688239 & 8.28399 & 79999999 & 5.5812 \\
\hline CHEMBL1379729 & 688239 & 4.5362 & 5.7028 & TRN \\
\hline CHEMBL1560779 & 688239 & 6.4362 & 5.4536 & TST \\
\hline CHEMBL1448028 & 688239 & 4.5362 & 5.4933 & TRN \\
\hline CHEMBL1416026 & 688239 & 4.5362 & 5.4632 & TRN \\
\hline CHEMBL1596030 & 688239 & 4.9362 & 5.4839 & TST \\
\hline CHEMBL1558580 & 688239 & 4.8862 & 5.4607 & TST \\
\hline CHEMBL1569699 & 688239 & 5.3362 & 5.4649 & TST \\
\hline CHEMBL1534372 & 688239 & 6.1862 & 5.529 & TRN \\
\hline CHEMBL1430788 & 688239 & 4.6862 & 5.4229 & 9999999 \\
\hline
\end{tabular}


Supplemental Table S2.txt

\begin{tabular}{|c|c|c|c|c|c|}
\hline CHEMBL1520383 & 688239 & 6.9363 & 5.684 & TRN & \\
\hline CHEMBL1326021 & 688239 & 5.5362 & 5.4905 & TST & \\
\hline CHEMBL1536840 & 688239 & 4.9362 & 5.2994 & TRN & \\
\hline CHEMBL1332557 & 688239 & 5.2362 & 5.6915 & TRN & \\
\hline CHEMBL1346679 & 688239 & 4.5362 & 5.4592 & TRN & \\
\hline CHEMBL1371437 & 688239 & 4.8362 & 5.4669 & TRN & \\
\hline CHEMBL1345650 & 688239 & 4.5362 & 5.5422 & TST & \\
\hline CHEMBL1453353 & 688239 & 5.7362 & 5.5521 & TRN & \\
\hline CHEMBL1389505 & 688239 & 8.2366 & 5.4595 & TRN & \\
\hline CHEMBL1565118 & 688239 & 4.4862 & 5.4437 & TRN & \\
\hline CHEMBL 3208970 & 688239 & 5.2862 & 5.3528 & TRN & \\
\hline CHEMBL1994856 & 688239 & 6.4862 & 5.3991 & TRN & \\
\hline CHEMBL1384469 & 688239 & 5.1862 & 5.6149 & TRN & \\
\hline CHEMBL1589027 & 688239 & 5.2862 & 5.5211 & TRN & \\
\hline CHEMBL1344865 & 688239 & 5.6862 & 5.2986 & TST & \\
\hline CHEMBL1369278 & 688239 & 4.7362 & 5.4112 & TRN & \\
\hline CHEMBL1381663 & 688239 & 4.4862 & 5.4195 & TRN & \\
\hline CHEMBL1388425 & 688239 & 5.1862 & 5.5657 & TRN & \\
\hline CHEMBL1525039 & 688239 & 4.7862 & 5.5018 & TRN & \\
\hline CHEMBL1399427 & 688239 & 5.4362 & 5.6436 & TRN & \\
\hline CHEMBL1390583 & 688239 & 4.5362 & 5.4611 & TRN & \\
\hline CHEMBL1439671 & 688239 & 5.6862 & 5.5472 & TRN & \\
\hline CHEMBL1469057 & 688239 & 4.6862 & 5.3582 & TRN & \\
\hline CHEMBL 3213749 & 688239 & 5.6862 & 5.4958 & TRN & \\
\hline CHEMBL1532701 & 688239 & 4.5362 & 5.5072 & TST & \\
\hline CHEMBL1529504 & 688239 & 4.5362 & 5.4831 & TRN & \\
\hline CHEMBL1359871 & 688239 & 4.5362 & 5.4261 & TRN & \\
\hline CHEMBL1595258 & 688239 & 8.28399 & 99999999 & 99 & 5.5151 \\
\hline CHEMBL1502584 & 688239 & 7.2366 & 5.3753 & TRN & \\
\hline CHEMBL1312505 & 688239 & 4.5362 & 5.6576 & TRN & \\
\hline CHEMBL1316704 & 688239 & 4.5862 & 5.4193 & TRN & \\
\hline CHEMBL1538253 & 688239 & 4.6862 & 5.6248 & TRN & \\
\hline CHEMBL1417825 & 688239 & 5.8362 & 5.5472 & TRN & \\
\hline CHEMBL1511235 & 688239 & 5.3862 & 5.5828 & TST & \\
\hline CHEMBL1347804 & 688239 & 6.1862 & 5.3631 & TST & \\
\hline CHEMBL1568689 & 688239 & 4.5362 & 5.471 & TRN & \\
\hline CHEMBL 3208361 & 688239 & 4.5362 & 5.3719 & TST & \\
\hline CHEMBL1608899 & 688239 & 6.3863 & 5.5414 & TRN & \\
\hline CHEMBL1342102 & 688239 & 5.8362 & 5.6224 & TRN & \\
\hline CHEMBL1376843 & 688239 & 5.5862 & 5.5203 & TST & \\
\hline CHEMBL1510511 & 688239 & 6.3863 & 5.5107 & TRN & \\
\hline CHEMBL1598569 & 688239 & 6.2362 & 5.2531 & TRN & \\
\hline CHEMBL3211356 & 688239 & 6.0862 & 5.1764 & TRN & \\
\hline CHEMBL1324730 & 688239 & 6.0862 & 5.4311 & TST & \\
\hline CHEMBL1403585 & 688239 & 6.0862 & 5.419 & TRN & \\
\hline CHEMBL1338425 & 688239 & 4.5362 & 5.3676 & TRN & \\
\hline CHEMBL1404586 & 688239 & 6.2362 & 5.5774 & TRN & \\
\hline CHEMBL1503860 & 688239 & 6.9863 & 5.5162 & TST & \\
\hline
\end{tabular}


Supplemental Table S2.txt

\begin{tabular}{|c|c|c|c|c|c|}
\hline CHEMBL1303969 & 688239 & 5.4862 & 5.3725 & TST & \\
\hline CHEMBL1463992 & 688239 & 5.9362 & 5.5225 & TST & \\
\hline CHEMBL1430506 & 688239 & 4.6862 & 5.461 & TRN & \\
\hline CHEMBL1462188 & 688239 & 4.5362 & 5.5172 & TST & \\
\hline CHEMBL1496444 & 688239 & 7.3862 & 5.4426 & TRN & \\
\hline CHEMBL1536729 & 688239 & 5.2362 & 5.5432 & TST & \\
\hline CHEMBL1534269 & 688239 & 5.7862 & 5.5623 & TRN & \\
\hline CHEMBL3191690 & 688239 & 5.1862 & 5.5122 & TRN & \\
\hline CHEMBL1493503 & 688239 & 6.1862 & 5.3496 & TST & \\
\hline CHEMBL1547488 & 688239 & 5.1862 & 5.5168 & TST & \\
\hline CHEMBL1353058 & 688239 & 4.5362 & 5.4322 & TST & \\
\hline CHEMBL3211331 & 688239 & 4.85 & 5.4157 & TST & \\
\hline CHEMBL1421911 & 688239 & 5.3862 & 5.4376 & TRN & \\
\hline CHEMBL1341381 & 688239 & 6.3362 & 5.3319 & TRN & \\
\hline CHEMBL1447421 & 688239 & 5.0362 & 5.5593 & TRN & \\
\hline CHEMBL1557436 & 688239 & 5.8362 & 5.6462 & TST & \\
\hline CHEMBL1368623 & 688239 & 4.7362 & 5.5293 & TRN & \\
\hline CHEMBL1313007 & 688239 & 6.4862 & 5.5058 & TRN & \\
\hline CHEMBL1331171 & 688239 & 5.9362 & 5.4908 & TRN & \\
\hline CHEMBL1512445 & 688239 & 6.6362 & 5.5195 & TRN & \\
\hline CHEMBL1341368 & 688239 & 4.6862 & 5.4661 & TRN & \\
\hline CHEMBL1331362 & 688239 & 8.28399 & 99999999 & 5.5249 & TST \\
\hline CHEMBL1309778 & 688239 & 4.5362 & 5.5941 & TRN & \\
\hline CHEMBL1300747 & 688239 & 6.1862 & 5.5282 & TRN & \\
\hline CHEMBL1582596 & 688239 & 6.0362 & 5.3377 & TRN & \\
\hline CHEMBL1493950 & 688239 & 4.5362 & 5.5863 & TRN & \\
\hline CHEMBL1442944 & 688239 & 4.7362 & 5.3398 & TRN & \\
\hline CHEMBL1356475 & 688239 & 5.7362 & 5.5443 & TRN & \\
\hline CHEMBL3195983 & 688239 & 5.9362 & 5.516 & TRN & \\
\hline CHEMBL1460675 & 688239 & 4.5362 & 5.3705 & TRN & \\
\hline CHEMBL1388556 & 688239 & 4.9362 & 5.5679 & TRN & \\
\hline CHEMBL1586034 & 688239 & 4.5362 & 5.5767 & TRN & \\
\hline CHEMBL1560791 & 688239 & 6.6362 & 5.5682 & TRN & \\
\hline CHEMBL1302085 & 688239 & 6.6861 & 5.4612 & TRN & \\
\hline CHEMBL1573131 & 688239 & 6.9363 & 5.4012 & TRN & \\
\hline CHEMBL1327786 & 688239 & 4.5362 & 5.3274 & TRN & \\
\hline CHEMBL 294802 & 688239 & 4.7862 & 5.4253 & TRN & \\
\hline CHEMBL1366531 & 688239 & 4.5362 & 5.38200 & 0000000001 & TST \\
\hline CHEMBL1508548 & 688239 & 4.5362 & 5.4639 & TRN & \\
\hline CHEMBL1408632 & 688239 & 4.6362 & 5.5313 & TRN & \\
\hline CHEMBL1472622 & 688239 & 5.9362 & 5.5071 & TRN & \\
\hline CHEMBL1600675 & 688239 & 6.2362 & 5.391 & TRN & \\
\hline CHEMBL3189164 & 688239 & 7.1864 & 5.5755 & TRN & \\
\hline CHEMBL1508654 & 688239 & 5.3362 & 5.4355 & TRN & \\
\hline CHEMBL1531464 & 688239 & 5.1862 & 5.4862 & TRN & \\
\hline CHEMBL1588656 & 688239 & 4.8362 & 5.3068 & TRN & \\
\hline CHEMBL1335383 & 688239 & 5.8362 & 5.3534 & TRN & \\
\hline CHEMBL1352501 & 688239 & 5.4362 & 5.5256 & TRN & \\
\hline
\end{tabular}




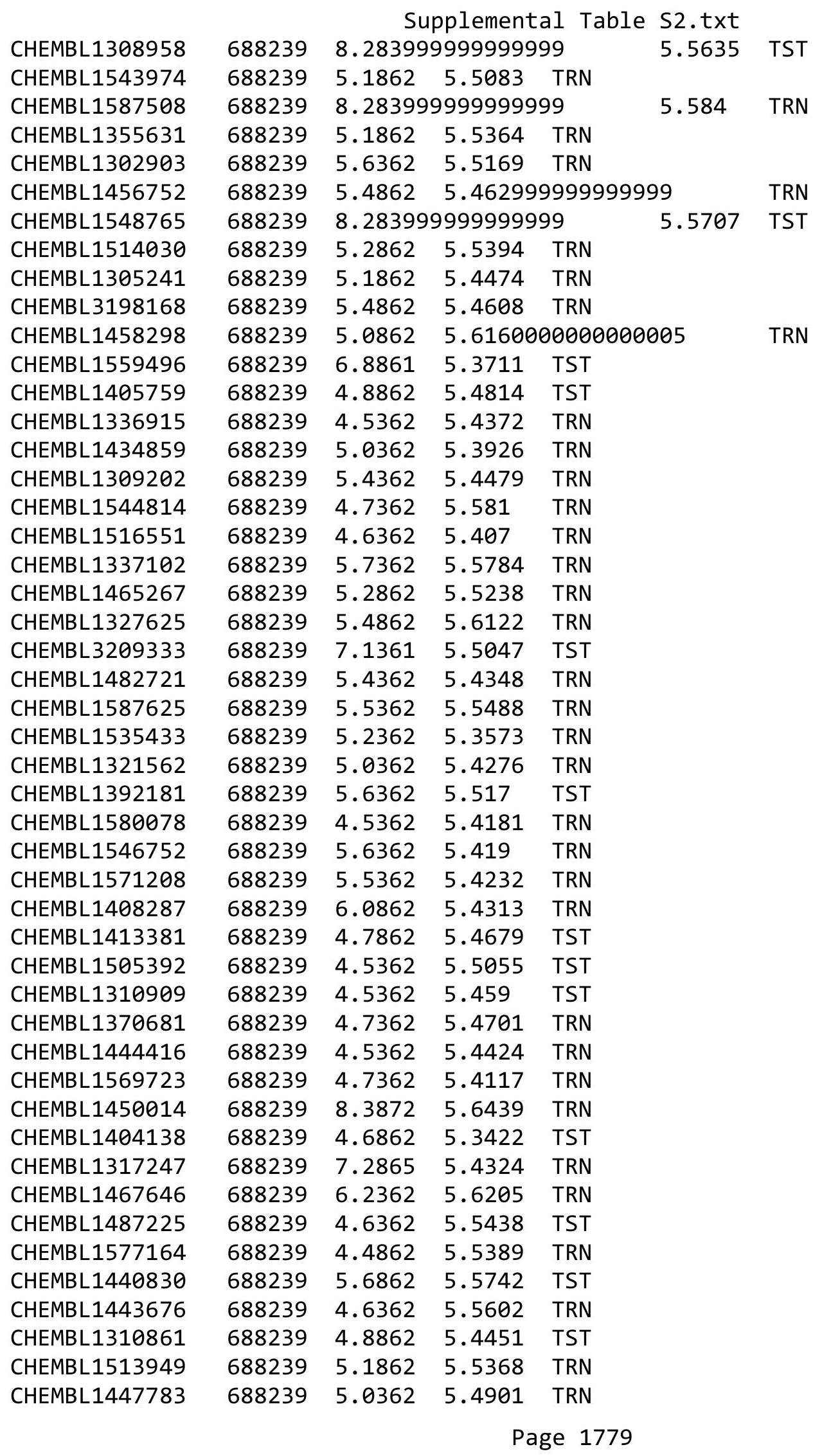


Supplemental Table S2.txt

\begin{tabular}{|c|c|c|c|c|}
\hline CHEMBL1407149 & 688239 & 6.1362 & 5.5081 & TRN \\
\hline CHEMBL1520386 & 688239 & 5.1862 & 5.4166 & TST \\
\hline CHEMBL3191032 & 688239 & 5.9862 & 5.4666 & TRN \\
\hline CHEMBL1545942 & 688239 & 6.2362 & 5.3516 & TST \\
\hline CHEMBL1462213 & 688239 & 5.1362 & 5.5207 & TRN \\
\hline CHEMBL1347538 & 688239 & 4.5862 & 5.4902 & TRN \\
\hline CHEMBL1491893 & 688239 & 6.4362 & 5.4888 & TST \\
\hline CHEMBL1578353 & 688239 & 6.9363 & 5.4738 & TRN \\
\hline CHEMBL1598261 & 688239 & 5.3362 & 5.5411 & TST \\
\hline CHEMBL1465628 & 688239 & 6.0862 & 5.5291 & TST \\
\hline CHEMBL1490277 & 688239 & 5.8362 & 5.4749 & TRN \\
\hline CHEMBL3195922 & 688239 & 5.0362 & 5.4749 & TST \\
\hline CHEMBL1554311 & 688239 & 5.0362 & 5.3781 & TRN \\
\hline CHEMBL1534586 & 688239 & 4.5362 & 5.4855 & TST \\
\hline CHEMBL1546211 & 688239 & 4.6862 & 5.6941 & TRN \\
\hline CHEMBL1434904 & 688239 & 5.9862 & 5.2948 & TRN \\
\hline CHEMBL1565028 & 688239 & 5.1862 & 5.5116 & TRN \\
\hline CHEMBL1585681 & 688239 & 6.8362 & 5.4998 & TRN \\
\hline CHEMBL1302139 & 688239 & 4.6362 & 5.4921 & TRN \\
\hline CHEMBL1567524 & 688239 & 4.7362 & 5.5574 & TRN \\
\hline CHEMBL1575393 & 688239 & 8.2366 & 5.4923 & TST \\
\hline CHEMBL3212462 & 688239 & 6.8362 & 5.34 & TRN \\
\hline CHEMBL1339690 & 688239 & 4.7862 & 5.6493 & TRN \\
\hline CHEMBL1491281 & 688239 & 6.1362 & 5.4265 & TRN \\
\hline CHEMBL1598441 & 688239 & 5.8862 & 5.5067 & TRN \\
\hline CHEMBL1383979 & 688239 & 5.7862 & 5.59 & TRN \\
\hline CHEMBL3207682 & 688239 & 6.8861 & 5.4935 & TRN \\
\hline CHEMBL1602953 & 688239 & 6.6861 & 5.5274 & TRN \\
\hline CHEMBL1610009 & 688239 & 5.3862 & 5.5268 & TRN \\
\hline CHEMBL1400365 & 688239 & 5.1862 & 5.4832 & TRN \\
\hline CHEMBL1380821 & 688239 & 5.1862 & 5.4207 & TST \\
\hline CHEMBL1537261 & 688239 & 4.8362 & 5.4265 & TRN \\
\hline CHEMBL1553432 & 688239 & 5.3862 & 5.642 & TRN \\
\hline CHEMBL1464417 & 688239 & 7.4868 & 5.6644 & TST \\
\hline CHEMBL1358291 & 688239 & 6.7862 & 5.4396 & TRN \\
\hline CHEMBL3198060 & 688239 & 6.95 & 5.3916 & TRN \\
\hline CHEMBL1351290 & 688239 & 4.7862 & 5.4282 & TRN \\
\hline CHEMBL1502826 & 688239 & 4.4862 & 5.6162 & TRN \\
\hline CHEMBL1595293 & 688239 & 4.5362 & 5.4602 & TRN \\
\hline CHEMBL1896185 & 688239 & 5.9362 & 5.462999 & 9999999999 \\
\hline CHEMBL1362205 & 688239 & 4.8362 & 5.4361 & TRN \\
\hline CHEMBL1496595 & 688239 & 6.2862 & 5.5176 & TRN \\
\hline CHEMBL1462595 & 688239 & 4.5362 & 5.4908 & TRN \\
\hline CHEMBL1550590 & 688239 & 5.1362 & 5.5093 & TST \\
\hline CHEMBL1511979 & 688239 & 7.5361 & 5.4035 & TRN \\
\hline CHEMBL1349651 & 688239 & 5.6862 & 5.6259 & TRN \\
\hline CHEMBL1347409 & 688239 & 5.3862 & 5.4686 & TRN \\
\hline CHEMBL1548413 & 688239 & 4.5862 & 5.5366 & TRN \\
\hline
\end{tabular}


Supplemental Table S2.txt

\begin{tabular}{|c|c|c|c|c|}
\hline 然 & & & & TRN \\
\hline $\mathrm{CHF}$ & 8239 & 5862 & & \\
\hline AEMBL1405171 & 8239 & 362 & & \\
\hline HEMBL1372024 & 88239 & 3372 & 4437 & \\
\hline 6594 & 88239 & 362 & 4699 & \\
\hline 33143 & 38239 & & 3919 & . \\
\hline IEMBL1359862 & 88239 & 2362 & 4234 & DM \\
\hline HEMBL3145194 & 88239 & 362 & .4693 & ST \\
\hline HEMBL1586201 & 88239 & .8862 & .3644 & \\
\hline AEMBL1543497 & 88239 & 862 & 419 & \\
\hline L1306867 & 88239 & 862 & .2908 & ST \\
\hline L1303351 & 88239 & 6.2862 & 5.51 & $\mathrm{RN}$ \\
\hline L1338656 & 88239 & 362 & 5742 & \\
\hline AEMBL1439397 & 88239 & 862 & 82 & \\
\hline L1332098 & 88239 & 862 & 167 & \\
\hline L1300197 & 88239 & & & RN \\
\hline L1487717 & 88239 & 862 & & [RN \\
\hline 674 & 882 & 62 & & \\
\hline IEMBL3210697 & 88239 & 862 & 3691 & DI \\
\hline L1420354 & 38239 & 62 & 19 & RIN \\
\hline L1582838 & 38239 & & & \\
\hline -1406293 & 88239 & & 5222 & ГRN \\
\hline 1424711 & 39 & & & \\
\hline 14 & 39 & & 88 & SI \\
\hline 13 & 39 & & 44 & RN \\
\hline 2 & 39 & & 368 & \\
\hline 1350991 & 39 & & & SI \\
\hline 26177 & 9 & & & TRN \\
\hline AEMBL1468124 & 39 & 62 & 887 & RN \\
\hline L15 & 39 & 62 & 65 & RN \\
\hline 59 & & & & $\mathrm{RN}$ \\
\hline & & & & IRN \\
\hline HEMBL14671 & & & & ГRN \\
\hline HEMBL1498025 & 88239 & 362 & 5.4833 & ГST \\
\hline 616 & 39 & 62 & 51 & TRN \\
\hline 54 & & & & TRN \\
\hline HEMBL1417634 & & & 5.4155 & TST \\
\hline AEMBL1425304 & 88239 & & & TST \\
\hline IEMBL14 & 88239 & 362 & 315 & 「RN \\
\hline 997 & 39 & 62 & 873 & IST \\
\hline & & & & $\Gamma \mathrm{RN}$ \\
\hline HEMBL1966872 & 88239 & 7362 & 5.4385 & TST \\
\hline IEMBL14 & 88239 & & 311 & $\Gamma R$ \\
\hline FEIMIBL 14 & 39 & & & RN \\
\hline HEMBL15 & & & .4194 & SI \\
\hline HEMBL1435349 & 88239 & 362 & 5.4867 & RN \\
\hline L1342175 & 88239 & 4.6362 & .5769 & 「RN \\
\hline HEMBL1467002 & 688239 & 5.5362 & 5.5587 & 「RN \\
\hline
\end{tabular}

Page 1781 
Supplemental Table S2.txt

\begin{tabular}{|c|c|c|c|c|c|}
\hline CHEMBL1409091 & 688239 & 6.1862 & 5.3487 & TST & \\
\hline CHEMBL1448496 & 688239 & 4.9362 & 5.6008 & TRN & \\
\hline CHEMBL1550213 & 688239 & 5.6362 & 5.5966 & TST & \\
\hline CHEMBL1351151 & 688239 & 5.7362 & 5.4982 & TRN & \\
\hline CHEMBL3191190 & 688239 & 4.5362 & 5.3623 & TRN & \\
\hline CHEMBL1372091 & 688239 & 4.5362 & 5.4575 & TRN & \\
\hline CHEMBL1532343 & 688239 & 4.4862 & 5.5147 & TRN & \\
\hline CHEMBL172172 & 688239 & 8.2366 & 5.42 & TRN & \\
\hline CHEMBL1425082 & 688239 & 5.7862 & 5.6483 & TRN & \\
\hline CHEMBL1436303 & 688239 & 6.9363 & 5.2581 & TRN & \\
\hline CHEMBL1474959 & 688239 & 5.5862 & 5.6065 & TRN & \\
\hline CHEMBL1597056 & 688239 & 5.1862 & 5.6342 & TRN & \\
\hline CHEMBL1407459 & 688239 & 5.4362 & 5.5099 & TRN & \\
\hline CHEMBL1501249 & 688239 & 4.6362 & 5.431 & TRN & \\
\hline CHEMBL1452795 & 688239 & 5.1862 & 5.5689 & TST & \\
\hline CHEMBL3213715 & 688239 & 6.0862 & 5.3333 & TRN & \\
\hline CHEMBL1596506 & 688239 & 6.5862 & 5.3567 & TRN & \\
\hline CHEMBL1507241 & 688239 & 4.4862 & 5.5332 & TST & \\
\hline CHEMBL1422294 & 688239 & 4.7362 & 5.4061 & TRN & \\
\hline CHEMBL1329569 & 688239 & 6.5363 & 5.4472 & TRN & \\
\hline CHEMBL 1485779 & 688239 & 5.6362 & 5.4629 & TRN & \\
\hline CHEMBL1370226 & 688239 & 4.5362 & 5.4017 & TST & \\
\hline CHEMBL1470256 & 688239 & 4.5362 & 5.2481 & TRN & \\
\hline CHEMBL1547611 & 688239 & 5.4862 & 5.4977 & TRN & \\
\hline CHEMBL1608262 & 688239 & 4.8862 & 5.4565 & TRN & \\
\hline CHEMBL1494422 & 688239 & 5.1862 & 5.4749 & TST & \\
\hline CHEMBL1318199 & 688239 & 6.9863 & 5.5405 & TRN & \\
\hline CHEMBL1436329 & 688239 & 5.1362 & 5.5922 & TRN & \\
\hline CHEMBL1505956 & 688239 & 5.2862 & 5.2251 & TST & \\
\hline CHEMBL1369781 & 688239 & 5.7362 & 5.5032 & TST & \\
\hline CHEMBL1375038 & 688239 & 4.9362 & 5.57799 & 9999999999 & TRN \\
\hline CHEMBL1468681 & 688239 & 6.7862 & 5.6481 & TRN & \\
\hline CHEMBL1375623 & 688239 & 4.9362 & 5.5091 & TRN & \\
\hline CHEMBL1588298 & 688239 & 4.6862 & 5.2299 & TST & \\
\hline CHEMBL1386374 & 688239 & 5.7362 & 5.484 & TST & \\
\hline CHEMBL1549748 & 688239 & 6.5862 & 5.5081 & TRN & \\
\hline CHEMBL1346552 & 688239 & 6.2862 & 5.5412 & TRN & \\
\hline CHEMBL1542015 & 688239 & 4.6862 & 5.3578 & TST & \\
\hline CHEMBL1495651 & 688239 & 4.6862 & 5.3843 & TRN & \\
\hline CHEMBL1430656 & 688239 & 5.4362 & 5.5282 & TRN & \\
\hline CHEMBL1560948 & 688239 & 5.1862 & 5.4541 & TRN & \\
\hline CHEMBL1497896 & 688239 & 5.8362 & 5.5861 & TRN & \\
\hline CHEMBL1508801 & 688239 & 6.0362 & 5.5826 & TST & \\
\hline CHEMBL1499549 & 688239 & 4.4862 & 5.6568 & TRN & \\
\hline CHEMBL1570451 & 688239 & 6.9863 & 5.4043 & TST & \\
\hline CHEMBL1580453 & 688239 & 6.6861 & 5.4974 & TRN & \\
\hline CHEMBL1419315 & 688239 & 4.5362 & 5.7249 & TRN & \\
\hline CHEMBL1572182 & 688239 & 4.5362 & 5.4852 & TST & \\
\hline
\end{tabular}


Supplemental Table S2.txt

\begin{tabular}{|c|c|c|c|c|c|}
\hline CHEMBL1431271 & 688239 & 8.3372 & 5.4707 & TRN & \\
\hline CHEMBL1438044 & 688239 & 6.5862 & 5.4241 & TRN & \\
\hline CHEMBL1569407 & 688239 & 4.5862 & 5.6233 & TRN & \\
\hline CHEMBL 260615 & 688239 & 4.7362 & 5.5973 & TRN & \\
\hline CHEMBL1349159 & 688239 & 6.8861 & 5.6167 & TST & \\
\hline CHEMBL1603676 & 688239 & 4.6362 & 5.631 & TRN & \\
\hline CHEMBL1458023 & 688239 & 4.5862 & 5.4964 & TST & \\
\hline CHEMBL1300751 & 688239 & 4.9 & 5.6245 & TRN & \\
\hline CHEMBL1522876 & 688239 & 4.6862 & 5.4682 & TST & \\
\hline CHEMBL1443701 & 688239 & 4.7362 & 5.3871 & TST & \\
\hline CHEMBL1385773 & 688239 & 5.1862 & 5.5655 & TRN & \\
\hline CHEMBL1558301 & 688239 & 4.7862 & 5.4609 & TRN & \\
\hline CHEMBL1484417 & 688239 & 4.5362 & 5.499 & TST & \\
\hline CHEMBL1596789 & 688239 & 5.4862 & 5.4937 & TRN & \\
\hline CHEMBL1541464 & 688239 & 8.1871 & 5.3661 & TST & \\
\hline CHEMBL1413951 & 688239 & 5.6862 & 5.4132 & TST & \\
\hline CHEMBL1306370 & 688239 & 5.7862 & 5.3743 & TRN & \\
\hline CHEMBL1558824 & 688239 & 6.8362 & 5.5489 & TST & \\
\hline CHEMBL1470693 & 688239 & 5.3862 & 5.51200 & 00000000005 & TRN \\
\hline CHEMBL1514992 & 688239 & 5.1862 & 5.4289 & TST & \\
\hline CHEMBL 3192201 & 688239 & 5.8862 & 5.4469 & TST & \\
\hline CHEMBL1486450 & 688239 & 4.7862 & 5.4431 & TST & \\
\hline CHEMBL1306580 & 688239 & 4.8862 & 5.5544 & TRN & \\
\hline CHEMBL1601014 & 688239 & 5.6362 & 5.4361 & TRN & \\
\hline CHEMBL1342093 & 688239 & 5.1862 & 5.28600 & 00000000005 & TST \\
\hline CHEMBL1497967 & 688239 & 4.6862 & 5.57600 & 00000000005 & TRN \\
\hline CHEMBL1460365 & 688239 & 5.6362 & 5.6151 & TRN & \\
\hline CHEMBL1597926 & 688239 & 4.9362 & 5.5185 & TRN & \\
\hline CHEMBL1345634 & 688239 & 5.0862 & 5.6158 & TRN & \\
\hline CHEMBL1597753 & 688239 & 7.5361 & 5.4609 & TST & \\
\hline CHEMBL1377946 & 688239 & 5.1862 & 5.3333 & TRN & \\
\hline CHEMBL1424484 & 688239 & 6.7862 & 5.3522 & TRN & \\
\hline CHEMBL1453700 & 688239 & 5.6362 & 5.4125 & TST & \\
\hline CHEMBL1337849 & 688239 & 4.8862 & 5.3697 & TRN & \\
\hline CHEMBL1428702 & 688239 & 4.5362 & 5.4647 & TRN & \\
\hline CHEMBL463563 & 688239 & 4.6362 & 5.4124 & TST & \\
\hline CHEMBL529939 & 688239 & 6.6861 & 5.4824 & TST & \\
\hline CHEMBL 3197471 & 688239 & 5.7362 & 5.4599 & TRN & \\
\hline CHEMBL1508931 & 688239 & 5.3862 & 5.4936 & TRN & \\
\hline CHEMBL1532151 & 688239 & 6.1862 & 5.5606 & TRN & \\
\hline CHEMBL1573690 & 688239 & 4.8362 & 5.3353 & TST & \\
\hline CHEMBL1521364 & 688239 & 4.5362 & 5.4991 & TRN & \\
\hline CHEMBL 3194191 & 688239 & 5.3362 & 5.5641 & TST & \\
\hline CHEMBL1302230 & 688239 & 5.5862 & 5.5017 & TST & \\
\hline CHEMBL1301119 & 688239 & 5.6362 & 5.5194 & TRN & \\
\hline CHEMBL1372357 & 688239 & 5.7362 & 5.4768 & TRN & \\
\hline CHEMBL1463234 & 688239 & 4.8362 & 5.3048 & TRN & \\
\hline CHEMBL1559609 & 688239 & 6.2862 & 5.5573 & TST & \\
\hline
\end{tabular}


Supplemental Table S2.txt

\begin{tabular}{|c|c|c|c|c|c|}
\hline CHEMBL1375627 & 688239 & 5.2362 & 5.3981 & TRN & \\
\hline CHEMBL1582008 & 688239 & 6.1862 & 5.6357 & TRN & \\
\hline CHEMBL1345735 & 688239 & 4.4862 & 5.5027 & TST & \\
\hline CHEMBL1593480 & 688239 & 4.7862 & 5.5489 & TST & \\
\hline CHEMBL1597716 & 688239 & 4.7862 & 5.5359 & TRN & \\
\hline CHEMBL1568843 & 688239 & 4.5862 & 5.3259 & TST & \\
\hline CHEMBL1405397 & 688239 & 5.2862 & 5.644 & TST & \\
\hline CHEMBL1429911 & 688239 & 4.5362 & 5.5725 & TST & \\
\hline CHEMBL1576339 & 688239 & 4.8862 & 5.5622 & TST & \\
\hline CHEMBL1531981 & 688239 & 5.2862 & 5.4345 & TRN & \\
\hline CHEMBL1466146 & 688239 & 5.9862 & 5.4987 & TRN & \\
\hline CHEMBL1612227 & 688239 & 4.4862 & 5.4811 & TST & \\
\hline CHEMBL1544137 & 688239 & 4.5862 & 5.6033 & TRN & \\
\hline CHEMBL1590178 & 688239 & 4.6862 & 5.6118 & TST & \\
\hline CHEMBL 3211668 & 688239 & 5.3862 & 5.4725 & TRN & \\
\hline CHEMBL1425450 & 688239 & 5.1862 & 5.3958 & TRN & \\
\hline CHEMBL1368058 & 688239 & 5.3362 & 5.5477 & TST & \\
\hline CHEMBL1311505 & 688239 & 4.7862 & 5.2975 & TRN & \\
\hline CHEMBL 3195460 & 688239 & 4.8362 & 5.4077 & TRN & \\
\hline CHEMBL1577848 & 688239 & 6.4862 & 5.4272 & TST & \\
\hline CHEMBL1431940 & 688239 & 5.4362 & 5.4483 & TRN & \\
\hline CHEMBL1514370 & 688239 & 4.7862 & 5.7085 & TST & \\
\hline CHEMBL1401270 & 688239 & 4.7362 & 5.465 & TRN & \\
\hline CHEMBL1477165 & 688239 & 4.7862 & 5.526 & TRN & \\
\hline CHEMBL1594896 & 688239 & 4.9362 & 5.4917 & TRN & \\
\hline CHEMBL1498322 & 688239 & 6.9863 & 5.6729 & TRN & \\
\hline CHEMBL1576768 & 688239 & 5.2362 & 5.5709 & TRN & \\
\hline CHEMBL1492749 & 688239 & 5.2862 & 5.4524 & TRN & \\
\hline CHEMBL1544110 & 688239 & 8.3372 & 5.5918 & TRN & \\
\hline CHEMBL1602325 & 688239 & 6.1862 & 5.4512 & TRN & \\
\hline CHEMBL1317814 & 688239 & 4.5362 & 5.6216 & TRN & \\
\hline CHEMBL 3197462 & 688239 & 5.1862 & 5.3108 & TRN & \\
\hline CHEMBL 3209078 & 688239 & 4.5362 & 5.45 & TRN & \\
\hline CHEMBL1571166 & 688239 & 6.6362 & 5.5498 & TST & \\
\hline CHEMBL1399981 & 688239 & 5.7862 & 5.55 & TRN & \\
\hline CHEMBL1576019 & 688239 & 7.9355 & 5.4415 & TST & \\
\hline CHEMBL1351158 & 688239 & 4.7862 & 5.2512 & TRN & \\
\hline CHEMBL1420333 & 688239 & 4.5362 & 5.4817 & TST & \\
\hline CHEMBL1601909 & 688239 & 8.28399 & 99999999 & 99 & 5.4454 \\
\hline CHEMBL1469886 & 688239 & 6.0362 & 5.4104 & TST & \\
\hline CHEMBL1479994 & 688239 & 4.5362 & 5.3366 & TRN & \\
\hline CHEMBL600505 & 688239 & 6.7862 & 5.5109 & TRN & \\
\hline CHEMBL1596154 & 688239 & 5.7362 & 5.3821 & TST & \\
\hline CHEMBL1381212 & 688239 & 6.5363 & 5.4358 & TRN & \\
\hline CHEMBL1306041 & 688239 & 6.8861 & 5.396 & TRN & \\
\hline CHEMBL1582426 & 688239 & 4.5362 & 5.5581 & TRN & \\
\hline CHEMBL1414132 & 688239 & 4.6862 & 5.5621 & TST & \\
\hline CHEMBL1584256 & 688239 & 5.3862 & 5.6587 & TRN & \\
\hline
\end{tabular}


Supplemental Table S2.txt

\begin{tabular}{|c|c|c|c|c|}
\hline CHEMBL1309195 & 688239 & 6.6362 & 5.4279 & TST \\
\hline CHEMBL1368461 & 688239 & 6.1862 & 5.5005 & TRN \\
\hline CHEMBL1467828 & 688239 & 5.1862 & 5.4806 & TRN \\
\hline CHEMBL1541503 & 688239 & 4.5362 & 5.4576 & TRN \\
\hline CHEMBL1522222 & 688239 & 5.8862 & 5.5682 & TRN \\
\hline CHEMBL1604725 & 688239 & 5.4862 & 5.4614 & TST \\
\hline CHEMBL1521204 & 688239 & 5.0362 & 5.4084 & TRN \\
\hline CHEMBL1597640 & 688239 & 6.1862 & 5.6075 & TRN \\
\hline CHEMBL1471020 & 688239 & 5.0862 & 5.4099 & TRN \\
\hline CHEMBL1401254 & 688239 & 5.5362 & 5.5025 & TRN \\
\hline CHEMBL1474120 & 688239 & 5.1862 & 5.5761 & TRN \\
\hline CHEMBL1412727 & 688239 & 5.5362 & 5.3851 & TRN \\
\hline CHEMBL1382783 & 688239 & 4.4862 & 5.3972 & TST \\
\hline CHEMBL1473798 & 688239 & 7.2366 & 5.4956 & TRN \\
\hline CHEMBL1538920 & 688239 & 4.5362 & 5.5316 & TRN \\
\hline CHEMBL562193 & 688239 & 4.7362 & 5.4363 & TRN \\
\hline CHEMBL1600069 & 688239 & 6.1862 & 5.486006 & 000000001 \\
\hline CHEMBL3145131 & 688239 & 5.0362 & 5.3465 & TST \\
\hline CHEMBL1466062 & 688239 & 4.5862 & 5.4474 & TRN \\
\hline CHEMBL1375115 & 688239 & 5.1862 & 5.4277 & TST \\
\hline CHEMBL1458943 & 688239 & 7.2366 & 5.4339 & TRN \\
\hline CHEMBL1443948 & 688239 & 5.7362 & 5.4169 & TRN \\
\hline CHEMBL1501940 & 688239 & 5.5862 & 5.4706 & TRN \\
\hline CHEMBL1530576 & 688239 & 6.6861 & 5.5911 & TRN \\
\hline CHEMBL1461123 & 688239 & 5.9862 & 5.3881 & TRN \\
\hline CHEMBL533082 & 688239 & 4.5362 & 5.4769 & TST \\
\hline CHEMBL1442840 & 688239 & 5.1862 & 5.4471 & TRN \\
\hline CHEMBL1380402 & 688239 & 5.4362 & 5.5163 & TST \\
\hline CHEMBL1356687 & 688239 & 4.8862 & 5.3867 & TST \\
\hline CHEMBL1481062 & 688239 & 8.0362 & 5.629 & TRN \\
\hline CHEMBL1361364 & 688239 & 5.3862 & 5.491006 & 0000000005 \\
\hline CHEMBL 70928 & 688239 & 4.7862 & 5.4216 & TST \\
\hline CHEMBL1414299 & 688239 & 5.4862 & 5.5508 & TRN \\
\hline CHEMBL1513856 & 688239 & 5.2362 & 5.3619 & TST \\
\hline CHEMBL1457763 & 688239 & 5.2862 & 5.4165 & TRN \\
\hline CHEMBL1401416 & 688239 & 6.4362 & 5.5077 & TRN \\
\hline CHEMBL1452328 & 688239 & 5.4862 & 5.5964 & TST \\
\hline CHEMBL1325301 & 688239 & 6.5363 & 5.4597 & TRN \\
\hline CHEMBL1346638 & 688239 & 5.6862 & 5.54 & TRN \\
\hline CHEMBL1478467 & 688239 & 4.5362 & $5.53100 e$ & 000000001 \\
\hline CHEMBL1325177 & 688239 & 5.7362 & 5.4852 & TRN \\
\hline CHEMBL1460020 & 688239 & 4.6362 & 5.4405 & TST \\
\hline CHEMBL1351987 & 688239 & 4.5362 & 5.4623 & TST \\
\hline CHEMBL1389434 & 688239 & 4.8362 & 5.6409 & TRN \\
\hline CHEMBL1539155 & 688239 & 4.5362 & 5.4426 & TRN \\
\hline CHEMBL1474173 & 688239 & 4.6862 & 5.5446 & TST \\
\hline CHEMBL1504872 & 688239 & 4.7362 & 5.4969 & TRN \\
\hline CHEMBL1309797 & 688239 & 7.1361 & 5.5486 & TRN \\
\hline
\end{tabular}


Supplemental Table S2.txt

\begin{tabular}{|c|c|c|c|c|}
\hline CHEMBL1393096 & 688239 & 4.8362 & 5.4291 & TRN \\
\hline CHEMBL1398872 & 688239 & 5.1862 & 5.5777 & TRN \\
\hline CHEMBL1452623 & 688239 & 6.0862 & 5.4326 & TRN \\
\hline CHEMBL1987094 & 688239 & 6.0362 & 5.3563 & TRN \\
\hline CHEMBL1310561 & 688239 & 5.1362 & 5.614 & TST \\
\hline CHEMBL1494596 & 688239 & 6.2362 & 5.6283 & TRN \\
\hline CHEMBL1555857 & 688239 & 5.8862 & 5.5462 & TRN \\
\hline CHEMBL1570021 & 688239 & 4.6862 & 5.4105 & TRN \\
\hline CHEMBL1568644 & 688239 & 4.7862 & 5.4613 & TRN \\
\hline CHEMBL1560513 & 688239 & 4.6862 & 5.5905 & TRN \\
\hline CHEMBL1545180 & 688239 & 4.6862 & 5.4861 & TRN \\
\hline CHEMBL1519829 & 688239 & 5.1862 & 5.40799 & 99999999995 \\
\hline CHEMBL1522412 & 688239 & 7.0862 & 5.4644 & TRN \\
\hline CHEMBL1354159 & 688239 & 8.4815 & 5.4331 & TRN \\
\hline CHEMBL1400132 & 688239 & 5.3362 & 5.3431 & TRN \\
\hline CHEMBL1605970 & 688239 & 4.8862 & 5.562 & TRN \\
\hline CHEMBL1486084 & 688239 & 5.2862 & 5.4919 & TRN \\
\hline CHEMBL1313324 & 688239 & 4.5362 & 5.4918 & TST \\
\hline CHEMBL1340748 & 688239 & 4.4862 & 5.4986 & TST \\
\hline CHEMBL254216 & 688239 & 4.5362 & 5.5516 & TRN \\
\hline CHEMBL1406315 & 688239 & 4.6362 & 5.5001 & TRN \\
\hline CHEMBL1567198 & 688239 & 4.5362 & 5.3801 & TST \\
\hline CHEMBL1484060 & 688239 & 5.8862 & 5.5364 & TRN \\
\hline CHEMBL1318866 & 688239 & 4.7862 & 5.5355 & TRN \\
\hline CHEMBL1429692 & 688239 & 6.6362 & 5.4681 & TRN \\
\hline CHEMBL1442470 & 688239 & 4.7362 & 5.4551 & TRN \\
\hline CHEMBL1464445 & 688239 & 4.5362 & 5.5141 & TRN \\
\hline CHEMBL1313521 & 688239 & 5.9862 & 5.2436 & TST \\
\hline CHEMBL1501432 & 688239 & 4.5362 & 5.4781 & TRN \\
\hline CHEMBL 3207644 & 688239 & 5.8862 & 5.3601 & TRN \\
\hline CHEMBL1540729 & 688239 & 4.8362 & 5.5282 & TST \\
\hline CHEMBL1443940 & 688239 & 5.6862 & 5.6029 & TRN \\
\hline CHEMBL1548503 & 688239 & 7.1864 & 5.5223 & TST \\
\hline CHEMBL1436934 & 688239 & 5.8862 & 5.4676 & TRN \\
\hline CHEMBL1538451 & 688239 & 5.5862 & 5.4568 & TRN \\
\hline CHEMBL1480567 & 688239 & 4.5362 & 5.63399 & 99999999995 \\
\hline CHEMBL1365475 & 688239 & 5.4362 & 5.4813 & TST \\
\hline CHEMBL1481533 & 688239 & 6.0862 & 5.5675 & TRN \\
\hline CHEMBL1371568 & 688239 & 4.6362 & 5.5827 & TRN \\
\hline CHEMBL1517733 & 688239 & 5.1862 & 5.4341 & TRN \\
\hline CHEMBL1494861 & 688239 & 6.5363 & 5.5725 & TRN \\
\hline CHEMBL1547915 & 688239 & 6.0362 & 5.4527 & TRN \\
\hline CHEMBL1582745 & 688239 & 5.9362 & 5.6065 & TST \\
\hline CHEMBL1494207 & 688239 & 5.7362 & 5.5978 & TRN \\
\hline CHEMBL1394508 & 688239 & 6.2362 & 5.5811 & TST \\
\hline CHEMBL1511696 & 688239 & 5.1862 & 5.5633 & TRN \\
\hline CHEMBL1353089 & 688239 & 5.8362 & 5.3748 & TRN \\
\hline CHEMBL1443417 & 688239 & 4.6362 & 5.535 & TRN \\
\hline
\end{tabular}


Supplemental Table S2.txt

\begin{tabular}{|c|c|c|c|c|}
\hline CHEMBL1466630 & 688239 & 5.5362 & 5.5666 & TST \\
\hline CHEMBL175296 & 688239 & 5.1362 & 5.5379 & TRN \\
\hline CHEMBL1557559 & 688239 & 4.6862 & 5.5445 & TRN \\
\hline CHEMBL1459940 & 688239 & 7.0362 & 5.4869 & TRN \\
\hline CHEMBL1405406 & 688239 & 4.4862 & 5.6129 & TRN \\
\hline CHEMBL1604570 & 688239 & 5.15 & 5.3778 & TRN \\
\hline CHEMBL1542237 & 688239 & 4.7862 & 5.4182 & TST \\
\hline CHEMBL1501632 & 688239 & 4.9862 & 5.3953 & TRN \\
\hline CHEMBL1502851 & 688239 & 4.7362 & 5.3016 & TRN \\
\hline CHEMBL1547789 & 688239 & 5.2862 & 5.6148 & TST \\
\hline CHEMBL1579398 & 688239 & 5.6362 & 5.812 & TRN \\
\hline CHEMBL1537470 & 688239 & 4.5362 & 5.5145 & TRN \\
\hline CHEMBL1598784 & 688239 & 4.5362 & 5.5836 & TST \\
\hline CHEMBL1379522 & 688239 & 5.5362 & 5.5451 & TRN \\
\hline CHEMBL1580635 & 688239 & 5.2362 & 5.57799 & 9999999999 \\
\hline CHEMBL1490825 & 688239 & 4.7862 & 5.50299 & 9999999999 \\
\hline CHEMBL1593109 & 688239 & 5.7862 & 5.4703 & TRN \\
\hline CHEMBL1571000 & 688239 & 5.3362 & 5.4107 & TRN \\
\hline CHEMBL406449 & 688239 & 4.7862 & 5.5131 & TRN \\
\hline CHEMBL1326889 & 688239 & 6.2362 & 5.7 & TRN \\
\hline CHEMBL1392772 & 688239 & 4.5362 & 5.5635 & TRN \\
\hline CHEMBL1531652 & 688239 & 5.1862 & 5.5749 & TRN \\
\hline CHEMBL1403584 & 688239 & 4.7862 & 5.6761 & TST \\
\hline CHEMBL529138 & 688239 & 4.8362 & 5.4088 & TST \\
\hline CHEMBL1531257 & 688239 & 6.1362 & 5.6101 & TRN \\
\hline CHEMBL1351500 & 688239 & 6.0862 & 5.45 & TRN \\
\hline CHEMBL1436425 & 688239 & 4.8862 & 5.5895 & TST \\
\hline CHEMBL1385919 & 688239 & 5.3362 & 5.4647 & TRN \\
\hline CHEMBL1349401 & 688239 & 4.5362 & 5.5209 & TRN \\
\hline CHEMBL1326317 & 688239 & 4.5362 & 5.5061 & TST \\
\hline CHEMBL1315822 & 688239 & 6.8362 & 5.4927 & TRN \\
\hline CHEMBL1379811 & 688239 & 5.1862 & 5.6574 & TST \\
\hline CHEMBL1356219 & 688239 & 8.3372 & 5.3048 & TRN \\
\hline CHEMBL1431009 & 688239 & 7.1361 & 5.5339 & TRN \\
\hline CHEMBL1429164 & 688239 & 5.8362 & 5.5543 & TRN \\
\hline CHEMBL1562735 & 688239 & 6.4362 & 5.4189 & TST \\
\hline CHEMBL1575129 & 688239 & 6.4862 & 5.5922 & TRN \\
\hline CHEMBL 295344 & 688239 & 7.0362 & 5.4518 & TRN \\
\hline CHEMBL1389480 & 688239 & 4.6862 & 5.4108 & TST \\
\hline CHEMBL1538205 & 688239 & 4.9362 & 5.3136 & TRN \\
\hline CHEMBL1447830 & 688239 & 5.3362 & 5.4047 & TRN \\
\hline CHEMBL1476940 & 688239 & 5.1862 & 5.4666 & TST \\
\hline CHEMBL1379893 & 688239 & 4.5362 & 5.3549 & TRN \\
\hline CHEMBL1605325 & 688239 & 7.1361 & 5.4732 & TRN \\
\hline CHEMBL1367400 & 688239 & 5.1862 & 5.3988 & TRN \\
\hline CHEMBL1435749 & 688239 & 6.2362 & 5.4525 & TRN \\
\hline CHEMBL1563231 & 688239 & 5.7862 & 5.4985 & TRN \\
\hline CHEMBL1549188 & 688239 & 5.3862 & 5.5879 & TRN \\
\hline
\end{tabular}


Supplemental Table S2.txt

\begin{tabular}{|c|c|c|c|c|c|}
\hline CHEMBL1459432 & 688239 & 5.7862 & 5.5299 & TRN & \\
\hline CHEMBL1350606 & 688239 & 5.9362 & 5.3315 & TST & \\
\hline CHEMBL1609682 & 688239 & 8.3372 & 5.434 & TST & \\
\hline CHEMBL1419580 & 688239 & 6.0362 & 5.4694 & TRN & \\
\hline CHEMBL1590725 & 688239 & 4.9362 & 5.4183 & TRN & \\
\hline CHEMBL1602562 & 688239 & 7.2366 & 5.4566 & TRN & \\
\hline CHEMBL1468861 & 688239 & 4.5362 & 5.5502 & TRN & \\
\hline CHEMBL1531770 & 688239 & 5.4362 & 5.5779 & TST & \\
\hline CHEMBL1597145 & 688239 & 6.1862 & 5.6435 & TRN & \\
\hline CHEMBL1504208 & 688239 & 4.5362 & 5.4318 & TST & \\
\hline CHEMBL1532719 & 688239 & 5.1362 & 5.3482 & TRN & \\
\hline CHEMBL1378931 & 688239 & 4.7862 & 5.4039 & TRN & \\
\hline CHEMBL1493429 & 688239 & 5.7862 & 5.4335 & TST & \\
\hline CHEMBL1481226 & 688239 & 6.3362 & 5.4703 & TRN & \\
\hline CHEMBL1304074 & 688239 & 4.8362 & 5.55 & TRN & \\
\hline CHEMBL1390840 & 688239 & 6.1362 & 5.5109 & TST & \\
\hline CHEMBL1424604 & 688239 & 8.2366 & 5.41700 & 2000000001 & TRN \\
\hline CHEMBL1412880 & 688239 & 4.5362 & 5.4685 & TRN & \\
\hline CHEMBL1411134 & 688239 & 5.1862 & 5.55200 & 00000000005 & TRN \\
\hline CHEMBL1367949 & 688239 & 6.2362 & 5.3764 & TRN & \\
\hline CHEMBL1517054 & 688239 & 6.1362 & 5.4816 & TRN & \\
\hline CHEMBL1558376 & 688239 & 6.9863 & 5.5807 & TRN & \\
\hline CHEMBL1605655 & 688239 & 6.0362 & 5.485 & TRN & \\
\hline CHEMBL1605122 & 688239 & 4.9362 & 5.5887 & TST & \\
\hline CHEMBL1554130 & 688239 & 6.2362 & 5.2928 & TRN & \\
\hline CHEMBL1449078 & 688239 & 5.1362 & 5.591 & TST & \\
\hline CHEMBL1586650 & 688239 & 6.1862 & 5.6602 & TST & \\
\hline CHEMBL1464188 & 688239 & 6.3863 & 5.3617 & TST & \\
\hline CHEMBL1458188 & 688239 & 5.0862 & 5.5757 & TST & \\
\hline CHEMBL1308751 & 688239 & 4.5862 & 5.3981 & TST & \\
\hline CHEMBL1349289 & 688239 & 4.5362 & 5.4491 & TRN & \\
\hline CHEMBL1576491 & 688239 & 7.5361 & 5.5941 & TRN & \\
\hline CHEMBL1502924 & 688239 & 4.5362 & 5.5455 & TRN & \\
\hline CHEMBL1375631 & 688239 & 5.2362 & 5.3741 & TRN & \\
\hline CHEMBL1404970 & 688239 & 4.7362 & 5.4752 & TRN & \\
\hline CHEMBL1487569 & 688239 & 4.5362 & 5.5008 & TST & \\
\hline CHEMBL1392655 & 688239 & 5.1862 & 5.6834 & TRN & \\
\hline CHEMBL1350084 & 688239 & 5.0862 & 5.3614 & TRN & \\
\hline CHEMBL1366420 & 688239 & 5.3362 & 5.5057 & TRN & \\
\hline CHEMBL1537031 & 688239 & 4.5362 & 5.4337 & TRN & \\
\hline CHEMBL1349127 & 688239 & 5.1862 & 5.5014 & TRN & \\
\hline CHEMBL1354282 & 688239 & 5.3862 & 5.4053 & TRN & \\
\hline CHEMBL1566938 & 688239 & 5.6862 & 5.5685 & TRN & \\
\hline CHEMBL1299963 & 688239 & 4.5362 & 5.4906 & TRN & \\
\hline CHEMBL1471713 & 688239 & 4.6362 & 5.4773 & TRN & \\
\hline CHEMBL1335809 & 688239 & 5.3362 & 5.4526 & TRN & \\
\hline CHEMBL1400427 & 688239 & 4.5362 & 5.3838 & TST & \\
\hline CHEMBL1431807 & 688239 & 5.4862 & 5.4507 & TRN & \\
\hline
\end{tabular}




\begin{tabular}{|c|c|c|c|c|c|}
\hline \multirow{3}{*}{$\begin{array}{l}\text { CHEMBL1465046 } \\
\text { CHFMBI } 1469590\end{array}$} & & \multicolumn{4}{|c|}{ Supplemental Table S2.txt } \\
\hline & 688239 & 5.6862 & 5.5360 & 00000000005 & TST \\
\hline & 688239 & 4.7362 & 5.5927 & TRN & \\
\hline CHEMBL1375839 & 688239 & 4.5362 & 5.6145 & TRN & \\
\hline CHEMBL1354819 & 688239 & 6.8362 & 5.6899 & TRN & \\
\hline CHEMBL1324597 & 688239 & 6.2362 & 5.4383 & TRN & \\
\hline CHEMBL1603868 & 688239 & 5.7862 & 5.7116 & TRN & \\
\hline CHEMBL1302771 & 688239 & 6.5862 & 5.5024 & TRN & \\
\hline CHEMBL1577120 & 688239 & 4.7362 & 5.5415 & TRN & \\
\hline CHEMBL1385664 & 688239 & 5.2362 & 5.3823 & TST & \\
\hline CHEMBL1393219 & 688239 & 4.5362 & 5.3747 & TRN & \\
\hline CHEMBL1331740 & 688239 & 4.5362 & 5.4253 & TRN & \\
\hline CHEMBL1547737 & 688239 & 6.2862 & 5.6338 & TRN & \\
\hline CHEMBL1381966 & 688239 & 7.0862 & 5.5613 & TRN & \\
\hline CHEMBL1504262 & 688239 & 6.2362 & 5.5283 & TRN & \\
\hline CHEMBL1601158 & 688239 & 5.1862 & 5.5561 & TST & \\
\hline CHEMBL512214 & 688239 & 4.6862 & 5.5579 & TRN & \\
\hline CHEMBL1573518 & 688239 & 4.5362 & 5.4924 & TRN & \\
\hline CHEMBL1415844 & 688239 & 6.8362 & 5.4957 & TRN & \\
\hline CHEMBL1388437 & 688239 & 5.6362 & 5.5817 & TRN & \\
\hline CHEMBL1565307 & 688239 & 6.2362 & 5.3142 & TRN & \\
\hline CHEMBL1576987 & 688239 & 6.9863 & 5.5925 & TRN & \\
\hline CHEMBL1544080 & 688239 & 4.5362 & 5.3966 & TRN & \\
\hline CHEMBL1463471 & 688239 & 5.2362 & 5.4696 & TST & \\
\hline CHEMBL3194462 & 688239 & 4.8362 & 5.2847 & TRN & \\
\hline CHEMBL1358016 & 688239 & 5.1862 & 5.5273 & TST & \\
\hline CHEMBL1336161 & 688239 & 7.0862 & 5.3898 & TRN & \\
\hline CHEMBL1491121 & 688239 & 4.6362 & 5.5471 & TRN & \\
\hline CHEMBL1355312 & 688239 & 4.7862 & 5.3619 & TRN & \\
\hline CHEMBL1533767 & 688239 & 4.6862 & 5.4376 & TST & \\
\hline CHEMBL1315386 & 688239 & 5.1862 & 5.4613 & TRN & \\
\hline CHEMBL1454987 & 688239 & 4.5362 & 5.4206 & TRN & \\
\hline CHEMBL1337873 & 688239 & 4.5362 & 5.329 & TRN & \\
\hline CHEMBL1383899 & 688239 & 5.2862 & 5.4247 & TST & \\
\hline CHEMBL1361202 & 688239 & 4.7362 & 5.2995 & TRN & \\
\hline CHEMBL1478556 & 688239 & 4.5362 & 5.5252 & TRN & \\
\hline CHEMBL3211195 & 688239 & 6.0862 & 5.3559 & TRN & \\
\hline CHEMBL1419945 & 688239 & 4.7862 & 5.4794 & TRN & \\
\hline CHEMBL3196515 & 688239 & 4.5362 & 5.3178 & TST & \\
\hline CHEMBL1595372 & 688239 & 4.5362 & 5.5256 & TRN & \\
\hline CHEMBL1432426 & 688239 & 5.2862 & 5.3987 & TRN & \\
\hline CHEMBL1543198 & 688239 & 6.5862 & 5.655 & TRN & \\
\hline CHEMBL1390354 & 688239 & 4.5362 & 5.225 & TRN & \\
\hline CHEMBL1536171 & 688239 & 4.5362 & 5.5376 & TRN & \\
\hline CHEMBL1386551 & 688239 & 4.5362 & 5.5379 & TST & \\
\hline CHEMBL3145124 & 688239 & 4.7362 & 5.5091 & TRN & \\
\hline CHEMBL1981200 & 688239 & 4.5362 & 5.3057 & TRN & \\
\hline CHEMBL1468185 & 688239 & 4.5362 & 5.4974 & TRN & \\
\hline CHEMBL1598762 & 688239 & 5.0362 & 5.5914 & TST & \\
\hline
\end{tabular}




\begin{tabular}{|c|c|c|c|c|c|}
\hline \multicolumn{6}{|c|}{ Supplemental Table S2.txt } \\
\hline CHEMBL1425425 & 688239 & 7.5361 & 5.5622 & TRN & \\
\hline CHEMBL1368210 & 688239 & 4.7362 & 5.2737 & TRN & \\
\hline CHEMBL1325299 & 688239 & 5.2362 & 5.5297 & TRN & \\
\hline CHEMBL1432015 & 688239 & 5.8362 & 5.4105 & TRN & \\
\hline CHEMBL1433564 & 688239 & 5.8862 & 5.4726 & TRN & \\
\hline CHEMBL1320372 & 688239 & 6.0362 & 5.5226 & TRN & \\
\hline CHEMBL1381711 & 688239 & 5.2362 & 5.5205 & TRN & \\
\hline CHEMBL 3211650 & 688239 & 5.6862 & 5.4388 & TST & \\
\hline CHEMBL1998521 & 688239 & 4.6362 & 5.4897 & TRN & \\
\hline CHEMBL1457073 & 688239 & 5.3362 & 5.57600 & 00000000005 & TRN \\
\hline CHEMBL1322351 & 688239 & 4.8362 & 5.5215 & TRN & \\
\hline CHEMBL1519550 & 688239 & 5.2862 & 5.5893 & TRN & \\
\hline CHEMBL1594174 & 688239 & 6.6362 & 5.439 & TST & \\
\hline CHEMBL1409010 & 688239 & 6.2862 & 5.437 & TST & \\
\hline CHEMBL1358240 & 688239 & 5.5362 & 5.3444 & TRN & \\
\hline CHEMBL1470289 & 688239 & 6.1862 & 5.4495 & TST & \\
\hline CHEMBL1969492 & 688239 & 4.8862 & 5.3676 & TST & \\
\hline CHEMBL1312925 & 688239 & 4.7362 & 5.5127 & TST & \\
\hline CHEMBL1351275 & 688239 & 5.5362 & 5.6042 & TRN & \\
\hline CHEMBL1541421 & 688239 & 6.8362 & 5.5245 & TRN & \\
\hline CHEMBL1444832 & 688239 & 4.7362 & 5.5348 & TRN & \\
\hline CHEMBL1447773 & 688239 & 6.3362 & 5.4768 & TRN & \\
\hline CHEMBL1535942 & 688239 & 4.8862 & 5.5165 & TRN & \\
\hline CHEMBL1609654 & 688239 & 4.8362 & 5.63299 & 9999999999 & TRN \\
\hline CHEMBL1540264 & 688239 & 6.0862 & 5.4934 & TRN & \\
\hline CHEMBL1430840 & 688239 & 4.5362 & 5.4854 & TST & \\
\hline CHEMBL1544657 & 688239 & 7.8861 & 5.5997 & TST & \\
\hline CHEMBL1386344 & 688239 & 4.5362 & 5.348 & TRN & \\
\hline CHEMBL1328683 & 688239 & 5.1862 & 5.2829 & TRN & \\
\hline CHEMBL1332483 & 688239 & 6.9363 & 5.6906 & TST & \\
\hline CHEMBL1544571 & 688239 & 4.7862 & 5.6018 & TRN & \\
\hline CHEMBL1370596 & 688239 & 4.5862 & 5.5795 & TRN & \\
\hline CHEMBL1450536 & 688239 & 6.4362 & 5.4442 & TRN & \\
\hline CHEMBL1534526 & 688239 & 4.5362 & 5.5985 & TRN & \\
\hline CHEMBL1533891 & 688239 & 5.7362 & 5.6274 & TRN & \\
\hline CHEMBL1558978 & 688239 & 5.0362 & 5.5541 & TST & \\
\hline CHEMBL1326065 & 688239 & 5.2362 & 5.5364 & TST & \\
\hline CHEMBL1440729 & 688239 & 5.1862 & 5.3436 & TRN & \\
\hline CHEMBL1586071 & 688239 & 5.5862 & 5.5246 & TST & \\
\hline CHEMBL1424031 & 688239 & 5.0362 & 5.5748 & TST & \\
\hline CHEMBL1584762 & 688239 & 5.2362 & 5.4305 & TRN & \\
\hline CHEMBL1482876 & 688239 & 4.8362 & 5.4088 & TRN & \\
\hline CHEMBL1398116 & 688239 & 6.1362 & 5.4654 & TRN & \\
\hline CHEMBL1497115 & 688239 & 4.5362 & 5.399 & TRN & \\
\hline CHEMBL1366394 & 688239 & 6.5862 & 5.516 & TRN & \\
\hline CHEMBL1609644 & 688239 & 4.8362 & 5.5681 & TRN & \\
\hline CHEMBL1452736 & 688239 & 4.5362 & 5.4616 & TRN & \\
\hline CHEMBL1526555 & 688239 & 6.5862 & 5.5083 & TST & \\
\hline
\end{tabular}


Supplemental Table S2.txt

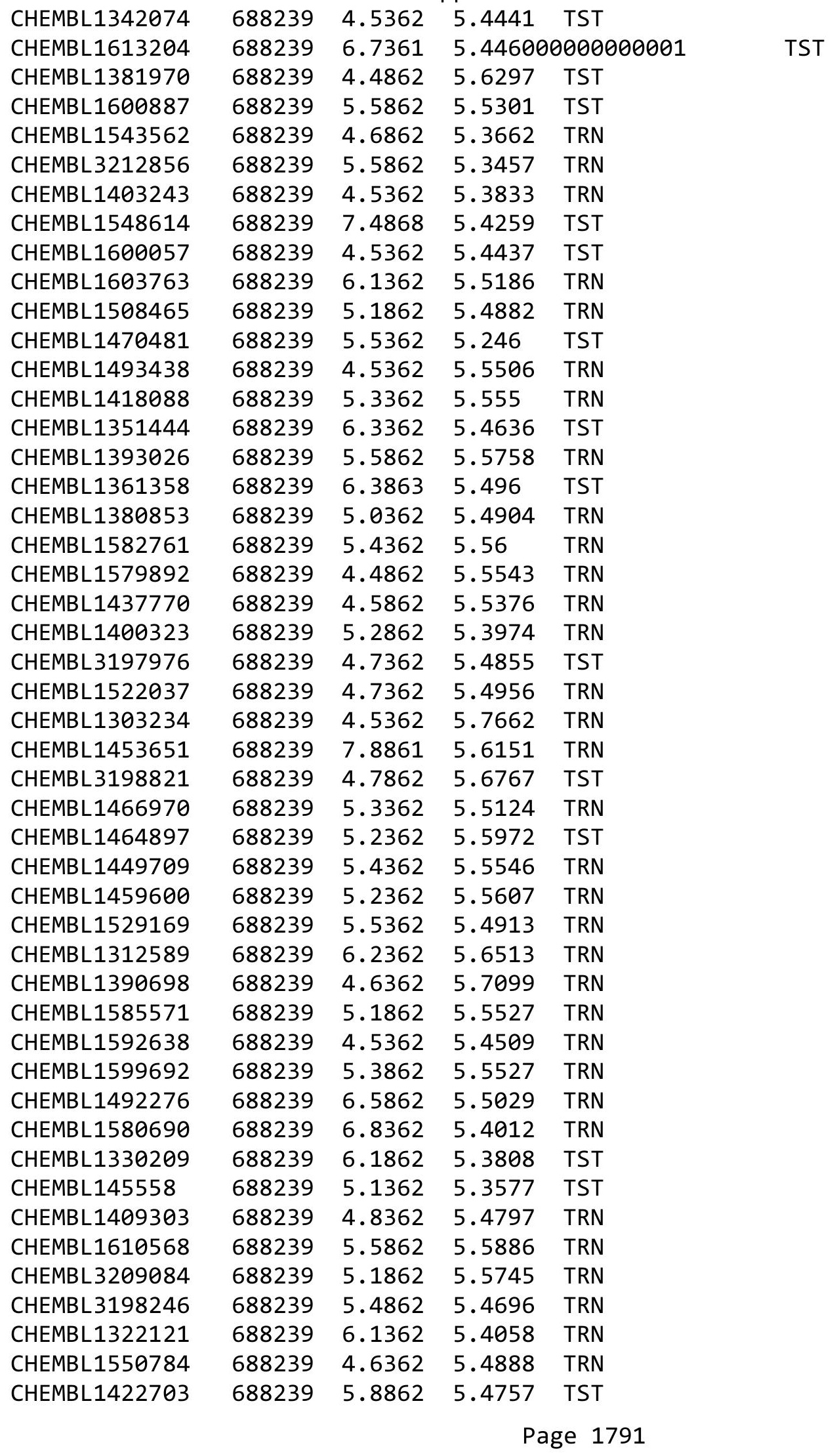


Supplemental Table S2.txt

\begin{tabular}{|c|c|c|c|c|c|c|}
\hline CHEMBL1599122 & 688239 & 4.8362 & 5.4639 & TST & & \\
\hline CHEMBL1312759 & 688239 & 6.9863 & 5.5756 & TRN & & \\
\hline CHEMBL1514521 & 688239 & 5.2362 & 5.5741 & TRN & & \\
\hline CHEMBL1384772 & 688239 & 6.7862 & 5.3888 & TRN & & \\
\hline CHEMBL1368536 & 688239 & 5.6362 & 5.4901 & TRN & & \\
\hline CHEMBL1568686 & 688239 & 4.5362 & 5.4985 & TRN & & \\
\hline CHEMBL 3194715 & 688239 & 4.5362 & 5.4382 & TST & & \\
\hline CHEMBL1515347 & 688239 & 4.5362 & 5.5268 & TRN & & \\
\hline CHEMBL1505217 & 688239 & 4.5362 & 5.4032 & TRN & & \\
\hline CHEMBL1394442 & 688239 & 6.3362 & 5.5677 & TRN & & \\
\hline CHEMBL 3210601 & 688239 & 4.6362 & 5.3444 & TRN & & \\
\hline CHEMBL1564972 & 688239 & 5.3862 & 5.5183 & TRN & & \\
\hline CHEMBL1343952 & 688239 & 5.3362 & 5.4115 & TRN & & \\
\hline CHEMBL1310200 & 688239 & 6.9363 & 5.4723 & TRN & & \\
\hline CHEMBL1481858 & 688239 & 5.9362 & 5.5292 & TRN & & \\
\hline CHEMBL1380087 & 688239 & 4.6862 & 5.4056 & TRN & & \\
\hline CHEMBL1388634 & 688239 & 4.5362 & 5.3869 & TRN & & \\
\hline CHEMBL1391966 & 688239 & 6.2362 & 5.4364 & TRN & & \\
\hline CHEMBL 3212606 & 688239 & 6.1362 & 5.6105 & TST & & \\
\hline CHEMBL1585037 & 688239 & 4.5362 & 5.2853 & TRN & & \\
\hline CHEMBL1322281 & 688239 & \multicolumn{3}{|c|}{8.283999999999999} & 5.4684 & TRN \\
\hline CHEMBL1423795 & 688239 & 6.9363 & 5.5553 & TRN & & \\
\hline CHEMBL1575222 & 688239 & 4.5362 & 5.4454 & TRN & & \\
\hline CHEMBL1454388 & 688239 & 4.6862 & 5.3992 & TST & & \\
\hline CHEMBL1379706 & 688239 & 5.1862 & 5.4629 & TRN & & \\
\hline CHEMBL1434974 & 688239 & 6.3362 & 5.5279 & TRN & & \\
\hline CHEMBL1534924 & 688239 & 6.7862 & 5.3983 & TRN & & \\
\hline CHEMBL1479480 & 688239 & 4.5362 & 5.586 & TST & & \\
\hline CHEMBL1324988 & 688239 & 5.6862 & 5.4351 & TRN & & \\
\hline CHEMBL1569446 & 688239 & 6.2862 & 5.5056 & TST & & \\
\hline CHEMBL1472099 & 688239 & 4.6862 & 5.4685 & TRN & & \\
\hline CHEMBL1502744 & 688239 & 5.1862 & 5.4272 & TRN & & \\
\hline CHEMBL1488120 & 688239 & 4.5362 & 5.5003 & TRN & & \\
\hline CHEMBL1314861 & 688239 & 5.3862 & 5.6334 & TRN & & \\
\hline CHEMBL1494967 & 688239 & 4.8862 & 5.4169 & TRN & & \\
\hline CHEMBL1545409 & 688239 & 6.8362 & 5.4551 & TRN & & \\
\hline CHEMBL1401157 & 688239 & 7.1361 & 5.4949 & TST & & \\
\hline CHEMBL1532124 & 688239 & 5.0362 & 5.6355 & TST & & \\
\hline CHEMBL1501949 & 688239 & 4.5362 & 5.4944 & TRN & & \\
\hline CHEMBL1406818 & 688239 & 4.7362 & 5.3932 & TRN & & \\
\hline CHEMBL1452683 & 688239 & \multicolumn{3}{|c|}{8.283999999999999} & 5.4378 & Into \\
\hline CHEMBL1405665 & 688239 & \multicolumn{3}{|c|}{8.283999999999999} & 5.4002 & \\
\hline CHEMBL1584121 & 688239 & 5.2862 & 5.6174 & TRN & & \\
\hline CHEMBL1404217 & 688239 & 5.6362 & 5.377999 & 9999999999 & & \\
\hline CHEMBL1544266 & 688239 & 5.2862 & 5.6147 & TRN & & \\
\hline CHEMBL1303782 & 688239 & 4.5362 & 5.4723 & TST & & \\
\hline CHEMBL1594719 & 688239 & 8.3372 & 5.5063 & TRN & & \\
\hline CHEMBL1337736 & 688239 & 4.5362 & 5.7006 & TRN & & \\
\hline
\end{tabular}


Supplemental Table S2.txt

\begin{tabular}{|c|c|c|c|c|c|}
\hline CHEMBL1529624 & 688239 & 6.1862 & 5.5146 & TRN & \\
\hline CHEMBL1374594 & 688239 & 4.8862 & 5.4159 & TRN & \\
\hline CHEMBL1526686 & 688239 & 5.6362 & 5.5852 & TRN & \\
\hline CHEMBL1430427 & 688239 & 4.6362 & 5.4189 & TRN & \\
\hline CHEMBL1483359 & 688239 & 4.5362 & 5.4321 & TST & \\
\hline CHEMBL1458053 & 688239 & 5.8862 & 5.5466 & TRN & \\
\hline CHEMBL1511028 & 688239 & 5.1862 & 5.5828 & TST & \\
\hline CHEMBL1510699 & 688239 & 4.7362 & 5.544 & TRN & \\
\hline CHEMBL1538488 & 688239 & 6.6861 & 5.6389 & TRN & \\
\hline CHEMBL1608900 & 688239 & 5.1862 & 5.4329 & TRN & \\
\hline CHEMBL1491843 & 688239 & 5.7362 & 5.4696 & TRN & \\
\hline CHEMBL1436336 & 688239 & 6.2862 & 5.4594 & TRN & \\
\hline CHEMBL1318860 & 688239 & 6.2362 & 5.3946 & TST & \\
\hline CHEMBL1523448 & 688239 & 4.5362 & 5.4554 & TRN & \\
\hline CHEMBL1338764 & 688239 & 4.4862 & 5.5064 & TRN & \\
\hline CHEMBL1465175 & 688239 & 4.6362 & 5.5125 & TRN & \\
\hline CHEMBL1330342 & 688239 & 4.5362 & 5.5052 & TRN & \\
\hline CHEMBL1434080 & 688239 & 5.2362 & 5.5261 & TRN & \\
\hline CHEMBL1349324 & 688239 & 5.1362 & 5.5102 & TRN & \\
\hline CHEMBL1463019 & 688239 & 5.1862 & 5.50799 & 9999999999 & TRN \\
\hline CHEMBL1369857 & 688239 & 4.5362 & 5.4778 & TRN & \\
\hline CHEMBL1547580 & 688239 & 5.8862 & 5.5089 & TRN & \\
\hline CHEMBL1452088 & 688239 & 4.7362 & 5.5477 & TRN & \\
\hline CHEMBL1439586 & 688239 & 4.7862 & 5.5397 & TRN & \\
\hline CHEMBL1416256 & 688239 & 6.8362 & 5.4845 & TRN & \\
\hline CHEMBL1385579 & 688239 & 4.4862 & 5.4996 & TRN & \\
\hline CHEMBL1306417 & 688239 & 6.3362 & 5.4598 & TRN & \\
\hline CHEMBL1526345 & 688239 & 4.8362 & 5.42299 & 9999999999 & TRN \\
\hline CHEMBL1551281 & 688239 & 5.0362 & 5.5397 & TRN & \\
\hline CHEMBL1382950 & 688239 & 6.2862 & 5.4048 & TST & \\
\hline CHEMBL1299347 & 688239 & 5.2862 & 5.4962 & TST & \\
\hline CHEMBL1328262 & 688239 & 4.4862 & 5.6025 & TRN & \\
\hline CHEMBL1319701 & 688239 & 4.6862 & 5.4589 & TRN & \\
\hline CHEMBL1573175 & 688239 & 4.5362 & 5.5077 & TRN & \\
\hline CHEMBL1516916 & 688239 & 6.7361 & 5.5918 & TRN & \\
\hline CHEMBL1568673 & 688239 & 5.4862 & 5.6536 & TRN & \\
\hline CHEMBL1456557 & 688239 & 5.9862 & 5.4915 & TRN & \\
\hline CHEMBL1548958 & 688239 & 4.5362 & 5.5174 & TRN & \\
\hline CHEMBL1425440 & 688239 & 5.1862 & 5.4213 & TRN & \\
\hline CHEMBL3212953 & 688239 & 4.5362 & 5.2893 & TRN & \\
\hline CHEMBL1476706 & 688239 & 5.4362 & 5.5452 & TRN & \\
\hline CHEMBL1501724 & 688239 & 4.5362 & 5.5108 & TST & \\
\hline CHEMBL1309612 & 688239 & 4.5362 & 5.4183 & TRN & \\
\hline CHEMBL3208779 & 688239 & 6.0862 & 5.4267 & TRN & \\
\hline CHEMBL1600114 & 688239 & 4.6362 & 5.4445 & TST & \\
\hline CHEMBL1519468 & 688239 & 8.2366 & 5.4574 & TST & \\
\hline CHEMBL1380742 & 688239 & 5.3862 & 5.3988 & TRN & \\
\hline CHEMBL1400341 & 688239 & 4.7362 & 5.4141 & TRN & \\
\hline
\end{tabular}


Supplemental Table S2.txt

\begin{tabular}{|c|c|c|c|c|}
\hline CHEMBL3191941 & 688239 & 5.1862 & 5.5478 & TRN \\
\hline CHEMBL1326610 & 688239 & 7.2366 & 5.5369 & TST \\
\hline CHEMBL1504181 & 688239 & 6.3863 & 5.5186 & TRN \\
\hline CHEMBL1302222 & 688239 & 5.8362 & 5.4729 & TRN \\
\hline CHEMBL1597826 & 688239 & 5.2362 & 5.4831 & TRN \\
\hline CHEMBL328910 & 688239 & 5.9362 & 5.4897 & TST \\
\hline CHEMBL1598894 & 688239 & 5.5862 & 5.43 & TRN \\
\hline CHEMBL1509694 & 688239 & 5.2362 & 5.3777 & TST \\
\hline CHEMBL1456620 & 688239 & 6.9363 & 5.5861 & TST \\
\hline CHEMBL1392812 & 688239 & 5.4862 & 5.4799 & TRN \\
\hline CHEMBL1451951 & 688239 & 4.8362 & \multicolumn{2}{|c|}{5.452000000000001} \\
\hline CHEMBL1456401 & 688239 & 4.5362 & 5.4122 & TRN \\
\hline CHEMBL1319027 & 688239 & 5.6362 & 5.3807 & TRN \\
\hline CHEMBL1564795 & 688239 & 7.0862 & 5.6664 & TST \\
\hline CHEMBL1505905 & 688239 & 4.4862 & 5.316 & TST \\
\hline CHEMBL1311619 & 688239 & 6.6861 & 5.5303 & TRN \\
\hline CHEMBL1509669 & 688239 & 7.0362 & 5.5268 & TST \\
\hline CHEMBL1517917 & 688239 & 6.9363 & 5.4694 & TRN \\
\hline CHEMBL1482190 & 688239 & 5.7862 & 5.5128 & TRN \\
\hline CHEMBL1500898 & 688239 & 6.6861 & 5.6065 & TRN \\
\hline CHEMBL1438617 & 688239 & 4.4862 & 5.5644 & TRN \\
\hline CHEMBL1398630 & 688239 & 6.5862 & 5.4705 & TRN \\
\hline CHEMBL1516613 & 688239 & 4.5362 & 5.501 & TRN \\
\hline CHEMBL1307675 & 688239 & 5.2862 & \multicolumn{2}{|c|}{5.531000000000001} \\
\hline CHEMBL1509682 & 688239 & 4.9862 & 5.4195 & TRN \\
\hline CHEMBL1511411 & 688239 & 4.5862 & 5.5022 & TST \\
\hline CHEMBL1553571 & 688239 & 5.0362 & 5.5487 & TRN \\
\hline CHEMBL1439445 & 688239 & 5.8862 & 5.6747 & TRN \\
\hline CHEMBL1418301 & 688239 & 6.4362 & 5.3793 & TRN \\
\hline CHEMBL1602085 & 688239 & 5.2362 & 5.4526 & TRN \\
\hline CHEMBL1325490 & 688239 & 6.1862 & 5.3978 & TRN \\
\hline CHEMBL1366940 & 688239 & 4.5362 & 5.6614 & TRN \\
\hline CHEMBL1377648 & 688239 & 6.1862 & 5.5043 & TRN \\
\hline CHEMBL1513088 & 688239 & 5.6862 & 5.6932 & TRN \\
\hline CHEMBL1561669 & 688239 & 5.1862 & 5.6486 & TRN \\
\hline CHEMBL1359311 & 688239 & 5.3362 & 5.3213 & TRN \\
\hline CHEMBL1555055 & 688239 & 5.4862 & 5.4616 & TRN \\
\hline CHEMBL 295786 & 688239 & 4.5362 & 5.501 & TRN \\
\hline CHEMBL1471698 & 688239 & 4.5362 & 5.4735 & TRN \\
\hline CHEMBL1507560 & 688239 & 5.2862 & 5.4753 & TRN \\
\hline CHEMBL1307750 & 688239 & 5.1862 & 5.4905 & TRN \\
\hline CHEMBL1565995 & 688239 & 5.0362 & 5.5649 & TST \\
\hline CHEMBL1392436 & 688239 & 8.3372 & 5.38 & TRN \\
\hline CHEMBL1391681 & 688239 & 5.4362 & 5.4571 & TRN \\
\hline CHEMBL1454879 & 688239 & 5.5862 & 5.4213 & TRN \\
\hline CHEMBL1315481 & 688239 & 4.7362 & 5.4278 & TRN \\
\hline CHEMBL1395260 & 688239 & 4.5362 & 5.6866 & TRN \\
\hline CHEMBL1474397 & 688239 & 4.5862 & 5.5032 & TRN \\
\hline
\end{tabular}


Supplemental Table S2.txt

\begin{tabular}{|c|c|c|c|c|}
\hline & & & & \\
\hline AEMBL13 & 8239 & 3372 & 4771 & \\
\hline IEMBL1418982 & 8239 & 362 & 5251 & \\
\hline HEMBL1481480 & 239 & 362 & 791 & \\
\hline 36062 & 239 & & & \\
\hline IEMBL1431225 & 239 & & & \\
\hline AEMBL1459000 & 88239 & 362 & & \\
\hline AEMBL1516984 & 88239 & 862 & 037 & \\
\hline AEMBL1386428 & 239 & & & \\
\hline IEMBL1523297 & 239 & & & \\
\hline IEMBL1527936 & 39 & & & \\
\hline AEMBL1457289 & 688239 & 862 & & \\
\hline AEMBL1540566 & 239 & & & \\
\hline IEMBL1335066 & & & & \\
\hline IEMBL14 & & & & \\
\hline AEMBL1390871 & & & & \\
\hline AEMBL1315080 & 239 & & & \\
\hline AEMBL1608442 & & & & \\
\hline EMBL1516022 & & & & \\
\hline EMBL1522129 & & & & \\
\hline IEMBL1388520 & & & & - \\
\hline HEMBL1328869 & & & & RN \\
\hline IEMBL1608873 & & & & \\
\hline IEMBL1515888 & & & & \\
\hline IEMBL14 & & & & $\mathrm{RN}$ \\
\hline IFMRI 31 & & & & I \\
\hline HEMBL1440037 & & & & RN \\
\hline IEMBL1570599 & & & & \\
\hline IEMBL1497466 & & & & RI \\
\hline L1429924 & & & & . \\
\hline 555 & & & & $\mathrm{RN}$ \\
\hline HEMBL1304256 & & & & RN \\
\hline AEMBL1339655 & & & & $\mathrm{RI}$ \\
\hline AEMBL1553667 & & & & RI \\
\hline AEMBL1602935 & & & & 2. \\
\hline 888 & & & & -6 \\
\hline AEMBL1426062 & & & & S \\
\hline AEMBL1344808 & & & & $\mathrm{R}$ \\
\hline IEMBL1396325 & & & & RI \\
\hline AEMBL1352158 & & & & 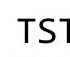 \\
\hline & & & & RN \\
\hline AEMBL1568053 & & & & RN \\
\hline IEMBL1505297 & & & & $T R$ \\
\hline EMBL3210005 & & & & TS \\
\hline CHEMBL1304156 & & & & $\mathrm{ST}$ \\
\hline CHEMBL1460891 & & & & RN \\
\hline AEMBL1551985 & 38239 & 4.7362 & 5.5229 & $\mathrm{TR}$ \\
\hline HFMRI 1392851 & 688239 & 4.6862 & 5.5964 & \\
\hline
\end{tabular}

Page 1795 
Supplemental Table S2.txt

\begin{tabular}{|c|c|c|c|c|}
\hline CHEMBL1425835 & 688239 & 6.2362 & 5.5554 & TRN \\
\hline CHEMBL1564630 & 688239 & 4.5362 & 5.4149 & TST \\
\hline CHEMBL1586886 & 688239 & 6.3362 & 5.4462 & TST \\
\hline CHEMBL1498509 & 688239 & 5.6362 & 5.3453 & TST \\
\hline CHEMBL1582531 & 688239 & 6.2862 & 5.4636 & TRN \\
\hline CHEMBL3195146 & 688239 & 4.7362 & 5.3344 & TST \\
\hline CHEMBL346151 & 688239 & 6.3362 & 5.4543 & TST \\
\hline CHEMBL1343074 & 688239 & 5.4862 & 5.5662 & TRN \\
\hline CHEMBL1549565 & 688239 & 5.2362 & 5.5759 & TRN \\
\hline CHEMBL1257634 & 688239 & 5.9362 & 5.3761 & TST \\
\hline CHEMBL1464206 & 688239 & 4.6362 & 5.4075 & TRN \\
\hline CHEMBL 2006988 & 688239 & 4.5362 & 5.3981 & TRN \\
\hline CHEMBL1368715 & 688239 & 4.5362 & 5.4032 & TRN \\
\hline CHEMBL1411192 & 688239 & 8.3372 & 5.4378 & TRN \\
\hline CHEMBL1380446 & 688239 & 6.3362 & 5.5338 & TRN \\
\hline CHEMBL1379333 & 688239 & 6.2362 & 5.4695 & TRN \\
\hline CHEMBL3192054 & 688239 & 4.7862 & 5.2609 & TST \\
\hline CHEMBL1471981 & 688239 & 4.4862 & 5.3678 & TRN \\
\hline CHEMBL1392055 & 688239 & 5.1862 & 5.6689 & TRN \\
\hline CHEMBL1567902 & 688239 & 6.1862 & 5.5066 & TRN \\
\hline CHEMBL1466418 & 688239 & 4.5362 & 5.4713 & TRN \\
\hline CHEMBL1459378 & 688239 & 4.5862 & 5.5241 & TRN \\
\hline CHEMBL1304045 & 688239 & 5.4862 & 5.5441 & TRN \\
\hline CHEMBL1393442 & 688239 & 4.5362 & 5.5045 & TRN \\
\hline CHEMBL1438646 & 688239 & 5.4862 & 5.6494 & TRN \\
\hline CHEMBL 3212648 & 688239 & 4.8862 & 5.2858 & TRN \\
\hline CHEMBL1384333 & 688239 & 5.5862 & 5.3174 & TRN \\
\hline CHEMBL1535098 & 688239 & 5.0362 & 5.5287 & TST \\
\hline CHEMBL1449787 & 688239 & 5.4862 & 5.3979 & TST \\
\hline CHEMBL1503926 & 688239 & 4.5362 & 5.5185 & TRN \\
\hline CHEMBL1421045 & 688239 & 5.1862 & 5.4949 & TRN \\
\hline CHEMBL1568872 & 688239 & 5.6362 & 5.3324 & TRN \\
\hline CHEMBL1351879 & 688239 & 4.5862 & 5.4303 & TRN \\
\hline CHEMBL1418690 & 688239 & 6.8362 & 5.4814 & TRN \\
\hline CHEMBL1582665 & 688239 & 5.1862 & 5.4334 & TRN \\
\hline CHEMBL1565699 & 688239 & 4.5362 & 5.4412 & TRN \\
\hline CHEMBL1410299 & 688239 & 6.8861 & 5.3958 & TRN \\
\hline CHEMBL1309215 & 688239 & 7.0862 & 5.4487 & TRN \\
\hline CHEMBL1411962 & 688239 & 4.5362 & 5.4892 & TST \\
\hline CHEMBL1377912 & 688239 & 4.6862 & 5.4996 & TRN \\
\hline CHEMBL1427683 & 688239 & 4.7362 & 5.45 & TRN \\
\hline CHEMBL1985829 & 688239 & 5.0362 & 5.4292 & TRN \\
\hline CHEMBL1522846 & 688239 & 4.8362 & 5.3751 & TST \\
\hline CHEMBL1379965 & 688239 & 5.1862 & 5.3406 & TST \\
\hline CHEMBL1479134 & 688239 & 5.9362 & \multicolumn{2}{|c|}{ 5.417999999999999 } \\
\hline CHEMBL1582406 & 688239 & 6.6861 & 5.5685 & TRN \\
\hline CHEMBL1475287 & 688239 & 4.7362 & 5.5485 & TRN \\
\hline CHEMBL1498598 & 688239 & 6.3863 & 5.4683 & TST \\
\hline
\end{tabular}




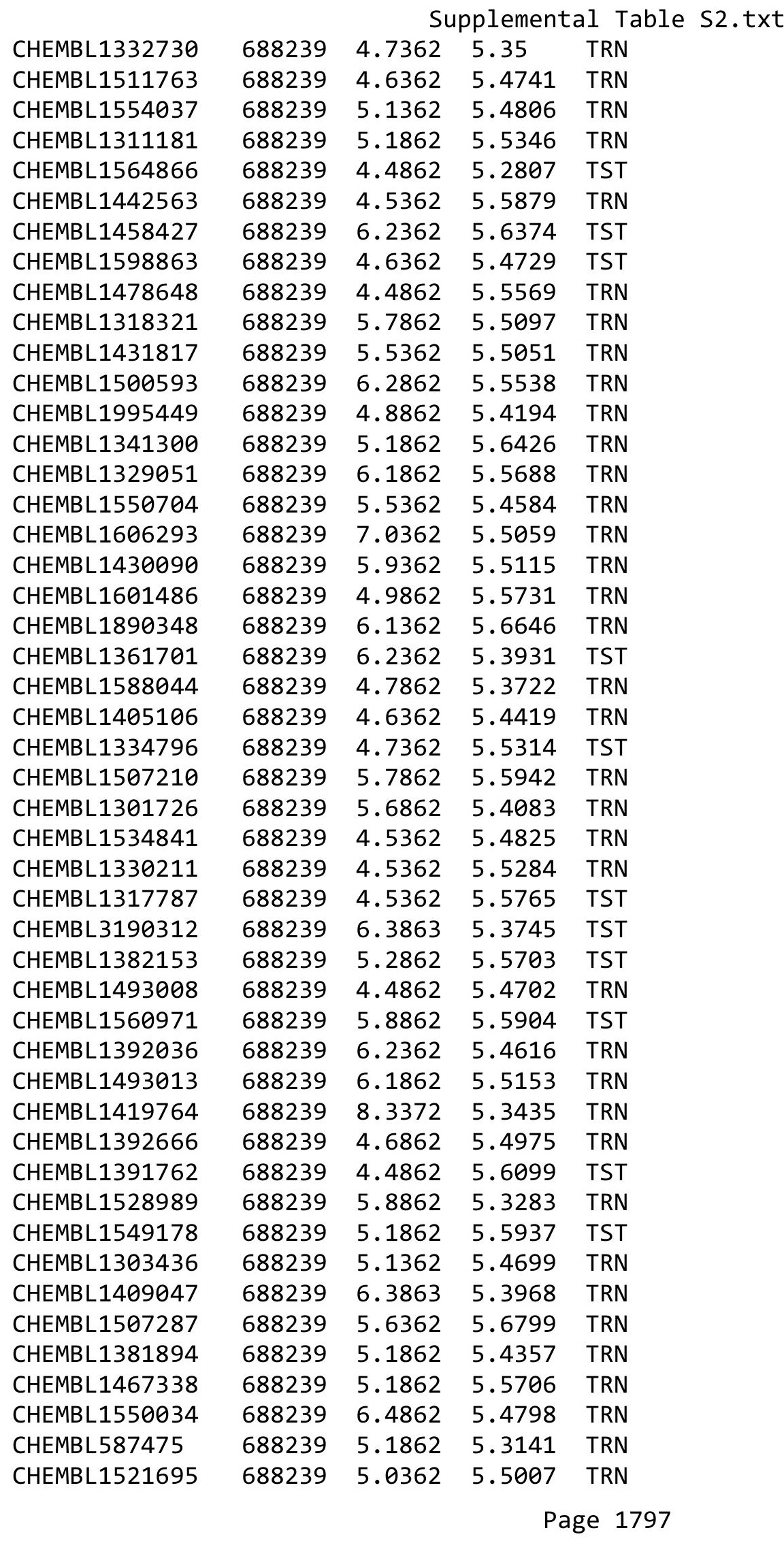


Supplemental Table S2.txt

\begin{tabular}{|c|c|c|c|c|}
\hline The & & 7362 & & \\
\hline & & .4362 & & \\
\hline & & & & \\
\hline IEMBL1 & & 362 & & \\
\hline AEMBL1527761 & 8239 & & & \\
\hline HEMBL1341097 & 88239 & 6.0 & 4663 & \\
\hline HEMBL1566072 & 239 & 861 & & \\
\hline 03470 & & & & \\
\hline AEMBL394385 & & 362 & & \\
\hline HEMBL1493827 & 38239 & 362 & & \\
\hline HEMBL1340735 & 239 & 863 & & \\
\hline IEMBL134 & 239 & 861 & & \\
\hline IEMBL1 & & & & \\
\hline HEMBL1592281 & & 862 & & \\
\hline HEMBL149 & & 62 & & \\
\hline AEMBL1521 & 39 & 862 & & \\
\hline AEMBL1C & & 862 & & \\
\hline HEMBL1558 & & & & \\
\hline AEMBL1489325 & & 862 & & \\
\hline IEMBL14 & & 62 & & \\
\hline 化MBLI & & 62 & & MTV \\
\hline AEMBL1 & & & & RN \\
\hline AEMBL1 & & & & \\
\hline 11465 & & 862 & & \\
\hline IEMBL1560 & & & & I NIV \\
\hline HEMBL1 & & 62 & & RN \\
\hline AEMBL] & & & & (1) \\
\hline AFMRI 1 & & 62 & & \\
\hline HEMBL1 & & & & I RIV \\
\hline HEMBL1425701 & & & & IRN \\
\hline HEMBL1 & & 62 & & RIV \\
\hline HEMBLI & & 62 & & RN \\
\hline $15 \mathrm{MPI}$ & & & & \\
\hline HEMBL1602764 & & & & R \\
\hline HEMBL1591553 & & 362 & & TRN \\
\hline HEMBL1: & & & & קט \\
\hline 1 & & & & \\
\hline HEMBL1 & & & & IST \\
\hline HEMBL1610681 & & & & TRN \\
\hline AEMBL14 & & 362 & & TRN \\
\hline HEMBL15322 & & 861 & & \\
\hline LHEMBL1534774 & & & & ГST \\
\hline HEMBL1470485 & & & & RN \\
\hline AEMBL1554926 & 39 & 362 & & TP \\
\hline MBL1 & & 362 & & \\
\hline HEMBL13 & & & & \\
\hline CHEMBL3190346 & & 862 & 5.1737 & \\
\hline HEMBL142474 & 688239 & 4.6862 & 5.4048 & ГRN \\
\hline
\end{tabular}

Page 1798 
Supplemental Table S2.txt

\begin{tabular}{|c|c|c|c|c|}
\hline 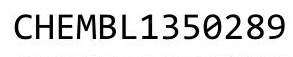 & & & & \\
\hline AEMBL1376326 & 38239 & 362 & 709 & \\
\hline HEMBL1364960 & 239 & 362 & 546 & \\
\hline 87 & 39 & 862 & & \\
\hline IEMBL1332947 & & 362 & & \\
\hline AEMBL1380949 & 88239 & 862 & 355 & \\
\hline AEMBL1496812 & 88239 & 872 & 856 & \\
\hline HEMBL1419382 & & & & \\
\hline EMBL1: & 39 & 362 & & \\
\hline IEMBL1597950 & & 862 & & \\
\hline AEMBL1425534 & 39 & 862 & & \\
\hline AEMBL1378442 & & 362 & & \\
\hline AEMBL1543958 & & 362 & & \\
\hline JEMBL16 & & 362 & & \\
\hline HEMBL13 & & 362 & & \\
\hline AEMBL1406702 & & 862 & 24 & \\
\hline AEMBL1378285 & & 862 & & \\
\hline IEMBL15852 & & 62 & & \\
\hline IEMBL15049 & & 62 & & \\
\hline AEMBL1606 & & & & \\
\hline AEMBL1353963 & & 362 & & \\
\hline AEMBL1308049 & & 62 & & \\
\hline IEMBL1414 & & 62 & & \\
\hline AFMRI 145 & & 62 & & \\
\hline AFMRI 15 & & 862 & & \\
\hline AEMBL1535659 & & 862 & & \\
\hline IEMBL1305072 & & 361 & & \\
\hline EMBL15830 & & 62 & & \\
\hline IFMP & & 52 & & \\
\hline 1 & & 62 & & \\
\hline AEMBL1449833 & & 62 & & \\
\hline AEMBL1550432 & & 362 & & \\
\hline 14 & & 62 & & \\
\hline 2 & & 52 & & \\
\hline & & & & RN \\
\hline AEMBL1306871 & & 362 & & \\
\hline IEMBL 3192165 & & 362 & & \\
\hline & & 62 & & \\
\hline (2MO & & & & $\mathrm{RN}$ \\
\hline HEMBL1513935 & & & & ST \\
\hline AEMBL1347187 & & 362 & 21 & $\mathrm{R}$ \\
\hline IEMBL15814 & & 362 & & -5 \\
\hline HEMBL1395327 & & & & \\
\hline HEMBL1308487 & & & & ST \\
\hline AEMBL3210162 & & & & S \\
\hline IEMBL15473 & & 362 & 47 & $\Gamma R$ \\
\hline 150 & & & & \\
\hline HEMBL1397 & & & .5089 & \\
\hline
\end{tabular}

Page 1799 
Supplemental Table S2.txt

\begin{tabular}{|c|c|c|c|c|c|}
\hline CHEMBL1450551 & 688239 & 4.9862 & 5.3612 & TRN & \\
\hline CHEMBL1323117 & 688239 & 8.3372 & 5.5491 & TRN & \\
\hline CHEMBL1304603 & 688239 & 4.4862 & 5.6063 & TST & \\
\hline CHEMBL1548504 & 688239 & 5.1862 & \multicolumn{2}{|c|}{5.422000000000001} & TRN \\
\hline CHEMBL1516875 & 688239 & 6.2362 & 5.5001 & TST & \\
\hline CHEMBL1426881 & 688239 & 4.6862 & 5.5984 & TRN & \\
\hline CHEMBL1443626 & 688239 & 5.1862 & 5.6018 & TST & \\
\hline CHEMBL1444104 & 688239 & 8.3372 & 5.5667 & TST & \\
\hline CHEMBL3194511 & 688239 & 5.0862 & 5.5232 & TRN & \\
\hline CHEMBL1505268 & 688239 & 6.2362 & 5.4645 & TST & \\
\hline CHEMBL1399683 & 688239 & 4.4862 & 5.5402 & TRN & \\
\hline CHEMBL1396512 & 688239 & 6.1362 & 5.4437 & TRN & \\
\hline CHEMBL3197757 & 688239 & 4.5362 & 5.5375 & TRN & \\
\hline CHEMBL1586107 & 688239 & 5.1362 & 5.5695 & TRN & \\
\hline CHEMBL1570259 & 688239 & 6.1862 & 5.4186 & TRN & \\
\hline CHEMBL1539467 & 688239 & 5.6362 & 5.6301 & TST & \\
\hline CHEMBL1964878 & 688239 & 4.6362 & 5.4238 & TRN & \\
\hline CHEMBL1481892 & 688239 & 4.5362 & 5.4669 & TRN & \\
\hline CHEMBL1339903 & 688239 & 4.5362 & 5.5464 & TRN & \\
\hline CHEMBL1324139 & 688239 & 4.7362 & \multicolumn{2}{|c|}{5.468999999999999} & TRN \\
\hline CHEMBL1339139 & 688239 & 4.7362 & 5.449 & TRN & \\
\hline CHEMBL1388936 & 688239 & 6.2362 & 5.3958 & TRN & \\
\hline CHEMBL1493396 & 688239 & 4.7362 & 5.3691 & TST & \\
\hline CHEMBL1452367 & 688239 & 5.6362 & \multicolumn{2}{|c|}{5.553999999999999} & TRN \\
\hline CHEMBL602163 & 688239 & 4.6862 & 5.6681 & TRN & \\
\hline CHEMBL1598328 & 688239 & 6.2862 & 5.5926 & TST & \\
\hline CHEMBL1460405 & 688239 & 5.1862 & 5.285 & TRN & \\
\hline CHEMBL1486034 & 688239 & 6.1362 & 5.4367 & TST & \\
\hline CHEMBL1308027 & 688239 & 6.0362 & 5.4943 & TRN & \\
\hline CHEMBL1568730 & 688239 & 4.5362 & 5.3949 & TST & \\
\hline CHEMBL1324210 & 688239 & 4.5362 & 5.4406 & TRN & \\
\hline CHEMBL1422215 & 688239 & 6.8861 & 5.5878 & TST & \\
\hline CHEMBL1535493 & 688239 & 4.6362 & 5.6001 & TRN & \\
\hline CHEMBL1357541 & 688239 & 5.0862 & 5.558 & TRN & \\
\hline CHEMBL1339041 & 688239 & 5.7362 & 5.4397 & TRN & \\
\hline CHEMBL1590186 & 688239 & 6.6861 & 5.4772 & TRN & \\
\hline CHEMBL1442808 & 688239 & 5.1862 & 5.2348 & TRN & \\
\hline CHEMBL1413852 & 688239 & 4.7362 & 5.513 & TRN & \\
\hline CHEMBL3207854 & 688239 & 4.5362 & 5.3789 & TST & \\
\hline CHEMBL1319683 & 688239 & 4.7362 & 5.5545 & TRN & \\
\hline CHEMBL1573213 & 688239 & 5.9362 & 5.5763 & TRN & \\
\hline CHEMBL1456623 & 688239 & 4.6362 & 5.6455 & TST & \\
\hline CHEMBL1389664 & 688239 & 5.6362 & 5.6349 & TRN & \\
\hline CHEMBL1490566 & 688239 & 4.4862 & 5.3011 & TRN & \\
\hline CHEMBL1452685 & 688239 & 4.6362 & 5.5749 & TRN & \\
\hline CHEMBL3192176 & 688239 & 7.0362 & 5.3445 & TRN & \\
\hline CHEMBL1585893 & 688239 & 7.2366 & 5.4913 & TRN & \\
\hline CHEMBL1492979 & 688239 & 6.7361 & 5.5317 & TRN & \\
\hline
\end{tabular}


Supplemental Table S2.txt

\begin{tabular}{|c|c|c|c|c|}
\hline CHEMBL1386563 & 688239 & 5.0862 & 5.5687 & TRN \\
\hline CHEMBL1459260 & 688239 & 4.9862 & 5.4067 & TRN \\
\hline CHEMBL1482220 & 688239 & 5.8862 & 5.615 & TST \\
\hline CHEMBL1592619 & 688239 & 5.7862 & 5.5372 & TRN \\
\hline CHEMBL1440919 & 688239 & 4.7862 & 5.5069 & TST \\
\hline CHEMBL1408040 & 688239 & 6.1862 & 5.5039 & TST \\
\hline CHEMBL1573101 & 688239 & 4.8862 & 5.544 & TRN \\
\hline CHEMBL1449012 & 688239 & 5.1362 & 5.5133 & TRN \\
\hline CHEMBL1495960 & 688239 & 5.1862 & 5.5748 & TRN \\
\hline CHEMBL1382063 & 688239 & 6.8861 & 5.4243 & TRN \\
\hline CHEMBL1303212 & 688239 & 4.5862 & 5.6207 & TRN \\
\hline CHEMBL1309046 & 688239 & 4.5862 & 5.4955 & TRN \\
\hline CHEMBL1558071 & 688239 & 5.5862 & 5.5119 & TRN \\
\hline CHEMBL1528090 & 688239 & 4.8362 & 5.3151 & TST \\
\hline CHEMBL1373278 & 688239 & 5.1862 & 5.5435 & TRN \\
\hline CHEMBL1544268 & 688239 & 5.6362 & 5.3263 & TRN \\
\hline CHEMBL1571742 & 688239 & 4.9362 & 5.5961 & TRN \\
\hline CHEMBL1565150 & 688239 & 4.9862 & 5.6579 & TRN \\
\hline CHEMBL1489376 & 688239 & 5.1862 & 5.5673 & TRN \\
\hline CHEMBL1531256 & 688239 & 4.6862 & 5.6209 & TRN \\
\hline CHEMBL1597234 & 688239 & 7.2366 & 5.3976 & TRN \\
\hline CHEMBL1541854 & 688239 & 5.1862 & 5.5436 & TST \\
\hline CHEMBL1513235 & 688239 & 5.1862 & 5.4576 & TRN \\
\hline CHEMBL1381421 & 688239 & 6.1362 & 5.4916 & TST \\
\hline CHEMBL1353097 & 688239 & 5.8362 & 5.4756 & TRN \\
\hline CHEMBL3212625 & 688239 & 4.7362 & 5.4904 & TRN \\
\hline CHEMBL1460105 & 688239 & 7.0362 & 5.4745 & TRN \\
\hline CHEMBL1458639 & 688239 & 5.1362 & 5.3778 & TST \\
\hline CHEMBL1383832 & 688239 & 4.5362 & 5.3742 & TRN \\
\hline CHEMBL1371649 & 688239 & 7.1361 & 5.4575 & TRN \\
\hline CHEMBL1324923 & 688239 & 5.1362 & 5.3768 & TST \\
\hline CHEMBL1414579 & 688239 & 4.5362 & 5.3462 & TRN \\
\hline CHEMBL1540248 & 688239 & 6.0362 & 5.4753 & TST \\
\hline CHEMBL1299782 & 688239 & 5.1862 & 5.5591 & TRN \\
\hline CHEMBL1367454 & 688239 & 4.6862 & 5.4939 & TST \\
\hline CHEMBL1385993 & 688239 & 4.6862 & 5.5257 & TST \\
\hline CHEMBL1559379 & 688239 & 4.9862 & 5.4067 & TRN \\
\hline CHEMBL1312268 & 688239 & 6.0362 & 5.3969 & TST \\
\hline CHEMBL1509122 & 688239 & 4.6862 & 5.5625 & TST \\
\hline CHEMBL1402893 & 688239 & 4.7362 & 5.5274 & TRN \\
\hline CHEMBL1518087 & 688239 & 4.6862 & 5.59399 & 9999999999 \\
\hline CHEMBL1441438 & 688239 & 4.5362 & 5.5313 & TST \\
\hline CHEMBL1332121 & 688239 & 4.5362 & 5.5438 & TRN \\
\hline CHEMBL1545504 & 688239 & 7.4868 & 5.4734 & TRN \\
\hline CHEMBL1421304 & 688239 & 4.6362 & 5.4751 & TRN \\
\hline CHEMBL1539427 & 688239 & 7.2366 & 5.4727 & TST \\
\hline CHEMBL1439516 & 688239 & 4.5862 & 5.5046 & TRN \\
\hline CHEMBL1576601 & 688239 & 5.8362 & 5.4632 & TST \\
\hline
\end{tabular}


Supplemental Table S2.txt

\begin{tabular}{|c|c|c|c|c|c|}
\hline CHEMBL1545027 & 688239 & 5.0362 & 5.5159 & TST & \\
\hline CHEMBL1467143 & 688239 & 6.8861 & 5.5194 & TRN & \\
\hline CHEMBL1515462 & 688239 & 7.0362 & 5.5127 & TRN & \\
\hline CHEMBL1612757 & 688239 & 5.7362 & 5.4795 & TRN & \\
\hline CHEMBL412059 & 688239 & 5.4862 & 5.4808 & TST & \\
\hline CHEMBL1410489 & 688239 & 5.1362 & 5.3959 & TST & \\
\hline CHEMBL1564709 & 688239 & 6.8861 & 5.6284 & TRN & \\
\hline CHEMBL1390021 & 688239 & 4.5362 & 5.4951 & TST & \\
\hline CHEMBL1361858 & 688239 & 4.5362 & 5.6138 & TRN & \\
\hline CHEMBL1349075 & 688239 & 5.6362 & 5.4624 & TRN & \\
\hline CHEMBL1460906 & 688239 & 5.3862 & 5.5465 & TRN & \\
\hline CHEMBL1450393 & 688239 & 5.2862 & 5.5375 & TST & \\
\hline CHEMBL1514544 & 688239 & 8.3372 & 5.4209 & TRN & \\
\hline CHEMBL 3210541 & 688239 & 5.1862 & 5.3815 & TST & \\
\hline CHEMBL1330060 & 688239 & 5.6862 & 5.6281 & TRN & \\
\hline CHEMBL1432039 & 688239 & 4.5362 & 5.4786 & TST & \\
\hline CHEMBL1309443 & 688239 & 4.5362 & 5.5531 & TRN & \\
\hline CHEMBL 3208051 & 688239 & 5.0362 & 5.5382 & TRN & \\
\hline CHEMBL1358101 & 688239 & 6.9863 & 5.487 & TRN & \\
\hline CHEMBL1452061 & 688239 & 5.8362 & 5.4476 & TST & \\
\hline CHEMBL1396208 & 688239 & 5.6862 & 5.4542 & TST & \\
\hline CHEMBL1510396 & 688239 & 5.2362 & 5.4103 & TST & \\
\hline CHEMBL1439171 & 688239 & 6.9863 & 5.3394 & TRN & \\
\hline CHEMBL1456906 & 688239 & 5.2862 & 5.3592 & TRN & \\
\hline CHEMBL1388663 & 688239 & 5.1362 & 5.4421 & TST & \\
\hline CHEMBL1560828 & 688239 & 7.0362 & \multicolumn{2}{|c|}{5.617000000000001} & TRN \\
\hline CHEMBL1309972 & 688239 & 4.8862 & 5.4808 & TRN & \\
\hline CHEMBL1478214 & 688239 & 4.9362 & 5.5574 & TRN & \\
\hline CHEMBL1523977 & 688239 & 6.7862 & 5.4822 & TRN & \\
\hline CHEMBL1325800 & 688239 & 5.6362 & 5.5467 & TRN & \\
\hline CHEMBL1541527 & 688239 & 5.7362 & 5.4642 & TRN & \\
\hline CHEMBL1502205 & 688239 & 7.4868 & 5.6243 & TRN & \\
\hline CHEMBL1601134 & 688239 & 4.8862 & 5.4579 & TRN & \\
\hline CHEMBL1506649 & 688239 & 4.7862 & 5.4618 & TRN & \\
\hline CHEMBL1459869 & 688239 & 5.1862 & \multicolumn{2}{|c|}{5.492000000000001} & TRN \\
\hline CHEMBL1546873 & 688239 & 4.9862 & 5.6545 & TST & \\
\hline CHEMBL1560966 & 688239 & 6.1362 & 5.5926 & TRN & \\
\hline CHEMBL1467004 & 688239 & 5.3862 & 5.6639 & TRN & \\
\hline CHEMBL1387973 & 688239 & 5.4362 & 5.3013 & TRN & \\
\hline CHEMBL1456618 & 688239 & 4.9362 & 5.5937 & TRN & \\
\hline CHEMBL1306413 & 688239 & 6.8362 & 5.6486 & TRN & \\
\hline CHEMBL1605411 & 688239 & 5.2362 & 5.343 & TST & \\
\hline CHEMBL1508244 & 688239 & 4.5362 & 5.4327 & TRN & \\
\hline CHEMBL1581244 & 688239 & 7.1864 & 5.4486 & TRN & \\
\hline CHEMBL1527656 & 688239 & 4.7862 & 5.5218 & TRN & \\
\hline CHEMBL1537511 & 688239 & 6.2362 & 5.4158 & TRN & \\
\hline CHEMBL1561545 & 688239 & 5.1862 & 5.4442 & TRN & \\
\hline CHEMBL1584209 & 688239 & 4.5362 & 5.5966 & TST & \\
\hline
\end{tabular}


Supplemental Table S2.txt

CHEMBL1568067
CHEMBL1419947
CHEMBL1311849
CHEMBL1507973
CHEMBL1553130
CHEMBL1540845
CHEMBL1340209
CHEMBL593944
CHEMBL1528207
CHEMBL1488092
CHEMBL1391834
CHEMBL1365171
CHEMBL1539348
CHEMBL1340301
CHEMBL1371328
CHEMBL1309932
CHEMBL1564420
CHEMBL1527876
CHEMBL1549179
CHEMBL1382719
CHEMBL1551868
CHEMBL1610270
CHEMBL106969
CHEMBL1432761
CHEMBL1421862
CHEMBL1526498
CHEMBL1587106
CHEMBL180798
CHEMBL1570420
CHEMBL1591603
CHEMBL1587333
CHEMBL1380817
CHEMBL1508565
CHEMBL1432673
CHEMBL1531686
CHEMEMBL1479 697159
CHEMBL1363239
CHEMBL1561067
CHEMBL3209821
CHEMBL1470154
CHEMBL1403008
CHEMBL13212720
6

$\begin{array}{llll}688239 & 4.5362 & 5.5591 & \text { TRN } \\ 688239 & 5.7862 & 5.565 & \text { TRN } \\ 688239 & 4.6362 & 5.4007 & \text { TST } \\ 688239 & 5.2362 & 5.4298 & \text { TST } \\ 688239 & 5.4362 & 5.4288 & \text { TRN } \\ 688239 & 4.7862 & 5.4218 & \text { TRN } \\ 688239 & 6.1862 & 5.5189 & \text { TST } \\ 688239 & 5.0362 & 5.379 & \text { TST } \\ 688239 & 5.1862 & 5.4085 & \text { TRN } \\ 688239 & 6.0862 & 5.5329 & \text { TST } \\ 688239 & 5.4362 & 5.4853 & \text { TRN } \\ 688239 & 6.3863 & 5.7084 & \text { TRN } \\ 688239 & 7.5867 & 5.5939 & \text { TST } \\ 688239 & 5.1862 & 5.3515 & \text { TST } \\ 688239 & 4.5362 & 5.5665 & \text { TRN } \\ 688239 & 4.5362 & 5.5667 & \text { TRN } \\ 688239 & 6.7361 & 5.5598 & \text { TST } \\ 688239 & 5.1362 & 5.42 & \text { TST } \\ 688239 & 5.1362 & 5.6287 & \text { TRN } \\ 688239 & 5.3362 & 5.4022 & \text { TRN } \\ 688239 & 8.1871 & 5.4088 & \text { TRN } \\ 688239 & 4.5362 & 5.445 & \text { TRN } \\ 688239 & 5.1862 & 5.348 & \text { TRN } \\ 688239 & 6.5363 & 5.5102 & \text { TRN } \\ 688239 & 6.1362 & 5.332000000000001 \\ 688239 & 4.5362 & 5.515 & \text { TRN } \\ 688239 & 6.3863 & 5.5701 & \text { TST } \\ 688239 & 4.5362 & 5.3615 & \text { TRN } \\ 688239 & 6.2362 & 5.5811 & \text { TRN } \\ 688239 & 5.4362 & 5.6063 & \text { TRN } \\ 688239 & 5.1362 & 5.371 & \text { TST } \\ 688239 & 4.4862 & 5.3976 & \text { TRN } \\ 688239 & 5.0362 & 5.5637 & \text { TRN } \\ 688239 & 5.5362 & 5.5723 & \text { TST } \\ 688239 & 5.1362 & 5.4395 & \text { TRN } \\ 688239 & 4.6862 & 5.539 & \text { TRN } \\ 688239 & 4.5362 & 5.45 & \text { TRN } \\ 688239 & 4.5362 & 5.4678 & \text { TRN } \\ 688239 & 4.6862 & 5.6913 & \text { TRN } \\ 688239 & 6.9363 & 5.4575 & \text { TRN } \\ 688239 & 5.7362 & 5.4332 & \text { TRN } \\ 688239 & 4.5362 & 5.3362 & \text { TRN } \\ 688239 & 5.2862 & 5.5532 & \text { TST } \\ 688239 & 4.8862 & 5.5055 & \text { TRN } \\ 688239 & 5.1862 & 5.459 & \text { TRN } \\ 688239 & 5.4862 & 5.4452 & \text { TRN } \\ 688239 & 4.9362 & 5.4886 & \text { TRN } \\ & 6.5862 & 5.49 & \text { TRN } \\ & & & \text { Page } 1803 \\ \text { TST }\end{array}$


Supplemental Table S2.txt

\begin{tabular}{|c|c|c|c|c|}
\hline IE & & 52 & & \\
\hline UГMDI 120050 & & .1362 & 5.6468 & \\
\hline ITS & & & & \\
\hline IEMBL 14 & & & & \\
\hline AEMBL1379139 & 8239 & & & \\
\hline HEMBL1522824 & 88239 & 362 & 5544 & \\
\hline HEMBL130 & 239 & 362 & 835 & \\
\hline IFMBI & & & & \\
\hline AEMBL1301951 & & & & \\
\hline HEMBL3192905 & 88239 & 852 & . 3447 & \\
\hline AEMBL1350618 & 239 & 362 & 05 & \\
\hline IEMBL14 & 239 & & 376 & \\
\hline IEMBL3 & & & & \\
\hline HEMBL15 & & & & \\
\hline AEMBL13 & & & & \\
\hline AEMBL1 & 39 & 62 & 98 & \\
\hline HEMBL1: & & & & \\
\hline HEMBL1: & & & & \\
\hline AEMBL15 & & & & \\
\hline IEMBL14 & & & & \\
\hline HEMBI & & & 98 & \\
\hline HEMBL1C & & & & \\
\hline HEMBL13 & & & & $2 \mathrm{~N}$ \\
\hline AEMBL14 & & & & \\
\hline AEMBL13 & & & & RN \\
\hline HEMBL1 & & & & \\
\hline HEMBL1 & & & & 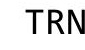 \\
\hline HFMBI 1 & & & & RN \\
\hline HEMBL15 & & & & I \\
\hline HEMBL1353389 & & & & RN \\
\hline HEMBL1: & & & & \\
\hline $\mathrm{AFMB}$ & & & & Niv \\
\hline 27 & & & & ST \\
\hline HEMBL1516 & & & & RN \\
\hline HEMBL1424382 & & & & $\mathrm{RN}$ \\
\hline HEMBL1 & & & & \\
\hline HᄃMP = & & & & RN \\
\hline HEMBL1 & & & & RN \\
\hline HEMBL1327109 & 88239 & & & TRN \\
\hline EMBL1 & & & & RN \\
\hline HEMBL1 & & & & \\
\hline CHEMBL13 & & & & RN \\
\hline HEMBL14 & & & & $\mathrm{RN}$ \\
\hline AEMBL13 & & & & TRN \\
\hline EBL1 & & & & \\
\hline HEMBL13 & & & & \\
\hline LHEMBL1388816 & & & 5.4575 & \\
\hline CHEMBL1320758 & 688239 & 4.5362 & 5.3966 & ГRN \\
\hline
\end{tabular}

Page 1804 
Supplemental Table S2.txt

\begin{tabular}{|c|c|c|c|c|c|c|}
\hline CHEMBL1515450 & 688239 & 5.1862 & \multicolumn{3}{|c|}{5.497999999999999} & TST \\
\hline CHEMBL1426528 & 688239 & 4.5362 & 5.4871 & TRN & & \\
\hline CHEMBL3199165 & 688239 & 4.5362 & 5.5003 & TRN & & \\
\hline CHEMBL1351998 & 688239 & 6.8362 & 5.3632 & TST & & \\
\hline CHEMBL1587722 & 688239 & 4.5362 & 5.4393 & TRN & & \\
\hline CHEMBL1503648 & 688239 & 4.95 & 5.6912 & TRN & & \\
\hline CHEMBL1505452 & 688239 & 5.0862 & 5.5421 & TRN & & \\
\hline CHEMBL1336664 & 688239 & 4.7862 & 5.3784 & TST & & \\
\hline CHEMBL1483115 & 688239 & 5.6362 & 5.5515 & TRN & & \\
\hline CHEMBL1363798 & 688239 & 5.6362 & 5.4425 & TRN & & \\
\hline CHEMBL1322690 & 688239 & 6.5862 & 5.4126 & TST & & \\
\hline CHEMBL1391733 & 688239 & 5.7362 & 5.4856 & TRN & & \\
\hline CHEMBL3211161 & 688239 & 6.4862 & 5.6479 & TRN & & \\
\hline CHEMBL1509950 & 688239 & 5.4362 & 5.4224 & TRN & & \\
\hline CHEMBL1517902 & 688239 & 6.0362 & 5.5201 & TRN & & \\
\hline CHEMBL1578773 & 688239 & 4.4862 & 5.5385 & TRN & & \\
\hline CHEMBL1340592 & 688239 & 4.5362 & 5.3788 & TST & & \\
\hline CHEMBL1479007 & 688239 & 8.28399 & 99999999 & 99 & 5.5244 & \\
\hline CHEMBL1334230 & 688239 & 4.7862 & 5.4246 & TRN & & \\
\hline CHEMBL1553784 & 688239 & 5.4362 & 5.655 & TRN & & \\
\hline CHEMBL1306737 & 688239 & 5.8362 & 5.4181 & TRN & & \\
\hline CHEMBL1593484 & 688239 & 4.7362 & 5.3299 & TRN & & \\
\hline CHEMBL1539056 & 688239 & 4.9362 & 5.49200 & 000000000 & & \\
\hline CHEMBL1445902 & 688239 & 5.2862 & 5.4586 & TST & & \\
\hline CHEMBL1329312 & 688239 & 6.8362 & 5.4371 & TST & & \\
\hline CHEMBL1583868 & 688239 & 5.1362 & 5.7044 & TRN & & \\
\hline CHEMBL375673 & 688239 & 5.1862 & 5.3597 & TRN & & \\
\hline CHEMBL1474946 & 688239 & 6.1362 & 5.4638 & TRN & & \\
\hline CHEMBL1596841 & 688239 & 4.5362 & 5.516 & TST & & \\
\hline CHEMBL1569324 & 688239 & 5.7862 & 5.5987 & TRN & & \\
\hline CHEMBL1404406 & 688239 & 6.8861 & 5.4135 & TRN & & \\
\hline CHEMBL1426408 & 688239 & 4.5862 & 5.4619 & TST & & \\
\hline CHEMBL 3211075 & 688239 & 4.6862 & 5.3554 & TST & & \\
\hline CHEMBL1606215 & 688239 & 4.7362 & 5.4164 & TST & & \\
\hline CHEMBL3194408 & 688239 & 4.5862 & 5.3168 & TST & & \\
\hline CHEMBL1444407 & 688239 & 4.5862 & 5.5782 & TST & & \\
\hline CHEMBL1534321 & 688239 & 6.8861 & 5.4159 & TRN & & \\
\hline CHEMBL1516116 & 688239 & 5.2862 & 5.5196 & TRN & & \\
\hline CHEMBL1487256 & 688239 & 4.8362 & 5.5087 & TRN & & \\
\hline CHEMBL1581319 & 688239 & 5.7362 & 5.5641 & TRN & & \\
\hline CHEMBL1319864 & 688239 & 6.2862 & 5.481 & TRN & & \\
\hline CHEMBL1515273 & 688239 & 8.2366 & 5.5526 & TRN & & \\
\hline CHEMBL1379380 & 688239 & 7.0862 & 5.4345 & TST & & \\
\hline CHEMBL1536993 & 688239 & 5.6862 & 5.4276 & TRN & & \\
\hline CHEMBL1429000 & 688239 & 4.7862 & 5.4222 & TRN & & \\
\hline CHEMBL1588143 & 688239 & 8.28399 & 99999999 & 99 & 5.4632 & \\
\hline CHEMBL1385296 & 688239 & 5.3362 & 5.5101 & TRN & & \\
\hline CHEMBL1365446 & 688239 & 5.1862 & 5.5064 & TRN & & \\
\hline
\end{tabular}


Supplemental Table S2.txt

\begin{tabular}{|c|c|c|c|c|}
\hline CHEMBL1529769 & 688239 & 5.6862 & 5.5727 & TRN \\
\hline CHEMBL1309487 & 688239 & 5.6862 & 5.4788 & TRN \\
\hline CHEMBL1582922 & 688239 & 4.4862 & 5.5549 & TRN \\
\hline CHEMBL1399206 & 688239 & 6.6362 & 5.5178 & TRN \\
\hline CHEMBL1369790 & 688239 & 5.4362 & 5.4834 & TRN \\
\hline CHEMBL1401806 & 688239 & 6.4362 & 5.598 & TRN \\
\hline CHEMBL1470030 & 688239 & 5.1862 & 5.5404 & TRN \\
\hline CHEMBL3193945 & 688239 & 6.0862 & 5.5839 & TRN \\
\hline CHEMBL1595988 & 688239 & 5.5862 & \multicolumn{2}{|c|}{5.577000000000001} \\
\hline CHEMBL1301048 & 688239 & 5.1862 & 5.5959 & TRN \\
\hline CHEMBL1505875 & 688239 & 5.2362 & 5.2362 & TRN \\
\hline CHEMBL1315462 & 688239 & 8.1871 & \multicolumn{2}{|c|}{5.696000000000001} \\
\hline CHEMBL1466795 & 688239 & 5.4362 & 5.4257 & TRN \\
\hline CHEMBL3196311 & 688239 & 4.6362 & 5.5203 & TRN \\
\hline CHEMBL1372141 & 688239 & 5.5862 & 5.5222 & TST \\
\hline CHEMBL1526261 & 688239 & 5.0862 & 5.7565 & TRN \\
\hline CHEMBL1462129 & 688239 & 5.9362 & 5.4866 & TRN \\
\hline CHEMBL1318980 & 688239 & 5.5 & 5.6021 & TRN \\
\hline CHEMBL 3213113 & 688239 & 8.2366 & 5.3947 & TRN \\
\hline CHEMBL1533100 & 688239 & 4.5362 & 5.3454 & TRN \\
\hline CHEMBL1500979 & 688239 & 4.5862 & 5.4766 & TST \\
\hline CHEMBL1364282 & 688239 & 5.3862 & 5.4656 & TRN \\
\hline CHEMBL1545892 & 688239 & 4.5362 & 5.4735 & TRN \\
\hline CHEMBL1373387 & 688239 & 5.7362 & 5.6767 & TRN \\
\hline CHEMBL3196165 & 688239 & 5.1362 & 5.3608 & TST \\
\hline CHEMBL1520807 & 688239 & 4.5362 & 5.6773 & TRN \\
\hline CHEMBL1333548 & 688239 & 5.4862 & 5.5138 & TST \\
\hline CHEMBL1368633 & 688239 & 5.1862 & 5.3594 & TRN \\
\hline CHEMBL1441111 & 688239 & 4.7362 & 5.4976 & TST \\
\hline CHEMBL3210641 & 688239 & 5.6362 & 5.4717 & TRN \\
\hline CHEMBL1376073 & 688239 & 4.8862 & 5.5401 & TRN \\
\hline CHEMBL1481774 & 688239 & 6.9863 & 5.4595 & TST \\
\hline CHEMBL1443898 & 688239 & 5.6362 & 5.3906 & TST \\
\hline CHEMBL1498465 & 688239 & 5.9362 & 5.5202 & TRN \\
\hline CHEMBL1543094 & 688239 & 4.6862 & \multicolumn{2}{|c|}{5.4639999999999995} \\
\hline CHEMBL 3197220 & 688239 & 6.7862 & 5.436 & TRN \\
\hline CHEMBL1321427 & 688239 & 4.5362 & 5.3471 & TRN \\
\hline CHEMBL1341024 & 688239 & 5.2862 & 5.5723 & TRN \\
\hline CHEMBL1499626 & 688239 & 4.6862 & 5.3906 & TRN \\
\hline CHEMBL1439725 & 688239 & 6.1362 & 5.5725 & TRN \\
\hline CHEMBL1302779 & 688239 & 4.5362 & 5.4139 & TRN \\
\hline CHEMBL1339841 & 688239 & 6.0362 & 5.4445 & TST \\
\hline CHEMBL1429856 & 688239 & 4.6862 & 5.4507 & TRN \\
\hline CHEMBL1455077 & 688239 & 6.1362 & 5.3788 & TRN \\
\hline CHEMBL1516744 & 688239 & 5.1862 & 5.5758 & TRN \\
\hline CHEMBL1477705 & 688239 & 4.8862 & 5.5788 & TST \\
\hline CHEMBL 319042 & 688239 & 5.4862 & 5.5093 & TRN \\
\hline CHEMBL1343341 & 688239 & 6.1362 & 5.5464 & TST \\
\hline
\end{tabular}


Supplemental Table S2.txt

\begin{tabular}{|c|c|c|c|c|}
\hline IE & & & & \\
\hline UГMDI 151060 & & .2362 & & \\
\hline & & & & \\
\hline HEMBL153 & & 57 & & \\
\hline AEMBL1330740 & 38239 & -0 & & \\
\hline HEMBL1587892 & 88239 & .6862 & 5504 & \\
\hline 81 & 239 & & & \\
\hline 37 & & & & \\
\hline HEMBL159 & & 862 & & \\
\hline HEMBL134! & 88239 & 362 & & \\
\hline HEMBL154 & 239 & 862 & & \\
\hline IEMBL1 & 239 & 362 & & \\
\hline AEMBL3 & & & & \\
\hline HEMBL1 & & 862 & & \\
\hline HEMBL1 & & & & \\
\hline AEMBL1 & 39 & 862 & 44 & \\
\hline HEMBL1 & & & & \\
\hline HEMBL1 & & & & \\
\hline HEMBL137 & & 861 & & \\
\hline AEMBL1 & & & & \\
\hline HEMBL & & 52 & & \\
\hline HEMBL: & & & & \\
\hline HEMBLI & & & & \\
\hline 05 & & & & \\
\hline AEMBL1 & & & & IRIV \\
\hline HEMBL & & 1 & & \\
\hline HEMBL & & & & \\
\hline $\mathrm{AFMB} \mid 1$ & & & & RN \\
\hline HEMBL1 & & & & 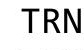 \\
\hline HEMBL150 & & & & IRN \\
\hline HEMBL1 & & & & RN \\
\hline $\mathrm{AFMB}$ & & & & Niv \\
\hline 5 & & & & RN \\
\hline HEMBL145 & & & & Th \\
\hline HEMBL143437 & & & & ГRN \\
\hline HEMBL1 & & & & \\
\hline HᄃMP 1 & & & & ST \\
\hline HEMBL134 & & & & ГST \\
\hline HEMBL1538609 & 88239 & & & TST \\
\hline AEMBL1 & & & & RN \\
\hline HEMBL1 & & 62 & & \\
\hline CHEMBL1 & & & & ST \\
\hline HEMBL1 & & 862 & & $\mathrm{RN}$ \\
\hline AEMBL 3192 & 39 & 362 & & TRN \\
\hline EMBL1 & & & & RN \\
\hline CHEMBL146e & & & & \\
\hline CHEMBL1328 & & & 5.5713 & \\
\hline CHEMBL137147] & 688239 & 5.2862 & 5.5528 & ГRN \\
\hline
\end{tabular}


Supplemental Table S2.txt

\begin{tabular}{|c|c|c|c|c|c|}
\hline CHEMBL1544054 & 688239 & 4.6862 & 5.4567 & TRN & \\
\hline CHEMBL1355258 & 688239 & 5.6862 & 5.6135 & TRN & \\
\hline CHEMBL1457532 & 688239 & 5.1862 & 5.4338 & TRN & \\
\hline CHEMBL1442142 & 688239 & 5.1862 & 5.3115 & TST & \\
\hline CHEMBL1463439 & 688239 & 6.3362 & 5.3716 & TRN & \\
\hline CHEMBL1517292 & 688239 & 5.5862 & 5.4865 & TRN & \\
\hline CHEMBL1364830 & 688239 & 5.7362 & 5.7207 & TRN & \\
\hline CHEMBL1392138 & 688239 & 4.5362 & 5.4353 & TRN & \\
\hline CHEMBL1303074 & 688239 & 5.7362 & 5.3419 & TRN & \\
\hline CHEMBL1435726 & 688239 & 4.5362 & 5.3769 & TRN & \\
\hline CHEMBL1553233 & 688239 & 4.5362 & 5.6244 & TRN & \\
\hline CHEMBL1472739 & 688239 & 5.4362 & 5.4326 & TST & \\
\hline CHEMBL1345771 & 688239 & 5.9362 & 5.4909 & TRN & \\
\hline CHEMBL1453528 & 688239 & 5.1862 & 5.6217 & TRN & \\
\hline CHEMBL1503916 & 688239 & 5.4362 & 5.5449 & TRN & \\
\hline CHEMBL1453927 & 688239 & 6.6861 & 5.6586 & TRN & \\
\hline CHEMBL3199364 & 688239 & 4.7362 & 5.3427 & TST & \\
\hline CHEMBL1374544 & 688239 & 6.0862 & 5.5747 & TST & \\
\hline CHEMBL1586044 & 688239 & 7.0862 & 5.4091 & TRN & \\
\hline CHEMBL1327617 & 688239 & 4.7362 & 5.4081 & TRN & \\
\hline CHEMBL1412680 & 688239 & 5.1862 & 5.4296 & TRN & \\
\hline CHEMBL1412113 & 688239 & 5.1862 & 5.4898 & TRN & \\
\hline CHEMBL1430734 & 688239 & 4.9362 & 5.5165 & TRN & \\
\hline CHEMBL 3193787 & 688239 & 4.7862 & 5.4056 & TRN & \\
\hline CHEMBL1599815 & 688239 & 6.8362 & 5.4164 & TST & \\
\hline CHEMBL1316583 & 688239 & 4.4862 & 5.4119 & TRN & \\
\hline CHEMBL1356984 & 688239 & 5.8362 & 5.4965 & TRN & \\
\hline CHEMBL1551411 & 688239 & 5.2862 & 5.5197 & TRN & \\
\hline CHEMBL1454356 & 688239 & 6.6362 & 5.3808 & TRN & \\
\hline CHEMBL1379905 & 688239 & 5.1862 & 5.3821 & TRN & \\
\hline CHEMBL1481675 & 688239 & 7.5867 & 5.4277 & TRN & \\
\hline CHEMBL1463284 & 688239 & 5.0862 & 5.5618 & TST & \\
\hline CHEMBL1513444 & 688239 & 6.2362 & 5.6421 & TRN & \\
\hline CHEMBL1609307 & 688239 & 4.7862 & 5.5335 & TRN & \\
\hline CHEMBL1543301 & 688239 & 6.2362 & 5.4041 & TRN & \\
\hline CHEMBL1376287 & 688239 & 4.5362 & 5.5438 & TRN & \\
\hline CHEMBL3213163 & 688239 & 5.1362 & 5.3966 & TST & \\
\hline CHEMBL1558284 & 688239 & 8.28399 & 99999999 & 99 & 5.4236 \\
\hline CHEMBL1580190 & 688239 & 6.0862 & 5.5924 & TRN & \\
\hline CHEMBL1480718 & 688239 & 4.5362 & 5.3604 & TRN & \\
\hline CHEMBL1361063 & 688239 & 4.7362 & 5.2805 & TRN & \\
\hline CHEMBL1545061 & 688239 & 5.1862 & 5.568 & TRN & \\
\hline CHEMBL1522549 & 688239 & 4.7362 & 5.4123 & TRN & \\
\hline CHEMBL1362904 & 688239 & 4.5362 & 5.5186 & TRN & \\
\hline CHEMBL1407850 & 688239 & 5.4862 & 5.5607 & TRN & \\
\hline CHEMBL1506415 & 688239 & 4.7362 & 5.4177 & TRN & \\
\hline CHEMBL1301892 & 688239 & 5.7862 & 5.3793 & TRN & \\
\hline CHEMBL1351479 & 688239 & 4.5362 & 5.5235 & TST & \\
\hline
\end{tabular}


Supplemental Table S2.txt

\begin{tabular}{|c|c|c|c|c|c|}
\hline CHEMBL1465794 & 688239 & 4.6862 & 5.4879 & TRN & \\
\hline CHEMBL1427920 & 688239 & 4.5362 & 5.4049 & TST & \\
\hline CHEMBL1612653 & 688239 & 5.2362 & 5.7548 & TRN & \\
\hline CHEMBL1612927 & 688239 & 5.2362 & 5.5323 & TRN & \\
\hline CHEMBL1987510 & 688239 & 4.4862 & 5.4323 & TRN & \\
\hline CHEMBL1473531 & 688239 & 5.4362 & 5.6224 & TST & \\
\hline CHEMBL1363009 & 688239 & 4.5362 & 5.4444 & TST & \\
\hline CHEMBL1464933 & 688239 & 5.0362 & 5.6445 & TRN & \\
\hline CHEMBL84010 & 688239 & 4.4862 & 5.354 & TRN & \\
\hline CHEMBL1539299 & 688239 & 6.9863 & 5.4603 & TST & \\
\hline CHEMBL1299743 & 688239 & 4.7362 & 5.4214 & TRN & \\
\hline CHEMBL1509763 & 688239 & 5.3362 & 5.4917 & TRN & \\
\hline CHEMBL 3207486 & 688239 & 6.2362 & 5.4466 & TRN & \\
\hline CHEMBL1551854 & 688239 & 4.7362 & 5.4227 & TRN & \\
\hline CHEMBL1458158 & 688239 & 6.6861 & 5.5459 & TRN & \\
\hline CHEMBL1392317 & 688239 & 5.5362 & 5.4347 & TRN & \\
\hline CHEMBL1333561 & 688239 & 5.3862 & 5.6758 & TRN & \\
\hline CHEMBL1343594 & 688239 & 5.1362 & 5.64 & TRN & \\
\hline CHEMBL1464889 & 688239 & 5.2362 & 5.5205 & TRN & \\
\hline CHEMBL1429844 & 688239 & 4.5362 & 5.4685 & TRN & \\
\hline CHEMBL1415291 & 688239 & 6.5862 & 5.5712 & TST & \\
\hline CHEMBL1424799 & 688239 & 4.9862 & 5.3143 & TRN & \\
\hline CHEMBL1473028 & 688239 & 4.5362 & 5.4519 & TRN & \\
\hline CHEMBL1465338 & 688239 & 4.6862 & 5.3692 & TRN & \\
\hline CHEMBL1421553 & 688239 & 5.8362 & 5.4006 & TRN & \\
\hline CHEMBL1337067 & 688239 & 4.5362 & 5.457000 & 000000001 & TRN \\
\hline CHEMBL1450831 & 688239 & 7.0362 & 5.584 & TRN & \\
\hline CHEMBL1352413 & 688239 & 4.5362 & 5.4515 & TRN & \\
\hline CHEMBL1572224 & 688239 & 5.1362 & 5.4782 & TRN & \\
\hline CHEMBL1405052 & 688239 & 5.1 & 5.4531 & TRN & \\
\hline CHEMBL1392522 & 688239 & 4.5362 & 5.6024 & TRN & \\
\hline CHEMBL1405975 & 688239 & 6.3362 & 5.506 & TST & \\
\hline CHEMBL3193949 & 688239 & 4.8362 & 5.4393 & TST & \\
\hline CHEMBL1518900 & 688239 & 4.9362 & 5.4668 & TST & \\
\hline CHEMBL1454529 & 688239 & 7.5361 & 5.4975 & TRN & \\
\hline CHEMBL1385256 & 688239 & 4.8362 & 5.5311 & TRN & \\
\hline CHEMBL1409053 & 688239 & 4.5362 & 5.5204 & TRN & \\
\hline CHEMBL3198759 & 688239 & 8.3372 & 5.3943 & TRN & \\
\hline CHEMBL1532225 & 688239 & 8.28399 & 99999999 & 5.4516 & $\mid \mathrm{RI}$ \\
\hline CHEMBL1577093 & 688239 & 5.0362 & 5.4648 & TST & \\
\hline CHEMBL1473316 & 688239 & 4.4862 & 5.4024 & TRN & \\
\hline CHEMBL1384299 & 688239 & 4.5362 & 5.4259 & TRN & \\
\hline CHEMBL1424385 & 688239 & 6.0862 & 5.6827 & TRN & \\
\hline CHEMBL3193302 & 688239 & 4.7862 & 5.4751 & TST & \\
\hline CHEMBL1413210 & 688239 & 5.1862 & 5.4579 & TRN & \\
\hline CHEMBL1358434 & 688239 & 4.5362 & 5.473 & TRN & \\
\hline CHEMBL1518966 & 688239 & 4.5362 & 5.7286 & TRN & \\
\hline CHEMBL1412902 & 688239 & 4.5362 & 5.3885 & TST & \\
\hline
\end{tabular}


Supplemental Table S2.txt

\begin{tabular}{|c|c|c|c|c|}
\hline CHEMBL1383403 & 688239 & 4.6362 & 5.6124 & TRN \\
\hline CHEMBL1449736 & 688239 & 5.4862 & 5.4122 & TRN \\
\hline CHEMBL1302611 & 688239 & 4.9362 & 5.5784 & TRN \\
\hline CHEMBL1370584 & 688239 & 6.0862 & 5.5866 & TST \\
\hline CHEMBL1401844 & 688239 & 5.1362 & 5.5175 & TRN \\
\hline CHEMBL1575888 & 688239 & 5.3362 & 5.5208 & TST \\
\hline CHEMBL1390423 & 688239 & 4.8862 & 5.597 & TRN \\
\hline CHEMBL1581398 & 688239 & 4.6862 & 5.3743 & TRN \\
\hline CHEMBL1596338 & 688239 & 5.2362 & 5.5251 & TRN \\
\hline CHEMBL1478370 & 688239 & 6.9863 & 5.4457 & TRN \\
\hline CHEMBL1322816 & 688239 & 8.3372 & 5.4878 & TRN \\
\hline CHEMBL1516759 & 688239 & 4.6862 & 5.6425 & TRN \\
\hline CHEMBL1405875 & 688239 & 6.5862 & 5.4513 & TRN \\
\hline CHEMBL1595691 & 688239 & 6.5862 & 5.5496 & TRN \\
\hline CHEMBL 3208718 & 688239 & 5.5362 & 5.5206 & TRN \\
\hline CHEMBL1434328 & 688239 & 5.1862 & 5.4046 & TRN \\
\hline CHEMBL1396192 & 688239 & 8.28399 & 99999999 & 5.4277 \\
\hline CHEMBL1394009 & 688239 & 5.3862 & 5.6829 & TRN \\
\hline CHEMBL1307704 & 688239 & 5.9862 & 5.4103 & TRN \\
\hline CHEMBL1440868 & 688239 & 4.6862 & 5.2981 & TRN \\
\hline CHEMBL1336887 & 688239 & 4.7862 & 5.5488 & TRN \\
\hline CHEMBL1562828 & 688239 & 6.9363 & 5.3733 & TRN \\
\hline CHEMBL1576561 & 688239 & 4.5362 & 5.5136 & TRN \\
\hline CHEMBL1565241 & 688239 & 5.7362 & 5.5693 & TRN \\
\hline CHEMBL1483484 & 688239 & 5.0362 & 5.3014 & TRN \\
\hline CHEMBL1431021 & 688239 & 5.4362 & 5.3591 & TRN \\
\hline CHEMBL1567393 & 688239 & 4.8862 & 5.5068 & TRN \\
\hline CHEMBL1600848 & 688239 & 6.2862 & 5.5329 & TRN \\
\hline CHEMBL1473079 & 688239 & 6.0362 & 5.4284 & TRN \\
\hline CHEMBL1386055 & 688239 & 4.5362 & 5.4925 & TRN \\
\hline CHEMBL1305764 & 688239 & 5.1862 & 5.5653 & TRN \\
\hline CHEMBL1336429 & 688239 & 4.5862 & 5.4851 & TRN \\
\hline CHEMBL1609629 & 688239 & 4.4862 & 5.5512 & TRN \\
\hline CHEMBL3210401 & 688239 & 4.5862 & 5.4953 & TST \\
\hline CHEMBL1443764 & 688239 & 8.1367 & 5.5327 & TST \\
\hline CHEMBL1501939 & 688239 & 4.6862 & 5.7118 & TRN \\
\hline CHEMBL1438288 & 688239 & 4.5362 & 5.4939 & TRN \\
\hline CHEMBL1314904 & 688239 & 5.1862 & 5.6947 & TRN \\
\hline CHEMBL1477855 & 688239 & 5.6862 & 5.5504 & TRN \\
\hline CHEMBL1550329 & 688239 & 6.7862 & 5.4217 & TRN \\
\hline CHEMBL1318546 & 688239 & 5.2862 & 5.4448 & TRN \\
\hline CHEMBL1405815 & 688239 & 5.6362 & 5.695 & TRN \\
\hline CHEMBL1495526 & 688239 & 4.5362 & 5.3333 & TRN \\
\hline CHEMBL1314909 & 688239 & 8.3372 & 5.446000 & $\partial 000000001$ \\
\hline CHEMBL1468552 & 688239 & 4.6362 & 5.4278 & TST \\
\hline CHEMBL1434327 & 688239 & 6.1862 & 5.5926 & TST \\
\hline CHEMBL1356803 & 688239 & 4.5362 & 5.5025 & TRN \\
\hline CHEMBL1510626 & 688239 & 4.5362 & 5.4278 & TRN \\
\hline
\end{tabular}


Supplemental Table S2.txt

\begin{tabular}{|c|c|c|c|c|c|}
\hline CHEMBL1330452 & 688239 & 4.5362 & 5.5413 & TRN & \\
\hline CHEMBL1581886 & 688239 & 5.4862 & 5.496 & TRN & \\
\hline CHEMBL1568743 & 688239 & 5.6862 & 5.531000 & 000000001 & \\
\hline CHEMBL1468147 & 688239 & 4.5362 & 5.3232 & TRN & \\
\hline CHEMBL1452721 & 688239 & 4.5362 & 5.5709 & TRN & \\
\hline CHEMBL1332196 & 688239 & 5.6362 & 5.4502 & TRN & \\
\hline CHEMBL1561135 & 688239 & 4.7362 & 5.5271 & TRN & \\
\hline CHEMBL1468023 & 688239 & 4.5362 & 5.4593 & TRN & \\
\hline CHEMBL1527878 & 688239 & 8.2366 & 5.5228 & TRN & \\
\hline CHEMBL1353098 & 688239 & 5.1362 & 5.4696 & TRN & \\
\hline CHEMBL1557276 & 688239 & 5.0362 & 5.5704 & TRN & \\
\hline CHEMBL1403933 & 688239 & 7.2865 & 5.3815 & TRN & \\
\hline CHEMBL1390926 & 688239 & 5.8862 & 5.5458 & TST & \\
\hline CHEMBL1997293 & 688239 & 5.1862 & 5.4118 & TST & \\
\hline CHEMBL1466177 & 688239 & 5.1862 & 5.4027 & TRN & \\
\hline CHEMBL1588438 & 688239 & 4.5362 & 5.4263 & TRN & \\
\hline CHEMBL1377629 & 688239 & 5.8862 & 5.3121 & TRN & \\
\hline CHEMBL1335437 & 688239 & 6.0 & 5.5154 & TST & \\
\hline CHEMBL1556667 & 688239 & 5.3862 & 5.5618 & TRN & \\
\hline CHEMBL1598582 & 688239 & 4.9362 & 5.5645 & TST & \\
\hline CHEMBL1581337 & 688239 & 4.5362 & 5.2597 & TRN & \\
\hline CHEMBL1379289 & 688239 & 5.1862 & 5.4388 & TST & \\
\hline CHEMBL1404992 & 688239 & 5.7362 & 5.5848 & TRN & \\
\hline CHEMBL1538239 & 688239 & 4.5362 & 5.383999 & 9999999995 & \\
\hline CHEMBL3208035 & 688239 & 5.0 & 5.4556 & TRN & \\
\hline CHEMBL1522119 & 688239 & 4.45 & 5.5046 & TRN & \\
\hline CHEMBL3213219 & 688239 & 5.5862 & 5.5134 & TRN & \\
\hline CHEMBL1454459 & 688239 & 6.1862 & 5.5924 & TRN & \\
\hline CHEMBL1533660 & 688239 & 5.5362 & 5.6917 & TST & \\
\hline CHEMBL1573311 & 688239 & 4.5362 & 5.468999 & 999999999 & \\
\hline CHEMBL1345183 & 688239 & 6.7361 & 5.5727 & TRN & \\
\hline CHEMBL1585899 & 688239 & 5.7862 & 5.4062 & TRN & \\
\hline CHEMBL1429311 & 688239 & 4.5362 & 5.4206 & TRN & \\
\hline CHEMBL1346083 & 688239 & 5.6362 & 5.4673 & TRN & \\
\hline CHEMBL1564607 & 688239 & 5.7862 & 5.5955 & TRN & \\
\hline CHEMBL1516754 & 688239 & 6.8362 & 5.5937 & TRN & \\
\hline CHEMBL1608606 & 688239 & 6.8861 & 5.495 & TRN & \\
\hline CHEMBL1478900 & 688239 & 6.8362 & 5.5908 & TRN & \\
\hline CHEMBL1383995 & 688239 & 6.2862 & 5.5535 & TRN & \\
\hline CHEMBL1598010 & 688239 & 6.1862 & 5.4587 & TST & \\
\hline CHEMBL1468595 & 688239 & 8.28399 & )99999999 & 5.5067 & \\
\hline CHEMBL1315020 & 688239 & 4.5362 & 5.5636 & TRN & \\
\hline CHEMBL1306915 & 688239 & 7.0362 & 5.3884 & TST & \\
\hline CHEMBL1306554 & 688239 & 5.2862 & 5.5292 & TRN & \\
\hline CHEMBL1320153 & 688239 & 6.9863 & 5.4807 & TRN & \\
\hline CHEMBL1475077 & 688239 & 4.7862 & 5.4226 & TRN & \\
\hline CHEMBL1562012 & 688239 & 5.6362 & 5.6114 & TRN & \\
\hline CHEMBL1310270 & 688239 & 6.9863 & 5.4519 & TRN & \\
\hline
\end{tabular}


Supplemental Table S2.txt

\begin{tabular}{|c|c|c|c|c|}
\hline CHEMBL1337717 & 688239 & 4.6362 & 5.4911 & TRN \\
\hline CHEMBL1306279 & 688239 & 5.5862 & 5.6389 & TRN \\
\hline CHEMBL1425180 & 688239 & 5.1362 & 5.5464 & TST \\
\hline CHEMBL1557420 & 688239 & 5.1362 & 5.5639 & TRN \\
\hline CHEMBL1427669 & 688239 & 6.7361 & 5.662999 & 999999999 \\
\hline CHEMBL1523632 & 688239 & 6.1362 & 5.6498 & TRN \\
\hline CHEMBL1496971 & 688239 & 5.2862 & 5.5372 & TST \\
\hline CHEMBL1425023 & 688239 & 4.6362 & 5.5515 & TRN \\
\hline CHEMBL1301744 & 688239 & 6.9363 & 5.4619 & TRN \\
\hline CHEMBL1426090 & 688239 & 6.8861 & 5.5046 & TST \\
\hline CHEMBL1474587 & 688239 & 6.8861 & 5.4428 & TRN \\
\hline CHEMBL1576203 & 688239 & 4.4862 & 5.5067 & TRN \\
\hline CHEMBL3191756 & 688239 & 4.7362 & 5.3235 & TRN \\
\hline CHEMBL1404985 & 688239 & 4.8862 & 5.6252 & TRN \\
\hline CHEMBL1322604 & 688239 & 6.8362 & 5.5091 & TRN \\
\hline CHEMBL1607852 & 688239 & 5.4862 & 5.6047 & TRN \\
\hline CHEMBL1414147 & 688239 & 6.0862 & 5.5074 & TST \\
\hline CHEMBL1448611 & 688239 & 5.1862 & 5.4944 & TRN \\
\hline CHEMBL1575336 & 688239 & 4.7862 & 5.4994 & TRN \\
\hline CHEMBL1335472 & 688239 & 4.5362 & 5.5722 & TRN \\
\hline CHEMBL1547200 & 688239 & 6.1862 & 5.4533 & TRN \\
\hline CHEMBL1377826 & 688239 & 4.5362 & 5.5453 & TRN \\
\hline CHEMBL1610114 & 688239 & 6.7862 & 5.5886 & TRN \\
\hline CHEMBL1371918 & 688239 & 8.3372 & 5.3752 & TST \\
\hline CHEMBL1578803 & 688239 & 5.1362 & 5.5935 & TRN \\
\hline CHEMBL1608612 & 688239 & 6.8362 & 5.5717 & TRN \\
\hline CHEMBL1451822 & 688239 & 4.5362 & 5.3922 & TRN \\
\hline CHEMBL1367231 & 688239 & 5.5362 & 5.5562 & TRN \\
\hline CHEMBL1372022 & 688239 & 4.5362 & 5.5004 & TST \\
\hline CHEMBL1370841 & 688239 & 4.7862 & 5.4321 & TRN \\
\hline CHEMBL1489995 & 688239 & 6.2362 & 5.4976 & TRN \\
\hline CHEMBL1548676 & 688239 & 7.1361 & 5.5574 & TST \\
\hline CHEMBL1425998 & 688239 & 4.6862 & 5.3818 & TRN \\
\hline CHEMBL1350954 & 688239 & 4.6862 & 5.465 & TST \\
\hline CHEMBL1445386 & 688239 & 4.5362 & 5.4455 & TST \\
\hline CHEMBL1310857 & 688239 & 4.5362 & 5.3108 & TST \\
\hline CHEMBL1330991 & 688239 & 6.8362 & 5.3929 & TST \\
\hline CHEMBL1573017 & 688239 & 5.6862 & 5.4204 & TRN \\
\hline CHEMBL1612633 & 688239 & 4.5362 & 5.5186 & TST \\
\hline CHEMBL411085 & 688239 & 5.6862 & 5.5104 & TRN \\
\hline CHEMBL578162 & 688239 & 5.0362 & 5.3086 & TST \\
\hline CHEMBL1571927 & 688239 & 4.6862 & 5.4979 & TST \\
\hline CHEMBL1442391 & 688239 & 4.5362 & 5.4858 & TRN \\
\hline CHEMBL1352643 & 688239 & 5.1862 & 5.6135 & TRN \\
\hline CHEMBL1517126 & 688239 & 4.5362 & 5.5724 & TRN \\
\hline CHEMBL1312092 & 688239 & 5.3862 & 5.4839 & TRN \\
\hline CHEMBL1550172 & 688239 & 4.5862 & 5.5051 & TRN \\
\hline CHEMBL1494415 & 688239 & 4.9362 & 5.4449 & TRN \\
\hline
\end{tabular}




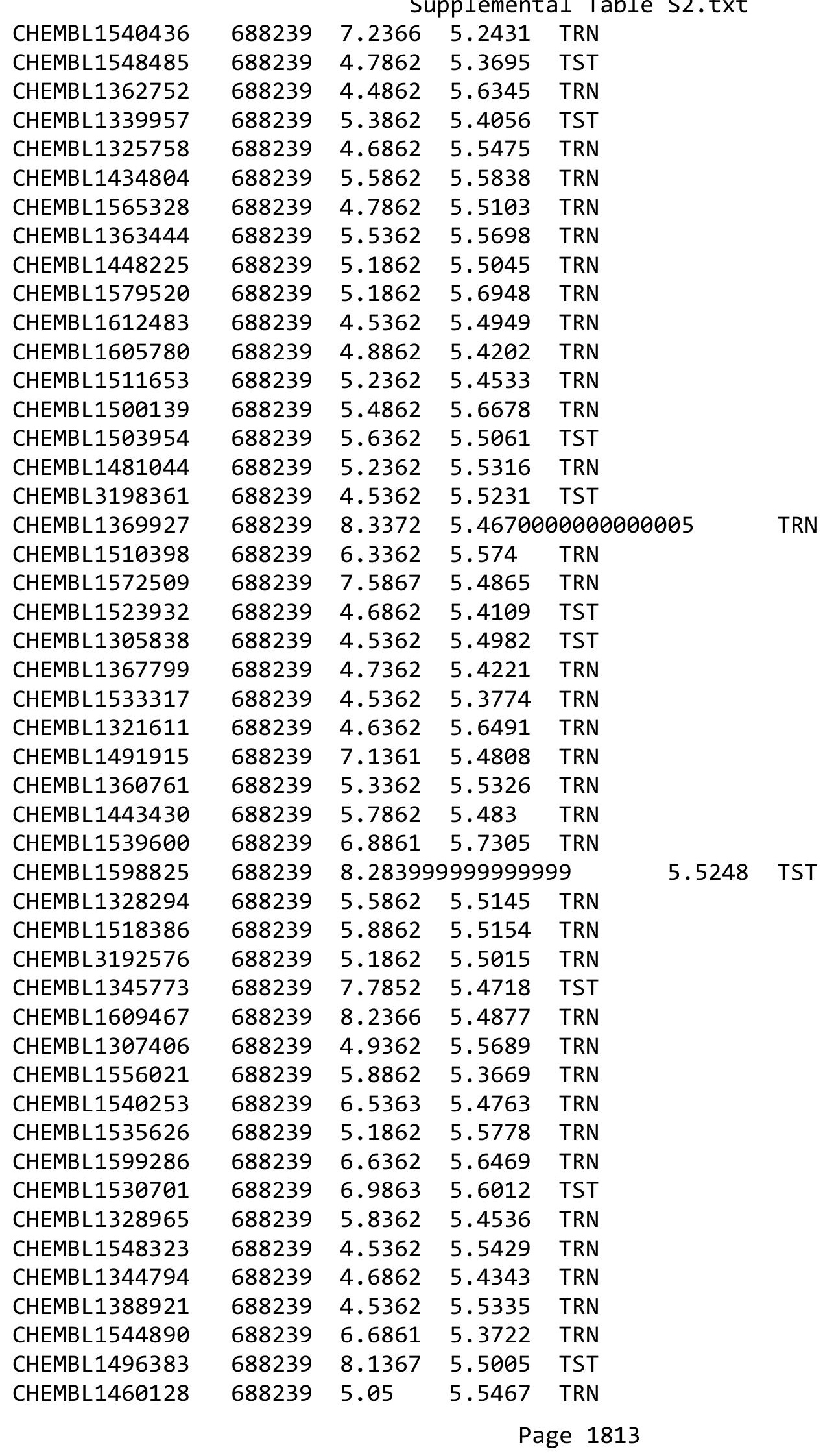


Supplemental Table S2.txt

\begin{tabular}{|c|c|c|c|c|c|}
\hline CHEMBL1513865 & 688239 & 5.0862 & 5.5042 & TRN & \\
\hline CHEMBL1309943 & 688239 & 4.5862 & 5.4608 & TRN & \\
\hline CHEMBL3210745 & 688239 & 6.3863 & 5.629 & TST & \\
\hline CHEMBL1331480 & 688239 & 8.3372 & 5.6325 & TRN & \\
\hline CHEMBL1379258 & 688239 & 4.5362 & 5.5457 & TRN & \\
\hline CHEMBL1331753 & 688239 & 6.0862 & 5.3476 & TST & \\
\hline CHEMBL1426292 & 688239 & 4.7862 & 5.5108 & TST & \\
\hline CHEMBL1508249 & 688239 & 6.3362 & 5.5837 & TRN & \\
\hline CHEMBL1517959 & 688239 & 8.3372 & 5.4808 & TRN & \\
\hline CHEMBL1331270 & 688239 & 6.1 & 5.4279 & TST & \\
\hline CHEMBL1594562 & 688239 & 5.1862 & 5.6659 & TRN & \\
\hline CHEMBL1445719 & 688239 & 5.0862 & 5.566 & TRN & \\
\hline CHEMBL595273 & 688239 & 6.1362 & 5.4512 & TRN & \\
\hline CHEMBL1387046 & 688239 & 5.4362 & 5.6752 & TRN & \\
\hline CHEMBL1373268 & 688239 & 4.5362 & 5.4761 & TRN & \\
\hline CHEMBL1479852 & 688239 & 5.1862 & 5.4215 & TRN & \\
\hline CHEMBL1333584 & 688239 & 5.4362 & 5.5521 & TRN & \\
\hline CHEMBL1406058 & 688239 & 7.5361 & 5.4947 & TRN & \\
\hline CHEMBL1343800 & 688239 & 5.8362 & 5.3091 & TST & \\
\hline CHEMBL1351639 & 688239 & 4.4862 & 5.54200 & 0000000001 & TRN \\
\hline CHEMBL1322110 & 688239 & 4.5362 & 5.4357 & TST & \\
\hline CHEMBL1485482 & 688239 & 5.7362 & 5.4685 & TRN & \\
\hline CHEMBL1370950 & 688239 & 5.4362 & 5.4584 & TRN & \\
\hline CHEMBL1973995 & 688239 & 8.2366 & 5.3731 & TRN & \\
\hline CHEMBL1479835 & 688239 & 5.1862 & 5.45299 & 7999999999 & TRN \\
\hline CHEMBL1522143 & 688239 & 4.5362 & 5.2933 & TRN & \\
\hline CHEMBL1490225 & 688239 & 4.8362 & 5.3592 & TRN & \\
\hline CHEMBL589703 & 688239 & 4.5362 & 5.3456 & TRN & \\
\hline CHEMBL1566263 & 688239 & 5.1362 & 5.3899 & TRN & \\
\hline CHEMBL1364606 & 688239 & 5.3862 & 5.5496 & TST & \\
\hline CHEMBL1543696 & 688239 & \multicolumn{3}{|c|}{8.283999999999999} & TRN \\
\hline CHEMBL1305086 & 688239 & 4.6862 & 5.5735 & TRN & \\
\hline CHEMBL3196149 & 688239 & 5.6862 & 5.4826 & TRN & \\
\hline CHEMBL1559631 & 688239 & 4.5362 & 5.5985 & TRN & \\
\hline CHEMBL1373624 & 688239 & 5.4362 & 5.4765 & TST & \\
\hline CHEMBL1321533 & 688239 & 5.0362 & 5.3498 & TRN & \\
\hline CHEMBL1512206 & 688239 & 4.6862 & 5.4431 & TRN & \\
\hline CHEMBL1370640 & 688239 & 5.7362 & 5.5214 & TRN & \\
\hline CHEMBL1302791 & 688239 & 4.5362 & 5.5304 & TRN & \\
\hline CHEMBL1416877 & 688239 & 5.1862 & 5.5121 & TRN & \\
\hline CHEMBL1530537 & 688239 & 4.7862 & 5.4858 & TST & \\
\hline CHEMBL1579090 & 688239 & 5.1862 & 5.6156 & TRN & \\
\hline CHEMBL1485261 & 688239 & 4.5862 & 5.5508 & TST & \\
\hline CHEMBL1551811 & 688239 & 4.5362 & 5.1927 & TRN & \\
\hline CHEMBL1571213 & 688239 & 5.7862 & 5.41799 & 9999999999 & $\mathrm{In}$ \\
\hline CHEMBL1561706 & 688239 & 6.8861 & 5.4558 & TST & \\
\hline CHEMBL1508072 & 688239 & 5.1862 & 5.4581 & TST & \\
\hline CHEMBL1432296 & 688239 & 4.7362 & 5.3942 & TST & \\
\hline
\end{tabular}


Supplemental Table S2.txt

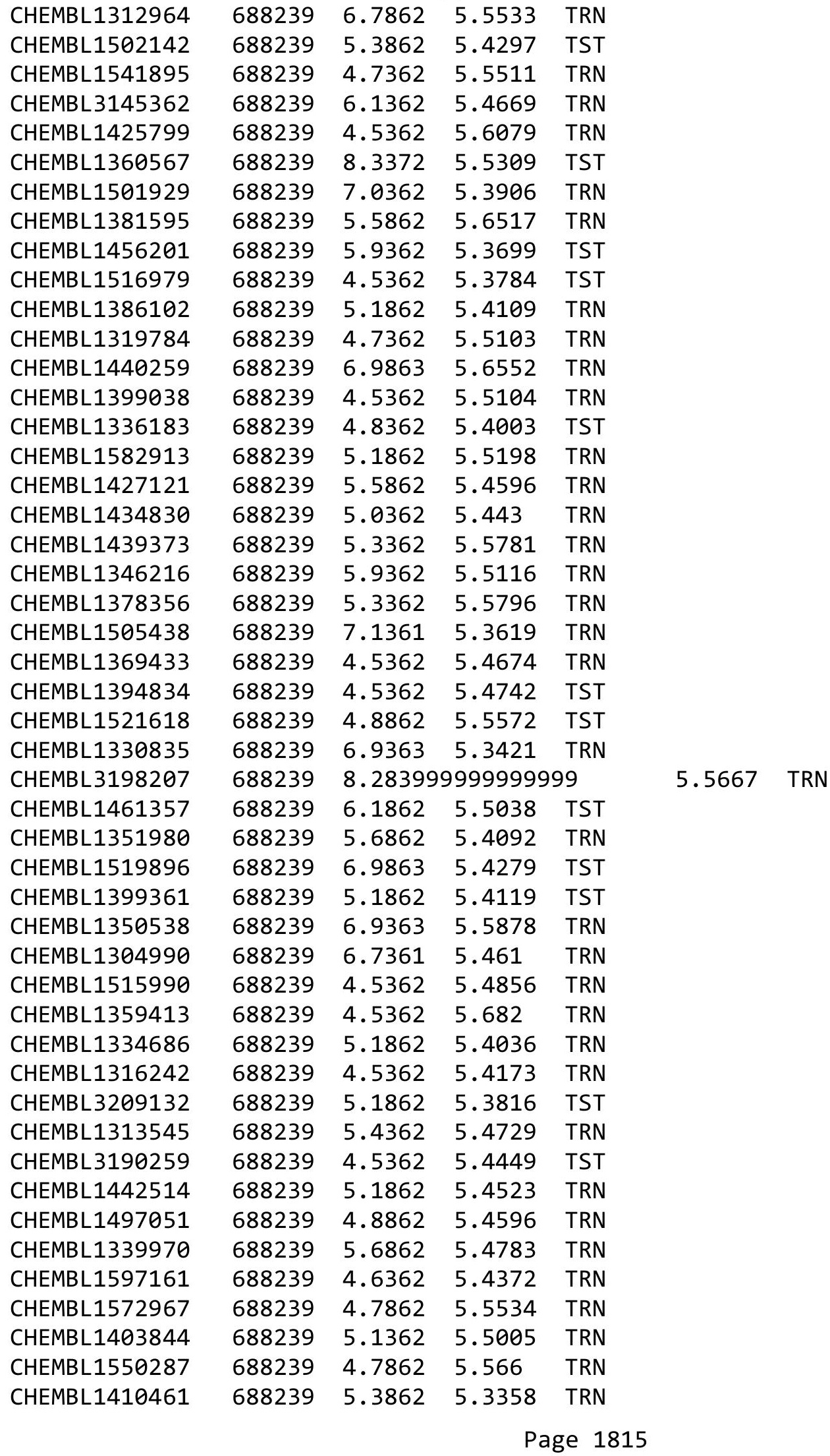


Supplemental Table S2.txt

\begin{tabular}{|c|c|c|c|c|}
\hline CHEMBL1311787 & 688239 & 4.9862 & 5.5633 & TRN \\
\hline CHEMBL1543806 & 688239 & 4.5362 & 5.6587 & TRN \\
\hline CHEMBL1542910 & 688239 & 5.3862 & 5.4184 & TRN \\
\hline CHEMBL1538087 & 688239 & 6.8861 & 5.5428 & TRN \\
\hline CHEMBL1600678 & 688239 & 4.5362 & 5.4896 & TRN \\
\hline CHEMBL1558430 & 688239 & 5.1862 & 5.4128 & TST \\
\hline CHEMBL1530687 & 688239 & 5.9862 & 5.5438 & TST \\
\hline CHEMBL1468097 & 688239 & 5.1862 & 5.4178 & TST \\
\hline CHEMBL1565316 & 688239 & 4.7362 & 5.5143 & TST \\
\hline CHEMBL1416618 & 688239 & 4.5862 & 5.5157 & TST \\
\hline CHEMBL1493197 & 688239 & 5.8862 & 5.4315 & TST \\
\hline CHEMBL1379454 & 688239 & 6.0862 & 5.5627 & TRN \\
\hline CHEMBL1582683 & 688239 & 4.8362 & 5.5632 & TST \\
\hline CHEMBL1581057 & 688239 & 6.5363 & 5.588999 & 9999999995 \\
\hline CHEMBL1484112 & 688239 & 8.283999 & 999999999 & 5.4863 \\
\hline CHEMBL1421868 & 688239 & 4.5362 & 5.5072 & TRN \\
\hline CHEMBL1481849 & 688239 & 4.6362 & 5.1243 & TRN \\
\hline CHEMBL1325857 & 688239 & 5.4362 & 5.5933 & TRN \\
\hline CHEMBL1415520 & 688239 & 4.5362 & 5.5703 & TST \\
\hline CHEMBL1393856 & 688239 & 5.4362 & 5.4615 & TRN \\
\hline CHEMBL1509787 & 688239 & 5.7862 & 5.4872 & TST \\
\hline CHEMBL1441681 & 688239 & 5.6862 & 5.4205 & TRN \\
\hline CHEMBL1545214 & 688239 & 4.6862 & 5.4613 & TRN \\
\hline CHEMBL 3190412 & 688239 & 4.5362 & 5.3383 & TRN \\
\hline CHEMBL1326230 & 688239 & 7.0862 & 5.4103 & TRN \\
\hline CHEMBL1585461 & 688239 & 5.1862 & 5.5999 & TRN \\
\hline CHEMBL1541879 & 688239 & 5.3862 & 5.6462 & TRN \\
\hline CHEMBL1370083 & 688239 & 4.5362 & 5.6134 & TST \\
\hline CHEMBL1401821 & 688239 & 4.6862 & 5.4343 & TRN \\
\hline CHEMBL1353260 & 688239 & 4.5362 & 5.3603 & TRN \\
\hline CHEMBL1318973 & 688239 & 4.5362 & 5.5222 & TRN \\
\hline CHEMBL1311912 & 688239 & 4.7862 & 5.3207 & TRN \\
\hline CHEMBL1550321 & 688239 & 4.7362 & 5.4859 & TRN \\
\hline CHEMBL1483952 & 688239 & 8.3372 & 5.5362 & TRN \\
\hline CHEMBL1331787 & 688239 & 6.1862 & 5.4117 & TRN \\
\hline CHEMBL1576266 & 688239 & 4.5362 & 5.4076 & TRN \\
\hline CHEMBL1392338 & 688239 & 5.1862 & 5.5853 & TRN \\
\hline CHEMBL1581117 & 688239 & 5.8862 & 5.4396 & TRN \\
\hline CHEMBL1451107 & 688239 & 6.1362 & 5.3747 & TRN \\
\hline CHEMBL1606623 & 688239 & 5.1362 & 5.5297 & TST \\
\hline CHEMBL1527528 & 688239 & 6.8861 & 5.3279 & TRN \\
\hline CHEMBL1567155 & 688239 & 6.1862 & 5.5434 & TRN \\
\hline CHEMBL1393641 & 688239 & 4.5362 & 5.4399 & TRN \\
\hline CHEMBL 3199665 & 688239 & 4.7362 & 5.3518 & TST \\
\hline CHEMBL1565713 & 688239 & 6.1362 & 5.4652 & TST \\
\hline CHEMBL1608709 & 688239 & 5.5862 & 5.414 & TRN \\
\hline CHEMBL1382031 & 688239 & 6.5862 & 5.4489 & TRN \\
\hline CHEMBL1592295 & 688239 & 6.2362 & 5.5471 & TRN \\
\hline
\end{tabular}




\begin{tabular}{|c|c|c|c|c|c|}
\hline \multicolumn{6}{|c|}{ Supplemental Table S2.txt } \\
\hline CHEMBL1337768 & 688239 & 5.4362 & 5.5694 & TST & \\
\hline CHEMBL1377188 & 688239 & 4.5362 & 5.5619 & TST & \\
\hline CHEMBL1417193 & 688239 & 5.7362 & 5.5019 & TRN & \\
\hline CHEMBL1433663 & 688239 & 4.5362 & 5.4039 & TRN & \\
\hline CHEMBL1384079 & 688239 & 4.5362 & 5.3802 & TRN & \\
\hline CHEMBL1488412 & 688239 & 4.9862 & 5.3873 & TST & \\
\hline CHEMBL1497270 & 688239 & 6.1362 & 5.4939 & TST & \\
\hline CHEMBL1403111 & 688239 & 6.2862 & 5.5499 & TRN & \\
\hline CHEMBL1341292 & 688239 & 5.4862 & 5.561 & TRN & \\
\hline CHEMBL1579260 & 688239 & 5.0862 & 5.4911 & TRN & \\
\hline CHEMBL1425943 & 688239 & 4.7862 & 5.3231 & TRN & \\
\hline CHEMBL1503753 & 688239 & 6.6861 & 5.4784 & TRN & \\
\hline CHEMBL1302865 & 688239 & 5.1362 & 5.46200 & 3000000001 & TRN \\
\hline CHEMBL1301281 & 688239 & 7.0862 & 5.4129 & TRN & \\
\hline CHEMBL1487586 & 688239 & 5.3362 & 5.3645 & TRN & \\
\hline CHEMBL1569030 & 688239 & 5.4362 & 5.5721 & TST & \\
\hline CHEMBL1407664 & 688239 & 6.8362 & 5.4612 & TRN & \\
\hline CHEMBL1304509 & 688239 & 4.9362 & 5.6099 & TRN & \\
\hline CHEMBL1505802 & 688239 & 5.5862 & 5.3478 & TRN & \\
\hline CHEMBL1567275 & 688239 & 5.5862 & 5.5059 & TRN & \\
\hline CHEMBL1354980 & 688239 & 4.7862 & 5.5038 & TRN & \\
\hline CHEMBL1511147 & 688239 & 5.6862 & 5.5251 & TST & \\
\hline CHEMBL1459514 & 688239 & 4.5862 & 5.3131 & TST & \\
\hline CHEMBL1577573 & 688239 & 6.9363 & 5.46 & TRN & \\
\hline CHEMBL1345235 & 688239 & 5.6862 & 5.45700 & 0000000001 & TRN \\
\hline CHEMBL1579827 & 688239 & 5.1862 & 5.4037 & TST & \\
\hline CHEMBL1608870 & 688239 & 5.0362 & 5.3618 & TRN & \\
\hline CHEMBL1485657 & 688239 & 5.2362 & 5.3704 & TRN & \\
\hline CHEMBL1497035 & 688239 & 5.4862 & 5.5806 & TRN & \\
\hline CHEMBL1449795 & 688239 & 5.1862 & 5.5864 & TST & \\
\hline CHEMBL1303872 & 688239 & 4.7862 & 5.5179 & TRN & \\
\hline CHEMBL1498148 & 688239 & 5.6362 & 5.4499 & TRN & \\
\hline CHEMBL1499027 & 688239 & 5.3862 & 5.4414 & TRN & \\
\hline CHEMBL1603022 & 688239 & 6.9363 & 5.5129 & TST & \\
\hline CHEMBL1562503 & 688239 & 5.7362 & 5.6104 & TRN & \\
\hline CHEMBL3191173 & 688239 & 4.5362 & 5.6559 & TST & \\
\hline CHEMBL1309717 & 688239 & 4.7862 & 5.3728 & TRN & \\
\hline CHEMBL1401996 & 688239 & 5.5862 & 5.4764 & TRN & \\
\hline CHEMBL1506193 & 688239 & 4.6362 & 5.3813 & TST & \\
\hline CHEMBL1498253 & 688239 & 5.4362 & 5.5435 & TRN & \\
\hline CHEMBL1593040 & 688239 & 6.9863 & 5.2804 & TRN & \\
\hline CHEMBL1344918 & 688239 & 5.5362 & 5.3792 & TRN & \\
\hline CHEMBL1369979 & 688239 & 4.6862 & 5.5622 & TRN & \\
\hline CHEMBL1393436 & 688239 & 5.3862 & 5.47 & TRN & \\
\hline CHEMBL1312169 & 688239 & 4.7362 & 5.3998 & TRN & \\
\hline CHEMBL1361040 & 688239 & 5.4362 & 5.4084 & TST & \\
\hline CHEMBL1582908 & 688239 & 4.7362 & 5.5135 & TRN & \\
\hline CHEMBL1516017 & 688239 & 5.0362 & 5.4858 & TRN & \\
\hline
\end{tabular}


Supplemental Table S2.txt

\begin{tabular}{|c|c|c|c|c|c|}
\hline CHEMBL1556517 & 688239 & 5.0362 & 5.3681 & TRN & \\
\hline CHEMBL1328081 & 688239 & 5.7362 & 5.6443 & TRN & \\
\hline CHEMBL1512696 & 688239 & 5.9362 & 5.546 & TRN & \\
\hline CHEMBL1362312 & 688239 & 4.7362 & 5.5407 & TRN & \\
\hline CHEMBL1601521 & 688239 & 4.5362 & 5.5563 & TRN & \\
\hline CHEMBL1421430 & 688239 & 7.2366 & 5.6579 & TRN & \\
\hline CHEMBL1551891 & 688239 & 5.6362 & 5.5766 & TRN & \\
\hline CHEMBL1556900 & 688239 & 4.4862 & 5.4658 & TST & \\
\hline CHEMBL1341489 & 688239 & 5.6362 & 5.4879 & TRN & \\
\hline CHEMBL1488842 & 688239 & 6.5363 & 5.4281 & TRN & \\
\hline CHEMBL1493512 & 688239 & 5.3362 & 5.6269 & TRN & \\
\hline CHEMBL1575094 & 688239 & 6.1862 & 5.3705 & TST & \\
\hline CHEMBL1374761 & 688239 & 5.9862 & 5.6421 & TRN & \\
\hline CHEMBL1612933 & 688239 & 6.9863 & 5.3967 & TST & \\
\hline CHEMBL1351817 & 688239 & 5.5362 & 5.4967 & TRN & \\
\hline CHEMBL1580066 & 688239 & 4.7362 & 5.484 & TRN & \\
\hline CHEMBL1362492 & 688239 & 4.5362 & 5.6536 & TRN & \\
\hline CHEMBL1399111 & 688239 & 6.7361 & 5.4678 & TST & \\
\hline CHEMBL3199874 & 688239 & 5.8862 & 5.3594 & TST & \\
\hline CHEMBL1327012 & 688239 & 6.1862 & 5.4549 & TRN & \\
\hline CHEMBL1587223 & 688239 & 5.1362 & 5.5737 & TRN & \\
\hline CHEMBL1575308 & 688239 & 6.8861 & 5.4851 & TRN & \\
\hline CHEMBL1993612 & 688239 & 5.5862 & 5.6115 & TRN & \\
\hline CHEMBL1471104 & 688239 & 5.4862 & 5.428999 & 999999999 & TRN \\
\hline CHEMBL1381866 & 688239 & 6.0862 & 5.6155 & TST & \\
\hline CHEMBL1499889 & 688239 & 4.5362 & 5.4466 & TRN & \\
\hline CHEMBL1340790 & 688239 & 5.4362 & 5.484 & TRN & \\
\hline CHEMBL1371187 & 688239 & 5.5362 & 5.6036 & TRN & \\
\hline CHEMBL1572274 & 688239 & 5.9362 & 5.5995 & TRN & \\
\hline CHEMBL1388315 & 688239 & 4.9362 & 5.4119 & TRN & \\
\hline CHEMBL1368653 & 688239 & 6.3863 & 5.4477 & TRN & \\
\hline CHEMBL1428704 & 688239 & 6.5363 & 5.5393 & TRN & \\
\hline CHEMBL3208939 & 688239 & 7.8356 & 5.3922 & TRN & \\
\hline CHEMBL1325980 & 688239 & 6.8861 & 5.5086 & TRN & \\
\hline CHEMBL1439322 & 688239 & 4.4862 & 5.3226 & TRN & \\
\hline CHEMBL1462384 & 688239 & 6.0862 & 5.6238 & TRN & \\
\hline CHEMBL1528399 & 688239 & 5.3862 & 5.4742 & TRN & \\
\hline CHEMBL1518078 & 688239 & 4.5362 & 5.4697 & TRN & \\
\hline CHEMBL1448456 & 688239 & 6.2362 & 5.4719 & TRN & \\
\hline CHEMBL1580587 & 688239 & 5.9362 & 5.4567 & TST & \\
\hline CHEMBL1472276 & 688239 & 6.8362 & 5.4226 & TRN & \\
\hline CHEMBL1526700 & 688239 & 4.4862 & 5.5173 & TST & \\
\hline CHEMBL1442215 & 688239 & 7.4365 & 5.4188 & TST & \\
\hline CHEMBL1425893 & 688239 & 5.7362 & 5.507000 & 000000001 & TST \\
\hline CHEMBL1472560 & 688239 & 4.7362 & 5.3897 & TST & \\
\hline CHEMBL1537275 & 688239 & 8.28399 & 999999999 & 5.4133 & $\mathrm{TKT}$ \\
\hline CHEMBL1339737 & 688239 & 5.3862 & 5.4796 & TRN & \\
\hline CHEMBL1508375 & 688239 & 6.0 & 5.4039 & TRN & \\
\hline
\end{tabular}


Supplemental Table S2.txt

\begin{tabular}{|c|c|c|c|c|c|}
\hline CHEMBL1376003 & 688239 & 4.7862 & 5.4387 & TRN & \\
\hline CHEMBL1324387 & 688239 & 7.0862 & 5.4565 & TRN & \\
\hline CHEMBL1499342 & 688239 & 8.28399 & 99999999 & 5.3164 & TRN \\
\hline CHEMBL1341361 & 688239 & 4.8362 & 5.5082 & TST & \\
\hline CHEMBL1481330 & 688239 & 5.6862 & 5.507999 & 9999999999 & TRN \\
\hline CHEMBL1411917 & 688239 & 5.8362 & 5.4725 & TRN & \\
\hline CHEMBL1477518 & 688239 & 4.5362 & 5.4035 & TRN & \\
\hline CHEMBL1343563 & 688239 & 6.8362 & 5.5159 & TRN & \\
\hline CHEMBL1453355 & 688239 & 6.8861 & 5.3621 & TRN & \\
\hline CHEMBL1507781 & 688239 & 4.5362 & 5.5236 & TST & \\
\hline CHEMBL1469102 & 688239 & 4.7862 & 5.3975 & TRN & \\
\hline CHEMBL1458751 & 688239 & 4.5362 & 5.4706 & TRN & \\
\hline CHEMBL1382052 & 688239 & 8.3372 & 5.4711 & TRN & \\
\hline CHEMBL1584283 & 688239 & 6.2862 & 5.5261 & TRN & \\
\hline CHEMBL3195845 & 688239 & 5.8362 & 5.3631 & TST & \\
\hline CHEMBL3192785 & 688239 & 6.8362 & 5.5596 & TST & \\
\hline CHEMBL1402217 & 688239 & 4.7862 & 5.5186 & TRN & \\
\hline CHEMBL1607349 & 688239 & 5.9362 & 5.382000 & 0000000001 & TST \\
\hline CHEMBL1380834 & 688239 & 5.0362 & 5.5912 & TRN & \\
\hline CHEMBL3209553 & 688239 & 5.1862 & 5.4046 & TRN & \\
\hline CHEMBL1240756 & 688239 & 4.5362 & 5.6326 & TRN & \\
\hline CHEMBL1523708 & 688239 & 5.1862 & 5.446000 & 0000000001 & TRN \\
\hline CHEMBL1477836 & 688239 & 4.5362 & 5.3763 & TST & \\
\hline CHEMBL3208579 & 688239 & 4.7362 & 5.5237 & TRN & \\
\hline CHEMBL1370839 & 688239 & 6.4862 & 5.4245 & TRN & \\
\hline CHEMBL1315629 & 688239 & 5.6862 & 5.5476 & TRN & \\
\hline CHEMBL1505034 & 688239 & 4.5362 & 5.396 & TRN & \\
\hline CHEMBL1993199 & 688239 & 6.9363 & 5.2656 & TST & \\
\hline CHEMBL1502732 & 688239 & 5.1362 & 5.4467 & TRN & \\
\hline CHEMBL1361094 & 688239 & 6.7862 & 5.5 & TRN & \\
\hline CHEMBL1453110 & 688239 & 8.2366 & 5.5093 & TST & \\
\hline CHEMBL1430886 & 688239 & 4.5362 & 5.4195 & TRN & \\
\hline CHEMBL1426035 & 688239 & 6.2362 & 5.4551 & TRN & \\
\hline CHEMBL3197391 & 688239 & 5.1862 & 5.2175 & TRN & \\
\hline CHEMBL1429386 & 688239 & 6.9863 & 5.4283 & TRN & \\
\hline CHEMBL1477433 & 688239 & 5.5362 & 5.592000 & 30000000005 & TRN \\
\hline CHEMBL 1483073 & 688239 & 4.7862 & 5.3681 & TRN & \\
\hline CHEMBL1541241 & 688239 & 4.7862 & 5.3504 & TST & \\
\hline CHEMBL1528265 & 688239 & 5.2862 & 5.4045 & TST & \\
\hline CHEMBL1502115 & 688239 & 6.1862 & 5.5327 & TRN & \\
\hline CHEMBL1531736 & 688239 & 4.5362 & 5.5987 & TRN & \\
\hline CHEMBL 1408002 & 688239 & 6.4862 & 5.4912 & TRN & \\
\hline CHEMBL1567584 & 688239 & 4.7362 & 5.4285 & TST & \\
\hline CHEMBL1462498 & 688239 & 6.8861 & 5.5665 & TRN & \\
\hline CHEMBL1410566 & 688239 & 4.5362 & 5.5495 & TST & \\
\hline CHEMBL1556788 & 688239 & 6.1862 & 5.3875 & TRN & \\
\hline CHEMBL1349064 & 688239 & 4.5362 & 5.4875 & TRN & \\
\hline CHEMBL3209638 & 688239 & 6.7862 & 5.4407 & TRN & \\
\hline
\end{tabular}


Supplemental Table S2.txt

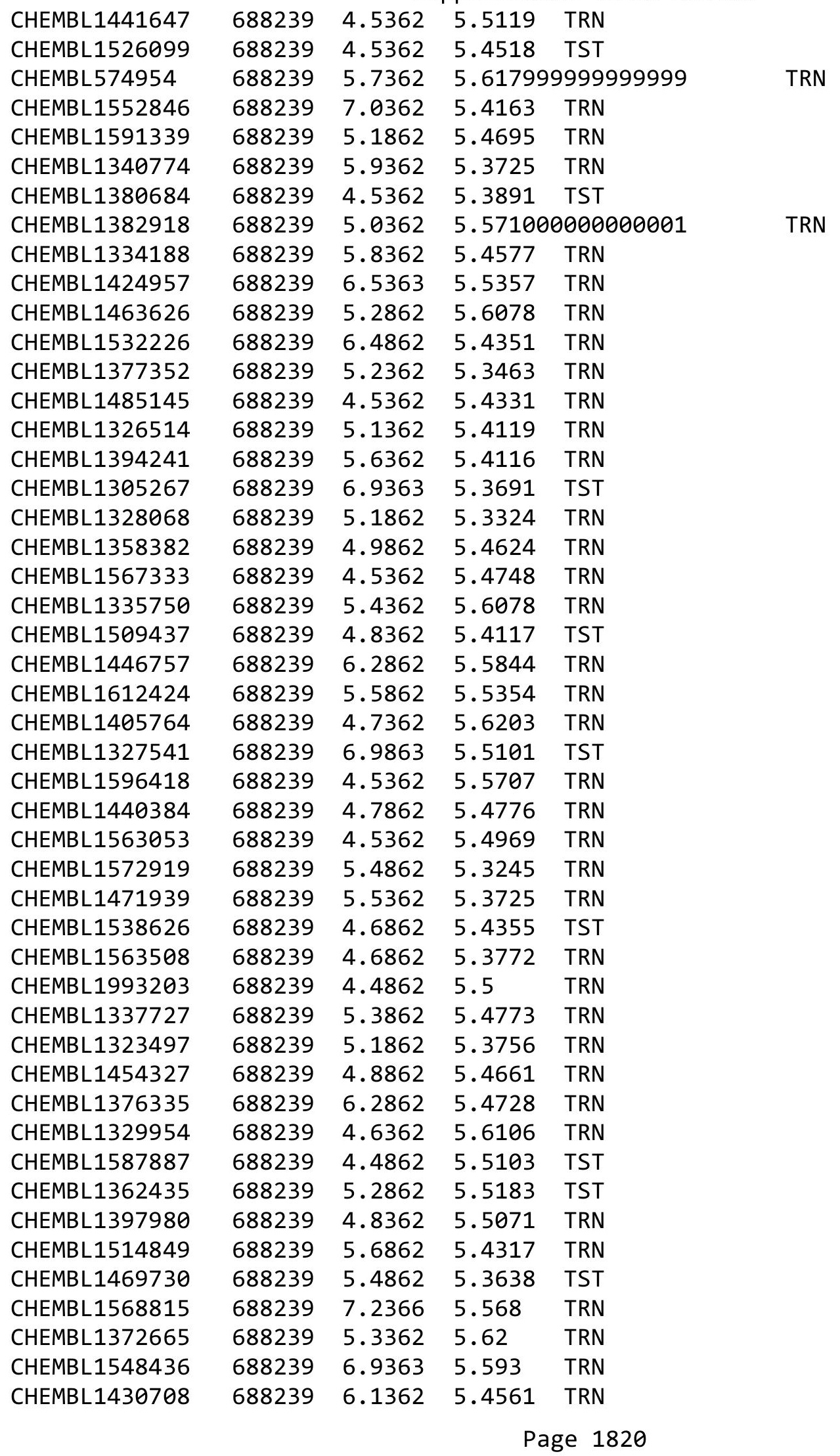


Supplemental Table S2.txt

\begin{tabular}{|c|c|c|c|c|c|}
\hline CHEMBL1435162 & 688239 & 4.5362 & 5.5325 & TRN & \\
\hline CHEMBL1476336 & 688239 & 6.9863 & 5.6606 & TRN & \\
\hline CHEMBL1558448 & 688239 & 6.6861 & 5.5196 & TST & \\
\hline CHEMBL1402120 & 688239 & 5.8862 & 5.6676 & TRN & \\
\hline CHEMBL1399333 & 688239 & 4.6862 & 5.391 & TRN & \\
\hline CHEMBL 3212210 & 688239 & 5.0862 & 5.4362 & TRN & \\
\hline CHEMBL1542193 & 688239 & 6.4862 & 5.5038 & TRN & \\
\hline CHEMBL1307248 & 688239 & 5.3362 & 5.4482 & TRN & \\
\hline CHEMBL1579296 & 688239 & 6.0362 & 5.4338 & TRN & \\
\hline CHEMBL1308129 & 688239 & 5.0862 & 5.4563 & TRN & \\
\hline CHEMBL1546865 & 688239 & 4.5362 & 5.6362 & TRN & \\
\hline CHEMBL1445474 & 688239 & 6.1862 & 5.593999 & 999999999 & TRN \\
\hline CHEMBL1460309 & 688239 & 5.7 & 5.3468 & TRN & \\
\hline CHEMBL1328665 & 688239 & 5.7862 & 5.6335 & TRN & \\
\hline CHEMBL1546079 & 688239 & 7.2366 & 5.3994 & TST & \\
\hline CHEMBL1504315 & 688239 & 5.6362 & 5.6073 & TRN & \\
\hline CHEMBL1596359 & 688239 & 6.2362 & 5.4265 & TRN & \\
\hline CHEMBL1393792 & 688239 & 5.1362 & 5.5341 & TRN & \\
\hline CHEMBL1580244 & 688239 & 5.4362 & 5.4797 & TST & \\
\hline CHEMBL1573024 & 688239 & 5.4362 & 5.3911 & TRN & \\
\hline CHEMBL1319637 & 688239 & 5.3362 & 5.4201 & TRN & \\
\hline CHEMBL1600091 & 688239 & 6.5363 & 5.5757 & TRN & \\
\hline CHEMBL1561328 & 688239 & 4.5362 & 5.3421 & TST & \\
\hline CHEMBL1599610 & 688239 & 5.1362 & 5.3062 & TRN & \\
\hline CHEMBL1335002 & 688239 & 5.0862 & 5.385 & TST & \\
\hline CHEMBL1978989 & 688239 & 4.8862 & 5.4297 & TRN & \\
\hline CHEMBL1345673 & 688239 & 6.1362 & 5.6241 & TRN & \\
\hline CHEMBL 3207298 & 688239 & 5.4862 & 5.499 & TRN & \\
\hline CHEMBL1333942 & 688239 & 4.7862 & 5.5433 & TRN & \\
\hline CHEMBL1606468 & 688239 & 5.1362 & 5.5145 & TRN & \\
\hline CHEMBL1355621 & 688239 & 4.5362 & 5.4926 & TRN & \\
\hline CHEMBL1593092 & 688239 & 5.1862 & 5.6587 & TRN & \\
\hline CHEMBL1375926 & 688239 & 8.3372 & 5.3577 & TRN & \\
\hline CHEMBL1553799 & 688239 & 4.5362 & 5.5132 & TRN & \\
\hline CHEMBL1324979 & 688239 & 5.9862 & 5.4501 & TST & \\
\hline CHEMBL1319555 & 688239 & 8.28399 & 99999999 & 5.482 & TR \\
\hline CHEMBL1584527 & 688239 & 6.2862 & 5.5499 & TRN & \\
\hline CHEMBL1392394 & 688239 & 4.6862 & 5.4147 & TRN & \\
\hline CHEMBL1537874 & 688239 & 5.1862 & 5.4372 & TST & \\
\hline CHEMBL1605376 & 688239 & 6.1862 & 5.4587 & TRN & \\
\hline CHEMBL1527620 & 688239 & 4.6862 & 5.4188 & TRN & \\
\hline CHEMBL1603553 & 688239 & 4.7 & 5.506 & TRN & \\
\hline CHEMBL3199386 & 688239 & 5.1862 & 5.5254 & TRN & \\
\hline CHEMBL1611293 & 688239 & 5.1862 & 5.5402 & TRN & \\
\hline CHEMBL1579108 & 688239 & 5.8862 & 5.367000 & 000000001 & 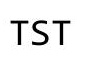 \\
\hline CHEMBL581880 & 688239 & 4.7362 & 5.3034 & TRN & \\
\hline CHEMBL1569474 & 688239 & 8.28399 & 99999999 & 5.6326 & S \\
\hline CHEMBL1537683 & 688239 & 7.7352 & 5.5068 & TRN & \\
\hline
\end{tabular}


Supplemental Table S2.txt

\begin{tabular}{|c|c|c|c|c|}
\hline CHEMBL1335097 & 688239 & 4.9362 & 5.5187 & TRN \\
\hline CHEMBL1554168 & 688239 & 5.5862 & 5.6351 & TRN \\
\hline CHEMBL1532314 & 688239 & 4.5362 & 5.5572 & TST \\
\hline CHEMBL1539002 & 688239 & 5.7362 & 5.4806 & TRN \\
\hline CHEMBL1592937 & 688239 & 5.2862 & 5.2682 & TRN \\
\hline CHEMBL1567500 & 688239 & 4.9862 & 5.5077 & TRN \\
\hline CHEMBL1544636 & 688239 & 5.0362 & 5.5918 & TST \\
\hline CHEMBL 3190760 & 688239 & 5.6362 & 5.5184 & TRN \\
\hline CHEMBL1419784 & 688239 & 6.3863 & 5.5757 & TRN \\
\hline CHEMBL1347057 & 688239 & 5.3362 & 5.4348 & TST \\
\hline CHEMBL1402884 & 688239 & 7.8861 & 5.3578 & TST \\
\hline CHEMBL1359079 & 688239 & 6.6362 & 5.6172 & TRN \\
\hline CHEMBL1437674 & 688239 & 5.7362 & 5.568 & TRN \\
\hline CHEMBL3197439 & 688239 & 5.0862 & 5.34200 & 00000000005 \\
\hline CHEMBL423409 & 688239 & 6.95 & 5.4875 & TRN \\
\hline CHEMBL1976412 & 688239 & 5.0362 & 5.474 & TST \\
\hline CHEMBL1422212 & 688239 & 7.0362 & 5.5397 & TST \\
\hline CHEMBL1340016 & 688239 & 5.6862 & 5.4608 & TRN \\
\hline CHEMBL1387479 & 688239 & 4.5362 & 5.4448 & TST \\
\hline CHEMBL1596376 & 688239 & 5.3862 & 5.3809 & TRN \\
\hline CHEMBL3190131 & 688239 & 5.3862 & 5.4717 & TST \\
\hline CHEMBL1455837 & 688239 & 5.1862 & 5.4058 & TST \\
\hline CHEMBL1303432 & 688239 & 4.7862 & 5.6723 & TRN \\
\hline CHEMBL1443288 & 688239 & 6.9863 & 5.4144 & TST \\
\hline CHEMBL1439528 & 688239 & 6.1362 & 5.4754 & TRN \\
\hline CHEMBL1422058 & 688239 & 4.7862 & 5.63 & TRN \\
\hline CHEMBL1474078 & 688239 & 4.5362 & 5.45200 & 0000000001 \\
\hline CHEMBL1567430 & 688239 & 4.5362 & 5.3796 & TRN \\
\hline CHEMBL1574634 & 688239 & 5.2362 & 5.5138 & TRN \\
\hline CHEMBL1529890 & 688239 & 4.45 & 5.3818 & TRN \\
\hline CHEMBL1482078 & 688239 & 5.1862 & 5.3974 & TRN \\
\hline CHEMBL1577308 & 688239 & 6.0862 & 5.4286 & TRN \\
\hline CHEMBL1372571 & 688239 & 5.5362 & 5.4486 & TRN \\
\hline CHEMBL1488133 & 688239 & 5.7862 & 5.437 & TST \\
\hline CHEMBL1496080 & 688239 & 4.45 & 5.5283 & TRN \\
\hline CHEMBL1362378 & 688239 & 4.5862 & 5.5062 & TRN \\
\hline CHEMBL1340733 & 688239 & 4.7362 & 5.5806 & TRN \\
\hline CHEMBL1611593 & 688239 & 4.5362 & 5.4355 & TRN \\
\hline CHEMBL1448962 & 688239 & 5.1862 & 5.5346 & TST \\
\hline CHEMBL1318908 & 688239 & 6.8362 & 5.5823 & TRN \\
\hline CHEMBL1329730 & 688239 & 5.9362 & 5.4412 & TRN \\
\hline CHEMBL1590634 & 688239 & 6.1862 & 5.5942 & TRN \\
\hline CHEMBL1465952 & 688239 & 5.2362 & 5.5516 & TRN \\
\hline CHEMBL1981103 & 688239 & 4.4862 & 5.365 & TST \\
\hline CHEMBL1596213 & 688239 & 5.6862 & 5.6766 & TRN \\
\hline CHEMBL1548613 & 688239 & 4.4862 & 5.4897 & TST \\
\hline CHEMBL1447405 & 688239 & 4.5862 & 5.4941 & TRN \\
\hline CHEMBL1592330 & 688239 & 4.9862 & 5.5316 & TRN \\
\hline
\end{tabular}


Supplemental Table S2.txt

\begin{tabular}{|c|c|c|c|c|c|}
\hline CHEMBL1500729 & 688239 & 4.7362 & 5.4814 & TRN & \\
\hline CHEMBL1443471 & 688239 & 5.1862 & 5.4559 & TRN & \\
\hline CHEMBL1313304 & 688239 & 4.7362 & 5.5016 & TST & \\
\hline CHEMBL1596054 & 688239 & 4.4862 & 5.3846 & TRN & \\
\hline CHEMBL1353575 & 688239 & 7.0862 & 5.4902 & TRN & \\
\hline CHEMBL1358521 & 688239 & 5.1862 & 5.4313 & TST & \\
\hline CHEMBL1337333 & 688239 & 4.5362 & 5.6657 & TRN & \\
\hline CHEMBL1340675 & 688239 & 4.5362 & 5.3432 & TST & \\
\hline CHEMBL1567296 & 688239 & 5.8362 & 5.5229 & TRN & \\
\hline CHEMBL1356173 & 688239 & 5.0362 & 5.5811 & TRN & \\
\hline CHEMBL1543584 & 688239 & 6.8861 & 5.4725 & TST & \\
\hline CHEMBL1395313 & 688239 & 6.1862 & 5.3751 & TRN & \\
\hline CHEMBL1310299 & 688239 & 7.8356 & 5.3415 & TRN & \\
\hline CHEMBL3189386 & 688239 & 6.3863 & 5.4275 & TST & \\
\hline CHEMBL1310148 & 688239 & 6.8861 & 5.4373 & TRN & \\
\hline CHEMBL1404154 & 688239 & 6.2362 & 5.5179 & TRN & \\
\hline CHEMBL1511732 & 688239 & 5.1862 & 5.3288 & TST & \\
\hline CHEMBL1568929 & 688239 & 5.1862 & 5.6595 & TRN & \\
\hline CHEMBL3189399 & 688239 & 4.5362 & 5.4547 & TST & \\
\hline CHEMBL1598240 & 688239 & 5.3362 & 5.5337 & TRN & \\
\hline CHEMBL1971316 & 688239 & 6.1862 & 5.2487 & TST & \\
\hline CHEMBL1546288 & 688239 & 4.6862 & 5.5993 & TST & \\
\hline CHEMBL3191490 & 688239 & 4.9362 & 5.5852 & TST & \\
\hline CHEMBL1392762 & 688239 & 4.5362 & 5.4996 & TRN & \\
\hline CHEMBL1485872 & 688239 & 7.5361 & 5.5325 & TRN & \\
\hline CHEMBL1547764 & 688239 & 4.6362 & 5.3407 & TST & \\
\hline CHEMBL1591192 & 688239 & 5.1862 & 5.5236 & TRN & \\
\hline CHEMBL1524090 & 688239 & 4.7862 & 5.449 & TRN & \\
\hline CHEMBL1376111 & 688239 & 6.6362 & 5.66100 & 00000000005 & TRN \\
\hline CHEMBL1343614 & 688239 & 8.0862 & 5.4213 & TRN & \\
\hline CHEMBL1519124 & 688239 & 4.8362 & 5.5875 & TRN & \\
\hline CHEMBL1407169 & 688239 & 5.0362 & 5.3943 & TST & \\
\hline CHEMBL1367783 & 688239 & 6.1862 & 5.6754 & TRN & \\
\hline CHEMBL1328056 & 688239 & 4.5362 & 5.4051 & TRN & \\
\hline CHEMBL1603263 & 688239 & 4.6862 & 5.5713 & TRN & \\
\hline CHEMBL1303289 & 688239 & 5.5862 & 5.4472 & TRN & \\
\hline CHEMBL1414514 & 688239 & 5.0362 & 5.5267 & TRN & \\
\hline CHEMBL1588982 & 688239 & 6.2362 & 5.4302 & TRN & \\
\hline CHEMBL3213573 & 688239 & 4.6862 & 5.5031 & TST & \\
\hline CHEMBL1531568 & 688239 & 5.7862 & 5.5434 & TRN & \\
\hline CHEMBL1531300 & 688239 & 5.4862 & 5.5008 & TST & \\
\hline CHEMBL1301093 & 688239 & 4.5362 & 5.5031 & TRN & \\
\hline CHEMBL1428778 & 688239 & 4.7862 & 5.4785 & TRN & \\
\hline CHEMBL1598195 & 688239 & 5.3362 & 5.4533 & TRN & \\
\hline CHEMBL1394081 & 688239 & 6.2362 & 5.4441 & TRN & \\
\hline CHEMBL1377162 & 688239 & 5.7362 & 5.5502 & TRN & \\
\hline CHEMBL1577286 & 688239 & 5.7362 & 5.6315 & TST & \\
\hline CHEMBL1523678 & 688239 & 7.1864 & 5.5251 & TRN & \\
\hline
\end{tabular}


Supplemental Table S2.txt

\begin{tabular}{|c|c|c|c|c|c|}
\hline CHEMBL1467181 & 688239 & 4.5362 & 5.4471 & TST & \\
\hline CHEMBL1595986 & 688239 & 4.7362 & 5.4539 & TRN & \\
\hline CHEMBL1368156 & 688239 & 4.6862 & 5.3337 & TRN & \\
\hline CHEMBL1611174 & 688239 & 6.8362 & 5.5841 & TRN & \\
\hline CHEMBL1512030 & 688239 & 5.2362 & 5.377000 & 000000001 & $T$ \\
\hline CHEMBL1329376 & 688239 & 5.1862 & 5.5017 & TRN & \\
\hline CHEMBL1448268 & 688239 & 5.3862 & 5.3719 & TRN & \\
\hline CHEMBL1522832 & 688239 & 6.1862 & 5.5082 & TRN & \\
\hline CHEMBL1518914 & 688239 & 4.6362 & 5.4396 & TST & \\
\hline CHEMBL1478508 & 688239 & 5.5362 & 5.4108 & TRN & \\
\hline CHEMBL1549807 & 688239 & 5.4862 & 5.5239 & TST & \\
\hline CHEMBL1466633 & 688239 & 7.0362 & 5.5001 & TRN & \\
\hline CHEMBL1975721 & 688239 & 4.7362 & 5.57 & TST & \\
\hline CHEMBL1535745 & 688239 & 4.7862 & 5.5517 & TST & \\
\hline CHEMBL1495442 & 688239 & 4.5362 & 5.5857 & TRN & \\
\hline CHEMBL1543531 & 688239 & 6.1362 & 5.5434 & TST & \\
\hline CHEMBL1545467 & 688239 & 4.8362 & 5.5485 & TST & \\
\hline CHEMBL1316559 & 688239 & 4.4862 & 5.4578 & TRN & \\
\hline CHEMBL417213 & 688239 & 6.9363 & 5.446000 & 000000001 & \\
\hline CHEMBL1379015 & 688239 & 5.3862 & 5.3684 & TRN & \\
\hline CHEMBL1468058 & 688239 & 4.8362 & 5.5473 & TRN & \\
\hline CHEMBL1317867 & 688239 & 4.5362 & 5.4207 & TRN & \\
\hline CHEMBL1380642 & 688239 & 6.0362 & 5.5475 & TRN & \\
\hline CHEMBL1568576 & 688239 & 5.1862 & 5.4784 & TRN & \\
\hline CHEMBL1328055 & 688239 & 5.4862 & 5.4629 & TRN & \\
\hline CHEMBL1536943 & 688239 & 4.4862 & 5.4286 & TRN & \\
\hline CHEMBL1425489 & 688239 & 5.0862 & 5.4814 & TST & \\
\hline CHEMBL1465891 & 688239 & 4.6362 & 5.2413 & TRN & \\
\hline CHEMBL1303602 & 688239 & 5.8362 & 5.5309 & TST & \\
\hline CHEMBL1520256 & 688239 & 5.4862 & 5.4601 & TST & \\
\hline CHEMBL1451761 & 688239 & 6.5363 & 5.6019 & TST & \\
\hline CHEMBL1602992 & 688239 & 4.4862 & 5.592000 & 0000000005 & \\
\hline CHEMBL1586918 & 688239 & 6.6861 & 5.635 & TRN & \\
\hline CHEMBL1353741 & 688239 & 4.5362 & 5.5452 & TRN & \\
\hline CHEMBL1613024 & 688239 & 6.8362 & 5.5057 & TRN & \\
\hline CHEMBL1338397 & 688239 & 6.2362 & 5.5383 & TRN & \\
\hline CHEMBL1408273 & 688239 & 5.2862 & 5.4538 & TRN & \\
\hline CHEMBL1485345 & 688239 & 6.8861 & 5.5744 & TRN & \\
\hline CHEMBL1613326 & 688239 & 6.2362 & 5.5497 & TRN & \\
\hline CHEMBL1585769 & 688239 & 5.2862 & 5.6461 & TST & \\
\hline CHEMBL1584069 & 688239 & 5.6362 & 5.4431 & TRN & \\
\hline CHEMBL1429044 & 688239 & 7.3363 & 5.4021 & TST & \\
\hline CHEMBL1358311 & 688239 & 4.6362 & 5.5342 & TST & \\
\hline CHEMBL1322159 & 688239 & 8.28399 & 99999999 & 5.4522 & \\
\hline CHEMBL1522738 & 688239 & 5.2862 & 5.343 & TRN & \\
\hline CHEMBL1598427 & 688239 & 7.1361 & 5.6393 & TST & \\
\hline CHEMBL3192864 & 688239 & 5.6862 & 5.4384 & TRN & \\
\hline CHEMBL1359477 & 688239 & 8.3372 & 5.5212 & TRN & \\
\hline
\end{tabular}


Supplemental Table S2.txt

\begin{tabular}{|c|c|c|c|c|c|}
\hline CHEMBL1571690 & 688239 & 4.8362 & 5.3742 & TRN & \\
\hline CHEMBL1453390 & 688239 & 6.9363 & 5.4809 & TRN & \\
\hline CHEMBL1605594 & 688239 & 5.2862 & 5.6355 & TRN & \\
\hline CHEMBL1480659 & 688239 & 5.6862 & 5.489 & TRN & \\
\hline CHEMBL1560667 & 688239 & 6.8861 & 5.562 & TRN & \\
\hline CHEMBL 2000167 & 688239 & 5.7362 & 5.422999 & 999999999 & TST \\
\hline CHEMBL1361501 & 688239 & 6.1362 & 5.531000 & 000000001 & \\
\hline CHEMBL1604410 & 688239 & 8.3872 & 5.5 & TRN & \\
\hline CHEMBL1575848 & 688239 & 5.1862 & 5.5003 & TRN & \\
\hline CHEMBL582070 & 688239 & 4.5862 & 5.4172 & TRN & \\
\hline CHEMBL1606383 & 688239 & 6.6861 & 5.3203 & TRN & \\
\hline CHEMBL1516531 & 688239 & 5.1862 & 5.4476 & TRN & \\
\hline CHEMBL1392546 & 688239 & 5.6862 & 5.6187 & TRN & \\
\hline CHEMBL1483250 & 688239 & 4.5862 & 5.5925 & TRN & \\
\hline CHEMBL 3211465 & 688239 & 5.3862 & 5.5517 & TRN & \\
\hline CHEMBL1549401 & 688239 & 4.7362 & 5.4397 & TST & \\
\hline CHEMBL1534287 & 688239 & 5.7862 & 5.6761 & TRN & \\
\hline CHEMBL1485814 & 688239 & 5.3862 & 5.5458 & TRN & \\
\hline CHEMBL1597616 & 688239 & 4.8862 & 5.5056 & TRN & \\
\hline CHEMBL1517681 & 688239 & 5.1862 & 5.5571 & TST & \\
\hline CHEMBL1491509 & 688239 & 5.6362 & 5.4251 & TRN & \\
\hline CHEMBL1328346 & 688239 & 4.6362 & 5.5749 & TST & \\
\hline CHEMBL1483023 & 688239 & 4.5362 & 5.3899 & TRN & \\
\hline CHEMBL1402584 & 688239 & 4.7862 & 5.4344 & TRN & \\
\hline CHEMBL1999678 & 688239 & 7.0362 & 5.3239 & TRN & \\
\hline CHEMBL1990716 & 688239 & 5.6862 & 5.3698 & TST & \\
\hline CHEMBL1603161 & 688239 & 5.1862 & 5.4019 & TST & \\
\hline CHEMBL1321184 & 688239 & 5.2862 & 5.4367 & TRN & \\
\hline CHEMBL1487750 & 688239 & 4.5362 & 5.3465 & TRN & \\
\hline CHEMBL1524964 & 688239 & 5.3362 & 5.6426 & TRN & \\
\hline CHEMBL1353076 & 688239 & 6.1362 & 5.4688 & TRN & \\
\hline CHEMBL1496161 & 688239 & 5.2362 & 5.4904 & TRN & \\
\hline CHEMBL1304294 & 688239 & 4.7362 & 5.4548 & TRN & \\
\hline CHEMBL1451574 & 688239 & 6.8861 & 5.4447 & TRN & \\
\hline CHEMBL1509413 & 688239 & 5.1362 & 5.654 & TRN & \\
\hline CHEMBL1536154 & 688239 & 6.1862 & 5.546 & TRN & \\
\hline CHEMBL1481914 & 688239 & 5.1862 & 5.6268 & TRN & \\
\hline CHEMBL1318072 & 688239 & 8.28399 & 99999999 & 5.5218 & NI \\
\hline CHEMBL1359845 & 688239 & 4.8862 & 5.4408 & TRN & \\
\hline CHEMBL1532545 & 688239 & 6.1362 & 5.4463 & TRN & \\
\hline CHEMBL1578960 & 688239 & 5.1862 & 5.5715 & TST & \\
\hline CHEMBL1528932 & 688239 & 5.7362 & 5.4174 & TST & \\
\hline CHEMBL1531393 & 688239 & 5.8362 & 5.4426 & TRN & \\
\hline CHEMBL1604216 & 688239 & 4.5362 & 5.487 & TRN & \\
\hline CHEMBL1528400 & 688239 & 5.9362 & 5.3988 & TRN & \\
\hline CHEMBL1506353 & 688239 & 6.8861 & 5.3675 & TRN & \\
\hline CHEMBL1597341 & 688239 & 6.9363 & 5.6299 & TRN & \\
\hline CHEMBL3209393 & 688239 & 4.7862 & 5.5771 & TRN & \\
\hline
\end{tabular}


Supplemental Table S2.txt

\begin{tabular}{|c|c|c|c|c|c|}
\hline CHEMBL1336732 & 688239 & 5.6362 & 5.4776 & TRN & \\
\hline CHEMBL1329616 & 688239 & 4.5862 & 5.4549 & TRN & \\
\hline CHEMBL1549804 & 688239 & 4.5362 & 5.5098 & TRN & \\
\hline CHEMBL1564425 & 688239 & 5.3362 & 5.5039 & TRN & \\
\hline CHEMBL1382987 & 688239 & 6.6362 & 5.5359 & TRN & \\
\hline CHEMBL1507655 & 688239 & 4.6862 & 5.3931 & TRN & \\
\hline CHEMBL1416663 & 688239 & 6.1362 & 5.6858 & TRN & \\
\hline CHEMBL1451679 & 688239 & 6.5862 & 5.5181 & TRN & \\
\hline CHEMBL1600837 & 688239 & 6.3362 & 5.5807 & TRN & \\
\hline CHEMBL1388690 & 688239 & 8.28399 & 99999999 & 99 & 5.3894 \\
\hline CHEMBL1509360 & 688239 & 7.5867 & 5.3866 & TRN & \\
\hline CHEMBL1359161 & 688239 & 6.7361 & 5.5542 & TST & \\
\hline CHEMBL3191670 & 688239 & 4.5362 & 5.3062 & TRN & \\
\hline CHEMBL1303794 & 688239 & 5.8362 & 5.4481 & TRN & \\
\hline CHEMBL1515474 & 688239 & 4.7862 & 5.4994 & TRN & \\
\hline CHEMBL1519469 & 688239 & 7.1864 & 5.5923 & TRN & \\
\hline CHEMBL1426210 & 688239 & 5.6862 & 5.4418 & TST & \\
\hline CHEMBL1523105 & 688239 & 7.4365 & 5.6008 & TRN & \\
\hline CHEMBL1370652 & 688239 & 4.6862 & 5.4493 & TRN & \\
\hline CHEMBL1328954 & 688239 & 5.3862 & 5.4758 & TRN & \\
\hline CHEMBL1444072 & 688239 & 5.1362 & 5.5311 & TRN & \\
\hline CHEMBL1534678 & 688239 & 4.5362 & 5.4176 & TST & \\
\hline CHEMBL1518457 & 688239 & 6.9863 & 5.4826 & TRN & \\
\hline CHEMBL1340390 & 688239 & 4.4862 & 5.4157 & TRN & \\
\hline CHEMBL1350075 & 688239 & 4.6362 & 5.5541 & TRN & \\
\hline CHEMBL1545245 & 688239 & 6.7361 & 5.442 & TRN & \\
\hline CHEMBL1317838 & 688239 & 7.1361 & 5.7085 & TRN & \\
\hline CHEMBL1308670 & 688239 & 5.9362 & 5.4999 & TRN & \\
\hline CHEMBL 2002898 & 688239 & 4.7362 & 5.4566 & TRN & \\
\hline CHEMBL1459411 & 688239 & 5.7362 & 5.5695 & TRN & \\
\hline CHEMBL1428517 & 688239 & 5.1862 & 5.5344 & TST & \\
\hline CHEMBL1494147 & 688239 & 5.5862 & 5.6049 & TRN & \\
\hline CHEMBL1333849 & 688239 & 4.5362 & 5.5078 & TST & \\
\hline CHEMBL1327696 & 688239 & 5.4362 & 5.4712 & TRN & \\
\hline CHEMBL1371006 & 688239 & 4.8862 & 5.5901 & TRN & \\
\hline CHEMBL1309326 & 688239 & 4.6862 & 5.4847 & TRN & \\
\hline CHEMBL1588552 & 688239 & 6.3362 & 5.3692 & TRN & \\
\hline CHEMBL1302630 & 688239 & 4.8362 & 5.5887 & TRN & \\
\hline CHEMBL1346972 & 688239 & 4.9362 & 5.4425 & TRN & \\
\hline CHEMBL1515177 & 688239 & 4.6862 & 5.546 & TRN & \\
\hline CHEMBL1335401 & 688239 & 5.7362 & 5.4775 & TST & \\
\hline CHEMBL1343578 & 688239 & 6.8861 & 5.4521 & TRN & \\
\hline CHEMBL1581964 & 688239 & 4.9362 & 5.308 & TRN & \\
\hline CHEMBL3190468 & 688239 & 4.5362 & 5.317 & TRN & \\
\hline CHEMBL1606191 & 688239 & 6.0862 & 5.6076 & TST & \\
\hline CHEMBL3198729 & 688239 & 4.5362 & 5.3955 & TST & \\
\hline CHEMBL1439108 & 688239 & 4.6362 & 5.6887 & TRN & \\
\hline CHEMBL1557849 & 688239 & 4.4862 & 5.4473 & TRN & \\
\hline
\end{tabular}




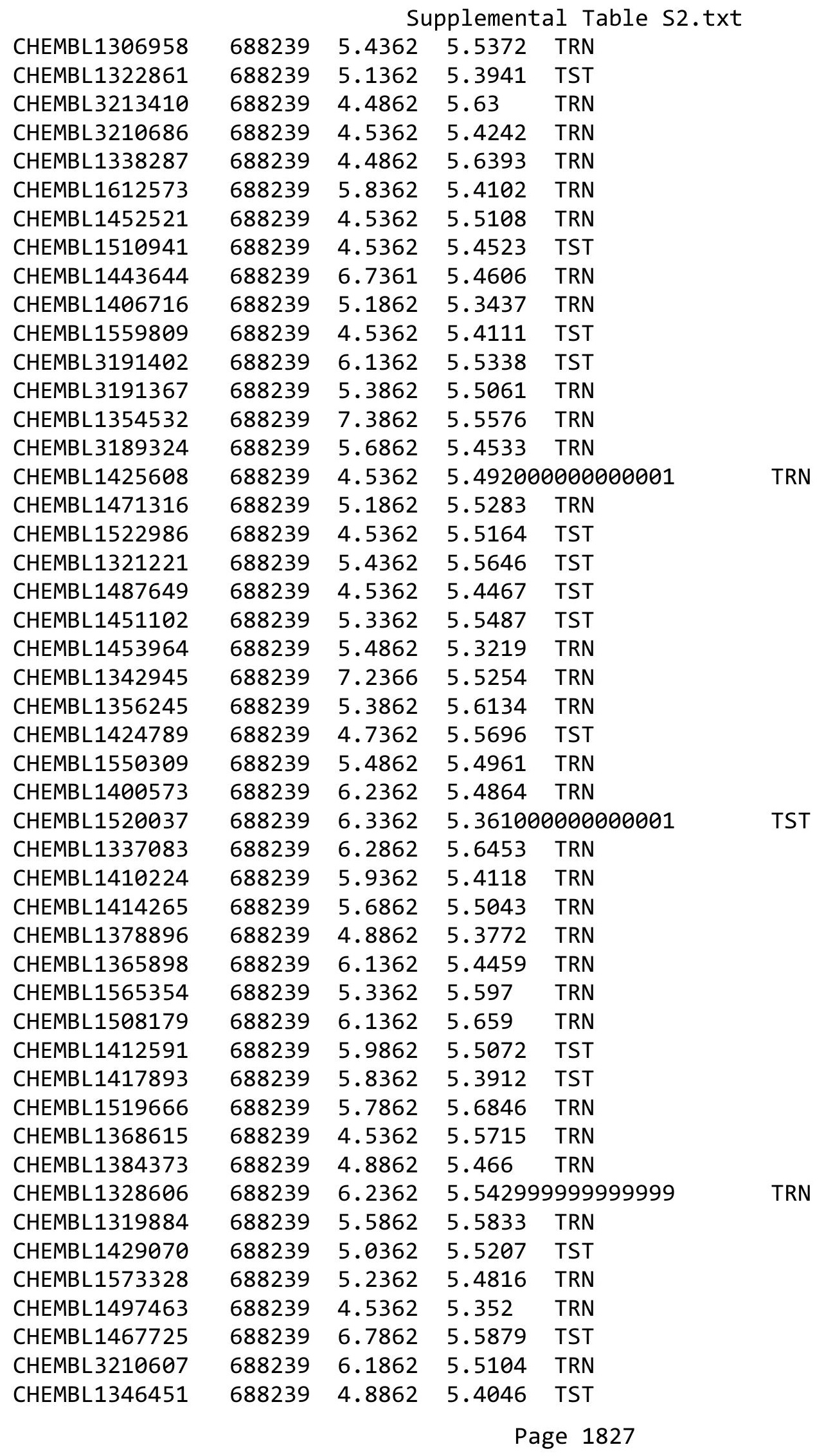


Supplemental Table S2.txt

\begin{tabular}{|c|c|c|c|c|c|}
\hline CHEMBL1534665 & 688239 & 6.0862 & 5.5211 & TRN & \\
\hline CHEMBL1571393 & 688239 & 6.0862 & 5.63899 & 9999999999 & TRN \\
\hline CHEMBL3190452 & 688239 & 8.3372 & 5.4596 & TRN & \\
\hline CHEMBL1482838 & 688239 & 7.0362 & 5.4046 & TRN & \\
\hline CHEMBL1378379 & 688239 & 6.2362 & 5.5583 & TRN & \\
\hline CHEMBL1407470 & 688239 & 5.6862 & 5.5768 & TRN & \\
\hline CHEMBL1597405 & 688239 & 5.1862 & 5.5221 & TST & \\
\hline CHEMBL1526778 & 688239 & 5.2862 & 5.5828 & TST & \\
\hline CHEMBL1441437 & 688239 & 7.0362 & 5.3645 & TRN & \\
\hline CHEMBL1302038 & 688239 & 4.5362 & 5.4873 & TRN & \\
\hline CHEMBL1411136 & 688239 & 4.5362 & 5.4747 & TRN & \\
\hline CHEMBL1500155 & 688239 & 5.2862 & 5.375 & TRN & \\
\hline CHEMBL1485656 & 688239 & 6.6861 & 5.6638 & TRN & \\
\hline CHEMBL1524647 & 688239 & 5.5362 & 5.4856 & TRN & \\
\hline CHEMBL1577304 & 688239 & 5.9362 & 5.5292 & TRN & \\
\hline CHEMBL1391422 & 688239 & 5.1862 & 5.482 & TRN & \\
\hline CHEMBL1362988 & 688239 & 4.5362 & 5.4123 & TRN & \\
\hline CHEMBL1348754 & 688239 & 6.0 & 5.5657 & TST & \\
\hline CHEMBL1472310 & 688239 & 4.8862 & 5.5547 & TRN & \\
\hline CHEMBL1573695 & 688239 & 5.7362 & 5.5999 & TRN & \\
\hline CHEMBL528451 & 688239 & 6.1862 & 5.5774 & TRN & \\
\hline CHEMBL1419511 & 688239 & 5.4362 & 5.6263 & TRN & \\
\hline CHEMBL1594905 & 688239 & 5.1862 & \multicolumn{2}{|c|}{5.5329999999999995} & TRN \\
\hline CHEMBL1323420 & 688239 & 5.6362 & 5.4058 & TST & \\
\hline CHEMBL 1605858 & 688239 & 4.6862 & 5.6075 & TST & \\
\hline CHEMBL1500408 & 688239 & 4.6362 & 5.4302 & TRN & \\
\hline CHEMBL1603063 & 688239 & 5.7862 & 5.5139 & TRN & \\
\hline CHEMBL1469710 & 688239 & 4.5362 & 5.374 & TRN & \\
\hline CHEMBL1434685 & 688239 & 5.0862 & 5.5607 & TST & \\
\hline CHEMBL1490929 & 688239 & 4.4862 & 5.5024 & TST & \\
\hline CHEMBL1547453 & 688239 & 6.2362 & 5.5557 & TRN & \\
\hline CHEMBL1462447 & 688239 & 4.7862 & 5.7424 & TRN & \\
\hline CHEMBL1482978 & 688239 & 5.5862 & 5.5259 & TRN & \\
\hline CHEMBL1324992 & 688239 & 4.9362 & 5.5186 & TRN & \\
\hline CHEMBL1491307 & 688239 & 4.5362 & 5.4494 & TRN & \\
\hline CHEMBL1462703 & 688239 & 4.5362 & 5.3724 & TRN & \\
\hline CHEMBL1426281 & 688239 & 4.9862 & 5.479 & TRN & \\
\hline CHEMBL1488114 & 688239 & 6.6861 & \multicolumn{2}{|c|}{5.587999999999999} & TRN \\
\hline CHEMBL1446455 & 688239 & 5.6862 & 5.2998 & TST & \\
\hline CHEMBL 1574572 & 688239 & 4.5362 & 5.4506 & TRN & \\
\hline CHEMBL1513788 & 688239 & 5.0362 & 5.4657 & TRN & \\
\hline CHEMBL 1443192 & 688239 & 4.5362 & 5.5231 & TST & \\
\hline CHEMBL1393267 & 688239 & 5.8362 & 5.4617 & TRN & \\
\hline CHEMBL1520617 & 688239 & 5.4362 & 5.6289 & TRN & \\
\hline CHEMBL1380191 & 688239 & 4.5362 & 5.5301 & TST & \\
\hline CHEMBL3193288 & 688239 & 6.8362 & 5.4618 & TST & \\
\hline CHEMBL 1578259 & 688239 & 7.3862 & 5.6771 & TRN & \\
\hline CHEMBL379005 & 688239 & 4.7362 & 5.4094 & TRN & \\
\hline
\end{tabular}




\begin{tabular}{|c|c|c|c|c|c|c|}
\hline & & \multicolumn{5}{|c|}{ Supplemental Table S2.txt } \\
\hline CHEMBL388959 & 688239 & 4.4862 & 5.5457 & TRN & & \\
\hline CHEMBL1380172 & 688239 & 8.28399 & 99999999 & 99 & 5.459 & TRN \\
\hline CHEMBL3199833 & 688239 & 4.6362 & 5.4535 & TRN & & \\
\hline CHEMBL1318505 & 688239 & 5.3862 & 5.4196 & TST & & \\
\hline CHEMBL1329946 & 688239 & 6.3362 & 5.6673 & TRN & & \\
\hline CHEMBL3197353 & 688239 & 4.6362 & 5.3955 & TRN & & \\
\hline CHEMBL1595340 & 688239 & 5.1862 & 5.4945 & TRN & & \\
\hline CHEMBL1351863 & 688239 & 7.6364 & 5.5354 & TST & & \\
\hline CHEMBL1402244 & 688239 & 5.0862 & 5.3986 & TRN & & \\
\hline CHEMBL1537998 & 688239 & 6.8861 & 5.5447 & TRN & & \\
\hline CHEMBL1596042 & 688239 & 5.4862 & 5.5523 & TRN & & \\
\hline CHEMBL1401135 & 688239 & 6.0362 & 5.5927 & TRN & & \\
\hline CHEMBL1598951 & 688239 & 4.5362 & 5.5259 & TRN & & \\
\hline CHEMBL3195507 & 688239 & 4.5362 & 5.3289 & TST & & \\
\hline CHEMBL1369590 & 688239 & 4.9362 & 5.43 & TRN & & \\
\hline CHEMBL1554370 & 688239 & 6.5862 & 5.3877 & TRN & & \\
\hline CHEMBL1558664 & 688239 & 4.6862 & 5.5267 & TRN & & \\
\hline CHEMBL1584626 & 688239 & 4.5362 & 5.5832 & TRN & & \\
\hline CHEMBL1512457 & 688239 & 5.7862 & 5.6918 & TRN & & \\
\hline CHEMBL1613643 & 688239 & 4.5362 & 5.4734 & TRN & & \\
\hline CHEMBL1478754 & 688239 & 4.6362 & 5.4942 & TST & & \\
\hline CHEMBL412646 & 688239 & 4.6862 & 5.5221 & TRN & & \\
\hline CHEMBL3195456 & 688239 & 5.6362 & 5.4317 & TST & & \\
\hline CHEMBL1343365 & 688239 & 5.6362 & 5.5676 & TRN & & \\
\hline CHEMBL1375058 & 688239 & 4.9362 & 5.4355 & TRN & & \\
\hline CHEMBL1325226 & 688239 & 5.1862 & 5.3782 & TRN & & \\
\hline CHEMBL1574268 & 688239 & 4.5362 & 5.63 & TRN & & \\
\hline CHEMBL155265 & 688239 & 4.5362 & 5.5043 & TRN & & \\
\hline CHEMBL1537863 & 688239 & 5.2862 & 5.3569 & TRN & & \\
\hline CHEMBL1371590 & 688239 & 4.4862 & 5.4028 & TRN & & \\
\hline CHEMBL1430991 & 688239 & 4.6362 & 5.4179 & TRN & & \\
\hline CHEMBL1362949 & 688239 & 4.6362 & 5.5189 & TRN & & \\
\hline CHEMBL1420613 & 688239 & 4.5362 & 5.4732 & TRN & & \\
\hline CHEMBL1525402 & 688239 & 6.9363 & 5.5386 & TRN & & \\
\hline CHEMBL1396154 & 688239 & 4.5362 & 5.6417 & TST & & \\
\hline CHEMBL1552142 & 688239 & 4.8362 & 5.5297 & TRN & & \\
\hline CHEMBL1368417 & 688239 & 4.6362 & 5.5179 & TRN & & \\
\hline CHEMBL 2006072 & 688239 & 6.8362 & 5.4224 & TRN & & \\
\hline CHEMBL1480377 & 688239 & 5.9362 & 5.5715 & TRN & & \\
\hline CHEMBL1391541 & 688239 & 5.1862 & 5.2964 & TRN & & \\
\hline CHEMBL1393086 & 688239 & 4.7862 & 5.3307 & TRN & & \\
\hline CHEMBL1572809 & 688239 & 5.1862 & 5.4279 & TRN & & \\
\hline CHEMBL1418284 & 688239 & 6.0862 & 5.565 & TRN & & \\
\hline CHEMBL1469775 & 688239 & 5.1862 & 5.4321 & TST & & \\
\hline CHEMBL1420396 & 688239 & 5.1862 & 5.4276 & TST & & \\
\hline CHEMBL1497736 & 688239 & 4.5362 & 5.4707 & TRN & & \\
\hline CHEMBL1353697 & 688239 & 4.9362 & 5.4232 & TRN & & \\
\hline CHEMBL1479462 & 688239 & 4.5362 & 5.4675 & TST & & \\
\hline
\end{tabular}


Supplemental Table S2.txt

\begin{tabular}{|c|c|c|c|c|}
\hline CHEMBL1375045 & 688239 & 4.8362 & 5.4284 & TRN \\
\hline CHEMBL1544250 & 688239 & 4.5362 & 5.4553 & TRN \\
\hline CHEMBL1374145 & 688239 & 5.6362 & 5.4331 & TRN \\
\hline CHEMBL1339398 & 688239 & 4.8362 & 5.4898 & TST \\
\hline CHEMBL1505079 & 688239 & 6.2362 & 5.5593 & TRN \\
\hline CHEMBL1579681 & 688239 & 4.5362 & 5.4286 & TRN \\
\hline CHEMBL1441072 & 688239 & 4.6362 & 5.4641 & TRN \\
\hline CHEMBL1357998 & 688239 & 5.4862 & 5.4955 & TRN \\
\hline CHEMBL1341691 & 688239 & 5.3362 & 5.5007 & TRN \\
\hline CHEMBL 3190651 & 688239 & 4.5362 & 5.4292 & TRN \\
\hline CHEMBL1481889 & 688239 & 4.7862 & 5.4639 & TRN \\
\hline CHEMBL1360631 & 688239 & 4.5362 & 5.4395 & TRN \\
\hline CHEMBL1343216 & 688239 & 6.2862 & 5.4777 & TRN \\
\hline CHEMBL1318806 & 688239 & 4.6862 & 5.50299 & э999999999 \\
\hline CHEMBL1483052 & 688239 & 5.0362 & 5.3233 & TST \\
\hline CHEMBL1344308 & 688239 & 6.1862 & 5.5645 & TRN \\
\hline CHEMBL1345548 & 688239 & 5.6862 & 5.5232 & TRN \\
\hline CHEMBL1491994 & 688239 & 6.1862 & 5.4474 & TST \\
\hline CHEMBL1545038 & 688239 & 6.8362 & 5.3371 & TST \\
\hline CHEMBL1422248 & 688239 & 6.4862 & 5.3684 & TRN \\
\hline CHEMBL1405141 & 688239 & 4.9362 & 5.6847 & TRN \\
\hline CHEMBL1387306 & 688239 & 5.4362 & 5.5134 & TRN \\
\hline CHEMBL1392592 & 688239 & 4.5362 & 5.1995 & TRN \\
\hline CHEMBL1548742 & 688239 & 4.6862 & 5.3219 & TRN \\
\hline CHEMBL1449475 & 688239 & 4.7862 & 5.4703 & TRN \\
\hline CHEMBL1575122 & 688239 & 4.5362 & 5.5514 & TRN \\
\hline CHEMBL1495310 & 688239 & 5.5362 & 5.57299 & 99999999995 \\
\hline CHEMBL1554601 & 688239 & 6.1862 & 5.6168 & TRN \\
\hline CHEMBL1547264 & 688239 & 4.6362 & 5.4938 & TRN \\
\hline CHEMBL1413667 & 688239 & 5.6862 & 5.5854 & TRN \\
\hline CHEMBL1374699 & 688239 & 5.3862 & 5.4681 & TRN \\
\hline CHEMBL1612515 & 688239 & 4.7362 & 5.67299 & 9999999999 \\
\hline CHEMBL1463863 & 688239 & 4.5862 & 5.4334 & TST \\
\hline CHEMBL1522066 & 688239 & 4.85 & 5.4617 & TRN \\
\hline CHEMBL1418773 & 688239 & 5.4362 & 5.5113 & TST \\
\hline CHEMBL1520301 & 688239 & 4.5362 & 5.3983 & TRN \\
\hline CHEMBL1509804 & 688239 & 4.5362 & 5.5261 & TRN \\
\hline CHEMBL 2163817 & 688239 & 4.5362 & 5.3647 & TRN \\
\hline CHEMBL3213091 & 688239 & 4.5362 & 5.3735 & TRN \\
\hline CHEMBL1309505 & 688239 & 5.8362 & 5.4519 & TRN \\
\hline CHEMBL1500197 & 688239 & 4.7362 & 5.3663 & TRN \\
\hline CHEMBL1366024 & 688239 & 4.5862 & 5.3068 & TRN \\
\hline CHEMBL1314822 & 688239 & 4.5362 & 5.5143 & TRN \\
\hline CHEMBL1344630 & 688239 & 5.9862 & 5.5188 & TRN \\
\hline CHEMBL1504325 & 688239 & 6.4362 & 5.6043 & TRN \\
\hline CHEMBL1494740 & 688239 & 5.8862 & 5.5529 & TRN \\
\hline CHEMBL1361258 & 688239 & 4.2362 & 5.4764 & TRN \\
\hline \multirow[t]{2}{*}{ CHEMBL3189699 } & 688239 & 4.9862 & 5.37700 & 0000000001 \\
\hline & & \multicolumn{3}{|c|}{ Page 1830} \\
\hline
\end{tabular}


Supplemental Table S2.txt

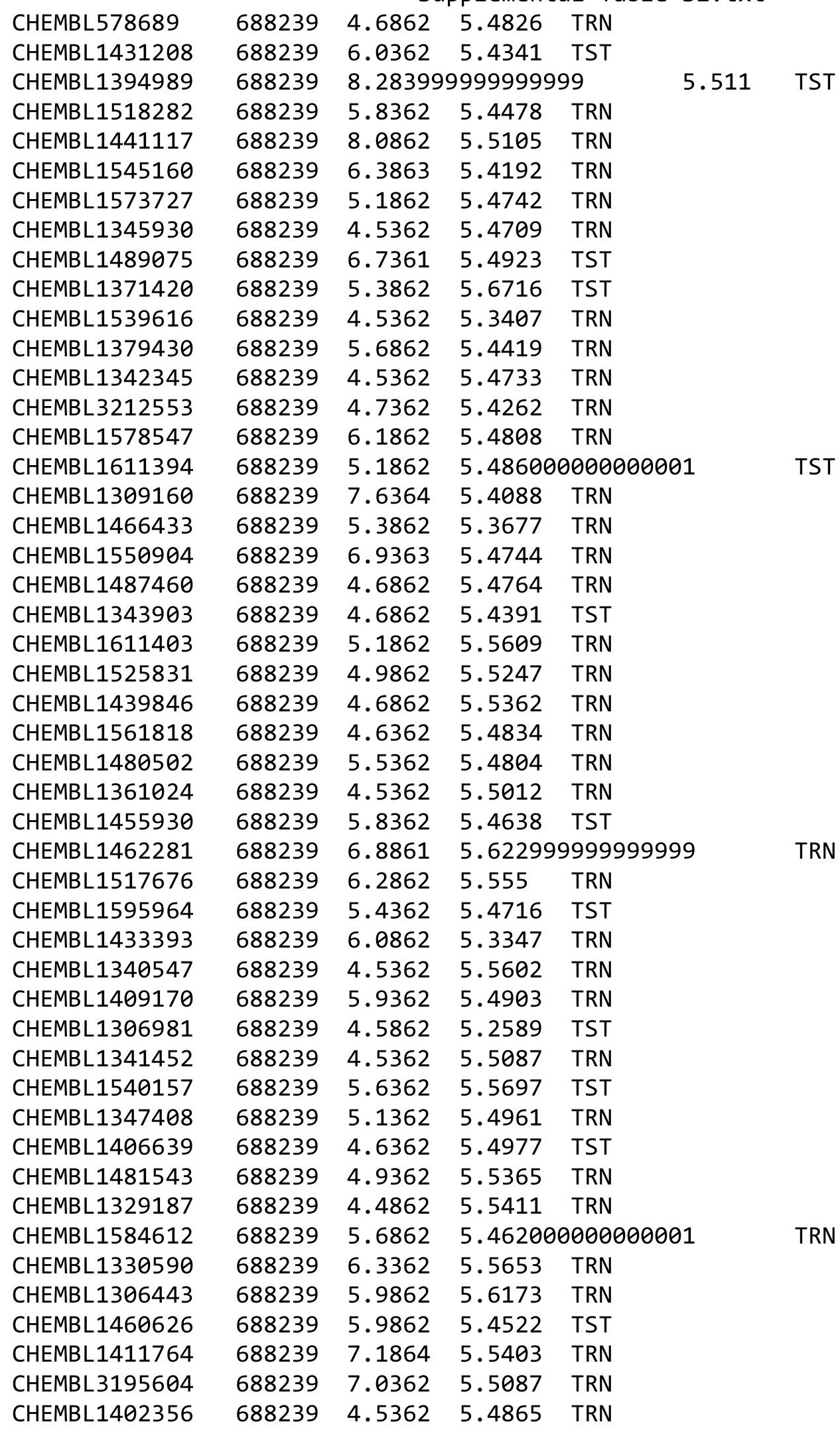

Page 1831 


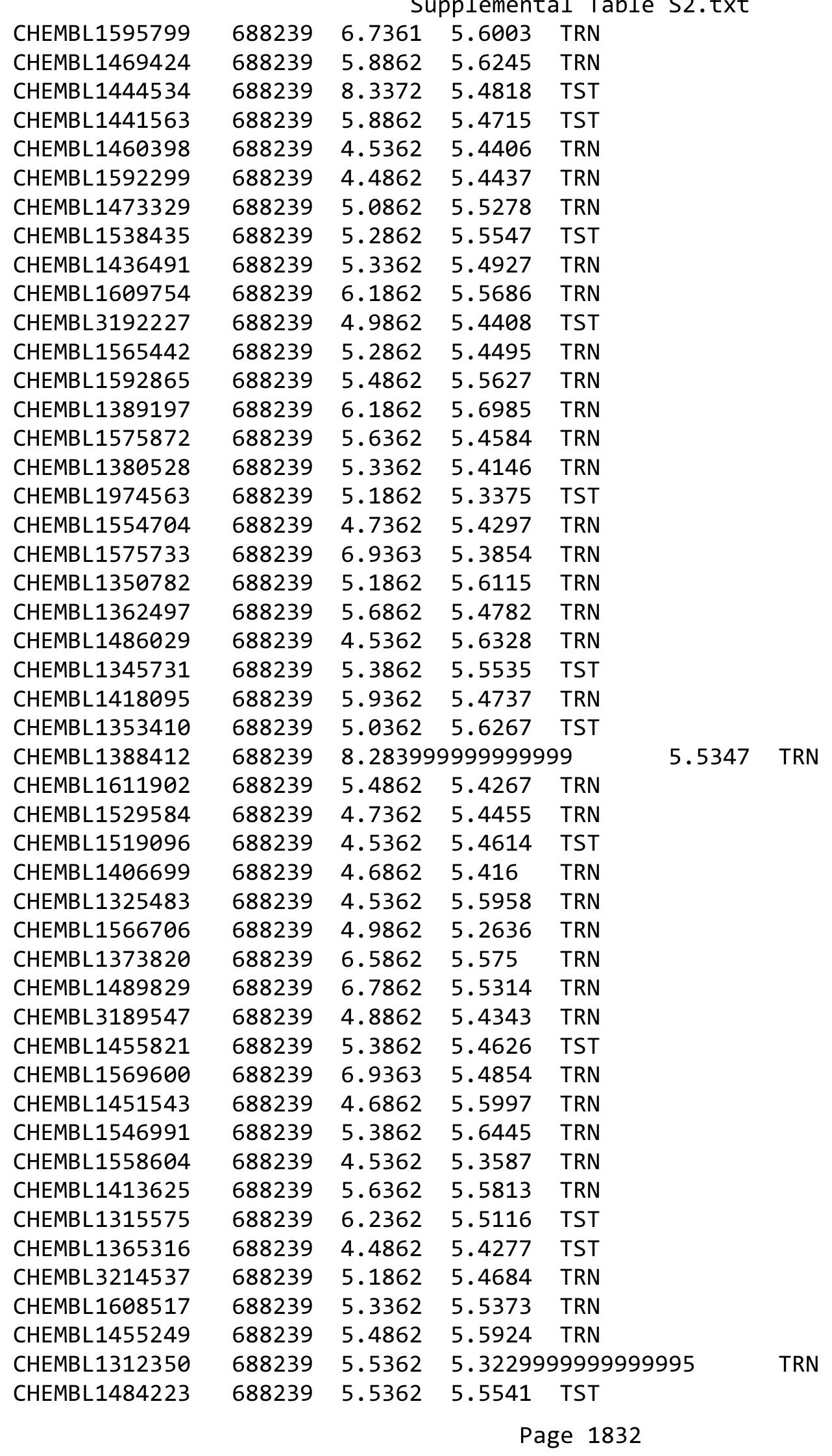


Supplemental Table S2.txt

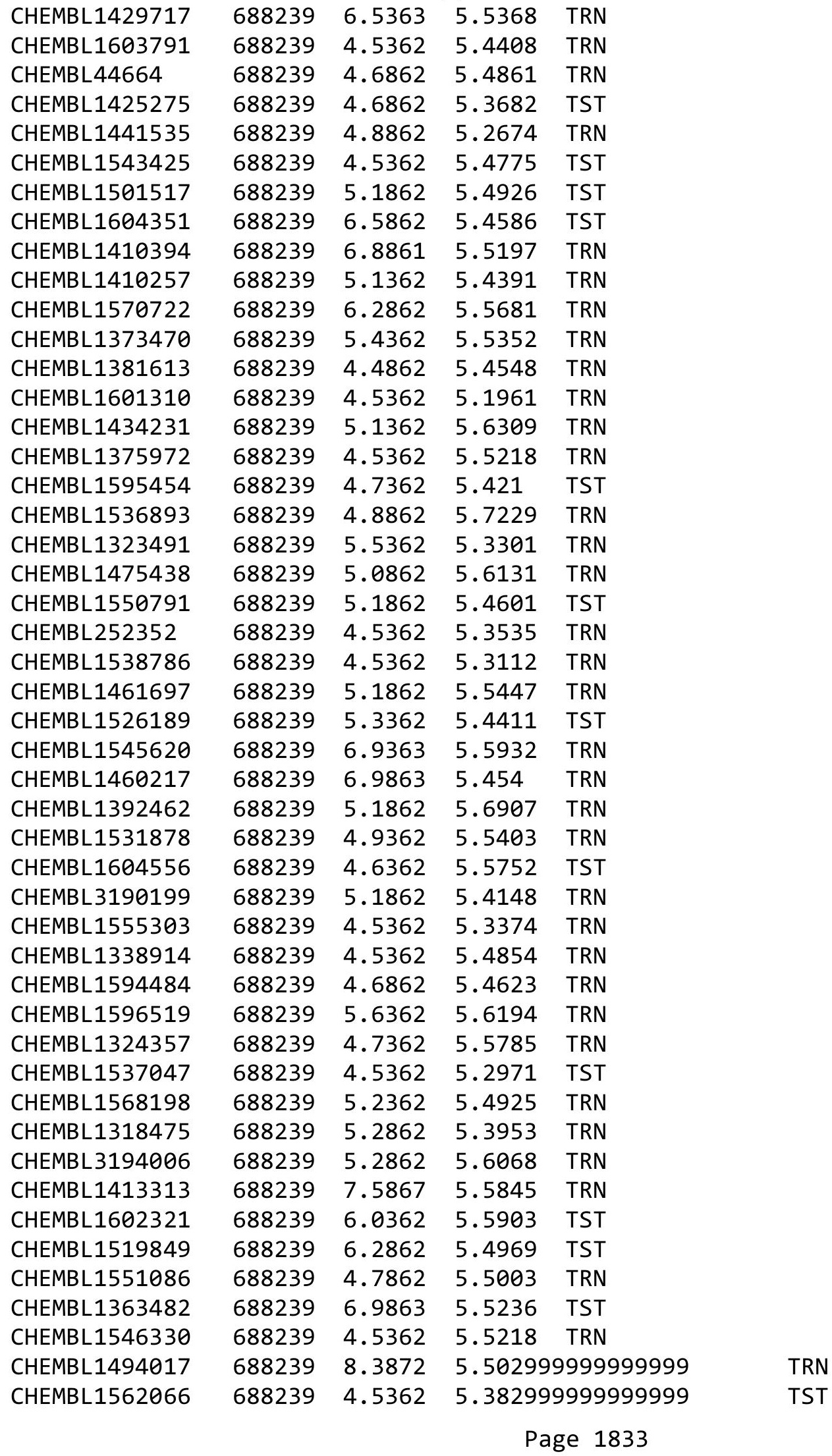


Supplemental Table S2.txt

\begin{tabular}{|c|c|c|c|c|c|}
\hline CHEMBL1324345 & 688239 & 4.5362 & 5.5293 & TST & \\
\hline CHEMBL1587840 & 688239 & 4.9362 & 5.5301 & TRN & \\
\hline CHEMBL1340062 & 688239 & 4.5362 & 5.5507 & TST & \\
\hline CHEMBL1451959 & 688239 & 4.5362 & 5.4908 & TRN & \\
\hline CHEMBL1563365 & 688239 & 4.8362 & 5.638 & TRN & \\
\hline CHEMBL1457741 & 688239 & 8.3372 & 5.6126 & TST & \\
\hline CHEMBL1366425 & 688239 & 7.1361 & 5.4955 & TST & \\
\hline CHEMBL1427826 & 688239 & 4.7362 & 5.5623 & TRN & \\
\hline CHEMBL1444760 & 688239 & 4.5362 & 5.3017 & TRN & \\
\hline CHEMBL1592732 & 688239 & 5.1862 & 5.396 & TST & \\
\hline CHEMBL1323228 & 688239 & 4.5362 & 5.4638 & TRN & \\
\hline CHEMBL1505522 & 688239 & 4.9362 & 5.4845 & TRN & \\
\hline CHEMBL1348985 & 688239 & 4.5362 & 5.4881 & TRN & \\
\hline CHEMBL1500484 & 688239 & 4.4862 & 5.4579 & TRN & \\
\hline CHEMBL1401403 & 688239 & 5.4362 & 5.5058 & TST & \\
\hline CHEMBL1546355 & 688239 & 4.5862 & 5.6604 & TST & \\
\hline CHEMBL1407657 & 688239 & 5.6362 & 5.4365 & TST & \\
\hline CHEMBL1438202 & 688239 & 5.7862 & 5.5824 & TRN & \\
\hline CHEMBL1537321 & 688239 & 4.8362 & 5.5777 & TRN & \\
\hline CHEMBL1344194 & 688239 & 6.6861 & 5.3183 & TRN & \\
\hline CHEMBL1445162 & 688239 & 5.9362 & 5.5564 & TRN & \\
\hline CHEMBL1430610 & 688239 & 4.6362 & 5.5273 & TRN & \\
\hline CHEMBL1406375 & 688239 & 6.9863 & 5.357 & TRN & \\
\hline CHEMBL1382921 & 688239 & 6.1362 & 5.6952 & TST & \\
\hline CHEMBL1346767 & 688239 & 5.8362 & 5.4731 & TRN & \\
\hline CHEMBL1314383 & 688239 & 6.2362 & 5.3778 & TST & \\
\hline CHEMBL1463785 & 688239 & 4.7362 & 5.4566 & TRN & \\
\hline CHEMBL1535145 & 688239 & 5.2362 & 5.48600 & 0000000001 & TRN \\
\hline CHEMBL1313692 & 688239 & 5.0862 & 5.3565 & TRN & \\
\hline CHEMBL1577203 & 688239 & 5.6362 & 5.4204 & TST & \\
\hline CHEMBL1568695 & 688239 & 5.2862 & 5.4154 & TST & \\
\hline CHEMBL1506034 & 688239 & 5.1862 & 5.5375 & TRN & \\
\hline CHEMBL1345458 & 688239 & 4.5362 & 5.4223 & TRN & \\
\hline CHEMBL1454516 & 688239 & 4.8862 & 5.4392 & TRN & \\
\hline CHEMBL3198195 & 688239 & 5.4362 & 5.3931 & TST & \\
\hline CHEMBL1303210 & 688239 & 5.6362 & 5.4173 & TRN & \\
\hline CHEMBL1546214 & 688239 & 5.4862 & 5.6731 & TRN & \\
\hline CHEMBL1518360 & 688239 & 6.8362 & 5.4721 & TRN & \\
\hline CHEMBL1338431 & 688239 & 5.5362 & 5.5189 & TRN & \\
\hline CHEMBL1381095 & 688239 & 4.7862 & 5.4317 & TRN & \\
\hline CHEMBL1442060 & 688239 & 4.5362 & 5.6379 & TRN & \\
\hline CHEMBL1308859 & 688239 & 4.4862 & 5.4114 & TST & \\
\hline CHEMBL1302337 & 688239 & 5.6362 & 5.4758 & TRN & \\
\hline CHEMBL1341253 & 688239 & 4.6862 & 5.5537 & TRN & \\
\hline CHEMBL1532021 & 688239 & 4.5362 & 5.4512 & TRN & \\
\hline CHEMBL 1585582 & 688239 & 4.6362 & 5.5871 & TRN & \\
\hline CHEMBL1479953 & 688239 & 7.5361 & 5.5106 & TRN & \\
\hline CHEMBL1315337 & 688239 & 5.3862 & 5.5481 & TRN & \\
\hline
\end{tabular}


Supplemental Table S2.txt

\begin{tabular}{|c|c|c|c|c|}
\hline CHEMBL1321538 & 688239 & 5.0362 & 5.4326 & TST \\
\hline CHEMBL1542028 & 688239 & 4.6362 & 5.6248 & TRN \\
\hline CHEMBL1549845 & 688239 & 8.3372 & 5.5102 & TST \\
\hline CHEMBL1407219 & 688239 & 4.5862 & 5.3733 & TST \\
\hline CHEMBL1303272 & 688239 & 5.1862 & 5.4864 & TRN \\
\hline CHEMBL1393074 & 688239 & 6.8861 & 5.5061 & TST \\
\hline CHEMBL1586505 & 688239 & 5.5362 & 5.4456 & TRN \\
\hline CHEMBL1310079 & 688239 & 6.2862 & 5.4063 & TRN \\
\hline CHEMBL1323136 & 688239 & 4.5362 & 5.3968 & TRN \\
\hline CHEMBL1385732 & 688239 & 5.7362 & 5.4669 & TRN \\
\hline CHEMBL1416312 & 688239 & 4.5362 & 5.3996 & TRN \\
\hline CHEMBL1552188 & 688239 & 5.1362 & 5.5496 & TRN \\
\hline CHEMBL1484827 & 688239 & 5.8362 & 5.4944 & TRN \\
\hline CHEMBL1361295 & 688239 & 5.1862 & 5.6031 & TST \\
\hline CHEMBL1496982 & 688239 & 4.9862 & 5.3725 & TRN \\
\hline CHEMBL1559389 & 688239 & 5.5362 & 5.5124 & TRN \\
\hline CHEMBL1481737 & 688239 & 4.5362 & 5.3144 & TST \\
\hline CHEMBL1502827 & 688239 & 4.7862 & 5.4599 & TRN \\
\hline CHEMBL1572641 & 688239 & 6.5363 & 5.5285 & TRN \\
\hline CHEMBL591519 & 688239 & 8.2366 & 5.3854 & TRN \\
\hline CHEMBL1580455 & 688239 & 6.3362 & 5.6709 & TRN \\
\hline CHEMBL1415772 & 688239 & 5.6362 & 5.6188 & TRN \\
\hline CHEMBL1594828 & 688239 & 6.0862 & 5.4773 & TRN \\
\hline CHEMBL1504910 & 688239 & 5.1862 & 5.4519 & TRN \\
\hline CHEMBL1513056 & 688239 & 4.6362 & 5.2404 & TRN \\
\hline CHEMBL1442379 & 688239 & 4.6862 & 5.3301 & TRN \\
\hline CHEMBL1355690 & 688239 & 5.0862 & 5.5368 & TRN \\
\hline CHEMBL1431379 & 688239 & 5.2362 & 5.5498 & TST \\
\hline CHEMBL1466072 & 688239 & 5.4362 & 5.5605 & TRN \\
\hline CHEMBL1415489 & 688239 & 5.7362 & 5.4941 & TRN \\
\hline CHEMBL1314704 & 688239 & 4.5862 & 5.5748 & TRN \\
\hline CHEMBL1598899 & 688239 & 6.0862 & 5.407999 & 99999999995 \\
\hline CHEMBL1610966 & 688239 & 5.1862 & 5.4699 & TST \\
\hline CHEMBL1531428 & 688239 & 4.4862 & 5.5242 & TRN \\
\hline CHEMBL1541363 & 688239 & 4.5362 & 5.4774 & TRN \\
\hline CHEMBL1465567 & 688239 & 8.3372 & 5.4524 & TST \\
\hline CHEMBL1455662 & 688239 & 4.6862 & 5.4717 & TST \\
\hline CHEMBL1503520 & 688239 & 5.5862 & 5.411006 & 00000000005 \\
\hline CHEMBL1382899 & 688239 & 6.1862 & 5.4249 & TRN \\
\hline CHEMBL1482432 & 688239 & 6.8362 & 5.6145 & TST \\
\hline CHEMBL1446489 & 688239 & 5.7862 & 5.5391 & TRN \\
\hline CHEMBL1419731 & 688239 & 5.4862 & 5.3911 & TRN \\
\hline CHEMBL1339069 & 688239 & 5.4362 & 5.5225 & TRN \\
\hline CHEMBL1483707 & 688239 & 6.7361 & 5.6289 & TRN \\
\hline CHEMBL1355979 & 688239 & 5.6862 & 5.5377 & TRN \\
\hline CHEMBL1612765 & 688239 & 5.0862 & 5.3006 & TST \\
\hline CHEMBL1608392 & 688239 & 4.9362 & 5.4145 & TRN \\
\hline CHEMBL1486346 & 688239 & 5.0862 & 5.5678 & TRN \\
\hline
\end{tabular}




\begin{tabular}{|c|c|c|c|c|c|}
\hline & & & & & \\
\hline CHEMBL1379508 & 688239 & 4.4862 & 5.5559 & TST & \\
\hline CHEMBL1443447 & 688239 & 6.0862 & 5.5137 & TST & \\
\hline CHEMBL3213874 & 688239 & 6.3362 & 5.5992 & TRN & \\
\hline CHEMBL1998716 & 688239 & 5.0362 & 5.3698 & TRN & \\
\hline CHEMBL1485620 & 688239 & 6.1362 & 5.4774 & TST & \\
\hline CHEMBL1581177 & 688239 & 5.1862 & 5.4336 & TST & \\
\hline CHEMBL1371728 & 688239 & 4.5862 & 5.3294 & TRN & \\
\hline CHEMBL1319615 & 688239 & 5.1862 & 5.4347 & TST & \\
\hline CHEMBL1307197 & 688239 & 6.7361 & 5.5352 & TRN & \\
\hline CHEMBL1402323 & 688239 & 5.9362 & 5.4805 & TRN & \\
\hline CHEMBL1557676 & 688239 & 4.5862 & 5.4627 & TRN & \\
\hline CHEMBL1570964 & 688239 & 4.5362 & 5.7152 & TRN & \\
\hline CHEMBL1594144 & 688239 & 6.1362 & 5.5533 & TRN & \\
\hline CHEMBL3199041 & 688239 & 4.5362 & 5.4305 & TRN & \\
\hline CHEMBL1409907 & 688239 & 4.5362 & 5.5805 & TRN & \\
\hline CHEMBL1401850 & 688239 & 6.2862 & 5.4921 & TRN & \\
\hline CHEMBL1405702 & 688239 & 7.1361 & 5.5941 & TRN & \\
\hline CHEMBL1580639 & 688239 & 4.5362 & 5.3706 & TRN & \\
\hline CHEMBL 2003872 & 688239 & 8.3372 & 5.42700 & 00000000005 & TRN \\
\hline CHEMBL1597158 & 688239 & 4.5862 & 5.3176 & TRN & \\
\hline CHEMBL1429183 & 688239 & 4.4862 & 5.7225 & TRN & \\
\hline CHEMBL1530442 & 688239 & 6.1862 & 5.5059 & TRN & \\
\hline CHEMBL1499810 & 688239 & 8.0862 & 5.4879 & TRN & \\
\hline CHEMBL1364190 & 688239 & 4.5362 & 5.4106 & TST & \\
\hline CHEMBL1339500 & 688239 & 6.5862 & 5.4754 & TRN & \\
\hline CHEMBL1342041 & 688239 & 5.7362 & 5.3779 & TRN & \\
\hline CHEMBL1532527 & 688239 & 5.8862 & 5.5197 & TRN & \\
\hline CHEMBL1334312 & 688239 & 4.5362 & 5.4715 & TRN & \\
\hline CHEMBL1441107 & 688239 & 6.7862 & 5.4555 & TST & \\
\hline CHEMBL1571953 & 688239 & 4.5362 & 5.5439 & TRN & \\
\hline CHEMBL1599596 & 688239 & 8.1367 & 5.5401 & TRN & \\
\hline CHEMBL3195050 & 688239 & 4.5362 & 5.4958 & TRN & \\
\hline CHEMBL3213553 & 688239 & 5.6362 & 5.4306 & TRN & \\
\hline CHEMBL1549130 & 688239 & 6.9363 & 5.4873 & TRN & \\
\hline CHEMBL1390877 & 688239 & 5.1362 & 5.49100 & 00000000005 & TRN \\
\hline CHEMBL1396129 & 688239 & 6.4362 & 5.6529 & TRN & \\
\hline CHEMBL1460137 & 688239 & 5.4862 & 5.4865 & TRN & \\
\hline CHEMBL1385478 & 688239 & 4.6362 & 5.4782 & TRN & \\
\hline CHEMBL1535637 & 688239 & 6.9363 & 5.62200 & $\partial 000000001$ & TST \\
\hline CHEMBL1999436 & 688239 & 6.4862 & 5.34 & TST & \\
\hline CHEMBL1426569 & 688239 & 5.6362 & 5.4449 & TRN & \\
\hline CHEMBL1299334 & 688239 & 8.28399 & 99999999 & 5.5054 & TRN \\
\hline CHEMBL1412887 & 688239 & 4.5362 & 5.3229 & TRN & \\
\hline CHEMBL1498686 & 688239 & 6.3362 & 5.5643 & TRN & \\
\hline CHEMBL1406992 & 688239 & 4.5862 & 5.5432 & TST & \\
\hline CHEMBL1566991 & 688239 & 6.8362 & 5.4505 & TRN & \\
\hline CHEMBL1320024 & 688239 & 8.3372 & 5.4174 & TST & \\
\hline CHEMBL1466790 & 688239 & 4.5362 & 5.4648 & TST & \\
\hline
\end{tabular}


Supplemental Table S2.txt

\begin{tabular}{|c|c|c|c|c|c|}
\hline CHEMBL1347051 & 688239 & 4.5362 & 5.6186 & TRN & \\
\hline CHEMBL 3190671 & 688239 & 4.8862 & 5.5071 & TRN & \\
\hline CHEMBL1440106 & 688239 & 5.4362 & 5.6007 & TST & \\
\hline CHEMBL1508146 & 688239 & 4.5362 & 5.5427 & TST & \\
\hline CHEMBL1349435 & 688239 & 5.1362 & 5.5734 & TRN & \\
\hline CHEMBL1351041 & 688239 & 5.9362 & 5.6226 & TRN & \\
\hline CHEMBL1364913 & 688239 & 7.1864 & 5.4434 & TRN & \\
\hline CHEMBL1562006 & 688239 & 5.3362 & 5.5734 & TST & \\
\hline CHEMBL3193850 & 688239 & 4.4862 & 5.5168 & TRN & \\
\hline CHEMBL1299435 & 688239 & 4.9362 & 5.6251 & TRN & \\
\hline CHEMBL1404324 & 688239 & 6.1862 & 5.4534 & TST & \\
\hline CHEMBL1352203 & 688239 & 4.5362 & 5.4996 & TRN & \\
\hline CHEMBL1312504 & 688239 & 4.7862 & 5.4508 & TRN & \\
\hline CHEMBL599098 & 688239 & 4.8362 & 5.2788 & TST & \\
\hline CHEMBL1304355 & 688239 & 5.0862 & 5.4433 & TST & \\
\hline CHEMBL1330207 & 688239 & 6.1862 & 5.6404 & TRN & \\
\hline CHEMBL1607383 & 688239 & 4.5362 & 5.3656 & TRN & \\
\hline CHEMBL 3211041 & 688239 & 5.4362 & 5.5167 & TRN & \\
\hline CHEMBL1425465 & 688239 & 5.0862 & 5.5672 & TRN & \\
\hline CHEMBL1311578 & 688239 & 5.8862 & 5.5366 & TRN & \\
\hline CHEMBL1576759 & 688239 & 6.9363 & 5.4394 & TRN & \\
\hline CHEMBL1381473 & 688239 & 8.3872 & 5.4047 & TRN & \\
\hline CHEMBL1608993 & 688239 & 5.1862 & 5.5844 & TRN & \\
\hline CHEMBL1491433 & 688239 & 4.5362 & 5.4806 & TST & \\
\hline CHEMBL1330501 & 688239 & 4.9862 & \multicolumn{2}{|c|}{5.4670000000000005} & TRN \\
\hline CHEMBL1603954 & 688239 & 6.4362 & 5.4075 & TRN & \\
\hline CHEMBL3197123 & 688239 & 6.7862 & 5.4584 & TST & \\
\hline CHEMBL1392323 & 688239 & 6.7361 & 5.5233 & TRN & \\
\hline CHEMBL1606794 & 688239 & 8.2366 & 5.4801 & TRN & \\
\hline CHEMBL1403256 & 688239 & 6.9363 & \multicolumn{2}{|c|}{5.531000000000001} & TST \\
\hline CHEMBL1538821 & 688239 & 6.2362 & 5.4442 & TRN & \\
\hline CHEMBL1484080 & 688239 & 6.2362 & 5.516 & TRN & \\
\hline CHEMBL1600456 & 688239 & 6.1362 & 5.5301 & TRN & \\
\hline CHEMBL1433711 & 688239 & 5.2362 & 5.6456 & TRN & \\
\hline CHEMBL1508180 & 688239 & 5.9862 & 5.5217 & TRN & \\
\hline CHEMBL 3189254 & 688239 & 6.6861 & \multicolumn{2}{|c|}{5.382999999999999} & TRN \\
\hline CHEMBL1542529 & 688239 & 4.5362 & 5.4673 & TRN & \\
\hline CHEMBL1440131 & 688239 & 5.6362 & 5.6746 & TRN & \\
\hline CHEMBL1468911 & 688239 & 4.8362 & 5.4777 & TRN & \\
\hline CHEMBL1577465 & 688239 & 5.6862 & 5.5041 & TRN & \\
\hline CHEMBL1378916 & 688239 & 4.8362 & 5.4339 & TRN & \\
\hline CHEMBL1486861 & 688239 & 5.1862 & 5.5406 & TST & \\
\hline CHEMBL1602406 & 688239 & 4.5362 & 5.4527 & TRN & \\
\hline CHEMBL1569886 & 688239 & 5.8862 & 5.4924 & TRN & \\
\hline CHEMBL1608256 & 688239 & 6.0862 & 5.4654 & TRN & \\
\hline CHEMBL1505215 & 688239 & 4.5362 & 5.6361 & TRN & \\
\hline CHEMBL1365794 & 688239 & 4.6862 & 5.4233 & TST & \\
\hline CHEMBL1374333 & 688239 & 6.1362 & 5.6284 & TRN & \\
\hline
\end{tabular}


Supplemental Table S2.txt

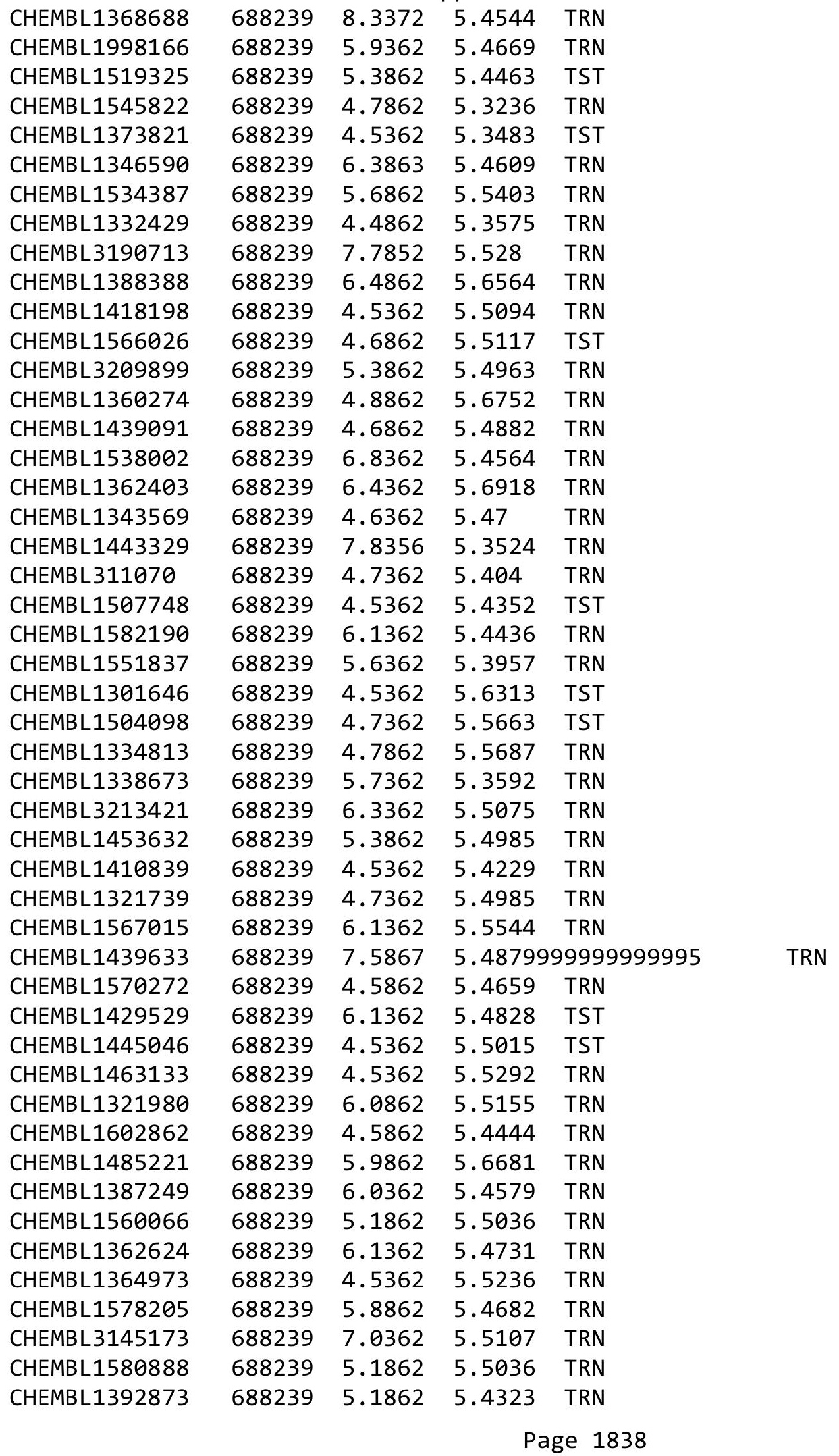


Supplemental Table S2.txt

\begin{tabular}{|c|c|c|c|c|}
\hline CHEMBL1311854 & 688239 & 4.7362 & 5.4833 & TST \\
\hline CHEMBL1463872 & 688239 & 6.8861 & 5.5479 & TST \\
\hline CHEMBL1588555 & 688239 & 5.4862 & 5.3926 & TRN \\
\hline CHEMBL1304169 & 688239 & 6.9863 & 5.4782 & TST \\
\hline CHEMBL1969590 & 688239 & 5.5862 & 5.3864 & TRN \\
\hline CHEMBL1575480 & 688239 & 6.2362 & 5.5285 & TRN \\
\hline CHEMBL1398060 & 688239 & 5.1862 & 5.3929 & TRN \\
\hline CHEMBL1463665 & 688239 & 4.5362 & 5.5406 & TRN \\
\hline CHEMBL1304950 & 688239 & 7.0862 & 5.5638 & TRN \\
\hline CHEMBL1537249 & 688239 & 4.6862 & 5.4886 & TRN \\
\hline CHEMBL1474808 & 688239 & 4.7862 & 5.2963 & TRN \\
\hline CHEMBL1594342 & 688239 & 4.5362 & 5.3907 & TRN \\
\hline CHEMBL1490276 & 688239 & 5.8862 & 5.4763 & TST \\
\hline CHEMBL 3198607 & 688239 & 5.0862 & 5.492999 & 9999999999 \\
\hline CHEMBL1376098 & 688239 & 5.9862 & 5.5193 & TRN \\
\hline CHEMBL 1550663 & 688239 & 4.6362 & 5.48 & TRN \\
\hline CHEMBL1598561 & 688239 & 5.1862 & 5.3574 & TST \\
\hline CHEMBL1422377 & 688239 & 4.5362 & 5.5209 & TRN \\
\hline CHEMBL1363270 & 688239 & 4.8862 & 5.4226 & TRN \\
\hline CHEMBL1363678 & 688239 & 7.4365 & 5.6764 & TRN \\
\hline CHEMBL3191824 & 688239 & 5.5862 & 5.5053 & TRN \\
\hline CHEMBL1588749 & 688239 & 5.6862 & 5.4836 & TST \\
\hline CHEMBL1488081 & 688239 & 8.28399 & 99999999 & 5.4945 \\
\hline CHEMBL1611197 & 688239 & 4.8862 & 5.3812 & TST \\
\hline CHEMBL1424867 & 688239 & 4.7862 & 5.3099 & TRN \\
\hline CHEMBL1396265 & 688239 & 7.2865 & 5.5441 & TST \\
\hline CHEMBL1400559 & 688239 & 7.0362 & 5.5567 & TRN \\
\hline CHEMBL1328958 & 688239 & 6.8362 & 5.5709 & TRN \\
\hline CHEMBL1350457 & 688239 & 5.8862 & 5.5414 & TRN \\
\hline CHEMBL1385389 & 688239 & 5.4862 & 5.4045 & TRN \\
\hline CHEMBL1493936 & 688239 & 5.1862 & 5.35 & TST \\
\hline CHEMBL1575776 & 688239 & 5.1862 & 5.4585 & TST \\
\hline CHEMBL1430024 & 688239 & 5.2862 & 5.4644 & TRN \\
\hline CHEMBL1369727 & 688239 & 5.6362 & 5.3926 & TRN \\
\hline CHEMBL1487473 & 688239 & 5.9862 & 5.5914 & TRN \\
\hline CHEMBL1319036 & 688239 & 6.0862 & 5.5174 & TRN \\
\hline CHEMBL1538684 & 688239 & 5.3862 & 5.5897 & TST \\
\hline CHEMBL1305360 & 688239 & 8.3372 & 5.544 & TRN \\
\hline CHEMBL1342097 & 688239 & 5.6362 & 5.5565 & TRN \\
\hline CHEMBL1359641 & 688239 & 4.5362 & 5.473 & TST \\
\hline CHEMBL1391006 & 688239 & 5.6362 & 5.5309 & TRN \\
\hline CHEMBL1578389 & 688239 & 4.8362 & 5.5908 & TRN \\
\hline CHEMBL1372793 & 688239 & 4.6862 & 5.4101 & TRN \\
\hline CHEMBL1480939 & 688239 & 4.5362 & 5.5085 & TST \\
\hline CHEMBL1599819 & 688239 & 5.8362 & 5.5525 & TST \\
\hline CHEMBL1582836 & 688239 & 5.1862 & 5.4758 & TRN \\
\hline CHEMBL1510084 & 688239 & 5.8862 & 5.4938 & TST \\
\hline CHEMBL1367943 & 688239 & 8.2366 & 5.3139 & TRN \\
\hline
\end{tabular}


Supplemental Table S2.txt

\begin{tabular}{|c|c|c|c|c|c|}
\hline CHEMBL1321687 & 688239 & 6.2362 & 5.4472 & TRN & \\
\hline CHEMBL1342178 & 688239 & 6.8861 & 5.5129 & TRN & \\
\hline CHEMBL1338949 & 688239 & 5.3862 & 5.4452 & TRN & \\
\hline CHEMBL1317493 & 688239 & 5.6362 & 5.5325 & TRN & \\
\hline CHEMBL 3193493 & 688239 & 4.5362 & 5.3259 & TRN & \\
\hline CHEMBL1522629 & 688239 & 6.3863 & 5.4073 & TRN & \\
\hline CHEMBL1453887 & 688239 & 4.6362 & 5.5849 & TRN & \\
\hline CHEMBL1383783 & 688239 & 4.5362 & 5.4078 & TRN & \\
\hline CHEMBL1501710 & 688239 & 4.5362 & 5.5683 & TST & \\
\hline CHEMBL1602991 & 688239 & 6.3863 & 5.6973 & TST & \\
\hline CHEMBL1411994 & 688239 & 5.2862 & 5.4437 & TRN & \\
\hline CHEMBL3193721 & 688239 & 5.1862 & 5.5719 & TRN & \\
\hline CHEMBL1567341 & 688239 & 5.6362 & 5.4814 & TRN & \\
\hline CHEMBL1503897 & 688239 & 6.8362 & 5.5549 & TRN & \\
\hline CHEMBL1365771 & 688239 & 4.6862 & 5.1951 & TRN & \\
\hline CHEMBL1353204 & 688239 & 4.5362 & 5.4074 & TRN & \\
\hline CHEMBL1468226 & 688239 & 4.5362 & 5.3615 & TRN & \\
\hline CHEMBL1559626 & 688239 & 5.3862 & 5.5812 & TRN & \\
\hline CHEMBL1347834 & 688239 & 4.9362 & 5.5051 & TRN & \\
\hline CHEMBL3207372 & 688239 & 4.5362 & 5.3915 & TRN & \\
\hline CHEMBL1509702 & 688239 & 5.9362 & 5.5241 & TRN & \\
\hline CHEMBL1997052 & 688239 & 4.5862 & 5.1906 & TRN & \\
\hline CHEMBL1514046 & 688239 & 4.6362 & 5.6276 & TRN & \\
\hline CHEMBL1577754 & 688239 & 5.1862 & 5.4823 & TRN & \\
\hline CHEMBL1571235 & 688239 & 4.5362 & 5.5459 & TST & \\
\hline CHEMBL1518158 & 688239 & 5.8362 & 5.59 & TRN & \\
\hline CHEMBL1611140 & 688239 & 7.1864 & 5.5129 & TST & \\
\hline CHEMBL1531396 & 688239 & 5.2362 & 5.5651 & TST & \\
\hline CHEMBL1522320 & 688239 & 4.5362 & 5.4533 & TST & \\
\hline CHEMBL1509332 & 688239 & 5.3862 & 5.4079 & TST & \\
\hline CHEMBL1306196 & 688239 & 5.0862 & 5.5542 & TRN & \\
\hline CHEMBL1534228 & 688239 & 7.2366 & 5.6043 & TST & \\
\hline CHEMBL1348148 & 688239 & 5.4362 & 5.4805 & TRN & \\
\hline CHEMBL1599698 & 688239 & 6.9863 & 5.5814 & TRN & \\
\hline CHEMBL1329174 & 688239 & 5.7862 & 5.4858 & TRN & \\
\hline CHEMBL1358458 & 688239 & 5.4362 & 5.4634 & TRN & \\
\hline CHEMBL1423026 & 688239 & 6.9363 & 5.4312 & TRN & \\
\hline CHEMBL1334040 & 688239 & 4.4362 & 5.3202 & TST & \\
\hline CHEMBL1588218 & 688239 & 5.9862 & 5.57100 & 2000000001 & TRN \\
\hline CHEMBL1306203 & 688239 & 5.8362 & 5.5568 & TRN & \\
\hline CHEMBL1397768 & 688239 & 4.5862 & 5.2944 & TRN & \\
\hline CHEMBL1331348 & 688239 & 5.8362 & 5.4911 & TST & \\
\hline CHEMBL1392725 & 688239 & 5.3862 & 5.4276 & TRN & \\
\hline CHEMBL1390242 & 688239 & 4.5362 & 5.4476 & TRN & \\
\hline CHEMBL1359967 & 688239 & 4.5362 & 5.5428 & TRN & \\
\hline CHEMBL1487939 & 688239 & 6.8362 & 5.4363 & TRN & \\
\hline CHEMBL1452290 & 688239 & 5.4362 & 5.4664 & TRN & \\
\hline CHEMBL1540541 & 688239 & 6.2362 & 5.409 & TRN & \\
\hline
\end{tabular}


Supplemental Table S2.txt

\begin{tabular}{|c|c|c|c|c|c|}
\hline CHEMBL1320124 & 688239 & 4.6862 & 5.3293 & TST & \\
\hline CHEMBL1423599 & 688239 & 4.7362 & 5.4804 & TRN & \\
\hline CHEMBL1352846 & 688239 & 4.5362 & 5.4381 & TRN & \\
\hline CHEMBL1463206 & 688239 & 5.1862 & 5.5306 & TRN & \\
\hline CHEMBL1443816 & 688239 & 5.5362 & 5.5471 & TRN & \\
\hline CHEMBL1333546 & 688239 & 4.9362 & 5.4351 & TRN & \\
\hline CHEMBL1352016 & 688239 & 5.0362 & 5.5191 & TST & \\
\hline CHEMBL1591287 & 688239 & 6.8362 & \multicolumn{2}{|c|}{5.486000000000001} & TRN \\
\hline CHEMBL533293 & 688239 & 4.6862 & 5.3771 & TST & \\
\hline CHEMBL1535914 & 688239 & 6.0862 & 5.4396 & TRN & \\
\hline CHEMBL1600965 & 688239 & 4.5362 & 5.4936 & TRN & \\
\hline CHEMBL1579152 & 688239 & 5.1362 & 5.4176 & TRN & \\
\hline CHEMBL3189391 & 688239 & 4.7862 & 5.5306 & TRN & \\
\hline CHEMBL1609280 & 688239 & 5.6862 & 5.388 & TRN & \\
\hline CHEMBL1353925 & 688239 & 4.6862 & 5.4203 & TRN & \\
\hline CHEMBL1457385 & 688239 & 5.4862 & \multicolumn{2}{|c|}{5.492000000000001} & TRN \\
\hline CHEMBL1554815 & 688239 & \multicolumn{3}{|c|}{8.283999999999999} & .406000000000001 \\
\hline CHEMBL1464999 & 688239 & 8.3372 & 5.4668 & TST & \\
\hline CHEMBL1366768 & 688239 & 5.5862 & 5.6334 & TST & \\
\hline CHEMBL1535075 & 688239 & 6.8861 & 5.5021 & TRN & \\
\hline CHEMBL1332066 & 688239 & 5.0362 & 5.6692 & TRN & \\
\hline CHEMBL1411960 & 688239 & 4.6862 & 5.4109 & TRN & \\
\hline CHEMBL1544586 & 688239 & 5.9862 & 5.586 & TRN & \\
\hline CHEMBL1558107 & 688239 & 6.7862 & 5.4125 & TST & \\
\hline CHEMBL1538805 & 688239 & 5.1862 & 5.5726 & TRN & \\
\hline CHEMBL1418200 & 688239 & 4.5362 & 5.505 & TST & \\
\hline CHEMBL1495285 & 688239 & 5.2362 & 5.4936 & TRN & \\
\hline CHEMBL1471457 & 688239 & 5.3862 & 5.4487 & TST & \\
\hline CHEMBL1341432 & 688239 & 4.9362 & 5.4741 & TRN & \\
\hline CHEMBL1477952 & 688239 & 5.4862 & 5.3897 & TST & \\
\hline CHEMBL1582559 & 688239 & 4.6362 & 5.5044 & TRN & \\
\hline CHEMBL1490586 & 688239 & 7.2865 & 5.5015 & TRN & \\
\hline CHEMBL1380443 & 688239 & 4.5862 & 5.447999 & 99999999995 & TRN \\
\hline CHEMBL1350118 & 688239 & 7.0862 & 5.7132 & TRN & \\
\hline CHEMBL1375966 & 688239 & 4.5362 & 5.5486 & TRN & \\
\hline CHEMBL1449194 & 688239 & 5.0862 & 5.4282 & TRN & \\
\hline CHEMBL1545488 & 688239 & 8.3372 & 5.5206 & TST & \\
\hline CHEMBL1342426 & 688239 & 6.8861 & 5.5991 & TRN & \\
\hline CHEMBL1351899 & 688239 & 4.7862 & 5.4082 & TRN & \\
\hline CHEMBL1415259 & 688239 & 6.3362 & 5.3807 & TRN & \\
\hline CHEMBL1343820 & 688239 & 4.7362 & 5.4364 & TST & \\
\hline CHEMBL1359406 & 688239 & 4.5862 & 5.4382 & TRN & \\
\hline CHEMBL1550066 & 688239 & 4.5362 & 5.4757 & TRN & \\
\hline CHEMBL1458133 & 688239 & 4.5862 & 5.4746 & TST & \\
\hline CHEMBL1400310 & 688239 & 6.1362 & 5.6388 & TRN & \\
\hline CHEMBL1570953 & 688239 & 6.0862 & 5.6055 & TRN & \\
\hline CHEMBL1598263 & 688239 & 4.7362 & 5.5092 & TRN & \\
\hline CHEMBL1550303 & 688239 & 6.1862 & 5.5286 & TRN & \\
\hline
\end{tabular}


Supplemental Table S2.txt

\begin{tabular}{|c|c|c|c|c|}
\hline 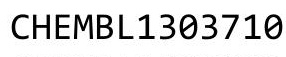 & & & & \\
\hline HEMBL1586393 & 88239 & 4862 & 4919 & \\
\hline HEMBL13 & 88239 & 562 & 6102 & \\
\hline & & & & \\
\hline EMBL1: & & & 187 & \\
\hline HEMBL1500681 & 88239 & 362 & 4286 & \\
\hline HEMBL3208612 & 88239 & 862 & .5472 & \\
\hline HEMBL1327470 & & & & \\
\hline IEMBL: & 39 & & 5515 & \\
\hline IEMBL1543025 & 39 & & & \\
\hline HEMBL1378053 & 88239 & 862 & 5295 & \\
\hline HEMBL1581389 & 39 & .2362 & .5863 & \\
\hline HEMBL1500131 & 39 & & 4345 & \\
\hline AEME & 39 & 62 & 55 & \\
\hline HEMBL 144 & 39 & & & \\
\hline HEMBL1578203 & 39 & & .435 & \\
\hline HEMBL1601063 & 39 & & 568 & \\
\hline HEMBL1483600 & 9 & & 93 & \\
\hline HEM & 9 & & & \\
\hline HEME & 39 & & & \\
\hline HEMBL155 & 39 & & 373 & \\
\hline HEMBL1453775 & 39 & & & \\
\hline HEMBL144 & 39 & & & \\
\hline HEMBL14 & & & 33 & \\
\hline HEM & 39 & & & \\
\hline HEMBL152 & 39 & & & \\
\hline HEMBL1559929 & 39 & & .5761 & IRN \\
\hline HEMBL151 & 9 & & & \\
\hline HEM & & & & RN \\
\hline HEM & & & 58 & RN \\
\hline HEMBL1597 & 9 & & & $\mathbf{v}$ \\
\hline HEMBL 3197 & 39 & & 5362 & TRN \\
\hline HEMBL15 & & & & KIN \\
\hline HEM & 9 & & 09 & RN \\
\hline HEM & & & 342 & $\mathrm{RN}$ \\
\hline HEMBL1301937 & 39 & & 265 & IRN \\
\hline HEMBL1503445 & 39 & & 25 & $\Gamma R N$ \\
\hline 3 & & & & \\
\hline (10 10 & 39 & & 01 & \\
\hline HEMBL13 & & & & $\mathrm{RN}$ \\
\hline HEMBL1980259 & 88239 & & 5.5185 & ГST \\
\hline HEMBL1400658 & 39 & & 35 & RN \\
\hline HEM & & & & \\
\hline CHEMBL1363540 & 88239 & & & \\
\hline HEMBL1330258 & & & .3707 & $\mathrm{RN}$ \\
\hline HEMBL1600911 & 39 & 62 & .5075 & \\
\hline HEMBL153 & & & & \\
\hline HEMPI 130026 & & & .4509 & \\
\hline
\end{tabular}

Page 1842 
Supplemental Table S2.txt

\begin{tabular}{|c|c|c|c|c|}
\hline CHEMBL1438495 & 688239 & 5.1862 & 5.4202 & TRN \\
\hline CHEMBL1303068 & 688239 & 4.5362 & 5.2731 & TRN \\
\hline CHEMBL1609757 & 688239 & 5.2362 & 5.5817 & TRN \\
\hline CHEMBL1530446 & 688239 & 4.5362 & 5.5327 & TRN \\
\hline CHEMBL1329121 & 688239 & 5.4362 & 5.4242 & TRN \\
\hline CHEMBL1392509 & 688239 & 4.5362 & 5.5109 & TRN \\
\hline CHEMBL1510443 & 688239 & 5.1862 & 5.4632 & TRN \\
\hline CHEMBL1545317 & 688239 & 4.5362 & 5.3979 & TRN \\
\hline CHEMBL1304885 & 688239 & 4.8362 & 5.5403 & TRN \\
\hline CHEMBL1362166 & 688239 & 6.0862 & 5.5505 & TST \\
\hline CHEMBL1382181 & 688239 & 4.7362 & 5.4438 & TST \\
\hline CHEMBL1320170 & 688239 & 5.6862 & 5.359 & TRN \\
\hline CHEMBL1396058 & 688239 & 4.8362 & 5.3524 & TRN \\
\hline CHEMBL1506979 & 688239 & 4.5362 & 5.4622 & TST \\
\hline CHEMBL1358917 & 688239 & 4.4862 & 5.4843 & TRN \\
\hline CHEMBL1451212 & 688239 & 5.4862 & 5.4878 & TST \\
\hline CHEMBL1576356 & 688239 & 4.7862 & 5.4243 & TRN \\
\hline CHEMBL213580 & 688239 & 4.5862 & 5.4426 & TST \\
\hline CHEMBL1585085 & 688239 & 4.5362 & 5.4996 & TRN \\
\hline CHEMBL1308724 & 688239 & 4.8362 & 5.53 & TST \\
\hline CHEMBL1509395 & 688239 & 8.28399 & 99999999 & 5.4256 \\
\hline CHEMBL1789993 & 688239 & 4.8862 & 5.431 & TST \\
\hline CHEMBL1610026 & 688239 & 4.6862 & 5.6055 & TRN \\
\hline CHEMBL1427184 & 688239 & 5.1862 & 5.5411 & TRN \\
\hline CHEMBL1498842 & 688239 & 5.1862 & 5.5564 & TRN \\
\hline CHEMBL1550893 & 688239 & 4.5362 & 5.4838 & TRN \\
\hline CHEMBL1524378 & 688239 & 6.1362 & 5.5164 & TRN \\
\hline CHEMBL1588751 & 688239 & 5.4362 & 5.423999 & 99999999995 \\
\hline CHEMBL1428965 & 688239 & 5.1862 & 5.5446 & TRN \\
\hline CHEMBL 3194328 & 688239 & 5.5362 & 5.2792 & TRN \\
\hline CHEMBL1527854 & 688239 & 5.4362 & 5.6376 & TRN \\
\hline CHEMBL1599522 & 688239 & 4.5362 & 5.5472 & TRN \\
\hline CHEMBL1370024 & 688239 & 4.7362 & 5.5746 & TST \\
\hline CHEMBL1389307 & 688239 & 6.6362 & 5.4597 & TRN \\
\hline CHEMBL1562855 & 688239 & 5.4362 & 5.5131 & TRN \\
\hline CHEMBL1301723 & 688239 & 5.1362 & 5.4423 & TRN \\
\hline CHEMBL3212973 & 688239 & 6.5363 & 5.4587 & TST \\
\hline CHEMBL1335034 & 688239 & 5.1862 & 5.4921 & TRN \\
\hline CHEMBL1393195 & 688239 & 4.5862 & 5.3795 & TRN \\
\hline CHEMBL1527883 & 688239 & 5.8862 & 5.6923 & TRN \\
\hline CHEMBL1528552 & 688239 & 6.2362 & 5.4785 & TRN \\
\hline CHEMBL1469158 & 688239 & 4.9362 & 5.4266 & TST \\
\hline CHEMBL1453811 & 688239 & 5.3862 & 5.5192 & TST \\
\hline CHEMBL1495936 & 688239 & 5.5862 & 5.5716 & TST \\
\hline CHEMBL1613458 & 688239 & 5.1362 & 5.4485 & TRN \\
\hline CHEMBL1512112 & 688239 & 5.1862 & 5.4018 & TRN \\
\hline CHEMBL1493635 & 688239 & 6.1862 & 5.4894 & TRN \\
\hline CHEMBL1599507 & 688239 & 4.5862 & 5.3911 & TRN \\
\hline
\end{tabular}


Supplemental Table S2.txt

\begin{tabular}{|c|c|c|c|c|}
\hline HEM & & 362 & & \\
\hline & & .1862 & & \\
\hline & & & & \\
\hline AEMBL161 & & & & \\
\hline AEMBL153 & 8239 & & & \\
\hline HEMBL1342081 & 88239 & 6862 & 4445 & \\
\hline HEMBL1 & 239 & 362 & & \\
\hline FMB 12 & & & & \\
\hline AEMBL1569255 & 239 & 862 & & \\
\hline HEMBL1387798 & 38239 & 862 & & \\
\hline HEMBL1362745 & 239 & 862 & & \\
\hline IEMBL1 & 239 & & & \\
\hline IEMBL1 & & 52 & & \\
\hline HEMBL135 & & & & \\
\hline AEMBL151 & & & & \\
\hline AEMBL1 & 39 & 62 & 42 & \\
\hline HEMBL1 & & 362 & & . \\
\hline HEMBL1 & & & & \\
\hline AEMBL1 & & 362 & & \\
\hline IEMBL1 & & & & \\
\hline 555 & & 62 & & 31 \\
\hline AEMBL: & & & & RN \\
\hline HEMBL: & & 62 & & \\
\hline 059 & & 862 & & \\
\hline IEMBL1 & & & & T- \\
\hline AEMBL & & & & I RN \\
\hline AEME & & & & וד וכ \\
\hline 416 & & & & \\
\hline AEMBL: & & & & 13 \\
\hline HEMBL1384508 & & & & 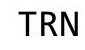 \\
\hline HEMBL1 & & & & SI \\
\hline HEMBL & & & & ST \\
\hline 55 & & & & \\
\hline HEMBL1405339 & & & & is \\
\hline HEMBL1322437 & & & & TRN \\
\hline HEMBL & & & & RN \\
\hline HFMRI 1 & & 2 & & IRIV \\
\hline HEMBL1 & & & & IST \\
\hline HEMBL1398666 & & 362 & & TST \\
\hline AEMBL1 & & 62 & & TST \\
\hline HEMBL1 & & 362 & & TRN \\
\hline HEMBL 1 & & & & TRN \\
\hline HEMBL1 & & 362 & 5.4166 & IST \\
\hline AEMBL1352348 & 39 & 362 & & TR \\
\hline HEMBL1 & & 52 & & \\
\hline HEMBL1 & & & & \\
\hline CHEMBL1466594 & & & 5.5837 & \\
\hline HEMBL3198286 & 688239 & 4.5362 & 5.3942 & ГST \\
\hline
\end{tabular}

Page 1844 


\begin{tabular}{|c|c|c|c|c|c|}
\hline & & & & & \\
\hline CHEMBL1399096 & 688239 & 4.7862 & 5.4737 & TRN & \\
\hline CHEMBL3213162 & 688239 & 5.1862 & 5.5939 & TRN & \\
\hline CHEMBL1579779 & 688239 & 5.8362 & 5.4748 & TST & \\
\hline CHEMBL 3197437 & 688239 & 5.2862 & 5.5503 & TRN & \\
\hline CHEMBL1372664 & 688239 & 5.7862 & 5.4752 & TRN & \\
\hline CHEMBL1345167 & 688239 & 6.0862 & 5.6134 & TST & \\
\hline CHEMBL1302283 & 688239 & 5.6862 & 5.535 & TRN & \\
\hline CHEMBL1420401 & 688239 & 6.2862 & 5.5805 & TRN & \\
\hline CHEMBL1541314 & 688239 & 4.8862 & 5.415 & TRN & \\
\hline CHEMBL1356355 & 688239 & 6.1362 & 5.5207 & TRN & \\
\hline CHEMBL1350465 & 688239 & 4.5362 & 5.6677 & TRN & \\
\hline CHEMBL1390085 & 688239 & 5.5862 & 5.4925 & TRN & \\
\hline CHEMBL1386755 & 688239 & 4.7362 & 5.49200 & 0000000001 & TRN \\
\hline CHEMBL1572016 & 688239 & 5.0862 & 5.4871 & TRN & \\
\hline CHEMBL1428538 & 688239 & 6.5862 & 5.3961 & TST & \\
\hline CHEMBL1469654 & 688239 & 8.3372 & 5.5404 & TRN & \\
\hline CHEMBL3189411 & 688239 & 5.7362 & 5.4393 & TST & \\
\hline CHEMBL1388098 & 688239 & 6.7862 & 5.5696 & TRN & \\
\hline CHEMBL1998092 & 688239 & 4.5862 & 5.4414 & TRN & \\
\hline CHEMBL1459836 & 688239 & 5.7362 & 5.5469 & TRN & \\
\hline CHEMBL1445120 & 688239 & 5.1362 & 5.4639 & TRN & \\
\hline CHEMBL1583931 & 688239 & 5.3362 & 5.5873 & TRN & \\
\hline CHEMBL1419640 & 688239 & 4.4862 & 5.4224 & TRN & \\
\hline CHEMBL1570909 & 688239 & 4.8862 & 5.4632 & TST & \\
\hline CHEMBL1480837 & 688239 & 4.95 & 5.41700 & 0000000001 & TRN \\
\hline CHEMBL1413375 & 688239 & 4.5362 & 5.4224 & TRN & \\
\hline CHEMBL1344722 & 688239 & 6.8861 & 5.4519 & TRN & \\
\hline CHEMBL1420873 & 688239 & 4.5862 & 5.3681 & TRN & \\
\hline CHEMBL1342722 & 688239 & 4.7362 & 5.3911 & TRN & \\
\hline CHEMBL1495391 & 688239 & 6.2362 & 5.6839 & TRN & \\
\hline CHEMBL1398797 & 688239 & 4.8862 & 5.3364 & TRN & \\
\hline CHEMBL1467626 & 688239 & 4.8862 & 5.3572 & TRN & \\
\hline CHEMBL1327940 & 688239 & 5.4362 & 5.4704 & TST & \\
\hline CHEMBL1503028 & 688239 & 4.6362 & 5.5092 & TST & \\
\hline CHEMBL1498044 & 688239 & 5.1862 & 5.3559 & TRN & \\
\hline CHEMBL1501152 & 688239 & 6.7361 & 5.4095 & TRN & \\
\hline CHEMBL1464664 & 688239 & 8.3872 & 5.694 & TRN & \\
\hline CHEMBL1557016 & 688239 & 5.2362 & 5.6116 & TRN & \\
\hline CHEMBL1441444 & 688239 & 6.0862 & 5.4455 & TRN & \\
\hline CHEMBL2369275 & 688239 & 4.8362 & 5.57100 & 0000000001 & TRN \\
\hline CHEMBL1310028 & 688239 & 5.6862 & 5.484 & TRN & \\
\hline CHEMBL1390976 & 688239 & 6.7361 & 5.5579 & TRN & \\
\hline CHEMBL1442341 & 688239 & 4.6362 & 5.4113 & TRN & \\
\hline CHEMBL1407166 & 688239 & 4.5362 & 5.4728 & TRN & \\
\hline CHEMBL3189912 & 688239 & 6.1862 & 5.3514 & TST & \\
\hline CHEMBL1415925 & 688239 & 5.6862 & 5.4013 & TST & \\
\hline CHEMBL1544774 & 688239 & 6.5363 & 5.5192 & TRN & \\
\hline CHEMBL1390924 & 688239 & 5.1362 & 5.5265 & TRN & \\
\hline
\end{tabular}


Supplemental Table S2.txt

\begin{tabular}{|c|c|c|c|c|}
\hline 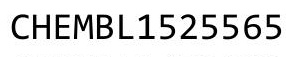 & & & 4038 & \\
\hline HEMBL1459093 & 88239 & 5362 & 5298 & \\
\hline HEMBL13 & 88239 & 6862 & 5607 & \\
\hline 10 & & & 521 & \\
\hline EMBL1: & & 63 & 4477 & \\
\hline HEMBL1495314 & 88239 & 362 & 3908 & \\
\hline HEMBL1435601 & 88239 & .1862 & 5098 & \\
\hline HEMBL1476498 & & & & \\
\hline 513 & 39 & 862 & .6267 & \\
\hline IEMBL15 & 39 & 362 & .6831 & \\
\hline HEMBL1359168 & 88239 & 362 & .4773 & \\
\hline HEMBL1318984 & 39 & 5862 & .4853 & \\
\hline HEMBL1478795 & 39 & 62 & 3977 & \\
\hline 513 & 39 & & 317 & \\
\hline HEMBL60 & 39 & & 5966 & \\
\hline AEMBL1323400 & 39 & 862 & 5043 & \\
\hline HEMBL1561807 & 39 & 862 & & \\
\hline HEMBL 14 & 9 & 62 & 398 & \\
\hline HEMBL15 & 9 & & & \\
\hline HEMBL14 & 39 & & .3119 & \\
\hline HEMBL13. & 39 & 62 & & \\
\hline HEMBL1329507 & 39 & & & \\
\hline HEMBL132 & 9 & 62 & 91 & \\
\hline HEMBL13 & & & & \\
\hline 415 & 39 & & 61 & \\
\hline AEMBL 237 & 39 & & & ST \\
\hline HEMBL1369154 & 39 & & & ГRN \\
\hline HEMBL13 & 9 & & & \\
\hline 754 & & & & \\
\hline 527 & & 62 & 12 & RN \\
\hline HEMBL1438106 & 9 & & & IRN \\
\hline HEMBL1308666 & 39 & 62 & 898 & ГRN \\
\hline HEMBL1: & & & 87 & 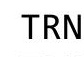 \\
\hline 7 & 9 & & & RN \\
\hline HEMBL15 & & & & RN \\
\hline HEMBL1601816 & 39 & & & $\Gamma R$ \\
\hline HEMBL1426664 & 39 & 362 & 274 & ГRN \\
\hline 948 & 39 & & .72 & $\cdots$ \\
\hline ז1 ובחות & & & & RIV \\
\hline HEMBL 16 & & & & RN \\
\hline HEMBL1548002 & 39 & 62 & 887 & $\Gamma R$ \\
\hline HEMBL 15 & 39 & 362 & 135 & R \\
\hline HEMBL1329063 & & & 5.5152 & \\
\hline HEMBL1553517 & & & 5.3674 & $\mid$ \\
\hline HEMBL1299482 & & 5862 & .5324 & TST \\
\hline HEMBL1532722 & 88 & 362 & .6496 & RN \\
\hline L145 & & & & \\
\hline HᄃMDI 121670 & & & & \\
\hline
\end{tabular}

Page 1846 
Supplemental Table S2.txt

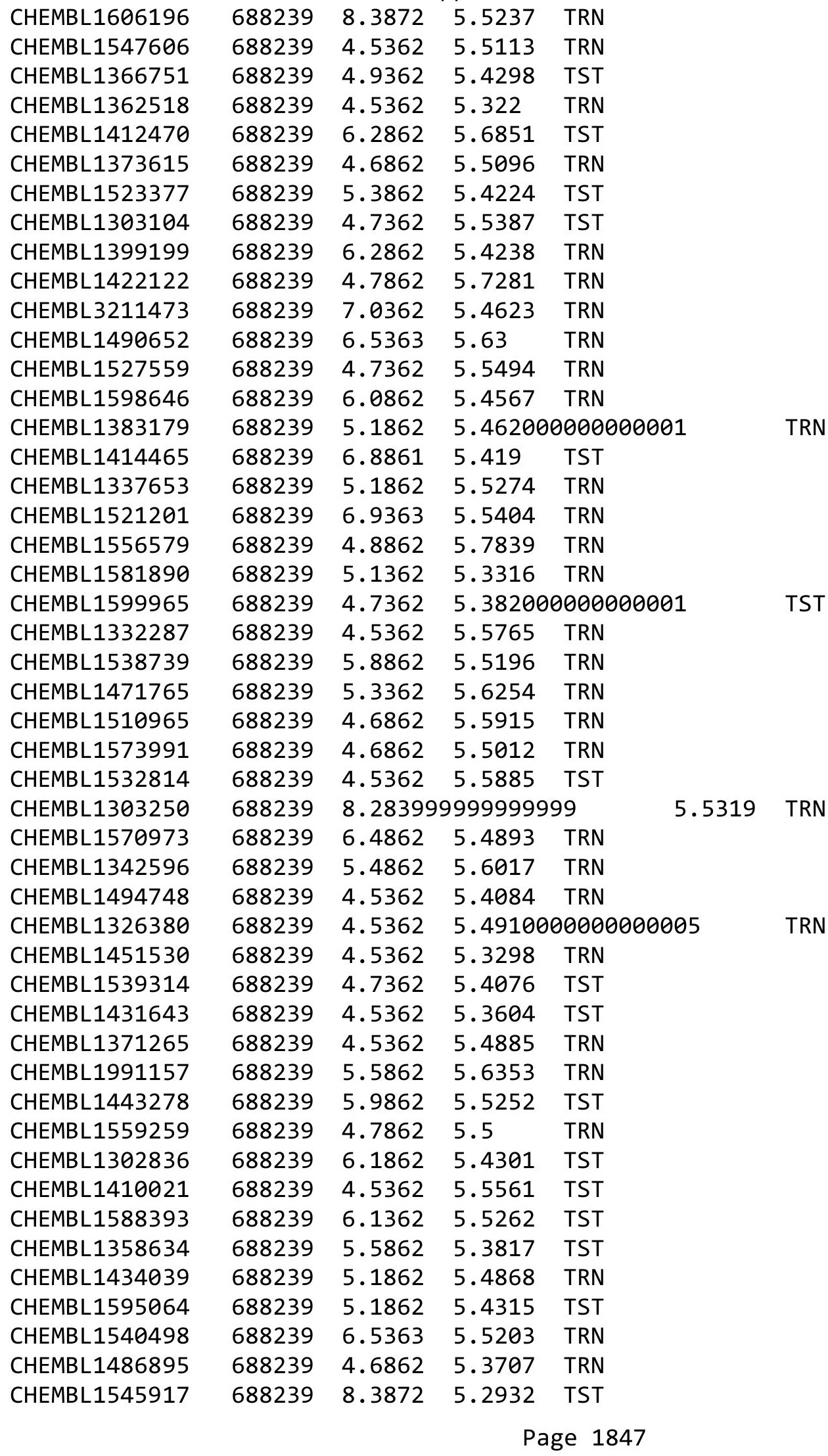


Supplemental Table S2.txt

\begin{tabular}{|c|c|c|c|c|}
\hline CHEMBL1541253 & 688239 & 6.7862 & 5.4901 & TRN \\
\hline CHEMBL1372581 & 688239 & 6.8861 & 5.4802 & TRN \\
\hline CHEMBL1318008 & 688239 & 4.5362 & 5.4489 & TRN \\
\hline CHEMBL1493204 & 688239 & 4.9362 & 5.5129 & TRN \\
\hline CHEMBL1432812 & 688239 & 4.6362 & 5.4964 & TRN \\
\hline CHEMBL1584823 & 688239 & 4.5362 & 5.3488 & TRN \\
\hline CHEMBL1458416 & 688239 & 5.4362 & 5.5262 & TRN \\
\hline CHEMBL1560045 & 688239 & 4.5362 & 5.4181 & TRN \\
\hline CHEMBL1432495 & 688239 & 5.7362 & 5.4608 & TRN \\
\hline CHEMBL1312782 & 688239 & 5.6362 & 5.4578 & TRN \\
\hline CHEMBL1317770 & 688239 & 5.8362 & 5.4838 & TST \\
\hline CHEMBL1577104 & 688239 & 4.5362 & 5.6653 & TRN \\
\hline CHEMBL1540777 & 688239 & 6.2362 & 5.4047 & TRN \\
\hline CHEMBL1304281 & 688239 & 5.1862 & 5.5289 & TRN \\
\hline CHEMBL1330330 & 688239 & 4.8362 & 5.5064 & TRN \\
\hline CHEMBL1509789 & 688239 & 7.4868 & 5.4645 & TRN \\
\hline CHEMBL1388051 & 688239 & 6.4362 & 5.6187 & TRN \\
\hline CHEMBL1391543 & 688239 & 6.9363 & 5.6605 & TRN \\
\hline CHEMBL1583492 & 688239 & 5.1862 & 5.4034 & TST \\
\hline CHEMBL1394770 & 688239 & 5.7362 & 5.5837 & TRN \\
\hline CHEMBL1495529 & 688239 & 8.3372 & 5.5298 & TST \\
\hline CHEMBL1317874 & 688239 & 4.5362 & 5.5368 & TRN \\
\hline CHEMBL1330496 & 688239 & 5.4362 & 5.4117 & TRN \\
\hline CHEMBL1306393 & 688239 & 4.8362 & 5.4872 & TRN \\
\hline CHEMBL1405374 & 688239 & 4.9862 & 5.3243 & TRN \\
\hline CHEMBL1565135 & 688239 & 4.4862 & 5.3895 & TRN \\
\hline CHEMBL1462029 & 688239 & 8.28399 & 99999999 & 5.4811 \\
\hline CHEMBL1533471 & 688239 & 4.5862 & 5.297000 & 000000001 \\
\hline CHEMBL1392134 & 688239 & 7.3862 & 5.4322 & TST \\
\hline CHEMBL1560915 & 688239 & 4.5362 & 5.3699 & TRN \\
\hline CHEMBL1324711 & 688239 & 8.2366 & 5.5371 & TRN \\
\hline CHEMBL1577702 & 688239 & 4.5362 & 5.5852 & TRN \\
\hline CHEMBL1523025 & 688239 & 4.5362 & 5.5275 & TST \\
\hline CHEMBL1532603 & 688239 & 6.8362 & 5.4964 & TRN \\
\hline CHEMBL1328083 & 688239 & 4.6362 & 5.4631 & TRN \\
\hline CHEMBL1342323 & 688239 & 5.2362 & 5.5432 & TRN \\
\hline CHEMBL1423146 & 688239 & 5.5862 & 5.5981 & TST \\
\hline CHEMBL1419304 & 688239 & 4.8362 & 5.4262 & TRN \\
\hline CHEMBL1471410 & 688239 & 5.1862 & 5.4555 & TRN \\
\hline CHEMBL1313062 & 688239 & 5.1862 & 5.4857 & TRN \\
\hline CHEMBL1511275 & 688239 & 4.5362 & 5.5706 & TRN \\
\hline CHEMBL1405905 & 688239 & 5.8362 & 5.4527 & TRN \\
\hline CHEMBL1403537 & 688239 & 5.9362 & 5.5923 & TRN \\
\hline CHEMBL1480034 & 688239 & 6.1862 & 5.3671 & TRN \\
\hline CHEMBL1339254 & 688239 & 6.2862 & 5.4971 & TRN \\
\hline CHEMBL1456127 & 688239 & 7.0362 & 5.4895 & TRN \\
\hline CHEMBL1389749 & 688239 & 4.6862 & 5.5216 & TRN \\
\hline CHEMBL1482215 & 688239 & 6.2862 & 5.4278 & TST \\
\hline
\end{tabular}


Supplemental Table S2.txt

\begin{tabular}{|c|c|c|c|c|}
\hline CHEMBL1572621 & 688239 & 6.0362 & 5.6258 & TRN \\
\hline CHEMBL1600666 & 688239 & 4.6862 & 5.4035 & TRN \\
\hline CHEMBL1612287 & 688239 & 4.5362 & 5.6022 & TST \\
\hline CHEMBL1414230 & 688239 & 6.3362 & \multicolumn{2}{|c|}{5.4670000000000005} \\
\hline CHEMBL1445517 & 688239 & 4.6362 & 5.4376 & TRN \\
\hline CHEMBL1493526 & 688239 & 7.5361 & 5.375 & TRN \\
\hline CHEMBL1303165 & 688239 & 4.6862 & 5.349 & TST \\
\hline CHEMBL1480827 & 688239 & 4.8862 & 5.3589 & TST \\
\hline CHEMBL1370445 & 688239 & 6.3362 & 5.5527 & TRN \\
\hline CHEMBL1325275 & 688239 & 4.4862 & 5.431 & TST \\
\hline CHEMBL1327892 & 688239 & 5.2362 & 5.364 & TST \\
\hline CHEMBL1501202 & 688239 & 4.5362 & 5.3481 & TRN \\
\hline CHEMBL1549892 & 688239 & 6.1362 & 5.5381 & TST \\
\hline CHEMBL1345674 & 688239 & 5.1862 & 5.5036 & TST \\
\hline CHEMBL1339448 & 688239 & 4.5362 & 5.4649 & TRN \\
\hline CHEMBL1558255 & 688239 & 4.6362 & 5.3711 & TRN \\
\hline CHEMBL3209449 & 688239 & 5.6362 & 5.526 & TRN \\
\hline CHEMBL1365713 & 688239 & 4.4862 & 5.5149 & TRN \\
\hline CHEMBL1443171 & 688239 & 6.0862 & 5.6354 & TRN \\
\hline CHEMBL1603359 & 688239 & 5.3862 & 5.3746 & TRN \\
\hline CHEMBL1495494 & 688239 & 5.1862 & 5.5367 & TRN \\
\hline CHEMBL1608523 & 688239 & 5.1862 & 5.6353 & TST \\
\hline CHEMBL1345107 & 688239 & 6.1862 & 5.6207 & TRN \\
\hline CHEMBL1303817 & 688239 & 6.2362 & 5.5131 & TRN \\
\hline CHEMBL1347621 & 688239 & 4.7362 & 5.5573 & TST \\
\hline CHEMBL1965373 & 688239 & 6.5363 & 5.4358 & TST \\
\hline CHEMBL1612400 & 688239 & 6.5862 & 5.4022 & TRN \\
\hline CHEMBL1602576 & 688239 & 7.4868 & 5.6055 & TST \\
\hline CHEMBL1345547 & 688239 & 4.6862 & 5.4166 & TST \\
\hline CHEMBL1548999 & 688239 & 6.2362 & 5.566 & TRN \\
\hline CHEMBL1573424 & 688239 & 4.5862 & 5.4751 & TRN \\
\hline CHEMBL1508957 & 688239 & 7.2865 & 5.5659 & TRN \\
\hline CHEMBL1361147 & 688239 & 6.5363 & 5.6291 & TRN \\
\hline CHEMBL1543819 & 688239 & 4.6362 & 5.4418 & TRN \\
\hline CHEMBL1484004 & 688239 & 4.6862 & 5.3951 & TRN \\
\hline CHEMBL485907 & 688239 & 4.7362 & 5.4634 & TRN \\
\hline CHEMBL1542915 & 688239 & 5.1862 & 5.4978 & TRN \\
\hline CHEMBL1557675 & 688239 & 4.6862 & 5.4563 & TRN \\
\hline CHEMBL 3197386 & 688239 & 7.8356 & 5.502999 & 999999999 \\
\hline CHEMBL1482266 & 688239 & 6.5862 & 5.4054 & TST \\
\hline CHEMBL1379558 & 688239 & 5.2862 & 5.4986 & TST \\
\hline CHEMBL1316022 & 688239 & 4.5362 & 5.3736 & TST \\
\hline CHEMBL1403291 & 688239 & 4.7362 & 5.5124 & TRN \\
\hline CHEMBL1414655 & 688239 & 4.6862 & 5.4437 & TRN \\
\hline CHEMBL1362754 & 688239 & 5.9862 & 5.5801 & TRN \\
\hline CHEMBL1473305 & 688239 & 5.1362 & 5.4413 & TRN \\
\hline CHEMBL1473581 & 688239 & 5.4362 & 5.4197 & TRN \\
\hline CHEMBL1350353 & 688239 & 5.8862 & 5.4414 & TST \\
\hline
\end{tabular}


Supplemental Table S2.txt

\begin{tabular}{|c|c|c|c|c|}
\hline CHEMBL56654 & 688239 & 5.6362 & 5.4402 & TST \\
\hline CHEMBL1511382 & 688239 & 8.3372 & 5.5051 & TST \\
\hline CHEMBL1461084 & 688239 & 4.5362 & 5.443 & TST \\
\hline CHEMBL1457228 & 688239 & 6.1862 & 5.472 & TRN \\
\hline CHEMBL1496104 & 688239 & 6.7361 & 5.5851 & TRN \\
\hline CHEMBL1387662 & 688239 & 6.1362 & 5.723 & TRN \\
\hline CHEMBL3208917 & 688239 & 4.5862 & 5.5313 & TRN \\
\hline CHEMBL1612999 & 688239 & 4.5362 & 5.311 & TST \\
\hline CHEMBL1585313 & 688239 & 4.7862 & 5.4511 & TRN \\
\hline CHEMBL1304903 & 688239 & 6.5363 & 5.4771 & TST \\
\hline CHEMBL1406020 & 688239 & 7.1361 & 5.5178 & TRN \\
\hline CHEMBL1320949 & 688239 & 5.6862 & 5.3609 & TRN \\
\hline CHEMBL1610561 & 688239 & 5.9362 & 5.5284 & TRN \\
\hline CHEMBL1436457 & 688239 & 4.5362 & 5.6524 & TRN \\
\hline CHEMBL1509059 & 688239 & 4.8362 & 5.5382 & TRN \\
\hline CHEMBL1483670 & 688239 & 4.5362 & 5.421 & TST \\
\hline CHEMBL1433841 & 688239 & 5.1862 & 5.5068 & TRN \\
\hline CHEMBL1431454 & 688239 & 5.4362 & 5.5298 & TRN \\
\hline CHEMBL1327099 & 688239 & 5.8362 & 5.4531 & TRN \\
\hline CHEMBL1582949 & 688239 & 4.5362 & 5.5278 & TRN \\
\hline CHEMBL1544206 & 688239 & 5.6862 & 5.5576 & TRN \\
\hline CHEMBL1327543 & 688239 & 5.7862 & 5.5201 & TRN \\
\hline CHEMBL1488233 & 688239 & 4.5362 & \multicolumn{2}{|c|}{5.6770000000000005} \\
\hline CHEMBL1368314 & 688239 & 5.3862 & 5.5315 & TRN \\
\hline CHEMBL1392552 & 688239 & 4.5362 & 5.4069 & TST \\
\hline CHEMBL1457679 & 688239 & 6.3362 & 5.5297 & TRN \\
\hline CHEMBL1587594 & 688239 & 6.4862 & 5.3963 & TRN \\
\hline CHEMBL1577787 & 688239 & 5.9362 & 5.4492 & TRN \\
\hline CHEMBL1443069 & 688239 & 4.7862 & 5.5415 & TRN \\
\hline CHEMBL1386024 & 688239 & 4.4862 & 5.4625 & TST \\
\hline CHEMBL3213595 & 688239 & 4.4862 & 5.4755 & TST \\
\hline CHEMBL1560961 & 688239 & 4.6862 & \multicolumn{2}{|c|}{5.611000000000001} \\
\hline CHEMBL1472440 & 688239 & 5.2362 & 5.598 & TRN \\
\hline CHEMBL 3197263 & 688239 & 5.8862 & 5.3938 & TRN \\
\hline CHEMBL 1475718 & 688239 & 5.2362 & 5.4226 & TST \\
\hline CHEMBL1340904 & 688239 & 8.3372 & 5.4473 & TRN \\
\hline CHEMBL1601549 & 688239 & 4.5362 & 5.4058 & TST \\
\hline CHEMBL1412965 & 688239 & 5.1862 & 5.6929 & TRN \\
\hline CHEMBL1551430 & 688239 & 5.1862 & 5.4406 & TRN \\
\hline CHEMBL1492017 & 688239 & 5.1862 & 5.4327 & TRN \\
\hline CHEMBL1337835 & 688239 & 5.8362 & 5.6006 & TRN \\
\hline CHEMBL1528895 & 688239 & 4.5362 & 5.4442 & TRN \\
\hline CHEMBL1344292 & 688239 & 4.9862 & 5.3502 & TST \\
\hline CHEMBL1363822 & 688239 & 4.7862 & 5.6158 & TRN \\
\hline CHEMBL3191245 & 688239 & 6.1362 & \multicolumn{2}{|c|}{5.5329999999999995} \\
\hline CHEMBL1318362 & 688239 & 6.9363 & 5.3873 & TRN \\
\hline CHEMBL1416071 & 688239 & 4.5362 & 5.4645 & TRN \\
\hline CHEMBL1450928 & 688239 & 4.5362 & 5.4218 & TST \\
\hline
\end{tabular}


Supplemental Table S2.txt

\begin{tabular}{|c|c|c|c|c|c|}
\hline CHEMBL1336807 & 688239 & 4.5362 & 5.4931 & TST & \\
\hline CHEMBL1510395 & 688239 & 5.1862 & 5.495 & TRN & \\
\hline CHEMBL1507386 & 688239 & 6.1362 & 5.5245 & TRN & \\
\hline CHEMBL1429935 & 688239 & 4.8862 & 5.4764 & TST & \\
\hline CHEMBL1437641 & 688239 & 7.2366 & 5.4126 & TRN & \\
\hline CHEMBL1519847 & 688239 & 5.7362 & 5.6193 & TRN & \\
\hline CHEMBL1490227 & 688239 & 5.2362 & 5.462999 & 999999999 & TRN \\
\hline CHEMBL1310201 & 688239 & 4.5862 & 5.5496 & TRN & \\
\hline CHEMBL1546665 & 688239 & 5.4362 & 5.5677 & TRN & \\
\hline CHEMBL1346709 & 688239 & 5.0362 & 5.3752 & TRN & \\
\hline CHEMBL1328413 & 688239 & 4.4862 & 5.53 & TRN & \\
\hline CHEMBL1325717 & 688239 & 6.1362 & 5.5993 & TRN & \\
\hline CHEMBL1490715 & 688239 & 5.7362 & 5.5375 & TRN & \\
\hline CHEMBL1456465 & 688239 & 4.5362 & 5.4929 & TST & \\
\hline CHEMBL 3193193 & 688239 & 5.7862 & 5.5062 & TST & \\
\hline CHEMBL1607033 & 688239 & 5.2862 & 5.4568 & TST & \\
\hline CHEMBL3207492 & 688239 & 4.5862 & 5.5023 & TRN & \\
\hline CHEMBL1361571 & 688239 & 5.0362 & 5.414 & TRN & \\
\hline CHEMBL1371283 & 688239 & 4.9362 & 5.3612 & TST & \\
\hline CHEMBL 3190787 & 688239 & 5.4362 & 5.564 & TRN & \\
\hline CHEMBL1336306 & 688239 & 7.2865 & 5.5501 & TRN & \\
\hline CHEMBL1404973 & 688239 & 4.5862 & 5.468999 & 999999999 & TRN \\
\hline CHEMBL1362191 & 688239 & 6.2362 & 5.6564 & TRN & \\
\hline CHEMBL1389656 & 688239 & 6.2362 & 5.5282 & TRN & \\
\hline CHEMBL1301190 & 688239 & 8.28399 & 99999999 & 5.4595 & \\
\hline CHEMBL1335748 & 688239 & 5.1362 & 5.4692 & TRN & \\
\hline CHEMBL1408871 & 688239 & 4.7862 & 5.495 & TST & \\
\hline CHEMBL1458963 & 688239 & 5.6862 & 5.4655 & TRN & \\
\hline CHEMBL1524719 & 688239 & 5.1862 & 5.4178 & TST & \\
\hline CHEMBL1357302 & 688239 & 7.5361 & 5.4963 & TRN & \\
\hline CHEMBL1490958 & 688239 & 5.9362 & 5.5788 & TST & \\
\hline CHEMBL1386161 & 688239 & 4.8362 & 5.3815 & TRN & \\
\hline CHEMBL1313943 & 688239 & 4.5362 & 5.3829 & TRN & \\
\hline CHEMBL1392014 & 688239 & 6.9363 & 5.4927 & TST & \\
\hline CHEMBL1319490 & 688239 & 4.9862 & 5.504 & TST & \\
\hline CHEMBL1383512 & 688239 & 5.8862 & 5.6012 & TRN & \\
\hline CHEMBL1425299 & 688239 & 7.0862 & 5.3734 & TRN & \\
\hline CHEMBL1371873 & 688239 & 4.6362 & 5.4052 & TST & \\
\hline CHEMBL1341598 & 688239 & 5.5362 & 5.4875 & TST & \\
\hline CHEMBL1367820 & 688239 & 4.5362 & 5.5525 & TRN & \\
\hline CHEMBL1502470 & 688239 & 4.6862 & 5.414 & TRN & \\
\hline CHEMBL1369610 & 688239 & 6.0 & 5.5577 & TST & \\
\hline CHEMBL3191929 & 688239 & 4.5362 & 5.3874 & TRN & \\
\hline CHEMBL1576212 & 688239 & 4.6362 & 5.374 & TST & \\
\hline CHEMBL1491864 & 688239 & 4.7362 & 5.3925 & TRN & \\
\hline CHEMBL3196676 & 688239 & 6.7361 & 5.3651 & TRN & \\
\hline CHEMBL1299348 & 688239 & 5.5862 & 5.5329 & TST & \\
\hline CHEMBL1493931 & 688239 & 4.9362 & 5.5684 & TRN & \\
\hline
\end{tabular}


Supplemental Table S2.txt

\begin{tabular}{|c|c|c|c|c|}
\hline 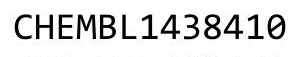 & & & & \\
\hline HEMBL1482474 & 38239 & 861 & & \\
\hline AEMBL1611651 & 239 & 862 & & \\
\hline 909 & 39 & 362 & & \\
\hline IEMBL3199407 & 39 & & & \\
\hline AEMBL1495426 & 88239 & 362 & 523 & \\
\hline AEMBL1348849 & 88239 & 362 & 3703 & \\
\hline JEMBL12 & & 862 & & \\
\hline EMBL14 & 39 & 362 & & \\
\hline IEMBL13 & & 862 & & \\
\hline AEMBL1500930 & 39 & 362 & 49 & \\
\hline HEMBL1609670 & & 362 & & \\
\hline AEMBL1610002 & & & & \\
\hline IEMBL16 & & & & \\
\hline AEMBL135 & & & & \\
\hline AEMBL1508867 & & 362 & & \\
\hline AEMBL1444574 & & 862 & & \\
\hline AEMBL132 & & & & \\
\hline IEMBL15 & & & & \\
\hline IEMBL153 & & & & \\
\hline AFMPI 150 & & 62 & & \\
\hline HEMBL153 & & & & \\
\hline AEMBL153 & & & & \\
\hline AFMRI 13 & & & & \\
\hline 57 & & 62 & & \\
\hline בר 12 & & 362 & & \\
\hline IEMBL1575 & & & & \\
\hline EMBL159 & & & & \\
\hline AFMR & & & & \\
\hline 20 & & & & \\
\hline AEMBL160 & & & & \\
\hline HEMBL1587634 & & & & \\
\hline & & & & \\
\hline 4 & & & & \\
\hline HEMBL139 & & & & \\
\hline AEMBL1371871 & & & & \\
\hline AEMBL1562873 & & 62 & & \\
\hline & & & & \\
\hline SIM & & & & 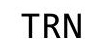 \\
\hline HEMBL1522618 & & & & RI \\
\hline AEMBL1383958 & & 62 & & $\lceil\mathrm{~F}$ \\
\hline AEMBL147 & & & & 3 \\
\hline & & & & \\
\hline HEMBL1324693 & & & & \\
\hline AEMBL3210750 & & & & RN \\
\hline AEMBL 142 & & 362 & & 11 \\
\hline 130 & & & & \\
\hline HEMBL47936 & & & & \\
\hline
\end{tabular}

Page 1852 
Supplemental Table S2.txt

\begin{tabular}{|c|c|c|c|c|}
\hline CHEMBL1569167 & 688239 & 5.7362 & 5.5136 & TRN \\
\hline CHEMBL1359558 & 688239 & 5.4862 & 5.5489 & TRN \\
\hline CHEMBL1516266 & 688239 & 5.7862 & 5.4381 & TRN \\
\hline CHEMBL1552769 & 688239 & 4.5362 & 5.3781 & TST \\
\hline CHEMBL1325063 & 688239 & 5.0862 & 5.5255 & TRN \\
\hline CHEMBL1562686 & 688239 & 6.2862 & 5.4575 & TRN \\
\hline CHEMBL1519410 & 688239 & 4.7362 & 5.5693 & TRN \\
\hline CHEMBL1470929 & 688239 & 5.4362 & 5.6504 & TRN \\
\hline CHEMBL1503254 & 688239 & 4.5862 & 5.2926 & TRN \\
\hline CHEMBL1468966 & 688239 & 5.1862 & 5.3789 & TRN \\
\hline CHEMBL1347502 & 688239 & 5.5362 & 5.4373 & TRN \\
\hline CHEMBL1542401 & 688239 & 4.6862 & 5.5308 & TRN \\
\hline CHEMBL1363974 & 688239 & 4.7862 & 5.7353 & TRN \\
\hline CHEMBL 3192163 & 688239 & 5.6362 & 5.5512 & TRN \\
\hline CHEMBL1389156 & 688239 & 4.4862 & 5.4084 & TRN \\
\hline CHEMBL1419476 & 688239 & 4.6362 & 5.4027 & TRN \\
\hline CHEMBL1433250 & 688239 & 5.0862 & 5.4313 & TRN \\
\hline CHEMBL1412271 & 688239 & 5.2362 & 5.3548 & TST \\
\hline CHEMBL1449649 & 688239 & 4.5862 & 5.5973 & TRN \\
\hline CHEMBL1414385 & 688239 & 6.9363 & 5.485 & TRN \\
\hline CHEMBL1447222 & 688239 & 4.9862 & 5.415 & TRN \\
\hline CHEMBL1372306 & 688239 & 7.1864 & 5.5411 & TRN \\
\hline CHEMBL1477406 & 688239 & 4.7862 & 5.6072 & TRN \\
\hline CHEMBL1373859 & 688239 & 4.5362 & 5.4661 & TRN \\
\hline CHEMBL1411442 & 688239 & 4.5362 & 5.4217 & TRN \\
\hline CHEMBL1527230 & 688239 & 5.4862 & 5.462999 & 9999999999 \\
\hline CHEMBL1493094 & 688239 & 6.2362 & 5.4687 & TST \\
\hline CHEMBL1455624 & 688239 & 5.5862 & 5.5147 & TRN \\
\hline CHEMBL1499783 & 688239 & 8.28399 & 999999999 & 5.5199 \\
\hline CHEMBL1481071 & 688239 & 6.0862 & 5.5611 & TRN \\
\hline CHEMBL1467260 & 688239 & 6.1862 & 5.6317 & TRN \\
\hline CHEMBL1320091 & 688239 & 5.6862 & 5.5239 & TST \\
\hline CHEMBL1564756 & 688239 & 5.7862 & 5.4848 & TRN \\
\hline CHEMBL1564945 & 688239 & 6.0862 & 5.4066 & TST \\
\hline CHEMBL1566401 & 688239 & 6.0862 & 5.3811 & TRN \\
\hline CHEMBL1442829 & 688239 & 4.8862 & 5.664 & TRN \\
\hline CHEMBL1541360 & 688239 & 5.2362 & 5.3385 & TST \\
\hline CHEMBL 3198380 & 688239 & 5.4362 & 5.3267 & TRN \\
\hline CHEMBL1596984 & 688239 & 6.0862 & 5.6606 & TRN \\
\hline CHEMBL1334676 & 688239 & 5.6862 & 5.6195 & TRN \\
\hline CHEMBL1587151 & 688239 & 4.5362 & 5.5535 & TRN \\
\hline CHEMBL1405008 & 688239 & 6.9363 & 5.6454 & TRN \\
\hline CHEMBL1501833 & 688239 & 4.5362 & 5.621 & TRN \\
\hline CHEMBL1521284 & 688239 & 7.7352 & 5.6268 & TST \\
\hline CHEMBL1553754 & 688239 & 6.4362 & 5.3712 & TRN \\
\hline CHEMBL1581579 & 688239 & 4.5362 & 5.4007 & TRN \\
\hline CHEMBL1481352 & 688239 & 6.4862 & 5.6775 & TRN \\
\hline CHEMBL1453560 & 688239 & 4.7862 & 5.4084 & TRN \\
\hline
\end{tabular}


Supplemental Table S2.txt

\begin{tabular}{|c|c|c|c|c|}
\hline CHEMBL1361867 & 688239 & 5.5362 & 5.5198 & TST \\
\hline CHEMBL1518523 & 688239 & 4.4862 & 5.3703 & TST \\
\hline CHEMBL1382219 & 688239 & 4.5362 & 5.3718 & TRN \\
\hline CHEMBL1347099 & 688239 & 5.0862 & 5.4453 & TRN \\
\hline CHEMBL1575715 & 688239 & 4.7362 & 5.2994 & TST \\
\hline CHEMBL1348930 & 688239 & 5.9862 & 5.4509 & TRN \\
\hline CHEMBL1361003 & 688239 & 7.0362 & 5.6375 & TRN \\
\hline CHEMBL 3192640 & 688239 & 5.6362 & 5.3883 & TRN \\
\hline CHEMBL1441869 & 688239 & 4.7362 & 5.593999 & 999999999 \\
\hline CHEMBL1333109 & 688239 & 4.5862 & 5.6413 & TRN \\
\hline CHEMBL1418582 & 688239 & 5.9362 & 5.332006 & 000000001 \\
\hline CHEMBL1559438 & 688239 & 4.6862 & 5.4431 & TRN \\
\hline CHEMBL1564713 & 688239 & 4.6362 & 5.5324 & TRN \\
\hline CHEMBL1534053 & 688239 & 4.6362 & 5.4276 & TRN \\
\hline CHEMBL1449965 & 688239 & 6.8362 & 5.4698 & TRN \\
\hline CHEMBL1473777 & 688239 & 5.5362 & 5.5614 & TRN \\
\hline CHEMBL1316488 & 688239 & 4.5362 & 5.5361 & TRN \\
\hline CHEMBL1377316 & 688239 & 4.9362 & 5.4124 & TRN \\
\hline CHEMBL1454105 & 688239 & 6.9363 & 5.5023 & TRN \\
\hline CHEMBL 3212360 & 688239 & 6.8861 & 5.5501 & TRN \\
\hline CHEMBL1445542 & 688239 & 5.1862 & 5.4503 & TRN \\
\hline CHEMBL1354799 & 688239 & 6.1362 & 5.5163 & TRN \\
\hline CHEMBL1611187 & 688239 & 6.2362 & 5.4945 & TRN \\
\hline CHEMBL1516897 & 688239 & 4.5362 & 5.4353 & TRN \\
\hline CHEMBL1347074 & 688239 & 6.9363 & 5.5324 & TRN \\
\hline CHEMBL1369527 & 688239 & 5.1862 & 5.3285 & TST \\
\hline CHEMBL1494194 & 688239 & 5.3862 & 5.5491 & TRN \\
\hline CHEMBL 2001474 & 688239 & 5.7362 & 5.5228 & TRN \\
\hline CHEMBL1540923 & 688239 & 4.5362 & 5.4691 & TRN \\
\hline CHEMBL1354933 & 688239 & 6.2362 & 5.4532 & TRN \\
\hline CHEMBL1403850 & 688239 & 4.4862 & 5.6037 & TRN \\
\hline CHEMBL1560473 & 688239 & 6.8362 & 5.632999 & 999999999 \\
\hline CHEMBL1486711 & 688239 & 5.8362 & 5.4697 & TST \\
\hline CHEMBL1405578 & 688239 & 5.6862 & 5.5744 & TRN \\
\hline CHEMBL1447761 & 688239 & 6.5363 & 5.5701 & TRN \\
\hline CHEMBL1550412 & 688239 & 6.9863 & 5.5628 & TST \\
\hline CHEMBL1362944 & 688239 & 4.5362 & 5.3862 & TRN \\
\hline CHEMBL1562891 & 688239 & 4.6362 & 5.5153 & TRN \\
\hline CHEMBL1572032 & 688239 & 5.2362 & 5.5451 & TRN \\
\hline CHEMBL1574197 & 688239 & 5.6362 & 5.4886 & TRN \\
\hline CHEMBL1299250 & 688239 & 5.3862 & 5.4436 & TRN \\
\hline CHEMBL1574050 & 688239 & 6.7862 & 5.5997 & TRN \\
\hline CHEMBL1611053 & 688239 & 4.5862 & 5.3771 & TRN \\
\hline CHEMBL1611183 & 688239 & 6.5862 & 5.4594 & TST \\
\hline CHEMBL1373110 & 688239 & 5.6862 & 5.5647 & TRN \\
\hline CHEMBL1461803 & 688239 & 6.4862 & 5.4392 & TST \\
\hline CHEMBL1423391 & 688239 & 8.3372 & 5.5554 & TRN \\
\hline CHEMBL1459889 & 688239 & 8.2366 & 5.5238 & TST \\
\hline
\end{tabular}


Supplemental Table S2.txt

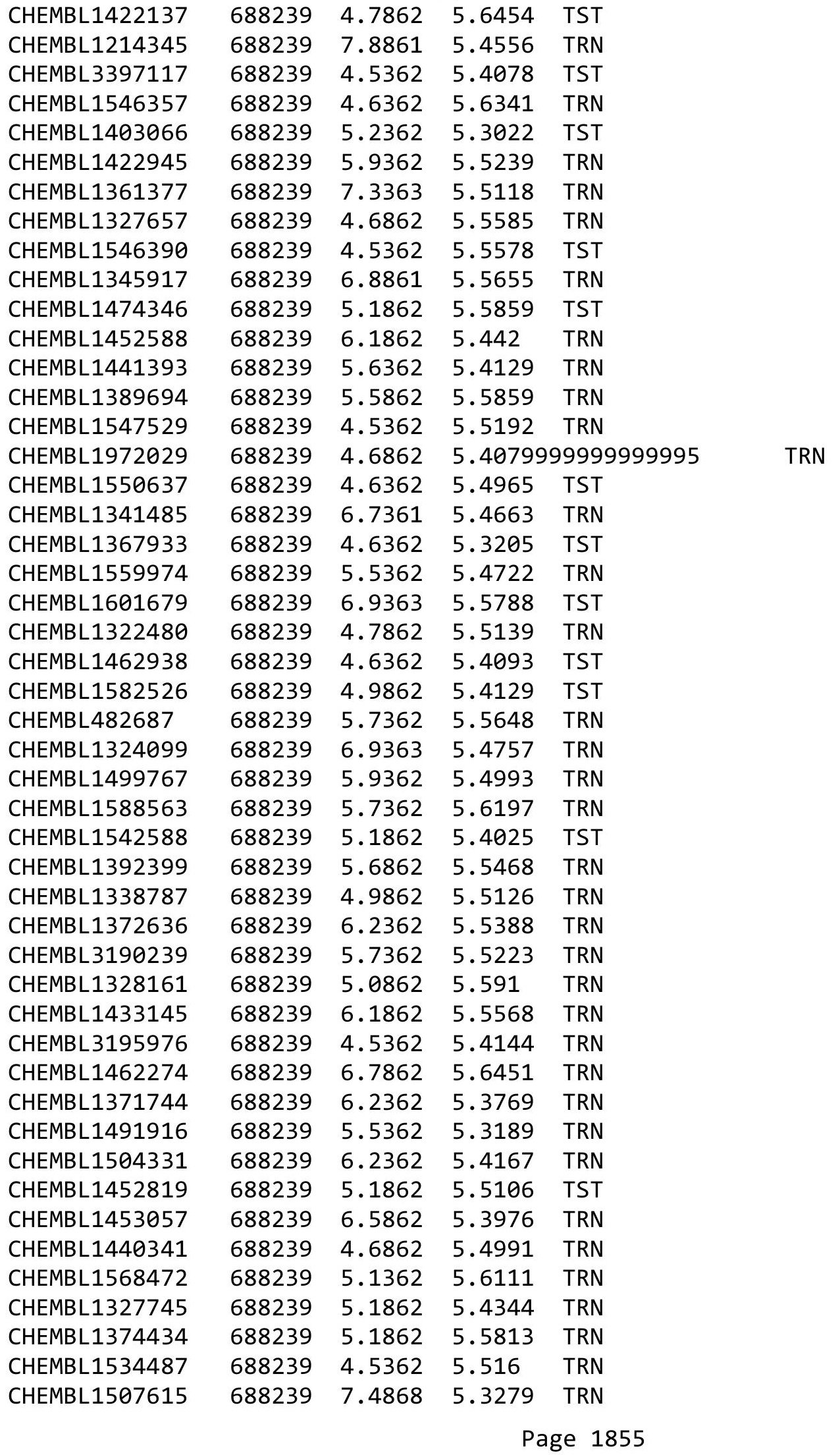


Supplemental Table S2.txt

\begin{tabular}{|c|c|c|c|c|}
\hline 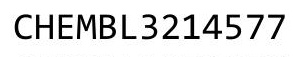 & & & & \\
\hline HEMBL1370178 & 38239 & 862 & & \\
\hline AEMBL1437141 & 239 & 362 & & \\
\hline 385 & & & & \\
\hline EMBL158 & 39 & 362 & & \\
\hline AEMBL3212211 & 88239 & 362 & 088 & \\
\hline AEMBL1543232 & 88239 & 362 & 053 & \\
\hline AEMBL1521404 & & & & \\
\hline EMBL14C & 39 & 862 & & \\
\hline IEMBL1450108 & & & & \\
\hline AEMBL1419385 & 39 & 362 & 5 & \\
\hline AEMBL1420968 & & 372 & & \\
\hline AEMBL1520615 & & & & \\
\hline HEMBL1523228 & & & & \\
\hline AEMBL1518401 & & & & \\
\hline AEMBL1415000 & & 362 & & \\
\hline AEMBL1383707 & & 862 & & \\
\hline IEMBL13587 & & & & \\
\hline AEMBL1582324 & & & & \\
\hline AEMBL15 & & & & \\
\hline AEMPI 15 & & 862 & & \\
\hline JEMBL14 & & & & \\
\hline HEMBL15 & & 62 & & \\
\hline AFMRI 15 & & & & \\
\hline 690 & & & & \\
\hline AEMBL1486176 & & 62 & & \\
\hline IEMBL1427603 & & & & \\
\hline IEMBL13572 & & & & \\
\hline 5 & & & & \\
\hline 53 & & & & \\
\hline AEMBL1536857 & & & & \\
\hline IEMBL 250574 & & & & \\
\hline & & & & \\
\hline 4 & & & & \\
\hline & & & & \\
\hline AEMBL1602241 & & & & \\
\hline AEMBL1370254 & & 62 & & \\
\hline & & 62 & & \\
\hline 1350067 & & & & \\
\hline HEMBL1518014 & & & & $\mathrm{RN}$ \\
\hline AEMBL1421379 & & 62 & 25 & TS \\
\hline AEMBL 2006390 & & & & TS \\
\hline & & & & \\
\hline HEMBL1411283 & & & & r \\
\hline AEMBL1426304 & & & & $\mathrm{R}$ \\
\hline MBL1334689 & & 362 & & TR \\
\hline & & & & \\
\hline $5-700$ & & & 5.4267 & \\
\hline
\end{tabular}

Page 1856 
Supplemental Table S2.txt

\begin{tabular}{|c|c|c|c|c|}
\hline 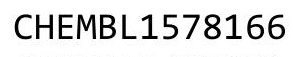 & & & & \\
\hline HEMBL1497831 & 38239 & 362 & & \\
\hline HEMBL1458698 & 239 & 862 & 342 & \\
\hline EMBL14 & 39 & 862 & & \\
\hline IEMBL14 & 39 & 362 & & \\
\hline AEMBL1489235 & 88239 & 862 & & \\
\hline AEMBL3194999 & 88239 & 862 & 5139 & \\
\hline AEMBL16 & & & & \\
\hline EMBL14 & 39 & 362 & & \\
\hline IEMBL13 & & & & \\
\hline AEMBL1475437 & 39 & 862 & 85 & \\
\hline AEMBL1445987 & 39 & 362 & & \\
\hline AEMBL15 & & & & \\
\hline AEMBL31 & & & & \\
\hline HEMBL15 & & & & \\
\hline IEMBL14 & & 862 & & \\
\hline JEMBL15 & & 362 & & \\
\hline IEMBL15 & & 64 & & \\
\hline AEMBL32 & & & & \\
\hline AEMBL15 & & & & \\
\hline JEMBL13 & & 361 & & \\
\hline JEMBL14 & & 62 & & \\
\hline AEMBL16 & & 62 & & \\
\hline 940 & & & & \\
\hline 688 & & & & \\
\hline 897 & & 62 & & \\
\hline IEMBL13 & & & & \\
\hline IEMBL15 & & & & \\
\hline 287 & & 62 & & \\
\hline 003 & & 62 & & \\
\hline AEMBL1303154 & & & & \\
\hline AEMBL1317108 & & 362 & & \\
\hline 350 & & 62 & & \\
\hline 655 & & 52 & & \\
\hline & & & & \\
\hline AEMBL1608850 & & 862 & & \\
\hline AEMBL1443070 & & 862 & & \\
\hline & & 62 & & \\
\hline 944 & & & & \\
\hline HEMBL1409557 & & & & ST \\
\hline AEMBL1575421 & & 362 & & \\
\hline 795 & & 62 & & \\
\hline HEMBL1398295 & & & & \\
\hline & & & & \\
\hline AEMBL1477514 & & & .4104 & RN \\
\hline AEMBL1420691 & 68 & 5.9862 & 29 & \\
\hline 70 & & & & \\
\hline HEMBL158305 & & & & \\
\hline
\end{tabular}

Page 1857 
Supplemental Table S2.txt

\begin{tabular}{|c|c|c|c|c|}
\hline CHEMBL1325176 & 688239 & 4.7362 & 5.6631 & TRN \\
\hline CHEMBL1400074 & 688239 & 8.3372 & 5.5133 & TRN \\
\hline CHEMBL1337903 & 688239 & 5.2862 & 5.4901 & TRN \\
\hline CHEMBL1482666 & 688239 & 5.1362 & 5.3498 & TRN \\
\hline CHEMBL1305797 & 688239 & 5.7362 & 5.6144 & TRN \\
\hline CHEMBL1547290 & 688239 & 4.7862 & 5.5859 & TRN \\
\hline CHEMBL1593729 & 688239 & 4.8362 & 5.4644 & TRN \\
\hline CHEMBL1367893 & 688239 & 4.5362 & 5.5365 & TRN \\
\hline CHEMBL1367029 & 688239 & 5.1862 & 5.5242 & TRN \\
\hline CHEMBL1604167 & 688239 & 4.7362 & 5.5723 & TRN \\
\hline CHEMBL1538638 & 688239 & 6.1862 & 5.5715 & TST \\
\hline CHEMBL1333667 & 688239 & 6.7862 & 5.6754 & TRN \\
\hline CHEMBL1412056 & 688239 & 5.1362 & 5.5686 & TRN \\
\hline CHEMBL1531465 & 688239 & 5.1862 & 5.6 & TRN \\
\hline CHEMBL1581682 & 688239 & 4.5362 & 5.525 & TRN \\
\hline CHEMBL1570612 & 688239 & 6.0362 & 5.5123 & TRN \\
\hline CHEMBL1582595 & 688239 & 4.6362 & 5.5253 & TRN \\
\hline CHEMBL1372695 & 688239 & 6.9863 & 5.4264 & TRN \\
\hline CHEMBL1349067 & 688239 & 5.7362 & 5.5695 & TRN \\
\hline CHEMBL1541775 & 688239 & 5.1862 & 5.4342 & TST \\
\hline CHEMBL1493849 & 688239 & 6.3362 & 5.5838 & TRN \\
\hline CHEMBL1476719 & 688239 & 6.9363 & 5.6448 & TRN \\
\hline CHEMBL1302590 & 688239 & 6.7361 & 5.6886 & TRN \\
\hline CHEMBL1384824 & 688239 & 6.5862 & 5.5026 & TRN \\
\hline CHEMBL1301092 & 688239 & 4.7862 & 5.5297 & TST \\
\hline CHEMBL1426032 & 688239 & 5.4862 & 5.3436 & TST \\
\hline CHEMBL3193674 & 688239 & 4.5362 & 5.5961 & TRN \\
\hline CHEMBL1403384 & 688239 & 5.4862 & 5.6145 & TRN \\
\hline CHEMBL1334218 & 688239 & 4.5362 & 5.6247 & TRN \\
\hline CHEMBL1336043 & 688239 & 4.9862 & 5.6298 & TRN \\
\hline CHEMBL1404775 & 688239 & 5.6862 & 5.5958 & TRN \\
\hline CHEMBL1540104 & 688239 & 6.5862 & 5.4659 & TRN \\
\hline CHEMBL1579571 & 688239 & 4.4862 & 5.3471 & TRN \\
\hline CHEMBL1446372 & 688239 & 6.9363 & 5.4915 & TST \\
\hline CHEMBL1328760 & 688239 & 5.2362 & 5.546 & TRN \\
\hline CHEMBL3198355 & 688239 & 4.4862 & 5.4079 & TRN \\
\hline CHEMBL1502859 & 688239 & 5.8862 & 5.5189 & TRN \\
\hline CHEMBL1613378 & 688239 & 4.5362 & 5.4216 & TRN \\
\hline CHEMBL1466005 & 688239 & 6.2362 & 5.4363 & TST \\
\hline CHEMBL1998859 & 688239 & 5.7862 & 5.3926 & TRN \\
\hline CHEMBL1367100 & 688239 & 5.5862 & 5.3486 & TRN \\
\hline CHEMBL3195191 & 688239 & 5.1862 & 5.67399 & 99999999995 \\
\hline CHEMBL1488088 & 688239 & 5.1862 & 5.4435 & TRN \\
\hline CHEMBL1455585 & 688239 & 4.5862 & 5.5949 & TRN \\
\hline CHEMBL1571343 & 688239 & 5.0362 & 5.4601 & TRN \\
\hline CHEMBL1518130 & 688239 & 6.0862 & 5.6757 & TRN \\
\hline CHEMBL3212349 & 688239 & 4.7362 & 5.4905 & TRN \\
\hline CHEMBL1560221 & 688239 & 6.9363 & 5.5706 & TST \\
\hline
\end{tabular}


Supplemental Table S2.txt

\begin{tabular}{|c|c|c|c|c|}
\hline CHEMBL1568835 & 688239 & 4.7862 & 5.5915 & TRN \\
\hline CHEMBL1478213 & 688239 & 5.7862 & 5.4702 & TST \\
\hline CHEMBL1309416 & 688239 & 5.8362 & 5.5633 & TRN \\
\hline CHEMBL1392595 & 688239 & 6.0862 & 5.6837 & TRN \\
\hline CHEMBL1405260 & 688239 & 4.7862 & 5.4472 & TRN \\
\hline CHEMBL1360206 & 688239 & 5.1862 & 5.5357 & TRN \\
\hline CHEMBL1329912 & 688239 & 4.6862 & 5.5996 & TRN \\
\hline CHEMBL3199741 & 688239 & 5.3862 & 5.4105 & TRN \\
\hline CHEMBL1376578 & 688239 & 4.5362 & 5.4553 & TST \\
\hline CHEMBL1358362 & 688239 & 4.5362 & 5.5093 & TRN \\
\hline CHEMBL1613065 & 688239 & 5.3362 & 5.4763 & TRN \\
\hline CHEMBL1393100 & 688239 & 6.0362 & 5.4915 & TRN \\
\hline CHEMBL1304706 & 688239 & 6.0862 & 5.5417 & TST \\
\hline CHEMBL 1457517 & 688239 & 5.0362 & 5.6332 & TRN \\
\hline CHEMBL1600384 & 688239 & 6.2362 & 5.6926 & TRN \\
\hline CHEMBL1506917 & 688239 & 4.5362 & 5.4748 & TRN \\
\hline CHEMBL1561741 & 688239 & 4.5362 & 5.5534 & TRN \\
\hline CHEMBL1343462 & 688239 & 5.6862 & 5.5007 & TRN \\
\hline CHEMBL1610166 & 688239 & 4.7862 & 5.4329 & TRN \\
\hline CHEMBL 2004487 & 688239 & 4.4862 & 5.4116 & TRN \\
\hline CHEMBL1483166 & 688239 & 5.1862 & 5.5131 & TST \\
\hline CHEMBL1385540 & 688239 & 5.1862 & 5.576006 & 00000000005 \\
\hline CHEMBL1587180 & 688239 & 6.5862 & 5.4659 & TRN \\
\hline CHEMBL1417935 & 688239 & 4.7862 & 5.4827 & TRN \\
\hline CHEMBL1546597 & 688239 & 8.28399 & 99999999 & 5.579 \\
\hline CHEMBL1405003 & 688239 & 4.7862 & 5.4195 & TRN \\
\hline CHEMBL1363552 & 688239 & 6.8362 & 5.3908 & TRN \\
\hline CHEMBL1529522 & 688239 & 4.4862 & 5.5494 & TRN \\
\hline CHEMBL1584289 & 688239 & 6.3863 & 5.4981 & TRN \\
\hline CHEMBL1353216 & 688239 & 5.8362 & 5.4242 & TRN \\
\hline CHEMBL1333249 & 688239 & 4.7362 & 5.6258 & TRN \\
\hline CHEMBL1500896 & 688239 & 5.3362 & 5.4137 & TST \\
\hline CHEMBL1345358 & 688239 & 5.7362 & 5.5379 & TRN \\
\hline CHEMBL1487150 & 688239 & 4.5362 & 5.416 & TRN \\
\hline CHEMBL1310080 & 688239 & 6.9863 & 5.4519 & TRN \\
\hline CHEMBL1450314 & 688239 & 4.4862 & 5.4536 & TST \\
\hline CHEMBL 3196938 & 688239 & 6.2362 & 5.3869 & TST \\
\hline CHEMBL1611955 & 688239 & 4.5362 & 5.4428 & TST \\
\hline CHEMBL 3145022 & 688239 & 5.0362 & 5.3823 & TRN \\
\hline CHEMBL1399957 & 688239 & 5.4862 & 5.4864 & TRN \\
\hline CHEMBL30193 & 688239 & 4.7862 & 5.3907 & TST \\
\hline CHEMBL1476739 & 688239 & 6.8362 & 5.4786 & TRN \\
\hline CHEMBL 3192127 & 688239 & 4.8362 & 5.3987 & TRN \\
\hline CHEMBL1427367 & 688239 & 5.5362 & 5.5548 & TST \\
\hline CHEMBL1481960 & 688239 & 4.7862 & 5.5143 & TRN \\
\hline CHEMBL1479294 & 688239 & 4.6862 & 5.5246 & TRN \\
\hline CHEMBL1374012 & 688239 & 4.6362 & 5.3168 & TRN \\
\hline CHEMBL1519324 & 688239 & 6.1862 & 5.5687 & TRN \\
\hline
\end{tabular}


Supplemental Table S2.txt

\begin{tabular}{|c|c|c|c|c|c|}
\hline CHEMBL1387684 & 688239 & 6.9863 & \multicolumn{2}{|c|}{5.287000000000001} & TRN \\
\hline CHEMBL1481520 & 688239 & 6.7361 & 5.5176 & TRN & \\
\hline CHEMBL1551848 & 688239 & 4.6362 & 5.5454 & TRN & \\
\hline CHEMBL1457591 & 688239 & 5.7362 & 5.5903 & TRN & \\
\hline CHEMBL1389728 & 688239 & 4.6862 & 5.3646 & TRN & \\
\hline CHEMBL1509640 & 688239 & 6.1862 & \multicolumn{2}{|c|}{5.542999999999999} & TRN \\
\hline CHEMBL1458332 & 688239 & 4.6862 & 5.4659 & TRN & \\
\hline CHEMBL1450202 & 688239 & 4.4862 & 5.3216 & TST & \\
\hline CHEMBL1300830 & 688239 & 6.8861 & 5.4777 & TRN & \\
\hline CHEMBL1595082 & 688239 & 4.5362 & 5.4449 & TRN & \\
\hline CHEMBL1584132 & 688239 & 5.6362 & 5.3719 & TST & \\
\hline CHEMBL1528001 & 688239 & 6.9363 & 5.4945 & TRN & \\
\hline CHEMBL1373351 & 688239 & 5.4362 & 5.5451 & TRN & \\
\hline CHEMBL1304433 & 688239 & 5.6362 & 5.5683 & TRN & \\
\hline CHEMBL1518286 & 688239 & 4.9862 & 5.3938 & TST & \\
\hline CHEMBL3210822 & 688239 & 5.4862 & 5.3968 & TRN & \\
\hline CHEMBL1509590 & 688239 & 4.5362 & 5.4057 & TRN & \\
\hline CHEMBL1589205 & 688239 & 4.7862 & 5.5004 & TRN & \\
\hline CHEMBL1583818 & 688239 & 5.7362 & 5.6486 & TRN & \\
\hline CHEMBL1333650 & 688239 & 4.6362 & 5.4499 & TRN & \\
\hline CHEMBL1471002 & 688239 & 7.1864 & 5.4392 & TRN & \\
\hline CHEMBL1424961 & 688239 & 5.3362 & 5.7162 & TST & \\
\hline CHEMBL1462621 & 688239 & 5.1862 & 5.5968 & TRN & \\
\hline CHEMBL1607099 & 688239 & 4.9862 & 5.6536 & TRN & \\
\hline CHEMBL1436087 & 688239 & 5.3362 & 5.6069 & TRN & \\
\hline CHEMBL1521698 & 688239 & 4.8862 & 5.3711 & TRN & \\
\hline CHEMBL68908 & 688239 & 6.0 & 5.5135 & TST & \\
\hline CHEMBL1473827 & 688239 & 6.0862 & 5.6725 & TRN & \\
\hline CHEMBL1487826 & 688239 & 4.9362 & 5.6815 & TRN & \\
\hline CHEMBL1389682 & 688239 & 4.5362 & 5.5618 & TRN & \\
\hline CHEMBL3213794 & 688239 & 5.0862 & 5.6544 & TRN & \\
\hline CHEMBL1441881 & 688239 & 5.1862 & 5.5484 & TRN & \\
\hline CHEMBL1511961 & 688239 & 4.8862 & 5.4682 & TRN & \\
\hline CHEMBL1515875 & 688239 & 4.7362 & 5.4876 & TRN & \\
\hline CHEMBL1365034 & 688239 & 6.1362 & 5.4576 & TRN & \\
\hline CHEMBL1345329 & 688239 & 5.9362 & 5.5394 & TRN & \\
\hline CHEMBL1303718 & 688239 & 4.6362 & 5.5693 & TRN & \\
\hline CHEMBL1315486 & 688239 & 4.5362 & 5.4202 & TST & \\
\hline CHEMBL1522802 & 688239 & 4.5862 & 5.2423 & TRN & \\
\hline CHEMBL1607412 & 688239 & 4.6862 & 5.5062 & TST & \\
\hline CHEMBL545184 & 688239 & 6.7862 & 5.6394 & TST & \\
\hline CHEMBL1340281 & 688239 & 4.5362 & 5.4856 & TRN & \\
\hline CHEMBL3191446 & 688239 & 7.1361 & 5.4111 & TST & \\
\hline CHEMBL1399356 & 688239 & 5.0862 & 5.43 & TRN & \\
\hline CHEMBL1507990 & 688239 & 4.5362 & 5.2515 & TRN & \\
\hline CHEMBL1555490 & 688239 & 5.1362 & 5.5914 & TRN & \\
\hline CHEMBL1600275 & 688239 & 5.2862 & 5.4682 & TRN & \\
\hline CHEMBL1561955 & 688239 & 4.7362 & 5.4357 & TST & \\
\hline
\end{tabular}


Supplemental Table S2.txt

\begin{tabular}{|c|c|c|c|c|}
\hline 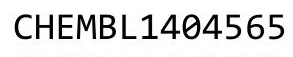 & & & & \\
\hline HEMBL1471853 & 38239 & 862 & 35 & \\
\hline AEMBL135 & 239 & 362 & 359 & \\
\hline & 39 & 862 & & \\
\hline IEMBL135 & 39 & 862 & & \\
\hline AEMBL1613606 & 88239 & 362 & 509 & \\
\hline AEMBL1596814 & 88239 & & 5077 & \\
\hline HEMBL1587224 & & & & \\
\hline EMBL13 & 239 & 362 & & \\
\hline IEMBL144 & & & & \\
\hline AEMBL1305616 & 239 & 362 & & \\
\hline AEMBL1585323 & & & & \\
\hline AEMBL1545825 & & & & \\
\hline JEMBL319 & & & & \\
\hline AEMBL157 & & & & \\
\hline AEMBL1528964 & & 62 & & \\
\hline AEMBL1386738 & & & & \\
\hline IEMBL1530198 & & & & \\
\hline AEMBL1513097 & & & & \\
\hline JEMBL148 & & & & \\
\hline AEMBL1474662 & & & & \\
\hline AEMBL1492693 & & & & \\
\hline AEMBL15 & & & & \\
\hline HFMBI 14 & & & & \\
\hline 14 & & & & \\
\hline HEMBL198 & & & & \\
\hline IEMBL1479709 & & & & \\
\hline EMBL131 & & & & \\
\hline AFMRI 14 & & & & \\
\hline 49 & & & & \\
\hline AEMBL1509125 & & & & \\
\hline HEMBL1568324 & & & & \\
\hline 20 & & & & \\
\hline 73 & & & & \\
\hline AEMBL3197322 & & & & \\
\hline AEMBL1457248 & & & & \\
\hline AEMBL1319705 & & & & \\
\hline & & & & \\
\hline 55 & & & & \\
\hline HEMBL1241420 & & & & ST \\
\hline AEMBL1496750 & & & & $\mathrm{F}$ \\
\hline HEMBL134 & & & & \\
\hline & & & & \\
\hline CHEMBL3194752 & & & & \\
\hline AEMBL1443993 & & & & RI \\
\hline MBL3197100 & & 5. & & \\
\hline 210 & & & & \\
\hline HEMBL155042 & & & & \\
\hline
\end{tabular}

Page 1861 
Supplemental Table S2.txt

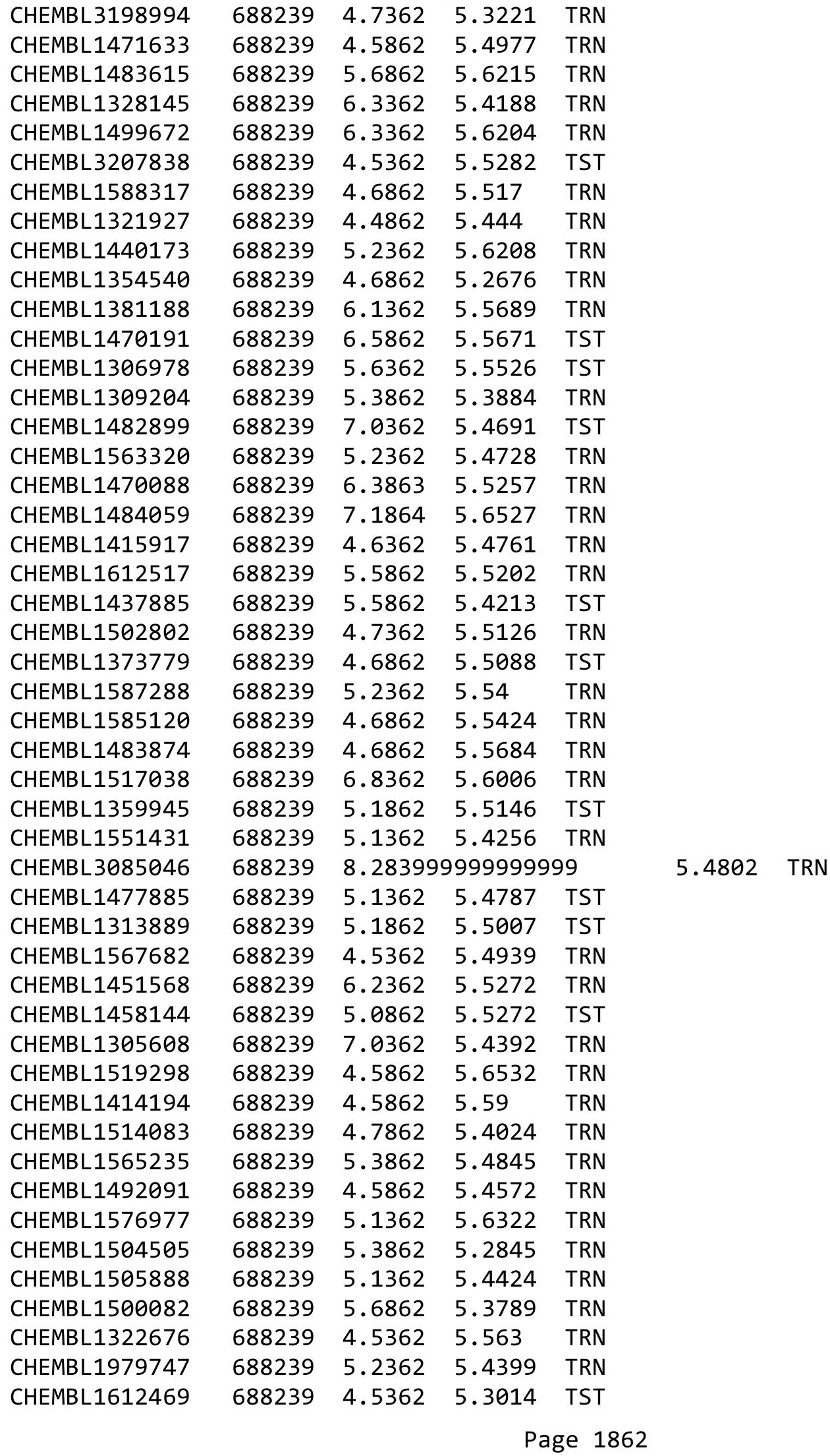


Supplemental Table S2.txt

\begin{tabular}{|c|c|c|c|c|}
\hline CHEMBL1348267 & 688239 & 5.1862 & 5.4197 & TRN \\
\hline CHEMBL1411185 & 688239 & 4.8862 & 5.4727 & TRN \\
\hline CHEMBL1473922 & 688239 & 4.6862 & 5.5182 & TRN \\
\hline CHEMBL1445986 & 688239 & 6.6861 & 5.4472 & TRN \\
\hline CHEMBL1519421 & 688239 & 4.7862 & 5.3909 & TRN \\
\hline CHEMBL1434539 & 688239 & 5.1862 & 5.4217 & TRN \\
\hline CHEMBL1567630 & 688239 & 5.5862 & 5.6438 & TST \\
\hline CHEMBL1425606 & 688239 & 5.5862 & 5.3482 & TRN \\
\hline CHEMBL1521961 & 688239 & 4.7362 & 5.4852 & TRN \\
\hline CHEMBL1356647 & 688239 & 5.6362 & 5.5299 & TRN \\
\hline CHEMBL1368920 & 688239 & 7.4365 & 5.5157 & TRN \\
\hline CHEMBL608564 & 688239 & 8.3372 & 5.4314 & TRN \\
\hline CHEMBL1328828 & 688239 & 6.7361 & 5.4211 & TRN \\
\hline CHEMBL1375584 & 688239 & 8.28399 & 99999999 & 5.5004 \\
\hline CHEMBL1465806 & 688239 & 6.0362 & 5.4387 & TRN \\
\hline CHEMBL1490048 & 688239 & 4.6862 & 5.497000 & 0000000001 \\
\hline CHEMBL1337164 & 688239 & 4.5362 & 5.4902 & TST \\
\hline CHEMBL1317095 & 688239 & 4.7862 & 5.4639 & TST \\
\hline CHEMBL1348319 & 688239 & 4.7862 & 5.4103 & TRN \\
\hline CHEMBL1518876 & 688239 & 7.5361 & 5.5414 & TRN \\
\hline CHEMBL1447133 & 688239 & 4.9862 & 5.5055 & TRN \\
\hline CHEMBL1330993 & 688239 & 6.0362 & 5.6275 & TRN \\
\hline CHEMBL1575227 & 688239 & 6.8861 & 5.4344 & TRN \\
\hline CHEMBL1441331 & 688239 & 5.0362 & 5.4031 & TRN \\
\hline CHEMBL1589426 & 688239 & 6.0362 & 5.4596 & TRN \\
\hline CHEMBL1451197 & 688239 & 6.3362 & 5.5732 & TRN \\
\hline CHEMBL1567793 & 688239 & 4.5362 & 5.5952 & TRN \\
\hline CHEMBL1478199 & 688239 & 5.3862 & 5.629 & TRN \\
\hline CHEMBL 2369168 & 688239 & 4.5362 & 5.3719 & TST \\
\hline CHEMBL1374281 & 688239 & 4.5362 & 5.4957 & TRN \\
\hline CHEMBL1561630 & 688239 & 4.5362 & 5.6427 & TRN \\
\hline CHEMBL1390022 & 688239 & 6.0862 & 5.5643 & TRN \\
\hline CHEMBL1380815 & 688239 & 5.0862 & 5.5264 & TRN \\
\hline CHEMBL1312385 & 688239 & 6.7862 & 5.4345 & TST \\
\hline CHEMBL1518222 & 688239 & 5.7862 & 5.5002 & TRN \\
\hline CHEMBL1504236 & 688239 & 5.2862 & 5.6191 & TRN \\
\hline CHEMBL3212323 & 688239 & 4.5362 & 5.3062 & TRN \\
\hline CHEMBL1388131 & 688239 & 4.4862 & 5.6319 & TRN \\
\hline CHEMBL1338173 & 688239 & 5.7862 & 5.5773 & TRN \\
\hline CHEMBL1344611 & 688239 & 6.7862 & 5.3472 & TRN \\
\hline CHEMBL1605503 & 688239 & 5.1862 & 5.5149 & TRN \\
\hline CHEMBL1411102 & 688239 & 6.1362 & 5.4774 & TST \\
\hline CHEMBL1305077 & 688239 & 5.7362 & 5.5348 & TST \\
\hline CHEMBL1560008 & 688239 & 4.5362 & 5.2012 & TRN \\
\hline CHEMBL1382334 & 688239 & 4.5362 & 5.5206 & TRN \\
\hline CHEMBL1319469 & 688239 & 6.0 & 5.5155 & TST \\
\hline CHEMBL1425877 & 688239 & 5.3362 & 5.3448 & TST \\
\hline CHEMBL1506543 & 688239 & 5.5362 & 5.605 & TST \\
\hline
\end{tabular}


Supplemental Table S2.txt

\begin{tabular}{|c|c|c|c|c|}
\hline CHEMBL3213417 & 688239 & 5.1862 & 5.5543 & TRN \\
\hline CHEMBL1472400 & 688239 & 4.5362 & 5.3906 & TRN \\
\hline CHEMBL1576363 & 688239 & 6.2362 & 5.5899 & TRN \\
\hline CHEMBL1414642 & 688239 & 5.0362 & 5.407 & TRN \\
\hline CHEMBL1463714 & 688239 & 4.6862 & 5.3614 & TRN \\
\hline CHEMBL1569232 & 688239 & 4.7362 & 5.4739 & TRN \\
\hline CHEMBL1474602 & 688239 & 5.4362 & 5.5864 & TRN \\
\hline CHEMBL1608423 & 688239 & 5.3862 & 5.5266 & TST \\
\hline CHEMBL1451251 & 688239 & 5.0862 & 5.5232 & TRN \\
\hline CHEMBL 3189871 & 688239 & 6.4862 & 5.475 & TST \\
\hline CHEMBL1332380 & 688239 & 5.2362 & 5.6954 & TRN \\
\hline CHEMBL1313069 & 688239 & 5.4362 & 5.6243 & TRN \\
\hline CHEMBL1537097 & 688239 & 5.1862 & 5.4152 & TRN \\
\hline CHEMBL1505349 & 688239 & 4.5362 & 5.5297 & TRN \\
\hline CHEMBL1564707 & 688239 & 5.1862 & 5.4669 & TRN \\
\hline CHEMBL 1587708 & 688239 & 5.6362 & 5.4876 & TRN \\
\hline CHEMBL1351376 & 688239 & 6.6861 & 5.6046 & TRN \\
\hline CHEMBL1356988 & 688239 & 6.9863 & 5.5154 & TRN \\
\hline CHEMBL1300625 & 688239 & 4.7362 & 5.5039 & TRN \\
\hline CHEMBL1444217 & 688239 & 5.1862 & 5.5889 & TRN \\
\hline CHEMBL1478599 & 688239 & 5.1862 & 5.6743 & TRN \\
\hline CHEMBL1377121 & 688239 & 4.6362 & 5.3581 & TRN \\
\hline CHEMBL1566746 & 688239 & 6.9363 & 5.4514 & TRN \\
\hline CHEMBL1388482 & 688239 & 4.7862 & 5.5482 & TST \\
\hline CHEMBL1479159 & 688239 & 5.1862 & 5.553999 & 999999999 \\
\hline CHEMBL1588062 & 688239 & 6.7862 & 5.4441 & TRN \\
\hline CHEMBL1534004 & 688239 & 5.2862 & 5.471 & TRN \\
\hline CHEMBL1539910 & 688239 & 6.9863 & 5.5651 & TST \\
\hline CHEMBL1471305 & 688239 & 8.3872 & 5.4174 & TRN \\
\hline CHEMBL1391587 & 688239 & 8.28399 & 999999999 & 5.5123 \\
\hline CHEMBL1456633 & 688239 & 6.7862 & 5.576000 & 0000000005 \\
\hline CHEMBL1494149 & 688239 & 6.2362 & 5.5505 & TRN \\
\hline CHEMBL1541671 & 688239 & 6.0862 & 5.6165 & TRN \\
\hline CHEMBL1499872 & 688239 & 4.8862 & 5.6634 & TRN \\
\hline CHEMBL1493976 & 688239 & 5.6362 & 5.5257 & TRN \\
\hline CHEMBL1384588 & 688239 & 6.3863 & 5.532 & TRN \\
\hline CHEMBL1594892 & 688239 & 6.9863 & 5.5067 & TRN \\
\hline CHEMBL1404161 & 688239 & 5.1862 & 5.4563 & TRN \\
\hline CHEMBL1330524 & 688239 & 8.0862 & 5.3397 & TST \\
\hline CHEMBL1427270 & 688239 & 6.1862 & 5.5584 & TRN \\
\hline CHEMBL1439707 & 688239 & 6.2362 & 5.6571 & TRN \\
\hline CHEMBL1310101 & 688239 & 6.0862 & 5.5039 & TRN \\
\hline CHEMBL1310641 & 688239 & 6.3863 & 5.5509 & TRN \\
\hline CHEMBL1481156 & 688239 & 5.4362 & 5.5726 & TRN \\
\hline CHEMBL1425897 & 688239 & 4.5362 & 5.4954 & TRN \\
\hline CHEMBL1594478 & 688239 & 6.0362 & 5.4537 & TRN \\
\hline CHEMBL1402774 & 688239 & 6.1862 & 5.3781 & TRN \\
\hline CHEMBL1429133 & 688239 & 4.7862 & 5.6548 & TST \\
\hline
\end{tabular}


Supplemental Table S2.txt

\begin{tabular}{|c|c|c|c|c|}
\hline & & & & \\
\hline AEMBL1 & 38239 & 1862 & & \\
\hline IEMBL1480702 & 8239 & 362 & 503 & \\
\hline AEMBL15 & 239 & 862 & 981 & \\
\hline & 239 & & & \\
\hline AEMBL153 & 239 & 62 & 838 & \\
\hline AEMBL1472271 & 88239 & 362 & 339 & \\
\hline AEMBL1546695 & 88239 & 362 & 086 & \\
\hline AEMBL1456367 & 239 & 362 & 905 & \\
\hline IEMBL14 & 239 & 362 & 945 & \\
\hline AEMBL 148 & 239 & & & \\
\hline AEMBL1324163 & 688239 & 862 & 284 & \\
\hline AEMBL1325289 & 239 & 862 & & \\
\hline IEMBL32 & & 863 & & \\
\hline IEMBL13 & & & 96 & \\
\hline HEMBL155 & & & & \\
\hline AEMBL1342925 & 239 & 862 & 797 & \\
\hline AEMBL1381529 & & 62 & 08 & \\
\hline IEMBL13 & & 4. & 52 & \\
\hline HEMBL14 & & & & \\
\hline AEMBL 57 & & & & \\
\hline HEMBL14 & & & & \\
\hline HEMBL152 & & & & \\
\hline IEMBL14 & & & & \\
\hline HEMBL19 & & & 29 & \\
\hline AFMBI 32 & & 4 & 97 & \\
\hline JEMBL155 & & & 281 & \\
\hline AEMBL1602672 & & & & \\
\hline AEMBL1370207 & & & 74 & \\
\hline JEMBL199 & & & 28 & \\
\hline 717 & & & & \\
\hline HEMBL1522496 & & & & \\
\hline AEMBL1421660 & & & & \\
\hline AEMBL133 & & & 59 & \\
\hline HEMBL152 & & & 85 & \\
\hline & & & & \\
\hline AEMBL1387648 & & & 502 & \\
\hline AEMBL1406448 & & & 748 & \\
\hline AEMBL155 & & & 06 & \\
\hline 15M 1 & & & 22 & \\
\hline & & & 272 & \\
\hline HEMBL1449513 & & 362 & 5773 & RI \\
\hline IEMBL14 & & & 962 & \\
\hline HEMBL14 & & & & \\
\hline CHEMBL1601176 & & & & \\
\hline CHEMBL3193789 & & & 283 & \\
\hline HEMBL138708 & 8239 & 4.6862 & 5.4271 & \\
\hline HFMRI 1516985 & 688239 & 6.0362 & 5.3204 & \\
\hline
\end{tabular}

Page 1865 
Supplemental Table S2.txt

\begin{tabular}{|c|c|c|c|c|}
\hline CHEMBL1328408 & 688239 & 6.4862 & 5.5588 & TRN \\
\hline CHEMBL1393129 & 688239 & 4.5362 & 5.5013 & TST \\
\hline CHEMBL3199415 & 688239 & 5.6362 & 5.3583 & TRN \\
\hline CHEMBL1387313 & 688239 & 7.0362 & 5.5148 & TRN \\
\hline CHEMBL1968789 & 688239 & 7.2865 & 5.3911 & TRN \\
\hline CHEMBL 244645 & 688239 & 6.9363 & 5.2532 & TST \\
\hline CHEMBL1460339 & 688239 & 5.1862 & 5.6297 & TRN \\
\hline CHEMBL1442257 & 688239 & 4.8862 & 5.5394 & TRN \\
\hline CHEMBL1463601 & 688239 & 5.4362 & 5.567 & TRN \\
\hline CHEMBL1305055 & 688239 & 4.5362 & 5.4736 & TRN \\
\hline CHEMBL1553045 & 688239 & 6.7862 & 5.4878 & TRN \\
\hline CHEMBL1367684 & 688239 & 4.7862 & 5.5346 & TST \\
\hline CHEMBL1371792 & 688239 & 5.4362 & 5.4698 & TRN \\
\hline CHEMBL1355806 & 688239 & 4.6362 & 5.561 & TRN \\
\hline CHEMBL1442877 & 688239 & 4.8862 & 5.4816 & TST \\
\hline CHEMBL 3190525 & 688239 & 4.6362 & 5.6524 & TRN \\
\hline CHEMBL1331512 & 688239 & 6.5363 & 5.4319 & TRN \\
\hline CHEMBL1323173 & 688239 & 6.1362 & 5.4164 & TRN \\
\hline CHEMBL1391382 & 688239 & 4.6862 & 5.4427 & TRN \\
\hline CHEMBL1344651 & 688239 & 5.1862 & 5.4817 & TST \\
\hline CHEMBL1564175 & 688239 & 5.1862 & 5.3407 & TST \\
\hline CHEMBL1540290 & 688239 & 4.7362 & 5.4854 & TST \\
\hline CHEMBL1428923 & 688239 & 5.1862 & 5.6214 & TST \\
\hline CHEMBL1609113 & 688239 & 5.7862 & 5.5238 & TST \\
\hline CHEMBL1413534 & 688239 & 4.5862 & 5.4479 & TRN \\
\hline CHEMBL1561515 & 688239 & 4.7862 & 5.605 & TRN \\
\hline CHEMBL1327007 & 688239 & 5.3862 & 5.5727 & TRN \\
\hline CHEMBL 3197454 & 688239 & 5.1862 & 5.4908 & TRN \\
\hline CHEMBL1468847 & 688239 & 5.0862 & 5.5298 & TRN \\
\hline CHEMBL1584152 & 688239 & 7.0362 & 5.5269 & TST \\
\hline CHEMBL3213950 & 688239 & 5.5862 & 5.5827 & TRN \\
\hline CHEMBL1491725 & 688239 & 5.1862 & 5.6623 & TRN \\
\hline CHEMBL1418249 & 688239 & 4.6862 & 5.4726 & TST \\
\hline CHEMBL1605347 & 688239 & 5.1862 & 5.5696 & TRN \\
\hline CHEMBL1968220 & 688239 & 6.9363 & 5.3516 & TRN \\
\hline CHEMBL1569498 & 688239 & 7.2366 & 5.3893 & TRN \\
\hline CHEMBL1419747 & 688239 & 6.5363 & 5.5498 & TST \\
\hline CHEMBL1565595 & 688239 & 4.7862 & 5.5485 & TST \\
\hline CHEMBL1887938 & 688239 & 4.7362 & 5.4402 & TRN \\
\hline CHEMBL1508711 & 688239 & 5.5362 & 5.3252 & TST \\
\hline CHEMBL1562905 & 688239 & 7.1361 & 5.6391 & TRN \\
\hline CHEMBL1326978 & 688239 & 4.5362 & 5.3947 & TRN \\
\hline CHEMBL1547754 & 688239 & 4.6362 & 5.4726 & TRN \\
\hline CHEMBL1971151 & 688239 & 4.5362 & 5.4395 & TST \\
\hline CHEMBL1419417 & 688239 & 6.5862 & 5.4471 & TST \\
\hline CHEMBL563957 & 688239 & 4.5362 & \multicolumn{2}{|c|}{5.462000000000001} \\
\hline CHEMBL1404270 & 688239 & 5.1862 & 5.5296 & TRN \\
\hline CHEMBL1521693 & 688239 & 4.7362 & 5.3827 & TST \\
\hline
\end{tabular}


Supplemental Table S2.txt

\begin{tabular}{|c|c|c|c|c|c|}
\hline CHEMBL1975918 & 688239 & 8.3372 & \multicolumn{2}{|c|}{5.5329999999999995} & \multirow[t]{6}{*}{ TRN } \\
\hline CHEMBL1538202 & 688239 & 4.5362 & 5.4644 & TST & \\
\hline CHEMBL1346487 & 688239 & 4.9362 & 5.4736 & TST & \\
\hline CHEMBL1379648 & 688239 & 4.5862 & 5.4917 & TRN & \\
\hline CHEMBL1482315 & 688239 & 5.1862 & 5.4201 & TST & \\
\hline CHEMBL1573102 & 688239 & 8.3372 & 5.5897 & TRN & \\
\hline CHEMBL1576354 & 688239 & 4.5362 & \multicolumn{2}{|c|}{5.6160000000000005} & TRN \\
\hline CHEMBL1590215 & 688239 & 4.7862 & 5.4277 & TRN & \\
\hline CHEMBL1475111 & 688239 & 5.1862 & 5.4133 & TRN & \\
\hline CHEMBL1571290 & 688239 & 5.0362 & 5.4333 & TST & \\
\hline CHEMBL1581849 & 688239 & 5.6862 & 5.6174 & TST & \\
\hline CHEMBL1431418 & 688239 & 4.8862 & 5.4625 & TRN & \\
\hline CHEMBL1401716 & 688239 & 6.7361 & 5.4697 & TST & \\
\hline CHEMBL1444181 & 688239 & 4.6362 & 5.4201 & TRN & \\
\hline CHEMBL1350273 & 688239 & 5.1362 & 5.6523 & TRN & \\
\hline CHEMBL1359683 & 688239 & 5.8862 & 5.4078 & TRN & \\
\hline CHEMBL1583089 & 688239 & 6.3362 & 5.6329 & TRN & \\
\hline CHEMBL1350880 & 688239 & 5.6362 & 5.5884 & TRN & \\
\hline CHEMBL1416333 & 688239 & 4.6862 & 5.4701 & TST & \\
\hline CHEMBL1527395 & 688239 & 4.5362 & 5.6168 & TRN & \\
\hline CHEMBL1348690 & 688239 & 5.8362 & 5.5183 & TRN & \\
\hline CHEMBL1349647 & 688239 & 5.7862 & 5.5173 & TRN & \\
\hline CHEMBL1522033 & 688239 & 4.7362 & 5.5217 & TRN & \\
\hline CHEMBL1448231 & 688239 & 6.1362 & 5.5125 & TRN & \\
\hline CHEMBL1418850 & 688239 & 6.2862 & 5.4635 & TRN & \\
\hline CHEMBL1457245 & 688239 & 5.1862 & 5.3786 & TST & \\
\hline CHEMBL1511136 & 688239 & 6.6362 & 5.4819 & TRN & \\
\hline CHEMBL1411646 & 688239 & 5.0862 & 5.2697 & TRN & \\
\hline CHEMBL1444774 & 688239 & 4.5362 & 5.4724 & TST & \\
\hline CHEMBL1494004 & 688239 & 5.3362 & 5.4896 & TRN & \\
\hline CHEMBL1421250 & 688239 & 4.5362 & 5.5623 & TRN & \\
\hline CHEMBL1500985 & 688239 & 4.5362 & 5.5988 & TRN & \\
\hline CHEMBL1476435 & 688239 & 5.9862 & 5.4916 & TRN & \\
\hline CHEMBL1553921 & 688239 & 4.6362 & 5.4486 & TRN & \\
\hline CHEMBL1606671 & 688239 & 4.6862 & 5.5211 & TRN & \\
\hline CHEMBL1436564 & 688239 & 4.7362 & 5.5052 & TRN & \\
\hline CHEMBL1419299 & 688239 & 6.8362 & 5.4897 & TRN & \\
\hline CHEMBL1430471 & 688239 & 6.2362 & 5.7481 & TRN & \\
\hline CHEMBL9632 & 688239 & 4.5362 & 5.4173 & TST & \\
\hline CHEMBL1611957 & 688239 & 4.5362 & 5.2548 & TRN & \\
\hline CHEMBL1418698 & 688239 & 5.4362 & 5.6551 & TST & \\
\hline CHEMBL1354078 & 688239 & 7.2366 & 5.7156 & TST & \\
\hline CHEMBL1387064 & 688239 & 5.3862 & 5.4782 & TRN & \\
\hline CHEMBL1568114 & 688239 & 5.1862 & 5.4432 & TRN & \\
\hline CHEMBL3194546 & 688239 & 4.6862 & 5.5103 & TRN & \\
\hline CHEMBL1466729 & 688239 & 4.6862 & 5.4843 & TRN & \\
\hline CHEMBL1300631 & 688239 & 6.3863 & 5.5312 & TRN & \\
\hline CHEMBL1373709 & 688239 & 5.2862 & 5.5137 & TST & \\
\hline
\end{tabular}


Supplemental Table S2.txt

\begin{tabular}{|c|c|c|c|c|}
\hline CHEMBL1535439 & 688239 & 4.6362 & 5.3923 & TRN \\
\hline CHEMBL1569115 & 688239 & 5.6362 & 5.4214 & TST \\
\hline CHEMBL585591 & 688239 & 5.5862 & 5.3213 & TST \\
\hline CHEMBL1478392 & 688239 & 7.0862 & 5.4791 & TST \\
\hline CHEMBL1442842 & 688239 & 8.3372 & 5.6325 & TRN \\
\hline CHEMBL1387367 & 688239 & 7.2366 & 5.5303 & TRN \\
\hline CHEMBL1304623 & 688239 & 4.5362 & 5.4462 & TRN \\
\hline CHEMBL1530013 & 688239 & 5.6362 & 5.541 & TST \\
\hline CHEMBL1541336 & 688239 & 4.5362 & 5.244 & TST \\
\hline CHEMBL1379800 & 688239 & 4.5362 & 5.6045 & TST \\
\hline CHEMBL1551890 & 688239 & 5.5862 & 5.5198 & TRN \\
\hline CHEMBL1431610 & 688239 & 4.7862 & 5.4292 & TST \\
\hline CHEMBL1456863 & 688239 & 5.2362 & 5.6016 & TST \\
\hline CHEMBL1356243 & 688239 & 5.4362 & 5.4367 & TRN \\
\hline CHEMBL1493905 & 688239 & 4.4862 & 5.3125 & TST \\
\hline CHEMBL1322904 & 688239 & 7.2865 & 5.3347 & TST \\
\hline CHEMBL1555247 & 688239 & 5.7362 & 5.4016 & TRN \\
\hline CHEMBL1402489 & 688239 & 5.5862 & 5.4739 & TST \\
\hline CHEMBL1528702 & 688239 & 5.4362 & 5.5285 & TRN \\
\hline CHEMBL3197201 & 688239 & 4.45 & 5.4755 & TRN \\
\hline CHEMBL1539294 & 688239 & 5.1862 & 5.54299 & 9999999999 \\
\hline CHEMBL1546460 & 688239 & 8.2366 & 5.53600 & 00000000005 \\
\hline CHEMBL1385249 & 688239 & 4.7362 & 5.5165 & TRN \\
\hline CHEMBL1428109 & 688239 & 4.8862 & 5.5682 & TRN \\
\hline CHEMBL1404806 & 688239 & 5.1862 & 5.5695 & TST \\
\hline CHEMBL1315265 & 688239 & 4.5362 & 5.5776 & TRN \\
\hline CHEMBL1503439 & 688239 & 6.1862 & 5.5262 & TRN \\
\hline CHEMBL1579830 & 688239 & 5.6362 & 5.445 & TRN \\
\hline CHEMBL1605204 & 688239 & 8.3372 & 5.4258 & TRN \\
\hline CHEMBL1428714 & 688239 & 5.6862 & 5.3305 & TST \\
\hline CHEMBL1333880 & 688239 & 4.9862 & 5.1965 & TST \\
\hline CHEMBL1336610 & 688239 & 6.9363 & 5.5413 & TRN \\
\hline CHEMBL1496168 & 688239 & 4.5362 & 5.4542 & TST \\
\hline CHEMBL1572933 & 688239 & 5.2362 & 5.6514 & TRN \\
\hline CHEMBL1476238 & 688239 & 4.7362 & 5.4228 & TST \\
\hline CHEMBL1300434 & 688239 & 6.2862 & 5.471 & TST \\
\hline CHEMBL1488898 & 688239 & 4.7362 & 5.2093 & TRN \\
\hline CHEMBL1439297 & 688239 & 5.2862 & 5.5281 & TRN \\
\hline CHEMBL1468798 & 688239 & 5.8362 & 5.4139 & TST \\
\hline CHEMBL1580940 & 688239 & 4.9862 & 5.4387 & TRN \\
\hline CHEMBL1359281 & 688239 & 4.5362 & 5.64 & TRN \\
\hline CHEMBL1603051 & 688239 & 6.2862 & 5.6453 & TRN \\
\hline CHEMBL1364900 & 688239 & 4.8362 & 5.5662 & TRN \\
\hline CHEMBL1530483 & 688239 & 5.6862 & 5.4222 & TRN \\
\hline CHEMBL1311482 & 688239 & 5.1862 & 5.439 & TRN \\
\hline CHEMBL1386829 & 688239 & 4.7862 & 5.4727 & TRN \\
\hline CHEMBL1420496 & 688239 & 6.0362 & 5.3782 & TRN \\
\hline CHEMBL1600318 & 688239 & 6.8861 & 5.5769 & TRN \\
\hline
\end{tabular}

Page 1868 
Supplemental Table S2.txt

\begin{tabular}{|c|c|c|c|c|}
\hline 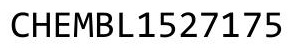 & & & & \\
\hline HEN & 8239 & 362 & & \\
\hline HEMBL1986086 & 38239 & 362 & 4045 & \\
\hline HEMBL1349473 & 88239 & 9362 & 5747 & \\
\hline & 39 & & & \\
\hline IEMBL1316697 & 239 & 62 & 525 & \\
\hline AEMBL1429193 & 88239 & 862 & 3661 & \\
\hline HEMBL3209015 & 88239 & 362 & 5563 & \\
\hline HEMBL3209466 & 88239 & & & \\
\hline EMBL1520096 & 239 & & 81 & \\
\hline IEMBL1525232 & 239 & & & \\
\hline HEMBL1309274 & 88239 & 362 & .4006 & \\
\hline HEMBL1611170 & 88239 & & 4514 & ST \\
\hline EMMBL14 & 88 & & 64 & \\
\hline IEMBL1431529 & 38239 & & & \\
\hline IEMBL1439615 & 38239 & & & \\
\hline AEMBL1322419 & 88239 & & 5.2918 & ST \\
\hline AEMBL1348714 & 88239 & & & RN \\
\hline L31 & 39 & & 2 & \\
\hline L138 & 39 & & 41 & \\
\hline L138 & 39 & & & RN \\
\hline L1574992 & 88239 & & 5.4465 & \\
\hline AEMBL1470874 & 39 & & & RIN \\
\hline EMBL14 & 39 & & 94 & \\
\hline L14 & & & & RN \\
\hline 45 & 39 & & & RN \\
\hline L31S & 39 & & & ST \\
\hline AEMBL14 & 39 & & & RN \\
\hline IEMBL14 & 39 & & 96 & ST \\
\hline L3] & & & 57 & RN \\
\hline 24 & 39 & & 34 & $\mathrm{RN}$ \\
\hline AEMBL1538434 & & & & RN \\
\hline AEMBL1488299 & & & & RN \\
\hline JEMBL13 & 39 & & 275 & ST \\
\hline 26 & & & 24 & ST \\
\hline & & & & ST \\
\hline HEMBL1547852 & 88239 & & 5.4935 & RN \\
\hline AEMBL1365513 & & & & ST \\
\hline AEMBL14 & & & & RN \\
\hline 4 & & & & RIN \\
\hline L14 & 9 & & 166 & RN \\
\hline HEMBL1309996 & 88239 & & 5.3869 & TRN \\
\hline AEMBL1581698 & 39 & & 53 & ST \\
\hline HEMBL1602096 & & & & \\
\hline & & & & ST \\
\hline HEMBL1563309 & 39 & & 5.5884 & RN \\
\hline L1572200 & 88239 & 4.5362 & 5.5352 & TRN \\
\hline CHEMBL1435876 & 688239 & 5.3362 & 5.4273 & TRN \\
\hline
\end{tabular}

Page 1869 
Supplemental Table S2.txt

\begin{tabular}{|c|c|c|c|c|}
\hline CHEMBL1353817 & 688239 & 6.1362 & \multicolumn{2}{|c|}{5.452000000000001} \\
\hline CHEMBL1380688 & 688239 & 6.1362 & 5.6178 & TRN \\
\hline CHEMBL1577997 & 688239 & 5.7362 & 5.4304 & TRN \\
\hline CHEMBL1609779 & 688239 & 5.1862 & 5.3922 & TRN \\
\hline CHEMBL1414840 & 688239 & 5.1862 & 5.5178 & TRN \\
\hline CHEMBL1341969 & 688239 & 6.8362 & 5.6586 & TRN \\
\hline CHEMBL1450199 & 688239 & 4.4862 & 5.3371 & TRN \\
\hline CHEMBL1538534 & 688239 & 5.8862 & 5.4105 & TRN \\
\hline CHEMBL1316124 & 688239 & 5.3862 & 5.5025 & TRN \\
\hline CHEMBL1514847 & 688239 & 6.3863 & 5.5554 & TRN \\
\hline CHEMBL1469040 & 688239 & 7.9355 & 5.4081 & TRN \\
\hline CHEMBL1370381 & 688239 & 5.1862 & 5.3743 & TRN \\
\hline CHEMBL1521457 & 688239 & 6.1362 & 5.4222 & TRN \\
\hline CHEMBL1543436 & 688239 & 5.0862 & 5.5861 & TRN \\
\hline CHEMBL1505601 & 688239 & 6.0 & 5.5776 & TRN \\
\hline CHEMBL1545460 & 688239 & 4.4862 & 5.5379 & TST \\
\hline CHEMBL1601257 & 688239 & 5.4862 & 5.5631 & TST \\
\hline CHEMBL1504064 & 688239 & 5.5362 & 5.4952 & TRN \\
\hline CHEMBL1417660 & 688239 & 4.5362 & 5.5311 & TRN \\
\hline CHEMBL1604891 & 688239 & 8.2366 & 5.4897 & TRN \\
\hline CHEMBL1440042 & 688239 & 4.5362 & 5.4596 & TRN \\
\hline CHEMBL1404578 & 688239 & 5.1862 & 5.4326 & TRN \\
\hline CHEMBL1386577 & 688239 & 4.6862 & 5.5273 & TRN \\
\hline CHEMBL1600907 & 688239 & 5.2862 & 5.5314 & TRN \\
\hline CHEMBL1471396 & 688239 & 5.6362 & 5.3215 & TST \\
\hline CHEMBL1310439 & 688239 & 4.5362 & 5.4911 & TRN \\
\hline CHEMBL1582797 & 688239 & 5.5862 & 5.457999 & 9999999999 \\
\hline CHEMBL3196067 & 688239 & 5.6362 & 5.5887 & TRN \\
\hline CHEMBL1511470 & 688239 & 5.7362 & 5.6056 & TRN \\
\hline CHEMBL1361452 & 688239 & 5.6862 & 5.5333 & TRN \\
\hline CHEMBL1604758 & 688239 & 6.7361 & 5.4868 & TRN \\
\hline CHEMBL1540811 & 688239 & 4.5362 & 5.5409 & TST \\
\hline CHEMBL1536216 & 688239 & 4.5362 & 5.4748 & TST \\
\hline CHEMBL1595998 & 688239 & 6.0362 & 5.3933 & TRN \\
\hline CHEMBL3190582 & 688239 & 6.3863 & 5.4531 & TRN \\
\hline CHEMBL1612456 & 688239 & 5.6362 & 5.7306 & TRN \\
\hline CHEMBL1414426 & 688239 & 4.5362 & 5.4766 & TRN \\
\hline CHEMBL2369209 & 688239 & 6.5363 & 5.479 & TST \\
\hline CHEMBL1433913 & 688239 & 4.5362 & 5.4843 & TRN \\
\hline CHEMBL1560720 & 688239 & 6.2362 & 5.5749 & TRN \\
\hline CHEMBL1492387 & 688239 & 5.9362 & 5.4887 & TRN \\
\hline CHEMBL1460632 & 688239 & 5.3362 & 5.5015 & TRN \\
\hline CHEMBL1602942 & 688239 & 5.1862 & 5.4475 & TRN \\
\hline CHEMBL1342527 & 688239 & 4.5362 & 5.4188 & TST \\
\hline CHEMBL3199760 & 688239 & 5.2862 & 5.5341 & TRN \\
\hline CHEMBL1393359 & 688239 & 4.5362 & 5.6329 & TRN \\
\hline CHEMBL1484416 & 688239 & 5.8362 & 5.3071 & TST \\
\hline CHEMBL1346675 & 688239 & 7.4365 & 5.5499 & TRN \\
\hline
\end{tabular}


Supplemental Table S2.txt

\begin{tabular}{|c|c|c|c|c|c|}
\hline CHEMBL1582489 & 688239 & 4.5862 & 5.4612 & TRN & \\
\hline CHEMBL1537444 & 688239 & 6.0862 & 5.4333 & TRN & \\
\hline CHEMBL1322564 & 688239 & 4.5362 & 5.351 & TRN & \\
\hline CHEMBL1417039 & 688239 & 5.7362 & 5.5927 & TRN & \\
\hline CHEMBL1466979 & 688239 & 4.5362 & 5.4731 & TRN & \\
\hline CHEMBL1387525 & 688239 & 8.2366 & 5.477 & TRN & \\
\hline CHEMBL1351668 & 688239 & 4.5362 & 5.3879 & TRN & \\
\hline CHEMBL1323351 & 688239 & 6.3362 & 5.6307 & TRN & \\
\hline CHEMBL1391729 & 688239 & 6.3863 & 5.5376 & TRN & \\
\hline CHEMBL1430256 & 688239 & 4.6862 & 5.3654 & TST & \\
\hline CHEMBL1389343 & 688239 & 5.5362 & 5.5215 & TRN & \\
\hline CHEMBL1381311 & 688239 & 7.6861 & 5.6099 & TRN & \\
\hline CHEMBL1570404 & 688239 & 6.2862 & 5.5891 & TRN & \\
\hline CHEMBL 3210132 & 688239 & 6.9363 & 5.4593 & TST & \\
\hline CHEMBL1440220 & 688239 & 4.6362 & 5.4395 & TST & \\
\hline CHEMBL 3214273 & 688239 & 5.1862 & 5.403 & TRN & \\
\hline CHEMBL1348400 & 688239 & 4.7862 & 5.4513 & TRN & \\
\hline CHEMBL1369052 & 688239 & 4.9362 & 5.4727 & TRN & \\
\hline CHEMBL1431022 & 688239 & 6.9363 & 5.4606 & TRN & \\
\hline CHEMBL1390898 & 688239 & 6.1362 & 5.5467 & TRN & \\
\hline CHEMBL1421035 & 688239 & 6.0862 & 5.5073 & TST & \\
\hline CHEMBL1376664 & 688239 & 5.8862 & 5.5046 & TST & \\
\hline CHEMBL1407740 & 688239 & 4.5362 & 5.4056 & TRN & \\
\hline CHEMBL1536571 & 688239 & 5.7862 & 5.4718 & TRN & \\
\hline CHEMBL1337869 & 688239 & 5.3862 & 5.595 & TRN & \\
\hline CHEMBL1420164 & 688239 & 8.28399 & 199999999 & 5.5506 & TST \\
\hline CHEMBL1470704 & 688239 & 4.5362 & 5.4798 & TRN & \\
\hline CHEMBL1376366 & 688239 & 5.5362 & 5.6376 & TRN & \\
\hline CHEMBL1344470 & 688239 & 4.8862 & 5.3778 & TST & \\
\hline CHEMBL 3212809 & 688239 & 4.9362 & 5.4998 & TRN & \\
\hline CHEMBL1583155 & 688239 & 5.4362 & 5.4688 & TRN & \\
\hline CHEMBL1582504 & 688239 & 4.95 & 5.4865 & TRN & \\
\hline CHEMBL1396056 & 688239 & 4.5862 & 5.4646 & TST & \\
\hline CHEMBL1570137 & 688239 & 4.7362 & 5.407 & TRN & \\
\hline CHEMBL1308699 & 688239 & 5.7362 & 5.4476 & TRN & \\
\hline CHEMBL1504912 & 688239 & 4.5362 & 5.462000 & 000000001 & TRI \\
\hline CHEMBL1441260 & 688239 & 6.5862 & 5.5973 & TRN & \\
\hline CHEMBL1387538 & 688239 & 5.6862 & 5.5572 & TRN & \\
\hline CHEMBL1580385 & 688239 & 5.1862 & 5.4873 & TRN & \\
\hline CHEMBL1520855 & 688239 & 6.1362 & 5.4355 & TRN & \\
\hline CHEMBL1311545 & 688239 & 8.28399 & 99999999 & 5.5295 & $1 \mathrm{KN}$ \\
\hline CHEMBL1413749 & 688239 & 4.4862 & 5.4754 & TST & \\
\hline CHEMBL1472225 & 688239 & 5.7862 & 5.5601 & TRN & \\
\hline CHEMBL1516641 & 688239 & 4.8362 & 5.5435 & TRN & \\
\hline CHEMBL1571451 & 688239 & 5.1862 & 5.5128 & TRN & \\
\hline CHEMBL1351867 & 688239 & 6.9863 & 5.605 & TRN & \\
\hline CHEMBL1566193 & 688239 & 4.6362 & 5.6286 & TST & \\
\hline CHEMBL1539224 & 688239 & 4.5862 & 5.3086 & TST & \\
\hline
\end{tabular}


Supplemental Table S2.txt

\begin{tabular}{|c|c|c|c|c|c|}
\hline CHEMBL1341262 & 688239 & 5.2862 & 5.419 & TRN & \\
\hline CHEMBL1599447 & 688239 & 4.5362 & 5.445 & TST & \\
\hline CHEMBL1415811 & 688239 & 4.5362 & 5.4586 & TRN & \\
\hline CHEMBL1439470 & 688239 & 5.1862 & 5.407999 & 9999999995 & in \\
\hline CHEMBL1571809 & 688239 & 6.3362 & 5.5292 & TRN & \\
\hline CHEMBL1557954 & 688239 & 6.4362 & 5.4282 & TRN & \\
\hline CHEMBL1398151 & 688239 & 5.1362 & 5.5067 & TST & \\
\hline CHEMBL1418801 & 688239 & 5.7862 & 5.5653 & TRN & \\
\hline CHEMBL1603821 & 688239 & 5.1362 & 5.507999 & 999999999 & \\
\hline CHEMBL1580262 & 688239 & 5.4862 & 5.3889 & TRN & \\
\hline CHEMBL1408382 & 688239 & 4.4862 & 5.4597 & TRN & \\
\hline CHEMBL1568230 & 688239 & 4.5362 & 5.3452 & TRN & \\
\hline CHEMBL1587950 & 688239 & 5.5862 & 5.4702 & TRN & \\
\hline CHEMBL1400899 & 688239 & 4.6862 & 5.6304 & TRN & \\
\hline CHEMBL1392352 & 688239 & 4.7862 & 5.6097 & TST & \\
\hline CHEMBL464467 & 688239 & 5.4862 & 5.3501 & TST & \\
\hline CHEMBL1382815 & 688239 & 7.5361 & 5.4697 & TST & \\
\hline CHEMBL1553564 & 688239 & 6.1362 & 5.4769 & TRN & \\
\hline CHEMBL1393705 & 688239 & 4.5362 & 5.3704 & TRN & \\
\hline CHEMBL1547018 & 688239 & 6.9363 & 5.485 & TRN & \\
\hline CHEMBL1352013 & 688239 & 5.5862 & 5.5064 & TRN & \\
\hline CHEMBL1522818 & 688239 & 4.5362 & 5.5279 & TRN & \\
\hline CHEMBL1394635 & 688239 & 5.5862 & 5.5485 & TRN & \\
\hline CHEMBL1385457 & 688239 & 5.3862 & 5.3857 & TRN & \\
\hline CHEMBL1386022 & 688239 & 5.1862 & 5.5629 & TRN & \\
\hline CHEMBL1433581 & 688239 & 7.0862 & 5.5034 & TRN & \\
\hline CHEMBL1471435 & 688239 & 4.6362 & 5.3396 & TRN & \\
\hline CHEMBL1411525 & 688239 & 6.1362 & 5.5577 & TRN & \\
\hline CHEMBL1415900 & 688239 & 4.5362 & 5.4264 & TRN & \\
\hline CHEMBL3197168 & 688239 & 7.6861 & 5.6813 & TST & \\
\hline CHEMBL1508485 & 688239 & 7.0862 & 5.4785 & TRN & \\
\hline CHEMBL1480423 & 688239 & 5.6362 & 5.6228 & TRN & \\
\hline CHEMBL1585855 & 688239 & 4.5362 & 5.43 & TRN & \\
\hline CHEMBL1598346 & 688239 & 4.6362 & 5.3926 & TRN & \\
\hline CHEMBL1498839 & 688239 & 4.7862 & 5.5319 & TRN & \\
\hline CHEMBL1541013 & 688239 & 4.7862 & 5.5098 & TST & \\
\hline CHEMBL1438170 & 688239 & 8.28399 & 99999999 & 5.4372 & \\
\hline CHEMBL1542712 & 688239 & 5.1862 & 5.4864 & TRN & \\
\hline CHEMBL1330970 & 688239 & 5.1362 & 5.5011 & TRN & \\
\hline CHEMBL1541648 & 688239 & 5.4362 & 5.504 & TST & \\
\hline CHEMBL1329067 & 688239 & 4.6862 & 5.3938 & TRN & \\
\hline CHEMBL1353439 & 688239 & 5.7362 & 5.5559 & TRN & \\
\hline CHEMBL1486308 & 688239 & 5.1362 & 5.482 & TRN & \\
\hline CHEMBL1423302 & 688239 & 4.6362 & 5.4893 & TRN & \\
\hline CHEMBL1324265 & 688239 & 6.0862 & 5.2857 & TRN & \\
\hline CHEMBL1478252 & 688239 & 6.8362 & 5.3561 & TST & \\
\hline CHEMBL1609047 & 688239 & 4.6362 & 5.4998 & TST & \\
\hline CHEMBL1543082 & 688239 & 5.4862 & 5.4209 & TST & \\
\hline
\end{tabular}




\begin{tabular}{|c|c|c|c|c|c|}
\hline \multicolumn{6}{|c|}{ 5 } \\
\hline CHEMBL1609439 & 688239 & 6.0 & 5.5396 & TST & \\
\hline CHEMBL1337323 & 688239 & 4.5362 & 5.5179 & TRN & \\
\hline CHEMBL1578081 & 688239 & 6.3863 & 5.4367 & TRN & \\
\hline CHEMBL1433602 & 688239 & 4.7362 & 5.565 & TRN & \\
\hline CHEMBL1381927 & 688239 & 5.1862 & 5.53700 & 0000000001 & TST \\
\hline CHEMBL1613487 & 688239 & 5.0362 & 5.5443 & TRN & \\
\hline CHEMBL1470109 & 688239 & 8.28399 & 99999999 & 5.4906 & TST \\
\hline CHEMBL1312428 & 688239 & 4.5362 & 5.4922 & TRN & \\
\hline CHEMBL1511059 & 688239 & 6.1362 & 5.50299 & 9999999999 & TRN \\
\hline CHEMBL1528521 & 688239 & 6.9363 & 5.6368 & TRN & \\
\hline CHEMBL1390982 & 688239 & 6.0862 & 5.3005 & TRN & \\
\hline CHEMBL3212259 & 688239 & 4.5362 & 5.6253 & TRN & \\
\hline CHEMBL1371392 & 688239 & 5.1862 & 5.5069 & TST & \\
\hline CHEMBL1493709 & 688239 & 5.4362 & 5.6463 & TRN & \\
\hline CHEMBL1450042 & 688239 & 5.1862 & 5.6931 & TRN & \\
\hline CHEMBL1358446 & 688239 & 5.2362 & 5.53100 & 0000000001 & TRN \\
\hline CHEMBL1567603 & 688239 & 5.3862 & 5.5239 & TRN & \\
\hline CHEMBL1456107 & 688239 & 4.7362 & 5.4602 & TRN & \\
\hline CHEMBL1467404 & 688239 & 5.3862 & 5.5392 & TRN & \\
\hline CHEMBL1601494 & 688239 & 7.0362 & 5.6626 & TRN & \\
\hline CHEMBL3195156 & 688239 & 4.7362 & 5.3451 & TST & \\
\hline CHEMBL1454636 & 688239 & 5.1862 & 5.5684 & TRN & \\
\hline CHEMBL3213420 & 688239 & 5.7362 & 5.5704 & TST & \\
\hline CHEMBL1376509 & 688239 & 7.7352 & 5.4583 & TRN & \\
\hline CHEMBL1567824 & 688239 & 7.0362 & 5.2497 & TRN & \\
\hline CHEMBL1431766 & 688239 & 6.9863 & 5.5934 & TRN & \\
\hline CHEMBL1582635 & 688239 & 4.8862 & 5.6048 & TRN & \\
\hline CHEMBL1565893 & 688239 & 4.9362 & 5.4625 & TRN & \\
\hline CHEMBL1301384 & 688239 & 5.1862 & 5.6021 & TRN & \\
\hline CHEMBL3198631 & 688239 & 4.7862 & 5.2831 & TST & \\
\hline CHEMBL1539250 & 688239 & 6.2362 & 5.602 & TRN & \\
\hline CHEMBL3211623 & 688239 & 4.5362 & 5.3576 & TST & \\
\hline CHEMBL 2000619 & 688239 & 5.6862 & 5.3955 & TRN & \\
\hline CHEMBL1485650 & 688239 & 5.6362 & 5.3684 & TST & \\
\hline CHEMBL1451581 & 688239 & 6.0862 & 5.5657 & TRN & \\
\hline CHEMBL1436223 & 688239 & 6.0 & 5.53100 & $\partial 000000001$ & TRN \\
\hline CHEMBL1496502 & 688239 & 5.7362 & 5.4678 & TRN & \\
\hline CHEMBL1506778 & 688239 & 4.4862 & 5.4801 & TST & \\
\hline CHEMBL1555231 & 688239 & 5.6862 & 5.4392 & TRN & \\
\hline CHEMBL1325741 & 688239 & 4.5362 & 5.4343 & TRN & \\
\hline CHEMBL1563307 & 688239 & 5.0362 & 5.5662 & TRN & \\
\hline CHEMBL1479941 & 688239 & 5.3362 & 5.4356 & TST & \\
\hline CHEMBL1446272 & 688239 & 6.3362 & 5.5642 & TRN & \\
\hline CHEMBL1546578 & 688239 & 4.7862 & 5.6678 & TRN & \\
\hline CHEMBL1304879 & 688239 & 5.2362 & 5.3738 & TST & \\
\hline CHEMBL1393098 & 688239 & 4.5362 & 5.2774 & TST & \\
\hline CHEMBL1483428 & 688239 & 5.3862 & 5.4987 & TRN & \\
\hline CHEMBL1567095 & 688239 & 4.8862 & 5.4331 & TRN & \\
\hline
\end{tabular}


Supplemental Table S2.txt

\begin{tabular}{|c|c|c|c|c|}
\hline CHEMBL 3189714 & 688239 & 4.9862 & 5.3784 & TRN \\
\hline CHEMBL1436080 & 688239 & 4.9362 & 5.5222 & TRN \\
\hline CHEMBL1483064 & 688239 & 5.1862 & 5.5374 & TRN \\
\hline CHEMBL1397584 & 688239 & 5.6862 & 5.5777 & TRN \\
\hline CHEMBL1485015 & 688239 & 5.6362 & 5.3489 & TRN \\
\hline CHEMBL3196264 & 688239 & 4.5362 & 5.3269 & TST \\
\hline CHEMBL1417257 & 688239 & 4.5362 & 5.6654 & TRN \\
\hline CHEMBL1374025 & 688239 & 5.1862 & 5.4217 & TRN \\
\hline CHEMBL1299194 & 688239 & 5.4362 & 5.5638 & TRN \\
\hline CHEMBL1420790 & 688239 & 5.7862 & 5.6379 & TST \\
\hline CHEMBL1594033 & 688239 & 6.2862 & \multicolumn{2}{|c|}{5.462999999999999} \\
\hline CHEMBL1457022 & 688239 & 4.8362 & 5.4418 & TRN \\
\hline CHEMBL1548372 & 688239 & 4.7862 & 5.5011 & TST \\
\hline CHEMBL 3192626 & 688239 & 5.0862 & 5.4313 & TRN \\
\hline CHEMBL1500291 & 688239 & 4.7862 & 5.5517 & TST \\
\hline CHEMBL1319439 & 688239 & 4.5362 & 5.5787 & TRN \\
\hline CHEMBL3194132 & 688239 & 5.1862 & 5.4892 & TRN \\
\hline CHEMBL1300068 & 688239 & 5.7362 & 5.5122 & TRN \\
\hline CHEMBL1307833 & 688239 & 5.7362 & 5.4377 & TST \\
\hline CHEMBL1360184 & 688239 & 4.5362 & 5.3969 & TRN \\
\hline CHEMBL1308413 & 688239 & 4.4862 & 5.5643 & TST \\
\hline CHEMBL1586028 & 688239 & 6.0362 & 5.3802 & TST \\
\hline CHEMBL1565968 & 688239 & 6.3863 & 5.5115 & TRN \\
\hline CHEMBL 3214422 & 688239 & 5.5362 & 5.4952 & TRN \\
\hline CHEMBL1359694 & 688239 & 4.8362 & 5.4215 & TRN \\
\hline CHEMBL1973626 & 688239 & 4.9362 & 5.4828 & TRN \\
\hline CHEMBL1609531 & 688239 & 4.8862 & 5.5736 & TST \\
\hline CHEMBL1305239 & 688239 & 5.2862 & 5.3881 & TRN \\
\hline CHEMBL1451993 & 688239 & 4.8862 & 5.4779 & TRN \\
\hline CHEMBL1384633 & 688239 & 5.4862 & 5.5003 & TRN \\
\hline CHEMBL1526913 & 688239 & 7.1361 & 5.4372 & TRN \\
\hline CHEMBL1424184 & 688239 & 5.4362 & 5.4853 & TRN \\
\hline CHEMBL1449907 & 688239 & 4.7362 & 5.7351 & TST \\
\hline CHEMBL1344682 & 688239 & 4.7362 & 5.5402 & TST \\
\hline CHEMBL1391273 & 688239 & 4.4862 & 5.5608 & TRN \\
\hline CHEMBL1498077 & 688239 & 4.5362 & 5.6446 & TST \\
\hline CHEMBL1374153 & 688239 & 8.2366 & 5.4941 & TRN \\
\hline CHEMBL1320025 & 688239 & 4.5362 & 5.4987 & TRN \\
\hline CHEMBL 3193771 & 688239 & 8.2366 & 5.3555 & TRN \\
\hline CHEMBL1349645 & 688239 & 5.9862 & \multicolumn{2}{|c|}{5.5360000000000005} \\
\hline CHEMBL1390172 & 688239 & 5.3362 & 5.5792 & TRN \\
\hline CHEMBL1320740 & 688239 & 4.5362 & 5.4591 & TRN \\
\hline CHEMBL1973921 & 688239 & 5.7362 & 5.3624 & TRN \\
\hline CHEMBL1418539 & 688239 & 4.7862 & 5.6055 & TRN \\
\hline CHEMBL1587879 & 688239 & 6.2362 & 5.5245 & TRN \\
\hline CHEMBL1078717 & 688239 & 5.1862 & 5.6084 & TRN \\
\hline CHEMBL1601999 & 688239 & 5.1862 & 5.4723 & TST \\
\hline CHEMBL1332102 & 688239 & 4.7362 & 5.3809 & TRN \\
\hline
\end{tabular}


Supplemental Table S2.txt

\begin{tabular}{|c|c|c|c|c|}
\hline CHEMBL1466537 & 688239 & 4.5362 & 5.3943 & TRN \\
\hline CHEMBL1490850 & 688239 & 7.1864 & 5.4803 & TRN \\
\hline CHEMBL1526668 & 688239 & 6.4362 & 5.5387 & TRN \\
\hline CHEMBL1359995 & 688239 & 5.1862 & 5.5893 & TRN \\
\hline CHEMBL1473343 & 688239 & 5.0862 & 5.5485 & TRN \\
\hline CHEMBL1601712 & 688239 & 4.5362 & 5.4583 & TST \\
\hline CHEMBL1331952 & 688239 & 6.9863 & 5.5202 & TRN \\
\hline CHEMBL1517657 & 688239 & 5.6862 & 5.5026 & TRN \\
\hline CHEMBL1448241 & 688239 & 4.7362 & 5.4636 & TST \\
\hline CHEMBL1573074 & 688239 & 6.4862 & 5.4869 & TRN \\
\hline CHEMBL 3193552 & 688239 & 6.4862 & 5.4657 & TRN \\
\hline CHEMBL1365355 & 688239 & 7.1361 & 5.4676 & TRN \\
\hline CHEMBL1502997 & 688239 & 4.6362 & 5.6209 & TRN \\
\hline CHEMBL1334735 & 688239 & 5.2862 & 5.5679 & TRN \\
\hline CHEMBL1574164 & 688239 & 4.6862 & 5.4426 & TRN \\
\hline CHEMBL1500751 & 688239 & 4.7862 & 5.5625 & TST \\
\hline CHEMBL1510404 & 688239 & 5.7862 & 5.6792 & TRN \\
\hline CHEMBL1436643 & 688239 & 5.1862 & 5.5562 & TST \\
\hline CHEMBL3195153 & 688239 & 5.5362 & 5.5038 & TST \\
\hline CHEMBL1359603 & 688239 & 5.0862 & 5.6825 & TRN \\
\hline CHEMBL1396676 & 688239 & 5.6362 & 5.6003 & TST \\
\hline CHEMBL1468164 & 688239 & 5.0362 & 5.5224 & TST \\
\hline CHEMBL1549777 & 688239 & 4.5362 & 5.4184 & TST \\
\hline CHEMBL1345160 & 688239 & 5.2862 & 5.5804 & TRN \\
\hline CHEMBL1504196 & 688239 & 5.2362 & 5.7521 & TRN \\
\hline CHEMBL 3194046 & 688239 & 6.2362 & 5.5076 & TRN \\
\hline CHEMBL1462644 & 688239 & 4.7362 & 5.4478 & TST \\
\hline CHEMBL1477917 & 688239 & 4.5362 & 5.3551 & TRN \\
\hline CHEMBL1430449 & 688239 & 4.5862 & 5.487 & TRN \\
\hline CHEMBL1541922 & 688239 & 6.5862 & 5.53600 & 00000000005 \\
\hline CHEMBL1469402 & 688239 & 4.6862 & 5.5929 & TRN \\
\hline CHEMBL 3213177 & 688239 & 4.7862 & 5.4588 & TST \\
\hline CHEMBL1601107 & 688239 & 6.1862 & 5.4866 & TST \\
\hline CHEMBL1476654 & 688239 & 5.5362 & 5.4549 & TRN \\
\hline CHEMBL1399440 & 688239 & 4.8362 & 5.6377 & TRN \\
\hline CHEMBL1361455 & 688239 & 5.3862 & 5.5069 & TRN \\
\hline CHEMBL1500530 & 688239 & 4.5362 & 5.5616 & TRN \\
\hline CHEMBL1362680 & 688239 & 4.4862 & 5.4745 & TST \\
\hline CHEMBL1407868 & 688239 & 5.9862 & 5.4317 & TRN \\
\hline CHEMBL1323889 & 688239 & 4.7862 & 5.6015 & TRN \\
\hline CHEMBL1342410 & 688239 & 5.7362 & 5.3749 & TRN \\
\hline CHEMBL1506264 & 688239 & 5.3862 & 5.3903 & TRN \\
\hline CHEMBL1516971 & 688239 & 5.7362 & 5.4081 & TRN \\
\hline CHEMBL1548259 & 688239 & 6.4862 & 5.473 & TRN \\
\hline CHEMBL1504242 & 688239 & 6.5862 & 5.4459 & TRN \\
\hline CHEMBL1526194 & 688239 & 5.6362 & 5.5711 & TRN \\
\hline CHEMBL1342227 & 688239 & 4.9362 & 5.4274 & TRN \\
\hline CHEMBL1594254 & 688239 & 5.0362 & 5.5456 & TRN \\
\hline
\end{tabular}


Supplemental Table S2.txt

\begin{tabular}{|c|c|c|c|c|c|}
\hline CHEMBL1397432 & 688239 & 4.7862 & 5.3348 & TST & \\
\hline CHEMBL1393235 & 688239 & 5.4862 & 5.3497 & TRN & \\
\hline CHEMBL1465037 & 688239 & 5.1862 & 5.4319 & TRN & \\
\hline CHEMBL1590966 & 688239 & 6.2362 & 5.5313 & TRN & \\
\hline CHEMBL1475115 & 688239 & 4.7862 & 5.3672 & TRN & \\
\hline CHEMBL1555185 & 688239 & 5.6862 & 5.4819 & TRN & \\
\hline CHEMBL1384127 & 688239 & 4.5362 & 5.5074 & TRN & \\
\hline CHEMBL1413928 & 688239 & 4.6362 & 5.4086 & TRN & \\
\hline CHEMBL1511289 & 688239 & 4.6362 & 5.3992 & TRN & \\
\hline CHEMBL1442812 & 688239 & 6.6861 & 5.6585 & TRN & \\
\hline CHEMBL1525526 & 688239 & 5.5362 & 5.5052 & TST & \\
\hline CHEMBL1380814 & 688239 & 4.4862 & 5.5716 & TST & \\
\hline CHEMBL1598245 & 688239 & 5.1862 & 5.6131 & TRN & \\
\hline CHEMBL1398826 & 688239 & 5.4862 & 5.5184 & TRN & \\
\hline CHEMBL1327525 & 688239 & 4.7862 & 5.4238 & TRN & \\
\hline CHEMBL1611129 & 688239 & 4.5362 & 5.4153 & TST & \\
\hline CHEMBL1333893 & 688239 & 4.5362 & 5.5306 & TRN & \\
\hline CHEMBL1425658 & 688239 & 4.5362 & 5.5292 & TRN & \\
\hline CHEMBL1300942 & 688239 & 5.2862 & 5.5824 & TST & \\
\hline CHEMBL1544848 & 688239 & 4.6362 & 5.4548 & TRN & \\
\hline CHEMBL1370066 & 688239 & 4.4862 & 5.5347 & TRN & \\
\hline CHEMBL1322949 & 688239 & 4.5362 & 5.4072 & TST & \\
\hline CHEMBL1556581 & 688239 & 4.5362 & 5.5118 & TRN & \\
\hline CHEMBL1489256 & 688239 & 4.7362 & 5.3769 & TRN & \\
\hline CHEMBL1366423 & 688239 & 4.5362 & 5.4708 & TRN & \\
\hline CHEMBL1529050 & 688239 & 4.9362 & 5.4292 & TRN & \\
\hline CHEMBL1305745 & 688239 & 6.5862 & 5.5187 & TRN & \\
\hline CHEMBL546576 & 688239 & 5.2362 & 5.6487 & TRN & \\
\hline CHEMBL1571454 & 688239 & 4.5362 & 5.4777 & TST & \\
\hline CHEMBL1379696 & 688239 & 4.5362 & 5.6121 & TRN & \\
\hline CHEMBL1408369 & 688239 & 6.8362 & 5.5649 & TRN & \\
\hline CHEMBL1530541 & 688239 & 5.1862 & 5.5592 & TRN & \\
\hline CHEMBL1302387 & 688239 & 5.4362 & 5.5724 & TRN & \\
\hline CHEMBL1517137 & 688239 & 5.5862 & 5.4309 & TRN & \\
\hline CHEMBL1444877 & 688239 & 4.6362 & 5.41299 & 9999999999 & TRN \\
\hline CHEMBL1581765 & 688239 & 6.95 & 5.6423 & TRN & \\
\hline CHEMBL1313923 & 688239 & 5.0362 & 5.3915 & TST & \\
\hline CHEMBL1590328 & 688239 & 4.5362 & 5.4248 & TRN & \\
\hline CHEMBL3198082 & 688239 & 5.3362 & 5.4204 & TRN & \\
\hline CHEMBL1500482 & 688239 & 5.4862 & 5.5674 & TRN & \\
\hline CHEMBL1403703 & 688239 & 5.1862 & 5.4527 & TRN & \\
\hline CHEMBL1312657 & 688239 & 4.7362 & 5.3855 & TRN & \\
\hline CHEMBL1315864 & 688239 & 4.9362 & 5.5287 & TRN & \\
\hline CHEMBL1987938 & 688239 & 4.9362 & 5.5933 & TRN & \\
\hline CHEMBL1372908 & 688239 & 5.2862 & 5.5122 & TRN & \\
\hline CHEMBL1550453 & 688239 & 6.9363 & 5.5422 & TST & \\
\hline CHEMBL1486444 & 688239 & 6.2362 & 5.4357 & TRN & \\
\hline CHEMBL1478148 & 688239 & 5.4362 & 5.3447 & TRN & \\
\hline
\end{tabular}




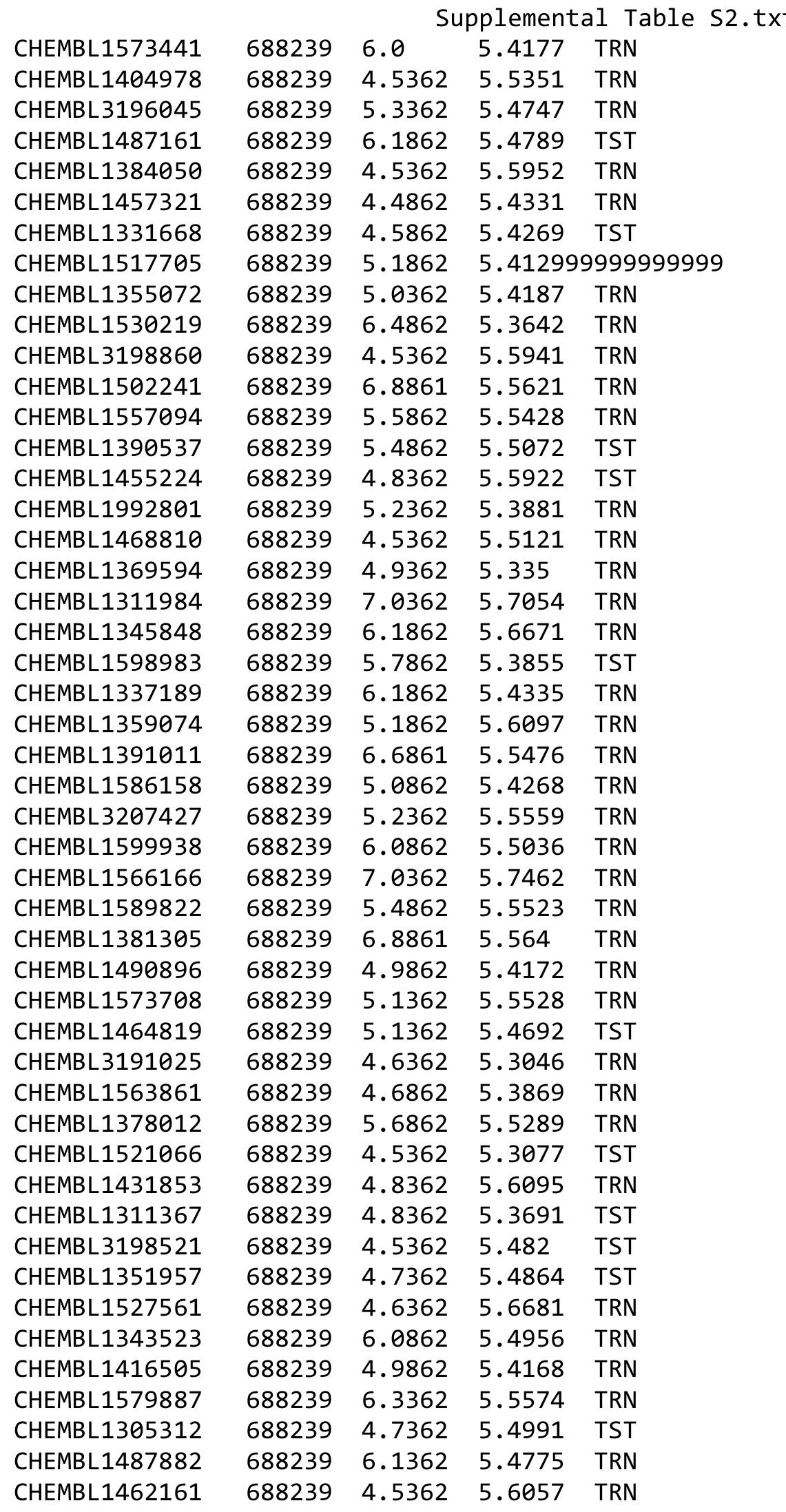


Supplemental Table S2.txt

\begin{tabular}{|c|c|c|c|c|}
\hline 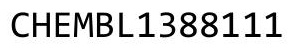 & & & & \\
\hline HEM & 38239 & 7862 & & \\
\hline AEMBL1327768 & 88239 & 5362 & 4458 & \\
\hline HEMBL 2000172 & 88239 & 6862 & .5239 & \\
\hline & 239 & 363 & & \\
\hline AEMBL 142 & 239 & 862 & .5524 & \\
\hline AEMBL1592200 & 88239 & 8662 & 5338 & \\
\hline HEMBL1467940 & 88239 & .0362 & 5.2994 & \\
\hline HEMBL141 & 88239 & 362 & a & \\
\hline AEMBL13S & 88239 & 362 & 97 & \\
\hline HEMBL148 & 38239 & 362 & & \\
\hline HEMBL1457875 & 88239 & 862 & 5.5017 & \\
\hline HEMBL1544692 & 88239 & 362 & 5.472 & \\
\hline AEMBL15 & 882 & & 5. & \\
\hline IEMBL152 & 38239 & 362 & & \\
\hline AEMBL146 & 88239 & 362 & & \\
\hline AEMBL1365379 & 88239 & 362 & 5.5718 & \\
\hline HEMBL135 & 88239 & 362 & & \\
\hline IEMBL13 & 39 & 62 & 97 & \\
\hline L13 & 239 & 62 & & \\
\hline EMBL14: & 239 & 362 & & \\
\hline HEMBL1581 & 88239 & 862 & & \\
\hline HEMBL 15 & 39 & & & \\
\hline AEMBL14 & 39 & 62 & & \\
\hline L14 & & & & \\
\hline 116 & 39 & 62 & & \\
\hline L13: & 88239 & & & \\
\hline AEMBL13 & 39 & & & \\
\hline JEMBL15 & 39 & 63 & 94 & $5 T$ \\
\hline L13 & 39 & & & RN \\
\hline L16 & 39 & 62 & 5.61 & RN \\
\hline JEMBL14 & & & & RN \\
\hline HEMBL1484031 & & & & $\mathrm{R}$ \\
\hline HEMBL15 & 39 & 62 & 96 & $\mathrm{RN}$ \\
\hline L15 & 39 & 62 & & RN \\
\hline 15 & & & & RN \\
\hline HEMBL 238002 & 88239 & & 5.5242 & ST \\
\hline HEMBL150 & & & & RN \\
\hline HEMBL15 & & 363 & & RN \\
\hline 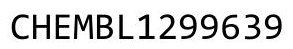 & & & & SI \\
\hline-13 & 9 & & & RN \\
\hline HEMBL1373524 & 88239 & 362 & 5.4242 & RN \\
\hline IEMBL14 & 39 & & & RN \\
\hline HEIMISL 13 & & & & \\
\hline HEMBL14 & & & & \\
\hline HEMBL $15 €$ & 39 & 361 & 5.5306 & RN \\
\hline LL14045 & 88239 & 4.4862 & 5.4671 & \\
\hline CHEMBL1463775 & 688239 & 6.1862 & 5.5986 & \\
\hline
\end{tabular}


Supplemental Table S2.txt

\begin{tabular}{|c|c|c|c|c|}
\hline CHEMBL1527881 & 688239 & 5.2362 & 5.3889 & TST \\
\hline CHEMBL1558130 & 688239 & 4.5362 & 5.5667 & TST \\
\hline CHEMBL1607557 & 688239 & 4.4862 & 5.593 & TRN \\
\hline CHEMBL1313417 & 688239 & 5.5862 & 5.4354 & TST \\
\hline CHEMBL1299702 & 688239 & 5.7862 & 5.5078 & TRN \\
\hline CHEMBL3190047 & 688239 & 5.1862 & 5.4874 & TRN \\
\hline CHEMBL1450853 & 688239 & 5.9362 & 5.4387 & TST \\
\hline CHEMBL1587174 & 688239 & 5.7862 & 5.4853 & TRN \\
\hline CHEMBL1482521 & 688239 & 6.3863 & 5.3448 & TRN \\
\hline CHEMBL1589643 & 688239 & 5.5362 & 5.6412 & TRN \\
\hline CHEMBL1464149 & 688239 & 4.8862 & 5.5285 & TRN \\
\hline CHEMBL1570650 & 688239 & 4.6862 & 5.4386 & TRN \\
\hline CHEMBL1413433 & 688239 & 5.1862 & 5.5465 & TRN \\
\hline CHEMBL539507 & 688239 & 4.5362 & 5.3382 & TRN \\
\hline CHEMBL1592537 & 688239 & 4.5362 & 5.5943 & TRN \\
\hline CHEMBL1431347 & 688239 & 5.1862 & 5.4168 & TRN \\
\hline CHEMBL1604101 & 688239 & 8.1367 & 5.5589 & TST \\
\hline CHEMBL1457388 & 688239 & 4.6362 & 5.4814 & TST \\
\hline CHEMBL1455103 & 688239 & 5.3862 & 5.3962 & TST \\
\hline CHEMBL1432842 & 688239 & 5.0862 & 5.4966 & TST \\
\hline CHEMBL1442280 & 688239 & 4.5362 & 5.4171 & TRN \\
\hline CHEMBL1452897 & 688239 & 4.9362 & 5.3364 & TRN \\
\hline CHEMBL1480286 & 688239 & 5.6362 & 5.3852 & TRN \\
\hline CHEMBL583558 & 688239 & 5.1362 & 5.3419 & TRN \\
\hline CHEMBL1359601 & 688239 & 6.0362 & 5.5393 & TRN \\
\hline CHEMBL1518785 & 688239 & 6.0362 & 5.6754 & TRN \\
\hline CHEMBL1392557 & 688239 & 5.2362 & 5.49700 & 3000000001 \\
\hline CHEMBL1312842 & 688239 & 5.4362 & 5.3266 & TRN \\
\hline CHEMBL46535 & 688239 & 4.5362 & 5.4737 & TRN \\
\hline CHEMBL1992631 & 688239 & 6.1362 & 5.3392 & TRN \\
\hline CHEMBL1502771 & 688239 & 4.9362 & 5.46 & TRN \\
\hline CHEMBL1561047 & 688239 & 5.4362 & 5.5317 & TRN \\
\hline CHEMBL1348555 & 688239 & 4.6862 & 5.3708 & TRN \\
\hline CHEMBL1573006 & 688239 & 5.4362 & 5.5686 & TST \\
\hline CHEMBL1415476 & 688239 & 4.6862 & 5.5201 & TRN \\
\hline CHEMBL1516861 & 688239 & 4.5362 & 5.4836 & TRN \\
\hline CHEMBL1565606 & 688239 & 4.7362 & 5.5495 & TST \\
\hline CHEMBL1449111 & 688239 & 5.3362 & 5.569 & TRN \\
\hline CHEMBL1331861 & 688239 & 6.8861 & 5.4714 & TRN \\
\hline CHEMBL1603483 & 688239 & 5.5862 & 5.4612 & TST \\
\hline CHEMBL1452948 & 688239 & 5.6362 & 5.4727 & TRN \\
\hline CHEMBL1556228 & 688239 & 5.8362 & 5.4612 & TRN \\
\hline CHEMBL1566758 & 688239 & 4.4862 & 5.4123 & TRN \\
\hline CHEMBL1333312 & 688239 & 4.5362 & 5.2673 & TST \\
\hline CHEMBL1459934 & 688239 & 6.1362 & 5.3859 & TRN \\
\hline CHEMBL1989847 & 688239 & 4.7362 & 5.4411 & TST \\
\hline CHEMBL1483477 & 688239 & 5.1862 & 5.4806 & TRN \\
\hline CHEMBL1500387 & 688239 & 4.5362 & 5.5196 & TRN \\
\hline
\end{tabular}


Supplemental Table S2.txt

\begin{tabular}{|c|c|c|c|c|}
\hline CHEMBL1470921 & 688239 & 5.4362 & 5.5487 & TRN \\
\hline CHEMBL1596909 & 688239 & 8.3872 & 5.4229 & TRN \\
\hline CHEMBL1317254 & 688239 & 5.5362 & 5.5188 & TRN \\
\hline CHEMBL1438880 & 688239 & 4.5362 & 5.4729 & TST \\
\hline CHEMBL1459612 & 688239 & 4.5862 & 5.5036 & TST \\
\hline CHEMBL1544063 & 688239 & 5.3362 & 5.4668 & TRN \\
\hline CHEMBL1574560 & 688239 & 4.7862 & 5.4589 & TRN \\
\hline CHEMBL1475837 & 688239 & 4.4862 & 5.5954 & TST \\
\hline CHEMBL1301124 & 688239 & 6.2862 & 5.5221 & TRN \\
\hline CHEMBL1543123 & 688239 & 4.5362 & 5.4397 & TRN \\
\hline CHEMBL 3214482 & 688239 & 6.6362 & 5.4086 & TST \\
\hline CHEMBL1462923 & 688239 & 6.1862 & 5.4773 & TRN \\
\hline CHEMBL1607463 & 688239 & 5.9362 & 5.4775 & TST \\
\hline CHEMBL1415916 & 688239 & 4.5362 & 5.4546 & TRN \\
\hline CHEMBL1325837 & 688239 & 4.5362 & 5.3452 & TST \\
\hline CHEMBL1496548 & 688239 & 4.9862 & 5.393 & TRN \\
\hline CHEMBL1370981 & 688239 & 6.9863 & 5.445 & TRN \\
\hline CHEMBL1520932 & 688239 & 4.6362 & 5.3837 & TRN \\
\hline CHEMBL1347779 & 688239 & 4.7362 & 5.4717 & TRN \\
\hline CHEMBL 227423 & 688239 & 4.5362 & 5.2745 & TRN \\
\hline CHEMBL1431808 & 688239 & 4.5362 & 5.5801 & TST \\
\hline CHEMBL1562733 & 688239 & 6.8861 & 5.5592 & TRN \\
\hline CHEMBL3212691 & 688239 & 4.8862 & 5.3578 & TRN \\
\hline CHEMBL1386868 & 688239 & 4.7362 & 5.4017 & TRN \\
\hline CHEMBL 25048 & 688239 & 4.8362 & 5.4784 & TRN \\
\hline CHEMBL1318742 & 688239 & 6.8362 & 5.6505 & TRN \\
\hline CHEMBL1482957 & 688239 & 6.4862 & $5.36100 e$ & 000000001 \\
\hline CHEMBL1377010 & 688239 & 6.9863 & 5.5288 & TRN \\
\hline CHEMBL1430120 & 688239 & 5.4362 & 5.5084 & TRN \\
\hline CHEMBL1351901 & 688239 & 4.5362 & 5.4442 & TRN \\
\hline CHEMBL1603835 & 688239 & 5.9362 & 5.5434 & TRN \\
\hline CHEMBL1597603 & 688239 & 6.0362 & 5.4656 & TST \\
\hline CHEMBL1471078 & 688239 & 5.7362 & 5.5685 & TRN \\
\hline CHEMBL1477214 & 688239 & 5.6862 & 5.4414 & TRN \\
\hline CHEMBL1518765 & 688239 & 4.5362 & 5.4357 & TRN \\
\hline CHEMBL1360481 & 688239 & 5.2362 & 5.5927 & TST \\
\hline CHEMBL472437 & 688239 & 4.7862 & 5.4159 & TST \\
\hline CHEMBL1478922 & 688239 & 6.9363 & 5.5079 & TST \\
\hline CHEMBL1376147 & 688239 & 4.5362 & 5.4973 & TRN \\
\hline CHEMBL1539085 & 688239 & 5.5362 & 5.5135 & TRN \\
\hline CHEMBL1366285 & 688239 & 4.8862 & 5.6138 & TRN \\
\hline CHEMBL1589805 & 688239 & 6.5862 & 5.6924 & TRN \\
\hline CHEMBL1374124 & 688239 & 6.2362 & 5.5557 & TRN \\
\hline CHEMBL1536217 & 688239 & 5.1862 & 5.4386 & TRN \\
\hline CHEMBL1531315 & 688239 & 5.1862 & 5.5607 & TRN \\
\hline CHEMBL1562877 & 688239 & 6.1362 & 5.4812 & TRN \\
\hline CHEMBL1451844 & 688239 & 4.6362 & 5.47 & TRN \\
\hline CHEMBL1504837 & 688239 & 4.5362 & 5.5346 & TST \\
\hline
\end{tabular}


Supplemental Table S2.txt

\begin{tabular}{|c|c|c|c|c|}
\hline CHEMBL1330643 & 688239 & 6.1362 & 5.4084 & TRN \\
\hline CHEMBL1375210 & 688239 & 4.5862 & 5.5122 & TRN \\
\hline CHEMBL1387705 & 688239 & 5.6362 & 5.5087 & TRN \\
\hline CHEMBL1590661 & 688239 & 5.1862 & 5.4437 & TST \\
\hline CHEMBL1321119 & 688239 & 6.8861 & 5.4908 & TST \\
\hline CHEMBL1354995 & 688239 & 7.1864 & 5.4733 & TST \\
\hline CHEMBL1335571 & 688239 & 4.8862 & 5.4212 & TST \\
\hline CHEMBL1355757 & 688239 & 5.2862 & 5.4536 & TRN \\
\hline CHEMBL1338432 & 688239 & 4.9862 & 5.552006 & 20000000005 \\
\hline CHEMBL1501036 & 688239 & 5.1862 & 5.5626 & TRN \\
\hline CHEMBL1562600 & 688239 & 4.5362 & 5.6276 & TRN \\
\hline CHEMBL1537506 & 688239 & 5.4362 & 5.3813 & TRN \\
\hline CHEMBL1408326 & 688239 & 5.4362 & 5.4964 & TRN \\
\hline CHEMBL1416887 & 688239 & 5.7362 & 5.5333 & TRN \\
\hline CHEMBL1341015 & 688239 & 5.9862 & 5.4528 & TRN \\
\hline CHEMBL1498334 & 688239 & 8.3872 & 5.5312 & TRN \\
\hline CHEMBL1582165 & 688239 & 4.7862 & 5.5477 & TRN \\
\hline CHEMBL1400782 & 688239 & 4.5362 & 5.5826 & TRN \\
\hline CHEMBL1579154 & 688239 & 4.5362 & 5.6247 & TRN \\
\hline CHEMBL1311880 & 688239 & 6.8861 & 5.3317 & TRN \\
\hline CHEMBL1996133 & 688239 & 4.5362 & 5.4713 & TRN \\
\hline CHEMBL1347585 & 688239 & 4.6362 & 5.5022 & TRN \\
\hline CHEMBL1440523 & 688239 & 5.1362 & 5.5066 & TRN \\
\hline CHEMBL1440105 & 688239 & 4.7362 & 5.4124 & TRN \\
\hline CHEMBL1370875 & 688239 & 5.9362 & 5.3858 & TST \\
\hline CHEMBL1390343 & 688239 & 5.3862 & 5.5501 & TRN \\
\hline CHEMBL565486 & 688239 & 6.4362 & 5.4959 & TST \\
\hline CHEMBL1432696 & 688239 & 5.0362 & 5.3175 & TRN \\
\hline CHEMBL1313208 & 688239 & 6.2362 & 5.5965 & TRN \\
\hline CHEMBL1356266 & 688239 & 6.8861 & 5.4815 & TRN \\
\hline CHEMBL1539844 & 688239 & 5.5862 & 5.5481 & TRN \\
\hline CHEMBL1307608 & 688239 & 4.7862 & 5.6364 & TRN \\
\hline CHEMBL1504171 & 688239 & 4.9362 & 5.4231 & TST \\
\hline CHEMBL1491446 & 688239 & 4.8862 & 5.3937 & TRN \\
\hline CHEMBL1503152 & 688239 & 5.1862 & 5.3535 & TRN \\
\hline CHEMBL1526428 & 688239 & 5.4362 & 5.4597 & TST \\
\hline CHEMBL1572923 & 688239 & 6.1862 & 5.4638 & TRN \\
\hline CHEMBL1535833 & 688239 & 5.0862 & 5.5435 & TRN \\
\hline CHEMBL1573187 & 688239 & 7.1864 & 5.4976 & TRN \\
\hline CHEMBL1362373 & 688239 & 5.9362 & 5.5332 & TRN \\
\hline CHEMBL153505 & 688239 & 4.6362 & 5.3866 & TRN \\
\hline CHEMBL 3213150 & 688239 & 6.1862 & 5.4686 & TRN \\
\hline CHEMBL1475958 & 688239 & 4.9862 & 5.4459 & TRN \\
\hline CHEMBL1372268 & 688239 & 8.3372 & 5.4532 & TRN \\
\hline CHEMBL1603001 & 688239 & 5.3862 & 5.5169 & TRN \\
\hline CHEMBL1578407 & 688239 & 6.1362 & 5.598 & TST \\
\hline CHEMBL1525654 & 688239 & 5.8862 & 5.4247 & TRN \\
\hline CHEMBL1548545 & 688239 & 6.1362 & 5.3811 & TST \\
\hline
\end{tabular}


Supplemental Table S2.txt

\begin{tabular}{|c|c|c|c|c|c|}
\hline CHEMBL1376384 & 688239 & 4.7862 & 5.5133 & TST & \\
\hline CHEMBL1565590 & 688239 & 5.1862 & 5.4526 & TRN & \\
\hline CHEMBL1325442 & 688239 & 6.2362 & 5.4811 & TST & \\
\hline CHEMBL1341505 & 688239 & 5.3362 & 5.4295 & TST & \\
\hline CHEMBL1375207 & 688239 & 5.7862 & 5.5723 & TRN & \\
\hline CHEMBL1368242 & 688239 & 5.9862 & 5.6382 & TRN & \\
\hline CHEMBL1369039 & 688239 & 6.1362 & 5.5124 & TRN & \\
\hline CHEMBL1520857 & 688239 & 4.5362 & 5.5024 & TST & \\
\hline CHEMBL1487706 & 688239 & 4.5362 & 5.4655 & TST & \\
\hline CHEMBL1485593 & 688239 & 5.8362 & 5.371 & TRN & \\
\hline CHEMBL1331840 & 688239 & 5.3862 & 5.6146 & TST & \\
\hline CHEMBL1543510 & 688239 & 4.8362 & 5.4981 & TST & \\
\hline CHEMBL1342800 & 688239 & 4.5362 & 5.4536 & TRN & \\
\hline CHEMBL1472828 & 688239 & 5.3862 & 5.561 & TRN & \\
\hline CHEMBL1526649 & 688239 & 6.1362 & 5.4263 & TRN & \\
\hline CHEMBL1366252 & 688239 & 4.8362 & 5.475 & TST & \\
\hline CHEMBL1572177 & 688239 & 8.3372 & 5.5275 & TRN & \\
\hline CHEMBL1418923 & 688239 & 4.5362 & 5.5624 & TRN & \\
\hline CHEMBL1408049 & 688239 & 4.5362 & 5.4964 & TRN & \\
\hline CHEMBL1466857 & 688239 & 4.5362 & 5.4816 & TRN & \\
\hline CHEMBL1334745 & 688239 & 8.3372 & 5.57799 & 9999999999 & TRN \\
\hline CHEMBL1322272 & 688239 & 5.1362 & 5.5296 & TRN & \\
\hline CHEMBL1424814 & 688239 & 4.8362 & 5.6477 & TRN & \\
\hline CHEMBL1408863 & 688239 & 4.8862 & 5.5936 & TRN & \\
\hline CHEMBL1539541 & 688239 & 5.2362 & 5.4771 & TRN & \\
\hline CHEMBL1544666 & 688239 & 5.1362 & 5.4934 & TRN & \\
\hline CHEMBL1600588 & 688239 & 5.8362 & 5.6379 & TRN & \\
\hline CHEMBL1521189 & 688239 & 4.5862 & 5.4407 & TRN & \\
\hline CHEMBL1503681 & 688239 & 6.5862 & 5.4733 & TRN & \\
\hline CHEMBL1328701 & 688239 & 5.1862 & 5.52 & TRN & \\
\hline CHEMBL1582718 & 688239 & 7.2865 & 5.5253 & TRN & \\
\hline CHEMBL1568974 & 688239 & 6.0862 & 5.5823 & TRN & \\
\hline CHEMBL1300002 & 688239 & 4.7862 & 5.4793 & TRN & \\
\hline CHEMBL1414118 & 688239 & 5.0862 & 5.5434 & TRN & \\
\hline CHEMBL1409291 & 688239 & 5.5362 & 5.398 & TRN & \\
\hline CHEMBL1599823 & 688239 & 8.3372 & 5.4603 & TST & \\
\hline CHEMBL1358768 & 688239 & 4.5362 & 5.4591 & TST & \\
\hline CHEMBL1382274 & 688239 & 4.7362 & 5.5896 & TRN & \\
\hline CHEMBL1321621 & 688239 & 6.8861 & 5.473 & TRN & \\
\hline CHEMBL1496130 & 688239 & 4.5362 & 5.6116 & TRN & \\
\hline CHEMBL1495080 & 688239 & 5.1862 & 5.5458 & TRN & \\
\hline CHEMBL1481080 & 688239 & 6.1362 & 5.555 & TST & \\
\hline CHEMBL1491927 & 688239 & 4.5362 & 5.4658 & TRN & \\
\hline CHEMBL1574643 & 688239 & 5.0862 & 5.5428 & TRN & \\
\hline CHEMBL1568531 & 688239 & 5.8362 & 5.4335 & TRN & \\
\hline CHEMBL1426373 & 688239 & 7.0862 & 5.481 & TRN & \\
\hline CHEMBL1419659 & 688239 & 4.5362 & 5.3537 & TRN & \\
\hline CHEMBL1409552 & 688239 & 4.6862 & 5.4929 & TRN & \\
\hline
\end{tabular}


Supplemental Table S2.txt

\begin{tabular}{|c|c|c|c|c|c|}
\hline CHEMBL1413022 & 688239 & 5.6862 & 5.4401 & TRN & \\
\hline CHEMBL1388216 & 688239 & 5.6362 & 5.6311 & TRN & \\
\hline CHEMBL1420038 & 688239 & 5.9362 & 5.476 & TRN & \\
\hline CHEMBL1461080 & 688239 & 4.5362 & 5.4136 & TRN & \\
\hline CHEMBL1569682 & 688239 & 7.0862 & 5.6174 & TRN & \\
\hline CHEMBL1527565 & 688239 & 4.7362 & 5.4375 & TST & \\
\hline CHEMBL1612599 & 688239 & 4.5362 & 5.2442 & TRN & \\
\hline CHEMBL1399418 & 688239 & 4.5362 & 5.6893 & TST & \\
\hline CHEMBL1539775 & 688239 & 5.7862 & 5.4254 & TRN & \\
\hline CHEMBL1496647 & 688239 & 5.7362 & 5.4775 & TRN & \\
\hline CHEMBL1488050 & 688239 & 7.6861 & 5.4152 & TST & \\
\hline CHEMBL1553115 & 688239 & 5.3362 & 5.4803 & TRN & \\
\hline CHEMBL1406647 & 688239 & 5.6862 & 5.5621 & TST & \\
\hline CHEMBL1436604 & 688239 & 5.3862 & 5.5736 & TRN & \\
\hline CHEMBL1347888 & 688239 & 4.5362 & 5.268 & TRN & \\
\hline CHEMBL1374315 & 688239 & 8.3372 & 5.3056 & TRN & \\
\hline CHEMBL1339835 & 688239 & 7.0362 & 5.5428 & TST & \\
\hline CHEMBL1458339 & 688239 & 5.1862 & 5.3162 & TST & \\
\hline CHEMBL1528881 & 688239 & 8.3372 & 5.5323 & TRN & \\
\hline CHEMBL1350194 & 688239 & 4.7862 & 5.5139 & TRN & \\
\hline CHEMBL1365885 & 688239 & 4.5362 & 5.3634 & TRN & \\
\hline CHEMBL1373969 & 688239 & 4.7362 & 5.3636 & TRN & \\
\hline CHEMBL1397758 & 688239 & 5.3862 & 5.4228 & TRN & \\
\hline CHEMBL1374229 & 688239 & 4.5862 & 5.4712 & TRN & \\
\hline CHEMBL3211792 & 688239 & 5.4362 & 5.5357 & TST & \\
\hline CHEMBL1579813 & 688239 & 5.3862 & 5.5354 & TRN & \\
\hline CHEMBL1518791 & 688239 & 4.6362 & 5.564 & TST & \\
\hline CHEMBL1505676 & 688239 & 4.5362 & 5.5186 & TRN & \\
\hline CHEMBL1411699 & 688239 & 6.2362 & 5.5567 & TRN & \\
\hline CHEMBL1977524 & 688239 & 4.7362 & 5.55 & TST & \\
\hline CHEMBL1522259 & 688239 & 6.3863 & 5.4605 & TRN & \\
\hline CHEMBL1386172 & 688239 & 6.0362 & 5.3897 & TRN & \\
\hline CHEMBL1516868 & 688239 & 6.1362 & 5.4634 & TST & \\
\hline CHEMBL1344694 & 688239 & 5.0362 & 5.5267 & TRN & \\
\hline CHEMBL1453513 & 688239 & 4.5362 & 5.4865 & TRN & \\
\hline CHEMBL1515538 & 688239 & 4.8362 & 5.4727 & TRN & \\
\hline CHEMBL1356252 & 688239 & 8.28399 & 99999999 & 9 & 5.4833 \\
\hline CHEMBL3211058 & 688239 & 5.1362 & 5.4742 & TRN & \\
\hline CHEMBL1546457 & 688239 & 6.0862 & 5.4904 & TRN & \\
\hline CHEMBL1483963 & 688239 & 4.5362 & 5.5695 & TRN & \\
\hline CHEMBL1517715 & 688239 & 4.6862 & 5.4477 & TRN & \\
\hline CHEMBL1425007 & 688239 & 4.4862 & 5.4454 & TST & \\
\hline CHEMBL1460299 & 688239 & 6.4362 & 5.5699 & TRN & \\
\hline CHEMBL1337570 & 688239 & 4.5362 & 5.4881 & TRN & \\
\hline CHEMBL3213067 & 688239 & 6.1862 & 5.4837 & TRN & \\
\hline CHEMBL1510288 & 688239 & 4.5862 & 5.5111 & TRN & \\
\hline CHEMBL1317541 & 688239 & 5.7862 & 5.5131 & TRN & \\
\hline CHEMBL1364383 & 688239 & 4.6862 & 5.4436 & TRN & \\
\hline
\end{tabular}


Supplemental Table S2.txt

\begin{tabular}{|c|c|c|c|c|}
\hline CHEMBL1552012 & 688239 & 4.6862 & 5.4506 & TST \\
\hline CHEMBL1330039 & 688239 & 6.7862 & 5.6029 & TST \\
\hline CHEMBL 3190152 & 688239 & 4.6862 & 5.3854 & TST \\
\hline CHEMBL1555092 & 688239 & 5.6362 & 5.4963 & TRN \\
\hline CHEMBL1465542 & 688239 & 4.8862 & 5.5675 & TRN \\
\hline CHEMBL1438668 & 688239 & 5.3862 & 5.4389 & TST \\
\hline CHEMBL1325657 & 688239 & 6.0862 & 5.3503 & TRN \\
\hline CHEMBL1401610 & 688239 & 4.8362 & 5.4193 & TRN \\
\hline CHEMBL1598805 & 688239 & 4.6862 & 5.4514 & TRN \\
\hline CHEMBL1381166 & 688239 & 5.0362 & 5.3444 & TRN \\
\hline CHEMBL1582023 & 688239 & 5.7862 & 5.4032 & TST \\
\hline CHEMBL1328466 & 688239 & 6.0362 & 5.4322 & TRN \\
\hline CHEMBL1565167 & 688239 & 5.3862 & 5.5468 & TRN \\
\hline CHEMBL1409705 & 688239 & 6.9363 & 5.3591 & TST \\
\hline CHEMBL1351432 & 688239 & 6.2362 & 5.5401 & TRN \\
\hline CHEMBL1562694 & 688239 & 4.7362 & 5.5363 & TST \\
\hline CHEMBL1404143 & 688239 & 6.4862 & 5.4683 & TRN \\
\hline CHEMBL1308282 & 688239 & 4.7362 & 5.6296 & TRN \\
\hline CHEMBL1520190 & 688239 & 6.9363 & 5.524 & TRN \\
\hline CHEMBL1397210 & 688239 & 5.0362 & 5.6725 & TRN \\
\hline CHEMBL 3190663 & 688239 & 6.0862 & 5.4297 & TRN \\
\hline CHEMBL3198468 & 688239 & 5.1862 & 5.4703 & TST \\
\hline CHEMBL1414999 & 688239 & 5.7862 & 5.5469 & TST \\
\hline CHEMBL1546995 & 688239 & 4.5362 & 5.4993 & TRN \\
\hline CHEMBL 3199034 & 688239 & 5.1862 & \multicolumn{2}{|c|}{5.292000000000001} \\
\hline CHEMBL1383329 & 688239 & 6.7361 & \multicolumn{2}{|c|}{5.412999999999999} \\
\hline CHEMBL1463680 & 688239 & 7.7352 & 5.4972 & TRN \\
\hline CHEMBL1366220 & 688239 & 4.5362 & 5.5521 & TRN \\
\hline CHEMBL1452468 & 688239 & 5.1862 & 5.4092 & TRN \\
\hline CHEMBL1327852 & 688239 & 4.4862 & 5.4404 & TRN \\
\hline CHEMBL1443441 & 688239 & 4.6362 & 5.3812 & TRN \\
\hline CHEMBL1588849 & 688239 & 4.7862 & 5.3284 & TRN \\
\hline CHEMBL1578653 & 688239 & 7.4868 & \multicolumn{2}{|c|}{5.4639999999999995} \\
\hline CHEMBL1403058 & 688239 & 4.7362 & 5.5982 & TRN \\
\hline CHEMBL1484264 & 688239 & 4.9862 & 5.4983 & TRN \\
\hline CHEMBL1586197 & 688239 & 5.0862 & 5.5593 & TRN \\
\hline CHEMBL1542145 & 688239 & 5.2862 & 5.5179 & TRN \\
\hline CHEMBL1489272 & 688239 & 4.8862 & 5.5206 & TRN \\
\hline CHEMBL1396004 & 688239 & 5.7862 & 5.4427 & TRN \\
\hline CHEMBL1457306 & 688239 & 5.3362 & 5.4499 & TST \\
\hline CHEMBL1585311 & 688239 & 6.8861 & 5.5616 & TRN \\
\hline CHEMBL1472985 & 688239 & 4.6862 & 5.3441 & TRN \\
\hline CHEMBL1308374 & 688239 & 5.7362 & 5.4852 & TST \\
\hline CHEMBL1367298 & 688239 & 4.5362 & 5.681 & TST \\
\hline CHEMBL1450897 & 688239 & 4.5362 & 5.3808 & TST \\
\hline CHEMBL 259841 & 688239 & 5.3862 & 5.5559 & TRN \\
\hline CHEMBL1318720 & 688239 & 5.1362 & \multicolumn{2}{|c|}{5.507000000000001} \\
\hline CHEMBL1391563 & 688239 & 6.1362 & 5.2952 & TST \\
\hline
\end{tabular}


Supplemental Table S2.txt

\begin{tabular}{|c|c|c|c|c|}
\hline CHEMBL1307993 & 688239 & 4.5862 & 5.5069 & TST \\
\hline CHEMBL1532031 & 688239 & 6.9363 & 5.4168 & TST \\
\hline CHEMBL1376807 & 688239 & 4.5362 & 5.5969 & TRN \\
\hline CHEMBL1564865 & 688239 & 5.7362 & 5.6888 & TRN \\
\hline CHEMBL1596347 & 688239 & 5.3362 & 5.3638 & TST \\
\hline CHEMBL1545444 & 688239 & 5.3862 & 5.5201 & TRN \\
\hline CHEMBL1600377 & 688239 & 4.5362 & \multicolumn{2}{|c|}{5.507000000000001} \\
\hline CHEMBL3199209 & 688239 & 4.5362 & 5.5771 & TST \\
\hline CHEMBL1338788 & 688239 & 6.1862 & 5.5145 & TST \\
\hline CHEMBL1607148 & 688239 & 5.3362 & 5.522 & TST \\
\hline CHEMBL1431697 & 688239 & 5.7862 & 5.5003 & TST \\
\hline CHEMBL1597869 & 688239 & 8.3872 & 5.535 & TRN \\
\hline CHEMBL1382436 & 688239 & 6.0362 & 5.5492 & TRN \\
\hline CHEMBL1567629 & 688239 & 5.5362 & 5.4584 & TRN \\
\hline CHEMBL1434451 & 688239 & 4.4862 & 5.5477 & TST \\
\hline CHEMBL 3195240 & 688239 & 4.8862 & 5.3335 & TST \\
\hline CHEMBL1389948 & 688239 & 4.5362 & 5.481 & TRN \\
\hline CHEMBL1358293 & 688239 & 4.7362 & 5.5242 & TST \\
\hline CHEMBL1370837 & 688239 & 6.7862 & 5.7069 & TRN \\
\hline CHEMBL1448267 & 688239 & 5.3362 & 5.3455 & TRN \\
\hline CHEMBL1455957 & 688239 & 4.5362 & 5.4949 & TST \\
\hline CHEMBL1399879 & 688239 & 4.6862 & 5.5575 & TRN \\
\hline CHEMBL1378937 & 688239 & 4.5862 & 5.4046 & TRN \\
\hline CHEMBL1587982 & 688239 & 4.6862 & 5.6226 & TST \\
\hline CHEMBL1382581 & 688239 & 5.9862 & 5.6145 & TST \\
\hline CHEMBL1349091 & 688239 & 6.2362 & 5.4173 & TRN \\
\hline CHEMBL1524949 & 688239 & 6.5862 & 5.4801 & TST \\
\hline CHEMBL 3209415 & 688239 & 5.4362 & 5.4801 & TRN \\
\hline CHEMBL1390890 & 688239 & 4.5362 & 5.3905 & TRN \\
\hline CHEMBL1304216 & 688239 & 4.5362 & 5.5458 & TRN \\
\hline CHEMBL1379657 & 688239 & 5.5862 & 5.6351 & TRN \\
\hline CHEMBL1393735 & 688239 & 6.4362 & 5.4325 & TST \\
\hline CHEMBL1340146 & 688239 & 4.8862 & 5.5303 & TRN \\
\hline CHEMBL1565450 & 688239 & 5.8362 & 5.432 & TST \\
\hline CHEMBL1470817 & 688239 & 4.5362 & 5.5468 & TRN \\
\hline CHEMBL3210635 & 688239 & 6.5363 & 5.3943 & TRN \\
\hline CHEMBL1409673 & 688239 & 6.3863 & 5.5235 & TST \\
\hline CHEMBL1399853 & 688239 & 6.9363 & 5.5109 & TRN \\
\hline CHEMBL1319786 & 688239 & 4.5362 & 5.4744 & TRN \\
\hline CHEMBL1377247 & 688239 & 6.1862 & 5.4622 & TRN \\
\hline CHEMBL1578410 & 688239 & 6.7862 & 5.4169 & TST \\
\hline CHEMBL1372131 & 688239 & 4.4862 & 5.5956 & TST \\
\hline CHEMBL1427693 & 688239 & 4.7362 & 5.5911 & TRN \\
\hline CHEMBL1301251 & 688239 & 4.9362 & 5.425 & TRN \\
\hline CHEMBL1442680 & 688239 & 6.1862 & 5.5822 & TRN \\
\hline CHEMBL1346031 & 688239 & 5.5862 & 5.5067 & TRN \\
\hline CHEMBL1324105 & 688239 & 5.3862 & 5.5893 & TST \\
\hline CHEMBL1357535 & 688239 & 4.7362 & 5.4696 & TST \\
\hline
\end{tabular}


Supplemental Table S2.txt

\begin{tabular}{|c|c|c|c|c|c|}
\hline CHEMBL1319316 & 688239 & 4.8862 & 5.4094 & TST & \\
\hline CHEMBL1400170 & 688239 & 4.6362 & 5.49 & TRN & \\
\hline CHEMBL1548745 & 688239 & 4.5362 & 5.3975 & TRN & \\
\hline CHEMBL1411040 & 688239 & 4.5362 & 5.5919 & TRN & \\
\hline CHEMBL1428144 & 688239 & 7.6861 & 5.4553 & TST & \\
\hline CHEMBL1306954 & 688239 & 4.6862 & 5.4704 & TRN & \\
\hline CHEMBL1578774 & 688239 & 4.8362 & 5.4599 & TRN & \\
\hline CHEMBL1599257 & 688239 & 4.4862 & 5.3748 & TRN & \\
\hline CHEMBL1536681 & 688239 & 5.8862 & 5.5037 & TST & \\
\hline CHEMBL1366288 & 688239 & 4.7862 & 5.5764 & TRN & \\
\hline CHEMBL1462006 & 688239 & 5.0862 & 5.4236 & TST & \\
\hline CHEMBL1469106 & 688239 & 4.9862 & 5.4985 & TRN & \\
\hline CHEMBL1334588 & 688239 & 5.2362 & 5.4759 & TRN & \\
\hline CHEMBL 259355 & 688239 & 5.7362 & 5.4832 & TRN & \\
\hline CHEMBL1438093 & 688239 & 5.1362 & 5.4614 & TRN & \\
\hline CHEMBL1429247 & 688239 & 4.5362 & 5.4472 & TRN & \\
\hline CHEMBL1599554 & 688239 & 4.5362 & 5.41299 & 9999999999 & TRN \\
\hline CHEMBL1312420 & 688239 & 5.6862 & 5.4976 & TRN & \\
\hline CHEMBL1538493 & 688239 & 4.7862 & 5.5042 & TRN & \\
\hline CHEMBL1565332 & 688239 & 5.4862 & 5.4528 & TST & \\
\hline CHEMBL1610948 & 688239 & 6.1362 & 5.5862 & TRN & \\
\hline CHEMBL1400710 & 688239 & 5.5862 & 5.6797 & TRN & \\
\hline CHEMBL398245 & 688239 & 6.8861 & 5.5491 & TRN & \\
\hline CHEMBL1442698 & 688239 & 5.4362 & 5.4299 & TRN & \\
\hline CHEMBL1351749 & 688239 & 5.6362 & 5.4372 & TST & \\
\hline CHEMBL1368187 & 688239 & 4.6862 & 5.601 & TRN & \\
\hline CHEMBL1541843 & 688239 & 5.8862 & 5.4054 & TRN & \\
\hline CHEMBL1354108 & 688239 & 4.6862 & 5.4143 & TST & \\
\hline CHEMBL1539624 & 688239 & 4.5362 & 5.4475 & TRN & \\
\hline CHEMBL1555406 & 688239 & 6.2862 & 5.5059 & TST & \\
\hline CHEMBL1353541 & 688239 & 5.9362 & 5.4471 & TRN & \\
\hline CHEMBL3192749 & 688239 & 5.8362 & 5.3854 & TST & \\
\hline CHEMBL1362042 & 688239 & 5.9862 & 5.4276 & TRN & \\
\hline CHEMBL1537028 & 688239 & 4.5362 & 5.5728 & TRN & \\
\hline CHEMBL1570598 & 688239 & 6.9363 & 5.5211 & TST & \\
\hline CHEMBL1469127 & 688239 & 6.2362 & 5.5159 & TRN & \\
\hline CHEMBL1323721 & 688239 & 8.1367 & 5.4525 & TRN & \\
\hline CHEMBL1447158 & 688239 & 4.8862 & 5.6126 & TRN & \\
\hline CHEMBL1349487 & 688239 & 5.4862 & 5.6092 & TRN & \\
\hline CHEMBL1544307 & 688239 & 4.5362 & 5.5091 & TST & \\
\hline CHEMBL1320344 & 688239 & 8.2366 & 5.57100 & 0000000001 & TST \\
\hline CHEMBL1470307 & 688239 & 8.1871 & 5.3989 & TRN & \\
\hline CHEMBL1599031 & 688239 & 4.5362 & 5.4786 & TRN & \\
\hline CHEMBL1595678 & 688239 & 4.7862 & 5.5404 & TST & \\
\hline CHEMBL1302317 & 688239 & 5.5862 & 5.4207 & TRN & \\
\hline CHEMBL1302935 & 688239 & 5.1362 & 5.5097 & TST & \\
\hline CHEMBL1300156 & 688239 & 5.1862 & 5.4955 & TST & \\
\hline CHEMBL1565306 & 688239 & 5.1862 & 5.359 & TRN & \\
\hline
\end{tabular}


Supplemental Table S2.txt

\begin{tabular}{|c|c|c|c|c|c|}
\hline CHEMBL1508012 & 688239 & 4.5362 & 5.5534 & TRN & \\
\hline CHEMBL1575214 & 688239 & 5.0862 & 5.4136 & TRN & \\
\hline CHEMBL1458338 & 688239 & 5.1862 & 5.4318 & TST & \\
\hline CHEMBL1488082 & 688239 & 5.3862 & 5.5199 & TRN & \\
\hline CHEMBL1477909 & 688239 & 5.2362 & 5.4921 & TRN & \\
\hline CHEMBL1353300 & 688239 & 4.8862 & 5.4691 & TRN & \\
\hline CHEMBL1376283 & 688239 & 4.6862 & 5.5274 & TRN & \\
\hline CHEMBL1325106 & 688239 & 5.1862 & 5.7325 & TRN & \\
\hline CHEMBL1446156 & 688239 & 4.6362 & 5.5807 & TST & \\
\hline CHEMBL1380221 & 688239 & 4.4862 & 5.3951 & TRN & \\
\hline CHEMBL1502726 & 688239 & 5.2362 & 5.5051 & TRN & \\
\hline CHEMBL454173 & 688239 & 4.5362 & 5.38399 & 99999999995 & TST \\
\hline CHEMBL1384853 & 688239 & 5.3362 & 5.42899 & 9999999999 & TST \\
\hline CHEMBL1339019 & 688239 & 5.4362 & 5.3967 & TRN & \\
\hline CHEMBL1367169 & 688239 & 5.1862 & 5.3502 & TRN & \\
\hline CHEMBL1312784 & 688239 & 4.5362 & 5.371 & TRN & \\
\hline CHEMBL1379399 & 688239 & 6.1862 & 5.6316 & TRN & \\
\hline CHEMBL1343721 & 688239 & 6.2362 & 5.49200 & 0000000001 & TST \\
\hline CHEMBL1500708 & 688239 & 4.8362 & 5.481 & TST & \\
\hline CHEMBL1580132 & 688239 & 4.7362 & 5.4472 & TST & \\
\hline CHEMBL1486942 & 688239 & 6.9863 & 5.5638 & TRN & \\
\hline CHEMBL1337463 & 688239 & 5.6862 & 5.5314 & TRN & \\
\hline CHEMBL1466297 & 688239 & 4.6862 & 5.57700 & 0000000001 & TRN \\
\hline CHEMBL1600527 & 688239 & 4.5362 & 5.5401 & TRN & \\
\hline CHEMBL 2004942 & 688239 & 6.0862 & 5.5671 & TRN & \\
\hline CHEMBL1557250 & 688239 & 4.5362 & 5.3722 & TRN & \\
\hline CHEMBL1349365 & 688239 & 4.7362 & 5.3943 & TRN & \\
\hline CHEMBL1526861 & 688239 & 6.0862 & 5.4321 & TRN & \\
\hline CHEMBL1379870 & 688239 & 5.5362 & 5.5139 & TRN & \\
\hline CHEMBL1468139 & 688239 & 5.3362 & 5.5724 & TRN & \\
\hline CHEMBL1593628 & 688239 & 6.1862 & 5.5402 & TST & \\
\hline CHEMBL1499325 & 688239 & 6.8861 & 5.5604 & TST & \\
\hline CHEMBL1356275 & 688239 & 5.9362 & 5.439 & TRN & \\
\hline CHEMBL1462070 & 688239 & 4.7362 & 5.3628 & TRN & \\
\hline CHEMBL1344234 & 688239 & 5.6362 & 5.3419 & TRN & \\
\hline CHEMBL1321185 & 688239 & 4.5362 & 5.4061 & TRN & \\
\hline CHEMBL1570560 & 688239 & 5.8862 & 5.4502 & TST & \\
\hline CHEMBL1998627 & 688239 & 5.1862 & 5.5515 & TST & \\
\hline CHEMBL1492805 & 688239 & 5.8862 & 5.5962 & TRN & \\
\hline CHEMBL1501037 & 688239 & 8.3372 & 5.7285 & TRN & \\
\hline CHEMBL1306485 & 688239 & 4.6362 & 5.5068 & TRN & \\
\hline CHEMBL1596643 & 688239 & 5.7862 & 5.5725 & TRN & \\
\hline CHEMBL1409770 & 688239 & 6.1362 & 5.4569 & TRN & \\
\hline CHEMBL1399888 & 688239 & 6.1362 & 5.4627 & TRN & \\
\hline CHEMBL1597894 & 688239 & 5.9362 & 5.5891 & TRN & \\
\hline CHEMBL1534921 & 688239 & 5.5362 & 5.5099 & TRN & \\
\hline CHEMBL1478669 & 688239 & 4.5362 & 5.5737 & TST & \\
\hline \multirow[t]{2}{*}{ CHEMBL1344576 } & 688239 & 5.3362 & \multicolumn{2}{|c|}{5.6370000000000005} & TRN \\
\hline & & & & e 1887 & \\
\hline
\end{tabular}


Supplemental Table S2.txt

\begin{tabular}{|c|c|c|c|c|}
\hline 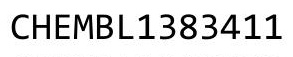 & & & & \\
\hline HEMBL1346439 & 88239 & 2862 & 6 & \\
\hline HEMBL1384862 & 88239 & 9863 & & \\
\hline IEMBL1 & & & & \\
\hline EMBL1; & & 362 & & \\
\hline AEMBL1592896 & 88239 & 362 & 3401 & \\
\hline HEMBL1609159 & 88239 & .0862 & .5517 & \\
\hline HEMBL1403136 & 239 & 362 & 147 & \\
\hline IEMBL13 & 39 & 362 & .5986 & \\
\hline IEMBL15 & 39 & 362 & & \\
\hline HEMBL1490329 & 88239 & 362 & 6021 & \\
\hline HEMBL1363087 & 39 & 8862 & .4576 & \\
\hline HEMBL1469662 & 39 & 361 & 7052 & \\
\hline HEMBL13. & & & 592 & \\
\hline HEMBL15 & 39 & & .5844 & \\
\hline HEMBL1594750 & 39 & 862 & .65 & \\
\hline HEMBL1313716 & 88 & 862 & 5965 & \\
\hline HEMBL139 & 39 & 362 & 83 & \\
\hline HEMBL15 & & & & \\
\hline HEME & 9 & & & נח \\
\hline HEMBL158 & 39 & & & \\
\hline AEMBL1465603 & 39 & 63 & 12 & RN \\
\hline HEMBL 15 & 39 & 362 & 09 & \\
\hline HEMBL 15 & & & & \\
\hline 65 & & & & RN \\
\hline AEMBL137 & 39 & & & 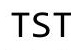 \\
\hline HEMBL3209772 & 39 & 862 & & $\mathrm{R} N$ \\
\hline HEMBL1496916 & 39 & 862 & 371 & $\mathrm{RN}$ \\
\hline HEM & & & & RN \\
\hline HEM & & & & RN \\
\hline HEMBL132 & & & & RN \\
\hline HEMBL1497425 & 39 & 362 & 195 & RN \\
\hline HEMBL 15 & 39 & 63 & 36 & 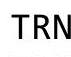 \\
\hline 4 & & & & RN \\
\hline HEMBL157 & & & & ST \\
\hline HEMBL1499167 & 39 & 63 & & ST \\
\hline HEMBL1335446 & 39 & 362 & 882 & RN \\
\hline JEMBL159 & 39 & 62 & 842 & RN \\
\hline 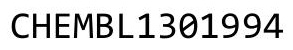 & & & & RN \\
\hline HEMBL142 & & & 5.4048 & RN \\
\hline HEMBL154 & 39 & 362 & 294 & RN \\
\hline HEMBL 14 & 39 & 362 & 39 & RN \\
\hline HEMBL15 & & & & \\
\hline & & & & ST \\
\hline HEMBL13 & & & .5142 & RN \\
\hline HEMBL1536682 & 88 & 362 & 03 & ST \\
\hline 14 & & & & \\
\hline & & & & \\
\hline
\end{tabular}




\begin{tabular}{|c|c|c|c|c|c|}
\hline & & \multicolumn{4}{|c|}{ Supplemental Table s2.txt } \\
\hline CHEMBL3198558 & 688239 & 4.7362 & 5.2796 & TRN & \\
\hline CHEMBL1400662 & 688239 & 6.6861 & 5.4171 & TST & \\
\hline CHEMBL1421363 & 688239 & 6.7862 & 5.5879 & TRN & \\
\hline CHEMBL1520591 & 688239 & 4.8862 & 5.4339 & TRN & \\
\hline CHEMBL1450866 & 688239 & 6.9363 & 5.5069 & TRN & \\
\hline CHEMBL1361058 & 688239 & 5.2862 & 5.5287 & TRN & \\
\hline CHEMBL1372733 & 688239 & 7.0862 & 5.4933 & TRN & \\
\hline CHEMBL1563040 & 688239 & 4.5362 & 5.3917 & TRN & \\
\hline CHEMBL1562696 & 688239 & 5.5362 & 5.5845 & TRN & \\
\hline CHEMBL1357769 & 688239 & 5.7362 & 5.4391 & TRN & \\
\hline CHEMBL1330421 & 688239 & 4.7362 & 5.3854 & TRN & \\
\hline CHEMBL1586585 & 688239 & 5.2862 & 5.379 & TRN & \\
\hline CHEMBL1419256 & 688239 & 5.4362 & 5.3915 & TST & \\
\hline CHEMBL1330627 & 688239 & 6.0862 & 5.6294 & TRN & \\
\hline CHEMBL1412473 & 688239 & 5.1362 & 5.5599 & TRN & \\
\hline CHEMBL1432080 & 688239 & 6.7862 & 5.4475 & TRN & \\
\hline CHEMBL1537868 & 688239 & 5.8362 & 5.50200 & 0000000001 & TRN \\
\hline CHEMBL1309666 & 688239 & 6.0862 & 5.516 & TST & \\
\hline CHEMBL1441677 & 688239 & 4.5362 & 5.3737 & TRN & \\
\hline CHEMBL1543317 & 688239 & 4.9362 & 5.4899 & TRN & \\
\hline CHEMBL1300409 & 688239 & 4.4862 & 5.5723 & TRN & \\
\hline CHEMBL1497462 & 688239 & 4.5362 & 5.4953 & TRN & \\
\hline CHEMBL1472553 & 688239 & 4.6362 & 5.3937 & TST & \\
\hline CHEMBL1433991 & 688239 & 4.7862 & 5.629 & TRN & \\
\hline CHEMBL1363771 & 688239 & 5.1862 & 5.4567 & TRN & \\
\hline CHEMBL1350111 & 688239 & 5.5862 & 5.4058 & TRN & \\
\hline CHEMBL1497424 & 688239 & 4.5362 & 5.5234 & TRN & \\
\hline CHEMBL1548102 & 688239 & 6.3362 & 5.3976 & TRN & \\
\hline CHEMBL1606259 & 688239 & 4.5362 & 5.3129 & TRN & \\
\hline CHEMBL1324613 & 688239 & 6.9863 & 5.4818 & TST & \\
\hline CHEMBL1497618 & 688239 & 4.5862 & 5.4656 & TST & \\
\hline CHEMBL1452077 & 688239 & 8.2366 & 5.5387 & TST & \\
\hline CHEMBL1425096 & 688239 & 5.2862 & 5.5012 & TST & \\
\hline CHEMBL1468220 & 688239 & 4.8862 & 5.4657 & TRN & \\
\hline CHEMBL1334099 & 688239 & 4.9862 & 5.5161 & TRN & \\
\hline CHEMBL1463409 & 688239 & 6.9363 & 5.5972 & TRN & \\
\hline CHEMBL1363717 & 688239 & 5.5362 & 5.4505 & TRN & \\
\hline CHEMBL1418762 & 688239 & 4.5362 & 5.5117 & TRN & \\
\hline CHEMBL1553733 & 688239 & 5.2862 & 5.5059 & TRN & \\
\hline CHEMBL1591306 & 688239 & 4.6362 & 5.49200 & 0000000001 & TST \\
\hline CHEMBL1575028 & 688239 & 6.0862 & 5.5796 & TRN & \\
\hline CHEMBL1579797 & 688239 & 4.5862 & 5.5883 & TST & \\
\hline CHEMBL1426245 & 688239 & 5.0362 & 5.4416 & TRN & \\
\hline CHEMBL1393627 & 688239 & 5.1862 & 5.4135 & TRN & \\
\hline CHEMBL1349565 & 688239 & 6.6861 & 5.5615 & TRN & \\
\hline CHEMBL1582731 & 688239 & 4.6862 & 5.3983 & TRN & \\
\hline CHEMBL1309912 & 688239 & 5.0862 & 5.53100 & 0000000001 & TST \\
\hline CHEMBL3193004 & 688239 & 8.3372 & 5.4016 & TST & \\
\hline
\end{tabular}


Supplemental Table S2.txt

\begin{tabular}{|c|c|c|c|c|}
\hline CHEMBL1612042 & 688239 & 5.0862 & 5.4762 & TRN \\
\hline CHEMBL1607088 & 688239 & 5.7862 & 5.4882 & TST \\
\hline CHEMBL1339920 & 688239 & 5.8362 & 5.5071 & TRN \\
\hline CHEMBL1323749 & 688239 & 6.2362 & 5.5412 & TRN \\
\hline CHEMBL1577394 & 688239 & 4.6362 & 5.5222 & TRN \\
\hline CHEMBL1430116 & 688239 & 4.5862 & 5.3273 & TST \\
\hline CHEMBL1338447 & 688239 & 5.1362 & 5.4392 & TST \\
\hline CHEMBL1591784 & 688239 & 5.3362 & 5.4775 & TRN \\
\hline CHEMBL1451513 & 688239 & 6.3362 & 5.4723 & TRN \\
\hline CHEMBL1517284 & 688239 & 4.8362 & 5.4237 & TRN \\
\hline CHEMBL1559812 & 688239 & 6.3362 & 5.456 & TRN \\
\hline CHEMBL1525261 & 688239 & 6.8362 & 5.5253 & TRN \\
\hline CHEMBL3212674 & 688239 & 5.4362 & 5.4201 & TRN \\
\hline CHEMBL1534329 & 688239 & 5.6862 & 5.5162 & TST \\
\hline CHEMBL1471829 & 688239 & 5.1862 & 5.4276 & TRN \\
\hline CHEMBL1428065 & 688239 & 4.9362 & 5.545 & TRN \\
\hline CHEMBL1580225 & 688239 & 6.3362 & 5.3816 & TST \\
\hline CHEMBL1307834 & 688239 & 6.9363 & 5.4724 & TRN \\
\hline CHEMBL1382116 & 688239 & 4.5362 & 5.3693 & TST \\
\hline CHEMBL3214295 & 688239 & 5.5362 & 5.3827 & TRN \\
\hline CHEMBL3190095 & 688239 & 5.4362 & 5.4487 & TST \\
\hline CHEMBL1403271 & 688239 & 4.6362 & 5.4639 & TST \\
\hline CHEMBL1428639 & 688239 & 4.5362 & 5.5248 & TRN \\
\hline CHEMBL1338029 & 688239 & 5.2862 & 5.4468 & TRN \\
\hline CHEMBL1305647 & 688239 & 6.7862 & 5.5554 & TST \\
\hline CHEMBL1359263 & 688239 & 5.5862 & 5.4891 & TST \\
\hline CHEMBL1488625 & 688239 & 6.6362 & 5.381 & TRN \\
\hline CHEMBL1360978 & 688239 & 5.3862 & 5.3986 & TRN \\
\hline CHEMBL1357354 & 688239 & 5.0862 & 5.388 & TRN \\
\hline CHEMBL1400690 & 688239 & 4.5362 & 5.4151 & TST \\
\hline CHEMBL1464986 & 688239 & 8.3872 & 5.5818 & TST \\
\hline CHEMBL1478100 & 688239 & 7.0862 & 5.3379 & TRN \\
\hline CHEMBL1434020 & 688239 & 6.3362 & 5.4412 & TRN \\
\hline CHEMBL1332227 & 688239 & 5.6862 & 5.4484 & TRN \\
\hline CHEMBL1451664 & 688239 & 4.6862 & 5.669 & TRN \\
\hline CHEMBL1574376 & 688239 & 6.2362 & 5.5623 & TST \\
\hline CHEMBL1574980 & 688239 & 4.6862 & 5.4169 & TRN \\
\hline CHEMBL1565626 & 688239 & 4.7862 & 5.4814 & TRN \\
\hline CHEMBL1540798 & 688239 & 4.5362 & 5.5382 & TRN \\
\hline CHEMBL1320974 & 688239 & 5.0362 & 5.3937 & TRN \\
\hline CHEMBL1342047 & 688239 & 5.3862 & 5.3396 & TRN \\
\hline CHEMBL1320477 & 688239 & 6.2362 & 5.4797 & TRN \\
\hline CHEMBL1339921 & 688239 & 6.1862 & 5.4929 & TST \\
\hline CHEMBL1394341 & 688239 & 5.1362 & 5.6091 & TRN \\
\hline CHEMBL1464130 & 688239 & 6.2862 & 5.57600 & 0000000005 \\
\hline CHEMBL1532070 & 688239 & 5.1862 & 5.4379 & TRN \\
\hline CHEMBL3192739 & 688239 & 8.0362 & 5.5122 & TRN \\
\hline CHEMBL541411 & 688239 & 6.6861 & 5.604 & TRN \\
\hline
\end{tabular}


Supplemental Table S2.txt

\begin{tabular}{|c|c|c|c|c|}
\hline 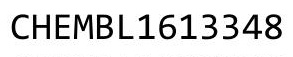 & & & & \\
\hline HEMBL1328136 & 88239 & 2362 & & \\
\hline HEMBL1381021 & 88239 & 1862 & & \\
\hline IEMBL1 & & & & \\
\hline EMBL16 & & 864 & & \\
\hline HEMBL1346206 & 88239 & 862 & 4788 & \\
\hline HEMBL1520746 & 88239 & .4862 & 3715 & \\
\hline HEMBL1505080 & 239 & 362 & & \\
\hline 652 & 39 & 862 & & \\
\hline IEMBL13 & 39 & 862 & & \\
\hline HEMBL1509286 & 88239 & 1862 & & \\
\hline HEMBL1500146 & 39 & 0362 & .4787 & \\
\hline HEMBL1326901 & 39 & 362 & 43 & \\
\hline HEMBL132 & & & & \\
\hline HEMBL 14 & 39 & 862 & & \\
\hline HEMBL138 & 39 & 362 & & \\
\hline HEMBL1469451 & 88 & 862 & 39 & \\
\hline HEMBL15 & 39 & 863 & & \\
\hline HEMBL 31 & & & & \\
\hline HEMBL1C & 9 & & & \\
\hline HEMBL 31 & 39 & 362 & & \\
\hline HEMBL146 & 88 & 862 & 78 & RN \\
\hline HEMBL 14 & 39 & 362 & & \\
\hline HEMBL15 & & & & \\
\hline AEMBL1 14 & 39 & 362 & & ST \\
\hline HEMBL15 & 39 & & & RN \\
\hline HEMBL1487183 & 39 & 362 & 48 & II \\
\hline HEMBL144 & 39 & 861 & & $\mathrm{RN}$ \\
\hline HEM & & 52 & & RN \\
\hline HEM & & & & RN \\
\hline HEMBL135 & 9 & & & $\mathrm{R}$ \\
\hline HEMBL1575 & 88 & 362 & & RN \\
\hline HEMBL135 & 39 & 63 & & RN \\
\hline 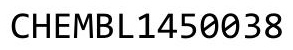 & & & & RN \\
\hline HEMBL13 & & & & RN \\
\hline HEMBL1380869 & 39 & & & $2 \mathrm{~N}-2-2-3-2$ \\
\hline HEMBL1388499 & 39 & 362 & & RN \\
\hline HEMBL153 & 39 & 62 & & NIV \\
\hline 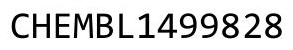 & & & & ST \\
\hline HEMBL1335470 & & & & RN \\
\hline HEMBL1438 & 39 & 362 & & RN \\
\hline HEMBL 146 & 39 & 362 & & \\
\hline HEMBL319 & & & & \\
\hline & & & & RN \\
\hline HEMBL15 & & & & RN \\
\hline HEMBL1461 & 39 & 362 & 57 & RN \\
\hline 32 & & & 5. & \\
\hline & & & 5.3739 & \\
\hline
\end{tabular}

Page 1891 
Supplemental Table S2.txt

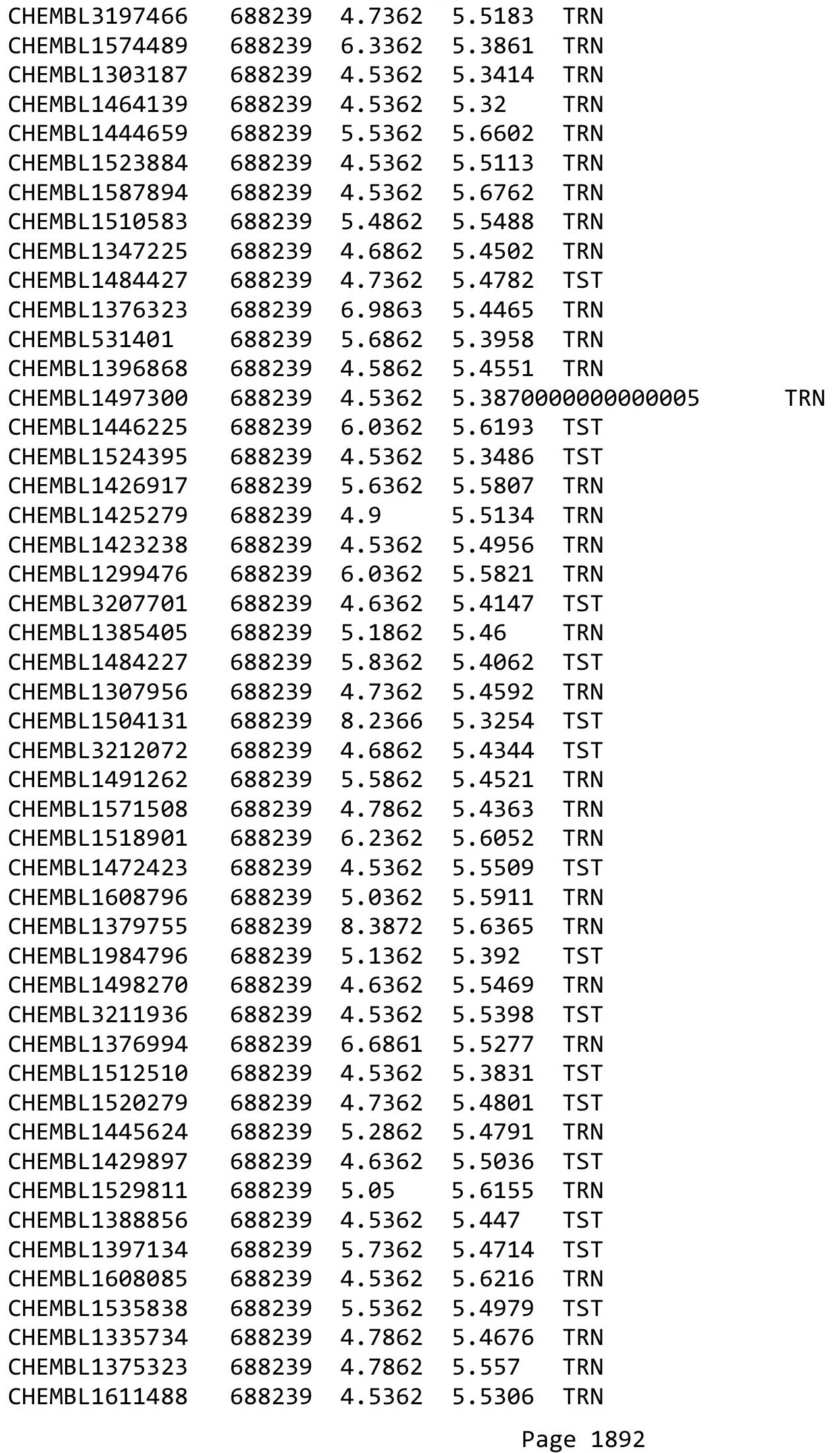




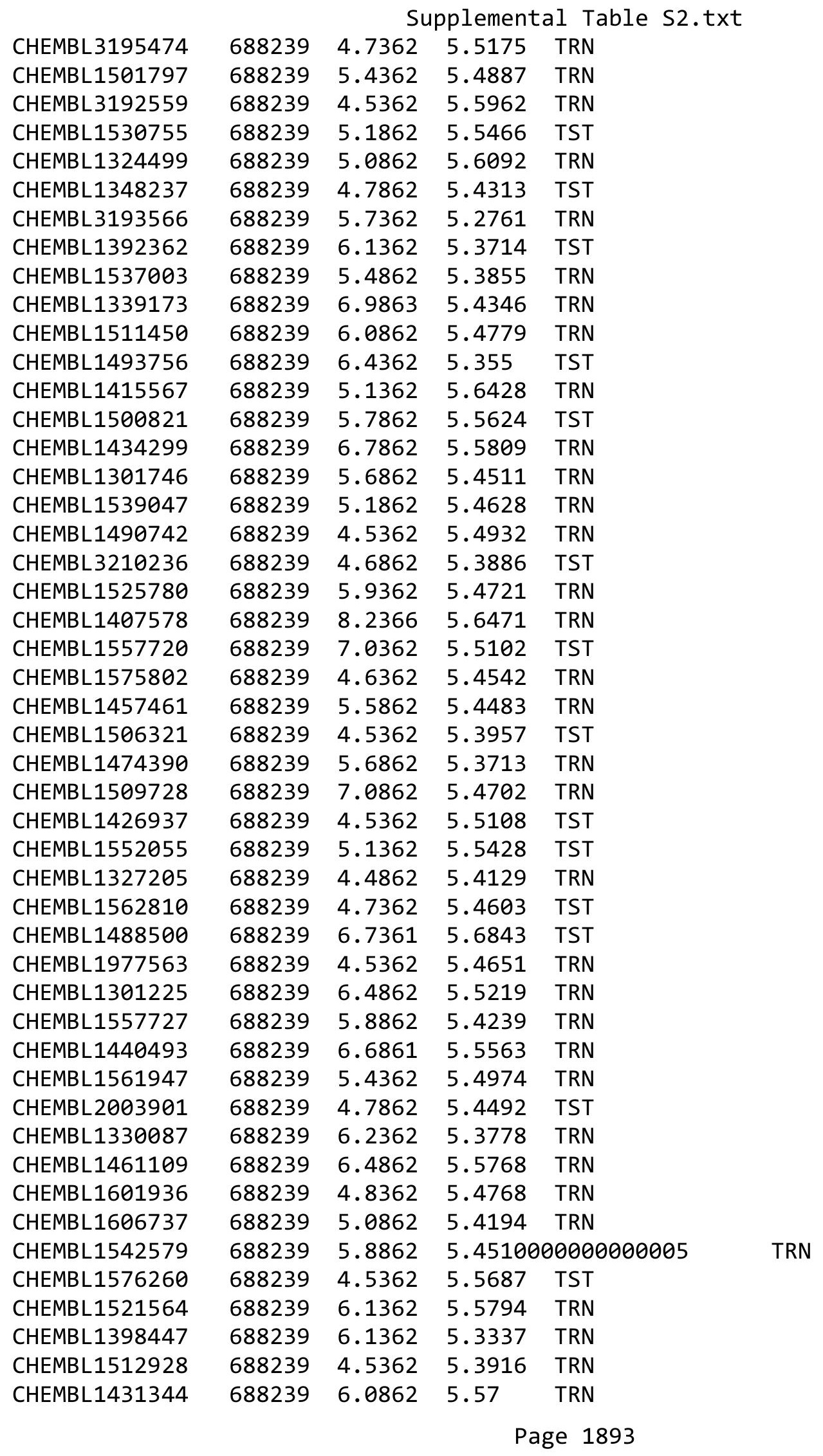


Supplemental Table S2.txt

\begin{tabular}{|c|c|c|c|c|}
\hline CHEMBL1581176 & 688239 & 5.0362 & 5.5787 & TRN \\
\hline CHEMBL1381405 & 688239 & 6.1362 & 5.5508 & TRN \\
\hline CHEMBL1532085 & 688239 & 5.1862 & 5.568 & TRN \\
\hline CHEMBL1304683 & 688239 & 5.7862 & 5.485 & TRN \\
\hline CHEMBL1438945 & 688239 & 5.7362 & 5.2993 & TST \\
\hline CHEMBL1500095 & 688239 & 4.5362 & 5.5362 & TRN \\
\hline CHEMBL1407760 & 688239 & 5.2862 & 5.4722 & TRN \\
\hline CHEMBL1444782 & 688239 & 5.1862 & 5.7191 & TRN \\
\hline CHEMBL1316501 & 688239 & 5.1362 & 5.3904 & TRN \\
\hline CHEMBL1461781 & 688239 & 4.6362 & 5.6197 & TRN \\
\hline CHEMBL 3190251 & 688239 & 4.6362 & 5.34 & TST \\
\hline CHEMBL1429125 & 688239 & 4.7862 & 5.4899 & TRN \\
\hline CHEMBL1303469 & 688239 & 5.0362 & 5.3219 & TRN \\
\hline CHEMBL1603585 & 688239 & 5.5862 & 5.5518 & TST \\
\hline CHEMBL1360703 & 688239 & 6.8362 & 5.5014 & TRN \\
\hline CHEMBL1589098 & 688239 & 4.5362 & 5.5826 & TRN \\
\hline CHEMBL1350961 & 688239 & 4.9362 & 5.4945 & TST \\
\hline CHEMBL1544737 & 688239 & 4.7862 & 5.3427 & TRN \\
\hline CHEMBL1573747 & 688239 & 5.6362 & 5.6199 & TRN \\
\hline CHEMBL1579838 & 688239 & 4.5362 & 5.4161 & TRN \\
\hline CHEMBL1601890 & 688239 & 4.6362 & 5.5188 & TST \\
\hline CHEMBL1605813 & 688239 & 5.1862 & 5.4611 & TST \\
\hline CHEMBL1363377 & 688239 & 4.8362 & 5.6004 & TRN \\
\hline CHEMBL1341182 & 688239 & 6.4362 & 5.4515 & TRN \\
\hline CHEMBL1398969 & 688239 & 7.0362 & 5.4471 & TRN \\
\hline CHEMBL1410452 & 688239 & 5.3862 & 5.3467 & TST \\
\hline CHEMBL531672 & 688239 & 5.1362 & 5.7952 & TRN \\
\hline CHEMBL1301350 & 688239 & 4.5862 & 5.3707 & TRN \\
\hline CHEMBL1326374 & 688239 & 5.0862 & 5.5027 & TRN \\
\hline CHEMBL1374970 & 688239 & 5.2862 & 5.4323 & TST \\
\hline CHEMBL1450439 & 688239 & 5.1862 & 5.3685 & TRN \\
\hline CHEMBL1581470 & 688239 & 7.1361 & 5.4947 & TST \\
\hline CHEMBL1333603 & 688239 & 5.0862 & 5.3567 & TRN \\
\hline CHEMBL1330061 & 688239 & 4.5362 & 5.3877 & TRN \\
\hline CHEMBL1510834 & 688239 & 6.2862 & 5.4783 & TRN \\
\hline CHEMBL1587501 & 688239 & 4.5362 & 5.5838 & TRN \\
\hline CHEMBL1312309 & 688239 & 6.7361 & 5.5045 & TRN \\
\hline CHEMBL1480907 & 688239 & 8.3872 & 5.5752 & TRN \\
\hline CHEMBL1515929 & 688239 & 6.2862 & 5.6063 & TRN \\
\hline CHEMBL1514344 & 688239 & 6.2362 & 5.3772 & TRN \\
\hline CHEMBL1562128 & 688239 & 4.7862 & 5.54200 & 0000000001 \\
\hline CHEMBL1605260 & 688239 & 4.5362 & 5.4882 & TRN \\
\hline CHEMBL1609775 & 688239 & 5.1862 & 5.4951 & TRN \\
\hline CHEMBL3194599 & 688239 & 6.8362 & 5.3433 & TST \\
\hline CHEMBL1389847 & 688239 & 7.0362 & 5.4713 & TRN \\
\hline CHEMBL607553 & 688239 & 5.0862 & 5.4629 & TRN \\
\hline CHEMBL1414454 & 688239 & 5.6362 & 5.3986 & TRN \\
\hline CHEMBL1355282 & 688239 & 4.6862 & 5.4203 & TRN \\
\hline
\end{tabular}


Supplemental Table S2.txt

\begin{tabular}{|c|c|c|c|c|}
\hline CHEMBL1468731 & 688239 & 5.7862 & 5.5429 & TRN \\
\hline CHEMBL1303892 & 688239 & 5.1862 & 5.5836 & TRN \\
\hline CHEMBL1610645 & 688239 & 4.5362 & 5.5285 & TST \\
\hline CHEMBL1452658 & 688239 & 4.9362 & 5.4731 & TRN \\
\hline CHEMBL1350004 & 688239 & 6.9863 & 5.6741 & TST \\
\hline CHEMBL1589097 & 688239 & 6.7361 & 5.4644 & TRN \\
\hline CHEMBL1542849 & 688239 & 5.8362 & 5.5265 & TRN \\
\hline CHEMBL1496818 & 688239 & 4.5362 & 5.5264 & TRN \\
\hline CHEMBL1457951 & 688239 & 5.1362 & 5.4259 & TST \\
\hline CHEMBL1444055 & 688239 & 6.2862 & 5.6061 & TRN \\
\hline CHEMBL1463980 & 688239 & 5.2862 & 5.4426 & TRN \\
\hline CHEMBL1576727 & 688239 & 6.2862 & 5.4929 & TRN \\
\hline CHEMBL1299626 & 688239 & 4.4862 & 5.3419 & TRN \\
\hline CHEMBL3195552 & 688239 & 5.7362 & 5.3814 & TRN \\
\hline CHEMBL1404510 & 688239 & 5.3862 & 5.7114 & TRN \\
\hline CHEMBL1304505 & 688239 & 6.1362 & 5.5527 & TST \\
\hline CHEMBL1508135 & 688239 & 4.5362 & 5.6028 & TRN \\
\hline CHEMBL3209443 & 688239 & 4.5362 & 5.3939 & TRN \\
\hline CHEMBL1519874 & 688239 & 7.2366 & 5.4155 & TRN \\
\hline CHEMBL1315006 & 688239 & 4.6362 & 5.4853 & TRN \\
\hline CHEMBL1480227 & 688239 & 4.7362 & 5.4772 & TRN \\
\hline CHEMBL1392681 & 688239 & 4.5362 & 5.3453 & TRN \\
\hline CHEMBL3197627 & 688239 & 4.5362 & 5.4648 & TST \\
\hline CHEMBL1351238 & 688239 & 4.8862 & 5.518 & TRN \\
\hline CHEMBL1497768 & 688239 & 5.4862 & 5.4432 & TRN \\
\hline CHEMBL1423587 & 688239 & 4.5362 & 5.3199 & TST \\
\hline CHEMBL1995204 & 688239 & 5.1862 & 5.4917 & TRN \\
\hline CHEMBL1341036 & 688239 & 4.7362 & 5.4825 & TST \\
\hline CHEMBL1968992 & 688239 & 5.0362 & 5.3881 & TRN \\
\hline CHEMBL1507106 & 688239 & 5.8362 & 5.4468 & TST \\
\hline CHEMBL1539266 & 688239 & 4.8362 & 5.5255 & TRN \\
\hline CHEMBL1449611 & 688239 & 8.3372 & 5.5261 & TRN \\
\hline CHEMBL1562749 & 688239 & 5.1862 & 5.3961 & TRN \\
\hline CHEMBL1483561 & 688239 & 4.9362 & 5.5496 & TRN \\
\hline CHEMBL1567027 & 688239 & 7.1361 & 5.5038 & TRN \\
\hline CHEMBL1398219 & 688239 & 5.4362 & 5.4871 & TRN \\
\hline CHEMBL1378607 & 688239 & 5.5362 & 5.4044 & TRN \\
\hline CHEMBL1367627 & 688239 & 5.7862 & 5.487 & TST \\
\hline CHEMBL1376334 & 688239 & 4.5362 & 5.4678 & TRN \\
\hline CHEMBL1307904 & 688239 & 5.2362 & 5.45100 & 00000000005 \\
\hline CHEMBL1407213 & 688239 & 4.7862 & 5.51200 & 30000000005 \\
\hline CHEMBL1560731 & 688239 & 4.8362 & 5.5051 & TRN \\
\hline CHEMBL1325549 & 688239 & 4.7862 & 5.4435 & TRN \\
\hline CHEMBL1358447 & 688239 & 4.9362 & 5.5185 & TRN \\
\hline CHEMBL1521386 & 688239 & 7.7852 & 5.441 & TRN \\
\hline CHEMBL1491814 & 688239 & 5.7362 & 5.2742 & TRN \\
\hline CHEMBL1408891 & 688239 & 7.2366 & 5.3561 & TST \\
\hline CHEMBL1511962 & 688239 & 4.5362 & 5.4994 & TST \\
\hline
\end{tabular}


Supplemental Table S2.txt

\begin{tabular}{|c|c|c|c|c|}
\hline CHEMBL1338179 & 688239 & 6.8362 & 5.3243 & TST \\
\hline CHEMBL1518863 & 688239 & 5.1862 & 5.5685 & TRN \\
\hline CHEMBL1408758 & 688239 & 5.6862 & 5.4693 & TRN \\
\hline CHEMBL1530212 & 688239 & 4.5362 & 5.5328 & TRN \\
\hline CHEMBL1371173 & 688239 & 5.7862 & 5.4639 & TST \\
\hline CHEMBL1377455 & 688239 & 4.6862 & 5.4158 & TRN \\
\hline CHEMBL1596312 & 688239 & 6.0862 & 5.4953 & TRN \\
\hline CHEMBL3195290 & 688239 & 6.3863 & 5.3874 & TRN \\
\hline CHEMBL1553374 & 688239 & 4.5862 & 5.3823 & TRN \\
\hline CHEMBL1557533 & 688239 & 8.28399 & 99999999 & 5.5032 \\
\hline CHEMBL1478488 & 688239 & 4.5862 & 5.4172 & TRN \\
\hline CHEMBL1360064 & 688239 & 4.5362 & 5.6039 & TRN \\
\hline CHEMBL1392901 & 688239 & 4.5862 & 5.5221 & TRN \\
\hline CHEMBL1978228 & 688239 & 5.5362 & 5.4742 & TST \\
\hline CHEMBL1427084 & 688239 & 5.7362 & 5.4838 & TRN \\
\hline CHEMBL1358451 & 688239 & 4.4362 & 5.4684 & TRN \\
\hline CHEMBL1609680 & 688239 & 4.4862 & 5.593999 & 999999999 \\
\hline CHEMBL1506842 & 688239 & 6.7862 & 5.5104 & TRN \\
\hline CHEMBL1600773 & 688239 & 4.8362 & 5.5736 & TST \\
\hline CHEMBL1588628 & 688239 & 6.3362 & 5.4163 & TRN \\
\hline CHEMBL1582184 & 688239 & 4.9362 & 5.4745 & TST \\
\hline CHEMBL1385829 & 688239 & 4.5362 & 5.5387 & TRN \\
\hline CHEMBL1496559 & 688239 & 5.7362 & 5.5279 & TRN \\
\hline CHEMBL1555978 & 688239 & 6.3362 & 5.3777 & TST \\
\hline CHEMBL1463027 & 688239 & 5.1862 & 5.6207 & TRN \\
\hline CHEMBL1377655 & 688239 & 5.4362 & 5.4241 & TST \\
\hline CHEMBL1309647 & 688239 & 5.7362 & 5.431 & TRN \\
\hline CHEMBL1403670 & 688239 & 5.2362 & 5.4744 & TRN \\
\hline CHEMBL1559762 & 688239 & 6.5363 & 5.4823 & TST \\
\hline CHEMBL1538526 & 688239 & 7.1361 & 5.3962 & TRN \\
\hline CHEMBL1393473 & 688239 & 6.6861 & 5.5451 & TRN \\
\hline CHEMBL1598229 & 688239 & 5.4362 & 5.5627 & TRN \\
\hline CHEMBL1581694 & 688239 & 4.5362 & 5.6116 & TRN \\
\hline CHEMBL1428600 & 688239 & 4.6862 & 5.4993 & TST \\
\hline CHEMBL3208862 & 688239 & 4.5362 & 5.5393 & TRN \\
\hline CHEMBL3210948 & 688239 & 5.0862 & 5.4859 & TST \\
\hline CHEMBL1387765 & 688239 & 5.1862 & 5.6258 & TRN \\
\hline CHEMBL1374897 & 688239 & 5.3862 & 5.39 & TRN \\
\hline CHEMBL1571299 & 688239 & 5.1862 & 5.608 & TST \\
\hline CHEMBL1537658 & 688239 & 4.7862 & 5.4992 & TST \\
\hline CHEMBL1416149 & 688239 & 5.1862 & 5.4394 & TRN \\
\hline CHEMBL1429702 & 688239 & 5.0862 & 5.4091 & TST \\
\hline CHEMBL1588246 & 688239 & 4.5862 & 5.3837 & TST \\
\hline CHEMBL1382069 & 688239 & 4.7362 & 5.4524 & TST \\
\hline CHEMBL1304638 & 688239 & 4.5362 & 5.4752 & TRN \\
\hline CHEMBL1351332 & 688239 & 5.1862 & 5.5591 & TRN \\
\hline CHEMBL1477372 & 688239 & 4.6362 & 5.7028 & TRN \\
\hline CHEMBL1567865 & 688239 & 5.3362 & 5.3617 & TST \\
\hline
\end{tabular}


Supplemental Table S2.txt

\begin{tabular}{|c|c|c|c|c|c|c|}
\hline CHEMBL1598244 & 688239 & 6.7862 & 5.5622 & TST & & \\
\hline CHEMBL 2373646 & 688239 & 6.025 & 5.3979 & TST & & \\
\hline CHEMBL1306024 & 688239 & 5.2362 & 5.5629 & TRN & & \\
\hline CHEMBL1522529 & 688239 & 5.1862 & 5.6795 & TST & & \\
\hline CHEMBL1332480 & 688239 & 4.7362 & 5.5892 & TST & & \\
\hline CHEMBL1580116 & 688239 & 4.5362 & 5.3236 & TRN & & \\
\hline CHEMBL1550808 & 688239 & 5.1862 & 5.4121 & TRN & & \\
\hline CHEMBL1531860 & 688239 & 4.8862 & 5.499 & TST & & \\
\hline CHEMBL1536573 & 688239 & 6.2362 & 5.5178 & TRN & & \\
\hline CHEMBL1401644 & 688239 & 4.5362 & 5.2707 & TST & & \\
\hline CHEMBL1565642 & 688239 & 5.1862 & 5.5717 & TRN & & \\
\hline CHEMBL1548053 & 688239 & 4.5362 & 5.511 & TRN & & \\
\hline CHEMBL3196772 & 688239 & 8.28399 & 99999999 & & 5.4864 & TRN \\
\hline CHEMBL1384868 & 688239 & 7.2865 & 5.4464 & TRN & & \\
\hline CHEMBL119888 & 688239 & 5.9862 & 5.5141 & TRN & & \\
\hline CHEMBL1541898 & 688239 & 4.8362 & 5.6335 & TRN & & \\
\hline CHEMBL1457356 & 688239 & 4.8362 & 5.5185 & TRN & & \\
\hline CHEMBL610198 & 688239 & 5.5362 & 5.518 & TRN & & \\
\hline CHEMBL1323292 & 688239 & 7.9355 & 5.5012 & TRN & & \\
\hline CHEMBL1401645 & 688239 & 4.4862 & 5.4115 & TRN & & \\
\hline CHEMBL1535166 & 688239 & 5.2862 & 5.359 & TRN & & \\
\hline CHEMBL1593091 & 688239 & 5.0862 & 5.5628 & TRN & & \\
\hline CHEMBL1581010 & 688239 & 4.5362 & 5.4262 & TRN & & \\
\hline CHEMBL3197033 & 688239 & 8.28399 & 99999999 & 9 & 5.4615 & \\
\hline CHEMBL 3214013 & 688239 & 5.3362 & 5.4799 & TRN & & \\
\hline CHEMBL1340197 & 688239 & 4.5862 & 5.4611 & TRN & & \\
\hline CHEMBL1354756 & 688239 & 5.4362 & 5.5322 & TST & & \\
\hline CHEMBL1348090 & 688239 & 5.5362 & 5.4936 & TRN & & \\
\hline CHEMBL1611175 & 688239 & 4.6862 & 5.5158 & TRN & & \\
\hline CHEMBL1598566 & 688239 & 4.8862 & 5.4926 & TRN & & \\
\hline CHEMBL1473485 & 688239 & 6.1362 & 5.4538 & TRN & & \\
\hline CHEMBL1331541 & 688239 & 5.0862 & 5.4116 & TRN & & \\
\hline CHEMBL1994599 & 688239 & 4.5362 & 5.4328 & TRN & & \\
\hline CHEMBL1399034 & 688239 & 4.6862 & 5.4064 & TRN & & \\
\hline CHEMBL1462401 & 688239 & 5.8862 & 5.4808 & TRN & & \\
\hline CHEMBL1324779 & 688239 & 4.6362 & 5.4697 & TRN & & \\
\hline CHEMBL1463222 & 688239 & 6.9863 & 5.5262 & TRN & & \\
\hline CHEMBL1578151 & 688239 & 6.8861 & 5.4124 & TRN & & \\
\hline CHEMBL1583276 & 688239 & 4.4862 & 5.2791 & TST & & \\
\hline CHEMBL1542268 & 688239 & 5.4362 & 5.5051 & TRN & & \\
\hline CHEMBL1537305 & 688239 & 6.5363 & 5.5951 & TST & & \\
\hline CHEMBL1536722 & 688239 & 5.6862 & 5.5551 & TRN & & \\
\hline CHEMBL1478301 & 688239 & 5.4362 & 5.5081 & TRN & & \\
\hline CHEMBL 1314260 & 688239 & 6.1362 & 5.4833 & TST & & \\
\hline CHEMBL1359309 & 688239 & 5.0862 & 5.5854 & TRN & & \\
\hline CHEMBL1307079 & 688239 & 6.1362 & 5.4564 & TST & & \\
\hline CHEMBL1439773 & 688239 & 4.6362 & 5.4771 & TRN & & \\
\hline CHEMBL1492175 & 688239 & 5.0362 & 5.3853 & TRN & & \\
\hline
\end{tabular}




\begin{tabular}{|c|c|c|c|c|c|c|}
\hline & & \multicolumn{5}{|c|}{ Supplemental Table S2.txt } \\
\hline CHEMBL1610236 & 688239 & 6.7361 & 5.5352 & TRN & & \\
\hline CHEMBL1416697 & 688239 & 4.7862 & 5.5106 & TRN & & \\
\hline CHEMBL1513401 & 688239 & 4.6862 & 5.4527 & TRN & & \\
\hline CHEMBL1542924 & 688239 & 4.7362 & 5.4675 & TRN & & \\
\hline CHEMBL1393301 & 688239 & 4.5862 & 5.3692 & TRN & & \\
\hline CHEMBL1442806 & 688239 & 4.4862 & 5.4216 & TRN & & \\
\hline CHEMBL1473005 & 688239 & 4.7362 & 5.5571 & TST & & \\
\hline CHEMBL1374550 & 688239 & 5.8862 & 5.4086 & TRN & & \\
\hline CHEMBL1335317 & 688239 & 4.5362 & 5.4631 & TRN & & \\
\hline CHEMBL1459360 & 688239 & 4.5362 & 5.6164 & TST & & \\
\hline CHEMBL1602091 & 688239 & 4.5862 & 5.5292 & TST & & \\
\hline CHEMBL1554313 & 688239 & 6.2362 & 5.6458 & TST & & \\
\hline CHEMBL1369192 & 688239 & 7.2366 & 5.4383 & TST & & \\
\hline CHEMBL1369292 & 688239 & 4.5362 & 5.5517 & TRN & & \\
\hline CHEMBL1430762 & 688239 & 5.8362 & 5.4109 & TST & & \\
\hline CHEMBL1404453 & 688239 & 4.5362 & 5.4779 & TRN & & \\
\hline CHEMBL1419000 & 688239 & 5.1862 & 5.3383 & TRN & & \\
\hline CHEMBL3191045 & 688239 & 8.3372 & 5.6218 & TST & & \\
\hline CHEMBL1359032 & 688239 & 4.7362 & 5.4803 & TRN & & \\
\hline CHEMBL1392172 & 688239 & 5.0362 & 5.4466 & TST & & \\
\hline CHEMBL1438909 & 688239 & 4.7362 & 5.5747 & TRN & & \\
\hline CHEMBL1444919 & 688239 & 4.5362 & 5.7021 & TST & & \\
\hline CHEMBL1378750 & 688239 & 4.6362 & 5.5567 & TRN & & \\
\hline CHEMBL1514250 & 688239 & 4.5362 & 5.5653 & TRN & & \\
\hline CHEMBL3194612 & 688239 & 5.1862 & 5.4488 & TST & & \\
\hline CHEMBL1333134 & 688239 & 5.8362 & 5.5534 & TRN & & \\
\hline CHEMBL1320336 & 688239 & 5.5862 & 5.47 & TRN & & \\
\hline CHEMBL1346366 & 688239 & 6.2362 & 5.4504 & TST & & \\
\hline CHEMBL1966666 & 688239 & 4.5362 & 5.4196 & TRN & & \\
\hline CHEMBL492886 & 688239 & 5.6862 & 5.3123 & TST & & \\
\hline CHEMBL1328871 & 688239 & 5.3362 & 5.5603 & TST & & \\
\hline CHEMBL1540795 & 688239 & 5.1862 & 5.4411 & TST & & \\
\hline CHEMBL1555413 & 688239 & 5.1862 & 5.5846 & TRN & & \\
\hline CHEMBL1580390 & 688239 & 6.0862 & 5.3792 & TRN & & \\
\hline CHEMBL1505057 & 688239 & 5.7862 & 5.483 & TRN & & \\
\hline CHEMBL1425401 & 688239 & 6.7862 & 5.5819 & TST & & \\
\hline CHEMBL1494131 & 688239 & 6.3362 & 5.46 & TRN & & \\
\hline CHEMBL1599782 & 688239 & 5.3862 & 5.5179 & TRN & & \\
\hline CHEMBL3208034 & 688239 & 8.3872 & 5.5139 & TRN & & \\
\hline CHEMBL1508459 & 688239 & 5.6362 & 5.5435 & TST & & \\
\hline CHEMBL3193648 & 688239 & 4.6862 & 5.4976 & TST & & \\
\hline CHEMBL1343504 & 688239 & 6.0362 & 5.5301 & TRN & & \\
\hline CHEMBL1572885 & 688239 & 8.3372 & 5.3663 & TRN & & \\
\hline CHEMBL1470979 & 688239 & 4.5362 & 5.5738 & TRN & & \\
\hline CHEMBL1598712 & 688239 & 8.28399 & 999999999 & 99 & 5.5776 & TRN \\
\hline CHEMBL1352287 & 688239 & 4.7362 & 5.6143 & TRN & & \\
\hline CHEMBL1445973 & 688239 & 5.6862 & 5.5497 & TRN & & \\
\hline CHEMBL1300195 & 688239 & 5.3862 & 5.5645 & TRN & & \\
\hline
\end{tabular}


Supplemental Table S2.txt

\begin{tabular}{|c|c|c|c|c|c|}
\hline CHEMBL1400290 & 688239 & 4.6362 & 5.5916 & TRN & \\
\hline CHEMBL1538218 & 688239 & 6.4862 & 5.5509 & TRN & \\
\hline CHEMBL1373184 & 688239 & 4.8362 & 5.479 & TST & \\
\hline CHEMBL1384245 & 688239 & 5.6362 & 5.5887 & TST & \\
\hline CHEMBL1504959 & 688239 & 5.8862 & 5.6378 & TRN & \\
\hline CHEMBL1503808 & 688239 & 5.9362 & 5.3082 & TRN & \\
\hline CHEMBL1471549 & 688239 & 5.6862 & 5.687 & TRN & \\
\hline CHEMBL1459043 & 688239 & 4.9362 & 5.5419 & TRN & \\
\hline CHEMBL3195039 & 688239 & 4.6862 & 5.4646 & TRN & \\
\hline CHEMBL1424766 & 688239 & 5.3862 & 5.5991 & TRN & \\
\hline CHEMBL1599584 & 688239 & 5.5862 & 5.4431 & TRN & \\
\hline CHEMBL1350496 & 688239 & 4.7362 & 5.4193 & TRN & \\
\hline CHEMBL1435029 & 688239 & 4.7862 & 5.4933 & TRN & \\
\hline CHEMBL3195671 & 688239 & 6.5363 & 5.5054 & TST & \\
\hline CHEMBL 3191048 & 688239 & 6.1862 & 5.3649 & TRN & \\
\hline CHEMBL1318629 & 688239 & 4.9362 & 5.3877 & TRN & \\
\hline CHEMBL1444486 & 688239 & 5.6862 & 5.4561 & TRN & \\
\hline CHEMBL1531409 & 688239 & 4.4862 & 5.5043 & TST & \\
\hline CHEMBL1450095 & 688239 & 6.6362 & 5.5784 & TST & \\
\hline CHEMBL1437981 & 688239 & 4.6862 & 5.5728 & TRN & \\
\hline CHEMBL1559984 & 688239 & 8.3372 & 5.5287 & TRN & \\
\hline CHEMBL1390175 & 688239 & 5.7862 & 5.46 & TRN & \\
\hline CHEMBL1454460 & 688239 & 6.2362 & 5.5168 & TST & \\
\hline CHEMBL1363895 & 688239 & 5.6862 & 5.4646 & TRN & \\
\hline CHEMBL1361724 & 688239 & 4.5362 & 5.4648 & TRN & \\
\hline CHEMBL1502423 & 688239 & 6.3863 & 5.3205 & TRN & \\
\hline CHEMBL3210239 & 688239 & 5.1862 & 5.5078 & TRN & \\
\hline CHEMBL1504471 & 688239 & 5.7862 & 5.4103 & TST & \\
\hline CHEMBL1341117 & 688239 & 5.1362 & 5.5061 & TST & \\
\hline CHEMBL1329155 & 688239 & 4.6362 & 5.2887 & TRN & \\
\hline CHEMBL3196335 & 688239 & 4.5362 & 5.4515 & TRN & \\
\hline CHEMBL1553862 & 688239 & 5.6362 & 5.5438 & TRN & \\
\hline CHEMBL1367163 & 688239 & 4.9362 & 5.4855 & TRN & \\
\hline CHEMBL1554436 & 688239 & 5.1862 & 5.6498 & TRN & \\
\hline CHEMBL1461734 & 688239 & 5.5362 & 5.7014 & TRN & \\
\hline CHEMBL1467649 & 688239 & 5.1362 & 5.4357 & TRN & \\
\hline CHEMBL1346297 & 688239 & 4.5362 & 5.5879 & TST & \\
\hline CHEMBL304621 & 688239 & 5.1862 & 5.5176 & TRN & \\
\hline CHEMBL1378421 & 688239 & 6.1362 & 5.5155 & TRN & \\
\hline CHEMBL1431353 & 688239 & 5.7362 & 5.3681 & TRN & \\
\hline CHEMBL1549337 & 688239 & 5.4362 & 5.41200 & 000000001 & TR \\
\hline CHEMBL1359011 & 688239 & 6.9363 & 5.5381 & TRN & \\
\hline CHEMBL3195260 & 688239 & 4.9862 & 5.4269 & TRN & \\
\hline CHEMBL1596401 & 688239 & 8.28399 & 79999999 & 5.5683 & TS \\
\hline CHEMBL1424216 & 688239 & 5.2862 & 5.4755 & TST & \\
\hline CHEMBL1302238 & 688239 & 5.1862 & 5.3539 & TRN & \\
\hline CHEMBL1371971 & 688239 & 6.2362 & 5.651 & TRN & \\
\hline CHEMBL1427657 & 688239 & 7.0362 & 5.5586 & TRN & \\
\hline
\end{tabular}


Supplemental Table S2.txt

\begin{tabular}{|c|c|c|c|c|}
\hline CHEMBL1598230 & 688239 & 4.5362 & 5.489 & TRN \\
\hline CHEMBL576404 & 688239 & 6.3362 & 5.4281 & TRN \\
\hline CHEMBL1450659 & 688239 & 7.2865 & 5.5932 & TST \\
\hline CHEMBL1471329 & 688239 & 4.6362 & 5.6595 & TRN \\
\hline CHEMBL1597080 & 688239 & 4.7862 & 5.4385 & TST \\
\hline CHEMBL1534102 & 688239 & 4.7862 & 5.4123 & TST \\
\hline CHEMBL1353971 & 688239 & 5.1862 & 5.4467 & TST \\
\hline CHEMBL1449906 & 688239 & 5.2362 & 5.4717 & TST \\
\hline CHEMBL1334812 & 688239 & 5.1862 & 5.6037 & TST \\
\hline CHEMBL1548261 & 688239 & 4.4862 & 5.5391 & TST \\
\hline CHEMBL1490527 & 688239 & 6.2362 & 5.4675 & TRN \\
\hline CHEMBL 3207982 & 688239 & 5.1862 & 5.3895 & TRN \\
\hline CHEMBL1495329 & 688239 & 7.1864 & 5.5212 & TRN \\
\hline CHEMBL1494862 & 688239 & 5.6862 & 5.4877 & TRN \\
\hline CHEMBL1374884 & 688239 & 5.1862 & 5.4055 & TRN \\
\hline CHEMBL1612718 & 688239 & 5.1362 & 5.5059 & TST \\
\hline CHEMBL1508245 & 688239 & 4.5362 & 5.5613 & TRN \\
\hline CHEMBL1584536 & 688239 & 4.5862 & 5.4849 & TRN \\
\hline CHEMBL1300455 & 688239 & 6.5862 & 5.3896 & TST \\
\hline CHEMBL1365747 & 688239 & 4.9362 & 5.4271 & TRN \\
\hline CHEMBL1560116 & 688239 & 5.3862 & 5.4518 & TRN \\
\hline CHEMBL1446375 & 688239 & 4.7362 & 5.4216 & TRN \\
\hline CHEMBL1523074 & 688239 & 4.5362 & 5.4165 & TRN \\
\hline CHEMBL1465182 & 688239 & 5.0862 & 5.4029 & TRN \\
\hline CHEMBL1513286 & 688239 & 5.3862 & 5.5035 & TRN \\
\hline CHEMBL1460032 & 688239 & 4.7862 & 5.4171 & TRN \\
\hline CHEMBL1448393 & 688239 & 5.7862 & 5.422006 & 0000000001 \\
\hline CHEMBL1464944 & 688239 & 7.5361 & 5.4807 & TRN \\
\hline CHEMBL1306718 & 688239 & 5.1362 & 5.3756 & TRN \\
\hline CHEMBL1540360 & 688239 & 5.2362 & 5.4963 & TST \\
\hline CHEMBL1479236 & 688239 & 5.7362 & 5.5384 & TRN \\
\hline CHEMBL1419023 & 688239 & 4.5362 & 5.3845 & TRN \\
\hline CHEMBL1396525 & 688239 & 4.6362 & 5.5191 & TRN \\
\hline CHEMBL1568291 & 688239 & 4.5362 & 5.5384 & TRN \\
\hline CHEMBL1353688 & 688239 & 4.8862 & 5.4468 & TRN \\
\hline CHEMBL1377336 & 688239 & 5.1362 & 5.4648 & TRN \\
\hline CHEMBL1417282 & 688239 & 4.5862 & 5.3691 & TST \\
\hline CHEMBL1353710 & 688239 & 4.6362 & 5.3886 & TRN \\
\hline CHEMBL1337935 & 688239 & 7.1361 & 5.4951 & TRN \\
\hline CHEMBL1482217 & 688239 & 5.3862 & 5.4557 & TRN \\
\hline CHEMBL 3191281 & 688239 & 4.5362 & 5.4699 & TRN \\
\hline CHEMBL1470608 & 688239 & 4.9362 & 5.6406 & TRN \\
\hline CHEMBL1361756 & 688239 & 5.6362 & 5.4586 & TRN \\
\hline CHEMBL1471443 & 688239 & 4.5362 & 5.4451 & TRN \\
\hline CHEMBL1378703 & 688239 & 5.3862 & 5.4627 & TRN \\
\hline CHEMBL1319236 & 688239 & 6.8861 & 5.5553 & TRN \\
\hline CHEMBL1309114 & 688239 & 5.1862 & 5.4867 & TST \\
\hline CHEMBL1348722 & 688239 & 5.6362 & 5.3968 & TRN \\
\hline
\end{tabular}


Supplemental Table S2.txt

\begin{tabular}{|c|c|c|c|c|}
\hline & & & & \\
\hline HEMBL1465549 & 88239 & 362 & 058 & \\
\hline AEMBL1347633 & 39 & 52 & & \\
\hline IEMBL3194269 & & & & \\
\hline AEMBL1510564 & & & & \\
\hline AEMBL1429847 & 88239 & 361 & & \\
\hline AEMBL1336036 & 88239 & 362 & 26 & \\
\hline HEMBL1595460 & & & & \\
\hline AEMBL13 & & & & \\
\hline HEMBL158 & & & & \\
\hline HEMBL1545972 & 68 & & & \\
\hline AEMBL1528299 & 39 & 6. & & \\
\hline HEMBL3191894 & & & & \\
\hline JEMBL139 & & & & \\
\hline HEMBL16€ & & & & \\
\hline HEMBL1492738 & & & & \\
\hline AEMBL1544079 & & & & \\
\hline HEMBL 148 & & & & \\
\hline HEMBL16 & & & & \\
\hline HEMBL13 & & & & \\
\hline AEMBL1309847 & & & & \\
\hline HEMBL149 & & & & \\
\hline AEMBL15 & & & & \\
\hline HEMBL13 & & & & \\
\hline AFMRI 14 & & & & \\
\hline$\partial 24$ & & & & \\
\hline AEMBL1487872 & & & & \\
\hline HEMBL130 & & & & \\
\hline 84 & & & & \\
\hline 45 & & & & \\
\hline AEMBL1562134 & & & & \\
\hline HEMBL1367706 & & & & \\
\hline 31 & & & & \\
\hline 5 & & & & \\
\hline 36 & & & & \\
\hline AEMBL1307489 & & & & \\
\hline AEMBL1518695 & & & & $s$ \\
\hline & & & & \\
\hline 17 & & & 27 & \\
\hline HEMBL1327404 & & & & $\mathrm{R}$ \\
\hline AEMBL566061 & & & & $\mathrm{R}$ \\
\hline AEMBL1326687 & & & & \\
\hline & & & & \\
\hline HEMBL1569785 & & & & \\
\hline AEMBL1383965 & & & & IST \\
\hline MBL1312325 & & & 97 & TF \\
\hline 120 & & & & \\
\hline roso & & & 5.6067 & \\
\hline
\end{tabular}

Page 1901 
Supplemental Table S2.txt

\begin{tabular}{|c|c|c|c|c|c|}
\hline CHEMBL1563668 & 688239 & 5.3862 & 5.517 & TST & \\
\hline CHEMBL1401246 & 688239 & 5.3862 & 5.5314 & TST & \\
\hline CHEMBL1542697 & 688239 & 5.9362 & 5.3924 & TRN & \\
\hline CHEMBL1460000 & 688239 & 5.6862 & 5.4468 & TRN & \\
\hline CHEMBL1410152 & 688239 & 5.6362 & 5.5698 & TRN & \\
\hline CHEMBL1586419 & 688239 & 4.5362 & 5.5054 & TRN & \\
\hline CHEMBL1472449 & 688239 & 6.8861 & 5.4403 & TST & \\
\hline CHEMBL1438431 & 688239 & 8.3372 & 5.6373 & TRN & \\
\hline CHEMBL1458772 & 688239 & 4.8362 & 5.5776 & TRN & \\
\hline CHEMBL1387200 & 688239 & 6.7361 & 5.5233 & TRN & \\
\hline CHEMBL1413354 & 688239 & 5.4862 & 5.5366 & TRN & \\
\hline CHEMBL1501360 & 688239 & 4.5362 & 5.4691 & TRN & \\
\hline CHEMBL1497843 & 688239 & 5.0362 & 5.3813 & TST & \\
\hline CHEMBL1480258 & 688239 & 4.6862 & 5.4975 & TRN & \\
\hline CHEMBL1505990 & 688239 & 4.6862 & 5.4563 & TRN & \\
\hline CHEMBL1368321 & 688239 & 6.2862 & 5.4869 & TST & \\
\hline CHEMBL1423500 & 688239 & 4.7862 & 5.4183 & TRN & \\
\hline CHEMBL1355942 & 688239 & 5.9362 & 5.4157 & TST & \\
\hline CHEMBL1544367 & 688239 & 6.4362 & 5.5579 & TRN & \\
\hline CHEMBL1338178 & 688239 & 4.8862 & 5.474 & TRN & \\
\hline CHEMBL1367920 & 688239 & 7.8356 & 5.5041 & TRN & \\
\hline CHEMBL 3199238 & 688239 & 7.0862 & 5.3692 & TRN & \\
\hline CHEMBL1490224 & 688239 & 5.8362 & 5.4831 & TRN & \\
\hline CHEMBL1351404 & 688239 & 8.3372 & 5.4768 & TST & \\
\hline CHEMBL 3197242 & 688239 & 4.5362 & 5.3953 & TRN & \\
\hline CHEMBL1365302 & 688239 & 4.7362 & 5.4805 & TRN & \\
\hline CHEMBL1486911 & 688239 & 5.0862 & 5.5129 & TRN & \\
\hline CHEMBL1408402 & 688239 & 4.6862 & 5.4725 & TST & \\
\hline CHEMBL1580234 & 688239 & 5.1862 & 5.4852 & TST & \\
\hline CHEMBL1506289 & 688239 & 6.8861 & 5.4925 & TST & \\
\hline CHEMBL1478152 & 688239 & 6.1362 & 5.4821 & TRN & \\
\hline CHEMBL1544258 & 688239 & 6.8362 & 5.71299 & 9999999999 & TRN \\
\hline CHEMBL1544076 & 688239 & 5.9362 & 5.5913 & TST & \\
\hline CHEMBL1539353 & 688239 & 4.7362 & 5.3866 & TRN & \\
\hline CHEMBL1613423 & 688239 & 5.6862 & 5.5045 & TRN & \\
\hline CHEMBL1349363 & 688239 & 4.7362 & 5.482 & TRN & \\
\hline CHEMBL 3191547 & 688239 & 6.1362 & 5.5313 & TRN & \\
\hline CHEMBL1360084 & 688239 & 5.8362 & 5.4103 & TRN & \\
\hline CHEMBL1505447 & 688239 & 5.6362 & 5.5872 & TRN & \\
\hline CHEMBL1498 & 688239 & 6.1362 & 5.5503 & TRN & \\
\hline CHEMBL1410837 & 688239 & 5.1862 & 5.5269 & TRN & \\
\hline CHEMBL1528051 & 688239 & 5.6362 & 5.4369 & TRN & \\
\hline CHEMBL1442943 & 688239 & 4.5362 & 5.5745 & TRN & \\
\hline CHEMBL1386955 & 688239 & 5.2362 & 5.75 & TRN & \\
\hline CHEMBL1390464 & 688239 & 8.3372 & 5.4198 & TST & \\
\hline CHEMBL1503800 & 688239 & 6.2862 & 5.5388 & TRN & \\
\hline CHEMBL1388250 & 688239 & 6.9363 & 5.5793 & TRN & \\
\hline CHEMBL1523385 & 688239 & 6.2362 & 5.3717 & TRN & \\
\hline
\end{tabular}




\begin{tabular}{|c|c|c|c|c|c|}
\hline \multicolumn{6}{|c|}{ Supplemental Table S2.txt } \\
\hline CHEMBL1599935 & 688239 & 4.6 & 5.5591 & TRN & \\
\hline CHEMBL1346704 & 688239 & 5.0862 & 5.3946 & TRN & \\
\hline CHEMBL1426544 & 688239 & 6.0862 & 5.6547 & TRN & \\
\hline CHEMBL1573722 & 688239 & 5.7862 & 5.5716 & TST & \\
\hline CHEMBL1352916 & 688239 & 4.5362 & 5.3408 & TRN & \\
\hline CHEMBL1445008 & 688239 & 6.1362 & 5.5497 & TRN & \\
\hline CHEMBL1385996 & 688239 & 5.2362 & 5.3346 & TST & \\
\hline CHEMBL1484457 & 688239 & 6.9363 & 5.5833 & TRN & \\
\hline CHEMBL3190509 & 688239 & 4.6862 & 5.5365 & TST & \\
\hline CHEMBL1371251 & 688239 & 5.0362 & 5.5225 & TRN & \\
\hline CHEMBL1343354 & 688239 & 6.0362 & 5.6089 & TRN & \\
\hline CHEMBL1497662 & 688239 & 5.0862 & 5.379 & TRN & \\
\hline CHEMBL3193313 & 688239 & 6.2862 & 5.5545 & TRN & \\
\hline CHEMBL1316836 & 688239 & 6.1362 & 5.4176 & TRN & \\
\hline CHEMBL1499554 & 688239 & 5.9362 & 5.4209 & TST & \\
\hline CHEMBL1414231 & 688239 & 5.0862 & 5.5405 & TRN & \\
\hline CHEMBL1313909 & 688239 & 8.28399 & 999999999 & 5.5671 & TRN \\
\hline CHEMBL1376755 & 688239 & 5.4362 & 5.4499 & TRN & \\
\hline CHEMBL1378409 & 688239 & 6.2362 & 5.7222 & TST & \\
\hline CHEMBL1426548 & 688239 & 5.4362 & 5.5321 & TRN & \\
\hline CHEMBL1605969 & 688239 & 4.4862 & 5.36 & TRN & \\
\hline CHEMBL1573659 & 688239 & 8.28399 & 999999999 & 5.5108 & TRN \\
\hline CHEMBL586830 & 688239 & 5.3862 & 5.3425 & TRN & \\
\hline CHEMBL1595306 & 688239 & 4.6362 & 5.4092 & TRN & \\
\hline CHEMBL1417765 & 688239 & 6.8861 & 5.456 & TRN & \\
\hline CHEMBL1474677 & 688239 & 6.9863 & 5.5063 & TST & \\
\hline CHEMBL1363141 & 688239 & 5.5362 & 5.4861 & TRN & \\
\hline CHEMBL1572789 & 688239 & 4.8362 & 5.5482 & TST & \\
\hline CHEMBL1315696 & 688239 & 5.0862 & 5.4046 & TRN & \\
\hline CHEMBL1541595 & 688239 & 5.1862 & 5.6172 & TRN & \\
\hline CHEMBL1450770 & 688239 & 4.8362 & 5.4952 & TST & \\
\hline CHEMBL1521832 & 688239 & 7.2366 & 5.587999 & 9999999999 & TRN \\
\hline CHEMBL1431086 & 688239 & 6.8362 & 5.565 & TRN & \\
\hline CHEMBL1380173 & 688239 & 5.3862 & 5.4383 & TST & \\
\hline CHEMBL1316578 & 688239 & 4.5362 & 5.5476 & TRN & \\
\hline CHEMBL1496534 & 688239 & 4.6362 & 5.3963 & TST & \\
\hline CHEMBL1387559 & 688239 & 4.6862 & 5.4533 & TRN & \\
\hline CHEMBL1506685 & 688239 & 5.5362 & 5.4629 & TRN & \\
\hline CHEMBL1422473 & 688239 & 5.8862 & 5.447999 & 99999999995 & TRN \\
\hline CHEMBL1330281 & 688239 & 4.7862 & 5.385 & TRN & \\
\hline CHEMBL1413442 & 688239 & 4.5362 & 5.4759 & TRN & \\
\hline CHEMBL1349773 & 688239 & 4.6362 & 5.5377 & TRN & \\
\hline CHEMBL1312950 & 688239 & 5.1862 & 5.4195 & TRN & \\
\hline CHEMBL1506938 & 688239 & 4.5362 & 5.4223 & TST & \\
\hline CHEMBL1416163 & 688239 & 4.6362 & 5.4006 & TRN & \\
\hline CHEMBL1567118 & 688239 & 8.3372 & 5.5586 & TRN & \\
\hline CHEMBL1462270 & 688239 & 4.5362 & 5.3255 & TRN & \\
\hline CHEMBL1405015 & 688239 & 4.6862 & 5.4133 & TRN & \\
\hline
\end{tabular}


Supplemental Table S2.txt

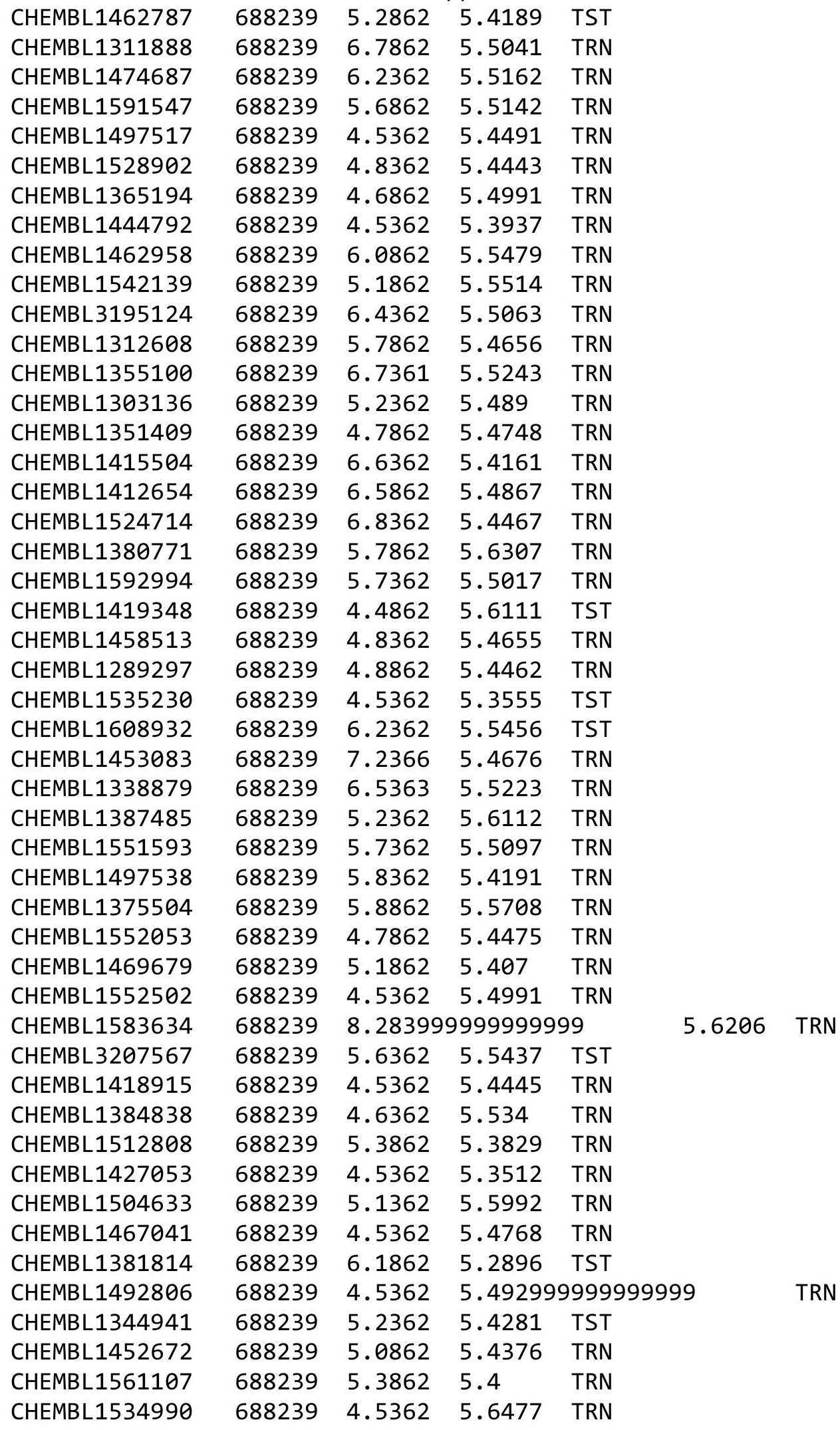

Page 1904 
Supplemental Table S2.txt

\begin{tabular}{|c|c|c|c|c|c|}
\hline CHEMBL1327771 & 688239 & 4.7362 & 5.5835 & TRN & \\
\hline CHEMBL1373862 & 688239 & 6.3863 & 5.5902 & TRN & \\
\hline CHEMBL1578474 & 688239 & 5.0362 & 5.4985 & TRN & \\
\hline CHEMBL1376127 & 688239 & 5.1862 & 5.5512 & TRN & \\
\hline CHEMBL1582276 & 688239 & 5.3862 & 5.4748 & TST & \\
\hline CHEMBL1439684 & 688239 & 5.3362 & 5.3926 & TRN & \\
\hline CHEMBL1536611 & 688239 & 4.7362 & 5.3998 & TRN & \\
\hline CHEMBL1358408 & 688239 & 8.3372 & 5.584 & TRN & \\
\hline CHEMBL1611380 & 688239 & 4.5362 & 5.5375 & TRN & \\
\hline CHEMBL1397073 & 688239 & 4.8862 & 5.4169 & TRN & \\
\hline CHEMBL1581277 & 688239 & 4.6362 & 5.3507 & TST & \\
\hline CHEMBL3191996 & 688239 & 5.0362 & 5.4912 & TRN & \\
\hline CHEMBL1546362 & 688239 & 5.1862 & 5.5276 & TRN & \\
\hline CHEMBL1582445 & 688239 & 5.4362 & 5.5068 & TRN & \\
\hline CHEMBL1468018 & 688239 & 4.5362 & 5.5019 & TST & \\
\hline CHEMBL1411987 & 688239 & 5.3862 & 5.6645 & TRN & \\
\hline CHEMBL1471984 & 688239 & 4.6862 & 5.5647 & TRN & \\
\hline CHEMBL1612303 & 688239 & 5.1862 & 5.5307 & TST & \\
\hline CHEMBL1504126 & 688239 & 4.5362 & 5.4213 & TRN & \\
\hline CHEMBL1542400 & 688239 & 5.4862 & 5.4193 & TRN & \\
\hline CHEMBL1341587 & 688239 & 5.1862 & 5.638 & TRN & \\
\hline CHEMBL1465535 & 688239 & 5.1862 & 5.3848 & TRN & \\
\hline CHEMBL1515653 & 688239 & 4.5362 & 5.4081 & TRN & \\
\hline CHEMBL1542221 & 688239 & 5.4362 & 5.3244 & TRN & \\
\hline CHEMBL1570119 & 688239 & 5.3362 & 5.3346 & TRN & \\
\hline CHEMBL1599579 & 688239 & 4.5362 & 5.3753 & TST & \\
\hline CHEMBL1351043 & 688239 & 4.7362 & 5.5161 & TRN & \\
\hline CHEMBL1377417 & 688239 & 4.8362 & 5.3156 & TRN & \\
\hline CHEMBL1608827 & 688239 & 8.2366 & 5.5023 & TRN & \\
\hline CHEMBL1586517 & 688239 & 6.1362 & 5.4559 & TRN & \\
\hline CHEMBL3209394 & 688239 & 4.6362 & 5.5091 & TRN & \\
\hline CHEMBL1441539 & 688239 & \multicolumn{4}{|c|}{8.283999999999999} \\
\hline CHEMBL1455263 & 688239 & 5.9862 & 5.5058 & TST & \\
\hline CHEMBL1534058 & 688239 & 4.5362 & 5.303999 & 9999999999 & $1 \mathrm{~N}$ \\
\hline CHEMBL1405701 & 688239 & 4.5362 & 5.4313 & TRN & \\
\hline CHEMBL1471612 & 688239 & 4.9862 & 5.3309 & TRN & \\
\hline CHEMBL1524934 & 688239 & 4.6362 & 5.3925 & TRN & \\
\hline CHEMBL1429334 & 688239 & 4.5362 & 5.5581 & TRN & \\
\hline CHEMBL1411963 & 688239 & 4.5862 & 5.596 & TRN & \\
\hline CHEMBL1589264 & 688239 & 4.5362 & 5.5556 & TST & \\
\hline CHEMBL570400 & 688239 & 5.0862 & 5.3269 & TRN & \\
\hline CHEMBL1544511 & 688239 & 4.6 & 5.2493 & TRN & \\
\hline CHEMBL1575682 & 688239 & 5.3362 & 5.4829 & TRN & \\
\hline CHEMBL1557703 & 688239 & 4.4862 & 5.4292 & TST & \\
\hline CHEMBL1471708 & 688239 & 4.8862 & 5.5407 & TRN & \\
\hline CHEMBL1347693 & 688239 & 7.0362 & 5.5605 & TST & \\
\hline CHEMBL1497452 & 688239 & 4.5362 & 5.4413 & TST & \\
\hline CHEMBL1314851 & 688239 & 4.5362 & 5.461 & TRN & \\
\hline
\end{tabular}


Supplemental Table S2.txt

\begin{tabular}{|c|c|c|c|c|}
\hline CHEMBL1389636 & 688239 & 4.5362 & 5.3662 & TST \\
\hline CHEMBL1374078 & 688239 & 4.5362 & 5.3576 & TRN \\
\hline CHEMBL1596310 & 688239 & 5.1862 & 5.4692 & TRN \\
\hline CHEMBL1334758 & 688239 & 5.1862 & 5.4871 & TRN \\
\hline CHEMBL1448248 & 688239 & 4.4862 & 5.5632 & TST \\
\hline CHEMBL1613447 & 688239 & 5.3862 & 5.4918 & TRN \\
\hline CHEMBL1583405 & 688239 & 6.6362 & 5.4838 & TST \\
\hline CHEMBL1395294 & 688239 & 5.4362 & 5.5308 & TRN \\
\hline CHEMBL1571642 & 688239 & 5.7362 & 5.4319 & TRN \\
\hline CHEMBL3195674 & 688239 & 4.5362 & 5.4953 & TRN \\
\hline CHEMBL1580977 & 688239 & 6.8362 & 5.3613 & TST \\
\hline CHEMBL1400232 & 688239 & 8.28399 & 99999999 & 5.5622 \\
\hline CHEMBL1594211 & 688239 & 6.8362 & 5.4365 & TST \\
\hline CHEMBL1611412 & 688239 & 5.1862 & 5.4379 & TRN \\
\hline CHEMBL1347385 & 688239 & 4.5362 & 5.3784 & TST \\
\hline CHEMBL1592034 & 688239 & 4.9862 & 5.4824 & TRN \\
\hline CHEMBL1360948 & 688239 & 6.0862 & 5.4101 & TRN \\
\hline CHEMBL1522085 & 688239 & 4.5862 & 5.5399 & TRN \\
\hline CHEMBL3212560 & 688239 & 4.8862 & 5.3692 & TRN \\
\hline CHEMBL1367986 & 688239 & 4.5362 & 5.4458 & TST \\
\hline CHEMBL1515996 & 688239 & 5.6862 & 5.4829 & TRN \\
\hline CHEMBL1336965 & 688239 & 5.6862 & 5.5793 & TRN \\
\hline CHEMBL3199893 & 688239 & 4.5362 & 5.308 & TRN \\
\hline CHEMBL1325188 & 688239 & 5.1862 & 5.5533 & TST \\
\hline CHEMBL1523762 & 688239 & 7.0362 & 5.5262 & TST \\
\hline CHEMBL1598509 & 688239 & 8.2366 & 5.4968 & TRN \\
\hline CHEMBL1511144 & 688239 & 4.8862 & 5.4384 & TRN \\
\hline CHEMBL1545994 & 688239 & 4.5362 & 5.5345 & TRN \\
\hline CHEMBL1445945 & 688239 & 5.4362 & 5.5124 & TST \\
\hline CHEMBL1545642 & 688239 & 4.5362 & 5.547000 & 3000000001 \\
\hline CHEMBL1494348 & 688239 & 4.5862 & 5.5362 & TRN \\
\hline CHEMBL1467421 & 688239 & 4.7362 & 5.4881 & TRN \\
\hline CHEMBL1410652 & 688239 & 7.2366 & 5.4238 & TST \\
\hline CHEMBL1453915 & 688239 & 6.5862 & 5.5057 & TRN \\
\hline CHEMBL1452312 & 688239 & 5.9862 & 5.4246 & TST \\
\hline CHEMBL1524559 & 688239 & 5.4862 & 5.2945 & TRN \\
\hline CHEMBL1327231 & 688239 & 6.1362 & 5.5071 & TST \\
\hline CHEMBL1382074 & 688239 & 5.1862 & 5.5984 & TST \\
\hline CHEMBL1336041 & 688239 & 4.9362 & 5.5917 & TRN \\
\hline CHEMBL1424044 & 688239 & 5.1862 & 5.504 & TRN \\
\hline CHEMBL1429732 & 688239 & 4.5362 & 5.6699 & TRN \\
\hline CHEMBL1529715 & 688239 & 5.9362 & 5.581 & TRN \\
\hline CHEMBL1398491 & 688239 & 5.2362 & 5.4728 & TRN \\
\hline CHEMBL1378789 & 688239 & 5.2362 & 5.5269 & TRN \\
\hline CHEMBL1389653 & 688239 & 4.5362 & 5.2985 & TST \\
\hline CHEMBL1370019 & 688239 & 6.7862 & 5.5446 & TRN \\
\hline CHEMBL1572726 & 688239 & 5.1862 & 5.605 & TST \\
\hline CHEMBL1375883 & 688239 & 6.6362 & 5.4218 & TST \\
\hline
\end{tabular}


Supplemental Table S2.txt

\begin{tabular}{|c|c|c|c|c|c|}
\hline CHEMBL1569371 & 688239 & 5.8862 & \multicolumn{2}{|c|}{5.457999999999999} & TRN \\
\hline CHEMBL1423204 & 688239 & 4.9362 & 5.5896 & TST & \\
\hline CHEMBL1439750 & 688239 & 5.5862 & 5.691 & TRN & \\
\hline CHEMBL1451439 & 688239 & 4.4862 & 5.6002 & TRN & \\
\hline CHEMBL1325462 & 688239 & 4.7362 & 5.6274 & TRN & \\
\hline CHEMBL3197679 & 688239 & 4.7862 & 5.2817 & TRN & \\
\hline CHEMBL1573717 & 688239 & 5.1862 & 5.4355 & TRN & \\
\hline CHEMBL1607547 & 688239 & 6.1862 & 5.487999 & 99999999995 & \\
\hline CHEMBL1467554 & 688239 & 4.5362 & 5.4113 & TRN & \\
\hline CHEMBL1457261 & 688239 & 4.7362 & 5.5236 & TRN & \\
\hline CHEMBL1386069 & 688239 & 6.5363 & 5.601 & TRN & \\
\hline CHEMBL462430 & 688239 & 5.1862 & 5.5351 & TRN & \\
\hline CHEMBL1343268 & 688239 & 6.2362 & 5.6133 & TRN & \\
\hline CHEMBL1594377 & 688239 & 5.0362 & 5.5891 & TRN & \\
\hline CHEMBL1353114 & 688239 & 4.4862 & 5.5577 & TST & \\
\hline CHEMBL1379677 & 688239 & 4.5362 & 5.5162 & TRN & \\
\hline CHEMBL1577267 & 688239 & 6.3362 & 5.565 & TRN & \\
\hline CHEMBL1572822 & 688239 & 4.8362 & 5.4245 & TST & \\
\hline CHEMBL1613004 & 688239 & 5.1862 & 5.3988 & TST & \\
\hline CHEMBL1376613 & 688239 & 6.2362 & 5.3114 & TST & \\
\hline CHEMBL1530041 & 688239 & 4.6862 & 5.5088 & TRN & \\
\hline CHEMBL1374255 & 688239 & 6.5363 & 5.5137 & TRN & \\
\hline CHEMBL1394637 & 688239 & 4.7862 & 5.4121 & TRN & \\
\hline CHEMBL1526867 & 688239 & 6.1362 & 5.474 & TST & \\
\hline CHEMBL1499400 & 688239 & 7.0362 & 5.6677 & TST & \\
\hline CHEMBL1600363 & 688239 & 4.8362 & 5.4746 & TRN & \\
\hline CHEMBL1584426 & 688239 & 4.5362 & 5.4855 & TRN & \\
\hline CHEMBL1348609 & 688239 & 5.1862 & 5.3008 & TRN & \\
\hline CHEMBL1375294 & 688239 & 6.5363 & 5.4617 & TRN & \\
\hline CHEMBL1555714 & 688239 & 5.1862 & 5.5593 & TRN & \\
\hline CHEMBL1455476 & 688239 & 8.3372 & 5.4219 & TRN & \\
\hline CHEMBL1483271 & 688239 & 4.5362 & 5.512000 & 00000000005 & \\
\hline CHEMBL1560325 & 688239 & 4.5362 & 5.4752 & TRN & \\
\hline CHEMBL1327463 & 688239 & 6.1362 & 5.4916 & TRN & \\
\hline CHEMBL1378641 & 688239 & 5.6362 & 5.3771 & TST & \\
\hline CHEMBL1553538 & 688239 & 5.1862 & 5.4578 & TRN & \\
\hline CHEMBL1323222 & 688239 & 6.5363 & 5.4771 & TRN & \\
\hline CHEMBL1339533 & 688239 & 5.6362 & 5.4436 & TST & \\
\hline CHEMBL1436595 & 688239 & 8.3372 & 5.3733 & TST & \\
\hline CHEMBL1478039 & 688239 & 4.5862 & 5.5103 & TRN & \\
\hline CHEMBL1461791 & 688239 & 5.1862 & 5.4961 & TRN & \\
\hline CHEMBL1412713 & 688239 & 8.28399 & 999999999 & 5.5607 & \\
\hline CHEMBL1599387 & 688239 & 4.7362 & 5.4189 & TRN & \\
\hline CHEMBL1560491 & 688239 & 6.0862 & 5.3709 & TRN & \\
\hline CHEMBL1366402 & 688239 & 5.7862 & 5.4387 & TRN & \\
\hline CHEMBL1377137 & 688239 & 5.1362 & 5.4665 & TRN & \\
\hline CHEMBL1399820 & 688239 & 6.9363 & 5.5969 & TRN & \\
\hline CHEMBL1502506 & 688239 & 5.2362 & 5.5887 & TRN & \\
\hline
\end{tabular}


Supplemental Table S2.txt

\begin{tabular}{|c|c|c|c|c|}
\hline CHEMBL1525513 & 688239 & 4.7862 & 5.5294 & TRN \\
\hline CHEMBL1540391 & 688239 & 4.6362 & 5.2199 & TRN \\
\hline CHEMBL1367306 & 688239 & 4.5362 & 5.5184 & TRN \\
\hline CHEMBL1509215 & 688239 & 4.7362 & 5.592006 & 0000000005 \\
\hline CHEMBL1503645 & 688239 & 5.8362 & 5.4677 & TRN \\
\hline CHEMBL1515702 & 688239 & 4.7862 & 5.4216 & TRN \\
\hline CHEMBL1539087 & 688239 & 4.5362 & 5.4147 & TRN \\
\hline CHEMBL1418045 & 688239 & 4.5362 & 5.5864 & TRN \\
\hline CHEMBL1327177 & 688239 & 4.7362 & 5.4867 & TRN \\
\hline CHEMBL1431007 & 688239 & 4.5362 & 5.3629 & TST \\
\hline CHEMBL1451634 & 688239 & 5.1862 & 5.5595 & TRN \\
\hline CHEMBL1429604 & 688239 & 4.7362 & 5.5227 & TRN \\
\hline CHEMBL1538497 & 688239 & 6.6861 & 5.3627 & TRN \\
\hline CHEMBL1392953 & 688239 & 6.9363 & 5.5208 & TRN \\
\hline CHEMBL1470377 & 688239 & 5.7862 & 5.4707 & TST \\
\hline CHEMBL1538250 & 688239 & 4.6362 & 5.4753 & TRN \\
\hline CHEMBL1586771 & 688239 & 5.1362 & 5.3311 & TRN \\
\hline CHEMBL1411719 & 688239 & 4.5362 & 5.4042 & TST \\
\hline CHEMBL 3208238 & 688239 & 5.7362 & 5.4295 & TRN \\
\hline CHEMBL1482084 & 688239 & 4.6362 & 5.4761 & TST \\
\hline CHEMBL1347168 & 688239 & 6.0862 & 5.5815 & TRN \\
\hline CHEMBL1464290 & 688239 & 4.45 & 5.6068 & TRN \\
\hline CHEMBL1579396 & 688239 & 6.6362 & 5.5824 & TRN \\
\hline CHEMBL1584486 & 688239 & 7.0362 & 5.4997 & TST \\
\hline CHEMBL1507115 & 688239 & 6.8362 & 5.6505 & TRN \\
\hline CHEMBL1440622 & 688239 & 5.0862 & 5.3842 & TRN \\
\hline CHEMBL1337549 & 688239 & 4.7862 & 5.5854 & TRN \\
\hline CHEMBL1439768 & 688239 & 5.9362 & 5.5436 & TRN \\
\hline CHEMBL3198854 & 688239 & 5.7362 & 5.4268 & TRN \\
\hline CHEMBL1415327 & 688239 & 5.5362 & 5.4909 & TST \\
\hline CHEMBL3212763 & 688239 & 5.6862 & 5.473 & TRN \\
\hline CHEMBL1359463 & 688239 & 4.5362 & 5.612 & TRN \\
\hline CHEMBL1414195 & 688239 & 4.6862 & 5.4789 & TRN \\
\hline CHEMBL1581267 & 688239 & 8.3372 & 5.4853 & TRN \\
\hline CHEMBL1467019 & 688239 & 5.3862 & 5.4492 & TRN \\
\hline CHEMBL1391527 & 688239 & 4.6362 & 5.3297 & TRN \\
\hline CHEMBL1352607 & 688239 & 5.0862 & 5.4274 & TRN \\
\hline CHEMBL1478036 & 688239 & 6.4862 & 5.4856 & TST \\
\hline CHEMBL1543658 & 688239 & 6.4862 & 5.4792 & TRN \\
\hline CHEMBL1522869 & 688239 & 4.5362 & 5.4334 & TST \\
\hline CHEMBL1476349 & 688239 & 5.6862 & 5.3475 & TST \\
\hline CHEMBL1610772 & 688239 & 5.4362 & 5.3619 & TST \\
\hline CHEMBL1532781 & 688239 & 5.1862 & 5.309 & TRN \\
\hline CHEMBL1460151 & 688239 & 4.5362 & 5.314 & TRN \\
\hline CHEMBL1547842 & 688239 & 4.8862 & 5.6962 & TRN \\
\hline CHEMBL1578804 & 688239 & 6.1862 & 5.6454 & TRN \\
\hline CHEMBL1400933 & 688239 & 4.8362 & 5.4549 & TRN \\
\hline CHEMBL1349014 & 688239 & 5.4362 & 5.5408 & TRN \\
\hline
\end{tabular}


Supplemental Table S2.txt

\begin{tabular}{|c|c|c|c|c|c|c|}
\hline CHEMBL1311570 & 688239 & 4.5362 & 5.5213 & TRN & & \\
\hline CHEMBL1439558 & 688239 & 6.2362 & 5.6539 & TRN & & \\
\hline CHEMBL1587957 & 688239 & 4.5362 & 5.5651 & TRN & & \\
\hline CHEMBL1549547 & 688239 & 4.5362 & \multicolumn{3}{|c|}{5.507000000000001} & 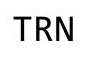 \\
\hline CHEMBL269317 & 688239 & 8.28399 & 99999999 & & 5.605 & \\
\hline CHEMBL1512736 & 688239 & 5.3362 & 5.5503 & TRN & & \\
\hline CHEMBL1310303 & 688239 & 5.1362 & 5.461 & TRN & & \\
\hline CHEMBL1439634 & 688239 & 6.3362 & 5.4083 & TRN & & \\
\hline CHEMBL1582052 & 688239 & 4.5362 & 5.5037 & TRN & & \\
\hline CHEMBL1434976 & 688239 & 5.1862 & 5.4608 & TRN & & \\
\hline CHEMBL1542989 & 688239 & 4.6862 & 5.5267 & TRN & & \\
\hline CHEMBL1537988 & 688239 & 4.6362 & 5.6009 & TRN & & \\
\hline CHEMBL 3213744 & 688239 & 5.4362 & 5.5108 & TRN & & \\
\hline CHEMBL1535782 & 688239 & 4.7362 & 5.3532 & TRN & & \\
\hline CHEMBL1537721 & 688239 & 5.1862 & 5.3813 & TRN & & \\
\hline CHEMBL1381683 & 688239 & 5.3362 & 5.4983 & TRN & & \\
\hline CHEMBL1448690 & 688239 & 5.3362 & 5.4415 & TRN & & \\
\hline CHEMBL1337704 & 688239 & 6.6362 & 5.3904 & TRN & & \\
\hline CHEMBL1448183 & 688239 & 5.7362 & 5.4144 & TRN & & \\
\hline CHEMBL1408775 & 688239 & 5.1862 & 5.5164 & TRN & & \\
\hline CHEMBL1575502 & 688239 & 5.6862 & 5.3261 & TRN & & \\
\hline CHEMBL1498997 & 688239 & 4.7362 & 5.3721 & TRN & & \\
\hline CHEMBL1438722 & 688239 & 4.4862 & 5.5035 & TST & & \\
\hline CHEMBL1450622 & 688239 & 5.1862 & 5.3263 & TRN & & \\
\hline CHEMBL1612107 & 688239 & 5.6362 & 5.5147 & TRN & & \\
\hline CHEMBL1451043 & 688239 & 4.6362 & 5.5223 & TRN & & \\
\hline CHEMBL1559671 & 688239 & 4.8362 & 5.377000 & 0000000001 & & \\
\hline CHEMBL1358213 & 688239 & 4.8862 & 5.5575 & TRN & & \\
\hline CHEMBL1442043 & 688239 & 4.6862 & 5.5935 & TRN & & \\
\hline CHEMBL1317667 & 688239 & 4.6862 & 5.5294 & TRN & & \\
\hline CHEMBL1390891 & 688239 & 6.3863 & 5.4349 & TST & & \\
\hline CHEMBL1527367 & 688239 & 6.5363 & 5.5115 & TST & & \\
\hline CHEMBL1353821 & 688239 & 4.8362 & 5.3399 & TRN & & \\
\hline CHEMBL1423511 & 688239 & 8.28399 & 99999999 & 99 & 5.6607 & \\
\hline CHEMBL1314481 & 688239 & 4.6362 & 5.379 & TRN & & \\
\hline CHEMBL597888 & 688239 & 4.6362 & 5.526 & TRN & & \\
\hline CHEMBL1612378 & 688239 & 6.5862 & 5.5157 & TRN & & \\
\hline CHEMBL1584252 & 688239 & 5.7362 & 5.4707 & TRN & & \\
\hline CHEMBL1463476 & 688239 & 4.5362 & 5.3825 & TRN & & \\
\hline CHEMBL1572872 & 688239 & 4.5362 & 5.5228 & TRN & & \\
\hline CHEMBL1464227 & 688239 & 4.5862 & 5.4299 & TRN & & \\
\hline CHEMBL3209262 & 688239 & 4.5362 & 5.3694 & TRN & & \\
\hline CHEMBL1347253 & 688239 & 6.4862 & 5.564 & TRN & & \\
\hline CHEMBL1464879 & 688239 & 6.4862 & 5.6191 & TRN & & \\
\hline CHEMBL1544491 & 688239 & 4.5362 & 5.4891 & TRN & & \\
\hline CHEMBL1491807 & 688239 & 5.8862 & 5.494 & TRN & & \\
\hline CHEMBL1385757 & 688239 & 4.5362 & 5.6121 & TST & & \\
\hline CHEMBL1430023 & 688239 & 6.1862 & 5.4394 & TRN & & \\
\hline
\end{tabular}


Supplemental Table S2.txt

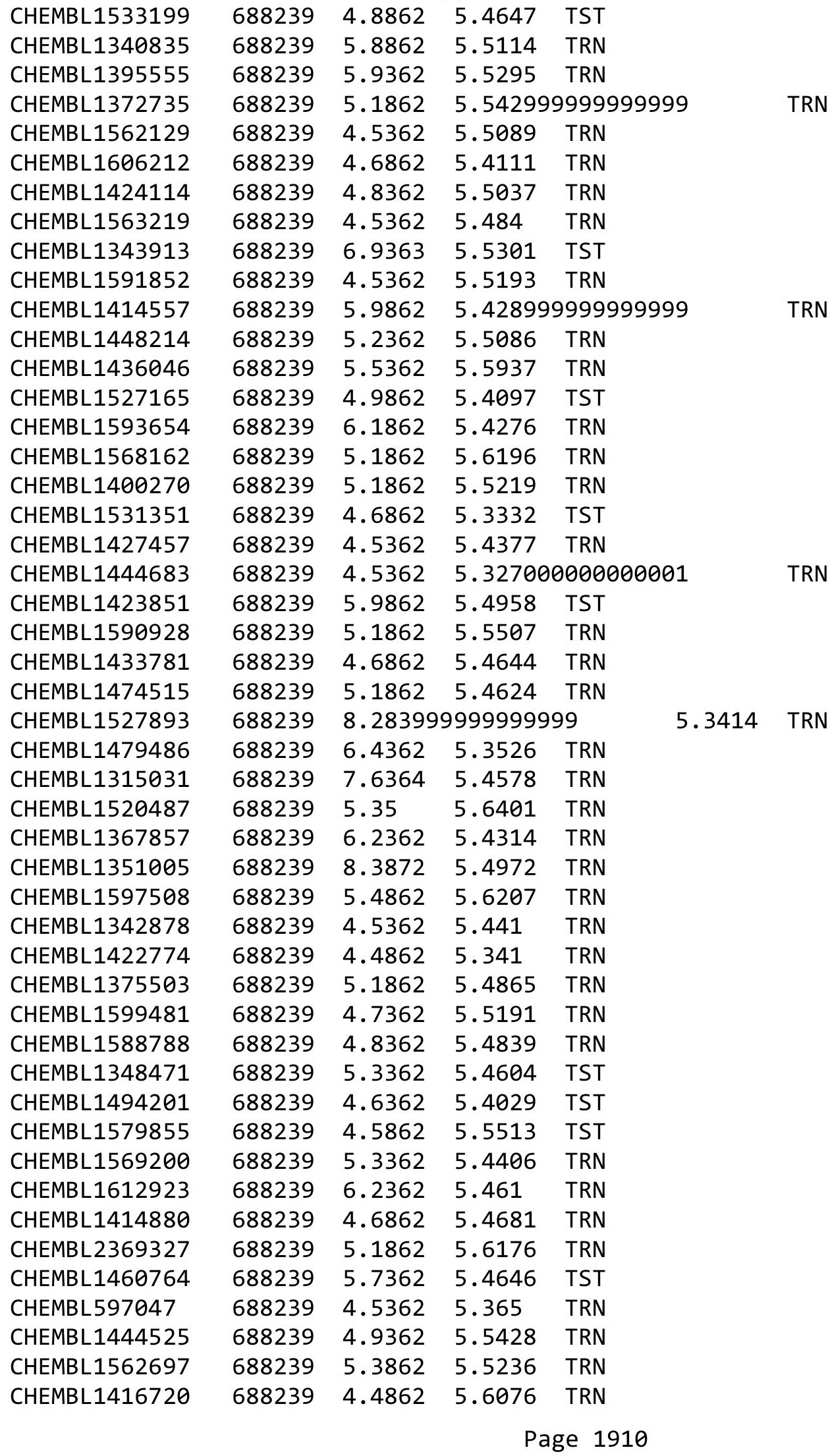




\begin{tabular}{|c|c|c|c|c|}
\hline & & & & \\
\hline MBL1511080 & 88 & 362 & 03 & TST \\
\hline CHEMBL1467215 & 688239 & 4.5362 & 5.5062 & \\
\hline AEMBL3194416 & 88239 & 3362 & & \\
\hline HEMBL3214099 & 88239 & 4.5362 & 4001 & \\
\hline HEMBL1548575 & 88239 & 5.5862 & & \\
\hline HEMBL1367941 & 38239 & 362 & 952 & \\
\hline HEMBL1583658 & 688239 & 862 & 5243 & \\
\hline HEMBL1556603 & 88239 & 6.2362 & 3333 & \\
\hline CHEMBL1555837 & 688 & 862 & 119 & \\
\hline HEMBL15 & 39 & 862 & 204 & \\
\hline HEMBL14 & 39 & 362 & 5.3576 & \\
\hline HEMBL1520412 & 688239 & 7.0862 & 5.4115 & \\
\hline HEMBL1479269 & 39 & 362 & 737 & \\
\hline HEMBL1 & $68 \varepsilon$ & 862 & 5.5159 & \\
\hline HEMBL: & 39 & 362 & 064 & \\
\hline HEMBL: & 68 & 362 & 856 & \\
\hline HEMBL & $68 \varepsilon$ & 362 & 5.6053 & \\
\hline HEMBL1: & $68 \varepsilon$ & 362 & 442 & \\
\hline HEMBL: & 68 & 52 & 286 & \\
\hline HEMBL: & 9 & 62 & 761 & \\
\hline HEMBL: & 39 & 62 & 035 & \\
\hline HEMBL: & 688 & 362 & 747 & \\
\hline CHEMBL 1 & 68 & 362 & 051 & \\
\hline CHEMBL & 68 & 62 & 702 & \\
\hline CHEMBL & 9 & 62 & 204 & \\
\hline HFMBI & 39 & 62 & 508 & \\
\hline HEMBL: & 68 & 362 & 076 & \\
\hline CHEMBL13 & 68 & 62 & 577 & \\
\hline CHEMBL15 & 688 & 362 & 5.4496 & \\
\hline CHEMBL1 & 39 & 62 & 755 & \\
\hline CHEMBL & & 72 & 442 & \\
\hline HEMBL: & 688 & & 211 & \\
\hline CHEMBL1436078 & 688 & 362 & 473 & \\
\hline CHEMBL 1 & 68 & 62 & 075 & \\
\hline CHEMBL & 688 & 62 & 5.4331 & \\
\hline & & & 327 & \\
\hline CHEMBL1 & 688 & 362 & 5.3179 & $\mathrm{TS}$ \\
\hline CHEMBL1 & 39 & 4.8362 & 491 & \\
\hline CHEMBL & 68 & & 958 & Tा \\
\hline CHEMBL 1 & $68 \varepsilon$ & 52 & 5.4479 & $T$ \\
\hline CHEMBL1 & 688 & 362 & 5.6002 & $\mathrm{TR}$ \\
\hline CHEMBL1 & 688239 & 362 & 5.364 & $\mathrm{TP}$ \\
\hline CHEMBL 1 & 688 & 67 & 103 & TR \\
\hline CHEMBL15 & & & 5.4898 & \\
\hline CHEMBL13. & 688239 & 4.6862 & 5.5613 & \\
\hline CHEMBL1476482 & 688239 & 5.1862 & 5.4205 & TR \\
\hline CHEMBL1426879 & 688 & 6.0362 & 5.5072 & TR \\
\hline CHEMBL1523833 & 688239 & 5.5862 & 5.4509 & $\mathrm{R}$ \\
\hline
\end{tabular}

Page 1911 
Supplemental Table S2.txt

\begin{tabular}{|c|c|c|c|c|}
\hline CHEMBL1520735 & 688239 & 5.5862 & 5.3875 & TRN \\
\hline CHEMBL1998652 & 688239 & 6.9363 & 5.3741 & TRN \\
\hline CHEMBL1583749 & 688239 & 6.2362 & 5.6313 & TRN \\
\hline CHEMBL1497862 & 688239 & 5.9862 & 5.4558 & TRN \\
\hline CHEMBL1350216 & 688239 & 6.1362 & 5.441 & TST \\
\hline CHEMBL1515479 & 688239 & 7.1361 & 5.4202 & TRN \\
\hline CHEMBL1405677 & 688239 & 6.3362 & 5.4172 & TRN \\
\hline CHEMBL1573428 & 688239 & 5.6362 & 5.496 & TRN \\
\hline CHEMBL1569735 & 688239 & 4.6862 & \multicolumn{2}{|c|}{5.5120000000000005} \\
\hline CHEMBL1563859 & 688239 & 6.0362 & 5.4452 & TRN \\
\hline CHEMBL1521908 & 688239 & 6.8861 & 5.4853 & TRN \\
\hline CHEMBL1357144 & 688239 & 5.1862 & 5.6023 & TRN \\
\hline CHEMBL1980600 & 688239 & 4.7862 & 5.2968 & TST \\
\hline CHEMBL1423111 & 688239 & 4.6362 & 5.3473 & TST \\
\hline CHEMBL1466671 & 688239 & 5.1862 & 5.5824 & TRN \\
\hline CHEMBL1507105 & 688239 & 6.8861 & 5.4407 & TST \\
\hline CHEMBL1453033 & 688239 & 4.5362 & 5.5944 & TRN \\
\hline CHEMBL1471298 & 688239 & 6.0362 & 5.3806 & TRN \\
\hline CHEMBL1588844 & 688239 & 4.8862 & 5.4713 & TRN \\
\hline CHEMBL1602242 & 688239 & 5.9362 & 5.5473 & TRN \\
\hline CHEMBL1525178 & 688239 & 6.1862 & 5.5462 & TST \\
\hline CHEMBL1548649 & 688239 & 4.4862 & 5.4871 & TRN \\
\hline CHEMBL269277 & 688239 & 5.4862 & 5.4014 & TST \\
\hline CHEMBL1584590 & 688239 & 5.6362 & 5.6237 & TRN \\
\hline CHEMBL1336775 & 688239 & 4.6362 & 5.4163 & TST \\
\hline CHEMBL1496948 & 688239 & 4.4862 & 5.4899 & TRN \\
\hline CHEMBL1579381 & 688239 & 5.4362 & \multicolumn{2}{|c|}{5.571000000000001} \\
\hline CHEMBL1510635 & 688239 & 6.0362 & 5.3947 & TRN \\
\hline CHEMBL1381672 & 688239 & 4.7862 & 5.5677 & TRN \\
\hline CHEMBL1550328 & 688239 & 4.7862 & 5.6285 & TRN \\
\hline CHEMBL3199479 & 688239 & 4.9362 & 5.3054 & TRN \\
\hline CHEMBL1582540 & 688239 & 5.6362 & 5.4561 & TST \\
\hline CHEMBL1325065 & 688239 & 5.1862 & 5.5496 & TST \\
\hline CHEMBL1579891 & 688239 & 5.1862 & 5.5308 & TST \\
\hline CHEMBL3209047 & 688239 & 6.6861 & 5.3727 & TRN \\
\hline CHEMBL1401466 & 688239 & 4.5362 & 5.6113 & TRN \\
\hline CHEMBL3197300 & 688239 & 5.1862 & 5.3632 & TRN \\
\hline CHEMBL3195766 & 688239 & 6.8861 & 5.5154 & TRN \\
\hline CHEMBL1426061 & 688239 & 5.1862 & 5.5149 & TRN \\
\hline CHEMBL1597571 & 688239 & 4.9362 & 5.4212 & TRN \\
\hline CHEMBL1513616 & 688239 & 5.1362 & 5.428 & TRN \\
\hline CHEMBL1375551 & 688239 & 5.8362 & 5.5942 & TRN \\
\hline CHEMBL1335878 & 688239 & 8.1871 & 5.6418 & TRN \\
\hline CHEMBL1414419 & 688239 & 4.9362 & 5.4723 & TST \\
\hline CHEMBL1363797 & 688239 & 5.1862 & 5.4573 & TRN \\
\hline CHEMBL1517983 & 688239 & 4.7862 & 5.3244 & TRN \\
\hline CHEMBL1365748 & 688239 & 4.8362 & 5.5372 & TRN \\
\hline CHEMBL1410604 & 688239 & 6.1362 & 5.5369 & TRN \\
\hline
\end{tabular}

Page 1912 
Supplemental Table S2.txt

\begin{tabular}{|c|c|c|c|c|c|}
\hline CHEMBL581574 & 688239 & 4.5362 & 5.5061 & TRN & \\
\hline CHEMBL1422571 & 688239 & 5.1862 & 5.4401 & TRN & \\
\hline CHEMBL1389759 & 688239 & 5.2862 & 5.5198 & TST & \\
\hline CHEMBL1380447 & 688239 & 4.6862 & 5.539 & TRN & \\
\hline CHEMBL1423334 & 688239 & 6.7862 & 5.4993 & TST & \\
\hline CHEMBL1505812 & 688239 & 6.1362 & 5.4591 & TST & \\
\hline CHEMBL1547531 & 688239 & 5.1862 & 5.5178 & TRN & \\
\hline CHEMBL1469766 & 688239 & 6.0362 & 5.6094 & TRN & \\
\hline CHEMBL1448326 & 688239 & 5.4362 & 5.4411 & TRN & \\
\hline CHEMBL1372464 & 688239 & 5.3362 & 5.2649 & TRN & \\
\hline CHEMBL1431504 & 688239 & 5.4862 & 5.5269 & TRN & \\
\hline CHEMBL1449236 & 688239 & 5.1862 & 5.3349 & TST & \\
\hline CHEMBL1572863 & 688239 & 5.0362 & 5.44 & TRN & \\
\hline CHEMBL1480556 & 688239 & 4.6862 & 5.4353 & TRN & \\
\hline CHEMBL1392561 & 688239 & 7.6364 & 5.5593 & TRN & \\
\hline CHEMBL1321449 & 688239 & 4.7362 & 5.3342 & TRN & \\
\hline CHEMBL1384907 & 688239 & 5.6362 & 5.5864 & TRN & \\
\hline CHEMBL1492433 & 688239 & 5.4862 & 5.4806 & TST & \\
\hline CHEMBL1598341 & 688239 & 4.5362 & 5.553 & TST & \\
\hline CHEMBL1478986 & 688239 & 7.5361 & 5.4463 & TRN & \\
\hline CHEMBL1388201 & 688239 & 4.7362 & 5.51399 & 9999999999 & TRN \\
\hline CHEMBL1331486 & 688239 & 4.7362 & 5.5799 & TRN & \\
\hline CHEMBL1995997 & 688239 & 5.2362 & 5.3929 & TRN & \\
\hline CHEMBL1594415 & 688239 & 5.3362 & 5.4903 & TRN & \\
\hline CHEMBL1341739 & 688239 & 6.2862 & 5.4102 & TRN & \\
\hline CHEMBL1484909 & 688239 & 6.3362 & 5.3058 & TST & \\
\hline CHEMBL1469931 & 688239 & 4.4862 & 5.4107 & TRN & \\
\hline CHEMBL1377596 & 688239 & 5.3362 & 5.551 & TRN & \\
\hline CHEMBL1501758 & 688239 & 6.8861 & 5.4873 & TRN & \\
\hline CHEMBL1561189 & 688239 & 5.7362 & 5.5618 & TRN & \\
\hline CHEMBL1346863 & 688239 & 4.5362 & 5.6626 & TST & \\
\hline CHEMBL1609077 & 688239 & 5.0362 & 5.4563 & TRN & \\
\hline CHEMBL1572666 & 688239 & 5.3862 & 5.4549 & TRN & \\
\hline CHEMBL1389782 & 688239 & 5.6862 & 5.5933 & TRN & \\
\hline CHEMBL1338761 & 688239 & 4.7862 & 5.5812 & TRN & \\
\hline CHEMBL1613118 & 688239 & 5.5362 & 5.599 & TRN & \\
\hline CHEMBL1449335 & 688239 & 5.8362 & 5.3793 & TRN & \\
\hline CHEMBL1503381 & 688239 & 4.5362 & 5.2502 & TST & \\
\hline CHEMBL1516663 & 688239 & 6.2862 & 5.4634 & TRN & \\
\hline CHEMBL1590826 & 688239 & 5.1362 & 5.4864 & TRN & \\
\hline CHEMBL3210227 & 688239 & 5.1862 & 5.4875 & TRN & \\
\hline CHEMBL1326019 & 688239 & 4.8862 & 5.6398 & TRN & \\
\hline CHEMBL1426979 & 688239 & 4.5362 & 5.4838 & TST & \\
\hline CHEMBL1500822 & 688239 & 5.1362 & 5.5053 & TRN & \\
\hline CHEMBL1609407 & 688239 & 5.1862 & 5.4237 & TRN & \\
\hline CHEMBL1586704 & 688239 & 4.5362 & 5.4346 & TRN & \\
\hline CHEMBL1588417 & 688239 & 5.4862 & 5.2563 & TRN & \\
\hline CHEMBL1401934 & 688239 & 4.5362 & 5.4156 & TRN & \\
\hline
\end{tabular}




\begin{tabular}{|c|c|c|c|c|c|}
\hline \multicolumn{6}{|c|}{ Supplemental Table S2.txt } \\
\hline CHEMBL1459830 & 688239 & 5.3862 & 5.5233 & TRN & \\
\hline CHEMBL1564658 & 688239 & 5.8862 & 5.4794 & TST & \\
\hline CHEMBL1417080 & 688239 & 4.5362 & 5.465 & TST & \\
\hline CHEMBL1595295 & 688239 & 5.0862 & 5.3698 & TRN & \\
\hline CHEMBL1393402 & 688239 & 4.6862 & 5.6122 & TRN & \\
\hline CHEMBL1363962 & 688239 & 6.2362 & 5.615 & TRN & \\
\hline CHEMBL1301777 & 688239 & 7.1864 & 5.41 & TST & \\
\hline CHEMBL1580005 & 688239 & 5.1862 & 5.4983 & TRN & \\
\hline CHEMBL1563907 & 688239 & 6.3362 & 5.5436 & TST & \\
\hline CHEMBL1572178 & 688239 & 4.6362 & 5.5236 & TRN & \\
\hline CHEMBL3210844 & 688239 & 6.1862 & 5.4415 & TST & \\
\hline CHEMBL 249987 & 688239 & 5.1362 & 5.4781 & TRN & \\
\hline CHEMBL1546623 & 688239 & 4.6862 & 5.4537 & TRN & \\
\hline CHEMBL1453435 & 688239 & 6.7862 & 5.4287 & TRN & \\
\hline CHEMBL1341066 & 688239 & 4.5362 & 5.5935 & TST & \\
\hline CHEMBL1300438 & 688239 & 6.1862 & 5.6849 & TRN & \\
\hline CHEMBL1514127 & 688239 & 4.7862 & 5.4598 & TRN & \\
\hline CHEMBL1524621 & 688239 & 4.7862 & 5.54700 & 0000000001 & TRN \\
\hline CHEMBL1322679 & 688239 & 5.6362 & 5.5675 & TRN & \\
\hline CHEMBL1606979 & 688239 & 4.5362 & 5.5401 & TRN & \\
\hline CHEMBL1544803 & 688239 & 4.5362 & 5.4269 & TRN & \\
\hline CHEMBL1436033 & 688239 & 6.1862 & 5.6373 & TRN & \\
\hline CHEMBL1389205 & 688239 & 6.3362 & 5.4135 & TRN & \\
\hline CHEMBL1571244 & 688239 & 5.5362 & 5.4128 & TST & \\
\hline CHEMBL1499936 & 688239 & 7.0362 & 5.5841 & TRN & \\
\hline CHEMBL1311910 & 688239 & 5.6362 & 5.4311 & TRN & \\
\hline CHEMBL1307184 & 688239 & 5.3362 & 5.4957 & TRN & \\
\hline CHEMBL1527164 & 688239 & 5.1862 & 5.5948 & TRN & \\
\hline CHEMBL1299871 & 688239 & 5.5862 & 5.5403 & TST & \\
\hline CHEMBL1321325 & 688239 & 5.6362 & 5.57799 & 9999999999 & TRN \\
\hline CHEMBL1377793 & 688239 & 5.6862 & 5.5435 & TRN & \\
\hline CHEMBL3214157 & 688239 & 4.7362 & 5.3444 & TRN & \\
\hline CHEMBL1446178 & 688239 & 5.1862 & 5.4473 & TRN & \\
\hline CHEMBL 3198844 & 688239 & 5.8362 & 5.4865 & TRN & \\
\hline CHEMBL1375258 & 688239 & 4.8362 & 5.6426 & TST & \\
\hline CHEMBL1479497 & 688239 & 6.8861 & 5.5678 & TRN & \\
\hline CHEMBL1346525 & 688239 & 5.0862 & 5.5519 & TRN & \\
\hline CHEMBL1490272 & 688239 & 8.28399 & 99999999 & 5.4775 & TRN \\
\hline CHEMBL1335745 & 688239 & 4.5362 & 5.4784 & TRN & \\
\hline CHEMBL1470010 & 688239 & 4.5362 & 5.6586 & TRN & \\
\hline CHEMBL1329995 & 688239 & 4.6862 & 5.4255 & TST & \\
\hline CHEMBL1362934 & 688239 & 5.1862 & 5.3411 & TRN & \\
\hline CHEMBL1382199 & 688239 & 4.6362 & 5.3755 & TRN & \\
\hline CHEMBL1546224 & 688239 & 4.7362 & 5.605 & TST & \\
\hline CHEMBL1257130 & 688239 & 4.8362 & 5.3897 & TST & \\
\hline CHEMBL1461588 & 688239 & 5.3862 & 5.5979 & TST & \\
\hline CHEMBL1568313 & 688239 & 4.7862 & 5.73600 & 0000000001 & TRN \\
\hline CHEMBL1411277 & 688239 & 5.1862 & 5.4346 & TRN & \\
\hline
\end{tabular}


Supplemental Table S2.txt

\begin{tabular}{|c|c|c|c|c|c|}
\hline CHEMBL1331492 & 688239 & 6.5363 & 5.6702 & TRN & \\
\hline CHEMBL3197002 & 688239 & 5.5362 & 5.4458 & TRN & \\
\hline CHEMBL1234594 & 688239 & 6.0362 & 5.4046 & TST & \\
\hline CHEMBL1365494 & 688239 & 5.5862 & 5.5022 & TRN & \\
\hline CHEMBL1301200 & 688239 & 4.5362 & 5.5316 & TRN & \\
\hline CHEMBL1596546 & 688239 & 6.2362 & 5.3638 & TRN & \\
\hline CHEMBL1389375 & 688239 & 5.1862 & 5.4082 & TRN & \\
\hline CHEMBL1434503 & 688239 & 5.0862 & 5.5086 & TST & \\
\hline CHEMBL1465972 & 688239 & 5.4362 & 5.4971 & TST & \\
\hline CHEMBL1320521 & 688239 & 4.4862 & 5.3622 & TRN & \\
\hline CHEMBL1581384 & 688239 & 5.1862 & 5.3979 & TST & \\
\hline CHEMBL1350362 & 688239 & 5.1862 & 5.5847 & TST & \\
\hline CHEMBL1526367 & 688239 & 4.5362 & 5.3587 & TRN & \\
\hline CHEMBL1500993 & 688239 & 6.5363 & 5.4678 & TST & \\
\hline CHEMBL1407032 & 688239 & 4.5362 & 5.5045 & TRN & \\
\hline CHEMBL 3197214 & 688239 & 4.6862 & \multicolumn{2}{|c|}{5.5920000000000005} & TST \\
\hline CHEMBL1597702 & 688239 & 7.0362 & 5.3776 & TST & \\
\hline CHEMBL1327510 & 688239 & 4.7362 & \multicolumn{2}{|c|}{5.507000000000001} & TRN \\
\hline CHEMBL1492135 & 688239 & 6.8861 & 5.6022 & TRN & \\
\hline CHEMBL1472178 & 688239 & 4.6362 & 5.4604 & TRN & \\
\hline CHEMBL1400377 & 688239 & 4.7862 & 5.4892 & TST & \\
\hline CHEMBL1388005 & 688239 & 6.3362 & 5.5733 & TRN & \\
\hline CHEMBL1419500 & 688239 & 4.5362 & \multicolumn{2}{|c|}{5.361000000000001} & TRN \\
\hline CHEMBL1591890 & 688239 & 4.7362 & 5.558 & TST & \\
\hline CHEMBL1385413 & 688239 & 6.0 & 5.4227 & TRN & \\
\hline CHEMBL1586088 & 688239 & 4.7862 & 5.4336 & TRN & \\
\hline CHEMBL1466283 & 688239 & 5.8862 & \multicolumn{2}{|c|}{5.587000000000001} & TST \\
\hline CHEMBL1590883 & 688239 & 4.5362 & \multicolumn{2}{|c|}{5.662000000000001} & TRN \\
\hline CHEMBL1395068 & 688239 & 8.3372 & 5.6386 & TRN & \\
\hline CHEMBL1538439 & 688239 & 4.6862 & 5.5649 & TST & \\
\hline CHEMBL1394860 & 688239 & 4.7362 & 5.4037 & TRN & \\
\hline CHEMBL1479071 & 688239 & 5.1862 & 5.5255 & TRN & \\
\hline CHEMBL1372064 & 688239 & 6.1862 & 5.5046 & TRN & \\
\hline CHEMBL1508716 & 688239 & 8.3372 & 5.4576 & TRN & \\
\hline CHEMBL1364206 & 688239 & 4.7362 & 5.3882 & TST & \\
\hline CHEMBL1426216 & 688239 & 5.1862 & \multicolumn{2}{|c|}{5.486000000000001} & TRN \\
\hline CHEMBL3207697 & 688239 & 4.5362 & 5.2915 & TST & \\
\hline CHEMBL1454782 & 688239 & 5.5362 & 5.4696 & TRN & \\
\hline CHEMBL1451275 & 688239 & 4.4862 & 5.4263 & TST & \\
\hline CHEMBL1609883 & 688239 & 6.3863 & 5.5879 & TRN & \\
\hline CHEMBL1611553 & 688239 & 4.6362 & 5.4784 & TRN & \\
\hline CHEMBL1545515 & 688239 & 6.1362 & 5.6211 & TRN & \\
\hline CHEMBL1417991 & 688239 & 4.8862 & 5.5176 & TRN & \\
\hline CHEMBL1445952 & 688239 & 4.6862 & 5.4601 & TRN & \\
\hline CHEMBL1492054 & 688239 & 4.5362 & 5.5935 & TRN & \\
\hline CHEMBL1586910 & 688239 & 4.5362 & 5.5163 & TRN & \\
\hline CHEMBL1344964 & 688239 & 6.3362 & 5.6522 & TRN & \\
\hline CHEMBL252925 & 688239 & 6.8861 & 5.5386 & TST & \\
\hline
\end{tabular}


Supplemental Table S2.txt

\begin{tabular}{|c|c|c|c|c|c|}
\hline CHEMBL1583571 & 688239 & 4.5362 & 5.612 & TRN & \\
\hline CHEMBL1362543 & 688239 & 4.5862 & 5.5828 & TRN & \\
\hline CHEMBL1555999 & 688239 & 4.8362 & 5.5556 & TST & \\
\hline CHEMBL1510664 & 688239 & 4.6362 & 5.5344 & TST & \\
\hline CHEMBL1547239 & 688239 & 4.7362 & 5.5279 & TRN & \\
\hline CHEMBL1311228 & 688239 & 4.6862 & 5.5782 & TRN & \\
\hline CHEMBL1330446 & 688239 & 5.3862 & 5.5236 & TRN & \\
\hline CHEMBL1558649 & 688239 & 5.1862 & 5.4772 & TRN & \\
\hline CHEMBL1453957 & 688239 & 5.2862 & 5.3802 & TRN & \\
\hline CHEMBL1555292 & 688239 & 6.6362 & 5.5348 & TRN & \\
\hline CHEMBL1467968 & 688239 & 5.3862 & 5.5479 & TRN & \\
\hline CHEMBL1469146 & 688239 & 6.0362 & 5.3994 & TRN & \\
\hline CHEMBL1478837 & 688239 & 5.3862 & 5.506 & TRN & \\
\hline CHEMBL1391984 & 688239 & 8.3372 & 5.3983 & TST & \\
\hline CHEMBL1578681 & 688239 & 6.8362 & 5.5744 & TST & \\
\hline CHEMBL1339678 & 688239 & 5.5362 & 5.4473 & TRN & \\
\hline CHEMBL 3212880 & 688239 & 8.3372 & 5.341 & TRN & \\
\hline CHEMBL1566271 & 688239 & 4.5362 & 5.38399 & 99999999995 & TRN \\
\hline CHEMBL1339908 & 688239 & 6.0862 & 5.5197 & TRN & \\
\hline CHEMBL1535475 & 688239 & 4.5362 & 5.4134 & TRN & \\
\hline CHEMBL1511270 & 688239 & 6.0862 & 5.4114 & TRN & \\
\hline CHEMBL392673 & 688239 & 5.7362 & 5.4844 & TRN & \\
\hline CHEMBL1332396 & 688239 & 4.8362 & 5.5563 & TRN & \\
\hline CHEMBL1353209 & 688239 & 4.5362 & 5.4816 & TRN & \\
\hline CHEMBL1457549 & 688239 & 4.9862 & 5.4391 & TST & \\
\hline CHEMBL1472983 & 688239 & 6.5363 & 5.4208 & TRN & \\
\hline CHEMBL1421475 & 688239 & 4.5862 & 5.3739 & TRN & \\
\hline CHEMBL1490768 & 688239 & 6.5862 & 5.6967 & TRN & \\
\hline CHEMBL1371284 & 688239 & 6.3863 & 5.5718 & TRN & \\
\hline CHEMBL1403143 & 688239 & 4.6362 & 5.4096 & TST & \\
\hline CHEMBL1306766 & 688239 & 4.9862 & 5.5008 & TRN & \\
\hline CHEMBL1364961 & 688239 & 6.7862 & 5.5456 & TRN & \\
\hline CHEMBL1375885 & 688239 & 6.0362 & 5.42 & TRN & \\
\hline CHEMBL3199779 & 688239 & 4.5362 & 5.4344 & TST & \\
\hline CHEMBL1338044 & 688239 & 6.1862 & 5.5244 & TST & \\
\hline CHEMBL1572615 & 688239 & 5.0862 & 5.4585 & TRN & \\
\hline CHEMBL1436421 & 688239 & 5.1862 & 5.5509 & TRN & \\
\hline CHEMBL1340876 & 688239 & 5.0362 & 5.6647 & TRN & \\
\hline CHEMBL1499367 & 688239 & 5.3362 & 5.3847 & TST & \\
\hline CHEMBL1566516 & 688239 & 7.6861 & 5.5364 & TST & \\
\hline CHEMBL1414127 & 688239 & 4.5362 & 5.3193 & TST & \\
\hline CHEMBL1518804 & 688239 & 4.5362 & 5.3584 & TRN & \\
\hline CHEMBL1376824 & 688239 & 5.0862 & 5.54 & TRN & \\
\hline CHEMBL1406162 & 688239 & 4.6862 & 5.4775 & TST & \\
\hline CHEMBL1491832 & 688239 & 6.2862 & 5.3672 & TST & \\
\hline CHEMBL3209795 & 688239 & 4.5362 & 5.6663 & TST & \\
\hline CHEMBL1336179 & 688239 & 5.7862 & 5.6032 & TRN & \\
\hline CHEMBL1464793 & 688239 & 4.6862 & 5.4747 & TRN & \\
\hline
\end{tabular}




\begin{tabular}{|c|c|c|c|c|c|}
\hline \multicolumn{6}{|c|}{ Supplemental Table s2.txt } \\
\hline CHEMBL1368770 & 688239 & 7.5867 & 5.5423 & TRN & \\
\hline CHEMBL1453682 & 688239 & 4.5362 & 5.6165 & TRN & \\
\hline CHEMBL1310797 & 688239 & 8.1871 & 5.5587 & TST & \\
\hline CHEMBL1386654 & 688239 & 5.5362 & 5.5648 & TRN & \\
\hline CHEMBL1299761 & 688239 & 4.7362 & 5.643 & TRN & \\
\hline CHEMBL3198809 & 688239 & 7.2865 & 5.3812 & TRN & \\
\hline CHEMBL1302942 & 688239 & 5.6362 & 5.5611 & TRN & \\
\hline CHEMBL1425426 & 688239 & 4.7362 & 5.5057 & TRN & \\
\hline CHEMBL1584124 & 688239 & 5.7362 & 5.5087 & TST & \\
\hline CHEMBL3191850 & 688239 & 4.6362 & 5.3379 & TST & \\
\hline CHEMBL1564499 & 688239 & 5.5362 & 5.5675 & TRN & \\
\hline CHEMBL1470487 & 688239 & 5.8862 & 5.7671 & TST & \\
\hline CHEMBL1600234 & 688239 & 6.0862 & 5.4942 & TRN & \\
\hline CHEMBL1367137 & 688239 & 5.1862 & 5.6782 & TRN & \\
\hline CHEMBL1379575 & 688239 & 6.1362 & 5.3866 & TRN & \\
\hline CHEMBL1355951 & 688239 & 4.6862 & 5.5906 & TRN & \\
\hline CHEMBL1509458 & 688239 & 4.5362 & 5.4876 & TST & \\
\hline CHEMBL1364079 & 688239 & 5.1862 & 5.4402 & TST & \\
\hline CHEMBL1555196 & 688239 & 4.5362 & 5.649 & TRN & \\
\hline CHEMBL1450851 & 688239 & 6.1862 & 5.604 & TRN & \\
\hline CHEMBL1501405 & 688239 & 4.5362 & 5.6229 & TRN & \\
\hline CHEMBL1564687 & 688239 & 5.5362 & 5.5036 & TST & \\
\hline CHEMBL1559616 & 688239 & 6.2362 & 5.4256 & TRN & \\
\hline CHEMBL1441024 & 688239 & 5.7862 & 5.4333 & TST & \\
\hline CHEMBL1479311 & 688239 & 4.5362 & 5.5017 & TST & \\
\hline CHEMBL1580023 & 688239 & 6.1362 & 5.5978 & TRN & \\
\hline CHEMBL1551374 & 688239 & 7.0362 & 5.5504 & TRN & \\
\hline CHEMBL1405911 & 688239 & 4.5362 & 5.5653 & TST & \\
\hline CHEMBL1610458 & 688239 & 4.5362 & 5.4749 & TRN & \\
\hline CHEMBL1353112 & 688239 & 5.5862 & 5.4483 & TRN & \\
\hline CHEMBL1522794 & 688239 & 5.0862 & 5.4039 & TST & \\
\hline CHEMBL1505436 & 688239 & 5.3362 & 5.4199 & TRN & \\
\hline CHEMBL1507593 & 688239 & 4.5862 & 5.3228 & TRN & \\
\hline CHEMBL1311959 & 688239 & 5.0862 & 5.4275 & TRN & \\
\hline CHEMBL1532250 & 688239 & 5.3362 & 5.5693 & TST & \\
\hline CHEMBL1605140 & 688239 & 4.5362 & 5.4871 & TRN & \\
\hline CHEMBL1323468 & 688239 & 5.0862 & 5.66200 & 0000000001 & TRN \\
\hline CHEMBL1341787 & 688239 & 5.1862 & 5.5218 & TRN & \\
\hline CHEMBL1552822 & 688239 & 4.7862 & 5.4947 & TST & \\
\hline CHEMBL1606529 & 688239 & 5.3362 & 5.4797 & TRN & \\
\hline CHEMBL1542548 & 688239 & 8.28399 & 99999999 & 5.5197 & TRN \\
\hline CHEMBL1536575 & 688239 & 4.6862 & 5.69799 & 99999999995 & TST \\
\hline CHEMBL1413464 & 688239 & 6.6861 & 5.5732 & TRN & \\
\hline CHEMBL1477453 & 688239 & 5.1862 & 5.5541 & TRN & \\
\hline CHEMBL1556559 & 688239 & 6.0862 & 5.5046 & TRN & \\
\hline CHEMBL1307979 & 688239 & 4.5362 & 5.5243 & TRN & \\
\hline CHEMBL1543129 & 688239 & 5.0362 & 5.5257 & TRN & \\
\hline CHEMBL1342676 & 688239 & 4.9362 & 5.3869 & TST & \\
\hline
\end{tabular}


Supplemental Table S2.txt

\begin{tabular}{|c|c|c|c|c|c|}
\hline CHEMBL1491147 & 688239 & 6.6362 & 5.4473 & TRN & \\
\hline CHEMBL1446460 & 688239 & 6.1362 & 5.5738 & TRN & \\
\hline CHEMBL1576905 & 688239 & 4.5362 & 5.3749 & TRN & \\
\hline CHEMBL3198964 & 688239 & 5.7362 & 5.4961 & TRN & \\
\hline CHEMBL1452426 & 688239 & 4.5362 & 5.5237 & TRN & \\
\hline CHEMBL1592991 & 688239 & 4.8862 & 5.6307 & TRN & \\
\hline CHEMBL1568895 & 688239 & 4.7362 & 5.4825 & TRN & \\
\hline CHEMBL1347748 & 688239 & 5.3862 & 5.5984 & TST & \\
\hline CHEMBL1467069 & 688239 & 4.5362 & 5.4557 & TST & \\
\hline CHEMBL1439851 & 688239 & 4.7862 & 5.6466 & TST & \\
\hline CHEMBL1459782 & 688239 & 6.8362 & 5.5257 & TST & \\
\hline CHEMBL1514790 & 688239 & 4.5362 & 5.2135 & TST & \\
\hline CHEMBL580891 & 688239 & 5.1862 & 5.4676 & TRN & \\
\hline CHEMBL1562001 & 688239 & 6.0862 & 5.5563 & TRN & \\
\hline CHEMBL1527902 & 688239 & 4.9862 & 5.4983 & TRN & \\
\hline CHEMBL1559370 & 688239 & 5.4862 & 5.5087 & TST & \\
\hline CHEMBL1406214 & 688239 & 4.5362 & 5.3463 & TRN & \\
\hline CHEMBL1537269 & 688239 & 4.5362 & 5.4372 & TST & \\
\hline CHEMBL1536938 & 688239 & 5.2862 & 5.4519 & TST & \\
\hline CHEMBL1498660 & 688239 & 5.3862 & 5.3811 & TRN & \\
\hline CHEMBL1597500 & 688239 & 6.3362 & 5.6052 & TRN & \\
\hline CHEMBL1371222 & 688239 & 5.2862 & 5.3769 & TRN & \\
\hline CHEMBL1540803 & 688239 & 4.7362 & 5.5594 & TRN & \\
\hline CHEMBL1445996 & 688239 & 5.2362 & 5.5811 & TRN & \\
\hline CHEMBL1387279 & 688239 & 5.1862 & 5.5626 & TRN & \\
\hline CHEMBL1372845 & 688239 & 4.5362 & 5.5282 & TRN & \\
\hline CHEMBL1402837 & 688239 & 4.6362 & 5.4457 & TST & \\
\hline CHEMBL1567346 & 688239 & 5.1862 & 5.51399 & 9999999999 & TRN \\
\hline CHEMBL1427760 & 688239 & 5.3862 & 5.3208 & TST & \\
\hline CHEMBL1516803 & 688239 & 5.0862 & 5.5444 & TST & \\
\hline CHEMBL1350290 & 688239 & 4.6862 & 5.4093 & TRN & \\
\hline CHEMBL1601153 & 688239 & 4.5362 & 5.5374 & TST & \\
\hline CHEMBL1494424 & 688239 & 4.5862 & 5.5437 & TRN & \\
\hline CHEMBL1473946 & 688239 & 6.9863 & 5.5744 & TRN & \\
\hline CHEMBL3392058 & 688239 & 5.1862 & 5.5167 & TST & \\
\hline CHEMBL1558937 & 688239 & 5.1862 & 5.4437 & TRN & \\
\hline CHEMBL1502252 & 688239 & 6.5363 & 5.4435 & TRN & \\
\hline CHEMBL1407352 & 688239 & 6.2362 & 5.4423 & TRN & \\
\hline CHEMBL1305854 & 688239 & 7.6364 & 5.3803 & TST & \\
\hline CHEMBL1468022 & 688239 & 4.5862 & 5.6163 & TRN & \\
\hline CHEMBL1449893 & 688239 & 4.7362 & 5.444 & TRN & \\
\hline CHEMBL1562632 & 688239 & 4.5362 & 5.4958 & TRN & \\
\hline CHEMBL1502605 & 688239 & 4.5362 & 5.5853 & TRN & \\
\hline CHEMBL1466999 & 688239 & 5.3862 & 5.4106 & TST & \\
\hline CHEMBL1322823 & 688239 & 4.7862 & 5.44 & TST & \\
\hline CHEMBL1429371 & 688239 & 6.6362 & 5.4676 & TRN & \\
\hline CHEMBL1506661 & 688239 & 4.6862 & 5.5283 & TST & \\
\hline CHEMBL1399209 & 688239 & 8.3372 & 5.3502 & TRN & \\
\hline
\end{tabular}


Supplemental Table S2.txt

\begin{tabular}{|c|c|c|c|c|}
\hline CHEMBL1530976 & 688239 & 4.8362 & 5.6074 & TST \\
\hline CHEMBL1479646 & 688239 & 6.2362 & 5.62 & TRN \\
\hline CHEMBL1574764 & 688239 & 6.2362 & 5.4812 & TST \\
\hline CHEMBL1580522 & 688239 & 6.1362 & 5.4823 & TRN \\
\hline CHEMBL1594403 & 688239 & 4.5362 & 5.6212 & TST \\
\hline CHEMBL1544647 & 688239 & 4.5362 & 5.3881 & TRN \\
\hline CHEMBL1332688 & 688239 & 5.9862 & 5.5917 & TRN \\
\hline CHEMBL1601384 & 688239 & 6.4862 & 5.3746 & TST \\
\hline CHEMBL1376609 & 688239 & 4.4862 & 5.5651 & TRN \\
\hline CHEMBL1519060 & 688239 & 5.0862 & 5.4844 & TRN \\
\hline CHEMBL1583055 & 688239 & 4.5362 & 5.4015 & TRN \\
\hline CHEMBL1325319 & 688239 & 4.5362 & 5.53600 & 00000000005 \\
\hline CHEMBL1399007 & 688239 & 4.5362 & 5.4821 & TRN \\
\hline CHEMBL 3192225 & 688239 & 5.7862 & 5.4598 & TRN \\
\hline CHEMBL1513921 & 688239 & 5.6862 & 5.3855 & TRN \\
\hline CHEMBL1396456 & 688239 & 5.0862 & 5.5182 & TRN \\
\hline CHEMBL1351220 & 688239 & 5.4862 & 5.5145 & TRN \\
\hline CHEMBL1481839 & 688239 & 5.4862 & 5.5 & TRN \\
\hline CHEMBL1332460 & 688239 & 4.7362 & 5.3681 & TST \\
\hline CHEMBL1445357 & 688239 & 4.5362 & 5.3928 & TRN \\
\hline CHEMBL1612974 & 688239 & 6.2862 & 5.4158 & TRN \\
\hline CHEMBL1495952 & 688239 & 6.8861 & 5.4886 & TRN \\
\hline CHEMBL1487746 & 688239 & 5.1362 & 5.5975 & TRN \\
\hline CHEMBL1361981 & 688239 & 5.3862 & 5.6763 & TRN \\
\hline CHEMBL1490257 & 688239 & 5.8362 & 5.6171 & TRN \\
\hline CHEMBL1389550 & 688239 & 5.6862 & 5.3819 & TRN \\
\hline CHEMBL1545127 & 688239 & 5.6362 & 5.3775 & TRN \\
\hline CHEMBL1485570 & 688239 & 5.4862 & 5.3977 & TRN \\
\hline CHEMBL1323326 & 688239 & 5.3862 & 5.4538 & TST \\
\hline CHEMBL1585982 & 688239 & 4.8862 & 5.375 & TRN \\
\hline CHEMBL1428089 & 688239 & 5.0362 & 5.3579 & TRN \\
\hline CHEMBL1446801 & 688239 & 8.2366 & 5.655 & TRN \\
\hline CHEMBL1337754 & 688239 & 4.5362 & 5.5357 & TRN \\
\hline CHEMBL1343104 & 688239 & 4.7862 & 5.5614 & TST \\
\hline CHEMBL1589265 & 688239 & 5.0362 & 5.57 & TRN \\
\hline CHEMBL1531380 & 688239 & 6.7862 & 5.6634 & TRN \\
\hline CHEMBL1556470 & 688239 & 4.7862 & 5.4755 & TST \\
\hline CHEMBL1402790 & 688239 & 5.4362 & 5.5462 & TRN \\
\hline CHEMBL1432609 & 688239 & 5.1862 & 5.4691 & TRN \\
\hline CHEMBL1464557 & 688239 & 4.8362 & 5.5117 & TRN \\
\hline CHEMBL1559448 & 688239 & 4.9362 & 5.6873 & TRN \\
\hline CHEMBL601588 & 688239 & 5.3862 & 5.4232 & TST \\
\hline CHEMBL1387244 & 688239 & 4.7362 & 5.4783 & TST \\
\hline CHEMBL1442317 & 688239 & 5.0362 & 5.4288 & TRN \\
\hline CHEMBL1352084 & 688239 & 4.5362 & 5.4384 & TST \\
\hline CHEMBL1309449 & 688239 & 6.1862 & 5.5419 & TRN \\
\hline CHEMBL1373267 & 688239 & 5.2362 & 5.4087 & TST \\
\hline CHEMBL1515186 & 688239 & 5.1862 & 5.4858 & TST \\
\hline
\end{tabular}


Supplemental Table S2.txt

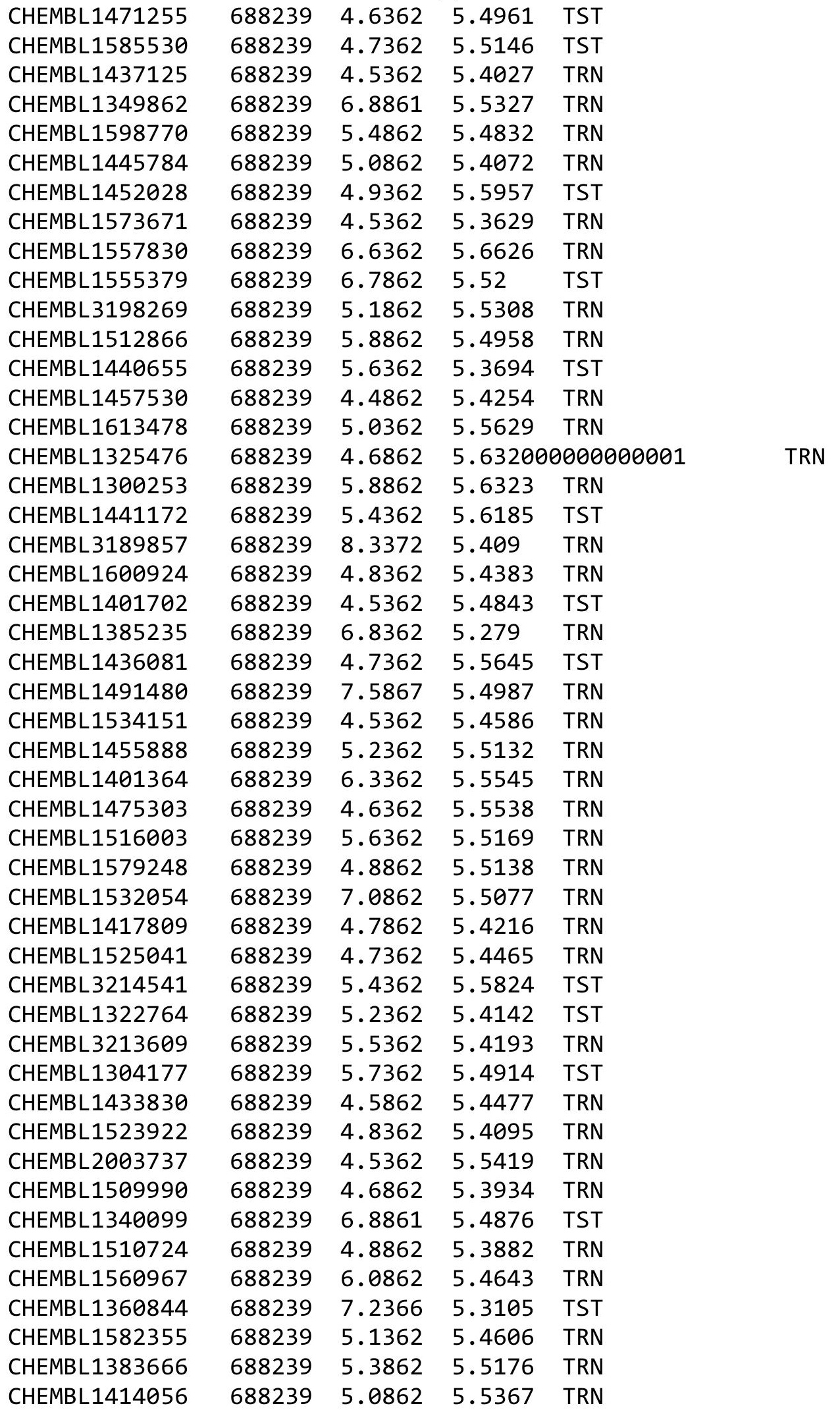

Page 1920 


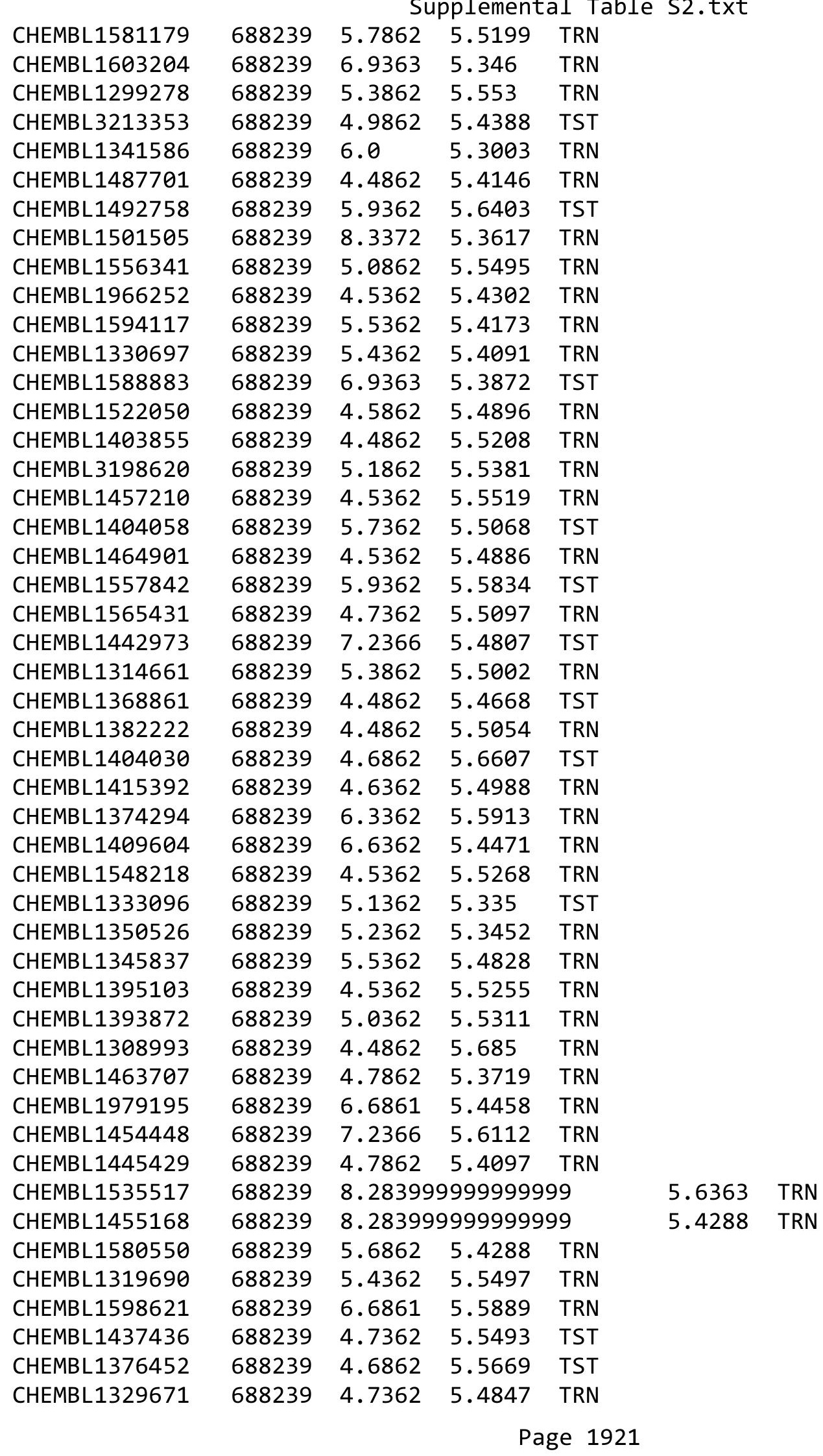


Supplemental Table S2.txt

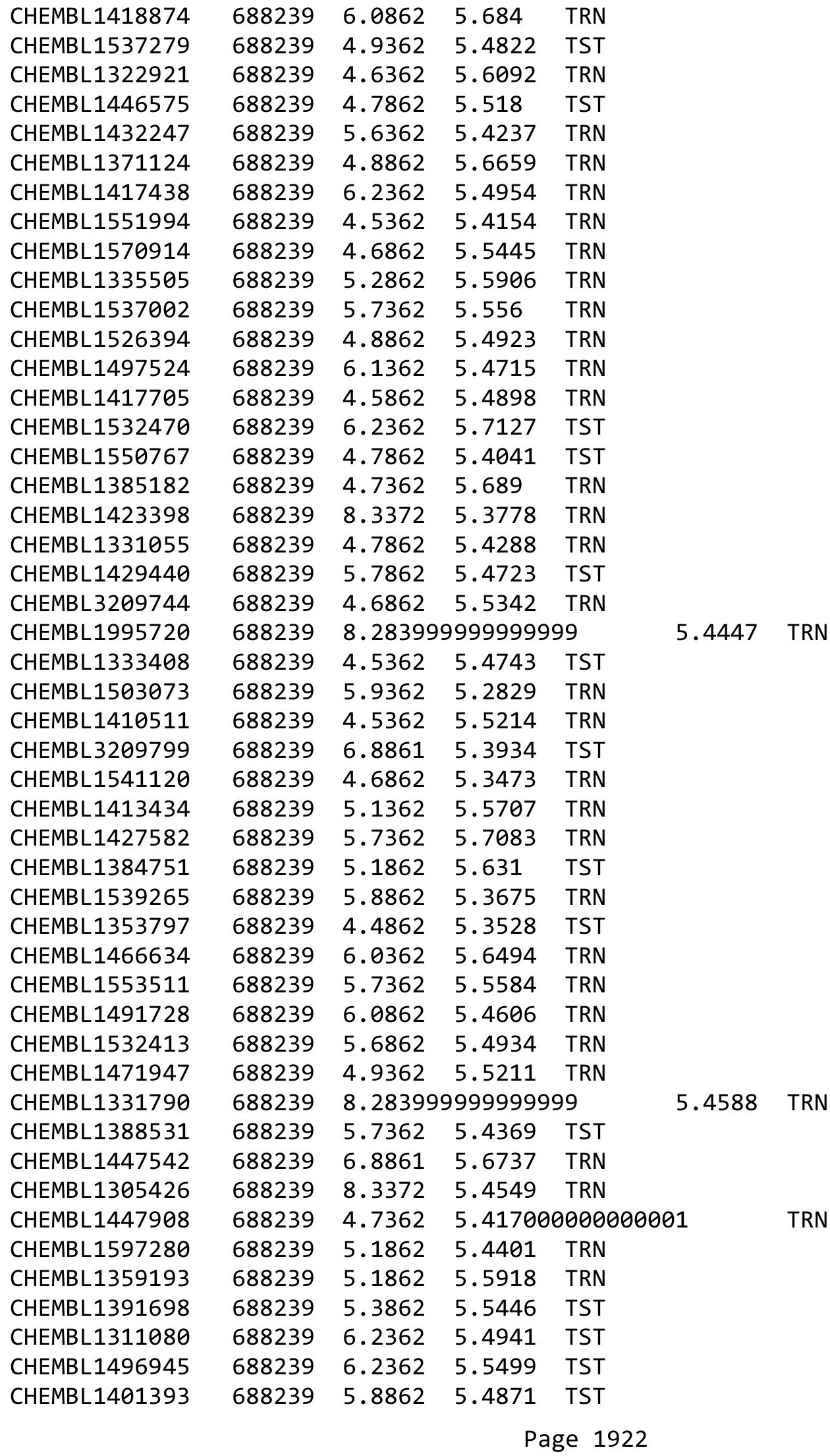


Supplemental Table S2.txt

\begin{tabular}{|c|c|c|c|c|}
\hline CHEMBL1319990 & 688239 & 5.1862 & 5.4436 & TST \\
\hline CHEMBL1347928 & 688239 & 4.5362 & 5.5353 & TRN \\
\hline CHEMBL1313669 & 688239 & 5.4362 & 5.5397 & TST \\
\hline CHEMBL1316791 & 688239 & 4.7362 & 5.4147 & TRN \\
\hline CHEMBL1523820 & 688239 & 6.4862 & 5.4306 & TRN \\
\hline CHEMBL1446379 & 688239 & 6.2862 & 5.4272 & TRN \\
\hline CHEMBL1304309 & 688239 & 6.9363 & 5.7049 & TST \\
\hline CHEMBL1503483 & 688239 & 5.9362 & 5.5148 & TRN \\
\hline CHEMBL1428323 & 688239 & 5.2862 & 5.5175 & TRN \\
\hline CHEMBL1507034 & 688239 & 4.9862 & 5.355 & TST \\
\hline CHEMBL1388009 & 688239 & 6.0862 & 5.4542 & TRN \\
\hline CHEMBL1467240 & 688239 & 6.1362 & 5.4956 & TRN \\
\hline CHEMBL1561274 & 688239 & 6.8861 & 5.399 & TST \\
\hline CHEMBL1361118 & 688239 & 6.8861 & 5.6156 & TRN \\
\hline CHEMBL1324488 & 688239 & 5.1862 & 5.587006 & 000000001 \\
\hline CHEMBL1362960 & 688239 & 8.0362 & 5.5751 & TRN \\
\hline CHEMBL1373511 & 688239 & 5.1862 & 5.4652 & TRN \\
\hline CHEMBL1587205 & 688239 & 4.5362 & 5.4124 & TRN \\
\hline CHEMBL1420670 & 688239 & 5.9362 & 5.6364 & TST \\
\hline CHEMBL1388418 & 688239 & 5.1862 & 5.5325 & TRN \\
\hline CHEMBL1489900 & 688239 & 5.8862 & 5.4898 & TRN \\
\hline CHEMBL1372135 & 688239 & 5.0362 & 5.3913 & TRN \\
\hline CHEMBL1495742 & 688239 & 5.3862 & 5.5123 & TRN \\
\hline CHEMBL1344926 & 688239 & 4.6862 & 5.2995 & TRN \\
\hline CHEMBL1303440 & 688239 & 6.0862 & 5.3332 & TRN \\
\hline CHEMBL1353920 & 688239 & 8.28399 & 99999999 & 5.6528 \\
\hline CHEMBL1472363 & 688239 & 4.5362 & 5.5456 & TRN \\
\hline CHEMBL1426787 & 688239 & 5.1862 & 5.603 & TRN \\
\hline CHEMBL1598641 & 688239 & 6.3362 & 5.4013 & TST \\
\hline CHEMBL1532452 & 688239 & 4.6862 & 5.4692 & TST \\
\hline CHEMBL1338874 & 688239 & 4.7862 & 5.4844 & TRN \\
\hline CHEMBL1378036 & 688239 & 4.5862 & 5.5543 & TRN \\
\hline CHEMBL1355352 & 688239 & 5.4862 & 5.5212 & TRN \\
\hline CHEMBL 3214260 & 688239 & 6.9863 & 5.5053 & TST \\
\hline CHEMBL1427929 & 688239 & 5.7362 & 5.5354 & TRN \\
\hline CHEMBL 1438520 & 688239 & 4.5362 & 5.3073 & TRN \\
\hline CHEMBL 3145322 & 688239 & 4.6362 & 5.5393 & TST \\
\hline CHEMBL1335624 & 688239 & 4.9862 & 5.5236 & TST \\
\hline CHEMBL1326664 & 688239 & 6.9863 & 5.5509 & TRN \\
\hline CHEMBL1508688 & 688239 & 5.1362 & 5.4437 & TRN \\
\hline CHEMBL1313357 & 688239 & 6.7361 & 5.6385 & TRN \\
\hline CHEMBL1354627 & 688239 & 5.3362 & 5.4345 & TRN \\
\hline CHEMBL1597486 & 688239 & 8.2366 & 5.4358 & TST \\
\hline CHEMBL1526471 & 688239 & 4.5362 & 5.4346 & TRN \\
\hline CHEMBL1469286 & 688239 & 5.5362 & 5.5632 & TRN \\
\hline CHEMBL1461983 & 688239 & 6.1862 & 5.5171 & TRN \\
\hline CHEMBL1448095 & 688239 & 6.0862 & 5.495 & TRN \\
\hline CHEMBL1328119 & 688239 & 4.5862 & 5.3944 & TRN \\
\hline
\end{tabular}




\begin{tabular}{|c|c|c|c|c|c|}
\hline & & & 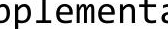 & & \\
\hline CHEMBL1580668 & 688239 & 6.2362 & 5.5422 & TST & \\
\hline CHEMBL1970872 & 688239 & 4.8362 & 5.2982 & TRN & \\
\hline CHEMBL1453236 & 688239 & 5.4862 & 5.4797 & TRN & \\
\hline CHEMBL1369619 & 688239 & 4.8362 & 5.41700 & 0000000001 & TST \\
\hline CHEMBL1310005 & 688239 & 6.6362 & 5.5025 & TRN & \\
\hline CHEMBL1348406 & 688239 & 5.0862 & 5.4635 & TRN & \\
\hline CHEMBL1531707 & 688239 & 5.6362 & 5.5029 & TRN & \\
\hline CHEMBL1457103 & 688239 & 4.5362 & 5.4695 & TRN & \\
\hline CHEMBL1625031 & 688239 & 4.5362 & 5.3598 & TRN & \\
\hline CHEMBL1530256 & 688239 & 4.4862 & 5.5453 & TRN & \\
\hline CHEMBL1301575 & 688239 & 6.4862 & 5.5387 & TRN & \\
\hline CHEMBL1306490 & 688239 & 5.6862 & 5.5359 & TRN & \\
\hline CHEMBL1501101 & 688239 & 4.6862 & 5.4692 & TRN & \\
\hline CHEMBL1565967 & 688239 & 5.6362 & 5.6274 & TST & \\
\hline CHEMBL1444096 & 688239 & 5.1862 & 5.4472 & TST & \\
\hline CHEMBL1536894 & 688239 & 6.8861 & 5.5465 & TRN & \\
\hline CHEMBL1304490 & 688239 & 4.5362 & 5.5401 & TST & \\
\hline CHEMBL1473854 & 688239 & 4.8362 & 5.4542 & TRN & \\
\hline CHEMBL1572115 & 688239 & 5.4862 & 5.3818 & TST & \\
\hline CHEMBL1499072 & 688239 & 4.5362 & 5.4691 & TRN & \\
\hline CHEMBL1441028 & 688239 & 5.1862 & 5.5782 & TRN & \\
\hline CHEMBL1551530 & 688239 & 5.0862 & 5.4038 & TRN & \\
\hline CHEMBL1563763 & 688239 & 4.7862 & 5.3995 & TRN & \\
\hline CHEMBL1327230 & 688239 & 5.1362 & 5.4286 & TRN & \\
\hline CHEMBL1480051 & 688239 & 5.3862 & 5.6415 & TRN & \\
\hline CHEMBL1487297 & 688239 & 7.0862 & 5.5012 & TRN & \\
\hline CHEMBL1387177 & 688239 & 6.2362 & 5.3796 & TRN & \\
\hline CHEMBL1405161 & 688239 & 4.7362 & 5.5266 & TRN & \\
\hline CHEMBL1555850 & 688239 & 8.3372 & 5.4643 & TRN & \\
\hline CHEMBL1522758 & 688239 & 4.7862 & 5.4838 & TST & \\
\hline CHEMBL1354847 & 688239 & 6.1862 & 5.4469 & TRN & \\
\hline CHEMBL1407586 & 688239 & 6.3362 & 5.5079 & TRN & \\
\hline CHEMBL3195120 & 688239 & 4.8862 & 5.3484 & TRN & \\
\hline CHEMBL1354757 & 688239 & 8.1367 & 5.4846 & TST & \\
\hline CHEMBL3214535 & 688239 & 8.3872 & 5.38700 & 00000000005 & TRN \\
\hline CHEMBL1483370 & 688239 & 4.9362 & 5.4118 & TST & \\
\hline CHEMBL1329055 & 688239 & 5.3362 & 5.5213 & TST & \\
\hline CHEMBL1380406 & 688239 & 5.4862 & 5.4922 & TST & \\
\hline CHEMBL1551581 & 688239 & 5.1362 & 5.54899 & 99999999995 & TRN \\
\hline CHEMBL1485391 & 688239 & 5.1862 & 5.4587 & TRN & \\
\hline CHEMBL1390051 & 688239 & 4.5362 & 5.5731 & TST & \\
\hline CHEMBL1789987 & 688239 & 4.5362 & 5.4623 & TST & \\
\hline CHEMBL1314874 & 688239 & 4.5362 & 5.4681 & TRN & \\
\hline CHEMBL1377589 & 688239 & 8.3372 & 5.3949 & TRN & \\
\hline CHEMBL1308851 & 688239 & 6.0362 & 5.4539 & TRN & \\
\hline CHEMBL1350192 & 688239 & 5.3362 & 5.4697 & TRN & \\
\hline CHEMBL1494367 & 688239 & 4.8362 & 5.3718 & TST & \\
\hline CHEMBL1365248 & 688239 & 5.9362 & 5.5621 & TRN & \\
\hline
\end{tabular}


Supplemental Table S2.txt

\begin{tabular}{|c|c|c|c|c|}
\hline CHEMBL 2134007 & 688239 & 5.1862 & 5.4477 & TST \\
\hline CHEMBL1307934 & 688239 & 5.4862 & 5.2834 & TRN \\
\hline CHEMBL1404310 & 688239 & 8.3372 & 5.3095 & TRN \\
\hline CHEMBL1389492 & 688239 & 5.2362 & 5.5365 & TRN \\
\hline CHEMBL1379365 & 688239 & 5.6862 & 5.3889 & TRN \\
\hline CHEMBL1568848 & 688239 & 4.5362 & 5.4186 & TRN \\
\hline CHEMBL1543090 & 688239 & 4.5362 & 5.5029 & TRN \\
\hline CHEMBL1335249 & 688239 & 6.1362 & 5.5377 & TST \\
\hline CHEMBL1447338 & 688239 & 5.6362 & 5.3991 & TRN \\
\hline CHEMBL1345510 & 688239 & 5.8362 & 5.4567 & TST \\
\hline CHEMBL1419831 & 688239 & 5.2362 & 5.5309 & TRN \\
\hline CHEMBL1398679 & 688239 & 5.6862 & 5.5623 & TRN \\
\hline CHEMBL1568741 & 688239 & 6.7862 & 5.434 & TST \\
\hline CHEMBL1478164 & 688239 & 6.9863 & 5.4836 & TRN \\
\hline CHEMBL1424543 & 688239 & 4.5362 & 5.397 & TRN \\
\hline CHEMBL1409049 & 688239 & 6.8362 & 5.4969 & TRN \\
\hline CHEMBL1602873 & 688239 & 6.2862 & 5.4918 & TST \\
\hline CHEMBL1612381 & 688239 & 5.1862 & 5.6418 & TRN \\
\hline CHEMBL1507240 & 688239 & 5.0862 & 5.5896 & TRN \\
\hline CHEMBL1521736 & 688239 & 6.8362 & 5.5494 & TRN \\
\hline CHEMBL1398879 & 688239 & 5.8362 & 5.3134 & TRN \\
\hline CHEMBL1555990 & 688239 & 8.3372 & 5.4594 & TST \\
\hline CHEMBL1596236 & 688239 & 4.5362 & 5.5023 & TRN \\
\hline CHEMBL1311132 & 688239 & 5.3862 & 5.388999 & 9999999999 \\
\hline CHEMBL1557388 & 688239 & 5.3362 & 5.5257 & TST \\
\hline CHEMBL1539207 & 688239 & 4.5362 & 5.4366 & TRN \\
\hline CHEMBL1557782 & 688239 & 4.6362 & 5.4227 & TST \\
\hline CHEMBL1422166 & 688239 & 5.1862 & 5.5724 & TRN \\
\hline CHEMBL3198124 & 688239 & 4.5862 & 5.4925 & TRN \\
\hline CHEMBL1447660 & 688239 & 4.5362 & 5.5578 & TRN \\
\hline CHEMBL1538477 & 688239 & 5.5362 & 5.6034 & TRN \\
\hline CHEMBL1355489 & 688239 & 4.6362 & 5.4024 & TST \\
\hline CHEMBL1422326 & 688239 & 5.5362 & 5.4636 & TST \\
\hline CHEMBL1426027 & 688239 & 4.5362 & 5.4593 & TST \\
\hline CHEMBL156609 & 688239 & 4.5362 & $5.55200 e$ & 00000000005 \\
\hline CHEMBL1479527 & 688239 & 5.8862 & 5.4785 & TRN \\
\hline CHEMBL1510416 & 688239 & 4.7862 & 5.5646 & TST \\
\hline CHEMBL1448492 & 688239 & 5.0362 & 5.5744 & TRN \\
\hline CHEMBL1531724 & 688239 & 6.9863 & 5.3549 & TRN \\
\hline CHEMBL1349382 & 688239 & 4.9362 & 5.5829 & TRN \\
\hline CHEMBL1462345 & 688239 & 5.4362 & 5.5738 & TRN \\
\hline CHEMBL3189310 & 688239 & 4.4862 & 5.5363 & TRN \\
\hline CHEMBL1430648 & 688239 & 5.2362 & 5.4895 & TST \\
\hline CHEMBL1302128 & 688239 & 4.6362 & 5.3799 & TRN \\
\hline CHEMBL1400098 & 688239 & 5.1362 & 5.4844 & TRN \\
\hline CHEMBL1528585 & 688239 & 6.9363 & 5.5517 & TRN \\
\hline CHEMBL1401211 & 688239 & 4.7862 & 5.4128 & TST \\
\hline CHEMBL1593417 & 688239 & 6.8861 & 5.5739 & TRN \\
\hline
\end{tabular}


Supplemental Table S2.txt

\begin{tabular}{|c|c|c|c|c|c|}
\hline CHEMBL1397173 & 688239 & 5.9862 & 5.4491 & TRN & \\
\hline CHEMBL1493283 & 688239 & 5.4362 & 5.4731 & TST & \\
\hline CHEMBL1428633 & 688239 & 6.8861 & 5.5926 & TRN & \\
\hline CHEMBL1365572 & 688239 & 5.3362 & 5.6227 & TRN & \\
\hline CHEMBL1357433 & 688239 & 4.5862 & 5.5825 & TRN & \\
\hline CHEMBL1501643 & 688239 & 7.1361 & 5.7629 & TRN & \\
\hline CHEMBL1578268 & 688239 & 4.9862 & 5.4697 & TRN & \\
\hline CHEMBL1410900 & 688239 & 5.2362 & 5.57700 & 0000000001 & TRN \\
\hline CHEMBL1514032 & 688239 & 4.8862 & 5.5478 & TRN & \\
\hline CHEMBL1559222 & 688239 & 6.9863 & 5.4727 & TST & \\
\hline CHEMBL1347166 & 688239 & 5.1362 & 5.4673 & TRN & \\
\hline CHEMBL1518891 & 688239 & 5.1862 & 5.5782 & TRN & \\
\hline CHEMBL1427842 & 688239 & 5.9362 & 5.5931 & TRN & \\
\hline CHEMBL1378635 & 688239 & 5.3362 & 5.4856 & TST & \\
\hline CHEMBL1334833 & 688239 & 4.7862 & 5.3819 & TRN & \\
\hline CHEMBL1404528 & 688239 & 4.5362 & 5.2378 & TRN & \\
\hline CHEMBL3192045 & 688239 & 5.2362 & 5.3774 & TST & \\
\hline CHEMBL1508970 & 688239 & 4.5362 & 5.4472 & TRN & \\
\hline CHEMBL1423906 & 688239 & 8.3372 & 5.5393 & TRN & \\
\hline CHEMBL1590594 & 688239 & 5.2362 & 5.5674 & TRN & \\
\hline CHEMBL1405242 & 688239 & 5.1862 & 5.5998 & TST & \\
\hline CHEMBL1345020 & 688239 & 4.5362 & 5.4728 & TRN & \\
\hline CHEMBL1513842 & 688239 & 6.4362 & 5.7139 & TRN & \\
\hline CHEMBL1309149 & 688239 & 4.7362 & 5.4548 & TST & \\
\hline CHEMBL1557729 & 688239 & 8.3372 & 5.5436 & TST & \\
\hline CHEMBL1379181 & 688239 & 5.1862 & 5.4603 & TST & \\
\hline CHEMBL1555050 & 688239 & 4.7862 & 5.34399 & 9999999999 & TST \\
\hline CHEMBL1515254 & 688239 & 5.2362 & 5.3638 & TRN & \\
\hline CHEMBL1432691 & 688239 & 6.1362 & 5.3355 & TST & \\
\hline CHEMBL1469676 & 688239 & 5.0362 & 5.44600 & 0000000001 & ות \\
\hline CHEMBL1573815 & 688239 & 5.1862 & 5.6033 & TRN & \\
\hline CHEMBL1373614 & 688239 & 6.3863 & 5.6518 & TRN & \\
\hline CHEMBL1544286 & 688239 & 5.2362 & 5.5361 & TRN & \\
\hline CHEMBL1330511 & 688239 & 5.1862 & 5.441 & TST & \\
\hline CHEMBL1486843 & 688239 & 4.9362 & 5.3793 & TRN & \\
\hline CHEMBL1431522 & 688239 & 4.5362 & 5.4682 & TRN & \\
\hline CHEMBL1458085 & 688239 & 8.28399 & 99999999 & 5.5154 & כו \\
\hline CHEMBL1600085 & 688239 & 5.6362 & 5.3006 & TRN & \\
\hline CHEMBL1537580 & 688239 & 7.0362 & 5.5487 & TST & \\
\hline CHEMBL3199273 & 688239 & 4.7862 & 5.3946 & TRN & \\
\hline CHEMBL1388745 & 688239 & 4.7362 & 5.5462 & TRN & \\
\hline CHEMBL1472006 & 688239 & 6.6861 & 5.4808 & TRN & \\
\hline CHEMBL1340060 & 688239 & 4.4862 & 5.4841 & TST & \\
\hline CHEMBL1387975 & 688239 & 6.8861 & 5.4981 & TRN & \\
\hline CHEMBL1513093 & 688239 & 4.5862 & 5.5029 & TRN & \\
\hline CHEMBL1536465 & 688239 & 4.9362 & 5.499 & TRN & \\
\hline CHEMBL1466339 & 688239 & 6.9863 & 5.5856 & TST & \\
\hline CHEMBL3190410 & 688239 & 4.7362 & 5.3844 & TRN & \\
\hline
\end{tabular}


Supplemental Table S2.txt

\begin{tabular}{|c|c|c|c|c|c|c|}
\hline CHEMBL1505687 & 688239 & 4.7362 & 5.4972 & TRN & & \\
\hline CHEMBL1350759 & 688239 & 4.5862 & 5.5227 & TRN & & \\
\hline CHEMBL3196004 & 688239 & 4.6862 & 5.4621 & TRN & & \\
\hline CHEMBL1301755 & 688239 & 7.0362 & 5.5691 & TRN & & \\
\hline CHEMBL1303167 & 688239 & 5.0862 & 5.447 & TRN & & \\
\hline CHEMBL1522185 & 688239 & 4.8862 & 5.4657 & TRN & & \\
\hline CHEMBL317047 & 688239 & 5.6862 & 5.4891 & TST & & \\
\hline CHEMBL1597291 & 688239 & 5.1362 & 5.5614 & TRN & & \\
\hline CHEMBL1519252 & 688239 & 4.7362 & 5.4291 & TST & & \\
\hline CHEMBL1541081 & 688239 & 4.5362 & 5.5362 & TRN & & \\
\hline CHEMBL1453036 & 688239 & 5.3362 & 5.5407 & TRN & & \\
\hline CHEMBL1314691 & 688239 & 5.6862 & 5.4715 & TRN & & \\
\hline CHEMBL1451778 & 688239 & 5.4 & 5.5246 & TST & & \\
\hline CHEMBL1452402 & 688239 & 5.9362 & 5.4061 & TRN & & \\
\hline CHEMBL1441736 & 688239 & 4.6862 & 5.5905 & TRN & & \\
\hline CHEMBL3213915 & 688239 & 6.0862 & 5.3519 & TST & & \\
\hline CHEMBL1494442 & 688239 & 4.5862 & 5.4897 & TRN & & \\
\hline CHEMBL1387475 & 688239 & 5.1862 & 5.4888 & TST & & \\
\hline CHEMBL1464680 & 688239 & 5.3862 & 5.4687 & TRN & & \\
\hline CHEMBL 3208433 & 688239 & 5.0862 & 5.4702 & TRN & & \\
\hline CHEMBL1372038 & 688239 & 4.7362 & 5.504 & TRN & & \\
\hline CHEMBL1507797 & 688239 & 4.5362 & 5.5403 & TRN & & \\
\hline CHEMBL1583166 & 688239 & 4.5362 & 5.3962 & TST & & \\
\hline CHEMBL1548336 & 688239 & 5.5362 & 5.4587 & TST & & \\
\hline CHEMBL1374027 & 688239 & 5.1862 & 5.4082 & TRN & & \\
\hline CHEMBL1432468 & 688239 & 4.6862 & 5.4976 & TRN & & \\
\hline CHEMBL1381207 & 688239 & 4.5862 & 5.5265 & TRN & & \\
\hline CHEMBL1426697 & 688239 & 8.28399 & 99999999 & 9 & 5.4426 & TST \\
\hline CHEMBL 1445644 & 688239 & 4.5362 & 5.4594 & TRN & & \\
\hline CHEMBL1404308 & 688239 & 5.4862 & 5.5241 & TRN & & \\
\hline CHEMBL1337769 & 688239 & 5.1362 & 5.4288 & TRN & & \\
\hline CHEMBL1466564 & 688239 & 6.7361 & 5.6474 & TRN & & \\
\hline CHEMBL1415297 & 688239 & 4.7362 & 5.7591 & TRN & & \\
\hline CHEMBL1459112 & 688239 & 4.5362 & 5.4691 & TST & & \\
\hline CHEMBL1417078 & 688239 & 5.6862 & 5.6365 & TRN & & \\
\hline CHEMBL1492260 & 688239 & 6.1362 & 5.4828 & TRN & & \\
\hline CHEMBL1585343 & 688239 & 5.5862 & 5.5304 & TRN & & \\
\hline CHEMBL1389970 & 688239 & 5.6362 & 5.3781 & TRN & & \\
\hline CHEMBL1468051 & 688239 & 5.3862 & 5.4121 & TRN & & \\
\hline CHEMBL1585955 & 688239 & 5.4362 & 5.5035 & TRN & & \\
\hline CHEMBL1405431 & 688239 & 4.5362 & 5.4393 & TRN & & \\
\hline CHEMBL1440554 & 688239 & 5.8862 & 5.4002 & TRN & & \\
\hline CHEMBL1306265 & 688239 & 5.0362 & 5.4731 & TST & & \\
\hline CHEMBL1588784 & 688239 & 4.5362 & 5.5505 & TRN & & \\
\hline CHEMBL1425032 & 688239 & 6.1362 & 5.3939 & TST & & \\
\hline CHEMBL1345982 & 688239 & 5.1862 & 5.5709 & TRN & & \\
\hline CHEMBL1484448 & 688239 & 5.1862 & 5.5719 & TRN & & \\
\hline CHEMBL1509359 & 688239 & 4.5362 & 5.3539 & TRN & & \\
\hline
\end{tabular}

Page 1927 


\begin{tabular}{|c|c|c|c|c|c|c|}
\hline & & \multicolumn{5}{|c|}{ Supplemental Table S2.txt } \\
\hline CHEMBL1447482 & 688239 & 4.4862 & 5.5048 & TRN & & \\
\hline CHEMBL1504068 & 688239 & 4.8 & 5.4131 & TRN & & \\
\hline CHEMBL1455211 & 688239 & 6.4362 & 5.4143 & TRN & & \\
\hline CHEMBL1492049 & 688239 & 4.5362 & 5.5081 & TST & & \\
\hline CHEMBL400585 & 688239 & 5.8362 & 5.5117 & TRN & & \\
\hline CHEMBL 3210054 & 688239 & 6.1862 & 5.3449 & TST & & \\
\hline CHEMBL1522735 & 688239 & 8.28399 & 99999999 & 99 & 5.5685 & TRN \\
\hline CHEMBL1573942 & 688239 & 4.5362 & 5.3122 & TST & & \\
\hline CHEMBL586061 & 688239 & 5.8862 & 5.402 & TRN & & \\
\hline CHEMBL1407037 & 688239 & 7.0362 & 5.5768 & TRN & & \\
\hline CHEMBL1355032 & 688239 & 5.8862 & 5.4598 & TST & & \\
\hline CHEMBL1438150 & 688239 & 5.2862 & 5.4802 & TRN & & \\
\hline CHEMBL1328422 & 688239 & 5.8362 & 5.6821 & TRN & & \\
\hline CHEMBL1609196 & 688239 & 5.1862 & 5.6015 & TRN & & \\
\hline CHEMBL1525191 & 688239 & 4.7362 & 5.4367 & TST & & \\
\hline CHEMBL1464315 & 688239 & 6.2362 & 5.4732 & TRN & & \\
\hline CHEMBL1522300 & 688239 & 5.9862 & 5.5525 & TRN & & \\
\hline CHEMBL1561483 & 688239 & 5.4362 & 5.4156 & TST & & \\
\hline CHEMBL1583936 & 688239 & 5.0362 & 5.4789 & TRN & & \\
\hline CHEMBL1415931 & 688239 & 5.1362 & 5.5532 & TRN & & \\
\hline CHEMBL1613239 & 688239 & 4.4362 & 5.4857 & TRN & & \\
\hline CHEMBL1514627 & 688239 & 4.5362 & 5.5634 & TRN & & \\
\hline CHEMBL1440255 & 688239 & 4.8362 & 5.5135 & TRN & & \\
\hline CHEMBL1556891 & 688239 & 4.5362 & 5.3413 & TRN & & \\
\hline CHEMBL1442219 & 688239 & 6.2362 & 5.4838 & TST & & \\
\hline CHEMBL1304010 & 688239 & 6.1862 & 5.5625 & TRN & & \\
\hline CHEMBL1352272 & 688239 & 4.7362 & 5.5282 & TRN & & \\
\hline CHEMBL1563626 & 688239 & 6.5363 & 5.5938 & TST & & \\
\hline CHEMBL3212583 & 688239 & 4.9362 & 5.5227 & TRN & & \\
\hline CHEMBL1499803 & 688239 & 6.2862 & 5.5254 & TRN & & \\
\hline CHEMBL1550631 & 688239 & 4.6362 & 5.5672 & TRN & & \\
\hline CHEMBL1334545 & 688239 & 4.7862 & 5.6184 & TST & & \\
\hline CHEMBL1309678 & 688239 & 7.5361 & 5.6311 & TST & & \\
\hline CHEMBL1374786 & 688239 & 6.1862 & 5.5721 & TRN & & \\
\hline CHEMBL1517933 & 688239 & 5.1862 & 5.5307 & TRN & & \\
\hline CHEMBL1596134 & 688239 & 4.5862 & 5.5489 & TRN & & \\
\hline CHEMBL1413032 & 688239 & 6.2362 & 5.6193 & TRN & & \\
\hline CHEMBL1365836 & 688239 & 4.5362 & 5.4963 & TRN & & \\
\hline CHEMBL503422 & 688239 & 6.1362 & 5.4438 & TST & & \\
\hline CHEMBL1426356 & 688239 & 5.9362 & 5.5856 & TRN & & \\
\hline CHEMBL1483498 & 688239 & 5.5862 & 5.6235 & TRN & & \\
\hline CHEMBL1398181 & 688239 & 4.7362 & 5.3245 & TST & & \\
\hline CHEMBL1579121 & 688239 & 6.1862 & 5.54700 & 0000000001 & & TRN \\
\hline CHEMBL1432825 & 688239 & 5.4362 & 5.6146 & TST & & \\
\hline CHEMBL1491001 & 688239 & 5.1862 & 5.4301 & TRN & & \\
\hline CHEMBL1526798 & 688239 & 6.2862 & 5.6993 & TRN & & \\
\hline CHEMBL1523355 & 688239 & 6.1862 & 5.443 & TRN & & \\
\hline CHEMBL1456101 & 688239 & 5.8862 & 5.4886 & TRN & & \\
\hline
\end{tabular}


Supplemental Table S2.txt

\begin{tabular}{|c|c|c|c|c|c|}
\hline CHEMBL1509195 & 688239 & 6.4362 & 5.4646 & TRN & \\
\hline CHEMBL1417548 & 688239 & 4.5862 & 5.4358 & TRN & \\
\hline CHEMBL1326789 & 688239 & 5.4862 & 5.4819 & TRN & \\
\hline CHEMBL1339435 & 688239 & 8.3372 & 5.4776 & TRN & \\
\hline CHEMBL1352317 & 688239 & 6.2862 & 5.5596 & TRN & \\
\hline CHEMBL1439938 & 688239 & 5.2862 & 5.5338 & TST & \\
\hline CHEMBL1413316 & 688239 & 4.7862 & 5.4314 & TRN & \\
\hline CHEMBL1333819 & 688239 & 5.7862 & 5.5565 & TRN & \\
\hline CHEMBL1388133 & 688239 & 5.2362 & 5.4763 & TRN & \\
\hline CHEMBL1532838 & 688239 & 5.8862 & 5.5927 & TRN & \\
\hline CHEMBL1611609 & 688239 & \multicolumn{3}{|c|}{8.283999999999999} & 5.4737 \\
\hline CHEMBL1409746 & 688239 & 6.0362 & 5.42 & TRN & \\
\hline CHEMBL1508675 & 688239 & 4.5362 & 5.6231 & TRN & \\
\hline CHEMBL1431815 & 688239 & 4.5362 & 5.3914 & TST & \\
\hline CHEMBL1299485 & 688239 & 4.5362 & 5.4302 & TRN & \\
\hline CHEMBL1336003 & 688239 & 6.4362 & 5.733 & TRN & \\
\hline CHEMBL1523125 & 688239 & 5.4862 & 5.3661 & TRN & \\
\hline CHEMBL1484998 & 688239 & 5.1862 & 5.4881 & TRN & \\
\hline CHEMBL1572782 & 688239 & 6.7862 & 5.4434 & TST & \\
\hline CHEMBL1360980 & 688239 & 5.5862 & 5.4759 & TST & \\
\hline CHEMBL1605646 & 688239 & 4.5362 & 5.5293 & TRN & \\
\hline CHEMBL1492193 & 688239 & 5.3362 & 5.5795 & TRN & \\
\hline CHEMBL1495259 & 688239 & 5.7362 & 5.6082 & TRN & \\
\hline CHEMBL1365573 & 688239 & 5.8362 & 5.4758 & TRN & \\
\hline CHEMBL1540134 & 688239 & 5.3362 & 5.3929 & TRN & \\
\hline CHEMBL1515208 & 688239 & 6.1362 & 5.5312 & TRN & \\
\hline CHEMBL1433087 & 688239 & 6.9363 & 5.4018 & TRN & \\
\hline CHEMBL1599313 & 688239 & 7.0362 & 5.4661 & TST & \\
\hline CHEMBL1539379 & 688239 & 5.3862 & 5.5267 & TRN & \\
\hline CHEMBL1482065 & 688239 & 4.5362 & 5.4261 & TRN & \\
\hline CHEMBL1507500 & 688239 & 5.4362 & 5.3322 & TRN & \\
\hline CHEMBL3198908 & 688239 & 4.8362 & 5.3447 & TST & \\
\hline CHEMBL1539004 & 688239 & 6.1362 & 5.7173 & TRN & \\
\hline CHEMBL1599021 & 688239 & 4.4862 & 5.456 & TRN & \\
\hline CHEMBL1319819 & 688239 & 4.6862 & 5.3441 & TRN & \\
\hline CHEMBL1306682 & 688239 & 4.4862 & 5.4837 & TRN & \\
\hline CHEMBL1302445 & 688239 & 4.7362 & 5.625 & TRN & \\
\hline CHEMBL1439955 & 688239 & 6.1862 & 5.3805 & TRN & \\
\hline CHEMBL1526016 & 688239 & 7.0862 & 5.4723 & TRN & \\
\hline CHEMBL1324157 & 688239 & 5.1862 & 5.5942 & TRN & \\
\hline CHEMBL 3192020 & 688239 & 4.5362 & 5.3312 & TRN & \\
\hline CHEMBL1527906 & 688239 & 6.7862 & 5.5172 & TRN & \\
\hline CHEMBL1461879 & 688239 & 4.5362 & 5.4624 & TST & \\
\hline CHEMBL 3392026 & 688239 & 4.9862 & 5.5611 & TRN & \\
\hline CHEMBL1317855 & 688239 & 4.8362 & 5.4232 & TRN & \\
\hline CHEMBL1513998 & 688239 & 4.6862 & 5.3791 & TRN & \\
\hline CHEMBL1448952 & 688239 & 5.1862 & 5.5223 & TRN & \\
\hline CHEMBL1502138 & 688239 & 5.1862 & 5.5422 & TRN & \\
\hline
\end{tabular}


Supplemental Table S2.txt

\begin{tabular}{|c|c|c|c|c|}
\hline 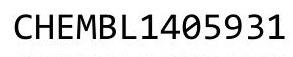 & & & & \\
\hline HEMBL1529576 & 38239 & 862 & 3231 & \\
\hline AEMBL1447530 & 239 & 362 & 565 & \\
\hline 758 & 39 & & & \\
\hline AEMBL31C & 239 & & & \\
\hline AEMBL1564135 & 88239 & 862 & 3951 & \\
\hline AEMBL3210225 & 88239 & 362 & 324 & \\
\hline AEMBL1340107 & & & & \\
\hline IEMBL136 & 39 & 362 & & \\
\hline IEMBL32 & & & & \\
\hline AEMBL1336449 & 239 & 862 & & \\
\hline AEMBL1478958 & 39 & 362 & & \\
\hline HEMBL 319 & & 362 & & \\
\hline HEMBL138 & & & & \\
\hline HEMBL14 & & & & \\
\hline HEMBL145 & & 362 & & \\
\hline JEMBL16 & & 362 & & \\
\hline HEMBL138 & & & & \\
\hline AEMBL136 & & & & \\
\hline HEMBL19 & & & & \\
\hline HEMBL 321 & & 62 & & \\
\hline AEMBL1333334 & & & & \\
\hline HEMBL14 & & & & \\
\hline AEMBL 13 & & & & \\
\hline 520 & & & & \\
\hline 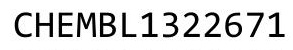 & & & & \\
\hline HEMBL150 & & & & \\
\hline AEMBL16e & & & & \\
\hline AFME $-2-P A$ & & & & \\
\hline 15M & & & & \\
\hline HEMBL158 & & & & \\
\hline AEMBL1351419 & & & & \\
\hline & & & & \\
\hline 1 & & & & \\
\hline HEMBL1486171 & & & & \\
\hline AEMBL1543683 & & & & \\
\hline AEMBL1526134 & & & & \\
\hline & & & & \\
\hline (2MO & & & & \\
\hline HEMBL1506720 & & & & RN \\
\hline AEMBL1334122 & & & & \\
\hline HEMBL135 & & & & \\
\hline & & & & \\
\hline CHEMBL1512419 & & & & \\
\hline AEMBL1608768 & & & & RN \\
\hline AEMBL1463352 & 68 & 362 & 82 & $\mathrm{TR}$ \\
\hline MBL1612 & & & & \\
\hline HEMBL154642 & & & & \\
\hline
\end{tabular}

Page 1930 
Supplemental Table S2.txt

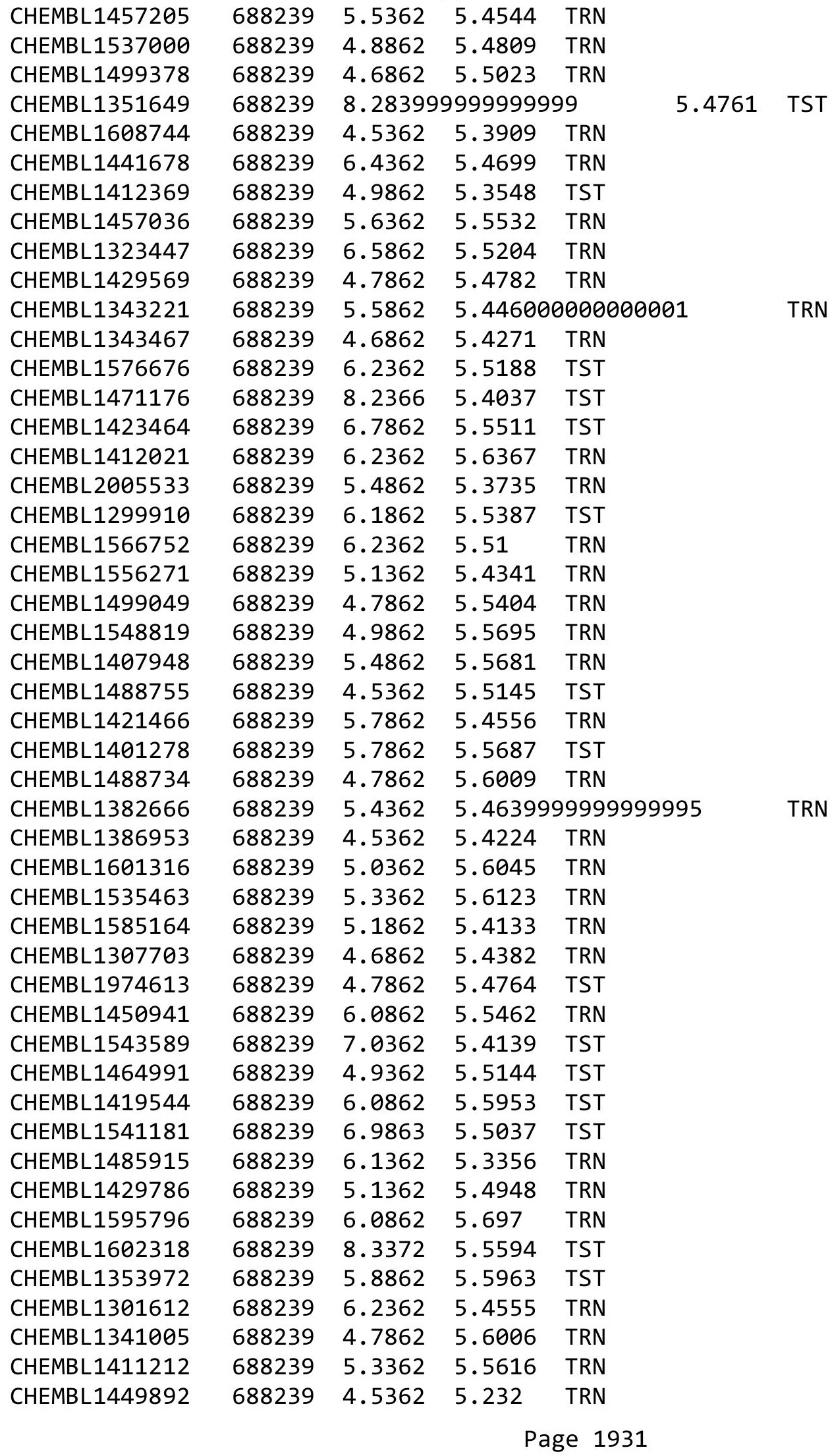


Supplemental Table S2.txt

\begin{tabular}{|c|c|c|c|c|c|}
\hline CHEMBL1563996 & 688239 & 5.1862 & 5.5851 & TRN & \\
\hline CHEMBL1408423 & 688239 & 5.7862 & 5.4478 & TRN & \\
\hline CHEMBL1311867 & 688239 & 5.4862 & 5.5614 & TRN & \\
\hline CHEMBL1434152 & 688239 & 5.1862 & 5.4936 & TRN & \\
\hline CHEMBL1429072 & 688239 & 6.8861 & 5.52 & TST & \\
\hline CHEMBL1371732 & 688239 & 4.7862 & 5.5023 & TST & \\
\hline CHEMBL1319056 & 688239 & 5.1862 & 5.4697 & TRN & \\
\hline CHEMBL1404478 & 688239 & 4.4862 & 5.4924 & TST & \\
\hline CHEMBL1362819 & 688239 & 6.3362 & 5.5141 & TRN & \\
\hline CHEMBL1553850 & 688239 & 4.6862 & 5.3736 & TRN & \\
\hline CHEMBL1319858 & 688239 & 4.8362 & 5.5523 & TRN & \\
\hline CHEMBL1329313 & 688239 & 5.6362 & 5.4667 & TRN & \\
\hline CHEMBL1451085 & 688239 & 5.4862 & 5.5434 & TRN & \\
\hline CHEMBL1475590 & 688239 & 6.8861 & 5.4088 & TRN & \\
\hline CHEMBL1345099 & 688239 & 4.5362 & 5.4726 & TRN & \\
\hline CHEMBL1396253 & 688239 & 5.3862 & 5.5623 & TRN & \\
\hline CHEMBL1527986 & 688239 & 5.6862 & 5.5201 & TRN & \\
\hline CHEMBL1462337 & 688239 & 5.0862 & 5.5429 & TRN & \\
\hline CHEMBL1406657 & 688239 & 5.4862 & 5.46899 & 9999999999 & TRN \\
\hline CHEMBL 235260 & 688239 & 6.9863 & 5.5636 & TRN & \\
\hline CHEMBL146710 & 688239 & 4.5362 & 5.5793 & TST & \\
\hline CHEMBL1316737 & 688239 & 6.7862 & 5.599 & TRN & \\
\hline CHEMBL1472714 & 688239 & 4.7362 & 5.5021 & TRN & \\
\hline CHEMBL1452971 & 688239 & 5.1862 & 5.5622 & TRN & \\
\hline CHEMBL1553976 & 688239 & 5.7362 & 5.482 & TRN & \\
\hline CHEMBL1394665 & 688239 & 5.1862 & 5.2727 & TRN & \\
\hline CHEMBL1378836 & 688239 & 7.7852 & 5.5921 & TRN & \\
\hline CHEMBL 3190983 & 688239 & 6.1362 & 5.3211 & TRN & \\
\hline CHEMBL1366114 & 688239 & 5.0362 & 5.4027 & TRN & \\
\hline CHEMBL1464293 & 688239 & 5.5862 & 5.6092 & TRN & \\
\hline CHEMBL1355361 & 688239 & 4.5362 & 5.3831 & TRN & \\
\hline CHEMBL1304449 & 688239 & 4.8862 & 5.3515 & TRN & \\
\hline CHEMBL1446623 & 688239 & 4.8862 & 5.5538 & TRN & \\
\hline CHEMBL1583484 & 688239 & 8.2366 & 5.4146 & TRN & \\
\hline CHEMBL1459187 & 688239 & 6.6861 & 5.6337 & TRN & \\
\hline CHEMBL1573306 & 688239 & 5.1862 & 5.487 & TRN & \\
\hline CHEMBL3208129 & 688239 & 8.3872 & 5.5514 & TST & \\
\hline CHEMBL1563600 & 688239 & 7.9355 & 5.6562 & TST & \\
\hline CHEMBL1589415 & 688239 & 5.2362 & 5.4319 & TST & \\
\hline CHEMBL1446846 & 688239 & 4.5362 & 5.4297 & TRN & \\
\hline CHEMBL1511625 & 688239 & 4.5362 & 5.4239 & TRN & \\
\hline CHEMBL1425359 & 688239 & 5.3362 & 5.58899 & 99999999995 & TRN \\
\hline CHEMBL1612556 & 688239 & 4.5362 & 5.5519 & TRN & \\
\hline CHEMBL1611451 & 688239 & 6.1862 & 5.6051 & TRN & \\
\hline CHEMBL1610558 & 688239 & 6.5862 & 5.4788 & TRN & \\
\hline CHEMBL1463802 & 688239 & 4.6862 & 5.5498 & TRN & \\
\hline CHEMBL1498030 & 688239 & 5.7362 & 5.5502 & TRN & \\
\hline CHEMBL1558286 & 688239 & 5.3362 & 5.4311 & TST & \\
\hline
\end{tabular}


Supplemental Table S2.txt

\begin{tabular}{|c|c|c|c|c|c|c|}
\hline CHEMBL1311487 & 688239 & 5.7362 & 5.3732 & TST & & \\
\hline CHEMBL1524962 & 688239 & 4.5362 & 5.3485 & TRN & & \\
\hline CHEMBL3210571 & 688239 & 4.8862 & 5.4928 & TRN & & \\
\hline CHEMBL1456624 & 688239 & 5.1862 & 5.3143 & TRN & & \\
\hline CHEMBL1534505 & 688239 & 5.2862 & 5.5065 & TRN & & \\
\hline CHEMBL1437342 & 688239 & 6.0862 & 5.5614 & TRN & & \\
\hline CHEMBL1464697 & 688239 & 4.7362 & 5.4621 & TRN & & \\
\hline CHEMBL1610331 & 688239 & 4.6862 & 5.4261 & TRN & & \\
\hline CHEMBL1350904 & 688239 & 5.3362 & 5.4823 & TST & & \\
\hline CHEMBL1351932 & 688239 & 6.8861 & 5.4456 & TST & & \\
\hline CHEMBL1510936 & 688239 & 6.7862 & 5.5406 & TRN & & \\
\hline CHEMBL1486306 & 688239 & 4.7362 & 5.3753 & TRN & & \\
\hline CHEMBL1362851 & 688239 & 5.6862 & 5.4983 & TRN & & \\
\hline CHEMBL1431024 & 688239 & 4.7862 & 5.4209 & TST & & \\
\hline CHEMBL1485916 & 688239 & 5.1862 & 5.5081 & TST & & \\
\hline CHEMBL1585335 & 688239 & 4.8362 & 5.6595 & TRN & & \\
\hline CHEMBL107231 & 688239 & 4.8362 & 5.3669 & TRN & & \\
\hline CHEMBL1317420 & 688239 & 4.5362 & 5.4925 & TRN & & \\
\hline CHEMBL1581795 & 688239 & 6.8362 & 5.1909 & TRN & & \\
\hline CHEMBL1299442 & 688239 & 6.1362 & 5.4299 & TRN & & \\
\hline CHEMBL1576438 & 688239 & 4.8862 & 5.4958 & TRN & & \\
\hline CHEMBL1387221 & 688239 & 5.4862 & 5.6634 & TRN & & \\
\hline CHEMBL1365401 & 688239 & 6.1862 & 5.5103 & TST & & \\
\hline CHEMBL1569977 & 688239 & 6.6362 & 5.3668 & TRN & & \\
\hline CHEMBL1623897 & 688239 & 4.6362 & 5.3212 & TRN & & \\
\hline CHEMBL1321658 & 688239 & 5.7862 & 5.4505 & TRN & & \\
\hline CHEMBL1507861 & 688239 & 5.5862 & 5.6457 & TRN & & \\
\hline CHEMBL1514597 & 688239 & 5.3362 & 5.3246 & TRN & & \\
\hline CHEMBL592068 & 688239 & 6.6362 & 5.3949 & TRN & & \\
\hline CHEMBL1337445 & 688239 & 4.5362 & 5.3032 & TST & & \\
\hline CHEMBL1573617 & 688239 & 8.3372 & 5.4905 & TST & & \\
\hline CHEMBL1307027 & 688239 & 8.283999 & 99999999 & 9 & 5.4954 & TRN \\
\hline CHEMBL1550294 & 688239 & 4.4862 & 5.4846 & TRN & & \\
\hline CHEMBL1529957 & 688239 & 5.3862 & 5.4434 & TRN & & \\
\hline CHEMBL1437773 & 688239 & 4.7362 & 5.351 & TRN & & \\
\hline CHEMBL1559213 & 688239 & 5.2862 & 5.4474 & TRN & & \\
\hline CHEMBL1593202 & 688239 & 4.6362 & 5.5317 & TRN & & \\
\hline CHEMBL1416120 & 688239 & 4.6362 & 5.6075 & TRN & & \\
\hline CHEMBL1559749 & 688239 & 5.1362 & 5.4159 & TRN & & \\
\hline CHEMBL1612807 & 688239 & 8.283999 & 99999999 & 9 & 5.4846 & TRN \\
\hline CHEMBL1320494 & 688239 & 5.1362 & 5.473 & TRN & & \\
\hline CHEMBL1551825 & 688239 & 4.5362 & 5.4514 & TRN & & \\
\hline CHEMBL1518108 & 688239 & 5.0362 & 5.5005 & TRN & & \\
\hline CHEMBL1409297 & 688239 & 6.2862 & 5.4899 & TRN & & \\
\hline CHEMBL1511332 & 688239 & 5.1362 & 5.5066 & TRN & & \\
\hline CHEMBL1476587 & 688239 & 5.2362 & 5.4214 & TST & & \\
\hline CHEMBL1579202 & 688239 & 4.8862 & 5.4628 & TRN & & \\
\hline CHEMBL1367447 & 688239 & 4.6362 & 5.4641 & TRN & & \\
\hline
\end{tabular}


Supplemental Table S2.txt

\begin{tabular}{|c|c|c|c|c|c|}
\hline CHEMBL1473006 & 688239 & 5.1862 & 5.4169 & TRN & \\
\hline CHEMBL1313694 & 688239 & 4.6362 & 5.305 & TST & \\
\hline CHEMBL1603003 & 688239 & 4.5362 & 5.5558 & TST & \\
\hline CHEMBL1515484 & 688239 & 5.4362 & 5.4813 & TRN & \\
\hline CHEMBL3191172 & 688239 & 5.3362 & 5.3369 & TRN & \\
\hline CHEMBL1522296 & 688239 & 4.9362 & 5.4063 & TRN & \\
\hline CHEMBL1502377 & 688239 & 5.4362 & 5.5226 & TST & \\
\hline CHEMBL1510817 & 688239 & 4.8362 & 5.372000 & 0000000001 & TST \\
\hline CHEMBL1421627 & 688239 & 4.7862 & 5.5311 & TRN & \\
\hline CHEMBL3207942 & 688239 & 4.5362 & 5.4401 & TST & \\
\hline CHEMBL1371640 & 688239 & 5.1362 & 5.4312 & TRN & \\
\hline CHEMBL1488246 & 688239 & 4.4862 & 5.5036 & TRN & \\
\hline CHEMBL1567082 & 688239 & 6.5862 & 5.4875 & TRN & \\
\hline CHEMBL1353584 & 688239 & 6.0862 & 5.5041 & TRN & \\
\hline CHEMBL1596426 & 688239 & 4.5362 & 5.3365 & TST & \\
\hline CHEMBL1331874 & 688239 & 4.6362 & 5.6909 & TST & \\
\hline CHEMBL1553668 & 688239 & 5.7362 & 5.5663 & TRN & \\
\hline CHEMBL1449968 & 688239 & 4.5362 & 5.4426 & TST & \\
\hline CHEMBL1421357 & 688239 & 7.5361 & 5.4979 & TRN & \\
\hline CHEMBL1528923 & 688239 & 4.5362 & 5.571000 & 0000000001 & 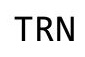 \\
\hline CHEMBL1352606 & 688239 & 4.5362 & 5.3672 & TRN & \\
\hline CHEMBL1457008 & 688239 & 6.3362 & 5.4764 & TST & \\
\hline CHEMBL1570286 & 688239 & 4.5362 & 5.4835 & TST & \\
\hline CHEMBL1360375 & 688239 & 6.0362 & 5.2658 & TRN & \\
\hline CHEMBL1300774 & 688239 & 6.0362 & 5.4278 & TST & \\
\hline CHEMBL1493617 & 688239 & 5.1862 & 5.4454 & TRN & \\
\hline CHEMBL 3198343 & 688239 & 4.5362 & 5.5808 & TRN & \\
\hline CHEMBL 290217 & 688239 & 5.3862 & 5.4256 & TST & \\
\hline CHEMBL1404102 & 688239 & 6.1362 & 5.5187 & TST & \\
\hline CHEMBL1513533 & 688239 & 6.0862 & 5.6273 & TRN & \\
\hline CHEMBL1417447 & 688239 & 4.5362 & 5.433 & TRN & \\
\hline CHEMBL1422668 & 688239 & 5.1862 & 5.3985 & TST & \\
\hline CHEMBL1538743 & 688239 & 7.4868 & 5.4381 & TRN & \\
\hline CHEMBL1570771 & 688239 & 4.5362 & 5.4964 & TRN & \\
\hline CHEMBL1396081 & 688239 & 5.0362 & 5.4425 & TRN & \\
\hline CHEMBL1435000 & 688239 & 5.4362 & 5.393 & TRN & \\
\hline CHEMBL1420503 & 688239 & 5.4862 & 5.512000 & 00000000005 & t \\
\hline CHEMBL1494200 & 688239 & 5.5862 & 5.6765 & TRN & \\
\hline CHEMBL1527975 & 688239 & 5.4362 & 5.3512 & TST & \\
\hline CHEMBL1318662 & 688239 & 4.7862 & 5.4351 & TRN & \\
\hline CHEMBL1586375 & 688239 & 4.6362 & 5.4561 & TRN & \\
\hline CHEMBL1601106 & 688239 & 8.3372 & 5.6085 & TST & \\
\hline CHEMBL1439208 & 688239 & 4.5362 & 5.4479 & TRN & \\
\hline CHEMBL1609210 & 688239 & 5.3362 & 5.5153 & TRN & \\
\hline CHEMBL1533172 & 688239 & 5.5862 & 5.5508 & TST & \\
\hline CHEMBL1446896 & 688239 & 6.2862 & 5.4969 & TRN & \\
\hline CHEMBL1452232 & 688239 & 8.28399 & 999999999 & 5.4043 & 1 \\
\hline CHEMBL1375475 & 688239 & 4.5362 & 5.5229 & TST & \\
\hline
\end{tabular}


Supplemental Table S2.txt

\begin{tabular}{|c|c|c|c|c|c|}
\hline CHEMBL1509544 & 688239 & 5.1362 & 5.465 & TST & \\
\hline CHEMBL1594710 & 688239 & 5.2862 & 5.6207 & TRN & \\
\hline CHEMBL1604239 & 688239 & 4.5362 & 5.6863 & TST & \\
\hline CHEMBL 3211617 & 688239 & 4.6362 & 5.5423 & TST & \\
\hline CHEMBL1422162 & 688239 & 5.55 & 5.5695 & TRN & \\
\hline CHEMBL1319431 & 688239 & 4.5862 & 5.4491 & TRN & \\
\hline CHEMBL1592149 & 688239 & 4.5362 & 5.535 & TRN & \\
\hline CHEMBL1499504 & 688239 & 7.0862 & 5.5125 & TST & \\
\hline CHEMBL562743 & 688239 & 4.5362 & 5.6327 & TST & \\
\hline CHEMBL1530912 & 688239 & 4.5362 & 5.5635 & TRN & \\
\hline CHEMBL1375491 & 688239 & 4.5362 & 5.5179 & TRN & \\
\hline CHEMBL1304304 & 688239 & 4.7862 & 5.5626 & TST & \\
\hline CHEMBL1378830 & 688239 & 5.7362 & 5.5164 & TRN & \\
\hline CHEMBL1388904 & 688239 & 4.8362 & 5.5139 & TST & \\
\hline CHEMBL1395462 & 688239 & 5.4862 & 5.4898 & TRN & \\
\hline CHEMBL1482665 & 688239 & 4.5362 & 5.7161 & TRN & \\
\hline CHEMBL1464058 & 688239 & 4.5362 & 5.3892 & TST & \\
\hline CHEMBL502842 & 688239 & 4.4862 & 5.3682 & TRN & \\
\hline CHEMBL1542098 & 688239 & 4.6362 & 5.5876 & TST & \\
\hline CHEMBL1507187 & 688239 & 4.5362 & 5.5036 & TRN & \\
\hline CHEMBL1596874 & 688239 & 6.5862 & 5.5769 & TRN & \\
\hline CHEMBL1359841 & 688239 & 8.28399 & 99999999 & 9 & 5.4244 \\
\hline CHEMBL1483745 & 688239 & 5.1862 & 5.3908 & TRN & \\
\hline CHEMBL1328648 & 688239 & 5.4362 & 5.477 & TST & \\
\hline CHEMBL1309261 & 688239 & 4.5362 & 5.4234 & TST & \\
\hline CHEMBL1606407 & 688239 & 5.0862 & 5.4413 & TST & \\
\hline CHEMBL1449762 & 688239 & 5.3862 & 5.4835 & TRN & \\
\hline CHEMBL1373359 & 688239 & 5.2362 & 5.6924 & TST & \\
\hline CHEMBL1315653 & 688239 & 4.6362 & 5.4203 & TRN & \\
\hline CHEMBL 3191537 & 688239 & 4.5362 & 5.2362 & TST & \\
\hline CHEMBL1598307 & 688239 & 5.1862 & 5.6583 & TRN & \\
\hline CHEMBL1580238 & 688239 & 5.1862 & 5.5236 & TRN & \\
\hline CHEMBL3211716 & 688239 & 4.9362 & 5.2944 & TRN & \\
\hline CHEMBL1424139 & 688239 & 7.7352 & 5.5291 & TRN & \\
\hline CHEMBL1302873 & 688239 & 4.8862 & 5.5869 & TST & \\
\hline CHEMBL1490077 & 688239 & 4.5362 & 5.4638 & TRN & \\
\hline CHEMBL1508314 & 688239 & 4.6862 & 5.4287 & TST & \\
\hline CHEMBL1497375 & 688239 & 4.5362 & 5.2516 & TST & \\
\hline CHEMBL1581934 & 688239 & 6.1862 & 5.5722 & TRN & \\
\hline CHEMBL1590254 & 688239 & 6.3362 & 5.495 & TRN & \\
\hline CHEMBL1458725 & 688239 & 8.1871 & 5.4013 & TRN & \\
\hline CHEMBL1340562 & 688239 & 5.1862 & 5.5422 & TRN & \\
\hline CHEMBL1425583 & 688239 & 5.1362 & 5.4433 & TRN & \\
\hline CHEMBL1424997 & 688239 & 8.2366 & 5.5433 & TST & \\
\hline CHEMBL1453284 & 688239 & 5.1862 & 5.4656 & TRN & \\
\hline CHEMBL1324261 & 688239 & 5.3362 & 5.4505 & TRN & \\
\hline CHEMBL1404027 & 688239 & 5.6362 & 5.5495 & TRN & \\
\hline CHEMBL1341901 & 688239 & 6.4862 & 5.4565 & TRN & \\
\hline
\end{tabular}


Supplemental Table S2.txt

\begin{tabular}{|c|c|c|c|c|c|}
\hline CHEMBL1357570 & 688239 & 5.1862 & 5.4161 & TRN & \\
\hline CHEMBL1517596 & 688239 & 4.6362 & 5.4685 & TRN & \\
\hline CHEMBL1361615 & 688239 & 7.1864 & 5.55 & TRN & \\
\hline CHEMBL 3209429 & 688239 & 5.1862 & 5.4472 & TRN & \\
\hline CHEMBL1574358 & 688239 & 4.5362 & 5.601 & TRN & \\
\hline CHEMBL1408290 & 688239 & 5.7362 & 5.4667 & TRN & \\
\hline CHEMBL1363292 & 688239 & 4.5362 & 5.4691 & TRN & \\
\hline CHEMBL1363366 & 688239 & 4.7862 & 5.5708 & TRN & \\
\hline CHEMBL1365932 & 688239 & 6.8362 & 5.4411 & TRN & \\
\hline CHEMBL1585536 & 688239 & 7.2366 & 5.6011 & TST & \\
\hline CHEMBL1409399 & 688239 & 7.0862 & 5.5815 & TRN & \\
\hline CHEMBL1597040 & 688239 & 5.8362 & 5.4898 & TRN & \\
\hline CHEMBL 3212546 & 688239 & 7.1361 & 5.5296 & TRN & \\
\hline CHEMBL1496081 & 688239 & 4.9362 & 5.4462 & TRN & \\
\hline CHEMBL1305811 & 688239 & 8.3872 & 5.3559 & TST & \\
\hline CHEMBL1306079 & 688239 & 4.7362 & 5.4963 & TRN & \\
\hline CHEMBL1535877 & 688239 & 5.0862 & 5.4446 & TRN & \\
\hline CHEMBL1501334 & 688239 & 6.1362 & 5.3512 & TRN & \\
\hline CHEMBL1326624 & 688239 & 4.8362 & 5.4912 & TRN & \\
\hline CHEMBL1312096 & 688239 & 4.5362 & 5.4965 & TST & \\
\hline CHEMBL3208991 & 688239 & 4.5362 & 5.5314 & TRN & \\
\hline CHEMBL1337807 & 688239 & 5.7862 & 5.5032 & TRN & \\
\hline CHEMBL 1405760 & 688239 & 4.5362 & 5.6485 & TRN & \\
\hline CHEMBL1315396 & 688239 & 5.8362 & 5.4784 & TRN & \\
\hline CHEMBL1374675 & 688239 & 8.3372 & 5.5794 & TRN & \\
\hline CHEMBL1439420 & 688239 & 5.6362 & 5.5218 & TST & \\
\hline CHEMBL1536890 & 688239 & 6.1862 & 5.4626 & TRN & \\
\hline CHEMBL1338609 & 688239 & 4.8862 & 5.4841 & TRN & \\
\hline CHEMBL1381469 & 688239 & 4.8362 & 5.5077 & TRN & \\
\hline CHEMBL1440579 & 688239 & 6.2362 & 5.3923 & TRN & \\
\hline CHEMBL1331944 & 688239 & 4.5362 & 5.4776 & TRN & \\
\hline CHEMBL1561584 & 688239 & 5.3862 & 5.5396 & TRN & \\
\hline CHEMBL1336253 & 688239 & 5.7862 & 5.5578 & TRN & \\
\hline CHEMBL1568103 & 688239 & 5.1362 & 5.5467 & TRN & \\
\hline CHEMBL1407976 & 688239 & 4.6862 & 5.4987 & TST & \\
\hline CHEMBL1307078 & 688239 & 8.3372 & 5.4851 & TST & \\
\hline CHEMBL1465143 & 688239 & 5.6362 & 5.5607 & TST & \\
\hline CHEMBL1520303 & 688239 & 4.6362 & 5.4008 & TRN & \\
\hline CHEMBL1331573 & 688239 & 4.8862 & 5.4086 & TRN & \\
\hline CHEMBL1431780 & 688239 & 6.1862 & 5.4894 & TRN & \\
\hline CHEMBL1565343 & 688239 & 5.1862 & 5.3652 & TRN & \\
\hline CHEMBL1413500 & 688239 & 5.1862 & 5.5828 & TRN & \\
\hline CHEMBL1471407 & 688239 & 4.9362 & 5.4959 & TRN & \\
\hline CHEMBL1487139 & 688239 & 8.283999 & 99999999 & 9 & 5.4526 \\
\hline CHEMBL1538171 & 688239 & 4.9362 & 5.6783 & TRN & \\
\hline CHEMBL1546056 & 688239 & 4.7362 & 5.6473 & TST & \\
\hline CHEMBL1365585 & 688239 & 4.5862 & 5.4697 & TRN & \\
\hline CHEMBL1468876 & 688239 & 5.1862 & 5.6249 & TST & \\
\hline
\end{tabular}


Supplemental Table S2.txt

\begin{tabular}{|c|c|c|c|c|}
\hline CHEMBL3194437 & 688239 & 5.1862 & 5.3352 & TRN \\
\hline CHEMBL1346332 & 688239 & 4.4862 & 5.4321 & TRN \\
\hline CHEMBL1595560 & 688239 & 5.3362 & 5.5465 & TST \\
\hline CHEMBL1410374 & 688239 & 4.6362 & 5.5385 & TRN \\
\hline CHEMBL1566701 & 688239 & 5.7862 & 5.45200 & 3000000001 \\
\hline CHEMBL1565259 & 688239 & 4.6362 & 5.5205 & TST \\
\hline CHEMBL1503713 & 688239 & 6.6861 & 5.4932 & TRN \\
\hline CHEMBL1527320 & 688239 & 5.2362 & 5.7189 & TRN \\
\hline CHEMBL1457150 & 688239 & 4.4862 & 5.5958 & TRN \\
\hline CHEMBL1497993 & 688239 & 4.7362 & 5.3239 & TRN \\
\hline CHEMBL1459467 & 688239 & 4.5362 & 5.4431 & TRN \\
\hline CHEMBL1500245 & 688239 & 4.8362 & 5.4882 & TRN \\
\hline CHEMBL 3145375 & 688239 & 4.5362 & 5.5221 & TRN \\
\hline CHEMBL1497765 & 688239 & 4.4862 & 5.5768 & TRN \\
\hline CHEMBL1381730 & 688239 & 4.5362 & 5.5557 & TST \\
\hline CHEMBL1385810 & 688239 & 4.7862 & 5.4857 & TST \\
\hline CHEMBL1975473 & 688239 & 4.5362 & 5.4987 & TST \\
\hline CHEMBL1342103 & 688239 & 6.0862 & 5.4966 & TST \\
\hline CHEMBL 79589 & 688239 & 4.7862 & 5.5726 & TRN \\
\hline CHEMBL1582617 & 688239 & 4.4862 & 5.4784 & TST \\
\hline CHEMBL1417015 & 688239 & 5.3862 & 5.6411 & TST \\
\hline CHEMBL1514808 & 688239 & 5.4862 & 5.4373 & TRN \\
\hline CHEMBL1378946 & 688239 & 5.1862 & 5.6083 & TRN \\
\hline CHEMBL1367510 & 688239 & 5.3862 & 5.5873 & TRN \\
\hline CHEMBL1544800 & 688239 & 5.0862 & 5.6686 & TST \\
\hline CHEMBL1431577 & 688239 & 5.3362 & 5.6021 & TRN \\
\hline CHEMBL1400023 & 688239 & 4.4862 & 5.6397 & TRN \\
\hline CHEMBL1495942 & 688239 & 4.5362 & 5.5294 & TRN \\
\hline CHEMBL1337358 & 688239 & 4.9362 & 5.6208 & TRN \\
\hline CHEMBL1402105 & 688239 & 4.5362 & 5.4805 & TRN \\
\hline CHEMBL1575690 & 688239 & 5.4862 & 5.3124 & TRN \\
\hline CHEMBL1495415 & 688239 & 5.1862 & 5.5709 & TRN \\
\hline CHEMBL1457068 & 688239 & 4.7862 & 5.3519 & TRN \\
\hline CHEMBL1594536 & 688239 & 4.7862 & 5.3831 & TRN \\
\hline CHEMBL1477662 & 688239 & 5.2362 & 5.5962 & TST \\
\hline CHEMBL1565940 & 688239 & 6.1362 & 5.6276 & TST \\
\hline CHEMBL1376481 & 688239 & 4.4862 & 5.4412 & TRN \\
\hline CHEMBL1462861 & 688239 & 8.3372 & 5.4398 & TST \\
\hline CHEMBL1363957 & 688239 & 5.1862 & 5.4579 & TRN \\
\hline CHEMBL1417167 & 688239 & 5.2362 & 5.3409 & TST \\
\hline CHEMBL1340967 & 688239 & 5.2362 & 5.4664 & TST \\
\hline CHEMBL1392268 & 688239 & 6.6861 & 5.4273 & TRN \\
\hline CHEMBL565654 & 688239 & 5.3362 & 5.3944 & TRN \\
\hline CHEMBL1427422 & 688239 & 5.2362 & 5.5219 & TRN \\
\hline CHEMBL1604881 & 688239 & 5.1862 & 5.4554 & TRN \\
\hline CHEMBL1477107 & 688239 & 4.4862 & 5.5422 & TST \\
\hline CHEMBL2007274 & 688239 & 5.1862 & 5.5393 & TRN \\
\hline CHEMBL1382615 & 688239 & 4.6362 & 5.6319 & TRN \\
\hline
\end{tabular}


Supplemental Table S2.txt

\begin{tabular}{|c|c|c|c|c|}
\hline CHEMBL1421155 & 688239 & 5.8362 & 5.4798 & TRN \\
\hline CHEMBL1388876 & 688239 & 4.5362 & 5.4407 & TRN \\
\hline CHEMBL1351861 & 688239 & 6.7862 & 5.6656 & TRN \\
\hline CHEMBL1524673 & 688239 & 5.1362 & 5.4895 & TRN \\
\hline CHEMBL1416190 & 688239 & 4.6362 & 5.4699 & TRN \\
\hline CHEMBL196228 & 688239 & 4.5362 & 5.4515 & TRN \\
\hline CHEMBL1543590 & 688239 & 5.1862 & 5.501 & TRN \\
\hline CHEMBL1406912 & 688239 & 4.5862 & 5.5437 & TRN \\
\hline CHEMBL1484496 & 688239 & 4.5362 & 5.6081 & TRN \\
\hline CHEMBL3192855 & 688239 & 5.2362 & 5.4956 & TRN \\
\hline CHEMBL3196698 & 688239 & 5.5362 & 5.3669 & TST \\
\hline CHEMBL1357905 & 688239 & 5.1862 & 5.4725 & TRN \\
\hline CHEMBL3192618 & 688239 & 4.5362 & 5.4511 & TRN \\
\hline CHEMBL1308459 & 688239 & 4.7362 & 5.4343 & TST \\
\hline CHEMBL1454653 & 688239 & 4.5862 & 5.5644 & TST \\
\hline CHEMBL1552189 & 688239 & 4.7862 & 5.5817 & TRN \\
\hline CHEMBL1310058 & 688239 & 6.2362 & 5.4303 & TRN \\
\hline CHEMBL1313565 & 688239 & 4.5362 & 5.5118 & TRN \\
\hline CHEMBL1356646 & 688239 & 5.2862 & 5.4012 & TRN \\
\hline CHEMBL1455079 & 688239 & 6.8861 & 5.3781 & TST \\
\hline CHEMBL1431920 & 688239 & 6.9363 & 5.5923 & TRN \\
\hline CHEMBL1415888 & 688239 & 4.5362 & 5.7221 & TRN \\
\hline CHEMBL1581004 & 688239 & 5.75 & 5.6043 & TRN \\
\hline CHEMBL1477672 & 688239 & 4.5362 & 5.3905 & TRN \\
\hline CHEMBL 3213747 & 688239 & 5.7362 & 5.4489 & TRN \\
\hline CHEMBL1500015 & 688239 & 5.7862 & 5.4369 & TRN \\
\hline CHEMBL1596948 & 688239 & 4.5362 & 5.5229 & TRN \\
\hline CHEMBL1348922 & 688239 & 4.4862 & 5.4422 & TST \\
\hline CHEMBL3195910 & 688239 & 5.8862 & 5.5722 & TST \\
\hline CHEMBL1513467 & 688239 & 4.8362 & 5.4517 & TRN \\
\hline CHEMBL1316404 & 688239 & 6.0862 & 5.5409 & TST \\
\hline CHEMBL1353345 & 688239 & 6.2362 & 5.4641 & TRN \\
\hline CHEMBL1369190 & 688239 & 4.6362 & 5.5374 & TST \\
\hline CHEMBL1498752 & 688239 & 6.2362 & 5.6465 & TRN \\
\hline CHEMBL1330469 & 688239 & 6.3362 & 5.6595 & TRN \\
\hline CHEMBL1301935 & 688239 & 4.8362 & 5.5637 & TST \\
\hline CHEMBL1517333 & 688239 & 4.6862 & 5.369 & TST \\
\hline CHEMBL3198582 & 688239 & 6.1862 & 5.463999 & э99999999995 \\
\hline CHEMBL1408826 & 688239 & 5.3362 & 5.4176 & TRN \\
\hline CHEMBL1429132 & 688239 & 6.3362 & 5.5063 & TST \\
\hline CHEMBL1305047 & 688239 & 5.3362 & 5.4679 & TRN \\
\hline CHEMBL1438375 & 688239 & 7.2865 & 5.5582 & TRN \\
\hline CHEMBL3191002 & 688239 & 4.6862 & 5.4827 & TRN \\
\hline CHEMBL1464025 & 688239 & 4.5362 & 5.4748 & TRN \\
\hline CHEMBL1554869 & 688239 & 4.9862 & 5.5689 & TRN \\
\hline CHEMBL1557006 & 688239 & 4.6862 & 5.3844 & TRN \\
\hline CHEMBL1522589 & 688239 & 6.2362 & 5.3569 & TRN \\
\hline CHEMBL1525469 & 688239 & 5.8862 & 5.5357 & TST \\
\hline
\end{tabular}


Supplemental Table S2.txt

\begin{tabular}{|c|c|c|c|c|c|}
\hline CHEMBL1364827 & 688239 & 6.2362 & 5.572 & TRN & \\
\hline CHEMBL1348223 & 688239 & 4.6862 & 5.6502 & TRN & \\
\hline CHEMBL 3198073 & 688239 & 6.5363 & 5.3017 & TRN & \\
\hline CHEMBL1432567 & 688239 & 4.5362 & 5.4947 & TST & \\
\hline CHEMBL1475178 & 688239 & 5.1862 & 5.4104 & TRN & \\
\hline CHEMBL1588937 & 688239 & 5.1862 & 5.4207 & TRN & \\
\hline CHEMBL1563868 & 688239 & 5.2 & 5.593999 & 9999999999 & TRN \\
\hline CHEMBL1596307 & 688239 & 4.6862 & 5.3427 & TRN & \\
\hline CHEMBL1542399 & 688239 & 4.5362 & 5.5934 & TRN & \\
\hline CHEMBL1370413 & 688239 & 4.4862 & 5.474 & TST & \\
\hline CHEMBL1300557 & 688239 & 5.1862 & 5.5018 & TRN & \\
\hline CHEMBL1537427 & 688239 & 4.7862 & 5.5363 & TRN & \\
\hline CHEMBL1359083 & 688239 & 4.6862 & 5.3919 & TRN & \\
\hline CHEMBL1350974 & 688239 & 4.5362 & 5.4253 & TRN & \\
\hline CHEMBL1551251 & 688239 & 5.3862 & 5.4999 & TRN & \\
\hline CHEMBL1566181 & 688239 & 8.28399 & 9999999 & 5.5988 & TRN \\
\hline CHEMBL1440329 & 688239 & 5.1862 & 5.3535 & TRN & \\
\hline CHEMBL1587249 & 688239 & 5.3862 & 5.6044 & TRN & \\
\hline CHEMBL1306405 & 688239 & 4.7862 & 5.4093 & TRN & \\
\hline CHEMBL1300882 & 688239 & 7.5867 & 5.541 & TRN & \\
\hline CHEMBL3195446 & 688239 & 4.6862 & 5.4776 & TRN & \\
\hline CHEMBL1494854 & 688239 & 4.4862 & 5.56 & TRN & \\
\hline CHEMBL1458589 & 688239 & 5.1862 & 5.5451 & TRN & \\
\hline CHEMBL1305910 & 688239 & 4.6362 & 5.4216 & TRN & \\
\hline CHEMBL 3198872 & 688239 & 4.7362 & 5.6079 & TRN & \\
\hline CHEMBL1368624 & 688239 & 5.5362 & 5.4755 & TRN & \\
\hline CHEMBL1531604 & 688239 & 5.0862 & 5.5356 & TRN & \\
\hline CHEMBL1377915 & 688239 & 5.1862 & 5.4387 & TST & \\
\hline CHEMBL1566835 & 688239 & 4.7362 & 5.5174 & TST & \\
\hline CHEMBL1343332 & 688239 & 6.4362 & 5.4649 & TST & \\
\hline CHEMBL1361898 & 688239 & 4.5362 & 5.5841 & TST & \\
\hline CHEMBL1359877 & 688239 & 5.8862 & 5.6398 & TRN & \\
\hline CHEMBL1410656 & 688239 & 5.6362 & 5.4521 & TRN & \\
\hline CHEMBL1544640 & 688239 & 5.5862 & 5.37 & TRN & \\
\hline CHEMBL1488571 & 688239 & 6.3362 & 5.3973 & TST & \\
\hline CHEMBL1390745 & 688239 & 4.8362 & 5.3972 & TST & \\
\hline CHEMBL1606169 & 688239 & 5.8362 & 5.6358 & TRN & \\
\hline CHEMBL1593776 & 688239 & 4.6362 & 5.452999 & 9999999999 & ות \\
\hline CHEMBL1496051 & 688239 & 5.7362 & 5.3672 & TRN & \\
\hline CHEMBL1594696 & 688239 & 8.3872 & 5.6942 & TRN & \\
\hline CHEMBL1570158 & 688239 & 4.5362 & 5.499 & TST & \\
\hline CHEMBL1425101 & 688239 & 4.5362 & 5.4438 & TRN & \\
\hline CHEMBL1444207 & 688239 & 5.0362 & 5.4962 & TRN & \\
\hline CHEMBL 94512 & 688239 & 4.7362 & 5.5116 & TRN & \\
\hline CHEMBL1529244 & 688239 & 6.9363 & 5.5085 & TRN & \\
\hline CHEMBL1602920 & 688239 & 6.5862 & 5.4609 & TRN & \\
\hline CHEMBL1385222 & 688239 & 5.1862 & 5.5953 & TST & \\
\hline CHEMBL1336550 & 688239 & 5.3862 & 5.4261 & TRN & \\
\hline
\end{tabular}


Supplemental Table S2.txt

\begin{tabular}{|c|c|c|c|c|}
\hline CHEMBL 2373682 & 688239 & 5.8862 & 5.3379 & TRN \\
\hline CHEMBL1597438 & 688239 & 5.7362 & 5.442 & TRN \\
\hline CHEMBL1502617 & 688239 & 4.6862 & 5.3138 & TRN \\
\hline CHEMBL1389840 & 688239 & 7.9355 & 5.391 & TRN \\
\hline CHEMBL1317188 & 688239 & 5.1862 & 5.4567 & TRN \\
\hline CHEMBL1381853 & 688239 & 4.5362 & 5.4495 & TRN \\
\hline CHEMBL1558248 & 688239 & 4.5362 & 5.5167 & TST \\
\hline CHEMBL1412176 & 688239 & 4.5362 & 5.4545 & TRN \\
\hline CHEMBL1530749 & 688239 & 5.3862 & 5.4639 & TRN \\
\hline CHEMBL1417917 & 688239 & 4.8362 & 5.6082 & TRN \\
\hline CHEMBL1566133 & 688239 & 5.7862 & 5.4267 & TRN \\
\hline CHEMBL1359029 & 688239 & 6.4862 & 5.5222 & TRN \\
\hline CHEMBL1610481 & 688239 & 4.9362 & 5.5355 & TRN \\
\hline CHEMBL1442427 & 688239 & 4.8362 & 5.3684 & TRN \\
\hline CHEMBL1428793 & 688239 & 4.6862 & 5.641 & TRN \\
\hline CHEMBL1600416 & 688239 & 4.6362 & 5.5019 & TST \\
\hline CHEMBL1602875 & 688239 & 4.5362 & 5.5385 & TST \\
\hline CHEMBL1317459 & 688239 & 4.6862 & 5.4488 & TRN \\
\hline CHEMBL1423137 & 688239 & 5.7862 & 5.5024 & TRN \\
\hline CHEMBL3208476 & 688239 & 7.7852 & 5.4207 & TRN \\
\hline CHEMBL1397649 & 688239 & 4.5362 & 5.3691 & TRN \\
\hline CHEMBL1532510 & 688239 & 4.6862 & 5.5191 & TRN \\
\hline CHEMBL1386805 & 688239 & 4.8862 & 5.4625 & TST \\
\hline CHEMBL352690 & 688239 & 4.6862 & 5.4181 & TRN \\
\hline CHEMBL1381890 & 688239 & 4.5362 & 5.4433 & TRN \\
\hline CHEMBL1393598 & 688239 & 4.7362 & 5.5668 & TRN \\
\hline CHEMBL1600844 & 688239 & 4.5362 & 5.4021 & TRN \\
\hline CHEMBL1502081 & 688239 & 4.4862 & 5.5213 & TRN \\
\hline CHEMBL1471168 & 688239 & 6.6362 & 5.4463 & TRN \\
\hline CHEMBL1333332 & 688239 & 4.6362 & 5.5139 & TST \\
\hline CHEMBL1379555 & 688239 & 4.5362 & 5.5069 & TRN \\
\hline CHEMBL1580994 & 688239 & 4.5362 & 5.4628 & TRN \\
\hline CHEMBL1350467 & 688239 & 4.8862 & 5.4755 & TRN \\
\hline CHEMBL1465321 & 688239 & 4.5362 & 5.4547 & TRN \\
\hline CHEMBL1316814 & 688239 & 5.5362 & 5.5622 & TRN \\
\hline CHEMBL1312462 & 688239 & 4.6362 & 5.4733 & TST \\
\hline CHEMBL1458883 & 688239 & 5.1862 & 5.5072 & TST \\
\hline CHEMBL3192282 & 688239 & 7.1864 & 5.43 & TST \\
\hline CHEMBL1574939 & 688239 & 5.6862 & 5.6229 & TRN \\
\hline CHEMBL1580412 & 688239 & 5.1862 & 5.5814 & TRN \\
\hline CHEMBL1488613 & 688239 & 4.5862 & 5.57100 & 0000000001 \\
\hline CHEMBL1409570 & 688239 & 5.3362 & 5.4976 & TRN \\
\hline CHEMBL1597723 & 688239 & 5.5862 & 5.4006 & TRN \\
\hline CHEMBL1467742 & 688239 & 5.0862 & 5.495 & TRN \\
\hline CHEMBL1523904 & 688239 & 6.1362 & 5.4441 & TRN \\
\hline CHEMBL1448793 & 688239 & 5.1362 & 5.4696 & TST \\
\hline CHEMBL3196317 & 688239 & 4.6862 & 5.3807 & TRN \\
\hline CHEMBL1433385 & 688239 & 4.5362 & 5.4121 & TRN \\
\hline
\end{tabular}


Supplemental Table S2.txt

\begin{tabular}{|c|c|c|c|c|c|}
\hline CHEMBL1464105 & 688239 & 4.6862 & 5.4375 & TRN & \\
\hline CHEMBL1430263 & 688239 & 4.7862 & 5.6104 & TST & \\
\hline CHEMBL1611379 & 688239 & 5.1862 & 5.416 & TRN & \\
\hline CHEMBL1323245 & 688239 & 5.1862 & 5.3866 & TST & \\
\hline CHEMBL1416813 & 688239 & 4.9362 & 5.5991 & TRN & \\
\hline CHEMBL1382679 & 688239 & 6.7862 & 5.5526 & TRN & \\
\hline CHEMBL1613220 & 688239 & 4.5362 & 5.4175 & TST & \\
\hline CHEMBL1570955 & 688239 & 4.6862 & 5.4576 & TRN & \\
\hline CHEMBL1470851 & 688239 & 4.4862 & 5.6319 & TRN & \\
\hline CHEMBL1457122 & 688239 & 6.9363 & 5.5133 & TRN & \\
\hline CHEMBL1607007 & 688239 & 4.4862 & \multicolumn{2}{|c|}{5.372000000000001} & TRN \\
\hline CHEMBL1341751 & 688239 & 4.5362 & 5.4338 & TRN & \\
\hline CHEMBL1577215 & 688239 & 7.0362 & 5.5777 & TRN & \\
\hline CHEMBL1404311 & 688239 & 5.5862 & 5.5034 & TRN & \\
\hline CHEMBL1420861 & 688239 & 4.5362 & 5.5629 & TRN & \\
\hline CHEMBL1399108 & 688239 & 5.4862 & 5.5924 & TRN & \\
\hline CHEMBL1530819 & 688239 & 5.2862 & 5.6089 & TRN & \\
\hline CHEMBL1438376 & 688239 & 6.1362 & 5.4884 & TRN & \\
\hline CHEMBL1598371 & 688239 & 5.0362 & 5.6271 & TST & \\
\hline CHEMBL1389507 & 688239 & 6.1862 & 5.5595 & TRN & \\
\hline CHEMBL1563715 & 688239 & 5.1862 & 5.4894 & TRN & \\
\hline CHEMBL1360460 & 688239 & 4.5362 & 5.5913 & TRN & \\
\hline CHEMBL1511758 & 688239 & 5.8862 & 5.4951 & TRN & \\
\hline CHEMBL1429184 & 688239 & 5.1862 & 5.5188 & TST & \\
\hline CHEMBL1506522 & 688239 & 5.5362 & 5.5593 & TRN & \\
\hline CHEMBL1396935 & 688239 & 4.9862 & 5.34 & TRN & \\
\hline CHEMBL1410802 & 688239 & 4.7362 & 5.4961 & TST & \\
\hline CHEMBL1418365 & 688239 & 4.6862 & 5.5135 & TRN & \\
\hline CHEMBL1473783 & 688239 & 5.6862 & 5.4442 & TRN & \\
\hline CHEMBL1465559 & 688239 & 4.5862 & \multicolumn{2}{|c|}{5.382999999999999} & TST \\
\hline CHEMBL1463203 & 688239 & 6.4362 & 5.5528 & TST & \\
\hline CHEMBL 3199467 & 688239 & 5.3862 & 5.4097 & TST & \\
\hline CHEMBL1469033 & 688239 & 6.9363 & 5.473 & TRN & \\
\hline CHEMBL1510875 & 688239 & 5.6862 & 5.4349 & TRN & \\
\hline CHEMBL 3212410 & 688239 & 4.4862 & 5.3083 & TRN & \\
\hline CHEMBL1352826 & 688239 & 5.7362 & 5.6727 & TST & \\
\hline CHEMBL1435732 & 688239 & 5.0862 & 5.4127 & TST & \\
\hline CHEMBL1514574 & 688239 & 5.0862 & 5.5857 & TRN & \\
\hline CHEMBL1609445 & 688239 & 6.5363 & 5.3805 & TRN & \\
\hline CHEMBL1431956 & 688239 & 5.1862 & 5.6099 & TST & \\
\hline CHEMBL1601922 & 688239 & 5.1862 & 5.529 & TRN & \\
\hline CHEMBL1589140 & 688239 & 5.1362 & 5.4967 & TRN & \\
\hline CHEMBL1331984 & 688239 & 5.4362 & 5.3979 & TRN & \\
\hline CHEMBL1538944 & 688239 & 5.1862 & 5.5114 & TST & \\
\hline CHEMBL1484008 & 688239 & 6.0362 & 5.4814 & TST & \\
\hline CHEMBL1332119 & 688239 & 6.0862 & 5.4538 & TRN & \\
\hline CHEMBL1524135 & 688239 & 5.5862 & 5.4559 & TRN & \\
\hline CHEMBL1502525 & 688239 & 6.5862 & 5.562 & TRN & \\
\hline
\end{tabular}


Supplemental Table S2.txt

\begin{tabular}{|c|c|c|c|c|}
\hline CHEMBL1604663 & 688239 & 6.2362 & 5.2383 & TST \\
\hline CHEMBL1348980 & 688239 & 5.6362 & 5.438 & TST \\
\hline CHEMBL1597504 & 688239 & 4.9862 & 5.5239 & TRN \\
\hline CHEMBL1470261 & 688239 & 5.2862 & 5.5686 & TST \\
\hline CHEMBL1412769 & 688239 & 6.8362 & 5.4271 & TRN \\
\hline CHEMBL1468225 & 688239 & 6.0362 & 5.3786 & TRN \\
\hline CHEMBL1440305 & 688239 & 8.3372 & 5.5193 & TRN \\
\hline CHEMBL1319262 & 688239 & 5.4362 & 5.5167 & TRN \\
\hline CHEMBL1581845 & 688239 & 4.6362 & \multicolumn{2}{|c|}{5.4270000000000005} \\
\hline CHEMBL1491599 & 688239 & 5.1862 & 5.3965 & TRN \\
\hline CHEMBL1516067 & 688239 & 4.8362 & 5.4733 & TRN \\
\hline CHEMBL1581558 & 688239 & 4.6862 & 5.4837 & TRN \\
\hline CHEMBL1589128 & 688239 & 6.3863 & 5.4703 & TST \\
\hline CHEMBL1552659 & 688239 & 7.3363 & 5.7092 & TRN \\
\hline CHEMBL1561995 & 688239 & 6.8362 & 5.3785 & TRN \\
\hline CHEMBL3190759 & 688239 & 5.9862 & 5.3288 & TRN \\
\hline CHEMBL1343164 & 688239 & 5.1862 & 5.4371 & TRN \\
\hline CHEMBL1504375 & 688239 & 5.4362 & 5.5675 & TRN \\
\hline CHEMBL1526784 & 688239 & 6.6861 & 5.5722 & TRN \\
\hline CHEMBL1498139 & 688239 & 4.6362 & 5.4655 & TST \\
\hline CHEMBL1442859 & 688239 & 4.9362 & \multicolumn{2}{|c|}{5.4879999999999995} \\
\hline CHEMBL1484315 & 688239 & 5.5862 & 5.522 & TRN \\
\hline CHEMBL1443122 & 688239 & 5.9362 & 5.4556 & TRN \\
\hline CHEMBL1602630 & 688239 & 4.5362 & 5.4543 & TRN \\
\hline CHEMBL1466471 & 688239 & 4.5362 & 5.3639 & TRN \\
\hline CHEMBL1300976 & 688239 & 4.5362 & 5.5574 & TRN \\
\hline CHEMBL1448713 & 688239 & 4.9 & 5.5078 & TRN \\
\hline CHEMBL1520165 & 688239 & 6.4362 & 5.4656 & TRN \\
\hline CHEMBL1399833 & 688239 & 5.1362 & 5.4947 & TRN \\
\hline CHEMBL1550123 & 688239 & 6.9363 & 5.49 & TRN \\
\hline CHEMBL1403741 & 688239 & 7.9355 & 5.5288 & TST \\
\hline CHEMBL1484053 & 688239 & 5.1362 & 5.5243 & TRN \\
\hline CHEMBL 3207751 & 688239 & 5.6362 & 5.6067 & TST \\
\hline CHEMBL1575352 & 688239 & 7.4868 & 5.524 & TRN \\
\hline CHEMBL1306925 & 688239 & 5.1862 & 5.3787 & TRN \\
\hline CHEMBL1436199 & 688239 & 6.2362 & 5.4761 & TRN \\
\hline CHEMBL1561827 & 688239 & 7.0362 & 5.4238 & TST \\
\hline CHEMBL3397122 & 688239 & 4.5362 & 5.3421 & TST \\
\hline CHEMBL1605273 & 688239 & 7.1361 & 5.4425 & TRN \\
\hline CHEMBL1511632 & 688239 & 7.0362 & 5.4014 & TRN \\
\hline CHEMBL1332255 & 688239 & 5.6862 & 5.4335 & TRN \\
\hline CHEMBL1428950 & 688239 & 4.5362 & 5.3861 & TRN \\
\hline CHEMBL1602616 & 688239 & 4.6862 & 5.5249 & TRN \\
\hline CHEMBL1340508 & 688239 & 6.9363 & 5.5989 & TST \\
\hline CHEMBL1533249 & 688239 & 8.3372 & 5.516 & TRN \\
\hline CHEMBL1343442 & 688239 & 5.4862 & 5.517 & TRN \\
\hline CHEMBL1486041 & 688239 & 6.4362 & 5.4482 & TRN \\
\hline CHEMBL1440955 & 688239 & 6.8362 & 5.6178 & TRN \\
\hline
\end{tabular}


Supplemental Table S2.txt

\begin{tabular}{|c|c|c|c|c|}
\hline HEM & & 362 & 5.4205 & .1. \\
\hline & & 5.1862 & & \\
\hline ICMP 1 & & & & \\
\hline IEMBL1 & & 863 & & \\
\hline AEMBL1571344 & 88239 & 862 & 548 & \\
\hline HEMBL1430328 & 39 & 362 & 154 & \\
\hline HEMBL1 & & 862 & & \\
\hline AEMBL13 & & 861 & & \\
\hline HEMBL3197120 & 88239 & 1862 & 3863 & \\
\hline HEMBL3197775 & 88239 & 9862 & 971 & \\
\hline HEMBL153 & 39 & 3362 & & \\
\hline IEMBL: & & 862 & 36 & \\
\hline AEMBL1: & & 362 & & \\
\hline HEMBL1393865 & 88239 & 3372 & 5713 & \\
\hline HEMBL1383514 & & 862 & & \\
\hline AEMBL32 & & 62 & & \\
\hline HEMBL1 & & & & \\
\hline HEMBL1: & & 862 & & \\
\hline HEMBL15 & & 862 & 215 & \\
\hline AEMBL13 & & 62 & & \\
\hline HEMBL: & & 62 & & \\
\hline HEM & & & & \\
\hline AEMBL & & 62 & & \\
\hline 10 & & 862 & & 151 \\
\hline HEMBL14 & & 362 & 62 & IRN \\
\hline AEMBL1 & & 362 & & SI \\
\hline HEMBL 1 & & & & RN \\
\hline 79 & & 66 & & \\
\hline AEMBL1 & & & & | \\
\hline AEMBL1606 & & 862 & & TRN \\
\hline HEMBLI & & 362 & & TRN \\
\hline 2 & & & & \\
\hline 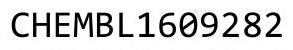 & & & & 「RN \\
\hline HEMBL13 & & & & 「RN \\
\hline HEMBL154e & & 863 & & RN \\
\hline 1 & & 62 & & TRN \\
\hline 0 & & & & ГRN \\
\hline HEMBL13 & & & & TRN \\
\hline HEMBL16 & & 362 & & $\Gamma R$ \\
\hline 13 & & 362 & & RN \\
\hline HEMBL1: & & 362 & & TRN \\
\hline HEMBL14 & & 62 & 51 & RN \\
\hline HEMBL15 & & 862 & & {$[R$} \\
\hline HEMBL13 & & 362 & & TR \\
\hline CHEMBL1410351 & & & & \\
\hline HEMBL1 & & 862 & & \\
\hline HEMBL1384830 & & 4.5362 & 5.5475 & \\
\hline LHEMBL141532 & 688239 & 4.5362 & 5.4544 & \\
\hline
\end{tabular}

Page 1943 
Supplemental Table S2.txt

\begin{tabular}{|c|c|c|c|c|c|}
\hline CHEMBL1490380 & 688239 & 5.2862 & 5.3846 & TRN & \\
\hline CHEMBL1521178 & 688239 & 5.4862 & 5.5276 & TRN & \\
\hline CHEMBL1511793 & 688239 & 5.1862 & 5.4302 & TST & \\
\hline CHEMBL1544691 & 688239 & 5.5862 & 5.5188 & TRN & \\
\hline CHEMBL1599709 & 688239 & 6.0862 & 5.4757 & TST & \\
\hline CHEMBL3195395 & 688239 & 5.2862 & 5.5398 & TRN & \\
\hline CHEMBL1583380 & 688239 & 4.5362 & 5.4207 & TST & \\
\hline CHEMBL1606832 & 688239 & 5.5862 & 5.6157 & TRN & \\
\hline CHEMBL1612635 & 688239 & 6.9363 & 5.5023 & TRN & \\
\hline CHEMBL 3212157 & 688239 & 5.2862 & 5.4473 & TRN & \\
\hline CHEMBL1452921 & 688239 & 5.6362 & 5.6274 & TRN & \\
\hline CHEMBL1526479 & 688239 & 4.7862 & 5.3992 & TRN & \\
\hline CHEMBL1496507 & 688239 & 5.7862 & 5.4543 & TST & \\
\hline CHEMBL1490613 & 688239 & 4.8862 & 5.3377 & TRN & \\
\hline CHEMBL1445863 & 688239 & 6.9363 & 5.3813 & TRN & \\
\hline CHEMBL1370174 & 688239 & 5.5362 & 5.4912 & TRN & \\
\hline CHEMBL1321863 & 688239 & 5.3862 & 5.3769 & TRN & \\
\hline CHEMBL1451552 & 688239 & 6.2362 & 5.5085 & TST & \\
\hline CHEMBL1501295 & 688239 & 8.28399 & 999999999 & 9 & 5.4429 \\
\hline CHEMBL1486481 & 688239 & 4.5362 & 5.7113 & TST & \\
\hline CHEMBL1358210 & 688239 & 4.6362 & 5.4073 & TRN & \\
\hline CHEMBL1559138 & 688239 & 5.1362 & 5.5328 & TRN & \\
\hline CHEMBL1509882 & 688239 & 4.5362 & 5.5722 & TRN & \\
\hline CHEMBL1578569 & 688239 & 5.3862 & 5.3464 & TRN & \\
\hline CHEMBL1454185 & 688239 & 4.7862 & 5.4502 & TRN & \\
\hline CHEMBL1391921 & 688239 & 5.2862 & 5.4541 & TRN & \\
\hline CHEMBL1479401 & 688239 & 4.7862 & 5.5157 & TRN & \\
\hline CHEMBL1389813 & 688239 & 5.0862 & 5.6201 & TRN & \\
\hline CHEMBL1573682 & 688239 & 5.4362 & 5.4333 & TRN & \\
\hline CHEMBL3194548 & 688239 & 4.6862 & 5.4961 & TRN & \\
\hline CHEMBL1301894 & 688239 & 6.8362 & 5.4453 & TRN & \\
\hline CHEMBL1338196 & 688239 & 4.7862 & 5.5539 & TRN & \\
\hline CHEMBL1360220 & 688239 & 4.5362 & 5.5066 & TRN & \\
\hline CHEMBL1507057 & 688239 & 6.6861 & 5.519 & TRN & \\
\hline CHEMBL1594109 & 688239 & 4.7862 & 5.3585 & TRN & \\
\hline CHEMBL1512125 & 688239 & 6.0862 & 5.5451 & TRN & \\
\hline CHEMBL1406413 & 688239 & 4.9362 & 5.4622 & TST & \\
\hline CHEMBL1353457 & 688239 & 6.1362 & 5.4405 & TRN & \\
\hline CHEMBL1391188 & 688239 & 5.0862 & 5.436 & TRN & \\
\hline CHEMBL1488838 & 688239 & 6.8362 & 5.4029 & TRN & \\
\hline CHEMBL1496170 & 688239 & 5.3362 & 5.5277 & TRN & \\
\hline CHEMBL1591359 & 688239 & 4.9862 & 5.3842 & TST & \\
\hline CHEMBL1430848 & 688239 & 5.1862 & 5.5502 & TRN & \\
\hline CHEMBL1425792 & 688239 & 5.3862 & 5.4378 & TRN & \\
\hline CHEMBL1532876 & 688239 & 4.7362 & 5.5866 & TRN & \\
\hline CHEMBL1318283 & 688239 & 8.2366 & 5.5232 & TRN & \\
\hline CHEMBL1306727 & 688239 & 6.1862 & 5.7036 & TRN & \\
\hline CHEMBL1530000 & 688239 & 6.6362 & 5.5408 & TRN & \\
\hline
\end{tabular}


Supplemental Table S2.txt

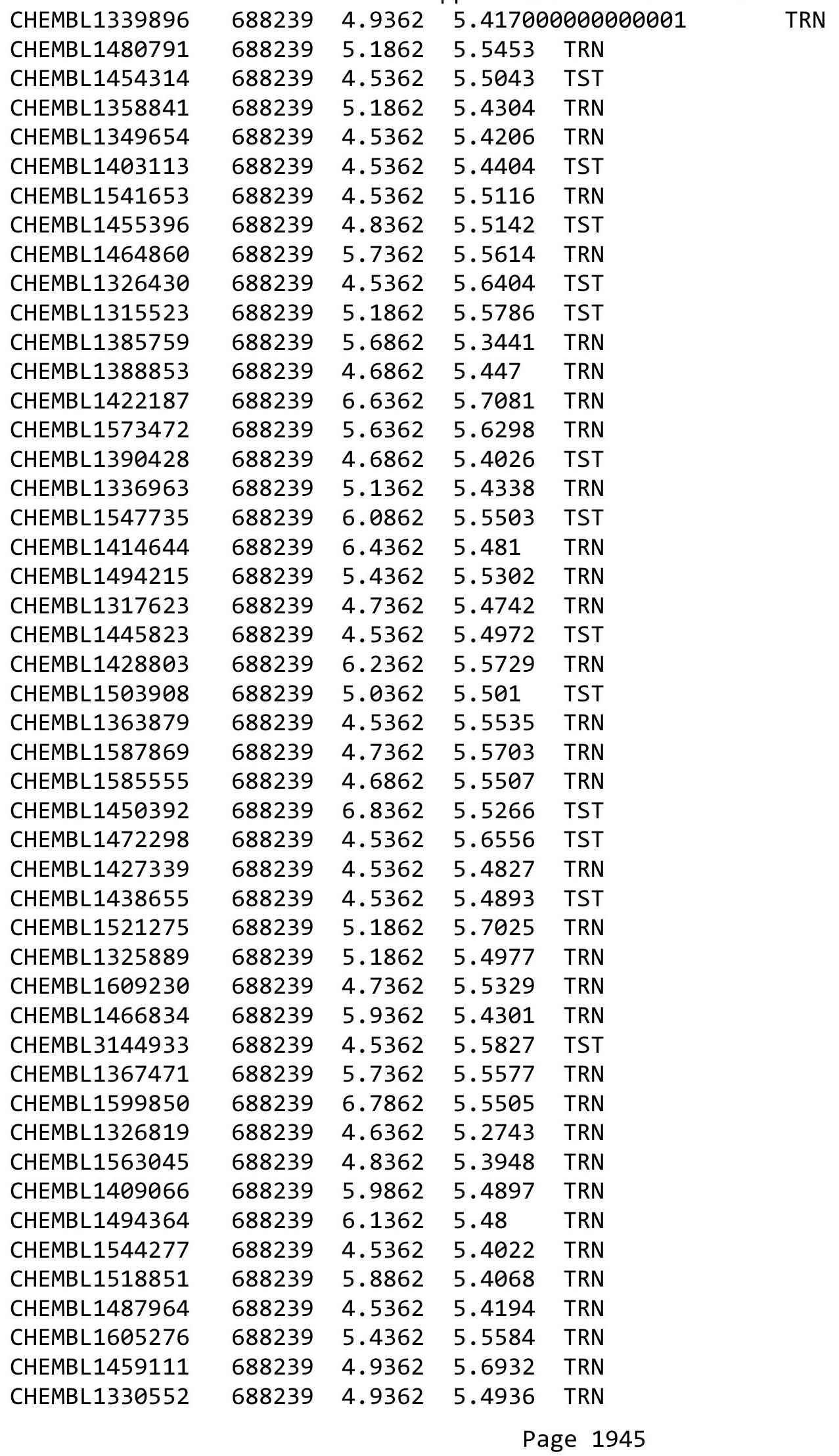


Supplemental Table S2.txt

\begin{tabular}{|c|c|c|c|c|}
\hline 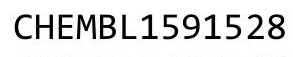 & & & & \\
\hline HEMBL1465708 & 38239 & 362 & 57 & \\
\hline AEMBL1409474 & 239 & 1862 & & \\
\hline 3723 & 39 & 362 & & \\
\hline IEMBL511979 & 39 & 862 & & \\
\hline AEMBL1308458 & 88239 & 862 & & \\
\hline AEMBL1311109 & 88239 & 366 & 3433 & \\
\hline HEMBL1326420 & & 862 & & \\
\hline IEMBL1554908 & 39 & 362 & & \\
\hline IEMBL1326331 & & 862 & & \\
\hline AEMBL3195935 & 239 & 862 & & \\
\hline AEMBL1329245 & 39 & 862 & & \\
\hline AEMBL1344472 & & 862 & & \\
\hline AEMBL1470674 & & 362 & & \\
\hline HEMBL1485987 & & 362 & & \\
\hline AEMBL1433051 & & 362 & & \\
\hline AEMBL1305604 & & 862 & & \\
\hline IEMBL1338 & & 62 & & \\
\hline AEMBL1437 & & & & \\
\hline AEMBL1549302 & & & & \\
\hline AEMBL1392037 & & 362 & & \\
\hline AEMBL1443854 & & 362 & & \\
\hline AEMBL157 & & 62 & & \\
\hline AFMRI 149 & & & & \\
\hline 37 & & 62 & & \\
\hline AEMBL3198810 & & 862 & & \\
\hline IEMBL1418657 & & 62 & & \\
\hline IEMBL13158 & & 62 & & \\
\hline IFMP 127 & & & & \\
\hline 1 & & 362 & & \\
\hline AEMBL1587988 & & & & \\
\hline AEMBL1458712 & & 362 & & \\
\hline 152 & & 62 & & \\
\hline 1 & & 52 & & \\
\hline AEMBL1315875 & & & & RN \\
\hline AEMBL3209111 & & 362 & & \\
\hline AEMBL1526118 & & 362 & & \\
\hline & & & & \\
\hline דבר & & & & \\
\hline HEMBL1372529 & & & & RN \\
\hline AEMBL1502443 & & 362 & & $\mathrm{R}$ \\
\hline AEMBL3209806 & & 63 & & \\
\hline HEMBL1578628 & & & & \\
\hline CHEMBL1463448 & & & & \\
\hline AEMBL1594002 & & 4.5362 & & RN \\
\hline IEMBL13348 & & 864 & 56 & TR \\
\hline דבחי ניחני & & & & \\
\hline HEMBL158896 & & & .5435 & \\
\hline
\end{tabular}

Page 1946 


\begin{tabular}{|c|c|c|c|c|c|}
\hline \multicolumn{6}{|c|}{ splemental lable s2.txt } \\
\hline CHEMBL1335149 & 688239 & 7.8356 & 5.3033 & TST & \\
\hline CHEMBL1330891 & 688239 & 4.4862 & 5.4889 & TRN & \\
\hline CHEMBL1359566 & 688239 & 4.5862 & 5.5647 & TRN & \\
\hline CHEMBL1604735 & 688239 & 4.8862 & 5.3407 & TRN & \\
\hline CHEMBL3209130 & 688239 & 4.5362 & 5.386 & TRN & \\
\hline CHEMBL1386617 & 688239 & 6.3362 & 5.5256 & TRN & \\
\hline CHEMBL3190344 & 688239 & 6.0362 & 5.3922 & TST & \\
\hline CHEMBL1409306 & 688239 & 5.6362 & 5.5231 & TRN & \\
\hline CHEMBL1558209 & 688239 & 8.3372 & 5.5544 & TRN & \\
\hline CHEMBL1471502 & 688239 & 5.4862 & 5.4579 & TRN & \\
\hline CHEMBL1600861 & 688239 & 4.5362 & 5.5644 & TST & \\
\hline CHEMBL1329639 & 688239 & 6.0862 & 5.5343 & TST & \\
\hline CHEMBL3212492 & 688239 & 6.2362 & 5.522 & TRN & \\
\hline CHEMBL1452543 & 688239 & 8.28399 & 99999999 & 5.4448 & TRN \\
\hline CHEMBL1405149 & 688239 & 5.8362 & 5.4309 & TST & \\
\hline CHEMBL1338171 & 688239 & 5.4862 & 5.3554 & TRN & \\
\hline CHEMBL1433098 & 688239 & 4.8362 & 5.5733 & TRN & \\
\hline CHEMBL1434175 & 688239 & 4.6862 & 5.4175 & TRN & \\
\hline CHEMBL1385165 & 688239 & 4.7362 & 5.6052 & TRN & \\
\hline CHEMBL1500425 & 688239 & 5.0862 & 5.5686 & TRN & \\
\hline CHEMBL1436496 & 688239 & 4.9362 & 5.528 & TRN & \\
\hline CHEMBL1513037 & 688239 & 6.0862 & 5.3725 & TRN & \\
\hline CHEMBL1437505 & 688239 & 5.1362 & 5.5019 & TRN & \\
\hline CHEMBL1384224 & 688239 & 5.8862 & 5.7252 & TRN & \\
\hline CHEMBL1407211 & 688239 & 5.3862 & 5.739 & TST & \\
\hline CHEMBL1422622 & 688239 & 6.8861 & 5.4458 & TST & \\
\hline CHEMBL1564867 & 688239 & 4.5362 & 5.5324 & TRN & \\
\hline CHEMBL1444439 & 688239 & 5.4862 & 5.46299 & 9999999999 & TRN \\
\hline CHEMBL1314772 & 688239 & 6.8362 & 5.4827 & TRN & \\
\hline CHEMBL1439996 & 688239 & 6.8362 & 5.5906 & TRN & \\
\hline CHEMBL1455511 & 688239 & 6.7862 & 5.51399 & 9999999999 & TRN \\
\hline CHEMBL1495434 & 688239 & 4.4862 & 5.4022 & TST & \\
\hline CHEMBL1421794 & 688239 & 8.3372 & 5.5068 & TRN & \\
\hline CHEMBL3192312 & 688239 & 8.2366 & 5.2954 & TRN & \\
\hline CHEMBL1575251 & 688239 & 5.0362 & 5.4296 & TST & \\
\hline CHEMBL1457735 & 688239 & 5.7362 & 5.4884 & TRN & \\
\hline CHEMBL1459473 & 688239 & 5.1862 & 5.5767 & TRN & \\
\hline CHEMBL1306504 & 688239 & 8.3372 & 5.5471 & TRN & \\
\hline CHEMBL1592129 & 688239 & 5.8362 & 5.3918 & TRN & \\
\hline CHEMBL1505992 & 688239 & 5.0362 & 5.731 & TRN & \\
\hline CHEMBL1337064 & 688239 & 6.5363 & 5.5592 & TRN & \\
\hline CHEMBL1344915 & 688239 & 5.2362 & 5.4471 & TRN & \\
\hline CHEMBL1411975 & 688239 & 7.1864 & 5.5248 & TRN & \\
\hline CHEMBL1574296 & 688239 & 4.6862 & 5.4441 & TRN & \\
\hline CHEMBL1586807 & 688239 & 4.7362 & 5.41299 & 9999999999 & TRN \\
\hline CHEMBL1531147 & 688239 & 4.6862 & 5.5241 & TRN & \\
\hline CHEMBL1400874 & 688239 & 8.2366 & 5.4459 & TRN & \\
\hline CHEMBL1583651 & 688239 & 5.4862 & 5.4487 & TST & \\
\hline
\end{tabular}


Supplemental Table S2.txt

\begin{tabular}{|c|c|c|c|c|}
\hline CHEMBL1524477 & 688239 & 4.5362 & 5.318 & TST \\
\hline CHEMBL1595025 & 688239 & 4.9362 & 5.4822 & TRN \\
\hline CHEMBL1442019 & 688239 & 6.2362 & 5.6052 & TRN \\
\hline CHEMBL 3194578 & 688239 & 4.5362 & 5.4184 & TST \\
\hline CHEMBL1455328 & 688239 & 6.1862 & 5.5285 & TST \\
\hline CHEMBL1315019 & 688239 & 4.5362 & 5.5283 & TRN \\
\hline CHEMBL1300677 & 688239 & 4.9862 & 5.522 & TST \\
\hline CHEMBL1594746 & 688239 & 4.6862 & 5.2905 & TRN \\
\hline CHEMBL 3212315 & 688239 & 5.3862 & 5.5384 & TRN \\
\hline CHEMBL1443607 & 688239 & 6.2362 & 5.5525 & TRN \\
\hline CHEMBL 3214123 & 688239 & 6.2362 & 5.5891 & TRN \\
\hline CHEMBL1435122 & 688239 & 5.0862 & 5.4847 & TRN \\
\hline CHEMBL1422153 & 688239 & 5.1862 & 5.5948 & TRN \\
\hline CHEMBL1335443 & 688239 & 6.1362 & 5.4094 & TRN \\
\hline CHEMBL1379422 & 688239 & 6.6861 & 5.6179 & TRN \\
\hline CHEMBL1482390 & 688239 & 6.4862 & 5.5244 & TRN \\
\hline CHEMBL3209403 & 688239 & 4.5362 & 5.3548 & TRN \\
\hline CHEMBL3191023 & 688239 & 4.5362 & 5.4481 & TST \\
\hline CHEMBL1345121 & 688239 & 6.0362 & 5.4612 & TST \\
\hline CHEMBL1446665 & 688239 & 7.4365 & 5.3836 & TST \\
\hline CHEMBL1577520 & 688239 & 4.5362 & 5.4431 & TRN \\
\hline CHEMBL1505172 & 688239 & 5.1862 & 5.5441 & TRN \\
\hline CHEMBL1369510 & 688239 & 4.5362 & 5.4336 & TRN \\
\hline CHEMBL499296 & 688239 & 4.5862 & 5.3399 & TRN \\
\hline CHEMBL1585198 & 688239 & 5.1862 & 5.4539 & TRN \\
\hline CHEMBL1564361 & 688239 & 4.7362 & 5.3746 & TRN \\
\hline CHEMBL1462554 & 688239 & 5.5362 & 5.5568 & TST \\
\hline CHEMBL1306742 & 688239 & 4.6862 & 5.3354 & TRN \\
\hline CHEMBL1464038 & 688239 & 4.5362 & 5.44799 & 79999999995 \\
\hline CHEMBL1310221 & 688239 & 4.8862 & 5.4755 & TRN \\
\hline CHEMBL1535607 & 688239 & 8.3372 & 5.4578 & TST \\
\hline CHEMBL1324653 & 688239 & 5.2362 & 5.473 & TRN \\
\hline CHEMBL1416178 & 688239 & 6.7862 & 5.4221 & TST \\
\hline CHEMBL1604109 & 688239 & 4.9362 & 5.629 & TRN \\
\hline CHEMBL1496885 & 688239 & 5.5862 & 5.51399 & э999999999 \\
\hline CHEMBL1428984 & 688239 & 4.6362 & 5.4284 & TRN \\
\hline CHEMBL3189814 & 688239 & 4.7862 & 5.3211 & TRN \\
\hline CHEMBL1482932 & 688239 & 5.3862 & 5.4998 & TST \\
\hline CHEMBL1341261 & 688239 & 4.6362 & 5.5642 & TRN \\
\hline CHEMBL1429784 & 688239 & 6.3863 & 5.3249 & TST \\
\hline CHEMBL1503283 & 688239 & 4.4862 & 5.3259 & TST \\
\hline CHEMBL1575549 & 688239 & 6.0862 & 5.46299 & 9999999999 \\
\hline CHEMBL1601541 & 688239 & 4.5362 & 5.3351 & TRN \\
\hline CHEMBL1421530 & 688239 & 5.6362 & 5.511 & TST \\
\hline CHEMBL1437170 & 688239 & 4.5362 & 5.5116 & TRN \\
\hline CHEMBL1514830 & 688239 & 6.1362 & 5.4016 & TRN \\
\hline CHEMBL1399392 & 688239 & 5.1862 & 5.4626 & TRN \\
\hline CHEMBL1392117 & 688239 & 4.5362 & 5.5134 & TST \\
\hline
\end{tabular}


Supplemental Table S2.txt

\begin{tabular}{|c|c|c|c|c|c|}
\hline CHEMBL1486303 & 688239 & 5.1862 & 5.3647 & TRN & \\
\hline CHEMBL1402669 & 688239 & 4.6362 & 5.4213 & TST & \\
\hline CHEMBL1450508 & 688239 & 4.5362 & 5.7414 & TRN & \\
\hline CHEMBL1504662 & 688239 & 5.4362 & 5.7477 & TRN & \\
\hline CHEMBL1447280 & 688239 & 4.7362 & 5.3522 & TRN & \\
\hline CHEMBL1341640 & 688239 & 7.5361 & 5.3907 & TRN & \\
\hline CHEMBL1601959 & 688239 & 5.0362 & 5.5205 & TST & \\
\hline CHEMBL1402442 & 688239 & 5.8862 & 5.5149 & TST & \\
\hline CHEMBL1577492 & 688239 & 4.6362 & 5.5152 & TRN & \\
\hline CHEMBL1332578 & 688239 & 5.0362 & 5.5649 & TRN & \\
\hline CHEMBL1587040 & 688239 & 5.7362 & 5.4422 & TRN & \\
\hline CHEMBL1353535 & 688239 & 5.0862 & 5.407999 & 99999999995 & TST \\
\hline CHEMBL1301304 & 688239 & 5.8862 & 5.4409 & TRN & \\
\hline CHEMBL1478935 & 688239 & 7.4868 & 5.4147 & TST & \\
\hline CHEMBL1309822 & 688239 & 6.2362 & 5.5693 & TST & \\
\hline CHEMBL 1412378 & 688239 & 5.7362 & 5.6105 & TST & \\
\hline CHEMBL1881714 & 688239 & 4.5362 & 5.422999 & 9999999999 & TRN \\
\hline CHEMBL1463374 & 688239 & 4.5362 & 5.5427 & TRN & \\
\hline CHEMBL1530652 & 688239 & 6.2362 & 5.5787 & TRN & \\
\hline CHEMBL1534375 & 688239 & 6.7361 & 5.5944 & TST & \\
\hline CHEMBL 3198100 & 688239 & 5.1862 & 5.4512 & TRN & \\
\hline CHEMBL1391745 & 688239 & 6.7862 & 5.3904 & TRN & \\
\hline CHEMBL1379388 & 688239 & 6.1362 & 5.5377 & TRN & \\
\hline CHEMBL1501317 & 688239 & 6.1862 & 5.3781 & TST & \\
\hline CHEMBL1425132 & 688239 & 4.9862 & 5.319 & TRN & \\
\hline CHEMBL 3198764 & 688239 & 4.9362 & 5.4677 & TST & \\
\hline CHEMBL1300396 & 688239 & 5.7362 & 5.6964 & TRN & \\
\hline CHEMBL1512304 & 688239 & 6.5862 & 5.5704 & TRN & \\
\hline CHEMBL1486515 & 688239 & 8.1367 & 5.4769 & TRN & \\
\hline CHEMBL1500508 & 688239 & 5.0862 & 5.5401 & TRN & \\
\hline CHEMBL1299694 & 688239 & 6.3362 & 5.6331 & TRN & \\
\hline CHEMBL1589147 & 688239 & 6.0862 & 5.5181 & TRN & \\
\hline CHEMBL1559441 & 688239 & 5.6362 & 5.474 & TRN & \\
\hline CHEMBL1418720 & 688239 & 4.5362 & 5.4929 & TRN & \\
\hline CHEMBL1351618 & 688239 & 4.6362 & 5.3976 & TRN & \\
\hline CHEMBL1351763 & 688239 & 5.1862 & 5.4179 & TRN & \\
\hline CHEMBL1580299 & 688239 & 4.4862 & 5.5224 & TST & \\
\hline CHEMBL1555817 & 688239 & 6.8861 & 5.5732 & TRN & \\
\hline CHEMBL1526754 & 688239 & 4.5362 & 5.5304 & TST & \\
\hline CHEMBL1589882 & 688239 & 4.5362 & 5.3135 & TRN & \\
\hline CHEMBL1511177 & 688239 & 6.0362 & 5.4324 & TRN & \\
\hline CHEMBL1570768 & 688239 & 4.4862 & 5.3429 & TRN & \\
\hline CHEMBL1518948 & 688239 & 4.6362 & 5.5526 & TRN & \\
\hline CHEMBL1562708 & 688239 & 6.7361 & 5.5004 & TST & \\
\hline CHEMBL1562948 & 688239 & 6.1362 & 5.4956 & TRN & \\
\hline CHEMBL 3208479 & 688239 & 6.6362 & 5.4193 & TRN & \\
\hline CHEMBL1467599 & 688239 & 6.5363 & 5.6543 & TRN & \\
\hline CHEMBL1592745 & 688239 & 5.1862 & 5.4419 & TRN & \\
\hline
\end{tabular}




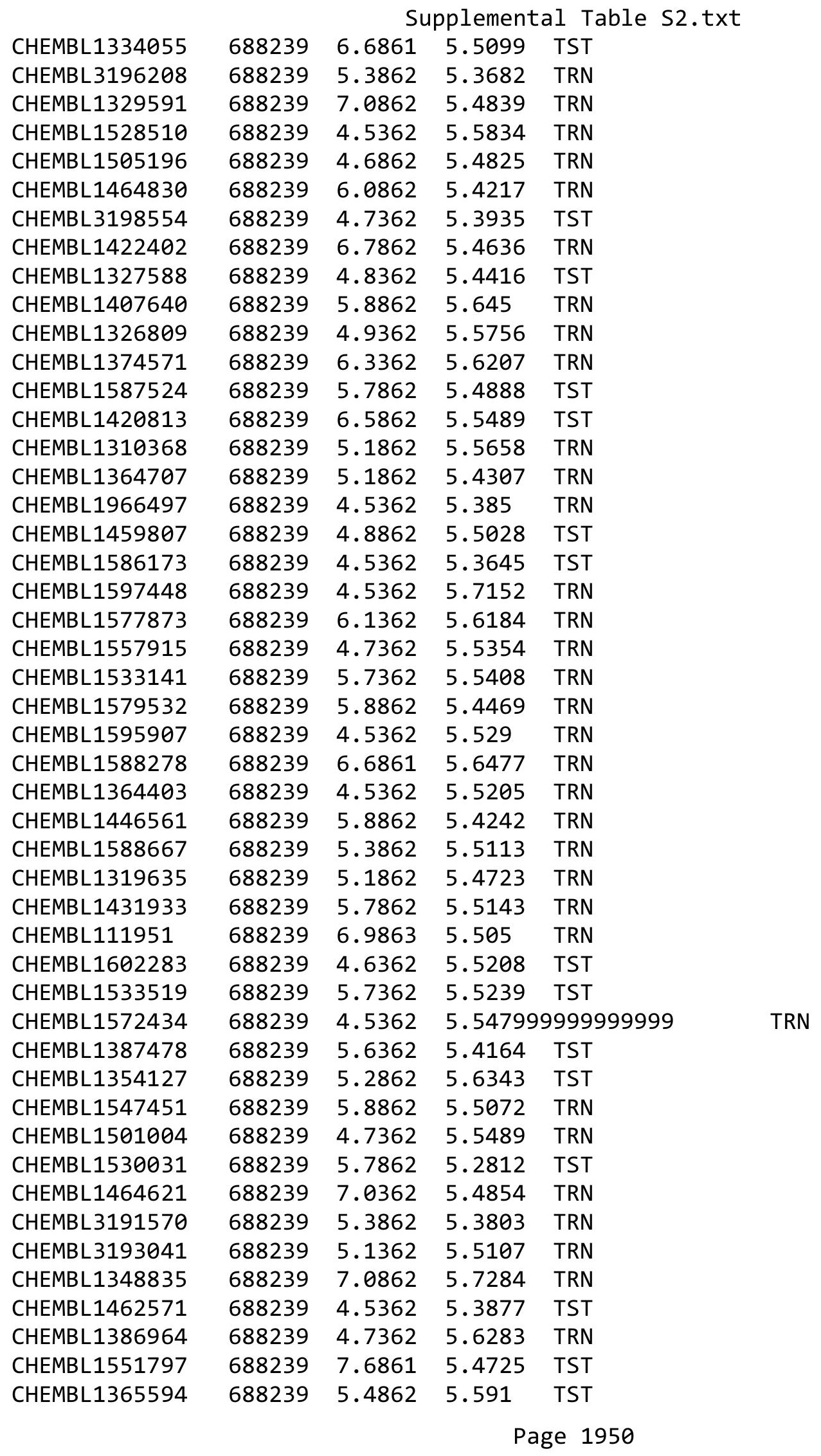




\begin{tabular}{|c|c|c|c|c|c|c|}
\hline \multirow[b]{2}{*}{ CHEMBL1451248 } & \multirow[b]{2}{*}{688239} & \multicolumn{5}{|c|}{ Supplemental Table S2.txt } \\
\hline & & 5.1862 & 5.559 & TST & & \\
\hline CHEMBL1388067 & 688239 & 8.28399 & 99999999 & 99 & 5.2956 & TRN \\
\hline CHEMBL1367492 & 688239 & 5.8862 & 5.6269 & TRN & & \\
\hline CHEMBL1303366 & 688239 & 8.28399 & 99999999 & 99 & 5.4784 & TRN \\
\hline CHEMBL1564258 & 688239 & 4.5862 & 5.5413 & TRN & & \\
\hline CHEMBL1572277 & 688239 & 8.28399 & 99999999 & 99 & 5.5995 & TRN \\
\hline CHEMBL1504304 & 688239 & 4.6862 & 5.598 & TST & & \\
\hline CHEMBL1612684 & 688239 & 4.9862 & 5.5031 & TRN & & \\
\hline CHEMBL3213956 & 688239 & 5.9362 & 5.398 & TST & & \\
\hline CHEMBL 1463867 & 688239 & 4.4862 & 5.4045 & TRN & & \\
\hline CHEMBL1569443 & 688239 & 5.1362 & 5.6873 & TST & & \\
\hline CHEMBL1573381 & 688239 & 4.7362 & 5.4631 & TRN & & \\
\hline CHEMBL1312368 & 688239 & 4.5362 & 5.4205 & TRN & & \\
\hline CHEMBL3210917 & 688239 & 4.8362 & 5.3026 & TST & & \\
\hline CHEMBL1371523 & 688239 & 4.5362 & 5.3939 & TRN & & \\
\hline CHEMBL1462636 & 688239 & 5.6362 & 5.3598 & TRN & & \\
\hline CHEMBL1439853 & 688239 & 6.5862 & 5.6534 & TRN & & \\
\hline CHEMBL1546235 & 688239 & 4.7362 & 5.4458 & TRN & & \\
\hline CHEMBL1312989 & 688239 & 6.5363 & 5.5586 & TRN & & \\
\hline CHEMBL1364681 & 688239 & 4.6862 & 5.5362 & TRN & & \\
\hline CHEMBL1576518 & 688239 & 5.7862 & 5.5579 & TRN & & \\
\hline CHEMBL1306564 & 688239 & 4.6362 & 5.6264 & TRN & & \\
\hline CHEMBL1362367 & 688239 & 5.4862 & 5.5895 & TST & & \\
\hline CHEMBL1322365 & 688239 & 4.5362 & 5.5615 & TST & & \\
\hline CHEMBL1469904 & 688239 & 4.6362 & 5.3098 & TRN & & \\
\hline CHEMBL3191487 & 688239 & 5.7862 & 5.4373 & TRN & & \\
\hline CHEMBL1425761 & 688239 & 4.6862 & 5.4087 & TRN & & \\
\hline CHEMBL1308299 & 688239 & 4.9862 & 5.7113 & TRN & & \\
\hline CHEMBL1431594 & 688239 & 5.3862 & 5.6329 & TRN & & \\
\hline CHEMBL1384522 & 688239 & 5.7362 & 5.5446 & TST & & \\
\hline CHEMBL1424286 & 688239 & 4.6362 & 5.6313 & TRN & & \\
\hline CHEMBL1482701 & 688239 & 6.0862 & 5.6269 & TRN & & \\
\hline CHEMBL1301165 & 688239 & 5.2362 & 5.5858 & TST & & \\
\hline CHEMBL1549183 & 688239 & 5.1862 & 5.511 & TRN & & \\
\hline CHEMBL1576951 & 688239 & 5.0862 & 5.4497 & TRN & & \\
\hline CHEMBL1423015 & 688239 & 6.3863 & 5.4767 & TRN & & \\
\hline CHEMBL 1410636 & 688239 & 5.1862 & 5.6214 & TRN & & \\
\hline CHEMBL1612994 & 688239 & 6.8362 & 5.6593 & TST & & \\
\hline CHEMBL1570813 & 688239 & 6.8362 & 5.5465 & TST & & \\
\hline CHEMBL1391159 & 688239 & 4.5362 & 5.6074 & TRN & & \\
\hline CHEMBL3193595 & 688239 & 5.1862 & 5.4512 & TST & & \\
\hline CHEMBL1515941 & 688239 & 4.8362 & 5.4636 & TRN & & \\
\hline CHEMBL1607808 & 688239 & 6.1362 & 5.405 & TRN & & \\
\hline CHEMBL1367271 & 688239 & 4.5362 & 5.4645 & TRN & & \\
\hline CHEMBL1603516 & 688239 & 5.1862 & 5.5242 & TRN & & \\
\hline CHEMBL1380575 & 688239 & 4.5362 & 5.5865 & TRN & & \\
\hline CHEMBL1416416 & 688239 & 5.4362 & 5.456 & TRN & & \\
\hline CHEMBL1351939 & 688239 & 7.5361 & 5.5054 & TST & & \\
\hline
\end{tabular}


Supplemental Table S2.txt

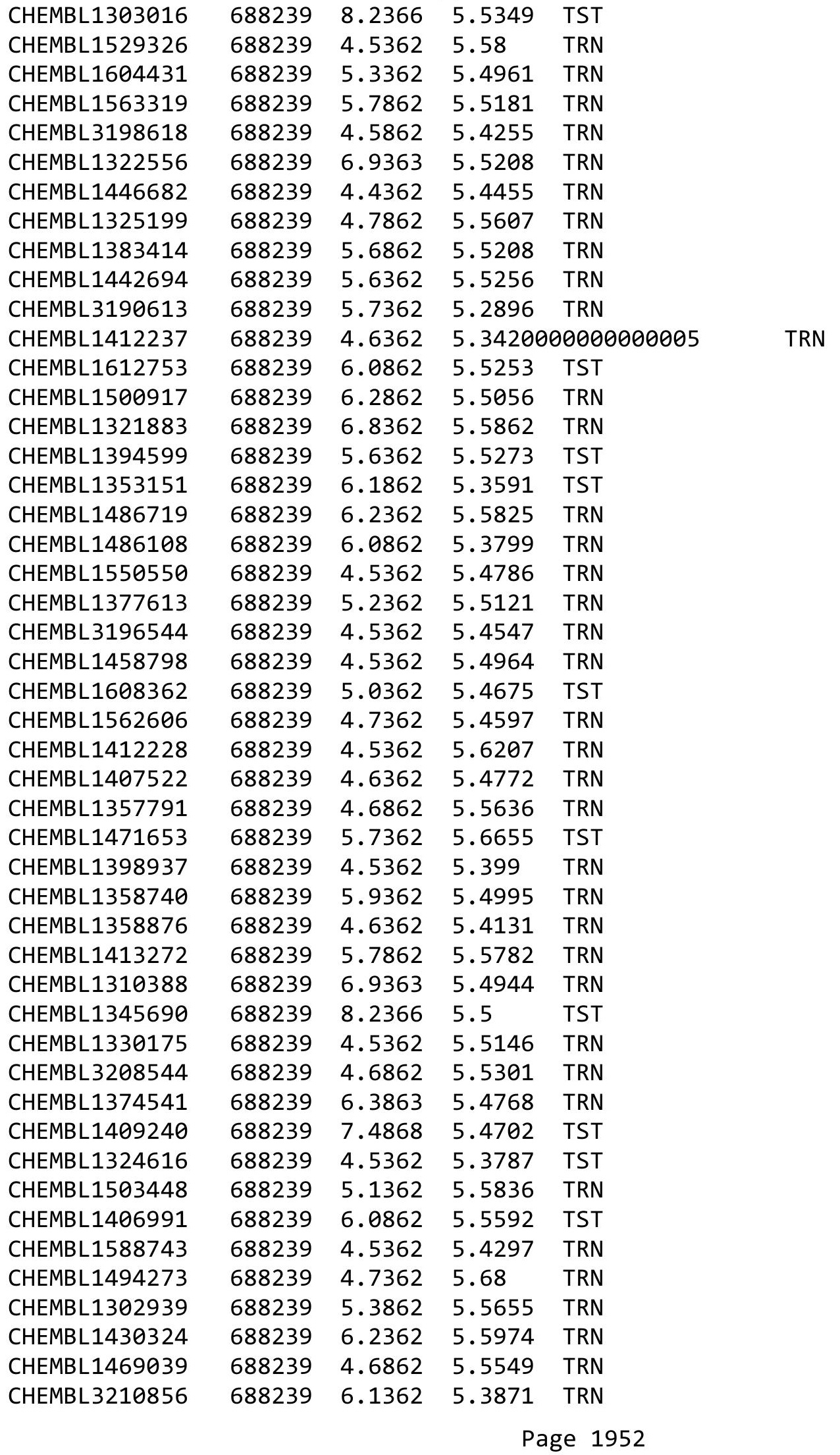


Supplemental Table S2.txt

\begin{tabular}{|c|c|c|c|c|}
\hline CHEMBL1365891 & 688239 & 6.4362 & 5.5258 & TRN \\
\hline CHEMBL1597482 & 688239 & 4.5362 & 5.53 & TRN \\
\hline CHEMBL1363784 & 688239 & 5.4862 & 5.4208 & TST \\
\hline CHEMBL1506241 & 688239 & 4.5362 & 5.3927 & TRN \\
\hline CHEMBL1554922 & 688239 & 4.5362 & 5.4093 & TRN \\
\hline CHEMBL1372846 & 688239 & 6.0862 & 5.6002 & TRN \\
\hline CHEMBL1527875 & 688239 & 5.4362 & 5.4958 & TRN \\
\hline CHEMBL1550899 & 688239 & 4.5862 & 5.4445 & TRN \\
\hline CHEMBL1370158 & 688239 & 4.8862 & 5.4613 & TRN \\
\hline CHEMBL1320591 & 688239 & 6.9363 & 5.443 & TRN \\
\hline CHEMBL1445710 & 688239 & 4.6862 & 5.3554 & TRN \\
\hline CHEMBL1491213 & 688239 & 4.4862 & 5.5309 & TRN \\
\hline CHEMBL1429479 & 688239 & 6.0 & 5.49100 & 00000000005 \\
\hline CHEMBL 3210013 & 688239 & 5.1862 & 5.5927 & TRN \\
\hline CHEMBL1530176 & 688239 & 5.1862 & 5.4846 & TRN \\
\hline CHEMBL527584 & 688239 & 4.4862 & 5.3363 & TRN \\
\hline CHEMBL3189683 & 688239 & 5.1862 & 5.3357 & TRN \\
\hline CHEMBL1325201 & 688239 & 5.5362 & 5.6829 & TRN \\
\hline CHEMBL1414887 & 688239 & 5.1862 & 5.5209 & TRN \\
\hline CHEMBL1442746 & 688239 & 5.6862 & 5.4086 & TRN \\
\hline CHEMBL1458569 & 688239 & 4.7362 & 5.4361 & TST \\
\hline CHEMBL1606528 & 688239 & 8.3372 & 5.5221 & TRN \\
\hline CHEMBL1447656 & 688239 & 5.8362 & 5.4933 & TRN \\
\hline CHEMBL1453087 & 688239 & 6.1862 & 5.6025 & TST \\
\hline CHEMBL1424036 & 688239 & 4.5862 & 5.4498 & TRN \\
\hline CHEMBL1319284 & 688239 & 5.6862 & 5.5659 & TRN \\
\hline CHEMBL1382441 & 688239 & 4.9362 & 5.4307 & TRN \\
\hline CHEMBL1533974 & 688239 & 5.3862 & 5.4134 & TRN \\
\hline CHEMBL3197526 & 688239 & 6.1362 & 5.3659 & TST \\
\hline CHEMBL1345217 & 688239 & 4.8362 & 5.5801 & TRN \\
\hline CHEMBL1408732 & 688239 & 4.5362 & 5.4792 & TRN \\
\hline CHEMBL1565620 & 688239 & 4.6362 & 5.4755 & TRN \\
\hline CHEMBL1491256 & 688239 & 4.5362 & 5.5118 & TRN \\
\hline CHEMBL1333495 & 688239 & 6.8861 & 5.4835 & TRN \\
\hline CHEMBL1385280 & 688239 & 4.6862 & 5.3511 & TRN \\
\hline CHEMBL1387709 & 688239 & 4.7862 & 5.4506 & TRN \\
\hline CHEMBL1378180 & 688239 & 6.0862 & 5.4878 & TRN \\
\hline CHEMBL1508532 & 688239 & 6.4862 & 5.4276 & TRN \\
\hline CHEMBL1508052 & 688239 & 8.3872 & 5.2683 & TRN \\
\hline CHEMBL1439909 & 688239 & 6.2862 & \multicolumn{2}{|c|}{5.5489999999999995} \\
\hline CHEMBL1595846 & 688239 & 5.2862 & 5.4542 & TRN \\
\hline CHEMBL1574030 & 688239 & 8.3372 & 5.4862 & TRN \\
\hline CHEMBL1318322 & 688239 & 4.8362 & 5.4426 & TRN \\
\hline CHEMBL1408161 & 688239 & 4.6862 & \multicolumn{2}{|c|}{5.377000000000001} \\
\hline CHEMBL1368008 & 688239 & 5.5362 & 5.4724 & TRN \\
\hline CHEMBL1456720 & 688239 & 5.5362 & 5.3763 & TRN \\
\hline CHEMBL1420604 & 688239 & 7.4868 & 5.646 & TRN \\
\hline CHEMBL1471231 & 688239 & 6.2362 & 5.4389 & TRN \\
\hline
\end{tabular}

Page 1953 
Supplemental Table S2.txt

\begin{tabular}{|c|c|c|c|c|}
\hline 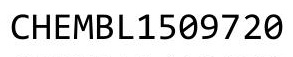 & & & & \\
\hline HEMBL1413030 & 88239 & 1862 & 5377 & \\
\hline HEMBL1599531 & 88239 & 5362 & & \\
\hline IEMBL1 & & & & \\
\hline EMBL15 & & 362 & & \\
\hline HEMBL1584334 & 88239 & 362 & 5809 & \\
\hline HEMBL1318940 & 88239 & 4.9362 & .6181 & \\
\hline HEMBL1538577 & 88239 & 862 & 3991 & \\
\hline IEMBL14 & 39 & 362 & 3956 & \\
\hline IEMBL13 & 39 & & & \\
\hline HEMBL1391487 & 88239 & 362 & & \\
\hline HEMBL1515349 & 39 & 372 & & \\
\hline AEMBL146 & 39 & 362 & 72 & \\
\hline HEMBL10 & & & 44 & \\
\hline HEMBL15 & 39 & & & \\
\hline HEMBL134 & 39 & 62 & & \\
\hline HEMBL1560931 & 39 & 4. & 79 & \\
\hline HEMBL13 & 39 & & 43 & \\
\hline HEMBL14 & & & & \\
\hline HEMBL15 & 39 & & & \\
\hline HEMBL16e & 39 & & & \\
\hline HEMBL135 & 39 & 4. & 91 & RN \\
\hline HEMBL 21 & 39 & 62 & & \\
\hline HEMBL13 & & & & \\
\hline 52 & & & & $5 T$ \\
\hline AEMBL161 & 39 & & & RN \\
\hline HEMBL132 & 39 & & & RN \\
\hline HEMBL149 & 39 & 62 & & $\mathrm{RN}$ \\
\hline HEM & & & & RN \\
\hline HEME & & & & RN \\
\hline HEMBL 143 & 9 & & & RN \\
\hline HEMBL1391067 & 39 & & & RN \\
\hline HEMBL 15 & 39 & & & \\
\hline 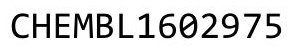 & & & & RN \\
\hline HEMBL13 & & & & RN \\
\hline HEMBL1602548 & 39 & & & $\mathrm{RN}$ \\
\hline HEMBL154 & 39 & & 92 & RN \\
\hline JEMBL13e & 39 & & & NIV \\
\hline 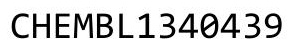 & & & & RN \\
\hline HEMBL318 & & & & RN \\
\hline HEMBL149 & 39 & & & ST \\
\hline HEMBL15 & 39 & & & RI \\
\hline HEMBL151 & & & & \\
\hline & & & & RN \\
\hline HEMBL14 & & & & ST \\
\hline HEMBL 147 & 39 & 362 & 77 & ST \\
\hline 16 & & & & \\
\hline & & & .4145 & \\
\hline
\end{tabular}

Page 1954 
Supplemental Table S2.txt

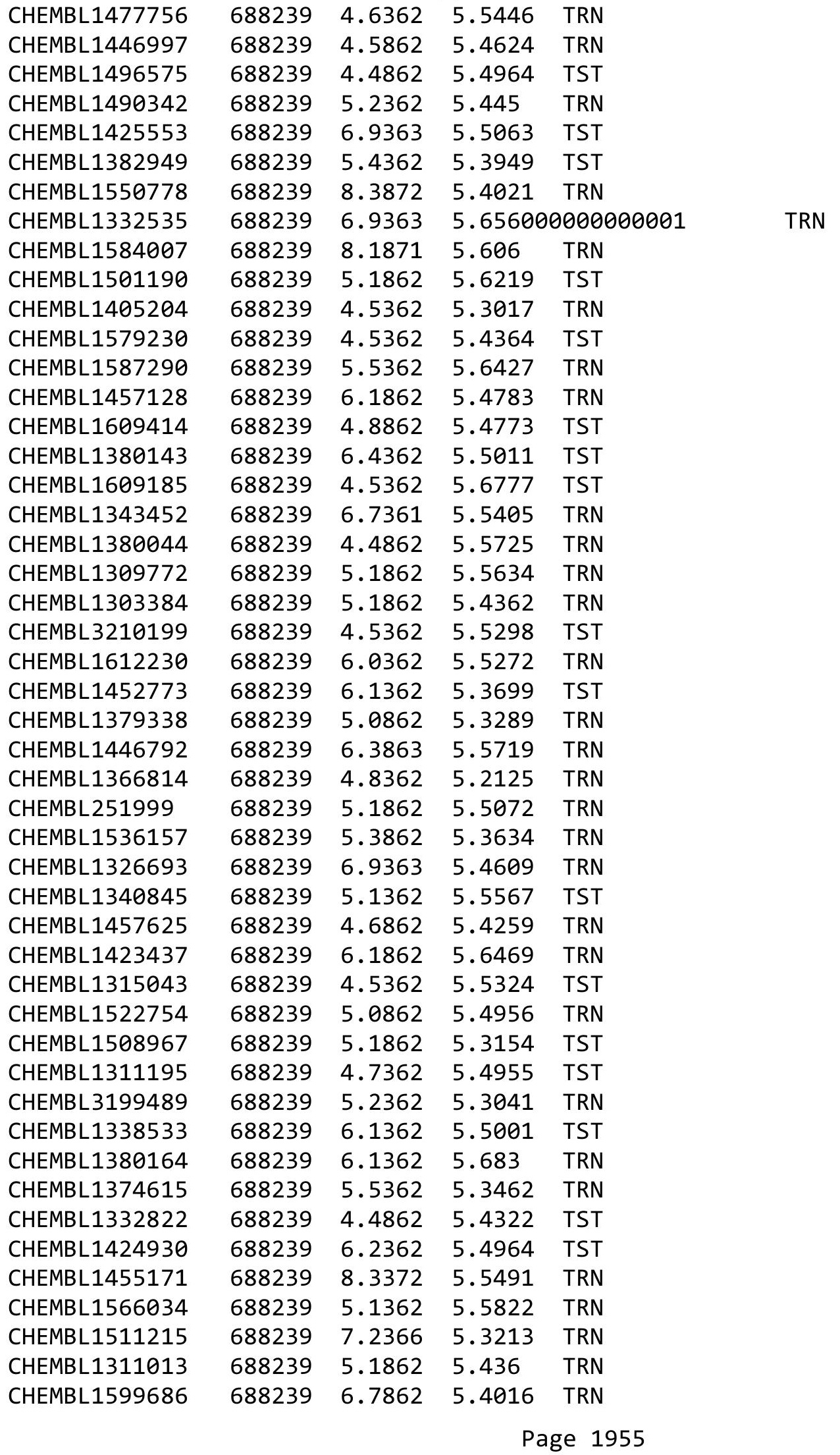




\begin{tabular}{|c|c|c|c|c|c|}
\hline \multirow[b]{2}{*}{ CHEMBL1455492 } & \multicolumn{5}{|c|}{ Supplemental Table S2.txt } \\
\hline & 688239 & 5.4362 & 5.5224 & TRN & \\
\hline CHEMBL1369789 & 688239 & 5.6362 & 5.38299 & 9999999999 & TRN \\
\hline CHEMBL1304698 & 688239 & 4.5362 & 5.4994 & TRN & \\
\hline CHEMBL1486655 & 688239 & 5.9862 & 5.4556 & TRN & \\
\hline CHEMBL1454463 & 688239 & 5.1862 & 5.4139 & TRN & \\
\hline CHEMBL1414234 & 688239 & 7.0362 & 5.629 & TRN & \\
\hline CHEMBL1412826 & 688239 & 5.4862 & 5.4879 & TRN & \\
\hline CHEMBL1536313 & 688239 & 4.7362 & 5.4205 & TRN & \\
\hline CHEMBL1571904 & 688239 & 5.8362 & 5.7018 & TRN & \\
\hline CHEMBL1506532 & 688239 & 4.7862 & 5.5944 & TRN & \\
\hline CHEMBL1597855 & 688239 & 4.9362 & 5.4979 & TST & \\
\hline CHEMBL1446011 & 688239 & 4.6362 & 5.3799 & TRN & \\
\hline CHEMBL1413206 & 688239 & 5.4362 & 5.6228 & TST & \\
\hline CHEMBL1441469 & 688239 & 4.5362 & 5.4431 & TRN & \\
\hline CHEMBL1446606 & 688239 & 8.3372 & 5.5022 & TRN & \\
\hline CHEMBL1470897 & 688239 & 5.9362 & 5.5941 & TRN & \\
\hline CHEMBL1322255 & 688239 & 5.1862 & 5.5093 & TRN & \\
\hline CHEMBL1392866 & 688239 & 4.6862 & 5.5561 & TRN & \\
\hline CHEMBL1399632 & 688239 & 4.7862 & 5.4807 & TRN & \\
\hline CHEMBL1391773 & 688239 & 4.5362 & 5.5152 & TRN & \\
\hline CHEMBL1385021 & 688239 & 4.5362 & 5.5009 & TRN & \\
\hline CHEMBL1403976 & 688239 & 6.9363 & 5.6251 & TST & \\
\hline CHEMBL1351014 & 688239 & 4.6362 & 5.3678 & TRN & \\
\hline CHEMBL1427605 & 688239 & 4.5362 & 5.3717 & TST & \\
\hline CHEMBL1330834 & 688239 & 4.5362 & 5.3647 & TST & \\
\hline CHEMBL1522432 & 688239 & 4.7862 & 5.4008 & TST & \\
\hline CHEMBL1480439 & 688239 & 6.2362 & 5.5825 & TST & \\
\hline CHEMBL1523277 & 688239 & 5.6862 & 5.5625 & TRN & \\
\hline CHEMBL1556820 & 688239 & 4.5862 & 5.3347 & TST & \\
\hline CHEMBL1513339 & 688239 & 5.3862 & 5.5396 & TRN & \\
\hline CHEMBL1511128 & 688239 & 4.5362 & 5.3467 & TRN & \\
\hline CHEMBL1605409 & 688239 & 4.5362 & 5.5534 & TRN & \\
\hline CHEMBL1500267 & 688239 & 6.5862 & 5.3557 & TRN & \\
\hline CHEMBL1303306 & 688239 & 6.0862 & 5.5473 & TRN & \\
\hline CHEMBL1608446 & 688239 & 6.5363 & 5.6732 & TRN & \\
\hline CHEMBL1483150 & 688239 & 4.5362 & 5.4032 & TRN & \\
\hline CHEMBL1413642 & 688239 & 6.7361 & 5.564 & TRN & \\
\hline CHEMBL1385210 & 688239 & 5.4862 & 5.4689 & TRN & \\
\hline CHEMBL1459114 & 688239 & 6.2362 & 5.6437 & TRN & \\
\hline CHEMBL1316835 & 688239 & 4.5362 & 5.474 & TST & \\
\hline CHEMBL1461454 & 688239 & 7.2366 & 5.5095 & TST & \\
\hline CHEMBL1593531 & 688239 & 6.2862 & 5.6441 & TST & \\
\hline CHEMBL1317035 & 688239 & 5.5362 & 5.474 & TRN & \\
\hline CHEMBL3192839 & 688239 & 7.0362 & 5.3683 & TRN & \\
\hline CHEMBL1386480 & 688239 & 4.7362 & 5.5052 & TRN & \\
\hline CHEMBL3212502 & 688239 & 4.5362 & 5.4171 & TRN & \\
\hline CHEMBL 1405972 & 688239 & 6.5363 & 5.5126 & TRN & \\
\hline CHEMBL3213552 & 688239 & 5.6362 & 5.5017 & TST & \\
\hline
\end{tabular}


Supplemental Table S2.txt

\begin{tabular}{|c|c|c|c|c|c|}
\hline CHEMBL1589202 & 688239 & 4.5362 & 5.4647 & TST & \\
\hline CHEMBL1570897 & 688239 & 7.0862 & 5.4412 & TRN & \\
\hline CHEMBL1551694 & 688239 & 5.0862 & 5.455 & TRN & \\
\hline CHEMBL1514943 & 688239 & 5.1862 & 5.3129 & TRN & \\
\hline CHEMBL1535155 & 688239 & 4.8862 & 5.422999 & 999999999 & RN \\
\hline CHEMBL1431795 & 688239 & 6.8362 & 5.6424 & TRN & \\
\hline CHEMBL1383362 & 688239 & 8.283999 & 99999999 & 5.3705 & \\
\hline CHEMBL1467022 & 688239 & 4.5362 & 5.5527 & TRN & \\
\hline CHEMBL1467666 & 688239 & 4.5362 & 5.4765 & TRN & \\
\hline CHEMBL1483614 & 688239 & 6.6362 & 5.6419 & TRN & \\
\hline CHEMBL1464658 & 688239 & 4.6862 & 5.5007 & TRN & \\
\hline CHEMBL1446851 & 688239 & 4.8362 & 5.5642 & TRN & \\
\hline CHEMBL1364080 & 688239 & 5.3862 & 5.4144 & TST & \\
\hline CHEMBL1354102 & 688239 & 5.1862 & 5.596 & TRN & \\
\hline CHEMBL1477106 & 688239 & 4.5362 & 5.4843 & TRN & \\
\hline CHEMBL1425842 & 688239 & 4.7362 & 5.4208 & TST & \\
\hline CHEMBL1511287 & 688239 & 4.5362 & 5.5559 & TST & \\
\hline CHEMBL1478461 & 688239 & 6.2862 & 5.5245 & TRN & \\
\hline CHEMBL1330319 & 688239 & 4.9862 & 5.5217 & TRN & \\
\hline CHEMBL1400615 & 688239 & 4.5362 & 5.7527 & TRN & \\
\hline CHEMBL1327521 & 688239 & 6.0 & 5.2811 & TRN & \\
\hline CHEMBL1387480 & 688239 & 6.3362 & 5.3799 & TRN & \\
\hline CHEMBL1579103 & 688239 & 5.1862 & 5.447999 & 9999999995 & \\
\hline CHEMBL1390203 & 688239 & 6.1362 & 5.6451 & TRN & \\
\hline CHEMBL1445955 & 688239 & 6.8362 & 5.4612 & TRN & \\
\hline CHEMBL1535941 & 688239 & 5.4362 & 5.4753 & TRN & \\
\hline CHEMBL3193019 & 688239 & 6.9363 & 5.4848 & TRN & \\
\hline CHEMBL1573139 & 688239 & 5.3862 & 5.5488 & TST & \\
\hline CHEMBL1482454 & 688239 & 4.7862 & 5.571000 & 000000001 & \\
\hline CHEMBL1304899 & 688239 & 5.3862 & 5.6034 & TRN & \\
\hline CHEMBL1468972 & 688239 & 5.7862 & 5.4371 & TRN & \\
\hline CHEMBL1354042 & 688239 & 4.5362 & 5.4818 & TRN & \\
\hline CHEMBL1548100 & 688239 & 4.8362 & 5.467000 & 0000000005 & \\
\hline CHEMBL1347071 & 688239 & 5.3862 & 5.2898 & TRN & \\
\hline CHEMBL3189883 & 688239 & 5.5362 & 5.4559 & TRN & \\
\hline CHEMBL1513991 & 688239 & 5.5862 & 5.4547 & TRN & \\
\hline CHEMBL1235157 & 688239 & 6.9363 & 5.4761 & TST & \\
\hline CHEMBL1428369 & 688239 & 5.5362 & 5.4762 & TRN & \\
\hline CHEMBL1425019 & 688239 & 6.4362 & 5.3971 & TRN & \\
\hline CHEMBL1425530 & 688239 & 5.5862 & 5.5068 & TST & \\
\hline CHEMBL1422988 & 688239 & 4.5362 & 5.4173 & TRN & \\
\hline CHEMBL1391940 & 688239 & 5.1862 & 5.4713 & TST & \\
\hline CHEMBL1513946 & 688239 & 4.5362 & 5.4875 & TST & \\
\hline CHEMBL1972735 & 688239 & 4.6862 & 5.5472 & TRN & \\
\hline CHEMBL1386811 & 688239 & 4.6362 & 5.476 & TRN & \\
\hline CHEMBL1383493 & 688239 & 4.9362 & 5.4586 & TST & \\
\hline CHEMBL 3199473 & 688239 & 5.5362 & 5.4249 & TST & \\
\hline CHEMBL1408684 & 688239 & 6.8861 & 5.3638 & TRN & \\
\hline
\end{tabular}


Supplemental Table S2.txt

\begin{tabular}{|c|c|c|c|c|c|}
\hline CHEMBL1566543 & 688239 & 5.2362 & 5.4279 & TRN & \\
\hline CHEMBL3195732 & 688239 & 5.4862 & 5.3223 & TST & \\
\hline CHEMBL3195165 & 688239 & 4.5362 & 5.4643 & TST & \\
\hline CHEMBL1582393 & 688239 & 5.2862 & 5.513 & TST & \\
\hline CHEMBL1458033 & 688239 & 6.8861 & 5.5107 & TRN & \\
\hline CHEMBL1332009 & 688239 & 4.8862 & 5.3455 & TRN & \\
\hline CHEMBL1582733 & 688239 & 5.1862 & 5.4561 & TRN & \\
\hline CHEMBL1584490 & 688239 & 4.5362 & 5.4536 & TRN & \\
\hline CHEMBL3193680 & 688239 & 6.9863 & 5.5097 & TRN & \\
\hline CHEMBL1468391 & 688239 & 4.6862 & 5.537000 & 000000001 & $T R I$ \\
\hline CHEMBL1475179 & 688239 & 4.6362 & 5.6203 & TRN & \\
\hline CHEMBL1354129 & 688239 & 4.6862 & 5.4956 & TST & \\
\hline CHEMBL1528835 & 688239 & 7.0362 & 5.382000 & 000000001 & \\
\hline CHEMBL1408066 & 688239 & 4.7362 & 5.4863 & TRN & \\
\hline CHEMBL1418889 & 688239 & 4.5362 & 5.4086 & TRN & \\
\hline CHEMBL1582087 & 688239 & 5.3862 & 5.4216 & TRN & \\
\hline CHEMBL1402708 & 688239 & 6.0862 & 5.5896 & TRN & \\
\hline CHEMBL1375441 & 688239 & 4.9862 & 5.3986 & TST & \\
\hline CHEMBL1480589 & 688239 & 4.9362 & 5.4684 & TRN & \\
\hline CHEMBL1581722 & 688239 & 5.1862 & 5.5367 & TRN & \\
\hline CHEMBL1504537 & 688239 & 4.7862 & 5.4672 & TST & \\
\hline CHEMBL1385418 & 688239 & 4.7362 & 5.6149 & TRN & \\
\hline CHEMBL1345042 & 688239 & 4.5862 & 5.4751 & TRN & \\
\hline CHEMBL 1467790 & 688239 & 6.9363 & 5.3781 & TRN & \\
\hline CHEMBL1531601 & 688239 & 6.3863 & 5.5993 & TST & \\
\hline CHEMBL1349317 & 688239 & 4.5362 & 5.4251 & TRN & \\
\hline CHEMBL1541524 & 688239 & 4.5362 & 5.551 & TRN & \\
\hline CHEMBL1535777 & 688239 & 5.1862 & 5.4531 & TRN & \\
\hline CHEMBL1541938 & 688239 & 5.0862 & 5.5401 & TRN & \\
\hline CHEMBL1353869 & 688239 & 6.9363 & 5.5535 & TST & \\
\hline CHEMBL1586941 & 688239 & 4.5362 & 5.6032 & TRN & \\
\hline CHEMBL1485493 & 688239 & 6.9363 & 5.4973 & TRN & \\
\hline CHEMBL1537938 & 688239 & 4.5362 & 5.5952 & TRN & \\
\hline CHEMBL1304318 & 688239 & 5.0862 & 5.4167 & TST & \\
\hline CHEMBL1577885 & 688239 & 4.5362 & 5.4424 & TRN & \\
\hline CHEMBL1375071 & 688239 & 4.9862 & 5.5827 & TRN & \\
\hline CHEMBL1441508 & 688239 & 4.7362 & 5.271 & TST & \\
\hline CHEMBL1417181 & 688239 & 6.2862 & 5.5079 & TST & \\
\hline CHEMBL 1403460 & 688239 & 5.1362 & 5.4335 & TRN & \\
\hline CHEMBL1504451 & 688239 & 5.0362 & 5.3636 & TRN & \\
\hline CHEMBL1372786 & 688239 & 4.5862 & 5.4724 & TST & \\
\hline CHEMBL1301534 & 688239 & 4.5862 & 5.4171 & TRN & \\
\hline CHEMBL1325685 & 688239 & 8.28399 & 99999999 & 5.5282 & S \\
\hline CHEMBL1503696 & 688239 & 7.0362 & 5.5925 & TRN & \\
\hline CHEMBL1540249 & 688239 & 4.5362 & 5.5634 & TRN & \\
\hline CHEMBL1304837 & 688239 & 4.9862 & 5.3927 & TRN & \\
\hline CHEMBL1355711 & 688239 & 8.3372 & 5.5246 & TRN & \\
\hline CHEMBL3197799 & 688239 & 5.1862 & 5.4039 & TRN & \\
\hline
\end{tabular}


Supplemental Table S2.txt

\begin{tabular}{|c|c|c|c|c|}
\hline CHEMBL1431332 & 688239 & 4.5362 & 5.4427 & TST \\
\hline CHEMBL1540237 & 688239 & 5.4862 & 5.4416 & TRN \\
\hline CHEMBL1578585 & 688239 & 6.8362 & 5.6244 & TRN \\
\hline CHEMBL1541592 & 688239 & 4.5362 & 5.4975 & TRN \\
\hline CHEMBL1499439 & 688239 & 4.9362 & 5.5481 & TST \\
\hline CHEMBL1478865 & 688239 & 4.5362 & 5.5541 & TRN \\
\hline CHEMBL3189895 & 688239 & 6.8861 & 5.4864 & TST \\
\hline CHEMBL1470193 & 688239 & 6.0362 & 5.3927 & TRN \\
\hline CHEMBL1480396 & 688239 & 4.5362 & 5.5222 & TRN \\
\hline CHEMBL1370357 & 688239 & 5.7362 & 5.3576 & TST \\
\hline CHEMBL1440856 & 688239 & 5.1862 & 5.436 & TRN \\
\hline CHEMBL1590784 & 688239 & 6.4862 & 5.4782 & TST \\
\hline CHEMBL1431154 & 688239 & 4.5362 & 5.41 & TST \\
\hline CHEMBL1396873 & 688239 & 4.5362 & 5.6066 & TRN \\
\hline CHEMBL3207692 & 688239 & 4.5362 & 5.4714 & TST \\
\hline CHEMBL1545204 & 688239 & 5.0862 & 5.4938 & TST \\
\hline CHEMBL1545912 & 688239 & 4.5362 & 5.4768 & TRN \\
\hline CHEMBL1351801 & 688239 & 4.5362 & 5.636 & TRN \\
\hline CHEMBL1416958 & 688239 & 4.5362 & 5.4831 & TRN \\
\hline CHEMBL1353771 & 688239 & 4.6362 & 5.4941 & TRN \\
\hline CHEMBL1503523 & 688239 & 5.8862 & 5.6277 & TRN \\
\hline CHEMBL1300922 & 688239 & 5.4362 & 5.2735 & TRN \\
\hline CHEMBL1562009 & 688239 & 6.8861 & 5.3286 & TRN \\
\hline CHEMBL1438630 & 688239 & 6.1362 & 5.5238 & TRN \\
\hline CHEMBL1368033 & 688239 & 5.4362 & 5.5977 & TRN \\
\hline CHEMBL1373988 & 688239 & 5.1862 & 5.5565 & TRN \\
\hline CHEMBL1479363 & 688239 & 5.3862 & 5.5034 & TRN \\
\hline CHEMBL1387811 & 688239 & 5.1862 & 5.48 & TRN \\
\hline CHEMBL1448732 & 688239 & 4.6362 & 5.4303 & TST \\
\hline CHEMBL1422653 & 688239 & 5.4362 & 5.4445 & TRN \\
\hline CHEMBL1388919 & 688239 & 4.5862 & 5.3768 & TRN \\
\hline CHEMBL1971815 & 688239 & 4.4862 & 5.5867 & TST \\
\hline CHEMBL1601429 & 688239 & 4.4862 & 5.5329 & TRN \\
\hline CHEMBL1599160 & 688239 & 6.9863 & 5.4705 & TST \\
\hline CHEMBL1438819 & 688239 & 5.3362 & 5.4757 & TRN \\
\hline CHEMBL1542639 & 688239 & 6.7361 & 5.601 & TRN \\
\hline CHEMBL1524517 & 688239 & 4.5362 & 5.6649 & TST \\
\hline CHEMBL1589063 & 688239 & 9.1549 & 5.4816 & TRN \\
\hline CHEMBL1562621 & 688239 & 4.4862 & 5.6635 & TRN \\
\hline CHEMBL3197404 & 688239 & 5.9862 & 5.492999 & 9999999999 \\
\hline CHEMBL1491818 & 688239 & 5.0362 & 5.5334 & TRN \\
\hline CHEMBL1365893 & 688239 & 5.3862 & 5.5518 & TST \\
\hline CHEMBL1519591 & 688239 & 6.2362 & 5.553 & TRN \\
\hline CHEMBL1471238 & 688239 & 7.1864 & 5.5484 & TRN \\
\hline CHEMBL1591220 & 688239 & 8.1871 & 5.4252 & TRN \\
\hline CHEMBL1539815 & 688239 & 4.5362 & 5.5069 & TRN \\
\hline CHEMBL1561369 & 688239 & 5.9362 & 5.5832 & TRN \\
\hline CHEMBL1577682 & 688239 & 6.9363 & 5.4034 & TRN \\
\hline
\end{tabular}


Supplemental Table S2.txt

\begin{tabular}{|c|c|c|c|c|c|}
\hline CHEMBL1543718 & 688239 & 4.7862 & 5.5628 & TRN & \\
\hline CHEMBL1340347 & 688239 & 5.8362 & 5.5906 & TRN & \\
\hline CHEMBL1318111 & 688239 & 6.8861 & 5.5129 & TRN & \\
\hline CHEMBL1490170 & 688239 & 6.8362 & 5.5719 & TRN & \\
\hline CHEMBL1381567 & 688239 & 5.9362 & 5.2127 & TRN & \\
\hline CHEMBL1509746 & 688239 & 4.6862 & 5.4525 & TST & \\
\hline CHEMBL1445777 & 688239 & 7.0362 & 5.5079 & TST & \\
\hline CHEMBL1407401 & 688239 & 4.7362 & 5.4415 & TRN & \\
\hline CHEMBL1386748 & 688239 & 5.3862 & 5.3516 & TRN & \\
\hline CHEMBL1338551 & 688239 & 6.3362 & 5.4688 & TST & \\
\hline CHEMBL1446818 & 688239 & 6.3863 & 5.5023 & TST & \\
\hline CHEMBL1434924 & 688239 & 6.0862 & 5.6123 & TRN & \\
\hline CHEMBL1508176 & 688239 & 6.9863 & 5.4855 & TRN & \\
\hline CHEMBL3190908 & 688239 & 5.5862 & 5.4991 & TRN & \\
\hline CHEMBL1478497 & 688239 & 6.0362 & 5.476 & TRN & \\
\hline CHEMBL1522486 & 688239 & 4.4862 & 5.5373 & TST & \\
\hline CHEMBL1502371 & 688239 & 4.7862 & 5.527 & TRN & \\
\hline CHEMBL1329614 & 688239 & 5.4362 & 5.4192 & TRN & \\
\hline CHEMBL1496056 & 688239 & 5.0362 & 5.5566 & TRN & \\
\hline CHEMBL1978488 & 688239 & 4.5362 & 5.5614 & TRN & \\
\hline CHEMBL1317210 & 688239 & 4.8862 & 5.4725 & TRN & \\
\hline CHEMBL1325880 & 688239 & 4.5362 & 5.4706 & TRN & \\
\hline CHEMBL1560627 & 688239 & 5.8362 & 5.5498 & TST & \\
\hline CHEMBL1567229 & 688239 & 5.1862 & 5.5416 & TRN & \\
\hline CHEMBL3210798 & 688239 & 4.5362 & 5.4357 & TRN & \\
\hline CHEMBL1565775 & 688239 & 4.7862 & 5.4831 & TRN & \\
\hline CHEMBL1449691 & 688239 & 5.6362 & 5.5512 & TRN & \\
\hline CHEMBL1343957 & 688239 & 5.6362 & 5.5934 & TRN & \\
\hline CHEMBL2000815 & 688239 & 4.7862 & 5.3294 & TST & \\
\hline CHEMBL1532340 & 688239 & 5.5862 & 5.577000 & 000000001 & TST \\
\hline CHEMBL88326 & 688239 & 4.6362 & 5.4127 & TST & \\
\hline CHEMBL1343747 & 688239 & 5.0862 & 5.5427 & TRN & \\
\hline CHEMBL1533595 & 688239 & 5.6862 & 5.4754 & TRN & \\
\hline CHEMBL1540881 & 688239 & 5.3862 & 5.5897 & TRN & \\
\hline CHEMBL1335546 & 688239 & 6.9363 & 5.4834 & TST & \\
\hline CHEMBL3194392 & 688239 & 6.5862 & 5.4561 & TRN & \\
\hline CHEMBL1426472 & 688239 & 4.7862 & 5.4082 & TRN & \\
\hline CHEMBL1579874 & 688239 & 4.7862 & 5.5491 & TRN & \\
\hline CHEMBL1613179 & 688239 & 4.6862 & 5.5619 & TRN & \\
\hline CHEMBL1390687 & 688239 & 5.9362 & 5.4544 & TRN & \\
\hline CHEMBL1400752 & 688239 & 4.5362 & 5.2923 & TST & \\
\hline CHEMBL1354790 & 688239 & 6.3863 & 5.6126 & TRN & \\
\hline CHEMBL1407223 & 688239 & 8.28399 & 999999999 & 5.4803 & TRN \\
\hline CHEMBL1561090 & 688239 & 4.5362 & 5.6241 & TRN & \\
\hline CHEMBL1384278 & 688239 & 7.0362 & 5.5507 & TRN & \\
\hline CHEMBL1571971 & 688239 & 4.6362 & 5.5111 & TRN & \\
\hline CHEMBL1470606 & 688239 & 6.0862 & 5.5652 & TST & \\
\hline CHEMBL1391569 & 688239 & 4.7862 & 5.4918 & TRN & \\
\hline
\end{tabular}


Supplemental Table S2.txt

\begin{tabular}{|c|c|c|c|c|}
\hline CHEMBL1521370 & 688239 & 6.9363 & 5.4262 & TRN \\
\hline CHEMBL1521846 & 688239 & 5.0362 & 5.3759 & TRN \\
\hline CHEMBL1314276 & 688239 & 4.9362 & 5.4299 & TRN \\
\hline CHEMBL1356823 & 688239 & 6.1862 & 5.5026 & TRN \\
\hline CHEMBL3214316 & 688239 & 5.1862 & 5.5707 & TRN \\
\hline CHEMBL1365828 & 688239 & 5.1862 & 5.5167 & TRN \\
\hline CHEMBL1408647 & 688239 & 5.8362 & \multicolumn{2}{|c|}{5.492999999999999} \\
\hline CHEMBL1586934 & 688239 & 4.5362 & 5.5174 & TST \\
\hline CHEMBL 2006684 & 688239 & 5.2862 & 5.3733 & TRN \\
\hline CHEMBL1607185 & 688239 & 5.1862 & \multicolumn{2}{|c|}{5.497000000000001} \\
\hline CHEMBL1420345 & 688239 & 4.5362 & 5.3203 & TRN \\
\hline CHEMBL1404564 & 688239 & 6.6362 & 5.5022 & TRN \\
\hline CHEMBL1301719 & 688239 & 6.8861 & 5.6854 & TRN \\
\hline CHEMBL1429774 & 688239 & 5.2362 & 5.4161 & TRN \\
\hline CHEMBL1466460 & 688239 & 5.2862 & 5.3637 & TST \\
\hline CHEMBL3213313 & 688239 & 5.1862 & 5.5203 & TRN \\
\hline CHEMBL1592058 & 688239 & 5.3362 & 5.3971 & TRN \\
\hline CHEMBL1446613 & 688239 & 6.2362 & 5.6026 & TRN \\
\hline CHEMBL1485098 & 688239 & 4.7362 & 5.3803 & TRN \\
\hline CHEMBL1610320 & 688239 & 8.3372 & 5.5232 & TRN \\
\hline CHEMBL1479396 & 688239 & 4.5362 & 5.4892 & TRN \\
\hline CHEMBL1344434 & 688239 & 4.8362 & 5.4472 & TRN \\
\hline CHEMBL1545177 & 688239 & 4.5362 & 5.4302 & TRN \\
\hline CHEMBL1520694 & 688239 & 4.7362 & 5.277 & TRN \\
\hline CHEMBL1415978 & 688239 & 4.5362 & 5.4593 & TRN \\
\hline CHEMBL1319563 & 688239 & 6.9363 & 5.7812 & TST \\
\hline CHEMBL1581471 & 688239 & 5.1862 & 5.499 & TRN \\
\hline CHEMBL1463903 & 688239 & 4.6862 & 5.3646 & TRN \\
\hline CHEMBL1493585 & 688239 & 4.7362 & 5.3705 & TRN \\
\hline CHEMBL1303297 & 688239 & 6.2362 & 5.3079 & TST \\
\hline CHEMBL1967772 & 688239 & 5.1362 & 5.4528 & TRN \\
\hline CHEMBL1363143 & 688239 & 4.6862 & 5.511 & TRN \\
\hline CHEMBL1410836 & 688239 & 6.4362 & 5.4514 & TRN \\
\hline CHEMBL1412931 & 688239 & 5.6862 & 5.6065 & TRN \\
\hline CHEMBL3190245 & 688239 & 6.1362 & 5.4766 & TRN \\
\hline CHEMBL1415940 & 688239 & 5.9362 & 5.5227 & TRN \\
\hline CHEMBL1348205 & 688239 & 5.3362 & 5.3628 & TRN \\
\hline CHEMBL1558695 & 688239 & 4.6362 & 5.4821 & TRN \\
\hline CHEMBL1485176 & 688239 & 6.0862 & 5.5053 & TST \\
\hline CHEMBL1326615 & 688239 & 4.5362 & 5.4621 & TRN \\
\hline CHEMBL1360603 & 688239 & 6.1862 & 5.5927 & TRN \\
\hline CHEMBL1467992 & 688239 & 6.8861 & 5.5701 & TRN \\
\hline CHEMBL1550828 & 688239 & 5.1862 & 5.4027 & TST \\
\hline CHEMBL1373654 & 688239 & 4.6362 & 5.3011 & TST \\
\hline CHEMBL3214134 & 688239 & 4.5362 & 5.6624 & TRN \\
\hline CHEMBL1488668 & 688239 & 4.5362 & 5.5307 & TST \\
\hline CHEMBL3190967 & 688239 & 4.6862 & 5.3011 & TRN \\
\hline CHEMBL1562365 & 688239 & 5.1862 & 5.4343 & TRN \\
\hline
\end{tabular}


Supplemental Table S2.txt

\begin{tabular}{|c|c|c|c|c|}
\hline CHEMBL1372955 & 688239 & 5.5862 & 5.5259 & TRN \\
\hline CHEMBL1480410 & 688239 & 5.2362 & 5.4362 & TRN \\
\hline CHEMBL1357039 & 688239 & 5.1362 & 5.3976 & TRN \\
\hline CHEMBL3213555 & 688239 & 4.7862 & 5.4497 & TST \\
\hline CHEMBL1529793 & 688239 & 5.4362 & 5.3557 & TST \\
\hline CHEMBL1544365 & 688239 & 6.1862 & 5.4542 & TRN \\
\hline CHEMBL1604527 & 688239 & 4.9362 & 5.3956 & TRN \\
\hline CHEMBL1608761 & 688239 & 5.7862 & 5.3393 & TRN \\
\hline CHEMBL1549539 & 688239 & 5.9362 & 5.5226 & TRN \\
\hline CHEMBL1387175 & 688239 & 5.0362 & 5.4 & TRN \\
\hline CHEMBL1343252 & 688239 & 5.5862 & 5.5395 & TST \\
\hline CHEMBL1471709 & 688239 & 5.8362 & 5.4634 & TST \\
\hline CHEMBL3214389 & 688239 & 5.1862 & 5.3938 & TST \\
\hline CHEMBL1310518 & 688239 & 4.7362 & 5.6627 & TRN \\
\hline CHEMBL1421392 & 688239 & 6.4862 & 5.3771 & TRN \\
\hline CHEMBL1596305 & 688239 & 5.3362 & 5.5757 & TST \\
\hline CHEMBL1599952 & 688239 & 5.4862 & 5.4993 & TRN \\
\hline CHEMBL1567889 & 688239 & 4.5362 & 5.4997 & TRN \\
\hline CHEMBL 2373588 & 688239 & 5.1862 & 5.5324 & TRN \\
\hline CHEMBL1542001 & 688239 & 6.3362 & 5.6314 & TST \\
\hline CHEMBL1504123 & 688239 & 5.3362 & 5.5141 & TST \\
\hline CHEMBL1466412 & 688239 & 6.0862 & 5.5886 & TRN \\
\hline CHEMBL1408573 & 688239 & 5.4362 & 5.5299 & TST \\
\hline CHEMBL1439594 & 688239 & 6.0862 & 5.6913 & TRN \\
\hline CHEMBL3189333 & 688239 & 4.7362 & 5.3391 & TST \\
\hline CHEMBL1374232 & 688239 & 6.8362 & 5.4339 & TST \\
\hline CHEMBL1560226 & 688239 & 8.0862 & 5.4849 & TRN \\
\hline CHEMBL1586983 & 688239 & 6.1362 & 5.303 & TST \\
\hline CHEMBL1601332 & 688239 & 4.7362 & 5.4701 & TST \\
\hline CHEMBL1612177 & 688239 & 4.5362 & 5.473 & TRN \\
\hline CHEMBL1523744 & 688239 & 5.1862 & 5.5262 & TRN \\
\hline CHEMBL1539198 & 688239 & 6.3362 & 5.3634 & TRN \\
\hline CHEMBL1320543 & 688239 & 6.6861 & 5.5598 & TRN \\
\hline CHEMBL1359716 & 688239 & 4.9862 & 5.5629 & TST \\
\hline CHEMBL1384284 & 688239 & 6.1362 & 5.5705 & TRN \\
\hline CHEMBL1412947 & 688239 & 4.4862 & 5.5341 & TRN \\
\hline CHEMBL1442892 & 688239 & 6.1862 & 5.6009 & TRN \\
\hline CHEMBL1395539 & 688239 & 4.5862 & 5.452999 & 9999999999 \\
\hline CHEMBL1568817 & 688239 & 6.3863 & 5.6102 & TST \\
\hline CHEMBL1315905 & 688239 & 5.7362 & 5.4775 & TRN \\
\hline CHEMBL1468822 & 688239 & 4.5362 & 5.4426 & TRN \\
\hline CHEMBL1585913 & 688239 & 4.7362 & 5.4139 & TRN \\
\hline CHEMBL1309791 & 688239 & 5.6862 & 5.3567 & TRN \\
\hline CHEMBL3193170 & 688239 & 6.9363 & 5.2398 & TST \\
\hline CHEMBL1334809 & 688239 & 4.6362 & 5.4147 & TST \\
\hline CHEMBL1331345 & 688239 & 5.9362 & 5.6332 & TRN \\
\hline CHEMBL1526750 & 688239 & 4.7362 & 5.6152 & TRN \\
\hline CHEMBL1560074 & 688239 & 6.5363 & 5.4006 & TRN \\
\hline
\end{tabular}




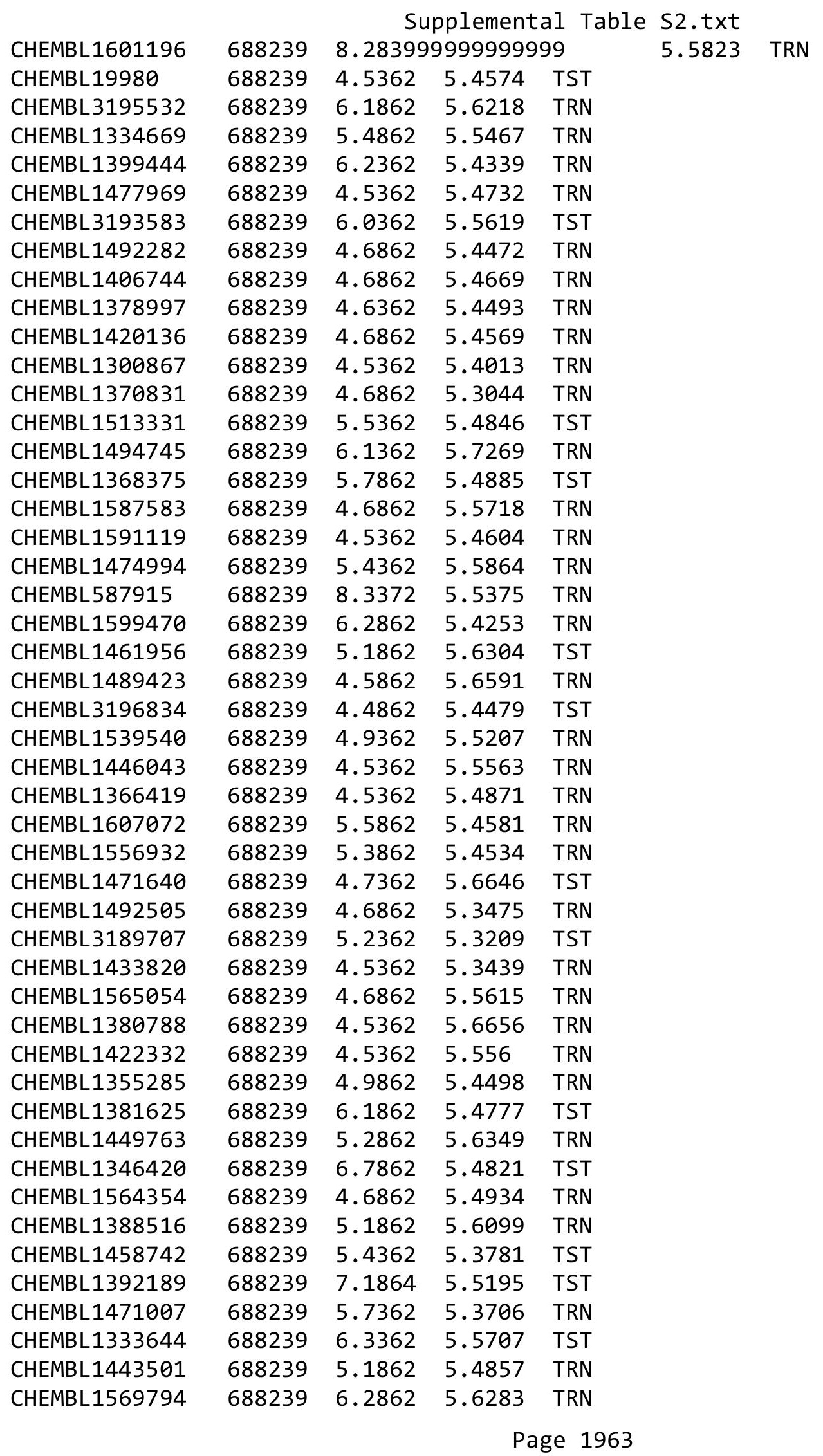


Supplemental Table S2.txt

\begin{tabular}{|c|c|c|c|c|c|}
\hline CHEMBL1546030 & 688239 & 4.5362 & 5.4414 & TRN & \\
\hline CHEMBL 3213058 & 688239 & 4.5362 & 5.3449 & TRN & \\
\hline CHEMBL1409800 & 688239 & 4.5362 & 5.4697 & TRN & \\
\hline CHEMBL1449688 & 688239 & 4.5362 & \multicolumn{2}{|c|}{5.468999999999999} & TRN \\
\hline CHEMBL1431314 & 688239 & 4.5362 & 5.4645 & TRN & \\
\hline CHEMBL1587391 & 688239 & 4.5362 & 5.5561 & TRN & \\
\hline CHEMBL1317957 & 688239 & 4.7862 & 5.3239 & TRN & \\
\hline CHEMBL1386649 & 688239 & 4.5362 & 5.5751 & TST & \\
\hline CHEMBL1381671 & 688239 & 6.0362 & 5.4813 & TRN & \\
\hline CHEMBL1519894 & 688239 & 4.5362 & 5.4063 & TRN & \\
\hline CHEMBL1398772 & 688239 & 5.1362 & 5.5737 & TRN & \\
\hline CHEMBL1558308 & 688239 & 5.2862 & 5.5356 & TRN & \\
\hline CHEMBL175822 & 688239 & 6.7862 & 5.4296 & TRN & \\
\hline CHEMBL1381085 & 688239 & 6.1362 & 5.4104 & TRN & \\
\hline CHEMBL1604907 & 688239 & 6.8362 & 5.3914 & TRN & \\
\hline CHEMBL3191763 & 688239 & 5.3362 & 5.4236 & TRN & \\
\hline CHEMBL1433430 & 688239 & 5.4362 & 5.473 & TRN & \\
\hline CHEMBL1466772 & 688239 & 6.9363 & 5.6239 & TRN & \\
\hline CHEMBL1311261 & 688239 & 5.8862 & 5.5087 & TRN & \\
\hline CHEMBL1430584 & 688239 & 5.4862 & 5.4514 & TST & \\
\hline CHEMBL1482011 & 688239 & 6.0862 & 5.3986 & TST & \\
\hline CHEMBL1487932 & 688239 & 4.6362 & 5.5797 & TRN & \\
\hline CHEMBL1562324 & 688239 & 5.1862 & 5.4711 & TST & \\
\hline CHEMBL1503125 & 688239 & 5.4362 & \multicolumn{2}{|c|}{5.4910000000000005} & TST \\
\hline CHEMBL1305876 & 688239 & 6.9363 & 5.6734 & TRN & \\
\hline CHEMBL1430058 & 688239 & 4.6862 & 5.4154 & TRN & \\
\hline CHEMBL1558035 & 688239 & 5.4362 & 5.4794 & TRN & \\
\hline CHEMBL1419892 & 688239 & 4.6862 & 5.4814 & TST & \\
\hline CHEMBL1317875 & 688239 & 5.2862 & 5.3945 & TRN & \\
\hline CHEMBL1536505 & 688239 & 6.8861 & 5.5263 & TST & \\
\hline CHEMBL1336284 & 688239 & 5.1862 & 5.5471 & TST & \\
\hline CHEMBL1605840 & 688239 & 6.9363 & 5.4899 & TRN & \\
\hline CHEMBL1506847 & 688239 & 4.8862 & 5.4012 & TRN & \\
\hline CHEMBL1413861 & 688239 & 4.8862 & 5.5317 & TRN & \\
\hline CHEMBL1591554 & 688239 & 6.2362 & 5.6433 & TRN & \\
\hline CHEMBL1494086 & 688239 & 4.8862 & 5.5297 & TST & \\
\hline CHEMBL1477304 & 688239 & 4.8362 & 5.3989 & TST & \\
\hline CHEMBL1300708 & 688239 & 6.2862 & 5.4804 & TRN & \\
\hline CHEMBL1331369 & 688239 & 4.5362 & 5.5449 & TRN & \\
\hline CHEMBL1484939 & 688239 & 5.8862 & 5.485 & TRN & \\
\hline CHEMBL1480203 & 688239 & 5.3362 & 5.5397 & TRN & \\
\hline CHEMBL1545657 & 688239 & 4.9362 & 5.4924 & TRN & \\
\hline CHEMBL1396818 & 688239 & 4.5862 & 5.5814 & TRN & \\
\hline CHEMBL1532073 & 688239 & 5.0862 & 5.391 & TST & \\
\hline CHEMBL1535012 & 688239 & 6.4362 & 5.6618 & TRN & \\
\hline CHEMBL1594339 & 688239 & 6.2362 & 5.6185 & TRN & \\
\hline CHEMBL2000368 & 688239 & 5.2862 & \multicolumn{2}{|c|}{5.202000000000001} & TRN \\
\hline CHEMBL1315419 & 688239 & 5.2362 & 5.4889 & TST & \\
\hline
\end{tabular}


Supplemental Table S2.txt

\begin{tabular}{|c|c|c|c|c|}
\hline CHEMBL1409765 & 688239 & 6.1862 & 5.4966 & TRN \\
\hline CHEMBL1415159 & 688239 & 4.7862 & 5.4178 & TRN \\
\hline CHEMBL1465235 & 688239 & 8.1367 & 5.3485 & TRN \\
\hline CHEMBL1416335 & 688239 & 6.1362 & 5.4692 & TST \\
\hline CHEMBL1538935 & 688239 & 8.3372 & 5.3501 & TRN \\
\hline CHEMBL1518479 & 688239 & 5.1362 & 5.3508 & TRN \\
\hline CHEMBL1299892 & 688239 & 6.9363 & 5.4648 & TRN \\
\hline CHEMBL1586792 & 688239 & 4.8362 & 5.5549 & TRN \\
\hline CHEMBL1445704 & 688239 & 4.8362 & 5.4629 & TRN \\
\hline CHEMBL1309374 & 688239 & 6.1862 & 5.6871 & TRN \\
\hline CHEMBL1311739 & 688239 & 5.6862 & 5.4975 & TRN \\
\hline CHEMBL1309156 & 688239 & 5.1862 & 5.5821 & TRN \\
\hline CHEMBL1578351 & 688239 & 7.1361 & 5.4561 & TRN \\
\hline CHEMBL3195173 & 688239 & 6.5363 & 5.4027 & TRN \\
\hline CHEMBL1437020 & 688239 & 6.1362 & 5.4946 & TRN \\
\hline CHEMBL1464828 & 688239 & 6.9363 & 5.52 & TST \\
\hline CHEMBL1478425 & 688239 & 4.4362 & 5.454 & TRN \\
\hline CHEMBL1420162 & 688239 & 5.4362 & 5.6702 & TRN \\
\hline CHEMBL1585105 & 688239 & 4.6362 & 5.4523 & TRN \\
\hline CHEMBL1446163 & 688239 & 5.4362 & 5.5404 & TRN \\
\hline CHEMBL1522135 & 688239 & 5.7362 & 5.5305 & TST \\
\hline CHEMBL1314494 & 688239 & 6.7361 & 5.5098 & TRN \\
\hline CHEMBL1498677 & 688239 & 5.5362 & 5.55 & TRN \\
\hline CHEMBL1382787 & 688239 & 4.8362 & 5.5846 & TRN \\
\hline CHEMBL3211776 & 688239 & 4.7862 & 5.3922 & TRN \\
\hline CHEMBL1572499 & 688239 & 4.5362 & 5.4478 & TRN \\
\hline CHEMBL1357300 & 688239 & 7.5867 & 5.5266 & TST \\
\hline CHEMBL1345238 & 688239 & 5.4862 & 5.4424 & TRN \\
\hline CHEMBL1311846 & 688239 & 4.5862 & 5.6013 & TRN \\
\hline CHEMBL1469527 & 688239 & 5.0362 & 5.5549 & TRN \\
\hline CHEMBL1373023 & 688239 & 6.5862 & 5.4818 & TRN \\
\hline CHEMBL1471203 & 688239 & 5.3862 & 5.4955 & TRN \\
\hline CHEMBL3212782 & 688239 & 4.6362 & 5.3431 & TST \\
\hline CHEMBL1503397 & 688239 & 7.1361 & 5.6065 & TRN \\
\hline CHEMBL578515 & 688239 & 5.3862 & 5.2237 & TRN \\
\hline CHEMBL1373871 & 688239 & 4.8862 & 5.3876 & TST \\
\hline CHEMBL1424368 & 688239 & 4.7362 & 5.5717 & TST \\
\hline CHEMBL1305201 & 688239 & 6.9863 & 5.6484 & TRN \\
\hline CHEMBL1320583 & 688239 & 4.5862 & 5.4465 & TRN \\
\hline CHEMBL1324228 & 688239 & 6.2362 & 5.4838 & TRN \\
\hline CHEMBL3209714 & 688239 & 6.7361 & 5.4813 & TST \\
\hline CHEMBL1593063 & 688239 & 4.7862 & 5.4727 & TRN \\
\hline CHEMBL1431757 & 688239 & 8.3372 & 5.4405 & TST \\
\hline CHEMBL1388430 & 688239 & 4.45 & 5.6026 & TRN \\
\hline CHEMBL1431879 & 688239 & 5.1362 & 5.423999 & 99999999995 \\
\hline CHEMBL1549077 & 688239 & 4.7862 & 5.3664 & TRN \\
\hline CHEMBL1530757 & 688239 & 6.0862 & 5.5072 & TRN \\
\hline CHEMBL1351161 & 688239 & 5.8362 & 5.5175 & TRN \\
\hline
\end{tabular}


Supplemental Table S2.txt

\begin{tabular}{|c|c|c|c|c|c|}
\hline CHEMBL1307637 & 688239 & 6.6362 & 5.5714 & TRN & \\
\hline CHEMBL3196170 & 688239 & 4.5362 & \multicolumn{2}{|c|}{5.4270000000000005} & TRN \\
\hline CHEMBL1473090 & 688239 & 5.1862 & 5.3215 & TRN & \\
\hline CHEMBL1510903 & 688239 & 6.4862 & 5.4795 & TRN & \\
\hline CHEMBL3212876 & 688239 & 5.9862 & 5.4364 & TRN & \\
\hline CHEMBL1392842 & 688239 & 4.5362 & 5.5304 & TRN & \\
\hline CHEMBL1381973 & 688239 & 6.8861 & 5.3865 & TST & \\
\hline CHEMBL1559709 & 688239 & 5.2862 & 5.525 & TST & \\
\hline CHEMBL1564737 & 688239 & 4.8362 & 5.4935 & TRN & \\
\hline CHEMBL1424609 & 688239 & 5.1862 & 5.4903 & TRN & \\
\hline CHEMBL1420331 & 688239 & 5.6862 & 5.6795 & TRN & \\
\hline CHEMBL1478267 & 688239 & 4.5362 & 5.4464 & TRN & \\
\hline CHEMBL1551526 & 688239 & 6.7361 & 5.5237 & TST & \\
\hline CHEMBL3208334 & 688239 & 6.7361 & 5.5069 & TST & \\
\hline CHEMBL1313183 & 688239 & 5.1862 & 5.5484 & TST & \\
\hline CHEMBL1299187 & 688239 & 4.5862 & 5.5339 & TRN & \\
\hline CHEMBL1414170 & 688239 & 5.5362 & 5.5917 & TRN & \\
\hline CHEMBL1532807 & 688239 & 6.8362 & 5.5784 & TRN & \\
\hline CHEMBL1588208 & 688239 & 6.6861 & 5.4622 & TST & \\
\hline CHEMBL1299303 & 688239 & 5.4862 & 5.6381 & TST & \\
\hline CHEMBL1425305 & 688239 & 7.0862 & 5.5042 & TST & \\
\hline CHEMBL1569849 & 688239 & 4.5362 & 5.2884 & TST & \\
\hline CHEMBL1365966 & 688239 & 4.5862 & 5.3796 & TRN & \\
\hline CHEMBL1471679 & 688239 & 5.1362 & 5.5854 & TRN & \\
\hline CHEMBL1461384 & 688239 & 5.6362 & 5.5691 & TRN & \\
\hline CHEMBL1522219 & 688239 & 5.1362 & 5.4726 & TRN & \\
\hline CHEMBL1586279 & 688239 & 4.6362 & 5.4838 & TRN & \\
\hline CHEMBL1548359 & 688239 & 4.5362 & 5.5602 & TRN & \\
\hline CHEMBL1601282 & 688239 & 5.2362 & 5.5766 & TRN & \\
\hline CHEMBL1463309 & 688239 & 6.2862 & 5.4536 & TRN & \\
\hline CHEMBL1459654 & 688239 & 6.0362 & 5.4793 & TRN & \\
\hline CHEMBL1559976 & 688239 & 4.7362 & 5.49 & TRN & \\
\hline CHEMBL1544926 & 688239 & 5.6362 & 5.6165 & TRN & \\
\hline CHEMBL1596704 & 688239 & 4.5362 & 5.3909 & TST & \\
\hline CHEMBL1353074 & 688239 & 5.1862 & 5.6334 & TST & \\
\hline CHEMBL1359333 & 688239 & 5.6362 & 5.5227 & TRN & \\
\hline CHEMBL1415005 & 688239 & 5.5362 & 5.6211 & TST & \\
\hline CHEMBL1607320 & 688239 & 5.1862 & 5.5376 & TRN & \\
\hline CHEMBL1346880 & 688239 & 4.6362 & 5.5571 & TRN & \\
\hline CHEMBL1417031 & 688239 & 5.6862 & 5.386 & TRN & \\
\hline CHEMBL1496394 & 688239 & 5.1862 & 5.4324 & TRN & \\
\hline CHEMBL1355508 & 688239 & 4.8362 & 5.4625 & TRN & \\
\hline CHEMBL1578860 & 688239 & 5.3862 & 5.5722 & TRN & \\
\hline CHEMBL1498265 & 688239 & 4.7862 & 5.5262 & TRN & \\
\hline CHEMBL1366228 & 688239 & 5.4362 & 5.5295 & TRN & \\
\hline CHEMBL1370603 & 688239 & 4.5862 & 5.4814 & TRN & \\
\hline CHEMBL1390150 & 688239 & 4.6862 & 5.5594 & TRN & \\
\hline CHEMBL1385987 & 688239 & 5.5862 & 5.6487 & TRN & \\
\hline
\end{tabular}


Supplemental Table S2.txt

\begin{tabular}{|c|c|c|c|c|c|}
\hline CHEMBL1484292 & 688239 & 5.0862 & 5.2896 & TRN & \\
\hline CHEMBL1572233 & 688239 & 4.5362 & 5.4434 & TRN & \\
\hline CHEMBL1515489 & 688239 & 8.3372 & 5.532 & TST & \\
\hline CHEMBL1326855 & 688239 & 4.5362 & 5.5292 & TRN & \\
\hline CHEMBL1366517 & 688239 & 7.6364 & 5.4713 & TRN & \\
\hline CHEMBL1392246 & 688239 & 7.0862 & 5.4892 & TRN & \\
\hline CHEMBL1428145 & 688239 & 5.7362 & 5.4707 & TRN & \\
\hline CHEMBL1536001 & 688239 & 4.7862 & 5.4927 & TRN & \\
\hline CHEMBL1610620 & 688239 & 4.5862 & 5.5507 & TRN & \\
\hline CHEMBL 3194471 & 688239 & 6.1362 & 5.5626 & TRN & \\
\hline CHEMBL1541721 & 688239 & 6.9863 & 5.5269 & TRN & \\
\hline CHEMBL1410776 & 688239 & 4.7362 & 5.5337 & TST & \\
\hline CHEMBL1558491 & 688239 & 6.3863 & 5.4138 & TST & \\
\hline CHEMBL1308801 & 688239 & 4.7362 & 5.3312 & TRN & \\
\hline CHEMBL1458897 & 688239 & 4.4862 & 5.4583 & TRN & \\
\hline CHEMBL1443205 & 688239 & 4.7862 & \multicolumn{2}{|c|}{5.417000000000001} & TRN \\
\hline CHEMBL1511182 & 688239 & 4.8862 & 5.4625 & TST & \\
\hline CHEMBL1561305 & 688239 & 7.1361 & 5.4773 & TRN & \\
\hline CHEMBL1441354 & 688239 & 5.2862 & 5.479 & TST & \\
\hline CHEMBL1578797 & 688239 & 5.9862 & 5.5069 & TRN & \\
\hline CHEMBL1341396 & 688239 & 5.7862 & 5.4876 & TRN & \\
\hline CHEMBL1416311 & 688239 & 5.7362 & 5.5286 & TRN & \\
\hline CHEMBL 3213042 & 688239 & 4.5362 & 5.5045 & TRN & \\
\hline CHEMBL1502126 & 688239 & 6.2362 & \multicolumn{2}{|c|}{5.5920000000000005} & TRN \\
\hline CHEMBL1609948 & 688239 & 5.1862 & 5.6515 & TRN & \\
\hline CHEMBL1380322 & 688239 & 5.4862 & 5.5641 & TRN & \\
\hline CHEMBL1386436 & 688239 & 4.5362 & 5.5137 & TRN & \\
\hline CHEMBL1322325 & 688239 & 6.1862 & 5.5378 & TRN & \\
\hline CHEMBL1429455 & 688239 & 5.3862 & 5.6685 & TRN & \\
\hline CHEMBL 3212480 & 688239 & 6.2362 & 5.4553 & TRN & \\
\hline CHEMBL1361805 & 688239 & 6.8362 & 5.5506 & TRN & \\
\hline CHEMBL1535793 & 688239 & 4.5362 & 5.4403 & TRN & \\
\hline CHEMBL1507458 & 688239 & 6.4862 & 5.3502 & TRN & \\
\hline CHEMBL3190063 & 688239 & 4.8862 & 5.2948 & TST & \\
\hline CHEMBL1457718 & 688239 & 5.1862 & 5.5629 & TRN & \\
\hline CHEMBL1504493 & 688239 & 4.6862 & 5.3694 & TRN & \\
\hline CHEMBL1570884 & 688239 & 5.2362 & 5.4049 & TRN & \\
\hline CHEMBL1386764 & 688239 & 4.6362 & 5.5603 & TRN & \\
\hline CHEMBL1306721 & 688239 & 6.1362 & 5.5684 & TRN & \\
\hline CHEMBL 3212695 & 688239 & 5.3862 & 5.2899 & TST & \\
\hline CHEMBL1417368 & 688239 & 6.6362 & 5.6083 & TRN & \\
\hline CHEMBL1609838 & 688239 & 5.2362 & 5.4445 & TRN & \\
\hline CHEMBL1378537 & 688239 & 4.5362 & \multicolumn{2}{|c|}{5.343999999999999} & TRN \\
\hline CHEMBL1546701 & 688239 & 4.9362 & 5.5124 & TRN & \\
\hline CHEMBL1613219 & 688239 & 5.1362 & 5.6178 & TRN & \\
\hline CHEMBL601119 & 688239 & 4.8862 & 5.4277 & TRN & \\
\hline CHEMBL1568353 & 688239 & 4.6362 & 5.4567 & TRN & \\
\hline CHEMBL3213917 & 688239 & 7.2366 & 5.4462 & TRN & \\
\hline
\end{tabular}


Supplemental Table S2.txt

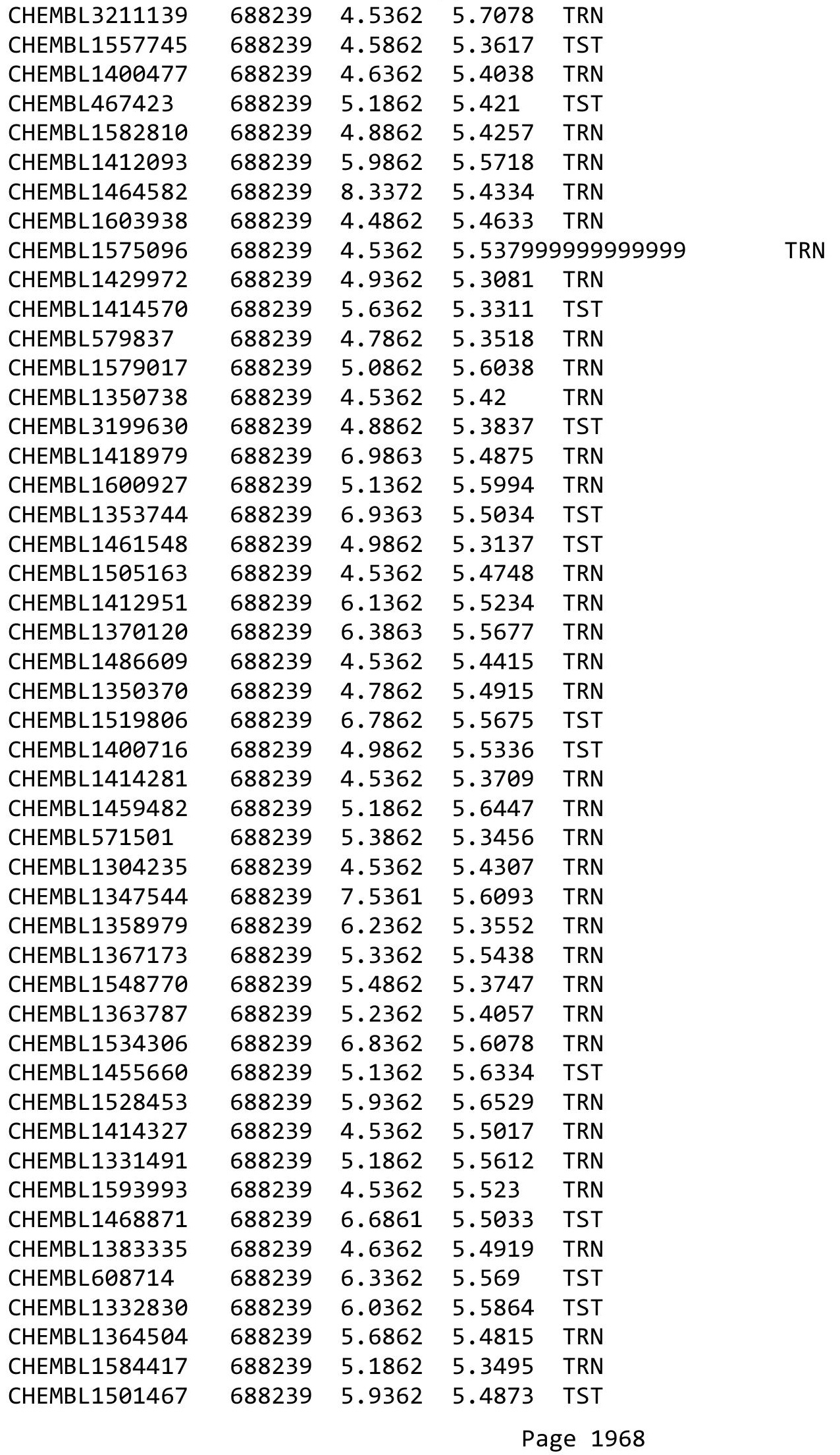


Supplemental Table S2.txt

\begin{tabular}{|c|c|c|c|c|}
\hline CHEMBL1598315 & 688239 & 6.3863 & 5.5649 & TRN \\
\hline CHEMBL1522722 & 688239 & 8.2366 & 5.4596 & TST \\
\hline CHEMBL1440979 & 688239 & 5.5362 & 5.5773 & TRN \\
\hline CHEMBL1395821 & 688239 & 6.2362 & 5.6258 & TRN \\
\hline CHEMBL1602048 & 688239 & 5.7862 & 5.3769 & TRN \\
\hline CHEMBL1572661 & 688239 & 6.3362 & \multicolumn{2}{|c|}{5.4479999999999995} \\
\hline CHEMBL1538409 & 688239 & 4.7362 & 5.4026 & TRN \\
\hline CHEMBL1474692 & 688239 & 5.1862 & 5.396 & TRN \\
\hline CHEMBL1385043 & 688239 & 5.6362 & 5.5717 & TRN \\
\hline CHEMBL1322158 & 688239 & 4.5362 & 5.5459 & TST \\
\hline CHEMBL1581123 & 688239 & 5.4862 & \multicolumn{2}{|c|}{5.537999999999999} \\
\hline CHEMBL1472451 & 688239 & 4.5862 & 5.5891 & TRN \\
\hline CHEMBL1400056 & 688239 & 5.1862 & 5.3703 & TRN \\
\hline CHEMBL1309333 & 688239 & 6.7361 & 5.5305 & TRN \\
\hline CHEMBL1415241 & 688239 & 5.9362 & 5.6334 & TRN \\
\hline CHEMBL1436499 & 688239 & 4.5362 & 5.437 & TRN \\
\hline CHEMBL1599833 & 688239 & 6.9363 & 5.4778 & TRN \\
\hline CHEMBL 272922 & 688239 & 4.5362 & 5.516 & TRN \\
\hline CHEMBL1473903 & 688239 & 5.7862 & 5.4257 & TRN \\
\hline CHEMBL1580331 & 688239 & 6.8861 & 5.6662 & TST \\
\hline CHEMBL1395427 & 688239 & 5.1862 & 5.5497 & TRN \\
\hline CHEMBL1397516 & 688239 & 5.8862 & 5.5152 & TRN \\
\hline CHEMBL1409090 & 688239 & 4.8862 & 5.5583 & TRN \\
\hline CHEMBL1502645 & 688239 & 5.3862 & 5.5991 & TRN \\
\hline CHEMBL 3192216 & 688239 & 4.5362 & 5.4298 & TST \\
\hline CHEMBL1366137 & 688239 & 6.3863 & 5.5724 & TRN \\
\hline CHEMBL1336163 & 688239 & 5.1862 & 5.6636 & TRN \\
\hline CHEMBL1419084 & 688239 & 4.4862 & 5.5146 & TRN \\
\hline CHEMBL1555291 & 688239 & 4.5362 & 5.5388 & TRN \\
\hline CHEMBL1552033 & 688239 & 5.6862 & 5.4157 & TRN \\
\hline CHEMBL1303518 & 688239 & 6.0362 & 5.4279 & TRN \\
\hline CHEMBL1330362 & 688239 & 5.4362 & 5.322 & TRN \\
\hline CHEMBL1543528 & 688239 & 4.7862 & 5.4856 & TST \\
\hline CHEMBL1354404 & 688239 & 4.7362 & 5.3553 & TRN \\
\hline CHEMBL1314579 & 688239 & 6.8362 & 5.5328 & TRN \\
\hline CHEMBL1596634 & 688239 & 5.8362 & 5.4411 & TST \\
\hline CHEMBL 3210768 & 688239 & 5.7362 & 5.4521 & TRN \\
\hline CHEMBL1402736 & 688239 & 5.6362 & 5.6201 & TRN \\
\hline CHEMBL595378 & 688239 & 4.6362 & 5.4615 & TRN \\
\hline CHEMBL1326493 & 688239 & 4.4862 & 5.5221 & TRN \\
\hline CHEMBL1331100 & 688239 & 4.9362 & 5.5535 & TST \\
\hline CHEMBL1352550 & 688239 & 5.4362 & 5.5926 & TRN \\
\hline CHEMBL1970032 & 688239 & 4.5362 & 5.5002 & TRN \\
\hline CHEMBL1584861 & 688239 & 4.5362 & 5.5049 & TRN \\
\hline CHEMBL1341220 & 688239 & 5.4862 & 5.4835 & TRN \\
\hline CHEMBL 2005996 & 688239 & 4.6862 & 5.5038 & TRN \\
\hline CHEMBL1452281 & 688239 & 6.1862 & 5.3665 & TRN \\
\hline CHEMBL1988798 & 688239 & 4.6862 & 5.3567 & TRN \\
\hline
\end{tabular}


Supplemental Table S2.txt

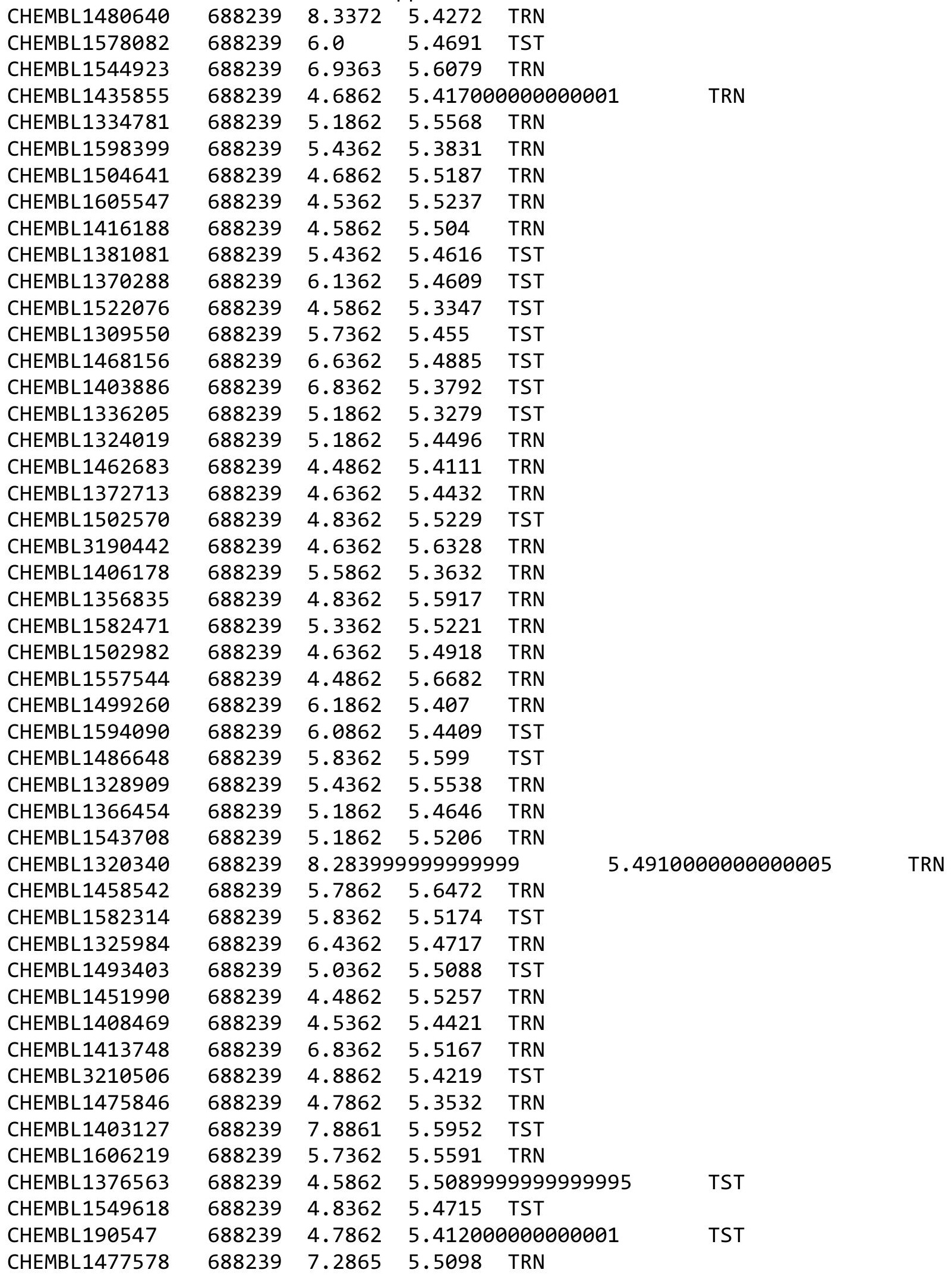

Page 1970 
Supplemental Table S2.txt

\begin{tabular}{|c|c|c|c|c|c|}
\hline CHEMBL3192694 & 688239 & 6.0362 & 5.5738 & TRN & \\
\hline CHEMBL6742 & 688239 & 6.4362 & 5.5362 & TST & \\
\hline CHEMBL1370002 & 688239 & 5.8362 & 5.6331 & TRN & \\
\hline CHEMBL1437529 & 688239 & 6.4862 & 5.478 & TRN & \\
\hline CHEMBL1501108 & 688239 & 5.0362 & 5.4748 & TRN & \\
\hline CHEMBL3197787 & 688239 & 6.2362 & 5.3563 & TRN & \\
\hline CHEMBL1360453 & 688239 & 4.5362 & 5.6257 & TRN & \\
\hline CHEMBL1312185 & 688239 & 5.1862 & 5.4596 & TRN & \\
\hline CHEMBL1533865 & 688239 & 5.5862 & 5.3642 & TRN & \\
\hline CHEMBL1523545 & 688239 & 4.6362 & 5.4348 & TST & \\
\hline CHEMBL1579715 & 688239 & 5.2862 & 5.4187 & TST & \\
\hline CHEMBL1459756 & 688239 & 4.5862 & 5.5378 & TRN & \\
\hline CHEMBL1446728 & 688239 & 5.6862 & 5.5187 & TST & \\
\hline CHEMBL1362629 & 688239 & 4.5362 & 5.4238 & TST & \\
\hline CHEMBL1591204 & 688239 & 6.3362 & 5.5261 & TST & \\
\hline CHEMBL1588842 & 688239 & 5.0362 & 5.4317 & TRN & \\
\hline CHEMBL1570005 & 688239 & 5.4362 & 5.4315 & TST & \\
\hline CHEMBL1528160 & 688239 & 4.6362 & 5.347 & TRN & \\
\hline CHEMBL1478541 & 688239 & 5.1862 & \multicolumn{2}{|c|}{5.531000000000001} & TRN \\
\hline CHEMBL1480477 & 688239 & 6.6861 & 5.4802 & TRN & \\
\hline CHEMBL1572576 & 688239 & 7.1864 & 5.5445 & TRN & \\
\hline CHEMBL1487765 & 688239 & 6.7361 & 5.3708 & TRN & \\
\hline CHEMBL1500890 & 688239 & 6.0862 & 5.6486 & TRN & \\
\hline CHEMBL1535070 & 688239 & 4.9862 & 5.4533 & TRN & \\
\hline CHEMBL1433218 & 688239 & 4.5862 & \multicolumn{2}{|c|}{5.537999999999999} & TST \\
\hline CHEMBL1380255 & 688239 & 5.4862 & 5.631 & TST & \\
\hline CHEMBL1558034 & 688239 & 5.0862 & 5.4898 & TRN & \\
\hline CHEMBL1552591 & 688239 & 6.6861 & 5.375 & TRN & \\
\hline CHEMBL1533845 & 688239 & 6.2362 & 5.6181 & TRN & \\
\hline CHEMBL1494963 & 688239 & 5.3862 & \multicolumn{2}{|c|}{5.457999999999999} & TRN \\
\hline CHEMBL1406445 & 688239 & 5.1862 & 5.4913 & TST & \\
\hline CHEMBL1473199 & 688239 & 5.1362 & 5.5604 & TRN & \\
\hline CHEMBL1452529 & 688239 & 5.6862 & 5.4845 & TRN & \\
\hline CHEMBL1390681 & 688239 & 6.1862 & 5.3658 & TRN & \\
\hline CHEMBL1524431 & 688239 & 5.1362 & 5.4553 & TRN & \\
\hline CHEMBL1420155 & 688239 & 4.7862 & \multicolumn{2}{|c|}{5.4879999999999995} & TRN \\
\hline CHEMBL1571495 & 688239 & 5.0862 & 5.4185 & TRN & \\
\hline CHEMBL1443859 & 688239 & 4.6362 & \multicolumn{2}{|c|}{5.486000000000001} & TRN \\
\hline CHEMBL1575399 & 688239 & 4.5362 & 5.5487 & TST & \\
\hline CHEMBL1343546 & 688239 & 5.4362 & 5.6422 & TRN & \\
\hline CHEMBL1516167 & 688239 & 6.1862 & 5.4664 & TRN & \\
\hline CHEMBL1971379 & 688239 & 4.5362 & 5.4427 & TRN & \\
\hline CHEMBL1485363 & 688239 & 4.7862 & 5.5974 & TRN & \\
\hline CHEMBL1394064 & 688239 & 6.1362 & 5.5227 & TRN & \\
\hline CHEMBL1579116 & 688239 & 5.3862 & 5.528 & TRN & \\
\hline CHEMBL1336467 & 688239 & 4.6362 & 5.4991 & TRN & \\
\hline CHEMBL1501639 & 688239 & 5.4362 & 5.5152 & TRN & \\
\hline CHEMBL1430166 & 688239 & 4.6862 & 5.5261 & TST & \\
\hline
\end{tabular}




\begin{tabular}{|c|c|c|c|c|}
\hline \multicolumn{5}{|c|}{ Supplementa] } \\
\hline 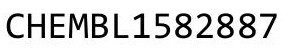 & 年 & & & \\
\hline IEMBL 3208674 & 88239 & so & & \\
\hline HEMBL1589489 & 88239 & 52 & 8 & \\
\hline HEMBL1305845 & & & & \\
\hline AEMBL1424765 & & & & \\
\hline HEMBL1365435 & 88239 & 3861 & & \\
\hline HEMBL1608136 & 88239 & .3863 & & \\
\hline HEMBL1 & 9 & & & \\
\hline HEMBL1 & & & & \\
\hline HEMBL1 & & & & \\
\hline HEMBL1546396 & 88239 & 362 & & \\
\hline HEMBL1421704 & 39 & & & \\
\hline HEMBL1 & 9 & & & \\
\hline AEMBL: & & & & \\
\hline HEMBL: & & & & \\
\hline HEMBL1 & & & & \\
\hline HEMBL: & & & & \\
\hline HEMBL: & 68 & & & \\
\hline AEMBL & & & & \\
\hline HEMBL & & & & \\
\hline AFMRI & & & & \\
\hline HEMBL & & & & \\
\hline HEMBL & 68 & & & \\
\hline HEMBL & & & & \\
\hline IFMR & & & & \\
\hline AEMPI & & & & \\
\hline HEMBL] & & & & \\
\hline ל > & & & & \\
\hline 5 & & & & \\
\hline 6 & & & & \\
\hline JCMDI. & & & & \\
\hline HEMBL & & & & \\
\hline & & & & \\
\hline 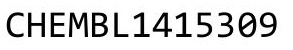 & & & & \\
\hline 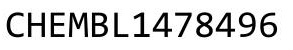 & & & & \\
\hline HEMBL1 & & & & \\
\hline HEMBL: & & & & \\
\hline Int & & & & Ih \\
\hline 1 & & & 57 & \\
\hline CHEMBL 2 & & & & TR \\
\hline CHEMBL & & & & \\
\hline ABL & & & & \\
\hline CHEMBL: & & & & \\
\hline CHEMBL3 & & & 5.4 & \\
\hline CHEMBL1485215 & & & & TR \\
\hline CHEMBL 1 & & & 5. & \\
\hline & & & & \\
\hline CHEMBL1 & 688239 & 4.5362 & 5.4233 & \\
\hline
\end{tabular}

Page 1972 
Supplemental Table S2.txt

\begin{tabular}{|c|c|c|c|c|c|}
\hline CHEMBL1583579 & 688239 & 4.6362 & \multicolumn{2}{|c|}{5.537000000000001} & TST \\
\hline CHEMBL1455530 & 688239 & 4.7862 & 5.2683 & TST & \\
\hline CHEMBL1516417 & 688239 & 5.5862 & 5.5671 & TRN & \\
\hline CHEMBL1339545 & 688239 & 5.8362 & 5.3674 & TST & \\
\hline CHEMBL1317427 & 688239 & 4.5362 & 5.4264 & TRN & \\
\hline CHEMBL1408535 & 688239 & 4.4862 & 5.2139 & TRN & \\
\hline CHEMBL1501236 & 688239 & 6.2362 & 5.4655 & TRN & \\
\hline CHEMBL1426390 & 688239 & 4.5362 & 5.4816 & TRN & \\
\hline CHEMBL1595422 & 688239 & 5.7862 & 5.3521 & TRN & \\
\hline CHEMBL1347266 & 688239 & 5.2862 & 5.4993 & TRN & \\
\hline CHEMBL1554840 & 688239 & 4.5862 & 5.5091 & TRN & \\
\hline CHEMBL1336228 & 688239 & 4.5362 & 5.4825 & TRN & \\
\hline CHEMBL1600791 & 688239 & 6.2862 & 5.4675 & TRN & \\
\hline CHEMBL1534138 & 688239 & 5.4362 & 5.4803 & TRN & \\
\hline CHEMBL1361362 & 688239 & 5.2862 & 5.4636 & TRN & \\
\hline CHEMBL1524616 & 688239 & 4.4862 & 5.4803 & TRN & \\
\hline CHEMBL1316109 & 688239 & 4.7362 & 5.5141 & TRN & \\
\hline CHEMBL1387061 & 688239 & 4.5362 & 5.491006 & 00000000005 & \\
\hline CHEMBL1360808 & 688239 & 4.6862 & 5.2307 & TST & \\
\hline CHEMBL1414706 & 688239 & 5.1862 & 5.4908 & TRN & \\
\hline CHEMBL1491792 & 688239 & 4.8362 & 5.3923 & TRN & \\
\hline CHEMBL1379860 & 688239 & 4.7862 & 5.4607 & TRN & \\
\hline CHEMBL1324018 & 688239 & 5.7862 & 5.321006 & 0000000001 & \\
\hline CHEMBL1482609 & 688239 & 6.8861 & 5.5885 & TRN & \\
\hline CHEMBL1346637 & 688239 & 6.3863 & 5.5297 & TRN & \\
\hline CHEMBL1533009 & 688239 & 4.5362 & 5.6027 & TRN & \\
\hline CHEMBL1420422 & 688239 & 5.8862 & 5.4028 & TST & \\
\hline CHEMBL1577116 & 688239 & 4.6862 & 5.3659 & TST & \\
\hline CHEMBL1509485 & 688239 & 5.1862 & 5.3062 & TRN & \\
\hline CHEMBL1305172 & 688239 & 5.0862 & 5.5955 & TRN & \\
\hline CHEMBL 241598 & 688239 & 5.1362 & 5.411006 & 30000000005 & \\
\hline CHEMBL1416270 & 688239 & 4.5362 & 5.5167 & TRN & \\
\hline CHEMBL1583872 & 688239 & 6.2362 & 5.4121 & TRN & \\
\hline CHEMBL1470601 & 688239 & 5.1862 & 5.4878 & TRN & \\
\hline CHEMBL1567810 & 688239 & 6.8861 & 5.513999 & 9999999999 & \\
\hline CHEMBL1418811 & 688239 & 6.9863 & 5.4497 & TRN & \\
\hline CHEMBL1536716 & 688239 & 4.7362 & 5.4897 & TRN & \\
\hline CHEMBL1319822 & 688239 & 6.3863 & 5.4821 & TRN & \\
\hline CHEMBL1463003 & 688239 & 5.0862 & 5.4204 & TRN & \\
\hline CHEMBL1445513 & 688239 & 5.1862 & 5.3798 & TRN & \\
\hline CHEMBL1484303 & 688239 & 5.1862 & 5.3861 & TRN & \\
\hline CHEMBL1503376 & 688239 & 8.28399 & 99999999 & 5.5748 & \\
\hline CHEMBL1308555 & 688239 & 5.9862 & 5.4657 & TRN & \\
\hline CHEMBL1527426 & 688239 & 6.4362 & 5.5341 & TRN & \\
\hline CHEMBL1384313 & 688239 & 5.3362 & 5.5766 & TST & \\
\hline CHEMBL1362248 & 688239 & 4.6362 & 5.3666 & TRN & \\
\hline CHEMBL1446482 & 688239 & 5.1862 & 5.5225 & TRN & \\
\hline CHEMBL1313643 & 688239 & 6.1362 & 5.4315 & TST & \\
\hline
\end{tabular}


Supplemental Table S2.txt

\begin{tabular}{|c|c|c|c|c|}
\hline CHEMBL1455265 & 688239 & 4.6862 & 5.4947 & TST \\
\hline CHEMBL1578052 & 688239 & 4.5362 & 5.4495 & TRN \\
\hline CHEMBL1517514 & 688239 & 4.5362 & 5.4961 & TST \\
\hline CHEMBL1328528 & 688239 & 7.2865 & 5.4224 & TST \\
\hline CHEMBL1367063 & 688239 & 4.7862 & 5.434 & TRN \\
\hline CHEMBL1315150 & 688239 & 4.6362 & 5.5687 & TST \\
\hline CHEMBL3191907 & 688239 & 5.0862 & 5.4442 & TRN \\
\hline CHEMBL1484131 & 688239 & 5.0862 & 5.5935 & TST \\
\hline CHEMBL1376468 & 688239 & 4.7862 & 5.5669 & TRN \\
\hline CHEMBL1411588 & 688239 & 6.8362 & 5.6064 & TRN \\
\hline CHEMBL1527792 & 688239 & 6.9863 & 5.525 & TST \\
\hline CHEMBL1433858 & 688239 & 6.2362 & 5.3125 & TST \\
\hline CHEMBL1538328 & 688239 & 6.9363 & 5.4563 & TST \\
\hline CHEMBL 3199945 & 688239 & 6.9363 & 5.4789 & TRN \\
\hline CHEMBL 3192336 & 688239 & 8.3372 & 5.4667 & TRN \\
\hline CHEMBL 3213308 & 688239 & 5.9862 & 5.4156 & TST \\
\hline CHEMBL1463394 & 688239 & 4.4862 & 5.5958 & TRN \\
\hline CHEMBL1348873 & 688239 & 4.6362 & 5.4988 & TRN \\
\hline CHEMBL1372178 & 688239 & 6.2862 & 5.5314 & TRN \\
\hline CHEMBL1361067 & 688239 & 5.1862 & 5.597 & TRN \\
\hline CHEMBL1595036 & 688239 & 4.6862 & 5.5866 & TST \\
\hline CHEMBL1396789 & 688239 & 5.4362 & 5.5768 & TRN \\
\hline CHEMBL1548986 & 688239 & 6.3362 & 5.4195 & TRN \\
\hline CHEMBL1543534 & 688239 & 4.6362 & 5.6858 & TRN \\
\hline CHEMBL1992835 & 688239 & 5.1362 & 5.4974 & TST \\
\hline CHEMBL1608658 & 688239 & 6.0862 & 5.40799 & 99999999995 \\
\hline CHEMBL1467455 & 688239 & 6.2362 & 5.4549 & TRN \\
\hline CHEMBL1459582 & 688239 & 5.6362 & 5.4324 & TRN \\
\hline CHEMBL1546987 & 688239 & 5.9862 & 5.3408 & TRN \\
\hline CHEMBL1482106 & 688239 & 4.5362 & 5.5226 & TRN \\
\hline CHEMBL1415260 & 688239 & 4.5362 & 5.4291 & TRN \\
\hline CHEMBL1342547 & 688239 & 5.9862 & 5.3732 & TST \\
\hline CHEMBL1447717 & 688239 & 5.1862 & 5.5547 & TRN \\
\hline CHEMBL 3189447 & 688239 & 4.5362 & 5.3761 & TRN \\
\hline CHEMBL1445970 & 688239 & 8.3372 & 5.5882 & TRN \\
\hline CHEMBL1550468 & 688239 & 4.5862 & 5.5421 & TRN \\
\hline CHEMBL1320343 & 688239 & 4.5362 & 5.5345 & TRN \\
\hline CHEMBL1373868 & 688239 & 5.9362 & 5.5199 & TRN \\
\hline CHEMBL1428227 & 688239 & 4.5362 & 5.5316 & TRN \\
\hline CHEMBL1424718 & 688239 & 4.7362 & 5.4685 & TRN \\
\hline CHEMBL1386915 & 688239 & 5.3362 & 5.3978 & TRN \\
\hline CHEMBL1357610 & 688239 & 4.5362 & 5.3432 & TRN \\
\hline CHEMBL1558197 & 688239 & 4.7362 & 5.527 & TST \\
\hline CHEMBL1526300 & 688239 & 4.7862 & 5.4333 & TST \\
\hline CHEMBL1387895 & 688239 & 6.2862 & 5.5307 & TST \\
\hline CHEMBL1370074 & 688239 & 4.5362 & 5.3913 & TRN \\
\hline CHEMBL1303073 & 688239 & 4.9862 & 5.5455 & TRN \\
\hline CHEMBL1497441 & 688239 & 5.1862 & 5.566 & TRN \\
\hline
\end{tabular}

Page 1974 
Supplemental Table S2.txt

\begin{tabular}{|c|c|c|c|c|c|}
\hline CHEMBL1507682 & 688239 & 5.1862 & 5.4355 & TST & \\
\hline CHEMBL1300404 & 688239 & 4.6862 & 5.552000 & 00000000005 & TRN \\
\hline CHEMBL1302313 & 688239 & 6.9363 & 5.3939 & TRN & \\
\hline CHEMBL1302028 & 688239 & 4.5862 & 5.4354 & TRN & \\
\hline CHEMBL1547153 & 688239 & 6.8362 & 5.4995 & TRN & \\
\hline CHEMBL1508920 & 688239 & 6.0862 & 5.6351 & TRN & \\
\hline CHEMBL1470328 & 688239 & 5.6862 & 5.4527 & TRN & \\
\hline CHEMBL1521458 & 688239 & 4.5362 & 5.5919 & TRN & \\
\hline CHEMBL1558008 & 688239 & 6.8861 & 5.7072 & TRN & \\
\hline CHEMBL1331814 & 688239 & 4.7362 & 5.4467 & TRN & \\
\hline CHEMBL1434445 & 688239 & 5.1862 & 5.2321 & TST & \\
\hline CHEMBL1586076 & 688239 & 5.2862 & 5.4188 & TRN & \\
\hline CHEMBL1587148 & 688239 & 6.5862 & 5.4737 & TST & \\
\hline CHEMBL1542770 & 688239 & 5.4362 & 5.7404 & TRN & \\
\hline CHEMBL1537004 & 688239 & 5.8362 & 5.6285 & TST & \\
\hline CHEMBL1385492 & 688239 & 5.4362 & 5.5518 & TRN & \\
\hline CHEMBL1515360 & 688239 & 5.0862 & 5.4408 & TRN & \\
\hline CHEMBL1536929 & 688239 & 5.1862 & 5.481 & TRN & \\
\hline CHEMBL1310511 & 688239 & 5.8362 & 5.4533 & TRN & \\
\hline CHEMBL1466186 & 688239 & 5.0862 & 5.3324 & TST & \\
\hline CHEMBL1431591 & 688239 & 4.5362 & 5.4127 & TST & \\
\hline CHEMBL3211828 & 688239 & 4.8862 & 5.5571 & TRN & \\
\hline CHEMBL1563408 & 688239 & 6.2862 & 5.5365 & TRN & \\
\hline CHEMBL 3199044 & 688239 & 6.9363 & 5.3429 & TRN & \\
\hline CHEMBL1413848 & 688239 & 5.1862 & 5.528 & TRN & \\
\hline CHEMBL1327339 & 688239 & 4.9362 & 5.4028 & TRN & \\
\hline CHEMBL1461336 & 688239 & 5.4362 & 5.5473 & TRN & \\
\hline CHEMBL1508788 & 688239 & 4.7862 & 5.4032 & TRN & \\
\hline CHEMBL1609200 & 688239 & 8.283999 & 999999999 & 5.5088 & \\
\hline CHEMBL1518745 & 688239 & 6.6362 & 5.5923 & TST & \\
\hline CHEMBL1311424 & 688239 & 4.9862 & 5.5357 & TRN & \\
\hline CHEMBL1577636 & 688239 & 5.6362 & 5.4633 & TST & \\
\hline CHEMBL1519316 & 688239 & 5.3862 & 5.3575 & TRN & \\
\hline CHEMBL1548229 & 688239 & 6.4862 & 5.492999 & 9999999999 & \\
\hline CHEMBL1506715 & 688239 & 4.5362 & 5.4963 & TRN & \\
\hline CHEMBL1585892 & 688239 & 4.5362 & 5.4458 & TRN & \\
\hline CHEMBL1607141 & 688239 & 6.2862 & 5.4852 & TST & \\
\hline CHEMBL1449938 & 688239 & 5.6362 & 5.5835 & TRN & \\
\hline CHEMBL1364413 & 688239 & 5.1862 & 5.437 & TRN & \\
\hline CHEMBL1492100 & 688239 & 5.8362 & 5.6478 & TRN & \\
\hline CHEMBL1540716 & 688239 & 5.3862 & 5.5126 & TRN & \\
\hline CHEMBL1554100 & 688239 & 5.8862 & 5.4866 & TRN & \\
\hline CHEMBL1468078 & 688239 & 5.1862 & 5.6141 & TRN & \\
\hline CHEMBL1565059 & 688239 & 5.4362 & 5.4034 & TRN & \\
\hline CHEMBL 2007180 & 688239 & 4.5362 & 5.269 & TST & \\
\hline CHEMBL1413278 & 688239 & 5.5362 & 5.3935 & TST & \\
\hline CHEMBL1491279 & 688239 & 4.9862 & 5.4805 & TRN & \\
\hline CHEMBL1410149 & 688239 & 4.5362 & 5.4664 & TRN & \\
\hline
\end{tabular}




\begin{tabular}{|c|c|c|c|c|c|}
\hline \multicolumn{6}{|c|}{ Supplemental Table S2.txt } \\
\hline CHEMBL1465194 & 688239 & 5.4862 & 5.5053 & TRN & \\
\hline CHEMBL1462864 & 688239 & 7.1361 & 5.4081 & TRN & \\
\hline CHEMBL1538077 & 688239 & 5.1862 & 5.4942 & TRN & \\
\hline CHEMBL1410068 & 688239 & 4.6862 & 5.3574 & TST & \\
\hline CHEMBL1598453 & 688239 & 5.2362 & 5.4124 & TRN & \\
\hline CHEMBL1302067 & 688239 & 6.8362 & 5.5318 & TRN & \\
\hline CHEMBL1507613 & 688239 & 5.1862 & 5.4872 & TRN & \\
\hline CHEMBL1535748 & 688239 & 5.1862 & 5.48600 & 3000000001 & TRN \\
\hline CHEMBL1545073 & 688239 & 5.1862 & 5.5327 & TRN & \\
\hline CHEMBL473107 & 688239 & 5.0862 & 5.5499 & TST & \\
\hline CHEMBL1459035 & 688239 & 5.0362 & 5.5967 & TRN & \\
\hline CHEMBL1590146 & 688239 & 5.4862 & 5.53700 & 0000000001 & TRN \\
\hline CHEMBL1552268 & 688239 & 5.8862 & 5.5512 & TRN & \\
\hline CHEMBL1428409 & 688239 & 5.0362 & 5.3411 & TST & \\
\hline CHEMBL1582582 & 688239 & 6.1362 & 5.6281 & TST & \\
\hline CHEMBL1325328 & 688239 & 4.8862 & 5.5049 & TST & \\
\hline CHEMBL1369717 & 688239 & 6.5862 & 5.5604 & TRN & \\
\hline CHEMBL1427384 & 688239 & 4.5862 & 5.3872 & TST & \\
\hline CHEMBL1527088 & 688239 & 6.3863 & 5.4742 & TRN & \\
\hline CHEMBL1498080 & 688239 & 4.5362 & 5.5239 & TRN & \\
\hline CHEMBL1365728 & 688239 & 7.0862 & 5.4803 & TRN & \\
\hline CHEMBL1312389 & 688239 & 8.3372 & 5.6273 & TRN & \\
\hline CHEMBL230683 & 688239 & 5.1362 & 5.4099 & TRN & \\
\hline CHEMBL1597535 & 688239 & 5.5362 & 5.5534 & TRN & \\
\hline CHEMBL1387447 & 688239 & 4.7862 & 5.4464 & TRN & \\
\hline CHEMBL1356088 & 688239 & 4.5362 & 5.3144 & TRN & \\
\hline CHEMBL1593276 & 688239 & 5.1862 & 5.4269 & TRN & \\
\hline CHEMBL1562822 & 688239 & 4.7362 & 5.4029 & TRN & \\
\hline CHEMBL1546315 & 688239 & 5.5862 & 5.336 & TRN & \\
\hline CHEMBL1393798 & 688239 & 6.6861 & 5.6384 & TRN & \\
\hline CHEMBL1573699 & 688239 & 4.5362 & 5.4796 & TRN & \\
\hline CHEMBL1368719 & 688239 & 4.5362 & 5.3521 & TRN & \\
\hline CHEMBL1502092 & 688239 & 5.7862 & 5.4342 & TRN & \\
\hline CHEMBL1349904 & 688239 & 4.7362 & 5.4918 & TRN & \\
\hline CHEMBL1518528 & 688239 & 6.1362 & 5.5688 & TST & \\
\hline CHEMBL1453971 & 688239 & 5.1362 & 5.4569 & TRN & \\
\hline CHEMBL1508219 & 688239 & 7.2366 & 5.4244 & TST & \\
\hline CHEMBL1447154 & 688239 & 4.5362 & 5.4206 & TST & \\
\hline CHEMBL1372530 & 688239 & 6.1862 & 5.3302 & TRN & \\
\hline CHEMBL1339553 & 688239 & 5.1862 & 5.5895 & TRN & \\
\hline CHEMBL1412399 & 688239 & 8.2366 & 5.5451 & TRN & \\
\hline CHEMBL1459133 & 688239 & 5.4362 & 5.5276 & TST & \\
\hline CHEMBL1548591 & 688239 & 5.4362 & 5.5763 & TST & \\
\hline CHEMBL1379361 & 688239 & 5.4862 & 5.6121 & TST & \\
\hline CHEMBL1882689 & 688239 & 4.7362 & 5.3701 & TRN & \\
\hline CHEMBL 1457474 & 688239 & 5.8862 & 5.4785 & TST & \\
\hline CHEMBL1412818 & 688239 & 4.4862 & 5.6055 & TST & \\
\hline CHEMBL1594215 & 688239 & 6.2362 & 5.381 & TST & \\
\hline
\end{tabular}


Supplemental Table S2.txt

\begin{tabular}{|c|c|c|c|c|}
\hline & & & & \\
\hline HEMBL1436277 & 38239 & 362 & $\partial 1$ & \\
\hline AEMBL1429166 & 239 & 362 & & \\
\hline EMBL16e & 39 & 862 & & \\
\hline EMBL1405004 & 39 & & & \\
\hline AEMBL1352444 & 88239 & 862 & & \\
\hline AEMBL1387415 & 88239 & 4.4862 & 312 & \\
\hline AEMBL1508303 & & 862 & & \\
\hline EMBL1567863 & 39 & 862 & & \\
\hline IEMBL1449252 & & 362 & & \\
\hline AEMBL1601443 & 39 & 362 & 571 & \\
\hline HEMBL1305830 & & 362 & 061 & \\
\hline AEMBL1406878 & & 862 & 37 & \\
\hline JEMBL16 & & 62 & & \\
\hline AEMBL157 & & 62 & & \\
\hline AEMBL1468677 & & 862 & 654 & \\
\hline AEMBL1453292 & & 362 & & \\
\hline AEMBL15€ & & 62 & & \\
\hline IEMBL14 & & & & \\
\hline AEMBL16 & & & & \\
\hline AEMBL1555633 & & 862 & & \\
\hline AEMBL1558760 & & 62 & & \\
\hline IEMBL1301 & & 62 & & \\
\hline AFMRI 1481 & & & & \\
\hline 28 & & & & \\
\hline AEMBL1445442 & & 862 & & \\
\hline IEMBL3198636 & & & & \\
\hline 3L1383 & & 62 & & \\
\hline$A E M D^{2}$ & & 52 & & \\
\hline 14 & & 62 & 28 & \\
\hline AEMBL15059 & & & 08 & \\
\hline IEMBL 3208797 & & 62 & 822 & \\
\hline & & & & \\
\hline 4 & & & 77 & \\
\hline AEMBL1554548 & & & & \\
\hline AEMBL1426015 & & & 395 & $S$ \\
\hline AEMBL1479541 & & 362 & & S \\
\hline 35 & & 62 & 03 & \\
\hline 190 & & & & \\
\hline HEMBL1373385 & & & & $\mathrm{RI}$ \\
\hline AEMBL1351715 & & 362 & 845 & $\mathrm{R}$ \\
\hline EMBL1351 & & 62 & & \\
\hline 1524921 & & & & \\
\hline HEMBL1488607 & & & & \\
\hline AEMBL1384369 & & & & RN \\
\hline IEMBL1410 & & 366 & 1097 & s \\
\hline & & & & \\
\hline 19005 & & & & \\
\hline
\end{tabular}

Page 1977 
Supplemental Table S2.txt

\begin{tabular}{|c|c|c|c|c|}
\hline CHEMBL1352285 & 688239 & 5.3362 & 5.5841 & TRN \\
\hline CHEMBL1424984 & 688239 & 6.0862 & 5.5771 & TRN \\
\hline CHEMBL1538800 & 688239 & 4.7362 & 5.4132 & TRN \\
\hline CHEMBL1474280 & 688239 & 4.6362 & 5.5353 & TRN \\
\hline CHEMBL1511100 & 688239 & 7.2366 & 5.4229 & TRN \\
\hline CHEMBL1575431 & 688239 & 6.3863 & \multicolumn{2}{|c|}{5.542000000000001} \\
\hline CHEMBL1313575 & 688239 & 5.4362 & 5.7036 & TRN \\
\hline CHEMBL1581250 & 688239 & 4.5362 & 5.303 & TRN \\
\hline CHEMBL1585861 & 688239 & 5.8862 & 5.5694 & TST \\
\hline CHEMBL1375326 & 688239 & 4.9862 & 5.6462 & TRN \\
\hline CHEMBL1580398 & 688239 & 5.4362 & 5.4454 & TRN \\
\hline CHEMBL1391731 & 688239 & 8.3372 & 5.552000 & 0000000005 \\
\hline CHEMBL1522098 & 688239 & 6.8362 & 5.6647 & TRN \\
\hline CHEMBL1388826 & 688239 & 4.4862 & 5.4908 & TST \\
\hline CHEMBL1361723 & 688239 & 5.2862 & 5.3927 & TRN \\
\hline CHEMBL1432229 & 688239 & 7.0362 & 5.6394 & TRN \\
\hline CHEMBL1453192 & 688239 & 4.5362 & 5.5827 & TRN \\
\hline CHEMBL1452794 & 688239 & 4.7862 & 5.399 & TST \\
\hline CHEMBL1485879 & 688239 & 4.5862 & 5.5067 & TST \\
\hline CHEMBL1413056 & 688239 & 5.7362 & 5.5219 & TST \\
\hline CHEMBL1526667 & 688239 & 5.3862 & 5.5611 & TRN \\
\hline CHEMBL1433216 & 688239 & 5.3362 & 5.2969 & TRN \\
\hline CHEMBL1553672 & 688239 & 5.6362 & 5.5632 & TRN \\
\hline CHEMBL1973341 & 688239 & 5.8362 & 5.443 & TRN \\
\hline CHEMBL1527808 & 688239 & 4.5362 & 5.6197 & TRN \\
\hline CHEMBL1582045 & 688239 & 6.9363 & 5.4996 & TST \\
\hline CHEMBL1476696 & 688239 & 7.0862 & 5.3739 & TST \\
\hline CHEMBL1421705 & 688239 & 5.5362 & 5.4587 & TST \\
\hline CHEMBL1605007 & 688239 & 4.7362 & 5.4934 & TST \\
\hline CHEMBL1448293 & 688239 & 4.6862 & 5.3603 & TRN \\
\hline CHEMBL1299452 & 688239 & 4.5362 & 5.5181 & TRN \\
\hline CHEMBL1457877 & 688239 & 8.3372 & 5.4721 & TRN \\
\hline CHEMBL1568364 & 688239 & 5.3862 & 5.5029 & TRN \\
\hline CHEMBL1594527 & 688239 & 5.0362 & 5.4486 & TRN \\
\hline CHEMBL1530118 & 688239 & 6.3863 & 5.4718 & TRN \\
\hline CHEMBL1410819 & 688239 & 4.5362 & 5.4651 & TRN \\
\hline CHEMBL1305342 & 688239 & 4.5362 & 5.5355 & TRN \\
\hline CHEMBL1414600 & 688239 & 5.9362 & 5.5525 & TRN \\
\hline CHEMBL1474152 & 688239 & 4.5362 & 5.6783 & TRN \\
\hline CHEMBL3198641 & 688239 & 4.8362 & 5.4644 & TRN \\
\hline CHEMBL1394678 & 688239 & 5.1862 & 5.4879 & TRN \\
\hline CHEMBL1570058 & 688239 & 4.6862 & 5.49100 & 00000000005 \\
\hline CHEMBL1596221 & 688239 & 4.5362 & 5.5945 & TRN \\
\hline CHEMBL1557136 & 688239 & 6.0862 & 5.4359 & TRN \\
\hline CHEMBL1379576 & 688239 & 6.3362 & 5.5846 & TRN \\
\hline CHEMBL1578125 & 688239 & 4.5362 & 5.524 & TRN \\
\hline CHEMBL1348753 & 688239 & 4.6362 & 5.5666 & TRN \\
\hline CHEMBL1327694 & 688239 & 5.6362 & 5.5729 & TST \\
\hline
\end{tabular}


Supplemental Table S2.txt

\begin{tabular}{|c|c|c|c|c|}
\hline 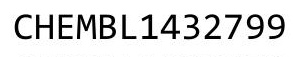 & & & & \\
\hline HEMBL1326450 & 38239 & 372 & 747 & \\
\hline AEMBL1332652 & 239 & 362 & 511 & \\
\hline 57 & 39 & 362 & & \\
\hline IEMBL1420504 & 39 & & & \\
\hline AEMBL1340846 & 88239 & 862 & 03 & \\
\hline AEMBL1563432 & 88239 & 362 & 2804 & \\
\hline HEMBL1318949 & & 362 & & \\
\hline IEMBL1510860 & 39 & 862 & 722 & \\
\hline IEMBL1351967 & & 362 & & \\
\hline AEMBL1327454 & 39 & 362 & 78 & \\
\hline AEMBL1425681 & & 362 & .5602 & \\
\hline AEMBL1315298 & & 62 & 37 & \\
\hline AEMBL1416242 & & & & \\
\hline HEMBL1302480 & & & & \\
\hline AEMBL1587072 & & 862 & 29 & \\
\hline AEMBL1328778 & & 362 & & \\
\hline IEMBL1483101 & & 52 & & \\
\hline AEMBL1331397 & & & & \\
\hline AEMBL14 & & & & \\
\hline AEMBL1588963 & & 362 & & \\
\hline AEMBL3209974 & & & & \\
\hline IEMBL1445575 & & & & \\
\hline AEMBL1463699 & & & & \\
\hline 308 & & & & \\
\hline 1507994 & & & & \\
\hline IEMBL1386362 & & & & \\
\hline EMBL1500782 & & & & \\
\hline $316 c$ & & & & \\
\hline AEMBL1547441 & & & & \\
\hline AEMBL1497479 & & & & \\
\hline AEMBL1396511 & & & & \\
\hline & & & & \\
\hline 33 & & & & \\
\hline AEMBL1416262 & & & & \\
\hline AEMBL1376139 & & & & \\
\hline AEMBL1338502 & & 61 & & \\
\hline & & & & \\
\hline 3208610 & & & & \\
\hline HEMBL1429078 & & & & $\mathrm{RI}$ \\
\hline IEMBL1365515 & & 62 & & s \\
\hline AEMBL1350966 & & 62 & & \\
\hline HEMBL3192715 & & & & \\
\hline HEMBL1439478 & & & & \\
\hline AEMBL1373188 & & & & RN \\
\hline IEMBL1461449 & & 4. & & \\
\hline 19 & & & & \\
\hline & & & .5268 & \\
\hline
\end{tabular}

Page 1979 
Supplemental Table S2.txt

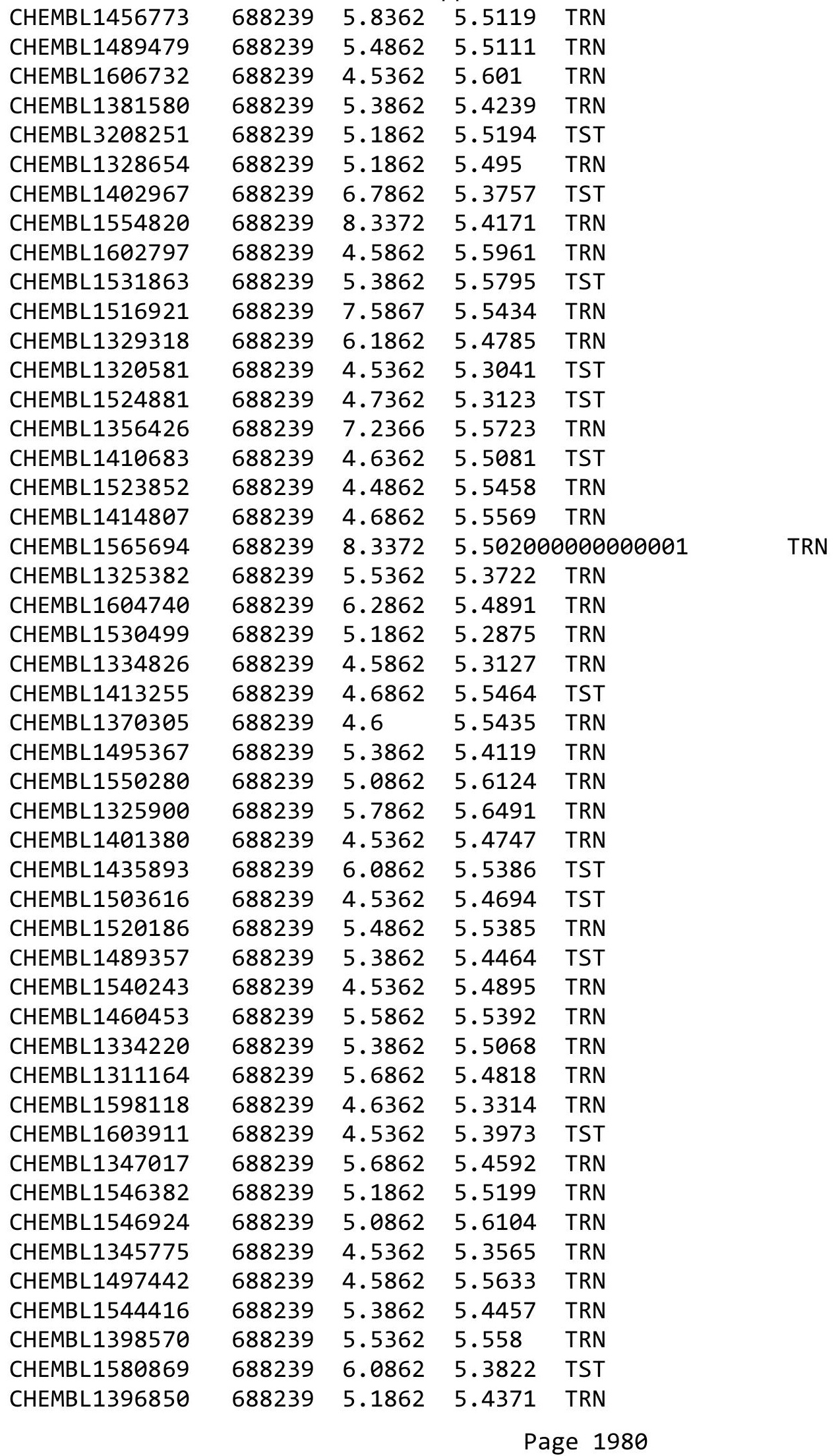


Supplemental Table S2.txt

\begin{tabular}{|c|c|c|c|c|}
\hline HEMBL13 & & 862 & & \\
\hline & & .5362 & & \\
\hline & & & & \\
\hline AEMBL15 & & & & ג \\
\hline AEMBL1485239 & 8239 & 362 & 3771 & \\
\hline HEMBL1358357 & 88239 & 6362 & 5442 & \\
\hline HEMBL 31 & 239 & & & \\
\hline IFMBI 150 & & & & קח \\
\hline HEMBL1450 & 239 & 362 & & \\
\hline HEMBL1256667 & 88239 & 362 & & \\
\hline HEMBL1522786 & 239 & 862 & & \\
\hline IEMBL147 & 239 & 862 & & \\
\hline AEMBL143 & & & & \\
\hline HEMBL1449 & & 362 & & \\
\hline AEMBL158 & & & & \\
\hline AEMBL1388 & 39 & 63 & 79 & \\
\hline HEMBL153 & 39 & & & \\
\hline HEMBL160 & & & & \\
\hline HEMBL137 & & 362 & & \\
\hline IEMBL13 & & & & \\
\hline AEIMBLS & & 52 & & \\
\hline HEMBL13 & & & & 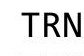 \\
\hline HEMBL13 & & & & \\
\hline AEMBL13 & & & & \\
\hline HEMBL138 & & & & I NIV \\
\hline HEMBL13 & & & & RIV \\
\hline HEMBL5 & & & & ודב \\
\hline HFMBI 14 & & & & \\
\hline AEMBL14 & & & & IK \\
\hline HEMBL135 & & & & s \\
\hline HEMBL153 & & & & RN \\
\hline HEMBL1 & & & & RN \\
\hline $15 \mathrm{MPI}$ & & & & $\mathrm{RN}$ \\
\hline HEMBL1355 & & & & IRN \\
\hline HEMBL1575847 & & & & TRN \\
\hline HEMBL14 & & & & RN \\
\hline HEMDI 15 & & & & $\Gamma \mathrm{RN}$ \\
\hline HEMBL133 & & & & RN \\
\hline HEMBL1455722 & 88239 & & & TRN \\
\hline AEMBL150 & & & & ГRN \\
\hline HEMBL1383 & & & & \\
\hline HEMBL145 & & & & TRN \\
\hline HEMBL1414 & & 62 & & RN \\
\hline AEMBL1734 & 39 & 362 & & TR \\
\hline HEMBL 32 & & & & ב \\
\hline CHEMBL 15 & & & & \\
\hline CHEMBL1322090 & & & & \\
\hline HEMBL160895 & 688239 & 4.8862 & 5.4043 & \\
\hline
\end{tabular}

Page 1981 
Supplemental Table S2.txt

\begin{tabular}{|c|c|c|c|c|}
\hline CHEMBL1558147 & 688239 & 6.1862 & 5.5405 & TRN \\
\hline CHEMBL1544743 & 688239 & 5.1862 & 5.5583 & TRN \\
\hline CHEMBL1509793 & 688239 & 5.9362 & 5.3318 & TRN \\
\hline CHEMBL1448680 & 688239 & 5.0862 & 5.4702 & TRN \\
\hline CHEMBL1516927 & 688239 & 5.3862 & 5.5106 & TRN \\
\hline CHEMBL1499755 & 688239 & 4.6862 & 5.5877 & TST \\
\hline CHEMBL1165028 & 688239 & 8.3372 & 5.5129 & TRN \\
\hline CHEMBL1373440 & 688239 & 6.9863 & 5.5314 & TST \\
\hline CHEMBL1996490 & 688239 & 5.5862 & 5.4374 & TRN \\
\hline CHEMBL3194458 & 688239 & 4.4862 & 5.5571 & TRN \\
\hline CHEMBL1577598 & 688239 & 6.2862 & 5.5104 & TRN \\
\hline CHEMBL1417100 & 688239 & 4.7362 & 5.3662 & TRN \\
\hline CHEMBL1446010 & 688239 & 5.1862 & 5.4272 & TRN \\
\hline CHEMBL1498695 & 688239 & 4.7362 & 5.3183 & TST \\
\hline CHEMBL1380799 & 688239 & 4.5862 & 5.6432 & TRN \\
\hline CHEMBL1497936 & 688239 & 7.1864 & 5.525 & TRN \\
\hline CHEMBL1428618 & 688239 & 5.6362 & 5.5395 & TRN \\
\hline CHEMBL1432610 & 688239 & 6.9863 & 5.5687 & TRN \\
\hline CHEMBL1543357 & 688239 & 5.4362 & 5.5337 & TRN \\
\hline CHEMBL1379169 & 688239 & 6.2862 & 5.5209 & TST \\
\hline CHEMBL1576739 & 688239 & 6.4362 & 5.601 & TRN \\
\hline CHEMBL1439767 & 688239 & 6.1362 & 5.5719 & TST \\
\hline CHEMBL1352894 & 688239 & 4.8362 & 5.4623 & TST \\
\hline CHEMBL1494129 & 688239 & 4.5362 & 5.4251 & TRN \\
\hline CHEMBL1587206 & 688239 & 5.6362 & 5.4895 & TRN \\
\hline CHEMBL1310041 & 688239 & 4.8862 & 5.5539 & TST \\
\hline CHEMBL1536721 & 688239 & 5.6862 & 5.5404 & TRN \\
\hline CHEMBL1474217 & 688239 & 8.2366 & 5.604 & TST \\
\hline CHEMBL1521156 & 688239 & 5.7362 & 5.3999 & TRN \\
\hline CHEMBL1571170 & 688239 & 5.1862 & 5.4751 & TRN \\
\hline CHEMBL1433357 & 688239 & 4.8862 & 5.4991 & TRN \\
\hline CHEMBL3189229 & 688239 & 5.4362 & 5.4571 & TRN \\
\hline CHEMBL1454829 & 688239 & 5.4862 & 5.4842 & TRN \\
\hline CHEMBL1317398 & 688239 & 5.4362 & 5.3692 & TRN \\
\hline CHEMBL1341707 & 688239 & 4.8862 & 5.6066 & TRN \\
\hline CHEMBL1965122 & 688239 & 6.2362 & 5.4912 & TST \\
\hline CHEMBL1408843 & 688239 & 5.2862 & 5.5382 & TRN \\
\hline CHEMBL1320755 & 688239 & 5.4362 & 5.4026 & TRN \\
\hline CHEMBL1399817 & 688239 & 5.4362 & \multicolumn{2}{|c|}{5.5760000000000005} \\
\hline CHEMBL1425040 & 688239 & 4.4862 & 5.4817 & TRN \\
\hline CHEMBL3193044 & 688239 & 6.2862 & 5.3904 & TST \\
\hline CHEMBL3192802 & 688239 & 6.9863 & 5.4123 & TRN \\
\hline CHEMBL1610927 & 688239 & 5.8862 & 5.5729 & TRN \\
\hline CHEMBL1347551 & 688239 & 5.5862 & 5.6129 & TRN \\
\hline CHEMBL1424731 & 688239 & 6.6861 & \multicolumn{2}{|c|}{5.672999999999999} \\
\hline CHEMBL1392198 & 688239 & 4.5362 & 5.5297 & TRN \\
\hline CHEMBL1489524 & 688239 & 6.8861 & 5.4529 & TRN \\
\hline CHEMBL1463742 & 688239 & 6.7361 & 5.4347 & TST \\
\hline
\end{tabular}


Supplemental Table S2.txt

\begin{tabular}{|c|c|c|c|c|}
\hline CHEMBL1524013 & 688239 & 5.7862 & 5.5887 & TST \\
\hline CHEMBL1440280 & 688239 & 6.0362 & 5.5458 & TRN \\
\hline CHEMBL1411113 & 688239 & 4.9362 & 5.4599 & TRN \\
\hline CHEMBL1535412 & 688239 & 4.5362 & 5.5042 & TRN \\
\hline CHEMBL1564120 & 688239 & 6.4362 & 5.5484 & TRN \\
\hline CHEMBL 241149 & 688239 & 4.5362 & 5.5247 & TRN \\
\hline CHEMBL585622 & 688239 & 4.5362 & 5.3905 & TRN \\
\hline CHEMBL1366635 & 688239 & 8.2366 & 5.4262 & TST \\
\hline CHEMBL531043 & 688239 & 4.5362 & 5.4508 & TST \\
\hline CHEMBL1558002 & 688239 & 7.0362 & 5.6396 & TRN \\
\hline CHEMBL1468102 & 688239 & 4.9862 & 5.4987 & TST \\
\hline CHEMBL1550863 & 688239 & 4.5362 & 5.3968 & TRN \\
\hline CHEMBL1596655 & 688239 & 5.2362 & 5.4087 & TST \\
\hline CHEMBL1509027 & 688239 & 4.4862 & 5.4775 & TST \\
\hline CHEMBL1507493 & 688239 & 4.7862 & 5.4002 & TRN \\
\hline CHEMBL1307785 & 688239 & 4.5362 & 5.4492 & TRN \\
\hline CHEMBL1319069 & 688239 & 6.3362 & 5.5299 & TRN \\
\hline CHEMBL1537836 & 688239 & 5.1862 & 5.5269 & TST \\
\hline CHEMBL1373543 & 688239 & 5.6362 & 5.632999 & 9999999999 \\
\hline CHEMBL1589528 & 688239 & 6.4362 & 5.595 & TST \\
\hline CHEMBL1592639 & 688239 & 7.0862 & 5.4889 & TRN \\
\hline CHEMBL1473181 & 688239 & 6.7361 & 5.4799 & TRN \\
\hline CHEMBL1542707 & 688239 & 5.1862 & 5.383999 & 99999999995 \\
\hline CHEMBL1338751 & 688239 & 5.0362 & 5.6406 & TRN \\
\hline CHEMBL1486608 & 688239 & 4.8362 & 5.3782 & TST \\
\hline CHEMBL1486429 & 688239 & 5.4862 & 5.4973 & TST \\
\hline CHEMBL1362861 & 688239 & 7.2366 & 5.6611 & TRN \\
\hline CHEMBL1329210 & 688239 & 4.5362 & 5.4472 & TRN \\
\hline CHEMBL1371300 & 688239 & 4.6862 & 5.4845 & TRN \\
\hline CHEMBL1470801 & 688239 & 6.2362 & 5.5803 & TST \\
\hline CHEMBL1467548 & 688239 & 6.2362 & 5.4182 & TRN \\
\hline CHEMBL1444488 & 688239 & 4.6862 & 5.4958 & TRN \\
\hline CHEMBL541847 & 688239 & 7.0362 & 5.5705 & TRN \\
\hline CHEMBL3189624 & 688239 & 5.6862 & 5.6112 & TST \\
\hline CHEMBL1997171 & 688239 & 4.5362 & 5.4115 & TRN \\
\hline CHEMBL1397263 & 688239 & 4.5362 & 5.4142 & TRN \\
\hline CHEMBL1591604 & 688239 & 5.2362 & 5.5013 & TST \\
\hline CHEMBL1440641 & 688239 & 4.7362 & 5.444 & TRN \\
\hline CHEMBL3211071 & 688239 & 5.4362 & 5.2506 & TST \\
\hline CHEMBL1392307 & 688239 & 5.5362 & 5.486006 & 0000000001 \\
\hline CHEMBL1487889 & 688239 & 5.0862 & 5.584 & TRN \\
\hline CHEMBL1459586 & 688239 & 4.6862 & 5.5932 & TRN \\
\hline CHEMBL1442314 & 688239 & 4.8862 & 5.3413 & TRN \\
\hline CHEMBL1345599 & 688239 & 5.4862 & 5.7151 & TRN \\
\hline CHEMBL3212598 & 688239 & 5.2362 & 5.4613 & TST \\
\hline CHEMBL3208313 & 688239 & 7.2366 & 5.7958 & TST \\
\hline CHEMBL1485349 & 688239 & 6.9863 & 5.4178 & TRN \\
\hline CHEMBL1502214 & 688239 & 4.7862 & 5.3248 & TST \\
\hline
\end{tabular}


Supplemental Table S2.txt

\begin{tabular}{|c|c|c|c|c|c|}
\hline CHEMBL1518176 & 688239 & 5.8362 & 5.5554 & TRN & \\
\hline CHEMBL1301780 & 688239 & 5.3362 & 5.5567 & TRN & \\
\hline CHEMBL1523973 & 688239 & 4.8362 & 5.4527 & TRN & \\
\hline CHEMBL1509319 & 688239 & 5.5362 & 5.5173 & TRN & \\
\hline CHEMBL1419403 & 688239 & 7.4868 & 5.5737 & TRN & \\
\hline CHEMBL1558763 & 688239 & 6.1362 & 5.5086 & TRN & \\
\hline CHEMBL1608304 & 688239 & 4.5362 & 5.5872 & TRN & \\
\hline CHEMBL1308414 & 688239 & 5.0362 & 5.4414 & TST & \\
\hline CHEMBL1507429 & 688239 & 5.4362 & 5.5375 & TRN & \\
\hline CHEMBL473106 & 688239 & 4.7362 & 5.5562 & TST & \\
\hline CHEMBL1513819 & 688239 & 5.4362 & 5.5969 & TRN & \\
\hline CHEMBL1547114 & 688239 & 6.8 & 5.6425 & TST & \\
\hline CHEMBL1299501 & 688239 & 8.3372 & 5.5775 & TST & \\
\hline CHEMBL1411337 & 688239 & 5.3862 & 5.4844 & TRN & \\
\hline CHEMBL1549344 & 688239 & 6.3863 & 5.6294 & TST & \\
\hline CHEMBL1415491 & 688239 & 5.6862 & 5.3567 & TRN & \\
\hline CHEMBL1551455 & 688239 & 5.4362 & 5.5627 & TST & \\
\hline CHEMBL1347173 & 688239 & 4.5862 & 5.3515 & TRN & \\
\hline CHEMBL1432179 & 688239 & 5.6862 & 5.407 & TRN & \\
\hline CHEMBL1318106 & 688239 & 5.9362 & 5.4517 & TRN & \\
\hline CHEMBL118378 & 688239 & 6.2362 & 5.5276 & TRN & \\
\hline CHEMBL1390865 & 688239 & 5.8362 & 5.4847 & TRN & \\
\hline CHEMBL1379101 & 688239 & 7.2366 & 5.5676 & TRN & \\
\hline CHEMBL1326194 & 688239 & 4.4862 & 5.2403 & TRN & \\
\hline CHEMBL1417956 & 688239 & 4.6362 & 5.5608 & TRN & \\
\hline CHEMBL1380939 & 688239 & 4.7862 & 5.5639 & TRN & \\
\hline CHEMBL1593452 & 688239 & 5.0862 & 5.3527 & TRN & \\
\hline CHEMBL3193397 & 688239 & 4.4862 & 5.5296 & TST & \\
\hline CHEMBL1546306 & 688239 & 4.5862 & 5.5302 & TRN & \\
\hline CHEMBL1540469 & 688239 & 4.6862 & 5.2488 & TST & \\
\hline CHEMBL1340579 & 688239 & 4.8362 & 5.6254 & TRN & \\
\hline CHEMBL1347104 & 688239 & 4.8362 & 5.45299 & 9999999999 & TRN \\
\hline CHEMBL1542637 & 688239 & 6.1362 & 5.6058 & TRN & \\
\hline CHEMBL1429143 & 688239 & 5.4362 & 5.5292 & TST & \\
\hline CHEMBL1378446 & 688239 & 5.5362 & 5.6038 & TRN & \\
\hline CHEMBL1602810 & 688239 & 5.7862 & 5.5187 & TRN & \\
\hline CHEMBL1404158 & 688239 & 5.7362 & 5.6019 & TRN & \\
\hline CHEMBL1420799 & 688239 & 5.5862 & 5.4766 & TRN & \\
\hline CHEMBL1505025 & 688239 & 4.7362 & 5.5451 & TRN & \\
\hline CHEMBL1493076 & 688239 & 4.8362 & 5.5138 & TST & \\
\hline CHEMBL1544182 & 688239 & 4.7862 & 5.4798 & TST & \\
\hline CHEMBL1338068 & 688239 & 4.5362 & 5.4081 & TRN & \\
\hline CHEMBL1324379 & 688239 & 7.5867 & 5.5646 & TRN & \\
\hline CHEMBL1482167 & 688239 & 4.7362 & 5.5013 & TRN & \\
\hline CHEMBL1395475 & 688239 & 7.0862 & 5.6416 & TRN & \\
\hline CHEMBL1612863 & 688239 & 6.1362 & 5.5055 & TRN & \\
\hline CHEMBL1412392 & 688239 & 6.0362 & 5.4965 & TST & \\
\hline CHEMBL1551457 & 688239 & 7.0362 & 5.5542 & TRN & \\
\hline
\end{tabular}


Supplemental Table S2.txt

\begin{tabular}{|c|c|c|c|c|}
\hline & & & & \\
\hline HEMBL1577066 & 88239 & 5867 & & \\
\hline HEMBL1557917 & 3239 & 52 & & \\
\hline 13 & & & & \\
\hline EMBL15 & 239 & & & \\
\hline AEMBL1526195 & 88239 & 4862 & 65 & \\
\hline HEMBL3212895 & 88239 & .0862 & 5116 & \\
\hline AEMBL1605014 & 39 & & & \\
\hline IEMBL14 & 239 & 362 & & \\
\hline IEMBL3] & & & & \\
\hline AEMBL192767 & 88239 & 4.5362 & & \\
\hline HEMBL1338635 & 88239 & 4.5362 & & \\
\hline HEMBL13 & 39 & & 14 & \\
\hline IEMBL] & & & & \\
\hline AEMBL: & & & & \\
\hline AEMBL3199637 & 88239 & 362 & & \\
\hline AEMBL1514955 & & & & \\
\hline HEMBLI & 9 & 6. & & \\
\hline AEMBL: & & & & \\
\hline HEMBL: & & & & \\
\hline IEMBL1508672 & 39 & 362 & & \\
\hline AEMBL151 & & & & \\
\hline HEMBL1. & 39 & & & \\
\hline AEMBL: & & & & \\
\hline IEMB & & 4. & & \\
\hline EMBL & & & & \\
\hline AEMBL1320561 & & & & \\
\hline HEMBL15 & & 4. & & \\
\hline IEMB & & 4 . & & \\
\hline 11 & 39 & 62 & & \\
\hline IEMBL1 & & & & \\
\hline AEMBL1312411 & & & & \\
\hline AEMBL & & & & \\
\hline 2 & & 52 & & \\
\hline AEMBL13 & & 62 & & $\mathrm{RN}$ \\
\hline IEMBL1 & & & & \\
\hline AEMBL1480252 & & 5.1862 & & \\
\hline 7 & & & & \\
\hline 1 & & 2 & & \\
\hline 22 & & & & 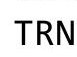 \\
\hline IEMBL 2001408 & 39 & 4.5362 & & \\
\hline AEMBL3 & & 362 & & \\
\hline 26 & & & & \\
\hline & & & & \\
\hline CHEMBL] & & & & \\
\hline IEMBL1 & 9 & 362 & & \\
\hline HEMBL] & & & & \\
\hline CHEMBL1598613 & & & 5.5268 & \\
\hline
\end{tabular}

Page 1985 
Supplemental Table S2.txt

\begin{tabular}{|c|c|c|c|c|}
\hline CHEMBL1427792 & 688239 & 8.2366 & 5.4699 & TRN \\
\hline CHEMBL1561414 & 688239 & 6.1362 & 5.6683 & TST \\
\hline CHEMBL3192514 & 688239 & 5.7862 & 5.3865 & TST \\
\hline CHEMBL1996263 & 688239 & 5.4362 & 5.506 & TRN \\
\hline CHEMBL1595929 & 688239 & 4.7362 & 5.4091 & TST \\
\hline CHEMBL1560172 & 688239 & 4.4862 & 5.4724 & TRN \\
\hline CHEMBL1575985 & 688239 & 4.5362 & 5.504 & TRN \\
\hline CHEMBL1468233 & 688239 & 4.5362 & 5.5569 & TRN \\
\hline CHEMBL1599143 & 688239 & 6.1862 & 5.5082 & TRN \\
\hline CHEMBL1596737 & 688239 & 5.9862 & 5.548999 & 99999999995 \\
\hline CHEMBL1471688 & 688239 & 5.3862 & 5.513 & TRN \\
\hline CHEMBL1418701 & 688239 & 5.1862 & 5.7035 & TRN \\
\hline CHEMBL1438535 & 688239 & 5.9362 & 5.6193 & TRN \\
\hline CHEMBL1495393 & 688239 & 5.6362 & 5.4322 & TRN \\
\hline CHEMBL1484565 & 688239 & 4.7362 & 5.4104 & TRN \\
\hline CHEMBL1360817 & 688239 & 4.4862 & 5.5152 & TRN \\
\hline CHEMBL1380676 & 688239 & 6.2862 & 5.3231 & TRN \\
\hline CHEMBL1384328 & 688239 & 4.5362 & 5.4784 & TRN \\
\hline CHEMBL1307226 & 688239 & 6.2862 & 5.6222 & TRN \\
\hline CHEMBL1547342 & 688239 & 4.5362 & 5.3992 & TRN \\
\hline CHEMBL1441632 & 688239 & 4.4862 & 5.3913 & TRN \\
\hline CHEMBL1336722 & 688239 & 7.0362 & 5.3011 & TRN \\
\hline CHEMBL1341713 & 688239 & 4.5362 & 5.4619 & TST \\
\hline CHEMBL1384466 & 688239 & 5.1862 & 5.4397 & TRN \\
\hline CHEMBL1564619 & 688239 & 6.8861 & 5.4724 & TRN \\
\hline CHEMBL1425576 & 688239 & 5.7862 & 5.4247 & TST \\
\hline CHEMBL1396852 & 688239 & 4.9862 & 5.3825 & TRN \\
\hline CHEMBL1390052 & 688239 & 4.5362 & 5.6059 & TRN \\
\hline CHEMBL1594237 & 688239 & 4.4862 & 5.535 & TRN \\
\hline CHEMBL1546004 & 688239 & 6.2362 & 5.5637 & TRN \\
\hline CHEMBL1556553 & 688239 & 4.5362 & 5.442 & TRN \\
\hline CHEMBL1523320 & 688239 & 4.6362 & 5.519 & TST \\
\hline CHEMBL1541445 & 688239 & 6.2362 & 5.5082 & TRN \\
\hline CHEMBL1550010 & 688239 & 5.2362 & 5.5789 & TRN \\
\hline CHEMBL1350698 & 688239 & 4.6862 & 5.5863 & TRN \\
\hline CHEMBL1314470 & 688239 & 5.8862 & 5.4709 & TST \\
\hline CHEMBL1452191 & 688239 & 6.1862 & 5.4996 & TRN \\
\hline CHEMBL1489935 & 688239 & 5.2362 & 5.4493 & TRN \\
\hline CHEMBL1565152 & 688239 & 6.2362 & 5.5671 & TST \\
\hline CHEMBL1518081 & 688239 & 5.4362 & 5.4985 & TST \\
\hline CHEMBL1563212 & 688239 & 8.0862 & 5.5036 & TRN \\
\hline CHEMBL1380360 & 688239 & 4.6862 & 5.574 & TRN \\
\hline CHEMBL1302079 & 688239 & 4.5362 & 5.5868 & TRN \\
\hline CHEMBL1537294 & 688239 & 5.6362 & 5.3623 & TRN \\
\hline CHEMBL1425116 & 688239 & 4.7362 & 5.4621 & TRN \\
\hline CHEMBL1427709 & 688239 & 5.9362 & 5.5487 & TRN \\
\hline CHEMBL1465355 & 688239 & 4.6362 & 5.3292 & TST \\
\hline CHEMBL452409 & 688239 & 6.5363 & 5.4987 & TRN \\
\hline
\end{tabular}


Supplemental Table S2.txt

\begin{tabular}{|c|c|c|c|c|c|}
\hline CHEMBL1466438 & 688239 & 6.1362 & 5.5838 & TRN & \\
\hline CHEMBL1395659 & 688239 & 5.9362 & 5.4678 & TST & \\
\hline CHEMBL1374961 & 688239 & 5.5362 & 5.4656 & TST & \\
\hline CHEMBL1558612 & 688239 & 6.0862 & 5.4926 & TRN & \\
\hline CHEMBL1432001 & 688239 & 5.7362 & 5.6122 & TRN & \\
\hline CHEMBL1445602 & 688239 & 6.1862 & 5.3632 & TRN & \\
\hline CHEMBL1525758 & 688239 & 5.1362 & 5.4031 & TRN & \\
\hline CHEMBL1593705 & 688239 & 5.1362 & 5.55 & TST & \\
\hline CHEMBL1412314 & 688239 & 5.2862 & 5.4852 & TRN & \\
\hline CHEMBL1470131 & 688239 & 4.5862 & 5.3937 & TRN & \\
\hline CHEMBL1521773 & 688239 & 5.3362 & 5.541 & TRN & \\
\hline CHEMBL1404526 & 688239 & 6.0362 & 5.4667 & TRN & \\
\hline CHEMBL1381522 & 688239 & 4.5362 & 5.3074 & TRN & \\
\hline CHEMBL1398724 & 688239 & 6.1362 & 5.419 & TRN & \\
\hline CHEMBL1587880 & 688239 & 4.7362 & 5.3812 & TRN & \\
\hline CHEMBL1338762 & 688239 & 6.7361 & 5.54200 & 0000000001 & TRN \\
\hline CHEMBL1539470 & 688239 & 4.5362 & 5.4996 & TST & \\
\hline CHEMBL1347222 & 688239 & 4.6862 & 5.5185 & TRN & \\
\hline CHEMBL1601497 & 688239 & 5.5862 & 5.484 & TRN & \\
\hline CHEMBL1578938 & 688239 & 7.8861 & 5.6007 & TRN & \\
\hline CHEMBL1601441 & 688239 & 7.0362 & 5.5694 & TST & \\
\hline CHEMBL1326464 & 688239 & 5.2862 & 5.4232 & TRN & \\
\hline CHEMBL1416981 & 688239 & 5.3862 & 5.348 & TST & \\
\hline CHEMBL1485417 & 688239 & 5.5862 & 5.489 & TRN & \\
\hline CHEMBL1439438 & 688239 & 5.0862 & 5.6437 & TRN & \\
\hline CHEMBL1532868 & 688239 & 4.5862 & 5.5829 & TRN & \\
\hline CHEMBL1471754 & 688239 & 4.4862 & 5.5831 & TRN & \\
\hline CHEMBL1403622 & 688239 & 5.5862 & 5.5332 & TST & \\
\hline CHEMBL1455707 & 688239 & 4.5362 & 5.4631 & TST & \\
\hline CHEMBL1400623 & 688239 & 6.6362 & 5.4518 & TRN & \\
\hline CHEMBL1526310 & 688239 & 5.4362 & 5.5865 & TRN & \\
\hline CHEMBL1612447 & 688239 & 4.5362 & 5.5591 & TRN & \\
\hline CHEMBL1516830 & 688239 & 6.9863 & 5.48600 & 0000000001 & TRN \\
\hline CHEMBL 3214573 & 688239 & 5.6862 & 5.499 & TRN & \\
\hline CHEMBL1381558 & 688239 & 4.5362 & 5.6334 & TRN & \\
\hline CHEMBL1381837 & 688239 & 5.3362 & 5.4601 & TRN & \\
\hline CHEMBL1465729 & 688239 & 5.1362 & 5.5762 & TRN & \\
\hline CHEMBL1996030 & 688239 & 4.6862 & 5.4694 & TST & \\
\hline CHEMBL1441576 & 688239 & 6.0862 & 5.5202 & TRN & \\
\hline CHEMBL1605430 & 688239 & 6.2362 & 5.5549 & TRN & \\
\hline CHEMBL1360158 & 688239 & 4.7362 & 5.563 & TRN & \\
\hline CHEMBL1611503 & 688239 & 5.3362 & 5.544 & TRN & \\
\hline CHEMBL1466362 & 688239 & 6.3863 & 5.5176 & TST & \\
\hline CHEMBL1510800 & 688239 & 5.5862 & 5.5703 & TRN & \\
\hline CHEMBL1553292 & 688239 & 5.2362 & 5.5239 & TRN & \\
\hline CHEMBL1502349 & 688239 & 6.8861 & 5.5813 & TST & \\
\hline CHEMBL1505131 & 688239 & 5.9862 & 5.4594 & TST & \\
\hline CHEMBL1310004 & 688239 & 7.4365 & 5.4021 & TRN & \\
\hline
\end{tabular}


Supplemental Table S2.txt

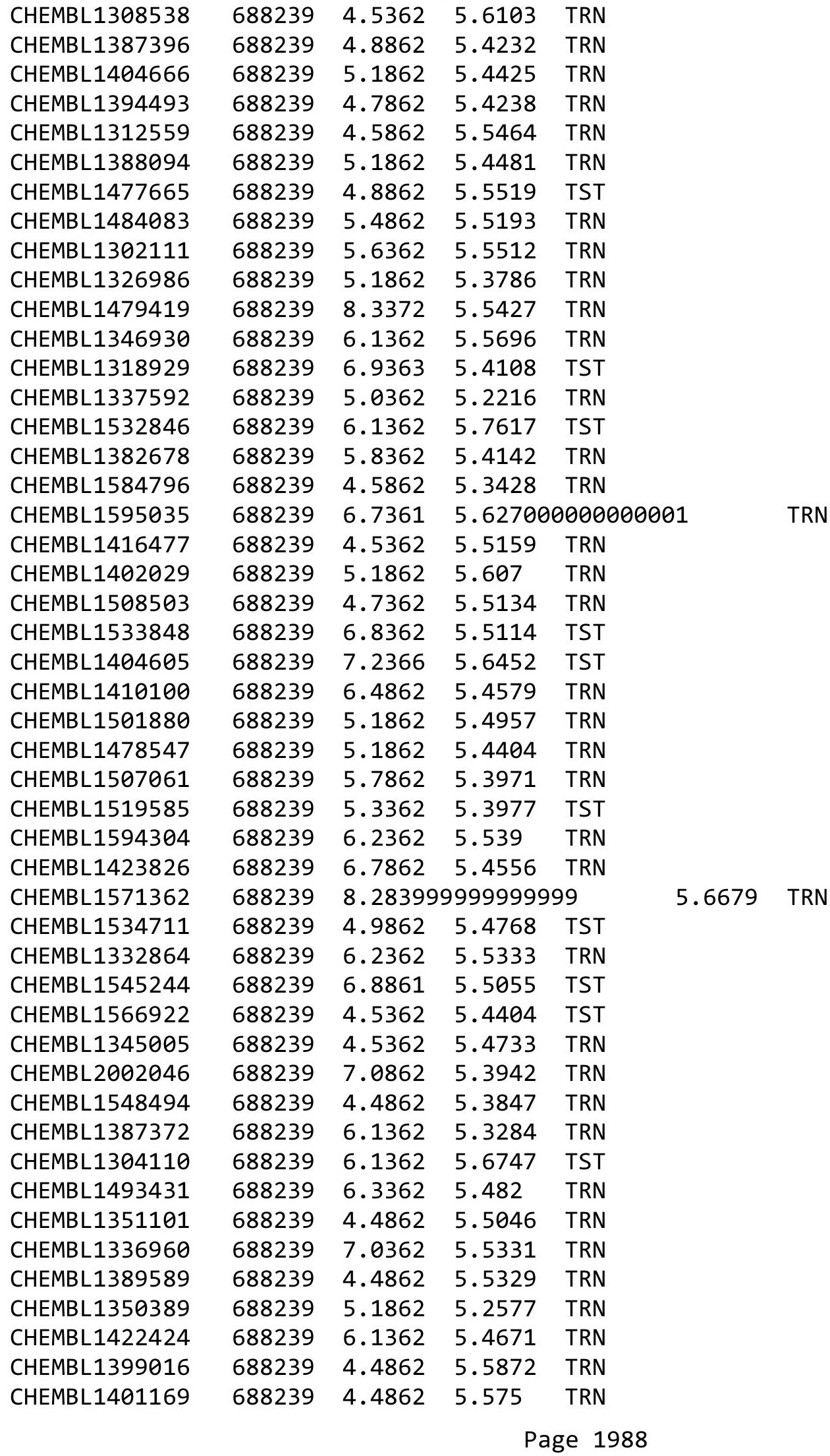


Supplemental Table S2.txt

\begin{tabular}{|c|c|c|c|c|c|c|}
\hline CHEMBL2001331 & 688239 & 6.9363 & 5.4778 & TRN & & \\
\hline CHEMBL1604634 & 688239 & 6.3863 & 5.5191 & TST & & \\
\hline CHEMBL1386116 & 688239 & 4.7362 & 5.5079 & TST & & \\
\hline CHEMBL1387605 & 688239 & 5.0862 & 5.4153 & TRN & & \\
\hline CHEMBL1429522 & 688239 & 4.5362 & 5.5193 & TRN & & \\
\hline CHEMBL1540053 & 688239 & 5.6862 & 5.3424 & TST & & \\
\hline CHEMBL1479679 & 688239 & 4.8362 & 5.4485 & TRN & & \\
\hline CHEMBL1302137 & 688239 & 8.28399 & 99999999 & & 5.4574 & TST \\
\hline CHEMBL1347976 & 688239 & 6.9363 & 5.4666 & TRN & & \\
\hline CHEMBL1524965 & 688239 & 4.9862 & 5.4879 & TRN & & \\
\hline CHEMBL1472285 & 688239 & 6.1862 & 5.5435 & TRN & & \\
\hline CHEMBL1316287 & 688239 & 5.1862 & 5.5085 & TRN & & \\
\hline CHEMBL1414245 & 688239 & 4.5362 & 5.3904 & TRN & & \\
\hline CHEMBL1433275 & 688239 & 4.7862 & 5.4845 & TST & & \\
\hline CHEMBL1585434 & 688239 & 4.4862 & 5.5881 & TRN & & \\
\hline CHEMBL1424605 & 688239 & 4.7362 & 5.4911 & TRN & & \\
\hline CHEMBL1545527 & 688239 & 4.5362 & 5.481 & TRN & & \\
\hline CHEMBL1477449 & 688239 & 4.4862 & 5.5254 & TRN & & \\
\hline CHEMBL1380254 & 688239 & 6.0362 & 5.478 & TRN & & \\
\hline CHEMBL3209769 & 688239 & 5.0362 & 5.3272 & TRN & & \\
\hline CHEMBL1436787 & 688239 & 6.2362 & 5.4804 & TRN & & \\
\hline CHEMBL1475942 & 688239 & 5.6862 & 5.3861 & TRN & & \\
\hline CHEMBL1610582 & 688239 & 5.6862 & 5.5258 & TRN & & \\
\hline CHEMBL1501809 & 688239 & 5.8362 & 5.3821 & TRN & & \\
\hline CHEMBL1351329 & 688239 & 4.7862 & 5.4506 & TRN & & \\
\hline CHEMBL1446750 & 688239 & 6.8861 & 5.4104 & TRN & & \\
\hline CHEMBL1334385 & 688239 & 6.2362 & 5.4726 & TST & & \\
\hline CHEMBL1578958 & 688239 & 4.4862 & 5.4663 & TRN & & \\
\hline CHEMBL1579144 & 688239 & 4.6362 & 5.4554 & TST & & \\
\hline CHEMBL1495975 & 688239 & 5.0362 & 5.5294 & TST & & \\
\hline CHEMBL1381246 & 688239 & 4.7362 & 5.5513 & TRN & & \\
\hline CHEMBL1376035 & 688239 & 6.1862 & 5.5666 & TRN & & \\
\hline CHEMBL1493038 & 688239 & 5.7362 & 5.5341 & TRN & & \\
\hline CHEMBL1487246 & 688239 & 5.4362 & 5.575 & TRN & & \\
\hline CHEMBL1555917 & 688239 & 7.0362 & 5.5624 & TRN & & \\
\hline CHEMBL1439921 & 688239 & 5.7362 & 5.5782 & TRN & & \\
\hline CHEMBL1303937 & 688239 & 5.1862 & 5.4699 & TRN & & \\
\hline CHEMBL1372516 & 688239 & 6.6362 & 5.6389 & TRN & & \\
\hline CHEMBL1377986 & 688239 & 6.4362 & 5.5104 & TRN & & \\
\hline CHEMBL3212469 & 688239 & 5.5862 & 5.3754 & TRN & & \\
\hline CHEMBL1360361 & 688239 & 4.5362 & 5.4036 & TST & & \\
\hline CHEMBL1566898 & 688239 & 4.5362 & 5.3941 & TST & & \\
\hline CHEMBL1570616 & 688239 & 4.5362 & 5.3719 & TRN & & \\
\hline CHEMBL1319074 & 688239 & 5.2862 & 5.4927 & TRN & & \\
\hline CHEMBL1456613 & 688239 & 5.1862 & 5.4403 & TRN & & \\
\hline CHEMBL1532219 & 688239 & 5.3362 & 5.6377 & TRN & & \\
\hline CHEMBL1429014 & 688239 & 6.0862 & 5.4809 & TRN & & \\
\hline CHEMBL1608712 & 688239 & 6.7361 & 5.3906 & TRN & & \\
\hline
\end{tabular}


Supplemental Table S2.txt

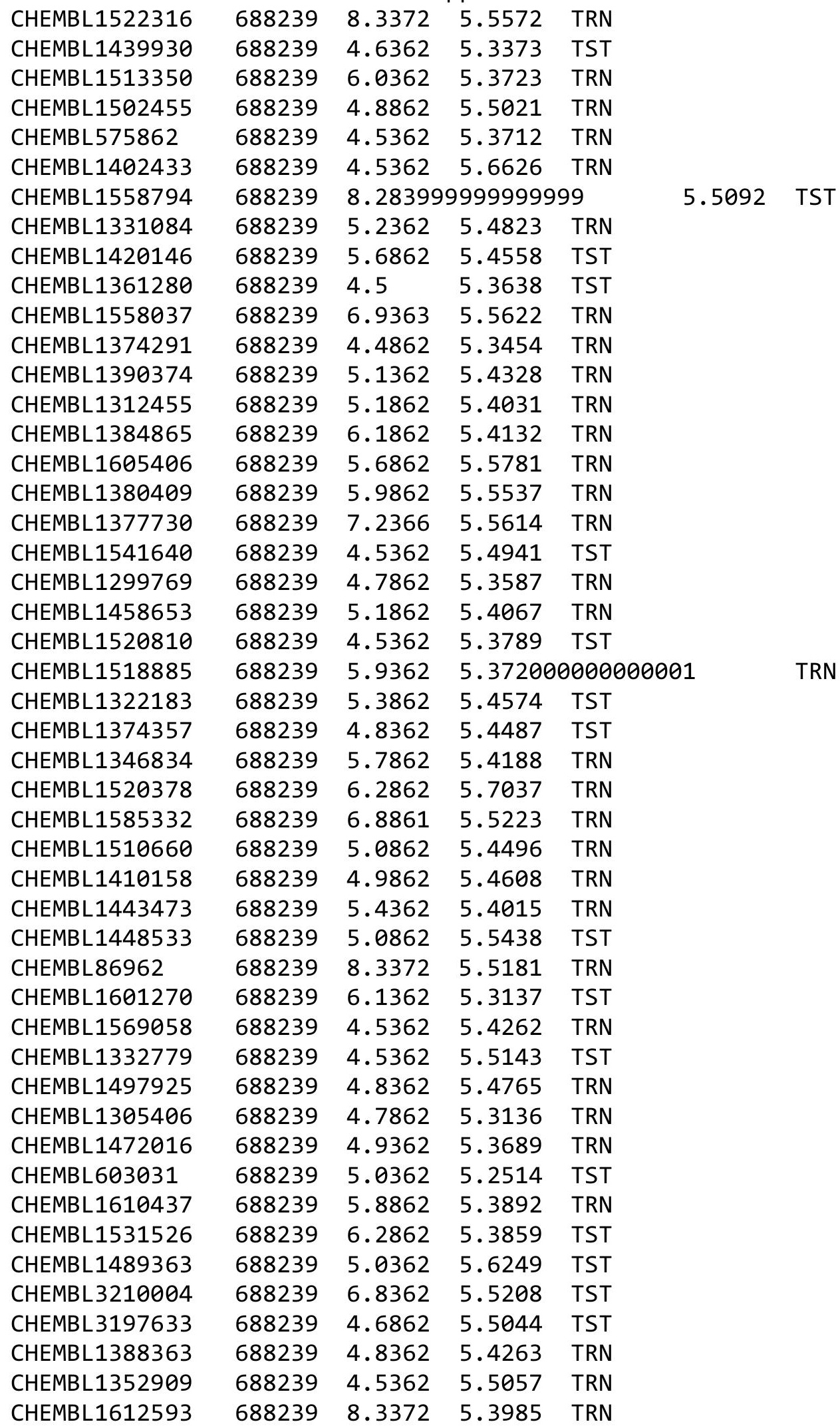

Page 1990 
Supplemental Table S2.txt

\begin{tabular}{|c|c|c|c|c|c|}
\hline CHEMBL1398069 & 688239 & 4.5362 & 5.4366 & TRN & \\
\hline CHEMBL1458606 & 688239 & 6.1862 & 5.5245 & TST & \\
\hline CHEMBL1527389 & 688239 & 6.0862 & 5.4313 & TST & \\
\hline CHEMBL1583573 & 688239 & 6.9863 & 5.5067 & TRN & \\
\hline CHEMBL1444804 & 688239 & 6.7862 & 5.4427 & TRN & \\
\hline CHEMBL1310717 & 688239 & 4.5362 & 5.5488 & TRN & \\
\hline CHEMBL1530214 & 688239 & 6.3863 & 5.6277 & TST & \\
\hline CHEMBL1608902 & 688239 & 4.8362 & 5.6189 & TRN & \\
\hline CHEMBL1309576 & 688239 & 5.5362 & 5.5222 & TST & \\
\hline CHEMBL1437933 & 688239 & 6.2362 & 5.5249 & TRN & \\
\hline CHEMBL1477761 & 688239 & 4.5362 & 5.4395 & TRN & \\
\hline CHEMBL1574538 & 688239 & 5.1862 & 5.5365 & TRN & \\
\hline CHEMBL1493309 & 688239 & 5.8862 & 5.4765 & TRN & \\
\hline CHEMBL1374123 & 688239 & 4.7862 & 5.3794 & TRN & \\
\hline CHEMBL1601424 & 688239 & 4.6362 & 5.68 & TRN & \\
\hline CHEMBL 2007227 & 688239 & 6.1862 & 5.5347 & TST & \\
\hline CHEMBL1324248 & 688239 & 4.4862 & 5.5311 & TRN & \\
\hline CHEMBL1549940 & 688239 & 4.7862 & 5.485 & TRN & \\
\hline CHEMBL1411556 & 688239 & 5.0862 & 5.4312 & TST & \\
\hline CHEMBL1537152 & 688239 & 4.5362 & 5.6487 & TRN & \\
\hline CHEMBL547285 & 688239 & 5.0862 & 5.3857 & TRN & \\
\hline CHEMBL566707 & 688239 & 6.6861 & 5.5519 & TRN & \\
\hline CHEMBL1431726 & 688239 & 4.6362 & 5.6526 & TRN & \\
\hline CHEMBL1411363 & 688239 & 6.7361 & 5.5777 & TST & \\
\hline CHEMBL1448240 & 688239 & 4.6862 & 5.5002 & TRN & \\
\hline CHEMBL3199437 & 688239 & 5.7862 & 5.575 & TRN & \\
\hline CHEMBL1556102 & 688239 & 5.9862 & 5.4258 & TRN & \\
\hline CHEMBL1449122 & 688239 & 6.7361 & 5.617999 & 9999999999 & TRN \\
\hline CHEMBL1577206 & 688239 & 7.0862 & 5.6202 & TRN & \\
\hline CHEMBL1423560 & 688239 & 7.1361 & 5.4324 & TRN & \\
\hline CHEMBL1470592 & 688239 & 8.28399 & 99999999 & 5.5517 & TRN \\
\hline CHEMBL1411974 & 688239 & 4.7862 & 5.625 & TRN & \\
\hline CHEMBL1313204 & 688239 & 4.5362 & 5.4491 & TST & \\
\hline CHEMBL1370114 & 688239 & 4.5362 & 5.4625 & TRN & \\
\hline CHEMBL1411632 & 688239 & 8.3372 & 5.4473 & TST & \\
\hline CHEMBL3197517 & 688239 & 4.7862 & 5.4057 & TRN & \\
\hline CHEMBL1444686 & 688239 & 4.7362 & 5.4665 & TST & \\
\hline CHEMBL1444567 & 688239 & 5.4862 & 5.4352 & TRN & \\
\hline CHEMBL1439623 & 688239 & 4.5362 & 5.5282 & TST & \\
\hline CHEMBL1361128 & 688239 & 7.0862 & 5.3372 & TRN & \\
\hline CHEMBL1481295 & 688239 & 6.1362 & 5.5336 & TRN & \\
\hline CHEMBL1502071 & 688239 & 5.4362 & 5.5763 & TST & \\
\hline CHEMBL1369071 & 688239 & 5.2362 & 5.5318 & TST & \\
\hline CHEMBL1416268 & 688239 & 5.2862 & 5.4482 & TST & \\
\hline CHEMBL1517889 & 688239 & 4.4862 & 5.36600 & 00000000005 & TRN \\
\hline CHEMBL3210946 & 688239 & 7.6861 & 5.4667 & TRN & \\
\hline CHEMBL1405775 & 688239 & 6.9863 & 5.4368 & TST & \\
\hline CHEMBL1342854 & 688239 & 4.7362 & 5.5266 & TRN & \\
\hline
\end{tabular}


Supplemental Table S2.txt

\begin{tabular}{|c|c|c|c|c|}
\hline CHEMBL1520435 & 688239 & 8.3372 & 5.4987 & TRN \\
\hline CHEMBL1322669 & 688239 & 5.9362 & 5.7042 & TRN \\
\hline CHEMBL1421545 & 688239 & 4.5862 & 5.4281 & TRN \\
\hline CHEMBL1546334 & 688239 & 4.5362 & 5.4409 & TST \\
\hline CHEMBL1566744 & 688239 & 6.1362 & 5.4401 & TRN \\
\hline CHEMBL1339133 & 688239 & 5.8862 & 5.6063 & TRN \\
\hline CHEMBL1339752 & 688239 & 4.5362 & 5.4164 & TRN \\
\hline CHEMBL1471850 & 688239 & 6.6362 & 5.7201 & TRN \\
\hline CHEMBL1970824 & 688239 & 5.3362 & 5.3062 & TRN \\
\hline CHEMBL1483303 & 688239 & 4.6362 & 5.3465 & TRN \\
\hline CHEMBL1475863 & 688239 & 5.2362 & 5.4922 & TRN \\
\hline CHEMBL1415364 & 688239 & 6.8362 & 5.481 & TRN \\
\hline CHEMBL1310892 & 688239 & 4.5362 & 5.4184 & TRN \\
\hline CHEMBL3210591 & 688239 & 6.4362 & 5.5336 & TRN \\
\hline CHEMBL1560468 & 688239 & 5.9862 & 5.4113 & TST \\
\hline CHEMBL1302261 & 688239 & 6.9363 & 5.4548 & TST \\
\hline CHEMBL1528115 & 688239 & 5.4862 & 5.3922 & TRN \\
\hline CHEMBL1355753 & 688239 & 4.5362 & 5.3133 & TRN \\
\hline CHEMBL1312108 & 688239 & 6.2862 & 5.5247 & TST \\
\hline CHEMBL1305042 & 688239 & 5.6862 & 5.4493 & TRN \\
\hline CHEMBL1301782 & 688239 & 4.6862 & 5.5802 & TRN \\
\hline CHEMBL1366289 & 688239 & 6.2862 & 5.456 & TRN \\
\hline CHEMBL1350836 & 688239 & 4.4862 & 5.491006 & 30000000005 \\
\hline CHEMBL1979221 & 688239 & 4.5362 & 5.4605 & TST \\
\hline CHEMBL1491329 & 688239 & 6.6362 & 5.5023 & TST \\
\hline CHEMBL1479866 & 688239 & 5.2362 & 5.4455 & TRN \\
\hline CHEMBL1360312 & 688239 & 5.1862 & 5.5768 & TRN \\
\hline CHEMBL1484326 & 688239 & 4.6862 & 5.5441 & TST \\
\hline CHEMBL1335890 & 688239 & 5.1362 & 5.3009 & TRN \\
\hline CHEMBL1498526 & 688239 & 5.4862 & 5.5318 & TRN \\
\hline CHEMBL1512643 & 688239 & 4.5362 & 5.5181 & TRN \\
\hline CHEMBL1610470 & 688239 & 6.2862 & 5.4983 & TRN \\
\hline CHEMBL1392093 & 688239 & 4.7362 & 5.5534 & TST \\
\hline CHEMBL1357284 & 688239 & 6.9363 & 5.6184 & TRN \\
\hline CHEMBL1566294 & 688239 & 5.1862 & 5.2929 & TRN \\
\hline CHEMBL1523148 & 688239 & 4.9362 & 5.5721 & TRN \\
\hline CHEMBL1319698 & 688239 & 6.4362 & 5.6558 & TRN \\
\hline CHEMBL1413238 & 688239 & 4.7362 & 5.3801 & TRN \\
\hline CHEMBL1336866 & 688239 & 6.2862 & 5.3959 & TRN \\
\hline CHEMBL1394410 & 688239 & 5.4862 & 5.4747 & TST \\
\hline CHEMBL1407651 & 688239 & 5.0362 & 5.5145 & TRN \\
\hline CHEMBL1462813 & 688239 & 4.5362 & 5.4337 & TST \\
\hline CHEMBL1490093 & 688239 & 4.5362 & 5.5414 & TST \\
\hline CHEMBL1581978 & 688239 & 5.3862 & 5.5794 & TRN \\
\hline CHEMBL1431975 & 688239 & 5.5862 & 5.5283 & TRN \\
\hline CHEMBL1347343 & 688239 & 5.1862 & 5.6423 & TRN \\
\hline CHEMBL1520621 & 688239 & 4.5362 & 5.397 & TST \\
\hline CHEMBL187263 & 688239 & 4.5362 & 5.4341 & TRN \\
\hline
\end{tabular}


Supplemental Table S2.txt

\begin{tabular}{|c|c|c|c|c|}
\hline CHEMBL1585438 & 688239 & 5.0362 & 5.5418 & TRN \\
\hline CHEMBL1360255 & 688239 & 4.5862 & 5.3666 & TRN \\
\hline CHEMBL1457881 & 688239 & 5.7862 & 5.4376 & TST \\
\hline CHEMBL1557847 & 688239 & 4.5362 & 5.4479 & TRN \\
\hline CHEMBL1533406 & 688239 & 4.5362 & 5.5214 & TST \\
\hline CHEMBL1318576 & 688239 & 5.4362 & 5.5528 & TRN \\
\hline CHEMBL1371188 & 688239 & 4.5862 & 5.3957 & TRN \\
\hline CHEMBL1325518 & 688239 & 7.1864 & 5.5608 & TRN \\
\hline CHEMBL1539076 & 688239 & 6.0362 & 5.4655 & TRN \\
\hline CHEMBL1598475 & 688239 & 5.6362 & 5.5605 & TRN \\
\hline CHEMBL1434952 & 688239 & 4.5362 & 5.5895 & TRN \\
\hline CHEMBL1345924 & 688239 & 5.7362 & 5.4985 & TST \\
\hline CHEMBL1575860 & 688239 & 6.8861 & 5.5941 & TRN \\
\hline CHEMBL1571155 & 688239 & 6.9363 & 5.481 & TRN \\
\hline CHEMBL1540038 & 688239 & 4.5362 & 5.3157 & TST \\
\hline CHEMBL1496027 & 688239 & 5.1362 & 5.6917 & TRN \\
\hline CHEMBL1341406 & 688239 & 4.5362 & 5.468 & TRN \\
\hline CHEMBL1361370 & 688239 & 8.28399 & 999999999 & 5.58 \\
\hline CHEMBL1512406 & 688239 & 5.7862 & 5.4983 & TST \\
\hline CHEMBL1508089 & 688239 & 5.7362 & 5.4511 & TRN \\
\hline CHEMBL1559109 & 688239 & 5.6862 & 5.4849 & TST \\
\hline CHEMBL1539013 & 688239 & 5.0362 & 5.6434 & TRN \\
\hline CHEMBL1326472 & 688239 & 5.1362 & 5.5279 & TRN \\
\hline CHEMBL1325410 & 688239 & 5.2362 & 5.5178 & TRN \\
\hline CHEMBL1496446 & 688239 & 4.9362 & 5.6239 & TRN \\
\hline CHEMBL 3213114 & 688239 & 4.6362 & 5.5787 & TST \\
\hline CHEMBL1553147 & 688239 & 6.9363 & 5.5217 & TRN \\
\hline CHEMBL1595591 & 688239 & 4.5362 & 5.5186 & TRN \\
\hline CHEMBL1450543 & 688239 & 4.5362 & 5.5009 & TST \\
\hline CHEMBL1356117 & 688239 & 4.5362 & 5.457999 & 999999999 \\
\hline CHEMBL1607409 & 688239 & 5.0862 & 5.5023 & TRN \\
\hline CHEMBL1369994 & 688239 & 6.7361 & 5.6727 & TRN \\
\hline CHEMBL1479039 & 688239 & 6.5862 & 5.5309 & TRN \\
\hline CHEMBL1391037 & 688239 & 4.5362 & 5.4848 & TST \\
\hline CHEMBL1341909 & 688239 & 6.2362 & 5.575 & TRN \\
\hline CHEMBL1463895 & 688239 & 5.1862 & 5.5223 & TST \\
\hline CHEMBL1320200 & 688239 & 5.8862 & 5.3154 & TRN \\
\hline CHEMBL1551903 & 688239 & 5.7862 & 5.5302 & TRN \\
\hline CHEMBL1309373 & 688239 & 5.5862 & 5.512000 & 0000000005 \\
\hline CHEMBL1548411 & 688239 & 6.1362 & 5.4073 & TRN \\
\hline CHEMBL1587008 & 688239 & 4.7862 & 5.51399 & 999999999 \\
\hline CHEMBL1415464 & 688239 & 5.2362 & 5.4157 & TRN \\
\hline CHEMBL1408745 & 688239 & 5.1362 & 5.5385 & TRN \\
\hline CHEMBL1459167 & 688239 & 5.1862 & 5.5746 & TST \\
\hline CHEMBL1423271 & 688239 & 4.7362 & 5.3488 & TRN \\
\hline CHEMBL1413111 & 688239 & 5.0362 & 5.4677 & TST \\
\hline CHEMBL1430334 & 688239 & 6.5862 & 5.5355 & TRN \\
\hline CHEMBL1472432 & 688239 & 4.6862 & 5.4988 & TST \\
\hline
\end{tabular}


Supplemental Table S2.txt

\begin{tabular}{|c|c|c|c|c|}
\hline 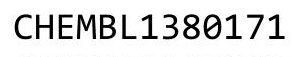 & & & & \\
\hline HEMBL1345369 & 38239 & 862 & 275 & \\
\hline AEMBL1427705 & 239 & 362 & 5458 & \\
\hline JEMBL14 & 39 & & & \\
\hline IEMBL1595967 & 39 & & & \\
\hline AEMBL1477231 & 88239 & 362 & 1014 & \\
\hline AEMBL1469817 & 88239 & 362 & . 4919 & \\
\hline AEMBL15 & & & & \\
\hline AEMBL13 & 39 & 62 & & \\
\hline IEMBL13 & & & & \\
\hline AEMBL1378626 & 239 & 862 & 596 & \\
\hline AEMBL1361 & 39 & 862 & & \\
\hline HEMBL130 & & 62 & & \\
\hline AEMBL13: & & & & \\
\hline HEMBL13 & & & & \\
\hline HEMBL158 & & 867 & & \\
\hline HEMBL144 & & 362 & & \\
\hline AEMBL15 & & 62 & & \\
\hline HEME & & & & \\
\hline HEMBL31 & & & & \\
\hline HEMBL133 & & 362 & & \\
\hline HEMBL132 & & & & \\
\hline AEMBL31C & & & & \\
\hline AFMRI 15 & & & & \\
\hline 6 & & & & \\
\hline ICMDI & & 62 & & \\
\hline AEMBL135 & & & & \\
\hline JEMBL14ع & & 62 & & \\
\hline AFMRI 31 & & 52 & & \\
\hline 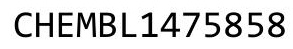 & & 62 & & \\
\hline HEMBL137 & & & & \\
\hline HEMBL147 & & 62 & & \\
\hline & & & & \\
\hline 7 & & 51 & & \\
\hline HEMBL153 & & & & \\
\hline HEMBL139. & & & & \\
\hline HEMBL 319 & & 862 & & \\
\hline & & & & \\
\hline 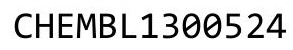 & & & & \\
\hline HEMBL149 & & & & RN \\
\hline AEMBL151 & & 862 & & \\
\hline JEMBL15ع & & 62 & & \\
\hline & & & & \\
\hline CHEMBL150 & & & & \\
\hline AEMBL134; & & & & RN \\
\hline HEMBL137 & & 362 & 02 & \\
\hline - & & & & \\
\hline HEMBL143810 & & 4.9862 & 5.3278 & \\
\hline
\end{tabular}

Page 1994 
Supplemental Table S2.txt

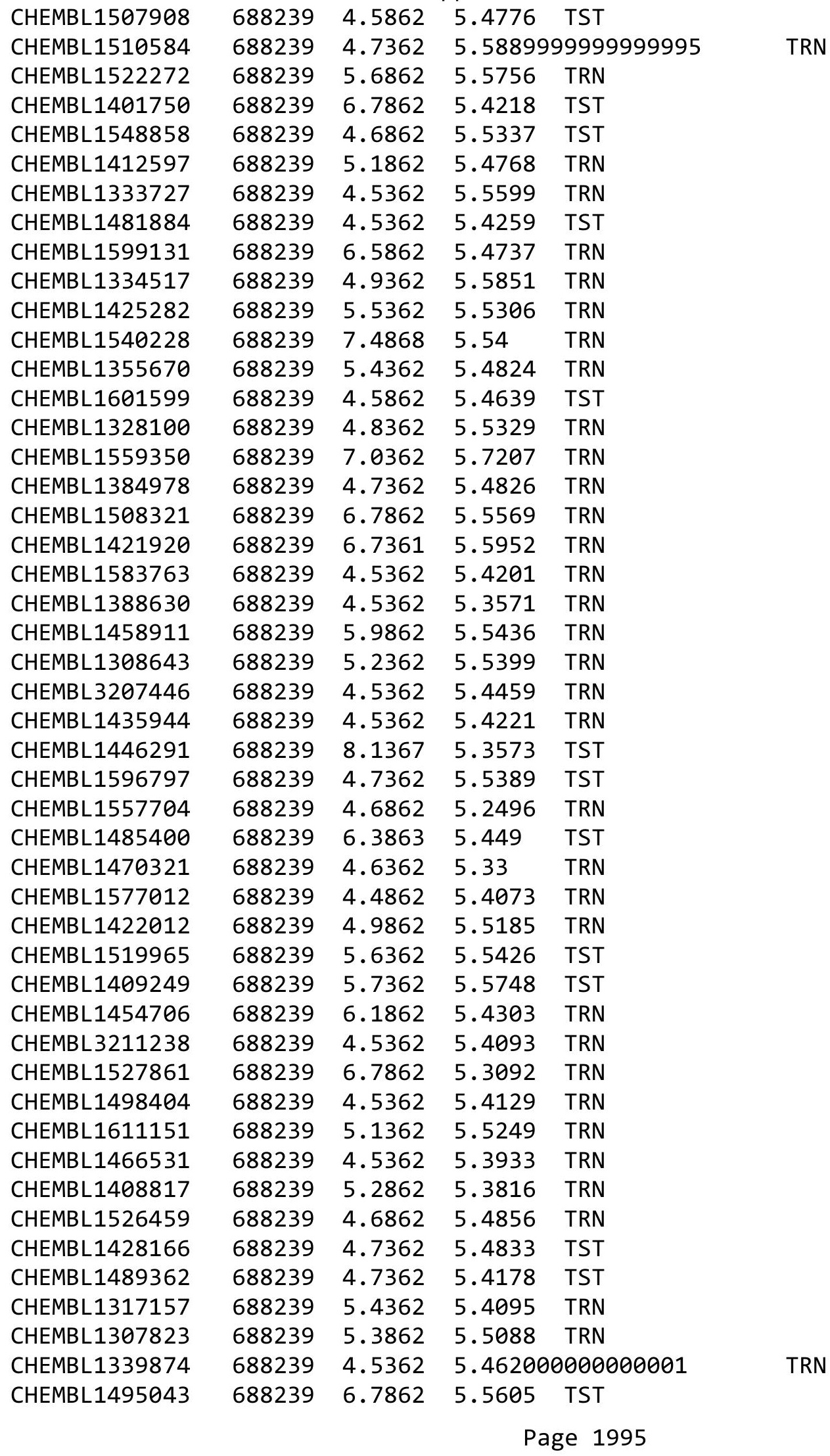


Supplemental Table S2.txt

\begin{tabular}{|c|c|c|c|c|c|}
\hline CHEMBL1403484 & 688239 & 5.6862 & 5.5358 & TRN & \\
\hline CHEMBL1599858 & 688239 & 4.5362 & 5.4984 & TRN & \\
\hline CHEMBL3194846 & 688239 & 8.28399 & 99999999 & 5.5083 & TRN \\
\hline CHEMBL1536168 & 688239 & 5.8362 & 5.5298 & TRN & \\
\hline CHEMBL1993279 & 688239 & 5.9862 & 5.6285 & TRN & \\
\hline CHEMBL 3196545 & 688239 & 5.1862 & 5.4786 & TRN & \\
\hline CHEMBL1608221 & 688239 & 4.5362 & 5.5433 & TRN & \\
\hline CHEMBL1602290 & 688239 & 4.6362 & 5.4124 & TST & \\
\hline CHEMBL1459505 & 688239 & 5.6862 & 5.4301 & TRN & \\
\hline CHEMBL1557059 & 688239 & 5.1862 & 5.6989 & TST & \\
\hline CHEMBL1389199 & 688239 & 5.4862 & 5.3224 & TST & \\
\hline CHEMBL1417345 & 688239 & 5.8862 & 5.3715 & TRN & \\
\hline CHEMBL1384477 & 688239 & 4.4862 & 5.3593 & TRN & \\
\hline CHEMBL1371257 & 688239 & 4.5362 & 5.4978 & TRN & \\
\hline CHEMBL1562362 & 688239 & 7.1361 & 5.5872 & TRN & \\
\hline CHEMBL 2369211 & 688239 & 6.1862 & 5.3783 & TST & \\
\hline CHEMBL1573977 & 688239 & 6.5862 & 5.5791 & TRN & \\
\hline CHEMBL1529945 & 688239 & 4.6862 & 5.4906 & TRN & \\
\hline CHEMBL1414549 & 688239 & 5.1862 & 5.5691 & TRN & \\
\hline CHEMBL1549390 & 688239 & 4.6362 & 5.4171 & TRN & \\
\hline CHEMBL1540262 & 688239 & 4.5362 & 5.5608 & TRN & \\
\hline CHEMBL1328613 & 688239 & 5.0362 & 5.5217 & TRN & \\
\hline CHEMBL217920 & 688239 & 4.7862 & 5.5088 & TST & \\
\hline CHEMBL1542406 & 688239 & 5.7362 & 5.3528 & TST & \\
\hline CHEMBL1547099 & 688239 & 5.1862 & 5.2907 & TST & \\
\hline CHEMBL1576114 & 688239 & 5.5362 & 5.5234 & TRN & \\
\hline CHEMBL1440607 & 688239 & 6.2362 & 5.4011 & TRN & \\
\hline CHEMBL1383753 & 688239 & 6.2362 & 5.4324 & TRN & \\
\hline CHEMBL1533913 & 688239 & 5.3862 & 5.4441 & TRN & \\
\hline CHEMBL1339073 & 688239 & 6.1362 & 5.6031 & TRN & \\
\hline CHEMBL1332069 & 688239 & 5.5862 & 5.5607 & TRN & \\
\hline CHEMBL1374236 & 688239 & 5.3862 & 5.5886 & TRN & \\
\hline CHEMBL1540107 & 688239 & 4.7362 & 5.4014 & TRN & \\
\hline CHEMBL1565576 & 688239 & 6.1862 & 5.5077 & TRN & \\
\hline CHEMBL1348057 & 688239 & 4.5362 & 5.4692 & TST & \\
\hline CHEMBL1490452 & 688239 & 4.7362 & 5.5803 & TRN & \\
\hline CHEMBL1352164 & 688239 & 4.5862 & 5.717006 & 00000000005 & \\
\hline CHEMBL1573510 & 688239 & 4.4862 & 5.4636 & TRN & \\
\hline CHEMBL1468745 & 688239 & 8.3872 & 5.4853 & TRN & \\
\hline CHEMBL1527688 & 688239 & 6.7361 & 5.572 & TRN & \\
\hline CHEMBL1329023 & 688239 & 6.9363 & 5.5666 & TRN & \\
\hline CHEMBL1300826 & 688239 & 4.8862 & 5.5533 & TRN & \\
\hline CHEMBL1491869 & 688239 & 4.6362 & 5.3196 & TRN & \\
\hline CHEMBL1516238 & 688239 & 5.3862 & 5.5109 & TRN & \\
\hline CHEMBL1502125 & 688239 & 5.2362 & 5.5292 & TRN & \\
\hline CHEMBL1330600 & 688239 & 5.1862 & 5.5668 & TRN & \\
\hline CHEMBL1559521 & 688239 & 6.9363 & 5.5602 & TRN & \\
\hline CHEMBL1343936 & 688239 & 4.9362 & 5.4083 & TST & \\
\hline
\end{tabular}

Page 1996 
Supplemental Table S2.txt

\begin{tabular}{|c|c|c|c|c|}
\hline 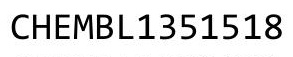 & & & . & \\
\hline HEMBL1322391 & 38239 & 3362 & 5531 & \\
\hline HEMBL3191667 & 88239 & 6862 & & \\
\hline IEMBL1 & & & & \\
\hline EMBL13 & & 362 & 5862 & \\
\hline HEMBL1523029 & 88239 & 3862 & 4305 & \\
\hline HEMBL1510338 & 88239 & 1362 & .4427 & \\
\hline HEMBL131 & 39 & 862 & .4411 & \\
\hline IEMBL14 & 39 & 362 & .4617 & \\
\hline IEMBL339 & 39 & 362 & . 4917 & \\
\hline HEMBL1420612 & 39 & 862 & .5194 & \\
\hline HEMBL1336577 & 39 & 362 & .4759 & \\
\hline HEMBL132 & 39 & 864 & 4509 & \\
\hline HEMBL1593691 & & & .5571 & \\
\hline HEMBL15 & 9 & & .5167 & \\
\hline AEMBL14 & 39 & 362 & .555 & \\
\hline HEMBL1415920 & 39 & 862 & 1319 & \\
\hline HEMBL13 & 39 & 862 & 95 & \\
\hline HEMBL15 & & & & \\
\hline HEME & 9 & & & \\
\hline HEMBL13 & 39 & 362 & & \\
\hline AEMBL147 & 39 & 62 & 34 & \\
\hline HEMBL42 & 39 & 862 & .71 & \\
\hline 340 & & & & \\
\hline 792 & & & & וכס \\
\hline AEMBL15 & 39 & & & RN \\
\hline HEMBL1337823 & 39 & 862 & 758 & RN \\
\hline HEMBL16 & 39 & 362 & 37 & RN \\
\hline 61 & & & & RN \\
\hline 89 & & & 28 & ST \\
\hline IEMBL13 & & & & $\mathrm{RN}$ \\
\hline HEMBL1393358 & 88 & 862 & 207 & RN \\
\hline HEMBL15 & 39 & 362 & 632 & \\
\hline 86 & & & & ST \\
\hline HEMBL 14 & & & & ST \\
\hline HEMBL1405234 & 39 & & & RN \\
\hline HEMBL196 & 39 & 362 & .2496 & RN \\
\hline HEMBL319 & 39 & 62 & 956 & KIV \\
\hline 81 & & & & RN \\
\hline HEMBL14 & & & 4934 & RN \\
\hline HEMBL 200 & 39 & 362 & 561 & ST \\
\hline HEMBL15 & 39 & 362 & 159 & RN \\
\hline HEMBL138 & & & 5.4182 & \\
\hline & & & 5.5623 & RN \\
\hline HEMBL14 & & & .6008 & RN \\
\hline HEMBL13 & 39 & 862 & 085 & ST \\
\hline 2 & & & & \\
\hline & & & & \\
\hline
\end{tabular}

Page 1997 
Supplemental Table S2.txt

\begin{tabular}{|c|c|c|c|c|c|}
\hline CHEMBL1390536 & 688239 & 4.5362 & 5.4085 & TRN & \\
\hline CHEMBL1362059 & 688239 & 4.9862 & 5.5836 & TRN & \\
\hline CHEMBL1401067 & 688239 & 6.1862 & 5.5369 & TRN & \\
\hline CHEMBL1438583 & 688239 & 5.1862 & 5.4529 & TRN & \\
\hline CHEMBL1498962 & 688239 & \multicolumn{3}{|c|}{8.283999999999999} & TRN \\
\hline CHEMBL 2369247 & 688239 & 4.5362 & 5.5892 & TST & \\
\hline CHEMBL1482726 & 688239 & 6.8861 & 5.4886 & TRN & \\
\hline CHEMBL1448013 & 688239 & 4.7862 & 5.4918 & TRN & \\
\hline CHEMBL1305478 & 688239 & 6.5363 & 5.2528 & TRN & \\
\hline CHEMBL1326265 & 688239 & 5.8362 & 5.4952 & TRN & \\
\hline CHEMBL1334780 & 688239 & 4.4862 & 5.6044 & TRN & \\
\hline CHEMBL1544438 & 688239 & 6.7361 & 5.5493 & TST & \\
\hline CHEMBL1391441 & 688239 & 4.5362 & 5.3936 & TRN & \\
\hline CHEMBL1403541 & 688239 & 5.1862 & 5.5939 & TRN & \\
\hline CHEMBL1372596 & 688239 & 5.2362 & 5.5948 & TRN & \\
\hline CHEMBL1494117 & 688239 & 4.7862 & 5.3974 & TRN & \\
\hline CHEMBL1333463 & 688239 & 5.6862 & 5.3455 & TRN & \\
\hline CHEMBL1532749 & 688239 & 6.0362 & 5.4975 & TST & \\
\hline CHEMBL1569556 & 688239 & 6.0862 & 5.4722 & TRN & \\
\hline CHEMBL 1345723 & 688239 & 5.9862 & 5.5229 & TRN & \\
\hline CHEMBL1507084 & 688239 & 5.2362 & 5.3816 & TRN & \\
\hline CHEMBL1367079 & 688239 & 5.7862 & 5.4501 & TRN & \\
\hline CHEMBL1321066 & 688239 & 6.0862 & 5.6455 & TRN & \\
\hline CHEMBL1312857 & 688239 & 4.5362 & 5.4891 & TRN & \\
\hline CHEMBL1520197 & 688239 & \multicolumn{3}{|c|}{8.283999999999999} & TRN \\
\hline CHEMBL1470960 & 688239 & 4.6862 & 5.3064 & TRN & \\
\hline CHEMBL1495258 & 688239 & 5.1862 & 5.2788 & TST & \\
\hline CHEMBL1310956 & 688239 & 5.2362 & 5.5941 & TRN & \\
\hline CHEMBL1602609 & 688239 & 6.0862 & 5.36799 & 9999999999 & TST \\
\hline CHEMBL1417496 & 688239 & 4.9362 & 5.4868 & TRN & \\
\hline CHEMBL1604893 & 688239 & 4.6362 & 5.4662 & TRN & \\
\hline CHEMBL1519206 & 688239 & 5.4362 & 5.4428 & TRN & \\
\hline CHEMBL531709 & 688239 & 4.4862 & 5.3973 & TRN & \\
\hline CHEMBL1582480 & 688239 & 5.4362 & 5.6037 & TRN & \\
\hline CHEMBL3197072 & 688239 & 6.9863 & 5.4429 & TST & \\
\hline CHEMBL1426527 & 688239 & 6.1362 & 5.3612 & TRN & \\
\hline CHEMBL1410591 & 688239 & 6.3362 & 5.5254 & TRN & \\
\hline CHEMBL1508971 & 688239 & 4.6362 & 5.5738 & TRN & \\
\hline CHEMBL1463567 & 688239 & 5.3862 & 5.5052 & TRN & \\
\hline CHEMBL1514239 & 688239 & 4.5362 & 5.3916 & TRN & \\
\hline CHEMBL1463026 & 688239 & 6.6362 & 5.48600 & 0000000001 & TRN \\
\hline CHEMBL1321520 & 688239 & 5.7362 & 5.3825 & TRN & \\
\hline CHEMBL1527753 & 688239 & 4.8862 & 5.6063 & TRN & \\
\hline CHEMBL1612008 & 688239 & 4.7362 & 5.5614 & TRN & \\
\hline CHEMBL1368020 & 688239 & 4.5362 & 5.3769 & TRN & \\
\hline CHEMBL1330853 & 688239 & 4.7362 & 5.4475 & TRN & \\
\hline CHEMBL1523597 & 688239 & 4.6362 & 5.2696 & TRN & \\
\hline CHEMBL3192236 & 688239 & 6.1862 & 5.4545 & TST & \\
\hline
\end{tabular}


Supplemental Table S2.txt

\begin{tabular}{|c|c|c|c|c|}
\hline CHEMBL1343538 & 688239 & 4.5362 & 5.6256 & TRN \\
\hline CHEMBL1409590 & 688239 & 6.1362 & 5.6182 & TRN \\
\hline CHEMBL1515269 & 688239 & 5.0362 & 5.2416 & TRN \\
\hline CHEMBL1588228 & 688239 & 4.5362 & 5.4235 & TRN \\
\hline CHEMBL1426977 & 688239 & 5.1862 & 5.5898 & TST \\
\hline CHEMBL1378014 & 688239 & 4.9362 & 5.4963 & TRN \\
\hline CHEMBL1607709 & 688239 & 4.8362 & 5.3698 & TRN \\
\hline CHEMBL1357479 & 688239 & 5.1862 & 5.6029 & TRN \\
\hline CHEMBL1462835 & 688239 & 6.0362 & 5.4947 & TRN \\
\hline CHEMBL1411673 & 688239 & 6.1362 & 5.4492 & TRN \\
\hline CHEMBL3196339 & 688239 & 4.6362 & 5.3832 & TRN \\
\hline CHEMBL1427537 & 688239 & 4.4862 & 5.4506 & TRN \\
\hline CHEMBL1598551 & 688239 & 7.2366 & 5.5201 & TRN \\
\hline CHEMBL1462078 & 688239 & 4.8862 & 5.5384 & TST \\
\hline CHEMBL1526325 & 688239 & 4.5862 & 5.3965 & TRN \\
\hline CHEMBL1307527 & 688239 & 5.1862 & 5.4586 & TRN \\
\hline CHEMBL1406481 & 688239 & 8.3372 & 5.5246 & TRN \\
\hline CHEMBL1581059 & 688239 & 5.4362 & 5.6115 & TST \\
\hline CHEMBL1303569 & 688239 & 5.4862 & 5.4602 & TRN \\
\hline CHEMBL1386858 & 688239 & 4.5862 & 5.4464 & TRN \\
\hline CHEMBL1400227 & 688239 & 4.4862 & 5.3702 & TRN \\
\hline CHEMBL1379880 & 688239 & 5.4362 & 5.4169 & TST \\
\hline CHEMBL1470963 & 688239 & 5.3362 & 5.6015 & TRN \\
\hline CHEMBL1594120 & 688239 & 4.5362 & 5.49700 & 0000000001 \\
\hline CHEMBL1308327 & 688239 & 4.5362 & 5.4335 & TRN \\
\hline CHEMBL1448885 & 688239 & 5.9862 & 5.5278 & TRN \\
\hline CHEMBL1382945 & 688239 & 5.3362 & 5.4044 & TST \\
\hline CHEMBL1483067 & 688239 & 5.7862 & 5.527 & TRN \\
\hline CHEMBL1461285 & 688239 & 5.6862 & 5.3643 & TRN \\
\hline CHEMBL1404513 & 688239 & 4.4862 & 5.4748 & TRN \\
\hline CHEMBL1581810 & 688239 & 5.3862 & 5.4082 & TRN \\
\hline CHEMBL1575756 & 688239 & 4.9362 & 5.5092 & TRN \\
\hline CHEMBL1440779 & 688239 & 4.7862 & 5.7172 & TRN \\
\hline CHEMBL1465098 & 688239 & 8.3372 & 5.6413 & TRN \\
\hline CHEMBL1322846 & 688239 & 6.2362 & 5.4488 & TRN \\
\hline CHEMBL1345153 & 688239 & 5.1862 & 5.63 & TRN \\
\hline CHEMBL1401402 & 688239 & 4.7862 & 5.3284 & TRN \\
\hline CHEMBL1458451 & 688239 & 4.7862 & 5.2289 & TRN \\
\hline CHEMBL1336440 & 688239 & 4.8362 & 5.6541 & TRN \\
\hline CHEMBL1588966 & 688239 & 4.5362 & 5.3328 & TRN \\
\hline CHEMBL1555937 & 688239 & 4.4862 & 5.4992 & TRN \\
\hline CHEMBL1372372 & 688239 & 4.5362 & 5.4224 & TST \\
\hline CHEMBL1549709 & 688239 & 4.5362 & 5.5038 & TRN \\
\hline CHEMBL1525326 & 688239 & 5.3362 & 5.44799 & 99999999995 \\
\hline CHEMBL1317657 & 688239 & 8.3372 & 5.5335 & TRN \\
\hline CHEMBL1467147 & 688239 & 5.7862 & 5.4828 & TRN \\
\hline CHEMBL1357786 & 688239 & 6.6861 & 5.4578 & TST \\
\hline CHEMBL1608973 & 688239 & 4.7862 & 5.6437 & TRN \\
\hline
\end{tabular}


Supplemental Table S2.txt

\begin{tabular}{|c|c|c|c|c|c|}
\hline CHEMBL1453757 & 688239 & 4.5362 & 5.5982 & TRN & \\
\hline CHEMBL1453784 & 688239 & 5.2362 & 5.4562 & TRN & \\
\hline CHEMBL1415832 & 688239 & 4.5362 & 5.5985 & TRN & \\
\hline CHEMBL1343369 & 688239 & 4.5362 & 5.4766 & TRN & \\
\hline CHEMBL1456343 & 688239 & 6.3362 & \multicolumn{2}{|c|}{5.5360000000000005} & TRN \\
\hline CHEMBL1530066 & 688239 & 5.8862 & 5.487 & TRN & \\
\hline CHEMBL3199268 & 688239 & 4.8862 & 5.4136 & TST & \\
\hline CHEMBL1485633 & 688239 & 5.1362 & 5.6759 & TRN & \\
\hline CHEMBL1602400 & 688239 & 5.7362 & 5.5745 & TRN & \\
\hline CHEMBL1424111 & 688239 & 4.9862 & 5.4552 & TRN & \\
\hline CHEMBL1465744 & 688239 & 6.6362 & 5.4693 & TRN & \\
\hline CHEMBL1522323 & 688239 & 4.5362 & 5.4115 & TRN & \\
\hline CHEMBL1596689 & 688239 & 5.6862 & 5.3308 & TRN & \\
\hline CHEMBL1309304 & 688239 & 4.6362 & 5.4498 & TRN & \\
\hline CHEMBL1453968 & 688239 & 4.5362 & 5.7679 & TRN & \\
\hline CHEMBL1393643 & 688239 & 4.7362 & 5.6024 & TRN & \\
\hline CHEMBL1507270 & 688239 & 6.6362 & 5.604 & TRN & \\
\hline CHEMBL1517866 & 688239 & 5.1862 & 5.3477 & TST & \\
\hline CHEMBL1423200 & 688239 & 6.8861 & 5.4919 & TRN & \\
\hline CHEMBL1374883 & 688239 & 4.7362 & 5.5387 & TRN & \\
\hline CHEMBL1436231 & 688239 & 4.5362 & 5.5469 & TRN & \\
\hline CHEMBL1596097 & 688239 & 4.6862 & \multicolumn{2}{|c|}{5.4639999999999995} & TRN \\
\hline CHEMBL1474336 & 688239 & 4.6862 & 5.4613 & TRN & \\
\hline CHEMBL1488799 & 688239 & 6.9363 & 5.4988 & TRN & \\
\hline CHEMBL1353999 & 688239 & 4.5362 & 5.5621 & TRN & \\
\hline CHEMBL1555884 & 688239 & 9.699 & 5.3014 & TST & \\
\hline CHEMBL1389969 & 688239 & 5.4862 & 5.5642 & TRN & \\
\hline CHEMBL1542530 & 688239 & 5.6862 & 5.4409 & TRN & \\
\hline CHEMBL1598288 & 688239 & 5.3862 & 5.5308 & TRN & \\
\hline CHEMBL1354679 & 688239 & 6.7862 & 5.5528 & TRN & \\
\hline CHEMBL1487465 & 688239 & 5.1862 & 5.5978 & TRN & \\
\hline CHEMBL1572494 & 688239 & 4.5362 & 5.5124 & TRN & \\
\hline CHEMBL1450339 & 688239 & 5.6862 & 5.234 & TRN & \\
\hline CHEMBL1458705 & 688239 & 4.5362 & 5.5057 & TRN & \\
\hline CHEMBL1470713 & 688239 & 4.5362 & 5.4494 & TRN & \\
\hline CHEMBL1321837 & 688239 & 4.6362 & 5.4057 & TRN & \\
\hline CHEMBL1497167 & 688239 & 6.2362 & 5.3244 & TRN & \\
\hline CHEMBL1372769 & 688239 & 4.5362 & 5.4155 & TRN & \\
\hline CHEMBL1589033 & 688239 & 4.7362 & 5.5937 & TRN & \\
\hline CHEMBL1506076 & 688239 & 5.1862 & 5.5877 & TST & \\
\hline CHEMBL1305877 & 688239 & 4.5362 & 5.5429 & TST & \\
\hline CHEMBL1519801 & 688239 & 5.3362 & 5.4065 & TRN & \\
\hline CHEMBL1348004 & 688239 & 5.1862 & 5.5599 & TST & \\
\hline CHEMBL1329804 & 688239 & 5.5362 & 5.3543 & TRN & \\
\hline CHEMBL1521358 & 688239 & 5.2362 & 5.5314 & TST & \\
\hline CHEMBL1606913 & 688239 & 6.9363 & 5.5739 & TRN & \\
\hline CHEMBL1376049 & 688239 & 6.4362 & 5.5109 & TRN & \\
\hline CHEMBL1342193 & 688239 & 5.3862 & 5.4258 & TRN & \\
\hline
\end{tabular}


Supplemental Table S2.txt

\begin{tabular}{|c|c|c|c|c|c|}
\hline CHEMBL1524997 & 688239 & 4.5362 & 5.4348 & TST & \\
\hline CHEMBL1350077 & 688239 & 5.7862 & 5.3359 & TST & \\
\hline CHEMBL1342496 & 688239 & 4.6862 & 5.4516 & TRN & \\
\hline CHEMBL3196904 & 688239 & 4.4862 & 5.3027 & TST & \\
\hline CHEMBL1539270 & 688239 & 4.4862 & 5.5558 & TRN & \\
\hline CHEMBL1301845 & 688239 & 4.7362 & 5.559 & TRN & \\
\hline CHEMBL1439862 & 688239 & 5.8362 & 5.4745 & TRN & \\
\hline CHEMBL 2373622 & 688239 & 5.1862 & 5.5094 & TST & \\
\hline CHEMBL1557778 & 688239 & 5.5362 & 5.5771 & TRN & \\
\hline CHEMBL1461239 & 688239 & 5.1862 & 5.5615 & TRN & \\
\hline CHEMBL1546466 & 688239 & 5.9362 & 5.4893 & TST & \\
\hline CHEMBL1487477 & 688239 & 4.6862 & 5.4356 & TRN & \\
\hline CHEMBL1557398 & 688239 & 4.4862 & 5.4712 & TRN & \\
\hline CHEMBL3213328 & 688239 & 4.5362 & 5.4689 & TRN & \\
\hline CHEMBL1386524 & 688239 & 5.1362 & 5.6027 & TST & \\
\hline CHEMBL1310068 & 688239 & 4.5362 & 5.4146 & TRN & \\
\hline CHEMBL1401698 & 688239 & 4.7362 & 5.4274 & TRN & \\
\hline CHEMBL1497791 & 688239 & 5.7862 & 5.467000 & 00000000005 & TRN \\
\hline CHEMBL1539838 & 688239 & 5.2862 & 5.4779 & TRN & \\
\hline CHEMBL3198669 & 688239 & 5.1862 & 5.3482 & TRN & \\
\hline CHEMBL1362124 & 688239 & 7.5361 & 5.4922 & TRN & \\
\hline CHEMBL251603 & 688239 & 4.6362 & 5.541 & TRN & \\
\hline CHEMBL1478259 & 688239 & 7.1864 & 5.343 & TST & \\
\hline CHEMBL1471892 & 688239 & 5.1862 & 5.516 & TRN & \\
\hline CHEMBL1403417 & 688239 & 5.8862 & 5.487 & TST & \\
\hline CHEMBL1455281 & 688239 & 4.8362 & 5.4703 & TST & \\
\hline CHEMBL1491758 & 688239 & 4.7862 & 5.416 & TRN & \\
\hline CHEMBL1458412 & 688239 & 4.6362 & 5.4189 & TST & \\
\hline CHEMBL1454738 & 688239 & 4.5362 & 5.4968 & TRN & \\
\hline CHEMBL1483754 & 688239 & 5.8362 & 5.5958 & TST & \\
\hline CHEMBL1487095 & 688239 & 7.0862 & 5.392 & TRN & \\
\hline CHEMBL1347395 & 688239 & 5.5862 & 5.2731 & TRN & \\
\hline CHEMBL1421263 & 688239 & 7.3862 & 5.5806 & TRN & \\
\hline CHEMBL3214447 & 688239 & 6.0862 & 5.3856 & TRN & \\
\hline CHEMBL1509912 & 688239 & 5.7362 & 5.5157 & TRN & \\
\hline CHEMBL1479309 & 688239 & 5.6862 & 5.4244 & TRN & \\
\hline CHEMBL1333245 & 688239 & 4.6862 & 5.7033 & TRN & \\
\hline CHEMBL1403246 & 688239 & 4.7362 & 5.6336 & TRN & \\
\hline CHEMBL3198298 & 688239 & 5.1862 & 5.4383 & TRN & \\
\hline CHEMBL1511583 & 688239 & 5.3862 & 5.5269 & TST & \\
\hline CHEMBL1308825 & 688239 & 8.2366 & 5.4761 & TRN & \\
\hline CHEMBL1533744 & 688239 & 5.5862 & 5.4142 & TST & \\
\hline CHEMBL1369159 & 688239 & 4.7362 & 5.3608 & TRN & \\
\hline CHEMBL1465706 & 688239 & 4.8862 & 5.3505 & TRN & \\
\hline CHEMBL1307692 & 688239 & 5.7862 & 5.3662 & TRN & \\
\hline CHEMBL1541971 & 688239 & 4.5362 & 5.4557 & TRN & \\
\hline CHEMBL1493190 & 688239 & 4.5362 & 5.622999 & 9999999999 & TST \\
\hline CHEMBL1609264 & 688239 & 4.5362 & 5.4992 & TRN & \\
\hline
\end{tabular}


Supplemental Table S2.txt

\begin{tabular}{|c|c|c|c|c|}
\hline & & & & \\
\hline HEMBL1505936 & 88239 & 5.2862 & & \\
\hline HEMBL1464044 & 3239 & 52 & & \\
\hline 533 & & & & \\
\hline 708 & & 862 & & \\
\hline AEMBL1428568 & 38239 & 1362 & & \\
\hline HEMBL1417820 & 88239 & .5362 & 5257 & \\
\hline HEMBL13: & & & & \\
\hline IEMBL1 & 239 & 862 & & \\
\hline IEMBL] & & & & \\
\hline AEMBL14 & 88239 & 4.6862 & & \\
\hline HEMBL1356261 & 88239 & 5.7362 & & \\
\hline HEMBL13 & & & & \\
\hline IEMBL] & & & & \\
\hline AEMBL: & & & & \\
\hline AEMBL1 & 88239 & 862 & & \\
\hline HEMBL15 & & & & \\
\hline HEMBL1 & 9 & 4. & & \\
\hline AEMBL: & & & & \\
\hline AEMBL: & & & & \\
\hline AEMBL: & 39 & 362 & & \\
\hline AEMBL13 & & & & \\
\hline HEMBL1 & 39 & 4. & & \\
\hline AEMBL: & & & & \\
\hline HEMB & & & & \\
\hline 33 & & & & \\
\hline IEMBL14 & & & & \\
\hline AEMBL1 & & & & \\
\hline EMB & & & & \\
\hline 78 & 39 & 62 & & RN \\
\hline IEMBL] & & & & \\
\hline HEMBL1 & & & & $\mathrm{RI}$ \\
\hline AEMBL & & & & \\
\hline 58 & & 52 & & \\
\hline 41 & & & & \\
\hline IEMBL1 & & & & \\
\hline AEMBL1 & & 862 & & \\
\hline 17 & & & & \\
\hline 29 & & & & \\
\hline & & & & RN \\
\hline AEMBL15 & 39 & 862 & & \\
\hline AEMBL: & & 862 & & \\
\hline CHEME & & & & \\
\hline HEMBL & & & & \\
\hline CHEMBL1 & & 362 & & \\
\hline IEMBL: & 39 & 862 & & \\
\hline CHEMBL: & & & & \\
\hline CHEMBL133574 & & & 5.3429 & \\
\hline
\end{tabular}

Page 2002 
Supplemental Table S2.txt

\begin{tabular}{|c|c|c|c|c|c|}
\hline CHEMBL1427542 & 688239 & 6.0362 & 5.6478 & TRN & \\
\hline CHEMBL1603941 & 688239 & 6.2362 & 5.5419 & TRN & \\
\hline CHEMBL 3195881 & 688239 & 4.7362 & 5.5386 & TST & \\
\hline CHEMBL1495677 & 688239 & 5.2862 & 5.4931 & TST & \\
\hline CHEMBL1452283 & 688239 & 5.7362 & 5.4809 & TRN & \\
\hline CHEMBL1350321 & 688239 & 6.8362 & 5.3634 & TRN & \\
\hline CHEMBL1582323 & 688239 & 7.0362 & 5.5411 & TRN & \\
\hline CHEMBL1355615 & 688239 & 4.7362 & 5.5499 & TRN & \\
\hline CHEMBL1487998 & 688239 & 6.6861 & 5.526 & TST & \\
\hline CHEMBL1992808 & 688239 & 5.0362 & 5.278 & TST & \\
\hline CHEMBL1576736 & 688239 & 6.0862 & 5.437 & TRN & \\
\hline CHEMBL1611938 & 688239 & 5.1862 & 5.542999 & 999999999 & TRN \\
\hline CHEMBL 3190173 & 688239 & 4.4862 & 5.4105 & TST & \\
\hline CHEMBL1342703 & 688239 & 5.5362 & 5.5191 & TRN & \\
\hline CHEMBL1368902 & 688239 & 4.5362 & 5.5184 & TRN & \\
\hline CHEMBL1471066 & 688239 & 4.8362 & 5.5091 & TRN & \\
\hline CHEMBL1492611 & 688239 & 4.5862 & 5.5191 & TRN & \\
\hline CHEMBL1439461 & 688239 & 4.5362 & 5.499 & TRN & \\
\hline CHEMBL1479658 & 688239 & 4.7362 & 5.4369 & TRN & \\
\hline CHEMBL1308307 & 688239 & 4.8862 & 5.5583 & TRN & \\
\hline CHEMBL1481875 & 688239 & 5.9362 & 5.5701 & TRN & \\
\hline CHEMBL1597964 & 688239 & 5.2862 & 5.5261 & TRN & \\
\hline CHEMBL1329425 & 688239 & 6.7862 & 5.3433 & TST & \\
\hline CHEMBL1422919 & 688239 & 4.5862 & 5.3916 & TRN & \\
\hline CHEMBL1588399 & 688239 & 6.1862 & 5.5233 & TRN & \\
\hline CHEMBL1464012 & 688239 & 5.2862 & 5.5668 & TST & \\
\hline CHEMBL1307191 & 688239 & 4.7362 & 5.4098 & TRN & \\
\hline CHEMBL 3207557 & 688239 & 4.5362 & 5.3636 & TRN & \\
\hline CHEMBL1600715 & 688239 & 6.7361 & 5.6697 & TST & \\
\hline CHEMBL3198115 & 688239 & 5.3862 & 5.5096 & TST & \\
\hline CHEMBL1385637 & 688239 & 4.5362 & 5.6451 & TST & \\
\hline CHEMBL1328353 & 688239 & 5.1362 & 5.4961 & TST & \\
\hline CHEMBL1573917 & 688239 & 6.2362 & 5.545 & TRN & \\
\hline CHEMBL1549403 & 688239 & 5.1862 & 5.2974 & TRN & \\
\hline CHEMBL1471516 & 688239 & 5.6362 & 5.4186 & TST & \\
\hline CHEMBL3198667 & 688239 & 4.5862 & 5.3652 & TRN & \\
\hline CHEMBL1374693 & 688239 & 4.6362 & 5.5401 & TST & \\
\hline CHEMBL1307405 & 688239 & 4.9362 & 5.4543 & TRN & \\
\hline CHEMBL1522079 & 688239 & 6.3362 & 5.4844 & TST & \\
\hline CHEMBL3195640 & 688239 & 4.5362 & 5.5379 & TRN & \\
\hline CHEMBL1301022 & 688239 & 5.1862 & 5.5573 & TRN & \\
\hline CHEMBL1370343 & 688239 & 8.28399 & 99999999 & 5.5547 & I \\
\hline CHEMBL1368027 & 688239 & 6.0 & 5.5174 & TRN & \\
\hline CHEMBL1500328 & 688239 & 4.4862 & 5.627000 & 000000001 & RI \\
\hline CHEMBL1558408 & 688239 & 5.4362 & 5.5726 & TRN & \\
\hline CHEMBL1361672 & 688239 & 4.5362 & 5.6664 & TRN & \\
\hline CHEMBL1462218 & 688239 & 5.0862 & 5.636 & TRN & \\
\hline CHEMBL1484765 & 688239 & 4.5362 & 5.425 & TRN & \\
\hline
\end{tabular}




\begin{tabular}{|c|c|c|c|c|c|}
\hline & & \multicolumn{4}{|c|}{ Supplemental Table s2.txt } \\
\hline CHEMBL1485571 & 688239 & 6.7361 & 5.3738 & TRN & \\
\hline CHEMBL1445564 & 688239 & 4.5362 & 5.4957 & TRN & \\
\hline CHEMBL1542117 & 688239 & 4.7862 & 5.5304 & TRN & \\
\hline CHEMBL1371682 & 688239 & 6.0862 & 5.5926 & TST & \\
\hline CHEMBL1587460 & 688239 & 5.0862 & 5.5526 & TRN & \\
\hline CHEMBL1384185 & 688239 & 4.8862 & 5.5278 & TRN & \\
\hline CHEMBL1390828 & 688239 & 5.3862 & 5.5635 & TRN & \\
\hline CHEMBL1556706 & 688239 & 5.3862 & 5.4369 & TRN & \\
\hline CHEMBL1519765 & 688239 & 4.5362 & 5.3949 & TST & \\
\hline CHEMBL1401614 & 688239 & 6.2362 & 5.4254 & TRN & \\
\hline CHEMBL1453238 & 688239 & 5.1862 & 5.4368 & TRN & \\
\hline CHEMBL1487986 & 688239 & 5.3362 & 5.3763 & TRN & \\
\hline CHEMBL3207807 & 688239 & 4.5362 & 5.3769 & TST & \\
\hline CHEMBL1419724 & 688239 & 6.2362 & 5.5567 & TRN & \\
\hline CHEMBL1470075 & 688239 & 7.0362 & 5.5235 & TRN & \\
\hline CHEMBL1569052 & 688239 & 5.7362 & 5.5435 & TRN & \\
\hline CHEMBL1384883 & 688239 & 6.9863 & 5.5369 & TRN & \\
\hline CHEMBL1330720 & 688239 & 5.5862 & 5.5937 & TST & \\
\hline CHEMBL1491002 & 688239 & 4.4862 & 5.5634 & TRN & \\
\hline CHEMBL1456560 & 688239 & 4.7862 & 5.3674 & TRN & \\
\hline CHEMBL1502994 & 688239 & 4.9362 & 5.5844 & TST & \\
\hline CHEMBL1488546 & 688239 & 4.7862 & 5.6694 & TRN & \\
\hline CHEMBL1498955 & 688239 & 4.6362 & 5.2787 & TRN & \\
\hline CHEMBL 3209587 & 688239 & 4.4862 & 5.4085 & TRN & \\
\hline CHEMBL1538876 & 688239 & 4.5362 & 5.5174 & TRN & \\
\hline CHEMBL1512236 & 688239 & 4.8362 & 5.4153 & TST & \\
\hline CHEMBL1372173 & 688239 & 8.28399 & 99999999 & 5.5453 & TRN \\
\hline CHEMBL1502475 & 688239 & 5.1862 & 5.4911 & TRN & \\
\hline CHEMBL1351147 & 688239 & 5.1862 & 5.6118 & TRN & \\
\hline CHEMBL1425727 & 688239 & 4.8862 & 5.3852 & TRN & \\
\hline CHEMBL1448765 & 688239 & 5.3362 & $5.59200 t$ & 00000000005 & TRN \\
\hline CHEMBL1384128 & 688239 & 4.8862 & 5.6622 & TRN & \\
\hline CHEMBL1469037 & 688239 & 4.8362 & 5.4616 & TRN & \\
\hline CHEMBL1608563 & 688239 & 4.7362 & 5.4926 & TRN & \\
\hline CHEMBL3189494 & 688239 & 4.9862 & 5.3248 & TRN & \\
\hline CHEMBL1379675 & 688239 & 5.0362 & 5.3774 & TRN & \\
\hline CHEMBL1481072 & 688239 & 4.5362 & 5.45299 & 9999999999 & TST \\
\hline CHEMBL1461712 & 688239 & 8.2366 & 5.5624 & TST & \\
\hline CHEMBL1435348 & 688239 & 5.2362 & 5.53799 & 9999999999 & TRN \\
\hline CHEMBL1508687 & 688239 & 7.7852 & 5.3837 & TST & \\
\hline CHEMBL1568918 & 688239 & 4.5362 & 5.5638 & TRN & \\
\hline CHEMBL1467021 & 688239 & 4.9862 & 5.5668 & TRN & \\
\hline CHEMBL1304592 & 688239 & 5.9862 & 5.5997 & TRN & \\
\hline CHEMBL1494763 & 688239 & 6.9863 & 5.4655 & TRN & \\
\hline CHEMBL1532974 & 688239 & 4.5362 & 5.4247 & TRN & \\
\hline CHEMBL1517272 & 688239 & 6.0862 & 5.5088 & TRN & \\
\hline CHEMBL3212445 & 688239 & 4.6862 & 5.2551 & TST & \\
\hline CHEMBL1382996 & 688239 & 6.8362 & 5.5101 & TRN & \\
\hline
\end{tabular}


Supplemental Table S2.txt

\begin{tabular}{|c|c|c|c|c|c|}
\hline CHEMBL3209236 & 688239 & 5.5862 & 5.6268 & TRN & \\
\hline CHEMBL1597131 & 688239 & 5.3362 & 5.4176 & TRN & \\
\hline CHEMBL1460742 & 688239 & 4.7362 & 5.4192 & TST & \\
\hline CHEMBL1335658 & 688239 & 4.5362 & 5.4602 & TST & \\
\hline CHEMBL1357079 & 688239 & 6.9363 & 5.3596 & TRN & \\
\hline CHEMBL1419217 & 688239 & 7.1361 & 5.4745 & TST & \\
\hline CHEMBL1302685 & 688239 & 6.2362 & 5.4277 & TRN & \\
\hline CHEMBL1507085 & 688239 & 5.8362 & 5.4859 & TRN & \\
\hline CHEMBL1391519 & 688239 & 5.4362 & 5.468999 & 99999999999 & TRN \\
\hline CHEMBL1346505 & 688239 & 5.0362 & 5.3421 & TRN & \\
\hline CHEMBL1589450 & 688239 & 5.8862 & 5.577000 & 000000001 & TRN \\
\hline CHEMBL1522231 & 688239 & 6.0362 & 5.615 & TST & \\
\hline CHEMBL1548197 & 688239 & 5.1362 & 5.5224 & TRN & \\
\hline CHEMBL1556150 & 688239 & 5.2362 & 5.4767 & TRN & \\
\hline CHEMBL1541084 & 688239 & 6.2862 & 5.3613 & TRN & \\
\hline CHEMBL1420062 & 688239 & 4.5362 & 5.5369 & TRN & \\
\hline CHEMBL1538074 & 688239 & 4.8362 & 5.4688 & TRN & \\
\hline CHEMBL1489172 & 688239 & 5.1862 & 5.5349 & TST & \\
\hline CHEMBL2004918 & 688239 & 4.6362 & 5.2197 & TRN & \\
\hline CHEMBL1519012 & 688239 & 4.5362 & 5.4759 & TRN & \\
\hline CHEMBL1590998 & 688239 & 4.5362 & 5.3517 & TRN & \\
\hline CHEMBL1509322 & 688239 & 5.5862 & 5.579 & TRN & \\
\hline CHEMBL1342566 & 688239 & 4.5362 & 5.5207 & TRN & \\
\hline CHEMBL1418928 & 688239 & 6.2362 & 5.3956 & TRN & \\
\hline CHEMBL1431118 & 688239 & 6.0862 & 5.5856 & TST & \\
\hline CHEMBL1565605 & 688239 & 6.0362 & 5.5743 & TRN & \\
\hline CHEMBL1511342 & 688239 & 4.5862 & 5.6428 & TST & \\
\hline CHEMBL1443211 & 688239 & 4.5362 & 5.3997 & TRN & \\
\hline CHEMBL1427886 & 688239 & 6.3863 & 5.5042 & TRN & \\
\hline CHEMBL1363978 & 688239 & 4.5362 & 5.6463 & TRN & \\
\hline CHEMBL1508745 & 688239 & 5.8362 & 5.4543 & TST & \\
\hline CHEMBL1429373 & 688239 & 4.4862 & 5.5333 & TRN & \\
\hline CHEMBL1518683 & 688239 & 4.5362 & 5.4446 & TRN & \\
\hline CHEMBL1331868 & 688239 & 6.6861 & 5.4924 & TRN & \\
\hline CHEMBL1343792 & 688239 & 5.2362 & 5.4032 & TRN & \\
\hline CHEMBL3207907 & 688239 & 6.2362 & 5.5916 & TST & \\
\hline CHEMBL1557980 & 688239 & 4.6862 & 5.659 & TRN & \\
\hline CHEMBL1405288 & 688239 & 6.1362 & 5.4627 & TST & \\
\hline CHEMBL1490853 & 688239 & 5.1362 & 5.4977 & TRN & \\
\hline CHEMBL1320642 & 688239 & 5.5862 & 5.472 & TRN & \\
\hline CHEMBL1389691 & 688239 & 4.8862 & 5.4302 & TRN & \\
\hline CHEMBL1458515 & 688239 & 4.8862 & 5.4739 & TRN & \\
\hline CHEMBL1300566 & 688239 & 4.7862 & 5.5061 & TST & \\
\hline CHEMBL3214025 & 688239 & 8.28399 & 999999999 & 5.5399 & TRN \\
\hline CHEMBL1448528 & 688239 & 4.5362 & 5.401 & TRN & \\
\hline CHEMBL1399963 & 688239 & 5.9362 & 5.4998 & TRN & \\
\hline CHEMBL1583759 & 688239 & 4.4862 & 5.521 & TRN & \\
\hline CHEMBL1416398 & 688239 & 5.1362 & 5.3822 & TRN & \\
\hline
\end{tabular}


Supplemental Table S2.txt

\begin{tabular}{|c|c|c|c|c|}
\hline CHEMBL1371948 & 688239 & 5.6862 & 5.5824 & TST \\
\hline CHEMBL1587538 & 688239 & 5.3362 & 5.4937 & TST \\
\hline CHEMBL1569773 & 688239 & 5.5362 & 5.5551 & TRN \\
\hline CHEMBL1314283 & 688239 & 5.4862 & 5.1924 & TRN \\
\hline CHEMBL1570278 & 688239 & 4.6362 & 5.523 & TRN \\
\hline CHEMBL1554761 & 688239 & 4.8862 & 5.4986 & TST \\
\hline CHEMBL1471404 & 688239 & 4.4862 & 5.5428 & TST \\
\hline CHEMBL1552234 & 688239 & 4.5362 & 5.5929 & TRN \\
\hline CHEMBL1380594 & 688239 & 5.0862 & 5.4184 & TRN \\
\hline CHEMBL1515358 & 688239 & 4.6362 & 5.5346 & TRN \\
\hline CHEMBL1412437 & 688239 & 6.0862 & 5.441 & TST \\
\hline CHEMBL1577912 & 688239 & 6.4862 & 5.5995 & TST \\
\hline CHEMBL587579 & 688239 & 4.7362 & 5.4447 & TRN \\
\hline CHEMBL1549450 & 688239 & 5.3862 & 5.4259 & TRN \\
\hline CHEMBL1345811 & 688239 & 5.1862 & 5.4822 & TRN \\
\hline CHEMBL1506786 & 688239 & 5.1862 & 5.5764 & TRN \\
\hline CHEMBL1427067 & 688239 & 5.4362 & 5.447 & TRN \\
\hline CHEMBL1340111 & 688239 & 6.1862 & 5.6052 & TST \\
\hline CHEMBL528791 & 688239 & 4.5362 & 5.3716 & TRN \\
\hline CHEMBL3211657 & 688239 & 6.0862 & 5.3301 & TST \\
\hline CHEMBL1403362 & 688239 & 6.5363 & 5.4473 & TRN \\
\hline CHEMBL1483295 & 688239 & 4.7362 & 5.7337 & TRN \\
\hline CHEMBL36484 & 688239 & 4.6862 & 5.5646 & TRN \\
\hline CHEMBL1352661 & 688239 & 5.7862 & 5.505 & TST \\
\hline CHEMBL1565545 & 688239 & 6.5862 & 5.4438 & TST \\
\hline CHEMBL1366306 & 688239 & 4.5362 & 5.5931 & TST \\
\hline CHEMBL1604401 & 688239 & 4.5362 & 5.4678 & TRN \\
\hline CHEMBL1350128 & 688239 & 5.1362 & 5.4187 & TRN \\
\hline CHEMBL1392373 & 688239 & 4.6862 & 5.5393 & TRN \\
\hline CHEMBL1419392 & 688239 & 5.3862 & 5.42399 & 99999999995 \\
\hline CHEMBL1437106 & 688239 & 5.0862 & 5.4004 & TRN \\
\hline CHEMBL1440322 & 688239 & 4.4862 & 5.5395 & TST \\
\hline CHEMBL1543499 & 688239 & 6.0862 & 5.3597 & TRN \\
\hline CHEMBL1467547 & 688239 & 5.1862 & 5.5561 & TRN \\
\hline CHEMBL1412606 & 688239 & 4.9362 & 5.5449 & TRN \\
\hline CHEMBL1526760 & 688239 & 5.1862 & 5.6053 & TRN \\
\hline CHEMBL1519029 & 688239 & 6.9863 & 5.5887 & TST \\
\hline CHEMBL1351535 & 688239 & 5.9862 & 5.4578 & TRN \\
\hline CHEMBL1455932 & 688239 & 5.1362 & 5.442 & TRN \\
\hline CHEMBL1312333 & 688239 & 5.5862 & 5.57600 & 00000000005 \\
\hline CHEMBL1428284 & 688239 & 4.6362 & 5.5114 & TRN \\
\hline CHEMBL1451012 & 688239 & 6.6362 & 5.4671 & TST \\
\hline CHEMBL1588974 & 688239 & 6.8362 & 5.5335 & TRN \\
\hline CHEMBL1499005 & 688239 & 5.6862 & 5.5298 & TST \\
\hline CHEMBL1604692 & 688239 & 5.6862 & 5.5876 & TRN \\
\hline CHEMBL1489648 & 688239 & 4.5362 & 5.5103 & TRN \\
\hline CHEMBL1566409 & 688239 & 4.5362 & 5.6455 & TRN \\
\hline CHEMBL1494747 & 688239 & 6.3362 & 5.53299 & 999999 \\
\hline
\end{tabular}


Supplemental Table S2.txt

\begin{tabular}{|c|c|c|c|c|}
\hline Th & & 1862 & & \\
\hline UГMDI 110074 & & .8862 & 5.6326 & \\
\hline & & & & \\
\hline AEMBL1 & & & & \\
\hline AEMBL1513410 & 8239 & & & \\
\hline HEMBL 576180 & 88239 & 366 & 5011 & \\
\hline HEMBL1 & 239 & 362 & & \\
\hline 0222 & & & & \\
\hline AEMBL1479725 & & 862 & & \\
\hline HEMBL1410189 & 88239 & 362 & 501 & \\
\hline HEMBL1572386 & 239 & 362 & 184 & \\
\hline IEMBL14 & 39 & 362 & & \\
\hline IEMBL14 & & & & \\
\hline HEMBL1546157 & & 362 & & \\
\hline AEMBL15 & & & & \\
\hline AEMBL1431373 & 39 & 62 & 15 & \\
\hline AEMBL15 & & & & \\
\hline HEMBL15 & & & & \\
\hline AEMBL1572197 & & 62 & & \\
\hline AEMBL15 & & & & \\
\hline HEMBLIC & & & 22 & \\
\hline AEMBL13 & & & & RN \\
\hline HEMBL31 & & 62 & & \\
\hline AEMBL14 & & 362 & & \\
\hline AEMBL15 & & & & ISI \\
\hline HEMBL1 & & & 12 & I RN \\
\hline AEMBL: & & & & 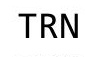 \\
\hline HFMBI 1 & & 62 & & \\
\hline AEMBL14 & & & & RIV \\
\hline HEMBL1344796 & & & & I RN \\
\hline HEMBL1 & & & & RIV \\
\hline HEMBL & & & & RN \\
\hline HEMBL & & & & \\
\hline HEMBL3191152 & & & & T \\
\hline HEMBL1348724 & & & & $2 \mathrm{~N}$ \\
\hline HEMBL15 & & & & SI \\
\hline HᄃMP 1 & & & & TRN \\
\hline HEMBL1: & & & & RN \\
\hline HEMBL1449899 & 88239 & 63 & 5.5658 & TR \\
\hline IEMBL13 & & & 5323 & 「RN \\
\hline HEMBL15 & & & 11 & \\
\hline HEMBL13 & & & & TRN \\
\hline HEMBL59 & & & 5.4814 & RN \\
\hline IEMBL14 & 39 & 62 & 67 & TR \\
\hline MBL14 & & & 27 & $\mathbf{I}$ \\
\hline HEMBL15 & & & & \\
\hline HEMBL13 & & .5362 & 5.4889 & \\
\hline CHEMBL1365791 & 688239 & 5.2362 & 5.5132 & ГST \\
\hline
\end{tabular}

Page 2007 
Supplemental Table S2.txt

\begin{tabular}{|c|c|c|c|c|}
\hline CHEMBL1529602 & 688239 & 6.3863 & 5.5165 & TRN \\
\hline CHEMBL1304386 & 688239 & 5.4362 & 5.4237 & TRN \\
\hline CHEMBL1555951 & 688239 & 4.5362 & 5.4448 & TST \\
\hline CHEMBL1609238 & 688239 & 8.2366 & 5.6065 & TST \\
\hline CHEMBL1515668 & 688239 & 4.6362 & 5.3772 & TRN \\
\hline CHEMBL1474116 & 688239 & 4.4862 & 5.4313 & TRN \\
\hline CHEMBL1571607 & 688239 & 5.1862 & 5.43 & TRN \\
\hline CHEMBL1499535 & 688239 & 4.7862 & 5.5145 & TRN \\
\hline CHEMBL1336112 & 688239 & 4.7862 & 5.537006 & 000000001 \\
\hline CHEMBL1387308 & 688239 & 5.3362 & 5.5433 & TRN \\
\hline CHEMBL1322401 & 688239 & 6.0362 & 5.5263 & TRN \\
\hline CHEMBL1588949 & 688239 & 8.0862 & 5.6867 & TRN \\
\hline CHEMBL1528279 & 688239 & 5.1362 & 5.5309 & TRN \\
\hline CHEMBL1601641 & 688239 & 7.0362 & 5.5445 & TRN \\
\hline CHEMBL1449246 & 688239 & 6.9863 & 5.5168 & TRN \\
\hline CHEMBL1458228 & 688239 & 8.3372 & 5.3707 & TST \\
\hline CHEMBL1580647 & 688239 & 7.0862 & 5.5616 & TST \\
\hline CHEMBL1367009 & 688239 & 6.8362 & 5.4681 & TRN \\
\hline CHEMBL1305231 & 688239 & 6.1862 & 5.5313 & TRN \\
\hline CHEMBL1388435 & 688239 & 5.1862 & 5.5418 & TRN \\
\hline CHEMBL1381363 & 688239 & 4.5362 & 5.3995 & TRN \\
\hline CHEMBL1406745 & 688239 & 6.6362 & 5.4986 & TRN \\
\hline CHEMBL1350661 & 688239 & 4.6862 & 5.5371 & TRN \\
\hline CHEMBL1505798 & 688239 & 5.6862 & 5.5536 & TRN \\
\hline CHEMBL 3198790 & 688239 & 4.7862 & 5.3353 & TST \\
\hline CHEMBL1309758 & 688239 & 4.8362 & 5.545 & TRN \\
\hline CHEMBL1471028 & 688239 & 6.9363 & 5.4979 & TRN \\
\hline CHEMBL1588653 & 688239 & 6.1362 & 5.5726 & TRN \\
\hline CHEMBL 1304080 & 688239 & 6.5363 & 5.5125 & TRN \\
\hline CHEMBL1484394 & 688239 & 6.6362 & 5.4831 & TRN \\
\hline CHEMBL1388470 & 688239 & 5.7862 & 5.5864 & TST \\
\hline CHEMBL1375378 & 688239 & 4.8862 & 5.4858 & TST \\
\hline CHEMBL1489806 & 688239 & 6.8362 & 5.5143 & TST \\
\hline CHEMBL1299864 & 688239 & 4.5862 & 5.421 & TRN \\
\hline CHEMBL1330126 & 688239 & 4.5362 & 5.4975 & TRN \\
\hline CHEMBL1315242 & 688239 & 5.0362 & 5.4199 & TRN \\
\hline CHEMBL1500336 & 688239 & 4.5362 & 5.4494 & TRN \\
\hline CHEMBL1335086 & 688239 & 5.3862 & 5.5435 & TRN \\
\hline CHEMBL1403337 & 688239 & 6.7862 & 5.4118 & TST \\
\hline CHEMBL1604308 & 688239 & 5.7362 & 5.5056 & TRN \\
\hline CHEMBL1326027 & 688239 & 5.1362 & 5.5304 & TRN \\
\hline CHEMBL1464163 & 688239 & 4.9362 & 5.5414 & TRN \\
\hline CHEMBL1500169 & 688239 & 5.1862 & 5.5341 & TRN \\
\hline CHEMBL 2373642 & 688239 & 6.0862 & 5.4642 & TRN \\
\hline CHEMBL1606117 & 688239 & 6.9363 & 5.4749 & TRN \\
\hline CHEMBL1416455 & 688239 & 5.1362 & 5.5599 & TRN \\
\hline CHEMBL1310508 & 688239 & 5.0362 & 5.2948 & TRN \\
\hline CHEMBL1575530 & 688239 & 8.3872 & 5.5889 & TRN \\
\hline
\end{tabular}


Supplemental Table S2.txt

\begin{tabular}{|c|c|c|c|c|}
\hline- & & & & \\
\hline HEMBL1611861 & 38239 & 363 & & \\
\hline AEMBL3211637 & 39 & 862 & & \\
\hline & 39 & 862 & 704 & \\
\hline IEMBL15 & & 862 & & \\
\hline AEMBL1550350 & 88239 & 862 & 3946 & \\
\hline AEMBL1398779 & 88239 & 862 & 5047 & \\
\hline HEMBL1463524 & & 862 & 3819 & \\
\hline EMBL15 & 39 & 362 & 22 & \\
\hline IEMBL1505886 & & 362 & 777 & \\
\hline AEMBL1490725 & 39 & 362 & 5494 & \\
\hline AEMBL1483054 & & 362 & 406 & \\
\hline AEMBL3211448 & & 62 & 55 & \\
\hline JEMBL 32 & & 62 & & \\
\hline HEMBL131 & & & & \\
\hline AEMBL1554970 & & 863 & 875 & \\
\hline AEMBL1356513 & & 862 & & \\
\hline AEMBL132 & & 62 & & \\
\hline IEMBL14 & & & & \\
\hline AEMBL14 & & 63 & & \\
\hline AEMPI 11 & & 862 & & \\
\hline IEMBL15 & & 62 & & \\
\hline HEMBL15 & & 62 & & \\
\hline HFMBI 15 & & & & \\
\hline 21 & & 62 & & \\
\hline 940 & & 362 & & \\
\hline EMBL14 & & & & \\
\hline EMBL147 & & 62 & & \\
\hline AFMR & & & & \\
\hline (ICMDI 1 & & 62 & & \\
\hline HEMBL136 & & & & \\
\hline HEMBL1353087 & & 362 & & \\
\hline 2 & & & & \\
\hline 8 & & 52 & & \\
\hline & & & & \\
\hline AEMBL1534663 & & & & \\
\hline AEMBL1405432 & & 362 & & \\
\hline & & 62 & & \\
\hline 1 & & & & \\
\hline HEMBL156 & & & & RN \\
\hline AEMBL1408128 & & 62 & 218 & $s$ \\
\hline IEMBL14 & & 362 & & \\
\hline 促 & & & & \\
\hline HEMBL1555043 & & & & \\
\hline HEMBL141 & & 4.5362 & 575 & RN \\
\hline IEMBL1465085 & & 362 & 341 & $T$ \\
\hline 14. & & & & \\
\hline 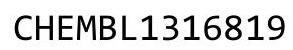 & & & & \\
\hline
\end{tabular}

Page 2009 
Supplemental Table S2.txt

\begin{tabular}{|c|c|c|c|c|}
\hline CHEMBL1421394 & 688239 & 5.9362 & 5.6489 & TST \\
\hline CHEMBL1565600 & 688239 & 4.7362 & 5.5406 & TST \\
\hline CHEMBL1373306 & 688239 & 4.5362 & 5.5301 & TRN \\
\hline CHEMBL1331865 & 688239 & 5.2362 & 5.3322 & TRN \\
\hline CHEMBL1567164 & 688239 & 4.5362 & 5.4597 & TST \\
\hline CHEMBL1465597 & 688239 & 5.1862 & 5.5816 & TRN \\
\hline CHEMBL1570345 & 688239 & 5.1862 & 5.4873 & TRN \\
\hline CHEMBL1543466 & 688239 & 6.5363 & 5.4228 & TRN \\
\hline CHEMBL1535948 & 688239 & 5.1862 & 5.4728 & TRN \\
\hline CHEMBL1337201 & 688239 & 6.5862 & 5.4521 & TRN \\
\hline CHEMBL1525305 & 688239 & 4.8362 & 5.3709 & TRN \\
\hline CHEMBL1442509 & 688239 & 6.9863 & \multicolumn{2}{|c|}{5.497999999999999} \\
\hline CHEMBL1383007 & 688239 & 4.7862 & 5.5856 & TRN \\
\hline CHEMBL1465786 & 688239 & 8.3372 & \multicolumn{2}{|c|}{5.462999999999999} \\
\hline CHEMBL1489157 & 688239 & 5.3862 & 5.5366 & TRN \\
\hline CHEMBL1516078 & 688239 & 5.5862 & 5.5499 & TRN \\
\hline CHEMBL1543805 & 688239 & 6.2362 & 5.4567 & TRN \\
\hline CHEMBL1612165 & 688239 & 4.5862 & 5.6428 & TRN \\
\hline CHEMBL1990078 & 688239 & 5.2862 & 5.5537 & TRN \\
\hline CHEMBL1374517 & 688239 & 7.4868 & 5.6006 & TRN \\
\hline CHEMBL1595336 & 688239 & 6.1862 & 5.6377 & TRN \\
\hline CHEMBL1435264 & 688239 & 5.7362 & 5.586 & TRN \\
\hline CHEMBL3209199 & 688239 & 5.2362 & 5.516 & TRN \\
\hline CHEMBL555689 & 688239 & 4.5362 & 5.6414 & TRN \\
\hline CHEMBL1326814 & 688239 & 5.5362 & 5.4941 & TRN \\
\hline CHEMBL1383293 & 688239 & 6.9863 & \multicolumn{2}{|c|}{5.531000000000001} \\
\hline CHEMBL1542097 & 688239 & 5.1862 & 5.4438 & TRN \\
\hline CHEMBL1537883 & 688239 & 7.9872 & 5.5367 & TST \\
\hline CHEMBL1330392 & 688239 & 6.9863 & 5.5514 & TRN \\
\hline CHEMBL1488787 & 688239 & 5.8862 & 5.664 & TRN \\
\hline CHEMBL1303924 & 688239 & 8.3372 & 5.4056 & TRN \\
\hline CHEMBL1483936 & 688239 & 5.4862 & 5.4971 & TST \\
\hline CHEMBL1350437 & 688239 & 5.0362 & 5.4752 & TRN \\
\hline CHEMBL1986889 & 688239 & 5.9862 & 5.315 & TRN \\
\hline CHEMBL1465359 & 688239 & 4.5362 & 5.5307 & TRN \\
\hline CHEMBL1437469 & 688239 & 4.5362 & 5.4956 & TRN \\
\hline CHEMBL1360936 & 688239 & 5.1862 & 5.3968 & TST \\
\hline CHEMBL1415847 & 688239 & 6.1862 & 5.3746 & TRN \\
\hline CHEMBL1504841 & 688239 & 4.5362 & 5.4022 & TRN \\
\hline CHEMBL1604516 & 688239 & 4.5862 & 5.5071 & TST \\
\hline CHEMBL1320492 & 688239 & 4.7362 & 5.5748 & TST \\
\hline CHEMBL1522232 & 688239 & 4.8862 & 5.4689 & TRN \\
\hline CHEMBL1501969 & 688239 & 4.5362 & 5.5062 & TST \\
\hline CHEMBL1583909 & 688239 & 4.7362 & 5.4619 & TRN \\
\hline CHEMBL1484713 & 688239 & 5.1862 & 5.4569 & TRN \\
\hline CHEMBL1377421 & 688239 & 6.8362 & 5.5937 & TRN \\
\hline CHEMBL1330733 & 688239 & 8.3372 & 5.4278 & TRN \\
\hline CHEMBL599830 & 688239 & 6.1862 & 5.4389 & TRN \\
\hline
\end{tabular}


Supplemental Table S2.txt

\begin{tabular}{|c|c|c|c|c|}
\hline CHEMBL1458394 & 688239 & 5.0362 & 5.5303 & TRN \\
\hline CHEMBL3207850 & 688239 & 4.7362 & 5.3707 & TST \\
\hline CHEMBL1487960 & 688239 & 5.8862 & 5.648 & TRN \\
\hline CHEMBL3194081 & 688239 & 5.1862 & 5.50200 & 0000000001 \\
\hline CHEMBL1579480 & 688239 & 5.2362 & 5.6063 & TRN \\
\hline CHEMBL3213204 & 688239 & 6.5363 & 5.6961 & TRN \\
\hline CHEMBL1487245 & 688239 & 4.5362 & 5.5408 & TST \\
\hline CHEMBL1589154 & 688239 & 6.7862 & 5.4151 & TRN \\
\hline CHEMBL1434945 & 688239 & 7.3363 & 5.5534 & TRN \\
\hline CHEMBL1316115 & 688239 & 5.1862 & 5.4326 & TRN \\
\hline CHEMBL1578693 & 688239 & 4.8362 & 5.5353 & TRN \\
\hline CHEMBL3207881 & 688239 & 6.9863 & 5.5655 & TRN \\
\hline CHEMBL1468541 & 688239 & 5.0 & 5.5548 & TRN \\
\hline CHEMBL1476258 & 688239 & 5.3362 & 5.3329 & TST \\
\hline CHEMBL1512893 & 688239 & 6.0862 & 5.5027 & TST \\
\hline CHEMBL1580620 & 688239 & 4.5362 & 5.4686 & TRN \\
\hline CHEMBL1529687 & 688239 & 5.1862 & 5.5951 & TRN \\
\hline CHEMBL3192073 & 688239 & 6.2862 & 5.6456 & TRN \\
\hline CHEMBL3213309 & 688239 & 6.8861 & 5.5442 & TRN \\
\hline CHEMBL1571684 & 688239 & 5.3862 & 5.6373 & TRN \\
\hline CHEMBL1508854 & 688239 & 6.3863 & 5.6307 & TST \\
\hline CHEMBL1426231 & 688239 & 6.8861 & 5.5502 & TRN \\
\hline CHEMBL1498932 & 688239 & 4.5362 & 5.4268 & TRN \\
\hline CHEMBL1523469 & 688239 & 4.5362 & 5.4188 & TRN \\
\hline CHEMBL1446117 & 688239 & 7.2366 & 5.5755 & TRN \\
\hline CHEMBL1336314 & 688239 & 5.6362 & 5.5908 & TST \\
\hline CHEMBL1577229 & 688239 & 4.4862 & 5.5043 & TRN \\
\hline CHEMBL1478314 & 688239 & 4.7362 & 5.5556 & TST \\
\hline CHEMBL1314197 & 688239 & 4.7862 & 5.4818 & TRN \\
\hline CHEMBL1360709 & 688239 & 5.5362 & 5.5281 & TRN \\
\hline CHEMBL1442673 & 688239 & 5.2362 & 5.456 & TRN \\
\hline CHEMBL1584295 & 688239 & 5.2862 & 5.67 & TRN \\
\hline CHEMBL1353722 & 688239 & 5.3362 & 5.4714 & TRN \\
\hline CHEMBL1449826 & 688239 & 5.3862 & 5.5763 & TRN \\
\hline CHEMBL1530593 & 688239 & 4.6362 & 5.3566 & TRN \\
\hline CHEMBL1541391 & 688239 & 4.5362 & 5.2855 & TRN \\
\hline CHEMBL1346583 & 688239 & 7.0362 & 5.6072 & TRN \\
\hline CHEMBL3196319 & 688239 & 4.7362 & 5.2785 & TST \\
\hline CHEMBL1596061 & 688239 & 6.0862 & 5.5973 & TST \\
\hline CHEMBL1450981 & 688239 & 4.6862 & 5.7098 & TRN \\
\hline CHEMBL1367932 & 688239 & 4.5362 & 5.4613 & TST \\
\hline CHEMBL1400380 & 688239 & 6.1362 & 5.5862 & TRN \\
\hline CHEMBL1393731 & 688239 & 4.7362 & 5.4826 & TRN \\
\hline CHEMBL1369966 & 688239 & 7.4868 & 5.2805 & TRN \\
\hline CHEMBL1379968 & 688239 & 4.4862 & 5.5802 & TST \\
\hline CHEMBL1586063 & 688239 & 4.5362 & 5.5308 & TRN \\
\hline CHEMBL1416689 & 688239 & 5.4862 & 5.4335 & TRN \\
\hline CHEMBL1302523 & 688239 & 4.8862 & 5.3189 & TRN \\
\hline
\end{tabular}




\begin{tabular}{|c|c|c|c|c|c|}
\hline \multicolumn{6}{|c|}{ Supplemental Table S2.txt } \\
\hline CHEMBL1502276 & 688239 & 4.4862 & 5.6493 & TRN & \\
\hline CHEMBL1309275 & 688239 & 4.9862 & 5.7057 & TRN & \\
\hline CHEMBL1408558 & 688239 & 5.1862 & 5.3846 & TRN & \\
\hline CHEMBL1322212 & 688239 & 5.1862 & 5.4524 & TRN & \\
\hline CHEMBL1311025 & 688239 & 4.5362 & 5.3961 & TRN & \\
\hline CHEMBL1495242 & 688239 & 6.8861 & 5.4823 & TST & \\
\hline CHEMBL1587479 & 688239 & 6.5862 & 5.5343 & TRN & \\
\hline CHEMBL1543013 & 688239 & 5.2362 & 5.374 & TRN & \\
\hline CHEMBL1373239 & 688239 & 6.0362 & 5.5309 & TRN & \\
\hline CHEMBL1554678 & 688239 & 4.7862 & 5.4744 & TRN & \\
\hline CHEMBL1478580 & 688239 & 6.3362 & 5.4115 & TRN & \\
\hline CHEMBL 3199553 & 688239 & 4.5362 & 5.5749 & TRN & \\
\hline CHEMBL1559750 & 688239 & 6.9363 & 5.5689 & TRN & \\
\hline CHEMBL90089 & 688239 & 5.1862 & 5.5233 & TRN & \\
\hline CHEMBL1466330 & 688239 & 4.7862 & 5.5252 & TST & \\
\hline CHEMBL1418028 & 688239 & 4.6362 & 5.5696 & TRN & \\
\hline CHEMBL1549213 & 688239 & 5.0362 & 5.4868 & TRN & \\
\hline CHEMBL1495783 & 688239 & 4.5362 & 5.5263 & TST & \\
\hline CHEMBL1343782 & 688239 & 4.5362 & 5.4877 & TRN & \\
\hline CHEMBL1256173 & 688239 & 5.7362 & 5.4662 & TST & \\
\hline CHEMBL1415057 & 688239 & 7.1864 & 5.4206 & TRN & \\
\hline CHEMBL1524261 & 688239 & 6.5862 & 5.475 & TST & \\
\hline CHEMBL1978069 & 688239 & 4.5362 & 5.4528 & TST & \\
\hline CHEMBL1333618 & 688239 & 4.9362 & 5.6159 & TRN & \\
\hline CHEMBL1567742 & 688239 & 4.6862 & 5.4875 & TST & \\
\hline CHEMBL1563341 & 688239 & 4.4862 & 5.4948 & TST & \\
\hline CHEMBL1395279 & 688239 & 4.6862 & 5.4962 & TRN & \\
\hline CHEMBL1327260 & 688239 & 4.6862 & 5.5538 & TRN & \\
\hline CHEMBL1493675 & 688239 & 4.7362 & 5.3912 & TST & \\
\hline CHEMBL1499356 & 688239 & 6.7862 & 5.4282 & TRN & \\
\hline CHEMBL1381214 & 688239 & 5.8362 & 5.5632 & TRN & \\
\hline CHEMBL1494486 & 688239 & 5.3362 & 5.5786 & TRN & \\
\hline CHEMBL1526073 & 688239 & 4.5362 & 5.4252 & TST & \\
\hline CHEMBL1408512 & 688239 & 6.5862 & 5.4777 & TRN & \\
\hline CHEMBL1457706 & 688239 & 5.0362 & 5.4923 & TRN & \\
\hline CHEMBL1540547 & 688239 & 4.7862 & 5.5299 & TRN & \\
\hline CHEMBL1336870 & 688239 & 5.9362 & 5.6602 & TRN & \\
\hline CHEMBL1496209 & 688239 & 4.6862 & 5.44600 & 0000000001 & TRN \\
\hline CHEMBL1362783 & 688239 & 5.1862 & 5.4752 & TST & \\
\hline CHEMBL1447935 & 688239 & 6.1862 & 5.5636 & TRN & \\
\hline CHEMBL1439387 & 688239 & 4.6862 & 5.4523 & TST & \\
\hline CHEMBL3209687 & 688239 & 5.2862 & 5.4009 & TRN & \\
\hline CHEMBL1459069 & 688239 & 4.6862 & 5.4291 & TST & \\
\hline CHEMBL1426016 & 688239 & 4.7362 & 5.398 & TRN & \\
\hline CHEMBL1441251 & 688239 & 5.1862 & 5.4118 & TST & \\
\hline CHEMBL1547827 & 688239 & 5.6862 & 5.5632 & TRN & \\
\hline CHEMBL1443148 & 688239 & 5.4862 & 5.4589 & TRN & \\
\hline CHEMBL1444571 & 688239 & 5.1862 & 5.5458 & TST & \\
\hline
\end{tabular}


Supplemental Table S2.txt

\begin{tabular}{|c|c|c|c|c|c|}
\hline CHEMBL1357250 & 688239 & 5.8362 & 5.4916 & TRN & \\
\hline CHEMBL1964306 & 688239 & 4.5362 & 5.4954 & TST & \\
\hline CHEMBL1445926 & 688239 & 5.1862 & 5.5204 & TST & \\
\hline CHEMBL1472879 & 688239 & 4.5862 & 5.5556 & TST & \\
\hline CHEMBL1600833 & 688239 & 8.283999 & 99999999 & 5.4181 & TRN \\
\hline CHEMBL1477237 & 688239 & 6.7361 & 5.4598 & TST & \\
\hline CHEMBL1319867 & 688239 & 5.4862 & 5.3276 & TRN & \\
\hline CHEMBL1598521 & 688239 & 4.5362 & 5.5258 & TRN & \\
\hline CHEMBL1517040 & 688239 & 6.1362 & 5.602 & TRN & \\
\hline CHEMBL1419885 & 688239 & 5.1862 & 5.4733 & TRN & \\
\hline CHEMBL1343963 & 688239 & 5.1862 & 5.3886 & TRN & \\
\hline CHEMBL1501258 & 688239 & 5.6862 & 5.3772 & TRN & \\
\hline CHEMBL1562185 & 688239 & 5.8362 & 5.532999 & 99999999995 & TRN \\
\hline CHEMBL1365020 & 688239 & 4.9862 & 5.528 & TRN & \\
\hline CHEMBL1590159 & 688239 & 5.4862 & 5.4221 & TST & \\
\hline CHEMBL1307595 & 688239 & 4.6862 & 5.539 & TRN & \\
\hline CHEMBL1485665 & 688239 & 6.2362 & 5.4433 & TRN & \\
\hline CHEMBL1332269 & 688239 & 4.6362 & 5.4119 & TRN & \\
\hline CHEMBL1486408 & 688239 & 6.1362 & 5.473 & TRN & \\
\hline CHEMBL1342452 & 688239 & 4.5362 & 5.3861 & TRN & \\
\hline CHEMBL1438595 & 688239 & 4.6862 & 5.442 & TRN & \\
\hline CHEMBL1445707 & 688239 & 5.3862 & 5.3212 & TRN & \\
\hline CHEMBL601751 & 688239 & 4.5862 & 5.412000 & 0000000001 & RN \\
\hline CHEMBL1487255 & 688239 & 4.8862 & 5.6321 & TRN & \\
\hline CHEMBL1601903 & 688239 & 6.0362 & 5.5772 & TRN & \\
\hline CHEMBL1393444 & 688239 & 5.1862 & 5.3433 & TRN & \\
\hline CHEMBL1520413 & 688239 & 5.1862 & 5.4066 & TST & \\
\hline CHEMBL1515573 & 688239 & 6.2362 & 5.4618 & TRN & \\
\hline CHEMBL1419439 & 688239 & 4.7862 & 5.484 & TRN & \\
\hline CHEMBL1503722 & 688239 & 4.85 & 5.449 & TRN & \\
\hline CHEMBL1512266 & 688239 & 4.7862 & 5.3358 & TRN & \\
\hline CHEMBL1385741 & 688239 & 5.4862 & 5.4052 & TRN & \\
\hline CHEMBL 2002875 & 688239 & 6.3362 & 5.5803 & TRN & \\
\hline CHEMBL1533054 & 688239 & 6.1862 & 5.5172 & TRN & \\
\hline CHEMBL1359475 & 688239 & 6.3362 & 5.4238 & TRN & \\
\hline CHEMBL1522120 & 688239 & 5.2862 & 5.5938 & TRN & \\
\hline CHEMBL1582403 & 688239 & 4.6862 & 5.4854 & TRN & \\
\hline CHEMBL1357957 & 688239 & 4.7362 & 5.4486 & TRN & \\
\hline CHEMBL1572937 & 688239 & 6.6861 & 5.4534 & TST & \\
\hline CHEMBL1356178 & 688239 & 5.2862 & 5.4539 & TRN & \\
\hline CHEMBL1494220 & 688239 & 5.7862 & 5.4335 & TRN & \\
\hline CHEMBL1578229 & 688239 & 5.0362 & 5.4591 & TRN & \\
\hline CHEMBL1969934 & 688239 & 4.9862 & 5.4752 & TST & \\
\hline CHEMBL1369049 & 688239 & 4.7862 & 5.4512 & TRN & \\
\hline CHEMBL3193291 & 688239 & 4.6362 & 5.4127 & TRN & \\
\hline CHEMBL1518096 & 688239 & 6.8861 & 5.3597 & TST & \\
\hline CHEMBL1351882 & 688239 & 8.283999 & 99999999 & 5.575 & 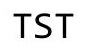 \\
\hline CHEMBL1333417 & 688239 & 4.8362 & 5.5093 & TST & \\
\hline
\end{tabular}

Page 2013 
Supplemental Table S2.txt

\begin{tabular}{|c|c|c|c|c|}
\hline CHEMBL1607654 & 688239 & 5.3862 & 5.5788 & TRN \\
\hline CHEMBL1342718 & 688239 & 5.4362 & 5.5204 & TST \\
\hline CHEMBL1333979 & 688239 & 6.7862 & 5.4744 & TRN \\
\hline CHEMBL1497863 & 688239 & 7.2366 & 5.6338 & TRN \\
\hline CHEMBL1334502 & 688239 & 8.3372 & 5.5458 & TRN \\
\hline CHEMBL1499047 & 688239 & 6.1862 & 5.6756 & TRN \\
\hline CHEMBL1299938 & 688239 & 5.8862 & 5.5641 & TRN \\
\hline CHEMBL1378486 & 688239 & 5.4362 & 5.4674 & TRN \\
\hline CHEMBL1543451 & 688239 & 4.7862 & 5.6485 & TST \\
\hline CHEMBL1320145 & 688239 & 4.6862 & 5.4057 & TRN \\
\hline CHEMBL1390344 & 688239 & 5.5862 & 5.5186 & TRN \\
\hline CHEMBL1405781 & 688239 & 5.2362 & 5.3714 & TST \\
\hline CHEMBL3197650 & 688239 & 6.9863 & 5.3756 & TRN \\
\hline CHEMBL1369302 & 688239 & 4.5362 & 5.4168 & TRN \\
\hline CHEMBL1368296 & 688239 & 5.6862 & 5.6901 & TRN \\
\hline CHEMBL1511990 & 688239 & 4.6362 & 5.5122 & TRN \\
\hline CHEMBL1327817 & 688239 & 7.0362 & 5.41299 & 9999999999 \\
\hline CHEMBL1328895 & 688239 & 7.1864 & 5.36600 & 00000000005 \\
\hline CHEMBL1337454 & 688239 & 4.7862 & 5.476 & TRN \\
\hline CHEMBL1325888 & 688239 & 5.2362 & 5.559 & TRN \\
\hline CHEMBL1354027 & 688239 & 7.0862 & 5.3879 & TRN \\
\hline CHEMBL1429103 & 688239 & 4.6862 & 5.4322 & TRN \\
\hline CHEMBL1299454 & 688239 & 5.9362 & 5.4762 & TRN \\
\hline CHEMBL1421651 & 688239 & 5.5362 & 5.5676 & TRN \\
\hline CHEMBL1580051 & 688239 & 8.3372 & 5.4827 & TRN \\
\hline CHEMBL1567541 & 688239 & 7.2366 & 5.4973 & TRN \\
\hline CHEMBL1577560 & 688239 & 4.8862 & 5.4543 & TRN \\
\hline CHEMBL1607578 & 688239 & 5.0862 & 5.5304 & TRN \\
\hline CHEMBL1600415 & 688239 & 6.5862 & 5.4302 & TST \\
\hline CHEMBL1559921 & 688239 & 5.4862 & 5.4348 & TRN \\
\hline CHEMBL1609153 & 688239 & 4.5362 & 5.5432 & TRN \\
\hline CHEMBL1368740 & 688239 & 5.2362 & 5.4983 & TRN \\
\hline CHEMBL1302363 & 688239 & 4.8362 & 5.586 & TRN \\
\hline CHEMBL1477683 & 688239 & 5.3362 & 5.5973 & TRN \\
\hline CHEMBL1560714 & 688239 & 4.5362 & 5.4039 & TRN \\
\hline CHEMBL1572051 & 688239 & 5.4362 & 5.3803 & TRN \\
\hline CHEMBL1354407 & 688239 & 6.2362 & 5.4691 & TRN \\
\hline CHEMBL1409094 & 688239 & 4.6862 & 5.4326 & TRN \\
\hline CHEMBL1520834 & 688239 & 6.3863 & 5.4823 & TRN \\
\hline CHEMBL1478098 & 688239 & 4.5362 & 5.5078 & TST \\
\hline CHEMBL1570224 & 688239 & 4.5362 & 5.6001 & TRN \\
\hline CHEMBL3212250 & 688239 & 6.9363 & 5.5124 & TRN \\
\hline CHEMBL1457061 & 688239 & 6.1362 & 5.4617 & TRN \\
\hline CHEMBL1517523 & 688239 & 5.6862 & 5.4355 & TST \\
\hline CHEMBL1559108 & 688239 & 5.1862 & 5.6032 & TRN \\
\hline CHEMBL1490482 & 688239 & 5.3862 & 5.5644 & TST \\
\hline CHEMBL513436 & 688239 & 4.7362 & 5.4097 & TRN \\
\hline CHEMBL1410015 & 688239 & 5.2862 & 5.4691 & TST \\
\hline
\end{tabular}

Page 2014 
Supplemental Table S2.txt

\begin{tabular}{|c|c|c|c|c|c|}
\hline CHEMBL1357811 & 688239 & 6.1362 & \multicolumn{2}{|c|}{5.281000000000001} & TR \\
\hline CHEMBL3192696 & 688239 & 6.2362 & 5.4355 & TRN & \\
\hline CHEMBL1317842 & 688239 & 4.5362 & 5.3845 & TST & \\
\hline CHEMBL1484531 & 688239 & 5.9862 & 5.4873 & TRN & \\
\hline CHEMBL1368470 & 688239 & 4.5362 & 5.6128 & TRN & \\
\hline CHEMBL1490308 & 688239 & 4.9862 & 5.3714 & TST & \\
\hline CHEMBL1485246 & 688239 & 5.7362 & 5.3824 & TST & \\
\hline CHEMBL1561649 & 688239 & 4.5362 & 5.4729 & TST & \\
\hline CHEMBL1481499 & 688239 & 4.8862 & 5.558 & TRN & \\
\hline CHEMBL1398190 & 688239 & 4.5362 & 5.3462 & TRN & \\
\hline CHEMBL1402430 & 688239 & 4.5362 & 5.5281 & TRN & \\
\hline CHEMBL1527697 & 688239 & 6.8362 & 5.5168 & TRN & \\
\hline CHEMBL1336156 & 688239 & 4.5862 & 5.4613 & TRN & \\
\hline CHEMBL1363764 & 688239 & 4.8862 & 5.5617 & TRN & \\
\hline CHEMBL1575657 & 688239 & 6.9863 & 5.5099 & TRN & \\
\hline CHEMBL1402033 & 688239 & 4.7862 & 5.6013 & TRN & \\
\hline CHEMBL1460719 & 688239 & 5.7362 & 5.5674 & TRN & \\
\hline CHEMBL1526059 & 688239 & 5.5362 & 5.4156 & TRN & \\
\hline CHEMBL1411840 & 688239 & 5.8362 & 5.4338 & TST & \\
\hline CHEMBL1338558 & 688239 & 6.2362 & 5.4421 & TRN & \\
\hline CHEMBL1359578 & 688239 & 4.6862 & 5.4602 & TST & \\
\hline CHEMBL1302804 & 688239 & 5.6362 & 5.3958 & TRN & \\
\hline CHEMBL1971361 & 688239 & 7.1361 & 5.5613 & TRN & \\
\hline CHEMBL1487278 & 688239 & 7.2366 & 5.4503 & TRN & \\
\hline CHEMBL1394870 & 688239 & 6.4362 & 5.5149 & TST & \\
\hline CHEMBL1354061 & 688239 & 5.3862 & 5.4609 & TRN & \\
\hline CHEMBL1448054 & 688239 & 5.8862 & 5.5076 & TRN & \\
\hline CHEMBL3213312 & 688239 & 7.1864 & 5.4929 & TRN & \\
\hline CHEMBL1561033 & 688239 & 6.8861 & 5.5921 & TRN & \\
\hline CHEMBL1559602 & 688239 & 6.2862 & 5.6144 & TRN & \\
\hline CHEMBL3194240 & 688239 & 5.3862 & 5.5618 & TST & \\
\hline CHEMBL1327008 & 688239 & 4.5362 & 5.5003 & TRN & \\
\hline CHEMBL1539034 & 688239 & 5.5362 & 5.3823 & TRN & \\
\hline CHEMBL1336498 & 688239 & 6.8362 & 5.4006 & TST & \\
\hline CHEMBL1394795 & 688239 & 4.5362 & 5.6089 & TRN & \\
\hline CHEMBL1321952 & 688239 & 5.6362 & 5.46399 & 99999999995 & \\
\hline CHEMBL1555784 & 688239 & 5.1362 & 5.4116 & TRN & \\
\hline CHEMBL1317832 & 688239 & 5.2362 & 5.5401 & TST & \\
\hline CHEMBL1457427 & 688239 & 4.7862 & 5.3967 & TRN & \\
\hline CHEMBL1970965 & 688239 & 5.6862 & 5.4739 & TRN & \\
\hline CHEMBL1303971 & 688239 & 7.0362 & 5.4287 & TRN & \\
\hline CHEMBL1330165 & 688239 & 4.8362 & 5.4782 & TRN & \\
\hline CHEMBL1502954 & 688239 & 5.1862 & 5.3849 & TRN & \\
\hline CHEMBL3198539 & 688239 & 4.6362 & 5.3747 & TRN & \\
\hline CHEMBL1303831 & 688239 & 5.0362 & 5.3003 & TRN & \\
\hline CHEMBL1395813 & 688239 & 5.3862 & 5.5608 & TRN & \\
\hline CHEMBL1384454 & 688239 & 4.9862 & 5.6447 & TST & \\
\hline CHEMBL1388151 & 688239 & 5.4862 & 5.5533 & TST & \\
\hline
\end{tabular}

Page 2015 
Supplemental Table S2.txt

\begin{tabular}{|c|c|c|c|c|c|}
\hline CHEMBL1408468 & 688239 & 4.6362 & 5.3758 & TRN & \\
\hline CHEMBL1303506 & 688239 & 4.7862 & 5.6436 & TRN & \\
\hline CHEMBL1491862 & 688239 & 6.4862 & 5.3532 & TRN & \\
\hline CHEMBL1563094 & 688239 & 4.5362 & 5.5525 & TST & \\
\hline CHEMBL1449756 & 688239 & 8.1871 & 5.5062 & TRN & \\
\hline CHEMBL1472407 & 688239 & 4.5362 & 5.5126 & TRN & \\
\hline CHEMBL1455652 & 688239 & 5.3362 & 5.5447 & TRN & \\
\hline CHEMBL1365618 & 688239 & 7.6364 & 5.5022 & TST & \\
\hline CHEMBL1460886 & 688239 & 5.1862 & 5.5033 & TST & \\
\hline CHEMBL1349272 & 688239 & 6.5363 & 5.5562 & TRN & \\
\hline CHEMBL1471607 & 688239 & 4.5362 & 5.3639 & TRN & \\
\hline CHEMBL1336039 & 688239 & 4.5362 & 5.475 & TST & \\
\hline CHEMBL1610891 & 688239 & 5.3862 & 5.4931 & TRN & \\
\hline CHEMBL1365247 & 688239 & 5.9862 & 5.5578 & TRN & \\
\hline CHEMBL1449195 & 688239 & 6.1862 & 5.5403 & TRN & \\
\hline CHEMBL1352004 & 688239 & 5.1862 & 5.4009 & TST & \\
\hline CHEMBL1355624 & 688239 & 4.6862 & 5.4324 & TST & \\
\hline CHEMBL3209544 & 688239 & 6.3362 & 5.5268 & TRN & \\
\hline CHEMBL1476308 & 688239 & 5.3862 & 5.4827 & TRN & \\
\hline CHEMBL1370549 & 688239 & 4.4862 & 5.5411 & TRN & \\
\hline CHEMBL1457000 & 688239 & 5.5862 & 5.6379 & TRN & \\
\hline CHEMBL1316546 & 688239 & 6.8861 & 5.3878 & TST & \\
\hline CHEMBL1414294 & 688239 & 4.6862 & 5.3405 & TRN & \\
\hline CHEMBL1483621 & 688239 & 5.6362 & 5.566 & TST & \\
\hline CHEMBL1439359 & 688239 & 5.3362 & 5.4014 & TRN & \\
\hline CHEMBL1566069 & 688239 & 6.1362 & 5.553999 & э9999999999 & TST \\
\hline CHEMBL1610706 & 688239 & 4.5362 & 5.3625 & TRN & \\
\hline CHEMBL1436785 & 688239 & 4.5362 & 5.5026 & TST & \\
\hline CHEMBL1312094 & 688239 & 5.1862 & 5.5522 & TST & \\
\hline CHEMBL1400220 & 688239 & 4.6362 & 5.5942 & TST & \\
\hline CHEMBL1456534 & 688239 & 4.7362 & 5.3558 & TRN & \\
\hline CHEMBL1403563 & 688239 & 5.6362 & 5.4396 & TRN & \\
\hline CHEMBL1322473 & 688239 & 5.9362 & 5.3849 & TRN & \\
\hline CHEMBL3214617 & 688239 & 6.2362 & 5.6349 & TRN & \\
\hline CHEMBL1398370 & 688239 & 5.6862 & 5.5535 & TRN & \\
\hline CHEMBL1387613 & 688239 & 4.5362 & 5.451000 & 30000000005 & $\mathrm{TR}$ \\
\hline CHEMBL1485104 & 688239 & 4.5362 & 5.4726 & TRN & \\
\hline CHEMBL1364632 & 688239 & 4.7362 & 5.4407 & TRN & \\
\hline CHEMBL1610869 & 688239 & 4.4862 & 5.4983 & TRN & \\
\hline CHEMBL1497360 & 688239 & 5.8362 & 5.5777 & TRN & \\
\hline CHEMBL1448108 & 688239 & 4.5362 & 5.6472 & TRN & \\
\hline CHEMBL1468163 & 688239 & 5.2362 & 5.4187 & TRN & \\
\hline CHEMBL1430812 & 688239 & 4.7862 & 5.4368 & TRN & \\
\hline CHEMBL1593254 & 688239 & 8.28399 & 99999999 & 5.5642 & TRN \\
\hline CHEMBL1543609 & 688239 & 4.4862 & 5.3088 & TST & \\
\hline CHEMBL1593677 & 688239 & 4.6862 & 5.2941 & TRN & \\
\hline CHEMBL1316651 & 688239 & 4.9362 & 5.5306 & TST & \\
\hline CHEMBL478754 & 688239 & 4.7862 & 5.5341 & TRN & \\
\hline
\end{tabular}




\begin{tabular}{|c|c|c|c|c|c|}
\hline \multicolumn{6}{|c|}{ Supplemental Table S2.txt } \\
\hline CHEMBL1414078 & 688239 & 4.45 & 5.2799 & TRN & \\
\hline CHEMBL1569698 & 688239 & 7.1361 & 5.3747 & TST & \\
\hline CHEMBL1324691 & 688239 & 6.2362 & 5.524 & TRN & \\
\hline CHEMBL1492688 & 688239 & 4.5362 & 5.4021 & TRN & \\
\hline CHEMBL1300817 & 688239 & 4.7362 & 5.6027 & TRN & \\
\hline CHEMBL1992793 & 688239 & 4.5362 & 5.4151 & TST & \\
\hline CHEMBL1323764 & 688239 & 4.4862 & 5.5696 & TRN & \\
\hline CHEMBL3196218 & 688239 & 4.5362 & 5.5448 & TRN & \\
\hline CHEMBL1423261 & 688239 & 6.8861 & 5.5062 & TST & \\
\hline CHEMBL1493629 & 688239 & 4.5362 & 5.4834 & TRN & \\
\hline CHEMBL1583712 & 688239 & 4.5362 & 5.4755 & TRN & \\
\hline CHEMBL1414440 & 688239 & 4.7362 & 5.4742 & TRN & \\
\hline CHEMBL1439049 & 688239 & 4.5362 & 5.3648 & TRN & \\
\hline CHEMBL1510675 & 688239 & 6.3863 & 5.5686 & TRN & \\
\hline CHEMBL1447940 & 688239 & 6.0862 & 5.3473 & TRN & \\
\hline CHEMBL1309710 & 688239 & 6.3863 & 5.4457 & TST & \\
\hline CHEMBL1611638 & 688239 & 5.2862 & 5.5024 & TRN & \\
\hline CHEMBL1440184 & 688239 & 4.7362 & 5.5134 & TST & \\
\hline CHEMBL1487280 & 688239 & 6.0 & 5.4957 & TRN & \\
\hline CHEMBL1414239 & 688239 & 6.2362 & 5.4656 & TRN & \\
\hline CHEMBL1447389 & 688239 & 6.7862 & 5.4642 & TST & \\
\hline CHEMBL1398337 & 688239 & 5.6362 & 5.5177 & TRN & \\
\hline CHEMBL 3192382 & 688239 & 5.8362 & 5.5758 & TRN & \\
\hline CHEMBL412080 & 688239 & 6.8362 & 5.516 & TST & \\
\hline CHEMBL1313822 & 688239 & 5.8362 & 5.4118 & TRN & \\
\hline CHEMBL1459498 & 688239 & 4.5362 & 5.4707 & TST & \\
\hline CHEMBL1522489 & 688239 & 5.3862 & 5.3888 & TST & \\
\hline CHEMBL1342670 & 688239 & 5.5862 & 5.4203 & TRN & \\
\hline CHEMBL1583708 & 688239 & 4.6362 & 5.4155 & TRN & \\
\hline CHEMBL1490116 & 688239 & 4.7362 & 5.48 & TRN & \\
\hline CHEMBL3199491 & 688239 & 6.5862 & 5.3182 & TRN & \\
\hline CHEMBL1552758 & 688239 & 5.1862 & 5.5127 & TRN & \\
\hline CHEMBL1561551 & 688239 & 5.3862 & 5.4694 & TRN & \\
\hline CHEMBL1370863 & 688239 & 6.2362 & 5.5627 & TRN & \\
\hline CHEMBL 2003662 & 688239 & 4.5362 & 5.4739 & TRN & \\
\hline CHEMBL1374317 & 688239 & 8.3372 & 5.4965 & TRN & \\
\hline CHEMBL1557699 & 688239 & 4.7362 & 5.4388 & TST & \\
\hline CHEMBL1392188 & 688239 & 6.5363 & 5.4862 & TRN & \\
\hline CHEMBL1611487 & 688239 & 5.6862 & 5.5377 & TRN & \\
\hline CHEMBL1499815 & 688239 & 4.6362 & 5.5311 & TST & \\
\hline CHEMBL1605622 & 688239 & 5.0862 & 5.41200 & 0000000001 & TST \\
\hline CHEMBL1442138 & 688239 & 4.7862 & 5.5279 & TRN & \\
\hline CHEMBL1374744 & 688239 & 4.7862 & 5.4391 & TST & \\
\hline CHEMBL1307452 & 688239 & 7.7352 & 5.3229 & TRN & \\
\hline CHEMBL1507498 & 688239 & 5.1862 & 5.45700 & 0000000001 & TST \\
\hline CHEMBL1579692 & 688239 & 8.3372 & 5.6601 & TRN & \\
\hline CHEMBL1315477 & 688239 & 4.5862 & 5.37700 & 0000000001 & TRN \\
\hline CHEMBL1348008 & 688239 & 5.6862 & 5.4548 & TRN & \\
\hline
\end{tabular}


Supplemental Table S2.txt

\begin{tabular}{|c|c|c|c|c|c|}
\hline CHEMBL1608380 & 688239 & 4.9362 & 5.4702 & TRN & \\
\hline CHEMBL1434168 & 688239 & 4.5362 & 5.5003 & TRN & \\
\hline CHEMBL1322113 & 688239 & 4.7862 & 5.5757 & TRN & \\
\hline CHEMBL1397945 & 688239 & 4.5362 & 5.5069 & TRN & \\
\hline CHEMBL1522492 & 688239 & 4.5362 & 5.3431 & TRN & \\
\hline CHEMBL1407023 & 688239 & 6.1862 & 5.655 & TRN & \\
\hline CHEMBL1430228 & 688239 & 5.6362 & 5.478 & TST & \\
\hline CHEMBL1586953 & 688239 & 8.28399 & 79999999 & 99 & 5.4585 \\
\hline CHEMBL1427836 & 688239 & 6.0862 & 5.5554 & TRN & \\
\hline CHEMBL1487484 & 688239 & 6.1362 & 5.5604 & TST & \\
\hline CHEMBL1568316 & 688239 & 5.3862 & 5.5914 & TST & \\
\hline CHEMBL1542413 & 688239 & 4.5362 & 5.5149 & TST & \\
\hline CHEMBL1422934 & 688239 & 6.2362 & 5.619 & TRN & \\
\hline CHEMBL1489621 & 688239 & 4.5362 & 5.4935 & TRN & \\
\hline CHEMBL1464071 & 688239 & 5.0862 & 5.5865 & TRN & \\
\hline CHEMBL1549072 & 688239 & 5.0362 & 5.4825 & TRN & \\
\hline CHEMBL3199608 & 688239 & 5.1862 & 5.4299 & TRN & \\
\hline CHEMBL1525127 & 688239 & 4.5362 & 5.7044 & TRN & \\
\hline CHEMBL1387044 & 688239 & 4.4862 & 5.5649 & TST & \\
\hline CHEMBL1334182 & 688239 & 5.8862 & 5.5403 & TRN & \\
\hline CHEMBL1443418 & 688239 & 6.3362 & 5.3941 & TST & \\
\hline CHEMBL1339592 & 688239 & 5.1862 & 5.4727 & TRN & \\
\hline CHEMBL1319248 & 688239 & 7.3363 & 5.4466 & TRN & \\
\hline CHEMBL1613411 & 688239 & 4.7862 & 5.607 & TRN & \\
\hline CHEMBL1388824 & 688239 & 4.5362 & 5.4264 & TST & \\
\hline CHEMBL1387777 & 688239 & 4.6362 & 5.5385 & TRN & \\
\hline CHEMBL1442160 & 688239 & 4.6862 & 5.534 & TST & \\
\hline CHEMBL1513148 & 688239 & 6.2862 & 5.4233 & TRN & \\
\hline CHEMBL1561002 & 688239 & 4.9862 & 5.6061 & TRN & \\
\hline CHEMBL3208913 & 688239 & 4.7362 & 5.519 & TST & \\
\hline CHEMBL1575573 & 688239 & 6.7862 & 5.4674 & TRN & \\
\hline CHEMBL1463563 & 688239 & 4.5362 & 5.4509 & TST & \\
\hline CHEMBL1526839 & 688239 & 4.6362 & 5.5879 & TRN & \\
\hline CHEMBL1557182 & 688239 & 7.5361 & 5.5232 & TRN & \\
\hline CHEMBL1405188 & 688239 & 4.7862 & 5.4541 & TST & \\
\hline CHEMBL1466866 & 688239 & 6.2862 & 5.3865 & TRN & \\
\hline CHEMBL1422989 & 688239 & 4.5362 & 5.5551 & TRN & \\
\hline CHEMBL1586926 & 688239 & 5.6862 & 5.398 & TRN & \\
\hline CHEMBL1586896 & 688239 & 4.6362 & 5.6519 & TRN & \\
\hline CHEMBL1412615 & 688239 & 5.8862 & 5.5168 & TRN & \\
\hline CHEMBL1324699 & 688239 & 5.6862 & 5.4858 & TST & \\
\hline CHEMBL1529048 & 688239 & 4.7362 & 5.4764 & TRN & \\
\hline CHEMBL3211086 & 688239 & 5.8362 & 5.5986 & TST & \\
\hline CHEMBL1348108 & 688239 & 4.4862 & 5.4361 & TRN & \\
\hline CHEMBL1589029 & 688239 & 4.5362 & 5.3911 & TST & \\
\hline CHEMBL1495268 & 688239 & 4.5362 & 5.4677 & TRN & \\
\hline CHEMBL1524324 & 688239 & 4.9362 & 5.3791 & TRN & \\
\hline CHEMBL1600006 & 688239 & 5.7862 & 5.4341 & TRN & \\
\hline
\end{tabular}


Supplemental Table S2.txt

\begin{tabular}{|c|c|c|c|c|}
\hline CHEMBL1482723 & 688239 & 5.9362 & 5.4246 & TRN \\
\hline CHEMBL1444481 & 688239 & 4.6362 & 5.3496 & TRN \\
\hline CHEMBL1510369 & 688239 & 4.7862 & 5.5694 & TRN \\
\hline CHEMBL1401747 & 688239 & 5.4862 & 5.5851 & TST \\
\hline CHEMBL1415148 & 688239 & 6.0862 & 5.4633 & TST \\
\hline CHEMBL1448929 & 688239 & 5.3862 & 5.4656 & TRN \\
\hline CHEMBL1427000 & 688239 & 5.6362 & 5.4988 & TRN \\
\hline CHEMBL3207506 & 688239 & 6.5363 & 5.4107 & TRN \\
\hline CHEMBL1609418 & 688239 & 4.4862 & 5.2311 & TRN \\
\hline CHEMBL1360336 & 688239 & 5.1862 & 5.3361 & TRN \\
\hline CHEMBL1316822 & 688239 & 6.7361 & 5.2462 & TRN \\
\hline CHEMBL1329862 & 688239 & 6.2362 & 5.4811 & TST \\
\hline CHEMBL1599588 & 688239 & 6.6362 & 5.5956 & TST \\
\hline CHEMBL1300326 & 688239 & 4.5362 & 5.2882 & TRN \\
\hline CHEMBL594783 & 688239 & 5.0362 & 5.4978 & TRN \\
\hline CHEMBL1449114 & 688239 & 4.7862 & 5.5798 & TST \\
\hline CHEMBL1416791 & 688239 & 5.1862 & 5.4264 & TRN \\
\hline CHEMBL1389096 & 688239 & 4.9362 & 5.3792 & TRN \\
\hline CHEMBL1571085 & 688239 & 6.1862 & 5.5869 & TRN \\
\hline CHEMBL1401577 & 688239 & 6.8861 & 5.5338 & TRN \\
\hline CHEMBL1446481 & 688239 & 6.9363 & 5.4083 & TRN \\
\hline CHEMBL1413686 & 688239 & 4.5362 & 5.4761 & TRN \\
\hline CHEMBL1517409 & 688239 & 6.1362 & 5.6129 & TRN \\
\hline CHEMBL1310492 & 688239 & 4.6862 & 5.5324 & TRN \\
\hline CHEMBL1469363 & 688239 & 4.5862 & 5.5057 & TRN \\
\hline CHEMBL1590317 & 688239 & 4.8362 & 5.5916 & TRN \\
\hline CHEMBL1522090 & 688239 & 4.5362 & 5.4674 & TRN \\
\hline CHEMBL 2373620 & 688239 & 4.5362 & 5.45700 & 0000000001 \\
\hline CHEMBL1363134 & 688239 & 5.4362 & 5.4663 & TRN \\
\hline CHEMBL1444298 & 688239 & 4.4862 & 5.5786 & TST \\
\hline CHEMBL1396234 & 688239 & 4.5362 & 5.5852 & TRN \\
\hline CHEMBL1500310 & 688239 & 5.5362 & 5.4583 & TST \\
\hline CHEMBL1609620 & 688239 & 5.2362 & 5.4051 & TST \\
\hline CHEMBL1493948 & 688239 & 6.1362 & 5.4553 & TRN \\
\hline CHEMBL1540944 & 688239 & 4.4862 & 5.4899 & TST \\
\hline CHEMBL1312118 & 688239 & 5.7362 & 5.3986 & TST \\
\hline CHEMBL1330274 & 688239 & 4.5362 & 5.6127 & TST \\
\hline CHEMBL1556017 & 688239 & 4.5862 & 5.4265 & TST \\
\hline CHEMBL1367944 & 688239 & 4.5362 & 5.3913 & TRN \\
\hline CHEMBL1350938 & 688239 & 4.8362 & 5.4623 & TRN \\
\hline CHEMBL1987461 & 688239 & 5.3362 & 5.442 & TRN \\
\hline CHEMBL1600593 & 688239 & 5.2362 & 5.3896 & TRN \\
\hline CHEMBL1379918 & 688239 & 5.2862 & 5.2952 & TRN \\
\hline CHEMBL1388415 & 688239 & 4.8362 & 5.5284 & TRN \\
\hline CHEMBL 3212702 & 688239 & 6.8362 & 5.4835 & TST \\
\hline CHEMBL1323151 & 688239 & 4.5362 & 5.2242 & TRN \\
\hline CHEMBL1424546 & 688239 & 8.3372 & 5.305 & TRN \\
\hline CHEMBL1328371 & 688239 & 5.4862 & 5.5202 & TRN \\
\hline
\end{tabular}


Supplemental Table S2.txt

\begin{tabular}{|c|c|c|c|c|c|}
\hline CHEMBL1332723 & 688239 & 6.2862 & 5.4814 & TRN & \\
\hline CHEMBL1973042 & 688239 & 6.7862 & 5.4196 & TRN & \\
\hline CHEMBL1326241 & 688239 & 5.7362 & 5.4507 & TRN & \\
\hline CHEMBL1305848 & 688239 & 5.3862 & 5.4039 & TST & \\
\hline CHEMBL1505008 & 688239 & 6.7361 & 5.6153 & TRN & \\
\hline CHEMBL1415457 & 688239 & 5.4362 & 5.3972 & TST & \\
\hline CHEMBL1453470 & 688239 & 6.6861 & 5.6097 & TRN & \\
\hline CHEMBL1378381 & 688239 & 5.6362 & 5.5167 & TRN & \\
\hline CHEMBL1365047 & 688239 & 5.1862 & 5.4065 & TRN & \\
\hline CHEMBL1446569 & 688239 & 5.5862 & 5.5278 & TRN & \\
\hline CHEMBL1403756 & 688239 & 5.5362 & 5.4585 & TRN & \\
\hline CHEMBL1527746 & 688239 & 6.9863 & 5.666 & TRN & \\
\hline CHEMBL1524279 & 688239 & 6.2362 & 5.6027 & TRN & \\
\hline CHEMBL1515980 & 688239 & 4.7862 & 5.5024 & TRN & \\
\hline CHEMBL1611989 & 688239 & 4.8362 & 5.5324 & TRN & \\
\hline CHEMBL1463725 & 688239 & 8.28399 & 999999999 & 5.6048 & TRN \\
\hline CHEMBL1316130 & 688239 & 6.4362 & 5.4554 & TRN & \\
\hline CHEMBL1333003 & 688239 & 4.45 & 5.4292 & TRN & \\
\hline CHEMBL1558201 & 688239 & 4.5362 & 5.3078 & TRN & \\
\hline CHEMBL1576402 & 688239 & 6.1862 & 5.5368 & TRN & \\
\hline CHEMBL1588007 & 688239 & 5.2362 & 5.6363 & TRN & \\
\hline CHEMBL1542634 & 688239 & 5.4362 & 5.5779 & TST & \\
\hline CHEMBL1323357 & 688239 & 5.3862 & 5.4361 & TRN & \\
\hline CHEMBL1569468 & 688239 & 4.7362 & 5.4969 & TRN & \\
\hline CHEMBL1399841 & 688239 & 4.5862 & 5.3936 & TRN & \\
\hline CHEMBL1368836 & 688239 & 6.0862 & 5.4795 & TRN & \\
\hline CHEMBL1310885 & 688239 & 4.6362 & 5.6609 & TRN & \\
\hline CHEMBL1516600 & 688239 & 4.8362 & 5.4455 & TRN & \\
\hline CHEMBL1607873 & 688239 & 5.7862 & 5.6387 & TRN & \\
\hline CHEMBL1502618 & 688239 & 5.3862 & 5.4135 & TRN & \\
\hline CHEMBL1404691 & 688239 & 7.3363 & 5.4131 & TRN & \\
\hline CHEMBL1609048 & 688239 & 4.5362 & 5.6684 & TRN & \\
\hline CHEMBL1474731 & 688239 & 4.5362 & 5.5527 & TRN & \\
\hline CHEMBL1577114 & 688239 & 5.6362 & 5.5267 & TRN & \\
\hline CHEMBL1516070 & 688239 & 5.7362 & 5.5676 & TRN & \\
\hline CHEMBL1454325 & 688239 & 5.7362 & 5.5215 & TRN & \\
\hline CHEMBL3214464 & 688239 & 6.9363 & 5.5389 & TRN & \\
\hline CHEMBL1428776 & 688239 & 4.6362 & 5.56 & TRN & \\
\hline CHEMBL1339943 & 688239 & 6.4862 & 5.4369 & TST & \\
\hline CHEMBL1596408 & 688239 & 4.4862 & 5.6216 & TRN & \\
\hline CHEMBL1326799 & 688239 & 4.6362 & 5.4173 & TRN & \\
\hline CHEMBL1351285 & 688239 & 4.5362 & 5.3618 & TRN & \\
\hline CHEMBL1509771 & 688239 & \multicolumn{3}{|c|}{8.283999999999999} & TRN \\
\hline CHEMBL1401487 & 688239 & 6.0362 & 5.5352 & TRN & \\
\hline CHEMBL1537441 & 688239 & 5.2362 & 5.5395 & TRN & \\
\hline CHEMBL1608029 & 688239 & 4.5362 & 5.5786 & TST & \\
\hline CHEMBL1607076 & 688239 & 6.6861 & 5.452999 & 9999999999 & ודו \\
\hline CHEMBL1602148 & 688239 & 6.9363 & 5.5036 & TRN & \\
\hline
\end{tabular}


Supplemental Table S2.txt

\begin{tabular}{|c|c|c|c|c|}
\hline CHEMBL1457938 & 688239 & 5.1862 & 5.348 & TST \\
\hline CHEMBL1343969 & 688239 & 5.7862 & 5.3958 & TST \\
\hline CHEMBL1340945 & 688239 & 6.6861 & 5.5707 & TRN \\
\hline CHEMBL1306184 & 688239 & 4.5362 & 5.4818 & TRN \\
\hline CHEMBL1564698 & 688239 & 7.2366 & 5.606 & TST \\
\hline CHEMBL1500570 & 688239 & 5.7862 & 5.5742 & TRN \\
\hline CHEMBL1429918 & 688239 & 6.0862 & 5.4796 & TST \\
\hline CHEMBL1463930 & 688239 & 4.7862 & 5.4455 & TST \\
\hline CHEMBL1478490 & 688239 & 4.7862 & 5.2019 & TRN \\
\hline CHEMBL1518011 & 688239 & 4.5362 & 5.4949 & TRN \\
\hline CHEMBL1303118 & 688239 & 4.5362 & 5.4421 & TST \\
\hline CHEMBL1502304 & 688239 & 6.8861 & 5.5637 & TRN \\
\hline CHEMBL1357757 & 688239 & 5.0362 & 5.3552 & TRN \\
\hline CHEMBL1318433 & 688239 & 5.5362 & 5.3999 & TRN \\
\hline CHEMBL1567337 & 688239 & 6.1362 & 5.4667 & TRN \\
\hline CHEMBL1321075 & 688239 & 5.1862 & 5.3431 & TRN \\
\hline CHEMBL1405245 & 688239 & 5.0362 & 5.45700 & 0000000001 \\
\hline CHEMBL1488887 & 688239 & 6.1362 & 5.6175 & TRN \\
\hline CHEMBL1435130 & 688239 & 4.7862 & 5.552006 & 00000000005 \\
\hline CHEMBL1402421 & 688239 & 4.5362 & 5.3939 & TRN \\
\hline CHEMBL1334619 & 688239 & 5.1862 & 5.5231 & TRN \\
\hline CHEMBL1364510 & 688239 & 4.6362 & 5.5188 & TRN \\
\hline CHEMBL1613327 & 688239 & 5.1862 & 5.4353 & TST \\
\hline CHEMBL1377485 & 688239 & 8.28399 & 79999999 & 5.4693 \\
\hline CHEMBL1426074 & 688239 & 5.6862 & 5.5837 & TRN \\
\hline CHEMBL1492659 & 688239 & 6.3863 & 5.5614 & TRN \\
\hline CHEMBL1613732 & 688239 & 4.7862 & 5.3341 & TST \\
\hline CHEMBL1481082 & 688239 & 4.5362 & 5.44 & TRN \\
\hline CHEMBL1346951 & 688239 & 6.9363 & 5.4999 & TRN \\
\hline CHEMBL1492045 & 688239 & 4.7362 & 5.4773 & TRN \\
\hline CHEMBL1582892 & 688239 & 5.4862 & 5.5013 & TRN \\
\hline CHEMBL1463482 & 688239 & 8.3372 & 5.5272 & TST \\
\hline CHEMBL1454385 & 688239 & 4.5862 & 5.4668 & TST \\
\hline CHEMBL1514657 & 688239 & 6.6362 & 5.4083 & TST \\
\hline CHEMBL1610505 & 688239 & 4.5362 & 5.5523 & TRN \\
\hline CHEMBL1491838 & 688239 & 4.8362 & 5.4748 & TRN \\
\hline CHEMBL1308456 & 688239 & 6.1862 & 5.6027 & TRN \\
\hline CHEMBL1360417 & 688239 & 5.9362 & 5.579 & TRN \\
\hline CHEMBL1567601 & 688239 & 4.4862 & 5.4426 & TST \\
\hline CHEMBL 1487838 & 688239 & 5.2362 & 5.3597 & TRN \\
\hline CHEMBL1513641 & 688239 & 4.9362 & 5.3963 & TRN \\
\hline CHEMBL1370864 & 688239 & 6.9863 & 5.4837 & TRN \\
\hline CHEMBL 303483 & 688239 & 5.1862 & 5.4567 & TRN \\
\hline CHEMBL1524249 & 688239 & 5.4862 & 5.3975 & TRN \\
\hline CHEMBL1457600 & 688239 & 4.5362 & 5.4277 & TST \\
\hline CHEMBL1495917 & 688239 & 5.7862 & 5.5897 & TST \\
\hline CHEMBL1466082 & 688239 & 5.3862 & 5.4872 & TRN \\
\hline CHEMBL1445917 & 688239 & 4.5862 & 5.528 & TRN \\
\hline
\end{tabular}


Supplemental Table S2.txt

\begin{tabular}{|c|c|c|c|c|c|}
\hline CHEMBL1426361 & 688239 & 5.1862 & 5.5057 & TRN & \\
\hline CHEMBL1343609 & 688239 & 4.5362 & 5.3506 & TST & \\
\hline CHEMBL1329474 & 688239 & 4.7362 & 5.4676 & TST & \\
\hline CHEMBL1326691 & 688239 & 4.5362 & 5.4831 & TRN & \\
\hline CHEMBL1434457 & 688239 & 4.5862 & 5.4194 & TRN & \\
\hline CHEMBL1500783 & 688239 & 6.1862 & 5.4555 & TRN & \\
\hline CHEMBL1603707 & 688239 & 5.7862 & \multicolumn{2}{|c|}{5.412000000000001} & TRN \\
\hline CHEMBL1521408 & 688239 & 4.5362 & 5.5816 & TRN & \\
\hline CHEMBL1372681 & 688239 & 5.1862 & 5.5334 & TST & \\
\hline CHEMBL1405119 & 688239 & 5.2862 & 5.3743 & TRN & \\
\hline CHEMBL1305781 & 688239 & 5.7362 & 5.4111 & TRN & \\
\hline CHEMBL1531456 & 688239 & 4.4862 & 5.5351 & TRN & \\
\hline CHEMBL1606359 & 688239 & 6.9363 & 5.4738 & TRN & \\
\hline CHEMBL1303126 & 688239 & 5.0362 & 5.5918 & TST & \\
\hline CHEMBL1562639 & 688239 & 6.3863 & 5.4364 & TRN & \\
\hline CHEMBL1255944 & 688239 & 6.7361 & 5.3251 & TST & \\
\hline CHEMBL1575981 & 688239 & 4.5362 & 5.3492 & TRN & \\
\hline CHEMBL1466029 & 688239 & 6.8861 & 5.5817 & TST & \\
\hline CHEMBL1996203 & 688239 & 4.6362 & 5.2194 & TST & \\
\hline CHEMBL1383135 & 688239 & 6.2362 & \multicolumn{2}{|c|}{5.412999999999999} & TRN \\
\hline CHEMBL1583134 & 688239 & 5.7362 & 5.6026 & TRN & \\
\hline CHEMBL1360610 & 688239 & 5.0862 & 5.3379 & TRN & \\
\hline CHEMBL1524700 & 688239 & 5.9362 & 5.4673 & TRN & \\
\hline CHEMBL1364266 & 688239 & 5.5862 & 5.6072 & TRN & \\
\hline CHEMBL1386631 & 688239 & 6.0362 & 5.4619 & TRN & \\
\hline CHEMBL1310268 & 688239 & 6.3362 & 5.5119 & TST & \\
\hline CHEMBL1386808 & 688239 & 5.1862 & 5.5144 & TRN & \\
\hline CHEMBL1560296 & 688239 & 6.2862 & 5.4169 & TRN & \\
\hline CHEMBL1484366 & 688239 & 5.3862 & \multicolumn{2}{|c|}{5.542000000000001} & TRN \\
\hline CHEMBL1341795 & 688239 & 6.2362 & 5.5028 & TRN & \\
\hline CHEMBL1320969 & 688239 & 7.1361 & 5.4306 & TRN & \\
\hline CHEMBL1538525 & 688239 & 4.5362 & 5.4743 & TST & \\
\hline CHEMBL1351575 & 688239 & 6.0362 & 5.3011 & TST & \\
\hline CHEMBL 3209430 & 688239 & 6.2362 & 5.606 & TRN & \\
\hline CHEMBL1576790 & 688239 & 4.5362 & 5.3711 & TRN & \\
\hline CHEMBL1575898 & 688239 & 5.4862 & 5.5302 & TRN & \\
\hline CHEMBL1566975 & 688239 & 4.9862 & 5.459 & TRN & \\
\hline CHEMBL1465527 & 688239 & 5.2362 & 5.4523 & TST & \\
\hline CHEMBL1500486 & 688239 & 5.5362 & 5.5006 & TRN & \\
\hline CHEMBL1444801 & 688239 & 4.5362 & 5.5463 & TRN & \\
\hline CHEMBL1377473 & 688239 & 6.3863 & 5.5146 & TRN & \\
\hline CHEMBL1424786 & 688239 & 5.4862 & 5.5438 & TRN & \\
\hline CHEMBL1547215 & 688239 & 6.5862 & 5.5559 & TST & \\
\hline CHEMBL1430959 & 688239 & 5.3862 & 5.4553 & TRN & \\
\hline CHEMBL1334148 & 688239 & 6.5862 & 5.3837 & TRN & \\
\hline CHEMBL1435180 & 688239 & 5.9362 & 5.5949 & TRN & \\
\hline CHEMBL1381436 & 688239 & 4.4362 & 5.3374 & TST & \\
\hline CHEMBL1535451 & 688239 & 5.0862 & 5.558 & TST & \\
\hline
\end{tabular}


Supplemental Table S2.txt

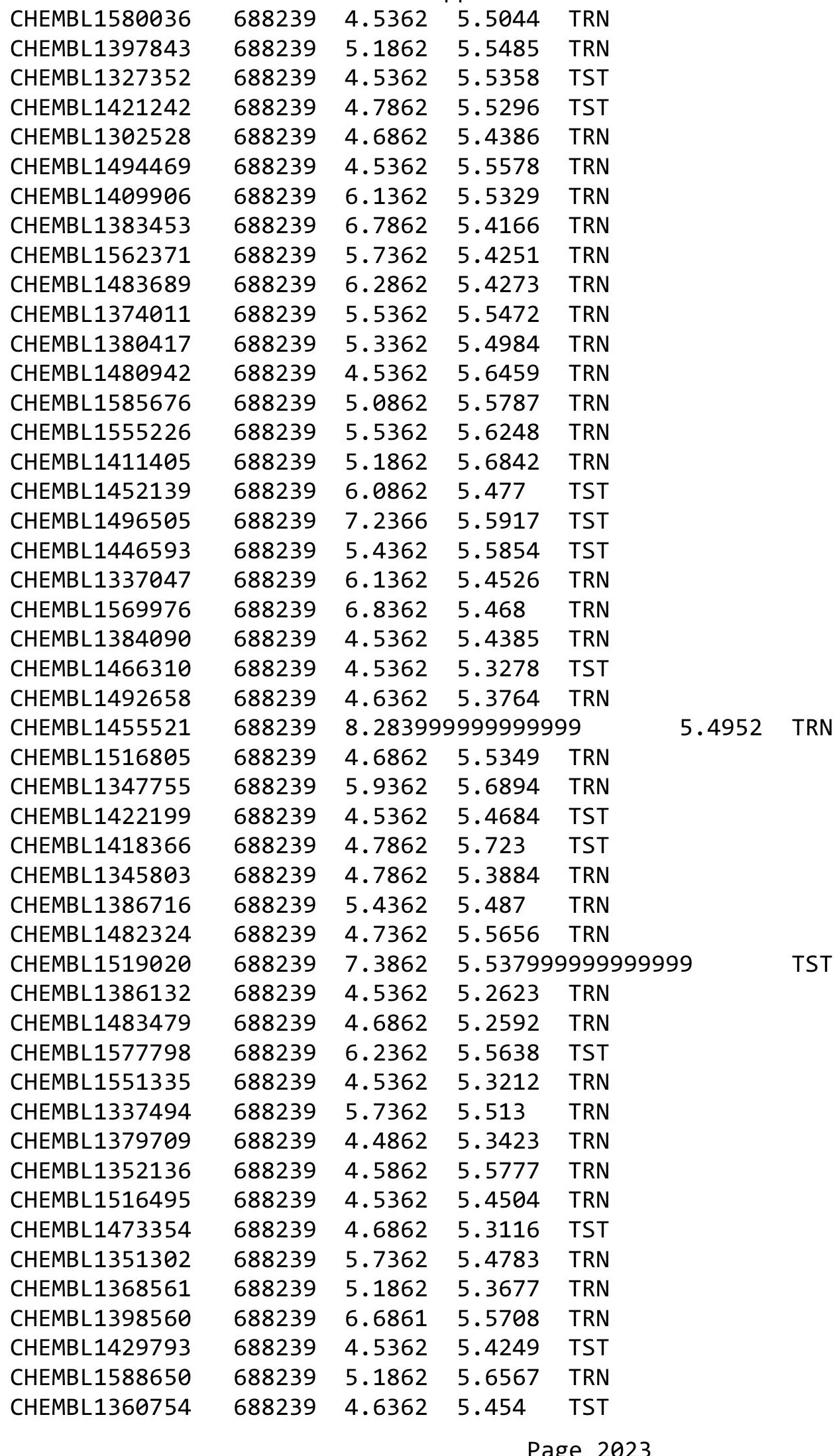


Supplemental Table S2.txt

\begin{tabular}{|c|c|c|c|c|c|}
\hline CHEMBL1591307 & 688239 & 6.9863 & 5.4336 & TRN & \\
\hline CHEMBL1367597 & 688239 & 4.8362 & 5.5733 & TRN & \\
\hline CHEMBL1374122 & 688239 & 6.1862 & 5.7169 & TST & \\
\hline CHEMBL1488840 & 688239 & 4.6362 & 5.563 & TST & \\
\hline CHEMBL1416933 & 688239 & 6.1362 & 5.5137 & TRN & \\
\hline CHEMBL1323648 & 688239 & 4.7862 & 5.4764 & TST & \\
\hline CHEMBL1416366 & 688239 & 5.1862 & 5.4242 & TRN & \\
\hline CHEMBL1384600 & 688239 & 6.2862 & 5.433 & TST & \\
\hline CHEMBL3190491 & 688239 & 4.5362 & 5.4611 & TRN & \\
\hline CHEMBL3214468 & 688239 & 6.9863 & 5.5002 & TRN & \\
\hline CHEMBL1575582 & 688239 & 4.6362 & 5.3708 & TST & \\
\hline CHEMBL1596411 & 688239 & 4.6362 & 5.5287 & TRN & \\
\hline CHEMBL1577429 & 688239 & 4.5362 & 5.379 & TRN & \\
\hline CHEMBL1301298 & 688239 & 5.1862 & 5.6884 & TRN & \\
\hline CHEMBL1463481 & 688239 & 4.5362 & 5.375 & TRN & \\
\hline CHEMBL1455701 & 688239 & 6.1362 & 5.5446 & TRN & \\
\hline CHEMBL1532232 & 688239 & 4.4862 & 5.4952 & TRN & \\
\hline CHEMBL1453230 & 688239 & 5.9362 & 5.5521 & TRN & \\
\hline CHEMBL1557722 & 688239 & 4.9362 & 5.6396 & TRN & \\
\hline CHEMBL1306669 & 688239 & 4.5862 & 5.4234 & TRN & \\
\hline CHEMBL3207643 & 688239 & 6.6861 & 5.40799 & 99999999995 & TRN \\
\hline CHEMBL1316732 & 688239 & 6.4362 & 5.4276 & TRN & \\
\hline CHEMBL1271916 & 688239 & 4.7862 & 5.3882 & TRN & \\
\hline CHEMBL1579545 & 688239 & 7.5361 & 5.5493 & TST & \\
\hline CHEMBL1494981 & 688239 & 6.4862 & 5.3472 & TST & \\
\hline CHEMBL1315256 & 688239 & 4.6862 & 5.4674 & TRN & \\
\hline CHEMBL1561874 & 688239 & 5.1362 & 5.4409 & TRN & \\
\hline CHEMBL1432803 & 688239 & 4.7362 & 5.4551 & TRN & \\
\hline CHEMBL1596838 & 688239 & 4.5362 & 5.5123 & TRN & \\
\hline CHEMBL1427953 & 688239 & 4.8862 & 5.4363 & TRN & \\
\hline CHEMBL1577354 & 688239 & 5.6362 & 5.5229 & TST & \\
\hline CHEMBL1313445 & 688239 & 5.0862 & 5.5597 & TRN & \\
\hline CHEMBL1314823 & 688239 & 4.5362 & 5.5183 & TRN & \\
\hline CHEMBL1550369 & 688239 & 6.2862 & 5.4642 & TRN & \\
\hline CHEMBL1495089 & 688239 & 5.1862 & 5.4927 & TRN & \\
\hline CHEMBL3212836 & 688239 & 4.8862 & 5.2846 & TST & \\
\hline CHEMBL3197613 & 688239 & 5.1862 & 5.4743 & TRN & \\
\hline CHEMBL1311032 & 688239 & 5.8862 & 5.5439 & TRN & \\
\hline CHEMBL1479325 & 688239 & 5.2862 & 5.6263 & TST & \\
\hline CHEMBL1385716 & 688239 & 5.2362 & 5.4824 & TRN & \\
\hline CHEMBL1407080 & 688239 & 4.5862 & 5.4899 & TST & \\
\hline CHEMBL1439629 & 688239 & 6.8861 & 5.419 & TRN & \\
\hline CHEMBL1566517 & 688239 & 4.8362 & 5.5239 & TRN & \\
\hline CHEMBL1351121 & 688239 & 6.7361 & 5.4836 & TST & \\
\hline CHEMBL1559043 & 688239 & 6.0362 & 5.6688 & TST & \\
\hline CHEMBL1454779 & 688239 & 4.5362 & 5.6098 & TRN & \\
\hline CHEMBL1360387 & 688239 & 5.4362 & 5.6417 & TRN & \\
\hline CHEMBL1505541 & 688239 & 5.3862 & 5.6471 & TRN & \\
\hline
\end{tabular}


Supplemental Table S2.txt

\begin{tabular}{|c|c|c|c|c|c|}
\hline CHEMBL1535822 & 688239 & 5.2362 & 5.5396 & TRN & \\
\hline CHEMBL1531304 & 688239 & 4.7362 & 5.5341 & TRN & \\
\hline CHEMBL1414857 & 688239 & 4.9362 & 5.439 & TST & \\
\hline CHEMBL1378888 & 688239 & 4.9862 & 5.5049 & TRN & \\
\hline CHEMBL1421464 & 688239 & 5.4362 & 5.5656 & TRN & \\
\hline CHEMBL1558192 & 688239 & 4.9362 & 5.3848 & TST & \\
\hline CHEMBL1442864 & 688239 & 5.6362 & 5.542999 & 999999999 & TST \\
\hline CHEMBL1332290 & 688239 & 4.5362 & 5.4773 & TRN & \\
\hline CHEMBL1567270 & 688239 & 5.6362 & 5.4476 & TST & \\
\hline CHEMBL1502208 & 688239 & 4.5362 & 5.4598 & TRN & \\
\hline CHEMBL1496313 & 688239 & 5.9862 & 5.4508 & TST & \\
\hline CHEMBL1408723 & 688239 & 6.4862 & 5.5794 & TRN & \\
\hline CHEMBL1406686 & 688239 & 5.2362 & 5.5426 & TST & \\
\hline CHEMBL1414013 & 688239 & 5.1362 & 5.4766 & TRN & \\
\hline CHEMBL1299715 & 688239 & 6.9363 & 5.4536 & TST & \\
\hline CHEMBL1529534 & 688239 & 5.5362 & 5.4867 & TRN & \\
\hline CHEMBL1350009 & 688239 & 4.5362 & 5.5396 & TRN & \\
\hline CHEMBL1502245 & 688239 & 6.0362 & 5.321000 & 000000001 & 151 \\
\hline CHEMBL1408924 & 688239 & 6.4862 & 5.4265 & TRN & \\
\hline CHEMBL1420384 & 688239 & 6.9863 & 5.3953 & TRN & \\
\hline CHEMBL1303578 & 688239 & 5.1862 & 5.4934 & TRN & \\
\hline CHEMBL1578943 & 688239 & 5.1362 & 5.5275 & TRN & \\
\hline CHEMBL1451970 & 688239 & 5.4862 & 5.5064 & TRN & \\
\hline CHEMBL1483847 & 688239 & 4.6862 & 5.4361 & TRN & \\
\hline CHEMBL1501649 & 688239 & 5.4862 & 5.2458 & TST & \\
\hline CHEMBL1407610 & 688239 & 4.8362 & 5.4983 & TST & \\
\hline CHEMBL1388670 & 688239 & 6.0862 & 5.3909 & TRN & \\
\hline CHEMBL1324550 & 688239 & 5.2362 & 5.4244 & TRN & \\
\hline CHEMBL1476602 & 688239 & 5.7862 & 5.4665 & TRN & \\
\hline CHEMBL1410236 & 688239 & 5.3362 & 5.5345 & TST & \\
\hline CHEMBL1506713 & 688239 & 5.4362 & 5.4562 & TST & \\
\hline CHEMBL1419765 & 688239 & 6.9863 & 5.5259 & TRN & \\
\hline CHEMBL1408894 & 688239 & 4.5362 & 5.5458 & TST & \\
\hline CHEMBL1455569 & 688239 & 6.0362 & 5.4725 & TRN & \\
\hline CHEMBL1320137 & 688239 & 5.1862 & 5.5089 & TRN & \\
\hline CHEMBL1606116 & 688239 & 4.5362 & 5.5283 & TRN & \\
\hline CHEMBL1540182 & 688239 & 5.8362 & 5.4141 & TRN & \\
\hline CHEMBL1541008 & 688239 & 8.28399 & 99999999 & 5.3614 & וב \\
\hline CHEMBL1587839 & 688239 & 5.4362 & 5.4983 & TRN & \\
\hline CHEMBL 3193694 & 688239 & 4.5362 & 5.2847 & TRN & \\
\hline CHEMBL1441339 & 688239 & 4.6362 & 5.4162 & TRN & \\
\hline CHEMBL1306127 & 688239 & 4.6362 & 5.4919 & TRN & \\
\hline CHEMBL1512718 & 688239 & 6.5862 & 5.5209 & TRN & \\
\hline CHEMBL1551117 & 688239 & 5.0862 & 5.4865 & TRN & \\
\hline CHEMBL1497516 & 688239 & 5.7362 & 5.4624 & TST & \\
\hline CHEMBL1385804 & 688239 & 4.7362 & 5.6388 & TRN & \\
\hline CHEMBL1424663 & 688239 & 7.0362 & 5.6355 & TST & \\
\hline CHEMBL1460955 & 688239 & 5.1862 & 5.5898 & TST & \\
\hline
\end{tabular}

Page 2025 
Supplemental Table S2.txt

\begin{tabular}{|c|c|c|c|c|}
\hline CHEMBL3190978 & 688239 & 5.1862 & 5.4991 & TRN \\
\hline CHEMBL1340092 & 688239 & 4.5362 & 5.5447 & TRN \\
\hline CHEMBL1422952 & 688239 & 4.4862 & 5.4409 & TRN \\
\hline CHEMBL1345664 & 688239 & 6.8362 & 5.5045 & TST \\
\hline CHEMBL1497598 & 688239 & 6.1862 & 5.4189 & TRN \\
\hline CHEMBL1426526 & 688239 & 4.4862 & \multicolumn{2}{|c|}{5.4639999999999995} \\
\hline CHEMBL1404111 & 688239 & 5.1862 & 5.5116 & TRN \\
\hline CHEMBL1613612 & 688239 & 5.9362 & 5.5685 & TST \\
\hline CHEMBL1429827 & 688239 & 6.9863 & 5.5949 & TRN \\
\hline CHEMBL1582735 & 688239 & 5.6362 & 5.6134 & TRN \\
\hline CHEMBL1510201 & 688239 & 5.1862 & 5.5929 & TRN \\
\hline CHEMBL1401578 & 688239 & 7.2366 & 5.6117 & TST \\
\hline CHEMBL1476018 & 688239 & 4.5362 & 5.473 & TST \\
\hline CHEMBL3109023 & 688239 & 4.6862 & \multirow{2}{*}{\multicolumn{2}{|c|}{5.337000000000001}} \\
\hline CHEMBL1518056 & 688239 & 5.1862 & & \\
\hline CHEMBL1410244 & 688239 & 5.3862 & 5.4034 & TRN \\
\hline CHEMBL1438626 & 688239 & 5.3862 & 5.5613 & TRN \\
\hline CHEMBL1492953 & 688239 & 6.6861 & 5.5872 & TRN \\
\hline CHEMBL1587943 & 688239 & 4.8862 & 5.5092 & TST \\
\hline CHEMBL1473419 & 688239 & 8.3372 & 5.5132 & TRN \\
\hline CHEMBL1381385 & 688239 & 5.5862 & 5.4738 & TRN \\
\hline CHEMBL1501268 & 688239 & 6.2362 & 5.6717 & TRN \\
\hline CHEMBL1534693 & 688239 & 5.9862 & 5.7742 & TRN \\
\hline CHEMBL1595284 & 688239 & 8.3372 & 5.5533 & TRN \\
\hline CHEMBL1534830 & 688239 & 5.1862 & 5.4586 & TST \\
\hline CHEMBL1440055 & 688239 & 5.5862 & 5.4951 & TST \\
\hline CHEMBL1594171 & 688239 & 5.7362 & 5.3934 & TST \\
\hline CHEMBL3211052 & 688239 & 6.3863 & 5.6401 & TST \\
\hline CHEMBL1499698 & 688239 & 4.5362 & 5.4363 & TRN \\
\hline CHEMBL1361939 & 688239 & 5.7862 & 5.4685 & TRN \\
\hline CHEMBL1350283 & 688239 & 5.1862 & 5.539 & TRN \\
\hline CHEMBL1308959 & 688239 & 4.6362 & 5.5236 & TRN \\
\hline CHEMBL1424904 & 688239 & 8.3372 & 5.6019 & TRN \\
\hline CHEMBL1424913 & 688239 & 6.6861 & 5.6813 & TRN \\
\hline CHEMBL1351024 & 688239 & 5.2362 & 5.6126 & TRN \\
\hline CHEMBL1392526 & 688239 & 5.7862 & 5.5125 & TRN \\
\hline CHEMBL1338448 & 688239 & 4.4862 & 5.5273 & TST \\
\hline CHEMBL1478212 & 688239 & 5.1862 & 5.5868 & TRN \\
\hline CHEMBL1452612 & 688239 & 4.5362 & 5.4657 & TRN \\
\hline CHEMBL1466621 & 688239 & 5.7362 & 5.4363 & TRN \\
\hline CHEMBL1409803 & 688239 & 5.7362 & 5.5657 & TRN \\
\hline CHEMBL1332298 & 688239 & 5.8362 & 5.6165 & TRN \\
\hline CHEMBL1544952 & 688239 & 4.7362 & 5.5133 & TRN \\
\hline CHEMBL1583877 & 688239 & 7.1864 & 5.5529 & TST \\
\hline CHEMBL1574227 & 688239 & 5.8862 & 5.3536 & TRN \\
\hline CHEMBL1490149 & 688239 & 7.2366 & 5.3104 & TRN \\
\hline CHEMBL1575229 & 688239 & 6.3863 & 5.473 & TST \\
\hline CHEMBL1597151 & 688239 & 4.5362 & 5.5376 & TRN \\
\hline
\end{tabular}

Page 2026 
Supplemental Table S2.txt

\begin{tabular}{|c|c|c|c|c|}
\hline CHEMBL1495010 & 688239 & 4.7862 & 5.3828 & TST \\
\hline CHEMBL547175 & 688239 & 4.9862 & 5.3782 & TRN \\
\hline CHEMBL1370908 & 688239 & 4.6362 & 5.3976 & TRN \\
\hline CHEMBL1426326 & 688239 & 4.7362 & 5.4532 & TRN \\
\hline CHEMBL1466622 & 688239 & 4.5362 & 5.4967 & TRN \\
\hline CHEMBL1458710 & 688239 & 4.5362 & 5.403 & TRN \\
\hline CHEMBL1503399 & 688239 & 5.3862 & 5.4695 & TST \\
\hline CHEMBL1471507 & 688239 & 5.1862 & 5.445 & TRN \\
\hline CHEMBL1338592 & 688239 & 8.3372 & 5.443 & TRN \\
\hline CHEMBL1373297 & 688239 & 5.0362 & 5.5684 & TRN \\
\hline CHEMBL1473367 & 688239 & 5.6362 & \multicolumn{2}{|c|}{5.486000000000001} \\
\hline CHEMBL3209159 & 688239 & 4.7862 & 5.3774 & TRN \\
\hline CHEMBL1362238 & 688239 & 4.4862 & 5.5718 & TRN \\
\hline CHEMBL1606030 & 688239 & 4.4862 & 5.5521 & TST \\
\hline CHEMBL1351782 & 688239 & 6.6861 & 5.4992 & TRN \\
\hline CHEMBL1319808 & 688239 & 5.1862 & 5.4638 & TRN \\
\hline CHEMBL1329487 & 688239 & 6.9863 & 5.3645 & TRN \\
\hline CHEMBL1468002 & 688239 & 5.3862 & 5.5306 & TRN \\
\hline CHEMBL1475329 & 688239 & 4.5862 & 5.5777 & TST \\
\hline CHEMBL1415517 & 688239 & 4.6862 & 5.6547 & TRN \\
\hline CHEMBL1418181 & 688239 & 5.1862 & 5.4973 & TRN \\
\hline CHEMBL1606811 & 688239 & 4.8862 & \multicolumn{2}{|c|}{5.417999999999999} \\
\hline CHEMBL1521150 & 688239 & 4.6862 & 5.46 & TRN \\
\hline CHEMBL1500228 & 688239 & 5.7862 & 5.6398 & TRN \\
\hline CHEMBL1351295 & 688239 & 4.7862 & 5.6072 & TRN \\
\hline CHEMBL1450850 & 688239 & 4.8862 & 5.4667 & TRN \\
\hline CHEMBL1494221 & 688239 & 4.8362 & 5.4021 & TST \\
\hline CHEMBL1314335 & 688239 & 4.7862 & 5.5279 & TST \\
\hline CHEMBL1477289 & 688239 & 6.1362 & 5.3032 & TRN \\
\hline CHEMBL1520749 & 688239 & 5.1862 & 5.4475 & TRN \\
\hline CHEMBL1581301 & 688239 & 6.0 & 5.425 & TRN \\
\hline CHEMBL1541478 & 688239 & 8.3372 & 5.4365 & TRN \\
\hline CHEMBL1558262 & 688239 & 5.9862 & \multicolumn{2}{|c|}{5.577000000000001} \\
\hline CHEMBL1437185 & 688239 & 5.1362 & 5.5143 & TST \\
\hline CHEMBL1585631 & 688239 & 5.1862 & 5.6054 & TST \\
\hline CHEMBL1304179 & 688239 & 5.5862 & 5.4196 & TRN \\
\hline CHEMBL1530335 & 688239 & 6.2862 & 5.5783 & TRN \\
\hline CHEMBL1368039 & 688239 & 4.7362 & 5.5364 & TRN \\
\hline CHEMBL1375973 & 688239 & 4.5362 & 5.5622 & TRN \\
\hline CHEMBL585804 & 688239 & 5.3362 & 5.4781 & TRN \\
\hline CHEMBL1405390 & 688239 & 8.3872 & 5.5071 & TRN \\
\hline CHEMBL1349937 & 688239 & 5.6862 & 5.4969 & TRN \\
\hline CHEMBL1428915 & 688239 & 5.3362 & 5.553 & TRN \\
\hline CHEMBL1429944 & 688239 & 5.1862 & 5.5553 & TST \\
\hline CHEMBL1484469 & 688239 & 6.9363 & 5.7158 & TRN \\
\hline CHEMBL1474892 & 688239 & 4.5362 & 5.5422 & TRN \\
\hline CHEMBL1373837 & 688239 & 5.4362 & 5.4165 & TRN \\
\hline CHEMBL3212712 & 688239 & 5.0362 & 5.4887 & TST \\
\hline
\end{tabular}


Supplemental Table S2.txt

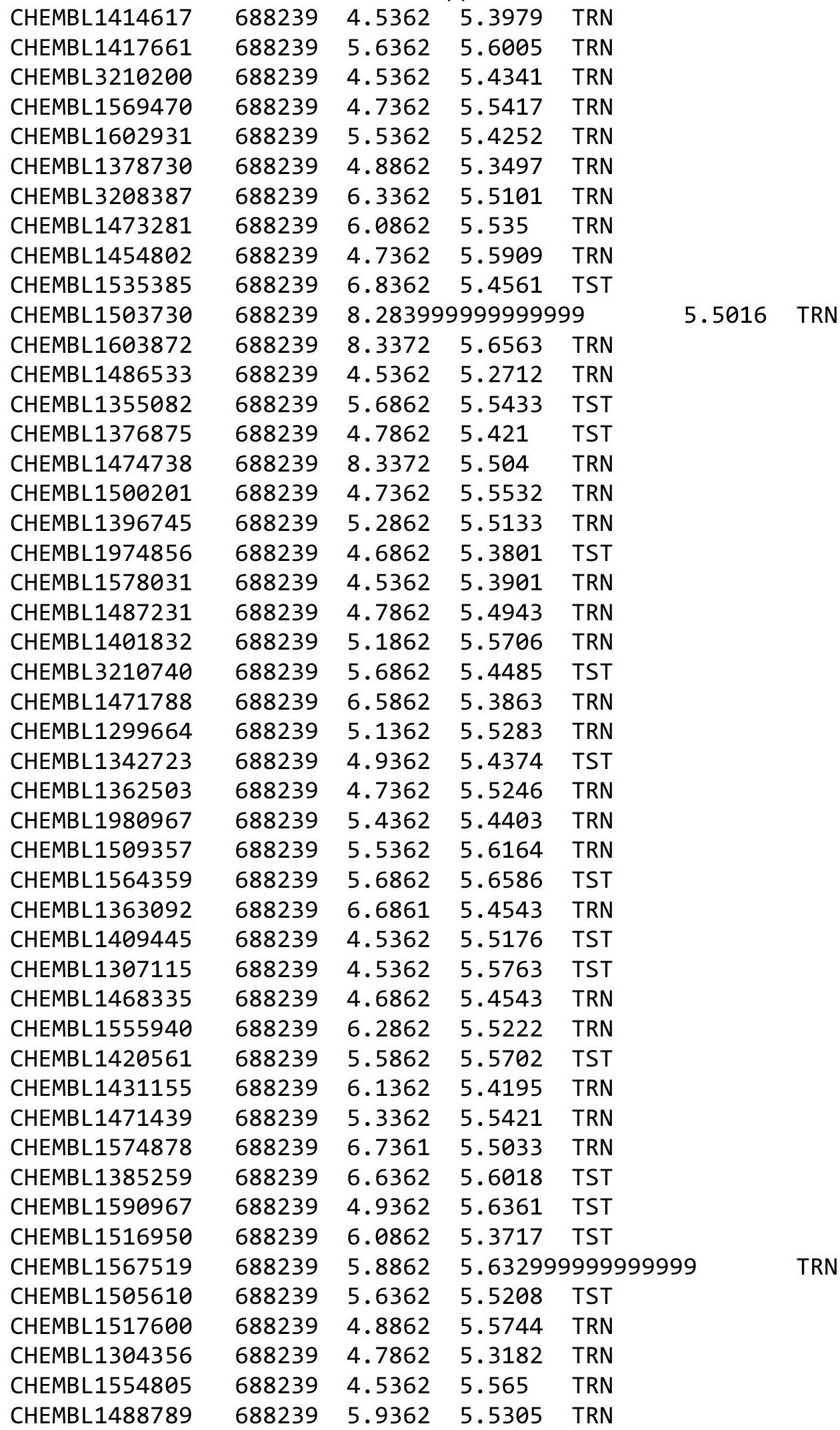


Supplemental Table S2.txt

\begin{tabular}{|c|c|c|c|c|}
\hline CHEMBL1305733 & 688239 & 6.8362 & 5.5451 & TRN \\
\hline CHEMBL1597729 & 688239 & 6.0862 & 5.4848 & TST \\
\hline CHEMBL1331890 & 688239 & 6.1862 & 5.6327 & TRN \\
\hline CHEMBL1446722 & 688239 & 5.5362 & 5.4709 & TST \\
\hline CHEMBL1308179 & 688239 & 5.1862 & \multicolumn{2}{|c|}{5.5120000000000005} \\
\hline CHEMBL1545225 & 688239 & 4.6862 & 5.2989 & TRN \\
\hline CHEMBL1551275 & 688239 & 4.5362 & 5.5058 & TRN \\
\hline CHEMBL1596771 & 688239 & 4.6862 & 5.4835 & TST \\
\hline CHEMBL1342712 & 688239 & 5.5862 & 5.4224 & TRN \\
\hline CHEMBL1441630 & 688239 & 5.0362 & 5.5229 & TRN \\
\hline CHEMBL1527585 & 688239 & 6.8861 & 5.5105 & TRN \\
\hline CHEMBL1302953 & 688239 & 4.7362 & 5.4159 & TRN \\
\hline CHEMBL1470542 & 688239 & 8.3372 & 5.3475 & TRN \\
\hline CHEMBL1373910 & 688239 & 5.6862 & 5.5138 & TRN \\
\hline CHEMBL1318767 & 688239 & 6.9363 & 5.4844 & TRN \\
\hline CHEMBL1339059 & 688239 & 6.7361 & 5.5579 & TRN \\
\hline CHEMBL1471088 & 688239 & 7.6364 & 5.3305 & TST \\
\hline CHEMBL1463825 & 688239 & 5.3862 & 5.3937 & TRN \\
\hline CHEMBL1477063 & 688239 & 7.2865 & 5.546 & TST \\
\hline CHEMBL1395690 & 688239 & 5.4862 & 5.5198 & TRN \\
\hline CHEMBL1315189 & 688239 & 5.3362 & 5.6153 & TRN \\
\hline CHEMBL1471098 & 688239 & 4.5362 & 5.5436 & TRN \\
\hline CHEMBL1316214 & 688239 & 4.5862 & 5.4883 & TRN \\
\hline CHEMBL1337840 & 688239 & 5.2362 & 5.5937 & TRN \\
\hline CHEMBL1392154 & 688239 & 4.5362 & 5.5769 & TRN \\
\hline CHEMBL1475189 & 688239 & 4.9362 & 5.471 & TRN \\
\hline CHEMBL1566000 & 688239 & 4.4862 & 5.5195 & TRN \\
\hline CHEMBL1544208 & 688239 & 4.7862 & 5.4461 & TRN \\
\hline CHEMBL1572886 & 688239 & 4.5362 & 5.5391 & TRN \\
\hline CHEMBL1561638 & 688239 & 5.2362 & 5.3818 & TRN \\
\hline CHEMBL1354217 & 688239 & 5.1862 & 5.4066 & TRN \\
\hline CHEMBL1608412 & 688239 & 5.1862 & 5.5509 & TRN \\
\hline CHEMBL3197343 & 688239 & 5.3862 & 5.3341 & TST \\
\hline CHEMBL1500359 & 688239 & 4.8362 & 5.5295 & TRN \\
\hline CHEMBL1535099 & 688239 & 4.8862 & 5.4116 & TRN \\
\hline CHEMBL1534910 & 688239 & 5.4862 & 5.4624 & TRN \\
\hline CHEMBL1453913 & 688239 & 6.4362 & 5.4762 & TST \\
\hline CHEMBL1340907 & 688239 & 7.2865 & 5.5928 & TST \\
\hline CHEMBL1456848 & 688239 & 4.7362 & 5.3803 & TRN \\
\hline CHEMBL1338285 & 688239 & 5.9362 & 5.5286 & TST \\
\hline CHEMBL1529685 & 688239 & 6.5862 & 5.4961 & TST \\
\hline CHEMBL1516013 & 688239 & 4.6862 & 5.4073 & TST \\
\hline CHEMBL1377693 & 688239 & 4.6862 & 5.5111 & TST \\
\hline CHEMBL1344717 & 688239 & 5.1862 & 5.5711 & TRN \\
\hline CHEMBL1386235 & 688239 & 5.1862 & 5.5304 & TRN \\
\hline CHEMBL1526174 & 688239 & 5.2362 & 5.3338 & TRN \\
\hline CHEMBL1495565 & 688239 & 7.2366 & 5.523 & TRN \\
\hline CHEMBL1443884 & 688239 & 4.6862 & 5.4512 & TRN \\
\hline
\end{tabular}


Supplemental Table S2.txt

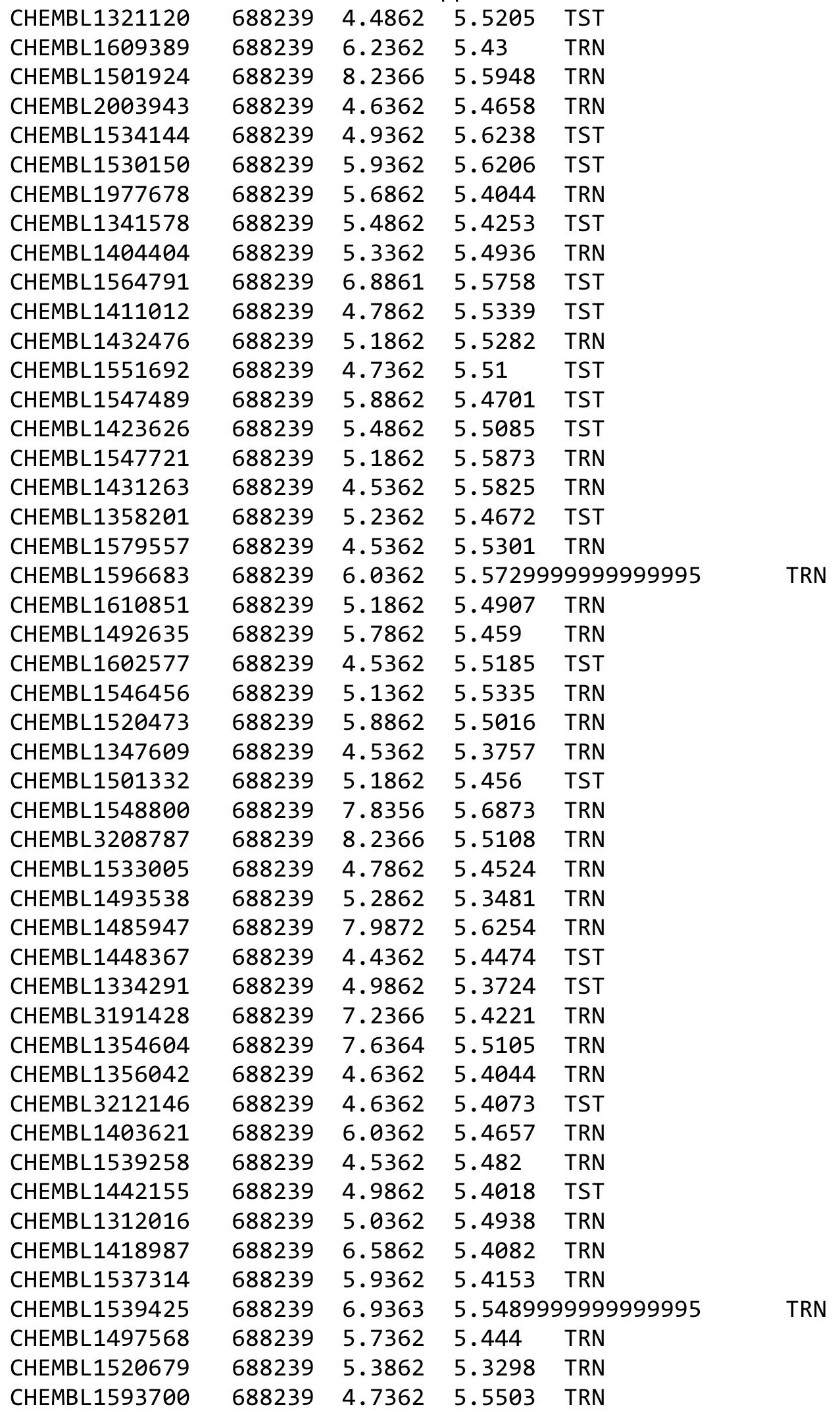

Page 2030 
Supplemental Table S2.txt

\begin{tabular}{|c|c|c|c|c|c|}
\hline CHEMBL1524662 & 688239 & 6.2362 & 5.5275 & TRN & \\
\hline CHEMBL1606194 & 688239 & 4.5362 & 5.3707 & TRN & \\
\hline CHEMBL1460265 & 688239 & 6.7361 & 5.6241 & TST & \\
\hline CHEMBL1401200 & 688239 & 4.5362 & 5.4525 & TRN & \\
\hline CHEMBL1993855 & 688239 & 5.6862 & 5.6222 & TRN & \\
\hline CHEMBL1306455 & 688239 & 4.5362 & 5.6663 & TRN & \\
\hline CHEMBL1602984 & 688239 & 6.2362 & 5.5744 & TRN & \\
\hline CHEMBL1476771 & 688239 & 5.7362 & 5.4541 & TST & \\
\hline CHEMBL1559999 & 688239 & 5.8862 & 5.516 & TST & \\
\hline CHEMBL1337580 & 688239 & 7.5867 & 5.5154 & TRN & \\
\hline CHEMBL1545543 & 688239 & 5.2362 & 5.4276 & TRN & \\
\hline CHEMBL1546775 & 688239 & 5.1862 & 5.4715 & TRN & \\
\hline CHEMBL1363462 & 688239 & 5.7362 & 5.4498 & TST & \\
\hline CHEMBL1373299 & 688239 & 5.1362 & 5.5241 & TRN & \\
\hline CHEMBL1543907 & 688239 & 5.3862 & 5.4526 & TRN & \\
\hline CHEMBL1491905 & 688239 & 6.7361 & 5.6027 & TRN & \\
\hline CHEMBL1536976 & 688239 & 4.6862 & 5.4169 & TRN & \\
\hline CHEMBL1545033 & 688239 & 6.8362 & 5.4665 & TRN & \\
\hline CHEMBL1583136 & 688239 & 5.1862 & 5.4172 & TRN & \\
\hline CHEMBL1363710 & 688239 & 5.6362 & 5.4924 & TRN & \\
\hline CHEMBL1571089 & 688239 & 5.9362 & 5.4615 & TST & \\
\hline CHEMBL1424210 & 688239 & 4.7862 & 5.4992 & TRN & \\
\hline CHEMBL1443213 & 688239 & 6.8362 & 5.4274 & TRN & \\
\hline CHEMBL1473857 & 688239 & 5.1862 & 5.548999 & 99999999995 & 10 \\
\hline CHEMBL1320829 & 688239 & 6.7862 & 5.2996 & TRN & \\
\hline CHEMBL1375026 & 688239 & 5.1362 & 5.4683 & TST & \\
\hline CHEMBL1304288 & 688239 & 5.8862 & 5.4603 & TRN & \\
\hline CHEMBL1496221 & 688239 & 5.1862 & 5.5876 & TRN & \\
\hline CHEMBL1328462 & 688239 & 6.2362 & 5.3826 & TRN & \\
\hline CHEMBL1303198 & 688239 & 5.1862 & 5.4863 & TRN & \\
\hline CHEMBL1612670 & 688239 & 5.5862 & 5.5574 & TRN & \\
\hline CHEMBL1409824 & 688239 & 5.1862 & 5.5452 & TRN & \\
\hline CHEMBL1485413 & 688239 & 5.1862 & 5.5724 & TST & \\
\hline CHEMBL1438066 & 688239 & 4.7862 & 5.5249 & TRN & \\
\hline CHEMBL1380121 & 688239 & 4.5362 & 5.3944 & TRN & \\
\hline CHEMBL1427037 & 688239 & 4.7362 & 5.4554 & TRN & \\
\hline CHEMBL1364644 & 688239 & 5.0862 & 5.4594 & TST & \\
\hline CHEMBL1351008 & 688239 & 6.3362 & 5.574 & TRN & \\
\hline CHEMBL1353577 & 688239 & 5.1862 & 5.5488 & TST & \\
\hline CHEMBL1382902 & 688239 & 4.5362 & 5.4519 & TST & \\
\hline CHEMBL1448266 & 688239 & \multicolumn{3}{|c|}{8.283999999999999} & TRN \\
\hline CHEMBL 3198323 & 688239 & 4.7862 & 5.3059 & TST & \\
\hline CHEMBL1328949 & 688239 & 5.9362 & 5.3554 & TRN & \\
\hline CHEMBL 3194383 & 688239 & 6.6362 & 5.405 & TST & \\
\hline CHEMBL1469703 & 688239 & 6.8861 & 5.6091 & TRN & \\
\hline CHEMBL1355249 & 688239 & 4.7862 & 5.516 & TRN & \\
\hline CHEMBL1312669 & 688239 & 5.2862 & 5.3733 & TST & \\
\hline CHEMBL1478888 & 688239 & 5.0862 & 5.5562 & TRN & \\
\hline
\end{tabular}

Page 2031 


\begin{tabular}{|c|c|c|c|c|c|}
\hline & & & & & \\
\hline CHEMBL1495199 & 688239 & 4.7862 & 5.4971 & TST & \\
\hline CHEMBL1363330 & 688239 & 5.1862 & 5.4847 & TRN & \\
\hline CHEMBL1328185 & 688239 & 4.5362 & 5.4309 & TRN & \\
\hline CHEMBL1401302 & 688239 & 6.0862 & 5.4808 & TST & \\
\hline CHEMBL1310066 & 688239 & 5.8862 & 5.4568 & TRN & \\
\hline CHEMBL1413917 & 688239 & 5.3862 & 5.5236 & TRN & \\
\hline CHEMBL1497082 & 688239 & 6.2862 & 5.4192 & TRN & \\
\hline CHEMBL1377216 & 688239 & 4.7862 & 5.522 & TST & \\
\hline CHEMBL1423020 & 688239 & 5.8362 & 5.444 & TRN & \\
\hline CHEMBL1453782 & 688239 & 4.6862 & 5.50799 & 9999999999 & TRN \\
\hline CHEMBL1500480 & 688239 & 4.5362 & 5.3544 & TRN & \\
\hline CHEMBL1537460 & 688239 & 6.0362 & 5.5457 & TRN & \\
\hline CHEMBL1376240 & 688239 & 5.8862 & 5.50700 & 3000000001 & TRN \\
\hline CHEMBL1341553 & 688239 & 4.5362 & 5.3604 & TRN & \\
\hline CHEMBL1426235 & 688239 & 4.5362 & 5.5612 & TRN & \\
\hline CHEMBL1481948 & 688239 & 5.4362 & 5.574 & TRN & \\
\hline CHEMBL1493341 & 688239 & 5.4862 & 5.5745 & TRN & \\
\hline CHEMBL1508207 & 688239 & 5.4862 & 5.6273 & TRN & \\
\hline CHEMBL1580055 & 688239 & 4.7362 & 5.41 & TST & \\
\hline CHEMBL1496824 & 688239 & 7.1864 & 5.4785 & TRN & \\
\hline CHEMBL1564823 & 688239 & 4.5362 & 5.4781 & TRN & \\
\hline CHEMBL 3212430 & 688239 & 5.0362 & 5.3674 & TRN & \\
\hline CHEMBL1379439 & 688239 & 4.9362 & 5.4305 & TRN & \\
\hline CHEMBL1585650 & 688239 & 4.5362 & 5.4996 & TST & \\
\hline CHEMBL3197628 & 688239 & 4.8362 & 5.4904 & TRN & \\
\hline CHEMBL1599563 & 688239 & 4.7862 & 5.4996 & TRN & \\
\hline CHEMBL1421834 & 688239 & 4.5362 & 5.7382 & TRN & \\
\hline CHEMBL1507419 & 688239 & 4.5362 & 5.455 & TST & \\
\hline CHEMBL1525512 & 688239 & 5.4862 & 5.4282 & TRN & \\
\hline CHEMBL1586537 & 688239 & 4.9362 & 5.5335 & TRN & \\
\hline CHEMBL1371709 & 688239 & 4.4862 & 5.59200 & 20000000005 & TST \\
\hline CHEMBL1420570 & 688239 & 4.7362 & 5.6316 & TRN & \\
\hline CHEMBL1383211 & 688239 & 4.9362 & 5.4936 & TRN & \\
\hline CHEMBL1479865 & 688239 & 5.3862 & 5.4721 & TST & \\
\hline CHEMBL1552770 & 688239 & 4.9362 & 5.4032 & TST & \\
\hline CHEMBL1446138 & 688239 & 4.8362 & 5.3806 & TRN & \\
\hline CHEMBL1375871 & 688239 & 4.8362 & 5.5465 & TRN & \\
\hline CHEMBL1571622 & 688239 & 6.3863 & 5.614 & TRN & \\
\hline CHEMBL1366774 & 688239 & 4.45 & 5.3683 & TRN & \\
\hline CHEMBL1994902 & 688239 & 4.5362 & 5.4657 & TST & \\
\hline CHEMBL1361369 & 688239 & 5.5862 & 5.5394 & TST & \\
\hline CHEMBL1366081 & 688239 & 5.9862 & 5.3821 & TST & \\
\hline CHEMBL1471933 & 688239 & 5.9862 & 5.4036 & TST & \\
\hline CHEMBL1567622 & 688239 & 5.1862 & 5.5904 & TRN & \\
\hline CHEMBL1551456 & 688239 & 5.1862 & 5.3619 & TRN & \\
\hline CHEMBL1585479 & 688239 & 4.5362 & 5.473 & TST & \\
\hline CHEMBL1371176 & 688239 & 4.7362 & 5.3939 & TRN & \\
\hline CHEMBL1577026 & 688239 & 5.2362 & 5.4181 & TST & \\
\hline
\end{tabular}


Supplemental Table S2.txt

\begin{tabular}{|c|c|c|c|c|c|}
\hline CHEMBL1392174 & 688239 & 5.3862 & 5.5998 & TRN & \\
\hline CHEMBL1310993 & 688239 & 5.5362 & 5.5836 & TST & \\
\hline CHEMBL1553277 & 688239 & 5.1862 & 5.4324 & TRN & \\
\hline CHEMBL1570958 & 688239 & 5.4362 & 5.5449 & TRN & \\
\hline CHEMBL1382003 & 688239 & 4.8362 & 5.4719 & TST & \\
\hline CHEMBL1560355 & 688239 & 6.3362 & 5.5177 & TST & \\
\hline CHEMBL1434740 & 688239 & 4.6362 & 5.435 & TRN & \\
\hline CHEMBL1398766 & 688239 & 5.1862 & 5.4672 & TRN & \\
\hline CHEMBL1528341 & 688239 & 6.2862 & 5.5085 & TST & \\
\hline CHEMBL1404280 & 688239 & 5.6362 & 5.5009 & TRN & \\
\hline CHEMBL1299727 & 688239 & 4.6862 & 5.5193 & TRN & \\
\hline CHEMBL578539 & 688239 & 6.8861 & 5.5815 & TRN & \\
\hline CHEMBL1366071 & 688239 & 6.1362 & 5.4444 & TST & \\
\hline CHEMBL1588265 & 688239 & 5.7362 & 5.5215 & TRN & \\
\hline CHEMBL1422813 & 688239 & 5.2362 & 5.5568 & TRN & \\
\hline CHEMBL1570163 & 688239 & 4.7862 & 5.6219 & TRN & \\
\hline CHEMBL1465804 & 688239 & 4.5362 & 5.4757 & TRN & \\
\hline CHEMBL1500623 & 688239 & 5.1362 & 5.5448 & TRN & \\
\hline CHEMBL1333850 & 688239 & 5.1862 & 5.5757 & TST & \\
\hline CHEMBL1463642 & 688239 & 6.6861 & 5.5667 & TRN & \\
\hline CHEMBL1558043 & 688239 & 6.2862 & 5.4876 & TRN & \\
\hline CHEMBL 1450525 & 688239 & 5.9862 & 5.474 & TST & \\
\hline CHEMBL1592335 & 688239 & 6.0862 & 5.5754 & TRN & \\
\hline CHEMBL1557786 & 688239 & 8.28399 & 99999999 & 9 & 5.5928 \\
\hline CHEMBL1562051 & 688239 & 5.9362 & 5.4881 & TRN & \\
\hline CHEMBL1586968 & 688239 & 6.2862 & 5.5019 & TRN & \\
\hline CHEMBL1477778 & 688239 & 4.8862 & 5.2673 & TRN & \\
\hline CHEMBL1371847 & 688239 & 4.7362 & 5.4908 & TRN & \\
\hline CHEMBL1559065 & 688239 & 4.5362 & 5.4411 & TST & \\
\hline CHEMBL1458689 & 688239 & 4.5362 & 5.4399 & TRN & \\
\hline CHEMBL1406577 & 688239 & 4.6862 & 5.4823 & TRN & \\
\hline CHEMBL1339123 & 688239 & 5.6362 & 5.4444 & TRN & \\
\hline CHEMBL1461696 & 688239 & 4.5362 & 5.6522 & TST & \\
\hline CHEMBL1341584 & 688239 & 6.0 & 5.4052 & TRN & \\
\hline CHEMBL1460515 & 688239 & 6.5862 & 5.6515 & TRN & \\
\hline CHEMBL1523966 & 688239 & 5.4862 & 5.5908 & TRN & \\
\hline CHEMBL1485377 & 688239 & 5.0862 & 5.6576 & TRN & \\
\hline CHEMBL1389185 & 688239 & 4.8362 & 5.3303 & TRN & \\
\hline CHEMBL1579769 & 688239 & 5.7362 & 5.5185 & TRN & \\
\hline CHEMBL1488436 & 688239 & 4.7362 & 5.535 & TRN & \\
\hline CHEMBL1364060 & 688239 & 4.4862 & 5.3231 & TRN & \\
\hline CHEMBL1488687 & 688239 & 4.5362 & 5.4045 & TRN & \\
\hline CHEMBL3209573 & 688239 & 5.4862 & 5.4732 & TRN & \\
\hline CHEMBL1322180 & 688239 & 4.5362 & 5.4956 & TST & \\
\hline CHEMBL1565804 & 688239 & 4.9862 & 5.544 & TRN & \\
\hline CHEMBL1385289 & 688239 & 4.5362 & 5.4402 & TST & \\
\hline CHEMBL1399323 & 688239 & 4.7862 & 5.4671 & TST & \\
\hline CHEMBL1364314 & 688239 & 5.3862 & 5.5551 & TST & \\
\hline
\end{tabular}

Page 2033 
Supplemental Table S2.txt

\begin{tabular}{|c|c|c|c|c|c|}
\hline CHEMBL1608468 & 688239 & 4.9362 & 5.4984 & TRN & \\
\hline CHEMBL1382463 & 688239 & 6.6861 & 5.4785 & TRN & \\
\hline CHEMBL123 & 688239 & 4.9362 & 5.5651 & TST & \\
\hline CHEMBL1567138 & 688239 & 5.3362 & 5.5312 & TRN & \\
\hline CHEMBL1580280 & 688239 & 4.9362 & 5.4652 & TRN & \\
\hline CHEMBL1448872 & 688239 & 4.4862 & 5.4271 & TST & \\
\hline CHEMBL1352903 & 688239 & 5.6862 & 5.2775 & TST & \\
\hline CHEMBL1487526 & 688239 & 5.3862 & 5.3839 & TRN & \\
\hline CHEMBL1475841 & 688239 & 6.6362 & 5.3882 & TRN & \\
\hline CHEMBL1412009 & 688239 & 6.2362 & 5.4975 & TST & \\
\hline CHEMBL1363614 & 688239 & 5.8862 & 5.4178 & TST & \\
\hline CHEMBL1427413 & 688239 & 4.6862 & 5.5338 & TST & \\
\hline CHEMBL1386864 & 688239 & 6.5862 & 5.3621 & TRN & \\
\hline CHEMBL1999014 & 688239 & 4.7362 & \multicolumn{2}{|c|}{5.361000000000001} & TRN \\
\hline CHEMBL1417267 & 688239 & 5.6862 & 5.5118 & TRN & \\
\hline CHEMBL1345118 & 688239 & 4.7362 & 5.438 & TST & \\
\hline CHEMBL1393615 & 688239 & 5.2362 & 5.32 & TRN & \\
\hline CHEMBL1430218 & 688239 & 5.1362 & 5.5239 & TRN & \\
\hline CHEMBL1338134 & 688239 & 4.6362 & 5.5151 & TRN & \\
\hline CHEMBL1323723 & 688239 & 6.8861 & 5.6532 & TRN & \\
\hline CHEMBL1391047 & 688239 & 4.4862 & 5.5355 & TRN & \\
\hline CHEMBL1563943 & 688239 & 6.1862 & 5.3552 & TRN & \\
\hline CHEMBL1358928 & 688239 & 5.2862 & 5.5391 & TST & \\
\hline CHEMBL1559149 & 688239 & 4.5362 & 5.4337 & TST & \\
\hline CHEMBL1595685 & 688239 & 5.2862 & 5.4242 & TRN & \\
\hline CHEMBL1561010 & 688239 & 5.1862 & 5.5989 & TRN & \\
\hline CHEMBL1466352 & 688239 & 6.5862 & 5.37 & TST & \\
\hline CHEMBL1459486 & 688239 & 4.6862 & 5.566 & TRN & \\
\hline CHEMBL1343883 & 688239 & 4.5362 & 5.4226 & TRN & \\
\hline CHEMBL1442667 & 688239 & 5.6362 & 5.5857 & TST & \\
\hline CHEMBL1507518 & 688239 & 4.7862 & 5.4796 & TRN & \\
\hline CHEMBL1337735 & 688239 & 4.5362 & 5.4158 & TST & \\
\hline CHEMBL1371177 & 688239 & 5.7362 & 5.4983 & TRN & \\
\hline CHEMBL1431407 & 688239 & 5.2362 & 5.4984 & TRN & \\
\hline CHEMBL3199651 & 688239 & 4.5362 & 5.479 & TRN & \\
\hline CHEMBL1344250 & 688239 & 4.6362 & 5.3305 & TRN & \\
\hline CHEMBL1579686 & 688239 & 6.0862 & 5.3848 & TRN & \\
\hline CHEMBL1383700 & 688239 & 4.7362 & 5.3667 & TRN & \\
\hline CHEMBL1329258 & 688239 & 5.9362 & 5.3443 & TRN & \\
\hline CHEMBL1390246 & 688239 & 5.1862 & 5.3939 & TST & \\
\hline CHEMBL1534503 & 688239 & 4.7362 & 5.3403 & TRN & \\
\hline CHEMBL1323900 & 688239 & 4.5362 & 5.2606 & TRN & \\
\hline CHEMBL1577608 & 688239 & 5.4862 & 5.4014 & TRN & \\
\hline CHEMBL1582468 & 688239 & 4.6362 & 5.6841 & TRN & \\
\hline CHEMBL1514803 & 688239 & 4.6362 & 5.59399 & 9999999999 & TRN \\
\hline CHEMBL1452459 & 688239 & 5.3862 & 5.5484 & TRN & \\
\hline CHEMBL1428944 & 688239 & 4.5362 & 5.5923 & TRN & \\
\hline \multirow[t]{2}{*}{ CHEMBL1586660 } & 688239 & 4.5862 & \multicolumn{2}{|c|}{5.537000000000001} & TRN \\
\hline & & & & ge 2034 & \\
\hline
\end{tabular}


Supplemental Table S2.txt

\begin{tabular}{|c|c|c|c|c|c|}
\hline CHEMBL1586363 & 688239 & 5.1862 & 5.5822 & TRN & \\
\hline CHEMBL1328127 & 688239 & 4.5862 & 5.4517 & TRN & \\
\hline CHEMBL1609110 & 688239 & 4.5362 & 5.3998 & TRN & \\
\hline CHEMBL1537644 & 688239 & 5.5862 & 5.5036 & TRN & \\
\hline CHEMBL1311514 & 688239 & 5.1362 & 5.5436 & TRN & \\
\hline CHEMBL1430246 & 688239 & 4.5362 & 5.5631 & TRN & \\
\hline CHEMBL1446620 & 688239 & 4.6362 & 5.4085 & TST & \\
\hline CHEMBL1403602 & 688239 & 5.8862 & 5.6495 & TST & \\
\hline CHEMBL1494590 & 688239 & 4.5362 & 5.4385 & TRN & \\
\hline CHEMBL1601204 & 688239 & 5.1362 & 5.4489 & TST & \\
\hline CHEMBL1309570 & 688239 & 5.7362 & 5.5266 & TST & \\
\hline CHEMBL1433533 & 688239 & 4.5362 & 5.5659 & TST & \\
\hline CHEMBL1483195 & 688239 & 4.5362 & 5.5119 & TRN & \\
\hline CHEMBL3193021 & 688239 & 4.7862 & 5.412000 & 0000000001 & $\mathrm{TR}$ \\
\hline CHEMBL3214324 & 688239 & 4.5362 & 5.4685 & TST & \\
\hline CHEMBL1372917 & 688239 & 4.6362 & 5.341 & TRN & \\
\hline CHEMBL1453874 & 688239 & 5.3862 & 5.6575 & TRN & \\
\hline CHEMBL1386443 & 688239 & 4.5862 & 5.4342 & TRN & \\
\hline CHEMBL1964556 & 688239 & 4.6862 & 5.5431 & TRN & \\
\hline CHEMBL1590687 & 688239 & 5.5862 & 5.4522 & TST & \\
\hline CHEMBL1509361 & 688239 & 6.2362 & 5.5408 & TRN & \\
\hline CHEMBL1427011 & 688239 & 4.7362 & 5.5176 & TRN & \\
\hline CHEMBL1536016 & 688239 & 6.0862 & 5.5078 & TRN & \\
\hline CHEMBL1537566 & 688239 & 5.3862 & 5.3957 & TRN & \\
\hline CHEMBL1430922 & 688239 & 4.5362 & 5.5499 & TRN & \\
\hline CHEMBL1551084 & 688239 & 5.1862 & 5.4107 & TRN & \\
\hline CHEMBL1324755 & 688239 & 6.8362 & 5.3437 & TRN & \\
\hline CHEMBL1499674 & 688239 & 5.2862 & 5.6029 & TRN & \\
\hline CHEMBL1449112 & 688239 & \multicolumn{2}{|c|}{8.283999999999999} & 5.3363 & $\mathrm{TR}$ \\
\hline CHEMBL1505879 & 688239 & 8.3372 & 5.4586 & TRN & \\
\hline CHEMBL1312768 & 688239 & 5.2362 & 5.5968 & TRN & \\
\hline CHEMBL1302599 & 688239 & 4.7862 & 5.4262 & TST & \\
\hline CHEMBL1334023 & 688239 & 4.6862 & 5.5105 & TRN & \\
\hline CHEMBL1383521 & 688239 & 4.8862 & 5.4491 & TRN & \\
\hline CHEMBL1419203 & 688239 & 4.7362 & \multicolumn{2}{|c|}{5.497000000000001} & TST \\
\hline CHEMBL1373193 & 688239 & 4.6862 & 5.5224 & TRN & \\
\hline CHEMBL1367555 & 688239 & 5.1862 & 5.6098 & TRN & \\
\hline CHEMBL1465454 & 688239 & 4.5862 & \multicolumn{2}{|c|}{5.547000000000001} & 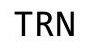 \\
\hline CHEMBL1564183 & 688239 & 5.4862 & 5.4368 & TRN & \\
\hline CHEMBL1301889 & 688239 & 4.5362 & 5.5341 & TRN & \\
\hline CHEMBL3197175 & 688239 & 4.9862 & 5.3688 & TRN & \\
\hline CHEMBL1348770 & 688239 & 6.1862 & 5.454 & TRN & \\
\hline CHEMBL3195003 & 688239 & 6.9863 & 5.5126 & TST & \\
\hline CHEMBL1517776 & 688239 & 4.5362 & 5.4024 & TST & \\
\hline CHEMBL1351062 & 688239 & 5.7862 & 5.5597 & TRN & \\
\hline CHEMBL1587585 & 688239 & 8.28399 & 999999999 & 5.6148 & In \\
\hline CHEMBL1579588 & 688239 & 4.6862 & 5.4199 & TST & \\
\hline CHEMBL1342140 & 688239 & 4.7362 & 5.4828 & TRN & \\
\hline
\end{tabular}


Supplemental Table S2.txt

\begin{tabular}{|c|c|c|c|c|c|c|}
\hline CHEMBL3213642 & 688239 & 4.9362 & 5.4824 & TRN & & \\
\hline CHEMBL1312744 & 688239 & 6.9363 & 5.55399 & 9999999999 & & TRN \\
\hline CHEMBL1388101 & 688239 & 4.7862 & 5.3892 & TRN & & \\
\hline CHEMBL1300743 & 688239 & 5.2862 & 5.5524 & TRN & & \\
\hline CHEMBL1581496 & 688239 & 6.7361 & 5.4466 & TST & & \\
\hline CHEMBL1470111 & 688239 & 4.5362 & 5.5879 & TRN & & \\
\hline CHEMBL1413383 & 688239 & 5.1862 & 5.479 & TRN & & \\
\hline CHEMBL1329882 & 688239 & 8.28399 & 99999999 & 99 & 5.4058 & TRN \\
\hline CHEMBL1532559 & 688239 & 5.4862 & 5.5217 & TRN & & \\
\hline CHEMBL1395901 & 688239 & 5.2362 & 5.4861 & TRN & & \\
\hline CHEMBL1371575 & 688239 & 5.4862 & 5.4518 & TRN & & \\
\hline CHEMBL1789989 & 688239 & 5.3862 & 5.5172 & TST & & \\
\hline CHEMBL3211369 & 688239 & 4.5362 & 5.5636 & TST & & \\
\hline CHEMBL3193762 & 688239 & 4.6862 & 5.4814 & TST & & \\
\hline CHEMBL1500789 & 688239 & 6.1862 & 5.5115 & TST & & \\
\hline CHEMBL3209112 & 688239 & 4.5362 & 5.4552 & TRN & & \\
\hline CHEMBL1440892 & 688239 & 7.5867 & 5.4501 & TST & & \\
\hline CHEMBL1451476 & 688239 & 6.8362 & 5.5232 & TRN & & \\
\hline CHEMBL1386767 & 688239 & 6.1862 & 5.5505 & TST & & \\
\hline CHEMBL3209045 & 688239 & 4.8862 & 5.44 & TST & & \\
\hline CHEMBL1521747 & 688239 & 5.2862 & 5.5294 & TRN & & \\
\hline CHEMBL1488983 & 688239 & 4.9362 & 5.3751 & TRN & & \\
\hline CHEMBL1564860 & 688239 & 4.5862 & 5.4266 & TRN & & \\
\hline CHEMBL3211750 & 688239 & 4.4862 & 5.4542 & TRN & & \\
\hline CHEMBL 1497658 & 688239 & 4.7362 & 5.3896 & TRN & & \\
\hline CHEMBL1414765 & 688239 & 4.5362 & 5.5306 & TRN & & \\
\hline CHEMBL1475690 & 688239 & 4.6362 & 5.4576 & TRN & & \\
\hline CHEMBL1451368 & 688239 & 4.5362 & 5.5278 & TRN & & \\
\hline CHEMBL1361841 & 688239 & 4.5362 & 5.6222 & TRN & & \\
\hline CHEMBL1414837 & 688239 & 5.3362 & 5.3804 & TST & & \\
\hline CHEMBL1313773 & 688239 & 4.8362 & 5.5502 & TRN & & \\
\hline CHEMBL1428324 & 688239 & 5.1862 & 5.665 & TRN & & \\
\hline CHEMBL1347126 & 688239 & 4.5362 & 5.6356 & TRN & & \\
\hline CHEMBL1318817 & 688239 & 6.0 & 5.4283 & TRN & & \\
\hline CHEMBL 1455954 & 688239 & 4.7362 & 5.3346 & TRN & & \\
\hline CHEMBL1314887 & 688239 & 6.3362 & 5.4493 & TRN & & \\
\hline CHEMBL1325968 & 688239 & 5.8362 & 5.5758 & TRN & & \\
\hline CHEMBL1368018 & 688239 & 4.7862 & 5.4131 & TRN & & \\
\hline CHEMBL1571341 & 688239 & 6.0862 & 5.4482 & TRN & & \\
\hline CHEMBL1581847 & 688239 & 4.4862 & 5.5249 & TRN & & \\
\hline CHEMBL3208237 & 688239 & 6.8362 & 5.3482 & TRN & & \\
\hline CHEMBL1343312 & 688239 & 7.1361 & 5.5092 & TRN & & \\
\hline CHEMBL1528319 & 688239 & 4.6862 & 5.337006 & 3000000001 & & TRN \\
\hline CHEMBL1516933 & 688239 & 7.5361 & 5.5523 & TRN & & \\
\hline CHEMBL1409226 & 688239 & 4.5362 & 5.5996 & TRN & & \\
\hline CHEMBL1541872 & 688239 & 5.7862 & 5.4267 & TRN & & \\
\hline CHEMBL567967 & 688239 & 5.0362 & 5.4159 & TST & & \\
\hline CHEMBL1419340 & 688239 & 5.1362 & 5.4273 & TRN & & \\
\hline
\end{tabular}




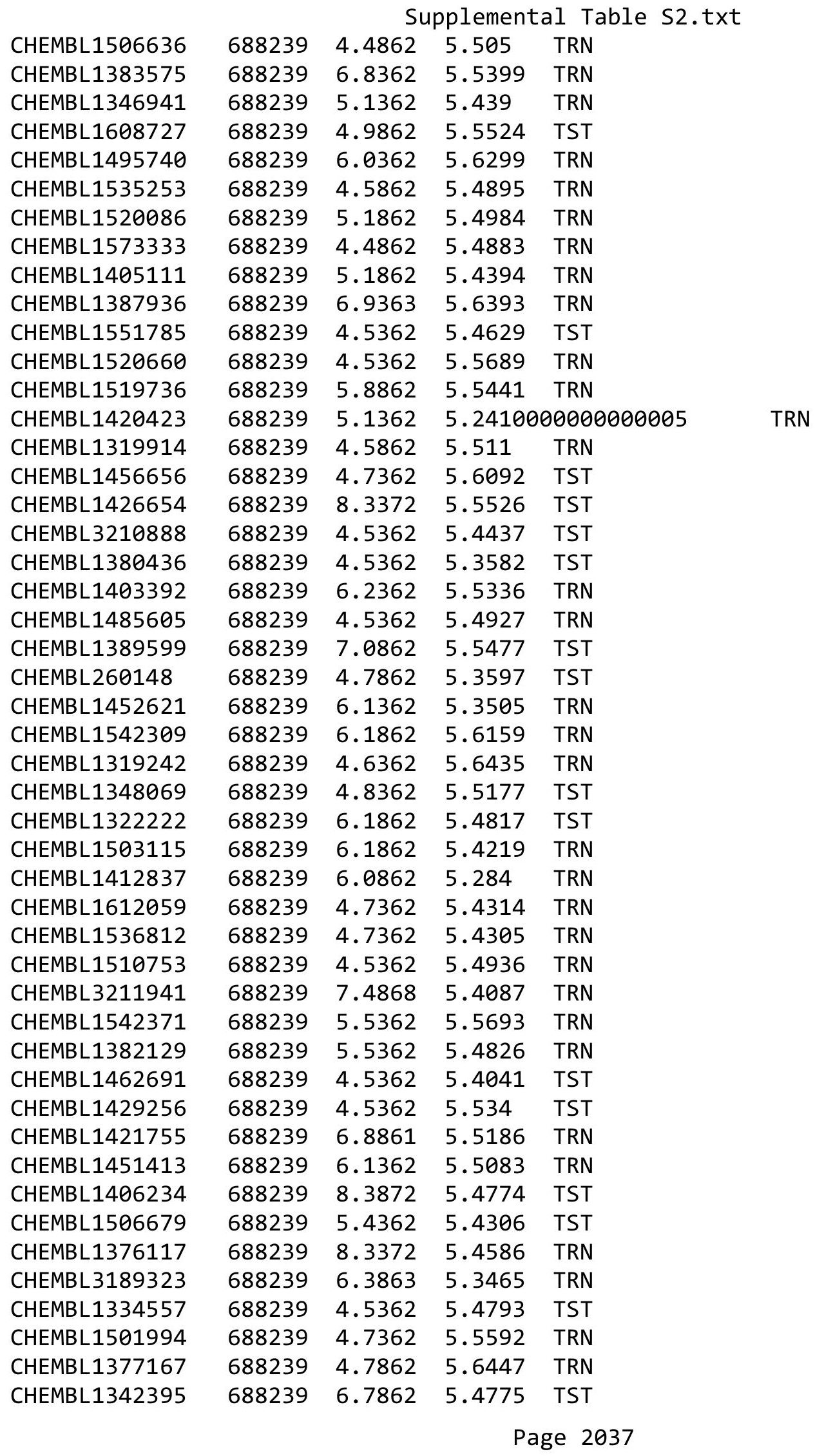


Supplemental Table S2.txt

\begin{tabular}{|c|c|c|c|c|c|}
\hline CHEMBL1346808 & 688239 & 5.9862 & 5.7046 & TRN & \\
\hline CHEMBL1429704 & 688239 & 4.5362 & 5.4859 & TRN & \\
\hline CHEMBL1307907 & 688239 & 5.5362 & 5.6363 & TST & \\
\hline CHEMBL1416412 & 688239 & 6.0862 & 5.591 & TST & \\
\hline CHEMBL1441023 & 688239 & 6.8362 & 5.4508 & TRN & \\
\hline CHEMBL1557489 & 688239 & 4.5362 & 5.4974 & TST & \\
\hline CHEMBL1383812 & 688239 & 4.7362 & 5.5882 & TST & \\
\hline CHEMBL1473694 & 688239 & 5.6862 & 5.5064 & TRN & \\
\hline CHEMBL1530218 & 688239 & 4.5362 & 5.4564 & TRN & \\
\hline CHEMBL1375565 & 688239 & 4.5362 & 5.4739 & TRN & \\
\hline CHEMBL3212166 & 688239 & 5.8362 & 5.481 & TRN & \\
\hline CHEMBL3212713 & 688239 & 4.5362 & 5.4834 & TRN & \\
\hline CHEMBL1488994 & 688239 & 6.5363 & 5.5327 & TST & \\
\hline CHEMBL1564947 & 688239 & 4.7862 & 5.5392 & TRN & \\
\hline CHEMBL1492880 & 688239 & 5.8362 & 5.4784 & TST & \\
\hline CHEMBL1500067 & 688239 & 4.5362 & 5.4497 & TRN & \\
\hline CHEMBL1488498 & 688239 & 4.5362 & 5.6429 & TRN & \\
\hline CHEMBL1353580 & 688239 & 5.1862 & 5.4146 & TST & \\
\hline CHEMBL1449511 & 688239 & 5.1862 & 5.4577 & TRN & \\
\hline CHEMBL1324781 & 688239 & 4.8862 & 5.351 & TRN & \\
\hline CHEMBL1523224 & 688239 & 4.4862 & 5.4006 & TST & \\
\hline CHEMBL1310035 & 688239 & 4.7862 & 5.5128 & TRN & \\
\hline CHEMBL1587149 & 688239 & 5.6862 & 5.4832 & TST & \\
\hline CHEMBL1442712 & 688239 & 5.4862 & 5.3813 & TRN & \\
\hline CHEMBL3211380 & 688239 & 6.8861 & 5.3395 & TST & \\
\hline CHEMBL1449991 & 688239 & 4.9862 & 5.5635 & TRN & \\
\hline CHEMBL3190856 & 688239 & 4.5362 & 5.4753 & TST & \\
\hline CHEMBL1313013 & 688239 & 4.9362 & 5.5447 & TRN & \\
\hline CHEMBL1561382 & 688239 & 4.9362 & 5.4244 & TST & \\
\hline CHEMBL1520493 & 688239 & 6.2862 & 5.5688 & TRN & \\
\hline CHEMBL1530706 & 688239 & 4.5362 & 5.4296 & TRN & \\
\hline CHEMBL1435282 & 688239 & 4.5362 & 5.5485 & TST & \\
\hline CHEMBL3211283 & 688239 & 6.4862 & 5.4145 & TRN & \\
\hline CHEMBL3211135 & 688239 & 5.1862 & \multicolumn{2}{|c|}{5.457000000000001} & TRN \\
\hline CHEMBL1494891 & 688239 & 4.6362 & 5.3201 & TRN & \\
\hline CHEMBL3208999 & 688239 & 5.2862 & 5.6316 & TRN & \\
\hline CHEMBL1588722 & 688239 & 5.1862 & 5.3582 & TRN & \\
\hline CHEMBL1577080 & 688239 & 5.5362 & 5.3885 & TST & \\
\hline CHEMBL1458855 & 688239 & 4.5862 & 5.515 & TRN & \\
\hline CHEMBL1406523 & 688239 & 4.8362 & 5.4541 & TRN & \\
\hline CHEMBL1446863 & 688239 & 4.5362 & 5.2772 & TST & \\
\hline CHEMBL1277546 & 688239 & 8.3372 & 5.374 & TST & \\
\hline CHEMBL1520533 & 688239 & 5.8362 & 5.5107 & TRN & \\
\hline CHEMBL3195783 & 688239 & 4.5362 & 5.3238 & TRN & \\
\hline CHEMBL1595826 & 688239 & 7.2366 & 5.5113 & TRN & \\
\hline CHEMBL1406705 & 688239 & 4.4862 & 5.449 & TRN & \\
\hline CHEMBL3209930 & 688239 & 5.0862 & 5.4584 & TRN & \\
\hline CHEMBL1571333 & 688239 & 5.3862 & 5.5001 & TRN & \\
\hline
\end{tabular}


Supplemental Table S2.txt

\begin{tabular}{|c|c|c|c|c|c|}
\hline CHEMBL1380859 & 688239 & 5.6362 & \multicolumn{2}{|c|}{5.712999999999999} & TRN \\
\hline CHEMBL1301713 & 688239 & 4.5362 & 5.6098 & TRN & \\
\hline CHEMBL1453196 & 688239 & 5.4862 & 5.5166 & TRN & \\
\hline CHEMBL1495125 & 688239 & 4.5362 & 5.3046 & TRN & \\
\hline CHEMBL1558525 & 688239 & 5.0362 & 5.5534 & TRN & \\
\hline CHEMBL1507533 & 688239 & 5.4362 & 5.4756 & TRN & \\
\hline CHEMBL1598640 & 688239 & 4.6362 & 5.403 & TRN & \\
\hline CHEMBL1351814 & 688239 & 6.8861 & 5.5092 & TRN & \\
\hline CHEMBL1419057 & 688239 & 6.2862 & 5.5375 & TRN & \\
\hline CHEMBL1547862 & 688239 & 6.8861 & 5.4073 & TST & \\
\hline CHEMBL1468013 & 688239 & 4.8362 & 5.45700 & 0000000001 & TRN \\
\hline CHEMBL1425193 & 688239 & 4.5862 & 5.4523 & TRN & \\
\hline CHEMBL1473905 & 688239 & 4.6862 & 5.3811 & TRN & \\
\hline CHEMBL1451470 & 688239 & 4.7362 & 5.4786 & TST & \\
\hline CHEMBL1468879 & 688239 & 4.8862 & 5.5096 & TRN & \\
\hline CHEMBL1564906 & 688239 & 5.6862 & 5.4515 & TST & \\
\hline CHEMBL1601225 & 688239 & 4.6862 & 5.3548 & TRN & \\
\hline CHEMBL1588772 & 688239 & 6.2862 & 5.5961 & TRN & \\
\hline CHEMBL1558399 & 688239 & 4.9362 & 5.5002 & TRN & \\
\hline CHEMBL1522083 & 688239 & 4.6362 & 5.2902 & TRN & \\
\hline CHEMBL1362867 & 688239 & 4.8862 & 5.4661 & TRN & \\
\hline CHEMBL3213297 & 688239 & 4.6362 & 5.6222 & TRN & \\
\hline CHEMBL3207811 & 688239 & 5.0362 & 5.4418 & TST & \\
\hline CHEMBL1595677 & 688239 & 4.8362 & 5.49700 & 0000000001 & TRN \\
\hline CHEMBL1376891 & 688239 & 6.3863 & 5.4514 & TST & \\
\hline CHEMBL1552047 & 688239 & 4.5362 & 5.40799 & 99999999995 & TRN \\
\hline CHEMBL1556529 & 688239 & 5.1862 & 5.6326 & TRN & \\
\hline CHEMBL1371571 & 688239 & 5.5862 & 5.4827 & TST & \\
\hline CHEMBL1499200 & 688239 & 4.5362 & 5.6011 & TRN & \\
\hline CHEMBL3210685 & 688239 & 5.8862 & 5.4609 & TRN & \\
\hline CHEMBL1484833 & 688239 & 6.2362 & 5.4426 & TRN & \\
\hline CHEMBL1547386 & 688239 & 4.5362 & 5.5483 & TRN & \\
\hline CHEMBL1553679 & 688239 & 4.9862 & 5.6227 & TRN & \\
\hline CHEMBL1967619 & 688239 & 5.6362 & 5.4754 & TRN & \\
\hline CHEMBL1484858 & 688239 & 4.5862 & 5.4018 & TST & \\
\hline CHEMBL1390281 & 688239 & 4.5362 & 5.7197 & TRN & \\
\hline CHEMBL1452689 & 688239 & 4.7362 & 5.6377 & TRN & \\
\hline CHEMBL1516570 & 688239 & 4.5362 & 5.5608 & TRN & \\
\hline CHEMBL1613587 & 688239 & 4.8362 & 5.4156 & TRN & \\
\hline CHEMBL1483210 & 688239 & 5.1862 & 5.4499 & TRN & \\
\hline CHEMBL1306459 & 688239 & 4.8862 & 5.5363 & TRN & \\
\hline CHEMBL1522163 & 688239 & 6.3362 & 5.5184 & TRN & \\
\hline CHEMBL1383259 & 688239 & 5.1862 & 5.2734 & TST & \\
\hline CHEMBL1457514 & 688239 & 6.1862 & 5.3858 & TRN & \\
\hline CHEMBL1496486 & 688239 & 5.3862 & 5.3432 & TRN & \\
\hline CHEMBL1465788 & 688239 & 7.2865 & 5.4788 & TST & \\
\hline CHEMBL1521936 & 688239 & 7.0862 & 5.4655 & TST & \\
\hline CHEMBL1468797 & 688239 & 5.7362 & 5.4648 & TRN & \\
\hline
\end{tabular}


Supplemental Table S2.txt

\begin{tabular}{|c|c|c|c|c|c|}
\hline CHEMBL1334495 & 688239 & 4.7862 & 5.4813 & TRN & \\
\hline CHEMBL1326748 & 688239 & 6.9863 & 5.4824 & TRN & \\
\hline CHEMBL1374200 & 688239 & 4.7362 & 5.4275 & TST & \\
\hline CHEMBL1568986 & 688239 & 5.4362 & 5.61799 & 9999999999 & TRN \\
\hline CHEMBL1468716 & 688239 & 4.5362 & 5.4621 & TRN & \\
\hline CHEMBL1305355 & 688239 & 4.5862 & 5.6352 & TRN & \\
\hline CHEMBL1571388 & 688239 & 4.4862 & 5.3875 & TRN & \\
\hline CHEMBL1514308 & 688239 & 5.3862 & 5.4289 & TRN & \\
\hline CHEMBL1534894 & 688239 & 4.8862 & 5.6115 & TRN & \\
\hline CHEMBL1549214 & 688239 & 4.5362 & 5.481 & TRN & \\
\hline CHEMBL1488438 & 688239 & 5.9862 & 5.4627 & TRN & \\
\hline CHEMBL1339092 & 688239 & 5.1862 & 5.4563 & TST & \\
\hline CHEMBL1363766 & 688239 & 4.5362 & 5.4669 & TRN & \\
\hline CHEMBL1393761 & 688239 & 4.7362 & 5.2093 & TST & \\
\hline CHEMBL1340386 & 688239 & 4.7362 & 5.334 & TRN & \\
\hline CHEMBL1444295 & 688239 & 5.1862 & 5.567 & TRN & \\
\hline CHEMBL1441562 & 688239 & 4.5362 & 5.5521 & TRN & \\
\hline CHEMBL1350876 & 688239 & 6.1362 & 5.5894 & TST & \\
\hline CHEMBL1503075 & 688239 & 4.5362 & 5.4321 & TST & \\
\hline CHEMBL1576439 & 688239 & 4.5362 & 5.5496 & TRN & \\
\hline CHEMBL1592385 & 688239 & 5.8362 & 5.5439 & TRN & \\
\hline CHEMBL1561359 & 688239 & 6.8861 & 5.5502 & TRN & \\
\hline CHEMBL1612344 & 688239 & 6.8861 & 5.3346 & TRN & \\
\hline CHEMBL1404640 & 688239 & 6.5862 & 5.6929 & TRN & \\
\hline CHEMBL 3208861 & 688239 & 4.8362 & \multicolumn{2}{|c|}{5.468999999999999} & TRN \\
\hline CHEMBL1560323 & 688239 & 4.6362 & 5.5019 & TST & \\
\hline CHEMBL1325494 & 688239 & 5.0362 & 5.5606 & TRN & \\
\hline CHEMBL1472598 & 688239 & 5.7362 & 5.5878 & TRN & \\
\hline CHEMBL1391055 & 688239 & 4.6862 & 5.371 & TRN & \\
\hline CHEMBL1429575 & 688239 & 4.7862 & 5.5825 & TST & \\
\hline CHEMBL1558567 & 688239 & 5.4862 & 5.6148 & TRN & \\
\hline CHEMBL1374688 & 688239 & 4.7362 & 5.3838 & TST & \\
\hline CHEMBL1389756 & 688239 & 6.8861 & 5.6029 & TRN & \\
\hline CHEMBL1496405 & 688239 & 6.2362 & 5.4849 & TRN & \\
\hline CHEMBL1322032 & 688239 & 4.7862 & 5.5637 & TRN & \\
\hline CHEMBL3213237 & 688239 & 7.5867 & 5.428 & TRN & \\
\hline CHEMBL 3198769 & 688239 & 4.5362 & \multicolumn{2}{|c|}{5.4510000000000005} & TST \\
\hline CHEMBL1495828 & 688239 & 5.3862 & 5.6271 & TRN & \\
\hline CHEMBL1323032 & 688239 & 8.0362 & 5.4723 & TST & \\
\hline CHEMBL1400633 & 688239 & 5.4362 & 5.3978 & TST & \\
\hline CHEMBL1510280 & 688239 & 5.6362 & 5.4414 & TST & \\
\hline CHEMBL1476166 & 688239 & 8.2366 & 5.4085 & TRN & \\
\hline CHEMBL1364982 & 688239 & 5.1862 & 5.5476 & TST & \\
\hline CHEMBL1322917 & 688239 & 5.7362 & 5.5733 & TRN & \\
\hline CHEMBL1455309 & 688239 & 4.5362 & 5.3288 & TRN & \\
\hline CHEMBL1420135 & 688239 & 4.6862 & 5.4894 & TRN & \\
\hline CHEMBL 3210576 & 688239 & 5.4862 & 5.4189 & TRN & \\
\hline CHEMBL1340330 & 688239 & 4.7362 & 5.6636 & TRN & \\
\hline
\end{tabular}


Supplemental Table S2.txt

\begin{tabular}{|c|c|c|c|c|c|}
\hline CHEMBL1441282 & 688239 & 4.5362 & 5.381 & TRN & \\
\hline CHEMBL1465510 & 688239 & 6.0362 & 5.4641 & TST & \\
\hline CHEMBL1305019 & 688239 & 8.1871 & 5.6154 & TRN & \\
\hline CHEMBL1596460 & 688239 & 6.2362 & 5.441 & TRN & \\
\hline CHEMBL1458526 & 688239 & 6.9363 & 5.4635 & TRN & \\
\hline CHEMBL1404576 & 688239 & 4.5362 & 5.5583 & TST & \\
\hline CHEMBL1490881 & 688239 & 7.0362 & 5.4905 & TST & \\
\hline CHEMBL1573713 & 688239 & 5.1862 & 5.4334 & TRN & \\
\hline CHEMBL1563038 & 688239 & 4.7362 & 5.5381 & TRN & \\
\hline CHEMBL1498050 & 688239 & 5.1862 & 5.5413 & TST & \\
\hline CHEMBL1568017 & 688239 & 5.1862 & 5.4745 & TRN & \\
\hline CHEMBL1303379 & 688239 & 4.7862 & 5.4569 & TRN & \\
\hline CHEMBL1403921 & 688239 & 5.6862 & 5.409 & TRN & \\
\hline CHEMBL1358739 & 688239 & 6.3863 & 5.5054 & TRN & \\
\hline CHEMBL1503484 & 688239 & 5.0862 & 5.3982 & TRN & \\
\hline CHEMBL1970785 & 688239 & 4.8862 & 5.3351 & TST & \\
\hline CHEMBL3194307 & 688239 & 6.9863 & 5.4532 & TRN & \\
\hline CHEMBL1610252 & 688239 & 6.9363 & 5.66799 & 9999999999 & TRN \\
\hline CHEMBL1366808 & 688239 & 4.7862 & 5.441 & TST & \\
\hline CHEMBL1335909 & 688239 & 4.6362 & 5.472 & TRN & \\
\hline CHEMBL1352856 & 688239 & 5.1862 & 5.518 & TRN & \\
\hline CHEMBL1478654 & 688239 & 6.1362 & 5.807 & TRN & \\
\hline CHEMBL1417986 & 688239 & 6.0362 & 5.4772 & TRN & \\
\hline CHEMBL1552703 & 688239 & 4.5362 & 5.38299 & 9999999999 & TRN \\
\hline CHEMBL359374 & 688239 & 6.2862 & 5.6402 & TRN & \\
\hline CHEMBL1484610 & 688239 & 5.3862 & 5.5854 & TRN & \\
\hline CHEMBL1505419 & 688239 & 5.9362 & 5.4379 & TST & \\
\hline CHEMBL1353658 & 688239 & 5.6362 & 5.4919 & TRN & \\
\hline CHEMBL1391596 & 688239 & 8.3872 & 5.4372 & TRN & \\
\hline CHEMBL1419723 & 688239 & 5.9862 & 5.4889 & TRN & \\
\hline CHEMBL1597230 & 688239 & 4.9862 & 5.4528 & TRN & \\
\hline CHEMBL1551901 & 688239 & 6.8861 & 5.357 & TRN & \\
\hline CHEMBL1333885 & 688239 & 5.8862 & 5.6352 & TST & \\
\hline CHEMBL1369504 & 688239 & 6.9363 & 5.5382 & TRN & \\
\hline CHEMBL3212518 & 688239 & 4.5862 & 5.4601 & TST & \\
\hline CHEMBL1565886 & 688239 & 7.6364 & 5.4378 & TST & \\
\hline CHEMBL1581989 & 688239 & 5.1362 & 5.4374 & TRN & \\
\hline CHEMBL1528188 & 688239 & 4.5362 & 5.4878 & TRN & \\
\hline CHEMBL1339909 & 688239 & 5.0862 & 5.4457 & TRN & \\
\hline CHEMBL1375320 & 688239 & 4.5362 & 5.4261 & TRN & \\
\hline CHEMBL1314498 & 688239 & 4.5362 & 5.6573 & TRN & \\
\hline CHEMBL1341448 & 688239 & 5.8862 & 5.6519 & TRN & \\
\hline CHEMBL1533307 & 688239 & 4.7862 & 5.5338 & TRN & \\
\hline CHEMBL1402147 & 688239 & 4.8362 & 5.4823 & TST & \\
\hline CHEMBL1403371 & 688239 & 5.1362 & 5.7059 & TRN & \\
\hline CHEMBL1469903 & 688239 & 5.6362 & 5.5983 & TRN & \\
\hline CHEMBL1428719 & 688239 & 5.6362 & 5.4138 & TST & \\
\hline CHEMBL1585107 & 688239 & 5.1862 & 5.4275 & TRN & \\
\hline
\end{tabular}


Supplemental Table S2.txt

\begin{tabular}{|c|c|c|c|c|c|}
\hline CHEMBL1469559 & 688239 & 6.0362 & 5.5554 & TRN & \\
\hline CHEMBL586870 & 688239 & 5.3362 & 5.5103 & TRN & \\
\hline CHEMBL1331781 & 688239 & 5.8362 & 5.5119 & TRN & \\
\hline CHEMBL1413133 & 688239 & 5.4862 & 5.5674 & TST & \\
\hline CHEMBL1382450 & 688239 & 5.5362 & 5.6712 & TRN & \\
\hline CHEMBL1495777 & 688239 & 5.7862 & 5.4768 & TRN & \\
\hline CHEMBL1554446 & 688239 & 4.6862 & 5.4879 & TST & \\
\hline CHEMBL1380314 & 688239 & 4.5362 & 5.5347 & TRN & \\
\hline CHEMBL1501623 & 688239 & 5.7862 & 5.4378 & TRN & \\
\hline CHEMBL 3195351 & 688239 & 4.6862 & 5.4044 & TRN & \\
\hline CHEMBL1500443 & 688239 & 6.1862 & 5.4817 & TST & \\
\hline CHEMBL1455494 & 688239 & 5.1862 & 5.4875 & TRN & \\
\hline CHEMBL1503122 & 688239 & 4.7862 & 5.5503 & TRN & \\
\hline CHEMBL1422658 & 688239 & 6.2362 & 5.51 & TST & \\
\hline CHEMBL1359278 & 688239 & 6.3362 & 5.4319 & TRN & \\
\hline CHEMBL1580751 & 688239 & 8.28399 & 999999999 & 5.3158 & TRN \\
\hline CHEMBL1358324 & 688239 & 6.2362 & \multicolumn{2}{|c|}{5.468999999999999} & TST \\
\hline CHEMBL1600899 & 688239 & 4.7862 & 5.5019 & TRN & \\
\hline CHEMBL1612340 & 688239 & 5.4362 & 5.5783 & TST & \\
\hline CHEMBL1562329 & 688239 & 5.2362 & 5.6153 & TRN & \\
\hline CHEMBL1394701 & 688239 & 6.5363 & 5.5175 & TRN & \\
\hline CHEMBL1346743 & 688239 & 6.1362 & 5.4679 & TRN & \\
\hline CHEMBL1412589 & 688239 & 4.5362 & 5.5248 & TRN & \\
\hline CHEMBL1530581 & 688239 & 5.2862 & 5.5455 & TRN & \\
\hline CHEMBL1441032 & 688239 & 4.4862 & 5.407 & TRN & \\
\hline CHEMBL1594510 & 688239 & 4.7862 & 5.4289 & TRN & \\
\hline CHEMBL1419049 & 688239 & 5.4862 & 5.4344 & TST & \\
\hline CHEMBL1514991 & 688239 & 5.4362 & 5.4761 & TRN & \\
\hline CHEMBL1460853 & 688239 & 6.4362 & 5.5754 & TRN & \\
\hline CHEMBL 3198941 & 688239 & 4.9362 & 5.4296 & TRN & \\
\hline CHEMBL1539531 & 688239 & 5.8862 & 5.6333 & TRN & \\
\hline CHEMBL1371872 & 688239 & 4.6362 & 5.5503 & TRN & \\
\hline CHEMBL1531783 & 688239 & 4.5362 & 5.528 & TRN & \\
\hline CHEMBL1339615 & 688239 & 4.7362 & 5.5049 & TST & \\
\hline CHEMBL1505730 & 688239 & 6.1362 & 5.4337 & TRN & \\
\hline CHEMBL1367964 & 688239 & 6.3362 & 5.56 & TST & \\
\hline CHEMBL1374454 & 688239 & 4.6862 & 5.5024 & TRN & \\
\hline CHEMBL1496445 & 688239 & 6.3362 & 5.343999 & 9999999999 & TRN \\
\hline CHEMBL1477088 & 688239 & 7.7852 & 5.4522 & TRN & \\
\hline CHEMBL1436929 & 688239 & 4.5362 & 5.5331 & TRN & \\
\hline CHEMBL1381340 & 688239 & 5.7362 & 5.489 & TST & \\
\hline CHEMBL1579754 & 688239 & 7.9872 & 5.3049 & TRN & \\
\hline CHEMBL1467219 & 688239 & 4.4862 & 5.5376 & TRN & \\
\hline CHEMBL1604802 & 688239 & 5.9362 & 5.4366 & TST & \\
\hline CHEMBL1495057 & 688239 & 7.4868 & 5.3462 & TRN & \\
\hline CHEMBL1426701 & 688239 & 5.2362 & 5.387000 & 30000000005 & TRN \\
\hline CHEMBL1421101 & 688239 & 5.0862 & 5.5618 & TRN & \\
\hline CHEMBL1449309 & 688239 & 6.0362 & 5.5747 & TRN & \\
\hline
\end{tabular}


Supplemental Table S2.txt

\begin{tabular}{|c|c|c|c|c|}
\hline CHEMBL1360614 & 688239 & 5.1862 & 5.4974 & TRN \\
\hline CHEMBL1471738 & 688239 & 5.8862 & 5.7072 & TRN \\
\hline CHEMBL1467095 & 688239 & 5.5862 & 5.4526 & TRN \\
\hline CHEMBL1479520 & 688239 & 4.9862 & \multicolumn{2}{|c|}{5.287000000000001} \\
\hline CHEMBL1422638 & 688239 & 5.6362 & 5.5834 & TRN \\
\hline CHEMBL1396882 & 688239 & 4.5862 & 5.5556 & TRN \\
\hline CHEMBL1345653 & 688239 & 6.9363 & 5.6001 & TST \\
\hline CHEMBL1364224 & 688239 & 5.1862 & 5.4298 & TRN \\
\hline CHEMBL1443437 & 688239 & 7.0862 & 5.5538 & TRN \\
\hline CHEMBL1550041 & 688239 & 5.6362 & 5.4391 & TRN \\
\hline CHEMBL1312535 & 688239 & 6.7361 & 5.5832 & TST \\
\hline CHEMBL1571719 & 688239 & 5.3362 & 5.4826 & TRN \\
\hline CHEMBL1345370 & 688239 & 4.8862 & 5.5692 & TST \\
\hline CHEMBL1504285 & 688239 & 6.2362 & 5.561 & TRN \\
\hline CHEMBL1418231 & 688239 & 6.3362 & 5.6111 & TST \\
\hline CHEMBL1430059 & 688239 & 4.7362 & 5.3898 & TRN \\
\hline CHEMBL1353703 & 688239 & 8.1367 & 5.3932 & TST \\
\hline CHEMBL1363720 & 688239 & 5.3362 & 5.4404 & TRN \\
\hline CHEMBL1561627 & 688239 & 4.9862 & 5.485 & TRN \\
\hline CHEMBL1305989 & 688239 & 6.0862 & 5.4875 & TST \\
\hline CHEMBL1380681 & 688239 & 4.4862 & 5.4974 & TRN \\
\hline CHEMBL408636 & 688239 & 5.1862 & 5.5622 & TRN \\
\hline CHEMBL1472513 & 688239 & 5.0862 & 5.506 & TRN \\
\hline CHEMBL1450233 & 688239 & 6.8362 & 5.529 & TRN \\
\hline CHEMBL1390384 & 688239 & 4.5362 & 5.3564 & TST \\
\hline CHEMBL1361171 & 688239 & 4.4862 & 5.4707 & TRN \\
\hline CHEMBL1408592 & 688239 & 6.8362 & 5.4686 & TRN \\
\hline CHEMBL1415437 & 688239 & 4.5862 & 5.5095 & TST \\
\hline CHEMBL1300740 & 688239 & 5.1862 & 5.5258 & TRN \\
\hline CHEMBL1351750 & 688239 & 4.7862 & 5.2563 & TRN \\
\hline CHEMBL1483161 & 688239 & 4.6362 & 5.376 & TST \\
\hline CHEMBL1504210 & 688239 & 5.5862 & 5.4191 & TRN \\
\hline CHEMBL1313482 & 688239 & 4.5362 & 5.3985 & TRN \\
\hline CHEMBL1326897 & 688239 & 4.5362 & 5.4153 & TST \\
\hline CHEMBL1311052 & 688239 & 4.7862 & 5.3234 & TRN \\
\hline CHEMBL3208491 & 688239 & 5.1862 & 5.3218 & TST \\
\hline CHEMBL1506743 & 688239 & 5.7862 & 5.4749 & TRN \\
\hline CHEMBL252901 & 688239 & 6.1862 & 5.5763 & TRN \\
\hline CHEMBL1322077 & 688239 & 5.1862 & 5.3132 & TRN \\
\hline CHEMBL3214235 & 688239 & 5.1362 & 5.3927 & TRN \\
\hline CHEMBL223453 & 688239 & 4.7362 & 5.2247 & TRN \\
\hline CHEMBL1299565 & 688239 & 4.5362 & 5.5027 & TST \\
\hline CHEMBL1534374 & 688239 & 5.1862 & 5.5099 & TRN \\
\hline CHEMBL1607858 & 688239 & 6.0362 & 5.5431 & TRN \\
\hline CHEMBL1361740 & 688239 & 5.6362 & 5.5682 & TST \\
\hline CHEMBL1557827 & 688239 & 4.7362 & 5.5807 & TRN \\
\hline CHEMBL1403420 & 688239 & 4.5362 & 5.3315 & TRN \\
\hline CHEMBL1599337 & 688239 & 5.9362 & 5.6679 & TRN \\
\hline
\end{tabular}


Supplemental Table S2.txt

\begin{tabular}{|c|c|c|c|c|}
\hline 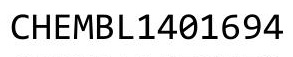 & & & & \\
\hline HEMBL1578472 & 88239 & 1362 & 59 & \\
\hline HEMBL1487472 & 88239 & 1862 & & \\
\hline IEMBL28324 & & 862 & 4353 & \\
\hline IEMBL16 & & 862 & 3564 & \\
\hline HEMBL1362838 & 88239 & 362 & 4759 & \\
\hline HEMBL1476068 & 88239 & .7862 & .5606 & \\
\hline HEMBL151 & & 862 & & \\
\hline IEMBL1 & 39 & 863 & .551 & \\
\hline IEMBL13 & 39 & 862 & 531 & \\
\hline HEMBL1388695 & 88239 & .6862 & 3993 & \\
\hline HEMBL1310452 & 39 & .2362 & .5137 & \\
\hline HEMBL 227 & 39 & 861 & 5581 & \\
\hline AEMBL1C & 39 & 862 & 953 & \\
\hline AEMBL13 & 39 & 362 & & \\
\hline HEMBL137 & 39 & 862 & 5166 & \\
\hline HEMBL138 & 39 & 362 & & \\
\hline HEMBL153 & 9 & 52 & 47 & \\
\hline HEM & 39 & & & \\
\hline AEMBL14 & 39 & 862 & 252 & \\
\hline HEMBL13 & 39 & 862 & & \\
\hline HEMBL155 & 39 & & 41 & \\
\hline HEMBL14 & 39 & 62 & 26 & \\
\hline HEMBL 14 & & & & RIV \\
\hline HEME & & 62 & & RN \\
\hline HEMBL15 & 39 & 862 & & RIN \\
\hline HEMBL137 & 39 & 862 & & SI \\
\hline HEMBL14 & 9 & 862 & & RN \\
\hline HEME & 9 & 52 & & KIV \\
\hline HEM & & 62 & 31 & RN \\
\hline HEMBL 146 & 9 & 62 & & IST \\
\hline HEMBL152 & 39 & 862 & 86 & TRN \\
\hline HEMBL1C & & 62 & & וכ וכ \\
\hline 5 & 9 & & & RN \\
\hline HEMBL137 & & & 5.5819 & $\mathrm{RN}$ \\
\hline HEMBL151 & 39 & 862 & & RN \\
\hline HEMBL157 & 39 & 862 & 5.5471 & RN \\
\hline 0 & 39 & 52 & 51 & RN \\
\hline ז1 & & 52 & 54 & RIN \\
\hline HEMBL13 & & & 193 & ST \\
\hline HEMBL130 & 39 & 862 & 5.5012 & ST \\
\hline HEMBL153 & 39 & 372 & 731 & RN \\
\hline 74 & & & 5.3989 & \\
\hline LHEMBL136 & 39 & 362 & .4396 & RN \\
\hline HEMBL1327402 & & .5362 & .4521 & RN \\
\hline HEMBL 319 & 88 & 862 & 5.4669 & $\mathrm{~N}$ \\
\hline L15 & & & & \\
\hline 19 & & & & \\
\hline
\end{tabular}

Page 2044 
Supplemental Table S2.txt

\begin{tabular}{|c|c|c|c|c|}
\hline CHEMBL3196320 & 688239 & 6.3362 & 5.3562 & TST \\
\hline CHEMBL1301135 & 688239 & 4.4862 & 5.5251 & TRN \\
\hline CHEMBL1487365 & 688239 & 6.1362 & 5.4812 & TRN \\
\hline CHEMBL1524119 & 688239 & 4.9862 & 5.2768 & TRN \\
\hline CHEMBL3211767 & 688239 & 4.4862 & 5.5484 & TST \\
\hline CHEMBL1507296 & 688239 & 6.8362 & 5.6203 & TRN \\
\hline CHEMBL1413241 & 688239 & 5.3362 & 5.5859 & TST \\
\hline CHEMBL1423613 & 688239 & 5.1862 & 5.5854 & TST \\
\hline CHEMBL1549164 & 688239 & 5.0862 & 5.5647 & TRN \\
\hline CHEMBL1404652 & 688239 & 8.3372 & 5.5341 & TRN \\
\hline CHEMBL1537831 & 688239 & 5.2862 & 5.2942 & TRN \\
\hline CHEMBL1528029 & 688239 & 5.5862 & 5.3924 & TRN \\
\hline CHEMBL3145281 & 688239 & 4.4862 & 5.4538 & TST \\
\hline CHEMBL1471940 & 688239 & 4.9362 & 5.4606 & TRN \\
\hline CHEMBL1498284 & 688239 & 4.5362 & 5.5413 & TST \\
\hline CHEMBL3207369 & 688239 & 5.4862 & 5.4693 & TRN \\
\hline CHEMBL1456857 & 688239 & 4.7362 & 5.556 & TRN \\
\hline CHEMBL1565194 & 688239 & 4.7862 & 5.5849 & TST \\
\hline CHEMBL1314237 & 688239 & 4.5362 & 5.4655 & TRN \\
\hline CHEMBL1428800 & 688239 & 5.1362 & 5.5104 & TRN \\
\hline CHEMBL1597952 & 688239 & 4.5362 & 5.5456 & TRN \\
\hline CHEMBL1321819 & 688239 & 6.1862 & 5.4999 & TRN \\
\hline CHEMBL1375452 & 688239 & 4.6362 & 5.3769 & TST \\
\hline CHEMBL1453383 & 688239 & 5.7362 & 5.3913 & TST \\
\hline CHEMBL1548150 & 688239 & 6.7862 & 5.4095 & TST \\
\hline CHEMBL1343877 & 688239 & 7.2366 & 5.4331 & TST \\
\hline CHEMBL3210540 & 688239 & 4.8862 & 5.4013 & TRN \\
\hline CHEMBL1572510 & 688239 & 6.6362 & 5.6267 & TRN \\
\hline CHEMBL1453974 & 688239 & 7.5867 & 5.2804 & TRN \\
\hline CHEMBL1338878 & 688239 & 6.8861 & 5.4571 & TRN \\
\hline CHEMBL1311779 & 688239 & 5.6362 & 5.4813 & TRN \\
\hline CHEMBL1561144 & 688239 & 4.6362 & 5.502000 & 000000001 \\
\hline CHEMBL1455375 & 688239 & 4.7362 & 5.4996 & TST \\
\hline CHEMBL1600639 & 688239 & 4.4862 & 5.4174 & TST \\
\hline CHEMBL1310673 & 688239 & 4.8362 & 5.4606 & TRN \\
\hline CHEMBL1528868 & 688239 & 5.3362 & 5.5598 & TRN \\
\hline CHEMBL1441974 & 688239 & 4.5862 & 5.5817 & TST \\
\hline CHEMBL1562366 & 688239 & 8.28399 & 99999999 & 5.5286 \\
\hline CHEMBL1403186 & 688239 & 5.0862 & 5.5679 & TRN \\
\hline CHEMBL1449790 & 688239 & 5.1362 & 5.3995 & TRN \\
\hline CHEMBL1305557 & 688239 & 4.5362 & 5.5083 & TRN \\
\hline CHEMBL1573810 & 688239 & 6.8861 & 5.6148 & TRN \\
\hline CHEMBL1499546 & 688239 & 6.3362 & 5.4913 & TRN \\
\hline CHEMBL1544097 & 688239 & 4.7862 & 5.2137 & TST \\
\hline CHEMBL1377159 & 688239 & 6.4362 & 5.3868 & TST \\
\hline CHEMBL1565205 & 688239 & 5.7362 & 5.4355 & TRN \\
\hline CHEMBL3213373 & 688239 & 7.0862 & 5.5679 & TRN \\
\hline CHEMBL1495527 & 688239 & 4.5862 & 5.3786 & TRN \\
\hline
\end{tabular}


Supplemental Table S2.txt

\begin{tabular}{|c|c|c|c|c|c|c|}
\hline CHEMBL1979948 & 688239 & 6.8362 & 5.4209 & TRN & & \\
\hline CHEMBL1306124 & 688239 & 6.9363 & 5.4112 & TRN & & \\
\hline CHEMBL1303589 & 688239 & 6.3863 & 5.3744 & TRN & & \\
\hline CHEMBL1480429 & 688239 & 6.3863 & 5.6707 & TRN & & \\
\hline CHEMBL3193181 & 688239 & 6.0862 & 5.5077 & TST & & \\
\hline CHEMBL1492461 & 688239 & 4.5862 & 5.4508 & TRN & & \\
\hline CHEMBL1304613 & 688239 & 5.5362 & 5.45 & TRN & & \\
\hline CHEMBL1370027 & 688239 & 4.6862 & 5.4444 & TRN & & \\
\hline CHEMBL1375776 & 688239 & 6.1862 & 5.5552 & TRN & & \\
\hline CHEMBL1350629 & 688239 & 6.1862 & 5.6178 & TRN & & \\
\hline CHEMBL1329662 & 688239 & 4.5362 & 5.4039 & TRN & & \\
\hline CHEMBL3195175 & 688239 & 5.4362 & 5.3574 & TRN & & \\
\hline CHEMBL1489644 & 688239 & 8.28399 & 99999999 & & 5.6363 & TRN \\
\hline CHEMBL1316384 & 688239 & 5.7362 & 5.3901 & TRN & & \\
\hline CHEMBL1416604 & 688239 & 4.8362 & 5.6124 & TRN & & \\
\hline CHEMBL1340763 & 688239 & 5.8362 & 5.5011 & TRN & & \\
\hline CHEMBL1452505 & 688239 & 6.6362 & 5.4039 & TRN & & \\
\hline CHEMBL1315770 & 688239 & 4.6362 & 5.3712 & TRN & & \\
\hline CHEMBL1331276 & 688239 & 5.1862 & 5.4833 & TRN & & \\
\hline CHEMBL1398317 & 688239 & 4.6362 & 5.4056 & TRN & & \\
\hline CHEMBL1327195 & 688239 & 4.5362 & 5.5023 & TST & & \\
\hline CHEMBL1607179 & 688239 & 4.7862 & 5.6322 & TRN & & \\
\hline CHEMBL1577664 & 688239 & 8.3372 & 5.4914 & TRN & & \\
\hline CHEMBL1530941 & 688239 & 7.0862 & 5.5764 & TST & & \\
\hline CHEMBL1373645 & 688239 & 4.5862 & 5.4723 & TRN & & \\
\hline CHEMBL1316331 & 688239 & 8.1871 & 5.4802 & TRN & & \\
\hline CHEMBL1350229 & 688239 & 5.1362 & 5.5016 & TRN & & \\
\hline CHEMBL1330661 & 688239 & 4.6862 & 5.5322 & TRN & & \\
\hline CHEMBL1524610 & 688239 & 4.5862 & 5.4528 & TRN & & \\
\hline CHEMBL1599202 & 688239 & 4.5362 & 5.3358 & TST & & \\
\hline CHEMBL1609960 & 688239 & 6.9363 & 5.4783 & TST & & \\
\hline CHEMBL441370 & 688239 & 6.7862 & 5.4945 & TST & & \\
\hline CHEMBL1981093 & 688239 & 5.5362 & 5.3823 & TST & & \\
\hline CHEMBL3212538 & 688239 & 6.1862 & 5.5875 & TRN & & \\
\hline CHEMBL1305679 & 688239 & 4.5362 & 5.5479 & TRN & & \\
\hline CHEMBL1549704 & 688239 & 5.5862 & 5.3718 & TRN & & \\
\hline CHEMBL1504646 & 688239 & 4.9862 & 5.6263 & TRN & & \\
\hline CHEMBL1539713 & 688239 & 4.6862 & 5.5103 & TST & & \\
\hline CHEMBL1411635 & 688239 & 8.28399 & 99999999 & 9 & 5.525 & I RI \\
\hline CHEMBL1539281 & 688239 & 6.0362 & 5.4605 & TRN & & \\
\hline CHEMBL1309298 & 688239 & 6.1862 & 5.4533 & TRN & & \\
\hline CHEMBL3193185 & 688239 & 8.2366 & 5.5379 & TST & & \\
\hline CHEMBL1375079 & 688239 & 4.5362 & 5.5357 & TRN & & \\
\hline CHEMBL1350780 & 688239 & 4.7362 & 5.3881 & TRN & & \\
\hline CHEMBL1577400 & 688239 & 5.4362 & 5.6613 & TRN & & \\
\hline CHEMBL1349531 & 688239 & 6.8861 & 5.5682 & TRN & & \\
\hline CHEMBL1525768 & 688239 & 5.1862 & 5.3608 & TRN & & \\
\hline CHEMBL1400627 & 688239 & 5.3862 & 5.4919 & TRN & & \\
\hline
\end{tabular}


Supplemental Table S2.txt

\begin{tabular}{|c|c|c|c|c|}
\hline CHEMBL1418752 & 688239 & 6.0862 & 5.4072 & TRN \\
\hline CHEMBL1383452 & 688239 & 5.3362 & 5.6305 & TRN \\
\hline CHEMBL1578982 & 688239 & 6.8861 & 5.3567 & TST \\
\hline CHEMBL1461995 & 688239 & 6.1362 & 5.5625 & TRN \\
\hline CHEMBL1518053 & 688239 & 6.9863 & 5.4274 & TST \\
\hline CHEMBL1571789 & 688239 & 6.1862 & 5.4844 & TRN \\
\hline CHEMBL1577127 & 688239 & 4.8862 & 5.5002 & TRN \\
\hline CHEMBL1329844 & 688239 & 5.3862 & 5.5374 & TRN \\
\hline CHEMBL1485602 & 688239 & 5.1362 & 5.4818 & TST \\
\hline CHEMBL1569327 & 688239 & 7.2366 & 5.6237 & TST \\
\hline CHEMBL1323487 & 688239 & 5.2362 & 5.6009 & TRN \\
\hline CHEMBL1464558 & 688239 & 6.2862 & 5.5487 & TRN \\
\hline CHEMBL1413424 & 688239 & 4.4862 & 5.4976 & TRN \\
\hline CHEMBL1338001 & 688239 & 7.1864 & 5.5522 & TRN \\
\hline CHEMBL1350049 & 688239 & 5.4862 & 5.6228 & TRN \\
\hline CHEMBL1320709 & 688239 & 5.1862 & 5.5037 & TRN \\
\hline CHEMBL1326711 & 688239 & 4.5362 & 5.557 & TRN \\
\hline CHEMBL1534597 & 688239 & 5.2862 & 5.678 & TST \\
\hline CHEMBL1541310 & 688239 & 5.4862 & 5.3363 & TST \\
\hline CHEMBL1555913 & 688239 & 8.1871 & 5.4946 & TRN \\
\hline CHEMBL1347130 & 688239 & 4.7362 & 5.5308 & TRN \\
\hline CHEMBL1373076 & 688239 & 4.7862 & 5.6095 & TRN \\
\hline CHEMBL1358228 & 688239 & 5.4362 & 5.3733 & TRN \\
\hline CHEMBL1505200 & 688239 & 4.5362 & 5.4473 & TRN \\
\hline CHEMBL1428562 & 688239 & 7.5361 & 5.3312 & TRN \\
\hline CHEMBL1534290 & 688239 & 6.0362 & 5.5519 & TST \\
\hline CHEMBL1555749 & 688239 & 6.9363 & 5.5516 & TRN \\
\hline CHEMBL1610720 & 688239 & 5.5862 & 5.4947 & TRN \\
\hline CHEMBL1392039 & 688239 & 4.8862 & 5.5278 & TST \\
\hline CHEMBL1479635 & 688239 & 4.9362 & 5.4745 & TRN \\
\hline CHEMBL1472313 & 688239 & 5.3862 & 5.4038 & TST \\
\hline CHEMBL1589384 & 688239 & 7.8356 & 5.3607 & TST \\
\hline CHEMBL1349697 & 688239 & 5.3362 & 5.5098 & TRN \\
\hline CHEMBL3193518 & 688239 & 5.9862 & 5.4869 & TRN \\
\hline CHEMBL1611414 & 688239 & 4.5362 & 5.5997 & TRN \\
\hline CHEMBL1401006 & 688239 & 4.6362 & 5.6589 & TST \\
\hline CHEMBL1461394 & 688239 & 6.1862 & 5.5559 & TST \\
\hline CHEMBL1483031 & 688239 & 6.8362 & 5.5204 & TST \\
\hline CHEMBL1474228 & 688239 & 4.4862 & 5.4889 & TRN \\
\hline CHEMBL1525615 & 688239 & 4.45 & 5.4232 & TRN \\
\hline CHEMBL1494865 & 688239 & 5.1862 & 5.5 & TRN \\
\hline CHEMBL1456907 & 688239 & 4.5362 & 5.36600 & 30000000005 \\
\hline CHEMBL1385628 & 688239 & 4.8362 & 5.5924 & TRN \\
\hline CHEMBL1526847 & 688239 & 4.5362 & 5.5063 & TRN \\
\hline CHEMBL1359971 & 688239 & 6.2862 & 5.5137 & TST \\
\hline CHEMBL1447186 & 688239 & 4.4862 & 5.4765 & TRN \\
\hline CHEMBL1356634 & 688239 & 5.2862 & 5.6457 & TRN \\
\hline CHEMBL1547243 & 688239 & 4.5362 & 5.4783 & TRN \\
\hline
\end{tabular}


Supplemental Table S2.txt

\begin{tabular}{|c|c|c|c|c|}
\hline HEMBL13 & & 3372 & 5.477 & \\
\hline & & .9863 & 5.5291 & \\
\hline & & & & \\
\hline AEMBL132 & & 862 & 4438 & $\mathrm{MI}$ \\
\hline AEMBL1992262 & 8239 & 362 & 3986 & \\
\hline HEMBL1464377 & 88239 & 2362 & 4809 & \\
\hline HEMBL13 & 239 & 862 & 1907 & \\
\hline IFMBI 13 & & & & \\
\hline AEMBL15 & 88239 & 362 & 5776 & \\
\hline HEMBL134 & 88239 & 362 & 5655 & \\
\hline AEMBL154 & 239 & 861 & 6532 & \\
\hline IEMBL15 & 39 & 372 & 513 & \\
\hline IEMBL15 & & & & \\
\hline HEMBL15e & & 362 & 5.5254 & \\
\hline AEMBL158 & & & & \\
\hline AEMBL15 & 39 & 372 & 99 & \\
\hline HEMBL15 & & 862 & & \\
\hline HEMBL13 & & & & \\
\hline HEMBL15 & & 862 & & \\
\hline IEMBL15 & & & & \\
\hline HEMBLIS & & 52 & 34 & 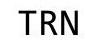 \\
\hline HEMBL31 & & & & (1) \\
\hline HEMBL13 & & & & \\
\hline JEMPI 15 & & & & \\
\hline IEMBL 14 & & & & I RIV \\
\hline HEMBL1 & & & & RN \\
\hline HEMBL1: & & & & TRN \\
\hline HFMRI 1 & & & & \\
\hline AEMBL16 & & & & 13 \\
\hline HEMBL14e & & & & 15 \\
\hline HEMBL1C & & & & RIN \\
\hline HEMBL1 & & & & ST \\
\hline $15 M P$ & & & & ST \\
\hline HEMBL132 & & & & IR \\
\hline HEMBL160 & & 862 & 5.4944 & TRN \\
\hline HEMBL15 & & 1 & 18 & RN \\
\hline HЕMPI 1 & & & & TRN \\
\hline HEMBL13 & & & 717 & 「RN \\
\hline HEMBL149 & 88239 & & & $\Gamma \mathrm{RN}$ \\
\hline AEMBL14 & & & & $\mathrm{RN}$ \\
\hline HEMBL15 & & 52 & 718 & DNA \\
\hline CHEMBL14 & & & & TRN \\
\hline HEMBL 31 & & 362 & 5.631 & $\mathrm{R}$ \\
\hline AEMBL152 & 8239 & 362 & 5.5245 & TS \\
\hline MRI 1 & & & & 15 \\
\hline HEMBL15 & & & & \\
\hline CHEMBL153 & & & 5.5737 & \\
\hline HEMBL1418272 & 688239 & 4.5362 & 5.4665 & ГST \\
\hline
\end{tabular}

Page 2048 
Supplemental Table S2.txt

\begin{tabular}{|c|c|c|c|c|}
\hline CHEMBL1418331 & 688239 & 4.8362 & 5.5022 & TRN \\
\hline CHEMBL1980322 & 688239 & 4.5362 & 5.4488 & TRN \\
\hline CHEMBL1423864 & 688239 & 8.3372 & 5.4275 & TRN \\
\hline CHEMBL1571219 & 688239 & 6.6362 & 5.5165 & TRN \\
\hline CHEMBL1365112 & 688239 & 5.6862 & 5.4797 & TRN \\
\hline CHEMBL1415102 & 688239 & 5.0362 & 5.4404 & TST \\
\hline CHEMBL1381491 & 688239 & 5.7862 & 5.6202 & TRN \\
\hline CHEMBL1309051 & 688239 & 4.5862 & 5.4475 & TRN \\
\hline CHEMBL1411114 & 688239 & 6.9363 & 5.4985 & TRN \\
\hline CHEMBL1563485 & 688239 & 5.2362 & 5.5753 & TRN \\
\hline CHEMBL1559707 & 688239 & 4.8362 & 5.4324 & TRN \\
\hline CHEMBL461 & 688239 & 7.2366 & 5.5936 & TRN \\
\hline CHEMBL1483154 & 688239 & 5.4862 & 5.6171 & TRN \\
\hline CHEMBL1608481 & 688239 & 4.5362 & 5.4875 & TST \\
\hline CHEMBL1413890 & 688239 & 6.3863 & 5.3848 & TST \\
\hline CHEMBL1362075 & 688239 & 4.5362 & 5.376 & TRN \\
\hline CHEMBL1580925 & 688239 & 4.8862 & 5.4801 & TRN \\
\hline CHEMBL1573782 & 688239 & 5.4862 & 5.4443 & TRN \\
\hline CHEMBL1604991 & 688239 & 4.5362 & 5.605 & TRN \\
\hline CHEMBL3189441 & 688239 & 5.3362 & 5.6086 & TRN \\
\hline CHEMBL1329800 & 688239 & 5.1862 & 5.5231 & TRN \\
\hline CHEMBL1580680 & 688239 & 4.5362 & 5.5426 & TRN \\
\hline CHEMBL1557991 & 688239 & 5.2362 & 5.5998 & TST \\
\hline CHEMBL1998759 & 688239 & 5.1862 & 5.5083 & TRN \\
\hline CHEMBL1320341 & 688239 & 5.1862 & 5.5454 & TRN \\
\hline CHEMBL1406526 & 688239 & 6.1362 & 5.4711 & TST \\
\hline CHEMBL1389351 & 688239 & 6.3362 & 5.521 & TST \\
\hline CHEMBL1515517 & 688239 & 5.2362 & 5.44600 & 0000000001 \\
\hline CHEMBL1492208 & 688239 & 5.7362 & 5.4494 & TRN \\
\hline CHEMBL1416381 & 688239 & 5.6362 & 5.4318 & TRN \\
\hline CHEMBL1450445 & 688239 & 4.5862 & 5.4681 & TST \\
\hline CHEMBL1336882 & 688239 & 4.5362 & 5.4617 & TRN \\
\hline CHEMBL1393786 & 688239 & 6.1862 & 5.4718 & TRN \\
\hline CHEMBL3214250 & 688239 & 8.1871 & 5.523 & TRN \\
\hline CHEMBL1394062 & 688239 & 5.8362 & 5.5961 & TST \\
\hline CHEMBL1578524 & 688239 & 4.5362 & 5.5408 & TST \\
\hline CHEMBL1548049 & 688239 & 6.9363 & 5.6699 & TRN \\
\hline CHEMBL1582259 & 688239 & 6.2862 & 5.5379 & TRN \\
\hline CHEMBL1391676 & 688239 & 5.1862 & 5.65 & TRN \\
\hline CHEMBL1306301 & 688239 & 5.0862 & 5.3963 & TRN \\
\hline CHEMBL1513039 & 688239 & 4.5362 & 5.4567 & TRN \\
\hline CHEMBL1340333 & 688239 & 4.9862 & 5.4857 & TRN \\
\hline CHEMBL1554946 & 688239 & 4.7362 & 5.4319 & TRN \\
\hline CHEMBL1483036 & 688239 & 5.0362 & 5.5127 & TRN \\
\hline CHEMBL1432965 & 688239 & 5.0862 & 5.5441 & TRN \\
\hline CHEMBL1385984 & 688239 & 4.45 & 5.3872 & TST \\
\hline CHEMBL1501774 & 688239 & 6.4862 & 5.5332 & TRN \\
\hline CHEMBL1320653 & 688239 & 6.0 & 5.4379 & TRN \\
\hline
\end{tabular}


Supplemental Table S2.txt

\begin{tabular}{|c|c|c|c|c|}
\hline CHEMBL1404244 & 688239 & 4.5362 & 5.4678 & TRN \\
\hline CHEMBL1411221 & 688239 & 6.1862 & 5.5581 & TST \\
\hline CHEMBL1418103 & 688239 & 6.5862 & 5.4305 & TRN \\
\hline CHEMBL1465683 & 688239 & 6.2362 & 5.5657 & TRN \\
\hline CHEMBL1314718 & 688239 & 7.2366 & 5.454 & TST \\
\hline CHEMBL1304726 & 688239 & 4.6862 & 5.3973 & TST \\
\hline CHEMBL1353918 & 688239 & 4.7862 & 5.3589 & TST \\
\hline CHEMBL1569380 & 688239 & 5.4862 & 5.5064 & TST \\
\hline CHEMBL1311612 & 688239 & 4.6862 & 5.5342 & TST \\
\hline CHEMBL1357776 & 688239 & 5.4362 & 5.4753 & TRN \\
\hline CHEMBL1213476 & 688239 & 6.5363 & 5.5457 & TRN \\
\hline CHEMBL3211149 & 688239 & 6.9363 & 5.3511 & TST \\
\hline CHEMBL1382250 & 688239 & 4.5362 & 5.5721 & TRN \\
\hline CHEMBL1465579 & 688239 & 5.3862 & 5.4135 & TRN \\
\hline CHEMBL1323092 & 688239 & 6.4862 & 5.4057 & TST \\
\hline CHEMBL1319894 & 688239 & 7.0862 & 5.5305 & TRN \\
\hline CHEMBL1361451 & 688239 & 5.0362 & 5.5675 & TRN \\
\hline CHEMBL1343893 & 688239 & 4.9362 & 5.5924 & TRN \\
\hline CHEMBL1395476 & 688239 & 5.1362 & 5.5091 & TRN \\
\hline CHEMBL1447341 & 688239 & 4.7362 & 5.5041 & TRN \\
\hline CHEMBL1496137 & 688239 & 4.6862 & 5.5299 & TRN \\
\hline CHEMBL1607854 & 688239 & 4.5362 & 5.5757 & TRN \\
\hline CHEMBL1447840 & 688239 & 4.6362 & 5.4569 & TRN \\
\hline CHEMBL1566853 & 688239 & 5.1362 & 5.4468 & TRN \\
\hline CHEMBL 3211765 & 688239 & 4.8362 & 5.4452 & TRN \\
\hline CHEMBL1559937 & 688239 & 4.5362 & 5.4738 & TST \\
\hline CHEMBL1519240 & 688239 & 6.2362 & 5.4778 & TRN \\
\hline CHEMBL1521960 & 688239 & 4.9862 & 5.3038 & TST \\
\hline CHEMBL1394214 & 688239 & 4.5362 & 5.4916 & TRN \\
\hline CHEMBL1485076 & 688239 & 5.8362 & 5.4864 & TRN \\
\hline CHEMBL1307875 & 688239 & 5.8362 & 5.4276 & TST \\
\hline CHEMBL1989260 & 688239 & 4.5362 & 5.434 & TST \\
\hline CHEMBL1375318 & 688239 & 5.1862 & 5.5203 & TRN \\
\hline CHEMBL1607857 & 688239 & 4.7362 & 5.5189 & TST \\
\hline CHEMBL1498614 & 688239 & 6.8362 & 5.5492 & TRN \\
\hline CHEMBL1419157 & 688239 & 4.6862 & 5.437 & TRN \\
\hline CHEMBL3213018 & 688239 & 8.28399 & 99999999 & 5.5 \\
\hline CHEMBL1971376 & 688239 & 5.1862 & 5.5627 & TRN \\
\hline CHEMBL1566781 & 688239 & 5.3862 & 5.4131 & TRN \\
\hline CHEMBL3191624 & 688239 & 6.9363 & 5.4936 & TRN \\
\hline CHEMBL1435693 & 688239 & 4.8362 & 5.492999 & 9999999999 \\
\hline CHEMBL1429992 & 688239 & 5.0362 & 5.4532 & TRN \\
\hline CHEMBL1319794 & 688239 & 4.6862 & 5.4651 & TRN \\
\hline CHEMBL1301044 & 688239 & 4.8362 & 5.3848 & TRN \\
\hline CHEMBL1474401 & 688239 & 5.4362 & 5.5123 & TST \\
\hline CHEMBL1386648 & 688239 & 5.6362 & 5.3827 & TST \\
\hline CHEMBL1425899 & 688239 & 4.6862 & 5.4152 & TRN \\
\hline CHEMBL1597693 & 688239 & 6.1862 & 5.3469 & TRN \\
\hline
\end{tabular}

Page 2050 
Supplemental Table S2.txt

\begin{tabular}{|c|c|c|c|c|}
\hline AEMBL & & & 35 & TR \\
\hline HEMRI 1193883 & 38239 & 862 & & \\
\hline AEMBL1 & & 362 & & \\
\hline AEMBL1597943 & 8239 & 862 & 3854 & \\
\hline HEMBL1556386 & 88239 & 5362 & 6059 & \\
\hline HEMBL135 & 8239 & 362 & 161 & \\
\hline AFMRI 31 & & & & \\
\hline IEMBL 14 & 38239 & 862 & 4391 & \\
\hline HEMBL1551789 & 88239 & 366 & 5591 & \\
\hline HEMBL1335770 & 88239 & 362 & 5.484 & \\
\hline AEMBL152 & 239 & 862 & 428 & \\
\hline AEMBL136 & & & & \\
\hline HEMBL135 & 39 & 862 & & \\
\hline IEMBL1498794 & 39 & 862 & & \\
\hline AEMBL3189570 & 39 & 862 & 665 & \\
\hline IEMBL15 & & 862 & & \\
\hline IEMBL16 & & & & \\
\hline AEMBL1 14 & & 362 & 5524 & \\
\hline AEMBL14 & & 62 & & \\
\hline AEMBL156 & 39 & 62 & 346 & \\
\hline IEMBL32 & & 62 & & \\
\hline IEMBL1 & & & & \\
\hline AEMBL & & 862 & 33 & \\
\hline AEMBL13 & & 62 & & \\
\hline AEMBL15 & 39 & 62 & 399 & IRN \\
\hline IEMBL16 & & 62 & & ונס \\
\hline EM & & & & RN \\
\hline 4 & & & & \\
\hline IEMBL13 & & & & IRN \\
\hline IEMBL1509965 & 39 & 862 & 2 & RN \\
\hline FMBI 15 & & 62 & & $\mathrm{RN}$ \\
\hline 3 & & & & \\
\hline & & & & RN \\
\hline AEMBL161 & & & & IRN \\
\hline AEMBL1534193 & 39 & 362 & 5323 & ГST \\
\hline IFMRI 13 & & 62 & 86 & RN \\
\hline & & & & \\
\hline HEMBL13 & & & & TRN \\
\hline AEMBL1588204 & & 62 & & ГRN \\
\hline EMBL13 & & 362 & & RN \\
\hline HEMBL131 & & 62 & & Mir \\
\hline & & & & ST \\
\hline HEMBL142 & & & 5248 & TST \\
\hline IEMBL14 & & 62 & & TR \\
\hline 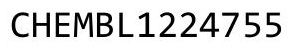 & & & & \\
\hline HEMBL 145 & & & 5.4835 & \\
\hline CHEMBL1427732 & & 862 & 5.4893 & \\
\hline CHEMBL1608888 & 688239 & 4.8862 & 5.5672 & ГST \\
\hline
\end{tabular}

Page 2051 
Supplemental Table S2.txt

\begin{tabular}{|c|c|c|c|c|c|}
\hline CHEMBL1574393 & 688239 & 7.2865 & 5.4458 & TRN & \\
\hline CHEMBL1574008 & 688239 & 5.1362 & 5.5304 & TRN & \\
\hline CHEMBL1520106 & 688239 & 5.4362 & 5.4403 & TRN & \\
\hline CHEMBL1315787 & 688239 & 4.5362 & 5.4602 & TRN & \\
\hline CHEMBL1389293 & 688239 & 8.2366 & 5.4285 & TRN & \\
\hline CHEMBL 3195016 & 688239 & 5.7362 & 5.5403 & TRN & \\
\hline CHEMBL1535956 & 688239 & 4.7862 & 5.5474 & TRN & \\
\hline CHEMBL1301861 & 688239 & 4.8862 & 5.4428 & TRN & \\
\hline CHEMBL1350982 & 688239 & 4.5362 & 5.324 & TRN & \\
\hline CHEMBL1317273 & 688239 & 6.3362 & 5.5115 & TRN & \\
\hline CHEMBL1434582 & 688239 & 5.8862 & 5.4347 & TRN & \\
\hline CHEMBL1389278 & 688239 & 5.4862 & 5.4683 & TRN & \\
\hline CHEMBL1392848 & 688239 & 5.0362 & 5.4777 & TST & \\
\hline CHEMBL1549533 & 688239 & 7.0362 & 5.4527 & TST & \\
\hline CHEMBL1610697 & 688239 & 5.4362 & 5.4063 & TRN & \\
\hline CHEMBL1313988 & 688239 & 6.3362 & 5.5194 & TRN & \\
\hline CHEMBL1345765 & 688239 & 6.0862 & 5.5171 & TRN & \\
\hline CHEMBL1494613 & 688239 & 6.6362 & 5.3981 & TRN & \\
\hline CHEMBL3199150 & 688239 & 4.5362 & 5.3731 & TRN & \\
\hline CHEMBL1500028 & 688239 & 5.6862 & 5.6188 & TRN & \\
\hline CHEMBL1595077 & 688239 & 5.3362 & 5.4283 & TRN & \\
\hline CHEMBL3212924 & 688239 & 4.5362 & 5.3425 & TRN & \\
\hline CHEMBL1349805 & 688239 & 4.7362 & 5.495 & TRN & \\
\hline CHEMBL1337892 & 688239 & 5.3362 & 5.3907 & TRN & \\
\hline CHEMBL1414271 & 688239 & 6.1862 & 5.3301 & TRN & \\
\hline CHEMBL1422055 & 688239 & 5.1862 & 5.4225 & TST & \\
\hline CHEMBL 3198708 & 688239 & 6.5363 & 5.5762 & TRN & \\
\hline CHEMBL1437908 & 688239 & 4.6862 & 5.5011 & TRN & \\
\hline CHEMBL1465911 & 688239 & 6.9863 & 5.6108 & TRN & \\
\hline CHEMBL1464344 & 688239 & 4.5362 & 5.2652 & TRN & \\
\hline CHEMBL 3197893 & 688239 & 4.6862 & 5.3312 & TRN & \\
\hline CHEMBL1516595 & 688239 & 6.1862 & 5.6353 & TRN & \\
\hline CHEMBL1498873 & 688239 & 4.5362 & 5.4265 & TRN & \\
\hline CHEMBL1596685 & 688239 & 4.4862 & 5.5428 & TST & \\
\hline CHEMBL3198164 & 688239 & 5.3862 & 5.4224 & TRN & \\
\hline CHEMBL1456821 & 688239 & 4.6862 & 5.3972 & TRN & \\
\hline CHEMBL1452397 & 688239 & 4.5362 & 5.6304 & TRN & \\
\hline CHEMBL1526890 & 688239 & 6.5363 & 5.4937 & TRN & \\
\hline CHEMBL1571913 & 688239 & 6.0862 & 5.5542 & TRN & \\
\hline CHEMBL1360995 & 688239 & 4.7362 & 5.616000 & 0000000005 & TRN \\
\hline CHEMBL1319664 & 688239 & 4.8862 & 5.5697 & TRN & \\
\hline CHEMBL1481355 & 688239 & 8.28399 & 99999999 & 5.3498 & Т KI \\
\hline CHEMBL1351000 & 688239 & 6.9363 & 5.5047 & TST & \\
\hline CHEMBL1313119 & 688239 & 7.1361 & 5.5263 & TRN & \\
\hline CHEMBL1353454 & 688239 & 6.5363 & 5.4204 & TST & \\
\hline CHEMBL1607427 & 688239 & 6.0362 & 5.4488 & TRN & \\
\hline CHEMBL1448743 & 688239 & 6.5862 & 5.5572 & TRN & \\
\hline CHEMBL1309145 & 688239 & 5.8362 & 5.4251 & TRN & \\
\hline
\end{tabular}


Supplemental Table S2.txt

\begin{tabular}{|c|c|c|c|c|c|}
\hline CHEMBL1454791 & 688239 & 6.5363 & 5.5295 & TRN & \\
\hline CHEMBL1549010 & 688239 & 5.0862 & 5.5926 & TRN & \\
\hline CHEMBL1390785 & 688239 & 6.5862 & 5.3357 & TRN & \\
\hline CHEMBL1545875 & 688239 & 6.2362 & 5.4132 & TRN & \\
\hline CHEMBL1483356 & 688239 & 8.3372 & 5.4173 & TST & \\
\hline CHEMBL3198121 & 688239 & 5.8862 & 5.4983 & TRN & \\
\hline CHEMBL1484826 & 688239 & 6.1862 & 5.3782 & TST & \\
\hline CHEMBL1351804 & 688239 & 5.1862 & 5.6041 & TRN & \\
\hline CHEMBL1387575 & 688239 & 4.5362 & 5.5102 & TRN & \\
\hline CHEMBL3210652 & 688239 & 5.9362 & 5.3333 & TST & \\
\hline CHEMBL1510822 & 688239 & 5.1862 & 5.4953 & TRN & \\
\hline CHEMBL1525861 & 688239 & 6.1862 & 5.4593 & TRN & \\
\hline CHEMBL1304138 & 688239 & 5.1862 & 5.43 & TRN & \\
\hline CHEMBL1476818 & 688239 & 5.4362 & 5.439 & TRN & \\
\hline CHEMBL1526858 & 688239 & 6.2362 & 5.7747 & TRN & \\
\hline CHEMBL1331625 & 688239 & 6.3863 & 5.7609 & TRN & \\
\hline CHEMBL1348991 & 688239 & 6.8861 & 5.5447 & TRN & \\
\hline CHEMBL1574472 & 688239 & 4.5362 & 5.4881 & TST & \\
\hline CHEMBL1495708 & 688239 & 6.3863 & 5.4026 & TRN & \\
\hline CHEMBL1610628 & 688239 & 5.1862 & 5.4426 & TST & \\
\hline CHEMBL1431748 & 688239 & 5.3362 & 5.706 & TRN & \\
\hline CHEMBL3190119 & 688239 & 4.6362 & 5.4614 & TRN & \\
\hline CHEMBL1503723 & 688239 & 6.1362 & 5.5024 & TST & \\
\hline CHEMBL1557741 & 688239 & 5.6362 & 5.5147 & TST & \\
\hline CHEMBL1497773 & 688239 & 4.8362 & 5.5243 & TRN & \\
\hline CHEMBL1603247 & 688239 & 6.7862 & 5.4481 & TST & \\
\hline CHEMBL1479516 & 688239 & 4.5362 & 5.5799 & TRN & \\
\hline CHEMBL1357784 & 688239 & 5.6362 & 5.435 & TRN & \\
\hline CHEMBL1496096 & 688239 & 5.7362 & 5.4624 & TRN & \\
\hline CHEMBL3209751 & 688239 & 4.5862 & 5.5571 & TRN & \\
\hline CHEMBL285157 & 688239 & 5.1362 & 5.3503 & TST & \\
\hline CHEMBL1519426 & 688239 & 6.2362 & 5.4898 & TST & \\
\hline CHEMBL1408236 & 688239 & 4.8862 & 5.5382 & TRN & \\
\hline CHEMBL1506189 & 688239 & 5.0862 & 5.4435 & TST & \\
\hline CHEMBL1535427 & 688239 & 4.6362 & 5.4318 & TST & \\
\hline CHEMBL1477958 & 688239 & 5.5862 & 5.58 & TRN & \\
\hline CHEMBL1452874 & 688239 & 5.4362 & 5.407999 & 99999999995 & TRN \\
\hline CHEMBL1606944 & 688239 & 6.1862 & 5.7051 & TRN & \\
\hline CHEMBL1523931 & 688239 & 6.6362 & 5.4415 & TRN & \\
\hline CHEMBL1538499 & 688239 & 8.28399 & 99999999 & 5.5473 & TRN \\
\hline CHEMBL572576 & 688239 & 8.3372 & 5.6463 & TRN & \\
\hline CHEMBL1300240 & 688239 & 7.0362 & 5.6647 & TRN & \\
\hline CHEMBL1377858 & 688239 & 6.7361 & 5.5174 & TRN & \\
\hline CHEMBL1560911 & 688239 & 8.3872 & 5.546 & TRN & \\
\hline CHEMBL1542242 & 688239 & 6.2362 & 5.5115 & TRN & \\
\hline CHEMBL1501444 & 688239 & 5.0862 & 5.4166 & TRN & \\
\hline CHEMBL1600664 & 688239 & 5.6862 & 5.5059 & TST & \\
\hline CHEMBL1314455 & 688239 & 4.7862 & $5.54200 e$ & 000000001 & TRN \\
\hline
\end{tabular}

Page 2053 
Supplemental Table S2.txt

\begin{tabular}{|c|c|c|c|c|c|}
\hline CHEMBL1503417 & 688239 & 8.3372 & 5.5437 & TRN & \\
\hline CHEMBL1459410 & 688239 & 4.7862 & 5.4603 & TRN & \\
\hline CHEMBL1576734 & 688239 & 5.1362 & 5.4261 & TRN & \\
\hline CHEMBL1481943 & 688239 & 4.6362 & 5.4415 & TRN & \\
\hline CHEMBL1450524 & 688239 & 6.7862 & 5.3856 & TRN & \\
\hline CHEMBL1396115 & 688239 & 5.9362 & 5.4712 & TRN & \\
\hline CHEMBL1413247 & 688239 & 5.4862 & 5.6317 & TRN & \\
\hline CHEMBL1269896 & 688239 & 6.8861 & 5.5408 & TRN & \\
\hline CHEMBL1487064 & 688239 & 4.7862 & 5.3793 & TRN & \\
\hline CHEMBL1581448 & 688239 & 5.8862 & 5.5167 & TRN & \\
\hline CHEMBL1546609 & 688239 & 6.8362 & 5.3887 & TRN & \\
\hline CHEMBL1612203 & 688239 & 6.3863 & 5.5682 & TRN & \\
\hline CHEMBL3189509 & 688239 & 5.2362 & 5.5016 & TRN & \\
\hline CHEMBL1435121 & 688239 & 5.7862 & 5.3767 & TRN & \\
\hline CHEMBL1351081 & 688239 & 5.0362 & 5.4689 & TRN & \\
\hline CHEMBL557419 & 688239 & 4.6362 & 5.5307 & TRN & \\
\hline CHEMBL1998516 & 688239 & 4.5362 & 5.3982 & TST & \\
\hline CHEMBL1567007 & 688239 & 4.7362 & 5.59200 & 00000000005 & TRN \\
\hline CHEMBL1308143 & 688239 & 5.0362 & 5.472 & TRN & \\
\hline CHEMBL1307408 & 688239 & 8.1367 & 5.5087 & TST & \\
\hline CHEMBL1335046 & 688239 & 4.7362 & 5.5948 & TRN & \\
\hline CHEMBL 2007425 & 688239 & 5.5862 & 5.3585 & TST & \\
\hline CHEMBL1481264 & 688239 & 4.5362 & 5.436 & TST & \\
\hline CHEMBL1611073 & 688239 & 5.1862 & 5.4195 & TST & \\
\hline CHEMBL1348003 & 688239 & 5.6362 & 5.5648 & TRN & \\
\hline CHEMBL1431718 & 688239 & 4.7 & 5.4207 & TRN & \\
\hline CHEMBL601933 & 688239 & 5.7862 & 5.4796 & TRN & \\
\hline CHEMBL1364757 & 688239 & 6.1862 & 5.6137 & TRN & \\
\hline CHEMBL1494275 & 688239 & 6.1362 & 5.4657 & TRN & \\
\hline CHEMBL1522537 & 688239 & 4.5362 & 5.5405 & TST & \\
\hline CHEMBL1523087 & 688239 & 4.5362 & 5.4794 & TRN & \\
\hline CHEMBL1395834 & 688239 & 5.7362 & 5.473 & TRN & \\
\hline CHEMBL1256095 & 688239 & 5.1862 & 5.4471 & TRN & \\
\hline CHEMBL1392795 & 688239 & 6.1862 & 5.4637 & TRN & \\
\hline CHEMBL1596692 & 688239 & 5.0862 & 5.3558 & TRN & \\
\hline CHEMBL1347697 & 688239 & 4.7862 & 5.4438 & TST & \\
\hline CHEMBL1329863 & 688239 & 5.1862 & 5.5375 & TRN & \\
\hline CHEMBL1432162 & 688239 & 5.6862 & 5.4977 & TRN & \\
\hline CHEMBL1465521 & 688239 & 4.6362 & \multicolumn{2}{|c|}{5.582999999999999} & TRN \\
\hline CHEMBL1344742 & 688239 & 4.6862 & 5.48 & TST & \\
\hline CHEMBL1365140 & 688239 & 4.5362 & 5.324 & TRN & \\
\hline CHEMBL1605160 & 688239 & 7.0362 & 5.4124 & TRN & \\
\hline CHEMBL1382855 & 688239 & 5.5362 & 5.5143 & TRN & \\
\hline CHEMBL1455912 & 688239 & 8.3372 & 5.4415 & TST & \\
\hline CHEMBL362941 & 688239 & 5.4862 & \multicolumn{2}{|c|}{5.577000000000001} & TRN \\
\hline CHEMBL226664 & 688239 & 6.2362 & 5.4548 & TRN & \\
\hline CHEMBL1366605 & 688239 & 6.6362 & 5.4481 & TRN & \\
\hline CHEMBL1507738 & 688239 & 6.1362 & 5.5807 & TRN & \\
\hline
\end{tabular}

Page 2054 


\begin{tabular}{|c|c|c|c|c|}
\hline & & & & \\
\hline MBL1458029 & 88239 & & 574 & TST \\
\hline & 88239 & 6862 & & \\
\hline IEMBL] & 8239 & & & \\
\hline IEMBL1522378 & 88239 & 362 & & \\
\hline AEMBL1551261 & 88239 & 362 & & \\
\hline AEMBL1 & 88239 & 864 & & \\
\hline 09 & & 362 & & \\
\hline IEMBL & & 362 & & \\
\hline AEMBL1445159 & 88239 & 362 & & \\
\hline HEMBL1 & 88239 & 362 & & \\
\hline IEMBL: & 88239 & 362 & & \\
\hline 25 & & 362 & & \\
\hline AEMBL & 39 & & & \\
\hline AEMBL: & 39 & 862 & & \\
\hline AEMBL: & 39 & 862 & & \\
\hline 95 & 9 & 362 & & \\
\hline & & & & \\
\hline 24 & 39 & 362 & & \\
\hline 309 & 39 & 862 & & \\
\hline IEMBL: & 9 & 362 & & \\
\hline 92 & 9 & 362 & & \\
\hline 27 & & & & \\
\hline 98 & & 362 & & \\
\hline 72 & 39 & 362 & & \\
\hline IEMBL & 9 & 362 & & \\
\hline 34 & 9 & 362 & & \\
\hline & & 362 & & \\
\hline & & & & \\
\hline & & & & \\
\hline IEMBL & 9 & 366 & & \\
\hline 10 & & 364 & & \\
\hline & & & & \\
\hline & & & & \\
\hline EMBL & & & & \\
\hline$M B L$ & 9 & 362 & & \\
\hline 44 & & 363 & & \\
\hline & & & & \\
\hline & & & & \\
\hline MBL & & 361 & & \\
\hline & 9 & 62 & & \\
\hline & & & & \\
\hline & & & & TRI \\
\hline EMBL & & & & \\
\hline MBL & & 363 & & 11 \\
\hline & & & & \\
\hline & & & & \\
\hline CHEMBL3 & & 362 & 99 & \\
\hline 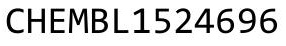 & 080 & 5.6862 & 6036 & \\
\hline
\end{tabular}

Page 2055 
Supplemental Table S2.txt

\begin{tabular}{|c|c|c|c|c|c|}
\hline CHEMBL1510314 & 688239 & 4.6862 & 5.4388 & TST & \\
\hline CHEMBL1432207 & 688239 & 4.7362 & 5.5068 & TRN & \\
\hline CHEMBL1605455 & 688239 & 5.4362 & 5.5237 & TST & \\
\hline CHEMBL1560784 & 688239 & 5.4862 & 5.4639 & TST & \\
\hline CHEMBL1369030 & 688239 & 5.6362 & 5.5605 & TRN & \\
\hline CHEMBL1420544 & 688239 & 5.3362 & 5.3844 & TRN & \\
\hline CHEMBL1607986 & 688239 & 5.7862 & 5.5011 & TRN & \\
\hline CHEMBL1409569 & 688239 & 4.7862 & 5.5125 & TRN & \\
\hline CHEMBL1472082 & 688239 & 6.2362 & 5.5606 & TRN & \\
\hline CHEMBL1305651 & 688239 & 4.5362 & 5.4543 & TRN & \\
\hline CHEMBL3193769 & 688239 & 4.5362 & 5.3157 & TRN & \\
\hline CHEMBL1449433 & 688239 & 6.2862 & 5.425 & TRN & \\
\hline CHEMBL1521687 & 688239 & 4.6362 & 5.4975 & TST & \\
\hline CHEMBL3213789 & 688239 & 6.3362 & 5.4409 & TST & \\
\hline CHEMBL1346229 & 688239 & 5.4362 & 5.5907 & TRN & \\
\hline CHEMBL1370479 & 688239 & 4.5362 & 5.5584 & TRN & \\
\hline CHEMBL1332389 & 688239 & 4.8862 & 5.4359 & TRN & \\
\hline CHEMBL1523392 & 688239 & 4.5362 & 5.4806 & TST & \\
\hline CHEMBL1436749 & 688239 & 8.2366 & 5.4659 & TRN & \\
\hline CHEMBL1374478 & 688239 & 5.7362 & 5.5804 & TRN & \\
\hline CHEMBL1365992 & 688239 & 4.5362 & 5.6275 & TRN & \\
\hline CHEMBL1537331 & 688239 & 5.3862 & 5.5085 & TST & \\
\hline CHEMBL1395265 & 688239 & 5.2862 & 5.4719 & TRN & \\
\hline CHEMBL1421095 & 688239 & 6.1862 & 5.6801 & TST & \\
\hline CHEMBL1308879 & 688239 & 4.7862 & 5.3862 & TRN & \\
\hline CHEMBL1300733 & 688239 & 5.5362 & 5.5168 & TRN & \\
\hline CHEMBL1311893 & 688239 & 5.3362 & 5.4773 & TRN & \\
\hline CHEMBL1598687 & 688239 & 4.9862 & 5.4662 & TST & \\
\hline CHEMBL1978504 & 688239 & 4.5362 & 5.4567 & TRN & \\
\hline CHEMBL1422864 & 688239 & 5.5362 & 5.4734 & TRN & \\
\hline CHEMBL1344741 & 688239 & 5.4862 & 5.561 & TRN & \\
\hline CHEMBL1532960 & 688239 & 5.7862 & 5.4969 & TRN & \\
\hline CHEMBL1575551 & 688239 & 4.6862 & 5.4084 & TRN & \\
\hline CHEMBL1572275 & 688239 & 4.5362 & 5.44600 & 2000000001 & TRN \\
\hline CHEMBL1535093 & 688239 & 4.5362 & 5.6383 & TST & \\
\hline CHEMBL1317585 & 688239 & 5.6362 & 5.4606 & TST & \\
\hline CHEMBL1480262 & 688239 & 5.0362 & 5.41 & TRN & \\
\hline CHEMBL1314011 & 688239 & 4.5362 & 5.2947 & TRN & \\
\hline CHEMBL1320990 & 688239 & 5.3862 & 5.5592 & TRN & \\
\hline CHEMBL1507445 & 688239 & 4.5362 & 5.3996 & TST & \\
\hline CHEMBL1399426 & 688239 & 4.5862 & 5.49799 & 9999999999 & TRN \\
\hline CHEMBL1504802 & 688239 & 5.4362 & 5.4131 & TRN & \\
\hline CHEMBL1497902 & 688239 & 4.5362 & 5.4443 & TRN & \\
\hline CHEMBL1599152 & 688239 & 8.2366 & 5.4339 & TRN & \\
\hline CHEMBL1533673 & 688239 & 6.9363 & 5.4965 & TRN & \\
\hline CHEMBL3210879 & 688239 & 4.5862 & 5.5802 & TRN & \\
\hline CHEMBL1313506 & 688239 & 5.1362 & 5.3469 & TRN & \\
\hline CHEMBL3213394 & 688239 & 5.4862 & 5.3702 & TRN & \\
\hline
\end{tabular}


Supplemental Table S2.txt

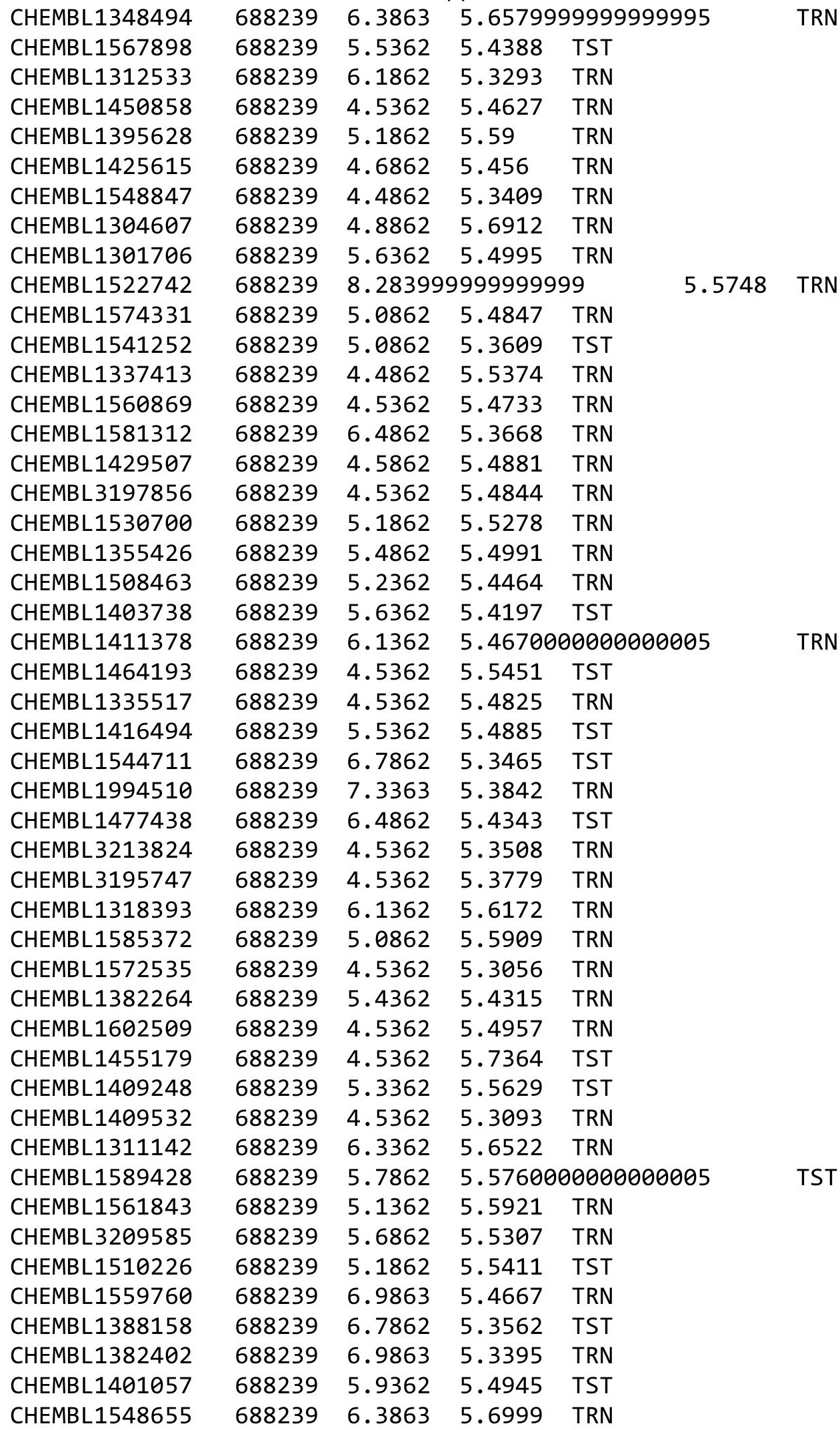

Page 2057 
Supplemental Table S2.txt

\begin{tabular}{|c|c|c|c|c|c|}
\hline CHEMBL1424326 & 688239 & 5.4362 & 5.4696 & TRN & \\
\hline CHEMBL1376534 & 688239 & 4.7862 & 5.5452 & TRN & \\
\hline CHEMBL1568209 & 688239 & 5.4862 & 5.5322 & TRN & \\
\hline CHEMBL1370361 & 688239 & 4.6362 & 5.4132 & TRN & \\
\hline CHEMBL1312386 & 688239 & 4.5362 & 5.5676 & TRN & \\
\hline CHEMBL1484650 & 688239 & 5.6 & 5.5848 & TST & \\
\hline CHEMBL1581843 & 688239 & 4.6862 & 5.4563 & TRN & \\
\hline CHEMBL1472417 & 688239 & 5.4862 & 5.4443 & TRN & \\
\hline CHEMBL1346903 & 688239 & 7.0362 & 5.4354 & TST & \\
\hline CHEMBL1428775 & 688239 & 5.0862 & 5.5197 & TST & \\
\hline CHEMBL1384986 & 688239 & 4.6862 & 5.489 & TRN & \\
\hline CHEMBL1331821 & 688239 & 4.9362 & 5.3809 & TST & \\
\hline CHEMBL1350400 & 688239 & 5.6362 & 5.4568 & TST & \\
\hline CHEMBL1308823 & 688239 & 5.6362 & 5.4467 & TST & \\
\hline CHEMBL3214054 & 688239 & 5.3362 & 5.6206 & TST & \\
\hline CHEMBL1320554 & 688239 & 4.8862 & 5.404 & TRN & \\
\hline CHEMBL1363805 & 688239 & 5.7362 & 5.4206 & TRN & \\
\hline CHEMBL1381609 & 688239 & 5.3362 & 5.5585 & TST & \\
\hline CHEMBL1595545 & 688239 & 8.3372 & 5.6521 & TRN & \\
\hline CHEMBL1305234 & 688239 & 6.8362 & 5.393 & TRN & \\
\hline CHEMBL1551136 & 688239 & 7.0862 & 5.4775 & TRN & \\
\hline CHEMBL1391498 & 688239 & 7.8861 & 5.5436 & TRN & \\
\hline CHEMBL3191104 & 688239 & 4.5362 & 5.5232 & TST & \\
\hline CHEMBL1574798 & 688239 & 4.6862 & 5.4603 & TRN & \\
\hline CHEMBL1469851 & 688239 & 4.6362 & 5.449 & TST & \\
\hline CHEMBL1483921 & 688239 & 6.2362 & 5.5946 & TST & \\
\hline CHEMBL3198418 & 688239 & 5.6362 & 5.4193 & TRN & \\
\hline CHEMBL1557470 & 688239 & 6.3362 & 5.6563 & TRN & \\
\hline CHEMBL1582749 & 688239 & 4.5862 & 5.4112 & TRN & \\
\hline CHEMBL1563989 & 688239 & 4.8862 & 5.5104 & TRN & \\
\hline CHEMBL1490813 & 688239 & 5.1362 & 5.5132 & TRN & \\
\hline CHEMBL1348121 & 688239 & 4.9862 & 5.5497 & TRN & \\
\hline CHEMBL1452834 & 688239 & 5.6362 & 5.5075 & TRN & \\
\hline CHEMBL1480134 & 688239 & 8.1871 & 5.5027 & TRN & \\
\hline CHEMBL1565363 & 688239 & 4.5362 & 5.5285 & TRN & \\
\hline CHEMBL3194233 & 688239 & 5.4862 & 5.4604 & TRN & \\
\hline CHEMBL1306450 & 688239 & 4.4862 & 5.6319 & TRN & \\
\hline CHEMBL1578440 & 688239 & 4.5362 & 5.2757 & TRN & \\
\hline CHEMBL299228 & 688239 & 4.6362 & 5.4786 & TRN & \\
\hline CHEMBL1599835 & 688239 & 6.8362 & 5.4534 & TST & \\
\hline CHEMBL1303385 & 688239 & 5.3862 & 5.4742 & TRN & \\
\hline CHEMBL1445289 & 688239 & 5.1862 & 5.4935 & TRN & \\
\hline CHEMBL1501489 & 688239 & 5.1362 & 5.3484 & TRN & \\
\hline CHEMBL 2359467 & 688239 & 5.0862 & 5.3519 & TST & \\
\hline CHEMBL1306650 & 688239 & 4.7362 & 5.4615 & TRN & \\
\hline CHEMBL1354850 & 688239 & 4.5362 & 5.5292 & TRN & \\
\hline CHEMBL1375131 & 688239 & 8.28399 & 999999999 & 99 & 5.4202 \\
\hline CHEMBL1418607 & 688239 & 6.1862 & 5.5744 & TRN & \\
\hline
\end{tabular}


Supplemental Table S2.txt

\begin{tabular}{|c|c|c|c|c|}
\hline CHEMBL1489984 & 688239 & 4.6362 & 5.4682 & TRN \\
\hline CHEMBL1313823 & 688239 & 4.5362 & 5.4227 & TRN \\
\hline CHEMBL1510694 & 688239 & 4.7862 & 5.558 & TST \\
\hline CHEMBL1460909 & 688239 & 5.3862 & 5.5149 & TRN \\
\hline CHEMBL1376020 & 688239 & 4.5362 & 5.4816 & TST \\
\hline CHEMBL 2004417 & 688239 & 4.5362 & 5.2816 & TRN \\
\hline CHEMBL1377967 & 688239 & 4.9862 & 5.4435 & TRN \\
\hline CHEMBL1310834 & 688239 & 4.6862 & 5.4457 & TST \\
\hline CHEMBL1389022 & 688239 & 6.7361 & 5.5854 & TRN \\
\hline CHEMBL1519025 & 688239 & 4.5362 & 5.4885 & TST \\
\hline CHEMBL1422189 & 688239 & 4.5362 & 5.49299 & 9999999999 \\
\hline CHEMBL1446387 & 688239 & 5.7362 & 5.385 & TRN \\
\hline CHEMBL1343495 & 688239 & 4.5362 & 5.6659 & TRN \\
\hline CHEMBL3213057 & 688239 & 6.1862 & 5.5854 & TRN \\
\hline CHEMBL1585695 & 688239 & 8.2366 & 5.4888 & TST \\
\hline CHEMBL1332056 & 688239 & 5.1862 & 5.3882 & TRN \\
\hline CHEMBL1378366 & 688239 & 5.0362 & 5.4391 & TST \\
\hline CHEMBL3193853 & 688239 & 7.0862 & 5.4399 & TST \\
\hline CHEMBL1413207 & 688239 & 7.0362 & 5.4239 & TRN \\
\hline CHEMBL1333231 & 688239 & 5.1862 & 5.5612 & TRN \\
\hline CHEMBL1447632 & 688239 & 5.2362 & 5.5778 & TRN \\
\hline CHEMBL1460445 & 688239 & 4.5362 & 5.459 & TRN \\
\hline CHEMBL1593136 & 688239 & 4.8362 & 5.5828 & TRN \\
\hline CHEMBL1505067 & 688239 & 6.0862 & 5.4979 & TRN \\
\hline CHEMBL1383199 & 688239 & 6.5862 & 5.5896 & TST \\
\hline CHEMBL1424994 & 688239 & 4.5362 & 5.5957 & TRN \\
\hline CHEMBL1302635 & 688239 & 5.0862 & 5.5002 & TRN \\
\hline CHEMBL1385407 & 688239 & 5.7362 & 5.3836 & TRN \\
\hline CHEMBL1599586 & 688239 & 5.4862 & 5.4082 & TRN \\
\hline CHEMBL 1447342 & 688239 & 7.2366 & 5.4119 & TRN \\
\hline CHEMBL1493737 & 688239 & 4.5362 & 5.4268 & TRN \\
\hline CHEMBL1992234 & 688239 & 5.5362 & 5.6082 & TRN \\
\hline CHEMBL1367720 & 688239 & 8.2366 & 5.5432 & TRN \\
\hline CHEMBL1540619 & 688239 & 6.9363 & 5.5091 & TRN \\
\hline CHEMBL1319220 & 688239 & 7.1361 & 5.5072 & TRN \\
\hline CHEMBL1585094 & 688239 & 5.1862 & 5.3849 & TRN \\
\hline CHEMBL1552804 & 688239 & 4.6862 & 5.4251 & TRN \\
\hline CHEMBL1303839 & 688239 & 5.5362 & 5.5234 & TRN \\
\hline CHEMBL1404516 & 688239 & 4.6362 & 5.4552 & TRN \\
\hline CHEMBL1320810 & 688239 & 5.4862 & 5.5008 & TRN \\
\hline CHEMBL1429565 & 688239 & 4.9362 & 5.5383 & TRN \\
\hline CHEMBL1424783 & 688239 & 5.0362 & 5.3458 & TST \\
\hline CHEMBL1414932 & 688239 & 4.5362 & 5.4551 & TRN \\
\hline CHEMBL1504795 & 688239 & 4.6362 & 5.4856 & TRN \\
\hline CHEMBL1561933 & 688239 & 5.7362 & 5.4285 & TST \\
\hline CHEMBL1460383 & 688239 & 5.2862 & 5.4892 & TRN \\
\hline CHEMBL1596267 & 688239 & 6.1362 & 5.4869 & TST \\
\hline CHEMBL1417642 & 688239 & 4.5362 & 5.5333 & TRN \\
\hline
\end{tabular}


Supplemental Table S2.txt

\begin{tabular}{|c|c|c|c|c|}
\hline CHEMBL1595187 & 688239 & 5.1862 & 5.6428 & TRN \\
\hline CHEMBL1400464 & 688239 & 5.3862 & 5.4462 & TRN \\
\hline CHEMBL1441487 & 688239 & 6.0862 & 5.4857 & TRN \\
\hline CHEMBL1562467 & 688239 & 4.4362 & 5.5996 & TRN \\
\hline CHEMBL1467433 & 688239 & 5.9362 & 5.5234 & TRN \\
\hline CHEMBL1554382 & 688239 & 4.8362 & 5.4346 & TRN \\
\hline CHEMBL1382208 & 688239 & 6.7862 & 5.4082 & TST \\
\hline CHEMBL1390492 & 688239 & 5.5362 & 5.4709 & TRN \\
\hline CHEMBL1440360 & 688239 & 4.4862 & 5.6823 & TRN \\
\hline CHEMBL1452433 & 688239 & 4.8362 & 5.4605 & TRN \\
\hline CHEMBL1405401 & 688239 & 7.7352 & 5.351 & TRN \\
\hline CHEMBL1426722 & 688239 & 4.5362 & 5.4369 & TRN \\
\hline CHEMBL1603837 & 688239 & 4.8862 & 5.4785 & TRN \\
\hline CHEMBL3190100 & 688239 & 5.2862 & 5.5107 & TRN \\
\hline CHEMBL1610182 & 688239 & 4.8862 & 5.2841 & TRN \\
\hline CHEMBL585502 & 688239 & 5.2362 & 5.3656 & TRN \\
\hline CHEMBL1476548 & 688239 & 4.5362 & 5.4382 & TRN \\
\hline CHEMBL1431362 & 688239 & 4.5362 & 5.4668 & TRN \\
\hline CHEMBL1538610 & 688239 & 4.7862 & 5.5305 & TRN \\
\hline CHEMBL1389248 & 688239 & 4.4862 & 5.5656 & TST \\
\hline CHEMBL1595744 & 688239 & 4.6862 & 5.5058 & TRN \\
\hline CHEMBL1416577 & 688239 & 6.0862 & 5.45799 & 9999999999 \\
\hline CHEMBL1532205 & 688239 & 6.8861 & 5.544 & TRN \\
\hline CHEMBL1403947 & 688239 & 5.3862 & 5.5102 & TRN \\
\hline CHEMBL1508344 & 688239 & 5.3362 & 5.67299 & 9999999999 \\
\hline CHEMBL1502059 & 688239 & 6.9863 & 5.4377 & TRN \\
\hline CHEMBL1339925 & 688239 & 5.1862 & 5.5397 & TRN \\
\hline CHEMBL1535688 & 688239 & 5.1862 & 5.5662 & TST \\
\hline CHEMBL1496400 & 688239 & 6.0862 & 5.4872 & TST \\
\hline CHEMBL1561792 & 688239 & 6.8861 & 5.6131 & TST \\
\hline CHEMBL1352031 & 688239 & 5.2362 & 5.5411 & TRN \\
\hline CHEMBL384903 & 688239 & 4.7362 & 5.3364 & TST \\
\hline CHEMBL1312060 & 688239 & 5.1862 & 5.4748 & TRN \\
\hline CHEMBL1502925 & 688239 & 5.1862 & 5.5049 & TRN \\
\hline CHEMBL1319777 & 688239 & 5.1862 & 5.4414 & TRN \\
\hline CHEMBL1466193 & 688239 & 4.6862 & 5.376 & TST \\
\hline CHEMBL1564136 & 688239 & 6.6362 & 5.4668 & TST \\
\hline CHEMBL1449390 & 688239 & 4.6862 & 5.5938 & TRN \\
\hline CHEMBL1487685 & 688239 & 5.1862 & 5.49200 & 2000000001 \\
\hline CHEMBL1592710 & 688239 & 4.7362 & 5.3934 & TST \\
\hline CHEMBL1524419 & 688239 & 7.5361 & 5.5822 & TRN \\
\hline CHEMBL1478607 & 688239 & 4.6362 & 5.4633 & TST \\
\hline CHEMBL1581549 & 688239 & 6.3863 & 5.5162 & TST \\
\hline CHEMBL1384554 & 688239 & 8.1871 & 5.5617 & TST \\
\hline CHEMBL1517527 & 688239 & 6.8861 & 5.3772 & TRN \\
\hline CHEMBL1371615 & 688239 & 6.2362 & 5.5449 & TRN \\
\hline CHEMBL1547238 & 688239 & 5.1362 & 5.5247 & TRN \\
\hline CHEMBL1595220 & 688239 & 4.6862 & 5.4372 & TRN \\
\hline
\end{tabular}


Supplemental Table S2.txt

\begin{tabular}{|c|c|c|c|c|}
\hline $\mathrm{HEI}$ & 9 & 862 & & . \\
\hline HEMBL1429677 & & 5.1862 & 5.5359 & \\
\hline 33 & & & & \\
\hline AEMBL15 & & & & \\
\hline AEMBL1602516 & 38239 & 363 & & \\
\hline HEMBL1527673 & 88239 & 372 & 767 & \\
\hline HFMBI 133 & 239 & 362 & & \\
\hline IFMBI 15 & & & & \\
\hline IEMBL 14 & & & & \\
\hline HEMBL153 & 88239 & 62 & 323 & \\
\hline AEMBL143 & 239 & & & \\
\hline IEMBL14 & 39 & & & \\
\hline AEMBL13 & & & & \\
\hline HEMBL 32 & & & & \\
\hline AEMBL31 & & & & \\
\hline AEMBL13 & 39 & 62 & & \\
\hline HEMBL14 & & & & \\
\hline HEMBL13 & & & & \\
\hline HEMBL15 & & 62 & & \\
\hline AEMBL14 & & & & \\
\hline AEMBLLIS & & & & \\
\hline AEMBL13 & & & & \\
\hline HEMBL 31 & & & & \\
\hline HEMBL13 & & & 202 & \\
\hline AEMBL15 & & & & 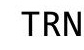 \\
\hline HEMBL19 & & & & \\
\hline HEMBL1 & & & & \\
\hline HFMBI 32 & & & & RN \\
\hline HEMBL14 & & & & \\
\hline HEMBL 321 & & & & RIN \\
\hline HEMBL14 & & & & RN \\
\hline HEMBL12 & & & & NIV \\
\hline HEMBL1. & & & & ST \\
\hline НEMBL 14 & & & & RN \\
\hline HEMBL1426872 & & & 5.5108 & TST \\
\hline HEMBL14 & & & 884 & RN \\
\hline HEMDI 15 & & & & RN \\
\hline HEMBL15 & & & & RN \\
\hline HEMBL1609054 & 88239 & & 5.3013 & TST \\
\hline AEMBL13 & & & 5.3722 & IST \\
\hline HEMBL136 & & & 5.3779 & I \\
\hline CHEMBL13 & & & & RN \\
\hline HEMBL14 & & & 4508 & RN \\
\hline AEMBL144 & 39 & 362 & & RN \\
\hline EMBL1L & & & & \\
\hline CHEMBL137 & & & 5.4525 & \\
\hline CHEMBL134 & & 6.1862 & 5.5201 & \\
\hline SHEMBL141865 & 688239 & 8.3372 & 5.4834 & RN \\
\hline
\end{tabular}

Page 2061 
Supplemental Table S2.txt

\begin{tabular}{|c|c|c|c|c|}
\hline & & & & \\
\hline AEMBL1450277 & 88239 & 9862 & & \\
\hline AEMBL1537867 & 39 & 52 & & \\
\hline & & & & \\
\hline AEMBL1505748 & & & & \\
\hline AEMBL1531555 & 88239 & 362 & & \\
\hline AEMBL1411373 & 88239 & 4.4862 & 82 & \\
\hline HEMBL1353296 & & 4. & & \\
\hline AEMBL1425802 & & & & \\
\hline AEMBL1322718 & & & & \\
\hline AEMBL1512588 & 39 & 362 & & \\
\hline AEMBL1399179 & 39 & 362 & & \\
\hline HEMBL1383408 & & & & \\
\hline AEMBL1332443 & & & & \\
\hline AEMBL1558327 & & & & \\
\hline AEMBL1495950 & & 862 & & \\
\hline AEMBL1549799 & & & & \\
\hline AEMBL1439 & & & & \\
\hline AEMBL143 & & & & \\
\hline HEMBL15 & & & & \\
\hline AEMBL1595562 & & & & \\
\hline AEMBL1336464 & & & & \\
\hline AEMBL1607 & & & & \\
\hline HEMBL133 & & & & \\
\hline AFMBI 157 & & & & \\
\hline AEMBL1499317 & & & & \\
\hline AEMBL1570363 & & & & \\
\hline AEMBL13614 & & & & \\
\hline 99 & & & & \\
\hline AFMRI 14 & & 52 & & \\
\hline AEMBL1309700 & & & & \\
\hline AEMBL1427379 & & & & \\
\hline 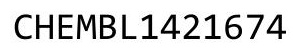 & & & & \\
\hline 0 & & & & \\
\hline 53 & & & & \\
\hline AEMBL1372646 & & & & \\
\hline AEMBL1998562 & & & & \\
\hline & & & & \\
\hline 72 & & & & \\
\hline L1458 & & & & $\mathrm{RN}$ \\
\hline AEMBL1364936 & & 72 & & \\
\hline JEMBL14€ & & & & \\
\hline & & & & \\
\hline HEMBL1477086 & & & & \\
\hline AEMBL1542473 & & & & RN \\
\hline EMBL1512922 & & 362 & & \\
\hline 30 & & & & \\
\hline 14709 & & & 5.504 & \\
\hline
\end{tabular}

Page 2062 
Supplemental Table S2.txt

\begin{tabular}{|c|c|c|c|c|c|}
\hline CHEMBL1514622 & 688239 & 4.9362 & 5.444 & TRN & \\
\hline CHEMBL1359688 & 688239 & 5.7362 & 5.4776 & TRN & \\
\hline CHEMBL1303998 & 688239 & 6.2362 & 5.4887 & TRN & \\
\hline CHEMBL1581555 & 688239 & 6.3362 & 5.455 & TRN & \\
\hline CHEMBL 3212532 & 688239 & 6.2862 & 5.4902 & TST & \\
\hline CHEMBL1533720 & 688239 & 5.4362 & 5.4354 & TRN & \\
\hline CHEMBL1309658 & 688239 & 5.5 & 5.4404 & TRN & \\
\hline CHEMBL1463588 & 688239 & 4.9862 & 5.3756 & TRN & \\
\hline CHEMBL1516877 & 688239 & 5.1862 & 5.5251 & TST & \\
\hline CHEMBL1561778 & 688239 & 4.7362 & 5.6347 & TRN & \\
\hline CHEMBL 3189694 & 688239 & 4.7862 & 5.2378 & TRN & \\
\hline CHEMBL1390722 & 688239 & 5.1362 & 5.5847 & TRN & \\
\hline CHEMBL1520904 & 688239 & 4.5362 & 5.5749 & TST & \\
\hline CHEMBL1531650 & 688239 & 5.9362 & 5.4044 & TRN & \\
\hline CHEMBL1587544 & 688239 & 6.5363 & 5.4634 & TRN & \\
\hline CHEMBL1590136 & 688239 & 6.0862 & 5.50799 & Э999999999 & TRN \\
\hline CHEMBL1446196 & 688239 & 6.1862 & 5.4469 & TRN & \\
\hline CHEMBL1527355 & 688239 & 4.5362 & 5.5637 & TST & \\
\hline CHEMBL1469382 & 688239 & 4.5362 & 5.564 & TRN & \\
\hline CHEMBL1497511 & 688239 & 5.1362 & 5.6476 & TST & \\
\hline CHEMBL1494423 & 688239 & 6.6861 & 5.4635 & TRN & \\
\hline CHEMBL1377491 & 688239 & 6.5363 & 5.4811 & TST & \\
\hline CHEMBL1424070 & 688239 & 4.4862 & 5.3926 & TRN & \\
\hline CHEMBL1372946 & 688239 & 8.3372 & 5.4645 & TRN & \\
\hline CHEMBL1380165 & 688239 & 6.1862 & 5.4561 & TST & \\
\hline CHEMBL1525750 & 688239 & 6.3362 & 5.6841 & TRN & \\
\hline CHEMBL1439602 & 688239 & 4.6862 & 5.5064 & TST & \\
\hline CHEMBL1317105 & 688239 & 4.6862 & \multicolumn{2}{|c|}{5.507000000000001} & TRIV \\
\hline CHEMBL1582348 & 688239 & 6.4862 & 5.4683 & TRN & \\
\hline CHEMBL1365386 & 688239 & 5.8362 & 5.527 & TRN & \\
\hline CHEMBL1507215 & 688239 & 4.7862 & 5.4277 & TST & \\
\hline CHEMBL1555841 & 688239 & 4.5362 & 5.3018 & TRN & \\
\hline CHEMBL1499959 & 688239 & 5.6362 & 5.5485 & TST & \\
\hline CHEMBL1508468 & 688239 & 5.7862 & 5.4573 & TRN & \\
\hline CHEMBL1357843 & 688239 & 4.5362 & 5.4604 & TST & \\
\hline CHEMBL1303111 & 688239 & 4.5362 & 5.5073 & TST & \\
\hline CHEMBL1468071 & 688239 & 4.5362 & \multicolumn{2}{|c|}{5.537000000000001} & TRN \\
\hline CHEMBL 3189462 & 688239 & 6.7862 & 5.6767 & TST & \\
\hline CHEMBL1470078 & 688239 & \multicolumn{3}{|c|}{ 8.283999999999999 } & TST \\
\hline CHEMBL1325581 & 688239 & 5.0362 & 5.5343 & TST & \\
\hline CHEMBL1332399 & 688239 & 6.1862 & 5.4572 & TRN & \\
\hline CHEMBL1500439 & 688239 & 4.5362 & 5.5176 & TRN & \\
\hline CHEMBL1515744 & 688239 & 7.2366 & 5.4255 & TRN & \\
\hline CHEMBL1543976 & 688239 & 4.5362 & 5.4316 & TRN & \\
\hline CHEMBL579362 & 688239 & 5.9362 & 5.5966 & TRN & \\
\hline CHEMBL1369768 & 688239 & 5.6862 & 5.5728 & TRN & \\
\hline CHEMBL1539037 & 688239 & 6.3362 & 5.6302 & TRN & \\
\hline CHEMBL1410767 & 688239 & 6.7862 & 5.5761 & TRN & \\
\hline
\end{tabular}




\begin{tabular}{|c|c|c|c|c|c|}
\hline \multicolumn{6}{|c|}{ Supplemental Table S2.txt } \\
\hline CHEMBL1390211 & 688239 & 5.05 & 5.3641 & TST & \\
\hline CHEMBL1480802 & 688239 & 5.6362 & 5.3581 & TRN & \\
\hline CHEMBL1443956 & 688239 & 5.2362 & 5.7134 & TRN & \\
\hline CHEMBL1330797 & 688239 & 5.1862 & 5.4617 & TRN & \\
\hline CHEMBL1563069 & 688239 & 4.6862 & 5.5224 & TRN & \\
\hline CHEMBL1460247 & 688239 & 5.4362 & 5.3824 & TRN & \\
\hline CHEMBL1306110 & 688239 & 4.6862 & 5.526 & TRN & \\
\hline CHEMBL3189273 & 688239 & 6.3362 & 5.6775 & TRN & \\
\hline CHEMBL1315420 & 688239 & 4.5362 & 5.4776 & TRN & \\
\hline CHEMBL1495972 & 688239 & 4.5362 & 5.6149 & TRN & \\
\hline CHEMBL1419608 & 688239 & 8.28399 & 999999999 & 5.5248 & TST \\
\hline CHEMBL1525249 & 688239 & 5.1862 & 5.4366 & TRN & \\
\hline CHEMBL1314042 & 688239 & 4.5362 & 5.454 & TRN & \\
\hline CHEMBL1533762 & 688239 & 4.5362 & 5.4277 & TRN & \\
\hline CHEMBL1471793 & 688239 & 5.4862 & 5.5022 & TRN & \\
\hline CHEMBL1514392 & 688239 & 5.5362 & 5.4024 & TRN & \\
\hline CHEMBL1391662 & 688239 & 5.1862 & 5.3723 & TRN & \\
\hline CHEMBL1421905 & 688239 & 4.4862 & 5.3531 & TRN & \\
\hline CHEMBL1591807 & 688239 & 4.8862 & 5.6148 & TRN & \\
\hline CHEMBL1486485 & 688239 & 5.1862 & 5.5569 & TRN & \\
\hline CHEMBL1318833 & 688239 & 4.4862 & 5.4717 & TRN & \\
\hline CHEMBL1584472 & 688239 & 4.8862 & 5.2786 & TST & \\
\hline CHEMBL1491754 & 688239 & 6.5363 & 5.5718 & TST & \\
\hline CHEMBL1417505 & 688239 & 6.5862 & 5.5169 & TRN & \\
\hline CHEMBL1557725 & 688239 & 6.8362 & 5.518 & TRN & \\
\hline CHEMBL541230 & 688239 & 5.2362 & 5.5674 & TRN & \\
\hline CHEMBL1316649 & 688239 & 4.8362 & 5.5628 & TRN & \\
\hline CHEMBL1508647 & 688239 & 5.1862 & 5.3666 & TRN & \\
\hline CHEMBL1442946 & 688239 & 5.5362 & 5.653 & TRN & \\
\hline CHEMBL1469377 & 688239 & 6.2362 & 5.5683 & TRN & \\
\hline CHEMBL1526709 & 688239 & 5.2862 & 5.4603 & TRN & \\
\hline CHEMBL1509302 & 688239 & 6.3863 & 5.5657 & TST & \\
\hline CHEMBL1583728 & 688239 & 5.1862 & 5.3918 & TST & \\
\hline CHEMBL1439783 & 688239 & 4.5362 & 5.5672 & TRN & \\
\hline CHEMBL462227 & 688239 & 5.1862 & 5.5668 & TRN & \\
\hline CHEMBL1989179 & 688239 & 7.6861 & 5.5027 & TRN & \\
\hline CHEMBL1403035 & 688239 & 5.3862 & 5.3867 & TRN & \\
\hline CHEMBL1558445 & 688239 & 5.6362 & 5.5035 & TRN & \\
\hline CHEMBL1430488 & 688239 & 5.0862 & 5.5002 & TST & \\
\hline CHEMBL1449937 & 688239 & 4.4862 & 5.342000 & 00000000005 & TST \\
\hline CHEMBL3211249 & 688239 & 6.6362 & 5.4697 & TRN & \\
\hline CHEMBL1494199 & 688239 & 5.2362 & 5.4699 & TRN & \\
\hline CHEMBL1518390 & 688239 & 5.1862 & 5.3888 & TRN & \\
\hline CHEMBL1505386 & 688239 & 5.8862 & 5.3662 & TRN & \\
\hline CHEMBL1344359 & 688239 & 6.2862 & 5.5043 & TRN & \\
\hline CHEMBL1340871 & 688239 & 4.5362 & 5.3933 & TRN & \\
\hline CHEMBL1368206 & 688239 & 4.5862 & 5.5595 & TRN & \\
\hline CHEMBL1552428 & 688239 & 5.4862 & 5.4903 & TRN & \\
\hline
\end{tabular}


Supplemental Table S2.txt

\begin{tabular}{|c|c|c|c|c|}
\hline HEN & & 5862 & & \\
\hline & & 5.4862 & 5.5776 & \\
\hline & & & & \\
\hline AEMBL16e & & & & S \\
\hline AEMBL1330493 & 8239 & & & \\
\hline HEMBL1542886 & 88239 & 7862 & 4695 & \\
\hline & 239 & 362 & 563 & \\
\hline IFMBI 160 & & & & \\
\hline HEMBL1318858 & & & & \\
\hline HEMBL1554952 & 88239 & 362 & 5641 & \\
\hline HEMBL1450 & 239 & & 5139 & \\
\hline IEMBL14 & 39 & & & \\
\hline IEMBL1 & & & & \\
\hline HEMBL130 & & & .4711 & \\
\hline AEMBL1507 & & & & \\
\hline AEMBL 287 & 39 & & 57 & \\
\hline AEMBL159 & & & 82 & \\
\hline HEMBL149 & & & & \\
\hline AEMBL1608 & & & 3631 & \\
\hline AEMBL153 & & & & \\
\hline $\mathrm{E} / \mathrm{MBL}$ & & & 13 & RIN \\
\hline AEMBL14 & & & & 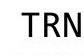 \\
\hline HEMBL15 & & & & \\
\hline AEMBL139 & & & & \\
\hline IEMBL 375 & & & & I RIV \\
\hline HEMBL3 & & & & II \\
\hline HEMBL1 & & & & RN \\
\hline HFMBI $13=$ & & & & \\
\hline HEMBL143: & & & & in \\
\hline HEMBL1417 & & & & 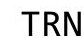 \\
\hline HEMBL14 & & & 584 & RN \\
\hline HEMBL1 & & & & RN \\
\hline $15 M P$ & & & 88 & \\
\hline HEMBL1389925 & & & 212 & IRN \\
\hline HEMBL13381] & & & 5.5689 & TRN \\
\hline HEMBL13. & & & 266 & RN \\
\hline HEMPI 2 & & & 23 & I RIV \\
\hline HEMBL139 & & & 805 & TRN \\
\hline HEMBL14232 & 88239 & & 5.3847 & TST \\
\hline AEMBL143 & & & & $\Gamma \mathrm{RN}$ \\
\hline HEMBL1386 & & & 878 & \\
\hline HEMBL1583914 & & & & NIV \\
\hline HEMBL1502396 & & & 1984 & RN \\
\hline AEMBL1599980 & 39 & 62 & 5833 & TR \\
\hline HEMBL1508 & & & & $\mathrm{N}$ \\
\hline HEMBL1 14 & & & .5276 & \\
\hline CHEMBL1483 & & & 5.4731 & \\
\hline LHEMBL1487857 & 688239 & 5.4362 & 5.5879 & \\
\hline
\end{tabular}

Page 2065 
Supplemental Table S2.txt

\begin{tabular}{|c|c|c|c|c|}
\hline 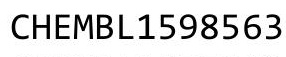 & & & & \\
\hline HEMBL1557142 & 88239 & 5362 & 3469 & \\
\hline HEMBL1504591 & 88239 & 8862 & 3897 & \\
\hline EMBL1 & & & & \\
\hline EMBL139 & & 362 & 43 & \\
\hline HEMBL3189295 & 88239 & 5862 & 4132 & \\
\hline HEMBL1329560 & 88239 & .4362 & .4944 & \\
\hline HEMBL142 & & & & \\
\hline EMBL13: & 39 & & & \\
\hline IEMBL16e & 39 & 862 & .4819 & \\
\hline HEMBL3195744 & 88239 & 862 & .4746 & \\
\hline HEMBL1353944 & 39 & 3862 & .4944 & \\
\hline HEMBL1582218 & 39 & 62 & 5027 & \\
\hline HEMBL14 & 39 & & 55 & \\
\hline JEMBL15 & 39 & 362 & & \\
\hline HEMBL152 & 39 & 362 & & \\
\hline HEMBL133 & 39 & 861 & & \\
\hline HEMBL $32 e$ & 9 & 62 & 45 & \\
\hline HEMBL 14 & 9 & & & \\
\hline HEMBL14 & 39 & & & \\
\hline HEMBL 155 & 39 & 362 & & \\
\hline HEMBL138 & 39 & 862 & & \\
\hline HEMBL142 & 39 & 362 & & \\
\hline HEMBL 14 & & & & \\
\hline 69 & 39 & 62 & & \\
\hline HEMBL14 & 39 & 362 & & \\
\hline JEMBL144 & 39 & & & RN \\
\hline HEMBL14 & 39 & & & \\
\hline HEMBL14 & & & & \\
\hline HEMBL13 & & & & ST \\
\hline HEMBL159 & 9 & & & IST \\
\hline HEMBL136 & 39 & 362 & & ST \\
\hline HEMBL13 & & & & RIV \\
\hline HEM & 9 & & & RN \\
\hline HEMBL15 & & & & RN \\
\hline HEMBL148 & 39 & & 558 & RN \\
\hline HEMBL 142 & 39 & 362 & & RN \\
\hline 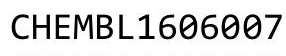 & & & & SI \\
\hline 1 & 39 & & & RN \\
\hline HEMBL 15 & & & & RN \\
\hline HEMBL 148 & 39 & 362 & 84 & RN \\
\hline HEMBL15 & 39 & 362 & 79 & RN \\
\hline 393 & & & 5.4583 & \\
\hline LHEMBL148 & & & & RN \\
\hline HEMBL 3207410 & & 4.5362 & 5.4832 & ST \\
\hline HEMBL 149 & 39 & 362 & 5.2754 & ST \\
\hline HEMBL $14 €$ & & & & \\
\hline 1 & & & & \\
\hline
\end{tabular}

Page 2066 
Supplemental Table S2.txt

\begin{tabular}{|c|c|c|c|c|c|}
\hline CHEMBL1587124 & 688239 & 4.5362 & 5.6135 & TRN & \\
\hline CHEMBL1313806 & 688239 & 6.8362 & 5.6535 & TRN & \\
\hline CHEMBL1369548 & 688239 & 7.1361 & 5.5868 & TRN & \\
\hline CHEMBL1361809 & 688239 & 4.4862 & 5.5365 & TST & \\
\hline CHEMBL1418567 & 688239 & 4.7862 & 5.5495 & TST & \\
\hline CHEMBL1335772 & 688239 & 4.6362 & 5.5889 & TRN & \\
\hline CHEMBL1337291 & 688239 & 7.2366 & 5.6119 & TRN & \\
\hline CHEMBL1461938 & 688239 & 4.6862 & 5.6072 & TRN & \\
\hline CHEMBL1392141 & 688239 & 6.0862 & 5.46299 & 9999999999 & TST \\
\hline CHEMBL1473204 & 688239 & 4.5362 & 5.4206 & TRN & \\
\hline CHEMBL1532120 & 688239 & 5.1862 & 5.40799 & 99999999995 & TRN \\
\hline CHEMBL1564861 & 688239 & 5.3362 & 5.6659 & TRN & \\
\hline CHEMBL1529506 & 688239 & 5.4862 & 5.4945 & TRN & \\
\hline CHEMBL3210405 & 688239 & 5.0362 & 5.4097 & TRN & \\
\hline CHEMBL1489530 & 688239 & 5.4862 & 5.5152 & TST & \\
\hline CHEMBL1386226 & 688239 & 5.7862 & 5.51 & TRN & \\
\hline CHEMBL1386881 & 688239 & 5.1862 & 5.3535 & TRN & \\
\hline CHEMBL1365463 & 688239 & 6.1362 & 5.4412 & TST & \\
\hline CHEMBL1613668 & 688239 & 8.3372 & 5.5619 & TST & \\
\hline CHEMBL1491567 & 688239 & 4.4862 & 5.3768 & TST & \\
\hline CHEMBL1491326 & 688239 & 5.9362 & 5.6576 & TST & \\
\hline CHEMBL1365700 & 688239 & 5.0862 & 5.4391 & TRN & \\
\hline CHEMBL3194319 & 688239 & 4.6362 & 5.5261 & TRN & \\
\hline CHEMBL1422388 & 688239 & 5.2862 & 5.6192 & TRN & \\
\hline CHEMBL1606411 & 688239 & 5.1862 & 5.4099 & TRN & \\
\hline CHEMBL1612662 & 688239 & 5.1862 & 5.4691 & TRN & \\
\hline CHEMBL1565709 & 688239 & 4.6362 & 5.6497 & TRN & \\
\hline CHEMBL1572058 & 688239 & 6.0862 & 5.3964 & TRN & \\
\hline CHEMBL1509674 & 688239 & 6.7862 & 5.4483 & TRN & \\
\hline CHEMBL3190807 & 688239 & 4.8862 & 5.4447 & TST & \\
\hline CHEMBL3195942 & 688239 & 5.4862 & 5.4241 & TST & \\
\hline CHEMBL1302110 & 688239 & 6.2362 & 5.4692 & TRN & \\
\hline CHEMBL3195823 & 688239 & 6.9363 & 5.6192 & TRN & \\
\hline CHEMBL1450648 & 688239 & 4.6362 & 5.3816 & TST & \\
\hline CHEMBL1323229 & 688239 & 5.2362 & 5.5803 & TRN & \\
\hline CHEMBL2374018 & 688239 & 6.275 & 5.3978 & TRN & \\
\hline CHEMBL1463170 & 688239 & 5.9362 & 5.5758 & TRN & \\
\hline CHEMBL1544116 & 688239 & 5.8362 & 5.6414 & TRN & \\
\hline CHEMBL1477260 & 688239 & 4.5362 & 5.4381 & TRN & \\
\hline CHEMBL1308624 & 688239 & 6.1862 & 5.5173 & TRN & \\
\hline CHEMBL3197800 & 688239 & 6.1362 & 5.5058 & TRN & \\
\hline CHEMBL1330662 & 688239 & 4.6862 & 5.5354 & TST & \\
\hline CHEMBL1424769 & 688239 & 6.0862 & 5.4025 & TST & \\
\hline CHEMBL1334062 & 688239 & 4.9362 & 5.5109 & TRN & \\
\hline CHEMBL1589274 & 688239 & 4.7862 & 5.6773 & TRN & \\
\hline CHEMBL1334968 & 688239 & 4.5362 & 5.4038 & TRN & \\
\hline CHEMBL1313697 & 688239 & 4.6362 & 5.6611 & TST & \\
\hline CHEMBL1385975 & 688239 & 5.7862 & 5.4436 & TRN & \\
\hline
\end{tabular}


Supplemental Table S2.txt

\begin{tabular}{|c|c|c|c|c|}
\hline CHEMBL1510457 & 688239 & 4.5362 & 5.5026 & TRN \\
\hline CHEMBL1540682 & 688239 & 6.0362 & 5.3655 & TST \\
\hline CHEMBL3210673 & 688239 & 4.6362 & 5.4336 & TRN \\
\hline CHEMBL1498689 & 688239 & 6.9863 & 5.5541 & TRN \\
\hline CHEMBL1463766 & 688239 & 4.5362 & 5.5316 & TRN \\
\hline CHEMBL1313542 & 688239 & 4.4862 & 5.449 & TST \\
\hline CHEMBL1401648 & 688239 & 5.9362 & 5.5405 & TRN \\
\hline CHEMBL1402661 & 688239 & 4.5862 & 5.5815 & TRN \\
\hline CHEMBL1403817 & 688239 & 4.6862 & 5.4772 & TRN \\
\hline CHEMBL1403701 & 688239 & 4.5362 & 5.4269 & TRN \\
\hline CHEMBL1464861 & 688239 & 4.6862 & 5.3804 & TRN \\
\hline CHEMBL1597017 & 688239 & 4.6362 & 5.5268 & TRN \\
\hline CHEMBL1600120 & 688239 & 4.7362 & 5.5304 & TST \\
\hline CHEMBL1299668 & 688239 & 5.1862 & 5.4988 & TRN \\
\hline CHEMBL1554279 & 688239 & 6.1862 & 5.3182 & TST \\
\hline CHEMBL1595459 & 688239 & 7.1864 & 5.5167 & TST \\
\hline CHEMBL1468337 & 688239 & 5.1862 & 5.4185 & TST \\
\hline CHEMBL1334279 & 688239 & 4.6362 & 5.5076 & TRN \\
\hline CHEMBL1302700 & 688239 & 4.8362 & 5.4599 & TRN \\
\hline CHEMBL1561498 & 688239 & 5.6362 & 5.4678 & TRN \\
\hline CHEMBL1391142 & 688239 & 6.5862 & 5.5361 & TRN \\
\hline CHEMBL1434534 & 688239 & 4.7862 & 5.5631 & TRN \\
\hline CHEMBL592592 & 688239 & 4.8362 & 5.4287 & TRN \\
\hline CHEMBL1526691 & 688239 & 4.5362 & 5.5008 & TRN \\
\hline CHEMBL1528701 & 688239 & 6.7862 & 5.4714 & TRN \\
\hline CHEMBL1391429 & 688239 & 4.7862 & 5.4074 & TST \\
\hline CHEMBL1536949 & 688239 & 5.9862 & 5.437 & TRN \\
\hline CHEMBL1521061 & 688239 & 5.6862 & 5.4843 & TRN \\
\hline CHEMBL1410726 & 688239 & 5.1862 & 5.6502 & TRN \\
\hline CHEMBL1418603 & 688239 & 8.3372 & 5.4168 & TST \\
\hline CHEMBL1311494 & 688239 & 7.2366 & 5.6206 & TRN \\
\hline CHEMBL1550856 & 688239 & 4.5362 & 5.5129 & TRN \\
\hline CHEMBL1415703 & 688239 & 4.9362 & 5.2601 & TST \\
\hline CHEMBL1467919 & 688239 & 5.9362 & 5.5331 & TST \\
\hline CHEMBL1544102 & 688239 & 8.0862 & 5.4465 & TST \\
\hline CHEMBL1587665 & 688239 & 6.9863 & 5.4165 & TST \\
\hline CHEMBL1586722 & 688239 & 4.7362 & 5.5298 & TST \\
\hline CHEMBL1558861 & 688239 & 8.2366 & 5.5168 & TST \\
\hline CHEMBL1335016 & 688239 & 4.6362 & 5.3249 & TST \\
\hline CHEMBL1481036 & 688239 & 5.0362 & 5.5142 & TST \\
\hline CHEMBL1489986 & 688239 & 4.8362 & 5.4539 & TRN \\
\hline CHEMBL1422499 & 688239 & 5.1862 & 5.3325 & TST \\
\hline CHEMBL596836 & 688239 & 5.1862 & 5.4327 & TRN \\
\hline CHEMBL577222 & 688239 & 4.9362 & 5.4977 & TRN \\
\hline CHEMBL 24850 & 688239 & 6.8861 & 5.3379 & TRN \\
\hline CHEMBL1432285 & 688239 & 4.4862 & 5.422999 & 9999999999 \\
\hline CHEMBL1533659 & 688239 & 6.2362 & 5.5782 & TST \\
\hline CHEMBL1592232 & 688239 & 7.0862 & 5.5591 & TRN \\
\hline
\end{tabular}


Supplemental Table S2.txt

\begin{tabular}{|c|c|c|c|c|}
\hline CHEMBL1601763 & 688239 & 4.6862 & 5.4455 & TRN \\
\hline CHEMBL1550300 & 688239 & 5.0862 & 5.317 & TRN \\
\hline CHEMBL1302271 & 688239 & 5.1862 & 5.4252 & TST \\
\hline CHEMBL1472577 & 688239 & 5.8362 & 5.3357 & TRN \\
\hline CHEMBL1498422 & 688239 & 5.7362 & 5.5786 & TRN \\
\hline CHEMBL1334458 & 688239 & 5.3862 & 5.64 & TRN \\
\hline CHEMBL1397317 & 688239 & 5.9362 & 5.4433 & TRN \\
\hline CHEMBL1376905 & 688239 & 4.6362 & 5.4432 & TRN \\
\hline CHEMBL 3199021 & 688239 & 6.3863 & 5.3661 & TRN \\
\hline CHEMBL1598122 & 688239 & 4.8362 & 5.6535 & TRN \\
\hline CHEMBL 3196568 & 688239 & 4.8362 & 5.5691 & TRN \\
\hline CHEMBL1302627 & 688239 & 4.4862 & 5.5051 & TRN \\
\hline CHEMBL167542 & 688239 & 7.0362 & 5.5073 & TST \\
\hline CHEMBL1410058 & 688239 & 6.8861 & 5.5278 & TST \\
\hline CHEMBL1578014 & 688239 & 5.6862 & 5.4673 & TRN \\
\hline CHEMBL1472131 & 688239 & 4.7862 & 5.4017 & TST \\
\hline CHEMBL1457093 & 688239 & 5.0362 & 5.4763 & TRN \\
\hline CHEMBL1545904 & 688239 & 4.6862 & 5.4205 & TRN \\
\hline CHEMBL1455148 & 688239 & 5.4362 & 5.4843 & TST \\
\hline CHEMBL1316375 & 688239 & 4.7862 & 5.5294 & TRN \\
\hline CHEMBL1996189 & 688239 & 5.5362 & 5.2973 & TRN \\
\hline CHEMBL1511567 & 688239 & 4.5362 & 5.5058 & TRN \\
\hline CHEMBL1353961 & 688239 & 4.5362 & 5.5536 & TRN \\
\hline CHEMBL1585369 & 688239 & 5.6362 & 5.4741 & TST \\
\hline CHEMBL1485929 & 688239 & 4.6362 & 5.5309 & TST \\
\hline CHEMBL1583431 & 688239 & 5.2862 & 5.5628 & TRN \\
\hline CHEMBL1579988 & 688239 & 6.6362 & 5.3728 & TRN \\
\hline CHEMBL1528949 & 688239 & 5.1862 & 5.4516 & TRN \\
\hline CHEMBL1513080 & 688239 & 5.4362 & 5.5454 & TRN \\
\hline CHEMBL1510481 & 688239 & 5.1862 & 5.5562 & TST \\
\hline CHEMBL1509270 & 688239 & 4.5362 & 5.5598 & TST \\
\hline CHEMBL1444662 & 688239 & 8.3872 & 5.3217 & TST \\
\hline CHEMBL1476921 & 688239 & 4.7862 & 5.3906 & TRN \\
\hline CHEMBL3211695 & 688239 & 5.0362 & 5.3743 & TST \\
\hline CHEMBL1382930 & 688239 & 5.0862 & 5.4142 & TRN \\
\hline CHEMBL1390775 & 688239 & 7.2366 & 5.444 & TRN \\
\hline CHEMBL1510689 & 688239 & 5.7862 & 5.5494 & TRN \\
\hline CHEMBL 3199370 & 688239 & 5.1862 & 5.4664 & TRN \\
\hline CHEMBL1333043 & 688239 & 5.0862 & 5.3907 & TRN \\
\hline CHEMBL1484239 & 688239 & 5.8862 & 5.5118 & TRN \\
\hline CHEMBL1418962 & 688239 & 6.1862 & 5.4467 & TRN \\
\hline CHEMBL1495060 & 688239 & 5.2362 & 5.41700 & 0000000001 \\
\hline CHEMBL1557330 & 688239 & 4.9862 & 5.5147 & TST \\
\hline CHEMBL1499561 & 688239 & 5.6362 & 5.4689 & TST \\
\hline CHEMBL1449052 & 688239 & 4.6862 & 5.4266 & TRN \\
\hline CHEMBL1445715 & 688239 & 4.5362 & 5.5529 & TST \\
\hline CHEMBL1556013 & 688239 & 5.1862 & 5.6075 & TRN \\
\hline CHEMBL1509996 & 688239 & 4.5362 & 5.3969 & TRN \\
\hline
\end{tabular}

Page 2069 
Supplemental Table S2.txt

\begin{tabular}{|c|c|c|c|c|}
\hline CHEMBL1345528 & 688239 & 4.7862 & 5.4283 & TST \\
\hline CHEMBL1430782 & 688239 & 4.4862 & 5.6199 & TRN \\
\hline CHEMBL1448142 & 688239 & 5.2862 & 5.49299 & 7999999999 \\
\hline CHEMBL1467325 & 688239 & 4.4862 & 5.5905 & TRN \\
\hline CHEMBL1457738 & 688239 & 6.9863 & 5.4544 & TRN \\
\hline CHEMBL1552905 & 688239 & 5.5862 & 5.5133 & TRN \\
\hline CHEMBL1419108 & 688239 & 7.1361 & 5.4105 & TRN \\
\hline CHEMBL1431925 & 688239 & 5.1862 & 5.5927 & TRN \\
\hline CHEMBL1608789 & 688239 & 6.1362 & 5.4623 & TRN \\
\hline CHEMBL1339307 & 688239 & 5.4862 & 5.2855 & TRN \\
\hline CHEMBL1392025 & 688239 & 5.0362 & 5.5592 & TRN \\
\hline CHEMBL1410809 & 688239 & 4.5362 & 5.4659 & TRN \\
\hline CHEMBL1579717 & 688239 & 4.5362 & 5.5119 & TST \\
\hline CHEMBL1437218 & 688239 & 5.5362 & 5.4916 & TRN \\
\hline CHEMBL1408005 & 688239 & 5.1862 & 5.5164 & TRN \\
\hline CHEMBL1308250 & 688239 & 5.0362 & 5.485 & TRN \\
\hline CHEMBL1372085 & 688239 & 4.8362 & 5.3928 & TST \\
\hline CHEMBL1365139 & 688239 & 5.0862 & 5.535 & TRN \\
\hline CHEMBL1541251 & 688239 & 6.8362 & 5.5513 & TRN \\
\hline CHEMBL1421580 & 688239 & 5.9862 & 5.5178 & TST \\
\hline CHEMBL1401556 & 688239 & 5.9862 & 5.4898 & TRN \\
\hline CHEMBL1388335 & 688239 & 5.6362 & 5.5887 & TRN \\
\hline CHEMBL1379513 & 688239 & 4.5362 & 5.3348 & TRN \\
\hline CHEMBL1300818 & 688239 & 6.2362 & 5.5335 & TRN \\
\hline CHEMBL3199524 & 688239 & 5.1862 & 5.4374 & TST \\
\hline CHEMBL1325332 & 688239 & 6.9863 & 5.3924 & TRN \\
\hline CHEMBL3212385 & 688239 & 6.1362 & 5.4857 & TRN \\
\hline CHEMBL1531809 & 688239 & 6.9863 & 5.5198 & TRN \\
\hline CHEMBL1483406 & 688239 & 5.7362 & 5.4364 & TRN \\
\hline CHEMBL1540019 & 688239 & 4.6362 & 5.5824 & TRN \\
\hline CHEMBL1448237 & 688239 & 5.1862 & 5.4648 & TRN \\
\hline CHEMBL1496280 & 688239 & 5.7862 & 5.5873 & TST \\
\hline CHEMBL1427495 & 688239 & 4.5362 & 5.5702 & TST \\
\hline CHEMBL1544519 & 688239 & 5.8362 & 5.4334 & TRN \\
\hline CHEMBL1533838 & 688239 & 8.0862 & 5.4172 & TST \\
\hline CHEMBL1590794 & 688239 & 6.3362 & 5.4655 & TRN \\
\hline CHEMBL1402705 & 688239 & 6.1862 & 5.5489 & TST \\
\hline CHEMBL167997 & 688239 & 6.2862 & 5.5675 & TRN \\
\hline CHEMBL1401015 & 688239 & 7.3363 & 5.4348 & TRN \\
\hline CHEMBL1585648 & 688239 & 4.5362 & 5.5795 & TST \\
\hline CHEMBL1529190 & 688239 & 5.3862 & 5.3963 & TRN \\
\hline CHEMBL1410567 & 688239 & 6.3362 & 5.394 & TRN \\
\hline CHEMBL1458012 & 688239 & 6.4362 & 5.4058 & TRN \\
\hline CHEMBL1568345 & 688239 & 5.6862 & 5.3364 & TRN \\
\hline CHEMBL1406458 & 688239 & 5.1862 & 5.5164 & TRN \\
\hline CHEMBL1377943 & 688239 & 6.8362 & 5.5977 & TRN \\
\hline CHEMBL1307593 & 688239 & 5.6362 & 5.5895 & TRN \\
\hline CHEMBL1309196 & 688239 & 5.9362 & 5.4445 & TRN \\
\hline
\end{tabular}


Supplemental Table S2.txt

\begin{tabular}{|c|c|c|c|c|}
\hline IE & & 52 & & \\
\hline UГMDI 1107500 & & 4.9862 & 5.5244 & \\
\hline 24 & & & & \\
\hline IEMBL1 & & 5362 & 863 & \\
\hline AEMBL156 & 8239 & 863 & & \\
\hline HEMBL1381199 & 88239 & 3372 & 4273 & \\
\hline HEMBL1C & 239 & 362 & & \\
\hline IFMBI 13 & & & & \\
\hline HEMBL152 & & 863 & & \\
\hline HEMBL145 & 88239 & 862 & 5325 & \\
\hline JEMBL14 & 88239 & 861 & 66 & \\
\hline IEMBL15 & 39 & 62 & 571 & \\
\hline IEMBL14 & & & & \\
\hline HEMBL14 & & 362 & & \\
\hline AEMBL13: & & & & \\
\hline AEMBL14 & 39 & 62 & 552 & \\
\hline HEMBL15 & & & & \\
\hline HEMBL15 & & & & \\
\hline HEMBL14 & & 62 & & \\
\hline AEMBL15 & & & & \\
\hline HEIMBLIL & & & 54 & \\
\hline AEMBL14 & & & & \\
\hline HEMBL13 & & & & \\
\hline AEMBL14 & & & & \\
\hline AEMBL14 & & & & IIT \\
\hline HEMBL1: & & 52 & 48 & \\
\hline HEMBL1: & & & & \\
\hline HFMBI 14 & & & & RN \\
\hline HEMBL13 & & & & TRN \\
\hline HEMBL135 & & & 25 & ISI \\
\hline HEMBL13 & & & & $\mathrm{RN}$ \\
\hline AFMBI 1 & & & & KIV \\
\hline 72 & & & & RN \\
\hline HEMBL153 & & & & SI \\
\hline HEMBL1571087 & & 62 & 5.5557 & $\Gamma \mathrm{RN}$ \\
\hline HEMBL13 & & & .6406 & RN \\
\hline HEMP I 1 & & & & RN \\
\hline HEMBL13 & & & & RN \\
\hline HEMBL150 & 88239 & 62 & 461 & $\Gamma \mathrm{RN}$ \\
\hline AEMBL16 & & 362 & 91 & IST \\
\hline HEMBL13 & & 862 & & \\
\hline CHEMBL15 & & & & ST \\
\hline HEMBL13. & & 362 & 5.535 & $\mathrm{RN}$ \\
\hline AEMBL142 & 8239 & 862 & 135 & TRN \\
\hline EMBL13 & & & 57 & \\
\hline HEMBL13 & & & 5.3931 & \\
\hline CHEMBL14. & & & 5.4025 & \\
\hline HEMBL1442565 & 688239 & 4.6362 & 5.3284 & ГST \\
\hline
\end{tabular}

Page 2071 
Supplemental Table S2.txt

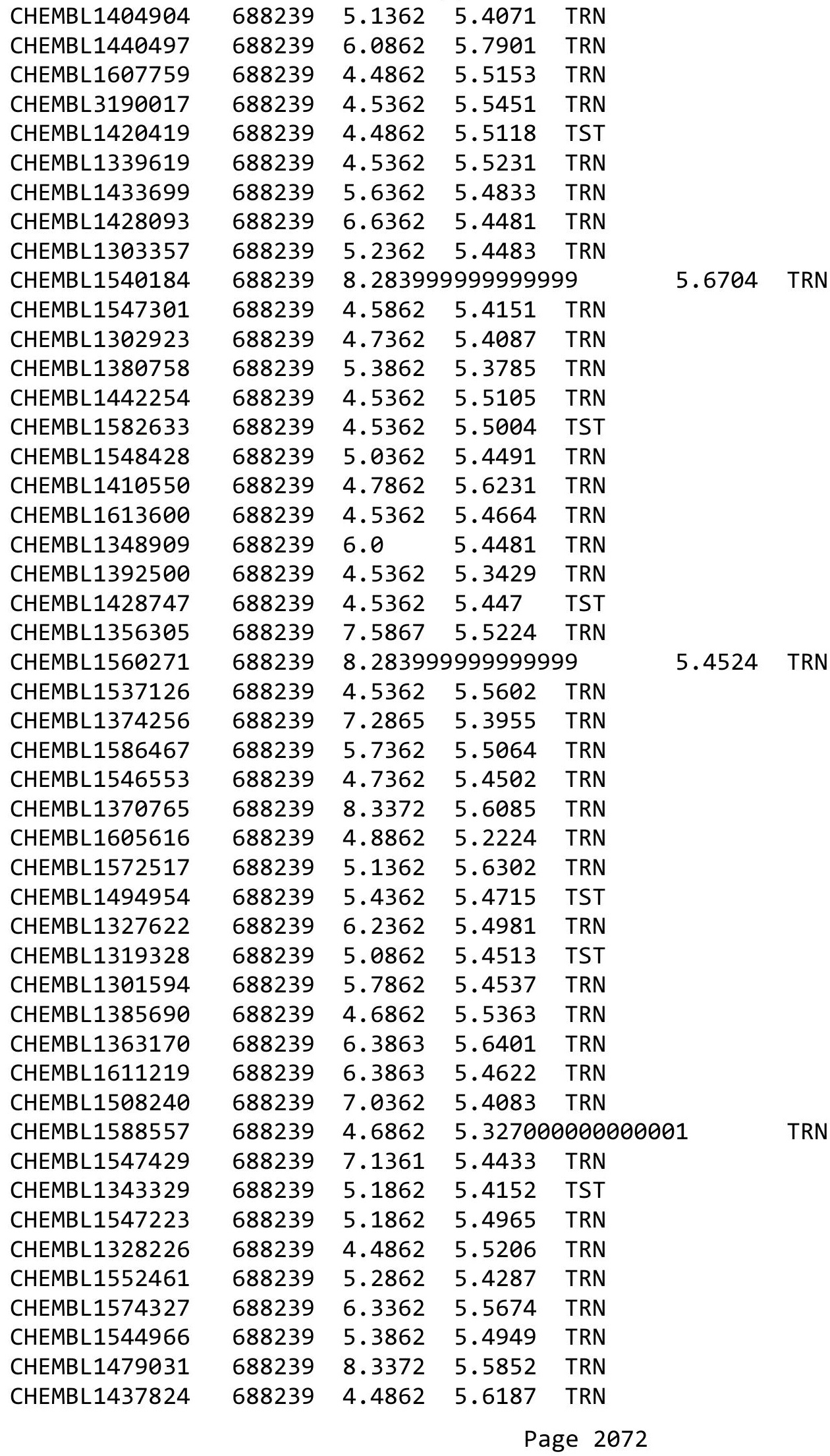


Supplemental Table S2.txt

\begin{tabular}{|c|c|c|c|c|c|}
\hline CHEMBL1408158 & 688239 & 4.5362 & 5.434 & TRN & \\
\hline CHEMBL1580089 & 688239 & 4.5362 & 5.4874 & TRN & \\
\hline CHEMBL1332548 & 688239 & 4.5362 & 5.4682 & TRN & \\
\hline CHEMBL1433340 & 688239 & 5.7862 & 5.3206 & TRN & \\
\hline CHEMBL1583287 & 688239 & 4.5862 & 5.4179 & TRN & \\
\hline CHEMBL1367640 & 688239 & 5.1362 & 5.5203 & TST & \\
\hline CHEMBL1377922 & 688239 & 4.5362 & 5.6136 & TST & \\
\hline CHEMBL1597440 & 688239 & 6.1862 & 5.5769 & TST & \\
\hline CHEMBL1411943 & 688239 & 4.6862 & 5.397 & TRN & \\
\hline CHEMBL1425801 & 688239 & 6.8362 & 5.4715 & TRN & \\
\hline CHEMBL1529683 & 688239 & 8.28399 & 99999999 & 5.5724 & TST \\
\hline CHEMBL1515294 & 688239 & 5.0362 & \multicolumn{3}{|c|}{$\begin{array}{ll}5.617999999999999 & \text { TRN }\end{array}$} \\
\hline CHEMBL1497307 & 688239 & 4.7362 & 5.4739 & TST & \\
\hline CHEMBL1413184 & 688239 & 5.3862 & 5.6159 & TRN & \\
\hline CHEMBL1414270 & 688239 & 7.1864 & 5.5083 & TRN & \\
\hline CHEMBL1478756 & 688239 & 4.4862 & 5.4799 & TRN & \\
\hline CHEMBL1415162 & 688239 & 4.5362 & 5.5687 & TST & \\
\hline CHEMBL1464294 & 688239 & 4.7362 & 5.6034 & TRN & \\
\hline CHEMBL1514353 & 688239 & 4.8362 & 5.4907 & TRN & \\
\hline CHEMBL1541300 & 688239 & 4.7862 & 5.3022 & TRN & \\
\hline CHEMBL1376091 & 688239 & 4.6362 & 5.2425 & TRN & \\
\hline CHEMBL1331757 & 688239 & 5.4362 & 5.4257 & TRN & \\
\hline CHEMBL1515181 & 688239 & 5.4362 & 5.4078 & TRN & \\
\hline CHEMBL1491062 & 688239 & 6.5862 & 5.5385 & TRN & \\
\hline CHEMBL1475579 & 688239 & 5.4362 & 5.5342 & TRN & \\
\hline CHEMBL1393656 & 688239 & 5.0362 & 5.4782 & TRN & \\
\hline CHEMBL1489247 & 688239 & 5.1862 & 5.5324 & TST & \\
\hline CHEMBL1358948 & 688239 & 4.6862 & 5.3618 & TST & \\
\hline CHEMBL1586867 & 688239 & 8.3372 & 5.4529 & TRN & \\
\hline CHEMBL1531031 & 688239 & 6.1862 & 5.5248 & TRN & \\
\hline CHEMBL1558109 & 688239 & 6.7361 & 5.4719 & TST & \\
\hline CHEMBL1408780 & 688239 & 6.2862 & 5.6056 & TRN & \\
\hline CHEMBL3191328 & 688239 & 4.7862 & 5.4471 & TRN & \\
\hline CHEMBL1508951 & 688239 & 5.4362 & 5.2864 & TRN & \\
\hline CHEMBL1313127 & 688239 & 5.1862 & \multicolumn{2}{|c|}{5.457000000000001} & RN \\
\hline CHEMBL1460367 & 688239 & 4.6362 & 5.4512 & TRN & \\
\hline CHEMBL1470105 & 688239 & 4.5362 & 5.6156 & TST & \\
\hline CHEMBL1609962 & 688239 & 4.5362 & 5.5331 & TRN & \\
\hline CHEMBL3209658 & 688239 & 5.0362 & 5.3708 & TRN & \\
\hline CHEMBL1432367 & 688239 & 4.4862 & 5.6818 & TST & \\
\hline CHEMBL1336816 & 688239 & 5.0862 & 5.5 & TST & \\
\hline CHEMBL3193029 & 688239 & 4.9862 & 5.3798 & TST & \\
\hline CHEMBL1444164 & 688239 & 4.5862 & 5.3574 & TRN & \\
\hline CHEMBL1577609 & 688239 & 6.0362 & 5.4515 & TRN & \\
\hline CHEMBL1558413 & 688239 & 6.5862 & 5.4161 & TRN & \\
\hline CHEMBL1516325 & 688239 & 7.2366 & 5.6322 & TST & \\
\hline CHEMBL1471552 & 688239 & 5.6362 & 5.4073 & TST & \\
\hline CHEMBL1487309 & 688239 & 5.5862 & 5.4058 & TST & \\
\hline
\end{tabular}




\begin{tabular}{|c|c|c|c|c|c|}
\hline \multicolumn{6}{|c|}{ Supplemental Table S2.txt } \\
\hline CHEMBL1524877 & 688239 & 4.4862 & 5.49 & TRN & \\
\hline CHEMBL1477268 & 688239 & 8.3372 & 5.4394 & TST & \\
\hline CHEMBL1445828 & 688239 & 8.2366 & 5.5396 & TRN & \\
\hline CHEMBL1498877 & 688239 & 6.1362 & 5.4073 & TRN & \\
\hline CHEMBL1975834 & 688239 & 4.5362 & 5.3664 & TRN & \\
\hline CHEMBL1340895 & 688239 & 4.4862 & 5.3712 & TRN & \\
\hline CHEMBL1566846 & 688239 & 5.6862 & 5.4172 & TST & \\
\hline CHEMBL1575312 & 688239 & 5.2362 & 5.5296 & TRN & \\
\hline CHEMBL1483095 & 688239 & 6.0862 & 5.5813 & TRN & \\
\hline CHEMBL1572074 & 688239 & 5.3862 & 5.5969 & TRN & \\
\hline CHEMBL1584344 & 688239 & 4.7362 & 5.5633 & TST & \\
\hline CHEMBL1411682 & 688239 & 5.3862 & 5.5331 & TST & \\
\hline CHEMBL1377330 & 688239 & 4.6862 & 5.4576 & TST & \\
\hline CHEMBL1970636 & 688239 & 4.9362 & 5.3992 & TRN & \\
\hline CHEMBL1524482 & 688239 & 4.5362 & 5.45 & TRN & \\
\hline CHEMBL1609109 & 688239 & 6.4362 & 5.5237 & TRN & \\
\hline CHEMBL1429357 & 688239 & 4.6362 & 5.5681 & TRN & \\
\hline CHEMBL1529256 & 688239 & 5.9862 & 5.3196 & TRN & \\
\hline CHEMBL1516730 & 688239 & 7.0362 & 5.4957 & TRN & \\
\hline CHEMBL1318596 & 688239 & 6.3362 & 5.6576 & TRN & \\
\hline CHEMBL1384771 & 688239 & 6.6362 & 5.4951 & TST & \\
\hline CHEMBL1449118 & 688239 & 5.6362 & 5.5447 & TRN & \\
\hline CHEMBL 2131940 & 688239 & 4.7862 & 5.6357 & TRN & \\
\hline CHEMBL1519450 & 688239 & 5.1862 & 5.4015 & TRN & \\
\hline CHEMBL1466580 & 688239 & 5.9862 & 5.38700 & 00000000005 & TST \\
\hline CHEMBL1536582 & 688239 & 6.0362 & 5.5809 & TST & \\
\hline CHEMBL1390703 & 688239 & 4.6362 & 5.4923 & TRN & \\
\hline CHEMBL1344513 & 688239 & 5.0862 & 5.3781 & TRN & \\
\hline CHEMBL1577630 & 688239 & 5.7862 & 5.4632 & TRN & \\
\hline CHEMBL1588587 & 688239 & 4.9862 & 5.5837 & TRN & \\
\hline CHEMBL1569276 & 688239 & 4.5362 & 5.5353 & TRN & \\
\hline CHEMBL1564563 & 688239 & 4.7862 & 5.6159 & TRN & \\
\hline CHEMBL1536425 & 688239 & 6.6861 & 5.3435 & TRN & \\
\hline CHEMBL1571277 & 688239 & 4.9362 & 5.6209 & TRN & \\
\hline CHEMBL1496185 & 688239 & 6.1362 & 5.6202 & TRN & \\
\hline CHEMBL1540367 & 688239 & 4.8362 & 5.561 & TRN & \\
\hline CHEMBL1392104 & 688239 & 4.6362 & 5.4266 & TRN & \\
\hline CHEMBL1434868 & 688239 & 5.0362 & 5.6477 & TRN & \\
\hline CHEMBL1339048 & 688239 & 4.9362 & 5.5382 & TRN & \\
\hline CHEMBL 2006258 & 688239 & 5.6362 & 5.3503 & TRN & \\
\hline CHEMBL1426539 & 688239 & 4.8862 & 5.44799 & 99999999995 & TRN \\
\hline CHEMBL1354410 & 688239 & 4.7862 & 5.4937 & TRN & \\
\hline CHEMBL1589983 & 688239 & 4.7362 & 5.4458 & TRN & \\
\hline CHEMBL1538181 & 688239 & 5.3362 & 5.4011 & TRN & \\
\hline CHEMBL1406861 & 688239 & 5.2862 & 5.5573 & TRN & \\
\hline CHEMBL1568774 & 688239 & 5.9362 & 5.4484 & TRN & \\
\hline CHEMBL1468338 & 688239 & 4.5362 & 5.4905 & TRN & \\
\hline CHEMBL3193399 & 688239 & 5.7362 & 5.5236 & TRN & \\
\hline
\end{tabular}




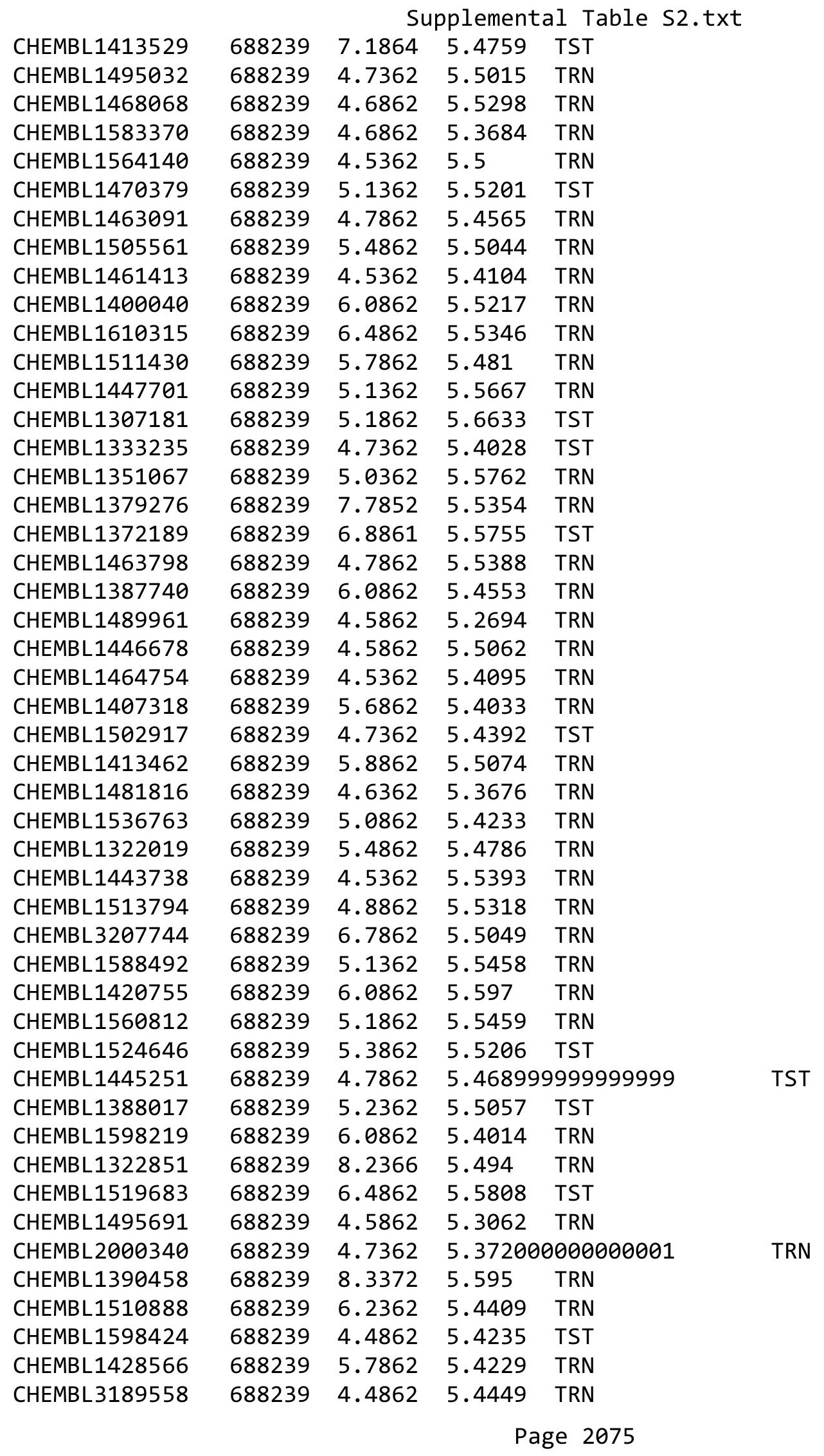


Supplemental Table S2.txt

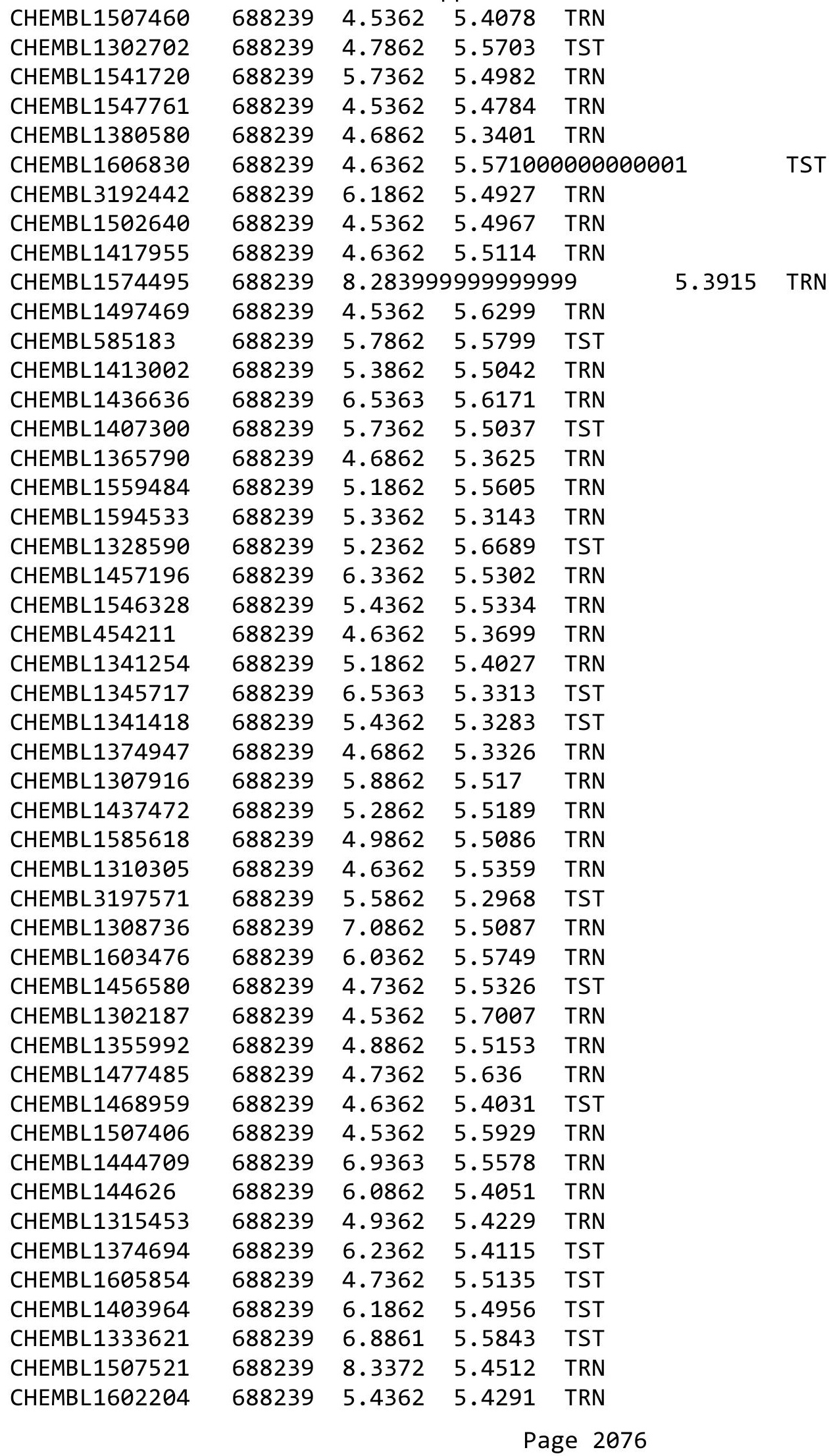


Supplemental Table S2.txt

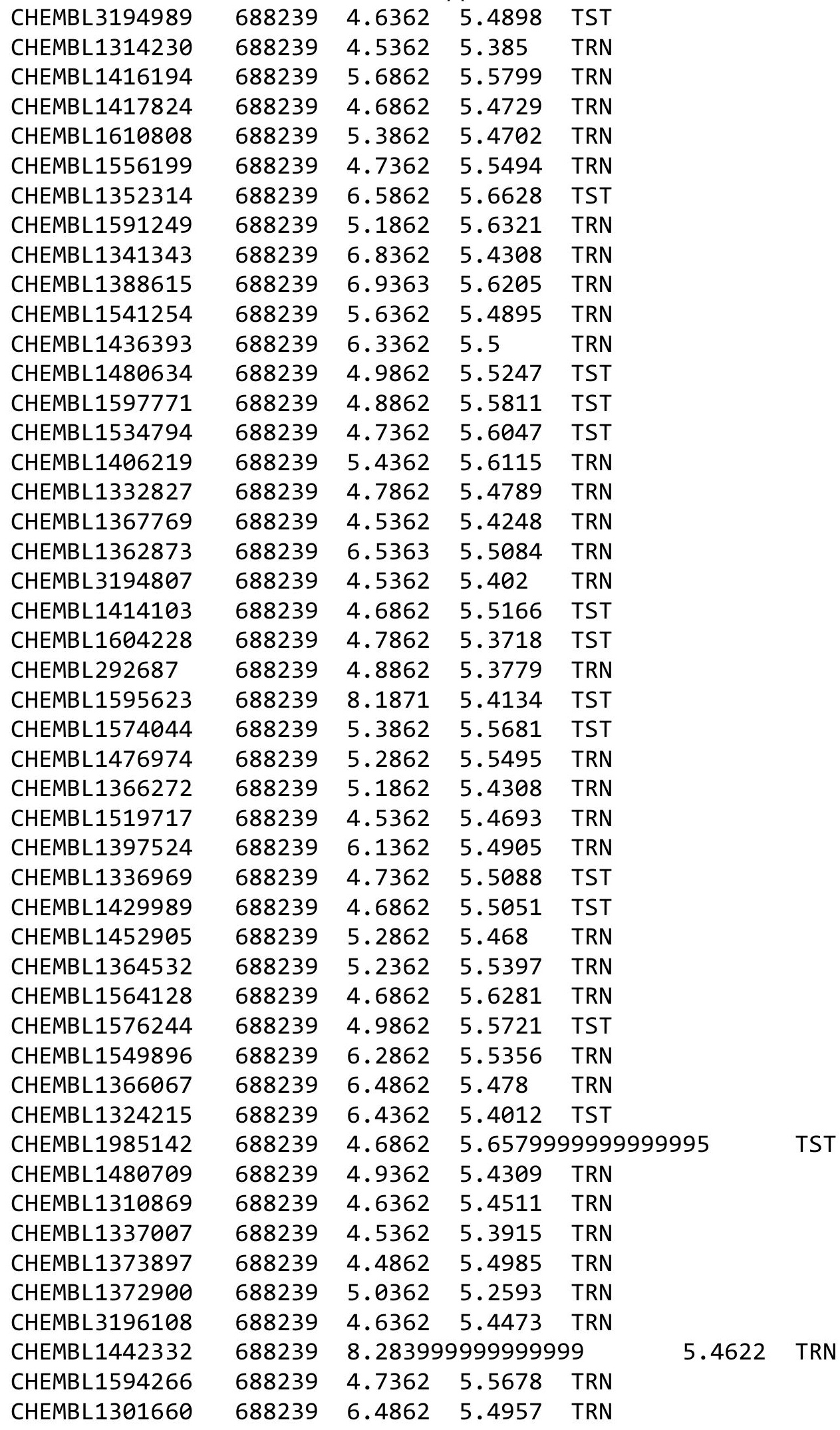

Page 2077 


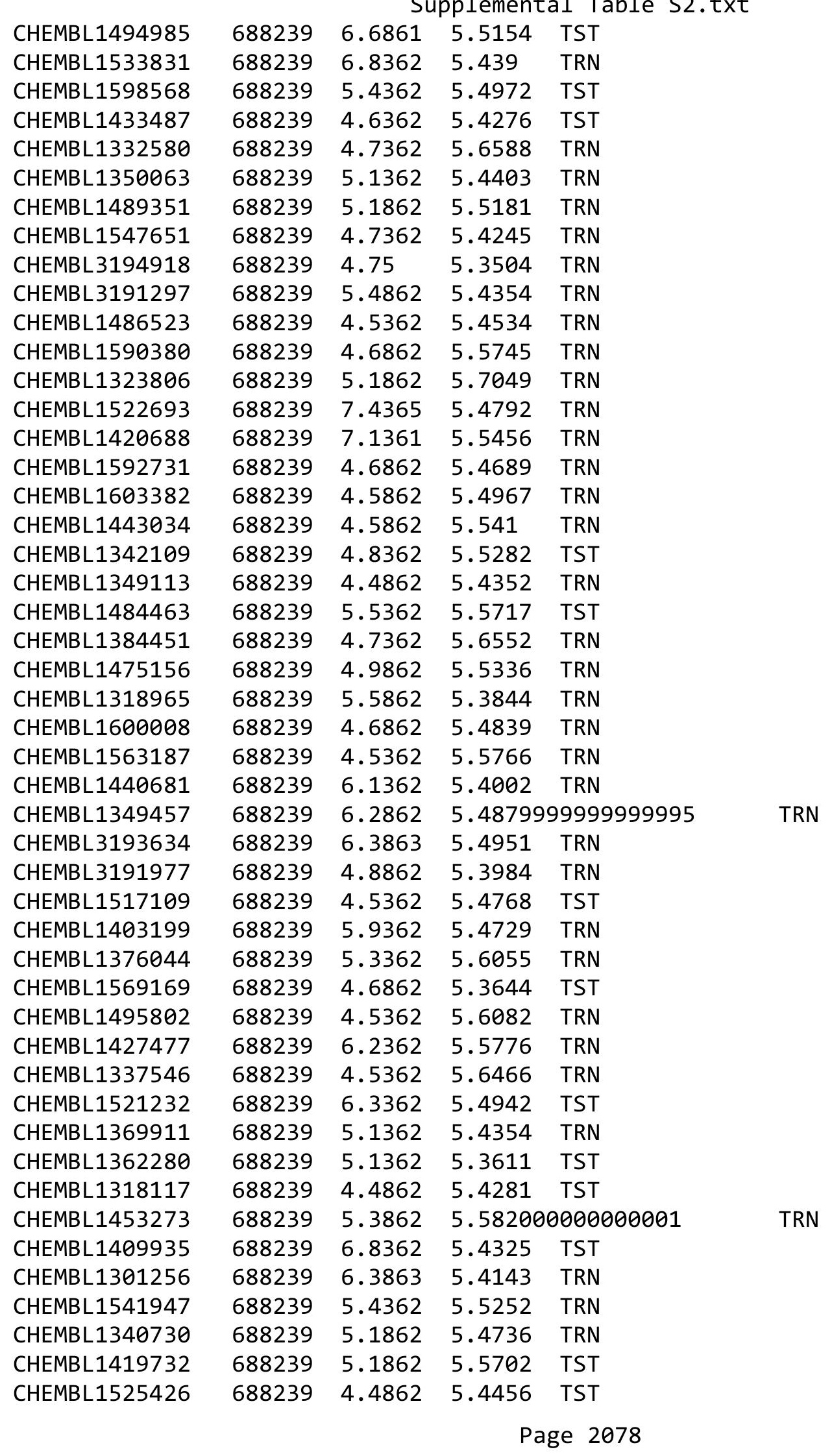


Supplemental Table S2.txt

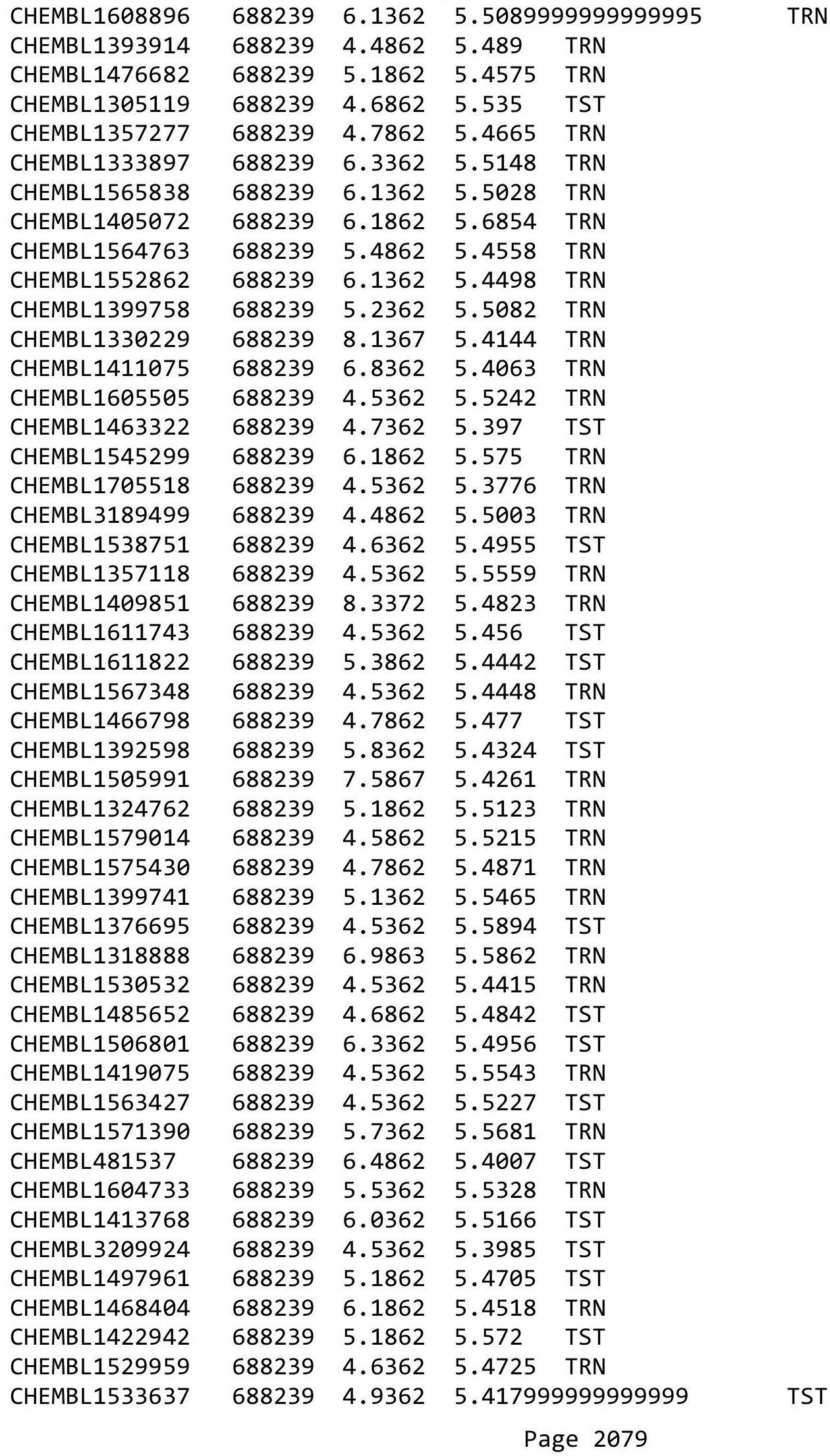


Supplemental Table S2.txt

\begin{tabular}{|c|c|c|c|c|c|}
\hline CHEMBL1541009 & 688239 & 6.1862 & 5.4976 & TST & \\
\hline CHEMBL1410483 & 688239 & 5.3362 & 5.49700 & 0000000001 & TRN \\
\hline CHEMBL1585993 & 688239 & 5.7862 & 5.5652 & TRN & \\
\hline CHEMBL1543607 & 688239 & 5.5862 & 5.471 & TRN & \\
\hline CHEMBL1497562 & 688239 & 6.8861 & 5.6231 & TRN & \\
\hline CHEMBL1381935 & 688239 & 4.6862 & 5.4788 & TRN & \\
\hline CHEMBL1581140 & 688239 & 6.0862 & 5.5901 & TST & \\
\hline CHEMBL1388703 & 688239 & 5.0862 & 5.3205 & TRN & \\
\hline CHEMBL1392308 & 688239 & 5.1862 & 5.4919 & TRN & \\
\hline CHEMBL 3210340 & 688239 & 5.0862 & 5.5976 & TRN & \\
\hline CHEMBL1525744 & 688239 & 5.4362 & 5.5447 & TRN & \\
\hline CHEMBL1550413 & 688239 & 6.8861 & 5.5578 & TRN & \\
\hline CHEMBL1423569 & 688239 & 5.0862 & 5.5248 & TRN & \\
\hline CHEMBL1312834 & 688239 & 4.5862 & 5.5155 & TRN & \\
\hline CHEMBL1370501 & 688239 & 4.5862 & 5.3584 & TRN & \\
\hline CHEMBL1518453 & 688239 & 6.1362 & 5.5322 & TRN & \\
\hline CHEMBL1461680 & 688239 & 4.9362 & 5.5386 & TRN & \\
\hline CHEMBL1462942 & 688239 & 7.5361 & 5.5199 & TST & \\
\hline CHEMBL1600910 & 688239 & 8.3372 & 5.4495 & TST & \\
\hline CHEMBL1482960 & 688239 & 8.3372 & 5.4916 & TRN & \\
\hline CHEMBL577011 & 688239 & 5.1862 & 5.5062 & TRN & \\
\hline CHEMBL1485480 & 688239 & 5.1862 & 5.4671 & TRN & \\
\hline CHEMBL1462095 & 688239 & 5.5362 & 5.5399 & TRN & \\
\hline CHEMBL1347782 & 688239 & 4.6862 & 5.3337 & TRN & \\
\hline CHEMBL1365521 & 688239 & 5.6862 & 5.4446 & TRN & \\
\hline CHEMBL1403782 & 688239 & 4.7362 & 5.5418 & TRN & \\
\hline CHEMBL1381213 & 688239 & 4.5362 & 5.49 & TST & \\
\hline CHEMBL1501881 & 688239 & 4.7862 & 5.5098 & TRN & \\
\hline CHEMBL3211799 & 688239 & 5.1862 & 5.5374 & TRN & \\
\hline CHEMBL1306081 & 688239 & 6.8861 & 5.5027 & TRN & \\
\hline CHEMBL1381554 & 688239 & 5.0862 & 5.5532 & TRN & \\
\hline CHEMBL1432205 & 688239 & 4.6862 & 5.7012 & TRN & \\
\hline CHEMBL1442452 & 688239 & 6.9363 & 5.4902 & TRN & \\
\hline CHEMBL1574235 & 688239 & 5.6362 & 5.5104 & TRN & \\
\hline CHEMBL1311107 & 688239 & 5.1862 & 5.4266 & TST & \\
\hline CHEMBL1611899 & 688239 & 4.7362 & 5.4857 & TRN & \\
\hline CHEMBL1450407 & 688239 & 5.1862 & 5.4691 & TRN & \\
\hline CHEMBL1365653 & 688239 & 4.4862 & 5.4054 & TRN & \\
\hline CHEMBL1394624 & 688239 & 5.8862 & 5.4397 & TRN & \\
\hline CHEMBL1504863 & 688239 & 4.8362 & 5.4348 & TST & \\
\hline CHEMBL1348466 & 688239 & 5.9862 & 5.4101 & TRN & \\
\hline CHEMBL1555997 & 688239 & 4.8862 & 5.4227 & TRN & \\
\hline CHEMBL1385618 & 688239 & 5.3862 & 5.5055 & TST & \\
\hline CHEMBL1576360 & 688239 & 8.3372 & 5.6149 & TRN & \\
\hline CHEMBL1589721 & 688239 & 4.4862 & 5.49 & TRN & \\
\hline CHEMBL1445239 & 688239 & 4.5362 & 5.6251 & TRN & \\
\hline CHEMBL1521522 & 688239 & 6.4362 & 5.6303 & TRN & \\
\hline CHEMBL1977983 & 688239 & 5.4862 & 5.41 & TRN & \\
\hline
\end{tabular}


Supplemental Table S2.txt

\begin{tabular}{|c|c|c|c|c|c|}
\hline CHEMBL1412816 & 688239 & 5.1862 & 5.6341 & TRN & \\
\hline CHEMBL1390036 & 688239 & 4.7862 & 5.4236 & TRN & \\
\hline CHEMBL1493697 & 688239 & 4.6862 & 5.4972 & TST & \\
\hline CHEMBL1539081 & 688239 & 6.2862 & 5.6319 & TRN & \\
\hline CHEMBL1613283 & 688239 & 5.2362 & 5.3593 & TRN & \\
\hline CHEMBL1318748 & 688239 & 5.1862 & 5.5314 & TST & \\
\hline CHEMBL1789997 & 688239 & \multicolumn{2}{|c|}{8.283999999999999} & 5.3768 & TRN \\
\hline CHEMBL3195580 & 688239 & 7.0362 & 5.4686 & TRN & \\
\hline CHEMBL1565115 & 688239 & 4.9362 & 5.426 & TRN & \\
\hline CHEMBL1424013 & 688239 & 6.2362 & 5.5763 & TRN & \\
\hline CHEMBL1568408 & 688239 & 4.5362 & 5.5516 & TRN & \\
\hline CHEMBL1532977 & 688239 & 5.1862 & 5.4791 & TRN & \\
\hline CHEMBL1559481 & 688239 & 6.9363 & 5.5201 & TRN & \\
\hline CHEMBL1456469 & 688239 & 4.9362 & 5.3998 & TRN & \\
\hline CHEMBL1307393 & 688239 & 4.5362 & 5.5497 & TRN & \\
\hline CHEMBL528724 & 688239 & 4.7862 & 5.6295 & TST & \\
\hline CHEMBL1314030 & 688239 & 6.1362 & 5.5321 & TST & \\
\hline CHEMBL1458667 & 688239 & 4.7362 & 5.5932 & TST & \\
\hline CHEMBL1523534 & 688239 & 6.9363 & 5.6396 & TRN & \\
\hline CHEMBL1490237 & 688239 & 6.0862 & 5.4003 & TRN & \\
\hline CHEMBL1510071 & 688239 & 6.5363 & 5.404 & TRN & \\
\hline CHEMBL1360408 & 688239 & 4.7862 & 5.4728 & TRN & \\
\hline CHEMBL1575821 & 688239 & 4.7362 & 5.4192 & TRN & \\
\hline CHEMBL1455496 & 688239 & 4.5362 & 5.4037 & TRN & \\
\hline CHEMBL3197468 & 688239 & 5.5862 & 5.7075 & TRN & \\
\hline CHEMBL1378775 & 688239 & 5.4362 & 5.4221 & TRN & \\
\hline CHEMBL1496821 & 688239 & 4.8862 & 5.3355 & TRN & \\
\hline CHEMBL1459509 & 688239 & 6.7862 & 5.6681 & TRN & \\
\hline CHEMBL1400602 & 688239 & 4.5362 & 5.5245 & TRN & \\
\hline CHEMBL1470749 & 688239 & 6.0862 & 5.4676 & TRN & \\
\hline CHEMBL1495123 & 688239 & 6.1362 & 5.5255 & TRN & \\
\hline CHEMBL1401116 & 688239 & 7.1361 & 5.4763 & TST & \\
\hline CHEMBL1365260 & 688239 & 5.4862 & 5.3035 & TRN & \\
\hline CHEMBL1510359 & 688239 & 4.5362 & 5.4294 & TST & \\
\hline CHEMBL1587809 & 688239 & 7.3363 & 5.487 & TRN & \\
\hline CHEMBL1609537 & 688239 & 4.4862 & 5.4632 & TST & \\
\hline CHEMBL1577742 & 688239 & 6.4862 & 5.5069 & TRN & \\
\hline CHEMBL1509312 & 688239 & 4.6362 & 5.3393 & TRN & \\
\hline CHEMBL1310946 & 688239 & 4.8862 & 5.5502 & TST & \\
\hline CHEMBL1328538 & 688239 & 4.8362 & 5.5065 & TRN & \\
\hline CHEMBL1497165 & 688239 & 5.4362 & 5.4606 & TRN & \\
\hline CHEMBL1528286 & 688239 & 4.5362 & 5.5005 & TST & \\
\hline CHEMBL1406280 & 688239 & 6.0362 & 5.508999 & 99999999995 & $1 \mathrm{KI}$ \\
\hline CHEMBL1520625 & 688239 & 4.7862 & 5.5083 & TRN & \\
\hline CHEMBL1387103 & 688239 & 5.1862 & 5.486000 & 0000000001 & N \\
\hline CHEMBL1562260 & 688239 & 6.1862 & 5.6533 & TRN & \\
\hline CHEMBL1375828 & 688239 & 5.1862 & 5.4773 & TST & \\
\hline CHEMBL1521055 & 688239 & 6.6861 & 5.3571 & TRN & \\
\hline
\end{tabular}


Supplemental Table S2.txt

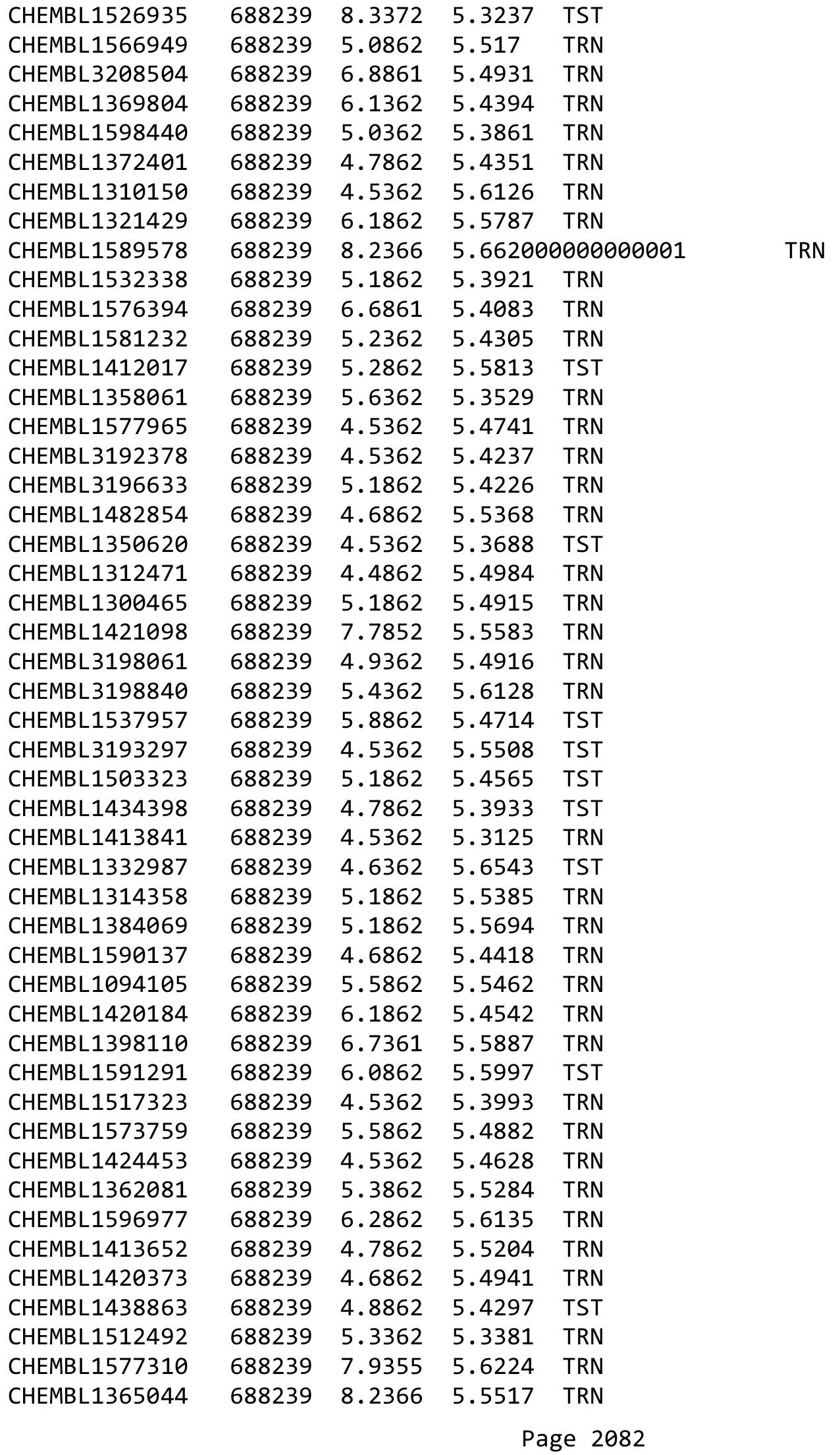


Supplemental Table S2.txt

\begin{tabular}{|c|c|c|c|c|c|}
\hline CHEMBL1527097 & 688239 & 4.6362 & 5.4134 & TRN & \\
\hline CHEMBL1541219 & 688239 & 4.5862 & 5.3821 & TRN & \\
\hline CHEMBL1601788 & 688239 & 4.5362 & 5.3266 & TST & \\
\hline CHEMBL1386605 & 688239 & 4.5362 & 5.38700 & 20000000005 & TRN \\
\hline CHEMBL1546296 & 688239 & 6.8362 & 5.5077 & TST & \\
\hline CHEMBL1402436 & 688239 & 4.5362 & 5.4905 & TRN & \\
\hline CHEMBL1423104 & 688239 & 6.0362 & 5.4336 & TRN & \\
\hline CHEMBL1480371 & 688239 & 5.1362 & 5.4608 & TST & \\
\hline CHEMBL1407751 & 688239 & 6.0862 & 5.5791 & TRN & \\
\hline CHEMBL3196726 & 688239 & 4.8362 & 5.4752 & TRN & \\
\hline CHEMBL1511794 & 688239 & 6.2862 & 5.5417 & TRN & \\
\hline CHEMBL1472733 & 688239 & 4.5362 & 5.5827 & TRN & \\
\hline CHEMBL1300203 & 688239 & 4.7862 & 5.6058 & TRN & \\
\hline CHEMBL1299757 & 688239 & 5.6862 & 5.3815 & TST & \\
\hline CHEMBL1601665 & 688239 & 5.1862 & 5.5378 & TRN & \\
\hline CHEMBL1317089 & 688239 & 5.9362 & 5.5852 & TST & \\
\hline CHEMBL1517617 & 688239 & 4.5362 & 5.5112 & TST & \\
\hline CHEMBL1311901 & 688239 & 6.7862 & 5.5654 & TST & \\
\hline CHEMBL1438980 & 688239 & 4.5362 & 5.4292 & TRN & \\
\hline CHEMBL1392482 & 688239 & 5.7362 & 5.4259 & TST & \\
\hline CHEMBL1468075 & 688239 & 4.8362 & 5.5405 & TRN & \\
\hline CHEMBL1538701 & 688239 & 5.7362 & 5.4163 & TRN & \\
\hline CHEMBL3208608 & 688239 & 5.3362 & 5.2342 & TRN & \\
\hline CHEMBL3197682 & 688239 & 5.1862 & 5.5637 & TST & \\
\hline CHEMBL1480404 & 688239 & 5.0862 & 5.4597 & TRN & \\
\hline CHEMBL1524608 & 688239 & 7.2865 & 5.4197 & TRN & \\
\hline CHEMBL1527637 & 688239 & 4.7362 & 5.6011 & TRN & \\
\hline CHEMBL8197 & 688239 & 5.8362 & 5.46899 & 9999999999 & TRN \\
\hline CHEMBL584074 & 688239 & 4.6862 & 5.3739 & TRN & \\
\hline CHEMBL1606935 & 688239 & 4.5362 & 5.4922 & TRN & \\
\hline CHEMBL1345815 & 688239 & 4.6862 & 5.4807 & TRN & \\
\hline CHEMBL1984764 & 688239 & 4.8862 & 5.54 & TST & \\
\hline CHEMBL1577234 & 688239 & 8.3372 & 5.6148 & TRN & \\
\hline CHEMBL1446161 & 688239 & 4.5362 & 5.4844 & TST & \\
\hline CHEMBL1516133 & 688239 & 6.9863 & 5.48 & TRN & \\
\hline CHEMBL1598094 & 688239 & 8.2366 & 5.5438 & TRN & \\
\hline CHEMBL1302539 & 688239 & 5.1862 & 5.3611 & TST & \\
\hline CHEMBL1462503 & 688239 & 4.9862 & 5.5024 & TRN & \\
\hline CHEMBL1421223 & 688239 & 4.5362 & 5.3479 & TRN & \\
\hline CHEMBL1321490 & 688239 & 6.0862 & 5.4802 & TRN & \\
\hline CHEMBL1581944 & 688239 & 5.4862 & 5.4915 & TST & \\
\hline CHEMBL1346541 & 688239 & 5.1362 & 5.3824 & TRN & \\
\hline CHEMBL1538057 & 688239 & 6.0862 & 5.6446 & TST & \\
\hline CHEMBL1427963 & 688239 & 6.1862 & 5.5821 & TRN & \\
\hline CHEMBL1534010 & 688239 & 4.5362 & 5.3579 & TRN & \\
\hline CHEMBL1436806 & 688239 & 6.7361 & 5.4249 & TRN & \\
\hline CHEMBL3194857 & 688239 & 7.1361 & 5.3961 & TRN & \\
\hline CHEMBL1308022 & 688239 & 5.1862 & 5.5356 & TST & \\
\hline
\end{tabular}


Supplemental Table S2.txt

\begin{tabular}{|c|c|c|c|c|}
\hline 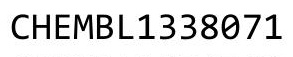 & & & & \\
\hline HEMBL1554760 & 88239 & 8862 & 3665 & \\
\hline HEMBL1525534 & 88239 & 361 & & \\
\hline 35 & & & & \\
\hline EMBL1 & & & 7427 & \\
\hline HEMBL1992276 & 88239 & 862 & 4402 & \\
\hline HEMBL1363956 & 88239 & .5867 & . 3942 & \\
\hline HEMBL3195825 & 39 & 862 & & \\
\hline IEMBL: & 39 & & .5007 & \\
\hline IEMBL14 & 39 & & .4147 & \\
\hline HEMBL1546176 & 88239 & 862 & .4653 & \\
\hline HEMBL1361794 & 39 & 362 & .5715 & \\
\hline HEMBL3209739 & 39 & 62 & 5625 & \\
\hline 58 & 39 & & .3256 & \\
\hline AEMBL14 & 39 & & .5676 & \\
\hline HEMBL144 & 39 & 62 & 4497 & \\
\hline HEMBL1416082 & 39 & & 6074 & \\
\hline HEMBL 319 & 9 & & 64 & \\
\hline HEMBL15ऽ & 9 & & 17 & \\
\hline HEMBL13 & 39 & & & \\
\hline HEMBL $14 €$ & 39 & & & \\
\hline HEMBL1563851 & 39 & & 69 & | \\
\hline HEMBL13ع & 39 & & 94 & \\
\hline HEMBL 14 & & & & \\
\hline 74 & & & 237 & ST \\
\hline HEMBL13 & 39 & & 252 & \\
\hline HEMBL149 & 39 & & 751 & IRN \\
\hline HEMBL15 & 9 & & 265 & RN \\
\hline HEME & & & & RN \\
\hline HEMBL32 & & & 5.3806 & RN \\
\hline HEMBL1241452 & 9 & & & v \\
\hline HEMBL3207699 & 88 & & & ГRN \\
\hline HEMBL3 & 39 & & 91 & ונס \\
\hline 3 & 9 & & 75 & RN \\
\hline HEMBL135 & & & 694 & RN \\
\hline HEMBL1483058 & 39 & & 1599 & IRN \\
\hline HEMBL1393251 & 39 & & 415 & RN \\
\hline 6 & 39 & & 599 & \\
\hline 9 & & & & RIN \\
\hline HEMBL137 & & & 5.3891 & RN \\
\hline HEMBL1522314 & 88239 & 62 & 5.4173 & RN \\
\hline HEMBL13 & 39 & & 5.4853 & ST \\
\hline 19 & & & 5.5208 & \\
\hline HEMBL1306436 & & & 5.4927 & ST \\
\hline HEMBL1310577 & & & 5.4071 & ST \\
\hline HEMBL158. & 88 & 62 & .5641 & RN \\
\hline & & & & \\
\hline 1 & & & & \\
\hline
\end{tabular}


Supplemental Table S2.txt

\begin{tabular}{|c|c|c|c|c|}
\hline CHEMBL1478642 & 688239 & 4.5362 & 5.4643 & TST \\
\hline CHEMBL1557268 & 688239 & 4.8862 & 5.5101 & TST \\
\hline CHEMBL1467522 & 688239 & 4.8362 & 5.3621 & TRN \\
\hline CHEMBL1424777 & 688239 & 4.8862 & 5.3831 & TRN \\
\hline CHEMBL1611558 & 688239 & 4.5362 & 5.3857 & TRN \\
\hline CHEMBL1388854 & 688239 & 8.3872 & 5.5654 & TRN \\
\hline CHEMBL1483511 & 688239 & 6.2862 & 5.6716 & TRN \\
\hline CHEMBL1360693 & 688239 & 4.4862 & 5.4194 & TST \\
\hline CHEMBL1532174 & 688239 & 5.1362 & 5.5673 & TST \\
\hline CHEMBL1481100 & 688239 & 4.5362 & 5.7107 & TST \\
\hline CHEMBL1432180 & 688239 & 5.0362 & 5.3975 & TRN \\
\hline CHEMBL1397199 & 688239 & 5.1862 & 5.4849 & TRN \\
\hline CHEMBL1349580 & 688239 & 5.4362 & 5.5247 & TRN \\
\hline CHEMBL1548222 & 688239 & 6.1862 & 5.4648 & TST \\
\hline CHEMBL1465356 & 688239 & 4.4862 & 5.641 & TRN \\
\hline CHEMBL1542483 & 688239 & 8.3372 & 5.5457 & TRN \\
\hline CHEMBL1403276 & 688239 & 5.7362 & 5.4595 & TRN \\
\hline CHEMBL1418346 & 688239 & 6.0862 & 5.4629 & TRN \\
\hline CHEMBL1585378 & 688239 & 5.4862 & 5.4638 & TRN \\
\hline CHEMBL1320781 & 688239 & 4.7362 & 5.2739 & TRN \\
\hline CHEMBL1483492 & 688239 & 5.7362 & 5.6034 & TRN \\
\hline CHEMBL1548981 & 688239 & 6.5363 & 5.4568 & TRN \\
\hline CHEMBL1458520 & 688239 & 4.6362 & 5.5234 & TRN \\
\hline CHEMBL1468188 & 688239 & 4.7862 & 5.405 & TST \\
\hline CHEMBL1544326 & 688239 & 6.8861 & 5.3809 & TRN \\
\hline CHEMBL1400563 & 688239 & 6.8861 & 5.5374 & TRN \\
\hline CHEMBL1360897 & 688239 & 5.4862 & 5.4419 & TRN \\
\hline CHEMBL1457131 & 688239 & 4.6862 & 5.5193 & TRN \\
\hline CHEMBL1610967 & 688239 & 4.5362 & 5.4279 & TRN \\
\hline CHEMBL 3197552 & 688239 & 4.5362 & 5.3587 & TRN \\
\hline CHEMBL1376672 & 688239 & 4.7862 & 5.3834 & TRN \\
\hline CHEMBL1581505 & 688239 & 4.4862 & 5.4424 & TRN \\
\hline CHEMBL1505934 & 688239 & 5.5862 & 5.5429 & TRN \\
\hline CHEMBL1468452 & 688239 & 5.9362 & 5.4589 & TRN \\
\hline CHEMBL1408455 & 688239 & 4.5362 & 5.6411 & TST \\
\hline CHEMBL1460167 & 688239 & 4.7862 & 5.454 & TRN \\
\hline CHEMBL1581773 & 688239 & 4.5362 & 5.3737 & TST \\
\hline CHEMBL1343757 & 688239 & 6.7862 & 5.4819 & TST \\
\hline CHEMBL1360138 & 688239 & 6.6362 & 5.4362 & TRN \\
\hline CHEMBL1540957 & 688239 & 6.2862 & 5.5327 & TRN \\
\hline CHEMBL1483853 & 688239 & 4.5362 & 5.5215 & TST \\
\hline CHEMBL1585733 & 688239 & 4.9362 & 5.4525 & TRN \\
\hline CHEMBL1386655 & 688239 & 5.2862 & 5.4334 & TRN \\
\hline CHEMBL1437574 & 688239 & 4.6862 & 5.4926 & TRN \\
\hline CHEMBL1528699 & 688239 & 6.9863 & \multicolumn{2}{|c|}{5.617000000000001} \\
\hline CHEMBL1527412 & 688239 & 7.6364 & 5.5532 & TRN \\
\hline CHEMBL1574578 & 688239 & 4.5362 & 5.4248 & TRN \\
\hline CHEMBL1337898 & 688239 & 5.1362 & 5.4036 & TRN \\
\hline
\end{tabular}


Supplemental Table S2.txt

\begin{tabular}{|c|c|c|c|c|c|c|c|}
\hline CHEMBL1307687 & 688239 & 5.1862 & 5.6309 & TRN & & & \\
\hline CHEMBL1377450 & 688239 & 6.8362 & 5.5489 & TRN & & & \\
\hline CHEMBL1519244 & 688239 & 6.9363 & 5.5558 & TRN & & & \\
\hline CHEMBL1389639 & 688239 & 8.3372 & 5.4535 & TRN & & & \\
\hline CHEMBL1409561 & 688239 & 4.9362 & 5.3062 & TRN & & & \\
\hline CHEMBL1547655 & 688239 & 4.4862 & 5.4397 & TST & & & \\
\hline CHEMBL3190881 & 688239 & 5.4862 & 5.405 & TRN & & & \\
\hline CHEMBL3196246 & 688239 & 8.3872 & 5.3341 & TRN & & & \\
\hline CHEMBL1546233 & 688239 & 4.7862 & 5.5386 & TRN & & & \\
\hline CHEMBL1523429 & 688239 & 4.7362 & 5.4277 & TRN & & & \\
\hline CHEMBL1488711 & 688239 & 5.7862 & 5.6628 & TST & & & \\
\hline CHEMBL1309520 & 688239 & 4.6862 & 5.3837 & TRN & & & \\
\hline CHEMBL1345147 & 688239 & 4.7362 & 5.4785 & TRN & & & \\
\hline CHEMBL1595664 & 688239 & 6.1862 & 5.4141 & TST & & & \\
\hline CHEMBL1467289 & 688239 & 5.1862 & 5.4765 & TRN & & & \\
\hline CHEMBL1532828 & 688239 & 5.2862 & 5.2348 & TST & & & \\
\hline CHEMBL1489457 & 688239 & 4.5362 & 5.4586 & TST & & & \\
\hline CHEMBL1610239 & 688239 & 5.9862 & 5.5752 & TST & & & \\
\hline CHEMBL1404589 & 688239 & 4.5362 & 5.5094 & TST & & & \\
\hline CHEMBL3212683 & 688239 & 8.28399 & 79999999 & 99 & 5.3893 & TRN & \\
\hline CHEMBL1605408 & 688239 & 5.1862 & 5.5336 & TRN & & & \\
\hline CHEMBL1589185 & 688239 & 5.7862 & 5.4548 & TST & & & \\
\hline CHEMBL1406596 & 688239 & 5.2362 & 5.5044 & TST & & & \\
\hline CHEMBL1437826 & 688239 & 5.4862 & 5.4695 & TRN & & & \\
\hline CHEMBL243216 & 688239 & 4.5362 & 5.5032 & TRN & & & \\
\hline CHEMBL1325120 & 688239 & 6.9863 & 5.4086 & TRN & & & \\
\hline CHEMBL1341488 & 688239 & 5.4362 & 5.5261 & TRN & & & \\
\hline CHEMBL1547448 & 688239 & 4.5362 & 5.52 & TRN & & & \\
\hline CHEMBL1969992 & 688239 & 8.3372 & 5.3845 & TRN & & & \\
\hline CHEMBL1598820 & 688239 & 4.9362 & 5.3948 & TST & & & \\
\hline CHEMBL1549265 & 688239 & 6.0362 & 5.4114 & TRN & & & \\
\hline CHEMBL1481518 & 688239 & 6.3362 & 5.5466 & TST & & & \\
\hline CHEMBL1478906 & 688239 & 6.1362 & 5.6479 & TRN & & & \\
\hline CHEMBL1389835 & 688239 & 4.5362 & 5.4578 & TST & & & \\
\hline CHEMBL1313706 & 688239 & 6.5363 & 5.36700 & 0000000001 & & TST & \\
\hline CHEMBL1514064 & 688239 & 6.8362 & 5.4062 & TRN & & & \\
\hline CHEMBL1330939 & 688239 & 6.3362 & 5.3275 & TRN & & & \\
\hline CHEMBL1345286 & 688239 & 7.2366 & 5.7137 & TRN & & & \\
\hline CHEMBL1455119 & 688239 & 4.6362 & 5.5429 & TRN & & & \\
\hline CHEMBL1599765 & 688239 & 6.3863 & 5.6408 & TRN & & & \\
\hline CHEMBL1404854 & 688239 & 5.8362 & 5.4976 & TRN & & & \\
\hline CHEMBL1586184 & 688239 & 8.28399 & 99999999 & & 5.5194 & TRN & \\
\hline CHEMBL1466086 & 688239 & 8.28399 & 79999999 & & 5.468999 & 9999999999 & TRN \\
\hline CHEMBL1590649 & 688239 & 4.7362 & 5.3823 & TRN & & & \\
\hline CHEMBL1329306 & 688239 & 5.4862 & 5.638 & TRN & & & \\
\hline CHEMBL1542911 & 688239 & 4.7362 & 5.3956 & TST & & & \\
\hline CHEMBL2369228 & 688239 & 5.0362 & 5.4434 & TST & & & \\
\hline CHEMBL 3145126 & 688239 & 5.3862 & 5.3712 & TST & & & \\
\hline
\end{tabular}




\begin{tabular}{|c|c|c|c|c|c|}
\hline & & & & & \\
\hline CHEMBL1490578 & 688239 & 4.7362 & 5.6987 & TRN & \\
\hline CHEMBL1576609 & 688239 & 6.9863 & 5.4944 & TRN & \\
\hline CHEMBL3212089 & 688239 & 4.4862 & 5.3871 & TRN & \\
\hline CHEMBL1443365 & 688239 & 5.2362 & 5.5996 & TRN & \\
\hline CHEMBL1375442 & 688239 & 6.8362 & 5.4388 & TRN & \\
\hline CHEMBL1475101 & 688239 & 8.28399 & 99999999 & 5.5636 & TST \\
\hline CHEMBL1354902 & 688239 & 4.8862 & 5.4026 & TRN & \\
\hline CHEMBL1413886 & 688239 & 5.4362 & 5.4963 & TRN & \\
\hline CHEMBL3211109 & 688239 & 4.8362 & 5.4916 & TST & \\
\hline CHEMBL1503890 & 688239 & 4.6862 & 5.4907 & TST & \\
\hline CHEMBL1368783 & 688239 & 4.5362 & 5.5376 & TST & \\
\hline CHEMBL1430819 & 688239 & 6.2362 & 5.4952 & TST & \\
\hline CHEMBL1598985 & 688239 & 5.3362 & 5.4523 & TRN & \\
\hline CHEMBL1611714 & 688239 & 6.8362 & 5.3681 & TRN & \\
\hline CHEMBL1313878 & 688239 & 5.1862 & 5.4619 & TRN & \\
\hline CHEMBL1421178 & 688239 & 6.4862 & 5.4152 & TST & \\
\hline CHEMBL1384343 & 688239 & 6.1862 & 5.4303 & TST & \\
\hline CHEMBL1511607 & 688239 & 6.1362 & 5.4594 & TRN & \\
\hline CHEMBL1321627 & 688239 & 6.9363 & 5.2978 & TRN & \\
\hline CHEMBL1428941 & 688239 & 5.1862 & 5.5028 & TRN & \\
\hline CHEMBL1351433 & 688239 & 5.5362 & 5.4902 & TST & \\
\hline CHEMBL1376063 & 688239 & 6.2862 & 5.4852 & TRN & \\
\hline CHEMBL1374386 & 688239 & 4.7862 & 5.4597 & TRN & \\
\hline CHEMBL1411036 & 688239 & 5.8362 & 5.4028 & TRN & \\
\hline CHEMBL1326894 & 688239 & 6.8362 & 5.5657 & TST & \\
\hline CHEMBL1348706 & 688239 & 6.2362 & 5.38299 & 9999999999 & TST \\
\hline CHEMBL1601431 & 688239 & 6.1362 & 5.5068 & TRN & \\
\hline CHEMBL1441100 & 688239 & 6.6861 & 5.6217 & TST & \\
\hline CHEMBL1563662 & 688239 & 4.5362 & 5.5787 & TRN & \\
\hline CHEMBL1429566 & 688239 & 4.5362 & 5.4567 & TRN & \\
\hline CHEMBL1314756 & 688239 & 4.7362 & 5.4358 & TRN & \\
\hline CHEMBL1534115 & 688239 & 8.2366 & 5.6306 & TRN & \\
\hline CHEMBL1586733 & 688239 & 5.3862 & 5.61299 & 99999999995 & TRN \\
\hline CHEMBL1423227 & 688239 & 4.9362 & 5.4184 & TST & \\
\hline CHEMBL1522065 & 688239 & 4.8362 & 5.29899 & 99999999995 & TST \\
\hline CHEMBL1576568 & 688239 & 5.8862 & 5.5491 & TRN & \\
\hline CHEMBL1372052 & 688239 & 5.2362 & 5.3094 & TST & \\
\hline CHEMBL1545432 & 688239 & 5.2362 & 5.4853 & TRN & \\
\hline CHEMBL1479238 & 688239 & 5.0862 & 5.4836 & TRN & \\
\hline CHEMBL159895 & 688239 & 4.4862 & 5.4742 & TRN & \\
\hline CHEMBL601192 & 688239 & 5.7862 & 5.5665 & TRN & \\
\hline CHEMBL1540956 & 688239 & 4.6862 & 5.5589 & TST & \\
\hline CHEMBL3213876 & 688239 & 4.9362 & 5.4079 & TRN & \\
\hline CHEMBL1556029 & 688239 & 8.1871 & 5.4671 & TRN & \\
\hline CHEMBL1458896 & 688239 & 4.9362 & 5.4644 & TRN & \\
\hline CHEMBL1396954 & 688239 & 5.0862 & 5.5576 & TRN & \\
\hline CHEMBL1562516 & 688239 & 4.6362 & 5.682 & TRN & \\
\hline CHEMBL1557695 & 688239 & 4.5362 & 5.5025 & TRN & \\
\hline
\end{tabular}


Supplemental Table S2.txt

\begin{tabular}{|c|c|c|c|c|c|}
\hline CHEMBL1341596 & 688239 & 4.8362 & 5.4127 & TRN & \\
\hline CHEMBL1381410 & 688239 & 4.9362 & 5.5047 & TRN & \\
\hline CHEMBL1583739 & 688239 & 4.5362 & 5.3912 & TST & \\
\hline CHEMBL1514763 & 688239 & 4.8362 & 5.4948 & TRN & \\
\hline CHEMBL1575543 & 688239 & 4.5362 & 5.5058 & TRN & \\
\hline CHEMBL1394441 & 688239 & 4.7362 & 5.5447 & TST & \\
\hline CHEMBL1969046 & 688239 & 4.5362 & 5.2016 & TRN & \\
\hline CHEMBL1354020 & 688239 & 4.5862 & 5.2463 & TRN & \\
\hline CHEMBL1553778 & 688239 & 4.5362 & 5.3679 & TRN & \\
\hline CHEMBL1330605 & 688239 & 4.8862 & 5.5983 & TRN & \\
\hline CHEMBL1454956 & 688239 & 4.7862 & 5.4254 & TRN & \\
\hline CHEMBL1395291 & 688239 & 4.4862 & 5.4061 & TRN & \\
\hline CHEMBL1443320 & 688239 & 4.8362 & 5.5508 & TRN & \\
\hline CHEMBL1471371 & 688239 & 5.1362 & 5.4665 & TRN & \\
\hline CHEMBL1430784 & 688239 & 7.8861 & 5.5922 & TRN & \\
\hline CHEMBL1173145 & 688239 & 6.2362 & 5.4732 & TRN & \\
\hline CHEMBL1454431 & 688239 & 5.3862 & 5.2295 & TRN & \\
\hline CHEMBL1578946 & 688239 & 5.4362 & 5.4175 & TRN & \\
\hline CHEMBL1514961 & 688239 & 4.7362 & 5.49700 & 3000000001 & TRN \\
\hline CHEMBL1430445 & 688239 & 5.7362 & 5.5485 & TRN & \\
\hline CHEMBL1986475 & 688239 & 7.8861 & 5.3406 & TST & \\
\hline CHEMBL1388533 & 688239 & 6.6362 & 5.6241 & TRN & \\
\hline CHEMBL1506932 & 688239 & 6.8861 & 5.5635 & TST & \\
\hline CHEMBL1549267 & 688239 & 4.5362 & 5.3842 & TST & \\
\hline CHEMBL1426031 & 688239 & 4.5362 & 5.4693 & TRN & \\
\hline CHEMBL1584217 & 688239 & 4.5362 & 5.5073 & TRN & \\
\hline CHEMBL1310076 & 688239 & 5.5362 & 5.4236 & TRN & \\
\hline CHEMBL1321289 & 688239 & 5.1862 & 5.546 & TRN & \\
\hline CHEMBL343409 & 688239 & 5.1862 & 5.51399 & 9999999999 & TRN \\
\hline CHEMBL1301129 & 688239 & 4.6862 & 5.4011 & TRN & \\
\hline CHEMBL1458458 & 688239 & 5.8362 & 5.4394 & TST & \\
\hline CHEMBL1358612 & 688239 & 6.7862 & 5.5179 & TST & \\
\hline CHEMBL1386230 & 688239 & 4.5362 & 5.6084 & TRN & \\
\hline CHEMBL1581859 & 688239 & 6.2362 & 5.4837 & TRN & \\
\hline CHEMBL1540155 & 688239 & 4.7862 & 5.4771 & TRN & \\
\hline CHEMBL1513240 & 688239 & 4.6862 & 5.2758 & TRN & \\
\hline CHEMBL1421646 & 688239 & 6.2862 & 5.5025 & TRN & \\
\hline CHEMBL1409798 & 688239 & 6.4862 & 5.4905 & TRN & \\
\hline CHEMBL1377479 & 688239 & 4.5362 & 5.405 & TRN & \\
\hline CHEMBL1539264 & 688239 & 4.5362 & 5.4888 & TRN & \\
\hline CHEMBL1360669 & 688239 & 4.4862 & 5.4943 & TST & \\
\hline CHEMBL1591658 & 688239 & 6.5862 & 5.5288 & TRN & \\
\hline CHEMBL1517459 & 688239 & 5.5362 & 5.5413 & TRN & \\
\hline CHEMBL1566115 & 688239 & 6.1362 & 5.3783 & TRN & \\
\hline CHEMBL1504402 & 688239 & 4.5362 & 5.6026 & TRN & \\
\hline CHEMBL1603197 & 688239 & 7.0862 & 5.4312 & TRN & \\
\hline CHEMBL3193169 & 688239 & 4.5362 & 5.57 & TRN & \\
\hline CHEMBL1544175 & 688239 & 5.1862 & 5.5044 & TST & \\
\hline
\end{tabular}




\begin{tabular}{|c|c|c|c|c|c|}
\hline \multicolumn{6}{|c|}{ ple } \\
\hline CHEMBL1612080 & 688239 & 6.2362 & 5.6478 & TRN & \\
\hline CHEMBL1435603 & 688239 & 5.6362 & 5.6792 & TRN & \\
\hline CHEMBL1398509 & 688239 & 4.5362 & 5.4262 & TRN & \\
\hline CHEMBL1325447 & 688239 & 5.1862 & 5.4383 & TRN & \\
\hline CHEMBL1434014 & 688239 & 4.9862 & 5.436 & TRN & \\
\hline CHEMBL1392278 & 688239 & 5.2362 & 5.6137 & TST & \\
\hline CHEMBL3145303 & 688239 & 6.5862 & 5.51399 & 9999999999 & TRN \\
\hline CHEMBL1484269 & 688239 & 5.6362 & 5.4487 & TRN & \\
\hline CHEMBL1432466 & 688239 & 4.5362 & 5.5577 & TST & \\
\hline CHEMBL3207712 & 688239 & 5.8362 & 5.3882 & TRN & \\
\hline CHEMBL1422359 & 688239 & 4.5362 & 5.5902 & TRN & \\
\hline CHEMBL1486037 & 688239 & 4.7362 & 5.3225 & TST & \\
\hline CHEMBL1550188 & 688239 & 4.5362 & 5.4974 & TRN & \\
\hline CHEMBL1581183 & 688239 & 5.1362 & 5.4706 & TRN & \\
\hline CHEMBL1307236 & 688239 & 6.8362 & 5.5703 & TST & \\
\hline CHEMBL1972688 & 688239 & 4.6362 & 5.5104 & TRN & \\
\hline CHEMBL3211785 & 688239 & 4.9862 & 5.4005 & TST & \\
\hline CHEMBL1322187 & 688239 & 4.5362 & 5.4762 & TRN & \\
\hline CHEMBL1312207 & 688239 & 6.2362 & 5.4379 & TRN & \\
\hline CHEMBL1482046 & 688239 & 4.5362 & 5.4227 & TRN & \\
\hline CHEMBL1327701 & 688239 & 5.4862 & 5.41299 & 9999999999 & TRN \\
\hline CHEMBL3212643 & 688239 & 4.5362 & 5.6017 & TRN & \\
\hline CHEMBL1545190 & 688239 & 8.2366 & 5.7425 & TRN & \\
\hline CHEMBL1397161 & 688239 & 5.4362 & 5.4686 & TRN & \\
\hline CHEMBL1520433 & 688239 & 6.4362 & 5.4943 & TRN & \\
\hline CHEMBL1504300 & 688239 & 7.5361 & 5.6567 & TRN & \\
\hline CHEMBL1482605 & 688239 & 4.7362 & 5.58799 & 9999999999 & TRN \\
\hline CHEMBL1299392 & 688239 & 4.5362 & 5.349 & TRN & \\
\hline CHEMBL1393485 & 688239 & 6.3863 & 5.5478 & TST & \\
\hline CHEMBL1322572 & 688239 & 4.5362 & 5.5393 & TST & \\
\hline CHEMBL1613019 & 688239 & 4.6862 & 5.6962 & TST & \\
\hline CHEMBL1337179 & 688239 & 6.0862 & 5.455 & TST & \\
\hline CHEMBL1596482 & 688239 & 6.9863 & 5.4801 & TRN & \\
\hline CHEMBL1402426 & 688239 & 5.0862 & 5.5144 & TRN & \\
\hline CHEMBL1460990 & 688239 & 4.6362 & 5.5152 & TRN & \\
\hline CHEMBL3209976 & 688239 & 5.6362 & 5.50299 & 9999999999 & TST \\
\hline CHEMBL3210814 & 688239 & 6.1862 & 5.6095 & TRN & \\
\hline CHEMBL1331977 & 688239 & 5.3362 & 5.5664 & TRN & \\
\hline CHEMBL1301928 & 688239 & 4.7862 & 5.4191 & TST & \\
\hline CHEMBL3194187 & 688239 & 4.8362 & 5.4379 & TRN & \\
\hline CHEMBL1381248 & 688239 & 4.4862 & 5.6206 & TRN & \\
\hline CHEMBL1523192 & 688239 & 4.7362 & 5.3961 & TST & \\
\hline CHEMBL1386371 & 688239 & 5.6862 & 5.5343 & TST & \\
\hline CHEMBL1317408 & 688239 & 4.8362 & 5.4174 & TRN & \\
\hline CHEMBL1404164 & 688239 & 6.7862 & 5.5878 & TST & \\
\hline CHEMBL1485743 & 688239 & 5.4362 & 5.6261 & TRN & \\
\hline CHEMBL1595492 & 688239 & 5.4862 & 5.4941 & TRN & \\
\hline CHEMBL1567159 & 688239 & 4.5362 & 5.3887 & TRN & \\
\hline
\end{tabular}


Supplemental Table S2.txt

\begin{tabular}{|c|c|c|c|c|c|}
\hline CHEMBL1318925 & 688239 & 4.6862 & 5.4971 & TRN & \\
\hline CHEMBL1385327 & 688239 & 4.6862 & 5.379 & TST & \\
\hline CHEMBL1448487 & 688239 & 6.1362 & 5.4465 & TRN & \\
\hline CHEMBL1342651 & 688239 & 5.4862 & 5.4255 & TRN & \\
\hline CHEMBL1340192 & 688239 & 5.3 & 5.4774 & TRN & \\
\hline CHEMBL1470676 & 688239 & 5.4362 & 5.5424 & TRN & \\
\hline CHEMBL1589440 & 688239 & 5.5862 & 5.4448 & TST & \\
\hline CHEMBL1367970 & 688239 & 5.5862 & 5.4859 & TRN & \\
\hline CHEMBL1577128 & 688239 & 4.7862 & 5.3485 & TRN & \\
\hline CHEMBL1496192 & 688239 & 6.6861 & 5.6198 & TRN & \\
\hline CHEMBL1371783 & 688239 & 6.1362 & 5.5608 & TST & \\
\hline CHEMBL1440357 & 688239 & 5.4862 & 5.5689 & TRN & \\
\hline CHEMBL1332611 & 688239 & 6.4362 & 5.5163 & TRN & \\
\hline CHEMBL1419809 & 688239 & 5.4362 & 5.3577 & TST & \\
\hline CHEMBL1387947 & 688239 & 6.4362 & 5.3475 & TRN & \\
\hline CHEMBL1545647 & 688239 & 5.4362 & 5.4871 & TRN & \\
\hline CHEMBL1603380 & 688239 & 4.7862 & 5.4834 & TRN & \\
\hline CHEMBL1519387 & 688239 & 5.4862 & 5.4761 & TST & \\
\hline CHEMBL1497677 & 688239 & 4.6362 & 5.3667 & TRN & \\
\hline CHEMBL1529426 & 688239 & 4.5362 & 5.5103 & TST & \\
\hline CHEMBL1342685 & 688239 & 6.6861 & 5.5053 & TST & \\
\hline CHEMBL1465032 & 688239 & 5.6862 & 5.58799 & 9999999999 & TRN \\
\hline CHEMBL1469488 & 688239 & 4.6362 & 5.6436 & TRN & \\
\hline CHEMBL1437462 & 688239 & 6.0362 & 5.4842 & TRN & \\
\hline CHEMBL1456440 & 688239 & 4.6862 & 5.3801 & TRN & \\
\hline CHEMBL1494764 & 688239 & 5.6362 & 5.7301 & TST & \\
\hline CHEMBL1568890 & 688239 & 4.4862 & 5.4759 & TST & \\
\hline CHEMBL3213383 & 688239 & 4.5362 & 5.3236 & TRN & \\
\hline CHEMBL1332050 & 688239 & 6.1862 & 5.2677 & TST & \\
\hline CHEMBL1383417 & 688239 & 4.5862 & 5.4459 & TST & \\
\hline CHEMBL1965698 & 688239 & 5.6362 & 5.4084 & TST & \\
\hline CHEMBL1583000 & 688239 & 4.7362 & 5.3789 & TRN & \\
\hline CHEMBL1598019 & 688239 & 6.5363 & 5.6406 & TST & \\
\hline CHEMBL1311719 & 688239 & 6.0362 & 5.5518 & TST & \\
\hline CHEMBL1523476 & 688239 & 5.1862 & 5.4246 & TRN & \\
\hline CHEMBL1415867 & 688239 & 6.8362 & 5.5113 & TRN & \\
\hline CHEMBL1434491 & 688239 & 4.5362 & 5.5297 & TRN & \\
\hline CHEMBL1541933 & 688239 & 4.7862 & 5.5403 & TST & \\
\hline CHEMBL1430941 & 688239 & 6.4362 & 5.4632 & TRN & \\
\hline CHEMBL1422794 & 688239 & 4.8362 & \multicolumn{2}{|c|}{5.361000000000001} & TST \\
\hline CHEMBL1346168 & 688239 & 4.5362 & 5.5179 & TRN & \\
\hline CHEMBL1307654 & 688239 & 6.6362 & 5.403 & TRN & \\
\hline CHEMBL1606814 & 688239 & 5.3862 & \multicolumn{2}{|c|}{5.4510000000000005} & TRN \\
\hline CHEMBL1458089 & 688239 & 4.9362 & 5.5623 & TRN & \\
\hline CHEMBL3198893 & 688239 & 5.6362 & 5.3646 & TRN & \\
\hline CHEMBL1387688 & 688239 & 4.5362 & 5.3942 & TST & \\
\hline CHEMBL1380923 & 688239 & 5.1862 & 5.5805 & TRN & \\
\hline CHEMBL1552378 & 688239 & 8.3872 & 5.6182 & TRN & \\
\hline
\end{tabular}


Supplemental Table S2.txt

\begin{tabular}{|c|c|c|c|c|}
\hline CHEMBL1341449 & 688239 & 5.1862 & 5.5934 & TST \\
\hline CHEMBL1453838 & 688239 & 5.3862 & 5.4519 & TRN \\
\hline CHEMBL1456827 & 688239 & 6.9863 & 5.4137 & TRN \\
\hline CHEMBL1570857 & 688239 & 6.7862 & 5.3728 & TRN \\
\hline CHEMBL1350150 & 688239 & 6.8861 & 5.465 & TRN \\
\hline CHEMBL1408046 & 688239 & 5.6862 & 5.3548 & TRN \\
\hline CHEMBL1420865 & 688239 & 5.1862 & 5.5153 & TRN \\
\hline CHEMBL1498867 & 688239 & 5.9362 & 5.5133 & TST \\
\hline CHEMBL1377762 & 688239 & 4.8862 & 5.4574 & TRN \\
\hline CHEMBL1529876 & 688239 & 4.7862 & 5.4174 & TST \\
\hline CHEMBL1370703 & 688239 & 4.7862 & 5.511 & TRN \\
\hline CHEMBL1505083 & 688239 & 6.0362 & 5.5423 & TRN \\
\hline CHEMBL1975982 & 688239 & 4.6362 & 5.4216 & TRN \\
\hline CHEMBL3195336 & 688239 & 5.7862 & 5.489 & TST \\
\hline CHEMBL1596421 & 688239 & 7.2366 & 5.4297 & TRN \\
\hline CHEMBL1994815 & 688239 & 4.7362 & 5.449 & TRN \\
\hline CHEMBL1343711 & 688239 & 4.9862 & 5.3442 & TRN \\
\hline CHEMBL1444468 & 688239 & 6.0362 & 5.3555 & TRN \\
\hline CHEMBL1544090 & 688239 & 4.6862 & 5.3746 & TRN \\
\hline CHEMBL1598015 & 688239 & 4.5362 & 5.5445 & TRN \\
\hline CHEMBL1478192 & 688239 & 5.9362 & 5.6607 & TRN \\
\hline CHEMBL1500867 & 688239 & 8.3372 & 5.5509 & TST \\
\hline CHEMBL1584413 & 688239 & 5.4862 & 5.7065 & TRN \\
\hline CHEMBL1523226 & 688239 & 5.3862 & 5.3556 & TRN \\
\hline CHEMBL1527794 & 688239 & 5.7362 & 5.5133 & TRN \\
\hline CHEMBL1455333 & 688239 & 5.5862 & 5.5587 & TRN \\
\hline CHEMBL1330702 & 688239 & 5.3862 & 5.5392 & TRN \\
\hline CHEMBL1474018 & 688239 & 6.1362 & 5.3727 & TRN \\
\hline CHEMBL1425833 & 688239 & 5.7862 & 5.5699 & TST \\
\hline CHEMBL1461913 & 688239 & 5.6862 & 5.3868 & TRN \\
\hline CHEMBL1437211 & 688239 & 5.5362 & 5.6426 & TRN \\
\hline CHEMBL1480137 & 688239 & 4.9362 & 5.42700 & 30000000005 \\
\hline CHEMBL1438290 & 688239 & 5.6362 & 5.4881 & TST \\
\hline CHEMBL1336583 & 688239 & 5.5362 & 5.5651 & TST \\
\hline CHEMBL1602939 & 688239 & 5.1862 & 5.49 & TRN \\
\hline CHEMBL1586427 & 688239 & 5.9862 & 5.5036 & TST \\
\hline CHEMBL1351345 & 688239 & 4.6362 & 5.6139 & TRN \\
\hline CHEMBL1425923 & 688239 & 5.1862 & 5.4141 & TRN \\
\hline CHEMBL1369847 & 688239 & 5.5362 & 5.5166 & TRN \\
\hline CHEMBL1370028 & 688239 & 6.7862 & 5.6196 & TRN \\
\hline CHEMBL 3208636 & 688239 & 5.2362 & 5.489 & TST \\
\hline CHEMBL1424387 & 688239 & 4.5362 & 5.4137 & TRN \\
\hline CHEMBL1507546 & 688239 & 4.5362 & 5.6154 & TST \\
\hline CHEMBL1305159 & 688239 & 5.2362 & 5.7153 & TRN \\
\hline CHEMBL1433068 & 688239 & 5.1362 & 5.6647 & TRN \\
\hline CHEMBL1575841 & 688239 & 4.7362 & 5.5116 & TST \\
\hline CHEMBL3199526 & 688239 & 4.5862 & 5.3389 & TRN \\
\hline CHEMBL1312112 & 688239 & 4.7362 & 5.4796 & TST \\
\hline
\end{tabular}


Supplemental Table S2.txt

\begin{tabular}{|c|c|c|c|c|}
\hline CHEMBL 3194048 & 688239 & 5.1862 & 5.4092 & TRN \\
\hline CHEMBL3214338 & 688239 & 4.6862 & 5.3259 & TRN \\
\hline CHEMBL1598241 & 688239 & 5.5862 & 5.5522 & TRN \\
\hline CHEMBL1490281 & 688239 & 4.8862 & 5.6683 & TRN \\
\hline CHEMBL1389659 & 688239 & 4.7362 & 5.535 & TRN \\
\hline CHEMBL1355298 & 688239 & 5.1862 & 5.5771 & TRN \\
\hline CHEMBL1552262 & 688239 & 5.7862 & 5.5928 & TRN \\
\hline CHEMBL1338153 & 688239 & 4.7362 & 5.4547 & TRN \\
\hline CHEMBL1342244 & 688239 & 6.0862 & \multicolumn{2}{|c|}{5.547999999999999} \\
\hline CHEMBL 3214555 & 688239 & 5.0362 & 5.4315 & TST \\
\hline CHEMBL 3214120 & 688239 & 4.7862 & 5.4543 & TRN \\
\hline CHEMBL1571548 & 688239 & 6.8362 & 5.4582 & TRN \\
\hline CHEMBL1497733 & 688239 & 5.4362 & 5.6185 & TRN \\
\hline CHEMBL1350282 & 688239 & 5.4362 & 5.6871 & TST \\
\hline CHEMBL1369355 & 688239 & 5.2862 & 5.539 & TRN \\
\hline CHEMBL1333600 & 688239 & 5.1862 & 5.4262 & TST \\
\hline CHEMBL1524865 & 688239 & 6.5363 & 5.2637 & TRN \\
\hline CHEMBL1508986 & 688239 & 6.2362 & 5.3602 & TRN \\
\hline CHEMBL1361592 & 688239 & 4.7362 & 5.4054 & TST \\
\hline CHEMBL1505393 & 688239 & 4.4862 & 5.7165 & TRN \\
\hline CHEMBL1473308 & 688239 & 4.6862 & 5.4629 & TRN \\
\hline CHEMBL1319481 & 688239 & 5.2862 & 5.6393 & TST \\
\hline CHEMBL1339034 & 688239 & 6.8362 & 5.4665 & TRN \\
\hline CHEMBL 3193997 & 688239 & 5.1362 & 5.3589 & TRN \\
\hline CHEMBL1464822 & 688239 & 5.0362 & 5.4567 & TRN \\
\hline CHEMBL1569381 & 688239 & 5.9362 & 5.5264 & TST \\
\hline CHEMBL1508279 & 688239 & 6.3362 & 5.5622 & TRN \\
\hline CHEMBL1412452 & 688239 & 4.7862 & 5.4303 & TRN \\
\hline CHEMBL1552641 & 688239 & 7.2865 & 5.4419 & TRN \\
\hline CHEMBL3211435 & 688239 & 4.6862 & 5.5631 & TST \\
\hline CHEMBL1328236 & 688239 & 5.4362 & 5.5066 & TRN \\
\hline CHEMBL1380347 & 688239 & 5.0862 & 5.3877 & TRN \\
\hline CHEMBL3190755 & 688239 & 4.7862 & 5.3824 & TST \\
\hline CHEMBL1377289 & 688239 & 4.5362 & 5.483 & TRN \\
\hline CHEMBL1414852 & 688239 & 5.4362 & 5.5426 & TRN \\
\hline CHEMBL1364738 & 688239 & 5.1362 & 5.4083 & TRN \\
\hline CHEMBL1497287 & 688239 & 6.1862 & 5.4456 & TRN \\
\hline CHEMBL1517603 & 688239 & 5.8362 & 5.5226 & TRN \\
\hline CHEMBL 3198107 & 688239 & 6.1362 & 5.5068 & TST \\
\hline CHEMBL1607151 & 688239 & 6.9363 & 5.516 & TRN \\
\hline CHEMBL1393827 & 688239 & 4.5362 & 5.4568 & TRN \\
\hline CHEMBL1409996 & 688239 & 4.6862 & 5.3302 & TRN \\
\hline CHEMBL1375080 & 688239 & 5.3362 & 5.71200 & 0000000001 \\
\hline CHEMBL1409362 & 688239 & 4.5862 & 5.3838 & TRN \\
\hline CHEMBL1314595 & 688239 & 5.0862 & 5.3657 & TST \\
\hline CHEMBL1307986 & 688239 & 5.3862 & 5.5774 & TRN \\
\hline CHEMBL1306942 & 688239 & 4.8362 & 5.4904 & TST \\
\hline CHEMBL1488878 & 688239 & 6.1362 & 5.5905 & TRN \\
\hline
\end{tabular}

Page 2092 
Supplemental Table S2.txt

\begin{tabular}{|c|c|c|c|c|}
\hline-3 & & & & \\
\hline HEMBL1388058 & 88239 & 2862 & 5.5611 & \\
\hline 72 & & & & \\
\hline 172 & 39 & 62 & & \\
\hline IEMBL1388132 & 38239 & 5862 & & \\
\hline IEMBL406387 & 88239 & 8862 & 5533 & \\
\hline HEMBL1354764 & 88239 & 9362 & 2909 & \\
\hline 213 & 8239 & 362 & & \\
\hline EMBL14 & 88239 & 362 & & \\
\hline AEMBL1580596 & 88239 & 862 & 5279 & \\
\hline HEMBL1339107 & 88239 & 362 & 2795 & \\
\hline AEMBL1322304 & 88239 & 862 & .4561 & \\
\hline IEMBL15 & & & & \\
\hline AEMBL15 & 88239 & 362 & & \\
\hline UEMBL1599590 & 88239 & 362 & & \\
\hline AEMBL1311287 & 88239 & 867 & 42 & \\
\hline HEMBL15 & 88239 & 62 & 19 & \\
\hline HEMBL14 & 38239 & & & \\
\hline 37 & 88239 & & & \\
\hline IEMBL13 & 38239 & 62 & & ST \\
\hline EMBL144 & 239 & 362 & 56 & ST \\
\hline HEMBL32 & 88239 & 62 & 17 & \\
\hline HEMBL1: & 38239 & & & \\
\hline 934 & & & & \\
\hline IEMBL 321 & 39 & & & RN \\
\hline 19 & 8239 & 62 & 79 & RN \\
\hline 577 & 8239 & 62 & & RN \\
\hline 94 & 39 & & & \\
\hline 557 & & & & ST \\
\hline AEMBL1308828 & 39 & 62 & & RN \\
\hline AEMBL1324258 & 38239 & 62 & & \\
\hline 114 & 39 & & & \\
\hline 32 & & & & RN \\
\hline HEMBL1327962 & & & & 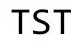 \\
\hline AEMBL1608354 & 88239 & 62 & .4363 & RN \\
\hline AEMBL14 & 39 & 62 & 51 & $\mathrm{RN}$ \\
\hline HEMRI 15 & 39 & & & RN \\
\hline HEMBL1418547 & & & & RN \\
\hline HEMBL1546776 & 88239 & & 48 & RN \\
\hline IEMBL1392090 & 39 & 362 & 57 & RN \\
\hline HEMBL1313724 & 39 & 362 & .4959 & ו \\
\hline 1 & & & & ST \\
\hline HEMBL1990734 & 38239 & 372 & 5.3646 & ST \\
\hline AEMBL3190696 & 88239 & 862 & 5.1511 & ST \\
\hline EMBL71 & 88239 & 362 & .3669 & \\
\hline HEMBL1573643 & 588239 & & .5653 & \\
\hline 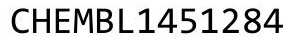 & 88239 & 362 & 5.3555 & \\
\hline CHEMBL1411925 & 688239 & 4.6862 & 5.5748 & RN \\
\hline
\end{tabular}

Page 2093 
Supplemental Table S2.txt

\begin{tabular}{|c|c|c|c|c|}
\hline CHEMBL1341919 & 688239 & 4.5362 & 5.4332 & TST \\
\hline CHEMBL1302808 & 688239 & 5.9362 & 5.5123 & TST \\
\hline CHEMBL1420723 & 688239 & 5.0362 & 5.5728 & TRN \\
\hline CHEMBL3190532 & 688239 & 4.7362 & 5.3835 & TST \\
\hline CHEMBL494326 & 688239 & 5.1862 & 5.319 & TRN \\
\hline CHEMBL1340847 & 688239 & 6.6362 & 5.5573 & TRN \\
\hline CHEMBL1421072 & 688239 & 5.1862 & 5.528 & TRN \\
\hline CHEMBL1353281 & 688239 & 5.9862 & 5.4603 & TRN \\
\hline CHEMBL1408999 & 688239 & 6.2362 & 5.4174 & TRN \\
\hline CHEMBL1454670 & 688239 & 6.8861 & 5.5317 & TRN \\
\hline CHEMBL1504393 & 688239 & 5.0362 & \multicolumn{2}{|c|}{5.547000000000001} \\
\hline CHEMBL3199773 & 688239 & 4.5362 & 5.5367 & TRN \\
\hline CHEMBL1422958 & 688239 & 4.5362 & 5.3868 & TRN \\
\hline CHEMBL1482359 & 688239 & 4.6862 & 5.4931 & TRN \\
\hline CHEMBL1606656 & 688239 & 5.6862 & 5.5099 & TST \\
\hline CHEMBL1405868 & 688239 & 5.2862 & 5.3507 & TRN \\
\hline CHEMBL1469045 & 688239 & 5.0862 & 5.4601 & TRN \\
\hline CHEMBL1540073 & 688239 & 4.5362 & 5.5084 & TRN \\
\hline CHEMBL311039 & 688239 & 4.8362 & 5.3972 & TRN \\
\hline CHEMBL1530274 & 688239 & 6.1362 & \multicolumn{2}{|c|}{5.587000000000001} \\
\hline CHEMBL1559741 & 688239 & 5.2862 & 5.4457 & TRN \\
\hline CHEMBL1368852 & 688239 & 4.5862 & 5.5238 & TST \\
\hline CHEMBL1542576 & 688239 & 5.3362 & 5.5143 & TRN \\
\hline CHEMBL1312045 & 688239 & 5.8862 & 5.4667 & TRN \\
\hline CHEMBL1309733 & 688239 & 4.7362 & 5.1783 & TRN \\
\hline CHEMBL3189384 & 688239 & 4.8362 & 5.3935 & TRN \\
\hline CHEMBL1583057 & 688239 & 4.6862 & \multicolumn{2}{|c|}{5.3870000000000005} \\
\hline CHEMBL3207809 & 688239 & 5.8862 & 5.4294 & TRN \\
\hline CHEMBL1352325 & 688239 & 5.1862 & 5.6139 & TRN \\
\hline CHEMBL1460242 & 688239 & 7.0862 & 5.3465 & TST \\
\hline CHEMBL1462231 & 688239 & 4.5362 & 5.4529 & TRN \\
\hline CHEMBL1466073 & 688239 & 5.5862 & 5.4128 & TST \\
\hline CHEMBL1417037 & 688239 & 5.6862 & 5.4462 & TRN \\
\hline CHEMBL1413323 & 688239 & 5.4362 & 5.4301 & TST \\
\hline CHEMBL1403047 & 688239 & 4.5362 & 5.444 & TRN \\
\hline CHEMBL1362112 & 688239 & 5.0362 & 5.3834 & TST \\
\hline CHEMBL1394389 & 688239 & 5.7362 & 5.4397 & TRN \\
\hline CHEMBL585651 & 688239 & 6.8861 & 5.3921 & TRN \\
\hline CHEMBL1383947 & 688239 & 6.9363 & 5.5266 & TRN \\
\hline CHEMBL1314831 & 688239 & 5.2362 & 5.5315 & TRN \\
\hline CHEMBL1543878 & 688239 & 5.0862 & 5.4869 & TRN \\
\hline CHEMBL1547055 & 688239 & 5.1862 & 5.5762 & TRN \\
\hline CHEMBL3210475 & 688239 & 4.6862 & 5.3696 & TRN \\
\hline CHEMBL1492622 & 688239 & 8.0862 & \multicolumn{2}{|c|}{5.5360000000000005} \\
\hline CHEMBL1485322 & 688239 & 5.1862 & 5.5108 & TRN \\
\hline CHEMBL1373078 & 688239 & 7.9355 & 5.6501 & TST \\
\hline CHEMBL1344225 & 688239 & 5.4362 & 5.3807 & TRN \\
\hline CHEMBL 2373585 & 688239 & 5.6862 & 5.4079 & TST \\
\hline
\end{tabular}




\begin{tabular}{|c|c|c|c|c|c|}
\hline \multirow[b]{2}{*}{ CHEMBL1565934 } & & \multicolumn{4}{|c|}{ Supplemental Table S2.txt } \\
\hline & 688239 & 6.8861 & 5.40600 & 3000000001 & TRN \\
\hline CHEMBL1573051 & 688239 & 4.5362 & 5.4165 & TRN & \\
\hline CHEMBL1455914 & 688239 & 4.4862 & 5.4374 & TRN & \\
\hline CHEMBL1405734 & 688239 & 6.7862 & 5.3535 & TST & \\
\hline CHEMBL1466197 & 688239 & 4.5362 & 5.4983 & TRN & \\
\hline CHEMBL1560036 & 688239 & 6.1362 & 5.2668 & TST & \\
\hline CHEMBL1588877 & 688239 & 5.1862 & 5.6956 & TRN & \\
\hline CHEMBL1379062 & 688239 & 4.5362 & 5.5809 & TRN & \\
\hline CHEMBL1470860 & 688239 & 4.5362 & 5.4801 & TRN & \\
\hline CHEMBL1370789 & 688239 & 6.8861 & 5.4309 & TRN & \\
\hline CHEMBL1410526 & 688239 & 5.4862 & 5.5576 & TRN & \\
\hline CHEMBL 3198877 & 688239 & 5.4362 & 5.4033 & TRN & \\
\hline CHEMBL1335618 & 688239 & 4.6862 & 5.4958 & TRN & \\
\hline CHEMBL1354399 & 688239 & 5.8362 & 5.5694 & TRN & \\
\hline CHEMBL1403412 & 688239 & 6.9363 & 5.7726 & TRN & \\
\hline CHEMBL1611168 & 688239 & 4.6362 & 5.6101 & TST & \\
\hline CHEMBL1495127 & 688239 & 5.8862 & 5.4293 & TRN & \\
\hline CHEMBL1421221 & 688239 & 5.1362 & 5.4528 & TRN & \\
\hline CHEMBL1324770 & 688239 & 4.5362 & 5.4573 & TRN & \\
\hline CHEMBL1545574 & 688239 & 5.1862 & 5.5326 & TRN & \\
\hline CHEMBL1580229 & 688239 & 4.7362 & 5.4833 & TRN & \\
\hline CHEMBL1467097 & 688239 & 4.5362 & 5.5186 & TRN & \\
\hline CHEMBL1420780 & 688239 & 7.1361 & 5.5447 & TST & \\
\hline CHEMBL1320742 & 688239 & 6.3863 & 5.6374 & TST & \\
\hline CHEMBL1604355 & 688239 & 8.3372 & 5.526 & TST & \\
\hline CHEMBL1588436 & 688239 & 4.6862 & 5.4033 & TRN & \\
\hline CHEMBL1510264 & 688239 & 6.8861 & 5.3821 & TST & \\
\hline CHEMBL1534097 & 688239 & 5.6862 & 5.5093 & TRN & \\
\hline CHEMBL1351610 & 688239 & 4.7862 & 5.3853 & TST & \\
\hline CHEMBL1311442 & 688239 & 4.8362 & 5.5599 & TRN & \\
\hline CHEMBL1323781 & 688239 & 5.4862 & 5.5311 & TRN & \\
\hline CHEMBL1362163 & 688239 & 4.6362 & 5.4407 & TST & \\
\hline CHEMBL1432679 & 688239 & 4.6862 & 5.3562 & TRN & \\
\hline CHEMBL1605353 & 688239 & 4.7862 & 5.4994 & TST & \\
\hline CHEMBL1526030 & 688239 & 5.4362 & 5.494 & TRN & \\
\hline CHEMBL1486721 & 688239 & 5.7362 & 5.25700 & 0000000001 & TRN \\
\hline CHEMBL1529539 & 688239 & 4.5362 & 5.5761 & TRN & \\
\hline CHEMBL1471768 & 688239 & 5.15 & 5.517 & TRN & \\
\hline CHEMBL1548032 & 688239 & 7.2366 & 5.4657 & TST & \\
\hline CHEMBL1310928 & 688239 & 4.5362 & 5.473 & TST & \\
\hline CHEMBL1374298 & 688239 & 5.4362 & 5.3519 & TRN & \\
\hline CHEMBL1490719 & 688239 & 4.45 & 5.4919 & TRN & \\
\hline CHEMBL1400179 & 688239 & 4.5362 & 5.4819 & TST & \\
\hline CHEMBL1496589 & 688239 & 5.7362 & 5.6155 & TRN & \\
\hline CHEMBL1558497 & 688239 & 4.5362 & 5.5572 & TRN & \\
\hline CHEMBL1568236 & 688239 & 6.8362 & 5.4863 & TRN & \\
\hline CHEMBL1323921 & 688239 & 5.0862 & 5.4627 & TRN & \\
\hline CHEMBL1494233 & 688239 & 5.7862 & 5.3792 & TRN & \\
\hline
\end{tabular}


Supplemental Table S2.txt

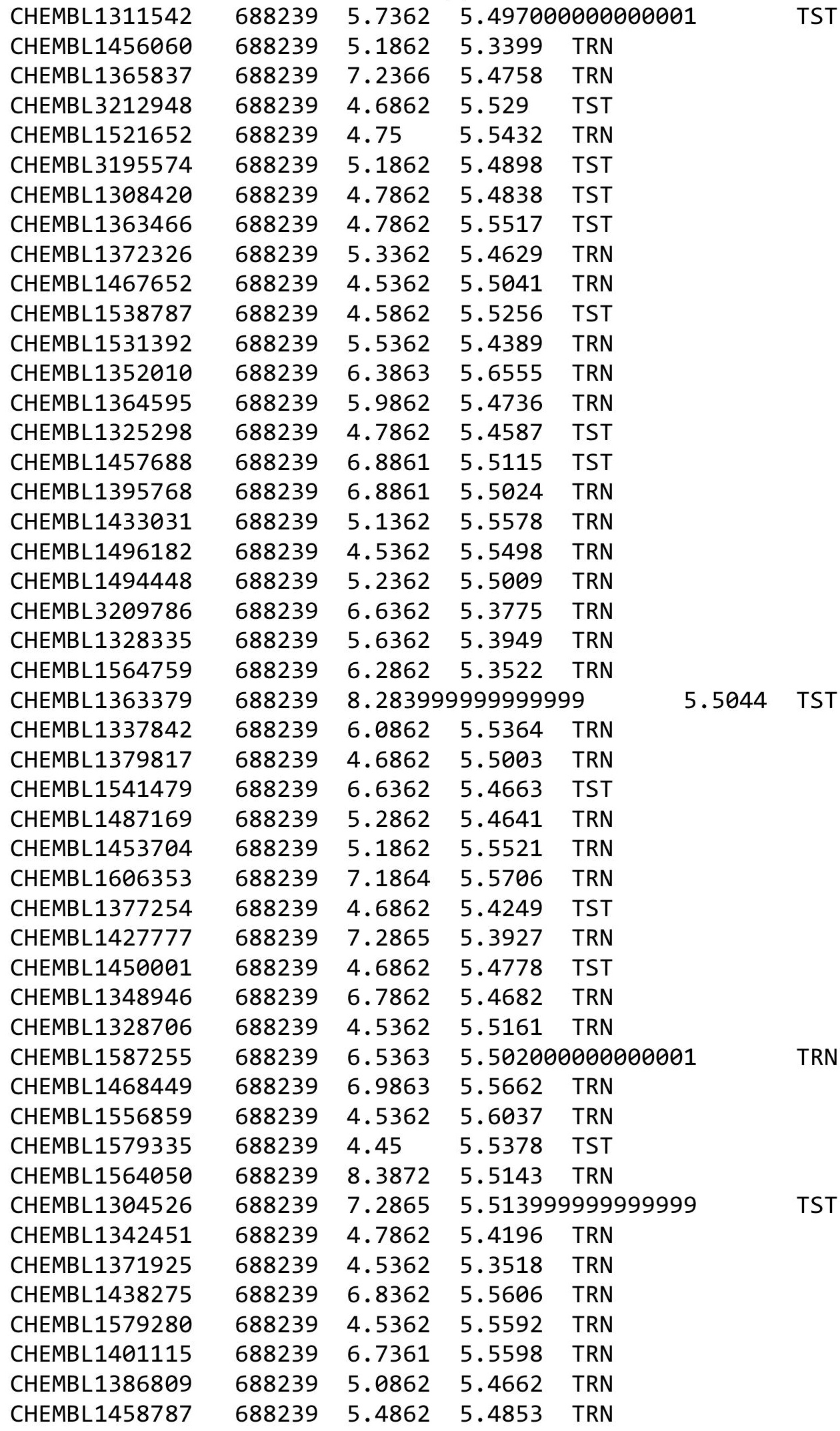


Supplemental Table S2.txt

\begin{tabular}{|c|c|c|c|c|}
\hline - & & & & \\
\hline HEMBL1412066 & 88239 & .0362 & 5.4929 & \\
\hline & & & & \\
\hline 77746 & 39 & & 68 & \\
\hline IEMBL1231667 & 38239 & 362 & 35 & \\
\hline AEMBL1592387 & 88239 & 5362 & .41 & \\
\hline HEMBL1534998 & 88239 & 862 & 5304 & \\
\hline AEMBL15 & 239 & & & \\
\hline AEMBL1532975 & 88239 & & 1602 & \\
\hline AEMBL1426783 & 88239 & 362 & .487 & \\
\hline AEMBL1334201 & 88239 & 862 & 5611 & \\
\hline AEMBL3213088 & 88239 & 362 & 596 & \\
\hline AEMBL1 & & & & \\
\hline AEMBL1 & 88239 & & 067 & \\
\hline AEMBL1501139 & 88239 & 62 & 5164 & \\
\hline AEMBL1336340 & 88239 & 62 & 5992 & \\
\hline AEMBL15 & 88239 & 62 & & \\
\hline HEMBL15 & 38239 & & & \\
\hline 331 & 88239 & & 135 & \\
\hline AEMBL42 & 38239 & 52 & 68 & RN \\
\hline IEMBL14 & 239 & & $\partial 68$ & IRN \\
\hline HEMBL13 & 38239 & & 618 & וד \\
\hline AEMBL15 & 38239 & & 572 & \\
\hline 24 & 39 & & 3614 & \\
\hline IEMBL13 & 39 & & 989 & SI \\
\hline 50 & 8239 & & 482 & RN \\
\hline IEM & 239 & & 129 & NIV \\
\hline 9 & & & & \\
\hline 94 & & & & 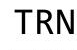 \\
\hline IEMBL14 & 39 & & 99 & RN \\
\hline AEMBL13 & 38239 & & 108 & RN \\
\hline AFMBI 16 & 39 & & & RN \\
\hline & & & & RN \\
\hline HEMBL157. & & & & IST \\
\hline AEMBL1382941 & 88239 & & 696 & RN \\
\hline AEMBL15 & 39 & & & \\
\hline - 2 & & & & RIV \\
\hline & & & 5.4025 & ST \\
\hline HEMBL1996724 & 88239 & & 5.3448 & RN \\
\hline EMBL13 & 39 & & 595 & RN \\
\hline HEMBL14 & 39 & & .4734 & 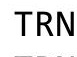 \\
\hline & & & & RN \\
\hline HEMBL1582964 & 38239 & & 5.4266 & ST \\
\hline IEMBL1522591 & 88239 & 62 & .6182 & ST \\
\hline MRI 130 & & & . 4648 & \\
\hline HEMBL15 & & & .5186 & \\
\hline 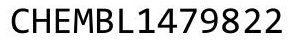 & 88239 & 5.6862 & 5.5104 & \\
\hline HEMBL1425828 & 688239 & 6.7862 & 5.4936 & \\
\hline
\end{tabular}

Page 2097 
Supplemental Table S2.txt

\begin{tabular}{|c|c|c|c|c|}
\hline CHEMBL1300734 & 688239 & 5.3862 & 5.4412 & TRN \\
\hline CHEMBL1905960 & 688239 & 8.3372 & 5.4355 & TRN \\
\hline CHEMBL1340841 & 688239 & 6.9363 & 5.5418 & TST \\
\hline CHEMBL1462191 & 688239 & 5.5862 & 5.4844 & TRN \\
\hline CHEMBL1553309 & 688239 & 5.5862 & 5.516 & TRN \\
\hline CHEMBL1460235 & 688239 & 5.2862 & 5.5315 & TRN \\
\hline CHEMBL1491505 & 688239 & 5.3362 & 5.3995 & TST \\
\hline CHEMBL1525463 & 688239 & 5.1862 & 5.4534 & TRN \\
\hline CHEMBL 3210829 & 688239 & 5.3862 & 5.6094 & TRN \\
\hline CHEMBL1609327 & 688239 & 6.1862 & 5.3074 & TST \\
\hline CHEMBL1520069 & 688239 & 4.7362 & 5.3892 & TRN \\
\hline CHEMBL1392532 & 688239 & 6.7361 & 5.3975 & TRN \\
\hline CHEMBL1425914 & 688239 & 7.0362 & 5.441 & TRN \\
\hline CHEMBL1340698 & 688239 & 4.8862 & 5.5603 & TRN \\
\hline CHEMBL1420683 & 688239 & 5.2362 & 5.555 & TRN \\
\hline CHEMBL1344534 & 688239 & 5.0862 & 5.5375 & TRN \\
\hline CHEMBL1466627 & 688239 & 6.9363 & 5.3732 & TST \\
\hline CHEMBL3196161 & 688239 & 6.8362 & 5.5523 & TST \\
\hline CHEMBL1391554 & 688239 & 4.7862 & 5.4506 & TST \\
\hline CHEMBL1306652 & 688239 & 6.1362 & 5.584 & TRN \\
\hline CHEMBL1518118 & 688239 & 4.5362 & 5.5922 & TRN \\
\hline CHEMBL1530676 & 688239 & 8.2366 & 5.5835 & TRN \\
\hline CHEMBL1540767 & 688239 & 5.1862 & 5.4692 & TRN \\
\hline CHEMBL1533955 & 688239 & 6.0862 & 5.5982 & TRN \\
\hline CHEMBL1508800 & 688239 & 6.4362 & 5.5026 & TST \\
\hline CHEMBL1405602 & 688239 & 6.8362 & 5.4353 & TRN \\
\hline CHEMBL1427100 & 688239 & 6.0862 & 5.5372 & TRN \\
\hline CHEMBL1514264 & 688239 & 4.7862 & 5.4608 & TRN \\
\hline CHEMBL1541946 & 688239 & 5.5362 & 5.5318 & TST \\
\hline CHEMBL1481109 & 688239 & 4.7862 & 5.28799 & 9999999999 \\
\hline CHEMBL1319002 & 688239 & 4.7862 & 5.4749 & TRN \\
\hline CHEMBL 3208341 & 688239 & 4.7862 & 5.5226 & TRN \\
\hline CHEMBL1610214 & 688239 & 5.1862 & 5.3989 & TRN \\
\hline CHEMBL1328457 & 688239 & 8.1871 & 5.3684 & TRN \\
\hline CHEMBL1578594 & 688239 & 4.8362 & 5.4075 & TRN \\
\hline CHEMBL1597920 & 688239 & 4.5362 & 5.4377 & TST \\
\hline CHEMBL1565625 & 688239 & 4.9362 & 5.5489 & TRN \\
\hline CHEMBL1537382 & 688239 & 4.5362 & 5.4019 & TRN \\
\hline CHEMBL1450604 & 688239 & 8.3872 & 5.5574 & TRN \\
\hline CHEMBL1334999 & 688239 & 5.5362 & 5.5336 & TRN \\
\hline CHEMBL1364688 & 688239 & 4.6862 & 5.3371 & TRN \\
\hline CHEMBL1310381 & 688239 & 6.3362 & 5.4495 & TRN \\
\hline CHEMBL1318699 & 688239 & 6.1862 & 5.3512 & TST \\
\hline CHEMBL1563527 & 688239 & 4.5362 & 5.3674 & TRN \\
\hline CHEMBL1361532 & 688239 & 6.2862 & 5.4896 & TRN \\
\hline CHEMBL1414842 & 688239 & 7.0362 & 5.566 & TRN \\
\hline CHEMBL 210208 & 688239 & 4.7362 & 5.30399 & 9999999999 \\
\hline CHEMBL1567792 & 688239 & 5.3862 & 5.5167 & TRN \\
\hline
\end{tabular}


Supplemental Table S2.txt

\begin{tabular}{|c|c|c|c|c|}
\hline CHEMBL 3196799 & 688239 & 5.1362 & 5.449 & TST \\
\hline CHEMBL1507188 & 688239 & 5.1862 & 5.54 & TRN \\
\hline CHEMBL1331745 & 688239 & 4.8362 & 5.4203 & TRN \\
\hline CHEMBL1502929 & 688239 & 4.7362 & 5.393 & TRN \\
\hline CHEMBL1536698 & 688239 & 5.4362 & 5.4405 & TRN \\
\hline CHEMBL1550712 & 688239 & 5.2362 & 5.4814 & TRN \\
\hline CHEMBL1581601 & 688239 & 6.2362 & 5.512000 & 0000000005 \\
\hline CHEMBL 3199221 & 688239 & 6.1362 & 5.3206 & TRN \\
\hline CHEMBL1509479 & 688239 & 6.8861 & 5.6066 & TRN \\
\hline CHEMBL1432185 & 688239 & 5.1862 & 5.3044 & TRN \\
\hline CHEMBL1351172 & 688239 & 5.6362 & 5.2902 & TRN \\
\hline CHEMBL1543716 & 688239 & 5.2862 & 5.5218 & TRN \\
\hline CHEMBL1390598 & 688239 & 5.7862 & 5.5444 & TRN \\
\hline CHEMBL1543035 & 688239 & 5.9362 & 5.627999 & 999999999 \\
\hline CHEMBL1556804 & 688239 & 8.28399 & 999999999 & 5.3268 \\
\hline CHEMBL1511949 & 688239 & 4.6362 & 5.3858 & TRN \\
\hline CHEMBL1338339 & 688239 & 4.8362 & 5.5345 & TRN \\
\hline CHEMBL1435663 & 688239 & 6.1362 & 5.4949 & TRN \\
\hline CHEMBL1576531 & 688239 & 6.0862 & 5.3818 & TRN \\
\hline CHEMBL1602020 & 688239 & 5.1862 & 5.3981 & TRN \\
\hline CHEMBL1602343 & 688239 & 4.4862 & 5.438 & TRN \\
\hline CHEMBL1433060 & 688239 & 4.8862 & 5.5767 & TRN \\
\hline CHEMBL497939 & 688239 & 6.0 & 5.4873 & TRN \\
\hline CHEMBL1436364 & 688239 & 5.1862 & 5.3523 & TRN \\
\hline CHEMBL 3190307 & 688239 & 6.2362 & 5.5676 & TRN \\
\hline CHEMBL1601376 & 688239 & 4.5862 & 5.5744 & TRN \\
\hline CHEMBL1343195 & 688239 & 6.0862 & 5.4937 & TST \\
\hline CHEMBL1584706 & 688239 & 4.5862 & 5.4349 & TRN \\
\hline CHEMBL1527789 & 688239 & 5.8862 & 5.5503 & TRN \\
\hline CHEMBL1503598 & 688239 & 4.6862 & 5.4389 & TRN \\
\hline CHEMBL1510400 & 688239 & 4.8862 & 5.4813 & TST \\
\hline CHEMBL1385181 & 688239 & 4.7362 & 5.5875 & TRN \\
\hline CHEMBL1343378 & 688239 & 5.6362 & 5.4567 & TST \\
\hline CHEMBL1487748 & 688239 & 4.7862 & 5.3896 & TRN \\
\hline CHEMBL1501671 & 688239 & 6.3863 & 5.4676 & TRN \\
\hline CHEMBL1397756 & 688239 & 4.5362 & 5.4836 & TRN \\
\hline CHEMBL1590018 & 688239 & 5.9862 & 5.4278 & TRN \\
\hline CHEMBL1328784 & 688239 & 4.9862 & 5.3653 & TST \\
\hline CHEMBL1484211 & 688239 & 4.9862 & 5.528 & TRN \\
\hline CHEMBL1613525 & 688239 & 4.75 & 5.3089 & TRN \\
\hline CHEMBL1495557 & 688239 & 4.7362 & 5.4232 & TRN \\
\hline CHEMBL1443317 & 688239 & 6.9363 & 5.5937 & TRN \\
\hline CHEMBL1347899 & 688239 & 4.6862 & 5.532 & TRN \\
\hline CHEMBL1418114 & 688239 & 5.6862 & 5.4426 & TRN \\
\hline CHEMBL1303962 & 688239 & 5.1862 & 5.6058 & TRN \\
\hline CHEMBL1482506 & 688239 & 5.0362 & 5.4164 & TST \\
\hline CHEMBL1589190 & 688239 & 5.1862 & 5.439 & TST \\
\hline CHEMBL466933 & 688239 & 4.6862 & 5.6822 & TRN \\
\hline
\end{tabular}


Supplemental Table S2.txt

\begin{tabular}{|c|c|c|c|c|}
\hline CHEMBL1307285 & 688239 & 5.8862 & 5.5003 & TRN \\
\hline CHEMBL1317616 & 688239 & 5.2362 & 5.5632 & TRN \\
\hline CHEMBL1558393 & 688239 & 5.3862 & 5.4979 & TRN \\
\hline CHEMBL3213683 & 688239 & 4.8862 & 5.5139 & TRN \\
\hline CHEMBL1350867 & 688239 & 4.4862 & 5.3911 & TRN \\
\hline CHEMBL1311585 & 688239 & 5.9362 & 5.4383 & TST \\
\hline CHEMBL3145021 & 688239 & 4.5362 & 5.5251 & TRN \\
\hline CHEMBL3211917 & 688239 & 4.4862 & 5.4132 & TRN \\
\hline CHEMBL1474192 & 688239 & 4.6362 & 5.3272 & TRN \\
\hline CHEMBL1597354 & 688239 & 6.0862 & 5.5088 & TRN \\
\hline CHEMBL1560594 & 688239 & 5.2362 & 5.6516 & TRN \\
\hline CHEMBL1574613 & 688239 & 5.3862 & 5.4398 & TRN \\
\hline CHEMBL1613274 & 688239 & 7.2366 & 5.544 & TRN \\
\hline CHEMBL1522672 & 688239 & 4.7862 & 5.4447 & TRN \\
\hline CHEMBL3199296 & 688239 & 5.3862 & 5.5875 & TST \\
\hline CHEMBL1304772 & 688239 & 6.2862 & 5.5443 & TRN \\
\hline CHEMBL1416139 & 688239 & 5.5362 & 5.5468 & TRN \\
\hline CHEMBL1523266 & 688239 & 4.7862 & 5.3502 & TST \\
\hline CHEMBL1373310 & 688239 & 6.9363 & 5.5042 & TRN \\
\hline CHEMBL1470745 & 688239 & 4.6862 & 5.4937 & TRN \\
\hline CHEMBL1392981 & 688239 & 4.5362 & 5.2933 & TRN \\
\hline CHEMBL1411148 & 688239 & 4.5362 & 5.4867 & TST \\
\hline CHEMBL1418018 & 688239 & 5.5862 & 5.566 & TRN \\
\hline CHEMBL1392319 & 688239 & 5.1862 & 5.5203 & TRN \\
\hline CHEMBL1565232 & 688239 & 6.8362 & 5.5084 & TRN \\
\hline CHEMBL1463529 & 688239 & 5.1862 & 5.5156 & TRN \\
\hline CHEMBL1351687 & 688239 & 5.1862 & 5.5347 & TRN \\
\hline CHEMBL1574842 & 688239 & 4.5362 & 5.5481 & TST \\
\hline CHEMBL1359121 & 688239 & 6.1362 & 5.3278 & TRN \\
\hline CHEMBL1504577 & 688239 & 7.1864 & 5.5276 & TRN \\
\hline CHEMBL1590734 & 688239 & 8.3372 & 5.61100 & 0000000001 \\
\hline CHEMBL3192573 & 688239 & 6.8362 & 5.4115 & TST \\
\hline CHEMBL1547854 & 688239 & 5.3862 & 5.5263 & TRN \\
\hline CHEMBL1445438 & 688239 & 4.8862 & 5.4796 & TRN \\
\hline CHEMBL1421551 & 688239 & 6.0862 & 5.5451 & TRN \\
\hline CHEMBL1301931 & 688239 & 5.1862 & 5.5586 & TRN \\
\hline CHEMBL1517706 & 688239 & 6.0862 & 5.5285 & TST \\
\hline CHEMBL1594344 & 688239 & 6.9863 & 5.4654 & TRN \\
\hline CHEMBL1532855 & 688239 & 5.9362 & 5.4617 & TRN \\
\hline CHEMBL1333712 & 688239 & 4.4862 & 5.4864 & TRN \\
\hline CHEMBL1558429 & 688239 & 4.5362 & 5.5248 & TRN \\
\hline CHEMBL1549523 & 688239 & 8.3372 & 5.4717 & TRN \\
\hline CHEMBL1459628 & 688239 & 6.0362 & 5.5106 & TRN \\
\hline CHEMBL1506791 & 688239 & 4.5362 & 5.4479 & TST \\
\hline CHEMBL1520699 & 688239 & 4.8362 & 5.4294 & TST \\
\hline CHEMBL1466733 & 688239 & 5.4862 & 5.5428 & TRN \\
\hline CHEMBL1572686 & 688239 & 6.5363 & 5.3263 & TRN \\
\hline CHEMBL1490692 & 688239 & 6.6861 & 5.2175 & TRN \\
\hline
\end{tabular}

Page 2100 


\begin{tabular}{|c|c|c|c|c|c|c|}
\hline & & \multicolumn{5}{|c|}{ Supplemental Table S2.txt } \\
\hline CHEMBL1592225 & 688239 & 4.5362 & 5.6336 & TRN & & \\
\hline CHEMBL1574063 & 688239 & 5.0862 & 5.6372 & TRN & & \\
\hline CHEMBL1313223 & 688239 & 5.9862 & 5.4135 & TRN & & \\
\hline CHEMBL1584847 & 688239 & 5.5362 & 5.4844 & TRN & & \\
\hline CHEMBL1558412 & 688239 & \multicolumn{3}{|c|}{8.283999999999999} & .5753 & TRN \\
\hline CHEMBL1310061 & 688239 & 7.4365 & 5.5747 & TRN & & \\
\hline CHEMBL3195056 & 688239 & 5.3362 & 5.4456 & TRN & & \\
\hline CHEMBL1397146 & 688239 & 4.8862 & 5.3906 & TRN & & \\
\hline CHEMBL1430551 & 688239 & 4.4862 & 5.5192 & TRN & & \\
\hline CHEMBL1518984 & 688239 & 5.6362 & 5.5669 & TRN & & \\
\hline CHEMBL1601700 & 688239 & 8.3872 & 5.5881 & TRN & & \\
\hline CHEMBL1568946 & 688239 & 4.5362 & 5.4367 & TST & & \\
\hline CHEMBL1464960 & 688239 & 4.5362 & 5.4141 & TST & & \\
\hline CHEMBL1381237 & 688239 & 6.2862 & 5.55399 & 9999999999 & & TRN \\
\hline CHEMBL1368875 & 688239 & 4.7862 & 5.6157 & TRN & & \\
\hline CHEMBL1450037 & 688239 & 4.5362 & 5.5894 & TRN & & \\
\hline CHEMBL1503436 & 688239 & 6.3362 & 5.5988 & TRN & & \\
\hline CHEMBL1602177 & 688239 & 4.5362 & 5.5943 & TRN & & \\
\hline CHEMBL1440035 & 688239 & 5.0362 & 5.5028 & TRN & & \\
\hline CHEMBL1511731 & 688239 & 5.4862 & 5.4851 & TST & & \\
\hline CHEMBL1350745 & 688239 & 7.0362 & 5.6001 & TST & & \\
\hline CHEMBL1422387 & 688239 & 7.1361 & 5.4954 & TST & & \\
\hline CHEMBL3210092 & 688239 & 5.8 & 5.3859 & TRN & & \\
\hline CHEMBL1402308 & 688239 & \multicolumn{3}{|c|}{8.283999999999999} & .3662 & TST \\
\hline CHEMBL1432451 & 688239 & 5.4362 & 5.5277 & TRN & & \\
\hline CHEMBL1398682 & 688239 & 5.2362 & 5.3978 & TRN & & \\
\hline CHEMBL1359205 & 688239 & 6.6362 & 5.5439 & TRN & & \\
\hline CHEMBL1516748 & 688239 & 4.5362 & 5.4584 & TST & & \\
\hline CHEMBL1533851 & 688239 & 4.5362 & 5.5105 & TRN & & \\
\hline CHEMBL1566851 & 688239 & 5.5862 & 5.5262 & TRN & & \\
\hline CHEMBL1461225 & 688239 & 4.6862 & 5.4632 & TST & & \\
\hline CHEMBL1529397 & 688239 & 6.3362 & 5.465 & TST & & \\
\hline CHEMBL1393021 & 688239 & 5.8862 & 5.5439 & TST & & \\
\hline CHEMBL1305045 & 688239 & 6.8362 & 5.6354 & TST & & \\
\hline CHEMBL1607522 & 688239 & 7.1361 & 5.6047 & TRN & & \\
\hline CHEMBL1482959 & 688239 & 4.6362 & 5.3083 & TRN & & \\
\hline CHEMBL1408559 & 688239 & 4.4862 & 5.4234 & TST & & \\
\hline CHEMBL1379881 & 688239 & 4.5362 & 5.3277 & TST & & \\
\hline CHEMBL1430882 & 688239 & 6.6861 & 5.3799 & TST & & \\
\hline CHEMBL3208934 & 688239 & 4.8362 & 5.3858 & TRN & & \\
\hline CHEMBL1478062 & 688239 & 4.6362 & 5.57299 & 99999999995 & & TRN \\
\hline CHEMBL1427619 & 688239 & 4.4862 & 5.4394 & TRN & & \\
\hline CHEMBL1539272 & 688239 & 5.1362 & 5.4014 & TRN & & \\
\hline CHEMBL1611116 & 688239 & 4.5362 & 5.5222 & TRN & & \\
\hline CHEMBL3196922 & 688239 & 4.7362 & 5.5688 & TRN & & \\
\hline CHEMBL1547346 & 688239 & 5.4362 & 5.5382 & TST & & \\
\hline CHEMBL1366871 & 688239 & 5.1862 & 5.3178 & TRN & & \\
\hline CHEMBL1452619 & 688239 & 6.3362 & 5.5674 & TRN & & \\
\hline
\end{tabular}


Supplemental Table S2.txt

\begin{tabular}{|c|c|c|c|c|}
\hline 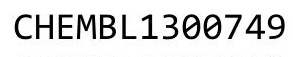 & & & & \\
\hline AEMBL1325912 & 38239 & 362 & & \\
\hline AEMBL3197618 & 239 & 361 & & \\
\hline & 39 & 362 & & \\
\hline IEMBL13 & 39 & 862 & & \\
\hline AEMBL1547068 & 88239 & 864 & 5048 & \\
\hline AEMBL1378958 & 88239 & 4.9862 & 3214 & \\
\hline HEMBL150 & & & & \\
\hline AEMBL139 & 39 & 362 & & \\
\hline IEMBL156 & & & & \\
\hline AEMBL1408595 & 239 & 862 & 25 & \\
\hline AEMBL1327919 & 39 & 862 & & \\
\hline HEMBL 385 & & 62 & & \\
\hline HEMBL1490248 & & & & \\
\hline AEMBL130 & & & & \\
\hline HEMBL142 & & 362 & & \\
\hline HEMBL146 & & 862 & & \\
\hline AEMBL31S & & 62 & & \\
\hline AEMBL13: & & & & \\
\hline HEMBL15 & & & & \\
\hline AEMBL14S & & 362 & & \\
\hline AEMBL15 & & 362 & & \\
\hline HEMBL15 & & 62 & & \\
\hline AEMBL 15 & & & & \\
\hline AFM & & 62 & & \\
\hline 12 & & 862 & & \\
\hline IEMBL148 & & 62 & & \\
\hline HEMBL14 & & 62 & & \\
\hline AFMRI 32 & & 52 & & \\
\hline IEMPI 11 & & 62 & & \\
\hline HEMBL156 & & & & \\
\hline HEMBL $144 €$ & & 362 & & \\
\hline & & & & \\
\hline 7 & & 52 & & \\
\hline HEMBL153 & & & & ST \\
\hline AEMBL1443 & & 362 & & $\mathrm{R}$ \\
\hline AEMBL1462800 & & 862 & & \\
\hline 9 & & & & \\
\hline (2MO & & & & RN \\
\hline HEMBL1496037 & & & & ST \\
\hline AEMBL1412191 & & 362 & & TS \\
\hline AEMBL15 & & 62 & & \\
\hline & & & & \\
\hline CHEMBL1406257 & & 362 & & \\
\hline AEMBL1506200 & & 862 & & RN \\
\hline AEMBL1375 & & 862 & 61 & TR \\
\hline (1-0 & & & & \\
\hline НГMD & & תזרי & .4936 & \\
\hline
\end{tabular}

Page 2102 
Supplemental Table S2.txt

\begin{tabular}{|c|c|c|c|c|}
\hline CHEMBL1417323 & 688239 & 4.5362 & 5.5701 & TST \\
\hline CHEMBL 3195637 & 688239 & 6.9363 & 5.5497 & TST \\
\hline CHEMBL1452074 & 688239 & 5.4362 & 5.2963 & TST \\
\hline CHEMBL1349417 & 688239 & 5.5862 & 5.4945 & TST \\
\hline CHEMBL1588027 & 688239 & 4.6862 & 5.4217 & TST \\
\hline CHEMBL 3213900 & 688239 & 5.1862 & 5.4833 & TRN \\
\hline CHEMBL1392623 & 688239 & 5.5862 & 5.6003 & TRN \\
\hline CHEMBL1336131 & 688239 & 6.8861 & 5.57299 & 99999999995 \\
\hline CHEMBL1463535 & 688239 & 6.8362 & 5.586 & TRN \\
\hline CHEMBL1375799 & 688239 & 4.6862 & 5.5415 & TRN \\
\hline CHEMBL1438846 & 688239 & 7.0362 & 5.6971 & TRN \\
\hline CHEMBL 3189938 & 688239 & 6.8861 & 5.5471 & TRN \\
\hline CHEMBL1524141 & 688239 & 5.0862 & 5.5128 & TRN \\
\hline CHEMBL1441669 & 688239 & 5.7362 & 5.3245 & TRN \\
\hline CHEMBL1389725 & 688239 & 4.5362 & 5.5044 & TRN \\
\hline CHEMBL1601687 & 688239 & 4.5362 & 5.5361 & TRN \\
\hline CHEMBL1607966 & 688239 & 5.1862 & 5.4586 & TRN \\
\hline CHEMBL1565213 & 688239 & 6.9363 & 5.5717 & TRN \\
\hline CHEMBL 3192387 & 688239 & 5.1862 & 5.4527 & TRN \\
\hline CHEMBL1332406 & 688239 & 5.1862 & 5.5671 & TRN \\
\hline CHEMBL1569589 & 688239 & 4.5362 & 5.5765 & TRN \\
\hline CHEMBL1509298 & 688239 & 4.45 & 5.6079 & TST \\
\hline CHEMBL 3194962 & 688239 & 4.7362 & 5.4807 & TRN \\
\hline CHEMBL1425044 & 688239 & 4.5362 & 5.6025 & TRN \\
\hline CHEMBL1533138 & 688239 & 6.1362 & 5.4659 & TRN \\
\hline CHEMBL 1448874 & 688239 & 6.9363 & 5.4274 & TRN \\
\hline CHEMBL1529581 & 688239 & 7.5361 & 5.5981 & TRN \\
\hline CHEMBL1305400 & 688239 & 4.5362 & 5.3901 & TST \\
\hline CHEMBL1370033 & 688239 & 5.4362 & 5.6306 & TRN \\
\hline CHEMBL1317497 & 688239 & 5.1862 & 5.5488 & TRN \\
\hline CHEMBL1352326 & 688239 & 4.7862 & 5.5142 & TRN \\
\hline CHEMBL1352987 & 688239 & 4.5362 & 5.6038 & TRN \\
\hline CHEMBL1442731 & 688239 & 5.9362 & 5.4169 & TST \\
\hline CHEMBL1612634 & 688239 & 5.2862 & 5.4876 & TST \\
\hline CHEMBL1409586 & 688239 & 5.7362 & 5.5135 & TRN \\
\hline CHEMBL1555208 & 688239 & 4.6862 & 5.3468 & TST \\
\hline CHEMBL1478513 & 688239 & 4.7362 & 5.3455 & TRN \\
\hline CHEMBL1471047 & 688239 & 5.7362 & 5.6604 & TRN \\
\hline CHEMBL1503090 & 688239 & 6.9363 & 5.5793 & TRN \\
\hline CHEMBL1328506 & 688239 & 5.7362 & 5.5253 & TRN \\
\hline CHEMBL1486988 & 688239 & 5.3862 & 5.3915 & TRN \\
\hline CHEMBL1340179 & 688239 & 5.1362 & 5.4064 & TRN \\
\hline CHEMBL1582888 & 688239 & 5.0862 & 5.5316 & TST \\
\hline CHEMBL1311197 & 688239 & 4.5362 & 5.4733 & TRN \\
\hline CHEMBL1595471 & 688239 & 5.0362 & 5.5363 & TRN \\
\hline CHEMBL1550125 & 688239 & 4.7862 & 5.5247 & TRN \\
\hline CHEMBL1581909 & 688239 & 4.7862 & 5.5884 & TRN \\
\hline CHEMBL1332185 & 688239 & 5.5862 & 5.6099 & TRN \\
\hline
\end{tabular}

Page 2103 
Supplemental Table S2.txt

\begin{tabular}{|c|c|c|c|c|}
\hline CHEMBL3209381 & 688239 & 4.8862 & 5.3631 & TRN \\
\hline CHEMBL520813 & 688239 & 6.0862 & 5.6088 & TRN \\
\hline CHEMBL1300959 & 688239 & 5.4362 & 5.3124 & TST \\
\hline CHEMBL1547691 & 688239 & 6.2362 & 5.5183 & TRN \\
\hline CHEMBL1612362 & 688239 & 6.8861 & 5.3877 & TRN \\
\hline CHEMBL1572963 & 688239 & 6.9363 & 5.3915 & TRN \\
\hline CHEMBL1613599 & 688239 & 4.5362 & 5.5958 & TRN \\
\hline CHEMBL1349894 & 688239 & 4.5362 & 5.5705 & TRN \\
\hline CHEMBL1403705 & 688239 & 5.9362 & 5.5657 & TRN \\
\hline CHEMBL1415514 & 688239 & 6.1862 & 5.5837 & TRN \\
\hline CHEMBL1406267 & 688239 & 5.1862 & 5.5557 & TRN \\
\hline CHEMBL1411585 & 688239 & 5.1862 & 5.443 & TRN \\
\hline CHEMBL1554544 & 688239 & 5.8862 & 5.6405 & TST \\
\hline CHEMBL 3208898 & 688239 & 6.5862 & 5.5184 & TRN \\
\hline CHEMBL1547225 & 688239 & 8.283999 & 999999999 & 5.4443 \\
\hline CHEMBL 3209177 & 688239 & 8.3372 & 5.4951 & TST \\
\hline CHEMBL1389875 & 688239 & 4.8362 & 5.6157 & TRN \\
\hline CHEMBL1560796 & 688239 & 4.4862 & 5.4731 & TRN \\
\hline CHEMBL1385160 & 688239 & 6.3362 & 5.4613 & TRN \\
\hline CHEMBL1325852 & 688239 & 4.6862 & 5.4634 & TST \\
\hline CHEMBL1395528 & 688239 & 4.6362 & 5.3564 & TRN \\
\hline CHEMBL1433333 & 688239 & 5.4362 & 5.4037 & TST \\
\hline CHEMBL1583643 & 688239 & 4.5362 & 5.6157 & TRN \\
\hline CHEMBL1343678 & 688239 & 5.5362 & 5.4098 & TRN \\
\hline CHEMBL1518481 & 688239 & 5.1862 & 5.5749 & TRN \\
\hline CHEMBL1581842 & 688239 & 5.4362 & 5.4157 & TRN \\
\hline CHEMBL1598647 & 688239 & 4.5362 & 5.4674 & TRN \\
\hline CHEMBL1367846 & 688239 & 5.1362 & 5.5818 & TST \\
\hline CHEMBL1445185 & 688239 & 8.283999 & 999999999 & 5.5048 \\
\hline CHEMBL1299463 & 688239 & 4.7362 & 5.3571 & TRN \\
\hline CHEMBL1524034 & 688239 & 4.6362 & 5.5226 & TRN \\
\hline CHEMBL1433034 & 688239 & 6.5862 & 5.4622 & TRN \\
\hline CHEMBL1454925 & 688239 & 6.2362 & 5.5375 & TRN \\
\hline CHEMBL1462352 & 688239 & 5.5862 & 5.5062 & TST \\
\hline CHEMBL 3208415 & 688239 & 4.7862 & 5.383999 & 99999999995 \\
\hline CHEMBL1357782 & 688239 & 4.6362 & 5.5498 & TRN \\
\hline CHEMBL 2003935 & 688239 & 5.7362 & 5.4534 & TRN \\
\hline CHEMBL 3195295 & 688239 & 6.2362 & 5.6487 & TRN \\
\hline CHEMBL 3189631 & 688239 & 5.4862 & 5.5139 & TRN \\
\hline CHEMBL 3214162 & 688239 & 5.7862 & 5.4489 & TRN \\
\hline CHEMBL1304363 & 688239 & 5.6862 & 5.4464 & TRN \\
\hline CHEMBL1567821 & 688239 & 4.5362 & 5.5402 & TRN \\
\hline CHEMBL1588887 & 688239 & 4.7362 & 5.5444 & TRN \\
\hline CHEMBL1540274 & 688239 & 6.9863 & 5.5403 & TRN \\
\hline CHEMBL1547766 & 688239 & 6.0862 & 5.5433 & TRN \\
\hline CHEMBL1352991 & 688239 & 5.3362 & 5.3997 & TRN \\
\hline CHEMBL1583677 & 688239 & 6.1362 & 5.6066 & TRN \\
\hline CHEMBL1538395 & 688239 & 4.8362 & 5.3422 & TRN \\
\hline
\end{tabular}


Supplemental Table S2.txt

\begin{tabular}{|c|c|c|c|c|}
\hline 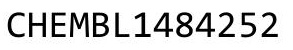 & & & & \\
\hline 624 & 8239 & 362 & & \\
\hline IEMBL1596536 & 38239 & 2862 & 4783 & \\
\hline AEMBL1371334 & 88239 & 3362 & 449 & \\
\hline 83 & 239 & & & \\
\hline EMBL1429671 & 239 & 2362 & & \\
\hline IEMBL3198196 & 88239 & 4362 & 432 & \\
\hline HEMBL1382400 & 88239 & .9862 & 5345 & \\
\hline AEMBL1377566 & 88239 & 8861 & & \\
\hline IEMBL157 & 38239 & 862 & & \\
\hline EMBL 3209512 & 239 & 862 & & \\
\hline AEMBL1360571 & 88239 & 5362 & 5.5156 & \\
\hline AEMBL1382593 & 88239 & 362 & 75 & \\
\hline IEMBL16e & 882 & 372 & 78 & \\
\hline EMBL140 & 38239 & 372 & 25 & \\
\hline IEMBL140 & 38239 & 362 & & \\
\hline IEMBL1383467 & 88239 & 862 & 5.5819 & DMU \\
\hline IEMBL1333841 & 88239 & 862 & & \\
\hline 246 & 9 & 62 & & \\
\hline 794 & 39 & 862 & & \\
\hline 615 & 39 & 362 & & \\
\hline L1410879 & 88239 & 862 & & Pus \\
\hline IEMBL14; & 39 & 362 & & ST \\
\hline IEMBL13 & 9 & 862 & & \\
\hline 323 & & 862 & & \\
\hline 126 & 39 & 362 & & \\
\hline L134 & 88239 & 362 & & RN \\
\hline IEMBL1380733 & & & & $\mathrm{RN}$ \\
\hline IEMBL14: & 9 & 62 & 5. & ST \\
\hline 30 & 39 & 62 & & ST \\
\hline 01 & 39 & 366 & & $\mathrm{RN}$ \\
\hline L600008 & & 362 & & RN \\
\hline IEMBL1334973 & & & & RN \\
\hline AEMBL150 & 39 & 362 & & ST \\
\hline 218 & & 62 & & RN \\
\hline 20 & & 62 & & RN \\
\hline IEMBL1478366 & 88239 & 362 & & ST \\
\hline EMBL1349168 & & 862 & & RN \\
\hline JEMBL13 & & 362 & & $\mathrm{RN}$ \\
\hline 492 & & 62 & & KIV \\
\hline 239 & 9 & & & ST \\
\hline IEMBL1484233 & 88239 & 5862 & 15 & ST \\
\hline EMBL14 & 9 & 62 & & RN \\
\hline HEIMIBL 14 & & & & RN \\
\hline & & & & \\
\hline HEMBL152 & & 362 & 34 & RN \\
\hline 756 & 88239 & 5.0362 & 5.5009 & TST \\
\hline HEMBL3195079 & 688239 & 4.5362 & 5.4197 & TST \\
\hline
\end{tabular}

Page 2105 
Supplemental Table S2.txt

\begin{tabular}{|c|c|c|c|c|}
\hline 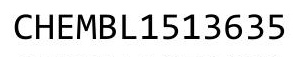 & & & & \\
\hline HEMBL1970221 & 38239 & 1862 & & \\
\hline AEMBL1531255 & 239 & 865 & & \\
\hline & 39 & 862 & & \\
\hline IEMBL13e & 39 & 862 & & \\
\hline AEMBL1596239 & 88239 & 363 & & \\
\hline AEMBL1563567 & 88239 & 362 & 1924 & \\
\hline AEMBL1541031 & & 362 & & \\
\hline IEMBL14: & 39 & 362 & & \\
\hline IEMBL1316193 & & 362 & & \\
\hline AEMBL3198553 & 239 & 862 & 86 & \\
\hline AEMBL1538308 & & 862 & & \\
\hline HEMBL1524267 & & 862 & & \\
\hline AEMBL1375108 & & 862 & & \\
\hline HEMBL 319 & & 862 & & \\
\hline AEMBL1507547 & & 862 & & \\
\hline AEMBL1378448 & & 362 & & \\
\hline IEMBL1358 & & 4. & & \\
\hline AEMBL138 & & 62 & & \\
\hline IEMBL156 & & & & \\
\hline AEMBL150 & & 862 & & \\
\hline AEMBL1531 & & 62 & & \\
\hline HEMBL130 & & 6 & & \\
\hline AFMRI 147 & & & & \\
\hline $\mathrm{HFM}$ & & 362 & & \\
\hline 111 & & 363 & & \\
\hline IEMBL1599305 & & & & \\
\hline IEMBL15 & & 4 & & \\
\hline 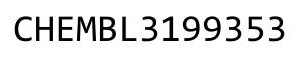 & & & & \\
\hline 7 & & 62 & & \\
\hline AEMBL1586 & & & & \\
\hline AEMBL3194044 & & & & \\
\hline & & & & \\
\hline 1 & & & & \\
\hline AEMBL1561 & & & & \\
\hline AEMBL1312341 & & & & \\
\hline AEMBL1585796 & & 4 & & \\
\hline & & & & \\
\hline 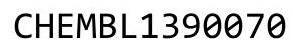 & & & & \\
\hline 9 & & & & 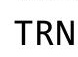 \\
\hline AEMBL1402072 & & 62 & & s \\
\hline AEMBL 3210 & & 7. & & \\
\hline & & & & \\
\hline HEMBL1523434 & & & & \\
\hline AEMBL1306064 & & & 4628 & RN \\
\hline AEMBL3213258 & & 366 & & \\
\hline 47 & & & & \\
\hline HEMBL135065 & & & & \\
\hline
\end{tabular}

Page 2106 
Supplemental Table S2.txt

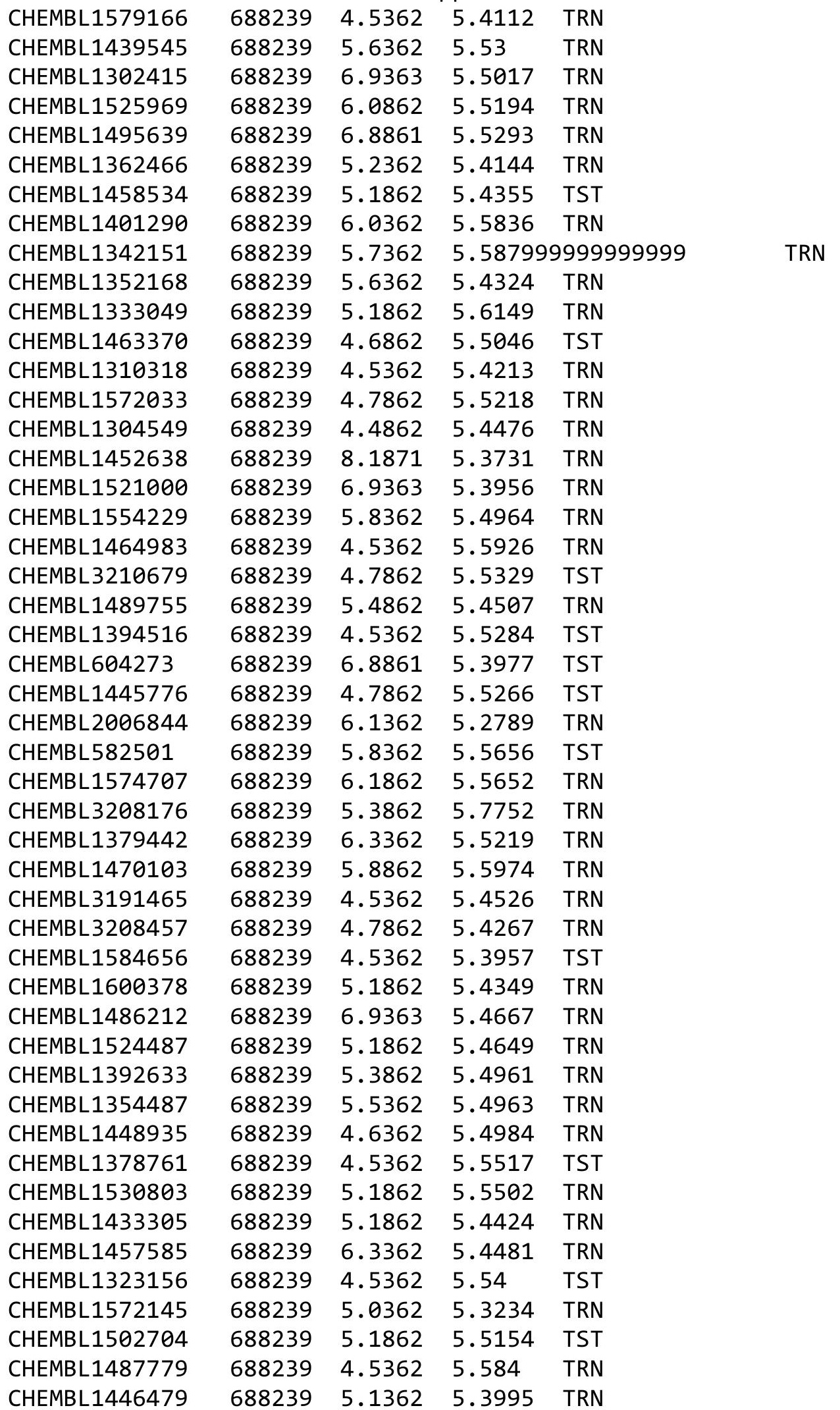


Supplemental Table S2.txt

\begin{tabular}{|c|c|c|c|c|}
\hline & & & & \\
\hline JEMBL14 & 38239 & 7362 & 5883 & \\
\hline IEMBL1305635 & 8239 & 9362 & 1362 & \\
\hline AEMBL1371618 & 239 & 4.7362 & 3928 & \\
\hline IEMBL1386447 & 239 & 862 & & \\
\hline EMBL1529563 & 239 & 862 & & \\
\hline AEMBL1319874 & 88239 & 362 & 5861 & \\
\hline AEMBL1397297 & 88239 & 362 & 5101 & \\
\hline AEMBL1414737 & 239 & 862 & 815 & \\
\hline IEMBL147 & 239 & 362 & & \\
\hline AEMBL1565081 & 39 & 362 & & \\
\hline AEMBL1508273 & 688239 & 862 & 5006 & \\
\hline AEMBL1383086 & 239 & 362 & 02 & \\
\hline IEMBL1363162 & & 362 & 363 & \\
\hline IEMBL1458957 & & 362 & & \\
\hline AEMBL1507924 & & & & \\
\hline AEMBL1536589 & 239 & 362 & 647 & \\
\hline AEMBL1429929 & & 862 & & \\
\hline EMBL133/294 & & 362 & & \\
\hline AEMBL1525448 & & 62 & & \\
\hline AEMBL1514625 & & 362 & & \\
\hline AEMBL1973722 & & 362 & & \\
\hline AEMBL1451417 & & 361 & & \\
\hline IEMBL13 & & 62 & & \\
\hline IEMBL13 & & 52 & & \\
\hline IFMPI 12 & & 62 & & \\
\hline AEMBL1534479 & & & & \\
\hline AEMBL1399325 & & & & \\
\hline AEMBL1439934 & & 61 & 66 & \\
\hline L145 & & 62 & 86 & \\
\hline 24 & & 62 & & \\
\hline HEMBL1586386 & & & & \\
\hline AEMBL3208356 & & & & \\
\hline AEMBL1364090 & & 362 & & \\
\hline AFMRI 1579 & & 62 & 91 & \\
\hline 5 & & & & \\
\hline AEMBL1522476 & & & & \\
\hline AEMBL1345525 & & & 975 & \\
\hline IEMBL $141 \varepsilon$ & & 62 & & \\
\hline -רבר וחנו & & & & \\
\hline 50 & & & & \\
\hline AEMBL1453841 & & 362 & 465 & R \\
\hline IEMBL1495364 & & & & \\
\hline EMBL156 & & & & \\
\hline CHEMBL1553363 & & & & \\
\hline CHEMBL1335838 & & 862 & 21 & \\
\hline HEMBL135963 & 88239 & 4.9862 & 5.4848 & \\
\hline HFMBI 1469895 & 688239 & 6.1862 & 5.4219 & \\
\hline
\end{tabular}

Page 2108 
Supplemental Table S2.txt

\begin{tabular}{|c|c|c|c|c|c|}
\hline CHEMBL 3194022 & 688239 & 6.0862 & 5.4068 & TRN & \\
\hline CHEMBL1599093 & 688239 & 4.8362 & 5.6152 & TST & \\
\hline CHEMBL1556296 & 688239 & 4.9362 & 5.575 & TST & \\
\hline CHEMBL215387 & 688239 & 4.4862 & 5.5003 & TRN & \\
\hline CHEMBL1498575 & 688239 & 5.1862 & 5.5211 & TRN & \\
\hline CHEMBL1406163 & 688239 & 6.5862 & 5.471 & TRN & \\
\hline CHEMBL1350513 & 688239 & 4.5362 & 5.4004 & TST & \\
\hline CHEMBL1546781 & 688239 & 4.5362 & 5.3505 & TST & \\
\hline CHEMBL1574703 & 688239 & 5.6362 & 5.5336 & TRN & \\
\hline CHEMBL1536084 & 688239 & 4.6862 & 5.4516 & TRN & \\
\hline CHEMBL1519667 & 688239 & 4.7862 & 5.4616 & TST & \\
\hline CHEMBL1563737 & 688239 & 6.1862 & 5.4822 & TRN & \\
\hline CHEMBL1442558 & 688239 & 4.7362 & 5.6438 & TRN & \\
\hline CHEMBL1328609 & 688239 & 5.2362 & 5.6076 & TRN & \\
\hline CHEMBL1461814 & 688239 & 8.2366 & 5.4502 & TST & \\
\hline CHEMBL1489860 & 688239 & 6.2862 & 5.4834 & TRN & \\
\hline CHEMBL1549329 & 688239 & 4.5362 & 5.3633 & TRN & \\
\hline CHEMBL1401113 & 688239 & 4.5362 & 5.4181 & TRN & \\
\hline CHEMBL1369726 & 688239 & 4.5362 & 5.4171 & TRN & \\
\hline CHEMBL1577290 & 688239 & 4.5362 & 5.561 & TST & \\
\hline CHEMBL1508700 & 688239 & 4.9862 & 5.3145 & TRN & \\
\hline CHEMBL3212568 & 688239 & 4.8862 & 5.5652 & TST & \\
\hline CHEMBL1507282 & 688239 & 4.4862 & 5.5514 & TST & \\
\hline CHEMBL1423657 & 688239 & 4.5362 & 5.5253 & TST & \\
\hline CHEMBL1312419 & 688239 & 5.0362 & 5.4923 & TRN & \\
\hline CHEMBL532452 & 688239 & 5.6362 & 5.5174 & TRN & \\
\hline CHEMBL1483233 & 688239 & 4.5362 & 5.4566 & TST & \\
\hline CHEMBL1393154 & 688239 & 5.4862 & 5.5238 & TRN & \\
\hline CHEMBL1490950 & 688239 & 4.4862 & 5.7239 & TST & \\
\hline CHEMBL1580070 & 688239 & 6.8861 & 5.4129 & TST & \\
\hline CHEMBL1442323 & 688239 & 4.5362 & 5.4369 & TRN & \\
\hline CHEMBL1509632 & 688239 & 7.2865 & 5.4287 & TST & \\
\hline CHEMBL1509920 & 688239 & 4.6862 & 5.5296 & TRN & \\
\hline CHEMBL1299987 & 688239 & 4.5362 & 5.6262 & TRN & \\
\hline CHEMBL1342875 & 688239 & 6.2862 & 5.5427 & TRN & \\
\hline CHEMBL1445584 & 688239 & 4.7862 & 5.4412 & TRN & \\
\hline CHEMBL1430442 & 688239 & 5.3362 & 5.4348 & TRN & \\
\hline CHEMBL1535539 & 688239 & 4.5862 & 5.353 & TST & \\
\hline CHEMBL597035 & 688239 & 4.5362 & 5.5103 & TRN & \\
\hline CHEMBL1434061 & 688239 & 4.4862 & 5.5899 & TRN & \\
\hline CHEMBL1413191 & 688239 & 7.2366 & 5.482 & TRN & \\
\hline CHEMBL1322800 & 688239 & 5.1362 & 5.5035 & TRN & \\
\hline CHEMBL1400851 & 688239 & 5.6362 & 5.4766 & TRN & \\
\hline CHEMBL 3190276 & 688239 & 4.5362 & 5.3507 & TST & \\
\hline CHEMBL1445338 & 688239 & 8.28399 & 99999999 & 99 & 5.6108 \\
\hline CHEMBL1583707 & 688239 & 6.7361 & 5.3836 & TRN & \\
\hline CHEMBL3197453 & 688239 & 7.0862 & 5.45 & TRN & \\
\hline CHEMBL1331910 & 688239 & 6.1862 & 5.5028 & TRN & \\
\hline
\end{tabular}


Supplemental Table S2.txt

\begin{tabular}{|c|c|c|c|c|c|}
\hline CHEMBL3197056 & 688239 & 5.0362 & \multicolumn{2}{|c|}{5.3629999999999995} & TRN \\
\hline CHEMBL1412445 & 688239 & 5.2362 & 5.399 & TRN & \\
\hline CHEMBL3197665 & 688239 & 5.7362 & 5.4871 & TRN & \\
\hline CHEMBL1388320 & 688239 & 4.8 & 5.5161 & TRN & \\
\hline CHEMBL1570174 & 688239 & 4.7862 & 5.5184 & TRN & \\
\hline CHEMBL3209668 & 688239 & 5.7862 & 5.579 & TRN & \\
\hline CHEMBL1345179 & 688239 & 4.8862 & 5.6273 & TRN & \\
\hline CHEMBL1360793 & 688239 & 5.2862 & 5.3381 & TRN & \\
\hline CHEMBL1434557 & 688239 & 5.1862 & 5.4822 & TRN & \\
\hline CHEMBL1529824 & 688239 & 5.3362 & 5.3745 & TST & \\
\hline CHEMBL1462100 & 688239 & 5.6362 & 5.436 & TRN & \\
\hline CHEMBL1441306 & 688239 & 7.0362 & 5.4649 & TST & \\
\hline CHEMBL1574740 & 688239 & 6.8861 & 5.5486 & TRN & \\
\hline CHEMBL1534291 & 688239 & 5.1862 & 5.5084 & TRN & \\
\hline CHEMBL1397703 & 688239 & 4.4862 & 5.4755 & TRN & \\
\hline CHEMBL1332509 & 688239 & 5.0362 & 5.5525 & TRN & \\
\hline CHEMBL1532311 & 688239 & 5.6362 & \multicolumn{2}{|c|}{5.452000000000001} & $\mathrm{TT}$ \\
\hline CHEMBL1308135 & 688239 & 5.1862 & 5.4715 & TRN & \\
\hline CHEMBL586465 & 688239 & 4.5362 & 5.3551 & TRN & \\
\hline CHEMBL1438381 & 688239 & 4.7862 & 5.3576 & TRN & \\
\hline CHEMBL1526303 & 688239 & 4.7362 & 5.3535 & TRN & \\
\hline CHEMBL1468130 & 688239 & 4.5362 & 5.4798 & TST & \\
\hline CHEMBL1428326 & 688239 & 4.6862 & 5.5286 & TRN & \\
\hline CHEMBL1576667 & 688239 & 5.2862 & 5.5363 & TRN & \\
\hline CHEMBL1316910 & 688239 & 4.7862 & 5.5472 & TRN & \\
\hline CHEMBL1464035 & 688239 & 5.4362 & 5.4654 & TST & \\
\hline CHEMBL1565623 & 688239 & 4.5362 & 5.4125 & TST & \\
\hline CHEMBL1595549 & 688239 & 4.9362 & 5.5077 & TST & \\
\hline CHEMBL1411352 & 688239 & 4.8862 & 5.4922 & TRN & \\
\hline CHEMBL1393554 & 688239 & 4.5362 & 5.4469 & TST & \\
\hline CHEMBL1374695 & 688239 & 5.0862 & 5.6211 & TRN & \\
\hline CHEMBL1394392 & 688239 & 4.5362 & 5.4016 & TRN & \\
\hline CHEMBL1387192 & 688239 & 5.6362 & 5.4846 & TRN & \\
\hline CHEMBL1475402 & 688239 & 4.7362 & 5.3628 & TRN & \\
\hline CHEMBL1409921 & 688239 & 4.5862 & 5.5817 & TRN & \\
\hline CHEMBL1490242 & 688239 & 4.4862 & 5.5744 & TRN & \\
\hline CHEMBL1476562 & 688239 & 4.7862 & 5.4751 & TRN & \\
\hline CHEMBL1521352 & 688239 & 5.4862 & 5.5954 & TRN & \\
\hline CHEMBL1533198 & 688239 & 5.1862 & 5.4486 & TRN & \\
\hline CHEMBL1539877 & 688239 & 4.6362 & 5.4969 & TST & \\
\hline CHEMBL1539542 & 688239 & 4.8362 & 5.4134 & TRN & \\
\hline CHEMBL1313033 & 688239 & 4.7362 & 5.5849 & TST & \\
\hline CHEMBL1197556 & 688239 & 5.5862 & 5.3219 & TRN & \\
\hline CHEMBL1523835 & 688239 & 4.6362 & 5.4713 & TST & \\
\hline CHEMBL1481760 & 688239 & 4.4862 & 5.3754 & TRN & \\
\hline CHEMBL1348712 & 688239 & 5.1862 & 5.585 & TRN & \\
\hline CHEMBL1447486 & 688239 & 6.1862 & 5.4424 & TRN & \\
\hline CHEMBL1571029 & 688239 & 6.8861 & 5.4769 & TRN & \\
\hline
\end{tabular}


Supplemental Table S2.txt

\begin{tabular}{|c|c|c|c|c|}
\hline & & & & \\
\hline AEMBL1504587 & 8239 & 7862 & & \\
\hline IEMBL1385968 & 8239 & 362 & 733 & \\
\hline AEMBL1333146 & 3239 & 8662 & 3 & \\
\hline 00989 & 239 & 362 & & \\
\hline IEMBL1409188 & 239 & 862 & & \\
\hline AEMBL1500777 & 88239 & 862 & & \\
\hline AEMBL1613412 & 88239 & 3861 & 5466 & \\
\hline AEMBL3197273 & 239 & 362 & & \\
\hline IEMBL138 & 239 & 362 & & \\
\hline IEMBL1571 & & & & \\
\hline AEMBL1518679 & 688239 & 862 & 227 & \\
\hline AEMBL1459303 & 239 & 362 & & $S$ \\
\hline EMBL1; & & 362 & & \\
\hline IEMBL1533187 & & 62 & & \\
\hline AEMBL1352462 & & & & \\
\hline AEMBL1456823 & 239 & 362 & & RN \\
\hline AEMBL1519610 & 39 & 362 & & ST \\
\hline IEMBLI334/63 & & 62 & & \\
\hline IEMBL15: & & 62 & & \\
\hline AEMBL 15 & & 62 & & \\
\hline AEMBL1471051 & & 862 & & \\
\hline IEMBL1467367 & & 862 & & \\
\hline IEMBL16 & & 362 & & \\
\hline EMBL1: & & 52 & & $\mathrm{RN}$ \\
\hline IFMBI 14 & & 62 & & \\
\hline AEMBL1322405 & & & & RN \\
\hline IEMBL1579800 & & & & \\
\hline IEMBL1604272 & & 62 & & RI \\
\hline HEMBL1430879 & & 62 & & . \\
\hline 1 & & 63 & & $\mathrm{RN}$ \\
\hline HEMBL1413684 & & & & RN \\
\hline AEMBL1531989 & & & & RI \\
\hline IEMBL1368324 & & 362 & & RI \\
\hline AFMRI 1 & & 62 & & 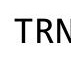 \\
\hline & & & & $\cdots$ \\
\hline AEMBL1471569 & & & & RN \\
\hline AEMBL1366930 & & & & \\
\hline IEMBL13564 & & 62 & & RI \\
\hline HEMBL1594636 & & & & \\
\hline HEMBL3197 & & & & RN \\
\hline AEMBL1307162 & & 6.2862 & & RN \\
\hline IEMBL1608046 & & 62 & & $\lceil R$ \\
\hline HEMBL1507e & & & & \\
\hline CHEMBL1550364 & & & & \\
\hline CHEMBL1459950 & & 362 & & rST \\
\hline AEMBL1342473 & 88239 & 4.6362 & 5.407 & TST \\
\hline HFMRI 1312869 & 688239 & 6.5363 & 5.5419 & \\
\hline
\end{tabular}

Page 2111 
Supplemental Table S2.txt

\begin{tabular}{|c|c|c|c|c|}
\hline CHEMBL1373833 & 688239 & 4.6362 & 5.4639 & TRN \\
\hline CHEMBL1568688 & 688239 & 5.1862 & 5.2957 & TRN \\
\hline CHEMBL1434425 & 688239 & 6.6861 & 5.7104 & TRN \\
\hline CHEMBL1302737 & 688239 & 7.0362 & 5.4936 & TRN \\
\hline CHEMBL1397839 & 688239 & 5.1862 & 5.7463 & TRN \\
\hline CHEMBL1365029 & 688239 & 5.8362 & 5.5161 & TRN \\
\hline CHEMBL1490186 & 688239 & 7.1864 & 5.6092 & TRN \\
\hline CHEMBL1493050 & 688239 & 5.1862 & 5.4611 & TRN \\
\hline CHEMBL1353990 & 688239 & 8.3372 & 5.6345 & TRN \\
\hline CHEMBL1488004 & 688239 & 4.4862 & 5.6891 & TRN \\
\hline CHEMBL1564513 & 688239 & 4.5362 & \multicolumn{2}{|c|}{5.507000000000001} \\
\hline CHEMBL1556393 & 688239 & 5.5362 & 5.4602 & TST \\
\hline CHEMBL1369000 & 688239 & 5.7362 & 5.4832 & TST \\
\hline CHEMBL1510178 & 688239 & 5.5362 & 5.5685 & TST \\
\hline CHEMBL1613045 & 688239 & 5.3862 & 5.4321 & TRN \\
\hline CHEMBL1441822 & 688239 & 5.1862 & 5.5159 & TRN \\
\hline CHEMBL1408895 & 688239 & 8.3872 & 5.54 & TST \\
\hline CHEMBL1310187 & 688239 & 5.7862 & 5.3898 & TRN \\
\hline CHEMBL1603229 & 688239 & 4.5362 & 5.4873 & TST \\
\hline CHEMBL1453007 & 688239 & 5.8362 & 5.4606 & TRN \\
\hline CHEMBL1357083 & 688239 & 6.7361 & 5.4539 & TRN \\
\hline CHEMBL1461116 & 688239 & 4.5362 & 5.5046 & TRN \\
\hline CHEMBL1580346 & 688239 & 5.2862 & 5.5908 & TRN \\
\hline CHEMBL1367315 & 688239 & 4.5362 & 5.5548 & TRN \\
\hline CHEMBL1381696 & 688239 & 6.0862 & 5.5389 & TRN \\
\hline CHEMBL1417069 & 688239 & 4.8362 & 5.4807 & TRN \\
\hline CHEMBL1305598 & 688239 & 5.1862 & 5.4665 & TRN \\
\hline CHEMBL1305489 & 688239 & 5.6862 & 5.4584 & TRN \\
\hline CHEMBL1482033 & 688239 & 5.9362 & 5.4995 & TST \\
\hline CHEMBL1478483 & 688239 & 6.1862 & 5.5318 & TRN \\
\hline CHEMBL 3214512 & 688239 & 6.0362 & 5.5722 & TRN \\
\hline CHEMBL1512861 & 688239 & 4.6862 & 5.4756 & TRN \\
\hline CHEMBL1549599 & 688239 & 7.1864 & 5.5485 & TST \\
\hline CHEMBL1365168 & 688239 & 4.6862 & 5.4723 & TST \\
\hline CHEMBL1470133 & 688239 & 4.5362 & 5.4154 & TRN \\
\hline CHEMBL1299522 & 688239 & 4.6862 & 5.4537 & TRN \\
\hline CHEMBL1526997 & 688239 & 6.6861 & 5.5226 & TRN \\
\hline CHEMBL1975006 & 688239 & 6.0862 & 5.5333 & TRN \\
\hline CHEMBL1588031 & 688239 & 8.3372 & 5.4131 & TRN \\
\hline CHEMBL353187 & 688239 & 8.3372 & 5.4123 & TST \\
\hline CHEMBL1526257 & 688239 & 6.1862 & 5.4267 & TST \\
\hline CHEMBL1299237 & 688239 & 4.4862 & 5.4758 & TRN \\
\hline CHEMBL1550777 & 688239 & 4.7362 & 5.3514 & TST \\
\hline CHEMBL1507490 & 688239 & 4.6862 & 5.5089 & TRN \\
\hline CHEMBL1344991 & 688239 & 4.6862 & 5.5106 & TST \\
\hline CHEMBL1501641 & 688239 & 6.6362 & 5.5604 & TRN \\
\hline CHEMBL1442989 & 688239 & 6.2862 & 5.5246 & TRN \\
\hline CHEMBL1352969 & 688239 & 4.5362 & 5.4403 & TRN \\
\hline
\end{tabular}

Page 2112 


\begin{tabular}{|c|c|c|c|c|}
\hline & & & pplement & al $\mathrm{T}$ \\
\hline CHEMBL1492639 & 688239 & 4.4862 & 5.4157 & TRN \\
\hline CHEMBL1461822 & 688239 & 4.8862 & 5.4746 & TST \\
\hline CHEMBL1459819 & 688239 & 4.5362 & 5.2688 & TRN \\
\hline CHEMBL1360509 & 688239 & 6.4862 & 5.5137 & TRN \\
\hline CHEMBL1404921 & 688239 & 5.4862 & 5.4388 & TRN \\
\hline CHEMBL1340393 & 688239 & 5.0862 & 5.5914 & TRN \\
\hline CHEMBL1567260 & 688239 & 5.1862 & 5.496 & TRN \\
\hline CHEMBL1393322 & 688239 & 5.5362 & 5.4214 & TRN \\
\hline CHEMBL1514081 & 688239 & 5.1362 & 5.5683 & TRN \\
\hline CHEMBL1401315 & 688239 & 4.6862 & 5.4041 & TST \\
\hline CHEMBL1331632 & 688239 & 6.4362 & 5.3906 & TST \\
\hline CHEMBL1535551 & 688239 & 4.8362 & 5.4097 & TST \\
\hline CHEMBL1573888 & 688239 & 7.4365 & 5.6531 & TST \\
\hline CHEMBL1346636 & 688239 & 5.3362 & 5.5706 & TRN \\
\hline CHEMBL1367928 & 688239 & 5.1862 & 5.3976 & TRN \\
\hline CHEMBL1457694 & 688239 & 6.3362 & 5.4636 & TST \\
\hline CHEMBL1511033 & 688239 & 5.7862 & 5.3483 & TST \\
\hline CHEMBL1437772 & 688239 & 4.5362 & 5.5511 & TRN \\
\hline CHEMBL1401687 & 688239 & 4.5362 & 5.4332 & TRN \\
\hline CHEMBL1367292 & 688239 & 5.0362 & 5.4469 & TRN \\
\hline CHEMBL1321349 & 688239 & 6.0 & 5.4006 & TRN \\
\hline CHEMBL1514195 & 688239 & 6.1362 & 5.5288 & TRN \\
\hline CHEMBL1477762 & 688239 & 4.7862 & 5.5572 & TRN \\
\hline CHEMBL1453136 & 688239 & 6.2362 & 5.4837 & TRN \\
\hline CHEMBL3210691 & 688239 & 5.2362 & 5.4664 & TST \\
\hline CHEMBL1361380 & 688239 & 4.5362 & 5.5036 & TST \\
\hline CHEMBL1537905 & 688239 & 4.7362 & 5.5261 & TRN \\
\hline CHEMBL1531910 & 688239 & 5.9362 & 5.595 & TRN \\
\hline CHEMBL1975147 & 688239 & 6.3362 & 5.42 & TRN \\
\hline CHEMBL1462704 & 688239 & 5.2362 & 5.4433 & TRN \\
\hline CHEMBL1308931 & 688239 & 4.5362 & 5.567 & TRN \\
\hline CHEMBL1495097 & 688239 & 6.8861 & 5.6541 & TST \\
\hline CHEMBL1591936 & 688239 & 5.7362 & 5.3722 & TRN \\
\hline CHEMBL1499972 & 688239 & 5.1862 & 5.5866 & TRN \\
\hline CHEMBL 3209246 & 688239 & 7.1361 & 5.3763 & TST \\
\hline CHEMBL1581519 & 688239 & 6.1862 & 5.4664 & TST \\
\hline CHEMBL 221190 & 688239 & 4.5862 & 5.4971 & TST \\
\hline CHEMBL1333316 & 688239 & 4.6362 & 5.3701 & TST \\
\hline CHEMBL1583297 & 688239 & 4.7362 & 5.4891 & TRN \\
\hline CHEMBL1606253 & 688239 & 6.3863 & 5.5283 & TRN \\
\hline CHEMBL1407939 & 688239 & 6.1862 & 5.4738 & TST \\
\hline CHEMBL1575438 & 688239 & 4.4862 & 5.3936 & TRN \\
\hline CHEMBL1490724 & 688239 & 4.6362 & 5.3761 & TRN \\
\hline CHEMBL3208748 & 688239 & 5.6862 & 5.6282 & TRN \\
\hline CHEMBL 3195078 & 688239 & 6.9863 & 5.6375 & TRN \\
\hline CHEMBL1452298 & 688239 & 5.4362 & 5.3894 & TRN \\
\hline CHEMBL 3207437 & 688239 & 4.5362 & 5.3843 & TST \\
\hline CHEMBL1449292 & 688239 & 8.1367 & 5.5172 & TST \\
\hline
\end{tabular}


Supplemental Table S2.txt

\begin{tabular}{|c|c|c|c|c|c|}
\hline CHEMBL1609974 & 688239 & 4.7362 & 5.4591 & TRN & \\
\hline CHEMBL1543880 & 688239 & 5.3862 & 5.5705 & TST & \\
\hline CHEMBL1347000 & 688239 & 5.5862 & 5.4921 & TRN & \\
\hline CHEMBL1577037 & 688239 & 4.7362 & 5.4536 & TST & \\
\hline CHEMBL1558378 & 688239 & 6.9363 & 5.3961 & TST & \\
\hline CHEMBL1610887 & 688239 & 4.5362 & 5.4925 & TRN & \\
\hline CHEMBL1546406 & 688239 & 5.1862 & 5.6298 & TRN & \\
\hline CHEMBL1454947 & 688239 & 5.0362 & 5.5084 & TRN & \\
\hline CHEMBL1599003 & 688239 & 5.1862 & 5.4958 & TRN & \\
\hline CHEMBL1393785 & 688239 & 4.7862 & 5.6673 & TRN & \\
\hline CHEMBL1355496 & 688239 & 5.3862 & 5.4751 & TRN & \\
\hline CHEMBL1585603 & 688239 & 4.8362 & 5.4085 & TRN & \\
\hline CHEMBL1373824 & 688239 & 4.5362 & 5.5154 & TRN & \\
\hline CHEMBL1607169 & 688239 & 4.5362 & 5.5947 & TST & \\
\hline CHEMBL1425675 & 688239 & 5.0362 & 5.3991 & TST & \\
\hline CHEMBL1319541 & 688239 & 5.8362 & 5.3478 & TST & \\
\hline CHEMBL1497686 & 688239 & 4.5362 & \multicolumn{2}{|c|}{5.667999999999999} & TRN \\
\hline CHEMBL1374560 & 688239 & 5.0362 & 5.5173 & TRN & \\
\hline CHEMBL1446034 & 688239 & 4.5862 & 5.5494 & TRN & \\
\hline CHEMBL1518071 & 688239 & 4.4862 & 5.3326 & TRN & \\
\hline CHEMBL1343001 & 688239 & 6.6861 & 5.3716 & TRN & \\
\hline CHEMBL1464717 & 688239 & 4.8862 & 5.4915 & TRN & \\
\hline CHEMBL1423158 & 688239 & 6.1862 & 5.6367 & TRN & \\
\hline CHEMBL1602515 & 688239 & 4.9862 & 5.3373 & TST & \\
\hline CHEMBL1375943 & 688239 & 5.8862 & 5.5293 & TRN & \\
\hline CHEMBL1503679 & 688239 & 5.6362 & 5.5922 & TST & \\
\hline CHEMBL1455899 & 688239 & 6.0862 & 5.4347 & TRN & \\
\hline CHEMBL1503596 & 688239 & 4.6362 & 5.5377 & TRN & \\
\hline CHEMBL1361785 & 688239 & 6.5862 & 5.4313 & TRN & \\
\hline CHEMBL1557099 & 688239 & 4.5362 & 5.4675 & TST & \\
\hline CHEMBL1424192 & 688239 & 5.1862 & 5.3796 & TRN & \\
\hline CHEMBL1577405 & 688239 & 4.5 & 5.4197 & TRN & \\
\hline CHEMBL1541060 & 688239 & 5.0862 & 5.3774 & TST & \\
\hline CHEMBL1450313 & 688239 & 5.1862 & 5.46299 & 9999999999 & TRN \\
\hline CHEMBL1377131 & 688239 & 5.8862 & 5.4172 & TRN & \\
\hline CHEMBL1557051 & 688239 & 8.3872 & 5.45700 & 0000000001 & TRN \\
\hline CHEMBL1462105 & 688239 & 4.9362 & 5.4361 & TRN & \\
\hline CHEMBL1602359 & 688239 & 7.0362 & 5.5564 & TRN & \\
\hline CHEMBL1469184 & 688239 & 4.4862 & 5.3418 & TRN & \\
\hline CHEMBL1418096 & 688239 & 5.1862 & 5.3542 & TST & \\
\hline CHEMBL1381575 & 688239 & 4.5362 & 5.4217 & TRN & \\
\hline CHEMBL1563449 & 688239 & 4.5362 & 5.4517 & TRN & \\
\hline CHEMBL1403588 & 688239 & 4.5862 & 5.5522 & TRN & \\
\hline CHEMBL3210957 & 688239 & 5.7862 & 5.4993 & TST & \\
\hline CHEMBL1466561 & 688239 & 4.5362 & 5.484 & TRN & \\
\hline CHEMBL1553677 & 688239 & 4.5362 & 5.4219 & TRN & \\
\hline CHEMBL3210514 & 688239 & 5.7862 & 5.4957 & TST & \\
\hline CHEMBL1566062 & 688239 & 5.7862 & 5.4699 & TRN & \\
\hline
\end{tabular}

Page 2114 
Supplemental Table S2.txt

\begin{tabular}{|c|c|c|c|c|}
\hline CHEMBL1604425 & 688239 & 6.4862 & 5.4979 & TRN \\
\hline CHEMBL1460831 & 688239 & 5.1362 & 5.4268 & TST \\
\hline CHEMBL1564332 & 688239 & 4.5362 & 5.5332 & TRN \\
\hline CHEMBL1555309 & 688239 & 6.9863 & 5.4983 & TRN \\
\hline CHEMBL1394391 & 688239 & 5.1862 & 5.4114 & TRN \\
\hline CHEMBL1319165 & 688239 & 5.3862 & 5.4444 & TRN \\
\hline CHEMBL1474826 & 688239 & 4.6862 & 5.4413 & TRN \\
\hline CHEMBL1477241 & 688239 & 6.0 & 5.3881 & TST \\
\hline CHEMBL 1440008 & 688239 & 4.4862 & 5.4901 & TRN \\
\hline CHEMBL1426004 & 688239 & 5.8862 & 5.4456 & TST \\
\hline CHEMBL 3199723 & 688239 & 4.4862 & 5.5433 & TRN \\
\hline CHEMBL1345663 & 688239 & 4.6362 & \multicolumn{2}{|c|}{5.486000000000001} \\
\hline CHEMBL1466413 & 688239 & 5.9862 & 5.5841 & TRN \\
\hline CHEMBL1484166 & 688239 & 5.4862 & 5.5477 & TRN \\
\hline CHEMBL1425525 & 688239 & 4.6862 & 5.4223 & TRN \\
\hline CHEMBL1547619 & 688239 & 5.1362 & 5.4131 & TRN \\
\hline CHEMBL1441045 & 688239 & 4.8862 & 5.6066 & TRN \\
\hline CHEMBL1518109 & 688239 & 6.0862 & 5.739 & TRN \\
\hline CHEMBL1563174 & 688239 & 5.6862 & 5.6689 & TRN \\
\hline CHEMBL1381956 & 688239 & 4.5362 & \multicolumn{2}{|c|}{5.537000000000001} \\
\hline CHEMBL1361102 & 688239 & 5.8362 & 5.4975 & TRN \\
\hline CHEMBL1504932 & 688239 & 5.3862 & 5.3537 & TRN \\
\hline CHEMBL608699 & 688239 & 4.6862 & 5.5902 & TRN \\
\hline CHEMBL1469210 & 688239 & 4.7862 & 5.597 & TRN \\
\hline CHEMBL1503929 & 688239 & 4.7362 & 5.5322 & TRN \\
\hline CHEMBL23731 & 688239 & 4.8862 & 5.6409 & TST \\
\hline CHEMBL1423165 & 688239 & 4.5362 & 5.5449 & TRN \\
\hline CHEMBL1523608 & 688239 & 5.1362 & 5.2296 & TST \\
\hline CHEMBL1460700 & 688239 & 5.5862 & 5.5508 & TRN \\
\hline CHEMBL3213818 & 688239 & 6.9363 & 5.4348 & TRN \\
\hline CHEMBL1370432 & 688239 & 5.1862 & 5.5518 & TRN \\
\hline CHEMBL1482076 & 688239 & 5.8362 & 5.574 & TRN \\
\hline CHEMBL1385322 & 688239 & 5.1362 & 5.3746 & TRN \\
\hline CHEMBL1578979 & 688239 & 4.8362 & 5.4247 & TRN \\
\hline CHEMBL1339406 & 688239 & 5.8362 & 5.5394 & TST \\
\hline CHEMBL3199171 & 688239 & 7.0362 & 5.428 & TRN \\
\hline CHEMBL1458130 & 688239 & 4.6862 & \multicolumn{2}{|c|}{5.5360000000000005} \\
\hline CHEMBL1412027 & 688239 & 6.8362 & 5.5619 & TRN \\
\hline CHEMBL3210252 & 688239 & 6.1862 & 5.6352 & TRN \\
\hline CHEMBL1302644 & 688239 & 5.6862 & 5.4308 & TRN \\
\hline CHEMBL1431864 & 688239 & 5.1862 & 5.5664 & TRN \\
\hline CHEMBL1309638 & 688239 & 5.0862 & 5.4893 & TRN \\
\hline CHEMBL1467724 & 688239 & 5.7862 & 5.3943 & TST \\
\hline CHEMBL1593277 & 688239 & 5.1862 & 5.5531 & TRN \\
\hline CHEMBL1419706 & 688239 & 4.5362 & 5.4326 & TRN \\
\hline CHEMBL1307931 & 688239 & 6.9863 & 5.567 & TST \\
\hline CHEMBL1503621 & 688239 & 6.2362 & 5.4885 & TRN \\
\hline CHEMBL1536528 & 688239 & 4.7362 & 5.3852 & TST \\
\hline
\end{tabular}

Page 2115 
Supplemental Table S2.txt

\begin{tabular}{|c|c|c|c|c|}
\hline CHEMBL1484714 & 688239 & 5.0862 & 5.4097 & TRN \\
\hline CHEMBL1977611 & 688239 & 4.9362 & 5.3392 & TST \\
\hline CHEMBL1568954 & 688239 & 6.8362 & 5.4925 & TRN \\
\hline CHEMBL1475681 & 688239 & 4.7362 & 5.4834 & TRN \\
\hline CHEMBL1549039 & 688239 & 4.6862 & 5.476 & TRN \\
\hline CHEMBL1583203 & 688239 & 5.6362 & 5.506 & TRN \\
\hline CHEMBL1502813 & 688239 & 5.1362 & 5.5249 & TRN \\
\hline CHEMBL3208750 & 688239 & 5.0362 & 5.4888 & TRN \\
\hline CHEMBL1308308 & 688239 & 4.5362 & 5.5147 & TRN \\
\hline CHEMBL1505866 & 688239 & 4.5362 & 5.23799 & 99999999995 \\
\hline CHEMBL1509349 & 688239 & 5.4362 & 5.4675 & TST \\
\hline CHEMBL1370264 & 688239 & 5.3862 & 5.4595 & TRN \\
\hline CHEMBL1584772 & 688239 & 6.1862 & 5.4933 & TRN \\
\hline CHEMBL1600149 & 688239 & 5.1862 & 5.3199 & TST \\
\hline CHEMBL3196242 & 688239 & 4.7362 & 5.3725 & TST \\
\hline CHEMBL1350902 & 688239 & 5.3862 & 5.3047 & TRN \\
\hline CHEMBL1491467 & 688239 & 6.8362 & 5.4892 & TRN \\
\hline CHEMBL3207779 & 688239 & 4.8362 & 5.3802 & TRN \\
\hline CHEMBL1431114 & 688239 & 4.6862 & 5.5053 & TST \\
\hline CHEMBL1418598 & 688239 & 4.6862 & 5.2561 & TRN \\
\hline CHEMBL1600926 & 688239 & 7.0862 & 5.3898 & TST \\
\hline CHEMBL1320921 & 688239 & 7.4365 & 5.476 & TRN \\
\hline CHEMBL1313561 & 688239 & 5.2362 & 5.3702 & TRN \\
\hline CHEMBL1331243 & 688239 & 8.1871 & 5.4601 & TST \\
\hline CHEMBL1496789 & 688239 & 5.8862 & 5.5005 & TST \\
\hline CHEMBL1304732 & 688239 & 6.0862 & 5.4997 & TRN \\
\hline CHEMBL1319394 & 688239 & 5.4362 & 5.526 & TRN \\
\hline CHEMBL1414131 & 688239 & 5.7862 & 5.4645 & TST \\
\hline CHEMBL1299970 & 688239 & 4.5362 & 5.6114 & TRN \\
\hline CHEMBL1530914 & 688239 & 4.7362 & 5.3883 & TRN \\
\hline CHEMBL1360364 & 688239 & 6.1362 & 5.4069 & TRN \\
\hline CHEMBL1533389 & 688239 & 6.2362 & 5.4745 & TRN \\
\hline CHEMBL1516654 & 688239 & 7.0362 & 5.5255 & TRN \\
\hline CHEMBL1562840 & 688239 & 4.8862 & 5.5936 & TRN \\
\hline CHEMBL1569587 & 688239 & 5.1862 & 5.5917 & TRN \\
\hline CHEMBL1437311 & 688239 & 5.1362 & 5.4515 & TRN \\
\hline CHEMBL1520701 & 688239 & 4.5362 & 5.4006 & TRN \\
\hline CHEMBL1345045 & 688239 & 4.4362 & 5.4804 & TRN \\
\hline CHEMBL1347139 & 688239 & 4.8362 & 5.4606 & TRN \\
\hline CHEMBL1584284 & 688239 & 5.7862 & 5.4828 & TRN \\
\hline CHEMBL1580664 & 688239 & 5.6862 & 5.4177 & TST \\
\hline CHEMBL1543933 & 688239 & 5.9862 & 5.3531 & TST \\
\hline CHEMBL3194122 & 688239 & 4.6862 & 5.4287 & TST \\
\hline CHEMBL1435815 & 688239 & 6.1862 & 5.3559 & TRN \\
\hline CHEMBL1464869 & 688239 & 6.3362 & 5.5609 & TRN \\
\hline CHEMBL1370477 & 688239 & 5.7862 & 5.5052 & TST \\
\hline CHEMBL1338383 & 688239 & 4.5862 & 5.5219 & TRN \\
\hline CHEMBL1507496 & 688239 & 5.3862 & 5.4562 & TRN \\
\hline
\end{tabular}


Supplemental Table S2.txt

\begin{tabular}{|c|c|c|c|c|}
\hline CHEMBL1375647 & 688239 & 4.5362 & 5.7625 & TRN \\
\hline CHEMBL1303280 & 688239 & 6.5363 & 5.4594 & TRN \\
\hline CHEMBL1581390 & 688239 & 5.6362 & 5.407 & TRN \\
\hline CHEMBL1482870 & 688239 & 5.3362 & \multicolumn{2}{|c|}{5.4510000000000005} \\
\hline CHEMBL1580554 & 688239 & 5.5862 & 5.5447 & TRN \\
\hline CHEMBL1544572 & 688239 & 5.2362 & 5.4162 & TRN \\
\hline CHEMBL1586809 & 688239 & 6.9863 & 5.3783 & TST \\
\hline CHEMBL1459149 & 688239 & 5.2862 & 5.3382 & TST \\
\hline CHEMBL1346236 & 688239 & 5.1862 & 5.4332 & TRN \\
\hline CHEMBL1455834 & 688239 & 5.1862 & 5.5058 & TRN \\
\hline CHEMBL1431321 & 688239 & 5.0862 & 5.4228 & TRN \\
\hline CHEMBL1458368 & 688239 & 4.9362 & 5.6095 & TRN \\
\hline CHEMBL1384396 & 688239 & 4.7362 & 5.3534 & TRN \\
\hline CHEMBL1556010 & 688239 & 5.1862 & 5.5684 & TRN \\
\hline CHEMBL1362102 & 688239 & 6.7862 & 5.442 & TST \\
\hline CHEMBL1548929 & 688239 & 4.5362 & 5.6 & TRN \\
\hline CHEMBL1404726 & 688239 & 6.4862 & 5.4743 & TRN \\
\hline CHEMBL1399097 & 688239 & 5.5862 & 5.6302 & TRN \\
\hline CHEMBL1536149 & 688239 & 4.5362 & 5.4638 & TRN \\
\hline CHEMBL1579668 & 688239 & 4.4862 & 5.4298 & TRN \\
\hline CHEMBL1315174 & 688239 & 6.7862 & 5.4684 & TRN \\
\hline CHEMBL1566880 & 688239 & 4.7862 & 5.6839 & TRN \\
\hline CHEMBL1431471 & 688239 & 7.4868 & 5.4151 & TST \\
\hline CHEMBL1600801 & 688239 & 5.0862 & 5.4534 & TRN \\
\hline CHEMBL1570284 & 688239 & 4.7362 & 5.6225 & TRN \\
\hline CHEMBL1332555 & 688239 & 4.5362 & 5.5032 & TRN \\
\hline CHEMBL1390255 & 688239 & 4.5362 & 5.4863 & TRN \\
\hline CHEMBL1448404 & 688239 & 5.8362 & 5.5081 & TRN \\
\hline CHEMBL1453568 & 688239 & 6.2862 & 5.5283 & TRN \\
\hline CHEMBL1568806 & 688239 & 6.1862 & 5.5686 & TRN \\
\hline CHEMBL1592867 & 688239 & 4.8862 & 5.4668 & TRN \\
\hline CHEMBL1404942 & 688239 & 4.4862 & 5.3935 & TST \\
\hline CHEMBL1500141 & 688239 & 5.1862 & 5.7195 & TRN \\
\hline CHEMBL1310783 & 688239 & 5.3862 & 5.4988 & TST \\
\hline CHEMBL1583994 & 688239 & 5.2362 & 5.4443 & TRN \\
\hline CHEMBL1519424 & 688239 & 4.4362 & 5.3738 & TRN \\
\hline CHEMBL1340363 & 688239 & 4.9362 & 5.5233 & TRN \\
\hline CHEMBL1472915 & 688239 & 4.6862 & 5.4664 & TRN \\
\hline CHEMBL1333513 & 688239 & 4.6362 & 5.5416 & TRN \\
\hline CHEMBL1486153 & 688239 & 4.5362 & 5.5437 & TRN \\
\hline CHEMBL1301560 & 688239 & 5.0362 & 5.3914 & TST \\
\hline CHEMBL1459256 & 688239 & 4.7862 & 5.4928 & TST \\
\hline CHEMBL1459931 & 688239 & 4.85 & 5.564 & TRN \\
\hline CHEMBL3212357 & 688239 & 4.5362 & 5.3912 & TRN \\
\hline CHEMBL1426895 & 688239 & 4.6862 & 5.4735 & TRN \\
\hline CHEMBL1438425 & 688239 & 4.8362 & 5.6119 & TRN \\
\hline CHEMBL1517750 & 688239 & 4.6362 & 5.3873 & TST \\
\hline CHEMBL1310832 & 688239 & 4.5362 & 5.4269 & TRN \\
\hline
\end{tabular}


Supplemental Table S2.txt

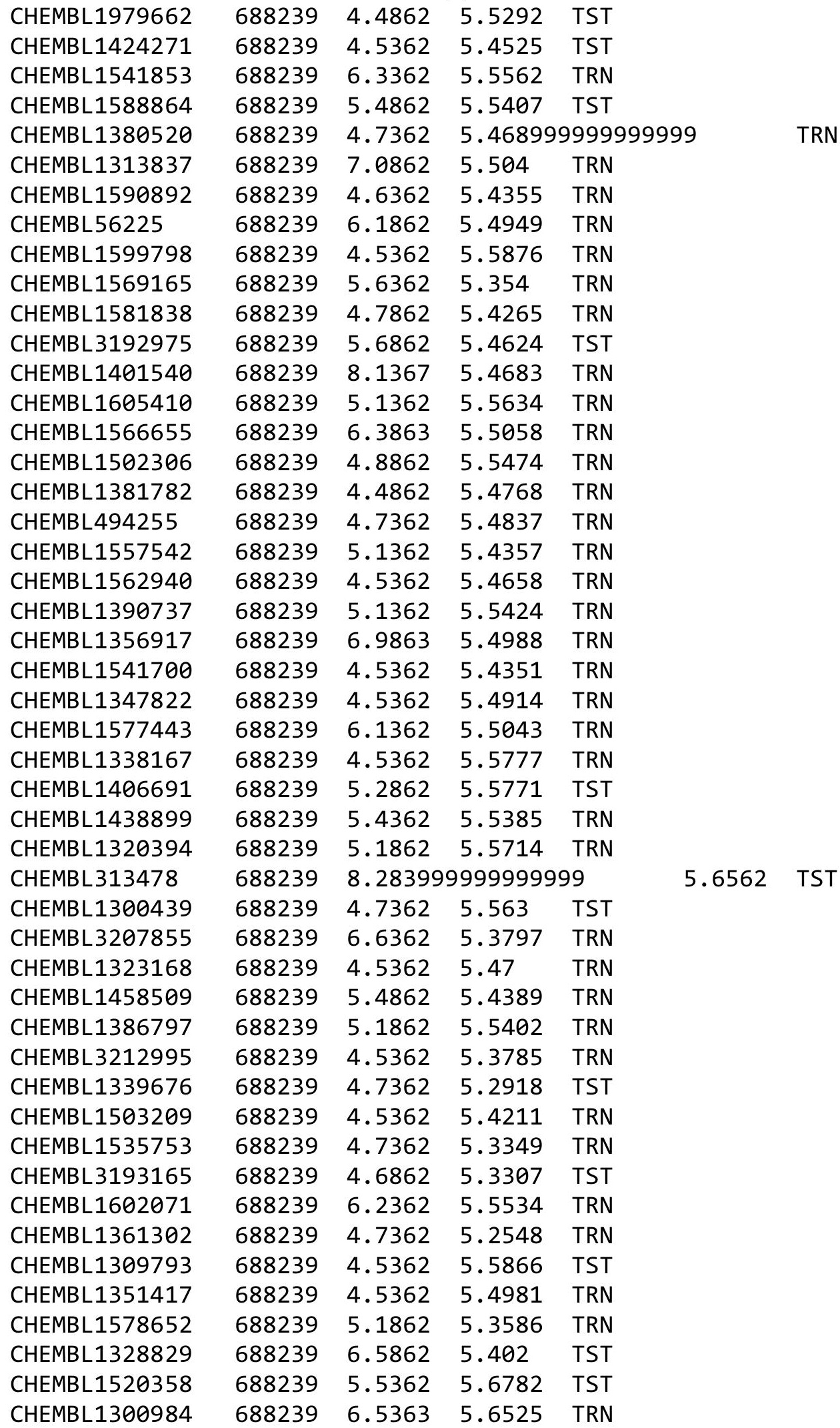

Page 2118 
Supplemental Table S2.txt

\begin{tabular}{|c|c|c|c|c|}
\hline 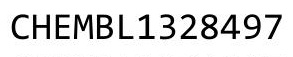 & & & & \\
\hline HEMBL1304147 & 88239 & 7862 & & \\
\hline HEMBL15 & 39 & 862 & 4905 & \\
\hline 26 & & 62 & & \\
\hline AEMBL1488724 & & 362 & & \\
\hline AEMBL1332166 & 88239 & 6862 & .3649 & \\
\hline HEMBL1576807 & 88239 & 8.3372 & .5631 & \\
\hline HEMBL1450624 & 39 & 3362 & & \\
\hline HEMBL14 & & 862 & & \\
\hline IEMBL32 & & 362 & & \\
\hline HEMBL1538847 & 88239 & 5362 & & \\
\hline HEMBL1481596 & 88239 & .1862 & & \\
\hline HEMBL 1465 & 39 & 362 & 18 & \\
\hline HEMBL15 & & 62 & & \\
\hline AEMBL14 & & 362 & & \\
\hline HEMBL1542889 & 88239 & 7862 & & \\
\hline HEMBL161 & & 862 & & \\
\hline HEMBL 14 & 39 & 8662 & 29 & \\
\hline L14 & & 362 & & \\
\hline HEMBL14 & & 862 & & \\
\hline HEMBL1353838 & & 3861 & & \\
\hline HEMBL146 & & & & \\
\hline HEMBL13. & 39 & 862 & 03 & \\
\hline HEMBL14 & & 362 & & \\
\hline 53 & & 362 & & \\
\hline L14 & & 362 & & \\
\hline HEMBL143 & & & & \\
\hline HEMBL 318 & & 52 & & \\
\hline L14 & & & & \\
\hline L13 & & 62 & & ST \\
\hline AEMBL153 & & & & RN \\
\hline HEMBL1328946 & & & & \\
\hline HEMBL14 & & & & \\
\hline 5 & & & & 年 \\
\hline 6 & & & & $\mathrm{RN}$ \\
\hline AEMBL1524780 & & 362 & & RN \\
\hline AEMBL1338695 & & 862 & & $\mathrm{RI}$ \\
\hline 8 & & & & \\
\hline 19 & & 62 & & 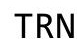 \\
\hline HEMBL138 & & & & ST \\
\hline AEMBL3191884 & & 862 & & ST \\
\hline HEMBL14 & & 372 & & RN \\
\hline & & 361 & & \\
\hline HEMBL14 & & & & \\
\hline HEMBL157 & & & & $\mathrm{RN}$ \\
\hline IEMBL137 & & 362 & 45 & \\
\hline HEMBL14 & & & & \\
\hline CHEMBL130430 & & 5.1862 & 5.3895 & \\
\hline
\end{tabular}

Page 2119 
Supplemental Table S2.txt

\begin{tabular}{|c|c|c|c|c|}
\hline CHEMBL1370613 & 688239 & 5.9862 & 5.5181 & TST \\
\hline CHEMBL1486688 & 688239 & 5.2362 & 5.5305 & TRN \\
\hline CHEMBL1479123 & 688239 & 4.8362 & 5.5876 & TST \\
\hline CHEMBL1502793 & 688239 & 6.5363 & 5.5719 & TRN \\
\hline CHEMBL1552725 & 688239 & 5.2362 & 5.5178 & TRN \\
\hline CHEMBL1556630 & 688239 & 6.2362 & 5.5472 & TRN \\
\hline CHEMBL1608990 & 688239 & 4.8362 & 5.4069 & TRN \\
\hline CHEMBL1384715 & 688239 & 4.6362 & 5.5201 & TRN \\
\hline CHEMBL1366030 & 688239 & 5.1862 & 5.4674 & TRN \\
\hline CHEMBL1371801 & 688239 & 5.5362 & 5.5914 & TRN \\
\hline CHEMBL1610353 & 688239 & 5.6862 & 5.4445 & TRN \\
\hline CHEMBL1488759 & 688239 & 5.3362 & 5.4771 & TRN \\
\hline CHEMBL1379827 & 688239 & 5.1862 & 5.485 & TST \\
\hline CHEMBL1312236 & 688239 & 5.1862 & 5.3978 & TRN \\
\hline CHEMBL1503718 & 688239 & 6.1362 & 5.4869 & TRN \\
\hline CHEMBL1430615 & 688239 & 6.3863 & 5.654 & TRN \\
\hline CHEMBL1431074 & 688239 & 5.7362 & 5.4743 & TRN \\
\hline CHEMBL1988416 & 688239 & 4.4862 & 5.3695 & TST \\
\hline CHEMBL1445553 & 688239 & 5.0362 & 5.6447 & TST \\
\hline CHEMBL1530350 & 688239 & 4.5362 & 5.494 & TRN \\
\hline CHEMBL1327816 & 688239 & 4.7362 & 5.4473 & TRN \\
\hline CHEMBL1499177 & 688239 & 4.5362 & 5.6941 & TRN \\
\hline CHEMBL1384148 & 688239 & 4.8362 & 5.5142 & TRN \\
\hline CHEMBL1381691 & 688239 & 4.7862 & 5.3892 & TRN \\
\hline CHEMBL1511519 & 688239 & 5.7362 & 5.605 & TST \\
\hline CHEMBL1522521 & 688239 & 4.7862 & 5.5094 & TRN \\
\hline CHEMBL1317230 & 688239 & 4.5362 & 5.4291 & TRN \\
\hline CHEMBL1456583 & 688239 & 5.1862 & 5.6263 & TRN \\
\hline CHEMBL1524333 & 688239 & 5.1362 & 5.4987 & TRN \\
\hline CHEMBL1379545 & 688239 & 4.6362 & 5.4514 & TRN \\
\hline CHEMBL1348314 & 688239 & 5.9862 & 5.46200 & 0000000001 \\
\hline CHEMBL1604369 & 688239 & 4.6362 & 5.5683 & TST \\
\hline CHEMBL1610244 & 688239 & 6.2862 & 5.2744 & TST \\
\hline CHEMBL1392651 & 688239 & 4.7862 & 5.3385 & TST \\
\hline CHEMBL1448336 & 688239 & 4.6862 & 5.5054 & TRN \\
\hline CHEMBL1323265 & 688239 & 4.5362 & 5.4556 & TRN \\
\hline CHEMBL1350897 & 688239 & 6.1862 & 5.4991 & TRN \\
\hline CHEMBL1426058 & 688239 & 5.4362 & 5.561 & TRN \\
\hline CHEMBL1368528 & 688239 & 4.5362 & 5.3759 & TRN \\
\hline CHEMBL1341357 & 688239 & 6.3863 & 5.405 & TST \\
\hline CHEMBL1599055 & 688239 & 4.7362 & 5.4967 & TRN \\
\hline CHEMBL 3190477 & 688239 & 4.7362 & 5.3697 & TRN \\
\hline CHEMBL1300841 & 688239 & 6.0862 & 5.4024 & TRN \\
\hline CHEMBL1370745 & 688239 & 6.6861 & 5.4732 & TRN \\
\hline CHEMBL1592840 & 688239 & 4.8362 & 5.3931 & TRN \\
\hline CHEMBL1461601 & 688239 & 4.6862 & 5.3812 & TRN \\
\hline CHEMBL1613505 & 688239 & 5.1862 & 5.4432 & TRN \\
\hline CHEMBL1456319 & 688239 & 6.7862 & 5.5143 & TRN \\
\hline
\end{tabular}

Page 2120 
Supplemental Table S2.txt

\begin{tabular}{|c|c|c|c|c|c|}
\hline CHEMBL1334306 & 688239 & 4.8862 & 5.5726 & TST & \\
\hline CHEMBL1364614 & 688239 & 5.3862 & 5.5702 & TRN & \\
\hline CHEMBL1390591 & 688239 & 5.2862 & 5.4449 & TRN & \\
\hline CHEMBL 3189147 & 688239 & 5.6362 & 5.4718 & TRN & \\
\hline CHEMBL1414025 & 688239 & 4.6862 & 5.5731 & TRN & \\
\hline CHEMBL1329204 & 688239 & 5.3862 & 5.5041 & TRN & \\
\hline CHEMBL1416360 & 688239 & 8.28399 & 99999999 & 5.3173 & TST \\
\hline CHEMBL1531224 & 688239 & 4.4862 & 5.5003 & TRN & \\
\hline CHEMBL1305462 & 688239 & 5.7862 & 5.4879 & TRN & \\
\hline CHEMBL1514925 & 688239 & 4.7862 & 5.4773 & TRN & \\
\hline CHEMBL1353939 & 688239 & 5.1362 & 5.4313 & TRN & \\
\hline CHEMBL1496176 & 688239 & 7.2865 & 5.54 & TRN & \\
\hline CHEMBL1383321 & 688239 & 4.6362 & 5.3667 & TST & \\
\hline CHEMBL1595490 & 688239 & 4.4862 & 5.381 & TST & \\
\hline CHEMBL578675 & 688239 & 6.0862 & 5.4952 & TRN & \\
\hline CHEMBL591628 & 688239 & 6.9363 & 5.2905 & TRN & \\
\hline CHEMBL1359325 & 688239 & 4.5362 & 5.512000 & 0000000005 & TRN \\
\hline CHEMBL1994683 & 688239 & 4.9862 & 5.402 & TRN & \\
\hline CHEMBL1453326 & 688239 & 6.2362 & 5.6329 & TRN & \\
\hline CHEMBL1469783 & 688239 & 6.5363 & 5.4941 & TRN & \\
\hline CHEMBL3207998 & 688239 & 4.5362 & 5.4949 & TRN & \\
\hline CHEMBL1417107 & 688239 & 6.8362 & 5.5908 & TRN & \\
\hline CHEMBL1352381 & 688239 & 4.5362 & 5.5164 & TRN & \\
\hline CHEMBL1511774 & 688239 & 4.5362 & 5.5804 & TRN & \\
\hline CHEMBL1425600 & 688239 & 4.5362 & 5.3498 & TRN & \\
\hline CHEMBL1580373 & 688239 & 5.1862 & 5.3941 & TRN & \\
\hline CHEMBL1364072 & 688239 & 4.4862 & 5.3601 & TRN & \\
\hline CHEMBL1491652 & 688239 & 4.6862 & 5.5089 & TRN & \\
\hline CHEMBL1370179 & 688239 & 5.4362 & 5.4671 & TST & \\
\hline CHEMBL1445512 & 688239 & 5.0862 & 5.4535 & TRN & \\
\hline CHEMBL1484712 & 688239 & 7.2366 & 5.4966 & TRN & \\
\hline CHEMBL1485202 & 688239 & 6.3362 & 5.5552 & TRN & \\
\hline CHEMBL1594247 & 688239 & 5.3862 & 5.5986 & TST & \\
\hline CHEMBL1402116 & 688239 & 4.5862 & 5.4997 & TRN & \\
\hline CHEMBL1503995 & 688239 & 4.7362 & 5.4072 & TRN & \\
\hline CHEMBL1320777 & 688239 & 4.7862 & 5.5404 & TRN & \\
\hline CHEMBL1414338 & 688239 & 4.9362 & 5.4172 & TRN & \\
\hline CHEMBL1435721 & 688239 & 5.9362 & 5.6857 & TRN & \\
\hline CHEMBL3192166 & 688239 & 4.7862 & 5.3634 & TRN & \\
\hline CHEMBL1380415 & 688239 & 4.5362 & 5.3707 & TST & \\
\hline CHEMBL1602505 & 688239 & 6.5363 & 5.479 & TST & \\
\hline CHEMBL1395518 & 688239 & 5.5862 & 5.5062 & TST & \\
\hline CHEMBL1500188 & 688239 & 5.2862 & 5.361000 & 000000001 & S \\
\hline CHEMBL 3212848 & 688239 & 5.5362 & 5.5959 & TST & \\
\hline CHEMBL1485606 & 688239 & 4.4862 & 5.468 & TST & \\
\hline CHEMBL1501239 & 688239 & 7.0862 & 5.5154 & TRN & \\
\hline CHEMBL3194011 & 688239 & 5.4362 & 5.5608 & TRN & \\
\hline CHEMBL1539638 & 688239 & 4.7862 & 5.5392 & TRN & \\
\hline
\end{tabular}

Page 2121 
Supplemental Table S2.txt

\begin{tabular}{|c|c|c|c|c|c|}
\hline CHEMBL1421222 & 688239 & 5.3862 & 5.4871 & TST & \\
\hline CHEMBL1519902 & 688239 & 4.5362 & 5.4126 & TRN & \\
\hline CHEMBL1343247 & 688239 & 5.3862 & 5.7362 & TRN & \\
\hline CHEMBL1423506 & 688239 & 4.5862 & 5.519 & TRN & \\
\hline CHEMBL1416694 & 688239 & 4.4862 & 5.5248 & TRN & \\
\hline CHEMBL1359300 & 688239 & 5.8862 & 5.4454 & TRN & \\
\hline CHEMBL1574463 & 688239 & 6.8362 & 5.4742 & TST & \\
\hline CHEMBL1528814 & 688239 & 5.2362 & 5.4555 & TRN & \\
\hline CHEMBL1445468 & 688239 & 5.1362 & 5.4312 & TRN & \\
\hline CHEMBL1327963 & 688239 & 5.3362 & 5.5599 & TRN & \\
\hline CHEMBL1431667 & 688239 & 7.6364 & 5.3583 & TRN & \\
\hline CHEMBL1550242 & 688239 & 4.6862 & 5.4659 & TRN & \\
\hline CHEMBL1592856 & 688239 & 4.4862 & 5.2136 & TRN & \\
\hline CHEMBL1409387 & 688239 & 5.0362 & 5.455 & TRN & \\
\hline CHEMBL1477698 & 688239 & 4.5362 & 5.4404 & TST & \\
\hline CHEMBL3192048 & 688239 & 4.6362 & 5.38299 & 9999999999 & TRN \\
\hline CHEMBL3210500 & 688239 & 5.0862 & 5.49 & TRN & \\
\hline CHEMBL1577138 & 688239 & 4.6362 & 5.3477 & TRN & \\
\hline CHEMBL1378201 & 688239 & 4.7862 & 5.4415 & TRN & \\
\hline CHEMBL1574654 & 688239 & 4.9862 & 5.3355 & TRN & \\
\hline CHEMBL1410498 & 688239 & 4.7362 & 5.4195 & TST & \\
\hline CHEMBL1428912 & 688239 & 4.6362 & 5.5199 & TRN & \\
\hline CHEMBL1341826 & 688239 & 4.5362 & 5.6332 & TRN & \\
\hline CHEMBL1383399 & 688239 & 4.5362 & 5.5034 & TRN & \\
\hline CHEMBL3208139 & 688239 & 4.5362 & 5.5103 & TRN & \\
\hline CHEMBL1533357 & 688239 & 5.1362 & 5.4969 & TRN & \\
\hline CHEMBL1493525 & 688239 & 6.6362 & 5.5518 & TRN & \\
\hline CHEMBL1467058 & 688239 & 5.7362 & 5.3606 & TRN & \\
\hline CHEMBL1458433 & 688239 & 4.6362 & 5.50799 & 9999999999 & TRN \\
\hline CHEMBL1410212 & 688239 & 5.3862 & 5.5066 & TRN & \\
\hline CHEMBL1328794 & 688239 & 5.0362 & 5.4549 & TRN & \\
\hline CHEMBL1374207 & 688239 & 6.2362 & 5.4542 & TRN & \\
\hline CHEMBL1445373 & 688239 & 6.1862 & 5.4077 & TST & \\
\hline CHEMBL1533866 & 688239 & 6.5862 & 5.6728 & TRN & \\
\hline CHEMBL1423890 & 688239 & 4.5362 & 5.4522 & TRN & \\
\hline CHEMBL1473310 & 688239 & 4.6862 & 5.4538 & TRN & \\
\hline CHEMBL1530906 & 688239 & 4.5362 & 5.2983 & TRN & \\
\hline CHEMBL1989310 & 688239 & 5.0862 & 5.5336 & TST & \\
\hline CHEMBL1387548 & 688239 & 5.9362 & 5.5047 & TRN & \\
\hline CHEMBL1543069 & 688239 & 5.9362 & 5.5127 & TRN & \\
\hline CHEMBL1408405 & 688239 & 6.4862 & 5.5089 & TRN & \\
\hline CHEMBL1321638 & 688239 & 4.5362 & 5.5397 & TRN & \\
\hline CHEMBL1312986 & 688239 & 4.5362 & 5.6585 & TRN & \\
\hline CHEMBL1578514 & 688239 & 7.9872 & 5.5823 & TRN & \\
\hline CHEMBL1589950 & 688239 & 4.7362 & 5.4962 & TST & \\
\hline CHEMBL1416383 & 688239 & 4.7862 & 5.6017 & TRN & \\
\hline CHEMBL1485501 & 688239 & 5.3862 & 5.4722 & TRN & \\
\hline CHEMBL1459784 & 688239 & 5.0862 & 5.5028 & TST & \\
\hline
\end{tabular}


Supplemental Table S2.txt

\begin{tabular}{|c|c|c|c|c|}
\hline CHEMBL1522424 & 688239 & 5.2862 & 5.3782 & TRN \\
\hline CHEMBL1448027 & 688239 & 5.7862 & 5.3624 & TRN \\
\hline CHEMBL1450562 & 688239 & 4.5362 & 5.5183 & TST \\
\hline CHEMBL1381314 & 688239 & 5.3862 & 5.3279 & TST \\
\hline CHEMBL1349917 & 688239 & 5.6362 & 5.5598 & TRN \\
\hline CHEMBL1521505 & 688239 & 5.0362 & 5.6125 & TRN \\
\hline CHEMBL1415397 & 688239 & 6.0862 & 5.4386 & TRN \\
\hline CHEMBL1547466 & 688239 & 4.7862 & 5.4358 & TRN \\
\hline CHEMBL1530685 & 688239 & 6.9363 & 5.5479 & TST \\
\hline CHEMBL1343769 & 688239 & 7.1361 & 5.5036 & TRN \\
\hline CHEMBL1342482 & 688239 & 5.4362 & 5.3907 & TRN \\
\hline CHEMBL1573660 & 688239 & 4.7362 & 5.4337 & TST \\
\hline CHEMBL1486352 & 688239 & 4.5362 & 5.3325 & TRN \\
\hline CHEMBL1369111 & 688239 & 7.2865 & 5.5069 & TRN \\
\hline CHEMBL1499037 & 688239 & 6.0362 & 5.3666 & TRN \\
\hline CHEMBL1367525 & 688239 & 5.0862 & 5.4868 & TST \\
\hline CHEMBL1433027 & 688239 & 4.6362 & 5.6572 & TRN \\
\hline CHEMBL1558781 & 688239 & 6.1362 & 5.6418 & TRN \\
\hline CHEMBL1393357 & 688239 & 5.2862 & \multicolumn{2}{|c|}{5.497999999999999} \\
\hline CHEMBL1529341 & 688239 & 5.5362 & 5.5838 & TRN \\
\hline CHEMBL1304939 & 688239 & 4.5362 & 5.4104 & TRN \\
\hline CHEMBL1595516 & 688239 & 5.6362 & 5.5208 & TRN \\
\hline CHEMBL1496686 & 688239 & 6.0362 & 5.55 & TRN \\
\hline CHEMBL1573115 & 688239 & 6.2362 & 5.6728 & TST \\
\hline CHEMBL1387002 & 688239 & 4.8362 & 5.5513 & TST \\
\hline CHEMBL1366915 & 688239 & 5.4362 & 5.6099 & TRN \\
\hline CHEMBL1303253 & 688239 & 6.3863 & 5.4664 & TRN \\
\hline CHEMBL1453918 & 688239 & 5.5862 & 5.5302 & TRN \\
\hline CHEMBL597684 & 688239 & 4.5362 & \multicolumn{2}{|c|}{5.5120000000000005} \\
\hline CHEMBL1531014 & 688239 & 5.1362 & 5.6009 & TRN \\
\hline CHEMBL 3211974 & 688239 & 4.8862 & 5.4802 & TRN \\
\hline CHEMBL1427779 & 688239 & 4.4862 & 5.3237 & TRN \\
\hline CHEMBL1608333 & 688239 & 4.9862 & 5.4378 & TRN \\
\hline CHEMBL1304730 & 688239 & 4.5362 & 5.5496 & TST \\
\hline CHEMBL1542926 & 688239 & 6.3863 & 5.4466 & TST \\
\hline CHEMBL1606320 & 688239 & 6.1362 & 5.5794 & TRN \\
\hline CHEMBL1408444 & 688239 & 6.9363 & 5.5421 & TST \\
\hline CHEMBL1577283 & 688239 & 4.5362 & 5.6061 & TRN \\
\hline CHEMBL 259018 & 688239 & 4.7362 & 5.4012 & TST \\
\hline CHEMBL1360091 & 688239 & 4.7862 & 5.3837 & TST \\
\hline CHEMBL1319764 & 688239 & 8.3372 & 5.4746 & TRN \\
\hline CHEMBL1355873 & 688239 & 4.8362 & 5.4963 & TST \\
\hline CHEMBL1439628 & 688239 & 6.8861 & 5.3747 & TRN \\
\hline CHEMBL1475673 & 688239 & 5.2862 & 5.4039 & TRN \\
\hline CHEMBL1481124 & 688239 & 8.2366 & 5.5181 & TST \\
\hline CHEMBL1363197 & 688239 & 6.2362 & 5.5303 & TST \\
\hline CHEMBL1595110 & 688239 & 6.8861 & 5.6452 & TRN \\
\hline CHEMBL1610007 & 688239 & 4.7362 & 5.4903 & TRN \\
\hline
\end{tabular}

Page 2123 
Supplemental Table S2.txt

\begin{tabular}{|c|c|c|c|c|}
\hline & & & & \\
\hline AEMBL13 & 38239 & 362 & 5238 & \\
\hline AEMBL1319307 & 38239 & 862 & & \\
\hline AEMBL1604491 & 239 & 362 & 105 & \\
\hline EMBL1462784 & 239 & & & \\
\hline IEMBL1537169 & 239 & 362 & & \\
\hline AEMBL1374068 & 88239 & 862 & 415 & \\
\hline AEMBL1392698 & 88239 & 372 & & \\
\hline AEMBL1309697 & 239 & 862 & & \\
\hline EMBL1361414 & 239 & 62 & & \\
\hline AEMBL1523016 & 239 & & & \\
\hline AEMBL1334655 & 688239 & 862 & 06 & \\
\hline AEMBL1504026 & 239 & 362 & & \\
\hline AEMBL1381 & & & & \\
\hline AEMBL1426 & & & & \\
\hline AEMBL131] & & & & \\
\hline AEMBL1524569 & 239 & & & \\
\hline AEMBL1526989 & 39 & 62 & & \\
\hline IEMBL1560 & & & & \\
\hline HEMBL1577 & & & & \\
\hline AEMBL1392 & & & & \\
\hline AEMBL1351271 & & & & \\
\hline AEMBL1500338 & & & & \\
\hline AEMBL157 & & & & \\
\hline HEMBL157 & & & & \\
\hline AFMRI 156 & & & & \\
\hline HEMBL1573 & & & & \\
\hline AEMBL1427892 & & & & \\
\hline AEMBL1415610 & & & & \\
\hline HEMBL13 & & & & \\
\hline 14 & & & & \\
\hline AEMBL1455502 & & & & \\
\hline AEMBL1599962 & & & & \\
\hline AEMBL1541 & & & & \\
\hline HEMBL1336 & & & & \\
\hline 147 & & & & \\
\hline AEMBL1549985 & & & & \\
\hline AEMBL1500553 & & & & \\
\hline IEMBL1350849 & & & & \\
\hline HEMBL1470916 & & & & \\
\hline HEMBL1399113 & & & & \\
\hline HEMBL1325316 & 239 & 4. & & \\
\hline AEMBL1529007 & & & & \\
\hline HEMBL1307 & & & & \\
\hline CHEMBL3210231 & & & & \\
\hline CHEMBL1732424 & & & 23 & \\
\hline AEMBL1372164 & 88239 & 5.8362 & 5.5739 & \\
\hline HFMBI 1589191 & 688239 & 5.2862 & 5.5301 & \\
\hline
\end{tabular}

Page 2124 
Supplemental Table S2.txt

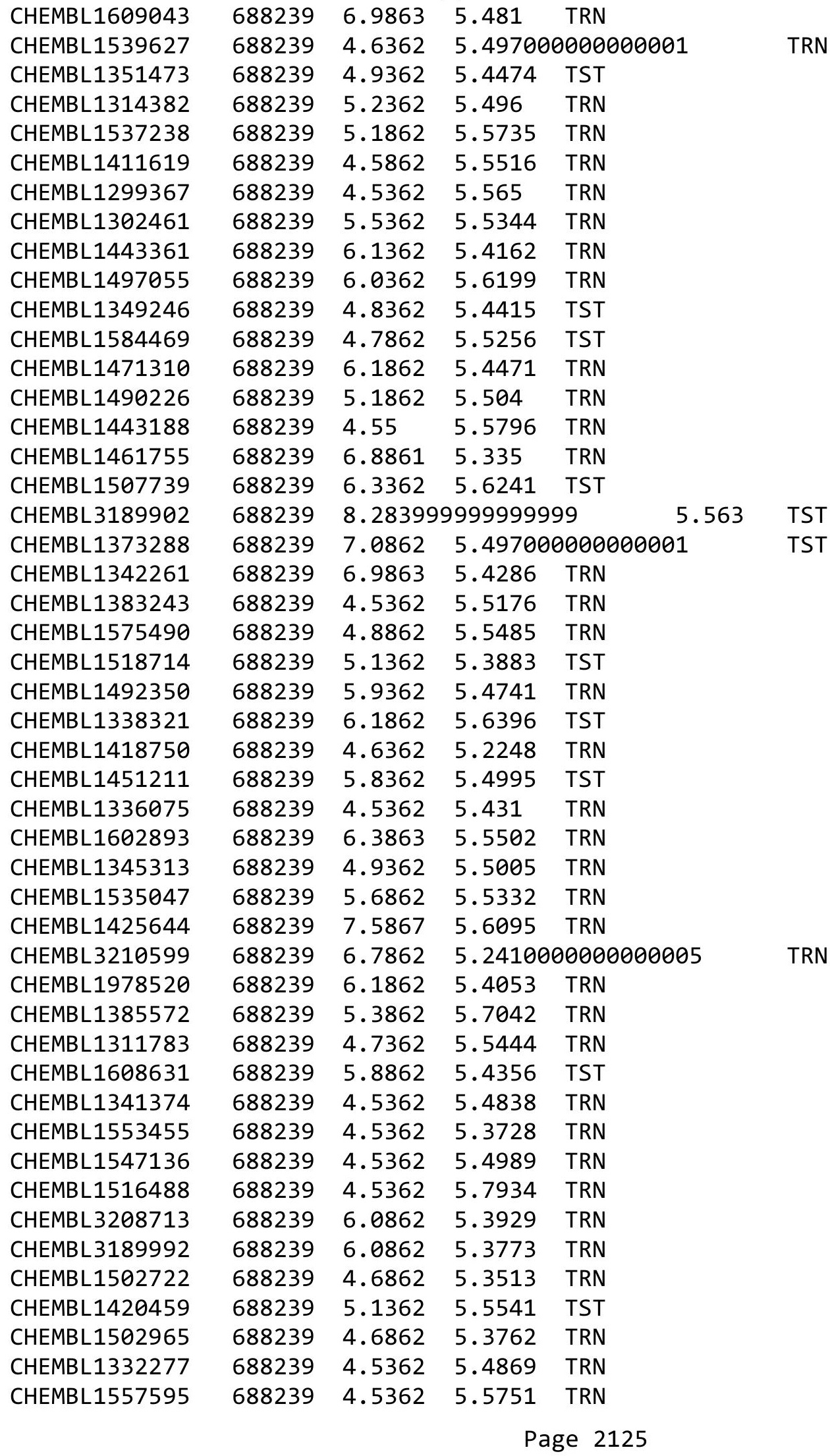


Supplemental Table S2.txt

\begin{tabular}{|c|c|c|c|c|}
\hline CHEMBL1467413 & 688239 & 4.5362 & 5.5708 & TRN \\
\hline CHEMBL1438955 & 688239 & 7.0862 & 5.4966 & TRN \\
\hline CHEMBL1355602 & 688239 & 7.0362 & 5.4791 & TST \\
\hline CHEMBL1313883 & 688239 & 4.7362 & 5.3227 & TRN \\
\hline CHEMBL1597404 & 688239 & 4.8362 & 5.5692 & TST \\
\hline CHEMBL446827 & 688239 & 4.7862 & 5.3853 & TRN \\
\hline CHEMBL1525284 & 688239 & 5.8362 & 5.4258 & TRN \\
\hline CHEMBL1487681 & 688239 & 5.7362 & 5.3425 & TST \\
\hline CHEMBL1472004 & 688239 & 4.5362 & 5.3254 & TRN \\
\hline CHEMBL1586067 & 688239 & 4.9862 & 5.3722 & TRN \\
\hline CHEMBL1345073 & 688239 & 5.4362 & 5.5354 & TRN \\
\hline CHEMBL1516712 & 688239 & 6.1362 & 5.4767 & TRN \\
\hline CHEMBL1306876 & 688239 & 6.6362 & 5.5176 & TRN \\
\hline CHEMBL1542116 & 688239 & 4.5362 & 5.3595 & TST \\
\hline CHEMBL1597940 & 688239 & 5.3862 & 5.4423 & TRN \\
\hline CHEMBL1497834 & 688239 & 4.7862 & 5.5685 & TRN \\
\hline CHEMBL1479352 & 688239 & 4.4862 & 5.6729 & TRN \\
\hline CHEMBL1519663 & 688239 & 6.7361 & 5.3869 & TST \\
\hline CHEMBL1596928 & 688239 & 8.2366 & 5.5519 & TRN \\
\hline CHEMBL1400581 & 688239 & 4.9362 & 5.5312 & TST \\
\hline CHEMBL355496 & 688239 & 5.5362 & 5.2665 & TST \\
\hline CHEMBL1343664 & 688239 & 6.1362 & 5.5598 & TST \\
\hline CHEMBL1304464 & 688239 & 5.3362 & 5.4745 & TRN \\
\hline CHEMBL1434031 & 688239 & 4.5362 & 5.4617 & TST \\
\hline CHEMBL1438548 & 688239 & 5.0862 & 5.519 & TRN \\
\hline CHEMBL1303319 & 688239 & 4.7362 & 5.5048 & TRN \\
\hline CHEMBL1324301 & 688239 & 4.6362 & 5.4643 & TRN \\
\hline CHEMBL1326334 & 688239 & 5.2362 & 5.4523 & TST \\
\hline CHEMBL1376467 & 688239 & 5.1 & 5.4736 & TRN \\
\hline CHEMBL1359476 & 688239 & 4.5862 & 5.5026 & TRN \\
\hline CHEMBL1414200 & 688239 & 6.5862 & 5.4985 & TRN \\
\hline CHEMBL1606707 & 688239 & 4.6862 & 5.5185 & TRN \\
\hline CHEMBL1449042 & 688239 & 5.5362 & 5.54200 & 0000000001 \\
\hline CHEMBL1378565 & 688239 & 4.8362 & 5.4245 & TRN \\
\hline CHEMBL1512887 & 688239 & 5.4362 & 5.4282 & TRN \\
\hline CHEMBL3209961 & 688239 & 4.7862 & 5.4981 & TST \\
\hline CHEMBL1325000 & 688239 & 6.9363 & 5.4132 & TRN \\
\hline CHEMBL1420870 & 688239 & 5.1862 & 5.4585 & TRN \\
\hline CHEMBL1533511 & 688239 & 4.5362 & 5.4295 & TRN \\
\hline CHEMBL1451537 & 688239 & 4.5362 & 5.4702 & TRN \\
\hline CHEMBL1327244 & 688239 & 5.7362 & 5.4952 & TST \\
\hline CHEMBL1440346 & 688239 & 4.6862 & 5.5621 & TST \\
\hline CHEMBL1400481 & 688239 & 4.5862 & 5.5118 & TST \\
\hline CHEMBL1565033 & 688239 & 6.7361 & 5.4994 & TRN \\
\hline CHEMBL1584974 & 688239 & 4.7362 & 5.38399 & 99999999995 \\
\hline CHEMBL1464080 & 688239 & 5.9862 & 5.7757 & TRN \\
\hline CHEMBL1368635 & 688239 & 4.5362 & 5.3806 & TST \\
\hline CHEMBL1576927 & 688239 & 5.6862 & 5.4545 & TST \\
\hline
\end{tabular}




\begin{tabular}{|c|c|c|c|c|c|}
\hline \multirow[b]{2}{*}{ CHEMBL1382105 } & \multicolumn{5}{|c|}{ Supplemental Table s2.txt } \\
\hline & 688239 & 7.5361 & 5.4913 & TRN & \\
\hline CHEMBL1500070 & 688239 & 5.1862 & 5.40799 & 99999999995 & TRN \\
\hline CHEMBL1432318 & 688239 & 4.8362 & 5.5307 & TST & \\
\hline CHEMBL1406143 & 688239 & 4.7362 & 5.4932 & TRN & \\
\hline CHEMBL1467180 & 688239 & 6.9863 & 5.3724 & TRN & \\
\hline CHEMBL3199569 & 688239 & 5.0362 & 5.4439 & TRN & \\
\hline CHEMBL1392180 & 688239 & 4.5862 & 5.3862 & TRN & \\
\hline CHEMBL1600227 & 688239 & 5.3362 & 5.4585 & TRN & \\
\hline CHEMBL1386657 & 688239 & 6.7862 & 5.5051 & TST & \\
\hline CHEMBL1536591 & 688239 & 5.6362 & 5.557 & TRN & \\
\hline CHEMBL1579673 & 688239 & 6.7862 & 5.4334 & TST & \\
\hline CHEMBL1603599 & 688239 & 4.5362 & 5.5432 & TRN & \\
\hline CHEMBL1308357 & 688239 & 4.6362 & 5.4315 & TRN & \\
\hline CHEMBL1502637 & 688239 & 5.1862 & 5.4157 & TRN & \\
\hline CHEMBL1357040 & 688239 & 5.8862 & 5.553 & TRN & \\
\hline CHEMBL1538056 & 688239 & 6.8861 & 5.4486 & TRN & \\
\hline CHEMBL3208116 & 688239 & 6.3362 & 5.5785 & TRN & \\
\hline CHEMBL1470378 & 688239 & 4.45 & 5.4142 & TRN & \\
\hline CHEMBL1488135 & 688239 & 4.5362 & 5.4312 & TRN & \\
\hline CHEMBL1345758 & 688239 & 5.1862 & 5.6092 & TRN & \\
\hline CHEMBL3194768 & 688239 & 4.6862 & 5.7674 & TRN & \\
\hline CHEMBL1546681 & 688239 & 4.5362 & 5.3319 & TRN & \\
\hline CHEMBL1576654 & 688239 & 4.6362 & 5.5135 & TRN & \\
\hline CHEMBL1324952 & 688239 & 4.7362 & 5.4452 & TRN & \\
\hline CHEMBL1606466 & 688239 & 5.7362 & 5.5287 & TRN & \\
\hline CHEMBL1382750 & 688239 & 4.9862 & 5.58 & TRN & \\
\hline CHEMBL1512360 & 688239 & 5.3362 & 5.4867 & TRN & \\
\hline CHEMBL1542264 & 688239 & 7.2865 & 5.5507 & TRN & \\
\hline CHEMBL1986505 & 688239 & 4.5362 & 5.4466 & TRN & \\
\hline CHEMBL3193772 & 688239 & 5.5862 & 5.5169 & TST & \\
\hline CHEMBL586937 & 688239 & 5.8362 & 5.4353 & TRN & \\
\hline CHEMBL1460298 & 688239 & 4.4862 & 5.6466 & TST & \\
\hline CHEMBL1475523 & 688239 & 4.7362 & 5.4813 & TRN & \\
\hline CHEMBL1502870 & 688239 & 4.5362 & 5.4141 & TRN & \\
\hline CHEMBL1370484 & 688239 & 6.0862 & 5.6698 & TRN & \\
\hline CHEMBL1443981 & 688239 & 5.8862 & 5.6397 & TRN & \\
\hline CHEMBL1404676 & 688239 & 4.6862 & 5.4914 & TRN & \\
\hline CHEMBL1408489 & 688239 & 5.9862 & 5.6159 & TST & \\
\hline CHEMBL1966665 & 688239 & 5.1362 & 5.63399 & 99999999995 & TRN \\
\hline CHEMBL1596752 & 688239 & 5.3362 & 5.4841 & TST & \\
\hline CHEMBL1445172 & 688239 & 6.6362 & 5.6606 & TST & \\
\hline CHEMBL1467327 & 688239 & 4.8862 & 5.4775 & TRN & \\
\hline CHEMBL1393506 & 688239 & 6.5862 & 5.3561 & TST & \\
\hline CHEMBL1549933 & 688239 & 5.6862 & 5.6113 & TST & \\
\hline CHEMBL1346123 & 688239 & 6.4862 & 5.5517 & TRN & \\
\hline CHEMBL1435955 & 688239 & 4.5362 & 5.2792 & TRN & \\
\hline CHEMBL1388310 & 688239 & 5.3862 & 5.3069 & TST & \\
\hline CHEMBL1457991 & 688239 & 4.5362 & 5.5284 & TST & \\
\hline
\end{tabular}


Supplemental Table S2.txt

\begin{tabular}{|c|c|c|c|c|}
\hline 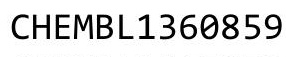 & & & & \\
\hline HEMBL1517879 & 88239 & 862 & 3952 & \\
\hline HEMBL1370964 & 88239 & 9363 & & \\
\hline IEMBL14 & & & & \\
\hline EMBL13 & & & & \\
\hline HEMBL1468858 & 88239 & 3861 & 5939 & \\
\hline HEMBL1500625 & 88239 & .4362 & .5886 & \\
\hline HEMBL129 & & & & \\
\hline IEMBL13 & 239 & 862 & 5262 & \\
\hline IEMBL16 & 39 & 362 & & \\
\hline HEMBL1308245 & 88239 & 362 & 5707 & \\
\hline HEMBL1379048 & 88239 & .2366 & .4924 & \\
\hline HEMBL1512033 & 39 & 861 & 96 & \\
\hline AEME & 39 & 62 & & \\
\hline HEMBL14 & 39 & & & \\
\hline HEMBL 319 & 39 & 862 & & \\
\hline HEMBL1585538 & 39 & & & \\
\hline HEMBL13 & 9 & 62 & 07 & RIV \\
\hline HEM & 9 & & & \\
\hline HEME & 39 & & & \\
\hline HEMBL13 & 39 & & & \\
\hline HEMBL160 & 88 & & & \\
\hline HEMBL13: & 39 & & & \\
\hline HEMBL15 & & & & \\
\hline HEME & 39 & & & $\mathrm{RN}$ \\
\hline HEMBL16 & 39 & & & \\
\hline HEMBL136 & 39 & & & IRN \\
\hline HEMBL15 & 39 & & & \\
\hline HEM & 9 & & & RN \\
\hline HEME & 39 & & & RN \\
\hline HEMBL14 & 9 & & & ( \\
\hline HEMBL14C & 39 & & & TRN \\
\hline HEMBL1C & & & & RIV \\
\hline HEM & 9 & & & RN \\
\hline HEMBL15 & & & & RN \\
\hline HEMBL1445589 & 39 & & & RN \\
\hline HEMBL1317969 & 882 & & & RN \\
\hline 348 & 39 & & & $\mathrm{RN}$ \\
\hline (1) & 39 & & & RIN \\
\hline HEMBL 13 & & & & RN \\
\hline HEMBL132 & 88239 & & & RN \\
\hline HEMBL 15 & 39 & & & 1 \\
\hline HEM & 9 & & & \\
\hline IHEMBL 321 & 88239 & & & RN \\
\hline HEMBL 145 & & & 5.4412 & $\mathrm{RN}$ \\
\hline HEMBL 146 & 688 & 62 & 102 & \\
\hline HEMBL1541747 & & & & \\
\hline 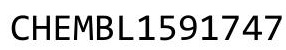 & & & & \\
\hline
\end{tabular}

Page 2128 


\begin{tabular}{|c|c|c|c|c|c|}
\hline & & \multicolumn{4}{|c|}{ Supplemental Table S2.txt } \\
\hline CHEMBL1476701 & 688239 & 8.2366 & 5.4168 & TRN & \\
\hline CHEMBL1507149 & 688239 & 5.0862 & 5.4205 & TRN & \\
\hline CHEMBL3199494 & 688239 & 4.5862 & 5.3445 & TST & \\
\hline CHEMBL1490593 & 688239 & 6.1862 & 5.4813 & TST & \\
\hline CHEMBL1306483 & 688239 & 4.4862 & 5.6792 & TRN & \\
\hline CHEMBL1320428 & 688239 & 8.3872 & 5.4808 & TRN & \\
\hline CHEMBL1546084 & 688239 & 5.4362 & 5.5919 & TST & \\
\hline CHEMBL1453694 & 688239 & 5.1862 & 5.5615 & TST & \\
\hline CHEMBL1384376 & 688239 & 6.8861 & 5.4476 & TST & \\
\hline CHEMBL1502083 & 688239 & 6.2862 & 5.3654 & TRN & \\
\hline CHEMBL1481243 & 688239 & 6.3362 & 5.5844 & TRN & \\
\hline CHEMBL1395775 & 688239 & 4.5362 & 5.407 & TRN & \\
\hline CHEMBL1613674 & 688239 & 5.7862 & 5.58 & TRN & \\
\hline CHEMBL1325465 & 688239 & 4.5362 & 5.4602 & TRN & \\
\hline CHEMBL1428539 & 688239 & 4.8862 & 5.5174 & TRN & \\
\hline CHEMBL1300256 & 688239 & 4.7862 & 5.5488 & TRN & \\
\hline CHEMBL1600263 & 688239 & 7.0862 & 5.5849 & TRN & \\
\hline CHEMBL1435602 & 688239 & 4.5362 & 5.3917 & TRN & \\
\hline CHEMBL1527630 & 688239 & 5.5362 & 5.4695 & TST & \\
\hline CHEMBL3213098 & 688239 & 5.4362 & 5.4124 & TRN & \\
\hline CHEMBL1321670 & 688239 & 5.4862 & 5.4618 & TRN & \\
\hline CHEMBL1584840 & 688239 & 5.4362 & 5.4132 & TRN & \\
\hline CHEMBL1336718 & 688239 & 4.5362 & 5.5665 & TST & \\
\hline CHEMBL1574284 & 688239 & 4.7362 & 5.535 & TRN & \\
\hline CHEMBL1544350 & 688239 & 4.5362 & 5.46399 & 99999999995 & TRN \\
\hline CHEMBL1369920 & 688239 & 6.3362 & 5.4456 & TRN & \\
\hline CHEMBL1480132 & 688239 & 8.3372 & 5.4369 & TRN & \\
\hline CHEMBL3210243 & 688239 & 5.4362 & 5.5265 & TST & \\
\hline CHEMBL 3214247 & 688239 & 4.5362 & 5.3983 & TRN & \\
\hline CHEMBL1378146 & 688239 & 5.0362 & 5.4938 & TRN & \\
\hline CHEMBL1341692 & 688239 & 5.4862 & 5.4993 & TRN & \\
\hline CHEMBL3191551 & 688239 & 5.9862 & 5.5567 & TRN & \\
\hline CHEMBL1612872 & 688239 & 5.0362 & 5.4806 & TRN & \\
\hline CHEMBL1340127 & 688239 & 6.5862 & 5.6673 & TRN & \\
\hline CHEMBL1311708 & 688239 & 4.5362 & 5.2497 & TRN & \\
\hline CHEMBL1591308 & 688239 & 5.2362 & 5.3993 & TRN & \\
\hline CHEMBL1379134 & 688239 & 5.2362 & 5.41299 & 9999999999 & TRN \\
\hline CHEMBL1507093 & 688239 & 4.9362 & 5.4857 & TRN & \\
\hline CHEMBL1352866 & 688239 & 4.7362 & 5.4449 & TRN & \\
\hline CHEMBL1366650 & 688239 & 6.0362 & 5.4646 & TRN & \\
\hline CHEMBL1393450 & 688239 & 5.6862 & 5.4533 & TRN & \\
\hline CHEMBL1427716 & 688239 & 5.7862 & 5.41299 & 9999999999 & TRN \\
\hline CHEMBL1326740 & 688239 & 4.5362 & 5.4671 & TRN & \\
\hline CHEMBL1434560 & 688239 & 6.9863 & 5.5765 & TST & \\
\hline CHEMBL131770 & 688239 & 5.0862 & 5.4472 & TRN & \\
\hline CHEMBL1355706 & 688239 & 4.5362 & 5.4885 & TST & \\
\hline CHEMBL1589211 & 688239 & 6.5862 & 5.4785 & TRN & \\
\hline CHEMBL1493245 & 688239 & 6.0362 & 5.5187 & TRN & \\
\hline
\end{tabular}


Supplemental Table S2.txt

\begin{tabular}{|c|c|c|c|c|}
\hline HEMBL & & .3362 & & . \\
\hline & & 5362 & & \\
\hline 001 & & & & \\
\hline AEMBLI & & & & \\
\hline AEMBL1557941 & 8239 & 362 & 5378 & \\
\hline HEMBL1409926 & 88239 & 1862 & 4395 & \\
\hline 538 & 239 & & & \\
\hline FMBI 1 & & & & \\
\hline AEMBL14 & & 862 & & \\
\hline HEMBL1392829 & 38239 & 862 & 5595 & \\
\hline HEMBL1300265 & 239 & 861 & 5423 & \\
\hline IEMBL14 & 239 & & & \\
\hline IEMBL1 & & & & \\
\hline HEMBL14 & & & 5.3549 & \\
\hline AEMBL14 & & & & \\
\hline AEMBL1 & 39 & 62 & 1236 & \\
\hline HEMBL1 & & & & \\
\hline HEMBL1C & & & & \\
\hline AEMBL15 & & 62 & 5005 & \\
\hline IEMBL1: & & & & \\
\hline HEMBI & & & $\partial 5$ & \\
\hline AEMBL1 & & & & \\
\hline AEMBL1 & & & & \\
\hline AEMBL1: & & & & \\
\hline AEMBL13 & & & & \\
\hline HEMBL1 & & & & RN \\
\hline HEMBL1 & & & & 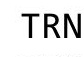 \\
\hline HFMBI 1 & & & & \\
\hline HEMBL1 & & & & TIV \\
\hline HEMBL1308261 & & & & r \\
\hline HEMBL1 & & & & RN \\
\hline HEMBL & & & & Niv \\
\hline IEMPI & & & 76 & \\
\hline HEMBL1322178 & & & & T \\
\hline HEMBL1336264 & & & 845 & TRN \\
\hline HEMBL & & & & \\
\hline 1 & & & & Niv \\
\hline HEMBL159 & & & 347 & IST \\
\hline HEMBL1560213 & 88239 & & 416 & TST \\
\hline AEMBL13 & & & & TRN \\
\hline HEMBL1 & & & 786 & ונSו \\
\hline HEMBL1 14 & & & & TRN \\
\hline HEMBL14 & & 4.7362 & 5.3628 & RN \\
\hline AEMBL1512376 & 39 & 362 & 5616 & TR \\
\hline MBL1 & & & & \\
\hline HEMBL15 & & & & \\
\hline HEMBL14 & & & 5.3925 & \\
\hline HEMBL1415473 & 688239 & 4.5362 & 5.6408 & \\
\hline
\end{tabular}

Page 2130 


\begin{tabular}{|c|c|c|c|c|}
\hline & & & oplement & al $\mathrm{T}$ \\
\hline CHEMBL1383560 & 688239 & 6.6861 & 5.561 & TRN \\
\hline CHEMBL1571198 & 688239 & 4.5362 & 5.5378 & TRN \\
\hline CHEMBL257475 & 688239 & 6.9863 & 5.5381 & TRN \\
\hline CHEMBL3208358 & 688239 & 6.1362 & 5.4252 & TST \\
\hline CHEMBL1542477 & 688239 & 4.7362 & 5.5852 & TRN \\
\hline CHEMBL1359500 & 688239 & 5.3862 & 5.4507 & TRN \\
\hline CHEMBL1315761 & 688239 & 7.0362 & 5.4976 & TRN \\
\hline CHEMBL1496167 & 688239 & 6.8861 & 5.5381 & TST \\
\hline CHEMBL1538108 & 688239 & 4.4862 & 5.4839 & TRN \\
\hline CHEMBL1407552 & 688239 & 4.8362 & 5.5039 & TST \\
\hline CHEMBL1326908 & 688239 & 4.5362 & 5.4431 & TRN \\
\hline CHEMBL1565918 & 688239 & 6.3362 & 5.563 & TRN \\
\hline CHEMBL1551032 & 688239 & 5.1862 & 5.624 & TRN \\
\hline CHEMBL1337175 & 688239 & 4.7862 & 5.4609 & TRN \\
\hline CHEMBL1328001 & 688239 & 7.1864 & 5.4922 & TRN \\
\hline CHEMBL1323521 & 688239 & 7.2366 & 5.4193 & TRN \\
\hline CHEMBL1518778 & 688239 & 4.5362 & 5.2642 & TRN \\
\hline CHEMBL1584924 & 688239 & 5.5362 & 5.4318 & TRN \\
\hline CHEMBL1511873 & 688239 & 4.5362 & 5.3117 & TST \\
\hline CHEMBL1559700 & 688239 & 4.7862 & 5.4426 & TRN \\
\hline CHEMBL1499084 & 688239 & 5.2362 & 5.481 & TRN \\
\hline CHEMBL1447298 & 688239 & 6.1862 & 5.3989 & TRN \\
\hline CHEMBL1531815 & 688239 & 5.0862 & 5.545 & TRN \\
\hline CHEMBL3213281 & 688239 & 5.1362 & 5.4332 & TRN \\
\hline CHEMBL1370379 & 688239 & 4.5362 & 5.5504 & TRN \\
\hline CHEMBL1417774 & 688239 & 6.4362 & 5.5912 & TRN \\
\hline CHEMBL1526738 & 688239 & 5.7362 & 5.539 & TRN \\
\hline CHEMBL1379748 & 688239 & 6.7862 & 5.3529 & TST \\
\hline CHEMBL1491626 & 688239 & 5.5862 & 5.2794 & TRN \\
\hline CHEMBL1307525 & 688239 & 7.3363 & 5.5388 & TRN \\
\hline CHEMBL1409415 & 688239 & 6.9363 & 5.4991 & TRN \\
\hline CHEMBL1370830 & 688239 & 5.8862 & 5.4511 & TRN \\
\hline CHEMBL1450372 & 688239 & 4.6862 & 5.4714 & TRN \\
\hline CHEMBL1436463 & 688239 & 5.1862 & 5.5012 & TRN \\
\hline CHEMBL1432981 & 688239 & 5.6862 & 5.5027 & TRN \\
\hline CHEMBL1387906 & 688239 & 4.7862 & 5.5186 & TRN \\
\hline CHEMBL1365311 & 688239 & 6.6362 & 5.4246 & TRN \\
\hline CHEMBL3207588 & 688239 & 4.7862 & 5.5389 & TRN \\
\hline CHEMBL1494092 & 688239 & 5.0362 & 5.4887 & TRN \\
\hline CHEMBL1520005 & 688239 & 4.5362 & 5.575 & TRN \\
\hline CHEMBL1589175 & 688239 & 5.3362 & 5.4082 & TST \\
\hline CHEMBL1435140 & 688239 & 4.7862 & 5.4427 & TRN \\
\hline CHEMBL1511254 & 688239 & 4.7362 & 5.6102 & TST \\
\hline CHEMBL1399729 & 688239 & 4.5362 & 5.5034 & TRN \\
\hline CHEMBL1526534 & 688239 & 8.3372 & 5.4861 & TRN \\
\hline CHEMBL1312334 & 688239 & 5.5862 & 5.4595 & TRN \\
\hline CHEMBL1448093 & 688239 & 4.5362 & 5.3081 & TRN \\
\hline CHEMBL1369312 & 688239 & 5.8862 & 5.5647 & TRN \\
\hline
\end{tabular}

Page 2131 
Supplemental Table S2.txt

\begin{tabular}{|c|c|c|c|c|c|}
\hline CHEMBL1574781 & 688239 & 5.6362 & 5.568 & TRN & \\
\hline CHEMBL1600218 & 688239 & 5.4362 & 5.5876 & TRN & \\
\hline CHEMBL1479888 & 688239 & 4.8862 & 5.3528 & TST & \\
\hline CHEMBL1307528 & 688239 & 5.7362 & 5.3978 & TRN & \\
\hline CHEMBL1543549 & 688239 & 5.3362 & 5.3734 & TST & \\
\hline CHEMBL1432042 & 688239 & 4.5362 & 5.4321 & TRN & \\
\hline CHEMBL1423594 & 688239 & 8.28399 & 999999999 & 5.4891 & TRN \\
\hline CHEMBL1479443 & 688239 & 8.2366 & 5.5264 & TRN & \\
\hline CHEMBL1501655 & 688239 & 4.6362 & 5.5214 & TRN & \\
\hline CHEMBL1352113 & 688239 & 4.6862 & 5.4842 & TRN & \\
\hline CHEMBL1545480 & 688239 & 4.9862 & 5.629 & TRN & \\
\hline CHEMBL1448861 & 688239 & 5.5362 & 5.5179 & TRN & \\
\hline CHEMBL1501388 & 688239 & 5.6362 & 5.4972 & TST & \\
\hline CHEMBL1547630 & 688239 & 5.6362 & 5.2815 & TRN & \\
\hline CHEMBL1575649 & 688239 & 4.6862 & 5.265 & TRN & \\
\hline CHEMBL1522385 & 688239 & 6.7862 & 5.3533 & TRN & \\
\hline CHEMBL1557957 & 688239 & 5.9362 & 5.6058 & TRN & \\
\hline CHEMBL1521280 & 688239 & 5.8362 & 5.6808 & TRN & \\
\hline CHEMBL1304919 & 688239 & 4.7862 & 5.4652 & TRN & \\
\hline CHEMBL1321013 & 688239 & 5.1862 & 5.4927 & TRN & \\
\hline CHEMBL1511184 & 688239 & 6.2362 & 5.5471 & TRN & \\
\hline CHEMBL1492676 & 688239 & 4.5862 & 5.5784 & TRN & \\
\hline CHEMBL1441210 & 688239 & 4.6362 & 5.4251 & TRN & \\
\hline CHEMBL1324768 & 688239 & 5.4362 & 5.4404 & TRN & \\
\hline CHEMBL1545691 & 688239 & 4.5362 & 5.2876 & TRN & \\
\hline CHEMBL1334168 & 688239 & 5.4362 & 5.4206 & TRN & \\
\hline CHEMBL1526308 & 688239 & 5.1862 & 5.3995 & TST & \\
\hline CHEMBL1542863 & 688239 & 5.1862 & 5.5095 & TST & \\
\hline CHEMBL1539014 & 688239 & 5.7862 & 5.4913 & TST & \\
\hline CHEMBL1566879 & 688239 & 8.3372 & 5.5076 & TRN & \\
\hline CHEMBL3212205 & 688239 & 6.0862 & 5.4425 & TRN & \\
\hline CHEMBL3209783 & 688239 & 7.0362 & 5.5037 & TRN & \\
\hline CHEMBL1431581 & 688239 & 4.9362 & 5.45200 & 0000000001 & \\
\hline CHEMBL3209168 & 688239 & 5.0862 & 5.3671 & TST & \\
\hline CHEMBL1478413 & 688239 & 4.7862 & 5.3947 & TRN & \\
\hline CHEMBL1586908 & 688239 & 4.45 & 5.4328 & TST & \\
\hline CHEMBL1349186 & 688239 & 4.8362 & 5.5001 & TRN & \\
\hline CHEMBL1422439 & 688239 & 5.6362 & 5.3773 & TRN & \\
\hline CHEMBL1549358 & 688239 & 7.5361 & 5.3144 & TRN & \\
\hline CHEMBL1528230 & 688239 & 4.5362 & 5.4986 & TRN & \\
\hline CHEMBL1449439 & 688239 & 5.1862 & 5.4184 & TRN & \\
\hline CHEMBL1403433 & 688239 & 6.6861 & 5.4137 & TRN & \\
\hline CHEMBL1346794 & 688239 & 4.8362 & 5.572999 & 99999999995 & RI \\
\hline CHEMBL602819 & 688239 & 4.5362 & 5.6426 & TRN & \\
\hline CHEMBL1345883 & 688239 & 6.2362 & 5.4532 & TST & \\
\hline CHEMBL1386051 & 688239 & 5.1862 & 5.5322 & TRN & \\
\hline CHEMBL1308981 & 688239 & 4.7862 & 5.4362 & TRN & \\
\hline CHEMBL1603481 & 688239 & 4.5362 & 5.5609 & TRN & \\
\hline
\end{tabular}

Page 2132 
Supplemental Table S2.txt

\begin{tabular}{|c|c|c|c|c|}
\hline 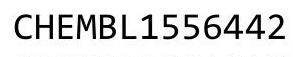 & & & & \\
\hline HEMBL1544218 & 38239 & 8861 & 3924 & \\
\hline HEMBL1340991 & 239 & & 5189 & \\
\hline & 39 & & & \\
\hline IEMBL13 & 39 & & & \\
\hline AEMBL1386904 & 88239 & 862 & 3948 & \\
\hline AEMBL1379936 & 88239 & 362 & 5219 & \\
\hline HEMBL1592467 & & & & \\
\hline EMBL15 & 39 & 362 & & \\
\hline IEMBL3189246 & & & & \\
\hline AEMBL1569519 & 39 & 362 & 133 & \\
\hline AEMBL1390565 & & 363 & 821 & \\
\hline AEMBL1592675 & & & & \\
\hline HEMBL319 & & & & \\
\hline HEMBL144 & & & & \\
\hline AEMBL1402817 & & 361 & 594 & \\
\hline AEMBL1532591 & & 362 & & \\
\hline AEMBL133 & & 62 & & \\
\hline HEMBL147 & & & & \\
\hline JEMBL15 & & & & \\
\hline AEMBL1481139 & & 62 & & \\
\hline HEMBL141 & & & & \\
\hline HEMBL32: & & 62 & & \\
\hline AFMRI 14 & & & & \\
\hline 38 & & & & \\
\hline 302 & & & & \\
\hline IEMBL1369991 & & & & \\
\hline IEMBL15363 & & 62 & & \\
\hline AEM & & 52 & & \\
\hline 1 & & & & \\
\hline AEMBL14193. & & & & \\
\hline HEMBL1582281 & & 362 & & \\
\hline & & & & \\
\hline 8 & & & & \\
\hline & & & & TST \\
\hline AEMBL1364428 & & & 699 & TS \\
\hline AEMBL1322417 & & 62 & 294 & 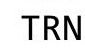 \\
\hline & & & 67 & \\
\hline Irmor & & & & \\
\hline & & & & $\mathrm{RI}$ \\
\hline AEMBL1350455 & & 62 & 578 & $\mathrm{R}$ \\
\hline AEMBL134 & & & & \\
\hline HEMBL1453310 & & & & \\
\hline HEMBL1564028 & & & & \\
\hline 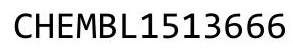 & & 4.7362 & & $\mathrm{R}$ \\
\hline IEMBL13584 & & 363 & 84 & $1 \mathrm{H}$ \\
\hline & & & & \\
\hline HEM & & & & \\
\hline
\end{tabular}

Page 2133 
Supplemental Table S2.txt

\begin{tabular}{|c|c|c|c|c|c|}
\hline CHEMBL1374774 & 688239 & 4.5362 & 5.5815 & TST & \\
\hline CHEMBL1338042 & 688239 & 4.6862 & 5.5685 & TRN & \\
\hline CHEMBL1408480 & 688239 & 5.7362 & 5.38399 & 99999999995 & TRN \\
\hline CHEMBL1447416 & 688239 & 6.7862 & 5.4683 & TST & \\
\hline CHEMBL1613105 & 688239 & 5.1862 & 5.4588 & TRN & \\
\hline CHEMBL1533898 & 688239 & 6.7361 & 5.4927 & TST & \\
\hline CHEMBL1573947 & 688239 & 6.2862 & 5.5183 & TRN & \\
\hline CHEMBL1310377 & 688239 & 6.9363 & 5.4469 & TST & \\
\hline CHEMBL1595844 & 688239 & 8.28399 & 9999999 & 5.5606 & TRN \\
\hline CHEMBL1576632 & 688239 & 5.1862 & 5.5274 & TRN & \\
\hline CHEMBL1334424 & 688239 & 4.6862 & 5.3162 & TRN & \\
\hline CHEMBL1316400 & 688239 & 5.6862 & 5.3576 & TRN & \\
\hline CHEMBL1540864 & 688239 & 4.5362 & 5.5674 & TST & \\
\hline CHEMBL1593590 & 688239 & 5.7362 & 5.4894 & TST & \\
\hline CHEMBL1413517 & 688239 & 5.1862 & 5.3252 & TRN & \\
\hline CHEMBL1305964 & 688239 & 6.3362 & 5.4562 & TRN & \\
\hline CHEMBL1349726 & 688239 & 6.8861 & 5.4445 & TRN & \\
\hline CHEMBL1507723 & 688239 & 5.1362 & 5.4052 & TST & \\
\hline CHEMBL1568070 & 688239 & 4.7362 & 5.2865 & TRN & \\
\hline CHEMBL1355059 & 688239 & 6.9863 & 5.5941 & TRN & \\
\hline CHEMBL1438629 & 688239 & 4.5362 & 5.5945 & TRN & \\
\hline CHEMBL1543629 & 688239 & 5.7862 & 5.4406 & TRN & \\
\hline CHEMBL1324681 & 688239 & 8.3372 & 5.4299 & TST & \\
\hline CHEMBL1528620 & 688239 & 6.3863 & 5.3546 & TRN & \\
\hline CHEMBL1343266 & 688239 & 6.6861 & 5.4561 & TRN & \\
\hline CHEMBL1570188 & 688239 & 4.5362 & 5.6291 & TRN & \\
\hline CHEMBL1308780 & 688239 & 6.8861 & 5.566 & TRN & \\
\hline CHEMBL1607534 & 688239 & 4.5362 & 5.3852 & TST & \\
\hline CHEMBL1535664 & 688239 & 4.9362 & 5.4466 & TRN & \\
\hline CHEMBL1544664 & 688239 & 5.0862 & 5.3168 & TST & \\
\hline CHEMBL1494363 & 688239 & 5.6362 & 5.4391 & TRN & \\
\hline CHEMBL1318712 & 688239 & 4.5362 & 5.4249 & TRN & \\
\hline CHEMBL1347148 & 688239 & 4.5362 & 5.5181 & TRN & \\
\hline CHEMBL1413121 & 688239 & 7.8861 & 5.4436 & TRN & \\
\hline CHEMBL1578882 & 688239 & 5.5362 & 5.5738 & TST & \\
\hline CHEMBL1319134 & 688239 & 5.4362 & 5.4216 & TRN & \\
\hline CHEMBL1343288 & 688239 & 5.1362 & 5.4081 & TST & \\
\hline CHEMBL1446686 & 688239 & 5.4362 & 5.4992 & TRN & \\
\hline CHEMBL1365588 & 688239 & 4.5862 & 5.5144 & TRN & \\
\hline CHEMBL1561017 & 688239 & 5.1862 & 5.5894 & TRN & \\
\hline CHEMBL1493581 & 688239 & 6.0362 & 5.541 & TRN & \\
\hline CHEMBL1592902 & 688239 & 4.5362 & 5.6815 & TRN & \\
\hline CHEMBL3197012 & 688239 & 4.7362 & 5.4743 & TRN & \\
\hline CHEMBL1381209 & 688239 & 4.5362 & 5.6028 & TRN & \\
\hline CHEMBL1300414 & 688239 & 4.6862 & 5.5402 & TST & \\
\hline CHEMBL1495501 & 688239 & 6.7862 & 5.6213 & TRN & \\
\hline CHEMBL1445873 & 688239 & 4.5362 & 5.5875 & TRN & \\
\hline CHEMBL1472578 & 688239 & 4.4862 & 5.4417 & TST & \\
\hline
\end{tabular}


Supplemental Table S2.txt

\begin{tabular}{|c|c|c|c|c|}
\hline CHEMBL1323230 & 688239 & 4.8862 & 5.4832 & TRN \\
\hline CHEMBL1591846 & 688239 & 6.8362 & 5.48 & TRN \\
\hline CHEMBL1510880 & 688239 & 5.9362 & 5.4846 & TRN \\
\hline CHEMBL1352214 & 688239 & 5.0362 & 5.441 & TST \\
\hline CHEMBL1410907 & 688239 & 4.7862 & 5.3894 & TRN \\
\hline CHEMBL1609207 & 688239 & 5.2362 & 5.5275 & TRN \\
\hline CHEMBL1461312 & 688239 & 5.1862 & 5.624 & TST \\
\hline CHEMBL1390546 & 688239 & 4.5362 & 5.4496 & TST \\
\hline CHEMBL3213986 & 688239 & 7.1864 & 5.2287 & TST \\
\hline CHEMBL1355606 & 688239 & 7.3862 & 5.3631 & TRN \\
\hline CHEMBL1571519 & 688239 & 5.6362 & 5.6292 & TRN \\
\hline CHEMBL1577958 & 688239 & 6.9863 & 5.4038 & TRN \\
\hline CHEMBL1423638 & 688239 & 5.3862 & 5.6764 & TRN \\
\hline CHEMBL1325192 & 688239 & 4.7362 & 5.3289 & TRN \\
\hline CHEMBL1527894 & 688239 & 4.5362 & 5.4901 & TST \\
\hline CHEMBL1315969 & 688239 & 6.1362 & 5.6553 & TRN \\
\hline CHEMBL1314487 & 688239 & 5.0362 & 5.5389 & TRN \\
\hline CHEMBL1559811 & 688239 & 4.6362 & 5.4848 & TRN \\
\hline CHEMBL1497748 & 688239 & 6.9363 & 5.5067 & TST \\
\hline CHEMBL1374410 & 688239 & 4.6862 & 5.617999 & 9999999999 \\
\hline CHEMBL1312068 & 688239 & 4.8362 & 5.4413 & TST \\
\hline CHEMBL1367604 & 688239 & 6.8362 & 5.5085 & TRN \\
\hline CHEMBL1550628 & 688239 & 8.3872 & 5.438 & TRN \\
\hline CHEMBL1573183 & 688239 & 4.4862 & 5.3399 & TRN \\
\hline CHEMBL117813 & 688239 & 6.4362 & 5.6206 & TRN \\
\hline CHEMBL1401559 & 688239 & 5.0862 & 5.4878 & TRN \\
\hline CHEMBL1500388 & 688239 & 6.7361 & 5.5263 & TRN \\
\hline CHEMBL1302016 & 688239 & 6.0862 & 5.4471 & TST \\
\hline CHEMBL1457378 & 688239 & 7.2366 & 5.4005 & TRN \\
\hline CHEMBL1591010 & 688239 & 4.5362 & 5.4658 & TRN \\
\hline CHEMBL3194654 & 688239 & 5.1362 & 5.2586 & TRN \\
\hline CHEMBL1390648 & 688239 & 4.8862 & 5.5319 & TST \\
\hline CHEMBL3196454 & 688239 & 5.4862 & 5.3862 & TRN \\
\hline CHEMBL1514134 & 688239 & 6.8861 & 5.388 & TRN \\
\hline CHEMBL1529332 & 688239 & 4.4862 & 5.4422 & TRN \\
\hline CHEMBL1458954 & 688239 & 6.9863 & 5.4635 & TRN \\
\hline CHEMBL1484071 & 688239 & 6.7862 & 5.3506 & TRN \\
\hline CHEMBL1413588 & 688239 & 6.0362 & 5.6107 & TRN \\
\hline CHEMBL1381442 & 688239 & 6.0862 & 5.4369 & TRN \\
\hline CHEMBL1586707 & 688239 & 4.5362 & 5.5327 & TRN \\
\hline CHEMBL1397461 & 688239 & 5.3362 & 5.5757 & TRN \\
\hline CHEMBL1341834 & 688239 & 5.0862 & 5.5403 & TRN \\
\hline CHEMBL1572921 & 688239 & 5.1362 & 5.5575 & TRN \\
\hline CHEMBL1439077 & 688239 & 5.3862 & 5.4795 & TRN \\
\hline CHEMBL1449254 & 688239 & 5.7862 & 5.5033 & TST \\
\hline CHEMBL1351314 & 688239 & 5.6362 & 5.6626 & TRN \\
\hline CHEMBL1385611 & 688239 & 6.1362 & \multicolumn{2}{|c|}{5.4879999999999995} \\
\hline CHEMBL1454911 & 688239 & 4.8862 & 5.4562 & TST \\
\hline
\end{tabular}


Supplemental Table S2.txt

\begin{tabular}{|c|c|c|c|c|c|}
\hline CHEMBL1525017 & 688239 & 4.6862 & 5.3773 & TRN & \\
\hline CHEMBL1331304 & 688239 & 5.5862 & 5.4276 & TRN & \\
\hline CHEMBL3190690 & 688239 & 4.6862 & 5.4374 & TST & \\
\hline CHEMBL1590305 & 688239 & 5.4862 & 5.5335 & TRN & \\
\hline CHEMBL1603965 & 688239 & 4.5362 & 5.6338 & TST & \\
\hline CHEMBL129208 & 688239 & 4.4862 & 5.4247 & TST & \\
\hline CHEMBL1600517 & 688239 & 4.7862 & \multicolumn{2}{|c|}{5.492999999999999} & TRN \\
\hline CHEMBL1306503 & 688239 & 4.5862 & 5.4646 & TRN & \\
\hline CHEMBL1430608 & 688239 & 6.0862 & 5.5676 & TRN & \\
\hline CHEMBL1385155 & 688239 & 4.5362 & 5.7701 & TRN & \\
\hline CHEMBL1451514 & 688239 & 4.7362 & 5.5283 & TRN & \\
\hline CHEMBL1566023 & 688239 & 6.8362 & 5.4282 & TST & \\
\hline CHEMBL1571174 & 688239 & 4.4862 & 5.6378 & TRN & \\
\hline CHEMBL1425736 & 688239 & 5.7862 & 5.2579 & TRN & \\
\hline CHEMBL1497643 & 688239 & 4.8862 & 5.49 & TRN & \\
\hline CHEMBL1477379 & 688239 & 6.3362 & 5.4974 & TRN & \\
\hline CHEMBL1608126 & 688239 & 7.0362 & 5.5666 & TST & \\
\hline CHEMBL1562461 & 688239 & 6.9363 & 5.5315 & TRN & \\
\hline CHEMBL1498825 & 688239 & 4.6362 & 5.4675 & TRN & \\
\hline CHEMBL1463254 & 688239 & 8.3872 & 5.4966 & TRN & \\
\hline CHEMBL1433179 & 688239 & 5.0362 & 5.5042 & TRN & \\
\hline CHEMBL1440112 & 688239 & 5.8862 & 5.5596 & TRN & \\
\hline CHEMBL1344871 & 688239 & 4.8862 & \multicolumn{2}{|c|}{5.4239999999999995} & TST \\
\hline CHEMBL1324247 & 688239 & 7.0362 & 5.4081 & TRN & \\
\hline CHEMBL1506010 & 688239 & 5.4862 & 5.5439 & TRN & \\
\hline CHEMBL1387105 & 688239 & 4.7862 & 5.391 & TRN & \\
\hline CHEMBL1349499 & 688239 & 5.3862 & 5.3776 & TRN & \\
\hline CHEMBL3194097 & 688239 & 6.4362 & 5.4013 & TST & \\
\hline CHEMBL1558529 & 688239 & 6.9863 & 5.5723 & TRN & \\
\hline CHEMBL1503737 & 688239 & 6.1362 & 5.4328 & TST & \\
\hline CHEMBL1303395 & 688239 & 4.7862 & 5.3863 & TRN & \\
\hline CHEMBL1393635 & 688239 & 7.6861 & 5.4801 & TRN & \\
\hline CHEMBL1393628 & 688239 & 8.3372 & 5.6557 & TRN & \\
\hline CHEMBL1532353 & 688239 & 5.6362 & 5.5144 & TRN & \\
\hline CHEMBL1338775 & 688239 & 5.6862 & 5.7182 & TRN & \\
\hline CHEMBL1410588 & 688239 & 4.4362 & 5.3609 & TRN & \\
\hline CHEMBL 3198500 & 688239 & 6.7862 & 5.3818 & TRN & \\
\hline CHEMBL1504833 & 688239 & 4.8862 & 5.2772 & TRN & \\
\hline CHEMBL1531302 & 688239 & 5.1362 & 5.5429 & TRN & \\
\hline CHEMBL1527992 & 688239 & 5.1362 & 5.4857 & TRN & \\
\hline CHEMBL1399791 & 688239 & 4.5362 & 5.4818 & TRN & \\
\hline CHEMBL1560386 & 688239 & 5.3862 & 5.4356 & TRN & \\
\hline CHEMBL1428258 & 688239 & 5.6862 & 5.5188 & TST & \\
\hline CHEMBL1542006 & 688239 & 6.1362 & 5.6258 & TRN & \\
\hline CHEMBL1404693 & 688239 & 6.8362 & 5.4922 & TRN & \\
\hline CHEMBL1441312 & 688239 & 4.4862 & 5.53 & TRN & \\
\hline CHEMBL1568321 & 688239 & 4.7362 & 5.5062 & TRN & \\
\hline CHEMBL1452097 & 688239 & 6.1862 & 5.4499 & TRN & \\
\hline
\end{tabular}


Supplemental Table S2.txt

\begin{tabular}{|c|c|c|c|c|c|}
\hline CHEMBL1604525 & 688239 & 5.5862 & 5.5517 & TRN & \\
\hline CHEMBL3211630 & 688239 & 4.5362 & 5.5544 & TST & \\
\hline CHEMBL1327406 & 688239 & 4.6362 & 5.5445 & TRN & \\
\hline CHEMBL 1455740 & 688239 & 4.8362 & 5.3384 & TST & \\
\hline CHEMBL1379650 & 688239 & 4.5362 & 5.7609 & TRN & \\
\hline CHEMBL1585903 & 688239 & 8.3372 & 5.576000 & 0000000005 & TRN \\
\hline CHEMBL3195758 & 688239 & 5.4862 & 5.5239 & TST & \\
\hline CHEMBL1439923 & 688239 & 4.5362 & 5.6104 & TRN & \\
\hline CHEMBL1399449 & 688239 & 4.5362 & 5.5244 & TRN & \\
\hline CHEMBL1583257 & 688239 & 4.7862 & 5.3995 & TRN & \\
\hline CHEMBL1525337 & 688239 & 4.5362 & 5.2956 & TRN & \\
\hline CHEMBL1304211 & 688239 & 6.8362 & 5.3775 & TRN & \\
\hline CHEMBL1610864 & 688239 & 6.4862 & 5.3644 & TRN & \\
\hline CHEMBL1434366 & 688239 & 4.5362 & 5.3877 & TRN & \\
\hline CHEMBL1329548 & 688239 & 4.7362 & 5.4954 & TRN & \\
\hline CHEMBL1534362 & 688239 & 4.5362 & 5.5564 & TRN & \\
\hline CHEMBL1323931 & 688239 & 6.0862 & 5.6147 & TRN & \\
\hline CHEMBL1360746 & 688239 & 6.9363 & 5.4559 & TST & \\
\hline CHEMBL 3213408 & 688239 & 4.5362 & 5.4655 & TST & \\
\hline CHEMBL1461729 & 688239 & 5.2862 & 5.5884 & TST & \\
\hline CHEMBL1583438 & 688239 & 7.0362 & 5.5838 & TRN & \\
\hline CHEMBL1383181 & 688239 & 4.7362 & 5.6346 & TST & \\
\hline CHEMBL 3210402 & 688239 & 7.4365 & 5.4753 & TRN & \\
\hline CHEMBL1603744 & 688239 & 4.7362 & 5.662999 & 999999999 & \\
\hline CHEMBL3197039 & 688239 & 5.7362 & 5.4828 & TST & \\
\hline CHEMBL1558321 & 688239 & 5.0862 & 5.5635 & TRN & \\
\hline CHEMBL1529891 & 688239 & 7.0362 & 5.5659 & TRN & \\
\hline CHEMBL1315245 & 688239 & 5.5362 & 5.4278 & TRN & \\
\hline CHEMBL1518827 & 688239 & 4.5862 & 5.3703 & TST & \\
\hline CHEMBL1316597 & 688239 & 5.1362 & 5.3594 & TRN & \\
\hline CHEMBL1472642 & 688239 & 4.6862 & 5.5158 & TRN & \\
\hline CHEMBL1453983 & 688239 & 8.28399 & 999999999 & 5.4967 & \\
\hline CHEMBL1420205 & 688239 & 5.3362 & 5.4442 & TRN & \\
\hline CHEMBL1387157 & 688239 & 4.6362 & 5.3423 & TST & \\
\hline CHEMBL1324617 & 688239 & 4.5862 & 5.5923 & TST & \\
\hline CHEMBL1462424 & 688239 & 4.5362 & 5.3175 & TRN & \\
\hline CHEMBL1558244 & 688239 & 6.0862 & 5.5811 & TST & \\
\hline CHEMBL1534871 & 688239 & 5.2362 & 5.3814 & TRN & \\
\hline CHEMBL1411138 & 688239 & 6.0362 & 5.6498 & TRN & \\
\hline CHEMBL1374493 & 688239 & 5.1862 & 5.473 & TRN & \\
\hline CHEMBL1388838 & 688239 & 6.7361 & 5.4418 & TRN & \\
\hline CHEMBL1382297 & 688239 & 6.1862 & 5.4785 & TRN & \\
\hline CHEMBL1419736 & 688239 & 5.6362 & 5.4699 & TRN & \\
\hline CHEMBL 3193417 & 688239 & 5.4362 & 5.4658 & TRN & \\
\hline CHEMBL1354808 & 688239 & 6.1362 & 5.4757 & TRN & \\
\hline CHEMBL1533072 & 688239 & 4.9862 & 5.3166 & TRN & \\
\hline CHEMBL1604464 & 688239 & 4.5362 & 5.5345 & TRN & \\
\hline CHEMBL1457421 & 688239 & 5.1362 & 5.5957 & TST & \\
\hline
\end{tabular}


Supplemental Table S2.txt

\begin{tabular}{|c|c|c|c|c|c|}
\hline CHEMBL1325957 & 688239 & 4.6862 & 5.3638 & TST & \\
\hline CHEMBL1397900 & 688239 & 4.7862 & 5.45100 & 00000000005 & TRN \\
\hline CHEMBL1599918 & 688239 & 5.1862 & 5.4985 & TRN & \\
\hline CHEMBL1399363 & 688239 & 5.8362 & 5.4076 & TRN & \\
\hline CHEMBL1533401 & 688239 & 4.5362 & 5.443 & TST & \\
\hline CHEMBL1308010 & 688239 & 4.7862 & 5.4402 & TRN & \\
\hline CHEMBL1449469 & 688239 & 4.7862 & 5.5596 & TST & \\
\hline CHEMBL1608731 & 688239 & 5.5362 & 5.3794 & TRN & \\
\hline CHEMBL1410025 & 688239 & 7.7352 & 5.7036 & TRN & \\
\hline CHEMBL1607343 & 688239 & 6.4862 & 5.364 & TST & \\
\hline CHEMBL1455815 & 688239 & 5.2862 & 5.4514 & TRN & \\
\hline CHEMBL1547211 & 688239 & 4.7862 & 5.5619 & TST & \\
\hline CHEMBL1387072 & 688239 & 5.3862 & 5.5804 & TRN & \\
\hline CHEMBL1547148 & 688239 & 6.9863 & 5.5172 & TRN & \\
\hline CHEMBL1310500 & 688239 & 5.6362 & 5.2756 & TRN & \\
\hline CHEMBL1511971 & 688239 & 6.2362 & 5.4366 & TRN & \\
\hline CHEMBL1578089 & 688239 & 4.7362 & 5.5057 & TST & \\
\hline CHEMBL1526347 & 688239 & 5.0362 & 5.4179 & TRN & \\
\hline CHEMBL1325276 & 688239 & 5.4362 & 5.6897 & TRN & \\
\hline CHEMBL1484367 & 688239 & 6.2362 & 5.4051 & TRN & \\
\hline CHEMBL1609046 & 688239 & 6.0862 & 5.4577 & TST & \\
\hline CHEMBL473735 & 688239 & 5.8862 & 5.4653 & TRN & \\
\hline CHEMBL1331723 & 688239 & 4.7362 & 5.5138 & TRN & \\
\hline CHEMBL1698037 & 688239 & 4.4862 & 5.4407 & TST & \\
\hline CHEMBL 3211904 & 688239 & 4.6862 & 5.6073 & TRN & \\
\hline CHEMBL1568944 & 688239 & 5.2362 & 5.4381 & TST & \\
\hline CHEMBL1347994 & 688239 & 5.1862 & 5.5405 & TRN & \\
\hline CHEMBL1413211 & 688239 & 8.3872 & 5.4199 & TRN & \\
\hline CHEMBL1491048 & 688239 & 7.6861 & 5.6056 & TST & \\
\hline CHEMBL1504481 & 688239 & 5.2362 & 5.4504 & TST & \\
\hline CHEMBL1409384 & 688239 & 5.1862 & 5.4836 & TRN & \\
\hline CHEMBL1374325 & 688239 & 4.5362 & 5.4261 & TRN & \\
\hline CHEMBL1522403 & 688239 & 4.7362 & 5.4027 & TST & \\
\hline CHEMBL1566959 & 688239 & 6.1362 & 5.585 & TRN & \\
\hline CHEMBL1318506 & 688239 & 4.7362 & 5.6437 & TRN & \\
\hline CHEMBL1498087 & 688239 & 4.7362 & 5.5231 & TRN & \\
\hline CHEMBL1465598 & 688239 & 4.8862 & 5.4731 & TST & \\
\hline CHEMBL1968356 & 688239 & 4.5862 & 5.4011 & TST & \\
\hline CHEMBL1557200 & 688239 & 4.9362 & 5.385 & TRN & \\
\hline CHEMBL1522708 & 688239 & 4.6862 & 5.4496 & TST & \\
\hline CHEMBL1524272 & 688239 & 4.9862 & 5.5664 & TRN & \\
\hline CHEMBL1301357 & 688239 & 4.7362 & 5.4524 & TRN & \\
\hline CHEMBL1971698 & 688239 & 4.6862 & 5.534 & TST & \\
\hline CHEMBL1433534 & 688239 & 5.1862 & 5.394 & TRN & \\
\hline CHEMBL601070 & 688239 & 4.6862 & 5.4043 & TST & \\
\hline CHEMBL1307341 & 688239 & 6.9363 & 5.4063 & TRN & \\
\hline CHEMBL1417952 & 688239 & 6.0862 & 5.5366 & TST & \\
\hline CHEMBL1608695 & 688239 & 6.3362 & 5.5375 & TRN & \\
\hline
\end{tabular}

Page 2138 
Supplemental Table S2.txt

\begin{tabular}{|c|c|c|c|c|c|}
\hline CHEMBL1318485 & 688239 & 5.6862 & 5.4361 & TRN & \\
\hline CHEMBL1454114 & 688239 & 5.3862 & 5.6113 & TRN & \\
\hline CHEMBL1369811 & 688239 & 5.6362 & 5.4654 & TRN & \\
\hline CHEMBL1508782 & 688239 & 6.0862 & 5.4772 & TRN & \\
\hline CHEMBL1581378 & 688239 & 4.8862 & 5.3896 & TST & \\
\hline CHEMBL379099 & 688239 & 6.3362 & 5.5817 & TRN & \\
\hline CHEMBL1455509 & 688239 & 6.1862 & 5.4751 & TRN & \\
\hline CHEMBL1594375 & 688239 & 6.9863 & 5.4049 & TST & \\
\hline CHEMBL1389936 & 688239 & 5.5862 & 5.4676 & TRN & \\
\hline CHEMBL1339923 & 688239 & 4.5362 & 5.4248 & TRN & \\
\hline CHEMBL3193761 & 688239 & 4.9862 & 5.3921 & TST & \\
\hline CHEMBL1525591 & 688239 & 6.0362 & 5.6085 & TRN & \\
\hline CHEMBL1433795 & 688239 & 5.1862 & 5.4955 & TRN & \\
\hline CHEMBL 3196060 & 688239 & 4.5862 & 5.3809 & TST & \\
\hline CHEMBL1589466 & 688239 & 4.7362 & \multicolumn{2}{|c|}{5.457000000000001} & TRN \\
\hline CHEMBL460273 & 688239 & 5.8362 & 5.5002 & TRN & \\
\hline CHEMBL1358630 & 688239 & 6.2362 & 5.4712 & TRN & \\
\hline CHEMBL1562094 & 688239 & 5.1862 & 5.4451 & TRN & \\
\hline CHEMBL1538699 & 688239 & 4.6362 & 5.5387 & TRN & \\
\hline CHEMBL1303722 & 688239 & 4.6362 & 5.3213 & TRN & \\
\hline CHEMBL1495467 & 688239 & 4.4862 & 5.5831 & TST & \\
\hline CHEMBL1555974 & 688239 & 5.6862 & 5.5 & TRN & \\
\hline CHEMBL1417970 & 688239 & 5.2862 & 5.4504 & TRN & \\
\hline CHEMBL3189650 & 688239 & 4.5862 & 5.532 & TRN & \\
\hline CHEMBL3192391 & 688239 & 6.1362 & 5.3754 & TRN & \\
\hline CHEMBL1608091 & 688239 & 4.4862 & 5.5082 & TRN & \\
\hline CHEMBL1367409 & 688239 & 6.2362 & 5.7 & TRN & \\
\hline CHEMBL1572043 & 688239 & 4.8862 & 5.615 & TRN & \\
\hline CHEMBL1430864 & 688239 & 5.3362 & 5.5321 & TRN & \\
\hline CHEMBL1317726 & 688239 & 6.4862 & 5.4379 & TRN & \\
\hline CHEMBL1501158 & 688239 & 8.3372 & 5.4893 & TRN & \\
\hline CHEMBL1371949 & 688239 & 5.7362 & 5.3909 & TRN & \\
\hline CHEMBL1451918 & 688239 & 5.6362 & 5.6074 & TRN & \\
\hline CHEMBL1470933 & 688239 & 4.6862 & 5.4356 & TRN & \\
\hline CHEMBL1575470 & 688239 & 4.5862 & 5.4777 & TRN & \\
\hline CHEMBL1500589 & 688239 & 4.5362 & 5.5373 & TRN & \\
\hline CHEMBL1321589 & 688239 & 4.8862 & 5.5172 & TRN & \\
\hline CHEMBL1569750 & 688239 & 8.3372 & 5.4246 & TRN & \\
\hline CHEMBL1511346 & 688239 & 5.1862 & 5.5384 & TRN & \\
\hline CHEMBL1429018 & 688239 & 7.2366 & 5.5119 & TRN & \\
\hline CHEMBL1567309 & 688239 & 5.1862 & 5.4183 & TRN & \\
\hline CHEMBL1407077 & 688239 & 6.1862 & 5.5194 & TRN & \\
\hline CHEMBL1333748 & 688239 & 4.5362 & 5.5027 & TRN & \\
\hline CHEMBL1604285 & 688239 & 5.4362 & 5.5504 & TST & \\
\hline CHEMBL1332258 & 688239 & 4.5362 & 5.3776 & TRN & \\
\hline CHEMBL1514825 & 688239 & 6.1362 & 5.526 & TRN & \\
\hline CHEMBL1341030 & 688239 & 4.5362 & 5.4969 & TRN & \\
\hline CHEMBL1552617 & 688239 & 4.7362 & 5.5002 & TRN & \\
\hline
\end{tabular}

Page 2139 
Supplemental Table S2.txt

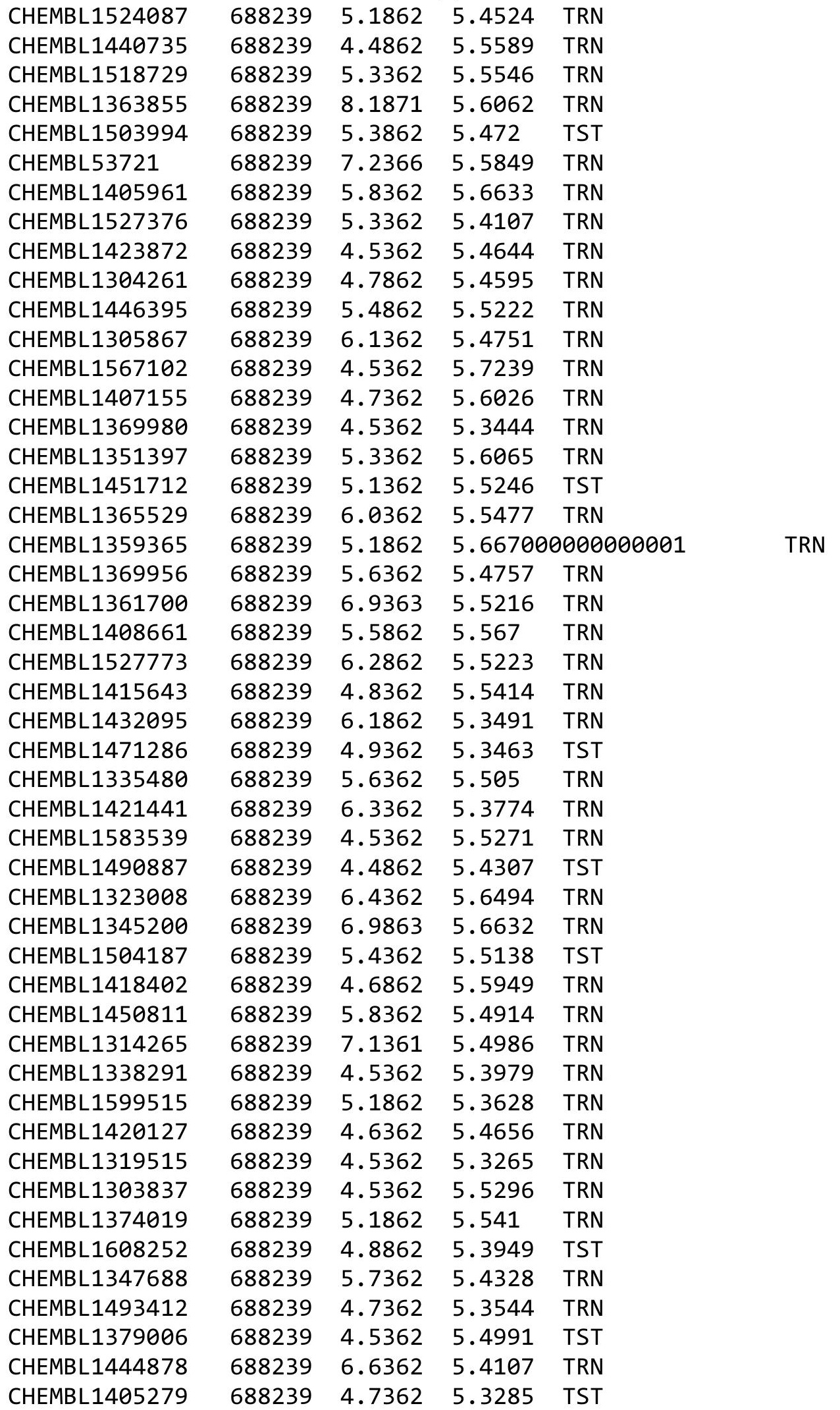

Page 2140 
Supplemental Table S2.txt

\begin{tabular}{|c|c|c|c|c|}
\hline CHEMBL1512486 & 688239 & 4.8362 & 5.4587 & TRN \\
\hline CHEMBL1592911 & 688239 & 4.8862 & 5.4 & TRN \\
\hline CHEMBL1399408 & 688239 & 5.0862 & 5.4675 & TST \\
\hline CHEMBL1583482 & 688239 & 4.5362 & 5.5052 & TRN \\
\hline CHEMBL1311185 & 688239 & 6.3362 & 5.4344 & TST \\
\hline CHEMBL1336177 & 688239 & 4.5362 & 5.5725 & TRN \\
\hline CHEMBL3210379 & 688239 & 4.7362 & 5.5264 & TRN \\
\hline CHEMBL1403359 & 688239 & 5.5862 & 5.5327 & TRN \\
\hline CHEMBL1520116 & 688239 & 6.9363 & \multicolumn{2}{|c|}{5.577000000000001} \\
\hline CHEMBL3212821 & 688239 & 4.8362 & 5.2559 & TRN \\
\hline CHEMBL1436854 & 688239 & 5.8362 & 5.4079 & TRN \\
\hline CHEMBL1605494 & 688239 & 4.5362 & 5.6215 & TRN \\
\hline CHEMBL1490686 & 688239 & 5.1862 & 5.3399 & TRN \\
\hline CHEMBL1469153 & 688239 & 8.3872 & 5.4159 & TST \\
\hline CHEMBL1507345 & 688239 & 5.9362 & 5.4715 & TST \\
\hline CHEMBL1338388 & 688239 & 4.5362 & 5.5865 & TRN \\
\hline CHEMBL1596696 & 688239 & 4.5362 & 5.4267 & TRN \\
\hline CHEMBL3207734 & 688239 & 5.5862 & 5.5385 & TRN \\
\hline CHEMBL1496236 & 688239 & 5.2862 & 5.5306 & TRN \\
\hline CHEMBL1559595 & 688239 & 6.0862 & 5.601 & TRN \\
\hline CHEMBL1477980 & 688239 & 7.6861 & 5.3896 & TRN \\
\hline CHEMBL1560772 & 688239 & 6.1362 & 5.3733 & TRN \\
\hline CHEMBL1464609 & 688239 & 4.6362 & 5.5345 & TST \\
\hline CHEMBL1355723 & 688239 & 7.1361 & 5.2352 & TRN \\
\hline CHEMBL1486660 & 688239 & 5.7862 & 5.5435 & TRN \\
\hline CHEMBL1325405 & 688239 & 5.2362 & 5.4969 & TRN \\
\hline CHEMBL1351673 & 688239 & 6.9863 & 5.6064 & TST \\
\hline CHEMBL1510251 & 688239 & 4.8862 & \multicolumn{2}{|c|}{5.531000000000001} \\
\hline CHEMBL1411071 & 688239 & 4.6862 & 5.5129 & TRN \\
\hline CHEMBL1530986 & 688239 & 4.5362 & 5.5888 & TRN \\
\hline CHEMBL1385362 & 688239 & 4.9362 & 5.5364 & TRN \\
\hline CHEMBL1536073 & 688239 & 7.2865 & 5.4541 & TRN \\
\hline CHEMBL1509967 & 688239 & 5.4362 & 5.6352 & TRN \\
\hline CHEMBL1354233 & 688239 & 6.1862 & 5.5003 & TRN \\
\hline CHEMBL 1337710 & 688239 & 4.6862 & 5.3573 & TRN \\
\hline CHEMBL1587614 & 688239 & 4.4862 & 5.4475 & TRN \\
\hline CHEMBL1998335 & 688239 & 7.1864 & 5.4469 & TRN \\
\hline CHEMBL1455088 & 688239 & 5.1862 & 5.4878 & TRN \\
\hline CHEMBL1988500 & 688239 & 4.7862 & 5.2713 & TRN \\
\hline CHEMBL1605373 & 688239 & 4.8862 & 5.5207 & TRN \\
\hline CHEMBL1373092 & 688239 & 4.8862 & 5.4727 & TRN \\
\hline CHEMBL1500616 & 688239 & 5.2862 & 5.3973 & TST \\
\hline CHEMBL1327241 & 688239 & 4.6862 & 5.4792 & TST \\
\hline CHEMBL1448399 & 688239 & 5.5362 & 5.6127 & TST \\
\hline CHEMBL1330306 & 688239 & 5.1362 & 5.4948 & TST \\
\hline CHEMBL1586673 & 688239 & 5.6362 & 5.5003 & TRN \\
\hline CHEMBL1319807 & 688239 & 4.5362 & 5.3389 & TRN \\
\hline CHEMBL1553250 & 688239 & 4.6862 & 5.4455 & TRN \\
\hline
\end{tabular}

Page 2141 
Supplemental Table S2.txt

\begin{tabular}{|c|c|c|c|c|c|}
\hline CHEMBL3198839 & 688239 & 5.6862 & 5.4842 & TRN & \\
\hline CHEMBL1429519 & 688239 & 5.3862 & 5.5011 & TRN & \\
\hline CHEMBL1495015 & 688239 & 5.5862 & 5.4623 & TRN & \\
\hline CHEMBL44876 & 688239 & 4.6362 & 5.4174 & TRN & \\
\hline CHEMBL1509581 & 688239 & 6.0862 & 5.4994 & TST & \\
\hline CHEMBL1393802 & 688239 & 6.9363 & 5.4731 & TRN & \\
\hline CHEMBL1530743 & 688239 & 8.3372 & 5.4428 & TRN & \\
\hline CHEMBL1371946 & 688239 & 4.5362 & 5.3636 & TST & \\
\hline CHEMBL1339018 & 688239 & 6.5862 & 5.6717 & TRN & \\
\hline CHEMBL1381083 & 688239 & 5.1862 & 5.4686 & TRN & \\
\hline CHEMBL1566433 & 688239 & 6.0862 & 5.3292 & TRN & \\
\hline CHEMBL1556902 & 688239 & 5.1362 & 5.4795 & TRN & \\
\hline CHEMBL1347397 & 688239 & 6.0362 & 5.4245 & TRN & \\
\hline CHEMBL1580937 & 688239 & 6.0862 & 5.5078 & TRN & \\
\hline CHEMBL1577915 & 688239 & 5.0862 & 5.5277 & TRN & \\
\hline CHEMBL1386419 & 688239 & 5.6362 & 5.3754 & TRN & \\
\hline CHEMBL1521169 & 688239 & 5.1862 & 5.5452 & TRN & \\
\hline CHEMBL1512252 & 688239 & 4.5362 & 5.4166 & TRN & \\
\hline CHEMBL1518595 & 688239 & 6.8861 & 5.7009 & TST & \\
\hline CHEMBL1462040 & 688239 & 5.7362 & 5.5873 & TST & \\
\hline CHEMBL1576045 & 688239 & 5.6862 & 5.4722 & TRN & \\
\hline CHEMBL1517098 & 688239 & 5.1862 & 5.5027 & TST & \\
\hline CHEMBL1566596 & 688239 & 5.6862 & 5.4925 & TRN & \\
\hline CHEMBL1454249 & 688239 & 4.6362 & 5.5613 & TRN & \\
\hline CHEMBL3212105 & 688239 & 4.7362 & 5.4215 & TRN & \\
\hline CHEMBL1581067 & 688239 & 5.1862 & 5.454 & TRN & \\
\hline CHEMBL1478658 & 688239 & 6.8362 & 5.5358 & TRN & \\
\hline CHEMBL1602108 & 688239 & 4.9862 & 5.6166 & TRN & \\
\hline CHEMBL1444634 & 688239 & 4.5862 & \multicolumn{2}{|c|}{5.547999999999999} & TRN \\
\hline CHEMBL1488538 & 688239 & 5.9862 & 5.6232 & TST & \\
\hline CHEMBL1300403 & 688239 & 6.0362 & 5.416 & TST & \\
\hline CHEMBL1313736 & 688239 & 6.8861 & \multicolumn{2}{|c|}{5.6339999999999995} & TRN \\
\hline CHEMBL1536441 & 688239 & 4.9362 & 5.5463 & TRN & \\
\hline CHEMBL1587891 & 688239 & 5.3362 & 5.4353 & TST & \\
\hline CHEMBL1322491 & 688239 & 6.1862 & 5.4654 & TRN & \\
\hline CHEMBL1600146 & 688239 & 4.6362 & 5.4806 & TRN & \\
\hline CHEMBL1455640 & 688239 & 5.1362 & \multicolumn{2}{|c|}{5.4110000000000005} & TRN \\
\hline CHEMBL1389258 & 688239 & 6.9363 & 5.4127 & TRN & \\
\hline CHEMBL 3193203 & 688239 & 4.7862 & 5.3601 & TRN & \\
\hline CHEMBL1557981 & 688239 & 5.9862 & 5.465 & TRN & \\
\hline CHEMBL1541177 & 688239 & 5.7862 & 5.3471 & TRN & \\
\hline CHEMBL1547166 & 688239 & 5.0362 & 5.5054 & TRN & \\
\hline CHEMBL1555711 & 688239 & 5.4362 & 5.4076 & TRN & \\
\hline CHEMBL1594720 & 688239 & 4.7362 & 5.3562 & TRN & \\
\hline CHEMBL1555994 & 688239 & 4.4862 & 5.6017 & TRN & \\
\hline CHEMBL1523700 & 688239 & 5.4862 & 5.3896 & TRN & \\
\hline CHEMBL1419174 & 688239 & 4.5362 & 5.5468 & TST & \\
\hline CHEMBL1311765 & 688239 & 5.7862 & 5.4457 & TRN & \\
\hline
\end{tabular}

Page 2142 
Supplemental Table S2.txt

\begin{tabular}{|c|c|c|c|c|}
\hline CHEMBL1332134 & 688239 & 4.7362 & 5.3269 & TST \\
\hline CHEMBL1549357 & 688239 & 6.5363 & 5.5175 & TRN \\
\hline CHEMBL1612467 & 688239 & 4.5362 & 5.3935 & TRN \\
\hline CHEMBL3190826 & 688239 & 5.3362 & 5.3311 & TRN \\
\hline CHEMBL1599084 & 688239 & 8.3372 & 5.5508 & TRN \\
\hline CHEMBL1516197 & 688239 & 6.1362 & 5.5127 & TRN \\
\hline CHEMBL1438500 & 688239 & 5.5362 & 5.5177 & TRN \\
\hline CHEMBL1331732 & 688239 & 4.5362 & 5.428999 & 9999999999 \\
\hline CHEMBL1359698 & 688239 & 5.1862 & 5.3539 & TST \\
\hline CHEMBL1464426 & 688239 & 6.1362 & 5.3966 & TRN \\
\hline CHEMBL1548577 & 688239 & 6.2362 & 5.4361 & TRN \\
\hline CHEMBL1563381 & 688239 & 4.8362 & 5.4786 & TRN \\
\hline CHEMBL1448343 & 688239 & 4.5862 & 5.3108 & TST \\
\hline CHEMBL1451435 & 688239 & 5.5862 & 5.5083 & TRN \\
\hline CHEMBL1473168 & 688239 & 4.7862 & 5.5389 & TST \\
\hline CHEMBL1401306 & 688239 & 5.4362 & 5.4443 & TRN \\
\hline CHEMBL1339594 & 688239 & 4.7362 & 5.2594 & TRN \\
\hline CHEMBL 3193131 & 688239 & 4.5362 & 5.5305 & TST \\
\hline CHEMBL1600793 & 688239 & 4.5362 & 5.4216 & TRN \\
\hline CHEMBL1333558 & 688239 & 4.5362 & 5.5026 & TST \\
\hline CHEMBL1427077 & 688239 & 8.3372 & 5.4922 & TST \\
\hline CHEMBL1444931 & 688239 & 6.8362 & 5.537006 & 3000000001 \\
\hline CHEMBL1570821 & 688239 & 4.5362 & 5.4954 & TRN \\
\hline CHEMBL1401585 & 688239 & 6.2362 & 5.5947 & TST \\
\hline CHEMBL1376055 & 688239 & 7.0862 & 5.5831 & TRN \\
\hline CHEMBL1492079 & 688239 & 5.4362 & 5.525 & TRN \\
\hline CHEMBL1389658 & 688239 & 6.5862 & 5.5578 & TRN \\
\hline CHEMBL1502065 & 688239 & 5.4362 & 5.3582 & TRN \\
\hline CHEMBL1387305 & 688239 & 6.1362 & 5.3523 & TST \\
\hline CHEMBL1383660 & 688239 & 4.9362 & 5.5604 & TST \\
\hline CHEMBL1442779 & 688239 & 5.5862 & 5.3537 & TST \\
\hline CHEMBL1413201 & 688239 & 7.1361 & 5.4647 & TRN \\
\hline CHEMBL1549766 & 688239 & 5.9362 & 5.5667 & TST \\
\hline CHEMBL1313508 & 688239 & 4.5862 & 5.409 & TRN \\
\hline CHEMBL1534260 & 688239 & 6.2362 & 5.3973 & TST \\
\hline CHEMBL1400224 & 688239 & 5.0362 & 5.5724 & TRN \\
\hline CHEMBL602763 & 688239 & 6.6362 & 5.3541 & TRN \\
\hline CHEMBL1426303 & 688239 & 5.9862 & 5.5987 & TST \\
\hline CHEMBL1367398 & 688239 & 6.9363 & 5.6502 & TRN \\
\hline CHEMBL1483888 & 688239 & 5.9862 & 5.4903 & TRN \\
\hline CHEMBL1558833 & 688239 & 5.5362 & 5.5432 & TRN \\
\hline CHEMBL1476156 & 688239 & 6.0862 & 5.3174 & TRN \\
\hline CHEMBL1466482 & 688239 & 4.6862 & 5.5077 & TRN \\
\hline CHEMBL1494471 & 688239 & 4.5362 & 5.4093 & TST \\
\hline CHEMBL1465198 & 688239 & 5.9362 & 5.4617 & TRN \\
\hline CHEMBL1447502 & 688239 & 4.5362 & 5.5363 & TRN \\
\hline CHEMBL1602749 & 688239 & 5.1362 & 5.5539 & TRN \\
\hline CHEMBL1377724 & 688239 & 5.6362 & 5.4543 & TRN \\
\hline
\end{tabular}


Supplemental Table S2.txt

\begin{tabular}{|c|c|c|c|c|c|}
\hline CHEMBL1596816 & 688239 & 5.1862 & 5.621 & TRN & \\
\hline CHEMBL1575371 & 688239 & 5.2362 & 5.5122 & TRN & \\
\hline CHEMBL1552087 & 688239 & 5.4862 & 5.4206 & TRN & \\
\hline CHEMBL1364298 & 688239 & 4.5362 & 5.5194 & TRN & \\
\hline CHEMBL1572160 & 688239 & 5.1862 & 5.5341 & TRN & \\
\hline CHEMBL1431992 & 688239 & 5.5862 & 5.5553 & TST & \\
\hline CHEMBL1493778 & 688239 & 6.1362 & 5.4762 & TRN & \\
\hline CHEMBL1473625 & 688239 & 5.3362 & 5.5928 & TRN & \\
\hline CHEMBL1438995 & 688239 & 6.8362 & 5.481 & TRN & \\
\hline CHEMBL1301495 & 688239 & 5.8362 & 5.3232 & TST & \\
\hline CHEMBL3214550 & 688239 & 4.5362 & 5.4367 & TRN & \\
\hline CHEMBL 2004157 & 688239 & 4.7862 & 5.2943 & TRN & \\
\hline CHEMBL1437538 & 688239 & 4.7362 & 5.5697 & TRN & \\
\hline CHEMBL1377324 & 688239 & 6.4862 & 5.4708 & TRN & \\
\hline CHEMBL1563809 & 688239 & 4.7862 & 5.4697 & TRN & \\
\hline CHEMBL1513423 & 688239 & 5.4362 & 5.4146 & TRN & \\
\hline CHEMBL1345096 & 688239 & 4.5362 & 5.3189 & TRN & \\
\hline CHEMBL1378179 & 688239 & 5.6362 & 5.56 & TST & \\
\hline CHEMBL1582176 & 688239 & 4.7362 & 5.2834 & TRN & \\
\hline CHEMBL1606680 & 688239 & 5.6862 & 5.4459 & TRN & \\
\hline CHEMBL1453779 & 688239 & 4.7362 & 5.391 & TRN & \\
\hline CHEMBL1363514 & 688239 & 4.6862 & 5.3499 & TRN & \\
\hline CHEMBL1590916 & 688239 & 6.0862 & 5.438 & TST & \\
\hline CHEMBL1333271 & 688239 & 4.9862 & 5.3853 & TST & \\
\hline CHEMBL1340437 & 688239 & 4.7362 & 5.3628 & TST & \\
\hline CHEMBL1354676 & 688239 & 5.2862 & 5.3905 & TST & \\
\hline CHEMBL1386073 & 688239 & 5.1862 & 5.5358 & TRN & \\
\hline CHEMBL1492714 & 688239 & 5.3362 & 5.6068 & TRN & \\
\hline CHEMBL1456304 & 688239 & 5.5862 & 5.3381 & TRN & \\
\hline CHEMBL1530083 & 688239 & 5.3862 & 5.3168 & TRN & \\
\hline CHEMBL1481493 & 688239 & 6.0862 & 5.4756 & TRN & \\
\hline CHEMBL1508928 & 688239 & 5.1862 & 5.4968 & TRN & \\
\hline CHEMBL1306569 & 688239 & 4.6862 & 5.3578 & TRN & \\
\hline CHEMBL1444678 & 688239 & 6.2362 & 5.4825 & TRN & \\
\hline CHEMBL1410601 & 688239 & 5.3862 & \multicolumn{2}{|c|}{5.486000000000001} & TRN \\
\hline CHEMBL1404334 & 688239 & 4.7362 & 5.4532 & TRN & \\
\hline CHEMBL1555735 & 688239 & 4.7862 & 5.6256 & TRN & \\
\hline CHEMBL1333815 & 688239 & 6.1862 & 5.5661 & TRN & \\
\hline CHEMBL3208833 & 688239 & 4.6362 & 5.5439 & TRN & \\
\hline CHEMBL1510278 & 688239 & 6.5363 & 5.4875 & TRN & \\
\hline CHEMBL1603265 & 688239 & 4.5362 & 5.5078 & TRN & \\
\hline CHEMBL1349671 & 688239 & 4.7862 & 5.4155 & TRN & \\
\hline CHEMBL1553857 & 688239 & 5.0862 & 5.5958 & TRN & \\
\hline CHEMBL1341468 & 688239 & 4.5362 & 5.4551 & TRN & \\
\hline CHEMBL1429906 & 688239 & 7.0362 & 5.4787 & TRN & \\
\hline CHEMBL1351669 & 688239 & 4.7862 & 5.506 & TRN & \\
\hline CHEMBL1508290 & 688239 & 4.6362 & 5.5515 & TRN & \\
\hline CHEMBL1353172 & 688239 & 5.9862 & 5.5277 & TRN & \\
\hline
\end{tabular}


Supplemental Table S2.txt

CHEMBL1478285
CHEMBL1525971
CHEMBL1387499
CHEMBL1463283
CHEMBL1370098
CHEMBL1340636
CHEMBL1382136
CHEMBL1496231

$\begin{array}{rrll}688239 & 4.5362 & 5.5565 & \text { TRN } \\ 688239 & 4.5362 & 5.5989 & \text { TRN } \\ 688239 & 4.5862 & 5.6067 & \text { TRN } \\ 688239 & 4.5362 & 5.452999999999999 \\ 688239 & 4.4862 & 5.5489 & \text { TST } \\ 688239 & 8.2366 & 5.5888 & \text { TRN } \\ 688239 & 4.5362 & 5.5993 & \text { TRN } \\ 688239 & 4.7862 & 5.5119 & \text { TST } \\ 688239 & 5.5862 & 5.4047 & \text { TST } \\ 688239 & 4.5362 & 5.3629 & \text { TRN } \\ 688239 & 5.6862 & 5.4931 & \text { TST } \\ 688239 & 5.5362 & 5.5913 & \text { TRN } \\ 688239 & 8.3372 & 5.5559 & \text { TRN } \\ 688239 & 5.4862 & 5.6046 & \text { TRN } \\ 688239 & 6.9863 & 5.4426 & \text { TRN } \\ 688239 & 4.5362 & 5.3483 & \text { TRN } \\ 688239 & 8.3372 & 5.5249 & \text { TRN } \\ 688239 & 4.9362 & 5.4214 & \text { TRN } \\ 688239 & 6.9363 & 5.4507 & \text { TRN } \\ 688239 & 6.9363 & 5.4288 & \text { TRN } \\ 688239 & 5.0862 & 5.4424 & \text { TRN } \\ 688239 & 4.5862 & 5.5392 & \text { TRN } \\ 688239 & 4.8362 & 5.5176 & \text { TRN } \\ 688239 & 7.5867 & 5.5496 & \text { TRN } \\ 688239 & 6.6362 & 5.4577 & \text { TRN } \\ 688239 & 6.2362 & 5.5339 & \text { TRN } \\ 688239 & 6.4862 & 5.5118 & \text { TRN } \\ 688239 & 4.7362 & 5.436 & \text { TRN } \\ 688239 & 6.5363 & 5.4057 & \text { TST } \\ 688239 & 5.0362 & 5.3602 & \text { TRN } \\ 688239 & 6.2362 & 5.4088 & \text { TRN } \\ 688239 & 5.1862 & 5.4516 & \text { TST } \\ 688239 & 6.8362 & 5.5243 & \text { TRN } \\ 688239 & 4.9362 & 5.4448 & \text { TRN } \\ 688239 & 5.6362 & 5.5466 & \text { TRN } \\ 688239 & 4.7862 & 5.3179 & \text { TST } \\ 688239 & 6.1362 & 5.4029 & \text { TRN } \\ 688239 & 5.2862 & 5.685 & \text { TRN } \\ 688239 & 5.6862 & 5.5546 & \text { TRN } \\ 688239 & 5.2362 & 5.4651 & \text { TST } \\ 688239 & 4.5362 & 5.4893 & \text { TST } \\ 688239 & 5.4362 & 5.5238 & \text { TRN } \\ 688239 & 4.4862 & 5.3459 & \text { TRN } \\ 688239 & 4.4862 & 5.6457 & \text { TRN } \\ 688239 & 4.7362 & 5.4552 & \text { TRN } \\ 688239 & 5.6862 & 5.3061 & \text { TRN } \\ 688239 & 4.5362 & 5.4526 & \text { TRN } \\ & 4.5862 & 5.5092 & \text { TRN } \\ & & & \text { Page } 2145 \\ 6 & & & \end{array}$


Supplemental Table S2.txt

\begin{tabular}{|c|c|c|c|c|c|}
\hline CHEMBL1384647 & 688239 & 5.5862 & 5.4555 & TST & \\
\hline CHEMBL1466593 & 688239 & 4.6362 & 5.4687 & TST & \\
\hline CHEMBL1546930 & 688239 & 4.5862 & 5.4995 & TRN & \\
\hline CHEMBL1465122 & 688239 & 6.4362 & 5.4722 & TST & \\
\hline CHEMBL1492192 & 688239 & 5.4862 & 5.4996 & TST & \\
\hline CHEMBL1478343 & 688239 & 6.6861 & 5.545 & TST & \\
\hline CHEMBL1464209 & 688239 & 5.1862 & 5.5902 & TRN & \\
\hline CHEMBL1555923 & 688239 & 6.3863 & 5.4481 & TRN & \\
\hline CHEMBL1394363 & 688239 & 4.7362 & 5.4537 & TRN & \\
\hline CHEMBL1461596 & 688239 & 6.3362 & 5.6169 & TRN & \\
\hline CHEMBL1314818 & 688239 & 4.5362 & 5.3875 & TRN & \\
\hline CHEMBL1330481 & 688239 & 8.3372 & 5.5452 & TRN & \\
\hline CHEMBL1382279 & 688239 & 4.6362 & 5.3305 & TST & \\
\hline CHEMBL1311083 & 688239 & 6.5862 & 5.4891 & TRN & \\
\hline CHEMBL1500699 & 688239 & 5.8862 & \multicolumn{2}{|c|}{5.4510000000000005} & TRN \\
\hline CHEMBL1444107 & 688239 & 6.9363 & 5.5536 & TST & \\
\hline CHEMBL1442237 & 688239 & 4.5362 & 5.3998 & TST & \\
\hline CHEMBL1570093 & 688239 & 5.3362 & 5.4722 & TRN & \\
\hline CHEMBL1459252 & 688239 & 4.9362 & 5.6627 & TRN & \\
\hline CHEMBL1393077 & 688239 & 5.5862 & 5.6194 & TST & \\
\hline CHEMBL1535004 & 688239 & 5.3362 & 5.5 & TRN & \\
\hline CHEMBL1522043 & 688239 & 5.4362 & 5.5321 & TST & \\
\hline CHEMBL1570510 & 688239 & 5.1362 & 5.4322 & TRN & \\
\hline CHEMBL1336763 & 688239 & 5.6862 & 5.4636 & TRN & \\
\hline CHEMBL1494578 & 688239 & 4.5862 & 5.5495 & TRN & \\
\hline CHEMBL1367414 & 688239 & 4.6862 & 5.5001 & TRN & \\
\hline CHEMBL1601931 & 688239 & 4.7362 & 5.5278 & TRN & \\
\hline CHEMBL1560456 & 688239 & 5.6362 & 5.6355 & TRN & \\
\hline CHEMBL1404235 & 688239 & 5.6362 & 5.527 & TRN & \\
\hline CHEMBL1421929 & 688239 & 4.5362 & 5.5109 & TRN & \\
\hline CHEMBL1412273 & 688239 & 5.1362 & 5.4772 & TRN & \\
\hline CHEMBL1591044 & 688239 & 6.8861 & 5.5252 & TRN & \\
\hline CHEMBL1534965 & 688239 & 5.1862 & 5.421 & TRN & \\
\hline CHEMBL3184145 & 688239 & 6.2862 & 5.4224 & TRN & \\
\hline CHEMBL 3198254 & 688239 & 4.9362 & 5.5202 & TRN & \\
\hline CHEMBL1374368 & 688239 & 6.2362 & 5.5183 & TST & \\
\hline CHEMBL1431020 & 688239 & 6.8362 & 5.5648 & TRN & \\
\hline CHEMBL1531320 & 688239 & 5.2362 & 5.5009 & TRN & \\
\hline CHEMBL1394270 & 688239 & 5.2862 & 5.2981 & TRN & \\
\hline CHEMBL1537287 & 688239 & 4.5362 & 5.3969 & TST & \\
\hline CHEMBL1470016 & 688239 & 6.2862 & \multicolumn{2}{|c|}{5.321000000000001} & TRN \\
\hline CHEMBL1551406 & 688239 & 5.1362 & 5.3966 & TRN & \\
\hline CHEMBL1392654 & 688239 & 7.0862 & 5.4556 & TRN & \\
\hline CHEMBL1364826 & 688239 & 7.1361 & 5.5849 & TRN & \\
\hline CHEMBL1575323 & 688239 & 4.5362 & 5.4501 & TST & \\
\hline CHEMBL1579910 & 688239 & 6.1362 & 5.5226 & TRN & \\
\hline CHEMBL1469709 & 688239 & 4.5362 & 5.4329 & TRN & \\
\hline CHEMBL1307929 & 688239 & 7.0862 & 5.6408 & TST & \\
\hline
\end{tabular}




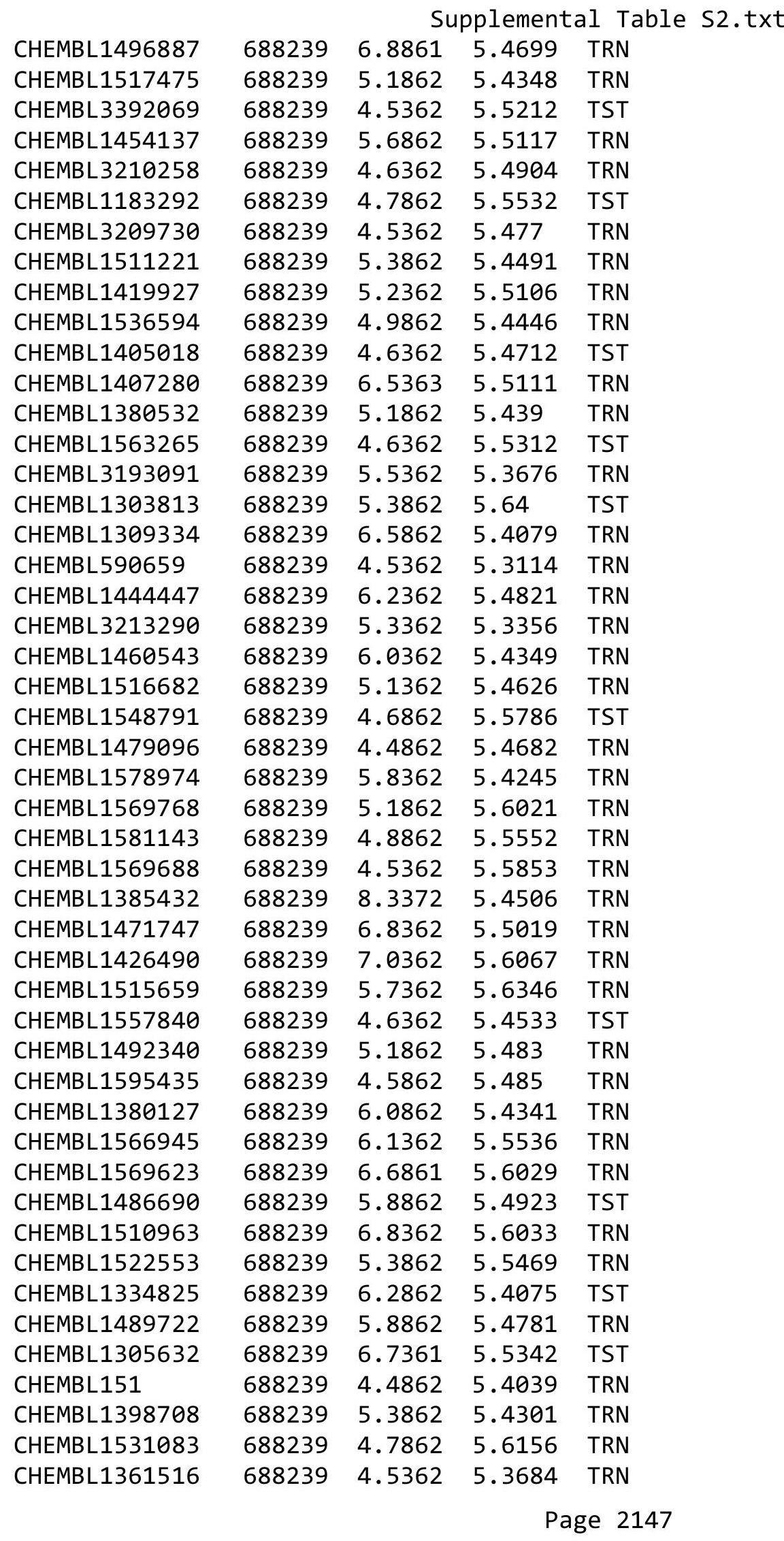


Supplemental Table S2.txt

\begin{tabular}{|c|c|c|c|c|}
\hline CHEMBL1583695 & 688239 & 4.6862 & 5.6107 & TRN \\
\hline CHEMBL1439741 & 688239 & 6.1362 & 5.5496 & TRN \\
\hline CHEMBL1555598 & 688239 & 4.8362 & 5.4433 & TRN \\
\hline CHEMBL1511354 & 688239 & 5.1862 & 5.5347 & TRN \\
\hline CHEMBL1375000 & 688239 & 4.6862 & 5.5158 & TRN \\
\hline CHEMBL1312624 & 688239 & 5.6862 & 5.4662 & TRN \\
\hline CHEMBL1548547 & 688239 & 4.5362 & 5.4264 & TRN \\
\hline CHEMBL1570941 & 688239 & 5.2862 & 5.5289 & TRN \\
\hline CHEMBL1497153 & 688239 & 4.5362 & 5.268 & TST \\
\hline CHEMBL1360195 & 688239 & 5.2862 & 5.4689 & TRN \\
\hline CHEMBL1382645 & 688239 & 4.5362 & 5.5412 & TST \\
\hline CHEMBL1321423 & 688239 & 6.8861 & 5.4746 & TRN \\
\hline CHEMBL1443550 & 688239 & 5.1862 & 5.5702 & TST \\
\hline CHEMBL1369916 & 688239 & 5.5362 & 5.3251 & TRN \\
\hline CHEMBL1612398 & 688239 & 4.7362 & 5.4102 & TST \\
\hline CHEMBL1451572 & 688239 & 6.2362 & 5.5039 & TRN \\
\hline CHEMBL1541873 & 688239 & 8.3372 & 5.3856 & TRN \\
\hline CHEMBL1608308 & 688239 & 5.5362 & 5.473 & TST \\
\hline CHEMBL1449590 & 688239 & 5.8362 & 5.4617 & TRN \\
\hline CHEMBL1440508 & 688239 & 5.4862 & 5.5409 & TRN \\
\hline CHEMBL1420734 & 688239 & 4.7862 & 5.5698 & TST \\
\hline CHEMBL1569884 & 688239 & 5.1362 & 5.5322 & TRN \\
\hline CHEMBL1506760 & 688239 & 4.5362 & 5.3649 & TST \\
\hline CHEMBL1549338 & 688239 & 4.9362 & 5.2816 & TRN \\
\hline CHEMBL1588041 & 688239 & 5.3362 & 5.581 & TRN \\
\hline CHEMBL1312929 & 688239 & 6.2862 & 5.5374 & TST \\
\hline CHEMBL1373690 & 688239 & 4.7362 & 5.5271 & TRN \\
\hline CHEMBL1517230 & 688239 & 7.1864 & 5.572999 & 99999999995 \\
\hline CHEMBL1417200 & 688239 & 4.8362 & 5.5528 & TRN \\
\hline CHEMBL1354723 & 688239 & 4.7862 & 5.4831 & TRN \\
\hline CHEMBL1496498 & 688239 & 4.5362 & 5.407 & TST \\
\hline CHEMBL1458613 & 688239 & 6.1362 & 5.4822 & TRN \\
\hline CHEMBL1606386 & 688239 & 4.5362 & 5.3537 & TRN \\
\hline CHEMBL1362787 & 688239 & 6.9863 & 5.4013 & TRN \\
\hline CHEMBL1460646 & 688239 & 4.5362 & 5.4319 & TRN \\
\hline CHEMBL1569907 & 688239 & 4.5362 & 5.5752 & TRN \\
\hline CHEMBL1363085 & 688239 & 7.3862 & 5.463999 & 99999999995 \\
\hline CHEMBL1338926 & 688239 & 4.6862 & 5.5999 & TRN \\
\hline CHEMBL1553630 & 688239 & 6.8362 & 5.4245 & TRN \\
\hline CHEMBL1371456 & 688239 & 5.4362 & 5.3897 & TST \\
\hline CHEMBL1324451 & 688239 & 4.5362 & 5.5098 & TRN \\
\hline CHEMBL1378968 & 688239 & 5.3862 & 5.5867 & TRN \\
\hline CHEMBL1328120 & 688239 & 4.5862 & 5.3422 & TRN \\
\hline CHEMBL1530563 & 688239 & 4.5362 & 5.6609 & TRN \\
\hline CHEMBL1517729 & 688239 & 6.8861 & 5.3659 & TST \\
\hline CHEMBL1578945 & 688239 & 4.7362 & 5.5043 & TRN \\
\hline CHEMBL1323065 & 688239 & 4.9862 & 5.4743 & TRN \\
\hline CHEMBL1503951 & 688239 & 5.3862 & 5.5458 & TST \\
\hline
\end{tabular}


Supplemental Table S2.txt

\begin{tabular}{|c|c|c|c|c|}
\hline- & & & 3.445 & \\
\hline HEMBL1597864 & 88239 & 6862 & 5.4581 & \\
\hline & & & & \\
\hline 17 & 39 & & & \\
\hline IEMBL1526108 & 38239 & 362 & 5566 & \\
\hline AEMBL1356906 & 88239 & 2862 & 4895 & \\
\hline AEMBL1603174 & 88239 & 865 & 5404 & \\
\hline 269 & & 862 & 041 & \\
\hline IEMBL1581334 & 88239 & 362 & .5835 & \\
\hline AEMBL1331733 & 88239 & 862 & 4886 & \\
\hline AEMBL1450265 & 88239 & 5862 & 4826 & \\
\hline IEMBL1339153 & 88239 & 362 & 054 & \\
\hline 99 & & & & \\
\hline AEMBL15 & 88239 & & 607 & \\
\hline IEMBL1421192 & 88239 & 362 & 2917 & \\
\hline IEMBL1 & 88239 & 362 & 11 & \\
\hline AEMBL13 & 8239 & 862 & 539 & \\
\hline HEMBL14 & 8239 & 62 & & RN \\
\hline 129 & 39 & 362 & 148 & \\
\hline IEMBL14 & 39 & 862 & 16 & זות \\
\hline AEIMBLL 15 & 39 & 61 & 729 & ISt a r a \\
\hline AEMBL14 & 8239 & 62 & 23 & $\mathrm{RN}$ \\
\hline 96 & 239 & & & \\
\hline 208 & & & & \\
\hline IEMBL14 & 39 & 52 & 43 & RIN \\
\hline 5555 & 39 & 62 & 43 & RN \\
\hline 697 & 239 & 62 & 97 & RN \\
\hline 24 & & & & \\
\hline 595 & & & & TST \\
\hline AEMBL1527599 & 39 & 62 & 672 & RN \\
\hline IEMBL1587761 & 39 & 862 & 832 & ST \\
\hline 45 & 39 & 52 & 26 & ST \\
\hline & & & & $2 \mathrm{~N}$ \\
\hline AEMBL1596 & & & & I \\
\hline AEMBL1356751 & 88 & 61 & 237 & IST \\
\hline IEMBL12 & 39 & 62 & 32 & RN \\
\hline 52 & & & & ST \\
\hline & & & & IRN \\
\hline HEMBL1483192 & 88239 & 862 & 697 & TRN \\
\hline IEMBL31 & 39 & 862 & 147 & RN \\
\hline HEMBL1503624 & 39 & 362 & .5994 & RN \\
\hline HEMBL1520639 & & & & \\
\hline HEMBL172 & & 862 & 5.2897 & IST \\
\hline IEMBL1446430 & 88239 & 362 & 5.4904 & TST \\
\hline EMBL15 & & & 5296 & ГRN \\
\hline HEMBL132 & 588239 & 362 & .5055 & \\
\hline לידגו & 88239 & 362 & 5.5764 & \\
\hline HEMBL154499 & 688239 & 6.4862 & 5.4949 & ГRN \\
\hline
\end{tabular}

Page 2149 
Supplemental Table S2.txt

\begin{tabular}{|c|c|c|c|c|}
\hline 7 & & 52 & & \\
\hline HEMBL1469767 & & .1871 & & \\
\hline ICMPI 1 & & & & \\
\hline AEMBL1 & & & & \\
\hline AEMBL1477635 & 8239 & 862 & & \\
\hline HEMBL3190090 & 88239 & 1862 & 4694 & \\
\hline HEMBL1407980 & 239 & 62 & & \\
\hline IFMBI 1316138 & & & & \\
\hline AEMBL1563221 & & 3872 & 1061 & \\
\hline HEMBL1448269 & 38239 & 862 & 5339 & \\
\hline HEMBL3191242 & 39 & 862 & 621 & \\
\hline IEMBL1; & 39 & 62 & 856 & \\
\hline IEMBL1 & & & & \\
\hline AEMBL1486506 & & 362 & 824 & \\
\hline AEMBL3212246 & & & 507 & \\
\hline AEMBL3194952 & 39 & 62 & 575 & \\
\hline AEMBL13 & & & & \\
\hline HEMBL19 & & & & \\
\hline AEMBL1591236 & & & 501 & \\
\hline AEMBL1372 & & & & \\
\hline EMB & & & 24 & \\
\hline AEMBL] & & & & \\
\hline AEMBL14 & & & & \\
\hline 605 & & & 116 & \\
\hline IEMBL14 & & & & I RIV \\
\hline HEMBL1C & & 52 & 111 & \\
\hline HEMBL1 & & & & \\
\hline HFMBI 1 & & 62 & 382 & RN \\
\hline HEMBL1333200 & & & & 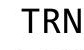 \\
\hline HEMBL13427 & & & & I RIV \\
\hline HEMBL153 & & & 875 & RN \\
\hline AFMB I & & & & RN \\
\hline 47 & & & & RN \\
\hline HEMBL1496375 & & & & IR \\
\hline HEMBL1321160 & & 65 & 668 & TST \\
\hline HEMBL13 & & 52 & 299 & RN \\
\hline 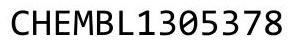 & & & & $\Gamma \mathrm{RN}$ \\
\hline HEMBL1: & & & & RN \\
\hline HEMBL1345296 & & & 5.6148 & TRN \\
\hline IEMBL13 & & 62 & .5544 & ST \\
\hline HEMBL14 & & 62 & .5903 & \\
\hline HEMBL14 & & & & RN \\
\hline HEMBL1450856 & & 362 & 5.4853 & RN \\
\hline AEMBL1542185 & 39 & 862 & 758 & TST \\
\hline MBL1 & & & 848 & \\
\hline CHEMBL150719 & & & 5.5714 & \\
\hline CHEMBL565759 & & & 5.4128 & \\
\hline HEMBL158227 & 688239 & 4.5862 & 5.5243 & ГRN \\
\hline
\end{tabular}

Page 2150 
Supplemental Table S2.txt

\begin{tabular}{|c|c|c|c|c|}
\hline 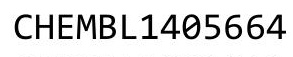 & & & & \\
\hline HEMBL1991311 & 38239 & 362 & & \\
\hline AEMBL1394002 & 239 & 362 & & \\
\hline 696 & 39 & & & \\
\hline AEMBL15c & 39 & 862 & & \\
\hline AEMBL1388880 & 88239 & 362 & & \\
\hline AEMBL1320979 & 88239 & 362 & 5175 & \\
\hline AEMBL1543410 & & 862 & & \\
\hline IEMBL153 & 39 & 362 & & \\
\hline AEMBL142 & & 362 & & \\
\hline AEMBL1368048 & 239 & 363 & & \\
\hline AEMBL1508378 & 39 & 862 & & \\
\hline AEMBL1574580 & & 62 & & \\
\hline HEMBL153 & & 62 & & \\
\hline JEMBL154 & & & & \\
\hline AEMBL1313527 & & 363 & & \\
\hline AEMBL1567466 & & 362 & & \\
\hline AEMBL16e & & 62 & & \\
\hline AEMBL15 & & & & \\
\hline HEMBL31 & & & & \\
\hline HEMBL132 & & 362 & & \\
\hline HEMBL139 & & 65 & & \\
\hline HEMBL14 & & & & \\
\hline AEMBL 15 & & & & \\
\hline 332 & & 66 & & \\
\hline 1 & & 862 & & \\
\hline IEMBL1383379 & & & & \\
\hline HEMBL15 & & 62 & & \\
\hline AFMRI 14 & & 52 & & \\
\hline 789 & & 62 & & \\
\hline AEMBL1373252 & & & & \\
\hline HEMBL1487686 & & 862 & & \\
\hline & & & & \\
\hline 8 & & & & \\
\hline HEMBL146 & & & & RN \\
\hline AEMBL1447281 & & & & \\
\hline AEMBL1406908 & & 362 & & \\
\hline & & & & \\
\hline 46 & & & & \\
\hline HEMBL1480621 & & & & RN \\
\hline AEMBL1485408 & & 63 & & \\
\hline HEMBL1491 & & 62 & & \\
\hline HEMBL 320 & & & & \\
\hline CHEMBL140 & & & & \\
\hline AEMBL1547161 & & & & RN \\
\hline IEMBL1324290 & & 862 & 78 & TS \\
\hline & & & & \\
\hline $127+2$ & & & & \\
\hline
\end{tabular}

Page 2151 
Supplemental Table S2.txt

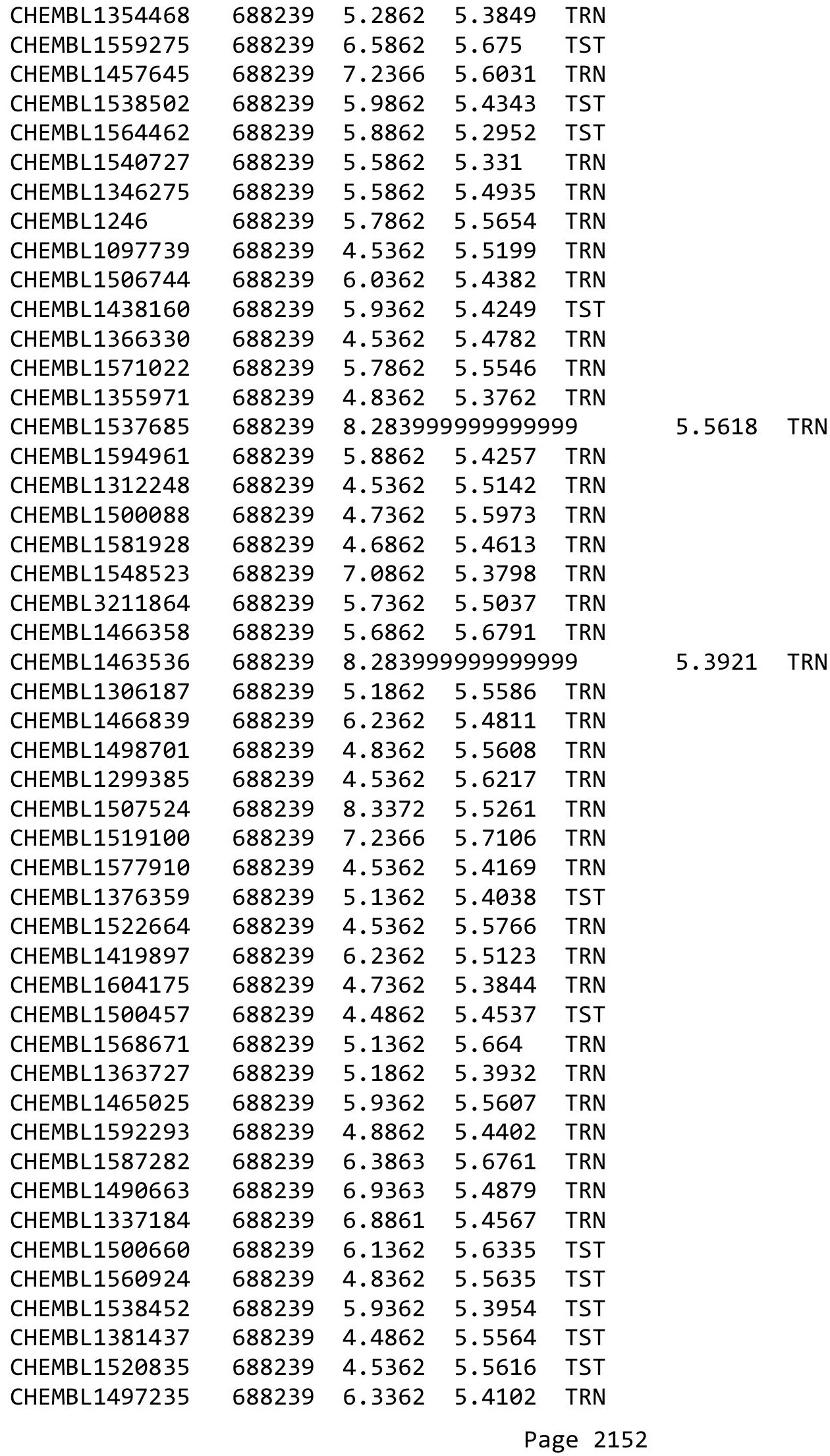


Supplemental Table S2.txt

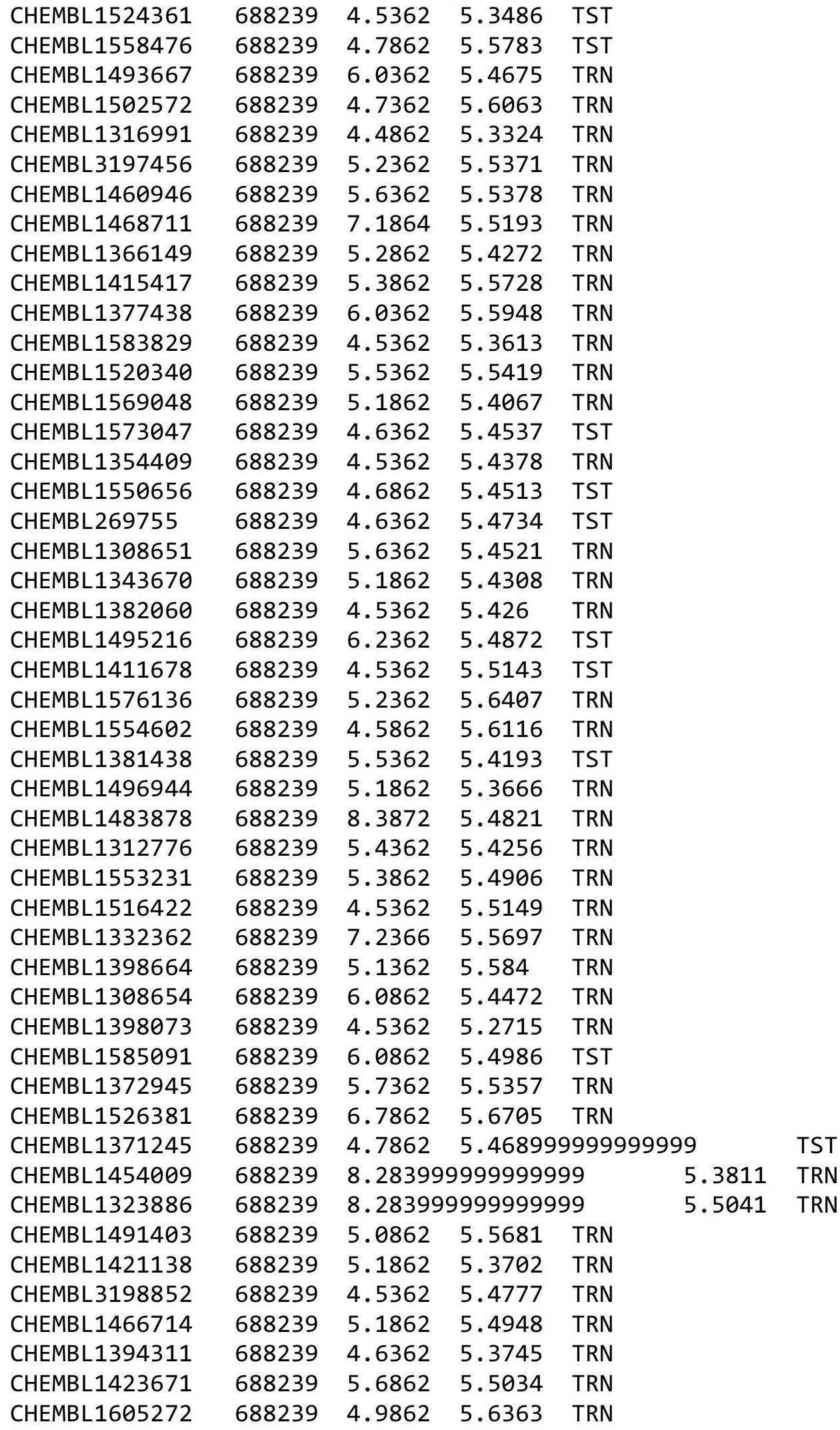

Page 2153 
Supplemental Table S2.txt

\begin{tabular}{|c|c|c|c|c|}
\hline CHEMBL1308559 & 688239 & 6.0362 & 5.4631 & TRN \\
\hline CHEMBL1339266 & 688239 & 6.0362 & 5.544 & TRN \\
\hline CHEMBL1363973 & 688239 & 5.7862 & 5.4249 & TRN \\
\hline CHEMBL1790007 & 688239 & 6.4862 & 5.4308 & TST \\
\hline CHEMBL1431735 & 688239 & 4.5362 & 5.5277 & TRN \\
\hline CHEMBL1504843 & 688239 & 6.1862 & 5.4899 & TRN \\
\hline CHEMBL1556167 & 688239 & 5.3862 & 5.5102 & TRN \\
\hline CHEMBL1317609 & 688239 & 5.1862 & 5.5031 & TRN \\
\hline CHEMBL3192372 & 688239 & 4.4862 & 5.2771 & TRN \\
\hline CHEMBL1545727 & 688239 & 5.3862 & 5.5002 & TRN \\
\hline CHEMBL1565876 & 688239 & 6.1362 & 5.567 & TRN \\
\hline CHEMBL592869 & 688239 & 4.5362 & 5.5134 & TRN \\
\hline CHEMBL1470559 & 688239 & 4.5362 & 5.5522 & TRN \\
\hline CHEMBL1333757 & 688239 & 6.1362 & 5.4694 & TRN \\
\hline CHEMBL1424641 & 688239 & 5.1862 & 5.5177 & TST \\
\hline CHEMBL1482188 & 688239 & 4.8362 & 5.6522 & TST \\
\hline CHEMBL1458948 & 688239 & 5.1862 & 5.6199 & TRN \\
\hline CHEMBL1434936 & 688239 & 5.0362 & 5.4746 & TRN \\
\hline CHEMBL1476720 & 688239 & 5.6362 & 5.5569 & TRN \\
\hline CHEMBL1606051 & 688239 & 5.1862 & 5.5421 & TRN \\
\hline CHEMBL1569238 & 688239 & 4.8862 & 5.26 & TST \\
\hline CHEMBL1440883 & 688239 & 6.3863 & 5.5496 & TRN \\
\hline CHEMBL1587028 & 688239 & 5.5862 & 5.3993 & TRN \\
\hline CHEMBL1489042 & 688239 & 4.7362 & 5.3011 & TRN \\
\hline CHEMBL1613684 & 688239 & 4.6862 & 5.3976 & TST \\
\hline CHEMBL1424897 & 688239 & 5.6362 & 5.58899 & 99999999995 \\
\hline CHEMBL1607404 & 688239 & 5.8862 & 5.5604 & TRN \\
\hline CHEMBL1399454 & 688239 & 6.5862 & 5.5577 & TRN \\
\hline CHEMBL1504035 & 688239 & 5.1862 & 5.5513 & TRN \\
\hline CHEMBL1384014 & 688239 & 6.9863 & 5.5697 & TRN \\
\hline CHEMBL1304573 & 688239 & 7.0362 & 5.401 & TRN \\
\hline CHEMBL3199761 & 688239 & 8.1871 & 5.3635 & TRN \\
\hline CHEMBL1541686 & 688239 & 4.5862 & 5.40799 & 79999999995 \\
\hline CHEMBL 3195343 & 688239 & 6.1862 & 5.2147 & TST \\
\hline CHEMBL1388007 & 688239 & 7.2865 & 5.3684 & TRN \\
\hline CHEMBL1375088 & 688239 & 6.6861 & 5.54299 & 9999999999 \\
\hline CHEMBL1605434 & 688239 & 5.6362 & 5.4918 & TRN \\
\hline CHEMBL1393988 & 688239 & 6.9363 & 5.4397 & TRN \\
\hline CHEMBL1546099 & 688239 & 4.5362 & 5.6315 & TRN \\
\hline CHEMBL1471181 & 688239 & 4.5362 & 5.4171 & TRN \\
\hline CHEMBL1402325 & 688239 & 4.5362 & 5.4453 & TRN \\
\hline CHEMBL1511810 & 688239 & 4.6362 & 5.4558 & TRN \\
\hline CHEMBL1484622 & 688239 & 4.7862 & 5.4545 & TRN \\
\hline CHEMBL1574705 & 688239 & 4.5862 & 5.3911 & TRN \\
\hline CHEMBL1330010 & 688239 & 6.4862 & 5.7515 & TRN \\
\hline CHEMBL1584452 & 688239 & 6.2862 & 5.4873 & TST \\
\hline CHEMBL1541887 & 688239 & 4.5862 & 5.61600 & 30000000005 \\
\hline CHEMBL1502342 & 688239 & 4.5862 & 5.2906 & TRN \\
\hline
\end{tabular}


Supplemental Table S2.txt

\begin{tabular}{|c|c|c|c|c|}
\hline & & & & \\
\hline JEMBL13 & 38239 & 6862 & & \\
\hline IEMBL1313448 & 8239 & 862 & & \\
\hline HEMBL1366587 & 239 & 362 & 18 & \\
\hline & 239 & 862 & & \\
\hline IFMRI 14 & 239 & 862 & & \\
\hline AEMBL1420905 & 88239 & 362 & 209 & \\
\hline AEMBL1593662 & 88239 & 362 & 86 & \\
\hline AEMBL1350722 & 239 & 864 & & \\
\hline IEMBL135 & 39 & 362 & & \\
\hline IEMBL474063 & & & & \\
\hline AEMBL1613695 & 688239 & 862 & 5581 & \\
\hline AEMBL1500577 & 239 & 862 & & $\mathrm{RI}$ \\
\hline IEMBL1307269 & & 862 & 33 & \\
\hline IEMBL154 & & 362 & & \\
\hline AEMBL1481246 & & & & \\
\hline AEMBL1467249 & 239 & 362 & & RN \\
\hline AEMBL1391120 & & 362 & & \\
\hline IEMBL15 & & 62 & & \\
\hline IEMBL16 & & & & \\
\hline AFMRI 140 & & 62 & & \\
\hline AEMBL1604988 & & 362 & & RN \\
\hline AEMBL156 & & 363 & & ST \\
\hline EMBL13 & & 62 & & \\
\hline IEMBL13 & & & & $\mathrm{RN}$ \\
\hline IFMDI 11 & & 62 & & ונה \\
\hline JEMBL141 & & 362 & & ST \\
\hline AEMBL1488642 & & & & \\
\hline AEMBL1524767 & & & & RI \\
\hline 253 & & 62 & & 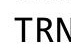 \\
\hline 571 & & 62 & & . \\
\hline AEMBL1517011 & & & & $\mathrm{RN}$ \\
\hline AEMBL1481845 & & & & ST \\
\hline AEMBL136 & & & 72 & RI \\
\hline HEMBL14 & & 52 & 36 & . \\
\hline & & & 97 & ST \\
\hline AEMBL1567187 & & & 169 & $\mathrm{R}$ \\
\hline AEMBL1400454 & & & & $\mathrm{K}$ \\
\hline IEMBL147 & & & & $S$ \\
\hline 274 & & & & \\
\hline HEMBL 130 & & & & RN \\
\hline AEMBL1568022 & & 862 & 18 & RI \\
\hline AEMBL146 & & & & $\mathrm{R}$ \\
\hline EMBL13: & & & & \\
\hline CHEMBL141 & & & & \\
\hline CHEMBL137 & & 862 & & RN \\
\hline AEMBL1468349 & 88239 & 4.6862 & 5.5977 & TS \\
\hline HFMBI 1532061 & 688239 & 4.5362 & 5.4633 & \\
\hline
\end{tabular}

Page 2155 
Supplemental Table S2.txt

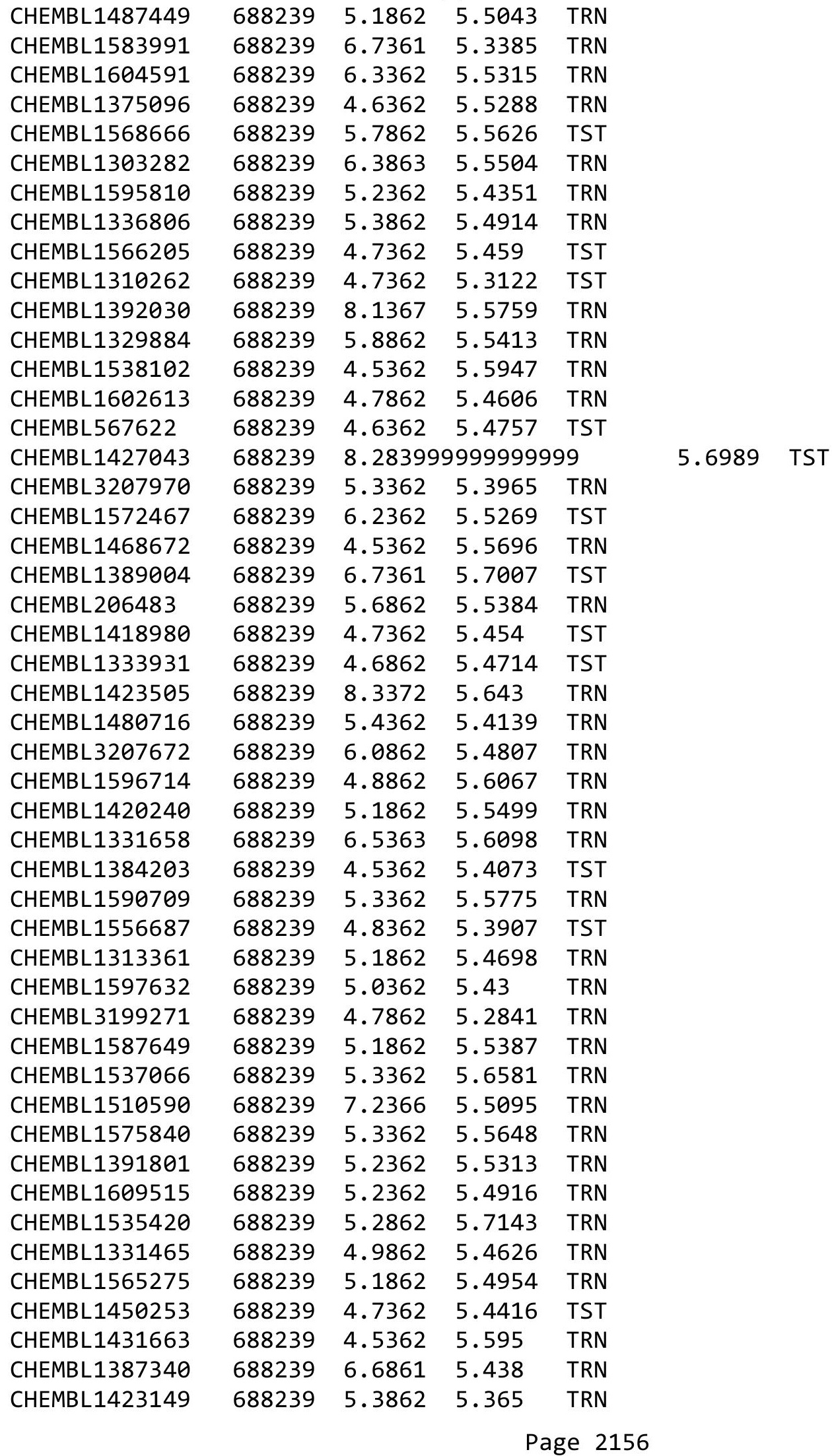




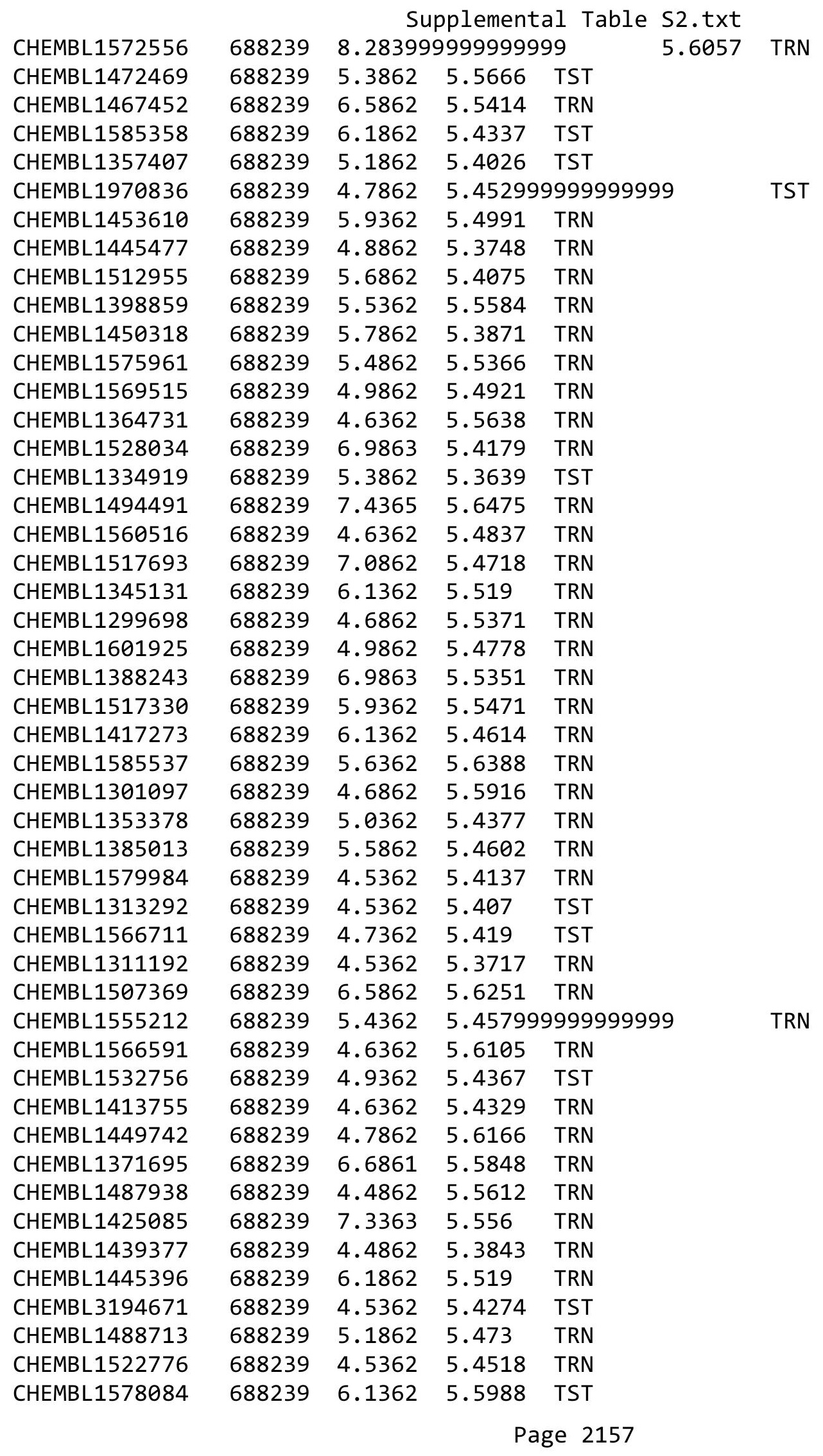


Supplemental Table S2.txt

\begin{tabular}{|c|c|c|c|c|c|}
\hline CHEMBL1529762 & 688239 & 4.5862 & 5.6122 & TST & \\
\hline CHEMBL1468320 & 688239 & 4.5362 & 5.5771 & TRN & \\
\hline CHEMBL3207337 & 688239 & 6.1362 & 5.6207 & TRN & \\
\hline CHEMBL1408967 & 688239 & 6.5862 & 5.359 & TST & \\
\hline CHEMBL581251 & 688239 & 5.6362 & 5.3563 & TST & \\
\hline CHEMBL1438408 & 688239 & 4.5362 & 5.4441 & TRN & \\
\hline CHEMBL1475809 & 688239 & 4.6862 & 5.4668 & TRN & \\
\hline CHEMBL1575899 & 688239 & 4.5862 & 5.5643 & TRN & \\
\hline CHEMBL3198847 & 688239 & 4.8362 & 5.4133 & TRN & \\
\hline CHEMBL1368124 & 688239 & 4.7362 & 5.6929 & TST & \\
\hline CHEMBL 88453 & 688239 & 5.1862 & 5.5401 & TST & \\
\hline CHEMBL1550033 & 688239 & 5.1362 & 5.4329 & TRN & \\
\hline CHEMBL1457374 & 688239 & 8.3372 & 5.5638 & TRN & \\
\hline CHEMBL1346163 & 688239 & 4.7362 & 5.5698 & TRN & \\
\hline CHEMBL1445723 & 688239 & 6.0862 & 5.5435 & TRN & \\
\hline CHEMBL1516312 & 688239 & 5.6862 & 5.655 & TRN & \\
\hline CHEMBL1586887 & 688239 & 6.1862 & 5.5873 & TRN & \\
\hline CHEMBL1607345 & 688239 & 5.9862 & 5.4707 & TRN & \\
\hline CHEMBL1458372 & 688239 & 4.9862 & 5.4416 & TST & \\
\hline CHEMBL3207775 & 688239 & 6.8362 & 5.4645 & TRN & \\
\hline CHEMBL1544529 & 688239 & 4.5362 & 5.6319 & TST & \\
\hline CHEMBL1400693 & 688239 & 4.7862 & 5.4667 & TRN & \\
\hline CHEMBL1462497 & 688239 & 7.1361 & 5.3591 & TST & \\
\hline CHEMBL1596746 & 688239 & 5.4862 & 5.4891 & TRN & \\
\hline CHEMBL1355681 & 688239 & 4.8362 & 5.5572 & TRN & \\
\hline CHEMBL1451919 & 688239 & 4.6362 & 5.5133 & TRN & \\
\hline CHEMBL1535707 & 688239 & 5.1862 & 5.5909 & TRN & \\
\hline CHEMBL1310771 & 688239 & 6.3362 & 5.46 & TRN & \\
\hline CHEMBL1554492 & 688239 & 6.0862 & 5.4214 & TRN & \\
\hline CHEMBL1528637 & 688239 & 6.4362 & 5.5743 & TRN & \\
\hline CHEMBL3190579 & 688239 & 6.5363 & 5.5077 & TST & \\
\hline CHEMBL1588716 & 688239 & 6.2362 & 5.3579 & TRN & \\
\hline CHEMBL1457497 & 688239 & 4.8362 & 5.6722 & TST & \\
\hline CHEMBL1444734 & 688239 & 4.6862 & 5.5685 & TST & \\
\hline CHEMBL1337933 & 688239 & 6.1362 & 5.5365 & TRN & \\
\hline CHEMBL1513994 & 688239 & 4.6862 & 5.3809 & TRN & \\
\hline CHEMBL3208865 & 688239 & 5.0862 & 5.4568 & TRN & \\
\hline CHEMBL1544463 & 688239 & 5.3362 & 5.4071 & TRN & \\
\hline CHEMBL1548084 & 688239 & 5.1862 & 5.4794 & TST & \\
\hline CHEMBL1376911 & 688239 & 6.8362 & 5.4142 & TRN & \\
\hline CHEMBL1309888 & 688239 & 4.5362 & 5.4775 & TST & \\
\hline CHEMBL1438395 & 688239 & 8.28399 & 99999999 & 9 & 5.4489 \\
\hline CHEMBL3198367 & 688239 & 5.7862 & 5.5007 & TRN & \\
\hline CHEMBL1550736 & 688239 & 5.3862 & 5.7199 & TRN & \\
\hline CHEMBL1520278 & 688239 & 6.5862 & 5.5715 & TST & \\
\hline CHEMBL1551693 & 688239 & 5.1362 & 5.3966 & TRN & \\
\hline CHEMBL1336912 & 688239 & 5.1862 & 5.5105 & TRN & \\
\hline CHEMBL1497917 & 688239 & 6.0862 & 5.4815 & TRN & \\
\hline
\end{tabular}


Supplemental Table S2.txt

\begin{tabular}{|c|c|c|c|c|c|}
\hline CHEMBL1353848 & 688239 & 6.2862 & 5.6916 & TRN & \\
\hline CHEMBL1452280 & 688239 & 4.4862 & 5.4543 & TST & \\
\hline CHEMBL1415688 & 688239 & 4.6862 & 5.4548 & TRN & \\
\hline CHEMBL1411995 & 688239 & 5.1862 & 5.4023 & TST & \\
\hline CHEMBL1612870 & 688239 & 4.5362 & 5.3696 & TST & \\
\hline CHEMBL1346208 & 688239 & 4.9362 & 5.5127 & TRN & \\
\hline CHEMBL1408578 & 688239 & 4.5362 & 5.4968 & TST & \\
\hline CHEMBL1443597 & 688239 & 5.3862 & 5.4468 & TST & \\
\hline CHEMBL1399948 & 688239 & 6.7862 & 5.4885 & TST & \\
\hline CHEMBL1387916 & 688239 & 4.5862 & 5.6507 & TRN & \\
\hline CHEMBL1435066 & 688239 & 4.5362 & 5.3979 & TST & \\
\hline CHEMBL1576693 & 688239 & 6.2362 & 5.7399 & TRN & \\
\hline CHEMBL1454037 & 688239 & 4.4862 & 5.4013 & TRN & \\
\hline CHEMBL1474229 & 688239 & 5.4862 & 5.3876 & TRN & \\
\hline CHEMBL1515311 & 688239 & 5.5362 & 5.473 & TRN & \\
\hline CHEMBL1497588 & 688239 & 5.3362 & 5.4514 & TRN & \\
\hline CHEMBL1547524 & 688239 & 5.7362 & 5.432 & TST & \\
\hline CHEMBL1469619 & 688239 & 5.6862 & 5.4741 & TRN & \\
\hline CHEMBL1412486 & 688239 & 4.5362 & 5.5852 & TRN & \\
\hline CHEMBL1548014 & 688239 & 4.8362 & 5.5625 & TRN & \\
\hline CHEMBL3195409 & 688239 & 6.2362 & 5.4505 & TRN & \\
\hline CHEMBL1492967 & 688239 & 4.5362 & 5.4445 & TRN & \\
\hline CHEMBL1309605 & 688239 & 5.3362 & 5.6205 & TRN & \\
\hline CHEMBL1523068 & 688239 & 5.3862 & 5.6773 & TRN & \\
\hline CHEMBL1475843 & 688239 & 6.6861 & 5.5769 & TST & \\
\hline CHEMBL1340521 & 688239 & 4.7862 & 5.5015 & TRN & \\
\hline CHEMBL1537873 & 688239 & 4.5362 & 5.4614 & TRN & \\
\hline CHEMBL1381435 & 688239 & 5.1362 & 5.5369 & TRN & \\
\hline CHEMBL1373097 & 688239 & 5.1362 & 5.4879 & TRN & \\
\hline CHEMBL1385456 & 688239 & 4.5862 & 5.5596 & TST & \\
\hline CHEMBL1413838 & 688239 & 5.8362 & 5.3634 & TST & \\
\hline CHEMBL 3211237 & 688239 & 4.6362 & 5.5127 & TRN & \\
\hline CHEMBL560073 & 688239 & 4.6362 & 5.5622 & TRN & \\
\hline CHEMBL1425851 & 688239 & 5.2862 & 5.3062 & TST & \\
\hline CHEMBL1581509 & 688239 & 4.4362 & \multicolumn{2}{|c|}{5.502000000000001} & TST \\
\hline CHEMBL1463774 & 688239 & 6.5862 & 5.4868 & TST & \\
\hline CHEMBL1477284 & 688239 & 6.3362 & 5.53700 & 0000000001 & TRN \\
\hline CHEMBL1560648 & 688239 & 6.1862 & 5.55399 & 9999999999 & TRN \\
\hline CHEMBL1534333 & 688239 & 5.4362 & 5.4907 & TST & \\
\hline CHEMBL1487424 & 688239 & 6.8362 & 5.476 & TRN & \\
\hline CHEMBL1328666 & 688239 & 4.5362 & 5.4606 & TRN & \\
\hline CHEMBL1461760 & 688239 & 4.6862 & 5.4143 & TRN & \\
\hline CHEMBL1605058 & 688239 & 5.5362 & 5.4387 & TRN & \\
\hline CHEMBL1486840 & 688239 & 4.5362 & 5.5102 & TRN & \\
\hline CHEMBL1381967 & 688239 & 5.7862 & 5.3922 & TRN & \\
\hline CHEMBL1375374 & 688239 & 5.7862 & 5.58 & TRN & \\
\hline CHEMBL1468666 & 688239 & 5.5862 & 5.3834 & TRN & \\
\hline CHEMBL1582828 & 688239 & 6.3863 & 5.511 & TRN & \\
\hline
\end{tabular}


Supplemental Table S2.txt

\begin{tabular}{|c|c|c|c|c|}
\hline CHEMBL1527623 & 688239 & 4.8362 & 5.5694 & TRN \\
\hline CHEMBL1322738 & 688239 & 5.1362 & 5.4986 & TST \\
\hline CHEMBL601585 & 688239 & 6.5862 & 5.5439 & TRN \\
\hline CHEMBL1525164 & 688239 & 6.8861 & 5.352 & TST \\
\hline CHEMBL1486251 & 688239 & 6.6861 & 5.4832 & TRN \\
\hline CHEMBL1542506 & 688239 & 4.5362 & 5.5176 & TRN \\
\hline CHEMBL1383651 & 688239 & 6.9863 & 5.5626 & TST \\
\hline CHEMBL1310130 & 688239 & 8.3372 & 5.4621 & TRN \\
\hline CHEMBL1550509 & 688239 & 4.5862 & 5.5073 & TST \\
\hline CHEMBL1591735 & 688239 & 4.5362 & 5.4357 & TST \\
\hline CHEMBL1376179 & 688239 & 4.5362 & 5.504 & TRN \\
\hline CHEMBL1604074 & 688239 & 6.4862 & 5.4693 & TST \\
\hline CHEMBL1504348 & 688239 & 6.1362 & 5.5332 & TST \\
\hline CHEMBL1383319 & 688239 & 5.1862 & 5.5004 & TRN \\
\hline CHEMBL1609929 & 688239 & 4.9862 & 5.4429 & TRN \\
\hline CHEMBL1425603 & 688239 & 5.5862 & 5.432 & TRN \\
\hline CHEMBL1512738 & 688239 & 5.1862 & 5.586 & TST \\
\hline CHEMBL1441892 & 688239 & 5.5862 & 5.4838 & TRN \\
\hline CHEMBL1605405 & 688239 & 4.9362 & 5.3349 & TRN \\
\hline CHEMBL1430386 & 688239 & 4.6862 & 5.3242 & TST \\
\hline CHEMBL1501430 & 688239 & 4.5862 & 5.4253 & TST \\
\hline CHEMBL1416888 & 688239 & 4.9362 & 5.3522 & TST \\
\hline CHEMBL1326526 & 688239 & 5.7862 & 5.5682 & TRN \\
\hline CHEMBL1533428 & 688239 & 5.0862 & 5.287999 & 999999999 \\
\hline CHEMBL1585395 & 688239 & 4.4862 & 5.3858 & TRN \\
\hline CHEMBL 3193781 & 688239 & 4.7362 & 5.5672 & TRN \\
\hline CHEMBL1589305 & 688239 & 4.9862 & 5.4603 & TRN \\
\hline CHEMBL1326347 & 688239 & 5.1862 & 5.4585 & TRN \\
\hline CHEMBL1539975 & 688239 & 4.5862 & 5.4125 & TRN \\
\hline CHEMBL1546628 & 688239 & 4.6362 & 5.6072 & TRN \\
\hline CHEMBL1448299 & 688239 & 5.3862 & 5.5406 & TST \\
\hline CHEMBL1485869 & 688239 & 5.7362 & 5.4722 & TRN \\
\hline CHEMBL1412373 & 688239 & 5.1362 & 5.6702 & TRN \\
\hline CHEMBL1416732 & 688239 & 5.0362 & 5.4622 & TRN \\
\hline CHEMBL1353406 & 688239 & 7.0362 & 5.5032 & TST \\
\hline CHEMBL1441564 & 688239 & 4.6862 & 5.462999 & 999999999 \\
\hline CHEMBL1472425 & 688239 & 5.8362 & 5.7246 & TRN \\
\hline CHEMBL3210993 & 688239 & 6.0862 & 5.2841 & TRN \\
\hline CHEMBL1591578 & 688239 & 5.1862 & 5.3705 & TRN \\
\hline CHEMBL1424999 & 688239 & 4.6362 & 5.4747 & TRN \\
\hline CHEMBL1465201 & 688239 & 5.7362 & 5.38 & TRN \\
\hline CHEMBL1483718 & 688239 & 4.5862 & 5.6891 & TRN \\
\hline CHEMBL1574114 & 688239 & 7.0362 & 5.5054 & TRN \\
\hline CHEMBL1968123 & 688239 & 6.5862 & 5.4373 & TRN \\
\hline CHEMBL3212033 & 688239 & 6.8861 & 5.5151 & TRN \\
\hline CHEMBL3212135 & 688239 & 4.6862 & 5.3404 & TRN \\
\hline CHEMBL1593813 & 688239 & 4.5362 & 5.4168 & TRN \\
\hline CHEMBL1392615 & 688239 & 6.9363 & 5.5439 & TRN \\
\hline
\end{tabular}

Page 2160 
Supplemental Table S2.txt

\begin{tabular}{|c|c|c|c|c|}
\hline 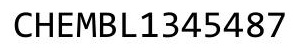 & & & & \\
\hline AEMBL13 & 38239 & 5362 & 6042 & \\
\hline IEMBL1414657 & 8239 & 362 & 6645 & \\
\hline AEMBL1333142 & 239 & 862 & 4648 & \\
\hline & 239 & & 3602 & \\
\hline IEMBL1335176 & 239 & & 557 & \\
\hline AEMBL1575647 & 88239 & 862 & 4578 & \\
\hline AEMBL1330002 & 88239 & 862 & 4342 & \\
\hline AEMBL152 & 239 & 62 & & \\
\hline IEMBL160 & 239 & & & \\
\hline IEMBL1565491 & & & & \\
\hline AEMBL1370380 & 688239 & 362 & 5813 & \\
\hline AEMBL1599422 & 239 & & & \\
\hline IEMBL1383255 & & & 67 & \\
\hline IEMBL1560945 & & & & \\
\hline AEMBL1441173 & & & & \\
\hline AEMBL1541160 & 239 & & 217 & \\
\hline AEMBL1605339 & 39 & & & \\
\hline IEMBL1512 & & 4. & 69 & \\
\hline AEMBL1352 & & & & \\
\hline AEMBL1566818 & & & & \\
\hline AEMBL248779 & & & & \\
\hline IEMBL1379543 & & & & \\
\hline IEMBL1323957 & & & & \\
\hline HEMBL1491240 & & & & \\
\hline AEMBL1372959 & & & & \\
\hline AEMBL1337965 & & & & \\
\hline AEMBL1588229 & & & & \\
\hline AEMBL1453683 & & & 01 & \\
\hline 36 & & & & \\
\hline 23 & & & & \\
\hline HEMBL1581324 & & & & \\
\hline AEMBL1435154 & & & & \\
\hline AEMBL1382051 & & & & \\
\hline AEMBL1551293 & & & 45 & \\
\hline 1477 & & & & \\
\hline AEMBL1423579 & & & & \\
\hline AEMBL3198126 & & & & \\
\hline EMBL1546 & & & & \\
\hline HEMBL1414824 & & & & \\
\hline HEMBL15 & & & & \\
\hline AEMBL1316876 & & 4. & 889 & ST \\
\hline AEMBL1548181 & & & & \\
\hline EMBL139 & & & & \\
\hline CHEMBL1967220 & & & & \\
\hline CHEMBL1399046 & & & 506 & \\
\hline AEMBL1362730 & 38239 & 4.6862 & 5.4704 & \\
\hline HFMBI 1466194 & 688239 & 4.6862 & 5.6115 & \\
\hline
\end{tabular}

Page 2161 
Supplemental Table S2.txt

\begin{tabular}{|c|c|c|c|c|c|}
\hline CHEMBL1304190 & 688239 & 4.9362 & 5.5101 & TST & \\
\hline CHEMBL1346907 & 688239 & 5.3362 & 5.4799 & TRN & \\
\hline CHEMBL3211120 & 688239 & 6.6861 & 5.6824 & TRN & \\
\hline CHEMBL1334640 & 688239 & 8.3372 & 5.4657 & TRN & \\
\hline CHEMBL 3193484 & 688239 & 4.5362 & 5.3871 & TST & \\
\hline CHEMBL1508982 & 688239 & 5.6862 & 5.3224 & TRN & \\
\hline CHEMBL1474207 & 688239 & 5.6862 & 5.4336 & TST & \\
\hline CHEMBL1529180 & 688239 & 5.7862 & 5.5323 & TRN & \\
\hline CHEMBL 3207782 & 688239 & 4.9862 & 5.4235 & TST & \\
\hline CHEMBL1404952 & 688239 & 6.1862 & 5.4665 & TST & \\
\hline CHEMBL1394687 & 688239 & 5.0362 & 5.3566 & TRN & \\
\hline CHEMBL1480361 & 688239 & 6.9863 & 5.5463 & TRN & \\
\hline CHEMBL1561891 & 688239 & 4.9362 & 5.5749 & TRN & \\
\hline CHEMBL 3208850 & 688239 & 5.1862 & 5.4869 & TST & \\
\hline CHEMBL1578759 & 688239 & 7.2865 & 5.5477 & TST & \\
\hline CHEMBL1455686 & 688239 & 4.5362 & 5.5944 & TST & \\
\hline CHEMBL1392136 & 688239 & 4.7862 & 5.3911 & TRN & \\
\hline CHEMBL 3195647 & 688239 & 4.9862 & 5.4934 & TST & \\
\hline CHEMBL1544352 & 688239 & 7.2366 & 5.5452 & TRN & \\
\hline CHEMBL1602087 & 688239 & 4.8362 & 5.5696 & TST & \\
\hline CHEMBL1528851 & 688239 & 6.1862 & 5.58299 & 9999999999 & TRN \\
\hline CHEMBL1437181 & 688239 & 5.6362 & 5.4209 & TRN & \\
\hline CHEMBL1325731 & 688239 & 5.6862 & 5.3006 & TRN & \\
\hline CHEMBL1488681 & 688239 & 4.7362 & 5.4809 & TRN & \\
\hline CHEMBL1365558 & 688239 & 5.2362 & 5.4508 & TRN & \\
\hline CHEMBL1407654 & 688239 & 5.1862 & 5.4591 & TRN & \\
\hline CHEMBL1423741 & 688239 & 5.1862 & 5.4458 & TST & \\
\hline CHEMBL1492705 & 688239 & 6.2862 & 5.6986 & TRN & \\
\hline CHEMBL1345004 & 688239 & 4.7362 & 5.5245 & TRN & \\
\hline CHEMBL1488149 & 688239 & 5.8862 & 5.57 & TRN & \\
\hline CHEMBL1561075 & 688239 & 4.5362 & 5.468 & TST & \\
\hline CHEMBL1607350 & 688239 & 4.7862 & 5.4715 & TRN & \\
\hline CHEMBL1338215 & 688239 & 5.1862 & 5.6446 & TRN & \\
\hline CHEMBL1589562 & 688239 & 4.5862 & 5.6361 & TRN & \\
\hline CHEMBL1443214 & 688239 & 5.8862 & 5.4927 & TRN & \\
\hline CHEMBL1390905 & 688239 & 5.7362 & 5.4946 & TRN & \\
\hline CHEMBL1607806 & 688239 & 4.8862 & 5.605 & TRN & \\
\hline CHEMBL1582055 & 688239 & 5.2362 & 5.4821 & TRN & \\
\hline CHEMBL1342042 & 688239 & 5.9862 & 5.4644 & TST & \\
\hline CHEMBL 3196572 & 688239 & 4.5362 & 5.4421 & TRN & \\
\hline CHEMBL1444542 & 688239 & 5.2362 & 5.6009 & TST & \\
\hline CHEMBL1401447 & 688239 & 4.5362 & 5.3986 & TRN & \\
\hline CHEMBL1576552 & 688239 & 4.5362 & 5.45799 & 9999999999 & TRN \\
\hline CHEMBL1439605 & 688239 & 5.1862 & 5.4702 & TRN & \\
\hline CHEMBL1429812 & 688239 & 5.0362 & 5.4044 & TRN & \\
\hline CHEMBL1450732 & 688239 & 5.1362 & 5.4615 & TRN & \\
\hline CHEMBL1429400 & 688239 & 4.4862 & 5.5103 & TRN & \\
\hline CHEMBL1467581 & 688239 & 4.9862 & 5.3949 & TST & \\
\hline
\end{tabular}


Supplemental Table S2.txt

\begin{tabular}{|c|c|c|c|c|}
\hline The & & 362 & & \\
\hline & & .1361 & 5.3916 & \\
\hline & & & & \\
\hline IEMBL155081 & & & & $\mathrm{MI}$ \\
\hline AEMBL1384982 & 8239 & 862 & 821 & \\
\hline HEMBL1435502 & 88239 & 362 & 5182 & \\
\hline HEMBL1601539 & 239 & & & \\
\hline EMBL1494961 & & & & \\
\hline IEMBL1349392 & & & & \\
\hline HEMBL1534370 & 38239 & 861 & & \\
\hline AEMBL1371754 & 239 & 362 & 22 & \\
\hline IEMBL1330832 & 39 & 62 & & \\
\hline IEMBL1300214 & & & & \\
\hline HEMBL1606277 & & & & \\
\hline AEMBL1597854 & & & & \\
\hline AEMBL1578054 & 39 & 62 & & \\
\hline AEMBL1328621 & & & & \\
\hline HEMBL3194009 & & & & \\
\hline AEMBL1506338 & & 862 & & \\
\hline AEMBL1611314 & & & & \\
\hline HEMBLI4S & & & & RIN \\
\hline AEMBL13 & & & & RN \\
\hline JEMBL 14 & & & & \\
\hline AEMBL1300200 & & 861 & & \\
\hline HEMBL137؟ & & & & (2) \\
\hline AEMBL1327 & & & & KIV \\
\hline HEMBL142 & & & & RN \\
\hline AFMBI 139 & & & & \\
\hline IEMBL154 & & & & I RIV \\
\hline HEMBL1392658 & & & & IRN \\
\hline HEMBL15906 & & & & SI \\
\hline HEMBL1 & & & & ST \\
\hline ALMPI 1 & & & & 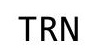 \\
\hline HEMBL2369268 & & & & is \\
\hline HEMBL1483142 & & 62 & & TRN \\
\hline HEMBL1573651 & & & & RN \\
\hline НЕMP 1 & & & & IRIV \\
\hline HEMBL15 & & & & $|S|$ \\
\hline HEMBL1389003 & & 62 & & TRN \\
\hline IEMBL146 & & & & TST \\
\hline HEMBL1529 & & & & RN \\
\hline HEMBL1277149 & & & & TRN \\
\hline HEMBL1427911 & & & & $\mathrm{R}$ \\
\hline AEMBL3198173 & 39 & 862 & & TR \\
\hline MBL15 & & & & $\mathrm{N}$ \\
\hline HEMBL13808 & & & & \\
\hline CHEMBL13124 & & .8862 & & \\
\hline HEMBL1360263 & 688239 & 4.5362 & 5.4693 & \\
\hline
\end{tabular}

Page 2163 
Supplemental Table S2.txt

\begin{tabular}{|c|c|c|c|c|}
\hline CHEMBL1585172 & 688239 & 4.5362 & 5.5742 & TRN \\
\hline CHEMBL1594840 & 688239 & 4.8362 & 5.5014 & TRN \\
\hline CHEMBL3189928 & 688239 & 5.2362 & 5.5119 & TRN \\
\hline CHEMBL1550136 & 688239 & 4.6862 & 5.6173 & TRN \\
\hline CHEMBL1350056 & 688239 & 5.0362 & 5.3884 & TST \\
\hline CHEMBL1508242 & 688239 & 5.1862 & 5.6523 & TST \\
\hline CHEMBL1445658 & 688239 & 4.7362 & 5.2983 & TST \\
\hline CHEMBL1443914 & 688239 & 6.2362 & 5.4916 & TST \\
\hline CHEMBL1469859 & 688239 & 4.5362 & 5.4719 & TRN \\
\hline CHEMBL1435246 & 688239 & 8.0362 & 5.4472 & TRN \\
\hline CHEMBL1582782 & 688239 & 4.5362 & 5.5399 & TST \\
\hline CHEMBL1339210 & 688239 & 5.6862 & 5.3064 & TRN \\
\hline CHEMBL1432620 & 688239 & 5.2362 & 5.3937 & TRN \\
\hline CHEMBL1546151 & 688239 & 6.2362 & 5.4472 & TRN \\
\hline CHEMBL1445350 & 688239 & 5.1362 & 5.5145 & TRN \\
\hline CHEMBL1610946 & 688239 & 4.5362 & 5.5825 & TST \\
\hline CHEMBL1602003 & 688239 & 4.5362 & 5.5755 & TRN \\
\hline CHEMBL1448096 & 688239 & 6.3863 & 5.4564 & TRN \\
\hline CHEMBL1317424 & 688239 & 5.7362 & 5.43 & TRN \\
\hline CHEMBL1451338 & 688239 & 4.7862 & 5.3817 & TRN \\
\hline CHEMBL1999046 & 688239 & 5.6862 & 5.3119 & TST \\
\hline CHEMBL1481663 & 688239 & 5.8362 & 5.5633 & TST \\
\hline CHEMBL1472896 & 688239 & 4.6862 & 5.3485 & TRN \\
\hline CHEMBL3195203 & 688239 & 5.1862 & 5.3762 & TRN \\
\hline CHEMBL1400496 & 688239 & 5.5362 & 5.3575 & TRN \\
\hline CHEMBL1404542 & 688239 & 4.7362 & 5.4938 & TST \\
\hline CHEMBL1545735 & 688239 & 4.5362 & 5.479 & TST \\
\hline CHEMBL1391928 & 688239 & 5.3862 & 5.42200 & 0000000001 \\
\hline CHEMBL1339659 & 688239 & 4.5362 & 5.5212 & TRN \\
\hline CHEMBL1402629 & 688239 & 4.4862 & 5.4662 & TST \\
\hline CHEMBL1480753 & 688239 & 5.5862 & 5.48799 & 99999999995 \\
\hline CHEMBL1331038 & 688239 & 6.6362 & 5.5572 & TST \\
\hline CHEMBL1502239 & 688239 & 5.8862 & 5.5562 & TRN \\
\hline CHEMBL1552828 & 688239 & 4.6362 & 5.5659 & TRN \\
\hline CHEMBL1580618 & 688239 & 4.7362 & 5.4387 & TRN \\
\hline CHEMBL3210283 & 688239 & 6.2862 & 5.4601 & TRN \\
\hline CHEMBL1575914 & 688239 & 4.7362 & 5.5639 & TRN \\
\hline CHEMBL1548315 & 688239 & 6.1862 & 5.5097 & TRN \\
\hline CHEMBL1342338 & 688239 & 5.6862 & 5.5564 & TRN \\
\hline CHEMBL1325892 & 688239 & 6.5363 & 5.4044 & TRN \\
\hline CHEMBL1507871 & 688239 & 6.0862 & 5.4964 & TRN \\
\hline CHEMBL1570711 & 688239 & 5.1862 & 5.5288 & TRN \\
\hline CHEMBL1573666 & 688239 & 6.6861 & 5.4752 & TRN \\
\hline CHEMBL1319724 & 688239 & 5.3362 & 5.5119 & TRN \\
\hline CHEMBL1570208 & 688239 & 5.1862 & 5.5745 & TRN \\
\hline CHEMBL3210602 & 688239 & 4.6862 & 5.3488 & TST \\
\hline CHEMBL1430259 & 688239 & 4.6862 & 5.3423 & TRN \\
\hline CHEMBL1470291 & 688239 & 5.7362 & 5.4995 & TRN \\
\hline
\end{tabular}

Page 2164 
Supplemental Table S2.txt

\begin{tabular}{|c|c|c|c|c|}
\hline 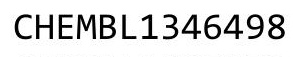 & & & & \\
\hline AEMBL1595559 & 38239 & 862 & 884 & \\
\hline AEMBL1342242 & 239 & 362 & & \\
\hline & 39 & & & \\
\hline IEMBL238 & & 362 & & \\
\hline AEMBL1389827 & 88239 & 862 & 841 & \\
\hline AEMBL1442607 & 88239 & 862 & 3847 & \\
\hline HEMBL1602964 & & & & \\
\hline EMBL1 & 39 & 862 & & \\
\hline EMBL14 & & 362 & & \\
\hline AEMBL1438877 & 239 & 362 & 75 & \\
\hline HEMBL1460095 & & 363 & & \\
\hline HEMBL157 & & & & \\
\hline AEMBL13 & & 862 & & \\
\hline HEMBL13 & & & & \\
\hline AEMBL136 & & 862 & & \\
\hline AEMBL1553415 & & 362 & & \\
\hline AEMBL153 & & 62 & & \\
\hline AEMBL 15 & & & & \\
\hline AEMBL15 & & & & \\
\hline HEMBL139 & & 362 & & \\
\hline AEMBL1529732 & & 62 & & \\
\hline IEMBL138 & & 62 & & \\
\hline AFMRI 31 & & & & \\
\hline 88 & & & & \\
\hline 2 & & 62 & & \\
\hline IEMBL14 & & 362 & & \\
\hline EMBL136 & & 862 & & \\
\hline JEM & & 52 & & \\
\hline 6 & & 62 & & \\
\hline 15 1 & & & & \\
\hline AEMBL 579 & & & & \\
\hline & & & & \\
\hline$\theta$ & & & & \\
\hline & & & & \\
\hline AEMBL1473953 & & & & $\mathrm{F}$ \\
\hline AEMBL1514207 & & 362 & & \\
\hline & & & & \\
\hline$\theta$ & & & & \\
\hline & & & & $S$ \\
\hline AEMBL 259176 & & 362 & & TR \\
\hline AEMBL138 & & 62 & & $1 \mathrm{~h}$ \\
\hline רתות & & & & \\
\hline HEMBL1531274 & & & & w \\
\hline AEMBL1436357 & & 4.7862 & & $\mathrm{R}$ \\
\hline IEMBL1585699 & & 4.5362 & 17 & TS \\
\hline 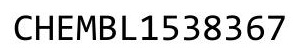 & & & & \\
\hline HEMBL1431 & & & & \\
\hline
\end{tabular}

Page 2165 


\begin{tabular}{|c|c|c|c|c|c|c|}
\hline & & & & & & \\
\hline CHEMBL1364376 & 688239 & 7.2366 & 5.6873 & TRN & & \\
\hline CHEMBL1597319 & 688239 & 4.5362 & 5.6804 & TRN & & \\
\hline CHEMBL1584559 & 688239 & 5.4862 & 5.5598 & TRN & & \\
\hline CHEMBL1428545 & 688239 & 4.4862 & 5.6106 & TRN & & \\
\hline CHEMBL1599628 & 688239 & 5.1862 & 5.4028 & TRN & & \\
\hline CHEMBL1378170 & 688239 & 4.5862 & 5.51399 & 99999999 & & TRN \\
\hline CHEMBL1601318 & 688239 & 5.6362 & 5.596 & TRN & & \\
\hline CHEMBL1371146 & 688239 & 4.8362 & 5.3797 & TRN & & \\
\hline CHEMBL1429646 & 688239 & 5.3362 & 5.5473 & TST & & \\
\hline CHEMBL1567221 & 688239 & 5.3362 & 5.5506 & TRN & & \\
\hline CHEMBL1488096 & 688239 & 4.9362 & 5.624 & TRN & & \\
\hline CHEMBL1455247 & 688239 & 4.5362 & 5.544 & TRN & & \\
\hline CHEMBL1336558 & 688239 & 6.7361 & 5.4823 & TRN & & \\
\hline CHEMBL596838 & 688239 & 4.5362 & 5.4895 & TRN & & \\
\hline CHEMBL1431831 & 688239 & 4.6362 & 5.42700 & 00000000 & 205 & TST \\
\hline CHEMBL1413711 & 688239 & 4.7362 & 5.4673 & TRN & & \\
\hline CHEMBL1350731 & 688239 & 4.5862 & 5.315 & TRN & & \\
\hline CHEMBL1974143 & 688239 & 4.7362 & 5.515 & TRN & & \\
\hline CHEMBL1604477 & 688239 & 5.7862 & 5.4474 & TRN & & \\
\hline CHEMBL1578138 & 688239 & 4.6362 & 5.5578 & TRN & & \\
\hline CHEMBL1343397 & 688239 & 4.7362 & 5.6338 & TRN & & \\
\hline CHEMBL1303975 & 688239 & 4.8362 & 5.4146 & TRN & & \\
\hline CHEMBL1360082 & 688239 & 8.28399 & 99999999 & & 5.5291 & TRN \\
\hline CHEMBL3192744 & 688239 & 8.28399 & 99999999 & 99 & 5.397 & TRN \\
\hline CHEMBL1443834 & 688239 & 4.8862 & 5.3452 & TST & & \\
\hline CHEMBL1595848 & 688239 & 4.7862 & 5.5217 & TST & & \\
\hline CHEMBL1415354 & 688239 & 4.5862 & 5.4362 & TRN & & \\
\hline CHEMBL1539674 & 688239 & 4.7362 & 5.5045 & TRN & & \\
\hline CHEMBL1438565 & 688239 & 6.8362 & 5.4578 & TRN & & \\
\hline CHEMBL1542674 & 688239 & 5.5362 & 5.2966 & TRN & & \\
\hline CHEMBL1534002 & 688239 & 6.1362 & 5.3375 & TST & & \\
\hline CHEMBL1318099 & 688239 & 4.7362 & 5.4159 & TRN & & \\
\hline CHEMBL1454556 & 688239 & 4.7862 & 5.276 & TRN & & \\
\hline CHEMBL1415700 & 688239 & 5.1862 & 5.6348 & TRN & & \\
\hline CHEMBL1302330 & 688239 & 5.1862 & 5.4554 & TST & & \\
\hline CHEMBL1594475 & 688239 & 5.3862 & 5.3806 & TRN & & \\
\hline CHEMBL1453038 & 688239 & 4.8 & 5.5648 & TRN & & \\
\hline CHEMBL1342520 & 688239 & 5.9362 & 5.4192 & TRN & & \\
\hline CHEMBL1445539 & 688239 & 4.9862 & 5.4925 & TRN & & \\
\hline CHEMBL1320130 & 688239 & 5.4362 & 5.659 & TRN & & \\
\hline CHEMBL1502232 & 688239 & 4.4862 & 5.7184 & TRN & & \\
\hline CHEMBL1483104 & 688239 & 6.8861 & 5.5158 & TRN & & \\
\hline CHEMBL1489169 & 688239 & 4.9362 & 5.5714 & TST & & \\
\hline CHEMBL1423272 & 688239 & 5.1862 & 5.3794 & TRN & & \\
\hline CHEMBL1536678 & 688239 & 4.5362 & 5.5544 & TRN & & \\
\hline CHEMBL1497295 & 688239 & 4.7362 & 5.3326 & TST & & \\
\hline CHEMBL1347629 & 688239 & 4.4862 & 5.3694 & TRN & & \\
\hline CHEMBL1444480 & 688239 & 4.5862 & 5.3844 & TST & & \\
\hline
\end{tabular}


Supplemental Table S2.txt

\begin{tabular}{|c|c|c|c|c|}
\hline 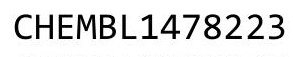 & & & & \\
\hline AEMBL3196605 & 38239 & 1862 & 4943 & \\
\hline AEMBL3192984 & 239 & 862 & & \\
\hline 226 & 39 & 862 & & \\
\hline IEMBL14 & 39 & 862 & & \\
\hline AEMBL1336769 & 88239 & 862 & 231 & \\
\hline AEMBL3208287 & 88239 & 362 & 4687 & \\
\hline AEMBL1371638 & & 362 & & \\
\hline EMBL13 & 39 & 862 & & \\
\hline IEMBL13 & & 862 & & \\
\hline AEMBL1503135 & 239 & 362 & 665 & \\
\hline AEMBL3212791 & & 362 & & \\
\hline AEMBL1435092 & & & & \\
\hline JEMBL14 & & & & \\
\hline AEMBL14 & & & & \\
\hline AEMBL1554747 & & 862 & & \\
\hline HEMBL1493934 & & 862 & & \\
\hline AEMBL151 & & 65 & & \\
\hline AEMBL1519188 & & 62 & & \\
\hline HEMBL133 & & 862 & & \\
\hline AEMBL1520957 & & 362 & & \\
\hline AEMBL1609677 & & 62 & & \\
\hline IEMBL1308227 & & 62 & & \\
\hline AFMBI 153 & & & & \\
\hline 554 & & & & \\
\hline AEMBL1444443 & & 863 & & \\
\hline IEMBL3212875 & & & & \\
\hline IEMBL1514 & & 62 & & \\
\hline AFMRI 132 & & & & \\
\hline 05 & & 62 & & \\
\hline AEMBL1314313 & & & & \\
\hline HEMBL1366739 & & 362 & & \\
\hline & & & & \\
\hline 6 & & & & \\
\hline HEMBL1478854 & & & & \\
\hline AEMBL1345821 & & & & \\
\hline AEMBL1531805 & & 862 & & \\
\hline & & & & \\
\hline$\partial 27$ & & & & \\
\hline HEMBL1609404 & & & & RN \\
\hline IEMBL1459519 & & 62 & & \\
\hline AEMBL 144 & & 62 & & \\
\hline HEMBL1520875 & & & & \\
\hline HEMBL1461086 & & & & \\
\hline AEMBL1419031 & & 4.7862 & & RN \\
\hline IEMBL1577079 & & 4.5362 & & \\
\hline ב2 & & & & \\
\hline HEMBL145099 & & & & \\
\hline
\end{tabular}

Page 2167 
Supplemental Table S2.txt

\begin{tabular}{|c|c|c|c|c|}
\hline CHEMBL1588108 & 688239 & 4.5362 & 5.5274 & TRN \\
\hline CHEMBL1469336 & 688239 & 5.3362 & \multicolumn{2}{|c|}{5.452999999999999} \\
\hline CHEMBL1357218 & 688239 & 5.3862 & 5.4985 & TRN \\
\hline CHEMBL1582182 & 688239 & 5.3862 & 5.4193 & TRN \\
\hline CHEMBL1564675 & 688239 & 6.1362 & 5.4512 & TRN \\
\hline CHEMBL1506364 & 688239 & 6.8362 & 5.5569 & TRN \\
\hline CHEMBL1352211 & 688239 & 4.5362 & 5.41299 & 9999999999 \\
\hline CHEMBL1586980 & 688239 & 4.5362 & 5.4929 & TRN \\
\hline CHEMBL1512865 & 688239 & 5.6362 & 5.6506 & TRN \\
\hline CHEMBL1383912 & 688239 & 5.6362 & 5.5743 & TRN \\
\hline CHEMBL1567468 & 688239 & 4.5362 & 5.3975 & TRN \\
\hline CHEMBL1432030 & 688239 & 5.4362 & 5.4623 & TST \\
\hline CHEMBL1477988 & 688239 & 6.3362 & 5.4604 & TRN \\
\hline CHEMBL1991815 & 688239 & 6.3362 & 5.5554 & TST \\
\hline CHEMBL1588146 & 688239 & 5.9362 & 5.4204 & TRN \\
\hline CHEMBL1427393 & 688239 & 4.6862 & 5.5869 & TRN \\
\hline CHEMBL1580057 & 688239 & 5.5862 & 5.5295 & TRN \\
\hline CHEMBL1347430 & 688239 & 4.8362 & 5.5279 & TST \\
\hline CHEMBL1429629 & 688239 & 7.0362 & 5.5679 & TST \\
\hline CHEMBL1448527 & 688239 & 4.5362 & 5.4615 & TRN \\
\hline CHEMBL1348568 & 688239 & 4.6862 & 5.6117 & TRN \\
\hline CHEMBL 3193664 & 688239 & 4.5362 & 5.3069 & TRN \\
\hline CHEMBL1340012 & 688239 & 6.5862 & 5.4806 & TRN \\
\hline CHEMBL1585119 & 688239 & 5.4862 & 5.3809 & TST \\
\hline CHEMBL1331271 & 688239 & 6.9863 & 5.5997 & TRN \\
\hline CHEMBL1327867 & 688239 & 4.5362 & 5.6172 & TRN \\
\hline CHEMBL1390010 & 688239 & 8.3372 & 5.428 & TRN \\
\hline CHEMBL1299186 & 688239 & 8.3372 & 5.3697 & TRN \\
\hline CHEMBL1487996 & 688239 & 4.5362 & 5.5302 & TST \\
\hline CHEMBL1307511 & 688239 & 4.6862 & 5.3504 & TRN \\
\hline CHEMBL1406860 & 688239 & 4.5362 & 5.4316 & TRN \\
\hline CHEMBL1562585 & 688239 & 4.7862 & 5.6657 & TST \\
\hline CHEMBL 3209171 & 688239 & 4.8862 & 5.3088 & TRN \\
\hline CHEMBL1329054 & 688239 & 6.4862 & 5.388 & TRN \\
\hline CHEMBL1421803 & 688239 & 4.7862 & 5.5223 & TST \\
\hline CHEMBL1538404 & 688239 & 6.2862 & 5.4653 & TRN \\
\hline CHEMBL1541771 & 688239 & 5.4362 & 5.5475 & TRN \\
\hline CHEMBL1383656 & 688239 & 4.5362 & 5.6807 & TRN \\
\hline CHEMBL1391264 & 688239 & 5.1362 & 5.496 & TST \\
\hline CHEMBL1349308 & 688239 & 4.4862 & 5.4773 & TST \\
\hline CHEMBL1332210 & 688239 & 5.3362 & 5.5267 & TST \\
\hline CHEMBL1595155 & 688239 & 6.0862 & 5.4244 & TRN \\
\hline CHEMBL1421685 & 688239 & 6.2362 & 5.5258 & TST \\
\hline CHEMBL1316873 & 688239 & 5.0362 & 5.4567 & TRN \\
\hline CHEMBL1394478 & 688239 & 4.7862 & 5.5165 & TRN \\
\hline CHEMBL1597539 & 688239 & 6.8861 & 5.4715 & TRN \\
\hline CHEMBL1453309 & 688239 & 6.8362 & 5.4113 & TRN \\
\hline CHEMBL1339528 & 688239 & 5.3362 & 5.4017 & TRN \\
\hline
\end{tabular}


Supplemental Table S2.txt

\begin{tabular}{|c|c|c|c|c|c|c|}
\hline CHEMBL3198739 & 688239 & 5.7862 & 5.3422 & TRN & & \\
\hline CHEMBL3212927 & 688239 & 4.6362 & 5.376 & TRN & & \\
\hline CHEMBL1343602 & 688239 & 5.7862 & 5.5529 & TRN & & \\
\hline CHEMBL1714415 & 688239 & 4.7362 & 5.4201 & TRN & & \\
\hline CHEMBL1596656 & 688239 & 5.1862 & 5.4938 & TRN & & \\
\hline CHEMBL1427136 & 688239 & 4.5362 & 5.5475 & TRN & & \\
\hline CHEMBL1406176 & 688239 & 6.1862 & 5.6089 & TRN & & \\
\hline CHEMBL1423229 & 688239 & 5.7362 & 5.4526 & TRN & & \\
\hline CHEMBL1439458 & 688239 & 4.9862 & 5.4683 & TRN & & \\
\hline CHEMBL1503282 & 688239 & 5.0362 & 5.4611 & TRN & & \\
\hline CHEMBL1321928 & 688239 & 6.1862 & 5.5152 & TST & & \\
\hline CHEMBL1346330 & 688239 & 8.28399 & 99999999 & 99 & 5.5595 & TST \\
\hline CHEMBL1544112 & 688239 & 4.9862 & 5.4983 & TRN & & \\
\hline CHEMBL1382254 & 688239 & 5.2862 & 5.5481 & TRN & & \\
\hline CHEMBL1383116 & 688239 & 4.9862 & 5.4361 & TST & & \\
\hline CHEMBL1333065 & 688239 & 5.1862 & 5.4514 & TRN & & \\
\hline CHEMBL1365231 & 688239 & 5.7862 & 5.5099 & TST & & \\
\hline CHEMBL1417110 & 688239 & 6.0862 & 5.6106 & TRN & & \\
\hline CHEMBL1396411 & 688239 & 5.2362 & 5.6688 & TRN & & \\
\hline CHEMBL1540136 & 688239 & 4.5362 & 5.4402 & TRN & & \\
\hline CHEMBL1582655 & 688239 & 4.5862 & 5.6333 & TRN & & \\
\hline CHEMBL1512735 & 688239 & 5.3862 & 5.5922 & TRN & & \\
\hline CHEMBL1572648 & 688239 & 5.4362 & 5.6368 & TRN & & \\
\hline CHEMBL1612081 & 688239 & 5.1862 & 5.3443 & TST & & \\
\hline CHEMBL1303312 & 688239 & 6.0862 & 5.5414 & TRN & & \\
\hline CHEMBL1596951 & 688239 & 6.2362 & 5.5373 & TRN & & \\
\hline CHEMBL1565289 & 688239 & 4.8862 & 5.598 & TRN & & \\
\hline CHEMBL3195168 & 688239 & 4.4862 & 5.5659 & TRN & & \\
\hline CHEMBL1440722 & 688239 & 5.0362 & 5.6363 & TRN & & \\
\hline CHEMBL1379008 & 688239 & 5.2362 & 5.2975 & TST & & \\
\hline CHEMBL1440801 & 688239 & 5.1862 & 5.2899 & TST & & \\
\hline CHEMBL1317005 & 688239 & 6.8861 & 5.4162 & TRN & & \\
\hline CHEMBL1326123 & 688239 & 4.6862 & 5.5959 & TRN & & \\
\hline CHEMBL1520214 & 688239 & 5.2862 & 5.3954 & TRN & & \\
\hline CHEMBL1407453 & 688239 & 5.1862 & 5.4536 & TRN & & \\
\hline CHEMBL1509383 & 688239 & 4.5362 & 5.5828 & TST & & \\
\hline CHEMBL1312055 & 688239 & 4.5362 & 5.5533 & TRN & & \\
\hline CHEMBL1579616 & 688239 & 4.7362 & 5.6116 & TRN & & \\
\hline CHEMBL1380654 & 688239 & 4.6862 & 5.5749 & TRN & & \\
\hline CHEMBL1322704 & 688239 & 5.1862 & 5.5636 & TRN & & \\
\hline CHEMBL1327238 & 688239 & 6.8362 & 5.4493 & TST & & \\
\hline CHEMBL1525896 & 688239 & 4.8862 & 5.7105 & TRN & & \\
\hline CHEMBL1546741 & 688239 & 4.5862 & 5.4362 & TRN & & \\
\hline CHEMBL1590316 & 688239 & 4.6862 & 5.5644 & TST & & \\
\hline CHEMBL1534859 & 688239 & 4.5362 & 5.4442 & TRN & & \\
\hline CHEMBL1309702 & 688239 & 4.5362 & 5.3853 & TRN & & \\
\hline CHEMBL1998852 & 688239 & 4.5362 & 5.4844 & TRN & & \\
\hline CHEMBL1590567 & 688239 & 4.6362 & 5.5628 & TRN & & \\
\hline
\end{tabular}




\begin{tabular}{|c|c|c|c|c|c|}
\hline & & & & & \\
\hline CHEMBL1371928 & 688239 & 6.3863 & 5.4809 & TRN & \\
\hline CHEMBL1423846 & 688239 & 4.5362 & 5.6038 & TST & \\
\hline CHEMBL1569004 & 688239 & 6.6861 & 5.4524 & TRN & \\
\hline CHEMBL1478315 & 688239 & 5.4362 & 5.4249 & TRN & \\
\hline CHEMBL1517738 & 688239 & 4.5362 & 5.4713 & TST & \\
\hline CHEMBL1577850 & 688239 & 8.28399 & 79999999 & 5.4805 & TST \\
\hline CHEMBL3207840 & 688239 & 4.9362 & 5.4887 & TRN & \\
\hline CHEMBL1458325 & 688239 & 8.3372 & 5.58799 & 9999999999 & TRN \\
\hline CHEMBL1312346 & 688239 & 6.4862 & 5.4596 & TST & \\
\hline CHEMBL1485193 & 688239 & 5.9362 & 5.4574 & TRN & \\
\hline CHEMBL1368002 & 688239 & 6.0862 & 5.387006 & 00000000005 & TST \\
\hline CHEMBL1499816 & 688239 & 5.0362 & 5.6446 & TRN & \\
\hline CHEMBL1308664 & 688239 & 4.5362 & 5.3504 & TRN & \\
\hline CHEMBL1399190 & 688239 & 4.6362 & 5.5021 & TRN & \\
\hline CHEMBL1504230 & 688239 & 6.1862 & 5.4428 & TRN & \\
\hline CHEMBL1400793 & 688239 & 4.6362 & 5.436 & TRN & \\
\hline CHEMBL1362555 & 688239 & 4.5362 & 5.4786 & TRN & \\
\hline CHEMBL1462007 & 688239 & 4.5362 & 5.3764 & TST & \\
\hline CHEMBL1435164 & 688239 & 5.7862 & 5.5244 & TRN & \\
\hline CHEMBL1489313 & 688239 & 6.3362 & 5.3995 & TRN & \\
\hline CHEMBL1310620 & 688239 & 5.1862 & 5.6 & TRN & \\
\hline CHEMBL1486278 & 688239 & 8.2366 & 5.4565 & TRN & \\
\hline CHEMBL1418158 & 688239 & 6.0362 & 5.4473 & TST & \\
\hline CHEMBL1385360 & 688239 & 5.3362 & 5.4755 & TRN & \\
\hline CHEMBL1416382 & 688239 & 5.2862 & 5.2092 & TRN & \\
\hline CHEMBL1458622 & 688239 & 5.7862 & 5.4392 & TRN & \\
\hline CHEMBL1352994 & 688239 & 5.9362 & 5.4216 & TRN & \\
\hline CHEMBL1350461 & 688239 & 5.0362 & 5.4312 & TST & \\
\hline CHEMBL1387550 & 688239 & 4.6862 & 5.4625 & TRN & \\
\hline CHEMBL1583307 & 688239 & 4.6362 & 5.4842 & TRN & \\
\hline CHEMBL1546105 & 688239 & 4.7362 & 5.5718 & TRN & \\
\hline CHEMBL3208524 & 688239 & 5.1362 & 5.3929 & TST & \\
\hline CHEMBL1548079 & 688239 & 6.6861 & 5.5599 & TRN & \\
\hline CHEMBL1385855 & 688239 & 4.6362 & 5.4526 & TRN & \\
\hline CHEMBL1602421 & 688239 & 5.1862 & 5.6123 & TRN & \\
\hline CHEMBL1602961 & 688239 & 4.5362 & 5.4858 & TRN & \\
\hline CHEMBL1539386 & 688239 & 6.1 & 5.6628 & TST & \\
\hline CHEMBL1508120 & 688239 & 4.6362 & 5.4141 & TST & \\
\hline CHEMBL1379305 & 688239 & 5.4862 & 5.4759 & TRN & \\
\hline CHEMBL1375262 & 688239 & 6.3362 & 5.5027 & TRN & \\
\hline CHEMBL1303421 & 688239 & 6.7862 & 5.4379 & TRN & \\
\hline CHEMBL1537292 & 688239 & 4.6362 & 5.4388 & TRN & \\
\hline CHEMBL1335916 & 688239 & 5.2362 & 5.542006 & 3000000001 & TRN \\
\hline CHEMBL1558296 & 688239 & 6.1862 & 5.3665 & TRN & \\
\hline CHEMBL1518886 & 688239 & 6.4362 & 5.4121 & TRN & \\
\hline CHEMBL1497737 & 688239 & 4.9862 & 5.4357 & TRN & \\
\hline CHEMBL1591955 & 688239 & 4.6362 & 5.3842 & TRN & \\
\hline CHEMBL1506482 & 688239 & 4.7862 & 5.3654 & TRN & \\
\hline
\end{tabular}


Supplemental Table S2.txt

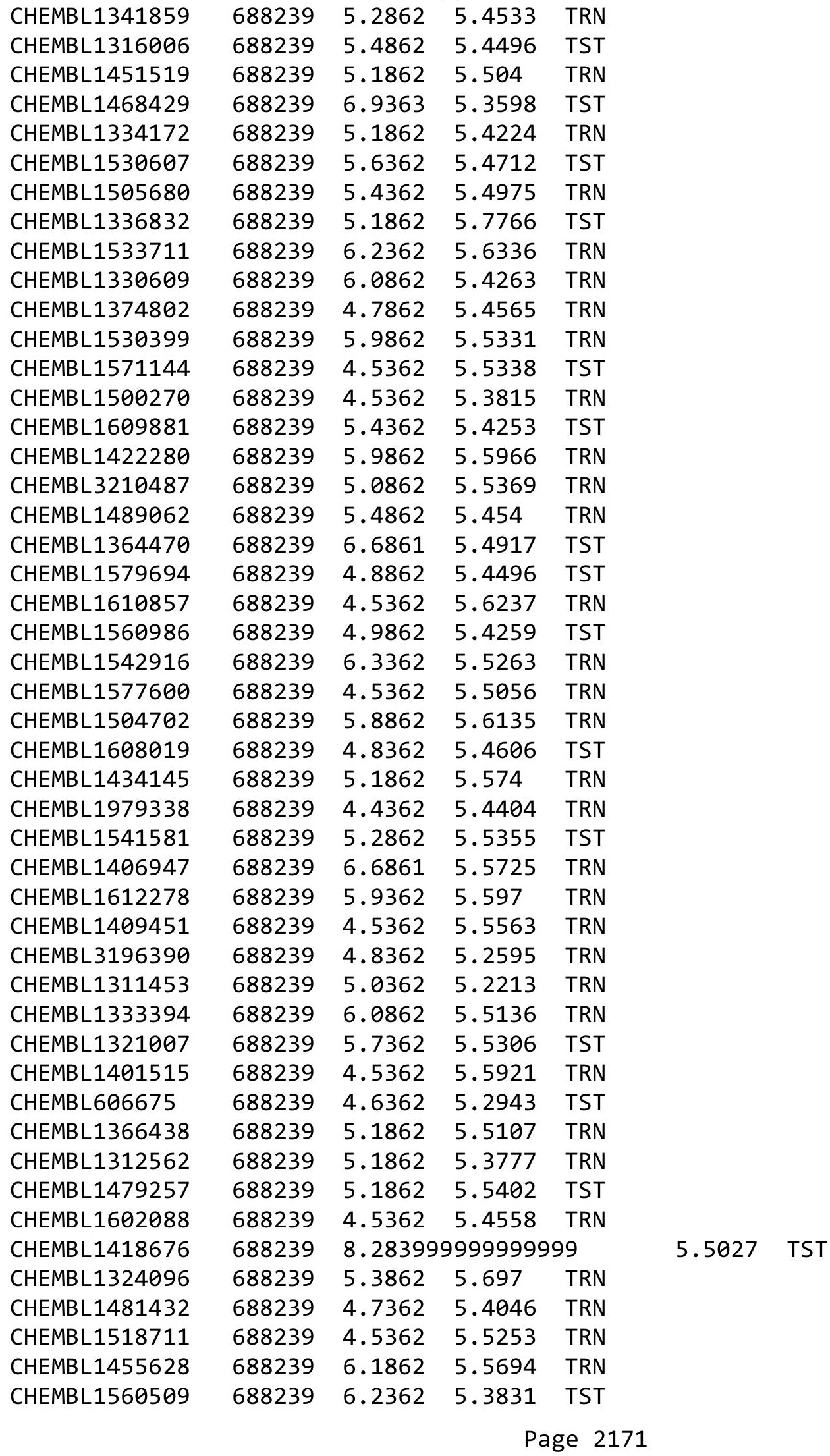


Supplemental Table S2.txt

\begin{tabular}{|c|c|c|c|c|}
\hline . & & & & \\
\hline HEMBL1402068 & 38239 & 362 & 5361 & \\
\hline AEMBL1611177 & 239 & 362 & & \\
\hline 944 & 39 & & & \\
\hline IEMBL15 & & & & \\
\hline AEMBL1611615 & 88239 & 362 & 459 & \\
\hline AEMBL1574280 & 88239 & 862 & 253 & \\
\hline HEMBL1322540 & & & & \\
\hline EMBL3212099 & 39 & 366 & & \\
\hline IEMBL1518701 & & 862 & & \\
\hline AEMBL1402934 & 39 & 362 & 201 & \\
\hline AEMBL3184468 & & 862 & & \\
\hline AEMBL1581720 & & & & \\
\hline IEMBL1445166 & & 362 & & \\
\hline IEMBL1448469 & & 362 & & \\
\hline AEMBL1572452 & & 362 & & \\
\hline AEMBL1557799 & & 862 & & \\
\hline IEMBL1430897 & & 62 & & \\
\hline IEMBL1548311 & & & & \\
\hline IEMBL1361687 & & & & \\
\hline AEMBL1387487 & & 362 & & \\
\hline AEMBL1550618 & & 362 & & \\
\hline AEMBL1536686 & & 62 & & \\
\hline AEMBL1412180 & & & & \\
\hline 841 & & 62 & & \\
\hline 7466 & & 362 & & \\
\hline IEMBL1584147 & & 62 & & \\
\hline AEMBL275000 & & 62 & & \\
\hline 28 & & & & \\
\hline 844 & & 62 & & \\
\hline AEMBL1357321 & & & & \\
\hline HEMBL1330388 & & 362 & & \\
\hline & & & & \\
\hline 53 & & & & \\
\hline & & & & \\
\hline AEMBL1499235 & & & & S \\
\hline AEMBL 2003595 & & 862 & & 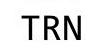 \\
\hline & & 62 & & \\
\hline 1502849 & & & & \\
\hline HEMBL1460306 & & & & RI \\
\hline AEMBL1490691 & & 62 & & $\mathrm{R}$ \\
\hline EMBL14 & & 62 & & \\
\hline 14960 & & & & \\
\hline HEMBL1562141 & & & & \\
\hline AEMBL1558482 & & & & s \\
\hline MBL1381103 & & 362 & & TS \\
\hline & & & & \\
\hline & & & & \\
\hline
\end{tabular}

Page 2172 
Supplemental Table S2.txt

\begin{tabular}{|c|c|c|c|c|c|}
\hline CHEMBL1459351 & 688239 & 4.7362 & 5.5399 & TRN & \\
\hline CHEMBL1419842 & 688239 & 6.8362 & 5.5474 & TRN & \\
\hline CHEMBL1466376 & 688239 & 5.4362 & 5.4867 & TRN & \\
\hline CHEMBL1977188 & 688239 & 4.8362 & 5.3797 & TRN & \\
\hline CHEMBL1467677 & 688239 & 4.9862 & 5.4326 & TRN & \\
\hline CHEMBL1405778 & 688239 & 4.7362 & 5.5995 & TST & \\
\hline CHEMBL1423614 & 688239 & 4.9362 & 5.4692 & TRN & \\
\hline CHEMBL1378982 & 688239 & 5.1862 & 5.4367 & TRN & \\
\hline CHEMBL1584460 & 688239 & 5.5862 & 5.5323 & TRN & \\
\hline CHEMBL1409499 & 688239 & 5.1362 & 5.5093 & TST & \\
\hline CHEMBL1576839 & 688239 & 5.1862 & 5.5002 & TRN & \\
\hline CHEMBL1315986 & 688239 & 6.1862 & 5.4329 & TRN & \\
\hline CHEMBL1498944 & 688239 & 4.5362 & 5.421 & TRN & \\
\hline CHEMBL1308655 & 688239 & 5.3862 & 5.4655 & TRN & \\
\hline CHEMBL1467456 & 688239 & 6.5862 & 5.5516 & TRN & \\
\hline CHEMBL1442615 & 688239 & 6.0862 & 5.4786 & TRN & \\
\hline CHEMBL1528511 & 688239 & 4.7362 & 5.5747 & TRN & \\
\hline CHEMBL1508461 & 688239 & 5.1862 & 5.4868 & TRN & \\
\hline CHEMBL1585428 & 688239 & 6.0362 & 5.5833 & TRN & \\
\hline CHEMBL1462228 & 688239 & 5.3862 & 5.3983 & TST & \\
\hline CHEMBL1578997 & 688239 & 4.6362 & 5.2938 & TRN & \\
\hline CHEMBL1543532 & 688239 & 5.3862 & 5.5658 & TRN & \\
\hline CHEMBL1479206 & 688239 & 5.2362 & 5.5446 & TRN & \\
\hline CHEMBL1595462 & 688239 & 4.7862 & 5.3471 & TST & \\
\hline CHEMBL1315423 & 688239 & 5.0862 & 5.5404 & TRN & \\
\hline CHEMBL1506164 & 688239 & 6.3863 & 5.472 & TST & \\
\hline CHEMBL1600295 & 688239 & 4.5362 & 5.4344 & TRN & \\
\hline CHEMBL1337575 & 688239 & 5.3862 & 5.5578 & TRN & \\
\hline CHEMBL1489028 & 688239 & 4.6862 & 5.609 & TRN & \\
\hline CHEMBL1302557 & 688239 & 6.8362 & 5.4911 & TRN & \\
\hline CHEMBL1339229 & 688239 & 4.6362 & 5.4602 & TST & \\
\hline CHEMBL1366436 & 688239 & 5.1862 & 5.5126 & TRN & \\
\hline CHEMBL1376112 & 688239 & 5.1862 & 5.6534 & TRN & \\
\hline CHEMBL1332888 & 688239 & 5.2362 & 5.7224 & TRN & \\
\hline CHEMBL1407355 & 688239 & 6.0862 & 5.49799 & э999999999 & TRN \\
\hline CHEMBL1534880 & 688239 & 5.9362 & 5.3736 & TRN & \\
\hline CHEMBL3193037 & 688239 & 7.2865 & 5.5253 & TRN & \\
\hline CHEMBL1522700 & 688239 & 5.4862 & 5.5536 & TRN & \\
\hline CHEMBL1401558 & 688239 & 6.4362 & 5.5607 & TRN & \\
\hline CHEMBL1392061 & 688239 & 8.3372 & 5.4729 & TRN & \\
\hline CHEMBL1583128 & 688239 & 6.1862 & 5.4411 & TST & \\
\hline CHEMBL1504031 & 688239 & 4.6862 & 5.4253 & TRN & \\
\hline CHEMBL1517282 & 688239 & 6.5363 & 5.4759 & TST & \\
\hline CHEMBL1603628 & 688239 & 6.5862 & 5.5411 & TRN & \\
\hline CHEMBL1534106 & 688239 & 4.7862 & 5.4879 & TRN & \\
\hline CHEMBL1589219 & 688239 & 4.6862 & 5.4853 & TST & \\
\hline CHEMBL1330047 & 688239 & 6.3362 & 5.5234 & TRN & \\
\hline CHEMBL1302782 & 688239 & 6.3863 & 5.4637 & TST & \\
\hline
\end{tabular}

Page 2173 
Supplemental Table S2.txt

\begin{tabular}{|c|c|c|c|c|}
\hline CHEMBL1607675 & 688239 & 4.5862 & 5.4609 & TRN \\
\hline CHEMBL1591610 & 688239 & 4.5862 & 5.5263 & TRN \\
\hline CHEMBL1496401 & 688239 & 5.7362 & 5.5857 & TRN \\
\hline CHEMBL1509082 & 688239 & 4.5362 & 5.5289 & TRN \\
\hline CHEMBL1564256 & 688239 & 6.7862 & 5.4295 & TRN \\
\hline CHEMBL1315565 & 688239 & 6.1362 & 5.369 & TRN \\
\hline CHEMBL3210974 & 688239 & 5.8362 & 5.4496 & TRN \\
\hline CHEMBL1490848 & 688239 & 6.8362 & 5.4977 & TRN \\
\hline CHEMBL3196429 & 688239 & 5.3862 & 5.4728 & TRN \\
\hline CHEMBL1577974 & 688239 & 5.6362 & 5.5778 & TST \\
\hline CHEMBL1425791 & 688239 & 5.1862 & 5.5029 & TRN \\
\hline CHEMBL1585839 & 688239 & 5.8862 & 5.4196 & TRN \\
\hline CHEMBL1516264 & 688239 & 4.4862 & 5.5546 & TRN \\
\hline CHEMBL1333132 & 688239 & 5.5362 & 5.4544 & TRN \\
\hline CHEMBL1370629 & 688239 & 5.7362 & 5.5024 & TST \\
\hline CHEMBL3198239 & 688239 & 4.5362 & 5.3257 & TRN \\
\hline CHEMBL1433568 & 688239 & 4.6862 & 5.5059 & TRN \\
\hline CHEMBL1322960 & 688239 & 4.5862 & 5.4732 & TRN \\
\hline CHEMBL1427532 & 688239 & 5.1862 & 5.476 & TRN \\
\hline CHEMBL1573470 & 688239 & 5.1862 & 5.5031 & TRN \\
\hline CHEMBL1418715 & 688239 & 4.5362 & 5.3856 & TRN \\
\hline CHEMBL1353729 & 688239 & 4.5362 & 5.504 & TRN \\
\hline CHEMBL1355947 & 688239 & 4.5362 & 5.59399 & 9999999999 \\
\hline CHEMBL1487722 & 688239 & 6.1862 & 5.407 & TRN \\
\hline CHEMBL1470641 & 688239 & 5.8362 & 5.5275 & TST \\
\hline CHEMBL1365554 & 688239 & 6.2862 & 5.5062 & TRN \\
\hline CHEMBL1571955 & 688239 & 7.0362 & 5.2718 & TST \\
\hline CHEMBL1469493 & 688239 & 4.6362 & 5.4669 & TST \\
\hline CHEMBL1336846 & 688239 & 5.4862 & 5.4939 & TRN \\
\hline CHEMBL1604633 & 688239 & 4.7862 & 5.5258 & TRN \\
\hline CHEMBL1502014 & 688239 & 5.2362 & 5.3064 & TST \\
\hline CHEMBL1427147 & 688239 & 4.6862 & 5.6889 & TST \\
\hline CHEMBL1542679 & 688239 & 8.3872 & 5.4184 & TRN \\
\hline CHEMBL1392084 & 688239 & 5.3862 & 5.5814 & TST \\
\hline CHEMBL1319429 & 688239 & 5.3362 & 5.4919 & TST \\
\hline CHEMBL1439138 & 688239 & 6.9863 & 5.398 & TRN \\
\hline CHEMBL1318359 & 688239 & 5.6862 & 5.4352 & TRN \\
\hline CHEMBL3192398 & 688239 & 5.4362 & 5.468 & TRN \\
\hline CHEMBL1471124 & 688239 & 5.7362 & 5.4587 & TRN \\
\hline CHEMBL1510360 & 688239 & 6.2362 & 5.5438 & TST \\
\hline CHEMBL1378752 & 688239 & 5.1362 & 5.4669 & TRN \\
\hline CHEMBL1411074 & 688239 & 4.5362 & 5.5082 & TRN \\
\hline CHEMBL1525413 & 688239 & 6.1362 & 5.4928 & TRN \\
\hline CHEMBL1397712 & 688239 & 4.5362 & 5.6272 & TRN \\
\hline CHEMBL1498989 & 688239 & 8.2366 & 5.3643 & TRN \\
\hline CHEMBL1514549 & 688239 & 4.8362 & 5.3561 & TRN \\
\hline CHEMBL1466944 & 688239 & 5.1862 & 5.3522 & TRN \\
\hline \multirow[t]{2}{*}{ CHEMBL1469768 } & 688239 & 5.7862 & 5.53700 & 0000000001 \\
\hline & & \multicolumn{3}{|c|}{ Page 2174} \\
\hline
\end{tabular}


Supplemental Table S2.txt

\begin{tabular}{|c|c|c|c|c|}
\hline CHEMBL1462525 & 688239 & 8.3872 & 5.4039 & TRN \\
\hline CHEMBL1325597 & 688239 & 4.9362 & 5.6636 & TST \\
\hline CHEMBL1544434 & 688239 & 4.5362 & 5.4131 & TST \\
\hline CHEMBL1584232 & 688239 & 6.7361 & 5.6415 & TRN \\
\hline CHEMBL1571557 & 688239 & 4.5362 & 5.466 & TST \\
\hline CHEMBL1353299 & 688239 & 4.5362 & 5.4196 & TST \\
\hline CHEMBL1566707 & 688239 & 4.5362 & 5.4084 & TST \\
\hline CHEMBL1307297 & 688239 & 6.8861 & 5.5273 & TST \\
\hline CHEMBL1476130 & 688239 & 5.1862 & 5.4157 & TRN \\
\hline CHEMBL3199248 & 688239 & 6.9363 & 5.487 & TRN \\
\hline CHEMBL1333333 & 688239 & 5.1862 & 5.4 & TST \\
\hline CHEMBL1562277 & 688239 & 5.7862 & 5.3555 & TRN \\
\hline CHEMBL1496371 & 688239 & 4.7362 & 5.4256 & TST \\
\hline CHEMBL1584425 & 688239 & 5.1862 & 5.511 & TRN \\
\hline CHEMBL1486458 & 688239 & 4.7362 & 5.579 & TRN \\
\hline CHEMBL1594676 & 688239 & 6.2862 & 5.5217 & TRN \\
\hline CHEMBL1419001 & 688239 & 5.6862 & 5.4972 & TRN \\
\hline CHEMBL1603952 & 688239 & 4.4862 & 5.4397 & TRN \\
\hline CHEMBL1402199 & 688239 & 6.7862 & 5.5303 & TRN \\
\hline CHEMBL1603749 & 688239 & 5.2362 & 5.5037 & TRN \\
\hline CHEMBL1455586 & 688239 & 4.5362 & 5.4453 & TRN \\
\hline CHEMBL1484159 & 688239 & 5.8862 & 5.7355 & TRN \\
\hline CHEMBL1541701 & 688239 & 4.5862 & 5.4981 & TST \\
\hline CHEMBL1476677 & 688239 & 6.5862 & 5.6883 & TST \\
\hline CHEMBL1534346 & 688239 & 5.4862 & 5.4847 & TRN \\
\hline CHEMBL1580974 & 688239 & 4.6362 & 5.4008 & TRN \\
\hline CHEMBL1370270 & 688239 & 4.5362 & 5.4447 & TST \\
\hline CHEMBL1393749 & 688239 & 4.5362 & 5.5071 & TRN \\
\hline CHEMBL1312311 & 688239 & 7.2865 & 5.5069 & TRN \\
\hline CHEMBL1385551 & 688239 & 5.1862 & 5.3446 & TRN \\
\hline CHEMBL1444735 & 688239 & 5.7362 & 5.411000 & 00000000005 \\
\hline CHEMBL1454245 & 688239 & 4.7862 & 5.4444 & TRN \\
\hline CHEMBL1495789 & 688239 & 8.2366 & 5.5813 & TRN \\
\hline CHEMBL1411501 & 688239 & 8.283999 & 999999999 & 5.3221 \\
\hline CHEMBL1411073 & 688239 & 6.8861 & 5.4448 & TRN \\
\hline CHEMBL1539347 & 688239 & 4.7362 & 5.5352 & TRN \\
\hline CHEMBL3192357 & 688239 & 5.0862 & 5.3653 & TRN \\
\hline CHEMBL1497930 & 688239 & 4.4862 & 5.3371 & TST \\
\hline CHEMBL1360868 & 688239 & 8.3372 & 5.3878 & TRN \\
\hline CHEMBL1417355 & 688239 & 8.2366 & 5.6378 & TRN \\
\hline CHEMBL3191688 & 688239 & 4.5862 & 5.3641 & TST \\
\hline CHEMBL1392562 & 688239 & 5.1862 & 5.5127 & TRN \\
\hline CHEMBL1329535 & 688239 & 4.8362 & 5.434 & TRN \\
\hline CHEMBL1394808 & 688239 & 4.6862 & 5.5269 & TRN \\
\hline CHEMBL1423597 & 688239 & 4.5362 & 5.5508 & TST \\
\hline CHEMBL1438196 & 688239 & 6.6362 & 5.4543 & TRN \\
\hline CHEMBL1360837 & 688239 & 4.7862 & 5.4672 & TRN \\
\hline CHEMBL1501209 & 688239 & 4.5362 & 5.5171 & TRN \\
\hline
\end{tabular}


Supplemental Table S2.txt

\begin{tabular}{|c|c|c|c|c|c|}
\hline CHEMBL1611228 & 688239 & 5.6362 & 5.4351 & TRN & \\
\hline CHEMBL1423211 & 688239 & 4.7362 & 5.4459 & TST & \\
\hline CHEMBL1360053 & 688239 & 4.4862 & 5.4125 & TRN & \\
\hline CHEMBL1471355 & 688239 & 6.1862 & 5.5897 & TRN & \\
\hline CHEMBL1538170 & 688239 & 4.5362 & 5.4557 & TRN & \\
\hline CHEMBL1307308 & 688239 & 5.9362 & 5.4055 & TRN & \\
\hline CHEMBL1480690 & 688239 & 5.1862 & 5.4759 & TST & \\
\hline CHEMBL1414002 & 688239 & 6.3863 & 5.6326 & TRN & \\
\hline CHEMBL1364531 & 688239 & 4.7862 & 5.3924 & TRN & \\
\hline CHEMBL1337506 & 688239 & 6.1362 & \multicolumn{2}{|c|}{5.321000000000001} & TRN \\
\hline CHEMBL1450965 & 688239 & 5.8362 & 5.7619 & TRN & \\
\hline CHEMBL1536410 & 688239 & 4.6862 & 5.5297 & TRN & \\
\hline CHEMBL1369475 & 688239 & 4.5362 & 5.4409 & TRN & \\
\hline CHEMBL1330256 & 688239 & 8.3372 & 5.4789 & TRN & \\
\hline CHEMBL1388179 & 688239 & 4.5362 & 5.5576 & TRN & \\
\hline CHEMBL 1425378 & 688239 & 7.5361 & 5.6741 & TRN & \\
\hline CHEMBL1357661 & 688239 & 4.7862 & 5.4028 & TRN & \\
\hline CHEMBL1312927 & 688239 & 4.8862 & 5.7221 & TRN & \\
\hline CHEMBL1324198 & 688239 & 5.7862 & 5.53 & TRN & \\
\hline CHEMBL1412971 & 688239 & 5.9362 & 5.4386 & TRN & \\
\hline CHEMBL1498996 & 688239 & 5.7362 & 5.6083 & TRN & \\
\hline CHEMBL1302584 & 688239 & 4.7362 & 5.4755 & TRN & \\
\hline CHEMBL1362094 & 688239 & 7.0362 & \multicolumn{2}{|c|}{5.492000000000001} & TRN \\
\hline CHEMBL1573939 & 688239 & 6.6362 & 5.3829 & TRN & \\
\hline CHEMBL1378525 & 688239 & 6.0362 & 5.4687 & TRN & \\
\hline CHEMBL1319694 & 688239 & 5.0362 & 5.4312 & TRN & \\
\hline CHEMBL1337871 & 688239 & 5.1862 & 5.441 & TST & \\
\hline CHEMBL1565878 & 688239 & 4.8362 & 5.5017 & TRN & \\
\hline CHEMBL1345679 & 688239 & 4.5362 & 5.4665 & TRN & \\
\hline CHEMBL1441828 & 688239 & 4.5362 & 5.4425 & TRN & \\
\hline CHEMBL1438861 & 688239 & 4.5362 & 5.5556 & TRN & \\
\hline CHEMBL1391548 & 688239 & 6.8362 & 5.6352 & TRN & \\
\hline CHEMBL1310145 & 688239 & 4.6862 & 5.4938 & TRN & \\
\hline CHEMBL1603067 & 688239 & 6.8861 & 5.3045 & TST & \\
\hline CHEMBL1325292 & 688239 & 4.5362 & 5.4964 & TST & \\
\hline CHEMBL1315370 & 688239 & 4.8362 & 5.415 & TRN & \\
\hline CHEMBL1371145 & 688239 & 6.2362 & 5.6587 & TRN & \\
\hline CHEMBL52884 & 688239 & 5.6862 & 5.4406 & TRN & \\
\hline CHEMBL1437524 & 688239 & 6.8362 & 5.4225 & TRN & \\
\hline CHEMBL1344838 & 688239 & 5.1862 & 5.5363 & TST & \\
\hline CHEMBL1589790 & 688239 & 4.5362 & 5.4449 & TRN & \\
\hline CHEMBL1543906 & 688239 & 5.8362 & 5.5407 & TRN & \\
\hline CHEMBL1500161 & 688239 & 5.1362 & 5.2652 & TRN & \\
\hline CHEMBL 3195051 & 688239 & 6.0362 & 5.3328 & TRN & \\
\hline CHEMBL 3194265 & 688239 & 6.8861 & 5.5043 & TRN & \\
\hline CHEMBL1470446 & 688239 & 4.5862 & 5.3583 & TST & \\
\hline CHEMBL1413855 & 688239 & 5.0362 & 5.7009 & TST & \\
\hline CHEMBL1485508 & 688239 & 4.5362 & 5.5138 & TRN & \\
\hline
\end{tabular}


Supplemental Table S2.txt

\begin{tabular}{|c|c|c|c|c|}
\hline CHEMBL3211831 & 688239 & 4.5862 & 5.3812 & TST \\
\hline CHEMBL1428420 & 688239 & 4.5362 & 5.285 & TRN \\
\hline CHEMBL1454803 & 688239 & 5.7362 & 5.4318 & TRN \\
\hline CHEMBL1412629 & 688239 & 5.5362 & 5.2693 & TST \\
\hline CHEMBL1376731 & 688239 & 5.9862 & 5.5286 & TRN \\
\hline CHEMBL1553522 & 688239 & 5.0362 & 5.5929 & TST \\
\hline CHEMBL1598650 & 688239 & 5.1862 & 5.5195 & TRN \\
\hline CHEMBL1409455 & 688239 & 4.9362 & 5.7295 & TRN \\
\hline CHEMBL1300138 & 688239 & 4.5362 & 5.5395 & TRN \\
\hline CHEMBL1534916 & 688239 & 6.0862 & 5.5421 & TRN \\
\hline CHEMBL1304379 & 688239 & 4.5862 & 5.3271 & TRN \\
\hline CHEMBL1444975 & 688239 & 4.6862 & 5.5089 & TRN \\
\hline CHEMBL1432055 & 688239 & 5.4862 & 5.5058 & TRN \\
\hline CHEMBL1540982 & 688239 & 5.1862 & 5.4371 & TRN \\
\hline CHEMBL1563242 & 688239 & 5.4862 & 5.5243 & TST \\
\hline CHEMBL1602914 & 688239 & 4.5362 & 5.6199 & TRN \\
\hline CHEMBL1602227 & 688239 & 4.5862 & 5.4902 & TRN \\
\hline CHEMBL1408580 & 688239 & 4.6362 & 5.4167 & TRN \\
\hline CHEMBL1417403 & 688239 & 5.1862 & \multicolumn{2}{|c|}{5.4670000000000005} \\
\hline CHEMBL1334238 & 688239 & 5.0862 & 5.4373 & TRN \\
\hline CHEMBL1470766 & 688239 & 5.3862 & 5.4556 & TRN \\
\hline CHEMBL1374723 & 688239 & 5.0362 & 5.7293 & TRN \\
\hline CHEMBL1439694 & 688239 & 4.8362 & 5.4744 & TST \\
\hline CHEMBL1424590 & 688239 & 5.2862 & 5.5521 & TRN \\
\hline CHEMBL1558651 & 688239 & 6.4362 & 5.7412 & TRN \\
\hline CHEMBL1598596 & 688239 & 6.7862 & 5.4203 & TRN \\
\hline CHEMBL1461310 & 688239 & 6.9863 & 5.3837 & TST \\
\hline CHEMBL1377754 & 688239 & 4.7362 & 5.6987 & TRN \\
\hline CHEMBL1418805 & 688239 & 5.0862 & 5.5389 & TRN \\
\hline CHEMBL1361373 & 688239 & 4.5362 & 5.5282 & TRN \\
\hline CHEMBL1312630 & 688239 & 4.5362 & 5.3668 & TRN \\
\hline CHEMBL1458111 & 688239 & 6.0362 & 5.4743 & TRN \\
\hline CHEMBL1347742 & 688239 & 4.5362 & 5.3613 & TST \\
\hline CHEMBL1346923 & 688239 & 6.9863 & 5.5356 & TRN \\
\hline CHEMBL1457197 & 688239 & 4.5862 & 5.4278 & TRN \\
\hline CHEMBL1542307 & 688239 & 6.3863 & 5.5336 & TRN \\
\hline CHEMBL1993708 & 688239 & 4.5362 & 5.4463 & TRN \\
\hline CHEMBL1578971 & 688239 & 7.2366 & 5.6069 & TRN \\
\hline CHEMBL1528505 & 688239 & 5.3862 & 5.473 & TST \\
\hline CHEMBL1458947 & 688239 & 4.8362 & 5.476 & TRN \\
\hline CHEMBL1493194 & 688239 & 4.5362 & \multicolumn{2}{|c|}{5.3260000000000005} \\
\hline CHEMBL1347333 & 688239 & 5.1362 & 5.4621 & TST \\
\hline CHEMBL1300290 & 688239 & 5.4862 & 5.6122 & TRN \\
\hline CHEMBL1319748 & 688239 & 5.0362 & 5.626 & TST \\
\hline CHEMBL1995377 & 688239 & 4.7362 & 5.2696 & TRN \\
\hline CHEMBL1413476 & 688239 & 5.7862 & 5.4951 & TST \\
\hline CHEMBL 3199575 & 688239 & 4.6362 & 5.4511 & TRN \\
\hline CHEMBL1479566 & 688239 & 4.6862 & 5.3934 & TRN \\
\hline
\end{tabular}


Supplemental Table S2.txt

\begin{tabular}{|c|c|c|c|c|}
\hline 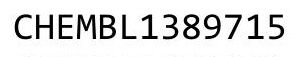 & & & & \\
\hline AEMBL1530261 & 38239 & 9362 & 92 & \\
\hline AEMBL1380691 & 239 & 862 & & \\
\hline & 39 & 362 & & \\
\hline IEMBL15 & 39 & 362 & & \\
\hline AEMBL1365415 & 88239 & 862 & & \\
\hline AEMBL3197486 & 88239 & 4.9862 & 556 & \\
\hline AEMBL1317084 & & & & \\
\hline IEMBL1430077 & 39 & 862 & & \\
\hline IEMBL1301540 & & 862 & & \\
\hline AEMBL1502914 & 239 & 862 & & \\
\hline HEMBL1509940 & 39 & 862 & & \\
\hline AEMBL1532189 & & 862 & & \\
\hline AEMBL1466722 & & 62 & & \\
\hline AEMBL1335452 & & 362 & & \\
\hline AEMBL1443391 & & 362 & & \\
\hline AEMBL1510183 & & 362 & & \\
\hline IEMBL 31941 & & 62 & & \\
\hline AEMBL 1481 & & & & \\
\hline AEMBL1583083 & & & & \\
\hline AEMBL1371833 & & 862 & & \\
\hline AEMBL1500121 & & 63 & & \\
\hline AEMBL1303 & & 62 & & \\
\hline AFMBI 1399 & & & & \\
\hline 30 & & & & \\
\hline AEMBL1395143 & & 862 & & \\
\hline IEMBL1334257 & & 861 & & \\
\hline EMBL151899 & & 63 & & \\
\hline 155 & & & & \\
\hline AEMBL1366743 & & 62 & & \\
\hline AEMBL1547171 & & & & \\
\hline HEMBL1607048 & & 62 & & \\
\hline & & & & \\
\hline$\theta$ & & 52 & & \\
\hline & & & & RN \\
\hline AEMBL1379890 & & & & S \\
\hline AEMBL1356839 & & 862 & & \\
\hline & & & & \\
\hline $3000+8$ & & & & \\
\hline & & & & RN \\
\hline AEMBL1611950 & & 362 & & \\
\hline AEMBL1335355 & & 62 & & \\
\hline חLIDL & & & & \\
\hline HEMBL1503653 & & & & \\
\hline AEMBL1561478 & & & & RN \\
\hline IEMBL1608883 & & 862 & & Ir \\
\hline (1) & & & & \\
\hline HEMBL148408 & & & .5265 & \\
\hline
\end{tabular}


Supplemental Table S2.txt

\begin{tabular}{|c|c|c|c|c|}
\hline & & & & \\
\hline AEMBL1 & 8239 & 363 & & \\
\hline IEMBL1332759 & 8239 & 5862 & 88 & \\
\hline HEMBL1484830 & 239 & .7362 & 1028 & \\
\hline & 239 & 862 & & \\
\hline AFMBI $31 c$ & 239 & 862 & 782 & \\
\hline AEMBL1566567 & 239 & 863 & 5131 & \\
\hline AEMBL1530530 & 88239 & 362 & 5892 & \\
\hline AEMBL1446061 & 239 & 862 & 5822 & \\
\hline IEMBL14 & 239 & 366 & 723 & \\
\hline AEMBL138 & & & & \\
\hline AEMBL1386130 & 688239 & 871 & 4842 & \\
\hline AEMBL1368799 & 239 & 863 & 98 & \\
\hline AEMBL15 & & 66 & & \\
\hline IEMBL14 & & 362 & & \\
\hline HEMBL 141 & & & & \\
\hline AEMBL1349262 & 239 & 862 & 882 & \\
\hline AEMBL1407344 & & 862 & & ST \\
\hline IEMBL15 & & 62 & & \\
\hline HEMBL14 & & & & \\
\hline AEMBL 13 & & 62 & & \\
\hline AEMBL1414740 & & 862 & & \\
\hline AEMBL158 & & 62 & & \\
\hline IEMBL13 & & 62 & & \\
\hline IEMBL15 & & & & $\mathrm{RN}$ \\
\hline AFMRI 15 & & 62 & & $N$ \\
\hline HEMBL131 & & & & RN \\
\hline HEMBL152 & & & & \\
\hline AEMBL 1406 & & 62 & 52 & RI \\
\hline HEMBL 14 & & 52 & 71 & -1 \\
\hline 32 & & 62 & & -8 \\
\hline HEMBL1458350 & & & & $\mathrm{RI}$ \\
\hline AEMBL1558513 & & & & RI \\
\hline IEMBL13 & & 62 & & RI \\
\hline AEMBL14 & & 62 & 87 & . \\
\hline 2 & & & & -6 \\
\hline AEMBL3212639 & & & & RN \\
\hline AEMBL1477645 & & & & \\
\hline IEMBL13 & & 62 & & $S$ \\
\hline רי נחוזו & & & 54 & \\
\hline 546 & & & & RN \\
\hline AEMBL1327118 & & 362 & 3837 & RN \\
\hline AEMBL137 & & & & 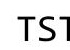 \\
\hline HEMBL135 & & & & \\
\hline CHEMBL1447029 & & & & \\
\hline CHEMBL1335085 & & 862 & & RN \\
\hline AEMBL1566561 & 8239 & 6.3362 & 5.4277 & TS \\
\hline HFMBI 1499629 & 688239 & 4.5862 & 5.5186 & \\
\hline
\end{tabular}


Supplemental Table S2.txt

\begin{tabular}{|c|c|c|c|c|c|}
\hline CHEMBL3192443 & 688239 & 5.4862 & 5.4183 & TST & \\
\hline CHEMBL1405146 & 688239 & 5.2362 & 5.4395 & TST & \\
\hline CHEMBL1364447 & 688239 & 5.5362 & 5.4563 & TST & \\
\hline CHEMBL1382467 & 688239 & 4.5362 & 5.3573 & TRN & \\
\hline CHEMBL1531701 & 688239 & 5.1862 & 5.5338 & TRN & \\
\hline CHEMBL3193919 & 688239 & 6.2362 & 5.4739 & TST & \\
\hline CHEMBL1371165 & 688239 & 4.5362 & 5.5521 & TRN & \\
\hline CHEMBL1360132 & 688239 & 4.5862 & 5.5267 & TRN & \\
\hline CHEMBL1610240 & 688239 & 5.6362 & 5.5445 & TRN & \\
\hline CHEMBL1456876 & 688239 & 6.8362 & 5.4157 & TRN & \\
\hline CHEMBL1383187 & 688239 & 4.9862 & 5.5384 & TRN & \\
\hline CHEMBL1300224 & 688239 & 4.6862 & 5.3952 & TRN & \\
\hline CHEMBL1595712 & 688239 & 6.9863 & 5.5058 & TST & \\
\hline CHEMBL1500215 & 688239 & 4.6862 & 5.4658 & TST & \\
\hline CHEMBL3199325 & 688239 & 6.9363 & 5.4669 & TRN & \\
\hline CHEMBL1981951 & 688239 & 5.1362 & 5.5912 & TRN & \\
\hline CHEMBL1331279 & 688239 & 4.5362 & 5.4314 & TST & \\
\hline CHEMBL3197869 & 688239 & 5.4362 & 5.4131 & TRN & \\
\hline CHEMBL1469678 & 688239 & 6.3362 & 5.4271 & TST & \\
\hline CHEMBL1512778 & 688239 & 5.4862 & \multicolumn{2}{|c|}{5.502999999999999} & TRN \\
\hline CHEMBL1471109 & 688239 & 8.3872 & 5.5735 & TRN & \\
\hline CHEMBL1324074 & 688239 & 4.5362 & 5.5007 & TST & \\
\hline CHEMBL1449391 & 688239 & 5.0862 & 5.5187 & TRN & \\
\hline CHEMBL1379348 & 688239 & 5.5862 & 5.435 & TRN & \\
\hline CHEMBL1324631 & 688239 & 5.3862 & 5.567 & TRN & \\
\hline CHEMBL1441379 & 688239 & 4.6862 & 5.5535 & TST & \\
\hline CHEMBL1481775 & 688239 & 5.5362 & 5.5345 & TRN & \\
\hline CHEMBL1591864 & 688239 & 5.9362 & 5.5751 & TRN & \\
\hline CHEMBL1463667 & 688239 & 4.4862 & 5.3475 & TRN & \\
\hline CHEMBL1543839 & 688239 & 4.8362 & 5.556 & TRN & \\
\hline CHEMBL1431859 & 688239 & 5.1862 & 5.635 & TST & \\
\hline CHEMBL1331506 & 688239 & 5.9362 & 5.5209 & TRN & \\
\hline CHEMBL1320402 & 688239 & 5.0862 & 5.4172 & TRN & \\
\hline CHEMBL1419753 & 688239 & 5.4362 & 5.5895 & TRN & \\
\hline CHEMBL1392808 & 688239 & 5.2862 & 5.5174 & TRN & \\
\hline CHEMBL1299711 & 688239 & 4.6362 & 5.4373 & TRN & \\
\hline CHEMBL1483532 & 688239 & 4.4862 & 5.6272 & TRN & \\
\hline CHEMBL1395716 & 688239 & 4.7862 & \multicolumn{2}{|c|}{5.468999999999999} & TRN \\
\hline CHEMBL1469556 & 688239 & 4.5362 & 5.4559 & TRN & \\
\hline CHEMBL1412613 & 688239 & 5.2862 & 5.416 & TRN & \\
\hline CHEMBL1322928 & 688239 & 6.1862 & 5.4915 & TST & \\
\hline CHEMBL1406978 & 688239 & 4.5362 & 5.5023 & TST & \\
\hline CHEMBL1439685 & 688239 & 5.0862 & 5.5449 & TRN & \\
\hline CHEMBL3209326 & 688239 & 4.8362 & \multicolumn{2}{|c|}{5.4879999999999995} & TRN \\
\hline CHEMBL1478114 & 688239 & 7.0862 & 5.5376 & TRN & \\
\hline CHEMBL1451260 & 688239 & 5.4862 & 5.5711 & TST & \\
\hline CHEMBL1585257 & 688239 & 4.6362 & 5.42299 & 9999999999 & TST \\
\hline CHEMBL1366546 & 688239 & 6.0862 & 5.51399 & 9999999999 & TRN \\
\hline
\end{tabular}

Page 2180 


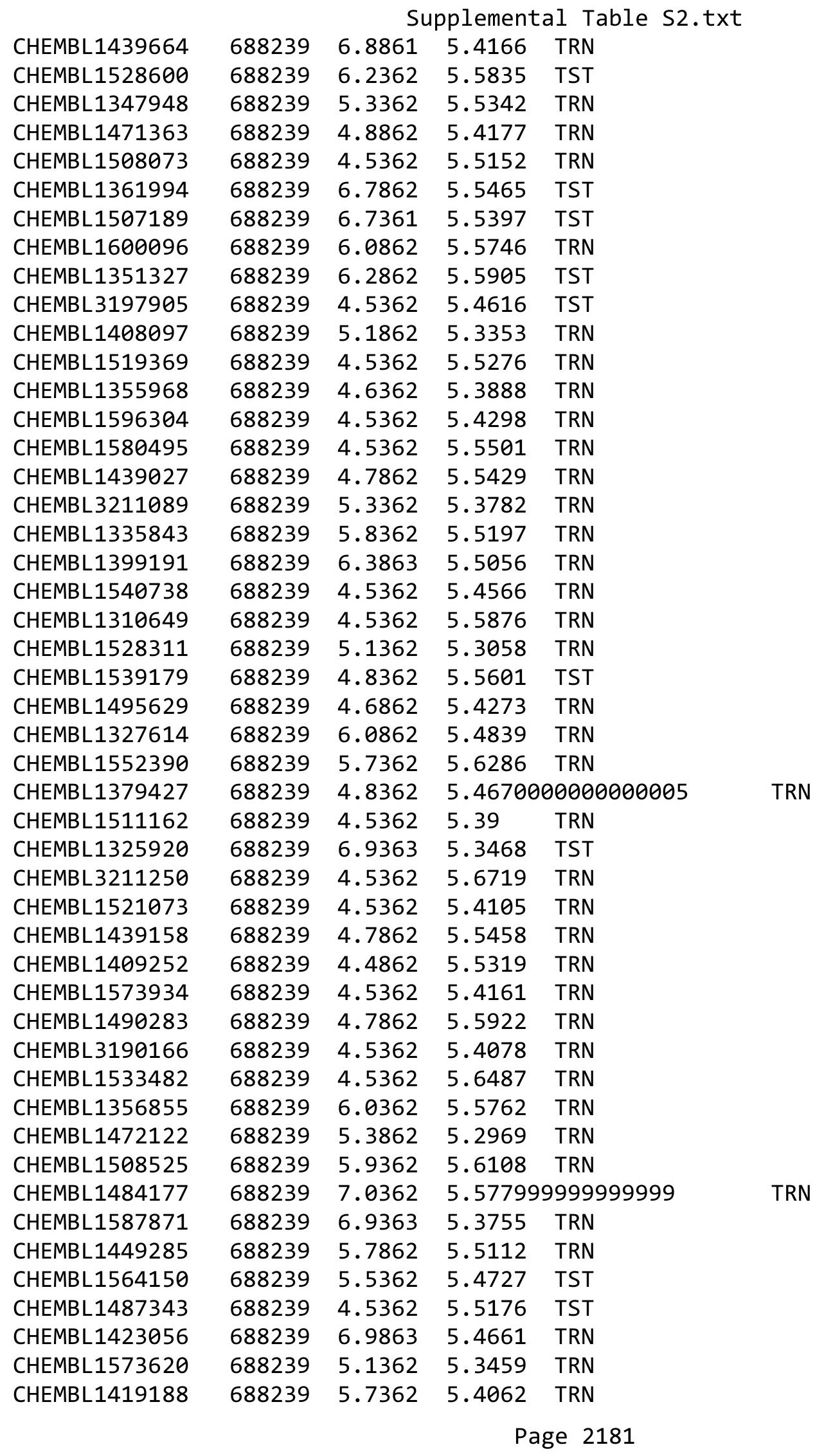


Supplemental Table S2.txt

\begin{tabular}{|c|c|c|c|c|}
\hline & & & & \\
\hline AEMBL16 & 8239 & 4862 & & \\
\hline IEMBL239322 & 8239 & 9863 & & \\
\hline AEMBL1572013 & 239 & .7862 & 46 & \\
\hline & 239 & 863 & & \\
\hline IEMBL1579619 & 239 & 862 & & \\
\hline AEMBL1495375 & 88239 & 862 & 887 & \\
\hline AEMBL1530453 & 88239 & 362 & 148 & \\
\hline AEMBL1454320 & 239 & 862 & & \\
\hline IEMBL31 & 239 & 362 & & \\
\hline AEMBL1495261 & & 62 & & \\
\hline AEMBL1551299 & 688239 & 862 & 79 & \\
\hline AEMBL3196130 & 239 & 362 & & \\
\hline IEMBL1348562 & & 62 & & \\
\hline IEMBL154 & & 362 & & \\
\hline HEMBL136 & & & & \\
\hline AEMBL1454051 & 39 & 362 & & \\
\hline AEMBL1608193 & & 862 & & \\
\hline IEMBL14 & & 362 & & \\
\hline HEMBL13 & & & & \\
\hline AFMRI 13 & & & & \\
\hline AEMBL1429865 & & 862 & & \\
\hline AEMBL1357435 & & 62 & & \\
\hline IEMBL 88 & & 362 & & \\
\hline IEMBL14 & & 72 & & \\
\hline AFMRI 14 & & 62 & & \\
\hline AEMBL388823 & & 862 & & \\
\hline AEMBL1304161 & & & & \\
\hline AEMBL1450067 & & 62 & & RN \\
\hline 944 & & 52 & & 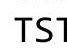 \\
\hline 958 & & 62 & & 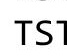 \\
\hline HEMBL1331857 & & & & ST \\
\hline AEMBL1433709 & & & & $\mathrm{RI}$ \\
\hline EMBL49: & & 862 & & ST 1 \\
\hline 642 & & 62 & & 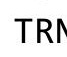 \\
\hline 5 & & & & 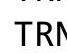 \\
\hline AEMBL1310392 & & & & ST 1 \\
\hline AEMBL3190230 & & & & $S T$ \\
\hline IEMBL13 & & 62 & & RI \\
\hline ב נחצו & & & & \\
\hline & & & & RI \\
\hline HEMBL1392289 & & 862 & & RI \\
\hline IEMBL1539824 & & & & \\
\hline - & & & & \\
\hline CHEMBL1479181 & & & & \\
\hline CHEMBL1408223 & & 362 & & RN \\
\hline AEMBL15587 & 8239 & 5.1862 & 5.4542 & \\
\hline HFMRI $149399 ?$ & 688239 & 5.3862 & 5.5952 & \\
\hline
\end{tabular}

Page 2182 


\begin{tabular}{|c|c|c|c|c|c|}
\hline \multicolumn{6}{|c|}{ Supplemental Table S2.txt } \\
\hline CHEMBL1410089 & 688239 & 8.2366 & 5.4002 & TRN & \\
\hline CHEMBL1310477 & 688239 & 4.5362 & 5.5717 & TRN & \\
\hline CHEMBL1551109 & 688239 & 6.6861 & 5.6094 & TRN & \\
\hline CHEMBL1600288 & 688239 & 5.3862 & 5.49700 & 0000000001 & TRN \\
\hline CHEMBL3211990 & 688239 & 5.1362 & 5.4801 & TRN & \\
\hline CHEMBL1565496 & 688239 & 4.7362 & 5.3086 & TST & \\
\hline CHEMBL3198619 & 688239 & 4.5362 & 5.5481 & TST & \\
\hline CHEMBL1568052 & 688239 & 4.5862 & 5.3085 & TRN & \\
\hline CHEMBL1344683 & 688239 & 6.6362 & 5.6461 & TRN & \\
\hline CHEMBL1492211 & 688239 & 5.4362 & 5.358 & TRN & \\
\hline CHEMBL1524694 & 688239 & 4.5362 & 5.4959 & TRN & \\
\hline CHEMBL1329330 & 688239 & 4.5362 & 5.3549 & TRN & \\
\hline CHEMBL1549860 & 688239 & 5.6862 & 5.4173 & TRN & \\
\hline CHEMBL1320796 & 688239 & 5.4862 & 5.334 & TRN & \\
\hline CHEMBL1590924 & 688239 & 8.3372 & 5.37799 & 7999999999 & TRN \\
\hline CHEMBL1348142 & 688239 & 5.1362 & 5.5126 & TRN & \\
\hline CHEMBL1310611 & 688239 & 5.1862 & 5.4688 & TRN & \\
\hline CHEMBL1445883 & 688239 & 4.8362 & 5.6262 & TST & \\
\hline CHEMBL3195263 & 688239 & 6.1862 & 5.4429 & TST & \\
\hline CHEMBL1578329 & 688239 & 4.8862 & 5.4652 & TRN & \\
\hline CHEMBL1467785 & 688239 & 4.6862 & 5.4742 & TRN & \\
\hline CHEMBL1583819 & 688239 & 6.2362 & 5.505 & TRN & \\
\hline CHEMBL1522031 & 688239 & 4.5362 & 5.4509 & TRN & \\
\hline CHEMBL1399597 & 688239 & 5.8362 & 5.3486 & TRN & \\
\hline CHEMBL1546050 & 688239 & 6.8861 & 5.5628 & TRN & \\
\hline CHEMBL1364310 & 688239 & 4.4862 & 5.8284 & TRN & \\
\hline CHEMBL1470361 & 688239 & 4.5362 & 5.7631 & TRN & \\
\hline CHEMBL1406181 & 688239 & 4.5862 & 5.6892 & TRN & \\
\hline CHEMBL1445741 & 688239 & 5.2862 & 5.5662 & TST & \\
\hline CHEMBL1461487 & 688239 & 4.7362 & 5.4816 & TRN & \\
\hline CHEMBL1458254 & 688239 & 4.5862 & 5.4621 & TST & \\
\hline CHEMBL1426224 & 688239 & 5.1862 & 5.4924 & TRN & \\
\hline CHEMBL1354085 & 688239 & 5.7362 & 5.59 & TRN & \\
\hline CHEMBL1534893 & 688239 & 5.6862 & 5.4218 & TRN & \\
\hline CHEMBL1594184 & 688239 & 4.6862 & 5.3855 & TST & \\
\hline CHEMBL1311347 & 688239 & 5.2362 & 5.3961 & TST & \\
\hline CHEMBL1415803 & 688239 & 4.6362 & 5.3841 & TRN & \\
\hline CHEMBL1564856 & 688239 & 5.0362 & 5.4117 & TRN & \\
\hline CHEMBL1557343 & 688239 & 4.8362 & 5.5966 & TRN & \\
\hline CHEMBL1460658 & 688239 & 4.5362 & 5.5263 & TRN & \\
\hline CHEMBL1438477 & 688239 & 5.1862 & 5.4172 & TRN & \\
\hline CHEMBL1580859 & 688239 & 4.6862 & 5.5451 & TRN & \\
\hline CHEMBL1494612 & 688239 & 4.5362 & 5.4755 & TRN & \\
\hline CHEMBL1427785 & 688239 & 5.1862 & 5.5767 & TRN & \\
\hline CHEMBL1462086 & 688239 & 6.4362 & 5.4418 & TST & \\
\hline CHEMBL1328698 & 688239 & 4.6362 & 5.3157 & TRN & \\
\hline CHEMBL1564041 & 688239 & 6.2862 & 5.695 & TRN & \\
\hline CHEMBL1323663 & 688239 & 5.1862 & 5.4928 & TST & \\
\hline
\end{tabular}




\begin{tabular}{|c|c|c|c|c|c|}
\hline & & & & & \\
\hline CHEMBL1376093 & 688239 & 6.7361 & 5.6452 & TRN & \\
\hline CHEMBL1322057 & 688239 & 4.7862 & 5.5523 & TRN & \\
\hline CHEMBL1432019 & 688239 & 5.1362 & 5.5342 & TRN & \\
\hline CHEMBL1528864 & 688239 & 4.5362 & 5.4089 & TST & \\
\hline CHEMBL1441208 & 688239 & 4.7362 & 5.6107 & TST & \\
\hline CHEMBL1376559 & 688239 & 5.6862 & 5.46899 & 9999999999 & TRN \\
\hline CHEMBL1378046 & 688239 & 6.0862 & 5.5251 & TRN & \\
\hline CHEMBL1378276 & 688239 & 4.6862 & 5.4144 & TRN & \\
\hline CHEMBL1572994 & 688239 & 6.3362 & 5.5118 & TRN & \\
\hline CHEMBL1486307 & 688239 & 4.7862 & 5.3805 & TRN & \\
\hline CHEMBL1569742 & 688239 & 4.5362 & 5.5106 & TRN & \\
\hline CHEMBL1505925 & 688239 & 6.2862 & 5.5178 & TST & \\
\hline CHEMBL1299890 & 688239 & 4.8362 & 5.5062 & TRN & \\
\hline CHEMBL1516419 & 688239 & 5.4362 & 5.5206 & TRN & \\
\hline CHEMBL1576331 & 688239 & 5.9362 & 5.6854 & TRN & \\
\hline CHEMBL1465026 & 688239 & 4.6862 & 5.5357 & TRN & \\
\hline CHEMBL1436473 & 688239 & 5.0362 & 5.3728 & TRN & \\
\hline CHEMBL1477326 & 688239 & 5.3862 & 5.5256 & TRN & \\
\hline CHEMBL1446929 & 688239 & 4.5862 & 5.5705 & TST & \\
\hline CHEMBL1540108 & 688239 & 5.1362 & 5.5454 & TRN & \\
\hline CHEMBL1561270 & 688239 & 4.7862 & 5.4652 & TRN & \\
\hline CHEMBL1469996 & 688239 & 4.5362 & 5.41 & TST & \\
\hline CHEMBL1405987 & 688239 & 4.7362 & 5.4185 & TRN & \\
\hline CHEMBL1602659 & 688239 & 5.4362 & 5.5393 & TRN & \\
\hline CHEMBL1591923 & 688239 & 5.6362 & 5.4308 & TST & \\
\hline CHEMBL1343399 & 688239 & 5.2862 & 5.4942 & TST & \\
\hline CHEMBL1299932 & 688239 & 4.6362 & 5.6443 & TRN & \\
\hline CHEMBL1378101 & 688239 & 6.2862 & 5.6279 & TRN & \\
\hline CHEMBL1305232 & 688239 & 5.4862 & 5.5467 & TRN & \\
\hline CHEMBL1580798 & 688239 & 5.6862 & 5.4841 & TRN & \\
\hline CHEMBL1323804 & 688239 & 6.7862 & 5.4369 & TRN & \\
\hline CHEMBL1366837 & 688239 & 4.7362 & 5.5153 & TRN & \\
\hline CHEMBL1556120 & 688239 & 5.6862 & 5.5006 & TRN & \\
\hline CHEMBL1534707 & 688239 & 5.2362 & 5.3903 & TRN & \\
\hline CHEMBL1386210 & 688239 & 6.0362 & 5.4691 & TRN & \\
\hline CHEMBL1480035 & 688239 & 4.6862 & 5.5039 & TST & \\
\hline CHEMBL1605864 & 688239 & 6.2362 & 5.5546 & TRN & \\
\hline CHEMBL1517691 & 688239 & 4.8862 & 5.4056 & TRN & \\
\hline CHEMBL1353997 & 688239 & 5.1862 & 5.372006 & 0000000001 & TRN \\
\hline CHEMBL1346570 & 688239 & 6.7862 & 5.445 & TRN & \\
\hline CHEMBL1595442 & 688239 & 6.1862 & 5.4849 & TST & \\
\hline CHEMBL1485852 & 688239 & 5.5362 & 5.5374 & TRN & \\
\hline CHEMBL1441513 & 688239 & 5.8862 & 5.4153 & TST & \\
\hline CHEMBL1388691 & 688239 & 4.5362 & 5.3838 & TRN & \\
\hline CHEMBL1551421 & 688239 & 4.5362 & 5.4312 & TRN & \\
\hline CHEMBL1390000 & 688239 & 5.1862 & 5.4057 & TRN & \\
\hline CHEMBL1430703 & 688239 & 5.1362 & 5.361006 & 0000000001 & TRN \\
\hline CHEMBL1301201 & 688239 & 5.4862 & 5.4442 & TRN & \\
\hline
\end{tabular}




\begin{tabular}{|c|c|c|c|c|c|c|}
\hline & & \multicolumn{4}{|c|}{ Supplemental Table S2.txt } & \multirow[b]{2}{*}{ TRN } \\
\hline CHEMBL 313443 & 688239 & 8.28399 & 79999999 & & 5.5233 & \\
\hline CHEMBL1485479 & 688239 & 5.1862 & 5.5468 & TST & & \\
\hline CHEMBL1546258 & 688239 & 5.1362 & 5.4553 & TRN & & \\
\hline CHEMBL1527782 & 688239 & 4.5362 & 5.4976 & TRN & & \\
\hline CHEMBL1303902 & 688239 & 6.3362 & 5.3552 & TRN & & \\
\hline CHEMBL1475447 & 688239 & 5.6362 & 5.4936 & TRN & & \\
\hline CHEMBL1356482 & 688239 & 6.1362 & 5.4332 & TST & & \\
\hline CHEMBL1333904 & 688239 & \multicolumn{3}{|c|}{8.283999999999999} & 5.4274 & TRN \\
\hline CHEMBL1965784 & 688239 & 6.6362 & 5.4375 & TRN & & \\
\hline CHEMBL1594349 & 688239 & 6.9363 & 5.4183 & TRN & & \\
\hline CHEMBL1432010 & 688239 & 4.5362 & 5.6154 & TRN & & \\
\hline CHEMBL1345429 & 688239 & 5.5362 & 5.4378 & TRN & & \\
\hline CHEMBL1566854 & 688239 & 4.6862 & 5.4845 & TST & & \\
\hline CHEMBL1444588 & 688239 & 6.9863 & 5.4379 & TRN & & \\
\hline CHEMBL1598311 & 688239 & 4.5362 & 5.3687 & TRN & & \\
\hline CHEMBL1390932 & 688239 & 5.1862 & 5.5782 & TST & & \\
\hline CHEMBL1399620 & 688239 & 6.5363 & 5.4545 & TRN & & \\
\hline CHEMBL1307657 & 688239 & 6.9363 & 5.6896 & TRN & & \\
\hline CHEMBL1327997 & 688239 & 6.1862 & 5.6614 & TRN & & \\
\hline CHEMBL1444159 & 688239 & 6.2862 & 5.5556 & TRN & & \\
\hline CHEMBL1529744 & 688239 & 5.1862 & \multicolumn{3}{|c|}{5.507000000000001} & TRN \\
\hline CHEMBL1426057 & 688239 & 6.7862 & 5.4281 & TST & & \\
\hline CHEMBL1600063 & 688239 & 6.1862 & 5.4896 & TRN & & \\
\hline CHEMBL1597766 & 688239 & 4.9862 & 5.5592 & TST & & \\
\hline CHEMBL1327017 & 688239 & 4.5362 & 5.4542 & TRN & & \\
\hline CHEMBL3192296 & 688239 & 4.7362 & 5.5339 & TRN & & \\
\hline CHEMBL1536361 & 688239 & 5.7362 & 5.4869 & TRN & & \\
\hline CHEMBL1367036 & 688239 & 6.9863 & 5.5942 & TST & & \\
\hline CHEMBL1316843 & 688239 & 8.1871 & 5.4015 & TRN & & \\
\hline CHEMBL1541330 & 688239 & 4.9862 & 5.5647 & TST & & \\
\hline CHEMBL1331533 & 688239 & \multicolumn{3}{|c|}{8.283999999999999} & 5.4493 & TRN \\
\hline CHEMBL1426948 & 688239 & 5.1862 & 5.4098 & TST & & \\
\hline CHEMBL1511746 & 688239 & 5.8362 & 5.4546 & TRN & & \\
\hline CHEMBL1525680 & 688239 & 5.1862 & 5.495 & TRN & & \\
\hline CHEMBL1462600 & 688239 & \multicolumn{3}{|c|}{8.283999999999999} & 5.5172 & TRN \\
\hline CHEMBL1558251 & 688239 & 7.2865 & 5.5918 & TST & & \\
\hline CHEMBL1359360 & 688239 & 4.5362 & 5.3507 & TRN & & \\
\hline CHEMBL1483240 & 688239 & 4.5362 & 5.5638 & TRN & & \\
\hline CHEMBL3207632 & 688239 & 6.9363 & 5.4864 & TRN & & \\
\hline CHEMBL1301370 & 688239 & 4.6862 & 5.4863 & TST & & \\
\hline CHEMBL1412570 & 688239 & 4.6362 & 5.4252 & TRN & & \\
\hline CHEMBL1339218 & 688239 & 5.0862 & 5.4228 & TRN & & \\
\hline CHEMBL1447655 & 688239 & 6.5363 & 5.5842 & TST & & \\
\hline CHEMBL1327298 & 688239 & 4.7362 & 5.5097 & TST & & \\
\hline CHEMBL3212066 & 688239 & 5.4362 & 5.4488 & TRN & & \\
\hline CHEMBL1368884 & 688239 & 5.3862 & 5.5395 & TRN & & \\
\hline CHEMBL 3212788 & 688239 & 6.1362 & 5.5405 & TRN & & \\
\hline CHEMBL1447134 & 688239 & 6.5363 & 5.3918 & TST & & \\
\hline
\end{tabular}


Supplemental Table S2.txt

\begin{tabular}{|c|c|c|c|c|c|}
\hline CHEMBL1385863 & 688239 & 6.5363 & \multicolumn{2}{|c|}{5.5089999999999995} & TRN \\
\hline CHEMBL1384845 & 688239 & 5.9362 & 5.4175 & TRN & \\
\hline CHEMBL1448603 & 688239 & 6.1362 & 5.4215 & TRN & \\
\hline CHEMBL1543690 & 688239 & 4.5362 & 5.4656 & TST & \\
\hline CHEMBL1489586 & 688239 & 5.2862 & 5.6406 & TRN & \\
\hline CHEMBL1535020 & 688239 & 4.4862 & 5.4968 & TST & \\
\hline CHEMBL1348886 & 688239 & 5.0362 & 5.4696 & TRN & \\
\hline CHEMBL1548667 & 688239 & 6.9863 & 5.6474 & TRN & \\
\hline CHEMBL1386251 & 688239 & 8.1871 & 5.3518 & TRN & \\
\hline CHEMBL1539715 & 688239 & 4.7862 & 5.5391 & TST & \\
\hline CHEMBL3208061 & 688239 & 8.3872 & 5.5343 & TRN & \\
\hline CHEMBL1425439 & 688239 & 6.9363 & 5.5141 & TST & \\
\hline CHEMBL1526565 & 688239 & 6.0 & 5.4551 & TST & \\
\hline CHEMBL1564893 & 688239 & 4.6862 & 5.483 & TRN & \\
\hline CHEMBL1415403 & 688239 & 4.6362 & 5.4861 & TRN & \\
\hline CHEMBL1476924 & 688239 & 4.7862 & 5.4638 & TRN & \\
\hline CHEMBL1459350 & 688239 & 4.5362 & 5.3988 & TST & \\
\hline CHEMBL1340533 & 688239 & 5.6362 & 5.4848 & TRN & \\
\hline CHEMBL1492290 & 688239 & 4.8862 & \multicolumn{2}{|c|}{5.5889999999999995} & TRN \\
\hline CHEMBL1379644 & 688239 & 4.6362 & 5.4515 & TRN & \\
\hline CHEMBL1368857 & 688239 & 7.2366 & 5.4526 & TST & \\
\hline CHEMBL1366638 & 688239 & 7.1361 & 5.4889 & TRN & \\
\hline CHEMBL3190271 & 688239 & 6.0862 & 5.4868 & TST & \\
\hline CHEMBL1421611 & 688239 & 5.0862 & 5.599 & TST & \\
\hline CHEMBL1449226 & 688239 & 5.8362 & 5.485 & TRN & \\
\hline CHEMBL1359594 & 688239 & 4.7362 & 5.4675 & TRN & \\
\hline CHEMBL1322835 & 688239 & 5.3862 & 5.4481 & TRN & \\
\hline CHEMBL1522007 & 688239 & 4.9862 & 5.4613 & TST & \\
\hline CHEMBL1339067 & 688239 & 5.7862 & 5.3586 & TRN & \\
\hline CHEMBL1543625 & 688239 & 6.2362 & 5.5091 & TRN & \\
\hline CHEMBL1467945 & 688239 & 5.5862 & 5.6228 & TRN & \\
\hline CHEMBL3208109 & 688239 & 4.5362 & 5.4818 & TRN & \\
\hline CHEMBL1450102 & 688239 & 5.4362 & 5.5069 & TST & \\
\hline CHEMBL1602388 & 688239 & 4.7362 & 5.4417 & TRN & \\
\hline CHEMBL1332981 & 688239 & 5.2362 & 5.659 & TST & \\
\hline CHEMBL1344362 & 688239 & 6.7361 & 5.394 & TRN & \\
\hline CHEMBL1386662 & 688239 & 5.9362 & 5.5621 & TST & \\
\hline CHEMBL1310283 & 688239 & 4.5362 & 5.5442 & TST & \\
\hline CHEMBL1499700 & 688239 & 6.0362 & 5.3672 & TRN & \\
\hline CHEMBL1493220 & 688239 & 6.3362 & 5.5776 & TST & \\
\hline CHEMBL1300071 & 688239 & 5.2862 & 5.4853 & TST & \\
\hline CHEMBL1317839 & 688239 & 4.5362 & 5.4317 & TRN & \\
\hline CHEMBL1452986 & 688239 & 4.8862 & 5.4795 & TST & \\
\hline CHEMBL1307378 & 688239 & 5.7362 & 5.5834 & TRN & \\
\hline CHEMBL1378308 & 688239 & 6.1362 & \multicolumn{2}{|c|}{5.5920000000000005} & TRN \\
\hline CHEMBL1505621 & 688239 & 4.5362 & 5.4932 & TRN & \\
\hline CHEMBL1550529 & 688239 & 5.1862 & 5.5241 & TRN & \\
\hline CHEMBL1604835 & 688239 & 5.9362 & 5.5102 & TRN & \\
\hline
\end{tabular}


Supplemental Table S2.txt

\begin{tabular}{|c|c|c|c|c|}
\hline CHEMBL1345778 & 688239 & 5.7862 & 5.6358 & TRN \\
\hline CHEMBL1497998 & 688239 & 4.9362 & 5.5539 & TST \\
\hline CHEMBL1304518 & 688239 & 8.28399 & 99999999 & 5.499 \\
\hline CHEMBL1383639 & 688239 & 5.3362 & 5.4495 & TRN \\
\hline CHEMBL1427571 & 688239 & 6.0862 & 5.4198 & TRN \\
\hline CHEMBL1499346 & 688239 & 4.6362 & 5.5249 & TRN \\
\hline CHEMBL1468126 & 688239 & 4.5362 & 5.4338 & TRN \\
\hline CHEMBL1370465 & 688239 & 4.7862 & 5.4727 & TRN \\
\hline CHEMBL1320334 & 688239 & 4.8362 & 5.5483 & TST \\
\hline CHEMBL1458484 & 688239 & 5.2862 & 5.3252 & TRN \\
\hline CHEMBL1474100 & 688239 & 6.0 & 5.4574 & TRN \\
\hline CHEMBL1450310 & 688239 & 4.5362 & 5.4357 & TRN \\
\hline CHEMBL1465564 & 688239 & 4.4862 & 5.6373 & TRN \\
\hline CHEMBL1415427 & 688239 & 5.2862 & 5.6474 & TST \\
\hline CHEMBL1493643 & 688239 & 6.3863 & 5.5106 & TRN \\
\hline CHEMBL451532 & 688239 & 5.0362 & 5.3317 & TST \\
\hline CHEMBL1501750 & 688239 & 4.4862 & 5.5226 & TRN \\
\hline CHEMBL1377510 & 688239 & 6.7361 & 5.5062 & TST \\
\hline CHEMBL1505485 & 688239 & 5.8362 & 5.4657 & TRN \\
\hline CHEMBL1443885 & 688239 & 6.6362 & 5.4788 & TRN \\
\hline CHEMBL1420596 & 688239 & 4.7362 & 5.4661 & TRN \\
\hline CHEMBL1359354 & 688239 & 4.9362 & 5.5822 & TRN \\
\hline CHEMBL1313134 & 688239 & 4.5362 & 5.4304 & TRN \\
\hline CHEMBL1504570 & 688239 & 6.8362 & 5.5846 & TRN \\
\hline CHEMBL1570777 & 688239 & 5.0362 & 5.6734 & TRN \\
\hline CHEMBL1401040 & 688239 & 6.2362 & 5.472 & TRN \\
\hline CHEMBL1478484 & 688239 & 4.5362 & 5.5606 & TST \\
\hline CHEMBL1581835 & 688239 & 5.4862 & 5.6127 & TRN \\
\hline CHEMBL1438087 & 688239 & 6.6861 & 5.6836 & TRN \\
\hline CHEMBL1542292 & 688239 & 6.6861 & 5.401 & TRN \\
\hline CHEMBL1587842 & 688239 & 5.6862 & 5.4858 & TRN \\
\hline CHEMBL1447202 & 688239 & 4.6362 & 5.6342 & TRN \\
\hline CHEMBL1586740 & 688239 & 6.6362 & 5.5163 & TRN \\
\hline CHEMBL1559832 & 688239 & 7.2865 & 5.5252 & TRN \\
\hline CHEMBL3197952 & 688239 & 4.5362 & 5.3689 & TST \\
\hline CHEMBL1398887 & 688239 & 4.9 & 5.4594 & TRN \\
\hline CHEMBL1498002 & 688239 & 4.6362 & 5.7383 & TRN \\
\hline CHEMBL1300911 & 688239 & 5.2862 & \multicolumn{2}{|c|}{5.5520000000000005} \\
\hline CHEMBL1436618 & 688239 & 5.8362 & 5.347 & TRN \\
\hline CHEMBL1557197 & 688239 & 4.5362 & 5.5668 & TRN \\
\hline CHEMBL1500290 & 688239 & 4.8362 & 5.5223 & TRN \\
\hline CHEMBL1384194 & 688239 & 5.3862 & 5.4673 & TRN \\
\hline CHEMBL1455945 & 688239 & 5.0862 & 5.5056 & TRN \\
\hline CHEMBL1564320 & 688239 & 5.6862 & 5.5429 & TRN \\
\hline CHEMBL1589722 & 688239 & 5.1862 & 5.4655 & TRN \\
\hline CHEMBL1299980 & 688239 & 4.5362 & 5.5491 & TST \\
\hline CHEMBL1482269 & 688239 & 5.0862 & 5.5394 & TST \\
\hline CHEMBL1361538 & 688239 & 5.3362 & 5.54 & TRN \\
\hline
\end{tabular}


Supplemental Table S2.txt

\begin{tabular}{|c|c|c|c|c|c|}
\hline CHEMBL1613141 & 688239 & 7.0862 & 5.4453 & TRN & \\
\hline CHEMBL1513790 & 688239 & 4.6862 & 5.4404 & TRN & \\
\hline CHEMBL1425428 & 688239 & 6.7862 & 5.3681 & TST & \\
\hline CHEMBL1536641 & 688239 & 7.2865 & 5.5784 & TST & \\
\hline CHEMBL1504879 & 688239 & 4.5362 & 5.5391 & TST & \\
\hline CHEMBL1532072 & 688239 & 4.6362 & 5.4451 & TRN & \\
\hline CHEMBL 3192148 & 688239 & 5.1862 & 5.4384 & TRN & \\
\hline CHEMBL1541206 & 688239 & 5.7862 & 5.4162 & TRN & \\
\hline CHEMBL1393757 & 688239 & 6.1862 & 5.4349 & TRN & \\
\hline CHEMBL1549914 & 688239 & 4.5362 & 5.5623 & TST & \\
\hline CHEMBL1417671 & 688239 & 5.0862 & 5.6773 & TST & \\
\hline CHEMBL 3194873 & 688239 & 5.1862 & 5.3509 & TRN & \\
\hline CHEMBL1546098 & 688239 & 5.3862 & 5.5476 & TRN & \\
\hline CHEMBL1587366 & 688239 & 5.0362 & 5.3297 & TST & \\
\hline CHEMBL1488440 & 688239 & 4.5362 & 5.4003 & TRN & \\
\hline CHEMBL1433304 & 688239 & 5.4862 & 5.6198 & TRN & \\
\hline CHEMBL1355334 & 688239 & 4.5362 & 5.4882 & TST & \\
\hline CHEMBL1581082 & 688239 & 4.5362 & 5.4335 & TRN & \\
\hline CHEMBL1489333 & 688239 & 4.5362 & 5.4349 & TRN & \\
\hline CHEMBL1353340 & 688239 & 6.6362 & 5.5015 & TST & \\
\hline CHEMBL1338860 & 688239 & 5.3362 & 5.3481 & TRN & \\
\hline CHEMBL1326813 & 688239 & 5.5362 & 5.456 & TST & \\
\hline CHEMBL1559491 & 688239 & 6.5363 & 5.4059 & TST & \\
\hline CHEMBL1321203 & 688239 & 6.9363 & 5.5381 & TRN & \\
\hline CHEMBL1417900 & 688239 & 4.5362 & 5.4873 & TST & \\
\hline CHEMBL1341779 & 688239 & 5.7362 & 5.657 & TRN & \\
\hline CHEMBL1604077 & 688239 & 5.7862 & 5.6801 & TST & \\
\hline CHEMBL1310848 & 688239 & 4.5362 & 5.3016 & TRN & \\
\hline CHEMBL1351184 & 688239 & 4.6362 & 5.3598 & TRN & \\
\hline CHEMBL1446108 & 688239 & 5.1862 & 5.7303 & TRN & \\
\hline CHEMBL1388260 & 688239 & 4.5362 & 5.4795 & TST & \\
\hline CHEMBL1597816 & 688239 & 6.1862 & 5.4188 & TRN & \\
\hline CHEMBL1313215 & 688239 & 7.6861 & 5.5364 & TRN & \\
\hline CHEMBL1519466 & 688239 & 4.6862 & 5.5747 & TRN & \\
\hline CHEMBL1539219 & 688239 & 6.0362 & 5.5354 & TRN & \\
\hline CHEMBL1515863 & 688239 & 4.5862 & 5.4436 & TRN & \\
\hline CHEMBL1347540 & 688239 & 6.1862 & 5.4392 & TRN & \\
\hline CHEMBL1492241 & 688239 & 5.6362 & 5.439 & TRN & \\
\hline CHEMBL1431246 & 688239 & 5.4862 & 5.46200 & 0000000001 & TRN \\
\hline CHEMBL1579544 & 688239 & 6.2362 & 5.5609 & TRN & \\
\hline CHEMBL1613644 & 688239 & 5.0862 & 5.3446 & TST & \\
\hline CHEMBL1303151 & 688239 & 5.5862 & 5.6374 & TRN & \\
\hline CHEMBL1344751 & 688239 & 6.0862 & 5.4914 & TRN & \\
\hline CHEMBL1564277 & 688239 & 4.8362 & 5.5818 & TRN & \\
\hline CHEMBL1407826 & 688239 & 5.6362 & 5.5746 & TST & \\
\hline CHEMBL1544934 & 688239 & 5.1862 & 5.354 & TRN & \\
\hline CHEMBL1594781 & 688239 & 5.6362 & 5.4081 & TRN & \\
\hline CHEMBL1353867 & 688239 & 5.1862 & 5.4908 & TRN & \\
\hline
\end{tabular}


Supplemental Table S2.txt

\begin{tabular}{|c|c|c|c|c|c|c|}
\hline CHEMBL1419356 & 688239 & 7.0862 & 5.5255 & TRN & & \\
\hline CHEMBL1336089 & 688239 & 4.5362 & 5.4704 & TRN & & \\
\hline CHEMBL1327443 & 688239 & 6.0 & 5.3592 & TRN & & \\
\hline CHEMBL1586431 & 688239 & 6.1862 & 5.4105 & TRN & & \\
\hline CHEMBL3212858 & 688239 & 5.1862 & 5.4603 & TRN & & \\
\hline CHEMBL1518150 & 688239 & 5.1362 & 5.5272 & TRN & & \\
\hline CHEMBL1310322 & 688239 & 4.8862 & 5.3412 & TST & & \\
\hline CHEMBL1490253 & 688239 & 4.6862 & 5.5132 & TRN & & \\
\hline CHEMBL1505311 & 688239 & 6.0362 & 5.5441 & TRN & & \\
\hline CHEMBL3214124 & 688239 & 4.6362 & 5.4013 & TRN & & \\
\hline CHEMBL1304069 & 688239 & 4.5362 & 5.5383 & TRN & & \\
\hline CHEMBL1509716 & 688239 & 7.0362 & 5.4375 & TST & & \\
\hline CHEMBL1476877 & 688239 & 4.7362 & 5.6027 & TST & & \\
\hline CHEMBL1324062 & 688239 & 4.4862 & 5.3696 & TRN & & \\
\hline CHEMBL3196432 & 688239 & 4.6362 & 5.4799 & TRN & & \\
\hline CHEMBL1548871 & 688239 & 6.8362 & 5.3866 & TRN & & \\
\hline CHEMBL1531531 & 688239 & 5.7362 & 5.5051 & TRN & & \\
\hline CHEMBL1444755 & 688239 & 5.7362 & 5.447 & TST & & \\
\hline CHEMBL1528139 & 688239 & 4.5362 & 5.5 & TRN & & \\
\hline CHEMBL1542072 & 688239 & 5.5862 & 5.5705 & TRN & & \\
\hline CHEMBL1328649 & 688239 & 4.7362 & 5.516 & TRN & & \\
\hline CHEMBL1487212 & 688239 & 6.0862 & 5.3475 & TST & & \\
\hline CHEMBL1336638 & 688239 & 6.5862 & 5.4351 & TRN & & \\
\hline CHEMBL1492237 & 688239 & 6.8861 & 5.4653 & TRN & & \\
\hline CHEMBL1593204 & 688239 & 4.5362 & 5.5276 & TRN & & \\
\hline CHEMBL1447616 & 688239 & 4.7862 & 5.4383 & TST & & \\
\hline CHEMBL1491030 & 688239 & 6.1362 & 5.5536 & TST & & \\
\hline CHEMBL1575836 & 688239 & 6.5862 & 5.513 & TST & & \\
\hline CHEMBL1393432 & 688239 & 6.7862 & 5.4308 & TRN & & \\
\hline CHEMBL1547666 & 688239 & 6.0862 & 5.5177 & TRN & & \\
\hline CHEMBL1477212 & 688239 & 4.5 & 5.5973 & TST & & \\
\hline CHEMBL1611525 & 688239 & 8.28399 & 99999999 & 9 & 5.4789 & TST \\
\hline CHEMBL1230004 & 688239 & 4.5362 & 5.5077 & TST & & \\
\hline CHEMBL1403692 & 688239 & 5.1362 & 5.5198 & TRN & & \\
\hline CHEMBL1544661 & 688239 & 5.1862 & 5.5814 & TRN & & \\
\hline CHEMBL1347375 & 688239 & 4.5362 & 5.3945 & TRN & & \\
\hline CHEMBL1367092 & 688239 & 4.5362 & 5.4564 & TST & & \\
\hline CHEMBL3197711 & 688239 & 4.4862 & 5.3895 & TRN & & \\
\hline CHEMBL1601250 & 688239 & 4.5362 & 5.5168 & TRN & & \\
\hline CHEMBL1516444 & 688239 & 6.8362 & 5.5535 & TRN & & \\
\hline CHEMBL1479856 & 688239 & 4.4862 & 5.4863 & TRN & & \\
\hline CHEMBL1452069 & 688239 & 5.8362 & 5.6353 & TRN & & \\
\hline CHEMBL1414940 & 688239 & 6.0862 & 5.5087 & TRN & & \\
\hline CHEMBL1451509 & 688239 & 5.7862 & 5.5437 & TRN & & \\
\hline CHEMBL1321144 & 688239 & 5.6362 & 5.4831 & TST & & \\
\hline CHEMBL1310856 & 688239 & 5.2362 & 5.567 & TRN & & \\
\hline CHEMBL1550962 & 688239 & 7.1864 & 5.4013 & TRN & & \\
\hline CHEMBL1165723 & 688239 & 5.1862 & 5.3202 & TRN & & \\
\hline
\end{tabular}

Page 2189 
Supplemental Table S2.txt

\begin{tabular}{|c|c|c|c|c|}
\hline CHEMBL1484772 & 688239 & 5.1862 & 5.4405 & TRN \\
\hline CHEMBL1613139 & 688239 & 5.4862 & 5.4271 & TRN \\
\hline CHEMBL1585124 & 688239 & 5.2362 & 5.4982 & TRN \\
\hline CHEMBL1505823 & 688239 & 5.2862 & 5.6162 & TRN \\
\hline CHEMBL1422460 & 688239 & 6.1862 & 5.5889 & TRN \\
\hline CHEMBL1965236 & 688239 & 5.4362 & 5.3761 & TRN \\
\hline CHEMBL1497589 & 688239 & 6.3362 & 5.5563 & TRN \\
\hline CHEMBL1523178 & 688239 & 5.7362 & 5.6182 & TRN \\
\hline CHEMBL3195415 & 688239 & 6.8861 & 5.6385 & TRN \\
\hline CHEMBL1352517 & 688239 & 4.8362 & 5.5986 & TRN \\
\hline CHEMBL1465083 & 688239 & 4.6362 & 5.5112 & TST \\
\hline CHEMBL1523874 & 688239 & 5.1862 & 5.343 & TRN \\
\hline CHEMBL1578781 & 688239 & 4.7362 & 5.4912 & TRN \\
\hline CHEMBL1308161 & 688239 & 4.5362 & 5.3963 & TRN \\
\hline CHEMBL1344192 & 688239 & 5.0862 & 5.617999 & 999999999 \\
\hline CHEMBL1610424 & 688239 & 5.4362 & 5.5037 & TRN \\
\hline CHEMBL1320073 & 688239 & 4.6862 & 5.3596 & TST \\
\hline CHEMBL1440695 & 688239 & 5.9362 & 5.38 & TRN \\
\hline CHEMBL1522189 & 688239 & 5.2362 & 5.4914 & TST \\
\hline CHEMBL1606372 & 688239 & 5.0862 & 5.5001 & TRN \\
\hline CHEMBL1328418 & 688239 & 6.4362 & 5.6007 & TST \\
\hline CHEMBL1530052 & 688239 & 5.4862 & 5.5505 & TRN \\
\hline CHEMBL1386129 & 688239 & 6.8362 & 5.4465 & TRN \\
\hline CHEMBL1336955 & 688239 & 5.1862 & 5.4349 & TRN \\
\hline CHEMBL1485045 & 688239 & 4.5362 & 5.5112 & TST \\
\hline CHEMBL1453118 & 688239 & 4.6362 & 5.4984 & TST \\
\hline CHEMBL1351136 & 688239 & 4.5362 & 5.6234 & TRN \\
\hline CHEMBL1463275 & 688239 & 4.5362 & 5.6039 & TRN \\
\hline CHEMBL1461991 & 688239 & 4.5362 & 5.4192 & TRN \\
\hline CHEMBL490355 & 688239 & 4.5362 & 5.3452 & TRN \\
\hline CHEMBL1426601 & 688239 & 4.9362 & 5.5575 & TRN \\
\hline CHEMBL1493191 & 688239 & 5.6862 & 5.4212 & TRN \\
\hline CHEMBL1350792 & 688239 & 4.6862 & 5.4473 & TRN \\
\hline CHEMBL1409989 & 688239 & 5.0862 & 5.5156 & TRN \\
\hline CHEMBL1366481 & 688239 & 6.0362 & \multicolumn{2}{|c|}{5.452000000000001} \\
\hline CHEMBL1423304 & 688239 & 6.3863 & 5.4661 & TRN \\
\hline CHEMBL1498017 & 688239 & 5.2862 & 5.5491 & TRN \\
\hline CHEMBL1439564 & 688239 & 6.3863 & 5.4867 & TRN \\
\hline CHEMBL3209160 & 688239 & 4.5362 & 5.6142 & TRN \\
\hline CHEMBL1407632 & 688239 & 4.5362 & 5.4956 & TRN \\
\hline CHEMBL1302160 & 688239 & 6.8362 & 5.5629 & TRN \\
\hline CHEMBL1532191 & 688239 & 4.5362 & 5.475 & TRN \\
\hline CHEMBL1400345 & 688239 & 4.7862 & 5.5973 & TRN \\
\hline CHEMBL1560002 & 688239 & 6.1362 & 5.5067 & TST \\
\hline CHEMBL1546883 & 688239 & 6.5862 & 5.5775 & TRN \\
\hline CHEMBL1549106 & 688239 & 6.4862 & 5.5639 & TST \\
\hline CHEMBL 3145286 & 688239 & 7.1361 & 5.3457 & TST \\
\hline CHEMBL1537623 & 688239 & 4.7362 & 5.4637 & TRN \\
\hline
\end{tabular}

Page 2190 
Supplemental Table S2.txt

\begin{tabular}{|c|c|c|c|c|}
\hline CHEMBL1327775 & 688239 & 6.1862 & 5.5104 & TRN \\
\hline CHEMBL1541781 & 688239 & 6.0862 & 5.6408 & TST \\
\hline CHEMBL1445060 & 688239 & 4.5362 & 5.5317 & TRN \\
\hline CHEMBL1392683 & 688239 & 5.8862 & \multicolumn{2}{|c|}{5.3629999999999995} \\
\hline CHEMBL1400572 & 688239 & 5.2362 & 5.5131 & TRN \\
\hline CHEMBL1469993 & 688239 & 5.0362 & 5.6332 & TRN \\
\hline CHEMBL1446935 & 688239 & 5.2362 & 5.4894 & TST \\
\hline CHEMBL1478975 & 688239 & 4.6862 & 5.4742 & TRN \\
\hline CHEMBL1361331 & 688239 & 5.4862 & 5.5452 & TST \\
\hline CHEMBL1524095 & 688239 & 5.3862 & \multicolumn{2}{|c|}{5.507999999999999} \\
\hline CHEMBL1612236 & 688239 & 6.1862 & 5.478 & TST \\
\hline CHEMBL1353322 & 688239 & 4.5362 & 5.4601 & TST \\
\hline CHEMBL1569740 & 688239 & 5.1862 & 5.561 & TRN \\
\hline CHEMBL1530766 & 688239 & 4.9362 & 5.4592 & TRN \\
\hline CHEMBL1501944 & 688239 & 5.1362 & 5.5465 & TST \\
\hline CHEMBL1381458 & 688239 & 5.5862 & 5.426 & TST \\
\hline CHEMBL1319956 & 688239 & 5.1862 & 5.3968 & TST \\
\hline CHEMBL1589586 & 688239 & 4.5362 & 5.6292 & TRN \\
\hline CHEMBL1326049 & 688239 & 6.0362 & 5.354 & TRN \\
\hline CHEMBL1337645 & 688239 & 6.3362 & 5.4412 & TRN \\
\hline CHEMBL1349890 & 688239 & 6.8362 & 5.4369 & TST \\
\hline CHEMBL1362194 & 688239 & 5.1862 & 5.6084 & TRN \\
\hline CHEMBL1430831 & 688239 & 4.4862 & 5.3627 & TST \\
\hline CHEMBL1325235 & 688239 & 5.9362 & 5.5217 & TRN \\
\hline CHEMBL1557427 & 688239 & 6.4862 & 5.5178 & TRN \\
\hline CHEMBL1575769 & 688239 & 6.3362 & 5.5246 & TRN \\
\hline CHEMBL1423996 & 688239 & 6.5363 & 5.4381 & TST \\
\hline CHEMBL1547053 & 688239 & 5.1862 & 5.4534 & TRN \\
\hline CHEMBL1524081 & 688239 & 4.6362 & 5.3046 & TRN \\
\hline CHEMBL 3192186 & 688239 & 4.7362 & 5.3543 & TRN \\
\hline CHEMBL1467470 & 688239 & 4.9862 & 5.5264 & TRN \\
\hline CHEMBL 3193350 & 688239 & 4.7862 & 5.3897 & TRN \\
\hline CHEMBL1324385 & 688239 & 5.4362 & \multicolumn{2}{|c|}{5.4910000000000005} \\
\hline CHEMBL1351296 & 688239 & 5.5862 & 5.6352 & TRN \\
\hline CHEMBL1499035 & 688239 & 6.8861 & 5.4095 & TST \\
\hline CHEMBL1378296 & 688239 & 6.2862 & 5.4939 & TST \\
\hline CHEMBL1403746 & 688239 & 4.5362 & 5.6152 & TRN \\
\hline CHEMBL1511511 & 688239 & 6.9363 & 5.5879 & TRN \\
\hline CHEMBL1367634 & 688239 & 5.7862 & 5.603 & TST \\
\hline CHEMBL1271322 & 688239 & 5.2362 & 5.4609 & TRN \\
\hline CHEMBL1995385 & 688239 & 4.6362 & 5.2235 & TRN \\
\hline CHEMBL1394233 & 688239 & 5.1862 & 5.48 & TRN \\
\hline CHEMBL1385756 & 688239 & 5.1862 & 5.5276 & TST \\
\hline CHEMBL1612710 & 688239 & 5.5862 & 5.5501 & TRN \\
\hline CHEMBL1557668 & 688239 & 5.2362 & 5.3723 & TRN \\
\hline CHEMBL1468322 & 688239 & 6.0362 & 5.5547 & TRN \\
\hline CHEMBL1372586 & 688239 & 4.5362 & 5.4861 & TST \\
\hline CHEMBL1544761 & 688239 & 4.9862 & 5.5325 & TRN \\
\hline
\end{tabular}

Page 2191 
Supplemental Table S2.txt

\begin{tabular}{|c|c|c|c|c|}
\hline CHEMBL1609566 & 688239 & 5.8862 & 5.4513 & TST \\
\hline CHEMBL1367459 & 688239 & 5.7362 & 5.3882 & TRN \\
\hline CHEMBL1449941 & 688239 & 5.6862 & 5.5474 & TST \\
\hline CHEMBL1523917 & 688239 & 4.8862 & 5.4744 & TRN \\
\hline CHEMBL1563875 & 688239 & 6.7862 & 5.5187 & TRN \\
\hline CHEMBL1333093 & 688239 & 5.4862 & 5.5256 & TRN \\
\hline CHEMBL1546453 & 688239 & 5.6362 & 5.5115 & TST \\
\hline CHEMBL1563886 & 688239 & 4.5862 & 5.6823 & TRN \\
\hline CHEMBL1385065 & 688239 & 5.0362 & 5.4458 & TRN \\
\hline CHEMBL1560248 & 688239 & 5.1862 & 5.5675 & TRN \\
\hline CHEMBL1363206 & 688239 & 4.5362 & 5.3108 & TRN \\
\hline CHEMBL 1486785 & 688239 & 4.6362 & 5.425 & TRN \\
\hline CHEMBL1482150 & 688239 & 6.1862 & 5.6248 & TST \\
\hline CHEMBL1579462 & 688239 & 5.7362 & 5.5513 & TST \\
\hline CHEMBL1373619 & 688239 & 5.3362 & 5.5832 & TRN \\
\hline CHEMBL1469474 & 688239 & 4.5362 & 5.4741 & TRN \\
\hline CHEMBL1474442 & 688239 & 6.6362 & 5.4957 & TRN \\
\hline CHEMBL1349141 & 688239 & 4.6862 & 5.4876 & TRN \\
\hline CHEMBL1593757 & 688239 & 6.1362 & 5.3585 & TST \\
\hline CHEMBL1427622 & 688239 & 4.8362 & 5.5574 & TRN \\
\hline CHEMBL1339588 & 688239 & 4.5362 & 5.5252 & TRN \\
\hline CHEMBL1471792 & 688239 & 4.6862 & 5.4903 & TST \\
\hline CHEMBL1595248 & 688239 & 4.5362 & 5.4962 & TRN \\
\hline CHEMBL1572329 & 688239 & 5.0362 & 5.3293 & TRN \\
\hline CHEMBL1299725 & 688239 & 7.0362 & 5.4736 & TRN \\
\hline CHEMBL1456949 & 688239 & 5.4362 & 5.2357 & TST \\
\hline CHEMBL1429446 & 688239 & 6.9863 & 5.4498 & TRN \\
\hline CHEMBL1314462 & 688239 & 5.2362 & 5.4454 & TRN \\
\hline CHEMBL1385017 & 688239 & 4.5362 & 5.468999 & 9999999999 \\
\hline CHEMBL1575641 & 688239 & 4.7362 & 5.5633 & TRN \\
\hline CHEMBL1377501 & 688239 & 8.28399 & 99999999 & 5.4908 \\
\hline CHEMBL1520729 & 688239 & 5.1362 & 5.4061 & TST \\
\hline CHEMBL1384625 & 688239 & 4.6862 & 5.5909 & TRN \\
\hline CHEMBL1560001 & 688239 & 5.1862 & 5.3365 & TRN \\
\hline CHEMBL1413691 & 688239 & 5.6862 & 5.5094 & TRN \\
\hline CHEMBL1354064 & 688239 & 4.7362 & 5.6092 & TRN \\
\hline CHEMBL1491187 & 688239 & 6.8861 & 5.4749 & TRN \\
\hline CHEMBL1563783 & 688239 & 5.7862 & 5.51 & TRN \\
\hline CHEMBL1470618 & 688239 & 4.7362 & 5.5889 & TRN \\
\hline CHEMBL1547110 & 688239 & 5.3362 & 5.6799 & TST \\
\hline CHEMBL1515191 & 688239 & 5.1862 & 5.5534 & TRN \\
\hline CHEMBL1562666 & 688239 & 4.5362 & 5.5733 & TRN \\
\hline CHEMBL1573534 & 688239 & 6.0 & 5.4931 & TRN \\
\hline CHEMBL1328257 & 688239 & 6.1862 & 5.5108 & TRN \\
\hline CHEMBL1523421 & 688239 & 8.1871 & 5.4739 & TRN \\
\hline CHEMBL1376451 & 688239 & 6.2362 & 5.4354 & TST \\
\hline CHEMBL198666 & 688239 & 5.4362 & 5.5402 & TRN \\
\hline CHEMBL1543612 & 688239 & 6.1362 & 5.6556 & TST \\
\hline
\end{tabular}


Supplemental Table S2.txt

\begin{tabular}{|c|c|c|c|c|c|}
\hline CHEMBL1565636 & 688239 & 4.7362 & 5.556 & TRN & \\
\hline CHEMBL1576853 & 688239 & 4.5362 & 5.5645 & TRN & \\
\hline CHEMBL1485465 & 688239 & 5.6862 & 5.5034 & TRN & \\
\hline CHEMBL1594767 & 688239 & 4.5362 & 5.4194 & TRN & \\
\hline CHEMBL1581754 & 688239 & 5.7362 & 5.643 & TRN & \\
\hline CHEMBL1330630 & 688239 & 4.5362 & 5.4868 & TRN & \\
\hline CHEMBL1608783 & 688239 & 5.1862 & 5.5395 & TRN & \\
\hline CHEMBL1301168 & 688239 & 6.5363 & 5.5519 & TST & \\
\hline CHEMBL1316371 & 688239 & 5.3862 & 5.4134 & TRN & \\
\hline CHEMBL1307642 & 688239 & 4.8362 & 5.457999 & 999999999 & $T$ \\
\hline CHEMBL1510524 & 688239 & 4.7362 & 5.5541 & TRN & \\
\hline CHEMBL1311750 & 688239 & 8.28399 & 99999999 & 5.5355 & וכו \\
\hline CHEMBL1579139 & 688239 & 4.5362 & 5.5489 & TRN & \\
\hline CHEMBL1520008 & 688239 & 4.6862 & 5.4951 & TRN & \\
\hline CHEMBL1443705 & 688239 & 4.45 & 5.5081 & TRN & \\
\hline CHEMBL1354434 & 688239 & 4.5362 & 5.4477 & TRN & \\
\hline CHEMBL1312404 & 688239 & 6.3362 & 5.5277 & TST & \\
\hline CHEMBL1576215 & 688239 & 4.5362 & 5.5251 & TST & \\
\hline CHEMBL1585267 & 688239 & 4.5362 & 5.4643 & TRN & \\
\hline CHEMBL1376067 & 688239 & 4.5862 & 5.3997 & TRN & \\
\hline CHEMBL1540187 & 688239 & 4.45 & 5.6292 & TST & \\
\hline CHEMBL1421984 & 688239 & 4.7862 & 5.6333 & TRN & \\
\hline CHEMBL3196316 & 688239 & 5.6862 & 5.4258 & TRN & \\
\hline CHEMBL1455928 & 688239 & 6.9863 & 5.5676 & TRN & \\
\hline CHEMBL1462414 & 688239 & 6.5363 & 5.4327 & TRN & \\
\hline CHEMBL1532150 & 688239 & 5.1862 & 5.5671 & TRN & \\
\hline CHEMBL1390494 & 688239 & 4.5362 & 5.4525 & TRN & \\
\hline CHEMBL1415184 & 688239 & 6.0362 & 5.5996 & TRN & \\
\hline CHEMBL1609236 & 688239 & 5.7362 & 5.3669 & TST & \\
\hline CHEMBL1430085 & 688239 & 4.6362 & 5.3661 & TRN & \\
\hline CHEMBL1457121 & 688239 & 5.4362 & 5.5803 & TST & \\
\hline CHEMBL1348906 & 688239 & 6.2362 & 5.4438 & TRN & \\
\hline CHEMBL1410935 & 688239 & 4.4862 & 5.4141 & TST & \\
\hline CHEMBL1985330 & 688239 & 5.5362 & 5.3392 & TRN & \\
\hline CHEMBL1582891 & 688239 & 4.8362 & 5.5687 & TRN & \\
\hline CHEMBL1411428 & 688239 & 8.3372 & 5.5955 & TST & \\
\hline CHEMBL1376889 & 688239 & 5.4862 & 5.5023 & TRN & \\
\hline CHEMBL1366524 & 688239 & 6.6861 & 5.3958 & TST & \\
\hline CHEMBL1320705 & 688239 & 5.0362 & 5.4354 & TST & \\
\hline CHEMBL1405840 & 688239 & 4.5362 & 5.3974 & TRN & \\
\hline CHEMBL1545391 & 688239 & 4.8362 & 5.5349 & TRN & \\
\hline CHEMBL1382901 & 688239 & 4.7362 & 5.577000 & 000000001 & $\mathrm{nI}$ \\
\hline CHEMBL1467811 & 688239 & 4.9 & 5.4994 & TST & \\
\hline CHEMBL1336345 & 688239 & 4.6862 & 5.4711 & TST & \\
\hline CHEMBL1567875 & 688239 & 6.0862 & 5.4599 & TRN & \\
\hline CHEMBL1323692 & 688239 & 5.8362 & 5.4198 & TRN & \\
\hline CHEMBL1322362 & 688239 & 6.4862 & 5.4912 & TRN & \\
\hline CHEMBL1552366 & 688239 & 4.7362 & 5.4033 & TRN & \\
\hline
\end{tabular}

Page 2193 
Supplemental Table S2.txt

\begin{tabular}{|c|c|c|c|c|}
\hline CHEMBL1603444 & 688239 & 4.5362 & 5.4253 & TRN \\
\hline CHEMBL1463127 & 688239 & 6.9863 & 5.4816 & TRN \\
\hline CHEMBL1490601 & 688239 & 4.6862 & 5.4996 & TRN \\
\hline CHEMBL1417473 & 688239 & 6.8861 & 5.4023 & TRN \\
\hline CHEMBL1444874 & 688239 & 6.2362 & 5.4691 & TRN \\
\hline CHEMBL1399154 & 688239 & 4.9362 & 5.5596 & TRN \\
\hline CHEMBL1316983 & 688239 & 4.7862 & \multicolumn{2}{|c|}{5.3660000000000005} \\
\hline CHEMBL1495655 & 688239 & 4.6862 & 5.4223 & TRN \\
\hline CHEMBL1360866 & 688239 & 4.7362 & 5.4071 & TRN \\
\hline CHEMBL1319210 & 688239 & 5.3362 & 5.4231 & TRN \\
\hline CHEMBL1501716 & 688239 & 5.2362 & 5.2715 & TRN \\
\hline CHEMBL1085765 & 688239 & 4.7362 & 5.2122 & TRN \\
\hline CHEMBL1392285 & 688239 & 5.0362 & 5.6652 & TRN \\
\hline CHEMBL 3210260 & 688239 & 4.5362 & 5.4826 & TRN \\
\hline CHEMBL1469893 & 688239 & 5.0362 & 5.3949 & TST \\
\hline CHEMBL1405530 & 688239 & 4.8362 & 5.5448 & TRN \\
\hline CHEMBL1347894 & 688239 & 5.5862 & 5.3912 & TRN \\
\hline CHEMBL1608134 & 688239 & 4.7862 & 5.42 & TRN \\
\hline CHEMBL1584961 & 688239 & 6.0862 & 5.4407 & TST \\
\hline CHEMBL1333585 & 688239 & 7.0362 & 5.5167 & TRN \\
\hline CHEMBL1547276 & 688239 & 4.7862 & 5.539 & TRN \\
\hline CHEMBL1364535 & 688239 & 5.1862 & 5.3847 & TST \\
\hline CHEMBL1489958 & 688239 & 4.5862 & 5.4055 & TRN \\
\hline CHEMBL1571987 & 688239 & 5.8362 & 5.6525 & TRN \\
\hline CHEMBL1491195 & 688239 & 5.0862 & 5.5231 & TRN \\
\hline CHEMBL1363927 & 688239 & 4.7362 & 5.3734 & TST \\
\hline CHEMBL1403228 & 688239 & 7.9355 & 5.6315 & TRN \\
\hline CHEMBL1508239 & 688239 & 5.4362 & 5.445 & TRN \\
\hline CHEMBL461579 & 688239 & 7.0862 & 5.3088 & TRN \\
\hline CHEMBL1358329 & 688239 & 5.1862 & 5.4797 & TST \\
\hline CHEMBL1510852 & 688239 & 5.0862 & 5.4092 & TRN \\
\hline CHEMBL1541988 & 688239 & 6.1362 & 5.5643 & TRN \\
\hline CHEMBL1320511 & 688239 & 5.7862 & 5.5993 & TRN \\
\hline CHEMBL1537051 & 688239 & 4.5362 & 5.4746 & TRN \\
\hline CHEMBL1482798 & 688239 & 5.6362 & 5.6118 & TRN \\
\hline CHEMBL1544164 & 688239 & 6.0862 & 5.4108 & TRN \\
\hline CHEMBL1389757 & 688239 & 6.1362 & 5.4987 & TRN \\
\hline CHEMBL1545624 & 688239 & 4.5362 & 5.6306 & TRN \\
\hline CHEMBL1304989 & 688239 & 6.0862 & 5.6905 & TRN \\
\hline CHEMBL1412784 & 688239 & 4.5362 & 5.398 & TRN \\
\hline CHEMBL1403511 & 688239 & 8.3372 & 5.6915 & TST \\
\hline CHEMBL1373548 & 688239 & 4.9862 & 5.447 & TRN \\
\hline CHEMBL1384397 & 688239 & 6.7862 & 5.3827 & TRN \\
\hline CHEMBL1341002 & 688239 & 4.4862 & 5.57799 & э999999999 \\
\hline CHEMBL1602694 & 688239 & 5.1362 & 5.5312 & TRN \\
\hline CHEMBL1432816 & 688239 & 4.6362 & 5.4043 & TRN \\
\hline CHEMBL1333448 & 688239 & 4.5862 & 5.559 & TRN \\
\hline CHEMBL 3211460 & 688239 & 6.3362 & 5.5345 & TRN \\
\hline
\end{tabular}

Page 2194 


\begin{tabular}{|c|c|c|c|c|c|c|}
\hline & & & & & & \\
\hline CHEMBL1479477 & 688239 & 6.7361 & 5.4765 & TST & & \\
\hline CHEMBL1552145 & 688239 & 4.5362 & 5.5394 & TRN & & \\
\hline CHEMBL1517355 & 688239 & 6.2362 & 5.4727 & TRN & & \\
\hline CHEMBL1463591 & 688239 & 5.1362 & 5.6069 & TST & & \\
\hline CHEMBL1324893 & 688239 & 6.3362 & 5.66299 & 9999999999 & & TRN \\
\hline CHEMBL1516011 & 688239 & 4.5362 & 5.7077 & TRN & & \\
\hline CHEMBL1520546 & 688239 & 7.2366 & 5.4639 & TRN & & \\
\hline CHEMBL1524542 & 688239 & 5.1862 & 5.4668 & TST & & \\
\hline CHEMBL1323540 & 688239 & 7.5867 & 5.473 & TRN & & \\
\hline CHEMBL1354360 & 688239 & 4.7362 & 5.4333 & TRN & & \\
\hline CHEMBL1556473 & 688239 & 4.5362 & 5.5151 & TST & & \\
\hline CHEMBL1595936 & 688239 & 4.6362 & 5.3474 & TST & & \\
\hline CHEMBL1484526 & 688239 & 5.3362 & 5.479 & TRN & & \\
\hline CHEMBL1331770 & 688239 & 4.8362 & 5.3831 & TST & & \\
\hline CHEMBL1383410 & 688239 & 5.6862 & 5.4421 & TST & & \\
\hline CHEMBL1424447 & 688239 & 8.28399 & 79999999ऽ & 99 & 5.6292 & TRN \\
\hline CHEMBL1522331 & 688239 & 4.45 & 5.3833 & TST & & \\
\hline CHEMBL1492827 & 688239 & 6.8861 & 5.6063 & TRN & & \\
\hline CHEMBL1399280 & 688239 & 5.3362 & 5.5219 & TST & & \\
\hline CHEMBL1376743 & 688239 & 4.8862 & 5.5957 & TRN & & \\
\hline CHEMBL1516731 & 688239 & 7.1864 & 5.5932 & TRN & & \\
\hline CHEMBL1441101 & 688239 & 5.5862 & 5.5723 & TRN & & \\
\hline CHEMBL1446480 & 688239 & 5.5862 & 5.5182 & TRN & & \\
\hline CHEMBL1543954 & 688239 & 5.7862 & 5.4869 & TRN & & \\
\hline CHEMBL1543279 & 688239 & 5.1862 & 5.4535 & TST & & \\
\hline CHEMBL1312692 & 688239 & 5.3362 & 5.46299 & 9999999999 & & TRN \\
\hline CHEMBL1440113 & 688239 & 5.1862 & 5.5599 & TRN & & \\
\hline CHEMBL1359886 & 688239 & 6.3362 & 5.4485 & TRN & & \\
\hline CHEMBL1976567 & 688239 & 4.8362 & 5.5602 & TRN & & \\
\hline CHEMBL1334626 & 688239 & 5.6862 & 5.5089 & TRN & & \\
\hline CHEMBL1428141 & 688239 & 4.5362 & 5.4139 & TRN & & \\
\hline CHEMBL 2004592 & 688239 & 6.0862 & 5.2844 & TRN & & \\
\hline CHEMBL 272551 & 688239 & 4.8362 & 5.4364 & TRN & & \\
\hline CHEMBL1560871 & 688239 & 4.5362 & 5.5489 & TRN & & \\
\hline CHEMBL3199020 & 688239 & 5.1862 & 5.3676 & TRN & & \\
\hline CHEMBL1313495 & 688239 & 6.2362 & 5.4961 & TRN & & \\
\hline CHEMBL1360668 & 688239 & 5.3862 & 5.5921 & TRN & & \\
\hline CHEMBL1964793 & 688239 & 8.3372 & 5.4472 & TRN & & \\
\hline CHEMBL1339559 & 688239 & 6.0862 & 5.4558 & TST & & \\
\hline CHEMBL1562848 & 688239 & 4.5362 & 5.4429 & TRN & & \\
\hline CHEMBL3196820 & 688239 & 4.6862 & 5.4701 & TRN & & \\
\hline CHEMBL1381400 & 688239 & 4.5362 & 5.7226 & TRN & & \\
\hline CHEMBL1303098 & 688239 & 5.1862 & 5.4278 & TRN & & \\
\hline CHEMBL1476081 & 688239 & 4.8862 & 5.4841 & TRN & & \\
\hline CHEMBL1470051 & 688239 & 4.6362 & $5.50200 t$ & 0000000001 & & TST \\
\hline CHEMBL1385142 & 688239 & 4.5362 & 5.5747 & TRN & & \\
\hline CHEMBL1321817 & 688239 & 4.7362 & 5.3851 & TRN & & \\
\hline CHEMBL1424104 & 688239 & 5.6862 & 5.5996 & TRN & & \\
\hline
\end{tabular}


Supplemental Table S2.txt

\begin{tabular}{|c|c|c|c|c|}
\hline CHEMBL1579094 & 688239 & 4.5362 & 5.5216 & TRN \\
\hline CHEMBL1572280 & 688239 & 5.9862 & 5.3363 & TST \\
\hline CHEMBL1319345 & 688239 & 5.8862 & 5.473 & TRN \\
\hline CHEMBL1585366 & 688239 & 5.3362 & 5.6377 & TRN \\
\hline CHEMBL1997827 & 688239 & 5.1862 & 5.5284 & TRN \\
\hline CHEMBL1561470 & 688239 & 4.8862 & \multicolumn{2}{|c|}{5.507999999999999} \\
\hline CHEMBL3197365 & 688239 & 6.2362 & 5.4145 & TRN \\
\hline CHEMBL 3197872 & 688239 & 6.1362 & 5.2564 & TRN \\
\hline CHEMBL1382673 & 688239 & 6.1362 & 5.4824 & TRN \\
\hline CHEMBL1541995 & 688239 & 6.0862 & 5.5872 & TRN \\
\hline CHEMBL1346074 & 688239 & 6.7862 & 5.5465 & TRN \\
\hline CHEMBL1361676 & 688239 & 4.7862 & 5.5761 & TRN \\
\hline CHEMBL1591200 & 688239 & 4.5362 & 5.3996 & TRN \\
\hline CHEMBL1438312 & 688239 & 5.6862 & 5.5461 & TRN \\
\hline CHEMBL1304880 & 688239 & 4.6862 & 5.5666 & TRN \\
\hline CHEMBL1594202 & 688239 & 5.4362 & 5.5869 & TRN \\
\hline CHEMBL1414319 & 688239 & 6.3362 & 5.5304 & TST \\
\hline CHEMBL1420809 & 688239 & 8.3372 & 5.546 & TRN \\
\hline CHEMBL1554652 & 688239 & 6.6861 & 5.4752 & TRN \\
\hline CHEMBL1466223 & 688239 & 5.4862 & 5.4836 & TST \\
\hline CHEMBL1327395 & 688239 & 5.5362 & 5.5243 & TRN \\
\hline CHEMBL1421052 & 688239 & 4.5362 & 5.3639 & TRN \\
\hline CHEMBL1473884 & 688239 & 4.7362 & 5.5553 & TRN \\
\hline CHEMBL1559483 & 688239 & 5.6862 & 5.3976 & TRN \\
\hline CHEMBL1393799 & 688239 & 5.4862 & 5.6264 & TST \\
\hline CHEMBL1441299 & 688239 & 5.1362 & 5.5725 & TRN \\
\hline CHEMBL 3192542 & 688239 & 4.5362 & 5.2934 & TST \\
\hline CHEMBL1414152 & 688239 & 5.1362 & 5.4144 & TST \\
\hline CHEMBL1384816 & 688239 & 6.7361 & 5.4232 & TST \\
\hline CHEMBL1416485 & 688239 & 4.8362 & 5.5731 & TST \\
\hline CHEMBL1352405 & 688239 & 5.2862 & 5.5584 & TRN \\
\hline CHEMBL1505199 & 688239 & 6.0862 & 5.4456 & TRN \\
\hline CHEMBL1487266 & 688239 & 5.3862 & 5.5159 & TST \\
\hline CHEMBL1520215 & 688239 & 4.6362 & 5.5128 & TRN \\
\hline CHEMBL1330285 & 688239 & 6.4862 & 5.5541 & TRN \\
\hline CHEMBL1466116 & 688239 & 4.5362 & 5.50700 & 3000000001 \\
\hline CHEMBL1605198 & 688239 & 5.1862 & 5.6216 & TST \\
\hline CHEMBL1558883 & 688239 & 6.0862 & 5.5138 & TRN \\
\hline CHEMBL1454201 & 688239 & 4.5362 & 5.5103 & TST \\
\hline CHEMBL1973192 & 688239 & 5.1862 & 5.4773 & TST \\
\hline CHEMBL1371116 & 688239 & 4.5362 & 5.3794 & TRN \\
\hline CHEMBL1419966 & 688239 & 4.5362 & 5.394 & TRN \\
\hline CHEMBL1513012 & 688239 & 4.7362 & 5.4275 & TRN \\
\hline CHEMBL3199586 & 688239 & 5.6362 & 5.5163 & TRN \\
\hline CHEMBL1531131 & 688239 & 4.7362 & 5.5661 & TRN \\
\hline CHEMBL1567145 & 688239 & 7.0862 & 5.381 & TST \\
\hline CHEMBL1309073 & 688239 & 6.1862 & 5.5998 & TRN \\
\hline CHEMBL1440671 & 688239 & 4.5362 & 5.4083 & TRN \\
\hline
\end{tabular}

Page 2196 


\begin{tabular}{|c|c|c|c|c|c|}
\hline \multirow[b]{2}{*}{ CHEMBL1554349 } & & \multicolumn{4}{|c|}{ Supplemental Table S2.txt } \\
\hline & 688239 & 5.3362 & 5.50799 & 9999999999 & TRN \\
\hline CHEMBL1383890 & 688239 & 6.1862 & 5.46399 & 99999999995 & TRN \\
\hline CHEMBL1612406 & 688239 & 5.7362 & 5.6024 & TST & \\
\hline CHEMBL1473889 & 688239 & 7.0862 & 5.5121 & TRN & \\
\hline CHEMBL1587736 & 688239 & 4.6862 & 5.2833 & TRN & \\
\hline CHEMBL1359517 & 688239 & 5.0862 & 5.3595 & TRN & \\
\hline CHEMBL1538185 & 688239 & 4.5362 & 5.5501 & TST & \\
\hline CHEMBL1380807 & 688239 & 4.6362 & 5.5377 & TRN & \\
\hline CHEMBL3392034 & 688239 & 4.5362 & 5.4525 & TST & \\
\hline CHEMBL1612629 & 688239 & 5.5862 & 5.5173 & TST & \\
\hline CHEMBL1438948 & 688239 & 4.6362 & 5.4045 & TST & \\
\hline CHEMBL1352502 & 688239 & 5.1862 & 5.5934 & TST & \\
\hline CHEMBL1558991 & 688239 & 4.6862 & 5.4128 & TRN & \\
\hline CHEMBL1495480 & 688239 & 4.6862 & 5.4894 & TRN & \\
\hline CHEMBL1419234 & 688239 & 6.0862 & 5.5489 & TRN & \\
\hline CHEMBL1447968 & 688239 & 6.0 & 5.4753 & TRN & \\
\hline CHEMBL1608703 & 688239 & 4.6862 & 5.5887 & TST & \\
\hline CHEMBL1537389 & 688239 & 6.1862 & 5.5122 & TRN & \\
\hline CHEMBL1555181 & 688239 & 5.8362 & 5.2825 & TRN & \\
\hline CHEMBL1505482 & 688239 & 6.0862 & 5.4477 & TRN & \\
\hline CHEMBL1401772 & 688239 & 4.7362 & 5.4627 & TST & \\
\hline CHEMBL1307827 & 688239 & 4.9362 & 5.5012 & TST & \\
\hline CHEMBL1485374 & 688239 & 5.8862 & 5.3907 & TRN & \\
\hline CHEMBL1459391 & 688239 & 4.5362 & 5.5839 & TRN & \\
\hline CHEMBL1383698 & 688239 & 4.5862 & 5.4019 & TRN & \\
\hline CHEMBL1304008 & 688239 & 5.8862 & 5.4884 & TRN & \\
\hline CHEMBL1402885 & 688239 & 4.9862 & 5.4402 & TRN & \\
\hline CHEMBL1574149 & 688239 & 4.9862 & 5.5075 & TRN & \\
\hline CHEMBL1447422 & 688239 & 6.1362 & 5.4165 & TRN & \\
\hline CHEMBL1490220 & 688239 & 8.3372 & 5.5178 & TST & \\
\hline CHEMBL1474428 & 688239 & 4.5362 & 5.4334 & TRN & \\
\hline CHEMBL1573542 & 688239 & 5.0362 & 5.4588 & TRN & \\
\hline CHEMBL1450592 & 688239 & 4.6362 & 5.3319 & TRN & \\
\hline CHEMBL1467550 & 688239 & 4.5362 & 5.4973 & TRN & \\
\hline CHEMBL1532834 & 688239 & 4.7862 & 5.4691 & TST & \\
\hline CHEMBL1422453 & 688239 & 5.0862 & 5.3143 & TRN & \\
\hline CHEMBL 1374353 & 688239 & 6.6861 & 5.4098 & TRN & \\
\hline CHEMBL1501147 & 688239 & 4.4862 & 5.5636 & TRN & \\
\hline CHEMBL1422180 & 688239 & 4.6362 & 5.2466 & TST & \\
\hline CHEMBL1508649 & 688239 & 4.7362 & 5.6432 & TRN & \\
\hline CHEMBL1458764 & 688239 & 5.7862 & 5.6419 & TST & \\
\hline CHEMBL1608418 & 688239 & 6.2862 & 5.4386 & TST & \\
\hline CHEMBL1322677 & 688239 & 5.1862 & 5.4882 & TST & \\
\hline CHEMBL 1305820 & 688239 & 4.5862 & 5.4549 & TRN & \\
\hline CHEMBL1553340 & 688239 & 6.1362 & 5.4379 & TRN & \\
\hline CHEMBL1310241 & 688239 & 6.1362 & 5.4626 & TST & \\
\hline CHEMBL1374894 & 688239 & 6.1362 & 5.4881 & TRN & \\
\hline CHEMBL1454210 & 688239 & 6.2362 & 5.443 & TRN & \\
\hline
\end{tabular}


Supplemental Table S2.txt

CHEMBL1496412
CHEMBL1534204
CHEMBL1385089
CHEMBL3193130
CHEMBL1593870
CHEMBL1337440
CHEMBL1332622

$\begin{array}{llll}688239 & 6.4862 & 5.3724 & \text { TRN }\end{array}$

$\begin{array}{llll}688239 & 5.7862 & 5.5634 & \text { TST }\end{array}$

$\begin{array}{llll}688239 & 5.8862 & 5.531000000000001 & \text { TRN }\end{array}$

$\begin{array}{llll}688239 & 5.1862 & 5.5203 & \text { TST }\end{array}$

$\begin{array}{llll}688239 & 5.7362 & 5.5328 & \text { TRN }\end{array}$

$6882395.3862 \quad 5.4671$ TRN

$\begin{array}{llll}688239 & 5.4362 & 5.6821 & \text { TRN }\end{array}$

CHEMBL1534545

688239

$6.1862 \quad 5.4471$ TRN

CHEMBL1320562

688239

688239

4.8362

5.3003 TST

CHEMBL1611205

CHEMBL1457583

CHEMBL1465027

CHEMBL1512779

CHEMBL1377687

CHEMBL1344757

CHEMBL1418353

CHEMBL1498702

CHEMBL1413988

CHEMBL1443952

CHEMBL1362057

CHEMBL590665

CHEMBL1603157

CHEMBL1367930

688239

688239

688239

688239

688239

688239

688239

688239

6.2862

5.5688

4.9862

6.2362

4.5362

5.5173 TRN

$\begin{array}{lll}5.7362 & 5.6544 & \text { TRN }\end{array}$

$\begin{array}{lll}4.6862 & 5.5407 & \text { TRN }\end{array}$

688239

6.8861

5.6238 TRN

4.48625 .3693 TRN

688239

6.4362

5.3733 TST

6.2862

5.5387 TRN

688239

6.2862

5.4211 TRN

688239

4.7862

5.2384

6.7862

5.4935

688239

4.6862

5.5006

TRN

688239

4.9862

5.4158

TST

CHEMBL1438621

CHEMBL1326943

688239

5.4862

5.5736

TST

688239

5.6862

5.6834

TRN

688239

5.1862

5.5907

TST

CHEMBL1401924

688239

4.5362

5.5162

TST

688239

4.6362

5.5281

TRN

688239

6.8362

5.5203

688239

5.6862

5.5113

CHEMBL1435722

CHEMBL1494782

CHEMBL1402387

CHEMBL1552927

688239

6.2862

5.6116

688239

6.8861

5.4331

688239

4.8862

5.4998

688239

5.2362

5.5163

CHEMBL1462018

688239

5.1862

5.2939

CHEMBL1470412

688239

5.3862

5.5538

688239

5.0362

688239

5.7362

5.4082

CHEMBL1468705

CHEMBL1376404

688239

6.0862

5.4569

TRN

CHEMBL1359041

688239

5.1862

688239

4.5362

5.648 TST

CHEMBL1348684

CHEMBL3208207

CHEMBL1586676

CHEMBL1397117

CHEMBL1533493

CHEMBL3196326

688239

5.7862

5.4339 TRN

688239

5.4362

5.5305 TST

688239

5.1862

5.539 TRN

688239

4.6362

5.3147 TST

688239

6.0362

5.5117 TRN

688239

4.6862

5.4457 TRN

5.5073 TRN

Page 2198 
Supplemental Table S2.txt

\begin{tabular}{|c|c|c|c|c|}
\hline & & & & \\
\hline AEMBL1 & 8239 & 5862 & & \\
\hline IEMBL1419431 & 3239 & 862 & 5272 & \\
\hline HEMBL1475498 & 239 & 862 & 4841 & \\
\hline & 239 & 362 & 039 & \\
\hline IEMBL1480015 & 239 & 362 & 805 & \\
\hline AEMBL1310341 & 239 & 862 & 385 & \\
\hline AEMBL1374904 & 88239 & 362 & 482 & \\
\hline AEMBL1530973 & 239 & 862 & 503 & \\
\hline IEMBL1486047 & 239 & 62 & & \\
\hline IEMBL1530438 & & & & \\
\hline AEMBL1307782 & 688239 & 362 & 759 & \\
\hline AEMBL1598026 & 239 & 862 & 527 & \\
\hline IEMBL1562930 & & 362 & 872 & \\
\hline EMBL1566952 & & 62 & 751 & \\
\hline AEMBL1436404 & & & 752 & \\
\hline AEMBL1610954 & 39 & 862 & 665 & \\
\hline AEMBL1580572 & & 862 & & \\
\hline IEMBLI600/02 & & 62 & & \\
\hline EMMBL1607034 & & & & \\
\hline AEMBL1538726 & & & 85 & \\
\hline AEMBL1584100 & & 362 & 558 & RN \\
\hline IEMBL1591161 & & 62 & & \\
\hline IEMBL151 & & 362 & & \\
\hline IEMBL320 & & 52 & 84 & RN \\
\hline IEMBL1542233 & & 71 & & \\
\hline HEMBL1473826 & & & & RN \\
\hline AEMBL1596209 & & & & \\
\hline AEMBL1975101 & & 62 & 95 & ST \\
\hline L1390796 & & 53 & 38 & RN \\
\hline 1313399 & & 62 & & RN \\
\hline HEMBL1405745 & & & & RN \\
\hline AEMBL1599663 & & & & $\mathrm{RI}$ \\
\hline IEMBL1434910 & & & & RI \\
\hline HEMBL1586 & & 52 & 67 & RIV \\
\hline $3 \operatorname{mos}^{2}$ & & & & ST \\
\hline HEMBL1604480 & & & 773 & $S$ \\
\hline AEMBL1501005 & & & & $\mathrm{R}$ \\
\hline EMBL1562598 & & & & RI \\
\hline AEMBL1529311 & & & 91 & \\
\hline 1471 & & & & RN \\
\hline AEMBL1496411 & & 862 & 281 & IST \\
\hline IEMBL1351634 & & & & TR \\
\hline EMBL154 & & & & TS \\
\hline HEMBL1452243 & & & & \\
\hline CHEMBL 1562874 & & 362 & 877 & RN \\
\hline AEMBL1454760 & 8239 & 5.3862 & 5.3709 & $\mathrm{TR}$ \\
\hline HFMRI 1421019 & 688239 & 4.5362 & 5.4839 & \\
\hline
\end{tabular}

Page 2199 
Supplemental Table S2.txt

\begin{tabular}{|c|c|c|c|c|c|}
\hline CHEMBL1530239 & 688239 & 4.5362 & 5.5118 & TRN & \\
\hline CHEMBL1302326 & 688239 & 5.0862 & 5.4618 & TRN & \\
\hline CHEMBL1406853 & 688239 & 5.1862 & 5.4491 & TRN & \\
\hline CHEMBL1550676 & 688239 & 5.8862 & 5.4681 & TST & \\
\hline CHEMBL1398843 & 688239 & 5.8362 & 5.2693 & TRN & \\
\hline CHEMBL1400950 & 688239 & 5.1862 & 5.4124 & TRN & \\
\hline CHEMBL1342907 & 688239 & 5.1862 & 5.2993 & TRN & \\
\hline CHEMBL1302828 & 688239 & 5.6362 & 5.5567 & TRN & \\
\hline CHEMBL1524664 & 688239 & 6.4362 & 5.5984 & TST & \\
\hline CHEMBL1353594 & 688239 & 7.1864 & 5.3805 & TRN & \\
\hline CHEMBL1591329 & 688239 & 5.1862 & 5.6478 & TRN & \\
\hline CHEMBL1516990 & 688239 & 5.1362 & 5.3999 & TRN & \\
\hline CHEMBL3189935 & 688239 & 8.28399 & 99999999 & 9 & 5.4268 \\
\hline CHEMBL1360065 & 688239 & 4.8362 & 5.5598 & TRN & \\
\hline CHEMBL1493832 & 688239 & 4.8862 & 5.5639 & TST & \\
\hline CHEMBL1586425 & 688239 & 5.2362 & 5.4889 & TRN & \\
\hline CHEMBL1425456 & 688239 & 6.1362 & 5.4963 & TRN & \\
\hline CHEMBL1301693 & 688239 & 4.5362 & 5.4528 & TST & \\
\hline CHEMBL1507163 & 688239 & 4.8862 & 5.4807 & TST & \\
\hline CHEMBL1577993 & 688239 & 5.0862 & 5.4334 & TRN & \\
\hline CHEMBL1551390 & 688239 & 6.3362 & 5.4343 & TRN & \\
\hline CHEMBL1500298 & 688239 & 5.3862 & 5.4739 & TRN & \\
\hline CHEMBL1503085 & 688239 & 4.8862 & 5.4948 & TRN & \\
\hline CHEMBL1384026 & 688239 & 4.5362 & 5.3708 & TRN & \\
\hline CHEMBL1428935 & 688239 & 5.6362 & 5.4025 & TRN & \\
\hline CHEMBL1451089 & 688239 & 4.6862 & 5.4209 & TRN & \\
\hline CHEMBL1560511 & 688239 & 4.5362 & 5.4448 & TST & \\
\hline CHEMBL1564660 & 688239 & 4.6862 & 5.3773 & TST & \\
\hline CHEMBL1353173 & 688239 & 4.5862 & 5.5506 & TST & \\
\hline CHEMBL1387829 & 688239 & 4.5362 & 5.4428 & TRN & \\
\hline CHEMBL1544126 & 688239 & 4.6362 & 5.4844 & TST & \\
\hline CHEMBL1397066 & 688239 & 6.9363 & 5.569 & TRN & \\
\hline CHEMBL1586203 & 688239 & 5.4862 & 5.478 & TRN & \\
\hline CHEMBL1506169 & 688239 & 4.6362 & 5.5243 & TRN & \\
\hline CHEMBL1607176 & 688239 & 6.7361 & 5.5577 & TST & \\
\hline CHEMBL1299369 & 688239 & 5.9362 & 5.6304 & TST & \\
\hline CHEMBL1588703 & 688239 & 4.7362 & 5.5105 & TST & \\
\hline CHEMBL1504727 & 688239 & 5.3862 & 5.3917 & TRN & \\
\hline CHEMBL1511331 & 688239 & 4.9362 & 5.4878 & TRN & \\
\hline CHEMBL1974901 & 688239 & 6.1862 & 5.4233 & TRN & \\
\hline CHEMBL1598722 & 688239 & 8.3872 & 5.5173 & TST & \\
\hline CHEMBL 2006594 & 688239 & 5.1362 & 5.4485 & TST & \\
\hline CHEMBL1387028 & 688239 & 5.1862 & 5.4061 & TST & \\
\hline CHEMBL1421639 & 688239 & 7.4365 & 5.5259 & TRN & \\
\hline CHEMBL 3195650 & 688239 & 6.1862 & 5.4359 & TRN & \\
\hline CHEMBL1520295 & 688239 & 7.4365 & 5.4716 & TST & \\
\hline CHEMBL1544023 & 688239 & 5.5362 & 5.431 & TST & \\
\hline CHEMBL1568919 & 688239 & 8.2366 & 5.5592 & TST & \\
\hline
\end{tabular}

Page 2200 
Supplemental Table S2.txt

\begin{tabular}{|c|c|c|c|c|}
\hline CHEMBL1981303 & 688239 & 5.9862 & 5.3884 & TST \\
\hline CHEMBL1424121 & 688239 & 6.8362 & 5.4138 & TST \\
\hline CHEMBL1314231 & 688239 & 4.6362 & 5.4063 & TST \\
\hline CHEMBL3199498 & 688239 & 5.0862 & 5.3073 & TRN \\
\hline CHEMBL1375513 & 688239 & 5.0862 & 5.4881 & TRN \\
\hline CHEMBL1312188 & 688239 & 4.8862 & 5.4656 & TRN \\
\hline CHEMBL1610397 & 688239 & 4.5362 & 5.3947 & TRN \\
\hline CHEMBL1514335 & 688239 & 5.0362 & 5.4125 & TRN \\
\hline CHEMBL1402273 & 688239 & 4.7362 & 5.406006 & 000000001 \\
\hline CHEMBL1540226 & 688239 & 6.1362 & 5.4085 & TRN \\
\hline CHEMBL170781 & 688239 & 5.9362 & 5.4554 & TST \\
\hline CHEMBL3207473 & 688239 & 6.2862 & 5.5203 & TRN \\
\hline CHEMBL1431885 & 688239 & 5.3862 & 5.5775 & TST \\
\hline CHEMBL1443606 & 688239 & 4.5362 & 5.3901 & TST \\
\hline CHEMBL1390050 & 688239 & 6.8362 & 5.6249 & TRN \\
\hline CHEMBL1423085 & 688239 & 4.5362 & 5.3891 & TRN \\
\hline CHEMBL1331903 & 688239 & 5.6362 & 5.6666 & TRN \\
\hline CHEMBL1598414 & 688239 & 5.1862 & 5.4445 & TRN \\
\hline CHEMBL1597302 & 688239 & 6.2362 & 5.38 & TST \\
\hline CHEMBL 3197400 & 688239 & 6.9863 & 5.5356 & TRN \\
\hline CHEMBL1320317 & 688239 & 4.7862 & 5.5119 & TRN \\
\hline CHEMBL1497476 & 688239 & 4.4862 & 5.568 & TRN \\
\hline CHEMBL1586301 & 688239 & 4.6362 & 5.4208 & TRN \\
\hline CHEMBL1481542 & 688239 & 4.8362 & 5.4599 & TRN \\
\hline CHEMBL1500956 & 688239 & 6.2362 & 5.5987 & TRN \\
\hline CHEMBL1327806 & 688239 & 4.6362 & 5.5244 & TRN \\
\hline CHEMBL1481319 & 688239 & 4.7862 & 5.4613 & TRN \\
\hline CHEMBL1425086 & 688239 & 4.5362 & 5.4925 & TRN \\
\hline CHEMBL1376928 & 688239 & 7.9872 & 5.4029 & TRN \\
\hline CHEMBL1467979 & 688239 & 4.5362 & 5.5268 & TST \\
\hline CHEMBL1383252 & 688239 & 4.4862 & 5.5564 & TRN \\
\hline CHEMBL1484477 & 688239 & 5.5362 & 5.4491 & TST \\
\hline CHEMBL1603736 & 688239 & 5.1862 & 5.6147 & TRN \\
\hline CHEMBL1536374 & 688239 & 4.9362 & 5.535 & TRN \\
\hline CHEMBL1395576 & 688239 & 4.5362 & 5.3516 & TRN \\
\hline CHEMBL3209965 & 688239 & 5.5362 & 5.4595 & TRN \\
\hline CHEMBL1398477 & 688239 & 5.8362 & 5.5744 & TRN \\
\hline CHEMBL1519645 & 688239 & 6.7862 & 5.5071 & TRN \\
\hline CHEMBL371107 & 688239 & 5.3362 & 5.5187 & TRN \\
\hline CHEMBL1347758 & 688239 & 4.8862 & 5.409 & TRN \\
\hline CHEMBL1414800 & 688239 & 5.7362 & 5.5282 & TST \\
\hline CHEMBL1311652 & 688239 & 5.6362 & 5.352 & TRN \\
\hline CHEMBL1552863 & 688239 & 4.7362 & 5.4274 & TRN \\
\hline CHEMBL1543775 & 688239 & 6.7361 & 5.4088 & TRN \\
\hline CHEMBL1503828 & 688239 & 5.9362 & 5.379 & TRN \\
\hline CHEMBL1580532 & 688239 & 4.5362 & 5.2488 & TRN \\
\hline CHEMBL1392064 & 688239 & 5.3362 & 5.4196 & TRN \\
\hline CHEMBL1458290 & 688239 & 7.1361 & 5.5382 & TRN \\
\hline
\end{tabular}

Page 2201 
Supplemental Table S2.txt

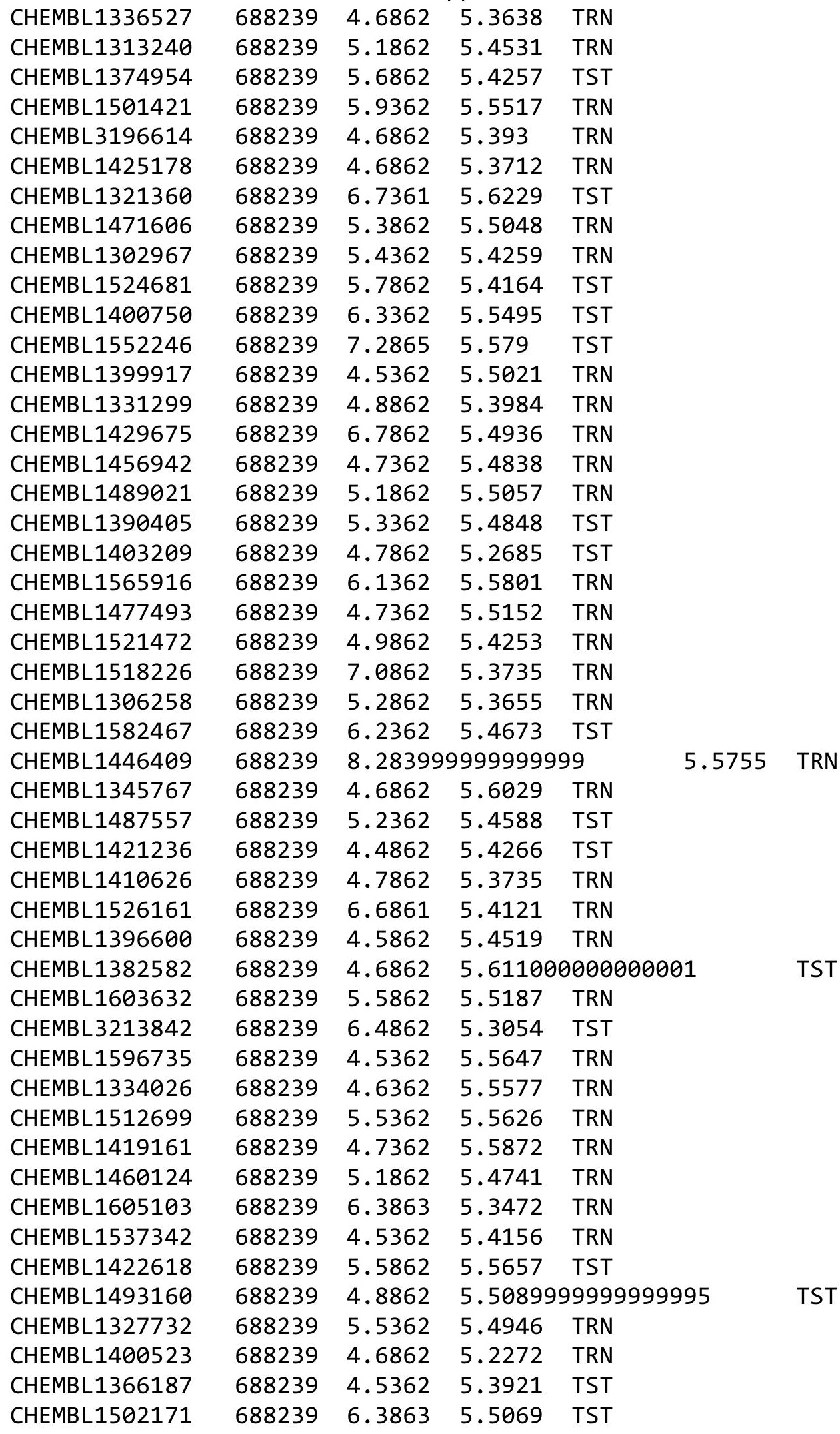

Page 2202 
Supplemental Table S2.txt

CHEMBL1510363
CHEMBL3191114
CHEMBL1552506
CHEMBL1403274
CHEMBL1446919
CHEMBL1334383
CHEMBL1457372

CHEMBL1578103

CHEMBL1570491

CHEMBL3190853

CHEMBL1313359

CHEMBL1326609

CHEMBL1397613

CHEMBL1316480

CHEMBL1304556

CHEMBL1598134

CHEMBL1407389

CHEMBL1312788

CHEMBL1392098

CHEMBL1433269

CHEMBL1515411

CHEMBL1410135

CHEMBL1535867

CHEMBL1378187

CHEMBL1476472

CHEMBL1342330

CHEMBL1350733

CHEMBL1444604

CHEMBL1583550

CHEMBL3197174

CHEMBL1495400

CHEMBL1503084

CHEMBL1541119

CHEMBL1489891

CHEMBL1568257

CHEMBL1513117

CHEMBL1432957

CHEMBL1310912

CHEMBL3212203

CHEMBL1544719

CHEMBL1313430

CHEMBL1317217

CHEMBL1495094

CHEMBL1488174

CHEMBL1428131

CHEMBL1430358

CHEMBL1605292

CHEMBL1596609

688239
688239
688239
688239
688239
688239
688239
688239
688239
688239
688239
688239
688239
688239
688239
688239
688239
688239
688239
688239
688239
688239
688239
688239
688239
688239
688239
688239
688239
688239
688239
688239
688239
688239
688239
688239
688239
688239
688239
688239
688239
688239
688239
688239
688239
688239
688239
688239
6

$\begin{array}{lll}4.5362 & 5.4463 & \text { TRN }\end{array}$

$\begin{array}{llll}4.5362 & 5.3906 & \text { TRN }\end{array}$

$\begin{array}{lll}5.6862 & 5.4247 & \text { TRN }\end{array}$

$\begin{array}{lll}5.1862 & 5.5094 & \text { TRN }\end{array}$

$\begin{array}{lll}5.9862 & 5.5726 & \text { TRN }\end{array}$

$\begin{array}{lll}7.4868 & 5.4655 & \text { TRN }\end{array}$

$\begin{array}{lll}5.5362 & 5.501 & \text { TRN }\end{array}$

$\begin{array}{lll}6.0862 & 5.6373 & \text { TRN }\end{array}$

$\begin{array}{lll}5.6362 & 5.5602 & \text { TST }\end{array}$

$\begin{array}{lll}4.4862 & 5.3304 & \text { TRN }\end{array}$

$\begin{array}{lll}5.0362 & 5.4666 & \text { TST }\end{array}$

$\begin{array}{lll}6.6861 & 5.5874 & \text { TST }\end{array}$

$\begin{array}{lll}8.3872 & 5.4322 & \text { TST }\end{array}$

$\begin{array}{lll}4.5362 & 5.2729 & \text { TRN }\end{array}$

$\begin{array}{lll}6.8362 & 5.5314 & \text { TRN }\end{array}$

6.08625 .5775 TRN

$\begin{array}{llll}6.8861 & 5.4469 & \text { TRN }\end{array}$

$\begin{array}{lll}4.7862 & 5.5114 & \text { TST }\end{array}$

$\begin{array}{llll}5.2362 & 5.6446 & \text { TRN }\end{array}$

$8.2366 \quad 5.653$ TRN

$\begin{array}{lll}8.3372 & 5.4171 & \text { TST }\end{array}$

6.23625 .3853 TRN

$\begin{array}{lll}5.9862 & 5.5159 & \text { TRN }\end{array}$

$\begin{array}{lll}4.5362 & 5.5069 & \text { TRN }\end{array}$

4.93625 .6176 TRN

6.73615 .4976 TRN

$\begin{array}{ll}4.5362 & 5.5252 \text { TRN }\end{array}$

$\begin{array}{lll}5.4862 & 5.49 & \text { TST }\end{array}$

$\begin{array}{lll}4.5362 & 5.4979 & \text { TRN }\end{array}$

$\begin{array}{lll}4.9362 & 5.5265 & \text { TRN }\end{array}$

$\begin{array}{llll}8.3372 & 5.3768 \text { TRN }\end{array}$

$\begin{array}{lll}6.1862 & 5.4932 & \text { TRN }\end{array}$

$\begin{array}{lll}4.7362 & 5.5652 & \text { TRN }\end{array}$

$\begin{array}{lll}5.5862 & 5.5991 & \text { TRN }\end{array}$

$\begin{array}{lll}4.6862 & 5.5009 & \text { TST }\end{array}$

$\begin{array}{llll}5.7862 & 5.4447 & \text { TRN }\end{array}$

$\begin{array}{lll}5.1862 & 5.5601 & \text { TST }\end{array}$

$\begin{array}{lll}5.9362 & 5.5078 \text { TRN }\end{array}$

6.08625 .4143 TRN

$8.3372 \quad 5.4683$ TRN

$\begin{array}{lll}4.7362 & 5.6209 & \text { TRN }\end{array}$

$\begin{array}{lll}4.5362 & 5.6012 & \text { TRN }\end{array}$

$\begin{array}{lll}4.5362 & 5.269 & \text { TRN }\end{array}$

$\begin{array}{lll}5.9862 & 5.4727 & \text { TST }\end{array}$

$\begin{array}{lll}5.5862 & 5.4143 \text { TRN }\end{array}$

$\begin{array}{lll}4.5362 & 5.568 \quad \text { TST }\end{array}$

$5.2862 \quad 5.428999999999999$

TST

6.73615 .4463 TRN

Page 2203 
Supplemental Table S2.txt

\begin{tabular}{|c|c|c|c|c|c|}
\hline CHEMBL1563958 & 688239 & 5.1362 & 5.5162 & TRN & \\
\hline CHEMBL1532655 & 688239 & 5.4862 & 5.5773 & TRN & \\
\hline CHEMBL1595103 & 688239 & 6.1362 & 5.5274 & TRN & \\
\hline CHEMBL1537495 & 688239 & 4.8862 & 5.5966 & TRN & \\
\hline CHEMBL1271764 & 688239 & 6.8861 & 5.4975 & TRN & \\
\hline CHEMBL1344508 & 688239 & 6.0862 & \multicolumn{2}{|c|}{5.542000000000001} & TRN \\
\hline CHEMBL1538336 & 688239 & 6.1362 & 5.5077 & TST & \\
\hline CHEMBL3198615 & 688239 & 6.8362 & 5.4473 & TRN & \\
\hline CHEMBL1344243 & 688239 & 6.8861 & 5.6372 & TRN & \\
\hline CHEMBL1479665 & 688239 & 4.5362 & 5.4878 & TRN & \\
\hline CHEMBL1587176 & 688239 & 8.3372 & 5.4478 & TST & \\
\hline CHEMBL1529883 & 688239 & 6.4362 & 5.4202 & TST & \\
\hline CHEMBL1429297 & 688239 & 4.7362 & 5.4038 & TRN & \\
\hline CHEMBL1570279 & 688239 & 6.0862 & 5.71299 & 9999999999 & TRN \\
\hline CHEMBL1338573 & 688239 & 7.7352 & 5.4491 & TRN & \\
\hline CHEMBL1502090 & 688239 & 7.1361 & 5.44600 & 0000000001 & TRN \\
\hline CHEMBL602314 & 688239 & 5.9862 & 5.4725 & TRN & \\
\hline CHEMBL1482865 & 688239 & 5.1862 & 5.4683 & TRN & \\
\hline CHEMBL1470416 & 688239 & 4.5862 & 5.3551 & TRN & \\
\hline CHEMBL1369471 & 688239 & 6.8861 & 5.4446 & TRN & \\
\hline CHEMBL1572318 & 688239 & 4.5362 & 5.4717 & TRN & \\
\hline CHEMBL1448364 & 688239 & \multicolumn{3}{|c|}{8.283999999999999} & TRN \\
\hline CHEMBL1388738 & 688239 & 4.7862 & 5.5537 & TRN & \\
\hline CHEMBL1610834 & 688239 & 5.6862 & 5.5905 & TRN & \\
\hline CHEMBL1968361 & 688239 & 4.7362 & 5.643 & TRN & \\
\hline CHEMBL1493924 & 688239 & 6.4862 & 5.3936 & TRN & \\
\hline CHEMBL1588475 & 688239 & 5.1862 & 5.5788 & TRN & \\
\hline CHEMBL1491071 & 688239 & 4.7362 & 5.5375 & TRN & \\
\hline CHEMBL1530658 & 688239 & 6.2862 & 5.4515 & TST & \\
\hline CHEMBL1561248 & 688239 & 6.9363 & 5.6181 & TRN & \\
\hline CHEMBL1478972 & 688239 & 6.2862 & 5.6356 & TST & \\
\hline CHEMBL1303201 & 688239 & 5.1862 & 5.4999 & TST & \\
\hline CHEMBL1369942 & 688239 & 4.5362 & 5.6176 & TRN & \\
\hline CHEMBL1553350 & 688239 & 6.1862 & 5.4719 & TRN & \\
\hline CHEMBL1521088 & 688239 & 4.5362 & 5.428 & TRN & \\
\hline CHEMBL1361627 & 688239 & 4.7362 & 5.4184 & TRN & \\
\hline CHEMBL 3196860 & 688239 & 5.1862 & 5.3313 & TRN & \\
\hline CHEMBL1435562 & 688239 & 6.2362 & 5.44 & TRN & \\
\hline CHEMBL1467228 & 688239 & 4.7362 & 5.5609 & TRN & \\
\hline CHEMBL1356239 & 688239 & 5.1862 & 5.5589 & TRN & \\
\hline CHEMBL1488966 & 688239 & 5.1862 & 5.3196 & TRN & \\
\hline CHEMBL1524660 & 688239 & 5.5862 & 5.6415 & TRN & \\
\hline CHEMBL1403715 & 688239 & 6.3863 & 5.5288 & TRN & \\
\hline CHEMBL1503893 & 688239 & 4.6362 & 5.4735 & TRN & \\
\hline CHEMBL1478910 & 688239 & 5.9362 & 5.5504 & TRN & \\
\hline CHEMBL3197909 & 688239 & 5.1862 & 5.5655 & TST & \\
\hline CHEMBL1504037 & 688239 & 4.5862 & 5.2521 & TRN & \\
\hline CHEMBL1305160 & 688239 & 5.1862 & 5.5136 & TST & \\
\hline
\end{tabular}


Supplemental Table S2.txt

\begin{tabular}{|c|c|c|c|c|c|}
\hline CHEMBL1436971 & 688239 & 4.7862 & 5.676 & TRN & \\
\hline CHEMBL1423717 & 688239 & 4.6862 & 5.5947 & TRN & \\
\hline CHEMBL1444163 & 688239 & 5.9862 & 5.5215 & TST & \\
\hline CHEMBL1344278 & 688239 & 5.0862 & 5.4621 & TST & \\
\hline CHEMBL1443100 & 688239 & 5.1862 & 5.4207 & TRN & \\
\hline CHEMBL1467391 & 688239 & 4.7862 & 5.3979 & TRN & \\
\hline CHEMBL1561591 & 688239 & 4.5362 & 5.3609 & TRN & \\
\hline CHEMBL1561223 & 688239 & 4.4362 & 5.622999 & 9999999999 & ISI \\
\hline CHEMBL3195142 & 688239 & 6.3362 & 5.2963 & TRN & \\
\hline CHEMBL1498658 & 688239 & 5.1362 & 5.41 & TST & \\
\hline CHEMBL1600350 & 688239 & 4.4862 & 5.4754 & TST & \\
\hline CHEMBL1495959 & 688239 & 4.7362 & 5.5657 & TRN & \\
\hline CHEMBL1313664 & 688239 & 8.28399 & 99999999 & 5.4978 & \\
\hline CHEMBL1347563 & 688239 & 4.5362 & 5.4629 & TRN & \\
\hline CHEMBL1345611 & 688239 & 4.8862 & 5.5101 & TRN & \\
\hline CHEMBL1533620 & 688239 & 4.8862 & 5.5015 & TST & \\
\hline CHEMBL1378586 & 688239 & 4.6362 & 5.5066 & TRN & \\
\hline CHEMBL1492457 & 688239 & 6.0862 & 5.518 & TST & \\
\hline CHEMBL1419981 & 688239 & 5.3362 & 5.4749 & TST & \\
\hline CHEMBL1386821 & 688239 & 4.7362 & 5.4787 & TRN & \\
\hline CHEMBL1563002 & 688239 & 5.3862 & 5.4436 & TST & \\
\hline CHEMBL1345344 & 688239 & 4.9862 & 5.6256 & TRN & \\
\hline CHEMBL1347481 & 688239 & 6.2862 & 5.4365 & TRN & \\
\hline CHEMBL1337391 & 688239 & 4.4862 & 5.4987 & TRN & \\
\hline CHEMBL1484639 & 688239 & 5.6362 & 5.4392 & TST & \\
\hline CHEMBL1545953 & 688239 & 5.0362 & 5.4666 & TRN & \\
\hline CHEMBL1382939 & 688239 & 4.8362 & 5.4794 & TST & \\
\hline CHEMBL1459050 & 688239 & 6.4862 & 5.34 & TRN & \\
\hline CHEMBL1500865 & 688239 & 5.4862 & 5.3489 & TST & \\
\hline CHEMBL363131 & 688239 & 6.5862 & 5.3166 & TRN & \\
\hline CHEMBL1416781 & 688239 & 4.7362 & \multicolumn{2}{|c|}{5.4910000000000005} & 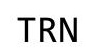 \\
\hline CHEMBL1309365 & 688239 & 5.6362 & 5.405 & TRN & \\
\hline CHEMBL458768 & 688239 & 4.6862 & 5.501 & TST & \\
\hline CHEMBL1299437 & 688239 & 5.7362 & 5.6215 & TRN & \\
\hline CHEMBL1575478 & 688239 & 5.4362 & 5.5462 & TRN & \\
\hline CHEMBL1574783 & 688239 & 4.9362 & 5.3859 & TRN & \\
\hline CHEMBL1502340 & 688239 & 5.4362 & 5.4779 & TRN & \\
\hline CHEMBL3190957 & 688239 & 4.7362 & 5.4132 & TRN & \\
\hline CHEMBL1530270 & 688239 & 4.8362 & 5.4011 & TRN & \\
\hline CHEMBL1467501 & 688239 & 5.5362 & 5.5022 & TRN & \\
\hline CHEMBL1981063 & 688239 & 4.7362 & 5.4578 & TRN & \\
\hline CHEMBL1535591 & 688239 & 5.1362 & 5.5316 & TRN & \\
\hline CHEMBL1437897 & 688239 & 5.0362 & 5.6576 & TRN & \\
\hline CHEMBL1521242 & 688239 & 4.5362 & 5.3436 & TST & \\
\hline CHEMBL1473502 & 688239 & 6.7361 & 5.516 & TRN & \\
\hline CHEMBL1417587 & 688239 & 6.8861 & 5.5614 & TST & \\
\hline CHEMBL1595596 & 688239 & 5.1862 & 5.4563 & TRN & \\
\hline CHEMBL1402001 & 688239 & 8.2366 & 5.4645 & TST & \\
\hline
\end{tabular}

Page 2205 
Supplemental Table S2.txt

\begin{tabular}{|c|c|c|c|c|}
\hline CHEMBL1438977 & 688239 & 4.9862 & 5.3585 & TRN \\
\hline CHEMBL1490671 & 688239 & 6.3362 & 5.5003 & TRN \\
\hline CHEMBL1481598 & 688239 & 6.0362 & 5.4581 & TRN \\
\hline CHEMBL 3145082 & 688239 & 4.7362 & 5.4094 & TST \\
\hline CHEMBL1430989 & 688239 & 7.1864 & 5.5431 & TRN \\
\hline CHEMBL1341390 & 688239 & 4.6862 & 5.6194 & TRN \\
\hline CHEMBL1538513 & 688239 & 6.8861 & 5.6315 & TRN \\
\hline CHEMBL 2007612 & 688239 & 5.3862 & 5.3373 & TRN \\
\hline CHEMBL3213637 & 688239 & 4.6862 & 5.4047 & TRN \\
\hline CHEMBL1300461 & 688239 & 4.6862 & 5.41200 & 0000000001 \\
\hline CHEMBL1506544 & 688239 & 4.6862 & 5.4302 & TRN \\
\hline CHEMBL1502858 & 688239 & 4.5362 & 5.306 & TRN \\
\hline CHEMBL1348627 & 688239 & 4.5362 & 5.5173 & TRN \\
\hline CHEMBL1424386 & 688239 & 4.9362 & 5.5065 & TRN \\
\hline CHEMBL3194881 & 688239 & 5.1862 & 5.4698 & TRN \\
\hline CHEMBL1409330 & 688239 & 8.2366 & 5.5165 & TST \\
\hline CHEMBL1577480 & 688239 & 5.4362 & 5.5478 & TRN \\
\hline CHEMBL1549082 & 688239 & 5.7362 & 5.5395 & TRN \\
\hline CHEMBL1575556 & 688239 & 6.6362 & 5.4556 & TRN \\
\hline CHEMBL1462711 & 688239 & 5.1862 & 5.4681 & TST \\
\hline CHEMBL1329138 & 688239 & 4.6862 & 5.6549 & TRN \\
\hline CHEMBL1376006 & 688239 & 7.1864 & 5.5747 & TRN \\
\hline CHEMBL1377579 & 688239 & 4.6362 & 5.4689 & TST \\
\hline CHEMBL1415002 & 688239 & 4.4862 & 5.3023 & TRN \\
\hline CHEMBL1431053 & 688239 & 5.1862 & 5.495 & TST \\
\hline CHEMBL1603099 & 688239 & 6.0862 & 5.5278 & TRN \\
\hline CHEMBL1481577 & 688239 & 5.3862 & 5.6666 & TRN \\
\hline CHEMBL1322655 & 688239 & 4.7862 & 5.5112 & TRN \\
\hline CHEMBL1553701 & 688239 & 5.7362 & 5.4268 & TRN \\
\hline CHEMBL1548133 & 688239 & 5.3862 & 5.4658 & TRN \\
\hline CHEMBL1393651 & 688239 & 7.9872 & 5.5255 & TRN \\
\hline CHEMBL1382401 & 688239 & 6.7862 & 5.4944 & TRN \\
\hline CHEMBL1421031 & 688239 & 4.6362 & 5.5537 & TRN \\
\hline CHEMBL570408 & 688239 & 4.5362 & 5.4569 & TRN \\
\hline CHEMBL1568994 & 688239 & 5.6862 & 5.5127 & TST \\
\hline CHEMBL1490710 & 688239 & 4.7862 & 5.5314 & TST \\
\hline CHEMBL1503475 & 688239 & 4.6362 & 5.539 & TRN \\
\hline CHEMBL1392243 & 688239 & 5.8362 & 5.6485 & TRN \\
\hline CHEMBL1595423 & 688239 & 4.5362 & 5.5343 & TRN \\
\hline CHEMBL1506377 & 688239 & 8.3872 & 5.3835 & TST \\
\hline CHEMBL1480461 & 688239 & 7.9355 & 5.5611 & TRN \\
\hline CHEMBL1609988 & 688239 & 5.7862 & 5.2647 & TRN \\
\hline CHEMBL1544337 & 688239 & 5.0862 & 5.5221 & TRN \\
\hline CHEMBL1372757 & 688239 & 6.0862 & 5.4314 & TRN \\
\hline CHEMBL1503288 & 688239 & 5.0862 & 5.47 & TRN \\
\hline CHEMBL1476142 & 688239 & 5.5862 & 5.4889 & TRN \\
\hline CHEMBL1351094 & 688239 & 5.6862 & 5.5435 & TST \\
\hline CHEMBL 2005042 & 688239 & 5.2362 & 5.3854 & TRN \\
\hline
\end{tabular}


Supplemental Table S2.txt

\begin{tabular}{|c|c|c|c|c|}
\hline CHEMBL1383489 & 688239 & 5.9862 & 5.4898 & TRN \\
\hline CHEMBL1579353 & 688239 & 4.6862 & 5.5518 & TRN \\
\hline CHEMBL1340844 & 688239 & 4.5362 & 5.4292 & TRN \\
\hline CHEMBL1519223 & 688239 & 4.6362 & 5.5264 & TRN \\
\hline CHEMBL1353656 & 688239 & 6.8861 & 5.4688 & TRN \\
\hline CHEMBL1429869 & 688239 & 4.6362 & 5.7003 & TRN \\
\hline CHEMBL1299226 & 688239 & 4.9862 & 5.5553 & TRN \\
\hline CHEMBL1434690 & 688239 & 6.0862 & 5.4362 & TRN \\
\hline CHEMBL1601170 & 688239 & 4.5362 & 5.3824 & TRN \\
\hline CHEMBL1561920 & 688239 & 5.8862 & 5.4207 & TRN \\
\hline CHEMBL1545606 & 688239 & 4.7362 & 5.5696 & TST \\
\hline CHEMBL1386643 & 688239 & 4.7362 & 5.518 & TRN \\
\hline CHEMBL1612382 & 688239 & 7.1864 & 5.3889 & TRN \\
\hline CHEMBL1543865 & 688239 & 4.5362 & 5.385 & TRN \\
\hline CHEMBL1454406 & 688239 & 6.2362 & 5.5726 & TRN \\
\hline CHEMBL1422379 & 688239 & 5.1862 & 5.4468 & TST \\
\hline CHEMBL1501457 & 688239 & 5.6362 & 5.4613 & TRN \\
\hline CHEMBL1554429 & 688239 & 4.6362 & 5.4393 & TST \\
\hline CHEMBL1478247 & 688239 & 4.9362 & 5.4678 & TST \\
\hline CHEMBL1414836 & 688239 & 5.8362 & 5.6057 & TRN \\
\hline CHEMBL1303689 & 688239 & 4.6362 & 5.4606 & TST \\
\hline CHEMBL1405902 & 688239 & 4.5362 & 5.5787 & TRN \\
\hline CHEMBL1582299 & 688239 & 6.4362 & 5.5644 & TRN \\
\hline CHEMBL1468536 & 688239 & 6.7862 & 5.4445 & TRN \\
\hline CHEMBL1477294 & 688239 & 6.2862 & 5.4889 & TRN \\
\hline CHEMBL1395398 & 688239 & 5.4862 & 5.5304 & TRN \\
\hline CHEMBL1410243 & 688239 & 4.5362 & 5.5868 & TRN \\
\hline CHEMBL1311269 & 688239 & 6.3362 & 5.3988 & TRN \\
\hline CHEMBL1536137 & 688239 & 4.5362 & 5.5861 & TRN \\
\hline CHEMBL1542977 & 688239 & 5.5362 & 5.4037 & TRN \\
\hline CHEMBL 3208665 & 688239 & 4.8862 & 5.4204 & TRN \\
\hline CHEMBL1592548 & 688239 & 5.5862 & 5.46700 & 00000000005 \\
\hline CHEMBL1307585 & 688239 & 4.9862 & 5.4594 & TST \\
\hline CHEMBL1381112 & 688239 & 4.5362 & 5.5395 & TRN \\
\hline CHEMBL1466827 & 688239 & 4.5362 & 5.3973 & TRN \\
\hline CHEMBL1609105 & 688239 & 4.7362 & 5.46200 & 0000000001 \\
\hline CHEMBL1526836 & 688239 & 4.6362 & 5.5402 & TRN \\
\hline CHEMBL1603675 & 688239 & 4.4862 & 5.4974 & TRN \\
\hline CHEMBL1306036 & 688239 & 5.5362 & 5.5173 & TRN \\
\hline CHEMBL1500892 & 688239 & 6.7862 & 5.5381 & TRN \\
\hline CHEMBL45637 & 688239 & 5.1862 & 5.4913 & TST \\
\hline CHEMBL1565165 & 688239 & 5.7862 & 5.4551 & TST \\
\hline CHEMBL1506740 & 688239 & 5.8362 & 5.5011 & TRN \\
\hline CHEMBL1498365 & 688239 & 6.8861 & 5.49 & TRN \\
\hline CHEMBL1301077 & 688239 & 4.5362 & 5.4724 & TRN \\
\hline CHEMBL1388726 & 688239 & 4.7362 & 5.6059 & TRN \\
\hline CHEMBL1435655 & 688239 & 4.5362 & 5.4416 & TRN \\
\hline CHEMBL1356684 & 688239 & 6.3362 & 5.4972 & TRN \\
\hline
\end{tabular}

Page 2207 
Supplemental Table S2.txt

\begin{tabular}{|c|c|c|c|c|c|}
\hline CHEMBL1322790 & 688239 & 4.6362 & 5.3724 & TRN & \\
\hline CHEMBL1483068 & 688239 & 4.8362 & 5.524 & TRN & \\
\hline CHEMBL1598284 & 688239 & 4.6862 & 5.5606 & TRN & \\
\hline CHEMBL1390240 & 688239 & 5.3362 & 5.5804 & TST & \\
\hline CHEMBL1319449 & 688239 & 6.8362 & 5.6303 & TRN & \\
\hline CHEMBL1331619 & 688239 & 5.4862 & 5.4462 & TST & \\
\hline CHEMBL1304644 & 688239 & 5.0362 & \multicolumn{2}{|c|}{5.5360000000000005} & TRN \\
\hline CHEMBL1200792 & 688239 & 6.3863 & 5.2774 & TST & \\
\hline CHEMBL1541877 & 688239 & 4.4862 & 5.5321 & TST & \\
\hline CHEMBL1573037 & 688239 & 4.5362 & 5.3805 & TRN & \\
\hline CHEMBL1491312 & 688239 & 5.1862 & 5.4316 & TRN & \\
\hline CHEMBL1378145 & 688239 & 5.8362 & 5.4212 & TRN & \\
\hline CHEMBL1306282 & 688239 & 5.4362 & \multicolumn{2}{|c|}{5.627000000000001} & TRN \\
\hline CHEMBL1303229 & 688239 & 5.7862 & 5.5516 & TRN & \\
\hline CHEMBL1515214 & 688239 & 4.6862 & 5.3956 & TRN & \\
\hline CHEMBL1363939 & 688239 & 4.4862 & 5.481 & TST & \\
\hline CHEMBL1470125 & 688239 & 4.7862 & 5.5208 & TRN & \\
\hline CHEMBL1385458 & 688239 & 5.4362 & 5.5515 & TST & \\
\hline CHEMBL1339447 & 688239 & 4.6862 & 5.4015 & TRN & \\
\hline CHEMBL1478516 & 688239 & 5.4362 & 5.4456 & TRN & \\
\hline CHEMBL1417800 & 688239 & 5.6862 & 5.3996 & TST & \\
\hline CHEMBL3212305 & 688239 & 6.1362 & 5.3976 & TRN & \\
\hline CHEMBL1385693 & 688239 & 6.4862 & 5.3721 & TRN & \\
\hline CHEMBL1484977 & 688239 & 6.2862 & 5.4603 & TRN & \\
\hline CHEMBL1309851 & 688239 & 5.2862 & 5.4331 & TRN & \\
\hline CHEMBL1364800 & 688239 & 6.7862 & 5.4744 & TRN & \\
\hline CHEMBL1563869 & 688239 & 6.0862 & 5.4564 & TRN & \\
\hline CHEMBL1370464 & 688239 & 4.9362 & 5.5574 & TRN & \\
\hline CHEMBL1482963 & 688239 & 4.7862 & 5.3739 & TRN & \\
\hline CHEMBL3191545 & 688239 & 5.2862 & 5.5683 & TRN & \\
\hline CHEMBL1474128 & 688239 & 5.2362 & 5.5294 & TRN & \\
\hline CHEMBL1577006 & 688239 & 5.4362 & 5.4689 & TST & \\
\hline CHEMBL3209442 & 688239 & 7.2366 & 5.3951 & TRN & \\
\hline CHEMBL1517465 & 688239 & 6.5363 & 5.4363 & TST & \\
\hline CHEMBL1342757 & 688239 & 4.5362 & 5.53 & TST & \\
\hline CHEMBL1458701 & 688239 & 6.3863 & 5.5051 & TRN & \\
\hline CHEMBL1370034 & 688239 & 4.7362 & 5.5089 & TST & \\
\hline CHEMBL1495419 & 688239 & 6.0362 & 5.5677 & TRN & \\
\hline CHEMBL1457687 & 688239 & 5.4862 & 5.5406 & TRN & \\
\hline CHEMBL1515684 & 688239 & 5.7862 & 5.6382 & TST & \\
\hline CHEMBL1373515 & 688239 & 5.4862 & 5.4906 & TRN & \\
\hline CHEMBL1500772 & 688239 & 4.7862 & 5.5141 & TRN & \\
\hline CHEMBL1584923 & 688239 & 4.5362 & 5.4277 & TST & \\
\hline CHEMBL1502403 & 688239 & 5.5362 & 5.3855 & TRN & \\
\hline CHEMBL1420568 & 688239 & 6.0862 & 5.5369 & TST & \\
\hline CHEMBL1306982 & 688239 & 6.4862 & 5.5408 & TRN & \\
\hline CHEMBL1323260 & 688239 & 4.9862 & 5.3154 & TRN & \\
\hline CHEMBL1303934 & 688239 & 6.5363 & 5.5726 & TRN & \\
\hline
\end{tabular}




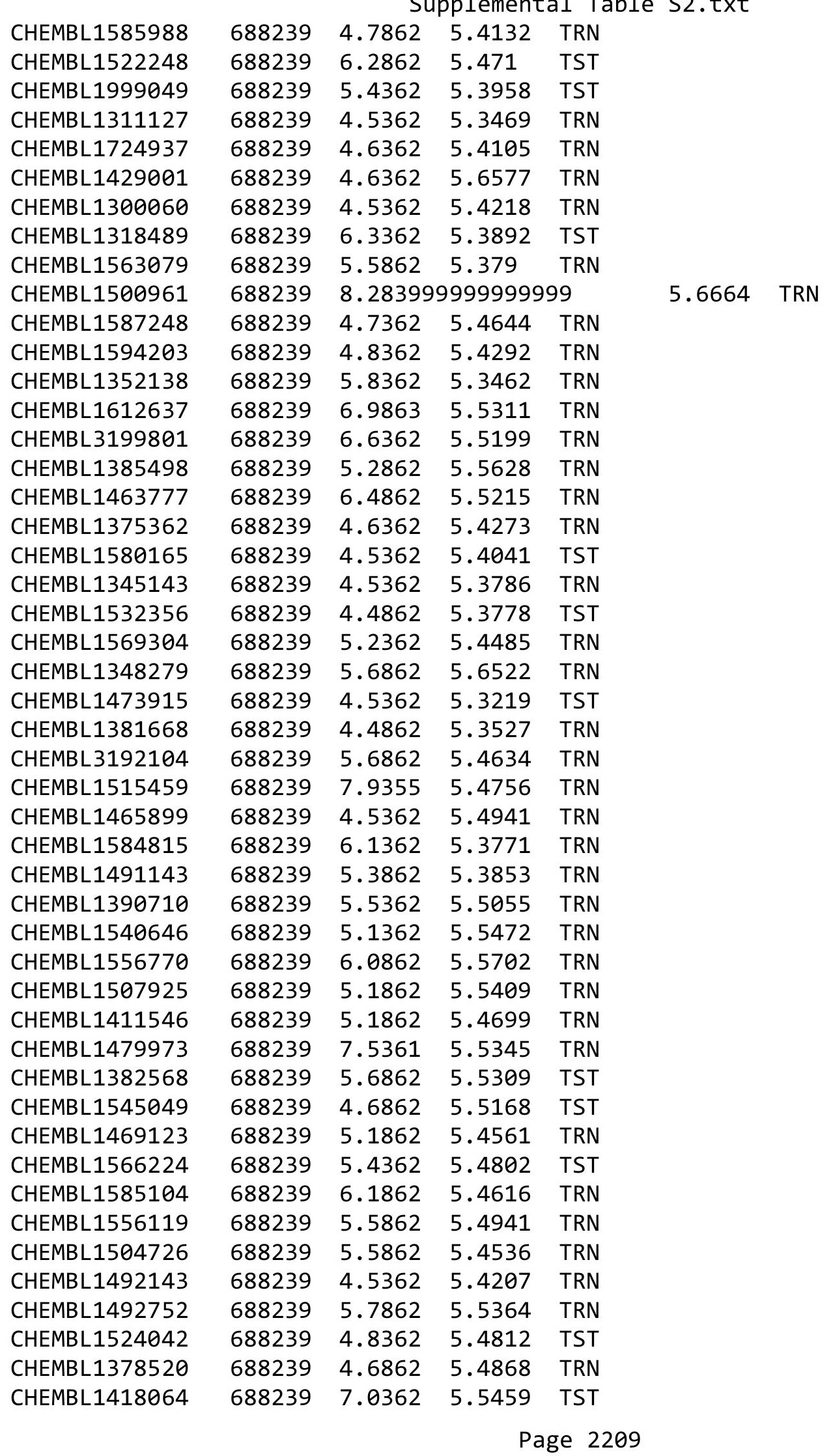




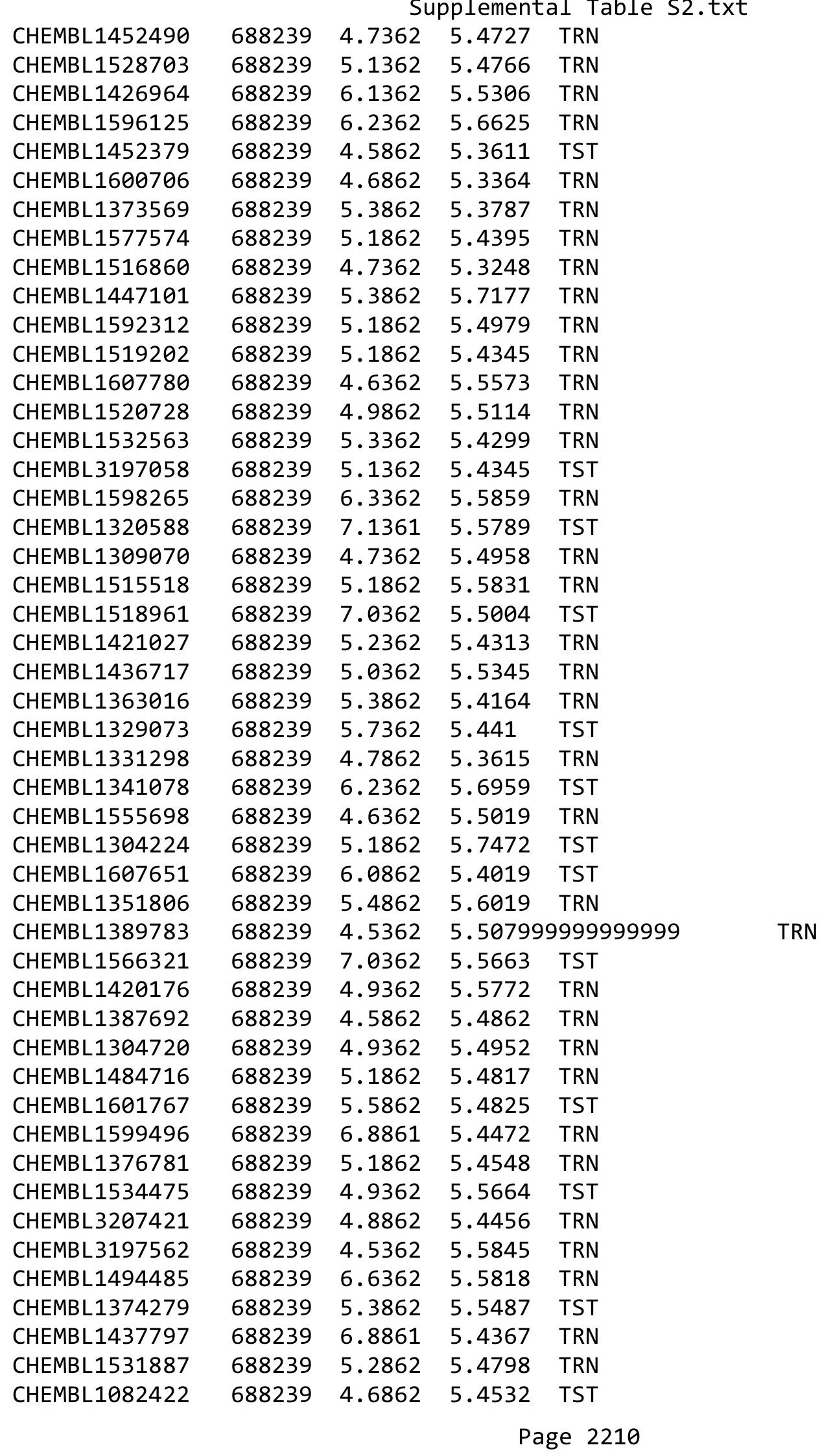


Supplemental Table S2.txt

\begin{tabular}{|c|c|c|c|c|}
\hline CHEMBL1410957 & 688239 & 7.0862 & 5.6511 & TRN \\
\hline CHEMBL1341110 & 688239 & 5.1862 & 5.4025 & TST \\
\hline CHEMBL1563453 & 688239 & 5.9362 & 5.5048 & TRN \\
\hline CHEMBL1494293 & 688239 & 5.2362 & 5.3711 & TRN \\
\hline CHEMBL3211639 & 688239 & 4.6862 & 5.5137 & TRN \\
\hline CHEMBL1484270 & 688239 & 6.2862 & 5.5398 & TRN \\
\hline CHEMBL1444362 & 688239 & 5.1862 & 5.2801 & TRN \\
\hline CHEMBL1406199 & 688239 & 6.9363 & 5.5906 & TRN \\
\hline CHEMBL1563850 & 688239 & 5.6862 & 5.5536 & TST \\
\hline CHEMBL60518 & 688239 & 4.5362 & 5.5096 & TST \\
\hline CHEMBL1353136 & 688239 & 6.1362 & 5.374 & TRN \\
\hline CHEMBL1370942 & 688239 & 5.1362 & 5.3378 & TRN \\
\hline CHEMBL1331731 & 688239 & 4.6862 & 5.4224 & TRN \\
\hline CHEMBL1458903 & 688239 & 8.28399 & 999999999 & 5.6002 \\
\hline CHEMBL1568693 & 688239 & 6.1862 & 5.6218 & TST \\
\hline CHEMBL1382298 & 688239 & 7.0362 & 5.6275 & TRN \\
\hline CHEMBL1384817 & 688239 & 5.9862 & 5.4315 & TRN \\
\hline CHEMBL1358742 & 688239 & 4.5362 & 5.4343 & TRN \\
\hline CHEMBL1391898 & 688239 & 4.6362 & 5.5635 & TRN \\
\hline CHEMBL1310362 & 688239 & 4.4862 & 5.3225 & TRN \\
\hline CHEMBL1437457 & 688239 & 4.5362 & 5.3162 & TRN \\
\hline CHEMBL1365555 & 688239 & 4.8362 & 5.4887 & TRN \\
\hline CHEMBL1559355 & 688239 & 5.9362 & 5.5046 & TRN \\
\hline CHEMBL1433360 & 688239 & 8.3372 & 5.4741 & TST \\
\hline CHEMBL3192664 & 688239 & 6.1862 & 5.4431 & TRN \\
\hline CHEMBL1431826 & 688239 & 4.5362 & 5.5346 & TRN \\
\hline CHEMBL1511303 & 688239 & 4.5862 & 5.302000 & 0000000005 \\
\hline CHEMBL1523326 & 688239 & 5.6862 & 5.5696 & TRN \\
\hline CHEMBL1613335 & 688239 & 4.7862 & 5.5714 & TRN \\
\hline CHEMBL1396492 & 688239 & 5.6862 & 5.4956 & TRN \\
\hline CHEMBL1490841 & 688239 & 6.5862 & 5.4962 & TST \\
\hline CHEMBL1356442 & 688239 & 5.2862 & 5.4583 & TRN \\
\hline CHEMBL1595172 & 688239 & 4.5862 & 5.694 & TRN \\
\hline CHEMBL1334009 & 688239 & 6.8362 & 5.5248 & TRN \\
\hline CHEMBL1454842 & 688239 & 6.1862 & 5.6331 & TST \\
\hline CHEMBL1318413 & 688239 & 8.3372 & 5.5333 & TRN \\
\hline CHEMBL3193995 & 688239 & 6.9863 & 5.3024 & TST \\
\hline CHEMBL1355052 & 688239 & 5.3862 & 5.3118 & TRN \\
\hline CHEMBL1606476 & 688239 & 5.6862 & 5.481 & TRN \\
\hline CHEMBL1441545 & 688239 & 5.2862 & 5.3781 & TRN \\
\hline CHEMBL1488608 & 688239 & 5.8862 & 5.4994 & TRN \\
\hline CHEMBL1416946 & 688239 & 5.6862 & 5.4031 & TRN \\
\hline CHEMBL 266997 & 688239 & 5.7362 & 5.364 & TRN \\
\hline CHEMBL1497026 & 688239 & 4.7362 & 5.5704 & TRN \\
\hline CHEMBL1387159 & 688239 & 6.2362 & 5.579 & TRN \\
\hline CHEMBL1992432 & 688239 & 4.6862 & 5.3898 & TST \\
\hline CHEMBL1584148 & 688239 & 6.1362 & 5.4886 & TRN \\
\hline CHEMBL1547736 & 688239 & 6.6861 & 5.4512 & TST \\
\hline
\end{tabular}


Supplemental Table S2.txt

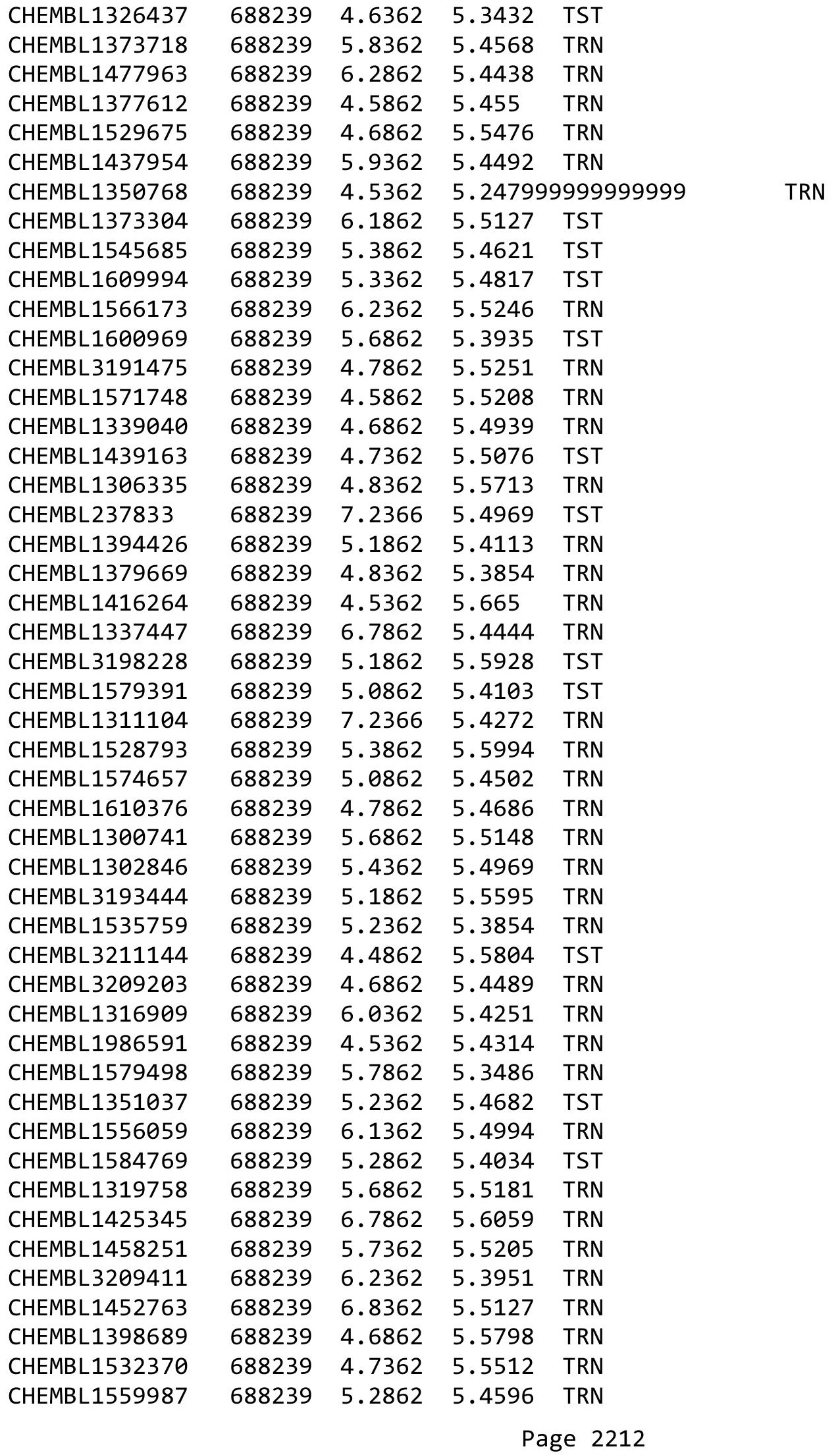




\begin{tabular}{|c|c|c|c|c|c|}
\hline \multirow[b]{2}{*}{ CHEMBL1443398 } & \\
\hline & 688239 & 7.2366 & 5.4983 & TST & \\
\hline CHEMBL1381374 & 688239 & 4.4862 & 5.4934 & TRN & \\
\hline CHEMBL1523706 & 688239 & 4.5362 & 5.4324 & TRN & \\
\hline CHEMBL1415382 & 688239 & 6.1362 & 5.3537 & TRN & \\
\hline CHEMBL1470910 & 688239 & 5.4862 & 5.4499 & TRN & \\
\hline CHEMBL1979727 & 688239 & 5.1862 & 5.4777 & TRN & \\
\hline CHEMBL1550715 & 688239 & 5.3862 & 5.5341 & TST & \\
\hline CHEMBL1436443 & 688239 & 6.8861 & \multicolumn{2}{|c|}{5.382000000000001} & TRN \\
\hline CHEMBL1556613 & 688239 & 5.5862 & 5.5134 & TRN & \\
\hline CHEMBL1347493 & 688239 & 4.7362 & 5.6338 & TRN & \\
\hline CHEMBL1613457 & 688239 & 6.1862 & 5.4971 & TRN & \\
\hline CHEMBL1342005 & 688239 & 5.1862 & 5.4962 & TRN & \\
\hline CHEMBL1322424 & 688239 & 5.1862 & 5.5455 & TRN & \\
\hline CHEMBL1543668 & 688239 & 5.1862 & 5.5409 & TRN & \\
\hline CHEMBL1300374 & 688239 & 5.1362 & 5.4901 & TST & \\
\hline CHEMBL1378624 & 688239 & 5.0362 & 5.4782 & TST & \\
\hline CHEMBL3196089 & 688239 & 5.1862 & 5.4716 & TRN & \\
\hline CHEMBL1501044 & 688239 & 6.2362 & 5.5117 & TRN & \\
\hline CHEMBL1502334 & 688239 & 6.2362 & 5.4816 & TRN & \\
\hline CHEMBL1595759 & 688239 & 4.6362 & 5.445 & TRN & \\
\hline CHEMBL1550290 & 688239 & 4.7362 & 5.3797 & TRN & \\
\hline CHEMBL1301018 & 688239 & 6.5363 & 5.5473 & TRN & \\
\hline CHEMBL1309511 & 688239 & 7.1361 & 5.5284 & TRN & \\
\hline CHEMBL1532092 & 688239 & 4.9862 & 5.351 & TST & \\
\hline CHEMBL1399818 & 688239 & 5.1862 & 5.5722 & TRN & \\
\hline CHEMBL1395612 & 688239 & 5.3362 & 5.2472 & TST & \\
\hline CHEMBL1602409 & 688239 & 6.8861 & 5.4832 & TRN & \\
\hline CHEMBL1382424 & 688239 & 6.8861 & 5.4948 & TRN & \\
\hline CHEMBL1457862 & 688239 & 5.5862 & 5.4368 & TRN & \\
\hline CHEMBL1350074 & 688239 & 5.1862 & 5.4951 & TST & \\
\hline CHEMBL1419307 & 688239 & 6.4362 & 5.6786 & TRN & \\
\hline CHEMBL1388349 & 688239 & 6.2362 & 5.5105 & TRN & \\
\hline CHEMBL1391307 & 688239 & 4.7862 & 5.4595 & TST & \\
\hline CHEMBL1344749 & 688239 & 7.8356 & 5.5849 & TST & \\
\hline CHEMBL1596745 & 688239 & 5.6362 & 5.3845 & TRN & \\
\hline CHEMBL1599730 & 688239 & 5.1862 & 5.5766 & TRN & \\
\hline CHEMBL1589124 & 688239 & 7.1864 & 5.4981 & TRN & \\
\hline CHEMBL1401674 & 688239 & 5.6362 & 5.4294 & TST & \\
\hline CHEMBL1446245 & 688239 & 8.3872 & 5.4482 & TST & \\
\hline CHEMBL1461668 & 688239 & 6.0362 & 5.37200 & 0000000001 & TST \\
\hline CHEMBL3208791 & 688239 & 5.3862 & 5.4385 & TST & \\
\hline CHEMBL1321372 & 688239 & 5.2862 & 5.6076 & TRN & \\
\hline CHEMBL1393537 & 688239 & 4.7862 & 5.5018 & TST & \\
\hline CHEMBL1278182 & 688239 & 5.4862 & 5.4567 & TRN & \\
\hline CHEMBL1573644 & 688239 & 4.6862 & 5.6003 & TRN & \\
\hline CHEMBL1520364 & 688239 & 5.7362 & 5.5093 & TRN & \\
\hline CHEMBL1455565 & 688239 & 5.0362 & 5.4198 & TRN & \\
\hline CHEMBL1407638 & 688239 & 4.5362 & 5.50899 & 99999999995 & TRN \\
\hline & & & & 213 & \\
\hline
\end{tabular}


Supplemental Table S2.txt

\begin{tabular}{|c|c|c|c|c|}
\hline & & & & \\
\hline HEMBL1509474 & 88239 & 5362 & 5242 & \\
\hline HEMBL1529430 & 3239 & & & \\
\hline HEMBL3207749 & & & & \\
\hline FMBL 1496895 & 239 & & & \\
\hline AEMBL1386413 & 88239 & 363 & 39 & \\
\hline HEMBL1400761 & 88239 & .8861 & 4123 & \\
\hline AEMBL1558680 & 39 & & & \\
\hline IEMBL1 & 239 & & 3918 & \\
\hline IEMBL] & & & & \\
\hline AEMBL1511263 & 88239 & 362 & 5.5004 & \\
\hline HEMBL1377571 & 88239 & 5.4862 & 5.5314 & \\
\hline HEMBL1605 & 39 & & & \\
\hline IEMBL: & & & 7274 & \\
\hline AEMBL: & & & & \\
\hline AEMBL1422429 & 88239 & & 5.4048 & \\
\hline AEMBL1433045 & & & & \\
\hline HEMBL1 & 9 & & 43 & \\
\hline EMBL: & & & & \\
\hline AEMBL: & & & & \\
\hline IEMBL1496329 & & & & \\
\hline AEMBL1438776 & & & & \\
\hline HEMBLI & 39 & & 96 & \\
\hline AEMBL & & & & \\
\hline EMB & & & & \\
\hline EMBL & & & & \\
\hline AEMBL1578045 & & & & \\
\hline AEMBL1603 & & & & \\
\hline EMB & & & & \\
\hline IEMB & 39 & & 28 & . \\
\hline IEMBL1370 & & & & \\
\hline HEMBL1380030 & & & & \\
\hline AEMBL & & & & ST \\
\hline 9 & & & & T \\
\hline 4 & & & & 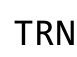 \\
\hline 15279 & & & & $5]$ \\
\hline AEMBL1442884 & & & 681 & ST \\
\hline & & & 54 & RI \\
\hline 6 & & & & \\
\hline 94 & & & 447 & ST \\
\hline AEMBL1565262 & 8239 & & 363 & $\mathrm{RI}$ \\
\hline AEMBL: & & & & $S$ \\
\hline CHEME & & & & \\
\hline & & & & \\
\hline CHEMBL] & & & 5.3492 & $\mathrm{R}$ \\
\hline IEMBL1 & 39 & 362 & .5555 & \\
\hline HEMBL $]$ & & & & \\
\hline CHEMBL146293 & & & 5.5466 & \\
\hline
\end{tabular}

Page 2214 
Supplemental Table S2.txt

\begin{tabular}{|c|c|c|c|c|}
\hline CHEMBL1465838 & 688239 & 7.2865 & 5.5522 & TRN \\
\hline CHEMBL1508679 & 688239 & 4.5362 & 5.6613 & TRN \\
\hline CHEMBL1403259 & 688239 & 5.3862 & 5.4075 & TRN \\
\hline CHEMBL1436853 & 688239 & 6.5862 & 5.5545 & TRN \\
\hline CHEMBL1488472 & 688239 & 5.9862 & 5.4719 & TRN \\
\hline CHEMBL1311890 & 688239 & 6.5363 & 5.4645 & TRN \\
\hline CHEMBL1402675 & 688239 & 6.0362 & 5.7043 & TRN \\
\hline CHEMBL1439486 & 688239 & 5.3862 & 5.5403 & TRN \\
\hline CHEMBL1086783 & 688239 & 5.3862 & 5.4931 & TRN \\
\hline CHEMBL1361594 & 688239 & 7.0862 & 5.4061 & TRN \\
\hline CHEMBL1488463 & 688239 & 5.2362 & 5.5184 & TST \\
\hline CHEMBL1546976 & 688239 & 5.6862 & 5.6396 & TRN \\
\hline CHEMBL 3191042 & 688239 & 6.9363 & 5.5813 & TRN \\
\hline CHEMBL1586315 & 688239 & 5.1862 & 5.3259 & TST \\
\hline CHEMBL1302633 & 688239 & 6.2362 & 5.4363 & TRN \\
\hline CHEMBL1362557 & 688239 & 5.1862 & 5.4172 & TST \\
\hline CHEMBL1338014 & 688239 & 4.5362 & 5.565 & TRN \\
\hline CHEMBL1602742 & 688239 & 6.1862 & 5.5873 & TRN \\
\hline CHEMBL1419677 & 688239 & 4.9862 & 5.472 & TRN \\
\hline CHEMBL1370965 & 688239 & 4.5362 & 5.3522 & TRN \\
\hline CHEMBL 3194177 & 688239 & 5.2862 & 5.5837 & TRN \\
\hline CHEMBL1494730 & 688239 & 5.1862 & 5.6118 & TRN \\
\hline CHEMBL1321583 & 688239 & 4.5362 & 5.3087 & TST \\
\hline CHEMBL1386122 & 688239 & 5.2362 & 5.3446 & TRN \\
\hline CHEMBL 3192133 & 688239 & 4.7862 & 5.4428 & TRN \\
\hline CHEMBL1375416 & 688239 & 6.8362 & 5.6317 & TST \\
\hline CHEMBL1494826 & 688239 & 5.1362 & 5.5711 & TRN \\
\hline CHEMBL1510589 & 688239 & 5.9862 & 5.53600 & 30000000005 \\
\hline CHEMBL1592499 & 688239 & 4.9862 & 5.4809 & TRN \\
\hline CHEMBL1607664 & 688239 & 5.0362 & 5.4998 & TRN \\
\hline CHEMBL1528120 & 688239 & 6.1362 & 5.4915 & TST \\
\hline CHEMBL1610885 & 688239 & 5.3362 & 5.5877 & TRN \\
\hline CHEMBL512649 & 688239 & 4.5362 & 5.4693 & TST \\
\hline CHEMBL1425195 & 688239 & 7.0362 & 5.4705 & TST \\
\hline CHEMBL1387857 & 688239 & 4.6 & 5.5135 & TRN \\
\hline CHEMBL1609910 & 688239 & 6.9863 & 5.4286 & TRN \\
\hline CHEMBL1480717 & 688239 & 5.9362 & 5.6255 & TRN \\
\hline CHEMBL 3209293 & 688239 & 4.6862 & 5.5631 & TRN \\
\hline CHEMBL1599120 & 688239 & 4.4862 & 5.3909 & TST \\
\hline CHEMBL1465812 & 688239 & 4.5362 & 5.5804 & TRN \\
\hline CHEMBL1386240 & 688239 & 6.8362 & 5.5108 & TRN \\
\hline CHEMBL1330129 & 688239 & 6.2362 & 5.4558 & TRN \\
\hline CHEMBL1385639 & 688239 & 4.6362 & 5.4594 & TST \\
\hline CHEMBL1547722 & 688239 & 4.9362 & 5.3515 & TRN \\
\hline CHEMBL1344162 & 688239 & 8.1871 & 5.3679 & TST \\
\hline CHEMBL1425004 & 688239 & 4.7362 & 5.2949 & TST \\
\hline CHEMBL1545730 & 688239 & 4.5362 & 5.5232 & TRN \\
\hline CHEMBL1504097 & 688239 & 5.1362 & 5.5247 & TRN \\
\hline
\end{tabular}

Page 2215 
Supplemental Table S2.txt

\begin{tabular}{|c|c|c|c|c|c|}
\hline CHEMBL1563682 & 688239 & 5.1862 & 5.436 & TRN & \\
\hline CHEMBL1542157 & 688239 & 4.5862 & 5.5381 & TRN & \\
\hline CHEMBL1361198 & 688239 & 5.9862 & 5.5771 & TST & \\
\hline CHEMBL82492 & 688239 & 4.5862 & 5.4784 & TST & \\
\hline CHEMBL1337712 & 688239 & 6.1362 & 5.6134 & TRN & \\
\hline CHEMBL1339189 & 688239 & 4.6862 & 5.4796 & TRN & \\
\hline CHEMBL1548515 & 688239 & 4.8362 & 5.3971 & TRN & \\
\hline CHEMBL1548215 & 688239 & 8.283999 & 99999999 & 5.4491 & \\
\hline CHEMBL1579570 & 688239 & 5.8362 & 5.3945 & TRN & \\
\hline CHEMBL1565326 & 688239 & 4.9862 & 5.5342 & TST & \\
\hline CHEMBL1350476 & 688239 & 6.6362 & 5.6258 & TRN & \\
\hline CHEMBL1539803 & 688239 & 4.6862 & 5.5428 & TRN & \\
\hline CHEMBL1550963 & 688239 & 4.5362 & 5.3925 & TRN & \\
\hline CHEMBL1504183 & 688239 & 5.6862 & 5.4339 & TST & \\
\hline CHEMBL1603629 & 688239 & 4.5362 & 5.467000 & 0000000005 & \\
\hline CHEMBL1351476 & 688239 & 4.7862 & 5.3361 & TRN & \\
\hline CHEMBL 3190566 & 688239 & 4.5362 & 5.3788 & TRN & \\
\hline CHEMBL1319173 & 688239 & 5.4362 & 5.5009 & TRN & \\
\hline CHEMBL1322609 & 688239 & 5.2862 & 5.445 & TRN & \\
\hline CHEMBL1479191 & 688239 & 5.8862 & 5.5956 & TRN & \\
\hline CHEMBL1557116 & 688239 & 8.3372 & 5.4676 & TST & \\
\hline CHEMBL1334515 & 688239 & 6.8362 & 5.6278 & TRN & \\
\hline CHEMBL1477263 & 688239 & 5.1862 & 5.3993 & TST & \\
\hline CHEMBL1399105 & 688239 & 5.8362 & 5.5895 & TRN & \\
\hline CHEMBL1335432 & 688239 & 6.0362 & 5.4395 & TRN & \\
\hline CHEMBL 1459878 & 688239 & 5.1862 & 5.497999 & 999999999 & \\
\hline CHEMBL1589537 & 688239 & 4.9362 & 5.4312 & TRN & \\
\hline CHEMBL 3198931 & 688239 & 4.5862 & 5.3524 & TRN & \\
\hline CHEMBL1337814 & 688239 & 6.6861 & 5.4728 & TRN & \\
\hline CHEMBL1454575 & 688239 & 4.5362 & 5.4635 & TRN & \\
\hline CHEMBL1583356 & 688239 & 5.7362 & 5.5031 & TST & \\
\hline CHEMBL1567728 & 688239 & 5.5362 & 5.4429 & TST & \\
\hline CHEMBL1604183 & 688239 & 8.283999 & 99999999 & 5.3794 & \\
\hline CHEMBL1420484 & 688239 & 7.0362 & 5.5769 & TST & \\
\hline CHEMBL1524615 & 688239 & 5.1862 & 5.558 & TRN & \\
\hline CHEMBL3210507 & 688239 & 4.5362 & 5.5598 & TRN & \\
\hline CHEMBL1551486 & 688239 & 5.1862 & 5.4613 & TRN & \\
\hline CHEMBL1555538 & 688239 & 5.5862 & 5.6277 & TRN & \\
\hline CHEMBL1596895 & 688239 & 4.5362 & 5.5636 & TRN & \\
\hline CHEMBL1964383 & 688239 & 4.5362 & 5.5318 & TRN & \\
\hline CHEMBL1324634 & 688239 & 6.2362 & 5.3317 & TRN & \\
\hline CHEMBL1313418 & 688239 & 4.6862 & 5.4388 & TRN & \\
\hline CHEMBL1426549 & 688239 & 5.2862 & 5.638999 & 999999999 & \\
\hline CHEMBL1482183 & 688239 & 4.7362 & 5.4228 & TST & \\
\hline CHEMBL1375595 & 688239 & 5.2362 & 5.5101 & TRN & \\
\hline CHEMBL1326189 & 688239 & 5.1862 & 5.4201 & TST & \\
\hline CHEMBL1576133 & 688239 & 5.4362 & 5.5193 & TRN & \\
\hline CHEMBL1479825 & 688239 & 6.6362 & 5.5816 & TRN & \\
\hline
\end{tabular}




\begin{tabular}{|c|c|c|c|c|c|c|}
\hline \multicolumn{7}{|c|}{ Supplemental Ta } \\
\hline CHEMBL3190840 & 688239 & 4.7362 & 5.4091 & TRN & & \\
\hline CHEMBL1336959 & 688239 & 5.4862 & 5.4664 & TRN & & \\
\hline CHEMBL1313004 & 688239 & 5.5362 & 5.6608 & TRN & & \\
\hline CHEMBL1529757 & 688239 & 4.9862 & 5.5977 & TRN & & \\
\hline CHEMBL1311926 & 688239 & 4.6862 & 5.5018 & TRN & & \\
\hline CHEMBL3196315 & 688239 & 5.1862 & 5.2403 & TST & & \\
\hline CHEMBL1531021 & 688239 & 5.1862 & 5.7126 & TRN & & \\
\hline CHEMBL1310576 & 688239 & 5.8362 & 5.5732 & TST & & \\
\hline CHEMBL3210125 & 688239 & 6.2362 & 5.5458 & TRN & & \\
\hline CHEMBL1312984 & 688239 & 5.1862 & 5.3882 & TST & & \\
\hline CHEMBL1407988 & 688239 & 6.9363 & 5.5753 & TRN & & \\
\hline CHEMBL1532088 & 688239 & 6.1862 & 5.5193 & TST & & \\
\hline CHEMBL1319486 & 688239 & 5.1862 & 5.5344 & TRN & & \\
\hline CHEMBL1548942 & 688239 & 4.5362 & 5.4493 & TRN & & \\
\hline CHEMBL1536508 & 688239 & 5.9362 & 5.4922 & TRN & & \\
\hline CHEMBL1361046 & 688239 & 4.9862 & 5.4818 & TRN & & \\
\hline CHEMBL1581486 & 688239 & 5.4862 & 5.3914 & TRN & & \\
\hline CHEMBL1468299 & 688239 & 5.6362 & 5.401 & TRN & & \\
\hline CHEMBL1415753 & 688239 & 4.5362 & 5.4365 & TRN & & \\
\hline CHEMBL1549220 & 688239 & 5.4362 & 5.4419 & TRN & & \\
\hline CHEMBL1427360 & 688239 & 5.1362 & 5.4781 & TST & & \\
\hline CHEMBL1333280 & 688239 & 4.6362 & 5.5077 & TRN & & \\
\hline CHEMBL1328717 & 688239 & 6.5363 & 5.5082 & TST & & \\
\hline CHEMBL3192261 & 688239 & 5.4362 & 5.5445 & TRN & & \\
\hline CHEMBL1456596 & 688239 & 6.9363 & 5.5278 & TST & & \\
\hline CHEMBL1405968 & 688239 & 4.6862 & 5.3 & TRN & & \\
\hline CHEMBL1491230 & 688239 & 4.6862 & 5.5775 & TST & & \\
\hline CHEMBL1540435 & 688239 & 4.5362 & 5.4851 & TRN & & \\
\hline CHEMBL1540849 & 688239 & 4.5862 & 5.5042 & TRN & & \\
\hline CHEMBL1333838 & 688239 & 6.3863 & 5.4678 & TRN & & \\
\hline CHEMBL1498756 & 688239 & 4.9362 & 5.459 & TRN & & \\
\hline CHEMBL1342137 & 688239 & 8.28399 & 99999999 & 99 & 5.4587 & TRN \\
\hline CHEMBL1467562 & 688239 & 4.8362 & 5.4602 & TRN & & \\
\hline CHEMBL1522740 & 688239 & 4.5362 & 5.5656 & TRN & & \\
\hline CHEMBL1414401 & 688239 & 5.6362 & 5.5578 & TRN & & \\
\hline CHEMBL1349944 & 688239 & 5.7362 & 5.5423 & TST & & \\
\hline CHEMBL1533627 & 688239 & 4.7362 & 5.3322 & TRN & & \\
\hline CHEMBL1455227 & 688239 & 4.5362 & 5.3315 & TRN & & \\
\hline CHEMBL1387350 & 688239 & 5.1862 & 5.7008 & TRN & & \\
\hline CHEMBL1503458 & 688239 & 6.9363 & 5.5941 & TRN & & \\
\hline CHEMBL1523799 & 688239 & 6.3362 & 5.3851 & TRN & & \\
\hline CHEMBL1341027 & 688239 & 4.5362 & 5.4349 & TRN & & \\
\hline CHEMBL1550429 & 688239 & 6.4862 & 5.2361 & TRN & & \\
\hline CHEMBL1473778 & 688239 & 5.3362 & 5.4304 & TST & & \\
\hline CHEMBL1429525 & 688239 & 4.4862 & 5.4985 & TRN & & \\
\hline CHEMBL1213050 & 688239 & 8.28399 & 99999999 & 99 & 5.6255 & TST \\
\hline CHEMBL1488131 & 688239 & 4.6862 & 5.4961 & TST & & \\
\hline CHEMBL1320338 & 688239 & 5.1862 & 5.4183 & TRN & & \\
\hline
\end{tabular}


Supplemental Table S2.txt

\begin{tabular}{|c|c|c|c|c|}
\hline CHEMBL1502986 & 688239 & 4.5362 & 5.3232 & TRN \\
\hline CHEMBL1482202 & 688239 & 5.1362 & 5.5574 & TST \\
\hline CHEMBL1599840 & 688239 & 5.4862 & 5.516 & TST \\
\hline CHEMBL1569184 & 688239 & 4.5362 & 5.5994 & TRN \\
\hline CHEMBL1545760 & 688239 & 4.8862 & \multicolumn{2}{|c|}{5.513999999999999} \\
\hline CHEMBL1380159 & 688239 & 4.7862 & 5.4259 & TRN \\
\hline CHEMBL1342821 & 688239 & 5.0362 & 5.2953 & TST \\
\hline CHEMBL1387778 & 688239 & 5.1362 & 5.4605 & TRN \\
\hline CHEMBL1987654 & 688239 & 6.0362 & 5.5978 & TRN \\
\hline CHEMBL1571847 & 688239 & 5.9362 & 5.5268 & TRN \\
\hline CHEMBL1360420 & 688239 & 5.1862 & 5.6008 & TRN \\
\hline CHEMBL1425049 & 688239 & 8.2366 & 5.4844 & TRN \\
\hline CHEMBL 3193768 & 688239 & 4.6362 & 5.4066 & TRN \\
\hline CHEMBL1602390 & 688239 & 5.1362 & 5.5093 & TST \\
\hline CHEMBL1556305 & 688239 & 6.2862 & 5.5429 & TRN \\
\hline CHEMBL1606461 & 688239 & 5.1862 & 5.3984 & TRN \\
\hline CHEMBL1349013 & 688239 & 4.5362 & 5.5887 & TRN \\
\hline CHEMBL1309017 & 688239 & 6.3863 & 5.4739 & TRN \\
\hline CHEMBL1375259 & 688239 & 6.0362 & 5.5947 & TRN \\
\hline CHEMBL1321781 & 688239 & 6.1862 & 5.4372 & TRN \\
\hline CHEMBL1528489 & 688239 & 6.1862 & 5.6102 & TRN \\
\hline CHEMBL1407290 & 688239 & 4.6362 & 5.4545 & TST \\
\hline CHEMBL1435038 & 688239 & 6.9363 & 5.5259 & TRN \\
\hline CHEMBL1363135 & 688239 & 7.2366 & 5.5773 & TST \\
\hline CHEMBL1537959 & 688239 & 5.9362 & 5.5608 & TRN \\
\hline CHEMBL1367067 & 688239 & 4.6362 & 5.5582 & TRN \\
\hline CHEMBL1438200 & 688239 & 4.5362 & 5.5646 & TRN \\
\hline CHEMBL1588951 & 688239 & 6.0362 & 5.3608 & TRN \\
\hline CHEMBL1573351 & 688239 & 4.6862 & 5.4952 & TRN \\
\hline CHEMBL1591550 & 688239 & 5.1362 & 5.471 & TST \\
\hline CHEMBL1574191 & 688239 & 4.7362 & 5.3133 & TST \\
\hline CHEMBL1379493 & 688239 & 4.95 & 5.4384 & TRN \\
\hline CHEMBL1570481 & 688239 & 5.3862 & 5.577006 & 0000000001 \\
\hline CHEMBL1539359 & 688239 & 4.5362 & 5.4364 & TRN \\
\hline CHEMBL1982334 & 688239 & 6.9363 & 5.2999 & TRN \\
\hline CHEMBL1594632 & 688239 & 5.1862 & 5.4824 & TRN \\
\hline CHEMBL1539354 & 688239 & 4.5362 & 5.4566 & TRN \\
\hline CHEMBL1567554 & 688239 & 4.7862 & 5.3984 & TRN \\
\hline CHEMBL1557578 & 688239 & 4.6362 & 5.4006 & TRN \\
\hline CHEMBL1510078 & 688239 & 6.2862 & 5.4465 & TST \\
\hline CHEMBL1556405 & 688239 & 6.1862 & 5.565 & TST \\
\hline CHEMBL1516876 & 688239 & 6.1862 & 5.4621 & TRN \\
\hline CHEMBL1330914 & 688239 & 4.7362 & 5.4058 & TRN \\
\hline CHEMBL1341053 & 688239 & 5.1862 & 5.5936 & TST \\
\hline CHEMBL1546710 & 688239 & 6.7361 & 5.5279 & TST \\
\hline CHEMBL1479721 & 688239 & 4.5362 & 5.4523 & TRN \\
\hline CHEMBL1578918 & 688239 & 6.0862 & 5.5654 & TST \\
\hline CHEMBL1386001 & 688239 & 8.1871 & 5.6964 & TRN \\
\hline
\end{tabular}


Supplemental Table S2.txt

\begin{tabular}{|c|c|c|c|c|c|}
\hline CHEMBL1553065 & 688239 & 4.5362 & 5.5151 & TRN & \\
\hline CHEMBL1608642 & 688239 & 5.4362 & 5.4142 & TRN & \\
\hline CHEMBL1377553 & 688239 & 5.1862 & 5.5542 & TRN & \\
\hline CHEMBL1427809 & 688239 & 4.5362 & 5.5039 & TRN & \\
\hline CHEMBL1502148 & 688239 & 4.7362 & 5.5851 & TRN & \\
\hline CHEMBL1599576 & 688239 & 4.5362 & 5.3969 & TST & \\
\hline CHEMBL1344276 & 688239 & 6.2862 & 5.5095 & TRN & \\
\hline CHEMBL1402174 & 688239 & 7.5361 & 5.4264 & TRN & \\
\hline CHEMBL1524622 & 688239 & 5.1862 & 5.4877 & TRN & \\
\hline CHEMBL1968421 & 688239 & 5.1862 & 5.371 & TST & \\
\hline CHEMBL1464469 & 688239 & 6.1862 & 5.4643 & TRN & \\
\hline CHEMBL1374183 & 688239 & 4.7862 & 5.4928 & TRN & \\
\hline CHEMBL1562280 & 688239 & 5.1862 & 5.492999 & э999999999 & TST \\
\hline CHEMBL1583162 & 688239 & 5.6862 & 5.4985 & TST & \\
\hline CHEMBL1533917 & 688239 & 5.4862 & 5.4773 & TST & \\
\hline CHEMBL1421799 & 688239 & 4.9362 & 5.5378 & TRN & \\
\hline CHEMBL1574311 & 688239 & 7.0362 & 5.6039 & TST & \\
\hline CHEMBL1346370 & 688239 & 4.7362 & 5.4776 & TRN & \\
\hline CHEMBL3192916 & 688239 & 5.7362 & 5.3907 & TST & \\
\hline CHEMBL1393029 & 688239 & 4.7862 & 5.4787 & TRN & \\
\hline CHEMBL1603706 & 688239 & 5.1362 & 5.5967 & TRN & \\
\hline CHEMBL1577315 & 688239 & 5.3862 & 5.5956 & TRN & \\
\hline CHEMBL1449722 & 688239 & 4.4862 & 5.4688 & TST & \\
\hline CHEMBL1478050 & 688239 & 4.6362 & 5.4944 & TRN & \\
\hline CHEMBL3212677 & 688239 & 5.4862 & 5.3692 & TRN & \\
\hline CHEMBL1327169 & 688239 & 5.1862 & 5.5 & TST & \\
\hline CHEMBL1344229 & 688239 & 5.1862 & 5.4406 & TRN & \\
\hline CHEMBL1392591 & 688239 & 5.2862 & 5.544 & TRN & \\
\hline CHEMBL1421425 & 688239 & 4.7362 & 5.6253 & TRN & \\
\hline CHEMBL1387942 & 688239 & 6.3362 & 5.604 & TRN & \\
\hline CHEMBL1420411 & 688239 & 5.7362 & 5.3583 & TRN & \\
\hline CHEMBL1300496 & 688239 & 5.3862 & 5.4547 & TRN & \\
\hline CHEMBL1370191 & 688239 & 4.5362 & 5.517 & TST & \\
\hline CHEMBL1514644 & 688239 & 5.3862 & 5.5291 & TRN & \\
\hline CHEMBL1544868 & 688239 & 5.1862 & 5.5132 & TRN & \\
\hline CHEMBL3190403 & 688239 & 5.6862 & $5.55200 e$ & 30000000005 & 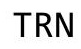 \\
\hline CHEMBL1486237 & 688239 & 6.1362 & 5.4339 & TRN & \\
\hline CHEMBL1321396 & 688239 & 5.3862 & 5.5882 & TRN & \\
\hline CHEMBL1426175 & 688239 & 4.8862 & 5.515 & TRN & \\
\hline CHEMBL1536596 & 688239 & 4.5362 & 5.4478 & TRN & \\
\hline CHEMBL1442015 & 688239 & 4.7862 & 5.2924 & TRN & \\
\hline CHEMBL1460289 & 688239 & 5.7362 & 5.5266 & TRN & \\
\hline CHEMBL1405089 & 688239 & 7.6861 & 5.6848 & TRN & \\
\hline CHEMBL1321026 & 688239 & \multicolumn{3}{|c|}{8.283999999999999} & 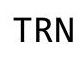 \\
\hline CHEMBL1423764 & 688239 & 6.0362 & 5.5086 & TRN & \\
\hline CHEMBL1569236 & 688239 & 4.5362 & 5.4787 & TST & \\
\hline CHEMBL3199067 & 688239 & 4.5362 & 5.4642 & TRN & \\
\hline CHEMBL1382509 & 688239 & 5.8862 & 5.5263 & TST & \\
\hline
\end{tabular}

Page 2219 
Supplemental Table S2.txt

\begin{tabular}{|c|c|c|c|c|c|}
\hline CHEMBL1484518 & 688239 & 6.0862 & 5.4767 & TRN & \\
\hline CHEMBL1417284 & 688239 & 5.1862 & 5.2889 & TRN & \\
\hline CHEMBL1558857 & 688239 & 5.8862 & 5.462999 & 9999999999 & TRN \\
\hline CHEMBL1595183 & 688239 & 4.5362 & 5.3676 & TRN & \\
\hline CHEMBL1449153 & 688239 & 4.5862 & 5.5577 & TRN & \\
\hline CHEMBL1320111 & 688239 & 7.6364 & 5.4396 & TRN & \\
\hline CHEMBL1484699 & 688239 & 5.3862 & 5.3919 & TRN & \\
\hline CHEMBL1419921 & 688239 & 6.1362 & 5.467000 & 00000000005 & TRN \\
\hline CHEMBL 3195223 & 688239 & 7.0362 & 5.5309 & TST & \\
\hline CHEMBL 3193054 & 688239 & 5.1362 & 5.4538 & TRN & \\
\hline CHEMBL1325785 & 688239 & 6.0862 & 5.6488 & TST & \\
\hline CHEMBL1591103 & 688239 & 4.6862 & 5.506 & TRN & \\
\hline CHEMBL1504153 & 688239 & 5.6362 & 5.4489 & TRN & \\
\hline CHEMBL1478076 & 688239 & 6.0362 & 5.4149 & TRN & \\
\hline CHEMBL1371466 & 688239 & 4.7362 & 5.5078 & TRN & \\
\hline CHEMBL3213944 & 688239 & 6.6861 & 5.5109 & TST & \\
\hline CHEMBL1349265 & 688239 & 7.2865 & 5.5735 & TST & \\
\hline CHEMBL1567538 & 688239 & 5.4362 & 5.5036 & TST & \\
\hline CHEMBL3196406 & 688239 & 5.7862 & 5.3908 & TRN & \\
\hline CHEMBL1455526 & 688239 & 4.7362 & 5.5108 & TST & \\
\hline CHEMBL1485945 & 688239 & 4.6362 & 5.3629 & TRN & \\
\hline CHEMBL1481453 & 688239 & 7.0362 & 5.4924 & TRN & \\
\hline CHEMBL1416782 & 688239 & 6.9863 & 5.6058 & TRN & \\
\hline CHEMBL1491174 & 688239 & 7.1361 & 5.4954 & TRN & \\
\hline CHEMBL1309852 & 688239 & 4.5362 & 5.5772 & TRN & \\
\hline CHEMBL1508765 & 688239 & 6.2862 & 5.5224 & TST & \\
\hline CHEMBL1377578 & 688239 & 5.2362 & 5.4528 & TRN & \\
\hline CHEMBL1484748 & 688239 & 4.6862 & 5.4599 & TST & \\
\hline CHEMBL1307087 & 688239 & 5.4362 & 5.4606 & TST & \\
\hline CHEMBL1503144 & 688239 & 6.2362 & 5.3612 & TRN & \\
\hline CHEMBL1406373 & 688239 & 6.1862 & 5.4667 & TRN & \\
\hline CHEMBL1606614 & 688239 & 4.7862 & 5.4499 & TRN & \\
\hline CHEMBL1553365 & 688239 & 6.2362 & 5.3896 & TRN & \\
\hline CHEMBL1466869 & 688239 & 5.4362 & 5.4373 & TRN & \\
\hline CHEMBL1492520 & 688239 & 5.8362 & \multicolumn{2}{|c|}{5.571000000000001} & TRN \\
\hline CHEMBL1449647 & 688239 & 5.9362 & 5.4844 & TRN & \\
\hline CHEMBL1421285 & 688239 & 4.7362 & 5.5013 & TRN & \\
\hline CHEMBL601878 & 688239 & 5.5862 & 5.4106 & TRN & \\
\hline CHEMBL1362305 & 688239 & 4.8362 & 5.6014 & TST & \\
\hline CHEMBL 3194294 & 688239 & 5.3362 & 5.5749 & TRN & \\
\hline CHEMBL1408873 & 688239 & 4.4862 & 5.5536 & TRN & \\
\hline CHEMBL1447628 & 688239 & 4.5362 & 5.4893 & TRN & \\
\hline CHEMBL1532415 & 688239 & 5.1862 & 5.5211 & TST & \\
\hline CHEMBL1366592 & 688239 & 4.5362 & 5.5206 & TRN & \\
\hline CHEMBL1394629 & 688239 & 6.8362 & 5.3071 & TRN & \\
\hline CHEMBL1594985 & 688239 & 6.9363 & 5.6128 & TRN & \\
\hline CHEMBL1606070 & 688239 & 4.8362 & 5.3931 & TRN & \\
\hline CHEMBL1306456 & 688239 & 4.5362 & 5.4804 & TRN & \\
\hline
\end{tabular}




\begin{tabular}{|c|c|c|c|c|c|}
\hline \multicolumn{6}{|c|}{ Supplemental Table S2.txt } \\
\hline CHEMBL1529877 & 688239 & 7.5361 & 5.5944 & TRN & \\
\hline CHEMBL1584752 & 688239 & 4.6362 & 5.3905 & TRN & \\
\hline CHEMBL1515536 & 688239 & 6.3863 & 5.5186 & TRN & \\
\hline CHEMBL1562306 & 688239 & 7.3363 & 5.6204 & TRN & \\
\hline CHEMBL1419637 & 688239 & 5.4362 & 5.4574 & TRN & \\
\hline CHEMBL1440237 & 688239 & 6.2862 & 5.4066 & TST & \\
\hline CHEMBL1422479 & 688239 & 6.6861 & 5.5495 & TRN & \\
\hline CHEMBL1303333 & 688239 & 4.6862 & 5.4228 & TRN & \\
\hline CHEMBL1382091 & 688239 & 5.4362 & 5.3685 & TST & \\
\hline CHEMBL1366380 & 688239 & 4.4862 & 5.5516 & TRN & \\
\hline CHEMBL 2006386 & 688239 & 4.5362 & 5.4691 & TRN & \\
\hline CHEMBL1485533 & 688239 & 5.1862 & 5.4445 & TST & \\
\hline CHEMBL1406555 & 688239 & 6.6861 & 5.5315 & TRN & \\
\hline CHEMBL1440038 & 688239 & 4.5362 & 5.5794 & TRN & \\
\hline CHEMBL1568119 & 688239 & 4.5862 & 5.4244 & TRN & \\
\hline CHEMBL1599445 & 688239 & 4.9362 & 5.4722 & TRN & \\
\hline CHEMBL1514302 & 688239 & 4.8862 & 5.45799 & 9999999999 & TRN \\
\hline CHEMBL3191869 & 688239 & 6.7361 & 5.4058 & TST & \\
\hline CHEMBL1472030 & 688239 & 4.5362 & 5.3476 & TRN & \\
\hline CHEMBL1348154 & 688239 & 6.1862 & 5.5435 & TST & \\
\hline CHEMBL1551600 & 688239 & 5.3862 & 5.4391 & TRN & \\
\hline CHEMBL1430894 & 688239 & 5.7362 & 5.481 & TST & \\
\hline CHEMBL1399465 & 688239 & 4.9362 & 5.4557 & TRN & \\
\hline CHEMBL1518152 & 688239 & 8.3372 & 5.569 & TRN & \\
\hline CHEMBL1443234 & 688239 & 4.5362 & 5.4052 & TRN & \\
\hline CHEMBL1503485 & 688239 & 5.6362 & 5.5393 & TRN & \\
\hline CHEMBL1427637 & 688239 & 5.3862 & 5.3422 & TST & \\
\hline CHEMBL1416327 & 688239 & 6.2862 & 5.5134 & TST & \\
\hline CHEMBL1454341 & 688239 & 5.5862 & 5.5614 & TRN & \\
\hline CHEMBL1374260 & 688239 & 4.5362 & 5.437 & TRN & \\
\hline CHEMBL1511031 & 688239 & 4.6362 & 5.4424 & TRN & \\
\hline CHEMBL1605641 & 688239 & 5.2862 & 5.4381 & TST & \\
\hline CHEMBL1392638 & 688239 & 4.7362 & 5.5282 & TST & \\
\hline CHEMBL1205690 & 688239 & 4.9362 & 5.5017 & TRN & \\
\hline CHEMBL1607592 & 688239 & 5.1862 & 5.5443 & TRN & \\
\hline CHEMBL1306102 & 688239 & 4.5362 & 5.5848 & TRN & \\
\hline CHEMBL1515076 & 688239 & 5.3362 & 5.1854 & TRN & \\
\hline CHEMBL1395580 & 688239 & 6.0362 & 5.5532 & TRN & \\
\hline CHEMBL1501200 & 688239 & 6.4362 & 5.3687 & TST & \\
\hline CHEMBL1459827 & 688239 & 4.5362 & 5.5014 & TRN & \\
\hline CHEMBL1364842 & 688239 & 6.1862 & 5.5362 & TST & \\
\hline CHEMBL1460017 & 688239 & 5.6862 & 5.5351 & TRN & \\
\hline CHEMBL1327628 & 688239 & 4.5862 & 5.523 & TRN & \\
\hline CHEMBL1438681 & 688239 & 4.5362 & 5.4643 & TRN & \\
\hline CHEMBL1396278 & 688239 & 6.1862 & 5.5586 & TRN & \\
\hline CHEMBL1382294 & 688239 & 6.1362 & 5.4633 & TRN & \\
\hline CHEMBL1326808 & 688239 & 4.6362 & 5.4771 & TST & \\
\hline CHEMBL1477735 & 688239 & 5.0862 & 5.3815 & TRN & \\
\hline
\end{tabular}


Supplemental Table S2.txt

\begin{tabular}{|c|c|c|c|c|c|}
\hline CHEMBL1310455 & 688239 & 5.7862 & 5.5215 & TRN & \\
\hline CHEMBL1378337 & 688239 & 8.3372 & 5.5189 & TRN & \\
\hline CHEMBL1512041 & 688239 & 6.9363 & 5.5264 & TST & \\
\hline CHEMBL1528831 & 688239 & 4.9362 & 5.5753 & TRN & \\
\hline CHEMBL3210355 & 688239 & 5.3862 & 5.3647 & TRN & \\
\hline CHEMBL1602415 & 688239 & 4.5362 & 5.3081 & TRN & \\
\hline CHEMBL1594313 & 688239 & 6.3863 & 5.6341 & TRN & \\
\hline CHEMBL1485115 & 688239 & 6.2862 & 5.4726 & TRN & \\
\hline CHEMBL1347953 & 688239 & 8.28399 & 79999999 & 5.5675 & TRN \\
\hline CHEMBL1343728 & 688239 & 4.5362 & 5.4036 & TST & \\
\hline CHEMBL1517922 & 688239 & 6.5862 & 5.5786 & TRN & \\
\hline CHEMBL1497533 & 688239 & 5.1362 & 5.4638 & TRN & \\
\hline CHEMBL1570155 & 688239 & 4.5362 & 5.5656 & TRN & \\
\hline CHEMBL1576904 & 688239 & 6.5862 & 5.5163 & TST & \\
\hline CHEMBL1345198 & 688239 & 5.1862 & 5.4746 & TST & \\
\hline CHEMBL1608303 & 688239 & 5.1862 & 5.5745 & TST & \\
\hline CHEMBL1608590 & 688239 & 8.3372 & 5.5026 & TRN & \\
\hline CHEMBL1386141 & 688239 & 5.0362 & 5.3859 & TRN & \\
\hline CHEMBL1597975 & 688239 & 5.5362 & 5.4092 & TRN & \\
\hline CHEMBL1585287 & 688239 & 5.5862 & 5.4493 & TRN & \\
\hline CHEMBL1573992 & 688239 & 4.6862 & 5.2689 & TRN & \\
\hline CHEMBL1486793 & 688239 & 4.8362 & 5.4372 & TRN & \\
\hline CHEMBL3191093 & 688239 & 5.1862 & 5.4262 & TST & \\
\hline CHEMBL1583814 & 688239 & 4.6362 & 5.4919 & TRN & \\
\hline CHEMBL1460080 & 688239 & 4.5362 & 5.5595 & TST & \\
\hline CHEMBL1385385 & 688239 & 4.7362 & 5.3369 & TST & \\
\hline CHEMBL1475749 & 688239 & 6.0 & 5.4253 & TRN & \\
\hline CHEMBL1348698 & 688239 & 5.1862 & 5.403 & TRN & \\
\hline CHEMBL1467631 & 688239 & 5.8862 & 5.4434 & TRN & \\
\hline CHEMBL1475183 & 688239 & 5.6862 & 5.4434 & TST & \\
\hline CHEMBL1391456 & 688239 & 5.0362 & 5.4615 & TRN & \\
\hline CHEMBL1423769 & 688239 & 5.7362 & 5.3788 & TRN & \\
\hline CHEMBL1327030 & 688239 & 6.8362 & 5.5254 & TRN & \\
\hline CHEMBL1381142 & 688239 & 6.0362 & \multicolumn{2}{|c|}{5.542999999999999} & TRN \\
\hline CHEMBL1464863 & 688239 & 4.5362 & 5.2917 & TRN & \\
\hline CHEMBL1476094 & 688239 & 6.8362 & 5.4619 & TRN & \\
\hline CHEMBL1404627 & 688239 & 5.3362 & 5.6369 & TRN & \\
\hline CHEMBL300389 & 688239 & 5.1862 & 5.2059 & TST & \\
\hline CHEMBL1345381 & 688239 & 4.8362 & 5.4496 & TRN & \\
\hline CHEMBL1469888 & 688239 & 6.3362 & 5.3786 & TRN & \\
\hline CHEMBL1395684 & 688239 & 4.5362 & \multicolumn{2}{|c|}{5.3870000000000005} & 13 \\
\hline CHEMBL1346111 & 688239 & 6.5363 & 5.4139 & TRN & \\
\hline CHEMBL1367981 & 688239 & 5.2362 & 5.4338 & TRN & \\
\hline CHEMBL1593748 & 688239 & 4.5362 & 5.3876 & TRN & \\
\hline CHEMBL1447268 & 688239 & 6.8861 & 5.5653 & TRN & \\
\hline CHEMBL1407989 & 688239 & 6.0362 & 5.5739 & TRN & \\
\hline CHEMBL1418068 & 688239 & 5.5362 & 5.4712 & TST & \\
\hline CHEMBL1498793 & 688239 & 6.2362 & 5.4692 & TRN & \\
\hline
\end{tabular}

Page 2222 
Supplemental Table S2.txt

\begin{tabular}{|c|c|c|c|c|}
\hline 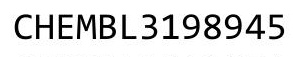 & & & & \\
\hline AEMBL1511374 & 38239 & 1362 & 6 & \\
\hline AEMBL1423617 & 239 & 862 & 892 & \\
\hline 514 & 39 & 862 & & \\
\hline IEMBL1307437 & & 862 & & \\
\hline AEMBL492468 & 88239 & 362 & 56 & \\
\hline AEMBL1435295 & 88239 & 862 & 5025 & \\
\hline HEMBL1499520 & & & & \\
\hline IEMBL146 & 39 & 862 & & \\
\hline IEMBL1088173 & & 362 & & \\
\hline AEMBL1497456 & 239 & 862 & & \\
\hline AEMBL1403917 & 39 & 861 & 975 & \\
\hline AEMBL1321580 & & 862 & & \\
\hline AEMBL13 & & 362 & & \\
\hline HEMBL1321348 & & 362 & & \\
\hline AEMBL1583154 & & 862 & & \\
\hline AEMBL1599400 & & 362 & & \\
\hline IEMBL1599878 & & 62 & & \\
\hline AEMBL1525170 & & 362 & & \\
\hline AEMBL1575709 & & 362 & & \\
\hline AEMBL1359275 & & 362 & & \\
\hline AEMBL1492927 & & 62 & & \\
\hline IEMBL1446313 & & 62 & & \\
\hline AEMBL1567893 & & 62 & & \\
\hline 123 & & 62 & & \\
\hline AEMBL1492566 & & 862 & & \\
\hline IEMBL1535358 & & 361 & & \\
\hline AEMBL1333506 & & 62 & & \\
\hline 055 & & 52 & & \\
\hline 141 & & 62 & & \\
\hline AEMBL3192761 & & & & \\
\hline HEMBL1391994 & & 362 & & \\
\hline 07 & & & & \\
\hline 5 & & 52 & & \\
\hline & & & & \\
\hline AEMBL1474660 & & 862 & & \\
\hline AEMBL1537205 & & 862 & & \\
\hline & & 62 & & \\
\hline 08 & & & & \\
\hline HEMBL1599681 & & & & $\mathrm{RI}$ \\
\hline AEMBL1464246 & & 362 & & s \\
\hline AEMBL1522 & & 62 & & \\
\hline t- & & & & \\
\hline CHEMBL1544809 & & & & \\
\hline AEMBL1381352 & & & & RN \\
\hline IEMBL1338711 & & 362 & 62 & TS \\
\hline 10 & & & & \\
\hline משתר 19 & & & & \\
\hline
\end{tabular}

Page 2223 
Supplemental Table S2.txt

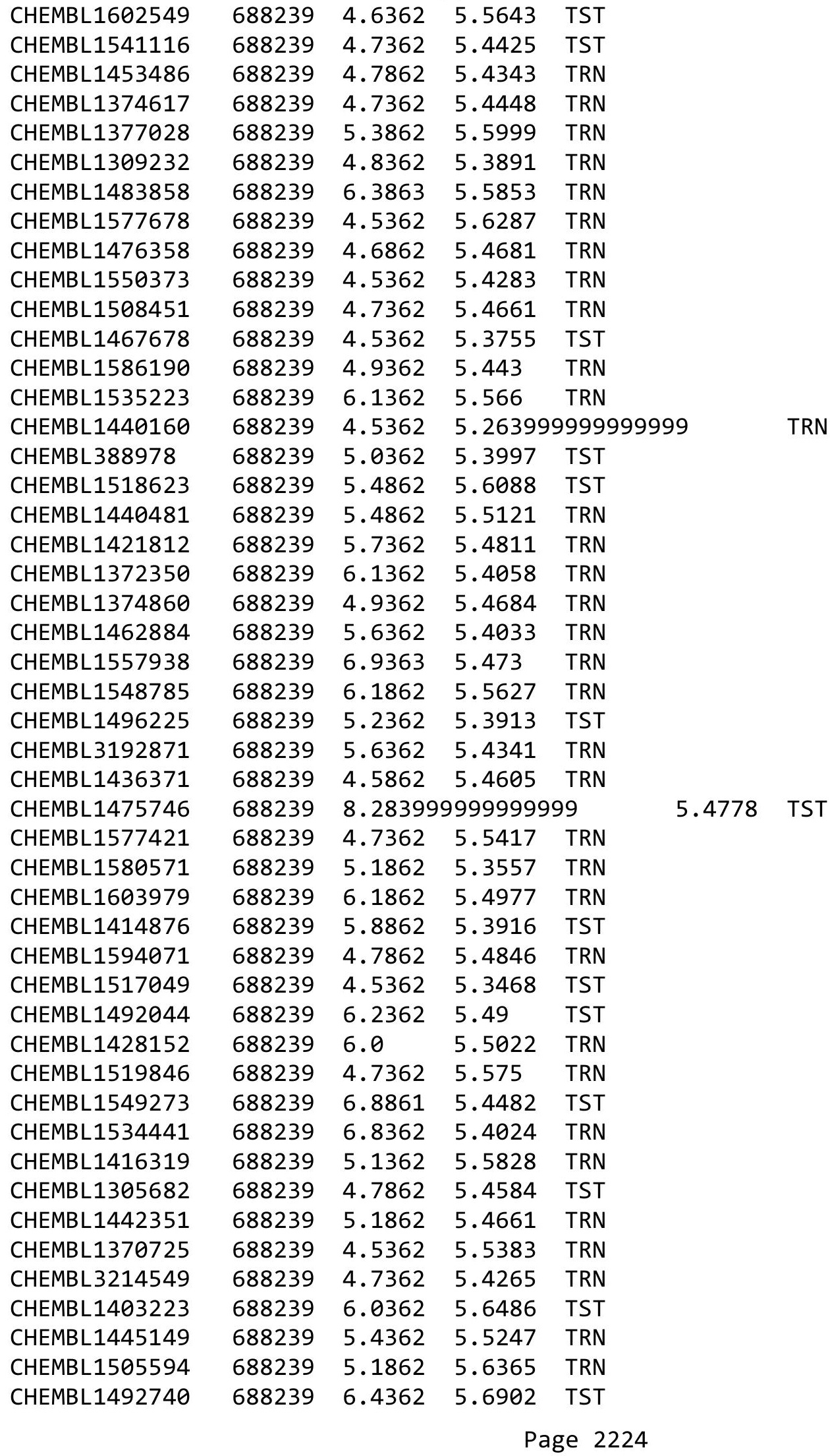


Supplemental Table S2.txt

\begin{tabular}{|c|c|c|c|c|c|}
\hline CHEMBL1489445 & 688239 & 6.8362 & 5.5252 & TST & \\
\hline CHEMBL1339145 & 688239 & 4.5362 & 5.5004 & TRN & \\
\hline CHEMBL1490003 & 688239 & 8.3872 & 5.5405 & TRN & \\
\hline CHEMBL1304459 & 688239 & 5.4362 & 5.4779 & TRN & \\
\hline CHEMBL1435484 & 688239 & 5.1362 & 5.6086 & TRN & \\
\hline CHEMBL1546714 & 688239 & 4.5862 & 5.6095 & TRN & \\
\hline CHEMBL1375668 & 688239 & 4.5362 & 5.4263 & TRN & \\
\hline CHEMBL1364999 & 688239 & 6.1362 & 5.4211 & TST & \\
\hline CHEMBL1455798 & 688239 & 5.7862 & 5.705 & TRN & \\
\hline CHEMBL1557054 & 688239 & 4.6362 & 5.5049 & TRN & \\
\hline CHEMBL1540954 & 688239 & 6.8362 & 5.5039 & TRN & \\
\hline CHEMBL1607911 & 688239 & 5.8862 & 5.5051 & TRN & \\
\hline CHEMBL1378549 & 688239 & 5.7362 & 5.4783 & TRN & \\
\hline CHEMBL1364723 & 688239 & 4.6862 & 5.4388 & TST & \\
\hline CHEMBL1365183 & 688239 & 4.5362 & 5.3187 & TST & \\
\hline CHEMBL1313891 & 688239 & 4.6362 & 5.4904 & TRN & \\
\hline CHEMBL1337110 & 688239 & 5.4862 & 5.5072 & TST & \\
\hline CHEMBL1487172 & 688239 & 5.8362 & 5.5383 & TRN & \\
\hline CHEMBL1585587 & 688239 & 4.5362 & 5.4442 & TRN & \\
\hline CHEMBL1462957 & 688239 & 5.0862 & 5.5665 & TRN & \\
\hline CHEMBL1419845 & 688239 & 6.9363 & 5.6342 & TRN & \\
\hline CHEMBL1340600 & 688239 & 6.1862 & 5.4191 & TRN & \\
\hline CHEMBL82134 & 688239 & 4.8362 & 5.2981 & TRN & \\
\hline CHEMBL1379646 & 688239 & 5.7862 & 5.4605 & TRN & \\
\hline CHEMBL1425697 & 688239 & 5.7362 & 5.5868 & TRN & \\
\hline CHEMBL1544927 & 688239 & 4.9362 & 5.4966 & TRN & \\
\hline CHEMBL1455601 & 688239 & 8.3872 & 5.536000 & 30000000005 & TST \\
\hline CHEMBL1539807 & 688239 & 4.6362 & 5.377000 & 3000000001 & TRN \\
\hline CHEMBL1601719 & 688239 & 5.9362 & 5.4474 & TRN & \\
\hline CHEMBL1360581 & 688239 & 4.5362 & 5.3731 & TRN & \\
\hline CHEMBL1381698 & 688239 & 4.6362 & 5.4672 & TRN & \\
\hline CHEMBL3208000 & 688239 & 4.8862 & 5.3978 & TRN & \\
\hline CHEMBL1604406 & 688239 & 6.1862 & 5.4311 & TST & \\
\hline CHEMBL1452374 & 688239 & 8.283999 & 999999999 & 5.4621 & TRI \\
\hline CHEMBL1343408 & 688239 & 6.6362 & 5.5559 & TRN & \\
\hline CHEMBL1387726 & 688239 & 5.9362 & 5.4572 & TRN & \\
\hline CHEMBL1584391 & 688239 & 4.8362 & 5.3976 & TRN & \\
\hline CHEMBL1476742 & 688239 & 4.5362 & 5.6891 & TRN & \\
\hline CHEMBL1455481 & 688239 & 6.8861 & 5.5348 & TST & \\
\hline CHEMBL1428134 & 688239 & 4.8362 & 5.4472 & TST & \\
\hline CHEMBL1323774 & 688239 & 5.7862 & 5.4917 & TRN & \\
\hline CHEMBL1572023 & 688239 & 4.5362 & 5.5325 & TST & \\
\hline CHEMBL1464718 & 688239 & 5.7362 & 5.5175 & TST & \\
\hline CHEMBL1597228 & 688239 & 5.4362 & 5.5113 & TRN & \\
\hline CHEMBL1459596 & 688239 & 5.1862 & 5.3956 & TRN & \\
\hline CHEMBL1550513 & 688239 & 5.5862 & 5.5455 & TRN & \\
\hline CHEMBL1484727 & 688239 & 6.7361 & 5.6109 & TRN & \\
\hline CHEMBL1384017 & 688239 & 5.2362 & 5.443 & TRN & \\
\hline
\end{tabular}


Supplemental Table S2.txt

\begin{tabular}{|c|c|c|c|c|}
\hline CHEMBL1599382 & 688239 & 5.1862 & 5.4219 & TST \\
\hline CHEMBL1494223 & 688239 & 4.6862 & 5.4371 & TST \\
\hline CHEMBL1546748 & 688239 & 4.7862 & 5.4911 & TRN \\
\hline CHEMBL1530109 & 688239 & 5.0362 & 5.433 & TST \\
\hline CHEMBL1549763 & 688239 & 4.4862 & \multicolumn{2}{|c|}{5.593999999999999} \\
\hline CHEMBL1351145 & 688239 & 5.6862 & 5.61 & TRN \\
\hline CHEMBL1547853 & 688239 & 4.5362 & 5.49 & TRN \\
\hline CHEMBL1412358 & 688239 & 5.5362 & 5.3579 & TRN \\
\hline CHEMBL1576326 & 688239 & 5.0862 & 5.5453 & TRN \\
\hline CHEMBL1596098 & 688239 & 5.1862 & 5.3831 & TST \\
\hline CHEMBL1450491 & 688239 & 4.7862 & 5.4267 & TRN \\
\hline CHEMBL1581570 & 688239 & 4.5862 & 5.5589 & TRN \\
\hline CHEMBL1327887 & 688239 & 4.5362 & 5.425 & TRN \\
\hline CHEMBL3211957 & 688239 & 5.5862 & 5.3657 & TRN \\
\hline CHEMBL1392533 & 688239 & 4.5362 & 5.5387 & TRN \\
\hline CHEMBL1527698 & 688239 & 4.5362 & 5.4831 & TST \\
\hline CHEMBL560919 & 688239 & 5.9862 & 5.3258 & TRN \\
\hline CHEMBL1325181 & 688239 & 6.8362 & 5.5096 & TRN \\
\hline CHEMBL1582996 & 688239 & 4.6862 & 5.4535 & TRN \\
\hline CHEMBL1343644 & 688239 & 6.1362 & 5.5323 & TST \\
\hline CHEMBL1399773 & 688239 & 5.7362 & 5.5133 & TST \\
\hline CHEMBL1482341 & 688239 & 6.6362 & 5.5687 & TRN \\
\hline CHEMBL1506747 & 688239 & 4.5362 & 5.7272 & TRN \\
\hline CHEMBL1581945 & 688239 & 5.4362 & 5.6171 & TRN \\
\hline CHEMBL1347352 & 688239 & 4.5362 & 5.5807 & TRN \\
\hline CHEMBL1363253 & 688239 & 4.8362 & 5.5332 & TRN \\
\hline CHEMBL1562063 & 688239 & 5.1862 & 5.5093 & TRN \\
\hline CHEMBL3197538 & 688239 & 5.1862 & 5.3606 & TRN \\
\hline CHEMBL1397844 & 688239 & 5.3862 & 5.3761 & TST \\
\hline CHEMBL1405579 & 688239 & 6.3863 & 5.4029 & TRN \\
\hline CHEMBL1465562 & 688239 & 5.4362 & 5.4042 & TST \\
\hline CHEMBL1543669 & 688239 & 5.4362 & 5.4393 & TRN \\
\hline CHEMBL1553913 & 688239 & 6.0862 & 5.5009 & TST \\
\hline CHEMBL1517552 & 688239 & 5.4362 & 5.5111 & TRN \\
\hline CHEMBL1543401 & 688239 & 8.3372 & 5.2464 & TST \\
\hline CHEMBL1498452 & 688239 & 4.6362 & 5.3567 & TST \\
\hline CHEMBL1305496 & 688239 & 5.6362 & 5.6765 & TRN \\
\hline CHEMBL1438856 & 688239 & 4.5362 & 5.5932 & TRN \\
\hline CHEMBL1559087 & 688239 & 7.8861 & 5.5657 & TRN \\
\hline CHEMBL1305128 & 688239 & 6.4362 & 5.5669 & TST \\
\hline CHEMBL1557350 & 688239 & 4.7362 & 5.5342 & TRN \\
\hline CHEMBL1560517 & 688239 & 4.7362 & 5.4994 & TRN \\
\hline CHEMBL1548901 & 688239 & 6.4362 & 5.5199 & TST \\
\hline CHEMBL1368319 & 688239 & 5.1362 & 5.4559 & TRN \\
\hline CHEMBL1563593 & 688239 & 4.5362 & 5.3979 & TRN \\
\hline CHEMBL1521595 & 688239 & 4.5362 & 5.4449 & TRN \\
\hline CHEMBL1373827 & 688239 & 4.5362 & 5.468 & TST \\
\hline CHEMBL1483452 & 688239 & 4.5362 & 5.6022 & TRN \\
\hline
\end{tabular}


Supplemental Table S2.txt

\begin{tabular}{|c|c|c|c|c|}
\hline AEMBL1513908 & 38239 & 5.0362 & 5.4422 & \\
\hline HEMBL1426574 & 88239 & 5.5862 & & \\
\hline 684 & & & & \\
\hline EMBL1 & & & & \\
\hline HEMBL1 & 8239 & 862 & & \\
\hline HEMBL1556792 & 88239 & 5362 & & \\
\hline AEMBL: & 3239 & 362 & & \\
\hline 328 & & & & \\
\hline AEMBL1 & & 862 & & \\
\hline AEMBL1 & 38239 & 862 & 367 & \\
\hline AEMBLI & 38239 & 862 & & \\
\hline IEMBL: & 39 & 362 & & \\
\hline IEMBL & & & & \\
\hline AEMBL & & 0362 & & \\
\hline AEMBL & & 362 & & \\
\hline EMBL & 39 & 362 & & \\
\hline AEMBL & & 362 & & \\
\hline AEMBL & & 362 & & \\
\hline IEMBL & & 362 & & \\
\hline IEMBL & & 62 & & QI \\
\hline 390 & & 362 & & \\
\hline 240 & & 3 & & \\
\hline 655 & & 62 & & \\
\hline 268 & & & & \\
\hline IEMBL & & & & KN \\
\hline AEMBL & & 62 & & \\
\hline 756 & & 52 & & 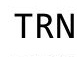 \\
\hline 723 & & 362 & & RN \\
\hline IEMBL & & & & \\
\hline AEMBL: & & & & IST \\
\hline IEMBL & & 61 & & RN \\
\hline 8 & & 52 & & . \\
\hline IEME & & 62 & & PD \\
\hline IEMBL & & & & RN \\
\hline HEMBL: & & 4.7362 & & rRN \\
\hline 719 & & 362 & & 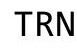 \\
\hline 9 & & & & . \\
\hline & & & & ST \\
\hline AEMBL: & & 862 & & $S T$ \\
\hline IEMBL & & 362 & & RN \\
\hline AEMBL & & 362 & & \\
\hline 212 & & & & RN \\
\hline HEMBL & & .0362 & & RI \\
\hline EMBL: & 39 & 7862 & & $R$ \\
\hline 70 & & 362 & & \\
\hline HEMBL & & & & \\
\hline CHEMBLI & & 4.7862 & 5.4452 & \\
\hline CHEMBL1563793 & 688239 & 6.1362 & 5.5965 & $\Gamma R$ \\
\hline
\end{tabular}

Page 2227 
Supplemental Table S2.txt

\begin{tabular}{|c|c|c|c|c|}
\hline CHEMBL1445479 & 688239 & 4.5362 & 5.4295 & TRN \\
\hline CHEMBL1572180 & 688239 & 5.8362 & 5.5059 & TRN \\
\hline CHEMBL1565037 & 688239 & 5.1862 & 5.3916 & TRN \\
\hline CHEMBL1408713 & 688239 & 5.4862 & 5.5325 & TST \\
\hline CHEMBL1322649 & 688239 & 5.4362 & 5.5616 & TRN \\
\hline CHEMBL1351764 & 688239 & 4.6862 & 5.5536 & TRN \\
\hline CHEMBL1486385 & 688239 & 5.1862 & 5.5924 & TRN \\
\hline CHEMBL3210537 & 688239 & 4.5362 & 5.375 & TRN \\
\hline CHEMBL3196968 & 688239 & 4.5862 & 5.4403 & TST \\
\hline CHEMBL1494398 & 688239 & 5.2362 & 5.5667 & TRN \\
\hline CHEMBL1459370 & 688239 & 4.7862 & 5.4817 & TST \\
\hline CHEMBL1378157 & 688239 & 5.8862 & 5.4467 & TST \\
\hline CHEMBL1583907 & 688239 & 6.7361 & 5.4952 & TRN \\
\hline CHEMBL1566388 & 688239 & 4.7362 & 5.5656 & TRN \\
\hline CHEMBL1544369 & 688239 & 5.9362 & 5.3648 & TRN \\
\hline CHEMBL1488061 & 688239 & 5.6362 & 5.6124 & TRN \\
\hline CHEMBL1520939 & 688239 & 5.5362 & 5.4972 & TRN \\
\hline CHEMBL1464508 & 688239 & 6.2862 & 5.5689 & TRN \\
\hline CHEMBL1563171 & 688239 & 5.5862 & 5.3663 & TST \\
\hline CHEMBL1495921 & 688239 & 5.1862 & 5.612 & TRN \\
\hline CHEMBL1387631 & 688239 & 4.5362 & 5.4225 & TRN \\
\hline CHEMBL1307619 & 688239 & 4.6862 & 5.6473 & TST \\
\hline CHEMBL1423347 & 688239 & 5.4862 & 5.4955 & TST \\
\hline CHEMBL3209774 & 688239 & 5.7862 & 5.5693 & TRN \\
\hline CHEMBL1327452 & 688239 & 5.3862 & 5.4901 & TRN \\
\hline CHEMBL1558863 & 688239 & 4.9362 & 5.5388 & TRN \\
\hline CHEMBL1585525 & 688239 & 5.1862 & 5.43 & TRN \\
\hline CHEMBL3213649 & 688239 & 5.4862 & 5.482 & TRN \\
\hline CHEMBL1316089 & 688239 & 5.8862 & 5.3717 & TRN \\
\hline CHEMBL1390967 & 688239 & 4.5362 & 5.4511 & TRN \\
\hline CHEMBL1515866 & 688239 & 6.3362 & 5.5241 & TRN \\
\hline CHEMBL1473130 & 688239 & 5.6362 & 5.5777 & TST \\
\hline CHEMBL1411027 & 688239 & 5.1862 & 5.6515 & TRN \\
\hline CHEMBL1578995 & 688239 & 6.8861 & 5.5277 & TRN \\
\hline CHEMBL1357710 & 688239 & 8.3372 & 5.4215 & TRN \\
\hline CHEMBL1398863 & 688239 & 6.7862 & 5.6025 & TRN \\
\hline CHEMBL1362963 & 688239 & 4.5362 & 5.3166 & TST \\
\hline CHEMBL1328589 & 688239 & 4.9862 & 5.3907 & TRN \\
\hline CHEMBL3196022 & 688239 & 4.5362 & 5.468999 & 9999999999 \\
\hline CHEMBL1612707 & 688239 & 5.3362 & 5.3614 & TRN \\
\hline CHEMBL1517855 & 688239 & 5.4862 & 5.5686 & TRN \\
\hline CHEMBL1487584 & 688239 & 4.4862 & 5.4783 & TST \\
\hline CHEMBL1330169 & 688239 & 5.1862 & 5.5864 & TRN \\
\hline CHEMBL1574545 & 688239 & 4.5362 & 5.4778 & TRN \\
\hline CHEMBL 3207542 & 688239 & 5.0862 & 5.3145 & TRN \\
\hline CHEMBL1357649 & 688239 & 4.8362 & 5.3707 & TRN \\
\hline CHEMBL1431066 & 688239 & 4.6862 & 5.4865 & TRN \\
\hline CHEMBL1359632 & 688239 & 4.5362 & 5.5472 & TRN \\
\hline
\end{tabular}


Supplemental Table S2.txt

\begin{tabular}{|c|c|c|c|c|}
\hline CHEMBL1517842 & 688239 & 5.1862 & 5.6072 & TST \\
\hline CHEMBL1464592 & 688239 & 6.1362 & 5.5621 & TRN \\
\hline CHEMBL1388231 & 688239 & 4.5362 & 5.5866 & TRN \\
\hline CHEMBL1429408 & 688239 & 6.1862 & 5.4151 & TRN \\
\hline CHEMBL1320094 & 688239 & 5.1362 & 5.4229 & TRN \\
\hline CHEMBL1327254 & 688239 & 5.4362 & 5.3622 & TRN \\
\hline CHEMBL1610362 & 688239 & 5.4862 & 5.519 & TRN \\
\hline CHEMBL1587041 & 688239 & 6.9363 & 5.5799 & TRN \\
\hline CHEMBL1514204 & 688239 & 6.8861 & 5.4916 & TRN \\
\hline CHEMBL1519986 & 688239 & 8.3372 & 5.5319 & TRN \\
\hline CHEMBL1381159 & 688239 & 4.8362 & 5.4714 & TRN \\
\hline CHEMBL1434489 & 688239 & 4.8862 & 5.5582 & TST \\
\hline CHEMBL3211892 & 688239 & 4.5362 & 5.5011 & TST \\
\hline CHEMBL1442786 & 688239 & 5.1862 & 5.4921 & TST \\
\hline CHEMBL1357197 & 688239 & 6.0862 & 5.4636 & TRN \\
\hline CHEMBL1546774 & 688239 & 6.1362 & 5.4991 & TST \\
\hline CHEMBL1354370 & 688239 & 5.2862 & 5.5422 & TRN \\
\hline CHEMBL1363018 & 688239 & 4.6862 & 5.5866 & TST \\
\hline CHEMBL1579210 & 688239 & 4.4862 & 5.5221 & TST \\
\hline CHEMBL1324908 & 688239 & 4.7362 & 5.4648 & TRN \\
\hline CHEMBL1385216 & 688239 & 4.7362 & 5.648 & TRN \\
\hline CHEMBL1500586 & 688239 & 5.1862 & 5.4036 & TRN \\
\hline CHEMBL1509613 & 688239 & 5.3862 & 5.4992 & TST \\
\hline CHEMBL1573148 & 688239 & 4.5362 & 5.5553 & TST \\
\hline CHEMBL1578106 & 688239 & 5.2362 & 5.4722 & TRN \\
\hline CHEMBL1599711 & 688239 & 4.5362 & 5.4981 & TRN \\
\hline CHEMBL1299988 & 688239 & 5.9362 & 5.4699 & TST \\
\hline CHEMBL3196997 & 688239 & 4.5362 & 5.3284 & TRN \\
\hline CHEMBL1343045 & 688239 & 4.5362 & 5.4538 & TRN \\
\hline CHEMBL1580848 & 688239 & 5.5862 & $5.50700 €$ & $\partial 000000001$ \\
\hline CHEMBL1520384 & 688239 & 5.6362 & 5.4232 & TRN \\
\hline CHEMBL 3207844 & 688239 & 5.1862 & 5.5442 & TRN \\
\hline CHEMBL1345890 & 688239 & 5.8362 & 5.5699 & TRN \\
\hline CHEMBL1493792 & 688239 & 5.3862 & 5.5928 & TST \\
\hline CHEMBL1409871 & 688239 & 6.3362 & 5.6371 & TRN \\
\hline CHEMBL1562463 & 688239 & 6.2362 & 5.4359 & TST \\
\hline CHEMBL1521209 & 688239 & 7.3363 & 5.5243 & TRN \\
\hline CHEMBL 210730 & 688239 & 5.1862 & 5.5179 & TRN \\
\hline CHEMBL1563554 & 688239 & 4.8862 & 5.5036 & TRN \\
\hline CHEMBL1479204 & 688239 & 4.4862 & 5.3549 & TST \\
\hline CHEMBL1529476 & 688239 & 6.2862 & 5.593 & TRN \\
\hline CHEMBL1440101 & 688239 & 4.5362 & 5.3873 & TRN \\
\hline CHEMBL1479144 & 688239 & 4.7362 & 5.4676 & TST \\
\hline CHEMBL1538750 & 688239 & 4.5362 & 5.6267 & TRN \\
\hline CHEMBL1601847 & 688239 & 5.9862 & 5.6376 & TRN \\
\hline CHEMBL1534786 & 688239 & 4.5362 & 5.5647 & TRN \\
\hline CHEMBL1457085 & 688239 & 5.9362 & 5.3339 & TRN \\
\hline CHEMBL1461825 & 688239 & 4.5362 & 5.4724 & TST \\
\hline
\end{tabular}


Supplemental Table S2.txt

\begin{tabular}{|c|c|c|c|c|c|}
\hline CHEMBL1576629 & 688239 & 4.5362 & 5.4995 & TST & \\
\hline CHEMBL1309718 & 688239 & 5.0362 & 5.4913 & TRN & \\
\hline CHEMBL546885 & 688239 & 4.6862 & 5.4787 & TST & \\
\hline CHEMBL1496776 & 688239 & 5.1362 & 5.684 & TST & \\
\hline CHEMBL1481657 & 688239 & 4.6362 & 5.4205 & TRN & \\
\hline CHEMBL1380015 & 688239 & 5.1862 & 5.58899 & 99999999995 & TRN \\
\hline CHEMBL3214116 & 688239 & 6.1862 & 5.4301 & TRN & \\
\hline CHEMBL1378472 & 688239 & 4.8362 & 5.4207 & TRN & \\
\hline CHEMBL1517301 & 688239 & 5.05 & 5.5071 & TRN & \\
\hline CHEMBL1556416 & 688239 & 5.5862 & 5.4571 & TST & \\
\hline CHEMBL1300075 & 688239 & 5.5362 & 5.4209 & TRN & \\
\hline CHEMBL1337943 & 688239 & 5.1862 & 5.4637 & TRN & \\
\hline CHEMBL1365110 & 688239 & 4.5362 & 5.4316 & TRN & \\
\hline CHEMBL1338370 & 688239 & 5.8362 & 5.5574 & TRN & \\
\hline CHEMBL1552020 & 688239 & 4.5362 & 5.3772 & TRN & \\
\hline CHEMBL1376922 & 688239 & 8.3372 & 5.3426 & TRN & \\
\hline CHEMBL1352240 & 688239 & 5.1362 & 5.4992 & TRN & \\
\hline CHEMBL1404139 & 688239 & 4.7362 & 5.3681 & TRN & \\
\hline CHEMBL1532584 & 688239 & 6.1362 & 5.5436 & TST & \\
\hline CHEMBL3208468 & 688239 & 6.1362 & 5.5759 & TST & \\
\hline CHEMBL1459005 & 688239 & 6.2862 & 5.3912 & TRN & \\
\hline CHEMBL1510558 & 688239 & 7.8861 & 5.5033 & TST & \\
\hline CHEMBL1384419 & 688239 & 4.9862 & 5.522 & TRN & \\
\hline CHEMBL1520073 & 688239 & \multicolumn{2}{|c|}{8.283999999999999} & 5.5742 & TRN \\
\hline CHEMBL3209180 & 688239 & 7.9872 & 5.524 & TST & \\
\hline CHEMBL1408905 & 688239 & 5.1862 & 5.69 & TRN & \\
\hline CHEMBL1510357 & 688239 & 6.1362 & 5.4984 & TST & \\
\hline CHEMBL1458877 & 688239 & 4.5362 & 5.5418 & TRN & \\
\hline CHEMBL1474014 & 688239 & 4.6862 & 5.5253 & TRN & \\
\hline CHEMBL1465602 & 688239 & 4.7362 & 5.6104 & TRN & \\
\hline CHEMBL1366952 & 688239 & 4.5362 & 5.6341 & TRN & \\
\hline CHEMBL1499887 & 688239 & 5.6362 & 5.4758 & TRN & \\
\hline CHEMBL1432413 & 688239 & 4.8862 & 5.4847 & TST & \\
\hline CHEMBL1481134 & 688239 & 5.1362 & 5.584 & TRN & \\
\hline CHEMBL1588474 & 688239 & 5.1862 & 5.4408 & TRN & \\
\hline CHEMBL1588997 & 688239 & 5.6862 & 5.4341 & TRN & \\
\hline CHEMBL1521702 & 688239 & 6.0 & 5.36799 & 9999999999 & TST \\
\hline CHEMBL1498496 & 688239 & 4.7862 & 5.4384 & TRN & \\
\hline CHEMBL1309877 & 688239 & 5.2362 & 5.4003 & TST & \\
\hline CHEMBL1573031 & 688239 & 4.5362 & 5.46399 & 99999999995 & TRN \\
\hline CHEMBL1401251 & 688239 & 4.8362 & 5.4074 & TRN & \\
\hline CHEMBL1543167 & 688239 & 4.6862 & 5.4394 & TRN & \\
\hline CHEMBL1604623 & 688239 & 4.5362 & 5.5607 & TRN & \\
\hline CHEMBL1472515 & 688239 & 5.1862 & 5.4346 & TST & \\
\hline CHEMBL1554193 & 688239 & 8.2366 & 5.4691 & TRN & \\
\hline CHEMBL1373716 & 688239 & 6.2862 & 5.61299 & 99999999995 & TRN \\
\hline CHEMBL1502980 & 688239 & 4.6862 & 5.3834 & TRN & \\
\hline CHEMBL3193806 & 688239 & 5.1862 & 5.46 & TRN & \\
\hline
\end{tabular}


Supplemental Table S2.txt

\begin{tabular}{|c|c|c|c|c|}
\hline 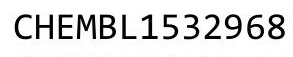 & & & & \\
\hline HEMBL1417775 & 38239 & 362 & 8 & \\
\hline AEMBL1583622 & 239 & 362 & 086 & \\
\hline 79 & 39 & & & \\
\hline IEMBL13 & 39 & 862 & & \\
\hline AEMBL1508624 & 88239 & 362 & 219 & \\
\hline AEMBL 2000338 & 88239 & 362 & 831 & \\
\hline HEMBL1602840 & & & & \\
\hline EMBL1378636 & 39 & 862 & & \\
\hline IEMBL1522094 & & 861 & & \\
\hline AEMBL1468238 & 239 & 362 & & \\
\hline AEMBL1506190 & 39 & 362 & & \\
\hline AEMBL1423099 & & & & \\
\hline HEMBL1598689 & & & & \\
\hline HEMBL1418020 & & & & \\
\hline AEMBL1559214 & & 862 & & \\
\hline AEMBL1478232 & & 862 & & \\
\hline IEMBL137 & & 52 & & \\
\hline HEMBL160 & & & & \\
\hline AEMBL1441 & & & & \\
\hline AEMBL1394145 & & 862 & & \\
\hline AEMBL1335104 & & 62 & & \\
\hline AEMBL15753 & & 61 & & \\
\hline HEMBL1488748 & & & & \\
\hline 139 & & & & \\
\hline AEMBL1517853 & & 862 & & \\
\hline IEMBL1572858 & & & & \\
\hline AEMBL1364 & & & & \\
\hline AFMRI $13=$ & & 62 & & \\
\hline IFMPI 1690 & & 62 & & \\
\hline AEMBL1407314 & & & & \\
\hline HEMBL1595194 & & 62 & & \\
\hline & & & & \\
\hline 2 & & 52 & & \\
\hline & & & & \\
\hline AEMBL1582395 & & & & KI \\
\hline AEMBL1431520 & & 363 & & \\
\hline & & & & \\
\hline 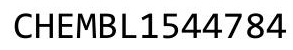 & & & & \\
\hline HEMBL1471626 & & & & RI \\
\hline AEMBL1324365 & & 362 & & \\
\hline AEMBL1325601 & & 62 & & \\
\hline HEMBL1503515 & & & & \\
\hline HEMBL1979954 & & & & \\
\hline HEMBL1581888 & & & & RN \\
\hline IEMBL3209269 & & 362 & & \\
\hline 136 & & & & \\
\hline HEMBL134537 & & & & \\
\hline
\end{tabular}

Page 2231 
Supplemental Table S2.txt

\begin{tabular}{|c|c|c|c|c|c|}
\hline CHEMBL1490785 & 688239 & 5.1362 & 5.4627 & TRN & \\
\hline CHEMBL 2006569 & 688239 & 4.5362 & 5.4034 & TRN & \\
\hline CHEMBL1380238 & 688239 & 6.4862 & 5.4914 & TRN & \\
\hline CHEMBL1491738 & 688239 & 5.1862 & 5.5383 & TST & \\
\hline CHEMBL1479449 & 688239 & 4.7362 & 5.5008 & TRN & \\
\hline CHEMBL1429949 & 688239 & 4.6862 & 5.4934 & TRN & \\
\hline CHEMBL1453903 & 688239 & 4.4862 & 5.3862 & TRN & \\
\hline CHEMBL1569708 & 688239 & 4.8862 & 5.5176 & TST & \\
\hline CHEMBL3194400 & 688239 & 5.7862 & 5.4578 & TRN & \\
\hline CHEMBL1444185 & 688239 & 4.5862 & 5.3904 & TST & \\
\hline CHEMBL1427830 & 688239 & 8.3872 & 5.5417 & TRN & \\
\hline CHEMBL1459623 & 688239 & 5.1862 & 5.4616 & TRN & \\
\hline CHEMBL1495220 & 688239 & 4.8362 & 5.5003 & TRN & \\
\hline CHEMBL1488950 & 688239 & 4.7362 & 5.6381 & TRN & \\
\hline CHEMBL1169930 & 688239 & 4.6862 & 5.5482 & TRN & \\
\hline CHEMBL1510468 & 688239 & 6.6362 & 5.5722 & TRN & \\
\hline CHEMBL1312304 & 688239 & 4.5362 & 5.5379 & TST & \\
\hline CHEMBL1337406 & 688239 & 4.6362 & 5.4438 & TRN & \\
\hline CHEMBL1432927 & 688239 & 7.2366 & 5.41 & TST & \\
\hline CHEMBL1332647 & 688239 & 8.1367 & 5.4859 & TST & \\
\hline CHEMBL1460751 & 688239 & 4.8362 & 5.3863 & TRN & \\
\hline CHEMBL1516612 & 688239 & 4.5362 & 5.5633 & TRN & \\
\hline CHEMBL1440367 & 688239 & 4.6862 & 5.5121 & TRN & \\
\hline CHEMBL1454088 & 688239 & 4.7862 & 5.4609 & TRN & \\
\hline CHEMBL1431410 & 688239 & 4.5362 & 5.5121 & TST & \\
\hline CHEMBL1538023 & 688239 & 4.5362 & 5.4297 & TRN & \\
\hline CHEMBL1405686 & 688239 & 7.2366 & 5.3991 & TRN & \\
\hline CHEMBL1365997 & 688239 & 4.8362 & 5.3345 & TST & \\
\hline CHEMBL3207366 & 688239 & 4.5362 & 5.5549 & TRN & \\
\hline CHEMBL1504052 & 688239 & 5.7862 & 5.4334 & TRN & \\
\hline CHEMBL1442241 & 688239 & 4.7362 & 5.4151 & TRN & \\
\hline CHEMBL66761 & 688239 & 5.6362 & 5.4914 & TST & \\
\hline CHEMBL1579047 & 688239 & 7.2865 & 5.4597 & TRN & \\
\hline CHEMBL1395365 & 688239 & 5.7862 & 5.5297 & TRN & \\
\hline CHEMBL1594283 & 688239 & 5.1862 & 5.3684 & TRN & \\
\hline CHEMBL1602732 & 688239 & 7.9355 & 5.5253 & TST & \\
\hline CHEMBL1428491 & 688239 & 7.2366 & 5.421 & TRN & \\
\hline CHEMBL1354632 & 688239 & 7.2366 & 5.4924 & TRN & \\
\hline CHEMBL1462381 & 688239 & 4.8862 & 5.3529 & TRN & \\
\hline CHEMBL1520943 & 688239 & 4.5362 & 5.42700 & 00000000005 & TRN \\
\hline CHEMBL1470728 & 688239 & 4.5362 & 5.3749 & TST & \\
\hline CHEMBL1529297 & 688239 & 6.3863 & 5.6339 & TRN & \\
\hline CHEMBL1451415 & 688239 & 5.8862 & 5.6457 & TST & \\
\hline CHEMBL1501952 & 688239 & 4.8362 & 5.3478 & TRN & \\
\hline CHEMBL1565863 & 688239 & 5.2362 & 5.5072 & TRN & \\
\hline CHEMBL1338710 & 688239 & 4.5862 & 5.5296 & TRN & \\
\hline CHEMBL1611258 & 688239 & 6.9363 & 5.5228 & TST & \\
\hline CHEMBL1354840 & 688239 & 6.1362 & 5.4351 & TRN & \\
\hline
\end{tabular}




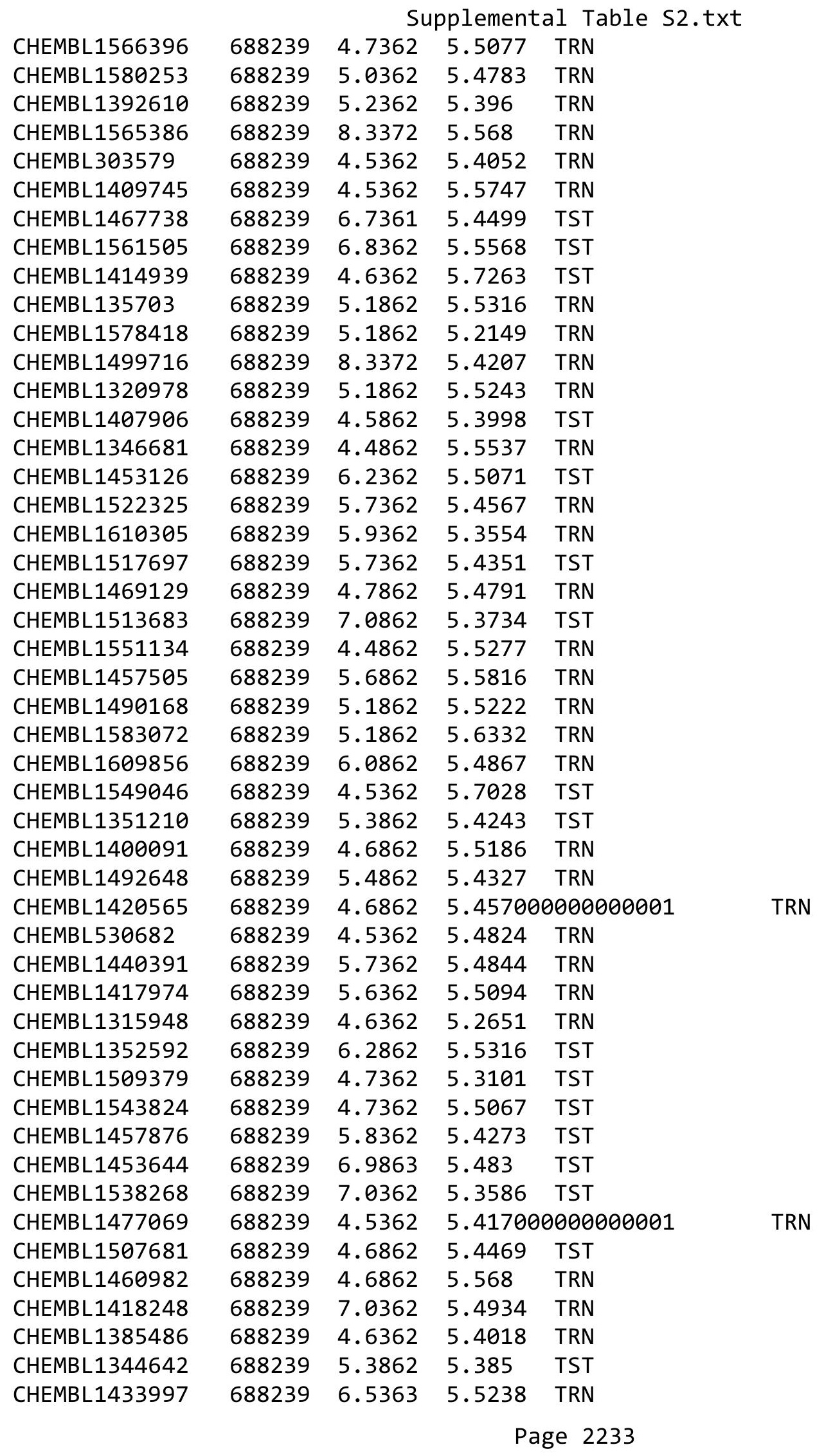


Supplemental Table S2.txt

\begin{tabular}{|c|c|c|c|c|c|}
\hline CHEMBL1360301 & 688239 & 6.7862 & 5.4783 & TRN & \\
\hline CHEMBL1477295 & 688239 & 4.6862 & 5.5195 & TRN & \\
\hline CHEMBL1424110 & 688239 & 4.7862 & 5.4123 & TRN & \\
\hline CHEMBL1536783 & 688239 & 6.3863 & 5.4646 & TRN & \\
\hline CHEMBL1967497 & 688239 & 4.7862 & 5.3304 & TRN & \\
\hline CHEMBL1546839 & 688239 & 5.2362 & 5.4405 & TRN & \\
\hline CHEMBL1571998 & 688239 & 5.0362 & 5.5323 & TRN & \\
\hline CHEMBL1341579 & 688239 & 4.5362 & 5.5133 & TRN & \\
\hline CHEMBL1366569 & 688239 & 6.7862 & 5.4758 & TST & \\
\hline CHEMBL1570657 & 688239 & 6.7862 & 5.3927 & TST & \\
\hline CHEMBL1611701 & 688239 & 4.6362 & 5.3559 & TRN & \\
\hline CHEMBL 2004916 & 688239 & 5.4862 & 5.2868 & TST & \\
\hline CHEMBL1352593 & 688239 & 5.6862 & 5.6635 & TRN & \\
\hline CHEMBL1414865 & 688239 & 4.9362 & 5.5352 & TRN & \\
\hline CHEMBL1352250 & 688239 & 4.5862 & 5.6534 & TRN & \\
\hline CHEMBL1441190 & 688239 & 4.5362 & 5.5795 & TRN & \\
\hline CHEMBL1332595 & 688239 & 4.5362 & 5.5371 & TRN & \\
\hline CHEMBL1574214 & 688239 & 4.6362 & 5.513999 & 9999999999 & TRN \\
\hline CHEMBL1320876 & 688239 & 5.1862 & 5.5653 & TRN & \\
\hline CHEMBL1597915 & 688239 & 5.1862 & 5.5745 & TRN & \\
\hline CHEMBL1590241 & 688239 & 4.5362 & 5.4524 & TRN & \\
\hline CHEMBL1448563 & 688239 & 5.3362 & 5.4539 & TST & \\
\hline CHEMBL1449733 & 688239 & 5.1862 & 5.4325 & TRN & \\
\hline CHEMBL1461766 & 688239 & 6.2362 & 5.4289 & TST & \\
\hline CHEMBL1404208 & 688239 & 5.9862 & 5.3593 & TST & \\
\hline CHEMBL1410301 & 688239 & 5.0362 & 5.5712 & TST & \\
\hline CHEMBL1467114 & 688239 & 6.1362 & 5.6561 & TRN & \\
\hline CHEMBL1374421 & 688239 & 4.6862 & 5.4366 & TST & \\
\hline CHEMBL1600308 & 688239 & 4.6862 & 5.4346 & TRN & \\
\hline CHEMBL3213537 & 688239 & 6.2362 & 5.428 & TRN & \\
\hline CHEMBL1463017 & 688239 & 5.1862 & 5.495 & TRN & \\
\hline CHEMBL1489622 & 688239 & 4.6862 & 5.4121 & TRN & \\
\hline CHEMBL1322924 & 688239 & 4.5362 & 5.5074 & TRN & \\
\hline CHEMBL1581268 & 688239 & 5.2862 & 5.5801 & TRN & \\
\hline CHEMBL1385781 & 688239 & 5.1362 & 5.5638 & TST & \\
\hline CHEMBL1400216 & 688239 & 4.7862 & 5.3866 & TRN & \\
\hline CHEMBL1358098 & 688239 & 4.8862 & 5.4137 & TRN & \\
\hline CHEMBL1609817 & 688239 & 5.1862 & 5.5681 & TST & \\
\hline CHEMBL1563602 & 688239 & 5.9362 & 5.5932 & TRN & \\
\hline CHEMBL1365496 & 688239 & 6.7862 & 5.4897 & TRN & \\
\hline CHEMBL1391428 & 688239 & \multicolumn{3}{|c|}{8.283999999999999} & TST \\
\hline CHEMBL1534971 & 688239 & 4.4862 & 5.671 & TRN & \\
\hline CHEMBL1313024 & 688239 & 5.5362 & 5.4807 & TRN & \\
\hline CHEMBL1533330 & 688239 & 5.8862 & 5.5896 & TRN & \\
\hline CHEMBL1612543 & 688239 & 4.7862 & 5.665 & TRN & \\
\hline CHEMBL1460608 & 688239 & 6.2862 & 5.5713 & TRN & \\
\hline CHEMBL1465448 & 688239 & 4.5362 & 5.5166 & TRN & \\
\hline CHEMBL1321929 & 688239 & 5.1862 & 5.5469 & TRN & \\
\hline
\end{tabular}


Supplemental Table S2.txt

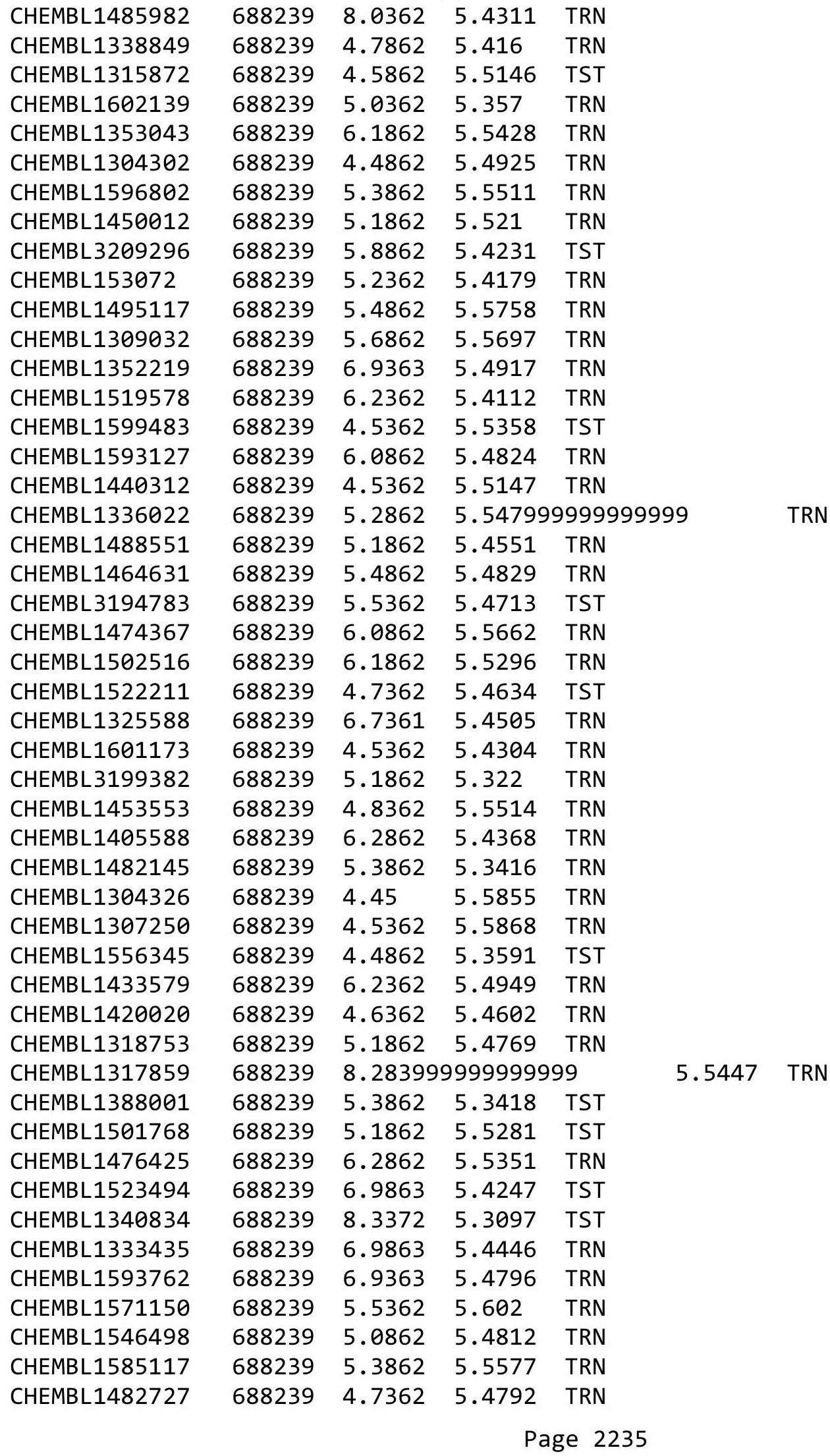


Supplemental Table S2.txt

\begin{tabular}{|c|c|c|c|c|}
\hline 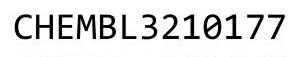 & & & & \\
\hline HEMBL1383978 & 38239 & 362 & 5614 & \\
\hline HEMBL1479926 & 239 & 863 & 925 & \\
\hline & 39 & & & \\
\hline IEMBL1605709 & 39 & 862 & & \\
\hline AEMBL1334631 & 88239 & 861 & & \\
\hline AEMBL1363351 & 88239 & 362 & 4725 & \\
\hline AEMBL3197871 & & 862 & & \\
\hline IEMBL13e & 39 & 362 & & \\
\hline IEMBL1304 & & 362 & & \\
\hline AEMBL3196702 & 239 & 362 & & \\
\hline AEMBL1580631 & 39 & 862 & & \\
\hline AEMBL1533550 & & 62 & & \\
\hline HEMBL1529168 & & & & \\
\hline HEMBL1446 & & & & \\
\hline AEMBL3191748 & & 362 & & \\
\hline AEMBL1574162 & & 362 & & \\
\hline IEMBL154 & & 52 & & \\
\hline L3199 & & & & \\
\hline IEMBL157 & & & & \\
\hline AEMBL1421 & & 366 & & \\
\hline AEMBL145 & & 362 & & \\
\hline HEMBL131 & & 62 & & \\
\hline AFMRI 159 & & & & \\
\hline 27 & & 64 & & \\
\hline AEMBL3214268 & & 372 & & \\
\hline IEMBL1480877 & & & & \\
\hline EMBL1351 & & 62 & & \\
\hline 1 & & & & \\
\hline 24 & & 62 & & \\
\hline AEMBL1397029 & & & & \\
\hline HEMBL1361288 & & 362 & & \\
\hline & & 62 & & \\
\hline 8 & & 52 & & \\
\hline AEMBL1337622 & & & & RN \\
\hline AEMBL1319722 & & 862 & & \\
\hline AEMBL1413099 & & 862 & & \\
\hline & & & & \\
\hline$\theta$ & & & & \\
\hline HEMBL1374515 & & & & $\mathrm{R}$ \\
\hline AEMBL3211197 & & 362 & & $\Gamma R$ \\
\hline AEMBL1317219 & & 362 & & TS \\
\hline בע & & & & \\
\hline CHEMBL135023 & & 862 & & \\
\hline AEMBL1545793 & & 5.0362 & & $\mathrm{R}$ \\
\hline MBL1369691 & & 6. & 53 & TR \\
\hline 1506 & & & & \\
\hline HEMBL138966 & & & 5.4436 & \\
\hline
\end{tabular}

Page 2236 
Supplemental Table S2.txt

\begin{tabular}{|c|c|c|c|c|}
\hline CHEMBL1584595 & 688239 & 4.6862 & 5.4245 & TRN \\
\hline CHEMBL1423153 & 688239 & 4.5362 & 5.5309 & TST \\
\hline CHEMBL1500706 & 688239 & 6.1362 & 5.4274 & TST \\
\hline CHEMBL1482630 & 688239 & 4.7362 & 5.3125 & TST \\
\hline CHEMBL1367559 & 688239 & 4.7362 & 5.6967 & TST \\
\hline CHEMBL1521946 & 688239 & 4.5362 & 5.5595 & TST \\
\hline CHEMBL1306936 & 688239 & 4.5362 & 5.3743 & TRN \\
\hline CHEMBL1394206 & 688239 & 5.6862 & 5.6237 & TRN \\
\hline CHEMBL1493119 & 688239 & 4.5362 & 5.5757 & TRN \\
\hline CHEMBL1488936 & 688239 & 6.3362 & 5.4637 & TRN \\
\hline CHEMBL1455602 & 688239 & 4.6362 & 5.6088 & TRN \\
\hline CHEMBL1505064 & 688239 & 4.7862 & 5.428999 & 9999999999 \\
\hline CHEMBL1336789 & 688239 & 4.7862 & 5.6197 & TRN \\
\hline CHEMBL1534225 & 688239 & 5.8862 & 5.4171 & TRN \\
\hline CHEMBL1590584 & 688239 & 4.5362 & 5.4056 & TRN \\
\hline CHEMBL1449020 & 688239 & 6.2862 & 5.6666 & TRN \\
\hline CHEMBL1521288 & 688239 & 6.0362 & 5.4966 & TST \\
\hline CHEMBL1597614 & 688239 & 4.7362 & 5.5157 & TRN \\
\hline CHEMBL1380048 & 688239 & 7.0362 & 5.5454 & TRN \\
\hline CHEMBL3195697 & 688239 & 6.7361 & 5.4272 & TRN \\
\hline CHEMBL1444958 & 688239 & 4.9862 & 5.4797 & TRN \\
\hline CHEMBL1459662 & 688239 & 4.7 & 5.5682 & TST \\
\hline CHEMBL1518665 & 688239 & 5.8362 & 5.5136 & TRN \\
\hline CHEMBL1324435 & 688239 & 8.3372 & 5.5228 & TRN \\
\hline CHEMBL1524334 & 688239 & 5.3362 & 5.6224 & TRN \\
\hline CHEMBL1470836 & 688239 & 4.7862 & 5.4988 & TRN \\
\hline CHEMBL1417422 & 688239 & 5.0862 & 5.5289 & TRN \\
\hline CHEMBL1448065 & 688239 & 4.6862 & 5.403 & TRN \\
\hline CHEMBL1582958 & 688239 & 5.4362 & 5.6084 & TRN \\
\hline CHEMBL1468571 & 688239 & 7.0362 & 5.5551 & TRN \\
\hline CHEMBL1489716 & 688239 & 5.3862 & 5.4861 & TRN \\
\hline CHEMBL3194809 & 688239 & 4.5362 & 5.3801 & TRN \\
\hline CHEMBL1390740 & 688239 & 5.7862 & 5.4036 & TRN \\
\hline CHEMBL1312312 & 688239 & 5.0862 & 5.3569 & TRN \\
\hline CHEMBL1342179 & 688239 & 6.3863 & 5.46 & TRN \\
\hline CHEMBL1448711 & 688239 & 4.7862 & 5.3599 & TRN \\
\hline CHEMBL1506610 & 688239 & 5.8862 & 5.4031 & TST \\
\hline CHEMBL1537363 & 688239 & 5.7862 & 5.4076 & TRN \\
\hline CHEMBL1571624 & 688239 & 5.2862 & 5.471 & TST \\
\hline CHEMBL1509491 & 688239 & 4.5862 & 5.5761 & TRN \\
\hline CHEMBL1579460 & 688239 & 6.3362 & 5.4426 & TRN \\
\hline CHEMBL1473327 & 688239 & 5.3862 & 5.6436 & TRN \\
\hline CHEMBL1354051 & 688239 & 4.5362 & 5.4643 & TRN \\
\hline CHEMBL1468298 & 688239 & 7.7352 & 5.4574 & TST \\
\hline CHEMBL 3195537 & 688239 & 4.7862 & 5.6698 & TRN \\
\hline CHEMBL 3211470 & 688239 & 5.1862 & 5.4381 & TRN \\
\hline CHEMBL1433056 & 688239 & 5.4862 & 5.4606 & TRN \\
\hline CHEMBL1559546 & 688239 & 5.1862 & 5.4211 & TRN \\
\hline
\end{tabular}


Supplemental Table S2.txt

\begin{tabular}{|c|c|c|c|c|}
\hline & & & & \\
\hline AEMBL15 & 8239 & 7862 & 5216 & \\
\hline IEMBL1329246 & 8239 & 862 & 5413 & \\
\hline HEMBL1385647 & 239 & 862 & 4927 & \\
\hline 508 & 239 & & 947 & \\
\hline IEMBL 3198556 & 239 & 62 & 832 & \\
\hline AEMBL1406314 & 88239 & 366 & 32 & \\
\hline AEMBL1551104 & 88239 & 861 & 1716 & \\
\hline AEMBL1543476 & 239 & 862 & & \\
\hline IEMBL14e & 239 & 362 & & \\
\hline IEMBL1482889 & & & & \\
\hline AEMBL1522793 & 688239 & 862 & 84 & \\
\hline AEMBL1556909 & 239 & 62 & & $w$ \\
\hline IEMBL1378694 & & & & \\
\hline IEMBL1598644 & & & & \\
\hline HEMBL156 & & & & \\
\hline AEMBL1440593 & 239 & & & \\
\hline AEMBL1531599 & & & & \\
\hline IEMBL132 & & & & \\
\hline IEMBL159 & & & & \\
\hline IEMBL1438723 & & & & \\
\hline AEMBL1437926 & & & 489 & TST \\
\hline IEMBL1331322 & & & & \\
\hline IEMBL13 & & & & \\
\hline IEMBL15 & & & & \\
\hline IFMRI 13 & & & & \\
\hline AEMBL 276 & & & & ГST \\
\hline IEMBL1430962 & & & & 「Rा \\
\hline AEMBL1511319 & & & & $\mathrm{RI}$ \\
\hline 404 & & & & 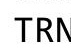 \\
\hline 426 & & & & . \\
\hline HEMBL1429707 & & & & RN \\
\hline AEMBL1317288 & & & & RI \\
\hline IEMBL1603863 & & & & R \\
\hline 552 & & & & ות \\
\hline 36 & & & & . \\
\hline AEMBL1550615 & & & & $\Gamma R$ \\
\hline AEMBL1579810 & & & & $h$ \\
\hline EMBL15 & & & & RI \\
\hline 794 & & & & \\
\hline 885 & & & 71 & RN \\
\hline AEMBL3191318 & & & 3993 & $\Gamma R$ \\
\hline-141 & & & & TR \\
\hline MBL136 & & & & \\
\hline HEMBL135 & & & & \\
\hline CHEMBL1998334 & & & 266 & $\mathrm{R}$ \\
\hline AEMBL1404100 & 8239 & 6.8362 & 5.5288 & TS \\
\hline HFMBI 1411692 & 688239 & 5.5862 & 5.6258 & 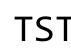 \\
\hline
\end{tabular}

Page 2238 
Supplemental Table S2.txt

\begin{tabular}{|c|c|c|c|c|c|}
\hline CHEMBL1368003 & 688239 & 4.5362 & 5.3651 & TST & \\
\hline CHEMBL1502672 & 688239 & 4.6862 & 5.4439 & TST & \\
\hline CHEMBL1578721 & 688239 & 5.8362 & 5.5229 & TST & \\
\hline CHEMBL3196124 & 688239 & 5.1862 & 5.3502 & TRN & \\
\hline CHEMBL1330474 & 688239 & 5.2362 & 5.5425 & TST & \\
\hline CHEMBL1559825 & 688239 & 4.6362 & 5.5462 & TST & \\
\hline CHEMBL1582224 & 688239 & 6.2362 & 5.5406 & TRN & \\
\hline CHEMBL1394867 & 688239 & 6.8861 & 5.5786 & TRN & \\
\hline CHEMBL1498473 & 688239 & 5.7362 & 5.5159 & TST & \\
\hline CHEMBL1310165 & 688239 & 5.4362 & 5.3255 & TST & \\
\hline CHEMBL1354406 & 688239 & 4.5362 & 5.4705 & TRN & \\
\hline CHEMBL1415997 & 688239 & 4.7862 & 5.3477 & TRN & \\
\hline CHEMBL1404240 & 688239 & 6.8362 & 5.6121 & TRN & \\
\hline CHEMBL1474770 & 688239 & 4.6362 & 5.5241 & TRN & \\
\hline CHEMBL1533222 & 688239 & 4.5362 & 5.4272 & TRN & \\
\hline CHEMBL1507471 & 688239 & 5.9862 & 5.4575 & TST & \\
\hline CHEMBL1571107 & 688239 & 5.6862 & 5.5538 & TRN & \\
\hline CHEMBL1535719 & 688239 & 4.6862 & 5.4833 & TRN & \\
\hline CHEMBL1612901 & 688239 & 5.8862 & 5.3711 & TRN & \\
\hline CHEMBL1496242 & 688239 & 6.1362 & 5.5282 & TRN & \\
\hline CHEMBL1589550 & 688239 & 6.9363 & 5.4883 & TRN & \\
\hline CHEMBL1611267 & 688239 & 7.1361 & 5.4829 & TRN & \\
\hline CHEMBL1453852 & 688239 & 6.7862 & 5.4488 & TST & \\
\hline CHEMBL1552218 & 688239 & 4.5362 & 5.547006 & 0000000001 & TRN \\
\hline CHEMBL3214078 & 688239 & 5.4862 & 5.6009 & TST & \\
\hline CHEMBL1597439 & 688239 & 5.5862 & 5.5461 & TRN & \\
\hline CHEMBL1414742 & 688239 & 6.1862 & 5.3996 & TRN & \\
\hline CHEMBL1464212 & 688239 & 4.6862 & 5.4042 & TRN & \\
\hline CHEMBL1505952 & 688239 & 4.4862 & 5.3726 & TRN & \\
\hline CHEMBL1430435 & 688239 & 5.3362 & 5.3468 & TST & \\
\hline CHEMBL1323224 & 688239 & 6.0362 & 5.5203 & TRN & \\
\hline CHEMBL1570826 & 688239 & 4.5362 & 5.487 & TRN & \\
\hline CHEMBL1590862 & 688239 & 4.8362 & 5.4563 & TRN & \\
\hline CHEMBL1355679 & 688239 & 4.5362 & 5.4796 & TRN & \\
\hline CHEMBL1533676 & 688239 & 8.3372 & 5.3594 & TST & \\
\hline CHEMBL1564505 & 688239 & 4.7362 & 5.4977 & TRN & \\
\hline CHEMBL1486440 & 688239 & 5.8362 & 5.4278 & TST & \\
\hline CHEMBL1569513 & 688239 & 5.3362 & 5.5274 & TRN & \\
\hline CHEMBL1483057 & 688239 & 4.6862 & 5.5441 & TRN & \\
\hline CHEMBL1582423 & 688239 & 6.1362 & 5.6482 & TST & \\
\hline CHEMBL234216 & 688239 & 8.3372 & 5.4996 & TST & \\
\hline CHEMBL1494722 & 688239 & 5.1862 & 5.4072 & TRN & \\
\hline CHEMBL1374091 & 688239 & 4.4862 & 5.5362 & TRN & \\
\hline CHEMBL1448757 & 688239 & 8.28399 & 99999999 & 5.4457 & TS \\
\hline CHEMBL597251 & 688239 & 4.5862 & 5.3623 & TST & \\
\hline CHEMBL1401230 & 688239 & 4.5362 & 5.6243 & TST & \\
\hline CHEMBL1397258 & 688239 & 4.7862 & 5.4907 & TRN & \\
\hline CHEMBL3189646 & 688239 & 5.5362 & 5.5558 & TRN & \\
\hline
\end{tabular}


Supplemental Table S2.txt

\begin{tabular}{|c|c|c|c|c|}
\hline CHEMBL1966984 & 688239 & 4.7362 & 5.3285 & TST \\
\hline CHEMBL1377802 & 688239 & 4.5362 & 5.6846 & TRN \\
\hline CHEMBL1402666 & 688239 & 8.3372 & 5.5164 & TST \\
\hline CHEMBL1514649 & 688239 & 5.2862 & 5.4672 & TRN \\
\hline CHEMBL1569629 & 688239 & 6.8861 & 5.4521 & TST \\
\hline CHEMBL1376512 & 688239 & 6.6362 & 5.4842 & TRN \\
\hline CHEMBL1456890 & 688239 & 6.6861 & 5.5338 & TST \\
\hline CHEMBL1575577 & 688239 & 4.4862 & 5.4478 & TRN \\
\hline CHEMBL1409784 & 688239 & 5.4362 & 5.5822 & TST \\
\hline CHEMBL1532935 & 688239 & 6.7862 & 5.4058 & TST \\
\hline CHEMBL1330023 & 688239 & 4.6862 & 5.5301 & TRN \\
\hline CHEMBL1580658 & 688239 & 4.5362 & 5.5213 & TRN \\
\hline CHEMBL1479006 & 688239 & 4.5362 & 5.4299 & TRN \\
\hline CHEMBL1564714 & 688239 & 4.5362 & 5.5196 & TRN \\
\hline CHEMBL1582900 & 688239 & 4.8362 & 5.4986 & TST \\
\hline CHEMBL1501766 & 688239 & 4.5362 & 5.5022 & TST \\
\hline CHEMBL1308455 & 688239 & 5.7862 & 5.501 & TRN \\
\hline CHEMBL1538754 & 688239 & 6.0362 & 5.5349 & TRN \\
\hline CHEMBL1569456 & 688239 & 4.4862 & 5.6313 & TST \\
\hline CHEMBL1346524 & 688239 & 4.5862 & 5.5523 & TRN \\
\hline CHEMBL1450932 & 688239 & 5.7862 & 5.5495 & TRN \\
\hline CHEMBL1579530 & 688239 & 4.7862 & 5.6208 & TRN \\
\hline CHEMBL1354891 & 688239 & 5.1362 & 5.6039 & TRN \\
\hline CHEMBL1479489 & 688239 & 4.5362 & 5.4683 & TRN \\
\hline CHEMBL1375732 & 688239 & 6.0 & 5.6935 & TRN \\
\hline CHEMBL1330427 & 688239 & 4.5362 & 5.5089 & TRN \\
\hline CHEMBL1418832 & 688239 & 5.7362 & 5.4656 & TRN \\
\hline CHEMBL1521971 & 688239 & 6.8362 & 5.4496 & TRN \\
\hline CHEMBL1414545 & 688239 & 4.75 & 5.5841 & TRN \\
\hline CHEMBL1358337 & 688239 & 5.0362 & 5.5598 & TRN \\
\hline CHEMBL1486629 & 688239 & 6.3362 & 5.5969 & TRN \\
\hline CHEMBL1499930 & 688239 & 5.7362 & 5.5793 & TST \\
\hline CHEMBL1422398 & 688239 & 4.5362 & 5.4483 & TRN \\
\hline CHEMBL1390043 & 688239 & 4.5362 & 5.4134 & TRN \\
\hline CHEMBL1358335 & 688239 & 5.7362 & 5.4452 & TRN \\
\hline CHEMBL1409431 & 688239 & 4.9862 & 5.4702 & TRN \\
\hline CHEMBL1384242 & 688239 & 5.1362 & 5.4174 & TRN \\
\hline CHEMBL1579369 & 688239 & 6.0362 & 5.38399 & 9999999995 \\
\hline CHEMBL1559664 & 688239 & 4.6862 & 5.3644 & TRN \\
\hline CHEMBL1325874 & 688239 & 4.6362 & 5.4351 & TRN \\
\hline CHEMBL1389996 & 688239 & 5.7862 & 5.53600 & 0000000005 \\
\hline CHEMBL1428036 & 688239 & 8.3372 & 5.4987 & TRN \\
\hline CHEMBL1458470 & 688239 & 4.4862 & 5.4594 & TST \\
\hline CHEMBL1612951 & 688239 & 5.7862 & 5.5455 & TRN \\
\hline CHEMBL1563059 & 688239 & 4.5362 & 5.5221 & TRN \\
\hline CHEMBL 1483025 & 688239 & 4.8362 & 5.6091 & TRN \\
\hline CHEMBL1463054 & 688239 & 6.2362 & 5.5917 & TRN \\
\hline CHEMBL3208676 & 688239 & 6.0862 & 5.4967 & TRN \\
\hline
\end{tabular}

Page 2240 
Supplemental Table S2.txt

\begin{tabular}{|c|c|c|c|c|}
\hline CHEMBL1474320 & 688239 & 5.5862 & 5.5008 & TRN \\
\hline CHEMBL1435892 & 688239 & 5.7362 & 5.529 & TRN \\
\hline CHEMBL1368389 & 688239 & 6.1862 & 5.6137 & TRN \\
\hline CHEMBL1344218 & 688239 & 4.9 & 5.506 & TRN \\
\hline CHEMBL1528204 & 688239 & 4.5362 & 5.5106 & TRN \\
\hline CHEMBL1320416 & 688239 & 5.3362 & 5.481 & TRN \\
\hline CHEMBL1414955 & 688239 & 4.9862 & 5.4043 & TRN \\
\hline CHEMBL1575576 & 688239 & 5.8862 & 5.4302 & TRN \\
\hline CHEMBL1360182 & 688239 & 5.9362 & 5.6022 & TRN \\
\hline CHEMBL1375205 & 688239 & 5.9862 & 5.4899 & TRN \\
\hline CHEMBL3209595 & 688239 & 6.9863 & 5.2873 & TST \\
\hline CHEMBL1533750 & 688239 & 4.6862 & 5.4091 & TRN \\
\hline CHEMBL1543088 & 688239 & 5.8862 & 5.5064 & TRN \\
\hline CHEMBL1370792 & 688239 & 6.8861 & 5.5577 & TST \\
\hline CHEMBL1518807 & 688239 & 5.6362 & 5.4257 & TRN \\
\hline CHEMBL1484942 & 688239 & 6.7862 & 5.3465 & TRN \\
\hline CHEMBL1414555 & 688239 & 4.6862 & 5.5476 & TRN \\
\hline CHEMBL 3194461 & 688239 & 4.9 & 5.5003 & TRN \\
\hline CHEMBL1524470 & 688239 & 4.8362 & 5.4759 & TRN \\
\hline CHEMBL1567151 & 688239 & 4.5362 & 5.7729 & TRN \\
\hline CHEMBL1384445 & 688239 & 5.3862 & 5.6379 & TRN \\
\hline CHEMBL1541680 & 688239 & 5.3862 & 5.5079 & TST \\
\hline CHEMBL1534938 & 688239 & 4.5362 & 5.5031 & TST \\
\hline CHEMBL1320353 & 688239 & 5.6362 & 5.5419 & TRN \\
\hline CHEMBL1418374 & 688239 & 5.1362 & 5.5078 & TST \\
\hline CHEMBL 3193891 & 688239 & 5.4862 & 5.6169 & TRN \\
\hline CHEMBL1372246 & 688239 & 7.2865 & 5.4662 & TRN \\
\hline CHEMBL1487349 & 688239 & 5.1862 & 5.6291 & TRN \\
\hline CHEMBL1518243 & 688239 & 5.2362 & 5.5005 & TRN \\
\hline CHEMBL1379952 & 688239 & 4.7862 & 5.4221 & TRN \\
\hline CHEMBL1505914 & 688239 & 7.1361 & 5.6984 & TRN \\
\hline CHEMBL 3190739 & 688239 & 4.7362 & 5.438 & TRN \\
\hline CHEMBL 3213861 & 688239 & 8.2366 & 5.5148 & TST \\
\hline CHEMBL1325812 & 688239 & 5.5862 & 5.456 & TRN \\
\hline CHEMBL1534648 & 688239 & 8.3372 & 5.3597 & TST \\
\hline CHEMBL1481927 & 688239 & 5.1862 & 5.36100 & 3000000001 \\
\hline CHEMBL1576373 & 688239 & 4.5362 & 5.5936 & TRN \\
\hline CHEMBL1533448 & 688239 & 5.0362 & 5.523 & TRN \\
\hline CHEMBL1457334 & 688239 & 6.9863 & 5.495 & TRN \\
\hline CHEMBL1326724 & 688239 & 6.7361 & 5.5213 & TST \\
\hline CHEMBL1501977 & 688239 & 4.7862 & 5.46200 & 0000000001 \\
\hline CHEMBL1302418 & 688239 & 5.8362 & 5.5101 & TST \\
\hline CHEMBL1371854 & 688239 & 4.5362 & 5.5192 & TRN \\
\hline CHEMBL1337707 & 688239 & 5.4362 & 5.4915 & TRN \\
\hline CHEMBL1351485 & 688239 & 4.5362 & 5.5247 & TRN \\
\hline CHEMBL1322717 & 688239 & 4.5362 & 5.5472 & TRN \\
\hline CHEMBL1414404 & 688239 & 5.0862 & 5.5503 & TRN \\
\hline CHEMBL1480068 & 688239 & 4.5362 & 5.5975 & TRN \\
\hline
\end{tabular}

Page 2241 
Supplemental Table S2.txt

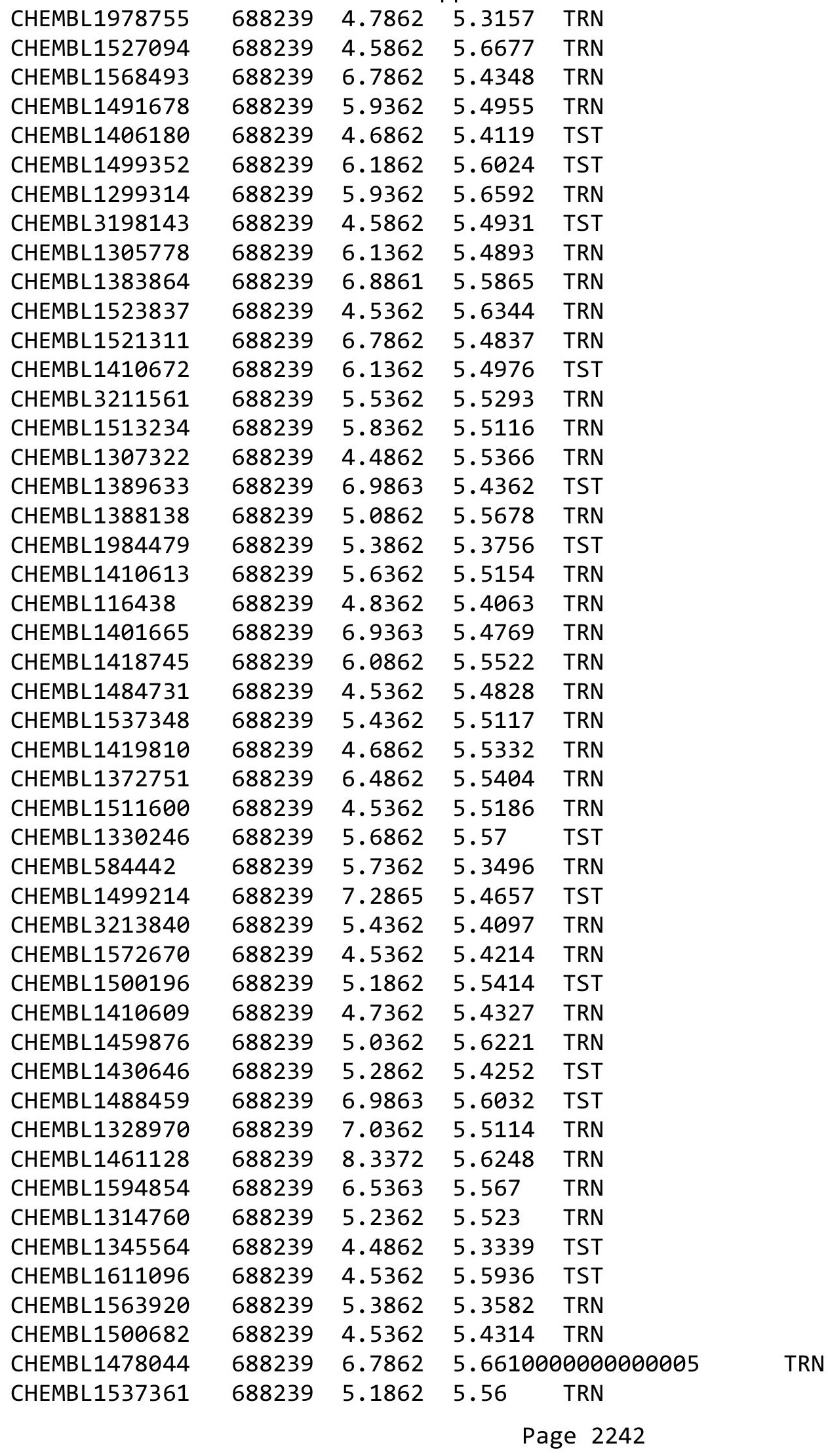




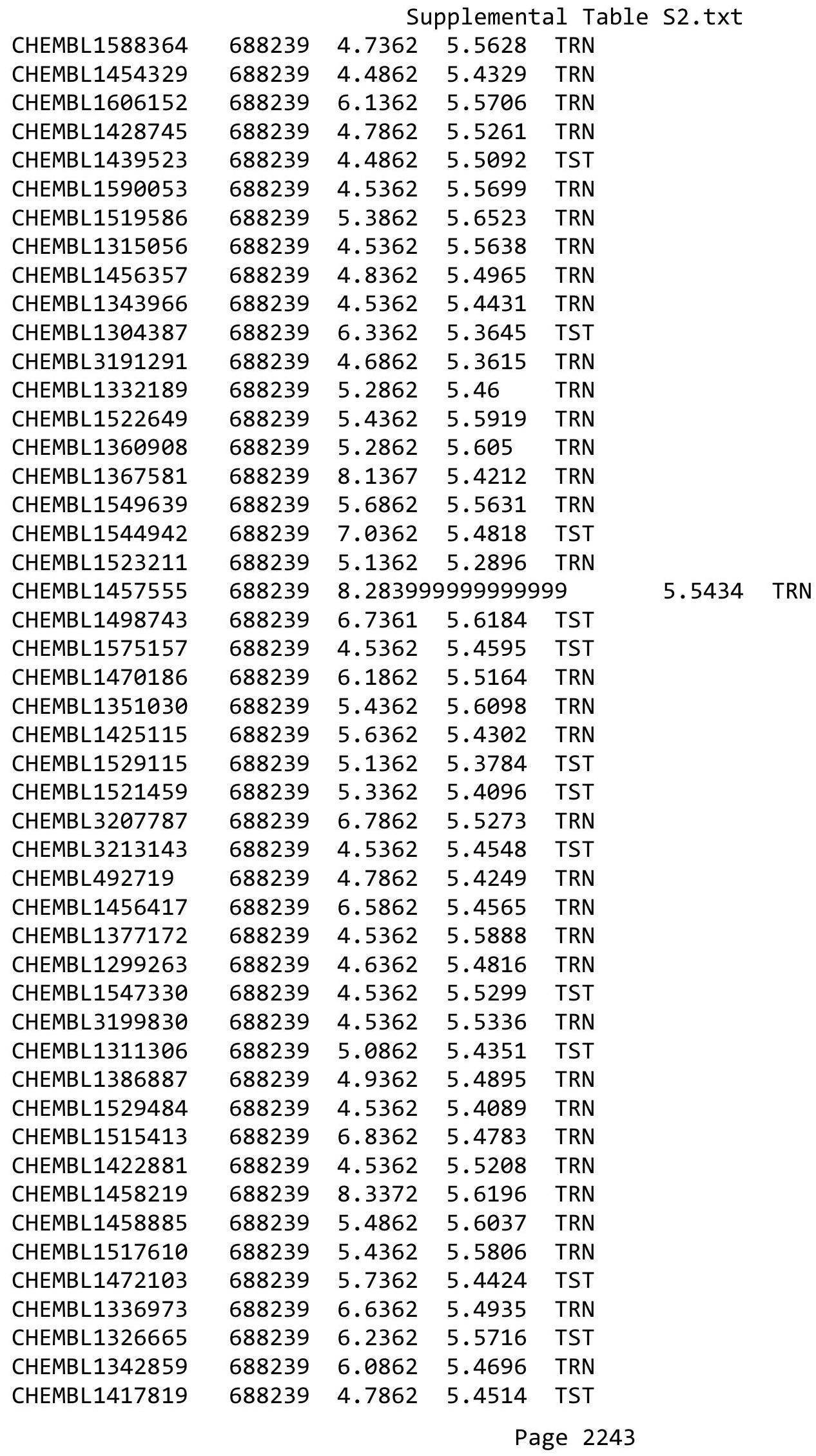


Supplemental Table S2.txt

\begin{tabular}{|c|c|c|c|c|c|}
\hline CHEMBL1526520 & 688239 & 4.5362 & 5.459 & TRN & \\
\hline CHEMBL1442271 & 688239 & 5.1862 & 5.354 & TST & \\
\hline CHEMBL1572574 & 688239 & 5.9862 & 5.3882 & TRN & \\
\hline CHEMBL1406204 & 688239 & 6.1862 & 5.5595 & TRN & \\
\hline CHEMBL1569762 & 688239 & 6.5862 & 5.4996 & TRN & \\
\hline CHEMBL1559850 & 688239 & 4.5362 & 5.5911 & TRN & \\
\hline CHEMBL1385363 & 688239 & 5.1862 & 5.6277 & TRN & \\
\hline CHEMBL1530478 & 688239 & 5.5362 & 5.5649 & TST & \\
\hline CHEMBL1469547 & 688239 & 5.1862 & 5.7428 & TRN & \\
\hline CHEMBL1405754 & 688239 & 5.3862 & 5.2516 & TRN & \\
\hline CHEMBL1373840 & 688239 & 5.9362 & 5.4698 & TRN & \\
\hline CHEMBL1320560 & 688239 & 5.0362 & 5.5133 & TRN & \\
\hline CHEMBL1556827 & 688239 & 4.5362 & 5.3198 & TRN & \\
\hline CHEMBL1519270 & 688239 & 7.0862 & 5.5646 & TST & \\
\hline CHEMBL1379816 & 688239 & 6.3863 & 5.5551 & TST & \\
\hline CHEMBL1588676 & 688239 & 4.7862 & 5.4904 & TRN & \\
\hline CHEMBL1602176 & 688239 & 5.9862 & 5.5481 & TST & \\
\hline CHEMBL1408920 & 688239 & 5.7362 & 5.5657 & TRN & \\
\hline CHEMBL1515340 & 688239 & 7.2366 & 5.5031 & TRN & \\
\hline CHEMBL1300105 & 688239 & 7.0862 & 5.50299 & 9999999999 & TRN \\
\hline CHEMBL1579666 & 688239 & 5.4362 & 5.5403 & TRN & \\
\hline CHEMBL1389798 & 688239 & 4.5362 & 5.4278 & TRN & \\
\hline CHEMBL1413305 & 688239 & 6.9363 & 5.4402 & TST & \\
\hline CHEMBL1363722 & 688239 & 5.0362 & 5.5484 & TRN & \\
\hline CHEMBL1583509 & 688239 & 4.5362 & 5.3737 & TRN & \\
\hline CHEMBL1340263 & 688239 & 5.9362 & 5.5624 & TRN & \\
\hline CHEMBL1368917 & 688239 & 4.5362 & 5.5021 & TRN & \\
\hline CHEMBL1476233 & 688239 & 4.9362 & 5.5084 & TST & \\
\hline CHEMBL1458182 & 688239 & 5.4362 & 5.5649 & TST & \\
\hline CHEMBL1609874 & 688239 & 5.4862 & 5.4543 & TST & \\
\hline CHEMBL1379207 & 688239 & 4.5862 & 5.5046 & TRN & \\
\hline CHEMBL1363863 & 688239 & 7.0362 & 5.664 & TRN & \\
\hline CHEMBL1610513 & 688239 & 4.7862 & 5.3661 & TRN & \\
\hline CHEMBL1362901 & 688239 & 5.1862 & 5.4792 & TRN & \\
\hline CHEMBL1598755 & 688239 & 4.5362 & 5.7454 & TRN & \\
\hline CHEMBL1572908 & 688239 & 6.1862 & 5.5295 & TRN & \\
\hline CHEMBL1419712 & 688239 & 4.7862 & 5.4066 & TRN & \\
\hline CHEMBL1307111 & 688239 & 8.3372 & 5.5495 & TST & \\
\hline CHEMBL1546205 & 688239 & 4.5362 & 5.4999 & TRN & \\
\hline CHEMBL1371889 & 688239 & 4.4862 & 5.4795 & TST & \\
\hline CHEMBL1477123 & 688239 & 6.2362 & 5.646 & TRN & \\
\hline CHEMBL1450803 & 688239 & 6.2362 & 5.4594 & TST & \\
\hline CHEMBL1542201 & 688239 & 5.1862 & 5.3884 & TST & \\
\hline CHEMBL1523990 & 688239 & 4.7362 & 5.4693 & TRN & \\
\hline CHEMBL1498471 & 688239 & 5.0862 & 5.5389 & TRN & \\
\hline CHEMBL1368060 & 688239 & 4.4862 & 5.4675 & TRN & \\
\hline CHEMBL1426364 & 688239 & 5.9862 & 5.4787 & TST & \\
\hline CHEMBL1417070 & 688239 & 6.5363 & 5.2839 & TST & \\
\hline
\end{tabular}

Page 2244 
Supplemental Table S2.txt

\begin{tabular}{|c|c|c|c|c|}
\hline 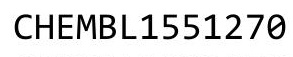 & & & & \\
\hline HEMBL1329576 & 38239 & 3362 & 3813 & \\
\hline AEMBL1554264 & 239 & 862 & 3698 & \\
\hline 767 & 39 & 362 & & \\
\hline IEMBL1495431 & 39 & 362 & & \\
\hline AEMBL1579775 & 88239 & 862 & & \\
\hline AEMBL1407832 & 88239 & 362 & 4514 & \\
\hline HEMBL1368061 & & & & \\
\hline EMBL157 & 39 & 362 & & \\
\hline IEMBL1593010 & & & & \\
\hline AEMBL1338936 & 239 & 862 & 623 & \\
\hline AEMBL1470053 & 39 & 361 & & \\
\hline AEMBL1483761 & & & & \\
\hline HEMBL1452224 & & 62 & & \\
\hline AEMBL3209324 & & & & \\
\hline AEMBL1491872 & & 862 & & \\
\hline AEMBL1315717 & & 862 & & \\
\hline IEMBL15766 & & 55 & & \\
\hline AEMBL3193610 & & & & \\
\hline AEMBL2369206 & & & & \\
\hline AEMBL1438304 & & 862 & & \\
\hline AEMBL1361933 & & 862 & & \\
\hline AEMBL13334 & & 61 & & \\
\hline AFMBI 13798 & & & & \\
\hline 39 & & & & \\
\hline AEMBL1466684 & & 862 & & \\
\hline IEMBL1470374 & & 62 & & \\
\hline IEMBL13574 & & 62 & & \\
\hline AFMRI 14 & & 53 & & \\
\hline ז & & 362 & & \\
\hline AEMBL3193923 & & 62 & & \\
\hline IEMBL1466476 & & 362 & & \\
\hline 7 & & & & \\
\hline 5 & & & & \\
\hline AEMBL3193183 & & & & \\
\hline AEMBL1429382 & & 862 & & \\
\hline AEMBL1369437 & & 862 & & \\
\hline & & 62 & & \\
\hline (2MO & & & & \\
\hline HEMBL1460252 & & & & ST \\
\hline AEMBL1340346 & & 362 & 46 & $\mathrm{~S}$ \\
\hline EMBL1613 & & 62 & & \\
\hline 1347272 & & & & \\
\hline CHEMBL1596946 & & & & \\
\hline AEMBL1313403 & & 5.4362 & 5173 & RN \\
\hline IEMBL1573519 & & 362 & 5025 & \\
\hline & & & & \\
\hline 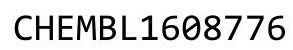 & & & & \\
\hline
\end{tabular}

Page 2245 
Supplemental Table S2.txt

\begin{tabular}{|c|c|c|c|c|}
\hline CHEMBL1351554 & 688239 & 6.0362 & 5.6064 & TRN \\
\hline CHEMBL1587787 & 688239 & 6.0362 & 5.2843 & TST \\
\hline CHEMBL1425280 & 688239 & 4.5362 & 5.6188 & TRN \\
\hline CHEMBL1585667 & 688239 & 6.2362 & 5.5972 & TRN \\
\hline CHEMBL1481145 & 688239 & 4.9362 & 5.5852 & TRN \\
\hline CHEMBL1335928 & 688239 & 7.1002 & 5.5962 & TRN \\
\hline CHEMBL1520125 & 688239 & 4.7862 & 5.4316 & TRN \\
\hline CHEMBL3210975 & 688239 & 4.6362 & 5.3842 & TRN \\
\hline CHEMBL1461686 & 688239 & 6.2362 & 5.5163 & TRN \\
\hline CHEMBL1449705 & 688239 & 5.5862 & 5.4388 & TST \\
\hline CHEMBL1573864 & 688239 & 4.8362 & \multicolumn{2}{|c|}{5.367000000000001} \\
\hline CHEMBL3196038 & 688239 & 5.8862 & 5.4688 & TRN \\
\hline CHEMBL1967761 & 688239 & 4.5362 & 5.4654 & TST \\
\hline CHEMBL1575828 & 688239 & 6.9363 & 5.6272 & TRN \\
\hline CHEMBL1304440 & 688239 & 6.7862 & 5.5958 & TST \\
\hline CHEMBL1334128 & 688239 & 6.7862 & 5.6152 & TRN \\
\hline CHEMBL1382575 & 688239 & 4.5362 & 5.405 & TRN \\
\hline CHEMBL1409164 & 688239 & 5.0362 & 5.3788 & TRN \\
\hline CHEMBL1414496 & 688239 & 5.6862 & 5.443 & TRN \\
\hline CHEMBL1554667 & 688239 & 4.5362 & 5.4881 & TRN \\
\hline CHEMBL1485518 & 688239 & 5.5862 & 5.4176 & TRN \\
\hline CHEMBL1315693 & 688239 & 6.0862 & 5.4271 & TRN \\
\hline CHEMBL1333163 & 688239 & 8.3372 & 5.6766 & TRN \\
\hline CHEMBL1542258 & 688239 & 4.5362 & 5.5259 & TRN \\
\hline CHEMBL1361351 & 688239 & 8.0862 & 5.5613 & TRN \\
\hline CHEMBL1428360 & 688239 & 6.3362 & 5.4464 & TRN \\
\hline CHEMBL1321398 & 688239 & 4.8362 & 5.2975 & TST \\
\hline CHEMBL1300926 & 688239 & 4.5362 & 5.4435 & TRN \\
\hline CHEMBL1453447 & 688239 & 4.5862 & 5.5769 & TRN \\
\hline CHEMBL3192754 & 688239 & 5.1862 & 5.5474 & TRN \\
\hline CHEMBL1735892 & 688239 & 4.7862 & 5.4337 & TRN \\
\hline CHEMBL1443209 & 688239 & 6.9363 & 5.3904 & TRN \\
\hline CHEMBL1430010 & 688239 & 4.7862 & 5.5965 & TRN \\
\hline CHEMBL1502854 & 688239 & 4.7362 & 5.4525 & TRN \\
\hline CHEMBL1443726 & 688239 & 4.5362 & 5.5442 & TRN \\
\hline CHEMBL1514414 & 688239 & 6.8362 & 5.5149 & TRN \\
\hline CHEMBL1528647 & 688239 & 6.2862 & 5.4934 & TRN \\
\hline CHEMBL3208972 & 688239 & 4.6862 & 5.4631 & TRN \\
\hline CHEMBL1368728 & 688239 & 6.4862 & 5.5053 & TRN \\
\hline CHEMBL1604829 & 688239 & 5.1362 & 5.5158 & TRN \\
\hline CHEMBL1609184 & 688239 & 4.5362 & 5.4304 & TRN \\
\hline CHEMBL1539371 & 688239 & 5.1862 & 5.5464 & TST \\
\hline CHEMBL1545873 & 688239 & 5.2862 & 5.4012 & TRN \\
\hline CHEMBL1380570 & 688239 & 5.8362 & 5.5266 & TRN \\
\hline CHEMBL1481668 & 688239 & 4.7862 & 5.3519 & TST \\
\hline CHEMBL3193750 & 688239 & 6.0862 & 5.5232 & TST \\
\hline CHEMBL1606797 & 688239 & 6.0862 & 5.4848 & TRN \\
\hline CHEMBL1529670 & 688239 & 4.5362 & 5.6052 & TRN \\
\hline
\end{tabular}

Page 2246 
Supplemental Table S2.txt

\begin{tabular}{|c|c|c|c|c|}
\hline CHEMBL1310454 & 688239 & 4.5362 & 5.2984 & TRN \\
\hline CHEMBL1566138 & 688239 & 6.1362 & 5.5317 & TST \\
\hline CHEMBL1501206 & 688239 & 4.5362 & 5.3567 & TRN \\
\hline CHEMBL1561783 & 688239 & 6.2362 & 5.4608 & TRN \\
\hline CHEMBL1486531 & 688239 & 5.6362 & 5.6333 & TRN \\
\hline CHEMBL1421578 & 688239 & 5.8862 & 5.4751 & TRN \\
\hline CHEMBL1309756 & 688239 & 4.5362 & 5.4769 & TST \\
\hline CHEMBL1539841 & 688239 & 4.7362 & 5.4953 & TRN \\
\hline CHEMBL1416260 & 688239 & 6.2362 & 5.6713 & TRN \\
\hline CHEMBL1586599 & 688239 & 5.2362 & 5.4281 & TRN \\
\hline CHEMBL1357659 & 688239 & 6.2362 & 5.4233 & TRN \\
\hline CHEMBL1300764 & 688239 & 5.1862 & 5.4973 & TST \\
\hline CHEMBL1997928 & 688239 & 4.4862 & 5.5136 & TRN \\
\hline CHEMBL1574902 & 688239 & 6.7361 & 5.6159 & TST \\
\hline CHEMBL1365084 & 688239 & 5.0862 & 5.582999 & 999999999 \\
\hline CHEMBL1367355 & 688239 & 4.5362 & 5.4538 & TRN \\
\hline CHEMBL1441840 & 688239 & 4.6862 & 5.5284 & TRN \\
\hline CHEMBL1351572 & 688239 & 6.8861 & 5.6249 & TRN \\
\hline CHEMBL 3192674 & 688239 & 4.9362 & 5.3089 & TST \\
\hline CHEMBL1562250 & 688239 & 4.6862 & 5.446006 & 000000001 \\
\hline CHEMBL1610171 & 688239 & 5.6362 & 5.2336 & TRN \\
\hline CHEMBL1493658 & 688239 & 4.8862 & 5.4725 & TRN \\
\hline CHEMBL1406582 & 688239 & 5.8362 & 5.4586 & TRN \\
\hline CHEMBL1567033 & 688239 & 5.6862 & 5.575 & TRN \\
\hline CHEMBL1473588 & 688239 & 6.0362 & 5.5119 & TRN \\
\hline CHEMBL1478852 & 688239 & 4.5362 & 5.4883 & TRN \\
\hline CHEMBL1377608 & 688239 & 4.5362 & 5.5038 & TST \\
\hline CHEMBL1577820 & 688239 & 5.9362 & 5.5947 & TST \\
\hline CHEMBL1537189 & 688239 & 5.9862 & 5.4799 & TRN \\
\hline CHEMBL1579393 & 688239 & 4.5362 & 5.4701 & TRN \\
\hline CHEMBL1426195 & 688239 & 5.1862 & 5.4146 & TRN \\
\hline CHEMBL1478032 & 688239 & 4.5362 & 5.4814 & TRN \\
\hline CHEMBL1459973 & 688239 & 6.1862 & 5.5345 & TRN \\
\hline CHEMBL1595786 & 688239 & 4.5362 & 5.4187 & TRN \\
\hline CHEMBL1454603 & 688239 & 4.5362 & 5.5163 & TRN \\
\hline CHEMBL1362208 & 688239 & 6.6861 & 5.438 & TST \\
\hline CHEMBL3214366 & 688239 & 5.6362 & 5.5201 & TST \\
\hline CHEMBL1386343 & 688239 & 5.1862 & 5.4526 & TRN \\
\hline CHEMBL1422615 & 688239 & 6.0362 & 5.602 & TRN \\
\hline CHEMBL1437134 & 688239 & 7.9872 & 5.4873 & TST \\
\hline CHEMBL1471247 & 688239 & 4.6862 & 5.3675 & TST \\
\hline CHEMBL1536701 & 688239 & 5.4362 & 5.5649 & TST \\
\hline CHEMBL1501300 & 688239 & 4.8362 & 5.2831 & TRN \\
\hline CHEMBL1539122 & 688239 & 7.1361 & 5.3629 & TST \\
\hline CHEMBL1496692 & 688239 & 4.8862 & 5.7135 & TRN \\
\hline CHEMBL1548681 & 688239 & 6.9363 & 5.552006 & 0000000005 \\
\hline CHEMBL1324325 & 688239 & 4.6862 & 5.4791 & TRN \\
\hline CHEMBL1415112 & 688239 & 5.7362 & 5.4354 & TRN \\
\hline
\end{tabular}


Supplemental Table S2.txt

\begin{tabular}{|c|c|c|c|c|}
\hline CHEMBL1442058 & 688239 & 5.9362 & 5.5488 & TST \\
\hline CHEMBL1413277 & 688239 & 4.8362 & 5.5695 & TST \\
\hline CHEMBL1608905 & 688239 & 6.9363 & 5.4171 & TST \\
\hline CHEMBL1402036 & 688239 & 5.4862 & 5.5536 & TRN \\
\hline CHEMBL1307031 & 688239 & 6.0362 & 5.5672 & TST \\
\hline CHEMBL1327662 & 688239 & 5.5362 & 5.3035 & TRN \\
\hline CHEMBL1595352 & 688239 & 7.0862 & 5.357 & TRN \\
\hline CHEMBL1451536 & 688239 & 4.7362 & 5.6189 & TRN \\
\hline CHEMBL1417758 & 688239 & 5.1362 & 5.5661 & TRN \\
\hline CHEMBL3192556 & 688239 & 5.2862 & 5.4909 & TRN \\
\hline CHEMBL1543169 & 688239 & 5.1862 & 5.4907 & TRN \\
\hline CHEMBL1366429 & 688239 & 5.1362 & 5.3924 & TRN \\
\hline CHEMBL585656 & 688239 & 4.8362 & 5.3483 & TST \\
\hline CHEMBL1420630 & 688239 & 7.0362 & 5.4464 & TRN \\
\hline CHEMBL1325770 & 688239 & 5.1862 & 5.6341 & TRN \\
\hline CHEMBL1371902 & 688239 & 5.0862 & 5.5866 & TST \\
\hline CHEMBL1510616 & 688239 & 6.9863 & 5.4198 & TST \\
\hline CHEMBL1533243 & 688239 & 4.7862 & 5.5481 & TRN \\
\hline CHEMBL1384289 & 688239 & 4.7362 & 5.3068 & TRN \\
\hline CHEMBL1520876 & 688239 & 4.7362 & 5.6257 & TST \\
\hline CHEMBL1477999 & 688239 & 4.5362 & 5.5231 & TRN \\
\hline CHEMBL1558975 & 688239 & 4.5862 & 5.4357 & TRN \\
\hline CHEMBL1391643 & 688239 & 5.0862 & 5.497999 & 9999999999 \\
\hline CHEMBL1501121 & 688239 & 6.7361 & 5.3585 & TST \\
\hline CHEMBL1552515 & 688239 & 4.7362 & 5.6055 & TRN \\
\hline CHEMBL1384787 & 688239 & 4.4862 & 5.5161 & TRN \\
\hline CHEMBL1479966 & 688239 & 7.7852 & 5.5282 & TRN \\
\hline CHEMBL1477781 & 688239 & 4.5362 & 5.4384 & TRN \\
\hline CHEMBL1368896 & 688239 & 4.5362 & 5.495 & TRN \\
\hline CHEMBL1606110 & 688239 & 4.5362 & 5.4672 & TRN \\
\hline CHEMBL1406435 & 688239 & 8.2366 & 5.4685 & TRN \\
\hline CHEMBL1551392 & 688239 & 4.5362 & 5.4251 & TRN \\
\hline CHEMBL1479022 & 688239 & 6.6861 & 5.5248 & TST \\
\hline CHEMBL1382725 & 688239 & 4.6362 & 5.3883 & TRN \\
\hline CHEMBL3195658 & 688239 & 5.6362 & 5.4041 & TRN \\
\hline CHEMBL1330634 & 688239 & 4.8862 & 5.53 & TRN \\
\hline CHEMBL1322211 & 688239 & 4.5362 & 5.4613 & TRN \\
\hline CHEMBL1561609 & 688239 & 4.8362 & 5.5132 & TRN \\
\hline CHEMBL1386583 & 688239 & 5.1862 & 5.5881 & TRN \\
\hline CHEMBL1480044 & 688239 & 6.8362 & 5.4495 & TRN \\
\hline CHEMBL1392443 & 688239 & 5.4862 & 5.4848 & TRN \\
\hline CHEMBL1459003 & 688239 & 6.8362 & 5.4731 & TRN \\
\hline CHEMBL1563481 & 688239 & 6.8861 & 5.472 & TRN \\
\hline CHEMBL3211632 & 688239 & 4.5362 & 5.4811 & TRN \\
\hline CHEMBL1377027 & 688239 & 4.5362 & 5.3664 & TRN \\
\hline CHEMBL3192012 & 688239 & 6.0362 & 5.4635 & TRN \\
\hline CHEMBL1315446 & 688239 & 7.1361 & 5.506 & TRN \\
\hline CHEMBL1519633 & 688239 & 5.6862 & 5.641 & TST \\
\hline
\end{tabular}


Supplemental Table S2.txt

\begin{tabular}{|c|c|c|c|c|}
\hline CHEMBL1520239 & 688239 & 5.1862 & 5.6253 & TRN \\
\hline CHEMBL1300489 & 688239 & 4.5862 & 5.4937 & TRN \\
\hline CHEMBL1610807 & 688239 & 4.6862 & 5.4908 & TRN \\
\hline CHEMBL1504565 & 688239 & 5.3862 & 5.5497 & TRN \\
\hline CHEMBL1414161 & 688239 & 6.9363 & 5.5545 & TST \\
\hline CHEMBL1572477 & 688239 & 6.8362 & 5.6102 & TRN \\
\hline CHEMBL1381757 & 688239 & 5.4362 & \multicolumn{2}{|c|}{5.507000000000001} \\
\hline CHEMBL1988056 & 688239 & 5.0862 & 5.3176 & TST \\
\hline CHEMBL1498159 & 688239 & 4.9862 & 5.4372 & TST \\
\hline CHEMBL1533071 & 688239 & 6.0862 & 5.4278 & TRN \\
\hline CHEMBL1460328 & 688239 & 4.5362 & 5.4662 & TRN \\
\hline CHEMBL1305484 & 688239 & 4.7862 & 5.4823 & TST \\
\hline CHEMBL1605550 & 688239 & 4.6362 & 5.365 & TRN \\
\hline CHEMBL1493860 & 688239 & 5.1862 & 5.5637 & TRN \\
\hline CHEMBL1305581 & 688239 & 6.8861 & 5.5995 & TRN \\
\hline CHEMBL1342195 & 688239 & 4.6862 & 5.4261 & TRN \\
\hline CHEMBL1394100 & 688239 & 4.6862 & 5.5145 & TRN \\
\hline CHEMBL1356956 & 688239 & 6.5862 & 5.396 & TRN \\
\hline CHEMBL1525882 & 688239 & 4.6862 & 5.449 & TST \\
\hline CHEMBL1525046 & 688239 & 5.9362 & 5.727 & TRN \\
\hline CHEMBL1392632 & 688239 & 6.2862 & 5.5889 & TRN \\
\hline CHEMBL1496376 & 688239 & 6.8861 & 5.5133 & TST \\
\hline CHEMBL1601706 & 688239 & 4.5362 & 5.5224 & TRN \\
\hline CHEMBL1413859 & 688239 & 4.5362 & 5.4848 & TRN \\
\hline CHEMBL1515737 & 688239 & 5.1862 & 5.6709 & TRN \\
\hline CHEMBL1391301 & 688239 & 5.0362 & \multicolumn{2}{|c|}{5.462000000000001} \\
\hline CHEMBL1567943 & 688239 & 6.0862 & 5.5892 & TST \\
\hline CHEMBL1343605 & 688239 & 4.5862 & 5.4055 & TRN \\
\hline CHEMBL1596140 & 688239 & 8.2366 & 5.4679 & TRN \\
\hline CHEMBL1609119 & 688239 & 4.7362 & 5.3559 & TRN \\
\hline CHEMBL1336943 & 688239 & 6.4362 & 5.5796 & TRN \\
\hline CHEMBL507264 & 688239 & 4.7362 & 5.5833 & TRN \\
\hline CHEMBL1573482 & 688239 & 4.9862 & 5.5116 & TRN \\
\hline CHEMBL1444460 & 688239 & 5.3862 & 5.4891 & TRN \\
\hline CHEMBL3194039 & 688239 & 4.5362 & 5.4548 & TRN \\
\hline CHEMBL1593740 & 688239 & 5.6362 & 5.4238 & TRN \\
\hline CHEMBL1418959 & 688239 & 4.9362 & 5.6407 & TRN \\
\hline CHEMBL1411958 & 688239 & 4.9862 & 5.4095 & TST \\
\hline CHEMBL1353560 & 688239 & 4.5362 & 5.4382 & TRN \\
\hline CHEMBL1542470 & 688239 & 5.1862 & 5.4931 & TRN \\
\hline CHEMBL1606627 & 688239 & 5.3862 & 5.5371 & TRN \\
\hline CHEMBL1611794 & 688239 & 4.7362 & 5.3233 & TRN \\
\hline CHEMBL1347618 & 688239 & 4.4862 & 5.4879 & TST \\
\hline CHEMBL1439666 & 688239 & 6.0362 & 5.5173 & TRN \\
\hline CHEMBL1467176 & 688239 & 4.7862 & \multicolumn{2}{|c|}{5.412000000000001} \\
\hline CHEMBL1351056 & 688239 & 5.3362 & 5.5502 & TRN \\
\hline CHEMBL1341530 & 688239 & 6.3863 & 5.6219 & TRN \\
\hline CHEMBL1360427 & 688239 & 6.1362 & 5.4677 & TRN \\
\hline
\end{tabular}

Page 2249 


\begin{tabular}{|c|c|c|c|c|c|}
\hline \multicolumn{6}{|c|}{ Supplemental Table S2.txt } \\
\hline CHEMBL1410958 & 688239 & 7.4365 & 5.5038 & TST & \\
\hline CHEMBL1517142 & 688239 & 6.6362 & 5.5349 & TRN & \\
\hline CHEMBL1580291 & 688239 & 5.5862 & 5.4121 & TST & \\
\hline CHEMBL1498486 & 688239 & 8.28399 & 99999999 & 5.5227 & TRN \\
\hline CHEMBL1412625 & 688239 & 4.5862 & 5.3868 & TST & \\
\hline CHEMBL1476474 & 688239 & 5.1362 & 5.50200 & 0000000001 & TRN \\
\hline CHEMBL1330338 & 688239 & 4.5362 & 5.5488 & TST & \\
\hline CHEMBL1398108 & 688239 & 6.0862 & 5.4942 & TRN & \\
\hline CHEMBL1493314 & 688239 & 5.6362 & 5.5929 & TRN & \\
\hline CHEMBL1475314 & 688239 & 4.7362 & 5.4889 & TST & \\
\hline CHEMBL1541234 & 688239 & 4.5362 & 5.6024 & TRN & \\
\hline CHEMBL1401484 & 688239 & 4.5362 & 5.4903 & TRN & \\
\hline CHEMBL1482353 & 688239 & 6.2362 & 5.4519 & TRN & \\
\hline CHEMBL1525441 & 688239 & 4.8862 & 5.4147 & TRN & \\
\hline CHEMBL1371486 & 688239 & 5.1362 & 5.6287 & TRN & \\
\hline CHEMBL1340253 & 688239 & 4.5362 & 5.421 & TRN & \\
\hline CHEMBL1390830 & 688239 & 7.5867 & 5.5284 & TRN & \\
\hline CHEMBL1526617 & 688239 & 5.6862 & 5.6511 & TRN & \\
\hline CHEMBL1345207 & 688239 & 6.6362 & 5.4739 & TST & \\
\hline CHEMBL1580692 & 688239 & 4.5862 & 5.5197 & TST & \\
\hline CHEMBL1450056 & 688239 & 5.4362 & 5.6482 & TRN & \\
\hline CHEMBL1508079 & 688239 & 6.1862 & 5.5908 & TRN & \\
\hline CHEMBL1509239 & 688239 & 4.4862 & 5.6355 & TST & \\
\hline CHEMBL1416019 & 688239 & 5.3862 & 5.3438 & TRN & \\
\hline CHEMBL1471339 & 688239 & 5.1862 & 5.5605 & TRN & \\
\hline CHEMBL1361482 & 688239 & 4.5362 & 5.3131 & TRN & \\
\hline CHEMBL1496265 & 688239 & 4.6862 & 5.6398 & TST & \\
\hline CHEMBL1587346 & 688239 & 4.4862 & 5.4937 & TRN & \\
\hline CHEMBL1332190 & 688239 & 4.6362 & 5.4602 & TRN & \\
\hline CHEMBL1447215 & 688239 & 5.7362 & 5.4628 & TRN & \\
\hline CHEMBL1389295 & 688239 & 5.9362 & 5.6028 & TRN & \\
\hline CHEMBL1502327 & 688239 & 4.7362 & 5.4445 & TST & \\
\hline CHEMBL1583273 & 688239 & 7.0362 & 5.5365 & TRN & \\
\hline CHEMBL1304932 & 688239 & 4.5362 & 5.5127 & TRN & \\
\hline CHEMBL1577739 & 688239 & 5.0862 & 5.4291 & TRN & \\
\hline CHEMBL1510170 & 688239 & 4.7362 & 5.5065 & TRN & \\
\hline CHEMBL1978643 & 688239 & 4.5362 & 5.5089 & TRN & \\
\hline CHEMBL1479990 & 688239 & 4.7362 & 5.5269 & TRN & \\
\hline CHEMBL1355861 & 688239 & 6.5862 & 5.6266 & TRN & \\
\hline CHEMBL1601143 & 688239 & 4.8362 & 5.5687 & TRN & \\
\hline CHEMBL1316923 & 688239 & 4.7362 & 5.4386 & TRN & \\
\hline CHEMBL1452306 & 688239 & 5.5362 & 5.4652 & TRN & \\
\hline CHEMBL1575752 & 688239 & 5.1862 & 5.3151 & TRN & \\
\hline CHEMBL1528762 & 688239 & 4.5362 & 5.4933 & TRN & \\
\hline CHEMBL1543151 & 688239 & 4.6362 & 5.4512 & TRN & \\
\hline CHEMBL1471506 & 688239 & 6.0862 & 5.5611 & TRN & \\
\hline CHEMBL1543386 & 688239 & 5.8362 & 5.5091 & TRN & \\
\hline CHEMBL1424823 & 688239 & 5.7362 & 5.5373 & TRN & \\
\hline
\end{tabular}


Supplemental Table S2.txt

\begin{tabular}{|c|c|c|c|c|}
\hline CHEMBL1314692 & 688239 & 4.5362 & 5.5268 & TRN \\
\hline CHEMBL1347998 & 688239 & 5.4862 & 5.5306 & TRN \\
\hline CHEMBL1377261 & 688239 & 6.2362 & 5.5159 & TRN \\
\hline CHEMBL3199198 & 688239 & 5.4362 & 5.5448 & TRN \\
\hline CHEMBL1458893 & 688239 & 4.5362 & 5.4189 & TRN \\
\hline CHEMBL1603748 & 688239 & 4.8862 & 5.5222 & TRN \\
\hline CHEMBL1386626 & 688239 & 4.5862 & 5.4473 & TST \\
\hline CHEMBL1323618 & 688239 & 5.1362 & 5.282 & TRN \\
\hline CHEMBL1419752 & 688239 & 5.4362 & 5.5218 & TRN \\
\hline CHEMBL171699 & 688239 & 5.8362 & 5.6383 & TST \\
\hline CHEMBL1368325 & 688239 & 6.9363 & 5.5028 & TRN \\
\hline CHEMBL1382721 & 688239 & 4.4862 & 5.5499 & TRN \\
\hline CHEMBL1308980 & 688239 & 4.5362 & 5.5083 & TRN \\
\hline CHEMBL1353028 & 688239 & 6.1362 & 5.5951 & TRN \\
\hline CHEMBL1302595 & 688239 & 5.6362 & 5.5585 & TRN \\
\hline CHEMBL1413073 & 688239 & 4.5362 & 5.4846 & TRN \\
\hline CHEMBL1384923 & 688239 & 6.1362 & 5.4171 & TRN \\
\hline CHEMBL1566871 & 688239 & 5.2862 & 5.4447 & TST \\
\hline CHEMBL1576986 & 688239 & 4.8862 & 5.4571 & TRN \\
\hline CHEMBL1444738 & 688239 & 4.9362 & 5.2735 & TRN \\
\hline CHEMBL1355697 & 688239 & 6.8861 & 5.4452 & TST \\
\hline CHEMBL1468371 & 688239 & 5.5362 & 5.3837 & TRN \\
\hline CHEMBL1355204 & 688239 & 4.4862 & 5.484 & TRN \\
\hline CHEMBL1502347 & 688239 & 4.5862 & 5.4841 & TST \\
\hline CHEMBL1427309 & 688239 & 4.5362 & 5.4528 & TST \\
\hline CHEMBL1375791 & 688239 & 5.4362 & 5.4528 & TRN \\
\hline CHEMBL1340285 & 688239 & 4.4862 & 5.3384 & TRN \\
\hline CHEMBL 224441 & 688239 & 8.3872 & 5.6115 & TST \\
\hline CHEMBL1408705 & 688239 & 5.3362 & 5.3615 & TRN \\
\hline CHEMBL1375043 & 688239 & 4.5362 & 5.4048 & TST \\
\hline CHEMBL1521801 & 688239 & 7.2366 & 5.4272 & TRN \\
\hline CHEMBL1473677 & 688239 & 5.1362 & 5.46899 & э999999999 \\
\hline CHEMBL1387263 & 688239 & 5.1362 & 5.5174 & TRN \\
\hline CHEMBL1440542 & 688239 & 4.5362 & 5.5709 & TRN \\
\hline CHEMBL1384766 & 688239 & 6.2362 & 5.5607 & TRN \\
\hline CHEMBL1386449 & 688239 & 4.5362 & 5.3617 & TRN \\
\hline CHEMBL1438987 & 688239 & 5.9362 & 5.6148 & TRN \\
\hline CHEMBL 3392044 & 688239 & 8.3872 & 5.4657 & TRN \\
\hline CHEMBL1486643 & 688239 & 4.5362 & 5.3993 & TRN \\
\hline CHEMBL1374624 & 688239 & 7.5361 & 5.4801 & TRN \\
\hline CHEMBL1579562 & 688239 & 5.8362 & 5.3681 & TRN \\
\hline CHEMBL1377355 & 688239 & 6.9363 & 5.6533 & TRN \\
\hline CHEMBL1484674 & 688239 & 6.3362 & 5.5453 & TRN \\
\hline CHEMBL1539289 & 688239 & 4.5362 & 5.6638 & TRN \\
\hline CHEMBL1343837 & 688239 & 5.4862 & 5.5987 & TRN \\
\hline CHEMBL1440451 & 688239 & 5.1362 & 5.4662 & TST \\
\hline CHEMBL1327996 & 688239 & 6.8861 & 5.6463 & TST \\
\hline CHEMBL1385236 & 688239 & 4.5362 & 5.4111 & TRN \\
\hline
\end{tabular}


Supplemental Table S2.txt

\begin{tabular}{|c|c|c|c|c|c|}
\hline CHEMBL1610247 & 688239 & 5.3862 & \multicolumn{2}{|c|}{5.507000000000001} & \multirow[t]{2}{*}{ TRN } \\
\hline CHEMBL1419014 & 688239 & 6.3863 & 5.4965 & TST & \\
\hline CHEMBL1304443 & 688239 & 4.5362 & 5.479 & TRN & \\
\hline CHEMBL1515909 & 688239 & 5.8862 & 5.3921 & TRN & \\
\hline CHEMBL1467372 & 688239 & 6.0862 & 5.5415 & TST & \\
\hline CHEMBL1551971 & 688239 & 6.9863 & 5.4597 & TRN & \\
\hline CHEMBL1469198 & 688239 & 4.5362 & 5.6339 & TRN & \\
\hline CHEMBL1504443 & 688239 & 6.3362 & 5.2906 & TRN & \\
\hline CHEMBL1521166 & 688239 & 5.1862 & 5.5411 & TST & \\
\hline CHEMBL3193247 & 688239 & 5.1862 & 5.5085 & TST & \\
\hline CHEMBL1330406 & 688239 & 5.1862 & 5.4612 & TRN & \\
\hline CHEMBL1517881 & 688239 & 4.7862 & 5.5278 & TRN & \\
\hline CHEMBL1308501 & 688239 & 5.2862 & 5.5083 & TRN & \\
\hline CHEMBL3210184 & 688239 & 5.6862 & 5.4534 & TRN & \\
\hline CHEMBL1351662 & 688239 & 4.7362 & 5.4359 & TST & \\
\hline CHEMBL1370709 & 688239 & 6.5862 & 5.3512 & TST & \\
\hline CHEMBL1451007 & 688239 & 6.2862 & 5.4573 & TRN & \\
\hline CHEMBL1603006 & 688239 & 5.0362 & 5.5509 & TRN & \\
\hline CHEMBL1344623 & 688239 & 6.2362 & 5.4926 & TRN & \\
\hline CHEMBL1494197 & 688239 & 4.9362 & 5.3673 & TST & \\
\hline CHEMBL1495277 & 688239 & 5.9362 & 5.4071 & TRN & \\
\hline CHEMBL1549199 & 688239 & 5.2862 & 5.4349 & TRN & \\
\hline CHEMBL1412640 & 688239 & 5.7862 & 5.6736 & TRN & \\
\hline CHEMBL1474852 & 688239 & 4.4862 & 5.566 & TRN & \\
\hline CHEMBL1385025 & 688239 & 4.9862 & 5.3897 & TRN & \\
\hline CHEMBL1088360 & 688239 & 4.5362 & 5.5373 & TST & \\
\hline CHEMBL1557232 & 688239 & 6.8861 & 5.4666 & TRN & \\
\hline CHEMBL1399941 & 688239 & 6.6861 & 5.4767 & TST & \\
\hline CHEMBL1969712 & 688239 & 4.5362 & 5.4149 & TRN & \\
\hline CHEMBL1329135 & 688239 & 6.3362 & 5.4081 & TRN & \\
\hline CHEMBL1349731 & 688239 & 8.3372 & 5.5043 & TST & \\
\hline CHEMBL1419998 & 688239 & 5.3862 & 5.4816 & TST & \\
\hline CHEMBL1359753 & 688239 & 4.5862 & 5.5462 & TRN & \\
\hline CHEMBL1304755 & 688239 & 4.5862 & 5.425 & TRN & \\
\hline CHEMBL1569192 & 688239 & 5.0862 & 5.4572 & TST & \\
\hline CHEMBL1598243 & 688239 & 5.4362 & 5.57299 & 99999999995 & TST \\
\hline CHEMBL1388993 & 688239 & 4.5362 & 5.568 & TST & \\
\hline CHEMBL1311714 & 688239 & 4.5362 & 5.6228 & TRN & \\
\hline CHEMBL1574153 & 688239 & 6.4362 & 5.531006 & 0000000001 & TRN \\
\hline CHEMBL1547626 & 688239 & 4.9862 & 5.5304 & TST & \\
\hline CHEMBL1396174 & 688239 & 4.5362 & 5.5434 & TRN & \\
\hline CHEMBL1609703 & 688239 & 6.8362 & 5.4398 & TST & \\
\hline CHEMBL1407847 & 688239 & 6.9363 & 5.4994 & TRN & \\
\hline CHEMBL1554482 & 688239 & 6.1862 & 5.4679 & TST & \\
\hline CHEMBL1470744 & 688239 & 4.6362 & 5.4891 & TRN & \\
\hline CHEMBL1514916 & 688239 & 4.6362 & 5.3241 & TST & \\
\hline CHEMBL1320599 & 688239 & 4.4862 & 5.622006 & 2000000001 & TRN \\
\hline CHEMBL1445641 & 688239 & 5.4862 & 5.4977 & TST & \\
\hline & & & & 2252 & \\
\hline
\end{tabular}


Supplemental Table S2.txt

\begin{tabular}{|c|c|c|c|c|c|c|}
\hline CHEMBL1339442 & 688239 & 5.3862 & 5.5017 & TRN & & \\
\hline CHEMBL1533794 & 688239 & 6.0362 & 5.5227 & TST & & \\
\hline CHEMBL171626 & 688239 & 4.8362 & 5.5161 & TRN & & \\
\hline CHEMBL1588761 & 688239 & 6.9363 & 5.4956 & TRN & & \\
\hline CHEMBL1534384 & 688239 & 6.2862 & 5.4118 & TRN & & \\
\hline CHEMBL1446580 & 688239 & 5.4862 & 5.5 & TST & & \\
\hline CHEMBL1506509 & 688239 & \multicolumn{3}{|c|}{8.283999999999999} & 5.6797 & TRN \\
\hline CHEMBL1573961 & 688239 & 4.9362 & 5.5285 & TRN & & \\
\hline CHEMBL3210134 & 688239 & 4.5362 & 5.5244 & TST & & \\
\hline CHEMBL1340849 & 688239 & 4.7362 & 5.2972 & TST & & \\
\hline CHEMBL1360168 & 688239 & \multicolumn{3}{|c|}{8.283999999999999} & 5.3694 & TST \\
\hline CHEMBL1444430 & 688239 & 5.1862 & 5.3996 & TRN & & \\
\hline CHEMBL1419694 & 688239 & 6.4862 & 5.4835 & TRN & & \\
\hline CHEMBL1522914 & 688239 & 5.4362 & 5.6914 & TRN & & \\
\hline CHEMBL1993929 & 688239 & 6.4362 & 5.3775 & TST & & \\
\hline CHEMBL1475373 & 688239 & 4.5862 & 5.4884 & TRN & & \\
\hline CHEMBL1441963 & 688239 & 5.6362 & 5.6031 & TRN & & \\
\hline CHEMBL1348737 & 688239 & 5.2862 & 5.5692 & TRN & & \\
\hline CHEMBL1395577 & 688239 & 5.3862 & 5.4305 & TRN & & \\
\hline CHEMBL1531695 & 688239 & 6.3362 & 5.3017 & TRN & & \\
\hline CHEMBL1525060 & 688239 & 6.2362 & 5.5538 & TRN & & \\
\hline CHEMBL 3194377 & 688239 & 4.6362 & 5.4955 & TST & & \\
\hline CHEMBL1337439 & 688239 & 6.8861 & 5.4449 & TRN & & \\
\hline CHEMBL1391579 & 688239 & 4.8862 & 5.4467 & TRN & & \\
\hline CHEMBL1463362 & 688239 & 4.6362 & 5.4903 & TST & & \\
\hline CHEMBL1381677 & 688239 & 5.2362 & 5.3807 & TRN & & \\
\hline CHEMBL1452196 & 688239 & 6.5363 & 5.5265 & TRN & & \\
\hline CHEMBL1347260 & 688239 & 4.5362 & 5.6231 & TRN & & \\
\hline CHEMBL1575287 & 688239 & 4.8862 & 5.4659 & TRN & & \\
\hline CHEMBL1604844 & 688239 & 4.7362 & 5.5175 & TRN & & \\
\hline CHEMBL1458406 & 688239 & 4.5362 & 5.7031 & TRN & & \\
\hline CHEMBL1483630 & 688239 & 7.6861 & 5.4982 & TRN & & \\
\hline CHEMBL1575242 & 688239 & 5.0362 & 5.3561 & TRN & & \\
\hline CHEMBL1582644 & 688239 & 4.4862 & 5.4591 & TRN & & \\
\hline CHEMBL1456756 & 688239 & 4.6862 & 5.4521 & TRN & & \\
\hline CHEMBL1440198 & 688239 & 4.6362 & 5.5439 & TRN & & \\
\hline CHEMBL3214479 & 688239 & 4.5362 & 5.6194 & TRN & & \\
\hline CHEMBL1406306 & 688239 & 6.5862 & 5.3461 & TST & & \\
\hline CHEMBL1539631 & 688239 & 4.5362 & 5.5908 & TRN & & \\
\hline CHEMBL1380371 & 688239 & 5.4362 & 5.6034 & TRN & & \\
\hline CHEMBL1433100 & 688239 & 6.8362 & 5.5098 & TST & & \\
\hline CHEMBL1417857 & 688239 & 5.1362 & 5.4894 & TRN & & \\
\hline CHEMBL1433702 & 688239 & 5.5362 & 5.4967 & TRN & & \\
\hline CHEMBL 3209254 & 688239 & 4.9362 & 5.4019 & TST & & \\
\hline CHEMBL1460800 & 688239 & 4.5362 & 5.4517 & TST & & \\
\hline CHEMBL1547970 & 688239 & 5.1862 & 5.3646 & TST & & \\
\hline CHEMBL316034 & 688239 & 4.5362 & 5.6052 & TST & & \\
\hline CHEMBL1489797 & 688239 & 7.1864 & 5.5763 & TRN & & \\
\hline
\end{tabular}

Page 2253 
Supplemental Table s2.txt

\begin{tabular}{|c|c|c|c|c|c|}
\hline CHEMBL1344271 & 688239 & 6.1862 & 5.4715 & TST & \\
\hline CHEMBL 3144896 & 688239 & 4.5362 & 5.41200 & 0000000001 & TRN \\
\hline CHEMBL1532741 & 688239 & 5.1862 & 5.4944 & TRN & \\
\hline CHEMBL1578224 & 688239 & 6.7862 & 5.4861 & TRN & \\
\hline CHEMBL1341674 & 688239 & 4.6362 & 5.6102 & TST & \\
\hline CHEMBL1425669 & 688239 & 6.2862 & 5.5874 & TRN & \\
\hline CHEMBL1602717 & 688239 & 4.5362 & 5.3816 & TRN & \\
\hline CHEMBL1374462 & 688239 & 5.3362 & 5.3202 & TRN & \\
\hline CHEMBL 3190786 & 688239 & 4.5362 & 5.4562 & TRN & \\
\hline CHEMBL1575919 & 688239 & 4.5362 & 5.5662 & TST & \\
\hline CHEMBL1594252 & 688239 & 4.4862 & 5.4967 & TST & \\
\hline CHEMBL1579745 & 688239 & 5.3362 & 5.278 & TST & \\
\hline CHEMBL1322285 & 688239 & 5.5862 & 5.4257 & TRN & \\
\hline CHEMBL1611354 & 688239 & 5.1862 & 5.5451 & TST & \\
\hline CHEMBL1390317 & 688239 & 4.6862 & 5.4688 & TST & \\
\hline CHEMBL1340216 & 688239 & 4.5362 & 5.5432 & TRN & \\
\hline CHEMBL1490750 & 688239 & 4.7362 & 5.2793 & TRN & \\
\hline CHEMBL1966295 & 688239 & 4.7862 & 5.5422 & TRN & \\
\hline CHEMBL1526491 & 688239 & 5.8362 & 5.4093 & TRN & \\
\hline CHEMBL1587997 & 688239 & 5.8362 & 5.5227 & TRN & \\
\hline CHEMBL1384925 & 688239 & 4.5362 & 5.4727 & TRN & \\
\hline CHEMBL1569451 & 688239 & 4.6862 & 5.5911 & TRN & \\
\hline CHEMBL1381811 & 688239 & 4.5362 & 5.3494 & TRN & \\
\hline CHEMBL1443416 & 688239 & 6.3362 & 5.4579 & TRN & \\
\hline CHEMBL1455075 & 688239 & 5.5862 & 5.5456 & TRN & \\
\hline CHEMBL1463885 & 688239 & 4.6362 & 5.4593 & TRN & \\
\hline CHEMBL1256686 & 688239 & 6.5862 & 5.3244 & TST & \\
\hline CHEMBL1571349 & 688239 & 5.9362 & 5.5507 & TRN & \\
\hline CHEMBL1410564 & 688239 & 5.1362 & 5.4206 & TRN & \\
\hline CHEMBL1527174 & 688239 & 4.4862 & 5.5613 & TST & \\
\hline CHEMBL1382207 & 688239 & 4.8362 & \multicolumn{2}{|c|}{5.632000000000001} & \\
\hline CHEMBL1350824 & 688239 & 4.6862 & 5.5359 & TRN & \\
\hline CHEMBL1318416 & 688239 & 5.0362 & 5.5822 & TST & \\
\hline CHEMBL1482832 & 688239 & 5.5862 & 5.4449 & TST & \\
\hline CHEMBL1332177 & 688239 & 6.2362 & 5.5524 & TRN & \\
\hline CHEMBL1562898 & 688239 & 4.7362 & 5.6102 & TST & \\
\hline CHEMBL1560223 & 688239 & 4.6862 & 5.5254 & TRN & \\
\hline CHEMBL 3208124 & 688239 & 5.2362 & 5.5426 & TST & \\
\hline CHEMBL1466527 & 688239 & 5.5362 & 5.4714 & TRN & \\
\hline CHEMBL1484317 & 688239 & 5.1862 & 5.5969 & TRN & \\
\hline CHEMBL1450698 & 688239 & 6.7862 & 5.3881 & TST & \\
\hline CHEMBL1351016 & 688239 & 4.7862 & 5.2785 & TRN & \\
\hline CHEMBL1576703 & 688239 & 4.5362 & 5.4585 & TRN & \\
\hline CHEMBL1555771 & 688239 & 6.1862 & 5.5723 & TRN & \\
\hline CHEMBL1345513 & 688239 & 5.4362 & 5.3921 & TST & \\
\hline CHEMBL1432557 & 688239 & 4.5362 & 5.579 & TRN & \\
\hline CHEMBL1352394 & 688239 & 5.2362 & 5.5195 & TRN & \\
\hline CHEMBL1529541 & 688239 & 8.28399 & 9999999 & 5.5625 & \\
\hline
\end{tabular}

Page 2254 


\begin{tabular}{|c|c|c|c|c|c|c|}
\hline & & \multicolumn{5}{|c|}{ Supplemental Table S2.txt } \\
\hline CHEMBL1451710 & 688239 & 4.4862 & 5.4962 & TRN & & \\
\hline CHEMBL1503325 & 688239 & 4.8862 & 5.4464 & TST & & \\
\hline CHEMBL1487936 & 688239 & 4.5862 & 5.3135 & TRN & & \\
\hline CHEMBL1445420 & 688239 & 5.1862 & 5.3765 & TST & & \\
\hline CHEMBL1360998 & 688239 & 8.28399 & 99999999 & 99 & 5.3051 & TST \\
\hline CHEMBL1306689 & 688239 & 4.5362 & 5.5058 & TRN & & \\
\hline CHEMBL1301967 & 688239 & 4.6362 & 5.6013 & TRN & & \\
\hline CHEMBL1427106 & 688239 & 5.4362 & 5.3828 & TST & & \\
\hline CHEMBL1462355 & 688239 & 5.6362 & 5.7213 & TRN & & \\
\hline CHEMBL1442781 & 688239 & 4.5362 & 5.4235 & TRN & & \\
\hline CHEMBL1320354 & 688239 & 4.5362 & 5.3143 & TRN & & \\
\hline CHEMBL1500975 & 688239 & 4.9862 & 5.5256 & TST & & \\
\hline CHEMBL1433180 & 688239 & 6.1362 & 5.5398 & TRN & & \\
\hline CHEMBL1439668 & 688239 & 4.8862 & 5.4979 & TST & & \\
\hline CHEMBL1448207 & 688239 & 6.1362 & 5.5278 & TRN & & \\
\hline CHEMBL1355549 & 688239 & 5.1862 & 5.523 & TRN & & \\
\hline CHEMBL1528369 & 688239 & 6.4862 & 5.2623 & TRN & & \\
\hline CHEMBL1372426 & 688239 & 4.9862 & 5.6553 & TRN & & \\
\hline CHEMBL1523316 & 688239 & 5.1862 & 5.4242 & TRN & & \\
\hline CHEMBL1586065 & 688239 & 5.1362 & 5.4996 & TST & & \\
\hline CHEMBL1461732 & 688239 & 6.7862 & 5.4035 & TRN & & \\
\hline CHEMBL1559456 & 688239 & 6.2862 & 5.5183 & TRN & & \\
\hline CHEMBL1398894 & 688239 & 7.2366 & 5.3125 & TRN & & \\
\hline CHEMBL1396280 & 688239 & 5.1862 & 5.5914 & TRN & & \\
\hline CHEMBL602213 & 688239 & 4.7362 & 5.4794 & TRN & & \\
\hline CHEMBL1451343 & 688239 & 4.4862 & 5.5135 & TRN & & \\
\hline CHEMBL1487083 & 688239 & 6.3362 & 5.6233 & TRN & & \\
\hline CHEMBL1307113 & 688239 & 4.5362 & 5.506 & TRN & & \\
\hline CHEMBL1403654 & 688239 & 4.7862 & 5.3993 & TRN & & \\
\hline CHEMBL1337517 & 688239 & 5.2862 & 5.3343 & TRN & & \\
\hline CHEMBL1409448 & 688239 & 5.0862 & 5.4233 & TRN & & \\
\hline CHEMBL1544221 & 688239 & 6.6362 & 5.4599 & TRN & & \\
\hline CHEMBL1552074 & 688239 & 5.8862 & 5.5501 & TRN & & \\
\hline CHEMBL1415878 & 688239 & 4.6362 & 5.5782 & TRN & & \\
\hline CHEMBL1382233 & 688239 & 5.7362 & 5.5719 & TST & & \\
\hline CHEMBL1557380 & 688239 & 4.7362 & 5.5941 & TRN & & \\
\hline CHEMBL1510388 & 688239 & 6.1362 & 5.5686 & TRN & & \\
\hline CHEMBL1360472 & 688239 & 5.1862 & 5.4859 & TRN & & \\
\hline CHEMBL1378160 & 688239 & 5.1862 & 5.4286 & TRN & & \\
\hline CHEMBL1419164 & 688239 & 4.5362 & 5.3052 & TRN & & \\
\hline CHEMBL1539136 & 688239 & 5.8862 & 5.4884 & TRN & & \\
\hline CHEMBL1452953 & 688239 & 5.4362 & 5.4744 & TRN & & \\
\hline CHEMBL1568340 & 688239 & 5.5362 & 5.5007 & TRN & & \\
\hline CHEMBL1437444 & 688239 & 4.6362 & 5.477 & TRN & & \\
\hline CHEMBL1448433 & 688239 & 4.5362 & 5.51 & TST & & \\
\hline CHEMBL1460745 & 688239 & 4.5362 & 5.5512 & TRN & & \\
\hline CHEMBL1334304 & 688239 & 5.4362 & 5.4746 & TRN & & \\
\hline CHEMBL1606122 & 688239 & 4.5862 & 5.438 & TRN & & \\
\hline
\end{tabular}


Supplemental Table S2.txt

\begin{tabular}{|c|c|c|c|c|}
\hline & & & & \\
\hline AEMBL1: & 688239 & 862 & & \\
\hline IEMBL1348637 & 3239 & 362 & 897 & \\
\hline AEMBL1489477 & 239 & 862 & 931 & \\
\hline & 239 & 362 & & \\
\hline EMBL13 & 239 & 862 & & \\
\hline AEMBL1602867 & 88239 & 862 & 262 & \\
\hline AEMBL1446976 & 88239 & 863 & 85 & \\
\hline AEMBL1092508 & 239 & 862 & & \\
\hline IEMBL155 & 239 & 362 & & \\
\hline IEMBL1529694 & & & & \\
\hline AEMBL1339803 & 688239 & 362 & 5696 & \\
\hline AEMBL1579358 & 239 & 862 & & \\
\hline IEMBL 160 & & 862 & & \\
\hline EMBL136 & & 362 & & \\
\hline HEMBL 146 & & & & \\
\hline AEMBL1585174 & 239 & 862 & & \\
\hline AEMBL1300491 & & 362 & & \\
\hline EMIBLL & & 62 & & \\
\hline IEMBL13 & & & & \\
\hline AFMBI 13 & & 62 & & \\
\hline AEMBL151 & & 862 & & \\
\hline AEMBL140 & & 62 & & \\
\hline EMBL13 & & 62 & & \\
\hline IEMBL14 & & 52 & & \\
\hline $15 M P \mid 11$ & & 62 & & \\
\hline HEMBL32: & & 862 & & \\
\hline AEMBL1459058 & & & & \\
\hline AEMBL1530078 & & & & \\
\hline 765 & & 61 & & \\
\hline 387 & & 62 & & \\
\hline HEMBL3209026 & & & & \\
\hline AEMBL1529150 & & & & \\
\hline HEMBL13ع & & 62 & & \\
\hline AFMPI 15 & & 62 & 21 & \\
\hline & & & & \\
\hline AEMBL1553388 & & & & \\
\hline AEMBL1527651 & & & & \\
\hline EMBL14 & & 362 & & \\
\hline 640 & & & & \\
\hline & & & & \\
\hline AEMBL1305803 & & 362 & & \\
\hline IEMBL1393374 & & 62 & & \\
\hline - & & & & \\
\hline & & & & \\
\hline CHEMBL 148 & & 862 & 68 & \\
\hline AEMBL1532229 & 688239 & 6.6861 & 5.7136 & \\
\hline HFMRI 1397560 & 688239 & 6.3362 & 5.4318 & \\
\hline
\end{tabular}

Page 2256 


\begin{tabular}{|c|c|c|c|c|c|}
\hline & & \\
\hline CHEMBL3213949 & 688239 & 6.3362 & 5.5027 & TRN & \\
\hline CHEMBL1997017 & 688239 & 4.6862 & \multicolumn{2}{|c|}{5.5520000000000005} & TST \\
\hline CHEMBL1309726 & 688239 & 5.0862 & 5.5892 & TRN & \\
\hline CHEMBL1442682 & 688239 & 5.8862 & 5.5897 & TRN & \\
\hline CHEMBL1300024 & 688239 & \multicolumn{3}{|c|}{8.283999999999999} & \multirow[t]{7}{*}{ TRN } \\
\hline CHEMBL1588024 & 688239 & 5.3362 & 5.4285 & TRN & \\
\hline CHEMBL1497693 & 688239 & 4.5362 & 5.4098 & TRN & \\
\hline CHEMBL 3214572 & 688239 & 5.3862 & 5.4171 & TRN & \\
\hline CHEMBL1402824 & 688239 & 4.6862 & 5.6096 & TRN & \\
\hline CHEMBL1437040 & 688239 & 4.5362 & 5.5429 & TRN & \\
\hline CHEMBL1586619 & 688239 & 7.0862 & 5.4952 & TRN & \\
\hline CHEMBL1318306 & 688239 & 4.5362 & \multicolumn{2}{|c|}{5.6129999999999995} & \multirow[t]{15}{*}{ TRN } \\
\hline CHEMBL1611988 & 688239 & 6.8861 & 5.5962 & TST & \\
\hline CHEMBL1429595 & 688239 & 4.5362 & 5.5623 & TRN & \\
\hline CHEMBL1402982 & 688239 & 7.0362 & 5.5303 & TST & \\
\hline CHEMBL1591778 & 688239 & 5.4862 & 5.5607 & TST & \\
\hline CHEMBL1302292 & 688239 & 6.3863 & 5.4713 & TST & \\
\hline CHEMBL1382773 & 688239 & 4.5862 & 5.3705 & TST & \\
\hline CHEMBL1465939 & 688239 & 4.6862 & 5.4963 & TRN & \\
\hline CHEMBL1307169 & 688239 & 6.6861 & 5.4271 & TRN & \\
\hline CHEMBL1489497 & 688239 & 6.2362 & 5.4963 & TRN & \\
\hline CHEMBL1411217 & 688239 & 7.0362 & 5.4659 & TRN & \\
\hline CHEMBL 1497020 & 688239 & 4.5362 & 5.4878 & TRN & \\
\hline CHEMBL1395013 & 688239 & 4.5362 & 5.4887 & TRN & \\
\hline CHEMBL1397101 & 688239 & 4.4862 & 5.5712 & TRN & \\
\hline CHEMBL1366287 & 688239 & 5.7862 & 5.5124 & TRN & \\
\hline CHEMBL1332583 & 688239 & 5.5362 & \multicolumn{2}{|c|}{5.4110000000000005} & TRN \\
\hline CHEMBL1300767 & 688239 & 5.4362 & 5.5312 & TRN & \\
\hline CHEMBL1583094 & 688239 & 5.6362 & 5.4014 & TRN & \\
\hline CHEMBL1522807 & 688239 & 5.4862 & 5.45 & TRN & \\
\hline CHEMBL1329869 & 688239 & 4.5362 & 5.3301 & TRN & \\
\hline CHEMBL1351360 & 688239 & 6.2362 & 5.4536 & TRN & \\
\hline CHEMBL1311684 & 688239 & 6.8362 & 5.349 & TRN & \\
\hline CHEMBL1478131 & 688239 & 5.1862 & 5.4539 & TRN & \\
\hline CHEMBL1425412 & 688239 & 5.9362 & \multicolumn{2}{|c|}{5.4479999999999995} & TRN \\
\hline CHEMBL1469119 & 688239 & 5.1862 & 5.4878 & TRN & \\
\hline CHEMBL1425648 & 688239 & 5.9362 & 5.5144 & TRN & \\
\hline CHEMBL1540386 & 688239 & 6.8861 & 5.4417 & TST & \\
\hline CHEMBL1566564 & 688239 & 5.6362 & 5.4338 & TRN & \\
\hline CHEMBL1380303 & 688239 & 7.1361 & 5.4926 & TRN & \\
\hline CHEMBL1515727 & 688239 & 5.1362 & 5.4256 & TRN & \\
\hline CHEMBL1433521 & 688239 & 5.5362 & 5.4693 & TRN & \\
\hline CHEMBL1531624 & 688239 & 4.8362 & 5.4707 & TRN & \\
\hline CHEMBL1496045 & 688239 & 6.2362 & 5.3699 & TRN & \\
\hline CHEMBL1403688 & 688239 & 4.5362 & 5.5574 & TRN & \\
\hline CHEMBL3211726 & 688239 & 4.6362 & 5.5027 & TRN & \\
\hline CHEMBL1513950 & 688239 & 4.6862 & 5.4527 & TRN & \\
\hline \multirow[t]{2}{*}{ CHEMBL1525599 } & 688239 & 6.0 & 5.41799 & 9999999999 & TST \\
\hline & & \multicolumn{3}{|c|}{ Page 2257} & \\
\hline
\end{tabular}


Supplemental Table S2.txt

\begin{tabular}{|c|c|c|c|c|}
\hline 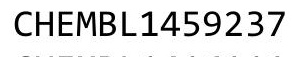 & & & & \\
\hline AEMBL1416111 & 8239 & 3362 & & \\
\hline AEMBL3213669 & 38239 & 862 & 045 & \\
\hline 1595879 & 88239 & 363 & & \\
\hline AEMBL1367228 & 239 & 362 & & \\
\hline AEMBL3212749 & 88239 & 362 & 5118 & \\
\hline AEMBL1299265 & 88239 & 862 & 1756 & \\
\hline AEMBL1540710 & 88239 & 862 & 91 & \\
\hline AEMBL1521114 & 239 & 362 & & \\
\hline IEMBL1537232 & 239 & & & \\
\hline AEMBL1356182 & 239 & 862 & 5 & \\
\hline AEMBL1484540 & 239 & 362 & 693 & \\
\hline AEMBL1346247 & 239 & 862 & 26 & \\
\hline IEMBL1404183 & 39 & 62 & 44 & \\
\hline AEMBL1309879 & & & & \\
\hline AEMBL1497078 & & 862 & & \\
\hline L1491696 & & 362 & & \\
\hline IEMBL3208132 & 39 & 862 & 43 & \\
\hline 8969 & & & & \\
\hline 97732 & & & & \\
\hline L1333627 & & 362 & & \\
\hline 1336704 & & 62 & & \\
\hline IEMBL1335215 & & 62 & & \\
\hline 1299200 & & & & \\
\hline 3209701 & & 62 & & \\
\hline 54531 & & & & \\
\hline 659 & & & & \\
\hline L1351993 & & 62 & & \\
\hline 1454816 & & 62 & & \\
\hline 1377264 & & 62 & & \\
\hline & & & & \\
\hline L1366665 & & & & \\
\hline L1551942 & & 862 & & \\
\hline 1420343 & & 62 & & \\
\hline 96 & & & & \\
\hline IEMBL1506209 & & & & \\
\hline AEMBL1415388 & & 362 & & \\
\hline 1460464 & & 62 & & \\
\hline MBL1329172 & & & 17 & \\
\hline & & & & \\
\hline AEMBL1575614 & & & 486 & RI \\
\hline AEMBL1579506 & & 362 & & \\
\hline 51402119 & & & & \\
\hline CHEMBL1439274 & & & 314 & \\
\hline CHEMBL1531905 & & & & RN \\
\hline AEMBL1424571 & 688239 & 862 & 5437 & \\
\hline HEMBL1393406 & & 362 & & \\
\hline 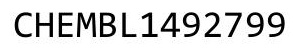 & 680230 & 5.2862 & & \\
\hline
\end{tabular}

Page 2258 


\begin{tabular}{|c|c|c|c|c|c|}
\hline \multirow{3}{*}{$\begin{array}{l}\text { CHEMBL1466596 } \\
\text { CHFMBI } 1588340\end{array}$} & & \multicolumn{4}{|c|}{ Supplemental Table s2.txt } \\
\hline & 688239 & 7.6861 & 5.57700 & 0000000001 & TRN \\
\hline & 688239 & 4.5362 & 5.4652 & TRN & \\
\hline CHEMBL1423297 & 688239 & 4.5362 & 5.3959 & TST & \\
\hline CHEMBL1550957 & 688239 & 4.5362 & 5.4192 & TST & \\
\hline CHEMBL1383747 & 688239 & 5.3362 & 5.625 & TRN & \\
\hline CHEMBL1486394 & 688239 & 5.3362 & 5.6645 & TRN & \\
\hline CHEMBL1531749 & 688239 & 6.8861 & 5.3439 & TRN & \\
\hline CHEMBL1432593 & 688239 & 6.2362 & 5.4344 & TRN & \\
\hline CHEMBL1479268 & 688239 & 4.5362 & 5.5286 & TRN & \\
\hline CHEMBL1549254 & 688239 & 4.6862 & 5.41299 & э999999999 & TST \\
\hline CHEMBL1606513 & 688239 & 7.2366 & 5.5098 & TRN & \\
\hline CHEMBL3208726 & 688239 & 6.5862 & 5.4143 & TRN & \\
\hline CHEMBL1336376 & 688239 & 6.0862 & 5.4052 & TST & \\
\hline CHEMBL1361300 & 688239 & 6.2362 & 5.5547 & TRN & \\
\hline CHEMBL3211450 & 688239 & 5.1862 & 5.3529 & TRN & \\
\hline CHEMBL1453373 & 688239 & 5.3362 & 5.3814 & TRN & \\
\hline CHEMBL1363704 & 688239 & 4.7862 & 5.5175 & TRN & \\
\hline CHEMBL1507074 & 688239 & 5.3362 & 5.5372 & TRN & \\
\hline CHEMBL1379429 & 688239 & 4.5362 & 5.5998 & TST & \\
\hline CHEMBL1453581 & 688239 & 6.8362 & 5.4199 & TRN & \\
\hline CHEMBL1313839 & 688239 & 4.6862 & 5.4377 & TRN & \\
\hline CHEMBL1317967 & 688239 & 6.7862 & 5.4917 & TRN & \\
\hline CHEMBL1580804 & 688239 & 8.3872 & 5.4733 & TRN & \\
\hline CHEMBL1540336 & 688239 & 5.4862 & 5.513 & TRN & \\
\hline CHEMBL1401312 & 688239 & 7.2366 & 5.4896 & TRN & \\
\hline CHEMBL3209462 & 688239 & 4.6862 & 5.4543 & TST & \\
\hline CHEMBL1305453 & 688239 & 4.7362 & 5.5582 & TRN & \\
\hline CHEMBL1303471 & 688239 & 5.1362 & 5.5341 & TRN & \\
\hline CHEMBL1466865 & 688239 & 4.5362 & 5.5114 & TST & \\
\hline CHEMBL1329555 & 688239 & 5.5862 & 5.5303 & TST & \\
\hline CHEMBL1995330 & 688239 & 5.6362 & 5.4122 & TRN & \\
\hline CHEMBL1591260 & 688239 & 5.1362 & 5.5173 & TST & \\
\hline CHEMBL1438498 & 688239 & 5.8362 & 5.4181 & TRN & \\
\hline CHEMBL1086350 & 688239 & 4.5862 & 5.5538 & TRN & \\
\hline CHEMBL1591637 & 688239 & 8.3372 & 5.5816 & TRN & \\
\hline CHEMBL1555759 & 688239 & 5.8862 & 5.4913 & TRN & \\
\hline CHEMBL1317322 & 688239 & 5.1862 & 5.5725 & TRN & \\
\hline CHEMBL1344084 & 688239 & 4.7362 & 5.4515 & TRN & \\
\hline CHEMBL1307998 & 688239 & 4.5362 & 5.4422 & TST & \\
\hline CHEMBL1440306 & 688239 & 6.2862 & 5.4681 & TRN & \\
\hline CHEMBL1397005 & 688239 & 6.1362 & 5.7461 & TRN & \\
\hline CHEMBL1447837 & 688239 & 5.3862 & 5.4082 & TRN & \\
\hline CHEMBL1358964 & 688239 & 5.6862 & 5.4673 & TST & \\
\hline CHEMBL1410763 & 688239 & 6.0862 & 5.4391 & TRN & \\
\hline CHEMBL1321168 & 688239 & 6.1362 & 5.5452 & TST & \\
\hline CHEMBL1325665 & 688239 & 5.4862 & 5.4466 & TRN & \\
\hline CHEMBL1511555 & 688239 & 6.1362 & 5.4672 & TRN & \\
\hline CHEMBL1566967 & 688239 & 5.1362 & 5.5464 & TRN & \\
\hline
\end{tabular}


Supplemental Table S2.txt

\begin{tabular}{|c|c|c|c|c|c|}
\hline CHEMBL1387209 & 688239 & 6.1862 & 5.4884 & TST & \\
\hline CHEMBL1307865 & 688239 & 7.2366 & 5.4714 & TRN & \\
\hline CHEMBL1299304 & 688239 & 8.2366 & 5.6021 & TST & \\
\hline CHEMBL1532852 & 688239 & 4.5362 & 5.5071 & TRN & \\
\hline CHEMBL1428560 & 688239 & 4.7362 & 5.4953 & TRN & \\
\hline CHEMBL1595114 & 688239 & 5.1862 & 5.4441 & TRN & \\
\hline CHEMBL1596905 & 688239 & 6.1362 & 5.5409 & TRN & \\
\hline CHEMBL1587058 & 688239 & 4.4862 & 5.5648 & TRN & \\
\hline CHEMBL1564727 & 688239 & 7.2865 & 5.5667 & TRN & \\
\hline CHEMBL1577176 & 688239 & 5.8862 & 5.5214 & TRN & \\
\hline CHEMBL567130 & 688239 & 4.5362 & 5.5651 & TRN & \\
\hline CHEMBL1518175 & 688239 & 5.0862 & 5.3716 & TRN & \\
\hline CHEMBL1563812 & 688239 & 6.1362 & 5.5713 & TRN & \\
\hline CHEMBL 3197140 & 688239 & 5.4862 & 5.5997 & TRN & \\
\hline CHEMBL1590748 & 688239 & 4.4862 & 5.3758 & TRN & \\
\hline CHEMBL1465287 & 688239 & 7.8356 & \multicolumn{2}{|c|}{5.4639999999999995} & TRN \\
\hline CHEMBL1446222 & 688239 & 6.3362 & 5.6724 & TRN & \\
\hline CHEMBL3208497 & 688239 & 5.3862 & 5.4001 & TST & \\
\hline CHEMBL1420945 & 688239 & 4.5862 & 5.3603 & TRN & \\
\hline CHEMBL1441986 & 688239 & 6.0 & 5.4428 & TRN & \\
\hline CHEMBL1491847 & 688239 & 5.0362 & 5.2214 & TRN & \\
\hline CHEMBL1544798 & 688239 & 4.8862 & 5.4325 & TRN & \\
\hline CHEMBL1524359 & 688239 & 5.3362 & 5.4892 & TRN & \\
\hline CHEMBL1542064 & 688239 & 5.1862 & 5.5606 & TST & \\
\hline CHEMBL1383282 & 688239 & 4.8362 & 5.5547 & TST & \\
\hline CHEMBL1553458 & 688239 & 5.3362 & 5.5842 & TRN & \\
\hline CHEMBL1520663 & 688239 & 5.3862 & 5.4283 & TRN & \\
\hline CHEMBL1551347 & 688239 & 5.1862 & 5.3697 & TRN & \\
\hline CHEMBL1491785 & 688239 & 6.2362 & 5.6412 & TRN & \\
\hline CHEMBL1466159 & 688239 & 8.2366 & 5.6569 & TRN & \\
\hline CHEMBL1484022 & 688239 & 5.7362 & 5.5899 & TRN & \\
\hline CHEMBL3208675 & 688239 & 4.6862 & 5.3308 & TST & \\
\hline CHEMBL1456946 & 688239 & 6.2362 & 5.4114 & TST & \\
\hline CHEMBL1542873 & 688239 & 5.0862 & 5.6071 & TRN & \\
\hline CHEMBL1413093 & 688239 & 5.1362 & 5.4982 & TST & \\
\hline CHEMBL1579225 & 688239 & 5.1862 & 5.4272 & TRN & \\
\hline CHEMBL1522903 & 688239 & 5.1862 & 5.4511 & TRN & \\
\hline CHEMBL1362006 & 688239 & 4.7362 & 5.2847 & TRN & \\
\hline CHEMBL3211761 & 688239 & 5.1862 & 5.4957 & TST & \\
\hline CHEMBL1324319 & 688239 & 4.5362 & \multicolumn{2}{|c|}{5.531000000000001} & TRN \\
\hline CHEMBL1386683 & 688239 & 6.0362 & 5.6054 & TST & \\
\hline CHEMBL1411796 & 688239 & 6.1362 & 5.5182 & TRN & \\
\hline CHEMBL3189980 & 688239 & 7.6364 & 5.4447 & TST & \\
\hline CHEMBL1429191 & 688239 & 5.4362 & 5.2631 & TRN & \\
\hline CHEMBL1417286 & 688239 & 4.5862 & 5.5796 & TRN & \\
\hline CHEMBL440951 & 688239 & 6.0362 & 5.545 & TRN & \\
\hline CHEMBL1548113 & 688239 & 5.1862 & 5.4621 & TRN & \\
\hline CHEMBL1346318 & 688239 & 6.7862 & 5.5018 & TST & \\
\hline
\end{tabular}


Supplemental Table S2.txt

\begin{tabular}{|c|c|c|c|c|}
\hline CHEMBL1375630 & 688239 & 6.1362 & 5.4613 & TST \\
\hline CHEMBL1459613 & 688239 & 5.1862 & 5.6371 & TRN \\
\hline CHEMBL1342918 & 688239 & 5.1862 & 5.3176 & TRN \\
\hline CHEMBL1411753 & 688239 & 4.7862 & 5.4426 & TRN \\
\hline CHEMBL1391659 & 688239 & 6.0362 & 5.4388 & TRN \\
\hline CHEMBL1365522 & 688239 & 5.3362 & 5.5103 & TRN \\
\hline CHEMBL1321276 & 688239 & 5.1862 & 5.5493 & TRN \\
\hline CHEMBL602135 & 688239 & 4.6862 & 5.3656 & TRN \\
\hline CHEMBL1417041 & 688239 & 4.6862 & 5.579 & TRN \\
\hline CHEMBL1541440 & 688239 & 5.7362 & 5.3925 & TST \\
\hline CHEMBL1326706 & 688239 & 4.7362 & 5.6678 & TST \\
\hline CHEMBL1486949 & 688239 & 5.2862 & 5.441 & TRN \\
\hline CHEMBL1349827 & 688239 & 4.8862 & 5.3977 & TST \\
\hline CHEMBL1445927 & 688239 & 4.6362 & 5.535 & TRN \\
\hline CHEMBL3145170 & 688239 & 4.7362 & 5.5544 & TST \\
\hline CHEMBL1372544 & 688239 & 4.6862 & 5.4946 & TRN \\
\hline CHEMBL1320596 & 688239 & 4.7862 & 5.4952 & TRN \\
\hline CHEMBL1611210 & 688239 & 5.5362 & 5.5157 & TRN \\
\hline CHEMBL1568955 & 688239 & 4.6862 & 5.4777 & TRN \\
\hline CHEMBL1414797 & 688239 & 4.5362 & 5.6214 & TRN \\
\hline CHEMBL1595679 & 688239 & 6.6362 & 5.4368 & TRN \\
\hline CHEMBL1518440 & 688239 & 4.6362 & 5.5676 & TRN \\
\hline CHEMBL1489437 & 688239 & 4.6862 & 5.5954 & TRN \\
\hline CHEMBL1325563 & 688239 & 4.5362 & 5.5314 & TST \\
\hline CHEMBL1516910 & 688239 & 5.8362 & 5.4178 & TRN \\
\hline CHEMBL1348291 & 688239 & 5.4862 & 5.5123 & TRN \\
\hline CHEMBL1450059 & 688239 & 6.6362 & 5.6645 & TRN \\
\hline CHEMBL1524462 & 688239 & 4.6362 & 5.4697 & TRN \\
\hline CHEMBL1304403 & 688239 & 5.1862 & 5.4771 & TST \\
\hline CHEMBL1499951 & 688239 & 5.4362 & 5.3974 & TRN \\
\hline CHEMBL1388386 & 688239 & 5.6362 & 5.4356 & TRN \\
\hline CHEMBL1537394 & 688239 & 6.8861 & 5.5521 & TRN \\
\hline CHEMBL1472494 & 688239 & 5.3362 & 5.4694 & TRN \\
\hline CHEMBL1500005 & 688239 & 6.1362 & 5.4967 & TRN \\
\hline CHEMBL1339703 & 688239 & 4.5362 & 5.4991 & TRN \\
\hline CHEMBL1499724 & 688239 & 5.3862 & 5.396 & TRN \\
\hline CHEMBL1313182 & 688239 & 4.7862 & 5.3869 & TRN \\
\hline CHEMBL1568077 & 688239 & 4.4362 & 5.435 & TST \\
\hline CHEMBL1324912 & 688239 & 4.7362 & 5.4934 & TRN \\
\hline CHEMBL1546542 & 688239 & 4.5362 & 5.6021 & TRN \\
\hline CHEMBL1538656 & 688239 & 6.2362 & 5.5146 & TRN \\
\hline CHEMBL1365644 & 688239 & 4.5362 & 5.4853 & TST \\
\hline CHEMBL1401091 & 688239 & 4.7362 & 5.5104 & TRN \\
\hline CHEMBL1300405 & 688239 & 4.5362 & 5.5607 & TRN \\
\hline CHEMBL1524104 & 688239 & 4.5362 & 5.3993 & TRN \\
\hline CHEMBL1484619 & 688239 & 7.0862 & 5.4881 & TRN \\
\hline CHEMBL1459557 & 688239 & 5.1862 & 5.4327 & TRN \\
\hline \multirow[t]{2}{*}{ CHEMBL1521916 } & 688239 & 4.9862 & 5.41100 & 000005 \\
\hline & & \multicolumn{3}{|c|}{ Page 2261} \\
\hline
\end{tabular}


Supplemental Table S2.txt

\begin{tabular}{|c|c|c|c|c|}
\hline CHEMBL1488322 & 688239 & 5.1362 & 5.3395 & TST \\
\hline CHEMBL1403809 & 688239 & 4.5362 & 5.4705 & TRN \\
\hline CHEMBL1396111 & 688239 & 4.6862 & 5.5253 & TRN \\
\hline CHEMBL1338006 & 688239 & 6.7862 & 5.6246 & TRN \\
\hline CHEMBL1509354 & 688239 & 6.1862 & 5.4696 & TST \\
\hline CHEMBL1580870 & 688239 & 5.8862 & 5.3405 & TRN \\
\hline CHEMBL1322323 & 688239 & 4.7362 & 5.4602 & TRN \\
\hline CHEMBL1565661 & 688239 & 5.5862 & 5.5492 & TST \\
\hline CHEMBL1339325 & 688239 & 6.8861 & 5.5553 & TST \\
\hline CHEMBL1525115 & 688239 & 6.9363 & 5.4312 & TST \\
\hline CHEMBL1304977 & 688239 & 7.0862 & 5.63 & TRN \\
\hline CHEMBL1609925 & 688239 & 5.7862 & 5.61 & TRN \\
\hline CHEMBL1337490 & 688239 & 5.4862 & 5.4645 & TST \\
\hline CHEMBL1327403 & 688239 & 5.2362 & 5.6715 & TST \\
\hline CHEMBL1381334 & 688239 & 6.7361 & 5.4082 & TRN \\
\hline CHEMBL1456421 & 688239 & 4.6362 & 5.5772 & TRN \\
\hline CHEMBL1474441 & 688239 & 5.6862 & 5.5755 & TRN \\
\hline CHEMBL1562518 & 688239 & 5.5362 & 5.4235 & TRN \\
\hline CHEMBL1341895 & 688239 & 5.4862 & 5.5069 & TRN \\
\hline CHEMBL1378792 & 688239 & 4.9862 & 5.7095 & TST \\
\hline CHEMBL1447496 & 688239 & 5.7362 & 5.4162 & TRN \\
\hline CHEMBL 3207331 & 688239 & 5.0362 & 5.3561 & TRN \\
\hline CHEMBL1332311 & 688239 & 5.5362 & 5.4702 & TST \\
\hline CHEMBL1438328 & 688239 & 6.0862 & 5.5721 & TRN \\
\hline CHEMBL1344000 & 688239 & 4.5362 & 5.282999 & 9999999995 \\
\hline CHEMBL1583798 & 688239 & 4.5362 & 5.3691 & TRN \\
\hline CHEMBL1440689 & 688239 & 6.1362 & 5.4454 & TRN \\
\hline CHEMBL1553306 & 688239 & 6.2862 & 5.3965 & TRN \\
\hline CHEMBL1349526 & 688239 & 6.0862 & 5.4022 & TST \\
\hline CHEMBL1432386 & 688239 & 5.1862 & 5.5063 & TRN \\
\hline CHEMBL1337055 & 688239 & 5.1862 & 5.5693 & TRN \\
\hline CHEMBL1449981 & 688239 & 6.2862 & 5.7073 & TRN \\
\hline CHEMBL1380008 & 688239 & 4.9862 & 5.4912 & TST \\
\hline CHEMBL 1378725 & 688239 & 4.6862 & 5.4288 & TRN \\
\hline CHEMBL1391164 & 688239 & 6.1862 & 5.604 & TRN \\
\hline CHEMBL1405200 & 688239 & 5.1362 & 5.3428 & TRN \\
\hline CHEMBL1335440 & 688239 & 7.0362 & 5.5132 & TRN \\
\hline CHEMBL1431506 & 688239 & 4.4862 & 5.5805 & TST \\
\hline CHEMBL1340026 & 688239 & 4.5362 & 5.5087 & TST \\
\hline CHEMBL1598875 & 688239 & 4.5362 & 5.5339 & TST \\
\hline CHEMBL1370431 & 688239 & 4.6362 & 5.6316 & TRN \\
\hline CHEMBL1442194 & 688239 & 5.8362 & 5.5073 & TST \\
\hline CHEMBL1509939 & 688239 & 5.1862 & 5.4179 & TST \\
\hline CHEMBL1332752 & 688239 & 5.8862 & 5.4955 & TRN \\
\hline CHEMBL1330110 & 688239 & 4.5362 & 5.5223 & TRN \\
\hline CHEMBL 2007056 & 688239 & 4.5362 & 5.4424 & TST \\
\hline CHEMBL1571281 & 688239 & 4.5362 & 5.4214 & TRN \\
\hline CHEMBL1421465 & 688239 & 5.7862 & 5.5859 & TST \\
\hline
\end{tabular}

Page 2262 
Supplemental Table S2.txt

\begin{tabular}{|c|c|c|c|c|}
\hline The & & .2362 & 5.4407 & \\
\hline & & .1362 & 5.3571 & \\
\hline & & & & \\
\hline AEMBL] & & & & \\
\hline AEMBL1483844 & 8239 & & 4122 & \\
\hline HEMBL1352321 & 88239 & 1862 & 3904 & \\
\hline HEMBL1535159 & 239 & 362 & 118 & \\
\hline |FMRI & & & 836 & \\
\hline AEMBL1406056 & & 861 & 5073 & \\
\hline HEMBL1609875 & 88239 & 862 & 4329 & \\
\hline HEMBL1524200 & 239 & 362 & 5812 & \\
\hline IEMBL1 & 39 & & 314 & \\
\hline AEMBL5 & & & & \\
\hline HEMBL19284 & & 362 & 2927 & \\
\hline IEMBL16 & & & 1028 & \\
\hline AEMBL134 & 39 & 65 & 4792 & \\
\hline AEMBL15 & & & 544 & \\
\hline HEMBL13 & & & 972 & \\
\hline AEMBL15 & & & 5214 & \\
\hline IEMBL19 & & & & \\
\hline AEMLI & & & 59 & Niv \\
\hline AEMBL14 & & & 67 & RN \\
\hline HEMBL14 & & & 21 & \\
\hline AFMRI 1 & & & & \\
\hline IEMBL14 & & & & I NIV \\
\hline HEMBL1 & & & & RN \\
\hline HEMBL1 & & & & (1) \\
\hline AFMBI 1 & & & & \\
\hline HEMBL14 & & & & in \\
\hline HEMBL14766 & & & & IRN \\
\hline HEMBL1 & & & 749 & RN \\
\hline HEMBL & & & 47 & RN \\
\hline HEMBL1 & & & 34 & 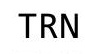 \\
\hline HEMBL3198526 & & & & T \\
\hline HEMBL1587208 & & & 5.5533 & TRN \\
\hline AEMBL14 & & & 5.4735 & TST \\
\hline HCMDI & & & 75 & TRN \\
\hline HEMBL1 & & & & ST \\
\hline HEMBL1409133 & 88239 & & 5.6398 & TRN \\
\hline IEMBL14 & & 52 & 5.4674 & 「RN \\
\hline HEMBL15 & & 52 & . 4992 & \\
\hline HEMBL151 & & & 5.4493 & RIV \\
\hline HEMBL1. & & & 1821 & ГRN \\
\hline AEMBL1503007 & 39 & 862 & 3935 & $\pi \Omega_{1}$ \\
\hline 11 & & & & IRN \\
\hline HEMBL156 & & & . 4917 & \\
\hline CHEMBL15556 & & & 5.5672 & \\
\hline LHEMBL1514258 & 688239 & 6.9863 & 5.4994 & ГST \\
\hline
\end{tabular}

Page 2263 
Supplemental Table S2.txt

\begin{tabular}{|c|c|c|c|c|}
\hline CHEMBL1588694 & 688239 & 6.3863 & 5.4492 & TRN \\
\hline CHEMBL1438217 & 688239 & 5.3862 & 5.4167 & TRN \\
\hline CHEMBL1349235 & 688239 & 5.4362 & 5.4655 & TRN \\
\hline CHEMBL1556435 & 688239 & 4.7362 & 5.4989 & TST \\
\hline CHEMBL1575018 & 688239 & 5.1862 & 5.5293 & TRN \\
\hline CHEMBL1370719 & 688239 & 4.5362 & 5.3418 & TRN \\
\hline CHEMBL1402114 & 688239 & 6.3362 & 5.5814 & TRN \\
\hline CHEMBL1505234 & 688239 & 4.9862 & 5.4945 & TRN \\
\hline CHEMBL1388032 & 688239 & 8.2366 & 5.5501 & TRN \\
\hline CHEMBL1338352 & 688239 & 8.3372 & 5.3453 & TRN \\
\hline CHEMBL1325185 & 688239 & 5.9862 & 5.5803 & TRN \\
\hline CHEMBL 3196509 & 688239 & 7.5361 & 5.6087 & TRN \\
\hline CHEMBL 2000067 & 688239 & 4.5362 & 5.4916 & TST \\
\hline CHEMBL1439025 & 688239 & 5.4362 & 5.4154 & TRN \\
\hline CHEMBL1434664 & 688239 & 4.5362 & 5.5066 & TRN \\
\hline CHEMBL1399942 & 688239 & 8.28399 & 99999999 & 5.2248 \\
\hline CHEMBL1338008 & 688239 & 6.9863 & 5.5596 & TRN \\
\hline CHEMBL1307573 & 688239 & 4.7362 & 5.477 & TRN \\
\hline CHEMBL1379925 & 688239 & 6.6861 & 5.6069 & TRN \\
\hline CHEMBL1573700 & 688239 & 4.5362 & 5.5283 & TST \\
\hline CHEMBL1368009 & 688239 & 4.6362 & 5.4763 & TRN \\
\hline CHEMBL1393225 & 688239 & 5.5862 & 5.4845 & TRN \\
\hline CHEMBL1339965 & 688239 & 6.9363 & 5.426 & TRN \\
\hline CHEMBL1579026 & 688239 & 6.7862 & 5.412999 & 999999999 \\
\hline CHEMBL1405059 & 688239 & 4.5362 & 5.4393 & TST \\
\hline CHEMBL 3195820 & 688239 & 4.5362 & 5.4108 & TST \\
\hline CHEMBL1307240 & 688239 & 4.8862 & 5.3177 & TST \\
\hline CHEMBL1426570 & 688239 & 7.1864 & 5.5138 & TRN \\
\hline CHEMBL1394898 & 688239 & 6.6861 & 5.4547 & TRN \\
\hline CHEMBL1507395 & 688239 & 4.6862 & 5.3325 & TRN \\
\hline CHEMBL1461591 & 688239 & 8.1367 & 5.5807 & TRN \\
\hline CHEMBL 1404780 & 688239 & 4.8362 & 5.4508 & TRN \\
\hline CHEMBL64827 & 688239 & 4.4862 & 5.5558 & TRN \\
\hline CHEMBL1369258 & 688239 & 5.1362 & 5.5865 & TRN \\
\hline CHEMBL1393090 & 688239 & 4.5362 & 5.4906 & TRN \\
\hline CHEMBL1535519 & 688239 & 6.6861 & 5.4286 & TRN \\
\hline CHEMBL1597930 & 688239 & 7.6364 & 5.5867 & TRN \\
\hline CHEMBL1521434 & 688239 & 4.5362 & 5.3894 & TRN \\
\hline CHEMBL 3192881 & 688239 & 4.5862 & 5.3891 & TST \\
\hline CHEMBL1329091 & 688239 & 5.3862 & 5.4626 & TRN \\
\hline CHEMBL1403434 & 688239 & 4.5362 & 5.3249 & TRN \\
\hline CHEMBL 3198128 & 688239 & 4.6862 & 5.4397 & TRN \\
\hline CHEMBL1427208 & 688239 & 6.5363 & 5.4518 & TRN \\
\hline CHEMBL1447503 & 688239 & 6.6362 & 5.5299 & TST \\
\hline CHEMBL 1453065 & 688239 & 6.8748 & 5.3257 & TRN \\
\hline CHEMBL1555743 & 688239 & 6.6362 & 5.4373 & TRN \\
\hline CHEMBL1528038 & 688239 & 4.5362 & 5.4898 & TST \\
\hline CHEMBL1330479 & 688239 & 5.3862 & 5.5037 & TRN \\
\hline
\end{tabular}


Supplemental Table S2.txt

\begin{tabular}{|c|c|c|c|c|c|}
\hline CHEMBL1542391 & 688239 & 6.9363 & \multicolumn{2}{|c|}{5.507999999999999} & TST \\
\hline CHEMBL1477869 & 688239 & 4.9362 & 5.3821 & TRN & \\
\hline CHEMBL1387110 & 688239 & 5.6862 & 5.5491 & TRN & \\
\hline CHEMBL1346013 & 688239 & 6.9363 & 5.7176 & TST & \\
\hline CHEMBL1595327 & 688239 & 6.7361 & 5.4415 & TRN & \\
\hline CHEMBL1425147 & 688239 & 5.1862 & 5.4338 & TRN & \\
\hline CHEMBL1484126 & 688239 & 5.1862 & 5.5315 & TRN & \\
\hline CHEMBL1361763 & 688239 & 4.5362 & 5.4779 & TRN & \\
\hline CHEMBL1557525 & 688239 & 6.9863 & 5.3778 & TST & \\
\hline CHEMBL1502970 & 688239 & 4.5362 & 5.6404 & TRN & \\
\hline CHEMBL1515217 & 688239 & 4.6862 & 5.4499 & TRN & \\
\hline CHEMBL1542799 & 688239 & 5.1862 & 5.5186 & TRN & \\
\hline CHEMBL1590684 & 688239 & 5.1862 & 5.5823 & TST & \\
\hline CHEMBL1562243 & 688239 & 4.5362 & 5.7382 & TRN & \\
\hline CHEMBL1431763 & 688239 & 4.8862 & 5.3755 & TRN & \\
\hline CHEMBL1351334 & 688239 & 4.7362 & 5.5326 & TRN & \\
\hline CHEMBL1393538 & 688239 & 4.5362 & 5.5591 & TST & \\
\hline CHEMBL1514282 & 688239 & 4.5362 & 5.8129 & TRN & \\
\hline CHEMBL1508528 & 688239 & 4.45 & 5.386 & TRN & \\
\hline CHEMBL1507096 & 688239 & 4.8362 & 5.5379 & TRN & \\
\hline CHEMBL1361821 & 688239 & 5.0862 & 5.4644 & TRN & \\
\hline CHEMBL1477353 & 688239 & 7.0862 & 5.3575 & TRN & \\
\hline CHEMBL1518776 & 688239 & 5.9362 & 5.3216 & TST & \\
\hline CHEMBL1479150 & 688239 & 4.7862 & 5.3888 & TST & \\
\hline CHEMBL1548682 & 688239 & 5.4362 & 5.5626 & TRN & \\
\hline CHEMBL1579683 & 688239 & 4.5362 & 5.3686 & TST & \\
\hline CHEMBL1580836 & 688239 & 6.0862 & 5.5473 & TRN & \\
\hline CHEMBL1302069 & 688239 & 6.0862 & 5.58200 & 000000001 & \\
\hline CHEMBL1422433 & 688239 & 4.5362 & 5.3778 & TRN & \\
\hline CHEMBL1518192 & 688239 & 4.7862 & 5.4728 & TRN & \\
\hline CHEMBL1424307 & 688239 & 4.6862 & 5.3979 & TRN & \\
\hline CHEMBL3192415 & 688239 & 5.4362 & 5.4716 & TST & \\
\hline CHEMBL1380188 & 688239 & 4.5862 & 5.396 & TRN & \\
\hline CHEMBL1444937 & 688239 & 6.8861 & 5.4249 & TRN & \\
\hline CHEMBL1572985 & 688239 & 4.4362 & 5.4896 & TRN & \\
\hline CHEMBL40274 & 688239 & 5.5362 & 5.5168 & TST & \\
\hline CHEMBL1550799 & 688239 & 6.9863 & 5.4776 & TRN & \\
\hline CHEMBL1461972 & 688239 & 4.6862 & 5.442 & TRN & \\
\hline CHEMBL1468996 & 688239 & 5.6362 & 5.4785 & TRN & \\
\hline CHEMBL1423364 & 688239 & 4.7862 & 5.4977 & TRN & \\
\hline CHEMBL1444695 & 688239 & 6.8362 & 5.5713 & TST & \\
\hline CHEMBL1083103 & 688239 & 5.5862 & 5.5906 & TRN & \\
\hline CHEMBL1609019 & 688239 & 6.1862 & 5.4561 & TRN & \\
\hline CHEMBL1414151 & 688239 & 5.0862 & 5.6242 & TRN & \\
\hline CHEMBL1535893 & 688239 & 4.6862 & 5.3856 & TRN & \\
\hline CHEMBL1585549 & 688239 & 4.8862 & 5.5405 & TRN & \\
\hline CHEMBL1460159 & 688239 & 4.6862 & 5.5416 & TRN & \\
\hline CHEMBL1337226 & 688239 & 6.4862 & 5.5033 & TST & \\
\hline
\end{tabular}

Page 2265 
Supplemental Table S2.txt

\begin{tabular}{|c|c|c|c|c|}
\hline CHEMBL1553492 & 688239 & 5.1362 & 5.4204 & TRN \\
\hline CHEMBL1545764 & 688239 & 5.4362 & 5.5021 & TST \\
\hline CHEMBL1339608 & 688239 & 6.9363 & 5.6016 & TRN \\
\hline CHEMBL 3196785 & 688239 & 6.3863 & 5.4826 & TRN \\
\hline CHEMBL1365334 & 688239 & 8.2366 & 5.4982 & TRN \\
\hline CHEMBL1541651 & 688239 & 6.8861 & 5.4656 & TST \\
\hline CHEMBL 3208140 & 688239 & 6.2362 & 5.5573 & TRN \\
\hline CHEMBL1333205 & 688239 & 4.6362 & 5.5165 & TRN \\
\hline CHEMBL1556231 & 688239 & 4.7362 & 5.4566 & TRN \\
\hline CHEMBL1389287 & 688239 & 5.1862 & 5.5061 & TRN \\
\hline CHEMBL1593810 & 688239 & 4.5362 & 5.4499 & TRN \\
\hline CHEMBL1446775 & 688239 & 5.5862 & 5.4542 & TRN \\
\hline CHEMBL1385066 & 688239 & 6.2362 & 5.4783 & TRN \\
\hline CHEMBL1382273 & 688239 & 4.5362 & 5.477 & TRN \\
\hline CHEMBL1517839 & 688239 & 5.1362 & 5.511 & TRN \\
\hline CHEMBL1434427 & 688239 & 5.4362 & 5.5158 & TRN \\
\hline CHEMBL1404849 & 688239 & 5.5362 & 5.5912 & TST \\
\hline CHEMBL1319161 & 688239 & 5.1862 & 5.598 & TRN \\
\hline CHEMBL1505134 & 688239 & 4.5362 & 5.3174 & TST \\
\hline CHEMBL1393430 & 688239 & 7.2865 & 5.5084 & TRN \\
\hline CHEMBL1428009 & 688239 & 6.1862 & 5.4654 & TST \\
\hline CHEMBL1498564 & 688239 & 4.6362 & 5.4479 & TRN \\
\hline CHEMBL1329537 & 688239 & 6.1862 & 5.3823 & TRN \\
\hline CHEMBL1373882 & 688239 & 6.0862 & 5.5693 & TRN \\
\hline CHEMBL1545386 & 688239 & 4.5362 & 5.5708 & TRN \\
\hline CHEMBL1309776 & 688239 & 6.9863 & 5.5996 & TRN \\
\hline CHEMBL1350727 & 688239 & 5.7862 & 5.4679 & TRN \\
\hline CHEMBL3190005 & 688239 & 4.5362 & 5.3729 & TST \\
\hline CHEMBL1372245 & 688239 & 5.0362 & 5.3866 & TRN \\
\hline CHEMBL1591125 & 688239 & 4.7362 & 5.6261 & TRN \\
\hline CHEMBL 1474564 & 688239 & 4.7862 & 5.4631 & TRN \\
\hline CHEMBL1540782 & 688239 & 4.8362 & 5.4047 & TRN \\
\hline CHEMBL1390489 & 688239 & 5.6862 & 5.6659 & TRN \\
\hline CHEMBL1409953 & 688239 & 6.1362 & 5.6072 & TRN \\
\hline CHEMBL1610595 & 688239 & 5.9862 & 5.5322 & TRN \\
\hline CHEMBL1585694 & 688239 & 4.6862 & 5.5677 & TRN \\
\hline CHEMBL1595528 & 688239 & 5.1862 & 5.5083 & TRN \\
\hline CHEMBL1499002 & 688239 & 4.4362 & 5.4017 & TRN \\
\hline CHEMBL1585882 & 688239 & 4.5362 & 5.376 & TST \\
\hline CHEMBL1537848 & 688239 & 5.1862 & 5.356 & TRN \\
\hline CHEMBL1341956 & 688239 & 5.1862 & 5.5788 & TRN \\
\hline CHEMBL1474492 & 688239 & 5.1362 & 5.4518 & TRN \\
\hline CHEMBL1483156 & 688239 & 5.4362 & 5.5854 & TRN \\
\hline CHEMBL1300795 & 688239 & 4.5362 & 5.4319 & TRN \\
\hline CHEMBL1443309 & 688239 & 4.6362 & 5.5725 & TRN \\
\hline CHEMBL1501720 & 688239 & 4.6862 & 5.41299 & 9999999999 \\
\hline CHEMBL1304160 & 688239 & 8.3372 & 5.4953 & TST \\
\hline CHEMBL1490369 & 688239 & 5.1862 & 5.5322 & TRN \\
\hline
\end{tabular}

Page 2266 
Supplemental Table S2.txt

\begin{tabular}{|c|c|c|c|c|c|}
\hline CHEMBL1379056 & 688239 & 4.8362 & 5.55 & TST & \\
\hline CHEMBL1367613 & 688239 & 6.6861 & 5.6022 & TRN & \\
\hline CHEMBL1466883 & 688239 & 4.4862 & 5.4765 & TRN & \\
\hline CHEMBL1462873 & 688239 & 5.1862 & 5.3003 & TRN & \\
\hline CHEMBL3196852 & 688239 & 4.4862 & 5.1843 & TST & \\
\hline CHEMBL1506147 & 688239 & 5.3862 & 5.537999 & 999999999 & TST \\
\hline CHEMBL1381432 & 688239 & 4.6862 & 5.5198 & TRN & \\
\hline CHEMBL1342904 & 688239 & 5.1862 & 5.6026 & TRN & \\
\hline CHEMBL1493531 & 688239 & 5.5362 & 5.4269 & TST & \\
\hline CHEMBL1585012 & 688239 & 5.1862 & 5.4561 & TST & \\
\hline CHEMBL1554781 & 688239 & 6.7361 & 5.5937 & TRN & \\
\hline CHEMBL1501227 & 688239 & 4.7862 & 5.5628 & TRN & \\
\hline CHEMBL1573772 & 688239 & 5.4362 & 5.3771 & TRN & \\
\hline CHEMBL1553707 & 688239 & 6.1362 & 5.5181 & TRN & \\
\hline CHEMBL1543078 & 688239 & 5.7362 & 5.4215 & TRN & \\
\hline CHEMBL1444376 & 688239 & 4.6362 & 5.4408 & TRN & \\
\hline CHEMBL1378696 & 688239 & 5.8862 & 5.6532 & TST & \\
\hline CHEMBL1439531 & 688239 & 4.5362 & 5.4754 & TRN & \\
\hline CHEMBL1588715 & 688239 & 6.6861 & 5.4966 & TRN & \\
\hline CHEMBL1531003 & 688239 & 4.5362 & 5.4523 & TRN & \\
\hline CHEMBL1507198 & 688239 & 5.1862 & 5.5023 & TST & \\
\hline CHEMBL1392206 & 688239 & 4.7362 & 5.4906 & TRN & \\
\hline CHEMBL1483001 & 688239 & 5.5362 & 5.7532 & TRN & \\
\hline CHEMBL1534791 & 688239 & 6.3362 & 5.5908 & TRN & \\
\hline CHEMBL1397245 & 688239 & 5.9362 & 5.4916 & TST & \\
\hline CHEMBL1588391 & 688239 & 6.9363 & 5.5396 & TST & \\
\hline CHEMBL1518013 & 688239 & 5.3862 & 5.3835 & TST & \\
\hline CHEMBL1576821 & 688239 & 5.6862 & 5.4772 & TRN & \\
\hline CHEMBL1569803 & 688239 & 6.3362 & 5.3683 & TRN & \\
\hline CHEMBL1394751 & 688239 & 5.9862 & 5.5842 & TRN & \\
\hline CHEMBL1468853 & 688239 & 4.5362 & 5.3395 & TRN & \\
\hline CHEMBL130867 & 688239 & 5.9362 & 5.525 & TRN & \\
\hline CHEMBL1417763 & 688239 & 4.6362 & 5.417000 & 000000001 & $\pi$ \\
\hline CHEMBL1391763 & 688239 & 4.5362 & 5.4786 & TST & \\
\hline CHEMBL1564105 & 688239 & 5.0862 & 5.4179 & TST & \\
\hline CHEMBL1304334 & 688239 & 8.2366 & 5.5414 & TST & \\
\hline CHEMBL1300080 & 688239 & 5.2862 & 5.5094 & TRN & \\
\hline CHEMBL1454342 & 688239 & 6.0862 & 5.5082 & TST & \\
\hline CHEMBL1463068 & 688239 & 5.1862 & 5.4617 & TST & \\
\hline CHEMBL1606817 & 688239 & 5.6862 & 5.357 & TRN & \\
\hline CHEMBL3210563 & 688239 & 8.28399 & 99999999 & 5.5057 & TIV \\
\hline CHEMBL1508708 & 688239 & 6.0362 & 5.6159 & TRN & \\
\hline CHEMBL1361465 & 688239 & 5.0362 & 5.5037 & TRN & \\
\hline CHEMBL1567169 & 688239 & 7.2366 & 5.4364 & TRN & \\
\hline CHEMBL1477346 & 688239 & 4.6362 & 5.4593 & TRN & \\
\hline CHEMBL1596615 & 688239 & 4.6862 & 5.4375 & TST & \\
\hline CHEMBL1306133 & 688239 & 4.4862 & 5.4965 & TRN & \\
\hline CHEMBL1440920 & 688239 & 6.8861 & 5.6251 & TST & \\
\hline
\end{tabular}


Supplemental Table S2.txt

\begin{tabular}{|c|c|c|c|c|}
\hline CHEMBL1971428 & 688239 & 5.1862 & 5.4887 & TRN \\
\hline CHEMBL1492745 & 688239 & 5.7362 & 5.6369 & TRN \\
\hline CHEMBL1307364 & 688239 & 5.1862 & 5.4832 & TST \\
\hline CHEMBL1469499 & 688239 & 5.8862 & 5.5191 & TST \\
\hline CHEMBL1304295 & 688239 & 4.7862 & 5.386 & TRN \\
\hline CHEMBL1349883 & 688239 & 4.5362 & 5.5123 & TRN \\
\hline CHEMBL1338928 & 688239 & 5.1862 & 5.5 & TST \\
\hline CHEMBL1548711 & 688239 & 6.7361 & 5.5277 & TRN \\
\hline CHEMBL1966472 & 688239 & 4.6862 & 5.4485 & TRN \\
\hline CHEMBL1304178 & 688239 & 4.9362 & 5.5166 & TRN \\
\hline CHEMBL1338954 & 688239 & 4.5362 & 5.516 & TRN \\
\hline CHEMBL1581617 & 688239 & 5.1862 & 5.4435 & TRN \\
\hline CHEMBL1477554 & 688239 & 5.8862 & 5.4321 & TRN \\
\hline CHEMBL1466265 & 688239 & 4.4862 & 5.5037 & TRN \\
\hline CHEMBL1407297 & 688239 & 7.2366 & 5.5373 & TST \\
\hline CHEMBL1539099 & 688239 & 7.5361 & 5.3998 & TRN \\
\hline CHEMBL1522414 & 688239 & 5.4362 & 5.4498 & TRN \\
\hline CHEMBL1432569 & 688239 & 4.9362 & 5.3999 & TRN \\
\hline CHEMBL3194550 & 688239 & 4.8362 & 5.4135 & TST \\
\hline CHEMBL1336186 & 688239 & 4.5362 & 5.587999 & э999999999 \\
\hline CHEMBL1491779 & 688239 & 5.1862 & 5.5346 & TRN \\
\hline CHEMBL1577506 & 688239 & 6.8861 & 5.5677 & TRN \\
\hline CHEMBL1342639 & 688239 & 4.5362 & 5.4454 & TRN \\
\hline CHEMBL1458675 & 688239 & 5.4362 & 5.4719 & TST \\
\hline CHEMBL1562352 & 688239 & 5.5362 & 5.5097 & TRN \\
\hline CHEMBL1395308 & 688239 & 5.2862 & 5.4131 & TRN \\
\hline CHEMBL1375437 & 688239 & 6.0862 & 5.3619 & TRN \\
\hline CHEMBL1604619 & 688239 & 4.5862 & 5.5902 & TST \\
\hline CHEMBL1393005 & 688239 & 6.0 & 5.398 & TST \\
\hline CHEMBL1594723 & 688239 & 5.4362 & 5.362999 & \\
\hline CHEMBL1526001 & 688239 & 4.6862 & 5.5646 & TST \\
\hline CHEMBL1601730 & 688239 & 4.5362 & 5.3244 & TST \\
\hline CHEMBL1311977 & 688239 & 6.9863 & 5.7855 & TRN \\
\hline CHEMBL1335798 & 688239 & 4.5362 & 5.6121 & TST \\
\hline CHEMBL1347192 & 688239 & 4.8862 & 5.4809 & TST \\
\hline CHEMBL1348208 & 688239 & 4.5362 & 5.5423 & TRN \\
\hline CHEMBL1443707 & 688239 & 5.5862 & 5.4918 & TRN \\
\hline CHEMBL1330816 & 688239 & 4.6862 & 5.5906 & TST \\
\hline CHEMBL1520138 & 688239 & 4.6862 & 5.4574 & TRN \\
\hline CHEMBL1443382 & 688239 & 5.1862 & 5.3806 & TRN \\
\hline CHEMBL1607635 & 688239 & 6.1362 & 5.3833 & TRN \\
\hline CHEMBL3210197 & 688239 & 5.6362 & 5.3423 & TRN \\
\hline CHEMBL1404507 & 688239 & 4.8362 & 5.2958 & TRN \\
\hline CHEMBL1361070 & 688239 & 4.8862 & 5.4969 & TRN \\
\hline CHEMBL1601612 & 688239 & 6.8861 & 5.4978 & TRN \\
\hline CHEMBL1497690 & 688239 & 4.8862 & 5.3935 & TRN \\
\hline CHEMBL1464050 & 688239 & 5.1862 & 5.4311 & TRN \\
\hline CHEMBL1580258 & 688239 & 4.5362 & 5.4335 & TST \\
\hline
\end{tabular}


Supplemental Table S2.txt

\begin{tabular}{|c|c|c|c|c|c|}
\hline CHEMBL1435138 & 688239 & 5.1862 & 5.5934 & TRN & \\
\hline CHEMBL1378455 & 688239 & 7.1361 & 5.5136 & TRN & \\
\hline CHEMBL1335157 & 688239 & 4.8362 & 5.5443 & TRN & \\
\hline CHEMBL1413445 & 688239 & 4.8362 & 5.4698 & TRN & \\
\hline CHEMBL1445184 & 688239 & 5.1362 & 5.4369 & TRN & \\
\hline CHEMBL1429695 & 688239 & 8.3372 & 5.5345 & TST & \\
\hline CHEMBL1525558 & 688239 & 4.7362 & 5.5701 & TRN & \\
\hline CHEMBL1608580 & 688239 & 4.7862 & 5.4834 & TRN & \\
\hline CHEMBL1582963 & 688239 & 5.6862 & 5.4427 & TST & \\
\hline CHEMBL1386833 & 688239 & 4.6362 & 5.461 & TRN & \\
\hline CHEMBL1499168 & 688239 & 4.5362 & 5.519 & TRN & \\
\hline CHEMBL3214564 & 688239 & 5.9862 & 5.5036 & TRN & \\
\hline CHEMBL1497242 & 688239 & 4.7862 & 5.6434 & TRN & \\
\hline CHEMBL1430057 & 688239 & 6.6362 & 5.562 & TRN & \\
\hline CHEMBL1369532 & 688239 & 5.1362 & 5.4109 & TST & \\
\hline CHEMBL1402451 & 688239 & 4.6862 & 5.5556 & TRN & \\
\hline CHEMBL1519679 & 688239 & 4.9362 & 5.4734 & TRN & \\
\hline CHEMBL1329359 & 688239 & 6.8362 & 5.5082 & TRN & \\
\hline CHEMBL1363652 & 688239 & 6.2362 & 5.4217 & TRN & \\
\hline CHEMBL1423554 & 688239 & 5.1362 & 5.6317 & TRN & \\
\hline CHEMBL1430485 & 688239 & 4.5362 & 5.615 & TRN & \\
\hline CHEMBL1384646 & 688239 & 5.1362 & 5.5551 & TST & \\
\hline CHEMBL1347513 & 688239 & 5.5362 & 5.511 & TST & \\
\hline CHEMBL 3193957 & 688239 & 6.3863 & 5.409 & TRN & \\
\hline CHEMBL1582997 & 688239 & 4.5362 & 5.3899 & TST & \\
\hline CHEMBL1579401 & 688239 & 6.0862 & 5.3445 & TRN & \\
\hline CHEMBL1486664 & 688239 & 5.5862 & 5.3867 & TRN & \\
\hline CHEMBL1359721 & 688239 & 6.1862 & 5.5014 & TST & \\
\hline CHEMBL1355729 & 688239 & 6.3362 & 5.7587 & TRN & \\
\hline CHEMBL1580134 & 688239 & 4.8362 & 5.46 & TRN & \\
\hline CHEMBL1444897 & 688239 & 5.3862 & 5.446000 & 000000001 & TST \\
\hline CHEMBL1340969 & 688239 & 4.6862 & 5.6017 & TRN & \\
\hline CHEMBL1596616 & 688239 & 6.9863 & 5.4717 & TRN & \\
\hline CHEMBL1499979 & 688239 & 4.5362 & 5.4918 & TRN & \\
\hline CHEMBL578164 & 688239 & 4.8862 & 5.4413 & TRN & \\
\hline CHEMBL1505532 & 688239 & 4.5362 & 5.5137 & TST & \\
\hline CHEMBL1597303 & 688239 & 8.28399 & 99999999 & 5.5603 & TRN \\
\hline CHEMBL1500974 & 688239 & 5.1362 & 5.3797 & TRN & \\
\hline CHEMBL1460774 & 688239 & 8.28399 & 99999999 & 5.5102 & TST \\
\hline CHEMBL1400756 & 688239 & 6.1362 & 5.6033 & TST & \\
\hline CHEMBL1311066 & 688239 & 4.5362 & 5.4605 & TRN & \\
\hline CHEMBL1309815 & 688239 & 4.6362 & 5.372999 & 999999999 & $1 \times 1$ \\
\hline CHEMBL1364630 & 688239 & 4.9362 & 5.3958 & TST & \\
\hline CHEMBL1465976 & 688239 & 6.1862 & 5.5857 & TRN & \\
\hline CHEMBL1429886 & 688239 & 5.9362 & 5.5015 & TRN & \\
\hline CHEMBL1305759 & 688239 & 6.0862 & 5.6057 & TRN & \\
\hline CHEMBL1446720 & 688239 & 4.5362 & 5.5022 & TRN & \\
\hline CHEMBL1529348 & 688239 & 4.6362 & 5.5163 & TRN & \\
\hline
\end{tabular}

Page 2269 
Supplemental Table S2.txt

\begin{tabular}{|c|c|c|c|c|}
\hline CHEMBL1557869 & 688239 & 5.3362 & 5.3895 & TRN \\
\hline CHEMBL1534368 & 688239 & 4.5362 & 5.4927 & TRN \\
\hline CHEMBL1598763 & 688239 & 5.0362 & 5.3909 & TRN \\
\hline CHEMBL1589432 & 688239 & 5.2362 & 5.5652 & TRN \\
\hline CHEMBL1597074 & 688239 & 4.9362 & 5.3666 & TST \\
\hline CHEMBL1395353 & 688239 & 5.7362 & 5.4262 & TRN \\
\hline CHEMBL 3212914 & 688239 & 6.7361 & 5.4471 & TRN \\
\hline CHEMBL1568882 & 688239 & 4.7862 & 5.5154 & TRN \\
\hline CHEMBL1428796 & 688239 & 6.3863 & 5.6348 & TRN \\
\hline CHEMBL1375160 & 688239 & 4.5362 & 5.5157 & TRN \\
\hline CHEMBL1581976 & 688239 & 5.6862 & 5.6457 & TRN \\
\hline CHEMBL 2373624 & 688239 & 4.9862 & 5.461 & TST \\
\hline CHEMBL1384713 & 688239 & 4.7362 & 5.6043 & TST \\
\hline CHEMBL1331300 & 688239 & 4.9362 & 5.5314 & TRN \\
\hline CHEMBL1479984 & 688239 & 8.3372 & 5.5934 & TRN \\
\hline CHEMBL1541412 & 688239 & 5.0862 & 5.4881 & TRN \\
\hline CHEMBL1453799 & 688239 & 7.2366 & 5.7789 & TRN \\
\hline CHEMBL1430921 & 688239 & 4.7862 & 5.5155 & TRN \\
\hline CHEMBL1380150 & 688239 & 4.8362 & 5.4031 & TST \\
\hline CHEMBL1592522 & 688239 & 5.0362 & 5.59 & TRN \\
\hline CHEMBL1350975 & 688239 & 5.1362 & 5.4137 & TST \\
\hline CHEMBL1406006 & 688239 & 4.6362 & 5.6009 & TRN \\
\hline CHEMBL1480408 & 688239 & 4.7862 & 5.5691 & TRN \\
\hline CHEMBL1419080 & 688239 & 4.4862 & 5.3802 & TRN \\
\hline CHEMBL1383325 & 688239 & 6.2362 & 5.5315 & TRN \\
\hline CHEMBL1453588 & 688239 & 6.8861 & 5.5015 & TRN \\
\hline CHEMBL1304660 & 688239 & 4.6862 & 5.3998 & TRN \\
\hline CHEMBL1501256 & 688239 & 5.1862 & 5.5425 & TRN \\
\hline CHEMBL1468192 & 688239 & 5.3362 & 5.3488 & TRN \\
\hline CHEMBL1309781 & 688239 & 5.2362 & 5.4758 & TRN \\
\hline CHEMBL1302134 & 688239 & 4.4362 & 5.3385 & TRN \\
\hline CHEMBL1483414 & 688239 & 4.5362 & 5.4301 & TRN \\
\hline CHEMBL1350191 & 688239 & 8.3372 & 5.6142 & TRN \\
\hline CHEMBL1528568 & 688239 & 5.3862 & 5.58899 & \\
\hline CHEMBL1375927 & 688239 & 6.7862 & 5.4309 & TRN \\
\hline CHEMBL1327863 & 688239 & 6.7862 & 5.2471 & TRN \\
\hline CHEMBL1608793 & 688239 & 6.9863 & 5.657 & TST \\
\hline CHEMBL1307268 & 688239 & 5.1862 & 5.5131 & TST \\
\hline CHEMBL1340401 & 688239 & 5.3362 & 5.5017 & TRN \\
\hline CHEMBL1512979 & 688239 & 5.3362 & 5.5736 & TRN \\
\hline CHEMBL1490290 & 688239 & 5.5862 & 5.5407 & TRN \\
\hline CHEMBL1455014 & 688239 & 8.3872 & 5.55 & TST \\
\hline CHEMBL1374812 & 688239 & 5.1862 & 5.55200 & 30000000005 \\
\hline CHEMBL1536026 & 688239 & 4.8862 & 5.605 & TRN \\
\hline CHEMBL1551928 & 688239 & 4.6862 & 5.5609 & TRN \\
\hline CHEMBL1495092 & 688239 & 5.4862 & 5.4048 & TST \\
\hline CHEMBL1484579 & 688239 & 5.0362 & 5.3979 & TRN \\
\hline CHEMBL1502922 & 688239 & 4.8362 & 5.4123 & TRN \\
\hline
\end{tabular}

Page 2270 
Supplemental Table S2.txt

\begin{tabular}{|c|c|c|c|c|c|}
\hline CHEMBL1477201 & 688239 & 4.4862 & 5.3595 & TRN & \\
\hline CHEMBL1407099 & 688239 & 5.4862 & 5.5914 & TRN & \\
\hline CHEMBL1455303 & 688239 & 5.1862 & 5.562 & TST & \\
\hline CHEMBL1415298 & 688239 & 5.1862 & 5.6255 & TRN & \\
\hline CHEMBL1548031 & 688239 & 6.1862 & 5.5811 & TST & \\
\hline CHEMBL1472485 & 688239 & 5.1862 & 5.5006 & TST & \\
\hline CHEMBL1369203 & 688239 & 4.5362 & 5.6028 & TRN & \\
\hline CHEMBL1382595 & 688239 & 6.9863 & 5.3446 & TRN & \\
\hline CHEMBL1416995 & 688239 & 5.1862 & 5.4522 & TRN & \\
\hline CHEMBL1489591 & 688239 & 5.6362 & 5.4647 & TRN & \\
\hline CHEMBL1374131 & 688239 & 4.6362 & 5.5064 & TRN & \\
\hline CHEMBL1445233 & 688239 & 5.7362 & 5.5619 & TRN & \\
\hline CHEMBL1361400 & 688239 & 5.8862 & 5.5686 & TST & \\
\hline CHEMBL1389192 & 688239 & 5.1362 & 5.44799 & 99999999995 & TRN \\
\hline CHEMBL1431997 & 688239 & 7.5867 & 5.5964 & TRN & \\
\hline CHEMBL1537018 & 688239 & 6.5363 & 5.5071 & TRN & \\
\hline CHEMBL1363626 & 688239 & 5.3862 & 5.5993 & TRN & \\
\hline CHEMBL1434578 & 688239 & 4.5362 & 5.5499 & TRN & \\
\hline CHEMBL1392670 & 688239 & 5.9862 & 5.3878 & TRN & \\
\hline CHEMBL1515285 & 688239 & 4.7362 & 5.5197 & TRN & \\
\hline CHEMBL1326726 & 688239 & 6.2362 & 5.5325 & TST & \\
\hline CHEMBL1542491 & 688239 & 4.7862 & 5.3177 & TST & \\
\hline CHEMBL1573129 & 688239 & 4.7862 & 5.5325 & TRN & \\
\hline CHEMBL1387573 & 688239 & 5.2362 & 5.4433 & TRN & \\
\hline CHEMBL1352086 & 688239 & 4.7362 & 5.5289 & TST & \\
\hline CHEMBL1594220 & 688239 & 4.6362 & 5.3875 & TRN & \\
\hline CHEMBL1459353 & 688239 & 4.8862 & 5.4554 & TRN & \\
\hline CHEMBL1413128 & 688239 & 4.5362 & 5.4727 & TRN & \\
\hline CHEMBL1992582 & 688239 & 4.7362 & 5.3726 & TRN & \\
\hline CHEMBL1443937 & 688239 & 4.7362 & 5.4707 & TRN & \\
\hline CHEMBL1389281 & 688239 & 4.5362 & 5.476 & TRN & \\
\hline CHEMBL1350160 & 688239 & 4.7362 & 5.3511 & TST & \\
\hline CHEMBL1377607 & 688239 & 4.9862 & 5.5309 & TST & \\
\hline CHEMBL1433589 & 688239 & 5.8362 & 5.4872 & TRN & \\
\hline CHEMBL1555723 & 688239 & 5.1862 & 5.4675 & TST & \\
\hline CHEMBL3193859 & 688239 & 6.9363 & 5.5989 & TRN & \\
\hline CHEMBL1519463 & 688239 & 4.7862 & 5.4285 & TST & \\
\hline CHEMBL1456766 & 688239 & 4.5362 & 5.3148 & TRN & \\
\hline CHEMBL1547452 & 688239 & 5.0362 & 5.6304 & TST & \\
\hline CHEMBL1301398 & 688239 & 6.1862 & 5.6099 & TRN & \\
\hline CHEMBL1331516 & 688239 & 6.1362 & 5.4445 & TRN & \\
\hline CHEMBL1524782 & 688239 & 5.6362 & 5.5224 & TRN & \\
\hline CHEMBL1599058 & 688239 & 4.5362 & 5.4296 & TRN & \\
\hline CHEMBL1398737 & 688239 & 4.7862 & 5.4658 & TRN & \\
\hline CHEMBL1344090 & 688239 & 8.3372 & 5.6376 & TRN & \\
\hline CHEMBL1440308 & 688239 & 4.5362 & 5.6464 & TRN & \\
\hline CHEMBL1535489 & 688239 & 6.2862 & 5.5166 & TRN & \\
\hline CHEMBL1967037 & 688239 & 5.2862 & 5.4618 & TRN & \\
\hline
\end{tabular}


Supplemental Table S2.txt

\begin{tabular}{|c|c|c|c|c|c|c|}
\hline CHEMBL1461819 & 688239 & 4.5362 & 5.5995 & TRN & & \\
\hline CHEMBL1527003 & 688239 & 4.5362 & 5.4452 & TRN & & \\
\hline CHEMBL1426221 & 688239 & 5.6362 & 5.5521 & TRN & & \\
\hline CHEMBL1442154 & 688239 & 6.0862 & 5.5961 & TRN & & \\
\hline CHEMBL1550560 & 688239 & 6.1862 & 5.5557 & TRN & & \\
\hline CHEMBL1479193 & 688239 & 4.5362 & 5.61 & TRN & & \\
\hline CHEMBL1335911 & 688239 & 6.3863 & 5.5671 & TRN & & \\
\hline CHEMBL1514621 & 688239 & 4.7362 & 5.5471 & TST & & \\
\hline CHEMBL1503382 & 688239 & 4.6862 & 5.5383 & TRN & & \\
\hline CHEMBL1403624 & 688239 & 4.5862 & 5.4684 & TRN & & \\
\hline CHEMBL1442345 & 688239 & 6.8362 & 5.4088 & TRN & & \\
\hline CHEMBL1483029 & 688239 & 8.28399 & 999999999 & & 5.5683 & TRN \\
\hline CHEMBL1364315 & 688239 & 5.8362 & 5.4444 & TRN & & \\
\hline CHEMBL1511298 & 688239 & 4.5362 & 5.3891 & TST & & \\
\hline CHEMBL1991935 & 688239 & 4.6862 & 5.4549 & TRN & & \\
\hline CHEMBL1374595 & 688239 & 6.0362 & 5.5431 & TRN & & \\
\hline CHEMBL1450349 & 688239 & 5.6862 & 5.4305 & TST & & \\
\hline CHEMBL1582873 & 688239 & 4.5362 & 5.5132 & TRN & & \\
\hline CHEMBL1601926 & 688239 & 4.5862 & 5.3397 & TRN & & \\
\hline CHEMBL1435657 & 688239 & 6.1362 & 5.5279 & TRN & & \\
\hline CHEMBL1517386 & 688239 & 6.1862 & 5.5022 & TST & & \\
\hline CHEMBL1341981 & 688239 & 4.7862 & 5.4865 & TST & & \\
\hline CHEMBL1424873 & 688239 & 4.5362 & 5.4823 & TRN & & \\
\hline CHEMBL1428040 & 688239 & 4.5362 & 5.5058 & TST & & \\
\hline CHEMBL1443273 & 688239 & 4.4862 & 5.4612 & TRN & & \\
\hline CHEMBL1324190 & 688239 & 5.8862 & 5.5544 & TST & & \\
\hline CHEMBL1597725 & 688239 & 6.2362 & 5.6652 & TRN & & \\
\hline CHEMBL1389306 & 688239 & 8.3372 & 5.4308 & TRN & & \\
\hline CHEMBL1447740 & 688239 & 4.5362 & 5.5183 & TRN & & \\
\hline CHEMBL1350558 & 688239 & 4.7862 & 5.4036 & TRN & & \\
\hline CHEMBL1320835 & 688239 & 5.1862 & 5.4875 & TRN & & \\
\hline CHEMBL1494279 & 688239 & 4.5862 & 5.3925 & TRN & & \\
\hline CHEMBL1413360 & 688239 & 6.9363 & 5.7088 & TRN & & \\
\hline CHEMBL3208971 & 688239 & 8.28399 & 999999999 & 99 & 5.4517 & \\
\hline CHEMBL1313663 & 688239 & 4.7362 & 5.4215 & TRN & & \\
\hline CHEMBL1529529 & 688239 & 8.28399 & 999999999 & 99 & 5.4343 & Tा \\
\hline CHEMBL1498501 & 688239 & 4.7362 & 5.4979 & TRN & & \\
\hline CHEMBL1430804 & 688239 & 5.1362 & 5.421 & TRN & & \\
\hline CHEMBL1597987 & 688239 & 4.8862 & 5.4738 & TRN & & \\
\hline CHEMBL1468737 & 688239 & 5.2862 & 5.4899 & TST & & \\
\hline CHEMBL1350099 & 688239 & 4.5362 & 5.6214 & TRN & & \\
\hline CHEMBL1397969 & 688239 & 4.5362 & 5.4263 & TRN & & \\
\hline CHEMBL1433156 & 688239 & 6.4362 & 5.5391 & TRN & & \\
\hline CHEMBL1356540 & 688239 & 6.5862 & 5.3606 & TST & & \\
\hline CHEMBL3211021 & 688239 & 4.5362 & 5.3235 & TST & & \\
\hline CHEMBL1357056 & 688239 & 5.0862 & 5.4198 & TRN & & \\
\hline CHEMBL1399867 & 688239 & 5.1862 & 5.5665 & TRN & & \\
\hline CHEMBL1592102 & 688239 & 4.9362 & 5.392 & TRN & & \\
\hline
\end{tabular}




\begin{tabular}{|c|c|c|c|c|c|c|}
\hline \multicolumn{7}{|c|}{ Supplemental Table S2.txt } \\
\hline CHEMBL1326385 & 688239 & 4.6862 & 5.5752 & TRN & & \\
\hline CHEMBL1333591 & 688239 & 4.7362 & 5.4547 & TST & & \\
\hline CHEMBL1588331 & 688239 & 4.6862 & 5.4029 & TRN & & \\
\hline CHEMBL1339433 & 688239 & 5.4862 & 5.3431 & TRN & & \\
\hline CHEMBL1561123 & 688239 & 4.5362 & 5.5986 & TST & & \\
\hline CHEMBL1349746 & 688239 & 4.5362 & 5.4646 & TRN & & \\
\hline CHEMBL1449824 & 688239 & 4.8362 & 5.5277 & TRN & & \\
\hline CHEMBL1381873 & 688239 & 7.1864 & 5.3341 & TST & & \\
\hline CHEMBL1373246 & 688239 & 8.28399 & 99999999 & 99 & 5.6218 & TST \\
\hline CHEMBL1472731 & 688239 & 5.5862 & 5.5827 & TRN & & \\
\hline CHEMBL1439295 & 688239 & 4.9362 & 5.4735 & TRN & & \\
\hline CHEMBL1366266 & 688239 & 6.5363 & 5.6755 & TRN & & \\
\hline CHEMBL1413155 & 688239 & 8.28399 & 99999999 & 99 & 5.4837 & \\
\hline CHEMBL1483623 & 688239 & 5.6362 & 5.4959 & TRN & & \\
\hline CHEMBL1300991 & 688239 & 5.1862 & 5.38200 & 0000000001 & & TST \\
\hline CHEMBL1478165 & 688239 & 6.9363 & 5.6315 & TRN & & \\
\hline CHEMBL1445344 & 688239 & 4.6362 & 5.3553 & TRN & & \\
\hline CHEMBL1480599 & 688239 & 5.1862 & 5.5006 & TST & & \\
\hline CHEMBL1504788 & 688239 & 5.1862 & 5.3969 & TRN & & \\
\hline CHEMBL1335162 & 688239 & 5.4362 & 5.4756 & TRN & & \\
\hline CHEMBL1609188 & 688239 & 6.1862 & 5.3983 & TRN & & \\
\hline CHEMBL3214240 & 688239 & 4.5362 & 5.4062 & TST & & \\
\hline CHEMBL1376343 & 688239 & 5.2862 & 5.6832 & TRN & & \\
\hline CHEMBL1575721 & 688239 & 5.9362 & 5.4341 & TRN & & \\
\hline CHEMBL1371380 & 688239 & 4.5362 & 5.2842 & TRN & & \\
\hline CHEMBL1454770 & 688239 & 4.6362 & 5.4531 & TST & & \\
\hline CHEMBL1973504 & 688239 & 4.6362 & 5.3054 & TRN & & \\
\hline CHEMBL1403320 & 688239 & 5.6862 & 5.44 & TRN & & \\
\hline CHEMBL1603154 & 688239 & 4.9362 & 5.5876 & TRN & & \\
\hline CHEMBL1382030 & 688239 & 4.8362 & 5.4393 & TRN & & \\
\hline CHEMBL1533039 & 688239 & 4.5862 & 5.3927 & TST & & \\
\hline CHEMBL1498477 & 688239 & 8.3372 & 5.5437 & TRN & & \\
\hline CHEMBL1345620 & 688239 & 5.0862 & 5.3729 & TRN & & \\
\hline CHEMBL1432231 & 688239 & 6.7361 & 5.5653 & TST & & \\
\hline CHEMBL1583047 & 688239 & 7.5361 & 5.5282 & TRN & & \\
\hline CHEMBL1313254 & 688239 & 4.5362 & 5.6175 & TRN & & \\
\hline CHEMBL1539454 & 688239 & 6.5862 & 5.5968 & TRN & & \\
\hline CHEMBL1491435 & 688239 & 4.4862 & 5.4931 & TRN & & \\
\hline CHEMBL3190968 & 688239 & 5.4862 & 5.4487 & TRN & & \\
\hline CHEMBL1380884 & 688239 & 4.8862 & 5.5031 & TRN & & \\
\hline CHEMBL1442183 & 688239 & 4.5362 & 5.5108 & TRN & & \\
\hline CHEMBL1344732 & 688239 & 4.6362 & 5.3958 & TRN & & \\
\hline CHEMBL1431919 & 688239 & 6.9863 & 5.4561 & TRN & & \\
\hline CHEMBL1594148 & 688239 & 5.4362 & 5.7039 & TST & & \\
\hline CHEMBL1433893 & 688239 & 5.0862 & 5.3664 & TRN & & \\
\hline CHEMBL1454843 & 688239 & 5.2362 & 5.5436 & TRN & & \\
\hline CHEMBL1312066 & 688239 & 6.9363 & 5.5681 & TST & & \\
\hline CHEMBL1338810 & 688239 & 7.2366 & 5.5033 & TRN & & \\
\hline
\end{tabular}




\begin{tabular}{|c|c|c|c|c|c|c|c|}
\hline \multicolumn{8}{|c|}{ 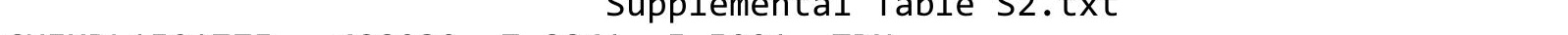 } \\
\hline CHEMBL1501775 & 688239 & 7.8861 & 5.5091 & TRN & & & \\
\hline CHEMBL1509927 & 688239 & 4.5362 & 5.55 & TRN & & & \\
\hline CHEMBL1599391 & 688239 & 6.4862 & 5.5613 & TRN & & & \\
\hline CHEMBL3210976 & 688239 & 6.6362 & 5.4899 & TRN & & & \\
\hline CHEMBL1374048 & 688239 & 4.5862 & 5.4608 & TRN & & & \\
\hline CHEMBL1439757 & 688239 & 5.5362 & 5.4332 & TRN & & & \\
\hline CHEMBL1529900 & 688239 & 4.5362 & 5.5321 & TST & & & \\
\hline CHEMBL1302439 & 688239 & 5.7362 & 5.566 & TST & & & \\
\hline CHEMBL1400279 & 688239 & 4.5362 & 5.3822 & TRN & & & \\
\hline CHEMBL1492995 & 688239 & 6.0862 & 5.518 & TRN & & & \\
\hline CHEMBL1412067 & 688239 & 4.5362 & 5.5578 & TRN & & & \\
\hline CHEMBL1429775 & 688239 & 4.7362 & 5.5633 & TRN & & & \\
\hline CHEMBL1597051 & 688239 & 8.28399 & 999999999 & 99 & 5.3911 & TRN & \\
\hline CHEMBL1348449 & 688239 & 4.6362 & 5.5052 & TRN & & & \\
\hline CHEMBL1582454 & 688239 & 5.6362 & 5.6349 & TRN & & & \\
\hline CHEMBL1971072 & 688239 & 5.4862 & 5.3502 & TST & & & \\
\hline CHEMBL1524367 & 688239 & 4.6862 & 5.4576 & TRN & & & \\
\hline CHEMBL1506604 & 688239 & 4.5362 & 5.5623 & TRN & & & \\
\hline CHEMBL1584509 & 688239 & 8.28399 & 999999999 & & 5.4120 & 0000000001 & TST \\
\hline CHEMBL1352833 & 688239 & 6.2862 & 5.5278 & TRN & & & \\
\hline CHEMBL1423760 & 688239 & 5.1862 & 5.4777 & TST & & & \\
\hline CHEMBL1355689 & 688239 & 7.3363 & 5.4546 & TRN & & & \\
\hline CHEMBL1412310 & 688239 & 4.9362 & 5.468999 & 999999999 & & TRN & \\
\hline CHEMBL592712 & 688239 & 8.3372 & 5.5268 & TST & & & \\
\hline CHEMBL1440462 & 688239 & 6.9363 & 5.5992 & TRN & & & \\
\hline CHEMBL1562978 & 688239 & 5.6362 & 5.4219 & TRN & & & \\
\hline CHEMBL1357793 & 688239 & 5.9362 & 5.5062 & TRN & & & \\
\hline CHEMBL1549004 & 688239 & 4.7862 & 5.4101 & TST & & & \\
\hline CHEMBL1594160 & 688239 & 4.5362 & 5.3639 & TRN & & & \\
\hline CHEMBL1525625 & 688239 & 4.5862 & 5.5271 & TST & & & \\
\hline CHEMBL1469321 & 688239 & 5.1862 & 5.4123 & TST & & & \\
\hline CHEMBL1608770 & 688239 & 7.1864 & 5.6313 & TRN & & & \\
\hline CHEMBL1572243 & 688239 & 6.8861 & 5.5132 & TRN & & & \\
\hline CHEMBL1454219 & 688239 & 6.1362 & 5.541 & TST & & & \\
\hline CHEMBL1526749 & 688239 & 5.1862 & 5.3496 & TRN & & & \\
\hline CHEMBL1612851 & 688239 & 5.1862 & 5.451000 & 000000000 & 05 & TST & \\
\hline CHEMBL1459753 & 688239 & 5.3862 & 5.3722 & TRN & & & \\
\hline CHEMBL1464382 & 688239 & 4.5362 & 5.4915 & TRN & & & \\
\hline CHEMBL1384019 & 688239 & 7.0362 & 5.603 & TRN & & & \\
\hline CHEMBL1545118 & 688239 & 4.6362 & 5.6246 & TST & & & \\
\hline CHEMBL1498361 & 688239 & 8.3372 & 5.5633 & TST & & & \\
\hline CHEMBL1458377 & 688239 & 5.6362 & 5.5329 & TRN & & & \\
\hline CHEMBL1361326 & 688239 & 8.28399 & 999999999 & 99 & 5.437 & TST & \\
\hline CHEMBL3191579 & 688239 & 6.7862 & 5.3308 & TST & & & \\
\hline CHEMBL1433006 & 688239 & 4.7362 & 5.4218 & TST & & & \\
\hline CHEMBL1602496 & 688239 & 5.4862 & 5.5658 & TRN & & & \\
\hline CHEMBL1349143 & 688239 & 5.8362 & 5.5574 & TRN & & & \\
\hline CHEMBL1496069 & 688239 & 4.9862 & 5.6017 & TRN & & & \\
\hline
\end{tabular}


Supplemental Table S2.txt

\begin{tabular}{|c|c|c|c|c|c|}
\hline CHEMBL1540423 & 688239 & 6.8362 & 5.5222 & TRN & \\
\hline CHEMBL1471216 & 688239 & 4.5362 & 5.5226 & TRN & \\
\hline CHEMBL1505192 & 688239 & 4.7862 & 5.2993 & TRN & \\
\hline CHEMBL1430607 & 688239 & 5.5362 & 5.496 & TRN & \\
\hline CHEMBL1485511 & 688239 & 5.1862 & 5.5134 & TST & \\
\hline CHEMBL 3212798 & 688239 & 8.3372 & 5.5227 & TST & \\
\hline CHEMBL1455988 & 688239 & 6.2862 & 5.50899 & 99999999995 & TRN \\
\hline CHEMBL1432677 & 688239 & 4.9862 & 5.5486 & TRN & \\
\hline CHEMBL1498268 & 688239 & 6.7862 & 5.4623 & TRN & \\
\hline CHEMBL3197762 & 688239 & 4.5362 & 5.4373 & TST & \\
\hline CHEMBL1571623 & 688239 & 4.5362 & 5.5184 & TST & \\
\hline CHEMBL1301284 & 688239 & 4.6862 & 5.5517 & TRN & \\
\hline CHEMBL1503202 & 688239 & 7.9355 & 5.6392 & TST & \\
\hline CHEMBL1598668 & 688239 & 6.8861 & 5.566 & TRN & \\
\hline CHEMBL1456092 & 688239 & 4.5362 & 5.4687 & TRN & \\
\hline CHEMBL1358550 & 688239 & 5.0362 & 5.5257 & TRN & \\
\hline CHEMBL1488844 & 688239 & 5.1862 & 5.455 & TRN & \\
\hline CHEMBL1478995 & 688239 & 5.0862 & 5.6548 & TRN & \\
\hline CHEMBL1527261 & 688239 & 5.8362 & 5.4547 & TRN & \\
\hline CHEMBL1398671 & 688239 & 5.1862 & 5.3146 & TRN & \\
\hline CHEMBL1421210 & 688239 & 6.2362 & 5.4278 & TRN & \\
\hline CHEMBL1307050 & 688239 & 5.9362 & 5.3552 & TRN & \\
\hline CHEMBL1547672 & 688239 & 5.1862 & 5.5649 & TRN & \\
\hline CHEMBL1455860 & 688239 & 4.5362 & 5.4869 & TRN & \\
\hline CHEMBL1466221 & 688239 & 4.5362 & 5.4055 & TRN & \\
\hline CHEMBL1435160 & 688239 & 8.2366 & 5.4547 & TRN & \\
\hline CHEMBL1371438 & 688239 & 6.9363 & 5.391 & TRN & \\
\hline CHEMBL1426150 & 688239 & 4.6362 & 5.4657 & TRN & \\
\hline CHEMBL1505994 & 688239 & 6.7862 & 5.6899 & TRN & \\
\hline CHEMBL3213235 & 688239 & 6.6861 & \multicolumn{2}{|c|}{5.582000000000001} & TST \\
\hline CHEMBL1334327 & 688239 & 6.6861 & 5.4667 & TST & \\
\hline CHEMBL1378542 & 688239 & 5.5362 & 5.4683 & TRN & \\
\hline CHEMBL1452764 & 688239 & 6.8362 & 5.4867 & TRN & \\
\hline CHEMBL1423793 & 688239 & 6.3863 & 5.4985 & TRN & \\
\hline CHEMBL1583996 & 688239 & 7.0362 & 5.5152 & TRN & \\
\hline CHEMBL1600474 & 688239 & 5.9362 & 5.4526 & TST & \\
\hline CHEMBL3189532 & 688239 & 4.5362 & 5.4893 & TRN & \\
\hline CHEMBL1387706 & 688239 & 5.1362 & 5.555 & TRN & \\
\hline CHEMBL1518608 & 688239 & 5.1862 & 5.3777 & TRN & \\
\hline CHEMBL1449477 & 688239 & 8.3372 & 5.4317 & TRN & \\
\hline CHEMBL1589487 & 688239 & 5.3362 & 5.6876 & TST & \\
\hline CHEMBL1353780 & 688239 & 6.1862 & 5.5798 & TRN & \\
\hline CHEMBL1576649 & 688239 & 4.5362 & 5.3562 & TST & \\
\hline CHEMBL1502955 & 688239 & 6.2862 & 5.4375 & TST & \\
\hline CHEMBL1414353 & 688239 & 4.5862 & 5.5486 & TRN & \\
\hline CHEMBL1441178 & 688239 & 4.5362 & 5.4423 & TST & \\
\hline CHEMBL1300925 & 688239 & 5.1862 & 5.5452 & TRN & \\
\hline CHEMBL1982471 & 688239 & 5.6362 & 5.4247 & TRN & \\
\hline
\end{tabular}




\begin{tabular}{|c|c|c|c|c|c|}
\hline & & \multicolumn{4}{|c|}{ Supplemental Table s2.txt } \\
\hline CHEMBL1413885 & 688239 & 4.9862 & 5.4596 & TRN & \\
\hline CHEMBL1416660 & 688239 & 5.6862 & 5.2867 & TRN & \\
\hline CHEMBL1975652 & 688239 & 4.7862 & 5.4305 & TST & \\
\hline CHEMBL1559216 & 688239 & 6.8861 & 5.476 & TRN & \\
\hline CHEMBL1577075 & 688239 & 6.6362 & 5.5191 & TRN & \\
\hline CHEMBL 3211424 & 688239 & 8.28399 & 99999999 & 5.4318 & TST \\
\hline CHEMBL1331252 & 688239 & 5.1862 & 5.4262 & TRN & \\
\hline CHEMBL3193189 & 688239 & 4.7862 & 5.4761 & TRN & \\
\hline CHEMBL1546707 & 688239 & 6.5363 & 5.7049 & TRN & \\
\hline CHEMBL1444316 & 688239 & 5.1862 & 5.5128 & TRN & \\
\hline CHEMBL1457924 & 688239 & 4.4862 & 5.4713 & TRN & \\
\hline CHEMBL1310244 & 688239 & 4.4862 & 5.3817 & TST & \\
\hline CHEMBL1594897 & 688239 & 5.1862 & 5.5746 & TST & \\
\hline CHEMBL1506273 & 688239 & 5.5862 & 5.37299 & 9999999999 & TRN \\
\hline CHEMBL3214097 & 688239 & 4.7362 & 5.4835 & TST & \\
\hline CHEMBL1572107 & 688239 & 4.5362 & 5.3279 & TRN & \\
\hline CHEMBL1406013 & 688239 & 6.0362 & 5.4987 & TRN & \\
\hline CHEMBL1457767 & 688239 & 5.1862 & 5.3462 & TRN & \\
\hline CHEMBL1612113 & 688239 & 5.9362 & 5.4571 & TRN & \\
\hline CHEMBL3214236 & 688239 & 5.1362 & 5.3833 & TRN & \\
\hline CHEMBL3198001 & 688239 & 5.6362 & 5.4549 & TRN & \\
\hline CHEMBL1388754 & 688239 & 6.2862 & 5.4429 & TRN & \\
\hline CHEMBL1378219 & 688239 & 4.9862 & 5.5339 & TST & \\
\hline CHEMBL1485800 & 688239 & 4.9362 & 5.5831 & TRN & \\
\hline CHEMBL1429345 & 688239 & 6.9363 & 5.3816 & TST & \\
\hline CHEMBL1481472 & 688239 & 4.7362 & 5.5 & TRN & \\
\hline CHEMBL1489775 & 688239 & 4.5362 & 5.3641 & TRN & \\
\hline CHEMBL1491025 & 688239 & 4.5362 & 5.486006 & 0000000001 & TST \\
\hline CHEMBL1367838 & 688239 & 5.4862 & 5.417006 & 0000000001 & TST \\
\hline CHEMBL1586639 & 688239 & 4.5362 & 5.3809 & TRN & \\
\hline CHEMBL18492 & 688239 & 6.9863 & 5.5187 & TST & \\
\hline CHEMBL1477692 & 688239 & 4.6862 & 5.4875 & TRN & \\
\hline CHEMBL1395960 & 688239 & 5.4862 & 5.358 & TRN & \\
\hline CHEMBL1427937 & 688239 & 5.1862 & 5.3352 & TRN & \\
\hline CHEMBL1373350 & 688239 & 5.9862 & 5.5037 & TRN & \\
\hline CHEMBL1365263 & 688239 & 6.3362 & 5.5527 & TST & \\
\hline CHEMBL1560858 & 688239 & 4.5362 & 5.6339 & TRN & \\
\hline CHEMBL1422079 & 688239 & 5.7362 & 5.427006 & 00000000005 & TRN \\
\hline CHEMBL1486205 & 688239 & 5.8862 & 5.5402 & TRN & \\
\hline CHEMBL1382699 & 688239 & 4.5362 & 5.5665 & TRN & \\
\hline CHEMBL541521 & 688239 & 5.5862 & 5.652 & TRN & \\
\hline CHEMBL1490747 & 688239 & 5.4862 & 5.3198 & TRN & \\
\hline CHEMBL3212499 & 688239 & 8.3372 & 5.4986 & TST & \\
\hline CHEMBL1405583 & 688239 & 5.4862 & 5.5436 & TRN & \\
\hline CHEMBL1557777 & 688239 & 5.3862 & 5.497006 & 0000000001 & TST \\
\hline CHEMBL1324356 & 688239 & 4.5362 & 5.6079 & TRN & \\
\hline CHEMBL1511868 & 688239 & 7.1361 & 5.5577 & TST & \\
\hline CHEMBL3207491 & 688239 & 6.1862 & 5.386 & TRN & \\
\hline
\end{tabular}




\begin{tabular}{|c|c|c|c|c|c|c|}
\hline & & \multicolumn{5}{|c|}{ Supplemental Table S2.txt } \\
\hline CHEMBL1337952 & 688239 & 7.5361 & 5.5458 & TRN & & \\
\hline CHEMBL1372822 & 688239 & 6.6362 & 5.5674 & TRN & & \\
\hline CHEMBL1459773 & 688239 & 4.4862 & 5.4382 & TST & & \\
\hline CHEMBL1330505 & 688239 & 5.9862 & 5.3824 & TRN & & \\
\hline CHEMBL1560710 & 688239 & 5.5862 & 5.4856 & TRN & & \\
\hline CHEMBL1374441 & 688239 & 6.2 & 5.4164 & TRN & & \\
\hline CHEMBL1339958 & 688239 & 4.5362 & 5.5064 & TRN & & \\
\hline CHEMBL1520808 & 688239 & 5.1862 & 5.5071 & TST & & \\
\hline CHEMBL1580445 & 688239 & 4.5362 & 5.4533 & TST & & \\
\hline CHEMBL1597070 & 688239 & 5.5862 & 5.5359 & TRN & & \\
\hline CHEMBL1611752 & 688239 & 5.5362 & 5.4867 & TRN & & \\
\hline CHEMBL1418250 & 688239 & 6.9863 & 5.474 & TRN & & \\
\hline CHEMBL1586695 & 688239 & 6.7862 & 5.6265 & TRN & & \\
\hline CHEMBL1971634 & 688239 & 4.8862 & 5.3528 & TRN & & \\
\hline CHEMBL1588310 & 688239 & 5.6362 & 5.4133 & TRN & & \\
\hline CHEMBL1479052 & 688239 & 5.1862 & 5.5101 & TRN & & \\
\hline CHEMBL1358155 & 688239 & 5.3862 & 5.5203 & TRN & & \\
\hline CHEMBL1492270 & 688239 & 6.2862 & 5.5521 & TRN & & \\
\hline CHEMBL3199384 & 688239 & 4.7362 & 5.421 & TST & & \\
\hline CHEMBL1524447 & 688239 & 4.6362 & 5.4129 & TRN & & \\
\hline CHEMBL1317996 & 688239 & 4.7362 & 5.3374 & TST & & \\
\hline CHEMBL1358949 & 688239 & 4.5362 & 5.5124 & TRN & & \\
\hline CHEMBL1469136 & 688239 & 4.9362 & 5.5864 & TRN & & \\
\hline CHEMBL1526831 & 688239 & 4.45 & 5.4786 & TRN & & \\
\hline CHEMBL1494297 & 688239 & 4.9362 & 5.5361 & TRN & & \\
\hline CHEMBL1410647 & 688239 & 4.7362 & 5.4306 & TRN & & \\
\hline CHEMBL1605274 & 688239 & 5.1362 & 5.4493 & TRN & & \\
\hline CHEMBL1302807 & 688239 & 5.4362 & 5.5029 & TRN & & \\
\hline CHEMBL1510348 & 688239 & 4.6362 & 5.5611 & TRN & & \\
\hline CHEMBL1544257 & 688239 & 4.5362 & 5.5534 & TST & & \\
\hline CHEMBL1503745 & 688239 & 6.9863 & 5.4184 & TRN & & \\
\hline CHEMBL1320788 & 688239 & 4.5362 & 5.5827 & TRN & & \\
\hline CHEMBL1300908 & 688239 & 4.9862 & 5.3158 & TRN & & \\
\hline CHEMBL1399195 & 688239 & 5.5862 & 5.4315 & TRN & & \\
\hline CHEMBL1477197 & 688239 & 6.2362 & 5.3608 & TRN & & \\
\hline CHEMBL1332282 & 688239 & 5.1862 & 5.4129 & TRN & & \\
\hline CHEMBL1555631 & 688239 & 4.7362 & 5.5595 & TRN & & \\
\hline CHEMBL1435619 & 688239 & 5.1862 & 5.3566 & TST & & \\
\hline CHEMBL1415909 & 688239 & 5.0862 & 5.5768 & TRN & & \\
\hline CHEMBL1344262 & 688239 & 7.2366 & 5.4063 & TST & & \\
\hline CHEMBL1408890 & 688239 & 8.28399 & 999999999 & 99 & 5.5135 & TST \\
\hline CHEMBL1488284 & 688239 & 4.6362 & 5.4091 & TRN & & \\
\hline CHEMBL1368701 & 688239 & 5.7362 & 5.4168 & TST & & \\
\hline CHEMBL1333753 & 688239 & 5.2862 & 5.3397 & TRN & & \\
\hline CHEMBL1534224 & 688239 & 4.5362 & 5.4545 & TRN & & \\
\hline CHEMBL1391593 & 688239 & 4.4862 & 5.3001 & TST & & \\
\hline CHEMBL1578644 & 688239 & 5.1862 & 5.4338 & TRN & & \\
\hline CHEMBL1458005 & 688239 & 5.5362 & 5.5679 & TRN & & \\
\hline
\end{tabular}


Supplemental Table S2.txt

\begin{tabular}{|c|c|c|c|c|}
\hline 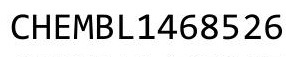 & & & & \\
\hline HEMBL1405867 & 88239 & 1862 & 4636 & \\
\hline HEMBL1460682 & 88239 & 3362 & & \\
\hline IEMBL1 & & & & \\
\hline EMBL14 & & 62 & 446 & \\
\hline HEMBL1399112 & 88239 & 862 & 6123 & \\
\hline HEMBL1534338 & 88239 & 4.6862 & .4902 & \\
\hline HEMBL13 & & 362 & 5041 & \\
\hline AEMBL135 & 39 & 862 & .4084 & \\
\hline EMBL15 & 39 & 362 & .46 & \\
\hline HEMBL1467637 & 88239 & 362 & .3298 & \\
\hline HEMBL1359132 & 39 & 362 & .4368 & \\
\hline HEMBL131 & 39 & 364 & 4618 & \\
\hline HEMBL15 & 39 & 862 & .5784 & \\
\hline AEMBL15 & 39 & 871 & .5201 & \\
\hline HEMBL 200 & 39 & 862 & 4604 & \\
\hline HEMBL 200 & 39 & 363 & 5.6113 & \\
\hline HEMBL 15 & 9 & 62 & 06 & \\
\hline HEMBL14 & 9 & & 18 & \\
\hline AEMBL14 & 39 & 62 & 974 & \\
\hline HEMBL15 & 39 & 363 & 3682 & \\
\hline HEMBL199 & 39 & & & \\
\hline HEMBL 58 & 9 & 862 & 55 & \\
\hline HEMBL13 & & 362 & 99 & \\
\hline HEM & 39 & 362 & 5.4571 & \\
\hline HEMBL 32 & 39 & 362 & & \\
\hline AEMBL14 & 39 & & 782 & RN \\
\hline HEMBL13 & 9 & 362 & 177 & \\
\hline HEM & 9 & 52 & & RN \\
\hline 75 & 39 & 62 & 848 & RN \\
\hline HEMBL13 & 9 & 61 & & RN \\
\hline HEMBL151 & 39 & 362 & & ГRN \\
\hline AEMBL3 & & 72 & & KIV \\
\hline HFM & 9 & 62 & 37 & RN \\
\hline HEMBL32 & & & 5301 & RN \\
\hline HEMBL1538926 & 39 & & 792 & $\mathrm{RN}$ \\
\hline HEMBL1451394 & 39 & 362 & & RN \\
\hline ILT & & & & I \\
\hline 76 & 39 & 62 & 52 & RIN \\
\hline HEMBL15 & & & & $\mathrm{RN}$ \\
\hline HEMBL130 & 88239 & 362 & 5.4106 & RN \\
\hline HEMBL16€ & 39 & 62 & 5.5128 & ST \\
\hline HEM & & & & \\
\hline CHEMBL1413318 & 88239 & & 5.5518 & ST \\
\hline HEMBL 14 & & & 5.6512 & $\mathrm{RN}$ \\
\hline HEMBL339 & 88 & 362 & 5.4128 & $\mathrm{~T}$ \\
\hline HEMBL 142 & & & & \\
\hline HFMRI 141940 & & סת & & \\
\hline
\end{tabular}

Page 2278 
Supplemental Table S2.txt

\begin{tabular}{|c|c|c|c|c|c|c|}
\hline CHEMBL1475704 & 688239 & 5.5862 & 5.4846 & TRN & & \\
\hline CHEMBL1394958 & 688239 & 4.4862 & 5.5189 & TRN & & \\
\hline CHEMBL1429471 & 688239 & 5.1362 & 5.5382 & TRN & & \\
\hline CHEMBL1472987 & 688239 & 4.5362 & 5.4395 & TRN & & \\
\hline CHEMBL1437853 & 688239 & 4.5362 & 5.5564 & TRN & & \\
\hline CHEMBL1443166 & 688239 & 6.9363 & 5.319 & TRN & & \\
\hline CHEMBL1559449 & 688239 & 6.7361 & 5.6361 & TST & & \\
\hline CHEMBL1447571 & 688239 & 5.5862 & 5.4882 & TRN & & \\
\hline CHEMBL1370069 & 688239 & 4.6862 & 5.54299 & 79999999 & TST & \\
\hline CHEMBL3209119 & 688239 & 7.5361 & 5.5024 & TST & & \\
\hline CHEMBL1487291 & 688239 & 6.2362 & 5.5983 & TRN & & \\
\hline CHEMBL1579902 & 688239 & 5.8862 & 5.489 & TST & & \\
\hline CHEMBL1545836 & 688239 & 5.9362 & 5.4284 & TRN & & \\
\hline CHEMBL1459409 & 688239 & 4.5362 & 5.5388 & TST & & \\
\hline CHEMBL1500864 & 688239 & 8.3872 & 5.4148 & TRN & & \\
\hline CHEMBL1397324 & 688239 & 5.1862 & 5.5922 & TRN & & \\
\hline CHEMBL1592565 & 688239 & 4.5862 & 5.5489 & TRN & & \\
\hline CHEMBL1541698 & 688239 & 4.5362 & 5.4143 & TST & & \\
\hline CHEMBL1401387 & 688239 & 4.6362 & 5.5701 & TRN & & \\
\hline CHEMBL1568339 & 688239 & 5.1862 & 5.6552 & TST & & \\
\hline CHEMBL1595882 & 688239 & 4.5362 & 5.5355 & TST & & \\
\hline CHEMBL1336753 & 688239 & 5.0862 & 5.5248 & TRN & & \\
\hline CHEMBL3212647 & 688239 & 4.5862 & 5.4594 & TRN & & \\
\hline CHEMBL1443221 & 688239 & 4.7862 & 5.4716 & TRN & & \\
\hline CHEMBL1555595 & 688239 & \multicolumn{3}{|c|}{8.283999999999999} & 5.5889999999999995 & TRN \\
\hline CHEMBL1299289 & 688239 & 5.9362 & 5.4921 & TRN & & \\
\hline CHEMBL1499414 & 688239 & 5.1362 & 5.5335 & TST & & \\
\hline CHEMBL1342444 & 688239 & 4.5362 & 5.4913 & TRN & & \\
\hline CHEMBL1477628 & 688239 & 4.6862 & 5.4543 & TST & & \\
\hline CHEMBL 3195484 & 688239 & 4.9362 & 5.4341 & TST & & \\
\hline CHEMBL1498726 & 688239 & 8.3372 & 5.541 & TRN & & \\
\hline CHEMBL1373049 & 688239 & 4.5362 & 5.4747 & TRN & & \\
\hline CHEMBL1400182 & 688239 & 6.2862 & 5.4046 & TRN & & \\
\hline CHEMBL1476041 & 688239 & 4.5362 & 5.4941 & TST & & \\
\hline CHEMBL1320691 & 688239 & 7.4868 & 5.5336 & TRN & & \\
\hline CHEMBL1343965 & 688239 & 4.5362 & 5.599 & TRN & & \\
\hline CHEMBL1573302 & 688239 & 4.4862 & 5.4907 & TST & & \\
\hline CHEMBL1402092 & 688239 & 5.1862 & 5.6184 & TST & & \\
\hline CHEMBL1519526 & 688239 & 7.0362 & 5.4577 & TRN & & \\
\hline CHEMBL1380866 & 688239 & 5.1862 & 5.5317 & TRN & & \\
\hline CHEMBL1563275 & 688239 & 5.0362 & 5.4294 & TRN & & \\
\hline CHEMBL1604162 & 688239 & 5.2362 & 5.5521 & TST & & \\
\hline CHEMBL1487901 & 688239 & 4.7862 & 5.4236 & TRN & & \\
\hline CHEMBL1514031 & 688239 & 4.7862 & 5.3818 & TST & & \\
\hline CHEMBL1356878 & 688239 & 5.9362 & 5.4329 & TRN & & \\
\hline CHEMBL1516412 & 688239 & 5.8362 & 5.5457 & TST & & \\
\hline CHEMBL494252 & 688239 & 4.6362 & 5.4548 & TST & & \\
\hline CHEMBL1342656 & 688239 & 7.0362 & 5.5073 & TST & & \\
\hline
\end{tabular}

Page 2279 
Supplemental Table S2.txt

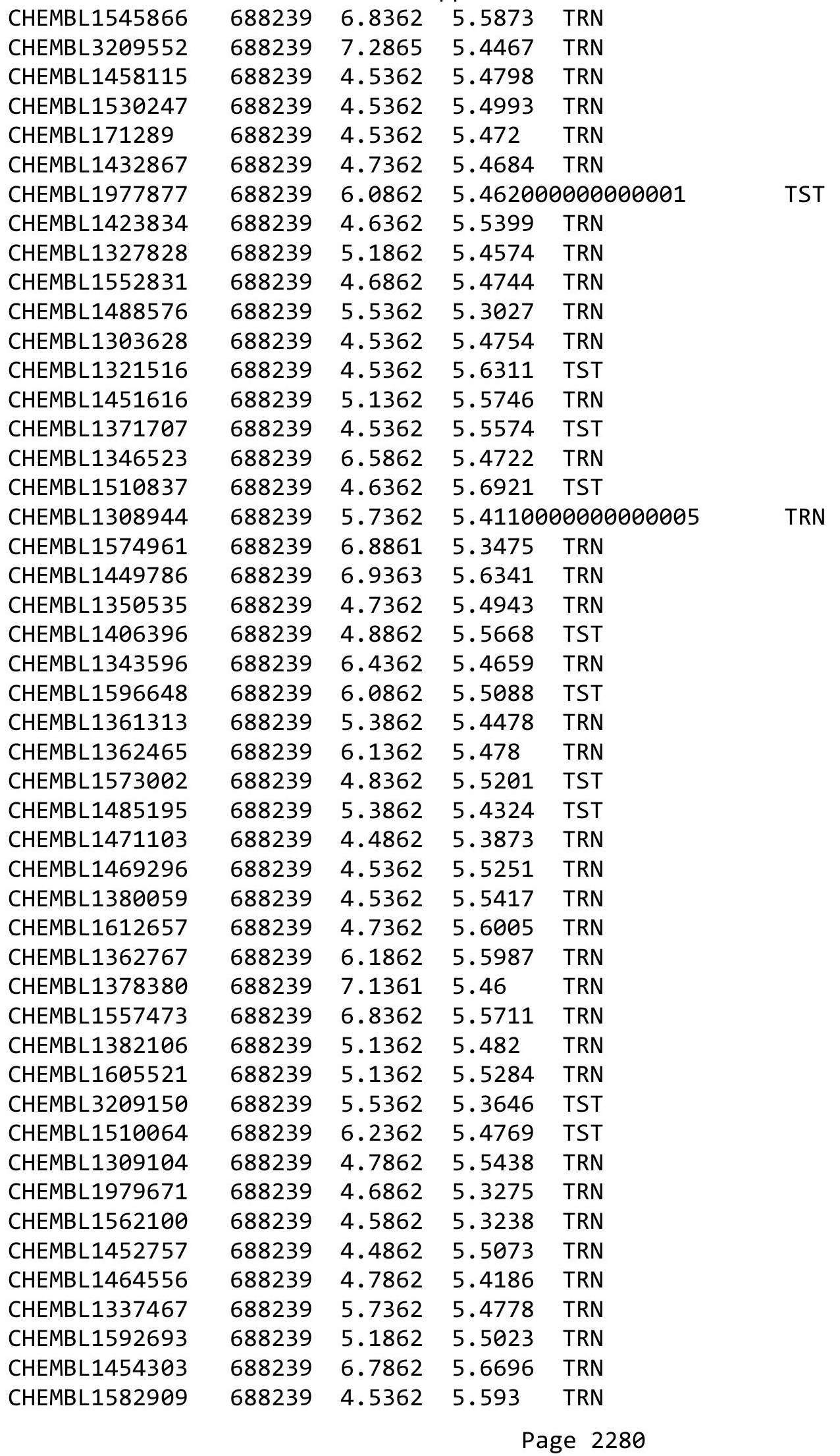




\begin{tabular}{|c|c|c|c|c|c|c|}
\hline & & \multicolumn{5}{|c|}{ Supplemental Table S2.txt } \\
\hline CHEMBL1333069 & 688239 & 6.2862 & \multicolumn{3}{|c|}{5.337000000000001} & TST \\
\hline CHEMBL1352895 & 688239 & 7.0362 & 5.4786 & TRN & & \\
\hline CHEMBL1589413 & 688239 & 6.1362 & 5.4364 & TST & & \\
\hline CHEMBL1547164 & 688239 & 4.5362 & 5.3683 & TRN & & \\
\hline CHEMBL3198266 & 688239 & 4.7862 & \multicolumn{3}{|c|}{5.428999999999999} & TRN \\
\hline CHEMBL1420711 & 688239 & 5.4362 & 5.4132 & TRN & & \\
\hline CHEMBL1320514 & 688239 & 5.8362 & 5.551 & TST & & \\
\hline CHEMBL1423551 & 688239 & 5.7362 & 5.5361 & TRN & & \\
\hline CHEMBL1505780 & 688239 & 4.8362 & 5.3924 & TST & & \\
\hline CHEMBL1300007 & 688239 & 6.1862 & 5.4685 & TRN & & \\
\hline CHEMBL1552687 & 688239 & 5.0362 & 5.4189 & TRN & & \\
\hline CHEMBL1589333 & 688239 & 4.7862 & 5.4829 & TRN & & \\
\hline CHEMBL1425438 & 688239 & 5.8362 & 5.3682 & TRN & & \\
\hline CHEMBL1451573 & 688239 & 4.6862 & 5.4413 & TRN & & \\
\hline CHEMBL1473339 & 688239 & 4.6862 & 5.5314 & TRN & & \\
\hline CHEMBL1402551 & 688239 & 5.2362 & 5.54299 & 9999999999 & & TRN \\
\hline CHEMBL1488460 & 688239 & 6.0862 & 5.5447 & TRN & & \\
\hline CHEMBL1602538 & 688239 & 6.5862 & 5.5339 & TRN & & \\
\hline CHEMBL1397152 & 688239 & 4.5362 & 5.3468 & TST & & \\
\hline CHEMBL1593245 & 688239 & \multicolumn{3}{|c|}{8.283999999999999} & 5.5011 & TRN \\
\hline CHEMBL1403416 & 688239 & 4.5362 & 5.4105 & TRN & & \\
\hline CHEMBL1585202 & 688239 & 4.7862 & 5.5235 & TST & & \\
\hline CHEMBL1576003 & 688239 & 5.1862 & 5.4457 & TRN & & \\
\hline CHEMBL1365362 & 688239 & 4.7362 & 5.6006 & TRN & & \\
\hline CHEMBL1583953 & 688239 & 5.1362 & 5.4837 & TST & & \\
\hline CHEMBL1397284 & 688239 & 4.7862 & 5.5218 & TRN & & \\
\hline CHEMBL1334307 & 688239 & 4.5362 & 5.4869 & TST & & \\
\hline CHEMBL52101 & 688239 & 4.6862 & 5.3787 & TRN & & \\
\hline CHEMBL1509258 & 688239 & 5.7362 & 5.4531 & TRN & & \\
\hline CHEMBL1604610 & 688239 & 4.5362 & 5.6059 & TST & & \\
\hline CHEMBL1384029 & 688239 & 5.5862 & 5.6073 & TRN & & \\
\hline CHEMBL1495190 & 688239 & 5.1862 & 5.3877 & TRN & & \\
\hline CHEMBL1413120 & 688239 & 4.5362 & 5.3046 & TST & & \\
\hline CHEMBL1566100 & 688239 & 5.5862 & 5.5406 & TRN & & \\
\hline CHEMBL1363363 & 688239 & 4.8862 & 5.4898 & TRN & & \\
\hline CHEMBL1610163 & 688239 & 4.5362 & 5.4796 & TRN & & \\
\hline CHEMBL 1374520 & 688239 & 4.5362 & 5.4871 & TRN & & \\
\hline CHEMBL1359000 & 688239 & 7.0362 & 5.5668 & TRN & & \\
\hline CHEMBL1553643 & 688239 & 4.7362 & 5.3989 & TRN & & \\
\hline CHEMBL1478184 & 688239 & 5.1862 & 5.4074 & TRN & & \\
\hline CHEMBL1509691 & 688239 & 8.3372 & 5.4849 & TRN & & \\
\hline CHEMBL1556108 & 688239 & 6.1862 & 5.443 & TST & & \\
\hline CHEMBL1379995 & 688239 & 5.5862 & 5.5496 & TST & & \\
\hline CHEMBL1340134 & 688239 & 4.6362 & 5.3955 & TST & & \\
\hline CHEMBL1373938 & 688239 & 5.6862 & 5.3072 & TST & & \\
\hline CHEMBL1348937 & 688239 & 4.7862 & 5.3988 & TST & & \\
\hline CHEMBL 1303752 & 688239 & 6.0362 & 5.5138 & TST & & \\
\hline CHEMBL1464300 & 688239 & 6.4362 & 5.3817 & TRN & & \\
\hline
\end{tabular}


Supplemental Table S2.txt

\begin{tabular}{|c|c|c|c|c|}
\hline CHEMBL1571314 & 688239 & 5.1862 & 5.4897 & TRN \\
\hline CHEMBL1353616 & 688239 & 5.7362 & 5.5324 & TRN \\
\hline CHEMBL1306111 & 688239 & 5.0862 & 5.5504 & TST \\
\hline CHEMBL1456799 & 688239 & 5.0362 & 5.3134 & TRN \\
\hline CHEMBL1491338 & 688239 & 5.4862 & 5.5309 & TRN \\
\hline CHEMBL1331848 & 688239 & 7.3862 & 5.5394 & TRN \\
\hline CHEMBL1415509 & 688239 & 6.1362 & 5.4755 & TST \\
\hline CHEMBL1540959 & 688239 & 4.5362 & 5.5685 & TRN \\
\hline CHEMBL1340999 & 688239 & 5.3362 & 5.432 & TRN \\
\hline CHEMBL1453220 & 688239 & 6.9863 & 5.4099 & TST \\
\hline CHEMBL1375387 & 688239 & 5.1862 & 5.472 & TRN \\
\hline CHEMBL1606763 & 688239 & 7.1864 & 5.4891 & TRN \\
\hline CHEMBL1419609 & 688239 & 4.9862 & 5.5698 & TST \\
\hline CHEMBL1426653 & 688239 & 4.5362 & 5.6757 & TRN \\
\hline CHEMBL1486263 & 688239 & 5.4362 & 5.416 & TST \\
\hline CHEMBL3214282 & 688239 & 6.0862 & 5.5918 & TRN \\
\hline CHEMBL1594253 & 688239 & 6.8861 & 5.5601 & TRN \\
\hline CHEMBL1405704 & 688239 & 6.1862 & 5.4807 & TRN \\
\hline CHEMBL1442392 & 688239 & 4.4862 & 5.3784 & TST \\
\hline CHEMBL1313021 & 688239 & 5.1862 & 5.4477 & TRN \\
\hline CHEMBL1449322 & 688239 & 6.8362 & 5.4689 & TRN \\
\hline CHEMBL1480520 & 688239 & 4.5362 & 5.5436 & TRN \\
\hline CHEMBL1434990 & 688239 & 5.7362 & 5.4699 & TRN \\
\hline CHEMBL1447217 & 688239 & 5.6862 & 5.4309 & TRN \\
\hline CHEMBL1488186 & 688239 & 4.7362 & 5.5049 & TST \\
\hline CHEMBL1520945 & 688239 & 6.2362 & 5.4696 & TRN \\
\hline CHEMBL1335846 & 688239 & 5.8362 & 5.38200 & 3000000001 \\
\hline CHEMBL1609584 & 688239 & 5.6862 & 5.3729 & TRN \\
\hline CHEMBL1460067 & 688239 & 4.5362 & 5.5201 & TST \\
\hline CHEMBL179512 & 688239 & 4.8362 & 5.3833 & TRN \\
\hline CHEMBL1529408 & 688239 & 8.3372 & 5.4777 & TRN \\
\hline CHEMBL1380670 & 688239 & 7.0362 & 5.4457 & TST \\
\hline CHEMBL1453461 & 688239 & 4.4862 & 5.585 & TRN \\
\hline CHEMBL3214285 & 688239 & 4.5362 & 5.4267 & TST \\
\hline CHEMBL1317771 & 688239 & 4.7362 & 5.5211 & TRN \\
\hline CHEMBL1429003 & 688239 & 4.6362 & 5.3853 & TRN \\
\hline CHEMBL1579765 & 688239 & 6.1362 & 5.4833 & TRN \\
\hline CHEMBL1462402 & 688239 & 4.8862 & 5.3033 & TST \\
\hline CHEMBL1466628 & 688239 & 5.0362 & 5.4303 & TRN \\
\hline CHEMBL1563340 & 688239 & 4.5362 & 5.3982 & TRN \\
\hline CHEMBL1477565 & 688239 & 4.9862 & 5.5935 & TRN \\
\hline CHEMBL1574468 & 688239 & 5.9862 & 5.477 & TST \\
\hline CHEMBL1581560 & 688239 & 5.5862 & 5.4682 & TST \\
\hline CHEMBL578487 & 688239 & 5.2362 & 5.3689 & TRN \\
\hline CHEMBL1483340 & 688239 & 5.3862 & 5.5238 & TST \\
\hline CHEMBL1460869 & 688239 & 5.6362 & 5.4444 & TRN \\
\hline CHEMBL1523968 & 688239 & 5.1862 & 5.3933 & TRN \\
\hline CHEMBL3213170 & 688239 & 5.6362 & 5.4317 & TRN \\
\hline
\end{tabular}


Supplemental Table S2.txt

\begin{tabular}{|c|c|c|c|c|c|}
\hline CHEMBL1338119 & 688239 & 5.1862 & 5.4474 & TRN & \\
\hline CHEMBL1996757 & 688239 & 4.4862 & 5.2974 & TST & \\
\hline CHEMBL1581688 & 688239 & 6.1362 & 5.4668 & TRN & \\
\hline CHEMBL1573034 & 688239 & 6.0862 & 5.5462 & TRN & \\
\hline CHEMBL1458022 & 688239 & 4.8862 & 5.5524 & TST & \\
\hline CHEMBL1352706 & 688239 & 5.5 & 5.4884 & TRN & \\
\hline CHEMBL518634 & 688239 & 5.1362 & 5.4741 & TRN & \\
\hline CHEMBL1310132 & 688239 & 4.7362 & 5.5047 & TRN & \\
\hline CHEMBL1596070 & 688239 & 6.0862 & 5.3968 & TRN & \\
\hline CHEMBL1529402 & 688239 & 6.8362 & 5.5519 & TST & \\
\hline CHEMBL1299901 & 688239 & 5.2362 & 5.4093 & TST & \\
\hline CHEMBL1435228 & 688239 & 4.5362 & 5.4574 & TST & \\
\hline CHEMBL1420175 & 688239 & 5.2862 & 5.4816 & TST & \\
\hline CHEMBL1505761 & 688239 & 5.1862 & 5.4418 & TRN & \\
\hline CHEMBL1325356 & 688239 & 6.2362 & 5.6923 & TST & \\
\hline CHEMBL1419490 & 688239 & 5.4362 & 5.4557 & TRN & \\
\hline CHEMBL1366446 & 688239 & 5.2362 & 5.4045 & TRN & \\
\hline CHEMBL1361231 & 688239 & 5.1862 & 5.4909 & TRN & \\
\hline CHEMBL1547653 & 688239 & 6.4362 & 5.7257 & TRN & \\
\hline CHEMBL1508610 & 688239 & 5.3862 & 5.5345 & TRN & \\
\hline CHEMBL1495040 & 688239 & 5.0862 & 5.5207 & TRN & \\
\hline CHEMBL1594999 & 688239 & 6.2862 & 5.5473 & TRN & \\
\hline CHEMBL1602981 & 688239 & 6.2362 & 5.4291 & TRN & \\
\hline CHEMBL1403210 & 688239 & 4.5362 & 5.4895 & TRN & \\
\hline CHEMBL1354984 & 688239 & 5.0862 & 5.6029 & TRN & \\
\hline CHEMBL1565417 & 688239 & 5.6862 & 5.6344 & TST & \\
\hline CHEMBL1462687 & 688239 & 5.7362 & 5.3394 & TRN & \\
\hline CHEMBL1539863 & 688239 & 4.9362 & 5.3331 & TRN & \\
\hline CHEMBL1300169 & 688239 & 4.7862 & 5.3922 & TRN & \\
\hline CHEMBL1321310 & 688239 & 5.1862 & 5.4911 & TRN & \\
\hline CHEMBL1413555 & 688239 & 7.0362 & 5.6219 & TRN & \\
\hline CHEMBL1473675 & 688239 & 6.8362 & 5.5685 & TRN & \\
\hline CHEMBL1434788 & 688239 & 6.3863 & 5.5953 & TRN & \\
\hline CHEMBL1306408 & 688239 & 8.3372 & 5.6748 & TRN & \\
\hline CHEMBL3207856 & 688239 & 5.7362 & 5.4227 & TRN & \\
\hline CHEMBL1571764 & 688239 & 6.8861 & 5.4893 & TRN & \\
\hline CHEMBL1305088 & 688239 & 4.7362 & 5.4276 & TRN & \\
\hline CHEMBL1507082 & 688239 & 6.6362 & 5.5379 & TRN & \\
\hline CHEMBL1301632 & 688239 & 4.6362 & 5.4321 & TRN & \\
\hline CHEMBL1493547 & 688239 & 4.5362 & 5.3771 & TST & \\
\hline CHEMBL1488277 & 688239 & 8.28399 & 99999999 & 99 & 5.6471 \\
\hline CHEMBL1507708 & 688239 & 4.6862 & 5.4772 & TRN & \\
\hline CHEMBL1449356 & 688239 & 6.0362 & 5.4653 & TRN & \\
\hline CHEMBL1505671 & 688239 & 7.2366 & 5.4361 & TST & \\
\hline CHEMBL1427629 & 688239 & 5.4862 & 5.4778 & TRN & \\
\hline CHEMBL1523867 & 688239 & 5.1862 & 5.3761 & TRN & \\
\hline CHEMBL1316967 & 688239 & 5.1862 & 5.5628 & TRN & \\
\hline CHEMBL1480435 & 688239 & 7.2865 & 5.5988 & TRN & \\
\hline
\end{tabular}




\begin{tabular}{|c|c|c|c|c|c|}
\hline \multicolumn{6}{|c|}{ Supplemental Table S2.txt } \\
\hline CHEMBL1425448 & 688239 & 4.7862 & 5.5929 & TRN & \\
\hline CHEMBL1432811 & 688239 & 6.7862 & 5.6679 & TRN & \\
\hline CHEMBL1332886 & 688239 & 4.6862 & 5.3988 & TST & \\
\hline CHEMBL1430546 & 688239 & 5.4362 & 5.4905 & TST & \\
\hline CHEMBL1535379 & 688239 & 7.0362 & 5.55399 & 9999999999 & TRN \\
\hline CHEMBL1418838 & 688239 & 5.4362 & 5.5964 & TRN & \\
\hline CHEMBL1533597 & 688239 & 5.1862 & 5.6 & TRN & \\
\hline CHEMBL1522100 & 688239 & 6.3863 & 5.6268 & TST & \\
\hline CHEMBL1439958 & 688239 & 4.6862 & 5.5356 & TRN & \\
\hline CHEMBL1318952 & 688239 & 4.5362 & 5.4526 & TRN & \\
\hline CHEMBL1300343 & 688239 & 6.4862 & 5.71899 & 9999999999 & TRN \\
\hline CHEMBL1586433 & 688239 & 6.1862 & 5.4556 & TST & \\
\hline CHEMBL1398054 & 688239 & 4.6862 & 5.5684 & TST & \\
\hline CHEMBL1594604 & 688239 & 4.7362 & 5.2102 & TRN & \\
\hline CHEMBL1529246 & 688239 & 4.6862 & 5.49100 & 00000000005 & TRN \\
\hline CHEMBL1489631 & 688239 & 5.4362 & 5.4326 & TRN & \\
\hline CHEMBL1585227 & 688239 & 5.25 & 5.53700 & 0000000001 & TRN \\
\hline CHEMBL1410430 & 688239 & 4.5362 & 5.4691 & TRN & \\
\hline CHEMBL1369846 & 688239 & 4.5362 & 5.4948 & TRN & \\
\hline CHEMBL11908 & 688239 & 4.5362 & 5.4726 & TRN & \\
\hline CHEMBL1470690 & 688239 & 5.1862 & 5.5229 & TRN & \\
\hline CHEMBL1892270 & 688239 & 4.6862 & 5.36 & TRN & \\
\hline CHEMBL1547450 & 688239 & 4.7862 & 5.3603 & TRN & \\
\hline CHEMBL1532735 & 688239 & 4.5362 & 5.4814 & TST & \\
\hline CHEMBL1578044 & 688239 & 6.2862 & 5.5415 & TRN & \\
\hline CHEMBL1524602 & 688239 & 5.1362 & 5.5026 & TST & \\
\hline CHEMBL1359758 & 688239 & 5.1862 & 5.5899 & TRN & \\
\hline CHEMBL1415090 & 688239 & 5.1862 & 5.4352 & TRN & \\
\hline CHEMBL1531244 & 688239 & 6.1862 & 5.5232 & TRN & \\
\hline CHEMBL1588911 & 688239 & 6.2362 & 5.3765 & TRN & \\
\hline CHEMBL1349397 & 688239 & 4.5362 & 5.5513 & TST & \\
\hline CHEMBL1400842 & 688239 & 5.5862 & 5.5422 & TRN & \\
\hline CHEMBL1502823 & 688239 & 6.1862 & 5.4996 & TST & \\
\hline CHEMBL1493958 & 688239 & 6.5363 & 5.4156 & TST & \\
\hline CHEMBL1500948 & 688239 & 6.9863 & 5.5125 & TRN & \\
\hline CHEMBL1529418 & 688239 & 5.6862 & 5.345 & TRN & \\
\hline CHEMBL1336269 & 688239 & 6.0362 & 5.4537 & TRN & \\
\hline CHEMBL1528638 & 688239 & 5.0862 & 5.5565 & TRN & \\
\hline CHEMBL608397 & 688239 & 4.8862 & 5.5481 & TRN & \\
\hline CHEMBL1571574 & 688239 & 6.1362 & 5.4932 & TRN & \\
\hline CHEMBL1317023 & 688239 & 6.1862 & 5.4357 & TRN & \\
\hline CHEMBL1481640 & 688239 & 5.3362 & 5.4769 & TRN & \\
\hline CHEMBL1408769 & 688239 & 5.0862 & 5.5249 & TST & \\
\hline CHEMBL1309312 & 688239 & 4.9362 & 5.4032 & TRN & \\
\hline CHEMBL1335687 & 688239 & 4.8362 & 5.4087 & TRN & \\
\hline CHEMBL1330486 & 688239 & 4.5862 & 5.4791 & TRN & \\
\hline CHEMBL1310799 & 688239 & 6.0862 & 5.5707 & TRN & \\
\hline CHEMBL1451419 & 688239 & 6.0862 & 5.5159 & TST & \\
\hline
\end{tabular}




\begin{tabular}{|c|c|c|c|c|c|}
\hline \multicolumn{6}{|c|}{ Supplemental Table S2.txt } \\
\hline CHEMBL1421193 & 688239 & 6.7361 & 5.6599 & TRN & \\
\hline CHEMBL1313741 & 688239 & 4.7362 & 5.3948 & TRN & \\
\hline CHEMBL3195356 & 688239 & 4.5362 & 5.3899 & TRN & \\
\hline CHEMBL1580181 & 688239 & 6.1862 & 5.3531 & TRN & \\
\hline CHEMBL1491346 & 688239 & 6.8861 & 5.4744 & TRN & \\
\hline CHEMBL1533262 & 688239 & 6.5862 & 5.4813 & TST & \\
\hline CHEMBL1452461 & 688239 & 4.7862 & 5.54200 & 0000000001 & TRN \\
\hline CHEMBL1301989 & 688239 & 5.3362 & 5.3853 & TST & \\
\hline CHEMBL1608368 & 688239 & 6.0362 & 5.6472 & TRN & \\
\hline CHEMBL 1607220 & 688239 & 6.1862 & 5.5617 & TRN & \\
\hline CHEMBL1546519 & 688239 & 5.0862 & 5.4758 & TST & \\
\hline CHEMBL1302298 & 688239 & 6.9863 & 5.5677 & TRN & \\
\hline CHEMBL1568406 & 688239 & 4.8362 & 5.4741 & TRN & \\
\hline CHEMBL1299199 & 688239 & 4.7862 & 5.4307 & TRN & \\
\hline CHEMBL1333544 & 688239 & 5.7362 & 5.4946 & TRN & \\
\hline CHEMBL1329570 & 688239 & 4.9862 & 5.5099 & TRN & \\
\hline CHEMBL1335986 & 688239 & 4.7862 & 5.3624 & TRN & \\
\hline CHEMBL1371796 & 688239 & 6.8861 & 5.5302 & TRN & \\
\hline CHEMBL1321954 & 688239 & 7.2366 & 5.5609 & TRN & \\
\hline CHEMBL1386618 & 688239 & 5.3862 & 5.4717 & TRN & \\
\hline CHEMBL1596456 & 688239 & 6.3 & 5.3537 & TRN & \\
\hline CHEMBL1437751 & 688239 & 6.8362 & 5.4263 & TST & \\
\hline CHEMBL1538520 & 688239 & 5.1362 & 5.5619 & TST & \\
\hline CHEMBL1386840 & 688239 & 6.2862 & 5.556 & TRN & \\
\hline CHEMBL1377094 & 688239 & 4.5362 & 5.5826 & TST & \\
\hline CHEMBL1418609 & 688239 & 5.2362 & 5.438 & TRN & \\
\hline CHEMBL3189508 & 688239 & 5.2362 & 5.4789 & TST & \\
\hline CHEMBL1447755 & 688239 & 6.2362 & 5.4801 & TRN & \\
\hline CHEMBL1422612 & 688239 & 4.5362 & 5.5484 & TST & \\
\hline CHEMBL1300450 & 688239 & 4.7362 & 5.394 & TRN & \\
\hline CHEMBL1564307 & 688239 & 4.5362 & 5.44 & TST & \\
\hline CHEMBL1487058 & 688239 & 8.3372 & 5.5613 & TRN & \\
\hline CHEMBL1613627 & 688239 & 4.5362 & 5.4834 & TRN & \\
\hline CHEMBL1566785 & 688239 & 8.3372 & 5.5003 & TST & \\
\hline CHEMBL1589254 & 688239 & 5.5862 & 5.6358 & TRN & \\
\hline CHEMBL1531889 & 688239 & 6.1362 & 5.3706 & TRN & \\
\hline CHEMBL1516020 & 688239 & 4.5362 & 5.4882 & TST & \\
\hline CHEMBL3190669 & 688239 & 4.6362 & 5.5088 & TRN & \\
\hline CHEMBL1488894 & 688239 & 5.4862 & 5.3575 & TRN & \\
\hline CHEMBL1373056 & 688239 & 4.5362 & 5.4913 & TRN & \\
\hline CHEMBL1341540 & 688239 & 4.5362 & 5.2333 & TRN & \\
\hline CHEMBL1541863 & 688239 & 6.8362 & 5.3557 & TRN & \\
\hline CHEMBL1396316 & 688239 & 6.2362 & 5.5301 & TRN & \\
\hline CHEMBL1365633 & 688239 & 4.6862 & 5.4169 & TRN & \\
\hline CHEMBL3194407 & 688239 & 6.8362 & 5.3207 & TRN & \\
\hline CHEMBL1303468 & 688239 & 5.1862 & 5.3784 & TST & \\
\hline CHEMBL1466568 & 688239 & 5.9862 & 5.6304 & TRN & \\
\hline CHEMBL1382587 & 688239 & 6.9363 & 5.4249 & TRN & \\
\hline
\end{tabular}


Supplemental Table S2.txt

\begin{tabular}{|c|c|c|c|c|c|c|}
\hline CHEMBL1501310 & 688239 & 8.3372 & 5.3846 & TRN & & \\
\hline CHEMBL1318030 & 688239 & 4.6862 & 5.4932 & TST & & \\
\hline CHEMBL1256147 & 688239 & 4.5362 & 5.5944 & TST & & \\
\hline CHEMBL3211696 & 688239 & 4.6362 & 5.6967 & TRN & & \\
\hline CHEMBL1404489 & 688239 & 4.7362 & 5.5706 & TRN & & \\
\hline CHEMBL1370180 & 688239 & 4.8862 & 5.6443 & TRN & & \\
\hline CHEMBL1514133 & 688239 & 5.7862 & 5.5445 & TRN & & \\
\hline CHEMBL1601857 & 688239 & 5.1862 & 5.3896 & TRN & & \\
\hline CHEMBL1321685 & 688239 & 5.0362 & 5.4908 & TRN & & \\
\hline CHEMBL1555604 & 688239 & 5.1862 & 5.4442 & TRN & & \\
\hline CHEMBL1393521 & 688239 & 5.1862 & 5.4423 & TRN & & \\
\hline CHEMBL1382690 & 688239 & 4.5362 & 5.3746 & TRN & & \\
\hline CHEMBL1316211 & 688239 & 7.2366 & 5.4351 & TRN & & \\
\hline CHEMBL1516146 & 688239 & 6.1862 & 5.4349 & TST & & \\
\hline CHEMBL1381678 & 688239 & 5.1362 & 5.5352 & TRN & & \\
\hline CHEMBL1345563 & 688239 & 5.1862 & 5.5515 & TRN & & \\
\hline CHEMBL3212831 & 688239 & 5.1362 & 5.4949 & TRN & & \\
\hline CHEMBL1376874 & 688239 & 5.7362 & 5.6309 & TRN & & \\
\hline CHEMBL1430017 & 688239 & 5.1862 & 5.6465 & TRN & & \\
\hline CHEMBL1550488 & 688239 & 5.6862 & 5.5901 & TST & & \\
\hline CHEMBL1555060 & 688239 & 4.7362 & 5.2359 & TRN & & \\
\hline CHEMBL1368396 & 688239 & 6.6861 & 5.5345 & TRN & & \\
\hline CHEMBL 1478554 & 688239 & 4.7862 & 5.6405 & TRN & & \\
\hline CHEMBL1312400 & 688239 & 4.7862 & 5.4051 & TRN & & \\
\hline CHEMBL1595157 & 688239 & 4.6362 & 5.4556 & TRN & & \\
\hline CHEMBL1469172 & 688239 & 5.9362 & 5.4225 & TRN & & \\
\hline CHEMBL1376588 & 688239 & 6.5862 & 5.5639 & TST & & \\
\hline CHEMBL1487879 & 688239 & 7.0362 & 5.5069 & TRN & & \\
\hline CHEMBL1547393 & 688239 & 8.28399 & 99999999 & 99 & 5.485 & Tा \\
\hline CHEMBL 3209380 & 688239 & 5.0862 & 5.4887 & TRN & & \\
\hline CHEMBL1311294 & 688239 & 6.7862 & 5.5874 & TRN & & \\
\hline CHEMBL1470562 & 688239 & 5.6362 & 5.3391 & TRN & & \\
\hline CHEMBL1608859 & 688239 & 4.7362 & 5.3589 & TRN & & \\
\hline CHEMBL1511712 & 688239 & 8.28399 & 99999999 & 99 & 5.4021 & TST \\
\hline CHEMBL1497835 & 688239 & 6.9363 & 5.5563 & TRN & & \\
\hline CHEMBL1427479 & 688239 & 5.8362 & 5.5119 & TRN & & \\
\hline CHEMBL1483889 & 688239 & 4.8862 & 5.4174 & TST & & \\
\hline CHEMBL1387600 & 688239 & 5.9862 & 5.4714 & TRN & & \\
\hline CHEMBL1544895 & 688239 & 4.5362 & 5.4345 & TRN & & \\
\hline CHEMBL1604872 & 688239 & 4.5362 & 5.4595 & TRN & & \\
\hline CHEMBL1347795 & 688239 & 5.1362 & 5.4187 & TRN & & \\
\hline CHEMBL1592141 & 688239 & 4.5362 & 5.5929 & TRN & & \\
\hline CHEMBL1576762 & 688239 & 5.5862 & 5.4301 & TRN & & \\
\hline CHEMBL1388855 & 688239 & 6.1862 & 5.4734 & TRN & & \\
\hline CHEMBL1321793 & 688239 & 5.0362 & 5.4798 & TRN & & \\
\hline CHEMBL1529864 & 688239 & 7.0362 & 5.5647 & TRN & & \\
\hline CHEMBL1371520 & 688239 & 5.6362 & 5.4968 & TST & & \\
\hline CHEMBL1523001 & 688239 & 5.5862 & 5.5163 & TRN & & \\
\hline
\end{tabular}


Supplemental Table S2.txt

\begin{tabular}{|c|c|c|c|c|}
\hline CHEMBL1504380 & 688239 & 6.3362 & 5.4755 & TRN \\
\hline CHEMBL1347291 & 688239 & 4.5362 & 5.5753 & TRN \\
\hline CHEMBL1480481 & 688239 & 4.8862 & 5.4917 & TRN \\
\hline CHEMBL1323321 & 688239 & 4.5362 & 5.5418 & TRN \\
\hline CHEMBL 3191649 & 688239 & 4.6862 & 5.3956 & TST \\
\hline CHEMBL1580878 & 688239 & 5.0862 & 5.5628 & TRN \\
\hline CHEMBL580340 & 688239 & 5.0862 & 5.2924 & TRN \\
\hline CHEMBL1523159 & 688239 & 8.3372 & 5.5999 & TRN \\
\hline CHEMBL1440336 & 688239 & 6.7361 & 5.4508 & TRN \\
\hline CHEMBL1364807 & 688239 & 5.3862 & 5.4295 & TRN \\
\hline CHEMBL1388384 & 688239 & 5.9362 & 5.5232 & TRN \\
\hline CHEMBL1578595 & 688239 & 8.2366 & 5.6052 & TST \\
\hline CHEMBL1418110 & 688239 & 4.5362 & 5.3734 & TST \\
\hline CHEMBL1563529 & 688239 & 6.9363 & 5.657 & TRN \\
\hline CHEMBL1505397 & 688239 & 4.4862 & 5.2777 & TST \\
\hline CHEMBL1465482 & 688239 & 5.5862 & 5.5046 & TST \\
\hline CHEMBL1345710 & 688239 & 7.0862 & 5.4717 & TRN \\
\hline CHEMBL1329816 & 688239 & 6.1362 & 5.5005 & TRN \\
\hline CHEMBL1399865 & 688239 & 6.6362 & 5.5589 & TRN \\
\hline CHEMBL1569161 & 688239 & 4.4862 & 5.4577 & TRN \\
\hline CHEMBL1331268 & 688239 & 5.4362 & 5.3204 & TST \\
\hline CHEMBL1518646 & 688239 & 5.1862 & 5.5004 & TRN \\
\hline CHEMBL1607313 & 688239 & 5.0362 & \multicolumn{2}{|c|}{5.406000000000001} \\
\hline CHEMBL1543061 & 688239 & 4.5362 & 5.535 & TRN \\
\hline CHEMBL1442573 & 688239 & 6.9863 & 5.4466 & TRN \\
\hline CHEMBL1964439 & 688239 & 4.5362 & 5.3377 & TST \\
\hline CHEMBL1342425 & 688239 & 4.5362 & 5.2507 & TRN \\
\hline CHEMBL1496186 & 688239 & 5.1862 & 5.3678 & TST \\
\hline CHEMBL588925 & 688239 & 4.8362 & 5.484 & TST \\
\hline CHEMBL1301536 & 688239 & 4.6862 & 5.5135 & TRN \\
\hline CHEMBL1463814 & 688239 & 6.1862 & 5.4965 & TST \\
\hline CHEMBL1328953 & 688239 & 4.7862 & 5.4766 & TST \\
\hline CHEMBL1417853 & 688239 & 4.5362 & \multicolumn{2}{|c|}{5.502000000000001} \\
\hline CHEMBL1474619 & 688239 & 5.5362 & 5.4677 & TRN \\
\hline CHEMBL1546902 & 688239 & 4.5362 & 5.5607 & TRN \\
\hline CHEMBL1558528 & 688239 & 5.6862 & 5.6133 & TRN \\
\hline CHEMBL 3210862 & 688239 & 5.9362 & 5.3126 & TRN \\
\hline CHEMBL1420638 & 688239 & 6.7361 & 5.5221 & TRN \\
\hline CHEMBL1302801 & 688239 & 5.4362 & 5.5345 & TRN \\
\hline CHEMBL1572254 & 688239 & 6.1362 & 5.4806 & TRN \\
\hline CHEMBL1452174 & 688239 & 4.7362 & 5.5206 & TRN \\
\hline CHEMBL1409492 & 688239 & 7.2366 & 5.5019 & TRN \\
\hline CHEMBL1483783 & 688239 & 4.8362 & 5.5153 & TRN \\
\hline CHEMBL1378395 & 688239 & 6.3362 & 5.4554 & TST \\
\hline CHEMBL1405705 & 688239 & 6.0862 & 5.4973 & TRN \\
\hline CHEMBL1592040 & 688239 & 5.5362 & 5.402 & TST \\
\hline CHEMBL151146 & 688239 & 4.7362 & 5.38899 & 9999999999 \\
\hline CHEMBL1490036 & 688239 & 6.4862 & 5.5549 & TRN \\
\hline
\end{tabular}




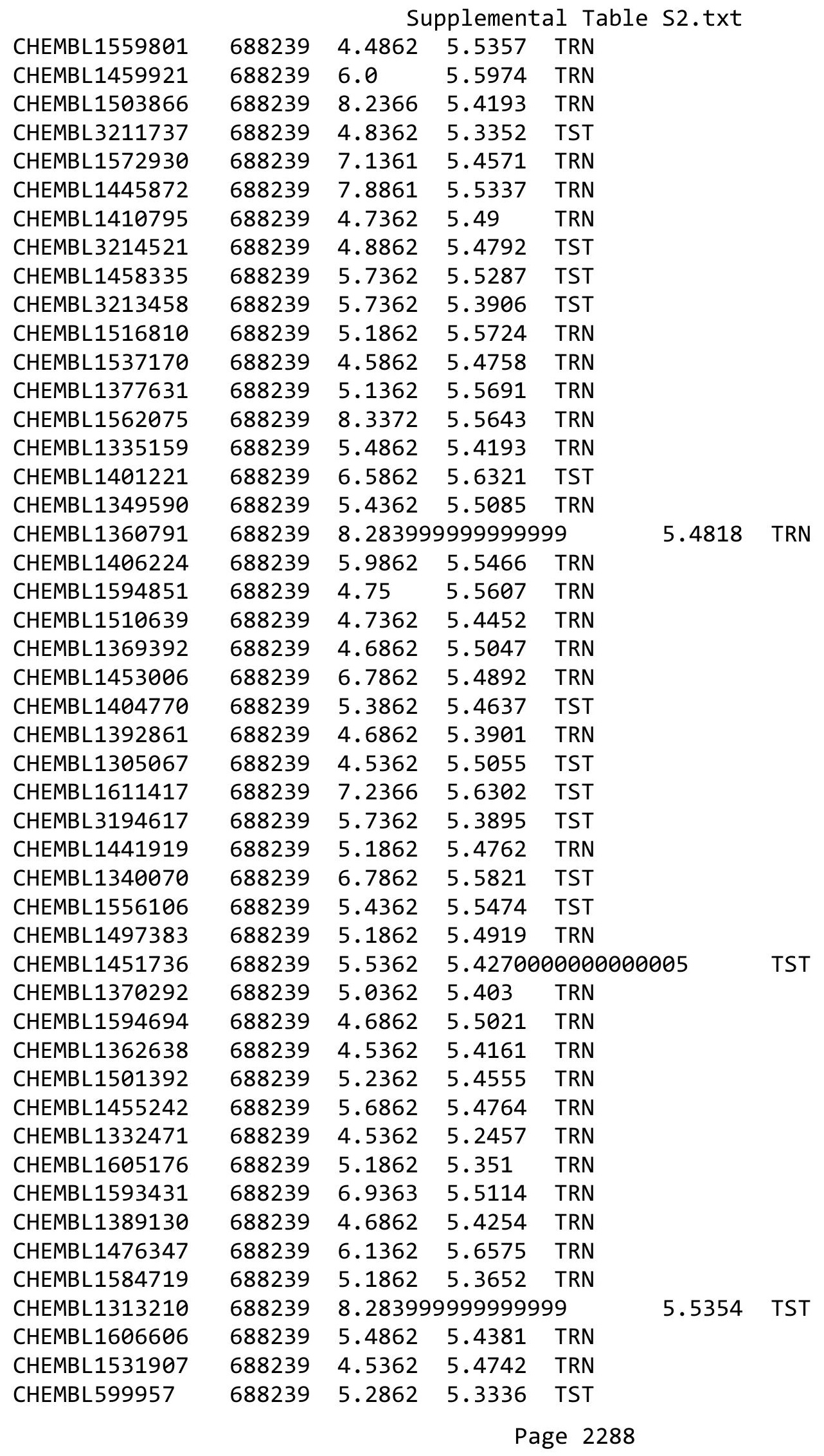


Supplemental Table S2.txt

\begin{tabular}{|c|c|c|c|c|}
\hline CHEMBL1334981 & 688239 & 6.1362 & 5.4491 & TRN \\
\hline CHEMBL1269508 & 688239 & 5.3362 & 5.4342 & TRN \\
\hline CHEMBL1335964 & 688239 & 6.0362 & 5.6275 & TRN \\
\hline CHEMBL1354005 & 688239 & 7.7852 & 5.4196 & TRN \\
\hline CHEMBL1383144 & 688239 & 4.5362 & 5.4598 & TRN \\
\hline CHEMBL1515487 & 688239 & 5.2862 & 5.4775 & TRN \\
\hline CHEMBL1393838 & 688239 & 5.6362 & 5.4802 & TRN \\
\hline CHEMBL1527665 & 688239 & 6.1862 & 5.4503 & TST \\
\hline CHEMBL1497122 & 688239 & 4.7862 & \multicolumn{2}{|c|}{5.617999999999999} \\
\hline CHEMBL1519912 & 688239 & 6.7862 & 5.4259 & TRN \\
\hline CHEMBL1328069 & 688239 & 4.8362 & 5.5142 & TRN \\
\hline CHEMBL1372801 & 688239 & 5.2362 & 5.4053 & TRN \\
\hline CHEMBL1583394 & 688239 & 4.5362 & 5.5187 & TRN \\
\hline CHEMBL1480288 & 688239 & 5.1862 & 5.7205 & TST \\
\hline CHEMBL1517123 & 688239 & 5.1862 & 5.4799 & TST \\
\hline CHEMBL1411327 & 688239 & 4.5362 & 5.516 & TRN \\
\hline CHEMBL1461131 & 688239 & 5.0362 & 5.4009 & TST \\
\hline CHEMBL1547740 & 688239 & 5.5362 & 5.3817 & TRN \\
\hline CHEMBL1357273 & 688239 & 8.3872 & 5.4509 & TRN \\
\hline CHEMBL1371734 & 688239 & 4.7862 & 5.4234 & TRN \\
\hline CHEMBL1547043 & 688239 & 4.5362 & 5.4859 & TRN \\
\hline CHEMBL1442637 & 688239 & 4.5362 & 5.5159 & TRN \\
\hline CHEMBL1606774 & 688239 & 5.8862 & 5.5727 & TRN \\
\hline CHEMBL1404502 & 688239 & 5.4362 & 5.4923 & TST \\
\hline CHEMBL1532793 & 688239 & 6.3863 & 5.4918 & TRN \\
\hline CHEMBL1366427 & 688239 & 4.6362 & 5.4888 & TRN \\
\hline CHEMBL1559159 & 688239 & 5.0862 & 5.5015 & TST \\
\hline CHEMBL1359875 & 688239 & 5.7862 & 5.4263 & TRN \\
\hline CHEMBL1487504 & 688239 & 4.7362 & 5.5403 & TRN \\
\hline CHEMBL1521734 & 688239 & 5.2362 & 5.6481 & TST \\
\hline CHEMBL1602079 & 688239 & 5.8362 & 5.4999 & TST \\
\hline CHEMBL1525782 & 688239 & 4.6862 & 5.4926 & TRN \\
\hline CHEMBL1560877 & 688239 & 6.4362 & 5.6665 & TRN \\
\hline CHEMBL1534654 & 688239 & 4.7862 & 5.3946 & TRN \\
\hline CHEMBL1569102 & 688239 & 6.1362 & 5.5824 & TRN \\
\hline CHEMBL1322305 & 688239 & 5.9862 & 5.513 & TRN \\
\hline CHEMBL3197738 & 688239 & 5.6362 & 5.4174 & TST \\
\hline CHEMBL1431028 & 688239 & 4.7362 & 5.4361 & TRN \\
\hline CHEMBL1468522 & 688239 & 6.1362 & 5.3998 & TRN \\
\hline CHEMBL1366525 & 688239 & 6.1862 & 5.4551 & TRN \\
\hline CHEMBL1307717 & 688239 & 4.7862 & 5.3636 & TRN \\
\hline CHEMBL1408264 & 688239 & 4.5362 & 5.4196 & TRN \\
\hline CHEMBL1533000 & 688239 & 4.5362 & 5.5078 & TST \\
\hline CHEMBL1311932 & 688239 & 5.1862 & 5.517 & TST \\
\hline CHEMBL1491474 & 688239 & 4.7862 & 5.4478 & TST \\
\hline CHEMBL1386998 & 688239 & 6.0862 & 5.42200 & 3000000001 \\
\hline CHEMBL3190661 & 688239 & 5.0862 & 5.5389 & TRN \\
\hline CHEMBL1336277 & 688239 & 5.3862 & 5.5144 & TST \\
\hline
\end{tabular}


Supplemental Table S2.txt

\begin{tabular}{|c|c|c|c|c|c|}
\hline CHEMBL1558313 & 688239 & 6.3362 & 5.4747 & TRN & \\
\hline CHEMBL1301823 & 688239 & 6.1362 & 5.5465 & TRN & \\
\hline CHEMBL1337347 & 688239 & 4.9862 & 5.5381 & TRN & \\
\hline CHEMBL1427183 & 688239 & 6.0862 & 5.5392 & TRN & \\
\hline CHEMBL1360612 & 688239 & 5.1862 & 5.532 & TRN & \\
\hline CHEMBL1305157 & 688239 & 4.8862 & 5.5156 & TRN & \\
\hline CHEMBL1479217 & 688239 & 8.28399 & 99999999 & & 5.5805 \\
\hline CHEMBL1584807 & 688239 & 4.5362 & 5.4301 & TRN & \\
\hline CHEMBL1333524 & 688239 & 5.8862 & 5.5298 & TRN & \\
\hline CHEMBL1333477 & 688239 & 4.5362 & 5.48 & TRN & \\
\hline CHEMBL1487782 & 688239 & 4.6862 & 5.4968 & TST & \\
\hline CHEMBL 3197166 & 688239 & 4.5362 & 5.4792 & TST & \\
\hline CHEMBL1531018 & 688239 & 6.1362 & 5.4792 & TST & \\
\hline CHEMBL1500905 & 688239 & 4.5362 & 5.5077 & TST & \\
\hline CHEMBL 3209612 & 688239 & 4.8862 & 5.4587 & TST & \\
\hline CHEMBL1410818 & 688239 & 5.1862 & 5.6675 & TRN & \\
\hline CHEMBL1379839 & 688239 & 6.0362 & 5.5096 & TRN & \\
\hline CHEMBL1385444 & 688239 & 6.5862 & 5.5466 & TRN & \\
\hline CHEMBL1383201 & 688239 & 7.0862 & 5.5565 & TRN & \\
\hline CHEMBL1611512 & 688239 & 4.4862 & 5.4824 & TRN & \\
\hline CHEMBL1458959 & 688239 & 6.2362 & 5.3882 & TST & \\
\hline CHEMBL1428120 & 688239 & 5.7362 & 5.535 & TRN & \\
\hline CHEMBL483324 & 688239 & 5.9862 & 5.5928 & TRN & \\
\hline CHEMBL1455113 & 688239 & 4.9862 & 5.3956 & TRN & \\
\hline CHEMBL1446416 & 688239 & 5.3862 & 5.4981 & TRN & \\
\hline CHEMBL1415736 & 688239 & 7.6861 & 5.5007 & TRN & \\
\hline CHEMBL1404675 & 688239 & 5.3862 & 5.5207 & TRN & \\
\hline CHEMBL1311165 & 688239 & 5.2362 & 5.4289 & TRN & \\
\hline CHEMBL1541073 & 688239 & 4.4862 & 5.4678 & TRN & \\
\hline CHEMBL1412451 & 688239 & 4.7362 & 5.5145 & TRN & \\
\hline CHEMBL 3197964 & 688239 & 5.8862 & 5.5276 & TST & \\
\hline CHEMBL1365969 & 688239 & 8.3872 & 5.5932 & TST & \\
\hline CHEMBL1537921 & 688239 & 6.6362 & 5.4021 & TST & \\
\hline CHEMBL3195566 & 688239 & 4.5362 & 5.4907 & TRN & \\
\hline CHEMBL1453356 & 688239 & 5.1862 & 5.6347 & TRN & \\
\hline CHEMBL1327869 & 688239 & 4.8862 & 5.465 & TRN & \\
\hline CHEMBL1507351 & 688239 & 4.7862 & 5.4578 & TST & \\
\hline CHEMBL1351683 & 688239 & 6.3362 & 5.4623 & TRN & \\
\hline CHEMBL1370532 & 688239 & 5.4862 & 5.5806 & TRN & \\
\hline CHEMBL1583915 & 688239 & 5.4362 & 5.4044 & TST & \\
\hline CHEMBL1305361 & 688239 & 4.7362 & 5.4562 & TRN & \\
\hline CHEMBL1482350 & 688239 & 4.5362 & 5.4432 & TRN & \\
\hline CHEMBL1563761 & 688239 & 5.1862 & 5.2681 & TRN & \\
\hline CHEMBL1391036 & 688239 & 6.6362 & 5.4705 & TRN & \\
\hline CHEMBL3213509 & 688239 & 6.2862 & 5.5386 & TRN & \\
\hline CHEMBL1567918 & 688239 & 4.4862 & 5.4717 & TRN & \\
\hline CHEMBL1503129 & 688239 & 4.5362 & 5.4953 & TRN & \\
\hline CHEMBL1401292 & 688239 & 4.5362 & 5.6194 & TRN & \\
\hline
\end{tabular}


Supplemental Table S2.txt

\begin{tabular}{|c|c|c|c|c|}
\hline 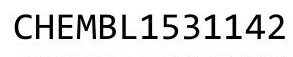 & & & & \\
\hline HEMBL1586328 & 38239 & 3862 & 17 & \\
\hline AEMBL1477571 & 239 & 862 & 05 & \\
\hline 605 & 39 & & & \\
\hline IEMBL1605559 & 39 & & & \\
\hline AEMBL1543251 & 88239 & 362 & & \\
\hline AEMBL1453814 & 88239 & 362 & 754 & \\
\hline HEMBL1368029 & & & & \\
\hline IEMBL1380703 & 39 & 361 & & \\
\hline IEMBL3198938 & & 362 & & \\
\hline AEMBL1310204 & 239 & 362 & & \\
\hline AEMBL3194041 & & 362 & & \\
\hline AEMBL1599354 & & & & \\
\hline AEMBL1547519 & & & & \\
\hline AEMBL1550595 & & & & \\
\hline AEMBL1415563 & & 362 & 62 & \\
\hline AEMBL1370645 & & 862 & & \\
\hline IEMBL130938 & & 62 & & \\
\hline HEMBL33715 & & & & \\
\hline AEMBL1583755 & & 62 & & \\
\hline AEMBL1580831 & & 363 & & \\
\hline AEMBL1567891 & & & & \\
\hline IEMBL1463995 & & 61 & & \\
\hline AEMBL1498713 & & & & \\
\hline 913 & & & & \\
\hline AEMBL1479255 & & & & \\
\hline IEMBL1481563 & & & & \\
\hline EMBL15 & & & & \\
\hline 9 & & 52 & & \\
\hline AEMP 156 & & 62 & & \\
\hline AEMBL1411913 & & & & \\
\hline AEMBL188423 & & 62 & & \\
\hline 42 & & & & \\
\hline 4 & & & & \\
\hline & & & & RN \\
\hline AEMBL1419381 & & & & $S T$ \\
\hline AEMBL3214410 & & 62 & & ST \\
\hline & & & & $\mathrm{R}$ \\
\hline 次 & & & & Trv \\
\hline HEMBL1352419 & & & & $\mathrm{RI}$ \\
\hline AEMBL1551955 & & & & $R$ \\
\hline AEMBL1315381 & & 62 & & \\
\hline 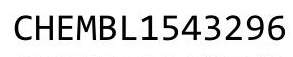 & & & & \\
\hline CHEMBL1312739 & & & & MT \\
\hline AEMBL1992166 & & & & ST \\
\hline MBL1384915 & & 362 & & $\mathrm{R}$ \\
\hline MBL13C & & & & \\
\hline HEMBL13326 & & & & \\
\hline
\end{tabular}

Page 2291 
Supplemental Table S2.txt

\begin{tabular}{|c|c|c|c|c|}
\hline CHEMBL1518836 & 688239 & 7.0362 & 5.5461 & TRN \\
\hline CHEMBL1307058 & 688239 & 4.8862 & 5.56 & TRN \\
\hline CHEMBL 2001554 & 688239 & 6.3362 & 5.4186 & TRN \\
\hline CHEMBL1468567 & 688239 & 4.7362 & 5.42700 & 00000000005 \\
\hline CHEMBL1444573 & 688239 & 4.6362 & 5.569 & TRN \\
\hline CHEMBL1466489 & 688239 & 4.5362 & 5.3798 & TRN \\
\hline CHEMBL1513753 & 688239 & 4.7862 & 5.4728 & TRN \\
\hline CHEMBL1407914 & 688239 & 5.8362 & 5.4602 & TRN \\
\hline CHEMBL1331922 & 688239 & 4.7862 & 5.5214 & TST \\
\hline CHEMBL1321943 & 688239 & 7.0362 & 5.5562 & TRN \\
\hline CHEMBL1299519 & 688239 & 6.4862 & 5.3856 & TST \\
\hline CHEMBL1351943 & 688239 & 7.0862 & 5.5423 & TST \\
\hline CHEMBL1533004 & 688239 & 4.9362 & 5.5224 & TRN \\
\hline CHEMBL3211391 & 688239 & 4.5862 & 5.4859 & TRN \\
\hline CHEMBL1308284 & 688239 & 4.5362 & 5.4748 & TRN \\
\hline CHEMBL1414257 & 688239 & 4.5362 & 5.5872 & TRN \\
\hline CHEMBL3198018 & 688239 & 6.8362 & 5.5405 & TRN \\
\hline CHEMBL1388313 & 688239 & 4.7362 & 5.4868 & TRN \\
\hline CHEMBL1424642 & 688239 & 5.4862 & 5.5397 & TRN \\
\hline CHEMBL1304419 & 688239 & 4.4862 & 5.4695 & TRN \\
\hline CHEMBL1349135 & 688239 & 4.5362 & 5.4436 & TST \\
\hline CHEMBL3214249 & 688239 & 6.2362 & 5.581 & TRN \\
\hline CHEMBL1507336 & 688239 & 5.0362 & 5.4374 & TST \\
\hline CHEMBL1463624 & 688239 & 5.2862 & 5.4444 & TST \\
\hline CHEMBL1403351 & 688239 & 6.2862 & 5.5728 & TRN \\
\hline CHEMBL1348504 & 688239 & 4.5362 & 5.5525 & TST \\
\hline CHEMBL1505986 & 688239 & 6.2362 & 5.5586 & TRN \\
\hline CHEMBL1407386 & 688239 & 4.7362 & 5.6102 & TST \\
\hline CHEMBL1578220 & 688239 & 5.4862 & 5.4625 & TRN \\
\hline CHEMBL3210797 & 688239 & 8.2366 & 5.5511 & TRN \\
\hline CHEMBL1440725 & 688239 & 5.6862 & 5.55 & TRN \\
\hline CHEMBL1582862 & 688239 & 5.5862 & 5.5277 & TST \\
\hline CHEMBL1975191 & 688239 & 4.5362 & 5.4232 & TRN \\
\hline CHEMBL1573869 & 688239 & 6.6861 & 5.3426 & TRN \\
\hline CHEMBL1327660 & 688239 & 6.5363 & 5.4701 & TRN \\
\hline CHEMBL1976540 & 688239 & 7.1864 & 5.5838 & TST \\
\hline CHEMBL3211337 & 688239 & 4.6862 & 5.4865 & TST \\
\hline CHEMBL1576128 & 688239 & 4.8362 & 5.3906 & TST \\
\hline CHEMBL1486771 & 688239 & 5.1862 & 5.4793 & TRN \\
\hline CHEMBL1510696 & 688239 & 4.9862 & 5.4695 & TRN \\
\hline CHEMBL1533120 & 688239 & 6.7361 & 5.3659 & TRN \\
\hline CHEMBL1409949 & 688239 & 5.6862 & 5.4574 & TRN \\
\hline CHEMBL1385564 & 688239 & 4.8862 & 5.4538 & TRN \\
\hline CHEMBL1334900 & 688239 & 4.6862 & 5.245 & TRN \\
\hline CHEMBL1305622 & 688239 & 4.5362 & 5.4642 & TRN \\
\hline CHEMBL1505847 & 688239 & 5.3362 & 5.4334 & TRN \\
\hline CHEMBL1586059 & 688239 & 5.1862 & 5.6142 & TST \\
\hline CHEMBL1560711 & 688239 & 5.4862 & 5.4267 & TRN \\
\hline
\end{tabular}

Page 2292 
Supplemental Table S2.txt

\begin{tabular}{|c|c|c|c|c|}
\hline CHEMBL1540577 & 688239 & 4.5362 & 5.3953 & TRN \\
\hline CHEMBL 3214193 & 688239 & 7.1864 & 5.4061 & TST \\
\hline CHEMBL1573070 & 688239 & 7.2366 & 5.4614 & TRN \\
\hline CHEMBL1308450 & 688239 & 5.1862 & 5.5049 & TRN \\
\hline CHEMBL1468259 & 688239 & 4.7362 & 5.5484 & TRN \\
\hline CHEMBL1456219 & 688239 & 4.8362 & 5.4253 & TRN \\
\hline CHEMBL 3192071 & 688239 & 4.5362 & 5.4893 & TRN \\
\hline CHEMBL1361265 & 688239 & 5.1362 & 5.5395 & TRN \\
\hline CHEMBL1447666 & 688239 & 5.7862 & 5.4379 & TST \\
\hline CHEMBL1446350 & 688239 & 6.6861 & 5.7009 & TRN \\
\hline CHEMBL1579942 & 688239 & 5.2362 & 5.6121 & TRN \\
\hline CHEMBL1504847 & 688239 & 4.6362 & 5.4777 & TRN \\
\hline CHEMBL1377896 & 688239 & 4.7362 & 5.5606 & TRN \\
\hline CHEMBL1492225 & 688239 & 4.8862 & 5.4499 & TRN \\
\hline CHEMBL1497124 & 688239 & 4.6862 & 5.5379 & TST \\
\hline CHEMBL1305386 & 688239 & 4.5362 & 5.5972 & TRN \\
\hline CHEMBL1442159 & 688239 & 7.0362 & 5.3642 & TRN \\
\hline CHEMBL1498417 & 688239 & 5.6862 & 5.5604 & TRN \\
\hline CHEMBL1539594 & 688239 & 4.5362 & 5.5314 & TRN \\
\hline CHEMBL 3197798 & 688239 & 4.6862 & 5.405 & TRN \\
\hline CHEMBL1448084 & 688239 & 4.7362 & 5.6593 & TST \\
\hline CHEMBL1307361 & 688239 & 4.5362 & 5.5574 & TRN \\
\hline CHEMBL 2358182 & 688239 & 5.1362 & 5.46 & TRN \\
\hline CHEMBL3190172 & 688239 & 5.6862 & 5.4961 & TST \\
\hline CHEMBL1553479 & 688239 & 5.2862 & 5.5548 & TRN \\
\hline CHEMBL1985428 & 688239 & 7.6364 & 5.5781 & TRN \\
\hline CHEMBL1430052 & 688239 & 5.8362 & 5.4874 & TRN \\
\hline CHEMBL1327779 & 688239 & 4.6362 & 5.6009 & TRN \\
\hline CHEMBL1541590 & 688239 & 6.3362 & 5.422000 & 000000001 \\
\hline CHEMBL1497151 & 688239 & 8.28399 & 99999999 & 5.455 \\
\hline CHEMBL1609696 & 688239 & 4.5362 & 5.4725 & TRN \\
\hline CHEMBL1595029 & 688239 & 5.1862 & 5.4928 & TST \\
\hline CHEMBL586670 & 688239 & 4.7862 & 5.5298 & TRN \\
\hline CHEMBL1542131 & 688239 & 5.6862 & 5.3356 & TST \\
\hline CHEMBL1471700 & 688239 & 7.0862 & 5.4961 & TST \\
\hline CHEMBL3210480 & 688239 & 5.6862 & 5.5252 & TRN \\
\hline CHEMBL1475453 & 688239 & 4.5362 & 5.5348 & TRN \\
\hline CHEMBL1502162 & 688239 & 4.95 & 5.3245 & TRN \\
\hline CHEMBL1582706 & 688239 & 6.9363 & 5.3776 & TRN \\
\hline CHEMBL 3211883 & 688239 & 6.0862 & 5.6261 & TRN \\
\hline CHEMBL1306612 & 688239 & 6.9363 & 5.5254 & TRN \\
\hline CHEMBL1326903 & 688239 & 4.9362 & 5.3522 & TRN \\
\hline CHEMBL1605764 & 688239 & 4.5362 & 5.3374 & TRN \\
\hline CHEMBL1497794 & 688239 & 4.8362 & 5.567 & TRN \\
\hline CHEMBL1572622 & 688239 & 5.6862 & 5.4411 & TRN \\
\hline CHEMBL1368391 & 688239 & 6.3362 & 5.5082 & TST \\
\hline CHEMBL1464358 & 688239 & 6.4362 & 5.4848 & TRN \\
\hline CHEMBL1480799 & 688239 & 6.2862 & 5.5525 & TST \\
\hline
\end{tabular}

Page 2293 
Supplemental Table S2.txt

\begin{tabular}{|c|c|c|c|c|c|}
\hline CHEMBL1525018 & 688239 & 8.3372 & 5.3996 & TST & \\
\hline CHEMBL1341416 & 688239 & 5.4362 & 5.5228 & TRN & \\
\hline CHEMBL1576503 & 688239 & 6.8861 & 5.5025 & TRN & \\
\hline CHEMBL1519217 & 688239 & 4.6862 & 5.5294 & TRN & \\
\hline CHEMBL1523465 & 688239 & 5.1862 & 5.3457 & TRN & \\
\hline CHEMBL1418341 & 688239 & 5.1862 & 5.4708 & TRN & \\
\hline CHEMBL1384873 & 688239 & 5.7362 & 5.5655 & TRN & \\
\hline CHEMBL1579595 & 688239 & 5.5362 & 5.4331 & TRN & \\
\hline CHEMBL1373613 & 688239 & 4.5362 & 5.5006 & TST & \\
\hline CHEMBL3144830 & 688239 & 6.3362 & 5.5101 & TRN & \\
\hline CHEMBL3190025 & 688239 & 5.3362 & 5.4189 & TRN & \\
\hline CHEMBL1529530 & 688239 & 5.2862 & 5.4355 & TRN & \\
\hline CHEMBL1503818 & 688239 & 5.3862 & 5.5393 & TRN & \\
\hline CHEMBL1516794 & 688239 & 4.5362 & 5.6994 & TRN & \\
\hline CHEMBL1502638 & 688239 & 5.7862 & 5.5758 & TST & \\
\hline CHEMBL1577624 & 688239 & 4.5362 & 5.4339 & TST & \\
\hline CHEMBL1514770 & 688239 & 5.1862 & 5.5104 & TRN & \\
\hline CHEMBL1306713 & 688239 & 5.0862 & 5.5556 & TRN & \\
\hline CHEMBL1603625 & 688239 & 4.5362 & 5.5594 & TRN & \\
\hline CHEMBL1435581 & 688239 & 5.5862 & 5.5231 & TST & \\
\hline CHEMBL1518064 & 688239 & 4.7862 & 5.5774 & TRN & \\
\hline CHEMBL1317865 & 688239 & 4.7362 & 5.4448 & TRN & \\
\hline CHEMBL1390129 & 688239 & 5.9862 & 5.5739 & TRN & \\
\hline CHEMBL1964967 & 688239 & 4.5362 & 5.4721 & TRN & \\
\hline CHEMBL1575789 & 688239 & 4.5362 & 5.6234 & TRN & \\
\hline CHEMBL1409131 & 688239 & 4.7862 & 5.535 & TRN & \\
\hline CHEMBL1332844 & 688239 & 5.2362 & 5.3746 & TST & \\
\hline CHEMBL1311499 & 688239 & 4.9862 & 5.4727 & TRN & \\
\hline CHEMBL1488338 & 688239 & 4.5362 & 5.3461 & TRN & \\
\hline CHEMBL1400474 & 688239 & 6.5862 & \multicolumn{2}{|c|}{5.4079999999999995} & TRN \\
\hline CHEMBL1504980 & 688239 & 4.5862 & 5.5432 & TRN & \\
\hline CHEMBL1453104 & 688239 & 6.1362 & 5.3348 & TST & \\
\hline CHEMBL1558446 & 688239 & 8.28399 & 9999999 & 5.4974 & TRN \\
\hline CHEMBL1499997 & 688239 & 4.5362 & \multicolumn{3}{|c|}{$5.497999999999999 \quad$ TRN } \\
\hline CHEMBL1605123 & 688239 & 5.6862 & 5.4828 & TRN & \\
\hline CHEMBL1538280 & 688239 & 6.9863 & 5.3724 & TRN & \\
\hline CHEMBL1610045 & 688239 & 6.1862 & 5.5137 & TRN & \\
\hline CHEMBL1478395 & 688239 & 6.2362 & 5.4872 & TST & \\
\hline CHEMBL1367750 & 688239 & 4.9362 & 5.4698 & TRN & \\
\hline CHEMBL1529340 & 688239 & 6.9863 & 5.5205 & TST & \\
\hline CHEMBL1496990 & 688239 & 5.0362 & 5.4159 & TRN & \\
\hline CHEMBL1405495 & 688239 & 5.5862 & 5.6664 & TST & \\
\hline CHEMBL1969332 & 688239 & 4.7362 & 5.4883 & TST & \\
\hline CHEMBL1549428 & 688239 & 6.1362 & 5.4343 & TRN & \\
\hline CHEMBL1372711 & 688239 & 4.8362 & 5.5573 & TRN & \\
\hline CHEMBL1572604 & 688239 & 5.7862 & 5.4471 & TRN & \\
\hline CHEMBL1353026 & 688239 & 4.6862 & 5.4387 & TRN & \\
\hline CHEMBL1452553 & 688239 & 6.1362 & 5.4575 & TST & \\
\hline
\end{tabular}

Page 2294 
Supplemental Table S2.txt

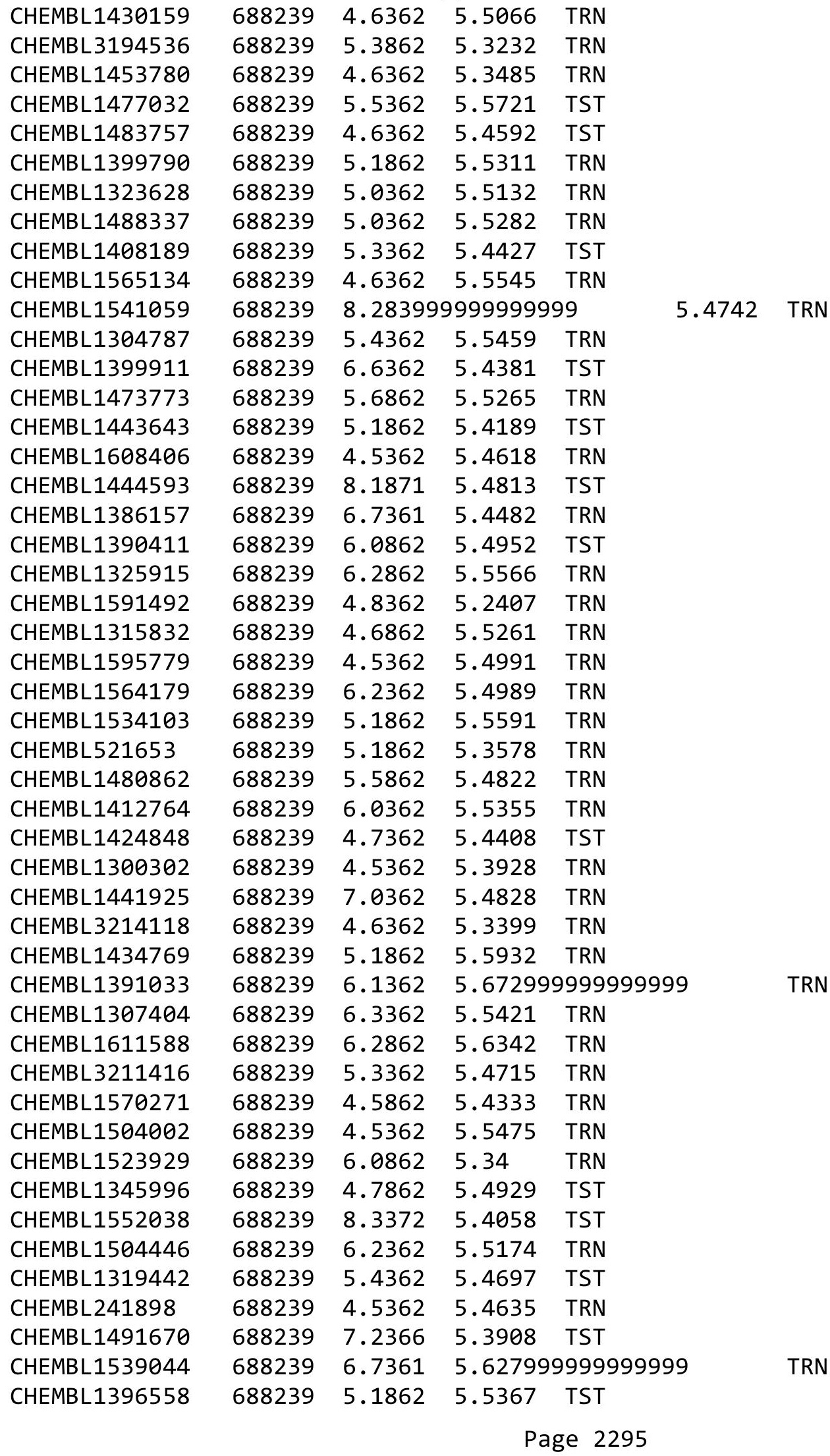


Supplemental Table S2.txt

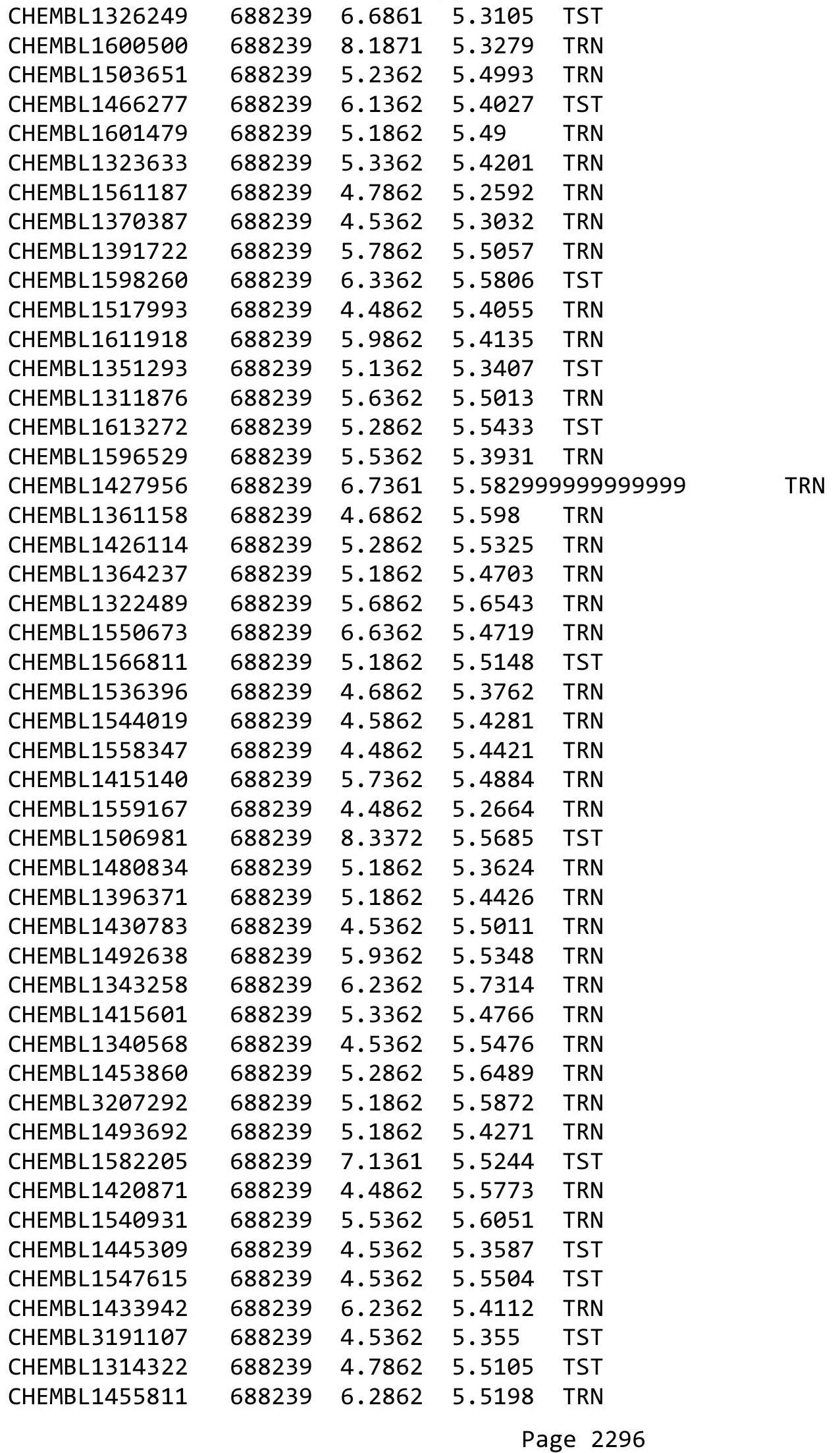


Supplemental Table S2.txt

\begin{tabular}{|c|c|c|c|c|}
\hline CHEMBL1545205 & 688239 & 4.5362 & 5.4096 & TRN \\
\hline CHEMBL1486813 & 688239 & 5.0362 & 5.5743 & TRN \\
\hline CHEMBL1532705 & 688239 & 6.8362 & 5.447 & TRN \\
\hline CHEMBL1442522 & 688239 & 6.1862 & 5.5675 & TST \\
\hline CHEMBL1483800 & 688239 & 4.8362 & 5.4163 & TRN \\
\hline CHEMBL1577098 & 688239 & 5.2362 & 5.5421 & TRN \\
\hline CHEMBL3199324 & 688239 & 4.5362 & 5.2688 & TRN \\
\hline CHEMBL1384702 & 688239 & 4.7862 & 5.3812 & TRN \\
\hline CHEMBL1475276 & 688239 & 5.8362 & 5.3566 & TRN \\
\hline CHEMBL1512024 & 688239 & 5.9362 & 5.6334 & TRN \\
\hline CHEMBL1383070 & 688239 & 5.6862 & 5.6464 & TRN \\
\hline CHEMBL1579741 & 688239 & 5.5362 & 5.4374 & TRN \\
\hline CHEMBL1514947 & 688239 & 4.5362 & 5.4291 & TRN \\
\hline CHEMBL1510678 & 688239 & 6.4362 & 5.5217 & TRN \\
\hline CHEMBL1401462 & 688239 & 6.8861 & 5.4377 & TST \\
\hline CHEMBL1301366 & 688239 & 6.3863 & 5.3296 & TRN \\
\hline CHEMBL1402870 & 688239 & 6.5862 & 5.4271 & TRN \\
\hline CHEMBL1383944 & 688239 & 7.4365 & 5.5367 & TRN \\
\hline CHEMBL1604762 & 688239 & 8.28399 & 99999999 & 5.6012 \\
\hline CHEMBL1524747 & 688239 & 4.5362 & 5.5064 & TRN \\
\hline CHEMBL1530812 & 688239 & 5.1862 & 5.4684 & TRN \\
\hline CHEMBL452465 & 688239 & 4.7362 & 5.382999 & 9999999999 \\
\hline CHEMBL1499154 & 688239 & 6.8362 & 5.5502 & TRN \\
\hline CHEMBL1469038 & 688239 & 4.5362 & 5.5474 & TRN \\
\hline CHEMBL1487138 & 688239 & 4.5862 & 5.4901 & TST \\
\hline CHEMBL3212458 & 688239 & 5.4862 & 5.6382 & TST \\
\hline CHEMBL1422613 & 688239 & 4.5362 & 5.3612 & TRN \\
\hline CHEMBL1593991 & 688239 & 5.0862 & 5.581 & TRN \\
\hline CHEMBL1595069 & 688239 & 4.7362 & 5.5586 & TRN \\
\hline CHEMBL1397456 & 688239 & 4.9862 & 5.4875 & TRN \\
\hline CHEMBL1468211 & 688239 & 5.1862 & 5.5531 & TST \\
\hline CHEMBL1419224 & 688239 & 5.7862 & 5.455 & TRN \\
\hline CHEMBL1511997 & 688239 & 5.8362 & 5.3369 & TRN \\
\hline CHEMBL1343169 & 688239 & 7.9872 & 5.4003 & TST \\
\hline CHEMBL1577094 & 688239 & 5.6862 & 5.4368 & TRN \\
\hline CHEMBL1334319 & 688239 & 7.5867 & 5.6323 & TRN \\
\hline CHEMBL1490358 & 688239 & 6.1362 & 5.4446 & TRN \\
\hline CHEMBL1549049 & 688239 & 6.2362 & 5.3878 & TRN \\
\hline CHEMBL1454133 & 688239 & 5.4362 & 5.6452 & TRN \\
\hline CHEMBL1319296 & 688239 & 5.4362 & 5.3241 & TRN \\
\hline CHEMBL1405093 & 688239 & 5.4362 & 5.5071 & TST \\
\hline CHEMBL1595216 & 688239 & 4.4862 & 5.4706 & TST \\
\hline CHEMBL1491594 & 688239 & 4.5362 & 5.4489 & TRN \\
\hline CHEMBL1540688 & 688239 & 4.5362 & 5.4253 & TRN \\
\hline CHEMBL1347781 & 688239 & 5.6862 & 5.3744 & TRN \\
\hline CHEMBL1571666 & 688239 & 5.2862 & 5.3384 & TRN \\
\hline CHEMBL572774 & 688239 & 4.5362 & 5.5469 & TRN \\
\hline CHEMBL1378329 & 688239 & 4.6362 & 5.4864 & TRN \\
\hline
\end{tabular}


Supplemental Table S2.txt

\begin{tabular}{|c|c|c|c|c|c|}
\hline CHEMBL1549411 & 688239 & 6.9863 & 5.4761 & TST & \\
\hline CHEMBL1582714 & 688239 & 5.8862 & 5.5336 & TST & \\
\hline CHEMBL1316761 & 688239 & 5.7862 & 5.3393 & TRN & \\
\hline CHEMBL1327833 & 688239 & 6.2362 & 5.645 & TRN & \\
\hline CHEMBL1462200 & 688239 & 6.9863 & 5.6145 & TST & \\
\hline CHEMBL1432395 & 688239 & 6.9363 & 5.4771 & TRN & \\
\hline CHEMBL1450034 & 688239 & 6.4862 & 5.6034 & TST & \\
\hline CHEMBL1461836 & 688239 & 4.6862 & 5.2849 & TRN & \\
\hline CHEMBL1527852 & 688239 & 6.3863 & 5.3945 & TRN & \\
\hline CHEMBL1480656 & 688239 & 7.2366 & 5.5784 & TRN & \\
\hline CHEMBL1347576 & 688239 & 5.6362 & 5.379 & TRN & \\
\hline CHEMBL1458785 & 688239 & 4.6862 & 5.5366 & TRN & \\
\hline CHEMBL1388410 & 688239 & 4.6862 & 5.6826 & TRN & \\
\hline CHEMBL1436566 & 688239 & 5.3862 & 5.4919 & TRN & \\
\hline CHEMBL1508394 & 688239 & 6.1362 & 5.4416 & TRN & \\
\hline CHEMBL1549886 & 688239 & 6.1862 & 5.4391 & TRN & \\
\hline CHEMBL3208216 & 688239 & 4.5362 & 5.4366 & TRN & \\
\hline CHEMBL1444421 & 688239 & 5.8362 & 5.455 & TST & \\
\hline CHEMBL1299319 & 688239 & 4.6862 & 5.5439 & TRN & \\
\hline CHEMBL1552856 & 688239 & 4.5362 & 5.5721 & TST & \\
\hline CHEMBL1313358 & 688239 & 6.8362 & 5.4243 & TRN & \\
\hline CHEMBL1385803 & 688239 & 4.5362 & 5.32700 & 0000000001 & TRN \\
\hline CHEMBL1355664 & 688239 & 4.4862 & 5.5731 & TRN & \\
\hline CHEMBL1368924 & 688239 & 4.7362 & 5.4763 & TRN & \\
\hline CHEMBL1340878 & 688239 & 5.0362 & 5.4591 & TRN & \\
\hline CHEMBL1592090 & 688239 & 6.5363 & 5.44 & TRN & \\
\hline CHEMBL1530420 & 688239 & 6.6362 & 5.5471 & TRN & \\
\hline CHEMBL3196415 & 688239 & 6.3362 & 5.5344 & TRN & \\
\hline CHEMBL1344228 & 688239 & 5.7862 & 5.3695 & TRN & \\
\hline CHEMBL1345817 & 688239 & 5.3862 & 5.6394 & TRN & \\
\hline CHEMBL1442788 & 688239 & 5.4362 & 5.4647 & TST & \\
\hline CHEMBL1473011 & 688239 & 6.8861 & 5.4345 & TRN & \\
\hline CHEMBL1557551 & 688239 & 4.5362 & 5.3851 & TST & \\
\hline CHEMBL1504440 & 688239 & 4.5362 & 5.5383 & TST & \\
\hline CHEMBL1316200 & 688239 & 4.7362 & 5.4832 & TRN & \\
\hline CHEMBL1562846 & 688239 & 4.7362 & 5.4225 & TRN & \\
\hline CHEMBL1492664 & 688239 & 6.5363 & 5.4801 & TRN & \\
\hline CHEMBL1576546 & 688239 & 6.1862 & 5.4803 & TRN & \\
\hline CHEMBL1483407 & 688239 & 6.1862 & 5.4914 & TRN & \\
\hline CHEMBL1485024 & 688239 & 5.1362 & 5.544 & TRN & \\
\hline CHEMBL1348384 & 688239 & 5.3862 & 5.4451 & TRN & \\
\hline CHEMBL1235693 & 688239 & 6.8362 & 5.5575 & TST & \\
\hline CHEMBL1492012 & 688239 & 5.6362 & 5.4349 & TST & \\
\hline CHEMBL1581725 & 688239 & 4.5362 & 5.358 & TRN & \\
\hline CHEMBL1549642 & 688239 & 4.6862 & 5.635 & TRN & \\
\hline CHEMBL3208973 & 688239 & 4.8862 & 5.5015 & TRN & \\
\hline CHEMBL1459656 & 688239 & 5.3362 & 5.5224 & TRN & \\
\hline CHEMBL1523847 & 688239 & 6.9363 & 5.6735 & TST & \\
\hline
\end{tabular}


Supplemental Table S2.txt

\begin{tabular}{|c|c|c|c|c|}
\hline CHEMBL1399669 & 688239 & 6.3362 & 5.4942 & TRN \\
\hline CHEMBL1573206 & 688239 & 5.1862 & 5.4355 & TRN \\
\hline CHEMBL3199109 & 688239 & 6.9863 & 5.4332 & TRN \\
\hline CHEMBL1344443 & 688239 & 5.4862 & 5.5311 & TRN \\
\hline CHEMBL1332394 & 688239 & 5.8862 & 5.5156 & TRN \\
\hline CHEMBL1550738 & 688239 & 6.2362 & 5.5115 & TRN \\
\hline CHEMBL1492442 & 688239 & 4.8362 & 5.3408 & TST \\
\hline CHEMBL 3212512 & 688239 & 4.6362 & 5.5226 & TRN \\
\hline CHEMBL1411661 & 688239 & 5.3862 & 5.3823 & TRN \\
\hline CHEMBL1441401 & 688239 & 6.1862 & 5.6688 & TRN \\
\hline CHEMBL1319542 & 688239 & 7.0362 & 5.4929 & TRN \\
\hline CHEMBL1300637 & 688239 & 4.5362 & 5.3956 & TRN \\
\hline CHEMBL1300676 & 688239 & 5.3362 & 5.6157 & TST \\
\hline CHEMBL1525897 & 688239 & 8.28399 & 99999999 & 5.4556 \\
\hline CHEMBL1531934 & 688239 & 5.0362 & 5.6489 & TRN \\
\hline CHEMBL1411946 & 688239 & 5.7862 & 5.5965 & TRN \\
\hline CHEMBL1317286 & 688239 & 5.1362 & 5.5525 & TRN \\
\hline CHEMBL1451068 & 688239 & 5.3862 & 5.5004 & TRN \\
\hline CHEMBL1473187 & 688239 & 5.7862 & 5.5287 & TRN \\
\hline CHEMBL1523791 & 688239 & 4.5362 & 5.6249 & TRN \\
\hline CHEMBL1402494 & 688239 & 4.5862 & 5.5585 & TST \\
\hline CHEMBL1372388 & 688239 & 4.5862 & 5.4386 & TRN \\
\hline CHEMBL1332011 & 688239 & 4.5362 & 5.5361 & TRN \\
\hline CHEMBL1351194 & 688239 & 5.4362 & 5.5623 & TRN \\
\hline CHEMBL1441557 & 688239 & 5.3862 & 5.5202 & TRN \\
\hline CHEMBL1490845 & 688239 & 4.5362 & 5.3586 & TRN \\
\hline CHEMBL1366712 & 688239 & 4.5362 & 5.3933 & TST \\
\hline CHEMBL1520934 & 688239 & 4.5362 & 5.5527 & TST \\
\hline CHEMBL1359639 & 688239 & 5.1362 & 5.4051 & TRN \\
\hline CHEMBL1304015 & 688239 & 4.7362 & 5.4066 & TRN \\
\hline CHEMBL1462152 & 688239 & 5.3362 & 5.4136 & TRN \\
\hline CHEMBL1476132 & 688239 & 4.9862 & 5.3953 & TRN \\
\hline CHEMBL1326402 & 688239 & 5.2862 & 5.6495 & TRN \\
\hline CHEMBL1517141 & 688239 & 5.6362 & 5.5326 & TRN \\
\hline CHEMBL1516139 & 688239 & 8.3372 & 5.3622 & TRN \\
\hline CHEMBL1351742 & 688239 & 5.9362 & 5.4757 & TRN \\
\hline CHEMBL1363608 & 688239 & 6.5363 & 5.551 & TST \\
\hline CHEMBL1431660 & 688239 & 5.3862 & 5.55200 & 00000000005 \\
\hline CHEMBL1360170 & 688239 & 4.8362 & 5.3693 & TRN \\
\hline CHEMBL1356981 & 688239 & 4.6362 & 5.5766 & TRN \\
\hline CHEMBL3144951 & 688239 & 4.5862 & 5.4211 & TRN \\
\hline CHEMBL1405333 & 688239 & 7.0362 & 5.4111 & TRN \\
\hline CHEMBL1382314 & 688239 & 6.1862 & 5.6346 & TRN \\
\hline CHEMBL1508403 & 688239 & 6.2362 & 5.5624 & TRN \\
\hline CHEMBL1612606 & 688239 & 4.5362 & 5.4521 & TRN \\
\hline CHEMBL1477721 & 688239 & 5.8862 & 5.4294 & TRN \\
\hline CHEMBL 606167 & 688239 & 4.5362 & 5.3806 & TST \\
\hline CHEMBL1357718 & 688239 & 4.6362 & 5.4578 & TRN \\
\hline
\end{tabular}


Supplemental Table S2.txt

\begin{tabular}{|c|c|c|c|c|}
\hline CHEMBL1425854 & 688239 & 6.6861 & 5.6051 & TRN \\
\hline CHEMBL1464852 & 688239 & 5.2862 & 5.3379 & TRN \\
\hline CHEMBL1376946 & 688239 & 4.5362 & 5.5474 & TST \\
\hline CHEMBL1355769 & 688239 & 5.1862 & 5.5555 & TRN \\
\hline CHEMBL1549802 & 688239 & 4.8862 & 5.5228 & TRN \\
\hline CHEMBL1556033 & 688239 & 5.1862 & 5.5001 & TRN \\
\hline CHEMBL1514930 & 688239 & 5.1862 & 5.5497 & TST \\
\hline CHEMBL1352486 & 688239 & 5.5362 & 5.6505 & TRN \\
\hline CHEMBL1412309 & 688239 & 5.1862 & 5.5258 & TRN \\
\hline CHEMBL1536977 & 688239 & 5.7862 & 5.569 & TST \\
\hline CHEMBL6395 & 688239 & 4.5362 & 5.4859 & TRN \\
\hline CHEMBL1093246 & 688239 & 5.3362 & 5.3099 & TRN \\
\hline CHEMBL1367665 & 688239 & 6.3863 & 5.5664 & TST \\
\hline CHEMBL1585581 & 688239 & 4.5862 & 5.4365 & TRN \\
\hline CHEMBL1377938 & 688239 & 6.7862 & 5.526 & TRN \\
\hline CHEMBL1400142 & 688239 & 6.1862 & 5.4149 & TST \\
\hline CHEMBL3189449 & 688239 & 4.5362 & 5.3947 & TRN \\
\hline CHEMBL1465186 & 688239 & 6.9863 & 5.4354 & TST \\
\hline CHEMBL1518267 & 688239 & 7.0862 & 5.7245 & TRN \\
\hline CHEMBL1606395 & 688239 & 6.5363 & 5.5444 & TRN \\
\hline CHEMBL1364039 & 688239 & 5.2362 & 5.4968 & TST \\
\hline CHEMBL1599144 & 688239 & 4.9362 & 5.546 & TRN \\
\hline CHEMBL1325723 & 688239 & 4.5362 & 5.5534 & TST \\
\hline CHEMBL1581787 & 688239 & 5.1862 & 5.5084 & TST \\
\hline CHEMBL1424840 & 688239 & 6.7361 & 5.5333 & TST \\
\hline CHEMBL1363125 & 688239 & 6.2362 & 5.3782 & TRN \\
\hline CHEMBL1300516 & 688239 & 7.1864 & 5.5972 & TST \\
\hline CHEMBL1506231 & 688239 & 4.7862 & 5.5043 & TRN \\
\hline CHEMBL1515681 & 688239 & 4.5362 & 5.4485 & TRN \\
\hline CHEMBL1522592 & 688239 & 6.6861 & 5.4851 & TST \\
\hline CHEMBL1315942 & 688239 & 6.1862 & 5.3399 & TRN \\
\hline CHEMBL1396766 & 688239 & 5.7862 & 5.5672 & TRN \\
\hline CHEMBL1548414 & 688239 & 5.1862 & 5.4829 & TRN \\
\hline CHEMBL1333847 & 688239 & 4.5362 & 5.4609 & TST \\
\hline CHEMBL1395205 & 688239 & 6.1362 & 5.3891 & TRN \\
\hline CHEMBL 2006329 & 688239 & 5.7362 & 5.45799 & 999999999 \\
\hline CHEMBL1421134 & 688239 & 4.5362 & 5.5357 & TRN \\
\hline CHEMBL1410632 & 688239 & 6.2862 & 5.4181 & TST \\
\hline CHEMBL1432455 & 688239 & 7.2366 & 5.5781 & TRN \\
\hline CHEMBL1389120 & 688239 & 5.6862 & 5.4189 & TRN \\
\hline CHEMBL1588363 & 688239 & 4.8862 & 5.4767 & TST \\
\hline CHEMBL1402568 & 688239 & 4.5862 & 5.6399 & TRN \\
\hline CHEMBL1606065 & 688239 & 4.7862 & 5.46399 & 9999999995 \\
\hline CHEMBL 1305774 & 688239 & 5.1862 & 5.4308 & TRN \\
\hline CHEMBL3208249 & 688239 & 4.5362 & 5.4235 & TRN \\
\hline CHEMBL1441939 & 688239 & 5.7362 & 5.5508 & TRN \\
\hline CHEMBL1421336 & 688239 & 6.3362 & 5.505 & TRN \\
\hline CHEMBL1444182 & 688239 & 5.6862 & 5.4835 & TRN \\
\hline
\end{tabular}

Page 2300 
Supplemental Table S2.txt

\begin{tabular}{|c|c|c|c|c|}
\hline CHEMBL1500735 & 688239 & 5.4862 & 5.3495 & TRN \\
\hline CHEMBL1365230 & 688239 & 5.4862 & 5.4598 & TRN \\
\hline CHEMBL1301737 & 688239 & 5.9362 & 5.4589 & TRN \\
\hline CHEMBL1329371 & 688239 & 6.2862 & 5.5156 & TRN \\
\hline CHEMBL1420910 & 688239 & 6.4362 & 5.6276 & TRN \\
\hline CHEMBL1405770 & 688239 & 5.6362 & 5.6606 & TRN \\
\hline CHEMBL1567369 & 688239 & 5.2362 & 5.4392 & TST \\
\hline CHEMBL1572289 & 688239 & 4.7862 & 5.4935 & TRN \\
\hline CHEMBL68442 & 688239 & 6.0362 & 5.4778 & TRN \\
\hline CHEMBL1544423 & 688239 & 4.5362 & 5.3772 & TRN \\
\hline CHEMBL1814509 & 688239 & 5.3862 & 5.2651 & TST \\
\hline CHEMBL1454827 & 688239 & 4.5362 & 5.4745 & TRN \\
\hline CHEMBL1524344 & 688239 & 4.9862 & 5.3945 & TRN \\
\hline CHEMBL1449846 & 688239 & 4.9862 & 5.5675 & TRN \\
\hline CHEMBL1386795 & 688239 & 5.6862 & 5.5999 & TRN \\
\hline CHEMBL1326337 & 688239 & 4.7862 & 5.5338 & TRN \\
\hline CHEMBL1470909 & 688239 & 8.3872 & 5.4133 & TRN \\
\hline CHEMBL1605389 & 688239 & 6.0862 & 5.5497 & TST \\
\hline CHEMBL1509615 & 688239 & 5.8862 & 5.3224 & TRN \\
\hline CHEMBL1446307 & 688239 & 4.5362 & 5.55 & TRN \\
\hline CHEMBL1516881 & 688239 & 4.7362 & 5.5024 & TRN \\
\hline CHEMBL1465912 & 688239 & 4.6862 & 5.5461 & TRN \\
\hline CHEMBL 1567740 & 688239 & 5.1862 & 5.4913 & TRN \\
\hline CHEMBL1565943 & 688239 & 4.4862 & 5.5208 & TRN \\
\hline CHEMBL1527976 & 688239 & 4.9362 & 5.4776 & TRN \\
\hline CHEMBL1351720 & 688239 & 6.7361 & 5.5619 & TRN \\
\hline CHEMBL1549197 & 688239 & 4.9362 & 5.4609 & TRN \\
\hline CHEMBL1533399 & 688239 & 4.5362 & 5.4639 & TRN \\
\hline CHEMBL1545713 & 688239 & 4.7362 & 5.4027 & TRN \\
\hline CHEMBL1359331 & 688239 & 5.1862 & 5.5726 & TRN \\
\hline CHEMBL 3213279 & 688239 & 4.5362 & 5.4965 & TRN \\
\hline CHEMBL1474203 & 688239 & 4.9862 & 5.3747 & TRN \\
\hline CHEMBL1485295 & 688239 & 6.8861 & 5.576000 & 30000000005 \\
\hline CHEMBL1436620 & 688239 & 4.6362 & 5.4728 & TRN \\
\hline CHEMBL1492248 & 688239 & 7.2366 & 5.4992 & TRN \\
\hline CHEMBL 1448840 & 688239 & 4.7362 & 5.3637 & TRN \\
\hline CHEMBL1560442 & 688239 & 4.5362 & 5.4601 & TRN \\
\hline CHEMBL1372338 & 688239 & 4.5362 & 5.5152 & TRN \\
\hline CHEMBL1353913 & 688239 & 4.7362 & 5.4527 & TRN \\
\hline CHEMBL1556990 & 688239 & 8.2366 & 5.4652 & TRN \\
\hline CHEMBL1553111 & 688239 & 4.9862 & 5.5303 & TRN \\
\hline CHEMBL1399823 & 688239 & 4.9362 & 5.7365 & TRN \\
\hline CHEMBL1468725 & 688239 & 4.5862 & 5.5869 & TRN \\
\hline CHEMBL1418210 & 688239 & 4.7862 & 5.6491 & TRN \\
\hline CHEMBL1486077 & 688239 & 6.2862 & 5.4822 & TRN \\
\hline CHEMBL1359334 & 688239 & 4.8862 & 5.462999 & 79999999999 \\
\hline CHEMBL1351052 & 688239 & 4.7862 & 5.3228 & TRN \\
\hline CHEMBL1578903 & 688239 & 5.9862 & 5.435 & TRN \\
\hline
\end{tabular}

Page 2301 
Supplemental Table S2.txt

\begin{tabular}{|c|c|c|c|c|c|}
\hline CHEMBL1451262 & 688239 & 4.5362 & \multicolumn{2}{|c|}{5.513999999999999} & TST \\
\hline CHEMBL1449454 & 688239 & 4.4862 & 5.4856 & TRN & \\
\hline CHEMBL1498836 & 688239 & 4.6862 & 5.5011 & TRN & \\
\hline CHEMBL1544685 & 688239 & 4.8862 & 5.5572 & TRN & \\
\hline CHEMBL1563863 & 688239 & 4.5362 & 5.3482 & TRN & \\
\hline CHEMBL1524403 & 688239 & 6.2362 & 5.2723 & TST & \\
\hline CHEMBL1505834 & 688239 & 7.4868 & 5.5815 & TRN & \\
\hline CHEMBL1582318 & 688239 & 6.0362 & 5.4615 & TST & \\
\hline CHEMBL1313216 & 688239 & 6.4862 & 5.5064 & TRN & \\
\hline CHEMBL1602714 & 688239 & 5.8862 & 5.541 & TRN & \\
\hline CHEMBL1382354 & 688239 & 5.3362 & 5.5638 & TRN & \\
\hline CHEMBL1337695 & 688239 & 5.9862 & 5.4311 & TST & \\
\hline CHEMBL1392191 & 688239 & 5.2362 & 5.4487 & TRN & \\
\hline CHEMBL1574229 & 688239 & 8.1367 & 5.4583 & TRN & \\
\hline CHEMBL1488766 & 688239 & 5.1862 & 5.5547 & TRN & \\
\hline CHEMBL1438781 & 688239 & 5.3862 & 5.4719 & TRN & \\
\hline CHEMBL1451276 & 688239 & 4.5862 & 5.4759 & TRN & \\
\hline CHEMBL1442852 & 688239 & 4.4862 & 5.6236 & TRN & \\
\hline CHEMBL1370037 & 688239 & 4.9362 & 5.4205 & TRN & \\
\hline CHEMBL1308821 & 688239 & 4.5362 & 5.3321 & TRN & \\
\hline CHEMBL1335535 & 688239 & 8.1367 & 5.7028 & TRN & \\
\hline CHEMBL1487436 & 688239 & 4.7862 & 5.4049 & TRN & \\
\hline CHEMBL1410246 & 688239 & 5.4862 & 5.3918 & TRN & \\
\hline CHEMBL1493995 & 688239 & 4.6862 & 5.6926 & TRN & \\
\hline CHEMBL1534719 & 688239 & 5.6862 & 5.5524 & TRN & \\
\hline CHEMBL1482460 & 688239 & 4.6362 & 5.4488 & TRN & \\
\hline CHEMBL1516456 & 688239 & 4.6862 & 5.3074 & TST & \\
\hline CHEMBL1392312 & 688239 & 4.7862 & 5.4839 & TRN & \\
\hline CHEMBL1376228 & 688239 & 6.0862 & 5.4954 & TRN & \\
\hline CHEMBL1533102 & 688239 & 4.5362 & 5.4379 & TRN & \\
\hline CHEMBL3207395 & 688239 & 6.5862 & 5.5182 & TRN & \\
\hline CHEMBL1986363 & 688239 & 6.3863 & 5.5143 & TST & \\
\hline CHEMBL1470626 & 688239 & 4.6862 & 5.502999 & 9999999999 & TRN \\
\hline CHEMBL1449155 & 688239 & 7.2366 & 5.6616 & TST & \\
\hline CHEMBL1565320 & 688239 & 5.0862 & 5.4223 & TRN & \\
\hline CHEMBL1515306 & 688239 & 5.3362 & 5.5082 & TRN & \\
\hline CHEMBL1475394 & 688239 & 4.6362 & 5.4146 & TRN & \\
\hline CHEMBL1338279 & 688239 & 4.8362 & 5.4638 & TRN & \\
\hline CHEMBL3213628 & 688239 & 4.5362 & 5.4282 & TST & \\
\hline CHEMBL1586339 & 688239 & 4.5362 & 5.4839 & TRN & \\
\hline CHEMBL1339038 & 688239 & 6.8861 & 5.396 & TRN & \\
\hline CHEMBL1590745 & 688239 & 8.1871 & 5.3847 & TST & \\
\hline CHEMBL1504526 & 688239 & 5.8362 & 5.4717 & TRN & \\
\hline CHEMBL1450341 & 688239 & 4.6862 & 5.4876 & TRN & \\
\hline CHEMBL1383803 & 688239 & 4.5862 & 5.5598 & TRN & \\
\hline CHEMBL1345782 & 688239 & 6.8861 & 5.4558 & TRN & \\
\hline CHEMBL1524619 & 688239 & 4.5362 & 5.5325 & TRN & \\
\hline CHEMBL1308514 & 688239 & 5.6862 & 5.568 & TRN & \\
\hline
\end{tabular}


Supplemental Table S2.txt

\begin{tabular}{|c|c|c|c|c|c|}
\hline CHEMBL1424177 & 688239 & 6.3362 & 5.5829 & TRN & \\
\hline CHEMBL1588140 & 688239 & 6.6362 & 5.431 & TRN & \\
\hline CHEMBL1334984 & 688239 & 4.5362 & 5.54299 & 9999999999 & TRN \\
\hline CHEMBL3194038 & 688239 & 6.0862 & 5.4361 & TRN & \\
\hline CHEMBL1561271 & 688239 & 5.6362 & 5.5032 & TRN & \\
\hline CHEMBL1303549 & 688239 & 5.8862 & 5.7625 & TRN & \\
\hline CHEMBL1556576 & 688239 & 4.5362 & 5.5351 & TST & \\
\hline CHEMBL1612404 & 688239 & 4.8362 & 5.4304 & TRN & \\
\hline CHEMBL1382958 & 688239 & 7.0362 & 5.6524 & TRN & \\
\hline CHEMBL1573734 & 688239 & 5.3362 & 5.5045 & TST & \\
\hline CHEMBL1304123 & 688239 & 5.1862 & 5.6034 & TRN & \\
\hline CHEMBL1414995 & 688239 & 4.7362 & 5.3686 & TST & \\
\hline CHEMBL1335879 & 688239 & 5.9862 & 5.4422 & TRN & \\
\hline CHEMBL1380280 & 688239 & 4.4862 & 5.5899 & TRN & \\
\hline CHEMBL3211624 & 688239 & 4.7862 & 5.2851 & TST & \\
\hline CHEMBL1310220 & 688239 & 7.2366 & 5.5651 & TRN & \\
\hline CHEMBL1361444 & 688239 & 4.8362 & 5.4553 & TRN & \\
\hline CHEMBL1470284 & 688239 & 8.3372 & 5.7097 & TRN & \\
\hline CHEMBL1329265 & 688239 & 4.6362 & 5.436 & TRN & \\
\hline CHEMBL1370173 & 688239 & 4.5362 & 5.6529 & TRN & \\
\hline CHEMBL1520071 & 688239 & 4.6862 & 5.5282 & TRN & \\
\hline CHEMBL1434911 & 688239 & 5.6862 & 5.6096 & TRN & \\
\hline CHEMBL1345520 & 688239 & 5.7362 & 5.4688 & TST & \\
\hline CHEMBL1610237 & 688239 & 6.3362 & 5.5224 & TRN & \\
\hline CHEMBL1483206 & 688239 & 6.2362 & 5.4743 & TRN & \\
\hline CHEMBL1410619 & 688239 & 5.7862 & 5.4649 & TRN & \\
\hline CHEMBL1314628 & 688239 & 6.3863 & 5.6161 & TST & \\
\hline CHEMBL1596496 & 688239 & 4.8362 & 5.5705 & TRN & \\
\hline CHEMBL1542189 & 688239 & 4.8362 & 5.5361 & TRN & \\
\hline CHEMBL1420051 & 688239 & 4.9362 & 5.5591 & TRN & \\
\hline CHEMBL1388003 & 688239 & 5.3862 & 5.5978 & TST & \\
\hline CHEMBL1471673 & 688239 & 4.5362 & 5.521 & TST & \\
\hline CHEMBL1312427 & 688239 & 6.5862 & 5.5296 & TST & \\
\hline CHEMBL1611089 & 688239 & 4.4862 & 5.5651 & TRN & \\
\hline CHEMBL1561113 & 688239 & 5.2362 & 5.5406 & TRN & \\
\hline CHEMBL1498313 & 688239 & 5.4362 & 5.5064 & TRN & \\
\hline CHEMBL1347808 & 688239 & 5.0862 & 5.5363 & TRN & \\
\hline CHEMBL1500548 & 688239 & 6.2862 & 5.4831 & TRN & \\
\hline CHEMBL1526541 & 688239 & 6.4362 & 5.5224 & TRN & \\
\hline CHEMBL1530450 & 688239 & 4.7862 & 5.2636 & TRN & \\
\hline CHEMBL1379819 & 688239 & 4.7362 & 5.5382 & TRN & \\
\hline CHEMBL1517303 & 688239 & 5.2862 & 5.4745 & TRN & \\
\hline CHEMBL1495582 & 688239 & 6.4362 & 5.5084 & TRN & \\
\hline CHEMBL1410577 & 688239 & 5.1862 & 5.3749 & TRN & \\
\hline CHEMBL1562212 & 688239 & 5.0362 & 5.409 & TRN & \\
\hline CHEMBL1490770 & 688239 & 6.4862 & 5.5503 & TRN & \\
\hline CHEMBL1447817 & 688239 & 8.3372 & 5.46899 & 9999999999 & TRN \\
\hline CHEMBL1555472 & 688239 & 5.0862 & 5.5192 & TRN & \\
\hline
\end{tabular}




\begin{tabular}{|c|c|c|c|c|c|}
\hline \multicolumn{6}{|c|}{ Supplemental Table S2.txt } \\
\hline CHEMBL1426186 & 688239 & 5.4362 & 5.501 & TRN & \\
\hline CHEMBL1581815 & 688239 & 4.8862 & 5.5317 & TST & \\
\hline CHEMBL1586931 & 688239 & 5.1862 & 5.5111 & TRN & \\
\hline CHEMBL1537226 & 688239 & 4.7362 & 5.4267 & TRN & \\
\hline CHEMBL1505947 & 688239 & 5.4362 & 5.4841 & TRN & \\
\hline CHEMBL1493118 & 688239 & 5.6862 & 5.4847 & TRN & \\
\hline CHEMBL1334668 & 688239 & 4.5362 & 5.3686 & TRN & \\
\hline CHEMBL1608021 & 688239 & 5.6362 & 5.6214 & TST & \\
\hline CHEMBL1356425 & 688239 & 4.5362 & 5.4312 & TRN & \\
\hline CHEMBL1421539 & 688239 & 4.5862 & 5.4242 & TRN & \\
\hline CHEMBL1388050 & 688239 & 4.7362 & 5.62 & TRN & \\
\hline CHEMBL3208416 & 688239 & 5.1862 & 5.5035 & TST & \\
\hline CHEMBL1575348 & 688239 & 5.8362 & 5.6492 & TRN & \\
\hline CHEMBL1398133 & 688239 & 4.5362 & 5.5732 & TRN & \\
\hline CHEMBL1573181 & 688239 & 5.3862 & 5.4713 & TRN & \\
\hline CHEMBL1349439 & 688239 & 4.5362 & 5.4673 & TRN & \\
\hline CHEMBL1483992 & 688239 & 7.0362 & 5.4831 & TRN & \\
\hline CHEMBL1383768 & 688239 & 5.3862 & 5.4805 & TRN & \\
\hline CHEMBL1584562 & 688239 & 4.7362 & 5.4089 & TRN & \\
\hline CHEMBL1332965 & 688239 & 4.7862 & 5.6314 & TRN & \\
\hline CHEMBL1527012 & 688239 & 8.3372 & 5.5168 & TST & \\
\hline CHEMBL1467292 & 688239 & 4.7362 & 5.4619 & TRN & \\
\hline CHEMBL1549554 & 688239 & 4.7362 & 5.4269 & TRN & \\
\hline CHEMBL1569145 & 688239 & 4.5362 & 5.4378 & TRN & \\
\hline CHEMBL1302135 & 688239 & 6.0862 & 5.4799 & TST & \\
\hline CHEMBL1318784 & 688239 & 6.2362 & 5.5317 & TRN & \\
\hline CHEMBL1390879 & 688239 & 5.4362 & 5.5755 & TRN & \\
\hline CHEMBL1348379 & 688239 & 6.6362 & 5.3607 & TST & \\
\hline CHEMBL1506843 & 688239 & 5.6862 & 5.5897 & TRN & \\
\hline CHEMBL1588909 & 688239 & 6.1862 & 5.5688 & TRN & \\
\hline CHEMBL1300082 & 688239 & 4.6862 & 5.42700 & 00000000005 & TST \\
\hline CHEMBL1597480 & 688239 & 4.7862 & 5.4416 & TRN & \\
\hline CHEMBL 3211040 & 688239 & 4.5362 & 5.5028 & TRN & \\
\hline CHEMBL1586580 & 688239 & 5.3362 & 5.4336 & TST & \\
\hline CHEMBL1308381 & 688239 & 6.6362 & 5.5522 & TRN & \\
\hline CHEMBL1424598 & 688239 & 5.0362 & 5.4302 & TRN & \\
\hline CHEMBL1454532 & 688239 & 4.4862 & 5.2954 & TRN & \\
\hline CHEMBL1355751 & 688239 & 4.5362 & 5.5265 & TRN & \\
\hline CHEMBL391123 & 688239 & 4.5862 & 5.37200 & 0000000001 & TST \\
\hline CHEMBL1347639 & 688239 & 4.4862 & 5.4593 & TST & \\
\hline CHEMBL1460468 & 688239 & 4.9362 & 5.35 & TRN & \\
\hline CHEMBL1424864 & 688239 & 5.2862 & 5.5708 & TRN & \\
\hline CHEMBL1585251 & 688239 & 4.7362 & 5.5042 & TRN & \\
\hline CHEMBL1313029 & 688239 & 6.0862 & 5.6598 & TRN & \\
\hline CHEMBL1596068 & 688239 & 5.5362 & 5.5257 & TRN & \\
\hline CHEMBL1537132 & 688239 & 5.4862 & 5.5187 & TRN & \\
\hline CHEMBL1308864 & 688239 & 5.0362 & 5.4853 & TST & \\
\hline CHEMBL1608633 & 688239 & 6.8861 & 5.4699 & TST & \\
\hline
\end{tabular}


Supplemental Table S2.txt

\begin{tabular}{|c|c|c|c|c|c|}
\hline CHEMBL1587630 & 688239 & 4.7362 & 5.4112 & TRN & \\
\hline CHEMBL1448980 & 688239 & 5.7862 & 5.5911 & TRN & \\
\hline CHEMBL1456604 & 688239 & 5.2862 & 5.4988 & TST & \\
\hline CHEMBL1324944 & 688239 & 4.5362 & 5.4275 & TRN & \\
\hline CHEMBL1364128 & 688239 & 4.5362 & 5.6058 & TRN & \\
\hline CHEMBL1330078 & 688239 & 5.8862 & 5.322 & TST & \\
\hline CHEMBL1449566 & 688239 & 6.8362 & 5.5679 & TST & \\
\hline CHEMBL1347824 & 688239 & 4.6862 & 5.5125 & TRN & \\
\hline CHEMBL1365733 & 688239 & 5.1362 & 5.4011 & TRN & \\
\hline CHEMBL1593689 & 688239 & 8.3372 & 5.2716 & TRN & \\
\hline CHEMBL1455431 & 688239 & 4.5862 & 5.4914 & TRN & \\
\hline CHEMBL1602606 & 688239 & 4.5362 & 5.6101 & TRN & \\
\hline CHEMBL1508080 & 688239 & 4.8362 & 5.4775 & TST & \\
\hline CHEMBL1379329 & 688239 & 4.6362 & 5.4765 & TRN & \\
\hline CHEMBL1415619 & 688239 & 5.1362 & 5.487 & TST & \\
\hline CHEMBL1328537 & 688239 & 4.5362 & 5.5228 & TRN & \\
\hline CHEMBL1355226 & 688239 & 4.5362 & 5.4665 & TST & \\
\hline CHEMBL1346018 & 688239 & 6.9363 & 5.5401 & TRN & \\
\hline CHEMBL1349611 & 688239 & 5.1862 & 5.5115 & TRN & \\
\hline CHEMBL1314100 & 688239 & 4.8362 & 5.3518 & TRN & \\
\hline CHEMBL3198281 & 688239 & 4.5862 & 5.2484 & TRN & \\
\hline CHEMBL1402962 & 688239 & 5.6362 & 5.41799 & 9999999999 & TRN \\
\hline CHEMBL1375263 & 688239 & 6.3863 & 5.455 & TRN & \\
\hline CHEMBL1389520 & 688239 & 5.8862 & 5.40799 & 99999999995 & TRN \\
\hline CHEMBL1517136 & 688239 & 5.4862 & 5.3843 & TRN & \\
\hline CHEMBL1520799 & 688239 & 4.5362 & 5.4179 & TRN & \\
\hline CHEMBL1411253 & 688239 & 4.7862 & 5.5261 & TRN & \\
\hline CHEMBL1452823 & 688239 & 4.5362 & 5.4108 & TRN & \\
\hline CHEMBL1436019 & 688239 & 4.5362 & 5.4586 & TRN & \\
\hline CHEMBL1469982 & 688239 & 5.7862 & 5.5438 & TRN & \\
\hline CHEMBL1592360 & 688239 & 8.1871 & 5.6757 & TRN & \\
\hline CHEMBL1299630 & 688239 & 4.7862 & 5.4048 & TRN & \\
\hline CHEMBL1305046 & 688239 & 6.8362 & 5.6252 & TRN & \\
\hline CHEMBL1597533 & 688239 & 4.5362 & 5.4096 & TRN & \\
\hline CHEMBL1612631 & 688239 & 4.7862 & 5.4982 & TRN & \\
\hline CHEMBL1556140 & 688239 & 6.4862 & 5.5486 & TRN & \\
\hline CHEMBL1588525 & 688239 & 5.3862 & 5.4448 & TRN & \\
\hline CHEMBL1171857 & 688239 & 5.8362 & 5.3064 & TRN & \\
\hline CHEMBL1391129 & 688239 & 6.9363 & 5.6846 & TRN & \\
\hline CHEMBL1345106 & 688239 & 4.5362 & 5.5352 & TST & \\
\hline CHEMBL1348832 & 688239 & 5.3362 & 5.4789 & TRN & \\
\hline CHEMBL1568834 & 688239 & 6.2362 & 5.4902 & TST & \\
\hline CHEMBL1378952 & 688239 & 4.5362 & 5.3411 & TRN & \\
\hline CHEMBL1458021 & 688239 & 4.6862 & 5.5505 & TRN & \\
\hline CHEMBL1328507 & 688239 & 5.9362 & 5.4061 & TRN & \\
\hline CHEMBL1470363 & 688239 & 4.7862 & 5.5128 & TST & \\
\hline CHEMBL594152 & 688239 & 6.0862 & 5.6488 & TST & \\
\hline CHEMBL1348368 & 688239 & 5.2362 & 5.511 & TST & \\
\hline
\end{tabular}




\begin{tabular}{|c|c|c|c|c|c|}
\hline \multicolumn{6}{|c|}{ Supplemental Table S2 } \\
\hline CHEMBL1419519 & 688239 & 4.4862 & 5.4156 & TST & \\
\hline CHEMBL1400537 & 688239 & 5.1862 & 5.6298 & TRN & \\
\hline CHEMBL 3195866 & 688239 & 7.0862 & 5.4526 & TRN & \\
\hline CHEMBL1502513 & 688239 & 4.6862 & 5.4268 & TST & \\
\hline CHEMBL1415311 & 688239 & 5.1862 & 5.4234 & TRN & \\
\hline CHEMBL1423285 & 688239 & 4.8862 & 5.4274 & TRN & \\
\hline CHEMBL1519692 & 688239 & 6.2362 & 5.45700 & 0000000001 & TRN \\
\hline CHEMBL1434384 & 688239 & 4.5362 & 5.3839 & TRN & \\
\hline CHEMBL1403204 & 688239 & 4.7362 & 5.4682 & TRN & \\
\hline CHEMBL1499552 & 688239 & 5.6862 & 5.5116 & TST & \\
\hline CHEMBL1971705 & 688239 & 4.4862 & 5.3734 & TRN & \\
\hline CHEMBL1340535 & 688239 & 4.9362 & 5.58799 & 9999999999 & TRN \\
\hline CHEMBL1302951 & 688239 & 5.2862 & 5.5116 & TRN & \\
\hline CHEMBL1980661 & 688239 & 4.8362 & 5.4255 & TRN & \\
\hline CHEMBL1333890 & 688239 & 5.2362 & 5.5262 & TST & \\
\hline CHEMBL1349833 & 688239 & 6.8362 & 5.3914 & TST & \\
\hline CHEMBL1491970 & 688239 & 6.0862 & 5.4653 & TRN & \\
\hline CHEMBL1464316 & 688239 & 6.1362 & 5.4718 & TRN & \\
\hline CHEMBL138394 & 688239 & 5.4362 & 5.3716 & TST & \\
\hline CHEMBL1526794 & 688239 & 5.4862 & 5.5605 & TRN & \\
\hline CHEMBL1613020 & 688239 & 5.1862 & 5.6622 & TRN & \\
\hline CHEMBL1313433 & 688239 & 4.7862 & 5.66700 & 0000000001 & TST \\
\hline CHEMBL1556300 & 688239 & 4.7862 & 5.4269 & TRN & \\
\hline CHEMBL39076 & 688239 & 4.5362 & 5.4436 & TRN & \\
\hline CHEMBL 2002972 & 688239 & 5.2362 & 5.5591 & TST & \\
\hline CHEMBL1456084 & 688239 & 5.1362 & 5.4599 & TST & \\
\hline CHEMBL1550802 & 688239 & 6.8362 & 5.54700 & 0000000001 & TRN \\
\hline CHEMBL1585175 & 688239 & 5.5862 & 5.3812 & TST & \\
\hline CHEMBL1366115 & 688239 & 4.8862 & 5.3882 & TST & \\
\hline CHEMBL1528525 & 688239 & 5.1362 & 5.4004 & TST & \\
\hline CHEMBL1470673 & 688239 & 4.5362 & 5.3828 & TRN & \\
\hline CHEMBL1408391 & 688239 & 4.7362 & 5.4897 & TRN & \\
\hline CHEMBL1609945 & 688239 & 4.5862 & 5.494 & TRN & \\
\hline CHEMBL1583788 & 688239 & 4.5362 & 5.5143 & TRN & \\
\hline CHEMBL1607395 & 688239 & 4.6362 & 5.6516 & TRN & \\
\hline CHEMBL1484124 & 688239 & 5.3862 & 5.528 & TRN & \\
\hline CHEMBL1412715 & 688239 & 6.0362 & 5.42899 & 9999999999 & TRN \\
\hline CHEMBL1560707 & 688239 & 5.9362 & 5.42399 & 99999999995 & TRN \\
\hline CHEMBL1325793 & 688239 & 4.5362 & 5.5419 & TRN & \\
\hline CHEMBL1462844 & 688239 & 4.6862 & 5.5259 & TRN & \\
\hline CHEMBL1333608 & 688239 & 4.6362 & 5.3745 & TRN & \\
\hline CHEMBL1578202 & 688239 & 4.5862 & 5.5642 & TRN & \\
\hline CHEMBL1565677 & 688239 & 6.8362 & 5.3978 & TRN & \\
\hline CHEMBL1334618 & 688239 & 6.2862 & 5.4936 & TRN & \\
\hline CHEMBL1420587 & 688239 & 4.6362 & 5.3982 & TRN & \\
\hline CHEMBL1592056 & 688239 & 6.1862 & 5.4959 & TRN & \\
\hline CHEMBL1550496 & 688239 & 6.3362 & 5.3647 & TST & \\
\hline CHEMBL1991885 & 688239 & 4.9362 & 5.2321 & TST & \\
\hline
\end{tabular}


Supplemental Table S2.txt

\begin{tabular}{|c|c|c|c|c|c|}
\hline CHEMBL1417476 & 688239 & 8.1871 & 5.4129 & TST & \\
\hline CHEMBL1489322 & 688239 & 6.6362 & 5.4586 & TRN & \\
\hline CHEMBL1429058 & 688239 & 4.5862 & 5.4594 & TRN & \\
\hline CHEMBL1567844 & 688239 & 4.5362 & 5.4841 & TST & \\
\hline CHEMBL1364343 & 688239 & 5.5362 & 5.537006 & 0000000001 & TRN \\
\hline CHEMBL1345305 & 688239 & 4.5362 & 5.5042 & TRN & \\
\hline CHEMBL1338492 & 688239 & 5.4362 & 5.3421 & TRN & \\
\hline CHEMBL1478964 & 688239 & 8.3372 & 5.6649 & TRN & \\
\hline CHEMBL1393520 & 688239 & 6.0862 & 5.3768 & TRN & \\
\hline CHEMBL1505180 & 688239 & 4.5362 & 5.5142 & TRN & \\
\hline CHEMBL1300231 & 688239 & 4.8862 & 5.4896 & TST & \\
\hline CHEMBL1510163 & 688239 & 6.1362 & 5.5895 & TRN & \\
\hline CHEMBL1520317 & 688239 & 4.9362 & 5.5369 & TST & \\
\hline CHEMBL1304078 & 688239 & 5.3862 & 5.3498 & TRN & \\
\hline CHEMBL1496436 & 688239 & 6.2862 & 5.5436 & TRN & \\
\hline CHEMBL1420439 & 688239 & 5.5362 & 5.5817 & TRN & \\
\hline CHEMBL1473053 & 688239 & 4.6862 & 5.4843 & TRN & \\
\hline CHEMBL1303935 & 688239 & 4.5362 & 5.3587 & TRN & \\
\hline CHEMBL1355182 & 688239 & 5.3362 & 5.5697 & TRN & \\
\hline CHEMBL1303835 & 688239 & 5.8362 & 5.395 & TRN & \\
\hline CHEMBL1369553 & 688239 & 5.6362 & 5.3955 & TRN & \\
\hline CHEMBL1591408 & 688239 & 5.0862 & 5.4811 & TRN & \\
\hline CHEMBL1417498 & 688239 & 4.6862 & 5.50899 & 99999999995 & TRN \\
\hline CHEMBL1345646 & 688239 & 5.3862 & 5.5344 & TRN & \\
\hline CHEMBL1309745 & 688239 & 6.0862 & 5.4396 & TRN & \\
\hline CHEMBL1447487 & 688239 & 4.4862 & 5.5772 & TRN & \\
\hline CHEMBL1536779 & 688239 & 5.1362 & 5.4693 & TST & \\
\hline CHEMBL1440984 & 688239 & 6.3362 & 5.6122 & TST & \\
\hline CHEMBL1502361 & 688239 & 4.6362 & 5.5912 & TRN & \\
\hline CHEMBL1443744 & 688239 & 6.2362 & \multicolumn{2}{|c|}{5.632999999999999} & TST \\
\hline CHEMBL1600294 & 688239 & 4.8362 & 5.4724 & TRN & \\
\hline CHEMBL1490552 & 688239 & 5.1862 & 5.4415 & TRN & \\
\hline CHEMBL1604926 & 688239 & 6.8362 & 5.4622 & TRN & \\
\hline CHEMBL1491297 & 688239 & 5.4362 & 5.6246 & TRN & \\
\hline CHEMBL1390214 & 688239 & 5.1862 & 5.5106 & TRN & \\
\hline CHEMBL1606573 & 688239 & 5.3362 & 5.4137 & TRN & \\
\hline CHEMBL1329771 & 688239 & 5.4362 & 5.5547 & TRN & \\
\hline CHEMBL1402754 & 688239 & 4.5362 & 5.6405 & TRN & \\
\hline CHEMBL1484095 & 688239 & 5.6362 & 5.6787 & TRN & \\
\hline CHEMBL1366059 & 688239 & 4.9862 & 5.4748 & TST & \\
\hline CHEMBL1430083 & 688239 & 4.5362 & 5.5516 & TRN & \\
\hline CHEMBL1502471 & 688239 & 6.4862 & 5.4313 & TRN & \\
\hline CHEMBL3195467 & 688239 & 4.5862 & 5.3336 & TRN & \\
\hline CHEMBL1400245 & 688239 & 4.7862 & 5.6158 & TST & \\
\hline CHEMBL1412686 & 688239 & 5.1362 & 5.6058 & TRN & \\
\hline CHEMBL 584520 & 688239 & 4.6862 & 5.5027 & TRN & \\
\hline CHEMBL1350482 & 688239 & 8.3372 & 5.4729 & TRN & \\
\hline CHEMBL1559952 & 688239 & 5.2362 & 5.4773 & TRN & \\
\hline
\end{tabular}


Supplemental Table S2.txt

\begin{tabular}{|c|c|c|c|c|}
\hline IE & & 52 & 13 & \\
\hline & & .1862 & & \\
\hline-1 & & & & \\
\hline AEMBL1 & & & & \\
\hline AEMBL1426440 & 8239 & 362 & & \\
\hline HEMBL1530928 & 88239 & 5862 & 789 & \\
\hline HEMBL1 & 239 & 362 & & \\
\hline IFMBI & & & & \\
\hline AEMBL153e & 239 & & & \\
\hline HEMBL145 & 88239 & 362 & & \\
\hline AEMBL1372 & 239 & 862 & & \\
\hline IEMBL1 & 39 & 362 & & \\
\hline IEMBL: & & & & \\
\hline JEMBL159 & & 5862 & & \\
\hline AEMBL1 & 39 & 372 & & \\
\hline AEMBL1 & 39 & 62 & & \\
\hline HEMBL1 & & & & \\
\hline HEMBL1 & & & & \\
\hline HEMBL1 & & & & \\
\hline IEMBL1 & & & & \\
\hline HEMBL: & & & & \\
\hline HEMBL & & & & \\
\hline HEMBL: & & & & \\
\hline 84 & & & & \\
\hline AEMBL13 & & & & בידו \\
\hline HEMBL: & & & & RI \\
\hline HEMBL & & & & \\
\hline HFMBI & & 62 & & RN \\
\hline HEMBL1 & & & & r \\
\hline HEMBL 142 & & & & ISI \\
\hline HEMBL1 & & & & RN \\
\hline HEMBL & & & & Niv \\
\hline 8 & & & & ST \\
\hline HEMBL1505 & & & & TRN \\
\hline HEMBL1543546 & & 871 & & TST \\
\hline HEMBL1 & & 63 & & RN \\
\hline - & & & & RN \\
\hline & & & & RN \\
\hline HEMBL1996779 & 88239 & 4.8362 & & ГST \\
\hline IEMBL1 & & 62 & & IST \\
\hline HEMBL1 & & 862 & & \\
\hline HEMBL1. & & & & NIV \\
\hline HEMBL158 & & 362 & & RN \\
\hline AEMBL1362500 & 39 & 862 & & TR \\
\hline MBLI & & & & \\
\hline CHEMBL134 & & & & \\
\hline CHEMBL151 & & 5.4362 & 5.7424 & \\
\hline CHEMBL1417051 & 688239 & 5.9362 & 5.5696 & - \\
\hline
\end{tabular}

Page 2308 
Supplemental Table S2.txt

\begin{tabular}{|c|c|c|c|c|}
\hline & & & & \\
\hline AEMBL13 & 8239 & 362 & & \\
\hline IEMBL1530056 & 3239 & 356 & 497 & \\
\hline AEMBL1467973 & 3239 & 862 & 5355 & \\
\hline & 239 & 862 & & \\
\hline IFMRI 14 & 239 & 362 & 275 & \\
\hline AEMBL3193015 & 88239 & 362 & 168 & \\
\hline AEMBL1509407 & 88239 & 362 & 924 & \\
\hline AEMBL1329310 & 239 & 362 & 024 & \\
\hline AEMBL152 & 239 & 362 & 308 & \\
\hline IEMBL1389654 & & & & \\
\hline AEMBL1392469 & 688239 & 362 & 932 & \\
\hline AEMBL1497137 & 239 & 862 & & RI \\
\hline AEMBL153 & & 362 & & \\
\hline IEMBL16 & & & & \\
\hline HEMBL 140 & & & & \\
\hline AEMBL1344013 & 239 & 362 & & RN \\
\hline HEMBL149 & & 62 & & \\
\hline IEMBL13 & & 62 & & \\
\hline IEMBL13 & & & & \\
\hline AEMBL15 & & 62 & & ST \\
\hline HEMBL135 & & & 371 & $x_{0}+2$ \\
\hline HEMBL152 & & 62 & & \\
\hline IEMBL14 & & 62 & & \\
\hline IEMBL15 & & & 82 & ST \\
\hline AFMRI 15 & & 62 & & NIV \\
\hline AEMBL148 & & 362 & & RN \\
\hline HEMBL149 & & & & \\
\hline HEMBL 229 & & 52 & 46 & $\mathrm{RI}$ \\
\hline HEMBL 14 & & & 67 & $x_{-1}+2$ \\
\hline 6 & & & & $x_{-1}+2+$ \\
\hline HEMBL1322109 & & & & RN \\
\hline AEMBL1502207 & & & & RI \\
\hline AEMBL142 & & 862 & 16 & RI \\
\hline HEMBL13 & & 62 & & 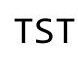 \\
\hline 1 & & & & $\theta$ \\
\hline AEMBL1525617 & & & & $\mathrm{RI}$ \\
\hline AEMBL1416340 & & & & $S$ \\
\hline IEMBL15 & & 62 & & $S$ \\
\hline 19 & & & 979 & $\cdots$ \\
\hline HEMBL14 & & & & RN \\
\hline HEMBL1526223 & & 862 & 139 & ST \\
\hline IEMBL1313 & & & & TR \\
\hline HEMBL 143 & & & & \\
\hline CHEMBL152 & & & .4802 & \\
\hline CHEMBL1597238 & & 362 & 5.3693 & ST \\
\hline AEMBL1382192 & 88239 & 5.6862 & 5.4887 & $T R$ \\
\hline HFMBI 1418976 & 688239 & 6.9863 & 5.3238 & \\
\hline
\end{tabular}

Page 2309 
Supplemental Table S2.txt

\begin{tabular}{|c|c|c|c|c|}
\hline 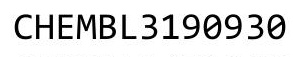 & & & & \\
\hline AEMBL1451866 & 38239 & 862 & 9 & \\
\hline AEMBL1539240 & 39 & 862 & & \\
\hline 85 & 39 & 362 & & \\
\hline IEMBL1305466 & 39 & 362 & & \\
\hline AEMBL1504750 & 88239 & 362 & 698 & \\
\hline AEMBL1315640 & 88239 & 4.7362 & 362 & \\
\hline AEMBL1593182 & & & & \\
\hline IEMBL14 & 39 & 862 & & \\
\hline IEMBL13 & & 362 & & \\
\hline AEMBL1438354 & 39 & 362 & 46 & \\
\hline AEMBL1503072 & & 362 & 5594 & \\
\hline AEMBL1421038 & & & 61 & \\
\hline HEMBL320 & & & & \\
\hline AEMBL1556001 & & & & \\
\hline AEMBL1358585 & & 362 & 841 & \\
\hline AEMBL1446772 & & 362 & & \\
\hline AEMBL132 & & & & \\
\hline AEMBL14] & & & & \\
\hline IEMBL1396900 & & 62 & & \\
\hline AEMBL1311615 & & 362 & & \\
\hline AEMBL1418063 & & 862 & & \\
\hline IEMBL1506828 & & 62 & & \\
\hline AEMBL1358611 & & & & \\
\hline 550 & & 61 & & \\
\hline AEMBL259851 & & 862 & & \\
\hline IEMBL 257943 & & & & \\
\hline EMBL1497203 & & 62 & & \\
\hline AFMR & & 52 & & \\
\hline 475 & & 62 & & \\
\hline AEMBL1328198 & & & & \\
\hline HEMBL1560670 & & 362 & & \\
\hline 965 & & 66 & & \\
\hline 771 & & 52 & 82 & \\
\hline & & & & \\
\hline AEMBL1465916 & & & 149 & \\
\hline AEMBL1555968 & & 362 & & \\
\hline & & & & \\
\hline 18 & & & & \\
\hline HEMBL1443258 & & & & $S$ \\
\hline IEMBL1310730 & & 862 & & $R$ \\
\hline 1575795 & & 62 & & \\
\hline HEMBL1444334 & & & & \\
\hline HEMBL 3190749 & & & 324 & \\
\hline HEMBL1398839 & & & 4227 & ST \\
\hline IEMBL1308466 & & 4.7362 & 5215 & $F$ \\
\hline 19071 & & & & \\
\hline 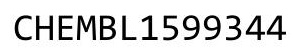 & & & & \\
\hline
\end{tabular}

Page 2310 
Supplemental Table S2.txt

\begin{tabular}{|c|c|c|c|c|c|}
\hline CHEMBL3192299 & 688239 & 4.5362 & 5.3619 & TRN & \\
\hline CHEMBL1535859 & 688239 & 4.7362 & 5.5261 & TRN & \\
\hline CHEMBL1411827 & 688239 & 5.2862 & 5.3763 & TRN & \\
\hline CHEMBL1471767 & 688239 & 4.7862 & 5.4648 & TRN & \\
\hline CHEMBL1526385 & 688239 & 5.1862 & 5.603 & TST & \\
\hline CHEMBL1411021 & 688239 & 5.1862 & 5.6606 & TRN & \\
\hline CHEMBL1301173 & 688239 & 5.0862 & 5.4046 & TRN & \\
\hline CHEMBL1354158 & 688239 & 4.6862 & 5.5885 & TST & \\
\hline CHEMBL1421726 & 688239 & 5.8362 & 5.6978 & TRN & \\
\hline CHEMBL1595770 & 688239 & 6.1 & 5.4642 & TRN & \\
\hline CHEMBL1349512 & 688239 & 6.5862 & 5.5239 & TRN & \\
\hline CHEMBL1524990 & 688239 & 6.1862 & 5.4229 & TST & \\
\hline CHEMBL1551636 & 688239 & 5.7862 & 5.3911 & TRN & \\
\hline CHEMBL1989500 & 688239 & 4.5362 & 5.5152 & TRN & \\
\hline CHEMBL1469263 & 688239 & 4.5362 & 5.3745 & TRN & \\
\hline CHEMBL1313999 & 688239 & 4.9362 & 5.4821 & TRN & \\
\hline CHEMBL1422500 & 688239 & 6.2362 & 5.5091 & TST & \\
\hline CHEMBL1399297 & 688239 & 4.9862 & 5.4405 & TRN & \\
\hline CHEMBL1399775 & 688239 & 4.6362 & 5.5072 & TRN & \\
\hline CHEMBL2369285 & 688239 & 5.0362 & 5.4405 & TST & \\
\hline CHEMBL1487202 & 688239 & 4.8362 & 5.3396 & TRN & \\
\hline CHEMBL1510077 & 688239 & 5.3862 & 5.5187 & TRN & \\
\hline CHEMBL1600023 & 688239 & 8.28399 & 99999999 & 5.5781 & TRN \\
\hline CHEMBL1465218 & 688239 & 5.1362 & 5.473 & TST & \\
\hline CHEMBL1427633 & 688239 & 4.8362 & 5.3039 & TRN & \\
\hline CHEMBL1347916 & 688239 & 5.7862 & 5.3956 & TRN & \\
\hline CHEMBL3193504 & 688239 & 6.9863 & 5.4195 & TRN & \\
\hline CHEMBL1348606 & 688239 & 8.283999 & 99999999 & 5.4557 & TRN \\
\hline CHEMBL1542324 & 688239 & 5.9862 & 5.5937 & TST & \\
\hline CHEMBL 3199260 & 688239 & 4.5362 & 5.4299 & TST & \\
\hline CHEMBL1589478 & 688239 & 4.6362 & 5.4059 & TRN & \\
\hline CHEMBL1313305 & 688239 & 4.7862 & 5.7007 & TST & \\
\hline CHEMBL1555458 & 688239 & 7.0862 & 5.6857 & TRN & \\
\hline CHEMBL1439210 & 688239 & 5.1362 & 5.4718 & TRN & \\
\hline CHEMBL1490666 & 688239 & 4.8362 & 5.4013 & TRN & \\
\hline CHEMBL1308978 & 688239 & 5.1862 & 5.4015 & TRN & \\
\hline CHEMBL1433806 & 688239 & 5.6362 & 5.4233 & TRN & \\
\hline CHEMBL1442539 & 688239 & 5.9862 & 5.5607 & TRN & \\
\hline CHEMBL1455877 & 688239 & 4.9362 & 5.4246 & TRN & \\
\hline CHEMBL1563547 & 688239 & 4.5362 & 5.48 & TRN & \\
\hline CHEMBL1415919 & 688239 & 4.8862 & 5.3745 & TRN & \\
\hline CHEMBL1513273 & 688239 & 4.7362 & 5.3743 & TST & \\
\hline CHEMBL1566384 & 688239 & 6.3863 & 5.4901 & TRN & \\
\hline CHEMBL1445864 & 688239 & 6.6861 & 5.3694 & TRN & \\
\hline CHEMBL1327031 & 688239 & 4.5862 & 5.4228 & TRN & \\
\hline CHEMBL1344017 & 688239 & 4.6862 & 5.50899 & 799999999995 & TRN \\
\hline CHEMBL1606306 & 688239 & 4.7362 & 5.474 & TRN & \\
\hline CHEMBL1579786 & 688239 & 5.3862 & 5.5063 & TRN & \\
\hline
\end{tabular}

Page 2311 
Supplemental Table S2.txt

\begin{tabular}{|c|c|c|c|c|c|}
\hline CHEMBL1355378 & 688239 & 6.1862 & 5.4846 & TRN & \\
\hline CHEMBL1366494 & 688239 & 6.1362 & 5.4249 & TST & \\
\hline CHEMBL1593238 & 688239 & 5.5362 & 5.5106 & TRN & \\
\hline CHEMBL1539578 & 688239 & 5.5862 & 5.4253 & TST & \\
\hline CHEMBL1607240 & 688239 & 4.5362 & 5.3956 & TRN & \\
\hline CHEMBL1597861 & 688239 & 4.5862 & 5.3934 & TRN & \\
\hline CHEMBL1572256 & 688239 & 5.5862 & 5.5619 & TRN & \\
\hline CHEMBL1451722 & 688239 & 5.1362 & 5.466 & TRN & \\
\hline CHEMBL1400145 & 688239 & 5.1862 & 5.395 & TRN & \\
\hline CHEMBL1420142 & 688239 & 5.2862 & 5.4538 & TRN & \\
\hline CHEMBL3192178 & 688239 & 6.8861 & 5.5262 & TRN & \\
\hline CHEMBL1567293 & 688239 & 4.9362 & 5.6906 & TRN & \\
\hline CHEMBL1608521 & 688239 & 4.5362 & 5.6888 & TST & \\
\hline CHEMBL1352201 & 688239 & 4.6362 & 5.551 & TRN & \\
\hline CHEMBL1541806 & 688239 & 5.0 & 5.426 & TRN & \\
\hline CHEMBL1384475 & 688239 & 4.6862 & 5.4165 & TRN & \\
\hline CHEMBL1473096 & 688239 & 5.7862 & 5.5432 & TRN & \\
\hline CHEMBL1434840 & 688239 & 5.3862 & 5.4775 & TRN & \\
\hline CHEMBL1488513 & 688239 & 5.7362 & 5.4897 & TRN & \\
\hline CHEMBL1355925 & 688239 & 5.0362 & 5.6558 & TST & \\
\hline CHEMBL1341161 & 688239 & \multicolumn{2}{|c|}{8.283999999999999} & 5.5323 & TST \\
\hline CHEMBL1477711 & 688239 & 5.1862 & 5.5195 & TRN & \\
\hline CHEMBL1609423 & 688239 & 7.0362 & 5.6116 & TRN & \\
\hline CHEMBL1482434 & 688239 & 6.7361 & 5.5504 & TST & \\
\hline CHEMBL1595676 & 688239 & 4.5862 & 5.3913 & TRN & \\
\hline CHEMBL1581298 & 688239 & 4.6862 & 5.54799 & 9999999999 & TRN \\
\hline CHEMBL1459296 & 688239 & 6.1362 & 5.3672 & TST & \\
\hline CHEMBL1545056 & 688239 & 4.6862 & 5.5871 & TRN & \\
\hline CHEMBL1551340 & 688239 & 4.5362 & 5.6804 & TST & \\
\hline CHEMBL1331340 & 688239 & 6.0 & 5.5009 & TRN & \\
\hline CHEMBL1473189 & 688239 & 5.1862 & 5.4208 & TRN & \\
\hline CHEMBL1434570 & 688239 & 5.6862 & 5.4493 & TRN & \\
\hline CHEMBL1979955 & 688239 & 6.8362 & 5.3601 & TRN & \\
\hline CHEMBL1461175 & 688239 & 6.1362 & 5.3824 & TRN & \\
\hline CHEMBL1573304 & 688239 & 6.2862 & 5.4854 & TRN & \\
\hline CHEMBL1429687 & 688239 & 5.5362 & 5.4573 & TST & \\
\hline CHEMBL3193709 & 688239 & 4.5362 & 5.4776 & TST & \\
\hline CHEMBL3189998 & 688239 & 4.6362 & 5.5694 & TRN & \\
\hline CHEMBL3195135 & 688239 & 4.7362 & 5.539 & TST & \\
\hline CHEMBL1487906 & 688239 & 4.5362 & 5.3031 & TRN & \\
\hline CHEMBL1429198 & 688239 & 6.9863 & 5.4901 & TRN & \\
\hline CHEMBL1449793 & 688239 & 4.5362 & 5.4258 & TRN & \\
\hline CHEMBL1374878 & 688239 & 4.5362 & 5.4563 & TRN & \\
\hline CHEMBL1332038 & 688239 & 8.3372 & 5.521 & TRN & \\
\hline CHEMBL1578992 & 688239 & 6.7862 & 5.4284 & TRN & \\
\hline CHEMBL1595896 & 688239 & 4.5362 & 5.6051 & TRN & \\
\hline CHEMBL3192125 & 688239 & 5.6862 & 5.5632 & TRN & \\
\hline CHEMBL3197900 & 688239 & 6.2362 & 5.5435 & TRN & \\
\hline
\end{tabular}

Page 2312 


\begin{tabular}{|c|c|c|c|c|c|c|}
\hline \multicolumn{7}{|c|}{ Supplemental Table S2.txt } \\
\hline CHEMBL1424924 & 688239 & 4.45 & 5.6148 & TRN & & \\
\hline CHEMBL1385812 & 688239 & 4.7862 & 5.518 & TRN & & \\
\hline CHEMBL1395856 & 688239 & 5.1362 & 5.5406 & TRN & & \\
\hline CHEMBL1450979 & 688239 & 4.6862 & 5.4782 & TRN & & \\
\hline CHEMBL1531237 & 688239 & 4.7362 & 5.3595 & TRN & & \\
\hline CHEMBL1320327 & 688239 & 5.1862 & 5.4884 & TRN & & \\
\hline CHEMBL1545794 & 688239 & 4.8862 & 5.371 & TRN & & \\
\hline CHEMBL1564189 & 688239 & 5.4362 & 5.5276 & TRN & & \\
\hline CHEMBL3196514 & 688239 & 5.5362 & 5.4617 & TST & & \\
\hline CHEMBL1456581 & 688239 & 5.1862 & 5.4985 & TRN & & \\
\hline CHEMBL3192563 & 688239 & 4.5362 & 5.4669 & TST & & \\
\hline CHEMBL1478035 & 688239 & 5.1862 & 5.5325 & TRN & & \\
\hline CHEMBL1569503 & 688239 & 4.6862 & 5.4278 & TRN & & \\
\hline CHEMBL1498559 & 688239 & 4.5862 & 5.306 & TST & & \\
\hline CHEMBL1588483 & 688239 & 8.28399 & 99999999 & 99 & 5.4172 TRN & \\
\hline CHEMBL1546725 & 688239 & 6.3863 & 5.4446 & TRN & & \\
\hline CHEMBL1449097 & 688239 & 5.4362 & 5.4697 & TRN & & \\
\hline CHEMBL1584257 & 688239 & 4.5362 & 5.5437 & TST & & \\
\hline CHEMBL1509213 & 688239 & 5.1862 & 5.4381 & TRN & & \\
\hline CHEMBL1464578 & 688239 & 4.4862 & 5.4527 & TRN & & \\
\hline CHEMBL1504852 & 688239 & 6.9363 & 5.4412 & TRN & & \\
\hline CHEMBL84316 & 688239 & 4.5362 & 5.545 & TST & & \\
\hline CHEMBL1518941 & 688239 & 8.1871 & 5.4744 & TRN & & \\
\hline CHEMBL1331578 & 688239 & 6.3863 & 5.5245 & TRN & & \\
\hline CHEMBL1343388 & 688239 & 4.5362 & 5.5089 & TRN & & \\
\hline CHEMBL1338857 & 688239 & 4.5362 & 5.5491 & TST & & \\
\hline CHEMBL1590448 & 688239 & 4.6862 & 5.477 & TRN & & \\
\hline CHEMBL1337919 & 688239 & 4.5362 & 5.517 & TST & & \\
\hline CHEMBL1457815 & 688239 & 5.1862 & 5.3755 & TRN & & \\
\hline CHEMBL1329758 & 688239 & 5.1862 & 5.3047 & TRN & & \\
\hline CHEMBL1563357 & 688239 & 5.2362 & 5.4396 & TST & & \\
\hline CHEMBL1535226 & 688239 & 8.28399 & 99999999 & 99 & 5.5089999999999995 & TRN \\
\hline CHEMBL1336724 & 688239 & 5.3362 & 5.3649 & TRN & & \\
\hline CHEMBL1564193 & 688239 & 5.3862 & 5.4624 & TRN & & \\
\hline CHEMBL1552402 & 688239 & 4.9362 & 5.4569 & TRN & & \\
\hline CHEMBL1334494 & 688239 & 5.1862 & 5.4737 & TRN & & \\
\hline CHEMBL1576192 & 688239 & 4.9362 & 5.5129 & TST & & \\
\hline CHEMBL1555429 & 688239 & 6.7862 & 5.459 & TST & & \\
\hline CHEMBL566901 & 688239 & 6.7862 & 5.4136 & TRN & & \\
\hline CHEMBL1348486 & 688239 & 5.6862 & 5.475 & TRN & & \\
\hline CHEMBL1514385 & 688239 & 5.7362 & 5.5536 & TRN & & \\
\hline CHEMBL1477900 & 688239 & 6.9363 & 5.5028 & TRN & & \\
\hline CHEMBL1555855 & 688239 & 5.4362 & 5.5998 & TRN & & \\
\hline CHEMBL1350810 & 688239 & 5.4862 & 5.4363 & TRN & & \\
\hline CHEMBL1464634 & 688239 & 4.5362 & 5.4839 & TST & & \\
\hline CHEMBL1525713 & 688239 & 5.1862 & 5.5563 & TRN & & \\
\hline CHEMBL3199539 & 688239 & 5.3362 & 5.3182 & TRN & & \\
\hline CHEMBL1517823 & 688239 & 5.1862 & 5.4853 & TST & & \\
\hline
\end{tabular}


Supplemental Table S2.txt

\begin{tabular}{|c|c|c|c|c|}
\hline CHEMBL1449077 & 688239 & 4.6862 & 5.54 & TRN \\
\hline CHEMBL1500190 & 688239 & 5.2862 & 5.4591 & TST \\
\hline CHEMBL1327044 & 688239 & 4.5362 & 5.4035 & TRN \\
\hline CHEMBL1372218 & 688239 & 4.7862 & 5.2533 & TRN \\
\hline CHEMBL1463461 & 688239 & 5.9862 & 5.4377 & TRN \\
\hline CHEMBL1479087 & 688239 & 4.5362 & 5.4441 & TRN \\
\hline CHEMBL1354048 & 688239 & 5.1862 & 5.5169 & TRN \\
\hline CHEMBL1374107 & 688239 & 4.5362 & 5.5695 & TRN \\
\hline CHEMBL1595774 & 688239 & 5.6362 & 5.347 & TRN \\
\hline CHEMBL1591888 & 688239 & 5.0362 & 5.3716 & TRN \\
\hline CHEMBL1583031 & 688239 & 5.7862 & 5.4345 & TST \\
\hline CHEMBL1467124 & 688239 & 5.6362 & 5.4795 & TRN \\
\hline CHEMBL1311439 & 688239 & 4.6862 & 5.5641 & TRN \\
\hline CHEMBL61559 & 688239 & 4.5362 & 5.4598 & TRN \\
\hline CHEMBL1604628 & 688239 & 5.4862 & 5.5867 & TRN \\
\hline CHEMBL1483157 & 688239 & 5.8862 & 5.4294 & TST \\
\hline CHEMBL1406986 & 688239 & 7.2865 & 5.5931 & TRN \\
\hline CHEMBL3194990 & 688239 & 5.2362 & 5.4984 & TRN \\
\hline CHEMBL1535787 & 688239 & 4.6362 & 5.5531 & TRN \\
\hline CHEMBL1364430 & 688239 & 8.2366 & 5.5453 & TST \\
\hline CHEMBL1439055 & 688239 & 4.5362 & 5.4584 & TST \\
\hline CHEMBL1453699 & 688239 & 4.9362 & 5.32799 & 9999999999 \\
\hline CHEMBL1390906 & 688239 & 5.1862 & 5.3381 & TST \\
\hline CHEMBL1392009 & 688239 & 4.5362 & 5.5799 & TRN \\
\hline CHEMBL1386366 & 688239 & 5.6862 & 5.3728 & TRN \\
\hline CHEMBL1525958 & 688239 & 6.2362 & 5.4722 & TST \\
\hline CHEMBL1376503 & 688239 & 5.3362 & 5.38899 & 9999999999 \\
\hline CHEMBL 2095095 & 688239 & 4.8862 & 5.2899 & TRN \\
\hline CHEMBL1372813 & 688239 & 5.8862 & 5.5206 & TRN \\
\hline CHEMBL1527572 & 688239 & 6.9363 & 5.5163 & TRN \\
\hline CHEMBL1609636 & 688239 & 5.6862 & 5.6014 & TRN \\
\hline CHEMBL1379895 & 688239 & 4.6362 & 5.4255 & TRN \\
\hline CHEMBL1456838 & 688239 & 6.3863 & 5.4279 & TST \\
\hline CHEMBL1334469 & 688239 & 6.2362 & 5.4857 & TST \\
\hline CHEMBL1569724 & 688239 & 4.8862 & 5.4981 & TRN \\
\hline CHEMBL1407168 & 688239 & 6.3362 & 5.631 & TRN \\
\hline CHEMBL1496004 & 688239 & 5.7362 & 5.4669 & TST \\
\hline CHEMBL1347750 & 688239 & 4.7362 & 5.6473 & TST \\
\hline CHEMBL1591900 & 688239 & 4.6362 & 5.5594 & TRN \\
\hline CHEMBL 3197834 & 688239 & 6.3362 & 5.3674 & TRN \\
\hline CHEMBL1482128 & 688239 & 5.2362 & 5.5045 & TST \\
\hline CHEMBL1319240 & 688239 & 6.5862 & 5.4939 & TRN \\
\hline CHEMBL1403962 & 688239 & 6.1362 & 5.4596 & TRN \\
\hline CHEMBL1318151 & 688239 & 5.1862 & 5.4802 & TST \\
\hline CHEMBL1367647 & 688239 & 6.8362 & 5.5202 & TRN \\
\hline CHEMBL1333359 & 688239 & 6.5862 & 5.6152 & TRN \\
\hline CHEMBL1483471 & 688239 & 5.6362 & 5.3745 & TRN \\
\hline CHEMBL1446587 & 688239 & 4.5362 & 5.3602 & TRN \\
\hline
\end{tabular}

Page 2314 
Supplemental Table S2.txt

\begin{tabular}{|c|c|c|c|c|c|}
\hline CHEMBL1457628 & 688239 & 5.9362 & 5.5182 & TST & \\
\hline CHEMBL1559192 & 688239 & 4.5362 & 5.5468 & TST & \\
\hline CHEMBL1504817 & 688239 & 6.1362 & 5.2878 & TST & \\
\hline CHEMBL1499380 & 688239 & 4.5362 & 5.3856 & TRN & \\
\hline CHEMBL1570004 & 688239 & 4.8862 & 5.5489 & TST & \\
\hline CHEMBL1368420 & 688239 & 4.7362 & 5.5283 & TRN & \\
\hline CHEMBL1357739 & 688239 & 5.3862 & 5.4466 & TRN & \\
\hline CHEMBL1380089 & 688239 & 5.2362 & 5.5007 & TRN & \\
\hline CHEMBL1365975 & 688239 & 4.6862 & 5.4778 & TRN & \\
\hline CHEMBL1401016 & 688239 & 6.0862 & 5.4256 & TRN & \\
\hline CHEMBL1547274 & 688239 & 6.9863 & 5.3801 & TRN & \\
\hline CHEMBL3212074 & 688239 & 6.2362 & 5.4676 & TRN & \\
\hline CHEMBL1603630 & 688239 & 4.5362 & 5.5954 & TRN & \\
\hline CHEMBL1534421 & 688239 & 5.1862 & 5.5911 & TRN & \\
\hline CHEMBL1592653 & 688239 & 4.6862 & 5.6673 & TRN & \\
\hline CHEMBL1575540 & 688239 & 4.5362 & 5.5866 & TRN & \\
\hline CHEMBL1508899 & 688239 & 6.6861 & 5.51399 & 9999999999 & TST \\
\hline CHEMBL1481595 & 688239 & 6.7862 & 5.4541 & TRN & \\
\hline CHEMBL1572066 & 688239 & 5.3862 & 5.4469 & TRN & \\
\hline CHEMBL1435320 & 688239 & 6.0862 & 5.49100 & 00000000005 & TRN \\
\hline CHEMBL1496584 & 688239 & 5.3362 & 5.6722 & TRN & \\
\hline CHEMBL1307468 & 688239 & 5.4362 & 5.3962 & TRN & \\
\hline CHEMBL1539426 & 688239 & 6.9363 & 5.48 & TRN & \\
\hline CHEMBL1610049 & 688239 & 4.7862 & 5.3814 & TST & \\
\hline CHEMBL1579987 & 688239 & 5.2862 & 5.5669 & TRN & \\
\hline CHEMBL1541788 & 688239 & 4.5362 & 5.6417 & TRN & \\
\hline CHEMBL1300375 & 688239 & 5.1862 & 5.4364 & TRN & \\
\hline CHEMBL1346109 & 688239 & 6.3863 & 5.559 & TRN & \\
\hline CHEMBL1313775 & 688239 & 4.5362 & 5.6912 & TRN & \\
\hline CHEMBL1612769 & 688239 & 4.8862 & 5.5742 & TRN & \\
\hline CHEMBL1328686 & 688239 & 6.5862 & 5.5401 & TST & \\
\hline CHEMBL1599592 & 688239 & 6.2362 & 5.49 & TST & \\
\hline CHEMBL1579220 & 688239 & 4.4862 & 5.4364 & TRN & \\
\hline CHEMBL1534618 & 688239 & 5.4862 & 5.3802 & TRN & \\
\hline CHEMBL1374476 & 688239 & 7.1361 & 5.4745 & TRN & \\
\hline CHEMBL1520981 & 688239 & 5.6862 & 5.5779 & TRN & \\
\hline CHEMBL1330262 & 688239 & 4.6362 & 5.5995 & TST & \\
\hline CHEMBL1601724 & 688239 & 5.1862 & 5.4379 & TRN & \\
\hline CHEMBL1426753 & 688239 & 6.8362 & 5.5395 & TRN & \\
\hline CHEMBL1307389 & 688239 & 6.2862 & 5.4856 & TRN & \\
\hline CHEMBL3208539 & 688239 & 5.2362 & 5.3758 & TRN & \\
\hline CHEMBL3197793 & 688239 & 4.5362 & 5.4005 & TRN & \\
\hline CHEMBL1553760 & 688239 & 6.8362 & 5.3715 & TRN & \\
\hline CHEMBL 3190273 & 688239 & 5.6362 & 5.3629 & TST & \\
\hline CHEMBL1369162 & 688239 & 4.7862 & 5.4165 & TRN & \\
\hline CHEMBL1549856 & 688239 & 6.5363 & 5.5611 & TRN & \\
\hline CHEMBL1431967 & 688239 & 5.4362 & 5.5191 & TRN & \\
\hline CHEMBL1560063 & 688239 & 4.7362 & 5.3544 & TRN & \\
\hline
\end{tabular}


Supplemental Table S2.txt

\begin{tabular}{|c|c|c|c|c|c|c|}
\hline CHEMBL 2373673 & 688239 & 5.1862 & 5.4436 & TRN & & \\
\hline CHEMBL1403617 & 688239 & 5.8862 & 5.4146 & TRN & & \\
\hline CHEMBL1459362 & 688239 & 5.3362 & 5.4812 & TRN & & \\
\hline CHEMBL425808 & 688239 & 4.6362 & 5.4611 & TRN & & \\
\hline CHEMBL1393161 & 688239 & 5.0862 & 5.4764 & TRN & & \\
\hline CHEMBL1439706 & 688239 & 4.5362 & 5.4535 & TRN & & \\
\hline CHEMBL1467557 & 688239 & 5.1862 & 5.5069 & TST & & \\
\hline CHEMBL1429574 & 688239 & 5.4362 & 5.447 & TST & & \\
\hline CHEMBL1482329 & 688239 & 5.3362 & 5.5112 & TRN & & \\
\hline CHEMBL1452598 & 688239 & 4.5362 & 5.4345 & TST & & \\
\hline CHEMBL1516374 & 688239 & 5.1862 & 5.4387 & TST & & \\
\hline CHEMBL1373970 & 688239 & 5.2862 & 5.401 & TST & & \\
\hline CHEMBL1523399 & 688239 & 8.3372 & 5.4848 & TST & & \\
\hline CHEMBL1370007 & 688239 & 5.1862 & 5.5102 & TRN & & \\
\hline CHEMBL1489858 & 688239 & 6.2362 & 5.5752 & TST & & \\
\hline CHEMBL 3213941 & 688239 & 5.3862 & 5.5802 & TRN & & \\
\hline CHEMBL1385581 & 688239 & 5.1862 & 5.4612 & TRN & & \\
\hline CHEMBL1332420 & 688239 & 5.8862 & 5.6342 & TRN & & \\
\hline CHEMBL1524721 & 688239 & 4.6862 & 5.4556 & TST & & \\
\hline CHEMBL1440726 & 688239 & 5.0362 & 5.4891 & TRN & & \\
\hline CHEMBL1596459 & 688239 & 8.28399 & 99999999 & 9 & 5.4323 & TRN \\
\hline CHEMBL1567492 & 688239 & 4.5362 & 5.4426 & TST & & \\
\hline CHEMBL1322256 & 688239 & 6.9363 & 5.4939 & TRN & & \\
\hline CHEMBL1515606 & 688239 & 4.6362 & 5.4516 & TRN & & \\
\hline CHEMBL1370971 & 688239 & 5.4862 & 5.3768 & TST & & \\
\hline CHEMBL1520280 & 688239 & 6.05 & 5.4662 & TRN & & \\
\hline CHEMBL1418843 & 688239 & 5.0362 & 5.4318 & TRN & & \\
\hline CHEMBL1400119 & 688239 & 5.6362 & 5.4433 & TRN & & \\
\hline CHEMBL1600990 & 688239 & 4.8862 & 5.4559 & TRN & & \\
\hline CHEMBL1989853 & 688239 & 4.6862 & 5.2518 & TST & & \\
\hline CHEMBL1518045 & 688239 & 8.2366 & 5.6584 & TST & & \\
\hline CHEMBL1569268 & 688239 & 6.5862 & 5.5204 & TRN & & \\
\hline CHEMBL1378002 & 688239 & 6.95 & 5.5514 & TRN & & \\
\hline CHEMBL1568638 & 688239 & 5.9862 & 5.5936 & TRN & & \\
\hline CHEMBL1543941 & 688239 & 5.1862 & 5.5885 & TRN & & \\
\hline CHEMBL1085163 & 688239 & 8.28399 & 99999999 & 9 & 5.5472 & TRN \\
\hline CHEMBL1363327 & 688239 & 6.2862 & 5.7036 & TRN & & \\
\hline CHEMBL1443860 & 688239 & 4.5362 & 5.3766 & TST & & \\
\hline CHEMBL1380444 & 688239 & 5.5362 & 5.4062 & TRN & & \\
\hline CHEMBL1523993 & 688239 & 5.2362 & 5.3747 & TRN & & \\
\hline CHEMBL1466764 & 688239 & 4.6362 & 5.4421 & TRN & & \\
\hline CHEMBL1520349 & 688239 & 7.4365 & 5.5854 & TRN & & \\
\hline CHEMBL1515665 & 688239 & 7.9872 & 5.6162 & TRN & & \\
\hline CHEMBL1428789 & 688239 & 4.6862 & 5.56 & TST & & \\
\hline CHEMBL 3210460 & 688239 & 5.0362 & 5.4799 & TRN & & \\
\hline CHEMBL1613694 & 688239 & 5.6862 & 5.4749 & TRN & & \\
\hline CHEMBL1389111 & 688239 & 5.1862 & 5.5318 & TRN & & \\
\hline CHEMBL1517105 & 688239 & 5.1862 & 5.6321 & TRN & & \\
\hline
\end{tabular}

Page 2316 


\begin{tabular}{|c|c|c|c|c|c|}
\hline & & & & & \\
\hline CHEMBL1320889 & 688239 & 6.7862 & 5.5383 & TRN & \\
\hline CHEMBL1582906 & 688239 & 4.7362 & 5.4151 & TRN & \\
\hline CHEMBL1547525 & 688239 & 5.3862 & 5.4822 & TRN & \\
\hline CHEMBL1352107 & 688239 & 5.1862 & 5.5723 & TST & \\
\hline CHEMBL1425873 & 688239 & 4.6862 & 5.5552 & TRN & \\
\hline CHEMBL1568983 & 688239 & 5.3362 & 5.5255 & TRN & \\
\hline CHEMBL1468793 & 688239 & 6.3362 & 5.53700 & 0000000001 & TST \\
\hline CHEMBL1356122 & 688239 & 4.5362 & 5.4379 & TRN & \\
\hline CHEMBL1505260 & 688239 & 5.1862 & 5.4223 & TST & \\
\hline CHEMBL1528201 & 688239 & 4.5362 & 5.6534 & TRN & \\
\hline CHEMBL1344198 & 688239 & 4.6362 & 5.4414 & TRN & \\
\hline CHEMBL1318028 & 688239 & 4.5362 & 5.6549 & TRN & \\
\hline CHEMBL1373287 & 688239 & 4.5362 & 5.3752 & TST & \\
\hline CHEMBL1597235 & 688239 & 5.4362 & 5.5264 & TRN & \\
\hline CHEMBL1427708 & 688239 & 6.7862 & 5.6396 & TRN & \\
\hline CHEMBL1612031 & 688239 & 6.8861 & 5.4921 & TST & \\
\hline CHEMBL3196874 & 688239 & 5.9862 & 5.3167 & TRN & \\
\hline CHEMBL54277 & 688239 & 6.8861 & 5.4818 & TRN & \\
\hline CHEMBL3199226 & 688239 & 4.5362 & 5.519 & TRN & \\
\hline CHEMBL1328699 & 688239 & 6.1362 & 5.5354 & TRN & \\
\hline CHEMBL534244 & 688239 & 5.4362 & 5.442 & TRN & \\
\hline CHEMBL1403755 & 688239 & 6.1362 & 5.351 & TRN & \\
\hline CHEMBL452723 & 688239 & 5.1862 & 5.4816 & TRN & \\
\hline CHEMBL504381 & 688239 & 5.0862 & 5.4818 & TST & \\
\hline CHEMBL1382209 & 688239 & 5.0862 & 5.4687 & TRN & \\
\hline CHEMBL1562699 & 688239 & 4.7362 & 5.41799 & 9999999999 & TRN \\
\hline CHEMBL1522108 & 688239 & 5.2862 & 5.6484 & TRN & \\
\hline CHEMBL1256359 & 688239 & 6.1862 & 5.3882 & TST & \\
\hline CHEMBL1418922 & 688239 & 4.6362 & 5.4262 & TRN & \\
\hline CHEMBL1576914 & 688239 & 4.5362 & 5.45700 & $\partial 000000001$ & TST \\
\hline CHEMBL1497183 & 688239 & 6.5363 & 5.3791 & TST & \\
\hline CHEMBL1377679 & 688239 & 5.1862 & 5.4701 & TRN & \\
\hline CHEMBL3195965 & 688239 & 5.1362 & 5.3624 & TRN & \\
\hline CHEMBL1425827 & 688239 & 5.3362 & 5.4682 & TST & \\
\hline CHEMBL1597627 & 688239 & 6.8861 & 5.4285 & TRN & \\
\hline CHEMBL1319643 & 688239 & 5.0862 & 5.4476 & TST & \\
\hline CHEMBL1308972 & 688239 & 4.7862 & 5.3788 & TRN & \\
\hline CHEMBL1388456 & 688239 & 5.1862 & 5.4144 & TST & \\
\hline CHEMBL1561177 & 688239 & 5.5362 & 5.5424 & TRN & \\
\hline CHEMBL1453819 & 688239 & 6.1362 & 5.4776 & TRN & \\
\hline CHEMBL1404364 & 688239 & 5.1862 & 5.5519 & TST & \\
\hline CHEMBL1585637 & 688239 & 4.9362 & 5.5498 & TRN & \\
\hline CHEMBL1470924 & 688239 & 4.5362 & 5.3892 & TST & \\
\hline CHEMBL1332847 & 688239 & 6.6362 & 5.614 & TST & \\
\hline CHEMBL1585693 & 688239 & 6.9363 & 5.4794 & TRN & \\
\hline CHEMBL1464811 & 688239 & 8.3872 & 5.4036 & TRN & \\
\hline CHEMBL1999359 & 688239 & 5.4862 & 5.4309 & TRN & \\
\hline CHEMBL3196580 & 688239 & 5.1862 & 5.3131 & TST & \\
\hline
\end{tabular}


Supplemental Table S2.txt

\begin{tabular}{|c|c|c|c|c|}
\hline CHEMBL1340808 & 688239 & 6.0362 & 5.5208 & TST \\
\hline CHEMBL1383117 & 688239 & 4.5362 & 5.4424 & TST \\
\hline CHEMBL1322378 & 688239 & 5.4362 & 5.4918 & TRN \\
\hline CHEMBL1418510 & 688239 & 4.5362 & 5.4384 & TRN \\
\hline CHEMBL1477334 & 688239 & 4.7362 & 5.4627 & TST \\
\hline CHEMBL1373404 & 688239 & 4.9362 & 5.4489 & TRN \\
\hline CHEMBL1341222 & 688239 & 4.5862 & 5.6026 & TRN \\
\hline CHEMBL1993380 & 688239 & 5.4862 & 5.3407 & TRN \\
\hline CHEMBL1529835 & 688239 & 5.8862 & 5.4792 & TRN \\
\hline CHEMBL1361087 & 688239 & 5.3362 & 5.5202 & TRN \\
\hline CHEMBL1375109 & 688239 & 4.8362 & 5.4191 & TRN \\
\hline CHEMBL3207722 & 688239 & 4.6862 & 5.3177 & TRN \\
\hline CHEMBL1360941 & 688239 & 4.7362 & 5.3577 & TRN \\
\hline CHEMBL1481435 & 688239 & 5.4862 & 5.5338 & TRN \\
\hline CHEMBL1366879 & 688239 & 4.6862 & 5.4572 & TRN \\
\hline CHEMBL1424868 & 688239 & 4.5362 & 5.4544 & TRN \\
\hline CHEMBL1536363 & 688239 & 4.9862 & 5.5576 & TRN \\
\hline CHEMBL1443752 & 688239 & 5.1862 & 5.505 & TST \\
\hline CHEMBL1584035 & 688239 & 6.6861 & 5.4554 & TRN \\
\hline CHEMBL1556184 & 688239 & 5.5362 & 5.5066 & TRN \\
\hline CHEMBL1565830 & 688239 & 5.6362 & 5.5375 & TRN \\
\hline CHEMBL1492518 & 688239 & 5.5362 & 5.5573 & TRN \\
\hline CHEMBL1541235 & 688239 & 6.8861 & 5.5291 & TRN \\
\hline CHEMBL1576344 & 688239 & 6.2862 & 5.5715 & TST \\
\hline CHEMBL3194335 & 688239 & 4.5362 & 5.4072 & TRN \\
\hline CHEMBL1606853 & 688239 & 5.6362 & 5.3613 & TRN \\
\hline CHEMBL1606450 & 688239 & 4.7362 & 5.3321 & TRN \\
\hline CHEMBL1336351 & 688239 & 7.2366 & 5.5778 & TRN \\
\hline CHEMBL1341626 & 688239 & 5.2862 & 5.6095 & TST \\
\hline CHEMBL1401413 & 688239 & 6.4362 & 5.5707 & TRN \\
\hline CHEMBL1355666 & 688239 & 4.4862 & 5.3217 & TRN \\
\hline CHEMBL1339060 & 688239 & 5.2862 & 5.5627 & TRN \\
\hline CHEMBL1551264 & 688239 & 4.5362 & 5.4531 & TRN \\
\hline CHEMBL1471447 & 688239 & 5.8862 & 5.4866 & TST \\
\hline CHEMBL1507576 & 688239 & 4.7862 & 5.5783 & TRN \\
\hline CHEMBL1513309 & 688239 & 4.5362 & 5.5459 & TRN \\
\hline CHEMBL1526766 & 688239 & 5.1862 & 5.34200 & 30000000005 \\
\hline CHEMBL3208494 & 688239 & 4.5362 & 5.4369 & TRN \\
\hline CHEMBL1574910 & 688239 & 4.5362 & 5.46200 & 0000000001 \\
\hline CHEMBL1483141 & 688239 & 4.7362 & 5.48 & TRN \\
\hline CHEMBL1468859 & 688239 & 5.1862 & 5.4207 & TRN \\
\hline CHEMBL1365859 & 688239 & 5.7362 & 5.6123 & TRN \\
\hline CHEMBL3199445 & 688239 & 5.5362 & 5.5463 & TRN \\
\hline CHEMBL1328170 & 688239 & 5.5862 & 5.4693 & TRN \\
\hline CHEMBL1438972 & 688239 & 4.9862 & 5.4469 & TRN \\
\hline CHEMBL1400708 & 688239 & 5.1862 & 5.4839 & TRN \\
\hline CHEMBL1386041 & 688239 & 6.9863 & 5.4978 & TRN \\
\hline CHEMBL1594813 & 688239 & 6.8362 & 5.5668 & TRN \\
\hline
\end{tabular}

Page 2318 
Supplemental Table S2.txt

\begin{tabular}{|c|c|c|c|c|}
\hline CHEMBL1490518 & 688239 & 5.1362 & 5.4626 & TST \\
\hline CHEMBL1476000 & 688239 & 5.0362 & 5.4083 & TRN \\
\hline CHEMBL1433014 & 688239 & 5.8862 & 5.4642 & TST \\
\hline CHEMBL1320261 & 688239 & 6.0862 & 5.6535 & TRN \\
\hline CHEMBL1471065 & 688239 & 5.1362 & 5.6737 & TRN \\
\hline CHEMBL1610025 & 688239 & 5.0362 & 5.3897 & TRN \\
\hline CHEMBL1966192 & 688239 & 4.5362 & 5.4466 & TRN \\
\hline CHEMBL1445505 & 688239 & 5.1862 & 5.5239 & TST \\
\hline CHEMBL1301518 & 688239 & 4.5362 & 5.5703 & TRN \\
\hline CHEMBL1486847 & 688239 & 6.9363 & \multicolumn{2}{|c|}{5.627000000000001} \\
\hline CHEMBL1471227 & 688239 & 4.6862 & 5.381 & TRN \\
\hline CHEMBL1570794 & 688239 & 5.8362 & 5.5475 & TST \\
\hline CHEMBL1511084 & 688239 & 5.0362 & 5.4811 & TRN \\
\hline CHEMBL1600526 & 688239 & 6.1862 & 5.3609 & TST \\
\hline CHEMBL3199499 & 688239 & 5.9362 & 5.4895 & TRN \\
\hline CHEMBL1399810 & 688239 & 5.1862 & 5.5085 & TST \\
\hline CHEMBL1358395 & 688239 & 6.7361 & 5.4872 & TST \\
\hline CHEMBL1318456 & 688239 & 4.5362 & 5.4369 & TRN \\
\hline CHEMBL1464522 & 688239 & 4.5362 & 5.5473 & TRN \\
\hline CHEMBL1603966 & 688239 & 5.7862 & 5.5185 & TRN \\
\hline CHEMBL1966366 & 688239 & 4.5362 & 5.4171 & TRN \\
\hline CHEMBL1349859 & 688239 & 6.3362 & 5.6831 & TRN \\
\hline CHEMBL1461931 & 688239 & 4.7362 & 5.5175 & TRN \\
\hline CHEMBL1406141 & 688239 & 6.7862 & 5.4801 & TRN \\
\hline CHEMBL1548101 & 688239 & 4.6862 & 5.4065 & TRN \\
\hline CHEMBL1421592 & 688239 & 5.1862 & 5.3193 & TRN \\
\hline CHEMBL1492341 & 688239 & 5.9362 & 5.459 & TST \\
\hline CHEMBL1342752 & 688239 & 6.6362 & \multicolumn{2}{|c|}{5.531000000000001} \\
\hline CHEMBL1380525 & 688239 & 6.0862 & 5.4913 & TRN \\
\hline CHEMBL1336521 & 688239 & 8.3372 & 5.4793 & TRN \\
\hline CHEMBL1338944 & 688239 & 4.8362 & 5.6637 & TRN \\
\hline CHEMBL1417657 & 688239 & 4.7862 & 5.4328 & TRN \\
\hline CHEMBL 3194862 & 688239 & 5.8862 & 5.4228 & TRN \\
\hline CHEMBL1477680 & 688239 & 4.7362 & 5.4223 & TRN \\
\hline CHEMBL548619 & 688239 & 4.8362 & 5.4796 & TRN \\
\hline CHEMBL 3214173 & 688239 & 6.1362 & 5.5343 & TRN \\
\hline CHEMBL1301670 & 688239 & 5.8862 & 5.7232 & TRN \\
\hline CHEMBL1374380 & 688239 & 4.5362 & 5.5168 & TRN \\
\hline CHEMBL1391481 & 688239 & 4.5362 & \multicolumn{2}{|c|}{5.6770000000000005} \\
\hline CHEMBL1312009 & 688239 & 4.9862 & 5.2967 & TRN \\
\hline CHEMBL1611188 & 688239 & 4.6862 & 5.6844 & TRN \\
\hline CHEMBL 2004690 & 688239 & 8.3372 & 5.5418 & TRN \\
\hline CHEMBL1420199 & 688239 & 4.6362 & 5.5539 & TRN \\
\hline CHEMBL 3212232 & 688239 & 5.4862 & 5.3281 & TRN \\
\hline CHEMBL1556276 & 688239 & 4.5362 & 5.4522 & TST \\
\hline CHEMBL1447127 & 688239 & 4.5862 & 5.6031 & TRN \\
\hline CHEMBL1367396 & 688239 & 4.6362 & 5.397 & TRN \\
\hline CHEMBL1613035 & 688239 & 4.8362 & 5.4533 & TST \\
\hline
\end{tabular}

Page 2319 
Supplemental Table S2.txt

\begin{tabular}{|c|c|c|c|c|}
\hline CHEMBL1377296 & 688239 & 4.8362 & 5.5343 & TRN \\
\hline CHEMBL1517223 & 688239 & 4.6862 & 5.461 & TRN \\
\hline CHEMBL1582010 & 688239 & 5.2862 & 5.5013 & TRN \\
\hline CHEMBL1324496 & 688239 & 6.1362 & 5.5223 & TRN \\
\hline CHEMBL1570378 & 688239 & 4.8862 & 5.479 & TST \\
\hline CHEMBL1413743 & 688239 & 4.5362 & 5.5786 & TRN \\
\hline CHEMBL121336 & 688239 & 5.5862 & 5.4552 & TRN \\
\hline CHEMBL1368486 & 688239 & 7.0862 & 5.5374 & TST \\
\hline CHEMBL1609242 & 688239 & 4.6862 & 5.4174 & TST \\
\hline CHEMBL1607890 & 688239 & 5.1862 & 5.4675 & TST \\
\hline CHEMBL3193889 & 688239 & 4.7362 & 5.4878 & TST \\
\hline CHEMBL1331853 & 688239 & 4.5362 & 5.5109 & TRN \\
\hline CHEMBL1316831 & 688239 & 4.5362 & 5.4021 & TST \\
\hline CHEMBL1528465 & 688239 & 4.4862 & 5.4448 & TRN \\
\hline CHEMBL1515886 & 688239 & 6.5363 & 5.4795 & TRN \\
\hline CHEMBL1466828 & 688239 & 4.5862 & 5.5151 & TRN \\
\hline CHEMBL1452671 & 688239 & 5.4362 & 5.3924 & TRN \\
\hline CHEMBL1484524 & 688239 & 5.1362 & 5.5031 & TST \\
\hline CHEMBL1378388 & 688239 & 4.8862 & 5.3812 & TRN \\
\hline CHEMBL1388933 & 688239 & 5.9362 & 5.5437 & TST \\
\hline CHEMBL1404279 & 688239 & 5.4362 & 5.3654 & TRN \\
\hline CHEMBL1982090 & 688239 & 5.6862 & 5.5507 & TRN \\
\hline CHEMBL1339326 & 688239 & 4.5862 & 5.4912 & TRN \\
\hline CHEMBL3198897 & 688239 & 5.6862 & 5.5229 & TRN \\
\hline CHEMBL600572 & 688239 & 4.6862 & 5.5041 & TRN \\
\hline CHEMBL1500007 & 688239 & 4.7362 & 5.6042 & TST \\
\hline CHEMBL1299281 & 688239 & 6.0862 & 5.4252 & TRN \\
\hline CHEMBL1423114 & 688239 & 6.2 & 5.5097 & TST \\
\hline CHEMBL1537558 & 688239 & 5.5362 & 5.5147 & TST \\
\hline CHEMBL1413239 & 688239 & 5.7862 & 5.5552 & TRN \\
\hline CHEMBL1578996 & 688239 & 4.6862 & 5.3168 & TST \\
\hline CHEMBL1422722 & 688239 & 5.4862 & 5.6025 & TRN \\
\hline CHEMBL1471930 & 688239 & 5.6862 & 5.4396 & TST \\
\hline CHEMBL1324106 & 688239 & 4.5362 & 5.5125 & TST \\
\hline CHEMBL1353106 & 688239 & 5.4862 & 5.5151 & TRN \\
\hline CHEMBL1435598 & 688239 & 6.1362 & 5.6525 & TRN \\
\hline CHEMBL1369987 & 688239 & 5.3362 & 5.4308 & TRN \\
\hline CHEMBL3190958 & 688239 & 5.1362 & 5.382999 & 9999999999 \\
\hline CHEMBL1345001 & 688239 & 4.7362 & 5.4411 & TRN \\
\hline CHEMBL1391195 & 688239 & 8.3372 & 5.561 & TST \\
\hline CHEMBL1451635 & 688239 & 4.4862 & 5.4271 & TRN \\
\hline CHEMBL1612565 & 688239 & 5.1862 & 5.4546 & TST \\
\hline CHEMBL1323967 & 688239 & 6.1362 & 5.4922 & TST \\
\hline CHEMBL1422604 & 688239 & 5.4362 & 5.6945 & TRN \\
\hline CHEMBL1452914 & 688239 & 5.8862 & 5.5646 & TRN \\
\hline CHEMBL1585207 & 688239 & 5.1862 & 5.6061 & TRN \\
\hline CHEMBL3195948 & 688239 & 4.5362 & 5.5192 & TRN \\
\hline CHEMBL1395581 & 688239 & 4.5362 & 5.3609 & TST \\
\hline
\end{tabular}

Page 2320 
Supplemental Table S2.txt

\begin{tabular}{|c|c|c|c|c|}
\hline CHEMBL1581073 & 688239 & 6.3362 & 5.489 & TRN \\
\hline CHEMBL1380538 & 688239 & 5.3862 & 5.5223 & TRN \\
\hline CHEMBL1379383 & 688239 & 4.5362 & 5.6121 & TRN \\
\hline CHEMBL1349605 & 688239 & 6.9863 & 5.6761 & TRN \\
\hline CHEMBL1489312 & 688239 & 5.1362 & 5.5866 & TRN \\
\hline CHEMBL1311838 & 688239 & 6.0362 & 5.5557 & TRN \\
\hline CHEMBL3212452 & 688239 & 5.0862 & 5.3751 & TST \\
\hline CHEMBL1523155 & 688239 & 4.9362 & 5.5397 & TRN \\
\hline CHEMBL1452167 & 688239 & 6.0362 & 5.5841 & TRN \\
\hline CHEMBL1413543 & 688239 & 5.1862 & 5.4156 & TRN \\
\hline CHEMBL3198411 & 688239 & 5.4862 & 5.5923 & TRN \\
\hline CHEMBL1503984 & 688239 & 7.0362 & 5.4183 & TRN \\
\hline CHEMBL3197603 & 688239 & 5.4862 & 5.2384 & TST \\
\hline CHEMBL1392269 & 688239 & 4.5362 & 5.4994 & TRN \\
\hline CHEMBL1386906 & 688239 & 5.3362 & 5.3462 & TST \\
\hline CHEMBL 3211746 & 688239 & 5.6362 & 5.5827 & TRN \\
\hline CHEMBL1568121 & 688239 & 5.1362 & 5.3951 & TST \\
\hline CHEMBL1588528 & 688239 & 6.7361 & 5.4499 & TST \\
\hline CHEMBL1546682 & 688239 & 5.9862 & 5.4659 & TRN \\
\hline CHEMBL1340566 & 688239 & 5.1862 & 5.7043 & TST \\
\hline CHEMBL1516630 & 688239 & 4.5362 & 5.6014 & TST \\
\hline CHEMBL1575309 & 688239 & 4.5362 & 5.3836 & TRN \\
\hline CHEMBL1526046 & 688239 & 6.9363 & 5.6349 & TRN \\
\hline CHEMBL3196250 & 688239 & 4.6362 & 5.393 & TST \\
\hline CHEMBL1472478 & 688239 & 4.6862 & 5.4381 & TST \\
\hline CHEMBL600526 & 688239 & 6.3863 & 5.48799 & 79999999995 \\
\hline CHEMBL1583330 & 688239 & 4.6862 & 5.4649 & TRN \\
\hline CHEMBL1345979 & 688239 & 5.2362 & 5.5074 & TST \\
\hline CHEMBL1301072 & 688239 & 4.5362 & 5.6534 & TST \\
\hline CHEMBL1548919 & 688239 & 5.1862 & 5.4397 & TRN \\
\hline CHEMBL1489569 & 688239 & 5.1862 & 5.3688 & TST \\
\hline CHEMBL1404579 & 688239 & 6.1362 & 5.4498 & TRN \\
\hline CHEMBL1375945 & 688239 & 4.8362 & 5.4478 & TRN \\
\hline CHEMBL1408786 & 688239 & 4.4862 & 5.5573 & TRN \\
\hline CHEMBL1300436 & 688239 & 5.1862 & 5.4819 & TRN \\
\hline CHEMBL1612194 & 688239 & 4.5362 & 5.5714 & TRN \\
\hline CHEMBL1565843 & 688239 & 5.4362 & 5.4896 & TRN \\
\hline CHEMBL1319203 & 688239 & 4.5362 & 5.3508 & TST \\
\hline CHEMBL1454561 & 688239 & 6.0862 & 5.4327 & TRN \\
\hline CHEMBL1311730 & 688239 & 4.6362 & 5.2672 & TRN \\
\hline CHEMBL1403142 & 688239 & 6.8362 & 5.49700 & 0000000001 \\
\hline CHEMBL1374299 & 688239 & 4.7862 & 5.5966 & TRN \\
\hline CHEMBL1517883 & 688239 & 4.7362 & 5.55200 & 00000000005 \\
\hline CHEMBL3192132 & 688239 & 4.5862 & 5.6422 & TRN \\
\hline CHEMBL1528397 & 688239 & 7.2865 & 5.5125 & TST \\
\hline CHEMBL1607632 & 688239 & 6.1862 & 5.501 & TST \\
\hline CHEMBL1385772 & 688239 & 5.4362 & 5.3356 & TST \\
\hline CHEMBL1554744 & 688239 & 5.3862 & 5.4449 & TRN \\
\hline
\end{tabular}


Supplemental Table S2.txt

\begin{tabular}{|c|c|c|c|c|c|}
\hline CHEMBL1415684 & 688239 & 4.5362 & 5.5147 & TRN & \\
\hline CHEMBL1352818 & 688239 & 4.5362 & 5.4095 & TRN & \\
\hline CHEMBL1398723 & 688239 & 5.1362 & 5.4364 & TRN & \\
\hline CHEMBL1579618 & 688239 & 4.5362 & 5.3891 & TRN & \\
\hline CHEMBL1598546 & 688239 & 4.4862 & 5.6837 & TRN & \\
\hline CHEMBL1336581 & 688239 & 6.9863 & 5.3758 & TRN & \\
\hline CHEMBL1390368 & 688239 & 5.9362 & 5.603 & TRN & \\
\hline CHEMBL1492650 & 688239 & 6.2862 & 5.5031 & TRN & \\
\hline CHEMBL1492808 & 688239 & 5.2362 & 5.5029 & TRN & \\
\hline CHEMBL1567969 & 688239 & 4.8862 & 5.5319 & TRN & \\
\hline CHEMBL492091 & 688239 & 4.5862 & 5.4032 & TRN & \\
\hline CHEMBL1449945 & 688239 & 5.2362 & 5.5736 & TRN & \\
\hline CHEMBL1423186 & 688239 & 5.2362 & 5.6102 & TRN & \\
\hline CHEMBL 3208602 & 688239 & 6.0362 & 5.4638 & TST & \\
\hline CHEMBL1542321 & 688239 & 4.6862 & 5.4372 & TST & \\
\hline CHEMBL 3199714 & 688239 & 6.8362 & 5.5064 & TRN & \\
\hline CHEMBL1497940 & 688239 & 4.6362 & 5.3926 & TST & \\
\hline CHEMBL1523331 & 688239 & 5.1362 & 5.5151 & TRN & \\
\hline CHEMBL1563562 & 688239 & 4.5362 & 5.4387 & TRN & \\
\hline CHEMBL1569984 & 688239 & 5.3362 & 5.4964 & TRN & \\
\hline CHEMBL1973188 & 688239 & 4.6862 & 5.3211 & TRN & \\
\hline CHEMBL1565209 & 688239 & 5.1862 & 5.55 & TST & \\
\hline CHEMBL1578136 & 688239 & 6.9863 & 5.4704 & TRN & \\
\hline CHEMBL1500913 & 688239 & 4.5362 & 5.6759 & TRN & \\
\hline CHEMBL1327883 & 688239 & 6.7862 & 5.5236 & TRN & \\
\hline CHEMBL1526415 & 688239 & 5.4362 & 5.5244 & TRN & \\
\hline CHEMBL1342423 & 688239 & 7.1361 & 5.4047 & TRN & \\
\hline CHEMBL1539241 & 688239 & 5.1862 & 5.5632 & TRN & \\
\hline CHEMBL1504461 & 688239 & 5.5862 & 5.2705 & TST & \\
\hline CHEMBL1417357 & 688239 & 5.4862 & 5.6382 & TRN & \\
\hline CHEMBL1545584 & 688239 & 4.5362 & 5.416 & TST & \\
\hline CHEMBL1445791 & 688239 & 5.1862 & 5.4934 & TRN & \\
\hline CHEMBL1380373 & 688239 & 6.0862 & 5.491000 & 0000000005 & $m$ \\
\hline CHEMBL1527716 & 688239 & 5.1362 & 5.6288 & TRN & \\
\hline CHEMBL1583088 & 688239 & 5.8362 & 5.5866 & TST & \\
\hline CHEMBL1366652 & 688239 & 7.5867 & 5.6668 & TRN & \\
\hline CHEMBL1346196 & 688239 & 4.6862 & 5.4341 & TST & \\
\hline CHEMBL1459740 & 688239 & 6.7361 & 5.5133 & TRN & \\
\hline CHEMBL1522534 & 688239 & 5.9362 & 5.5806 & TRN & \\
\hline CHEMBL1545388 & 688239 & 4.8862 & 5.4797 & TRN & \\
\hline CHEMBL1213608 & 688239 & 4.8362 & 5.4405 & TRN & \\
\hline CHEMBL1540567 & 688239 & 7.0362 & 5.4854 & TST & \\
\hline CHEMBL1434554 & 688239 & 5.4362 & 5.349 & TST & \\
\hline CHEMBL1326993 & 688239 & 8.283999 & 99999999 & 5.6301 & TRN \\
\hline CHEMBL1353566 & 688239 & 4.5362 & 5.3773 & TRN & \\
\hline CHEMBL1569275 & 688239 & 6.3863 & 5.3596 & TRN & \\
\hline CHEMBL1373410 & 688239 & 6.5363 & 5.5055 & TST & \\
\hline CHEMBL1562370 & 688239 & 4.7362 & 5.354 & TRN & \\
\hline
\end{tabular}


Supplemental Table S2.txt

\begin{tabular}{|c|c|c|c|c|c|}
\hline CHEMBL1568714 & 688239 & 4.9362 & 5.5854 & TRN & \\
\hline CHEMBL1423656 & 688239 & 5.4862 & 5.3275 & TRN & \\
\hline CHEMBL1470627 & 688239 & 6.3863 & 5.4856 & TST & \\
\hline CHEMBL1334450 & 688239 & 4.5362 & 5.5133 & TRN & \\
\hline CHEMBL1392244 & 688239 & 7.2865 & 5.4896 & TRN & \\
\hline CHEMBL1323099 & 688239 & 4.8862 & 5.563 & TRN & \\
\hline CHEMBL1372293 & 688239 & 4.7362 & 5.3577 & TRN & \\
\hline CHEMBL1302928 & 688239 & 4.6862 & 5.4985 & TRN & \\
\hline CHEMBL1383589 & 688239 & 5.1862 & 5.3692 & TRN & \\
\hline CHEMBL1601129 & 688239 & 5.2862 & 5.3712 & TRN & \\
\hline CHEMBL1528706 & 688239 & 7.0862 & 5.5466 & TRN & \\
\hline CHEMBL1313557 & 688239 & 4.7362 & 5.3887 & TRN & \\
\hline CHEMBL1312809 & 688239 & 6.4362 & 5.5901 & TST & \\
\hline CHEMBL1318284 & 688239 & 5.5862 & 5.3999 & TRN & \\
\hline CHEMBL1328602 & 688239 & 6.6861 & 5.4131 & TRN & \\
\hline CHEMBL3197784 & 688239 & 6.0362 & 5.403 & TST & \\
\hline CHEMBL1310794 & 688239 & 4.5362 & 5.6533 & TRN & \\
\hline CHEMBL1322340 & 688239 & 4.9862 & 5.4982 & TRN & \\
\hline CHEMBL1377814 & 688239 & 5.0362 & 5.4933 & TRN & \\
\hline CHEMBL1467918 & 688239 & 4.5362 & 5.5362 & TRN & \\
\hline CHEMBL1331146 & 688239 & 4.5362 & 5.5133 & TRN & \\
\hline CHEMBL1388564 & 688239 & 5.1862 & 5.4933 & TST & \\
\hline CHEMBL1582574 & 688239 & 4.5362 & 5.5639 & TRN & \\
\hline CHEMBL1351108 & 688239 & 4.5362 & 5.38299 & 9999999999 & TRN \\
\hline CHEMBL1572389 & 688239 & 5.9862 & 5.481 & TRN & \\
\hline CHEMBL1547590 & 688239 & 4.5362 & 5.5897 & TRN & \\
\hline CHEMBL1378405 & 688239 & 4.5362 & 5.4955 & TRN & \\
\hline CHEMBL1377313 & 688239 & 5.1862 & 5.529 & TRN & \\
\hline CHEMBL1415651 & 688239 & 5.6862 & 5.5192 & TRN & \\
\hline CHEMBL1538556 & 688239 & 4.8362 & 5.5989 & TST & \\
\hline CHEMBL1376449 & 688239 & 6.3863 & 5.3513 & TRN & \\
\hline CHEMBL3208723 & 688239 & 4.5362 & 5.4543 & TRN & \\
\hline CHEMBL1401500 & 688239 & 6.2862 & 5.4052 & TRN & \\
\hline CHEMBL1441103 & 688239 & 5.6862 & 5.4567 & TRN & \\
\hline CHEMBL1535286 & 688239 & 4.7862 & 5.4651 & TRN & \\
\hline CHEMBL1374877 & 688239 & 5.8862 & 5.48 & TST & \\
\hline CHEMBL1507880 & 688239 & 5.0362 & 5.5301 & TRN & \\
\hline CHEMBL1501896 & 688239 & 6.7361 & 5.5478 & TRN & \\
\hline CHEMBL3197969 & 688239 & 7.0362 & 5.459 & TRN & \\
\hline CHEMBL1317248 & 688239 & 5.4862 & 5.4068 & TRN & \\
\hline CHEMBL1323640 & 688239 & 5.3862 & 5.5159 & TRN & \\
\hline CHEMBL1476183 & 688239 & 4.5362 & 5.3903 & TST & \\
\hline CHEMBL1450616 & 688239 & 4.7362 & 5.41 & TRN & \\
\hline CHEMBL1558918 & 688239 & 4.5862 & 5.5331 & TRN & \\
\hline CHEMBL1448966 & 688239 & 4.4862 & 5.5359 & TRN & \\
\hline CHEMBL1563389 & 688239 & 5.5362 & 5.5097 & TRN & \\
\hline CHEMBL3192622 & 688239 & 5.1862 & 5.6319 & TST & \\
\hline CHEMBL3196688 & 688239 & 4.7362 & 5.5365 & TRN & \\
\hline
\end{tabular}

Page 2323 
Supplemental Table S2.txt

\begin{tabular}{|c|c|c|c|c|c|}
\hline CHEMBL1380508 & 688239 & 4.7862 & 5.5685 & TRN & \\
\hline CHEMBL1338901 & 688239 & 5.6362 & 5.4655 & TST & \\
\hline CHEMBL1448771 & 688239 & 4.6862 & 5.4684 & TST & \\
\hline CHEMBL1414895 & 688239 & 8.3372 & 5.3389 & TRN & \\
\hline CHEMBL1352097 & 688239 & 4.5362 & 5.4238 & TRN & \\
\hline CHEMBL1350591 & 688239 & 6.2362 & 5.5183 & TRN & \\
\hline CHEMBL1482159 & 688239 & 5.0862 & 5.5163 & TRN & \\
\hline CHEMBL3190643 & 688239 & 7.1361 & 5.5576 & TRN & \\
\hline CHEMBL1585972 & 688239 & 5.0362 & 5.5043 & TRN & \\
\hline CHEMBL1453379 & 688239 & 5.1862 & 5.4128 & TRN & \\
\hline CHEMBL1429064 & 688239 & 6.3362 & 5.6356 & TRN & \\
\hline CHEMBL1563262 & 688239 & 6.1362 & 5.3976 & TRN & \\
\hline CHEMBL1335645 & 688239 & 5.9862 & 5.5067 & TST & \\
\hline CHEMBL1367730 & 688239 & 7.5361 & 5.4359 & TST & \\
\hline CHEMBL1499861 & 688239 & 5.4362 & 5.4902 & TRN & \\
\hline CHEMBL1340529 & 688239 & 6.2862 & 5.4952 & TRN & \\
\hline CHEMBL1504391 & 688239 & 4.9362 & 5.6258 & TRN & \\
\hline CHEMBL1395254 & 688239 & 5.9362 & 5.2606 & TRN & \\
\hline CHEMBL1500083 & 688239 & 4.6862 & 5.426 & TRN & \\
\hline CHEMBL1458399 & 688239 & 5.3362 & 5.4885 & TRN & \\
\hline CHEMBL1349204 & 688239 & 4.7862 & 5.42200 & 0000000001 & TRN \\
\hline CHEMBL1562528 & 688239 & 4.5362 & 5.5821 & TRN & \\
\hline CHEMBL1375246 & 688239 & 6.3863 & 5.4198 & TRN & \\
\hline CHEMBL1527356 & 688239 & 6.1862 & 5.5204 & TRN & \\
\hline CHEMBL1559899 & 688239 & 6.8861 & 5.53299 & 99999999995 & TRN \\
\hline CHEMBL1379889 & 688239 & 5.0362 & 5.5471 & TST & \\
\hline CHEMBL1310939 & 688239 & 4.5362 & 5.6217 & TRN & \\
\hline CHEMBL1509043 & 688239 & 5.7362 & 5.4831 & TRN & \\
\hline CHEMBL1611180 & 688239 & 6.2862 & 5.4633 & TRN & \\
\hline CHEMBL1413173 & 688239 & 4.4862 & 5.5616 & TRN & \\
\hline CHEMBL1578956 & 688239 & 4.6862 & 5.5622 & TRN & \\
\hline CHEMBL1458038 & 688239 & 5.4862 & 5.4648 & TRN & \\
\hline CHEMBL1510287 & 688239 & 6.0362 & 5.5276 & TST & \\
\hline CHEMBL1470469 & 688239 & 4.7362 & 5.6079 & TRN & \\
\hline CHEMBL1302001 & 688239 & 4.7862 & 5.6215 & TST & \\
\hline CHEMBL1548915 & 688239 & 6.3863 & 5.6779 & TRN & \\
\hline CHEMBL1384972 & 688239 & 5.1862 & 5.4608 & TRN & \\
\hline CHEMBL 2002465 & 688239 & 4.5362 & 5.4437 & TRN & \\
\hline CHEMBL1355901 & 688239 & 5.0362 & 5.4837 & TRN & \\
\hline CHEMBL3212431 & 688239 & 4.7362 & 5.5174 & TST & \\
\hline CHEMBL1323477 & 688239 & 6.3362 & 5.3862 & TRN & \\
\hline CHEMBL1522889 & 688239 & 5.1862 & 5.3965 & TST & \\
\hline CHEMBL1485218 & 688239 & 7.0362 & 5.4219 & TRN & \\
\hline CHEMBL3197494 & 688239 & 4.6862 & 5.4782 & TST & \\
\hline CHEMBL1478927 & 688239 & 5.6862 & 5.4353 & TRN & \\
\hline CHEMBL1353845 & 688239 & 5.1862 & 5.3383 & TRN & \\
\hline CHEMBL1558055 & 688239 & 7.1361 & 5.5041 & TRN & \\
\hline CHEMBL3209945 & 688239 & 6.2362 & 5.5236 & TST & \\
\hline
\end{tabular}


Supplemental Table S2.txt

\begin{tabular}{|c|c|c|c|c|c|}
\hline CHEMBL1527622 & 688239 & 4.5362 & 5.4465 & TST & \\
\hline CHEMBL1450193 & 688239 & 6.5363 & 5.5568 & TST & \\
\hline CHEMBL1365889 & 688239 & 4.9862 & 5.3717 & TRN & \\
\hline CHEMBL1375275 & 688239 & 5.9362 & 5.6273 & TRN & \\
\hline CHEMBL1544742 & 688239 & 4.5362 & 5.5324 & TRN & \\
\hline CHEMBL1318887 & 688239 & 4.9362 & 5.4323 & TRN & \\
\hline CHEMBL1419333 & 688239 & 8.3372 & 5.5549 & TRN & \\
\hline CHEMBL3193642 & 688239 & 4.8362 & 5.5299 & TRN & \\
\hline CHEMBL1406247 & 688239 & 4.5862 & 5.4474 & TRN & \\
\hline CHEMBL1542092 & 688239 & 6.3863 & 5.563 & TRN & \\
\hline CHEMBL1420456 & 688239 & 4.4862 & 5.4591 & TRN & \\
\hline CHEMBL1427762 & 688239 & 5.3862 & 5.411000 & 0000000005 & TRN \\
\hline CHEMBL1350214 & 688239 & 5.1862 & 5.3418 & TRN & \\
\hline CHEMBL1431135 & 688239 & 4.5362 & 5.4967 & TRN & \\
\hline CHEMBL1514979 & 688239 & 5.5862 & 5.5047 & TRN & \\
\hline CHEMBL1570877 & 688239 & 4.5362 & 5.3801 & TRN & \\
\hline CHEMBL1358759 & 688239 & 4.7362 & 5.3148 & TRN & \\
\hline CHEMBL1374622 & 688239 & 6.1362 & 5.5697 & TRN & \\
\hline CHEMBL1423683 & 688239 & 8.1871 & 5.636 & TRN & \\
\hline CHEMBL1570652 & 688239 & 4.5362 & 5.3419 & TST & \\
\hline CHEMBL1356468 & 688239 & 6.1862 & 5.6361 & TRN & \\
\hline CHEMBL1390339 & 688239 & 6.5862 & 5.5235 & TRN & \\
\hline CHEMBL1465659 & 688239 & 5.0862 & 5.4936 & TRN & \\
\hline CHEMBL1535581 & 688239 & 6.2862 & 5.5289 & TRN & \\
\hline CHEMBL1322513 & 688239 & 5.7862 & 5.4799 & TRN & \\
\hline CHEMBL1520950 & 688239 & 4.7862 & 5.5375 & TRN & \\
\hline CHEMBL1576200 & 688239 & 6.5363 & 5.6441 & TRN & \\
\hline CHEMBL 3191345 & 688239 & 4.5362 & 5.3586 & TRN & \\
\hline CHEMBL 3213911 & 688239 & 5.5362 & 5.3917 & TRN & \\
\hline CHEMBL1438483 & 688239 & 4.8362 & 5.3517 & TRN & \\
\hline CHEMBL1529532 & 688239 & 6.8861 & 5.4192 & TRN & \\
\hline CHEMBL1455371 & 688239 & 4.7862 & 5.5326 & TRN & \\
\hline CHEMBL1327804 & 688239 & 5.6362 & 5.4753 & TRN & \\
\hline CHEMBL3196256 & 688239 & 5.3362 & 5.4972 & TRN & \\
\hline CHEMBL1591855 & 688239 & 7.0362 & 5.4681 & TST & \\
\hline CHEMBL1483738 & 688239 & 7.0362 & 5.4801 & TRN & \\
\hline CHEMBL3192698 & 688239 & 6.2862 & 5.4672 & TST & \\
\hline CHEMBL1482059 & 688239 & 5.3362 & 5.3718 & TRN & \\
\hline CHEMBL1333310 & 688239 & 4.6362 & 5.4392 & TRN & \\
\hline CHEMBL1187953 & 688239 & 4.8862 & 5.3668 & TST & \\
\hline CHEMBL226265 & 688239 & 5.3362 & 5.7255 & TRN & \\
\hline CHEMBL1434784 & 688239 & 5.7862 & 5.6045 & TST & \\
\hline CHEMBL1611650 & 688239 & 4.4862 & 5.4786 & TST & \\
\hline CHEMBL1490389 & 688239 & 4.5362 & 5.3963 & TRN & \\
\hline CHEMBL1580865 & 688239 & 8.28399 & 99999999 & 5.7309 & I \\
\hline CHEMBL1425659 & 688239 & 5.9862 & 5.4752 & TRN & \\
\hline CHEMBL1474960 & 688239 & 4.4862 & 5.4965 & TRN & \\
\hline CHEMBL1485612 & 688239 & 5.0862 & 5.4751 & TRN & \\
\hline
\end{tabular}


Supplemental Table S2.txt

\begin{tabular}{|c|c|c|c|c|c|}
\hline CHEMBL1363925 & 688239 & 4.6862 & 5.4747 & TRN & \\
\hline CHEMBL1516740 & 688239 & 5.2362 & 5.5868 & TRN & \\
\hline CHEMBL1433600 & 688239 & 8.3372 & 5.4393 & TST & \\
\hline CHEMBL1380892 & 688239 & 6.0862 & 5.6693 & TRN & \\
\hline CHEMBL1339519 & 688239 & 6.0362 & 5.5287 & TST & \\
\hline CHEMBL1559763 & 688239 & 4.6862 & 5.4262 & TRN & \\
\hline CHEMBL1575993 & 688239 & 5.1862 & 5.4792 & TRN & \\
\hline CHEMBL1319676 & 688239 & 5.0862 & 5.5012 & TRN & \\
\hline CHEMBL1458649 & 688239 & 6.1862 & 5.5291 & TRN & \\
\hline CHEMBL1432423 & 688239 & 4.4862 & 5.5115 & TST & \\
\hline CHEMBL1438979 & 688239 & 4.8362 & 5.451000 & 0000000005 & $\mathrm{TR}$ \\
\hline CHEMBL1351297 & 688239 & 4.5362 & 5.5319 & TRN & \\
\hline CHEMBL1419583 & 688239 & 5.7862 & 5.5042 & TRN & \\
\hline CHEMBL1349348 & 688239 & 4.8362 & 5.7043 & TRN & \\
\hline CHEMBL1547082 & 688239 & 4.7362 & 5.5824 & TRN & \\
\hline CHEMBL1311018 & 688239 & 5.2862 & 5.379 & TRN & \\
\hline CHEMBL3195216 & 688239 & 4.7362 & 5.3742 & TST & \\
\hline CHEMBL1533306 & 688239 & 4.8862 & 5.4134 & TST & \\
\hline CHEMBL1344862 & 688239 & 4.6362 & 5.5808 & TST & \\
\hline CHEMBL1345701 & 688239 & 6.0362 & 5.562 & TRN & \\
\hline CHEMBL1527125 & 688239 & 8.3372 & 5.5564 & TRN & \\
\hline CHEMBL1593167 & 688239 & 5.7362 & 5.4107 & TRN & \\
\hline CHEMBL1335768 & 688239 & 4.9862 & 5.3895 & TST & \\
\hline CHEMBL1471711 & 688239 & 5.1862 & 5.4703 & TRN & \\
\hline CHEMBL1563734 & 688239 & 4.5862 & 5.5339 & TST & \\
\hline CHEMBL1541526 & 688239 & 5.1862 & 5.5019 & TRN & \\
\hline CHEMBL1491079 & 688239 & 4.5362 & 5.3838 & TRN & \\
\hline CHEMBL1424630 & 688239 & 5.1862 & 5.4643 & TST & \\
\hline CHEMBL1329899 & 688239 & 4.8862 & 5.3658 & TRN & \\
\hline CHEMBL1507309 & 688239 & 5.1862 & 5.6179 & TRN & \\
\hline CHEMBL1342825 & 688239 & 4.8862 & 5.4608 & TRN & \\
\hline CHEMBL1315827 & 688239 & 5.3862 & 5.43 & TRN & \\
\hline CHEMBL1456637 & 688239 & 4.6862 & 5.4488 & TRN & \\
\hline CHEMBL1495321 & 688239 & 6.8861 & 5.6479 & TRN & \\
\hline CHEMBL1546654 & 688239 & 5.9362 & 5.5566 & TRN & \\
\hline CHEMBL1498006 & 688239 & 5.5862 & 5.4999 & TST & \\
\hline CHEMBL1509365 & 688239 & 4.8862 & 5.4623 & TST & \\
\hline CHEMBL1422666 & 688239 & 5.1862 & 5.5932 & TRN & \\
\hline CHEMBL1518553 & 688239 & 6.5862 & 5.5505 & TRN & \\
\hline CHEMBL3191350 & 688239 & 4.5362 & 5.5078 & TST & \\
\hline CHEMBL1508785 & 688239 & 6.9363 & 5.5435 & TRN & \\
\hline CHEMBL1447694 & 688239 & 5.6862 & 5.5121 & TRN & \\
\hline CHEMBL1559298 & 688239 & 4.5362 & 5.2766 & TRN & \\
\hline CHEMBL1568125 & 688239 & 5.1862 & 5.5235 & TRN & \\
\hline CHEMBL1392863 & 688239 & 5.3362 & 5.4158 & TST & \\
\hline CHEMBL1548278 & 688239 & 5.9862 & 5.4939 & TRN & \\
\hline CHEMBL1326964 & 688239 & 8.28399 & 99999999 & 5.472 & TST \\
\hline CHEMBL1490105 & 688239 & 5.3862 & 5.5641 & TST & \\
\hline
\end{tabular}


Supplemental Table S2.txt

\begin{tabular}{|c|c|c|c|c|}
\hline CHEMBL1587330 & 688239 & 4.5362 & 5.2581 & TRN \\
\hline CHEMBL1366248 & 688239 & 5.0862 & 5.5138 & TST \\
\hline CHEMBL1443710 & 688239 & 5.2362 & 5.5644 & TRN \\
\hline CHEMBL1303176 & 688239 & 4.5862 & 5.4768 & TRN \\
\hline CHEMBL1360443 & 688239 & 5.8362 & 5.4495 & TRN \\
\hline CHEMBL1566762 & 688239 & 4.5862 & 5.3841 & TST \\
\hline CHEMBL1471789 & 688239 & 4.5362 & 5.5013 & TST \\
\hline CHEMBL1588443 & 688239 & 6.1862 & 5.5609 & TRN \\
\hline CHEMBL1534554 & 688239 & 4.5362 & 5.4963 & TST \\
\hline CHEMBL1326279 & 688239 & 6.4362 & 5.5657 & TRN \\
\hline CHEMBL1415122 & 688239 & 4.6862 & 5.4299 & TST \\
\hline CHEMBL1482658 & 688239 & 4.5862 & 5.5585 & TRN \\
\hline CHEMBL1342269 & 688239 & 4.5362 & 5.5106 & TRN \\
\hline CHEMBL1299723 & 688239 & 7.0362 & 5.4149 & TRN \\
\hline CHEMBL1537969 & 688239 & 5.3862 & 5.3459 & TRN \\
\hline CHEMBL1603787 & 688239 & 5.0362 & 5.4936 & TST \\
\hline CHEMBL1999149 & 688239 & 5.7362 & 5.3956 & TST \\
\hline CHEMBL1475518 & 688239 & 5.7362 & 5.5662 & TRN \\
\hline CHEMBL1601043 & 688239 & 5.9362 & 5.4694 & TRN \\
\hline CHEMBL1446148 & 688239 & 4.6862 & 5.3462 & TRN \\
\hline CHEMBL3199908 & 688239 & 8.3372 & 5.4102 & TST \\
\hline CHEMBL1403818 & 688239 & 5.1862 & 5.546 & TRN \\
\hline CHEMBL1564188 & 688239 & 7.1361 & 5.4698 & TRN \\
\hline CHEMBL1510307 & 688239 & 4.7862 & 5.50700 & 0000000001 \\
\hline CHEMBL1384893 & 688239 & 4.5362 & 5.4351 & TRN \\
\hline CHEMBL1386950 & 688239 & 6.9863 & 5.6055 & TST \\
\hline CHEMBL1495152 & 688239 & 4.7862 & 5.49200 & 0000000001 \\
\hline CHEMBL1470409 & 688239 & 6.6362 & 5.6511 & TST \\
\hline CHEMBL1381792 & 688239 & 4.4862 & 5.4724 & TRN \\
\hline CHEMBL1303296 & 688239 & 5.7362 & 5.5115 & TRN \\
\hline CHEMBL1495934 & 688239 & 6.0362 & 5.4614 & TRN \\
\hline CHEMBL1589431 & 688239 & 4.5362 & 5.3644 & TRN \\
\hline CHEMBL1351282 & 688239 & 5.1862 & 5.426 & TRN \\
\hline CHEMBL1430300 & 688239 & 4.9362 & 5.4476 & TST \\
\hline CHEMBL1454359 & 688239 & 6.5363 & 5.6016 & TRN \\
\hline CHEMBL1521489 & 688239 & 6.1862 & 5.6212 & TRN \\
\hline CHEMBL1447972 & 688239 & 4.4862 & 5.4941 & TRN \\
\hline CHEMBL1317429 & 688239 & 4.9362 & 5.2564 & TRN \\
\hline CHEMBL1524153 & 688239 & 5.7362 & 5.5629 & TRN \\
\hline CHEMBL1420291 & 688239 & 5.2362 & 5.4962 & TRN \\
\hline CHEMBL1392920 & 688239 & 4.5862 & 5.3468 & TRN \\
\hline CHEMBL1371749 & 688239 & 4.5362 & 5.4903 & TST \\
\hline CHEMBL1583161 & 688239 & 7.2366 & 5.4223 & TRN \\
\hline CHEMBL1347320 & 688239 & 5.1362 & 5.5055 & TRN \\
\hline CHEMBL1583954 & 688239 & 5.1862 & 5.5873 & TST \\
\hline CHEMBL3207501 & 688239 & 5.6862 & 5.308 & TRN \\
\hline CHEMBL3191113 & 688239 & 4.8362 & 5.2679 & TRN \\
\hline CHEMBL1581021 & 688239 & 6.2862 & 5.4169 & TRN \\
\hline
\end{tabular}




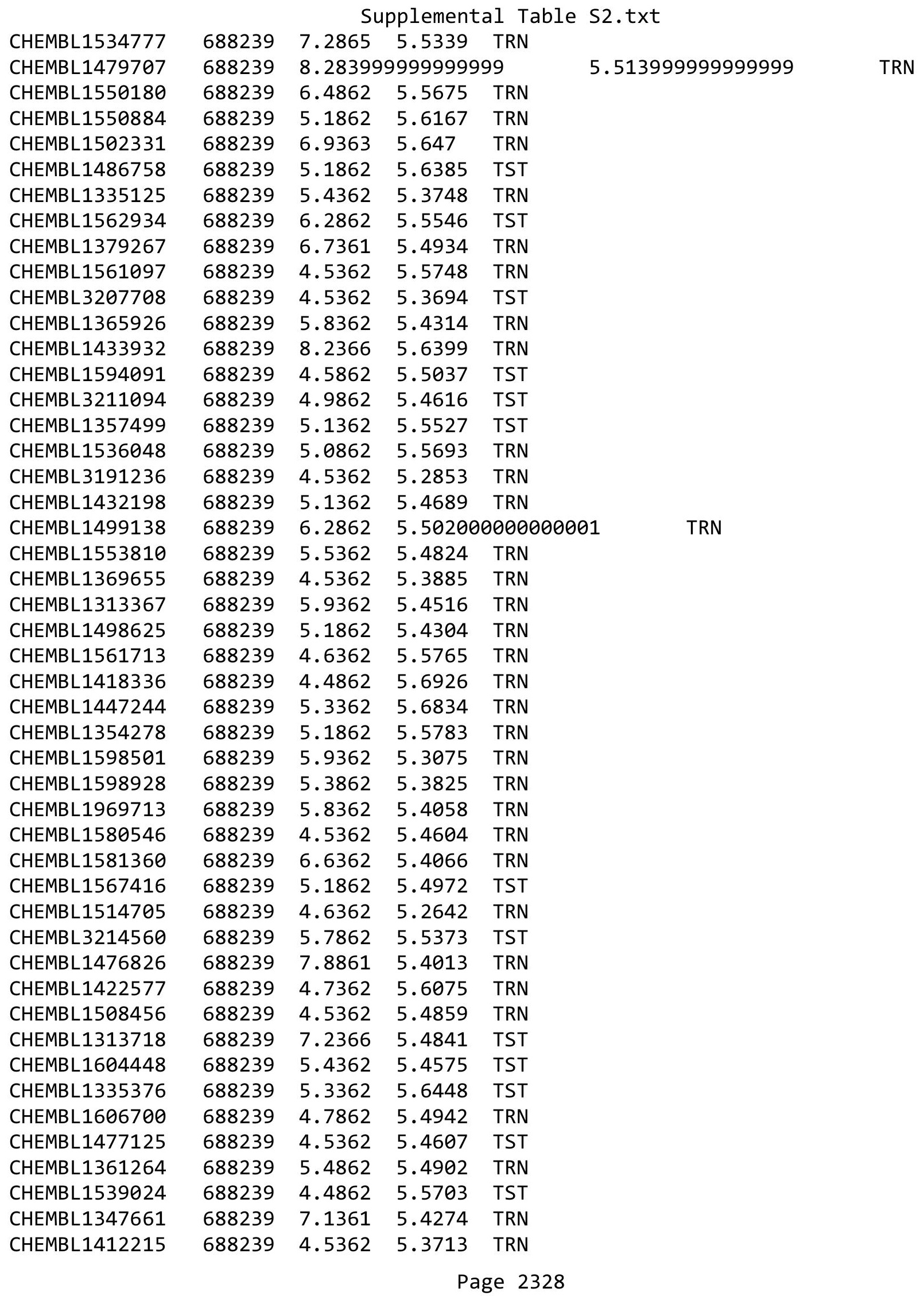


Supplemental Table S2.txt

\begin{tabular}{|c|c|c|c|c|c|}
\hline CHEMBL1439078 & 688239 & 5.3362 & 5.4297 & TST & \\
\hline CHEMBL1512691 & 688239 & 5.0862 & 5.4499 & TRN & \\
\hline CHEMBL1612235 & 688239 & 4.5362 & 5.54 & TST & \\
\hline CHEMBL1418758 & 688239 & 5.2862 & 5.5315 & TRN & \\
\hline CHEMBL1330488 & 688239 & 5.3362 & 5.4096 & TRN & \\
\hline CHEMBL1387563 & 688239 & 4.6862 & 5.3574 & TRN & \\
\hline CHEMBL1471791 & 688239 & 6.8861 & 5.4838 & TRN & \\
\hline CHEMBL1399368 & 688239 & 6.1862 & 5.5962 & TST & \\
\hline CHEMBL1491356 & 688239 & 5.2362 & 5.5306 & TRN & \\
\hline CHEMBL1606967 & 688239 & 5.8362 & 5.5669 & TRN & \\
\hline CHEMBL1346057 & 688239 & 8.3372 & 5.5321 & TRN & \\
\hline CHEMBL581194 & 688239 & 6.2362 & 5.3873 & TRN & \\
\hline CHEMBL1325934 & 688239 & 5.1862 & 5.5744 & TRN & \\
\hline CHEMBL1471258 & 688239 & 7.1361 & 5.4064 & TRN & \\
\hline CHEMBL1343283 & 688239 & 4.7362 & 5.5621 & TRN & \\
\hline CHEMBL591178 & 688239 & 4.6862 & 5.3291 & TRN & \\
\hline CHEMBL1473274 & 688239 & 5.1862 & 5.6027 & TRN & \\
\hline CHEMBL1534217 & 688239 & 4.4862 & 5.4402 & TRN & \\
\hline CHEMBL1575357 & 688239 & 7.1361 & 5.4788 & TRN & \\
\hline CHEMBL1505690 & 688239 & 6.1862 & 5.428 & TRN & \\
\hline CHEMBL1368413 & 688239 & 7.2366 & 5.51399 & 9999999999 & TRN \\
\hline CHEMBL1387708 & 688239 & 6.5363 & 5.4631 & TRN & \\
\hline CHEMBL1314828 & 688239 & 7.1864 & 5.4853 & TST & \\
\hline CHEMBL1325377 & 688239 & 5.6362 & 5.3766 & TRN & \\
\hline CHEMBL1504578 & 688239 & 4.5362 & 5.5125 & TST & \\
\hline CHEMBL1356238 & 688239 & 4.7362 & 5.4916 & TST & \\
\hline CHEMBL1522242 & 688239 & 5.6862 & 5.4748 & TRN & \\
\hline CHEMBL1343818 & 688239 & 5.7362 & 5.524 & TRN & \\
\hline CHEMBL1402810 & 688239 & 5.3862 & 5.4922 & TST & \\
\hline CHEMBL1583152 & 688239 & 5.4362 & 5.6025 & TRN & \\
\hline CHEMBL1549675 & 688239 & 4.5362 & 5.3412 & TRN & \\
\hline CHEMBL1587510 & 688239 & 4.5362 & 5.5289 & TRN & \\
\hline CHEMBL1539902 & 688239 & 4.5362 & 5.5414 & TRN & \\
\hline CHEMBL1511274 & 688239 & 5.2362 & 5.5316 & TRN & \\
\hline CHEMBL3196869 & 688239 & 5.7862 & 5.2553 & TST & \\
\hline CHEMBL1499052 & 688239 & 4.6362 & 5.5465 & TRN & \\
\hline CHEMBL1300381 & 688239 & 6.1362 & 5.3643 & TRN & \\
\hline CHEMBL1340917 & 688239 & 4.7362 & 5.5419 & TST & \\
\hline CHEMBL1515705 & 688239 & 4.9362 & 5.4637 & TRN & \\
\hline CHEMBL 3196300 & 688239 & 5.8862 & 5.5829 & TST & \\
\hline CHEMBL1570218 & 688239 & 4.5362 & 5.5145 & TST & \\
\hline CHEMBL1479923 & 688239 & 4.5362 & 5.5253 & TST & \\
\hline CHEMBL1517062 & 688239 & 4.5862 & 5.4984 & TRN & \\
\hline CHEMBL601528 & 688239 & 5.3862 & 5.4229 & TRN & \\
\hline CHEMBL1329715 & 688239 & 6.2362 & 5.4998 & TRN & \\
\hline CHEMBL1469744 & 688239 & 5.45 & 5.4469 & TRN & \\
\hline CHEMBL1315197 & 688239 & 5.1362 & 5.3343 & TRN & \\
\hline CHEMBL1502510 & 688239 & 4.5362 & 5.3068 & TRN & \\
\hline
\end{tabular}


Supplemental Table S2.txt

\begin{tabular}{|c|c|c|c|c|}
\hline CHEMBL1403673 & 688239 & 5.6362 & 5.5342 & TRN \\
\hline CHEMBL1443103 & 688239 & 4.5362 & 5.3085 & TRN \\
\hline CHEMBL1460489 & 688239 & 5.5862 & 5.4282 & TRN \\
\hline CHEMBL1562519 & 688239 & 6.9863 & 5.5937 & TRN \\
\hline CHEMBL1461276 & 688239 & 5.3862 & 5.5727 & TRN \\
\hline CHEMBL1524545 & 688239 & 5.7362 & 5.5033 & TST \\
\hline CHEMBL1589808 & 688239 & 4.6862 & 5.4148 & TRN \\
\hline CHEMBL1511433 & 688239 & 4.5362 & 5.4268 & TRN \\
\hline CHEMBL1604020 & 688239 & 8.3372 & 5.5063 & TRN \\
\hline CHEMBL1413867 & 688239 & 6.9363 & 5.6347 & TRN \\
\hline CHEMBL1374284 & 688239 & 6.3863 & 5.4446 & TST \\
\hline CHEMBL1379836 & 688239 & 5.1862 & 5.3063 & TST \\
\hline CHEMBL1385412 & 688239 & 5.1362 & 5.4899 & TRN \\
\hline CHEMBL1523504 & 688239 & 4.5362 & 5.6068 & TRN \\
\hline CHEMBL1327933 & 688239 & 4.7862 & 5.4415 & TST \\
\hline CHEMBL1545991 & 688239 & 5.0362 & 5.4295 & TST \\
\hline CHEMBL1558141 & 688239 & 5.0362 & 5.4259 & TRN \\
\hline CHEMBL1466570 & 688239 & 4.5362 & 5.4669 & TST \\
\hline CHEMBL1544081 & 688239 & 5.6362 & 5.5399 & TRN \\
\hline CHEMBL1383603 & 688239 & 4.6862 & 5.3414 & TRN \\
\hline CHEMBL1495979 & 688239 & 4.5362 & 5.7385 & TRN \\
\hline CHEMBL1364274 & 688239 & 5.3862 & 5.6383 & TRN \\
\hline CHEMBL1474147 & 688239 & 4.7362 & 5.475 & TRN \\
\hline CHEMBL1366854 & 688239 & 6.2862 & 5.4509 & TRN \\
\hline CHEMBL1318648 & 688239 & 4.5362 & 5.3506 & TRN \\
\hline CHEMBL1517483 & 688239 & 7.8861 & 5.6995 & TRN \\
\hline CHEMBL1310891 & 688239 & 6.1362 & 5.432 & TRN \\
\hline CHEMBL1379129 & 688239 & 5.1862 & 5.5108 & TRN \\
\hline CHEMBL1445852 & 688239 & 5.6362 & 5.5591 & TRN \\
\hline CHEMBL1493540 & 688239 & 5.1862 & 5.50700 & 000000001 \\
\hline CHEMBL1308687 & 688239 & 4.8362 & 5.3514 & TRN \\
\hline CHEMBL1413031 & 688239 & 6.0862 & 5.7023 & TRN \\
\hline CHEMBL1328572 & 688239 & 5.4362 & 5.3752 & TST \\
\hline CHEMBL1582240 & 688239 & 5.3862 & 5.5125 & TRN \\
\hline CHEMBL1610275 & 688239 & 5.4362 & 5.3404 & TRN \\
\hline CHEMBL1340077 & 688239 & 6.8861 & 5.4968 & TRN \\
\hline CHEMBL1362921 & 688239 & 6.7862 & 5.4758 & TST \\
\hline CHEMBL3193194 & 688239 & 5.4362 & 5.4053 & TRN \\
\hline CHEMBL1398239 & 688239 & 4.5362 & 5.4708 & TST \\
\hline CHEMBL1603534 & 688239 & 5.1862 & 5.4799 & TST \\
\hline CHEMBL1471565 & 688239 & 4.6362 & 5.54700 & 0000000001 \\
\hline CHEMBL1446654 & 688239 & 4.5362 & 5.5427 & TRN \\
\hline CHEMBL1582085 & 688239 & 4.4862 & 5.5052 & TRN \\
\hline CHEMBL1499916 & 688239 & 4.6362 & 5.3553 & TST \\
\hline CHEMBL1364523 & 688239 & 4.7362 & 5.4539 & TST \\
\hline CHEMBL1596146 & 688239 & 5.3362 & 5.4846 & TRN \\
\hline CHEMBL1461627 & 688239 & 8.2366 & 5.4216 & TRN \\
\hline CHEMBL1537020 & 688239 & 4.5362 & 5.4184 & TRN \\
\hline
\end{tabular}


Supplemental Table S2.txt

\begin{tabular}{|c|c|c|c|c|}
\hline & & & & \\
\hline 519 & 8239 & 362 & 5274 & \\
\hline IEMBL1577653 & 8239 & 9862 & & \\
\hline AEMBL1474525 & 239 & 362 & 5482 & \\
\hline 114 & 239 & 862 & & \\
\hline IEMBL1349835 & 239 & 362 & & \\
\hline HEMBL1352915 & 88239 & 862 & 5612 & \\
\hline AEMBL1459273 & 88239 & 362 & 2519 & \\
\hline AEMBL1607802 & 239 & 862 & & \\
\hline IEMBL15 & 239 & 862 & & \\
\hline IEMBL14: & & & & \\
\hline AEMBL1495114 & 688239 & 862 & 421 & \\
\hline AEMBL1550312 & 239 & 861 & & \\
\hline IEMBL1605061 & & 372 & 93 & \\
\hline EMBL13 & & 62 & & \\
\hline AEMBL15 & & & & \\
\hline AEMBL1301419 & 39 & 362 & & \\
\hline AEMBL1381321 & 39 & 62 & & \\
\hline EMBBL14 & & 52 & & \\
\hline IEMBL15 & & & & \\
\hline AEMBL32 & & & & \\
\hline AEMBL1599989 & & 362 & & \\
\hline AEMBL137 & & & & \\
\hline IEMBL13 & & & & \\
\hline AEMBL1 & & & & \\
\hline 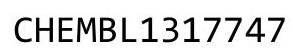 & & 62 & & \\
\hline JEMBL13 & & & & \\
\hline HEMBL 142 & & & & \\
\hline AEMBL1470712 & & 52 & & \\
\hline AEMBL13 & & 62 & & \\
\hline L1 & & 52 & & \\
\hline HEMBL1301635 & & & & \\
\hline AEMBL1376316 & & & & \\
\hline HEMBL145 & & 362 & & \\
\hline 564 & & 4. & 77 & \\
\hline 346 & & & & \\
\hline AEMBL1421996 & & & & \\
\hline AEMBL1486131 & & & & \\
\hline IEMBL13 & & 72 & & \\
\hline 1 & & 52 & 23 & \\
\hline & & & & Rू \\
\hline AEMBL1575673 & & 862 & & $R$ \\
\hline IEMBL1536464 & & 62 & & \\
\hline EMBL321 & & & & \\
\hline HEMBL133 & & & & \\
\hline CHEMBL1545017 & & 366 & & \\
\hline AEMBL1327706 & 38239 & 5.1862 & 5.4017 & \\
\hline HFMRI 1401615 & 688239 & 5.4362 & 5.5517 & \\
\hline
\end{tabular}

Page 2331 
Supplemental Table S2.txt

\begin{tabular}{|c|c|c|c|c|c|}
\hline CHEMBL1586506 & 688239 & 4.5362 & 5.5627 & TRN & \\
\hline CHEMBL1314474 & 688239 & 5.6862 & 5.5592 & TRN & \\
\hline CHEMBL1511939 & 688239 & 4.6362 & 5.4149 & TRN & \\
\hline CHEMBL1359402 & 688239 & 4.5362 & 5.5487 & TRN & \\
\hline CHEMBL1466924 & 688239 & 4.4862 & 5.3626 & TRN & \\
\hline CHEMBL1398345 & 688239 & 4.5362 & 5.5174 & TRN & \\
\hline CHEMBL1389662 & 688239 & 6.2362 & 5.4528 & TRN & \\
\hline CHEMBL1419308 & 688239 & 5.1862 & 5.3839 & TRN & \\
\hline CHEMBL475813 & 688239 & 5.3862 & 5.3967 & TRN & \\
\hline CHEMBL1485071 & 688239 & 5.3862 & 5.4304 & TRN & \\
\hline CHEMBL1521214 & 688239 & 5.5862 & 5.4623 & TRN & \\
\hline CHEMBL1980103 & 688239 & 4.7862 & 5.4164 & TST & \\
\hline CHEMBL1605245 & 688239 & 6.1862 & 5.5186 & TST & \\
\hline CHEMBL1398618 & 688239 & 5.8362 & 5.3997 & TST & \\
\hline CHEMBL1415047 & 688239 & 6.7361 & 5.4157 & TST & \\
\hline CHEMBL1335913 & 688239 & 4.5362 & 5.5561 & TRN & \\
\hline CHEMBL3197089 & 688239 & 5.1862 & 5.4934 & TRN & \\
\hline CHEMBL1557831 & 688239 & 5.1862 & 5.5562 & TST & \\
\hline CHEMBL1496427 & 688239 & 6.3863 & 5.5576 & TRN & \\
\hline CHEMBL1389961 & 688239 & 6.1362 & 5.6219 & TRN & \\
\hline CHEMBL1416951 & 688239 & 8.28399 & 99999999 & 99 & 5.499 \\
\hline CHEMBL1594363 & 688239 & 8.1367 & 5.6015 & TST & \\
\hline CHEMBL1475612 & 688239 & 6.0862 & 5.4052 & TRN & \\
\hline CHEMBL1307090 & 688239 & 4.9362 & 5.4685 & TRN & \\
\hline CHEMBL1522124 & 688239 & 6.1862 & 5.5668 & TRN & \\
\hline CHEMBL602828 & 688239 & 4.6862 & 5.2705 & TRN & \\
\hline CHEMBL1334571 & 688239 & 4.5862 & 5.4812 & TRN & \\
\hline CHEMBL1365759 & 688239 & 5.6362 & 5.4559 & TRN & \\
\hline CHEMBL1581668 & 688239 & 5.1862 & 5.5551 & TRN & \\
\hline CHEMBL1483886 & 688239 & 6.0862 & 5.5408 & TRN & \\
\hline CHEMBL1597998 & 688239 & 5.5362 & 5.5231 & TRN & \\
\hline CHEMBL1424597 & 688239 & 5.1862 & 5.5151 & TRN & \\
\hline CHEMBL1385046 & 688239 & 8.3372 & 5.4643 & TRN & \\
\hline CHEMBL1414646 & 688239 & 5.1362 & 5.3256 & TRN & \\
\hline CHEMBL1515128 & 688239 & 4.7362 & 5.3985 & TRN & \\
\hline CHEMBL3208714 & 688239 & 4.9362 & 5.447 & TRN & \\
\hline CHEMBL1393713 & 688239 & 5.1362 & 5.4899 & TRN & \\
\hline CHEMBL1582333 & 688239 & 7.0362 & 5.6286 & TRN & \\
\hline CHEMBL1425258 & 688239 & 4.5862 & 5.5887 & TRN & \\
\hline CHEMBL3196805 & 688239 & 5.7862 & 5.5021 & TRN & \\
\hline CHEMBL1320573 & 688239 & 4.5362 & 5.3612 & TRN & \\
\hline CHEMBL1369335 & 688239 & 6.5363 & 5.474 & TST & \\
\hline CHEMBL1488945 & 688239 & 4.6362 & 5.4296 & TST & \\
\hline CHEMBL1369149 & 688239 & 6.9863 & 5.5293 & TRN & \\
\hline CHEMBL586146 & 688239 & 4.5362 & 5.4484 & TST & \\
\hline CHEMBL1349743 & 688239 & 5.1362 & 5.6232 & TRN & \\
\hline CHEMBL1323731 & 688239 & 4.8362 & 5.5423 & TRN & \\
\hline CHEMBL1393851 & 688239 & 4.5362 & 5.6955 & TRN & \\
\hline
\end{tabular}

Page 2332 


\begin{tabular}{|c|c|c|c|c|c|}
\hline & & & & & \\
\hline CHEMBL1603320 & 688239 & 6.7361 & 5.4815 & TRN & \\
\hline CHEMBL1327877 & 688239 & 4.7362 & 5.6673 & TRN & \\
\hline CHEMBL1429397 & 688239 & 5.9862 & 5.5812 & TRN & \\
\hline CHEMBL3194796 & 688239 & 4.7862 & 5.4273 & TRN & \\
\hline CHEMBL1401274 & 688239 & 5.6362 & 5.5359 & TRN & \\
\hline CHEMBL1595595 & 688239 & 6.0 & 5.5179 & TRN & \\
\hline CHEMBL1454926 & 688239 & 6.8362 & 5.6412 & TST & \\
\hline CHEMBL1363572 & 688239 & 6.3362 & 5.5253 & TRN & \\
\hline CHEMBL1306157 & 688239 & 5.5362 & 5.5158 & TRN & \\
\hline CHEMBL1431810 & 688239 & 4.6862 & 5.4022 & TST & \\
\hline CHEMBL1604151 & 688239 & 5.0862 & 5.4885 & TRN & \\
\hline CHEMBL1326640 & 688239 & 4.9362 & 5.539 & TRN & \\
\hline CHEMBL1582070 & 688239 & 6.1362 & 5.5198 & TRN & \\
\hline CHEMBL547161 & 688239 & 4.5362 & 5.3227 & TRN & \\
\hline CHEMBL1399769 & 688239 & 6.8362 & 5.4931 & TRN & \\
\hline CHEMBL1595706 & 688239 & 5.6362 & 5.6132 & TRN & \\
\hline CHEMBL1410295 & 688239 & 6.1862 & 5.59200 & 00000000005 & TRN \\
\hline CHEMBL1354429 & 688239 & 5.9862 & 5.4874 & TRN & \\
\hline CHEMBL1438061 & 688239 & 4.7362 & 5.4415 & TST & \\
\hline CHEMBL1465295 & 688239 & 5.4862 & 5.5103 & TST & \\
\hline CHEMBL1407228 & 688239 & 4.7362 & 5.3825 & TST & \\
\hline CHEMBL441083 & 688239 & 5.5362 & 5.2934 & TRN & \\
\hline CHEMBL3197280 & 688239 & 5.7362 & 5.5501 & TRN & \\
\hline CHEMBL1605438 & 688239 & 5.5362 & 5.4649 & TRN & \\
\hline CHEMBL1548773 & 688239 & 4.6362 & 5.433 & TST & \\
\hline CHEMBL1589280 & 688239 & 5.7862 & 5.4323 & TRN & \\
\hline CHEMBL1482585 & 688239 & 4.7862 & 5.2899 & TRN & \\
\hline CHEMBL1371718 & 688239 & 5.7362 & 5.4961 & TRN & \\
\hline CHEMBL1487067 & 688239 & 5.6362 & 5.37200 & 0000000001 & TST \\
\hline CHEMBL1518799 & 688239 & 4.6362 & 5.4172 & TRN & \\
\hline CHEMBL1348115 & 688239 & 5.0862 & 5.5486 & TRN & \\
\hline CHEMBL596728 & 688239 & 7.5867 & 5.3657 & TRN & \\
\hline CHEMBL1554694 & 688239 & 5.8862 & 5.4568 & TRN & \\
\hline CHEMBL1549883 & 688239 & 6.9363 & 5.5569 & TRN & \\
\hline CHEMBL1446825 & 688239 & 4.6862 & 5.4206 & TST & \\
\hline CHEMBL1500873 & 688239 & 5.7862 & 5.478 & TRN & \\
\hline CHEMBL1589419 & 688239 & 4.6362 & 5.5382 & TRN & \\
\hline CHEMBL1441613 & 688239 & 5.8362 & 5.4685 & TST & \\
\hline CHEMBL1412559 & 688239 & 5.4862 & 5.5516 & TRN & \\
\hline CHEMBL1360003 & 688239 & 4.9862 & 5.4759 & TRN & \\
\hline CHEMBL1393674 & 688239 & 5.1862 & 5.4757 & TST & \\
\hline CHEMBL1505770 & 688239 & 6.9863 & 5.5476 & TRN & \\
\hline CHEMBL1531459 & 688239 & 5.5862 & 5.5343 & TST & \\
\hline CHEMBL1445712 & 688239 & 4.5362 & 5.6248 & TST & \\
\hline CHEMBL1395892 & 688239 & 4.8862 & 5.4834 & TST & \\
\hline CHEMBL1430906 & 688239 & 4.6362 & 5.3618 & TST & \\
\hline CHEMBL1338338 & 688239 & 6.1362 & 5.5574 & TRN & \\
\hline CHEMBL1559757 & 688239 & 5.1862 & 5.6085 & TRN & \\
\hline
\end{tabular}

Page 2333 
Supplemental Table S2.txt

\begin{tabular}{|c|c|c|c|c|}
\hline CHEMBL1489844 & 688239 & 5.1862 & 5.4763 & TRN \\
\hline CHEMBL1603795 & 688239 & 4.5362 & 5.4982 & TRN \\
\hline CHEMBL1502469 & 688239 & 5.9362 & 5.4509 & TST \\
\hline CHEMBL 3197687 & 688239 & 6.1362 & 5.4469 & TST \\
\hline CHEMBL1607230 & 688239 & 5.1862 & 5.6671 & TST \\
\hline CHEMBL1437635 & 688239 & 5.0862 & 5.4168 & TRN \\
\hline CHEMBL1387598 & 688239 & 5.8862 & 5.5711 & TRN \\
\hline CHEMBL1492598 & 688239 & 4.7862 & 5.4956 & TRN \\
\hline CHEMBL1318025 & 688239 & 4.6862 & 5.4604 & TRN \\
\hline CHEMBL1528553 & 688239 & 4.6862 & 5.3826 & TRN \\
\hline CHEMBL1315930 & 688239 & 4.5362 & 5.4499 & TRN \\
\hline CHEMBL 3212321 & 688239 & 4.5362 & 5.3059 & TRN \\
\hline CHEMBL1465396 & 688239 & 4.7 & 5.3775 & TRN \\
\hline CHEMBL1502942 & 688239 & 4.5362 & 5.4345 & TRN \\
\hline CHEMBL1492487 & 688239 & 5.6362 & 5.5153 & TRN \\
\hline CHEMBL1317101 & 688239 & 6.1362 & 5.4043 & TRN \\
\hline CHEMBL1582455 & 688239 & 6.3362 & 5.4561 & TRN \\
\hline CHEMBL1980697 & 688239 & 5.3862 & 5.3718 & TST \\
\hline CHEMBL1318745 & 688239 & 5.1362 & 5.5346 & TRN \\
\hline CHEMBL1429465 & 688239 & 5.3362 & 5.5328 & TST \\
\hline CHEMBL1587680 & 688239 & 5.3862 & 5.3835 & TST \\
\hline CHEMBL1415638 & 688239 & 4.7362 & 5.4749 & TST \\
\hline CHEMBL1409992 & 688239 & 4.5362 & 5.5189 & TRN \\
\hline CHEMBL1442631 & 688239 & 5.5362 & 5.5922 & TRN \\
\hline CHEMBL1523085 & 688239 & 4.5362 & 5.3828 & TRN \\
\hline CHEMBL1537352 & 688239 & 6.1862 & 5.44600 & 3000000001 \\
\hline CHEMBL1411926 & 688239 & 5.1862 & 5.4449 & TRN \\
\hline CHEMBL 3209664 & 688239 & 5.0862 & 5.4629 & TRN \\
\hline CHEMBL1350761 & 688239 & 6.0862 & 5.5001 & TRN \\
\hline CHEMBL1565517 & 688239 & 4.5362 & 5.4966 & TST \\
\hline CHEMBL1546755 & 688239 & 6.7862 & 5.5768 & TRN \\
\hline CHEMBL1344573 & 688239 & 6.8861 & 5.6219 & TRN \\
\hline CHEMBL1509988 & 688239 & 4.5362 & 5.405 & TST \\
\hline CHEMBL1580392 & 688239 & 4.9362 & 5.4446 & TST \\
\hline CHEMBL1602756 & 688239 & 4.5362 & 5.4863 & TRN \\
\hline CHEMBL1381279 & 688239 & 4.4862 & 5.2159 & TRN \\
\hline CHEMBL1401628 & 688239 & 4.5362 & 5.3966 & TST \\
\hline CHEMBL1444381 & 688239 & 4.5362 & 5.5249 & TRN \\
\hline CHEMBL1511186 & 688239 & 7.7352 & 5.7386 & TRN \\
\hline CHEMBL1534005 & 688239 & 4.5362 & 5.3161 & TST \\
\hline CHEMBL1373290 & 688239 & 8.3872 & 5.3709 & TRN \\
\hline CHEMBL1317973 & 688239 & 5.5362 & 5.4033 & TRN \\
\hline CHEMBL1564483 & 688239 & 6.8861 & 5.3341 & TRN \\
\hline CHEMBL1368363 & 688239 & 4.7362 & 5.3575 & TST \\
\hline CHEMBL1528329 & 688239 & 4.6862 & 5.5928 & TST \\
\hline CHEMBL1441060 & 688239 & 5.1862 & 5.5737 & TRN \\
\hline CHEMBL1566786 & 688239 & 5.1862 & 5.3558 & TRN \\
\hline \multirow[t]{2}{*}{ CHEMBL1389612 } & 688239 & 6.2862 & 5.58299 & 9999999999 \\
\hline & & \multicolumn{3}{|c|}{ Page 2334} \\
\hline
\end{tabular}


Supplemental Table S2.txt

\begin{tabular}{|c|c|c|c|c|c|}
\hline CHEMBL1472602 & 688239 & 6.1862 & 5.5594 & TRN & \\
\hline CHEMBL1338398 & 688239 & 8.3372 & 5.4767 & TRN & \\
\hline CHEMBL1450077 & 688239 & 5.5862 & 5.4269 & TRN & \\
\hline CHEMBL1475892 & 688239 & 5.4862 & 5.5185 & TRN & \\
\hline CHEMBL1340487 & 688239 & 4.5362 & 5.3336 & TRN & \\
\hline CHEMBL1461500 & 688239 & 6.2362 & 5.5 & TRN & \\
\hline CHEMBL1402467 & 688239 & \multicolumn{2}{|c|}{8.283999999999999} & 5.4222 & TRN \\
\hline CHEMBL1459032 & 688239 & 4.6362 & 5.4798 & TRN & \\
\hline CHEMBL3194835 & 688239 & 4.7362 & 5.5854 & TST & \\
\hline CHEMBL1557999 & 688239 & 4.4862 & 5.4893 & TST & \\
\hline CHEMBL1435755 & 688239 & 4.6862 & 5.4905 & TST & \\
\hline CHEMBL1412969 & 688239 & 4.4862 & 5.5195 & TRN & \\
\hline CHEMBL1405709 & 688239 & 4.5362 & 5.465 & TRN & \\
\hline CHEMBL1423163 & 688239 & 5.7362 & 5.5533 & TST & \\
\hline CHEMBL1545114 & 688239 & 4.7862 & 5.5233 & TRN & \\
\hline CHEMBL1479421 & 688239 & 5.4362 & 5.3329 & TRN & \\
\hline CHEMBL1480617 & 688239 & 5.3862 & 5.4621 & TRN & \\
\hline CHEMBL1504055 & 688239 & 5.6862 & 5.5271 & TST & \\
\hline CHEMBL1578438 & 688239 & 6.9363 & 5.4839 & TST & \\
\hline CHEMBL1532616 & 688239 & 5.7362 & 5.6833 & TRN & \\
\hline CHEMBL1460249 & 688239 & 4.6362 & 5.3444 & TST & \\
\hline CHEMBL1364070 & 688239 & 5.3362 & 5.5632 & TRN & \\
\hline CHEMBL1358121 & 688239 & 5.3362 & 5.5255 & TRN & \\
\hline CHEMBL1320339 & 688239 & 4.8362 & 5.4954 & TRN & \\
\hline CHEMBL1481588 & 688239 & 5.2362 & 5.32600 & 00000000005 & TRN \\
\hline CHEMBL1416192 & 688239 & 4.5362 & 5.4959 & TRN & \\
\hline CHEMBL1396914 & 688239 & 5.4362 & 5.4416 & TRN & \\
\hline CHEMBL1374814 & 688239 & 4.5362 & 5.4621 & TRN & \\
\hline CHEMBL3198723 & 688239 & \multicolumn{3}{|c|}{8.283999999999999} & TRN \\
\hline CHEMBL3209121 & 688239 & 4.9862 & 5.4066 & TRN & \\
\hline CHEMBL1409429 & 688239 & 5.8362 & 5.4873 & TRN & \\
\hline CHEMBL1468802 & 688239 & 5.3862 & 5.5977 & TRN & \\
\hline CHEMBL1422738 & 688239 & 5.1862 & 5.49200 & 0000000001 & TRN \\
\hline CHEMBL1458828 & 688239 & 4.8362 & 5.3706 & TRN & \\
\hline CHEMBL1550572 & 688239 & 5.3862 & 5.4187 & TRN & \\
\hline CHEMBL1569127 & 688239 & 4.5362 & 5.6117 & TRN & \\
\hline CHEMBL1521561 & 688239 & 5.2362 & 5.4992 & TRN & \\
\hline CHEMBL3199091 & 688239 & 4.7362 & 5.3681 & TRN & \\
\hline CHEMBL1354389 & 688239 & \multicolumn{3}{|c|}{8.283999999999999} & TRN \\
\hline CHEMBL3213129 & 688239 & 5.2862 & 5.4207 & TRN & \\
\hline CHEMBL487311 & 688239 & 5.8362 & 5.3697 & TST & \\
\hline CHEMBL1578069 & 688239 & 8.3372 & 5.5313 & TST & \\
\hline CHEMBL1429874 & 688239 & 7.1864 & 5.4772 & TRN & \\
\hline CHEMBL3212767 & 688239 & 5.3862 & 5.3816 & TST & \\
\hline CHEMBL1459828 & 688239 & 6.1362 & 5.4939 & TRN & \\
\hline CHEMBL1587703 & 688239 & 4.8362 & 5.5985 & TST & \\
\hline CHEMBL1305423 & 688239 & 6.1362 & 5.4316 & TST & \\
\hline CHEMBL1538155 & 688239 & 4.7362 & 5.4317 & TST & \\
\hline
\end{tabular}


Supplemental Table S2.txt

\begin{tabular}{|c|c|c|c|c|c|}
\hline CHEMBL1432411 & 688239 & 7.1864 & \multicolumn{2}{|c|}{5.428999999999999} & TRN \\
\hline CHEMBL1374722 & 688239 & 4.7862 & 5.5562 & TST & \\
\hline CHEMBL1531922 & 688239 & 6.8362 & 5.3818 & TRN & \\
\hline CHEMBL1565014 & 688239 & 5.1862 & 5.3481 & TRN & \\
\hline CHEMBL1579033 & 688239 & 4.7362 & 5.5459 & TST & \\
\hline CHEMBL3212383 & 688239 & 5.6362 & 5.2859 & TST & \\
\hline CHEMBL1426370 & 688239 & 5.6862 & 5.6345 & TRN & \\
\hline CHEMBL1335923 & 688239 & 4.6862 & 5.4162 & TRN & \\
\hline CHEMBL1435563 & 688239 & 5.4862 & 5.4952 & TRN & \\
\hline CHEMBL1569769 & 688239 & 4.5362 & 5.5261 & TRN & \\
\hline CHEMBL1421116 & 688239 & 4.8862 & 5.3536 & TRN & \\
\hline CHEMBL1300768 & 688239 & 5.8862 & 5.3982 & TST & \\
\hline CHEMBL1453023 & 688239 & 8.1367 & 5.4858 & TRN & \\
\hline CHEMBL1421126 & 688239 & 6.1362 & 5.4161 & TRN & \\
\hline CHEMBL1576740 & 688239 & 5.1862 & 5.4203 & TST & \\
\hline CHEMBL1519419 & 688239 & 6.9863 & 5.4066 & TRN & \\
\hline CHEMBL1523903 & 688239 & 5.6362 & 5.6221 & TRN & \\
\hline CHEMBL1450697 & 688239 & 5.2362 & 5.5751 & TRN & \\
\hline CHEMBL1319114 & 688239 & 7.0362 & 5.6202 & TRN & \\
\hline CHEMBL1360030 & 688239 & 4.5362 & 5.4352 & TRN & \\
\hline CHEMBL3214356 & 688239 & 4.5362 & 5.4539 & TRN & \\
\hline CHEMBL1396238 & 688239 & 5.6862 & 5.4896 & TRN & \\
\hline CHEMBL1512583 & 688239 & 6.8362 & 5.6513 & TRN & \\
\hline CHEMBL1572752 & 688239 & 4.7362 & 5.3767 & TRN & \\
\hline CHEMBL1500319 & 688239 & 4.9362 & 5.4021 & TST & \\
\hline CHEMBL1596424 & 688239 & 4.5362 & 5.4792 & TRN & \\
\hline CHEMBL3209992 & 688239 & 5.2 & 5.4362 & TST & \\
\hline CHEMBL1449525 & 688239 & 6.0862 & 5.5582 & TRN & \\
\hline CHEMBL3199850 & 688239 & 6.1362 & 5.4849 & TRN & \\
\hline CHEMBL3193791 & 688239 & 5.4362 & 5.5072 & TRN & \\
\hline CHEMBL1493115 & 688239 & 6.9863 & 5.5092 & TRN & \\
\hline CHEMBL3207636 & 688239 & 5.2362 & 5.5557 & TRN & \\
\hline CHEMBL1381203 & 688239 & 4.7362 & 5.3011 & TRN & \\
\hline CHEMBL1488056 & 688239 & 5.1862 & 5.4184 & TRN & \\
\hline CHEMBL1465772 & 688239 & 5.8862 & 5.4782 & TRN & \\
\hline CHEMBL1487092 & 688239 & 6.7862 & 5.6382 & TST & \\
\hline CHEMBL1402455 & 688239 & 6.8861 & 5.3681 & TST & \\
\hline CHEMBL1569989 & 688239 & 4.7362 & 5.4044 & TRN & \\
\hline CHEMBL1383808 & 688239 & 7.2865 & 5.4854 & TRN & \\
\hline CHEMBL1361276 & 688239 & 6.5862 & 5.544 & TRN & \\
\hline CHEMBL1445835 & 688239 & 6.3362 & 5.6847 & TRN & \\
\hline CHEMBL1570090 & 688239 & 4.5362 & 5.4214 & TST & \\
\hline CHEMBL1583461 & 688239 & 4.5362 & 5.2625 & TRN & \\
\hline CHEMBL1304826 & 688239 & 5.0362 & 5.4987 & TRN & \\
\hline CHEMBL1317746 & 688239 & 4.5362 & 5.3489 & TRN & \\
\hline CHEMBL1459159 & 688239 & 5.2362 & 5.604 & TST & \\
\hline CHEMBL1346782 & 688239 & 5.4862 & 5.3342 & TRN & \\
\hline CHEMBL1391810 & 688239 & 4.7862 & 5.4524 & TST & \\
\hline
\end{tabular}


Supplemental Table S2.txt

\begin{tabular}{|c|c|c|c|c|}
\hline CHEMBL1313523 & 688239 & 4.7862 & 5.4974 & TST \\
\hline CHEMBL1577981 & 688239 & 4.4862 & 5.3803 & TRN \\
\hline CHEMBL1332402 & 688239 & 4.5362 & 5.4345 & TRN \\
\hline CHEMBL443771 & 688239 & 4.6862 & 5.5149 & TRN \\
\hline CHEMBL1527908 & 688239 & 4.5362 & 5.4242 & TRN \\
\hline CHEMBL1348281 & 688239 & 5.3362 & 5.5392 & TST \\
\hline CHEMBL1474182 & 688239 & 4.7862 & 5.4664 & TRN \\
\hline CHEMBL1384064 & 688239 & 4.6362 & 5.6175 & TST \\
\hline CHEMBL1577106 & 688239 & 6.1362 & 5.3744 & TRN \\
\hline CHEMBL1488213 & 688239 & 4.5362 & 5.5896 & TRN \\
\hline CHEMBL1608348 & 688239 & 5.3862 & 5.5356 & TST \\
\hline CHEMBL1401122 & 688239 & 5.1862 & 5.5545 & TST \\
\hline CHEMBL1520777 & 688239 & 5.3862 & \multicolumn{2}{|c|}{5.2860000000000005} \\
\hline CHEMBL1559813 & 688239 & 5.2362 & 5.3216 & TRN \\
\hline CHEMBL1382359 & 688239 & 6.9863 & 5.437 & TRN \\
\hline CHEMBL1309508 & 688239 & 4.6362 & 5.4557 & TST \\
\hline CHEMBL1354705 & 688239 & 5.1862 & 5.5756 & TRN \\
\hline CHEMBL1982010 & 688239 & 4.5362 & 5.325 & TST \\
\hline CHEMBL1382552 & 688239 & 4.5362 & 5.5382 & TRN \\
\hline CHEMBL1317312 & 688239 & 6.9863 & 5.4226 & TRN \\
\hline CHEMBL1369902 & 688239 & 6.5862 & 5.5136 & TRN \\
\hline CHEMBL1716038 & 688239 & 5.6362 & 5.3753 & TST \\
\hline CHEMBL1549162 & 688239 & 4.6362 & 5.4446 & TRN \\
\hline CHEMBL1493490 & 688239 & 4.5362 & 5.4456 & TRN \\
\hline CHEMBL1536608 & 688239 & 6.1362 & 5.4471 & TST \\
\hline CHEMBL 3197450 & 688239 & 4.4862 & 5.3775 & TRN \\
\hline CHEMBL1572319 & 688239 & 5.3862 & 5.3938 & TST \\
\hline CHEMBL1410987 & 688239 & 6.9363 & 5.5787 & TRN \\
\hline CHEMBL1572090 & 688239 & 4.7862 & 5.5317 & TRN \\
\hline CHEMBL1473611 & 688239 & 4.7362 & 5.5241 & TRN \\
\hline CHEMBL1449942 & 688239 & 4.5362 & 5.5006 & TRN \\
\hline CHEMBL1378479 & 688239 & 4.7862 & 5.4999 & TRN \\
\hline CHEMBL 3192223 & 688239 & 5.1862 & 5.2804 & TRN \\
\hline CHEMBL1548759 & 688239 & 6.9363 & 5.4215 & TRN \\
\hline CHEMBL1378205 & 688239 & 4.9862 & 5.3838 & TRN \\
\hline CHEMBL1536881 & 688239 & 4.5362 & 5.5664 & TST \\
\hline CHEMBL1359966 & 688239 & 5.5362 & 5.5465 & TRN \\
\hline CHEMBL1584839 & 688239 & 5.7362 & \multicolumn{2}{|c|}{5.7139999999999995} \\
\hline CHEMBL1362857 & 688239 & 5.2362 & 5.5447 & TRN \\
\hline CHEMBL1520133 & 688239 & 6.2362 & 5.3876 & TRN \\
\hline CHEMBL1351542 & 688239 & 4.7362 & 5.3187 & TST \\
\hline CHEMBL1342856 & 688239 & 6.8861 & 5.5489 & TST \\
\hline CHEMBL1375341 & 688239 & 7.1361 & 5.6138 & TRN \\
\hline CHEMBL1348900 & 688239 & 6.5363 & 5.4895 & TRN \\
\hline CHEMBL1420591 & 688239 & 4.6862 & 5.5726 & TST \\
\hline CHEMBL1538152 & 688239 & 6.3362 & 5.5348 & TRN \\
\hline CHEMBL1306131 & 688239 & 5.3362 & 5.5691 & TST \\
\hline CHEMBL1505293 & 688239 & 5.6362 & 5.3854 & TRN \\
\hline
\end{tabular}


Supplemental Table S2.txt

\begin{tabular}{|c|c|c|c|c|}
\hline 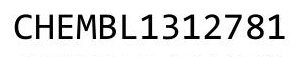 & & & & \\
\hline HEMBL1404302 & 38239 & 362 & 371 & \\
\hline AEMBL1380115 & 39 & 362 & & \\
\hline & 39 & 862 & & \\
\hline IEMBL14 & 39 & 362 & & \\
\hline AEMBL1348276 & 88239 & 362 & & \\
\hline AEMBL1467286 & 88239 & 361 & 233 & \\
\hline HEMBL1309788 & & & & \\
\hline EMBL1535984 & 39 & 362 & & \\
\hline IEMBL3211859 & & & & \\
\hline AEMBL1414050 & 39 & 862 & & \\
\hline AEMBL1375133 & & 362 & & \\
\hline AEMBL1450760 & & & & \\
\hline AEMBL1601758 & & & & \\
\hline HEMBL1509526 & & & & \\
\hline AEMBL1306464 & & 362 & & \\
\hline AEMBL1370968 & & 862 & & \\
\hline IEMBL 3209808 & & 62 & & \\
\hline AEMBL1525255 & & & & \\
\hline AEMBL1599978 & & & & \\
\hline AEMBL1611410 & & 362 & & \\
\hline AEMBL1548873 & & 362 & & \\
\hline IEMBL12562 & & 62 & & \\
\hline AFMBI 152 & & & & \\
\hline 359 & & 62 & & \\
\hline AEMBL1511976 & & 862 & & \\
\hline IEMBL1567114 & & 62 & & \\
\hline EMBL1594792 & & 62 & & \\
\hline AFMRI 156 & & 62 & & \\
\hline 51 & & 62 & & \\
\hline AEMBL1522392 & & & & \\
\hline HEMBL1446605 & & 362 & & \\
\hline & & & & \\
\hline 8 & & & & \\
\hline & & & & \\
\hline AEMBL1584431 & & & & \\
\hline AEMBL1549703 & & 862 & & \\
\hline & & 62 & & \\
\hline 6 & & & & . \\
\hline HEMBL1321177 & & & & ST \\
\hline AEMBL1508983 & & 861 & 26 & \\
\hline AEMBL1548635 & & 62 & & \\
\hline HEMBL1338049 & & & & \\
\hline & & & & \\
\hline AEMBL1515441 & & & & RN \\
\hline IEMBL1562312 & & 862 & & \\
\hline 32122 & & & & \\
\hline 21007 & & & & \\
\hline
\end{tabular}

Page 2338 
Supplemental Table S2.txt

\begin{tabular}{|c|c|c|c|c|}
\hline CHEMBL1442209 & 688239 & 6.9363 & 5.494 & TRN \\
\hline CHEMBL 3392240 & 688239 & 4.5362 & 5.4699 & TST \\
\hline CHEMBL1446629 & 688239 & 6.9363 & 5.567 & TRN \\
\hline CHEMBL 3196672 & 688239 & 5.6862 & 5.5519 & TST \\
\hline CHEMBL1566438 & 688239 & 4.6362 & 5.5094 & TST \\
\hline CHEMBL1339161 & 688239 & 4.5362 & 5.5319 & TRN \\
\hline CHEMBL1336518 & 688239 & 5.0362 & 5.4957 & TRN \\
\hline CHEMBL1400025 & 688239 & 4.5362 & 5.6779 & TRN \\
\hline CHEMBL 3213991 & 688239 & 6.0862 & 5.4383 & TRN \\
\hline CHEMBL3191314 & 688239 & 4.9362 & 5.5055 & TST \\
\hline CHEMBL1414961 & 688239 & 5.5362 & 5.4358 & TRN \\
\hline CHEMBL1381489 & 688239 & 5.2862 & 5.4737 & TRN \\
\hline CHEMBL1409433 & 688239 & 5.6362 & 5.4661 & TST \\
\hline CHEMBL1315023 & 688239 & 4.5362 & 5.3901 & TST \\
\hline CHEMBL1403495 & 688239 & 5.3362 & 5.5374 & TRN \\
\hline CHEMBL1459729 & 688239 & 4.6862 & 5.6159 & TRN \\
\hline CHEMBL1443667 & 688239 & 5.0362 & 5.4671 & TST \\
\hline CHEMBL1577660 & 688239 & 4.4862 & 5.5356 & TRN \\
\hline CHEMBL1310196 & 688239 & 8.3372 & \multirow{2}{*}{\multicolumn{2}{|c|}{$\begin{array}{l}5.486000000000001 \\
5.622000000000001\end{array}$}} \\
\hline CHEMBL1368650 & 688239 & 4.5362 & & \\
\hline CHEMBL1483269 & 688239 & 4.7362 & 5.4985 & TRN \\
\hline CHEMBL1568217 & 688239 & 6.8362 & 5.3965 & TRN \\
\hline CHEMBL 1435035 & 688239 & 4.5362 & 5.5864 & TRN \\
\hline CHEMBL1584384 & 688239 & 6.2362 & 5.4347 & TRN \\
\hline CHEMBL1385785 & 688239 & 4.6362 & 5.5379 & TRN \\
\hline CHEMBL1474412 & 688239 & 8.3872 & 5.5023 & TRN \\
\hline CHEMBL1328123 & 688239 & 5.4862 & 5.5809 & TRN \\
\hline CHEMBL1364186 & 688239 & 7.5867 & 5.596 & TST \\
\hline CHEMBL1581884 & 688239 & 4.8 & 5.4514 & TRN \\
\hline CHEMBL 3192535 & 688239 & 4.5362 & 5.4026 & TRN \\
\hline CHEMBL1414217 & 688239 & 5.6862 & \multicolumn{2}{|c|}{5.406000000000001} \\
\hline CHEMBL1607042 & 688239 & 4.5362 & 5.5765 & TST \\
\hline CHEMBL1303990 & 688239 & 4.6362 & 5.4582 & TST \\
\hline CHEMBL1568066 & 688239 & 5.0862 & 5.4754 & TRN \\
\hline CHEMBL1472210 & 688239 & 6.8362 & 5.39 & TRN \\
\hline CHEMBL1417945 & 688239 & 5.0362 & 5.5671 & TRN \\
\hline CHEMBL1541760 & 688239 & 4.5362 & 5.4699 & TRN \\
\hline CHEMBL1608801 & 688239 & 4.5362 & 5.4417 & TRN \\
\hline CHEMBL1611482 & 688239 & 8.2366 & 5.4921 & TRN \\
\hline CHEMBL1325152 & 688239 & 4.9862 & 5.439 & TST \\
\hline CHEMBL1393670 & 688239 & 5.0362 & 5.7477 & TRN \\
\hline CHEMBL1403289 & 688239 & 5.9362 & 5.5166 & TRN \\
\hline CHEMBL1436380 & 688239 & 6.6362 & 5.5561 & TRN \\
\hline CHEMBL1479657 & 688239 & 4.8862 & 5.438 & TST \\
\hline CHEMBL1440938 & 688239 & 5.2362 & 5.6332 & TRN \\
\hline CHEMBL1343348 & 688239 & 6.1362 & 5.4814 & TST \\
\hline CHEMBL1537048 & 688239 & 5.2362 & 5.5328 & TRN \\
\hline CHEMBL1341014 & 688239 & 7.2366 & 5.5059 & TST \\
\hline
\end{tabular}

Page 2339 
Supplemental Table S2.txt

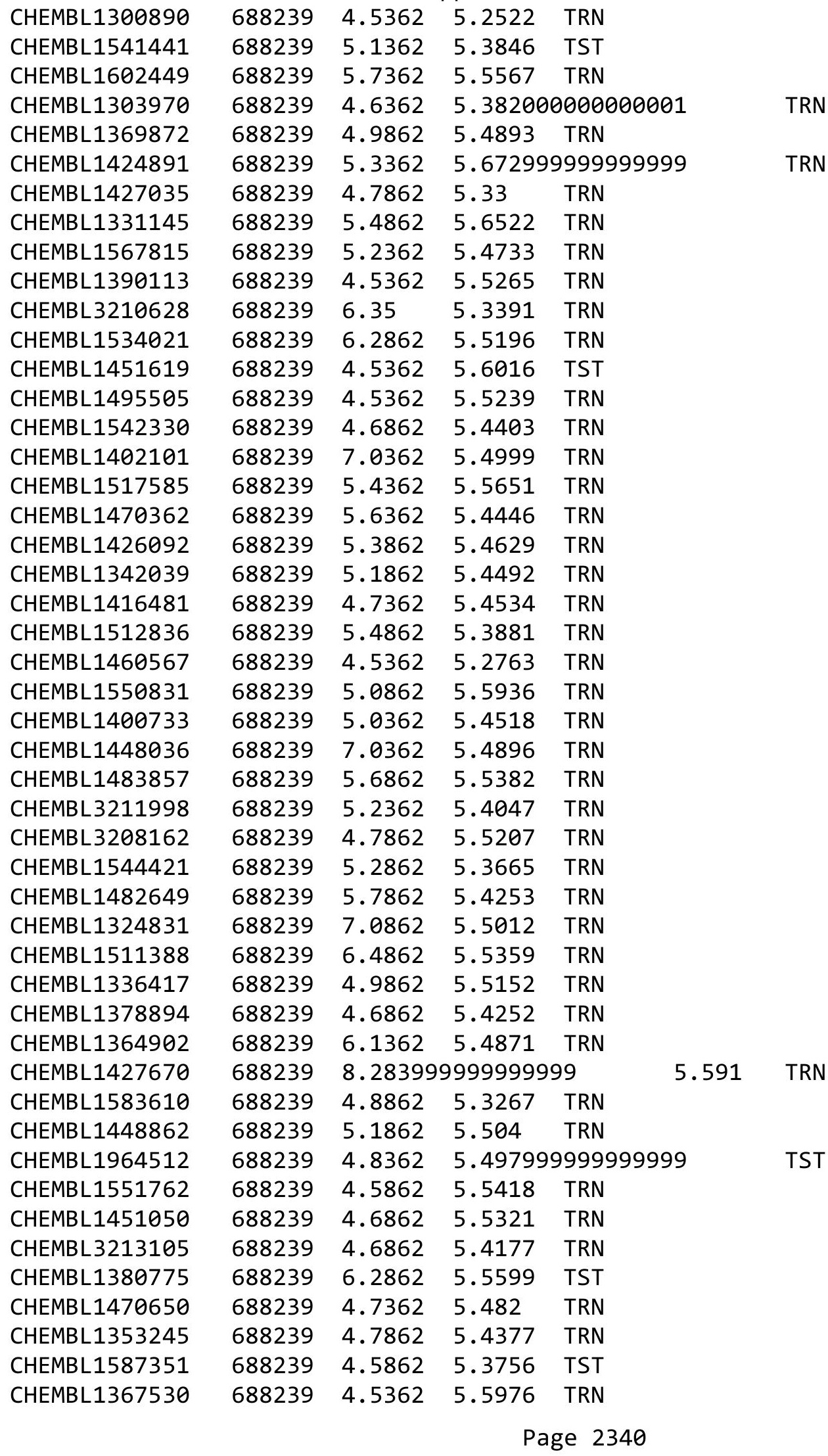


Supplemental Table S2.txt

\begin{tabular}{|c|c|c|c|c|}
\hline CHEMBL1465246 & 688239 & 5.1862 & 5.5581 & TST \\
\hline CHEMBL1548606 & 688239 & 5.6862 & 5.4301 & TST \\
\hline CHEMBL1577007 & 688239 & 4.5862 & 5.5006 & TST \\
\hline CHEMBL1375093 & 688239 & 5.7862 & 5.5214 & TRN \\
\hline CHEMBL1581425 & 688239 & 4.6362 & 5.3986 & TST \\
\hline CHEMBL1387763 & 688239 & 8.3372 & 5.5457 & TRN \\
\hline CHEMBL1436829 & 688239 & 4.5362 & 5.5385 & TRN \\
\hline CHEMBL1554728 & 688239 & 4.4862 & 5.3848 & TRN \\
\hline CHEMBL1359828 & 688239 & 6.0862 & 5.4847 & TRN \\
\hline CHEMBL1542394 & 688239 & 4.5362 & 5.5357 & TRN \\
\hline CHEMBL1431164 & 688239 & 5.7362 & 5.5686 & TST \\
\hline CHEMBL1571732 & 688239 & 8.3372 & 5.564 & TST \\
\hline CHEMBL1548452 & 688239 & 4.5362 & 5.4906 & TRN \\
\hline CHEMBL1321277 & 688239 & 6.3362 & 5.5843 & TRN \\
\hline CHEMBL1505440 & 688239 & 4.5362 & 5.4962 & TRN \\
\hline CHEMBL1555283 & 688239 & 5.6862 & 5.4313 & TRN \\
\hline CHEMBL1504015 & 688239 & 6.8861 & 5.4582 & TRN \\
\hline CHEMBL1374182 & 688239 & 4.7362 & 5.5149 & TRN \\
\hline CHEMBL1377702 & 688239 & 4.7862 & 5.3531 & TRN \\
\hline CHEMBL1390626 & 688239 & 6.5363 & 5.4125 & TRN \\
\hline CHEMBL1577777 & 688239 & 6.5363 & 5.5856 & TRN \\
\hline CHEMBL1379241 & 688239 & 6.1862 & 5.4149 & TST \\
\hline CHEMBL1358772 & 688239 & 5.1862 & 5.4813 & TST \\
\hline CHEMBL1456930 & 688239 & 6.0362 & 5.3998 & TRN \\
\hline CHEMBL1592627 & 688239 & 4.6862 & 5.457999 & 9999999999 \\
\hline CHEMBL1362659 & 688239 & 4.4862 & 5.2654 & TRN \\
\hline CHEMBL1569897 & 688239 & 6.5862 & 5.5558 & TST \\
\hline CHEMBL1452148 & 688239 & 5.4862 & 5.5168 & TRN \\
\hline CHEMBL1410317 & 688239 & 7.6364 & 5.3801 & TRN \\
\hline CHEMBL1370588 & 688239 & 4.5362 & 5.4474 & TRN \\
\hline CHEMBL1462850 & 688239 & 5.1362 & 5.5343 & TRN \\
\hline CHEMBL1527592 & 688239 & 6.8861 & 5.5217 & TRN \\
\hline CHEMBL1431498 & 688239 & 4.5362 & 5.4731 & TRN \\
\hline CHEMBL1427119 & 688239 & 4.6362 & 5.3394 & TST \\
\hline CHEMBL1382722 & 688239 & 4.5862 & 5.5338 & TRN \\
\hline CHEMBL1588274 & 688239 & 4.7362 & 5.4746 & TRN \\
\hline CHEMBL1302286 & 688239 & 4.5362 & 5.4165 & TRN \\
\hline CHEMBL1554394 & 688239 & 4.9362 & 5.3843 & TRN \\
\hline CHEMBL1372829 & 688239 & 4.5362 & 5.5332 & TST \\
\hline CHEMBL1589336 & 688239 & 8.3872 & 5.5518 & TRN \\
\hline CHEMBL1303500 & 688239 & 7.0362 & 5.3671 & TRN \\
\hline CHEMBL1553728 & 688239 & 6.2362 & 5.4813 & TRN \\
\hline CHEMBL1429568 & 688239 & 4.7362 & 5.5809 & TRN \\
\hline CHEMBL1451999 & 688239 & 5.1862 & 5.3973 & TRN \\
\hline CHEMBL1418718 & 688239 & 5.4362 & 5.5038 & TRN \\
\hline CHEMBL1399367 & 688239 & 5.4362 & 5.5112 & TRN \\
\hline CHEMBL1434487 & 688239 & 6.1362 & 5.5078 & TRN \\
\hline CHEMBL1387496 & 688239 & 5.5862 & 5.5929 & TST \\
\hline
\end{tabular}

Page 2341 
Supplemental Table S2.txt

\begin{tabular}{|c|c|c|c|c|c|c|}
\hline CHEMBL1462444 & 688239 & 6.1862 & 5.4265 & TST & & \\
\hline CHEMBL1540842 & 688239 & 6.2362 & 5.522 & TST & & \\
\hline CHEMBL1442401 & 688239 & 4.4862 & 5.476 & TST & & \\
\hline CHEMBL1523227 & 688239 & 5.1862 & 5.4278 & TRN & & \\
\hline CHEMBL1527578 & 688239 & 4.5362 & 5.6434 & TRN & & \\
\hline CHEMBL1562268 & 688239 & 5.0862 & 5.5743 & TRN & & \\
\hline CHEMBL1472569 & 688239 & 5.5862 & 5.6845 & TRN & & \\
\hline CHEMBL1451651 & 688239 & 6.2362 & 5.4512 & TRN & & \\
\hline CHEMBL1458835 & 688239 & 5.1862 & 5.566 & TRN & & \\
\hline CHEMBL1596341 & 688239 & 4.7862 & 5.5301 & TST & & \\
\hline CHEMBL1492198 & 688239 & 7.2366 & 5.3257 & TRN & & \\
\hline CHEMBL1379630 & 688239 & 4.7362 & 5.3702 & TST & & \\
\hline CHEMBL3208922 & 688239 & 6.2362 & 5.4765 & TRN & & \\
\hline CHEMBL3210244 & 688239 & 5.7362 & 5.4479 & TST & & \\
\hline CHEMBL1335286 & 688239 & 8.28399 & 9999999 & 99 & 5.3768 & TST \\
\hline CHEMBL1422505 & 688239 & 4.5362 & 5.4022 & TRN & & \\
\hline CHEMBL1546674 & 688239 & 5.8862 & 5.4328 & TRN & & \\
\hline CHEMBL1313879 & 688239 & 5.0362 & 5.4523 & TST & & \\
\hline CHEMBL1345984 & 688239 & 5.5862 & 5.3972 & TRN & & \\
\hline CHEMBL1509054 & 688239 & 6.8861 & 5.5154 & TRN & & \\
\hline CHEMBL1463031 & 688239 & 4.7362 & 5.347 & TRN & & \\
\hline CHEMBL1351119 & 688239 & 4.5362 & 5.4092 & TST & & \\
\hline CHEMBL1369273 & 688239 & 6.3863 & 5.4382 & TRN & & \\
\hline CHEMBL1381169 & 688239 & 5.0362 & 5.3733 & TRN & & \\
\hline CHEMBL1503027 & 688239 & 6.3863 & 5.5443 & TRN & & \\
\hline CHEMBL1307164 & 688239 & 5.4362 & 5.3399 & TRN & & \\
\hline CHEMBL1347754 & 688239 & 4.8362 & 5.4123 & TRN & & \\
\hline CHEMBL1454973 & 688239 & 4.5362 & 5.539 & TRN & & \\
\hline CHEMBL1299511 & 688239 & 4.5362 & 5.4751 & TRN & & \\
\hline CHEMBL1518580 & 688239 & 4.5362 & 5.444 & TRN & & \\
\hline CHEMBL1307507 & 688239 & 6.9863 & 5.5522 & TRN & & \\
\hline CHEMBL1425679 & 688239 & 5.1862 & 5.4322 & TRN & & \\
\hline CHEMBL3197319 & 688239 & 7.2366 & 5.5605 & TRN & & \\
\hline CHEMBL1330905 & 688239 & 4.6862 & 5.4419 & TST & & \\
\hline CHEMBL1398331 & 688239 & 6.1362 & 5.4262 & TST & & \\
\hline CHEMBL1415974 & 688239 & 5.1862 & 5.612 & TRN & & \\
\hline CHEMBL1476145 & 688239 & 4.6862 & 5.4674 & TRN & & \\
\hline CHEMBL1471438 & 688239 & 4.9362 & 5.6032 & TRN & & \\
\hline CHEMBL1563542 & 688239 & 4.7362 & 5.4971 & TRN & & \\
\hline CHEMBL553669 & 688239 & 6.1362 & 5.563 & TST & & \\
\hline CHEMBL1408311 & 688239 & 4.5362 & 5.4255 & TST & & \\
\hline CHEMBL1580818 & 688239 & 6.8362 & 5.5742 & TRN & & \\
\hline CHEMBL1492837 & 688239 & 5.6362 & 5.4051 & TRN & & \\
\hline CHEMBL1607119 & 688239 & 4.7362 & 5.4781 & TRN & & \\
\hline CHEMBL1396944 & 688239 & 5.2362 & 5.4779 & TRN & & \\
\hline CHEMBL1436814 & 688239 & 6.5363 & 5.38 & TRN & & \\
\hline CHEMBL1345222 & 688239 & 5.1862 & 5.4136 & TRN & & \\
\hline CHEMBL1427025 & 688239 & 4.5362 & 5.5103 & TRN & & \\
\hline
\end{tabular}

Page 2342 
Supplemental Table S2.txt

\begin{tabular}{|c|c|c|c|c|}
\hline IE & & 52 & & \\
\hline UГMDI 110057 & & .2862 & 5.3797 & \\
\hline 96 & & & & \\
\hline AEMBL13 & & 52 & & \\
\hline AEMBL1540119 & 8239 & & & \\
\hline HEMBL1605548 & 88239 & 1362 & .4456 & \\
\hline HEMBL13 & 239 & 362 & & \\
\hline IFMBI 14 & & & & \\
\hline HEMBL1369081 & & & & \\
\hline HEMBL13 & 88239 & & & \\
\hline AEMBL1531532 & 88239 & & 48 & \\
\hline AEMBL13 & 239 & & & \\
\hline AEMBL16 & & & & \\
\hline HEMBL13 & & & & \\
\hline JEMBL14 & & & & \\
\hline AEMBL15 & 39 & & 12 & \\
\hline HEMBL15 & 39 & & & \\
\hline HEMBL 14 & & & & \\
\hline HEMBL13 & & & & \\
\hline AEMBL14 & & & & \\
\hline AEMBLIS & & & & NIV \\
\hline HEMBL14 & & & & \\
\hline HEMBL14 & & & & \\
\hline AEMBL16 & & & & \\
\hline JEMBL13 & & & & ISI \\
\hline HEMBL1\& & & & & \\
\hline HEMBL1: & & & & \\
\hline HFMBI 17 & & & & KIV \\
\hline HEMBL15 & & & & 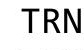 \\
\hline HEMBL15 & & & 52 & RIN \\
\hline HEMBL1 & & & & \\
\hline AFMBI 1 & & & & \\
\hline HEMBL1 & & & & RN \\
\hline HEMBL15 & & & & $\mathrm{RN}$ \\
\hline HEMBL147 & & & 5 . & TRN \\
\hline HEMBL15 & & & & \\
\hline HEMPI 2 & & & & ST \\
\hline HEMBL15 & & & & $\mathrm{RN}$ \\
\hline HEMBL134 & 88239 & & & TST \\
\hline IEMBL13 & & & & RN \\
\hline HEMBL13 & & & & \\
\hline CHEMBL13 & & & & RN \\
\hline HEMBL 20 & & & & RN \\
\hline HEMBL15 & 39 & 62 & 04 & ГST \\
\hline MBL1 & & & & \\
\hline CHEMBL15e & & & & \\
\hline CHEMBL14 & & & 5.5294 & \\
\hline CHEMBL159975 & 688239 & 4.8362 & 5.5646 & ГRN \\
\hline
\end{tabular}

Page 2343 
Supplemental Table S2.txt

\begin{tabular}{|c|c|c|c|c|c|c|}
\hline CHEMBL1354025 & 688239 & 5.9862 & \multicolumn{3}{|c|}{5.531000000000001} & RN \\
\hline CHEMBL1352339 & 688239 & 5.5862 & 5.4782 & TST & & \\
\hline CHEMBL1404596 & 688239 & 7.2366 & 5.553 & TRN & & \\
\hline CHEMBL1603792 & 688239 & 4.8862 & 5.388999 & 9999999999 & & \\
\hline CHEMBL3213756 & 688239 & 4.6862 & 5.3865 & TST & & \\
\hline CHEMBL1521315 & 688239 & 7.0362 & 5.6498 & TRN & & \\
\hline CHEMBL1346741 & 688239 & 5.2362 & 5.5142 & TRN & & \\
\hline CHEMBL1422380 & 688239 & 4.6862 & 5.4025 & TRN & & \\
\hline CHEMBL1495648 & 688239 & 4.6362 & 5.3487 & TRN & & \\
\hline CHEMBL451261 & 688239 & 8.3372 & 5.4845 & TST & & \\
\hline CHEMBL1439233 & 688239 & 4.5362 & 5.5759 & TST & & \\
\hline CHEMBL1390957 & 688239 & 4.5362 & 5.6311 & TRN & & \\
\hline CHEMBL1496156 & 688239 & 4.7862 & 5.4822 & TST & & \\
\hline CHEMBL1422689 & 688239 & 5.4362 & 5.4392 & TRN & & \\
\hline CHEMBL1330676 & 688239 & 4.8862 & 5.4662 & TRN & & \\
\hline CHEMBL1485449 & 688239 & 4.7862 & 5.5839 & TRN & & \\
\hline CHEMBL1333227 & 688239 & 6.0862 & 5.532 & TRN & & \\
\hline CHEMBL1378939 & 688239 & 5.1362 & 5.5142 & TRN & & \\
\hline CHEMBL1468653 & 688239 & 4.6362 & 5.4882 & TRN & & \\
\hline CHEMBL1488449 & 688239 & 4.6862 & 5.4486 & TRN & & \\
\hline CHEMBL1479574 & 688239 & 5.0862 & 5.5327 & TRN & & \\
\hline CHEMBL1608055 & 688239 & 5.3362 & 5.6995 & TRN & & \\
\hline CHEMBL1444056 & 688239 & 6.1862 & 5.5412 & TRN & & \\
\hline CHEMBL1322903 & 688239 & 5.6862 & 5.3574 & TRN & & \\
\hline CHEMBL 2006762 & 688239 & 7.5361 & 5.3352 & TRN & & \\
\hline CHEMBL1454871 & 688239 & 7.2366 & 5.5951 & TRN & & \\
\hline CHEMBL1352835 & 688239 & 5.7862 & 5.3259 & TRN & & \\
\hline CHEMBL1589121 & 688239 & 5.1862 & 5.4957 & TRN & & \\
\hline CHEMBL1587903 & 688239 & 4.7362 & 5.5772 & TRN & & \\
\hline CHEMBL1471893 & 688239 & 4.5362 & 5.4233 & TRN & & \\
\hline CHEMBL1583714 & 688239 & 5.1862 & 5.4128 & TRN & & \\
\hline CHEMBL1415308 & 688239 & 4.5362 & 5.3562 & TRN & & \\
\hline CHEMBL1547894 & 688239 & 5.1362 & 5.4776 & TRN & & \\
\hline CHEMBL1377080 & 688239 & 6.7862 & 5.3579 & TRN & & \\
\hline CHEMBL1517887 & 688239 & 4.5362 & 5.3758 & TST & & \\
\hline CHEMBL1425832 & 688239 & 6.6861 & 5.5829 & TST & & \\
\hline CHEMBL1469050 & 688239 & 8.2366 & 5.4766 & TRN & & \\
\hline CHEMBL1489250 & 688239 & 5.5362 & 5.5769 & TRN & & \\
\hline CHEMBL1332794 & 688239 & 4.6862 & 5.5259 & TRN & & \\
\hline CHEMBL1493821 & 688239 & 4.7862 & 5.7413 & TRN & & \\
\hline CHEMBL1323948 & 688239 & 4.5362 & 5.4878 & TRN & & \\
\hline CHEMBL1570544 & 688239 & 4.5362 & 5.367006 & 0000000001 & & \\
\hline CHEMBL578294 & 688239 & 4.7862 & 5.3472 & TRN & & \\
\hline CHEMBL1417614 & 688239 & 6.8861 & 5.5517 & TRN & & \\
\hline CHEMBL1507434 & 688239 & 5.0862 & 5.4078 & TRN & & \\
\hline CHEMBL1505946 & 688239 & 8.28399 & 99999999 & 99 & 5.4291 & \\
\hline CHEMBL1511171 & 688239 & 6.4362 & 5.6682 & TRN & & \\
\hline CHEMBL1596794 & 688239 & 7.2865 & 5.4788 & TRN & & \\
\hline
\end{tabular}


Supplemental Table S2.txt

\begin{tabular}{|c|c|c|c|c|c|c|}
\hline CHEMBL1609434 & 688239 & 5.1862 & 5.5195 & TRN & & \\
\hline CHEMBL1469540 & 688239 & 4.6862 & 5.4177 & TRN & & \\
\hline CHEMBL1372716 & 688239 & 4.7862 & 5.4458 & TRN & & \\
\hline CHEMBL1587059 & 688239 & 5.8362 & 5.5076 & TST & & \\
\hline CHEMBL1339642 & 688239 & 5.2862 & 5.539 & TRN & & \\
\hline CHEMBL1486838 & 688239 & 5.0862 & 5.4204 & TRN & & \\
\hline CHEMBL1487600 & 688239 & 5.0362 & 5.4797 & TRN & & \\
\hline CHEMBL1489049 & 688239 & 5.3862 & 5.4408 & TRN & & \\
\hline CHEMBL1470473 & 688239 & 7.0362 & 5.669 & TST & & \\
\hline CHEMBL1321595 & 688239 & 4.8862 & 5.4628 & TRN & & \\
\hline CHEMBL1525574 & 688239 & 5.4362 & 5.5924 & TRN & & \\
\hline CHEMBL1341800 & 688239 & 5.0362 & 5.5374 & TRN & & \\
\hline CHEMBL1479336 & 688239 & 4.4862 & 5.3222 & TRN & & \\
\hline CHEMBL1538529 & 688239 & 5.8862 & 5.5885 & TRN & & \\
\hline CHEMBL1607655 & 688239 & 4.6362 & 5.406000 & 000000001 & TRN & \\
\hline CHEMBL1446889 & 688239 & 4.7862 & 5.4518 & TRN & & \\
\hline CHEMBL1582534 & 688239 & 6.9363 & 5.4951 & TRN & & \\
\hline CHEMBL1374314 & 688239 & 6.1862 & 5.5248 & TRN & & \\
\hline CHEMBL1412190 & 688239 & 4.4862 & 5.3892 & TRN & & \\
\hline CHEMBL1537016 & 688239 & 6.8362 & 5.5203 & TRN & & \\
\hline CHEMBL1422562 & 688239 & 8.2366 & 5.4357 & TRN & & \\
\hline CHEMBL1340924 & 688239 & 4.9362 & 5.5438 & TRN & & \\
\hline CHEMBL1491563 & 688239 & 5.9862 & 5.537999 & 999999999 & TRN & \\
\hline CHEMBL1358403 & 688239 & 6.2362 & 5.4429 & TRN & & \\
\hline CHEMBL1476908 & 688239 & 8.28399 & 999999999 & 9 & 5.457000000000001 & TRN \\
\hline CHEMBL1331557 & 688239 & 6.0862 & 5.6916 & TRN & & \\
\hline CHEMBL1599009 & 688239 & 5.5862 & 5.5443 & TRN & & \\
\hline CHEMBL1588335 & 688239 & 5.5362 & 5.4019 & TRN & & \\
\hline CHEMBL 3196262 & 688239 & 5.4862 & 5.3314 & TST & & \\
\hline CHEMBL1491428 & 688239 & 5.3862 & 5.2111 & TRN & & \\
\hline CHEMBL1340684 & 688239 & 6.9363 & 5.5542 & TST & & \\
\hline CHEMBL1496102 & 688239 & 4.7362 & 5.3554 & TRN & & \\
\hline CHEMBL1470315 & 688239 & 4.7362 & 5.5421 & TRN & & \\
\hline CHEMBL1321035 & 688239 & 5.3362 & 5.4663 & TRN & & \\
\hline CHEMBL487356 & 688239 & 4.7862 & 5.6505 & TRN & & \\
\hline CHEMBL1517399 & 688239 & 4.5362 & 5.5289 & TST & & \\
\hline CHEMBL1475291 & 688239 & 5.1862 & 5.5425 & TRN & & \\
\hline CHEMBL1356961 & 688239 & 4.6362 & 5.2998 & TST & & \\
\hline CHEMBL1351070 & 688239 & 6.4862 & 5.5731 & TRN & & \\
\hline CHEMBL1414359 & 688239 & 4.5862 & 5.5515 & TRN & & \\
\hline CHEMBL1553920 & 688239 & 4.4862 & 5.4974 & TRN & & \\
\hline CHEMBL1419112 & 688239 & 5.3362 & 5.4239 & TST & & \\
\hline CHEMBL1423784 & 688239 & 4.5362 & 5.2924 & TRN & & \\
\hline CHEMBL1515247 & 688239 & 5.1862 & 5.5626 & TRN & & \\
\hline CHEMBL1589616 & 688239 & 4.5362 & 5.4206 & TRN & & \\
\hline CHEMBL1313108 & 688239 & 6.5363 & 5.5811 & TRN & & \\
\hline CHEMBL1519719 & 688239 & 5.1862 & 5.4967 & TST & & \\
\hline CHEMBL1377446 & 688239 & 4.6362 & 5.4326 & TRN & & \\
\hline
\end{tabular}


Supplemental Table S2.txt

\begin{tabular}{|c|c|c|c|c|c|}
\hline CHEMBL 3209720 & 688239 & 4.7862 & 5.4928 & TST & \\
\hline CHEMBL1577409 & 688239 & 4.6862 & 5.5148 & TRN & \\
\hline CHEMBL1353659 & 688239 & 4.5362 & 5.5121 & TRN & \\
\hline CHEMBL1422360 & 688239 & 6.1362 & 5.3773 & TST & \\
\hline CHEMBL 2004291 & 688239 & 4.5362 & 5.3617 & TRN & \\
\hline CHEMBL1442568 & 688239 & 5.5362 & 5.5822 & TRN & \\
\hline CHEMBL1311735 & 688239 & 5.1862 & 5.4234 & TST & \\
\hline CHEMBL1444171 & 688239 & 6.1362 & 5.5813 & TRN & \\
\hline CHEMBL1303474 & 688239 & 4.6862 & 5.4367 & TST & \\
\hline CHEMBL1502896 & 688239 & 5.2862 & 5.6321 & TST & \\
\hline CHEMBL1410361 & 688239 & 4.5362 & 5.4831 & TRN & \\
\hline CHEMBL1318240 & 688239 & 4.4862 & 5.4811 & TST & \\
\hline CHEMBL1381645 & 688239 & 6.6861 & 5.5708 & TRN & \\
\hline CHEMBL1323496 & 688239 & 4.4362 & 5.5362 & TRN & \\
\hline CHEMBL1418546 & 688239 & 5.1862 & 5.6032 & TST & \\
\hline CHEMBL1471356 & 688239 & 4.6362 & 5.4708 & TRN & \\
\hline CHEMBL1443009 & 688239 & 4.6862 & 5.4174 & TRN & \\
\hline CHEMBL1558627 & 688239 & 4.5362 & 5.5549 & TRN & \\
\hline CHEMBL1403202 & 688239 & 5.0362 & 5.4127 & TST & \\
\hline CHEMBL1301798 & 688239 & 5.7362 & 5.4118 & TRN & \\
\hline CHEMBL1401814 & 688239 & 5.1862 & 5.4168 & TRN & \\
\hline CHEMBL1410860 & 688239 & 5.3862 & 5.3331 & TRN & \\
\hline CHEMBL1372447 & 688239 & 5.1362 & $5.57100 e$ & 0000000001 & TRN \\
\hline CHEMBL1419595 & 688239 & 4.5362 & 5.4657 & TRN & \\
\hline CHEMBL1306929 & 688239 & 6.1362 & 5.5416 & TRN & \\
\hline CHEMBL1606870 & 688239 & 4.6862 & 5.4582 & TRN & \\
\hline CHEMBL3192013 & 688239 & 4.8862 & 5.4938 & TRN & \\
\hline CHEMBL1305225 & 688239 & 5.4362 & 5.4694 & TRN & \\
\hline CHEMBL1399419 & 688239 & 4.5362 & 5.2415 & TST & \\
\hline CHEMBL1509406 & 688239 & 5.4862 & 5.3763 & TRN & \\
\hline CHEMBL1509278 & 688239 & 5.7362 & 5.4209 & TRN & \\
\hline CHEMBL1583249 & 688239 & 4.5362 & 5.5479 & TRN & \\
\hline CHEMBL1419230 & 688239 & 5.4862 & 5.3633 & TRN & \\
\hline CHEMBL3194705 & 688239 & 6.1362 & 5.3578 & TRN & \\
\hline CHEMBL1983600 & 688239 & 6.1362 & 5.5383 & TRN & \\
\hline CHEMBL3211007 & 688239 & 6.1362 & 5.5293 & TST & \\
\hline CHEMBL3212388 & 688239 & 5.1362 & 5.5516 & TRN & \\
\hline CHEMBL1446612 & 688239 & 4.6362 & 5.5439 & TRN & \\
\hline CHEMBL1326180 & 688239 & 4.5362 & 5.3941 & TST & \\
\hline CHEMBL1594917 & 688239 & 4.5362 & 5.5355 & TRN & \\
\hline CHEMBL1383770 & 688239 & 5.8362 & 5.6488 & TRN & \\
\hline CHEMBL1324690 & 688239 & 5.5862 & 5.508999 & 99999999995 & TRN \\
\hline CHEMBL1578187 & 688239 & 5.1862 & 5.4877 & TRN & \\
\hline CHEMBL1429563 & 688239 & 4.4862 & 5.4421 & TRN & \\
\hline CHEMBL1314327 & 688239 & 6.3863 & 5.4224 & TRN & \\
\hline CHEMBL1408984 & 688239 & 4.5362 & 5.5026 & TRN & \\
\hline CHEMBL1332882 & 688239 & 6.2362 & 5.5058 & TST & \\
\hline CHEMBL1471975 & 688239 & 4.9862 & 5.4841 & TST & \\
\hline
\end{tabular}


Supplemental Table S2.txt

\begin{tabular}{|c|c|c|c|c|c|}
\hline CHEMBL1504531 & 688239 & 4.7862 & 5.4866 & TRN & \\
\hline CHEMBL1378491 & 688239 & 5.1862 & 5.4287 & TRN & \\
\hline CHEMBL1541889 & 688239 & 6.2362 & 5.4358 & TST & \\
\hline CHEMBL1528421 & 688239 & 5.1362 & 5.4884 & TRN & \\
\hline CHEMBL1472532 & 688239 & 4.5362 & 5.5886 & TST & \\
\hline CHEMBL1385875 & 688239 & 4.6862 & 5.4534 & TRN & \\
\hline CHEMBL 3189727 & 688239 & 5.8362 & 5.4024 & TST & \\
\hline CHEMBL1392408 & 688239 & 4.4862 & 5.5181 & TST & \\
\hline CHEMBL1482540 & 688239 & 4.5362 & 5.6072 & TRN & \\
\hline CHEMBL 3194528 & 688239 & 4.6862 & 5.3402 & TRN & \\
\hline CHEMBL1584545 & 688239 & 5.6862 & 5.542000 & 000000001 & $T S$ \\
\hline CHEMBL1525225 & 688239 & 5.4362 & 5.6185 & TRN & \\
\hline CHEMBL1424087 & 688239 & 6.6861 & 5.5153 & TRN & \\
\hline CHEMBL1595529 & 688239 & 5.5862 & 5.462999 & 999999999 & \\
\hline CHEMBL1522973 & 688239 & 6.8362 & 5.4043 & TRN & \\
\hline CHEMBL1330075 & 688239 & 4.9362 & 5.4572 & TST & \\
\hline CHEMBL1377708 & 688239 & 6.1362 & 5.5744 & TRN & \\
\hline CHEMBL1512998 & 688239 & 5.1862 & 5.4497 & TRN & \\
\hline CHEMBL1546333 & 688239 & 5.5362 & 5.5202 & TRN & \\
\hline CHEMBL1413679 & 688239 & 6.3863 & 5.4797 & TST & \\
\hline CHEMBL1489613 & 688239 & 7.0362 & 5.4678 & TST & \\
\hline CHEMBL1487412 & 688239 & 4.5862 & 5.4553 & TST & \\
\hline CHEMBL1306286 & 688239 & 4.9362 & 5.595 & TRN & \\
\hline CHEMBL1372162 & 688239 & 5.4362 & 5.5492 & TRN & \\
\hline CHEMBL399121 & 688239 & 5.1862 & 5.4382 & TRN & \\
\hline CHEMBL1420660 & 688239 & 4.4862 & 5.6038 & TRN & \\
\hline CHEMBL1372276 & 688239 & 4.5362 & 5.5758 & TST & \\
\hline CHEMBL1349294 & 688239 & 4.5362 & 5.4624 & TRN & \\
\hline CHEMBL 3193305 & 688239 & 7.0362 & 5.3803 & TRN & \\
\hline CHEMBL1416706 & 688239 & 4.5362 & 5.6182 & TRN & \\
\hline CHEMBL1409385 & 688239 & 4.7362 & 5.3966 & TRN & \\
\hline CHEMBL1559791 & 688239 & 6.3863 & 5.5229 & TRN & \\
\hline CHEMBL1560220 & 688239 & 8.4318 & 5.5349 & TRN & \\
\hline CHEMBL1356000 & 688239 & 6.3863 & 5.2493 & TRN & \\
\hline CHEMBL1357524 & 688239 & 5.6362 & 5.4844 & TRN & \\
\hline CHEMBL1359808 & 688239 & 5.4362 & 5.5913 & TRN & \\
\hline CHEMBL1441907 & 688239 & 5.1862 & 5.6103 & TRN & \\
\hline CHEMBL 2002008 & 688239 & 4.7862 & 5.3105 & TRN & \\
\hline CHEMBL1437061 & 688239 & 4.7862 & 5.5117 & TRN & \\
\hline CHEMBL1443355 & 688239 & 5.2362 & 5.6839 & TRN & \\
\hline CHEMBL1453627 & 688239 & 4.5362 & 5.437 & TRN & \\
\hline CHEMBL1380895 & 688239 & 8.28399 & 99999999 & 5.2498 & 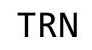 \\
\hline CHEMBL1371130 & 688239 & 4.6362 & 5.3676 & TRN & \\
\hline CHEMBL3209680 & 688239 & 5.4362 & 5.4704 & TRN & \\
\hline CHEMBL1581227 & 688239 & 4.5362 & 5.5439 & TRN & \\
\hline CHEMBL1312043 & 688239 & 5.0362 & 5.375 & TST & \\
\hline CHEMBL1599767 & 688239 & 5.7862 & 5.601 & TRN & \\
\hline CHEMBL1469070 & 688239 & 5.1862 & 5.3716 & TRN & \\
\hline
\end{tabular}


Supplemental Table S2.txt

\begin{tabular}{|c|c|c|c|c|}
\hline CHEMBL1325932 & 688239 & 4.4862 & 5.6893 & TRN \\
\hline CHEMBL553677 & 688239 & 5.5862 & 5.4011 & TRN \\
\hline CHEMBL3195040 & 688239 & 4.4862 & 5.4003 & TRN \\
\hline CHEMBL1414184 & 688239 & 5.1362 & 5.5819 & TRN \\
\hline CHEMBL1437590 & 688239 & 5.3362 & 5.3888 & TRN \\
\hline CHEMBL3210517 & 688239 & 4.6362 & 5.3779 & TRN \\
\hline CHEMBL1378068 & 688239 & 7.1361 & 5.6888 & TRN \\
\hline CHEMBL1443503 & 688239 & 4.5362 & 5.5151 & TST \\
\hline CHEMBL1511248 & 688239 & 5.2362 & 5.449 & TRN \\
\hline CHEMBL1464352 & 688239 & 5.3862 & 5.4201 & TST \\
\hline CHEMBL1404778 & 688239 & 6.1862 & 5.5092 & TST \\
\hline CHEMBL3212722 & 688239 & 4.5362 & 5.3544 & TST \\
\hline CHEMBL1552647 & 688239 & 6.3863 & 5.4908 & TRN \\
\hline CHEMBL1426095 & 688239 & 5.4362 & 5.4311 & TRN \\
\hline CHEMBL1543309 & 688239 & 6.0362 & 5.5606 & TRN \\
\hline CHEMBL1308039 & 688239 & 4.6362 & 5.4423 & TRN \\
\hline CHEMBL1565800 & 688239 & 4.7862 & 5.4015 & TRN \\
\hline CHEMBL1427828 & 688239 & 4.9362 & 5.4943 & TRN \\
\hline CHEMBL1493735 & 688239 & 4.5362 & 5.3791 & TST \\
\hline CHEMBL1352204 & 688239 & 5.7862 & 5.3691 & TRN \\
\hline CHEMBL1412479 & 688239 & 8.3872 & 5.5259 & TRN \\
\hline CHEMBL1485790 & 688239 & 5.9862 & 5.5175 & TRN \\
\hline CHEMBL1521651 & 688239 & 4.5362 & 5.4798 & TRN \\
\hline CHEMBL 21396 & 688239 & 5.0362 & 5.6098 & TST \\
\hline CHEMBL1360146 & 688239 & 4.5362 & 5.6146 & TRN \\
\hline CHEMBL1444044 & 688239 & 4.7362 & 5.2947 & TRN \\
\hline CHEMBL252659 & 688239 & 5.1862 & 5.465 & TST \\
\hline CHEMBL1300392 & 688239 & 5.1362 & 5.3825 & TRN \\
\hline CHEMBL1549936 & 688239 & 4.5362 & 5.5365 & TST \\
\hline CHEMBL1350501 & 688239 & 5.1362 & 5.5443 & TRN \\
\hline CHEMBL1354650 & 688239 & 5.3862 & 5.3631 & TRN \\
\hline CHEMBL1315937 & 688239 & 4.9362 & 5.6341 & TST \\
\hline CHEMBL1503877 & 688239 & 4.6862 & 5.565 & TRN \\
\hline CHEMBL1439852 & 688239 & 4.7862 & 5.4057 & TRN \\
\hline CHEMBL1327134 & 688239 & 5.4862 & 5.4593 & TRN \\
\hline CHEMBL1367989 & 688239 & 5.3862 & 5.4134 & TRN \\
\hline CHEMBL1501269 & 688239 & 5.1862 & 5.3727 & TRN \\
\hline CHEMBL1442300 & 688239 & 5.6362 & 5.4862 & TST \\
\hline CHEMBL3190231 & 688239 & 4.5362 & 5.3077 & TRN \\
\hline CHEMBL1355787 & 688239 & 6.1862 & 5.5474 & TRN \\
\hline CHEMBL1339506 & 688239 & 4.4862 & 5.5225 & TST \\
\hline CHEMBL1399405 & 688239 & 4.5862 & 5.4543 & TST \\
\hline CHEMBL3196601 & 688239 & 5.1862 & 5.4647 & TRN \\
\hline CHEMBL1409243 & 688239 & 4.6862 & 5.467006 & 00000000005 \\
\hline CHEMBL1572685 & 688239 & 5.1862 & 5.4204 & TRN \\
\hline CHEMBL1871132 & 688239 & 5.9362 & 5.5131 & TRN \\
\hline CHEMBL1585148 & 688239 & 5.1862 & 5.4889 & TRN \\
\hline CHEMBL1406492 & 688239 & 4.5362 & 5.3748 & TRN \\
\hline
\end{tabular}




\begin{tabular}{|c|c|c|c|c|}
\hline \multicolumn{5}{|c|}{ Supplemental Table S2.txt } \\
\hline CHEMBL1576115 & 688239 & 8.2366 & 5.5943 & TRN \\
\hline CHEMBL1432521 & 688239 & 4.5362 & 5.5358 & TRN \\
\hline CHEMBL1364675 & 688239 & 5.1862 & 5.4835 & TST \\
\hline CHEMBL1538273 & 688239 & 4.6862 & 5.3404 & TST \\
\hline CHEMBL1480537 & 688239 & 5.1362 & 5.4336 & TST \\
\hline CHEMBL1525631 & 688239 & 5.8362 & 5.4915 & TRN \\
\hline CHEMBL1359133 & 688239 & 8.3372 & 5.5161 & TST \\
\hline CHEMBL1419574 & 688239 & 6.2862 & 5.5231 & TRN \\
\hline CHEMBL1604155 & 688239 & 4.8362 & 5.4811 & TRN \\
\hline CHEMBL1428682 & 688239 & 5.6862 & 5.5728 & TRN \\
\hline CHEMBL353026 & 688239 & 4.5862 & 5.461 & TRN \\
\hline CHEMBL1456050 & 688239 & 5.8862 & 5.4573 & TRN \\
\hline CHEMBL1567842 & 688239 & 6.4862 & 5.5358 & TRN \\
\hline CHEMBL1371211 & 688239 & 4.6362 & 5.394 & TRN \\
\hline CHEMBL3212155 & 688239 & 4.5362 & 5.4403 & TST \\
\hline CHEMBL1444572 & 688239 & 6.9363 & 5.5577 & TRN \\
\hline CHEMBL1461981 & 688239 & 5.6362 & 5.5559 & TRN \\
\hline CHEMBL1422200 & 688239 & 5.0362 & 5.4136 & TST \\
\hline CHEMBL1316530 & 688239 & 7.0862 & 5.4564 & TRN \\
\hline CHEMBL1541907 & 688239 & 5.2362 & 5.5674 & TRN \\
\hline CHEMBL1593695 & 688239 & 4.8862 & 5.5186 & TRN \\
\hline CHEMBL1594422 & 688239 & 6.2862 & 5.5748 & TRN \\
\hline CHEMBL1468042 & 688239 & 8.3372 & 5.4666 & TST \\
\hline CHEMBL3208184 & 688239 & 8.3372 & 5.5584 & TRN \\
\hline CHEMBL1534959 & 688239 & 6.0 & 5.3867 & TRN \\
\hline CHEMBL1558769 & 688239 & 4.5362 & 5.6334 & TRN \\
\hline CHEMBL1405839 & 688239 & 6.8861 & 5.5386 & TST \\
\hline CHEMBL1473935 & 688239 & 5.1862 & 5.5702 & TRN \\
\hline CHEMBL3197358 & 688239 & 5.7362 & 5.4789 & TST \\
\hline CHEMBL1599349 & 688239 & 5.4362 & 5.4168 & TRN \\
\hline CHEMBL1370097 & 688239 & 5.1862 & 5.4779 & TST \\
\hline CHEMBL1385640 & 688239 & 4.9362 & 5.5884 & TST \\
\hline CHEMBL1348513 & 688239 & 7.0362 & 5.5186 & TRN \\
\hline CHEMBL1387066 & 688239 & 4.9862 & 5.5856 & TST \\
\hline CHEMBL1405557 & 688239 & 6.0862 & 5.4816 & TST \\
\hline CHEMBL1500320 & 688239 & 5.6862 & 5.4681 & TRN \\
\hline CHEMBL1477401 & 688239 & 5.1862 & 5.6612 & TRN \\
\hline CHEMBL1543870 & 688239 & 4.6362 & 5.4021 & TRN \\
\hline CHEMBL1453382 & 688239 & 5.2862 & 5.4898 & TST \\
\hline CHEMBL1409554 & 688239 & 5.2862 & 5.3941 & TRN \\
\hline CHEMBL1366579 & 688239 & 6.5862 & 5.4655 & TRN \\
\hline CHEMBL1475675 & 688239 & 5.1862 & 5.5228 & TRN \\
\hline CHEMBL1555877 & 688239 & 6.4362 & 5.6802 & TRN \\
\hline CHEMBL1317185 & 688239 & 5.0862 & 5.5499 & TRN \\
\hline CHEMBL1377238 & 688239 & 4.7862 & 5.5201 & TRN \\
\hline CHEMBL1463708 & 688239 & 6.5862 & 5.4475 & TRN \\
\hline CHEMBL1570926 & 688239 & 4.7862 & 5.6533 & TRN \\
\hline CHEMBL1355917 & 688239 & 4.5362 & 5.3644 & TRN \\
\hline
\end{tabular}


Supplemental Table S2.txt

\begin{tabular}{|c|c|c|c|c|c|}
\hline CHEMBL1581441 & 688239 & 4.5362 & 5.3 & TRN & \\
\hline CHEMBL1476899 & 688239 & 4.9362 & 5.4892 & TST & \\
\hline CHEMBL1422308 & 688239 & 5.4362 & 5.4635 & TST & \\
\hline CHEMBL1563344 & 688239 & 4.5362 & 5.5049 & TRN & \\
\hline CHEMBL1571484 & 688239 & 6.2862 & 5.3857 & TRN & \\
\hline CHEMBL1426637 & 688239 & 5.9362 & 5.3506 & TST & \\
\hline CHEMBL3209392 & 688239 & 4.6362 & 5.5685 & TST & \\
\hline CHEMBL1368663 & 688239 & 5.1862 & 5.528 & TST & \\
\hline CHEMBL1405230 & 688239 & 5.1862 & 5.6431 & TST & \\
\hline CHEMBL1506144 & 688239 & 5.6862 & 5.5691 & TRN & \\
\hline CHEMBL1374823 & 688239 & 4.6362 & 5.5232 & TRN & \\
\hline CHEMBL1337684 & 688239 & 4.8862 & 5.4237 & TRN & \\
\hline CHEMBL1526893 & 688239 & 4.5362 & 5.5427 & TRN & \\
\hline CHEMBL1413046 & 688239 & 4.7362 & 5.4456 & TRN & \\
\hline CHEMBL1496645 & 688239 & 4.5362 & 5.5411 & TST & \\
\hline CHEMBL1363394 & 688239 & 6.4862 & 5.3819 & TRN & \\
\hline CHEMBL1327868 & 688239 & 4.5362 & 5.4689 & TRN & \\
\hline CHEMBL3210372 & 688239 & 5.3862 & 5.5864 & TRN & \\
\hline CHEMBL3214126 & 688239 & 5.1362 & 5.3864 & TRN & \\
\hline CHEMBL1606507 & 688239 & 8.28399 & 99999999 & 9 & 5.5279 \\
\hline CHEMBL1359454 & 688239 & 6.0862 & 5.5251 & TRN & \\
\hline CHEMBL1444431 & 688239 & 7.1361 & 5.5743 & TRN & \\
\hline CHEMBL1332531 & 688239 & 5.4362 & 5.5162 & TST & \\
\hline CHEMBL1581897 & 688239 & 5.3362 & 5.4668 & TRN & \\
\hline CHEMBL1574189 & 688239 & 5.0362 & 5.5126 & TST & \\
\hline CHEMBL1446507 & 688239 & 5.3362 & 5.4613 & TST & \\
\hline CHEMBL1594542 & 688239 & 6.1862 & 5.3755 & TST & \\
\hline CHEMBL1601509 & 688239 & 4.5362 & 5.3998 & TRN & \\
\hline CHEMBL1447824 & 688239 & 5.5362 & 5.5921 & TRN & \\
\hline CHEMBL3209143 & 688239 & 5.9362 & 5.331 & TRN & \\
\hline CHEMBL1515153 & 688239 & 6.5363 & 5.3656 & TRN & \\
\hline CHEMBL1451344 & 688239 & 5.1862 & 5.5199 & TST & \\
\hline CHEMBL1449969 & 688239 & 5.6862 & 5.5673 & TRN & \\
\hline CHEMBL1579092 & 688239 & 4.5362 & 5.4267 & TRN & \\
\hline CHEMBL3194154 & 688239 & 4.7362 & 5.5087 & TST & \\
\hline CHEMBL1449912 & 688239 & 5.3362 & 5.4874 & TRN & \\
\hline CHEMBL1609190 & 688239 & 4.7362 & 5.445 & TRN & \\
\hline CHEMBL1451111 & 688239 & 4.5362 & 5.5189 & TRN & \\
\hline CHEMBL1405881 & 688239 & 5.5862 & 5.4911 & TRN & \\
\hline CHEMBL1403778 & 688239 & 6.5363 & 5.5701 & TRN & \\
\hline CHEMBL1436769 & 688239 & 4.5362 & 5.4556 & TRN & \\
\hline CHEMBL1594500 & 688239 & 5.8862 & 5.4321 & TRN & \\
\hline CHEMBL1323660 & 688239 & 7.0362 & 5.6222 & TRN & \\
\hline CHEMBL1595192 & 688239 & 5.0862 & 5.4728 & TRN & \\
\hline CHEMBL1613652 & 688239 & 5.6362 & 5.34 & TRN & \\
\hline CHEMBL1358818 & 688239 & 4.6862 & 5.4292 & TST & \\
\hline CHEMBL1324620 & 688239 & 6.5363 & 5.5116 & TRN & \\
\hline CHEMBL1475390 & 688239 & 5.2862 & 5.5798 & TRN & \\
\hline
\end{tabular}


Supplemental Table S2.txt

\begin{tabular}{|c|c|c|c|c|c|}
\hline CHEMBL1319320 & 688239 & 5.6862 & 5.5041 & TST & \\
\hline CHEMBL1426991 & 688239 & 4.5362 & 5.3857 & TRN & \\
\hline CHEMBL1462928 & 688239 & 6.1862 & 5.5168 & TST & \\
\hline CHEMBL1493761 & 688239 & 6.1862 & 5.4173 & TRN & \\
\hline CHEMBL1317079 & 688239 & 4.5362 & 5.3982 & TRN & \\
\hline CHEMBL1532222 & 688239 & 6.6861 & 5.5509 & TRN & \\
\hline CHEMBL1430038 & 688239 & 5.1862 & 5.4979 & TRN & \\
\hline CHEMBL1589215 & 688239 & 4.7362 & 5.428999 & 9999999999 & TST \\
\hline CHEMBL1525819 & 688239 & 5.5362 & 5.5728 & TRN & \\
\hline CHEMBL1505474 & 688239 & 4.7862 & 5.4475 & TRN & \\
\hline CHEMBL1384615 & 688239 & 5.5362 & 5.6107 & TRN & \\
\hline CHEMBL1376130 & 688239 & 4.5362 & 5.4542 & TRN & \\
\hline CHEMBL1542927 & 688239 & 4.8362 & 5.6128 & TST & \\
\hline CHEMBL1426153 & 688239 & 5.5862 & 5.4569 & TRN & \\
\hline CHEMBL1595051 & 688239 & 4.8362 & 5.5653 & TRN & \\
\hline CHEMBL1426502 & 688239 & 4.5862 & 5.5324 & TRN & \\
\hline CHEMBL1441414 & 688239 & 5.4862 & 5.4582 & TRN & \\
\hline CHEMBL1588568 & 688239 & 5.9362 & 5.5876 & TRN & \\
\hline CHEMBL1503155 & 688239 & 5.4362 & 5.4845 & TRN & \\
\hline CHEMBL1576587 & 688239 & 4.6362 & 5.5639 & TRN & \\
\hline CHEMBL1509538 & 688239 & 4.4862 & 5.507999 & 9999999999 & TRN \\
\hline CHEMBL1470179 & 688239 & 4.5862 & 5.5762 & TRN & \\
\hline CHEMBL1458966 & 688239 & 6.7361 & 5.4044 & TRN & \\
\hline CHEMBL1370437 & 688239 & 5.1862 & 5.5502 & TRN & \\
\hline CHEMBL1382797 & 688239 & 5.2862 & 5.5927 & TRN & \\
\hline CHEMBL1443359 & 688239 & 6.9363 & 5.4886 & TST & \\
\hline CHEMBL1360815 & 688239 & 4.9362 & 5.6018 & TST & \\
\hline CHEMBL1526031 & 688239 & 5.6862 & 5.4793 & TRN & \\
\hline CHEMBL1591883 & 688239 & 6.1862 & 5.553999 & 9999999999 & TRN \\
\hline CHEMBL1313095 & 688239 & 5.7362 & 5.3769 & TRN & \\
\hline CHEMBL1393581 & 688239 & 4.4862 & 5.5455 & TRN & \\
\hline CHEMBL1403794 & 688239 & 4.6862 & 5.6706 & TRN & \\
\hline CHEMBL1349667 & 688239 & 5.1862 & 5.4081 & TST & \\
\hline CHEMBL1585782 & 688239 & 4.6362 & 5.4522 & TRN & \\
\hline CHEMBL1359529 & 688239 & 4.7862 & 5.4417 & TST & \\
\hline CHEMBL1572026 & 688239 & 4.4862 & 5.3228 & TRN & \\
\hline CHEMBL1502866 & 688239 & 5.1862 & 5.3851 & TRN & \\
\hline CHEMBL1438547 & 688239 & 6.0862 & 5.5959 & TRN & \\
\hline CHEMBL1352094 & 688239 & 6.6861 & 5.4772 & TRN & \\
\hline CHEMBL1362368 & 688239 & 5.6862 & 5.5234 & TRN & \\
\hline CHEMBL1456847 & 688239 & 5.4862 & 5.5672 & TRN & \\
\hline CHEMBL1363662 & 688239 & 4.7362 & 5.3264 & TRN & \\
\hline CHEMBL1609951 & 688239 & 5.7862 & 5.5583 & TRN & \\
\hline CHEMBL1477862 & 688239 & 4.7362 & 5.4833 & TRN & \\
\hline CHEMBL3196646 & 688239 & 5.1862 & 5.593 & TRN & \\
\hline CHEMBL1451641 & 688239 & 4.7862 & 5.4129 & TST & \\
\hline CHEMBL1560583 & 688239 & 6.0862 & 5.6037 & TST & \\
\hline CHEMBL1304869 & 688239 & 4.7362 & 5.2901 & TST & \\
\hline
\end{tabular}


Supplemental Table S2.txt

\begin{tabular}{|c|c|c|c|c|c|}
\hline CHEMBL1510855 & 688239 & 4.5362 & 5.6159 & TRN & \\
\hline CHEMBL1431203 & 688239 & 5.8862 & 5.50799 & 9999999999 & TRN \\
\hline CHEMBL1347937 & 688239 & 4.5362 & 5.4242 & TRN & \\
\hline CHEMBL1344374 & 688239 & 4.5362 & 5.401 & TRN & \\
\hline CHEMBL1442475 & 688239 & 5.1862 & 5.4341 & TST & \\
\hline CHEMBL1489699 & 688239 & 6.7862 & 5.504 & TST & \\
\hline CHEMBL1396217 & 688239 & 7.2366 & 5.4088 & TRN & \\
\hline CHEMBL1421132 & 688239 & 6.3362 & 5.5628 & TRN & \\
\hline CHEMBL3193419 & 688239 & 4.5362 & 5.3707 & TRN & \\
\hline CHEMBL1558492 & 688239 & 4.8862 & 5.6422 & TRN & \\
\hline CHEMBL1412860 & 688239 & 4.5862 & 5.4501 & TRN & \\
\hline CHEMBL1531571 & 688239 & 6.1362 & 5.5517 & TRN & \\
\hline CHEMBL1588684 & 688239 & 4.7362 & 5.4444 & TRN & \\
\hline CHEMBL1471345 & 688239 & 5.7862 & 5.4295 & TRN & \\
\hline CHEMBL1992589 & 688239 & 4.5362 & 5.4664 & TRN & \\
\hline CHEMBL1412429 & 688239 & 4.5362 & 5.4335 & TST & \\
\hline CHEMBL1515415 & 688239 & 6.9363 & 5.4834 & TRN & \\
\hline CHEMBL1452979 & 688239 & 4.5862 & 5.5444 & TST & \\
\hline CHEMBL1515407 & 688239 & 6.8861 & 5.4822 & TST & \\
\hline CHEMBL483182 & 688239 & 4.5362 & 5.596 & TRN & \\
\hline CHEMBL1310503 & 688239 & 4.6362 & 5.4498 & TST & \\
\hline CHEMBL1541600 & 688239 & 6.7862 & 5.6649 & TRN & \\
\hline CHEMBL1423997 & 688239 & 5.6362 & 5.4547 & TRN & \\
\hline CHEMBL1369386 & 688239 & 6.1862 & 5.5062 & TRN & \\
\hline CHEMBL1338243 & 688239 & 5.2862 & 5.655 & TST & \\
\hline CHEMBL1412529 & 688239 & 4.9362 & 5.54 & TRN & \\
\hline CHEMBL1580119 & 688239 & 4.5362 & 5.5001 & TRN & \\
\hline CHEMBL1517336 & 688239 & 5.0862 & \multicolumn{2}{|c|}{5.486000000000001} & TRN \\
\hline CHEMBL 3212675 & 688239 & 6.2362 & 5.3446 & TST & \\
\hline CHEMBL1606296 & 688239 & 5.5362 & 5.6472 & TRN & \\
\hline CHEMBL1445887 & 688239 & 4.6862 & 5.4467 & TRN & \\
\hline CHEMBL1425102 & 688239 & 4.5362 & 5.6591 & TRN & \\
\hline CHEMBL 3190780 & 688239 & 6.3863 & 5.3833 & TST & \\
\hline CHEMBL1973435 & 688239 & 5.6862 & 5.5522 & TST & \\
\hline CHEMBL1356762 & 688239 & 5.1362 & 5.4581 & TRN & \\
\hline CHEMBL1366870 & 688239 & 4.7362 & 5.4511 & TRN & \\
\hline CHEMBL1339242 & 688239 & 4.7862 & 5.4588 & TST & \\
\hline CHEMBL1565786 & 688239 & 8.3872 & 5.4995 & TRN & \\
\hline CHEMBL1329993 & 688239 & 6.8861 & 5.6396 & TRN & \\
\hline CHEMBL3212091 & 688239 & 5.4862 & \multicolumn{2}{|c|}{5.3660000000000005} & TRN \\
\hline CHEMBL1576383 & 688239 & 5.7862 & 5.3975 & TRN & \\
\hline CHEMBL1414215 & 688239 & 4.5362 & 5.44 & TRN & \\
\hline CHEMBL1535270 & 688239 & 4.6362 & 5.5722 & TRN & \\
\hline CHEMBL1360519 & 688239 & 4.8362 & 5.271 & TRN & \\
\hline CHEMBL3210191 & 688239 & 6.1862 & 5.5395 & TRN & \\
\hline CHEMBL1401139 & 688239 & 4.8362 & 5.5007 & TST & \\
\hline CHEMBL1519476 & 688239 & 5.1862 & 5.5285 & TST & \\
\hline CHEMBL1415287 & 688239 & 6.4362 & 5.4707 & TRN & \\
\hline
\end{tabular}


Supplemental Table S2.txt

\begin{tabular}{|c|c|c|c|c|}
\hline CHEMBL1572044 & 688239 & 4.5362 & 5.511 & TRN \\
\hline CHEMBL1532496 & 688239 & 5.1362 & 5.4408 & TRN \\
\hline CHEMBL1520849 & 688239 & 4.5362 & 5.3035 & TRN \\
\hline CHEMBL1417507 & 688239 & 5.2362 & 5.5518 & TRN \\
\hline CHEMBL1576731 & 688239 & 5.4862 & 5.5184 & TST \\
\hline CHEMBL1557985 & 688239 & 6.6362 & 5.4453 & TRN \\
\hline CHEMBL1507301 & 688239 & 6.9363 & 5.337999 & 999999999 \\
\hline CHEMBL 250428 & 688239 & 5.6362 & 5.4949 & TRN \\
\hline CHEMBL1500042 & 688239 & 4.7362 & 5.3952 & TRN \\
\hline CHEMBL1481551 & 688239 & 5.1862 & 5.513 & TRN \\
\hline CHEMBL1312838 & 688239 & 5.9362 & 5.4456 & TST \\
\hline CHEMBL1448287 & 688239 & 4.6362 & 5.5577 & TRN \\
\hline CHEMBL1535460 & 688239 & 5.1862 & 5.4147 & TST \\
\hline CHEMBL 3213596 & 688239 & 4.4862 & 5.4889 & TRN \\
\hline CHEMBL1347964 & 688239 & 4.4862 & 5.5102 & TST \\
\hline CHEMBL1540725 & 688239 & 6.7862 & 5.3852 & TST \\
\hline CHEMBL1458318 & 688239 & 4.6862 & 5.367006 & 000000001 \\
\hline CHEMBL1399825 & 688239 & 5.6362 & 5.4872 & TST \\
\hline CHEMBL1534172 & 688239 & 5.3362 & 5.4927 & TRN \\
\hline CHEMBL1395844 & 688239 & 6.8861 & 5.4957 & TRN \\
\hline CHEMBL1486635 & 688239 & 4.7862 & 5.4836 & TRN \\
\hline CHEMBL1482064 & 688239 & 5.6362 & 5.6738 & TRN \\
\hline CHEMBL1516693 & 688239 & 5.4362 & 5.4184 & TST \\
\hline CHEMBL1318256 & 688239 & 6.7361 & 5.5564 & TRN \\
\hline CHEMBL1327438 & 688239 & 4.5362 & 5.5334 & TRN \\
\hline CHEMBL1371869 & 688239 & 4.6862 & 5.457999 & 999999999 \\
\hline CHEMBL1426726 & 688239 & 6.0862 & 5.4796 & TRN \\
\hline CHEMBL1474208 & 688239 & 4.6362 & 5.3392 & TST \\
\hline CHEMBL3198299 & 688239 & 4.5362 & 5.3203 & TRN \\
\hline CHEMBL1520839 & 688239 & 4.5362 & 5.4634 & TST \\
\hline CHEMBL1517108 & 688239 & 5.8862 & 5.6798 & TRN \\
\hline CHEMBL1440978 & 688239 & 6.6362 & 5.5178 & TRN \\
\hline CHEMBL1372502 & 688239 & 4.4862 & 5.5984 & TRN \\
\hline CHEMBL1369744 & 688239 & 4.7862 & 5.5038 & TST \\
\hline CHEMBL1542422 & 688239 & 5.7362 & 5.5842 & TRN \\
\hline CHEMBL1571034 & 688239 & 5.2862 & 5.4816 & TST \\
\hline CHEMBL1449421 & 688239 & 5.9862 & 5.5837 & TST \\
\hline CHEMBL1602199 & 688239 & 4.5362 & 5.5433 & TST \\
\hline CHEMBL1381295 & 688239 & 5.1862 & 5.4379 & TRN \\
\hline CHEMBL3211046 & 688239 & 6.5363 & 5.5152 & TRN \\
\hline CHEMBL1380266 & 688239 & 5.8362 & 5.5069 & TRN \\
\hline CHEMBL1592874 & 688239 & 5.2862 & 5.4416 & TRN \\
\hline CHEMBL1330029 & 688239 & 4.75 & 5.5402 & TRN \\
\hline CHEMBL195506 & 688239 & 5.6362 & 5.3825 & TRN \\
\hline CHEMBL1498937 & 688239 & 5.6362 & 5.6303 & TRN \\
\hline CHEMBL1468180 & 688239 & 5.4362 & 5.4906 & TRN \\
\hline CHEMBL 3192365 & 688239 & 5.4362 & 5.4221 & TRN \\
\hline CHEMBL1554191 & 688239 & 4.7362 & 5.4347 & TRN \\
\hline
\end{tabular}




\begin{tabular}{|c|c|c|c|c|c|}
\hline & & \multicolumn{4}{|c|}{ Supplemental Table S2.txt } \\
\hline CHEMBL1415973 & 688239 & 4.4862 & 5.5232 & TRN & \\
\hline CHEMBL3214330 & 688239 & 4.6862 & 5.4297 & TRN & \\
\hline CHEMBL1526413 & 688239 & 4.4862 & 5.5993 & TRN & \\
\hline CHEMBL1611907 & 688239 & 5.2862 & 5.5186 & TST & \\
\hline CHEMBL 3189344 & 688239 & 4.5862 & 5.3678 & TRN & \\
\hline CHEMBL1536261 & 688239 & 4.7362 & 5.4088 & TST & \\
\hline CHEMBL1541493 & 688239 & 5.4862 & 5.6121 & TRN & \\
\hline CHEMBL1454620 & 688239 & 4.6862 & 5.3119 & TRN & \\
\hline CHEMBL1529831 & 688239 & 5.4362 & 5.3742 & TST & \\
\hline CHEMBL1384468 & 688239 & 4.5362 & 5.6123 & TST & \\
\hline CHEMBL 3208755 & 688239 & 5.0362 & 5.5391 & TRN & \\
\hline CHEMBL1442689 & 688239 & 5.2862 & 5.5613 & TRN & \\
\hline CHEMBL1459988 & 688239 & 8.3372 & 5.5124 & TST & \\
\hline CHEMBL1508741 & 688239 & 6.1862 & 5.5803 & TRN & \\
\hline CHEMBL1348434 & 688239 & 4.5362 & 5.3766 & TRN & \\
\hline CHEMBL1525697 & 688239 & 6.5363 & 5.4715 & TRN & \\
\hline CHEMBL1389540 & 688239 & 6.6362 & 5.6301 & TRN & \\
\hline CHEMBL1432220 & 688239 & 4.5362 & 5.3485 & TRN & \\
\hline CHEMBL1992316 & 688239 & 5.5362 & 5.4594 & TST & \\
\hline CHEMBL1406394 & 688239 & 4.5862 & 5.4916 & TRN & \\
\hline CHEMBL1503593 & 688239 & 4.5362 & 5.5124 & TRN & \\
\hline CHEMBL1500907 & 688239 & 8.1871 & 5.4458 & TST & \\
\hline CHEMBL1333751 & 688239 & 4.7862 & 5.7003 & TRN & \\
\hline CHEMBL1556669 & 688239 & 5.6862 & 5.4106 & TRN & \\
\hline CHEMBL1570847 & 688239 & 6.7361 & 5.4468 & TRN & \\
\hline CHEMBL1472186 & 688239 & 4.5362 & 5.737 & TRN & \\
\hline CHEMBL1506485 & 688239 & 6.8362 & 5.4908 & TRN & \\
\hline CHEMBL1517592 & 688239 & 7.2366 & 5.6192 & TRN & \\
\hline CHEMBL1377182 & 688239 & 5.1862 & 5.4835 & TST & \\
\hline CHEMBL1380577 & 688239 & 4.9862 & 5.4411 & TRN & \\
\hline CHEMBL1598310 & 688239 & 4.6362 & 5.4686 & TRN & \\
\hline CHEMBL1320497 & 688239 & 7.2865 & 5.4842 & TST & \\
\hline CHEMBL1387112 & 688239 & 5.5862 & 5.5882 & TRN & \\
\hline CHEMBL1335300 & 688239 & 8.28399 & 99999999 & 5.6313 & TRN \\
\hline CHEMBL1431743 & 688239 & 5.6362 & 5.4477 & TST & \\
\hline CHEMBL1612764 & 688239 & 6.9363 & 5.41700 & 0000000001 & TST \\
\hline CHEMBL1461526 & 688239 & 4.8 & 5.4569 & TRN & \\
\hline CHEMBL1550672 & 688239 & 5.8362 & 5.2743 & TRN & \\
\hline CHEMBL1349048 & 688239 & 6.9363 & 5.5303 & TRN & \\
\hline CHEMBL1550466 & 688239 & 4.5362 & 5.55 & TRN & \\
\hline CHEMBL1323864 & 688239 & 5.6362 & 5.4949 & TRN & \\
\hline CHEMBL1311226 & 688239 & 4.5362 & 5.3578 & TRN & \\
\hline CHEMBL1309614 & 688239 & 4.8362 & 5.4809 & TRN & \\
\hline CHEMBL1342216 & 688239 & 6.1862 & 5.4757 & TST & \\
\hline CHEMBL1384973 & 688239 & 6.8861 & 5.6941 & TRN & \\
\hline CHEMBL1575937 & 688239 & 4.5362 & 5.6404 & TST & \\
\hline CHEMBL1551168 & 688239 & 4.8362 & 5.5188 & TRN & \\
\hline CHEMBL1387540 & 688239 & 5.4862 & 5.4687 & TRN & \\
\hline
\end{tabular}




\begin{tabular}{|c|c|c|c|c|c|}
\hline & & \multicolumn{4}{|c|}{ Supplemental Table s2.txt } \\
\hline CHEMBL1537857 & 688239 & 6.6861 & 5.3563 & TST & \\
\hline CHEMBL1486767 & 688239 & 6.7361 & 5.4561 & TRN & \\
\hline CHEMBL1458572 & 688239 & 5.3362 & 5.4909 & TRN & \\
\hline CHEMBL1410786 & 688239 & 4.6862 & 5.454 & TST & \\
\hline CHEMBL1370450 & 688239 & 5.1862 & 5.5181 & TST & \\
\hline CHEMBL1446251 & 688239 & 5.1862 & 5.5007 & TRN & \\
\hline CHEMBL1531849 & 688239 & 6.1362 & 5.4226 & TRN & \\
\hline CHEMBL1599250 & 688239 & 5.2362 & 5.5703 & TST & \\
\hline CHEMBL1428885 & 688239 & 7.5361 & 5.5036 & TRN & \\
\hline CHEMBL1468537 & 688239 & 4.6362 & 5.4363 & TRN & \\
\hline CHEMBL1533097 & 688239 & 4.5362 & 5.3592 & TRN & \\
\hline CHEMBL1320080 & 688239 & 5.1862 & 5.3002 & TST & \\
\hline CHEMBL1521920 & 688239 & 6.1862 & 5.4562 & TRN & \\
\hline CHEMBL1486499 & 688239 & 5.6862 & 5.6991 & TST & \\
\hline CHEMBL1458346 & 688239 & 5.6362 & 5.4336 & TRN & \\
\hline CHEMBL1381088 & 688239 & 4.8862 & 5.3175 & TST & \\
\hline CHEMBL1612750 & 688239 & 5.4862 & 5.5148 & TRN & \\
\hline CHEMBL1481912 & 688239 & 5.1362 & 5.5734 & TRN & \\
\hline CHEMBL1428674 & 688239 & 6.9863 & 5.5144 & TRN & \\
\hline CHEMBL1497585 & 688239 & 7.1864 & 5.4867 & TST & \\
\hline CHEMBL1423345 & 688239 & 5.4862 & 5.5512 & TRN & \\
\hline CHEMBL1380967 & 688239 & 5.1862 & 5.4594 & TST & \\
\hline CHEMBL1529127 & 688239 & 4.6362 & 5.51399 & 9999999999 & TRN \\
\hline CHEMBL1335074 & 688239 & 4.6862 & 5.598 & TRN & \\
\hline CHEMBL1343049 & 688239 & 5.1862 & 5.57 & TRN & \\
\hline CHEMBL1487642 & 688239 & 5.1862 & 5.5052 & TRN & \\
\hline CHEMBL3213946 & 688239 & 8.28399 & 99999999 & 5.5418 & TST \\
\hline CHEMBL1303995 & 688239 & 8.3372 & 5.5363 & TRN & \\
\hline CHEMBL1402573 & 688239 & 5.7362 & 5.609 & TST & \\
\hline CHEMBL1379401 & 688239 & 4.9362 & 5.4741 & TST & \\
\hline CHEMBL1399587 & 688239 & 4.8362 & 5.3613 & TRN & \\
\hline CHEMBL1994268 & 688239 & 8.3372 & 5.4438 & TST & \\
\hline CHEMBL1447865 & 688239 & 6.6362 & 5.5001 & TRN & \\
\hline CHEMBL514432 & 688239 & 6.3863 & 5.4505 & TST & \\
\hline CHEMBL1537214 & 688239 & 4.5362 & 5.6053 & TRN & \\
\hline CHEMBL1345896 & 688239 & 5.2862 & 5.6717 & TRN & \\
\hline CHEMBL1324376 & 688239 & 5.6362 & 5.3873 & TST & \\
\hline CHEMBL1469015 & 688239 & 6.2862 & 5.4923 & TST & \\
\hline CHEMBL1603896 & 688239 & 5.2362 & 5.4012 & TRN & \\
\hline CHEMBL1389697 & 688239 & 4.6362 & 5.501 & TRN & \\
\hline CHEMBL1537509 & 688239 & 5.0862 & 5.2466 & TST & \\
\hline CHEMBL1375509 & 688239 & 4.7362 & 5.4535 & TST & \\
\hline CHEMBL1345806 & 688239 & 4.5362 & 5.6821 & TRN & \\
\hline CHEMBL1392145 & 688239 & 6.1362 & 5.3628 & TRN & \\
\hline CHEMBL1581333 & 688239 & 4.9862 & 5.6732 & TRN & \\
\hline CHEMBL1593163 & 688239 & 5.1862 & 5.366006 & 00000000005 & TRN \\
\hline CHEMBL1432854 & 688239 & 4.8862 & 5.593 & TRN & \\
\hline CHEMBL1406649 & 688239 & 4.7862 & 5.4944 & TRN & \\
\hline
\end{tabular}


Supplemental Table S2.txt

\begin{tabular}{|c|c|c|c|c|c|}
\hline CHEMBL1345853 & 688239 & 4.5362 & 5.4267 & TRN & \\
\hline CHEMBL1545446 & 688239 & 4.5362 & 5.4885 & TRN & \\
\hline CHEMBL1468657 & 688239 & 4.9362 & 5.4473 & TST & \\
\hline CHEMBL1339271 & 688239 & 5.6862 & 5.5038 & TRN & \\
\hline CHEMBL1581584 & 688239 & 4.8362 & 5.5198 & TRN & \\
\hline CHEMBL1463131 & 688239 & 4.7362 & 5.3667 & TST & \\
\hline CHEMBL1437402 & 688239 & 4.5362 & 5.5323 & TST & \\
\hline CHEMBL1312912 & 688239 & 8.3372 & 5.5722 & TST & \\
\hline CHEMBL1375211 & 688239 & 4.5362 & 5.516 & TRN & \\
\hline CHEMBL1324060 & 688239 & 5.6862 & 5.4913 & TRN & \\
\hline CHEMBL1330082 & 688239 & 4.7862 & 5.4702 & TRN & \\
\hline CHEMBL1372365 & 688239 & 6.3863 & 5.5239 & TRN & \\
\hline CHEMBL1324194 & 688239 & 5.4862 & 5.4246 & TRN & \\
\hline CHEMBL1329693 & 688239 & 5.0362 & 5.4082 & TRN & \\
\hline CHEMBL1485154 & 688239 & 5.1862 & 5.273 & TST & \\
\hline CHEMBL1541094 & 688239 & 5.5862 & 5.5593 & TST & \\
\hline CHEMBL3189832 & 688239 & 4.6362 & 5.4635 & TRN & \\
\hline CHEMBL1488391 & 688239 & 6.0862 & 5.4273 & TRN & \\
\hline CHEMBL1381589 & 688239 & 6.2862 & 5.4681 & TRN & \\
\hline CHEMBL1397167 & 688239 & 4.7362 & 5.5167 & TST & \\
\hline CHEMBL1387965 & 688239 & 5.45 & 5.5943 & TRN & \\
\hline CHEMBL1441834 & 688239 & 5.1362 & 5.5023 & TST & \\
\hline CHEMBL1377214 & 688239 & 8.1367 & 5.6138 & TRN & \\
\hline CHEMBL1453477 & 688239 & 6.0862 & 5.4747 & TRN & \\
\hline CHEMBL1481096 & 688239 & 5.1862 & 5.6456 & TRN & \\
\hline CHEMBL1403560 & 688239 & 4.6862 & 5.5404 & TRN & \\
\hline CHEMBL1378240 & 688239 & 6.0862 & 5.4266 & TRN & \\
\hline CHEMBL1979106 & 688239 & 4.7362 & 5.3491 & TRN & \\
\hline CHEMBL1335114 & 688239 & 6.0362 & 5.4811 & TRN & \\
\hline CHEMBL1502731 & 688239 & 5.9362 & 5.4099 & TRN & \\
\hline CHEMBL3193513 & 688239 & 4.7362 & 5.3869 & TRN & \\
\hline CHEMBL1379807 & 688239 & 5.5362 & 5.5975 & TST & \\
\hline CHEMBL1441174 & 688239 & 6.2362 & 5.5277 & TRN & \\
\hline CHEMBL1383165 & 688239 & 6.0862 & 5.5062 & TRN & \\
\hline CHEMBL1370190 & 688239 & 5.1862 & 5.55200 & 00000000005 & TRN \\
\hline CHEMBL1571835 & 688239 & 5.1362 & 5.5327 & TRN & \\
\hline CHEMBL1323291 & 688239 & 4.5362 & 5.4766 & TRN & \\
\hline CHEMBL1584610 & 688239 & 4.6862 & 5.3892 & TRN & \\
\hline CHEMBL1517573 & 688239 & 4.5362 & 5.483 & TRN & \\
\hline CHEMBL1465720 & 688239 & 4.8362 & 5.3606 & TST & \\
\hline CHEMBL1395243 & 688239 & 4.5362 & 5.524 & TST & \\
\hline CHEMBL1541147 & 688239 & 6.3863 & 5.4448 & TST & \\
\hline CHEMBL1331087 & 688239 & 8.3372 & 5.534 & TRN & \\
\hline CHEMBL1547356 & 688239 & 6.0862 & 5.4879 & TRN & \\
\hline CHEMBL1367170 & 688239 & 5.1862 & 5.4766 & TST & \\
\hline CHEMBL1471091 & 688239 & 5.7362 & 5.4401 & TRN & \\
\hline CHEMBL1478943 & 688239 & 5.2362 & 5.5198 & TRN & \\
\hline CHEMBL1456418 & 688239 & 8.3372 & 5.5915 & TRN & \\
\hline
\end{tabular}

Page 2356 
Supplemental Table S2.txt

\begin{tabular}{|c|c|c|c|c|}
\hline CHEMBL1404583 & 688239 & 5.5362 & 5.5129 & TRN \\
\hline CHEMBL1557767 & 688239 & 6.7361 & 5.4608 & TRN \\
\hline CHEMBL1465128 & 688239 & 7.2865 & 5.4205 & TRN \\
\hline CHEMBL1546717 & 688239 & 5.6362 & 5.5216 & TST \\
\hline CHEMBL1482529 & 688239 & 5.1862 & 5.4438 & TRN \\
\hline CHEMBL1500683 & 688239 & 4.5362 & 5.2996 & TRN \\
\hline CHEMBL1556226 & 688239 & 6.7361 & 5.5626 & TRN \\
\hline CHEMBL1312227 & 688239 & 5.7362 & 5.6134 & TRN \\
\hline CHEMBL1592647 & 688239 & 4.7862 & 5.4241 & TRN \\
\hline CHEMBL1550349 & 688239 & 5.0862 & 5.4958 & TRN \\
\hline CHEMBL1411200 & 688239 & 4.5362 & 5.4123 & TST \\
\hline CHEMBL1406048 & 688239 & 6.5363 & 5.3224 & TRN \\
\hline CHEMBL1585374 & 688239 & 4.5362 & 5.3241 & TRN \\
\hline CHEMBL1572367 & 688239 & 4.7362 & 5.4209 & TST \\
\hline CHEMBL1536972 & 688239 & 4.5362 & 5.4303 & TRN \\
\hline CHEMBL1590596 & 688239 & 4.5362 & 5.3485 & TRN \\
\hline CHEMBL1390532 & 688239 & 4.4862 & 5.4854 & TRN \\
\hline CHEMBL1332712 & 688239 & 6.7862 & 5.5674 & TST \\
\hline CHEMBL1509878 & 688239 & 4.6362 & 5.5299 & TRN \\
\hline CHEMBL1611776 & 688239 & 4.4862 & 5.3943 & TRN \\
\hline CHEMBL1583964 & 688239 & 7.0362 & 5.4649 & TST \\
\hline CHEMBL1367073 & 688239 & 5.2862 & 5.4933 & TRN \\
\hline CHEMBL1307178 & 688239 & 6.8362 & 5.5233 & TRN \\
\hline CHEMBL1300604 & 688239 & 4.5362 & 5.572 & TRN \\
\hline CHEMBL1400052 & 688239 & 4.4862 & 5.5563 & TRN \\
\hline CHEMBL1367075 & 688239 & 5.7362 & 5.4134 & TRN \\
\hline CHEMBL1611119 & 688239 & 5.2362 & 5.3444 & TRN \\
\hline CHEMBL1373992 & 688239 & 5.4862 & 5.5225 & TST \\
\hline CHEMBL1603939 & 688239 & 6.9863 & 5.4999 & TRN \\
\hline CHEMBL1572744 & 688239 & 5.5362 & 5.4604 & TRN \\
\hline CHEMBL1430284 & 688239 & 4.5362 & 5.4795 & TST \\
\hline CHEMBL1500474 & 688239 & 5.1862 & 5.6292 & TRN \\
\hline CHEMBL1430881 & 688239 & 5.1862 & 5.4959 & TRN \\
\hline CHEMBL1377507 & 688239 & 6.3362 & 5.4611 & TST \\
\hline CHEMBL3192469 & 688239 & 5.1362 & 5.557 & TRN \\
\hline CHEMBL1312036 & 688239 & 4.5362 & 5.6154 & TST \\
\hline CHEMBL1565812 & 688239 & 6.6362 & 5.5547 & TST \\
\hline CHEMBL1418551 & 688239 & 6.8861 & 5.5799 & TRN \\
\hline CHEMBL1571323 & 688239 & 5.4862 & 5.672999 & э999999999 \\
\hline CHEMBL1608414 & 688239 & 6.1362 & 5.4787 & TST \\
\hline CHEMBL1380056 & 688239 & 5.1862 & 5.4765 & TRN \\
\hline CHEMBL1386614 & 688239 & 4.9362 & 5.4382 & TST \\
\hline CHEMBL1405567 & 688239 & 7.0862 & 5.4667 & TRN \\
\hline CHEMBL1480250 & 688239 & 5.1862 & 5.5294 & TRN \\
\hline CHEMBL1452852 & 688239 & 4.5362 & 5.4273 & TRN \\
\hline CHEMBL1555015 & 688239 & 6.5862 & 5.5122 & TRN \\
\hline CHEMBL1553166 & 688239 & 5.4362 & 5.5471 & TRN \\
\hline CHEMBL1469024 & 688239 & 4.5862 & 5.4228 & TST \\
\hline
\end{tabular}


Supplemental Table S2.txt

\begin{tabular}{|c|c|c|c|c|}
\hline HEMBL1316383 & & & & \\
\hline & & .6862 & 5.5319 & \\
\hline 20 & & & & \\
\hline AEMBL1 & & & & \\
\hline AEMBL1382411 & 8239 & 362 & 3979 & \\
\hline HEMBL1446493 & 88239 & 562 & 6594 & \\
\hline 768 & 239 & 362 & & \\
\hline 170 & & & & \\
\hline AEMBL1351536 & & & 5285 & \\
\hline HEMBL1343444 & 88239 & 362 & 5687 & \\
\hline HEMBL1431707 & 239 & 62 & 5183 & \\
\hline IEMBL1 & 39 & 62 & 155 & \\
\hline IEMBL: & & & & \\
\hline HEMBL1 & & 862 & & \\
\hline AEMBL3 & & 62 & & \\
\hline AEMBL1 & 39 & 62 & 79 & \\
\hline HEMBL1 & & & 322 & \\
\hline HEMBL1 & & & & \\
\hline AEMBL1 & & & & \\
\hline IEMBL1 & & & & \\
\hline HEMBL & & & 37 & \\
\hline AEMBL & & & & \\
\hline HEMBL: & & & & \\
\hline 266 & & & & \\
\hline AEMBL1 & & & & ונ \\
\hline HEMBL & & & & ST \\
\hline AEMBL & & & & \\
\hline $\mathrm{AFMB}$ & & & & RN \\
\hline HEMBL1 & & & & I RIV \\
\hline HEMBL1: & & & 872 & RIN \\
\hline AEMBL1 & & & 99 & \\
\hline AFMB & & & & Niv \\
\hline 7 & & & 366 & ST \\
\hline HEMBL1 & & & & RN \\
\hline HEMBL1415877 & & & 806 & RN \\
\hline HEMBL1 & & & 38 & \\
\hline - & & & & RN \\
\hline HEMBL13 & & & & $\mathrm{RN}$ \\
\hline HEMBL1307004 & 88239 & & 349 & $\Gamma \mathrm{R}$ \\
\hline AEMBL1 & & & 95 & \\
\hline HEMBL1 & & & 539 & \\
\hline HEMBL1 & & & & \\
\hline HEMBL1 & & & 011 & ГST \\
\hline AEMBL1410678 & 39 & 62 & 5.5228 & TRN \\
\hline EBL1 & & & & -5 \\
\hline CHEMBL1586709 & & & 5.4845 & \\
\hline CHEMBL1376665 & & & 5.5193 & \\
\hline HEMBL154654 & 688239 & 4.5362 & 5.4794 & ГRN \\
\hline
\end{tabular}

Page 2358 
Supplemental Table S2.txt

\begin{tabular}{|c|c|c|c|c|c|}
\hline CHEMBL1480424 & 688239 & 5.1862 & 5.2687 & TRN & \\
\hline CHEMBL1594742 & 688239 & 4.8362 & 5.553 & TRN & \\
\hline CHEMBL1363459 & 688239 & 4.6862 & 5.5078 & TST & \\
\hline CHEMBL1401170 & 688239 & 4.9862 & 5.5209 & TRN & \\
\hline CHEMBL1350136 & 688239 & 7.0862 & 5.6867 & TRN & \\
\hline CHEMBL1487742 & 688239 & 6.1862 & 5.4612 & TRN & \\
\hline CHEMBL1508105 & 688239 & 6.6861 & 5.5198 & TRN & \\
\hline CHEMBL1395526 & 688239 & 4.4862 & 5.5516 & TST & \\
\hline CHEMBL1366014 & 688239 & 8.28399 & 999999999 & 5.5361 & TRN \\
\hline CHEMBL3212023 & 688239 & 5.2362 & 5.3573 & TST & \\
\hline CHEMBL1422927 & 688239 & 5.7362 & 5.3606 & TST & \\
\hline CHEMBL1328019 & 688239 & 6.1362 & 5.4573 & TST & \\
\hline CHEMBL1594051 & 688239 & 4.5862 & 5.4471 & TRN & \\
\hline CHEMBL1523801 & 688239 & 5.4362 & 5.3806 & TST & \\
\hline CHEMBL1367722 & 688239 & 5.3362 & 5.581 & TRN & \\
\hline CHEMBL1407560 & 688239 & 6.1362 & 5.4098 & TRN & \\
\hline CHEMBL1595669 & 688239 & 4.5862 & 5.3587 & TRN & \\
\hline CHEMBL1442497 & 688239 & 6.2362 & 5.4739 & TRN & \\
\hline CHEMBL1349035 & 688239 & 5.9362 & 5.5301 & TRN & \\
\hline CHEMBL1461234 & 688239 & 4.7362 & 5.5218 & TRN & \\
\hline CHEMBL1493023 & 688239 & 6.1862 & \multicolumn{2}{|c|}{5.507000000000001} & TRN \\
\hline CHEMBL1344071 & 688239 & 5.1862 & 5.545 & TRN & \\
\hline CHEMBL1350378 & 688239 & 4.6362 & 5.2986 & TST & \\
\hline CHEMBL1459837 & 688239 & 6.7862 & 5.54 & TRN & \\
\hline CHEMBL1502400 & 688239 & 6.7361 & \multicolumn{2}{|c|}{5.5520000000000005} & TST \\
\hline CHEMBL1304764 & 688239 & 4.8362 & 5.4644 & TST & \\
\hline CHEMBL3198544 & 688239 & 4.5362 & 5.4803 & TRN & \\
\hline CHEMBL1382923 & 688239 & 4.4862 & 5.5463 & TST & \\
\hline CHEMBL1449779 & 688239 & 8.2366 & 5.4365 & TST & \\
\hline CHEMBL1549670 & 688239 & 6.6861 & 5.4405 & TRN & \\
\hline CHEMBL1528744 & 688239 & 8.3372 & 5.5022 & TST & \\
\hline CHEMBL1331357 & 688239 & 8.3372 & 5.5105 & TST & \\
\hline CHEMBL1426891 & 688239 & 4.5362 & 5.6213 & TRN & \\
\hline CHEMBL3195938 & 688239 & 4.7862 & 5.4031 & TRN & \\
\hline CHEMBL1453533 & 688239 & 8.3372 & \multicolumn{2}{|c|}{5.5120000000000005} & TRN \\
\hline CHEMBL1611065 & 688239 & 4.9862 & 5.2922 & TST & \\
\hline CHEMBL1428820 & 688239 & 5.1862 & 5.6087 & TRN & \\
\hline CHEMBL1413472 & 688239 & 5.3862 & 5.5582 & TRN & \\
\hline CHEMBL1970711 & 688239 & 4.5362 & 5.3864 & TRN & \\
\hline CHEMBL1501068 & 688239 & 5.2862 & 5.555 & TRN & \\
\hline CHEMBL1491765 & 688239 & 4.9362 & 5.4085 & TST & \\
\hline CHEMBL1534701 & 688239 & 5.7862 & 5.5517 & TRN & \\
\hline CHEMBL1477292 & 688239 & 4.6862 & 5.4853 & TRN & \\
\hline CHEMBL1428889 & 688239 & 4.5362 & 5.4849 & TRN & \\
\hline CHEMBL1313273 & 688239 & 5.6362 & 5.4892 & TRN & \\
\hline CHEMBL1353856 & 688239 & 5.1862 & 5.4431 & TRN & \\
\hline CHEMBL1316167 & 688239 & 6.2362 & \multicolumn{2}{|c|}{5.5520000000000005} & TRN \\
\hline CHEMBL1375194 & 688239 & 4.5362 & 5.5554 & TRN & \\
\hline
\end{tabular}


Supplemental Table S2.txt

\begin{tabular}{|c|c|c|c|c|}
\hline CHEMBL1496852 & 688239 & 5.8862 & 5.5417 & TRN \\
\hline CHEMBL1462736 & 688239 & 6.8362 & 5.5142 & TRN \\
\hline CHEMBL1355986 & 688239 & 5.5362 & 5.5746 & TRN \\
\hline CHEMBL1352429 & 688239 & 5.2862 & 5.5816 & TST \\
\hline CHEMBL1446201 & 688239 & 6.5363 & 5.6412 & TRN \\
\hline CHEMBL1315742 & 688239 & 5.8862 & 5.4306 & TRN \\
\hline CHEMBL1554180 & 688239 & 4.5362 & 5.5293 & TRN \\
\hline CHEMBL1425946 & 688239 & 4.5362 & 5.478 & TRN \\
\hline CHEMBL1440905 & 688239 & 5.1862 & 5.5155 & TRN \\
\hline CHEMBL1564379 & 688239 & 4.7862 & 5.5185 & TRN \\
\hline CHEMBL3191408 & 688239 & 5.1862 & 5.5257 & TRN \\
\hline CHEMBL1421895 & 688239 & 6.1862 & 5.5393 & TST \\
\hline CHEMBL1408039 & 688239 & 5.1862 & 5.4616 & TRN \\
\hline CHEMBL1613729 & 688239 & 4.5362 & 5.5391 & TRN \\
\hline CHEMBL1307391 & 688239 & 4.5362 & 5.5136 & TST \\
\hline CHEMBL1469222 & 688239 & 4.7862 & 5.6401 & TRN \\
\hline CHEMBL1472204 & 688239 & 4.6362 & 5.6594 & TST \\
\hline CHEMBL1508849 & 688239 & 7.6861 & 5.5513 & TRN \\
\hline CHEMBL1531179 & 688239 & 5.1362 & 5.5094 & TRN \\
\hline CHEMBL1521989 & 688239 & 4.6362 & 5.3388 & TST \\
\hline CHEMBL1229944 & 688239 & 6.9363 & 5.4485 & TST \\
\hline CHEMBL1532201 & 688239 & 4.5362 & 5.6364 & TRN \\
\hline CHEMBL3190099 & 688239 & 5.9862 & 5.4784 & TST \\
\hline CHEMBL1462986 & 688239 & 4.8862 & 5.5441 & TRN \\
\hline CHEMBL1466117 & 688239 & 4.6862 & 5.3211 & TRN \\
\hline CHEMBL1442904 & 688239 & 5.7862 & 5.2784 & TST \\
\hline CHEMBL1325075 & 688239 & 4.5362 & 5.6411 & TRN \\
\hline CHEMBL1496591 & 688239 & 4.5362 & 5.4424 & TST \\
\hline CHEMBL1992261 & 688239 & 4.5362 & 5.3574 & TRN \\
\hline CHEMBL1470116 & 688239 & 6.1362 & 5.5617 & TRN \\
\hline CHEMBL1406470 & 688239 & 7.2366 & 5.513 & TRN \\
\hline CHEMBL1373086 & 688239 & 5.4862 & 5.4689 & TST \\
\hline CHEMBL1584388 & 688239 & 5.6862 & 5.6144 & TRN \\
\hline CHEMBL1395312 & 688239 & 5.0862 & 5.4951 & TST \\
\hline CHEMBL1322711 & 688239 & 6.4862 & 5.3513 & TST \\
\hline CHEMBL1580811 & 688239 & 4.9362 & 5.445 & TST \\
\hline CHEMBL1494841 & 688239 & 4.7362 & 5.6429 & TRN \\
\hline CHEMBL1401881 & 688239 & 6.8362 & 5.5462 & TRN \\
\hline CHEMBL1436041 & 688239 & 4.5362 & 5.4667 & TRN \\
\hline CHEMBL1308033 & 688239 & 4.8362 & 5.5809 & TRN \\
\hline CHEMBL1307583 & 688239 & 4.7362 & 5.6345 & TRN \\
\hline CHEMBL3198259 & 688239 & 4.5362 & 5.3048 & TRN \\
\hline CHEMBL1306005 & 688239 & 4.7862 & \multicolumn{2}{|c|}{5.5760000000000005} \\
\hline CHEMBL1330621 & 688239 & 5.4362 & 5.5585 & TST \\
\hline CHEMBL1552934 & 688239 & 6.1862 & 5.6025 & TRN \\
\hline CHEMBL3189340 & 688239 & 4.5362 & 5.4353 & TRN \\
\hline CHEMBL1499811 & 688239 & 5.3362 & 5.5425 & TRN \\
\hline CHEMBL1346235 & 688239 & 4.7362 & 5.5438 & TRN \\
\hline
\end{tabular}


Supplemental Table S2.txt

\begin{tabular}{|c|c|c|c|c|}
\hline 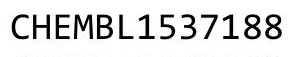 & & 562 & 急 & \\
\hline HEMBL1309562 & 88239 & 5362 & 5.4717 & \\
\hline HEMBL15 & 39 & 61 & 3847 & \\
\hline & & & & \\
\hline AEMBL1446625 & & & & \\
\hline AEMBL1431127 & 88239 & 6862 & & \\
\hline HEMBL1587866 & 88239 & .2862 & .4923 & \\
\hline HEMBL1398993 & & & 4753 & \\
\hline AEMBL1376698 & & & & \\
\hline HEMBL1394677 & & & & \\
\hline HEMBL1418369 & 88239 & .1862 & & \\
\hline HEMBL1581741 & 88239 & 0862 & 87 & \\
\hline HEMBL1498111 & 39 & 1862 & 4243 & \\
\hline HEMBL 14 & & & & \\
\hline JEMBL15 & & & & \\
\hline HEMBL1450107 & 88239 & 3362 & & \\
\hline HEMBL1580386 & & & & \\
\hline HEMBL136 & 39 & 52 & 92 & \\
\hline L13 & & & & \\
\hline AEMBL15 & & & & \\
\hline HEMBL1527920 & & 862 & & \\
\hline AEMBL1534466 & & & & \\
\hline HEMBL1385911 & 39 & & 66 & \\
\hline L13 & & & & \\
\hline 338 & & & & \\
\hline 950 & & & & \\
\hline IEMBL14 & & & & \\
\hline HEMBL1490218 & & & 49 & RN \\
\hline L13 & & & & RIV \\
\hline AFMRI 46 & & 52 & & \\
\hline AEMBL1474506 & & & & ST \\
\hline HEMBL1607558 & & & & RN \\
\hline AEMBL15 & & & & \\
\hline 4 & & & 72 & \\
\hline 34 & & & & RN \\
\hline AEMBL1541851 & & & & RN \\
\hline AEMBL1441501 & & & & RN \\
\hline & & & & \\
\hline רג ובסובו & & & & RIV \\
\hline HEMBL1594649 & & & & RN \\
\hline AEMBL1331292 & & 62 & & S \\
\hline JEMBL15 & & & & $\mathrm{RN}$ \\
\hline & & & & \\
\hline HEMBL1395701 & & & & RN \\
\hline HEMBL1333671 & & & 5.4209 & RN \\
\hline IEMBL321283 & & 362 & 64 & \\
\hline HEMBL 141 & & & & \\
\hline 1 & & 6.8861 & & \\
\hline
\end{tabular}

Page 2361 


\begin{tabular}{|c|c|c|c|c|c|}
\hline \multirow[b]{2}{*}{ CHEMBL1312600 } & \multicolumn{5}{|c|}{ IET } \\
\hline & 688239 & 5.3862 & 5.524 & TRN & \\
\hline CHEMBL1530610 & 688239 & 6.1862 & 5.2863 & TRN & \\
\hline CHEMBL1395329 & 688239 & 6.4862 & 5.477 & TRN & \\
\hline CHEMBL1457170 & 688239 & 4.7862 & 5.2966 & TRN & \\
\hline CHEMBL1606637 & 688239 & 6.9363 & 5.4595 & TRN & \\
\hline CHEMBL1441709 & 688239 & 4.5362 & 5.5318 & TST & \\
\hline CHEMBL1474132 & 688239 & 4.5362 & \multicolumn{2}{|c|}{5.462000000000001} & TRN \\
\hline CHEMBL1585406 & 688239 & 6.4862 & 5.6036 & TRN & \\
\hline CHEMBL1383279 & 688239 & 8.3872 & 5.6059 & TST & \\
\hline CHEMBL1522547 & 688239 & 4.6362 & 5.8084 & TRN & \\
\hline CHEMBL1398314 & 688239 & 5.3362 & 5.6025 & TST & \\
\hline CHEMBL1316101 & 688239 & 4.6862 & 5.5271 & TRN & \\
\hline CHEMBL1402758 & 688239 & 4.4862 & 5.6799 & TRN & \\
\hline CHEMBL1511070 & 688239 & 5.1862 & 5.4387 & TRN & \\
\hline CHEMBL1468600 & 688239 & 5.1862 & 5.3415 & TRN & \\
\hline CHEMBL1347038 & 688239 & 5.6862 & 5.3656 & TRN & \\
\hline CHEMBL1364530 & 688239 & 4.7362 & 5.4579 & TRN & \\
\hline CHEMBL1482276 & 688239 & 5.2362 & 5.7214 & TRN & \\
\hline CHEMBL3189856 & 688239 & 6.3362 & \multicolumn{2}{|c|}{5.5089999999999995} & TST \\
\hline CHEMBL1473811 & 688239 & 4.5862 & 5.4624 & TRN & \\
\hline CHEMBL1450746 & 688239 & 5.2862 & 5.6233 & TRN & \\
\hline CHEMBL1507608 & 688239 & 4.6862 & 5.4573 & TRN & \\
\hline CHEMBL1593516 & 688239 & 4.5362 & 5.3088 & TST & \\
\hline CHEMBL1481301 & 688239 & 4.7362 & 5.5271 & TRN & \\
\hline CHEMBL1519363 & 688239 & 4.5362 & 5.6262 & TRN & \\
\hline CHEMBL1546198 & 688239 & 5.8862 & \multicolumn{2}{|c|}{5.513999999999999} & TRN \\
\hline CHEMBL1592829 & 688239 & 4.6362 & 5.3657 & TRN & \\
\hline CHEMBL1450939 & 688239 & 4.7362 & 5.4716 & TRN & \\
\hline CHEMBL1405174 & 688239 & 5.1862 & 5.3852 & TST & \\
\hline CHEMBL1586851 & 688239 & 6.1862 & 5.4615 & TRN & \\
\hline CHEMBL1385575 & 688239 & 5.1862 & 5.3903 & TRN & \\
\hline CHEMBL1466381 & 688239 & 6.2362 & 5.4933 & TRN & \\
\hline CHEMBL1548890 & 688239 & 4.8862 & 5.4448 & TRN & \\
\hline CHEMBL1455032 & 688239 & 4.4862 & 5.4459 & TST & \\
\hline CHEMBL1460557 & 688239 & 4.6362 & 5.5552 & TRN & \\
\hline CHEMBL1560912 & 688239 & 5.6862 & 5.4449 & TST & \\
\hline CHEMBL1465139 & 688239 & 4.5362 & 5.3774 & TRN & \\
\hline CHEMBL1271013 & 688239 & 6.4362 & \multicolumn{2}{|c|}{5.5520000000000005} & TRN \\
\hline CHEMBL1323911 & 688239 & 7.0862 & 5.5809 & TRN & \\
\hline CHEMBL1357619 & 688239 & 4.5362 & 5.2829 & TRN & \\
\hline CHEMBL1584009 & 688239 & 5.1862 & 5.4874 & TRN & \\
\hline CHEMBL1316169 & 688239 & 5.1862 & 5.4366 & TST & \\
\hline CHEMBL1440903 & 688239 & 5.5862 & 5.5976 & TST & \\
\hline CHEMBL3208621 & 688239 & 7.2366 & 5.4249 & TRN & \\
\hline CHEMBL1392105 & 688239 & 4.5362 & 5.5169 & TRN & \\
\hline CHEMBL1428940 & 688239 & 8.3372 & 5.5252 & TRN & \\
\hline CHEMBL1367023 & 688239 & 5.6862 & \multicolumn{2}{|c|}{5.417000000000001} & TRN \\
\hline \multirow[t]{2}{*}{ CHEMBL1365216 } & 688239 & 7.2366 & 5.3867 & TRN & \\
\hline & & & & 2362 & \\
\hline
\end{tabular}


Supplemental Table S2.txt

\begin{tabular}{|c|c|c|c|c|c|}
\hline CHEMBL1426623 & 688239 & 4.5362 & 5.4068 & TRN & \\
\hline CHEMBL1409419 & 688239 & 5.0362 & 5.4848 & TRN & \\
\hline CHEMBL3213692 & 688239 & 5.1862 & 5.3324 & TRN & \\
\hline CHEMBL1349111 & 688239 & 5.6362 & 5.5242 & TRN & \\
\hline CHEMBL1487475 & 688239 & 5.5862 & 5.7064 & TRN & \\
\hline CHEMBL1489200 & 688239 & 6.2362 & 5.4553 & TST & \\
\hline CHEMBL1535757 & 688239 & 5.8862 & 5.4902 & TRN & \\
\hline CHEMBL1370899 & 688239 & 6.1362 & 5.4873 & TRN & \\
\hline CHEMBL1341742 & 688239 & 4.7362 & 5.6117 & TRN & \\
\hline CHEMBL1385484 & 688239 & 4.5862 & 5.4734 & TST & \\
\hline CHEMBL1405145 & 688239 & \multicolumn{2}{|c|}{8.283999999999999} & 5.5594 & TRN \\
\hline CHEMBL1610951 & 688239 & 4.5862 & 5.4684 & TRN & \\
\hline CHEMBL1391007 & 688239 & 5.7362 & 5.4243 & TRN & \\
\hline CHEMBL 3213023 & 688239 & 5.7362 & 5.3849 & TRN & \\
\hline CHEMBL1426462 & 688239 & 4.5362 & 5.416 & TRN & \\
\hline CHEMBL1322471 & 688239 & 5.9362 & 5.3953 & TRN & \\
\hline CHEMBL1315212 & 688239 & 6.0862 & 5.6265 & TRN & \\
\hline CHEMBL1497877 & 688239 & 4.9862 & 5.4755 & TRN & \\
\hline CHEMBL1573297 & 688239 & 6.4862 & 5.4548 & TST & \\
\hline CHEMBL1470972 & 688239 & 5.1862 & \multicolumn{2}{|c|}{5.3629999999999995} & TRN \\
\hline CHEMBL1518054 & 688239 & 6.5862 & 5.4683 & TRN & \\
\hline CHEMBL1481879 & 688239 & \multicolumn{3}{|c|}{8.283999999999999} & TRN \\
\hline CHEMBL1577177 & 688239 & 6.1362 & 5.5992 & TRN & \\
\hline CHEMBL3209793 & 688239 & 4.5362 & 5.5597 & TST & \\
\hline CHEMBL1365762 & 688239 & 5.1362 & 5.5888 & TRN & \\
\hline CHEMBL1470283 & 688239 & 7.0862 & \multicolumn{2}{|c|}{5.412999999999999} & TRN \\
\hline CHEMBL1507169 & 688239 & 6.3362 & 5.6255 & TRN & \\
\hline CHEMBL1376634 & 688239 & 4.5362 & 5.5968 & TST & \\
\hline CHEMBL3196412 & 688239 & 5.2362 & 5.5381 & TRN & \\
\hline CHEMBL1405962 & 688239 & 6.3362 & 5.4612 & TST & \\
\hline CHEMBL1459168 & 688239 & 4.7862 & 5.5542 & TRN & \\
\hline CHEMBL1585436 & 688239 & 4.7862 & \multicolumn{2}{|c|}{5.542999999999999} & TRN \\
\hline CHEMBL3196622 & 688239 & 4.6862 & \multicolumn{2}{|c|}{5.382999999999999} & TRN \\
\hline CHEMBL1503856 & 688239 & \multicolumn{2}{|c|}{8.283999999999999} & 5.4632 & TRN \\
\hline CHEMBL1605560 & 688239 & 5.2362 & 5.5683 & TST & \\
\hline CHEMBL3189851 & 688239 & 4.7362 & 5.5365 & TST & \\
\hline CHEMBL3190012 & 688239 & 6.1362 & 5.49299 & 9999999999 & ונI \\
\hline CHEMBL1311978 & 688239 & 5.1862 & 5.3416 & TRN & \\
\hline CHEMBL1432670 & 688239 & 4.5362 & 5.3767 & TRN & \\
\hline CHEMBL3207497 & 688239 & 4.5362 & 5.5332 & TST & \\
\hline CHEMBL1550966 & 688239 & 4.9862 & 5.5296 & TRN & \\
\hline CHEMBL1388234 & 688239 & 4.5362 & 5.2801 & TRN & \\
\hline CHEMBL1584393 & 688239 & 4.5362 & 5.4696 & TRN & \\
\hline CHEMBL1323969 & 688239 & 6.9863 & 5.5693 & TRN & \\
\hline CHEMBL578742 & 688239 & 5.1862 & 5.5998 & TRN & \\
\hline CHEMBL1351044 & 688239 & 4.9862 & 5.3444 & TRN & \\
\hline CHEMBL1429946 & 688239 & 5.1862 & 5.5055 & TST & \\
\hline CHEMBL1344072 & 688239 & 5.2362 & 5.5165 & TRN & \\
\hline
\end{tabular}

Page 2363 


\begin{tabular}{|c|c|c|c|c|c|}
\hline & & \multicolumn{4}{|c|}{ Supplemental Table S2.txt } \\
\hline CHEMBL1531269 & 688239 & 4.5362 & 5.3752 & TRN & \\
\hline CHEMBL1600519 & 688239 & 6.2 & 5.5132 & TRN & \\
\hline CHEMBL1337296 & 688239 & 5.4362 & 5.4735 & TRN & \\
\hline CHEMBL1423625 & 688239 & 4.8862 & 5.4143 & TRN & \\
\hline CHEMBL1451628 & 688239 & 4.5362 & 5.41700 & 0000000001 & TST \\
\hline CHEMBL1428468 & 688239 & 6.0862 & 5.3933 & TST & \\
\hline CHEMBL1368730 & 688239 & 5.1862 & 5.5689 & TRN & \\
\hline CHEMBL1491547 & 688239 & 4.6862 & 5.5164 & TRN & \\
\hline CHEMBL1992164 & 688239 & 5.1862 & 5.4529 & TRN & \\
\hline CHEMBL1559102 & 688239 & 6.1362 & 5.5248 & TST & \\
\hline CHEMBL1419939 & 688239 & 5.1862 & 5.54 & TRN & \\
\hline CHEMBL1591104 & 688239 & 7.3862 & 5.4822 & TST & \\
\hline CHEMBL1553774 & 688239 & 5.2362 & 5.4363 & TRN & \\
\hline CHEMBL1482309 & 688239 & 5.3362 & 5.4426 & TRN & \\
\hline CHEMBL1449943 & 688239 & 5.6362 & 5.5256 & TRN & \\
\hline CHEMBL1436392 & 688239 & 6.3362 & 5.6017 & TRN & \\
\hline CHEMBL1463152 & 688239 & 5.2362 & 5.62299 & 9999999999 & TRN \\
\hline CHEMBL1471585 & 688239 & 4.4862 & 5.4637 & TRN & \\
\hline CHEMBL1523625 & 688239 & 5.3362 & 5.6196 & TRN & \\
\hline CHEMBL1462728 & 688239 & 4.6862 & 5.5349 & TRN & \\
\hline CHEMBL1421148 & 688239 & 7.1361 & 5.5006 & TST & \\
\hline CHEMBL1346393 & 688239 & 6.9363 & 5.6089 & TRN & \\
\hline CHEMBL1442247 & 688239 & 4.5362 & 5.4759 & TST & \\
\hline CHEMBL1968095 & 688239 & 5.6362 & 5.4412 & TRN & \\
\hline CHEMBL1602908 & 688239 & 4.6362 & 5.4997 & TRN & \\
\hline CHEMBL1403190 & 688239 & 8.3372 & 5.5327 & TRN & \\
\hline CHEMBL3213608 & 688239 & 6.1862 & 5.4503 & TST & \\
\hline CHEMBL1404002 & 688239 & 4.4862 & 5.5632 & TRN & \\
\hline CHEMBL1301522 & 688239 & 5.0362 & 5.4744 & TRN & \\
\hline CHEMBL3191970 & 688239 & 5.3862 & 5.4003 & TST & \\
\hline CHEMBL1393421 & 688239 & 4.5362 & 5.5079 & TRN & \\
\hline CHEMBL1321631 & 688239 & 4.6862 & 5.3528 & TRN & \\
\hline CHEMBL1490928 & 688239 & 4.5362 & 5.5045 & TRN & \\
\hline CHEMBL1465848 & 688239 & 6.1862 & 5.5867 & TRN & \\
\hline CHEMBL1306418 & 688239 & 5.2862 & 5.5146 & TRN & \\
\hline CHEMBL1385688 & 688239 & 4.5362 & 5.4606 & TRN & \\
\hline CHEMBL1528198 & 688239 & 4.9862 & 5.4066 & TRN & \\
\hline CHEMBL1305328 & 688239 & 5.9362 & 5.6257 & TRN & \\
\hline CHEMBL1362141 & 688239 & 6.3863 & 5.5935 & TRN & \\
\hline CHEMBL1383013 & 688239 & 6.2362 & 5.6244 & TRN & \\
\hline CHEMBL1412457 & 688239 & 4.5362 & 5.4961 & TRN & \\
\hline CHEMBL1511524 & 688239 & 5.1362 & 5.4535 & TST & \\
\hline CHEMBL1576120 & 688239 & 5.9362 & 5.5117 & TRN & \\
\hline CHEMBL1376637 & 688239 & 4.8862 & 5.5129 & TRN & \\
\hline CHEMBL1398933 & 688239 & 5.2862 & 5.4967 & TRN & \\
\hline CHEMBL1342811 & 688239 & 4.8362 & 5.5995 & TRN & \\
\hline CHEMBL1552557 & 688239 & 6.2362 & 5.5943 & TRN & \\
\hline CHEMBL1430673 & 688239 & 4.5862 & 5.4691 & TST & \\
\hline
\end{tabular}


Supplemental Table S2.txt

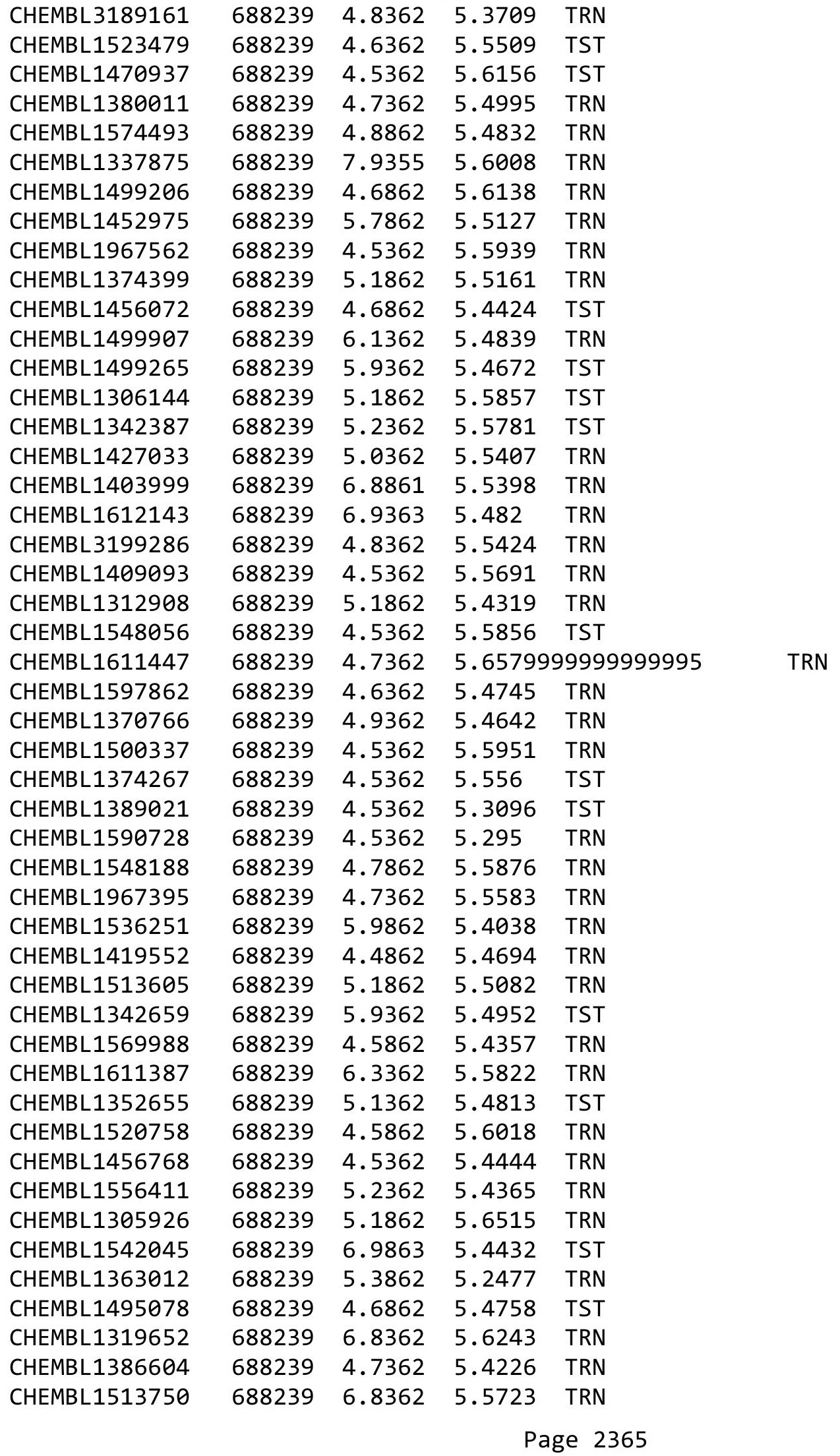


Supplemental Table S2.txt

\begin{tabular}{|c|c|c|c|c|}
\hline CHEMBL1474040 & 688239 & 4.6362 & 5.4865 & TRN \\
\hline CHEMBL1563942 & 688239 & 5.0362 & 5.3378 & TRN \\
\hline CHEMBL1557900 & 688239 & 6.1362 & 5.6558 & TRN \\
\hline CHEMBL1501672 & 688239 & 4.7362 & 5.4159 & TST \\
\hline CHEMBL1604539 & 688239 & 4.8362 & 5.5042 & TRN \\
\hline CHEMBL1324719 & 688239 & 5.9362 & 5.4706 & TST \\
\hline CHEMBL1471591 & 688239 & 4.5362 & 5.3941 & TRN \\
\hline CHEMBL1340273 & 688239 & 6.4362 & 5.4095 & TRN \\
\hline CHEMBL1435302 & 688239 & 4.5862 & 5.4872 & TRN \\
\hline CHEMBL1478665 & 688239 & 5.4862 & \multicolumn{2}{|c|}{5.446000000000001} \\
\hline CHEMBL1339810 & 688239 & 8.1871 & 5.3562 & TRN \\
\hline CHEMBL1559672 & 688239 & 5.2362 & 5.4862 & TST \\
\hline CHEMBL1457671 & 688239 & 4.5362 & 5.4988 & TRN \\
\hline CHEMBL1553138 & 688239 & 5.0862 & 5.3148 & TRN \\
\hline CHEMBL1532422 & 688239 & 6.9863 & 5.5261 & TRN \\
\hline CHEMBL1405332 & 688239 & 4.9862 & 5.4668 & TST \\
\hline CHEMBL1305609 & 688239 & 5.4362 & 5.5564 & TRN \\
\hline CHEMBL1454905 & 688239 & 5.1862 & 5.5489 & TRN \\
\hline CHEMBL1300901 & 688239 & 4.5362 & 5.4567 & TST \\
\hline CHEMBL1425559 & 688239 & 5.5362 & 5.4705 & TRN \\
\hline CHEMBL1529820 & 688239 & 4.6862 & 5.3782 & TRN \\
\hline CHEMBL 255311 & 688239 & 5.6862 & 5.4031 & TRN \\
\hline CHEMBL1455157 & 688239 & 4.9862 & 5.4679 & TRN \\
\hline CHEMBL1432709 & 688239 & 4.5362 & 5.5287 & TRN \\
\hline CHEMBL1335942 & 688239 & 6.0862 & 5.5993 & TST \\
\hline CHEMBL1379983 & 688239 & 5.0862 & 5.3512 & TRN \\
\hline CHEMBL1388129 & 688239 & 6.9363 & 5.4289 & TRN \\
\hline CHEMBL1306181 & 688239 & 4.8362 & 5.5371 & TRN \\
\hline CHEMBL1411474 & 688239 & 5.2362 & 5.4016 & TRN \\
\hline CHEMBL1501525 & 688239 & 5.2362 & 5.4932 & TST \\
\hline CHEMBL1303089 & 688239 & 4.4862 & 5.5126 & TST \\
\hline CHEMBL1461243 & 688239 & 4.6862 & 5.6306 & TST \\
\hline CHEMBL1337313 & 688239 & 6.2362 & 5.4186 & TST \\
\hline CHEMBL1305652 & 688239 & 5.4362 & 5.5144 & TST \\
\hline CHEMBL1585337 & 688239 & 4.7362 & 5.5761 & TRN \\
\hline CHEMBL1541915 & 688239 & 4.6362 & 5.6617 & TRN \\
\hline CHEMBL1499659 & 688239 & 4.4862 & 5.3776 & TRN \\
\hline CHEMBL483190 & 688239 & 5.1862 & 5.4421 & TRN \\
\hline CHEMBL1457850 & 688239 & 4.5362 & \multicolumn{2}{|c|}{5.622999999999999} \\
\hline CHEMBL1329585 & 688239 & 4.8362 & 5.4359 & TRN \\
\hline CHEMBL1609497 & 688239 & 4.5362 & 5.4257 & TST \\
\hline CHEMBL1478717 & 688239 & 7.6364 & 5.5066 & TRN \\
\hline CHEMBL1557021 & 688239 & 7.0362 & 5.4857 & TRN \\
\hline CHEMBL1989673 & 688239 & 5.8362 & 5.4303 & TST \\
\hline CHEMBL1304297 & 688239 & 5.4862 & 5.5859 & TST \\
\hline CHEMBL1442962 & 688239 & 6.6362 & 5.4658 & TRN \\
\hline CHEMBL1574737 & 688239 & 7.0362 & 5.4054 & TST \\
\hline CHEMBL1410143 & 688239 & 4.5362 & 5.4856 & TRN \\
\hline
\end{tabular}


Supplemental Table S2.txt

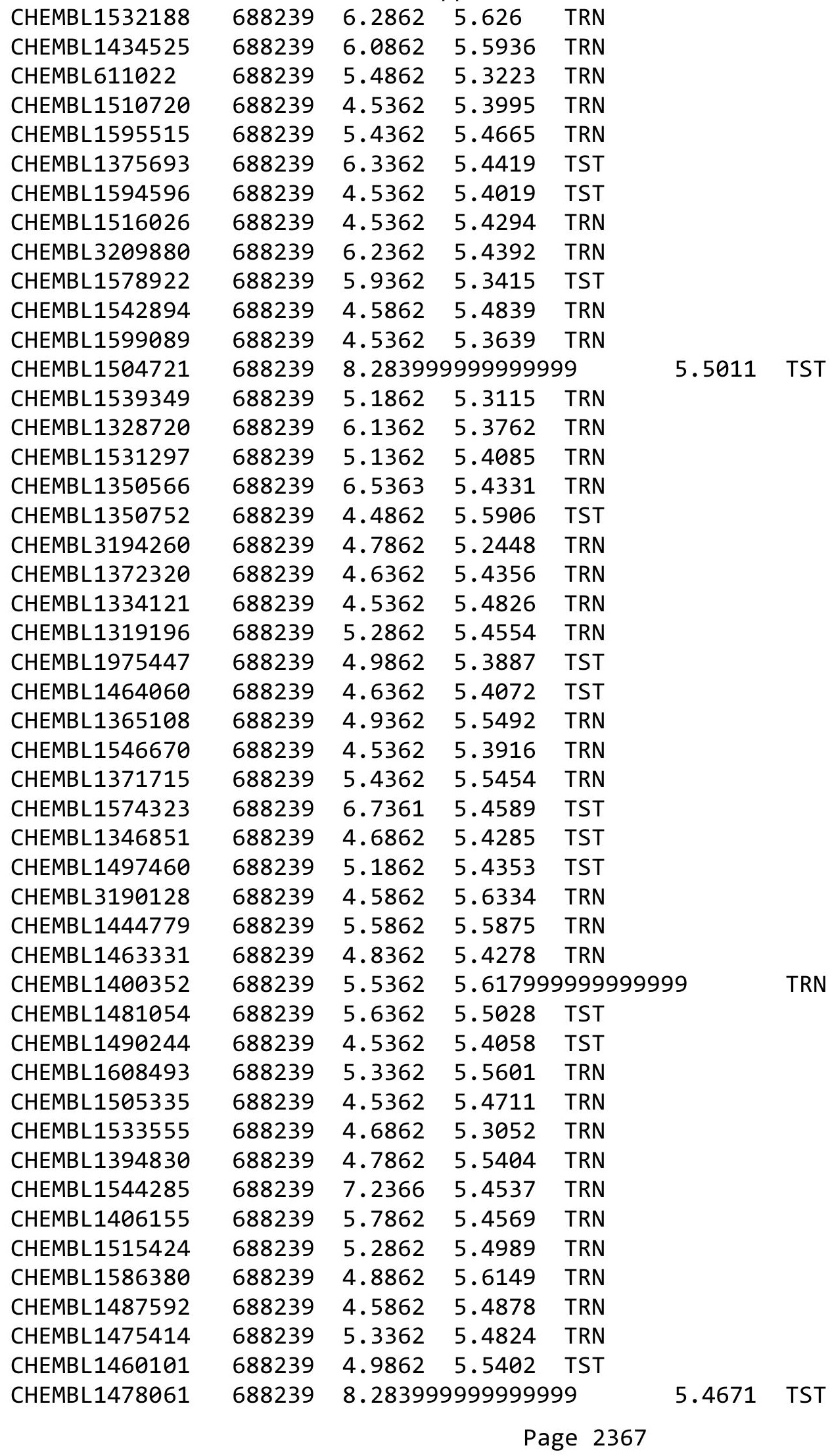




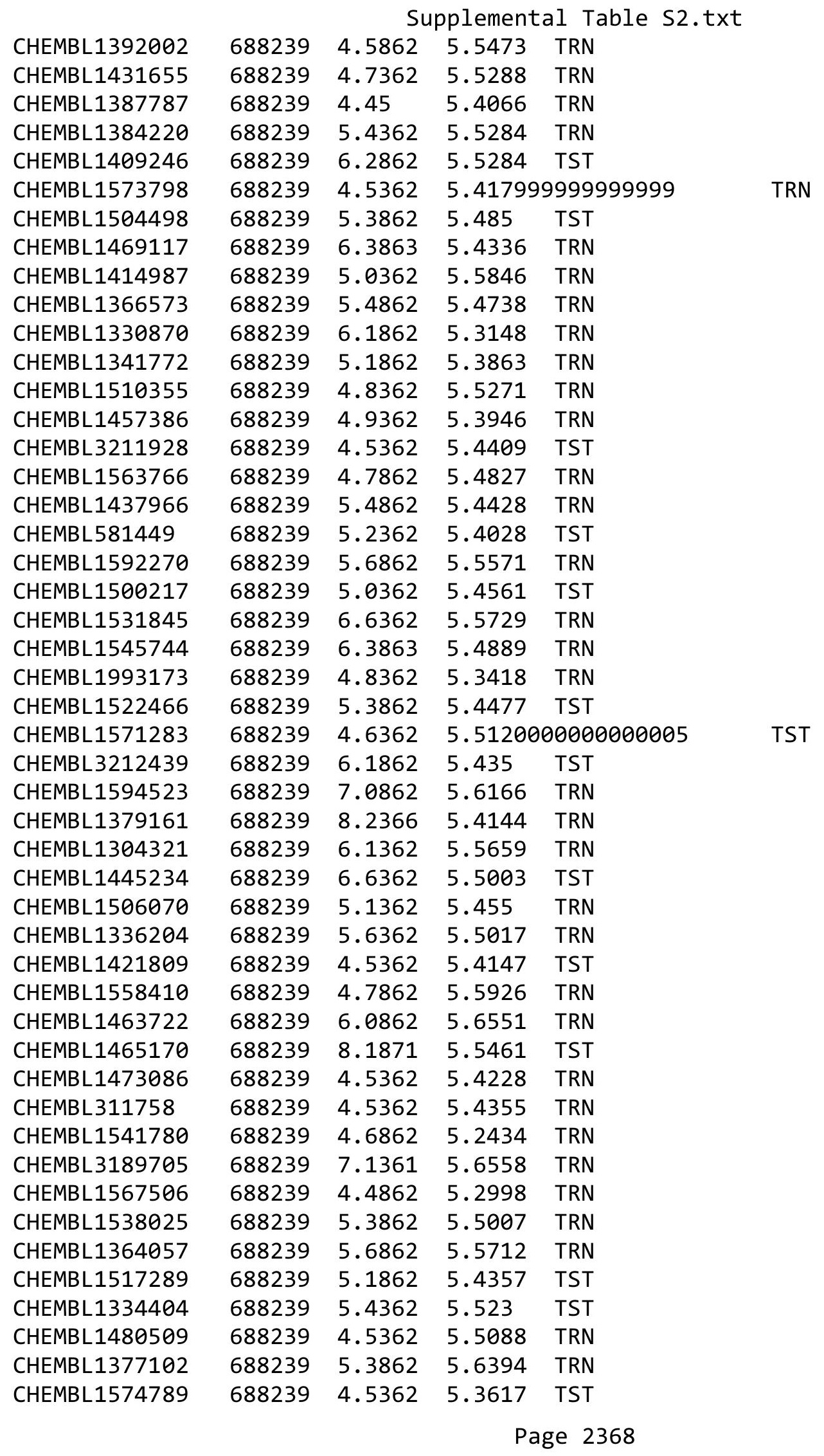


Supplemental Table S2.txt

\begin{tabular}{|c|c|c|c|c|}
\hline 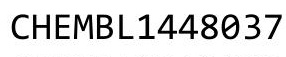 & & & & \\
\hline HEMBL3212299 & 88239 & 5362 & 4278 & \\
\hline HEMBL1538441 & 88239 & 5362 & 4979 & \\
\hline IEMBL1 & & & & \\
\hline EMBL13 & & & & \\
\hline HEMBL1376040 & 88239 & 362 & & \\
\hline HEMBL3198005 & 88239 & .4862 & .2487 & \\
\hline HEMBL13 & & & & \\
\hline IEMBL3. & 39 & & & \\
\hline IEMBL155 & 39 & & & \\
\hline HEMBL1456155 & 88239 & 362 & & \\
\hline HEMBL134 & 39 & 362 & & \\
\hline HEMBL151 & 39 & 65 & 57 & \\
\hline HEMBL14 & 39 & & & \\
\hline AEMBL13 & 39 & & & \\
\hline HEMBL15e & 39 & 62 & & \\
\hline HEMBL158 & 39 & & & \\
\hline HEMBL 148 & 9 & & & \\
\hline HEMBL14 & 9 & & & \\
\hline HEMBL15 & 39 & & & \\
\hline HEMBL15e & 39 & & & \\
\hline HEMBL133 & 39 & & & \\
\hline HEMBL14ع & 39 & & & \\
\hline HEMBL13 & & & & \\
\hline HEM & 39 & & & \\
\hline HEMBL 14 & 39 & & & \\
\hline AEMBL156 & 39 & & & IRN \\
\hline HEMBL13 & 39 & & & \\
\hline HEME & & & & \\
\hline HEN & & & & $\mathrm{RN}$ \\
\hline HEMBL132 & 9 & & & ( \\
\hline HEMBL148 & 39 & & & TRN \\
\hline HEMBL14 & & & & 31 \\
\hline HEM & 9 & & & 「RN \\
\hline HEMBL15 & & & & RN \\
\hline HEMBL3199835 & 39 & & & IST \\
\hline HEMBL1595407 & 39 & & & TRN \\
\hline 3 & 39 & & & \\
\hline 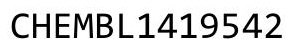 & 39 & & & \\
\hline HEMBL151 & & & & RN \\
\hline HEMBL 147 & 88239 & & & TRN \\
\hline HEMBL13 & 39 & & & \\
\hline 5 & & & & \\
\hline LHEMBL132 & & & & RIN \\
\hline HEMBL1499174 & & & & $2 \mathrm{~N}$ \\
\hline HEMBL154 & 39 & 62 & & \\
\hline L15 & & & & \\
\hline 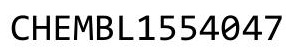 & & & & \\
\hline
\end{tabular}

Page 2369 
Supplemental Table S2.txt

\begin{tabular}{|c|c|c|c|c|}
\hline CHEMBL1472168 & 688239 & 6.6362 & 5.4193 & TRN \\
\hline CHEMBL1362318 & 688239 & 6.7862 & 5.386 & TST \\
\hline CHEMBL1447869 & 688239 & 4.5362 & 5.5088 & TRN \\
\hline CHEMBL1494072 & 688239 & 7.7852 & 5.5053 & TRN \\
\hline CHEMBL1366369 & 688239 & 5.6362 & 5.4114 & TRN \\
\hline CHEMBL1550058 & 688239 & 7.5361 & 5.6401 & TRN \\
\hline CHEMBL1470204 & 688239 & 5.8362 & 5.4884 & TST \\
\hline CHEMBL1342746 & 688239 & 5.3362 & 5.5043 & TRN \\
\hline CHEMBL1307727 & 688239 & 4.4862 & 5.4004 & TST \\
\hline CHEMBL1483090 & 688239 & 7.3363 & 5.3851 & TRN \\
\hline CHEMBL 3214257 & 688239 & 6.2362 & 5.4609 & TRN \\
\hline CHEMBL1302670 & 688239 & 4.9362 & 5.5556 & TST \\
\hline CHEMBL1532817 & 688239 & 5.6862 & 5.5492 & TST \\
\hline CHEMBL1546502 & 688239 & 5.1862 & 5.5584 & TRN \\
\hline CHEMBL1543254 & 688239 & 5.6362 & 5.4307 & TRN \\
\hline CHEMBL1495230 & 688239 & 5.5362 & 5.5226 & TRN \\
\hline CHEMBL1302241 & 688239 & 4.6362 & 5.3144 & TST \\
\hline CHEMBL1462146 & 688239 & 5.6362 & 5.4248 & TST \\
\hline CHEMBL 3210009 & 688239 & 6.9363 & 5.4799 & TRN \\
\hline CHEMBL1530686 & 688239 & 5.2362 & 5.4575 & TRN \\
\hline CHEMBL1325651 & 688239 & 6.2362 & 5.4335 & TRN \\
\hline CHEMBL1573899 & 688239 & 8.28399 & 99999999 & 5.4505 \\
\hline CHEMBL1525480 & 688239 & 5.2862 & 5.4031 & TRN \\
\hline CHEMBL1386178 & 688239 & 4.7862 & 5.522 & TRN \\
\hline CHEMBL1439079 & 688239 & 4.5362 & 5.5587 & TRN \\
\hline CHEMBL1324273 & 688239 & 5.1862 & 5.5115 & TRN \\
\hline CHEMBL1608292 & 688239 & 6.2362 & 5.5498 & TRN \\
\hline CHEMBL1577058 & 688239 & 5.2862 & 5.502006 & 0000000001 \\
\hline CHEMBL1488661 & 688239 & 6.7862 & 5.5125 & TRN \\
\hline CHEMBL1599703 & 688239 & 4.4862 & 5.4109 & TRN \\
\hline CHEMBL1330431 & 688239 & 4.7362 & 5.4088 & TRN \\
\hline CHEMBL1313283 & 688239 & 4.5362 & 5.3687 & TST \\
\hline CHEMBL1522471 & 688239 & 4.5362 & 5.6015 & TRN \\
\hline CHEMBL1462206 & 688239 & 4.5362 & 5.4887 & TRN \\
\hline CHEMBL1346853 & 688239 & 4.6862 & 5.4309 & TST \\
\hline CHEMBL1392711 & 688239 & 4.6862 & 5.5847 & TST \\
\hline CHEMBL1324772 & 688239 & 5.5862 & 5.6732 & TRN \\
\hline CHEMBL1609646 & 688239 & 5.0862 & 5.7002 & TST \\
\hline CHEMBL1481069 & 688239 & 4.5362 & 5.5778 & TST \\
\hline CHEMBL1988133 & 688239 & 4.5362 & 5.4593 & TRN \\
\hline CHEMBL1609752 & 688239 & 5.8362 & 5.5913 & TRN \\
\hline CHEMBL1308882 & 688239 & 6.4862 & 5.4433 & TRN \\
\hline CHEMBL1310151 & 688239 & 6.2362 & 5.4333 & TRN \\
\hline CHEMBL600976 & 688239 & 5.5362 & 5.5104 & TRN \\
\hline CHEMBL1523802 & 688239 & 5.1862 & 5.5302 & TRN \\
\hline CHEMBL1349225 & 688239 & 4.4862 & 5.2595 & TRN \\
\hline CHEMBL1411640 & 688239 & 6.9863 & 5.399 & TRN \\
\hline CHEMBL1529292 & 688239 & 4.4862 & 5.6414 & TRN \\
\hline
\end{tabular}


Supplemental Table S2.txt

CHEMBL1401853
CHEMBL1397778
CHEMBL1402772
CHEMBL1527503
CHEMBL1386050
CHEMBL1461706
CHEMBL1528695

CHEMBL1361153

CHEMBL1299705

CHEMBL1499660

CHEMBL1364341

CHEMBL1411789

CHEMBL1511117

CHEMBL1446852

CHEMBL1496496

CHEMBL1481206

CHEMBL1473829

CHEMBL1578699

CHEMBL1520713

CHEMBL1506270

CHEMBL1590985

CHEMBL1343821

CHEMBL1542067

CHEMBL1359149

CHEMBL1384648

CHEMBL1452593

CHEMBL1364591

CHEMBL1160544

CHEMBL1318912

CHEMBL1515716

CHEMBL1567532

CHEMBL1303736

CHEMBL1413553

CHEMBL1465721

CHEMBL1556137

CHEMBL1330221

CHEMBL1507589

CHEMBL3193286

CHEMBL1364819

CHEMBL1544500

CHEMBL1326336

CHEMBL1386208

CHEMBL 3193878

CHEMBL1429742

CHEMBL1321399

CHEMBL1605075

CHEMBL1328325

CHEMBL1608651

688239

688239

688239

688239

688239

688239

688239

688239

688239

688239

688239

688239

688239

688239

688239

688239

688239

688239

688239

688239

688239

688239

688239

688239

688239

688239

688239

688239

688239

688239

688239

688239

688239

688239

688239

688239

688239

688239

688239

688239

688239

688239

688239

688239

688239

688239

688239

688239 $\begin{array}{lll}4.5362 & 5.5138 \text { TRN }\end{array}$

$\begin{array}{lll}6.4862 & 5.532 & \text { TRN }\end{array}$

4.78625 .5343 TST

$4.5362 \quad 5.5142$ TST

4.63625 .4823 TRN

$\begin{array}{lll}5.9362 & 5.3526 & \text { TRN }\end{array}$

$6.0362 \quad 5.5446$ TRN

$4.8862 \quad 5.5044$ TST

$\begin{array}{lll}4.5362 & 5.454 & \text { TRN }\end{array}$

$\begin{array}{lll}5.4362 & 5.444 & \text { TRN }\end{array}$

$\begin{array}{lll}4.6862 & 5.3032 & \text { TRN }\end{array}$

$4.5362 \quad 5.4563$ TRN

$4.7362 \quad 5.6328$ TRN

$\begin{array}{lll}5.3862 & 5.382000000000001 & \text { TST }\end{array}$

$\begin{array}{llll}6.3863 & 5.3748 \text { TRN }\end{array}$

$\begin{array}{lll}5.3362 & 5.5328 & \text { TRN }\end{array}$

$5.2362 \quad 5.4488$ TRN

$\begin{array}{lll}4.4862 & 5.3317 & \text { TST }\end{array}$

$\begin{array}{lll}5.1862 & 5.5354 & \text { TRN }\end{array}$

$5.5362 \quad 5.4365$ TST

$\begin{array}{lll}7.0362 & 5.5302 & \text { TRN }\end{array}$

$\begin{array}{lll}4.7362 & 5.4888 & \text { TST }\end{array}$

$\begin{array}{lll}5.1862 & 5.4448 & \text { TST }\end{array}$

$\begin{array}{lll}6.3362 & 5.5184 & \text { TRN }\end{array}$

$\begin{array}{lll}4.5362 & 5.3739 & \text { TRN }\end{array}$

$\begin{array}{lll}4.7862 & 5.3681 & \text { TRN }\end{array}$

$\begin{array}{lll}4.8362 & 5.562 & \text { TRN }\end{array}$

$\begin{array}{lll}7.0362 & 5.3841 & \text { TST }\end{array}$

$\begin{array}{lll}5.7362 & 5.5172 & \text { TRN }\end{array}$

$6.8861 \quad 5.5448$ TRN

$5.4362 \quad 5.4452$ TRN

8.283999999999999

$\begin{array}{lll}4.5362 & 5.6685 & \text { TRN }\end{array}$

$\begin{array}{lll}4.4862 & 5.4179 & \text { TST }\end{array}$

$\begin{array}{lll}5.1862 & 5.5084 & \text { TRN }\end{array}$

$\begin{array}{lll}4.7862 & 5.5067 & \text { TRN }\end{array}$

$\begin{array}{lll}4.8362 & 5.3227 & \text { TRN }\end{array}$

$6.2862 \quad 5.3429$ TRN

$6.9363 \quad 5.5246$ TRN

$4.5362 \quad 5.393$ TRN

$\begin{array}{lll}4.5362 & 5.4379 & \text { TRN }\end{array}$

$\begin{array}{lll}5.7362 & 5.4962 & \text { TRN }\end{array}$

$\begin{array}{lll}4.5362 & 5.4315 & \text { TRN }\end{array}$

$8.3372 \quad 5.5853$ TRN

4.88625 .4561 TRN

$5.3862 \quad 5.4738$ TRN

4.63625 .4396 TRN

8.283999999999999
5.4605 TST

5.4605 TST

Page 2371

5.638999999999999

TST 
Supplemental Table S2.txt

\begin{tabular}{|c|c|c|c|c|}
\hline CHEMBL1564801 & 688239 & 4.7862 & 5.3173 & TST \\
\hline CHEMBL1506921 & 688239 & 5.1862 & 5.3899 & TST \\
\hline CHEMBL1402526 & 688239 & 4.6362 & 5.2961 & TRN \\
\hline CHEMBL1341696 & 688239 & 4.5362 & 5.4044 & TRN \\
\hline CHEMBL1300469 & 688239 & 6.6861 & 5.5373 & TRN \\
\hline CHEMBL1385817 & 688239 & 6.8861 & 5.5683 & TRN \\
\hline CHEMBL1370680 & 688239 & 5.8362 & 5.7358 & TRN \\
\hline CHEMBL1471894 & 688239 & 5.1862 & 5.5209 & TRN \\
\hline CHEMBL1340105 & 688239 & 4.6862 & 5.5058 & TRN \\
\hline CHEMBL1451580 & 688239 & 6.3362 & 5.4177 & TRN \\
\hline CHEMBL1561710 & 688239 & 5.3862 & 5.4771 & TRN \\
\hline CHEMBL1330351 & 688239 & 4.5362 & 5.4335 & TRN \\
\hline CHEMBL1434546 & 688239 & 5.5362 & 5.4902 & TRN \\
\hline CHEMBL1366756 & 688239 & 4.5862 & 5.4296 & TST \\
\hline CHEMBL1497172 & 688239 & 4.5362 & 5.5957 & TRN \\
\hline CHEMBL1600566 & 688239 & 4.5862 & 5.4021 & TRN \\
\hline CHEMBL1497139 & 688239 & 5.2862 & 5.4139 & TRN \\
\hline CHEMBL1613038 & 688239 & 6.9363 & 5.3497 & TRN \\
\hline CHEMBL 3214254 & 688239 & 7.1361 & 5.3327 & TST \\
\hline CHEMBL1537093 & 688239 & 4.6362 & 5.3868 & TRN \\
\hline CHEMBL1464740 & 688239 & 5.0862 & 5.3932 & TRN \\
\hline CHEMBL1510789 & 688239 & 6.3362 & 5.4752 & TRN \\
\hline CHEMBL1436885 & 688239 & 5.7362 & 5.46700 & 30000000005 \\
\hline CHEMBL1568603 & 688239 & 6.9863 & 5.4681 & TST \\
\hline CHEMBL1605596 & 688239 & 4.5862 & 5.3662 & TRN \\
\hline CHEMBL 3211405 & 688239 & 8.3872 & 5.4856 & TRN \\
\hline CHEMBL1438740 & 688239 & 5.1862 & 5.6347 & TRN \\
\hline CHEMBL1346786 & 688239 & 5.3862 & 5.3761 & TRN \\
\hline CHEMBL1406984 & 688239 & 6.5363 & 5.5333 & TRN \\
\hline CHEMBL 3195342 & 688239 & 6.9363 & 5.5086 & TRN \\
\hline CHEMBL3208039 & 688239 & 5.7362 & 5.4117 & TRN \\
\hline CHEMBL1312228 & 688239 & 6.1362 & 5.6164 & TST \\
\hline CHEMBL1582722 & 688239 & 6.1862 & 5.5479 & TRN \\
\hline CHEMBL1485087 & 688239 & 4.7862 & 5.3806 & TRN \\
\hline CHEMBL1577224 & 688239 & 4.6862 & 5.407 & TST \\
\hline CHEMBL1556275 & 688239 & 4.5362 & 5.466 & TRN \\
\hline CHEMBL1516757 & 688239 & 8.3372 & 5.5554 & TRN \\
\hline CHEMBL1563719 & 688239 & 5.4362 & 5.4453 & TRN \\
\hline CHEMBL1587451 & 688239 & 4.5362 & 5.5072 & TRN \\
\hline CHEMBL1611189 & 688239 & 4.9862 & 5.5293 & TRN \\
\hline CHEMBL1601559 & 688239 & 5.4862 & 5.5234 & TST \\
\hline CHEMBL1441777 & 688239 & 6.4362 & 5.4157 & TST \\
\hline CHEMBL1398566 & 688239 & 4.7862 & 5.5229 & TRN \\
\hline CHEMBL1490988 & 688239 & 4.5362 & 5.4044 & TST \\
\hline CHEMBL1401167 & 688239 & 5.0862 & 5.5392 & TRN \\
\hline CHEMBL1316575 & 688239 & 4.5362 & 5.4183 & TST \\
\hline CHEMBL 2000253 & 688239 & 8.3372 & 5.4228 & TRN \\
\hline CHEMBL1404875 & 688239 & 4.8362 & 5.5112 & TRN \\
\hline
\end{tabular}


Supplemental Table S2.txt

\begin{tabular}{|c|c|c|c|c|c|}
\hline CHEMBL1979987 & 688239 & 5.1362 & 5.388 & TRN & \\
\hline CHEMBL1611596 & 688239 & 4.6862 & 5.4981 & TST & \\
\hline CHEMBL1553954 & 688239 & 4.7862 & 5.4823 & TST & \\
\hline CHEMBL1547728 & 688239 & 5.0362 & 5.4809 & TST & \\
\hline CHEMBL1544264 & 688239 & 4.5362 & 5.4403 & TRN & \\
\hline CHEMBL1516519 & 688239 & 6.7361 & 5.4614 & TRN & \\
\hline CHEMBL1374250 & 688239 & 5.3362 & 5.5569 & TRN & \\
\hline CHEMBL1306143 & 688239 & 4.6862 & 5.5057 & TST & \\
\hline CHEMBL1538616 & 688239 & 5.3362 & 5.6962 & TRN & \\
\hline CHEMBL1515475 & 688239 & 5.7362 & 5.5489 & TRN & \\
\hline CHEMBL1378597 & 688239 & 6.6362 & 5.4941 & TRN & \\
\hline CHEMBL1551582 & 688239 & 6.0862 & 5.5029 & TRN & \\
\hline CHEMBL1397172 & 688239 & 6.8861 & 5.5413 & TST & \\
\hline CHEMBL1428836 & 688239 & 4.7862 & 5.6081 & TRN & \\
\hline CHEMBL1313811 & 688239 & 4.6862 & 5.532999 & 9999999995 & \\
\hline CHEMBL1443974 & 688239 & 6.9363 & 5.3908 & TST & \\
\hline CHEMBL1508238 & 688239 & 8.28399 & 99999999 & 5.4811 & Tार \\
\hline CHEMBL1342393 & 688239 & 4.6862 & 5.4434 & TRN & \\
\hline CHEMBL1320587 & 688239 & 6.7862 & 5.4859 & TRN & \\
\hline CHEMBL1461554 & 688239 & 4.8862 & 5.6445 & TRN & \\
\hline CHEMBL1612472 & 688239 & 4.4862 & 5.4945 & TRN & \\
\hline CHEMBL3196577 & 688239 & 5.8862 & 5.3539 & TRN & \\
\hline CHEMBL1379354 & 688239 & 5.4362 & 5.5197 & TRN & \\
\hline CHEMBL1528393 & 688239 & 4.5362 & 5.4956 & TRN & \\
\hline CHEMBL1322959 & 688239 & 5.5362 & 5.4279 & TRN & \\
\hline CHEMBL3193468 & 688239 & 5.1362 & 5.3768 & TRN & \\
\hline CHEMBL1581712 & 688239 & 4.9362 & 5.6816 & TRN & \\
\hline CHEMBL1503410 & 688239 & 4.7862 & 5.5266 & TST & \\
\hline CHEMBL1515433 & 688239 & 6.3362 & 5.4706 & TRN & \\
\hline CHEMBL1357457 & 688239 & 7.1361 & 5.2718 & TRN & \\
\hline CHEMBL57013 & 688239 & 4.5362 & 5.4933 & TST & \\
\hline CHEMBL1334221 & 688239 & 4.5362 & 5.6599 & TRN & \\
\hline CHEMBL1372909 & 688239 & 4.4862 & 5.5216 & TST & \\
\hline CHEMBL1495589 & 688239 & 6.8362 & 5.4966 & TRN & \\
\hline CHEMBL1506395 & 688239 & 6.2362 & 5.4019 & TST & \\
\hline CHEMBL1328379 & 688239 & 4.7362 & 5.5501 & TRN & \\
\hline CHEMBL1557024 & 688239 & 6.1862 & 5.3967 & TRN & \\
\hline CHEMBL1368384 & 688239 & 7.0862 & 5.4197 & TRN & \\
\hline CHEMBL1553077 & 688239 & 4.5362 & 5.4588 & TRN & \\
\hline CHEMBL1535343 & 688239 & 4.5362 & 5.5449 & TRN & \\
\hline CHEMBL1528757 & 688239 & 5.0362 & 5.4871 & TST & \\
\hline CHEMBL1491935 & 688239 & 6.3362 & 5.553999 & 999999999 & TRN \\
\hline CHEMBL1468557 & 688239 & 4.7362 & 5.513 & TST & \\
\hline CHEMBL1414341 & 688239 & 7.2865 & 5.4629 & TST & \\
\hline CHEMBL1337667 & 688239 & 4.5862 & 5.3671 & TRN & \\
\hline CHEMBL1429903 & 688239 & 4.5362 & 5.5772 & TRN & \\
\hline CHEMBL 3198047 & 688239 & 4.5362 & 5.6559 & TRN & \\
\hline CHEMBL 3207387 & 688239 & 5.5862 & 5.5758 & TRN & \\
\hline
\end{tabular}


Supplemental Table S2.txt

\begin{tabular}{|c|c|c|c|c|c|}
\hline CHEMBL1414160 & 688239 & 4.5362 & 5.4064 & TST & \\
\hline CHEMBL1447319 & 688239 & 5.5862 & 5.3824 & TST & \\
\hline CHEMBL1537551 & 688239 & 5.1362 & 5.4493 & TRN & \\
\hline CHEMBL1401857 & 688239 & 4.6862 & 5.3879 & TRN & \\
\hline CHEMBL1370460 & 688239 & 6.8362 & 5.4296 & TRN & \\
\hline CHEMBL1505719 & 688239 & 8.3372 & 5.7166 & TRN & \\
\hline CHEMBL1491685 & 688239 & 4.8862 & 5.4818 & TST & \\
\hline CHEMBL1455231 & 688239 & 5.0862 & 5.506 & TRN & \\
\hline CHEMBL1545530 & 688239 & 5.8362 & 5.635 & TRN & \\
\hline CHEMBL1525475 & 688239 & 5.0862 & 5.4924 & TST & \\
\hline CHEMBL1442489 & 688239 & 4.5862 & 5.2248 & TRN & \\
\hline CHEMBL1536926 & 688239 & 4.5362 & 5.5684 & TST & \\
\hline CHEMBL1549619 & 688239 & 4.5362 & 5.3561 & TST & \\
\hline CHEMBL1342356 & 688239 & 4.8862 & 5.6831 & TRN & \\
\hline CHEMBL1552374 & 688239 & 5.7362 & 5.4046 & TRN & \\
\hline CHEMBL1343831 & 688239 & 4.4862 & 5.5967 & TRN & \\
\hline CHEMBL1413993 & 688239 & 6.1862 & 5.4361 & TRN & \\
\hline CHEMBL1454363 & 688239 & 4.5362 & 5.50200 & 0000000001 & TRN \\
\hline CHEMBL1502573 & 688239 & 4.5362 & 5.5374 & TST & \\
\hline CHEMBL 208484 & 688239 & 6.9363 & 5.5376 & TST & \\
\hline CHEMBL1581972 & 688239 & 4.7862 & 5.3853 & TRN & \\
\hline CHEMBL1497661 & 688239 & 4.5362 & 5.5453 & TRN & \\
\hline CHEMBL1493668 & 688239 & 5.5862 & 5.4085 & TRN & \\
\hline CHEMBL1334175 & 688239 & 5.9862 & 5.379 & TRN & \\
\hline CHEMBL1349722 & 688239 & 4.5362 & \multicolumn{2}{|c|}{5.542000000000001} & TRN \\
\hline CHEMBL1509111 & 688239 & 5.1862 & 5.415 & TRN & \\
\hline CHEMBL1314361 & 688239 & 5.2862 & 5.4874 & TRN & \\
\hline CHEMBL1381903 & 688239 & 5.8362 & 5.7039 & TRN & \\
\hline CHEMBL1322785 & 688239 & 6.6362 & 5.4951 & TRN & \\
\hline CHEMBL1502435 & 688239 & 5.3362 & 5.4934 & TRN & \\
\hline CHEMBL1405878 & 688239 & 6.0862 & 5.3675 & TRN & \\
\hline CHEMBL1316090 & 688239 & 5.1362 & 5.3497 & TRN & \\
\hline CHEMBL1440058 & 688239 & 5.1862 & 5.331 & TRN & \\
\hline CHEMBL1602618 & 688239 & 5.7362 & 5.5243 & TST & \\
\hline CHEMBL1515847 & 688239 & 5.7362 & 5.4366 & TRN & \\
\hline CHEMBL1505653 & 688239 & 4.5362 & 5.4172 & TRN & \\
\hline CHEMBL1427861 & 688239 & 5.3362 & 5.3805 & TRN & \\
\hline CHEMBL1440661 & 688239 & 5.1862 & 5.5105 & TST & \\
\hline CHEMBL1489335 & 688239 & 4.5862 & 5.4984 & TST & \\
\hline CHEMBL1411421 & 688239 & 6.4362 & 5.5208 & TRN & \\
\hline CHEMBL1479331 & 688239 & 8.3872 & 5.5601 & TRN & \\
\hline CHEMBL1365870 & 688239 & 4.5362 & 5.5157 & TRN & \\
\hline CHEMBL1496460 & 688239 & 5.1862 & 5.3319 & TRN & \\
\hline CHEMBL1570088 & 688239 & 6.0862 & 5.6342 & TRN & \\
\hline CHEMBL1427140 & 688239 & 4.6362 & 5.4818 & TRN & \\
\hline CHEMBL1559661 & 688239 & 4.6862 & 5.4277 & TRN & \\
\hline CHEMBL1341273 & 688239 & 4.6862 & 5.5507 & TRN & \\
\hline CHEMBL 3197832 & 688239 & 5.7862 & 5.5712 & TST & \\
\hline
\end{tabular}


Supplemental Table S2.txt

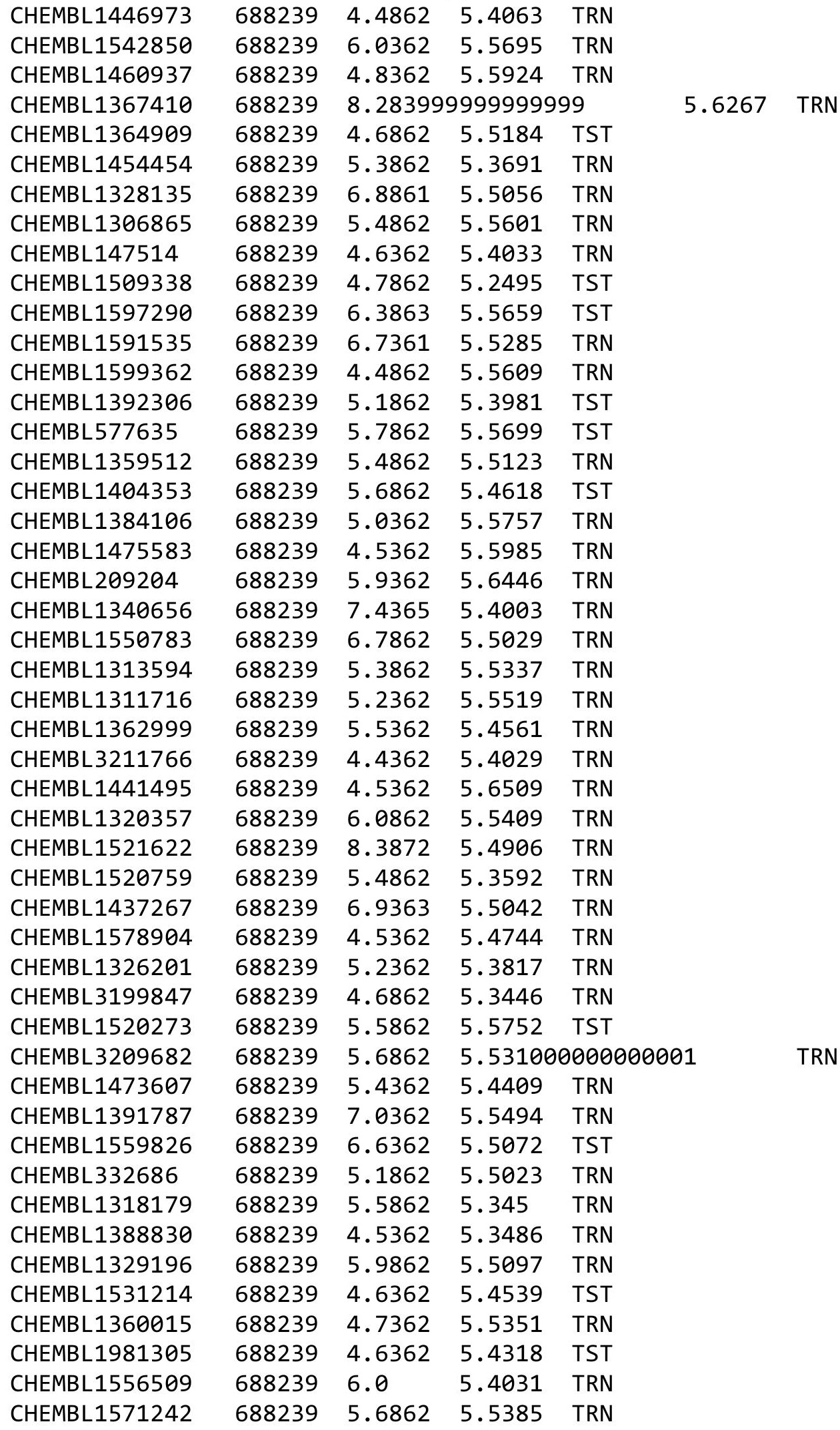


Supplemental Table S2.txt

\begin{tabular}{|c|c|c|c|c|}
\hline & & & & \\
\hline AEMBL 15 & 38239 & 4862 & 6039 & \\
\hline IEMBL3145078 & 8239 & 5362 & 4749 & \\
\hline AEMBL1345054 & 3239 & 1862 & 4049 & \\
\hline 298 & 239 & & & \\
\hline IEMBL1582639 & 239 & 62 & 718 & \\
\hline AEMBL1591625 & 88239 & 362 & 4771 & \\
\hline AEMBL1442885 & 88239 & 862 & 3779 & \\
\hline AEMBL1420812 & 239 & 362 & & \\
\hline IEMBL15 & 239 & 62 & & \\
\hline HEMBL 200 & & & & \\
\hline AEMBL1583678 & 688239 & 362 & & \\
\hline AEMBL1447151 & 239 & 862 & & \\
\hline AEMBL131 & & & & \\
\hline IEMBL14 & & & & \\
\hline HEMBL 148 & & & & \\
\hline AEMBL1370110 & 239 & 366 & & \\
\hline AEMBL16e & & 62 & & \\
\hline IEMBL1422140 & & 52 & & \\
\hline HEMBL13 & & & & \\
\hline AEMBL14 & & & & \\
\hline AEMBL1404915 & & & & \\
\hline JEMBL14 & & & & \\
\hline IEMBL31 & & & & \\
\hline EMBL14 & & & & \\
\hline AFMRI 15 & & & & \\
\hline AEMBL1527431 & & & & \\
\hline AEMBL3210332 & & & & \\
\hline AEMBL1340538 & & & 77 & \\
\hline HEMBL16 & & & 56 & \\
\hline 523 & & & & \\
\hline HEMBL1576088 & & & & \\
\hline AEMBL1558171 & & & & \\
\hline AEMBL1496377 & & & & \\
\hline AEMBL13 & & & & \\
\hline 160 & & & & \\
\hline AEMBL1350831 & & & & \\
\hline AEMBL1362386 & & 362 & & \\
\hline IEMBL134 & & & & \\
\hline חרי ובנזו & & & & \\
\hline HEMBL136 & & & & \\
\hline HEMBL1416997 & & 362 & + & \\
\hline IEMBL14 & & & & \\
\hline 509 & & & & \\
\hline CHEMBL1518450 & & & .5625 & \\
\hline CHEMBL130 & & & .55 & \\
\hline AEMBL3212216 & 88239 & 5.0862 & 5.5141 & \\
\hline HFMRI 1315861 & 688239 & 6.2362 & 5.5716 & \\
\hline
\end{tabular}

Page 2376 
Supplemental Table S2.txt

\begin{tabular}{|c|c|c|c|c|}
\hline CHEMBL3193319 & 688239 & 4.6362 & 5.5369 & TRN \\
\hline CHEMBL1521497 & 688239 & 4.4862 & 5.5125 & TRN \\
\hline CHEMBL1587713 & 688239 & 5.1862 & 5.6095 & TRN \\
\hline CHEMBL1491636 & 688239 & 4.7362 & 5.3713 & TST \\
\hline CHEMBL1320635 & 688239 & 6.4862 & 5.3551 & TRN \\
\hline CHEMBL1356527 & 688239 & 4.7862 & 5.5198 & TRN \\
\hline CHEMBL3210476 & 688239 & 5.5862 & 5.4415 & TRN \\
\hline CHEMBL1568182 & 688239 & 8.2366 & 5.5172 & TRN \\
\hline CHEMBL1582650 & 688239 & 5.1862 & 5.5816 & TRN \\
\hline CHEMBL3208729 & 688239 & 5.1862 & 5.4577 & TRN \\
\hline CHEMBL1516062 & 688239 & 4.5362 & 5.4259 & TRN \\
\hline CHEMBL1348403 & 688239 & 6.0862 & 5.4645 & TRN \\
\hline CHEMBL488803 & 688239 & 4.5362 & 5.4259 & TRN \\
\hline CHEMBL1607451 & 688239 & 5.1862 & 5.5176 & TRN \\
\hline CHEMBL1524033 & 688239 & 4.7862 & 5.4217 & TRN \\
\hline CHEMBL1575608 & 688239 & 4.6862 & 5.3848 & TRN \\
\hline CHEMBL1412382 & 688239 & 7.2366 & 5.5193 & TST \\
\hline CHEMBL1445951 & 688239 & 5.8862 & 5.5117 & TRN \\
\hline CHEMBL1613469 & 688239 & 5.1862 & 5.2813 & TRN \\
\hline CHEMBL1339632 & 688239 & 5.1862 & 5.3956 & TRN \\
\hline CHEMBL1387472 & 688239 & 5.4862 & 5.4651 & TST \\
\hline CHEMBL3195367 & 688239 & 4.7362 & 5.5406 & TRN \\
\hline CHEMBL600121 & 688239 & 4.8362 & 5.4254 & TRN \\
\hline CHEMBL1475962 & 688239 & 5.1862 & 5.4488 & TRN \\
\hline CHEMBL1598725 & 688239 & 5.6362 & 5.6193 & TRN \\
\hline CHEMBL1352597 & 688239 & 6.5363 & 5.4853 & TRN \\
\hline CHEMBL1408282 & 688239 & 6.0362 & 5.4647 & TRN \\
\hline CHEMBL3190699 & 688239 & 4.5362 & 5.4721 & TRN \\
\hline CHEMBL 3194904 & 688239 & 4.5862 & 5.489 & TRN \\
\hline CHEMBL1573407 & 688239 & 5.5862 & 5.356 & TRN \\
\hline CHEMBL1565900 & 688239 & 5.0862 & 5.5475 & TRN \\
\hline CHEMBL1474942 & 688239 & 5.5362 & 5.5948 & TST \\
\hline CHEMBL1332597 & 688239 & 5.6362 & 5.5072 & TRN \\
\hline CHEMBL1312011 & 688239 & 5.1862 & 5.5641 & TRN \\
\hline CHEMBL1534404 & 688239 & 5.6862 & 5.6697 & TRN \\
\hline CHEMBL1440742 & 688239 & 4.6362 & 5.5228 & TRN \\
\hline CHEMBL1302980 & 688239 & 4.7362 & 5.5899 & TRN \\
\hline CHEMBL1444872 & 688239 & 6.4862 & 5.7461 & TRN \\
\hline CHEMBL1424269 & 688239 & 4.6362 & 5.6466 & TRN \\
\hline CHEMBL1373727 & 688239 & 5.1862 & 5.36700 & 000000001 \\
\hline CHEMBL1322894 & 688239 & 4.9362 & 5.4997 & TRN \\
\hline CHEMBL1474391 & 688239 & 4.8862 & 5.2896 & TRN \\
\hline CHEMBL1563807 & 688239 & 6.9863 & 5.6783 & TRN \\
\hline CHEMBL1591827 & 688239 & 4.5362 & 5.4277 & TRN \\
\hline CHEMBL1379700 & 688239 & 6.0862 & 5.4626 & TRN \\
\hline CHEMBL1574799 & 688239 & 7.0862 & 5.3512 & TRN \\
\hline CHEMBL1330815 & 688239 & 4.5362 & 5.541 & TST \\
\hline CHEMBL1312116 & 688239 & 4.6362 & 5.5127 & TRN \\
\hline
\end{tabular}


Supplemental Table S2.txt

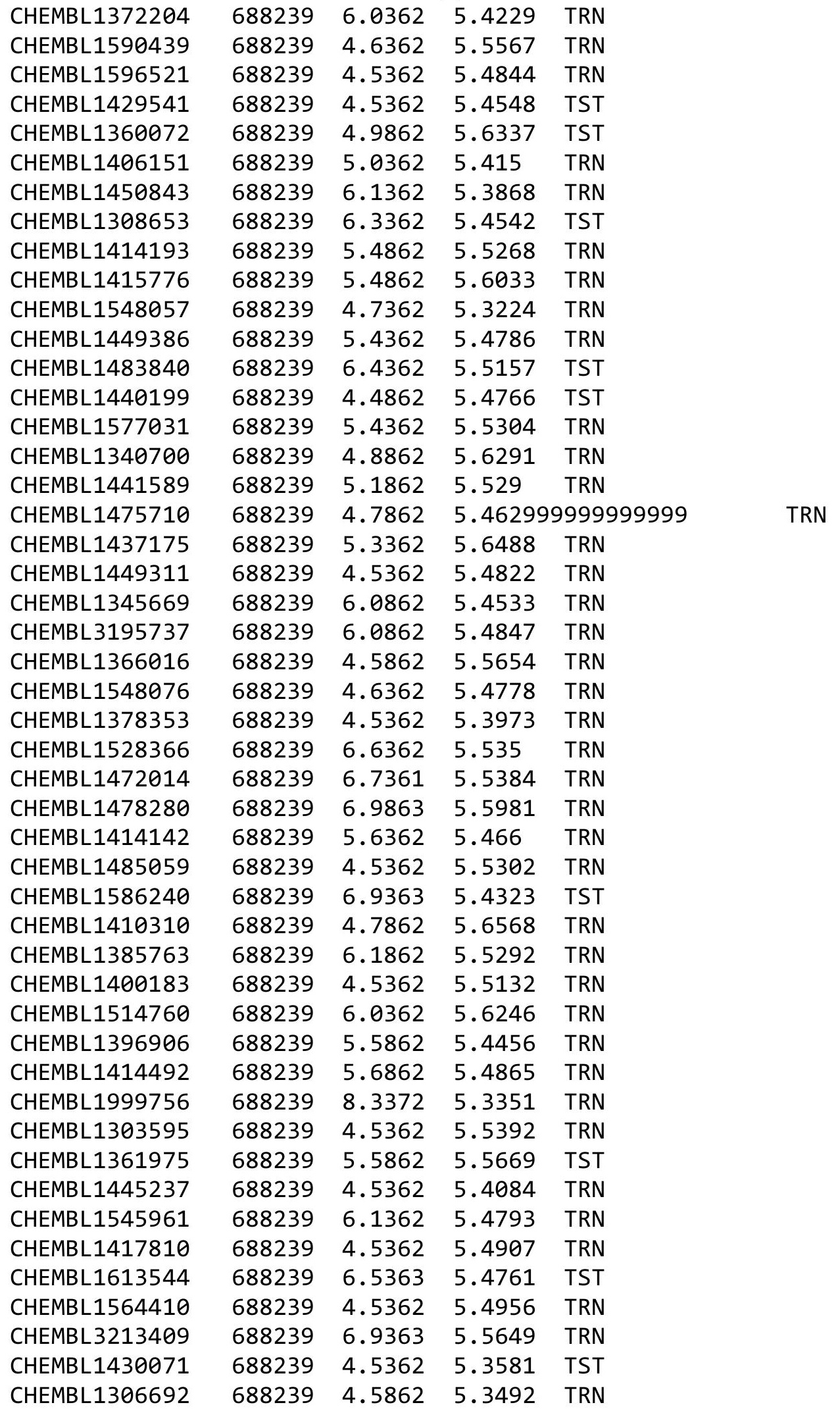


Supplemental Table S2.txt

\begin{tabular}{|c|c|c|c|c|c|}
\hline CHEMBL1372383 & 688239 & 4.5362 & 5.6283 & TRN & \\
\hline CHEMBL1585197 & 688239 & 4.8 & 5.3952 & TRN & \\
\hline CHEMBL1554079 & 688239 & 4.8862 & 5.38700 & 00000000005 & TRN \\
\hline CHEMBL1557947 & 688239 & 4.5362 & 5.4447 & TST & \\
\hline CHEMBL 3209363 & 688239 & 4.6862 & 5.4655 & TST & \\
\hline CHEMBL1473676 & 688239 & 6.0 & 5.3113 & TST & \\
\hline CHEMBL1422406 & 688239 & 4.5362 & 5.4075 & TRN & \\
\hline CHEMBL1416718 & 688239 & 4.5362 & 5.5488 & TST & \\
\hline CHEMBL1490425 & 688239 & 8.3372 & 5.5583 & TRN & \\
\hline CHEMBL1537704 & 688239 & 5.1862 & 5.4621 & TST & \\
\hline CHEMBL1327228 & 688239 & 4.6362 & 5.4065 & TST & \\
\hline CHEMBL1511456 & 688239 & 5.2362 & 5.4681 & TST & \\
\hline CHEMBL1366720 & 688239 & 5.9362 & 5.391 & TRN & \\
\hline CHEMBL3191885 & 688239 & 6.6362 & 5.4715 & TRN & \\
\hline CHEMBL 3207798 & 688239 & 4.6862 & 5.5657 & TST & \\
\hline CHEMBL1509995 & 688239 & 6.1862 & 5.4176 & TST & \\
\hline CHEMBL1558221 & 688239 & 4.8362 & 5.3757 & TRN & \\
\hline CHEMBL1613601 & 688239 & 4.5362 & 5.6469 & TRN & \\
\hline CHEMBL1458329 & 688239 & 8.3372 & 5.4436 & TST & \\
\hline CHEMBL1612812 & 688239 & 6.7361 & 5.5974 & TST & \\
\hline CHEMBL1518856 & 688239 & 5.2362 & 5.5858 & TST & \\
\hline CHEMBL1477308 & 688239 & 5.1362 & 5.3711 & TRN & \\
\hline CHEMBL1488212 & 688239 & 5.6362 & 5.4672 & TST & \\
\hline CHEMBL1413122 & 688239 & 6.5363 & 5.6469 & TST & \\
\hline CHEMBL1542042 & 688239 & 5.7862 & 5.5512 & TRN & \\
\hline CHEMBL1579013 & 688239 & 6.7862 & 5.32 & TST & \\
\hline CHEMBL1467426 & 688239 & 7.0362 & 5.4259 & TRN & \\
\hline CHEMBL1329900 & 688239 & 4.8362 & 5.5257 & TRN & \\
\hline CHEMBL1382702 & 688239 & 4.8362 & 5.4836 & TST & \\
\hline CHEMBL1427102 & 688239 & 5.1862 & 5.6103 & TST & \\
\hline CHEMBL1308668 & 688239 & 5.4862 & 5.4298 & TRN & \\
\hline CHEMBL1310051 & 688239 & 5.7862 & 5.5243 & TRN & \\
\hline CHEMBL1371049 & 688239 & 4.8862 & 5.5105 & TRN & \\
\hline CHEMBL1378367 & 688239 & 5.0362 & 5.4768 & TRN & \\
\hline CHEMBL1543947 & 688239 & 4.5862 & 5.3414 & TRN & \\
\hline CHEMBL1607938 & 688239 & 4.5362 & 5.5058 & TRN & \\
\hline CHEMBL1584654 & 688239 & 5.1362 & 5.5981 & TRN & \\
\hline CHEMBL1538310 & 688239 & 4.5362 & 5.4181 & TRN & \\
\hline CHEMBL1999390 & 688239 & 5.2362 & 5.4086 & TST & \\
\hline CHEMBL1447147 & 688239 & 4.7862 & 5.433 & TST & \\
\hline CHEMBL1453904 & 688239 & 4.8362 & 5.4664 & TRN & \\
\hline CHEMBL1534796 & 688239 & 5.7362 & 5.626 & TRN & \\
\hline CHEMBL1588122 & 688239 & 5.1862 & 5.6251 & TRN & \\
\hline CHEMBL1332299 & 688239 & 5.4862 & 5.4505 & TRN & \\
\hline CHEMBL1476176 & 688239 & 4.7862 & 5.5509 & TST & \\
\hline CHEMBL 3189317 & 688239 & 6.2862 & 5.4225 & TRN & \\
\hline CHEMBL1407938 & 688239 & 4.5362 & 5.3768 & TRN & \\
\hline CHEMBL1224685 & 688239 & 5.3862 & 5.5201 & TRN & \\
\hline
\end{tabular}


Supplemental Table S2.txt

\begin{tabular}{|c|c|c|c|c|}
\hline CHEMBL3213801 & 688239 & 4.5362 & 5.303 & TRN \\
\hline CHEMBL3191953 & 688239 & 4.6362 & 5.5269 & TRN \\
\hline CHEMBL1550193 & 688239 & 4.9362 & 5.3968 & TST \\
\hline CHEMBL1446549 & 688239 & 5.8362 & 5.5018 & TST \\
\hline CHEMBL1561327 & 688239 & 6.0362 & 5.4976 & TRN \\
\hline CHEMBL1444087 & 688239 & 4.5362 & 5.4345 & TRN \\
\hline CHEMBL1453554 & 688239 & 7.0362 & 5.7497 & TRN \\
\hline CHEMBL1506211 & 688239 & 6.1362 & 5.4167 & TRN \\
\hline CHEMBL2028179 & 688239 & 6.6861 & 5.4842 & TST \\
\hline CHEMBL3212414 & 688239 & 5.9862 & 5.5909 & TRN \\
\hline CHEMBL1981286 & 688239 & 4.7862 & 5.4333 & TRN \\
\hline CHEMBL1550021 & 688239 & 6.7361 & 5.4326 & TRN \\
\hline CHEMBL1548927 & 688239 & 4.5362 & 5.6267 & TST \\
\hline CHEMBL1536404 & 688239 & 6.8861 & 5.3579 & TRN \\
\hline CHEMBL 3190830 & 688239 & 4.7862 & 5.5258 & TST \\
\hline CHEMBL3198159 & 688239 & 7.4365 & 5.5255 & TST \\
\hline CHEMBL1602437 & 688239 & 4.5362 & 5.5435 & TRN \\
\hline CHEMBL1479277 & 688239 & 8.28399 & 999999999 & 5.417999999999999 \\
\hline CHEMBL1328962 & 688239 & 5.3362 & 5.6287 & TRN \\
\hline CHEMBL1376676 & 688239 & 5.5362 & 5.3942 & TRN \\
\hline CHEMBL1606966 & 688239 & 4.7362 & 5.6 & TRN \\
\hline CHEMBL1402388 & 688239 & 6.7862 & 5.4135 & TRN \\
\hline CHEMBL1555927 & 688239 & 5.9362 & 5.428999 & 9999999999 \\
\hline CHEMBL1423690 & 688239 & 4.6362 & 5.397 & TST \\
\hline CHEMBL1610527 & 688239 & 8.1871 & 5.4805 & TRN \\
\hline CHEMBL1606021 & 688239 & 6.3362 & 5.4004 & TRN \\
\hline CHEMBL1535024 & 688239 & 5.1862 & 5.5144 & TRN \\
\hline CHEMBL1549825 & 688239 & 5.6862 & 5.5279 & TRN \\
\hline CHEMBL1361825 & 688239 & 6.2362 & 5.5016 & TRN \\
\hline CHEMBL1360874 & 688239 & 4.9862 & 5.5003 & TRN \\
\hline CHEMBL1519011 & 688239 & 5.8862 & 5.7123 & TRN \\
\hline CHEMBL1596215 & 688239 & 6.5363 & 5.5828 & TRN \\
\hline CHEMBL1360026 & 688239 & 4.5362 & 5.5113 & TRN \\
\hline CHEMBL1514665 & 688239 & 4.9362 & 5.5396 & TRN \\
\hline CHEMBL1470663 & 688239 & 5.6862 & 5.4407 & TRN \\
\hline CHEMBL1600983 & 688239 & 6.2862 & 5.4969 & TST \\
\hline CHEMBL1463935 & 688239 & 4.5362 & 5.546 & TRN \\
\hline CHEMBL1536852 & 688239 & 5.3362 & 5.4839 & TRN \\
\hline CHEMBL1435669 & 688239 & 5.1362 & 5.4215 & TRN \\
\hline CHEMBL1486842 & 688239 & 5.9362 & 5.2879 & TRN \\
\hline CHEMBL1379850 & 688239 & 4.7362 & 5.5421 & TST \\
\hline CHEMBL1402793 & 688239 & 4.5362 & 5.5192 & TRN \\
\hline CHEMBL1557144 & 688239 & 5.5862 & 5.3933 & TRN \\
\hline CHEMBL1456753 & 688239 & 6.1362 & 5.3519 & TST \\
\hline CHEMBL1371189 & 688239 & 5.1362 & 5.5973 & TRN \\
\hline CHEMBL1488956 & 688239 & 6.2862 & 5.5792 & TRN \\
\hline CHEMBL1328331 & 688239 & 5.8362 & 5.4413 & TRN \\
\hline CHEMBL1530406 & 688239 & 4.7362 & 5.4329 & TST \\
\hline
\end{tabular}


Supplemental Table S2.txt

\begin{tabular}{|c|c|c|c|c|}
\hline 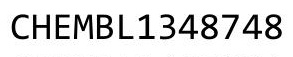 & & & & \\
\hline HEMBL1465324 & 88239 & 862 & 7045 & \\
\hline HEMBL 83330 & 88239 & 2862 & 5507 & \\
\hline 324 & & & & \\
\hline EMBL13 & & & 6 & \\
\hline HEMBL1532264 & 88239 & 5862 & 4365 & \\
\hline HEMBL1450181 & 88239 & 362 & .5749 & \\
\hline HEMBL 579143 & 239 & 362 & 534 & \\
\hline AEMBL: & 39 & 362 & 465 & \\
\hline IEMBL13 & 39 & & .473 & \\
\hline HEMBL1502952 & 88239 & 361 & 4828 & \\
\hline HEMBL1341224 & 39 & 862 & .4808 & \\
\hline HEMBL1559182 & 39 & 362 & 4387 & \\
\hline HEMBL1410806 & & & 62 & \\
\hline HEMBL15 & 39 & 362 & 94 & \\
\hline HEMBL1502828 & 39 & 862 & 4065 & \\
\hline HEMBL1326552 & 88 & 862 & 5009 & \\
\hline HEMBL157 & 39 & 62 & .4844 & \\
\hline HEMBL15 & & & & \\
\hline HEME & 9 & & & DNA \\
\hline HEMBL1415217 & 39 & 62 & & \\
\hline HEMBL1406076 & 39 & 62 & 47 & RN \\
\hline HEMBL1448718 & 39 & 862 & 29 & \\
\hline HEMBL13 & & & & \\
\hline HEMBL15 & 39 & & & $5 T$ \\
\hline HEMBL129 & 39 & & & RN \\
\hline HEMBL1329340 & 39 & 362 & 994 & KIV \\
\hline HEMBL1338369 & 39 & 862 & & RN \\
\hline HEM & & & & RN \\
\hline HEM & & & & RN \\
\hline HEMBL15941 & & & & $\mathrm{N}$ \\
\hline HEMBL1507602 & 88 & 362 & 5.4968 & RN \\
\hline HEMBL1309012 & 39 & 62 & 13 & RN \\
\hline 9 & & & & RN \\
\hline HEMBL1355315 & & & & ST \\
\hline HEMBL1461747 & 39 & & & RN \\
\hline HEMBL1506737 & 39 & 362 & .5064 & ST \\
\hline HFMRI 13 & 39 & 62 & 314 & RN \\
\hline 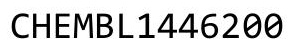 & & & & RN \\
\hline HEMBL1454420 & & & & RN \\
\hline HEMBL1992486 & 39 & 362 & 461 & ST \\
\hline HEMBL15 & 39 & 372 & 566 & ST \\
\hline HEMBL3199403 & & & & \\
\hline & & & & RN \\
\hline HEMBL152 & & 7862 & 5.3733 & RN \\
\hline HEMBL1322938 & 88 & 362 & 74 & RN \\
\hline S & & & & \\
\hline & & & & \\
\hline
\end{tabular}

Page 2381 
Supplemental Table S2.txt

\begin{tabular}{|c|c|c|c|c|}
\hline CHEMBL1436539 & 688239 & 4.5862 & 5.3517 & TRN \\
\hline CHEMBL1372814 & 688239 & 5.1862 & 5.5034 & TRN \\
\hline CHEMBL1363735 & 688239 & 7.0862 & 5.5761 & TRN \\
\hline CHEMBL1330698 & 688239 & 5.4862 & 5.5919 & TRN \\
\hline CHEMBL1459604 & 688239 & 4.5362 & 5.497999 & 9999999999 \\
\hline CHEMBL1498376 & 688239 & 4.5362 & 5.4935 & TST \\
\hline CHEMBL 3214246 & 688239 & 4.4862 & 5.5701 & TRN \\
\hline CHEMBL1372989 & 688239 & 7.6861 & 5.5247 & TST \\
\hline CHEMBL1561747 & 688239 & 4.5362 & 5.4617 & TRN \\
\hline CHEMBL1451714 & 688239 & 4.7362 & 5.4978 & TST \\
\hline CHEMBL1481776 & 688239 & 4.9862 & 5.4686 & TRN \\
\hline CHEMBL1384750 & 688239 & 6.2362 & 5.6323 & TRN \\
\hline CHEMBL1414823 & 688239 & 6.1862 & 5.5402 & TRN \\
\hline CHEMBL1374920 & 688239 & 4.7362 & 5.6138 & TRN \\
\hline CHEMBL1398959 & 688239 & 4.6362 & 5.5585 & TST \\
\hline CHEMBL1589989 & 688239 & 6.0862 & 5.4469 & TRN \\
\hline CHEMBL1432477 & 688239 & 5.3862 & 5.3604 & TRN \\
\hline CHEMBL1542669 & 688239 & 4.5862 & 5.5089 & TRN \\
\hline CHEMBL1444427 & 688239 & 4.7362 & 5.5092 & TRN \\
\hline CHEMBL1309296 & 688239 & 7.5867 & 5.525 & TST \\
\hline CHEMBL1502977 & 688239 & 5.1862 & 5.4686 & TRN \\
\hline CHEMBL3194284 & 688239 & 6.0362 & 5.5267 & TRN \\
\hline CHEMBL1598547 & 688239 & 8.3372 & 5.457999 & 9999999999 \\
\hline CHEMBL3144976 & 688239 & 4.6862 & 5.4202 & TRN \\
\hline CHEMBL1595287 & 688239 & 7.2366 & 5.4838 & TRN \\
\hline CHEMBL3197875 & 688239 & 6.5363 & 5.4173 & TST \\
\hline CHEMBL1598058 & 688239 & 5.9862 & 5.5475 & TRN \\
\hline CHEMBL1315203 & 688239 & 5.1362 & 5.4527 & TRN \\
\hline CHEMBL1339599 & 688239 & 5.3862 & 5.5031 & TRN \\
\hline CHEMBL1423758 & 688239 & 5.2362 & 5.4378 & TRN \\
\hline CHEMBL3210891 & 688239 & 5.0862 & 5.4734 & TRN \\
\hline CHEMBL1574803 & 688239 & 6.0362 & 5.761 & TRN \\
\hline CHEMBL1454042 & 688239 & 8.3872 & 5.5486 & TRN \\
\hline CHEMBL3212552 & 688239 & 5.3862 & 5.4358 & TRN \\
\hline CHEMBL1593972 & 688239 & 4.7362 & 5.3607 & TST \\
\hline CHEMBL1403174 & 688239 & 4.5362 & 5.4223 & TRN \\
\hline CHEMBL1497126 & 688239 & 4.6362 & 5.5247 & TRN \\
\hline CHEMBL1403864 & 688239 & 7.0362 & 5.4539 & TRN \\
\hline CHEMBL1450252 & 688239 & 5.6862 & 5.4642 & TRN \\
\hline CHEMBL1524071 & 688239 & 6.1862 & 5.6379 & TST \\
\hline CHEMBL1372114 & 688239 & 5.8862 & 5.5169 & TRN \\
\hline CHEMBL1576281 & 688239 & 8.0362 & 5.4189 & TRN \\
\hline CHEMBL 2007135 & 688239 & 4.7362 & 5.5313 & TRN \\
\hline CHEMBL1343892 & 688239 & 5.6362 & 5.4584 & TRN \\
\hline CHEMBL1086026 & 688239 & 7.0862 & 5.5263 & TST \\
\hline CHEMBL1370125 & 688239 & 4.8362 & 5.4956 & TRN \\
\hline CHEMBL1537461 & 688239 & 4.5362 & 5.4048 & TST \\
\hline CHEMBL1361753 & 688239 & 4.9862 & 5.349 & TRN \\
\hline
\end{tabular}


Supplemental Table S2.txt

\begin{tabular}{|c|c|c|c|c|c|}
\hline CHEMBL1353117 & 688239 & 4.7862 & 5.516 & TRN & \\
\hline CHEMBL1393850 & 688239 & 4.7362 & 5.4484 & TST & \\
\hline CHEMBL1372979 & 688239 & 5.6362 & 5.6353 & TRN & \\
\hline CHEMBL1492986 & 688239 & 5.3362 & 5.642 & TRN & \\
\hline CHEMBL1345269 & 688239 & 5.9362 & 5.50799 & 9999999999 & TRN \\
\hline CHEMBL1539015 & 688239 & 6.1362 & 5.4655 & TST & \\
\hline CHEMBL1529483 & 688239 & 6.0862 & 5.6575 & TST & \\
\hline CHEMBL1438831 & 688239 & 5.0862 & 5.3495 & TST & \\
\hline CHEMBL1458331 & 688239 & 7.2366 & 5.5839 & TRN & \\
\hline CHEMBL1610839 & 688239 & 4.5362 & 5.513 & TRN & \\
\hline CHEMBL1395202 & 688239 & 4.9862 & 5.5145 & TRN & \\
\hline CHEMBL1391539 & 688239 & 5.6862 & 5.4861 & TRN & \\
\hline CHEMBL1519854 & 688239 & 5.9862 & 5.6599 & TRN & \\
\hline CHEMBL1983351 & 688239 & 4.7862 & 5.3714 & TRN & \\
\hline CHEMBL1543015 & 688239 & 5.5362 & 5.4574 & TRN & \\
\hline CHEMBL1344473 & 688239 & 6.2862 & 5.5011 & TRN & \\
\hline CHEMBL1347570 & 688239 & 5.1862 & 5.3698 & TRN & \\
\hline CHEMBL1359946 & 688239 & 6.1362 & 5.4655 & TRN & \\
\hline CHEMBL1517558 & 688239 & 8.2366 & 5.3645 & TRN & \\
\hline CHEMBL1371424 & 688239 & 5.1862 & 5.3926 & TRN & \\
\hline CHEMBL1469846 & 688239 & 6.0362 & 5.4673 & TRN & \\
\hline CHEMBL1607354 & 688239 & 5.1362 & 5.5704 & TRN & \\
\hline CHEMBL1326370 & 688239 & 6.3362 & 5.696006 & $\partial 000000001$ & TRN \\
\hline CHEMBL1338066 & 688239 & 5.8862 & 5.5505 & TRN & \\
\hline CHEMBL1457450 & 688239 & 5.5362 & 5.5122 & TST & \\
\hline CHEMBL3145101 & 688239 & 5.3362 & 5.4751 & TRN & \\
\hline CHEMBL1468145 & 688239 & 6.7361 & 5.5008 & TST & \\
\hline CHEMBL1392982 & 688239 & 4.5362 & 5.371 & TRN & \\
\hline CHEMBL1409171 & 688239 & 4.6862 & 5.3474 & TRN & \\
\hline CHEMBL1524134 & 688239 & 6.5862 & 5.5552 & TRN & \\
\hline CHEMBL1601083 & 688239 & 4.6362 & 5.5217 & TRN & \\
\hline CHEMBL1461398 & 688239 & 8.3372 & 5.5547 & TST & \\
\hline CHEMBL1484682 & 688239 & 5.1362 & 5.574 & TST & \\
\hline CHEMBL1347919 & 688239 & 4.9862 & 5.6857 & TRN & \\
\hline CHEMBL3207531 & 688239 & 6.8861 & 5.4391 & TRN & \\
\hline CHEMBL1421375 & 688239 & 4.7862 & 5.4122 & TRN & \\
\hline CHEMBL1506798 & 688239 & 5.7362 & 5.49299 & 9999999999 & TST \\
\hline CHEMBL1574562 & 688239 & 6.8362 & 5.4187 & TRN & \\
\hline CHEMBL1587421 & 688239 & 5.8362 & 5.5236 & TRN & \\
\hline CHEMBL1549693 & 688239 & 6.9863 & 5.4786 & TST & \\
\hline CHEMBL1395519 & 688239 & 4.5362 & 5.5199 & TRN & \\
\hline CHEMBL1995550 & 688239 & 4.6862 & 5.3609 & TST & \\
\hline CHEMBL1494079 & 688239 & 4.9862 & 5.5614 & TRN & \\
\hline CHEMBL1366697 & 688239 & 4.4862 & 5.4961 & TRN & \\
\hline CHEMBL1355877 & 688239 & 5.9362 & 5.5115 & TST & \\
\hline CHEMBL1346149 & 688239 & 6.9363 & 5.5454 & TRN & \\
\hline CHEMBL3197635 & 688239 & 5.6862 & 5.5478 & TST & \\
\hline CHEMBL3211564 & 688239 & 5.0862 & 5.4669 & TST & \\
\hline
\end{tabular}


Supplemental Table S2.txt

\begin{tabular}{|c|c|c|c|c|c|c|}
\hline CHEMBL1418536 & 688239 & 5.9362 & 5.42 & TST & & \\
\hline CHEMBL1481855 & 688239 & 5.1862 & 5.4578 & TRN & & \\
\hline CHEMBL1581260 & 688239 & 5.1862 & 5.4185 & TRN & & \\
\hline CHEMBL1579277 & 688239 & 8.2366 & 5.4636 & TRN & & \\
\hline CHEMBL1364517 & 688239 & 6.1362 & 5.4351 & TRN & & \\
\hline CHEMBL1425857 & 688239 & 5.6362 & 5.4497 & TRN & & \\
\hline CHEMBL1498717 & 688239 & 5.5362 & 5.5285 & TRN & & \\
\hline CHEMBL1577920 & 688239 & 4.5362 & 5.4215 & TRN & & \\
\hline CHEMBL1338411 & 688239 & 6.0862 & 5.5176 & TRN & & \\
\hline CHEMBL1452170 & 688239 & 5.5362 & 5.5291 & TRN & & \\
\hline CHEMBL1432084 & 688239 & 5.1862 & 5.6011 & TRN & & \\
\hline CHEMBL1461202 & 688239 & 5.3862 & 5.4954 & TST & & \\
\hline CHEMBL1345408 & 688239 & 4.5362 & 5.4177 & TRN & & \\
\hline CHEMBL1350875 & 688239 & 6.0862 & 5.5529 & TRN & & \\
\hline CHEMBL1513938 & 688239 & 5.6862 & 5.5776 & TST & & \\
\hline CHEMBL1422209 & 688239 & 4.6362 & 5.6128 & TRN & & \\
\hline CHEMBL1477205 & 688239 & 5.7862 & 5.5164 & TRN & & \\
\hline CHEMBL1377337 & 688239 & 6.2862 & 5.4952 & TRN & & \\
\hline CHEMBL180427 & 688239 & 4.7362 & 5.3597 & TST & & \\
\hline CHEMBL1411534 & 688239 & 6.2362 & 5.4001 & TRN & & \\
\hline CHEMBL1478557 & 688239 & 4.7362 & 5.5584 & TRN & & \\
\hline CHEMBL1572396 & 688239 & 6.1362 & 5.5234 & TRN & & \\
\hline CHEMBL 3198297 & 688239 & 4.6862 & 5.4196 & TRN & & \\
\hline CHEMBL1332155 & 688239 & 4.5362 & 5.5205 & TRN & & \\
\hline CHEMBL1468803 & 688239 & 6.3863 & 5.5463 & TST & & \\
\hline CHEMBL1583011 & 688239 & 4.7362 & 5.2983 & TRN & & \\
\hline CHEMBL1301857 & 688239 & 5.3362 & 5.3794 & TST & & \\
\hline CHEMBL1446939 & 688239 & 4.5362 & 5.5162 & TST & & \\
\hline CHEMBL1596091 & 688239 & 4.5362 & 5.4485 & TRN & & \\
\hline CHEMBL1565353 & 688239 & 4.7362 & 5.5505 & TRN & & \\
\hline CHEMBL1493251 & 688239 & 4.8362 & 5.3959 & TST & & \\
\hline CHEMBL1537920 & 688239 & 4.9862 & 5.5347 & TRN & & \\
\hline CHEMBL1378889 & 688239 & 5.8362 & 5.5813 & TRN & & \\
\hline CHEMBL1576242 & 688239 & 5.1362 & 5.3984 & TRN & & \\
\hline CHEMBL1524847 & 688239 & 4.7362 & 5.505 & TRN & & \\
\hline CHEMBL1607944 & 688239 & 4.5362 & 5.4749 & TRN & & \\
\hline CHEMBL1465133 & 688239 & 6.9363 & 5.6417 & TST & & \\
\hline CHEMBL1397958 & 688239 & 5.4862 & 5.5472 & TRN & & \\
\hline CHEMBL 25280 & 688239 & \multicolumn{3}{|c|}{8.283999999999999} & 5.5089999999999995 & TST \\
\hline CHEMBL1575525 & 688239 & 4.5362 & 5.5894 & TRN & & \\
\hline CHEMBL1365531 & 688239 & 5.4362 & 5.6203 & TRN & & \\
\hline CHEMBL1613389 & 688239 & 4.6362 & 5.6023 & TRN & & \\
\hline CHEMBL1353394 & 688239 & 4.5362 & 5.4929 & TRN & & \\
\hline CHEMBL1472289 & 688239 & 4.8862 & 5.3938 & TRN & & \\
\hline CHEMBL1366642 & 688239 & 4.9862 & 5.4515 & TST & & \\
\hline CHEMBL1318993 & 688239 & 6.0 & 5.3967 & TRN & & \\
\hline CHEMBL1512297 & 688239 & 6.0362 & 5.6077 & TRN & & \\
\hline CHEMBL1444284 & 688239 & 4.5362 & 5.6263 & TRN & & \\
\hline
\end{tabular}


Supplemental Table S2.txt

\begin{tabular}{|c|c|c|c|c|c|}
\hline CHEMBL1549048 & 688239 & 5.2362 & 5.4712 & TRN & \\
\hline CHEMBL1458355 & 688239 & 5.9362 & 5.5353 & TRN & \\
\hline CHEMBL1391272 & 688239 & 4.5362 & 5.4931 & TST & \\
\hline CHEMBL1404396 & 688239 & 5.1862 & 5.4169 & TRN & \\
\hline CHEMBL1583734 & 688239 & 4.7362 & 5.4787 & TST & \\
\hline CHEMBL1408167 & 688239 & 7.5361 & 5.52 & TST & \\
\hline CHEMBL1300258 & 688239 & 4.5362 & 5.4779 & TRN & \\
\hline CHEMBL1324026 & 688239 & 4.7362 & 5.399 & TRN & \\
\hline CHEMBL1469046 & 688239 & 5.9862 & 5.5541 & TRN & \\
\hline CHEMBL1414689 & 688239 & 5.4362 & 5.57100 & 0000000001 & TRN \\
\hline CHEMBL1380189 & 688239 & 5.7362 & 5.6358 & TST & \\
\hline CHEMBL1432734 & 688239 & 4.5362 & 5.4718 & TST & \\
\hline CHEMBL1429875 & 688239 & 5.4862 & 5.6347 & TRN & \\
\hline CHEMBL1448388 & 688239 & 4.6362 & 5.5114 & TRN & \\
\hline CHEMBL1587392 & 688239 & 4.5362 & 5.4256 & TST & \\
\hline CHEMBL1416067 & 688239 & 5.4862 & 5.5061 & TRN & \\
\hline CHEMBL1369496 & 688239 & 4.6862 & 5.5437 & TRN & \\
\hline CHEMBL1427989 & 688239 & 6.1362 & 5.3962 & TRN & \\
\hline CHEMBL1519490 & 688239 & 4.7862 & 5.4459 & TST & \\
\hline CHEMBL1461119 & 688239 & 4.6862 & 5.2743 & TRN & \\
\hline CHEMBL1453635 & 688239 & 4.5362 & 5.4576 & TST & \\
\hline CHEMBL1516462 & 688239 & 4.4862 & 5.5834 & TRN & \\
\hline CHEMBL1304860 & 688239 & 5.4862 & 5.58299 & 9999999999 & TST \\
\hline CHEMBL1340419 & 688239 & 6.0362 & 5.4971 & TRN & \\
\hline CHEMBL1557639 & 688239 & 6.0362 & 5.4278 & TRN & \\
\hline CHEMBL1349995 & 688239 & 4.5862 & 5.5047 & TRN & \\
\hline CHEMBL1573439 & 688239 & 5.7362 & 5.3824 & TRN & \\
\hline CHEMBL1427931 & 688239 & 6.0362 & 5.5813 & TRN & \\
\hline CHEMBL3198694 & 688239 & 6.1862 & 5.4897 & TST & \\
\hline CHEMBL1386332 & 688239 & 5.8862 & 5.5547 & TST & \\
\hline CHEMBL1467970 & 688239 & 4.5362 & 5.5045 & TRN & \\
\hline CHEMBL1402801 & 688239 & 4.5862 & 5.4822 & TRN & \\
\hline CHEMBL3192988 & 688239 & 4.8362 & 5.3236 & TST & \\
\hline CHEMBL1461170 & 688239 & 7.0362 & 5.5168 & TRN & \\
\hline CHEMBL1417638 & 688239 & 5.1862 & 5.5328 & TRN & \\
\hline CHEMBL1463574 & 688239 & 6.8362 & 5.568 & TST & \\
\hline CHEMBL1482805 & 688239 & 4.8362 & 5.4021 & TRN & \\
\hline CHEMBL1482740 & 688239 & 4.5362 & 5.3393 & TST & \\
\hline CHEMBL1611216 & 688239 & 5.2862 & 5.6182 & TST & \\
\hline CHEMBL1473409 & 688239 & 4.5362 & 5.4325 & TRN & \\
\hline CHEMBL1458106 & 688239 & 4.9362 & 5.3816 & TRN & \\
\hline CHEMBL1594618 & 688239 & 5.6862 & 5.482 & TST & \\
\hline CHEMBL1389373 & 688239 & 4.8862 & 5.4954 & TRN & \\
\hline CHEMBL1455861 & 688239 & 4.5362 & 5.584 & TRN & \\
\hline CHEMBL1499 & 688239 & 6.0 & 5.4946 & TRN & \\
\hline CHEMBL1321933 & 688239 & 5.5862 & 5.4785 & TRN & \\
\hline CHEMBL1471194 & 688239 & 7.7352 & 5.4456 & TST & \\
\hline CHEMBL1350383 & 688239 & 5.1862 & 5.6187 & TRN & \\
\hline
\end{tabular}


Supplemental Table S2.txt

\begin{tabular}{|c|c|c|c|c|}
\hline 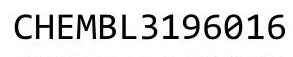 & & & & \\
\hline HEMBL1343879 & 38239 & 362 & 5552 & \\
\hline AEMBL1585468 & 239 & 362 & & \\
\hline AEMBL14 & 39 & 3863 & & \\
\hline IEMBL1537686 & & 862 & & \\
\hline AEMBL1422974 & 88239 & 362 & 669 & \\
\hline AEMBL1381752 & 88239 & 862 & 3679 & \\
\hline AEMBL589101 & & & & \\
\hline IEMBL14 & 39 & 366 & & \\
\hline IEMBL1590528 & & & & \\
\hline AEMBL1308740 & 39 & 862 & 49 & \\
\hline AEMBL1505387 & & 362 & & \\
\hline AEMBL1426781 & & & 98 & \\
\hline IEMBL15 & & & & \\
\hline AEMBL13 & & & & \\
\hline AEMBL1987092 & & 362 & 72 & \\
\hline AEMBL1439321 & & 862 & & \\
\hline AEMBL197 & & 4. & & \\
\hline IEMBL149 & & & & \\
\hline IEMBL158 & & & & \\
\hline AEMBL1466411 & & 862 & & \\
\hline AEMBL1483354 & & 862 & & \\
\hline HEMBL15 & & 4 . & & \\
\hline AFMRI 15 & & & & \\
\hline 84 & & 62 & & \\
\hline 12 & & 362 & & \\
\hline IEMBL1352268 & & 62 & & \\
\hline IEMBL1430855 & & & & \\
\hline 29 & & 6 & & \\
\hline 60 & & 52 & & \\
\hline AEMBL1524535 & & & & \\
\hline HEMBL1401847 & & 62 & & \\
\hline & & & & \\
\hline 19 & & 52 & & \\
\hline AEMBL1337327 & & & & RN \\
\hline AEMBL1452417 & & & & \\
\hline AEMBL1357902 & & 862 & & \\
\hline & & & & \\
\hline 1201 & & & & \\
\hline HEMBL1535426 & & & & RN \\
\hline AEMBL1448126 & & 62 & & \\
\hline IEMBL1596056 & & 62 & & \\
\hline 99 & & & & \\
\hline HEMBL1409517 & & & & \\
\hline HEMBL1389922 & & & 344 & ST \\
\hline IEMBL1376819 & & 862 & 471 & $\mathrm{~F}$ \\
\hline 1 & & & & \\
\hline HEMBL146035 & & & & \\
\hline
\end{tabular}

Page 2386 
Supplemental Table S2.txt

\begin{tabular}{|c|c|c|c|c|c|c|}
\hline CHEMBL1500599 & 688239 & 5.9862 & 5.5072 & TRN & & \\
\hline CHEMBL1560339 & 688239 & 6.8362 & 5.5153 & TRN & & \\
\hline CHEMBL1498478 & 688239 & 5.1862 & 5.5381 & TST & & \\
\hline CHEMBL1354072 & 688239 & 5.0862 & 5.6372 & TRN & & \\
\hline CHEMBL1413922 & 688239 & 5.1862 & 5.5054 & TRN & & \\
\hline CHEMBL1436757 & 688239 & 5.9362 & 5.5036 & TRN & & \\
\hline CHEMBL1500533 & 688239 & 4.8862 & 5.3848 & TRN & & \\
\hline CHEMBL1494015 & 688239 & 4.5862 & 5.5461 & TST & & \\
\hline CHEMBL1475568 & 688239 & 6.8362 & 5.5108 & TRN & & \\
\hline CHEMBL1478722 & 688239 & 6.6362 & 5.5796 & TRN & & \\
\hline CHEMBL1505870 & 688239 & 5.2862 & 5.6017 & TRN & & \\
\hline CHEMBL1510231 & 688239 & 5.8862 & 5.3914 & TRN & & \\
\hline CHEMBL1437331 & 688239 & 5.2862 & 5.5841 & TRN & & \\
\hline CHEMBL1580509 & 688239 & 5.2862 & 5.4515 & TRN & & \\
\hline CHEMBL1527800 & 688239 & 4.5362 & 5.4129 & TRN & & \\
\hline CHEMBL1385232 & 688239 & 7.2366 & 5.4798 & TST & & \\
\hline CHEMBL1452840 & 688239 & 5.7862 & 5.5006 & TRN & & \\
\hline CHEMBL1374089 & 688239 & 5.2362 & 5.4068 & TRN & & \\
\hline CHEMBL1537095 & 688239 & 6.2862 & 5.4971 & TRN & & \\
\hline CHEMBL1444764 & 688239 & 6.0 & 5.4238 & TRN & & \\
\hline CHEMBL1353116 & 688239 & 5.5862 & 5.4858 & TRN & & \\
\hline CHEMBL1457565 & 688239 & 4.7362 & 5.5061 & TRN & & \\
\hline CHEMBL1458663 & 688239 & 4.5362 & 5.6734 & TRN & & \\
\hline CHEMBL1434192 & 688239 & 5.6362 & 5.4851 & TRN & & \\
\hline CHEMBL1341286 & 688239 & 4.6362 & 5.4491 & TST & & \\
\hline CHEMBL1593279 & 688239 & 4.7362 & 5.5562 & TRN & & \\
\hline CHEMBL1497492 & 688239 & 4.4862 & 5.5773 & TRN & & \\
\hline CHEMBL1550197 & 688239 & 4.5862 & 5.44 & TRN & & \\
\hline CHEMBL1510563 & 688239 & 4.5362 & 5.6188 & TRN & & \\
\hline CHEMBL1494314 & 688239 & 4.6362 & 5.3984 & TRN & & \\
\hline CHEMBL1558926 & 688239 & 4.7362 & 5.4001 & TRN & & \\
\hline CHEMBL1518240 & 688239 & 4.8862 & 5.4307 & TST & & \\
\hline CHEMBL1583037 & 688239 & 8.3372 & 5.6264 & TST & & \\
\hline CHEMBL1568227 & 688239 & 5.6862 & 5.527 & TRN & & \\
\hline CHEMBL1539737 & 688239 & 5.7862 & 5.5018 & TRN & & \\
\hline CHEMBL1326431 & 688239 & 4.6862 & 5.2846 & TRN & & \\
\hline CHEMBL 3189394 & 688239 & 4.7362 & 5.4291 & TRN & & \\
\hline CHEMBL1370363 & 688239 & 8.3372 & 5.5411 & TRN & & \\
\hline CHEMBL1429470 & 688239 & 8.28399 & 99999999 & 99 & 5.5123 & TST \\
\hline CHEMBL1498556 & 688239 & 5.1862 & 5.4746 & TRN & & \\
\hline CHEMBL1430545 & 688239 & 8.4318 & 5.6141 & TRN & & \\
\hline CHEMBL1316473 & 688239 & 6.4862 & 5.5954 & TRN & & \\
\hline CHEMBL1519134 & 688239 & 4.7862 & 5.3416 & TRN & & \\
\hline CHEMBL 3214503 & 688239 & 4.6362 & 5.3793 & TST & & \\
\hline CHEMBL1558726 & 688239 & 4.4862 & 5.4692 & TRN & & \\
\hline CHEMBL1497370 & 688239 & 7.0862 & 5.4835 & TRN & & \\
\hline CHEMBL1574152 & 688239 & 5.1862 & 5.5262 & TRN & & \\
\hline CHEMBL1424394 & 688239 & 4.5862 & 5.4192 & TST & & \\
\hline
\end{tabular}


Supplemental Table S2.txt

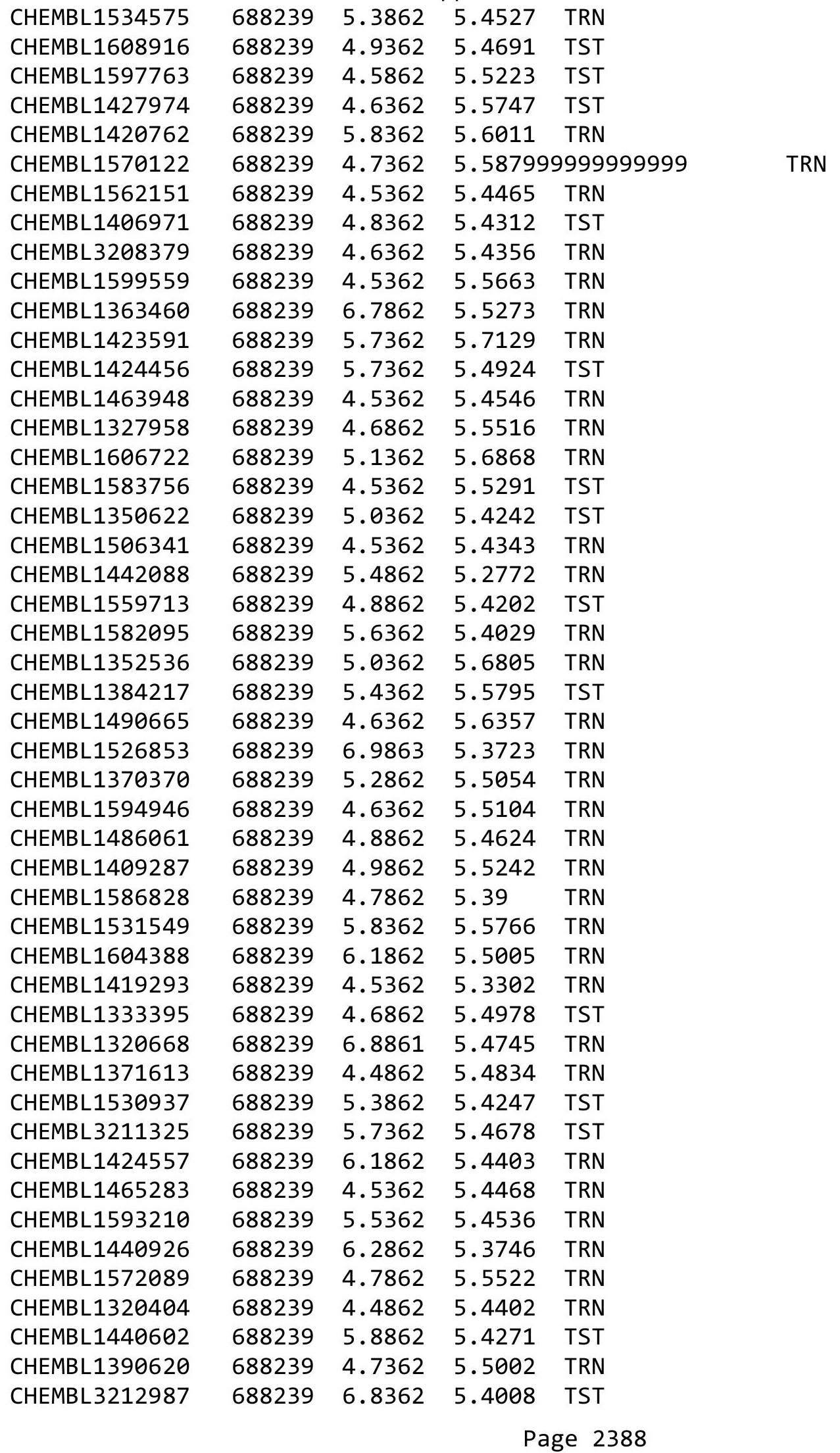


Supplemental Table S2.txt

\begin{tabular}{|c|c|c|c|c|}
\hline 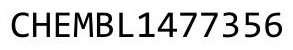 & & & & \\
\hline HEN & 38239 & 0362 & & \\
\hline HEMBL1387925 & 88239 & 4862 & 4704 & \\
\hline HEMBL1453922 & 88239 & 2362 & .5276 & \\
\hline & 239 & 363 & & \\
\hline AEMBL1335762 & 239 & 362 & & \\
\hline AEMBL1383267 & 88239 & 7362 & .4104 & \\
\hline HEMBL1304531 & 88239 & 5362 & 5536 & \\
\hline HEMBL3208401 & 88239 & 862 & & \\
\hline IEMBL1363545 & 38239 & 362 & & \\
\hline AEMBL1474186 & 38239 & 862 & & \\
\hline HEMBL1565049 & 88239 & 7362 & 06 & \\
\hline HEMBL1471211 & 88239 & 862 & & \\
\hline AEMBL1483050 & 88 & 362 & & \\
\hline IEMBL1550371 & 88239 & 861 & & \\
\hline AEMBL369142 & 88239 & 862 & & \\
\hline HEMBL1495284 & 88239 & 862 & & \\
\hline AEMBL51931 & 88239 & 362 & & \\
\hline AEMBL1335084 & $8 \varepsilon$ & 62 & & \\
\hline EMBL13247€ & 39 & 62 & & \\
\hline IEMBL 247378 & 39 & 362 & & \\
\hline HEMBL3213963 & 88239 & 862 & & \\
\hline HEMBL3209766 & 39 & 63 & & ST \\
\hline EMBL154 & 39 & & & \\
\hline L14 & & 62 & & \\
\hline 443 & 39 & 362 & & \\
\hline L45428 & 88239 & 862 & & \\
\hline AEMBL1590970 & 39 & & & \\
\hline AEMBL1373300 & 39 & 861 & 22 & RN \\
\hline L1571946 & 39 & & & RN \\
\hline 90 & 39 & 362 & & ST \\
\hline AEMBL1525368 & 39 & & & ST \\
\hline AEMBL1563245 & & & & RN \\
\hline AEMBL1407 & 39 & 862 & & $\mathrm{RN}$ \\
\hline L15 & 39 & 62 & & RN \\
\hline 149 & & & & RN \\
\hline HEMBL1378713 & 88239 & 862 & & RN \\
\hline AEMBL1463106 & 88239 & & & RN \\
\hline HEMBL1548921 & & 62 & & ST \\
\hline 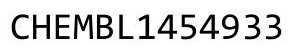 & & 52 & & RIN \\
\hline$\llcorner 14$ & 39 & 62 & & RN \\
\hline HEMBL1324933 & 88239 & 362 & 196 & RN \\
\hline AEMBL144 & 39 & & & RN \\
\hline HEMBL1353635 & & & & \\
\hline HEMBL1528131 & & & & \\
\hline HEMBL1541906 & 39 & 363 & 196 & $\mathrm{RN}$ \\
\hline L1976059 & 88239 & 4.5362 & 5.3974 & Iv \\
\hline CHEMBL1320244 & 688239 & 5.3862 & 5.4842 & \\
\hline
\end{tabular}

Page 2389 
Supplemental Table S2.txt

\begin{tabular}{|c|c|c|c|c|}
\hline CHEMBL1517365 & 688239 & 5.1862 & 5.5569 & TRN \\
\hline CHEMBL1309372 & 688239 & 5.1862 & 5.5908 & TST \\
\hline CHEMBL568092 & 688239 & 5.9362 & 5.4796 & TRN \\
\hline CHEMBL3190553 & 688239 & 7.0362 & 5.4548 & TST \\
\hline CHEMBL1358844 & 688239 & 4.5362 & 5.4523 & TRN \\
\hline CHEMBL1363994 & 688239 & 5.3862 & 5.5549 & TST \\
\hline CHEMBL1311390 & 688239 & 5.1862 & 5.4503 & TRN \\
\hline CHEMBL1567871 & 688239 & 4.8862 & 5.432 & TRN \\
\hline CHEMBL1592709 & 688239 & 5.1862 & 5.57 & TRN \\
\hline CHEMBL1215029 & 688239 & 4.5362 & 5.5308 & TRN \\
\hline CHEMBL3208649 & 688239 & 5.1362 & 5.5077 & TRN \\
\hline CHEMBL1400417 & 688239 & 4.7862 & 5.3845 & TRN \\
\hline CHEMBL1452771 & 688239 & 5.8862 & 5.4432 & TST \\
\hline CHEMBL1463768 & 688239 & 4.4862 & 5.4668 & TST \\
\hline CHEMBL1513497 & 688239 & 4.5362 & 5.5202 & TRN \\
\hline CHEMBL1352939 & 688239 & 5.4362 & 5.532999 & 9999999995 \\
\hline CHEMBL1403914 & 688239 & 4.9862 & 5.468999 & 999999999 \\
\hline CHEMBL3214107 & 688239 & 8.3372 & 5.5099 & TRN \\
\hline CHEMBL1580376 & 688239 & 5.1862 & 5.4748 & TST \\
\hline CHEMBL1441888 & 688239 & 4.5362 & 5.5342 & TRN \\
\hline CHEMBL1998531 & 688239 & 4.5862 & 5.3816 & TRN \\
\hline CHEMBL1468812 & 688239 & 5.1862 & 5.5832 & TRN \\
\hline CHEMBL1394823 & 688239 & 6.3863 & 5.3932 & TST \\
\hline CHEMBL1531943 & 688239 & 5.1862 & 5.5568 & TRN \\
\hline CHEMBL1512876 & 688239 & 6.0862 & 5.5266 & TRN \\
\hline CHEMBL1381425 & 688239 & 6.7361 & 5.4343 & TRN \\
\hline CHEMBL1520145 & 688239 & 4.8362 & 5.305 & TST \\
\hline CHEMBL1307647 & 688239 & 4.4862 & 5.4839 & TRN \\
\hline CHEMBL1370276 & 688239 & 4.6862 & 5.5679 & TRN \\
\hline CHEMBL1565644 & 688239 & 4.8362 & 5.4833 & TRN \\
\hline CHEMBL1545806 & 688239 & 6.1362 & 5.5141 & TRN \\
\hline CHEMBL1505359 & 688239 & 5.4862 & 5.5118 & TRN \\
\hline CHEMBL1318792 & 688239 & 4.5362 & 5.4745 & TST \\
\hline CHEMBL1305508 & 688239 & 5.1862 & 5.5494 & TRN \\
\hline CHEMBL1446123 & 688239 & 5.4862 & 5.6577 & TRN \\
\hline CHEMBL1464594 & 688239 & 5.1862 & 5.5238 & TRN \\
\hline CHEMBL1544548 & 688239 & 6.8362 & $5.41700 e$ & 000000001 \\
\hline CHEMBL1407061 & 688239 & 7.1361 & 5.4906 & TRN \\
\hline CHEMBL1424537 & 688239 & 5.8862 & 5.5628 & TST \\
\hline CHEMBL1501807 & 688239 & 5.5362 & 5.7573 & TRN \\
\hline CHEMBL1578662 & 688239 & 4.6862 & 5.5258 & TRN \\
\hline CHEMBL1580474 & 688239 & 8.1871 & 5.5442 & TRN \\
\hline CHEMBL1309611 & 688239 & 6.1862 & 5.5268 & TRN \\
\hline CHEMBL1313859 & 688239 & 5.3862 & 5.4274 & TST \\
\hline CHEMBL1509171 & 688239 & 5.1862 & 5.5864 & TRN \\
\hline CHEMBL1562994 & 688239 & 5.8362 & 5.3654 & TRN \\
\hline CHEMBL1552048 & 688239 & 4.9362 & 5.4434 & TRN \\
\hline CHEMBL1354057 & 688239 & 5.1362 & 5.4547 & TST \\
\hline
\end{tabular}


Supplemental Table S2.txt

\begin{tabular}{|c|c|c|c|c|c|}
\hline CHEMBL1493621 & 688239 & 4.8362 & 5.5213 & TRN & \\
\hline CHEMBL1571429 & 688239 & 4.5362 & 5.3694 & TST & \\
\hline CHEMBL1335226 & 688239 & 6.8861 & 5.4115 & TRN & \\
\hline CHEMBL3207695 & 688239 & 6.05 & 5.4952 & TRN & \\
\hline CHEMBL1481329 & 688239 & 5.1862 & 5.5831 & TRN & \\
\hline CHEMBL1364467 & 688239 & 4.5362 & 5.4979 & TRN & \\
\hline CHEMBL1551873 & 688239 & 5.5362 & 5.5473 & TRN & \\
\hline CHEMBL3194313 & 688239 & 4.5862 & 5.5224 & TST & \\
\hline CHEMBL1337139 & 688239 & 6.1362 & 5.4704 & TRN & \\
\hline CHEMBL3189881 & 688239 & 4.5362 & 5.4124 & TRN & \\
\hline CHEMBL1607835 & 688239 & 6.1862 & 5.4621 & TRN & \\
\hline CHEMBL3191729 & 688239 & 4.6362 & 5.3106 & TRN & \\
\hline CHEMBL1390040 & 688239 & 6.1362 & 5.3499 & TST & \\
\hline CHEMBL1327834 & 688239 & 4.4862 & 5.4398 & TRN & \\
\hline CHEMBL1523528 & 688239 & 4.6862 & 5.4316 & TST & \\
\hline CHEMBL1488961 & 688239 & 4.9362 & 5.7192 & TRN & \\
\hline CHEMBL1607769 & 688239 & 5.3862 & 5.6552 & TRN & \\
\hline CHEMBL1385231 & 688239 & 6.0362 & 5.4817 & TRN & \\
\hline CHEMBL1441071 & 688239 & 4.5362 & 5.5199 & TRN & \\
\hline CHEMBL1451181 & 688239 & 5.6862 & 5.35 & TST & \\
\hline CHEMBL3209906 & 688239 & 6.0362 & 5.5317 & TST & \\
\hline CHEMBL3209492 & 688239 & 4.5362 & 5.4976 & TST & \\
\hline CHEMBL1419964 & 688239 & 4.9362 & 5.5783 & TRN & \\
\hline CHEMBL1306576 & 688239 & 4.5362 & 5.46899 & 9999999999 & TRN \\
\hline CHEMBL1481253 & 688239 & 4.7862 & 5.5654 & TRN & \\
\hline CHEMBL3196948 & 688239 & 5.9862 & 5.5061 & TRN & \\
\hline CHEMBL1531970 & 688239 & 5.1862 & 5.5496 & TRN & \\
\hline CHEMBL1585779 & 688239 & 5.9362 & 5.5775 & TST & \\
\hline CHEMBL1346825 & 688239 & 5.1862 & 5.4692 & TRN & \\
\hline CHEMBL1509031 & 688239 & 5.2362 & 5.3725 & TRN & \\
\hline CHEMBL1523691 & 688239 & 6.2362 & 5.3889 & TRN & \\
\hline CHEMBL1316781 & 688239 & 5.6862 & 5.5392 & TRN & \\
\hline CHEMBL1384327 & 688239 & 4.9362 & 5.4005 & TRN & \\
\hline CHEMBL1368520 & 688239 & 4.8362 & 5.44799 & 99999999995 & TRN \\
\hline CHEMBL1310981 & 688239 & 6.1862 & 5.4371 & TST & \\
\hline CHEMBL1508620 & 688239 & 4.4862 & 5.4846 & TRN & \\
\hline CHEMBL3199804 & 688239 & 5.3862 & 5.4416 & TST & \\
\hline CHEMBL1551688 & 688239 & 6.0362 & 5.3694 & TRN & \\
\hline CHEMBL3190507 & 688239 & 6.2362 & 5.415 & TRN & \\
\hline CHEMBL1389380 & 688239 & 5.5862 & 5.6594 & TRN & \\
\hline CHEMBL1475847 & 688239 & 7.2366 & 5.4968 & TRN & \\
\hline CHEMBL1337894 & 688239 & 5.1362 & 5.4974 & TST & \\
\hline CHEMBL1597635 & 688239 & 5.2362 & 5.284 & TRN & \\
\hline CHEMBL1515807 & 688239 & 4.9862 & 5.5258 & TRN & \\
\hline CHEMBL1532217 & 688239 & 6.2862 & 5.6268 & TRN & \\
\hline CHEMBL1314261 & 688239 & 6.2862 & 5.5105 & TRN & \\
\hline CHEMBL1374534 & 688239 & 6.0 & 5.4525 & TST & \\
\hline CHEMBL1533552 & 688239 & 6.7862 & 5.4311 & TRN & \\
\hline
\end{tabular}


Supplemental Table S2.txt

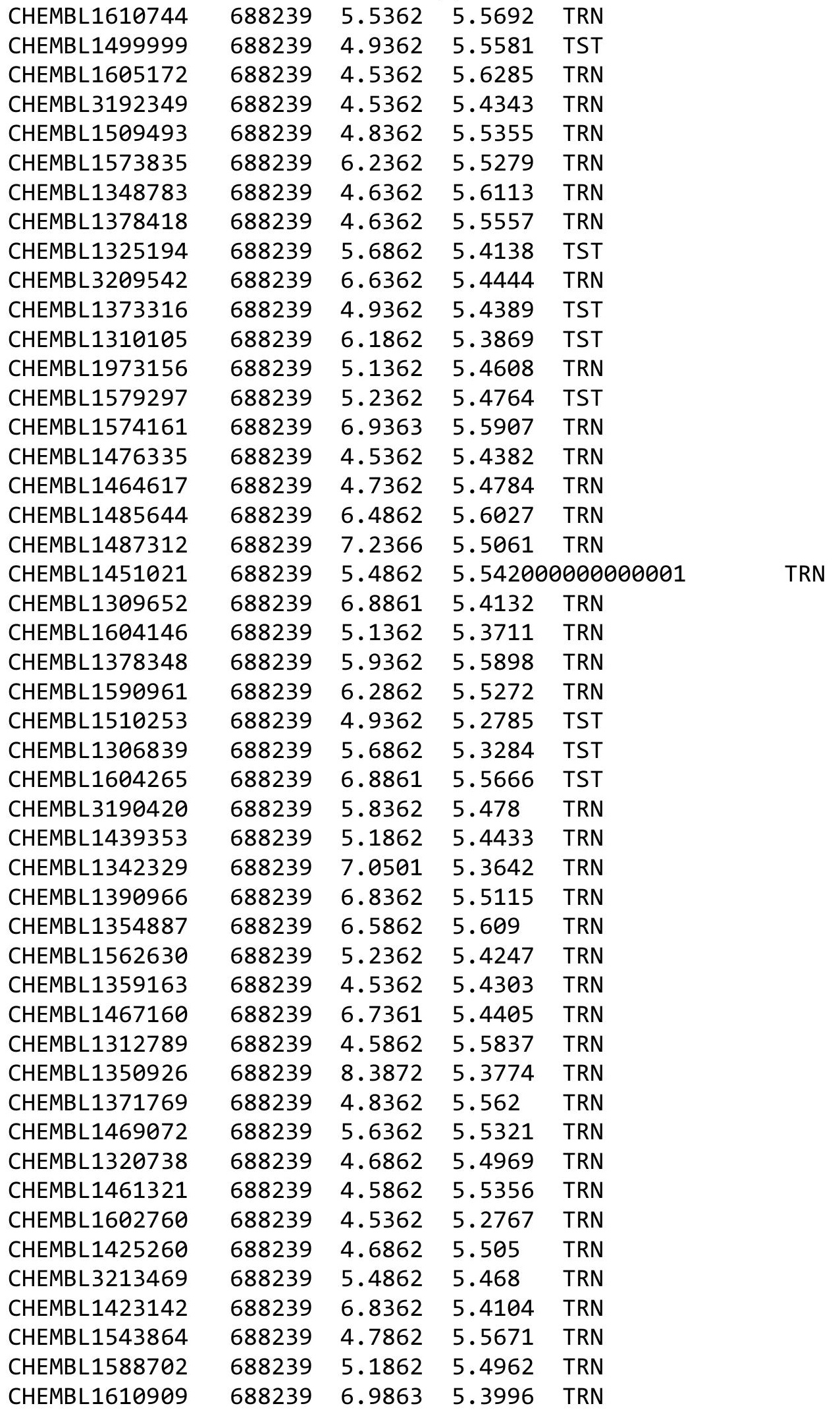

Page 2392 


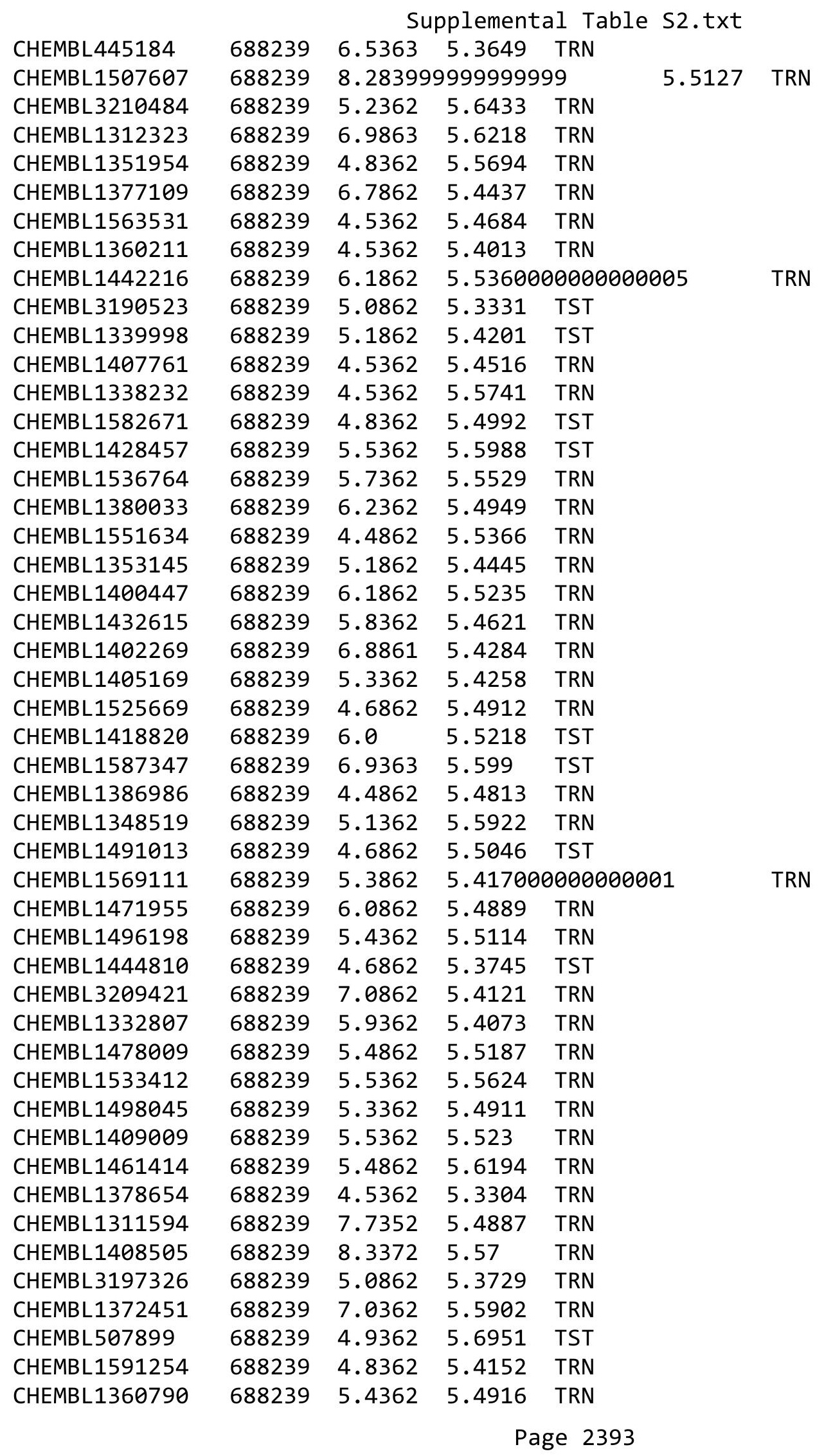


Supplemental Table S2.txt

\begin{tabular}{|c|c|c|c|c|c|}
\hline CHEMBL3195997 & 688239 & 4.5362 & 5.3417 & TRN & \\
\hline CHEMBL1504611 & 688239 & 5.9362 & 5.4507 & TST & \\
\hline CHEMBL1595760 & 688239 & 4.7362 & 5.5988 & TST & \\
\hline CHEMBL1350096 & 688239 & 5.7362 & 5.4994 & TRN & \\
\hline CHEMBL1361443 & 688239 & 4.5362 & 5.3797 & TRN & \\
\hline CHEMBL1586260 & 688239 & 5.7362 & 5.2988 & TRN & \\
\hline CHEMBL1394928 & 688239 & 4.7862 & 5.5183 & TST & \\
\hline CHEMBL1580980 & 688239 & 4.8862 & 5.5 & TST & \\
\hline CHEMBL1325772 & 688239 & 4.5362 & 5.345 & TRN & \\
\hline CHEMBL1428177 & 688239 & 6.5363 & 5.5112 & TRN & \\
\hline CHEMBL1603015 & 688239 & 4.7362 & 5.6791 & TRN & \\
\hline CHEMBL1537242 & 688239 & 4.5362 & 5.61600 & 00000000005 & TST \\
\hline CHEMBL1341028 & 688239 & 5.1862 & 5.5127 & TRN & \\
\hline CHEMBL1359323 & 688239 & 5.9362 & 5.5478 & TRN & \\
\hline CHEMBL1384819 & 688239 & 7.2366 & 5.6347 & TRN & \\
\hline CHEMBL1504430 & 688239 & 8.3372 & 5.5855 & TRN & \\
\hline CHEMBL1433136 & 688239 & 5.4862 & 5.49200 & 0000000001 & TRN \\
\hline CHEMBL1975032 & 688239 & 5.1362 & 5.4536 & TST & \\
\hline CHEMBL1483799 & 688239 & 8.3372 & 5.6263 & TRN & \\
\hline CHEMBL1498984 & 688239 & 5.0862 & 5.4324 & TST & \\
\hline CHEMBL1607429 & 688239 & 5.6862 & 5.5495 & TRN & \\
\hline CHEMBL1446780 & 688239 & 5.4862 & 5.6326 & TST & \\
\hline CHEMBL1471499 & 688239 & 6.7862 & 5.4481 & TST & \\
\hline CHEMBL1603680 & 688239 & 6.1362 & 5.5559 & TRN & \\
\hline CHEMBL1345736 & 688239 & 6.0362 & 5.4457 & TST & \\
\hline CHEMBL1591938 & 688239 & 6.3362 & 5.4356 & TRN & \\
\hline CHEMBL1383838 & 688239 & 4.5862 & 5.4821 & TRN & \\
\hline CHEMBL1433488 & 688239 & 4.7862 & 5.4431 & TRN & \\
\hline CHEMBL1372930 & 688239 & 4.7362 & 5.4577 & TRN & \\
\hline CHEMBL1316792 & 688239 & 5.6862 & 5.4275 & TRN & \\
\hline CHEMBL1546027 & 688239 & 4.6862 & 5.5917 & TRN & \\
\hline CHEMBL1382541 & 688239 & 5.0862 & 5.4374 & TRN & \\
\hline CHEMBL1506941 & 688239 & 6.5363 & 5.5151 & TRN & \\
\hline CHEMBL1526621 & 688239 & 5.1862 & 5.3802 & TRN & \\
\hline CHEMBL1532303 & 688239 & 6.3362 & 5.33 & TST & \\
\hline CHEMBL1300245 & 688239 & 6.6861 & 5.5755 & TRN & \\
\hline CHEMBL1497427 & 688239 & 5.1362 & 5.4861 & TRN & \\
\hline CHEMBL1480956 & 688239 & 4.7862 & 5.5701 & TRN & \\
\hline CHEMBL1541614 & 688239 & 5.1862 & 5.4951 & TRN & \\
\hline CHEMBL 3198714 & 688239 & 4.95 & 5.516 & TRN & \\
\hline CHEMBL1320683 & 688239 & 4.7362 & 5.3687 & TRN & \\
\hline CHEMBL 3214224 & 688239 & 4.7362 & 5.4531 & TST & \\
\hline CHEMBL1606969 & 688239 & 5.3362 & 5.3588 & TST & \\
\hline CHEMBL1304495 & 688239 & 6.5363 & 5.5778 & TST & \\
\hline CHEMBL 3196107 & 688239 & 4.5362 & 5.3287 & TST & \\
\hline CHEMBL1391083 & 688239 & 4.7862 & 5.4586 & TRN & \\
\hline CHEMBL1990510 & 688239 & 5.6362 & 5.4402 & TST & \\
\hline CHEMBL1420662 & 688239 & 4.5362 & 5.5522 & TRN & \\
\hline
\end{tabular}


Supplemental Table S2.txt

\begin{tabular}{|c|c|c|c|c|c|}
\hline CHEMBL1421640 & 688239 & 4.5362 & 5.6036 & TRN & \\
\hline CHEMBL1574742 & 688239 & 5.0362 & 5.4877 & TRN & \\
\hline CHEMBL1452472 & 688239 & 5.4862 & 5.3966 & TRN & \\
\hline CHEMBL1376516 & 688239 & 4.6362 & 5.3691 & TRN & \\
\hline CHEMBL1526594 & 688239 & 4.5362 & 5.4974 & TST & \\
\hline CHEMBL1359455 & 688239 & 6.5862 & 5.4965 & TRN & \\
\hline CHEMBL1612621 & 688239 & 5.3362 & 5.5147 & TST & \\
\hline CHEMBL1593173 & 688239 & 5.3362 & 5.6585 & TRN & \\
\hline CHEMBL 29878 & 688239 & 4.5362 & 5.4039 & TRN & \\
\hline CHEMBL1550439 & 688239 & 4.4862 & 5.5399 & TRN & \\
\hline CHEMBL1312823 & 688239 & 4.7362 & 5.3753 & TRN & \\
\hline CHEMBL1371632 & 688239 & 6.8362 & 5.4207 & TST & \\
\hline CHEMBL1358517 & 688239 & 4.5362 & 5.4038 & TRN & \\
\hline CHEMBL1566581 & 688239 & 6.7862 & 5.5613 & TRN & \\
\hline CHEMBL1351970 & 688239 & 5.0862 & 5.422999 & 999999999 & TST \\
\hline CHEMBL34730 & 688239 & 4.7862 & 5.5205 & TST & \\
\hline CHEMBL1489208 & 688239 & 5.0362 & 5.3874 & TRN & \\
\hline CHEMBL1320305 & 688239 & 4.6362 & 5.4539 & TRN & \\
\hline CHEMBL1478834 & 688239 & 4.4862 & 5.491000 & 0000000005 & \\
\hline CHEMBL1566058 & 688239 & 5.2362 & 5.4215 & TRN & \\
\hline CHEMBL1383058 & 688239 & 4.7362 & 5.4689 & TRN & \\
\hline CHEMBL1599295 & 688239 & 5.5362 & 5.581 & TRN & \\
\hline CHEMBL1361693 & 688239 & 5.6362 & 5.393 & TST & \\
\hline CHEMBL1547573 & 688239 & 4.5362 & 5.5167 & TST & \\
\hline CHEMBL1527802 & 688239 & 5.6862 & 5.5353 & TRN & \\
\hline CHEMBL3207619 & 688239 & 5.4862 & 5.4021 & TRN & \\
\hline CHEMBL1382471 & 688239 & 6.1362 & 5.6108 & TRN & \\
\hline CHEMBL1412678 & 688239 & 4.5362 & 5.5973 & TST & \\
\hline CHEMBL3190648 & 688239 & 6.7862 & 5.5215 & TRN & \\
\hline CHEMBL1437349 & 688239 & 4.8362 & 5.7065 & TRN & \\
\hline CHEMBL1485329 & 688239 & 5.3862 & 5.282999 & 9999999995 & TC \\
\hline CHEMBL1564219 & 688239 & 6.7862 & 5.4728 & TRN & \\
\hline CHEMBL1497766 & 688239 & 5.2862 & 5.5318 & TRN & \\
\hline CHEMBL1418819 & 688239 & 6.5862 & 5.4457 & TST & \\
\hline CHEMBL1481761 & 688239 & 5.7862 & 5.5065 & TRN & \\
\hline CHEMBL348588 & 688239 & 5.3362 & 5.3985 & TRN & \\
\hline CHEMBL 3191203 & 688239 & 8.28399 & 999999999 & 5.3591 & \\
\hline CHEMBL1346617 & 688239 & 5.7862 & 5.5119 & TRN & \\
\hline CHEMBL1467980 & 688239 & 5.7862 & 5.5006 & TRN & \\
\hline CHEMBL 3192545 & 688239 & 5.1862 & 5.3783 & TRN & \\
\hline CHEMBL1460737 & 688239 & 6.0862 & 5.3676 & TRN & \\
\hline CHEMBL1570011 & 688239 & 6.7862 & 5.5215 & TRN & \\
\hline CHEMBL1545902 & 688239 & 5.1862 & 5.5752 & TRN & \\
\hline CHEMBL1409089 & 688239 & 5.1862 & 5.6476 & TRN & \\
\hline CHEMBL1434250 & 688239 & 4.8362 & 5.5826 & TRN & \\
\hline CHEMBL1389940 & 688239 & 4.4862 & 5.4171 & TRN & \\
\hline CHEMBL1468868 & 688239 & 5.8862 & 5.6509 & TRN & \\
\hline CHEMBL1335801 & 688239 & 5.1362 & 5.475 & TRN & \\
\hline
\end{tabular}


Supplemental Table S2.txt

\begin{tabular}{|c|c|c|c|c|c|}
\hline CHEMBL1440937 & 688239 & 6.1862 & 5.5711 & TRN & \\
\hline CHEMBL1456561 & 688239 & 6.0362 & 5.5929 & TRN & \\
\hline CHEMBL1486072 & 688239 & 4.4862 & 5.466 & TRN & \\
\hline CHEMBL1570151 & 688239 & 5.5362 & 5.5907 & TRN & \\
\hline CHEMBL1550111 & 688239 & 5.5362 & 5.4059 & TRN & \\
\hline CHEMBL1512626 & 688239 & 4.9362 & 5.4201 & TRN & \\
\hline CHEMBL1471520 & 688239 & 5.4862 & 5.3913 & TST & \\
\hline CHEMBL1337767 & 688239 & 4.6362 & 5.3205 & TRN & \\
\hline CHEMBL1584002 & 688239 & 6.4862 & 5.5847 & TRN & \\
\hline CHEMBL1488340 & 688239 & 6.5862 & 5.5181 & TRN & \\
\hline CHEMBL1578581 & 688239 & 5.9362 & 5.5957 & TRN & \\
\hline CHEMBL1415503 & 688239 & 5.1862 & 5.5537 & TRN & \\
\hline CHEMBL1394553 & 688239 & 4.5362 & 5.4543 & TRN & \\
\hline CHEMBL 3145204 & 688239 & 4.7862 & 5.4255 & TRN & \\
\hline CHEMBL1381740 & 688239 & 6.9363 & 5.5129 & TRN & \\
\hline CHEMBL1450999 & 688239 & 4.5362 & 5.4371 & TRN & \\
\hline CHEMBL250916 & 688239 & 5.5362 & 5.5809 & TRN & \\
\hline CHEMBL1399448 & 688239 & 8.2366 & 5.5607 & TRN & \\
\hline CHEMBL1567352 & 688239 & 6.0862 & 5.5947 & TRN & \\
\hline CHEMBL1547609 & 688239 & 4.6862 & 5.4412 & TRN & \\
\hline CHEMBL1593355 & 688239 & 5.2362 & 5.4075 & TRN & \\
\hline CHEMBL1370331 & 688239 & 5.8862 & 5.5097 & TRN & \\
\hline CHEMBL1463955 & 688239 & 7.0862 & 5.5489 & TRN & \\
\hline CHEMBL1327351 & 688239 & 4.8362 & 5.1871 & TST & \\
\hline CHEMBL1352506 & 688239 & 5.1862 & 5.4297 & TRN & \\
\hline CHEMBL1406533 & 688239 & 4.5362 & 5.4069 & TRN & \\
\hline CHEMBL1392214 & 688239 & 5.1362 & 5.4249 & TRN & \\
\hline CHEMBL1327497 & 688239 & 4.5862 & 5.4196 & TST & \\
\hline CHEMBL1396699 & 688239 & 5.6862 & 5.3916 & TRN & \\
\hline CHEMBL1536369 & 688239 & 5.1362 & 5.4292 & TST & \\
\hline CHEMBL1323407 & 688239 & 5.1862 & 5.3291 & TST & \\
\hline CHEMBL1552563 & 688239 & 4.5862 & 5.4593 & TRN & \\
\hline CHEMBL 1414588 & 688239 & 4.7862 & 5.457999 & 9999999999 & TST \\
\hline CHEMBL1424744 & 688239 & 4.7362 & 5.5577 & TRN & \\
\hline CHEMBL1482041 & 688239 & 6.6362 & 5.3293 & TRN & \\
\hline CHEMBL1511010 & 688239 & 6.4362 & 5.4343 & TRN & \\
\hline CHEMBL1512761 & 688239 & 6.5363 & 5.4065 & TRN & \\
\hline CHEMBL1373011 & 688239 & 6.0862 & 5.4148 & TST & \\
\hline CHEMBL1336857 & 688239 & 6.5862 & 5.5248 & TST & \\
\hline CHEMBL1581299 & 688239 & 5.2362 & 5.3564 & TST & \\
\hline CHEMBL1440931 & 688239 & \multicolumn{3}{|c|}{8.283999999999999} & TRN \\
\hline CHEMBL1387051 & 688239 & 4.5362 & 5.6066 & TRN & \\
\hline CHEMBL1499306 & 688239 & 5.7862 & 5.4124 & TST & \\
\hline CHEMBL1516493 & 688239 & 6.1862 & 5.5049 & TST & \\
\hline CHEMBL1350995 & 688239 & 5.7362 & 5.5472 & TRN & \\
\hline CHEMBL1486395 & 688239 & 5.5862 & 5.3276 & TRN & \\
\hline CHEMBL1480529 & 688239 & 6.1862 & 5.4001 & TRN & \\
\hline CHEMBL1534464 & 688239 & 5.2362 & 5.383999 & 99999999995 & TRN \\
\hline
\end{tabular}

Page 2396 
Supplemental Table S2.txt

\begin{tabular}{|c|c|c|c|c|c|}
\hline CHEMBL1552700 & 688239 & 4.7362 & 5.3495 & TST & \\
\hline CHEMBL1363437 & 688239 & 4.5362 & 5.4272 & TRN & \\
\hline CHEMBL1307296 & 688239 & 8.3372 & 5.4575 & TST & \\
\hline CHEMBL1324006 & 688239 & 6.8861 & 5.5413 & TRN & \\
\hline CHEMBL3213422 & 688239 & 5.1362 & 5.3593 & TRN & \\
\hline CHEMBL1569606 & 688239 & 6.7862 & 5.3971 & TST & \\
\hline CHEMBL1526422 & 688239 & 5.8362 & 5.4331 & TRN & \\
\hline CHEMBL1332575 & 688239 & 7.6364 & 5.6568 & TRN & \\
\hline CHEMBL1366865 & 688239 & 7.0862 & 5.4267 & TRN & \\
\hline CHEMBL1475135 & 688239 & 4.7362 & 5.4455 & TRN & \\
\hline CHEMBL1409841 & 688239 & 6.1 & 5.4478 & TRN & \\
\hline CHEMBL1364346 & 688239 & 5.1862 & 5.6017 & TRN & \\
\hline CHEMBL1302885 & 688239 & 5.7862 & 5.5696 & TRN & \\
\hline CHEMBL 2369186 & 688239 & 5.4362 & 5.4825 & TRN & \\
\hline CHEMBL3195201 & 688239 & 4.5362 & 5.5805 & TRN & \\
\hline CHEMBL1342870 & 688239 & 4.5362 & 5.4804 & TRN & \\
\hline CHEMBL1562797 & 688239 & 5.1862 & 5.5602 & TRN & \\
\hline CHEMBL1589674 & 688239 & 4.5862 & 5.4816 & TRN & \\
\hline CHEMBL1344787 & 688239 & 5.8362 & 5.4982 & TST & \\
\hline CHEMBL1304348 & 688239 & 4.7862 & 5.5421 & TST & \\
\hline CHEMBL3192944 & 688239 & 4.7362 & 5.398 & TRN & \\
\hline CHEMBL1341676 & 688239 & 6.0862 & 5.4353 & TST & \\
\hline CHEMBL1303112 & 688239 & 4.5362 & 5.5165 & TRN & \\
\hline CHEMBL1482606 & 688239 & 6.7361 & 5.5257 & TRN & \\
\hline CHEMBL1359796 & 688239 & 4.8362 & 5.4989 & TST & \\
\hline CHEMBL1364941 & 688239 & 4.4862 & 5.5621 & TRN & \\
\hline CHEMBL1302902 & 688239 & 6.2862 & 5.4821 & TST & \\
\hline CHEMBL1304979 & 688239 & 5.1862 & 5.5336 & TRN & \\
\hline CHEMBL1449229 & 688239 & 8.3372 & 5.5999 & TRN & \\
\hline CHEMBL1450474 & 688239 & 4.6862 & 5.4747 & TRN & \\
\hline CHEMBL1085649 & 688239 & 4.6362 & 5.5072 & TRN & \\
\hline CHEMBL1560197 & 688239 & 5.5862 & 5.4032 & TRN & \\
\hline CHEMBL1572947 & 688239 & 8.3372 & 5.55399 & 9999999999 & TRN \\
\hline CHEMBL1582451 & 688239 & 6.5363 & 5.4509 & TRN & \\
\hline CHEMBL1424247 & 688239 & 6.0862 & 5.5589 & TRN & \\
\hline CHEMBL1359330 & 688239 & 6.0862 & 5.4856 & TST & \\
\hline CHEMBL1366842 & 688239 & 6.1862 & 5.5045 & TST & \\
\hline CHEMBL1592861 & 688239 & 4.7362 & 5.398 & TRN & \\
\hline CHEMBL1398354 & 688239 & 4.5362 & 5.5597 & TRN & \\
\hline CHEMBL1447414 & 688239 & 5.0362 & 5.459 & TST & \\
\hline CHEMBL1610920 & 688239 & 6.1862 & 5.608 & TRN & \\
\hline CHEMBL1303545 & 688239 & 5.7862 & 5.4479 & TST & \\
\hline CHEMBL1533312 & 688239 & 4.5362 & 5.4142 & TST & \\
\hline CHEMBL1521594 & 688239 & 6.7862 & 5.6037 & TRN & \\
\hline CHEMBL1322827 & 688239 & 8.3872 & 5.5027 & TRN & \\
\hline CHEMBL1326218 & 688239 & 4.7862 & 5.3929 & TST & \\
\hline CHEMBL3193310 & 688239 & 8.2366 & 5.5952 & TRN & \\
\hline CHEMBL1350721 & 688239 & 5.0862 & 5.5332 & TRN & \\
\hline
\end{tabular}

Page 2397 
Supplemental Table S2.txt

\begin{tabular}{|c|c|c|c|c|}
\hline CHEMBL1529925 & 688239 & 4.5862 & 5.4234 & TRN \\
\hline CHEMBL1563241 & 688239 & 4.7362 & 5.5469 & TRN \\
\hline CHEMBL3212820 & 688239 & 6.2362 & 5.5045 & TRN \\
\hline CHEMBL1383825 & 688239 & 7.1361 & 5.6275 & TRN \\
\hline CHEMBL3190547 & 688239 & 4.6862 & 5.4333 & TRN \\
\hline CHEMBL3191811 & 688239 & 6.2862 & 5.4853 & TRN \\
\hline CHEMBL1540613 & 688239 & 4.6862 & 5.4849 & TRN \\
\hline CHEMBL1541956 & 688239 & 5.5362 & 5.5229 & TRN \\
\hline CHEMBL1500908 & 688239 & 4.8362 & 5.5419 & TRN \\
\hline CHEMBL1472283 & 688239 & 6.8362 & 5.5636 & TRN \\
\hline CHEMBL1560733 & 688239 & 8.3372 & 5.49200 & 0006 \\
\hline CHEMBL1457686 & 688239 & 7.0862 & 5.3896 & TRN \\
\hline CHEMBL1375614 & 688239 & 4.5362 & 5.597 & TRN \\
\hline CHEMBL1581929 & 688239 & 5.3862 & 5.4719 & TST \\
\hline CHEMBL 3210687 & 688239 & 5.1362 & 5.479 & TST \\
\hline CHEMBL1442717 & 688239 & 4.6862 & 5.2143 & TRN \\
\hline CHEMBL1438697 & 688239 & 4.7862 & 5.4699 & TST \\
\hline CHEMBL1612735 & 688239 & 6.1362 & 5.3703 & TRN \\
\hline CHEMBL1608637 & 688239 & 4.7362 & 5.5029 & TRN \\
\hline CHEMBL1520865 & 688239 & 4.7862 & 5.5954 & TRN \\
\hline CHEMBL1500710 & 688239 & 4.7862 & 5.5059 & TST \\
\hline CHEMBL1344898 & 688239 & 4.5362 & 5.4402 & TRN \\
\hline CHEMBL1340657 & 688239 & 4.7362 & 5.7002 & TRN \\
\hline CHEMBL1350010 & 688239 & 4.5362 & 5.5028 & TRN \\
\hline CHEMBL1367262 & 688239 & 4.5362 & 5.2197 & TRN \\
\hline CHEMBL1448554 & 688239 & 4.5862 & 5.5536 & TRN \\
\hline CHEMBL590161 & 688239 & 5.4862 & 5.6158 & TRN \\
\hline CHEMBL1605174 & 688239 & 4.7362 & 5.5375 & TRN \\
\hline CHEMBL1599625 & 688239 & 5.1862 & 5.5967 & TRN \\
\hline CHEMBL1571476 & 688239 & 5.6862 & 5.4602 & TRN \\
\hline CHEMBL1304702 & 688239 & 4.5362 & 5.579 & TRN \\
\hline CHEMBL1435931 & 688239 & 5.1862 & 5.4969 & TRN \\
\hline CHEMBL1413896 & 688239 & 6.9863 & 5.4048 & TRN \\
\hline CHEMBL1569681 & 688239 & 5.1862 & 5.5436 & TRN \\
\hline CHEMBL1546590 & 688239 & 5.3362 & 5.4837 & TRN \\
\hline CHEMBL1516405 & 688239 & 4.5362 & 5.5193 & TRN \\
\hline CHEMBL1490173 & 688239 & 5.0362 & 5.5692 & TRN \\
\hline CHEMBL1528101 & 688239 & 5.4862 & 5.4741 & TST \\
\hline CHEMBL 1360363 & 688239 & 5.3362 & 5.4555 & TRN \\
\hline CHEMBL1518020 & 688239 & 5.0862 & 5.6175 & TRN \\
\hline CHEMBL1380523 & 688239 & 6.5363 & 5.5465 & TRN \\
\hline CHEMBL1401226 & 688239 & 5.1362 & 5.3165 & TRN \\
\hline CHEMBL1332112 & 688239 & 5.3362 & 5.709 & TRN \\
\hline CHEMBL1302167 & 688239 & 6.2862 & 5.5033 & TST \\
\hline CHEMBL1312249 & 688239 & 6.7862 & 5.3982 & TST \\
\hline CHEMBL1336553 & 688239 & 5.4862 & 5.4589 & TRN \\
\hline CHEMBL1526846 & 688239 & 6.8861 & 5.4417 & TRN \\
\hline CHEMBL104732 & 688239 & 4.5862 & 5.4435 & TRN \\
\hline
\end{tabular}


Supplemental Table S2.txt

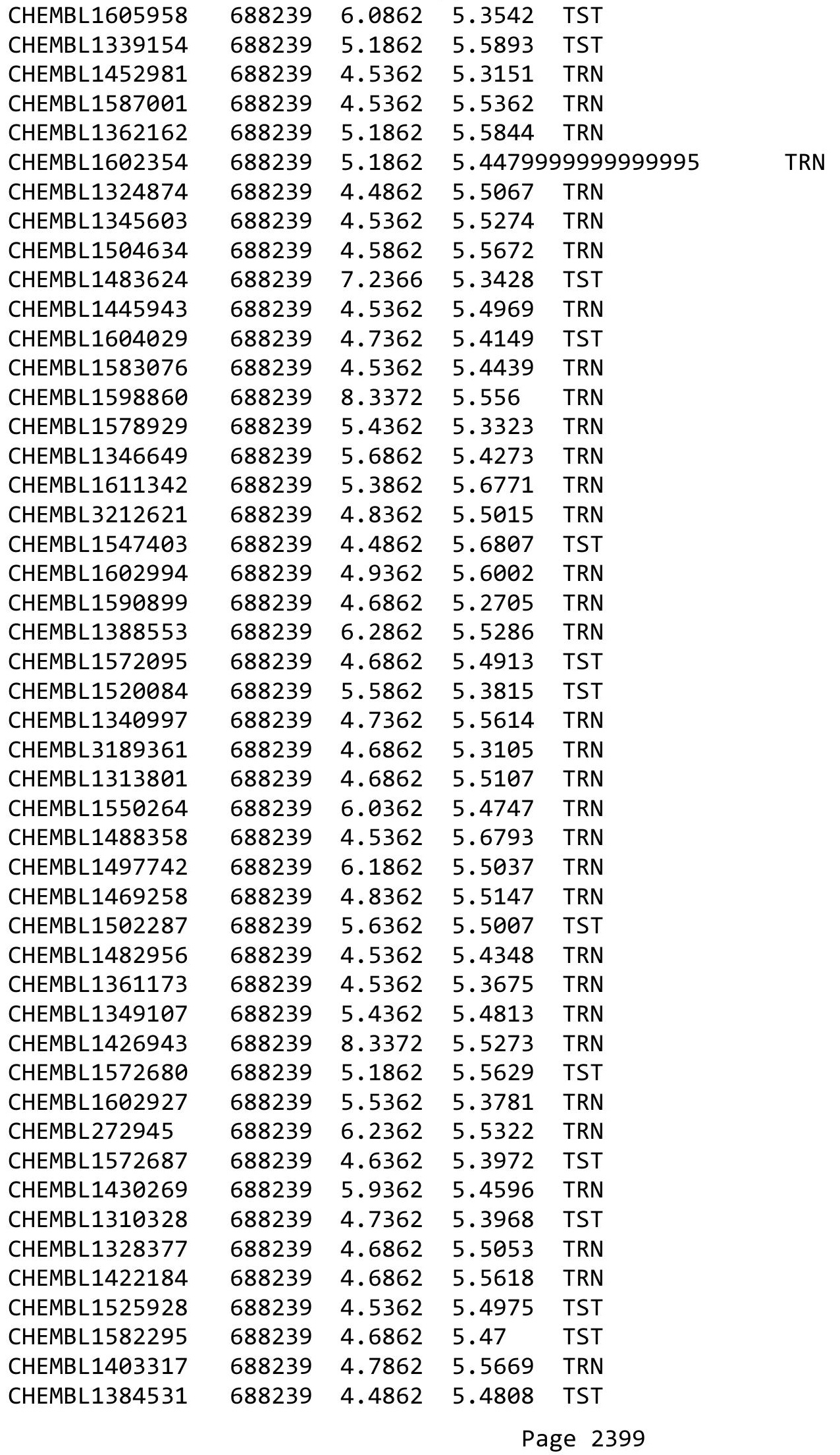


Supplemental Table S2.txt

\begin{tabular}{|c|c|c|c|c|c|}
\hline CHEMBL1561750 & 688239 & 5.1862 & 5.5501 & TRN & \\
\hline CHEMBL1403391 & 688239 & 7.0862 & 5.3693 & TRN & \\
\hline CHEMBL1601835 & 688239 & 4.5362 & 5.4468 & TRN & \\
\hline CHEMBL1563885 & 688239 & 4.7862 & 5.2598 & TRN & \\
\hline CHEMBL1409111 & 688239 & 6.9863 & 5.4678 & TRN & \\
\hline CHEMBL1467369 & 688239 & 5.6862 & 5.5542 & TRN & \\
\hline CHEMBL1990565 & 688239 & 6.4362 & 5.4166 & TRN & \\
\hline CHEMBL3198197 & 688239 & 5.1862 & 5.5599 & TRN & \\
\hline CHEMBL1553368 & 688239 & 6.2862 & 5.5067 & TST & \\
\hline CHEMBL1450376 & 688239 & 5.8862 & 5.4418 & TRN & \\
\hline CHEMBL1523761 & 688239 & 6.8362 & 5.5367 & TST & \\
\hline CHEMBL1579965 & 688239 & 4.5362 & 5.4193 & TRN & \\
\hline CHEMBL1311755 & 688239 & 4.5362 & 5.3052 & TRN & \\
\hline CHEMBL1459288 & 688239 & 5.1862 & 5.3836 & TST & \\
\hline CHEMBL1308190 & 688239 & 5.1862 & 5.4656 & TRN & \\
\hline CHEMBL1417768 & 688239 & 4.5362 & 5.3522 & TRN & \\
\hline CHEMBL1342385 & 688239 & 4.5362 & 5.5997 & TST & \\
\hline CHEMBL1414087 & 688239 & 4.5362 & 5.4025 & TST & \\
\hline CHEMBL1428179 & 688239 & 4.5362 & 5.4753 & TST & \\
\hline CHEMBL1418460 & 688239 & 4.5362 & 5.4508 & TRN & \\
\hline CHEMBL3212819 & 688239 & 6.1362 & 5.5149 & TRN & \\
\hline CHEMBL1571890 & 688239 & 6.1862 & 5.4779 & TRN & \\
\hline CHEMBL3196653 & 688239 & 6.8861 & 5.6653 & TRN & \\
\hline CHEMBL1303953 & 688239 & 6.1862 & 5.4127 & TRN & \\
\hline CHEMBL3197685 & 688239 & 5.1862 & 5.6023 & TRN & \\
\hline CHEMBL1360769 & 688239 & 7.1361 & 5.4912 & TRN & \\
\hline CHEMBL1460143 & 688239 & 5.2362 & 5.6289 & TRN & \\
\hline CHEMBL1378136 & 688239 & 6.2862 & 5.3942 & TRN & \\
\hline CHEMBL1570310 & 688239 & 5.0362 & 5.6006 & TRN & \\
\hline CHEMBL1611709 & 688239 & 5.3862 & 5.5873 & TRN & \\
\hline CHEMBL1538222 & 688239 & 7.7852 & 5.5361 & TST & \\
\hline CHEMBL1598033 & 688239 & 5.1862 & 5.5396 & TRN & \\
\hline CHEMBL1529861 & 688239 & 4.6862 & 5.4099 & TRN & \\
\hline CHEMBL1370829 & 688239 & 6.7862 & 5.46399 & 99999999995 & TRN \\
\hline CHEMBL1326162 & 688239 & 6.8861 & 5.5356 & TRN & \\
\hline CHEMBL1377462 & 688239 & 4.5362 & 5.4755 & TST & \\
\hline CHEMBL1487904 & 688239 & 5.6362 & 5.42299 & 9999999999 & TRN \\
\hline CHEMBL1507554 & 688239 & 4.5862 & 5.4684 & TRN & \\
\hline CHEMBL1558846 & 688239 & 5.1862 & 5.4946 & TRN & \\
\hline CHEMBL1400952 & 688239 & 5.9362 & 5.4072 & TST & \\
\hline CHEMBL1401166 & 688239 & 4.6362 & 5.6646 & TST & \\
\hline CHEMBL1525905 & 688239 & 5.1862 & 5.4791 & TRN & \\
\hline CHEMBL1383922 & 688239 & 4.6362 & 5.4621 & TRN & \\
\hline CHEMBL1405373 & 688239 & 6.9863 & 5.4978 & TRN & \\
\hline CHEMBL1418052 & 688239 & 5.3862 & 5.3729 & TST & \\
\hline CHEMBL1351309 & 688239 & 4.7362 & 5.5159 & TRN & \\
\hline CHEMBL1347471 & 688239 & 5.5862 & 5.6509 & TRN & \\
\hline CHEMBL1499587 & 688239 & 4.5362 & 5.5066 & TST & \\
\hline
\end{tabular}


Supplemental Table S2.txt

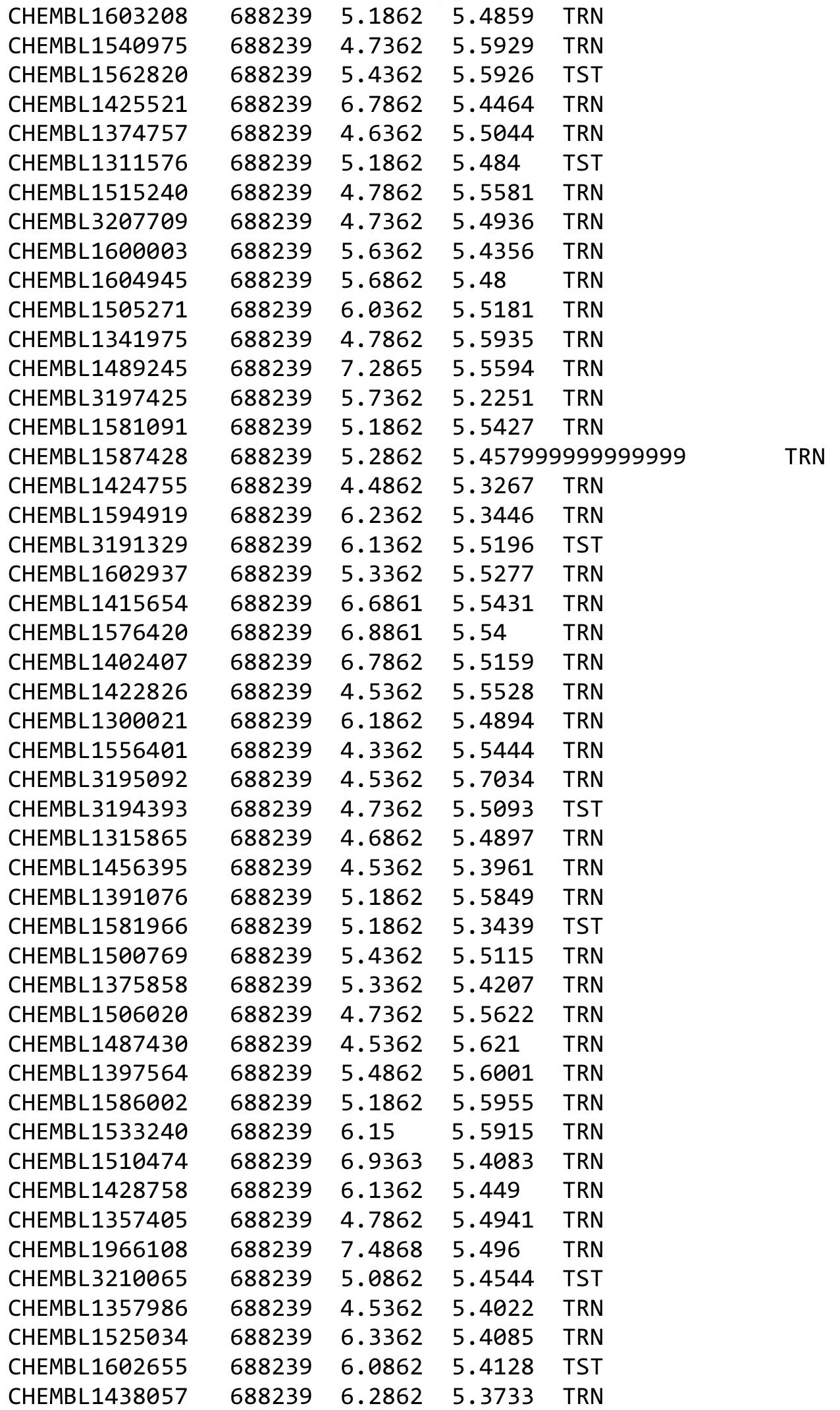

Page 2401 
Supplemental Table S2.txt

\begin{tabular}{|c|c|c|c|c|}
\hline & & & & \\
\hline AEMBL1479804 & 88239 & 362 & & \\
\hline HEMBL154 & 39 & & & \\
\hline & & & & \\
\hline AFMRI 13 & & & & \\
\hline AEMBL1352258 & 88239 & 362 & 5042 & \\
\hline AEMBL1554358 & 88239 & 362 & 5222 & \\
\hline HEMBL1442457 & & & & \\
\hline AEMBL14€ & & & & \\
\hline AEMBL15 & & & & \\
\hline AEMBL1407802 & 39 & & 63 & \\
\hline AEMBL1350949 & 39 & & & \\
\hline AEMBL1573 & & & & \\
\hline HEMBL136 & & & & \\
\hline JEMBL14] & & & & \\
\hline AEMBL1317225 & & & & \\
\hline HEMBL146 & & & & \\
\hline HEMBL139 & & & & \\
\hline HEMBL13 & & & & \\
\hline HEMBL 14 & & & & \\
\hline AEMBL1367695 & & & & \\
\hline AEMBL1358056 & & & & \\
\hline JEMBL 31 & & & & \\
\hline AEMBL13 & & & & \\
\hline AFMR 1 & & & & \\
\hline HEMBL157 & & & & \\
\hline AEMBL1586318 & & & & \\
\hline HEMBL152 & & & & \\
\hline AEM & & & & \\
\hline AFMRI 15 & & & & \\
\hline AEMBL1538854 & & & & \\
\hline HEMBL1558223 & & & & \\
\hline & & & & \\
\hline 8 & & & & \\
\hline 5 & & & & \\
\hline AEMBL1583153 & & & & \\
\hline AEMBL1570628 & & & & \\
\hline & & & & \\
\hline$\theta$ & & & & \\
\hline HEMBL1459334 & & & & RN \\
\hline AEMBL1601286 & & & & \\
\hline HEMBL152 & & & & \\
\hline & & & & \\
\hline HEMBL131 & & & & \\
\hline HEMBL1467245 & & & & $\mathrm{RN}$ \\
\hline IEMBL1391617 & 68 & & 832 & \\
\hline-1495590 & & & & \\
\hline בתמי & & & 5.4848 & \\
\hline
\end{tabular}

Page 2402 
Supplemental Table S2.txt

\begin{tabular}{|c|c|c|c|c|c|c|}
\hline CHEMBL1437459 & 688239 & 7.0362 & 5.4084 & TRN & & \\
\hline CHEMBL1446024 & 688239 & 5.7862 & 5.5308 & TRN & & \\
\hline CHEMBL1589235 & 688239 & 5.0862 & 5.3919 & TRN & & \\
\hline CHEMBL1337325 & 688239 & 6.8861 & 5.4678 & TST & & \\
\hline CHEMBL 364482 & 688239 & 5.9362 & 5.5542 & TRN & & \\
\hline CHEMBL1587370 & 688239 & 6.9363 & 5.5576 & TST & & \\
\hline CHEMBL1305942 & 688239 & 5.4862 & 5.485 & TRN & & \\
\hline CHEMBL1490241 & 688239 & 4.5362 & 5.5676 & TRN & & \\
\hline CHEMBL1533446 & 688239 & 5.4362 & 5.5923 & TST & & \\
\hline CHEMBL1409421 & 688239 & 4.8862 & 5.5188 & TRN & & \\
\hline CHEMBL1434314 & 688239 & 4.5362 & 5.3434 & TRN & & \\
\hline CHEMBL1509976 & 688239 & 5.1862 & 5.4593 & TRN & & \\
\hline CHEMBL1605224 & 688239 & 7.0862 & 5.4333 & TRN & & \\
\hline CHEMBL1542947 & 688239 & 4.4862 & 5.3918 & TRN & & \\
\hline CHEMBL1376387 & 688239 & 5.7862 & 5.5535 & TRN & & \\
\hline CHEMBL1500583 & 688239 & 4.7862 & 5.6003 & TRN & & \\
\hline CHEMBL1466286 & 688239 & 5.2362 & 5.5754 & TST & & \\
\hline CHEMBL1302612 & 688239 & 5.4862 & 5.4917 & TST & & \\
\hline CHEMBL1422175 & 688239 & 5.3362 & 5.4916 & TST & & \\
\hline CHEMBL1552251 & 688239 & 5.7862 & 5.5743 & TRN & & \\
\hline CHEMBL1332714 & 688239 & 5.0362 & 5.5433 & TRN & & \\
\hline CHEMBL1301786 & 688239 & 6.2362 & 5.3771 & TST & & \\
\hline CHEMBL1568312 & 688239 & 4.5362 & 5.6054 & TRN & & \\
\hline CHEMBL1478065 & 688239 & 4.5862 & 5.3857 & TST & & \\
\hline CHEMBL1412321 & 688239 & 5.4362 & 5.5468 & TRN & & \\
\hline CHEMBL 228482 & 688239 & 5.1362 & 5.5177 & TST & & \\
\hline CHEMBL1464951 & 688239 & 4.6862 & 5.3884 & TRN & & \\
\hline CHEMBL1484245 & 688239 & 5.3362 & 5.3816 & TST & & \\
\hline CHEMBL1455962 & 688239 & 4.5362 & 5.5016 & TRN & & \\
\hline CHEMBL1392879 & 688239 & 6.1362 & 5.5503 & TRN & & \\
\hline CHEMBL1410664 & 688239 & 4.9362 & 5.5379 & TRN & & \\
\hline CHEMBL1477740 & 688239 & 4.9362 & 5.722 & TRN & & \\
\hline CHEMBL1508393 & 688239 & 6.1862 & 5.3565 & TRN & & \\
\hline CHEMBL1600323 & 688239 & 5.1362 & 5.5146 & TRN & & \\
\hline CHEMBL1384292 & 688239 & 5.1862 & 5.5178 & TRN & & \\
\hline CHEMBL1436659 & 688239 & 4.5362 & 5.2653 & TRN & & \\
\hline CHEMBL1380506 & 688239 & 8.28399 & 99999999 & 9 & 5.4733 & TRN \\
\hline CHEMBL1595080 & 688239 & 4.5362 & 5.5475 & TST & & \\
\hline CHEMBL1420726 & 688239 & 5.2362 & 5.4232 & TRN & & \\
\hline CHEMBL1468934 & 688239 & 4.5362 & 5.4341 & TST & & \\
\hline CHEMBL1335180 & 688239 & 5.0862 & 5.5246 & TRN & & \\
\hline CHEMBL1414325 & 688239 & 4.7862 & 5.401 & TRN & & \\
\hline CHEMBL1596748 & 688239 & 8.28399 & 99999999 & 9 & 5.5412 & TRN \\
\hline CHEMBL1318733 & 688239 & 5.3862 & 5.4109 & TST & & \\
\hline CHEMBL1503337 & 688239 & 4.5362 & 5.5096 & TRN & & \\
\hline CHEMBL1351569 & 688239 & 6.9363 & 5.4778 & TST & & \\
\hline CHEMBL1462196 & 688239 & 5.9862 & 5.4911 & TST & & \\
\hline CHEMBL1486290 & 688239 & 4.5362 & 5.5376 & TRN & & \\
\hline
\end{tabular}


Supplemental Table S2.txt

\begin{tabular}{|c|c|c|c|c|c|}
\hline CHEMBL1491247 & 688239 & 4.5362 & 5.5856 & TRN & \\
\hline CHEMBL1448486 & 688239 & 4.5362 & 5.6137 & TST & \\
\hline CHEMBL1501635 & 688239 & 4.7362 & 5.4452 & TRN & \\
\hline CHEMBL1393724 & 688239 & 5.7862 & 5.4765 & TRN & \\
\hline CHEMBL1590449 & 688239 & 6.2362 & 5.5349 & TRN & \\
\hline CHEMBL1333875 & 688239 & 6.4362 & 5.5242 & TRN & \\
\hline CHEMBL1518180 & 688239 & 5.1862 & 5.6579 & TRN & \\
\hline CHEMBL1606024 & 688239 & 4.7862 & 5.4042 & TRN & \\
\hline CHEMBL1356270 & 688239 & 5.7862 & 5.4548 & TRN & \\
\hline CHEMBL1437606 & 688239 & 6.1362 & 5.51 & TRN & \\
\hline CHEMBL1534827 & 688239 & 5.3862 & 5.436 & TRN & \\
\hline CHEMBL1541960 & 688239 & 4.7362 & 5.3965 & TRN & \\
\hline CHEMBL1521569 & 688239 & 5.6862 & 5.4684 & TST & \\
\hline CHEMBL1551921 & 688239 & 4.5362 & 5.4932 & TRN & \\
\hline CHEMBL1538774 & 688239 & 4.5362 & 5.3646 & TST & \\
\hline CHEMBL1467784 & 688239 & 5.3362 & 5.4985 & TST & \\
\hline CHEMBL1310724 & 688239 & 5.7862 & 5.6447 & TST & \\
\hline CHEMBL1489293 & 688239 & 6.1362 & 5.4948 & TST & \\
\hline CHEMBL1411669 & 688239 & 4.5362 & 5.5934 & TST & \\
\hline CHEMBL1527776 & 688239 & 5.5362 & 5.6012 & TRN & \\
\hline CHEMBL1386111 & 688239 & 4.8862 & 5.5109 & TRN & \\
\hline CHEMBL1576961 & 688239 & 5.6362 & 5.3393 & TST & \\
\hline CHEMBL1442450 & 688239 & 5.5862 & 5.58 & TRN & \\
\hline CHEMBL1396846 & 688239 & 5.6862 & 5.4599 & TRN & \\
\hline CHEMBL1443877 & 688239 & 5.6362 & 5.447999 & 99999999995 & TRN \\
\hline CHEMBL1490011 & 688239 & 5.4862 & 5.4804 & TRN & \\
\hline CHEMBL 3194138 & 688239 & 4.5362 & 5.4748 & TST & \\
\hline CHEMBL1204230 & 688239 & 4.5362 & 5.3702 & TRN & \\
\hline CHEMBL1397642 & 688239 & 5.1862 & 5.6163 & TRN & \\
\hline CHEMBL1430499 & 688239 & 4.5362 & 5.5024 & TRN & \\
\hline CHEMBL1413240 & 688239 & 4.5862 & 5.4491 & TRN & \\
\hline CHEMBL1490420 & 688239 & 5.3362 & 5.3543 & TRN & \\
\hline CHEMBL1368278 & 688239 & 8.283999 & (999999999 & 5.5282 & 13 \\
\hline CHEMBL1598856 & 688239 & 4.6862 & 5.416 & TST & \\
\hline CHEMBL1343431 & 688239 & 5.2362 & 5.4621 & TRN & \\
\hline CHEMBL1384667 & 688239 & 4.8362 & 5.3948 & TRN & \\
\hline CHEMBL3192773 & 688239 & 4.5362 & 5.4945 & TST & \\
\hline CHEMBL1599389 & 688239 & 4.7362 & 5.4207 & TST & \\
\hline CHEMBL1587608 & 688239 & 4.6862 & 5.4732 & TRN & \\
\hline CHEMBL1339362 & 688239 & 4.5362 & 5.4358 & TST & \\
\hline CHEMBL1464169 & 688239 & 5.1862 & 5.3297 & TRN & \\
\hline CHEMBL1601609 & 688239 & 4.7862 & 5.4058 & TRN & \\
\hline CHEMBL1344929 & 688239 & 6.1862 & 5.4501 & TRN & \\
\hline CHEMBL1325200 & 688239 & 4.9362 & 5.5532 & TRN & \\
\hline CHEMBL1568293 & 688239 & 6.8861 & 5.63200 & 0000000001 & I \\
\hline CHEMBL1360992 & 688239 & 5.4862 & 5.4166 & TRN & \\
\hline CHEMBL1500143 & 688239 & 5.3862 & 5.4366 & TST & \\
\hline CHEMBL1392820 & 688239 & 6.5862 & 5.4288 & TRN & \\
\hline
\end{tabular}


Supplemental Table S2.txt

\begin{tabular}{|c|c|c|c|c|}
\hline & & & & \\
\hline HEMBL 144 & 8239 & 362 & 5522 & \\
\hline IEMBL1465684 & 8239 & 5862 & & \\
\hline AEMBL1328383 & 239 & 4.6862 & 356 & \\
\hline & 239 & 362 & & \\
\hline EMBL1578923 & 239 & 862 & 562 & \\
\hline AEMBL1536688 & 239 & 862 & 255 & \\
\hline AEMBL1428872 & 88239 & 862 & 503 & \\
\hline AEMBL3193716 & 239 & 362 & 167 & \\
\hline EMBL13 & 239 & 62 & 675 & \\
\hline AEMBL154 & & & 966 & \\
\hline AEMBL1321046 & 688239 & 863 & 218 & \\
\hline AEMBL1540162 & 239 & 862 & 972 & $S$ \\
\hline AEMBL132 & & 62 & 52 & \\
\hline IEMBL14] & & 362 & 37 & \\
\hline AEMBL1519288 & & & & \\
\hline AEMBL1553554 & 239 & 367 & 811 & \\
\hline AEMBL3199631 & & 861 & & \\
\hline IEMBL147 & & 62 & 213 & \\
\hline EMBL14 & & & 395 & \\
\hline AFMBI 15 & & & & \\
\hline HEMBL133 & & 862 & 761 & \\
\hline AEMBL1518024 & & 62 & & \\
\hline IEMBL14 & & 62 & & 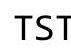 \\
\hline IEMBL13 & & 72 & 96 & $\mathrm{RN}$ \\
\hline ILMP 27 & & 62 & 18 & \\
\hline JEMBL130 & & & & ST \\
\hline AEMBL1582661 & & & & \\
\hline HEMBL142 & & 62 & 88 & RI \\
\hline-15 & & 62 & 56 & . \\
\hline$L 2$ & & 62 & 75 & - \\
\hline HEMBL1466513 & & & & RN \\
\hline AEMBL1536406 & & & & $\mathrm{RI}$ \\
\hline AEMBL15] & & 62 & 79 & RI \\
\hline HEMBL15 & & 52 & 83 & $\cdots$ \\
\hline 7 & & & & W \\
\hline AEMBL1411953 & & & & rRN \\
\hline AEMBL1537631 & & & & TST \\
\hline EMBL15 & & & 06 & RI \\
\hline רי וסנוזו & & & 39 & \\
\hline & & & & ST \\
\hline AEMBL1365193 & & 362 & 301 & $\mathrm{R}$ \\
\hline AEMBL139 & & & 772 & $T R$ \\
\hline EMBL15 & & & & TS \\
\hline HEMBL 14 & & & & זי \\
\hline CHEMBL1489652 & & & & ST \\
\hline AEMBL418562 & 8239 & 4.7862 & 5.4409 & $\mathrm{TR}$ \\
\hline HEMBL1505788 & 688239 & 6.3863 & 5.4569 & \\
\hline
\end{tabular}

Page 2405 
Supplemental Table S2.txt

\begin{tabular}{|c|c|c|c|c|}
\hline CHEMBL1575900 & 688239 & 4.7862 & 5.4126 & TRN \\
\hline CHEMBL3193976 & 688239 & 6.9363 & 5.4482 & TRN \\
\hline CHEMBL1343138 & 688239 & 6.1862 & 5.4708 & TRN \\
\hline CHEMBL1374438 & 688239 & 5.25 & 5.7161 & TRN \\
\hline CHEMBL1479409 & 688239 & 4.8862 & 5.3316 & TRN \\
\hline CHEMBL1426099 & 688239 & 5.3862 & 5.4863 & TRN \\
\hline CHEMBL1565519 & 688239 & 5.4862 & 5.3938 & TRN \\
\hline CHEMBL1486605 & 688239 & 5.0862 & 5.4091 & TRN \\
\hline CHEMBL1574511 & 688239 & 6.8861 & 5.5458 & TRN \\
\hline CHEMBL1422437 & 688239 & 5.6362 & 5.4925 & TST \\
\hline CHEMBL1448361 & 688239 & 5.7362 & 5.5248 & TRN \\
\hline CHEMBL3210738 & 688239 & 6.4362 & 5.3648 & TST \\
\hline CHEMBL1512549 & 688239 & 4.5362 & 5.3522 & TRN \\
\hline CHEMBL1352149 & 688239 & 5.7362 & 5.5824 & TRN \\
\hline CHEMBL1574354 & 688239 & 5.1862 & 5.5979 & TRN \\
\hline CHEMBL1374803 & 688239 & 5.6862 & 5.5737 & TRN \\
\hline CHEMBL1376899 & 688239 & 6.7862 & 5.5647 & TRN \\
\hline CHEMBL1303252 & 688239 & 5.3862 & 5.4632 & TRN \\
\hline CHEMBL1336714 & 688239 & 4.6862 & 5.3946 & TRN \\
\hline CHEMBL 3211851 & 688239 & 5.6362 & 5.4695 & TRN \\
\hline CHEMBL1442725 & 688239 & 6.5363 & 5.3613 & TRN \\
\hline CHEMBL1354231 & 688239 & 4.5362 & 5.4362 & TST \\
\hline CHEMBL1393689 & 688239 & 4.8862 & 5.4454 & TRN \\
\hline CHEMBL1373376 & 688239 & 4.6862 & 5.4961 & TST \\
\hline CHEMBL1420047 & 688239 & 6.3362 & 5.5143 & TRN \\
\hline CHEMBL1572379 & 688239 & 5.7362 & 5.6451 & TRN \\
\hline CHEMBL1535148 & 688239 & 6.3362 & 5.4888 & TRN \\
\hline CHEMBL1530129 & 688239 & 5.1862 & 5.4813 & TRN \\
\hline CHEMBL1347973 & 688239 & 4.5862 & 5.462999 & 9999999999 \\
\hline CHEMBL3196361 & 688239 & 4.6362 & 5.4803 & TRN \\
\hline CHEMBL1572578 & 688239 & 5.8862 & 5.5466 & TRN \\
\hline CHEMBL1352720 & 688239 & 5.1862 & 5.5857 & TST \\
\hline CHEMBL3194637 & 688239 & 4.5362 & 5.4174 & TST \\
\hline CHEMBL1337956 & 688239 & 4.9362 & 5.4139 & TRN \\
\hline CHEMBL1422441 & 688239 & 5.6362 & 5.5085 & TST \\
\hline CHEMBL1458070 & 688239 & 6.2362 & 5.3487 & TRN \\
\hline CHEMBL1414629 & 688239 & 5.5362 & 5.407 & TRN \\
\hline CHEMBL1585277 & 688239 & 5.6362 & 5.5668 & TST \\
\hline CHEMBL1373692 & 688239 & 8.3372 & 5.4072 & TST \\
\hline CHEMBL1308067 & 688239 & 5.1862 & 5.4572 & TRN \\
\hline CHEMBL1577288 & 688239 & 4.5362 & 5.5074 & TRN \\
\hline CHEMBL1494692 & 688239 & 6.9363 & 5.5367 & TRN \\
\hline CHEMBL1547847 & 688239 & 5.1862 & 5.3457 & TST \\
\hline CHEMBL1612154 & 688239 & 4.5362 & 5.5663 & TRN \\
\hline CHEMBL1538118 & 688239 & 6.1862 & 5.7096 & TRN \\
\hline CHEMBL1553020 & 688239 & 4.5362 & 5.5134 & TRN \\
\hline CHEMBL1416715 & 688239 & 6.2862 & 5.3868 & TRN \\
\hline CHEMBL3190794 & 688239 & 4.4862 & 5.4197 & TRN \\
\hline
\end{tabular}


Supplemental Table S2.txt

\begin{tabular}{|c|c|c|c|c|}
\hline & & & & \\
\hline HEMBL1386005 & 88239 & 3372 & & \\
\hline AEMBL14 & 39 & 52 & & \\
\hline & & & & \\
\hline AEMBI 13 & & & & \\
\hline AEMBL1440036 & 88239 & 862 & & \\
\hline AEMBL1565631 & 88239 & 6.1362 & 5153 & \\
\hline HEMBL1549898 & & & & \\
\hline HEMBL13 & & & & \\
\hline IEMBL13e & & & & \\
\hline AEMBL1591327 & 39 & 862 & & \\
\hline AEMBL1338924 & 39 & & & \\
\hline AEMBL1478011 & & & & \\
\hline AEMBL1527418 & & & & \\
\hline AEMBL1383194 & & & & \\
\hline AEMBL1431543 & & & & \\
\hline AEMBL1528753 & & & & \\
\hline HEMBL1334837 & & & & \\
\hline AEMBL1361193 & & & & \\
\hline AEMBL1447537 & & & & \\
\hline AEMBL1378925 & & & & \\
\hline AEMBL1378605 & & & & \\
\hline AEMBL1562261 & & & & \\
\hline AEMBL1477314 & & & & \\
\hline AEMBL1314115 & & & & \\
\hline AEMBL1500743 & & & & \\
\hline AEMBL1389626 & & & & \\
\hline AEMBL496633 & & & & \\
\hline 61 & & & & \\
\hline 587 & & & & \\
\hline AEMBL1365154 & & & & \\
\hline HEMBL1448360 & & & & \\
\hline & & & & \\
\hline 66 & & & & \\
\hline 85 & & & & \\
\hline AEMBL1332146 & & & & \\
\hline AEMBL1408248 & & & & \\
\hline & & & & \\
\hline 4 & & & & \\
\hline HEMBL1540354 & & & & RN \\
\hline AEMBL1513429 & & & & $\mathrm{R}$ \\
\hline IEMBL1423394 & & & & \\
\hline 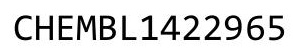 & & & & \\
\hline HEMBL1362464 & & & & \\
\hline AEMBL1345684 & & & & RN \\
\hline MBL1499048 & & & 12 & \\
\hline HEMBL1602787 & & & & \\
\hline 19125 & & & 5.5045 & \\
\hline
\end{tabular}


Supplemental Table S2.txt

\begin{tabular}{|c|c|c|c|c|}
\hline & & & & \\
\hline JEMBL14 & 8239 & 3362 & & \\
\hline IEMBL1518306 & 3239 & 3362 & 192 & \\
\hline AEMBL1322809 & 3239 & 4862 & 988 & \\
\hline EMBL1467857 & 239 & 862 & & \\
\hline EMBL1444821 & 239 & 862 & & \\
\hline AEMBL1572087 & 239 & 862 & 3045 & \\
\hline AEMBL145557 & 88239 & 362 & 268 & \\
\hline AEMBL1407469 & 239 & 862 & & \\
\hline IEMBL15] & 39 & 862 & & \\
\hline AEMBL1540267 & & 362 & & \\
\hline AEMBL1423291 & 688239 & 862 & & \\
\hline HEMBL1409900 & 239 & 862 & & w \\
\hline EMBL160 & & 361 & & \\
\hline EMBL 319 & & 362 & & \\
\hline HEMBL150 & & & & \\
\hline AEMBL1425724 & 239 & 362 & & RN \\
\hline AEMBL1337808 & & 362 & & \\
\hline IEMBL16 & & 362 & & \\
\hline IEMBL13 & & & & \\
\hline HEMBL13 & & 62 & & \\
\hline AEMBL1305252 & & 862 & & RN \\
\hline HEMBL 320 & & 863 & & ST \\
\hline IEMBL13 & & 62 & & \\
\hline IEMBL31 & & & & RN \\
\hline 11 & & 62 & & RN \\
\hline HEMBL130 & & 362 & & ST \\
\hline HEMBL129 & & & & RN \\
\hline AEMBL 148 & & & & $\mathrm{RI}$ \\
\hline 19 & & 52 & & $\omega_{-1}+2$ \\
\hline 67 & & 61 & & ST \\
\hline HEMBL1477082 & & & & RN \\
\hline AEMBL1350561 & & & & ST \\
\hline IEMBL1602444 & & 362 & & RI \\
\hline HEMBL14 & & 62 & & . \\
\hline 0 & & & & $\mathrm{RN}$ \\
\hline AEMBL1410032 & & & & ST \\
\hline AEMBL3195035 & & & & $\mathrm{RN}$ \\
\hline EMBL15 & & & & RI \\
\hline 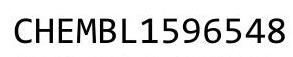 & & & & -3 \\
\hline & & & & RN \\
\hline AEMBL1348584 & & 362 & 54 & RN \\
\hline AEMBL 321 & & & & is \\
\hline EMBL134 & & & & \\
\hline & & & & \\
\hline CHEMBL150 & & 362 & & RN \\
\hline HEMBL1368693 & 8239 & 6.0362 & 5.4976 & $T R$ \\
\hline HFMRI 1361591 & 688239 & 4.6362 & 5.4088 & \\
\hline
\end{tabular}


Supplemental Table S2.txt

\begin{tabular}{|c|c|c|c|c|}
\hline CHEMBL1362364 & 688239 & 4.5862 & 5.4809 & TST \\
\hline CHEMBL1469454 & 688239 & 6.1862 & 5.5901 & TRN \\
\hline CHEMBL1592004 & 688239 & 6.0862 & 5.5645 & TRN \\
\hline CHEMBL1533643 & 688239 & 5.6362 & 5.4597 & TST \\
\hline CHEMBL1545141 & 688239 & 5.1862 & 5.3828 & TRN \\
\hline CHEMBL1531649 & 688239 & 6.8362 & 5.4679 & TST \\
\hline CHEMBL1529218 & 688239 & 6.9863 & 5.4718 & TRN \\
\hline CHEMBL1383598 & 688239 & 5.3362 & 5.4105 & TRN \\
\hline CHEMBL1576416 & 688239 & 4.5362 & 5.4584 & TST \\
\hline CHEMBL1393617 & 688239 & 5.8362 & 5.5718 & TRN \\
\hline CHEMBL1574409 & 688239 & 4.5362 & 5.5894 & TST \\
\hline CHEMBL1420635 & 688239 & 4.8362 & 5.5915 & TRN \\
\hline CHEMBL1540748 & 688239 & 4.5362 & 5.4303 & TST \\
\hline CHEMBL1449638 & 688239 & 5.4862 & 5.3818 & TRN \\
\hline CHEMBL3198456 & 688239 & 5.1862 & 5.4391 & TRN \\
\hline CHEMBL1604603 & 688239 & 4.6862 & 5.5392 & TST \\
\hline CHEMBL1463568 & 688239 & 4.5362 & 5.5998 & TRN \\
\hline CHEMBL1340467 & 688239 & 8.3372 & 5.6338 & TRN \\
\hline CHEMBL1608023 & 688239 & 5.1862 & 5.5378 & TRN \\
\hline CHEMBL1531962 & 688239 & 7.0362 & 5.649 & TRN \\
\hline CHEMBL1339008 & 688239 & 6.2362 & 5.4664 & TRN \\
\hline CHEMBL1341618 & 688239 & 6.2362 & 5.5599 & TRN \\
\hline CHEMBL1463981 & 688239 & 4.6362 & 5.5592 & TST \\
\hline CHEMBL1448322 & 688239 & 6.5862 & 5.4706 & TST \\
\hline CHEMBL3207363 & 688239 & 4.4862 & 5.5944 & TST \\
\hline CHEMBL1306156 & 688239 & 7.1361 & 5.4543 & TST \\
\hline CHEMBL1589663 & 688239 & 6.7862 & 5.517 & TST \\
\hline CHEMBL1600163 & 688239 & 7.1864 & 5.4154 & TRN \\
\hline CHEMBL1390081 & 688239 & 5.4862 & 5.5088 & TRN \\
\hline CHEMBL1494028 & 688239 & 4.5362 & 5.5867 & TRN \\
\hline CHEMBL1481034 & 688239 & 6.1862 & 5.4186 & TRN \\
\hline CHEMBL1400744 & 688239 & 5.8362 & 5.4232 & TRN \\
\hline CHEMBL1976786 & 688239 & 4.9862 & 5.4109 & TRN \\
\hline CHEMBL3195536 & 688239 & 4.6862 & 5.4339 & TRN \\
\hline CHEMBL1520127 & 688239 & 4.8362 & 5.4873 & TRN \\
\hline CHEMBL1340507 & 688239 & 6.0862 & 5.4765 & TRN \\
\hline CHEMBL1507408 & 688239 & 4.6362 & 5.5061 & TRN \\
\hline CHEMBL1308633 & 688239 & 4.5362 & 5.6356 & TRN \\
\hline CHEMBL1416598 & 688239 & 4.5362 & 5.64 & TRN \\
\hline CHEMBL1366582 & 688239 & 6.1362 & 5.66 & TST \\
\hline CHEMBL1347196 & 688239 & 4.5362 & 5.4186 & TST \\
\hline CHEMBL3193359 & 688239 & 4.8362 & 5.3961 & TRN \\
\hline CHEMBL3212771 & 688239 & 7.0862 & 5.5059 & TRN \\
\hline CHEMBL1489184 & 688239 & 4.5362 & 5.3418 & TRN \\
\hline CHEMBL1359073 & 688239 & 5.1362 & 5.7215 & TST \\
\hline CHEMBL1316088 & 688239 & 5.1862 & 5.5202 & TRN \\
\hline CHEMBL1590300 & 688239 & 5.1362 & 5.5936 & TRN \\
\hline \multirow[t]{2}{*}{ CHEMBL1508599 } & 688239 & 4.5362 & 5.40600 & 0000000001 \\
\hline & & \multicolumn{3}{|c|}{ Page 2409} \\
\hline
\end{tabular}


Supplemental Table S2.txt

\begin{tabular}{|c|c|c|c|c|c|}
\hline CHEMBL1598892 & 688239 & 4.4862 & 5.5169 & TRN & \\
\hline CHEMBL1335676 & 688239 & 4.5362 & 5.6231 & TST & \\
\hline CHEMBL1568518 & 688239 & 6.4862 & 5.4361 & TRN & \\
\hline CHEMBL1543388 & 688239 & 5.2362 & 5.369 & TST & \\
\hline CHEMBL1393024 & 688239 & 6.4862 & 5.4662 & TST & \\
\hline CHEMBL1591289 & 688239 & 6.7862 & 5.4694 & TRN & \\
\hline CHEMBL1585056 & 688239 & 4.7362 & 5.5367 & TRN & \\
\hline CHEMBL1499679 & 688239 & 6.8861 & 5.4283 & TST & \\
\hline CHEMBL1322836 & 688239 & 4.6862 & 5.3896 & TST & \\
\hline CHEMBL1342816 & 688239 & 4.6862 & 5.4565 & TST & \\
\hline CHEMBL1389037 & 688239 & 6.1362 & 5.5498 & TRN & \\
\hline CHEMBL1419688 & 688239 & 5.8862 & 5.4061 & TST & \\
\hline CHEMBL1314381 & 688239 & 4.5362 & 5.5879 & TRN & \\
\hline CHEMBL1480462 & 688239 & 5.4862 & 5.6068 & TRN & \\
\hline CHEMBL1502004 & 688239 & 4.9862 & 5.335 & TST & \\
\hline CHEMBL1433443 & 688239 & 4.6862 & 5.42700 & 00000000005 & Tror \\
\hline CHEMBL1551187 & 688239 & 5.4362 & 5.4243 & TRN & \\
\hline CHEMBL1391497 & 688239 & 6.6362 & 5.3545 & TST & \\
\hline CHEMBL1336571 & 688239 & 5.6362 & 5.4946 & TRN & \\
\hline CHEMBL1554045 & 688239 & 5.6362 & 5.5088 & TRN & \\
\hline CHEMBL1312723 & 688239 & 5.5862 & 5.5445 & TST & \\
\hline CHEMBL1421424 & 688239 & 6.0862 & 5.5801 & TRN & \\
\hline CHEMBL1547000 & 688239 & 4.7862 & 5.5804 & TRN & \\
\hline CHEMBL1520977 & 688239 & 5.3362 & 5.4732 & TRN & \\
\hline CHEMBL1438300 & 688239 & 5.8862 & 5.6941 & TRN & \\
\hline CHEMBL1466903 & 688239 & \multicolumn{3}{|c|}{ 8. 283999999999999} & TRN \\
\hline CHEMBL1477129 & 688239 & 4.6862 & 5.4832 & TRN & \\
\hline CHEMBL1491070 & 688239 & 6.6362 & 5.4636 & TRN & \\
\hline CHEMBL 1458874 & 688239 & 4.6362 & 5.4603 & TRN & \\
\hline CHEMBL1483152 & 688239 & 5.7362 & 5.6186 & TRN & \\
\hline CHEMBL1523916 & 688239 & 4.4862 & 5.2935 & TST & \\
\hline CHEMBL1324366 & 688239 & 6.3362 & 5.5747 & TRN & \\
\hline CHEMBL1502969 & 688239 & 4.7362 & 5.5029 & TRN & \\
\hline CHEMBL3190362 & 688239 & 5.0362 & 5.5593 & TRN & \\
\hline CHEMBL1484174 & 688239 & 5.5362 & 5.5125 & TST & \\
\hline CHEMBL1587146 & 688239 & 5.1862 & 5.5012 & TRN & \\
\hline CHEMBL1310382 & 688239 & 6.1862 & 5.3592 & TRN & \\
\hline CHEMBL1455994 & 688239 & 4.5362 & 5.428 & TST & \\
\hline CHEMBL1606597 & 688239 & 6.3863 & 5.5273 & TRN & \\
\hline CHEMBL1566174 & 688239 & 4.6862 & 5.4043 & TRN & \\
\hline CHEMBL1543128 & 688239 & 6.9863 & 5.4543 & TRN & \\
\hline CHEMBL1604343 & 688239 & 4.5862 & 5.3595 & TST & \\
\hline CHEMBL1355247 & 688239 & 6.4862 & 5.4052 & TRN & \\
\hline CHEMBL3211930 & 688239 & 5.2862 & 5.6139 & TRN & \\
\hline CHEMBL1305903 & 688239 & 6.1862 & 5.4922 & TRN & \\
\hline CHEMBL1386010 & 688239 & 6.8861 & 5.4127 & TRN & \\
\hline CHEMBL1403482 & 688239 & 5.1362 & 5.3142 & TST & \\
\hline CHEMBL1388197 & 688239 & 4.6362 & 5.2992 & TRN & \\
\hline
\end{tabular}

Page 2410 
Supplemental Table S2.txt

\begin{tabular}{|c|c|c|c|c|c|}
\hline CHEMBL1470520 & 688239 & 4.5362 & 5.4133 & TRN & \\
\hline CHEMBL1447124 & 688239 & 4.8862 & 5.4664 & TRN & \\
\hline CHEMBL1539641 & 688239 & 5.1862 & 5.4667 & TRN & \\
\hline CHEMBL1505463 & 688239 & 4.7362 & 5.6715 & TRN & \\
\hline CHEMBL1567973 & 688239 & 5.4862 & 5.4007 & TRN & \\
\hline CHEMBL1345955 & 688239 & 5.5362 & 5.5097 & TRN & \\
\hline CHEMBL1551987 & 688239 & 6.8861 & 5.4502 & TRN & \\
\hline CHEMBL1333655 & 688239 & 5.8362 & 5.5913 & TRN & \\
\hline CHEMBL1567707 & 688239 & 4.7362 & 5.4111 & TST & \\
\hline CHEMBL1375435 & 688239 & 5.2862 & 5.6515 & TRN & \\
\hline CHEMBL1471132 & 688239 & 8.3372 & 5.6007 & TRN & \\
\hline CHEMBL1348670 & 688239 & 4.6362 & 5.5433 & TST & \\
\hline CHEMBL1583236 & 688239 & 5.4362 & 5.5148 & TRN & \\
\hline CHEMBL1403195 & 688239 & 6.3863 & 5.4247 & TRN & \\
\hline CHEMBL1594146 & 688239 & 4.5362 & 5.475 & TST & \\
\hline CHEMBL1332858 & 688239 & 4.8862 & 5.5726 & TRN & \\
\hline CHEMBL1505006 & 688239 & 4.5362 & 5.4665 & TRN & \\
\hline CHEMBL1371539 & 688239 & 5.7862 & 5.4379 & TRN & \\
\hline CHEMBL1300850 & 688239 & 5.1862 & 5.5002 & TST & \\
\hline CHEMBL1464833 & 688239 & 5.5362 & 5.5608 & TRN & \\
\hline CHEMBL1483468 & 688239 & 5.7362 & 5.4074 & TRN & \\
\hline CHEMBL1391203 & 688239 & 5.1862 & 5.5616 & TRN & \\
\hline CHEMBL1382682 & 688239 & 4.7862 & 5.4624 & TRN & \\
\hline CHEMBL1439186 & 688239 & 5.1862 & 5.4971 & TRN & \\
\hline CHEMBL1579629 & 688239 & 5.7362 & 5.5333 & TRN & \\
\hline CHEMBL 3189581 & 688239 & 5.8862 & 5.5732 & TRN & \\
\hline CHEMBL1599421 & 688239 & 5.4862 & 5.4794 & TRN & \\
\hline CHEMBL1609880 & 688239 & 5.7862 & 5.3863 & TST & \\
\hline CHEMBL1605244 & 688239 & 5.1362 & 5.443 & TRN & \\
\hline CHEMBL1524289 & 688239 & 5.2862 & 5.3787 & TST & \\
\hline CHEMBL1392535 & 688239 & 5.3862 & 5.4105 & TRN & \\
\hline CHEMBL1338781 & 688239 & 6.1862 & 5.4778 & TRN & \\
\hline CHEMBL1468637 & 688239 & 4.5362 & 5.4968 & TST & \\
\hline CHEMBL1475585 & 688239 & 5.4862 & 5.585 & TRN & \\
\hline CHEMBL1471416 & 688239 & 5.2362 & 5.4438 & TST & \\
\hline CHEMBL1592545 & 688239 & 4.5362 & 5.5752 & TRN & \\
\hline CHEMBL1324004 & 688239 & 5.1362 & 5.5876 & TRN & \\
\hline CHEMBL1392799 & 688239 & 5.1362 & 5.4423 & TRN & \\
\hline CHEMBL1532137 & 688239 & 4.7862 & 5.4091 & TRN & \\
\hline CHEMBL1335439 & 688239 & 6.2862 & 5.4213 & TRN & \\
\hline CHEMBL1309285 & 688239 & 6.8861 & 5.2872 & TST & \\
\hline CHEMBL1451266 & 688239 & 5.4362 & 5.5806 & TST & \\
\hline CHEMBL1514167 & 688239 & 8.28399 & 999999999 & 99 & 5.6265 \\
\hline CHEMBL1587285 & 688239 & 7.1864 & 5.4243 & TST & \\
\hline CHEMBL 3209292 & 688239 & 5.7862 & 5.5979 & TRN & \\
\hline CHEMBL1488526 & 688239 & 4.7862 & 5.4422 & TRN & \\
\hline CHEMBL1409427 & 688239 & 4.5362 & 5.5022 & TST & \\
\hline CHEMBL1351170 & 688239 & 4.5362 & 5.4103 & TRN & \\
\hline
\end{tabular}

Page 2411 
Supplemental Table S2.txt

\begin{tabular}{|c|c|c|c|c|}
\hline CHEMBL1582710 & 688239 & 6.3863 & 5.5622 & TRN \\
\hline CHEMBL1448351 & 688239 & 5.0862 & 5.4814 & TRN \\
\hline CHEMBL1334852 & 688239 & 8.3872 & 5.4535 & TRN \\
\hline CHEMBL1583934 & 688239 & 6.1362 & 5.6405 & TST \\
\hline CHEMBL1329636 & 688239 & 6.1362 & 5.3925 & TRN \\
\hline CHEMBL1579623 & 688239 & 6.2862 & 5.5298 & TRN \\
\hline CHEMBL1464809 & 688239 & 6.8861 & 5.4005 & TRN \\
\hline CHEMBL1409290 & 688239 & 5.8362 & 5.6058 & TRN \\
\hline CHEMBL1430490 & 688239 & 4.5362 & 5.461 & TST \\
\hline CHEMBL1563129 & 688239 & 6.3362 & 5.6149 & TST \\
\hline CHEMBL1352844 & 688239 & 5.6862 & 5.4374 & TRN \\
\hline CHEMBL1421201 & 688239 & 5.7362 & 5.5971 & TRN \\
\hline CHEMBL1379300 & 688239 & 5.1862 & 5.4896 & TRN \\
\hline CHEMBL1365182 & 688239 & 5.1362 & 5.5001 & TRN \\
\hline CHEMBL1311151 & 688239 & 6.8861 & 5.5201 & TRN \\
\hline CHEMBL1403927 & 688239 & 7.0862 & 5.5071 & TST \\
\hline CHEMBL1383573 & 688239 & 5.8362 & 5.6247 & TRN \\
\hline CHEMBL1556485 & 688239 & 6.8861 & 5.4876 & TST \\
\hline CHEMBL1507852 & 688239 & 5.1362 & 5.4872 & TRN \\
\hline CHEMBL1421310 & 688239 & 5.1862 & 5.6382 & TRN \\
\hline CHEMBL1559838 & 688239 & 5.0862 & 5.71399 & 99999999995 \\
\hline CHEMBL1570024 & 688239 & 5.1862 & 5.5106 & TRN \\
\hline CHEMBL1511110 & 688239 & 4.5362 & 5.5194 & TRN \\
\hline CHEMBL1543527 & 688239 & 8.3372 & 5.3338 & TRN \\
\hline CHEMBL1457431 & 688239 & 5.4362 & 5.6454 & TST \\
\hline CHEMBL1300413 & 688239 & 6.9863 & 5.5943 & TST \\
\hline CHEMBL1610408 & 688239 & 5.4362 & 5.5668 & TRN \\
\hline CHEMBL1603932 & 688239 & 4.7862 & 5.5772 & TST \\
\hline CHEMBL1550830 & 688239 & 5.3862 & 5.42299 & 9999999999 \\
\hline CHEMBL1430585 & 688239 & 5.3362 & 5.6051 & TRN \\
\hline CHEMBL1390139 & 688239 & 4.5362 & 5.3146 & TST \\
\hline CHEMBL1480223 & 688239 & 5.7862 & 5.5511 & TRN \\
\hline CHEMBL1393753 & 688239 & 4.7362 & 5.6012 & TRN \\
\hline CHEMBL1605608 & 688239 & 4.5362 & 5.5238 & TRN \\
\hline CHEMBL3209209 & 688239 & 4.6862 & 5.3808 & TRN \\
\hline CHEMBL1383556 & 688239 & 5.0862 & 5.62 & TRN \\
\hline CHEMBL3198034 & 688239 & 5.6862 & 5.6276 & TRN \\
\hline CHEMBL3198229 & 688239 & 4.6362 & 5.4031 & TRN \\
\hline CHEMBL1518491 & 688239 & 5.1862 & 5.3828 & TRN \\
\hline CHEMBL1389878 & 688239 & 6.1862 & 5.6048 & TRN \\
\hline CHEMBL1312850 & 688239 & 6.2362 & 5.4629 & TRN \\
\hline CHEMBL1574078 & 688239 & 6.0362 & 5.524 & TST \\
\hline CHEMBL1378596 & 688239 & 4.5862 & 5.441 & TRN \\
\hline CHEMBL1528079 & 688239 & 5.7362 & 5.4609 & TRN \\
\hline CHEMBL1442407 & 688239 & 4.6862 & 5.5098 & TST \\
\hline CHEMBL1390353 & 688239 & 5.2362 & 5.4423 & TRN \\
\hline CHEMBL1369320 & 688239 & 5.7862 & 5.4392 & TST \\
\hline CHEMBL1359938 & 688239 & 5.2362 & 5.4583 & TRN \\
\hline
\end{tabular}

Page 2412 
Supplemental Table S2.txt

\begin{tabular}{|c|c|c|c|c|}
\hline CHEMBL1472438 & 688239 & 4.5362 & 5.4403 & TRN \\
\hline CHEMBL1604220 & 688239 & 4.7362 & 5.4647 & TRN \\
\hline CHEMBL1540035 & 688239 & 5.3362 & 5.5901 & TRN \\
\hline CHEMBL1577703 & 688239 & 6.1362 & 5.5542 & TST \\
\hline CHEMBL1591586 & 688239 & 4.7362 & 5.5431 & TRN \\
\hline CHEMBL1570849 & 688239 & 7.2865 & 5.432 & TST \\
\hline CHEMBL1363984 & 688239 & 5.6362 & 5.4633 & TRN \\
\hline CHEMBL 3196975 & 688239 & 8.1871 & \multicolumn{2}{|c|}{5.417000000000001} \\
\hline CHEMBL 3195378 & 688239 & 4.8362 & 5.3462 & TST \\
\hline CHEMBL1587948 & 688239 & 4.5362 & 5.4885 & TST \\
\hline CHEMBL1611313 & 688239 & 4.5362 & \multicolumn{2}{|c|}{5.492999999999999} \\
\hline CHEMBL1601986 & 688239 & 5.4862 & 5.6627 & TST \\
\hline CHEMBL1328631 & 688239 & 4.6362 & 5.3444 & TRN \\
\hline CHEMBL1555193 & 688239 & 7.5361 & 5.5108 & TRN \\
\hline CHEMBL1201113 & 688239 & 8.3872 & 5.3426 & TRN \\
\hline CHEMBL1594049 & 688239 & 5.275 & 5.3642 & TRN \\
\hline CHEMBL1314068 & 688239 & 5.3862 & 5.4903 & TRN \\
\hline CHEMBL1492031 & 688239 & 4.7862 & 5.5404 & TRN \\
\hline CHEMBL1491052 & 688239 & 6.2862 & 5.539 & TRN \\
\hline CHEMBL1398449 & 688239 & 4.7362 & 5.6499 & TRN \\
\hline CHEMBL1480261 & 688239 & 7.6364 & 5.5298 & TRN \\
\hline CHEMBL1515869 & 688239 & 5.4362 & 5.4702 & TRN \\
\hline CHEMBL1491912 & 688239 & 4.5362 & 5.6151 & TRN \\
\hline CHEMBL1534741 & 688239 & 5.1862 & 5.5975 & TRN \\
\hline CHEMBL1547786 & 688239 & 5.2362 & 5.5017 & TRN \\
\hline CHEMBL1343172 & 688239 & 5.1862 & 5.4897 & TST \\
\hline CHEMBL1336764 & 688239 & 8.2366 & 5.4074 & TRN \\
\hline CHEMBL1398880 & 688239 & 7.2366 & 5.4151 & TRN \\
\hline CHEMBL1358081 & 688239 & 5.4362 & 5.4698 & TRN \\
\hline CHEMBL1597470 & 688239 & 6.1862 & 5.6344 & TRN \\
\hline CHEMBL1318254 & 688239 & 4.5362 & 5.6013 & TRN \\
\hline CHEMBL1438803 & 688239 & 4.5362 & 5.3362 & TRN \\
\hline CHEMBL1427825 & 688239 & 5.6862 & 5.4636 & TRN \\
\hline CHEMBL1315433 & 688239 & 4.5362 & 5.4393 & TRN \\
\hline CHEMBL1544169 & 688239 & 5.3362 & 5.4288 & TRN \\
\hline CHEMBL1358775 & 688239 & 5.5862 & 5.4563 & TRN \\
\hline CHEMBL1391455 & 688239 & 5.1362 & \multicolumn{2}{|c|}{5.537000000000001} \\
\hline CHEMBL1319280 & 688239 & 4.5362 & 5.3285 & TRN \\
\hline CHEMBL1368983 & 688239 & 4.7362 & 5.4302 & TRN \\
\hline CHEMBL1479061 & 688239 & 4.8862 & 5.5509 & TRN \\
\hline CHEMBL1505296 & 688239 & 5.4362 & 5.5527 & TRN \\
\hline CHEMBL1386441 & 688239 & 4.5362 & 5.5197 & TRN \\
\hline CHEMBL1515031 & 688239 & 5.1362 & 5.4701 & TST \\
\hline CHEMBL1327486 & 688239 & 6.2862 & 5.5288 & TRN \\
\hline CHEMBL1345533 & 688239 & 5.7362 & 5.5875 & TST \\
\hline CHEMBL1484263 & 688239 & 5.2362 & 5.5388 & TRN \\
\hline CHEMBL1379837 & 688239 & 4.9862 & 5.5829 & TRN \\
\hline CHEMBL1592080 & 688239 & 4.5362 & 5.3783 & TRN \\
\hline
\end{tabular}


Supplemental Table S2.txt

\begin{tabular}{|c|c|c|c|c|c|}
\hline CHEMBL1560925 & 688239 & 4.6362 & 5.4325 & TRN & \\
\hline CHEMBL1433079 & 688239 & 4.6862 & 5.5105 & TST & \\
\hline CHEMBL1490957 & 688239 & 5.1862 & 5.5225 & TRN & \\
\hline CHEMBL1301643 & 688239 & 5.1862 & 5.6069 & TRN & \\
\hline CHEMBL1565127 & 688239 & 6.1362 & 5.5707 & TST & \\
\hline CHEMBL1405370 & 688239 & 4.8862 & 5.4716 & TST & \\
\hline CHEMBL1530251 & 688239 & 6.1862 & 5.5554 & TST & \\
\hline CHEMBL1610961 & 688239 & 4.6862 & 5.4268 & TRN & \\
\hline CHEMBL1393396 & 688239 & 4.6862 & 5.3916 & TRN & \\
\hline CHEMBL1333658 & 688239 & 4.5362 & 5.5031 & TST & \\
\hline CHEMBL1591812 & 688239 & 4.5362 & 5.5005 & TST & \\
\hline CHEMBL1378670 & 688239 & 4.7362 & 5.4668 & TST & \\
\hline CHEMBL1440190 & 688239 & 4.5362 & 5.4664 & TRN & \\
\hline CHEMBL1436803 & 688239 & 4.5362 & 5.4227 & TRN & \\
\hline CHEMBL1325222 & 688239 & 4.6862 & 5.3248 & TRN & \\
\hline CHEMBL1362331 & 688239 & 4.6362 & 5.5429 & TRN & \\
\hline CHEMBL1504439 & 688239 & 6.2362 & 5.4559 & TRN & \\
\hline CHEMBL1394611 & 688239 & 4.5362 & 5.5825 & TRN & \\
\hline CHEMBL1462684 & 688239 & 6.1862 & 5.3532 & TRN & \\
\hline CHEMBL 3189636 & 688239 & 4.6862 & 5.4686 & TRN & \\
\hline CHEMBL1454072 & 688239 & 4.7362 & 5.4893 & TRN & \\
\hline CHEMBL1510075 & 688239 & 4.6862 & 5.4616 & TRN & \\
\hline CHEMBL1572392 & 688239 & 6.1362 & 5.5963 & TRN & \\
\hline CHEMBL1474800 & 688239 & 5.1862 & 5.4723 & TRN & \\
\hline CHEMBL 3194425 & 688239 & 4.5362 & 5.3384 & TRN & \\
\hline CHEMBL 3208618 & 688239 & 6.6861 & 5.4649 & TST & \\
\hline CHEMBL1319963 & 688239 & 5.4862 & 5.5577 & TRN & \\
\hline CHEMBL1465871 & 688239 & 5.4862 & 5.5203 & TRN & \\
\hline CHEMBL3212008 & 688239 & 5.8862 & 5.3985 & TST & \\
\hline CHEMBL1558042 & 688239 & 4.5362 & 5.4882 & TRN & \\
\hline CHEMBL1562500 & 688239 & 4.6862 & 5.38 & TST & \\
\hline CHEMBL1527770 & 688239 & 6.1362 & 5.4369 & TRN & \\
\hline CHEMBL1371665 & 688239 & 5.1862 & 5.3682 & TRN & \\
\hline CHEMBL1308168 & 688239 & 4.5362 & 5.3814 & TRN & \\
\hline CHEMBL1391371 & 688239 & 5.2862 & 5.38399 & 99999999995 & TRN \\
\hline CHEMBL1376151 & 688239 & 6.1362 & 5.4585 & TRN & \\
\hline CHEMBL1316533 & 688239 & 4.7862 & 5.4471 & TRN & \\
\hline CHEMBL1343453 & 688239 & 4.8862 & 5.5397 & TST & \\
\hline CHEMBL1382399 & 688239 & 5.0862 & 5.4394 & TST & \\
\hline CHEMBL1555718 & 688239 & 6.1362 & 5.74299 & 9999999999 & TRN \\
\hline CHEMBL1547004 & 688239 & 4.8362 & 5.4139 & TRN & \\
\hline CHEMBL1494978 & 688239 & 5.8362 & 5.5089 & TRN & \\
\hline CHEMBL1380070 & 688239 & 5.2362 & 5.4719 & TST & \\
\hline CHEMBL1608042 & 688239 & 4.5862 & 5.7089 & TRN & \\
\hline CHEMBL1451301 & 688239 & 5.1862 & 5.4952 & TRN & \\
\hline CHEMBL485021 & 688239 & 4.5362 & 5.3675 & TST & \\
\hline CHEMBL1355900 & 688239 & 4.5362 & 5.5562 & TRN & \\
\hline CHEMBL1972090 & 688239 & 6.0862 & 5.5785 & TRN & \\
\hline
\end{tabular}


Supplemental Table S2.txt

\begin{tabular}{|c|c|c|c|c|}
\hline 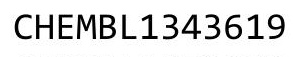 & & & & \\
\hline HEMBL1572830 & 38239 & 1862 & 124 & \\
\hline AEMBL1442659 & 239 & 363 & 563 & \\
\hline & 39 & & & \\
\hline IEMBL1487841 & 39 & 366 & & \\
\hline AEMBL1426450 & 88239 & 362 & 5608 & \\
\hline AEMBL1333708 & 88239 & 6.0862 & 4544 & \\
\hline AEMBL1437371 & & & & \\
\hline EMBL13 & 39 & 862 & & \\
\hline IEMBL19 & & 862 & & \\
\hline AEMBL1369552 & 39 & 363 & 3782 & \\
\hline AEMBL1461445 & & 362 & & \\
\hline AEMBL15564 & & 863 & & \\
\hline HEMBL160 & & 862 & & \\
\hline HEMBL135 & & 362 & 27 & \\
\hline AEMBL1502734 & & 363 & 227 & \\
\hline AEMBL1582632 & & 862 & & \\
\hline AEMBL143 & & & & \\
\hline AEMBL142 & & & & \\
\hline AEMBL14 & & & & \\
\hline HEMBL150 & & 862 & & \\
\hline AEMBL1372 & & 362 & & \\
\hline IEMBL14C & & 62 & & \\
\hline AFMRI 13 & & & & \\
\hline 12 & & & & \\
\hline 1 & & 63 & & \\
\hline IEMBL144 & & & & \\
\hline IEMBL16 & & 62 & & \\
\hline JEMPI 15 & & & & \\
\hline 26 & & 62 & & \\
\hline AEMBL1605313 & & & & \\
\hline AEMBL1403632 & & & & \\
\hline & & & & \\
\hline 55 & & & & \\
\hline & & & & \\
\hline AEMBL1373214 & & & & \\
\hline AEMBL1368807 & & 362 & & \\
\hline 541 & & 62 & 28 & \\
\hline 31 & & & & \\
\hline HEMBL3193631 & & & & $\mathrm{RI}$ \\
\hline AEMBL1457843 & & 62 & 172 & $R$ \\
\hline HEMBL157 & & 62 & & \\
\hline & & & & \\
\hline HEMBL1466835 & & & & \\
\hline AEMBL1606431 & & & 4906 & ST \\
\hline IEMBL1363849 & & 362 & 162 & TS \\
\hline & & & & \\
\hline תרבדרי & & & & \\
\hline
\end{tabular}

Page 2415 


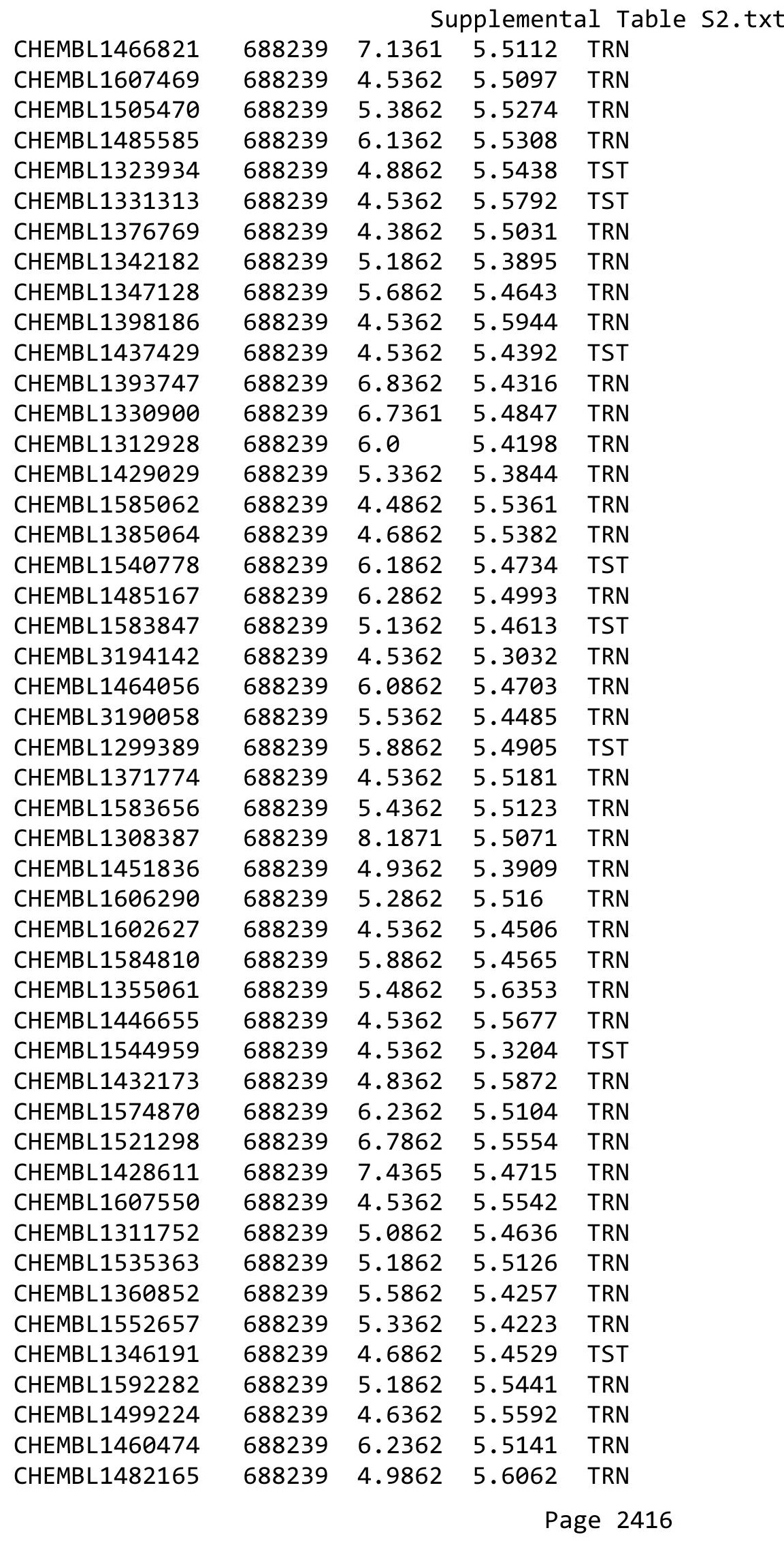


Supplemental Table S2.txt

\begin{tabular}{|c|c|c|c|c|}
\hline 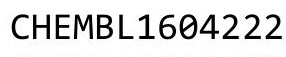 & & & & \\
\hline HEMBL1610132 & 88239 & 7862 & 5.4765 & $\pi$ \\
\hline HEMBL1548558 & 239 & 362 & 88 & \\
\hline HEMBL13 & & & & \\
\hline AEMBL14 & & 862 & 336 & \\
\hline AEMBL1581051 & 88239 & 5862 & .3087 & \\
\hline HEMBL1423945 & 88239 & .5862 & .4931 & \\
\hline HEMBL1331607 & 39 & 862 & 3846 & \\
\hline AEMBL15 & & 362 & & \\
\hline IEMBL1514724 & & 362 & & \\
\hline HEMBL1341644 & 88239 & 1862 & .4306 & \\
\hline HEMBL1543722 & 88239 & 0362 & .4544 & \\
\hline HEMBL1544034 & 39 & 362 & 4442 & \\
\hline AEMBL13 & & 363 & 14 & \\
\hline JEMBL 14 & & 362 & & \\
\hline HEMBL1443634 & 39 & 5862 & .4921 & \\
\hline AEMBL1523141 & & 5862 & & \\
\hline HEMBL131 & 9 & 362 & 01 & \\
\hline L15 & & 862 & & \\
\hline AEMBL15 & & 362 & & \\
\hline HEMBL1489954 & & 362 & & \\
\hline AEMBL83527 & & 362 & & \\
\hline HEMBL135 & 39 & 872 & 47 & \\
\hline L15 & & 62 & & \\
\hline 16 & & 62 & & \\
\hline L1336573 & & 362 & & \\
\hline AEMBL1320444 & & & & RN \\
\hline HEMBL14 & & 862 & 43 & \\
\hline HEN & & 2 & & \\
\hline 520 & & 61 & 23 & RN \\
\hline AEMBL 570337 & & & & RN \\
\hline AEMBL1478601 & & 362 & & RN \\
\hline AEMBL15 & & & & ST \\
\hline 9 & & & & RN \\
\hline 15 & & 62 & & ST \\
\hline AEMBL3194833 & & 362 & & $\mathrm{RN}$ \\
\hline AEMBL1564334 & & 862 & 34 & ST \\
\hline 9 & & & & RN \\
\hline 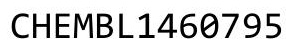 & & & $\partial 3$ & RIV \\
\hline HEMBL14 & & & & ST \\
\hline AEMBL1326530 & & 362 & 235 & $\mathrm{RN}$ \\
\hline JEMBL13 & & 62 & & \\
\hline & & & & \\
\hline HEMBL14 & & & & RIN \\
\hline HEMBL10 & & & & $\mathrm{RN}$ \\
\hline IEMBL1496 & & 4.5362 & & \\
\hline L14 & & & & \\
\hline $10-\pi$ & & & & \\
\hline
\end{tabular}


Supplemental Table S2.txt

\begin{tabular}{|c|c|c|c|c|c|}
\hline CHEMBL1520326 & 688239 & 4.8862 & 5.4362 & TST & \\
\hline CHEMBL1581352 & 688239 & 6.2862 & 5.4938 & TRN & \\
\hline CHEMBL1413417 & 688239 & 6.9363 & 5.489 & TRN & \\
\hline CHEMBL1400570 & 688239 & 4.4862 & 5.5299 & TRN & \\
\hline CHEMBL1482925 & 688239 & 4.4862 & 5.7076 & TRN & \\
\hline CHEMBL1448994 & 688239 & 4.8862 & 5.402 & TST & \\
\hline CHEMBL1987071 & 688239 & 4.7362 & 5.3993 & TRN & \\
\hline CHEMBL1338333 & 688239 & 4.8362 & 5.4596 & TRN & \\
\hline CHEMBL1594009 & 688239 & 8.3372 & 5.5687 & TRN & \\
\hline CHEMBL502057 & 688239 & 4.5362 & 5.5456 & TST & \\
\hline CHEMBL1552655 & 688239 & 4.7362 & 5.4217 & TRN & \\
\hline CHEMBL1336428 & 688239 & 4.5362 & 5.3582 & TRN & \\
\hline CHEMBL1569924 & 688239 & 4.5362 & 5.6236 & TRN & \\
\hline CHEMBL1382321 & 688239 & 4.5362 & 5.5451 & TRN & \\
\hline CHEMBL1459979 & 688239 & 8.3372 & 5.5111 & TST & \\
\hline CHEMBL1312813 & 688239 & 5.0362 & 5.4763 & TRN & \\
\hline CHEMBL1566604 & 688239 & 4.5362 & 5.4158 & TST & \\
\hline CHEMBL1981928 & 688239 & 4.6862 & 5.4254 & TST & \\
\hline CHEMBL1471369 & 688239 & 4.5362 & 5.3291 & TRN & \\
\hline CHEMBL1338481 & 688239 & 6.6861 & 5.3908 & TRN & \\
\hline CHEMBL1410426 & 688239 & 4.6862 & \multicolumn{2}{|c|}{5.422000000000001} & TRN \\
\hline CHEMBL1445501 & 688239 & 5.6862 & 5.5255 & TRN & \\
\hline CHEMBL1519540 & 688239 & 6.9863 & 5.5378 & TRN & \\
\hline CHEMBL1326613 & 688239 & 6.4362 & 5.4262 & TRN & \\
\hline CHEMBL1986090 & 688239 & 4.9862 & 5.4757 & TRN & \\
\hline CHEMBL1569099 & 688239 & 4.7862 & 5.5269 & TRN & \\
\hline CHEMBL3213714 & 688239 & 5.0362 & 5.3836 & TRN & \\
\hline CHEMBL1324155 & 688239 & 5.7862 & 5.4694 & TRN & \\
\hline CHEMBL1372517 & 688239 & 5.9362 & \multicolumn{2}{|c|}{5.622000000000001} & TST \\
\hline CHEMBL3211960 & 688239 & 6.0862 & 5.6149 & TRN & \\
\hline CHEMBL3211947 & 688239 & 6.6362 & 5.5114 & TRN & \\
\hline CHEMBL1339576 & 688239 & 7.1361 & 5.5495 & TRN & \\
\hline CHEMBL1333937 & 688239 & 6.2362 & 5.4057 & TRN & \\
\hline CHEMBL1403774 & 688239 & 4.9362 & 5.3931 & TRN & \\
\hline CHEMBL1519254 & 688239 & 5.6862 & 5.4564 & TRN & \\
\hline CHEMBL1586659 & 688239 & 5.7862 & 5.4356 & TRN & \\
\hline CHEMBL1563716 & 688239 & 7.5361 & 5.3375 & TST & \\
\hline CHEMBL1503913 & 688239 & 6.2362 & 5.2849 & TRN & \\
\hline CHEMBL1539602 & 688239 & 6.8861 & 5.5029 & TRN & \\
\hline CHEMBL1520196 & 688239 & 6.6362 & 5.4869 & TRN & \\
\hline CHEMBL1499293 & 688239 & 4.5362 & 5.557 & TRN & \\
\hline CHEMBL1570495 & 688239 & 4.8362 & 5.6081 & TRN & \\
\hline CHEMBL1326945 & 688239 & 6.9363 & 5.5761 & TRN & \\
\hline CHEMBL1505557 & 688239 & 5.6862 & 5.645 & TRN & \\
\hline CHEMBL1310520 & 688239 & 5.3862 & 5.4894 & TRN & \\
\hline CHEMBL1343888 & 688239 & 5.0362 & 5.5912 & TRN & \\
\hline CHEMBL1543751 & 688239 & 5.3362 & 5.4767 & TRN & \\
\hline CHEMBL1455937 & 688239 & 5.8862 & 5.6332 & TST & \\
\hline
\end{tabular}


Supplemental Table S2.txt

\begin{tabular}{|c|c|c|c|c|}
\hline CHEMBL1344205 & 688239 & 5.0362 & 5.6478 & TRN \\
\hline CHEMBL1556670 & 688239 & 4.5362 & 5.3751 & TST \\
\hline CHEMBL1572136 & 688239 & 5.5362 & 5.414 & TRN \\
\hline CHEMBL1455483 & 688239 & 4.7862 & 5.3488 & TRN \\
\hline CHEMBL3209669 & 688239 & 5.3362 & 5.5939 & TST \\
\hline CHEMBL3198989 & 688239 & 4.7362 & 5.3097 & TST \\
\hline CHEMBL1484937 & 688239 & 4.7862 & 5.584 & TRN \\
\hline CHEMBL3190022 & 688239 & 4.5362 & 5.4079 & TRN \\
\hline CHEMBL1543029 & 688239 & 4.8862 & 5.3592 & TRN \\
\hline CHEMBL1602731 & 688239 & 5.2862 & 5.4544 & TST \\
\hline CHEMBL1309400 & 688239 & 5.6362 & \multicolumn{2}{|c|}{5.6160000000000005} \\
\hline CHEMBL1467808 & 688239 & 5.2862 & 5.5523 & TRN \\
\hline CHEMBL1594325 & 688239 & 6.3863 & 5.5545 & TRN \\
\hline CHEMBL1412198 & 688239 & 5.1862 & 5.523 & TRN \\
\hline CHEMBL1471912 & 688239 & 6.2362 & 5.5864 & TRN \\
\hline CHEMBL3190432 & 688239 & 4.9862 & \multicolumn{2}{|c|}{5.462999999999999} \\
\hline CHEMBL1499122 & 688239 & 6.8362 & 5.4892 & TRN \\
\hline CHEMBL1378476 & 688239 & 4.6862 & 5.4226 & TRN \\
\hline CHEMBL1460792 & 688239 & 5.6862 & 5.5285 & TRN \\
\hline CHEMBL1362055 & 688239 & 6.8861 & 5.5233 & TRN \\
\hline CHEMBL1531489 & 688239 & 6.2362 & 5.4834 & TRN \\
\hline CHEMBL8129 & 688239 & 4.5362 & 5.3278 & TST \\
\hline CHEMBL1452639 & 688239 & 5.1862 & 5.5862 & TRN \\
\hline CHEMBL1578783 & 688239 & 5.9862 & 5.4522 & TRN \\
\hline CHEMBL1338971 & 688239 & 4.5362 & 5.6171 & TRN \\
\hline CHEMBL1352995 & 688239 & 4.8862 & 5.3363 & TRN \\
\hline CHEMBL1574299 & 688239 & 4.5362 & 5.6708 & TRN \\
\hline CHEMBL1320280 & 688239 & 6.6362 & 5.6786 & TRN \\
\hline CHEMBL1412029 & 688239 & 5.1862 & 5.4516 & TRN \\
\hline CHEMBL1382635 & 688239 & 7.0862 & 5.4298 & TRN \\
\hline CHEMBL1359810 & 688239 & 5.6362 & 5.4411 & TST \\
\hline CHEMBL1329484 & 688239 & 5.0362 & 5.3501 & TRN \\
\hline CHEMBL1427662 & 688239 & 6.2862 & 5.5587 & TRN \\
\hline CHEMBL1571131 & 688239 & 4.5362 & 5.4201 & TST \\
\hline CHEMBL1566990 & 688239 & 4.6362 & 5.6217 & TST \\
\hline CHEMBL1548894 & 688239 & 5.1862 & 5.5518 & TRN \\
\hline CHEMBL3197790 & 688239 & 4.6362 & 5.3562 & TRN \\
\hline CHEMBL1518596 & 688239 & 5.3862 & 5.4356 & TRN \\
\hline CHEMBL1487564 & 688239 & 6.8362 & 5.4524 & TRN \\
\hline CHEMBL1550505 & 688239 & 4.6862 & 5.3981 & TRN \\
\hline CHEMBL1605881 & 688239 & 4.5362 & 5.3892 & TRN \\
\hline CHEMBL1389713 & 688239 & 5.9362 & 5.3134 & TRN \\
\hline CHEMBL1516267 & 688239 & 5.3362 & 5.5127 & TRN \\
\hline CHEMBL1464733 & 688239 & 4.5362 & 5.28600 & 20000000005 \\
\hline CHEMBL1462764 & 688239 & 4.5362 & 5.4511 & TST \\
\hline CHEMBL1413613 & 688239 & 5.9862 & 5.4078 & TRN \\
\hline CHEMBL1490473 & 688239 & 7.2366 & 5.5202 & TRN \\
\hline CHEMBL1404600 & 688239 & 4.7862 & 5.5156 & TRN \\
\hline
\end{tabular}


Supplemental Table S2.txt

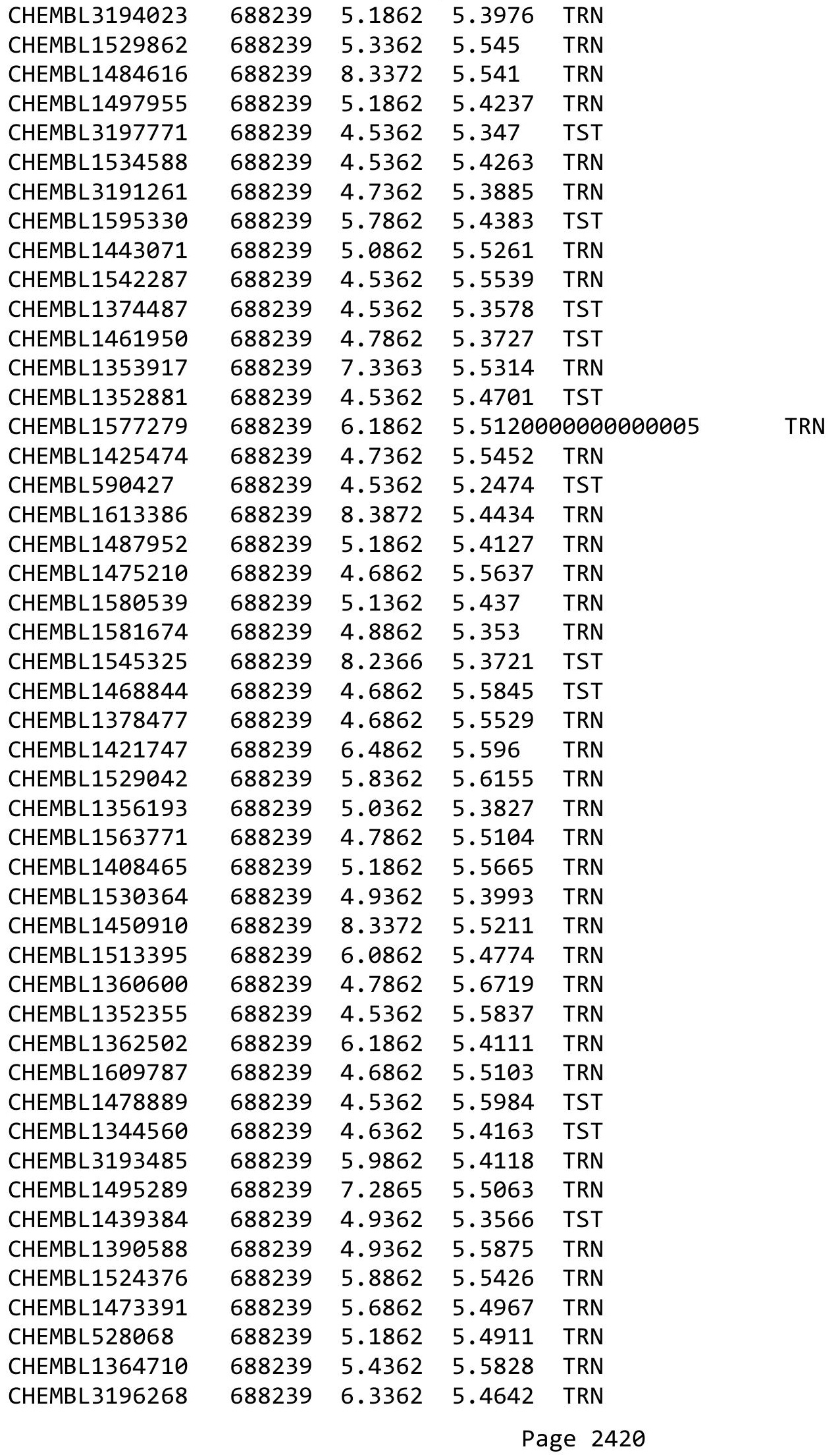


Supplemental Table S2.txt

\begin{tabular}{|c|c|c|c|c|c|}
\hline CHEMBL1426273 & 688239 & 5.1862 & 5.4708 & TST & \\
\hline CHEMBL1407767 & 688239 & 5.3862 & 5.4788 & TST & \\
\hline CHEMBL1330925 & 688239 & 4.5362 & 5.441 & TST & \\
\hline CHEMBL3198155 & 688239 & 4.5362 & 5.4474 & TRN & \\
\hline CHEMBL1354034 & 688239 & 8.3372 & 5.6349 & TRN & \\
\hline CHEMBL1607198 & 688239 & 6.2362 & 5.4675 & TRN & \\
\hline CHEMBL1455690 & 688239 & 5.5362 & 5.3936 & TRN & \\
\hline CHEMBL1347961 & 688239 & 4.5362 & 5.3987 & TRN & \\
\hline CHEMBL1549878 & 688239 & 7.0362 & 5.2834 & TST & \\
\hline CHEMBL1470036 & 688239 & 5.7362 & 5.2297 & TRN & \\
\hline CHEMBL1347208 & 688239 & 5.4362 & 5.459 & TRN & \\
\hline CHEMBL1375895 & 688239 & 5.8362 & 5.4853 & TST & \\
\hline CHEMBL1304824 & 688239 & 4.9862 & 5.5175 & TRN & \\
\hline CHEMBL1304352 & 688239 & 6.8362 & 5.6077 & TRN & \\
\hline CHEMBL1584279 & 688239 & 6.8861 & 5.4944 & TST & \\
\hline CHEMBL3213742 & 688239 & 7.2366 & 5.4125 & TST & \\
\hline CHEMBL1417429 & 688239 & 6.2362 & 5.3656 & TRN & \\
\hline CHEMBL1532996 & 688239 & 5.3362 & 5.3559 & TST & \\
\hline CHEMBL1448394 & 688239 & 4.6362 & 5.5638 & TRN & \\
\hline CHEMBL1326391 & 688239 & 5.1862 & 5.4295 & TST & \\
\hline CHEMBL1420665 & 688239 & 5.6862 & 5.4371 & TRN & \\
\hline CHEMBL1455632 & 688239 & 6.0362 & 5.4285 & TST & \\
\hline CHEMBL1531451 & 688239 & 7.3363 & 5.441 & TRN & \\
\hline CHEMBL1494564 & 688239 & 4.7362 & 5.3781 & TST & \\
\hline CHEMBL1302809 & 688239 & 4.5862 & 5.3579 & TST & \\
\hline CHEMBL1483018 & 688239 & 5.3362 & 5.5061 & TRN & \\
\hline CHEMBL1511252 & 688239 & 5.5862 & 5.5451 & TRN & \\
\hline CHEMBL1440239 & 688239 & 6.0862 & 5.3754 & TST & \\
\hline CHEMBL3207325 & 688239 & 6.1362 & 5.6225 & TRN & \\
\hline CHEMBL1457536 & 688239 & 5.7362 & 5.397 & TST & \\
\hline CHEMBL1304517 & 688239 & 4.8362 & \multicolumn{2}{|c|}{5.417000000000001} & TRN \\
\hline CHEMBL1473821 & 688239 & 4.5862 & 5.5145 & TRN & \\
\hline CHEMBL1576168 & 688239 & 4.4862 & 5.37299 & 9999999999 & TRN \\
\hline CHEMBL1518543 & 688239 & 6.6861 & 5.4663 & TRN & \\
\hline CHEMBL1409898 & 688239 & 4.5862 & 5.4673 & TRN & \\
\hline CHEMBL1417856 & 688239 & 5.2862 & 5.5671 & TRN & \\
\hline CHEMBL1572030 & 688239 & 6.2862 & 5.5944 & TRN & \\
\hline CHEMBL1562838 & 688239 & 5.2362 & 5.534 & TRN & \\
\hline CHEMBL1339354 & 688239 & 5.6862 & 5.5325 & TRN & \\
\hline CHEMBL1309934 & 688239 & 5.1862 & 5.4768 & TRN & \\
\hline CHEMBL1459990 & 688239 & 5.2862 & 5.5055 & TRN & \\
\hline CHEMBL1524831 & 688239 & 5.3862 & 5.4614 & TRN & \\
\hline CHEMBL1595620 & 688239 & 5.3362 & 5.6471 & TRN & \\
\hline CHEMBL1450899 & 688239 & 5.8862 & 5.6412 & TRN & \\
\hline CHEMBL1365770 & 688239 & 5.2362 & 5.5144 & TRN & \\
\hline CHEMBL1441327 & 688239 & 4.5362 & 5.505 & TST & \\
\hline CHEMBL1455331 & 688239 & 5.5862 & 5.4455 & TST & \\
\hline CHEMBL1385656 & 688239 & 5.9862 & 5.3631 & TRN & \\
\hline
\end{tabular}


Supplemental Table S2.txt

\begin{tabular}{|c|c|c|c|c|}
\hline CHEMBL1452178 & 688239 & 6.0862 & 5.6084 & TRN \\
\hline CHEMBL1359859 & 688239 & 5.0862 & 5.439 & TRN \\
\hline CHEMBL1352350 & 688239 & 5.6362 & 5.5712 & TST \\
\hline CHEMBL1609239 & 688239 & 4.5362 & 5.5849 & TRN \\
\hline CHEMBL1418469 & 688239 & 6.8362 & 5.3153 & TRN \\
\hline CHEMBL1450575 & 688239 & 6.9863 & 5.5147 & TRN \\
\hline CHEMBL1361230 & 688239 & 4.5862 & 5.4857 & TRN \\
\hline CHEMBL 3196751 & 688239 & 7.5361 & 5.4419 & TRN \\
\hline CHEMBL1464867 & 688239 & 5.6862 & 5.421 & TRN \\
\hline CHEMBL1406662 & 688239 & 5.5362 & 5.6782 & TRN \\
\hline CHEMBL1598419 & 688239 & 5.6362 & 5.5509 & TRN \\
\hline CHEMBL1456059 & 688239 & 4.5362 & 5.6504 & TRN \\
\hline CHEMBL 3212615 & 688239 & 4.5362 & 5.6212 & TRN \\
\hline CHEMBL 3191000 & 688239 & 5.6362 & 5.5027 & TRN \\
\hline CHEMBL1403459 & 688239 & 4.9362 & 5.5501 & TRN \\
\hline CHEMBL1403383 & 688239 & 5.0362 & 5.382006 & 000000001 \\
\hline CHEMBL1590271 & 688239 & 4.8862 & 5.5941 & TRN \\
\hline CHEMBL1362948 & 688239 & 4.7862 & 5.3375 & TRN \\
\hline CHEMBL1580655 & 688239 & 6.1862 & 5.5146 & TRN \\
\hline CHEMBL1584406 & 688239 & 4.5362 & 5.4736 & TRN \\
\hline CHEMBL1458216 & 688239 & 6.5862 & 5.5007 & TST \\
\hline CHEMBL1520496 & 688239 & 6.8861 & 5.6068 & TRN \\
\hline CHEMBL1303439 & 688239 & 4.5362 & 5.4732 & TST \\
\hline CHEMBL1398410 & 688239 & 6.2362 & 5.5101 & TRN \\
\hline CHEMBL1467202 & 688239 & 5.5362 & 5.3955 & TST \\
\hline CHEMBL1364202 & 688239 & 5.2362 & 5.4405 & TRN \\
\hline CHEMBL3195283 & 688239 & 6.3362 & 5.5033 & TST \\
\hline CHEMBL1477377 & 688239 & 5.3362 & 5.4532 & TRN \\
\hline CHEMBL1338272 & 688239 & 4.7362 & 5.4749 & TST \\
\hline CHEMBL1501486 & 688239 & 6.8861 & 5.4636 & TST \\
\hline CHEMBL1381535 & 688239 & 5.3362 & 5.4894 & TRN \\
\hline CHEMBL1495782 & 688239 & 4.7362 & 5.3649 & TRN \\
\hline CHEMBL1404692 & 688239 & 7.2366 & 5.3946 & TRN \\
\hline CHEMBL1539871 & 688239 & 5.1862 & 5.5021 & TRN \\
\hline CHEMBL1338144 & 688239 & 6.9863 & 5.55 & TRN \\
\hline CHEMBL1574086 & 688239 & 4.8862 & 5.3715 & TRN \\
\hline CHEMBL1967540 & 688239 & 5.9862 & 5.5979 & TRN \\
\hline CHEMBL1580541 & 688239 & 4.5362 & 5.638 & TRN \\
\hline CHEMBL1557447 & 688239 & 4.9362 & 5.4399 & TST \\
\hline CHEMBL1490395 & 688239 & 5.8862 & 5.6154 & TRN \\
\hline CHEMBL1586166 & 688239 & 5.1362 & 5.4325 & TRN \\
\hline CHEMBL1333036 & 688239 & 5.9 & 5.4931 & TRN \\
\hline CHEMBL1535761 & 688239 & 4.4362 & 5.4443 & TRN \\
\hline CHEMBL1366282 & 688239 & 6.6362 & 5.4856 & TST \\
\hline CHEMBL1396755 & 688239 & 5.1862 & 5.4123 & TRN \\
\hline CHEMBL1344060 & 688239 & 6.8362 & 5.5414 & TST \\
\hline CHEMBL1467596 & 688239 & 4.6362 & 5.5139 & TST \\
\hline CHEMBL1490222 & 688239 & 4.6362 & 5.3637 & TRN \\
\hline
\end{tabular}

Page 2422 


\begin{tabular}{|c|c|c|c|c|c|c|}
\hline & & \multicolumn{5}{|c|}{ Supplemental Table S2.txt } \\
\hline CHEMBL1459687 & 688239 & 5.2862 & 5.5528 & TRN & & \\
\hline CHEMBL1363900 & 688239 & 4.5362 & 5.6351 & TRN & & \\
\hline CHEMBL1598842 & 688239 & 5.4362 & 5.5435 & TST & & \\
\hline CHEMBL1419238 & 688239 & 4.7362 & 5.4604 & TRN & & \\
\hline CHEMBL1564446 & 688239 & 5.8362 & 5.5015 & TRN & & \\
\hline CHEMBL1379364 & 688239 & 6.2362 & 5.5121 & TRN & & \\
\hline CHEMBL1574440 & 688239 & 8.28399 & 99999999 & 99 & 5.4906 & TRN \\
\hline CHEMBL1416867 & 688239 & 5.9862 & 5.5708 & TST & & \\
\hline CHEMBL1461034 & 688239 & 4.5362 & 5.2928 & TRN & & \\
\hline CHEMBL1305445 & 688239 & 6.9863 & 5.2574 & TRN & & \\
\hline CHEMBL1341867 & 688239 & 5.3362 & 5.5039 & TST & & \\
\hline CHEMBL1426264 & 688239 & 8.3372 & 5.4041 & TST & & \\
\hline CHEMBL1374435 & 688239 & 6.8861 & 5.5026 & TRN & & \\
\hline CHEMBL1414694 & 688239 & 5.8862 & 5.455 & TRN & & \\
\hline CHEMBL1438335 & 688239 & 4.5362 & 5.4887 & TST & & \\
\hline CHEMBL3145285 & 688239 & 4.9362 & 5.3989 & TST & & \\
\hline CHEMBL1322347 & 688239 & 6.4862 & 5.5847 & TST & & \\
\hline CHEMBL1419076 & 688239 & 5.1362 & 5.5965 & TRN & & \\
\hline CHEMBL1458092 & 688239 & 4.7862 & 5.4201 & TRN & & \\
\hline CHEMBL1398950 & 688239 & 5.3862 & 5.5144 & TRN & & \\
\hline CHEMBL1581806 & 688239 & 4.5362 & 5.4332 & TRN & & \\
\hline CHEMBL1364139 & 688239 & 5.4862 & 5.5522 & TRN & & \\
\hline CHEMBL1421058 & 688239 & 7.0862 & 5.41299 & 9999999999 & & TRN \\
\hline CHEMBL560832 & 688239 & 5.4362 & 5.5302 & TRN & & \\
\hline CHEMBL1302531 & 688239 & 6.6362 & 5.346 & TRN & & \\
\hline CHEMBL1499560 & 688239 & 5.6862 & 5.5799 & TRN & & \\
\hline CHEMBL1332195 & 688239 & 4.5362 & 5.5958 & TRN & & \\
\hline CHEMBL1431670 & 688239 & 5.6362 & 5.4745 & TRN & & \\
\hline CHEMBL3199417 & 688239 & 6.2362 & 5.6341 & TRN & & \\
\hline CHEMBL1478649 & 688239 & 4.9862 & 5.3167 & TRN & & \\
\hline CHEMBL1582837 & 688239 & 6.7361 & 5.3213 & TRN & & \\
\hline CHEMBL1591834 & 688239 & 4.9362 & 5.5665 & TRN & & \\
\hline CHEMBL1547798 & 688239 & 4.9362 & 5.4255 & TRN & & \\
\hline CHEMBL1449855 & 688239 & 4.6862 & 5.4243 & TST & & \\
\hline CHEMBL1480140 & 688239 & 5.1862 & 5.5772 & TRN & & \\
\hline CHEMBL1306098 & 688239 & 4.5362 & 5.4795 & TRN & & \\
\hline CHEMBL1319445 & 688239 & 5.5362 & 5.5077 & TRN & & \\
\hline CHEMBL1383690 & 688239 & 4.4862 & 5.4634 & TRN & & \\
\hline CHEMBL1328616 & 688239 & 5.9862 & 5.4728 & TST & & \\
\hline CHEMBL1323977 & 688239 & 4.7362 & 5.56 & TRN & & \\
\hline CHEMBL1493524 & 688239 & 5.1362 & 5.2928 & TST & & \\
\hline CHEMBL1549324 & 688239 & 8.3372 & 5.504 & TST & & \\
\hline CHEMBL3102868 & 688239 & 4.5362 & 5.4778 & TRN & & \\
\hline CHEMBL1617452 & 688239 & 5.0862 & 5.5179 & TRN & & \\
\hline CHEMBL1377665 & 688239 & 6.8362 & 5.394 & TRN & & \\
\hline CHEMBL1346843 & 688239 & 6.6362 & 5.4971 & TRN & & \\
\hline CHEMBL1363219 & 688239 & 5.0362 & 5.3587 & TRN & & \\
\hline CHEMBL3207621 & 688239 & 5.4862 & 5.4543 & TRN & & \\
\hline
\end{tabular}


Supplemental Table S2.txt

\begin{tabular}{|c|c|c|c|c|c|}
\hline CHEMBL1377890 & 688239 & 5.3362 & \multicolumn{2}{|c|}{5.422999999999999} & TRN \\
\hline CHEMBL1971636 & 688239 & 5.7862 & 5.4905 & TST & \\
\hline CHEMBL1969164 & 688239 & 6.1362 & 5.4988 & TRN & \\
\hline CHEMBL1403061 & 688239 & 6.9363 & 5.4924 & TST & \\
\hline CHEMBL1447372 & 688239 & 5.7862 & 5.3817 & TRN & \\
\hline CHEMBL1577812 & 688239 & 5.1362 & 5.5461 & TRN & \\
\hline CHEMBL1401784 & 688239 & 7.1864 & 5.4599 & TRN & \\
\hline CHEMBL555260 & 688239 & 5.1862 & 5.4635 & TST & \\
\hline CHEMBL1399982 & 688239 & 6.1862 & 5.5401 & TRN & \\
\hline CHEMBL1586113 & 688239 & 7.0362 & 5.305 & TRN & \\
\hline CHEMBL1441819 & 688239 & 4.7862 & 5.398 & TRN & \\
\hline CHEMBL1308540 & 688239 & 5.4362 & 5.4069 & TRN & \\
\hline CHEMBL1417118 & 688239 & 4.5362 & 5.443 & TRN & \\
\hline CHEMBL1408974 & 688239 & 5.4362 & 5.6453 & TRN & \\
\hline CHEMBL1352519 & 688239 & 4.7362 & 5.5281 & TRN & \\
\hline CHEMBL202582 & 688239 & 4.6362 & 5.4336 & TRN & \\
\hline CHEMBL1415818 & 688239 & 4.7862 & 5.4499 & TRN & \\
\hline CHEMBL1442920 & 688239 & 5.8862 & 5.4391 & TRN & \\
\hline CHEMBL1499680 & 688239 & 4.5362 & 5.4505 & TST & \\
\hline CHEMBL1401082 & 688239 & 4.5362 & 5.3845 & TRN & \\
\hline CHEMBL1400175 & 688239 & 5.2362 & 5.4514 & TRN & \\
\hline CHEMBL1485615 & 688239 & 4.6362 & 5.3266 & TST & \\
\hline CHEMBL1350366 & 688239 & 4.5862 & 5.5035 & TST & \\
\hline CHEMBL1568964 & 688239 & 5.7362 & 5.4182 & TRN & \\
\hline CHEMBL1418494 & 688239 & 4.8862 & 5.45299 & 9999999999 & TRN \\
\hline CHEMBL601146 & 688239 & 5.2362 & 5.3763 & TRN & \\
\hline CHEMBL1400403 & 688239 & 5.1862 & 5.4957 & TRN & \\
\hline CHEMBL1372906 & 688239 & 5.5362 & 5.4813 & TRN & \\
\hline CHEMBL1304606 & 688239 & 6.1362 & 5.5644 & TRN & \\
\hline CHEMBL3210444 & 688239 & 4.8862 & 5.4694 & TRN & \\
\hline CHEMBL1466597 & 688239 & 5.6862 & 5.5593 & TRN & \\
\hline CHEMBL1970505 & 688239 & 4.5362 & 5.4723 & TRN & \\
\hline CHEMBL1578898 & 688239 & 4.45 & 5.5322 & TRN & \\
\hline CHEMBL1519485 & 688239 & 4.5362 & 5.5238 & TRN & \\
\hline CHEMBL1580409 & 688239 & 4.5362 & 5.4376 & TRN & \\
\hline CHEMBL1468351 & 688239 & 5.1862 & 5.5896 & TRN & \\
\hline CHEMBL1328628 & 688239 & 6.6861 & 5.6005 & TRN & \\
\hline CHEMBL1390895 & 688239 & 5.3862 & 5.5938 & TRN & \\
\hline CHEMBL1477509 & 688239 & 6.8861 & 5.6058 & TRN & \\
\hline CHEMBL1469100 & 688239 & 6.1862 & 5.4943 & TRN & \\
\hline CHEMBL1475237 & 688239 & 4.7862 & 5.3642 & TST & \\
\hline CHEMBL1368353 & 688239 & 4.5362 & 5.5086 & TST & \\
\hline CHEMBL1397581 & 688239 & 5.6862 & 5.4439 & TRN & \\
\hline CHEMBL1579509 & 688239 & 4.9862 & 5.4234 & TST & \\
\hline CHEMBL1345122 & 688239 & 4.6362 & 5.4184 & TRN & \\
\hline CHEMBL1412267 & 688239 & 5.7862 & 5.622006 & 0000000001 & TST \\
\hline CHEMBL3214480 & 688239 & 5.1862 & 5.4171 & TST & \\
\hline CHEMBL1324342 & 688239 & 5.4862 & 5.3246 & TRN & \\
\hline
\end{tabular}


Supplemental Table S2.txt

\begin{tabular}{|c|c|c|c|c|}
\hline CHEMBL1516058 & 688239 & 6.1862 & 5.5689 & TRN \\
\hline CHEMBL1475546 & 688239 & 5.3862 & 5.5402 & TRN \\
\hline CHEMBL1545353 & 688239 & 6.8861 & 5.5569 & TRN \\
\hline CHEMBL1508664 & 688239 & 5.5362 & 5.5479 & TRN \\
\hline CHEMBL1527502 & 688239 & 4.7362 & 5.3134 & TRN \\
\hline CHEMBL1483563 & 688239 & 6.9863 & 5.4346 & TST \\
\hline CHEMBL1391520 & 688239 & 5.2862 & 5.4586 & TST \\
\hline CHEMBL1352807 & 688239 & 6.3863 & 5.4788 & TRN \\
\hline CHEMBL483137 & 688239 & 6.0862 & 5.5804 & TRN \\
\hline CHEMBL1396921 & 688239 & 5.1862 & 5.428 & TRN \\
\hline CHEMBL1457681 & 688239 & 6.5862 & 5.4884 & TRN \\
\hline CHEMBL1544260 & 688239 & 6.5862 & 5.324 & TRN \\
\hline CHEMBL1454788 & 688239 & 4.5362 & 5.6173 & TRN \\
\hline CHEMBL1390157 & 688239 & 5.0862 & 5.58899 & 99999999995 \\
\hline CHEMBL1452330 & 688239 & 4.4862 & 5.3993 & TRN \\
\hline CHEMBL1424175 & 688239 & 4.5362 & 5.5652 & TRN \\
\hline CHEMBL1558180 & 688239 & 6.5862 & 5.4023 & TST \\
\hline CHEMBL1467304 & 688239 & 4.5362 & 5.3819 & TST \\
\hline CHEMBL1555840 & 688239 & 5.1862 & 5.4736 & TRN \\
\hline CHEMBL1476723 & 688239 & 6.4862 & 5.5633 & TRN \\
\hline CHEMBL1364157 & 688239 & 7.0862 & 5.5853 & TRN \\
\hline CHEMBL1438951 & 688239 & 5.0862 & 5.5755 & TRN \\
\hline CHEMBL1300982 & 688239 & 6.1362 & 5.5112 & TST \\
\hline CHEMBL1334635 & 688239 & 8.3372 & 5.5853 & TRN \\
\hline CHEMBL365356 & 688239 & 5.7362 & 5.5353 & TRN \\
\hline CHEMBL1446463 & 688239 & 4.4862 & 5.4777 & TRN \\
\hline CHEMBL1538445 & 688239 & 4.5862 & 5.4704 & TRN \\
\hline CHEMBL1305275 & 688239 & 5.6362 & 5.4973 & TRN \\
\hline CHEMBL1499867 & 688239 & 4.5862 & 5.5392 & TRN \\
\hline CHEMBL1472154 & 688239 & 4.8362 & 5.442 & TRN \\
\hline CHEMBL1423492 & 688239 & 5.1862 & 5.3077 & TST \\
\hline CHEMBL1528257 & 688239 & 5.0862 & 5.5057 & TST \\
\hline CHEMBL1314683 & 688239 & 6.9363 & 5.4088 & TRN \\
\hline CHEMBL1558959 & 688239 & 4.8862 & 5.5798 & TRN \\
\hline CHEMBL1540446 & 688239 & 6.9363 & 5.3754 & TRN \\
\hline CHEMBL1566018 & 688239 & 4.6362 & 5.5411 & TRN \\
\hline CHEMBL1474569 & 688239 & 5.4362 & 5.5479 & TRN \\
\hline CHEMBL1346002 & 688239 & 5.6862 & 5.5229 & TRN \\
\hline CHEMBL1442620 & 688239 & 5.4362 & 5.2658 & TST \\
\hline CHEMBL1349951 & 688239 & 4.5362 & 5.5767 & TRN \\
\hline CHEMBL1450461 & 688239 & 4.7362 & 5.495 & TRN \\
\hline CHEMBL1312271 & 688239 & 6.1362 & 5.5708 & TRN \\
\hline CHEMBL1342675 & 688239 & 6.8362 & 5.5773 & TRN \\
\hline CHEMBL1337074 & 688239 & 4.5362 & 5.4915 & TRN \\
\hline CHEMBL1360792 & 688239 & 4.7362 & 5.3997 & TST \\
\hline CHEMBL1301944 & 688239 & 4.6362 & 5.5203 & TRN \\
\hline CHEMBL1399054 & 688239 & 5.1862 & 5.4031 & TRN \\
\hline CHEMBL1540201 & 688239 & 5.2362 & 5.5597 & TRN \\
\hline
\end{tabular}

Page 2425 
Supplemental Table S2.txt

CHEMBL1568097
CHEMBL1384944
CHEMBL1585095
CHEMBL1606125
CHEMBL1501564
CHEMBL1391584
CHEMBL1492486

$\begin{array}{llll}688239 & 5.4362 & 5.5582 & \text { TRN } \\ 688239 & 4.8362 & 5.5863 & \text { TST }\end{array}$

$\begin{array}{llll}688239 & 6.5363 & 5.3753 & \text { TRN }\end{array}$

$\begin{array}{llll}688239 & 5.1362 & 5.5107 & \text { TRN }\end{array}$

$\begin{array}{llll}688239 & 5.4362 & 5.4038 & \text { TST }\end{array}$

$\begin{array}{llll}688239 & 4.6862 & 5.6395 & \text { TRN }\end{array}$

$\begin{array}{lllll}688239 & 4.5862 & 5.611000000000001 & \text { TST }\end{array}$

CHEMBL1536145

688239

688239

688239

688239

688239

688239

688239

688239

688239

688239

688239

6.4862

5.5271 TRN

$\begin{array}{lll}5.4362 & 5.4328 & \text { TRN }\end{array}$

$5.1862 \quad 5.5221$ TRN

CHEMBL1611844

MBL13792

CHEMBL1507420

CHEMBL1349388

CHEMBL1386653

CHEMBL1465693

CHEMBL1541776

CHEMBL1613137

688239

688239

4.5362

5.4554 TST

$\begin{array}{lll}5.7862 & 5.5937 & \text { TRN }\end{array}$

$\begin{array}{lll}4.5362 & 5.3364 & \text { TRN }\end{array}$

$\begin{array}{lll}5.1862 & 5.4173 & \text { TRN }\end{array}$

CHEMBL1354519

CHEMBL1560563

CHEMBL1489766

CHEMBL1396431

CHEMBL1386484

688239

688239

688239

4.7862

5.4733 TRN

5.1862

5.352 TRN

4.5362

5.3137 TST

6.9363

5.3362

5.4729 TST

5.3362

5.4952 TST

5.1362

5.4608 TRN

4.5862

5.5817 TRN

688239

6.3362

5.5511 TRN

CHEMBL1410472

688239

5.1862

5.5085 TRN

CHEMBL 1447080

688239

688239

4.5362

5.5219 TST

CHEMBL1334134

4.7862

5.6004 TRN

688239

6.3863

5.5609 TST

CHEMBL1604153

CHEMBL1529060

CHEMBL1434253

688239

6.9863

5.3562 TST

688239

6.2362

5.4495 TRN

688239

4.8362

5.5147 TRN

CHEMBL1455284

CHEMBL1524455

CHEMBL1455533

CHEMBL1386572

CHEMBL1552817

CHEMBL1993070

CHEMBL1491743

CHEMBL1352412

CHEMBL1608854

CHEMBL1326359

CHEMBL1504882

CHEMBL1353007

CHEMBL1349403

CHEMBL 1474850

CHEMBL1314346

CHEMBL1446949

CHEMBL1480269

688239

5.2362

5.6059 TRN

688239

5.9362

5.5621 TST

688239

4.5362

5.4549 TST

688239

8.1871

5.414 TRN

688239

4.7362

5.5691 TRN

688239

4.6362

5.55

TRN

688239

4.7862

5.3512 TRN

688239

5.2362

5.4653 TRN

688239

5.1862

5.5155 TRN

688239

6.8861

5.6594 TRN

688239

6.5862

5.348 TRN

688239

6.8861

5.5952 TRN

688239

4.6362

5.6845 TRN

688239

6.9363

5.5559

TRN

5.1862

5.4674 TRN

688239

688239

4.7362

5.5172 TRN

6.8861

5.445 TRN

688239

4.6862

5.4534 TRN

5.5678 TRN

Page 2426 
Supplemental Table S2.txt

\begin{tabular}{|c|c|c|c|c|}
\hline CHEMBL1421615 & 688239 & 4.5362 & 5.4661 & TRN \\
\hline CHEMBL1603392 & 688239 & 5.6862 & 5.5211 & TRN \\
\hline CHEMBL1378735 & 688239 & 4.7862 & 5.5441 & TRN \\
\hline CHEMBL1355137 & 688239 & 4.7862 & 5.4411 & TRN \\
\hline CHEMBL1406677 & 688239 & 5.1862 & 5.5901 & TRN \\
\hline CHEMBL1574101 & 688239 & 5.7362 & 5.6892 & TRN \\
\hline CHEMBL1399223 & 688239 & 5.1362 & 5.3636 & TRN \\
\hline CHEMBL1499275 & 688239 & 4.4862 & 5.51399 & 9999999999 \\
\hline CHEMBL1347855 & 688239 & 4.5362 & 5.4457 & TRN \\
\hline CHEMBL1470227 & 688239 & 4.4862 & 5.4896 & TRN \\
\hline CHEMBL1417073 & 688239 & 4.5362 & 5.6462 & TRN \\
\hline CHEMBL1334927 & 688239 & 6.0362 & 5.4843 & TST \\
\hline CHEMBL1449470 & 688239 & 4.5862 & 5.5052 & TRN \\
\hline CHEMBL1363370 & 688239 & 4.5362 & 5.4881 & TST \\
\hline CHEMBL1381127 & 688239 & 5.6362 & 5.4114 & TRN \\
\hline CHEMBL1556319 & 688239 & 4.6862 & 5.3421 & TRN \\
\hline CHEMBL1451571 & 688239 & 4.5362 & 5.4275 & TRN \\
\hline CHEMBL1344102 & 688239 & 6.2362 & 5.3436 & TRN \\
\hline CHEMBL1375060 & 688239 & 7.0862 & 5.4563 & TRN \\
\hline CHEMBL 3210787 & 688239 & 6.8362 & 5.4487 & TST \\
\hline CHEMBL1561596 & 688239 & 8.2366 & 5.5811 & TRN \\
\hline CHEMBL1566798 & 688239 & 5.2362 & 5.5402 & TRN \\
\hline CHEMBL1303807 & 688239 & 4.6862 & 5.4068 & TRN \\
\hline CHEMBL1571710 & 688239 & 4.6862 & \multicolumn{2}{|c|}{5.417999999999999} \\
\hline CHEMBL1466443 & 688239 & 6.3362 & 5.5811 & TRN \\
\hline CHEMBL1395979 & 688239 & 6.1362 & 5.3957 & TRN \\
\hline CHEMBL1348380 & 688239 & 4.6362 & 5.5227 & TRN \\
\hline CHEMBL1439123 & 688239 & 4.5362 & 5.5637 & TRN \\
\hline CHEMBL1463426 & 688239 & 4.5362 & 5.5229 & TST \\
\hline CHEMBL1595450 & 688239 & 4.8362 & 5.4447 & TRN \\
\hline CHEMBL1355311 & 688239 & 8.1871 & 5.599 & TRN \\
\hline CHEMBL1454455 & 688239 & 6.7862 & 5.6099 & TRN \\
\hline CHEMBL1416233 & 688239 & 5.4362 & 5.4547 & TRN \\
\hline CHEMBL1492226 & 688239 & 5.1862 & 5.4503 & TRN \\
\hline CHEMBL1377059 & 688239 & 4.4862 & 5.4229 & TRN \\
\hline CHEMBL3196750 & 688239 & 6.0862 & 5.4626 & TST \\
\hline CHEMBL1340418 & 688239 & 5.2862 & \multicolumn{2}{|c|}{5.502000000000001} \\
\hline CHEMBL1306470 & 688239 & 4.5362 & 5.5288 & TRN \\
\hline CHEMBL1610175 & 688239 & 8.3872 & 5.4153 & TRN \\
\hline CHEMBL1362054 & 688239 & 4.6862 & 5.3635 & TRN \\
\hline CHEMBL1592986 & 688239 & 4.9862 & 5.5699 & TRN \\
\hline CHEMBL1460562 & 688239 & 5.0362 & 5.6602 & TRN \\
\hline CHEMBL1529401 & 688239 & 5.9362 & 5.4905 & TRN \\
\hline CHEMBL1406051 & 688239 & 5.4862 & 5.5165 & TRN \\
\hline CHEMBL1412684 & 688239 & 4.6362 & 5.39 & TRN \\
\hline CHEMBL1348278 & 688239 & 4.5362 & 5.4242 & TST \\
\hline CHEMBL1340950 & 688239 & 4.7862 & 5.404 & TST \\
\hline CHEMBL1350567 & 688239 & 6.2362 & 5.5623 & TRN \\
\hline
\end{tabular}


Supplemental Table S2.txt

\begin{tabular}{|c|c|c|c|c|c|}
\hline CHEMBL1421103 & 688239 & 4.5862 & 5.4712 & TRN & \\
\hline CHEMBL1353790 & 688239 & 5.1862 & 5.4315 & TRN & \\
\hline CHEMBL1483182 & 688239 & 5.4362 & 5.5413 & TRN & \\
\hline CHEMBL1450669 & 688239 & 4.8862 & 5.2763 & TRN & \\
\hline CHEMBL1473566 & 688239 & 4.7862 & 5.4693 & TRN & \\
\hline CHEMBL1605611 & 688239 & 6.2362 & 5.6264 & TST & \\
\hline CHEMBL1504930 & 688239 & 5.1862 & 5.5677 & TST & \\
\hline CHEMBL1590003 & 688239 & 4.5362 & 5.4887 & TRN & \\
\hline CHEMBL1467789 & 688239 & 6.2362 & 5.69 & TRN & \\
\hline CHEMBL1586489 & 688239 & 5.4862 & 5.4051 & TRN & \\
\hline CHEMBL1466015 & 688239 & 4.7362 & 5.5707 & TST & \\
\hline CHEMBL1544408 & 688239 & 4.7862 & 5.4375 & TRN & \\
\hline CHEMBL1530268 & 688239 & 6.2362 & 5.4421 & TST & \\
\hline CHEMBL1527135 & 688239 & 5.1862 & 5.5637 & TRN & \\
\hline CHEMBL1539133 & 688239 & 6.3 & 5.3819 & TRN & \\
\hline CHEMBL1372774 & 688239 & 5.3862 & 5.5199 & TRN & \\
\hline CHEMBL1521342 & 688239 & 7.5361 & 5.492000 & 000000001 & TRN \\
\hline CHEMBL1376203 & 688239 & 4.8362 & 5.3743 & TRN & \\
\hline CHEMBL1575120 & 688239 & 4.6862 & 5.4017 & TRN & \\
\hline CHEMBL1379910 & 688239 & 5.6362 & 5.5136 & TST & \\
\hline CHEMBL1434929 & 688239 & 4.5362 & 5.4983 & TRN & \\
\hline CHEMBL1447350 & 688239 & 4.5862 & 5.4141 & TST & \\
\hline CHEMBL 3196858 & 688239 & 4.7862 & 5.4601 & TST & \\
\hline CHEMBL1475389 & 688239 & 4.5362 & 5.4454 & TRN & \\
\hline CHEMBL1604812 & 688239 & 6.0862 & 5.4916 & TST & \\
\hline CHEMBL1372654 & 688239 & 5.8362 & 5.5271 & TRN & \\
\hline CHEMBL1444884 & 688239 & 4.6362 & 5.5373 & TRN & \\
\hline CHEMBL1540594 & 688239 & 5.5362 & 5.4475 & TST & \\
\hline CHEMBL1422163 & 688239 & 4.6862 & 5.3822 & TST & \\
\hline CHEMBL1508577 & 688239 & 6.7361 & 5.5121 & TRN & \\
\hline CHEMBL1326048 & 688239 & 4.5362 & 5.4914 & TST & \\
\hline CHEMBL1533090 & 688239 & 6.7862 & 5.4579 & TRN & \\
\hline CHEMBL1457363 & 688239 & 6.0862 & 5.649 & TRN & \\
\hline CHEMBL1459713 & 688239 & 5.4862 & 5.4567 & TRN & \\
\hline CHEMBL1401502 & 688239 & 5.4862 & 5.3652 & TRN & \\
\hline CHEMBL1370166 & 688239 & 5.2362 & 5.4376 & TRN & \\
\hline CHEMBL1465722 & 688239 & 6.9863 & 5.4759 & TRN & \\
\hline CHEMBL1332001 & 688239 & 4.5362 & 5.3409 & TST & \\
\hline CHEMBL 2373590 & 688239 & 5.4362 & 5.4551 & TRN & \\
\hline CHEMBL1494546 & 688239 & 5.3862 & 5.5731 & TST & \\
\hline CHEMBL1485179 & 688239 & 4.7862 & 5.4299 & TRN & \\
\hline CHEMBL1457276 & 688239 & 5.1862 & 5.322999 & 9999999995 & TRN \\
\hline CHEMBL1441504 & 688239 & 5.9362 & 5.6681 & TRN & \\
\hline CHEMBL1341997 & 688239 & 4.7862 & 5.48 & TST & \\
\hline CHEMBL3214269 & 688239 & 6.8861 & 5.4215 & TST & \\
\hline CHEMBL1378646 & 688239 & 6.2862 & 5.5255 & TST & \\
\hline CHEMBL1564397 & 688239 & 5.4362 & 5.5406 & TST & \\
\hline CHEMBL1409219 & 688239 & 4.5362 & 5.5248 & TRN & \\
\hline
\end{tabular}




\begin{tabular}{|c|c|c|c|c|c|}
\hline \multirow{3}{*}{$\begin{array}{l}\text { CHEMBL1595781 } \\
\text { CHFMBI } 1434298\end{array}$} & \multirow{3}{*}{$\begin{array}{l}688239 \\
688239\end{array}$} & \multicolumn{4}{|c|}{ Supplemental Table S2.txt } \\
\hline & & 4.9862 & \multicolumn{2}{|c|}{5.507000000000001} & TRN \\
\hline & & 6.8861 & 5.6609 & TRN & \\
\hline CHEMBL1429171 & 688239 & 6.1362 & 5.4428 & TST & \\
\hline CHEMBL1449393 & 688239 & 4.5362 & 5.3605 & TRN & \\
\hline CHEMBL1488235 & 688239 & 5.5862 & 5.4047 & TRN & \\
\hline CHEMBL1570131 & 688239 & 5.2362 & 5.4429 & TRN & \\
\hline CHEMBL1391099 & 688239 & 4.9362 & \multicolumn{2}{|c|}{5.452000000000001} & TRN \\
\hline CHEMBL1431034 & 688239 & 5.7362 & 5.6287 & TRN & \\
\hline CHEMBL1325926 & 688239 & 5.1362 & 5.4991 & TRN & \\
\hline CHEMBL1538228 & 688239 & 8.3372 & 5.4815 & TRN & \\
\hline CHEMBL1437138 & 688239 & 5.7362 & 5.4543 & TST & \\
\hline CHEMBL1593872 & 688239 & 5.7362 & 5.4876 & TRN & \\
\hline CHEMBL1598433 & 688239 & 5.2862 & 5.6249 & TRN & \\
\hline CHEMBL387762 & 688239 & 4.6362 & 5.5741 & TST & \\
\hline CHEMBL1476024 & 688239 & 5.1862 & 5.5208 & TRN & \\
\hline CHEMBL1554367 & 688239 & 5.7862 & 5.398 & TRN & \\
\hline CHEMBL1442592 & 688239 & 4.5362 & 5.4447 & TRN & \\
\hline CHEMBL1541691 & 688239 & 4.5862 & 5.4483 & TST & \\
\hline CHEMBL1550901 & 688239 & 5.0362 & 5.4378 & TRN & \\
\hline CHEMBL1540747 & 688239 & 4.45 & 5.5003 & TRN & \\
\hline CHEMBL1385244 & 688239 & 5.4862 & 5.5117 & TRN & \\
\hline CHEMBL1402292 & 688239 & 5.1862 & 5.4306 & TST & \\
\hline CHEMBL1354009 & 688239 & 6.0862 & 5.4449 & TRN & \\
\hline CHEMBL1392800 & 688239 & 6.4862 & 5.6696 & TRN & \\
\hline CHEMBL1431084 & 688239 & 5.4862 & 5.4897 & TRN & \\
\hline CHEMBL1304236 & 688239 & 5.1862 & 5.5963 & TRN & \\
\hline CHEMBL1465704 & 688239 & 5.6362 & 5.3914 & TRN & \\
\hline CHEMBL1313756 & 688239 & 4.8362 & 5.6243 & TRN & \\
\hline CHEMBL1425942 & 688239 & 6.0362 & 5.5364 & TST & \\
\hline CHEMBL1467264 & 688239 & 5.4362 & 5.6737 & TRN & \\
\hline CHEMBL1601538 & 688239 & 5.7862 & 5.4756 & TRN & \\
\hline CHEMBL1407296 & 688239 & 4.5862 & 5.606 & TRN & \\
\hline CHEMBL1466463 & 688239 & 5.1362 & 5.2396 & TRN & \\
\hline CHEMBL1424762 & 688239 & 6.2862 & 5.3489 & TRN & \\
\hline CHEMBL1404479 & 688239 & 4.7362 & 5.607 & TST & \\
\hline CHEMBL1514636 & 688239 & 5.7862 & 5.4668 & TRN & \\
\hline CHEMBL1498834 & 688239 & 5.5862 & 5.5193 & TST & \\
\hline CHEMBL1558699 & 688239 & 6.2362 & 5.55 & TRN & \\
\hline CHEMBL3213155 & 688239 & 5.6362 & 5.4203 & TRN & \\
\hline CHEMBL2359911 & 688239 & 4.7862 & 5.4631 & TRN & \\
\hline CHEMBL1304867 & 688239 & 5.3862 & 5.5436 & TRN & \\
\hline CHEMBL1460002 & 688239 & 4.5362 & 5.54299 & 9999999999 & TRN \\
\hline CHEMBL1467977 & 688239 & 4.8362 & 5.4834 & TRN & \\
\hline CHEMBL1482592 & 688239 & 6.1862 & 5.4036 & TRN & \\
\hline CHEMBL1370141 & 688239 & 6.1862 & 5.4326 & TRN & \\
\hline CHEMBL1472908 & 688239 & 4.6862 & 5.483 & TRN & \\
\hline CHEMBL1495548 & 688239 & 4.4862 & 5.5537 & TRN & \\
\hline CHEMBL1602881 & 688239 & 5.1862 & 5.5139 & TRN & \\
\hline
\end{tabular}


Supplemental Table S2.txt

\begin{tabular}{|c|c|c|c|c|}
\hline CHEMBL1569106 & 688239 & 4.5362 & 5.3548 & TST \\
\hline CHEMBL1379040 & 688239 & 6.0862 & 5.5102 & TRN \\
\hline CHEMBL43459 & 688239 & 6.2362 & 5.5076 & TRN \\
\hline CHEMBL1478903 & 688239 & 4.5362 & 5.5807 & TRN \\
\hline CHEMBL1545077 & 688239 & 4.7862 & 5.4873 & TRN \\
\hline CHEMBL1347975 & 688239 & 5.4862 & 5.3832 & TST \\
\hline CHEMBL 2003153 & 688239 & 6.9363 & 5.4211 & TRN \\
\hline CHEMBL1382677 & 688239 & 5.6862 & 5.4624 & TRN \\
\hline CHEMBL1307054 & 688239 & 6.1862 & \multicolumn{2}{|c|}{5.587999999999999} \\
\hline CHEMBL1366399 & 688239 & 5.7862 & 5.3941 & TRN \\
\hline CHEMBL1337713 & 688239 & 4.7862 & 5.5009 & TRN \\
\hline CHEMBL1562407 & 688239 & 4.8862 & 5.4112 & TRN \\
\hline CHEMBL1524109 & 688239 & 6.9363 & 5.4734 & TRN \\
\hline CHEMBL1550706 & 688239 & 5.7362 & 5.2978 & TST \\
\hline CHEMBL1347936 & 688239 & 6.9363 & 5.5852 & TRN \\
\hline CHEMBL 3207724 & 688239 & 4.5362 & 5.5858 & TRN \\
\hline CHEMBL1395123 & 688239 & 7.1361 & 5.4557 & TRN \\
\hline CHEMBL1519637 & 688239 & 6.4862 & 5.5496 & TRN \\
\hline CHEMBL1468482 & 688239 & 5.3862 & 5.4629 & TRN \\
\hline CHEMBL1526474 & 688239 & 5.7362 & 5.6336 & TRN \\
\hline CHEMBL1377497 & 688239 & 5.1862 & 5.5487 & TST \\
\hline CHEMBL1364347 & 688239 & 5.5862 & 5.4792 & TRN \\
\hline CHEMBL1380711 & 688239 & 4.4862 & 5.4458 & TRN \\
\hline CHEMBL1456831 & 688239 & 4.7362 & 5.5943 & TRN \\
\hline CHEMBL1529866 & 688239 & 5.3362 & 5.5588 & TRN \\
\hline CHEMBL1467946 & 688239 & 6.0862 & 5.4621 & TRN \\
\hline CHEMBL1419908 & 688239 & 4.5362 & 5.5266 & TRN \\
\hline CHEMBL1563831 & 688239 & 6.6362 & 5.4614 & TRN \\
\hline CHEMBL1520956 & 688239 & 8.3372 & 5.5187 & TRN \\
\hline CHEMBL1313596 & 688239 & 4.5362 & 5.4985 & TRN \\
\hline CHEMBL1378484 & 688239 & 4.8362 & 5.5529 & TRN \\
\hline CHEMBL1603656 & 688239 & 4.8362 & 5.5394 & TRN \\
\hline CHEMBL1397065 & 688239 & 4.5362 & 5.5123 & TRN \\
\hline CHEMBL1412651 & 688239 & 6.9863 & 5.58899 & \\
\hline CHEMBL1561921 & 688239 & 4.5862 & 5.5309 & TRN \\
\hline CHEMBL1517419 & 688239 & 4.5362 & 5.4762 & TRN \\
\hline CHEMBL1369262 & 688239 & 4.5362 & 5.5297 & TST \\
\hline CHEMBL1366608 & 688239 & 4.4862 & 5.3342 & TRN \\
\hline CHEMBL1358789 & 688239 & 5.1862 & 5.4726 & TRN \\
\hline CHEMBL1432621 & 688239 & 5.1862 & 5.5237 & TRN \\
\hline CHEMBL1611481 & 688239 & 4.8862 & 5.4242 & TRN \\
\hline CHEMBL1383055 & 688239 & 5.3862 & 5.6596 & TRN \\
\hline CHEMBL1602140 & 688239 & 4.7362 & 5.54899 & 99999999995 \\
\hline CHEMBL1481236 & 688239 & 5.2362 & 5.6318 & TRN \\
\hline CHEMBL1311707 & 688239 & 4.7862 & 5.4643 & TST \\
\hline CHEMBL1491076 & 688239 & 4.8862 & 5.3393 & TRN \\
\hline CHEMBL1344349 & 688239 & 5.8362 & 5.5087 & TRN \\
\hline CHEMBL1303479 & 688239 & 6.7862 & 5.6611 & TST \\
\hline
\end{tabular}


Supplemental Table S2.txt

\begin{tabular}{|c|c|c|c|c|}
\hline IE & 9 & 52 & & \\
\hline UГMDI 192007 & & 4.5862 & 5.5204 & \\
\hline 279 & & & & \\
\hline AEMBL1414153 & & 61 & & \\
\hline HEMBL1475486 & 8239 & 362 & & \\
\hline HEMBL1482741 & 88239 & 8362 & $\$ 127$ & \\
\hline 006 & 239 & 862 & 684 & \\
\hline FMBI 1 & & & & \\
\hline AEMBL1412199 & & & 016 & \\
\hline HEMBL15 & 88239 & 362 & 264 & \\
\hline AEMBL15 & 239 & 862 & 553 & \\
\hline IEMBL1 & 239 & & 502 & \\
\hline AEMBL1 & & & & \\
\hline HEMBL13 & & 862 & 5062 & \\
\hline AEMBL13 & & & 417 & \\
\hline AEMBL1. & 39 & 63 & & \\
\hline HEMBL1 & & & & \\
\hline HEMBL1 & & & & \\
\hline HEMBL1: & & & & \\
\hline AEMBL14 & & & & \\
\hline HEMBI & & & 86 & \\
\hline HEMBL1 & & & & \\
\hline HEMBL1 & & & & \\
\hline HEMBL1: & & & 822 & \\
\hline AEMBL31 & & & 83 & 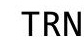 \\
\hline HEMBL3 & & & 429 & RI \\
\hline HEMBL: & & & & RN \\
\hline AFMBI 3 & & & & RN \\
\hline HEMBL3 & & & & TST \\
\hline HEMBL1: & & & 1747 & IRN \\
\hline HEMBL1 & & & 388 & \\
\hline $\mathrm{AFMB}$ & & & & RN \\
\hline HEMBL & & & & RN \\
\hline HEMBL32 & & & 1782 & TST \\
\hline HEMBL 32 & & & 4378 & $\Gamma \mathrm{RN}$ \\
\hline HEMBL1 & & & 229 & \\
\hline HᄃMDI - & & & & RN \\
\hline HEMBL1 & & & 051 & ST \\
\hline HEMBL1374204 & 88239 & 372 & 5681 & TRN \\
\hline AEMBL1 & & & 503 & RN \\
\hline HEMBL1 & & & 613 & \\
\hline CHEMBL1 14 & & & & ST \\
\hline HEMBL1 & & & 5643 & $\mathrm{RN}$ \\
\hline HEMBL14 & 8239 & 862 & 1644 & TRN \\
\hline MBLI & & & & RN \\
\hline CHEMBL14 & & & & \\
\hline CHEMBL 14 & & .1862 & 5.5516 & \\
\hline SHEMBL1451582 & 688239 & 6.2362 & 5.5324 & ГRN \\
\hline
\end{tabular}

Page 2431 
Supplemental Table S2.txt

\begin{tabular}{|c|c|c|c|c|}
\hline CHEMBL1479508 & 688239 & 6.2362 & 5.4758 & TST \\
\hline CHEMBL1350173 & 688239 & 4.5362 & 5.6708 & TST \\
\hline CHEMBL3190429 & 688239 & 6.8362 & 5.4035 & TST \\
\hline CHEMBL1352804 & 688239 & 6.2362 & 5.4785 & TST \\
\hline CHEMBL1498951 & 688239 & 4.5362 & 5.5501 & TRN \\
\hline CHEMBL1335481 & 688239 & 4.7862 & 5.4381 & TRN \\
\hline CHEMBL1341064 & 688239 & 4.5362 & 5.2911 & TRN \\
\hline CHEMBL1582316 & 688239 & 6.8861 & 5.5316 & TRN \\
\hline CHEMBL1376504 & 688239 & 5.5362 & 5.2912 & TST \\
\hline CHEMBL1418618 & 688239 & 6.5363 & 5.5308 & TST \\
\hline CHEMBL1598158 & 688239 & 5.9362 & 5.4558 & TRN \\
\hline CHEMBL492267 & 688239 & 4.5362 & 5.4739 & TRN \\
\hline CHEMBL1400883 & 688239 & 5.6862 & 5.6431 & TRN \\
\hline CHEMBL1599489 & 688239 & 6.2362 & 5.5754 & TRN \\
\hline CHEMBL1523096 & 688239 & 4.6862 & 5.5523 & TRN \\
\hline CHEMBL1502575 & 688239 & 4.7362 & 5.5302 & TRN \\
\hline CHEMBL1318381 & 688239 & 8.28399 & 99999999 & 5.4311 \\
\hline CHEMBL1513549 & 688239 & 4.5362 & 5.4897 & TRN \\
\hline CHEMBL1516388 & 688239 & 6.0 & 5.4355 & TST \\
\hline CHEMBL3197416 & 688239 & 5.3862 & 5.5374 & TRN \\
\hline CHEMBL1497822 & 688239 & 4.45 & 5.4377 & TST \\
\hline CHEMBL1602864 & 688239 & 5.1862 & 5.6262 & TRN \\
\hline CHEMBL579105 & 688239 & 5.6362 & 5.2872 & TRN \\
\hline CHEMBL1509219 & 688239 & 5.2862 & 5.3694 & TRN \\
\hline CHEMBL1324785 & 688239 & 5.7362 & 5.5636 & TRN \\
\hline CHEMBL1320597 & 688239 & 5.9362 & 5.7264 & TRN \\
\hline CHEMBL1484959 & 688239 & 5.1862 & 5.4414 & TRN \\
\hline CHEMBL1409136 & 688239 & 4.5862 & 5.6533 & TRN \\
\hline CHEMBL1988731 & 688239 & 5.9862 & 5.4156 & TRN \\
\hline CHEMBL1528900 & 688239 & 4.6862 & 5.5226 & TST \\
\hline CHEMBL1535255 & 688239 & 4.6862 & 5.5394 & TRN \\
\hline CHEMBL1429437 & 688239 & 5.0362 & 5.4929 & TST \\
\hline CHEMBL1543645 & 688239 & 4.5362 & 5.5511 & TST \\
\hline CHEMBL1566610 & 688239 & 5.5362 & 5.462999 & 9999999999 \\
\hline CHEMBL1534843 & 688239 & 6.2362 & 5.7049 & TRN \\
\hline CHEMBL583578 & 688239 & 5.7362 & 5.5673 & TRN \\
\hline CHEMBL1442399 & 688239 & 6.1362 & 5.3046 & TRN \\
\hline CHEMBL3192577 & 688239 & 5.2862 & 5.4806 & TRN \\
\hline CHEMBL1413843 & 688239 & 6.0862 & 5.5072 & TRN \\
\hline CHEMBL1481772 & 688239 & 4.5362 & 5.5528 & TRN \\
\hline CHEMBL1362341 & 688239 & 6.0862 & 5.4069 & TST \\
\hline CHEMBL1352383 & 688239 & 6.8861 & 5.5245 & TRN \\
\hline CHEMBL3189408 & 688239 & 4.6362 & 5.3958 & TST \\
\hline CHEMBL1473451 & 688239 & 5.3362 & 5.3557 & TRN \\
\hline CHEMBL1517636 & 688239 & 6.1862 & 5.5456 & TRN \\
\hline CHEMBL1552453 & 688239 & 5.3862 & 5.3945 & TRN \\
\hline CHEMBL1426638 & 688239 & 6.8861 & 5.5563 & TRN \\
\hline CHEMBL1424655 & 688239 & 7.2865 & 5.5718 & TST \\
\hline
\end{tabular}


Supplemental Table S2.txt

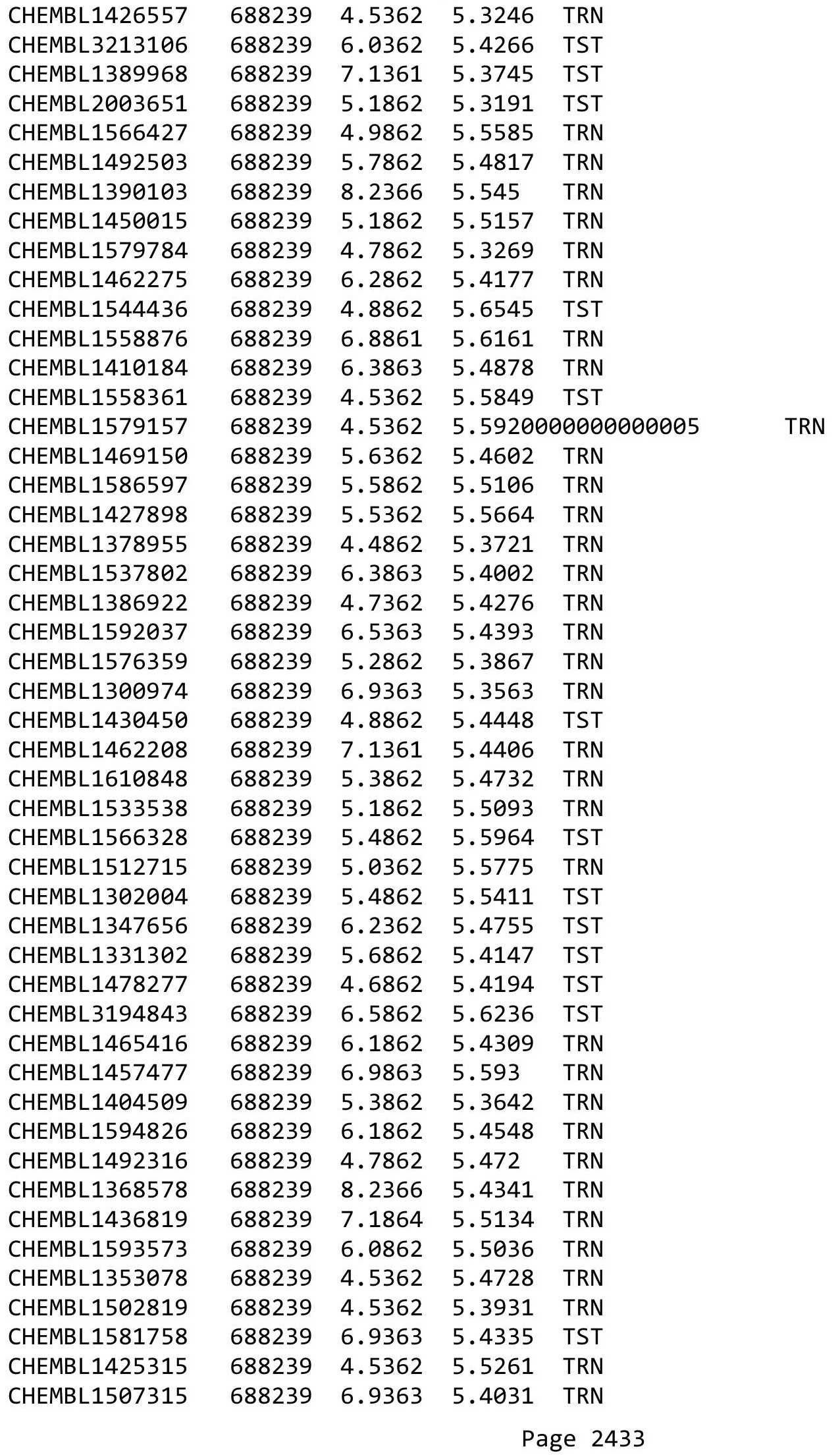


Supplemental Table S2.txt

\begin{tabular}{|c|c|c|c|c|}
\hline CHEMBL1343199 & 688239 & 4.5362 & 5.5832 & TST \\
\hline CHEMBL1983026 & 688239 & 6.7361 & 5.5972 & TRN \\
\hline CHEMBL1343674 & 688239 & 5.8862 & 5.5629 & TST \\
\hline CHEMBL1365441 & 688239 & 4.5362 & 5.4901 & TRN \\
\hline CHEMBL1401921 & 688239 & 5.1862 & 5.564 & TRN \\
\hline CHEMBL1306976 & 688239 & 6.8861 & 5.394 & TRN \\
\hline CHEMBL1360102 & 688239 & 4.6862 & 5.2567 & TRN \\
\hline CHEMBL1309368 & 688239 & 4.7862 & 5.4574 & TST \\
\hline CHEMBL1562303 & 688239 & 5.1862 & 5.3741 & TST \\
\hline CHEMBL1553823 & 688239 & 4.7362 & \multicolumn{2}{|c|}{5.5360000000000005} \\
\hline CHEMBL1388568 & 688239 & 4.5362 & 5.5624 & TRN \\
\hline CHEMBL1481722 & 688239 & 4.5362 & 5.5356 & TST \\
\hline CHEMBL1574526 & 688239 & 4.5862 & 5.4973 & TST \\
\hline CHEMBL1333185 & 688239 & 4.5362 & 5.4176 & TRN \\
\hline CHEMBL3198139 & 688239 & 6.0862 & 5.4603 & TRN \\
\hline CHEMBL1350195 & 688239 & 5.6362 & 5.5088 & TRN \\
\hline CHEMBL1321137 & 688239 & 4.7362 & 5.2903 & TST \\
\hline CHEMBL1405307 & 688239 & 8.3372 & 5.6203 & TRN \\
\hline CHEMBL1488509 & 688239 & 6.6362 & 5.4997 & TRN \\
\hline CHEMBL1463762 & 688239 & 5.2862 & 5.6326 & TRN \\
\hline CHEMBL1363624 & 688239 & 5.0862 & 5.5235 & TRN \\
\hline CHEMBL1441903 & 688239 & 4.5362 & 5.3944 & TRN \\
\hline CHEMBL1974679 & 688239 & 6.8362 & 5.6178 & TRN \\
\hline CHEMBL1427941 & 688239 & 6.1862 & 5.433 & TRN \\
\hline CHEMBL1564393 & 688239 & 4.7862 & 5.643 & TRN \\
\hline CHEMBL1459995 & 688239 & 5.1862 & 5.5506 & TRN \\
\hline CHEMBL1460862 & 688239 & 4.5362 & 5.4195 & TST \\
\hline CHEMBL1325603 & 688239 & 4.6862 & 5.4785 & TRN \\
\hline CHEMBL1607564 & 688239 & 6.6362 & 5.4936 & TST \\
\hline CHEMBL1443938 & 688239 & 5.3362 & 5.3802 & TRN \\
\hline CHEMBL1401224 & 688239 & 4.7362 & 5.5316 & TRN \\
\hline CHEMBL3210549 & 688239 & 4.5362 & 5.4621 & TST \\
\hline CHEMBL1300560 & 688239 & 6.1862 & 5.4369 & TRN \\
\hline CHEMBL1382024 & 688239 & 5.1862 & 5.4612 & TRN \\
\hline CHEMBL1525665 & 688239 & 4.8 & 5.4974 & TRN \\
\hline CHEMBL3208555 & 688239 & 4.8862 & 5.5724 & TRN \\
\hline CHEMBL1569072 & 688239 & 6.4862 & 5.5459 & TRN \\
\hline CHEMBL1305735 & 688239 & 5.5862 & 5.5089 & TST \\
\hline CHEMBL1432493 & 688239 & 7.0862 & \multicolumn{2}{|c|}{5.582000000000001} \\
\hline CHEMBL1374456 & 688239 & 4.6362 & 5.5253 & TRN \\
\hline CHEMBL1417882 & 688239 & 4.8362 & 5.5012 & TRN \\
\hline CHEMBL1332762 & 688239 & 5.9362 & 5.4881 & TRN \\
\hline CHEMBL1470719 & 688239 & 5.1862 & 5.5152 & TRN \\
\hline CHEMBL3191450 & 688239 & 4.4862 & 5.5137 & TRN \\
\hline CHEMBL1514261 & 688239 & 4.4862 & 5.3772 & TRN \\
\hline CHEMBL1482882 & 688239 & 6.9863 & 5.4253 & TRN \\
\hline CHEMBL1299566 & 688239 & 4.7862 & 5.5174 & TRN \\
\hline CHEMBL1579513 & 688239 & 5.6862 & 5.5027 & TRN \\
\hline
\end{tabular}


Supplemental Table S2.txt

\begin{tabular}{|c|c|c|c|c|c|}
\hline CHEMBL1550861 & 688239 & 5.1862 & 5.5397 & TRN & \\
\hline CHEMBL1490334 & 688239 & 6.1862 & 5.6258 & TRN & \\
\hline CHEMBL1590747 & 688239 & 4.6862 & 5.4526 & TRN & \\
\hline CHEMBL1426342 & 688239 & 6.1862 & 5.5296 & TRN & \\
\hline CHEMBL1515608 & 688239 & 4.7862 & 5.4507 & TRN & \\
\hline CHEMBL1307449 & 688239 & 5.8862 & 5.3178 & TST & \\
\hline CHEMBL1444127 & 688239 & 5.6362 & 5.4147 & TST & \\
\hline CHEMBL1342560 & 688239 & 5.4362 & 5.5923 & TST & \\
\hline CHEMBL1319873 & 688239 & 6.6362 & 5.4799 & TRN & \\
\hline CHEMBL1390503 & 688239 & 6.1862 & 5.4456 & TST & \\
\hline CHEMBL1613300 & 688239 & 4.7362 & 5.5315 & TST & \\
\hline CHEMBL1376774 & 688239 & 4.7862 & 5.5292 & TRN & \\
\hline CHEMBL3195459 & 688239 & 4.6862 & 5.5954 & TRN & \\
\hline CHEMBL1454470 & 688239 & 8.28399 & 99999999 & 5.5901 & \\
\hline CHEMBL1340954 & 688239 & 4.5362 & 5.438 & TST & \\
\hline CHEMBL1474457 & 688239 & 5.6862 & 5.5022 & TRN & \\
\hline CHEMBL1426152 & 688239 & 4.5362 & 5.5415 & TRN & \\
\hline CHEMBL1365519 & 688239 & 4.5362 & 5.3894 & TRN & \\
\hline CHEMBL1367025 & 688239 & 5.4362 & 5.5318 & TRN & \\
\hline CHEMBL1573228 & 688239 & 6.5363 & 5.5132 & TRN & \\
\hline CHEMBL1371112 & 688239 & 6.7862 & 5.5342 & TRN & \\
\hline CHEMBL1584908 & 688239 & 4.7862 & 5.4611 & TST & \\
\hline CHEMBL1519311 & 688239 & 6.0862 & 5.638 & TST & \\
\hline CHEMBL1476069 & 688239 & 4.8862 & 5.5452 & TST & \\
\hline CHEMBL1351109 & 688239 & 4.5362 & 5.6444 & TST & \\
\hline CHEMBL1424362 & 688239 & 5.6862 & 5.6004 & TRN & \\
\hline CHEMBL1462083 & 688239 & 6.6362 & 5.518 & TRN & \\
\hline CHEMBL1497695 & 688239 & 4.5362 & 5.6995 & TRN & \\
\hline CHEMBL1416730 & 688239 & 6.7361 & 5.4945 & TRN & \\
\hline CHEMBL 243596 & 688239 & 4.7362 & 5.4446 & TST & \\
\hline CHEMBL1332439 & 688239 & 5.6362 & 5.4983 & TRN & \\
\hline CHEMBL1565649 & 688239 & 4.8862 & 5.5861 & TRN & \\
\hline CHEMBL1429351 & 688239 & 4.5362 & \multicolumn{2}{|c|}{5.5360000000000005} & $\pi$ \\
\hline CHEMBL1431662 & 688239 & 4.5362 & 5.3425 & TST & \\
\hline CHEMBL1506351 & 688239 & 4.6362 & 5.4274 & TST & \\
\hline CHEMBL1364701 & 688239 & 5.1862 & 5.4102 & TRN & \\
\hline CHEMBL1324766 & 688239 & 7.4868 & 5.4632 & TRN & \\
\hline CHEMBL1506334 & 688239 & 4.8362 & 5.4931 & TRN & \\
\hline CHEMBL1568492 & 688239 & 6.6861 & 5.4503 & TRN & \\
\hline CHEMBL3195377 & 688239 & 6.8861 & 5.3939 & TST & \\
\hline CHEMBL1417452 & 688239 & 5.7862 & 5.5712 & TRN & \\
\hline CHEMBL1462057 & 688239 & 6.1362 & 5.5221 & TRN & \\
\hline CHEMBL1378793 & 688239 & 7.7852 & 5.4745 & TRN & \\
\hline CHEMBL1440163 & 688239 & 4.5362 & \multicolumn{2}{|c|}{5.337999999999999} & \\
\hline CHEMBL1380445 & 688239 & 5.1362 & 5.5669 & TRN & \\
\hline CHEMBL1529142 & 688239 & 4.6862 & 5.4356 & TST & \\
\hline CHEMBL1300023 & 688239 & 4.6862 & 5.5047 & TST & \\
\hline CHEMBL1611411 & 688239 & 4.5362 & 5.3937 & TRN & \\
\hline
\end{tabular}

Page 2435 
Supplemental Table S2.txt

\begin{tabular}{|c|c|c|c|c|c|}
\hline CHEMBL1563691 & 688239 & 4.8362 & 5.3171 & TRN & \\
\hline CHEMBL1378947 & 688239 & 4.5362 & 5.5229 & TRN & \\
\hline CHEMBL1387097 & 688239 & 5.3862 & 5.5323 & TST & \\
\hline CHEMBL1413250 & 688239 & 4.6362 & 5.4665 & TST & \\
\hline CHEMBL1556198 & 688239 & 5.1362 & 5.4933 & TST & \\
\hline CHEMBL1597525 & 688239 & 4.8362 & 5.5545 & TRN & \\
\hline CHEMBL1528013 & 688239 & 4.5362 & 5.3724 & TRN & \\
\hline CHEMBL1475682 & 688239 & 5.2362 & 5.4488 & TRN & \\
\hline CHEMBL1585572 & 688239 & 4.5362 & 5.5953 & TRN & \\
\hline CHEMBL1556366 & 688239 & 6.1362 & 5.5974 & TRN & \\
\hline CHEMBL1437496 & 688239 & 5.3362 & 5.4154 & TRN & \\
\hline CHEMBL1313792 & 688239 & 4.8862 & 5.4435 & TST & \\
\hline CHEMBL 2002332 & 688239 & 5.3362 & 5.5019 & TRN & \\
\hline CHEMBL1580342 & 688239 & 6.9363 & 5.4251 & TRN & \\
\hline CHEMBL1585649 & 688239 & 4.5362 & 5.5526 & TRN & \\
\hline CHEMBL1490081 & 688239 & 4.7362 & 5.5413 & TST & \\
\hline CHEMBL1474630 & 688239 & 4.6862 & 5.4087 & TRN & \\
\hline CHEMBL1583432 & 688239 & 5.5362 & 5.4043 & TRN & \\
\hline CHEMBL1546611 & 688239 & 5.7362 & 5.5311 & TRN & \\
\hline CHEMBL3197271 & 688239 & 6.8362 & 5.362999 & 9999999995 & TRN \\
\hline CHEMBL1304891 & 688239 & 4.8362 & 5.4603 & TRN & \\
\hline CHEMBL1491726 & 688239 & 5.2362 & 5.492000 & 000000001 & TRN \\
\hline CHEMBL3190246 & 688239 & 5.1862 & 5.5187 & TRN & \\
\hline CHEMBL1309802 & 688239 & 4.5362 & 5.4328 & TST & \\
\hline CHEMBL1355906 & 688239 & 5.6862 & 5.5708 & TRN & \\
\hline CHEMBL1446469 & 688239 & 5.0862 & 5.5519 & TRN & \\
\hline CHEMBL1581702 & 688239 & 5.8362 & 5.5257 & TRN & \\
\hline CHEMBL1563514 & 688239 & 4.7862 & 5.4539 & TRN & \\
\hline CHEMBL1527071 & 688239 & 4.9862 & 5.4678 & TRN & \\
\hline CHEMBL1374792 & 688239 & 4.7862 & 5.5165 & TRN & \\
\hline CHEMBL1578406 & 688239 & 4.5362 & 5.4906 & TRN & \\
\hline CHEMBL3211977 & 688239 & 5.1862 & 5.4556 & TRN & \\
\hline CHEMBL1363496 & 688239 & 5.8362 & 5.4931 & TRN & \\
\hline CHEMBL1278181 & 688239 & 6.2862 & 5.4667 & TST & \\
\hline CHEMBL1520038 & 688239 & 7.2865 & 5.341 & TRN & \\
\hline CHEMBL1383758 & 688239 & 4.8362 & 5.3866 & TRN & \\
\hline CHEMBL1339126 & 688239 & 6.8861 & 5.6181 & TRN & \\
\hline CHEMBL1483021 & 688239 & 4.7862 & 5.4289 & TST & \\
\hline CHEMBL1307392 & 688239 & 6.1862 & 5.6616 & TRN & \\
\hline CHEMBL1556615 & 688239 & 4.5862 & 5.5312 & TRN & \\
\hline CHEMBL1376667 & 688239 & 6.4362 & 5.6485 & TRN & \\
\hline CHEMBL1375234 & 688239 & 8.2366 & 5.4235 & TRN & \\
\hline CHEMBL1580872 & 688239 & 5.5862 & 5.6578 & TRN & \\
\hline CHEMBL1524343 & 688239 & 5.9862 & 5.617999 & 999999999 & TST \\
\hline CHEMBL1509529 & 688239 & 6.8362 & 5.4539 & TRN & \\
\hline CHEMBL1578712 & 688239 & 4.5362 & 5.4948 & TRN & \\
\hline CHEMBL1344672 & 688239 & 8.3372 & 5.5674 & TRN & \\
\hline CHEMBL1386692 & 688239 & 5.7862 & 5.7831 & TRN & \\
\hline
\end{tabular}




\begin{tabular}{|c|c|c|c|c|c|c|}
\hline \multicolumn{7}{|c|}{ Supplemental Table S2.txt } \\
\hline CHEMBL1445805 & 688239 & 5.3362 & 5.585 & TRN & & \\
\hline CHEMBL1565121 & 688239 & 4.7862 & 5.3934 & TRN & & \\
\hline CHEMBL1330062 & 688239 & 4.6862 & 5.4946 & TST & & \\
\hline CHEMBL1341205 & 688239 & 6.3863 & 5.6774 & TST & & \\
\hline CHEMBL1605514 & 688239 & 6.1362 & 5.5601 & TST & & \\
\hline CHEMBL1362024 & 688239 & 4.6862 & 5.4054 & TST & & \\
\hline CHEMBL1610749 & 688239 & 6.7862 & 5.4792 & TRN & & \\
\hline CHEMBL1402160 & 688239 & 8.28399 & 99999999 & 99 & 5.5245 & TRN \\
\hline CHEMBL1098175 & 688239 & 4.5362 & 5.4571 & TRN & & \\
\hline CHEMBL1447549 & 688239 & 7.1361 & 5.6573 & TRN & & \\
\hline CHEMBL1531712 & 688239 & 4.9362 & 5.477 & TRN & & \\
\hline CHEMBL1441123 & 688239 & 6.0862 & 5.484 & TST & & \\
\hline CHEMBL1329910 & 688239 & 5.5862 & 5.4145 & TST & & \\
\hline CHEMBL1314404 & 688239 & 6.5363 & 5.48 & TRN & & \\
\hline CHEMBL1574981 & 688239 & 4.9362 & 5.5309 & TST & & \\
\hline CHEMBL1393212 & 688239 & 4.5362 & 5.3769 & TRN & & \\
\hline CHEMBL1444366 & 688239 & 5.0362 & 5.4649 & TRN & & \\
\hline CHEMBL1327217 & 688239 & 4.5362 & 5.5782 & TRN & & \\
\hline CHEMBL1498522 & 688239 & 5.1862 & 5.3913 & TRN & & \\
\hline CHEMBL1331856 & 688239 & 4.7362 & 5.5431 & TRN & & \\
\hline CHEMBL1393307 & 688239 & 5.3862 & 5.6243 & TRN & & \\
\hline CHEMBL1539886 & 688239 & 6.0862 & 5.5729 & TRN & & \\
\hline CHEMBL1387808 & 688239 & 5.1862 & 5.4843 & TRN & & \\
\hline CHEMBL1521007 & 688239 & 5.7362 & 5.4735 & TRN & & \\
\hline CHEMBL1433050 & 688239 & 4.5362 & 5.4336 & TRN & & \\
\hline CHEMBL1442276 & 688239 & 5.1362 & 5.4995 & TRN & & \\
\hline CHEMBL1507680 & 688239 & 4.5362 & 5.5205 & TRN & & \\
\hline CHEMBL1376001 & 688239 & 4.6862 & 5.4416 & TRN & & \\
\hline CHEMBL1471156 & 688239 & 5.7362 & 5.6031 & TRN & & \\
\hline CHEMBL1542251 & 688239 & 4.5362 & 5.4185 & TRN & & \\
\hline CHEMBL1347717 & 688239 & 4.5362 & 5.5224 & TRN & & \\
\hline CHEMBL1330593 & 688239 & 8.28399 & 99999999 & 99 & 5.5271 & TRN \\
\hline CHEMBL1598615 & 688239 & 4.8862 & 5.5138 & TRN & & \\
\hline CHEMBL1599860 & 688239 & 7.1864 & 5.46 & TRN & & \\
\hline CHEMBL1439237 & 688239 & 6.0862 & 5.50799 & 9999999999 & & TST \\
\hline CHEMBL1349260 & 688239 & 4.4862 & 5.46200 & 0000000001 & & TST \\
\hline CHEMBL1583366 & 688239 & 5.7362 & 5.3826 & TRN & & \\
\hline CHEMBL1501595 & 688239 & 6.1862 & 5.6236 & TRN & & \\
\hline CHEMBL1484778 & 688239 & 5.2862 & 5.5823 & TRN & & \\
\hline CHEMBL1374252 & 688239 & 4.5362 & 5.4481 & TRN & & \\
\hline CHEMBL1425034 & 688239 & 6.5363 & 5.5055 & TRN & & \\
\hline CHEMBL1601500 & 688239 & 5.2362 & 5.5265 & TRN & & \\
\hline CHEMBL1495129 & 688239 & 4.7862 & 5.5055 & TRN & & \\
\hline CHEMBL3189754 & 688239 & 4.6362 & 5.4365 & TST & & \\
\hline CHEMBL1478073 & 688239 & 4.5362 & 5.4885 & TRN & & \\
\hline CHEMBL1593684 & 688239 & 4.8362 & 5.4894 & TRN & & \\
\hline CHEMBL1454473 & 688239 & 5.6362 & 5.4772 & TRN & & \\
\hline CHEMBL 2373674 & 688239 & 6.1362 & 5.4805 & TRN & & \\
\hline
\end{tabular}


Supplemental Table S2.txt

\begin{tabular}{|c|c|c|c|c|c|c|}
\hline CHEMBL1469181 & 688239 & 6.9863 & 5.4298 & TRN & & \\
\hline CHEMBL1327917 & 688239 & 6.2862 & 5.5057 & TST & & \\
\hline CHEMBL1587272 & 688239 & 4.5362 & 5.3533 & TRN & & \\
\hline CHEMBL1323620 & 688239 & 4.5362 & 5.6013 & TRN & & \\
\hline CHEMBL1583202 & 688239 & 5.6862 & 5.7467 & TST & & \\
\hline CHEMBL1611581 & 688239 & 5.7862 & 5.5584 & TRN & & \\
\hline CHEMBL1515291 & 688239 & 6.5862 & 5.6904 & TRN & & \\
\hline CHEMBL3196543 & 688239 & 5.4862 & 5.786006 & 000000000 & 005 & II \\
\hline CHEMBL3195730 & 688239 & 4.5362 & 5.638 & TRN & & \\
\hline CHEMBL1416047 & 688239 & 4.9862 & 5.3965 & TRN & & \\
\hline CHEMBL1501648 & 688239 & 4.7362 & 5.615 & TRN & & \\
\hline CHEMBL1474130 & 688239 & 6.8362 & 5.3555 & TRN & & \\
\hline CHEMBL1389315 & 688239 & 5.2362 & 5.3871 & TST & & \\
\hline CHEMBL1478361 & 688239 & 6.2362 & 5.6352 & TRN & & \\
\hline CHEMBL1502307 & 688239 & 5.1862 & 5.5746 & TST & & \\
\hline CHEMBL1540150 & 688239 & 4.6362 & 5.4224 & TRN & & \\
\hline CHEMBL1319211 & 688239 & 4.5362 & 5.537999 & 999999999 & & \\
\hline CHEMBL1405777 & 688239 & 5.9862 & 5.5246 & TRN & & \\
\hline CHEMBL1371967 & 688239 & 4.6862 & 5.4718 & TRN & & \\
\hline CHEMBL1569734 & 688239 & 5.5362 & 5.5625 & TRN & & \\
\hline CHEMBL1454574 & 688239 & 5.6362 & 5.4479 & TRN & & \\
\hline CHEMBL1484848 & 688239 & 6.3362 & 5.4614 & TRN & & \\
\hline CHEMBL1424288 & 688239 & 4.5862 & 5.4937 & TRN & & \\
\hline CHEMBL1565221 & 688239 & 5.3362 & 5.4319 & TST & & \\
\hline CHEMBL1381450 & 688239 & 4.7362 & 5.3374 & TST & & \\
\hline CHEMBL1440660 & 688239 & 7.1361 & 5.6318 & TST & & \\
\hline CHEMBL1306016 & 688239 & 4.7862 & 5.5005 & TRN & & \\
\hline CHEMBL1601005 & 688239 & 6.1362 & 5.4548 & TRN & & \\
\hline CHEMBL1348230 & 688239 & 4.5362 & 5.5687 & TRN & & \\
\hline CHEMBL3197307 & 688239 & 5.1362 & 5.3943 & TST & & \\
\hline CHEMBL1351547 & 688239 & 5.2362 & 5.4268 & TRN & & \\
\hline CHEMBL1578665 & 688239 & 4.6862 & 5.494 & TRN & & \\
\hline CHEMBL1393248 & 688239 & 4.7862 & 5.5924 & TRN & & \\
\hline CHEMBL1373402 & 688239 & 5.8362 & 5.45 & TRN & & \\
\hline CHEMBL1494046 & 688239 & 4.4862 & 5.5357 & TRN & & \\
\hline CHEMBL1509790 & 688239 & 4.5862 & 5.4463 & TRN & & \\
\hline CHEMBL1459724 & 688239 & 5.5362 & 5.4927 & TST & & \\
\hline CHEMBL1380326 & 688239 & 7.0362 & 5.3565 & TRN & & \\
\hline CHEMBL3190285 & 688239 & 4.5362 & 5.4259 & TRN & & \\
\hline CHEMBL1391258 & 688239 & \multicolumn{3}{|c|}{8.283999999999999} & 5.5488 & Tiv \\
\hline CHEMBL1339685 & 688239 & \multicolumn{3}{|c|}{8.283999999999999} & 5.5079 & \\
\hline CHEMBL1541707 & 688239 & 5.6862 & 5.4147 & TRN & & \\
\hline CHEMBL3194885 & 688239 & 5.0862 & 5.4334 & TST & & \\
\hline CHEMBL1347294 & 688239 & 4.5362 & 5.3721 & TRN & & \\
\hline CHEMBL1511367 & 688239 & 5.7862 & 5.4532 & TRN & & \\
\hline CHEMBL1322040 & 688239 & 8.3872 & 5.3475 & TRN & & \\
\hline CHEMBL1459993 & 688239 & 5.4862 & 5.5668 & TRN & & \\
\hline CHEMBL1548970 & 688239 & 5.5862 & 5.2728 & TRN & & \\
\hline
\end{tabular}


Supplemental Table S2.txt

\begin{tabular}{|c|c|c|c|c|c|}
\hline CHEMBL1465749 & 688239 & 5.7362 & 5.4963 & TST & \\
\hline CHEMBL1564894 & 688239 & 5.2362 & \multicolumn{2}{|c|}{5.486000000000001} & TRN \\
\hline CHEMBL1427320 & 688239 & 6.0362 & 5.5858 & TRN & \\
\hline CHEMBL1597715 & 688239 & 4.6862 & 5.6322 & TRN & \\
\hline CHEMBL1510076 & 688239 & 4.8362 & 5.6369 & TRN & \\
\hline CHEMBL1573746 & 688239 & 6.7862 & 5.3847 & TRN & \\
\hline CHEMBL1519600 & 688239 & 4.5362 & 5.567 & TRN & \\
\hline CHEMBL1339628 & 688239 & 6.1362 & 5.4996 & TST & \\
\hline CHEMBL3213995 & 688239 & 5.4362 & 5.4579 & TRN & \\
\hline CHEMBL1461890 & 688239 & 5.6862 & 5.5598 & TRN & \\
\hline CHEMBL1566005 & 688239 & 4.5362 & 5.6023 & TRN & \\
\hline CHEMBL1369853 & 688239 & 4.6862 & 5.59 & TRN & \\
\hline CHEMBL1485513 & 688239 & 6.1362 & 5.3602 & TST & \\
\hline CHEMBL1462824 & 688239 & 4.5362 & 5.5985 & TRN & \\
\hline CHEMBL1548912 & 688239 & 4.5362 & 5.4845 & TRN & \\
\hline CHEMBL3193906 & 688239 & 4.5362 & 5.3825 & TRN & \\
\hline CHEMBL1548969 & 688239 & 5.5362 & 5.5954 & TRN & \\
\hline CHEMBL1367561 & 688239 & 6.9363 & 5.4537 & TST & \\
\hline CHEMBL1411872 & 688239 & 6.8362 & 5.4546 & TRN & \\
\hline CHEMBL1427337 & 688239 & 4.45 & 5.4487 & TRN & \\
\hline CHEMBL1337225 & 688239 & 5.6362 & 5.4638 & TRN & \\
\hline CHEMBL1477500 & 688239 & 4.5362 & 5.5842 & TRN & \\
\hline CHEMBL1335963 & 688239 & 5.1862 & 5.5367 & TRN & \\
\hline CHEMBL1311985 & 688239 & 5.2362 & 5.45200 & 0000000001 & TRN \\
\hline CHEMBL1482191 & 688239 & 5.0862 & 5.2967 & TRN & \\
\hline CHEMBL3195187 & 688239 & 4.5362 & 5.6064 & TRN & \\
\hline CHEMBL1352824 & 688239 & 4.5362 & 5.4662 & TRN & \\
\hline CHEMBL1427387 & 688239 & 5.5362 & 5.5359 & TST & \\
\hline CHEMBL1526895 & 688239 & 5.7862 & 5.4897 & TRN & \\
\hline CHEMBL1334081 & 688239 & 4.5362 & 5.4498 & TST & \\
\hline CHEMBL1454326 & 688239 & 4.7362 & 5.3336 & TRN & \\
\hline CHEMBL1547822 & 688239 & 5.3862 & 5.4526 & TRN & \\
\hline CHEMBL1524389 & 688239 & 5.9362 & 5.5467 & TST & \\
\hline CHEMBL1464876 & 688239 & 4.5362 & 5.4568 & TST & \\
\hline CHEMBL1415534 & 688239 & 5.8362 & 5.5905 & TRN & \\
\hline CHEMBL1352808 & 688239 & 6.3362 & 5.4259 & TRN & \\
\hline CHEMBL1373601 & 688239 & 5.3862 & 5.6388 & TST & \\
\hline CHEMBL579621 & 688239 & 5.1862 & 5.3359 & TST & \\
\hline CHEMBL1571857 & 688239 & 4.5362 & 5.3557 & TRN & \\
\hline CHEMBL1568827 & 688239 & 5.2362 & 5.3288 & TRN & \\
\hline CHEMBL3194939 & 688239 & 4.5362 & 5.4072 & TRN & \\
\hline CHEMBL1339119 & 688239 & 5.1862 & 5.4475 & TST & \\
\hline CHEMBL3189829 & 688239 & 4.5362 & 5.3733 & TRN & \\
\hline CHEMBL3198676 & 688239 & 6.0862 & 5.3868 & TRN & \\
\hline CHEMBL1556532 & 688239 & 5.4862 & 5.6145 & TRN & \\
\hline CHEMBL1592425 & 688239 & 5.6362 & 5.5265 & TRN & \\
\hline CHEMBL1463942 & 688239 & 8.3372 & 5.4896 & TST & \\
\hline CHEMBL433547 & 688239 & 4.9862 & 5.6102 & TST & \\
\hline
\end{tabular}


Supplemental Table S2.txt

\begin{tabular}{|c|c|c|c|c|}
\hline CHEMBL1593958 & 688239 & 4.5362 & 5.35 & TRN \\
\hline CHEMBL1372313 & 688239 & 5.0362 & 5.4712 & TST \\
\hline CHEMBL1481752 & 688239 & 4.5362 & 5.4843 & TRN \\
\hline CHEMBL1510895 & 688239 & 4.5362 & 5.4727 & TRN \\
\hline CHEMBL1589623 & 688239 & 5.2862 & 5.4641 & TRN \\
\hline CHEMBL1362968 & 688239 & 4.7862 & 5.3255 & TRN \\
\hline CHEMBL1590614 & 688239 & 4.9862 & 5.6116 & TRN \\
\hline CHEMBL 3212882 & 688239 & 5.5862 & 5.4915 & TRN \\
\hline CHEMBL1453232 & 688239 & 4.8362 & 5.5413 & TRN \\
\hline CHEMBL1586654 & 688239 & 6.1862 & 5.3634 & TRN \\
\hline CHEMBL1588069 & 688239 & 8.1871 & 5.3783 & TRN \\
\hline CHEMBL3192555 & 688239 & 5.5862 & 5.2914 & TRN \\
\hline CHEMBL1535405 & 688239 & 7.2366 & 5.5323 & TRN \\
\hline CHEMBL1386776 & 688239 & 8.3372 & 5.5689 & TRN \\
\hline CHEMBL1587557 & 688239 & 4.5362 & 5.6066 & TRN \\
\hline CHEMBL1358048 & 688239 & 5.4862 & 5.5079 & TRN \\
\hline CHEMBL1300373 & 688239 & 5.9862 & 5.3778 & TRN \\
\hline CHEMBL1350442 & 688239 & 6.3863 & 5.4985 & TRN \\
\hline CHEMBL1344995 & 688239 & 5.7362 & 5.5965 & TST \\
\hline CHEMBL1589820 & 688239 & 5.3362 & 5.4375 & TRN \\
\hline CHEMBL1455376 & 688239 & 4.5362 & 5.5064 & TRN \\
\hline CHEMBL1449223 & 688239 & 4.4862 & 5.4833 & TRN \\
\hline CHEMBL1388339 & 688239 & 4.8362 & 5.3854 & TRN \\
\hline CHEMBL1344332 & 688239 & 6.9363 & 5.46 & TRN \\
\hline CHEMBL1993886 & 688239 & 6.1362 & 5.4719 & TST \\
\hline CHEMBL1542202 & 688239 & 4.7362 & 5.5702 & TRN \\
\hline CHEMBL1589109 & 688239 & 5.0862 & 5.4585 & TRN \\
\hline CHEMBL1312965 & 688239 & 6.7361 & 5.5873 & TRN \\
\hline CHEMBL1464721 & 688239 & 4.5362 & 5.2272 & TRN \\
\hline CHEMBL1401701 & 688239 & 5.8862 & 5.5332 & TRN \\
\hline CHEMBL1383368 & 688239 & 6.1362 & 5.457999 & 9999999999 \\
\hline CHEMBL1526740 & 688239 & 7.0362 & 5.4392 & TRN \\
\hline CHEMBL1418026 & 688239 & 4.5362 & 5.6487 & TRN \\
\hline CHEMBL1497684 & 688239 & 5.2362 & 5.7685 & TRN \\
\hline CHEMBL1506112 & 688239 & 4.6862 & 5.3989 & TST \\
\hline CHEMBL1328999 & 688239 & 4.7862 & 5.4071 & TRN \\
\hline CHEMBL1484819 & 688239 & 4.65 & 5.4892 & TRN \\
\hline CHEMBL1573719 & 688239 & 6.2862 & 5.5804 & TST \\
\hline CHEMBL1321834 & 688239 & 6.1362 & 5.5677 & TRN \\
\hline CHEMBL1442617 & 688239 & 5.3862 & 5.6124 & TRN \\
\hline CHEMBL1346302 & 688239 & 4.5362 & 5.4138 & TRN \\
\hline CHEMBL1513259 & 688239 & 6.3863 & 5.3715 & TRN \\
\hline CHEMBL1380612 & 688239 & 4.6362 & 5.4444 & TRN \\
\hline CHEMBL3207579 & 688239 & 5.4362 & 5.4853 & TRN \\
\hline CHEMBL1423128 & 688239 & 4.5362 & 5.3788 & TRN \\
\hline CHEMBL1424353 & 688239 & 4.7362 & 5.5171 & TRN \\
\hline CHEMBL1613550 & 688239 & 5.4362 & 5.3545 & TST \\
\hline CHEMBL1422664 & 688239 & 5.0362 & 5.5174 & TRN \\
\hline
\end{tabular}


Supplemental Table S2.txt

\begin{tabular}{|c|c|c|c|c|}
\hline CHEMBL1590021 & 688239 & 4.7362 & 5.4159 & TRN \\
\hline CHEMBL1484586 & 688239 & 5.0862 & 5.619 & TRN \\
\hline CHEMBL1502043 & 688239 & 4.5362 & 5.5292 & TST \\
\hline CHEMBL1563822 & 688239 & 5.1862 & 5.6475 & TST \\
\hline CHEMBL1429551 & 688239 & 4.9362 & 5.5423 & TRN \\
\hline CHEMBL1420661 & 688239 & 5.1862 & 5.4214 & TRN \\
\hline CHEMBL 3208010 & 688239 & 4.8362 & 5.3522 & TRN \\
\hline CHEMBL1378351 & 688239 & 6.1862 & 5.6271 & TRN \\
\hline CHEMBL1549259 & 688239 & 6.1862 & 5.5483 & TRN \\
\hline CHEMBL1410271 & 688239 & 4.8362 & 5.5282 & TST \\
\hline CHEMBL1518732 & 688239 & 4.4862 & 5.5489 & TRN \\
\hline CHEMBL1327611 & 688239 & 4.5362 & 5.4965 & TST \\
\hline CHEMBL1511611 & 688239 & 8.3372 & 5.6276 & TRN \\
\hline CHEMBL1310703 & 688239 & 4.6362 & 5.5019 & TRN \\
\hline CHEMBL1322345 & 688239 & 5.6362 & 5.4679 & TRN \\
\hline CHEMBL1526838 & 688239 & 6.9863 & 5.4994 & TRN \\
\hline CHEMBL1577637 & 688239 & 6.4862 & 5.4502 & TST \\
\hline CHEMBL1358989 & 688239 & 5.1862 & 5.6422 & TST \\
\hline CHEMBL1508457 & 688239 & 4.5362 & \multicolumn{2}{|c|}{5.452999999999999} \\
\hline CHEMBL1444051 & 688239 & 7.0362 & 5.5649 & TST \\
\hline CHEMBL1550376 & 688239 & 4.5362 & 5.4748 & TRN \\
\hline CHEMBL1494285 & 688239 & 4.7862 & 5.3824 & TST \\
\hline CHEMBL1546624 & 688239 & 5.7862 & 5.3778 & TRN \\
\hline CHEMBL1446017 & 688239 & 5.2862 & 5.3756 & TRN \\
\hline CHEMBL1607105 & 688239 & 6.2862 & \multicolumn{2}{|c|}{5.457999999999999} \\
\hline CHEMBL574 & 688239 & 5.9362 & 5.5309 & TRN \\
\hline CHEMBL1395019 & 688239 & 5.2362 & 5.4777 & TST \\
\hline CHEMBL1604756 & 688239 & 6.1362 & 5.4449 & TRN \\
\hline CHEMBL1382191 & 688239 & 4.8362 & 5.3762 & TST \\
\hline CHEMBL 3195083 & 688239 & 5.1862 & 5.4695 & TST \\
\hline CHEMBL1373751 & 688239 & 4.8862 & 5.4334 & TRN \\
\hline CHEMBL1612942 & 688239 & 6.2862 & 5.5 & TRN \\
\hline CHEMBL1328432 & 688239 & 5.5362 & 5.7537 & TRN \\
\hline CHEMBL1559300 & 688239 & 4.5362 & 5.6247 & TRN \\
\hline CHEMBL1469630 & 688239 & 4.6362 & 5.5573 & TST \\
\hline CHEMBL1462614 & 688239 & 5.5362 & 5.4896 & TRN \\
\hline CHEMBL1550415 & 688239 & 5.1862 & 5.4666 & TRN \\
\hline CHEMBL1597970 & 688239 & 5.7362 & 5.6047 & TST \\
\hline CHEMBL1546113 & 688239 & 6.5363 & 5.4837 & TRN \\
\hline CHEMBL1423045 & 688239 & 5.1862 & 5.5467 & TRN \\
\hline CHEMBL1405694 & 688239 & 5.5862 & 5.556 & TRN \\
\hline CHEMBL1606589 & 688239 & 6.9863 & 5.4855 & TRN \\
\hline CHEMBL1321165 & 688239 & 4.5362 & 5.6017 & TRN \\
\hline CHEMBL1548842 & 688239 & 7.1361 & 5.5091 & TRN \\
\hline CHEMBL1409062 & 688239 & 5.0862 & 5.4696 & TRN \\
\hline CHEMBL1602040 & 688239 & 5.6362 & 5.47 & TRN \\
\hline CHEMBL1529284 & 688239 & 7.5867 & 5.5176 & TRN \\
\hline CHEMBL1528984 & 688239 & 4.6362 & 5.4801 & TRN \\
\hline
\end{tabular}

Page 2441 
Supplemental Table S2.txt

\begin{tabular}{|c|c|c|c|c|c|}
\hline CHEMBL1491786 & 688239 & 4.8362 & 5.3782 & TRN & \\
\hline CHEMBL1523449 & 688239 & 4.7362 & 5.4577 & TST & \\
\hline CHEMBL1544428 & 688239 & 4.7862 & 5.5696 & TRN & \\
\hline CHEMBL1336792 & 688239 & 7.5361 & 5.5263 & TRN & \\
\hline CHEMBL1387875 & 688239 & 7.1361 & 5.3857 & TRN & \\
\hline CHEMBL1578040 & 688239 & 4.5362 & 5.4616 & TRN & \\
\hline CHEMBL1352131 & 688239 & 4.4862 & 5.4604 & TRN & \\
\hline CHEMBL1378932 & 688239 & 5.4362 & 5.6331 & TRN & \\
\hline CHEMBL1591777 & 688239 & 4.5362 & 5.5342 & TST & \\
\hline CHEMBL1320535 & 688239 & 4.7862 & 5.4439 & TST & \\
\hline CHEMBL1481462 & 688239 & 6.3863 & 5.569 & TRN & \\
\hline CHEMBL1374881 & 688239 & 4.5362 & 5.3262 & TRN & \\
\hline CHEMBL1608838 & 688239 & 4.5362 & 5.5265 & TRN & \\
\hline CHEMBL1420241 & 688239 & 4.8862 & 5.5965 & TRN & \\
\hline CHEMBL1491453 & 688239 & 4.6862 & 5.5299 & TRN & \\
\hline CHEMBL1468475 & 688239 & 6.2362 & 5.4632 & TRN & \\
\hline CHEMBL1509156 & 688239 & 6.4862 & 5.487999 & 9999999995 & TST \\
\hline CHEMBL1500602 & 688239 & 5.7862 & 5.5838 & TST & \\
\hline CHEMBL1611018 & 688239 & 5.9362 & 5.3723 & TRN & \\
\hline CHEMBL1344859 & 688239 & 6.8861 & 5.3951 & TRN & \\
\hline CHEMBL594707 & 688239 & 5.6862 & 5.5665 & TST & \\
\hline CHEMBL1374181 & 688239 & 4.6862 & 5.5547 & TRN & \\
\hline CHEMBL1591285 & 688239 & 5.1362 & 5.4443 & TRN & \\
\hline CHEMBL1318211 & 688239 & 4.7362 & 5.5383 & TRN & \\
\hline CHEMBL1491019 & 688239 & 5.3362 & 5.4338 & TST & \\
\hline CHEMBL1305350 & 688239 & 5.2362 & 5.4814 & TRN & \\
\hline CHEMBL1420560 & 688239 & 4.9362 & 5.5601 & TRN & \\
\hline CHEMBL1462390 & 688239 & 4.5362 & 5.4897 & TRN & \\
\hline CHEMBL1215474 & 688239 & 8.283999 & 999999999 & 5.4655 & ובו \\
\hline CHEMBL1373822 & 688239 & 5.6862 & 5.4217 & TRN & \\
\hline CHEMBL1322429 & 688239 & 4.7862 & 5.45 & TST & \\
\hline CHEMBL1537143 & 688239 & 6.7862 & 5.4583 & TRN & \\
\hline CHEMBL1451966 & 688239 & 6.0362 & 5.5639 & TST & \\
\hline CHEMBL1299470 & 688239 & 4.8362 & 5.3036 & TRN & \\
\hline CHEMBL1395964 & 688239 & 4.8362 & 5.4113 & TRN & \\
\hline CHEMBL1506141 & 688239 & 5.4862 & 5.382000 & 000000001 & TST \\
\hline CHEMBL1315326 & 688239 & 4.6862 & 5.5098 & TRN & \\
\hline CHEMBL1344977 & 688239 & 6.9363 & 5.4018 & TST & \\
\hline CHEMBL1547251 & 688239 & 4.6862 & 5.519 & TRN & \\
\hline CHEMBL1332994 & 688239 & 4.4862 & 5.539 & TRN & \\
\hline CHEMBL1314819 & 688239 & 6.0 & 5.4701 & TST & \\
\hline CHEMBL1519820 & 688239 & 6.1862 & 5.2423 & TST & \\
\hline CHEMBL1310363 & 688239 & 4.5362 & 5.5394 & TRN & \\
\hline CHEMBL1453203 & 688239 & 6.2362 & 5.5483 & TRN & \\
\hline CHEMBL586024 & 688239 & 4.5362 & 5.4439 & TST & \\
\hline CHEMBL1569819 & 688239 & 5.2862 & 5.5082 & TRN & \\
\hline CHEMBL1515571 & 688239 & 5.1862 & 5.5236 & TST & \\
\hline CHEMBL1475466 & 688239 & 5.1862 & 5.402 & TRN & \\
\hline
\end{tabular}


Supplemental Table S2.txt

\begin{tabular}{|c|c|c|c|c|}
\hline CHEMBL1471029 & 688239 & 6.8362 & 5.5033 & TRN \\
\hline CHEMBL1566825 & 688239 & 6.9363 & 5.4461 & TRN \\
\hline CHEMBL1601058 & 688239 & 5.7862 & 5.3969 & TRN \\
\hline CHEMBL1419955 & 688239 & 5.3862 & 5.4538 & TST \\
\hline CHEMBL1401661 & 688239 & 4.6362 & 5.3424 & TRN \\
\hline CHEMBL1472924 & 688239 & 4.5362 & 5.5715 & TST \\
\hline CHEMBL1383061 & 688239 & 5.4362 & 5.494 & TRN \\
\hline CHEMBL1544979 & 688239 & 6.6861 & 5.4022 & TRN \\
\hline CHEMBL1437295 & 688239 & 4.5362 & 5.4195 & TRN \\
\hline CHEMBL1975216 & 688239 & 8.3372 & 5.5443 & TRN \\
\hline CHEMBL1312394 & 688239 & 5.4862 & 5.5278 & TRN \\
\hline CHEMBL1484987 & 688239 & 4.5362 & 5.4746 & TRN \\
\hline CHEMBL1487479 & 688239 & 6.0362 & 5.4126 & TRN \\
\hline CHEMBL1469374 & 688239 & 5.4362 & 5.5897 & TRN \\
\hline CHEMBL1512060 & 688239 & 5.0862 & 5.528 & TRN \\
\hline CHEMBL1586062 & 688239 & 4.5362 & 5.4102 & TRN \\
\hline CHEMBL1347089 & 688239 & 4.5362 & 5.4638 & TRN \\
\hline CHEMBL1553611 & 688239 & 8.3372 & 5.4443 & TRN \\
\hline CHEMBL1403490 & 688239 & 4.8862 & 5.45 & TRN \\
\hline CHEMBL1499888 & 688239 & 4.5362 & 5.5862 & TRN \\
\hline CHEMBL1334298 & 688239 & 4.5362 & 5.6592 & TST \\
\hline CHEMBL3210409 & 688239 & 4.6862 & 5.4771 & TRN \\
\hline CHEMBL1579914 & 688239 & 4.5862 & 5.4986 & TRN \\
\hline CHEMBL1392297 & 688239 & 4.6862 & 5.2911 & TRN \\
\hline CHEMBL1543423 & 688239 & 6.6861 & 5.4837 & TRN \\
\hline CHEMBL1563063 & 688239 & 6.7361 & 5.4599 & TST \\
\hline CHEMBL1346904 & 688239 & 5.0862 & 5.2752 & TRN \\
\hline CHEMBL1363359 & 688239 & 5.1862 & 5.7217 & TRN \\
\hline CHEMBL1500504 & 688239 & 4.5362 & 5.4117 & TRN \\
\hline CHEMBL1561936 & 688239 & 6.0862 & 5.4067 & TRN \\
\hline CHEMBL1422349 & 688239 & 5.5362 & 5.5622 & TST \\
\hline CHEMBL 3210526 & 688239 & 8.3372 & 5.3484 & TST \\
\hline CHEMBL1445045 & 688239 & 8.3372 & 5.5206 & TRN \\
\hline CHEMBL1352400 & 688239 & 4.5362 & 5.4076 & TRN \\
\hline CHEMBL1505729 & 688239 & 4.5862 & 5.4817 & TRN \\
\hline CHEMBL1387199 & 688239 & 6.0362 & 5.4374 & TRN \\
\hline CHEMBL1434921 & 688239 & 6.9363 & 5.5031 & TST \\
\hline CHEMBL1606908 & 688239 & 5.8862 & 5.6083 & TST \\
\hline CHEMBL1461606 & 688239 & 4.5362 & 5.5803 & TRN \\
\hline CHEMBL1991177 & 688239 & 6.1862 & 5.455 & TRN \\
\hline CHEMBL1338548 & 688239 & 5.1862 & 5.4408 & TST \\
\hline CHEMBL1342125 & 688239 & 5.6362 & $5.45200 e$ & 0000000001 \\
\hline CHEMBL1396848 & 688239 & 4.8362 & 5.5957 & TRN \\
\hline CHEMBL1403888 & 688239 & 4.5862 & 5.3022 & TST \\
\hline CHEMBL138007 & 688239 & 4.8862 & 5.4234 & TRN \\
\hline CHEMBL1501160 & 688239 & 5.5362 & 5.5603 & TST \\
\hline CHEMBL1389328 & 688239 & 5.2362 & 5.4893 & TRN \\
\hline CHEMBL1596351 & 688239 & 5.2862 & 5.4096 & TRN \\
\hline
\end{tabular}


Supplemental Table S2.txt

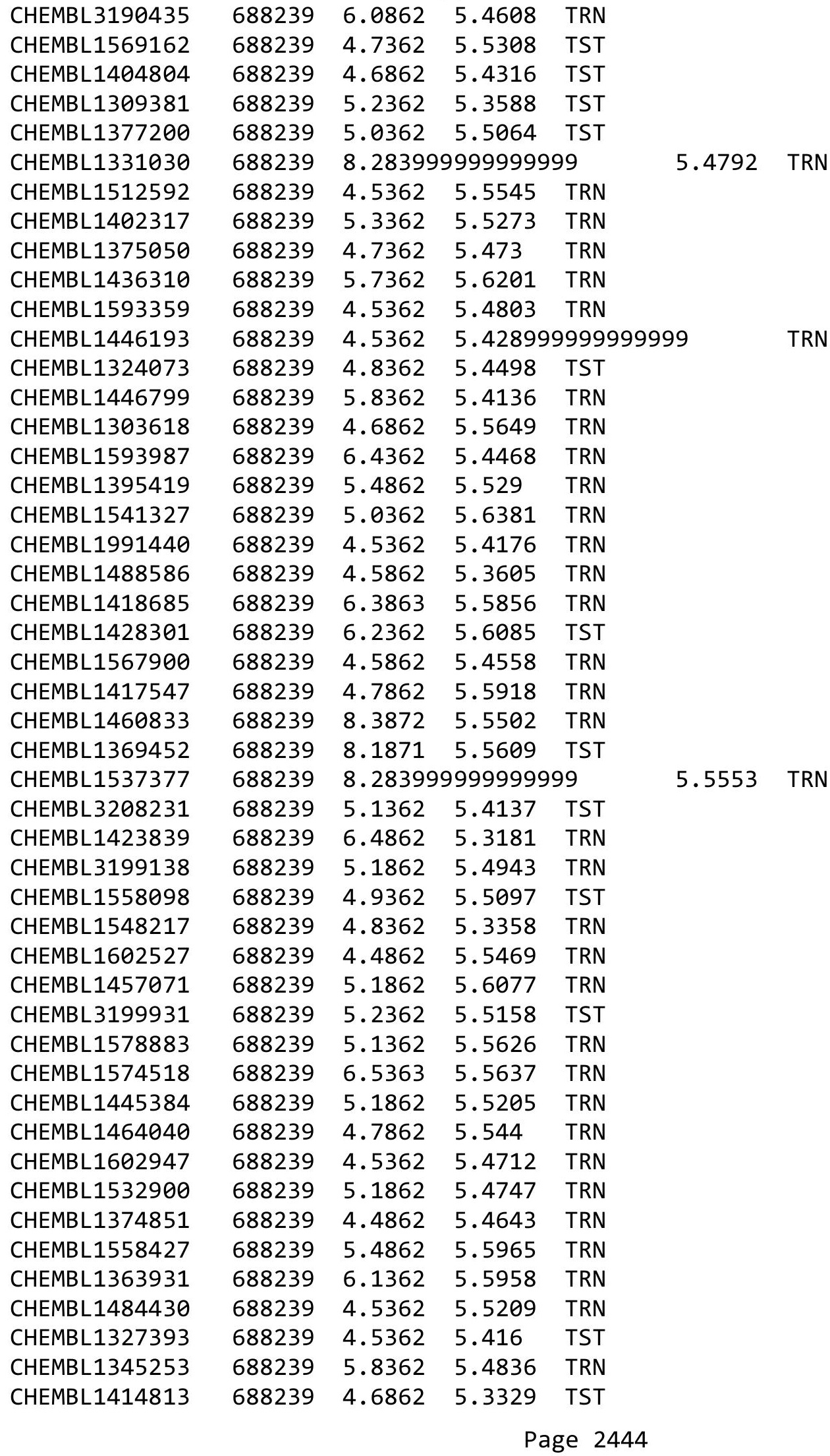


Supplemental Table S2.txt

\begin{tabular}{|c|c|c|c|c|}
\hline 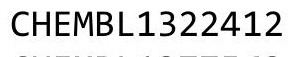 & & 52 & & \\
\hline HEMBL1377563 & 88239 & 8862 & 6342 & \\
\hline HEMBL1573218 & 88239 & 1862 & 6314 & \\
\hline HEMBL3198699 & 38239 & 1362 & 3307 & \\
\hline 8330 & 38239 & 362 & & \\
\hline IEMBL1191237 & 88239 & 3372 & 4322 & \\
\hline HEMBL1348468 & 88239 & .5362 & . 3179 & \\
\hline HEMBL1426317 & 88239 & .1362 & 4904 & \\
\hline AEMBL1580874 & 88239 & 862 & 5218 & \\
\hline IEMBL1480454 & 88239 & & & \\
\hline AEMBL1425349 & 88239 & 1862 & .4898 & \\
\hline AEMBL1380116 & 88239 & .1862 & .6015 & \\
\hline HEMBL1469315 & 88239 & 62 & .5398 & \\
\hline IEMBL15 & 239 & 62 & 6074 & \\
\hline 655 & & & & \\
\hline JEMBL14 & 88239 & 362 & 5.3692 & \\
\hline AEMBL13 & 39 & 62 & & \\
\hline HEMBL1488548 & 39 & 62 & .4748 & \\
\hline L152 & 39 & 62 & 79 & \\
\hline 73 & 39 & & & \\
\hline AFMBI 14 & 39 & 62 & & \\
\hline IEMBL14 & 39 & & & ST \\
\hline IEMBLIS & 39 & 62 & 11 & \\
\hline 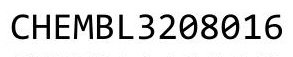 & & & & \\
\hline 0 & 39 & & & \\
\hline 21 & & & & \\
\hline AEMBL15e & & & & RN \\
\hline IEMBL14 & 39 & 62 & 025 & \\
\hline IEM & 39 & & 44 & \\
\hline 48 & 39 & & & RN \\
\hline & & & & \\
\hline IEMBL14 & & & & RN \\
\hline IEMBL1: & & & & \\
\hline IEMBL1 & 39 & & & \\
\hline 33 & 39 & & & ST \\
\hline & & & & ST \\
\hline AEMBL1569064 & 39 & & & $\mathrm{RN}$ \\
\hline IEMBL15 & & & & RN \\
\hline IFMR 121 & 39 & & 326 & \\
\hline & & & 59 & ST \\
\hline HEMBL1307599 & 88239 & & 5.5094 & RN \\
\hline HEMBL134 & 88239 & 62 & & RN \\
\hline 50 & & & & \\
\hline HEMBL1525077 & & & & \\
\hline HEMBL1365436 & 88239 & & 5.6309 & ST \\
\hline EMBL1407686 & 88239 & 1862 & 5.5229 & RN \\
\hline HEMBL1592484 & 88239 & 862 & 5.6212 & ST \\
\hline -HEMPI 121972 & 588239 & & & \\
\hline
\end{tabular}


Supplemental Table S2.txt

\begin{tabular}{|c|c|c|c|c|}
\hline CHEMBL1320696 & 688239 & 5.1862 & 5.6677 & TRN \\
\hline CHEMBL1394893 & 688239 & 4.5362 & 5.3845 & TRN \\
\hline CHEMBL1325896 & 688239 & 6.8861 & 5.6134 & TRN \\
\hline CHEMBL1353051 & 688239 & 4.5862 & 5.5423 & TST \\
\hline CHEMBL1520063 & 688239 & 4.6362 & 5.5211 & TST \\
\hline CHEMBL1508147 & 688239 & 4.8862 & 5.6025 & TRN \\
\hline CHEMBL1441428 & 688239 & 4.5362 & 5.3039 & TRN \\
\hline CHEMBL1524201 & 688239 & 5.3862 & 5.5099 & TRN \\
\hline CHEMBL1524669 & 688239 & 4.5362 & 5.633999 & 99999999995 \\
\hline CHEMBL1313047 & 688239 & 4.5362 & 5.4337 & TRN \\
\hline CHEMBL1602522 & 688239 & 4.6862 & 5.53 & TST \\
\hline CHEMBL1592251 & 688239 & 5.0362 & 5.3953 & TRN \\
\hline CHEMBL1445763 & 688239 & 6.1862 & 5.4964 & TRN \\
\hline CHEMBL1471745 & 688239 & 4.5362 & 5.506 & TRN \\
\hline CHEMBL3196181 & 688239 & 4.7362 & 5.2458 & TST \\
\hline CHEMBL1577483 & 688239 & 6.3863 & 5.5793 & TRN \\
\hline CHEMBL1610621 & 688239 & 4.5362 & 5.5499 & TST \\
\hline CHEMBL1365262 & 688239 & 5.1862 & 5.4681 & TRN \\
\hline CHEMBL1345371 & 688239 & 5.4862 & 5.4168 & TRN \\
\hline CHEMBL1302285 & 688239 & 5.1862 & 5.5201 & TRN \\
\hline CHEMBL1531385 & 688239 & 5.1862 & 5.5546 & TST \\
\hline CHEMBL 2373581 & 688239 & 6.0362 & 5.3521 & TRN \\
\hline CHEMBL1549333 & 688239 & 4.9862 & 5.4124 & TRN \\
\hline CHEMBL1572798 & 688239 & 5.1862 & 5.5458 & TRN \\
\hline CHEMBL1521290 & 688239 & 4.6862 & 5.3809 & TRN \\
\hline CHEMBL1319086 & 688239 & 5.9862 & 5.3389 & TST \\
\hline CHEMBL1497486 & 688239 & 4.5362 & 5.4097 & TRN \\
\hline CHEMBL1545746 & 688239 & 5.6362 & 5.5525 & TST \\
\hline CHEMBL1524783 & 688239 & 4.5362 & 5.2849 & TRN \\
\hline CHEMBL1528978 & 688239 & 4.6362 & 5.5431 & TRN \\
\hline CHEMBL1390647 & 688239 & 4.5362 & 5.4026 & TRN \\
\hline CHEMBL1457454 & 688239 & 5.1862 & 5.6741 & TRN \\
\hline CHEMBL1427375 & 688239 & 4.6862 & 5.5263 & TST \\
\hline CHEMBL1403147 & 688239 & 8.28399 & 999999999 & 5.5253 \\
\hline CHEMBL1604496 & 688239 & 5.3862 & 5.2305 & TST \\
\hline CHEMBL1425693 & 688239 & 6.3863 & 5.5784 & TRN \\
\hline CHEMBL1582390 & 688239 & 4.9862 & 5.4793 & TRN \\
\hline CHEMBL3211939 & 688239 & 6.1862 & 5.6074 & TRN \\
\hline CHEMBL1450954 & 688239 & 5.6362 & 5.5568 & TRN \\
\hline CHEMBL1487700 & 688239 & 4.7362 & 5.5024 & TST \\
\hline CHEMBL1412776 & 688239 & 4.7362 & 5.4166 & TRN \\
\hline CHEMBL1330881 & 688239 & 5.1862 & 5.4665 & TST \\
\hline CHEMBL1605755 & 688239 & 5.7362 & 5.6713 & TRN \\
\hline CHEMBL1405048 & 688239 & 4.5362 & 5.4273 & TRN \\
\hline CHEMBL1389353 & 688239 & 8.3872 & 5.5268 & TRN \\
\hline CHEMBL1352457 & 688239 & 4.7862 & 5.5098 & TRN \\
\hline CHEMBL1465055 & 688239 & 4.5362 & 5.5018 & TST \\
\hline CHEMBL1529939 & 688239 & 4.5362 & 5.4419 & TRN \\
\hline
\end{tabular}


Supplemental Table S2.txt

\begin{tabular}{|c|c|c|c|c|}
\hline & & & & \\
\hline HEMBL1538208 & 588239 & 2862 & 5185 & \\
\hline AEMBL13 & 39 & 862 & & \\
\hline & & & & \\
\hline AFMBI 14 & & & & \\
\hline AEMBL1402832 & 88239 & 7362 & 5065 & \\
\hline AEMBL1410190 & 88239 & 361 & 664 & \\
\hline AEMBL3199614 & & & & \\
\hline AEMBL154 & & & & \\
\hline IEMBL1580323 & & & & \\
\hline AEMBL3193430 & 68 & 362 & & \\
\hline AEMBL1344568 & 39 & 362 & & \\
\hline HEMBL1536214 & & & & \\
\hline AEMBL1465211 & & & & \\
\hline AEMBL1581493 & & & & \\
\hline AEMBL1584602 & & & & \\
\hline AEMBL1301430 & & & & \\
\hline HEMBL1402065 & & & & \\
\hline HEMBL1567 & & & & \\
\hline HEMB L144 & & & & \\
\hline AEMBL1336507 & & & & \\
\hline AEMBL1607822 & & & & \\
\hline AEMBL1507 & & & & \\
\hline HEMBL 3198 & & & & \\
\hline HEMBL1517247 & & & & \\
\hline AEMBL1485691 & & & & \\
\hline AEMBL1496729 & & & & \\
\hline AEMBL1566923 & & & & \\
\hline AEM & & & & \\
\hline AEMBL1486476 & & 52 & & \\
\hline AEMBL1391818 & & & & \\
\hline AEMBL1531066 & & & & \\
\hline & & & & \\
\hline 8 & & & & \\
\hline 56 & & & & \\
\hline AEMBL1503348 & & & & \\
\hline AEMBL1406797 & & & & \\
\hline & & & & \\
\hline 3 & & & & \\
\hline HEMBL1376762 & & & & RI \\
\hline AEMBL1591569 & & & & \\
\hline AEMBL561691 & & & & \\
\hline 144 & & & & \\
\hline HEMBL3211611 & & & & \\
\hline AEMBL1423450 & & & & $\mathrm{RN}$ \\
\hline IEMBL1343157 & & & & \\
\hline HEMBL1524723 & & & & \\
\hline 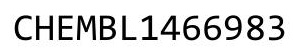 & & & 5.5137 & \\
\hline
\end{tabular}

Page 2447 
Supplemental Table S2.txt

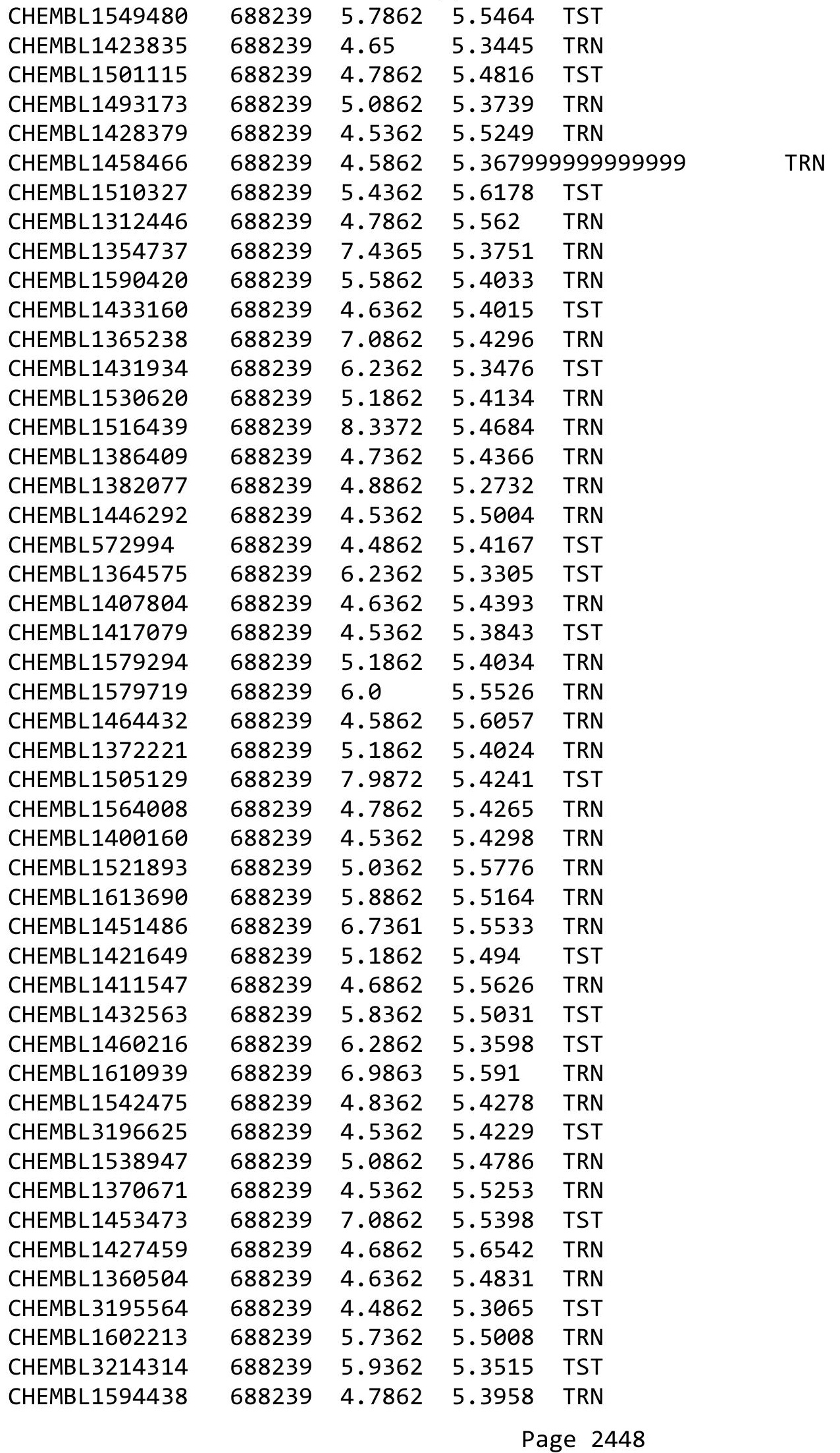


Supplemental Table S2.txt

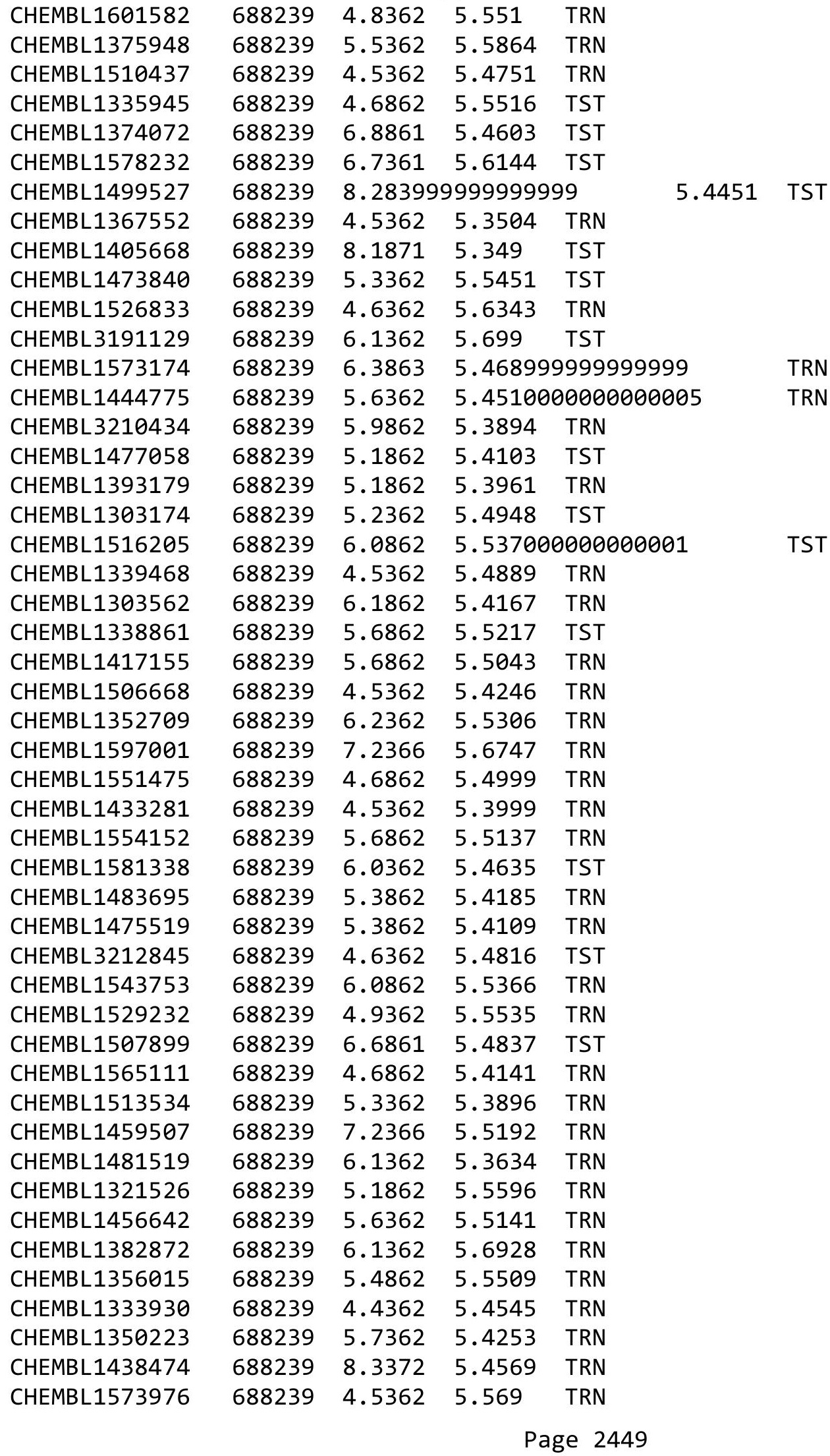


Supplemental Table S2.txt

\begin{tabular}{|c|c|c|c|c|c|}
\hline CHEMBL1372996 & 688239 & 4.5362 & 5.5301 & TRN & \\
\hline CHEMBL1582902 & 688239 & 6.8362 & 5.5767 & TST & \\
\hline CHEMBL3189788 & 688239 & 5.1362 & 5.356 & TST & \\
\hline CHEMBL1519932 & 688239 & 4.5362 & 5.641 & TRN & \\
\hline CHEMBL1501674 & 688239 & 5.7362 & 5.5475 & TRN & \\
\hline CHEMBL1308554 & 688239 & 5.0362 & 5.6141 & TRN & \\
\hline CHEMBL1482842 & 688239 & 6.6362 & 5.5894 & TST & \\
\hline CHEMBL1413364 & 688239 & 5.8862 & 5.5016 & TST & \\
\hline CHEMBL1421462 & 688239 & 4.7362 & 5.3412 & TRN & \\
\hline CHEMBL1507365 & 688239 & 5.1362 & 5.5046 & TST & \\
\hline CHEMBL1383054 & 688239 & 5.2862 & 5.5555 & TRN & \\
\hline CHEMBL1440484 & 688239 & 7.0862 & 5.5581 & TRN & \\
\hline CHEMBL1454819 & 688239 & 4.8862 & 5.3177 & TRN & \\
\hline CHEMBL1600840 & 688239 & 5.3862 & 5.586 & TRN & \\
\hline CHEMBL1577460 & 688239 & 7.2865 & 5.4731 & TRN & \\
\hline CHEMBL1387619 & 688239 & 5.4362 & 5.4463 & TST & \\
\hline CHEMBL1405160 & 688239 & 6.2362 & 5.4211 & TRN & \\
\hline CHEMBL1302254 & 688239 & 4.9362 & 5.4753 & TRN & \\
\hline CHEMBL1412444 & 688239 & 6.7361 & 5.5258 & TST & \\
\hline CHEMBL1449367 & 688239 & 5.9 & 5.5133 & TRN & \\
\hline CHEMBL1411080 & 688239 & 5.1862 & 5.393 & TRN & \\
\hline CHEMBL1585137 & 688239 & 6.2362 & 5.4879 & TRN & \\
\hline CHEMBL1306446 & 688239 & 5.1862 & 5.5647 & TST & \\
\hline CHEMBL1485843 & 688239 & 5.9862 & 5.5928 & TRN & \\
\hline CHEMBL1463999 & 688239 & 6.2362 & 5.6588 & TRN & \\
\hline CHEMBL1331964 & 688239 & 4.6362 & 5.4932 & TRN & \\
\hline CHEMBL1505103 & 688239 & 5.5862 & 5.5567 & TRN & \\
\hline CHEMBL1342889 & 688239 & 5.5862 & 5.4539 & TST & \\
\hline CHEMBL1444103 & 688239 & 5.1862 & 5.5006 & TST & \\
\hline CHEMBL1309330 & 688239 & 4.8362 & 5.6072 & TRN & \\
\hline CHEMBL1363215 & 688239 & 4.6862 & 5.4109 & TRN & \\
\hline CHEMBL1364899 & 688239 & 5.2362 & 5.3709 & TRN & \\
\hline CHEMBL1446089 & 688239 & 4.7362 & 5.5047 & TRN & \\
\hline CHEMBL1412731 & 688239 & 4.5862 & 5.5878 & TRN & \\
\hline CHEMBL1447834 & 688239 & 5.8862 & 5.5263 & TRN & \\
\hline CHEMBL1304639 & 688239 & 4.7362 & 5.6094 & TRN & \\
\hline CHEMBL1526685 & 688239 & 6.8861 & 5.6448 & TST & \\
\hline CHEMBL1469023 & 688239 & 6.1862 & 5.5004 & TRN & \\
\hline CHEMBL1313623 & 688239 & 4.6362 & 5.45200 & 0000000001 & TRN \\
\hline CHEMBL1391412 & 688239 & 4.5362 & 5.4884 & TST & \\
\hline CHEMBL1379565 & 688239 & 4.7362 & 5.4101 & TST & \\
\hline CHEMBL1608526 & 688239 & 6.3362 & 5.5258 & TRN & \\
\hline CHEMBL1454440 & 688239 & 8.3872 & 5.4728 & TRN & \\
\hline CHEMBL1489658 & 688239 & 4.5362 & 5.3566 & TRN & \\
\hline CHEMBL1482270 & 688239 & 6.9863 & 5.5601 & TST & \\
\hline CHEMBL 1500857 & 688239 & 4.4862 & 5.3777 & TRN & \\
\hline CHEMBL1501813 & 688239 & 5.1862 & 5.5063 & TST & \\
\hline CHEMBL1441945 & 688239 & 4.5362 & 5.6801 & TRN & \\
\hline
\end{tabular}


Supplemental Table S2.txt

\begin{tabular}{|c|c|c|c|c|c|}
\hline CHEMBL1305875 & 688239 & 4.9362 & 5.3944 & TRN & \\
\hline CHEMBL1561012 & 688239 & 7.0362 & 5.4818 & TRN & \\
\hline CHEMBL 3210860 & 688239 & 6.2862 & 5.5146 & TRN & \\
\hline CHEMBL1332360 & 688239 & 4.9362 & 5.564 & TRN & \\
\hline CHEMBL1398966 & 688239 & 4.7362 & 5.3622 & TRN & \\
\hline CHEMBL1505294 & 688239 & 6.1362 & 5.5927 & TRN & \\
\hline CHEMBL 3207971 & 688239 & 5.2862 & 5.5257 & TRN & \\
\hline CHEMBL1524595 & 688239 & 5.5362 & 5.5158 & TRN & \\
\hline CHEMBL1448166 & 688239 & 5.6862 & 5.4676 & TRN & \\
\hline CHEMBL1464043 & 688239 & 4.5362 & 5.4064 & TST & \\
\hline CHEMBL 3195463 & 688239 & 4.8362 & 5.5297 & TRN & \\
\hline CHEMBL1464532 & 688239 & 4.7862 & 5.4059 & TST & \\
\hline CHEMBL1526365 & 688239 & 8.283999 & 999999999 & 9 & 5.4655 \\
\hline CHEMBL1406976 & 688239 & 4.7362 & 5.3863 & TRN & \\
\hline CHEMBL1974521 & 688239 & 4.5362 & 5.4983 & TRN & \\
\hline CHEMBL1585567 & 688239 & 5.3862 & 5.5972 & TST & \\
\hline CHEMBL1525281 & 688239 & 6.2362 & 5.5128 & TRN & \\
\hline CHEMBL1303324 & 688239 & 8.3372 & 5.3779 & TRN & \\
\hline CHEMBL1348853 & 688239 & 5.9362 & 5.3792 & TRN & \\
\hline CHEMBL1566295 & 688239 & 4.7862 & 5.5037 & TRN & \\
\hline CHEMBL1434270 & 688239 & 4.7862 & 5.4876 & TRN & \\
\hline CHEMBL1384116 & 688239 & 5.1862 & 5.4709 & TRN & \\
\hline CHEMBL1389419 & 688239 & 5.4362 & 5.4095 & TRN & \\
\hline CHEMBL1470818 & 688239 & 6.8861 & 5.3611 & TRN & \\
\hline CHEMBL1536981 & 688239 & 6.7862 & 5.3891 & TRN & \\
\hline CHEMBL1545841 & 688239 & 4.7362 & 5.6231 & TRN & \\
\hline CHEMBL1431571 & 688239 & 4.7862 & 5.4642 & TRN & \\
\hline CHEMBL1351962 & 688239 & 4.6362 & 5.4882 & TRN & \\
\hline CHEMBL1349152 & 688239 & 6.2362 & 5.6629 & TST & \\
\hline CHEMBL1317830 & 688239 & 6.7862 & 5.6148 & TRN & \\
\hline CHEMBL1467064 & 688239 & 4.6862 & 5.6128 & TRN & \\
\hline CHEMBL1384533 & 688239 & 4.5362 & 5.5207 & TRN & \\
\hline CHEMBL1319933 & 688239 & 4.4862 & 5.441 & TRN & \\
\hline CHEMBL1567804 & 688239 & 4.5362 & 5.4358 & TRN & \\
\hline CHEMBL1449090 & 688239 & 6.2862 & 5.5119 & TST & \\
\hline CHEMBL1356185 & 688239 & 5.0362 & 5.4588 & TRN & \\
\hline CHEMBL1324066 & 688239 & 4.9362 & 5.5589 & TRN & \\
\hline CHEMBL1529768 & 688239 & 6.2362 & 5.4088 & TST & \\
\hline CHEMBL1479064 & 688239 & 7.0362 & 5.5801 & TRN & \\
\hline CHEMBL1348666 & 688239 & 4.5362 & 5.6042 & TRN & \\
\hline CHEMBL1540259 & 688239 & 8.3372 & 5.4248 & TST & \\
\hline CHEMBL1433961 & 688239 & 4.5362 & 5.4935 & TRN & \\
\hline CHEMBL 3194013 & 688239 & 6.0862 & 5.4819 & TST & \\
\hline CHEMBL1478645 & 688239 & 5.3862 & 5.489 & TRN & \\
\hline CHEMBL1595233 & 688239 & 5.1862 & 5.5292 & TRN & \\
\hline CHEMBL1587996 & 688239 & 5.4362 & 5.4085 & TRN & \\
\hline CHEMBL1540128 & 688239 & 4.5362 & 5.6023 & TRN & \\
\hline CHEMBL1510236 & 688239 & 5.0862 & 5.4743 & TST & \\
\hline
\end{tabular}


Supplemental Table S2.txt

\begin{tabular}{|c|c|c|c|c|}
\hline CHEMBL1972235 & 688239 & 4.5362 & 5.4248 & TST \\
\hline CHEMBL1972652 & 688239 & 4.7362 & 5.3797 & TRN \\
\hline CHEMBL1610910 & 688239 & 4.5362 & 5.5234 & TRN \\
\hline CHEMBL1460110 & 688239 & 4.7362 & 5.5065 & TST \\
\hline CHEMBL1538425 & 688239 & 4.8862 & 5.5203 & TRN \\
\hline CHEMBL1557431 & 688239 & 6.3863 & 5.4853 & TRN \\
\hline CHEMBL1530756 & 688239 & 5.0862 & 5.4259 & TST \\
\hline CHEMBL1508370 & 688239 & 4.9362 & 5.4552 & TRN \\
\hline CHEMBL1559800 & 688239 & 6.2362 & 5.5724 & TRN \\
\hline CHEMBL3198253 & 688239 & 5.3862 & 5.505 & TRN \\
\hline CHEMBL1422846 & 688239 & 5.4862 & 5.4618 & TST \\
\hline CHEMBL1343781 & 688239 & 8.1367 & 5.5359 & TRN \\
\hline CHEMBL1548724 & 688239 & 6.2862 & 5.4303 & TRN \\
\hline CHEMBL1393144 & 688239 & 5.7862 & 5.5958 & TRN \\
\hline CHEMBL1487657 & 688239 & 4.7362 & 5.3872 & TRN \\
\hline CHEMBL1373467 & 688239 & 4.6862 & 5.4791 & TST \\
\hline CHEMBL1347695 & 688239 & 5.5362 & 5.5103 & TRN \\
\hline CHEMBL1443045 & 688239 & 4.5362 & 5.4613 & TRN \\
\hline CHEMBL1608330 & 688239 & 4.5362 & 5.3388 & TST \\
\hline CHEMBL3197022 & 688239 & 5.6862 & 5.3985 & TRN \\
\hline CHEMBL3195063 & 688239 & 6.0862 & 5.3433 & TST \\
\hline CHEMBL3208209 & 688239 & 6.6362 & 5.4551 & TRN \\
\hline CHEMBL 317233 & 688239 & 4.6862 & 5.4359 & TRN \\
\hline CHEMBL1313022 & 688239 & 6.9363 & 5.5042 & TST \\
\hline CHEMBL1538265 & 688239 & 6.5363 & 5.5207 & TST \\
\hline CHEMBL1597479 & 688239 & 4.5362 & 5.5102 & TST \\
\hline CHEMBL1370700 & 688239 & 6.2862 & 5.5699 & TRN \\
\hline CHEMBL3190142 & 688239 & 5.0362 & 5.4116 & TRN \\
\hline CHEMBL1304327 & 688239 & 4.7362 & 5.4558 & TST \\
\hline CHEMBL1395076 & 688239 & 4.5362 & 5.468999 & 9999999999 \\
\hline CHEMBL1549393 & 688239 & 5.5862 & 5.6417 & TRN \\
\hline CHEMBL1397483 & 688239 & 7.0862 & 5.4208 & TRN \\
\hline CHEMBL3211156 & 688239 & 6.5363 & 5.4584 & TRN \\
\hline CHEMBL1476710 & 688239 & 5.0362 & 5.6434 & TRN \\
\hline CHEMBL1473614 & 688239 & 4.6362 & 5.6551 & TRN \\
\hline CHEMBL1597196 & 688239 & 6.8362 & 5.5794 & TST \\
\hline CHEMBL1568819 & 688239 & 6.4362 & 5.3591 & TRN \\
\hline CHEMBL1577715 & 688239 & 4.4862 & 5.422999 & 9999999999 \\
\hline CHEMBL1351703 & 688239 & 5.4362 & 5.5404 & TST \\
\hline CHEMBL1487910 & 688239 & 5.6862 & 5.6536 & TRN \\
\hline CHEMBL1348515 & 688239 & 6.4362 & 5.6282 & TST \\
\hline CHEMBL1508085 & 688239 & 7.9872 & 5.5266 & TST \\
\hline CHEMBL1608543 & 688239 & 4.5362 & 5.4853 & TST \\
\hline CHEMBL1456548 & 688239 & 7.2366 & 5.5401 & TRN \\
\hline CHEMBL1437043 & 688239 & 5.3862 & 5.5671 & TST \\
\hline CHEMBL1482965 & 688239 & 7.0362 & 5.5284 & TRN \\
\hline CHEMBL1500297 & 688239 & 8.3372 & 5.5315 & TRN \\
\hline CHEMBL3193720 & 688239 & 5.3362 & 5.6351 & TRN \\
\hline
\end{tabular}




\begin{tabular}{|c|c|c|c|c|c|c|}
\hline & & \multicolumn{5}{|c|}{ Supplemental Table S2.txt } \\
\hline CHEMBL1378216 & 688239 & 4.5862 & 5.5621 & TRN & & \\
\hline CHEMBL1337970 & 688239 & 4.4862 & 5.4707 & TRN & & \\
\hline CHEMBL1603997 & 688239 & 4.6862 & 5.5133 & TST & & \\
\hline CHEMBL1400751 & 688239 & 4.6362 & 5.5694 & TRN & & \\
\hline CHEMBL1331138 & 688239 & 5.1862 & 5.4456 & TST & & \\
\hline CHEMBL1561538 & 688239 & 4.4862 & 5.5084 & TRN & & \\
\hline CHEMBL1418626 & 688239 & 4.5862 & 5.5288 & TRN & & \\
\hline CHEMBL1410535 & 688239 & 5.3362 & 5.468 & TRN & & \\
\hline CHEMBL1406208 & 688239 & 5.3362 & 5.4958 & TRN & & \\
\hline CHEMBL1434622 & 688239 & 4.8362 & 5.435 & TRN & & \\
\hline CHEMBL1319249 & 688239 & 4.5362 & 5.3308 & TRN & & \\
\hline CHEMBL1490451 & 688239 & 5.1862 & 5.4864 & TRN & & \\
\hline CHEMBL1531222 & 688239 & 4.6862 & 5.5402 & TST & & \\
\hline CHEMBL1381720 & 688239 & 5.7362 & 5.5338 & TST & & \\
\hline CHEMBL3213196 & 688239 & 5.1862 & 5.4449 & TST & & \\
\hline CHEMBL1578658 & 688239 & 4.5362 & 5.4336 & TRN & & \\
\hline CHEMBL1514845 & 688239 & 8.28399 & 99999999 & 99 & .4364 & TRN \\
\hline CHEMBL1524266 & 688239 & 4.8362 & 5.5617 & TRN & & \\
\hline CHEMBL1472249 & 688239 & 4.5362 & 5.3706 & TST & & \\
\hline CHEMBL1548507 & 688239 & 4.7862 & 5.5947 & TST & & \\
\hline CHEMBL1535313 & 688239 & 8.28399 & 99999999 & & .4327 & TRN \\
\hline CHEMBL1433541 & 688239 & 5.0862 & 5.345 & TST & & \\
\hline CHEMBL1540352 & 688239 & 5.2362 & 5.6253 & TRN & & \\
\hline CHEMBL1362681 & 688239 & 4.6362 & 5.4457 & TST & & \\
\hline CHEMBL1597024 & 688239 & 4.7362 & 5.4831 & TRN & & \\
\hline CHEMBL1521735 & 688239 & 6.0362 & 5.45700 & 0000000001 & & TRN \\
\hline CHEMBL1453731 & 688239 & 4.6362 & 5.4414 & TRN & & \\
\hline CHEMBL1475734 & 688239 & 4.7362 & 5.6907 & TRN & & \\
\hline CHEMBL1422610 & 688239 & 7.3363 & 5.4559 & TRN & & \\
\hline CHEMBL1493141 & 688239 & 5.3862 & 5.4572 & TRN & & \\
\hline CHEMBL1457997 & 688239 & 4.7362 & 5.3896 & TRN & & \\
\hline CHEMBL1327534 & 688239 & 5.5362 & 5.425 & TRN & & \\
\hline CHEMBL1404141 & 688239 & 5.5362 & 5.4652 & TRN & & \\
\hline CHEMBL 278779 & 688239 & 7.0862 & 5.58299 & 9999999999 & & TST \\
\hline CHEMBL1499416 & 688239 & 5.3862 & 5.541 & TST & & \\
\hline CHEMBL3210273 & 688239 & 5.6862 & 5.45200 & 0000000001 & & TST \\
\hline CHEMBL1365900 & 688239 & 4.5362 & 5.4874 & TRN & & \\
\hline CHEMBL1557738 & 688239 & 5.1362 & 5.42899 & 9999999999 & & TRN \\
\hline CHEMBL1388128 & 688239 & 5.9362 & 5.4238 & TRN & & \\
\hline CHEMBL1443881 & 688239 & 4.5362 & 5.38399 & 99999999995 & & TRN \\
\hline CHEMBL1482231 & 688239 & 4.6862 & 5.3912 & TRN & & \\
\hline CHEMBL1564139 & 688239 & 6.3863 & 5.4449 & TRN & & \\
\hline CHEMBL1319898 & 688239 & 6.8362 & 5.6243 & TRN & & \\
\hline CHEMBL1313586 & 688239 & 5.5862 & 5.48600 & 0000000001 & & TRN \\
\hline CHEMBL1531908 & 688239 & 5.4862 & 5.5226 & TRN & & \\
\hline CHEMBL1333236 & 688239 & 6.5363 & 5.5296 & TRN & & \\
\hline CHEMBL1324999 & 688239 & 4.5362 & 5.392 & TRN & & \\
\hline CHEMBL1341327 & 688239 & 5.3862 & 5.4933 & TST & & \\
\hline
\end{tabular}


Supplemental Table S2.txt

\begin{tabular}{|c|c|c|c|c|}
\hline CHEMBL1482082 & 688239 & 4.5362 & 5.4625 & TST \\
\hline CHEMBL1469685 & 688239 & 4.5362 & 5.4237 & TST \\
\hline CHEMBL1349832 & 688239 & 6.0 & 5.2639 & TRN \\
\hline CHEMBL1345142 & 688239 & 6.9363 & 5.5497 & TRN \\
\hline CHEMBL1354221 & 688239 & 6.8861 & 5.6052 & TRN \\
\hline CHEMBL1447973 & 688239 & 5.1862 & 5.4675 & TST \\
\hline CHEMBL1485746 & 688239 & 6.6861 & 5.5058 & TRN \\
\hline CHEMBL 3214328 & 688239 & 6.8861 & 5.5258 & TRN \\
\hline CHEMBL1412224 & 688239 & 5.8362 & 5.5915 & TST \\
\hline CHEMBL1477287 & 688239 & 5.1862 & 5.3853 & TRN \\
\hline CHEMBL1547360 & 688239 & 4.8862 & 5.6456 & TRN \\
\hline CHEMBL 3193036 & 688239 & 4.5362 & 5.4772 & TRN \\
\hline CHEMBL163428 & 688239 & 4.5362 & 5.3905 & TRN \\
\hline CHEMBL1485577 & 688239 & 4.6362 & 5.5553 & TRN \\
\hline CHEMBL1569178 & 688239 & 5.5862 & 5.5681 & TRN \\
\hline CHEMBL518575 & 688239 & 5.1862 & 5.5134 & TST \\
\hline CHEMBL1552899 & 688239 & 5.3362 & 5.41100 & 30000000005 \\
\hline CHEMBL1606803 & 688239 & 5.5362 & 5.4634 & TRN \\
\hline CHEMBL1429392 & 688239 & 4.5362 & 5.4749 & TRN \\
\hline CHEMBL1303143 & 688239 & 4.5362 & 5.3242 & TRN \\
\hline CHEMBL1468698 & 688239 & 5.1362 & 5.4975 & TST \\
\hline CHEMBL1423576 & 688239 & 6.05 & 5.69 & TST \\
\hline CHEMBL1602172 & 688239 & 4.5362 & 5.4943 & TRN \\
\hline CHEMBL1458592 & 688239 & 4.8362 & 5.4498 & TRN \\
\hline CHEMBL1421444 & 688239 & 4.6862 & 5.6153 & TRN \\
\hline CHEMBL1526626 & 688239 & 6.0862 & 5.5863 & TRN \\
\hline CHEMBL1488210 & 688239 & 8.3872 & 5.4506 & TRN \\
\hline CHEMBL1597628 & 688239 & 4.5862 & 5.3845 & TRN \\
\hline CHEMBL1606519 & 688239 & 5.9362 & 5.7344 & TRN \\
\hline CHEMBL1338916 & 688239 & 5.6362 & 5.619 & TST \\
\hline CHEMBL1515471 & 688239 & 6.1362 & 5.5847 & TRN \\
\hline CHEMBL1428321 & 688239 & 7.1361 & 5.61700 & 0000000001 \\
\hline CHEMBL1462777 & 688239 & 6.7862 & 5.3416 & TRN \\
\hline CHEMBL1454195 & 688239 & 4.7362 & 5.3085 & TRN \\
\hline CHEMBL 3194994 & 688239 & 4.6362 & 5.4064 & TST \\
\hline CHEMBL1445108 & 688239 & 7.0862 & 5.4038 & TST \\
\hline CHEMBL1587875 & 688239 & 4.5362 & 5.4938 & TRN \\
\hline CHEMBL 3196730 & 688239 & 5.1862 & 5.5095 & TRN \\
\hline CHEMBL1418545 & 688239 & 4.5362 & 5.5354 & TST \\
\hline CHEMBL1601425 & 688239 & 4.6862 & 5.5185 & TRN \\
\hline CHEMBL1566049 & 688239 & 4.5362 & 5.4857 & TRN \\
\hline CHEMBL1299492 & 688239 & 4.7862 & 5.5648 & TST \\
\hline CHEMBL3189311 & 688239 & 6.5363 & 5.6205 & TRN \\
\hline CHEMBL1493571 & 688239 & 5.5362 & 5.4785 & TRN \\
\hline CHEMBL1316585 & 688239 & 4.7362 & 5.4217 & TRN \\
\hline CHEMBL1613494 & 688239 & 6.6861 & 5.343 & TRN \\
\hline CHEMBL1477357 & 688239 & 6.1362 & 5.3843 & TRN \\
\hline CHEMBL1389987 & 688239 & 5.5862 & 5.7607 & TRN \\
\hline
\end{tabular}


Supplemental Table S2.txt

\begin{tabular}{|c|c|c|c|c|c|}
\hline CHEMBL1370339 & 688239 & 6.3863 & 5.5165 & TST & \\
\hline CHEMBL1307968 & 688239 & 4.4862 & 5.6129 & TRN & \\
\hline CHEMBL1314258 & 688239 & 4.5362 & 5.4017 & TRN & \\
\hline CHEMBL1372448 & 688239 & 5.4362 & 5.6859 & TRN & \\
\hline CHEMBL1442554 & 688239 & 4.6862 & 5.5531 & TRN & \\
\hline CHEMBL1461947 & 688239 & 4.6862 & 5.4632 & TST & \\
\hline CHEMBL1613021 & 688239 & 5.1862 & 5.6313 & TRN & \\
\hline CHEMBL1345869 & 688239 & 4.5362 & 5.4084 & TRN & \\
\hline CHEMBL1222145 & 688239 & 4.5362 & 5.5998 & TRN & \\
\hline CHEMBL1589294 & 688239 & 6.3362 & 5.4054 & TST & \\
\hline CHEMBL1487774 & 688239 & 6.8362 & 5.3708 & TST & \\
\hline CHEMBL1379390 & 688239 & 4.7862 & 5.4131 & TRN & \\
\hline CHEMBL1487845 & 688239 & 4.7362 & 5.4966 & TST & \\
\hline CHEMBL1528813 & 688239 & 7.0362 & 5.4367 & TRN & \\
\hline CHEMBL1379191 & 688239 & 6.8861 & 5.4414 & TRN & \\
\hline CHEMBL1345704 & 688239 & 5.1862 & 5.4424 & TST & \\
\hline CHEMBL1570589 & 688239 & 7.4365 & 5.4973 & TST & \\
\hline CHEMBL1456680 & 688239 & 4.5362 & 5.4252 & TRN & \\
\hline CHEMBL1347777 & 688239 & 6.1862 & 5.5047 & TST & \\
\hline CHEMBL1488797 & 688239 & 5.0862 & 5.5732 & TRN & \\
\hline CHEMBL1389438 & 688239 & 4.9362 & 5.38 & TRN & \\
\hline CHEMBL1611137 & 688239 & 4.5362 & 5.4223 & TRN & \\
\hline CHEMBL1330399 & 688239 & 6.5862 & 5.3694 & TRN & \\
\hline CHEMBL1381831 & 688239 & 7.8861 & 5.5672 & TRN & \\
\hline CHEMBL1556183 & 688239 & 4.7362 & 5.5109 & TRN & \\
\hline CHEMBL1604323 & 688239 & 5.5362 & 5.527 & TST & \\
\hline CHEMBL1356518 & 688239 & 5.7362 & 5.6215 & TRN & \\
\hline CHEMBL1378355 & 688239 & 5.7362 & 5.2856 & TST & \\
\hline CHEMBL1446415 & 688239 & 4.7862 & 5.3407 & TST & \\
\hline CHEMBL1463122 & 688239 & 4.5362 & 5.4843 & TRN & \\
\hline CHEMBL1563367 & 688239 & 4.7362 & 5.6512 & TRN & \\
\hline CHEMBL1312790 & 688239 & 4.9362 & 5.5695 & TRN & \\
\hline CHEMBL1402623 & 688239 & 6.1862 & 5.4211 & TRN & \\
\hline CHEMBL1502546 & 688239 & 5.9862 & 5.557 & TRN & \\
\hline CHEMBL1490298 & 688239 & 6.5363 & 5.5464 & TST & \\
\hline CHEMBL1573636 & 688239 & 4.6862 & 5.5632 & TRN & \\
\hline CHEMBL1346483 & 688239 & 5.6362 & 5.37700 & 0000000001 & TRN \\
\hline CHEMBL1342716 & 688239 & 7.1864 & 5.6444 & TST & \\
\hline CHEMBL1307627 & 688239 & 4.4862 & 5.7189 & TRN & \\
\hline CHEMBL1557453 & 688239 & 5.2862 & 5.5677 & TRN & \\
\hline CHEMBL1515739 & 688239 & 4.9862 & 5.4358 & TST & \\
\hline CHEMBL3195036 & 688239 & 4.5362 & 5.3778 & TRN & \\
\hline CHEMBL1550024 & 688239 & 4.4862 & 5.5317 & TRN & \\
\hline CHEMBL1442178 & 688239 & 6.9863 & 5.3834 & TRN & \\
\hline CHEMBL3190798 & 688239 & 6.3863 & 5.3401 & TRN & \\
\hline CHEMBL 1564878 & 688239 & 7.0862 & 5.5309 & TRN & \\
\hline CHEMBL 3190620 & 688239 & 5.9362 & 5.472 & TST & \\
\hline CHEMBL1475017 & 688239 & 4.6862 & 5.569 & TST & \\
\hline
\end{tabular}


Supplemental Table S2.txt

\begin{tabular}{|c|c|c|c|c|c|}
\hline CHEMBL1526137 & 688239 & 5.9362 & 5.3302 & TRN & \\
\hline CHEMBL1865061 & 688239 & 5.5362 & 5.4103 & TRN & \\
\hline CHEMBL1323580 & 688239 & 6.2362 & 5.3434 & TRN & \\
\hline CHEMBL1558778 & 688239 & 4.5362 & \multicolumn{2}{|c|}{5.406000000000001} & TST \\
\hline CHEMBL1421315 & 688239 & 4.7862 & 5.6715 & TRN & \\
\hline CHEMBL1481576 & 688239 & 6.3362 & 5.5653 & TRN & \\
\hline CHEMBL1554646 & 688239 & 4.9862 & 5.2773 & TRN & \\
\hline CHEMBL3190849 & 688239 & 4.5362 & 5.3983 & TRN & \\
\hline CHEMBL1351654 & 688239 & 4.7862 & 5.5184 & TRN & \\
\hline CHEMBL1490721 & 688239 & 4.6362 & 5.4378 & TST & \\
\hline CHEMBL1379178 & 688239 & 6.0862 & 5.4118 & TST & \\
\hline CHEMBL1414216 & 688239 & 5.9362 & 5.4637 & TST & \\
\hline CHEMBL1551917 & 688239 & 4.8862 & 5.4303 & TRN & \\
\hline CHEMBL1409108 & 688239 & 5.1362 & 5.3697 & TST & \\
\hline CHEMBL1484042 & 688239 & 4.5362 & 5.4253 & TST & \\
\hline CHEMBL1555253 & 688239 & 4.8362 & \multicolumn{2}{|c|}{5.446000000000001} & TRN \\
\hline CHEMBL1356172 & 688239 & 4.6862 & 5.5784 & TRN & \\
\hline CHEMBL1557430 & 688239 & 4.5362 & 5.4853 & TRN & \\
\hline CHEMBL3197111 & 688239 & 6.1862 & 5.4439 & TRN & \\
\hline CHEMBL1340473 & 688239 & 4.5362 & 5.4253 & TRN & \\
\hline CHEMBL3190677 & 688239 & 5.1862 & 5.4975 & TRN & \\
\hline CHEMBL1485448 & 688239 & 6.9863 & 5.5578 & TRN & \\
\hline CHEMBL1378040 & 688239 & 5.1862 & 5.4537 & TRN & \\
\hline CHEMBL515248 & 688239 & 5.5362 & 5.4436 & TRN & \\
\hline CHEMBL1447165 & 688239 & 5.8862 & 5.4028 & TRN & \\
\hline CHEMBL1462364 & 688239 & 5.1862 & \multicolumn{2}{|c|}{5.337999999999999} & TRN \\
\hline CHEMBL1421053 & 688239 & 6.8362 & 5.4457 & TRN & \\
\hline CHEMBL1465221 & 688239 & 4.5362 & 5.419 & TRN & \\
\hline CHEMBL1428883 & 688239 & 4.6862 & 5.4555 & TRN & \\
\hline CHEMBL1348240 & 688239 & 4.9862 & \multicolumn{2}{|c|}{5.452999999999999} & TRN \\
\hline CHEMBL1456957 & 688239 & 4.5862 & 5.5402 & TRN & \\
\hline CHEMBL1331095 & 688239 & 6.8861 & 5.6559 & TST & \\
\hline CHEMBL1343815 & 688239 & 8.3372 & 5.3442 & TRN & \\
\hline CHEMBL1372834 & 688239 & 4.8862 & 5.4404 & TRN & \\
\hline CHEMBL1605743 & 688239 & 4.6362 & 5.4011 & TST & \\
\hline CHEMBL1326893 & 688239 & 6.0862 & 5.5044 & TRN & \\
\hline CHEMBL1410467 & 688239 & 5.4862 & 5.5555 & TRN & \\
\hline CHEMBL1448627 & 688239 & 6.4862 & 5.3504 & TST & \\
\hline CHEMBL1591102 & 688239 & 4.5362 & 5.5868 & TRN & \\
\hline CHEMBL1498285 & 688239 & 5.5862 & 5.325 & TRN & \\
\hline CHEMBL1482620 & 688239 & 4.7862 & 5.5252 & TRN & \\
\hline CHEMBL1519054 & 688239 & 6.4862 & 5.4596 & TRN & \\
\hline CHEMBL1370677 & 688239 & 5.3362 & \multicolumn{2}{|c|}{5.412000000000001} & TRN \\
\hline CHEMBL1527631 & 688239 & 5.5862 & 5.5378 & TST & \\
\hline CHEMBL1536249 & 688239 & 5.1862 & 5.4407 & TRN & \\
\hline CHEMBL1350429 & 688239 & 4.7862 & 5.4966 & TST & \\
\hline CHEMBL1376059 & 688239 & 4.5362 & 5.5204 & TST & \\
\hline CHEMBL1441423 & 688239 & 5.9862 & 5.6045 & TRN & \\
\hline
\end{tabular}




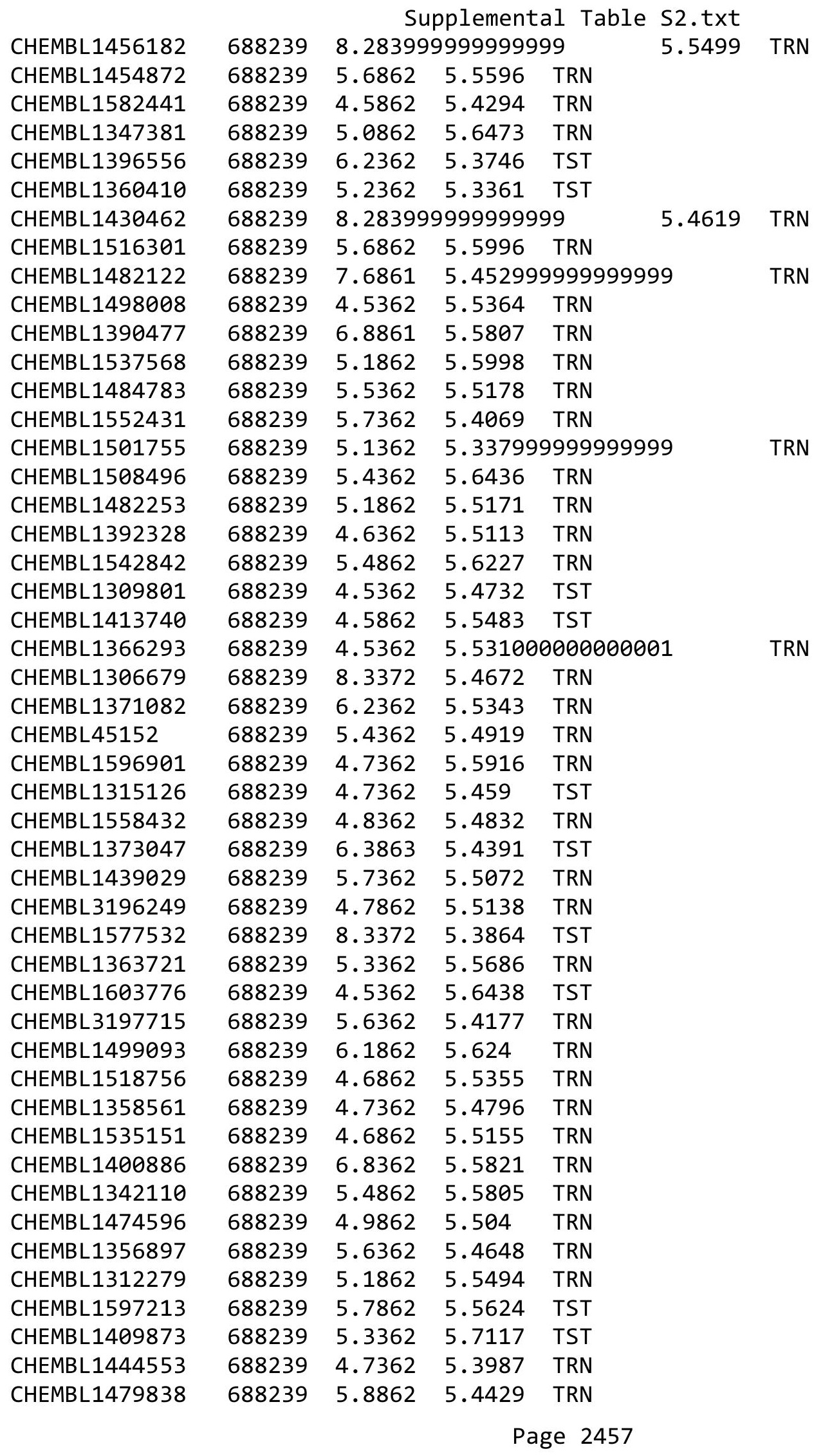


Supplemental Table S2.txt

\begin{tabular}{|c|c|c|c|c|}
\hline CHEMBL1302587 & 688239 & 7.9872 & 5.5845 & TRN \\
\hline CHEMBL1472839 & 688239 & 4.5362 & 5.374 & TRN \\
\hline CHEMBL1532769 & 688239 & 6.1862 & 5.5567 & TRN \\
\hline CHEMBL1584506 & 688239 & 4.8362 & 5.5456 & TRN \\
\hline CHEMBL1449449 & 688239 & 4.8862 & 5.484 & TRN \\
\hline CHEMBL1426792 & 688239 & 4.5362 & 5.4667 & TRN \\
\hline CHEMBL1407057 & 688239 & 5.8362 & 5.5255 & TRN \\
\hline CHEMBL605003 & 688239 & 5.2862 & 5.3879 & TST \\
\hline CHEMBL1382464 & 688239 & 4.6362 & 5.4599 & TRN \\
\hline CHEMBL1413293 & 688239 & 7.1361 & 5.5439 & TRN \\
\hline CHEMBL1405710 & 688239 & 5.3862 & 5.4765 & TRN \\
\hline CHEMBL1501590 & 688239 & 4.8362 & 5.4614 & TST \\
\hline CHEMBL1338350 & 688239 & 7.5361 & 5.5517 & TRN \\
\hline CHEMBL1492691 & 688239 & 5.4862 & 5.5511 & TST \\
\hline CHEMBL1447565 & 688239 & 5.2862 & 5.4282 & TRN \\
\hline CHEMBL1550109 & 688239 & 8.1871 & 5.4095 & TRN \\
\hline CHEMBL1566002 & 688239 & 5.8862 & 5.6276 & TST \\
\hline CHEMBL1476887 & 688239 & 6.3863 & 5.4972 & TRN \\
\hline CHEMBL1496466 & 688239 & 4.6862 & 5.5907 & TRN \\
\hline CHEMBL1310889 & 688239 & 6.2362 & 5.4894 & TRN \\
\hline CHEMBL1453419 & 688239 & 5.8862 & 5.5756 & TST \\
\hline CHEMBL1601278 & 688239 & 5.6862 & 5.5068 & TST \\
\hline CHEMBL1570343 & 688239 & 4.8862 & 5.4862 & TST \\
\hline CHEMBL1532715 & 688239 & 5.7362 & 5.7359 & TRN \\
\hline CHEMBL1450880 & 688239 & 5.3862 & 5.4311 & TRN \\
\hline CHEMBL1345577 & 688239 & 6.5862 & 5.5128 & TST \\
\hline CHEMBL1409256 & 688239 & 5.6862 & 5.3058 & TST \\
\hline CHEMBL1411087 & 688239 & 6.1862 & 5.5561 & TST \\
\hline CHEMBL1439608 & 688239 & 5.3362 & 5.4021 & TRN \\
\hline CHEMBL1321987 & 688239 & 4.8362 & 5.3495 & TRN \\
\hline CHEMBL1554726 & 688239 & 4.4862 & 5.4086 & TRN \\
\hline CHEMBL1316160 & 688239 & 5.7362 & 5.5003 & TRN \\
\hline CHEMBL1326270 & 688239 & 4.7362 & 5.5551 & TRN \\
\hline CHEMBL601825 & 688239 & 4.5362 & 5.4889 & TRN \\
\hline CHEMBL1475078 & 688239 & 4.5362 & 5.5467 & TRN \\
\hline CHEMBL 3212292 & 688239 & 4.5362 & 5.4193 & TST \\
\hline CHEMBL1401588 & 688239 & 6.1862 & 5.4937 & TRN \\
\hline CHEMBL180920 & 688239 & 4.6862 & 5.3534 & TST \\
\hline CHEMBL1546650 & 688239 & 4.6362 & 5.5751 & TRN \\
\hline CHEMBL1350725 & 688239 & 4.5362 & 5.5105 & TRN \\
\hline CHEMBL1562342 & 688239 & 4.5362 & 5.5703 & TRN \\
\hline CHEMBL1536724 & 688239 & 6.2362 & 5.5892 & TST \\
\hline CHEMBL1527148 & 688239 & 4.5862 & 5.6874 & TRN \\
\hline CHEMBL1554435 & 688239 & 5.3362 & 5.42200 & 0000000001 \\
\hline CHEMBL1359112 & 688239 & 6.2362 & 5.6834 & TRN \\
\hline CHEMBL1308612 & 688239 & 5.1362 & 5.53700 & 0000000001 \\
\hline CHEMBL1375815 & 688239 & 5.6362 & 5.3881 & TST \\
\hline CHEMBL1378950 & 688239 & 5.3362 & 5.5253 & TRN \\
\hline
\end{tabular}

Page 2458 
Supplemental Table S2.txt

\begin{tabular}{|c|c|c|c|c|}
\hline CHEMBL1481256 & 688239 & 5.0862 & 5.6642 & TRN \\
\hline CHEMBL1334734 & 688239 & 5.2362 & 5.5295 & TRN \\
\hline CHEMBL1314415 & 688239 & 5.1862 & 5.3737 & TRN \\
\hline CHEMBL1476885 & 688239 & 5.7362 & 5.4207 & TRN \\
\hline CHEMBL1464666 & 688239 & 4.8862 & 5.3932 & TRN \\
\hline CHEMBL1475357 & 688239 & 5.1862 & 5.3484 & TRN \\
\hline CHEMBL1464496 & 688239 & 5.8862 & 5.4927 & TST \\
\hline CHEMBL1580760 & 688239 & 5.2362 & 5.6167 & TRN \\
\hline CHEMBL 3198071 & 688239 & 5.8362 & 5.5081 & TRN \\
\hline CHEMBL1588733 & 688239 & 5.1362 & 5.5373 & TST \\
\hline CHEMBL1356877 & 688239 & 4.7362 & 5.5521 & TRN \\
\hline CHEMBL1472669 & 688239 & 7.5867 & 5.4815 & TRN \\
\hline CHEMBL1572690 & 688239 & 5.9362 & 5.5509 & TRN \\
\hline CHEMBL1376392 & 688239 & 5.4862 & 5.5494 & TRN \\
\hline CHEMBL1372390 & 688239 & 6.8861 & 5.4876 & TST \\
\hline CHEMBL1964591 & 688239 & 5.1362 & 5.3665 & TRN \\
\hline CHEMBL1387181 & 688239 & 5.1362 & 5.3982 & TST \\
\hline CHEMBL1443783 & 688239 & 4.5362 & 5.4352 & TRN \\
\hline CHEMBL1468754 & 688239 & 8.3372 & 5.4752 & TRN \\
\hline CHEMBL1600989 & 688239 & 4.9362 & 5.4545 & TST \\
\hline CHEMBL1316187 & 688239 & 5.4362 & 5.5063 & TST \\
\hline CHEMBL1429709 & 688239 & 4.6862 & 5.3539 & TST \\
\hline CHEMBL1302184 & 688239 & 5.1862 & 5.4281 & TST \\
\hline CHEMBL1540266 & 688239 & 5.9862 & 5.6172 & TRN \\
\hline CHEMBL1467478 & 688239 & 4.8362 & 5.435 & TRN \\
\hline CHEMBL 1470820 & 688239 & 4.6362 & 5.4252 & TST \\
\hline CHEMBL1301332 & 688239 & 4.7862 & 5.3892 & TRN \\
\hline CHEMBL1480358 & 688239 & 5.5862 & 5.6652 & TRN \\
\hline CHEMBL1526840 & 688239 & 6.9363 & 5.6992 & TRN \\
\hline CHEMBL1380564 & 688239 & 6.1862 & 5.455 & TRN \\
\hline CHEMBL1504392 & 688239 & 5.1862 & 5.6891 & TRN \\
\hline CHEMBL1585968 & 688239 & 4.6862 & 5.4723 & TST \\
\hline CHEMBL1361607 & 688239 & 5.6362 & 5.5997 & TST \\
\hline CHEMBL1380697 & 688239 & 6.1862 & 5.4945 & TRN \\
\hline CHEMBL1343707 & 688239 & 5.3862 & 5.4303 & TST \\
\hline CHEMBL1540359 & 688239 & 4.6862 & 5.42700 & 30000000005 \\
\hline CHEMBL1574359 & 688239 & 6.2362 & 5.4505 & TRN \\
\hline CHEMBL 3213560 & 688239 & 6.2862 & 5.5199 & TRN \\
\hline CHEMBL1366555 & 688239 & 6.1362 & 5.4954 & TRN \\
\hline CHEMBL1330050 & 688239 & 5.1862 & 5.54899 & 99999999995 \\
\hline CHEMBL1335780 & 688239 & 4.9862 & 5.5157 & TRN \\
\hline CHEMBL1425312 & 688239 & 7.4868 & 5.5226 & TRN \\
\hline CHEMBL1508896 & 688239 & 4.7362 & 5.4262 & TRN \\
\hline CHEMBL1486178 & 688239 & 8.2366 & 5.4868 & TRN \\
\hline CHEMBL1366798 & 688239 & 6.6861 & 5.5513 & TRN \\
\hline CHEMBL1377209 & 688239 & 4.5362 & 5.5023 & TST \\
\hline CHEMBL1373588 & 688239 & 8.3372 & 5.5203 & TST \\
\hline CHEMBL1531217 & 688239 & 5.1862 & 5.5887 & TRN \\
\hline
\end{tabular}

Page 2459 
Supplemental Table S2.txt

\begin{tabular}{|c|c|c|c|c|}
\hline CHEMBL1354544 & 688239 & 4.9362 & 5.4917 & TST \\
\hline CHEMBL1609009 & 688239 & 4.6362 & 5.5286 & TST \\
\hline CHEMBL1586652 & 688239 & 6.4362 & 5.4686 & TST \\
\hline CHEMBL1504607 & 688239 & 4.6862 & 5.3827 & TRN \\
\hline CHEMBL1523340 & 688239 & 4.8362 & 5.4475 & TRN \\
\hline CHEMBL1416409 & 688239 & 6.0862 & 5.4382 & TRN \\
\hline CHEMBL1964785 & 688239 & 5.1862 & 5.5649 & TRN \\
\hline CHEMBL1316505 & 688239 & 4.6862 & 5.461 & TRN \\
\hline CHEMBL1326167 & 688239 & 6.8362 & 5.5535 & TST \\
\hline CHEMBL1591686 & 688239 & 5.5362 & 5.63899 & 9999999999 \\
\hline CHEMBL1351167 & 688239 & 4.5362 & 5.4066 & TRN \\
\hline CHEMBL1392927 & 688239 & 4.5362 & 5.6092 & TRN \\
\hline CHEMBL1601064 & 688239 & 5.5362 & 5.6223 & TST \\
\hline CHEMBL1416572 & 688239 & 4.5862 & 5.4901 & TRN \\
\hline CHEMBL1572995 & 688239 & 5.1862 & 5.3963 & TRN \\
\hline CHEMBL1428837 & 688239 & 5.5362 & 5.6781 & TRN \\
\hline CHEMBL3191434 & 688239 & 4.4862 & 5.4243 & TST \\
\hline CHEMBL1351788 & 688239 & 7.8861 & 5.4683 & TRN \\
\hline CHEMBL1518833 & 688239 & 5.1862 & 5.5601 & TRN \\
\hline CHEMBL1511213 & 688239 & 6.9863 & 5.5503 & TRN \\
\hline CHEMBL1390131 & 688239 & 5.8362 & 5.5603 & TRN \\
\hline CHEMBL1566970 & 688239 & 4.6362 & 5.58200 & 0000000001 \\
\hline CHEMBL1417210 & 688239 & 5.1862 & 5.6966 & TST \\
\hline CHEMBL1311001 & 688239 & 5.6862 & 5.5019 & TST \\
\hline CHEMBL1457058 & 688239 & 4.4862 & 5.4801 & TRN \\
\hline CHEMBL1506115 & 688239 & 5.2362 & 5.4033 & TST \\
\hline CHEMBL1608361 & 688239 & 5.7362 & 5.5563 & TRN \\
\hline CHEMBL1609383 & 688239 & 4.6362 & 5.4451 & TRN \\
\hline CHEMBL1361116 & 688239 & 5.1862 & 5.3882 & TRN \\
\hline CHEMBL1496557 & 688239 & 6.0862 & 5.5172 & TRN \\
\hline CHEMBL1608714 & 688239 & 4.5362 & 5.5133 & TRN \\
\hline CHEMBL1396623 & 688239 & 5.3862 & 5.46700 & 00000000005 \\
\hline CHEMBL1450020 & 688239 & 4.6362 & 5.5726 & TST \\
\hline CHEMBL1372446 & 688239 & 5.4862 & 5.5839 & TRN \\
\hline CHEMBL1397397 & 688239 & 5.1862 & 5.5355 & TRN \\
\hline CHEMBL1320210 & 688239 & 6.1862 & 5.3894 & TRN \\
\hline CHEMBL1340672 & 688239 & 4.5362 & 5.6242 & TRN \\
\hline CHEMBL1472682 & 688239 & 4.5862 & 5.4792 & TST \\
\hline CHEMBL1390552 & 688239 & 5.2862 & 5.5132 & TRN \\
\hline CHEMBL1543379 & 688239 & 4.8862 & 5.5114 & TST \\
\hline CHEMBL1333583 & 688239 & 5.1862 & 5.3553 & TRN \\
\hline CHEMBL1605849 & 688239 & 4.5362 & 5.4745 & TRN \\
\hline CHEMBL1359572 & 688239 & 5.7862 & 5.5604 & TRN \\
\hline CHEMBL1590195 & 688239 & 5.3362 & 5.4033 & TRN \\
\hline CHEMBL1327172 & 688239 & 6.7862 & 5.4225 & TRN \\
\hline CHEMBL1520143 & 688239 & 5.4362 & 5.442 & TRN \\
\hline CHEMBL1538615 & 688239 & 4.7362 & 5.5476 & TRN \\
\hline CHEMBL3196680 & 688239 & 5.1862 & 5.441 & TST \\
\hline
\end{tabular}


Supplemental Table S2.txt

\begin{tabular}{|c|c|c|c|c|}
\hline 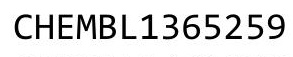 & & & & \\
\hline AEMBL1401636 & 38239 & 862 & 31 & \\
\hline AEMBL1552553 & 39 & & & \\
\hline & 39 & & & \\
\hline IEMBL14 & & & & \\
\hline AEMBL1311656 & 88239 & 362 & 827 & \\
\hline AEMBL1411849 & 88239 & 862 & 5667 & \\
\hline HEMBL1474919 & & & & \\
\hline AEMBL1348280 & 39 & & & \\
\hline IEMBL15 & & & & \\
\hline AEMBL1547560 & 39 & 862 & 01 & \\
\hline AEMBL1301188 & & & & \\
\hline AEMBL1361130 & & & 32 & \\
\hline AEMBL1357667 & & & & \\
\hline AEMBL1472389 & & & & \\
\hline AEMBL3197518 & & 62 & 29 & \\
\hline AEMBL1562859 & & & & \\
\hline IEMBL1548546 & & & & \\
\hline AEMBL1532678 & & & & \\
\hline HEMBL117 & & & & \\
\hline AEMBL3191206 & & & & \\
\hline AEMBL1519204 & & & & \\
\hline HEMBL3199 & & & & \\
\hline HEMBL1420600 & & & & \\
\hline 1318991 & & & & \\
\hline AEMBL1367266 & & & & \\
\hline IEMBL1476597 & & & & \\
\hline AEMBL1357 & & & & \\
\hline 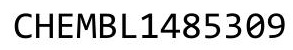 & & & & \\
\hline 05 & & & & \\
\hline AEMBL1308729 & & & & \\
\hline HEMBL1524800 & & & & \\
\hline & & & & \\
\hline 8 & & & & \\
\hline AEMBL1606214 & & & & \\
\hline AEMBL1507435 & & & & \\
\hline AEMBL1399912 & & & & \\
\hline & & & & \\
\hline$\theta$ & & & & \\
\hline HEMBL1445013 & & & & RN \\
\hline IEMBL1396061 & & & & $\mathrm{F}$ \\
\hline AEMBL1463288 & & & & \\
\hline HEMBL1595842 & & & & \\
\hline HEMBL1592007 & & & & \\
\hline AEMBL1585848 & & & & TST \\
\hline MBL1426076 & & & 76 & TS \\
\hline 1 & & & & \\
\hline HEMBL137191 & & & & \\
\hline
\end{tabular}

Page 2461 
Supplemental Table S2.txt

\begin{tabular}{|c|c|c|c|c|}
\hline CHEMBL1434033 & 688239 & 8.3872 & 5.4824 & TRN \\
\hline CHEMBL1545247 & 688239 & 4.5362 & 5.5739 & TST \\
\hline CHEMBL1575156 & 688239 & 4.9862 & 5.3905 & TST \\
\hline CHEMBL1582250 & 688239 & 4.4862 & 5.4717 & TRN \\
\hline CHEMBL1383650 & 688239 & 5.3362 & 5.4043 & TST \\
\hline CHEMBL1581023 & 688239 & 4.6362 & 5.4682 & TST \\
\hline CHEMBL1389687 & 688239 & 4.6862 & 5.4125 & TRN \\
\hline CHEMBL1374359 & 688239 & 5.1862 & 5.3904 & TST \\
\hline CHEMBL1520536 & 688239 & 4.8362 & 5.4945 & TRN \\
\hline CHEMBL1450298 & 688239 & 5.3362 & 5.4941 & TRN \\
\hline CHEMBL1299214 & 688239 & 5.3362 & 5.586 & TRN \\
\hline CHEMBL1525487 & 688239 & 4.8362 & 5.4181 & TRN \\
\hline CHEMBL1482992 & 688239 & 4.5362 & 5.4014 & TRN \\
\hline CHEMBL1472049 & 688239 & 5.7362 & 5.6688 & TRN \\
\hline CHEMBL1427284 & 688239 & 5.6862 & 5.4542 & TRN \\
\hline CHEMBL1427742 & 688239 & 4.5362 & 5.551 & TRN \\
\hline CHEMBL1337203 & 688239 & 5.1862 & 5.4295 & TRN \\
\hline CHEMBL 297784 & 688239 & 5.1862 & 5.598 & TST \\
\hline CHEMBL1491055 & 688239 & 8.0362 & 5.5559 & TST \\
\hline CHEMBL3190689 & 688239 & 5.4362 & 5.35 & TRN \\
\hline CHEMBL1354326 & 688239 & 5.1862 & 5.3205 & TST \\
\hline CHEMBL1342954 & 688239 & 4.6362 & 5.3291 & TRN \\
\hline CHEMBL1610125 & 688239 & 5.1862 & 5.4549 & TRN \\
\hline CHEMBL1368173 & 688239 & 4.5362 & 5.4655 & TRN \\
\hline CHEMBL 3211430 & 688239 & 4.6362 & 5.2545 & TST \\
\hline CHEMBL1519348 & 688239 & 5.7362 & 5.4947 & TRN \\
\hline CHEMBL1420229 & 688239 & 4.5362 & 5.5035 & TRN \\
\hline CHEMBL1595470 & 688239 & 7.1361 & 5.4665 & TRN \\
\hline CHEMBL1342663 & 688239 & 4.7862 & 5.427006 & 00000000005 \\
\hline CHEMBL1538808 & 688239 & 6.6362 & 5.3481 & TRN \\
\hline CHEMBL1580457 & 688239 & 5.1862 & 5.4104 & TRN \\
\hline CHEMBL1396239 & 688239 & 4.9362 & 5.581 & TRN \\
\hline CHEMBL1329592 & 688239 & 4.6862 & 5.527 & TRN \\
\hline CHEMBL1346605 & 688239 & 5.6362 & 5.4756 & TRN \\
\hline CHEMBL1606153 & 688239 & 4.5362 & 5.3927 & TST \\
\hline CHEMBL1566440 & 688239 & 5.3862 & 5.3969 & TRN \\
\hline CHEMBL3144909 & 688239 & 4.7362 & 5.5939 & TRN \\
\hline CHEMBL1473282 & 688239 & 5.1862 & 5.502999 & 9999999999 \\
\hline CHEMBL1540906 & 688239 & 4.6862 & 5.557 & TRN \\
\hline CHEMBL1384538 & 688239 & 4.4862 & 5.484 & TRN \\
\hline CHEMBL1590290 & 688239 & 4.4862 & 5.5972 & TRN \\
\hline CHEMBL1359857 & 688239 & 6.1862 & 5.6044 & TRN \\
\hline CHEMBL1483003 & 688239 & 4.7362 & 5.5052 & TRN \\
\hline CHEMBL1531848 & 688239 & 4.5862 & 5.4334 & TST \\
\hline CHEMBL1533833 & 688239 & 4.4862 & 5.5339 & TRN \\
\hline CHEMBL1424675 & 688239 & 6.8861 & 5.6315 & TRN \\
\hline CHEMBL1318145 & 688239 & 4.5362 & 5.3503 & TRN \\
\hline CHEMBL1570675 & 688239 & 5.8862 & 5.4486 & TST \\
\hline
\end{tabular}


Supplemental Table S2.txt

\begin{tabular}{|c|c|c|c|c|}
\hline & & & & \\
\hline AEMBL1392605 & 38239 & 9862 & & \\
\hline IEMBL1328581 & 8239 & 8362 & 5377 & \\
\hline AEMBL1566360 & 239 & 3362 & 5178 & \\
\hline & 239 & 862 & & \\
\hline AEMBL160 & 239 & 362 & & \\
\hline AEMBL1581830 & 88239 & 362 & 4541 & \\
\hline AEMBL1434242 & 88239 & 3863 & 394 & \\
\hline AEMBL1533857 & 239 & 362 & 34 & \\
\hline AEMBL1430 & 239 & 862 & & \\
\hline AEMBL1449081 & 239 & & & \\
\hline AEMBL1312477 & 688239 & 362 & 85 & \\
\hline AEMBL1343328 & 239 & 862 & & \\
\hline IEMBL15 & & 362 & & \\
\hline IEMBL 224343 & & 362 & & \\
\hline AEMBL1441948 & & & & \\
\hline AEMBL1409901 & 239 & 862 & & \\
\hline AEMBL1321563 & 39 & 362 & & \\
\hline EMBLIb/ & & 62 & & \\
\hline EMMBL1503861 & & & & \\
\hline AEMBL1417315 & & 62 & & \\
\hline AEMBL1515397 & & 862 & & \\
\hline AEMBL3212362 & & 62 & & \\
\hline AEMBL 141 & & 862 & & \\
\hline HEMBL1996 & & 62 & & \\
\hline AFMRI 1328 & & 62 & & \\
\hline AEMBL3197614 & & 362 & & \\
\hline AEMBL1546712 & & & & \\
\hline AEMBL1306528 & & 362 & 33 & \\
\hline HEMBL150 & & 71 & & \\
\hline-134 & & 62 & & \\
\hline HEMBL1455946 & & & & \\
\hline AEMBL1256719 & & & & \\
\hline HEMBL1368867 & & 862 & & \\
\hline HEMBL158 & & 62 & 09 & \\
\hline 153 & & & & \\
\hline AEMBL1448348 & & & 872 & \\
\hline AEMBL1410094 & & 362 & & \\
\hline IEMBL148 & & 362 & & \\
\hline 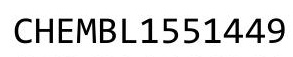 & & & & \\
\hline HEMBL136 & & & & 51 \\
\hline AEMBL1376965 & & 862 & 5465 & $\mathrm{RI}$ \\
\hline IEMBL1501058 & & 862 & & \\
\hline HEMBL1380 & & & & \\
\hline CHEMBL1364542 & & & & \\
\hline CHEMBL1412526 & & 362 & 91 & \\
\hline HEMBL1392087 & 8239 & 6.1362 & 5.4044 & \\
\hline HFMRI 1569176 & 688239 & 4.5362 & 5.3049 & \\
\hline
\end{tabular}

Page 2463 
Supplemental Table S2.txt

\begin{tabular}{|c|c|c|c|c|}
\hline 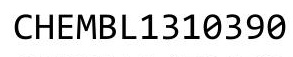 & & & & \\
\hline HEMBL1473109 & 38239 & 1862 & $\partial 1$ & \\
\hline AEMBL1334961 & 239 & 862 & 516 & \\
\hline & & 362 & & \\
\hline IEMBL 3194747 & & 862 & & \\
\hline AEMBL1469617 & 88239 & 362 & 5625 & \\
\hline AEMBL1553900 & 88239 & 361 & 1015 & \\
\hline AEMBL1390531 & & 363 & & \\
\hline IEMBL1 & 39 & 862 & & \\
\hline IEMBL1362990 & & & & \\
\hline AEMBL1352930 & 39 & 6 & & \\
\hline AEMBL1430308 & & 362 & & \\
\hline AEMBL3208596 & & 62 & & \\
\hline IEMBL1476916 & & 62 & & \\
\hline IEMBL1490865 & & & & \\
\hline AEMBL1434227 & & 362 & & \\
\hline AEMBL1450578 & & 366 & & \\
\hline IEMBL1371 & & 4. & & \\
\hline AEMBL1337 & & & & \\
\hline AEMBL1339785 & & & & \\
\hline AEMBL1509224 & & 862 & & \\
\hline IEMBL1381439 & & 862 & & \\
\hline AEMBL1459 & & 4 . & & \\
\hline AFMBI 137 & & & & \\
\hline 27 & & 62 & & \\
\hline AEMBL1343314 & & 62 & & \\
\hline EMBL15722 & & 62 & & \\
\hline EMBL1358 & & 62 & & \\
\hline 320 & & & & \\
\hline 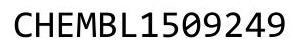 & & 62 & & \\
\hline AEMBL1388900 & & & & \\
\hline IEMBL1363915 & & 6 & & \\
\hline & & & & \\
\hline 1907 & & 52 & & \\
\hline & & & & \\
\hline AEMBL1530561 & & & & \\
\hline AEMBL1602827 & & 362 & 744 & \\
\hline & & & & \\
\hline 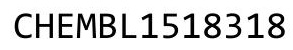 & & & & \\
\hline HEMBL 2001105 & & & & ST 1 \\
\hline IEMBL1560976 & & 362 & 39 & $\mathrm{~F}$ \\
\hline 3L3207853 & & 62 & & \\
\hline HEMBL1535462 & & & & \\
\hline HEMBL1566261 & & & & \\
\hline HEMBL159577 & & 4.7862 & 5293 & RI \\
\hline IEMBL1363300 & & 6.9363 & 027 & 17 \\
\hline 15024 & & & & \\
\hline HEMBL136184 & & & & \\
\hline
\end{tabular}


Supplemental Table S2.txt

\begin{tabular}{|c|c|c|c|c|c|}
\hline CHEMBL1560440 & 688239 & 4.6862 & 5.5214 & TST & \\
\hline CHEMBL1452482 & 688239 & 6.1362 & 5.3634 & TRN & \\
\hline CHEMBL1390141 & 688239 & 7.2865 & 5.5179 & TRN & \\
\hline CHEMBL602784 & 688239 & 5.4862 & 5.4993 & TRN & \\
\hline CHEMBL1341176 & 688239 & 7.6364 & 5.4679 & TRN & \\
\hline CHEMBL1346273 & 688239 & 5.1862 & 5.5021 & TRN & \\
\hline CHEMBL1365582 & 688239 & 6.1862 & 5.5587 & TRN & \\
\hline CHEMBL1529319 & 688239 & 5.0362 & 5.5368 & TRN & \\
\hline CHEMBL1352957 & 688239 & 7.4365 & 5.6551 & TST & \\
\hline CHEMBL1466665 & 688239 & 4.5862 & 5.5193 & TRN & \\
\hline CHEMBL1299916 & 688239 & 4.5362 & 5.4584 & TRN & \\
\hline CHEMBL3198678 & 688239 & 5.5362 & 5.2862 & TRN & \\
\hline CHEMBL1405268 & 688239 & 5.1862 & 5.508999 & 9999999995 & TR \\
\hline CHEMBL1566779 & 688239 & 4.5362 & 5.6543 & TRN & \\
\hline CHEMBL1541485 & 688239 & 6.8362 & 5.506 & TST & \\
\hline CHEMBL1543542 & 688239 & 4.5362 & 5.4126 & TRN & \\
\hline CHEMBL1339509 & 688239 & 4.5362 & 5.5928 & TST & \\
\hline CHEMBL1599665 & 688239 & 4.5362 & 5.447999 & 9999999995 & \\
\hline CHEMBL1970082 & 688239 & 5.3862 & 5.3773 & TRN & \\
\hline CHEMBL1560219 & 688239 & 4.8862 & 5.3696 & TST & \\
\hline CHEMBL1573692 & 688239 & 4.6862 & 5.467000 & 0000000005 & TM \\
\hline CHEMBL1594176 & 688239 & 4.4862 & 5.3998 & TRN & \\
\hline CHEMBL3212861 & 688239 & 4.5362 & 5.3493 & TRN & \\
\hline CHEMBL1339240 & 688239 & 7.2366 & 5.5274 & TRN & \\
\hline CHEMBL1449802 & 688239 & 5.8862 & 5.5512 & TRN & \\
\hline CHEMBL3191680 & 688239 & 5.8862 & 5.4681 & TRN & \\
\hline CHEMBL1575330 & 688239 & 8.3372 & 5.5955 & TRN & \\
\hline CHEMBL1357960 & 688239 & 5.3362 & 5.5025 & TRN & \\
\hline CHEMBL1382862 & 688239 & 4.7862 & 5.6219 & TST & \\
\hline CHEMBL1435954 & 688239 & 5.9862 & 5.4363 & TRN & \\
\hline CHEMBL1482637 & 688239 & 5.4362 & 5.3063 & TST & \\
\hline CHEMBL1322313 & 688239 & 6.0362 & 5.3725 & TST & \\
\hline CHEMBL1362219 & 688239 & 5.1862 & 5.5784 & TRN & \\
\hline CHEMBL1327860 & 688239 & 4.7862 & 5.4875 & TRN & \\
\hline CHEMBL1410810 & 688239 & 6.6362 & 5.5551 & TRN & \\
\hline CHEMBL1422640 & 688239 & 5.1362 & 5.4578 & TRN & \\
\hline CHEMBL1353987 & 688239 & 5.1862 & 5.5536 & TRN & \\
\hline CHEMBL1536351 & 688239 & 4.5362 & 5.4314 & TRN & \\
\hline CHEMBL1308097 & 688239 & 5.8362 & 5.4812 & TRN & \\
\hline CHEMBL1522783 & 688239 & 4.5362 & 5.3768 & TRN & \\
\hline CHEMBL1493114 & 688239 & 7.3862 & 5.4265 & TST & \\
\hline CHEMBL1385409 & 688239 & 6.7862 & 5.527 & TST & \\
\hline CHEMBL1407237 & 688239 & 4.6362 & 5.3392 & TST & \\
\hline CHEMBL1423514 & 688239 & 6.4362 & 5.3735 & TST & \\
\hline CHEMBL1433093 & 688239 & 4.8862 & 5.4795 & TRN & \\
\hline CHEMBL1392894 & 688239 & 4.5362 & 5.3347 & TST & \\
\hline CHEMBL 3210448 & 688239 & 8.28399 & 99999999 & 5.5472 & I \\
\hline CHEMBL1328579 & 688239 & 4.9362 & 5.4605 & TRN & \\
\hline
\end{tabular}




\begin{tabular}{|c|c|c|c|c|}
\hline & & & oplement & al $\mathrm{T}$ \\
\hline CHEMBL3197312 & 688239 & 4.4862 & 5.5422 & TST \\
\hline CHEMBL17784 & 688239 & 4.7362 & 5.5609 & TRN \\
\hline CHEMBL1610057 & 688239 & 4.5362 & 5.5432 & TRN \\
\hline CHEMBL1507343 & 688239 & 6.1362 & 5.4446 & TRN \\
\hline CHEMBL1470429 & 688239 & 6.0362 & 5.5337 & TST \\
\hline CHEMBL1444784 & 688239 & 6.3 & 5.5 & TRN \\
\hline CHEMBL1444065 & 688239 & 6.9363 & 5.527 & TRN \\
\hline CHEMBL1387325 & 688239 & 4.5362 & 5.4477 & TRN \\
\hline CHEMBL1540371 & 688239 & 4.6362 & 5.4865 & TST \\
\hline CHEMBL1362926 & 688239 & 5.0362 & 5.4986 & TST \\
\hline CHEMBL1460972 & 688239 & 4.5362 & 5.5419 & TRN \\
\hline CHEMBL1508437 & 688239 & 4.5362 & 5.3998 & TRN \\
\hline CHEMBL1558487 & 688239 & 5.7362 & 5.431 & TST \\
\hline CHEMBL1379098 & 688239 & 6.9363 & 5.4563 & TST \\
\hline CHEMBL1401883 & 688239 & 4.5362 & 5.5258 & TRN \\
\hline CHEMBL1475833 & 688239 & 4.6862 & 5.4096 & TRN \\
\hline CHEMBL1415746 & 688239 & 6.8861 & 5.6189 & TRN \\
\hline CHEMBL1308641 & 688239 & 8.3372 & 5.3825 & TRN \\
\hline CHEMBL1558817 & 688239 & 4.5362 & 5.4674 & TRN \\
\hline CHEMBL1326406 & 688239 & 6.8362 & 5.357 & TRN \\
\hline CHEMBL1324354 & 688239 & 6.9863 & 5.6078 & TRN \\
\hline CHEMBL1337993 & 688239 & 6.8861 & 5.6136 & TRN \\
\hline CHEMBL1309219 & 688239 & 4.7862 & 5.4915 & TRN \\
\hline CHEMBL1330021 & 688239 & 6.2362 & 5.495 & TRN \\
\hline CHEMBL1320440 & 688239 & 4.7362 & 5.5923 & TRN \\
\hline CHEMBL1485173 & 688239 & 6.3863 & 5.6135 & TRN \\
\hline CHEMBL1402376 & 688239 & 4.6362 & 5.5393 & TST \\
\hline CHEMBL1461401 & 688239 & 4.5362 & 5.5368 & TRN \\
\hline CHEMBL1514338 & 688239 & 6.8861 & 5.4773 & TRN \\
\hline CHEMBL1372070 & 688239 & 6.1362 & 5.4567 & TRN \\
\hline CHEMBL1380957 & 688239 & 5.7362 & 5.5614 & TRN \\
\hline CHEMBL1528795 & 688239 & 4.5362 & 5.3788 & TRN \\
\hline CHEMBL1349357 & 688239 & 5.6362 & 5.5733 & TRN \\
\hline CHEMBL1991329 & 688239 & 6.3863 & 5.513 & TRN \\
\hline CHEMBL1550602 & 688239 & 5.0362 & 5.4435 & TRN \\
\hline CHEMBL1347515 & 688239 & 5.0362 & 5.5148 & TRN \\
\hline CHEMBL1609992 & 688239 & 5.9862 & 5.5623 & TRN \\
\hline CHEMBL1384913 & 688239 & 4.5362 & 5.6145 & TRN \\
\hline CHEMBL1483005 & 688239 & 4.6362 & 5.4304 & TST \\
\hline CHEMBL1591791 & 688239 & 4.5362 & 5.3777 & TRN \\
\hline CHEMBL1324593 & 688239 & 5.0362 & 5.5248 & TRN \\
\hline CHEMBL1457512 & 688239 & 4.5862 & 5.5481 & TRN \\
\hline CHEMBL3214095 & 688239 & 5.4362 & 5.4892 & TRN \\
\hline CHEMBL1405138 & 688239 & 6.2362 & 5.4406 & TST \\
\hline CHEMBL1598772 & 688239 & 4.5362 & 5.4616 & TRN \\
\hline CHEMBL1321570 & 688239 & 6.1362 & 5.4673 & TRN \\
\hline CHEMBL1585641 & 688239 & 4.6362 & 5.3927 & TRN \\
\hline CHEMBL1504355 & 688239 & 8.2366 & 5.3879 & TRN \\
\hline
\end{tabular}


Supplemental Table S2.txt

\begin{tabular}{|c|c|c|c|c|}
\hline CHEMBL1548693 & 688239 & 5.7362 & 5.6208 & TRN \\
\hline CHEMBL3196162 & 688239 & 4.7362 & 5.3445 & TRN \\
\hline CHEMBL3196451 & 688239 & 4.6862 & 5.2667 & TRN \\
\hline CHEMBL1449281 & 688239 & 6.0362 & 5.4828 & TRN \\
\hline CHEMBL1517674 & 688239 & 5.1862 & 5.5025 & TST \\
\hline CHEMBL1562071 & 688239 & 5.1862 & 5.6789 & TST \\
\hline CHEMBL1545093 & 688239 & 4.5362 & 5.4318 & TRN \\
\hline CHEMBL1448899 & 688239 & 4.6362 & \multicolumn{2}{|c|}{5.492999999999999} \\
\hline CHEMBL501557 & 688239 & 5.6362 & 5.5639 & TRN \\
\hline CHEMBL1430884 & 688239 & 4.5362 & 5.4806 & TRN \\
\hline CHEMBL1475799 & 688239 & 5.1362 & 5.4736 & TRN \\
\hline CHEMBL1546090 & 688239 & 4.6362 & 5.4561 & TRN \\
\hline CHEMBL1593391 & 688239 & 4.5362 & 5.4539 & TRN \\
\hline CHEMBL1610704 & 688239 & 5.1362 & 5.4112 & TST \\
\hline CHEMBL1594513 & 688239 & 4.5362 & 5.5183 & TRN \\
\hline CHEMBL1432602 & 688239 & 5.4862 & 5.4049 & TRN \\
\hline CHEMBL1599990 & 688239 & 4.4862 & 5.4199 & TST \\
\hline CHEMBL1439187 & 688239 & 6.5363 & 5.5495 & TST \\
\hline CHEMBL1429433 & 688239 & 4.9862 & \multicolumn{2}{|c|}{5.507999999999999} \\
\hline CHEMBL1610463 & 688239 & 5.4362 & 5.3679 & TST \\
\hline CHEMBL1421292 & 688239 & 6.2362 & 5.6407 & TRN \\
\hline CHEMBL1342218 & 688239 & 5.5862 & 5.5801 & TRN \\
\hline CHEMBL1557307 & 688239 & 5.7862 & 5.4963 & TST \\
\hline CHEMBL 3208977 & 688239 & 4.6362 & 5.3547 & TST \\
\hline CHEMBL1347095 & 688239 & 5.0362 & 5.4809 & TST \\
\hline CHEMBL1991565 & 688239 & 5.0362 & 5.5672 & TRN \\
\hline CHEMBL1517434 & 688239 & 5.6362 & 5.4872 & TRN \\
\hline CHEMBL1305437 & 688239 & 4.5362 & 5.4519 & TST \\
\hline CHEMBL1379217 & 688239 & 6.0862 & 5.5848 & TST \\
\hline CHEMBL1348358 & 688239 & 6.2862 & 5.5943 & TRN \\
\hline CHEMBL 3207673 & 688239 & 6.9363 & 5.5748 & TRN \\
\hline CHEMBL1490433 & 688239 & 4.5362 & 5.6097 & TRN \\
\hline CHEMBL1440594 & 688239 & 5.3862 & 5.4903 & TRN \\
\hline CHEMBL1430582 & 688239 & 4.5362 & 5.4826 & TRN \\
\hline CHEMBL3190345 & 688239 & 6.0862 & 5.556 & TRN \\
\hline CHEMBL1554770 & 688239 & 4.5362 & 5.4573 & TRN \\
\hline CHEMBL1552798 & 688239 & 4.6862 & 5.4149 & TRN \\
\hline CHEMBL1377658 & 688239 & 6.4362 & 5.4417 & TRN \\
\hline CHEMBL1544597 & 688239 & 5.7362 & 5.7 & TRN \\
\hline CHEMBL1480593 & 688239 & 5.2862 & 5.419 & TRN \\
\hline CHEMBL1381608 & 688239 & 5.4362 & 5.5384 & TRN \\
\hline CHEMBL1546911 & 688239 & 4.4862 & 5.526 & TST \\
\hline CHEMBL1440659 & 688239 & 5.8862 & 5.474 & TRN \\
\hline CHEMBL1412992 & 688239 & 4.5362 & 5.3543 & TST \\
\hline CHEMBL1432014 & 688239 & 4.5362 & 5.4072 & TRN \\
\hline CHEMBL1391620 & 688239 & 6.2862 & 5.4753 & TRN \\
\hline CHEMBL1538088 & 688239 & 6.6362 & 5.5439 & TRN \\
\hline CHEMBL1526126 & 688239 & 5.7862 & 5.4865 & TST \\
\hline
\end{tabular}


Supplemental Table S2.txt

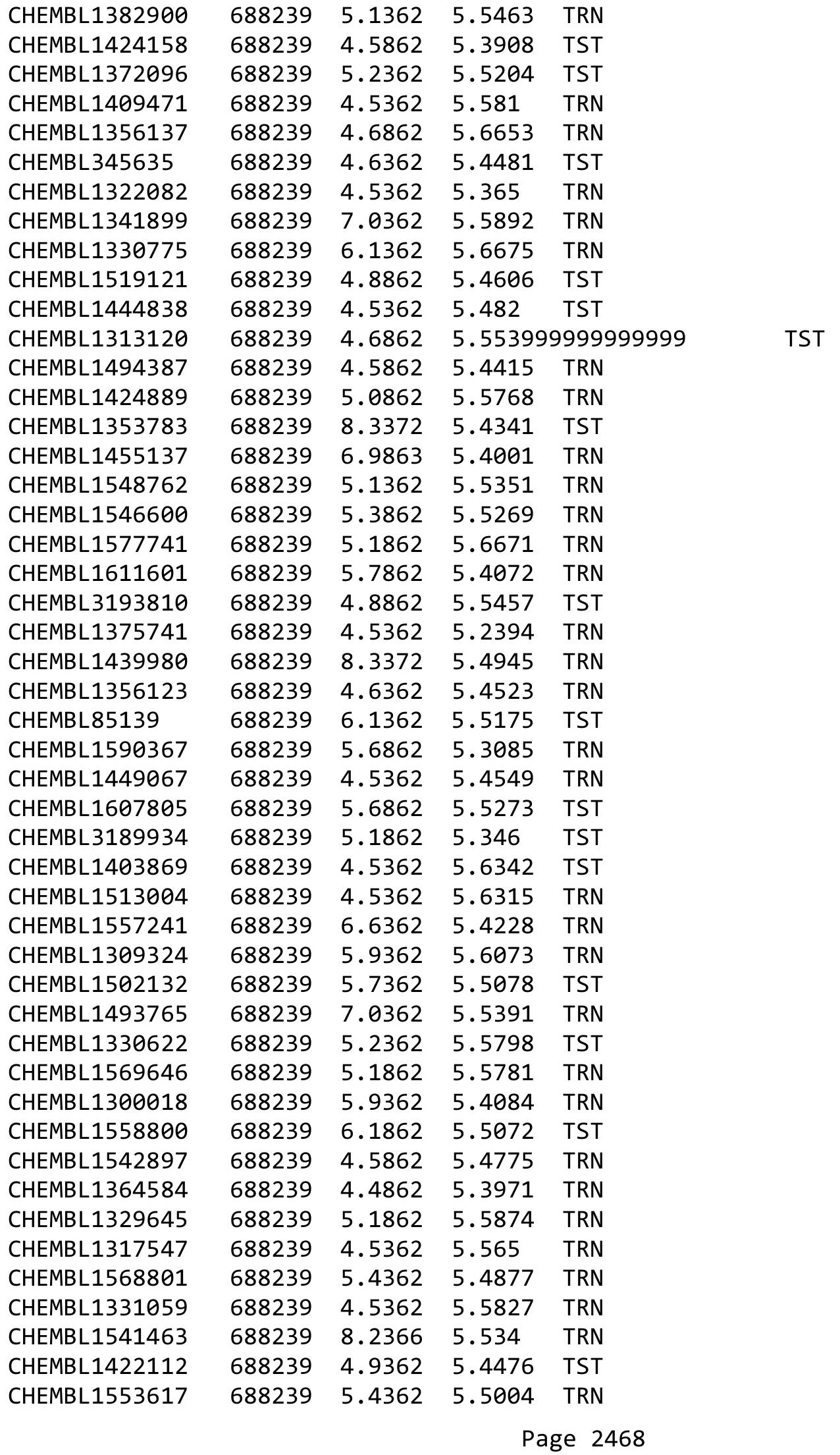


Supplemental Table S2.txt

\begin{tabular}{|c|c|c|c|c|}
\hline CHEMBL1558981 & 688239 & 4.6862 & 5.5616 & TRN \\
\hline CHEMBL1378199 & 688239 & 4.4862 & 5.5362 & TRN \\
\hline CHEMBL1569379 & 688239 & 4.5362 & 5.4223 & TRN \\
\hline CHEMBL1320887 & 688239 & 5.4862 & 5.4089 & TRN \\
\hline CHEMBL1533345 & 688239 & 8.3872 & 5.4498 & TRN \\
\hline CHEMBL407242 & 688239 & 4.5362 & 5.5703 & TRN \\
\hline CHEMBL1410971 & 688239 & 6.3362 & 5.6961 & TRN \\
\hline CHEMBL1329069 & 688239 & 4.6862 & 5.4248 & TST \\
\hline CHEMBL1307939 & 688239 & 5.9362 & 5.5854 & TRN \\
\hline CHEMBL1581947 & 688239 & 4.5362 & 5.4297 & TRN \\
\hline CHEMBL1517306 & 688239 & 4.7862 & 5.4887 & TRN \\
\hline CHEMBL1362298 & 688239 & 4.5362 & 5.5949 & TRN \\
\hline CHEMBL3210510 & 688239 & 8.2366 & 5.678999 & 9999999999 \\
\hline CHEMBL1341814 & 688239 & 5.8362 & 5.5458 & TRN \\
\hline CHEMBL1308226 & 688239 & 5.5362 & 5.6019 & TRN \\
\hline CHEMBL1602412 & 688239 & 7.0362 & 5.5024 & TRN \\
\hline CHEMBL1399470 & 688239 & 6.1862 & 5.5753 & TRN \\
\hline CHEMBL1436583 & 688239 & 4.5362 & 5.3574 & TRN \\
\hline CHEMBL1568555 & 688239 & 4.5362 & 5.2792 & TST \\
\hline CHEMBL1314805 & 688239 & 5.6862 & 5.4812 & TRN \\
\hline CHEMBL1330333 & 688239 & 6.0862 & 5.3213 & TST \\
\hline CHEMBL1328610 & 688239 & 6.0362 & 5.4198 & TRN \\
\hline CHEMBL1362660 & 688239 & 4.8362 & 5.5723 & TST \\
\hline CHEMBL1382418 & 688239 & 4.7362 & 5.4196 & TRN \\
\hline CHEMBL1499012 & 688239 & 4.7362 & 5.2685 & TST \\
\hline CHEMBL1547371 & 688239 & 5.0862 & 5.4854 & TRN \\
\hline CHEMBL1468054 & 688239 & 4.8362 & 5.4625 & TRN \\
\hline CHEMBL1306106 & 688239 & 4.5362 & 5.529 & TRN \\
\hline CHEMBL3208781 & 688239 & 4.5362 & 5.3538 & TST \\
\hline CHEMBL1519269 & 688239 & 6.2362 & 5.6843 & TRN \\
\hline CHEMBL3195267 & 688239 & 6.2862 & 5.452006 & 0000000001 \\
\hline CHEMBL1346010 & 688239 & 4.8362 & 5.4451 & TRN \\
\hline CHEMBL1352246 & 688239 & 4.5862 & 5.5143 & TRN \\
\hline CHEMBL1335723 & 688239 & 4.9362 & 5.6605 & TRN \\
\hline CHEMBL1439813 & 688239 & 4.5362 & 5.2584 & TRN \\
\hline CHEMBL1307565 & 688239 & 5.1862 & 5.5136 & TRN \\
\hline CHEMBL1338335 & 688239 & 7.1864 & 5.544 & TRN \\
\hline CHEMBL1305006 & 688239 & 6.8362 & 5.4832 & TST \\
\hline CHEMBL1420448 & 688239 & 4.5362 & 5.6016 & TST \\
\hline CHEMBL1401966 & 688239 & 4.5362 & 5.3571 & TRN \\
\hline CHEMBL1376801 & 688239 & 4.6362 & 5.4756 & TRN \\
\hline CHEMBL1605342 & 688239 & 5.1862 & 5.3645 & TST \\
\hline CHEMBL1466220 & 688239 & 5.1362 & 5.3897 & TST \\
\hline CHEMBL1539414 & 688239 & 5.7862 & 5.3754 & TRN \\
\hline CHEMBL1307769 & 688239 & 5.0862 & 5.4977 & TRN \\
\hline CHEMBL1361480 & 688239 & 6.2862 & 5.4442 & TST \\
\hline CHEMBL1411539 & 688239 & 6.9363 & 5.3886 & TRN \\
\hline CHEMBL3211559 & 688239 & 5.0362 & 5.5834 & TRN \\
\hline
\end{tabular}


Supplemental Table S2.txt

\begin{tabular}{|c|c|c|c|c|}
\hline CHEMBL1459845 & 688239 & 6.5862 & 5.4178 & TRN \\
\hline CHEMBL1539643 & 688239 & 5.7362 & 5.4513 & TRN \\
\hline CHEMBL1527285 & 688239 & 4.5362 & 5.4071 & TRN \\
\hline CHEMBL1362237 & 688239 & 4.4862 & 5.3933 & TST \\
\hline CHEMBL1308757 & 688239 & 4.6362 & 5.4371 & TRN \\
\hline CHEMBL1362757 & 688239 & 5.8362 & 5.5202 & TRN \\
\hline CHEMBL1543211 & 688239 & 8.3872 & 5.6229 & TRN \\
\hline CHEMBL1430027 & 688239 & 5.0362 & 5.5796 & TST \\
\hline CHEMBL1402465 & 688239 & 4.5362 & 5.5262 & TRN \\
\hline CHEMBL1382520 & 688239 & 6.8362 & 5.6225 & TRN \\
\hline CHEMBL1352803 & 688239 & 7.1361 & 5.6395 & TRN \\
\hline CHEMBL1391317 & 688239 & 4.6862 & 5.5971 & TRN \\
\hline CHEMBL1372172 & 688239 & 4.5362 & 5.6405 & TRN \\
\hline CHEMBL1370389 & 688239 & 5.0862 & 5.6756 & TRN \\
\hline CHEMBL1530723 & 688239 & 5.1862 & 5.3509 & TRN \\
\hline CHEMBL1300432 & 688239 & 5.2362 & 5.5842 & TRN \\
\hline CHEMBL1403085 & 688239 & 5.6362 & 5.3934 & TRN \\
\hline CHEMBL1601564 & 688239 & 6.1862 & 5.5627 & TRN \\
\hline CHEMBL1595890 & 688239 & 6.2862 & 5.688 & TRN \\
\hline CHEMBL1477779 & 688239 & 7.5361 & 5.6306 & TRN \\
\hline CHEMBL1456522 & 688239 & 6.0362 & 5.5739 & TRN \\
\hline CHEMBL1548389 & 688239 & 6.1362 & 5.5004 & TRN \\
\hline CHEMBL1552283 & 688239 & 5.6362 & 5.3869 & TST \\
\hline CHEMBL1324567 & 688239 & 5.2862 & 5.2638 & TRN \\
\hline CHEMBL1553918 & 688239 & 6.9363 & 5.4142 & TRN \\
\hline CHEMBL1319550 & 688239 & 5.4362 & 5.487999 & 99999999995 \\
\hline CHEMBL1337465 & 688239 & 4.7862 & 5.484 & TRN \\
\hline CHEMBL1359673 & 688239 & 5.4362 & 5.4059 & TRN \\
\hline CHEMBL1504934 & 688239 & 6.7361 & 5.6043 & TRN \\
\hline CHEMBL1423068 & 688239 & 4.5362 & 5.5497 & TRN \\
\hline CHEMBL1574143 & 688239 & 5.1862 & 5.4305 & TRN \\
\hline CHEMBL1437950 & 688239 & 5.2862 & 5.3613 & TRN \\
\hline CHEMBL1523886 & 688239 & 4.9362 & 5.5338 & TST \\
\hline CHEMBL1997376 & 688239 & 5.9362 & 5.4998 & TRN \\
\hline CHEMBL1577263 & 688239 & 4.8362 & 5.6081 & TRN \\
\hline CHEMBL1599412 & 688239 & 6.9363 & 5.5764 & TRN \\
\hline CHEMBL1494090 & 688239 & 4.5362 & 5.5344 & TRN \\
\hline CHEMBL1611922 & 688239 & 5.1362 & 5.5752 & TRN \\
\hline CHEMBL1551476 & 688239 & 6.8362 & 5.646 & TRN \\
\hline CHEMBL1327305 & 688239 & 4.7862 & 5.5596 & TST \\
\hline CHEMBL1486494 & 688239 & 4.5362 & 5.4156 & TST \\
\hline CHEMBL1309597 & 688239 & 5.3362 & 5.5125 & TRN \\
\hline CHEMBL1584787 & 688239 & 4.4362 & 5.4439 & TST \\
\hline CHEMBL1520664 & 688239 & 4.7862 & 5.3897 & TRN \\
\hline CHEMBL1400812 & 688239 & 6.2362 & 5.5816 & TRN \\
\hline CHEMBL1482367 & 688239 & 8.3372 & 5.4557 & TRN \\
\hline CHEMBL1387337 & 688239 & 5.6362 & 5.4507 & TRN \\
\hline CHEMBL1586469 & 688239 & 4.5362 & 5.331 & TRN \\
\hline
\end{tabular}


Supplemental Table S2.txt

\begin{tabular}{|c|c|c|c|c|c|}
\hline CHEMBL1501198 & 688239 & 4.5362 & 5.4776 & TRN & \\
\hline CHEMBL1466604 & 688239 & 4.8862 & 5.557 & TST & \\
\hline CHEMBL1423337 & 688239 & 4.5862 & 5.357 & TRN & \\
\hline CHEMBL1462693 & 688239 & 5.6862 & 5.4604 & TRN & \\
\hline CHEMBL1500566 & 688239 & 5.1862 & 5.532 & TRN & \\
\hline CHEMBL1432424 & 688239 & 6.8362 & 5.4359 & TRN & \\
\hline CHEMBL1333877 & 688239 & 5.3862 & 5.4542 & TST & \\
\hline CHEMBL1544623 & 688239 & 5.5862 & 5.5611 & TRN & \\
\hline CHEMBL1547250 & 688239 & 5.1362 & 5.4977 & TRN & \\
\hline CHEMBL1588939 & 688239 & 5.3862 & 5.3392 & TRN & \\
\hline CHEMBL494081 & 688239 & 6.5862 & 5.4853 & TRN & \\
\hline CHEMBL1563479 & 688239 & 4.6862 & 5.5461 & TRN & \\
\hline CHEMBL1363405 & 688239 & 5.4362 & 5.4185 & TRN & \\
\hline CHEMBL1583241 & 688239 & 5.5362 & 5.6424 & TRN & \\
\hline CHEMBL1559583 & 688239 & 4.7862 & 5.4943 & TRN & \\
\hline CHEMBL1301397 & 688239 & 7.0362 & 5.5256 & TST & \\
\hline CHEMBL1596826 & 688239 & 4.7862 & 5.4589 & TST & \\
\hline CHEMBL1377544 & 688239 & 4.5362 & 5.3349 & TRN & \\
\hline CHEMBL1446879 & 688239 & 8.28399 & 99999999 & 9 & 5.6263 \\
\hline CHEMBL1555561 & 688239 & 5.7362 & 5.5058 & TRN & \\
\hline CHEMBL1527145 & 688239 & 5.3362 & 5.5901 & TRN & \\
\hline CHEMBL1468773 & 688239 & 6.9863 & 5.3908 & TRN & \\
\hline CHEMBL1508259 & 688239 & 5.2362 & 5.4123 & TRN & \\
\hline CHEMBL1402031 & 688239 & 5.1862 & 5.5659 & TST & \\
\hline CHEMBL1557267 & 688239 & 6.3863 & 5.3791 & TRN & \\
\hline CHEMBL1590979 & 688239 & 4.6862 & 5.4621 & TRN & \\
\hline CHEMBL3190970 & 688239 & 4.7362 & 5.3218 & TST & \\
\hline CHEMBL1343276 & 688239 & 6.9363 & 5.4589 & TST & \\
\hline CHEMBL1458770 & 688239 & 5.0862 & 5.5016 & TRN & \\
\hline CHEMBL1388423 & 688239 & 5.1862 & 5.5433 & TRN & \\
\hline CHEMBL1536004 & 688239 & 5.1862 & 5.6224 & TST & \\
\hline CHEMBL1466078 & 688239 & 5.0362 & 5.3559 & TRN & \\
\hline CHEMBL1320378 & 688239 & 4.5362 & 5.4799 & TRN & \\
\hline CHEMBL1401201 & 688239 & 5.8862 & 5.6422 & TRN & \\
\hline CHEMBL1566235 & 688239 & 5.5362 & 5.4034 & TST & \\
\hline CHEMBL1574824 & 688239 & 5.3862 & 5.3991 & TRN & \\
\hline CHEMBL1486527 & 688239 & 5.8362 & 5.5221 & TRN & \\
\hline CHEMBL1527284 & 688239 & 6.7862 & 5.365 & TRN & \\
\hline CHEMBL1317919 & 688239 & 5.6362 & 5.3822 & TRN & \\
\hline CHEMBL1502912 & 688239 & 6.0862 & 5.6266 & TRN & \\
\hline CHEMBL1340984 & 688239 & 4.7862 & 5.6187 & TST & \\
\hline CHEMBL1361194 & 688239 & 5.4362 & 5.5837 & TST & \\
\hline CHEMBL1519449 & 688239 & 4.5362 & 5.4814 & TRN & \\
\hline CHEMBL1328808 & 688239 & 8.3372 & 5.5624 & TRN & \\
\hline CHEMBL1475961 & 688239 & 7.6861 & 5.4738 & TST & \\
\hline CHEMBL1324079 & 688239 & 4.5362 & 5.4734 & TRN & \\
\hline CHEMBL1438008 & 688239 & 4.5362 & 5.5423 & TRN & \\
\hline CHEMBL1513768 & 688239 & 6.9363 & 5.4478 & TRN & \\
\hline
\end{tabular}


Supplemental Table S2.txt

\begin{tabular}{|c|c|c|c|c|c|}
\hline CHEMBL1356523 & 688239 & 4.8362 & 5.4756 & TRN & \\
\hline CHEMBL1368556 & 688239 & 5.4362 & 5.4213 & TRN & \\
\hline CHEMBL1508252 & 688239 & 4.5362 & \multicolumn{2}{|c|}{5.4510000000000005} & TRN \\
\hline CHEMBL1337792 & 688239 & 5.7862 & 5.5014 & TST & \\
\hline CHEMBL1376423 & 688239 & 5.1862 & 5.3418 & TST & \\
\hline CHEMBL1497146 & 688239 & 4.7862 & 5.5413 & TST & \\
\hline CHEMBL1529499 & 688239 & 6.3863 & 5.6038 & TRN & \\
\hline CHEMBL1507366 & 688239 & 4.7362 & 5.599 & TRN & \\
\hline CHEMBL1579641 & 688239 & 5.1862 & 5.5675 & TST & \\
\hline CHEMBL1462916 & 688239 & 6.8362 & 5.4089 & TST & \\
\hline CHEMBL1375711 & 688239 & 4.5862 & 5.4711 & TRN & \\
\hline CHEMBL1529610 & 688239 & 5.1862 & 5.4705 & TRN & \\
\hline CHEMBL1520922 & 688239 & 4.7362 & 5.3792 & TRN & \\
\hline CHEMBL1392267 & 688239 & 5.0362 & 5.6366 & TST & \\
\hline CHEMBL1443406 & 688239 & 5.4362 & 5.5201 & TRN & \\
\hline CHEMBL1411629 & 688239 & 5.5862 & 5.4653 & TRN & \\
\hline CHEMBL1340094 & 688239 & 5.5362 & 5.5339 & TRN & \\
\hline CHEMBL1311548 & 688239 & 8.3372 & 5.5046 & TRN & \\
\hline CHEMBL1433828 & 688239 & 6.1862 & 5.4364 & TRN & \\
\hline CHEMBL1468680 & 688239 & 4.7362 & 5.3996 & TRN & \\
\hline CHEMBL1479701 & 688239 & 5.1862 & 5.3484 & TST & \\
\hline CHEMBL1577393 & 688239 & 4.4862 & 5.5778 & TRN & \\
\hline CHEMBL1464303 & 688239 & 4.6862 & 5.3748 & TRN & \\
\hline CHEMBL1351741 & 688239 & 4.5362 & \multicolumn{2}{|c|}{5.5760000000000005} & TRN \\
\hline CHEMBL1402926 & 688239 & 4.6362 & 5.484 & TRN & \\
\hline CHEMBL588038 & 688239 & 4.7362 & 5.3458 & TRN & \\
\hline CHEMBL1507339 & 688239 & 4.6862 & 5.4572 & TRN & \\
\hline CHEMBL1570245 & 688239 & 4.5362 & 5.4971 & TRN & \\
\hline CHEMBL1587332 & 688239 & 4.9 & 5.6248 & TRN & \\
\hline CHEMBL1457791 & 688239 & 5.1362 & 5.449 & TRN & \\
\hline CHEMBL1307081 & 688239 & 5.1862 & 5.4589 & TRN & \\
\hline CHEMBL1543792 & 688239 & 6.1862 & 5.6112 & TRN & \\
\hline CHEMBL1579628 & 688239 & 6.8362 & 5.5352 & TRN & \\
\hline CHEMBL1442389 & 688239 & 6.8861 & 5.5855 & TRN & \\
\hline CHEMBL1387020 & 688239 & 4.6862 & 5.5416 & TRN & \\
\hline CHEMBL3199817 & 688239 & 5.4862 & 5.4463 & TRN & \\
\hline CHEMBL1453280 & 688239 & 6.0862 & 5.4376 & TRN & \\
\hline CHEMBL1331911 & 688239 & 4.5362 & 5.391 & TRN & \\
\hline CHEMBL1511054 & 688239 & 5.1862 & 5.5013 & TRN & \\
\hline CHEMBL1530235 & 688239 & 4.6862 & \multicolumn{2}{|c|}{ 5.388999999999999 } & TRN \\
\hline CHEMBL1299710 & 688239 & 6.7361 & 5.4373 & TST & \\
\hline CHEMBL1589606 & 688239 & 6.3863 & 5.5503 & TRN & \\
\hline CHEMBL1302376 & 688239 & 4.9362 & 5.4349 & TRN & \\
\hline CHEMBL3190302 & 688239 & 4.9362 & 5.3795 & TRN & \\
\hline CHEMBL1525355 & 688239 & 8.3372 & 5.5474 & TRN & \\
\hline CHEMBL1550147 & 688239 & 4.5362 & 5.376 & TRN & \\
\hline CHEMBL1358021 & 688239 & 5.1862 & 5.5466 & TRN & \\
\hline CHEMBL1573043 & 688239 & 6.9863 & 5.388 & TRN & \\
\hline
\end{tabular}


Supplemental Table S2.txt

\begin{tabular}{|c|c|c|c|c|}
\hline CHEMBL1577452 & 688239 & 5.5362 & 5.5042 & TRN \\
\hline CHEMBL1327088 & 688239 & 5.4362 & 5.651 & TST \\
\hline CHEMBL1610008 & 688239 & 6.0862 & 5.4343 & TRN \\
\hline CHEMBL1492023 & 688239 & 4.5362 & 5.4367 & TST \\
\hline CHEMBL1605971 & 688239 & 5.7362 & 5.562 & TRN \\
\hline CHEMBL1330045 & 688239 & 4.6362 & 5.5156 & TST \\
\hline CHEMBL576208 & 688239 & 4.6862 & 5.4361 & TST \\
\hline CHEMBL1427262 & 688239 & 6.6362 & 5.5784 & TRN \\
\hline CHEMBL1408929 & 688239 & 4.6862 & 5.6204 & TRN \\
\hline CHEMBL1443088 & 688239 & 4.5362 & 5.3632 & TRN \\
\hline CHEMBL1409639 & 688239 & 4.5362 & 5.5514 & TRN \\
\hline CHEMBL1603761 & 688239 & 6.1362 & 5.6018 & TRN \\
\hline CHEMBL1328848 & 688239 & 8.3372 & 5.4495 & TST \\
\hline CHEMBL1554585 & 688239 & 5.1362 & 5.4743 & TRN \\
\hline CHEMBL1391772 & 688239 & 4.5862 & 5.353 & TST \\
\hline CHEMBL1329782 & 688239 & 6.1862 & 5.5412 & TRN \\
\hline CHEMBL1305178 & 688239 & 5.2862 & 5.5328 & TRN \\
\hline CHEMBL1480867 & 688239 & 4.9362 & 5.3438 & TRN \\
\hline CHEMBL3209410 & 688239 & 4.5362 & 5.3927 & TST \\
\hline CHEMBL1583732 & 688239 & 7.0362 & 5.6084 & TST \\
\hline CHEMBL1492729 & 688239 & 4.5862 & 5.6015 & TST \\
\hline CHEMBL1427142 & 688239 & 6.0862 & 5.3902 & TST \\
\hline CHEMBL1502068 & 688239 & 4.5362 & 5.3655 & TRN \\
\hline CHEMBL1364694 & 688239 & 4.9362 & 5.5361 & TRN \\
\hline CHEMBL1598079 & 688239 & 4.5362 & 5.6171 & TRN \\
\hline CHEMBL3198993 & 688239 & 6.8362 & 5.5594 & TST \\
\hline CHEMBL1421498 & 688239 & 4.6862 & 5.4699 & TRN \\
\hline CHEMBL1352613 & 688239 & 5.0362 & 5.3647 & TRN \\
\hline CHEMBL1464375 & 688239 & 4.6862 & 5.4282 & TRN \\
\hline CHEMBL1388171 & 688239 & 4.8862 & 5.5102 & TST \\
\hline CHEMBL1569070 & 688239 & 5.3862 & 5.5376 & TRN \\
\hline CHEMBL1428465 & 688239 & 5.3862 & 5.5314 & TRN \\
\hline CHEMBL1340414 & 688239 & 5.6862 & 5.5839 & TRN \\
\hline CHEMBL1383878 & 688239 & 4.7862 & 5.4544 & TST \\
\hline CHEMBL1608346 & 688239 & 4.9362 & 5.54799 & 9999999999 \\
\hline CHEMBL1576942 & 688239 & 4.4862 & 5.4374 & TST \\
\hline CHEMBL1456169 & 688239 & 6.1862 & 5.619 & TRN \\
\hline CHEMBL1447393 & 688239 & 6.1862 & 5.5928 & TRN \\
\hline CHEMBL1530754 & 688239 & 4.8862 & 5.4388 & TRN \\
\hline CHEMBL1604439 & 688239 & 6.2862 & 5.5361 & TRN \\
\hline CHEMBL1509751 & 688239 & 4.8862 & 5.5716 & TRN \\
\hline CHEMBL1565291 & 688239 & 4.5362 & 5.44600 & 0000000001 \\
\hline CHEMBL1313644 & 688239 & 5.5862 & 5.5127 & TRN \\
\hline CHEMBL1338689 & 688239 & 4.5362 & 5.6776 & TST \\
\hline CHEMBL1542792 & 688239 & 5.5362 & 5.5217 & TRN \\
\hline CHEMBL1512753 & 688239 & 5.1362 & 5.44 & TRN \\
\hline CHEMBL1369415 & 688239 & 4.5362 & 5.4785 & TRN \\
\hline CHEMBL1308335 & 688239 & 4.9862 & 5.3062 & TRN \\
\hline
\end{tabular}


Supplemental Table S2.txt

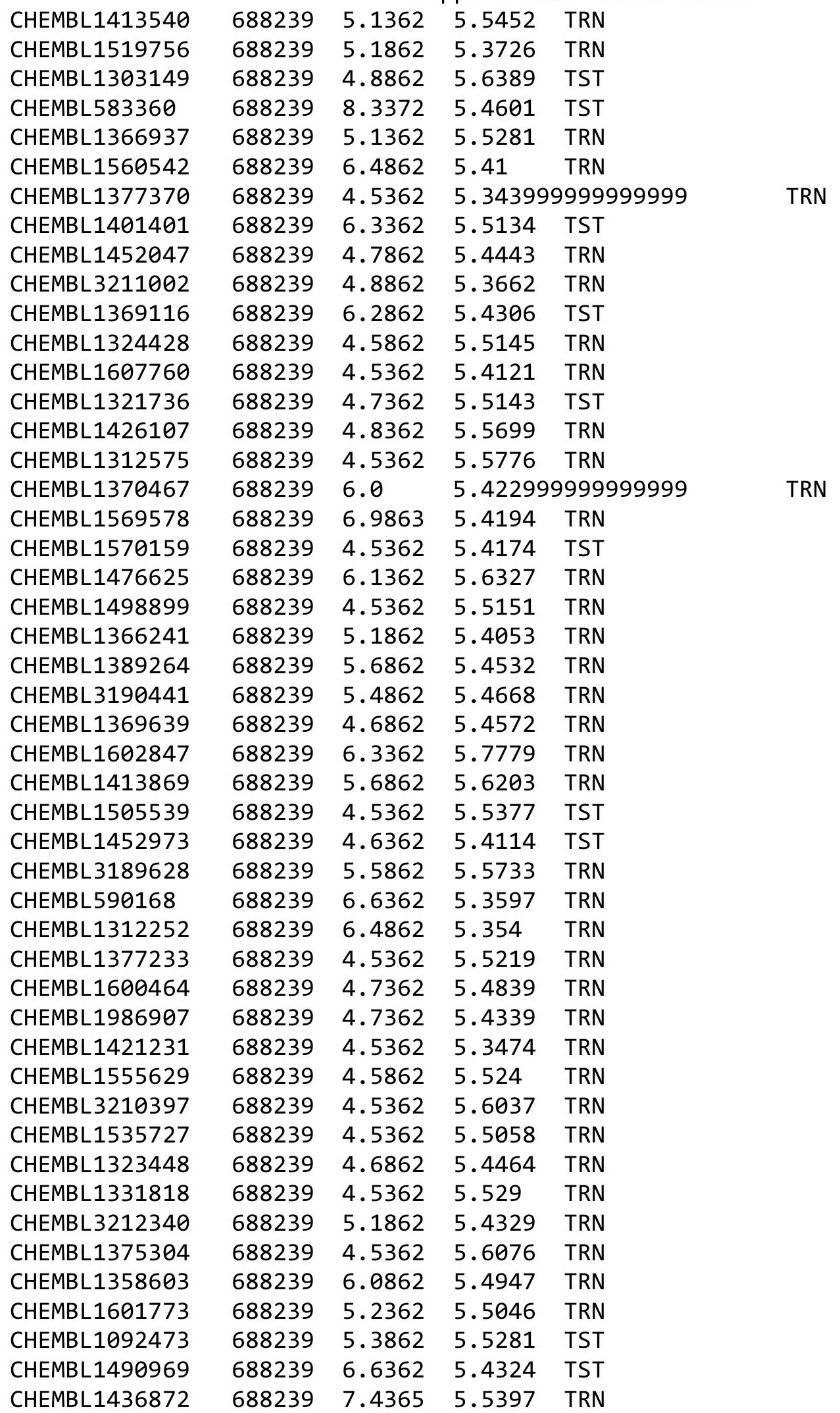

Page 2474 


\begin{tabular}{|c|c|c|c|c|}
\hline \multicolumn{5}{|c|}{ Supplementa] } \\
\hline HEITISLIJ98/48 & 80239 & 6.786 & 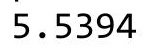 & \\
\hline HEMBL1454584 & 88239 & 2862 & 5.5193 & \\
\hline HEMBL154 & 8239 & & & \\
\hline IEMBL12 & & & & \\
\hline IEMBL13 & & & & \\
\hline HEMBL1610246 & 88239 & 1862 & 4348 & \\
\hline HEMBL13 & 88239 & .2366 & 5.4807 & \\
\hline HEMBL3 & & & 5306 & \\
\hline 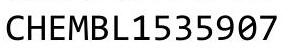 & & & 5.3756 & \\
\hline AEMBL & & & 5.4466 & \\
\hline HEMBL1 & 39 & 5362 & 5.4762 & \\
\hline 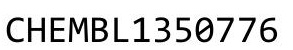 & & & & \\
\hline 7LIMIDL. & & & & \\
\hline 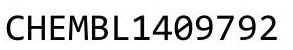 & & & & \\
\hline HEMBL: & & & 5.4908 & \\
\hline AFMBI & 39 & 362 & 556 & \\
\hline 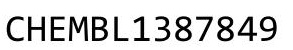 & & & & \\
\hline HEME & & & 05 & \\
\hline ק- & & & 908 & \\
\hline IFMDI & & & 5.528 & \\
\hline 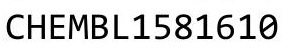 & & & & \\
\hline$=0$ & & & & \\
\hline 2 & & & & \\
\hline 6 & & & 59 & \\
\hline 8 & & & & \\
\hline 46 & & & & \\
\hline HEMBL: & & & & \\
\hline 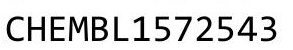 & & & & \\
\hline 4 & & & 73 & $1 \mathrm{~K}$ \\
\hline & & & & \\
\hline 79 & & & & \\
\hline HEMBL: & & & & \\
\hline 5 & & & & \\
\hline 0 & & 2 & 34 & \\
\hline & & & & \\
\hline HEMBL3 & & & & \\
\hline 0 & & & & \\
\hline 4 & & & 5. & \\
\hline 1 & & 2 & 4 & TRA \\
\hline HEMBL: & & & 5.6614 & $\mathrm{TR}$ \\
\hline MBL: & & & 5.4077 & \\
\hline CHEMBL & & & & $\cdots$ \\
\hline CHEMBL: & & & 5.4199 & $r R$ \\
\hline CHEMBL & & 62 & 5.34 & 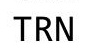 \\
\hline CHEMBL: & & 4.5362 & 5.4464 & ד \\
\hline CHEMBL & 9 & 5 . & 5.4635 & 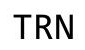 \\
\hline & & & 5.4834 & $\mathrm{TR}$ \\
\hline CHEMBL1427455 & 688239 & 5.1862 & 5.5377 & \\
\hline
\end{tabular}


Supplemental Table S2.txt

\begin{tabular}{|c|c|c|c|c|}
\hline 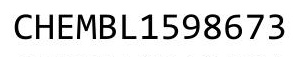 & & & & \\
\hline HEMBL 3212594 & 38239 & 862 & 3747 & \\
\hline AEMBL1415808 & 239 & 362 & 5619 & \\
\hline 855 & 39 & 862 & & \\
\hline IEMBL1447636 & 39 & 362 & & \\
\hline AEMBL1339812 & 88239 & 862 & 02 & \\
\hline AEMBL1333947 & 88239 & 362 & 3869 & \\
\hline HEMBL1364456 & & & & \\
\hline EMBL1473052 & 39 & 362 & & \\
\hline IEMBL1340996 & & & & \\
\hline AEMBL1489353 & 239 & 862 & & \\
\hline HEMBL1439974 & 39 & 863 & & \\
\hline AEMBL1368123 & & & & \\
\hline HEMBL3199898 & & & & \\
\hline HEMBL1532634 & & & & \\
\hline AEMBL1529739 & & 862 & & \\
\hline AEMBL1387104 & & 362 & & \\
\hline IEMBL134 & & & & \\
\hline IEM & & & & \\
\hline 467 & & & & \\
\hline AEMBL1373734 & & 362 & & \\
\hline AEMBL1363761 & & 62 & & \\
\hline IEMBL1368659 & & & & \\
\hline HFMBI 169 & & & & \\
\hline 1412531 & & 62 & & \\
\hline AEMBL1442367 & & 861 & & \\
\hline IEMBL3209052 & & & & \\
\hline EMBL1416078 & & 62 & & \\
\hline IFMRI $13 c$ & & & & \\
\hline (15MD150 156 & & 62 & & \\
\hline AEMBL1575292 & & & & \\
\hline HEMBL1428225 & & 362 & & \\
\hline & & & & \\
\hline 76 & & & & \\
\hline AEMBL1393727 & & & & RN \\
\hline AEMBL1410637 & & & & \\
\hline AEMBL1415232 & & 362 & & \\
\hline & & & & \\
\hline 次 & & & & \\
\hline HEMBL1454028 & & & & RN \\
\hline AEMBL3199288 & & 362 & & $\mathrm{R}$ \\
\hline AEMBL3211221 & & 62 & & -5 \\
\hline & & & & \\
\hline CHEMBL1417599 & & & & \\
\hline AEMBL1505184 & & & & RN \\
\hline MBL1420706 & & 362 & & \\
\hline 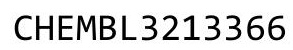 & & & & \\
\hline & & & & \\
\hline
\end{tabular}


Supplemental Table S2.txt

\begin{tabular}{|c|c|c|c|c|c|}
\hline CHEMBL1328267 & 688239 & 5.4362 & 5.5289 & TRN & \\
\hline CHEMBL1605810 & 688239 & 5.3862 & 5.3932 & TRN & \\
\hline CHEMBL1554225 & 688239 & 6.0862 & 5.3552 & TRN & \\
\hline CHEMBL1453249 & 688239 & 4.9862 & 5.6245 & TRN & \\
\hline CHEMBL 2007189 & 688239 & 6.5363 & 5.5149 & TST & \\
\hline CHEMBL3192410 & 688239 & 4.8362 & 5.5058 & TRN & \\
\hline CHEMBL1429767 & 688239 & 5.3862 & 5.5203 & TRN & \\
\hline CHEMBL1491400 & 688239 & 5.3362 & 5.5684 & TRN & \\
\hline CHEMBL1356047 & 688239 & 6.0362 & 5.5618 & TST & \\
\hline CHEMBL1474888 & 688239 & 5.9362 & 5.463999 & & TRN \\
\hline CHEMBL1504822 & 688239 & 4.7862 & 5.391 & TRN & \\
\hline CHEMBL1487221 & 688239 & 4.7362 & 5.4539 & TRN & \\
\hline CHEMBL1462419 & 688239 & 6.9863 & 5.5557 & TST & \\
\hline CHEMBL1343585 & 688239 & 7.2865 & 5.4628 & TRN & \\
\hline CHEMBL1463770 & 688239 & 5.4862 & 5.3389 & TRN & \\
\hline CHEMBL1309151 & 688239 & 7.5361 & 5.5277 & TRN & \\
\hline CHEMBL1491324 & 688239 & 4.5362 & 5.4073 & TRN & \\
\hline CHEMBL456586 & 688239 & 6.1362 & 5.4805 & TST & \\
\hline CHEMBL1583822 & 688239 & 4.6862 & 5.6764 & TST & \\
\hline CHEMBL3209731 & 688239 & 4.5362 & 5.4813 & TST & \\
\hline CHEMBL1421671 & 688239 & 5.9362 & 5.5385 & TRN & \\
\hline CHEMBL1441397 & 688239 & 6.3362 & 5.5075 & TRN & \\
\hline CHEMBL1555922 & 688239 & 8.3372 & 5.4114 & TRN & \\
\hline CHEMBL1327738 & 688239 & 4.5362 & 5.5441 & TST & \\
\hline CHEMBL1390250 & 688239 & 5.6362 & 5.5136 & TRN & \\
\hline CHEMBL3208749 & 688239 & 5.1862 & 5.5798 & TRN & \\
\hline CHEMBL1303363 & 688239 & 4.6362 & 5.5554 & TRN & \\
\hline CHEMBL1611340 & 688239 & 5.4862 & 5.4924 & TRN & \\
\hline CHEMBL3193095 & 688239 & 4.7862 & 5.2578 & TRN & \\
\hline CHEMBL1343760 & 688239 & 4.7862 & 5.4549 & TRN & \\
\hline CHEMBL1519576 & 688239 & 4.5362 & 5.4741 & TRN & \\
\hline CHEMBL1609365 & 688239 & 5.0862 & 5.553999 & 9999999999 & TST \\
\hline CHEMBL1450085 & 688239 & 6.7862 & 5.4944 & TRN & \\
\hline CHEMBL1593222 & 688239 & 5.3862 & 5.4145 & TST & \\
\hline CHEMBL1578528 & 688239 & 4.6362 & 5.4454 & TRN & \\
\hline CHEMBL1507129 & 688239 & 6.2862 & 5.3823 & TRN & \\
\hline CHEMBL3211730 & 688239 & 5.2862 & 5.3615 & TRN & \\
\hline CHEMBL1438092 & 688239 & 5.9862 & 5.521 & TRN & \\
\hline CHEMBL1406927 & 688239 & 5.9362 & 5.4666 & TST & \\
\hline CHEMBL11326 & 688239 & 4.5362 & 5.4878 & TRN & \\
\hline CHEMBL1503604 & 688239 & 5.0362 & 5.3432 & TST & \\
\hline CHEMBL1519439 & 688239 & 5.9862 & 5.6119 & TRN & \\
\hline CHEMBL1475418 & 688239 & 7.1864 & 5.555 & TRN & \\
\hline CHEMBL1466638 & 688239 & 7.5361 & 5.5798 & TRN & \\
\hline CHEMBL1348931 & 688239 & 4.7862 & 5.4224 & TRN & \\
\hline CHEMBL1485484 & 688239 & \multicolumn{3}{|c|}{8.283999999999999} & I \\
\hline CHEMBL1573104 & 688239 & 4.8362 & 5.4931 & TRN & \\
\hline CHEMBL1395689 & 688239 & 4.7862 & 5.4037 & TRN & \\
\hline
\end{tabular}


Supplemental Table S2.txt

\begin{tabular}{|c|c|c|c|c|c|}
\hline CHEMBL1421517 & 688239 & 5.2362 & 5.3239 & TRN & \\
\hline CHEMBL1562402 & 688239 & 5.0862 & 5.3809 & TRN & \\
\hline CHEMBL1471196 & 688239 & 5.1862 & 5.4368 & TRN & \\
\hline CHEMBL1478356 & 688239 & 4.5362 & 5.5529 & TRN & \\
\hline CHEMBL1338743 & 688239 & 4.7862 & 5.3348 & TRN & \\
\hline CHEMBL1493014 & 688239 & 5.4862 & 5.4337 & TRN & \\
\hline CHEMBL1364838 & 688239 & 8.3372 & 5.5605 & TRN & \\
\hline CHEMBL1551248 & 688239 & 5.4862 & 5.5766 & TST & \\
\hline CHEMBL1469502 & 688239 & 4.7362 & 5.5022 & TRN & \\
\hline CHEMBL1584905 & 688239 & 4.5362 & 5.5194 & TRN & \\
\hline CHEMBL3144916 & 688239 & 5.5362 & 5.5406 & TRN & \\
\hline CHEMBL1402461 & 688239 & 4.7862 & 5.4659 & TRN & \\
\hline CHEMBL1608639 & 688239 & 6.8861 & $5.61600 e$ & 00000000005 & TRN \\
\hline CHEMBL1495418 & 688239 & 5.4362 & 5.5834 & TRN & \\
\hline CHEMBL1574505 & 688239 & 5.4862 & 5.4678 & TST & \\
\hline CHEMBL1532980 & 688239 & 4.9862 & 5.4133 & TRN & \\
\hline CHEMBL1458605 & 688239 & 5.3362 & 5.4953 & TRN & \\
\hline CHEMBL1349684 & 688239 & 4.6862 & 5.6193 & TRN & \\
\hline CHEMBL1394133 & 688239 & 8.3872 & 5.5272 & TRN & \\
\hline CHEMBL1558379 & 688239 & 5.5362 & 5.4676 & TRN & \\
\hline CHEMBL1323249 & 688239 & 6.4862 & 5.5784 & TRN & \\
\hline CHEMBL1484385 & 688239 & 5.2862 & 5.582999 & 9999999999 & TRN \\
\hline CHEMBL1338061 & 688239 & 5.6862 & 5.3945 & TRN & \\
\hline CHEMBL1486062 & 688239 & 5.6862 & 5.412006 & 0000000001 & TRN \\
\hline CHEMBL1459563 & 688239 & 4.6862 & 5.5172 & TST & \\
\hline CHEMBL1604596 & 688239 & 4.5362 & 5.5744 & TRN & \\
\hline CHEMBL1440587 & 688239 & 5.1362 & 5.5406 & TRN & \\
\hline CHEMBL1330212 & 688239 & 4.6862 & 5.3883 & TRN & \\
\hline CHEMBL1313658 & 688239 & 8.3372 & 5.5409 & TRN & \\
\hline CHEMBL1387638 & 688239 & 5.5362 & 5.4967 & TRN & \\
\hline CHEMBL1584144 & 688239 & 5.8362 & 5.5166 & TRN & \\
\hline CHEMBL1398446 & 688239 & 4.5362 & 5.3999 & TRN & \\
\hline CHEMBL1374977 & 688239 & 7.2865 & 5.5427 & TRN & \\
\hline CHEMBL1468460 & 688239 & 5.9362 & 5.4778 & TRN & \\
\hline CHEMBL1508596 & 688239 & 6.9863 & 5.5498 & TRN & \\
\hline CHEMBL1299699 & 688239 & 4.6862 & 5.4801 & TRN & \\
\hline CHEMBL1974266 & 688239 & 4.4862 & 5.4481 & TST & \\
\hline CHEMBL1455874 & 688239 & 6.0862 & 5.6217 & TRN & \\
\hline CHEMBL1531122 & 688239 & 6.4362 & 5.4391 & TRN & \\
\hline CHEMBL3212708 & 688239 & 5.6862 & 5.2952 & TST & \\
\hline CHEMBL3198660 & 688239 & 4.5362 & 5.3745 & TRN & \\
\hline CHEMBL1379456 & 688239 & 5.1862 & 5.6831 & TRN & \\
\hline CHEMBL1568753 & 688239 & 4.8362 & 5.5802 & TRN & \\
\hline CHEMBL1609794 & 688239 & 5.1362 & 5.5979 & TST & \\
\hline CHEMBL1400360 & 688239 & 5.3862 & 5.3449 & TRN & \\
\hline CHEMBL1509524 & 688239 & 4.5362 & 5.4173 & TRN & \\
\hline CHEMBL1559538 & 688239 & 4.4862 & 5.3999 & TST & \\
\hline CHEMBL1336696 & 688239 & 5.4362 & 5.4629 & TST & \\
\hline
\end{tabular}


Supplemental Table S2.txt

\begin{tabular}{|c|c|c|c|c|c|c|}
\hline CHEMBL1374285 & 688239 & 4.7362 & 5.4968 & TST & & \\
\hline CHEMBL1459126 & 688239 & 4.4862 & 5.34 & TRN & & \\
\hline CHEMBL193872 & 688239 & 4.6362 & 5.3178 & TRN & & \\
\hline CHEMBL1432370 & 688239 & 8.2366 & 5.617006 & 000000006 & & TRN \\
\hline CHEMBL 3209472 & 688239 & 5.2862 & 5.4741 & TRN & & \\
\hline CHEMBL1598299 & 688239 & 5.3862 & 5.5326 & TST & & \\
\hline CHEMBL1389210 & 688239 & 5.0362 & 5.5054 & TRN & & \\
\hline CHEMBL1585179 & 688239 & 6.2862 & 5.4694 & TRN & & \\
\hline CHEMBL259388 & 688239 & 4.7362 & 5.4622 & TST & & \\
\hline CHEMBL1476475 & 688239 & 4.5362 & 5.3734 & TRN & & \\
\hline CHEMBL1470765 & 688239 & 5.1362 & 5.5721 & TRN & & \\
\hline CHEMBL1379049 & 688239 & 5.0362 & 5.5547 & TRN & & \\
\hline CHEMBL1594451 & 688239 & 4.8862 & 5.437 & TRN & & \\
\hline CHEMBL1478862 & 688239 & 5.4862 & 5.7381 & TRN & & \\
\hline CHEMBL1603102 & 688239 & 6.8362 & 5.4069 & TRN & & \\
\hline CHEMBL 3195827 & 688239 & 5.8862 & 5.4744 & TRN & & \\
\hline CHEMBL1592941 & 688239 & 5.3362 & 5.5577 & TRN & & \\
\hline CHEMBL1495143 & 688239 & 5.0862 & 5.5342 & TRN & & \\
\hline CHEMBL1578092 & 688239 & 4.5362 & 5.5366 & TRN & & \\
\hline CHEMBL1487997 & 688239 & 4.5362 & 5.5589 & TRN & & \\
\hline CHEMBL1390523 & 688239 & 5.1862 & 5.5926 & TRN & & \\
\hline CHEMBL493153 & 688239 & 4.8362 & 5.271 & TRN & & \\
\hline CHEMBL3199865 & 688239 & 4.5362 & 5.6354 & TRN & & \\
\hline CHEMBL1482862 & 688239 & 6.1862 & 5.5941 & TRN & & \\
\hline CHEMBL1390749 & 688239 & 4.5862 & 5.4343 & TRN & & \\
\hline CHEMBL1603141 & 688239 & 4.5362 & 5.496 & TRN & & \\
\hline CHEMBL1310552 & 688239 & 4.5362 & 5.2592 & TRN & & \\
\hline CHEMBL1457604 & 688239 & 8.3372 & 5.4478 & TRN & & \\
\hline CHEMBL1573623 & 688239 & 4.5862 & 5.5336 & TST & & \\
\hline CHEMBL1985103 & 688239 & 5.0362 & 5.511 & TRN & & \\
\hline CHEMBL1425875 & 688239 & 4.7362 & 5.3809 & TRN & & \\
\hline CHEMBL1490100 & 688239 & 5.0362 & 5.4942 & TRN & & \\
\hline CHEMBL1537786 & 688239 & 6.2362 & 5.4994 & TRN & & \\
\hline CHEMBL1312069 & 688239 & 6.6362 & 5.4911 & TRN & & \\
\hline CHEMBL1456129 & 688239 & 5.4362 & 5.6024 & TRN & & \\
\hline CHEMBL1519598 & 688239 & 5.1362 & 5.4418 & TRN & & \\
\hline CHEMBL1387216 & 688239 & 4.5362 & 5.5142 & TRN & & \\
\hline CHEMBL1460038 & 688239 & 5.4362 & 5.2148 & TRN & & \\
\hline CHEMBL1558921 & 688239 & 5.6862 & 5.3868 & TRN & & \\
\hline CHEMBL1593649 & 688239 & 4.9862 & 5.3465 & TRN & & \\
\hline CHEMBL1421693 & 688239 & 6.1362 & 5.3434 & TRN & & \\
\hline CHEMBL1559413 & 688239 & 6.5363 & 5.4619 & TRN & & \\
\hline CHEMBL1344900 & 688239 & 4.5362 & 5.4895 & TRN & & \\
\hline CHEMBL1385419 & 688239 & 5.0862 & 5.4854 & TST & & \\
\hline CHEMBL1308384 & 688239 & \multicolumn{3}{|c|}{ 8. 283999999999999} & 5.4005 & RIV \\
\hline CHEMBL1406015 & 688239 & 4.4862 & 5.5005 & TRN & & \\
\hline CHEMBL1522673 & 688239 & 5.1862 & 5.6164 & TST & & \\
\hline CHEMBL1559209 & 688239 & 5.1862 & 5.3597 & TRN & & \\
\hline
\end{tabular}

Page 2479 
Supplemental Table S2.txt

\begin{tabular}{|c|c|c|c|c|c|}
\hline CHEMBL3209187 & 688239 & 5.9362 & 5.4552 & TRN & \\
\hline CHEMBL1502326 & 688239 & 4.5362 & 5.7104 & TRN & \\
\hline CHEMBL1434297 & 688239 & 5.0362 & 5.5372 & TST & \\
\hline CHEMBL1471075 & 688239 & 4.7862 & 5.3982 & TST & \\
\hline CHEMBL 3145045 & 688239 & 4.8362 & 5.4737 & TRN & \\
\hline CHEMBL1428584 & 688239 & 5.7862 & 5.4641 & TRN & \\
\hline CHEMBL1415181 & 688239 & 5.7362 & 5.5661 & TRN & \\
\hline CHEMBL1598998 & 688239 & 4.5862 & 5.6407 & TRN & \\
\hline CHEMBL1535771 & 688239 & 4.6362 & 5.5036 & TRN & \\
\hline CHEMBL1364985 & 688239 & 5.9362 & 5.4953 & TST & \\
\hline CHEMBL1455228 & 688239 & 6.3863 & 5.4995 & TST & \\
\hline CHEMBL1348117 & 688239 & 6.3362 & 5.3675 & TST & \\
\hline CHEMBL1393420 & 688239 & 8.3372 & 5.404 & TST & \\
\hline CHEMBL1469484 & 688239 & 5.1862 & 5.5237 & TST & \\
\hline CHEMBL1329156 & 688239 & 4.5362 & 5.5073 & TRN & \\
\hline CHEMBL1570783 & 688239 & 4.6362 & 5.534 & TRN & \\
\hline CHEMBL1499851 & 688239 & 6.3362 & 5.4287 & TST & \\
\hline CHEMBL1436485 & 688239 & 4.7362 & 5.404 & TRN & \\
\hline CHEMBL1329180 & 688239 & 6.4862 & 5.4306 & TRN & \\
\hline CHEMBL1372298 & 688239 & 5.2862 & 5.6128 & TRN & \\
\hline CHEMBL 2369239 & 688239 & 5.0362 & 5.38 & TST & \\
\hline CHEMBL1345698 & 688239 & 5.4362 & 5.6416 & TRN & \\
\hline CHEMBL1399462 & 688239 & 5.8862 & 5.4008 & TRN & \\
\hline CHEMBL1593724 & 688239 & 4.7862 & 5.395 & TRN & \\
\hline CHEMBL1327870 & 688239 & 4.5362 & 5.3985 & TST & \\
\hline CHEMBL1446947 & 688239 & 5.1862 & 5.5361 & TRN & \\
\hline CHEMBL1556805 & 688239 & 5.9362 & 5.3448 & TRN & \\
\hline CHEMBL1325044 & 688239 & 4.5362 & 5.6374 & TRN & \\
\hline CHEMBL503375 & 688239 & 4.5362 & 5.4182 & TRN & \\
\hline CHEMBL1511867 & 688239 & 5.6362 & 5.4006 & TRN & \\
\hline CHEMBL1598771 & 688239 & 5.1862 & 5.5939 & TST & \\
\hline CHEMBL1459956 & 688239 & 6.2362 & 5.4257 & TST & \\
\hline CHEMBL1553028 & 688239 & 4.5362 & 5.218999 & 999999999 & TRN \\
\hline CHEMBL1605006 & 688239 & 6.1862 & 5.4595 & TRN & \\
\hline CHEMBL1463382 & 688239 & 5.3362 & 5.5397 & TRN & \\
\hline CHEMBL1381165 & 688239 & 4.5362 & 5.4617 & TRN & \\
\hline CHEMBL1314618 & 688239 & 5.1362 & 5.5753 & TRN & \\
\hline CHEMBL1318695 & 688239 & 4.5362 & 5.5922 & TRN & \\
\hline CHEMBL1589786 & 688239 & 5.9862 & 5.6046 & TRN & \\
\hline CHEMBL1312978 & 688239 & 4.5862 & 5.5555 & TRN & \\
\hline CHEMBL1224757 & 688239 & 4.8362 & 5.6199 & TRN & \\
\hline CHEMBL1389493 & 688239 & 4.7362 & 5.4963 & TRN & \\
\hline CHEMBL3211995 & 688239 & 6.7862 & 5.5098 & TRN & \\
\hline CHEMBL1524161 & 688239 & 6.1362 & 5.5529 & TRN & \\
\hline CHEMBL1561929 & 688239 & 5.7862 & 5.5498 & TRN & \\
\hline CHEMBL1492162 & 688239 & 4.4862 & 5.4956 & TRN & \\
\hline CHEMBL1440941 & 688239 & 5.5862 & 5.5316 & TRN & \\
\hline CHEMBL1599511 & 688239 & 6.1362 & 5.5699 & TRN & \\
\hline
\end{tabular}


Supplemental Table S2.txt

\begin{tabular}{|c|c|c|c|c|c|}
\hline CHEMBL1352160 & 688239 & 6.9863 & 5.5268 & TRN & \\
\hline CHEMBL1329270 & 688239 & 6.0362 & 5.3581 & TRN & \\
\hline CHEMBL1570938 & 688239 & 4.5362 & 5.5276 & TRN & \\
\hline CHEMBL1342073 & 688239 & 4.5862 & 5.5214 & TRN & \\
\hline CHEMBL1438152 & 688239 & 4.6362 & 5.3955 & TRN & \\
\hline CHEMBL1460967 & 688239 & 8.1871 & 5.5273 & TRN & \\
\hline CHEMBL1464570 & 688239 & 5.5362 & 5.4477 & TST & \\
\hline CHEMBL1403057 & 688239 & 6.1362 & 5.5649 & TST & \\
\hline CHEMBL1528973 & 688239 & 5.7862 & 5.3718 & TRN & \\
\hline CHEMBL3209935 & 688239 & 5.6862 & 5.4666 & TRN & \\
\hline CHEMBL1611828 & 688239 & 5.1862 & 5.5211 & TST & \\
\hline CHEMBL1985765 & 688239 & 5.7362 & 5.3955 & TRN & \\
\hline CHEMBL1330932 & 688239 & 6.0362 & 5.5557 & TRN & \\
\hline CHEMBL1595382 & 688239 & 5.7862 & 5.4573 & TRN & \\
\hline CHEMBL1392648 & 688239 & 4.4862 & 5.5074 & TRN & \\
\hline CHEMBL1587417 & 688239 & 4.5862 & 5.4672 & TRN & \\
\hline CHEMBL1303667 & 688239 & 4.4862 & 5.4501 & TRN & \\
\hline CHEMBL1434665 & 688239 & 4.6862 & 5.3114 & TRN & \\
\hline CHEMBL1479879 & 688239 & 4.7862 & 5.4862 & TST & \\
\hline CHEMBL1574698 & 688239 & 5.2362 & 5.5909 & TRN & \\
\hline CHEMBL1575749 & 688239 & 6.0362 & 5.54799 & 9999999999 & TRN \\
\hline CHEMBL1384684 & 688239 & 5.6362 & 5.4736 & TRN & \\
\hline CHEMBL1416681 & 688239 & 7.1361 & 5.5179 & TST & \\
\hline CHEMBL1421002 & 688239 & 4.5362 & 5.5371 & TRN & \\
\hline CHEMBL1600297 & 688239 & 5.4362 & 5.5275 & TST & \\
\hline CHEMBL1546005 & 688239 & 5.1362 & 5.5847 & TRN & \\
\hline CHEMBL1378631 & 688239 & 4.5362 & 5.5186 & TRN & \\
\hline CHEMBL1492941 & 688239 & 4.5362 & 5.3539 & TRN & \\
\hline CHEMBL1547462 & 688239 & 4.7862 & 5.3833 & TST & \\
\hline CHEMBL1344807 & 688239 & 6.5862 & 5.4304 & TST & \\
\hline CHEMBL1465539 & 688239 & 4.6862 & 5.5807 & TRN & \\
\hline CHEMBL1342849 & 688239 & 5.3362 & 5.4419 & TST & \\
\hline CHEMBL1538373 & 688239 & 6.9863 & 5.4451 & TST & \\
\hline CHEMBL1482346 & 688239 & 5.0362 & 5.3539 & TRN & \\
\hline CHEMBL1340587 & 688239 & 4.7862 & 5.5614 & TRN & \\
\hline CHEMBL1311712 & 688239 & 5.4362 & 5.4765 & TRN & \\
\hline CHEMBL1408726 & 688239 & 6.1362 & 5.5429 & TST & \\
\hline CHEMBL1367226 & 688239 & 6.4362 & 5.4348 & TRN & \\
\hline CHEMBL1414762 & 688239 & 4.6862 & 5.5164 & TST & \\
\hline CHEMBL1384416 & 688239 & 4.7362 & 5.4358 & TRN & \\
\hline CHEMBL1451146 & 688239 & 5.9362 & 5.4798 & TST & \\
\hline CHEMBL1526889 & 688239 & 6.0362 & 5.5213 & TRN & \\
\hline CHEMBL1550848 & 688239 & 5.1862 & 5.425 & TRN & \\
\hline CHEMBL1545853 & 688239 & 5.1862 & 5.4691 & TRN & \\
\hline CHEMBL1537744 & 688239 & 5.1862 & 5.5822 & TST & \\
\hline CHEMBL1611432 & 688239 & 6.2362 & 5.4457 & TRN & \\
\hline CHEMBL1321176 & 688239 & 6.2362 & 5.4651 & TRN & \\
\hline CHEMBL1431306 & 688239 & 6.7361 & 5.6615 & TRN & \\
\hline
\end{tabular}




\begin{tabular}{|c|c|c|c|c|c|c|}
\hline & & \multicolumn{5}{|c|}{ Supplemental Table S2.txt } \\
\hline CHEMBL1593886 & 688239 & 5.4862 & 5.6499 & TRN & & \\
\hline CHEMBL1568410 & 688239 & 5.0862 & 5.4853 & TRN & & \\
\hline CHEMBL1352108 & 688239 & 5.5862 & 5.5948 & TRN & & \\
\hline CHEMBL1327632 & 688239 & 7.5867 & 5.5569 & TST & & \\
\hline CHEMBL1453650 & 688239 & 8.28399 & 99999999 & 99 & 5.5569 & TRN \\
\hline CHEMBL1326896 & 688239 & 6.0862 & 5.7442 & TRN & & \\
\hline CHEMBL1364436 & 688239 & 4.85 & 5.4178 & TST & & \\
\hline CHEMBL1339274 & 688239 & 5.0362 & 5.5311 & TRN & & \\
\hline CHEMBL1478220 & 688239 & 4.5362 & 5.6355 & TRN & & \\
\hline CHEMBL1542870 & 688239 & 5.1862 & 5.619 & TST & & \\
\hline CHEMBL1585159 & 688239 & 8.3872 & 5.5645 & TRN & & \\
\hline CHEMBL1437338 & 688239 & 6.0862 & 5.5789 & TRN & & \\
\hline CHEMBL1379879 & 688239 & 6.1862 & 5.5588 & TRN & & \\
\hline CHEMBL1431678 & 688239 & 6.0862 & 5.4839 & TRN & & \\
\hline CHEMBL1522504 & 688239 & 5.5362 & 5.5366 & TRN & & \\
\hline CHEMBL1597879 & 688239 & 5.0 & 5.7214 & TRN & & \\
\hline CHEMBL1560175 & 688239 & 4.6862 & 5.4196 & TRN & & \\
\hline CHEMBL1325394 & 688239 & 5.7862 & 5.6062 & TRN & & \\
\hline CHEMBL1324662 & 688239 & 4.5362 & 5.4558 & TRN & & \\
\hline CHEMBL1392299 & 688239 & 6.1862 & 5.4892 & TST & & \\
\hline CHEMBL1340911 & 688239 & 5.1862 & 5.4818 & TRN & & \\
\hline CHEMBL1451478 & 688239 & 5.8862 & 5.4572 & TRN & & \\
\hline CHEMBL1505235 & 688239 & 5.1862 & 5.5001 & TRN & & \\
\hline CHEMBL 3212868 & 688239 & 4.6862 & 5.5409 & TRN & & \\
\hline CHEMBL1549689 & 688239 & 6.8861 & 5.4927 & TRN & & \\
\hline CHEMBL1382904 & 688239 & 4.7362 & 5.5847 & TRN & & \\
\hline CHEMBL1365126 & 688239 & 7.0362 & 5.5601 & TRN & & \\
\hline CHEMBL1334080 & 688239 & 5.8362 & 5.5732 & TRN & & \\
\hline CHEMBL1455460 & 688239 & 4.6862 & 5.3925 & TST & & \\
\hline CHEMBL1608980 & 688239 & 5.1362 & 5.6319 & TRN & & \\
\hline CHEMBL1400852 & 688239 & 4.8862 & 5.4987 & TRN & & \\
\hline CHEMBL1324446 & 688239 & 6.1362 & 5.5701 & TRN & & \\
\hline CHEMBL1465601 & 688239 & 5.7362 & 5.3388 & TRN & & \\
\hline CHEMBL1349939 & 688239 & 5.7362 & 5.5296 & TRN & & \\
\hline CHEMBL1603209 & 688239 & 5.4 & 5.4087 & TRN & & \\
\hline CHEMBL1299798 & 688239 & 7.2865 & 5.4705 & TRN & & \\
\hline CHEMBL1418015 & 688239 & 4.5862 & 5.5236 & TST & & \\
\hline CHEMBL1369090 & 688239 & 8.2366 & 5.6311 & TRN & & \\
\hline CHEMBL1407382 & 688239 & 6.9363 & 5.5028 & TRN & & \\
\hline CHEMBL1414106 & 688239 & 6.7862 & 5.4826 & TRN & & \\
\hline CHEMBL 3212570 & 688239 & 4.5362 & 5.4314 & TRN & & \\
\hline CHEMBL1527983 & 688239 & 8.3372 & 5.6194 & TRN & & \\
\hline CHEMBL1571442 & 688239 & 6.1862 & 5.534 & TRN & & \\
\hline CHEMBL1578545 & 688239 & 4.6362 & 5.5487 & TRN & & \\
\hline CHEMBL1570666 & 688239 & 6.0362 & 5.4777 & TRN & & \\
\hline CHEMBL1474993 & 688239 & 6.1862 & 5.4669 & TRN & & \\
\hline CHEMBL1573215 & 688239 & 6.7862 & 5.4908 & TRN & & \\
\hline CHEMBL1493504 & 688239 & 5.1862 & 5.3737 & TRN & & \\
\hline
\end{tabular}

Page 2482 
Supplemental Table S2.txt

\begin{tabular}{|c|c|c|c|c|}
\hline & & & & \\
\hline JEMBL14 & 38239 & 6.0862 & & \\
\hline IEMBL1597856 & 8239 & 862 & 928 & \\
\hline HEMBL1409781 & 239 & 362 & 186 & \\
\hline 506 & 239 & 362 & & \\
\hline IEMBL16 & 239 & 872 & 64 & \\
\hline AEMBL1409603 & 88239 & 862 & 709 & \\
\hline AEMBL1454643 & 88239 & 362 & 109 & \\
\hline AEMBL3192596 & 239 & 862 & & \\
\hline IEMBL145 & 239 & 362 & 23 & \\
\hline AEMBL1572841 & 39 & & & \\
\hline AEMBL1300735 & 688239 & 362 & 5337 & \\
\hline AEMBL1302684 & 239 & 362 & 96 & \\
\hline IEMBL1467 & & & & \\
\hline IEMBL153 & & & & \\
\hline HEMBL133 & & & & \\
\hline AEMBL1986081 & 239 & 862 & & \\
\hline AEMBL1368158 & & 62 & & \\
\hline IEMBL63 & & 62 & & \\
\hline JEMBL150 & & & & \\
\hline HEMBL137 & & 62 & & \\
\hline AEMBL1435059 & & 362 & & ST \\
\hline HEMBL 142 & & 62 & & \\
\hline IEMBL13 & & 61 & & SI \\
\hline AEMBL13 & & 62 & & ST \\
\hline JFMDI 11 & & 62 & & \\
\hline HEMBL152 & & & & RN \\
\hline AEMBL1609245 & & & & \\
\hline AEMBL131 & & 4 & & $\mathrm{RI}$ \\
\hline 31 & & 62 & & $\omega_{-1}+2$ \\
\hline 79 & & 62 & & . \\
\hline HEMBL1445849 & & & & RN \\
\hline AEMBL1572156 & & & & $\mathrm{RI}$ \\
\hline AEMBL160 & & & & S \\
\hline AEMBL14 & & 52 & & . \\
\hline 75 & & & & W \\
\hline AEMBL1534218 & & & & $\mathrm{R}$ \\
\hline AEMBL1341606 & & & & \\
\hline IEMBL15 & & & & RI \\
\hline תזי נחוזו & & & & \\
\hline & & & & $S T$ \\
\hline AEMBL1476247 & & 862 & 495 & RN \\
\hline-1569966 & & & & \\
\hline HEMBL132 & & & & \\
\hline HEMBL147 & & & & \\
\hline CHEMBL1417478 & & 4. & & RN \\
\hline AEMBL1364951 & 8239 & 4.5362 & 5.5107 & $T R$ \\
\hline HFMBI 1447760 & 688239 & 4.9362 & 5.4598 & \\
\hline
\end{tabular}




\begin{tabular}{|c|c|c|c|c|}
\hline & & & oplement & al $\mathrm{T}$ \\
\hline CHEMBL1456939 & 688239 & 5.4362 & 5.5266 & TRN \\
\hline CHEMBL1585792 & 688239 & 6.2362 & 5.5109 & TRN \\
\hline CHEMBL1576488 & 688239 & 4.9862 & 5.5698 & TST \\
\hline CHEMBL1376300 & 688239 & 4.8362 & 5.341 & TST \\
\hline CHEMBL1504654 & 688239 & 6.4362 & 5.6227 & TST \\
\hline CHEMBL1332898 & 688239 & 4.7862 & 5.5412 & TRN \\
\hline CHEMBL3198327 & 688239 & 5.7362 & 5.4551 & TRN \\
\hline CHEMBL3214587 & 688239 & 5.5862 & 5.4678 & TST \\
\hline CHEMBL1380637 & 688239 & 4.4862 & 5.4426 & TST \\
\hline CHEMBL1421989 & 688239 & 6.3863 & 5.4786 & TRN \\
\hline CHEMBL1582829 & 688239 & 6.1862 & 5.5373 & TRN \\
\hline CHEMBL1327112 & 688239 & 6.9863 & 5.5559 & TRN \\
\hline CHEMBL1587031 & 688239 & 4.8862 & 5.2773 & TST \\
\hline CHEMBL1372016 & 688239 & 6.1362 & 5.4849 & TRN \\
\hline CHEMBL1370608 & 688239 & 4.8862 & 5.5089 & TRN \\
\hline CHEMBL1569063 & 688239 & 4.5362 & 5.2399 & TRN \\
\hline CHEMBL1339355 & 688239 & 6.7862 & 5.4276 & TRN \\
\hline CHEMBL1563770 & 688239 & 6.5363 & 5.5131 & TRN \\
\hline CHEMBL2374046 & 688239 & 5.625 & 5.3641 & TRN \\
\hline CHEMBL1537878 & 688239 & 4.5362 & 5.4802 & TRN \\
\hline CHEMBL1409283 & 688239 & 4.5362 & 5.4455 & TST \\
\hline CHEMBL1422736 & 688239 & 5.1862 & 5.6293 & TST \\
\hline CHEMBL1391043 & 688239 & 5.3862 & 5.3175 & TST \\
\hline CHEMBL1536436 & 688239 & 4.5362 & 5.6685 & TRN \\
\hline CHEMBL1488483 & 688239 & 5.05 & 5.7621 & TST \\
\hline CHEMBL1439115 & 688239 & 5.6862 & 5.5218 & TRN \\
\hline CHEMBL1314069 & 688239 & 5.4862 & 5.2532 & TRN \\
\hline CHEMBL1611198 & 688239 & 4.8362 & 5.4484 & TRN \\
\hline CHEMBL1576723 & 688239 & 8.1871 & 5.4989 & TRN \\
\hline CHEMBL1357844 & 688239 & 5.3362 & 5.5979 & TRN \\
\hline CHEMBL1482940 & 688239 & 7.2366 & 5.5483 & TRN \\
\hline CHEMBL1416387 & 688239 & 8.2366 & 5.3558 & TRN \\
\hline CHEMBL3211309 & 688239 & 5.8862 & 5.5048 & TRN \\
\hline CHEMBL1497093 & 688239 & 4.7362 & 5.558 & TRN \\
\hline CHEMBL1418247 & 688239 & 6.2362 & 5.4213 & TRN \\
\hline CHEMBL1515303 & 688239 & 5.8362 & 5.6546 & TRN \\
\hline CHEMBL1395171 & 688239 & 6.0862 & 5.475 & TRN \\
\hline CHEMBL1522175 & 688239 & 4.7862 & 5.3832 & TST \\
\hline CHEMBL1560793 & 688239 & 5.4362 & 5.5649 & TRN \\
\hline CHEMBL1373581 & 688239 & 4.4862 & 5.5886 & TST \\
\hline CHEMBL1417166 & 688239 & 5.4362 & 5.4825 & TRN \\
\hline CHEMBL1540421 & 688239 & 5.4362 & 5.4611 & TST \\
\hline CHEMBL3210361 & 688239 & 4.5862 & 5.4954 & TRN \\
\hline CHEMBL1540808 & 688239 & 4.6 & 5.2744 & TRN \\
\hline CHEMBL1307696 & 688239 & 4.5862 & 5.3094 & TRN \\
\hline CHEMBL1417011 & 688239 & 6.2862 & 5.6157 & TRN \\
\hline CHEMBL1576249 & 688239 & 6.95 & 5.4568 & TRN \\
\hline CHEMBL266540 & 688239 & 6.1362 & 5.5293 & TST \\
\hline
\end{tabular}


Supplemental Table S2.txt

\begin{tabular}{|c|c|c|c|c|}
\hline CHEMBL1386629 & 688239 & 4.6862 & 5.5247 & TRN \\
\hline CHEMBL1477965 & 688239 & 5.9862 & 5.5086 & TST \\
\hline CHEMBL1612219 & 688239 & 5.5862 & 5.678 & TRN \\
\hline CHEMBL1597014 & 688239 & 5.5362 & 5.5555 & TRN \\
\hline CHEMBL1443104 & 688239 & 4.8362 & 5.49 & TRN \\
\hline CHEMBL1465438 & 688239 & 4.5862 & 5.3874 & TST \\
\hline CHEMBL1415738 & 688239 & 4.6362 & 5.5509 & TST \\
\hline CHEMBL1392449 & 688239 & 4.7862 & 5.5771 & TRN \\
\hline CHEMBL1406980 & 688239 & 4.7862 & 5.5343 & TRN \\
\hline CHEMBL3194615 & 688239 & 4.5362 & 5.5024 & TRN \\
\hline CHEMBL1431901 & 688239 & 5.0862 & 5.4406 & TRN \\
\hline CHEMBL1303873 & 688239 & 4.5862 & 5.504 & TST \\
\hline CHEMBL1605690 & 688239 & 5.3362 & 5.4662 & TRN \\
\hline CHEMBL523844 & 688239 & 6.1862 & 5.3732 & TST \\
\hline CHEMBL1613232 & 688239 & 5.3862 & 5.4148 & TRN \\
\hline CHEMBL1301031 & 688239 & 5.1862 & 5.3915 & TST \\
\hline CHEMBL1558707 & 688239 & 4.8862 & 5.5129 & TRN \\
\hline CHEMBL1546082 & 688239 & 6.8861 & 5.4001 & TRN \\
\hline CHEMBL1596716 & 688239 & 5.1362 & 5.4636 & TST \\
\hline CHEMBL1355430 & 688239 & 8.1871 & 5.3605 & TRN \\
\hline CHEMBL1398663 & 688239 & 4.5362 & 5.3772 & TST \\
\hline CHEMBL3193160 & 688239 & 5.3362 & 5.398 & TRN \\
\hline CHEMBL1344420 & 688239 & 4.5362 & 5.4692 & TRN \\
\hline CHEMBL3214281 & 688239 & 5.9862 & 5.4215 & TST \\
\hline CHEMBL3195149 & 688239 & 4.5362 & 5.4129 & TRN \\
\hline CHEMBL1595419 & 688239 & 5.8362 & 5.41200 & 0000000001 \\
\hline CHEMBL1482511 & 688239 & 4.5362 & 5.4713 & TRN \\
\hline CHEMBL1308904 & 688239 & 4.5362 & 5.3918 & TST \\
\hline CHEMBL1424906 & 688239 & 5.1862 & 5.6323 & TRN \\
\hline CHEMBL1507404 & 688239 & 4.5362 & 5.4644 & TST \\
\hline CHEMBL1548207 & 688239 & 4.6362 & 5.3425 & TRN \\
\hline CHEMBL1512287 & 688239 & 4.5362 & 5.5253 & TRN \\
\hline CHEMBL1454646 & 688239 & 4.8862 & 5.455 & TRN \\
\hline CHEMBL1509419 & 688239 & 6.0862 & 5.7757 & TRN \\
\hline CHEMBL1599067 & 688239 & 5.3362 & 5.3848 & TST \\
\hline CHEMBL1479416 & 688239 & 5.7362 & 5.4501 & TRN \\
\hline CHEMBL1418136 & 688239 & 6.5862 & 5.4873 & TRN \\
\hline CHEMBL1422008 & 688239 & 6.1362 & 5.6189 & TRN \\
\hline CHEMBL1362980 & 688239 & 6.9863 & 5.4203 & TRN \\
\hline CHEMBL1434919 & 688239 & 5.1362 & 5.4748 & TRN \\
\hline CHEMBL1549686 & 688239 & 4.5362 & 5.2842 & TST \\
\hline CHEMBL1542920 & 688239 & 4.5362 & 5.4432 & TST \\
\hline CHEMBL1514786 & 688239 & 4.7862 & 5.4636 & TRN \\
\hline CHEMBL1584615 & 688239 & 6.8861 & 5.5224 & TRN \\
\hline CHEMBL1345359 & 688239 & 5.9862 & 5.6785 & TRN \\
\hline CHEMBL1606955 & 688239 & 7.1864 & 5.6223 & TRN \\
\hline CHEMBL1341234 & 688239 & 4.8362 & 5.4507 & TRN \\
\hline CHEMBL1336445 & 688239 & 5.1862 & 5.4086 & TST \\
\hline
\end{tabular}


Supplemental Table S2.txt

\begin{tabular}{|c|c|c|c|c|}
\hline HEM & & & & \\
\hline HEMPI 1200014 & & .8362 & & \\
\hline & & & & \\
\hline AEMBL1 & & & & \\
\hline AEMBL1573463 & 8239 & & & \\
\hline HEMBL1559782 & 88239 & 362 & 6226 & \\
\hline HEMBL1426347 & 239 & 363 & & \\
\hline IFMBI 1525847 & & & & \\
\hline AEMBL1499403 & 239 & 362 & & \\
\hline HEMBL1598193 & 38239 & 862 & & \\
\hline HEMBL1570944 & 239 & 52 & & \\
\hline EMBL158 & 239 & & & \\
\hline IEMBL15 & & & & \\
\hline HEMBL1606724 & & 362 & & \\
\hline AEMBL1608217 & & & & \\
\hline AEMBL1329 & 39 & 52 & 55 & \\
\hline AEMBL154 & & & & \\
\hline HEMBL153 & & & & \\
\hline AEMBL1487980 & & & & \\
\hline IEMBL14 & & & & \\
\hline AEMBLIs & & & 17 & \\
\hline AEMBL14 & & & & \\
\hline HEMBL 33 & & & & \\
\hline 211 & & & & \\
\hline IEMBL 140 & & & & ras \\
\hline AEMBL13 & & & & RN \\
\hline AEMBL3] & & & & 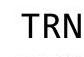 \\
\hline AFMBI 15 & & & & \\
\hline HEMBL1451011 & & & & 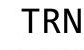 \\
\hline HEMBL1352646 & & & & r \\
\hline HEMBL1532 & & & & RN \\
\hline HEMBL1 & & & & KIV \\
\hline$\triangle 5 \mathrm{MPI} 11$ & & & & RN \\
\hline HEMBL1545236 & & & & is \\
\hline HEMBL1589433 & & & & TRN \\
\hline HEMBL1306 & & 51 & & ST \\
\hline HEMP I 1 & & & & RN \\
\hline HEMBL15 & & & & RN \\
\hline HEMBL1300178 & 88239 & & & TRN \\
\hline AEMBL15] & & & & ГRN \\
\hline HEMBL1490854 & & 62 & & \\
\hline CHEMBL1461982 & & & & RN \\
\hline HEMBL1387278 & & & & IST \\
\hline AEMBL1514474 & 39 & 862 & & TRN \\
\hline 5 & & & & $\mathrm{~N}$ \\
\hline HEMBL 14 & & & & \\
\hline CHEMBL1481 & & & 5.6002 & \\
\hline HEMBL1499423 & 688239 & 4.5862 & 5.4268 & RN \\
\hline
\end{tabular}

Page 2486 
Supplemental Table S2.txt

\begin{tabular}{|c|c|c|c|c|c|}
\hline CHEMBL1432879 & 688239 & 5.2862 & 5.425 & TRN & \\
\hline CHEMBL1372050 & 688239 & 4.4862 & 5.575 & TRN & \\
\hline CHEMBL1441935 & 688239 & 4.8862 & 5.5397 & TST & \\
\hline CHEMBL1412166 & 688239 & 5.1862 & 5.6133 & TST & \\
\hline CHEMBL1476734 & 688239 & 6.0862 & 5.4513 & TRN & \\
\hline CHEMBL1321216 & 688239 & 4.9862 & 5.5996 & TRN & \\
\hline CHEMBL3190495 & 688239 & 4.5362 & 5.4724 & TST & \\
\hline CHEMBL1595484 & 688239 & 4.6362 & 5.5438 & TRN & \\
\hline CHEMBL1419820 & 688239 & 5.1862 & \multicolumn{2}{|c|}{5.321000000000001} & TRN \\
\hline CHEMBL1365105 & 688239 & 5.1862 & 5.5132 & TRN & \\
\hline CHEMBL1439422 & 688239 & 5.4862 & 5.3813 & TRN & \\
\hline CHEMBL1406517 & 688239 & 5.1862 & 5.4191 & TRN & \\
\hline CHEMBL1603425 & 688239 & 4.5362 & 5.3591 & TRN & \\
\hline CHEMBL1498071 & 688239 & 4.5362 & 5.5995 & TST & \\
\hline CHEMBL1561581 & 688239 & 5.8862 & 5.5273 & TST & \\
\hline CHEMBL1549881 & 688239 & 5.9362 & 5.325 & TRN & \\
\hline CHEMBL1331416 & 688239 & 4.5362 & 5.5593 & TRN & \\
\hline CHEMBL1568790 & 688239 & 6.4862 & \multicolumn{2}{|c|}{5.582000000000001} & TST \\
\hline CHEMBL1488339 & 688239 & 5.1862 & 5.5101 & TRN & \\
\hline CHEMBL1256024 & 688239 & 5.1862 & 5.5685 & TST & \\
\hline CHEMBL1537674 & 688239 & 4.5362 & 5.7194 & TRN & \\
\hline CHEMBL1581279 & 688239 & 6.9863 & 5.4098 & TST & \\
\hline CHEMBL1321997 & 688239 & 5.3862 & 5.4474 & TST & \\
\hline CHEMBL1497457 & 688239 & 5.2362 & 5.4765 & TST & \\
\hline CHEMBL1711538 & 688239 & 5.3862 & 5.4246 & TRN & \\
\hline CHEMBL1308106 & 688239 & 5.0362 & 5.4445 & TRN & \\
\hline CHEMBL1534923 & 688239 & 5.5362 & 5.4142 & TRN & \\
\hline CHEMBL1455409 & 688239 & 4.7362 & 5.5327 & TRN & \\
\hline CHEMBL1480023 & 688239 & 5.1862 & 5.5733 & TRN & \\
\hline CHEMBL1370068 & 688239 & 4.5862 & 5.4771 & TST & \\
\hline CHEMBL1335556 & 688239 & 6.1362 & 5.5221 & TRN & \\
\hline CHEMBL1365668 & 688239 & 4.4862 & 5.4468 & TRN & \\
\hline CHEMBL1323811 & 688239 & 4.5362 & 5.6353 & TRN & \\
\hline CHEMBL1426878 & 688239 & 4.6362 & 5.5721 & TRN & \\
\hline CHEMBL1421153 & 688239 & 4.5362 & 5.4017 & TST & \\
\hline CHEMBL1595259 & 688239 & 4.7362 & 5.4847 & TST & \\
\hline CHEMBL1431628 & 688239 & 7.0362 & 5.6163 & TRN & \\
\hline CHEMBL1340848 & 688239 & 6.5363 & 5.5803 & TRN & \\
\hline CHEMBL1393392 & 688239 & 6.1362 & 5.6724 & TRN & \\
\hline CHEMBL1600048 & 688239 & 5.7862 & 5.4908 & TST & \\
\hline CHEMBL1499544 & 688239 & 4.7362 & 5.3365 & TST & \\
\hline CHEMBL1518287 & 688239 & 5.6362 & 5.4586 & TRN & \\
\hline CHEMBL1488087 & 688239 & 4.6862 & 5.4227 & TRN & \\
\hline CHEMBL1309315 & 688239 & 4.5362 & 5.4721 & TST & \\
\hline CHEMBL1485472 & 688239 & 5.1362 & 5.4236 & TRN & \\
\hline CHEMBL3214485 & 688239 & 7.6364 & 5.6444 & TST & \\
\hline CHEMBL1583687 & 688239 & 6.0362 & 5.6723 & TRN & \\
\hline CHEMBL1609685 & 688239 & 4.4862 & 5.4041 & TRN & \\
\hline
\end{tabular}


Supplemental Table S2.txt

\begin{tabular}{|c|c|c|c|c|}
\hline CHEMBL1382917 & 688239 & 5.0362 & 5.2873 & TRN \\
\hline CHEMBL1331725 & 688239 & 4.6362 & 5.4462 & TST \\
\hline CHEMBL1328200 & 688239 & 4.5362 & 5.5639 & TRN \\
\hline CHEMBL1372046 & 688239 & 4.5362 & 5.2966 & TST \\
\hline CHEMBL1496667 & 688239 & 5.6362 & 5.6327 & TRN \\
\hline CHEMBL1402252 & 688239 & 5.1862 & \multicolumn{2}{|c|}{5.507999999999999} \\
\hline CHEMBL1473108 & 688239 & 4.7862 & 5.4109 & TRN \\
\hline CHEMBL1494554 & 688239 & 5.1362 & 5.5733 & TRN \\
\hline CHEMBL1344693 & 688239 & 8.3372 & \multicolumn{2}{|c|}{5.377999999999999} \\
\hline CHEMBL1316247 & 688239 & 4.6362 & 5.515 & TRN \\
\hline CHEMBL1519277 & 688239 & 5.4862 & 5.4707 & TRN \\
\hline CHEMBL1573036 & 688239 & 6.9863 & 5.3951 & TRN \\
\hline CHEMBL3198221 & 688239 & 7.0862 & 5.6946 & TRN \\
\hline CHEMBL1489899 & 688239 & 4.5862 & 5.5247 & TST \\
\hline CHEMBL1570769 & 688239 & 4.6862 & 5.4229 & TRN \\
\hline CHEMBL1409157 & 688239 & 5.9362 & 5.4904 & TRN \\
\hline CHEMBL1378152 & 688239 & 5.4362 & \multicolumn{2}{|c|}{5.656000000000001} \\
\hline CHEMBL1505144 & 688239 & 6.9863 & 5.5522 & TST \\
\hline CHEMBL1446343 & 688239 & 4.5362 & 5.3365 & TRN \\
\hline CHEMBL1510013 & 688239 & 4.5862 & 5.4716 & TRN \\
\hline CHEMBL 3182828 & 688239 & 5.8362 & 5.4378 & TRN \\
\hline CHEMBL3190156 & 688239 & 4.5362 & 5.4026 & TST \\
\hline CHEMBL1434533 & 688239 & 6.2862 & 5.4896 & TRN \\
\hline CHEMBL1522749 & 688239 & 5.1362 & 5.5386 & TRN \\
\hline CHEMBL1449336 & 688239 & 4.7862 & 5.3557 & TST \\
\hline CHEMBL1540552 & 688239 & 4.7362 & \multicolumn{2}{|c|}{5.4110000000000005} \\
\hline CHEMBL1350342 & 688239 & 4.5362 & 5.407 & TRN \\
\hline CHEMBL1482817 & 688239 & 4.6862 & 5.6369 & TRN \\
\hline CHEMBL1559238 & 688239 & 5.7362 & 5.5318 & TRN \\
\hline CHEMBL1599018 & 688239 & 4.5362 & 5.3634 & TST \\
\hline CHEMBL1598992 & 688239 & 5.9362 & 5.5346 & TRN \\
\hline CHEMBL1541658 & 688239 & 5.3862 & 5.6098 & TRN \\
\hline CHEMBL1463035 & 688239 & 5.9862 & 5.3916 & TRN \\
\hline CHEMBL1452719 & 688239 & 4.5362 & \multicolumn{2}{|c|}{5.372000000000001} \\
\hline CHEMBL1548476 & 688239 & 5.8862 & 5.4663 & TRN \\
\hline CHEMBL1408456 & 688239 & 5.1862 & 5.5051 & TRN \\
\hline CHEMBL1381583 & 688239 & 4.5362 & 5.6455 & TRN \\
\hline CHEMBL1420131 & 688239 & 6.0862 & 5.5471 & TRN \\
\hline CHEMBL1409553 & 688239 & 5.6362 & 5.5774 & TRN \\
\hline CHEMBL1541425 & 688239 & 5.6362 & 5.4623 & TRN \\
\hline CHEMBL3211908 & 688239 & 5.0862 & 5.4922 & TRN \\
\hline CHEMBL1335807 & 688239 & 4.5362 & 5.4716 & TRN \\
\hline CHEMBL1425577 & 688239 & 5.3362 & 5.5537 & TST \\
\hline CHEMBL1349234 & 688239 & 5.1862 & 5.5914 & TRN \\
\hline CHEMBL1387188 & 688239 & 4.6862 & 5.4271 & TRN \\
\hline CHEMBL3207297 & 688239 & 4.8362 & 5.4301 & TRN \\
\hline CHEMBL1390528 & 688239 & 5.1862 & 5.3736 & TRN \\
\hline CHEMBL1387048 & 688239 & 5.1862 & 5.4867 & TST \\
\hline
\end{tabular}


Supplemental Table S2.txt

\begin{tabular}{|c|c|c|c|c|}
\hline 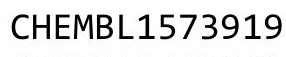 & & 862 & & \\
\hline HEMBL1449161 & 88239 & 5362 & 5.6665 & $\pi$ \\
\hline HEMBL1466864 & 39 & & & \\
\hline & & & & \\
\hline AEMBL13 & & & & \\
\hline AEMBL1392859 & 88239 & 2862 & .3704 & \\
\hline HEMBL1381884 & 88239 & .3372 & .5701 & \\
\hline HEMBL15 & 39 & & & \\
\hline AEMBL14 & & & & \\
\hline AEMBL16 & & & & \\
\hline HEMBL3199864 & 88239 & .1862 & .3369 & \\
\hline HEMBL1385713 & 88239 & 1362 & .5839 & \\
\hline HEMBL1603070 & 39 & 62 & 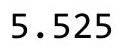 & \\
\hline HEMBL15 & & & & \\
\hline HEMBL14 & & & & \\
\hline HEMBL1334038 & 88239 & 862 & 5.4481 & \\
\hline HEMBL1456140 & & 62 & & \\
\hline HEMBL14 & 39 & & 66 & \\
\hline 414 & & & & \\
\hline AEMBL13 & & & & \\
\hline HEMBL1518605 & & 362 & & \\
\hline AEMBL1548249 & & & & \\
\hline HEMBL14 & 39 & & 66 & \\
\hline 252 & & & & \\
\hline 193 & & & & \\
\hline 151 & & & & \\
\hline AEMBL1413363 & & & & Iv \\
\hline HEMBL15 & & & & \\
\hline HEN & & & & KIV \\
\hline 877 & & & & RN \\
\hline JEMBL15 & & & & IRN \\
\hline AEMBL1312772 & & & 01 & IS \\
\hline AEMBL3 & & & & ST \\
\hline 0 & & & & RN \\
\hline 59 & & & & $\mathrm{RN}$ \\
\hline AEMBL1562125 & & & & IR \\
\hline AEMBL1332111 & & & & ST \\
\hline 1 & & & & RN \\
\hline ה 11 & & & & RIV \\
\hline HEMBL13 & & & 26 & ST \\
\hline AEMBL1483171 & & 62 & 883 & RN \\
\hline AEMBL13 & & & & \\
\hline & & & & \\
\hline HEMBL14 & & & & \\
\hline HEMBL14 & & & 512 & ST \\
\hline IEMBL1605558 & & & 77 & RN \\
\hline רי 12 & & & & \\
\hline 1919 & 688239 & 4.9362 & & \\
\hline
\end{tabular}


Supplemental Table S2.txt

\begin{tabular}{|c|c|c|c|c|}
\hline & & & & \\
\hline AEMBL 14 & 8239 & 6862 & 6053 & \\
\hline IEMBL1372285 & 8239 & 362 & 199 & \\
\hline AEMBL1385665 & 3239 & 3862 & 441 & \\
\hline IEMBL1590402 & 239 & 862 & 685 & \\
\hline IEMBL1319678 & 239 & 862 & 984 & \\
\hline AEMBL1571308 & 88239 & 362 & 5145 & \\
\hline AEMBL1362614 & 88239 & 362 & 1923 & \\
\hline AEMBL1548694 & 239 & 871 & 4702 & \\
\hline EMBL1481870 & 239 & 362 & 331 & \\
\hline AEMBL1439522 & & & & \\
\hline AEMBL1369734 & 688239 & 362 & 4115 & \\
\hline AEMBL1337485 & 239 & 362 & 397 & \\
\hline IEMBL1599077 & & 372 & 955 & \\
\hline IEMBL1303434 & & 62 & 87 & \\
\hline AEMBL1601692 & & & & \\
\hline AEMBL1430640 & 239 & 362 & 762 & \\
\hline AEMBL1413368 & & 862 & 37 & \\
\hline IEMBL1606016 & & 62 & 79 & \\
\hline IEMBL134 & & & 27 & \\
\hline AEMBL1315946 & & & 503 & \\
\hline AEMBL3207967 & & 862 & & \\
\hline AEMBL1505255 & & 62 & & \\
\hline IEMBL14 & & 62 & 82 & \\
\hline EMBL15 & & 52 & & \\
\hline AFMRI 15 & & 62 & 83 & \\
\hline AEMBL1333923 & & 863 & & \\
\hline AEMBL1579502 & & & & \\
\hline AEMBL1440300 & & 52 & 55 & \\
\hline 203 & & 62 & 71 & \\
\hline 652 & & 62 & & \\
\hline AEMBL1522555 & & & & \\
\hline AEMBL1341029 & & & & \\
\hline IEMBL1209369 & & 362 & 51 & \\
\hline HEMBL 14 & & 61 & 96 & \\
\hline 392 & & & & \\
\hline AEMBL1422213 & & & 861 & \\
\hline AEMBL1712384 & & & 658 & \\
\hline EMBL14C & & & & \\
\hline ריתובו & & & 19 & \\
\hline 994 & & & & \\
\hline AEMBL1317305 & & 862 & 1424 & $R$ \\
\hline AEMBL149 & & & & \\
\hline HEMBL150 & & & & \\
\hline HEMBL1392230 & & & & \\
\hline CHEMBL1447669 & & 362 & 732 & \\
\hline AEMBL1607357 & 38239 & 4.7862 & 5.4835 & \\
\hline HFMBI 1581351 & 688239 & 6.2362 & 5.4808 & \\
\hline
\end{tabular}

Page 2490 
Supplemental Table S2.txt

\begin{tabular}{|c|c|c|c|c|}
\hline CHEMBL1369948 & 688239 & 5.3362 & 5.5661 & TRN \\
\hline CHEMBL1373962 & 688239 & 4.5362 & 5.4779 & TRN \\
\hline CHEMBL3197070 & 688239 & 5.1862 & 5.5115 & TRN \\
\hline CHEMBL1469148 & 688239 & 5.6362 & 5.4373 & TST \\
\hline CHEMBL1497075 & 688239 & 7.0362 & 5.3283 & TRN \\
\hline CHEMBL1596554 & 688239 & 4.4862 & 5.5794 & TRN \\
\hline CHEMBL1332789 & 688239 & 4.6362 & 5.3328 & TRN \\
\hline CHEMBL1565676 & 688239 & 6.9863 & 5.4364 & TST \\
\hline CHEMBL3210642 & 688239 & 5.1862 & 5.4321 & TST \\
\hline CHEMBL1459945 & 688239 & 5.8862 & 5.6118 & TST \\
\hline CHEMBL1359401 & 688239 & 4.8362 & 5.3368 & TRN \\
\hline CHEMBL1309150 & 688239 & 6.2862 & 5.7019 & TRN \\
\hline CHEMBL1338989 & 688239 & 4.5362 & 5.5632 & TRN \\
\hline CHEMBL1496388 & 688239 & 6.1862 & 5.4302 & TRN \\
\hline CHEMBL1448204 & 688239 & 4.7862 & 5.319 & TRN \\
\hline CHEMBL1572546 & 688239 & 5.4362 & 5.3367 & TRN \\
\hline CHEMBL1555695 & 688239 & 4.5362 & 5.5002 & TST \\
\hline CHEMBL1518868 & 688239 & 5.7362 & 5.5919 & TST \\
\hline CHEMBL1553744 & 688239 & 5.3862 & 5.4184 & TRN \\
\hline CHEMBL1575250 & 688239 & 4.5362 & 5.4533 & TST \\
\hline CHEMBL1573049 & 688239 & 4.5362 & 5.4109 & TRN \\
\hline CHEMBL1357889 & 688239 & 4.9862 & 5.3902 & TST \\
\hline CHEMBL1595652 & 688239 & 6.0862 & 5.4875 & TRN \\
\hline CHEMBL1361924 & 688239 & 4.8862 & 5.3412 & TRN \\
\hline CHEMBL1393725 & 688239 & 6.5363 & 5.5263 & TST \\
\hline CHEMBL1409192 & 688239 & 7.5361 & 5.6034 & TRN \\
\hline CHEMBL1519014 & 688239 & 6.8861 & 5.4981 & TST \\
\hline CHEMBL1991710 & 688239 & 5.2862 & 5.4221 & TST \\
\hline CHEMBL1604781 & 688239 & 4.6362 & 5.4938 & TST \\
\hline CHEMBL1375002 & 688239 & 5.4862 & 5.7646 & TRN \\
\hline CHEMBL1310876 & 688239 & 4.5362 & 5.5123 & TST \\
\hline CHEMBL1421955 & 688239 & 4.6862 & 5.5248 & TRN \\
\hline CHEMBL1428958 & 688239 & 4.7362 & 5.5846 & TRN \\
\hline CHEMBL1474064 & 688239 & 4.5362 & 5.382999 & 9999999999 \\
\hline CHEMBL1602894 & 688239 & 4.7362 & 5.457000 & 0000000001 \\
\hline CHEMBL1462333 & 688239 & 4.7862 & 5.4104 & TST \\
\hline CHEMBL1469399 & 688239 & 6.4862 & 5.3998 & TRN \\
\hline CHEMBL1302877 & 688239 & 4.4862 & 5.4408 & TRN \\
\hline CHEMBL1439991 & 688239 & 5.2862 & 5.5274 & TRN \\
\hline CHEMBL1339956 & 688239 & 5.1862 & 5.3177 & TRN \\
\hline CHEMBL1362753 & 688239 & 4.5362 & 5.4476 & TRN \\
\hline CHEMBL1575204 & 688239 & 6.8362 & 5.4273 & TRN \\
\hline CHEMBL1338777 & 688239 & 5.7862 & 5.5946 & TRN \\
\hline CHEMBL1303816 & 688239 & 4.6362 & 5.4471 & TRN \\
\hline CHEMBL1428650 & 688239 & 4.6862 & 5.4623 & TRN \\
\hline CHEMBL3209295 & 688239 & 5.6862 & 5.6004 & TRN \\
\hline CHEMBL1604207 & 688239 & 6.3362 & 5.5876 & TST \\
\hline CHEMBL1403216 & 688239 & 5.0862 & 5.4349 & TRN \\
\hline
\end{tabular}


Supplemental Table S2.txt

\begin{tabular}{|c|c|c|c|c|}
\hline CHEMBL1430138 & 688239 & 4.7362 & 5.3437 & TST \\
\hline CHEMBL1366173 & 688239 & 4.5362 & 5.3894 & TRN \\
\hline CHEMBL1418806 & 688239 & 4.5362 & 5.4474 & TRN \\
\hline CHEMBL1343142 & 688239 & 5.2362 & 5.5479 & TRN \\
\hline CHEMBL1399704 & 688239 & 4.5362 & 5.4792 & TST \\
\hline CHEMBL1429953 & 688239 & 5.6862 & 5.567 & TRN \\
\hline CHEMBL1587944 & 688239 & 4.5362 & 5.5599 & TST \\
\hline CHEMBL1528822 & 688239 & 5.3362 & 5.4587 & TRN \\
\hline CHEMBL1436647 & 688239 & 4.7862 & 5.4655 & TRN \\
\hline CHEMBL1573865 & 688239 & 5.5862 & 5.5343 & TST \\
\hline CHEMBL1328111 & 688239 & 4.6862 & 5.5396 & TRN \\
\hline CHEMBL1375669 & 688239 & 4.5362 & 5.4606 & TRN \\
\hline CHEMBL3195278 & 688239 & 4.9362 & 5.4598 & TRN \\
\hline CHEMBL1532089 & 688239 & 4.5362 & 5.54899 & \\
\hline CHEMBL1546322 & 688239 & 4.5362 & 5.3789 & TRN \\
\hline CHEMBL1453042 & 688239 & 4.5362 & 5.4278 & TRN \\
\hline CHEMBL1550152 & 688239 & 4.6862 & 5.5591 & TRN \\
\hline CHEMBL1477938 & 688239 & 5.4362 & 5.3944 & TRN \\
\hline CHEMBL1603376 & 688239 & 8.3372 & 5.5992 & TRN \\
\hline CHEMBL1513079 & 688239 & 4.4862 & 5.4912 & TRN \\
\hline CHEMBL1300488 & 688239 & 6.9863 & 5.3934 & TRN \\
\hline CHEMBL1340678 & 688239 & 5.4862 & 5.6005 & TRN \\
\hline CHEMBL1426255 & 688239 & 6.1362 & 5.4949 & TST \\
\hline CHEMBL1362898 & 688239 & 5.6862 & 5.4494 & TRN \\
\hline CHEMBL1458690 & 688239 & 4.4862 & 5.6033 & TRN \\
\hline CHEMBL1403018 & 688239 & 8.3372 & 5.414 & TRN \\
\hline CHEMBL1430956 & 688239 & 4.8362 & 5.4409 & TRN \\
\hline CHEMBL1429841 & 688239 & 4.4862 & 5.4596 & TRN \\
\hline CHEMBL1375244 & 688239 & 6.3362 & 5.53700 & 0000000001 \\
\hline CHEMBL1334031 & 688239 & 5.1862 & 5.4486 & TRN \\
\hline CHEMBL1456475 & 688239 & 6.8861 & 5.4995 & TRN \\
\hline CHEMBL1488102 & 688239 & 5.1362 & 5.4696 & TRN \\
\hline CHEMBL1449944 & 688239 & 4.5362 & 5.5219 & TRN \\
\hline CHEMBL510279 & 688239 & 4.6862 & 5.4309 & TST \\
\hline CHEMBL1318834 & 688239 & 4.5362 & 5.4529 & TRN \\
\hline CHEMBL1429771 & 688239 & 6.3362 & 5.5492 & TRN \\
\hline CHEMBL1373028 & 688239 & 7.6861 & 5.6352 & TRN \\
\hline CHEMBL1528353 & 688239 & 6.6362 & 5.4518 & TRN \\
\hline CHEMBL3145293 & 688239 & 4.7862 & 5.4604 & TST \\
\hline CHEMBL1380778 & 688239 & 5.0362 & 5.409 & TST \\
\hline CHEMBL1337552 & 688239 & 4.75 & 5.5264 & TRN \\
\hline CHEMBL1381898 & 688239 & 5.1362 & 5.6522 & TRN \\
\hline CHEMBL1522580 & 688239 & 4.4862 & 5.516 & TRN \\
\hline CHEMBL1580989 & 688239 & 4.5362 & 5.4511 & TRN \\
\hline CHEMBL1505063 & 688239 & 5.1362 & 5.3474 & TRN \\
\hline CHEMBL1336648 & 688239 & 4.5362 & 5.53299 & 9999999995 \\
\hline CHEMBL1379602 & 688239 & 4.5362 & 5.6604 & TRN \\
\hline CHEMBL1492444 & 688239 & 6.7862 & 5.3812 & TST \\
\hline
\end{tabular}


Supplemental Table S2.txt

\begin{tabular}{|c|c|c|c|c|}
\hline CHEMBL1563934 & 688239 & 4.6362 & 5.3562 & TRN \\
\hline CHEMBL1419674 & 688239 & 4.5362 & 5.3934 & TST \\
\hline CHEMBL1387793 & 688239 & 4.5362 & 5.4289 & TRN \\
\hline CHEMBL1396802 & 688239 & 4.5362 & 5.5865 & TST \\
\hline CHEMBL1529575 & 688239 & 4.5362 & 5.3922 & TRN \\
\hline CHEMBL1486549 & 688239 & 7.5361 & 5.5027 & TRN \\
\hline CHEMBL1337361 & 688239 & 6.0862 & 5.5112 & TRN \\
\hline CHEMBL1344902 & 688239 & 4.5362 & 5.3601 & TRN \\
\hline CHEMBL1316803 & 688239 & 4.6862 & 5.4274 & TRN \\
\hline CHEMBL1449225 & 688239 & 5.1862 & 5.4701 & TRN \\
\hline CHEMBL1451745 & 688239 & 5.7362 & 5.449 & TRN \\
\hline CHEMBL1558917 & 688239 & 4.5362 & 5.4201 & TRN \\
\hline CHEMBL1612950 & 688239 & 5.2362 & 5.5427 & TRN \\
\hline CHEMBL1343823 & 688239 & 5.1862 & 5.42399 & 99999999995 \\
\hline CHEMBL1415542 & 688239 & 8.2366 & 5.5677 & TST \\
\hline CHEMBL3190594 & 688239 & 6.3362 & 5.4991 & TRN \\
\hline CHEMBL1347118 & 688239 & 4.5362 & 5.4441 & TRN \\
\hline CHEMBL1491524 & 688239 & 4.7362 & 5.5894 & TRN \\
\hline CHEMBL1351093 & 688239 & 4.9862 & 5.3877 & TRN \\
\hline CHEMBL1580339 & 688239 & 6.9863 & 5.5085 & TRN \\
\hline CHEMBL1479348 & 688239 & 4.5362 & 5.5336 & TRN \\
\hline CHEMBL1428690 & 688239 & 6.4862 & 5.494 & TRN \\
\hline CHEMBL1533434 & 688239 & 5.2362 & 5.4494 & TST \\
\hline CHEMBL1320512 & 688239 & 4.7362 & 5.4896 & TRN \\
\hline CHEMBL383200 & 688239 & 8.283999 & 79999999 & 5.5998 \\
\hline CHEMBL1531826 & 688239 & 5.7862 & 5.3665 & TRN \\
\hline CHEMBL1420418 & 688239 & 4.5362 & 5.4418 & TST \\
\hline CHEMBL1389675 & 688239 & 4.8862 & 5.5604 & TST \\
\hline CHEMBL1433151 & 688239 & 4.7862 & 5.6265 & TRN \\
\hline CHEMBL1605593 & 688239 & 4.5862 & 5.5045 & TRN \\
\hline CHEMBL1612630 & 688239 & 5.1362 & 5.5914 & TRN \\
\hline CHEMBL1566092 & 688239 & 6.5862 & 5.5338 & TRN \\
\hline CHEMBL1350205 & 688239 & 4.5362 & 5.6547 & TRN \\
\hline CHEMBL1403802 & 688239 & 5.3362 & 5.5386 & TST \\
\hline CHEMBL1472582 & 688239 & 5.8862 & 5.5683 & TST \\
\hline CHEMBL1346902 & 688239 & 7.0362 & 5.4373 & TST \\
\hline CHEMBL1502690 & 688239 & 7.1361 & 5.6335 & TRN \\
\hline CHEMBL1331376 & 688239 & 4.7862 & 5.2917 & TRN \\
\hline CHEMBL1327493 & 688239 & 5.3362 & 5.4201 & TRN \\
\hline CHEMBL1422138 & 688239 & 5.3362 & 5.5078 & TRN \\
\hline CHEMBL1508581 & 688239 & 6.4862 & 5.5356 & TRN \\
\hline CHEMBL1443085 & 688239 & 6.1362 & 5.4183 & TST \\
\hline CHEMBL1603372 & 688239 & 7.0862 & 5.3738 & TST \\
\hline CHEMBL1359099 & 688239 & 4.5362 & 5.3687 & TRN \\
\hline CHEMBL1592919 & 688239 & 5.1362 & 5.5819 & TRN \\
\hline CHEMBL1413437 & 688239 & 6.7862 & 5.6612 & TRN \\
\hline CHEMBL1403170 & 688239 & 4.5862 & 5.5645 & TRN \\
\hline CHEMBL1349434 & 688239 & 5.4362 & 5.3954 & TRN \\
\hline
\end{tabular}


Supplemental Table S2.txt

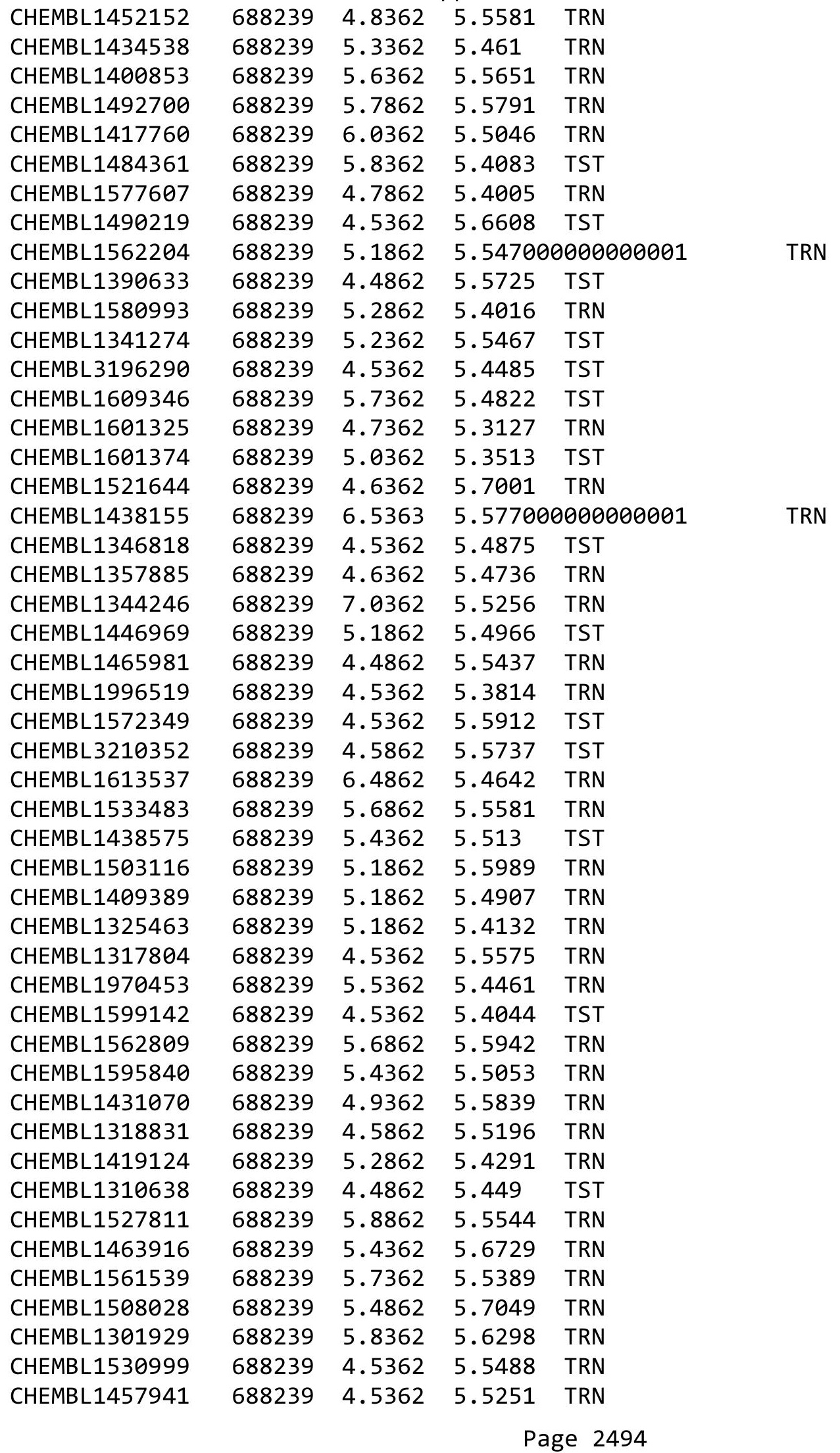


Supplemental Table S2.txt

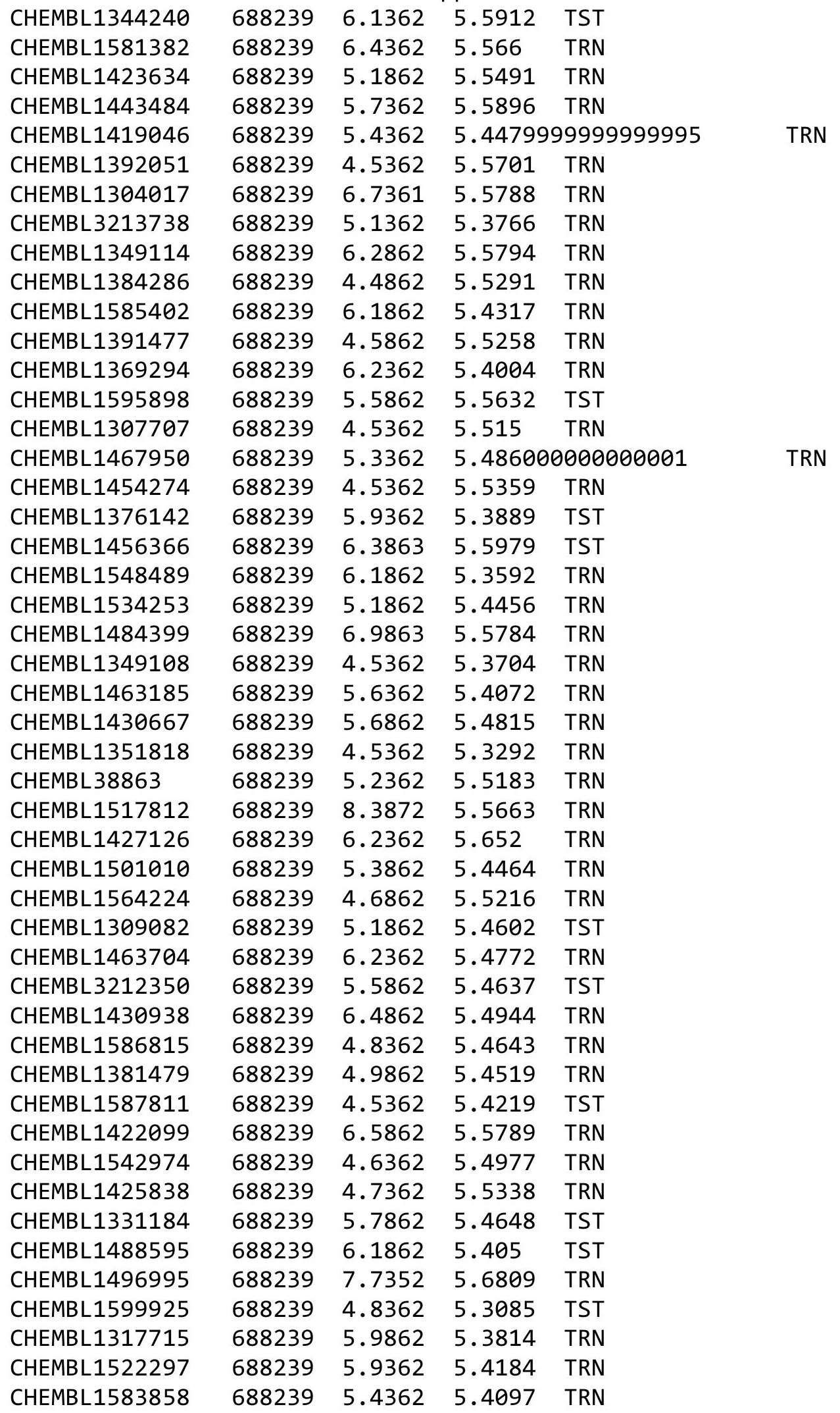

Page 2495 
Supplemental Table S2.txt

\begin{tabular}{|c|c|c|c|c|c|}
\hline CHEMBL1329860 & 688239 & 5.6862 & 5.5891 & TRN & \\
\hline CHEMBL1434256 & 688239 & 5.2362 & 5.5268 & TRN & \\
\hline CHEMBL1334886 & 688239 & 6.8362 & 5.4788 & TRN & \\
\hline CHEMBL1447642 & 688239 & 8.3372 & 5.4532 & TRN & \\
\hline CHEMBL3195306 & 688239 & 4.7862 & 5.5015 & TST & \\
\hline CHEMBL1426117 & 688239 & 6.3362 & 5.5141 & TRN & \\
\hline CHEMBL1445243 & 688239 & 5.6862 & 5.376 & TST & \\
\hline CHEMBL 3192779 & 688239 & 5.4862 & 5.4248 & TST & \\
\hline CHEMBL1332895 & 688239 & 4.7362 & 5.5101 & TRN & \\
\hline CHEMBL1421785 & 688239 & 5.6362 & 5.6174 & TST & \\
\hline CHEMBL1338564 & 688239 & 5.05 & 5.4833 & TRN & \\
\hline CHEMBL1487330 & 688239 & 8.3372 & 5.5755 & TRN & \\
\hline CHEMBL1343559 & 688239 & 6.5862 & 5.5191 & TST & \\
\hline CHEMBL1551111 & 688239 & 5.1362 & 5.6279 & TRN & \\
\hline CHEMBL 3192445 & 688239 & 4.6362 & 5.3994 & TST & \\
\hline CHEMBL1337244 & 688239 & 8.3372 & 5.3981 & TRN & \\
\hline CHEMBL1408448 & 688239 & 6.9363 & 5.5687 & TRN & \\
\hline CHEMBL1568087 & 688239 & 4.9362 & 5.4414 & TRN & \\
\hline CHEMBL1493136 & 688239 & 4.4862 & 5.6244 & TRN & \\
\hline CHEMBL1358261 & 688239 & 4.5862 & 5.5818 & TRN & \\
\hline CHEMBL1356454 & 688239 & 4.8362 & 5.4584 & TST & \\
\hline CHEMBL1460843 & 688239 & 4.7362 & 5.5087 & TST & \\
\hline CHEMBL1443566 & 688239 & 4.7362 & 5.4975 & TRN & \\
\hline CHEMBL1572017 & 688239 & 6.3362 & 5.5359 & TST & \\
\hline CHEMBL1441750 & 688239 & 6.9363 & 5.5852 & TRN & \\
\hline CHEMBL1332963 & 688239 & 5.1362 & 5.566 & TST & \\
\hline CHEMBL1380388 & 688239 & 4.9362 & 5.6492 & TRN & \\
\hline CHEMBL1577218 & 688239 & 5.1862 & 5.4229 & TRN & \\
\hline CHEMBL1411685 & 688239 & 4.6362 & 5.3511 & TRN & \\
\hline CHEMBL1354824 & 688239 & 5.4862 & 5.6197 & TRN & \\
\hline CHEMBL1526568 & 688239 & 6.3863 & 5.4669 & TRN & \\
\hline CHEMBL1299357 & 688239 & 5.5862 & 5.6063 & TRN & \\
\hline CHEMBL1509997 & 688239 & 4.7362 & 5.5974 & TRN & \\
\hline CHEMBL1427979 & 688239 & 5.6362 & 5.5504 & TRN & \\
\hline CHEMBL1444000 & 688239 & 6.9363 & 5.6734 & TRN & \\
\hline CHEMBL1526588 & 688239 & 5.6362 & 5.2587 & TRN & \\
\hline CHEMBL1343212 & 688239 & 4.5362 & 5.5727 & TRN & \\
\hline CHEMBL1536945 & 688239 & 5.9362 & 5.4556 & TRN & \\
\hline CHEMBL1382652 & 688239 & 5.6862 & 5.4388 & TRN & \\
\hline CHEMBL1378470 & 688239 & 6.2362 & 5.5195 & TST & \\
\hline CHEMBL1434987 & 688239 & 6.5363 & 5.5006 & TRN & \\
\hline CHEMBL1325945 & 688239 & 7.1361 & 5.6045 & TRN & \\
\hline CHEMBL1418694 & 688239 & 8.28399 & 99999999 & 99 & 5.5134 \\
\hline CHEMBL1448278 & 688239 & 6.4862 & 5.5316 & TRN & \\
\hline CHEMBL1384085 & 688239 & 5.1862 & 5.4762 & TRN & \\
\hline CHEMBL1460551 & 688239 & 5.1362 & 5.5381 & TRN & \\
\hline CHEMBL1444648 & 688239 & 4.8862 & 5.455 & TRN & \\
\hline CHEMBL1519563 & 688239 & 4.9862 & 5.3799 & TRN & \\
\hline
\end{tabular}


Supplemental Table S2.txt

\begin{tabular}{|c|c|c|c|c|c|}
\hline CHEMBL1346602 & 688239 & 4.7862 & 5.4689 & TRN & \\
\hline CHEMBL1377516 & 688239 & 4.5362 & 5.3417 & TRN & \\
\hline CHEMBL1565312 & 688239 & 4.5362 & 5.4659 & TST & \\
\hline CHEMBL1419481 & 688239 & 4.6362 & 5.4938 & TRN & \\
\hline CHEMBL1365894 & 688239 & 5.8362 & 5.6221 & TRN & \\
\hline CHEMBL1326309 & 688239 & 4.6862 & 5.3403 & TRN & \\
\hline CHEMBL1448020 & 688239 & 6.1362 & 5.4968 & TRN & \\
\hline CHEMBL1469027 & 688239 & 4.6862 & 5.5021 & TRN & \\
\hline CHEMBL1424725 & 688239 & 4.5362 & 5.5463 & TRN & \\
\hline CHEMBL1577679 & 688239 & 4.5362 & 5.552000 & 0000000005 & TS \\
\hline CHEMBL1351670 & 688239 & 5.0362 & 5.5731 & TRN & \\
\hline CHEMBL 3190723 & 688239 & 4.5362 & 5.4707 & TRN & \\
\hline CHEMBL1376959 & 688239 & 6.3362 & 5.4986 & TRN & \\
\hline CHEMBL1982178 & 688239 & 4.5862 & 5.4833 & TST & \\
\hline CHEMBL1457013 & 688239 & 4.5362 & 5.4801 & TRN & \\
\hline CHEMBL1458031 & 688239 & 4.8862 & 5.587999 & 999999999 & w. \\
\hline CHEMBL1390227 & 688239 & 4.5362 & 5.473 & TRN & \\
\hline CHEMBL585481 & 688239 & 4.5362 & 5.5109 & TST & \\
\hline CHEMBL1588197 & 688239 & 5.6862 & 5.4744 & TRN & \\
\hline CHEMBL1609419 & 688239 & 5.3862 & 5.4181 & TRN & \\
\hline CHEMBL1605230 & 688239 & 8.3372 & 5.4978 & TRN & \\
\hline CHEMBL1377635 & 688239 & 7.2366 & 5.5011 & TRN & \\
\hline CHEMBL1528812 & 688239 & 6.8362 & 5.5213 & TRN & \\
\hline CHEMBL1470023 & 688239 & 6.2862 & 5.4481 & TST & \\
\hline CHEMBL1369654 & 688239 & 4.7862 & 5.486000 & 000000001 & \\
\hline CHEMBL1404011 & 688239 & 4.5862 & 5.4067 & TRN & \\
\hline CHEMBL1322768 & 688239 & 6.6861 & 5.4006 & TST & \\
\hline CHEMBL1351923 & 688239 & 5.6362 & 5.6286 & TRN & \\
\hline CHEMBL1364845 & 688239 & 5.5362 & 5.3765 & TRN & \\
\hline CHEMBL1504291 & 688239 & 4.6862 & 5.5305 & TRN & \\
\hline CHEMBL1398283 & 688239 & 5.3362 & 5.4477 & TST & \\
\hline CHEMBL1591276 & 688239 & 5.0362 & 5.3151 & TRN & \\
\hline CHEMBL1311389 & 688239 & 4.5362 & 5.4176 & TRN & \\
\hline CHEMBL3196848 & 688239 & 6.6362 & 5.5103 & TST & \\
\hline CHEMBL1611125 & 688239 & 5.1862 & 5.4842 & TRN & \\
\hline CHEMBL1543468 & 688239 & 4.6362 & 5.5243 & TRN & \\
\hline CHEMBL1381949 & 688239 & 6.8362 & 5.3769 & TRN & \\
\hline CHEMBL1495206 & 688239 & 6.8861 & 5.5449 & TRN & \\
\hline CHEMBL1570360 & 688239 & 8.28399 & 99999999 & 5.6259 & \\
\hline CHEMBL1607840 & 688239 & 6.5363 & 5.3522 & TRN & \\
\hline CHEMBL1451510 & 688239 & 4.6862 & 5.4817 & TRN & \\
\hline CHEMBL1538992 & 688239 & 4.5362 & 5.3867 & TRN & \\
\hline CHEMBL1468954 & 688239 & 4.7362 & 5.5091 & TST & \\
\hline CHEMBL1500569 & 688239 & 4.5362 & 5.5613 & TST & \\
\hline CHEMBL1316900 & 688239 & 5.7862 & 5.4615 & TRN & \\
\hline CHEMBL1331897 & 688239 & 4.8862 & 5.5023 & TRN & \\
\hline CHEMBL1477149 & 688239 & 7.0862 & 5.4552 & TRN & \\
\hline CHEMBL1433123 & 688239 & 6.9863 & 5.3459 & TRN & \\
\hline
\end{tabular}




\begin{tabular}{|c|c|c|c|c|c|c|}
\hline \multirow[b]{2}{*}{ CHEMBL1585169 } & & \multicolumn{5}{|c|}{ Supplemental Table S2.txt } \\
\hline & 688239 & 4.6362 & 5.699 & TRN & & \\
\hline CHEMBL1318444 & 688239 & 8.28399 & 99999999 & & 5.3909 & TRN \\
\hline CHEMBL1574828 & 688239 & 8.28399 & 99999999 & 99 & 5.4739 & TRN \\
\hline CHEMBL1406416 & 688239 & 5.9362 & 5.3757 & TRN & & \\
\hline CHEMBL1336684 & 688239 & 5.4862 & 5.3372 & TRN & & \\
\hline CHEMBL1477489 & 688239 & 4.7862 & 5.5247 & TRN & & \\
\hline CHEMBL1389140 & 688239 & 4.5362 & 5.4336 & TRN & & \\
\hline CHEMBL1583866 & 688239 & 4.9862 & 5.4852 & TRN & & \\
\hline CHEMBL1417766 & 688239 & 6.5363 & 5.5024 & TST & & \\
\hline CHEMBL1422191 & 688239 & 5.1862 & 5.4756 & TRN & & \\
\hline CHEMBL1392705 & 688239 & 4.8362 & 5.5034 & TRN & & \\
\hline CHEMBL1465325 & 688239 & 5.0362 & 5.5746 & TRN & & \\
\hline CHEMBL1375161 & 688239 & 6.9363 & 5.4897 & TRN & & \\
\hline CHEMBL1504286 & 688239 & 4.7862 & 5.5789 & TRN & & \\
\hline CHEMBL1423486 & 688239 & 6.9363 & 5.7109 & TST & & \\
\hline CHEMBL1402784 & 688239 & 8.2366 & 5.4859 & TRN & & \\
\hline CHEMBL1594890 & 688239 & 4.7862 & 5.4377 & TST & & \\
\hline CHEMBL1541550 & 688239 & 4.5362 & 5.4239 & TRN & & \\
\hline CHEMBL1299509 & 688239 & 6.4362 & 5.4616 & TRN & & \\
\hline CHEMBL1590443 & 688239 & 4.7362 & 5.4739 & TRN & & \\
\hline CHEMBL3196641 & 688239 & 5.4862 & 5.3286 & TRN & & \\
\hline CHEMBL1363954 & 688239 & 5.6862 & 5.5475 & TRN & & \\
\hline CHEMBL3213536 & 688239 & 4.5362 & 5.4213 & TRN & & \\
\hline CHEMBL1326965 & 688239 & 4.6862 & 5.4706 & TST & & \\
\hline CHEMBL1327755 & 688239 & 7.5361 & 5.6418 & TRN & & \\
\hline CHEMBL1305249 & 688239 & 5.2362 & 5.6457 & TRN & & \\
\hline CHEMBL1482821 & 688239 & 6.1362 & 5.5355 & TST & & \\
\hline CHEMBL1531710 & 688239 & 6.8861 & 5.335 & TRN & & \\
\hline CHEMBL1562052 & 688239 & 5.7362 & 5.5692 & TRN & & \\
\hline CHEMBL1583781 & 688239 & 4.5362 & 5.5243 & TST & & \\
\hline CHEMBL1406798 & 688239 & 5.7362 & 5.3568 & TRN & & \\
\hline CHEMBL1507231 & 688239 & 6.5363 & 5.5639 & TRN & & \\
\hline CHEMBL1583590 & 688239 & 5.1862 & 5.4575 & TRN & & \\
\hline CHEMBL1518913 & 688239 & 5.0862 & 5.6366 & TRN & & \\
\hline CHEMBL1415680 & 688239 & 5.1362 & 5.5406 & TRN & & \\
\hline CHEMBL1589782 & 688239 & 4.7362 & 5.3155 & TRN & & \\
\hline CHEMBL1382528 & 688239 & 8.3872 & 5.494 & TRN & & \\
\hline CHEMBL1538037 & 688239 & 5.1862 & 5.6285 & TRN & & \\
\hline CHEMBL1493815 & 688239 & 5.4362 & 5.5253 & TST & & \\
\hline CHEMBL1393585 & 688239 & 6.2362 & 5.3576 & TST & & \\
\hline CHEMBL1322898 & 688239 & 5.4862 & 5.4185 & TST & & \\
\hline CHEMBL1515052 & 688239 & 4.4862 & 5.4352 & TRN & & \\
\hline CHEMBL3198064 & 688239 & 5.4362 & 5.274 & TRN & & \\
\hline CHEMBL1463268 & 688239 & 5.1862 & 5.5766 & TST & & \\
\hline CHEMBL1459996 & 688239 & 4.5362 & 5.49200 & 0000000001 & & TRN \\
\hline CHEMBL1357415 & 688239 & 4.5362 & 5.5115 & TST & & \\
\hline CHEMBL1363155 & 688239 & 5.1862 & 5.476 & TRN & & \\
\hline CHEMBL1584938 & 688239 & 5.1862 & 5.4125 & TST & & \\
\hline
\end{tabular}


Supplemental Table S2.txt

\begin{tabular}{|c|c|c|c|c|}
\hline 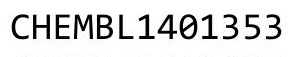 & & & & \\
\hline HEMBL1511825 & 88239 & 1862 & 5477 & \\
\hline HEMBL1376818 & 3239 & 2362 & 4464 & \\
\hline 89 & & 62 & 4822 & \\
\hline AEMBL1531462 & & 862 & & \\
\hline AEMBL1595930 & 88239 & 6862 & .684 & \\
\hline HEMBL1558828 & 88239 & 6.5862 & .4011 & \\
\hline HEMBL1402254 & 39 & 2366 & & \\
\hline AEMBL15 & & 862 & & \\
\hline AEMBL1613310 & & 862 & & \\
\hline HEMBL1604764 & 88239 & .0862 & .6854 & \\
\hline HEMBL1342075 & 88239 & 0862 & .3125 & \\
\hline HEMBL1309 & 39 & 3372 & 09 & \\
\hline HEMBL197 & & 362 & & \\
\hline HEMBL153 & & 362 & & \\
\hline HEMBL1459933 & 88239 & 5862 & .4873 & \\
\hline HEMBL1472912 & & $\partial 362$ & & \\
\hline HEMBL144 & 9 & 362 & 58 & \\
\hline L15 & & 52 & & \\
\hline L13 & & 362 & & \\
\hline AEMBL1469469 & & 1362 & & \\
\hline AEMBL1469430 & & & & \\
\hline HEMBL13 & 39 & 362 & 5 . & \\
\hline L31 & & 362 & & \\
\hline 08 & & 62 & & KIV \\
\hline L130 & & 862 & & \\
\hline AEMBL132 & & & & $R / N$ \\
\hline HEMBL139 & & 862 & & \\
\hline HEN & & 52 & & \\
\hline JEMBL132 & & 62 & & ST \\
\hline AEMBL1333277 & & & & \\
\hline HEMBL1526747 & & 862 & & ST \\
\hline AEMBL13 & & 52 & & RN \\
\hline 1 & & 52 & & RN \\
\hline 21 & & & & $\mathrm{RN}$ \\
\hline AEMBL1519437 & & 862 & & RN \\
\hline AEMBL1316664 & & 862 & & $2 \mathrm{~N}$ \\
\hline 312 & & 862 & & RIV \\
\hline- & & & & RIV \\
\hline 53 & & & & $\mathrm{RN}$ \\
\hline AEMBL3199356 & & 362 & 02 & ГST \\
\hline AEMBL15 & & 362 & & RN \\
\hline 433 & & 862 & & \\
\hline & & & & RN \\
\hline HEMBL1605120 & & 6.2862 & & ST \\
\hline IEMBL158 & & 5.7362 & 69 & RN \\
\hline & & & & \\
\hline HEMBL138690 & & & & \\
\hline
\end{tabular}

Page 2499 
Supplemental Table S2.txt

\begin{tabular}{|c|c|c|c|c|c|}
\hline CHEMBL1499368 & 688239 & 4.5362 & 5.4554 & TST & \\
\hline CHEMBL1462360 & 688239 & 5.3862 & 5.4815 & TST & \\
\hline CHEMBL1378237 & 688239 & 4.6362 & 5.3784 & TRN & \\
\hline CHEMBL1383642 & 688239 & 4.5862 & 5.5012 & TRN & \\
\hline CHEMBL1369488 & 688239 & 5.6362 & 5.5312 & TRN & \\
\hline CHEMBL1463901 & 688239 & 4.5362 & 5.3723 & TRN & \\
\hline CHEMBL1445447 & 688239 & 5.8862 & 5.6267 & TST & \\
\hline CHEMBL1436713 & 688239 & 4.5862 & 5.4462 & TRN & \\
\hline CHEMBL1978150 & 688239 & 4.5862 & 5.4159 & TST & \\
\hline CHEMBL1340334 & 688239 & 6.1862 & 5.4652 & TRN & \\
\hline CHEMBL1348329 & 688239 & 4.5362 & 5.3578 & TRN & \\
\hline CHEMBL3195989 & 688239 & 6.1362 & 5.2413 & TRN & \\
\hline CHEMBL1494292 & 688239 & 5.2862 & 5.4413 & TRN & \\
\hline CHEMBL1322252 & 688239 & 6.4862 & 5.4948 & TRN & \\
\hline CHEMBL1501841 & 688239 & 4.6862 & 5.351 & TRN & \\
\hline CHEMBL1510686 & 688239 & 5.1862 & 5.4168 & TRN & \\
\hline CHEMBL1379153 & 688239 & 7.0362 & 5.4808 & TRN & \\
\hline CHEMBL1369177 & 688239 & 4.5362 & 5.5184 & TST & \\
\hline CHEMBL1589579 & 688239 & 5.1862 & 5.4719 & TST & \\
\hline CHEMBL1421600 & 688239 & 8.3372 & 5.5752 & TST & \\
\hline CHEMBL1414576 & 688239 & 4.5862 & 5.5425 & TRN & \\
\hline CHEMBL1319488 & 688239 & 4.9362 & 5.3071 & TRN & \\
\hline CHEMBL1555438 & 688239 & 4.4862 & 5.3389 & TST & \\
\hline CHEMBL1385512 & 688239 & 8.3372 & 5.46399 & 99999999995 & TST \\
\hline CHEMBL1558462 & 688239 & 4.7362 & 5.3894 & TRN & \\
\hline CHEMBL1428368 & 688239 & 4.5362 & 5.4276 & TRN & \\
\hline CHEMBL1574894 & 688239 & 6.3863 & 5.5697 & TRN & \\
\hline CHEMBL1514331 & 688239 & 4.7862 & 5.433 & TRN & \\
\hline CHEMBL1373631 & 688239 & 5.1862 & 5.58299 & 7999999999 & TRN \\
\hline CHEMBL1414566 & 688239 & 5.3362 & 5.4556 & TRN & \\
\hline CHEMBL1427653 & 688239 & 4.7862 & 5.4868 & TRN & \\
\hline CHEMBL1430994 & 688239 & 5.8862 & 5.5408 & TRN & \\
\hline CHEMBL1477228 & 688239 & 6.2362 & 5.5625 & TRN & \\
\hline CHEMBL1498777 & 688239 & 6.9363 & 5.6184 & TRN & \\
\hline CHEMBL1412915 & 688239 & 6.4362 & 5.6597 & TRN & \\
\hline CHEMBL1600306 & 688239 & 4.5362 & 5.4822 & TRN & \\
\hline CHEMBL1430960 & 688239 & 4.5362 & 5.3335 & TRN & \\
\hline CHEMBL1334909 & 688239 & 5.3362 & 5.53100 & 0000000001 & TST \\
\hline CHEMBL1487204 & 688239 & 4.8362 & 5.4621 & TRN & \\
\hline CHEMBL1408060 & 688239 & 5.1862 & 5.5326 & TRN & \\
\hline CHEMBL1564431 & 688239 & 6.8362 & 5.48 & TRN & \\
\hline CHEMBL1535776 & 688239 & 4.7862 & 5.5237 & TRN & \\
\hline CHEMBL3207999 & 688239 & 4.4862 & 5.3916 & TST & \\
\hline CHEMBL1490289 & 688239 & 4.6862 & 5.4959 & TST & \\
\hline CHEMBL1353607 & 688239 & 8.28399 & 79999999 & 5.5048 & TRI \\
\hline CHEMBL1307851 & 688239 & 4.8362 & 5.5412 & TST & \\
\hline CHEMBL3196973 & 688239 & 5.2862 & 5.3945 & TRN & \\
\hline CHEMBL1345991 & 688239 & 4.6362 & 5.394 & TRN & \\
\hline
\end{tabular}


Supplemental Table S2.txt

\begin{tabular}{|c|c|c|c|c|c|}
\hline CHEMBL1302109 & 688239 & 4.6362 & 5.4616 & TRN & \\
\hline CHEMBL1308339 & 688239 & 5.5362 & 5.5485 & TRN & \\
\hline CHEMBL1613291 & 688239 & 4.9862 & 5.42200 & 0000000001 & \\
\hline CHEMBL1526374 & 688239 & 5.6362 & 5.5741 & TRN & \\
\hline CHEMBL1402297 & 688239 & 6.2862 & 5.5728 & TRN & \\
\hline CHEMBL1398688 & 688239 & 6.7361 & 5.4245 & TRN & \\
\hline CHEMBL1339352 & 688239 & 6.6861 & 5.4853 & TRN & \\
\hline CHEMBL1371332 & 688239 & 4.6362 & 5.5765 & TST & \\
\hline CHEMBL1322339 & 688239 & 5.2362 & 5.7 & TRN & \\
\hline CHEMBL1479542 & 688239 & 4.5362 & 5.4689 & TRN & \\
\hline CHEMBL1507872 & 688239 & 5.4362 & 5.307 & TST & \\
\hline CHEMBL1392359 & 688239 & 4.5362 & 5.46399 & 99999999995 & \\
\hline CHEMBL1580040 & 688239 & 6.9363 & 5.5255 & TRN & \\
\hline CHEMBL1305473 & 688239 & 6.9863 & 5.4256 & TST & \\
\hline CHEMBL1475819 & 688239 & 5.5862 & 5.4545 & TRN & \\
\hline CHEMBL1383600 & 688239 & 5.6362 & 5.5726 & TRN & \\
\hline CHEMBL1328652 & 688239 & 4.7362 & 5.6082 & TST & \\
\hline CHEMBL1381329 & 688239 & 7.9355 & 5.4165 & TRN & \\
\hline CHEMBL1419440 & 688239 & 4.5362 & 5.5272 & TRN & \\
\hline CHEMBL1462604 & 688239 & 5.5362 & 5.33299 & 9999999999 & \\
\hline CHEMBL1581152 & 688239 & 5.1862 & 5.5725 & TST & \\
\hline CHEMBL1310541 & 688239 & 6.2362 & 5.4178 & TRN & \\
\hline CHEMBL1486068 & 688239 & 8.28399 & 9999999 & 5.4715 & \\
\hline CHEMBL1320427 & 688239 & 5.6862 & 5.5646 & TRN & \\
\hline CHEMBL 3207861 & 688239 & 6.2362 & 5.347 & TST & \\
\hline CHEMBL1469371 & 688239 & 5.6862 & 5.4396 & TST & \\
\hline CHEMBL1415156 & 688239 & 6.8362 & 5.4956 & TRN & \\
\hline CHEMBL1375305 & 688239 & 8.2366 & 5.4207 & TRN & \\
\hline CHEMBL1544192 & 688239 & 5.0862 & 5.513 & TRN & \\
\hline CHEMBL1425117 & 688239 & 4.7862 & 5.4174 & TRN & \\
\hline CHEMBL1524220 & 688239 & 5.1862 & 5.41 & TRN & \\
\hline CHEMBL1433128 & 688239 & 4.5362 & 5.3685 & TRN & \\
\hline CHEMBL1443785 & 688239 & 5.1362 & 5.6025 & TRN & \\
\hline CHEMBL1461974 & 688239 & 4.7362 & 5.4807 & TRN & \\
\hline CHEMBL1374112 & 688239 & 6.0362 & 5.5291 & TRN & \\
\hline CHEMBL1378511 & 688239 & 4.5362 & 5.4168 & TRN & \\
\hline CHEMBL1518151 & 688239 & 6.1362 & 5.3468 & TRN & \\
\hline CHEMBL 3193422 & 688239 & 5.1862 & 5.5357 & TRN & \\
\hline CHEMBL1513672 & 688239 & 5.3862 & 5.4865 & TRN & \\
\hline CHEMBL1591322 & 688239 & 4.6862 & 5.4617 & TRN & \\
\hline CHEMBL1338466 & 688239 & 4.7362 & 5.5456 & TST & \\
\hline CHEMBL 2373628 & 688239 & 4.7362 & 5.42899 & 9999999999 & \\
\hline CHEMBL1508171 & 688239 & 5.3362 & 5.5159 & TST & \\
\hline CHEMBL1425099 & 688239 & 4.5362 & 5.2931 & TST & \\
\hline CHEMBL1397780 & 688239 & 4.6862 & 5.4491 & TRN & \\
\hline CHEMBL1438550 & 688239 & 5.6862 & 5.4991 & TST & \\
\hline CHEMBL1613371 & 688239 & 4.5362 & 5.4392 & TRN & \\
\hline CHEMBL1310851 & 688239 & 4.6862 & 5.4829 & TRN & \\
\hline
\end{tabular}

Page 2501 
Supplemental Table S2.txt

\begin{tabular}{|c|c|c|c|c|}
\hline 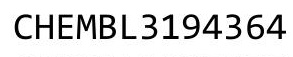 & & & & \\
\hline AEMBL1327455 & 38239 & 362 & 3931 & \\
\hline AEMBL1330032 & 239 & 862 & & \\
\hline HEMBL136 & 39 & 862 & & \\
\hline EMBL1462137 & 39 & 862 & & \\
\hline AEMBL1439300 & 88239 & 362 & 3498 & \\
\hline AEMBL1393124 & 88239 & 4.7362 & 3 & \\
\hline AEMBL1515453 & & 862 & & \\
\hline EMBL1360926 & 39 & 862 & & \\
\hline IEMBL1584039 & & 362 & & \\
\hline AEMBL3214370 & 39 & 862 & 36 & \\
\hline AEMBL1345613 & & 862 & & \\
\hline AEMBL1336590 & & 64 & & \\
\hline AEMBL132 & & 62 & & \\
\hline HEMBL31S & & 362 & & \\
\hline AEMBL1508255 & & 362 & & \\
\hline AEMBL1403680 & & 362 & & \\
\hline IEMBL14] & & 62 & & \\
\hline AEMBL15 & & & & \\
\hline AEMBL1569375 & & 62 & & \\
\hline AEMBL1351529 & & 862 & & \\
\hline AEMBL3197145 & & & & \\
\hline AEMBL154 & & & & \\
\hline AFMRI 138 & & & & \\
\hline 760 & & 62 & & \\
\hline 1564567 & & 862 & & \\
\hline IEMBL1539297 & & & & \\
\hline EMBL1382896 & & 52 & & \\
\hline 60 & & & & \\
\hline 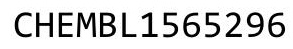 & & 62 & & \\
\hline AEMBL1304569 & & & & \\
\hline IEMBL 3191505 & & 4. & & \\
\hline & & & & \\
\hline 17 & & & & \\
\hline & & & & \\
\hline AEMBL1605322 & & & & \\
\hline AEMBL1389647 & & 362 & 71 & \\
\hline 8358 & & 62 & & \\
\hline 31 & & & & \\
\hline HEMBL3207452 & & & & $S$ \\
\hline AEMBL1439543 & & & & $\mathrm{R}$ \\
\hline EMBL14 & & 62 & & \\
\hline 92 & & & & \\
\hline HEMBL1391213 & & & & \\
\hline HEMBL 2000877 & & & .4505 & RN \\
\hline IEMBL1316960 & & 362 & 117 & 17 \\
\hline & & & & \\
\hline בחברתמ & & & & \\
\hline
\end{tabular}

Page 2502 
Supplemental Table S2.txt

\begin{tabular}{|c|c|c|c|c|c|}
\hline CHEMBL1319155 & 688239 & 5.1862 & 5.4265 & TRN & \\
\hline CHEMBL1603651 & 688239 & 7.0362 & 5.4531 & TST & \\
\hline CHEMBL1557127 & 688239 & 5.3362 & 5.4084 & TST & \\
\hline CHEMBL1599864 & 688239 & 4.45 & 5.4252 & TRN & \\
\hline CHEMBL1327460 & 688239 & 4.5862 & 5.558 & TRN & \\
\hline CHEMBL1401521 & 688239 & 4.7362 & 5.6636 & TRN & \\
\hline CHEMBL1598465 & 688239 & 5.1362 & 5.3697 & TST & \\
\hline CHEMBL1610468 & 688239 & 5.3362 & 5.5092 & TRN & \\
\hline CHEMBL1586169 & 688239 & 4.7362 & 5.2663 & TRN & \\
\hline CHEMBL1522665 & 688239 & 4.5362 & 5.3973 & TRN & \\
\hline CHEMBL1355012 & 688239 & 4.5362 & 5.4601 & TRN & \\
\hline CHEMBL1307317 & 688239 & 6.1362 & 5.4868 & TST & \\
\hline CHEMBL1467894 & 688239 & 5.2862 & 5.5759 & TRN & \\
\hline CHEMBL1365242 & 688239 & 5.7362 & 5.4185 & TRN & \\
\hline CHEMBL1367263 & 688239 & 5.1862 & 5.4106 & TST & \\
\hline CHEMBL1513567 & 688239 & 4.7362 & 5.4271 & TRN & \\
\hline CHEMBL1344965 & 688239 & 7.0362 & 5.5619 & TRN & \\
\hline CHEMBL1374039 & 688239 & 6.0362 & 5.6735 & TRN & \\
\hline CHEMBL1504415 & 688239 & 5.2862 & 5.511 & TRN & \\
\hline CHEMBL1536419 & 688239 & 5.9362 & 5.5247 & TST & \\
\hline CHEMBL1484220 & 688239 & 4.5362 & 5.5299 & TRN & \\
\hline CHEMBL1546500 & 688239 & 6.2362 & 5.3819 & TRN & \\
\hline CHEMBL143703 & 688239 & 6.0 & 5.5266 & TRN & \\
\hline CHEMBL1512273 & 688239 & 8.3372 & 5.6758 & TRN & \\
\hline CHEMBL1308703 & 688239 & 4.7362 & 5.434 & TRN & \\
\hline CHEMBL1579415 & 688239 & 5.9862 & 5.6198 & TRN & \\
\hline CHEMBL1508510 & 688239 & 4.5362 & 5.468999 & 9999999999 & TRN \\
\hline CHEMBL1350739 & 688239 & 6.1862 & 5.5854 & TRN & \\
\hline CHEMBL3189786 & 688239 & 8.3372 & 5.4677 & TRN & \\
\hline CHEMBL1338483 & 688239 & 4.5862 & 5.4209 & TRN & \\
\hline CHEMBL1388196 & 688239 & 4.5362 & 5.6417 & TRN & \\
\hline CHEMBL1484033 & 688239 & 5.1862 & 5.5256 & TRN & \\
\hline CHEMBL1596028 & 688239 & 4.5362 & 5.5348 & TST & \\
\hline CHEMBL1341582 & 688239 & 4.6362 & 5.5614 & TST & \\
\hline CHEMBL1382608 & 688239 & 5.1862 & $5.46200 €$ & 3000000001 & TRN \\
\hline CHEMBL1408503 & 688239 & 4.7362 & 5.6088 & TRN & \\
\hline CHEMBL1566495 & 688239 & 5.7862 & 5.5971 & TRN & \\
\hline CHEMBL1503223 & 688239 & 4.8362 & 5.6308 & TST & \\
\hline CHEMBL1442080 & 688239 & 4.8362 & 5.4926 & TRN & \\
\hline CHEMBL1420389 & 688239 & 7.1361 & 5.3539 & TRN & \\
\hline CHEMBL1584994 & 688239 & 6.8861 & 5.3862 & TST & \\
\hline CHEMBL1389992 & 688239 & 4.7862 & 5.4304 & TRN & \\
\hline CHEMBL1547892 & 688239 & 8.3372 & 5.4804 & TRN & \\
\hline CHEMBL1499986 & 688239 & 6.8861 & 5.4559 & TST & \\
\hline CHEMBL1346386 & 688239 & 5.1862 & 5.6181 & TST & \\
\hline CHEMBL1336214 & 688239 & 4.9862 & 5.5949 & TRN & \\
\hline CHEMBL1513255 & 688239 & 5.6862 & 5.4824 & TRN & \\
\hline CHEMBL3199560 & 688239 & 4.6362 & 5.4213 & TST & \\
\hline
\end{tabular}


Supplemental Table S2.txt

\begin{tabular}{|c|c|c|c|c|c|}
\hline CHEMBL1548172 & 688239 & 5.1362 & 5.5214 & TST & \\
\hline CHEMBL1439950 & 688239 & 4.6862 & 5.5293 & TRN & \\
\hline CHEMBL1452228 & 688239 & 4.5362 & 5.4726 & TRN & \\
\hline CHEMBL1461642 & 688239 & 5.3862 & 5.5465 & TRN & \\
\hline CHEMBL1510200 & 688239 & 5.8862 & 5.4657 & TRN & \\
\hline CHEMBL3208369 & 688239 & 5.1362 & 5.468 & TST & \\
\hline CHEMBL1369628 & 688239 & 4.6862 & 5.5318 & TRN & \\
\hline CHEMBL1401262 & 688239 & 5.1862 & 5.5138 & TST & \\
\hline CHEMBL1300328 & 688239 & 5.5362 & 5.4994 & TRN & \\
\hline CHEMBL1603902 & 688239 & 5.1862 & 5.5046 & TRN & \\
\hline CHEMBL1330423 & 688239 & 4.5362 & 5.4772 & TRN & \\
\hline CHEMBL1376707 & 688239 & 6.5363 & 5.3996 & TRN & \\
\hline CHEMBL1472213 & 688239 & 4.5362 & 5.4815 & TST & \\
\hline CHEMBL 210298 & 688239 & 4.5362 & 5.4045 & TRN & \\
\hline CHEMBL1331513 & 688239 & 5.4862 & 5.423999 & 9999999995 & TRN \\
\hline CHEMBL1347233 & 688239 & 5.1862 & 5.5147 & TST & \\
\hline CHEMBL444376 & 688239 & 4.6862 & 5.4954 & TRN & \\
\hline CHEMBL1580894 & 688239 & 4.8862 & 5.506 & TRN & \\
\hline CHEMBL1408283 & 688239 & 6.0862 & 5.4675 & TRN & \\
\hline CHEMBL1382929 & 688239 & 7.0362 & 5.4395 & TRN & \\
\hline CHEMBL1601863 & 688239 & 5.6362 & 5.5752 & TST & \\
\hline CHEMBL3208520 & 688239 & 5.8862 & 5.4777 & TST & \\
\hline CHEMBL1501934 & 688239 & 7.0862 & 5.4524 & TRN & \\
\hline CHEMBL3190157 & 688239 & 5.5362 & 5.4635 & TRN & \\
\hline CHEMBL1382200 & 688239 & 5.2862 & 5.3157 & TRN & \\
\hline CHEMBL1426056 & 688239 & 5.1862 & 5.415 & TST & \\
\hline CHEMBL1502456 & 688239 & 4.7862 & 5.569 & TRN & \\
\hline CHEMBL1404582 & 688239 & 5.1862 & 5.545 & TRN & \\
\hline CHEMBL3211492 & 688239 & 5.1862 & 5.415 & TRN & \\
\hline CHEMBL1579631 & 688239 & 4.7362 & 5.5506 & TRN & \\
\hline CHEMBL1970597 & 688239 & 4.5362 & 5.3369 & TRN & \\
\hline CHEMBL1362088 & 688239 & 4.7362 & 5.4403 & TRN & \\
\hline CHEMBL1446550 & 688239 & 5.1862 & 5.3817 & TRN & \\
\hline CHEMBL1454854 & 688239 & 5.6862 & 5.4547 & TRN & \\
\hline CHEMBL1610707 & 688239 & 5.1362 & 5.5649 & TST & \\
\hline CHEMBL1535421 & 688239 & 6.8362 & 5.5547 & TRN & \\
\hline CHEMBL1408453 & 688239 & 6.0362 & 5.4755 & TST & \\
\hline CHEMBL1606545 & 688239 & 6.9363 & 5.6051 & TRN & \\
\hline CHEMBL1565558 & 688239 & 6.8362 & 5.472 & TST & \\
\hline CHEMBL1367083 & 688239 & 5.4862 & 5.5255 & TRN & \\
\hline CHEMBL1532281 & 688239 & 5.3362 & 5.4306 & TRN & \\
\hline CHEMBL1531310 & 688239 & 4.5362 & 5.5289 & TRN & \\
\hline CHEMBL1487928 & 688239 & 7.4868 & 5.4949 & TRN & \\
\hline CHEMBL1453520 & 688239 & 5.0862 & 5.595 & TRN & \\
\hline CHEMBL1591269 & 688239 & 6.2362 & \multicolumn{2}{|c|}{5.422000000000001} & TST \\
\hline CHEMBL1391572 & 688239 & 5.3362 & 5.5051 & TRN & \\
\hline CHEMBL1463252 & 688239 & 7.0862 & 5.5329 & TST & \\
\hline CHEMBL1990545 & 688239 & 6.6362 & 5.3236 & TRN & \\
\hline
\end{tabular}


Supplemental Table S2.txt

\begin{tabular}{|c|c|c|c|c|}
\hline & & & & \\
\hline HEMBL1404371 & 38239 & 362 & 76 & \\
\hline AEMBL1396587 & 239 & 862 & 5168 & \\
\hline & & & & \\
\hline IEMBL1556210 & 39 & 862 & & \\
\hline AEMBL1600458 & 88239 & 862 & 667 & \\
\hline AEMBL1379977 & 88239 & 871 & 4624 & \\
\hline HEMBL1301299 & & & & \\
\hline EMBL1320329 & 39 & 862 & & \\
\hline IEMBL1521264 & & & & \\
\hline AEMBL1337522 & 39 & 362 & & \\
\hline AEMBL1472993 & 39 & 362 & & \\
\hline AEMBL3194175 & & 62 & & \\
\hline HEMBL136 & & & & \\
\hline HEMBL141; & & & & \\
\hline AEMBL1389744 & & 362 & & \\
\hline AEMBL535331 & & 862 & & \\
\hline IEMBL 3196 & & & & \\
\hline HEMBL150 & & & & \\
\hline AEMBL1725 & & & & \\
\hline AEMBL1301 & & 62 & & \\
\hline HEMBL1484 & & & & \\
\hline AEMBL130 & & & & \\
\hline JIMD 150 & & & & \\
\hline 56 & & & & \\
\hline AEMBL1607238 & & & & \\
\hline IEMBL1440595 & & & & \\
\hline AEMBL1573 & & & & \\
\hline AFMRI 13 & & & & \\
\hline 15 & & & & \\
\hline AEMBL1448476 & & & & \\
\hline AEMBL1271323 & & & & $s$ \\
\hline & & & & \\
\hline 5 & & & & \\
\hline HEMBL1382253 & & & & \\
\hline AEMBL1432599 & & & & F \\
\hline AEMBL1301180 & & & & \\
\hline & & & & \\
\hline 4 & & & & \\
\hline HEMBL1396993 & & & & RI \\
\hline AEMBL1364230 & & & & TS \\
\hline AEMBL1338595 & & & & $=-2+2$ \\
\hline HEMBL1322366 & & & & \\
\hline HEMBL1374061 & & & & \\
\hline HEMBL158379 & & 4.7362 & & $\mathrm{R}$ \\
\hline IEMBL1432 & & 362 & 03 & $1 \mathrm{H}$ \\
\hline & & & & \\
\hline 19 & & & & \\
\hline
\end{tabular}

Page 2505 


\begin{tabular}{|c|c|c|c|c|c|}
\hline \multicolumn{6}{|c|}{ Supplemental Table S2.txt } \\
\hline CHEMBL1508668 & 688239 & 5.4862 & 5.6545 & TRN & \\
\hline CHEMBL1599570 & 688239 & 6.0 & 5.455 & TRN & \\
\hline CHEMBL1560150 & 688239 & 6.7361 & 5.4128 & TRN & \\
\hline CHEMBL1449205 & 688239 & 4.5362 & 5.53700 & 0000000001 & TRN \\
\hline CHEMBL1518808 & 688239 & 5.9362 & 5.5507 & TRN & \\
\hline CHEMBL1402881 & 688239 & 4.5362 & 5.6548 & TRN & \\
\hline CHEMBL1462858 & 688239 & 4.5362 & 5.5374 & TRN & \\
\hline CHEMBL1335290 & 688239 & 7.2366 & 5.5376 & TRN & \\
\hline CHEMBL1496613 & 688239 & 5.1862 & 5.5632 & TRN & \\
\hline CHEMBL1533820 & 688239 & 4.8362 & 5.5323 & TRN & \\
\hline CHEMBL1547807 & 688239 & 6.4862 & 5.4557 & TRN & \\
\hline CHEMBL1592265 & 688239 & 5.1362 & 5.3928 & TRN & \\
\hline CHEMBL1329833 & 688239 & 5.1862 & 5.5104 & TRN & \\
\hline CHEMBL1505617 & 688239 & 5.3862 & 5.6508 & TRN & \\
\hline CHEMBL1603690 & 688239 & 5.1862 & 5.4179 & TRN & \\
\hline CHEMBL1304421 & 688239 & 5.7862 & 5.4149 & TRN & \\
\hline CHEMBL1404156 & 688239 & 5.1862 & 5.6068 & TRN & \\
\hline CHEMBL 2094484 & 688239 & 5.3862 & 5.5402 & TRN & \\
\hline CHEMBL1573745 & 688239 & 6.7361 & 5.5065 & TRN & \\
\hline CHEMBL1347902 & 688239 & 4.5862 & 5.4284 & TRN & \\
\hline CHEMBL1543948 & 688239 & 5.7862 & 5.5389 & TST & \\
\hline CHEMBL1489862 & 688239 & 6.0862 & 5.6302 & TRN & \\
\hline CHEMBL1304722 & 688239 & 5.0362 & 5.5688 & TRN & \\
\hline CHEMBL1325826 & 688239 & 4.4862 & 5.3554 & TST & \\
\hline CHEMBL 2373623 & 688239 & 5.6362 & 5.36 & TRN & \\
\hline CHEMBL1326454 & 688239 & 4.5362 & 5.45299 & 9999999999 & TRN \\
\hline CHEMBL1409914 & 688239 & 8.2366 & 5.3406 & TRN & \\
\hline CHEMBL1604249 & 688239 & 4.7362 & 5.3782 & TRN & \\
\hline CHEMBL 3194000 & 688239 & 6.7862 & 5.4375 & TRN & \\
\hline CHEMBL1315814 & 688239 & 4.4862 & 5.61299 & 99999999995 & TRN \\
\hline CHEMBL1359250 & 688239 & 7.0862 & 5.5281 & TST & \\
\hline CHEMBL1583411 & 688239 & 4.6362 & 5.4959 & TRN & \\
\hline CHEMBL1559587 & 688239 & 4.5862 & 5.6846 & TST & \\
\hline CHEMBL1562668 & 688239 & 5.4862 & 5.4822 & TRN & \\
\hline CHEMBL1370313 & 688239 & 5.4862 & 5.3871 & TRN & \\
\hline CHEMBL1428161 & 688239 & 6.1862 & 5.3406 & TRN & \\
\hline CHEMBL1535418 & 688239 & 4.4862 & 5.5206 & TRN & \\
\hline CHEMBL1307723 & 688239 & 4.5862 & 5.6175 & TST & \\
\hline CHEMBL1491253 & 688239 & 4.4862 & 5.5264 & TRN & \\
\hline CHEMBL1487745 & 688239 & 4.7362 & 5.4177 & TRN & \\
\hline CHEMBL1585229 & 688239 & 6.7361 & 5.5131 & TRN & \\
\hline CHEMBL1404694 & 688239 & 4.5362 & 5.5843 & TRN & \\
\hline CHEMBL1316630 & 688239 & 6.7361 & 5.4197 & TST & \\
\hline CHEMBL1390784 & 688239 & 6.5363 & 5.5214 & TRN & \\
\hline CHEMBL1230640 & 688239 & 7.2865 & 5.5402 & TRN & \\
\hline CHEMBL1455859 & 688239 & 5.8362 & 5.5134 & TRN & \\
\hline CHEMBL1460158 & 688239 & 6.8362 & 5.3867 & TRN & \\
\hline CHEMBL1308905 & 688239 & 5.0362 & 5.556 & TRN & \\
\hline
\end{tabular}


Supplemental Table S2.txt

\begin{tabular}{|c|c|c|c|c|c|}
\hline CHEMBL1547189 & 688239 & 4.8862 & 5.5723 & TRN & \\
\hline CHEMBL1343864 & 688239 & 4.9862 & 5.4057 & TRN & \\
\hline CHEMBL1376877 & 688239 & 5.1862 & 5.4576 & TST & \\
\hline CHEMBL1532576 & 688239 & 5.7362 & 5.3504 & TRN & \\
\hline CHEMBL1461077 & 688239 & 4.7862 & 5.4844 & TRN & \\
\hline CHEMBL1351398 & 688239 & 4.7862 & 5.4513 & TRN & \\
\hline CHEMBL1508691 & 688239 & 4.6862 & 5.4368 & TRN & \\
\hline CHEMBL1883149 & 688239 & 4.5362 & 5.352 & TRN & \\
\hline CHEMBL1382661 & 688239 & 5.4362 & 5.4609 & TST & \\
\hline CHEMBL1480460 & 688239 & 6.0862 & 5.4139 & TRN & \\
\hline CHEMBL1307942 & 688239 & 6.3863 & 5.5205 & TRN & \\
\hline CHEMBL1380064 & 688239 & 6.0862 & 5.4654 & TST & \\
\hline CHEMBL1581099 & 688239 & 5.7362 & 5.4482 & TRN & \\
\hline CHEMBL1574917 & 688239 & 6.1862 & 5.49200 & 000000001 & \\
\hline CHEMBL1308159 & 688239 & 6.8861 & 5.5202 & TRN & \\
\hline CHEMBL1585247 & 688239 & 5.4362 & 5.4658 & TRN & \\
\hline CHEMBL1423596 & 688239 & 5.5362 & 5.3567 & TRN & \\
\hline CHEMBL1412220 & 688239 & 4.9862 & 5.432 & TRN & \\
\hline CHEMBL1534040 & 688239 & 4.5362 & 5.4071 & TST & \\
\hline CHEMBL1429481 & 688239 & 4.5362 & 5.5816 & TRN & \\
\hline CHEMBL1447223 & 688239 & 8.28399 & 9999999 & 5.6184 & TST \\
\hline CHEMBL3192811 & 688239 & 6.0862 & 5.6021 & TRN & \\
\hline CHEMBL1424743 & 688239 & 4.6362 & 5.6519 & TRN & \\
\hline CHEMBL3193345 & 688239 & 5.2862 & 5.6708 & TRN & \\
\hline CHEMBL1331756 & 688239 & 4.5362 & 5.53700 & 000000001 & TR \\
\hline CHEMBL1373769 & 688239 & 4.5362 & 5.4382 & TRN & \\
\hline CHEMBL1308764 & 688239 & 4.5362 & 5.442 & TST & \\
\hline CHEMBL1582859 & 688239 & 5.5362 & 5.4121 & TST & \\
\hline CHEMBL1379434 & 688239 & 4.7862 & 5.3889 & TST & \\
\hline CHEMBL 3195584 & 688239 & 5.9862 & 5.3858 & TRN & \\
\hline CHEMBL1557891 & 688239 & 4.5362 & 5.4584 & TRN & \\
\hline CHEMBL1540513 & 688239 & 4.9862 & 5.5579 & TRN & \\
\hline CHEMBL370256 & 688239 & 4.6362 & 5.4745 & TRN & \\
\hline CHEMBL1540966 & 688239 & 5.3362 & 5.5414 & TRN & \\
\hline CHEMBL1551306 & 688239 & 7.1864 & 5.4637 & TRN & \\
\hline CHEMBL1376997 & 688239 & 5.2362 & 5.5575 & TRN & \\
\hline CHEMBL1503042 & 688239 & 6.2362 & 5.5118 & TST & \\
\hline CHEMBL1339832 & 688239 & 5.1862 & 5.4684 & TRN & \\
\hline CHEMBL 1471790 & 688239 & 4.8862 & 5.5145 & TRN & \\
\hline CHEMBL1352178 & 688239 & 5.4362 & 5.4715 & TRN & \\
\hline CHEMBL1584917 & 688239 & 5.6862 & 5.4856 & TST & \\
\hline CHEMBL1465600 & 688239 & 4.7862 & 5.4273 & TRN & \\
\hline CHEMBL1410515 & 688239 & 4.4862 & 5.4797 & TST & \\
\hline CHEMBL1605987 & 688239 & 5.7362 & 5.4672 & TST & \\
\hline CHEMBL1334320 & 688239 & 4.7862 & 5.5859 & TRN & \\
\hline CHEMBL1546534 & 688239 & 4.6362 & 5.4556 & TRN & \\
\hline CHEMBL1299655 & 688239 & 4.5362 & 5.4765 & TST & \\
\hline CHEMBL1494319 & 688239 & 5.7862 & 5.4595 & TRN & \\
\hline
\end{tabular}


Supplemental Table S2.txt

\begin{tabular}{|c|c|c|c|c|}
\hline CHEMBL1579737 & 688239 & 4.5362 & 5.4612 & TRN \\
\hline CHEMBL1503250 & 688239 & 6.5862 & 5.3821 & TST \\
\hline CHEMBL1428075 & 688239 & 6.7361 & 5.5089 & TST \\
\hline CHEMBL1381623 & 688239 & 5.1362 & 5.5599 & TST \\
\hline CHEMBL1368752 & 688239 & 4.5362 & 5.5435 & TRN \\
\hline CHEMBL1346056 & 688239 & 4.7362 & 5.376 & TST \\
\hline CHEMBL1595244 & 688239 & 8.2366 & 5.5174 & TST \\
\hline CHEMBL1523524 & 688239 & 4.5362 & 5.4875 & TRN \\
\hline CHEMBL1330895 & 688239 & 4.5362 & 5.4961 & TRN \\
\hline CHEMBL1312203 & 688239 & 4.6862 & 5.3745 & TST \\
\hline CHEMBL1338457 & 688239 & 5.5862 & \multicolumn{2}{|c|}{5.587999999999999} \\
\hline CHEMBL1412045 & 688239 & 5.1862 & 5.4067 & TRN \\
\hline CHEMBL1397368 & 688239 & 4.6862 & 5.4499 & TRN \\
\hline CHEMBL1319329 & 688239 & 4.4862 & 5.6653 & TRN \\
\hline CHEMBL1345544 & 688239 & 5.2362 & 5.4741 & TRN \\
\hline CHEMBL1469963 & 688239 & 4.5862 & 5.6914 & TRN \\
\hline CHEMBL1327620 & 688239 & 4.7362 & 5.54 & TRN \\
\hline CHEMBL1572889 & 688239 & 6.1862 & 5.4267 & TRN \\
\hline CHEMBL3196878 & 688239 & 6.1862 & 5.2934 & TRN \\
\hline CHEMBL 2006221 & 688239 & 4.6862 & 5.3558 & TRN \\
\hline CHEMBL1301634 & 688239 & 5.0362 & 5.5442 & TRN \\
\hline CHEMBL1331927 & 688239 & 6.5862 & 5.4491 & TRN \\
\hline CHEMBL1557192 & 688239 & 4.5362 & 5.4556 & TRN \\
\hline CHEMBL1499896 & 688239 & 5.1862 & 5.5249 & TRN \\
\hline CHEMBL1423234 & 688239 & 5.8862 & 5.5051 & TRN \\
\hline CHEMBL1422682 & 688239 & 5.9862 & 5.4547 & TRN \\
\hline CHEMBL3210216 & 688239 & 6.0862 & 5.3961 & TRN \\
\hline CHEMBL1352700 & 688239 & 5.1362 & 5.3203 & TRN \\
\hline CHEMBL3195015 & 688239 & 5.1862 & 5.3245 & TRN \\
\hline CHEMBL1604583 & 688239 & 6.2362 & 5.6897 & TRN \\
\hline CHEMBL1598031 & 688239 & 4.7862 & 5.5728 & TRN \\
\hline CHEMBL1403133 & 688239 & 6.9363 & 5.4873 & TRN \\
\hline CHEMBL1423440 & 688239 & 5.7862 & 5.4475 & TST \\
\hline CHEMBL1553443 & 688239 & 4.6862 & 5.4876 & TRN \\
\hline CHEMBL1585054 & 688239 & 4.5362 & 5.5516 & TRN \\
\hline CHEMBL1368352 & 688239 & 6.5363 & 5.3023 & TRN \\
\hline CHEMBL1589560 & 688239 & 4.5362 & 5.5315 & TRN \\
\hline CHEMBL3197776 & 688239 & 6.0862 & 5.5174 & TRN \\
\hline CHEMBL1524510 & 688239 & 4.7362 & 5.4261 & TRN \\
\hline CHEMBL1396891 & 688239 & 4.7862 & 5.541 & TRN \\
\hline CHEMBL1526930 & 688239 & 4.5362 & 5.399 & TST \\
\hline CHEMBL229760 & 688239 & 7.0362 & \multicolumn{2}{|c|}{5.422999999999999} \\
\hline CHEMBL1511089 & 688239 & 5.1862 & 5.5262 & TRN \\
\hline CHEMBL1568262 & 688239 & 6.8861 & 5.3783 & TRN \\
\hline CHEMBL1432868 & 688239 & 4.5362 & 5.4623 & TRN \\
\hline CHEMBL1558039 & 688239 & 5.8862 & 5.4705 & TST \\
\hline CHEMBL1327803 & 688239 & 4.8362 & 5.5896 & TRN \\
\hline CHEMBL3209164 & 688239 & 5.6362 & 5.5353 & TRN \\
\hline
\end{tabular}

Page 2508 


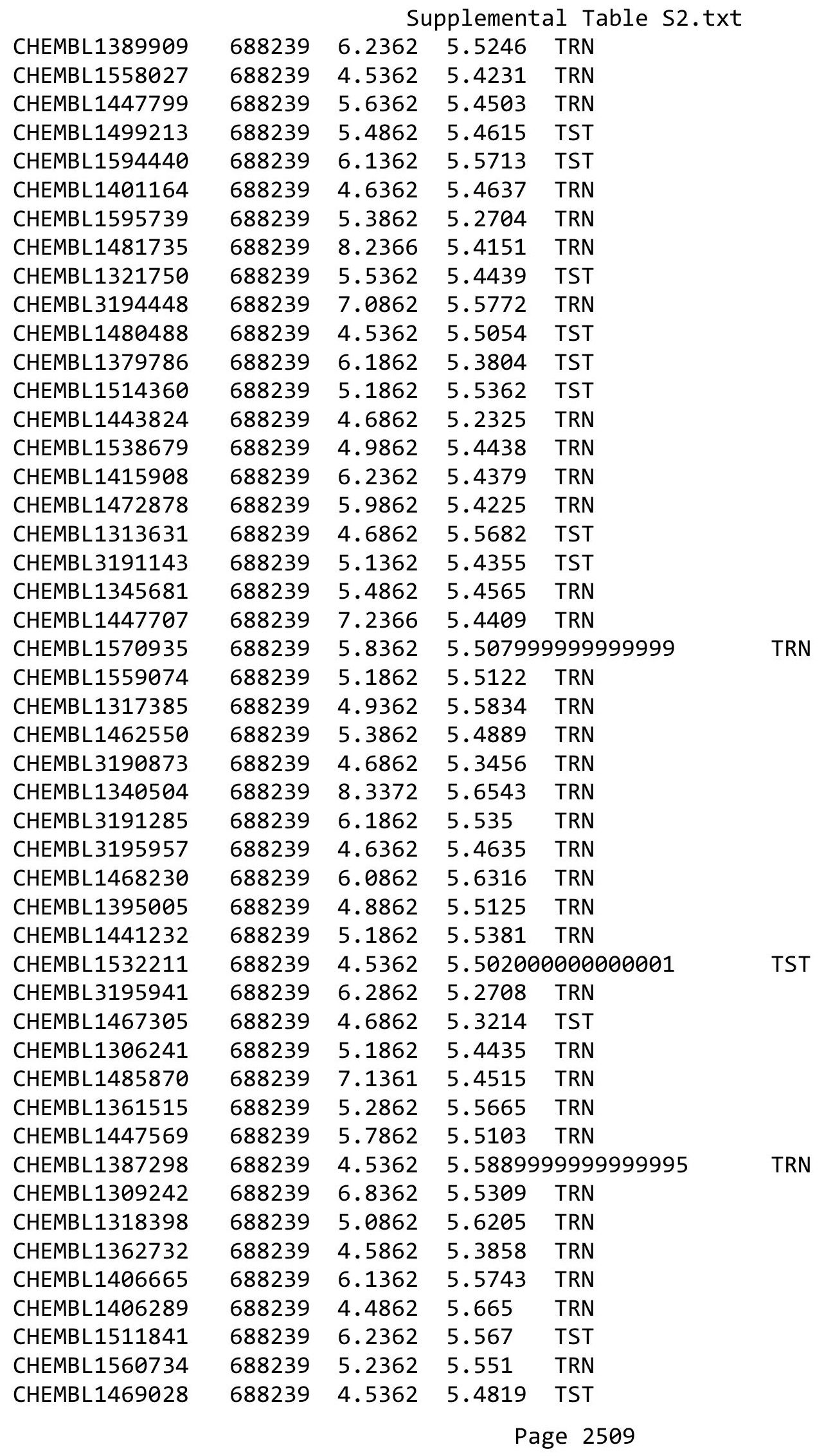


Supplemental Table S2.txt

\begin{tabular}{|c|c|c|c|c|}
\hline CHEMBL1348021 & 688239 & 4.6362 & 5.606 & TST \\
\hline CHEMBL1422365 & 688239 & 5.4362 & 5.3955 & TST \\
\hline CHEMBL1572267 & 688239 & 6.9863 & 5.472 & TRN \\
\hline CHEMBL1499795 & 688239 & 5.5362 & 5.6777 & TRN \\
\hline CHEMBL1608301 & 688239 & 5.6362 & 5.4011 & TRN \\
\hline CHEMBL1570875 & 688239 & 5.1862 & 5.6019 & TRN \\
\hline CHEMBL1311378 & 688239 & 4.5362 & 5.5943 & TRN \\
\hline CHEMBL1539714 & 688239 & 5.4862 & 5.6039 & TRN \\
\hline CHEMBL1386405 & 688239 & 4.7362 & 5.4245 & TST \\
\hline CHEMBL1419707 & 688239 & 6.4862 & 5.5951 & TRN \\
\hline CHEMBL1341127 & 688239 & 6.0362 & 5.572 & TRN \\
\hline CHEMBL1385748 & 688239 & 4.5362 & 5.5804 & TRN \\
\hline CHEMBL1603672 & 688239 & 5.6362 & 5.5156 & TRN \\
\hline CHEMBL1310487 & 688239 & 6.6861 & 5.4334 & TST \\
\hline CHEMBL1593445 & 688239 & 4.9862 & 5.6226 & TRN \\
\hline CHEMBL1319961 & 688239 & 6.9863 & 5.6557 & TRN \\
\hline CHEMBL1598720 & 688239 & 4.6362 & 5.5472 & TRN \\
\hline CHEMBL1504433 & 688239 & 6.2862 & 5.5383 & TRN \\
\hline CHEMBL1555252 & 688239 & 5.5862 & 5.6947 & TRN \\
\hline CHEMBL1549436 & 688239 & 7.0862 & 5.6085 & TRN \\
\hline CHEMBL1376309 & 688239 & 6.3362 & 5.4519 & TRN \\
\hline CHEMBL1576883 & 688239 & 5.1862 & 5.5667 & TST \\
\hline CHEMBL1419967 & 688239 & 6.2862 & 5.436 & TRN \\
\hline CHEMBL1527445 & 688239 & 6.2862 & 5.5646 & TRN \\
\hline CHEMBL1343123 & 688239 & 5.1862 & 5.557 & TST \\
\hline CHEMBL1376794 & 688239 & 5.6362 & 5.6496 & TST \\
\hline CHEMBL1493807 & 688239 & 4.5362 & 5.5955 & TRN \\
\hline CHEMBL1377016 & 688239 & 4.5362 & 5.2993 & TRN \\
\hline CHEMBL1505429 & 688239 & 5.8862 & 5.4498 & TRN \\
\hline CHEMBL1479385 & 688239 & 5.1862 & 5.4193 & TRN \\
\hline CHEMBL1351781 & 688239 & 5.4362 & 5.5336 & TRN \\
\hline CHEMBL1409818 & 688239 & 5.4362 & 5.6039 & TST \\
\hline CHEMBL1479282 & 688239 & 4.6362 & 5.572999 & 99999999995 \\
\hline CHEMBL1299473 & 688239 & 4.5862 & 5.5854 & TRN \\
\hline CHEMBL 2001950 & 688239 & 4.8362 & 5.4175 & TST \\
\hline CHEMBL 3191844 & 688239 & 5.3362 & 5.5183 & TRN \\
\hline CHEMBL 1485719 & 688239 & 6.1362 & 5.3811 & TRN \\
\hline CHEMBL2373665 & 688239 & 5.1862 & 5.4573 & TST \\
\hline CHEMBL1599994 & 688239 & 5.1362 & 5.3642 & TRN \\
\hline CHEMBL1444226 & 688239 & 6.2862 & 5.4019 & TRN \\
\hline CHEMBL1572697 & 688239 & 4.6862 & 5.5346 & TST \\
\hline CHEMBL1422520 & 688239 & 5.1862 & 5.4116 & TST \\
\hline CHEMBL1449569 & 688239 & 4.9362 & 5.3995 & TRN \\
\hline CHEMBL1589664 & 688239 & 4.5362 & 5.475 & TRN \\
\hline CHEMBL1501083 & 688239 & 5.4362 & 5.6756 & TRN \\
\hline CHEMBL1452304 & 688239 & 5.4362 & 5.4424 & TRN \\
\hline CHEMBL 3190949 & 688239 & 7.2366 & 5.4933 & TRN \\
\hline CHEMBL1587122 & 688239 & 4.7862 & 5.5249 & TRN \\
\hline
\end{tabular}

Page 2510 
Supplemental Table S2.txt

\begin{tabular}{|c|c|c|c|c|}
\hline CHEMBL1378577 & 688239 & 4.5362 & 5.5161 & TRN \\
\hline CHEMBL1590672 & 688239 & 5.7362 & 5.5393 & TRN \\
\hline CHEMBL1347832 & 688239 & 5.3862 & 5.3217 & TRN \\
\hline CHEMBL1586559 & 688239 & 4.9 & 5.5023 & TRN \\
\hline CHEMBL1344966 & 688239 & 4.4862 & 5.3721 & TRN \\
\hline CHEMBL1503731 & 688239 & 6.0862 & 5.4763 & TRN \\
\hline CHEMBL1387767 & 688239 & 4.6362 & 5.401 & TST \\
\hline CHEMBL1544483 & 688239 & 5.5862 & 5.4238 & TST \\
\hline CHEMBL1383096 & 688239 & 5.1862 & 5.4816 & TRN \\
\hline CHEMBL1319218 & 688239 & 4.7862 & 5.6187 & TRN \\
\hline CHEMBL 3210033 & 688239 & 5.4862 & 5.3442 & TRN \\
\hline CHEMBL1983418 & 688239 & 4.7862 & 5.5244 & TRN \\
\hline CHEMBL1568996 & 688239 & 4.5362 & 5.2534 & TST \\
\hline CHEMBL 2373627 & 688239 & 5.925 & 5.4235 & TST \\
\hline CHEMBL1520601 & 688239 & 5.8862 & 5.4318 & TST \\
\hline CHEMBL1511812 & 688239 & 5.1862 & 5.4944 & TST \\
\hline CHEMBL1531413 & 688239 & 6.2862 & 5.4972 & TRN \\
\hline CHEMBL1480703 & 688239 & 6.1362 & 5.3629 & TRN \\
\hline CHEMBL1385482 & 688239 & 6.6861 & 5.6047 & TRN \\
\hline CHEMBL1533094 & 688239 & 5.3862 & 5.3308 & TST \\
\hline CHEMBL1560688 & 688239 & 6.3362 & 5.494 & TRN \\
\hline CHEMBL1341071 & 688239 & 6.2362 & 5.3952 & TST \\
\hline CHEMBL1328477 & 688239 & 4.8362 & 5.4548 & TRN \\
\hline CHEMBL113830 & 688239 & 6.0862 & 5.3378 & TST \\
\hline CHEMBL1608048 & 688239 & 5.0362 & 5.3344 & TRN \\
\hline CHEMBL1486753 & 688239 & 4.5362 & 5.5549 & TRN \\
\hline CHEMBL595331 & 688239 & 4.5862 & 5.3567 & TRN \\
\hline CHEMBL1382370 & 688239 & 5.1862 & 5.5131 & TRN \\
\hline CHEMBL1392834 & 688239 & 7.1361 & 5.3361 & TST \\
\hline CHEMBL1459944 & 688239 & 4.8862 & 5.4689 & TRN \\
\hline CHEMBL1455895 & 688239 & 4.5362 & 5.5175 & TRN \\
\hline CHEMBL1522839 & 688239 & 4.5362 & 5.46399 & 99999999995 \\
\hline CHEMBL3210719 & 688239 & 7.6861 & 5.3914 & TST \\
\hline CHEMBL1304650 & 688239 & 5.2862 & 5.5736 & TRN \\
\hline CHEMBL1420474 & 688239 & 4.7862 & 5.5105 & TST \\
\hline CHEMBL1345279 & 688239 & 5.8862 & 5.5016 & TRN \\
\hline CHEMBL1439614 & 688239 & 7.2865 & 5.4244 & TRN \\
\hline CHEMBL 3192226 & 688239 & 5.0862 & 5.5322 & TRN \\
\hline CHEMBL1375662 & 688239 & 4.8362 & 5.4877 & TRN \\
\hline CHEMBL1421258 & 688239 & 5.1362 & 5.5356 & TRN \\
\hline CHEMBL1411691 & 688239 & 8.3872 & 5.444 & TRN \\
\hline CHEMBL1572816 & 688239 & 6.1862 & 5.4666 & TST \\
\hline CHEMBL1524936 & 688239 & 6.2862 & 5.4953 & TST \\
\hline CHEMBL1482468 & 688239 & 5.4862 & 5.7532 & TST \\
\hline CHEMBL1451699 & 688239 & 4.4862 & 5.4579 & TRN \\
\hline CHEMBL1431605 & 688239 & 4.5862 & 5.402 & TRN \\
\hline CHEMBL1310764 & 688239 & 5.5862 & 5.6122 & TRN \\
\hline CHEMBL1427955 & 688239 & 5.4862 & 5.4301 & TRN \\
\hline
\end{tabular}

Page 2511 
Supplemental Table S2.txt

\begin{tabular}{|c|c|c|c|c|c|}
\hline CHEMBL1526216 & 688239 & 4.5862 & 5.602 & TRN & \\
\hline CHEMBL1493073 & 688239 & 4.5362 & 5.4123 & TRN & \\
\hline CHEMBL1593146 & 688239 & 5.4362 & 5.4892 & TRN & \\
\hline CHEMBL1425981 & 688239 & 4.9862 & 5.4454 & TRN & \\
\hline CHEMBL1604154 & 688239 & 6.3863 & 5.32299 & 99999999995 & TRN \\
\hline CHEMBL1603957 & 688239 & 4.7362 & 5.5609 & TRN & \\
\hline CHEMBL3194935 & 688239 & 4.5362 & 5.4758 & TRN & \\
\hline CHEMBL1369887 & 688239 & 4.7362 & 5.5219 & TRN & \\
\hline CHEMBL1551345 & 688239 & 4.5862 & 5.4626 & TRN & \\
\hline CHEMBL1475483 & 688239 & 4.5362 & 5.4821 & TRN & \\
\hline CHEMBL1324757 & 688239 & 5.2362 & 5.5866 & TRN & \\
\hline CHEMBL1484657 & 688239 & 5.4862 & 5.5297 & TRN & \\
\hline CHEMBL1385797 & 688239 & 5.0862 & 5.4635 & TRN & \\
\hline CHEMBL1549127 & 688239 & 4.9862 & 5.58 & TRN & \\
\hline CHEMBL1312315 & 688239 & 8.3372 & 5.5661 & TRN & \\
\hline CHEMBL1353754 & 688239 & 5.1362 & 5.6062 & TST & \\
\hline CHEMBL1358334 & 688239 & 4.7862 & 5.4965 & TRN & \\
\hline CHEMBL1406518 & 688239 & 5.2362 & 5.4958 & TRN & \\
\hline CHEMBL1464200 & 688239 & 4.6362 & 5.4714 & TRN & \\
\hline CHEMBL1364191 & 688239 & 4.4862 & 5.4473 & TST & \\
\hline CHEMBL1512409 & 688239 & 4.7362 & 5.4338 & TRN & \\
\hline CHEMBL1576170 & 688239 & 5.2862 & 5.42299 & 9999999999 & TRN \\
\hline CHEMBL1402983 & 688239 & 4.6362 & 5.4903 & TRN & \\
\hline CHEMBL1435660 & 688239 & 6.1362 & 5.5512 & TST & \\
\hline CHEMBL1525747 & 688239 & 4.5362 & 5.4917 & TRN & \\
\hline CHEMBL1437297 & 688239 & 5.8862 & 5.3604 & TRN & \\
\hline CHEMBL3210205 & 688239 & 6.4862 & 5.4317 & TST & \\
\hline CHEMBL1528710 & 688239 & 8.1367 & 5.435 & TRN & \\
\hline CHEMBL1388455 & 688239 & 4.8362 & 5.4893 & TRN & \\
\hline CHEMBL1612155 & 688239 & 6.5862 & 5.5571 & TRN & \\
\hline CHEMBL1437654 & 688239 & 5.0862 & 5.5422 & TRN & \\
\hline CHEMBL1464233 & 688239 & 5.3862 & 5.4525 & TST & \\
\hline CHEMBL1342191 & 688239 & 6.5862 & 5.4303 & TRN & \\
\hline CHEMBL3199178 & 688239 & 6.2362 & 5.4011 & TST & \\
\hline CHEMBL1312295 & 688239 & 4.7362 & 5.6143 & TRN & \\
\hline CHEMBL1304472 & 688239 & 6.1362 & 5.5304 & TRN & \\
\hline CHEMBL1550787 & 688239 & 5.3862 & 5.3597 & TRN & \\
\hline CHEMBL1418509 & 688239 & 6.1862 & 5.5004 & TST & \\
\hline CHEMBL3209304 & 688239 & 5.1862 & 5.678 & TRN & \\
\hline CHEMBL1476116 & 688239 & 4.7362 & 5.5211 & TRN & \\
\hline CHEMBL1334623 & 688239 & 5.5862 & \multicolumn{2}{|c|}{5.582999999999999} & TST \\
\hline CHEMBL1318840 & 688239 & 4.6862 & 5.5209 & TST & \\
\hline CHEMBL1504065 & 688239 & 4.5362 & 5.5686 & TRN & \\
\hline CHEMBL1388104 & 688239 & 5.3362 & 5.4523 & TST & \\
\hline CHEMBL1432379 & 688239 & 4.7362 & 5.3916 & TRN & \\
\hline CHEMBL1580988 & 688239 & 6.1362 & 5.5226 & TRN & \\
\hline CHEMBL1354400 & 688239 & 5.1362 & 5.4462 & TRN & \\
\hline CHEMBL1420183 & 688239 & 4.7362 & 5.6756 & TST & \\
\hline
\end{tabular}


Supplemental Table S2.txt

\begin{tabular}{|c|c|c|c|c|c|c|}
\hline CHEMBL1337486 & 688239 & 5.6862 & 5.626 & TRN & & \\
\hline CHEMBL1363273 & 688239 & 4.5362 & 5.6224 & TRN & & \\
\hline CHEMBL1372632 & 688239 & 4.6362 & 5.5343 & TRN & & \\
\hline CHEMBL1428417 & 688239 & 4.6362 & 5.3873 & TRN & & \\
\hline CHEMBL1526228 & 688239 & 5.6862 & 5.4802 & TRN & & \\
\hline CHEMBL1531326 & 688239 & 5.7862 & 5.7208 & TRN & & \\
\hline CHEMBL1605296 & 688239 & 8.3372 & 5.2805 & TRN & & \\
\hline CHEMBL1398011 & 688239 & 4.4862 & 5.4859 & TRN & & \\
\hline CHEMBL1541834 & 688239 & 4.7862 & 5.3596 & TRN & & \\
\hline CHEMBL1378335 & 688239 & 4.7362 & 5.4151 & TRN & & \\
\hline CHEMBL1554598 & 688239 & 5.1862 & 5.5466 & TRN & & \\
\hline CHEMBL3211383 & 688239 & 8.28399 & 999999999 & & 5.5464 & TRN \\
\hline CHEMBL1452514 & 688239 & 6.1362 & 5.4158 & TRN & & \\
\hline CHEMBL1498630 & 688239 & 5.0362 & 5.4861 & TRN & & \\
\hline CHEMBL1569043 & 688239 & 5.0862 & 5.5652 & TRN & & \\
\hline CHEMBL1551082 & 688239 & 4.5862 & 5.5487 & TRN & & \\
\hline CHEMBL1482006 & 688239 & 6.6362 & 5.476 & TST & & \\
\hline CHEMBL1338824 & 688239 & 4.6862 & 5.5536 & TRN & & \\
\hline CHEMBL1409634 & 688239 & 5.3862 & 5.4176 & TST & & \\
\hline CHEMBL1596159 & 688239 & 6.7361 & 5.4785 & TRN & & \\
\hline CHEMBL1375296 & 688239 & 4.5362 & 5.4975 & TRN & & \\
\hline CHEMBL1321159 & 688239 & 4.9362 & 5.3306 & TRN & & \\
\hline CHEMBL1427811 & 688239 & 4.7362 & 5.5507 & TRN & & \\
\hline CHEMBL1405717 & 688239 & 5.3862 & 5.3359 & TST & & \\
\hline CHEMBL1507811 & 688239 & 5.2862 & 5.5489 & TRN & & \\
\hline CHEMBL1557939 & 688239 & 5.1862 & 5.4395 & TRN & & \\
\hline CHEMBL1436880 & 688239 & 4.7362 & 5.4872 & TRN & & \\
\hline CHEMBL1307821 & 688239 & 4.5362 & 5.4191 & TRN & & \\
\hline CHEMBL1587814 & 688239 & 5.4862 & 5.4264 & TRN & & \\
\hline CHEMBL1570080 & 688239 & 5.1862 & 5.3984 & TRN & & \\
\hline CHEMBL1574871 & 688239 & 6.4862 & 5.5667 & TST & & \\
\hline CHEMBL1601454 & 688239 & 6.0862 & 5.5911 & TRN & & \\
\hline CHEMBL1393340 & 688239 & 5.1362 & 5.4927 & TRN & & \\
\hline CHEMBL1453998 & 688239 & 5.1862 & 5.5068 & TRN & & \\
\hline CHEMBL3198930 & 688239 & 4.6362 & 5.5011 & TST & & \\
\hline CHEMBL1588586 & 688239 & 4.6862 & 5.3617 & TRN & & \\
\hline CHEMBL1566830 & 688239 & 7.3363 & 5.5216 & TRN & & \\
\hline CHEMBL1305396 & 688239 & 6.3362 & 5.2265 & TRN & & \\
\hline CHEMBL1094843 & 688239 & 5.1862 & 5.6214 & TST & & \\
\hline CHEMBL1598806 & 688239 & 4.45 & 5.4518 & TRN & & \\
\hline CHEMBL1407754 & 688239 & 4.7362 & 5.3909 & TRN & & \\
\hline CHEMBL1583458 & 688239 & 6.1862 & 5.5264 & TRN & & \\
\hline CHEMBL1300673 & 688239 & 8.28399 & 999999999 & 99 & 5.4751 & TST \\
\hline CHEMBL1976777 & 688239 & 4.7362 & 5.3825 & TRN & & \\
\hline CHEMBL1503751 & 688239 & 6.4862 & 5.5141 & TST & & \\
\hline CHEMBL1344971 & 688239 & 6.1862 & 5.4308 & TRN & & \\
\hline CHEMBL1585991 & 688239 & 4.5362 & 5.4172 & TRN & & \\
\hline CHEMBL3211171 & 688239 & 5.4362 & 5.3876 & TRN & & \\
\hline
\end{tabular}


Supplemental Table S2.txt

\begin{tabular}{|c|c|c|c|c|c|}
\hline CHEMBL1332824 & 688239 & 4.6862 & 5.3247 & TRN & \\
\hline CHEMBL1557172 & 688239 & 4.5362 & 5.5251 & TRN & \\
\hline CHEMBL1472339 & 688239 & 5.1862 & 5.4496 & TRN & \\
\hline CHEMBL1443419 & 688239 & 7.2366 & 5.5768 & TRN & \\
\hline CHEMBL1556877 & 688239 & 4.5362 & 5.763 & TRN & \\
\hline CHEMBL1476768 & 688239 & 5.1862 & 5.4896 & TRN & \\
\hline CHEMBL1304812 & 688239 & 5.8862 & 5.398 & TRN & \\
\hline CHEMBL1457824 & 688239 & 5.2862 & 5.5385 & TRN & \\
\hline CHEMBL1466840 & 688239 & 5.3862 & 5.4686 & TRN & \\
\hline CHEMBL3212328 & 688239 & 6.8362 & 5.4194 & TST & \\
\hline CHEMBL1542563 & 688239 & 4.5362 & 5.6779 & TRN & \\
\hline CHEMBL1346627 & 688239 & 5.6862 & 5.3367 & TST & \\
\hline CHEMBL1544255 & 688239 & 5.5 & 5.4105 & TRN & \\
\hline CHEMBL1578150 & 688239 & 4.5362 & 5.4162 & TST & \\
\hline CHEMBL1561240 & 688239 & 4.7862 & 5.2673 & TRN & \\
\hline CHEMBL1256716 & 688239 & 6.9363 & 5.4094 & TRN & \\
\hline CHEMBL1601942 & 688239 & 5.1862 & 5.4788 & TRN & \\
\hline CHEMBL1453270 & 688239 & 6.1362 & 5.5625 & TRN & \\
\hline CHEMBL1606118 & 688239 & 5.4362 & 5.4756 & TRN & \\
\hline CHEMBL1441615 & 688239 & 5.5362 & 5.5621 & TRN & \\
\hline CHEMBL1454685 & 688239 & 6.6861 & 5.5982 & TST & \\
\hline CHEMBL1491556 & 688239 & 5.9862 & 5.4447 & TRN & \\
\hline CHEMBL1463689 & 688239 & 4.7362 & 5.556 & TST & \\
\hline CHEMBL1578257 & 688239 & 5.3862 & 5.4339 & TRN & \\
\hline CHEMBL1394602 & 688239 & 4.8362 & 5.3938 & TST & \\
\hline CHEMBL1393252 & 688239 & 8.28399 & 99999999 & 99 & 5.5069 \\
\hline CHEMBL1578240 & 688239 & 4.7862 & 5.6106 & TRN & \\
\hline CHEMBL1533503 & 688239 & 4.7362 & 5.3917 & TRN & \\
\hline CHEMBL1391062 & 688239 & 5.5362 & 5.4786 & TRN & \\
\hline CHEMBL1345248 & 688239 & 5.3862 & 5.5865 & TST & \\
\hline CHEMBL1475491 & 688239 & 4.5362 & 5.4701 & TRN & \\
\hline CHEMBL1582054 & 688239 & 4.5862 & 5.5611 & TRN & \\
\hline CHEMBL1379240 & 688239 & 5.7362 & 5.3939 & TST & \\
\hline CHEMBL1544362 & 688239 & 5.1862 & 5.6052 & TRN & \\
\hline CHEMBL1311239 & 688239 & 5.5862 & 5.5244 & TRN & \\
\hline CHEMBL3209467 & 688239 & 4.8362 & 5.3749 & TRN & \\
\hline CHEMBL1390773 & 688239 & 5.1862 & 5.4043 & TST & \\
\hline CHEMBL1367735 & 688239 & 4.5362 & 5.5381 & TST & \\
\hline CHEMBL1603244 & 688239 & 5.2862 & 5.4432 & TRN & \\
\hline CHEMBL1402183 & 688239 & 5.7862 & 5.4869 & TRN & \\
\hline CHEMBL1498594 & 688239 & 6.7862 & 5.5462 & TRN & \\
\hline CHEMBL1609514 & 688239 & 4.5362 & 5.471 & TRN & \\
\hline CHEMBL1409897 & 688239 & 5.2362 & 5.4689 & TRN & \\
\hline CHEMBL1301940 & 688239 & 5.2862 & 5.3272 & TRN & \\
\hline CHEMBL1363342 & 688239 & 4.5362 & 5.6056 & TRN & \\
\hline CHEMBL1485144 & 688239 & 6.2362 & 5.5077 & TST & \\
\hline CHEMBL1354002 & 688239 & 4.6362 & 5.397 & TRN & \\
\hline CHEMBL1529807 & 688239 & 4.5362 & 5.4249 & TRN & \\
\hline
\end{tabular}

Page 2514 
Supplemental Table S2.txt

\begin{tabular}{|c|c|c|c|c|}
\hline CHEMBL1440601 & 688239 & 6.8861 & 5.3066 & TST \\
\hline CHEMBL1576330 & 688239 & 5.0862 & 5.5404 & TRN \\
\hline CHEMBL1538692 & 688239 & 5.1862 & 5.3334 & TRN \\
\hline CHEMBL1532683 & 688239 & 5.2362 & 5.3327 & TST \\
\hline CHEMBL1313899 & 688239 & 5.7362 & 5.5119 & TRN \\
\hline CHEMBL1559440 & 688239 & 6.6362 & 5.4913 & TST \\
\hline CHEMBL1464976 & 688239 & 4.4862 & 5.4456 & TST \\
\hline CHEMBL1324171 & 688239 & 5.5862 & 5.6168 & TRN \\
\hline CHEMBL1563372 & 688239 & 6.2362 & 5.3043 & TRN \\
\hline CHEMBL1992293 & 688239 & 4.5362 & 5.5754 & TST \\
\hline CHEMBL1417565 & 688239 & 5.5862 & 5.5433 & TST \\
\hline CHEMBL1485272 & 688239 & 6.35 & 5.3405 & TRN \\
\hline CHEMBL1454081 & 688239 & 6.2362 & 5.5872 & TST \\
\hline CHEMBL1533878 & 688239 & 6.0362 & 5.6398 & TRN \\
\hline CHEMBL1528673 & 688239 & 6.1862 & 5.4472 & TRN \\
\hline CHEMBL1376623 & 688239 & 5.1862 & 5.4478 & TRN \\
\hline CHEMBL1303477 & 688239 & 5.5362 & 5.6126 & TRN \\
\hline CHEMBL1342873 & 688239 & 4.5362 & 5.5089 & TRN \\
\hline CHEMBL1381695 & 688239 & 5.0362 & 5.4376 & TRN \\
\hline CHEMBL1493498 & 688239 & 4.45 & 5.5263 & TRN \\
\hline CHEMBL1533426 & 688239 & 4.8362 & 5.5857 & TRN \\
\hline CHEMBL1350131 & 688239 & 4.6362 & 5.521 & TRN \\
\hline CHEMBL1580267 & 688239 & 5.1862 & 5.4139 & TRN \\
\hline CHEMBL1462870 & 688239 & 5.4362 & 5.5514 & TRN \\
\hline CHEMBL1433766 & 688239 & 5.3862 & 5.4933 & TRN \\
\hline CHEMBL1507855 & 688239 & 4.6362 & 5.4243 & TRN \\
\hline CHEMBL1489851 & 688239 & 4.5362 & 5.6109 & TRN \\
\hline CHEMBL1533547 & 688239 & 6.4862 & 5.5804 & TST \\
\hline CHEMBL1509925 & 688239 & 5.1862 & 5.5056 & TST \\
\hline CHEMBL1505183 & 688239 & 4.4862 & 5.4964 & TRN \\
\hline CHEMBL201325 & 688239 & 4.5862 & 5.5121 & TST \\
\hline CHEMBL1613058 & 688239 & 5.1362 & 5.4994 & TST \\
\hline CHEMBL1473457 & 688239 & 5.3362 & 5.3593 & TRN \\
\hline CHEMBL1415956 & 688239 & 4.5362 & 5.659 & TRN \\
\hline CHEMBL1539931 & 688239 & 5.6862 & 5.5828 & TRN \\
\hline CHEMBL14282 & 688239 & 6.8362 & 5.5488 & TRN \\
\hline CHEMBL1355645 & 688239 & 4.7862 & 5.4013 & TRN \\
\hline CHEMBL1308352 & 688239 & 5.3862 & 5.5488 & TRN \\
\hline CHEMBL1370674 & 688239 & 7.9872 & 5.5466 & TST \\
\hline CHEMBL1375563 & 688239 & 4.5362 & 5.5073 & TRN \\
\hline CHEMBL1483986 & 688239 & 6.0862 & 5.2268 & TRN \\
\hline CHEMBL1400505 & 688239 & 4.7862 & 5.4021 & TRN \\
\hline CHEMBL1320128 & 688239 & 4.5362 & 5.5754 & TRN \\
\hline CHEMBL1336454 & 688239 & 5.3362 & 5.572999 & 99999999995 \\
\hline CHEMBL1311400 & 688239 & 4.6862 & 5.5358 & TST \\
\hline CHEMBL1427240 & 688239 & 6.6362 & 5.4694 & TST \\
\hline CHEMBL1515809 & 688239 & 4.7862 & 5.3277 & TRN \\
\hline CHEMBL1534620 & 688239 & 5.1862 & 5.5501 & TRN \\
\hline
\end{tabular}

Page 2515 
Supplemental Table S2.txt

\begin{tabular}{|c|c|c|c|c|c|}
\hline CHEMBL1489030 & 688239 & 5.1362 & 5.5821 & TRN & \\
\hline CHEMBL 3190804 & 688239 & 4.9362 & 5.3342 & TST & \\
\hline CHEMBL1574905 & 688239 & 4.7862 & 5.5657 & TRN & \\
\hline CHEMBL1399221 & 688239 & 4.5362 & \multicolumn{2}{|c|}{5.361000000000001} & TST \\
\hline CHEMBL1418371 & 688239 & 4.6362 & 5.5159 & TST & \\
\hline CHEMBL1350393 & 688239 & 4.7362 & 5.4725 & TRN & \\
\hline CHEMBL1549894 & 688239 & 5.1862 & 5.3662 & TRN & \\
\hline CHEMBL1514355 & 688239 & 4.5862 & 5.5378 & TRN & \\
\hline CHEMBL1484494 & 688239 & 4.8362 & 5.4205 & TRN & \\
\hline CHEMBL1378198 & 688239 & 5.4862 & 5.5421 & TRN & \\
\hline CHEMBL1353718 & 688239 & 5.7862 & 5.4711 & TRN & \\
\hline CHEMBL1480620 & 688239 & 4.9362 & 5.5507 & TST & \\
\hline CHEMBL1348879 & 688239 & 6.4862 & 5.5987 & TRN & \\
\hline CHEMBL1482452 & 688239 & 4.8362 & 5.6198 & TRN & \\
\hline CHEMBL1347020 & 688239 & 5.4362 & 5.5193 & TRN & \\
\hline CHEMBL1379336 & 688239 & 5.1862 & 5.5542 & TRN & \\
\hline CHEMBL1340125 & 688239 & 6.8861 & 5.4975 & TST & \\
\hline CHEMBL1612432 & 688239 & 4.7862 & 5.5088 & TRN & \\
\hline CHEMBL1376483 & 688239 & 6.4362 & 5.4463 & TRN & \\
\hline CHEMBL1486391 & 688239 & 5.4862 & 5.6382 & TRN & \\
\hline CHEMBL1389231 & 688239 & 5.1862 & 5.3737 & TST & \\
\hline CHEMBL1313598 & 688239 & 5.1862 & 5.5714 & TRN & \\
\hline CHEMBL3195312 & 688239 & 4.6862 & 5.4374 & TST & \\
\hline CHEMBL1528773 & 688239 & 5.6862 & 5.449 & TRN & \\
\hline CHEMBL1514540 & 688239 & 6.2362 & 5.4839 & TRN & \\
\hline CHEMBL1533546 & 688239 & 4.4862 & 5.4301 & TRN & \\
\hline CHEMBL1342271 & 688239 & 6.8861 & 5.4923 & TRN & \\
\hline CHEMBL 3195594 & 688239 & 5.0362 & 5.4648 & TRN & \\
\hline CHEMBL1409404 & 688239 & 4.8362 & 5.5173 & TST & \\
\hline CHEMBL1312934 & 688239 & 4.5362 & 5.5962 & TRN & \\
\hline CHEMBL1591837 & 688239 & 4.5362 & 5.4419 & TRN & \\
\hline CHEMBL1592883 & 688239 & 5.2362 & 5.5327 & TRN & \\
\hline CHEMBL1344781 & 688239 & 6.1362 & 5.5111 & TST & \\
\hline CHEMBL1371352 & 688239 & 5.0862 & 5.5736 & TST & \\
\hline CHEMBL1524318 & 688239 & 6.6861 & 5.6165 & TRN & \\
\hline CHEMBL1374582 & 688239 & 4.7862 & 5.6034 & TRN & \\
\hline CHEMBL1473250 & 688239 & 5.5362 & 5.4849 & TRN & \\
\hline CHEMBL1565437 & 688239 & 6.0862 & 5.49299 & 9999999999 & TRN \\
\hline CHEMBL1404022 & 688239 & 5.2362 & 5.6121 & TRN & \\
\hline CHEMBL1328012 & 688239 & 5.4362 & 5.4956 & TST & \\
\hline CHEMBL1551603 & 688239 & 8.3372 & 5.5424 & TRN & \\
\hline CHEMBL1393574 & 688239 & 5.1862 & 5.4955 & TRN & \\
\hline CHEMBL1500406 & 688239 & 5.1862 & 5.5083 & TRN & \\
\hline CHEMBL 3193090 & 688239 & 4.5362 & 5.4271 & TST & \\
\hline CHEMBL1362793 & 688239 & 5.4862 & 5.5277 & TRN & \\
\hline CHEMBL1473382 & 688239 & 6.0862 & 5.4863 & TRN & \\
\hline CHEMBL1384372 & 688239 & 6.3863 & 5.4558 & TST & \\
\hline CHEMBL1449530 & 688239 & 7.2865 & 5.5207 & TRN & \\
\hline
\end{tabular}


Supplemental Table S2.txt

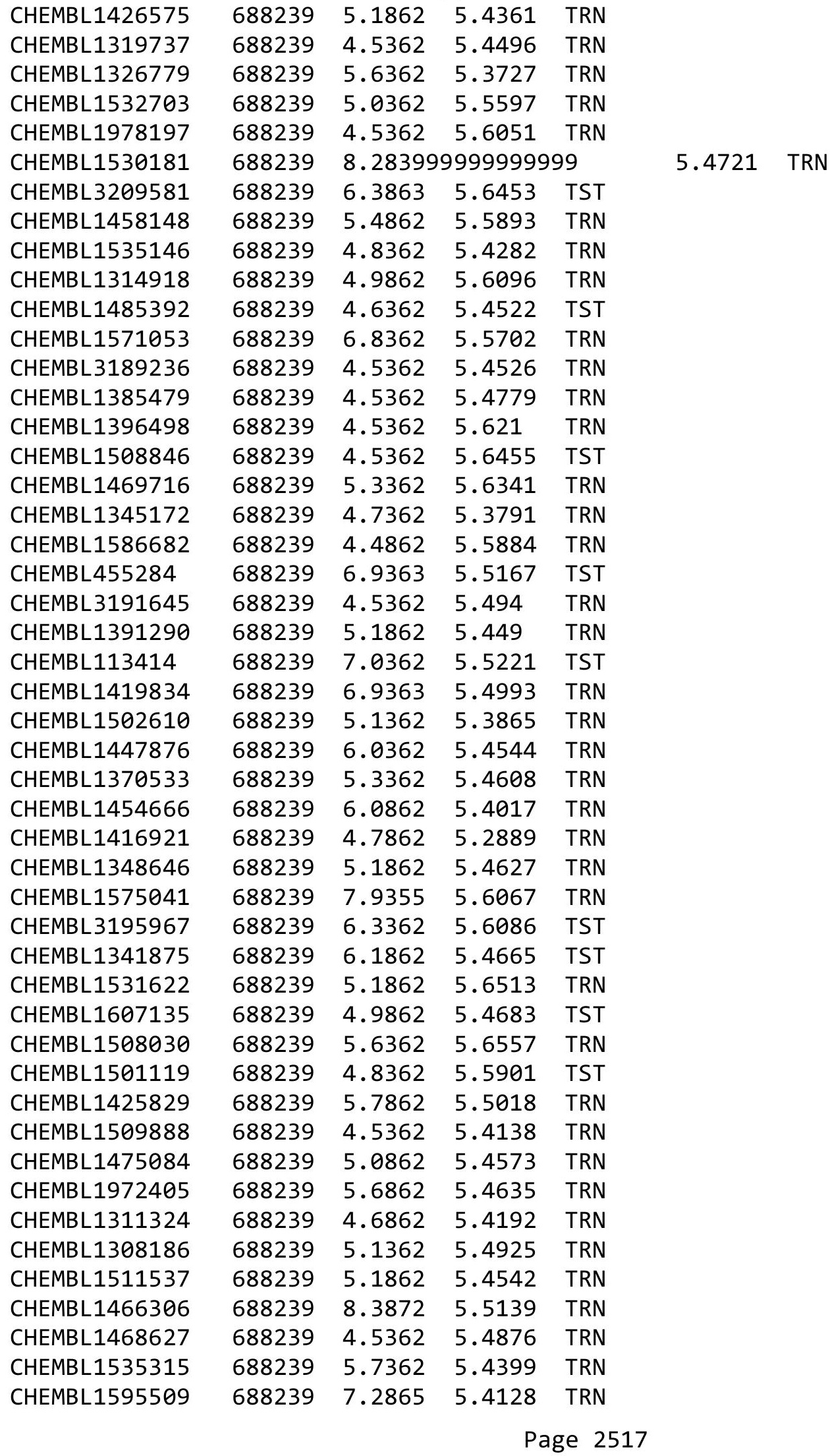


Supplemental Table S2.txt

\begin{tabular}{|c|c|c|c|c|c|}
\hline CHEMBL1371735 & 688239 & 6.3362 & 5.5028 & TST & \\
\hline CHEMBL1521475 & 688239 & 6.1862 & 5.4234 & TRN & \\
\hline CHEMBL1381835 & 688239 & 5.6362 & 5.5393 & TRN & \\
\hline CHEMBL1486011 & 688239 & 6.9363 & 5.5873 & TRN & \\
\hline CHEMBL1538759 & 688239 & 4.8362 & 5.4989 & TRN & \\
\hline CHEMBL1407487 & 688239 & 5.5362 & 5.4945 & TRN & \\
\hline CHEMBL1395017 & 688239 & 6.3863 & 5.3758 & TRN & \\
\hline CHEMBL1572831 & 688239 & 4.4862 & 5.37799 & 9999999999 & TRN \\
\hline CHEMBL1554591 & 688239 & 4.8362 & 5.4067 & TRN & \\
\hline CHEMBL1418652 & 688239 & 4.5362 & 5.5654 & TRN & \\
\hline CHEMBL1427437 & 688239 & 4.8362 & 5.5801 & TRN & \\
\hline CHEMBL1435703 & 688239 & 4.9862 & 5.405 & TRN & \\
\hline CHEMBL1560016 & 688239 & 5.2362 & 5.465 & TRN & \\
\hline CHEMBL1422969 & 688239 & 5.3362 & 5.4555 & TRN & \\
\hline CHEMBL1574279 & 688239 & 4.7362 & 5.5025 & TST & \\
\hline CHEMBL 3195984 & 688239 & 5.3362 & 5.5149 & TRN & \\
\hline CHEMBL1491996 & 688239 & 4.5362 & 5.4228 & TRN & \\
\hline CHEMBL1474820 & 688239 & 6.6362 & 5.4212 & TRN & \\
\hline CHEMBL1516430 & 688239 & 4.8362 & 5.4486 & TRN & \\
\hline CHEMBL1575205 & 688239 & 5.1362 & 5.5451 & TRN & \\
\hline CHEMBL1332936 & 688239 & 4.7362 & 5.4823 & TST & \\
\hline CHEMBL1349591 & 688239 & 6.9363 & 5.5261 & TRN & \\
\hline CHEMBL1362348 & 688239 & 6.5363 & 5.478 & TST & \\
\hline CHEMBL1449963 & 688239 & 6.1862 & 5.3546 & TRN & \\
\hline CHEMBL1463064 & 688239 & 4.5362 & \multicolumn{2}{|c|}{5.361000000000001} & TRN \\
\hline CHEMBL210846 & 688239 & 4.4862 & 5.4739 & TRN & \\
\hline CHEMBL1327356 & 688239 & 6.7862 & 5.5094 & TRN & \\
\hline CHEMBL1529493 & 688239 & 5.6362 & \multicolumn{2}{|c|}{5.4879999999999995} & TRN \\
\hline CHEMBL1469107 & 688239 & 7.1361 & 5.4709 & TST & \\
\hline CHEMBL1546134 & 688239 & 4.8862 & 5.4929 & TST & \\
\hline CHEMBL1448356 & 688239 & 5.8862 & 5.4214 & TST & \\
\hline CHEMBL1416465 & 688239 & 4.4862 & 5.6224 & TRN & \\
\hline CHEMBL1300575 & 688239 & 4.6862 & 5.5647 & TST & \\
\hline CHEMBL1379632 & 688239 & 4.7862 & 5.4209 & TRN & \\
\hline CHEMBL1574491 & 688239 & 5.0862 & 5.4119 & TRN & \\
\hline CHEMBL1383063 & 688239 & 5.1862 & 5.4943 & TRN & \\
\hline CHEMBL1604557 & 688239 & 5.8862 & 5.3666 & TST & \\
\hline CHEMBL1445583 & 688239 & 4.5362 & 5.5355 & TRN & \\
\hline CHEMBL1467965 & 688239 & 4.9862 & 5.3164 & TRN & \\
\hline CHEMBL1524658 & 688239 & 4.7862 & 5.5653 & TRN & \\
\hline CHEMBL1540396 & 688239 & 4.6862 & 5.4807 & TST & \\
\hline CHEMBL1321133 & 688239 & 8.3372 & 5.4745 & TRN & \\
\hline CHEMBL1465802 & 688239 & 6.2362 & 5.6141 & TRN & \\
\hline CHEMBL1303886 & 688239 & 5.0362 & 5.4679 & TRN & \\
\hline CHEMBL1371359 & 688239 & 6.8861 & 5.5999 & TRN & \\
\hline CHEMBL1318958 & 688239 & 5.3862 & \multicolumn{2}{|c|}{5.4270000000000005} & TRN \\
\hline CHEMBL 3208528 & 688239 & 4.6862 & 5.4017 & TRN & \\
\hline CHEMBL1381498 & 688239 & 4.8862 & 5.5448 & TRN & \\
\hline
\end{tabular}


Supplemental Table S2.txt

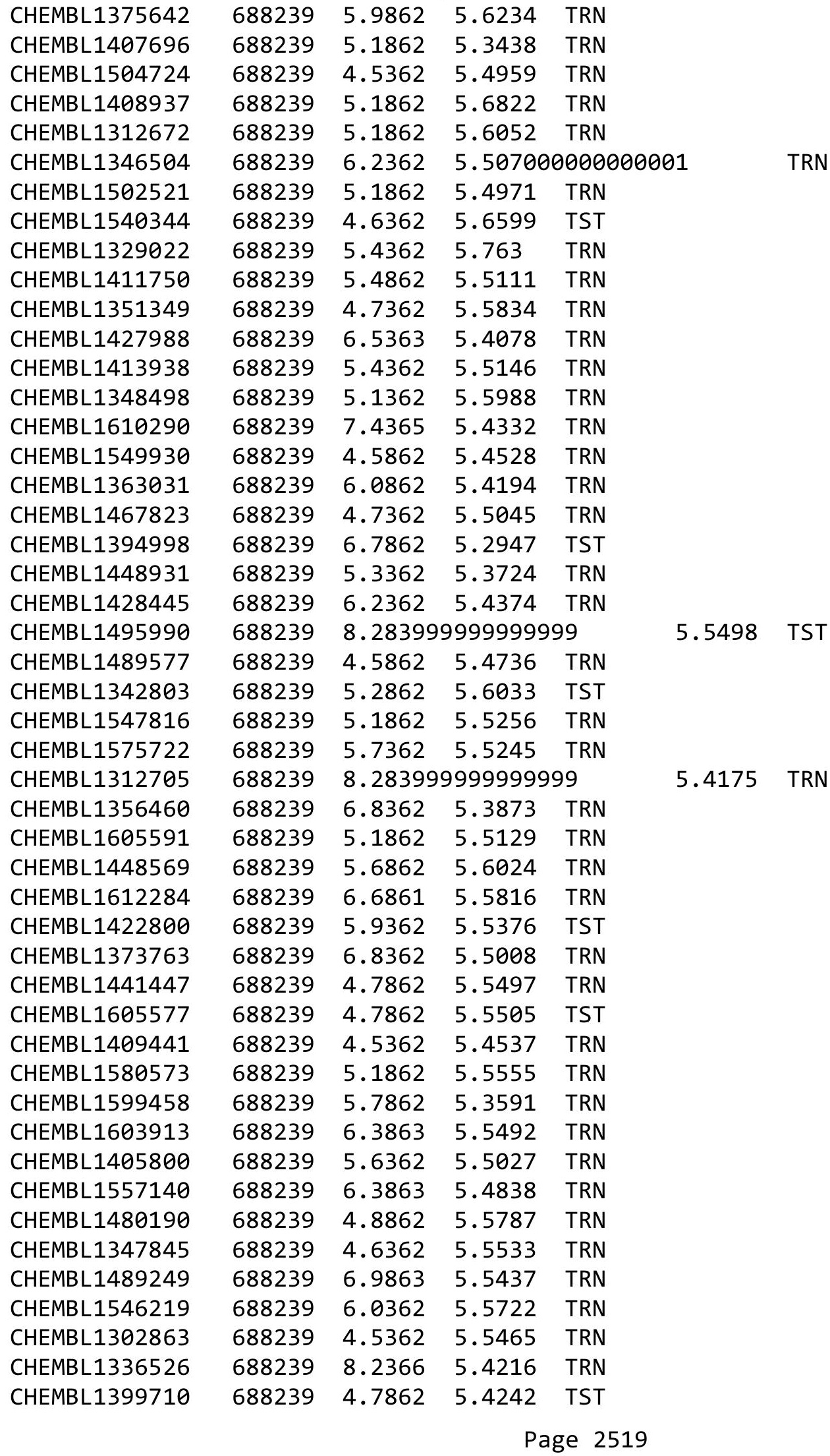


Supplemental Table S2.txt

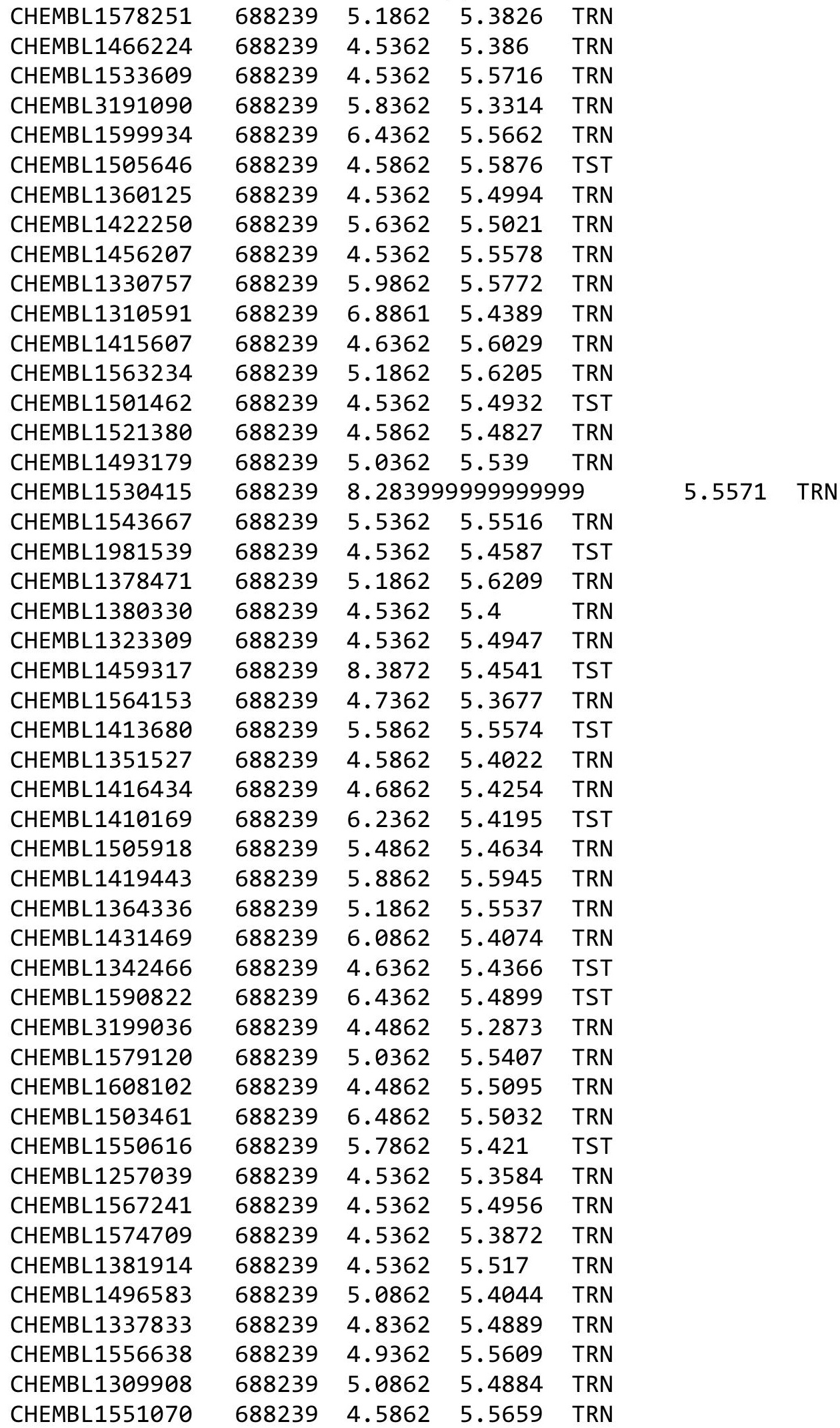

Page 2520 
Supplemental Table S2.txt

\begin{tabular}{|c|c|c|c|c|}
\hline & & & & \\
\hline AEMBL3190706 & 8239 & 9363 & & \\
\hline IEMBL1602174 & 8239 & 362 & 1067 & \\
\hline AEMBL1377318 & 239 & 5862 & 901 & \\
\hline & 239 & 862 & & \\
\hline IEMBL1363139 & 239 & 362 & 66 & \\
\hline AEMBL1519879 & 88239 & 362 & 4882 & \\
\hline AEMBL1312495 & 88239 & 862 & 1087 & \\
\hline AEMBL1525478 & 239 & 362 & 1755 & \\
\hline IEMBL139 & 239 & 862 & 189 & \\
\hline IEMBL1464655 & & & & \\
\hline AEMBL1392672 & 688239 & & 431 & \\
\hline AEMBL1489466 & 239 & 862 & 6 & \\
\hline IEMBL14ع & & 7. & & \\
\hline IEMBL15 & & 62 & & \\
\hline HEMBL156 & & & & \\
\hline AEMBL1422367 & 239 & & 876 & \\
\hline HEMBL319 & & 362 & & \\
\hline IEMBL13/ & & 62 & 99 & \\
\hline HEMBL13 & & & & \\
\hline HEMBL 15 & & & & \\
\hline AEMBL14 & & & & \\
\hline HEMBL138 & & & & \\
\hline IEMBL14 & & 62 & & \\
\hline AEMBL15 & & & & RN \\
\hline JEMDI 11 & & 62 & & \\
\hline JEMBL14ع & & & & RN \\
\hline HEMBL131 & & & & \\
\hline AEMBL142 & & 62 & 25 & ST \\
\hline HEMBL 15 & & 62 & 79 & $\omega_{-1}+2$ \\
\hline 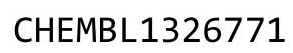 & & 62 & & ST \\
\hline HEMBL130 & & & & ST \\
\hline AEMBL1319731 & & & & RI \\
\hline AEMBL130 & & 862 & 33 & $\mathrm{RI}$ \\
\hline AFMRI 12 & & 62 & 16 & . \\
\hline 38 & & & & . \\
\hline AEMBL1374642 & & & 062 & R \\
\hline AEMBL1606037 & & & & \\
\hline IEMBL13S & & 62 & & RI \\
\hline 19 & & & 72 & \\
\hline 15 & & & & RN \\
\hline AEMBL3211374 & & 862 & 145 & RN \\
\hline IEMBL146 & & 362 & & \\
\hline HEMBL15 & & & & \\
\hline HEMBL141 & & & & \\
\hline CHEMBL137 & & 362 & & RN \\
\hline HEMBL133. & 88239 & 8.3372 & 5.5599 & $\mathrm{TR}$ \\
\hline HFMRI 1519821 & 688239 & 5.9362 & 5.6055 & \\
\hline
\end{tabular}

Page 2521 


\begin{tabular}{|c|c|c|c|c|c|}
\hline \multicolumn{6}{|c|}{ 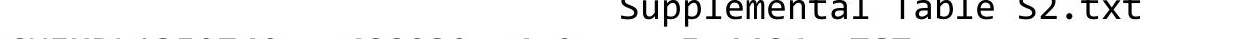 } \\
\hline CHEMBL1359749 & 688239 & 6.0 & 5.4486 & TST & \\
\hline CHEMBL1418355 & 688239 & 4.7862 & 5.6676 & TRN & \\
\hline CHEMBL1543247 & 688239 & 7.5867 & 5.4896 & TRN & \\
\hline CHEMBL1387269 & 688239 & 5.1862 & 5.4556 & TST & \\
\hline CHEMBL1545306 & 688239 & 4.5362 & 5.3534 & TRN & \\
\hline CHEMBL489 & 688239 & 4.6862 & 5.3634 & TST & \\
\hline CHEMBL1425887 & 688239 & 5.1862 & 5.5108 & TRN & \\
\hline CHEMBL1497578 & 688239 & 4.5362 & 5.6294 & TRN & \\
\hline CHEMBL1582091 & 688239 & 5.7862 & 5.4923 & TST & \\
\hline CHEMBL1412501 & 688239 & 4.7862 & 5.4836 & TRN & \\
\hline CHEMBL1439106 & 688239 & 4.5362 & 5.45299 & 9999999999 & TRN \\
\hline CHEMBL1299552 & 688239 & 5.3862 & 5.5556 & TRN & \\
\hline CHEMBL1361065 & 688239 & 5.6362 & 5.5664 & TRN & \\
\hline CHEMBL1419940 & 688239 & 6.9863 & 5.4495 & TRN & \\
\hline CHEMBL1439363 & 688239 & 4.5362 & 5.2959 & TRN & \\
\hline CHEMBL1571461 & 688239 & 5.7362 & 5.5728 & TST & \\
\hline CHEMBL1554532 & 688239 & 5.7362 & 5.4588 & TRN & \\
\hline CHEMBL1316362 & 688239 & 6.1362 & 5.5369 & TRN & \\
\hline CHEMBL1596288 & 688239 & 4.8362 & 5.5417 & TRN & \\
\hline CHEMBL1324627 & 688239 & 5.4862 & 5.5478 & TRN & \\
\hline CHEMBL1401982 & 688239 & 6.9363 & 5.5571 & TRN & \\
\hline CHEMBL3190510 & 688239 & 4.8362 & 5.496 & TRN & \\
\hline CHEMBL1610525 & 688239 & 7.6364 & 5.3835 & TRN & \\
\hline CHEMBL1453049 & 688239 & 4.7862 & 5.555 & TRN & \\
\hline CHEMBL1313877 & 688239 & 4.7862 & 5.5265 & TRN & \\
\hline CHEMBL1611278 & 688239 & 4.8862 & 5.6043 & TRN & \\
\hline CHEMBL1350554 & 688239 & 5.0862 & 5.3965 & TRN & \\
\hline CHEMBL1594347 & 688239 & 6.6362 & 5.6063 & TST & \\
\hline CHEMBL1454886 & 688239 & 5.0362 & 5.4554 & TRN & \\
\hline CHEMBL1559330 & 688239 & 5.7862 & 5.4818 & TRN & \\
\hline CHEMBL1331828 & 688239 & 4.8362 & 5.3026 & TRN & \\
\hline CHEMBL1313344 & 688239 & 4.5362 & 5.6077 & TRN & \\
\hline CHEMBL1973050 & 688239 & 5.1362 & 5.4163 & TRN & \\
\hline CHEMBL1572505 & 688239 & 4.9862 & 5.4925 & TST & \\
\hline CHEMBL3209469 & 688239 & 4.7862 & 5.3944 & TST & \\
\hline CHEMBL1496277 & 688239 & 6.8362 & 5.6094 & TST & \\
\hline CHEMBL533994 & 688239 & 4.6862 & 5.3392 & TRN & \\
\hline CHEMBL1522367 & 688239 & 5.1862 & 5.4613 & TST & \\
\hline CHEMBL1338182 & 688239 & 4.5362 & 5.5126 & TST & \\
\hline CHEMBL1345071 & 688239 & 6.1362 & 5.4704 & TRN & \\
\hline CHEMBL1336687 & 688239 & 4.6862 & 5.5174 & TRN & \\
\hline CHEMBL1604840 & 688239 & 6.1362 & 5.4652 & TRN & \\
\hline CHEMBL1375386 & 688239 & 4.5362 & 5.5811 & TRN & \\
\hline CHEMBL1510650 & 688239 & 5.1862 & 5.4977 & TRN & \\
\hline CHEMBL1480934 & 688239 & 4.5862 & 5.3995 & TST & \\
\hline CHEMBL1409546 & 688239 & 5.5862 & 5.4365 & TRN & \\
\hline CHEMBL1310614 & 688239 & 7.2366 & 5.479 & TRN & \\
\hline CHEMBL1341073 & 688239 & 5.9862 & 5.5046 & TST & \\
\hline
\end{tabular}


Supplemental Table S2.txt

\begin{tabular}{|c|c|c|c|c|c|c|}
\hline CHEMBL1347692 & 688239 & 5.4862 & 5.4077 & TRN & & \\
\hline CHEMBL1470390 & 688239 & 5.3362 & 5.4967 & TRN & & \\
\hline CHEMBL 2001216 & 688239 & 4.5362 & 5.3807 & TRN & & \\
\hline CHEMBL1583101 & 688239 & 5.5862 & 5.3962 & TST & & \\
\hline CHEMBL1429589 & 688239 & 5.1362 & 5.5759 & TRN & & \\
\hline CHEMBL1563950 & 688239 & 5.2862 & 5.4434 & TRN & & \\
\hline CHEMBL1386411 & 688239 & 5.4862 & 5.577000 & 0000000 & & TRN \\
\hline CHEMBL1394016 & 688239 & 5.7862 & 5.5391 & TRN & & \\
\hline CHEMBL1301688 & 688239 & 5.8362 & 5.52 & TRN & & \\
\hline CHEMBL1555104 & 688239 & 5.0362 & 5.4632 & TRN & & \\
\hline CHEMBL1314055 & 688239 & 6.0362 & 5.4227 & TRN & & \\
\hline CHEMBL1368928 & 688239 & 4.5362 & 5.5153 & TST & & \\
\hline CHEMBL1455447 & 688239 & 5.6862 & 5.4991 & TRN & & \\
\hline CHEMBL1503360 & 688239 & 5.2362 & 5.4791 & TRN & & \\
\hline CHEMBL1548388 & 688239 & 5.8862 & 5.6167 & TST & & \\
\hline CHEMBL1587901 & 688239 & 4.5362 & 5.5016 & TRN & & \\
\hline CHEMBL1479177 & 688239 & 5.1862 & 5.354 & TRN & & \\
\hline CHEMBL1582465 & 688239 & 4.5362 & 5.5106 & TRN & & \\
\hline CHEMBL1482964 & 688239 & 6.2862 & 5.403 & TRN & & \\
\hline CHEMBL1458547 & 688239 & 4.5362 & 5.4851 & TRN & & \\
\hline CHEMBL1446406 & 688239 & 5.0362 & 5.5693 & TRN & & \\
\hline CHEMBL1462622 & 688239 & 5.1862 & 5.4604 & TRN & & \\
\hline CHEMBL3198315 & 688239 & 6.0862 & 5.4157 & TRN & & \\
\hline CHEMBL1361426 & 688239 & 4.4862 & 5.6279 & TRN & & \\
\hline CHEMBL1433401 & 688239 & 6.8861 & 5.3683 & TRN & & \\
\hline CHEMBL3198087 & 688239 & 6.1362 & 5.5175 & TRN & & \\
\hline CHEMBL1430149 & 688239 & 4.6362 & 5.4156 & TST & & \\
\hline CHEMBL1367615 & 688239 & 5.3862 & 5.5532 & TRN & & \\
\hline CHEMBL1433857 & 688239 & 6.0862 & 5.5431 & TRN & & \\
\hline CHEMBL1447782 & 688239 & 4.7362 & 5.4161 & TRN & & \\
\hline CHEMBL3214053 & 688239 & 8.3872 & 5.4581 & TRN & & \\
\hline CHEMBL1590298 & 688239 & 4.5362 & 5.4548 & TRN & & \\
\hline CHEMBL1389189 & 688239 & 5.8862 & 5.4389 & TRN & & \\
\hline CHEMBL1603447 & 688239 & 5.1862 & 5.5928 & TST & & \\
\hline CHEMBL1509959 & 688239 & 6.4862 & 5.4582 & TST & & \\
\hline CHEMBL1399612 & 688239 & 8.0362 & 5.5575 & TRN & & \\
\hline CHEMBL3212183 & 688239 & 8.28399 & 99999999 & 9 & 5.4344 & \\
\hline CHEMBL1585929 & 688239 & 5.6862 & 5.489 & TRN & & \\
\hline CHEMBL1302209 & 688239 & 6.8362 & 5.574 & TRN & & \\
\hline CHEMBL1541619 & 688239 & 8.28399 & 99999999 & 9 & 5.527 & ти \\
\hline CHEMBL1521932 & 688239 & 6.2362 & 5.3727 & TRN & & \\
\hline CHEMBL1338266 & 688239 & 5.1862 & 5.4927 & TRN & & \\
\hline CHEMBL3211257 & 688239 & 4.6862 & 5.4541 & TRN & & \\
\hline CHEMBL1604411 & 688239 & 6.7361 & 5.4625 & TST & & \\
\hline CHEMBL1454445 & 688239 & 4.7862 & 5.3926 & TRN & & \\
\hline CHEMBL1477994 & 688239 & 5.1862 & 5.5729 & TRN & & \\
\hline CHEMBL1505620 & 688239 & 4.5862 & 5.4194 & TST & & \\
\hline CHEMBL1475641 & 688239 & 4.7862 & 5.3631 & TRN & & \\
\hline
\end{tabular}


Supplemental Table S2.txt

\begin{tabular}{|c|c|c|c|c|}
\hline 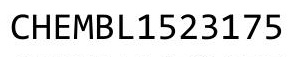 & & 5362 & & \\
\hline HEMBL1602055 & 88239 & 5363 & 5.4448 & \\
\hline HEMBL1552524 & 3239 & & 4719 & \\
\hline & & & & \\
\hline AEMBL1516363 & & & & \\
\hline IEMBL1404569 & 88239 & 3861 & .4504 & \\
\hline HEMBL1481531 & 88239 & .4362 & .4849 & \\
\hline HEMBL1378209 & 39 & & 5465 & \\
\hline AEMBL1329261 & & & & \\
\hline AEMBL532143 & & & & \\
\hline HEMBL1444675 & 88239 & 862 & .5483 & \\
\hline HEMBL1391094 & 88239 & 62 & .501 & \\
\hline HEMBL1460254 & 39 & & 3881 & \\
\hline HEMBL 1428 & & & & \\
\hline HEMBL159. & & & & \\
\hline HEMBL1486810 & 88239 & 362 & .4851 & \\
\hline HEMBL1480267 & & & & \\
\hline HEMBL1536 & 39 & & 68 & \\
\hline L32e & & & & \\
\hline AEMBL135 & & & & \\
\hline HEMBL1597298 & & 62 & & \\
\hline AEMBL3199333 & & & & 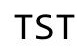 \\
\hline HEMBL319 & 39 & 62 & 5 . & \\
\hline L14 & & & & \\
\hline 13 & & & & \\
\hline L1432793 & & & & 1 \\
\hline AEMBL3209610 & & & & I RN \\
\hline HEMBL3209602 & & & 77 & \\
\hline 28 & & & & ST \\
\hline L14 & & 52 & & ST \\
\hline AEMBL1492631 & & & & IRN \\
\hline HEMBL1493123 & & & & ST \\
\hline IEMBL31 & & & & ST \\
\hline 6 & & & & RN \\
\hline L14 & & & & RN \\
\hline AEMBL1390326 & & & & TRN \\
\hline HEMBL1299802 & & & 37 & IST \\
\hline $5=$ & & & 67 & RN \\
\hline רי ובחזי & & & & I \\
\hline AEMBL132 & & & 5. & $\mathrm{RN}$ \\
\hline AEMBL1471353 & & 62 & & RN \\
\hline JEMBL 14 & & & & $R N$ \\
\hline 1437 & & & & \\
\hline HEMBL1321 & & & & RN \\
\hline HEMBL1389 & & & & RN \\
\hline IEMBL1440873 & & 4. & 5.3568 & \\
\hline & & & 5. & \\
\hline & 688239 & 8.3372 & & \\
\hline
\end{tabular}




\begin{tabular}{|c|c|c|c|c|}
\hline \multicolumn{5}{|c|}{ Supplemental Tab. } \\
\hline CHEMBL1534299 & 688239 & 5.4362 & 5.5503 & TRN \\
\hline CHEMBL1559445 & 688239 & 5.1362 & 5.4487 & TRN \\
\hline CHEMBL1593428 & 688239 & 4.7862 & 5.4869 & TRN \\
\hline CHEMBL1306535 & 688239 & 6.8362 & 5.4184 & TRN \\
\hline CHEMBL1578500 & 688239 & 5.8362 & 5.4908 & TRN \\
\hline CHEMBL1518314 & 688239 & 4.7862 & 5.5502 & TRN \\
\hline CHEMBL1347494 & 688239 & 4.4862 & 5.55 & TRN \\
\hline CHEMBL1576913 & 688239 & 5.6362 & 5.5852 & TRN \\
\hline CHEMBL1578800 & 688239 & 5.6862 & 5.5213 & TST \\
\hline CHEMBL1518129 & 688239 & 4.5862 & 5.5388 & TST \\
\hline CHEMBL1521443 & 688239 & 6.2362 & 5.5359 & TRN \\
\hline CHEMBL1443788 & 688239 & 5.6362 & 5.5008 & TST \\
\hline CHEMBL1509128 & 688239 & 6.1862 & 5.5215 & TRN \\
\hline CHEMBL1393308 & 688239 & 7.0362 & 5.4306 & TRN \\
\hline CHEMBL1386549 & 688239 & 4.8362 & 5.6632 & TRN \\
\hline CHEMBL3208045 & 688239 & 4.5362 & 5.4462 & TRN \\
\hline CHEMBL1576962 & 688239 & 4.5362 & 5.4667 & TST \\
\hline CHEMBL1387456 & 688239 & 6.8861 & 5.4831 & TRN \\
\hline CHEMBL1549661 & 688239 & 4.5362 & 5.5537 & TRN \\
\hline CHEMBL1352639 & 688239 & 7.2366 & 5.5636 & TRN \\
\hline CHEMBL1417097 & 688239 & 4.6862 & 5.5009 & TRN \\
\hline CHEMBL1423861 & 688239 & 6.9363 & 5.5231 & TST \\
\hline CHEMBL1574701 & 688239 & 5.0862 & 5.4988 & TST \\
\hline CHEMBL1384603 & 688239 & 4.5862 & 5.5519 & TRN \\
\hline CHEMBL1381702 & 688239 & 5.9362 & 5.5044 & TRN \\
\hline CHEMBL1369525 & 688239 & 5.0862 & 5.4125 & TRN \\
\hline CHEMBL1381264 & 688239 & 5.1862 & 5.4803 & TST \\
\hline CHEMBL1404048 & 688239 & 4.5362 & 5.4029 & TRN \\
\hline CHEMBL1509764 & 688239 & 5.0362 & 5.2703 & TST \\
\hline CHEMBL1372536 & 688239 & 7.3862 & 5.4644 & TRN \\
\hline CHEMBL1448087 & 688239 & 5.2862 & 5.5752 & TRN \\
\hline CHEMBL1310631 & 688239 & 5.1362 & 5.4774 & TST \\
\hline CHEMBL1311004 & 688239 & 6.4862 & 5.6491 & TRN \\
\hline CHEMBL1313795 & 688239 & 5.0862 & 5.5316 & TRN \\
\hline CHEMBL1390896 & 688239 & 5.4862 & 5.395 & TRN \\
\hline CHEMBL1581175 & 688239 & 4.6862 & 5.5794 & TRN \\
\hline CHEMBL1362247 & 688239 & 8.0862 & 5.3623 & TRN \\
\hline CHEMBL1486273 & 688239 & 7.1864 & 5.723 & TRN \\
\hline CHEMBL1557592 & 688239 & 5.8362 & 5.5103 & TRN \\
\hline CHEMBL1353221 & 688239 & 5.3362 & 5.5311 & TST \\
\hline CHEMBL1498164 & 688239 & 4.7362 & 5.4241 & TRN \\
\hline CHEMBL1330419 & 688239 & 4.7362 & 5.5239 & TRN \\
\hline CHEMBL1424882 & 688239 & 6.9863 & 5.6365 & TST \\
\hline CHEMBL1346492 & 688239 & 5.1862 & 5.6037 & TST \\
\hline CHEMBL1490503 & 688239 & 5.5 & 5.5099 & TRN \\
\hline CHEMBL1413471 & 688239 & 5.7862 & 5.6053 & TRN \\
\hline CHEMBL1607862 & 688239 & 5.7862 & 5.4775 & TRN \\
\hline CHEMBL1542093 & 688239 & 5.3362 & 5.4875 & TRN \\
\hline
\end{tabular}




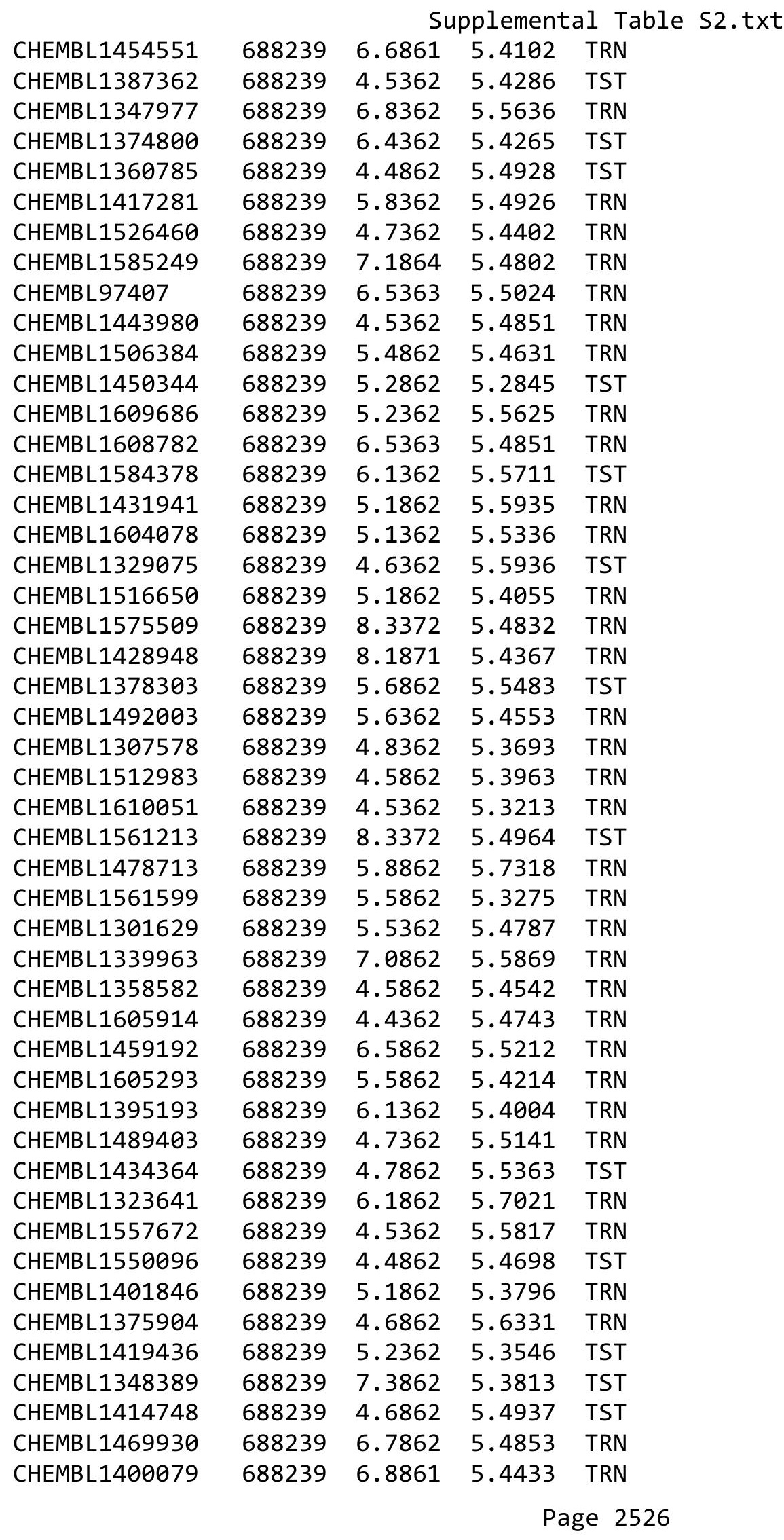


Supplemental Table S2.txt

\begin{tabular}{|c|c|c|c|c|c|}
\hline CHEMBL1465670 & 688239 & 5.1862 & 5.5337 & TST & \\
\hline CHEMBL1527828 & 688239 & 6.6362 & 5.7466 & TRN & \\
\hline CHEMBL1370597 & 688239 & 5.4862 & 5.5108 & TRN & \\
\hline CHEMBL1303045 & 688239 & 4.7362 & 5.6289 & TRN & \\
\hline CHEMBL1604999 & 688239 & 6.2362 & 5.4505 & TRN & \\
\hline CHEMBL1429800 & 688239 & 4.9862 & 5.5057 & TRN & \\
\hline CHEMBL1603557 & 688239 & 4.5362 & 5.5404 & TRN & \\
\hline CHEMBL1463736 & 688239 & 4.5862 & 5.4203 & TRN & \\
\hline CHEMBL1579814 & 688239 & 4.5362 & 5.4333 & TRN & \\
\hline CHEMBL1598785 & 688239 & 4.8362 & 5.3919 & TRN & \\
\hline CHEMBL1401531 & 688239 & 4.8362 & 5.4529 & TRN & \\
\hline CHEMBL1485934 & 688239 & 7.1864 & 5.5215 & TRN & \\
\hline CHEMBL1360192 & 688239 & 6.1862 & 5.4211 & TRN & \\
\hline CHEMBL1585612 & 688239 & 4.8362 & 5.4088 & TST & \\
\hline CHEMBL1302714 & 688239 & 5.1362 & 5.4203 & TST & \\
\hline CHEMBL1378252 & 688239 & 4.5862 & 5.3032 & TRN & \\
\hline CHEMBL1588058 & 688239 & 6.5363 & 5.6416 & TRN & \\
\hline CHEMBL1389921 & 688239 & 4.6862 & 5.5542 & TST & \\
\hline CHEMBL1386299 & 688239 & 8.28399 & و99999999 & 5.41 & TST \\
\hline CHEMBL1446074 & 688239 & 4.6862 & 5.7966 & TRN & \\
\hline CHEMBL1455111 & 688239 & 6.8362 & 5.5969 & TRN & \\
\hline CHEMBL1556750 & 688239 & 6.9363 & 5.4956 & TST & \\
\hline CHEMBL1447805 & 688239 & 5.4362 & 5.5348 & TRN & \\
\hline CHEMBL1518943 & 688239 & 5.7862 & 5.5847 & TRN & \\
\hline CHEMBL1576026 & 688239 & 4.8362 & 5.451000 & 20000000005 & TRN \\
\hline CHEMBL1360254 & 688239 & 6.1862 & 5.5939 & TRN & \\
\hline CHEMBL1384298 & 688239 & 6.1362 & 5.3156 & TRN & \\
\hline CHEMBL1601851 & 688239 & 5.1362 & 5.5198 & TRN & \\
\hline CHEMBL1542970 & 688239 & 4.5362 & 5.5425 & TRN & \\
\hline CHEMBL1386528 & 688239 & 4.7862 & 5.4279 & TST & \\
\hline CHEMBL1307611 & 688239 & 6.6362 & 5.5418 & TRN & \\
\hline CHEMBL1367041 & 688239 & 8.3372 & 5.4996 & TST & \\
\hline CHEMBL1530377 & 688239 & 4.5362 & 5.4815 & TRN & \\
\hline CHEMBL1602948 & 688239 & 5.0862 & 5.5254 & TRN & \\
\hline CHEMBL1541645 & 688239 & 4.5362 & 5.6483 & TRN & \\
\hline CHEMBL1408867 & 688239 & 4.4862 & 5.6358 & TRN & \\
\hline CHEMBL1454442 & 688239 & 5.1862 & 5.3709 & TRN & \\
\hline CHEMBL1339646 & 688239 & 4.5362 & 5.4219 & TRN & \\
\hline CHEMBL1561546 & 688239 & 6.4862 & 5.5232 & TRN & \\
\hline CHEMBL1457865 & 688239 & 6.3863 & 5.4595 & TRN & \\
\hline CHEMBL1501448 & 688239 & 5.7362 & 5.5926 & TST & \\
\hline CHEMBL1329594 & 688239 & 5.3362 & 5.5428 & TRN & \\
\hline CHEMBL1332949 & 688239 & 5.7862 & 5.5801 & TRN & \\
\hline CHEMBL1988210 & 688239 & 4.9862 & 5.4008 & TRN & \\
\hline CHEMBL3190672 & 688239 & 4.5362 & 5.3337 & TRN & \\
\hline CHEMBL1390401 & 688239 & \multicolumn{3}{|c|}{8.283999999999999} & TST \\
\hline CHEMBL1493521 & 688239 & 5.9862 & 5.5192 & TRN & \\
\hline CHEMBL1171338 & 688239 & 5.2862 & 5.5857 & TRN & \\
\hline
\end{tabular}


Supplemental Table S2.txt

\begin{tabular}{|c|c|c|c|c|}
\hline CHEMBL1584671 & 688239 & 8.1871 & 5.6187 & TRN \\
\hline CHEMBL1345522 & 688239 & 4.7862 & 5.49 & TRN \\
\hline CHEMBL1587786 & 688239 & 5.1362 & 5.3561 & TRN \\
\hline CHEMBL1530851 & 688239 & 5.4362 & 5.5789 & TRN \\
\hline CHEMBL1340208 & 688239 & 5.6862 & 5.4726 & TRN \\
\hline CHEMBL1306226 & 688239 & 5.3862 & 5.3578 & TRN \\
\hline CHEMBL582877 & 688239 & 6.0362 & 5.3724 & TRN \\
\hline CHEMBL1606017 & 688239 & 6.3863 & 5.4632 & TST \\
\hline CHEMBL1613170 & 688239 & 4.5362 & 5.4526 & TRN \\
\hline CHEMBL1417156 & 688239 & 6.0362 & 5.4667 & TRN \\
\hline CHEMBL1459717 & 688239 & 4.7862 & 5.4757 & TRN \\
\hline CHEMBL1338452 & 688239 & 4.5362 & 5.5605 & TRN \\
\hline CHEMBL1476283 & 688239 & 5.0862 & 5.5402 & TRN \\
\hline CHEMBL1412770 & 688239 & 6.3362 & 5.3556 & TRN \\
\hline CHEMBL1429126 & 688239 & 5.1862 & 5.4508 & TST \\
\hline CHEMBL1612984 & 688239 & 5.4362 & 5.5006 & TRN \\
\hline CHEMBL1452130 & 688239 & 4.5362 & 5.5036 & TST \\
\hline CHEMBL3208352 & 688239 & 4.9862 & 5.4134 & TRN \\
\hline CHEMBL1349560 & 688239 & 5.1862 & 5.4969 & TRN \\
\hline CHEMBL1494244 & 688239 & 5.5862 & 5.3552 & TRN \\
\hline CHEMBL1320236 & 688239 & 5.0862 & 5.3674 & TRN \\
\hline CHEMBL1549916 & 688239 & 4.5362 & 5.67700 & 00000000005 \\
\hline CHEMBL1364455 & 688239 & 4.5362 & 5.5725 & TRN \\
\hline CHEMBL1414133 & 688239 & 4.5362 & 5.2978 & TRN \\
\hline CHEMBL1552494 & 688239 & 4.8862 & 5.4642 & TRN \\
\hline CHEMBL1319392 & 688239 & 6.6362 & 5.4612 & TRN \\
\hline CHEMBL1372954 & 688239 & 4.8862 & 5.5706 & TRN \\
\hline CHEMBL1348958 & 688239 & 6.5363 & 5.4057 & TRN \\
\hline CHEMBL1553293 & 688239 & 5.7362 & 5.5691 & TRN \\
\hline CHEMBL1329743 & 688239 & 6.1862 & 5.621 & TRN \\
\hline CHEMBL1511803 & 688239 & 4.6362 & 5.5268 & TRN \\
\hline CHEMBL1477390 & 688239 & 5.1362 & 5.4388 & TRN \\
\hline CHEMBL1385342 & 688239 & 5.1862 & 5.4184 & TRN \\
\hline CHEMBL1536112 & 688239 & 5.1862 & 5.6003 & TST \\
\hline CHEMBL1576880 & 688239 & 4.9362 & 5.4924 & TST \\
\hline CHEMBL1378979 & 688239 & 6.3362 & 5.5206 & TST \\
\hline CHEMBL1337561 & 688239 & 8.3372 & 5.3622 & TRN \\
\hline CHEMBL1579388 & 688239 & 5.4862 & 5.6713 & TRN \\
\hline CHEMBL1464333 & 688239 & 6.2862 & 5.4948 & TRN \\
\hline CHEMBL1333297 & 688239 & 5.2862 & 5.515 & TRN \\
\hline CHEMBL1543750 & 688239 & 5.2362 & 5.4712 & TRN \\
\hline CHEMBL1375681 & 688239 & 6.1362 & 5.5164 & TRN \\
\hline CHEMBL1393928 & 688239 & 4.7862 & 5.6017 & TRN \\
\hline CHEMBL1335124 & 688239 & 4.9862 & 5.4334 & TRN \\
\hline CHEMBL1489688 & 688239 & 5.4862 & 5.4966 & TRN \\
\hline CHEMBL1305761 & 688239 & 4.5362 & 5.4626 & TRN \\
\hline CHEMBL1491494 & 688239 & 4.5362 & 5.5142 & TST \\
\hline CHEMBL1397660 & 688239 & 5.6862 & 5.5265 & TRN \\
\hline
\end{tabular}

Page 2528 
Supplemental Table S2.txt

\begin{tabular}{|c|c|c|c|c|c|}
\hline CHEMBL1501046 & 688239 & 4.4862 & 5.4869 & TRN & \\
\hline CHEMBL1406022 & 688239 & 5.6362 & 5.65 & TRN & \\
\hline CHEMBL1598623 & 688239 & 4.5362 & 5.4524 & TRN & \\
\hline CHEMBL1602333 & 688239 & 5.7862 & 5.593 & TRN & \\
\hline CHEMBL1604450 & 688239 & 5.5362 & 5.4146 & TRN & \\
\hline CHEMBL1503420 & 688239 & 5.1862 & 5.4725 & TRN & \\
\hline CHEMBL1536456 & 688239 & 5.1862 & 5.636 & TST & \\
\hline CHEMBL1445908 & 688239 & 4.9862 & 5.7339 & TRN & \\
\hline CHEMBL1311925 & 688239 & 6.0862 & 5.4143 & TRN & \\
\hline CHEMBL1352951 & 688239 & 6.4362 & 5.5591 & TRN & \\
\hline CHEMBL1378992 & 688239 & 5.0862 & 5.3611 & TRN & \\
\hline CHEMBL1531664 & 688239 & 4.5862 & 5.6614 & TRN & \\
\hline CHEMBL1312282 & 688239 & 5.8362 & 5.6719 & TST & \\
\hline CHEMBL1392538 & 688239 & 6.1362 & 5.5071 & TST & \\
\hline CHEMBL3211418 & 688239 & 6.9363 & 5.4597 & TRN & \\
\hline CHEMBL1416967 & 688239 & 4.5362 & 5.4964 & TST & \\
\hline CHEMBL1321020 & 688239 & 4.7362 & 5.3306 & TRN & \\
\hline CHEMBL1556362 & 688239 & 4.7862 & 5.5582 & TRN & \\
\hline CHEMBL1508004 & 688239 & 6.8362 & 5.4938 & TRN & \\
\hline CHEMBL3209504 & 688239 & 5.3362 & 5.4327 & TRN & \\
\hline CHEMBL1527461 & 688239 & 6.1362 & 5.4202 & TRN & \\
\hline CHEMBL1337927 & 688239 & 5.4362 & 5.432 & TRN & \\
\hline CHEMBL1432627 & 688239 & 4.5362 & 5.4025 & TRN & \\
\hline CHEMBL1983939 & 688239 & 4.5362 & 5.3097 & TRN & \\
\hline CHEMBL1416833 & 688239 & 4.4862 & 5.56 & TRN & \\
\hline CHEMBL1546501 & 688239 & 4.4862 & 5.4571 & TST & \\
\hline CHEMBL1570551 & 688239 & 4.5362 & 5.5086 & TRN & \\
\hline CHEMBL1412082 & 688239 & 4.7362 & 5.3422 & TST & \\
\hline CHEMBL1408734 & 688239 & 4.8862 & 5.6203 & TRN & \\
\hline CHEMBL1456271 & 688239 & 5.7862 & 5.5318 & TRN & \\
\hline CHEMBL1447364 & 688239 & 4.5362 & 5.51 & TRN & \\
\hline CHEMBL1299900 & 688239 & 4.8862 & 5.3384 & TRN & \\
\hline CHEMBL1471717 & 688239 & 6.0862 & 5.5488 & TRN & \\
\hline CHEMBL1475476 & 688239 & 5.9362 & 5.5361 & TST & \\
\hline CHEMBL1387687 & 688239 & 8.3372 & 5.5304 & TRN & \\
\hline CHEMBL1434197 & 688239 & 5.0362 & 5.5563 & TRN & \\
\hline CHEMBL1435466 & 688239 & 5.1862 & 5.58200 & 0000000001 & TRN \\
\hline CHEMBL1487268 & 688239 & 4.6362 & 5.4278 & TRN & \\
\hline CHEMBL1502498 & 688239 & 4.7862 & 5.5278 & TRN & \\
\hline CHEMBL1569012 & 688239 & 4.5362 & 5.3838 & TRN & \\
\hline CHEMBL3212659 & 688239 & 5.5362 & 5.5269 & TRN & \\
\hline CHEMBL1455020 & 688239 & 4.5362 & 5.4119 & TRN & \\
\hline CHEMBL1573752 & 688239 & 5.6362 & 5.415 & TRN & \\
\hline CHEMBL1400060 & 688239 & 4.8862 & 5.4253 & TST & \\
\hline CHEMBL1562478 & 688239 & 5.6362 & 5.6331 & TRN & \\
\hline CHEMBL1486066 & 688239 & 4.4862 & 5.3684 & TRN & \\
\hline CHEMBL1332043 & 688239 & 4.6862 & 5.3512 & TRN & \\
\hline CHEMBL1336680 & 688239 & 6.0862 & 5.557 & TST & \\
\hline
\end{tabular}

Page 2529 
Supplemental Table S2.txt

\begin{tabular}{|c|c|c|c|c|}
\hline CHEMBL1527291 & 688239 & 6.1362 & 5.4957 & TST \\
\hline CHEMBL1321829 & 688239 & 8.3872 & 5.3564 & TRN \\
\hline CHEMBL1558103 & 688239 & 4.7362 & 5.4139 & TRN \\
\hline CHEMBL1544130 & 688239 & 4.7362 & 5.5192 & TRN \\
\hline CHEMBL1474529 & 688239 & 6.1362 & 5.5348 & TRN \\
\hline CHEMBL1349739 & 688239 & 4.7362 & 5.3514 & TST \\
\hline CHEMBL1342975 & 688239 & 5.8362 & 5.6448 & TRN \\
\hline CHEMBL1303368 & 688239 & 6.3362 & 5.4884 & TRN \\
\hline CHEMBL1392709 & 688239 & 6.2362 & 5.4117 & TRN \\
\hline CHEMBL3197959 & 688239 & 4.7362 & 5.3735 & TRN \\
\hline CHEMBL1442668 & 688239 & 5.4362 & 5.3795 & TRN \\
\hline CHEMBL1380209 & 688239 & 4.5362 & 5.4979 & TRN \\
\hline CHEMBL1533311 & 688239 & 5.7362 & 5.4389 & TRN \\
\hline CHEMBL1347628 & 688239 & 5.4362 & 5.6479 & TRN \\
\hline CHEMBL1450351 & 688239 & 7.0362 & 5.5678 & TRN \\
\hline CHEMBL1481442 & 688239 & 8.3372 & 5.4731 & TRN \\
\hline CHEMBL1876078 & 688239 & 4.8362 & 5.4566 & TRN \\
\hline CHEMBL1477643 & 688239 & 5.8862 & 5.5725 & TST \\
\hline CHEMBL1389466 & 688239 & 4.5362 & 5.6183 & TST \\
\hline CHEMBL1564168 & 688239 & 4.9862 & 5.4615 & TST \\
\hline CHEMBL1254918 & 688239 & 4.5362 & 5.4985 & TRN \\
\hline CHEMBL1388598 & 688239 & 4.7862 & 5.5493 & TRN \\
\hline CHEMBL1517014 & 688239 & 5.1862 & 5.5164 & TRN \\
\hline CHEMBL1371962 & 688239 & 5.6862 & 5.4207 & TRN \\
\hline CHEMBL1368073 & 688239 & 5.8362 & 5.3733 & TST \\
\hline CHEMBL1347422 & 688239 & 6.8362 & 5.3966 & TST \\
\hline CHEMBL1593114 & 688239 & 4.8862 & 5.3337 & TRN \\
\hline CHEMBL1454885 & 688239 & 4.4862 & 5.6456 & TST \\
\hline CHEMBL1570059 & 688239 & 4.5362 & 5.3913 & TRN \\
\hline CHEMBL1410109 & 688239 & 5.3362 & 5.3489 & TST \\
\hline CHEMBL1457562 & 688239 & 6.3863 & 5.4477 & TST \\
\hline CHEMBL1499158 & 688239 & 5.1862 & 5.4537 & TRN \\
\hline CHEMBL1424585 & 688239 & 5.5362 & 5.399 & TRN \\
\hline CHEMBL1309099 & 688239 & 4.5362 & 5.5159 & TRN \\
\hline CHEMBL1343057 & 688239 & 6.8861 & 5.3591 & TRN \\
\hline CHEMBL1383892 & 688239 & 4.6862 & 5.4831 & TRN \\
\hline CHEMBL1545555 & 688239 & 5.5362 & 5.5264 & TRN \\
\hline CHEMBL3209076 & 688239 & 4.5362 & 5.4468 & TRN \\
\hline CHEMBL1335148 & 688239 & 6.7862 & 5.5222 & TST \\
\hline CHEMBL1310426 & 688239 & 4.5362 & 5.5411 & TRN \\
\hline CHEMBL1340584 & 688239 & 8.3372 & 5.3874 & TRN \\
\hline CHEMBL1341933 & 688239 & 5.3862 & 5.391 & TRN \\
\hline CHEMBL1448431 & 688239 & 4.7862 & 5.49799 & 9999999999 \\
\hline CHEMBL1524009 & 688239 & 5.6362 & 5.693 & TRN \\
\hline CHEMBL1482063 & 688239 & 5.5862 & 5.4485 & TRN \\
\hline CHEMBL1322220 & 688239 & 4.7862 & 5.4974 & TRN \\
\hline CHEMBL1436639 & 688239 & 7.2366 & 5.3189 & TRN \\
\hline CHEMBL1376206 & 688239 & 5.1862 & 5.6119 & TRN \\
\hline
\end{tabular}


Supplemental Table S2.txt

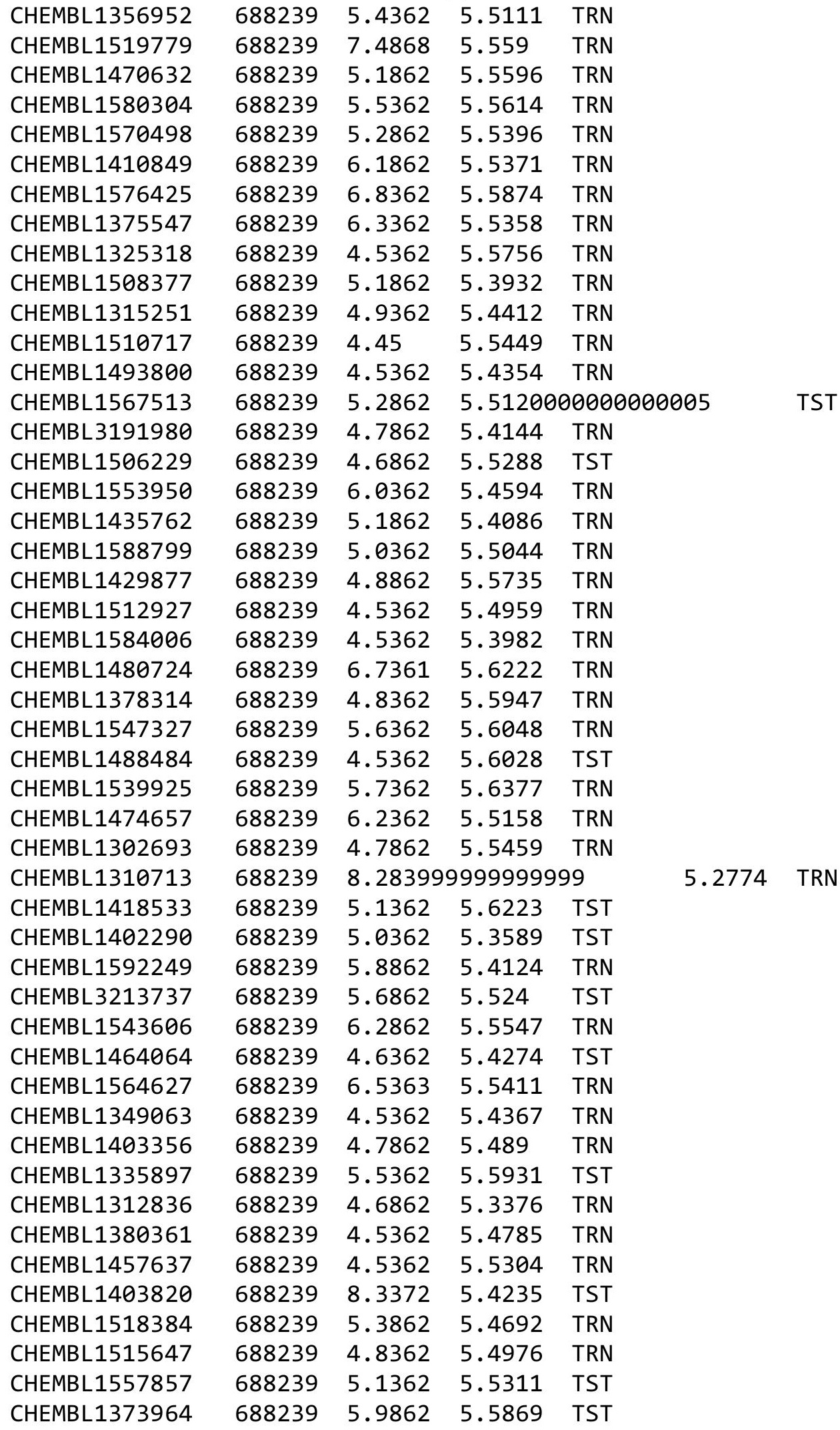

Page 2531 


\begin{tabular}{|c|c|c|c|c|c|c|}
\hline & & \multicolumn{5}{|c|}{ Le SL.txt } \\
\hline CHEMBL11875 & 688239 & 4.7362 & 5.5211 & TST & & \\
\hline CHEMBL1380336 & 688239 & 4.5362 & 5.4546 & TRN & & \\
\hline CHEMBL1413495 & 688239 & 4.9862 & 5.4671 & TRN & & \\
\hline CHEMBL1536240 & 688239 & 6.7862 & 5.4264 & TRN & & \\
\hline CHEMBL1343513 & 688239 & 5.4862 & 5.4616 & TST & & \\
\hline CHEMBL1529760 & 688239 & 5.1862 & 5.3849 & TRN & & \\
\hline CHEMBL1468144 & 688239 & 4.5362 & 5.64 & TRN & & \\
\hline CHEMBL1418672 & 688239 & \multicolumn{3}{|c|}{8.283999999999999} & 5.5443 & TST \\
\hline CHEMBL1349110 & 688239 & 6.8861 & 5.4754 & TRN & & \\
\hline CHEMBL1501062 & 688239 & 4.6862 & 5.5421 & TRN & & \\
\hline CHEMBL1489747 & 688239 & 4.5362 & 5.4546 & TRN & & \\
\hline CHEMBL1361658 & 688239 & 4.6862 & 5.5213 & TST & & \\
\hline CHEMBL1463297 & 688239 & 5.1862 & 5.5718 & TRN & & \\
\hline CHEMBL1488954 & 688239 & 5.8862 & 5.3392 & TRN & & \\
\hline CHEMBL1558013 & 688239 & 6.9863 & 5.4148 & TRN & & \\
\hline CHEMBL1515613 & 688239 & 5.4362 & 5.5504 & TRN & & \\
\hline CHEMBL1557135 & 688239 & 5.6862 & 5.4495 & TRN & & \\
\hline CHEMBL568419 & 688239 & 5.1362 & 5.5989 & TRN & & \\
\hline CHEMBL1445023 & 688239 & 6.6861 & 5.4523 & TRN & & \\
\hline CHEMBL1349142 & 688239 & 5.6362 & 5.4709 & TRN & & \\
\hline CHEMBL1583672 & 688239 & 5.3362 & 5.4853 & TRN & & \\
\hline CHEMBL1338865 & 688239 & 5.6862 & 5.4566 & TRN & & \\
\hline CHEMBL1486003 & 688239 & 4.5862 & 5.5404 & TRN & & \\
\hline CHEMBL1573490 & 688239 & 6.8362 & 5.505 & TRN & & \\
\hline CHEMBL1481602 & 688239 & 4.5362 & 5.3686 & TST & & \\
\hline CHEMBL1467779 & 688239 & 4.8362 & \multicolumn{3}{|c|}{5.587999999999999} & TRN \\
\hline CHEMBL1368372 & 688239 & 4.5362 & 5.5127 & TRN & & \\
\hline CHEMBL1504260 & 688239 & 5.4362 & 5.5452 & TRN & & \\
\hline CHEMBL1465672 & 688239 & 6.2362 & 5.3928 & TRN & & \\
\hline CHEMBL1475130 & 688239 & 4.5362 & 5.5322 & TRN & & \\
\hline CHEMBL1511002 & 688239 & 6.9863 & 5.6743 & TRN & & \\
\hline CHEMBL1407961 & 688239 & 4.8862 & 5.3559 & TRN & & \\
\hline CHEMBL1420338 & 688239 & 6.8362 & 5.4414 & TRN & & \\
\hline CHEMBL1475203 & 688239 & 4.5362 & 5.5757 & TRN & & \\
\hline CHEMBL1392364 & 688239 & 4.5362 & 5.5161 & TRN & & \\
\hline CHEMBL1518866 & 688239 & 5.7862 & 5.4379 & TRN & & \\
\hline CHEMBL1579837 & 688239 & 6.2862 & 5.5534 & TRN & & \\
\hline CHEMBL1556760 & 688239 & 5.1862 & 5.5389 & TST & & \\
\hline CHEMBL1347300 & 688239 & 4.45 & 5.4111 & TRN & & \\
\hline CHEMBL1463922 & 688239 & 5.1862 & 5.4857 & TRN & & \\
\hline CHEMBL1549988 & 688239 & 6.8362 & 5.4766 & TRN & & \\
\hline CHEMBL1527995 & 688239 & 4.8362 & 5.4095 & TST & & \\
\hline CHEMBL3214442 & 688239 & 6.1362 & 5.5849 & TST & & \\
\hline CHEMBL1340298 & 688239 & 6.3362 & 5.4487 & TRN & & \\
\hline CHEMBL1332253 & 688239 & 4.9862 & 5.4174 & TRN & & \\
\hline CHEMBL1413314 & 688239 & 6.1362 & 5.5146 & TRN & & \\
\hline CHEMBL1307847 & 688239 & 5.8362 & 5.5532 & TRN & & \\
\hline \multirow[t]{2}{*}{ CHEMBL3210625 } & 688239 & 6.3863 & 5.571006 & 0000000001 & & TST \\
\hline & & \multicolumn{5}{|c|}{ Page 2532} \\
\hline
\end{tabular}


Supplemental Table S2.txt

\begin{tabular}{|c|c|c|c|c|}
\hline CHEMBL1501297 & 688239 & 5.6862 & 5.2994 & TRN \\
\hline CHEMBL1419793 & 688239 & 5.6362 & 5.4009 & TRN \\
\hline CHEMBL1398907 & 688239 & 5.3362 & 5.5029 & TRN \\
\hline CHEMBL1487116 & 688239 & 4.5362 & 5.5234 & TRN \\
\hline CHEMBL1468419 & 688239 & 5.9362 & 5.537006 & 0000000001 \\
\hline CHEMBL1433528 & 688239 & 6.7862 & 5.6868 & TRN \\
\hline CHEMBL1511745 & 688239 & 4.5362 & 5.6471 & TRN \\
\hline CHEMBL1583520 & 688239 & 4.7362 & 5.4423 & TST \\
\hline CHEMBL1446656 & 688239 & 4.9862 & 5.6189 & TRN \\
\hline CHEMBL1383003 & 688239 & 5.0862 & 5.4664 & TST \\
\hline CHEMBL1979530 & 688239 & 4.5362 & 5.4288 & TST \\
\hline CHEMBL1302446 & 688239 & 5.3362 & 5.4196 & TRN \\
\hline CHEMBL1312335 & 688239 & 5.9362 & 5.4945 & TRN \\
\hline CHEMBL1469006 & 688239 & 5.8362 & 5.5252 & TST \\
\hline CHEMBL1970859 & 688239 & 5.1362 & 5.3018 & TRN \\
\hline CHEMBL1432531 & 688239 & 6.1362 & 5.4829 & TRN \\
\hline CHEMBL1464032 & 688239 & 5.1862 & 5.4708 & TST \\
\hline CHEMBL1480098 & 688239 & 4.5362 & 5.6492 & TRN \\
\hline CHEMBL1482097 & 688239 & 5.8362 & 5.4826 & TST \\
\hline CHEMBL1563696 & 688239 & 4.6362 & 5.5561 & TRN \\
\hline CHEMBL1373015 & 688239 & 6.6362 & 5.6203 & TRN \\
\hline CHEMBL1440064 & 688239 & 5.5862 & 5.5543 & TRN \\
\hline CHEMBL1446640 & 688239 & 5.0862 & 5.5614 & TRN \\
\hline CHEMBL1583395 & 688239 & 5.9362 & 5.4518 & TRN \\
\hline CHEMBL1377650 & 688239 & 6.3863 & 5.4034 & TRN \\
\hline CHEMBL1535250 & 688239 & 5.6862 & 5.4524 & TRN \\
\hline CHEMBL1545544 & 688239 & 4.5362 & 5.472 & TRN \\
\hline CHEMBL1381737 & 688239 & 4.6862 & 5.5545 & TRN \\
\hline CHEMBL1324003 & 688239 & 5.1862 & 5.6879 & TRN \\
\hline CHEMBL1330735 & 688239 & 8.3372 & 5.4454 & TRN \\
\hline CHEMBL1341481 & 688239 & 5.4362 & 5.5635 & TRN \\
\hline CHEMBL1423580 & 688239 & 6.8861 & 5.551 & TRN \\
\hline CHEMBL1421279 & 688239 & 4.7862 & 5.4211 & TRN \\
\hline CHEMBL1537620 & 688239 & 4.5362 & 5.4728 & TRN \\
\hline CHEMBL 3193602 & 688239 & 4.7362 & 5.4634 & TST \\
\hline CHEMBL1356365 & 688239 & 5.1862 & 5.5042 & TRN \\
\hline CHEMBL1328957 & 688239 & 5.1362 & 5.3849 & TRN \\
\hline CHEMBL1506903 & 688239 & 8.3372 & 5.4266 & TRN \\
\hline CHEMBL1471567 & 688239 & 4.5362 & 5.4956 & TRN \\
\hline CHEMBL1581517 & 688239 & 4.5362 & 5.5412 & TST \\
\hline CHEMBL1438386 & 688239 & 5.6862 & 5.5286 & TRN \\
\hline CHEMBL1596414 & 688239 & 4.5362 & 5.394 & TST \\
\hline CHEMBL1456226 & 688239 & 4.7862 & 5.481 & TST \\
\hline CHEMBL1588880 & 688239 & 6.6362 & 5.3614 & TRN \\
\hline CHEMBL1427726 & 688239 & 6.0 & 5.4561 & TRN \\
\hline CHEMBL1471697 & 688239 & 4.5362 & 5.3963 & TRN \\
\hline CHEMBL43065 & 688239 & 4.5362 & 5.3711 & TST \\
\hline CHEMBL1431289 & 688239 & 4.7862 & 5.5241 & TST \\
\hline
\end{tabular}


Supplemental Table S2.txt

\begin{tabular}{|c|c|c|c|c|}
\hline & & & & \\
\hline IEMBL16 & 688239 & 362 & & \\
\hline IEMBL1573259 & 3239 & 862 & 5258 & \\
\hline HEMBL1344130 & 239 & 362 & 35 & \\
\hline 208 & 239 & 862 & & \\
\hline EMBL1386302 & 239 & 862 & & \\
\hline AEMBL1517544 & 88239 & 862 & 5358 & \\
\hline AEMBL1355222 & 88239 & 362 & 3142 & \\
\hline AEMBL1471896 & 239 & 362 & & \\
\hline IEMBL13 & 239 & 362 & & \\
\hline AEMBL13 & & & & \\
\hline AEMBL1334776 & 688239 & 862 & & \\
\hline AEMBL15 & 239 & 362 & & \\
\hline IEMBL14 & & 862 & & \\
\hline EMBL13 & & 62 & & \\
\hline AEMBL 15 & & & & \\
\hline AEMBL1508285 & 239 & 362 & & RN \\
\hline HEMBL 144 & & 862 & & \\
\hline EMBL13 & & 62 & & \\
\hline EMBL13 & & & & \\
\hline AEMBL15 & & 61 & & \\
\hline AEMBL1454221 & & 862 & & RN \\
\hline IEMBL15 & & 862 & & ST \\
\hline IEMBL16 & & 62 & & 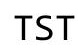 \\
\hline IEMBL12 & & & & RN \\
\hline IFMDI 11 & & 62 & & \\
\hline HEMBL50 & & & & RN \\
\hline HEMBL139 & & & & \\
\hline AEMBL31S & & 52 & & RI \\
\hline 750 & & 62 & & $x_{1}+2+$ \\
\hline 33 & & 62 & & ST \\
\hline AEMBL144 & & & & RN \\
\hline AEMBL1596488 & & & & \\
\hline IEMBL142 & & 362 & & RI \\
\hline 160 & & 52 & & m \\
\hline & & & & se \\
\hline AEMBL1578610 & & & & $\mathrm{R}$ \\
\hline AEMBL3207650 & & & & $S$ \\
\hline EMBL135 & & 62 & & $S$ \\
\hline תו יחוזו & & & & \\
\hline & & & & RN \\
\hline AEMBL1346264 & & 862 & & $\mathrm{R}$ \\
\hline IEMBL14e & & & & $\Gamma R$ \\
\hline EMBL14 & & & & is \\
\hline & & & & \\
\hline CHEMBL154 & & 862 & & IV \\
\hline HEMBL137 & 688239 & 5.5362 & 5.5204 & $\mathrm{TR}$ \\
\hline HFMRI 1588597 & 688239 & 5.4362 & 5.5785 & \\
\hline
\end{tabular}


Supplemental Table S2.txt

\begin{tabular}{|c|c|c|c|c|}
\hline CHEMBL1458873 & 688239 & 5.8362 & 5.4285 & TRN \\
\hline CHEMBL1548210 & 688239 & 4.5362 & 5.5358 & TST \\
\hline CHEMBL1970819 & 688239 & 4.5362 & 5.3324 & TRN \\
\hline CHEMBL1605156 & 688239 & 4.5362 & 5.3648 & TRN \\
\hline CHEMBL1310837 & 688239 & 4.5362 & 5.3363 & TST \\
\hline CHEMBL1428375 & 688239 & 5.0362 & 5.4852 & TRN \\
\hline CHEMBL1533605 & 688239 & 5.7862 & 5.4286 & TRN \\
\hline CHEMBL1417594 & 688239 & 5.5362 & 5.4693 & TRN \\
\hline CHEMBL1489039 & 688239 & 4.5362 & 5.5646 & TRN \\
\hline CHEMBL1548234 & 688239 & 4.9862 & 5.4787 & TRN \\
\hline CHEMBL 3208777 & 688239 & 4.5362 & 5.3173 & TRN \\
\hline CHEMBL1313842 & 688239 & 5.1362 & 5.4114 & TST \\
\hline CHEMBL1588580 & 688239 & 4.8862 & 5.4097 & TRN \\
\hline CHEMBL1460936 & 688239 & 4.5362 & 5.3446 & TRN \\
\hline CHEMBL1425201 & 688239 & 4.8362 & 5.4153 & TRN \\
\hline CHEMBL1574908 & 688239 & 4.6362 & 5.4176 & TST \\
\hline CHEMBL1317410 & 688239 & 5.1862 & 5.5387 & TRN \\
\hline CHEMBL1519694 & 688239 & 5.1362 & 5.4859 & TRN \\
\hline CHEMBL1451489 & 688239 & 4.5362 & 5.566 & TST \\
\hline CHEMBL1486936 & 688239 & 4.7362 & 5.4154 & TRN \\
\hline CHEMBL1585123 & 688239 & 5.7862 & 5.5396 & TRN \\
\hline CHEMBL1460397 & 688239 & 6.8861 & 5.6361 & TST \\
\hline CHEMBL1481689 & 688239 & 5.0862 & 5.4595 & TRN \\
\hline CHEMBL1565098 & 688239 & 4.9862 & 5.5946 & TRN \\
\hline CHEMBL1432117 & 688239 & 4.5362 & 5.3526 & TST \\
\hline CHEMBL 3210880 & 688239 & 6.1362 & 5.3006 & TST \\
\hline CHEMBL1362612 & 688239 & 4.6862 & 5.3296 & TRN \\
\hline CHEMBL1572827 & 688239 & 4.5362 & 5.5066 & TST \\
\hline CHEMBL1565035 & 688239 & 4.8362 & 5.42399 & 99999999995 \\
\hline CHEMBL1456290 & 688239 & 5.8362 & 5.3831 & TRN \\
\hline CHEMBL1481461 & 688239 & 4.7362 & 5.5574 & TRN \\
\hline CHEMBL1528025 & 688239 & 4.5362 & 5.5201 & TRN \\
\hline CHEMBL1389053 & 688239 & 5.0362 & 5.5406 & TST \\
\hline CHEMBL1423877 & 688239 & 6.0862 & 5.57600 & 0000000005 \\
\hline CHEMBL1446398 & 688239 & 4.5362 & 5.4749 & TST \\
\hline CHEMBL1357862 & 688239 & 4.6862 & 5.5797 & TRN \\
\hline CHEMBL1413224 & 688239 & 6.1862 & 5.5583 & TST \\
\hline CHEMBL1420826 & 688239 & 4.4862 & 5.3315 & TRN \\
\hline CHEMBL1588428 & 688239 & 6.9863 & 5.3918 & TRN \\
\hline CHEMBL1576127 & 688239 & 4.5362 & 5.4185 & TST \\
\hline CHEMBL1528386 & 688239 & 6.1362 & 5.484 & TST \\
\hline CHEMBL2001743 & 688239 & 5.4362 & 5.381 & TRN \\
\hline CHEMBL1438060 & 688239 & 5.8862 & 5.5791 & TRN \\
\hline CHEMBL1414000 & 688239 & 6.4862 & 5.6917 & TRN \\
\hline CHEMBL1500152 & 688239 & 5.1862 & 5.5061 & TRN \\
\hline CHEMBL1561247 & 688239 & 4.4862 & 5.5282 & TRN \\
\hline CHEMBL1424752 & 688239 & 5.0362 & 5.2969 & TRN \\
\hline CHEMBL1359076 & 688239 & 6.0 & 5.5196 & TST \\
\hline
\end{tabular}




\begin{tabular}{|c|c|c|c|c|c|}
\hline & & \multicolumn{4}{|c|}{ e SL. TXt } \\
\hline CHEMBL1585429 & 688239 & 6.4862 & 5.4444 & TST & \\
\hline CHEMBL1477615 & 688239 & 5.0362 & 5.3965 & TRN & \\
\hline CHEMBL220009 & 688239 & 4.9862 & 5.5059 & TRN & \\
\hline CHEMBL1607959 & 688239 & 4.7862 & 5.4724 & TRN & \\
\hline CHEMBL1078223 & 688239 & 6.1362 & 5.5526 & TRN & \\
\hline CHEMBL3189456 & 688239 & \multicolumn{2}{|c|}{8.283999999999999} & 5.5639 & TRN \\
\hline CHEMBL1435150 & 688239 & 5.3862 & 5.4645 & TRN & \\
\hline CHEMBL1538749 & 688239 & 4.5362 & 5.5596 & TRN & \\
\hline CHEMBL526776 & 688239 & 5.2362 & 5.4966 & TRN & \\
\hline CHEMBL1379940 & 688239 & 4.5362 & 5.4997 & TRN & \\
\hline CHEMBL1429075 & 688239 & 4.5362 & 5.4236 & TRN & \\
\hline CHEMBL1509933 & 688239 & 5.5862 & 5.6753 & TRN & \\
\hline CHEMBL1326683 & 688239 & 4.7362 & 5.6325 & TST & \\
\hline CHEMBL3214158 & 688239 & 6.5862 & 5.4992 & TRN & \\
\hline CHEMBL1458808 & 688239 & 7.1361 & 5.6344 & TRN & \\
\hline CHEMBL3212054 & 688239 & 4.7362 & \multicolumn{2}{|c|}{5.5120000000000005} & TRN \\
\hline CHEMBL1533308 & 688239 & 4.7362 & 5.5015 & TRN & \\
\hline CHEMBL1535053 & 688239 & 6.1362 & 5.3141 & TRN & \\
\hline CHEMBL437193 & 688239 & 6.7361 & 5.5558 & TST & \\
\hline CHEMBL1437924 & 688239 & 4.2362 & 5.4493 & TST & \\
\hline CHEMBL1556235 & 688239 & 4.6862 & 5.4875 & TST & \\
\hline CHEMBL1527540 & 688239 & 4.5362 & 5.5121 & TRN & \\
\hline CHEMBL1611677 & 688239 & 6.0362 & 5.3561 & TRN & \\
\hline CHEMBL1444961 & 688239 & 4.45 & 5.5815 & TRN & \\
\hline CHEMBL1331898 & 688239 & 4.5862 & 5.3898 & TRN & \\
\hline CHEMBL3194517 & 688239 & 4.6862 & 5.3674 & TRN & \\
\hline CHEMBL1550710 & 688239 & 4.9862 & 5.4556 & TST & \\
\hline CHEMBL1613000 & 688239 & 4.7862 & 5.5048 & TRN & \\
\hline CHEMBL1461260 & 688239 & 6.2862 & 5.4629 & TRN & \\
\hline CHEMBL1313931 & 688239 & 5.0362 & 5.4861 & TRN & \\
\hline CHEMBL1448491 & 688239 & 4.6362 & 5.4341 & TRN & \\
\hline CHEMBL1590600 & 688239 & 6.1862 & 5.5033 & TRN & \\
\hline CHEMBL 3212901 & 688239 & 5.0862 & 5.6167 & TRN & \\
\hline CHEMBL3192612 & 688239 & 4.5362 & 5.3951 & TST & \\
\hline CHEMBL1472475 & 688239 & 6.1862 & 5.3518 & TRN & \\
\hline CHEMBL1425574 & 688239 & 4.7862 & 5.4726 & TST & \\
\hline CHEMBL1542779 & 688239 & 7.2366 & \multicolumn{2}{|c|}{5.422999999999999} & TRN \\
\hline CHEMBL1414434 & 688239 & 5.2362 & 5.5145 & TRN & \\
\hline CHEMBL1328220 & 688239 & 5.8862 & 5.5494 & TRN & \\
\hline CHEMBL1342650 & 688239 & 5.1862 & 5.4956 & TRN & \\
\hline CHEMBL1348330 & 688239 & 6.0862 & 5.4782 & TRN & \\
\hline CHEMBL1361081 & 688239 & 5.4362 & \multicolumn{2}{|c|}{5.4670000000000005} & TRN \\
\hline CHEMBL1479699 & 688239 & 4.5362 & \multicolumn{2}{|c|}{5.287000000000001} & TST \\
\hline CHEMBL1407104 & 688239 & 4.2362 & 5.482 & TRN & \\
\hline CHEMBL1594583 & 688239 & 6.2862 & 5.4142 & TRN & \\
\hline CHEMBL1534140 & 688239 & 5.4362 & 5.4214 & TRN & \\
\hline CHEMBL1505236 & 688239 & 4.5362 & 5.4365 & TRN & \\
\hline CHEMBL1445785 & 688239 & 5.3362 & 5.3514 & TRN & \\
\hline
\end{tabular}


Supplemental Table S2.txt

\begin{tabular}{|c|c|c|c|c|}
\hline CHEMBL1352333 & 688239 & 6.0362 & 5.6187 & TST \\
\hline CHEMBL1384752 & 688239 & 6.3362 & 5.6203 & TRN \\
\hline CHEMBL1484794 & 688239 & 6.2862 & 5.5415 & TRN \\
\hline CHEMBL1436260 & 688239 & 4.5362 & 5.4665 & TRN \\
\hline CHEMBL1593135 & 688239 & 4.8862 & 5.4355 & TRN \\
\hline CHEMBL1376599 & 688239 & 4.6862 & 5.5651 & TRN \\
\hline CHEMBL1348556 & 688239 & 4.5362 & 5.5773 & TRN \\
\hline CHEMBL1521803 & 688239 & 6.1362 & 5.5004 & TRN \\
\hline CHEMBL1479340 & 688239 & 5.0862 & 5.195 & TST \\
\hline CHEMBL1610373 & 688239 & 5.7862 & 5.7173 & TRN \\
\hline CHEMBL1471311 & 688239 & 4.8362 & \multicolumn{2}{|c|}{5.4879999999999995} \\
\hline CHEMBL1488764 & 688239 & 4.5362 & 5.455 & TRN \\
\hline CHEMBL1348041 & 688239 & 4.5362 & 5.5231 & TST \\
\hline CHEMBL1610174 & 688239 & 4.5862 & 5.5646 & TRN \\
\hline CHEMBL1489154 & 688239 & 4.5362 & 5.5166 & TRN \\
\hline CHEMBL 3199177 & 688239 & 4.5362 & 5.3189 & TRN \\
\hline CHEMBL1608967 & 688239 & 5.4862 & 5.5038 & TRN \\
\hline CHEMBL1316475 & 688239 & 4.5362 & 5.5091 & TST \\
\hline CHEMBL1495433 & 688239 & 5.4362 & 5.3682 & TST \\
\hline CHEMBL1506594 & 688239 & 4.5362 & 5.4777 & TST \\
\hline CHEMBL1604286 & 688239 & 5.7862 & 5.4694 & TRN \\
\hline CHEMBL1420869 & 688239 & 4.4862 & 5.3087 & TST \\
\hline CHEMBL1441207 & 688239 & 5.1362 & 5.4934 & TST \\
\hline CHEMBL1535955 & 688239 & 4.5362 & 5.3547 & TRN \\
\hline CHEMBL 3191181 & 688239 & 4.5362 & 5.4423 & TRN \\
\hline CHEMBL186174 & 688239 & 6.0862 & 5.4519 & TST \\
\hline CHEMBL1342192 & 688239 & 5.1862 & 5.3557 & TRN \\
\hline CHEMBL1515219 & 688239 & 5.2362 & 5.5141 & TRN \\
\hline CHEMBL1504167 & 688239 & 7.5361 & \multicolumn{2}{|c|}{5.4639999999999995} \\
\hline CHEMBL 3190607 & 688239 & 4.5362 & 5.4636 & TRN \\
\hline CHEMBL1598436 & 688239 & 4.7362 & 5.4694 & TST \\
\hline CHEMBL1603321 & 688239 & 4.6362 & 5.5592 & TRN \\
\hline CHEMBL1431551 & 688239 & 5.3862 & 5.5983 & TRN \\
\hline CHEMBL1573878 & 688239 & 4.7362 & 5.4866 & TRN \\
\hline CHEMBL1341704 & 688239 & 4.5362 & 5.4102 & TRN \\
\hline CHEMBL1566703 & 688239 & 4.5362 & 5.4437 & TRN \\
\hline CHEMBL1593207 & 688239 & 4.6862 & 5.4596 & TRN \\
\hline CHEMBL1420530 & 688239 & 4.7362 & 5.4714 & TST \\
\hline CHEMBL1567056 & 688239 & 6.3362 & 5.5832 & TRN \\
\hline CHEMBL1391719 & 688239 & 5.3362 & 5.6497 & TRN \\
\hline CHEMBL1549969 & 688239 & 8.3372 & 5.5426 & TRN \\
\hline CHEMBL1561239 & 688239 & 6.0362 & 5.4045 & TRN \\
\hline CHEMBL116548 & 688239 & 4.8862 & \multicolumn{2}{|c|}{5.507000000000001} \\
\hline CHEMBL1378005 & 688239 & 4.5362 & 5.5094 & TRN \\
\hline CHEMBL1515709 & 688239 & 6.0862 & 5.5816 & TRN \\
\hline CHEMBL1461704 & 688239 & 4.8362 & 5.4402 & TST \\
\hline CHEMBL1475042 & 688239 & 5.1862 & 5.4528 & TST \\
\hline CHEMBL1976036 & 688239 & 4.8362 & 5.4457 & TRN \\
\hline
\end{tabular}

Page 2537 
Supplemental Table S2.txt

\begin{tabular}{|c|c|c|c|c|}
\hline CHEMBL1512494 & 688239 & 4.6862 & 5.4415 & TRN \\
\hline CHEMBL1603436 & 688239 & 4.7362 & 5.4374 & TST \\
\hline CHEMBL1482435 & 688239 & 4.9862 & 5.4459 & TRN \\
\hline CHEMBL1461171 & 688239 & 4.6362 & 5.4765 & TRN \\
\hline CHEMBL1345277 & 688239 & 6.1862 & 5.4744 & TRN \\
\hline CHEMBL1387135 & 688239 & 4.5362 & 5.5381 & TRN \\
\hline CHEMBL3196217 & 688239 & 6.7361 & 5.5325 & TST \\
\hline CHEMBL1547256 & 688239 & 4.9362 & 5.4377 & TRN \\
\hline CHEMBL1385238 & 688239 & 4.4862 & 5.5484 & TRN \\
\hline CHEMBL1566826 & 688239 & 6.1362 & 5.4428 & TST \\
\hline CHEMBL1424279 & 688239 & 5.1862 & 5.3855 & TST \\
\hline CHEMBL1511190 & 688239 & 4.5362 & 5.3512 & TST \\
\hline CHEMBL1499444 & 688239 & 7.9355 & 5.3433 & TRN \\
\hline CHEMBL1428247 & 688239 & 5.0362 & 5.441 & TRN \\
\hline CHEMBL1438424 & 688239 & 5.1362 & 5.4344 & TRN \\
\hline CHEMBL1605281 & 688239 & 5.1862 & 5.5095 & TST \\
\hline CHEMBL1590045 & 688239 & 4.5362 & 5.3958 & TRN \\
\hline CHEMBL1527149 & 688239 & 6.2862 & 5.4472 & TRN \\
\hline CHEMBL1347404 & 688239 & 8.3372 & 5.5354 & TRN \\
\hline CHEMBL1313360 & 688239 & 5.5362 & 5.6068 & TRN \\
\hline CHEMBL1372205 & 688239 & 6.0862 & 5.3548 & TST \\
\hline CHEMBL1322754 & 688239 & 4.9362 & 5.3759 & TST \\
\hline CHEMBL1489902 & 688239 & 4.7862 & 5.3383 & TST \\
\hline CHEMBL1366194 & 688239 & 5.6862 & 5.5925 & TST \\
\hline CHEMBL1504661 & 688239 & 4.5362 & 5.4923 & TST \\
\hline CHEMBL1363221 & 688239 & 4.5362 & 5.3411 & TRN \\
\hline CHEMBL1530037 & 688239 & 4.4862 & 5.5161 & TRN \\
\hline CHEMBL1521917 & 688239 & 5.7362 & 5.5014 & TRN \\
\hline CHEMBL1582110 & 688239 & 4.5362 & 5.5092 & TRN \\
\hline CHEMBL1574534 & 688239 & 5.7362 & 5.4765 & TRN \\
\hline CHEMBL1482099 & 688239 & 6.8861 & 5.3797 & TRN \\
\hline CHEMBL1604796 & 688239 & 6.1862 & 5.6259 & TRN \\
\hline CHEMBL3192866 & 688239 & 5.1362 & 5.5072 & TRN \\
\hline CHEMBL1608227 & 688239 & 4.7862 & 5.5888 & TST \\
\hline CHEMBL1306233 & 688239 & 6.4862 & 5.5592 & TRN \\
\hline CHEMBL1472295 & 688239 & 5.4862 & 5.553999 & 999999999 \\
\hline CHEMBL1587725 & 688239 & 4.7362 & 5.5217 & TST \\
\hline CHEMBL1514235 & 688239 & 8.3372 & 5.4847 & TRN \\
\hline CHEMBL1340351 & 688239 & 5.0362 & 5.3776 & TRN \\
\hline CHEMBL1485993 & 688239 & 4.6862 & 5.4468 & TRN \\
\hline CHEMBL1323817 & 688239 & 6.7361 & 5.5637 & TRN \\
\hline CHEMBL1520584 & 688239 & 4.7862 & 5.5572 & TST \\
\hline CHEMBL 3208743 & 688239 & 5.2362 & 5.4327 & TRN \\
\hline CHEMBL1392862 & 688239 & 4.5362 & 5.4664 & TRN \\
\hline CHEMBL1596014 & 688239 & 6.2862 & 5.5753 & TST \\
\hline CHEMBL1547565 & 688239 & 8.2366 & 5.4933 & TST \\
\hline CHEMBL1319317 & 688239 & 8.3372 & 5.603 & TRN \\
\hline CHEMBL3199743 & 688239 & 4.8862 & 5.5936 & TRN \\
\hline
\end{tabular}

Page 2538 
Supplemental Table S2.txt

\begin{tabular}{|c|c|c|c|c|c|}
\hline CHEMBL1352255 & 688239 & 5.5862 & 5.3722 & TRN & \\
\hline CHEMBL1310332 & 688239 & 4.6362 & 5.4843 & TRN & \\
\hline CHEMBL1335832 & 688239 & 6.1362 & 5.5834 & TRN & \\
\hline CHEMBL1514867 & 688239 & 6.1362 & 5.4462 & TRN & \\
\hline CHEMBL1570718 & 688239 & 4.4862 & 5.4915 & TRN & \\
\hline CHEMBL1490243 & 688239 & 6.1862 & 5.5832 & TRN & \\
\hline CHEMBL1384996 & 688239 & 4.6862 & 5.3357 & TRN & \\
\hline CHEMBL1583604 & 688239 & 4.8362 & 5.4494 & TRN & \\
\hline CHEMBL1584727 & 688239 & 5.1862 & 5.4099 & TRN & \\
\hline CHEMBL1527377 & 688239 & 5.8862 & 5.5727 & TRN & \\
\hline CHEMBL1450415 & 688239 & 4.8362 & 5.4467 & TRN & \\
\hline CHEMBL1528223 & 688239 & 6.1862 & 5.3892 & TRN & \\
\hline CHEMBL1306219 & 688239 & 4.5362 & 5.5039 & TRN & \\
\hline CHEMBL1383164 & 688239 & 7.2366 & 5.3808 & TRN & \\
\hline CHEMBL480142 & 688239 & 5.1862 & 5.4712 & TRN & \\
\hline CHEMBL1599660 & 688239 & 5.1862 & 5.3909 & TRN & \\
\hline CHEMBL1497990 & 688239 & 5.3862 & 5.4708 & TRN & \\
\hline CHEMBL1409878 & 688239 & 6.1362 & 5.4933 & TRN & \\
\hline CHEMBL1580757 & 688239 & 4.7862 & 5.5233 & TRN & \\
\hline CHEMBL1602375 & 688239 & 4.7862 & 5.4042 & TRN & \\
\hline CHEMBL1435807 & 688239 & 4.6362 & 5.4617 & TST & \\
\hline CHEMBL1341764 & 688239 & 6.9863 & 5.4481 & TST & \\
\hline CHEMBL1539097 & 688239 & 6.1362 & 5.3998 & TRN & \\
\hline CHEMBL1499787 & 688239 & 4.5362 & 5.4424 & TRN & \\
\hline CHEMBL1448838 & 688239 & 5.0862 & 5.3245 & TRN & \\
\hline CHEMBL1565106 & 688239 & 6.2862 & 5.4817 & TRN & \\
\hline CHEMBL1347995 & 688239 & 4.5362 & 5.4591 & TST & \\
\hline CHEMBL1369809 & 688239 & 6.1862 & 5.517 & TRN & \\
\hline CHEMBL1399771 & 688239 & 4.5362 & 5.5093 & TRN & \\
\hline CHEMBL1606068 & 688239 & 5.1862 & 5.4706 & TRN & \\
\hline CHEMBL1560587 & 688239 & 6.0362 & 5.7432 & TRN & \\
\hline CHEMBL1382480 & 688239 & 7.0362 & 5.4777 & TRN & \\
\hline CHEMBL1537301 & 688239 & 5.0862 & 5.6348 & TRN & \\
\hline CHEMBL1543646 & 688239 & 4.9362 & 5.5611 & TRN & \\
\hline CHEMBL1311393 & 688239 & 5.4862 & 5.4575 & TRN & \\
\hline CHEMBL1548385 & 688239 & 6.8362 & 5.5638 & TST & \\
\hline CHEMBL1508993 & 688239 & 5.3362 & 5.4182 & TRN & \\
\hline CHEMBL1400642 & 688239 & 4.5362 & 5.44600 & 2000000001 & TRN \\
\hline CHEMBL1509193 & 688239 & 4.8362 & 5.6041 & TRN & \\
\hline CHEMBL1486035 & 688239 & 4.5362 & 5.4663 & TRN & \\
\hline CHEMBL1480997 & 688239 & 4.5362 & 5.4608 & TRN & \\
\hline CHEMBL1465005 & 688239 & 6.2362 & 5.5421 & TRN & \\
\hline CHEMBL1322702 & 688239 & 5.6362 & 5.4261 & TST & \\
\hline CHEMBL1442288 & 688239 & 4.9862 & 5.4945 & TST & \\
\hline CHEMBL1543846 & 688239 & 6.7361 & 5.5874 & TST & \\
\hline CHEMBL1440951 & 688239 & 4.9362 & 5.4488 & TRN & \\
\hline CHEMBL1422587 & 688239 & 6.9863 & 5.5072 & TST & \\
\hline CHEMBL1346974 & 688239 & 4.7862 & 5.4206 & TRN & \\
\hline
\end{tabular}


Supplemental Table S2.txt

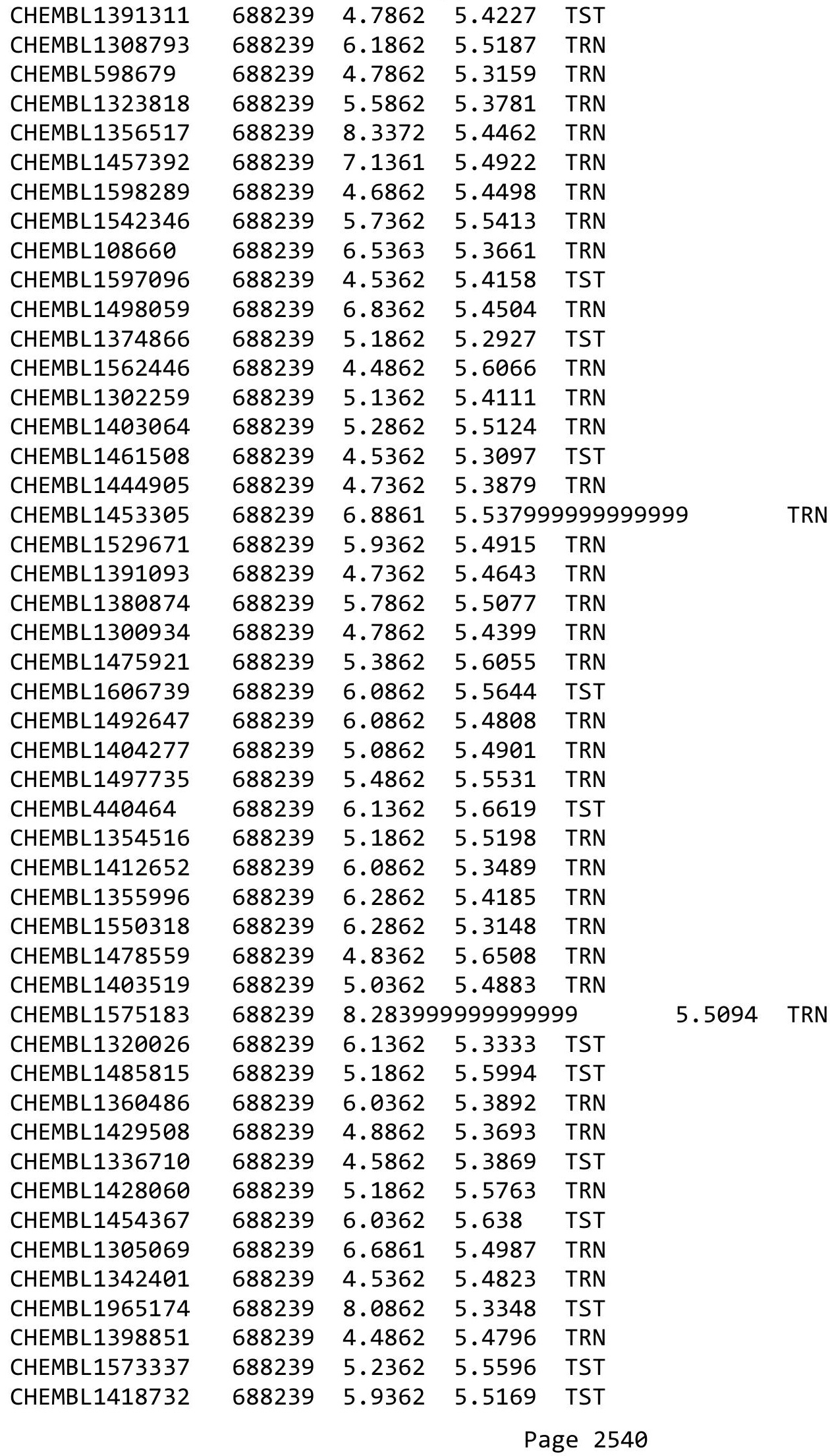


Supplemental Table S2.txt

\begin{tabular}{|c|c|c|c|c|c|}
\hline CHEMBL1310418 & 688239 & 4.5862 & 5.4639 & TST & \\
\hline CHEMBL1522781 & 688239 & 4.8362 & 5.4398 & TRN & \\
\hline CHEMBL1464041 & 688239 & 4.5362 & 5.4383 & TST & \\
\hline CHEMBL1436292 & 688239 & 4.9362 & 5.5557 & TRN & \\
\hline CHEMBL1362002 & 688239 & 4.8362 & 5.4216 & TRN & \\
\hline CHEMBL1482928 & 688239 & 5.7362 & 5.4263 & TRN & \\
\hline CHEMBL1399288 & 688239 & 5.2362 & 5.4101 & TRN & \\
\hline CHEMBL1599814 & 688239 & 8.1871 & 5.496 & TRN & \\
\hline CHEMBL1301183 & 688239 & 4.5362 & 5.4197 & TRN & \\
\hline CHEMBL1316574 & 688239 & 8.3372 & 5.4767 & TRN & \\
\hline CHEMBL1430484 & 688239 & 4.7862 & 5.5192 & TST & \\
\hline CHEMBL1354580 & 688239 & 4.7862 & 5.3886 & TRN & \\
\hline CHEMBL 3197537 & 688239 & 4.6862 & 5.3415 & TRN & \\
\hline CHEMBL1304777 & 688239 & 6.9363 & 5.6116 & TRN & \\
\hline CHEMBL1573033 & 688239 & 5.1862 & 5.414 & TRN & \\
\hline CHEMBL1302113 & 688239 & 5.2362 & 5.5526 & TST & \\
\hline CHEMBL1383925 & 688239 & 4.5362 & 5.3735 & TRN & \\
\hline CHEMBL 3210934 & 688239 & 5.3362 & 5.6369 & TRN & \\
\hline CHEMBL1326252 & 688239 & 6.0362 & 5.3757 & TRN & \\
\hline CHEMBL1506077 & 688239 & 7.0862 & 5.4408 & TRN & \\
\hline CHEMBL 3208989 & 688239 & 4.9862 & 5.3629 & TRN & \\
\hline CHEMBL1416005 & 688239 & 6.0862 & 5.4687 & TRN & \\
\hline CHEMBL1486933 & 688239 & 6.3863 & 5.4786 & TRN & \\
\hline CHEMBL1505193 & 688239 & 5.4362 & 5.5213 & TRN & \\
\hline CHEMBL1519484 & 688239 & 5.3862 & 5.621 & TRN & \\
\hline CHEMBL1585910 & 688239 & 5.9362 & 5.5198 & TRN & \\
\hline CHEMBL1388105 & 688239 & 5.1862 & 5.4761 & TRN & \\
\hline CHEMBL1502213 & 688239 & 6.0362 & 5.4837 & TRN & \\
\hline CHEMBL1326192 & 688239 & 8.2366 & 5.5085 & TRN & \\
\hline CHEMBL1598254 & 688239 & 4.7362 & 5.4713 & TRN & \\
\hline CHEMBL1593792 & 688239 & 4.8362 & 5.5578 & TST & \\
\hline CHEMBL1548461 & 688239 & 4.6862 & 5.5046 & TRN & \\
\hline CHEMBL1559324 & 688239 & 7.1361 & 5.4555 & TST & \\
\hline CHEMBL 3195803 & 688239 & 5.1862 & 5.3474 & TRN & \\
\hline CHEMBL1390765 & 688239 & 5.3862 & 5.3825 & TST & \\
\hline CHEMBL1517377 & 688239 & 5.3362 & 5.5794 & TRN & \\
\hline CHEMBL1475512 & 688239 & 8.28399 & 99999999 & 99 & 5.5308 \\
\hline CHEMBL1349195 & 688239 & 5.0862 & 5.4609 & TRN & \\
\hline CHEMBL1499825 & 688239 & 6.1362 & 5.4829 & TRN & \\
\hline CHEMBL1386201 & 688239 & 5.4362 & 5.437 & TRN & \\
\hline CHEMBL415959 & 688239 & 4.7362 & 5.3974 & TRN & \\
\hline CHEMBL1315161 & 688239 & 5.2362 & 5.4548 & TST & \\
\hline CHEMBL1325015 & 688239 & 6.2362 & 5.4571 & TST & \\
\hline CHEMBL1392810 & 688239 & 6.2862 & 5.5619 & TRN & \\
\hline CHEMBL1435653 & 688239 & 5.3362 & 5.5178 & TRN & \\
\hline CHEMBL1611173 & 688239 & 5.8862 & 5.4742 & TRN & \\
\hline CHEMBL1386249 & 688239 & 4.5362 & 5.5896 & TRN & \\
\hline CHEMBL1458783 & 688239 & 5.1862 & 5.6349 & TRN & \\
\hline
\end{tabular}

Page 2541 


\begin{tabular}{|c|c|c|c|c|c|}
\hline \multicolumn{6}{|c|}{ Supplemental Table S2.txt } \\
\hline CHEMBL1378073 & 688239 & 7.5867 & 5.4716 & TRN & \\
\hline CHEMBL1310317 & 688239 & 4.5362 & 5.4472 & TST & \\
\hline CHEMBL1581110 & 688239 & 5.2 & 5.54 & TST & \\
\hline CHEMBL1531363 & 688239 & 4.6362 & 5.4824 & TRN & \\
\hline CHEMBL1555716 & 688239 & 4.8862 & 5.4568 & TRN & \\
\hline CHEMBL1545378 & 688239 & 5.2362 & 5.5209 & TRN & \\
\hline CHEMBL1309181 & 688239 & 4.5362 & 5.5281 & TST & \\
\hline CHEMBL1587720 & 688239 & 5.5862 & 5.5505 & TRN & \\
\hline CHEMBL1311644 & 688239 & 4.8362 & 5.5699 & TRN & \\
\hline CHEMBL1387565 & 688239 & 7.2865 & 5.4026 & TRN & \\
\hline CHEMBL1374096 & 688239 & 5.3362 & 5.494 & TRN & \\
\hline CHEMBL1334155 & 688239 & 4.9862 & 5.5128 & TRN & \\
\hline CHEMBL1400965 & 688239 & 5.2862 & 5.2898 & TRN & \\
\hline CHEMBL1601071 & 688239 & 5.4362 & 5.6839 & TRN & \\
\hline CHEMBL3196547 & 688239 & 4.5362 & 5.4101 & TRN & \\
\hline CHEMBL1344551 & 688239 & 4.9862 & 5.47 & TRN & \\
\hline CHEMBL1391458 & 688239 & 6.6362 & 5.3582 & TRN & \\
\hline CHEMBL1518126 & 688239 & 4.7362 & 5.3982 & TRN & \\
\hline CHEMBL1433915 & 688239 & 5.1362 & 5.59200 & 00000000005 & TRN \\
\hline CHEMBL1499392 & 688239 & 5.4362 & 5.48600 & 0000000001 & TRN \\
\hline CHEMBL1393175 & 688239 & 5.4862 & 5.5073 & TRN & \\
\hline CHEMBL1349696 & 688239 & 5.2862 & 5.5417 & TRN & \\
\hline CHEMBL1329183 & 688239 & 5.1862 & 5.4269 & TRN & \\
\hline CHEMBL1539312 & 688239 & 4.5362 & 5.5162 & TST & \\
\hline CHEMBL1580619 & 688239 & 4.5362 & 5.5613 & TRN & \\
\hline CHEMBL10895 & 688239 & 5.6362 & 5.5477 & TRN & \\
\hline CHEMBL1349341 & 688239 & 4.7862 & 5.5114 & TRN & \\
\hline CHEMBL1388633 & 688239 & 5.3362 & 5.4714 & TST & \\
\hline CHEMBL1406566 & 688239 & 4.5362 & 5.5462 & TRN & \\
\hline CHEMBL1397094 & 688239 & 4.6362 & 5.4643 & TRN & \\
\hline CHEMBL1329665 & 688239 & 5.1862 & 5.5196 & TST & \\
\hline CHEMBL1419010 & 688239 & 5.3862 & 5.5336 & TST & \\
\hline CHEMBL1506548 & 688239 & 8.3372 & 5.335 & TRN & \\
\hline CHEMBL581471 & 688239 & 4.9862 & 5.34200 & 00000000005 & TST \\
\hline CHEMBL1411636 & 688239 & 4.4862 & 5.3476 & TRN & \\
\hline CHEMBL1507632 & 688239 & 6.9863 & 5.4776 & TRN & \\
\hline CHEMBL3191514 & 688239 & 4.4862 & 5.4213 & TRN & \\
\hline CHEMBL1357139 & 688239 & 7.0862 & 5.4989 & TRN & \\
\hline CHEMBL3189686 & 688239 & 4.4862 & 5.4259 & TRN & \\
\hline CHEMBL1316915 & 688239 & 6.0362 & 5.3443 & TRN & \\
\hline CHEMBL1536468 & 688239 & 7.8356 & 5.5405 & TRN & \\
\hline CHEMBL1439579 & 688239 & 4.5362 & 5.63200 & 0000000001 & TST \\
\hline CHEMBL1333971 & 688239 & 7.0862 & 5.5848 & TRN & \\
\hline CHEMBL1300008 & 688239 & 4.6362 & 5.5437 & TRN & \\
\hline CHEMBL1360001 & 688239 & 4.9362 & 5.4998 & TST & \\
\hline CHEMBL1521297 & 688239 & 4.6362 & 5.421 & TRN & \\
\hline CHEMBL1303649 & 688239 & 5.2362 & 5.3932 & TRN & \\
\hline CHEMBL1513748 & 688239 & 4.6362 & 5.5855 & TRN & \\
\hline
\end{tabular}


Supplemental Table S2.txt

\begin{tabular}{|c|c|c|c|c|}
\hline 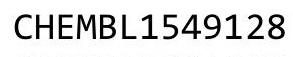 & & & & \\
\hline HEMBL1584146 & 38239 & 865 & 485 & \\
\hline HEMBL152 & 39 & 62 & & \\
\hline 0 & 39 & 861 & & \\
\hline EMBL150 & 39 & 862 & & \\
\hline AEMBL1589310 & 88239 & 861 & 42 & \\
\hline AEMBL1503074 & 88239 & 862 & 3338 & \\
\hline HEMBL137 & & & & \\
\hline EMBL14 & 39 & 362 & 58 & \\
\hline IEMBL150 & & 862 & & \\
\hline AEMBL1343302 & 239 & 5.2 & 5548 & \\
\hline AEMBL1389669 & & & 3654 & \\
\hline AEMBL1516839 & & & 385 & \\
\hline HEMBL1569039 & & & & \\
\hline JEMBL146 & & & & \\
\hline HEMBL 144 & & 362 & 83 & \\
\hline AEMBL16e & & 362 & & \\
\hline IEMBL14 & & 62 & 49 & \\
\hline AEMBL15 & & & & \\
\hline AEMBL 31 & & 62 & & \\
\hline HEMBL159 & & 362 & 772 & \\
\hline AEMBL1313 & & 62 & & \\
\hline HEMBL319 & & 62 & & \\
\hline AFMRI 156 & & & & \\
\hline 35 & & & 79 & \\
\hline ר 1 & & 862 & & \\
\hline AEMBL134 & & & & \\
\hline EMBL15] & & & & \\
\hline AFM & & & & \\
\hline 3 & & 62 & & \\
\hline AEMBL1528 & & & & \\
\hline AEMBL1528781 & & 362 & & \\
\hline & & & & \\
\hline 1 & & & & \\
\hline 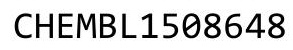 & & & & \\
\hline AEMBL1307651 & & & & \\
\hline AEMBL1462883 & & 362 & & \\
\hline & & & & \\
\hline (2MO & & & 58 & \\
\hline HEMBL1320 & & & & RI \\
\hline AEMBL1344093 & & 862 & 025 & TS \\
\hline IEMBL151 & & 62 & 564 & \\
\hline & & & 127 & \\
\hline HEMBL1405832 & & & 5713 & \\
\hline HEMBL131291 & & & 5408 & RI \\
\hline IEMBL130 & & 862 & 431 & 11 \\
\hline 1500 & & & & \\
\hline HEMBL149488 & & & .5599 & \\
\hline
\end{tabular}

Page 2543 
Supplemental Table S2.txt

\begin{tabular}{|c|c|c|c|c|c|c|}
\hline CHEMBL3209151 & 688239 & 6.1362 & 5.4887 & TRN & & \\
\hline CHEMBL1527577 & 688239 & 4.5862 & 5.4477 & TRN & & \\
\hline CHEMBL1352470 & 688239 & 4.8362 & 5.4968 & TRN & & \\
\hline CHEMBL1448016 & 688239 & 5.1862 & 5.6091 & TRN & & \\
\hline CHEMBL1421991 & 688239 & 5.1862 & 5.4886 & TRN & & \\
\hline CHEMBL1447881 & 688239 & 4.5362 & 5.4702 & TRN & & \\
\hline CHEMBL1361567 & 688239 & 4.7362 & 5.3952 & TST & & \\
\hline CHEMBL1603960 & 688239 & 5.2362 & 5.3996 & TST & & \\
\hline CHEMBL3213503 & 688239 & 6.0862 & 5.5301 & TRN & & \\
\hline CHEMBL1523097 & 688239 & 6.8861 & 5.5268 & TRN & & \\
\hline CHEMBL1481363 & 688239 & 5.1362 & 5.2894 & TST & & \\
\hline CHEMBL1557610 & 688239 & 8.2366 & 5.4729 & TRN & & \\
\hline CHEMBL1603507 & 688239 & 4.7862 & 5.5707 & TRN & & \\
\hline CHEMBL1362440 & 688239 & 5.1862 & 5.4985 & TRN & & \\
\hline CHEMBL1518172 & 688239 & 6.0862 & 5.5495 & TRN & & \\
\hline CHEMBL1576318 & 688239 & 5.1862 & 5.5017 & TRN & & \\
\hline CHEMBL1461149 & 688239 & 5.4362 & 5.4268 & TRN & & \\
\hline CHEMBL1356443 & 688239 & 6.8362 & 5.3968 & TRN & & \\
\hline CHEMBL1513018 & 688239 & 4.7862 & 5.4854 & TRN & & \\
\hline CHEMBL1430343 & 688239 & 4.7362 & 5.4042 & TRN & & \\
\hline CHEMBL1462994 & 688239 & 4.5362 & 5.4794 & TST & & \\
\hline CHEMBL1373669 & 688239 & 5.4362 & 5.4361 & TRN & & \\
\hline CHEMBL1455870 & 688239 & 6.2862 & 5.6046 & TST & & \\
\hline CHEMBL1486960 & 688239 & 5.0862 & 5.5424 & TRN & & \\
\hline CHEMBL 2369300 & 688239 & 6.3362 & 5.4457 & TST & & \\
\hline CHEMBL3193168 & 688239 & 4.7362 & 5.2915 & TST & & \\
\hline CHEMBL1588704 & 688239 & 5.3862 & 5.4856 & TST & & \\
\hline CHEMBL1591475 & 688239 & 4.8362 & 5.569 & TRN & & \\
\hline CHEMBL1400936 & 688239 & 5.0862 & 5.5726 & TRN & & \\
\hline CHEMBL1570006 & 688239 & 5.2362 & 5.544 & TRN & & \\
\hline CHEMBL1596055 & 688239 & 4.5362 & 5.3934 & TRN & & \\
\hline CHEMBL1344510 & 688239 & 8.2366 & 5.6195 & TRN & & \\
\hline CHEMBL1484345 & 688239 & 6.1862 & 5.403 & TRN & & \\
\hline CHEMBL1589390 & 688239 & 6.8861 & 5.5425 & TRN & & \\
\hline CHEMBL1555900 & 688239 & 6.4362 & 5.5013 & TRN & & \\
\hline CHEMBL1506133 & 688239 & 4.7362 & 5.5825 & TRN & & \\
\hline CHEMBL1389402 & 688239 & \multicolumn{3}{|c|}{8.283999999999999} & 5.696000000000001 & TST \\
\hline CHEMBL1567627 & 688239 & 6.0362 & 5.4107 & TRN & & \\
\hline CHEMBL1312120 & 688239 & 5.4362 & 5.4871 & TRN & & \\
\hline CHEMBL1502564 & 688239 & 6.0362 & 5.4845 & TST & & \\
\hline CHEMBL1474669 & 688239 & 7.0362 & 5.4076 & TRN & & \\
\hline CHEMBL1590697 & 688239 & 5.9862 & 5.5426 & TRN & & \\
\hline CHEMBL1528141 & 688239 & 4.8862 & 5.443 & TST & & \\
\hline CHEMBL3189907 & 688239 & 4.9862 & 5.6771 & TST & & \\
\hline CHEMBL1307614 & 688239 & 5.4862 & 5.4766 & TRN & & \\
\hline CHEMBL1463070 & 688239 & 6.9363 & 5.6133 & TRN & & \\
\hline CHEMBL1415823 & 688239 & 7.2865 & 5.48600 & 000000001 & TST & \\
\hline CHEMBL1573883 & 688239 & 5.1862 & 5.3866 & TRN & & \\
\hline
\end{tabular}

Page 2544 
Supplemental Table S2.txt

\begin{tabular}{|c|c|c|c|c|}
\hline 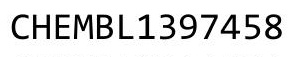 & & & & \\
\hline HEMBL3214434 & 88239 & 1862 & 4359 & \\
\hline HEMBL1408507 & 88239 & 7862 & & \\
\hline IEMBL1 & & 862 & & \\
\hline EMBL1: & & 862 & & \\
\hline HEMBL1361469 & 88239 & 2362 & 3277 & \\
\hline HEMBL1449560 & 88239 & .5362 & .5214 & \\
\hline HEMBL15 & 39 & 362 & 5952 & \\
\hline AEMBL1 & 39 & 362 & & \\
\hline IEMBL13 & 39 & 362 & & \\
\hline HEMBL1470611 & 88239 & 362 & & \\
\hline HEMBL1477849 & 39 & .7862 & 18 & \\
\hline HEMBL15 & 39 & 3862 & 57 & \\
\hline HEME & 39 & 362 & & \\
\hline AEM & 39 & 862 & & \\
\hline AEMBL4C & 39 & 362 & & \\
\hline HEMBL15 & 88 & 363 & & \\
\hline HEMBL 14 & 39 & 362 & & \\
\hline HEMBL13 & 9 & & & \\
\hline HEMBL1 & 39 & 862 & & \\
\hline HEMBL15 & 39 & 862 & & \\
\hline HEMBL15 & 88 & 862 & 9 & RN \\
\hline HEMBL13 & 882 & 862 & & \\
\hline HEMBL1: & & 62 & & \\
\hline HEM & 39 & 362 & & RN \\
\hline HEMBL15 & 39 & 362 & & RN \\
\hline HEMBL16 & 39 & 362 & 91 & RN \\
\hline HEMBL13 & 39 & 862 & & 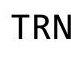 \\
\hline HEME & 9 & 62 & & ST \\
\hline HEME & & 372 & & ST \\
\hline HEMBL14 & 9 & & & RN \\
\hline HEMBL13 & 39 & 362 & 307 & RN \\
\hline HEMBL 31 & 39 & 362 & 46 & . \\
\hline 0 & 9 & & & RN \\
\hline HEMBL13 & & & & RN \\
\hline HEMBL14 & 39 & 362 & & RN \\
\hline HEMBL15 & 39 & 362 & 66 & RN \\
\hline HEMBL14 & 39 & 362 & & \\
\hline 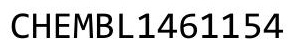 & & & & I \\
\hline HEMBL15 & & & & RN \\
\hline HEMBL14 & 39 & 362 & & RN \\
\hline HEMBL13 & 39 & & & $F$ \\
\hline HEMBL14 & & & & \\
\hline LHEMBL15 & & & & RN \\
\hline HEMBL14 & & 4.6862 & 5.6423 & ST \\
\hline HEMBL12 & 88239 & 8.3372 & 146 & ST \\
\hline II & & & & \\
\hline ז & & & 5.375 & \\
\hline
\end{tabular}

Page 2545 
Supplemental Table S2.txt

\begin{tabular}{|c|c|c|c|c|c|}
\hline CHEMBL1333314 & 688239 & 4.5362 & 5.5592 & TRN & \\
\hline CHEMBL1304431 & 688239 & 4.5362 & 5.5272 & TRN & \\
\hline CHEMBL1364081 & 688239 & 5.1862 & 5.3832 & TST & \\
\hline CHEMBL1561203 & 688239 & 5.4862 & 5.4796 & TST & \\
\hline CHEMBL3207671 & 688239 & 5.2362 & 5.5066 & TRN & \\
\hline CHEMBL1539331 & 688239 & 4.5362 & 5.4988 & TRN & \\
\hline CHEMBL1501141 & 688239 & 5.1862 & 5.5698 & TRN & \\
\hline CHEMBL526034 & 688239 & 5.7862 & 5.3003 & TST & \\
\hline CHEMBL1560093 & 688239 & 5.3862 & 5.4092 & TRN & \\
\hline CHEMBL3213403 & 688239 & 4.6362 & 5.4147 & TRN & \\
\hline CHEMBL1490221 & 688239 & 5.1862 & 5.4407 & TRN & \\
\hline CHEMBL1318726 & 688239 & 5.3862 & 5.5093 & TST & \\
\hline CHEMBL1604620 & 688239 & 4.5362 & 5.6109 & TRN & \\
\hline CHEMBL1544464 & 688239 & 5.9862 & 5.4434 & TST & \\
\hline CHEMBL1564403 & 688239 & 4.7862 & 5.4939 & TRN & \\
\hline CHEMBL1457379 & 688239 & 4.5362 & 5.5325 & TRN & \\
\hline CHEMBL1556627 & 688239 & 5.4862 & 5.4272 & TRN & \\
\hline CHEMBL1525946 & 688239 & 5.3862 & 5.6236 & TST & \\
\hline CHEMBL1387885 & 688239 & 5.1862 & 5.4279 & TRN & \\
\hline CHEMBL1369194 & 688239 & 6.0862 & 5.4358 & TST & \\
\hline CHEMBL1602759 & 688239 & 5.1862 & 5.5425 & TST & \\
\hline CHEMBL1311436 & 688239 & 4.8862 & 5.659 & TRN & \\
\hline CHEMBL1509812 & 688239 & 5.4862 & 5.5451 & TRN & \\
\hline CHEMBL1478544 & 688239 & 8.3372 & 5.5539 & TRN & \\
\hline CHEMBL1446987 & 688239 & 6.5363 & 5.52 & TRN & \\
\hline CHEMBL1341111 & 688239 & 5.4862 & 5.5266 & TRN & \\
\hline CHEMBL1590472 & 688239 & 5.6862 & 5.4789 & TRN & \\
\hline CHEMBL1412966 & 688239 & 4.5362 & 5.4286 & TST & \\
\hline CHEMBL1341502 & 688239 & 4.6862 & 5.5055 & TRN & \\
\hline CHEMBL1333430 & 688239 & 4.7362 & 5.5358 & TRN & \\
\hline CHEMBL1357493 & 688239 & 8.3372 & 5.434 & TRN & \\
\hline CHEMBL1423198 & 688239 & 7.8861 & 5.489 & TRN & \\
\hline CHEMBL1508115 & 688239 & 7.0362 & 5.4463 & TRN & \\
\hline CHEMBL1532926 & 688239 & 4.5362 & 5.4636 & TRN & \\
\hline CHEMBL1460439 & 688239 & 4.5362 & 5.4779 & TST & \\
\hline CHEMBL1500195 & 688239 & 6.4362 & 5.6023 & TRN & \\
\hline CHEMBL1510265 & 688239 & 8.3372 & 5.4785 & TRN & \\
\hline CHEMBL1548276 & 688239 & 4.5362 & 5.5734 & TRN & \\
\hline CHEMBL1484433 & 688239 & 4.7862 & 5.4885 & TRN & \\
\hline CHEMBL1403984 & 688239 & 4.5862 & 5.4218 & TRN & \\
\hline CHEMBL509579 & 688239 & 6.1862 & 5.497000 & 0000000001 & TST \\
\hline CHEMBL3196419 & 688239 & 5.5362 & 5.5319 & TRN & \\
\hline CHEMBL1299895 & 688239 & 4.6362 & 5.5372 & TRN & \\
\hline CHEMBL1500011 & 688239 & 4.5362 & 5.5602 & TRN & \\
\hline CHEMBL1494656 & 688239 & 4.5362 & 5.4181 & TRN & \\
\hline CHEMBL1519034 & 688239 & 5.8362 & 5.6542 & TRN & \\
\hline CHEMBL1471742 & 688239 & 8.28399 & 999999999 & 5.4555 & TRN \\
\hline CHEMBL3190169 & 688239 & 4.5862 & 5.4571 & TRN & \\
\hline
\end{tabular}




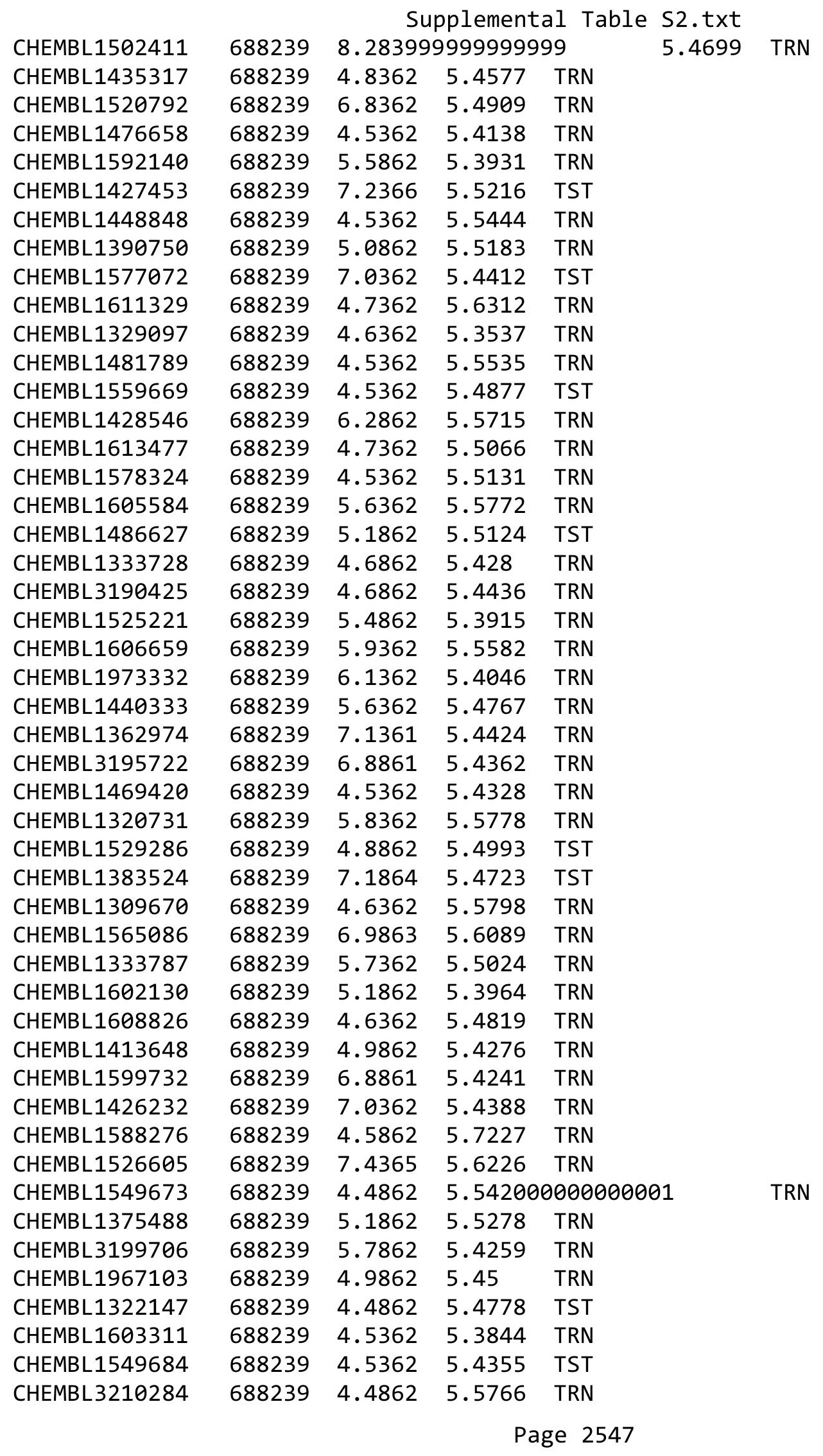


Supplemental Table S2.txt

\begin{tabular}{|c|c|c|c|c|}
\hline CHEMBL1556642 & 688239 & 6.3863 & 5.4578 & TRN \\
\hline CHEMBL1343763 & 688239 & 5.6862 & 5.5812 & TRN \\
\hline CHEMBL1605162 & 688239 & 5.7362 & 5.532999 & 99999999995 \\
\hline CHEMBL1546003 & 688239 & 5.2862 & 5.5793 & TRN \\
\hline CHEMBL1511570 & 688239 & 4.8362 & 5.5906 & TRN \\
\hline CHEMBL1375157 & 688239 & 5.5862 & 5.6446 & TRN \\
\hline CHEMBL1387345 & 688239 & 6.1862 & 5.5858 & TRN \\
\hline CHEMBL1569088 & 688239 & 4.5362 & 5.4263 & TST \\
\hline CHEMBL1479399 & 688239 & 6.0 & 5.5084 & TRN \\
\hline CHEMBL1529844 & 688239 & 6.1862 & 5.6126 & TRN \\
\hline CHEMBL1399311 & 688239 & 6.7361 & 5.5706 & TRN \\
\hline CHEMBL1481187 & 688239 & 5.4362 & 5.4268 & TRN \\
\hline CHEMBL1304233 & 688239 & 6.8362 & 5.4924 & TRN \\
\hline CHEMBL1502538 & 688239 & 5.6362 & 5.5923 & TST \\
\hline CHEMBL1500803 & 688239 & 5.2362 & 5.6877 & TRN \\
\hline CHEMBL1332245 & 688239 & 5.1862 & 5.5078 & TRN \\
\hline CHEMBL1485370 & 688239 & 5.6862 & 5.5482 & TRN \\
\hline CHEMBL1486144 & 688239 & 4.9362 & 5.3424 & TRN \\
\hline CHEMBL1541928 & 688239 & 6.2862 & 5.5036 & TST \\
\hline CHEMBL1301103 & 688239 & 6.2362 & 5.5497 & TRN \\
\hline CHEMBL1386872 & 688239 & 6.1862 & 5.426 & TRN \\
\hline CHEMBL1450791 & 688239 & 5.4862 & 5.5837 & TST \\
\hline CHEMBL1333131 & 688239 & 5.7362 & 5.5656 & TRN \\
\hline CHEMBL1385361 & 688239 & 6.3863 & 5.6289 & TRN \\
\hline CHEMBL1431550 & 688239 & 5.4862 & 5.3573 & TRN \\
\hline CHEMBL1323155 & 688239 & 4.5362 & 5.6883 & TRN \\
\hline CHEMBL1418218 & 688239 & 4.5362 & 5.6501 & TST \\
\hline CHEMBL1508695 & 688239 & 8.28399 & 99999999 & 5.4717 \\
\hline CHEMBL1466032 & 688239 & 4.8862 & 5.3562 & TST \\
\hline CHEMBL1413136 & 688239 & 5.7362 & 5.4879 & TRN \\
\hline CHEMBL1411434 & 688239 & 5.1862 & 5.4472 & TRN \\
\hline CHEMBL1333450 & 688239 & 5.9862 & 5.4832 & TST \\
\hline CHEMBL1396797 & 688239 & 6.8362 & 5.6417 & TRN \\
\hline CHEMBL1302895 & 688239 & 4.6362 & 5.5008 & TRN \\
\hline CHEMBL1467672 & 688239 & 5.0362 & 5.5429 & TST \\
\hline CHEMBL1360923 & 688239 & 5.1862 & 5.5516 & TRN \\
\hline CHEMBL1426491 & 688239 & 6.0362 & 5.4952 & TST \\
\hline CHEMBL1563728 & 688239 & 5.1862 & 5.3844 & TRN \\
\hline CHEMBL1356235 & 688239 & 4.5362 & 5.4241 & TRN \\
\hline CHEMBL1299748 & 688239 & 4.5362 & 5.5275 & TST \\
\hline CHEMBL1551043 & 688239 & 4.5862 & 5.2895 & TRN \\
\hline CHEMBL1497906 & 688239 & 6.1862 & 5.4849 & TRN \\
\hline CHEMBL3213119 & 688239 & 5.1862 & 5.5963 & TST \\
\hline CHEMBL3193351 & 688239 & 4.5362 & 5.3279 & TST \\
\hline CHEMBL1403135 & 688239 & 4.5862 & 5.5148 & TRN \\
\hline CHEMBL1386766 & 688239 & 4.8362 & 5.3964 & TST \\
\hline CHEMBL1391813 & 688239 & 4.5362 & 5.4032 & TRN \\
\hline CHEMBL1323834 & 688239 & 4.4862 & 5.5771 & TRN \\
\hline
\end{tabular}


Supplemental Table S2.txt

\begin{tabular}{|c|c|c|c|c|}
\hline CHEMBL1420817 & 688239 & 5.9862 & 5.6075 & TRN \\
\hline CHEMBL1532032 & 688239 & 4.4862 & 5.5388 & TST \\
\hline CHEMBL1386926 & 688239 & 7.1361 & 5.5704 & TRN \\
\hline CHEMBL1442995 & 688239 & 4.8862 & 5.4027 & TST \\
\hline CHEMBL1429052 & 688239 & 5.7862 & 5.5635 & TRN \\
\hline CHEMBL1461194 & 688239 & 5.1362 & 5.3735 & TRN \\
\hline CHEMBL1607625 & 688239 & 4.5362 & 5.508999 & 99999999995 \\
\hline CHEMBL1373838 & 688239 & 7.6364 & 5.3813 & TRN \\
\hline CHEMBL1534882 & 688239 & 8.3372 & 5.497006 & $\partial 000000001$ \\
\hline CHEMBL1300011 & 688239 & 6.8861 & 5.4986 & TRN \\
\hline CHEMBL1532818 & 688239 & 4.6862 & 5.7366 & TRN \\
\hline CHEMBL1546927 & 688239 & 5.1862 & 5.3789 & TST \\
\hline CHEMBL1981357 & 688239 & 8.3872 & 5.5606 & TST \\
\hline CHEMBL1536570 & 688239 & 5.7862 & 5.4034 & TST \\
\hline CHEMBL1476794 & 688239 & 4.5362 & 5.3972 & TST \\
\hline CHEMBL1606181 & 688239 & 4.7362 & 5.5741 & TST \\
\hline CHEMBL1425728 & 688239 & 4.6362 & 5.6163 & TRN \\
\hline CHEMBL1401625 & 688239 & 4.4862 & 5.4707 & TRN \\
\hline CHEMBL1500951 & 688239 & 6.2362 & 5.5058 & TRN \\
\hline CHEMBL1527289 & 688239 & 4.5362 & 5.51 & TRN \\
\hline CHEMBL1372382 & 688239 & 5.0862 & 5.4646 & TRN \\
\hline CHEMBL1430126 & 688239 & 8.3372 & 5.5665 & TST \\
\hline CHEMBL1464996 & 688239 & 5.3862 & 5.5087 & TST \\
\hline CHEMBL1447361 & 688239 & 4.5362 & 5.4535 & TRN \\
\hline CHEMBL1442915 & 688239 & 4.6362 & 5.5254 & TST \\
\hline CHEMBL1498441 & 688239 & 6.8861 & 5.5318 & TST \\
\hline CHEMBL1407944 & 688239 & 4.7862 & 5.4737 & TRN \\
\hline CHEMBL1351934 & 688239 & 4.5362 & 5.5827 & TRN \\
\hline CHEMBL1522356 & 688239 & 4.8862 & 5.3829 & TST \\
\hline CHEMBL1510168 & 688239 & 4.5362 & 5.5759 & TRN \\
\hline CHEMBL1365968 & 688239 & 5.8362 & 5.5057 & TRN \\
\hline CHEMBL1547537 & 688239 & 5.1862 & 5.3932 & TST \\
\hline CHEMBL1339865 & 688239 & 5.2362 & 5.3933 & TRN \\
\hline CHEMBL1534705 & 688239 & 7.8356 & 5.6484 & TRN \\
\hline CHEMBL1479342 & 688239 & 4.5362 & 5.3907 & TRN \\
\hline CHEMBL1565870 & 688239 & 4.5362 & 5.5067 & TRN \\
\hline CHEMBL1338094 & 688239 & 6.9863 & 5.6355 & TRN \\
\hline CHEMBL1575492 & 688239 & 6.0862 & 5.415 & TRN \\
\hline CHEMBL1340773 & 688239 & 4.5362 & 5.5126 & TST \\
\hline CHEMBL1438881 & 688239 & 5.5862 & 5.3252 & TRN \\
\hline CHEMBL1545240 & 688239 & 4.6862 & 5.5267 & TRN \\
\hline CHEMBL1408749 & 688239 & 4.7362 & 5.4201 & TRN \\
\hline CHEMBL1466892 & 688239 & 5.0362 & 5.5215 & TRN \\
\hline CHEMBL1519613 & 688239 & 5.6862 & 5.4164 & TRN \\
\hline CHEMBL1335040 & 688239 & 5.5862 & 5.3825 & TRN \\
\hline CHEMBL1524187 & 688239 & 4.5362 & 5.3689 & TRN \\
\hline CHEMBL1531781 & 688239 & 5.6362 & 5.4524 & TRN \\
\hline CHEMBL603020 & 688239 & 4.4862 & 5.3174 & TRN \\
\hline
\end{tabular}


Supplemental Table S2.txt

\begin{tabular}{|c|c|c|c|c|}
\hline & & & & \\
\hline AEMBL3210663 & 88239 & 362 & 6565 & \\
\hline JEMBL14 & 39 & 62 & & \\
\hline & & & & \\
\hline AFMRI 14 & & & & \\
\hline AEMBL203108 & 88239 & 862 & 3895 & \\
\hline AEMBL1489732 & 88239 & 862 & 5185 & \\
\hline HEMBL1460239 & & & & \\
\hline AEMBL13 & & & & \\
\hline IEMBL13 & & & & \\
\hline AEMBL1526440 & 39 & & & \\
\hline AEMBL3195662 & 39 & & & \\
\hline AEMBL3210012 & & & & \\
\hline AEMBL13. & & & & \\
\hline AEMBL13 & & & & \\
\hline AEMBL1453674 & & & & \\
\hline JEMBL14 & & & & \\
\hline HEMBL16 & & & & \\
\hline HEMBL13 & & & & \\
\hline AEMBL13 & & & & \\
\hline HEMBL1489871 & & & & \\
\hline AEMBL1371986 & & & & \\
\hline JEMBL13 & & & & \\
\hline AEMBL14 & & & & \\
\hline AFMRI 14 & & & & \\
\hline 275 & & & & \\
\hline AEMBL1341201 & & & & \\
\hline JEMBL14 & & & & \\
\hline 0 & & & & \\
\hline 273 & & & & \\
\hline AEMBL1490891 & & & & \\
\hline AEMBL1558360 & & & & \\
\hline & & & & \\
\hline 15 & & & & \\
\hline 64 & & & & \\
\hline AEMBL1599650 & & & & \\
\hline AEMBL1523041 & & & & $\Gamma s$ \\
\hline & & & & \\
\hline 81 & & & & \\
\hline IEMBL 14 & & & & RN \\
\hline AEMBL3199274 & & & & F \\
\hline 592 & & & & \\
\hline & & & & \\
\hline HEMBL1613711 & & & & \\
\hline HEMBL1972670 & & & & RN \\
\hline MBL1377759 & & & & 11 \\
\hline 502 & & & & \\
\hline 1900 & & & 5.3365 & \\
\hline
\end{tabular}

Page 2550 
Supplemental Table S2.txt

\begin{tabular}{|c|c|c|c|c|}
\hline CHEMBL1528118 & 688239 & 5.1862 & 5.4641 & TRN \\
\hline CHEMBL1344875 & 688239 & 4.5862 & 5.2234 & TRN \\
\hline CHEMBL1984052 & 688239 & 4.5362 & 5.349 & TRN \\
\hline CHEMBL1546208 & 688239 & 5.8362 & 5.4448 & TRN \\
\hline CHEMBL1366294 & 688239 & 5.2862 & 5.5336 & TRN \\
\hline CHEMBL1408146 & 688239 & 4.6862 & 5.3661 & TST \\
\hline CHEMBL1568444 & 688239 & 4.9362 & 5.3609 & TST \\
\hline CHEMBL1459916 & 688239 & 4.7362 & 5.4406 & TRN \\
\hline CHEMBL1583978 & 688239 & 5.5862 & 5.4991 & TRN \\
\hline CHEMBL1337950 & 688239 & 7.1864 & 5.5849 & TRN \\
\hline CHEMBL 2004884 & 688239 & 4.5362 & 5.4503 & TST \\
\hline CHEMBL1386638 & 688239 & 4.5362 & 5.4003 & TRN \\
\hline CHEMBL1518246 & 688239 & 6.6362 & 5.4142 & TRN \\
\hline CHEMBL1092480 & 688239 & 4.5362 & 5.5234 & TRN \\
\hline CHEMBL1609977 & 688239 & 4.8362 & 5.4899 & TST \\
\hline CHEMBL1564913 & 688239 & 4.5862 & 5.5208 & TRN \\
\hline CHEMBL1463201 & 688239 & 6.0862 & 5.6926 & TRN \\
\hline CHEMBL1489734 & 688239 & 4.9862 & 5.5087 & TRN \\
\hline CHEMBL1525621 & 688239 & 4.5362 & 5.5279 & TRN \\
\hline CHEMBL1318725 & 688239 & 5.0862 & 5.5703 & TRN \\
\hline CHEMBL1353528 & 688239 & 4.7362 & 5.4142 & TST \\
\hline CHEMBL1310289 & 688239 & 4.5862 & 5.455 & TRN \\
\hline CHEMBL510773 & 688239 & 5.5862 & 5.5146 & TRN \\
\hline CHEMBL1366435 & 688239 & 4.5362 & 5.4962 & TRN \\
\hline CHEMBL1432109 & 688239 & 4.7862 & 5.4073 & TRN \\
\hline CHEMBL1543852 & 688239 & 6.1862 & 5.5573 & TRN \\
\hline CHEMBL1410572 & 688239 & 4.5362 & 5.6447 & TRN \\
\hline CHEMBL1431184 & 688239 & 5.1862 & 5.4265 & TST \\
\hline CHEMBL1373061 & 688239 & 5.8362 & 5.4595 & TRN \\
\hline CHEMBL1360855 & 688239 & 5.7862 & $5.45100 e$ & 00000000005 \\
\hline CHEMBL3191327 & 688239 & 6.7862 & 5.4115 & TRN \\
\hline CHEMBL1562330 & 688239 & 4.6362 & 5.447999 & 99999999995 \\
\hline CHEMBL1372004 & 688239 & 6.1362 & 5.4787 & TRN \\
\hline CHEMBL1535938 & 688239 & 4.7362 & 5.3837 & TST \\
\hline CHEMBL1443196 & 688239 & 4.9362 & 5.4379 & TST \\
\hline CHEMBL1582946 & 688239 & 6.6861 & 5.4066 & TST \\
\hline CHEMBL1428175 & 688239 & 4.7362 & 5.4061 & TST \\
\hline CHEMBL1584072 & 688239 & 8.2366 & 5.4214 & TRN \\
\hline CHEMBL1455553 & 688239 & 5.7362 & 5.534 & TRN \\
\hline CHEMBL1361810 & 688239 & 4.7362 & 5.5077 & TRN \\
\hline CHEMBL1542492 & 688239 & 4.8362 & 5.4363 & TRN \\
\hline CHEMBL1324547 & 688239 & 4.9362 & 5.4553 & TRN \\
\hline CHEMBL1350778 & 688239 & 4.5362 & 5.2706 & TRN \\
\hline CHEMBL1353632 & 688239 & 6.1362 & 5.466 & TRN \\
\hline CHEMBL1601146 & 688239 & 4.7362 & 5.5163 & TRN \\
\hline CHEMBL1485401 & 688239 & 5.3862 & 5.517 & TRN \\
\hline CHEMBL1374619 & 688239 & 6.4862 & 5.4433 & TRN \\
\hline CHEMBL3207349 & 688239 & 5.3862 & 5.6107 & TRN \\
\hline
\end{tabular}


Supplemental Table S2.txt

\begin{tabular}{|c|c|c|c|c|}
\hline HEM & & & & \\
\hline & & 5.5862 & & \\
\hline & & & & \\
\hline JEMBL13 & & & & \\
\hline AEMBL1376015 & 8239 & & & \\
\hline HEMBL1443765 & 88239 & 862 & 4337 & \\
\hline & 239 & & & \\
\hline AFMB 156 & & & & \\
\hline HEMBL151 & 239 & & & \\
\hline HEMBL3195159 & 88239 & & 5904 & \\
\hline HEMBL3194225 & 239 & & 69 & \\
\hline IEMBL14 & 239 & & 865 & \\
\hline AEMBL1: & & & & \\
\hline HEMBL149 & & & 385 & \\
\hline AEMBL137 & & & & \\
\hline AEMBL1. & 39 & & 77 & \\
\hline HEMBL1 & & & & \\
\hline HEMBL13 & & & & \\
\hline HEMBL15 & & & & \\
\hline HEMBL137 & & & & \\
\hline HEMBL: & & & 5 & \\
\hline HEMBL1: & & & & RN \\
\hline HEMBL1 & & & & \\
\hline HFMRI 1 & & & & \\
\hline HEMBL13e & & & & \\
\hline HEMBL1 & & & & RN \\
\hline HEMBL1 & & & & 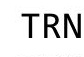 \\
\hline HFMBI 1 & & & & \\
\hline AEMBLI & & & & 151 \\
\hline HEMBL160 & & & & $\Gamma \mathrm{RN}$ \\
\hline HEMBL1 & & & & KIV \\
\hline HEMBL & & & & RIV \\
\hline $15 M P I$ & & & & RN \\
\hline HEMBL14 & & & & in \\
\hline HEMBL1404095 & & & & $\mathrm{RN}$ \\
\hline HEMBL: & & & & RN \\
\hline HFMRI 1 & & & & RIV \\
\hline HEMBL15 & & & & RN \\
\hline HEMBL152 & 88239 & & 37 & TRN \\
\hline AEMBL14 & & & & $\Gamma \mathrm{RN}$ \\
\hline HEMBL1 & & & & TRN \\
\hline CHEMBL 23 & & & & TRN \\
\hline HEMBL1 & & & 5.4417 & IST \\
\hline HEMBL144 & 38239 & 62 & 5.5005 & TRN \\
\hline HEMBL1 & & & 5.5223 & \\
\hline CHEMBL1 & & & & \\
\hline CHEMBL 319 & & & 5.4434 & \\
\hline LHEMBL1587009 & 688239 & 5.6862 & 5.5087 & RN \\
\hline
\end{tabular}

Page 2552 
Supplemental Table S2.txt

\begin{tabular}{|c|c|c|c|c|}
\hline CHEMBL1581700 & 688239 & 4.6362 & 5.4839 & TRN \\
\hline CHEMBL464449 & 688239 & 4.7862 & 5.4383 & TST \\
\hline CHEMBL1322814 & 688239 & 5.6862 & 5.6313 & TRN \\
\hline CHEMBL1578411 & 688239 & 5.7862 & 5.4327 & TRN \\
\hline CHEMBL1452412 & 688239 & 5.1862 & 5.5263 & TRN \\
\hline CHEMBL1430757 & 688239 & 5.0862 & 5.3133 & TRN \\
\hline CHEMBL1516717 & 688239 & 6.9363 & 5.4452 & TRN \\
\hline CHEMBL1346883 & 688239 & 4.8362 & 5.2617 & TST \\
\hline CHEMBL3211453 & 688239 & 6.5862 & 5.3689 & TRN \\
\hline CHEMBL1557819 & 688239 & 5.7362 & 5.454 & TRN \\
\hline CHEMBL1364593 & 688239 & 6.6362 & 5.5895 & TST \\
\hline CHEMBL1317045 & 688239 & 6.2362 & 5.6736 & TRN \\
\hline CHEMBL1595020 & 688239 & 6.8362 & 5.5483 & TRN \\
\hline CHEMBL1600856 & 688239 & 4.5362 & 5.5391 & TRN \\
\hline CHEMBL 2369208 & 688239 & 5.3862 & 5.475 & TST \\
\hline CHEMBL1540847 & 688239 & 4.5862 & 5.4786 & TRN \\
\hline CHEMBL1573045 & 688239 & 4.6862 & 5.3859 & TRN \\
\hline CHEMBL1997585 & 688239 & 4.5862 & 5.5304 & TST \\
\hline CHEMBL1387401 & 688239 & 5.7862 & 5.4486 & TRN \\
\hline CHEMBL1396645 & 688239 & 4.9862 & 5.5428 & TST \\
\hline CHEMBL1474000 & 688239 & 5.0362 & 5.5104 & TRN \\
\hline CHEMBL3189165 & 688239 & 4.4862 & 5.46200 & 0000000001 \\
\hline CHEMBL1397136 & 688239 & 8.3372 & 5.4894 & TRN \\
\hline CHEMBL1544536 & 688239 & 6.7862 & 5.5094 & TST \\
\hline CHEMBL1588533 & 688239 & 5.1362 & 5.5117 & TRN \\
\hline CHEMBL1555141 & 688239 & 4.8862 & 5.4808 & TRN \\
\hline CHEMBL1484849 & 688239 & 4.7362 & 5.5089 & TRN \\
\hline CHEMBL3195237 & 688239 & 4.7862 & 5.439 & TRN \\
\hline CHEMBL1310597 & 688239 & 8.2366 & 5.5206 & TST \\
\hline CHEMBL1569925 & 688239 & 7.1361 & 5.5448 & TRN \\
\hline CHEMBL1482794 & 688239 & 6.0362 & 5.5399 & TRN \\
\hline CHEMBL1533718 & 688239 & 4.5362 & 5.4474 & TST \\
\hline CHEMBL3209644 & 688239 & 5.3862 & 5.4781 & TRN \\
\hline CHEMBL1458212 & 688239 & 4.5362 & 5.6509 & TRN \\
\hline CHEMBL1546720 & 688239 & 4.7362 & 5.5757 & TRN \\
\hline CHEMBL1506750 & 688239 & 5.1862 & 5.4411 & TRN \\
\hline CHEMBL1565455 & 688239 & 8.1367 & 5.5218 & TRN \\
\hline CHEMBL1584734 & 688239 & 4.7362 & 5.6221 & TST \\
\hline CHEMBL1475382 & 688239 & 6.8362 & 5.5835 & TRN \\
\hline CHEMBL1414584 & 688239 & 4.5362 & 5.3472 & TRN \\
\hline CHEMBL1513493 & 688239 & 6.1862 & 5.5045 & TRN \\
\hline CHEMBL1556840 & 688239 & 5.1862 & 5.43 & TRN \\
\hline CHEMBL1501533 & 688239 & 5.2862 & 5.561 & TRN \\
\hline CHEMBL1466874 & 688239 & 6.7361 & 5.5186 & TRN \\
\hline CHEMBL1310579 & 688239 & 5.4862 & 5.4637 & TRN \\
\hline CHEMBL1596256 & 688239 & 5.2362 & 5.5201 & TRN \\
\hline CHEMBL1349328 & 688239 & 5.3862 & 5.4347 & TRN \\
\hline CHEMBL1451545 & 688239 & 4.6862 & 5.4996 & TRN \\
\hline
\end{tabular}


Supplemental Table S2.txt

\begin{tabular}{|c|c|c|c|c|}
\hline & & & & \\
\hline IEMBL1 & 688239 & 5862 & & \\
\hline IEMBL1608290 & 3239 & 863 & 697 & \\
\hline AEMBL1303343 & 239 & 862 & 1792 & \\
\hline 061 & 239 & 362 & 949 & \\
\hline IEMBL13. & 239 & 362 & & \\
\hline AEMBL1607465 & 88239 & 362 & 1015 & \\
\hline AEMBL1401756 & 88239 & 862 & 115 & \\
\hline AEMBL1435725 & 239 & 362 & & \\
\hline IEMBL15 & 239 & 362 & & \\
\hline IEMBL1322005 & & & & \\
\hline AEMBL1603271 & 688239 & 863 & & \\
\hline AEMBL1367875 & 239 & 62 & & \\
\hline IEMBL143 & & & & \\
\hline EMBL13 & & & & \\
\hline AEMBL 144 & & & & \\
\hline AEMBL1517433 & 239 & 862 & & \\
\hline IEMBL1474979 & & 862 & & \\
\hline EIMISL 15 & & 53 & & \\
\hline IEMBL14 & & & & \\
\hline FMB 13 & & 61 & & \\
\hline AEMBL1378042 & & 362 & & RN \\
\hline AEMBL152 & & 62 & & \\
\hline IEMBL13 & & 62 & & 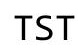 \\
\hline IEMBL13 & & & & RN \\
\hline IFMDI 11 & & & & וכ נד \\
\hline AEMBL1302932 & & & & RN \\
\hline AEMBL1368067 & & & & \\
\hline AEMBL1457074 & & 62 & & RI \\
\hline 124 & & 52 & & RN \\
\hline 51 & & 56 & & RN \\
\hline HEMBL1529201 & & & & ST \\
\hline AEMBL1454536 & & & & RI \\
\hline AEMBL15 & & 862 & & RI \\
\hline$A F M R \mid 12$ & & 62 & 42 & $\cdots$ \\
\hline 57 & & & & $\cdots$ \\
\hline HEMBL1399861 & & & & $\mathrm{R}$ \\
\hline AEMBL1422502 & & & & $S$ \\
\hline EMBL14 & & 62 & & RI \\
\hline רו נחצוני & & & & \\
\hline 61 & & & & ST \\
\hline AEMBL1559329 & & 862 & & $R$ \\
\hline-1398873 & & 62 & 324 & \\
\hline 502 & & & & \\
\hline & & & & \\
\hline CHEMBL1329978 & & 862 & & ( \\
\hline AEMBL1335599 & 88239 & 4.5362 & 5.6169 & $T R$ \\
\hline HFMRI 1695188 & 688239 & 6.1862 & 5.4623 & \\
\hline
\end{tabular}

Page 2554 
Supplemental Table S2.txt

\begin{tabular}{|c|c|c|c|c|}
\hline the & & & & \\
\hline HEMBL147 & 38239 & 6862 & & \\
\hline IEMBL1489285 & 8239 & 862 & 561 & \\
\hline HEMBL1587883 & 239 & 362 & 933 & \\
\hline & 239 & 862 & & \\
\hline IEMBL1390096 & 239 & 62 & & \\
\hline AEMBL3190612 & 88239 & 862 & 4633 & \\
\hline AEMBL1457704 & 88239 & 362 & 35 & \\
\hline AEMBL1377521 & 239 & 862 & & \\
\hline IEMBL1386363 & 239 & 62 & & \\
\hline AEMBL1480643 & & & & \\
\hline AEMBL1423610 & 688239 & 372 & & \\
\hline AEMBL1369897 & 239 & 362 & & \\
\hline IEMBL13 & & 62 & & \\
\hline IEMBL1458349 & & & & \\
\hline AEMBL3196540 & & & & \\
\hline AEMBL1423003 & 239 & & & \\
\hline AEMBL1352278 & & & & \\
\hline IEMBL1367098 & & & & \\
\hline IEMBL136 & & & & \\
\hline AEMBL1472351 & & & & \\
\hline AEMBL1307076 & 39 & & & \\
\hline AEMBL1402127 & & & & \\
\hline IEMBL14 & & & & \\
\hline IEMBL14 & & & & \\
\hline $15 M P 115$ & & & & \\
\hline AEMBL1454426 & & & & \\
\hline AEMBL1587530 & & & & \\
\hline AEMBL1311120 & & & & \\
\hline AEMBL1446964 & & & & \\
\hline 12 & & & & \\
\hline HEMBL1458981 & & & & \\
\hline AEMBL1555967 & & & & \\
\hline AEMBL1357634 & & & & \\
\hline HEMBL14 & & & & \\
\hline 90 & & & & \\
\hline AEMBL1527877 & & & & \\
\hline AEMBL1556288 & & & & \\
\hline IEMBL1525474 & & & & \\
\hline HEMBL1427816 & & & & \\
\hline & & & & \\
\hline HEMBL1303044 & 239 & 362 & & $\mathrm{RI}$ \\
\hline IEMBL1420674 & & & & \\
\hline EMBL1600499 & & & & \\
\hline CHEMBL1328163 & & & & \\
\hline CHEMBL1545603 & & & & \\
\hline AEMBL1364105 & 88239 & 4.7862 & 5.4112 & \\
\hline HFMRI 1328387 & 688239 & 4.8362 & 5.5107 & \\
\hline
\end{tabular}

Page 2555 
Supplemental Table S2.txt

\begin{tabular}{|c|c|c|c|c|c|}
\hline CHEMBL1543360 & 688239 & 5.1862 & 5.5556 & TST & \\
\hline CHEMBL3199003 & 688239 & 5.3862 & 5.5506 & TST & \\
\hline CHEMBL1420270 & 688239 & 5.8862 & 5.4414 & TRN & \\
\hline CHEMBL1508137 & 688239 & 6.7862 & 5.5385 & TRN & \\
\hline CHEMBL1500756 & 688239 & 5.7362 & 5.4919 & TRN & \\
\hline CHEMBL1430580 & 688239 & 5.4362 & 5.4671 & TRN & \\
\hline CHEMBL1376420 & 688239 & 6.7361 & 5.4608 & TRN & \\
\hline CHEMBL1372153 & 688239 & 5.2362 & 5.5363 & TRN & \\
\hline CHEMBL 2005602 & 688239 & 4.7362 & 5.4543 & TST & \\
\hline CHEMBL1464079 & 688239 & 4.7862 & 5.6231 & TRN & \\
\hline CHEMBL1472267 & 688239 & 5.9362 & 5.4837 & TST & \\
\hline CHEMBL1444047 & 688239 & 4.5362 & 5.5743 & TRN & \\
\hline CHEMBL1364054 & 688239 & 5.1862 & 5.5107 & TST & \\
\hline CHEMBL1578482 & 688239 & 4.5362 & 5.3266 & TRN & \\
\hline CHEMBL1450471 & 688239 & 5.7862 & 5.4497 & TRN & \\
\hline CHEMBL1472893 & 688239 & 4.8862 & 5.3945 & TRN & \\
\hline CHEMBL1500283 & 688239 & 5.3362 & 5.4824 & TRN & \\
\hline CHEMBL1522701 & 688239 & 6.8362 & 5.6164 & TRN & \\
\hline CHEMBL1488788 & 688239 & 4.6862 & 5.6861 & TST & \\
\hline CHEMBL1383210 & 688239 & 6.8362 & 5.4628 & TRN & \\
\hline CHEMBL1540611 & 688239 & 5.0362 & 5.6292 & TRN & \\
\hline CHEMBL1500047 & 688239 & 4.5362 & 5.3845 & TRN & \\
\hline CHEMBL1386720 & 688239 & 6.0862 & 5.4643 & TRN & \\
\hline CHEMBL1311885 & 688239 & 5.7862 & 5.4548 & TRN & \\
\hline CHEMBL1507122 & 688239 & 6.7862 & 5.5415 & TRN & \\
\hline CHEMBL1442200 & 688239 & 5.6862 & 5.4466 & TRN & \\
\hline CHEMBL1476650 & 688239 & 5.3862 & 5.3754 & TRN & \\
\hline CHEMBL1461949 & 688239 & 4.7362 & 5.5192 & TRN & \\
\hline CHEMBL1557913 & 688239 & 4.7362 & 5.4226 & TRN & \\
\hline CHEMBL1561880 & 688239 & 4.5362 & 5.4483 & TRN & \\
\hline CHEMBL1557161 & 688239 & 5.8862 & 5.5322 & TRN & \\
\hline CHEMBL1499051 & 688239 & 8.28399 & 99999999 & 9 & 5.4939 \\
\hline CHEMBL1539318 & 688239 & 6.8861 & 5.6207 & TRN & \\
\hline CHEMBL1436614 & 688239 & 5.1362 & 5.5981 & TRN & \\
\hline CHEMBL1312440 & 688239 & 4.6362 & 5.4512 & TRN & \\
\hline CHEMBL 2005825 & 688239 & 4.5362 & 5.5244 & TST & \\
\hline CHEMBL1471876 & 688239 & 4.7362 & 5.4678 & TRN & \\
\hline CHEMBL1581253 & 688239 & 5.1362 & 5.4233 & TRN & \\
\hline CHEMBL1509489 & 688239 & 6.1362 & 5.3334 & TRN & \\
\hline CHEMBL1411921 & 688239 & 6.9863 & 5.4277 & TRN & \\
\hline CHEMBL1422968 & 688239 & 6.1862 & 5.7429 & TRN & \\
\hline CHEMBL1353589 & 688239 & 5.1362 & 5.5385 & TRN & \\
\hline CHEMBL1375364 & 688239 & 4.9862 & 5.439 & TRN & \\
\hline CHEMBL 3214163 & 688239 & 5.9862 & 5.4398 & TRN & \\
\hline CHEMBL1447514 & 688239 & 5.6362 & 5.5856 & TRN & \\
\hline CHEMBL1405763 & 688239 & 4.5862 & 5.4213 & TRN & \\
\hline CHEMBL1493582 & 688239 & 6.3863 & 5.6159 & TRN & \\
\hline CHEMBL 3196031 & 688239 & 4.8862 & 5.4356 & TRN & \\
\hline
\end{tabular}

Page 2556 


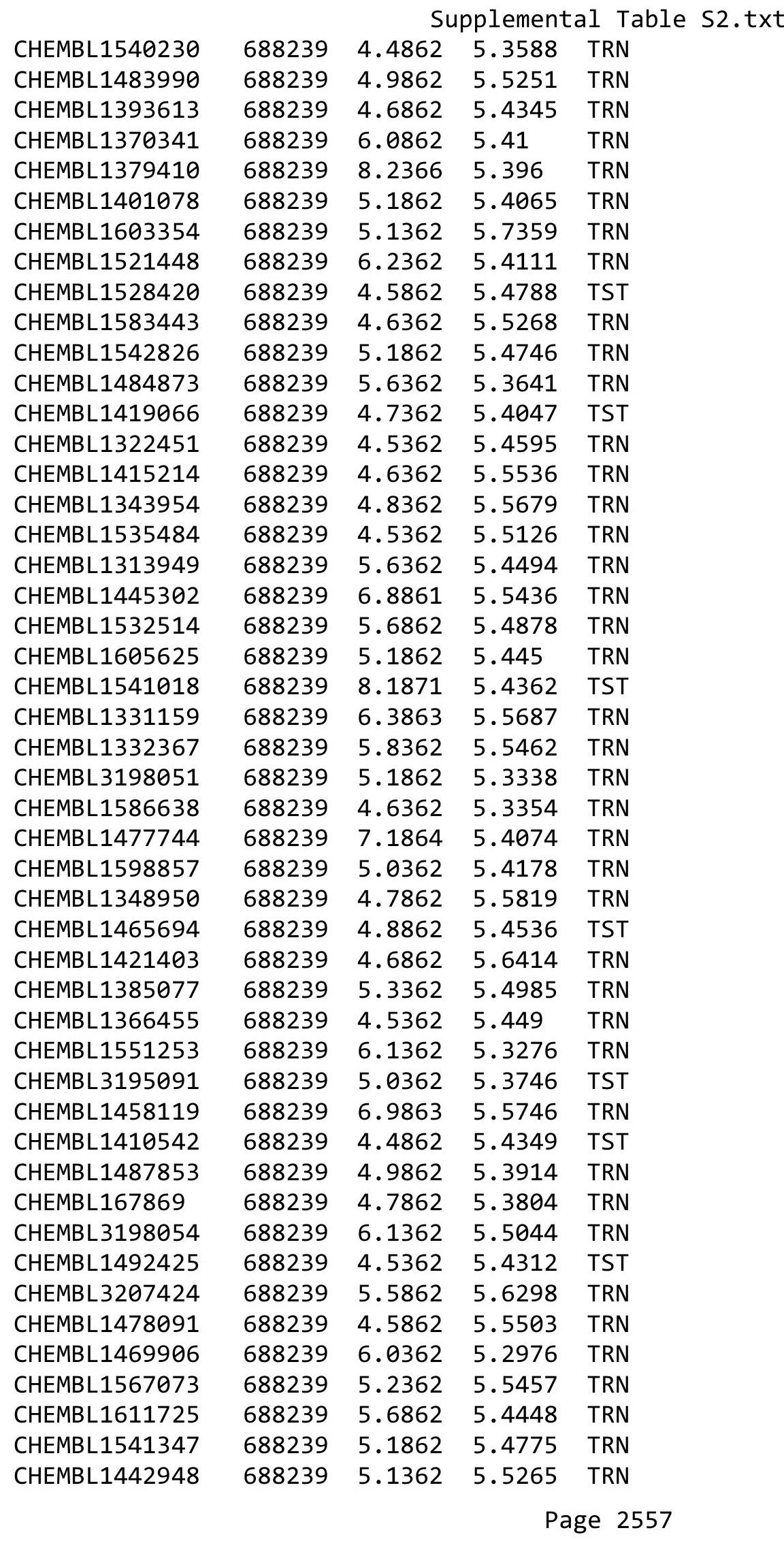


Supplemental Table S2.txt

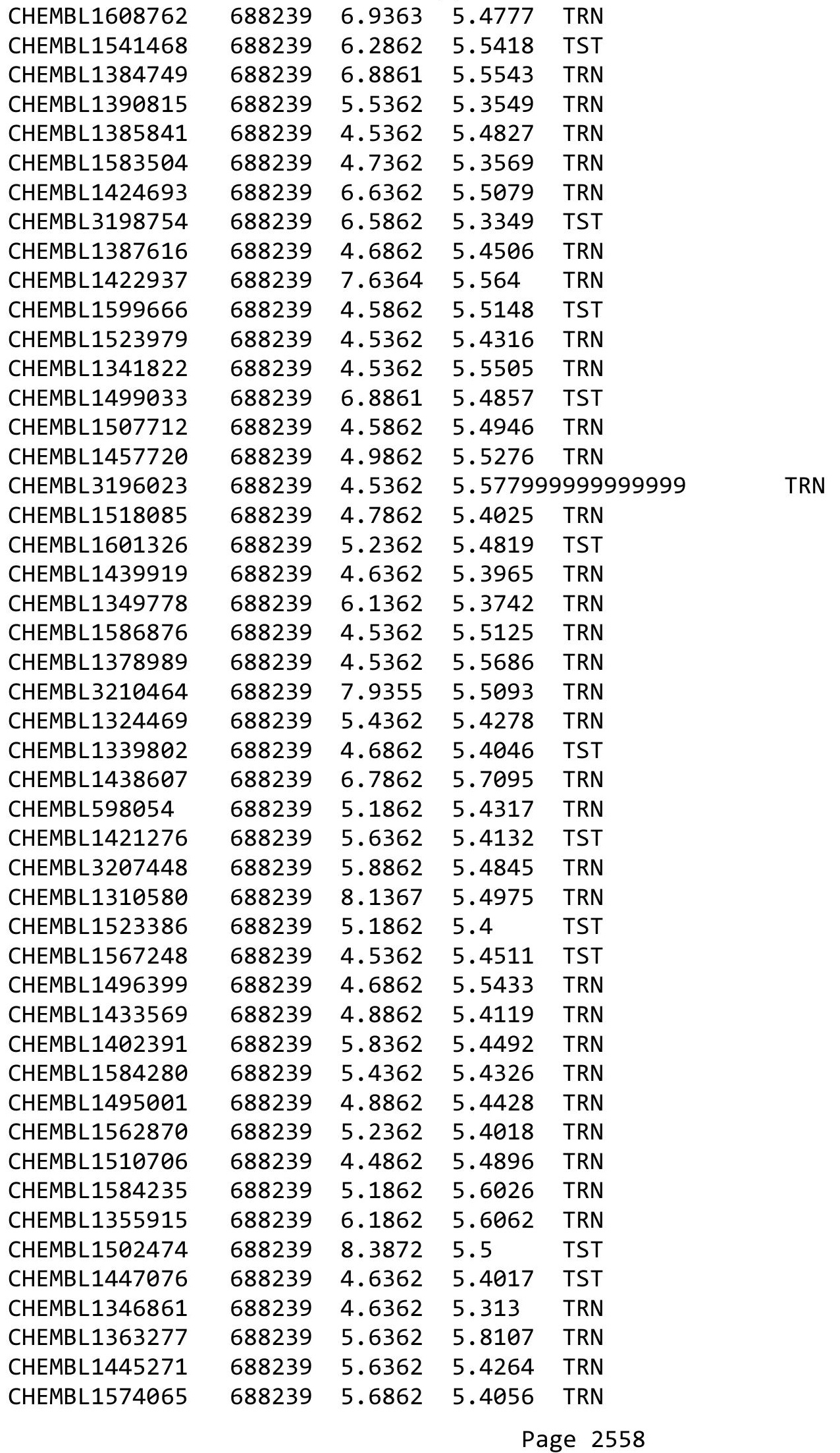


Supplemental Table S2.txt

\begin{tabular}{|c|c|c|c|c|c|}
\hline CHEMBL3191151 & 688239 & 4.6862 & 5.4345 & TST & \\
\hline CHEMBL3191857 & 688239 & 6.8362 & 5.5049 & TST & \\
\hline CHEMBL1481508 & 688239 & 4.5362 & 5.4314 & TRN & \\
\hline CHEMBL1337157 & 688239 & 6.8861 & 5.5612 & TRN & \\
\hline CHEMBL1573112 & 688239 & 6.2362 & 5.525 & TRN & \\
\hline CHEMBL1441002 & 688239 & 4.5362 & 5.6173 & TRN & \\
\hline CHEMBL1396777 & 688239 & 6.8362 & 5.4657 & TRN & \\
\hline CHEMBL1302203 & 688239 & 5.4362 & 5.4331 & TRN & \\
\hline CHEMBL1324027 & 688239 & 7.5361 & 5.4878 & TRN & \\
\hline CHEMBL1565670 & 688239 & 5.1862 & 5.3993 & TRN & \\
\hline CHEMBL1545137 & 688239 & 6.5862 & 5.5141 & TRN & \\
\hline CHEMBL1374238 & 688239 & 4.7862 & 5.4394 & TRN & \\
\hline CHEMBL1436301 & 688239 & 5.4362 & 5.5577 & TRN & \\
\hline CHEMBL1558634 & 688239 & 5.1862 & 5.6949 & TRN & \\
\hline CHEMBL 3193549 & 688239 & 6.0362 & 5.47 & TST & \\
\hline CHEMBL1321456 & 688239 & 5.1862 & 5.462999 & 999999999 & TRN \\
\hline CHEMBL1573145 & 688239 & 4.5362 & 5.3808 & TRN & \\
\hline CHEMBL1389726 & 688239 & 8.283999 & 99999999 & 5.3505 & TRN \\
\hline CHEMBL3198743 & 688239 & 4.5362 & 5.3782 & TRN & \\
\hline CHEMBL1431285 & 688239 & 4.6362 & 5.5862 & TRN & \\
\hline CHEMBL1467351 & 688239 & 6.8861 & 5.5707 & TRN & \\
\hline CHEMBL1493922 & 688239 & 6.1362 & 5.5985 & TST & \\
\hline CHEMBL1433925 & 688239 & 4.7362 & 5.5419 & TRN & \\
\hline CHEMBL1354157 & 688239 & 5.7362 & 5.5383 & TST & \\
\hline CHEMBL1440597 & 688239 & 4.5862 & 5.5273 & TRN & \\
\hline CHEMBL1595481 & 688239 & 6.6362 & 5.4642 & TRN & \\
\hline CHEMBL1564768 & 688239 & 5.5362 & 5.4313 & TRN & \\
\hline CHEMBL1503294 & 688239 & 4.5362 & 5.5448 & TRN & \\
\hline CHEMBL1365523 & 688239 & 4.7362 & 5.482 & TRN & \\
\hline CHEMBL1425963 & 688239 & 4.6862 & \multicolumn{2}{|c|}{5.4510000000000005} & TST \\
\hline CHEMBL1331517 & 688239 & 4.6362 & 5.5124 & TRN & \\
\hline CHEMBL1340523 & 688239 & 4.7362 & 5.4678 & TRN & \\
\hline CHEMBL1416862 & 688239 & 4.5362 & 5.5142 & TRN & \\
\hline CHEMBL1450571 & 688239 & 5.4362 & \multicolumn{2}{|c|}{5.537000000000001} & TRN \\
\hline CHEMBL1485436 & 688239 & 4.5362 & 5.4465 & TST & \\
\hline CHEMBL1574865 & 688239 & 4.5362 & 5.5547 & TRN & \\
\hline CHEMBL1608090 & 688239 & 5.1862 & 5.4306 & TRN & \\
\hline CHEMBL3194915 & 688239 & 4.8362 & 5.444 & TRN & \\
\hline CHEMBL1437921 & 688239 & 8.2366 & 5.5451 & TRN & \\
\hline CHEMBL1459057 & 688239 & 5.1862 & 5.7217 & TRN & \\
\hline CHEMBL1503548 & 688239 & 4.9862 & 5.5542 & TRN & \\
\hline CHEMBL1568462 & 688239 & 4.5862 & 5.6449 & TRN & \\
\hline CHEMBL1452515 & 688239 & 5.7362 & \multicolumn{2}{|c|}{5.422999999999999} & TRN \\
\hline CHEMBL1319205 & 688239 & 5.4362 & 5.6476 & TRN & \\
\hline CHEMBL1385661 & 688239 & 5.4362 & 5.4592 & TRN & \\
\hline CHEMBL1321841 & 688239 & 6.1862 & 5.5338 & TST & \\
\hline CHEMBL3198702 & 688239 & 6.1362 & 5.4349 & TST & \\
\hline CHEMBL1456022 & 688239 & 5.4862 & 5.4213 & TRN & \\
\hline
\end{tabular}


Supplemental Table S2.txt

\begin{tabular}{|c|c|c|c|c|}
\hline CHEMBL1332140 & 688239 & 5.1862 & 5.3709 & TRN \\
\hline CHEMBL1538475 & 688239 & 4.9862 & 5.3977 & TRN \\
\hline CHEMBL1350061 & 688239 & 5.1862 & 5.4803 & TRN \\
\hline CHEMBL1427517 & 688239 & 4.4862 & 5.5444 & TST \\
\hline CHEMBL1516000 & 688239 & 4.4862 & 5.5289 & TRN \\
\hline CHEMBL1345854 & 688239 & 5.5362 & 5.6761 & TRN \\
\hline CHEMBL1538035 & 688239 & 4.5362 & 5.3021 & TRN \\
\hline CHEMBL1382266 & 688239 & 4.4862 & 5.5971 & TRN \\
\hline CHEMBL1465709 & 688239 & 4.7362 & 5.327999 & 9999999999 \\
\hline CHEMBL1422408 & 688239 & 4.8362 & 5.5743 & TRN \\
\hline CHEMBL1545641 & 688239 & 5.4362 & 5.482 & TRN \\
\hline CHEMBL1450930 & 688239 & 4.8862 & 5.4924 & TRN \\
\hline CHEMBL1597877 & 688239 & 6.4862 & 5.5874 & TRN \\
\hline CHEMBL1327097 & 688239 & 5.0862 & 5.5253 & TRN \\
\hline CHEMBL1342751 & 688239 & 5.3362 & 5.4126 & TST \\
\hline CHEMBL1535294 & 688239 & 4.5362 & 5.4833 & TRN \\
\hline CHEMBL1306787 & 688239 & 5.7862 & 5.4763 & TRN \\
\hline CHEMBL1580919 & 688239 & 4.4862 & 5.5899 & TRN \\
\hline CHEMBL1303387 & 688239 & 7.2366 & 5.3635 & TRN \\
\hline CHEMBL1396422 & 688239 & 4.9862 & 5.3868 & TRN \\
\hline CHEMBL1416756 & 688239 & 6.2862 & 5.5003 & TRN \\
\hline CHEMBL1487106 & 688239 & 5.8862 & 5.5112 & TRN \\
\hline CHEMBL592894 & 688239 & 4.5362 & 5.4426 & TRN \\
\hline CHEMBL1569922 & 688239 & 5.3862 & 5.5109 & TRN \\
\hline CHEMBL1601673 & 688239 & 5.7362 & 5.3055 & TRN \\
\hline CHEMBL1379341 & 688239 & 4.5362 & 5.5728 & TRN \\
\hline CHEMBL1448808 & 688239 & 4.5362 & 5.362999 & 99999999995 \\
\hline CHEMBL1548377 & 688239 & 4.9362 & 5.1957 & TRN \\
\hline CHEMBL1978120 & 688239 & 4.7362 & 5.4123 & TRN \\
\hline CHEMBL3191942 & 688239 & 4.5362 & 5.58 & TRN \\
\hline CHEMBL1365133 & 688239 & 4.7362 & 5.4756 & TST \\
\hline CHEMBL1358596 & 688239 & 5.1862 & 5.44 & TRN \\
\hline CHEMBL1428607 & 688239 & 5.8362 & 5.5711 & TRN \\
\hline CHEMBL1450879 & 688239 & 6.1362 & 5.5124 & TST \\
\hline CHEMBL1498696 & 688239 & 4.6862 & 5.6174 & TRN \\
\hline CHEMBL1579944 & 688239 & 5.7362 & 5.5002 & TRN \\
\hline CHEMBL1472158 & 688239 & 4.8362 & 5.6402 & TRN \\
\hline CHEMBL1589234 & 688239 & 4.5362 & 5.5239 & TST \\
\hline CHEMBL1460530 & 688239 & 4.5362 & 5.6113 & TRN \\
\hline CHEMBL1412170 & 688239 & 4.5362 & 5.4162 & TRN \\
\hline CHEMBL1392678 & 688239 & 5.1862 & 5.5469 & TRN \\
\hline CHEMBL1438442 & 688239 & 4.5362 & 5.5383 & TRN \\
\hline CHEMBL1471583 & 688239 & 4.5362 & 5.4231 & TST \\
\hline CHEMBL1597597 & 688239 & 5.4862 & 5.3921 & TRN \\
\hline CHEMBL1426105 & 688239 & 6.0862 & \multicolumn{2}{|c|}{5.707000000000001} \\
\hline CHEMBL1343516 & 688239 & 8.3372 & 5.4029 & TST \\
\hline CHEMBL1356291 & 688239 & 6.5862 & 5.417000 & 0000000001 \\
\hline CHEMBL1418952 & 688239 & 5.1362 & 5.6037 & TST \\
\hline
\end{tabular}


Supplemental Table S2.txt

\begin{tabular}{|c|c|c|c|c|c|}
\hline CHEMBL1337269 & 688239 & 6.1362 & 5.5212 & TRN & \\
\hline CHEMBL1308427 & 688239 & 5.2362 & 5.4273 & TRN & \\
\hline CHEMBL1585729 & 688239 & 6.1862 & 5.5902 & TRN & \\
\hline CHEMBL1464816 & 688239 & 5.9362 & 5.665 & TST & \\
\hline CHEMBL1494071 & 688239 & 4.5362 & 5.5731 & TST & \\
\hline CHEMBL1612937 & 688239 & 5.0362 & \multicolumn{2}{|c|}{5.6160000000000005} & TRN \\
\hline CHEMBL1549103 & 688239 & 4.8862 & 5.4775 & TRN & \\
\hline CHEMBL1387810 & 688239 & 5.5862 & 5.5473 & TRN & \\
\hline CHEMBL1373997 & 688239 & 5.1862 & 5.5627 & TRN & \\
\hline CHEMBL1302481 & 688239 & 6.2862 & 5.4694 & TST & \\
\hline CHEMBL1325773 & 688239 & 4.5362 & 5.4041 & TRN & \\
\hline CHEMBL1563044 & 688239 & 5.3862 & 5.4145 & TST & \\
\hline CHEMBL1580676 & 688239 & 6.1362 & 5.5408 & TRN & \\
\hline CHEMBL1441442 & 688239 & 4.6862 & 5.3716 & TST & \\
\hline CHEMBL1597660 & 688239 & 5.6362 & 5.5804 & TRN & \\
\hline CHEMBL1372892 & 688239 & 4.8862 & 5.359 & TRN & \\
\hline CHEMBL1363166 & 688239 & 5.1862 & 5.5693 & TST & \\
\hline CHEMBL1391231 & 688239 & 6.6861 & 5.4682 & TRN & \\
\hline CHEMBL1571704 & 688239 & 4.5362 & 5.5304 & TRN & \\
\hline CHEMBL1381114 & 688239 & 4.6862 & 5.3933 & TST & \\
\hline CHEMBL1540601 & 688239 & 4.6362 & 5.4154 & TRN & \\
\hline CHEMBL1998715 & 688239 & 5.8862 & 5.4746 & TRN & \\
\hline CHEMBL1328341 & 688239 & 4.6862 & 5.5585 & TRN & \\
\hline CHEMBL1346577 & 688239 & 4.9862 & 5.4701 & TST & \\
\hline CHEMBL1576293 & 688239 & 5.4862 & 5.5036 & TRN & \\
\hline CHEMBL1380631 & 688239 & 6.4862 & 5.4883 & TST & \\
\hline CHEMBL1588325 & 688239 & 5.1862 & 5.3692 & TRN & \\
\hline CHEMBL1598125 & 688239 & 5.3862 & 5.4153 & TRN & \\
\hline CHEMBL1583454 & 688239 & 4.5362 & 5.3566 & TRN & \\
\hline CHEMBL1461692 & 688239 & 4.7862 & \multicolumn{2}{|c|}{5.497000000000001} & TRN \\
\hline CHEMBL1528224 & 688239 & 5.3362 & 5.3107 & TRN & \\
\hline CHEMBL1598833 & 688239 & 5.5862 & 5.4459 & TRN & \\
\hline CHEMBL1351685 & 688239 & 7.1361 & 5.4208 & TRN & \\
\hline CHEMBL1567769 & 688239 & 8.0862 & 5.5408 & TST & \\
\hline CHEMBL1323787 & 688239 & 6.1362 & 5.4815 & TRN & \\
\hline CHEMBL1415369 & 688239 & 5.4362 & 5.5262 & TRN & \\
\hline CHEMBL1414772 & 688239 & 4.6362 & 5.4128 & TRN & \\
\hline CHEMBL1559894 & 688239 & 4.7862 & 5.3823 & TRN & \\
\hline CHEMBL1547406 & 688239 & 6.8861 & 5.4924 & TRN & \\
\hline CHEMBL1992918 & 688239 & 6.5862 & 5.4076 & TST & \\
\hline CHEMBL1329962 & 688239 & 5.6362 & 5.4679 & TST & \\
\hline CHEMBL 3213315 & 688239 & 5.4862 & 5.4538 & TRN & \\
\hline CHEMBL 3145372 & 688239 & 4.7362 & 5.5372 & TRN & \\
\hline CHEMBL1428488 & 688239 & 6.0362 & 5.5151 & TRN & \\
\hline CHEMBL3210415 & 688239 & 6.2362 & 5.6702 & TRN & \\
\hline CHEMBL1383983 & 688239 & 5.1862 & 5.4352 & TRN & \\
\hline CHEMBL1459115 & 688239 & 4.6862 & 5.4265 & TRN & \\
\hline CHEMBL1611199 & 688239 & 4.6862 & 5.4007 & TRN & \\
\hline
\end{tabular}


Supplemental Table S2.txt

\begin{tabular}{|c|c|c|c|c|c|}
\hline CHEMBL1401043 & 688239 & 4.7362 & 5.4325 & TST & \\
\hline CHEMBL1364149 & 688239 & 5.4362 & 5.442 & TRN & \\
\hline CHEMBL1581776 & 688239 & 4.5862 & 5.4893 & TRN & \\
\hline CHEMBL1570475 & 688239 & 6.0362 & 5.3363 & TRN & \\
\hline CHEMBL1322045 & 688239 & 4.7362 & 5.3934 & TRN & \\
\hline CHEMBL1412600 & 688239 & 5.1862 & 5.4853 & TRN & \\
\hline CHEMBL1479660 & 688239 & 4.7362 & 5.4379 & TRN & \\
\hline CHEMBL1430254 & 688239 & 5.6362 & 5.4471 & TRN & \\
\hline CHEMBL1346839 & 688239 & 4.5862 & 5.5028 & TST & \\
\hline CHEMBL1532414 & 688239 & 7.1361 & 5.4521 & TRN & \\
\hline CHEMBL1459036 & 688239 & 5.4362 & 5.4514 & TST & \\
\hline CHEMBL1604453 & 688239 & 5.9362 & 5.5541 & TRN & \\
\hline CHEMBL1587927 & 688239 & 4.6862 & 5.5336 & TRN & \\
\hline CHEMBL1505612 & 688239 & 7.0862 & 5.4223 & TRN & \\
\hline CHEMBL1494570 & 688239 & 4.6362 & 5.3931 & TST & \\
\hline CHEMBL1386758 & 688239 & 4.6862 & 5.403 & TRN & \\
\hline CHEMBL1464831 & 688239 & 4.5362 & 5.6139 & TRN & \\
\hline CHEMBL1551124 & 688239 & 5.1862 & 5.5771 & TRN & \\
\hline CHEMBL1598907 & 688239 & 5.5862 & 5.546 & TST & \\
\hline CHEMBL1397445 & 688239 & 6.1862 & 5.467006 & 00000000005 & TRN \\
\hline CHEMBL1486196 & 688239 & 6.2362 & 5.5866 & TST & \\
\hline CHEMBL98398 & 688239 & 5.3862 & 5.5064 & TST & \\
\hline CHEMBL1537488 & 688239 & 4.6862 & 5.5103 & TRN & \\
\hline CHEMBL1404549 & 688239 & 8.2366 & 5.3707 & TST & \\
\hline CHEMBL1350473 & 688239 & 5.5362 & 5.352 & TRN & \\
\hline CHEMBL1595095 & 688239 & 5.6362 & 5.4973 & TRN & \\
\hline CHEMBL1445521 & 688239 & 5.1862 & 5.6044 & TST & \\
\hline CHEMBL1458895 & 688239 & 6.9863 & 5.5042 & TST & \\
\hline CHEMBL1485821 & 688239 & 5.0862 & 5.50799 & 9999999999 & TRN \\
\hline CHEMBL1574210 & 688239 & 4.5362 & 5.6028 & TRN & \\
\hline CHEMBL1422255 & 688239 & 6.5363 & 5.4258 & TRN & \\
\hline CHEMBL1478506 & 688239 & 6.2362 & 5.5758 & TRN & \\
\hline CHEMBL1573609 & 688239 & 6.2362 & 5.5034 & TRN & \\
\hline CHEMBL1426270 & 688239 & 5.5362 & 5.4241 & TRN & \\
\hline CHEMBL1495131 & 688239 & 8.2366 & 5.4649 & TRN & \\
\hline CHEMBL1290138 & 688239 & 5.0362 & 5.397 & TRN & \\
\hline CHEMBL1336790 & 688239 & 6.2362 & 5.6071 & TRN & \\
\hline CHEMBL1557752 & 688239 & 4.7362 & 5.5034 & TRN & \\
\hline CHEMBL1403130 & 688239 & 5.4362 & 5.5871 & TRN & \\
\hline CHEMBL1434617 & 688239 & 5.1862 & 5.5748 & TRN & \\
\hline CHEMBL1375755 & 688239 & 5.3862 & 5.5917 & TRN & \\
\hline CHEMBL1590481 & 688239 & 6.2862 & 5.3399 & TRN & \\
\hline CHEMBL1300523 & 688239 & 4.5362 & 5.4635 & TST & \\
\hline CHEMBL1370314 & 688239 & 4.5362 & 5.5972 & TRN & \\
\hline CHEMBL1383775 & 688239 & 6.0362 & 5.5545 & TRN & \\
\hline CHEMBL1503574 & 688239 & 5.1862 & 5.4569 & TRN & \\
\hline CHEMBL1553456 & 688239 & 5.7362 & 5.4516 & TRN & \\
\hline CHEMBL1583926 & 688239 & 4.5362 & 5.5364 & TRN & \\
\hline
\end{tabular}


Supplemental Table S2.txt

\begin{tabular}{|c|c|c|c|c|c|}
\hline CHEMBL1388858 & 688239 & 4.5362 & 5.3942 & TRN & \\
\hline CHEMBL1311706 & 688239 & 5.5362 & 5.3882 & TRN & \\
\hline CHEMBL1596017 & 688239 & 5.1862 & 5.4374 & TRN & \\
\hline CHEMBL1322640 & 688239 & 4.9362 & 5.5372 & TRN & \\
\hline CHEMBL1512364 & 688239 & 5.3862 & 5.3262 & TRN & \\
\hline CHEMBL379179 & 688239 & 5.6862 & 5.466 & TRN & \\
\hline CHEMBL1328489 & 688239 & 6.1862 & 5.4512 & TRN & \\
\hline CHEMBL1495636 & 688239 & 4.5362 & 5.5961 & TST & \\
\hline CHEMBL1593693 & 688239 & 6.2862 & 5.5134 & TRN & \\
\hline CHEMBL 282662 & 688239 & 6.9863 & 5.4387 & TST & \\
\hline CHEMBL1395700 & 688239 & 5.4362 & 5.5499 & TRN & \\
\hline CHEMBL1507354 & 688239 & 4.8862 & 5.3775 & TRN & \\
\hline CHEMBL1576852 & 688239 & 5.5862 & 5.516 & TRN & \\
\hline CHEMBL1302581 & 688239 & 5.1862 & 5.5091 & TST & \\
\hline CHEMBL1303472 & 688239 & 6.1862 & 5.3745 & TRN & \\
\hline CHEMBL1372168 & 688239 & 6.7361 & 5.5006 & TRN & \\
\hline CHEMBL1587770 & 688239 & 4.5362 & 5.616000 & 00000000005 & TRN \\
\hline CHEMBL1591743 & 688239 & 4.6362 & 5.3613 & TRN & \\
\hline CHEMBL1547437 & 688239 & 5.5862 & 5.5593 & TRN & \\
\hline CHEMBL1477232 & 688239 & 6.1362 & 5.4994 & TRN & \\
\hline CHEMBL1501273 & 688239 & 5.1362 & 5.3211 & TST & \\
\hline CHEMBL1411694 & 688239 & 5.3362 & 5.4283 & TRN & \\
\hline CHEMBL1469558 & 688239 & 5.2862 & 5.5097 & TRN & \\
\hline CHEMBL1374080 & 688239 & 5.1862 & 5.6313 & TRN & \\
\hline CHEMBL1590720 & 688239 & 5.9362 & 5.5132 & TRN & \\
\hline CHEMBL1426249 & 688239 & 4.5362 & 5.4563 & TRN & \\
\hline CHEMBL1406610 & 688239 & 6.9863 & 5.4269 & TRN & \\
\hline CHEMBL1316859 & 688239 & 5.1862 & 5.6164 & TST & \\
\hline CHEMBL1467999 & 688239 & 4.8362 & 5.5323 & TRN & \\
\hline CHEMBL1500830 & 688239 & 4.8862 & 5.3901 & TRN & \\
\hline CHEMBL1546366 & 688239 & 4.5362 & 5.4482 & TST & \\
\hline CHEMBL1576393 & 688239 & 4.5362 & 5.3474 & TRN & \\
\hline CHEMBL1382265 & 688239 & 4.6862 & 5.4032 & TRN & \\
\hline CHEMBL1328618 & 688239 & 5.3362 & 5.4107 & TRN & \\
\hline CHEMBL1574863 & 688239 & 4.4862 & 5.3999 & TRN & \\
\hline CHEMBL1343185 & 688239 & 5.7362 & 5.4802 & TST & \\
\hline CHEMBL1417264 & 688239 & 5.9362 & 5.4176 & TRN & \\
\hline CHEMBL1457027 & 688239 & 5.0362 & 5.587000 & 0000000001 & TRN \\
\hline CHEMBL3192935 & 688239 & 5.4362 & 5.4964 & TRN & \\
\hline CHEMBL1487351 & 688239 & 5.1362 & 5.535 & TST & \\
\hline CHEMBL1543917 & 688239 & 4.45 & 5.3509 & TST & \\
\hline CHEMBL1435277 & 688239 & 4.5862 & 5.5367 & TRN & \\
\hline CHEMBL1469588 & 688239 & 5.9862 & 5.4724 & TST & \\
\hline CHEMBL1374486 & 688239 & 6.1362 & 5.5364 & TRN & \\
\hline CHEMBL1475836 & 688239 & 4.5362 & 5.4281 & TRN & \\
\hline CHEMBL1535898 & 688239 & 6.0862 & 5.5072 & TRN & \\
\hline CHEMBL1545884 & 688239 & 8.28399 & 999999999 & 5.5635 & וSI \\
\hline CHEMBL1510089 & 688239 & 4.6862 & 5.4107 & TRN & \\
\hline
\end{tabular}


Supplemental Table S2.txt

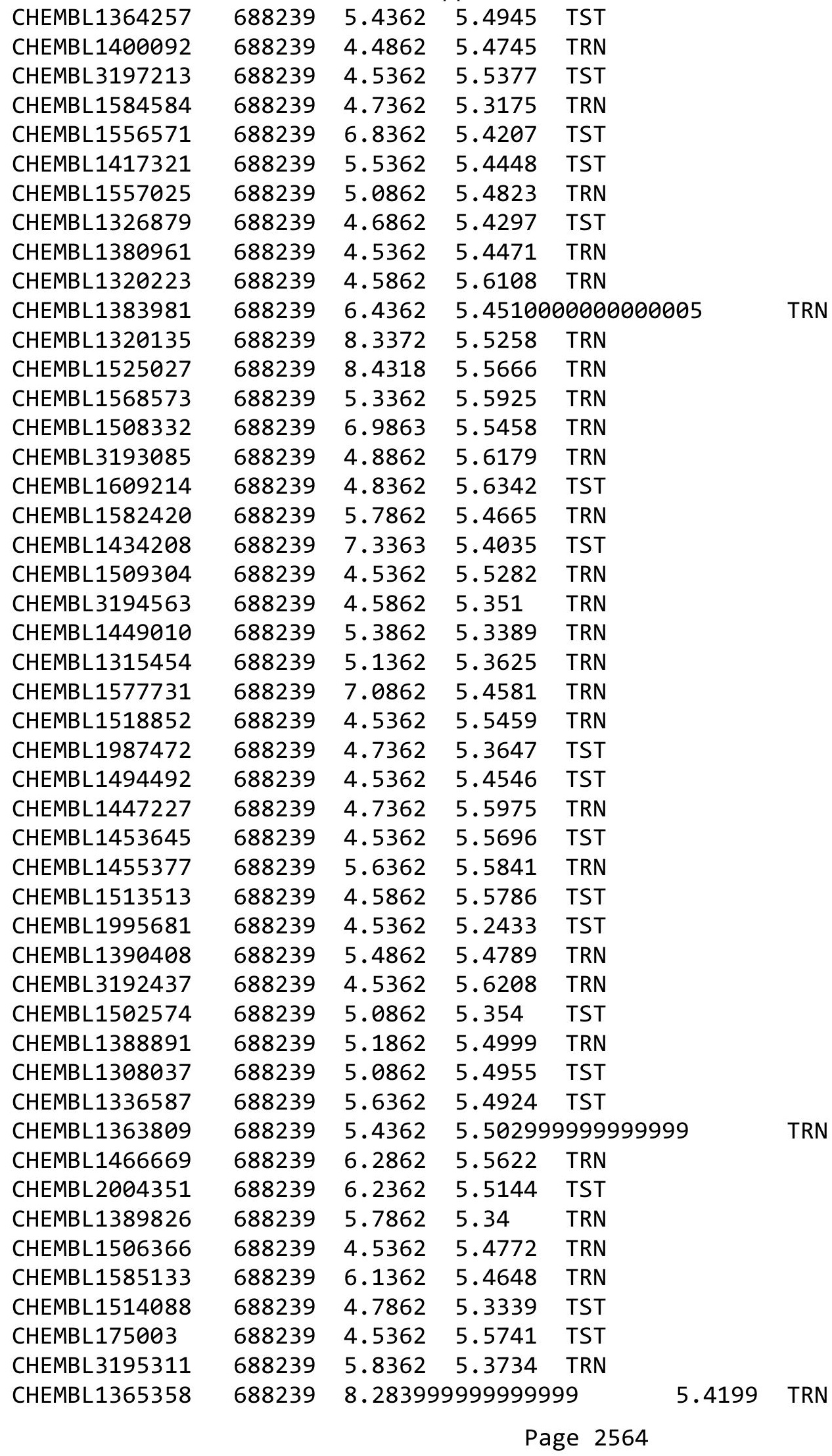


Supplemental Table S2.txt

\begin{tabular}{|c|c|c|c|c|}
\hline 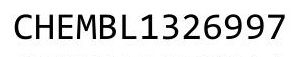 & & & & \\
\hline HEMBL1378114 & 38239 & 362 & 97 & \\
\hline AEMBL1314591 & 239 & 362 & & \\
\hline 33 & 39 & 362 & & \\
\hline IEMBL3195834 & 239 & 362 & & \\
\hline AEMBL1569427 & 88239 & 862 & & \\
\hline AEMBL1569748 & 88239 & 862 & 3993 & \\
\hline HEMBL1369260 & & & & \\
\hline IEMBL1405287 & 39 & 362 & & \\
\hline IEMBL1409011 & & & & \\
\hline AEMBL1319511 & 239 & 862 & & \\
\hline AEMBL1367610 & 39 & 862 & & \\
\hline HEMBL1389558 & & & & \\
\hline IEMBL1601098 & & & & \\
\hline AEMBL1191301 & & & & \\
\hline AEMBL3211567 & & 362 & & \\
\hline AEMBL1526079 & & 362 & & \\
\hline IEMBL1405919 & & 62 & & \\
\hline HEMBL1499245 & & & & \\
\hline AEMBL1367273 & & & & \\
\hline AEMBL1374000 & & 362 & & \\
\hline AEMBL137€ & & 62 & & \\
\hline IEMBL1466 & & 62 & & \\
\hline AEMBL 14 & & & & \\
\hline HFM & & & & \\
\hline AEMBL1597541 & & 862 & & \\
\hline IEMBL1393351 & & 62 & & \\
\hline IEMBL1334 & & 62 & & \\
\hline AFME $-2-P A$ & & 4. & & \\
\hline ILMP 15 ? & & 362 & & \\
\hline AEMBL3189258 & & & & \\
\hline HEMBL1393140 & & & & \\
\hline 3L147 & & & & \\
\hline IFMn & & & & \\
\hline & & & & RN \\
\hline AEMBL1352673 & & 862 & & \\
\hline AEMBL1301480 & & 362 & & \\
\hline & & & & \\
\hline 1250 & & & & \\
\hline HEMBL 346672 & & & & RN \\
\hline AEMBL1587387 & & 362 & & \\
\hline AEMBL1360309 & & 62 & & \\
\hline 6359 & & & & \\
\hline HEMBL1379743 & & & & \\
\hline HEMBL1490467 & & 6.0362 & & RN \\
\hline IEMBL1379269 & 68 & 7.7852 & 63 & \\
\hline MBL15541 & & & & \\
\hline HEMBL142826 & & & .5931 & \\
\hline
\end{tabular}

Page 2565 
Supplemental Table S2.txt

\begin{tabular}{|c|c|c|c|c|c|}
\hline CHEMBL1333399 & 688239 & 5.1862 & 5.3753 & TRN & \\
\hline CHEMBL1600134 & 688239 & 7.1361 & 5.3338 & TST & \\
\hline CHEMBL1405405 & 688239 & 6.3362 & 5.4684 & TST & \\
\hline CHEMBL1557344 & 688239 & 5.3362 & 5.5724 & TST & \\
\hline CHEMBL1374137 & 688239 & 5.1862 & 5.6413 & TST & \\
\hline CHEMBL1459531 & 688239 & 6.2362 & 5.4872 & TRN & \\
\hline CHEMBL1587651 & 688239 & 7.8356 & \multicolumn{2}{|c|}{5.502000000000001} & TRN \\
\hline CHEMBL1392629 & 688239 & 5.1862 & 5.4971 & TRN & \\
\hline CHEMBL1448667 & 688239 & 6.1862 & 5.4952 & TRN & \\
\hline CHEMBL1571640 & 688239 & 7.0862 & 5.4322 & TRN & \\
\hline CHEMBL1421986 & 688239 & 5.1862 & 5.5356 & TRN & \\
\hline CHEMBL1392005 & 688239 & 5.4362 & 5.5524 & TRN & \\
\hline CHEMBL1512569 & 688239 & 4.5862 & 5.4656 & TRN & \\
\hline CHEMBL1343562 & 688239 & 4.5362 & 5.5419 & TRN & \\
\hline CHEMBL1469718 & 688239 & 4.8362 & 5.4668 & TRN & \\
\hline CHEMBL3209977 & 688239 & 7.8861 & 5.2962 & TRN & \\
\hline CHEMBL3198638 & 688239 & 5.3362 & 5.5487 & TRN & \\
\hline CHEMBL1356075 & 688239 & 6.1362 & \multicolumn{2}{|c|}{5.4510000000000005} & TST \\
\hline CHEMBL1463364 & 688239 & 8.1367 & 5.5505 & TRN & \\
\hline CHEMBL1970812 & 688239 & 4.5362 & 5.3881 & TST & \\
\hline CHEMBL1378130 & 688239 & 4.5362 & 5.6519 & TRN & \\
\hline CHEMBL1589179 & 688239 & 6.5862 & 5.6922 & TRN & \\
\hline CHEMBL1397948 & 688239 & 5.9362 & 5.4777 & TRN & \\
\hline CHEMBL1584080 & 688239 & 6.9863 & 5.5174 & TRN & \\
\hline CHEMBL1525019 & 688239 & 4.5362 & 5.5267 & TRN & \\
\hline CHEMBL1494416 & 688239 & 4.5862 & 5.4626 & TRN & \\
\hline CHEMBL1338354 & 688239 & 5.4862 & 5.3574 & TRN & \\
\hline CHEMBL1597807 & 688239 & 4.5862 & 5.4579 & TRN & \\
\hline CHEMBL1533945 & 688239 & 8.3372 & 5.5835 & TRN & \\
\hline CHEMBL1544114 & 688239 & 5.5362 & 5.4034 & TRN & \\
\hline CHEMBL1494190 & 688239 & 5.1862 & 5.3904 & TRN & \\
\hline CHEMBL1384656 & 688239 & 6.1862 & 5.5528 & TRN & \\
\hline CHEMBL1481971 & 688239 & 8.1871 & 5.4687 & TRN & \\
\hline CHEMBL1570681 & 688239 & 5.3862 & 5.3612 & TRN & \\
\hline CHEMBL3192406 & 688239 & 8.3872 & 5.3024 & TST & \\
\hline CHEMBL1392447 & 688239 & 6.1362 & 5.5201 & TRN & \\
\hline CHEMBL1546928 & 688239 & 5.1862 & 5.5815 & TRN & \\
\hline CHEMBL1490972 & 688239 & 4.5362 & 5.3325 & TRN & \\
\hline CHEMBL1404008 & 688239 & 5.1862 & 5.4799 & TRN & \\
\hline CHEMBL1505432 & 688239 & 5.4362 & 5.459 & TST & \\
\hline CHEMBL1344967 & 688239 & 5.6362 & 5.4816 & TRN & \\
\hline CHEMBL1562377 & 688239 & 6.1362 & 5.4571 & TST & \\
\hline CHEMBL1444422 & 688239 & 6.0862 & 5.4597 & TRN & \\
\hline CHEMBL1331214 & 688239 & 4.6362 & 5.5501 & TST & \\
\hline CHEMBL1475973 & 688239 & 4.5362 & 5.4193 & TRN & \\
\hline CHEMBL1603874 & 688239 & 5.1862 & 5.6033 & TRN & \\
\hline CHEMBL1608909 & 688239 & 5.7362 & 5.4885 & TST & \\
\hline CHEMBL1345287 & 688239 & 5.1362 & 5.4212 & TRN & \\
\hline
\end{tabular}


Supplemental Table S2.txt

\begin{tabular}{|c|c|c|c|c|c|}
\hline CHEMBL1380911 & 688239 & 4.5362 & 5.5647 & TST & \\
\hline CHEMBL1334914 & 688239 & 6.3362 & 5.395 & TST & \\
\hline CHEMBL3190238 & 688239 & 8.28399 & 79999999 & 99 & 5.4023 \\
\hline CHEMBL1486051 & 688239 & 6.1362 & 5.2514 & TST & \\
\hline CHEMBL1413622 & 688239 & 6.2862 & 5.7306 & TST & \\
\hline CHEMBL1427305 & 688239 & 4.7862 & 5.2428 & TRN & \\
\hline CHEMBL1516093 & 688239 & 4.5362 & 5.6113 & TRN & \\
\hline CHEMBL1370798 & 688239 & 5.0362 & 5.4897 & TST & \\
\hline CHEMBL1565427 & 688239 & 8.3872 & 5.4718 & TST & \\
\hline CHEMBL1517237 & 688239 & 8.3872 & 5.5365 & TRN & \\
\hline CHEMBL3193014 & 688239 & 5.4862 & 5.5716 & TRN & \\
\hline CHEMBL1306379 & 688239 & 4.5362 & 5.4862 & TST & \\
\hline CHEMBL1441933 & 688239 & 5.0862 & 5.5005 & TRN & \\
\hline CHEMBL1403815 & 688239 & 6.8861 & 5.7189 & TRN & \\
\hline CHEMBL1344035 & 688239 & 6.8362 & 5.5129 & TRN & \\
\hline CHEMBL1477541 & 688239 & 4.5362 & 5.5603 & TRN & \\
\hline CHEMBL1411559 & 688239 & 4.5362 & 5.4091 & TRN & \\
\hline CHEMBL1449641 & 688239 & 4.5862 & 5.5155 & TRN & \\
\hline CHEMBL1320456 & 688239 & 5.1862 & 5.4234 & TRN & \\
\hline CHEMBL1367957 & 688239 & 6.7361 & 5.669 & TRN & \\
\hline CHEMBL1516616 & 688239 & 7.2366 & 5.4811 & TRN & \\
\hline CHEMBL1422639 & 688239 & 5.7862 & 5.6024 & TST & \\
\hline CHEMBL1492342 & 688239 & 4.7862 & 5.4563 & TRN & \\
\hline CHEMBL3191575 & 688239 & 5.1862 & 5.4233 & TRN & \\
\hline CHEMBL1590808 & 688239 & 5.1862 & 5.4194 & TRN & \\
\hline CHEMBL1549029 & 688239 & 5.8862 & 5.5388 & TRN & \\
\hline CHEMBL1480906 & 688239 & 6.9863 & 5.5304 & TST & \\
\hline CHEMBL1434381 & 688239 & 4.7362 & 5.4227 & TRN & \\
\hline CHEMBL1581013 & 688239 & 4.6862 & 5.5896 & TRN & \\
\hline CHEMBL1600175 & 688239 & 4.5362 & 5.4463 & TRN & \\
\hline CHEMBL1607216 & 688239 & 6.9363 & 5.5147 & TST & \\
\hline CHEMBL1544632 & 688239 & 4.5362 & 5.5519 & TRN & \\
\hline CHEMBL1384836 & 688239 & 6.0862 & 5.4348 & TRN & \\
\hline CHEMBL1527195 & 688239 & 6.6861 & 5.5261 & TRN & \\
\hline CHEMBL1320592 & 688239 & 4.6862 & 5.4117 & TRN & \\
\hline CHEMBL1541573 & 688239 & 6.6362 & 5.6049 & TRN & \\
\hline CHEMBL1605615 & 688239 & 6.9363 & 5.5476 & TRN & \\
\hline CHEMBL1478535 & 688239 & 4.5362 & 5.5138 & TST & \\
\hline CHEMBL1586998 & 688239 & 6.0862 & 5.4344 & TRN & \\
\hline CHEMBL1338767 & 688239 & 6.2862 & 5.6732 & TRN & \\
\hline CHEMBL1604678 & 688239 & 5.2362 & 5.5077 & TRN & \\
\hline CHEMBL1575184 & 688239 & 6.7862 & 5.5051 & TRN & \\
\hline CHEMBL1572114 & 688239 & 8.3372 & 5.5914 & TST & \\
\hline CHEMBL1320536 & 688239 & 4.5362 & 5.5737 & TRN & \\
\hline CHEMBL1587296 & 688239 & 4.5362 & 5.3933 & TST & \\
\hline CHEMBL1350795 & 688239 & 6.0862 & 5.4704 & TRN & \\
\hline CHEMBL1324453 & 688239 & 5.8362 & 5.5204 & TRN & \\
\hline CHEMBL1550162 & 688239 & 4.5362 & 5.4455 & TST & \\
\hline
\end{tabular}


Supplemental Table S2.txt

\begin{tabular}{|c|c|c|c|c|}
\hline (1) & & & 5.447 & \\
\hline 97774 & 688239 & 7362 & 5199 & \\
\hline AEMBL1389801 & 88239 & 1862 & 3672 & \\
\hline AEMBL1326707 & 88239 & 1862 & 5963 & \\
\hline 3708 & 239 & 862 & & \\
\hline AEMBL1592124 & 239 & 363 & 981 & \\
\hline AEMBL1335216 & 88239 & 1862 & 3371 & \\
\hline AEMBL1361666 & 88239 & 4.7862 & 1477 & \\
\hline AEMBL1585471 & 688239 & 5.2862 & .4624 & \\
\hline AEMBL1546847 & 88239 & 362 & & \\
\hline AEMBL1334606 & 88239 & 862 & 78 & \\
\hline AEMBL1378069 & 688239 & 6.9863 & 5401 & \\
\hline AEMBL1556729 & 688239 & 862 & & \\
\hline AEMBL1428939 & 688239 & 862 & & \\
\hline 44371 & 88239 & 362 & & \\
\hline AEMBL1611462 & 688239 & 862 & & \\
\hline AEMBL1369478 & 688239 & 372 & 526 & \\
\hline AEMBL1539058 & 688239 & 862 & & \\
\hline 29777 & 688 & 62 & 96 & \\
\hline 94956 & 88239 & 362 & & \\
\hline 15615 & 688239 & 862 & 62 & \\
\hline AEMBL1407911 & 688239 & 862 & & \\
\hline AEMBL: & 688239 & 62 & & \\
\hline 899 & 688 & 6 & & \\
\hline 26 & & & & \\
\hline 40769 & 688239 & 362 & 73 & \\
\hline 02364 & 688239 & 862 & & \\
\hline 32276 & 39 & & & \\
\hline AEMBL1374463 & 688 & 362 & 34 & \\
\hline 067 & 39 & 362 & & \\
\hline 153 & 39 & 62 & 47 & \\
\hline 69157 & 39 & & & \\
\hline AEMBL1447024 & 688 & & & \\
\hline AEMBL1558780 & 688 & 867 & 91 & \\
\hline 7156 & 39 & 62 & & \\
\hline 96 & 39 & 62 & & \\
\hline HEMBL1398781 & 688239 & 62 & 131 & \\
\hline HEMBL1552983 & 688239 & & 24 & \\
\hline HEMBL: & 68 & 362 & 533 & \\
\hline 10542 & 39 & 62 & 221 & \\
\hline 6021 & & 5. & 444 & \\
\hline HEMBL1321205 & 688239 & 5.7862 & 5385 & \\
\hline 87794 & 688239 & 362 & 951 & \\
\hline 99091 & & & & \\
\hline HEMBL1 & & & & \\
\hline HEMBL1492584 & 239 & 362 & 503 & \\
\hline HEMBL1395785 & 688239 & 5.4862 & 5.3837 & \\
\hline HFMBI 1342134 & 688239 & 5.0362 & 5.4314 & \\
\hline
\end{tabular}


Supplemental Table S2.txt

\begin{tabular}{|c|c|c|c|c|c|}
\hline CHEMBL1330578 & 688239 & 4.6362 & 5.3432 & TRN & \\
\hline CHEMBL1453391 & 688239 & 4.9862 & 5.4468 & TRN & \\
\hline CHEMBL1357276 & 688239 & 8.3372 & 5.693 & TRN & \\
\hline CHEMBL1490889 & 688239 & 5.1862 & 5.38 & TRN & \\
\hline CHEMBL1423720 & 688239 & 4.6362 & 5.4894 & TRN & \\
\hline CHEMBL1573544 & 688239 & 5.8362 & 5.4706 & TST & \\
\hline CHEMBL1413727 & 688239 & 4.7362 & 5.6786 & TRN & \\
\hline CHEMBL1564321 & 688239 & 5.8362 & 5.4842 & TRN & \\
\hline CHEMBL1606560 & 688239 & 4.4862 & 5.4486 & TRN & \\
\hline CHEMBL1385927 & 688239 & 4.7862 & 5.5066 & TRN & \\
\hline CHEMBL1442226 & 688239 & 6.1862 & 5.5826 & TRN & \\
\hline CHEMBL1543473 & 688239 & 4.5362 & 5.5006 & TRN & \\
\hline CHEMBL1576251 & 688239 & 5.3362 & 5.4165 & TRN & \\
\hline CHEMBL1320349 & 688239 & 5.1862 & 5.5481 & TRN & \\
\hline CHEMBL600660 & 688239 & 4.8362 & 5.4899 & TRN & \\
\hline CHEMBL1546183 & 688239 & 4.5362 & 5.2526 & TRN & \\
\hline CHEMBL1369643 & 688239 & 6.9863 & 5.4013 & TRN & \\
\hline CHEMBL1454692 & 688239 & 5.1862 & 5.547999 & 9999999999 & TR \\
\hline CHEMBL1490546 & 688239 & 4.7362 & 5.4879 & TRN & \\
\hline CHEMBL1353782 & 688239 & 4.6362 & 5.4988 & TRN & \\
\hline CHEMBL1366323 & 688239 & 8.3372 & 5.5164 & TRN & \\
\hline CHEMBL1299853 & 688239 & 5.6362 & 5.4491 & TRN & \\
\hline CHEMBL1430937 & 688239 & 4.8862 & 5.3215 & TRN & \\
\hline CHEMBL1345556 & 688239 & 5.1862 & 5.6693 & TRN & \\
\hline CHEMBL1352481 & 688239 & 6.3362 & 5.6188 & TST & \\
\hline CHEMBL1460705 & 688239 & 6.2362 & 5.4715 & TRN & \\
\hline CHEMBL1328174 & 688239 & 4.5362 & 5.4353 & TRN & \\
\hline CHEMBL1549370 & 688239 & 8.28399 & 99999999 & 5.4853 & TST \\
\hline CHEMBL1480349 & 688239 & 4.6362 & 5.5916 & TRN & \\
\hline CHEMBL1610563 & 688239 & 4.5362 & 5.435 & TST & \\
\hline CHEMBL1512903 & 688239 & 4.5862 & 5.496 & TRN & \\
\hline CHEMBL1548305 & 688239 & 6.0862 & 5.5053 & TRN & \\
\hline CHEMBL1384611 & 688239 & 4.6362 & 5.4682 & TRN & \\
\hline CHEMBL1415377 & 688239 & 4.7362 & 5.3742 & TRN & \\
\hline CHEMBL1525343 & 688239 & 4.6862 & 5.4246 & TRN & \\
\hline CHEMBL1479222 & 688239 & 5.5362 & 5.6042 & TRN & \\
\hline CHEMBL1480927 & 688239 & 5.5862 & 5.4517 & TST & \\
\hline CHEMBL1440472 & 688239 & 4.6862 & 5.4499 & TST & \\
\hline CHEMBL1417240 & 688239 & 4.5362 & 5.5286 & TRN & \\
\hline CHEMBL1391784 & 688239 & 7.1361 & 5.582999 & 9999999999 & $\pi$ \\
\hline CHEMBL1447657 & 688239 & 4.5362 & 5.4128 & TST & \\
\hline CHEMBL1471824 & 688239 & 6.8861 & 5.5566 & TRN & \\
\hline CHEMBL1381200 & 688239 & 4.5362 & 5.455 & TRN & \\
\hline CHEMBL1482386 & 688239 & 4.6862 & 5.3579 & TST & \\
\hline CHEMBL1299622 & 688239 & 5.2362 & 5.6594 & TST & \\
\hline CHEMBL1579873 & 688239 & 5.3862 & 5.4895 & TST & \\
\hline CHEMBL1426984 & 688239 & 6.0362 & 5.6668 & TRN & \\
\hline CHEMBL3209382 & 688239 & 4.4862 & 5.4858 & TRN & \\
\hline
\end{tabular}


Supplemental Table S2.txt

\begin{tabular}{|c|c|c|c|c|}
\hline CHEMBL1367288 & 688239 & 4.7362 & 5.4987 & TRN \\
\hline CHEMBL1483035 & 688239 & 5.7362 & 5.3943 & TRN \\
\hline CHEMBL1461490 & 688239 & 4.5362 & 5.4902 & TRN \\
\hline CHEMBL1562682 & 688239 & 4.5362 & 5.4996 & TST \\
\hline CHEMBL1527588 & 688239 & 4.5362 & 5.5319 & TST \\
\hline CHEMBL1414486 & 688239 & 8.3872 & 5.2842 & TRN \\
\hline CHEMBL3189761 & 688239 & 4.5362 & 5.4948 & TST \\
\hline CHEMBL1300601 & 688239 & 4.6862 & 5.4989 & TRN \\
\hline CHEMBL 388025 & 688239 & 6.2362 & 5.4849 & TRN \\
\hline CHEMBL1327596 & 688239 & 4.5362 & 5.5261 & TRN \\
\hline CHEMBL1394489 & 688239 & 4.9362 & 5.428 & TRN \\
\hline CHEMBL3196074 & 688239 & 7.1864 & 5.4278 & TRN \\
\hline CHEMBL1516692 & 688239 & 5.0362 & 5.5083 & TRN \\
\hline CHEMBL1580834 & 688239 & 5.1862 & 5.3727 & TST \\
\hline CHEMBL1406736 & 688239 & 5.3862 & 5.51 & TRN \\
\hline CHEMBL3211925 & 688239 & 4.4862 & 5.4408 & TRN \\
\hline CHEMBL1470262 & 688239 & 6.8861 & 5.4973 & TRN \\
\hline CHEMBL1597137 & 688239 & 4.7362 & 5.53299 & 99999999995 \\
\hline CHEMBL1601206 & 688239 & 5.6862 & 5.5004 & TRN \\
\hline CHEMBL1497849 & 688239 & 6.1862 & 5.2992 & TRN \\
\hline CHEMBL1498729 & 688239 & 8.3372 & 5.4741 & TRN \\
\hline CHEMBL1484283 & 688239 & 4.5362 & 5.4555 & TST \\
\hline CHEMBL1519004 & 688239 & 7.2366 & 5.5242 & TRN \\
\hline CHEMBL1306188 & 688239 & 4.5362 & 5.5427 & TRN \\
\hline CHEMBL1470144 & 688239 & 5.2862 & 5.5255 & TST \\
\hline CHEMBL1491193 & 688239 & 4.5362 & 5.5874 & TRN \\
\hline CHEMBL1537465 & 688239 & 5.0862 & 5.4681 & TST \\
\hline CHEMBL3194983 & 688239 & 6.1862 & 5.5423 & TRN \\
\hline CHEMBL1301150 & 688239 & 5.0862 & 5.2611 & TRN \\
\hline CHEMBL1465930 & 688239 & 6.7361 & 5.4006 & TST \\
\hline CHEMBL1428164 & 688239 & 5.1862 & 5.3419 & TST \\
\hline CHEMBL1382349 & 688239 & 5.8362 & 5.565 & TRN \\
\hline CHEMBL1328707 & 688239 & 5.2862 & 5.5496 & TRN \\
\hline CHEMBL578939 & 688239 & 5.1862 & 5.409 & TST \\
\hline CHEMBL1326118 & 688239 & 4.6362 & 5.226 & TRN \\
\hline CHEMBL1337402 & 688239 & 4.5362 & 5.5182 & TST \\
\hline CHEMBL1442593 & 688239 & 6.0862 & 5.7152 & TRN \\
\hline CHEMBL1468474 & 688239 & 6.6362 & 5.5912 & TRN \\
\hline CHEMBL1304492 & 688239 & 6.6362 & 5.5287 & TRN \\
\hline CHEMBL1507853 & 688239 & 5.5862 & 5.5085 & TRN \\
\hline CHEMBL1333453 & 688239 & 4.8362 & 5.4078 & TRN \\
\hline CHEMBL1429648 & 688239 & 4.7362 & 5.4516 & TST \\
\hline CHEMBL1465761 & 688239 & 5.2862 & 5.5592 & TST \\
\hline CHEMBL1453268 & 688239 & 4.4862 & 5.4992 & TRN \\
\hline CHEMBL1466558 & 688239 & 4.5862 & 5.3847 & TRN \\
\hline CHEMBL1529909 & 688239 & 5.6862 & 5.5911 & TRN \\
\hline CHEMBL1359210 & 688239 & 4.6362 & 5.5376 & TRN \\
\hline CHEMBL1396344 & 688239 & 5.9862 & 5.3978 & TRN \\
\hline
\end{tabular}


Supplemental Table S2.txt

\begin{tabular}{|c|c|c|c|c|c|}
\hline CHEMBL1538234 & 688239 & 4.7362 & 5.3343 & TRN & \\
\hline CHEMBL1532992 & 688239 & 5.6362 & 5.6649 & TRN & \\
\hline CHEMBL1608008 & 688239 & 5.0362 & 5.5073 & TST & \\
\hline CHEMBL1571973 & 688239 & 5.4362 & 5.1803 & TST & \\
\hline CHEMBL1425950 & 688239 & 4.5362 & 5.4722 & TRN & \\
\hline CHEMBL1495202 & 688239 & 5.4362 & 5.4883 & TST & \\
\hline CHEMBL1381508 & 688239 & 4.5362 & 5.6572 & TRN & \\
\hline CHEMBL1328193 & 688239 & 4.5362 & 5.4052 & TST & \\
\hline CHEMBL1487208 & 688239 & 8.3372 & 5.4906 & TST & \\
\hline CHEMBL1535450 & 688239 & 4.7862 & 5.4159 & TRN & \\
\hline CHEMBL265938 & 688239 & 4.8862 & 5.4717 & TRN & \\
\hline CHEMBL1496917 & 688239 & 4.5362 & 5.3882 & TST & \\
\hline CHEMBL1516873 & 688239 & 6.0 & 5.5415 & TRN & \\
\hline CHEMBL1478459 & 688239 & 4.7362 & 5.5908 & TST & \\
\hline CHEMBL1481423 & 688239 & 4.6862 & 5.6265 & TRN & \\
\hline CHEMBL1431054 & 688239 & 5.2362 & 5.6722 & TRN & \\
\hline CHEMBL1981214 & 688239 & 4.5362 & 5.4106 & TRN & \\
\hline CHEMBL1494063 & 688239 & 7.0862 & 5.5524 & TRN & \\
\hline CHEMBL1362916 & 688239 & 5.8362 & 5.4815 & TRN & \\
\hline CHEMBL1406588 & 688239 & 4.9862 & 5.5301 & TRN & \\
\hline CHEMBL1306383 & 688239 & 8.28399 & 99999999 & 99 & 5.4395 \\
\hline CHEMBL1371954 & 688239 & 4.5362 & 5.5047 & TRN & \\
\hline CHEMBL1350304 & 688239 & 6.2362 & 5.5287 & TRN & \\
\hline CHEMBL1576348 & 688239 & 5.8362 & 5.3997 & TRN & \\
\hline CHEMBL1454546 & 688239 & 4.7862 & 5.3766 & TRN & \\
\hline CHEMBL1348641 & 688239 & 5.5362 & 5.3635 & TST & \\
\hline CHEMBL1530220 & 688239 & 4.6862 & 5.4619 & TST & \\
\hline CHEMBL1543019 & 688239 & 5.7362 & 5.4607 & TRN & \\
\hline CHEMBL1484058 & 688239 & 6.7361 & 5.4391 & TRN & \\
\hline CHEMBL1350851 & 688239 & 4.4862 & 5.5438 & TST & \\
\hline CHEMBL1308819 & 688239 & 4.5362 & 5.4016 & TRN & \\
\hline CHEMBL1597481 & 688239 & 5.9862 & 5.5632 & TRN & \\
\hline CHEMBL1521806 & 688239 & 5.0862 & 5.3545 & TRN & \\
\hline CHEMBL1328469 & 688239 & 6.2362 & 5.3617 & TRN & \\
\hline CHEMBL1608016 & 688239 & 4.9362 & 5.5349 & TRN & \\
\hline CHEMBL1316950 & 688239 & 6.2362 & 5.6038 & TRN & \\
\hline CHEMBL1406089 & 688239 & 4.7362 & 5.5309 & TRN & \\
\hline CHEMBL1311376 & 688239 & 6.8362 & 5.4638 & TRN & \\
\hline CHEMBL1568887 & 688239 & 4.5362 & 5.3154 & TRN & \\
\hline CHEMBL1578572 & 688239 & 8.3372 & 5.5253 & TRN & \\
\hline CHEMBL1307800 & 688239 & 5.4862 & 5.3372 & TST & \\
\hline CHEMBL1317253 & 688239 & 5.0362 & 5.3674 & TRN & \\
\hline CHEMBL1420329 & 688239 & 4.5362 & 5.6917 & TST & \\
\hline CHEMBL1522256 & 688239 & 4.5362 & 5.4826 & TRN & \\
\hline CHEMBL1509926 & 688239 & 5.9862 & 5.4941 & TRN & \\
\hline CHEMBL 3208845 & 688239 & 4.5362 & 5.474 & TST & \\
\hline CHEMBL1556268 & 688239 & 4.5362 & 5.4914 & TRN & \\
\hline CHEMBL1413159 & 688239 & 5.1862 & 5.3968 & TRN & \\
\hline
\end{tabular}

Page 2571 
Supplemental Table S2.txt

\begin{tabular}{|c|c|c|c|c|}
\hline CHEMBL1600830 & 688239 & 4.5362 & 5.4223 & TST \\
\hline CHEMBL1422358 & 688239 & 6.0862 & 5.4489 & TRN \\
\hline CHEMBL1520826 & 688239 & 5.5862 & 5.5639 & TRN \\
\hline CHEMBL1541171 & 688239 & 4.85 & 5.4411 & TRN \\
\hline CHEMBL1441452 & 688239 & 4.4862 & 5.2966 & TRN \\
\hline CHEMBL1502549 & 688239 & 4.6362 & 5.5923 & TRN \\
\hline CHEMBL1508078 & 688239 & 8.3372 & 5.3957 & TRN \\
\hline CHEMBL1315379 & 688239 & 5.2362 & 5.5621 & TRN \\
\hline CHEMBL1309137 & 688239 & 6.2862 & 5.4365 & TRN \\
\hline CHEMBL1410517 & 688239 & 4.5362 & 5.5963 & TST \\
\hline CHEMBL1394336 & 688239 & 6.3362 & \multicolumn{2}{|c|}{5.571000000000001} \\
\hline CHEMBL1488519 & 688239 & 4.5362 & 5.6033 & TRN \\
\hline CHEMBL1496640 & 688239 & 4.6362 & 5.38399 & 99999999995 \\
\hline CHEMBL1328559 & 688239 & 6.4862 & 5.3023 & TST \\
\hline CHEMBL1485058 & 688239 & 4.5362 & 5.4054 & TRN \\
\hline CHEMBL1453047 & 688239 & 4.7862 & 5.5672 & TRN \\
\hline CHEMBL1446653 & 688239 & 5.3862 & 5.5172 & TRN \\
\hline CHEMBL1581913 & 688239 & 4.7362 & 5.5095 & TRN \\
\hline CHEMBL1538505 & 688239 & 5.1862 & 5.6506 & TRN \\
\hline CHEMBL1390499 & 688239 & 4.5362 & 5.5694 & TRN \\
\hline CHEMBL1613246 & 688239 & 4.6362 & 5.526 & TRN \\
\hline CHEMBL1368387 & 688239 & 4.7362 & 5.6217 & TRN \\
\hline CHEMBL1341287 & 688239 & 5.6862 & 5.6125 & TRN \\
\hline CHEMBL1528096 & 688239 & 6.1362 & 5.5356 & TRN \\
\hline CHEMBL1559923 & 688239 & 5.5862 & 5.4385 & TST \\
\hline CHEMBL1405127 & 688239 & 4.5362 & 5.6557 & TRN \\
\hline CHEMBL1465242 & 688239 & 6.3863 & 5.439 & TRN \\
\hline CHEMBL1560561 & 688239 & 6.1862 & 5.5226 & TST \\
\hline CHEMBL1603917 & 688239 & 7.5361 & 5.5178 & TRN \\
\hline CHEMBL1344389 & 688239 & 5.3862 & 5.5432 & TRN \\
\hline CHEMBL1335518 & 688239 & 5.7362 & 5.2949 & TRN \\
\hline CHEMBL1367327 & 688239 & 6.5862 & 5.4817 & TRN \\
\hline CHEMBL1409709 & 688239 & 4.5362 & 5.4149 & TST \\
\hline CHEMBL1421071 & 688239 & 5.1862 & 5.5278 & TRN \\
\hline CHEMBL 3191250 & 688239 & 4.7362 & 5.544 & TST \\
\hline CHEMBL1518480 & 688239 & 4.5362 & 5.4723 & TRN \\
\hline CHEMBL1308794 & 688239 & 5.4362 & 5.4116 & TRN \\
\hline CHEMBL1603581 & 688239 & 4.7362 & 5.2562 & TST \\
\hline CHEMBL1300395 & 688239 & 4.5862 & 5.49 & TST \\
\hline CHEMBL1337611 & 688239 & 4.5362 & 5.5313 & TRN \\
\hline CHEMBL1325698 & 688239 & 4.7362 & 5.6107 & TRN \\
\hline CHEMBL1305711 & 688239 & 6.2362 & 5.5902 & TRN \\
\hline CHEMBL 246713 & 688239 & 6.2362 & 5.54200 & 0000000001 \\
\hline CHEMBL1305074 & 688239 & 4.5362 & 5.4251 & TRN \\
\hline CHEMBL1556832 & 688239 & 6.8362 & 5.4916 & TRN \\
\hline CHEMBL1595626 & 688239 & 4.5362 & 5.5208 & TRN \\
\hline CHEMBL1546274 & 688239 & 5.8862 & 5.5533 & TRN \\
\hline CHEMBL1506936 & 688239 & 4.7862 & 5.5438 & TST \\
\hline
\end{tabular}


Supplemental Table S2.txt

\begin{tabular}{|c|c|c|c|c|c|}
\hline CHEMBL1304687 & 688239 & 6.5862 & 5.4966 & TRN & \\
\hline CHEMBL1463928 & 688239 & 4.4362 & 5.3822 & TRN & \\
\hline CHEMBL1521655 & 688239 & 4.5362 & 5.4775 & TRN & \\
\hline CHEMBL1398252 & 688239 & 4.7862 & 5.4635 & TRN & \\
\hline CHEMBL1538745 & 688239 & 4.7862 & 5.5114 & TST & \\
\hline CHEMBL1332435 & 688239 & 5.3862 & 5.5369 & TST & \\
\hline CHEMBL1421994 & 688239 & 7.0362 & 5.6032 & TRN & \\
\hline CHEMBL3191396 & 688239 & 5.1362 & 5.6868 & TRN & \\
\hline CHEMBL1519241 & 688239 & 4.5362 & 5.54200 & 0000000001 & $1 \mathrm{n}$ \\
\hline CHEMBL1485159 & 688239 & 4.5362 & 5.3577 & TST & \\
\hline CHEMBL1450212 & 688239 & 6.1362 & 5.6084 & TST & \\
\hline CHEMBL1361375 & 688239 & 4.6862 & 5.5222 & TRN & \\
\hline CHEMBL1563887 & 688239 & 5.8862 & 5.4537 & TRN & \\
\hline CHEMBL1389622 & 688239 & 5.2362 & 5.58799 & 9999999999 & \\
\hline CHEMBL1476117 & 688239 & 5.1862 & 5.4897 & TRN & \\
\hline CHEMBL1569506 & 688239 & 6.9363 & 5.5076 & TRN & \\
\hline CHEMBL1542960 & 688239 & 4.5862 & 5.3644 & TRN & \\
\hline CHEMBL1562173 & 688239 & 6.0362 & 5.3942 & TST & \\
\hline CHEMBL1578934 & 688239 & 5.1862 & 5.4848 & TRN & \\
\hline CHEMBL1490840 & 688239 & 6.6362 & 5.4208 & TST & \\
\hline CHEMBL1437191 & 688239 & 4.7362 & 5.4454 & TRN & \\
\hline CHEMBL1359982 & 688239 & 4.5362 & 5.4921 & TRN & \\
\hline CHEMBL1504179 & 688239 & 6.1862 & 5.5346 & TST & \\
\hline CHEMBL3197592 & 688239 & 4.5362 & 5.3932 & TST & \\
\hline CHEMBL 3214290 & 688239 & 4.5362 & 5.4687 & TST & \\
\hline CHEMBL 1413441 & 688239 & 6.9863 & 5.5168 & TRN & \\
\hline CHEMBL1359065 & 688239 & 5.3362 & 5.5379 & TRN & \\
\hline CHEMBL1434148 & 688239 & 4.6362 & 5.5313 & TST & \\
\hline CHEMBL1605348 & 688239 & 6.1362 & 5.4738 & TST & \\
\hline CHEMBL1420890 & 688239 & \multicolumn{3}{|c|}{8.283999999999999} & \\
\hline CHEMBL1453014 & 688239 & 8.2366 & 5.6133 & TST & \\
\hline CHEMBL1349177 & 688239 & 5.6862 & 5.7103 & TST & \\
\hline CHEMBL1426746 & 688239 & 5.2862 & 5.4865 & TRN & \\
\hline CHEMBL1576453 & 688239 & 4.4862 & 5.5077 & TST & \\
\hline CHEMBL1583530 & 688239 & 5.7362 & 5.57 & TRN & \\
\hline CHEMBL1330820 & 688239 & 5.8362 & 5.7113 & TRN & \\
\hline CHEMBL1460387 & 688239 & 4.9362 & 5.4699 & TRN & \\
\hline CHEMBL1489418 & 688239 & 6.4362 & 5.38299 & 9999999999 & \\
\hline CHEMBL1350213 & 688239 & 4.8 & 5.3305 & TST & \\
\hline CHEMBL1495528 & 688239 & 4.6362 & 5.4794 & TST & \\
\hline CHEMBL1571692 & 688239 & 4.7862 & 5.4747 & TST & \\
\hline CHEMBL1564911 & 688239 & 5.1862 & 5.6901 & TRN & \\
\hline CHEMBL1562126 & 688239 & 4.5362 & 5.53700 & 0000000001 & \\
\hline CHEMBL1358830 & 688239 & 5.4862 & 5.7026 & TRN & \\
\hline CHEMBL1350569 & 688239 & 5.4862 & 5.5191 & TRN & \\
\hline CHEMBL1606388 & 688239 & 7.6364 & 5.4061 & TST & \\
\hline CHEMBL1314050 & 688239 & 6.2362 & 5.6132 & TRN & \\
\hline CHEMBL1520790 & 688239 & 5.2862 & 5.6455 & TRN & \\
\hline
\end{tabular}


Supplemental Table S2.txt

\begin{tabular}{|c|c|c|c|c|}
\hline CHEMBL1484492 & 688239 & 6.8362 & 5.4427 & TRN \\
\hline CHEMBL1606134 & 688239 & 4.4862 & 5.532 & TRN \\
\hline CHEMBL1586630 & 688239 & 6.9363 & 5.5788 & TRN \\
\hline CHEMBL1384149 & 688239 & 5.6862 & 5.50299 & 9999999999 \\
\hline CHEMBL1427098 & 688239 & 4.6362 & 5.4484 & TRN \\
\hline CHEMBL1579458 & 688239 & 6.7862 & 5.5007 & TRN \\
\hline CHEMBL1389150 & 688239 & 8.3372 & 5.5448 & TRN \\
\hline CHEMBL1414777 & 688239 & 4.5362 & 5.4719 & TRN \\
\hline CHEMBL1340444 & 688239 & 7.1864 & 5.5279 & TRN \\
\hline CHEMBL1381600 & 688239 & 4.7362 & 5.4041 & TRN \\
\hline CHEMBL1490993 & 688239 & 4.5362 & 5.5796 & TRN \\
\hline CHEMBL567422 & 688239 & 5.6862 & 5.5938 & TST \\
\hline CHEMBL1582071 & 688239 & 4.8362 & 5.3014 & TST \\
\hline CHEMBL1603633 & 688239 & 5.1362 & 5.6041 & TRN \\
\hline CHEMBL1383674 & 688239 & 4.4862 & 5.5536 & TST \\
\hline CHEMBL1450225 & 688239 & 5.5362 & 5.5409 & TRN \\
\hline CHEMBL1456904 & 688239 & 5.4362 & 5.3886 & TRN \\
\hline CHEMBL1527262 & 688239 & 6.3863 & 5.4166 & TRN \\
\hline CHEMBL1516945 & 688239 & 5.8362 & 5.4928 & TRN \\
\hline CHEMBL1447021 & 688239 & 4.6862 & 5.4659 & TRN \\
\hline CHEMBL1385776 & 688239 & 5.4862 & 5.4882 & TRN \\
\hline CHEMBL1389837 & 688239 & 5.4362 & 5.4732 & TRN \\
\hline CHEMBL1364309 & 688239 & 5.8362 & 5.5924 & TRN \\
\hline CHEMBL1599252 & 688239 & 4.5362 & 5.4893 & TRN \\
\hline CHEMBL1576398 & 688239 & 5.4362 & 5.5854 & TST \\
\hline CHEMBL1351810 & 688239 & 7.1361 & 5.4088 & TRN \\
\hline CHEMBL1304214 & 688239 & 5.6862 & 5.5325 & TRN \\
\hline CHEMBL1521492 & 688239 & 6.9363 & 5.4944 & TRN \\
\hline CHEMBL1299560 & 688239 & 5.7362 & 5.4953 & TRN \\
\hline CHEMBL1485081 & 688239 & 5.6362 & 5.3672 & TST \\
\hline CHEMBL1467660 & 688239 & 5.2862 & 5.5307 & TST \\
\hline CHEMBL1592882 & 688239 & 5.1862 & 5.4708 & TRN \\
\hline CHEMBL1320539 & 688239 & 5.6862 & 5.5372 & TRN \\
\hline CHEMBL1373029 & 688239 & 5.4362 & 5.3725 & TRN \\
\hline CHEMBL1456992 & 688239 & 5.0862 & 5.624 & TRN \\
\hline CHEMBL1433537 & 688239 & 4.8362 & 5.6091 & TST \\
\hline CHEMBL1376083 & 688239 & 5.1862 & 5.5118 & TRN \\
\hline CHEMBL3208242 & 688239 & 4.5862 & 5.3391 & TRN \\
\hline CHEMBL1353188 & 688239 & 4.7862 & 5.4511 & TRN \\
\hline CHEMBL1334822 & 688239 & 5.4362 & 5.3956 & TRN \\
\hline CHEMBL1322860 & 688239 & 5.2862 & 5.6636 & TRN \\
\hline CHEMBL1431224 & 688239 & 5.1862 & 5.4528 & TRN \\
\hline CHEMBL1505638 & 688239 & 4.45 & 5.6192 & TRN \\
\hline CHEMBL1367249 & 688239 & 4.6862 & 5.485 & TRN \\
\hline CHEMBL3191365 & 688239 & 4.5362 & 5.3859 & TRN \\
\hline CHEMBL1376004 & 688239 & 5.0362 & 5.4658 & TRN \\
\hline CHEMBL1344145 & 688239 & 7.7352 & 5.3355 & TRN \\
\hline CHEMBL1472748 & 688239 & 5.8362 & 5.4942 & TRN \\
\hline
\end{tabular}


Supplemental Table S2.txt

\begin{tabular}{|c|c|c|c|c|c|}
\hline CHEMBL1552801 & 688239 & 4.6362 & 5.4118 & TRN & \\
\hline CHEMBL1381071 & 688239 & 4.5362 & 5.3455 & TRN & \\
\hline CHEMBL1472017 & 688239 & 4.6862 & 5.5519 & TRN & \\
\hline CHEMBL1497897 & 688239 & 5.7362 & 5.3968 & TRN & \\
\hline CHEMBL1361529 & 688239 & 6.7361 & 5.6087 & TRN & \\
\hline CHEMBL1568828 & 688239 & 6.9363 & 5.4821 & TRN & \\
\hline CHEMBL1306688 & 688239 & 4.7362 & 5.4698 & TRN & \\
\hline CHEMBL 3209584 & 688239 & 5.3862 & 5.341 & TRN & \\
\hline CHEMBL1521192 & 688239 & 5.2862 & 5.574 & TRN & \\
\hline CHEMBL1398556 & 688239 & 6.1362 & 5.5248 & TRN & \\
\hline CHEMBL1500208 & 688239 & 6.2362 & 5.5097 & TRN & \\
\hline CHEMBL1302211 & 688239 & 5.9362 & 5.6045 & TST & \\
\hline CHEMBL1419582 & 688239 & 6.8362 & 5.4891 & TST & \\
\hline CHEMBL1494780 & 688239 & 5.3862 & 5.5437 & TRN & \\
\hline CHEMBL1561095 & 688239 & 5.2362 & 5.4685 & TRN & \\
\hline CHEMBL1536205 & 688239 & 5.1862 & 5.5077 & TRN & \\
\hline CHEMBL1419241 & 688239 & 5.6862 & 5.383999 & 9999999995 & TRN \\
\hline CHEMBL1315427 & 688239 & 4.4862 & 5.513 & TST & \\
\hline CHEMBL1413604 & 688239 & 4.5362 & 5.5406 & TRN & \\
\hline CHEMBL1402557 & 688239 & 6.2862 & 5.4972 & TRN & \\
\hline CHEMBL1466388 & 688239 & 4.9362 & 5.5649 & TRN & \\
\hline CHEMBL1393208 & 688239 & 5.1862 & 5.6263 & TRN & \\
\hline CHEMBL1389628 & 688239 & 6.7862 & 5.3769 & TST & \\
\hline CHEMBL1335782 & 688239 & 6.8861 & 5.5804 & TRN & \\
\hline CHEMBL 3198603 & 688239 & 4.5362 & 5.3204 & TST & \\
\hline CHEMBL1372047 & 688239 & 4.5362 & 5.6163 & TRN & \\
\hline CHEMBL1301883 & 688239 & 4.6862 & 5.5836 & TRN & \\
\hline CHEMBL1467794 & 688239 & 6.6362 & 5.3932 & TST & \\
\hline CHEMBL1303599 & 688239 & 4.6362 & 5.4412 & TST & \\
\hline CHEMBL1487082 & 688239 & 5.1362 & 5.4434 & TRN & \\
\hline CHEMBL1478310 & 688239 & 4.7862 & 5.4811 & TST & \\
\hline CHEMBL1564253 & 688239 & 4.6862 & 5.4961 & TST & \\
\hline CHEMBL479685 & 688239 & 6.1362 & 5.631 & TRN & \\
\hline CHEMBL1350078 & 688239 & 4.7362 & 5.5355 & TRN & \\
\hline CHEMBL 3198525 & 688239 & 4.8362 & 5.4689 & TRN & \\
\hline CHEMBL1497749 & 688239 & 4.8862 & 5.6755 & TRN & \\
\hline CHEMBL1587611 & 688239 & 6.1362 & 5.4571 & TRN & \\
\hline CHEMBL1337999 & 688239 & 5.7362 & 5.3123 & TRN & \\
\hline CHEMBL1451320 & 688239 & 6.0362 & 5.5419 & TST & \\
\hline CHEMBL1371488 & 688239 & 4.5362 & 5.4678 & TST & \\
\hline CHEMBL1570025 & 688239 & 4.6862 & 5.5407 & TRN & \\
\hline CHEMBL1526173 & 688239 & 8.28399 & 99999999 & 5.4135 & $1 K \mathrm{~K}$ \\
\hline CHEMBL1322111 & 688239 & 4.7362 & 5.4213 & TRN & \\
\hline CHEMBL1379451 & 688239 & 5.9862 & 5.4091 & TST & \\
\hline CHEMBL1342203 & 688239 & 4.7862 & 5.4819 & TRN & \\
\hline CHEMBL1449667 & 688239 & 6.1362 & 5.3898 & TRN & \\
\hline CHEMBL1425223 & 688239 & 4.5862 & 5.4524 & TST & \\
\hline CHEMBL1402622 & 688239 & 4.4862 & 5.5498 & TST & \\
\hline
\end{tabular}


Supplemental Table S2.txt

\begin{tabular}{|c|c|c|c|c|}
\hline CHEMBL1455896 & 688239 & 4.5362 & 5.4886 & TST \\
\hline CHEMBL1523363 & 688239 & 5.6362 & 5.3299 & TRN \\
\hline CHEMBL1498862 & 688239 & 5.0862 & 5.4266 & TST \\
\hline CHEMBL1509321 & 688239 & 5.7362 & 5.426 & TRN \\
\hline CHEMBL1375532 & 688239 & 6.2862 & 5.4728 & TRN \\
\hline CHEMBL1314715 & 688239 & 6.0862 & 5.7158 & TRN \\
\hline CHEMBL3211262 & 688239 & 6.1862 & 5.4888 & TRN \\
\hline CHEMBL1495662 & 688239 & 4.6362 & 5.3891 & TRN \\
\hline CHEMBL1611113 & 688239 & 4.5362 & 5.5039 & TRN \\
\hline CHEMBL1334975 & 688239 & 4.5362 & 5.4754 & TRN \\
\hline CHEMBL1347671 & 688239 & 5.0862 & 5.5455 & TRN \\
\hline CHEMBL1469131 & 688239 & 4.5862 & 5.4272 & TRN \\
\hline CHEMBL1387363 & 688239 & 5.1862 & 5.403 & TRN \\
\hline CHEMBL1483197 & 688239 & 4.5362 & 5.5614 & TRN \\
\hline CHEMBL 3189597 & 688239 & 4.8862 & 5.3228 & TST \\
\hline CHEMBL1442932 & 688239 & 5.6362 & 5.605 & TRN \\
\hline CHEMBL1606132 & 688239 & 4.6362 & 5.5774 & TRN \\
\hline CHEMBL 3144974 & 688239 & 4.5862 & 5.4466 & TST \\
\hline CHEMBL1438590 & 688239 & 4.6862 & 5.5766 & TST \\
\hline CHEMBL1572266 & 688239 & 6.1862 & 5.4935 & TST \\
\hline CHEMBL1606379 & 688239 & 5.6862 & 5.5228 & TST \\
\hline CHEMBL3209833 & 688239 & 6.2362 & 5.2511 & TST \\
\hline CHEMBL1543675 & 688239 & 5.4862 & 5.3849 & TRN \\
\hline CHEMBL1309975 & 688239 & 5.5362 & 5.4633 & TRN \\
\hline CHEMBL1387297 & 688239 & 7.6364 & 5.4693 & TRN \\
\hline CHEMBL1503390 & 688239 & 4.6362 & 5.4711 & TRN \\
\hline CHEMBL1342635 & 688239 & 4.6362 & 5.3862 & TRN \\
\hline CHEMBL1413739 & 688239 & 5.9362 & 5.5582 & TST \\
\hline CHEMBL1458437 & 688239 & 8.1367 & 5.4029 & TRN \\
\hline CHEMBL1531072 & 688239 & 6.0862 & 5.3921 & TRN \\
\hline CHEMBL1310049 & 688239 & 5.0862 & 5.5427 & TST \\
\hline CHEMBL1551864 & 688239 & 4.5362 & 5.4557 & TST \\
\hline CHEMBL1451734 & 688239 & 6.8362 & 5.6922 & TRN \\
\hline CHEMBL1502881 & 688239 & 6.0862 & 5.5125 & TRN \\
\hline CHEMBL 3198435 & 688239 & 8.2366 & 5.3064 & TRN \\
\hline CHEMBL1563391 & 688239 & 5.6862 & 5.6213 & TST \\
\hline CHEMBL1306341 & 688239 & 4.5362 & 5.6213 & TRN \\
\hline CHEMBL1326924 & 688239 & 5.0362 & 5.6717 & TRN \\
\hline CHEMBL 20730 & 688239 & 6.0 & 5.42700 & 00000000005 \\
\hline CHEMBL1486220 & 688239 & 5.4362 & 5.5054 & TRN \\
\hline CHEMBL 3193984 & 688239 & 5.0362 & 5.5013 & TRN \\
\hline CHEMBL1535528 & 688239 & 4.7362 & 5.6166 & TRN \\
\hline CHEMBL1358962 & 688239 & 6.2862 & 5.4731 & TRN \\
\hline CHEMBL1523078 & 688239 & 6.6861 & 5.4522 & TRN \\
\hline CHEMBL1544368 & 688239 & 5.1862 & 5.3828 & TRN \\
\hline CHEMBL1384672 & 688239 & 7.0862 & 5.6881 & TST \\
\hline CHEMBL1364198 & 688239 & 4.5362 & 5.5666 & TRN \\
\hline CHEMBL1606561 & 688239 & 5.5362 & 5.5509 & TRN \\
\hline
\end{tabular}

Page 2576 
Supplemental Table S2.txt

\begin{tabular}{|c|c|c|c|c|}
\hline CHEMBL1363151 & 688239 & 5.2862 & 5.4487 & TRN \\
\hline CHEMBL1347737 & 688239 & 5.1862 & 5.3717 & TST \\
\hline CHEMBL1413151 & 688239 & 4.5362 & 5.5241 & TRN \\
\hline CHEMBL394108 & 688239 & 5.2862 & 5.5102 & TST \\
\hline CHEMBL1472013 & 688239 & 4.5362 & 5.4684 & TRN \\
\hline CHEMBL 3190937 & 688239 & 6.6362 & 5.4854 & TRN \\
\hline CHEMBL1468473 & 688239 & 4.8862 & 5.4952 & TRN \\
\hline CHEMBL1402631 & 688239 & 4.6362 & 5.5358 & TRN \\
\hline CHEMBL1474348 & 688239 & 4.5362 & 5.5756 & TRN \\
\hline CHEMBL1588773 & 688239 & 6.1362 & \multicolumn{2}{|c|}{5.537999999999999} \\
\hline CHEMBL1542931 & 688239 & 5.0862 & 5.2757 & TST \\
\hline CHEMBL1573485 & 688239 & 5.1862 & 5.5184 & TRN \\
\hline CHEMBL1609063 & 688239 & 4.6862 & 5.4737 & TST \\
\hline CHEMBL1412919 & 688239 & 5.3862 & 5.6457 & TST \\
\hline CHEMBL1324862 & 688239 & 5.5862 & 5.5459 & TST \\
\hline CHEMBL1299794 & 688239 & 4.5362 & 5.7103 & TRN \\
\hline CHEMBL1516937 & 688239 & 4.5362 & 5.3637 & TRN \\
\hline CHEMBL1542820 & 688239 & 5.8862 & 5.5952 & TRN \\
\hline CHEMBL1526602 & 688239 & 5.2862 & 5.6131 & TRN \\
\hline CHEMBL1482014 & 688239 & 8.3372 & 5.5458 & TRN \\
\hline CHEMBL1504337 & 688239 & 5.1862 & 5.5176 & TRN \\
\hline CHEMBL1585412 & 688239 & 6.0 & 5.4493 & TRN \\
\hline CHEMBL1591527 & 688239 & 6.1862 & 5.3183 & TRN \\
\hline CHEMBL1428130 & 688239 & 6.0862 & \multicolumn{2}{|c|}{5.422999999999999} \\
\hline CHEMBL1425089 & 688239 & 4.5362 & 5.5691 & TRN \\
\hline CHEMBL1458796 & 688239 & 4.5362 & 5.3997 & TRN \\
\hline CHEMBL1380146 & 688239 & 5.4362 & 5.5335 & TRN \\
\hline CHEMBL1582895 & 688239 & 4.8362 & 5.4644 & TST \\
\hline CHEMBL1579135 & 688239 & 4.7362 & 5.392 & TRN \\
\hline CHEMBL1482388 & 688239 & 4.5862 & 5.4959 & TRN \\
\hline CHEMBL1571875 & 688239 & 5.2362 & 5.4213 & TRN \\
\hline CHEMBL1979536 & 688239 & 6.2862 & 5.4285 & TRN \\
\hline CHEMBL1415624 & 688239 & 4.6862 & 5.584 & TRN \\
\hline CHEMBL1319906 & 688239 & 5.2362 & 5.5984 & TST \\
\hline CHEMBL1523009 & 688239 & 4.7362 & 5.3914 & TRN \\
\hline CHEMBL3191553 & 688239 & 5.3862 & 5.5287 & TST \\
\hline CHEMBL1318257 & 688239 & 5.2862 & 5.5637 & TST \\
\hline CHEMBL1375790 & 688239 & 5.1862 & 5.5863 & TST \\
\hline CHEMBL1497682 & 688239 & 4.6362 & 5.5541 & TST \\
\hline CHEMBL1510828 & 688239 & 5.1862 & 5.6599 & TRN \\
\hline CHEMBL1392287 & 688239 & 4.8862 & 5.4169 & TRN \\
\hline CHEMBL1596676 & 688239 & 6.8861 & 5.5762 & TRN \\
\hline CHEMBL1567173 & 688239 & 5.2362 & 5.4761 & TRN \\
\hline CHEMBL1465998 & 688239 & 4.9362 & 5.3754 & TRN \\
\hline CHEMBL1524219 & 688239 & 5.4362 & 5.3798 & TRN \\
\hline CHEMBL1495461 & 688239 & 4.5362 & 5.5936 & TRN \\
\hline CHEMBL1415425 & 688239 & 4.5362 & 5.4178 & TRN \\
\hline CHEMBL1353494 & 688239 & 4.6362 & 5.5935 & TST \\
\hline
\end{tabular}

Page 2577 


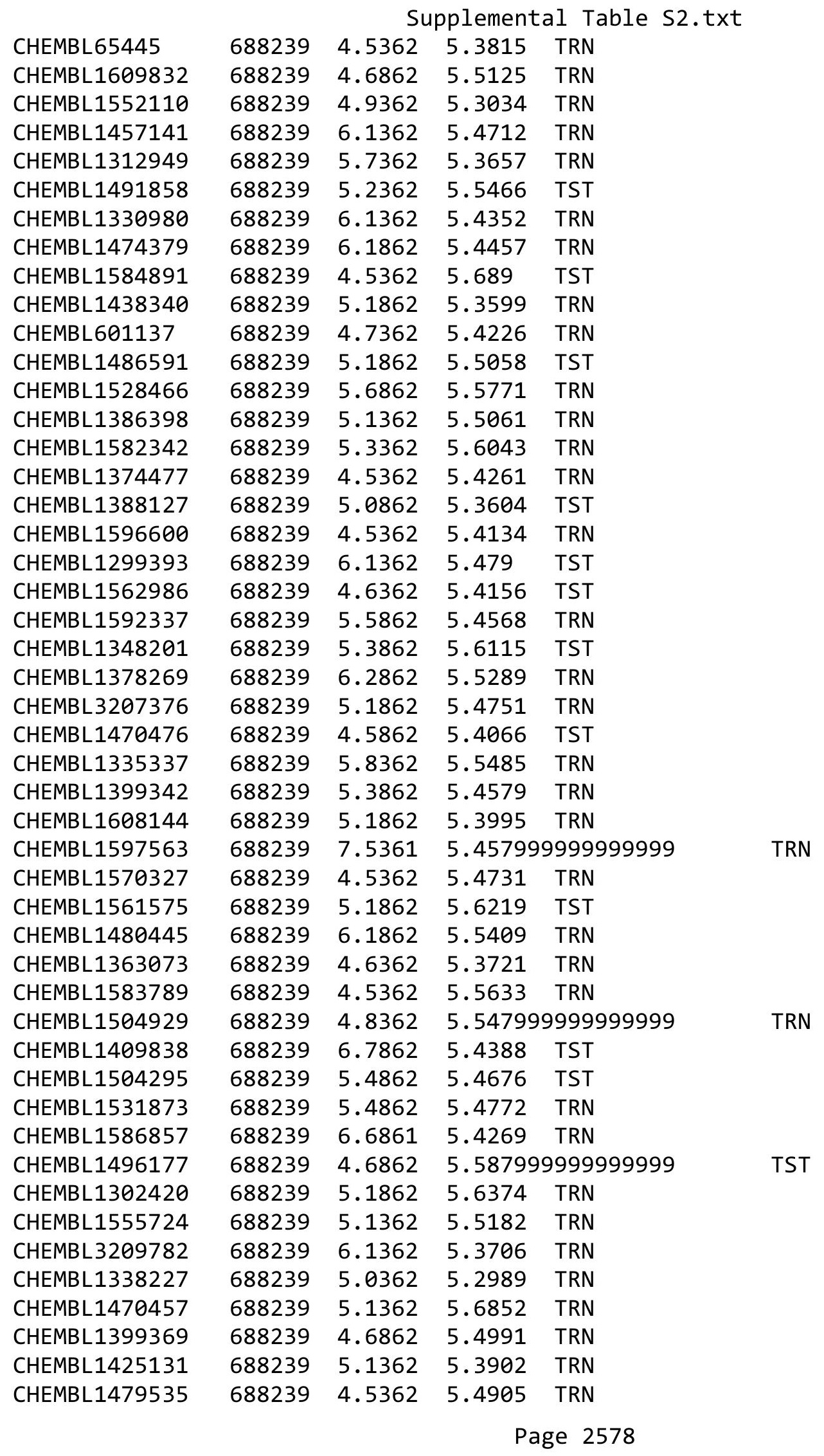


Supplemental Table S2.txt

\begin{tabular}{|c|c|c|c|c|c|}
\hline CHEMBL1529424 & 688239 & 4.7362 & 5.655 & TRN & \\
\hline CHEMBL1367829 & 688239 & 4.5362 & 5.5017 & TST & \\
\hline CHEMBL1389646 & 688239 & 4.5362 & 5.3162 & TRN & \\
\hline CHEMBL1591866 & 688239 & 4.6362 & 5.4025 & TRN & \\
\hline CHEMBL1581405 & 688239 & 4.6362 & 5.4715 & TRN & \\
\hline CHEMBL1539329 & 688239 & 5.7862 & 5.4956 & TRN & \\
\hline CHEMBL1407195 & 688239 & 4.6362 & 5.4833 & TRN & \\
\hline CHEMBL1361218 & 688239 & 6.8362 & 5.3871 & TRN & \\
\hline CHEMBL1468530 & 688239 & 5.5362 & 5.4396 & TST & \\
\hline CHEMBL1451843 & 688239 & 5.3862 & 5.528 & TST & \\
\hline CHEMBL1351766 & 688239 & 6.2362 & 5.4718 & TRN & \\
\hline CHEMBL1442097 & 688239 & 4.5862 & 5.4043 & TRN & \\
\hline CHEMBL1468466 & 688239 & 8.2366 & 5.6405 & TST & \\
\hline CHEMBL1530474 & 688239 & 4.6862 & 5.6301 & TRN & \\
\hline CHEMBL1561126 & 688239 & 4.5362 & 5.5204 & TRN & \\
\hline CHEMBL 1483560 & 688239 & 8.3372 & 5.6313 & TST & \\
\hline CHEMBL1315263 & 688239 & 6.8861 & 5.5665 & TRN & \\
\hline CHEMBL1384550 & 688239 & 5.7862 & 5.4039 & TST & \\
\hline CHEMBL1598024 & 688239 & 5.1862 & 5.6529 & TRN & \\
\hline CHEMBL1400845 & 688239 & 5.1862 & 5.369 & TRN & \\
\hline CHEMBL6816 & 688239 & 6.1862 & 5.5203 & TRN & \\
\hline CHEMBL1474063 & 688239 & 5.6862 & 5.53 & TRN & \\
\hline CHEMBL1360917 & 688239 & 4.5362 & 5.445 & TRN & \\
\hline CHEMBL1600585 & 688239 & 5.9862 & 5.4927 & TRN & \\
\hline CHEMBL1575624 & 688239 & 6.8861 & 5.4196 & TRN & \\
\hline CHEMBL1566749 & 688239 & 6.1862 & 5.6114 & TRN & \\
\hline CHEMBL1316558 & 688239 & 5.2362 & 5.5409 & TRN & \\
\hline CHEMBL1423807 & 688239 & 6.1862 & \multicolumn{2}{|c|}{5.617999999999999} & TRN \\
\hline CHEMBL1315858 & 688239 & 5.5862 & 5.4902 & TRN & \\
\hline CHEMBL1478162 & 688239 & 5.1862 & 5.5732 & TST & \\
\hline CHEMBL3209290 & 688239 & 6.5363 & 5.3869 & TRN & \\
\hline CHEMBL1315842 & 688239 & 4.6362 & 5.4279 & TRN & \\
\hline CHEMBL1559260 & 688239 & 4.7862 & 5.5242 & TST & \\
\hline CHEMBL1490962 & 688239 & 5.0362 & 5.6288 & TRN & \\
\hline CHEMBL1523944 & 688239 & 5.5362 & 5.5093 & TST & \\
\hline CHEMBL1415594 & 688239 & 5.5862 & 5.48 & TRN & \\
\hline CHEMBL1492549 & 688239 & 5.0862 & 5.6289 & TRN & \\
\hline CHEMBL1552726 & 688239 & 6.6861 & 5.414 & TRN & \\
\hline CHEMBL1496554 & 688239 & 4.4862 & \multicolumn{2}{|c|}{5.702000000000001} & TST \\
\hline CHEMBL504294 & 688239 & 5.3862 & 5.3902 & TRN & \\
\hline CHEMBL1580202 & 688239 & 5.9362 & 5.5495 & TRN & \\
\hline CHEMBL1300177 & 688239 & 4.7362 & 5.3158 & TRN & \\
\hline CHEMBL1477482 & 688239 & 5.1362 & 5.499 & TRN & \\
\hline CHEMBL1539967 & 688239 & 5.0862 & 5.5998 & TRN & \\
\hline CHEMBL1390125 & 688239 & 5.1862 & 5.4665 & TST & \\
\hline CHEMBL1540603 & 688239 & 5.5862 & 5.6475 & TST & \\
\hline CHEMBL1458945 & 688239 & 4.5362 & 5.5293 & TRN & \\
\hline CHEMBL1566187 & 688239 & 4.6362 & 5.6014 & TRN & \\
\hline
\end{tabular}




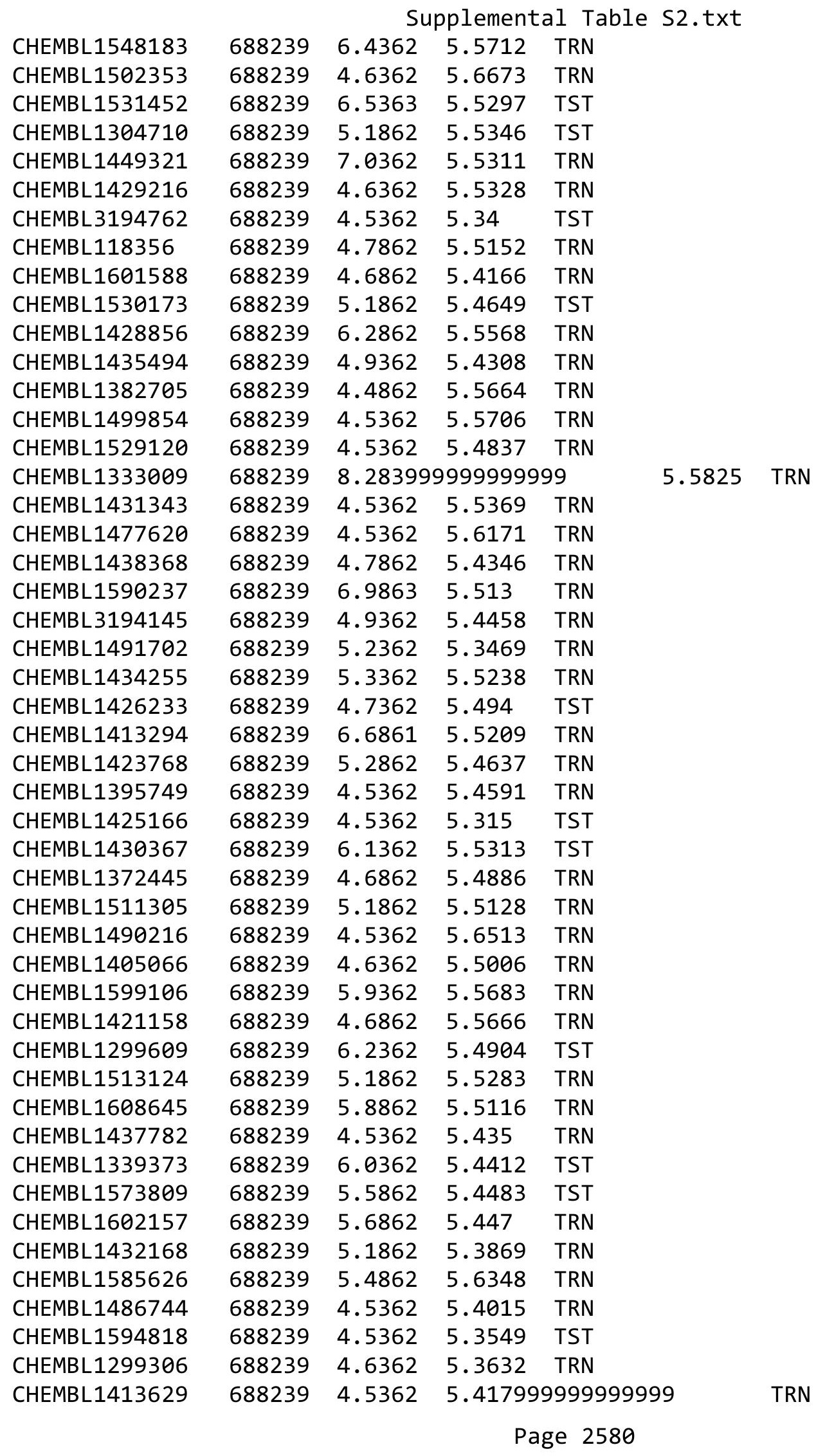


Supplemental Table S2.txt

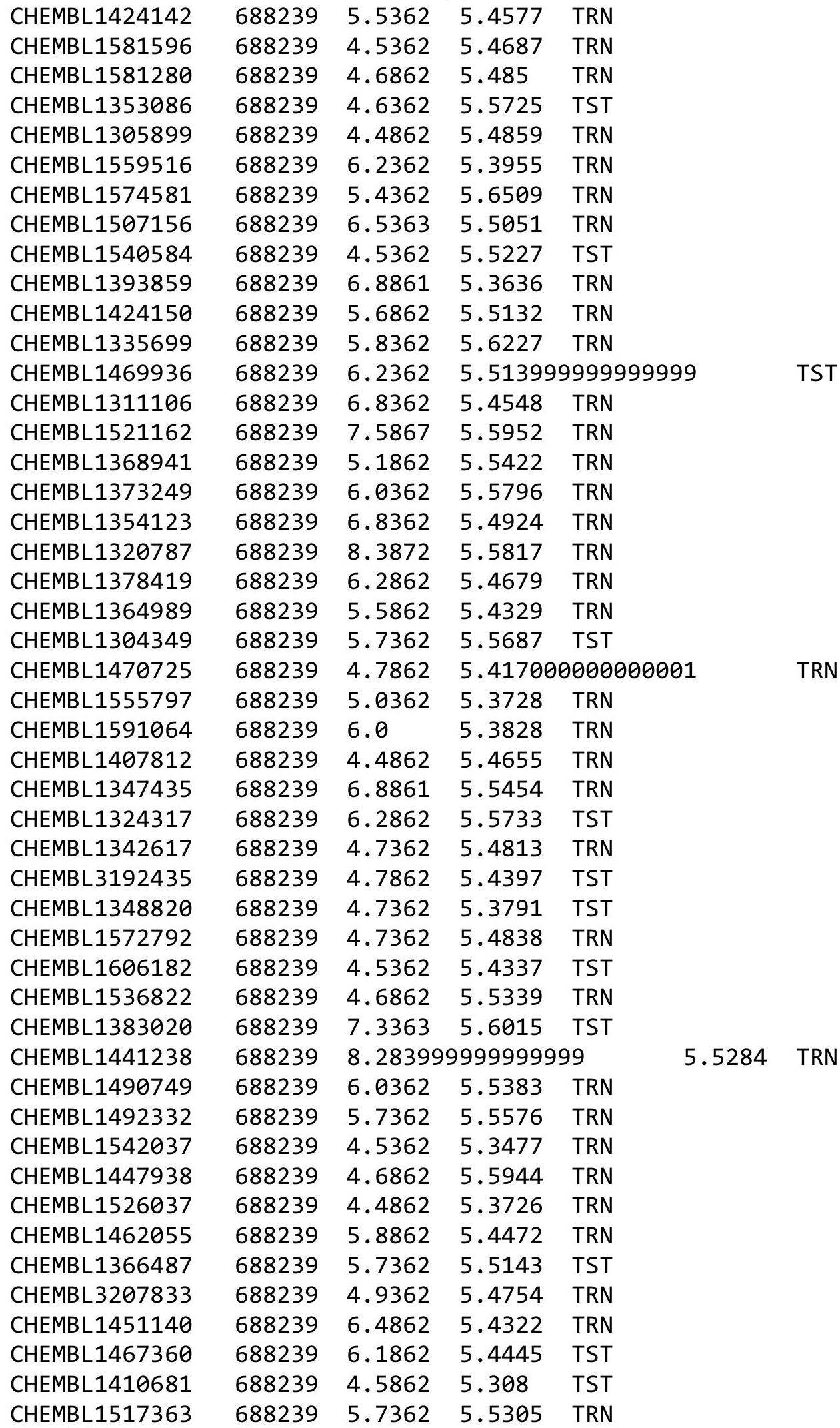

Page 2581 
Supplemental Table S2.txt

\begin{tabular}{|c|c|c|c|c|}
\hline CHEMBL1416846 & 688239 & 4.5362 & 5.6597 & TST \\
\hline CHEMBL1319051 & 688239 & 5.5362 & 5.4698 & TRN \\
\hline CHEMBL1399943 & 688239 & 4.5362 & 5.4628 & TRN \\
\hline CHEMBL1357747 & 688239 & 4.5362 & 5.5255 & TRN \\
\hline CHEMBL1533621 & 688239 & 5.1362 & 5.4436 & TRN \\
\hline CHEMBL1978193 & 688239 & 4.8362 & 5.4231 & TRN \\
\hline CHEMBL1394880 & 688239 & 5.6862 & 5.5633 & TRN \\
\hline CHEMBL1448652 & 688239 & 4.6862 & 5.4816 & TRN \\
\hline CHEMBL1581185 & 688239 & 4.6862 & 5.4864 & TST \\
\hline CHEMBL1974389 & 688239 & 5.7862 & 5.4324 & TST \\
\hline CHEMBL1302400 & 688239 & 4.4862 & 5.4406 & TRN \\
\hline CHEMBL1600386 & 688239 & 4.8862 & 5.417006 & 0000000001 \\
\hline CHEMBL1443001 & 688239 & 4.7862 & 5.3774 & TRN \\
\hline CHEMBL1517067 & 688239 & 5.1862 & 5.5808 & TST \\
\hline CHEMBL1302338 & 688239 & 5.3862 & 5.5884 & TRN \\
\hline CHEMBL1597039 & 688239 & 4.4862 & 5.4035 & TRN \\
\hline CHEMBL1509986 & 688239 & 5.5862 & 5.4071 & TRN \\
\hline CHEMBL1449959 & 688239 & 6.9863 & 5.4685 & TRN \\
\hline CHEMBL1398014 & 688239 & 6.8861 & 5.3101 & TRN \\
\hline CHEMBL1532641 & 688239 & 4.5362 & 5.5406 & TST \\
\hline CHEMBL3196639 & 688239 & 4.5362 & 5.4429 & TRN \\
\hline CHEMBL1312606 & 688239 & 5.1862 & 5.395 & TRN \\
\hline CHEMBL3195549 & 688239 & 5.1862 & 5.4008 & TRN \\
\hline CHEMBL 3207897 & 688239 & 6.15 & 5.6436 & TRN \\
\hline CHEMBL1467172 & 688239 & 4.7862 & 5.4547 & TRN \\
\hline CHEMBL1410603 & 688239 & 4.5862 & 5.5857 & TRN \\
\hline CHEMBL 3190554 & 688239 & 5.3862 & 5.5612 & TST \\
\hline CHEMBL1518668 & 688239 & 5.8862 & 5.6016 & TRN \\
\hline CHEMBL1428573 & 688239 & 5.3362 & 5.4197 & TRN \\
\hline CHEMBL1588102 & 688239 & 6.5862 & 5.3915 & TRN \\
\hline CHEMBL1403743 & 688239 & 4.7362 & 5.4468 & TRN \\
\hline CHEMBL1332788 & 688239 & 5.3362 & 5.4693 & TRN \\
\hline CHEMBL1499821 & 688239 & 6.1862 & 5.612999 & 99999999995 \\
\hline CHEMBL1529366 & 688239 & 6.1362 & 5.3843 & TST \\
\hline CHEMBL1350712 & 688239 & 4.6862 & 5.4999 & TRN \\
\hline CHEMBL1373393 & 688239 & 6.2362 & 5.4236 & TRN \\
\hline CHEMBL1504597 & 688239 & 6.8861 & 5.4277 & TRN \\
\hline CHEMBL1579249 & 688239 & 6.9363 & 5.5604 & TST \\
\hline CHEMBL1324605 & 688239 & 4.4862 & 5.527 & TRN \\
\hline CHEMBL1373816 & 688239 & 6.2362 & 5.7096 & TST \\
\hline CHEMBL1561217 & 688239 & 4.7862 & 5.4486 & TRN \\
\hline CHEMBL1491981 & 688239 & 5.3362 & 5.497999 & 9999999999 \\
\hline CHEMBL3191699 & 688239 & 5.3862 & 5.4507 & TST \\
\hline CHEMBL1533881 & 688239 & 6.1862 & 5.5162 & TRN \\
\hline CHEMBL1358509 & 688239 & 5.1862 & 5.4776 & TRN \\
\hline CHEMBL1449519 & 688239 & 5.5862 & 5.3973 & TRN \\
\hline CHEMBL1383736 & 688239 & 4.7362 & 5.3665 & TRN \\
\hline CHEMBL1533366 & 688239 & 4.7862 & 5.4835 & TRN \\
\hline
\end{tabular}

Page 2582 
Supplemental Table S2.txt

\begin{tabular}{|c|c|c|c|c|c|}
\hline CHEMBL1304031 & 688239 & 4.4862 & 5.5242 & TRN & \\
\hline CHEMBL1433684 & 688239 & 6.8362 & 5.6453 & TRN & \\
\hline CHEMBL1344196 & 688239 & 6.7361 & 5.5557 & TRN & \\
\hline CHEMBL1382126 & 688239 & 5.0862 & 5.6146 & TRN & \\
\hline CHEMBL1503695 & 688239 & 5.7862 & 5.6145 & TRN & \\
\hline CHEMBL1299747 & 688239 & 5.4362 & 5.4746 & TRN & \\
\hline CHEMBL1518838 & 688239 & 5.5362 & 5.4365 & TRN & \\
\hline CHEMBL1428543 & 688239 & 5.1862 & 5.6576 & TRN & \\
\hline CHEMBL1604399 & 688239 & 4.7362 & 5.621 & TRN & \\
\hline CHEMBL1438232 & 688239 & 4.9362 & 5.5827 & TRN & \\
\hline CHEMBL1540015 & 688239 & 5.2362 & 5.4385 & TRN & \\
\hline CHEMBL1583427 & 688239 & 6.2862 & 5.3627 & TRN & \\
\hline CHEMBL1423427 & 688239 & 5.9362 & 5.4441 & TRN & \\
\hline CHEMBL1331026 & 688239 & 4.5362 & 5.4231 & TST & \\
\hline CHEMBL1493385 & 688239 & 5.8862 & 5.3734 & TRN & \\
\hline CHEMBL1610817 & 688239 & 5.3862 & 5.5087 & TRN & \\
\hline CHEMBL1301026 & 688239 & 4.7862 & 5.4248 & TRN & \\
\hline CHEMBL1379712 & 688239 & 5.1362 & 5.5411 & TRN & \\
\hline CHEMBL1386009 & 688239 & 4.6362 & 5.3853 & TRN & \\
\hline CHEMBL1386433 & 688239 & 6.2862 & 5.4552 & TRN & \\
\hline CHEMBL1527248 & 688239 & 5.3362 & 5.6339 & TRN & \\
\hline CHEMBL1390867 & 688239 & 6.1862 & 5.5132 & TRN & \\
\hline CHEMBL1423253 & 688239 & 4.45 & 5.4696 & TRN & \\
\hline CHEMBL1545766 & 688239 & 6.4862 & 5.4962 & TRN & \\
\hline CHEMBL1387264 & 688239 & 4.5362 & 5.5236 & TRN & \\
\hline CHEMBL1371128 & 688239 & 4.5362 & 5.4606 & TRN & \\
\hline CHEMBL1350117 & 688239 & 4.6862 & 5.6546 & TRN & \\
\hline CHEMBL1358785 & 688239 & 5.1362 & 5.7112 & TRN & \\
\hline CHEMBL3196380 & 688239 & 4.5362 & 5.5576 & TRN & \\
\hline CHEMBL1578204 & 688239 & 5.1862 & 5.4836 & TRN & \\
\hline CHEMBL1430805 & 688239 & 5.7862 & 5.4287 & TST & \\
\hline CHEMBL1561465 & 688239 & 4.5362 & 5.4025 & TRN & \\
\hline CHEMBL1334441 & 688239 & 6.8861 & 5.626 & TRN & \\
\hline CHEMBL1551761 & 688239 & 6.6362 & 5.3248 & TRN & \\
\hline CHEMBL1329641 & 688239 & 5.6862 & 5.5938 & TRN & \\
\hline CHEMBL1556671 & 688239 & 4.7862 & 5.4953 & TRN & \\
\hline CHEMBL1515434 & 688239 & 7.2366 & 5.5127 & TRN & \\
\hline CHEMBL1421851 & 688239 & 7.0362 & 5.4461 & TRN & \\
\hline CHEMBL3197643 & 688239 & 6.1862 & 5.4952 & TRN & \\
\hline CHEMBL1607245 & 688239 & 8.28399 & 99999999 & 99 & 5.5237 \\
\hline CHEMBL1578771 & 688239 & 5.1862 & 5.6269 & TRN & \\
\hline CHEMBL1507890 & 688239 & 7.1361 & 5.4341 & TRN & \\
\hline CHEMBL1390093 & 688239 & 8.0362 & 5.4432 & TRN & \\
\hline CHEMBL1470325 & 688239 & 5.4362 & 5.4509 & TRN & \\
\hline CHEMBL1351823 & 688239 & 6.5862 & 5.3867 & TST & \\
\hline CHEMBL1507134 & 688239 & 5.6862 & 5.4475 & TRN & \\
\hline CHEMBL1432357 & 688239 & 6.4862 & 5.3961 & TST & \\
\hline CHEMBL1336061 & 688239 & 6.3863 & 5.443 & TRN & \\
\hline
\end{tabular}


Supplemental Table S2.txt

\begin{tabular}{|c|c|c|c|c|}
\hline CHEMBL3209114 & 688239 & 8.3372 & 5.4233 & TRN \\
\hline CHEMBL1392890 & 688239 & 4.9862 & 5.3677 & TST \\
\hline CHEMBL1549991 & 688239 & 5.1862 & 5.4754 & TRN \\
\hline CHEMBL1413893 & 688239 & 4.5862 & 5.313 & TRN \\
\hline CHEMBL1397750 & 688239 & 5.2362 & 5.4253 & TRN \\
\hline CHEMBL1353664 & 688239 & 4.5362 & 5.3846 & TRN \\
\hline CHEMBL1376513 & 688239 & 7.6364 & 5.3719 & TRN \\
\hline CHEMBL1410375 & 688239 & 6.8362 & \multicolumn{2}{|c|}{5.571000000000001} \\
\hline CHEMBL 2003539 & 688239 & 6.1362 & 5.4413 & TRN \\
\hline CHEMBL1492348 & 688239 & 4.6862 & 5.4745 & TRN \\
\hline CHEMBL1375201 & 688239 & 6.3863 & \multicolumn{2}{|c|}{5.4110000000000005} \\
\hline CHEMBL1359708 & 688239 & 4.4862 & 5.4974 & TRN \\
\hline CHEMBL1409422 & 688239 & 8.0862 & 5.5185 & TRN \\
\hline CHEMBL1580341 & 688239 & 4.4862 & 5.5518 & TRN \\
\hline CHEMBL1500517 & 688239 & 6.0862 & 5.3867 & TRN \\
\hline CHEMBL1308354 & 688239 & 6.0362 & 5.5767 & TST \\
\hline CHEMBL1485693 & 688239 & 5.1362 & 5.636 & TRN \\
\hline CHEMBL1351259 & 688239 & 4.8862 & 5.4748 & TRN \\
\hline CHEMBL1479368 & 688239 & 5.5862 & 5.4897 & TRN \\
\hline CHEMBL1571295 & 688239 & 4.9362 & 5.5108 & TRN \\
\hline CHEMBL1555261 & 688239 & 4.4862 & 5.6587 & TRN \\
\hline CHEMBL3198077 & 688239 & 4.7862 & 5.4413 & TRN \\
\hline CHEMBL1385323 & 688239 & 6.1362 & 5.3132 & TST \\
\hline CHEMBL1495670 & 688239 & 4.5362 & 5.395 & TRN \\
\hline CHEMBL1584523 & 688239 & 4.6362 & 5.4354 & TST \\
\hline CHEMBL1602803 & 688239 & 5.5362 & 5.4398 & TRN \\
\hline CHEMBL1300600 & 688239 & 6.9863 & 5.5191 & TRN \\
\hline CHEMBL1567992 & 688239 & 4.5362 & 5.4271 & TRN \\
\hline CHEMBL1410355 & 688239 & 5.4862 & 5.5309 & TST \\
\hline CHEMBL1381440 & 688239 & 5.1862 & 5.4915 & TRN \\
\hline CHEMBL1358258 & 688239 & 4.5362 & 5.5004 & TRN \\
\hline CHEMBL1313088 & 688239 & 4.5862 & 5.4019 & TST \\
\hline CHEMBL1511172 & 688239 & 5.2362 & 5.4861 & TRN \\
\hline CHEMBL1501633 & 688239 & 4.8362 & 5.5396 & TRN \\
\hline CHEMBL1425879 & 688239 & 6.2362 & 5.5556 & TRN \\
\hline CHEMBL1564312 & 688239 & 4.7362 & 5.4638 & TST \\
\hline CHEMBL1342936 & 688239 & 5.7862 & 5.4356 & TRN \\
\hline CHEMBL1985696 & 688239 & 4.5862 & 5.6374 & TRN \\
\hline CHEMBL1511707 & 688239 & 5.9862 & 5.4277 & TST \\
\hline CHEMBL1577935 & 688239 & 6.2362 & 5.6474 & TRN \\
\hline CHEMBL1425194 & 688239 & 4.5362 & 5.4169 & TRN \\
\hline CHEMBL 3195060 & 688239 & 5.4862 & 5.3907 & TRN \\
\hline CHEMBL1463350 & 688239 & 5.1862 & 5.435 & TRN \\
\hline CHEMBL1572358 & 688239 & 5.1862 & 5.5011 & TRN \\
\hline CHEMBL1606145 & 688239 & 5.1862 & 5.5067 & TRN \\
\hline CHEMBL3197606 & 688239 & 6.8362 & 5.4726 & TRN \\
\hline CHEMBL1402449 & 688239 & 6.1362 & 5.4512 & TRN \\
\hline CHEMBL1610980 & 688239 & 5.6362 & 5.4596 & TRN \\
\hline
\end{tabular}


Supplemental Table S2.txt

\begin{tabular}{|c|c|c|c|c|}
\hline CHEMBL1419096 & 688239 & 5.8862 & 5.6727 & TRN \\
\hline CHEMBL1541367 & 688239 & 4.4862 & 5.4649 & TRN \\
\hline CHEMBL1564902 & 688239 & 5.0862 & 5.4292 & TRN \\
\hline CHEMBL1405058 & 688239 & 7.0362 & 5.5365 & TST \\
\hline CHEMBL1589287 & 688239 & 4.5362 & 5.5512 & TRN \\
\hline CHEMBL1541242 & 688239 & 5.3362 & 5.5071 & TRN \\
\hline CHEMBL1360289 & 688239 & 5.5362 & 5.4515 & TRN \\
\hline CHEMBL1324555 & 688239 & 6.0862 & 5.3851 & TRN \\
\hline CHEMBL1571967 & 688239 & 4.5362 & 5.441 & TRN \\
\hline CHEMBL1575966 & 688239 & 4.5362 & 5.4473 & TST \\
\hline CHEMBL1503349 & 688239 & 5.2362 & 5.4817 & TST \\
\hline CHEMBL1320116 & 688239 & 4.6362 & 5.45200 & 0000000001 \\
\hline CHEMBL1537437 & 688239 & 5.1862 & 5.5414 & TST \\
\hline CHEMBL1310822 & 688239 & 4.9362 & 5.5157 & TRN \\
\hline CHEMBL1564891 & 688239 & 4.6362 & 5.4229 & TRN \\
\hline CHEMBL1424517 & 688239 & 4.7362 & 5.4791 & TRN \\
\hline CHEMBL1474631 & 688239 & 5.5862 & 5.5067 & TST \\
\hline CHEMBL1546270 & 688239 & 4.4862 & 5.4605 & TRN \\
\hline CHEMBL1561496 & 688239 & 6.6861 & 5.5513 & TRN \\
\hline CHEMBL1545980 & 688239 & 4.6362 & 5.669 & TRN \\
\hline CHEMBL1485810 & 688239 & 4.5362 & 5.5678 & TRN \\
\hline CHEMBL1434278 & 688239 & 5.6862 & 5.5607 & TRN \\
\hline CHEMBL1457771 & 688239 & 6.0862 & 5.4701 & TRN \\
\hline CHEMBL1429667 & 688239 & 5.1862 & 5.3997 & TST \\
\hline CHEMBL1587658 & 688239 & 5.1862 & 5.3847 & TRN \\
\hline CHEMBL3197076 & 688239 & 4.6862 & 5.4702 & TST \\
\hline CHEMBL1477246 & 688239 & 5.4362 & 5.5593 & TRN \\
\hline CHEMBL1426461 & 688239 & 4.5362 & 5.3674 & TST \\
\hline CHEMBL1505313 & 688239 & 4.6362 & 5.4347 & TST \\
\hline CHEMBL1409483 & 688239 & 6.3863 & 5.5296 & TRN \\
\hline CHEMBL1419741 & 688239 & 4.5362 & 5.3741 & TST \\
\hline CHEMBL1338722 & 688239 & 6.1362 & 5.5138 & TRN \\
\hline CHEMBL1537008 & 688239 & 4.4862 & 5.4568 & TST \\
\hline CHEMBL 3210417 & 688239 & 5.2362 & 5.3828 & TRN \\
\hline CHEMBL1341306 & 688239 & 5.0862 & 5.5679 & TRN \\
\hline CHEMBL1376052 & 688239 & 6.8362 & 5.6391 & TRN \\
\hline CHEMBL1365729 & 688239 & 6.6362 & 5.4404 & TRN \\
\hline CHEMBL1480539 & 688239 & 6.9863 & 5.5709 & TRN \\
\hline CHEMBL1429664 & 688239 & 4.9862 & 5.5557 & TRN \\
\hline CHEMBL1551626 & 688239 & 4.5862 & 5.4987 & TRN \\
\hline CHEMBL1558500 & 688239 & 7.1864 & 5.5736 & TRN \\
\hline CHEMBL1367065 & 688239 & 5.7862 & 5.4302 & TRN \\
\hline CHEMBL1597933 & 688239 & 5.7862 & 5.5967 & TST \\
\hline CHEMBL1407707 & 688239 & 4.4862 & 5.4675 & TRN \\
\hline CHEMBL1351935 & 688239 & 6.1862 & 5.4654 & TRN \\
\hline CHEMBL1346033 & 688239 & 6.4362 & 5.5082 & TRN \\
\hline CHEMBL1485817 & 688239 & 6.1362 & 5.5478 & TRN \\
\hline CHEMBL1579330 & 688239 & 5.1362 & 5.398 & TRN \\
\hline
\end{tabular}


Supplemental Table S2.txt

\begin{tabular}{|c|c|c|c|c|}
\hline CHEMBL1552018 & 688239 & 4.5862 & 5.481 & TRN \\
\hline CHEMBL1368839 & 688239 & 4.7862 & 5.4878 & TRN \\
\hline CHEMBL1323994 & 688239 & 5.4362 & 5.3955 & TRN \\
\hline CHEMBL1466989 & 688239 & 6.7361 & 5.4894 & TST \\
\hline CHEMBL1485204 & 688239 & 6.3863 & 5.5893 & TST \\
\hline CHEMBL1544712 & 688239 & 5.3862 & 5.5812 & TST \\
\hline CHEMBL1462173 & 688239 & 4.6362 & 5.496 & TRN \\
\hline CHEMBL1464222 & 688239 & 4.45 & 5.4968 & TST \\
\hline CHEMBL1586728 & 688239 & 5.0862 & 5.6501 & TST \\
\hline CHEMBL1304958 & 688239 & 6.9863 & 5.6287 & TRN \\
\hline CHEMBL1530525 & 688239 & 4.5362 & 5.4123 & TST \\
\hline CHEMBL1470767 & 688239 & 4.5362 & 5.6627 & TRN \\
\hline CHEMBL1477439 & 688239 & 6.1862 & 5.5059 & TST \\
\hline CHEMBL1573989 & 688239 & 5.7362 & 5.5996 & TRN \\
\hline CHEMBL1443346 & 688239 & 6.0862 & 5.6323 & TST \\
\hline CHEMBL1473650 & 688239 & 5.7862 & 5.3939 & TRN \\
\hline CHEMBL1351874 & 688239 & 5.0362 & 5.4555 & TRN \\
\hline CHEMBL1566219 & 688239 & 6.1362 & 5.5483 & TRN \\
\hline CHEMBL1571542 & 688239 & 5.4362 & 5.5428 & TRN \\
\hline CHEMBL 3213230 & 688239 & 4.5862 & 5.3877 & TRN \\
\hline CHEMBL1572468 & 688239 & 4.7862 & 5.5398 & TRN \\
\hline CHEMBL1447879 & 688239 & 6.7361 & 5.5166 & TST \\
\hline CHEMBL3189916 & 688239 & 4.5862 & 5.4088 & TST \\
\hline CHEMBL1398159 & 688239 & 6.3863 & 5.3602 & TRN \\
\hline CHEMBL1317376 & 688239 & 5.6362 & 5.5909 & TRN \\
\hline CHEMBL1312853 & 688239 & 4.6862 & 5.6518 & TRN \\
\hline CHEMBL1523699 & 688239 & 4.5862 & 5.4204 & TRN \\
\hline CHEMBL1427416 & 688239 & 5.1862 & 5.54200 & 0000000001 \\
\hline CHEMBL1479643 & 688239 & 5.4362 & 5.5651 & TRN \\
\hline CHEMBL1467910 & 688239 & 4.5362 & 5.4352 & TST \\
\hline CHEMBL1549375 & 688239 & 4.5362 & 5.379 & TST \\
\hline CHEMBL1547447 & 688239 & 6.1362 & 5.5135 & TRN \\
\hline CHEMBL1320870 & 688239 & 5.4862 & 5.5251 & TST \\
\hline CHEMBL1303457 & 688239 & 5.4862 & 5.3505 & TRN \\
\hline CHEMBL1540216 & 688239 & 5.3362 & 5.6325 & TST \\
\hline CHEMBL1527166 & 688239 & 6.3863 & 5.3823 & TST \\
\hline CHEMBL1421214 & 688239 & 5.3862 & 5.3995 & TRN \\
\hline CHEMBL1577047 & 688239 & 6.2862 & 5.5454 & TST \\
\hline CHEMBL1401534 & 688239 & 4.5362 & 5.4684 & TRN \\
\hline CHEMBL432044 & 688239 & 4.9862 & 5.5103 & TRN \\
\hline CHEMBL1361765 & 688239 & 4.6362 & 5.3985 & TRN \\
\hline CHEMBL1412938 & 688239 & 4.6362 & 5.4531 & TRN \\
\hline CHEMBL1470858 & 688239 & 5.4862 & 5.4371 & TRN \\
\hline CHEMBL1409348 & 688239 & 5.2862 & 5.4821 & TST \\
\hline CHEMBL1386204 & 688239 & 6.1362 & 5.4087 & TRN \\
\hline CHEMBL1332110 & 688239 & 4.5362 & 5.4002 & TRN \\
\hline CHEMBL1602996 & 688239 & 5.0862 & 5.5758 & TRN \\
\hline CHEMBL1361601 & 688239 & 4.9862 & 5.5399 & TRN \\
\hline
\end{tabular}

Page 2586 
Supplemental Table S2.txt

\begin{tabular}{|c|c|c|c|c|c|}
\hline CHEMBL3197459 & 688239 & 6.6362 & 5.2674 & TRN & \\
\hline CHEMBL1458447 & 688239 & 5.7862 & 5.4449 & TRN & \\
\hline CHEMBL1350217 & 688239 & 7.2366 & 5.5713 & TRN & \\
\hline CHEMBL1501936 & 688239 & 4.5862 & 5.4173 & TRN & \\
\hline CHEMBL1440680 & 688239 & 5.3362 & 5.5243 & TST & \\
\hline CHEMBL1411456 & 688239 & 6.7862 & 5.4857 & TRN & \\
\hline CHEMBL1568891 & 688239 & 5.4862 & 5.3829 & TST & \\
\hline CHEMBL1610916 & 688239 & 6.7862 & 5.5139 & TRN & \\
\hline CHEMBL3212004 & 688239 & 4.8862 & 5.4527 & TST & \\
\hline CHEMBL1362594 & 688239 & 6.1362 & 5.3591 & TRN & \\
\hline CHEMBL1526255 & 688239 & 6.6362 & 5.5742 & TRN & \\
\hline CHEMBL1437813 & 688239 & 6.8362 & 5.5533 & TRN & \\
\hline CHEMBL1432656 & 688239 & 5.5362 & 5.6519 & TRN & \\
\hline CHEMBL1562203 & 688239 & 5.6362 & 5.5264 & TRN & \\
\hline CHEMBL1345601 & 688239 & 4.5362 & 5.5889 & TST & \\
\hline CHEMBL1466888 & 688239 & 6.9863 & 5.6037 & TRN & \\
\hline CHEMBL1470834 & 688239 & 5.2362 & 5.4284 & TST & \\
\hline CHEMBL1470759 & 688239 & 6.0862 & 5.5681 & TRN & \\
\hline CHEMBL1471362 & 688239 & 4.5362 & 5.5293 & TST & \\
\hline CHEMBL1448567 & 688239 & 7.2366 & 5.4966 & TRN & \\
\hline CHEMBL1491344 & 688239 & 5.4862 & 5.4806 & TRN & \\
\hline CHEMBL1381115 & 688239 & 5.5362 & 5.5217 & TST & \\
\hline CHEMBL1426371 & 688239 & 4.5362 & 5.4121 & TST & \\
\hline CHEMBL 3190649 & 688239 & 5.5362 & 5.4149 & TRN & \\
\hline CHEMBL1356566 & 688239 & 5.3362 & 5.4962 & TRN & \\
\hline CHEMBL1526490 & 688239 & 4.5362 & 5.4386 & TRN & \\
\hline CHEMBL1545617 & 688239 & 6.9363 & 5.6314 & TRN & \\
\hline CHEMBL1608573 & 688239 & 5.2862 & 5.4432 & TRN & \\
\hline CHEMBL1529015 & 688239 & 6.2362 & 5.5039 & TRN & \\
\hline CHEMBL1305804 & 688239 & 4.5362 & 5.482 & TRN & \\
\hline CHEMBL1456689 & 688239 & 5.6362 & 5.4469 & TST & \\
\hline CHEMBL1405595 & 688239 & 6.8362 & 5.5556 & TRN & \\
\hline CHEMBL1460873 & 688239 & 4.5362 & 5.5772 & TRN & \\
\hline CHEMBL3190891 & 688239 & 4.5362 & 5.4545 & TST & \\
\hline CHEMBL1427607 & 688239 & 8.28399 & 99999999 & 99 & 5.3614 \\
\hline CHEMBL1525567 & 688239 & 5.6362 & 5.4915 & TRN & \\
\hline CHEMBL1471360 & 688239 & 4.5362 & 5.6588 & TRN & \\
\hline CHEMBL1387908 & 688239 & 4.5362 & 5.4885 & TRN & \\
\hline CHEMBL1507297 & 688239 & 6.3362 & 5.4957 & TRN & \\
\hline CHEMBL1612072 & 688239 & 6.1362 & 5.4744 & TRN & \\
\hline CHEMBL1536071 & 688239 & 5.8362 & 5.5172 & TRN & \\
\hline CHEMBL1428312 & 688239 & 8.2366 & 5.357 & TST & \\
\hline CHEMBL1510366 & 688239 & 5.6362 & 5.5436 & TST & \\
\hline CHEMBL1599633 & 688239 & 4.6 & 5.565 & TST & \\
\hline CHEMBL1384501 & 688239 & 4.5362 & 5.309 & TST & \\
\hline CHEMBL1592462 & 688239 & 4.5362 & 5.4548 & TRN & \\
\hline CHEMBL1563778 & 688239 & 4.6362 & 5.4795 & TRN & \\
\hline CHEMBL1554796 & 688239 & 8.2366 & 5.349 & TRN & \\
\hline
\end{tabular}


Supplemental Table S2.txt

\begin{tabular}{|c|c|c|c|c|c|}
\hline CHEMBL1432978 & 688239 & 4.5362 & 5.3694 & TRN & \\
\hline CHEMBL1368259 & 688239 & 4.6862 & 5.4991 & TRN & \\
\hline CHEMBL1437969 & 688239 & 4.5362 & 5.4003 & TRN & \\
\hline CHEMBL1423010 & 688239 & 5.5362 & 5.4592 & TRN & \\
\hline CHEMBL1428475 & 688239 & 4.7362 & 5.4442 & TRN & \\
\hline CHEMBL1308085 & 688239 & 6.8861 & 5.3531 & TRN & \\
\hline CHEMBL1588367 & 688239 & 5.7862 & 5.4746 & TST & \\
\hline CHEMBL1497908 & 688239 & 4.5362 & 5.5271 & TRN & \\
\hline CHEMBL1442331 & 688239 & 8.2366 & 5.5036 & TRN & \\
\hline CHEMBL1587971 & 688239 & 5.1862 & 5.6345 & TRN & \\
\hline CHEMBL1370821 & 688239 & 5.3862 & 5.5988 & TRN & \\
\hline CHEMBL1308392 & 688239 & 6.1862 & 5.5106 & TRN & \\
\hline CHEMBL1317525 & 688239 & 4.6862 & 5.5263 & TRN & \\
\hline CHEMBL1562014 & 688239 & 6.5363 & 5.4711 & TST & \\
\hline CHEMBL1418000 & 688239 & 5.0362 & 5.4548 & TRN & \\
\hline CHEMBL1269897 & 688239 & 7.2366 & 5.566 & TRN & \\
\hline CHEMBL1331545 & 688239 & 4.6362 & 5.609 & TRN & \\
\hline CHEMBL1594650 & 688239 & 4.6362 & 5.4823 & TRN & \\
\hline CHEMBL1317363 & 688239 & 4.9862 & 5.4145 & TRN & \\
\hline CHEMBL 3213060 & 688239 & 5.8362 & 5.4498 & TRN & \\
\hline CHEMBL1371158 & 688239 & 4.5362 & 5.5078 & TRN & \\
\hline CHEMBL 82949 & 688239 & 7.2865 & 5.5747 & TST & \\
\hline CHEMBL1602983 & 688239 & 6.2862 & 5.7218 & TRN & \\
\hline CHEMBL1364893 & 688239 & 5.1862 & 5.4045 & TRN & \\
\hline CHEMBL1524449 & 688239 & 6.3362 & 5.4995 & TRN & \\
\hline CHEMBL1580458 & 688239 & 4.7362 & 5.6932 & TRN & \\
\hline CHEMBL1387581 & 688239 & 5.4362 & 5.3536 & TRN & \\
\hline CHEMBL1471287 & 688239 & 5.0362 & 5.5209 & TST & \\
\hline CHEMBL1485117 & 688239 & 8.2366 & 5.4698 & TRN & \\
\hline CHEMBL1568007 & 688239 & 4.6862 & 5.4617 & TRN & \\
\hline CHEMBL1391012 & 688239 & 4.5362 & 5.4906 & TST & \\
\hline CHEMBL1588201 & 688239 & 5.4862 & 5.5317 & TRN & \\
\hline CHEMBL1302552 & 688239 & 4.6862 & 5.5825 & TRN & \\
\hline CHEMBL1525809 & 688239 & 4.5362 & 5.5143 & TRN & \\
\hline CHEMBL1404128 & 688239 & 5.5362 & \multicolumn{2}{|c|}{5.422000000000001} & TRN \\
\hline CHEMBL1326083 & 688239 & 4.6862 & 5.3355 & TRN & \\
\hline CHEMBL1939691 & 688239 & 4.4862 & 5.4035 & TRN & \\
\hline CHEMBL1323409 & 688239 & 5.0362 & 5.6363 & TRN & \\
\hline CHEMBL1439399 & 688239 & 6.1362 & 5.5349 & TRN & \\
\hline CHEMBL1443448 & 688239 & 5.5362 & \multicolumn{2}{|c|}{5.462000000000001} & TRN \\
\hline CHEMBL1466541 & 688239 & 5.1862 & 5.5677 & TRN & \\
\hline CHEMBL1487029 & 688239 & 4.7362 & 5.3974 & TST & \\
\hline CHEMBL1394976 & 688239 & 5.4862 & 5.4411 & TRN & \\
\hline CHEMBL1607602 & 688239 & 4.5362 & 5.3761 & TRN & \\
\hline CHEMBL1312097 & 688239 & 5.8862 & 5.4747 & TRN & \\
\hline CHEMBL 3198975 & 688239 & 4.7862 & 5.4268 & TST & \\
\hline CHEMBL1454903 & 688239 & 6.8362 & 5.4551 & TRN & \\
\hline CHEMBL1560179 & 688239 & 4.5362 & 5.6362 & TRN & \\
\hline
\end{tabular}




\begin{tabular}{|c|c|c|c|c|c|}
\hline \multirow[b]{2}{*}{ CHEMBL1511789 } & \\
\hline & 688239 & 7.8861 & 5.4779 & TRN & \\
\hline CHEMBL1549978 & 688239 & 4.5362 & 5.7 & TRN & \\
\hline CHEMBL1325537 & 688239 & 5.9862 & 5.4697 & TRN & \\
\hline CHEMBL1451131 & 688239 & 5.1862 & 5.5108 & TRN & \\
\hline CHEMBL1531773 & 688239 & 6.6861 & 5.4892 & TRN & \\
\hline CHEMBL1542801 & 688239 & 5.8362 & 5.574 & TRN & \\
\hline CHEMBL1524659 & 688239 & 6.2862 & 5.7434 & TRN & \\
\hline CHEMBL1597484 & 688239 & 5.9862 & 5.3447 & TST & \\
\hline CHEMBL3192058 & 688239 & 4.5862 & \multicolumn{2}{|c|}{5.547999999999999} & TST \\
\hline CHEMBL1483584 & 688239 & 5.3862 & 5.3597 & TST & \\
\hline CHEMBL1487514 & 688239 & 4.5362 & 5.2433 & TRN & \\
\hline CHEMBL1605859 & 688239 & 5.4362 & 5.4162 & TRN & \\
\hline CHEMBL1323690 & 688239 & 5.0862 & 5.5313 & TRN & \\
\hline CHEMBL1382443 & 688239 & 4.7362 & 5.5024 & TST & \\
\hline CHEMBL1508519 & 688239 & 4.8362 & 5.4727 & TRN & \\
\hline CHEMBL1546633 & 688239 & 5.6362 & 5.41 & TST & \\
\hline CHEMBL1395995 & 688239 & 5.9862 & 5.4967 & TRN & \\
\hline CHEMBL 2138770 & 688239 & 6.1362 & 5.4078 & TST & \\
\hline CHEMBL1613570 & 688239 & 5.1862 & 5.3483 & TRN & \\
\hline CHEMBL3199825 & 688239 & 5.8862 & 5.4724 & TST & \\
\hline CHEMBL1311199 & 688239 & 5.4362 & 5.574 & TRN & \\
\hline CHEMBL1507499 & 688239 & 4.5362 & 5.5968 & TRN & \\
\hline CHEMBL1406467 & 688239 & 5.1862 & 5.532 & TST & \\
\hline CHEMBL1315731 & 688239 & 4.6862 & 5.3262 & TRN & \\
\hline CHEMBL1598378 & 688239 & 7.0362 & 5.7053 & TST & \\
\hline CHEMBL1410315 & 688239 & 4.5362 & 5.4983 & TST & \\
\hline CHEMBL1421343 & 688239 & 6.6861 & 5.3367 & TRN & \\
\hline CHEMBL1597764 & 688239 & 4.7362 & 5.3761 & TRN & \\
\hline CHEMBL1506580 & 688239 & 4.6862 & 5.3068 & TRN & \\
\hline CHEMBL1481718 & 688239 & 5.3362 & 5.5691 & TST & \\
\hline CHEMBL1525045 & 688239 & 4.4862 & 5.5239 & TRN & \\
\hline CHEMBL1521899 & 688239 & 4.5362 & 5.4071 & TST & \\
\hline CHEMBL1586338 & 688239 & 5.9362 & 5.505 & TRN & \\
\hline CHEMBL1510386 & 688239 & 4.5362 & 5.357 & TST & \\
\hline CHEMBL1320970 & 688239 & 4.5862 & 5.5508 & TRN & \\
\hline CHEMBL1309703 & 688239 & 4.5362 & 5.5603 & TRN & \\
\hline CHEMBL3198250 & 688239 & 5.6862 & 5.7134 & TRN & \\
\hline CHEMBL1330943 & 688239 & 5.2862 & 5.5048 & TRN & \\
\hline CHEMBL1569961 & 688239 & 5.1862 & 5.483 & TRN & \\
\hline CHEMBL1434733 & 688239 & 4.5862 & 5.4467 & TRN & \\
\hline CHEMBL1546843 & 688239 & 5.1362 & 5.4812 & TST & \\
\hline CHEMBL1578305 & 688239 & 6.2362 & 5.46 & TRN & \\
\hline CHEMBL1426226 & 688239 & 4.9862 & 5.4353 & TST & \\
\hline CHEMBL1521345 & 688239 & 5.1862 & 5.5032 & TRN & \\
\hline CHEMBL1559326 & 688239 & 4.8362 & 5.5375 & TRN & \\
\hline CHEMBL1349992 & 688239 & 4.5362 & 5.3705 & TRN & \\
\hline CHEMBL1446769 & 688239 & 5.2362 & 5.5066 & TST & \\
\hline CHEMBL1598442 & 688239 & 4.8362 & 5.542006 & 0000000001 & TRN \\
\hline & & & & 2589 & \\
\hline
\end{tabular}


Supplemental Table S2.txt

\begin{tabular}{|c|c|c|c|c|}
\hline CHEMBL1344805 & 688239 & 6.2862 & 5.4201 & TRN \\
\hline CHEMBL1372625 & 688239 & 5.0362 & 5.4037 & TRN \\
\hline CHEMBL1509398 & 688239 & 7.0862 & 5.4588 & TRN \\
\hline CHEMBL1438612 & 688239 & 4.95 & 5.4816 & TRN \\
\hline CHEMBL 209521 & 688239 & 4.8362 & 5.3689 & TRN \\
\hline CHEMBL1451931 & 688239 & 4.6862 & \multicolumn{2}{|c|}{5.3839999999999995} \\
\hline CHEMBL 3208017 & 688239 & 4.6862 & 5.4532 & TST \\
\hline CHEMBL1572315 & 688239 & 4.6862 & 5.4636 & TRN \\
\hline CHEMBL1531608 & 688239 & 5.2862 & 5.6213 & TRN \\
\hline CHEMBL1438865 & 688239 & 4.5362 & 5.5236 & TRN \\
\hline CHEMBL1496368 & 688239 & 5.1862 & 5.4179 & TRN \\
\hline CHEMBL1412797 & 688239 & 4.9862 & 5.4892 & TRN \\
\hline CHEMBL1460729 & 688239 & 5.6862 & 5.5359 & TRN \\
\hline CHEMBL1511514 & 688239 & 5.1862 & 5.4868 & TRN \\
\hline CHEMBL1330801 & 688239 & 5.1862 & 5.5703 & TRN \\
\hline CHEMBL1366832 & 688239 & 6.3863 & 5.4534 & TRN \\
\hline CHEMBL1540323 & 688239 & 6.6362 & 5.561 & TRN \\
\hline CHEMBL1441665 & 688239 & 4.7862 & 5.4792 & TST \\
\hline CHEMBL1394485 & 688239 & 6.9863 & 5.5674 & TRN \\
\hline CHEMBL1534821 & 688239 & 4.5362 & 5.4264 & TRN \\
\hline CHEMBL1562108 & 688239 & 5.0862 & 5.5538 & TRN \\
\hline CHEMBL1503952 & 688239 & 5.9862 & 5.3539 & TRN \\
\hline CHEMBL1460337 & 688239 & 5.1862 & 5.6278 & TRN \\
\hline CHEMBL1604504 & 688239 & 4.5862 & 5.5475 & TRN \\
\hline CHEMBL1602999 & 688239 & 6.9863 & 5.5453 & TST \\
\hline CHEMBL1441484 & 688239 & 4.5362 & 5.5374 & TRN \\
\hline CHEMBL1567438 & 688239 & 4.5362 & 5.4141 & TRN \\
\hline CHEMBL1543323 & 688239 & 4.5862 & 5.4522 & TRN \\
\hline CHEMBL 2000960 & 688239 & 5.6862 & 5.5693 & TRN \\
\hline CHEMBL1341114 & 688239 & 4.7862 & 5.3009 & TRN \\
\hline CHEMBL1540400 & 688239 & 4.5362 & 5.4661 & TST \\
\hline CHEMBL1542272 & 688239 & 5.9362 & 5.6112 & TRN \\
\hline CHEMBL1340713 & 688239 & 5.2862 & 5.4004 & TST \\
\hline CHEMBL1357325 & 688239 & 6.1362 & 5.5258 & TRN \\
\hline CHEMBL1549146 & 688239 & 6.2362 & 5.5516 & TRN \\
\hline CHEMBL1425106 & 688239 & 6.3863 & 5.5935 & TRN \\
\hline CHEMBL1444664 & 688239 & 5.1862 & 5.5066 & TRN \\
\hline CHEMBL1423837 & 688239 & 4.5362 & 5.5113 & TRN \\
\hline CHEMBL 3212046 & 688239 & 4.7362 & 5.5837 & TRN \\
\hline CHEMBL1484683 & 688239 & 4.5362 & 5.4284 & TRN \\
\hline CHEMBL1313266 & 688239 & 5.4862 & 5.5473 & TRN \\
\hline CHEMBL1308795 & 688239 & 8.3372 & 5.5354 & TST \\
\hline CHEMBL1299607 & 688239 & 4.5362 & 5.4394 & TST \\
\hline CHEMBL1349232 & 688239 & 6.2362 & 5.505 & TRN \\
\hline CHEMBL1480182 & 688239 & 4.9862 & 5.4232 & TRN \\
\hline CHEMBL1505535 & 688239 & 5.2862 & 5.5666 & TRN \\
\hline CHEMBL1492585 & 688239 & 4.9362 & 5.3676 & TRN \\
\hline CHEMBL1335692 & 688239 & 5.2862 & 5.4301 & TST \\
\hline
\end{tabular}


Supplemental Table S2.txt

\begin{tabular}{|c|c|c|c|c|c|}
\hline CHEMBL1382429 & 688239 & 5.1862 & 5.2438 & TRN & \\
\hline CHEMBL1303801 & 688239 & 6.7862 & 5.5094 & TRN & \\
\hline CHEMBL1517626 & 688239 & 6.8861 & 5.4652 & TST & \\
\hline CHEMBL1381627 & 688239 & 8.3372 & 5.5706 & TRN & \\
\hline CHEMBL1388205 & 688239 & 6.4862 & 5.3974 & TRN & \\
\hline CHEMBL1411306 & 688239 & 6.7361 & 5.5639 & TRN & \\
\hline CHEMBL1518396 & 688239 & 6.9363 & 5.4472 & TRN & \\
\hline CHEMBL3207765 & 688239 & 5.1862 & 5.3968 & TRN & \\
\hline CHEMBL1538393 & 688239 & 6.8861 & 5.5129 & TRN & \\
\hline CHEMBL1299603 & 688239 & 6.5862 & 5.5179 & TRN & \\
\hline CHEMBL1609349 & 688239 & 5.5862 & 5.4823 & TRN & \\
\hline CHEMBL1502031 & 688239 & 6.6861 & 5.5597 & TRN & \\
\hline CHEMBL1366710 & 688239 & 5.0862 & 5.4584 & TST & \\
\hline CHEMBL1299990 & 688239 & 4.5362 & 5.4654 & TRN & \\
\hline CHEMBL1539712 & 688239 & 4.5362 & 5.3861 & TRN & \\
\hline CHEMBL1399515 & 688239 & 4.7862 & \multicolumn{2}{|c|}{5.632999999999999} & TRN \\
\hline CHEMBL1404906 & 688239 & 4.5362 & 5.5585 & TRN & \\
\hline CHEMBL1548628 & 688239 & 4.6862 & 5.4894 & TRN & \\
\hline CHEMBL1330425 & 688239 & 5.1362 & \multicolumn{2}{|c|}{5.3389999999999995} & TRN \\
\hline CHEMBL1505723 & 688239 & 4.5362 & 5.5206 & TRN & \\
\hline CHEMBL1607475 & 688239 & 4.7362 & 5.5809 & TST & \\
\hline CHEMBL1441112 & 688239 & 6.9363 & 5.4077 & TRN & \\
\hline CHEMBL1341313 & 688239 & 6.4862 & 5.4768 & TRN & \\
\hline CHEMBL1587580 & 688239 & 4.5362 & 5.4767 & TRN & \\
\hline CHEMBL1496533 & 688239 & 4.4862 & 5.5719 & TST & \\
\hline CHEMBL1438129 & 688239 & 5.1862 & 5.3813 & TRN & \\
\hline CHEMBL1368668 & 688239 & 4.7362 & 5.4931 & TST & \\
\hline CHEMBL1341447 & 688239 & 8.3872 & 5.4743 & TRN & \\
\hline CHEMBL1585766 & 688239 & 6.1862 & 5.5413 & TRN & \\
\hline CHEMBL1312576 & 688239 & 6.7862 & 5.5489 & TST & \\
\hline CHEMBL1350929 & 688239 & 4.8862 & 5.5007 & TRN & \\
\hline CHEMBL338474 & 688239 & 5.2362 & 5.4976 & TRN & \\
\hline CHEMBL1323745 & 688239 & 5.6362 & 5.4696 & TRN & \\
\hline CHEMBL1522502 & 688239 & 4.6862 & \multicolumn{2}{|c|}{5.417999999999999} & TRN \\
\hline CHEMBL1611453 & 688239 & 4.5362 & 5.4538 & TRN & \\
\hline CHEMBL1528036 & 688239 & 4.5362 & 5.4663 & TRN & \\
\hline CHEMBL1409612 & 688239 & 5.3862 & 5.4166 & TRN & \\
\hline CHEMBL1440802 & 688239 & 7.0362 & 5.3766 & TST & \\
\hline CHEMBL1455397 & 688239 & 5.8862 & 5.4725 & TST & \\
\hline CHEMBL1465370 & 688239 & 6.8861 & 5.6187 & TRN & \\
\hline CHEMBL1547248 & 688239 & 6.0362 & 5.4139 & TRN & \\
\hline CHEMBL1603975 & 688239 & 7.7352 & 5.6251 & TRN & \\
\hline CHEMBL1342396 & 688239 & 5.6362 & 5.5407 & TRN & \\
\hline CHEMBL 2369277 & 688239 & 4.6862 & 5.3412 & TRN & \\
\hline CHEMBL1402157 & 688239 & 4.7362 & 5.4242 & TRN & \\
\hline CHEMBL1411605 & 688239 & 4.7362 & 5.4415 & TRN & \\
\hline CHEMBL1392493 & 688239 & 5.1862 & 5.5078 & TRN & \\
\hline CHEMBL1457719 & 688239 & 4.95 & 5.4618 & TRN & \\
\hline
\end{tabular}


Supplemental Table S2.txt

\begin{tabular}{|c|c|c|c|c|c|}
\hline CHEMBL1360055 & 688239 & 4.5362 & 5.4832 & TRN & \\
\hline CHEMBL1582168 & 688239 & 6.1862 & 5.4729 & TRN & \\
\hline CHEMBL1326003 & 688239 & 4.7362 & 5.5445 & TRN & \\
\hline CHEMBL1368025 & 688239 & 5.0362 & 5.3279 & TRN & \\
\hline CHEMBL1416373 & 688239 & 4.5362 & 5.5134 & TRN & \\
\hline CHEMBL 3212855 & 688239 & 4.7862 & \multicolumn{2}{|c|}{5.5120000000000005} & TRN \\
\hline CHEMBL1341684 & 688239 & 6.2362 & 5.4609 & TRN & \\
\hline CHEMBL1464465 & 688239 & 6.9363 & 5.4216 & TRN & \\
\hline CHEMBL1560652 & 688239 & 6.7361 & 5.4116 & TRN & \\
\hline CHEMBL1333865 & 688239 & 4.4862 & 5.4881 & TRN & \\
\hline CHEMBL1299807 & 688239 & 5.0362 & 5.5664 & TRN & \\
\hline CHEMBL1375855 & 688239 & 4.7862 & 5.5474 & TRN & \\
\hline CHEMBL1509721 & 688239 & 4.5862 & 5.5021 & TRN & \\
\hline CHEMBL1539017 & 688239 & 6.1862 & 5.4581 & TRN & \\
\hline CHEMBL1553771 & 688239 & 5.6362 & 5.5028 & TRN & \\
\hline CHEMBL451574 & 688239 & 4.9862 & 5.3816 & TST & \\
\hline CHEMBL1322267 & 688239 & 5.4862 & 5.5346 & TRN & \\
\hline CHEMBL1514371 & 688239 & 6.5862 & 5.4626 & TST & \\
\hline CHEMBL1462631 & 688239 & 5.0862 & 5.2971 & TST & \\
\hline CHEMBL1307085 & 688239 & 7.1361 & 5.4621 & TRN & \\
\hline CHEMBL1448135 & 688239 & 4.5362 & 5.5924 & TRN & \\
\hline CHEMBL1461810 & 688239 & 7.2865 & 5.5782 & TRN & \\
\hline CHEMBL1468767 & 688239 & 5.1862 & 5.4095 & TRN & \\
\hline CHEMBL1322831 & 688239 & 5.1862 & 5.6583 & TRN & \\
\hline CHEMBL1347931 & 688239 & 4.6862 & 5.5277 & TRN & \\
\hline CHEMBL1596284 & 688239 & 5.1362 & 5.6311 & TRN & \\
\hline CHEMBL1299644 & 688239 & 6.8861 & 5.593999 & & TRN \\
\hline CHEMBL1371856 & 688239 & 4.5362 & 5.5227 & TRN & \\
\hline CHEMBL1527058 & 688239 & 4.7862 & 5.5578 & TST & \\
\hline CHEMBL428784 & 688239 & 4.5362 & 5.2718 & TST & \\
\hline CHEMBL1385530 & 688239 & 5.1862 & 5.404 & TRN & \\
\hline CHEMBL1556752 & 688239 & 5.4362 & 5.5342 & TST & \\
\hline CHEMBL1532644 & 688239 & 6.7862 & 5.3561 & TRN & \\
\hline CHEMBL1348578 & 688239 & 4.6862 & 5.4956 & TST & \\
\hline CHEMBL1574228 & 688239 & 7.0362 & 5.4831 & TRN & \\
\hline CHEMBL1452158 & 688239 & 5.0862 & 5.5803 & TST & \\
\hline CHEMBL1380576 & 688239 & 4.4862 & 5.4911 & TRN & \\
\hline CHEMBL1450444 & 688239 & 7.2366 & 5.5312 & TRN & \\
\hline CHEMBL1504077 & 688239 & 5.1862 & 5.3299 & TRN & \\
\hline CHEMBL1316290 & 688239 & 6.2362 & 5.4718 & TRN & \\
\hline CHEMBL1466377 & 688239 & 4.8362 & 5.3341 & TRN & \\
\hline CHEMBL1574771 & 688239 & 4.5362 & 5.5381 & TRN & \\
\hline CHEMBL1557177 & 688239 & 6.1362 & 5.4758 & TRN & \\
\hline CHEMBL1506172 & 688239 & 6.7361 & 5.5297 & TRN & \\
\hline CHEMBL1340935 & 688239 & 6.9363 & 5.603 & TRN & \\
\hline CHEMBL1553688 & 688239 & 7.2366 & 5.5643 & TRN & \\
\hline CHEMBL1359543 & 688239 & 5.1862 & 5.5713 & TRN & \\
\hline CHEMBL1459356 & 688239 & 5.5362 & 5.5415 & TRN & \\
\hline
\end{tabular}


Supplemental Table S2.txt

\begin{tabular}{|c|c|c|c|c|c|}
\hline CHEMBL3195032 & 688239 & 5.2362 & 5.3492 & TRN & \\
\hline CHEMBL1595775 & 688239 & 4.7362 & 5.4251 & TRN & \\
\hline CHEMBL3190272 & 688239 & 5.8862 & 5.6231 & TRN & \\
\hline CHEMBL1393345 & 688239 & 8.3372 & 5.4873 & TRN & \\
\hline CHEMBL1380046 & 688239 & 6.3362 & 5.4369 & TRN & \\
\hline CHEMBL1460024 & 688239 & 5.0862 & 5.6043 & TRN & \\
\hline CHEMBL1539617 & 688239 & 5.5862 & \multicolumn{2}{|c|}{5.502999999999999} & TRN \\
\hline CHEMBL3196059 & 688239 & 5.2862 & 5.4925 & TST & \\
\hline CHEMBL1599536 & 688239 & 5.5362 & 5.4935 & TRN & \\
\hline CHEMBL3209979 & 688239 & 8.3372 & 5.5663 & TST & \\
\hline CHEMBL1371892 & 688239 & 5.1862 & 5.3513 & TRN & \\
\hline CHEMBL1485492 & 688239 & 4.5362 & \multicolumn{2}{|c|}{5.5489999999999995} & TRN \\
\hline CHEMBL1302514 & 688239 & 5.4862 & \multicolumn{2}{|c|}{5.577999999999999} & TRN \\
\hline CHEMBL1406469 & 688239 & 5.6862 & 5.2927 & TRN & \\
\hline CHEMBL 3189918 & 688239 & 5.5362 & 5.5109 & TRN & \\
\hline CHEMBL1348352 & 688239 & 6.2362 & 5.6459 & TRN & \\
\hline CHEMBL1423747 & 688239 & 4.8362 & 5.5758 & TRN & \\
\hline CHEMBL1409272 & 688239 & 7.2366 & 5.3015 & TST & \\
\hline CHEMBL1350499 & 688239 & 5.1862 & 5.4803 & TRN & \\
\hline CHEMBL1542137 & 688239 & 5.6862 & 5.3878 & TRN & \\
\hline CHEMBL1504676 & 688239 & 4.5862 & 5.4028 & TRN & \\
\hline CHEMBL1441797 & 688239 & 4.5362 & 5.4266 & TRN & \\
\hline CHEMBL1566986 & 688239 & 5.1862 & 5.6039 & TRN & \\
\hline CHEMBL1511073 & 688239 & 6.4862 & 5.4361 & TRN & \\
\hline CHEMBL1499751 & 688239 & 4.6362 & 5.6778 & TST & \\
\hline CHEMBL1330409 & 688239 & 6.7862 & 5.5647 & TST & \\
\hline CHEMBL1388164 & 688239 & 6.9363 & 5.7638 & TRN & \\
\hline CHEMBL1415869 & 688239 & 6.1362 & 5.555 & TRN & \\
\hline CHEMBL1385267 & 688239 & 6.0362 & 5.6356 & TRN & \\
\hline CHEMBL1485475 & 688239 & 5.3362 & 5.5445 & TST & \\
\hline CHEMBL1607977 & 688239 & 5.8362 & 5.6565 & TRN & \\
\hline CHEMBL1430094 & 688239 & 4.6362 & 5.4757 & TRN & \\
\hline CHEMBL1445327 & 688239 & 4.9862 & 5.3655 & TRN & \\
\hline CHEMBL1532256 & 688239 & 5.9362 & 5.4689 & TRN & \\
\hline CHEMBL1390023 & 688239 & 8.3372 & 5.5913 & TRN & \\
\hline CHEMBL1404447 & 688239 & 4.5362 & 5.362999 & 9999999995 & TRN \\
\hline CHEMBL1519821 & 688239 & 5.6862 & 5.4594 & TST & \\
\hline CHEMBL1527601 & 688239 & 5.1862 & 5.4921 & TRN & \\
\hline CHEMBL1565075 & 688239 & 5.1862 & 5.4617 & TRN & \\
\hline CHEMBL1309020 & 688239 & 4.7862 & 5.4633 & TRN & \\
\hline CHEMBL1424094 & 688239 & 6.1862 & 5.677006 & 0000000005 & TRN \\
\hline CHEMBL1573000 & 688239 & 4.5362 & 5.3819 & TST & \\
\hline CHEMBL1505468 & 688239 & 7.0362 & 5.473 & TRN & \\
\hline CHEMBL1542734 & 688239 & 4.6362 & 5.6425 & TRN & \\
\hline CHEMBL1340014 & 688239 & 7.2865 & 5.5057 & TRN & \\
\hline CHEMBL1413960 & 688239 & 5.6362 & 5.5565 & TRN & \\
\hline CHEMBL1392933 & 688239 & 4.5362 & 5.5096 & TRN & \\
\hline CHEMBL1427950 & 688239 & 8.3872 & 5.4726 & TST & \\
\hline
\end{tabular}


Supplemental Table S2.txt

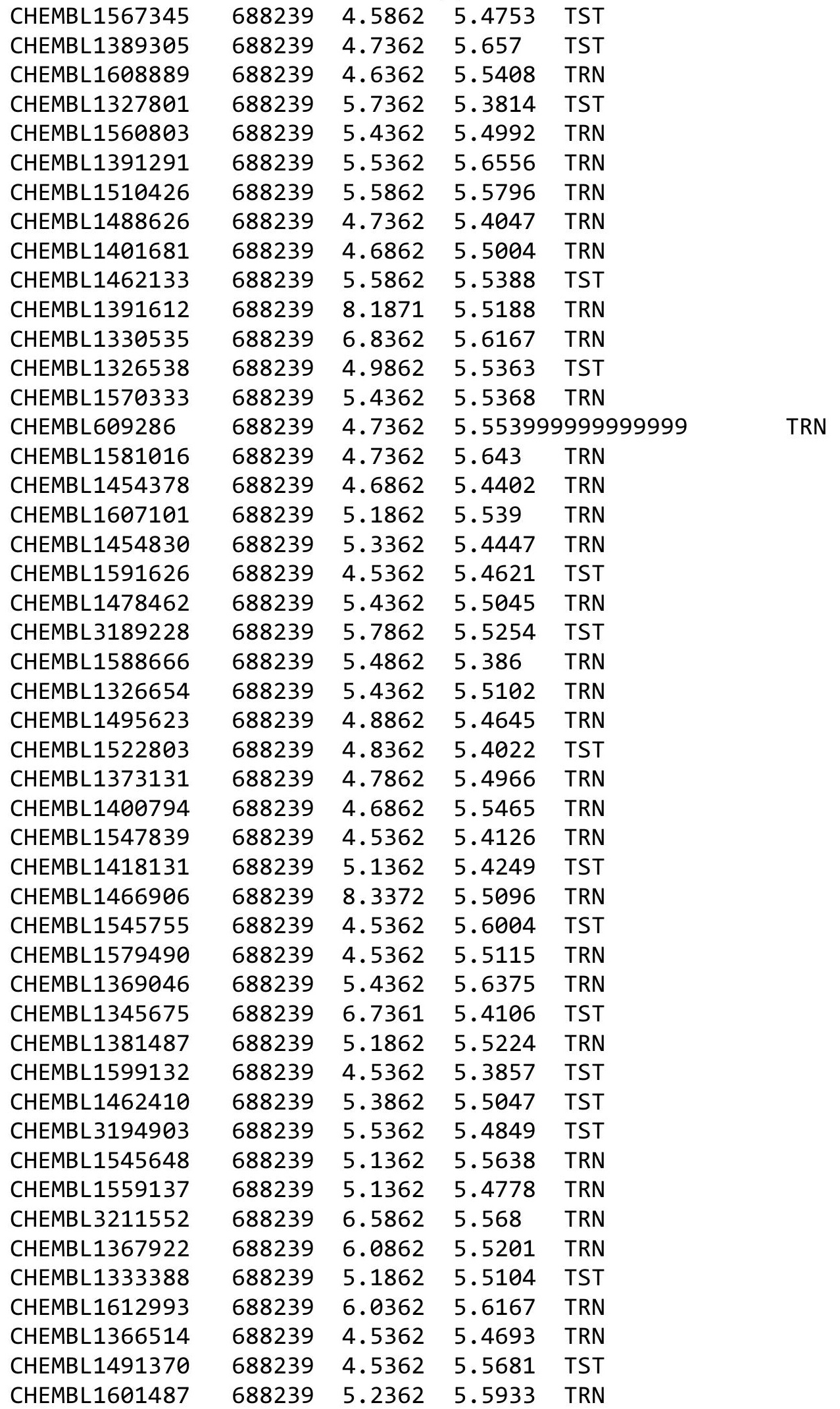


Supplemental Table S2.txt

\begin{tabular}{|c|c|c|c|c|c|c|}
\hline CHEMBL1466505 & 688239 & 4.7362 & 5.2554 & TRN & & \\
\hline CHEMBL1542778 & 688239 & 4.5362 & 5.2985 & TST & & \\
\hline CHEMBL1449411 & 688239 & 4.9862 & 5.5171 & TRN & & \\
\hline CHEMBL1401824 & 688239 & 6.8362 & 5.7011 & TRN & & \\
\hline CHEMBL1468556 & 688239 & 4.5362 & 5.3397 & TRN & & \\
\hline CHEMBL1461888 & 688239 & 4.6362 & 5.3819 & TRN & & \\
\hline CHEMBL1366278 & 688239 & 5.7862 & 5.4782 & TRN & & \\
\hline CHEMBL1401652 & 688239 & 4.6862 & 5.4154 & TRN & & \\
\hline CHEMBL1439946 & 688239 & 6.1862 & 5.4151 & TRN & & \\
\hline CHEMBL1550730 & 688239 & 4.7362 & 5.5417 & TST & & \\
\hline CHEMBL63883 & 688239 & 4.6862 & 5.365 & TRN & & \\
\hline CHEMBL1524322 & 688239 & 4.5362 & 5.3288 & TST & & \\
\hline CHEMBL1383107 & 688239 & 4.8862 & 5.4506 & TRN & & \\
\hline CHEMBL1359482 & 688239 & 4.5362 & 5.5996 & TRN & & \\
\hline CHEMBL1330814 & 688239 & 6.7361 & 5.6554 & TRN & & \\
\hline CHEMBL1381700 & 688239 & 6.0862 & 5.5066 & TRN & & \\
\hline CHEMBL1568752 & 688239 & 4.7862 & 5.3868 & TRN & & \\
\hline CHEMBL1340017 & 688239 & 6.1362 & 5.4771 & TRN & & \\
\hline CHEMBL1449060 & 688239 & 5.1862 & 5.5929 & TRN & & \\
\hline CHEMBL1984525 & 688239 & 6.0862 & 5.3677 & TRN & & \\
\hline CHEMBL1558133 & 688239 & 5.3862 & 5.4716 & TST & & \\
\hline CHEMBL1545453 & 688239 & 4.7862 & 5.5279 & TRN & & \\
\hline CHEMBL1357399 & 688239 & 4.5862 & 5.2981 & TST & & \\
\hline CHEMBL1405607 & 688239 & 6.8861 & 5.51 & TRN & & \\
\hline CHEMBL1610708 & 688239 & 4.5362 & 5.4732 & TRN & & \\
\hline CHEMBL1368032 & 688239 & 5.9862 & 5.3778 & TRN & & \\
\hline CHEMBL1347686 & 688239 & 4.8862 & 5.4036 & TRN & & \\
\hline CHEMBL3194427 & 688239 & 5.3362 & 5.4028 & TST & & \\
\hline CHEMBL1467525 & 688239 & 5.9362 & 5.445 & TRN & & \\
\hline CHEMBL1570668 & 688239 & 4.6862 & 5.4316 & TRN & & \\
\hline CHEMBL3212057 & 688239 & 5.6362 & 5.4001 & TRN & & \\
\hline CHEMBL1388359 & 688239 & 6.1362 & 5.5863 & TST & & \\
\hline CHEMBL1553122 & 688239 & 4.5362 & 5.3477 & TRN & & \\
\hline CHEMBL1401066 & 688239 & 5.2362 & 5.5564 & TRN & & \\
\hline CHEMBL1503253 & 688239 & 4.7362 & 5.4422 & TRN & & \\
\hline CHEMBL1312079 & 688239 & 6.2362 & 5.4693 & TST & & \\
\hline CHEMBL1337601 & 688239 & 4.5362 & 5.4544 & TRN & & \\
\hline CHEMBL1539857 & 688239 & 6.2362 & 5.4891 & TRN & & \\
\hline CHEMBL1401596 & 688239 & 5.1862 & 5.5441 & TST & & \\
\hline CHEMBL1384581 & 688239 & 4.7362 & 5.5611 & TRN & & \\
\hline CHEMBL1605512 & 688239 & 4.5362 & 5.4573 & TRN & & \\
\hline CHEMBL1560954 & 688239 & 4.8362 & 5.3168 & TRN & & \\
\hline CHEMBL3195689 & 688239 & \multicolumn{3}{|c|}{8.283999999999999} & 5.3745 & TRN \\
\hline CHEMBL1574985 & 688239 & \multicolumn{3}{|c|}{8.283999999999999} & 5.5631 & TRN \\
\hline CHEMBL1461309 & 688239 & 5.8362 & 5.4378 & TST & & \\
\hline CHEMBL1437569 & 688239 & 5.3362 & 5.6697 & TRN & & \\
\hline CHEMBL1606936 & 688239 & 4.8862 & 5.3747 & TRN & & \\
\hline CHEMBL1311896 & 688239 & 4.7362 & 5.4532 & TRN & & \\
\hline
\end{tabular}


Supplemental Table S2.txt

\begin{tabular}{|c|c|c|c|c|}
\hline 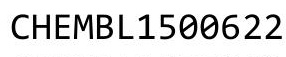 & & & & \\
\hline HEMBL1555362 & 88239 & 5862 & 605 & \\
\hline HEMBL1379875 & 88239 & 1862 & 494 & \\
\hline HEMBL4 & & & 842 & \\
\hline IEMBL1346956 & & 862 & 454 & \\
\hline HEMBL8441 & 88239 & 862 & 6202 & \\
\hline HEMBL445153 & 88239 & .9362 & .4715 & \\
\hline HEMBL14 & & & 5626 & \\
\hline IEMBL14 & 39 & 362 & 5769 & \\
\hline IEMBL13 & 39 & 862 & .5424 & \\
\hline HEMBL1603439 & 88239 & 362 & .4968 & \\
\hline HEMBL1566194 & 39 & 362 & .5524 & \\
\hline HEMBL1493350 & 39 & 62 & 4091 & \\
\hline 939 & 39 & & .489 & \\
\hline AEMBL13 & 39 & 362 & 4457 & \\
\hline HEMBL14C & 39 & 862 & 4918 & \\
\hline HEMBL1583264 & 39 & 362 & & \\
\hline HEMBL 14 & 9 & 62 & 12 & \\
\hline 327 & 9 & & 72 & \\
\hline 862 & 39 & & & \\
\hline HEMBL13 & 39 & 61 & & \\
\hline HEMBL139 & 39 & & & \\
\hline HEMBL13. & 9 & 62 & & \\
\hline HEMBL15 & & & & RN \\
\hline 692 & 39 & & & \\
\hline HEMBL143 & 39 & & & \\
\hline AEMBL13马 & 39 & & & RN \\
\hline HEMBL 32 & 9 & 64 & & \\
\hline HEM & & & & RIN \\
\hline 223 & & 62 & & RN \\
\hline HEMBL 14 & 9 & & & IRN \\
\hline HEMBL15e & 39 & 362 & 08 & ГST \\
\hline HEMBL3C & & & & - \\
\hline 391 & 9 & & & 「RN \\
\hline HEMBL13 & & & & RN \\
\hline HEMBL1566673 & 39 & & 509 & IST \\
\hline HEMBL1424619 & 39 & 362 & 5.3777 & $\Gamma R N$ \\
\hline 政T & 39 & & 5.5361 & I RIV \\
\hline Irm $>2>$ & & & & SI \\
\hline HEMBL 16 & & & & 「RN \\
\hline HEMBL1359540 & 39 & 372 & & IRN \\
\hline HEMBL15 & 39 & 62 & & \\
\hline ש & 9 & & & \\
\hline CHEMBL1508968 & 39 & & .4581 & ГRN \\
\hline HEMBL1515353 & & & & RN \\
\hline HEMBL1597956 & 39 & 862 & 78 & $N$ \\
\hline SHEM & & & & \\
\hline 6218 19 & & & & \\
\hline
\end{tabular}

Page 2596 
Supplemental Table S2.txt

\begin{tabular}{|c|c|c|c|c|c|}
\hline CHEMBL3211997 & 688239 & 4.7862 & 5.5335 & TRN & \\
\hline CHEMBL1522528 & 688239 & 5.1362 & 5.5717 & TRN & \\
\hline CHEMBL1358387 & 688239 & 5.1362 & 5.4457 & TRN & \\
\hline CHEMBL1477040 & 688239 & 8.3372 & 5.5686 & TRN & \\
\hline CHEMBL1376106 & 688239 & 4.5362 & 5.5261 & TST & \\
\hline CHEMBL1603652 & 688239 & 5.3362 & 5.336 & TRN & \\
\hline CHEMBL3195557 & 688239 & 5.3362 & 5.4224 & TRN & \\
\hline CHEMBL1498382 & 688239 & 4.8862 & 5.5351 & TRN & \\
\hline CHEMBL3213665 & 688239 & 5.3862 & 5.3597 & TRN & \\
\hline CHEMBL1308330 & 688239 & 5.4362 & 5.4819 & TRN & \\
\hline CHEMBL1570523 & 688239 & 5.1862 & 5.5893 & TRN & \\
\hline CHEMBL1438256 & 688239 & 6.5862 & 5.495 & TRN & \\
\hline CHEMBL1558715 & 688239 & 4.7362 & 5.4017 & TRN & \\
\hline CHEMBL1566794 & 688239 & 5.2362 & 5.3831 & TRN & \\
\hline CHEMBL3213233 & 688239 & 5.5862 & 5.4786 & TRN & \\
\hline CHEMBL1610297 & 688239 & 5.4862 & \multicolumn{2}{|c|}{5.321000000000001} & TRN \\
\hline CHEMBL3392070 & 688239 & 6.2862 & 5.3879 & TRN & \\
\hline CHEMBL1414506 & 688239 & 5.4362 & \multicolumn{2}{|c|}{5.537000000000001} & TRN \\
\hline CHEMBL1408530 & 688239 & 5.9362 & 5.2832 & TRN & \\
\hline CHEMBL3190964 & 688239 & 5.6362 & 5.4998 & TRN & \\
\hline CHEMBL3191212 & 688239 & 4.6862 & 5.2907 & TRN & \\
\hline CHEMBL1544263 & 688239 & 4.6362 & 5.4107 & TRN & \\
\hline CHEMBL1316921 & 688239 & 4.7862 & 5.4589 & TRN & \\
\hline CHEMBL1439323 & 688239 & 4.5362 & 5.5081 & TRN & \\
\hline CHEMBL1502646 & 688239 & 6.0 & 5.5733 & TST & \\
\hline CHEMBL1411630 & 688239 & 4.7862 & 5.4054 & TRN & \\
\hline CHEMBL1324579 & 688239 & 5.3862 & 5.394 & TRN & \\
\hline CHEMBL1581097 & 688239 & 4.8862 & 5.4797 & TRN & \\
\hline CHEMBL1588727 & 688239 & 5.7362 & 5.4865 & TRN & \\
\hline CHEMBL1497333 & 688239 & 4.5362 & 5.3947 & TRN & \\
\hline CHEMBL1569805 & 688239 & 6.0862 & 5.6459 & TRN & \\
\hline CHEMBL1383777 & 688239 & 5.4362 & 5.4112 & TRN & \\
\hline CHEMBL3191536 & 688239 & 5.4362 & 5.3804 & TRN & \\
\hline CHEMBL1306310 & 688239 & 6.3362 & 5.3062 & TRN & \\
\hline CHEMBL1385886 & 688239 & 5.1 & \multicolumn{2}{|c|}{5.5120000000000005} & TRN \\
\hline CHEMBL1423633 & 688239 & 4.7362 & 5.3199 & TRN & \\
\hline CHEMBL1568309 & 688239 & 6.3362 & 5.6161 & TRN & \\
\hline CHEMBL1321675 & 688239 & 5.6362 & 5.5592 & TRN & \\
\hline CHEMBL1389408 & 688239 & 5.7862 & 5.4377 & TRN & \\
\hline CHEMBL1527478 & 688239 & 4.5862 & 5.4183 & TRN & \\
\hline CHEMBL1535423 & 688239 & 4.5362 & 5.4661 & TST & \\
\hline CHEMBL1412873 & 688239 & 5.4362 & 5.4909 & TRN & \\
\hline CHEMBL1360795 & 688239 & 7.1864 & 5.3626 & TST & \\
\hline CHEMBL1313635 & 688239 & 7.3363 & 5.5173 & TRN & \\
\hline CHEMBL1361301 & 688239 & 6.7361 & 5.558 & TST & \\
\hline CHEMBL1316381 & 688239 & 4.5362 & 5.5827 & TRN & \\
\hline CHEMBL1330761 & 688239 & 5.1862 & 5.4415 & TRN & \\
\hline CHEMBL1340080 & 688239 & 6.0862 & 5.4585 & TRN & \\
\hline
\end{tabular}

Page 2597 


\begin{tabular}{|c|c|c|c|c|c|}
\hline & & & & & \\
\hline CHEMBL1448177 & 688239 & 6.7361 & 5.5267 & TRN & \\
\hline CHEMBL3197521 & 688239 & 4.8362 & 5.4012 & TST & \\
\hline CHEMBL1397154 & 688239 & 5.0862 & 5.5749 & TRN & \\
\hline CHEMBL1340560 & 688239 & 7.4365 & 5.5345 & TRN & \\
\hline CHEMBL1347302 & 688239 & 5.8362 & 5.3975 & TRN & \\
\hline CHEMBL1584817 & 688239 & 4.5362 & 5.5119 & TST & \\
\hline CHEMBL1469246 & 688239 & 4.6362 & 5.4797 & TRN & \\
\hline CHEMBL1311955 & 688239 & 6.7862 & 5.58899 & 99999999995 & TST \\
\hline CHEMBL1464039 & 688239 & 6.1362 & 5.4165 & TRN & \\
\hline CHEMBL1566124 & 688239 & 5.9862 & 5.6748 & TST & \\
\hline CHEMBL1574796 & 688239 & 4.7862 & 5.4377 & TRN & \\
\hline CHEMBL1990448 & 688239 & 4.5362 & 5.4287 & TRN & \\
\hline CHEMBL1473982 & 688239 & 6.3362 & 5.5309 & TRN & \\
\hline CHEMBL1503457 & 688239 & 5.1862 & 5.4907 & TST & \\
\hline CHEMBL1450248 & 688239 & 5.5862 & 5.5954 & TST & \\
\hline CHEMBL1359056 & 688239 & 6.8861 & 5.5016 & TRN & \\
\hline CHEMBL1533025 & 688239 & 4.5362 & 5.6074 & TRN & \\
\hline CHEMBL1479035 & 688239 & 5.3362 & 5.4891 & TRN & \\
\hline CHEMBL1524709 & 688239 & 5.1862 & 5.4756 & TRN & \\
\hline CHEMBL1423369 & 688239 & 5.2362 & 5.5608 & TRN & \\
\hline CHEMBL1428385 & 688239 & 5.4362 & 5.6264 & TRN & \\
\hline CHEMBL1422385 & 688239 & 4.5362 & 5.4459 & TRN & \\
\hline CHEMBL1340113 & 688239 & 4.6362 & 5.4429 & TRN & \\
\hline CHEMBL1370258 & 688239 & 5.7362 & 5.455 & TRN & \\
\hline CHEMBL1583486 & 688239 & 4.5362 & 5.5278 & TRN & \\
\hline CHEMBL1413203 & 688239 & 5.6862 & 5.4704 & TRN & \\
\hline CHEMBL1432517 & 688239 & 5.7862 & 5.4934 & TST & \\
\hline CHEMBL1530409 & 688239 & 5.3362 & 5.4623 & TRN & \\
\hline CHEMBL1451380 & 688239 & 4.5362 & 5.4233 & TST & \\
\hline CHEMBL1321217 & 688239 & 4.7862 & 5.5172 & TST & \\
\hline CHEMBL1399913 & 688239 & 5.1362 & 5.4319 & TST & \\
\hline CHEMBL1347009 & 688239 & 6.0862 & 5.5441 & TST & \\
\hline CHEMBL1317584 & 688239 & 6.2862 & 5.313 & TRN & \\
\hline CHEMBL1391897 & 688239 & 4.5362 & 5.49299 & 9999999999 & TRN \\
\hline CHEMBL1576162 & 688239 & 4.5362 & 5.6305 & TRN & \\
\hline CHEMBL1356648 & 688239 & 5.1862 & 5.3914 & TRN & \\
\hline CHEMBL1326873 & 688239 & 4.9862 & 5.5236 & TRN & \\
\hline CHEMBL3191656 & 688239 & 5.1862 & 5.4526 & TRN & \\
\hline CHEMBL1603240 & 688239 & 5.9362 & 5.5353 & TRN & \\
\hline CHEMBL1493856 & 688239 & 7.1361 & 5.4858 & TRN & \\
\hline CHEMBL1577397 & 688239 & 6.1862 & 5.5458 & TRN & \\
\hline CHEMBL1497776 & 688239 & 4.8862 & 5.3058 & TST & \\
\hline CHEMBL3190816 & 688239 & 6.1362 & 5.5309 & TRN & \\
\hline CHEMBL1508092 & 688239 & 6.5862 & 5.5169 & TRN & \\
\hline CHEMBL3212206 & 688239 & 4.9362 & 5.4118 & TRN & \\
\hline CHEMBL1607288 & 688239 & 4.5362 & 5.5936 & TRN & \\
\hline CHEMBL1451109 & 688239 & 5.8862 & 5.4546 & TRN & \\
\hline CHEMBL1568925 & 688239 & 8.3372 & 5.4435 & TST & \\
\hline
\end{tabular}


Supplemental Table S2.txt

\begin{tabular}{|c|c|c|c|c|}
\hline CHEMBL1472570 & 688239 & 4.5362 & 5.4578 & TRN \\
\hline CHEMBL1378322 & 688239 & 8.3372 & 5.393 & TRN \\
\hline CHEMBL1306830 & 688239 & 8.3372 & 5.5094 & TRN \\
\hline CHEMBL1534051 & 688239 & 5.1862 & 5.4456 & TRN \\
\hline CHEMBL1353724 & 688239 & 6.1362 & 5.567 & TRN \\
\hline CHEMBL1376108 & 688239 & 6.2862 & 5.5377 & TRN \\
\hline CHEMBL1490624 & 688239 & 4.7362 & 5.6409 & TRN \\
\hline CHEMBL1383205 & 688239 & 6.3362 & 5.3678 & TRN \\
\hline CHEMBL1539680 & 688239 & 5.1862 & 5.4328 & TST \\
\hline CHEMBL1483610 & 688239 & 4.7362 & 5.4686 & TRN \\
\hline CHEMBL1424455 & 688239 & 4.5362 & 5.4084 & TST \\
\hline CHEMBL1488473 & 688239 & 5.0362 & 5.3322 & TRN \\
\hline CHEMBL1386058 & 688239 & 5.3862 & 5.5525 & TRN \\
\hline CHEMBL1321428 & 688239 & 6.5363 & 5.5031 & TRN \\
\hline CHEMBL1404211 & 688239 & 4.7862 & 5.3319 & TRN \\
\hline CHEMBL1349810 & 688239 & 4.7862 & 5.401 & TRN \\
\hline CHEMBL1341391 & 688239 & 4.6862 & 5.3538 & TRN \\
\hline CHEMBL1604567 & 688239 & 6.3362 & 5.5124 & TST \\
\hline CHEMBL1523317 & 688239 & 5.4362 & 5.5831 & TST \\
\hline CHEMBL3193639 & 688239 & 4.8362 & 5.4628 & TRN \\
\hline CHEMBL1420073 & 688239 & 5.4362 & 5.5998 & TRN \\
\hline CHEMBL1483682 & 688239 & 5.1862 & 5.4549 & TRN \\
\hline CHEMBL1505902 & 688239 & 4.5862 & 5.5897 & TRN \\
\hline CHEMBL1479302 & 688239 & 5.1362 & 5.4873 & TST \\
\hline CHEMBL1473309 & 688239 & 5.0362 & 5.4832 & TRN \\
\hline CHEMBL 1456040 & 688239 & 5.1862 & 5.6081 & TRN \\
\hline CHEMBL1328874 & 688239 & 5.7362 & 5.6165 & TRN \\
\hline CHEMBL1542591 & 688239 & 6.1362 & 5.5782 & TST \\
\hline CHEMBL1455680 & 688239 & 5.0362 & 5.4723 & TRN \\
\hline CHEMBL1567350 & 688239 & 5.5862 & 5.3906 & TRN \\
\hline CHEMBL3209475 & 688239 & 5.1862 & 5.5841 & TRN \\
\hline CHEMBL1459647 & 688239 & 6.8362 & 5.5646 & TRN \\
\hline CHEMBL1518023 & 688239 & 4.5362 & 5.3896 & TST \\
\hline CHEMBL1491969 & 688239 & 6.5363 & 5.5888 & TRN \\
\hline CHEMBL1378587 & 688239 & 4.5362 & 5.3944 & TST \\
\hline CHEMBL1403676 & 688239 & 6.2862 & 5.4655 & TRN \\
\hline CHEMBL1309096 & 688239 & 6.1362 & 5.5546 & TRN \\
\hline CHEMBL587884 & 688239 & 4.6862 & 5.4985 & TST \\
\hline CHEMBL3207321 & 688239 & 4.8362 & 5.5015 & TRN \\
\hline CHEMBL1994148 & 688239 & 4.4862 & 5.3762 & TRN \\
\hline CHEMBL1526092 & 688239 & 6.2862 & 5.3956 & TRN \\
\hline CHEMBL1507774 & 688239 & 4.5362 & 5.3918 & TRN \\
\hline CHEMBL1994279 & 688239 & 6.2362 & 5.5025 & TST \\
\hline CHEMBL1434461 & 688239 & 6.9363 & 5.6366 & TRN \\
\hline CHEMBL1382857 & 688239 & 7.0362 & 5.5161 & TRN \\
\hline CHEMBL1441684 & 688239 & 6.2862 & 5.5166 & TRN \\
\hline CHEMBL1433195 & 688239 & 4.6862 & 5.41799 & 9999999999 \\
\hline \multirow[t]{2}{*}{ CHEMBL1363237 } & 688239 & 4.4862 & 5.42899 & 9999999999 \\
\hline & & \multicolumn{3}{|c|}{ Page 2599} \\
\hline
\end{tabular}


Supplemental Table S2.txt

\begin{tabular}{|c|c|c|c|c|}
\hline CHEMBL1547271 & 688239 & 6.5862 & 5.4412 & TST \\
\hline CHEMBL1430927 & 688239 & 4.5362 & 5.483 & TRN \\
\hline CHEMBL1475220 & 688239 & 4.5362 & 5.4433 & TRN \\
\hline CHEMBL1478930 & 688239 & 4.5362 & 5.5065 & TRN \\
\hline CHEMBL1577613 & 688239 & 5.1862 & 5.3905 & TRN \\
\hline CHEMBL1438260 & 688239 & 6.4362 & 5.4929 & TRN \\
\hline CHEMBL1537951 & 688239 & 5.6362 & 5.5018 & TRN \\
\hline CHEMBL1520914 & 688239 & 5.0362 & 5.3149 & TRN \\
\hline CHEMBL1557876 & 688239 & 5.5362 & 5.4887 & TRN \\
\hline CHEMBL1555866 & 688239 & 5.1862 & \multicolumn{2}{|c|}{5.537000000000001} \\
\hline CHEMBL1570929 & 688239 & 5.1862 & 5.42299 & 9999999999 \\
\hline CHEMBL1481701 & 688239 & 4.7862 & 5.6878 & TRN \\
\hline CHEMBL1510111 & 688239 & 7.1864 & 5.5061 & TRN \\
\hline CHEMBL1348891 & 688239 & 5.3862 & 5.774 & TRN \\
\hline CHEMBL1413704 & 688239 & 4.5862 & 5.6078 & TRN \\
\hline CHEMBL1576389 & 688239 & 4.6862 & 5.4853 & TRN \\
\hline CHEMBL1517402 & 688239 & 5.1862 & 5.5896 & TRN \\
\hline CHEMBL1408107 & 688239 & 5.1862 & 5.3667 & TST \\
\hline CHEMBL 338567 & 688239 & 8.3872 & 5.5384 & TRN \\
\hline CHEMBL1324153 & 688239 & 6.1362 & 5.4843 & TRN \\
\hline CHEMBL1420390 & 688239 & 5.4362 & 5.3491 & TST \\
\hline CHEMBL1351213 & 688239 & 4.8362 & 5.4297 & TRN \\
\hline CHEMBL1392980 & 688239 & 4.7362 & 5.3816 & TST \\
\hline CHEMBL1536804 & 688239 & 4.5362 & 5.5438 & TRN \\
\hline CHEMBL1435487 & 688239 & 4.9362 & 5.3858 & TRN \\
\hline CHEMBL1604932 & 688239 & 6.4362 & 5.4991 & TRN \\
\hline CHEMBL1501588 & 688239 & 6.0 & 5.4476 & TST \\
\hline CHEMBL1427643 & 688239 & 4.4862 & 5.5814 & TRN \\
\hline CHEMBL1547571 & 688239 & 5.4862 & 5.5046 & TRN \\
\hline CHEMBL1420943 & 688239 & 5.2862 & 5.2274 & TST \\
\hline CHEMBL1521111 & 688239 & 5.8362 & 5.5241 & TRN \\
\hline CHEMBL1578673 & 688239 & 5.4862 & 5.5076 & TRN \\
\hline CHEMBL1401197 & 688239 & 5.0362 & 5.426 & TRN \\
\hline CHEMBL1526243 & 688239 & 4.9362 & 5.5515 & TRN \\
\hline CHEMBL 3191271 & 688239 & 5.5362 & 5.4915 & TRN \\
\hline CHEMBL1464442 & 688239 & 6.3863 & 5.5893 & TRN \\
\hline CHEMBL1472251 & 688239 & 5.2362 & 5.4312 & TST \\
\hline CHEMBL1562157 & 688239 & 4.6862 & 5.4813 & TST \\
\hline CHEMBL1339601 & 688239 & 4.8362 & 5.4762 & TRN \\
\hline CHEMBL1493231 & 688239 & 5.1862 & 5.5231 & TRN \\
\hline CHEMBL1461352 & 688239 & 6.6362 & 5.4527 & TRN \\
\hline CHEMBL1525684 & 688239 & 5.1862 & 5.5451 & TRN \\
\hline CHEMBL1469735 & 688239 & 4.9862 & 5.5787 & TRN \\
\hline CHEMBL1393016 & 688239 & 5.4362 & 5.5177 & TRN \\
\hline CHEMBL1343921 & 688239 & 4.6862 & 5.5239 & TST \\
\hline CHEMBL1362789 & 688239 & 6.8362 & 5.3903 & TRN \\
\hline CHEMBL1412294 & 688239 & 5.0362 & 5.5207 & TRN \\
\hline CHEMBL1485305 & 688239 & 6.5862 & 5.5989 & TRN \\
\hline
\end{tabular}

Page 2600 
Supplemental Table S2.txt

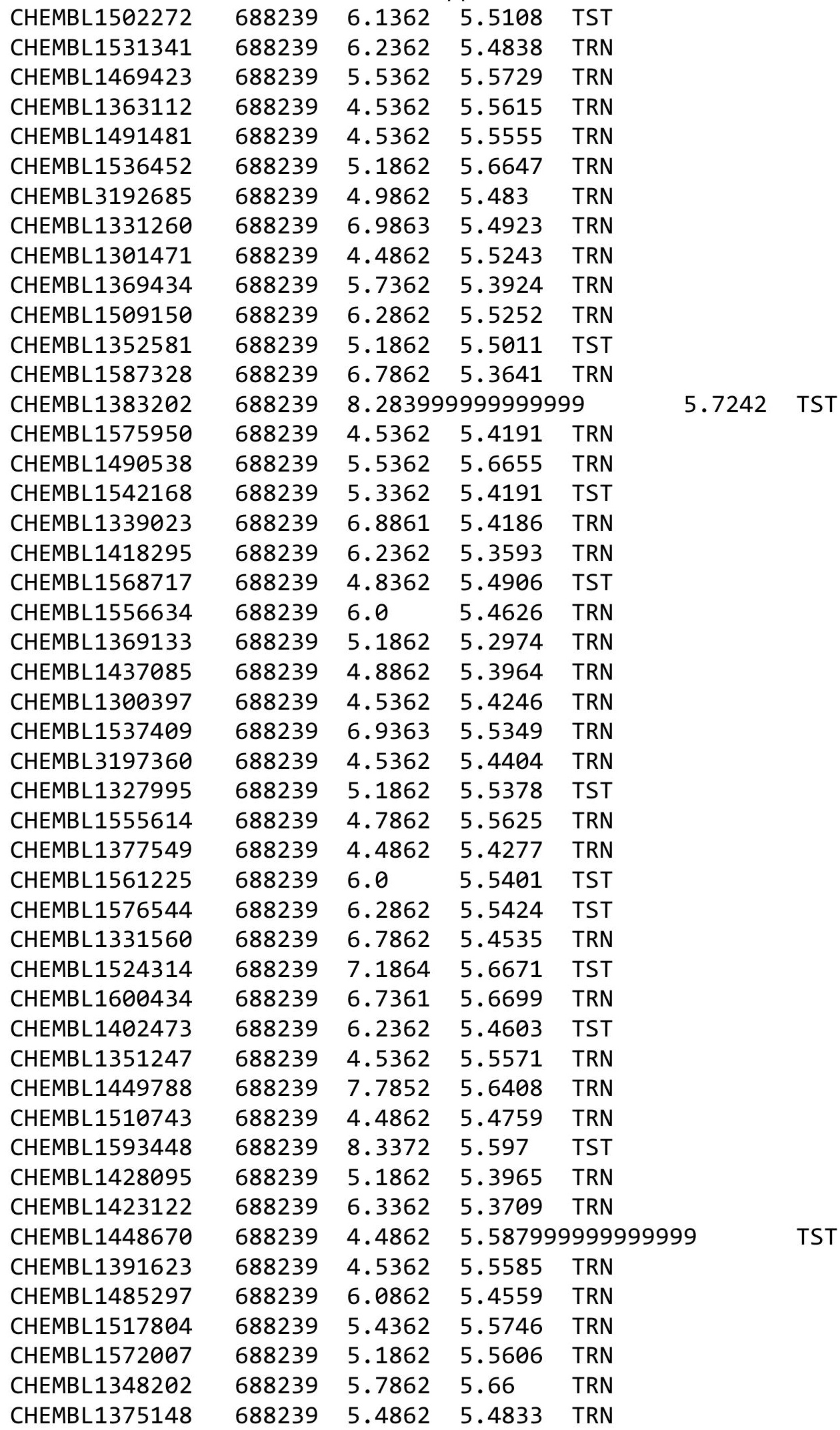

Page 2601 


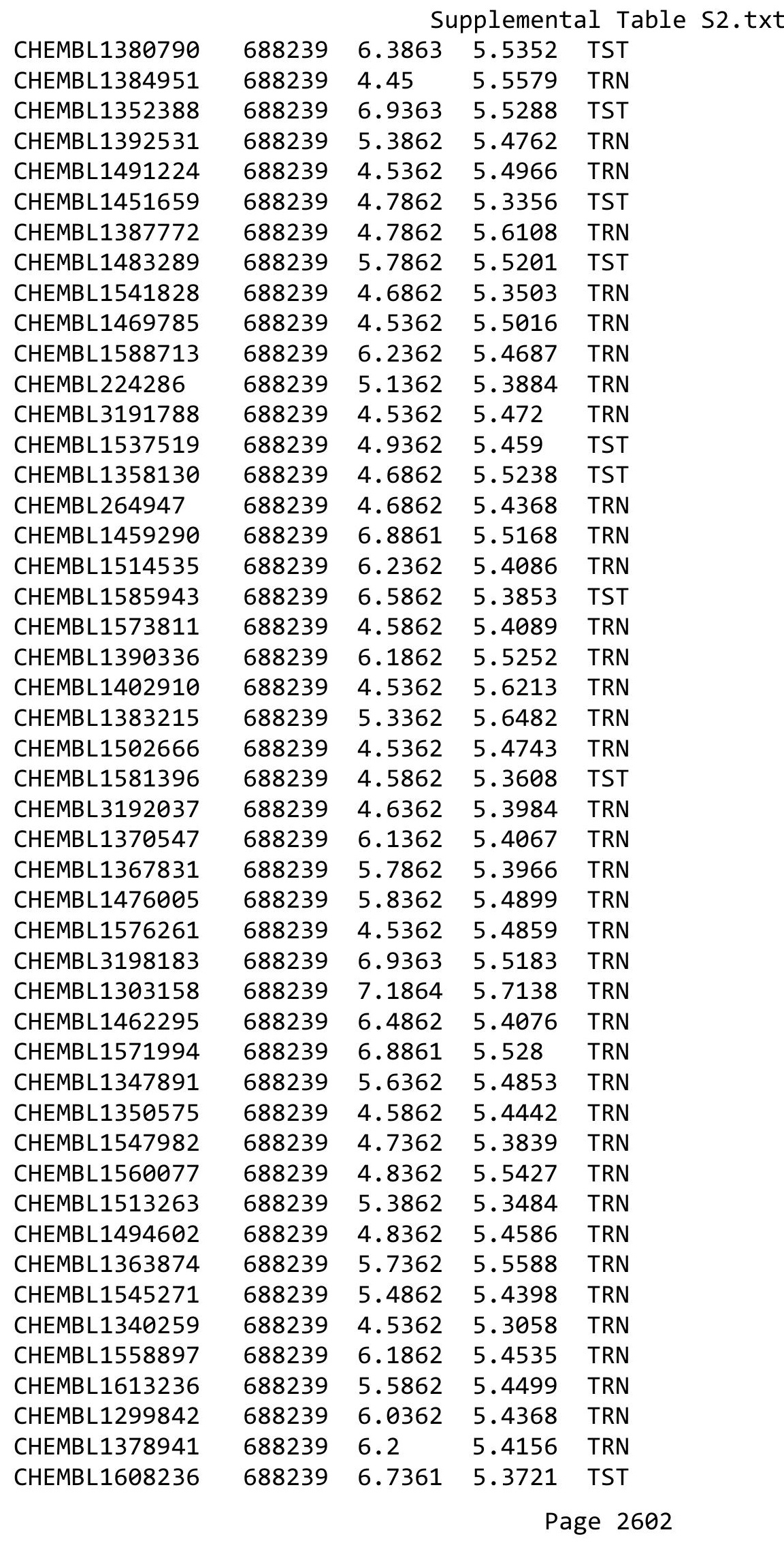


Supplemental Table S2.txt

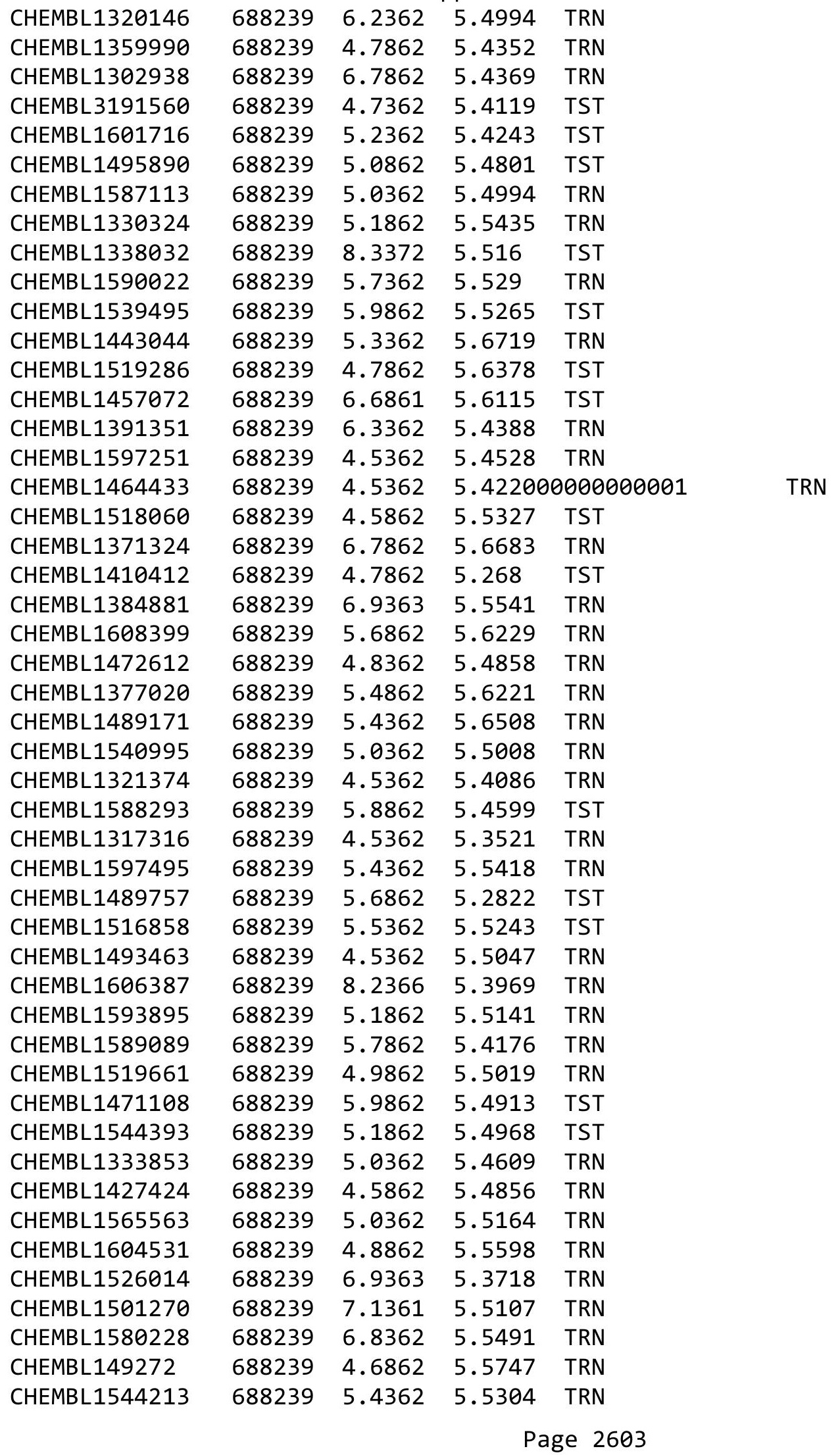


Supplemental Table S2.txt

\begin{tabular}{|c|c|c|c|c|}
\hline CHEMBL1522996 & 688239 & 5.5862 & 5.5147 & TRN \\
\hline CHEMBL1596749 & 688239 & 6.8362 & 5.5702 & TRN \\
\hline CHEMBL1302572 & 688239 & 4.6862 & 5.5266 & TRN \\
\hline CHEMBL1369621 & 688239 & 4.6862 & 5.6444 & TST \\
\hline CHEMBL 3211408 & 688239 & 8.3372 & 5.6914 & TRN \\
\hline CHEMBL1596501 & 688239 & 6.1862 & 5.3842 & TST \\
\hline CHEMBL1330147 & 688239 & 5.0862 & 5.4109 & TRN \\
\hline CHEMBL1402013 & 688239 & 4.5362 & 5.4368 & TRN \\
\hline CHEMBL1457927 & 688239 & 4.5362 & 5.4488 & TRN \\
\hline CHEMBL1608907 & 688239 & 4.5362 & 5.5162 & TRN \\
\hline CHEMBL 3198841 & 688239 & 4.7362 & 5.5057 & TRN \\
\hline CHEMBL1430344 & 688239 & 4.6862 & 5.4844 & TRN \\
\hline CHEMBL1398340 & 688239 & 5.7862 & 5.3879 & TRN \\
\hline CHEMBL1311815 & 688239 & 4.5362 & 5.4384 & TRN \\
\hline CHEMBL1480002 & 688239 & 5.2862 & 5.5651 & TRN \\
\hline CHEMBL1495201 & 688239 & 6.8861 & 5.3522 & TRN \\
\hline CHEMBL1543764 & 688239 & 5.0362 & 5.4732 & TST \\
\hline CHEMBL1396448 & 688239 & 4.7362 & 5.5066 & TRN \\
\hline CHEMBL1320502 & 688239 & 4.7862 & 5.5201 & TRN \\
\hline CHEMBL1452369 & 688239 & 6.9863 & 5.4271 & TRN \\
\hline CHEMBL1388469 & 688239 & 4.7362 & 5.5816 & TRN \\
\hline CHEMBL1391771 & 688239 & 4.7862 & 5.5387 & TRN \\
\hline CHEMBL1412413 & 688239 & 4.5362 & 5.5067 & TST \\
\hline CHEMBL1487969 & 688239 & 5.3862 & 5.362 & TRN \\
\hline CHEMBL1380566 & 688239 & 4.5362 & 5.65799 & 79999999995 \\
\hline CHEMBL1316681 & 688239 & 4.6862 & 5.58899 & 99999999995 \\
\hline CHEMBL1459551 & 688239 & 6.4362 & 5.504 & TST \\
\hline CHEMBL1481075 & 688239 & 4.5362 & 5.4762 & TRN \\
\hline CHEMBL1575302 & 688239 & 5.3862 & 5.5046 & TRN \\
\hline CHEMBL1591690 & 688239 & 5.5362 & 5.5655 & TST \\
\hline CHEMBL1454004 & 688239 & 8.2366 & 5.5704 & TRN \\
\hline CHEMBL1368936 & 688239 & 4.7362 & 5.3792 & TST \\
\hline CHEMBL1404114 & 688239 & 5.5362 & 5.4712 & TST \\
\hline CHEMBL1392689 & 688239 & 6.1862 & 5.6778 & TRN \\
\hline CHEMBL1458816 & 688239 & 6.6362 & 5.5597 & TRN \\
\hline CHEMBL1583027 & 688239 & 4.9362 & 5.4659 & TRN \\
\hline CHEMBL1447121 & 688239 & 5.1862 & 5.4659 & TRN \\
\hline CHEMBL1606268 & 688239 & 4.7862 & 5.5931 & TRN \\
\hline CHEMBL1984347 & 688239 & 4.5362 & 5.4515 & TRN \\
\hline CHEMBL1408159 & 688239 & 6.9363 & 5.6342 & TRN \\
\hline CHEMBL578276 & 688239 & 5.1862 & 5.5762 & TRN \\
\hline CHEMBL1368080 & 688239 & 6.8362 & 5.5242 & TRN \\
\hline CHEMBL1547335 & 688239 & 6.8362 & 5.5594 & TRN \\
\hline CHEMBL1534981 & 688239 & 4.7862 & 5.2115 & TRN \\
\hline CHEMBL 3144955 & 688239 & 6.9363 & 5.5236 & TST \\
\hline CHEMBL1096834 & 688239 & 5.8862 & 5.4285 & TRN \\
\hline CHEMBL1341340 & 688239 & 4.9862 & 5.3208 & TRN \\
\hline CHEMBL1510964 & 688239 & 5.6362 & 5.5249 & TRN \\
\hline
\end{tabular}

Page 2604 
Supplemental Table S2.txt

\begin{tabular}{|c|c|c|c|c|c|}
\hline CHEMBL1516633 & 688239 & 5.1862 & 5.5367 & TRN & \\
\hline CHEMBL1453890 & 688239 & 4.7862 & 5.40799 & 99999999995 & TRN \\
\hline CHEMBL1334472 & 688239 & 5.0862 & 5.5458 & TRN & \\
\hline CHEMBL1567859 & 688239 & 5.1362 & 5.3678 & TRN & \\
\hline CHEMBL1344429 & 688239 & 5.1362 & 5.4713 & TST & \\
\hline CHEMBL1487264 & 688239 & 5.7862 & 5.6267 & TRN & \\
\hline CHEMBL1578361 & 688239 & 7.1361 & 5.4666 & TRN & \\
\hline CHEMBL1595902 & 688239 & 4.8362 & \multicolumn{2}{|c|}{5.377000000000001} & TRN \\
\hline CHEMBL1318603 & 688239 & 6.8362 & 5.4672 & TRN & \\
\hline CHEMBL1326080 & 688239 & 5.0862 & \multicolumn{2}{|c|}{5.5729999999999995} & TRN \\
\hline CHEMBL1420696 & 688239 & 7.0362 & 5.5526 & TST & \\
\hline CHEMBL1393025 & 688239 & 6.7862 & 5.3777 & TST & \\
\hline CHEMBL1301956 & 688239 & 5.2862 & 5.5711 & TRN & \\
\hline CHEMBL1558607 & 688239 & 5.0862 & 5.5129 & TRN & \\
\hline CHEMBL1435982 & 688239 & 5.5862 & 5.4534 & TRN & \\
\hline CHEMBL1500940 & 688239 & 5.3362 & 5.5831 & TRN & \\
\hline CHEMBL1565757 & 688239 & 5.7862 & 5.5114 & TST & \\
\hline CHEMBL1459025 & 688239 & 4.7862 & 5.5379 & TST & \\
\hline CHEMBL1320680 & 688239 & 6.6362 & 5.4549 & TRN & \\
\hline CHEMBL1471941 & 688239 & 5.3862 & 5.4734 & TRN & \\
\hline CHEMBL1405793 & 688239 & 5.1862 & 5.3791 & TRN & \\
\hline CHEMBL3210693 & 688239 & 6.7862 & 5.4527 & TST & \\
\hline CHEMBL1376683 & 688239 & 4.7862 & 5.3085 & TRN & \\
\hline CHEMBL1512053 & 688239 & 4.5362 & 5.5156 & TRN & \\
\hline CHEMBL1302118 & 688239 & 5.1862 & 5.5886 & TRN & \\
\hline CHEMBL1469344 & 688239 & 6.9363 & 5.5639 & TRN & \\
\hline CHEMBL1429097 & 688239 & 4.5362 & 5.3899 & TRN & \\
\hline CHEMBL1542804 & 688239 & 4.5362 & 5.3155 & TRN & \\
\hline CHEMBL1469306 & 688239 & 4.5362 & 5.4424 & TRN & \\
\hline CHEMBL1465840 & 688239 & 4.5362 & 5.5581 & TRN & \\
\hline CHEMBL1323158 & 688239 & 5.4362 & 5.5248 & TRN & \\
\hline CHEMBL 3196375 & 688239 & 5.1862 & 5.3707 & TRN & \\
\hline CHEMBL1391732 & 688239 & 4.5362 & 5.5338 & TRN & \\
\hline CHEMBL1365695 & 688239 & 4.5362 & 5.5063 & TST & \\
\hline CHEMBL1609336 & 688239 & 5.2862 & 5.5799 & TRN & \\
\hline CHEMBL1334186 & 688239 & 4.9362 & 5.5354 & TST & \\
\hline CHEMBL1586527 & 688239 & 6.3863 & 5.596 & TRN & \\
\hline CHEMBL1472043 & 688239 & 6.9863 & 5.5535 & TST & \\
\hline CHEMBL1424992 & 688239 & 5.2862 & 5.5721 & TRN & \\
\hline CHEMBL1578346 & 688239 & 5.1362 & 5.4011 & TRN & \\
\hline CHEMBL1587836 & 688239 & 7.0362 & 5.36299 & 99999999995 & TRN \\
\hline CHEMBL1571841 & 688239 & 6.6362 & 5.4928 & TRN & \\
\hline CHEMBL1561445 & 688239 & 5.7862 & 5.5583 & TST & \\
\hline CHEMBL1455547 & 688239 & 4.8362 & 5.4081 & TST & \\
\hline CHEMBL1550928 & 688239 & 5.5362 & 5.4987 & TRN & \\
\hline CHEMBL1454421 & 688239 & 5.8362 & 5.5916 & TRN & \\
\hline CHEMBL1429292 & 688239 & 6.6861 & 5.529 & TRN & \\
\hline CHEMBL1496058 & 688239 & 4.7362 & 5.3945 & TRN & \\
\hline
\end{tabular}

Page 2605 
Supplemental Table S2.txt

\begin{tabular}{|c|c|c|c|c|c|}
\hline CHEMBL1581932 & 688239 & 5.4862 & 5.4238 & TST & \\
\hline CHEMBL1383628 & 688239 & 5.3362 & 5.6275 & TRN & \\
\hline CHEMBL3207358 & 688239 & 4.5362 & 5.6117 & TST & \\
\hline CHEMBL1316327 & 688239 & 7.5867 & 5.5956 & TRN & \\
\hline CHEMBL1585665 & 688239 & 4.9862 & 5.3389 & TRN & \\
\hline CHEMBL1351105 & 688239 & 4.5362 & 5.3967 & TST & \\
\hline CHEMBL1376635 & 688239 & 4.6862 & 5.2133 & TRN & \\
\hline CHEMBL1464943 & 688239 & 6.8362 & 5.5493 & TST & \\
\hline CHEMBL1478826 & 688239 & 4.5362 & 5.42 & TST & \\
\hline CHEMBL1465086 & 688239 & 4.5362 & 5.5253 & TRN & \\
\hline CHEMBL1341394 & 688239 & 6.9863 & 5.5126 & TRN & \\
\hline CHEMBL1391172 & 688239 & 4.5362 & 5.49799 & 9999999999 & TRN \\
\hline CHEMBL1516942 & 688239 & 5.3862 & 5.4474 & TRN & \\
\hline CHEMBL1595359 & 688239 & 5.0362 & 5.4086 & TRN & \\
\hline CHEMBL1487205 & 688239 & 5.8362 & 5.3233 & TST & \\
\hline CHEMBL1555117 & 688239 & \multicolumn{2}{|c|}{8.283999999999999} & 5.4695 & TST \\
\hline CHEMBL1389730 & 688239 & 4.4862 & 5.5099 & TRN & \\
\hline CHEMBL1345009 & 688239 & 7.2865 & 5.4984 & TRN & \\
\hline CHEMBL1299210 & 688239 & 5.8862 & 5.4601 & TRN & \\
\hline CHEMBL1595146 & 688239 & 8.3372 & 5.5606 & TRN & \\
\hline CHEMBL1330779 & 688239 & 5.1862 & 5.5648 & TRN & \\
\hline CHEMBL1346926 & 688239 & 4.6362 & 5.4354 & TRN & \\
\hline CHEMBL1325142 & 688239 & 6.9863 & 5.5648 & TRN & \\
\hline CHEMBL1602335 & 688239 & 5.4362 & 5.59200 & 0000000005 & \\
\hline CHEMBL1573264 & 688239 & 4.7362 & 5.5872 & TRN & \\
\hline CHEMBL1344552 & 688239 & 6.9863 & 5.5175 & TST & \\
\hline CHEMBL1513796 & 688239 & 6.2862 & 5.4392 & TRN & \\
\hline CHEMBL1385278 & 688239 & 5.6362 & 5.4508 & TST & \\
\hline CHEMBL1396466 & 688239 & 5.1362 & 5.4823 & TRN & \\
\hline CHEMBL1523819 & 688239 & 4.5362 & 5.6721 & TRN & \\
\hline CHEMBL1364393 & 688239 & 5.0362 & 5.5104 & TRN & \\
\hline CHEMBL1351267 & 688239 & 6.8861 & 5.5925 & TST & \\
\hline CHEMBL1427394 & 688239 & 4.6862 & 5.4636 & TST & \\
\hline CHEMBL1592837 & 688239 & 4.5362 & 5.4496 & TRN & \\
\hline CHEMBL1586420 & 688239 & 5.4362 & 5.5507 & TRN & \\
\hline CHEMBL1316668 & 688239 & 5.3362 & 5.4711 & TRN & \\
\hline CHEMBL1457060 & 688239 & 4.5862 & 5.6487 & TRN & \\
\hline CHEMBL1579564 & 688239 & 5.1862 & 5.4747 & TRN & \\
\hline CHEMBL1313314 & 688239 & 5.3862 & 5.5399 & TST & \\
\hline CHEMBL1464176 & 688239 & 5.8862 & 5.379 & TRN & \\
\hline CHEMBL1456700 & 688239 & 4.5362 & 5.6452 & TRN & \\
\hline CHEMBL1520481 & 688239 & 4.7862 & 5.5039 & TRN & \\
\hline CHEMBL1459116 & 688239 & 5.3362 & 5.3967 & TRN & \\
\hline CHEMBL1399799 & 688239 & 4.5362 & 5.3786 & TRN & \\
\hline CHEMBL1496212 & 688239 & 4.9362 & 5.4256 & TRN & \\
\hline CHEMBL1460931 & 688239 & 5.6862 & 5.5743 & TST & \\
\hline CHEMBL1601754 & 688239 & 6.2362 & 5.5005 & TRN & \\
\hline CHEMBL1439103 & 688239 & 5.6362 & 5.38899 & 7999999999 & \\
\hline
\end{tabular}


Supplemental Table S2.txt

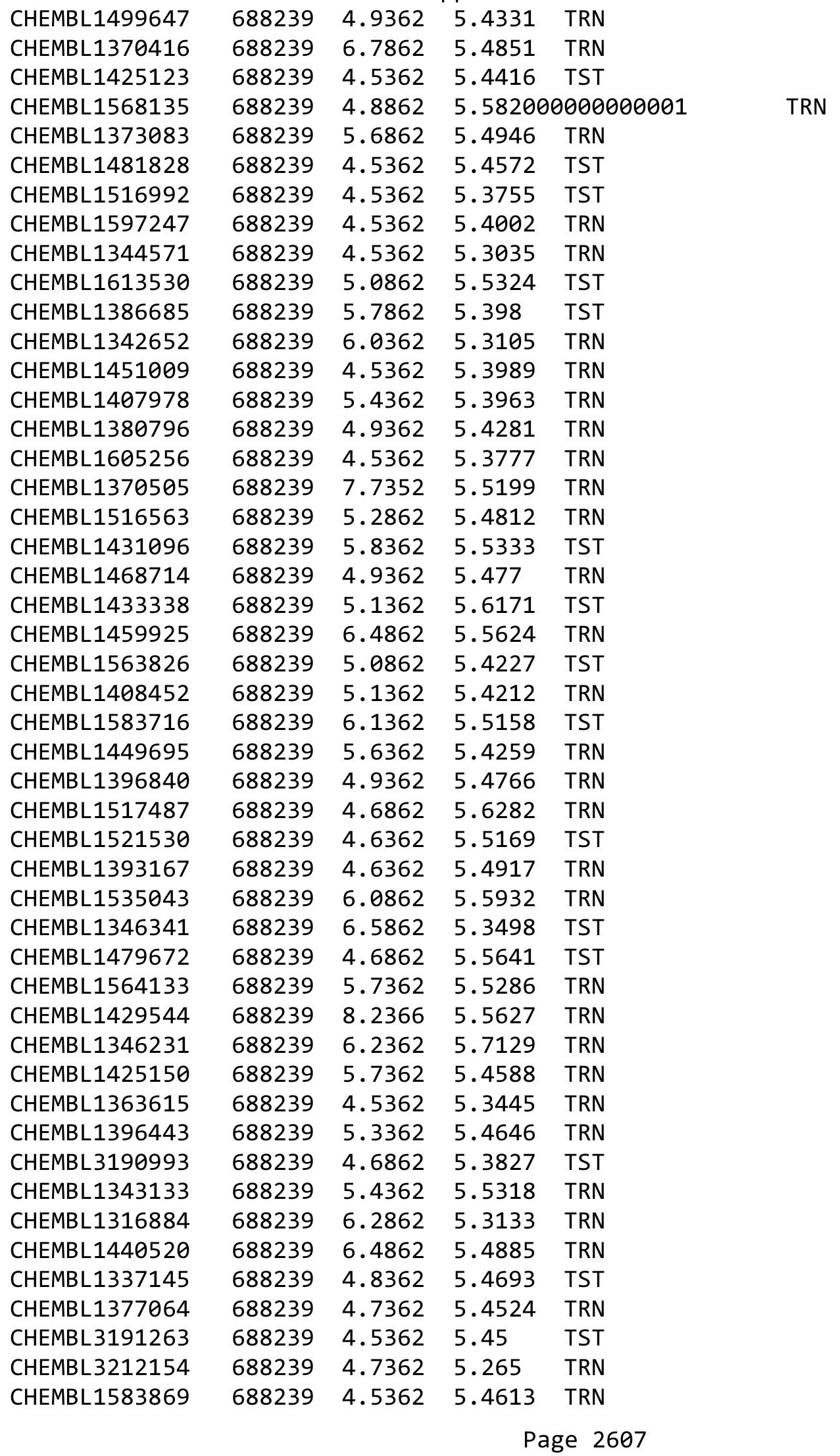


Supplemental Table S2.txt

\begin{tabular}{|c|c|c|c|c|c|}
\hline CHEMBL1344456 & 688239 & 5.8862 & 5.4643 & TRN & \\
\hline CHEMBL1556888 & 688239 & 6.3362 & 5.5698 & TRN & \\
\hline CHEMBL602366 & 688239 & 5.3362 & \multicolumn{2}{|c|}{5.422000000000001} & TST \\
\hline CHEMBL1307623 & 688239 & 4.5362 & 5.4179 & TST & \\
\hline CHEMBL1311440 & 688239 & 6.1362 & 5.3627 & TRN & \\
\hline CHEMBL1311385 & 688239 & 5.1362 & 5.6172 & TRN & \\
\hline CHEMBL1547591 & 688239 & 5.8362 & 5.4705 & TRN & \\
\hline CHEMBL1972347 & 688239 & 5.2862 & 5.4631 & TRN & \\
\hline CHEMBL1324130 & 688239 & 5.1862 & 5.541 & TRN & \\
\hline CHEMBL1505756 & 688239 & 4.5362 & 5.2531 & TRN & \\
\hline CHEMBL1370946 & 688239 & 6.5862 & 5.4143 & TRN & \\
\hline CHEMBL1511353 & 688239 & 6.9363 & 5.563 & TST & \\
\hline CHEMBL3192727 & 688239 & 4.8362 & 5.4315 & TRN & \\
\hline CHEMBL1375487 & 688239 & 6.1362 & 5.4942 & TRN & \\
\hline CHEMBL1339549 & 688239 & 7.5361 & 5.5431 & TST & \\
\hline CHEMBL1381124 & 688239 & 5.0362 & 5.5324 & TRN & \\
\hline CHEMBL1364769 & 688239 & 6.4862 & \multicolumn{2}{|c|}{5.327000000000001} & TRN \\
\hline CHEMBL1443799 & 688239 & 5.8862 & 5.6249 & TRN & \\
\hline CHEMBL1444898 & 688239 & 6.0362 & 5.5797 & TRN & \\
\hline CHEMBL1308970 & 688239 & 5.1862 & 5.6076 & TRN & \\
\hline CHEMBL1547999 & 688239 & 5.1362 & 5.3903 & TRN & \\
\hline CHEMBL1488025 & 688239 & 5.1862 & 5.5564 & TRN & \\
\hline CHEMBL1464959 & 688239 & 6.2362 & 5.5328 & TRN & \\
\hline CHEMBL1427513 & 688239 & 5.2862 & 5.3968 & TRN & \\
\hline CHEMBL1364524 & 688239 & 4.9862 & \multicolumn{2}{|c|}{5.502999999999999} & TST \\
\hline CHEMBL1467984 & 688239 & 6.0362 & 5.5083 & TRN & \\
\hline CHEMBL1541962 & 688239 & 4.7362 & 5.5038 & TRN & \\
\hline CHEMBL1569968 & 688239 & 7.1864 & 5.5948 & TRN & \\
\hline CHEMBL1566961 & 688239 & 6.1862 & 5.5063 & TST & \\
\hline CHEMBL1321558 & 688239 & 5.7862 & 5.5945 & TRN & \\
\hline CHEMBL1611162 & 688239 & 6.5363 & 5.4038 & TRN & \\
\hline CHEMBL1584580 & 688239 & 6.2362 & 5.4689 & TRN & \\
\hline CHEMBL1363858 & 688239 & 6.3362 & 5.6413 & TRN & \\
\hline CHEMBL1514954 & 688239 & 5.9362 & 5.4328 & TRN & \\
\hline CHEMBL1464306 & 688239 & 5.4362 & 5.3776 & TRN & \\
\hline CHEMBL1568176 & 688239 & 6.0862 & 5.4669 & TRN & \\
\hline CHEMBL1488872 & 688239 & 4.7362 & 5.5954 & TRN & \\
\hline CHEMBL1526332 & 688239 & 6.8861 & 5.4447 & TRN & \\
\hline CHEMBL1397769 & 688239 & 5.3862 & 5.5241 & TRN & \\
\hline CHEMBL1557033 & 688239 & 5.1862 & 5.4753 & TST & \\
\hline CHEMBL1463400 & 688239 & 5.4862 & 5.4125 & TRN & \\
\hline CHEMBL1418595 & 688239 & 6.7862 & 5.4714 & TRN & \\
\hline CHEMBL1310018 & 688239 & 5.6862 & 5.5392 & TST & \\
\hline CHEMBL1378686 & 688239 & 4.6862 & 5.5456 & TRN & \\
\hline CHEMBL3212150 & 688239 & 8.3372 & 5.4042 & TRN & \\
\hline CHEMBL1517525 & 688239 & 6.2862 & 5.61299 & 99999999995 & TRN \\
\hline CHEMBL1451941 & 688239 & 4.5862 & 5.4646 & TST & \\
\hline CHEMBL1533918 & 688239 & 4.4862 & 5.5427 & TRN & \\
\hline
\end{tabular}


Supplemental Table S2.txt

\begin{tabular}{|c|c|c|c|c|c|}
\hline CHEMBL1363554 & 688239 & 6.1362 & 5.4703 & TST & \\
\hline CHEMBL1427283 & 688239 & 4.5362 & 5.5515 & TST & \\
\hline CHEMBL1482589 & 688239 & 6.7862 & 5.5068 & TRN & \\
\hline CHEMBL1462176 & 688239 & 4.95 & 5.6011 & TRN & \\
\hline CHEMBL1576166 & 688239 & 4.5362 & 5.5438 & TRN & \\
\hline CHEMBL1583041 & 688239 & 4.9362 & 5.362 & TST & \\
\hline CHEMBL1495046 & 688239 & 4.5362 & 5.4544 & TRN & \\
\hline CHEMBL1575139 & 688239 & 4.5862 & 5.5512 & TRN & \\
\hline CHEMBL1534389 & 688239 & 5.1862 & 5.5181 & TRN & \\
\hline CHEMBL1599189 & 688239 & 5.4362 & 5.5413 & TST & \\
\hline CHEMBL 3197191 & 688239 & 7.0362 & 5.3412 & TRN & \\
\hline CHEMBL 3198584 & 688239 & 5.4862 & 5.468999 & 999999999 & TRN \\
\hline CHEMBL1438522 & 688239 & 6.9863 & 5.4421 & TRN & \\
\hline CHEMBL1301144 & 688239 & 5.9362 & 5.3633 & TST & \\
\hline CHEMBL 3189676 & 688239 & 6.2862 & 5.6025 & TRN & \\
\hline CHEMBL 2068165 & 688239 & 6.0 & 5.3904 & TRN & \\
\hline CHEMBL1193765 & 688239 & 5.4362 & 5.4029 & TST & \\
\hline CHEMBL1450176 & 688239 & 5.8862 & 5.4968 & TRN & \\
\hline CHEMBL1310516 & 688239 & 6.9363 & 5.375 & TRN & \\
\hline CHEMBL1568494 & 688239 & 4.5362 & 5.4836 & TRN & \\
\hline CHEMBL1610493 & 688239 & 8.3372 & 5.497000 & 000000001 & TST \\
\hline CHEMBL1583318 & 688239 & 5.1362 & 5.3968 & TRN & \\
\hline CHEMBL1308900 & 688239 & 4.5362 & 5.366000 & 0000000005 & \\
\hline CHEMBL1538627 & 688239 & 4.7362 & 5.3379 & TST & \\
\hline CHEMBL1428572 & 688239 & 6.4862 & 5.4854 & TRN & \\
\hline CHEMBL1432721 & 688239 & 4.6862 & 5.5591 & TRN & \\
\hline CHEMBL1464180 & 688239 & 5.7862 & 5.4817 & TRN & \\
\hline CHEMBL1471645 & 688239 & 4.7362 & 5.5188 & TRN & \\
\hline CHEMBL1390029 & 688239 & 4.6862 & 5.4316 & TRN & \\
\hline CHEMBL1349834 & 688239 & 5.7362 & 5.5657 & TRN & \\
\hline CHEMBL1408788 & 688239 & 5.7362 & 5.5382 & TRN & \\
\hline CHEMBL1570216 & 688239 & 4.5362 & 5.2853 & TRN & \\
\hline CHEMBL1542555 & 688239 & 6.8362 & 5.5681 & TRN & \\
\hline CHEMBL1585636 & 688239 & 4.5862 & 5.5595 & TST & \\
\hline CHEMBL1585039 & 688239 & 5.6362 & 5.4735 & TRN & \\
\hline CHEMBL1534003 & 688239 & 5.1362 & 5.728 & TRN & \\
\hline CHEMBL1584052 & 688239 & 4.5362 & 5.4113 & TRN & \\
\hline CHEMBL1557355 & 688239 & 4.6362 & 5.4002 & TRN & \\
\hline CHEMBL 3209600 & 688239 & 4.5362 & 5.3939 & TST & \\
\hline CHEMBL1565007 & 688239 & 5.6862 & 5.5053 & TRN & \\
\hline CHEMBL1556124 & 688239 & 4.5362 & 5.603 & TRN & \\
\hline CHEMBL1351140 & 688239 & 5.4862 & 5.6125 & TRN & \\
\hline CHEMBL1419195 & 688239 & 5.3362 & 5.5625 & TRN & \\
\hline CHEMBL1346023 & 688239 & 8.283999 & 999999999 & 5.6979 & \\
\hline CHEMBL1467679 & 688239 & 5.1862 & 5.5252 & TST & \\
\hline CHEMBL1316894 & 688239 & 5.1862 & 5.4808 & TRN & \\
\hline CHEMBL1332839 & 688239 & 5.3362 & 5.6641 & TST & \\
\hline CHEMBL1568912 & 688239 & 6.1362 & 5.5542 & TRN & \\
\hline
\end{tabular}


Supplemental Table S2.txt

\begin{tabular}{|c|c|c|c|c|c|c|}
\hline CHEMBL1307206 & 688239 & 4.5362 & 5.4682 & TRN & & \\
\hline CHEMBL1471985 & 688239 & 5.4862 & 5.5746 & TRN & & \\
\hline CHEMBL1438706 & 688239 & 5.1862 & 5.2831 & TRN & & \\
\hline CHEMBL3213920 & 688239 & 8.3372 & 5.4553 & TST & & \\
\hline CHEMBL1303135 & 688239 & 4.5362 & 5.572999 & 99999999995 & TRN & \\
\hline CHEMBL1334108 & 688239 & 5.7362 & 5.6099 & TRN & & \\
\hline CHEMBL3197974 & 688239 & 4.5362 & 5.606 & TRN & & \\
\hline CHEMBL1431818 & 688239 & 5.2862 & 5.4838 & TRN & & \\
\hline CHEMBL1483940 & 688239 & 5.1862 & 5.5222 & TRN & & \\
\hline CHEMBL1516808 & 688239 & 6.0862 & 5.5327 & TST & & \\
\hline CHEMBL1540903 & 688239 & 4.5362 & 5.4517 & TRN & & \\
\hline CHEMBL1608604 & 688239 & 4.5362 & 5.377000 & 0000000001 & TRN & \\
\hline CHEMBL1389121 & 688239 & 5.6362 & 5.4355 & TRN & & \\
\hline CHEMBL1507876 & 688239 & 4.6862 & 5.511 & TRN & & \\
\hline CHEMBL1488964 & 688239 & 4.6362 & 5.4346 & TST & & \\
\hline CHEMBL1473372 & 688239 & 8.28399 & 99999999 & 5.45100 & 00000000005 & TST \\
\hline CHEMBL1316058 & 688239 & 5.2862 & 5.5791 & TRN & & \\
\hline CHEMBL1334786 & 688239 & 8.28399 & 99999999 & 5.5402 & TRN & \\
\hline CHEMBL1469288 & 688239 & 5.3862 & 5.5246 & TRN & & \\
\hline CHEMBL1790003 & 688239 & 4.5362 & 5.552000 & 0000000005 & TRN & \\
\hline CHEMBL1605580 & 688239 & 4.5362 & 5.4792 & TRN & & \\
\hline CHEMBL1364445 & 688239 & 4.5362 & 5.5297 & TST & & \\
\hline CHEMBL1561617 & 688239 & 5.1362 & 5.5126 & TRN & & \\
\hline CHEMBL1414761 & 688239 & 4.5362 & 5.5927 & TRN & & \\
\hline CHEMBL 3209765 & 688239 & 5.9362 & 5.5144 & TRN & & \\
\hline CHEMBL3207394 & 688239 & 4.5362 & 5.4789 & TST & & \\
\hline CHEMBL1326641 & 688239 & 4.5362 & 5.5201 & TRN & & \\
\hline CHEMBL1581461 & 688239 & 4.5362 & 5.5784 & TST & & \\
\hline CHEMBL1540224 & 688239 & 5.6862 & 5.5184 & TRN & & \\
\hline CHEMBL1469334 & 688239 & 6.7862 & 5.4902 & TRN & & \\
\hline CHEMBL1392737 & 688239 & 4.8362 & 5.5402 & TRN & & \\
\hline CHEMBL1460022 & 688239 & 5.7362 & 5.5548 & TRN & & \\
\hline CHEMBL1334224 & 688239 & 6.2862 & 5.536000 & 00000000005 & TRN & \\
\hline CHEMBL1539565 & 688239 & 4.5362 & 5.5637 & TRN & & \\
\hline CHEMBL1426306 & 688239 & 5.4362 & 5.5322 & TST & & \\
\hline CHEMBL391997 & 688239 & 4.5862 & 5.2639 & TST & & \\
\hline CHEMBL3212307 & 688239 & 4.7362 & 5.3097 & TRN & & \\
\hline CHEMBL 3190475 & 688239 & 4.6862 & 5.5306 & TRN & & \\
\hline CHEMBL1543928 & 688239 & 4.5362 & 5.5217 & TST & & \\
\hline CHEMBL1536179 & 688239 & 5.7862 & 5.4496 & TRN & & \\
\hline CHEMBL1388667 & 688239 & 4.7862 & 5.5106 & TRN & & \\
\hline CHEMBL1491392 & 688239 & 5.0362 & 5.2831 & TRN & & \\
\hline CHEMBL1188078 & 688239 & 5.0862 & 5.5646 & TRN & & \\
\hline CHEMBL1339106 & 688239 & 6.9363 & 5.582999 & 9999999999 & TRN & \\
\hline CHEMBL1335578 & 688239 & 5.2362 & 5.4569 & TRN & & \\
\hline CHEMBL1382700 & 688239 & 5.4862 & 5.3998 & TST & & \\
\hline CHEMBL1438172 & 688239 & 5.8362 & 5.6363 & TRN & & \\
\hline CHEMBL1549973 & 688239 & 5.4362 & 5.5242 & TRN & & \\
\hline
\end{tabular}




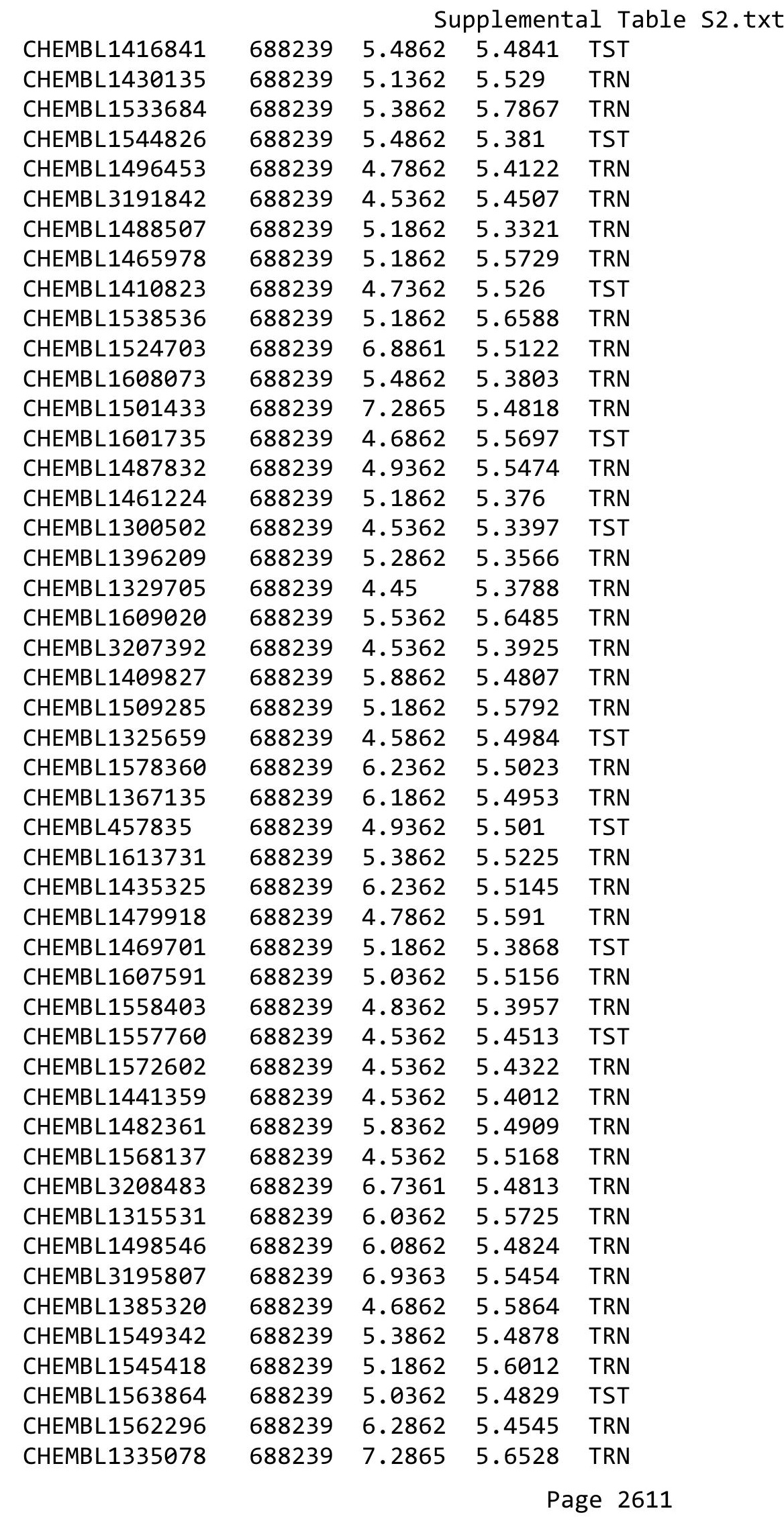


Supplemental Table S2.txt

\begin{tabular}{|c|c|c|c|c|c|}
\hline CHEMBL1541386 & 688239 & 5.8362 & 5.5882 & TST & \\
\hline CHEMBL1422669 & 688239 & 5.6362 & 5.5535 & TRN & \\
\hline CHEMBL1428155 & 688239 & 5.7862 & 5.5627 & TRN & \\
\hline CHEMBL1542638 & 688239 & 4.5362 & 5.487999 & 9999999995 & ד \\
\hline CHEMBL 3210713 & 688239 & 6.2362 & 5.5318 & TRN & \\
\hline CHEMBL1304081 & 688239 & 5.1862 & 5.3381 & TST & \\
\hline CHEMBL1439682 & 688239 & 6.2362 & 5.7086 & TRN & \\
\hline CHEMBL1441445 & 688239 & 4.5862 & 5.3977 & TRN & \\
\hline CHEMBL1532632 & 688239 & 5.0862 & 5.5738 & TRN & \\
\hline CHEMBL1505951 & 688239 & 4.7362 & 5.3905 & TST & \\
\hline CHEMBL1320625 & 688239 & 4.5362 & 5.5752 & TRN & \\
\hline CHEMBL1575521 & 688239 & 4.5362 & 5.5699 & TRN & \\
\hline CHEMBL1546706 & 688239 & 6.1862 & 5.3701 & TRN & \\
\hline CHEMBL1561255 & 688239 & 5.4362 & 5.3759 & TRN & \\
\hline CHEMBL 1478578 & 688239 & 5.1362 & 5.4009 & TRN & \\
\hline CHEMBL1422378 & 688239 & 4.5362 & 5.4236 & TST & \\
\hline CHEMBL1435528 & 688239 & 7.1361 & 5.4749 & TRN & \\
\hline CHEMBL1461552 & 688239 & 5.4862 & 5.4833 & TRN & \\
\hline CHEMBL1592938 & 688239 & 5.4362 & 5.5395 & TRN & \\
\hline CHEMBL1482694 & 688239 & 4.6862 & 5.5271 & TRN & \\
\hline CHEMBL1583941 & 688239 & 5.7862 & 5.4102 & TST & \\
\hline CHEMBL1331036 & 688239 & 5.3862 & 5.4308 & TST & \\
\hline CHEMBL1500264 & 688239 & 8.28399 & 999999999 & 5.5324 & \\
\hline CHEMBL1495620 & 688239 & 5.2862 & \multicolumn{3}{|c|}{$5.492000000000001 \quad$ TRN } \\
\hline CHEMBL1441857 & 688239 & 5.1862 & 5.4272 & TRN & \\
\hline CHEMBL1520057 & 688239 & 5.2862 & 5.5634 & TST & \\
\hline CHEMBL1373655 & 688239 & 4.8862 & 5.4422 & TST & \\
\hline CHEMBL1568104 & 688239 & 6.3863 & 5.4957 & TRN & \\
\hline CHEMBL1463192 & 688239 & 4.4862 & 5.4882 & TRN & \\
\hline CHEMBL1444809 & 688239 & 4.5362 & 5.6451 & TRN & \\
\hline CHEMBL1330941 & 688239 & 4.9362 & 5.4797 & TRN & \\
\hline CHEMBL1590541 & 688239 & 6.7361 & 5.5043 & TRN & \\
\hline CHEMBL1484847 & 688239 & 8.28399 & 999999999 & 5.5867 & \\
\hline CHEMBL1348830 & 688239 & 5.3362 & 5.501 & TST & \\
\hline CHEMBL1426316 & 688239 & 4.7362 & 5.5442 & TRN & \\
\hline CHEMBL1450658 & 688239 & 7.2865 & 5.4429 & TST & \\
\hline CHEMBL1354337 & 688239 & 5.6362 & 5.4273 & TRN & \\
\hline CHEMBL1561745 & 688239 & 4.5362 & 5.4514 & TST & \\
\hline CHEMBL1592594 & 688239 & 5.3862 & 5.3874 & TRN & \\
\hline CHEMBL 3194688 & 688239 & 5.5862 & 5.4889 & TST & \\
\hline CHEMBL1550127 & 688239 & 6.4862 & 5.3074 & TST & \\
\hline CHEMBL1472715 & 688239 & 5.1362 & 5.5253 & TRN & \\
\hline CHEMBL1435824 & 688239 & 6.6861 & 5.4741 & TRN & \\
\hline CHEMBL1611667 & 688239 & 8.3372 & 5.4941 & TRN & \\
\hline CHEMBL1404665 & 688239 & 4.5362 & 5.5865 & TRN & \\
\hline CHEMBL1302329 & 688239 & 4.6362 & 5.4151 & TST & \\
\hline CHEMBL 222646 & 688239 & 4.6362 & 5.5718 & TRN & \\
\hline CHEMBL1489434 & 688239 & 4.5362 & 5.4028 & TRN & \\
\hline
\end{tabular}


Supplemental Table S2.txt

\begin{tabular}{|c|c|c|c|c|c|}
\hline CHEMBL1350783 & 688239 & 4.8862 & 5.4239 & TRN & \\
\hline CHEMBL1534820 & 688239 & 4.8362 & 5.4498 & TRN & \\
\hline CHEMBL1334101 & 688239 & 6.0862 & 5.4711 & TRN & \\
\hline CHEMBL1385441 & 688239 & 4.4862 & 5.4561 & TRN & \\
\hline CHEMBL1588670 & 688239 & 6.1362 & 5.5108 & TST & \\
\hline CHEMBL1534065 & 688239 & 5.0862 & 5.3861 & TRN & \\
\hline CHEMBL1527464 & 688239 & 5.4862 & 5.4621 & TST & \\
\hline CHEMBL1511192 & 688239 & 4.5362 & 5.4507 & TST & \\
\hline CHEMBL1322148 & 688239 & 4.9362 & 5.5184 & TRN & \\
\hline CHEMBL179447 & 688239 & 6.1362 & 5.515 & TST & \\
\hline CHEMBL602776 & 688239 & 4.6862 & 5.4536 & TRN & \\
\hline CHEMBL1367994 & 688239 & 5.1862 & 5.4542 & TST & \\
\hline CHEMBL1588226 & 688239 & 4.6362 & 5.3638 & TRN & \\
\hline CHEMBL1393202 & 688239 & 4.7362 & 5.6894 & TRN & \\
\hline CHEMBL1590806 & 688239 & 5.6362 & 5.5712 & TRN & \\
\hline CHEMBL1340173 & 688239 & 4.5362 & 5.4774 & TST & \\
\hline CHEMBL1582251 & 688239 & 6.8861 & 5.6162 & TRN & \\
\hline CHEMBL1548605 & 688239 & 4.5362 & 5.337999 & 9999999999 & TRN \\
\hline CHEMBL1441813 & 688239 & 5.1362 & 5.4261 & TRN & \\
\hline CHEMBL1350292 & 688239 & 5.1862 & 5.5247 & TRN & \\
\hline CHEMBL1494998 & 688239 & 5.0362 & 5.4918 & TRN & \\
\hline CHEMBL1457908 & 688239 & 7.9872 & 5.6134 & TRN & \\
\hline CHEMBL1321236 & 688239 & 6.1862 & 5.5358 & TRN & \\
\hline CHEMBL1978101 & 688239 & 6.5862 & 5.5103 & TRN & \\
\hline CHEMBL1324462 & 688239 & 4.7362 & 5.4322 & TRN & \\
\hline CHEMBL1563798 & 688239 & 4.5362 & 5.3124 & TRN & \\
\hline CHEMBL1429780 & 688239 & 5.1862 & 5.5617 & TRN & \\
\hline CHEMBL1609648 & 688239 & 6.15 & 5.6168 & TRN & \\
\hline CHEMBL1528458 & 688239 & 7.5361 & 5.4573 & TST & \\
\hline CHEMBL1543894 & 688239 & 5.1362 & 5.5092 & TRN & \\
\hline CHEMBL1418706 & 688239 & 4.6862 & 5.6407 & TST & \\
\hline CHEMBL1323101 & 688239 & 4.5362 & 5.382999 & 9999999999 & TRN \\
\hline CHEMBL1977063 & 688239 & 5.5862 & 5.466 & TRN & \\
\hline CHEMBL1522193 & 688239 & 6.2862 & 5.4545 & TST & \\
\hline CHEMBL1484009 & 688239 & 5.5862 & 5.5262 & TRN & \\
\hline CHEMBL1359130 & 688239 & 6.8861 & 5.474 & TRN & \\
\hline CHEMBL1412572 & 688239 & 6.9863 & 5.591 & TST & \\
\hline CHEMBL1370092 & 688239 & 6.3362 & 5.4501 & TRN & \\
\hline CHEMBL1610596 & 688239 & 8.0862 & 5.3353 & TRN & \\
\hline CHEMBL 3191410 & 688239 & 5.4362 & 5.6614 & TRN & \\
\hline CHEMBL 2369236 & 688239 & 4.7362 & 5.4508 & TRN & \\
\hline CHEMBL1548088 & 688239 & 4.5362 & 5.6163 & TRN & \\
\hline CHEMBL1548425 & 688239 & 4.5362 & 5.6749 & TRN & \\
\hline CHEMBL1393407 & 688239 & 5.4862 & 5.5899 & TRN & \\
\hline CHEMBL1530081 & 688239 & 4.5362 & 5.5477 & TST & \\
\hline CHEMBL1450427 & 688239 & 6.8861 & 5.4025 & TRN & \\
\hline CHEMBL1502834 & 688239 & 4.5362 & 5.5552 & TRN & \\
\hline CHEMBL1365829 & 688239 & 4.6862 & 5.3897 & TRN & \\
\hline
\end{tabular}

Page 2613 
Supplemental Table S2.txt

\begin{tabular}{|c|c|c|c|c|}
\hline CHEMBL1600112 & 688239 & 5.6862 & 5.4281 & TRN \\
\hline CHEMBL1458063 & 688239 & 4.8362 & 5.4782 & TRN \\
\hline CHEMBL1339212 & 688239 & 5.2362 & 5.3654 & TRN \\
\hline CHEMBL1329710 & 688239 & 4.5362 & 5.5148 & TRN \\
\hline CHEMBL1608646 & 688239 & 6.9863 & 5.5572 & TRN \\
\hline CHEMBL1311547 & 688239 & 4.4862 & 5.5055 & TRN \\
\hline CHEMBL1371891 & 688239 & \multicolumn{2}{|c|}{8.283999999999999} & 5.5283 \\
\hline CHEMBL1380601 & 688239 & 5.8362 & 5.5378 & TRN \\
\hline CHEMBL1451517 & 688239 & 5.4362 & 5.4777 & TRN \\
\hline CHEMBL 3197189 & 688239 & 4.9362 & 5.376 & TST \\
\hline CHEMBL1370743 & 688239 & 6.1862 & 5.501 & TST \\
\hline CHEMBL1376333 & 688239 & 5.1862 & 5.5151 & TRN \\
\hline CHEMBL1334793 & 688239 & 4.5862 & 5.3656 & TRN \\
\hline CHEMBL1430233 & 688239 & 5.1862 & 5.5451 & TRN \\
\hline CHEMBL1343572 & 688239 & 6.8861 & 5.2976 & TRN \\
\hline CHEMBL1335115 & 688239 & 5.4862 & 5.3811 & TRN \\
\hline CHEMBL1401704 & 688239 & 4.5362 & 5.3587 & TRN \\
\hline CHEMBL1592712 & 688239 & 6.0862 & 5.4638 & TRN \\
\hline CHEMBL1579197 & 688239 & 6.8362 & 5.372006 & 0000000001 \\
\hline CHEMBL1556040 & 688239 & 6.2362 & 5.6488 & TRN \\
\hline CHEMBL1597951 & 688239 & 5.1862 & 5.4042 & TST \\
\hline CHEMBL1565760 & 688239 & 5.3862 & 5.5109 & TRN \\
\hline CHEMBL1318436 & 688239 & 5.1362 & 5.3539 & TST \\
\hline CHEMBL1608892 & 688239 & 6.7862 & 5.5333 & TST \\
\hline CHEMBL1601643 & 688239 & 4.6362 & 5.6037 & TRN \\
\hline CHEMBL1531829 & 688239 & 4.6862 & 5.5484 & TST \\
\hline CHEMBL1599787 & 688239 & 4.5362 & 5.3402 & TST \\
\hline CHEMBL1522062 & 688239 & 5.2362 & 5.6344 & TRN \\
\hline CHEMBL1549906 & 688239 & 7.2366 & 5.4064 & TRN \\
\hline CHEMBL1577681 & 688239 & 4.5362 & 5.4963 & TRN \\
\hline CHEMBL1607913 & 688239 & 5.1362 & 5.5177 & TRN \\
\hline CHEMBL1556237 & 688239 & 5.8862 & 5.5059 & TRN \\
\hline CHEMBL1437899 & 688239 & 5.7862 & 5.5136 & TRN \\
\hline CHEMBL1472254 & 688239 & 7.5361 & 5.7192 & TRN \\
\hline CHEMBL1391574 & 688239 & 5.1862 & 5.4863 & TRN \\
\hline CHEMBL1552455 & 688239 & 7.1864 & 5.608 & TRN \\
\hline CHEMBL 3189496 & 688239 & 6.8861 & 5.3775 & TRN \\
\hline CHEMBL1602660 & 688239 & 8.2366 & 5.4114 & TST \\
\hline CHEMBL1299447 & 688239 & 5.6362 & 5.4819 & TRN \\
\hline CHEMBL1568251 & 688239 & 4.7362 & 5.487 & TRN \\
\hline CHEMBL1377356 & 688239 & 5.3862 & 5.4279 & TRN \\
\hline CHEMBL1402413 & 688239 & 4.6862 & 5.4085 & TRN \\
\hline CHEMBL 3190686 & 688239 & 6.2362 & 5.4762 & TRN \\
\hline CHEMBL1493424 & 688239 & 5.4862 & 5.4738 & TRN \\
\hline CHEMBL1435489 & 688239 & 5.1862 & 5.3606 & TRN \\
\hline CHEMBL1470126 & 688239 & 5.1862 & 5.5609 & TRN \\
\hline CHEMBL1608462 & 688239 & 4.7362 & 5.5398 & TRN \\
\hline CHEMBL1345818 & 688239 & 6.7862 & 5.4352 & TST \\
\hline
\end{tabular}


Supplemental Table S2.txt

\begin{tabular}{|c|c|c|c|c|}
\hline CHEMBL1445840 & 688239 & 4.8862 & 5.4521 & TST \\
\hline CHEMBL1440557 & 688239 & 8.2366 & 5.6304 & TST \\
\hline CHEMBL1382255 & 688239 & 4.5362 & 5.5591 & TRN \\
\hline CHEMBL1527401 & 688239 & 5.3862 & 5.5593 & TST \\
\hline CHEMBL1582654 & 688239 & 5.5862 & 5.4654 & TRN \\
\hline CHEMBL1393922 & 688239 & 5.3362 & 5.4626 & TRN \\
\hline CHEMBL1431608 & 688239 & 5.3362 & 5.4757 & TRN \\
\hline CHEMBL1380959 & 688239 & 4.5362 & 5.367999 & 9999999999 \\
\hline CHEMBL1477733 & 688239 & 5.3862 & 5.49 & TRN \\
\hline CHEMBL3193628 & 688239 & 5.1862 & 5.4189 & TRN \\
\hline CHEMBL1453376 & 688239 & 6.2362 & 5.3035 & TRN \\
\hline CHEMBL1539872 & 688239 & 4.5862 & 5.6429 & TRN \\
\hline CHEMBL1339517 & 688239 & 6.6861 & 5.7105 & TRN \\
\hline CHEMBL1534369 & 688239 & 5.3362 & 5.4907 & TST \\
\hline CHEMBL1508591 & 688239 & 4.7862 & 5.3157 & TRN \\
\hline CHEMBL1597485 & 688239 & 6.2862 & 5.5788 & TST \\
\hline CHEMBL1595638 & 688239 & 6.2362 & 5.5701 & TRN \\
\hline CHEMBL1602269 & 688239 & 4.5362 & 5.3725 & TRN \\
\hline CHEMBL1549440 & 688239 & 4.5862 & 5.4551 & TST \\
\hline CHEMBL1456177 & 688239 & 6.1862 & 5.4964 & TRN \\
\hline CHEMBL1334704 & 688239 & 4.7862 & 5.3938 & TRN \\
\hline CHEMBL1334164 & 688239 & 4.7362 & 5.2685 & TST \\
\hline CHEMBL1546789 & 688239 & 6.0862 & 5.5157 & TRN \\
\hline CHEMBL1350313 & 688239 & 5.5362 & 5.3697 & TST \\
\hline CHEMBL1325532 & 688239 & 4.5862 & 5.6053 & TRN \\
\hline CHEMBL1512425 & 688239 & 5.3862 & 5.4741 & TST \\
\hline CHEMBL1324560 & 688239 & 5.8362 & 5.5075 & TRN \\
\hline CHEMBL1610821 & 688239 & 4.4862 & 5.3964 & TRN \\
\hline CHEMBL1467371 & 688239 & 5.1862 & 5.5146 & TRN \\
\hline CHEMBL1526217 & 688239 & 4.5362 & 5.2781 & TRN \\
\hline CHEMBL1400566 & 688239 & 5.7862 & 5.5191 & TST \\
\hline CHEMBL1360353 & 688239 & 5.4362 & 5.5081 & TRN \\
\hline CHEMBL1519566 & 688239 & 5.9862 & 5.5379 & TRN \\
\hline CHEMBL1511043 & 688239 & 5.1862 & 5.4504 & TRN \\
\hline CHEMBL1450473 & 688239 & 6.1862 & 5.6369 & TST \\
\hline CHEMBL1445617 & 688239 & 6.0862 & 5.3367 & TST \\
\hline CHEMBL1386277 & 688239 & 6.3863 & 5.4968 & TST \\
\hline CHEMBL1460497 & 688239 & 6.2362 & 5.4967 & TRN \\
\hline CHEMBL3197314 & 688239 & 5.0362 & 5.3555 & TST \\
\hline CHEMBL 1475420 & 688239 & 4.4862 & 5.3829 & TRN \\
\hline CHEMBL1544334 & 688239 & 4.5362 & 5.5565 & TRN \\
\hline CHEMBL1299931 & 688239 & 4.7362 & 5.4152 & TRN \\
\hline CHEMBL3214245 & 688239 & 8.3372 & 5.4328 & TST \\
\hline CHEMBL1610624 & 688239 & 5.1862 & 5.4546 & TRN \\
\hline CHEMBL1385337 & 688239 & 8.3872 & 5.3417 & TST \\
\hline CHEMBL1479562 & 688239 & 5.5862 & 5.5936 & TRN \\
\hline CHEMBL1521707 & 688239 & 4.4862 & \multicolumn{2}{|c|}{5.3870000000000005} \\
\hline CHEMBL1499635 & 688239 & 4.7862 & 5.5456 & TRN \\
\hline
\end{tabular}


Supplemental Table S2.txt

\begin{tabular}{|c|c|c|c|c|}
\hline CHEMBL1575967 & 688239 & 6.6362 & 5.5412 & TRN \\
\hline CHEMBL1436708 & 688239 & 4.7862 & 5.4154 & TST \\
\hline CHEMBL1402119 & 688239 & 5.8362 & 5.5083 & TRN \\
\hline CHEMBL1490772 & 688239 & 5.4362 & 5.4869 & TST \\
\hline CHEMBL1500306 & 688239 & 5.0862 & 5.5564 & TRN \\
\hline CHEMBL1454006 & 688239 & 6.0862 & 5.584 & TRN \\
\hline CHEMBL1305605 & 688239 & 6.5862 & 5.48799 & 99999999995 \\
\hline CHEMBL1307016 & 688239 & 4.7362 & 5.5061 & TRN \\
\hline CHEMBL1519882 & 688239 & 4.6862 & 5.4407 & TRN \\
\hline CHEMBL1463786 & 688239 & 8.2366 & 5.5396 & TRN \\
\hline CHEMBL1485477 & 688239 & 5.3862 & 5.5561 & TST \\
\hline CHEMBL1343567 & 688239 & 4.5362 & 5.5258 & TRN \\
\hline CHEMBL1404979 & 688239 & 4.5362 & 5.5227 & TST \\
\hline CHEMBL1321112 & 688239 & 5.0862 & 5.5568 & TRN \\
\hline CHEMBL1404581 & 688239 & 6.6362 & 5.6302 & TRN \\
\hline CHEMBL1465467 & 688239 & 5.2862 & 5.4351 & TRN \\
\hline CHEMBL1422869 & 688239 & 5.8362 & 5.4783 & TRN \\
\hline CHEMBL1417176 & 688239 & 4.4862 & 5.4219 & TRN \\
\hline CHEMBL1409681 & 688239 & 4.5362 & 5.4408 & TRN \\
\hline CHEMBL1445270 & 688239 & 6.1362 & 5.3287 & TRN \\
\hline CHEMBL1325496 & 688239 & 6.5363 & 5.3201 & TRN \\
\hline CHEMBL1596878 & 688239 & 6.8362 & 5.5726 & TRN \\
\hline CHEMBL1306686 & 688239 & 4.7862 & 5.5435 & TRN \\
\hline CHEMBL1332736 & 688239 & 8.2366 & 5.5861 & TRN \\
\hline CHEMBL1303202 & 688239 & 6.0862 & 5.4904 & TRN \\
\hline CHEMBL1348140 & 688239 & 5.3362 & 5.5822 & TRN \\
\hline CHEMBL1469945 & 688239 & 5.6362 & 5.3626 & TRN \\
\hline CHEMBL1543056 & 688239 & 5.1862 & 5.6372 & TRN \\
\hline CHEMBL1439956 & 688239 & 4.7862 & 5.5689 & TRN \\
\hline CHEMBL1339164 & 688239 & 5.4862 & 5.4587 & TRN \\
\hline CHEMBL1515467 & 688239 & 5.1862 & 5.5293 & TRN \\
\hline CHEMBL1499323 & 688239 & 6.2362 & 5.6777 & TRN \\
\hline CHEMBL1583960 & 688239 & 4.6362 & 5.478 & TRN \\
\hline CHEMBL1532060 & 688239 & 5.1362 & 5.5533 & TRN \\
\hline CHEMBL1605074 & 688239 & 4.9862 & 5.3697 & TRN \\
\hline CHEMBL1532679 & 688239 & 4.8362 & 5.4445 & TRN \\
\hline CHEMBL1432914 & 688239 & 4.5362 & 5.4788 & TRN \\
\hline CHEMBL1326001 & 688239 & 6.6362 & 5.3818 & TRN \\
\hline CHEMBL1378538 & 688239 & 6.0 & 5.398 & TRN \\
\hline CHEMBL1498599 & 688239 & 5.4362 & 5.3153 & TRN \\
\hline CHEMBL1302279 & 688239 & 5.3862 & 5.655 & TST \\
\hline CHEMBL1605170 & 688239 & 5.4862 & 5.6451 & TRN \\
\hline CHEMBL1537257 & 688239 & 6.9863 & 5.4884 & TST \\
\hline CHEMBL1439800 & 688239 & 5.1862 & 5.4232 & TRN \\
\hline CHEMBL1355707 & 688239 & 5.3362 & 5.4377 & TRN \\
\hline CHEMBL1307548 & 688239 & 6.8362 & 5.4413 & TRN \\
\hline CHEMBL3191403 & 688239 & 6.2362 & 5.5324 & TRN \\
\hline CHEMBL1353324 & 688239 & 4.5362 & 5.3438 & TRN \\
\hline
\end{tabular}


Supplemental Table S2.txt

\begin{tabular}{|c|c|c|c|c|}
\hline CHEMBL1342050 & 688239 & 4.9862 & 5.364 & TRN \\
\hline CHEMBL1574978 & 688239 & 6.0862 & 5.6395 & TST \\
\hline CHEMBL1476187 & 688239 & 5.4862 & 5.4806 & TRN \\
\hline CHEMBL1495452 & 688239 & 6.2362 & 5.5648 & TST \\
\hline CHEMBL1498333 & 688239 & 6.3362 & 5.468 & TRN \\
\hline CHEMBL1498680 & 688239 & 6.2362 & 5.4865 & TST \\
\hline CHEMBL1354345 & 688239 & 4.6862 & 5.4353 & TRN \\
\hline CHEMBL1396491 & 688239 & 4.5362 & 5.40600 & 000000001 \\
\hline CHEMBL1622981 & 688239 & 4.7862 & 5.4218 & TRN \\
\hline CHEMBL1565809 & 688239 & 4.7862 & 5.4657 & TRN \\
\hline CHEMBL1558834 & 688239 & 5.1862 & 5.5945 & TRN \\
\hline CHEMBL1531988 & 688239 & 6.2862 & 5.3861 & TRN \\
\hline CHEMBL1437144 & 688239 & 5.4862 & 5.6576 & TRN \\
\hline CHEMBL1494412 & 688239 & 4.6862 & 5.5444 & TRN \\
\hline CHEMBL1307891 & 688239 & 6.4862 & 5.5198 & TRN \\
\hline CHEMBL1382308 & 688239 & 4.6362 & 5.4964 & TRN \\
\hline CHEMBL1361774 & 688239 & 5.1862 & 5.3934 & TRN \\
\hline CHEMBL1334229 & 688239 & 5.8362 & 5.4712 & TRN \\
\hline CHEMBL1331589 & 688239 & 6.7862 & 5.6166 & TRN \\
\hline CHEMBL1385558 & 688239 & 4.5362 & 5.4358 & TRN \\
\hline CHEMBL1577615 & 688239 & 5.9862 & 5.5543 & TRN \\
\hline CHEMBL1360120 & 688239 & 5.5362 & 5.5116 & TRN \\
\hline CHEMBL1389141 & 688239 & 4.4862 & 5.5532 & TRN \\
\hline CHEMBL1560797 & 688239 & 4.5362 & 5.4106 & TRN \\
\hline CHEMBL1302071 & 688239 & 4.7362 & 5.4649 & TRN \\
\hline CHEMBL1445199 & 688239 & 4.5362 & 5.5388 & TRN \\
\hline CHEMBL1583311 & 688239 & 6.3863 & 5.6417 & TST \\
\hline CHEMBL1423012 & 688239 & 5.4362 & 5.5435 & TRN \\
\hline CHEMBL1484741 & 688239 & 4.9362 & 5.5543 & TRN \\
\hline CHEMBL1324078 & 688239 & 6.1362 & 5.5991 & TRN \\
\hline CHEMBL1592552 & 688239 & 5.5862 & 5.6071 & TRN \\
\hline CHEMBL1491988 & 688239 & 7.0862 & 5.5713 & TRN \\
\hline CHEMBL1323747 & 688239 & 6.0862 & 5.4887 & TRN \\
\hline CHEMBL1494206 & 688239 & 6.5862 & 5.5287 & TRN \\
\hline CHEMBL1312492 & 688239 & 5.7362 & 5.5737 & TRN \\
\hline CHEMBL1482863 & 688239 & 5.1862 & 5.3641 & TRN \\
\hline CHEMBL1605284 & 688239 & 4.5362 & 5.4967 & TST \\
\hline CHEMBL1457744 & 688239 & 5.1862 & 5.5306 & TST \\
\hline CHEMBL1585348 & 688239 & 5.5362 & 5.6531 & TRN \\
\hline CHEMBL1480950 & 688239 & 5.6362 & 5.4484 & TRN \\
\hline CHEMBL1410277 & 688239 & 4.5362 & 5.3574 & TST \\
\hline CHEMBL1437601 & 688239 & 5.0862 & 5.485 & TST \\
\hline CHEMBL1549467 & 688239 & 4.5362 & 5.4258 & TST \\
\hline CHEMBL1442649 & 688239 & 5.9862 & 5.4171 & TRN \\
\hline CHEMBL1557959 & 688239 & 4.5362 & 5.5506 & TRN \\
\hline CHEMBL1577134 & 688239 & 6.1362 & 5.5337 & TRN \\
\hline CHEMBL1600144 & 688239 & 5.1862 & 5.3132 & TRN \\
\hline CHEMBL1455258 & 688239 & 5.0862 & 5.5037 & TRN \\
\hline
\end{tabular}




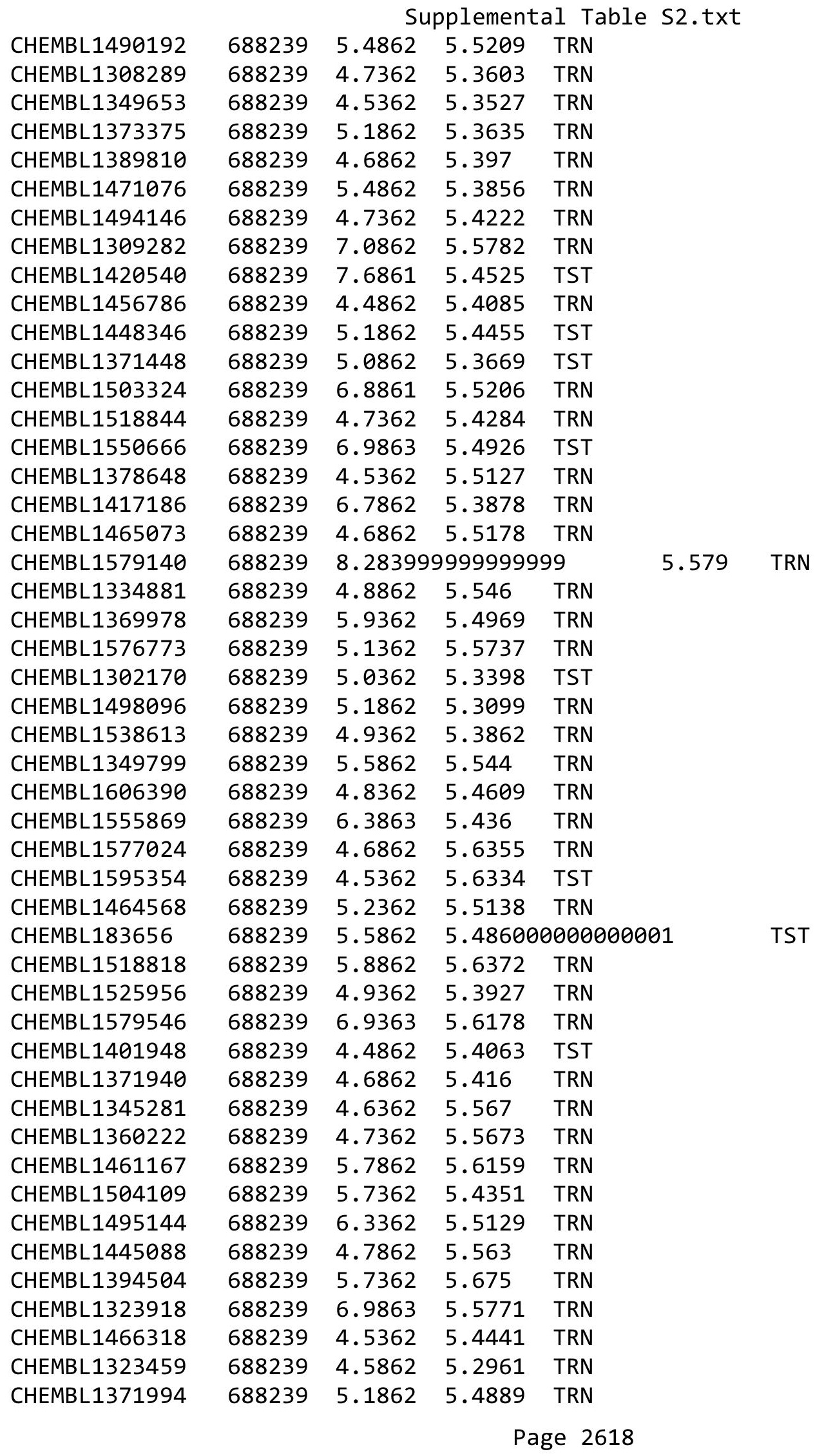


Supplemental Table S2.txt

\begin{tabular}{|c|c|c|c|c|}
\hline CHEMBL1610824 & 688239 & 5.6862 & 5.4422 & TRN \\
\hline CHEMBL1387441 & 688239 & 5.7862 & 5.5826 & TRN \\
\hline CHEMBL1312006 & 688239 & 6.2862 & 5.4975 & TRN \\
\hline CHEMBL 239864 & 688239 & 5.1862 & 5.5279 & TRN \\
\hline CHEMBL3213136 & 688239 & 5.5362 & 5.4399 & TRN \\
\hline CHEMBL1405469 & 688239 & 4.5362 & 5.3846 & TRN \\
\hline CHEMBL1469250 & 688239 & 6.0862 & 5.5631 & TRN \\
\hline CHEMBL1563975 & 688239 & 4.4862 & 5.4135 & TRN \\
\hline CHEMBL1448066 & 688239 & 5.8362 & 5.3863 & TRN \\
\hline CHEMBL1547893 & 688239 & 4.7862 & 5.3452 & TRN \\
\hline CHEMBL1535651 & 688239 & 4.5362 & 5.3856 & TRN \\
\hline CHEMBL1459049 & 688239 & 6.7862 & 5.63700 & 0000000005 \\
\hline CHEMBL1586464 & 688239 & 7.1864 & 5.5889 & TRN \\
\hline CHEMBL1575166 & 688239 & 5.1862 & 5.4499 & TRN \\
\hline CHEMBL3208473 & 688239 & 6.0362 & 5.6621 & TST \\
\hline CHEMBL1559520 & 688239 & 5.7362 & 5.4744 & TRN \\
\hline CHEMBL1535532 & 688239 & 6.9863 & 5.4121 & TST \\
\hline CHEMBL1534997 & 688239 & 4.4862 & 5.5791 & TRN \\
\hline CHEMBL1333125 & 688239 & 4.5362 & 5.5369 & TRN \\
\hline CHEMBL3195450 & 688239 & 4.7862 & 5.4245 & TST \\
\hline CHEMBL1547242 & 688239 & 4.5362 & 5.401 & TST \\
\hline CHEMBL1422713 & 688239 & 5.3862 & 5.478 & TRN \\
\hline CHEMBL1468905 & 688239 & 4.6362 & 5.5246 & TRN \\
\hline CHEMBL1382140 & 688239 & 4.8862 & 5.3566 & TRN \\
\hline CHEMBL1538919 & 688239 & 4.5362 & 5.2451 & TRN \\
\hline CHEMBL1349074 & 688239 & 5.1862 & 5.6389 & TRN \\
\hline CHEMBL1476478 & 688239 & 5.2362 & 5.5216 & TST \\
\hline CHEMBL1538702 & 688239 & 4.5362 & 5.6112 & TST \\
\hline CHEMBL1369557 & 688239 & 4.8862 & 5.3691 & TST \\
\hline CHEMBL1498304 & 688239 & 4.5362 & 5.4933 & TRN \\
\hline CHEMBL1450788 & 688239 & 5.1862 & 5.5889 & TST \\
\hline CHEMBL1357288 & 688239 & 5.7362 & 5.5264 & TRN \\
\hline CHEMBL1420583 & 688239 & 4.7862 & 5.3897 & TST \\
\hline CHEMBL1426320 & 688239 & 6.4362 & 5.3239 & TRN \\
\hline CHEMBL1507639 & 688239 & 6.2362 & 5.3283 & TRN \\
\hline CHEMBL1391930 & 688239 & 6.1362 & 5.3396 & TST \\
\hline CHEMBL1542614 & 688239 & 4.6862 & 5.5367 & TRN \\
\hline CHEMBL1303642 & 688239 & 4.5362 & 5.3601 & TRN \\
\hline CHEMBL1450902 & 688239 & 4.5362 & 5.5509 & TST \\
\hline CHEMBL1479093 & 688239 & 4.5362 & 5.4807 & TRN \\
\hline CHEMBL1416482 & 688239 & 6.8861 & 5.4922 & TRN \\
\hline CHEMBL1418049 & 688239 & 5.7362 & 5.6154 & TRN \\
\hline CHEMBL1422047 & 688239 & 4.6362 & 5.4632 & TRN \\
\hline CHEMBL1369699 & 688239 & 5.8862 & 5.398 & TST \\
\hline CHEMBL3212224 & 688239 & 5.0362 & 5.4549 & TST \\
\hline CHEMBL1563947 & 688239 & 4.4862 & 5.6552 & TRN \\
\hline CHEMBL1545983 & 688239 & 4.7362 & 5.4793 & TRN \\
\hline CHEMBL1432334 & 688239 & 5.1862 & 5.46 & TST \\
\hline
\end{tabular}


Supplemental Table S2.txt

\begin{tabular}{|c|c|c|c|c|}
\hline CHEMBL1495981 & 688239 & 4.5362 & 5.4348 & TRN \\
\hline CHEMBL3190982 & 688239 & 4.6862 & 5.4677 & TRN \\
\hline CHEMBL1597842 & 688239 & 6.1862 & 5.4917 & TRN \\
\hline CHEMBL 2002830 & 688239 & 5.7862 & 5.4187 & TRN \\
\hline CHEMBL1581355 & 688239 & 4.7362 & 5.4946 & TST \\
\hline CHEMBL260676 & 688239 & 4.8862 & 5.5605 & TRN \\
\hline CHEMBL1540517 & 688239 & 6.5363 & 5.6825 & TRN \\
\hline CHEMBL1340619 & 688239 & 4.6862 & 5.5178 & TRN \\
\hline CHEMBL1569146 & 688239 & 5.6862 & 5.3868 & TST \\
\hline CHEMBL1535676 & 688239 & 5.3862 & 5.4018 & TRN \\
\hline CHEMBL1392714 & 688239 & 6.8362 & 5.4211 & TRN \\
\hline CHEMBL1506160 & 688239 & 4.5362 & 5.4215 & TRN \\
\hline CHEMBL1427768 & 688239 & 4.8862 & 5.47 & TRN \\
\hline CHEMBL1473623 & 688239 & 5.5362 & 5.5344 & TRN \\
\hline CHEMBL1442674 & 688239 & 6.9863 & 5.4869 & TRN \\
\hline CHEMBL1368225 & 688239 & 6.2362 & 5.3841 & TRN \\
\hline CHEMBL1326598 & 688239 & 5.2862 & 5.5069 & TST \\
\hline CHEMBL1601562 & 688239 & 6.9363 & 5.5696 & TRN \\
\hline CHEMBL1523306 & 688239 & 5.9862 & 5.4932 & TRN \\
\hline CHEMBL1353071 & 688239 & 6.6362 & 5.6611 & TRN \\
\hline CHEMBL1607823 & 688239 & 4.5362 & 5.4697 & TST \\
\hline CHEMBL1389420 & 688239 & 4.5362 & 5.4035 & TRN \\
\hline CHEMBL1547601 & 688239 & 5.6862 & 5.5304 & TRN \\
\hline CHEMBL1521849 & 688239 & 4.5362 & 5.502006 & 0000000001 \\
\hline CHEMBL1413964 & 688239 & 5.7362 & 5.5477 & TST \\
\hline CHEMBL1532782 & 688239 & 5.1862 & 5.4367 & TRN \\
\hline CHEMBL1541890 & 688239 & 6.7862 & 5.3816 & TRN \\
\hline CHEMBL1485447 & 688239 & 5.0862 & 5.4791 & TRN \\
\hline CHEMBL1608601 & 688239 & 5.1862 & 5.5747 & TRN \\
\hline CHEMBL1508763 & 688239 & 5.5362 & 5.3068 & TRN \\
\hline CHEMBL1402922 & 688239 & 5.1362 & 5.4853 & TRN \\
\hline CHEMBL3192837 & 688239 & 4.5362 & 5.2516 & TRN \\
\hline CHEMBL1472352 & 688239 & 4.6862 & 5.5394 & TRN \\
\hline CHEMBL1334481 & 688239 & 6.9363 & 5.5058 & TRN \\
\hline CHEMBL1353966 & 688239 & 4.5362 & 5.565 & TST \\
\hline CHEMBL1395463 & 688239 & 4.5362 & 5.4882 & TST \\
\hline CHEMBL1481665 & 688239 & 6.6861 & 5.6554 & TRN \\
\hline CHEMBL1350332 & 688239 & 6.5363 & 5.4603 & TRN \\
\hline CHEMBL1493998 & 688239 & 4.5362 & 5.599 & TRN \\
\hline CHEMBL1439762 & 688239 & 4.8362 & 5.4224 & TRN \\
\hline CHEMBL1547473 & 688239 & 5.4362 & 5.435 & TST \\
\hline CHEMBL1533339 & 688239 & 5.1862 & 5.4443 & TRN \\
\hline CHEMBL1604961 & 688239 & 4.6862 & 5.4958 & TST \\
\hline CHEMBL1464179 & 688239 & 4.5362 & 5.3444 & TST \\
\hline CHEMBL1458508 & 688239 & 5.4862 & 5.5364 & TRN \\
\hline CHEMBL1364656 & 688239 & 5.0862 & 5.4673 & TRN \\
\hline CHEMBL1576848 & 688239 & 6.8362 & 5.4861 & TRN \\
\hline CHEMBL1382416 & 688239 & 6.2362 & 5.5155 & TRN \\
\hline
\end{tabular}

TST

Page 2620 
Supplemental Table S2.txt

\begin{tabular}{|c|c|c|c|c|}
\hline CHEMBL1577955 & 688239 & 4.5362 & 5.4609 & TRN \\
\hline CHEMBL1508200 & 688239 & 4.6362 & 5.6909 & TST \\
\hline CHEMBL 3191467 & 688239 & 5.1862 & 5.5409 & TST \\
\hline CHEMBL1358269 & 688239 & 4.5362 & 5.5865 & TRN \\
\hline CHEMBL1424785 & 688239 & 4.5362 & 5.5398 & TRN \\
\hline CHEMBL1451644 & 688239 & 6.2862 & 5.6082 & TRN \\
\hline CHEMBL1446081 & 688239 & 5.1362 & 5.4934 & TRN \\
\hline CHEMBL1579866 & 688239 & 6.0862 & 5.3946 & TRN \\
\hline CHEMBL1393156 & 688239 & 4.5362 & 5.4614 & TRN \\
\hline CHEMBL1317338 & 688239 & 4.6862 & 5.3222 & TRN \\
\hline CHEMBL1373540 & 688239 & 5.3862 & 5.4538 & TRN \\
\hline CHEMBL1363188 & 688239 & 4.7862 & 5.5996 & TRN \\
\hline CHEMBL1416511 & 688239 & 8.28399 & 99999999 & 5.4811 \\
\hline CHEMBL 3213810 & 688239 & 5.6362 & 5.3693 & TRN \\
\hline CHEMBL1546510 & 688239 & 5.5362 & 5.5161 & TRN \\
\hline CHEMBL1485952 & 688239 & 6.8362 & 5.4975 & TST \\
\hline CHEMBL1438920 & 688239 & 5.1362 & 5.5163 & TRN \\
\hline CHEMBL293749 & 688239 & 6.9363 & 5.3595 & TRN \\
\hline CHEMBL1345049 & 688239 & 8.3372 & 5.5117 & TRN \\
\hline CHEMBL1374062 & 688239 & 4.4862 & 5.5706 & TRN \\
\hline CHEMBL1552698 & 688239 & 5.6862 & 5.5188 & TRN \\
\hline CHEMBL1499832 & 688239 & 4.5362 & 5.4559 & TRN \\
\hline CHEMBL1457369 & 688239 & 5.3862 & 5.3778 & TRN \\
\hline CHEMBL1556098 & 688239 & 4.6362 & 5.4437 & TRN \\
\hline CHEMBL1520903 & 688239 & 7.0862 & 5.3863 & TRN \\
\hline CHEMBL1412453 & 688239 & 6.7361 & 5.5567 & TRN \\
\hline CHEMBL1354208 & 688239 & 5.3362 & 5.5765 & TRN \\
\hline CHEMBL1477162 & 688239 & 5.3862 & 5.532999 & 9999999995 \\
\hline CHEMBL1418214 & 688239 & 5.6362 & 5.3269 & TST \\
\hline CHEMBL1450560 & 688239 & 5.8862 & 5.5458 & TRN \\
\hline CHEMBL1470582 & 688239 & 5.1362 & 5.2825 & TRN \\
\hline CHEMBL1523438 & 688239 & 4.5862 & 5.5267 & TST \\
\hline CHEMBL1410425 & 688239 & 5.5862 & 5.5813 & TRN \\
\hline CHEMBL1597212 & 688239 & 4.5362 & 5.491000 & 0000000005 \\
\hline CHEMBL1503584 & 688239 & 5.0862 & 5.4738 & TRN \\
\hline CHEMBL1601357 & 688239 & 6.5862 & 5.5958 & TST \\
\hline CHEMBL1306740 & 688239 & 6.0862 & 5.4326 & TRN \\
\hline CHEMBL1336773 & 688239 & 5.3362 & 5.4715 & TRN \\
\hline CHEMBL1455005 & 688239 & 7.4868 & 5.4492 & TRN \\
\hline CHEMBL1576715 & 688239 & 4.5362 & 5.6225 & TST \\
\hline CHEMBL1538825 & 688239 & 5.3362 & 5.4753 & TST \\
\hline CHEMBL1425139 & 688239 & 4.8862 & 5.4707 & TRN \\
\hline CHEMBL1437977 & 688239 & 5.1862 & 5.5384 & TST \\
\hline CHEMBL1541490 & 688239 & 4.95 & 5.3439 & TRN \\
\hline CHEMBL1482207 & 688239 & 5.6862 & 5.4829 & TRN \\
\hline CHEMBL1414964 & 688239 & 5.1862 & 5.3645 & TST \\
\hline CHEMBL3189498 & 688239 & 5.0362 & 5.4872 & TRN \\
\hline CHEMBL1517493 & 688239 & 4.5362 & 5.5598 & TRN \\
\hline
\end{tabular}


Supplemental Table S2.txt

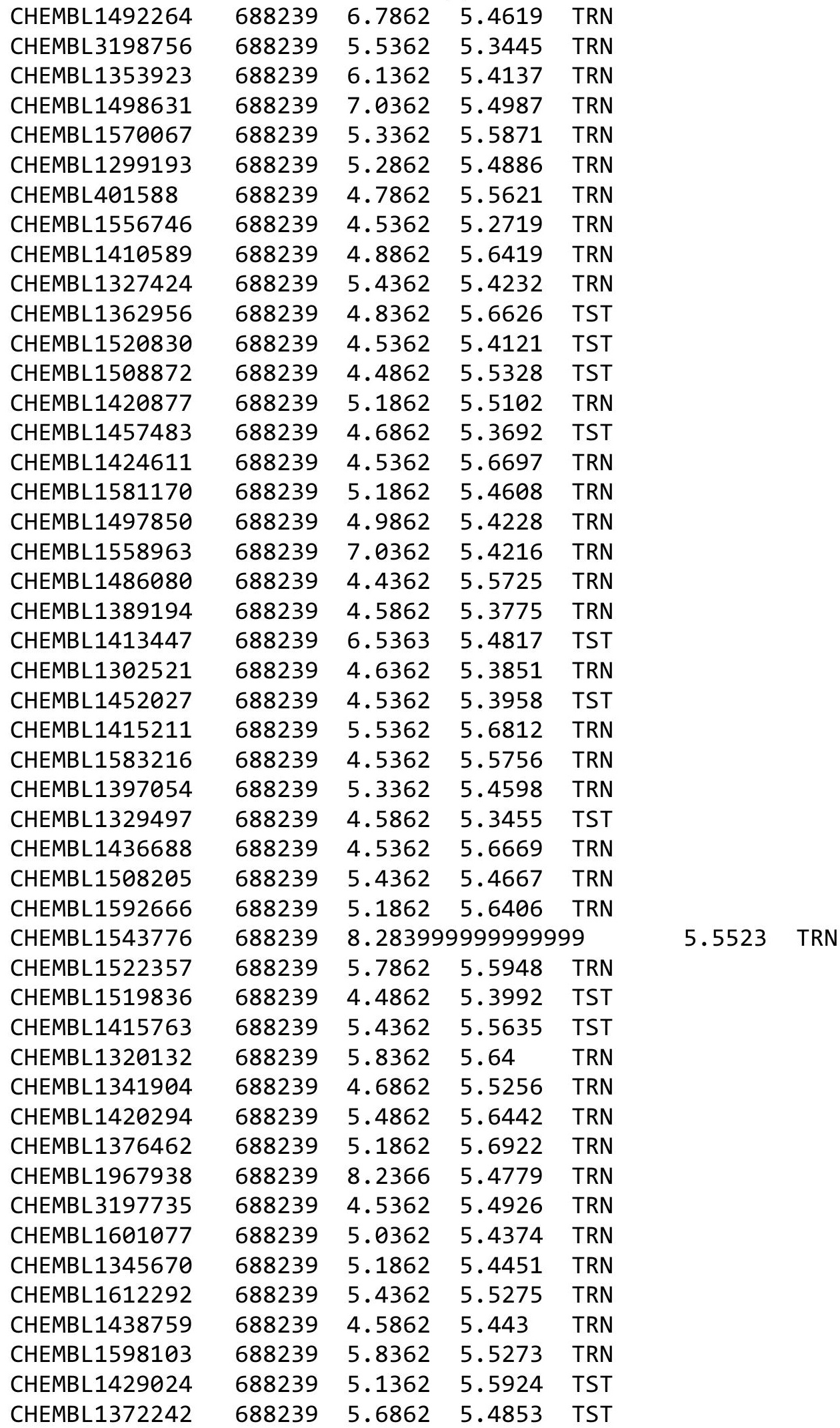

Page 2622 
Supplemental Table S2.txt

\begin{tabular}{|c|c|c|c|c|}
\hline CHEMBL1568658 & 688239 & 4.7362 & 5.4513 & TST \\
\hline CHEMBL1520226 & 688239 & 6.4362 & 5.7232 & TRN \\
\hline CHEMBL3195749 & 688239 & 4.5862 & 5.4127 & TRN \\
\hline CHEMBL1349458 & 688239 & 8.1871 & 5.6276 & TRN \\
\hline CHEMBL1526392 & 688239 & 6.9863 & 5.4972 & TRN \\
\hline CHEMBL1546539 & 688239 & 4.6362 & 5.6432 & TST \\
\hline CHEMBL3192111 & 688239 & 4.5362 & 5.4174 & TRN \\
\hline CHEMBL1505307 & 688239 & 5.0862 & 5.2714 & TRN \\
\hline CHEMBL1414084 & 688239 & 4.5862 & 5.4957 & TST \\
\hline CHEMBL3214027 & 688239 & 6.1362 & 5.4706 & TRN \\
\hline CHEMBL1405810 & 688239 & 6.1862 & \multicolumn{2}{|c|}{5.4879999999999995} \\
\hline CHEMBL1478646 & 688239 & 4.5362 & 5.438 & TRN \\
\hline CHEMBL1567952 & 688239 & 6.0862 & 5.3357 & TRN \\
\hline CHEMBL1542936 & 688239 & 4.7362 & 5.291 & TST \\
\hline CHEMBL1537338 & 688239 & 5.5362 & 5.5328 & TST \\
\hline CHEMBL1339613 & 688239 & 4.6862 & 5.4685 & TST \\
\hline CHEMBL1444022 & 688239 & 4.7862 & 5.4235 & TRN \\
\hline CHEMBL1473856 & 688239 & 5.0362 & 5.3416 & TST \\
\hline CHEMBL1334803 & 688239 & 5.1862 & 5.5591 & TRN \\
\hline CHEMBL1338442 & 688239 & 5.6862 & 5.5462 & TST \\
\hline CHEMBL1392033 & 688239 & 4.5362 & 5.5348 & TST \\
\hline CHEMBL1554136 & 688239 & 5.6362 & 5.4367 & TRN \\
\hline CHEMBL1366661 & 688239 & 4.9362 & 5.5071 & TST \\
\hline CHEMBL1323726 & 688239 & 4.7862 & 5.4355 & TRN \\
\hline CHEMBL 2138014 & 688239 & 4.5362 & 5.3378 & TST \\
\hline CHEMBL1441419 & 688239 & 4.6862 & 5.3731 & TRN \\
\hline CHEMBL1368814 & 688239 & 5.1862 & 5.5228 & TRN \\
\hline CHEMBL1364439 & 688239 & 4.5362 & 5.3171 & TST \\
\hline CHEMBL1569802 & 688239 & 4.4862 & 5.4651 & TRN \\
\hline CHEMBL 3208550 & 688239 & 5.7362 & \multicolumn{2}{|c|}{5.3629999999999995} \\
\hline CHEMBL1555828 & 688239 & 4.5362 & 5.6006 & TRN \\
\hline CHEMBL1558832 & 688239 & 8.3872 & 5.5137 & TRN \\
\hline CHEMBL1256749 & 688239 & 4.6862 & 5.3677 & TST \\
\hline CHEMBL1502266 & 688239 & 5.1862 & 5.4108 & TST \\
\hline CHEMBL1482834 & 688239 & 5.2362 & 5.4773 & TRN \\
\hline CHEMBL1355808 & 688239 & 7.0362 & 5.3594 & TRN \\
\hline CHEMBL1582051 & 688239 & 4.7862 & 5.51399 & 9999999999 \\
\hline CHEMBL1370297 & 688239 & 5.2862 & 5.5881 & TRN \\
\hline CHEMBL1456186 & 688239 & 5.1862 & 5.522 & TST \\
\hline CHEMBL1331962 & 688239 & 5.7362 & 5.4406 & TRN \\
\hline CHEMBL1601960 & 688239 & 6.1362 & 5.4323 & TRN \\
\hline CHEMBL1523270 & 688239 & 6.0862 & 5.5156 & TST \\
\hline CHEMBL259139 & 688239 & 4.7862 & 5.3185 & TST \\
\hline CHEMBL1429526 & 688239 & 5.3862 & 5.4526 & TRN \\
\hline CHEMBL1394056 & 688239 & 4.8862 & 5.4623 & TRN \\
\hline CHEMBL1468634 & 688239 & 4.5362 & 5.4379 & TRN \\
\hline CHEMBL1517401 & 688239 & 4.6862 & 5.4739 & TST \\
\hline CHEMBL1458479 & 688239 & 5.0862 & 5.4172 & TRN \\
\hline
\end{tabular}


Supplemental Table S2.txt

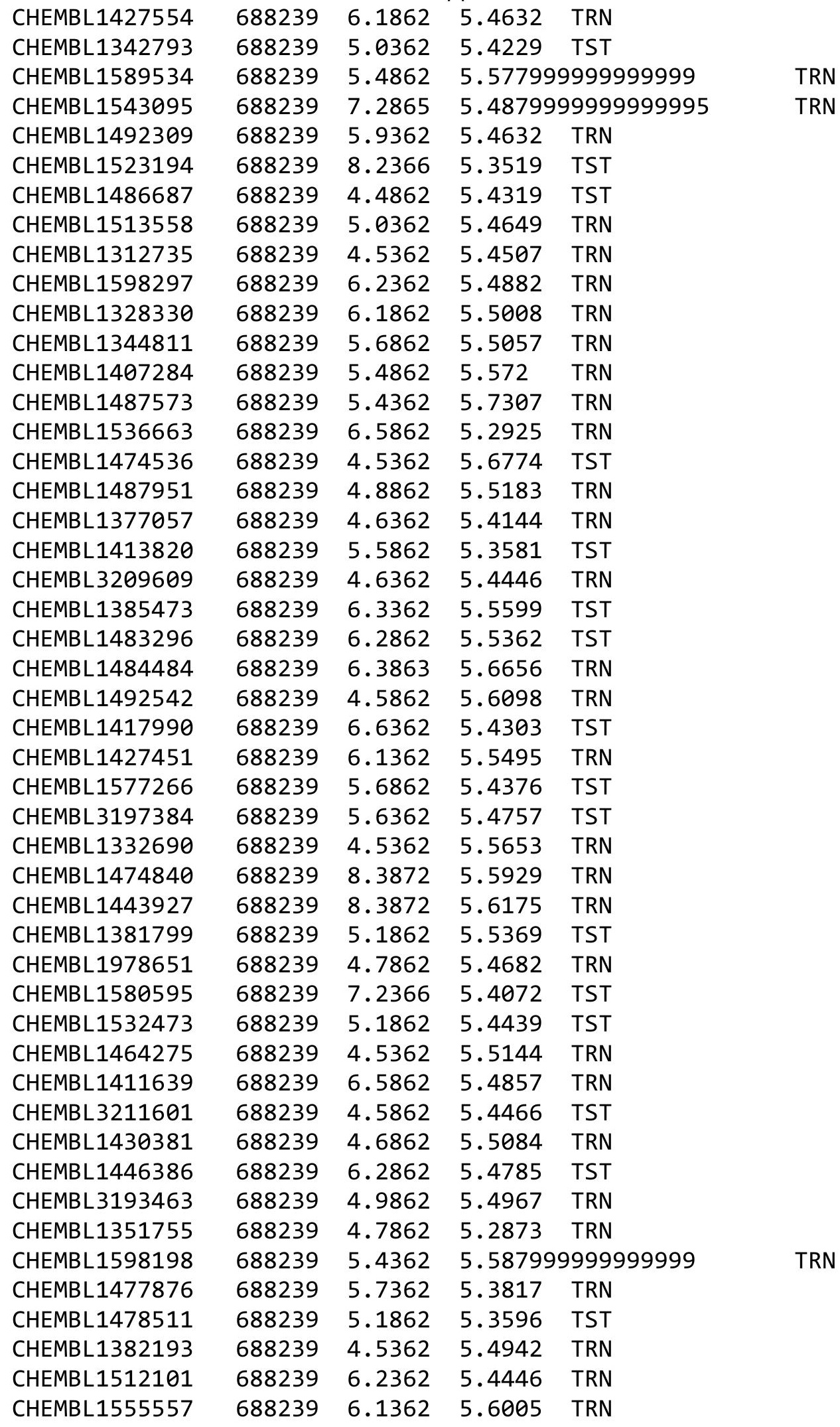

Page 2624 
Supplemental Table S2.txt

\begin{tabular}{|c|c|c|c|c|c|}
\hline CHEMBL1432535 & 688239 & 4.5862 & 5.4336 & TRN & \\
\hline CHEMBL3144874 & 688239 & 5.2862 & 5.3971 & TRN & \\
\hline CHEMBL1407723 & 688239 & 5.8862 & 5.4785 & TST & \\
\hline CHEMBL1359684 & 688239 & 4.5362 & 5.4367 & TRN & \\
\hline CHEMBL1446737 & 688239 & 6.1362 & 5.5724 & TRN & \\
\hline CHEMBL1520766 & 688239 & 5.8862 & 5.4498 & TRN & \\
\hline CHEMBL1471480 & 688239 & 4.6362 & 5.5523 & TRN & \\
\hline CHEMBL1471735 & 688239 & 4.5362 & 5.4768 & TRN & \\
\hline CHEMBL1517209 & 688239 & 5.0362 & 5.3533 & TRN & \\
\hline CHEMBL1535137 & 688239 & 6.7862 & 5.4514 & TST & \\
\hline CHEMBL1569831 & 688239 & 4.6362 & 5.4547 & TST & \\
\hline CHEMBL1338917 & 688239 & 4.5362 & 5.6198 & TRN & \\
\hline CHEMBL1387134 & 688239 & 6.7862 & 5.4367 & TRN & \\
\hline CHEMBL1379158 & 688239 & 4.5362 & 5.4217 & TRN & \\
\hline CHEMBL1609854 & 688239 & 5.6862 & 5.4366 & TST & \\
\hline CHEMBL1535243 & 688239 & 4.5362 & 5.5976 & TRN & \\
\hline CHEMBL1307976 & 688239 & 6.3362 & 5.5246 & TRN & \\
\hline CHEMBL1421681 & 688239 & 4.7862 & 5.5269 & TRN & \\
\hline CHEMBL1565419 & 688239 & 6.6362 & 5.4677 & TRN & \\
\hline CHEMBL1321619 & 688239 & 5.9362 & 5.4339 & TST & \\
\hline CHEMBL1303443 & 688239 & 4.5362 & 5.412999 & э9999999999 & TRN \\
\hline CHEMBL1319816 & 688239 & 5.1862 & 5.6078 & TRN & \\
\hline CHEMBL1312222 & 688239 & 6.0362 & 5.6037 & TST & \\
\hline CHEMBL1565586 & 688239 & 4.6862 & 5.4597 & TRN & \\
\hline CHEMBL1559290 & 688239 & 4.7362 & 5.4503 & TRN & \\
\hline CHEMBL1357054 & 688239 & 6.3362 & 5.5503 & TRN & \\
\hline CHEMBL1488035 & 688239 & 5.1362 & 5.5928 & TRN & \\
\hline CHEMBL1325503 & 688239 & 5.6862 & 5.5196 & TRN & \\
\hline CHEMBL1580237 & 688239 & 5.7362 & 5.6092 & TRN & \\
\hline CHEMBL1390069 & 688239 & 4.5362 & 5.5234 & TST & \\
\hline CHEMBL1550226 & 688239 & 4.6362 & 5.3142 & TRN & \\
\hline CHEMBL 2006508 & 688239 & 4.7862 & 5.4019 & TRN & \\
\hline CHEMBL1340536 & 688239 & 5.0362 & 5.6401 & TRN & \\
\hline CHEMBL1303423 & 688239 & 5.1862 & 5.6242 & TRN & \\
\hline CHEMBL1323219 & 688239 & 4.7862 & 5.7266 & TRN & \\
\hline CHEMBL1517786 & 688239 & 5.2362 & 5.4935 & TRN & \\
\hline CHEMBL1479445 & 688239 & 6.8861 & 5.486006 & 0000000001 & ונדו \\
\hline CHEMBL1359184 & 688239 & 5.2362 & 5.4503 & TST & \\
\hline CHEMBL3208870 & 688239 & 5.8362 & 5.5123 & TST & \\
\hline CHEMBL1412467 & 688239 & 4.5362 & 5.4778 & TST & \\
\hline CHEMBL1326578 & 688239 & 5.6362 & 5.4898 & TST & \\
\hline CHEMBL1559593 & 688239 & 5.1862 & 5.5509 & TRN & \\
\hline CHEMBL1488969 & 688239 & 5.1862 & 5.4213 & TRN & \\
\hline CHEMBL1469571 & 688239 & 5.6862 & 5.4509 & TRN & \\
\hline CHEMBL1453958 & 688239 & \multicolumn{3}{|c|}{8.283999999999999} & $\mathrm{nI}$ \\
\hline CHEMBL1606009 & 688239 & 6.1862 & 5.5584 & TST & \\
\hline CHEMBL3197489 & 688239 & 4.7862 & 5.3543 & TRN & \\
\hline CHEMBL1545910 & 688239 & 5.3362 & 5.4906 & TRN & \\
\hline
\end{tabular}


Supplemental Table S2.txt

\begin{tabular}{|c|c|c|c|c|c|}
\hline CHEMBL1525979 & 688239 & 5.4362 & 5.4806 & TRN & \\
\hline CHEMBL1472148 & 688239 & 5.5862 & 5.5324 & TRN & \\
\hline CHEMBL3212101 & 688239 & 6.1362 & 5.3301 & TRN & \\
\hline CHEMBL 3207345 & 688239 & 5.7362 & 5.4886 & TRN & \\
\hline CHEMBL1370308 & 688239 & 5.5862 & 5.4849 & TST & \\
\hline CHEMBL1353978 & 688239 & 6.2362 & 5.4988 & TRN & \\
\hline CHEMBL 3212847 & 688239 & 4.5362 & 5.4515 & TRN & \\
\hline CHEMBL1305319 & 688239 & 4.9862 & \multicolumn{2}{|c|}{5.327000000000001} & TRN \\
\hline CHEMBL1442802 & 688239 & 4.6862 & 5.5994 & TRN & \\
\hline CHEMBL1485431 & 688239 & 5.1862 & 5.5982 & TRN & \\
\hline CHEMBL1489908 & 688239 & 5.2362 & 5.5282 & TRN & \\
\hline CHEMBL1337558 & 688239 & 4.7862 & 5.4496 & TRN & \\
\hline CHEMBL1401874 & 688239 & 4.8862 & 5.3796 & TRN & \\
\hline CHEMBL1553671 & 688239 & 6.3362 & 5.4541 & TRN & \\
\hline CHEMBL1491336 & 688239 & 4.9362 & 5.6186 & TRN & \\
\hline CHEMBL1569463 & 688239 & 5.1862 & 5.5145 & TRN & \\
\hline CHEMBL1486968 & 688239 & 4.8862 & 5.4975 & TRN & \\
\hline CHEMBL1483167 & 688239 & 4.7362 & 5.5328 & TST & \\
\hline CHEMBL1379259 & 688239 & 4.6862 & 5.5384 & TRN & \\
\hline CHEMBL579318 & 688239 & 5.1862 & 5.5212 & TRN & \\
\hline CHEMBL1603499 & 688239 & 6.3362 & 5.6086 & TRN & \\
\hline CHEMBL1361688 & 688239 & 6.7361 & 5.6165 & TRN & \\
\hline CHEMBL1425363 & 688239 & 6.5862 & 5.3801 & TRN & \\
\hline CHEMBL1517375 & 688239 & 4.6862 & 5.6492 & TRN & \\
\hline CHEMBL1454917 & 688239 & 4.5362 & 5.3846 & TRN & \\
\hline CHEMBL1311477 & 688239 & 4.6362 & 5.5479 & TRN & \\
\hline CHEMBL1602771 & 688239 & 4.5362 & 5.3868 & TRN & \\
\hline CHEMBL1437224 & 688239 & 4.9862 & 5.6027 & TST & \\
\hline CHEMBL1547599 & 688239 & 6.1862 & 5.4991 & TRN & \\
\hline CHEMBL1571437 & 688239 & 6.2362 & 5.5462 & TRN & \\
\hline CHEMBL1561949 & 688239 & 4.8362 & 5.6102 & TST & \\
\hline CHEMBL1435524 & 688239 & 4.6362 & 5.4329 & TRN & \\
\hline CHEMBL1345306 & 688239 & 4.7862 & 5.5926 & TRN & \\
\hline CHEMBL3199122 & 688239 & 4.4862 & 5.4536 & TRN & \\
\hline CHEMBL1610027 & 688239 & 6.8861 & 5.4453 & TST & \\
\hline CHEMBL1595408 & 688239 & 6.7862 & 5.4419 & TRN & \\
\hline CHEMBL1477419 & 688239 & 5.0362 & 5.3233 & TRN & \\
\hline CHEMBL1386283 & 688239 & 4.5362 & 5.3894 & TST & \\
\hline CHEMBL1352305 & 688239 & 4.5362 & 5.42200 & 0000000001 & TRN \\
\hline CHEMBL3197217 & 688239 & 4.4862 & 5.3573 & TRN & \\
\hline CHEMBL3211841 & 688239 & 5.8862 & 5.5033 & TRN & \\
\hline CHEMBL1354363 & 688239 & 6.2862 & 5.5375 & TST & \\
\hline CHEMBL1419864 & 688239 & 5.1862 & 5.5627 & TRN & \\
\hline CHEMBL1307001 & 688239 & 7.7352 & 5.4731 & TRN & \\
\hline CHEMBL1606270 & 688239 & 6.0862 & 5.4904 & TRN & \\
\hline CHEMBL1306696 & 688239 & 4.5362 & 5.45100 & 30000000005 & TRN \\
\hline CHEMBL1542414 & 688239 & 4.8862 & 5.516 & TRN & \\
\hline CHEMBL1602559 & 688239 & 6.6362 & 5.5606 & TRN & \\
\hline
\end{tabular}


Supplemental Table S2.txt

\begin{tabular}{|c|c|c|c|c|}
\hline CHEMBL1367332 & 688239 & 5.6862 & 5.4397 & TRN \\
\hline CHEMBL1403164 & 688239 & 4.5362 & 5.5032 & TRN \\
\hline CHEMBL1383341 & 688239 & 5.1862 & 5.4188 & TRN \\
\hline CHEMBL1608347 & 688239 & 4.5862 & 5.5046 & TRN \\
\hline CHEMBL1315800 & 688239 & 6.1862 & 5.4779 & TRN \\
\hline CHEMBL1896042 & 688239 & 4.7362 & 5.5216 & TRN \\
\hline CHEMBL1507993 & 688239 & 5.5362 & 5.5537 & TST \\
\hline CHEMBL1335715 & 688239 & 4.5362 & 5.4363 & TRN \\
\hline CHEMBL1467985 & 688239 & 5.1862 & 5.5876 & TST \\
\hline CHEMBL1482544 & 688239 & 5.1862 & 5.4381 & TRN \\
\hline CHEMBL1488881 & 688239 & 5.1862 & 5.3392 & TST \\
\hline CHEMBL1608355 & 688239 & 4.5362 & 5.4015 & TRN \\
\hline CHEMBL1564750 & 688239 & 5.4362 & 5.5736 & TRN \\
\hline CHEMBL1516966 & 688239 & 5.0862 & 5.5002 & TST \\
\hline CHEMBL 3199028 & 688239 & 5.1862 & 5.4838 & TST \\
\hline CHEMBL1495674 & 688239 & 5.6862 & 5.4737 & TRN \\
\hline CHEMBL1531052 & 688239 & 5.2862 & 5.593 & TRN \\
\hline CHEMBL1428014 & 688239 & 4.7862 & 5.3241 & TST \\
\hline CHEMBL1515758 & 688239 & 6.4362 & 5.5173 & TRN \\
\hline CHEMBL1480222 & 688239 & 5.6862 & 5.5058 & TRN \\
\hline CHEMBL1586860 & 688239 & 5.7862 & 5.452999 & 9999999999 \\
\hline CHEMBL1439881 & 688239 & 4.5362 & 5.296 & TRN \\
\hline CHEMBL1342664 & 688239 & 6.6861 & 5.8029 & TRN \\
\hline CHEMBL1459418 & 688239 & 6.8362 & 5.5217 & TRN \\
\hline CHEMBL1479280 & 688239 & 4.6862 & 5.4468 & TRN \\
\hline CHEMBL1522915 & 688239 & 5.2362 & 5.3861 & TRN \\
\hline CHEMBL1585493 & 688239 & 6.1862 & 5.4783 & TRN \\
\hline CHEMBL1478606 & 688239 & 6.9863 & 5.5029 & TST \\
\hline CHEMBL1504142 & 688239 & 5.0862 & 5.5838 & TST \\
\hline CHEMBL1371668 & 688239 & 5.7862 & 5.4047 & TRN \\
\hline CHEMBL1600982 & 688239 & 4.5362 & 5.4394 & TRN \\
\hline CHEMBL1342260 & 688239 & 5.1862 & 5.2752 & TRN \\
\hline CHEMBL1559241 & 688239 & 6.8861 & 5.4406 & TRN \\
\hline CHEMBL1311929 & 688239 & 4.5362 & 5.6211 & TRN \\
\hline CHEMBL1569329 & 688239 & 6.1362 & 5.4287 & TRN \\
\hline CHEMBL1369322 & 688239 & 5.9862 & 5.433 & TRN \\
\hline CHEMBL1605710 & 688239 & 6.8362 & 5.6175 & TRN \\
\hline CHEMBL1479427 & 688239 & 4.5862 & 5.1728 & TRN \\
\hline CHEMBL1382387 & 688239 & 5.2862 & 5.5555 & TRN \\
\hline CHEMBL1521745 & 688239 & 6.1362 & 5.511 & TRN \\
\hline CHEMBL1469219 & 688239 & 5.1862 & 5.4801 & TRN \\
\hline CHEMBL1321089 & 688239 & 4.7862 & 5.3642 & TRN \\
\hline CHEMBL1451013 & 688239 & 5.3862 & 5.6003 & TST \\
\hline CHEMBL1399079 & 688239 & 7.0362 & 5.5014 & TRN \\
\hline CHEMBL1478904 & 688239 & 5.4362 & 5.5062 & TST \\
\hline CHEMBL1413297 & 688239 & 4.5362 & 5.504 & TRN \\
\hline CHEMBL1402354 & 688239 & 4.5362 & 5.7423 & TRN \\
\hline CHEMBL1488189 & 688239 & 6.8861 & 5.6966 & TRN \\
\hline
\end{tabular}




\begin{tabular}{|c|c|c|c|c|c|}
\hline & & & 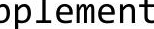 & & \\
\hline CHEMBL1411888 & 688239 & 5.2362 & 5.5756 & TRN & \\
\hline CHEMBL1500722 & 688239 & 6.0862 & 5.5224 & TRN & \\
\hline CHEMBL1560628 & 688239 & 4.5862 & 5.3161 & TST & \\
\hline CHEMBL1390570 & 688239 & 5.8862 & 5.485 & TST & \\
\hline CHEMBL1379013 & 688239 & 5.9362 & 5.4331 & TRN & \\
\hline CHEMBL1437258 & 688239 & 6.9363 & 5.6213 & TRN & \\
\hline CHEMBL1462459 & 688239 & 5.5362 & 5.3477 & TRN & \\
\hline CHEMBL1352375 & 688239 & 5.3862 & 5.5156 & TRN & \\
\hline CHEMBL1502550 & 688239 & 4.6862 & 5.3828 & TRN & \\
\hline CHEMBL1544170 & 688239 & 5.3362 & 5.5089 & TRN & \\
\hline CHEMBL1468480 & 688239 & 4.8862 & 5.4357 & TRN & \\
\hline CHEMBL1567153 & 688239 & 5.3862 & 5.6506 & TRN & \\
\hline CHEMBL1582284 & 688239 & 6.2362 & 5.7493 & TRN & \\
\hline CHEMBL1509781 & 688239 & 6.0862 & 5.5393 & TRN & \\
\hline CHEMBL1371828 & 688239 & 5.7362 & 5.3751 & TRN & \\
\hline CHEMBL3207896 & 688239 & 6.1862 & 5.4209 & TST & \\
\hline CHEMBL1523070 & 688239 & 5.2862 & 5.6015 & TRN & \\
\hline CHEMBL1400375 & 688239 & 4.9362 & 5.6029 & TST & \\
\hline CHEMBL1476508 & 688239 & 5.0362 & 5.5919 & TST & \\
\hline CHEMBL1551753 & 688239 & 5.3362 & 5.5153 & TRN & \\
\hline CHEMBL1364536 & 688239 & 4.9862 & 5.5676 & TRN & \\
\hline CHEMBL1447567 & 688239 & 5.7362 & 5.4833 & TRN & \\
\hline CHEMBL1484490 & 688239 & 7.0862 & 5.5434 & TRN & \\
\hline CHEMBL1401478 & 688239 & 4.6362 & 5.5177 & TRN & \\
\hline CHEMBL1382373 & 688239 & 7.0862 & 5.5917 & TRN & \\
\hline CHEMBL1343023 & 688239 & 4.8862 & 5.4791 & TRN & \\
\hline CHEMBL1578016 & 688239 & 4.6362 & 5.4034 & TRN & \\
\hline CHEMBL1383389 & 688239 & 4.5362 & 5.5551 & TRN & \\
\hline CHEMBL1367222 & 688239 & 4.6862 & 5.3697 & TRN & \\
\hline CHEMBL1361093 & 688239 & 6.5862 & 5.5138 & TRN & \\
\hline CHEMBL1564783 & 688239 & 6.9863 & 5.67200 & 3000000001 & TRN \\
\hline CHEMBL1299464 & 688239 & 4.7862 & 5.5379 & TST & \\
\hline CHEMBL1366932 & 688239 & 4.6862 & 5.4241 & TRN & \\
\hline CHEMBL1408529 & 688239 & 5.6862 & 5.4193 & TST & \\
\hline CHEMBL1415131 & 688239 & 4.5362 & 5.5284 & TRN & \\
\hline CHEMBL1389208 & 688239 & 5.4362 & 5.5641 & TRN & \\
\hline CHEMBL1430235 & 688239 & 6.1362 & 5.4638 & TST & \\
\hline CHEMBL1611006 & 688239 & 4.7362 & 5.50299 & 9999999999 & TRN \\
\hline CHEMBL1471731 & 688239 & 6.5363 & 5.3689 & TRN & \\
\hline CHEMBL1402498 & 688239 & 4.7862 & 5.5029 & TRN & \\
\hline CHEMBL1420016 & 688239 & 5.15 & 5.4643 & TST & \\
\hline CHEMBL1430532 & 688239 & 4.8362 & 5.57299 & 99999999995 & TRN \\
\hline CHEMBL1465445 & 688239 & 4.5362 & 5.5559 & TRN & \\
\hline CHEMBL 3212780 & 688239 & 5.8362 & 5.4832 & TRN & \\
\hline CHEMBL1308657 & 688239 & 4.4862 & 5.4085 & TRN & \\
\hline CHEMBL1488308 & 688239 & 6.7862 & 5.4473 & TRN & \\
\hline CHEMBL1341632 & 688239 & 4.5362 & 5.5377 & TST & \\
\hline CHEMBL1345363 & 688239 & 4.7362 & 5.6804 & TRN & \\
\hline
\end{tabular}




\begin{tabular}{|c|c|c|c|c|c|}
\hline \multicolumn{6}{|c|}{ supplemental } \\
\hline CHEMBL1598587 & 688239 & 7.1361 & 5.4187 & TRN & \\
\hline CHEMBL1384892 & 688239 & 6.1362 & 5.6229 & TRN & \\
\hline CHEMBL1437122 & 688239 & 6.1862 & 5.5396 & TRN & \\
\hline CHEMBL1299774 & 688239 & 4.4862 & 5.4529 & TRN & \\
\hline CHEMBL1325995 & 688239 & 4.7362 & 5.4595 & TST & \\
\hline CHEMBL1428937 & 688239 & 6.3863 & 5.5979 & TST & \\
\hline CHEMBL1456947 & 688239 & 4.6362 & 5.41100 & 00000000005 & TRN \\
\hline CHEMBL1463088 & 688239 & 4.7362 & 5.5747 & TST & \\
\hline CHEMBL1501987 & 688239 & 4.7362 & 5.5324 & TRN & \\
\hline CHEMBL1378275 & 688239 & 4.5362 & 5.4019 & TRN & \\
\hline CHEMBL1560620 & 688239 & 7.1361 & 5.4156 & TST & \\
\hline CHEMBL1586533 & 688239 & 5.4862 & 5.5967 & TRN & \\
\hline CHEMBL1597931 & 688239 & 4.7862 & 5.4684 & TST & \\
\hline CHEMBL1388394 & 688239 & 6.1862 & 5.6788 & TST & \\
\hline CHEMBL1505160 & 688239 & 5.2862 & 5.4806 & TRN & \\
\hline CHEMBL1492122 & 688239 & 7.0362 & 5.4108 & TRN & \\
\hline CHEMBL1482355 & 688239 & 4.5862 & 5.5639 & TRN & \\
\hline CHEMBL1438956 & 688239 & 4.5862 & 5.5055 & TRN & \\
\hline CHEMBL1613463 & 688239 & 4.6862 & 5.3861 & TST & \\
\hline CHEMBL1480731 & 688239 & 5.1862 & 5.3635 & TRN & \\
\hline CHEMBL1376614 & 688239 & 6.1362 & 5.5766 & TRN & \\
\hline CHEMBL1357057 & 688239 & 6.0862 & 5.3693 & TRN & \\
\hline CHEMBL3193020 & 688239 & 6.1362 & 5.3994 & TST & \\
\hline CHEMBL1438013 & 688239 & 4.5362 & 5.4847 & TRN & \\
\hline CHEMBL1599528 & 688239 & 5.1862 & 5.4052 & TRN & \\
\hline CHEMBL1316365 & 688239 & 6.8362 & 5.4417 & TRN & \\
\hline CHEMBL1348634 & 688239 & 5.1862 & 5.4117 & TRN & \\
\hline CHEMBL1612413 & 688239 & 6.8362 & 5.4837 & TRN & \\
\hline CHEMBL3199871 & 688239 & 4.5362 & 5.5476 & TST & \\
\hline CHEMBL1522634 & 688239 & 4.5362 & 5.4886 & TRN & \\
\hline CHEMBL1373107 & 688239 & 5.7862 & 5.5538 & TST & \\
\hline CHEMBL1370311 & 688239 & 4.8362 & 5.52 & TRN & \\
\hline CHEMBL1562819 & 688239 & 7.1864 & 5.5259 & TRN & \\
\hline CHEMBL1356175 & 688239 & 4.5362 & 5.4887 & TRN & \\
\hline CHEMBL1329661 & 688239 & 5.9862 & 5.489 & TRN & \\
\hline CHEMBL1415673 & 688239 & 4.7862 & 5.466 & TRN & \\
\hline CHEMBL1510568 & 688239 & 6.5363 & 5.4571 & TST & \\
\hline CHEMBL3194694 & 688239 & 4.8362 & 5.3944 & TST & \\
\hline CHEMBL1523722 & 688239 & 6.0862 & 5.654 & TRN & \\
\hline CHEMBL1598599 & 688239 & 4.5362 & 5.4029 & TRN & \\
\hline CHEMBL1497388 & 688239 & 4.5362 & 5.4831 & TRN & \\
\hline CHEMBL1452646 & 688239 & 5.4862 & 5.5439 & TRN & \\
\hline CHEMBL1522885 & 688239 & 4.5362 & 5.58200 & 0000000001 & TRN \\
\hline CHEMBL1464561 & 688239 & 4.7362 & 5.3405 & TRN & \\
\hline CHEMBL1385899 & 688239 & 7.6861 & 5.5249 & TRN & \\
\hline CHEMBL1361980 & 688239 & 7.0362 & 5.63 & TST & \\
\hline CHEMBL1351219 & 688239 & 4.5362 & 5.5505 & TRN & \\
\hline CHEMBL1464738 & 688239 & 5.1862 & 5.3808 & TST & \\
\hline
\end{tabular}


Supplemental Table S2.txt

\begin{tabular}{|c|c|c|c|c|c|}
\hline CHEMBL1420452 & 688239 & 6.0862 & 5.579 & TRN & \\
\hline CHEMBL1506762 & 688239 & 5.1862 & 5.4403 & TRN & \\
\hline CHEMBL1557086 & 688239 & 8.1871 & 5.4021 & TST & \\
\hline CHEMBL1445680 & 688239 & 6.1862 & 5.5667 & TRN & \\
\hline CHEMBL1438309 & 688239 & 5.7362 & 5.5093 & TST & \\
\hline CHEMBL1356224 & 688239 & 5.3862 & 5.4903 & TRN & \\
\hline CHEMBL1332161 & 688239 & 6.2862 & 5.6886 & TST & \\
\hline CHEMBL 3194518 & 688239 & 6.2362 & 5.3803 & TRN & \\
\hline CHEMBL1332476 & 688239 & 5.0362 & 5.5131 & TST & \\
\hline CHEMBL1419373 & 688239 & 5.1862 & 5.4372 & TRN & \\
\hline CHEMBL1338181 & 688239 & \multicolumn{2}{|c|}{8.283999999999999} & 5.7179 & $T$ \\
\hline CHEMBL3212129 & 688239 & 5.2362 & 5.6745 & TRN & \\
\hline CHEMBL1365444 & 688239 & 5.6362 & 5.4117 & TRN & \\
\hline CHEMBL1562102 & 688239 & 6.0362 & 5.445 & TRN & \\
\hline CHEMBL1592496 & 688239 & 5.4862 & 5.5285 & TST & \\
\hline CHEMBL1376496 & 688239 & 5.8862 & 5.4063 & TRN & \\
\hline CHEMBL1428892 & 688239 & 4.5362 & 5.4415 & TRN & \\
\hline CHEMBL 3207647 & 688239 & 6.7862 & 5.4014 & TRN & \\
\hline CHEMBL1433972 & 688239 & 6.3362 & 5.4639 & TRN & \\
\hline CHEMBL1505831 & 688239 & 4.5862 & 5.5109 & TST & \\
\hline CHEMBL1509951 & 688239 & 5.0862 & 5.4645 & TRN & \\
\hline CHEMBL1567733 & 688239 & 5.6362 & 5.5221 & TST & \\
\hline CHEMBL1488352 & 688239 & 4.5362 & 5.2719 & TRN & \\
\hline CHEMBL1362567 & 688239 & 4.7362 & 5.5539 & TRN & \\
\hline CHEMBL1434240 & 688239 & 6.7862 & 5.5185 & TRN & \\
\hline CHEMBL1345390 & 688239 & 4.6362 & 5.664 & TST & \\
\hline CHEMBL1561817 & 688239 & 4.6862 & 5.4818 & TRN & \\
\hline CHEMBL1389883 & 688239 & 6.2362 & 5.5025 & TRN & \\
\hline CHEMBL1563082 & 688239 & 6.0862 & 5.3987 & TRN & \\
\hline CHEMBL1423451 & 688239 & 6.6861 & 5.5674 & TRN & \\
\hline CHEMBL1408939 & 688239 & 4.5362 & 5.5776 & TRN & \\
\hline CHEMBL1602638 & 688239 & 5.1862 & 5.4338 & TRN & \\
\hline CHEMBL1503020 & 688239 & 5.1362 & 5.41100 & 30000000005 & \\
\hline CHEMBL1412332 & 688239 & 4.6862 & 5.4829 & TRN & \\
\hline CHEMBL1492774 & 688239 & 5.1862 & 5.4374 & TST & \\
\hline CHEMBL1403776 & 688239 & 4.6362 & 5.51200 & 00000000005 & ST \\
\hline CHEMBL1398862 & 688239 & 5.1862 & 5.5193 & TRN & \\
\hline CHEMBL1545689 & 688239 & 4.5362 & 5.4517 & TST & \\
\hline CHEMBL1474276 & 688239 & 4.6862 & 5.4745 & TST & \\
\hline CHEMBL1333487 & 688239 & 4.6362 & 5.4057 & TST & \\
\hline CHEMBL1317682 & 688239 & 4.5362 & 5.4607 & TST & \\
\hline CHEMBL1448255 & 688239 & 5.3862 & 5.4334 & TRN & \\
\hline CHEMBL1580898 & 688239 & 5.1362 & 5.5983 & TRN & \\
\hline CHEMBL1377490 & 688239 & 5.0862 & 5.5984 & TRN & \\
\hline CHEMBL1386310 & 688239 & 4.5862 & 5.4257 & TRN & \\
\hline CHEMBL1084057 & 688239 & 4.7862 & 5.5071 & TST & \\
\hline CHEMBL1597115 & 688239 & 4.9362 & 5.3774 & TRN & \\
\hline CHEMBL1535444 & 688239 & 5.0362 & 5.4803 & TRN & \\
\hline
\end{tabular}

Page 2630 
Supplemental Table S2.txt

\begin{tabular}{|c|c|c|c|c|}
\hline CHEMBL1463398 & 688239 & 6.5862 & 5.5445 & TRN \\
\hline CHEMBL1408563 & 688239 & 5.1862 & 5.5446 & TRN \\
\hline CHEMBL1469466 & 688239 & 6.0862 & 5.4263 & TRN \\
\hline CHEMBL1371161 & 688239 & 5.1862 & 5.5138 & TRN \\
\hline CHEMBL1556230 & 688239 & 5.7862 & 5.4186 & TST \\
\hline CHEMBL1522115 & 688239 & 4.7362 & 5.5141 & TST \\
\hline CHEMBL24450 & 688239 & 4.7862 & 5.5533 & TRN \\
\hline CHEMBL1440908 & 688239 & 4.7362 & 5.4855 & TRN \\
\hline CHEMBL1362761 & 688239 & 6.9363 & 5.4394 & TRN \\
\hline CHEMBL1398965 & 688239 & 6.5862 & 5.5229 & TRN \\
\hline CHEMBL1454557 & 688239 & 4.8362 & 5.3814 & TRN \\
\hline CHEMBL1600233 & 688239 & 7.9872 & 5.6012 & TST \\
\hline CHEMBL1336916 & 688239 & 4.7862 & 5.3708 & TRN \\
\hline CHEMBL1567663 & 688239 & 5.3862 & 5.4931 & TRN \\
\hline CHEMBL1420341 & 688239 & 4.5362 & 5.3684 & TRN \\
\hline CHEMBL1582007 & 688239 & 5.2362 & 5.3825 & TRN \\
\hline CHEMBL1589720 & 688239 & 5.3862 & 5.4386 & TRN \\
\hline CHEMBL255068 & 688239 & 5.1862 & 5.5435 & TRN \\
\hline CHEMBL1471568 & 688239 & 6.6 & 5.54899 & 99999999995 \\
\hline CHEMBL1360575 & 688239 & 6.9363 & 5.5422 & TST \\
\hline CHEMBL1382518 & 688239 & 6.1862 & 5.3117 & TRN \\
\hline CHEMBL1602010 & 688239 & 5.2862 & 5.5049 & TRN \\
\hline CHEMBL1314583 & 688239 & 6.5363 & 5.6733 & TRN \\
\hline CHEMBL1498651 & 688239 & 5.3862 & 5.6159 & TRN \\
\hline CHEMBL1520316 & 688239 & 6.3362 & 5.4563 & TRN \\
\hline CHEMBL1408094 & 688239 & 4.5862 & 5.3802 & TRN \\
\hline CHEMBL1407236 & 688239 & 5.8362 & 5.4261 & TRN \\
\hline CHEMBL1317944 & 688239 & 5.1862 & 5.415 & TRN \\
\hline CHEMBL1496389 & 688239 & 5.7862 & 5.6362 & TRN \\
\hline CHEMBL1335766 & 688239 & 5.5862 & 5.4584 & TRN \\
\hline CHEMBL1485950 & 688239 & 6.2362 & 5.3879 & TRN \\
\hline CHEMBL1417580 & 688239 & 5.1862 & 5.7192 & TST \\
\hline CHEMBL1440995 & 688239 & 5.2362 & 5.4813 & TRN \\
\hline CHEMBL1359989 & 688239 & 4.7862 & 5.6429 & TRN \\
\hline CHEMBL1570410 & 688239 & 5.4862 & 5.461 & TRN \\
\hline CHEMBL1471326 & 688239 & 5.3362 & 5.5332 & TRN \\
\hline CHEMBL1600420 & 688239 & 5.1862 & 5.4935 & TRN \\
\hline CHEMBL3392028 & 688239 & 6.5862 & 5.4055 & TST \\
\hline CHEMBL1476057 & 688239 & 5.8862 & 5.5195 & TST \\
\hline CHEMBL1594665 & 688239 & 5.2862 & 5.6159 & TRN \\
\hline CHEMBL1357171 & 688239 & 6.2862 & 5.5492 & TRN \\
\hline CHEMBL1501686 & 688239 & 4.7862 & 5.4447 & TST \\
\hline CHEMBL1389710 & 688239 & 5.3862 & 5.6117 & TRN \\
\hline CHEMBL1564310 & 688239 & 6.8861 & 5.441 & TRN \\
\hline CHEMBL1345639 & 688239 & 6.7862 & 5.5089 & TRN \\
\hline CHEMBL1516084 & 688239 & 5.2362 & 5.4913 & TRN \\
\hline CHEMBL1466390 & 688239 & 6.2362 & 5.5747 & TST \\
\hline CHEMBL1375081 & 688239 & 6.5363 & 5.5089 & TRN \\
\hline
\end{tabular}

Page 2631 
Supplemental Table S2.txt

\begin{tabular}{|c|c|c|c|c|c|}
\hline CHEMBL1368971 & 688239 & 4.5362 & \multicolumn{2}{|c|}{5.3870000000000005} & TRN \\
\hline CHEMBL1441250 & 688239 & 6.7361 & 5.447 & TST & \\
\hline CHEMBL1468904 & 688239 & 4.8862 & 5.4527 & TRN & \\
\hline CHEMBL1509816 & 688239 & 8.2366 & 5.5292 & TRN & \\
\hline CHEMBL1453385 & 688239 & 5.1362 & 5.7372 & TRN & \\
\hline CHEMBL1457537 & 688239 & 4.5362 & 5.5314 & TST & \\
\hline CHEMBL1587119 & 688239 & 4.6862 & 5.6021 & TRN & \\
\hline CHEMBL1506269 & 688239 & 4.5362 & 5.5569 & TST & \\
\hline CHEMBL1471841 & 688239 & 4.7362 & 5.532 & TRN & \\
\hline CHEMBL1577596 & 688239 & 6.9863 & 5.5533 & TRN & \\
\hline CHEMBL3192433 & 688239 & 5.3362 & 5.5829 & TST & \\
\hline CHEMBL1584756 & 688239 & 6.4862 & 5.3981 & TRN & \\
\hline CHEMBL1433643 & 688239 & 5.3862 & 5.5421 & TRN & \\
\hline CHEMBL1509899 & 688239 & 5.1362 & 5.7077 & TRN & \\
\hline CHEMBL3195743 & 688239 & 4.6862 & \multicolumn{2}{|c|}{5.5360000000000005} & \\
\hline CHEMBL1351204 & 688239 & 4.5362 & 5.5795 & TRN & \\
\hline CHEMBL1343112 & 688239 & 4.6862 & 5.6116 & TRN & \\
\hline CHEMBL1513375 & 688239 & 5.5362 & 5.6439 & TRN & \\
\hline CHEMBL1445638 & 688239 & 6.0 & 5.58 & TRN & \\
\hline CHEMBL1577219 & 688239 & 4.7362 & 5.5407 & TST & \\
\hline CHEMBL1978331 & 688239 & 6.5363 & 5.5271 & TRN & \\
\hline CHEMBL1303653 & 688239 & 4.5862 & \multicolumn{2}{|c|}{5.4510000000000005} & \\
\hline CHEMBL1360512 & 688239 & 4.7862 & 5.5344 & TRN & \\
\hline CHEMBL1326245 & 688239 & 6.9363 & 5.4207 & TRN & \\
\hline CHEMBL1308075 & 688239 & 4.7362 & 5.2825 & TRN & \\
\hline CHEMBL1502098 & 688239 & 4.7862 & 5.4362 & TRN & \\
\hline CHEMBL1358375 & 688239 & 6.0862 & 5.4432 & TST & \\
\hline CHEMBL1302965 & 688239 & 6.2862 & 5.4881 & TRN & \\
\hline CHEMBL1406378 & 688239 & 4.5362 & 5.499 & TRN & \\
\hline CHEMBL1341417 & 688239 & 4.9362 & 5.3902 & TRN & \\
\hline CHEMBL3199066 & 688239 & 5.5362 & 5.4314 & TST & \\
\hline CHEMBL3189148 & 688239 & 5.7862 & 5.2688 & TRN & \\
\hline CHEMBL1559473 & 688239 & 4.7862 & 5.5159 & TRN & \\
\hline CHEMBL1329604 & 688239 & 5.2862 & 5.3996 & TRN & \\
\hline CHEMBL3198685 & 688239 & 4.4862 & 5.56 & TST & \\
\hline CHEMBL1428563 & 688239 & 4.5362 & 5.4654 & TRN & \\
\hline CHEMBL1604259 & 688239 & 5.1862 & 5.5053 & TST & \\
\hline CHEMBL1472211 & 688239 & 4.7362 & 5.5308 & TRN & \\
\hline CHEMBL1455164 & 688239 & 6.9363 & 5.5657 & TRN & \\
\hline CHEMBL1356451 & 688239 & 5.2362 & 5.5543 & TRN & \\
\hline CHEMBL1519745 & 688239 & 4.5362 & 5.4685 & TRN & \\
\hline CHEMBL1499301 & 688239 & 4.5362 & 5.5099 & TRN & \\
\hline CHEMBL1383909 & 688239 & 5.3362 & 5.5682 & TRN & \\
\hline CHEMBL1546705 & 688239 & 8.3872 & 5.685 & TRN & \\
\hline CHEMBL1562640 & 688239 & 6.2362 & 5.3731 & TRN & \\
\hline CHEMBL3194082 & 688239 & 5.6862 & 5.3714 & TST & \\
\hline CHEMBL1440864 & 688239 & 5.1862 & 5.6638 & TRN & \\
\hline CHEMBL1456531 & 688239 & 6.9863 & 5.6325 & TRN & \\
\hline
\end{tabular}

Page 2632 
Supplemental Table S2.txt

\begin{tabular}{|c|c|c|c|c|}
\hline & & & & \\
\hline HEMBL1417437 & 38239 & 362 & 679 & \\
\hline AEMBL1404615 & 39 & 362 & & \\
\hline 8059 & 39 & 862 & 189 & \\
\hline IEMBL15 & 39 & 862 & & \\
\hline AEMBL1570609 & 88239 & 362 & 869 & \\
\hline AEMBL1337636 & 88239 & 4.7862 & 4819 & \\
\hline HEMBL1464519 & & 362 & & \\
\hline IEMBL1 & 39 & 862 & & \\
\hline IEMBL32 & & 362 & & \\
\hline AEMBL1736171 & 39 & 362 & 69 & \\
\hline AEMBL1513074 & & 362 & & \\
\hline AEMBL1507121 & & 861 & & \\
\hline AEMBL 31 & & 864 & & \\
\hline HEMBL14 & & 362 & & \\
\hline AEMBL1487907 & & 362 & & \\
\hline AEMBL1966952 & & 362 & & \\
\hline AEMBL13 & & 62 & & \\
\hline AEMBL12 & & 62 & & \\
\hline AEMBL15 & & & & \\
\hline AEMBL1599671 & & 362 & & \\
\hline AEMBL1484117 & & 63 & & \\
\hline HEMBL31 & & 62 & & \\
\hline 680 & & & & \\
\hline 871 & & & & \\
\hline 073 & & 862 & & \\
\hline IEMBL14 & & & & \\
\hline EMBL1C & & 62 & & \\
\hline 37 & & 52 & & \\
\hline 948 & & 62 & & \\
\hline 580 & & & & \\
\hline AEMBL1327291 & & 362 & & \\
\hline & & & & \\
\hline 5 & & & & \\
\hline 4660 & & & & \\
\hline AEMBL607577 & & & & [S] \\
\hline AEMBL1528310 & & 862 & & F \\
\hline & & & & 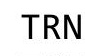 \\
\hline 944 & & & & - \\
\hline HEMBL1522829 & & & & $\Gamma S$ \\
\hline AEMBL1546703 & & 362 & & 50 \\
\hline 623 & & 62 & & \\
\hline & & & & \\
\hline HEMBL3199297 & & & & \\
\hline AEMBL1549321 & & 5.5862 & & $\mathrm{R}$ \\
\hline MBL13 & & 362 & 3507 & TR \\
\hline 1 & & & & \\
\hline . & & 4.45 & 3107 & \\
\hline
\end{tabular}

Page 2633 


\begin{tabular}{|c|c|c|c|c|c|c|}
\hline & & \multicolumn{5}{|c|}{ Supplemental Table S2.txt } \\
\hline CHEMBL1502770 & 688239 & 5.3362 & 5.4449 & TST & & \\
\hline CHEMBL1416926 & 688239 & 8.28399 & 999999999 & & 5.7231 & TRN \\
\hline CHEMBL1563042 & 688239 & 4.7362 & 5.4763 & TST & & \\
\hline CHEMBL1386760 & 688239 & 5.9362 & 5.3639 & TRN & & \\
\hline CHEMBL1545698 & 688239 & 6.1862 & 5.3972 & TRN & & \\
\hline CHEMBL1338105 & 688239 & 4.5362 & 5.4439 & TRN & & \\
\hline CHEMBL3191543 & 688239 & 4.4862 & 5.4063 & TRN & & \\
\hline CHEMBL1509597 & 688239 & 4.6362 & 5.3448 & TRN & & \\
\hline CHEMBL1481055 & 688239 & 4.5362 & 5.3814 & TRN & & \\
\hline CHEMBL1518463 & 688239 & 6.1362 & 5.4862 & TRN & & \\
\hline CHEMBL1355820 & 688239 & 7.0862 & 5.5277 & TRN & & \\
\hline CHEMBL1462394 & 688239 & 4.5362 & 5.605 & TRN & & \\
\hline CHEMBL1576608 & 688239 & 5.1862 & 5.6026 & TRN & & \\
\hline CHEMBL1444475 & 688239 & 6.4362 & 5.5345 & TRN & & \\
\hline CHEMBL600070 & 688239 & 5.7862 & 5.3625 & TST & & \\
\hline CHEMBL1321925 & 688239 & 4.5362 & 5.5852 & TRN & & \\
\hline CHEMBL1547709 & 688239 & 4.7362 & 5.4894 & TRN & & \\
\hline CHEMBL1322678 & 688239 & 5.1362 & 5.5838 & TST & & \\
\hline CHEMBL1350533 & 688239 & 5.4862 & 5.5115 & TRN & & \\
\hline CHEMBL3198492 & 688239 & 5.0362 & 5.4181 & TST & & \\
\hline CHEMBL1542472 & 688239 & 8.2366 & 5.5198 & TRN & & \\
\hline CHEMBL1351528 & 688239 & 6.1362 & 5.4731 & TRN & & \\
\hline CHEMBL1579587 & 688239 & 5.5362 & 5.6272 & TRN & & \\
\hline CHEMBL1309270 & 688239 & 5.4862 & 5.4669 & TRN & & \\
\hline CHEMBL1527977 & 688239 & 6.1362 & 5.357 & TRN & & \\
\hline CHEMBL1583890 & 688239 & 4.5362 & 5.53 & TRN & & \\
\hline CHEMBL1602288 & 688239 & 5.3862 & 5.521 & TRN & & \\
\hline CHEMBL1304857 & 688239 & 5.4362 & 5.2877 & TRN & & \\
\hline CHEMBL1427688 & 688239 & 4.7862 & 5.2494 & TST & & \\
\hline CHEMBL1380042 & 688239 & 5.4362 & 5.593 & TST & & \\
\hline CHEMBL1452537 & 688239 & 5.5862 & 5.3964 & TRN & & \\
\hline CHEMBL1520892 & 688239 & 5.1362 & 5.447 & TRN & & \\
\hline CHEMBL1501116 & 688239 & 5.5862 & 5.5169 & TRN & & \\
\hline CHEMBL1453062 & 688239 & 4.8362 & 5.4783 & TRN & & \\
\hline CHEMBL1407010 & 688239 & 4.6862 & 5.4297 & TRN & & \\
\hline CHEMBL1443493 & 688239 & 4.5362 & 5.5135 & TST & & \\
\hline CHEMBL1418254 & 688239 & 5.5362 & 5.6012 & TRN & & \\
\hline CHEMBL1380581 & 688239 & 7.3363 & 5.5059 & TST & & \\
\hline CHEMBL1577220 & 688239 & 4.5362 & 5.5689 & TRN & & \\
\hline CHEMBL1376741 & 688239 & 5.6862 & 5.366000 & 00000000 & כשטנ & 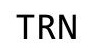 \\
\hline CHEMBL1447926 & 688239 & 6.1362 & 5.5504 & TRN & & \\
\hline CHEMBL1426033 & 688239 & 8.28399 & 999999999 & & 5.3908 & TRN \\
\hline CHEMBL3191186 & 688239 & 4.4862 & 5.4263 & TST & & \\
\hline CHEMBL1355267 & 688239 & 4.6362 & 5.5072 & TRN & & \\
\hline CHEMBL1495998 & 688239 & 6.7862 & 5.5135 & TRN & & \\
\hline CHEMBL1510529 & 688239 & 4.5362 & 5.4956 & TRN & & \\
\hline CHEMBL3193795 & 688239 & 4.5362 & 5.3838 & TRN & & \\
\hline CHEMBL1448263 & 688239 & 4.9362 & 5.2907 & TST & & \\
\hline
\end{tabular}


Supplemental Table S2.txt

\begin{tabular}{|c|c|c|c|c|}
\hline CHEMBL1582217 & 688239 & 6.9363 & 5.6631 & TRN \\
\hline CHEMBL1479645 & 688239 & 5.1862 & 5.3979 & TRN \\
\hline CHEMBL3195352 & 688239 & 4.8362 & 5.5422 & TRN \\
\hline CHEMBL1449706 & 688239 & 4.7362 & 5.4013 & TRN \\
\hline CHEMBL 3209747 & 688239 & 5.1862 & 5.3623 & TRN \\
\hline CHEMBL1312998 & 688239 & 5.1362 & 5.4828 & TRN \\
\hline CHEMBL1401754 & 688239 & 5.5362 & 5.4223 & TST \\
\hline CHEMBL1396251 & 688239 & 5.5362 & 5.486006 & 0000000001 \\
\hline CHEMBL1556493 & 688239 & 5.2362 & 5.4451 & TRN \\
\hline CHEMBL1457144 & 688239 & 6.8861 & 5.4936 & TRN \\
\hline CHEMBL1529607 & 688239 & 5.8862 & 5.517 & TRN \\
\hline CHEMBL1604690 & 688239 & 6.7862 & 5.5069 & TRN \\
\hline CHEMBL1455913 & 688239 & 4.6362 & 5.2812 & TRN \\
\hline CHEMBL1453088 & 688239 & 6.0362 & 5.4641 & TRN \\
\hline CHEMBL 3210548 & 688239 & 5.1862 & 5.4623 & TRN \\
\hline CHEMBL1563252 & 688239 & 6.1362 & 5.5071 & TST \\
\hline CHEMBL1453502 & 688239 & 6.5862 & 5.4384 & TRN \\
\hline CHEMBL1436003 & 688239 & 4.5362 & 5.3284 & TRN \\
\hline CHEMBL1370401 & 688239 & 4.6362 & 5.5181 & TST \\
\hline CHEMBL1587361 & 688239 & 6.2862 & 5.6388 & TRN \\
\hline CHEMBL1434382 & 688239 & 6.7862 & 5.4149 & TRN \\
\hline CHEMBL1476123 & 688239 & 5.1362 & 5.3781 & TRN \\
\hline CHEMBL1585957 & 688239 & 4.5362 & 5.5251 & TRN \\
\hline CHEMBL1517205 & 688239 & 5.7362 & 5.6617 & TRN \\
\hline CHEMBL1537112 & 688239 & 4.5362 & 5.4616 & TST \\
\hline CHEMBL1505350 & 688239 & 4.8862 & 5.5105 & TRN \\
\hline CHEMBL1309816 & 688239 & 5.4862 & 5.5713 & TST \\
\hline CHEMBL 3189874 & 688239 & 5.9362 & 5.6255 & TRN \\
\hline CHEMBL1521703 & 688239 & 5.3862 & 5.6103 & TRN \\
\hline CHEMBL1326145 & 688239 & 4.5362 & 5.5174 & TRN \\
\hline CHEMBL1495044 & 688239 & 5.6362 & 5.6178 & TRN \\
\hline CHEMBL1346406 & 688239 & 4.5362 & 5.5168 & TRN \\
\hline CHEMBL1572202 & 688239 & 4.7362 & 5.6071 & TRN \\
\hline CHEMBL1309447 & 688239 & 6.4362 & 5.4256 & TRN \\
\hline CHEMBL1562525 & 688239 & 4.6862 & 5.4585 & TRN \\
\hline CHEMBL1524413 & 688239 & 6.8362 & 5.4811 & TRN \\
\hline CHEMBL1519119 & 688239 & 8.3372 & 5.4661 & TST \\
\hline CHEMBL1535649 & 688239 & 4.6862 & 5.6581 & TRN \\
\hline CHEMBL1561763 & 688239 & 4.5362 & 5.5228 & TRN \\
\hline CHEMBL1613571 & 688239 & 5.1862 & 5.3565 & TRN \\
\hline CHEMBL1607797 & 688239 & 4.6862 & 5.3817 & TRN \\
\hline CHEMBL1307549 & 688239 & 6.2362 & 5.5424 & TRN \\
\hline CHEMBL1609536 & 688239 & 5.8362 & 5.5586 & TST \\
\hline CHEMBL1520881 & 688239 & 6.1362 & 5.6417 & TRN \\
\hline CHEMBL1372856 & 688239 & 4.5362 & 5.5474 & TST \\
\hline CHEMBL1609161 & 688239 & 6.4362 & 5.6792 & TRN \\
\hline CHEMBL1392722 & 688239 & 4.7362 & 5.2445 & TST \\
\hline CHEMBL1594656 & 688239 & 4.5362 & 5.5625 & TRN \\
\hline
\end{tabular}


Supplemental Table S2.txt

\begin{tabular}{|c|c|c|c|c|c|}
\hline CHEMBL1362316 & 688239 & 6.5862 & 5.5365 & TRN & \\
\hline CHEMBL1609590 & 688239 & 4.9362 & 5.5312 & TST & \\
\hline CHEMBL1426825 & 688239 & 6.1862 & 5.5424 & TRN & \\
\hline CHEMBL1520860 & 688239 & 6.2862 & 5.5996 & TRN & \\
\hline CHEMBL1449674 & 688239 & 6.6861 & 5.6138 & TRN & \\
\hline CHEMBL1337723 & 688239 & 4.5362 & 5.5509 & TST & \\
\hline CHEMBL1504133 & 688239 & 6.4362 & 5.3457 & TST & \\
\hline CHEMBL1383873 & 688239 & 5.1862 & 5.5928 & TST & \\
\hline CHEMBL3199023 & 688239 & 5.4362 & 5.4703 & TRN & \\
\hline CHEMBL1435840 & 688239 & 4.6862 & 5.5424 & TRN & \\
\hline CHEMBL1413062 & 688239 & 8.3372 & 5.4636 & TST & \\
\hline CHEMBL1359948 & 688239 & 4.7362 & 5.5116 & TRN & \\
\hline CHEMBL1425141 & 688239 & 6.9863 & 5.4313 & TRN & \\
\hline CHEMBL1543573 & 688239 & 4.8862 & 5.3742 & TRN & \\
\hline CHEMBL1302666 & 688239 & 5.0362 & 5.6528 & TRN & \\
\hline CHEMBL1367776 & 688239 & 4.9862 & 5.5282 & TRN & \\
\hline CHEMBL1391741 & 688239 & 6.0362 & 5.5048 & TST & \\
\hline CHEMBL1417511 & 688239 & 5.1862 & 5.4047 & TRN & \\
\hline CHEMBL1403421 & 688239 & 4.5362 & 5.3605 & TRN & \\
\hline CHEMBL3214412 & 688239 & 4.6362 & 5.3927 & TRN & \\
\hline CHEMBL1410899 & 688239 & 5.6362 & 5.4902 & TRN & \\
\hline CHEMBL1491826 & 688239 & 5.4362 & 5.4712 & TRN & \\
\hline CHEMBL1511340 & 688239 & 4.6362 & 5.5342 & TRN & \\
\hline CHEMBL1540625 & 688239 & 5.9362 & 5.6088 & TRN & \\
\hline CHEMBL3199610 & 688239 & 5.1862 & 5.5197 & TRN & \\
\hline CHEMBL1508980 & 688239 & 6.8861 & 5.5061 & TRN & \\
\hline CHEMBL1554332 & 688239 & 5.6862 & 5.3902 & TRN & \\
\hline CHEMBL1375169 & 688239 & 5.4862 & 5.5819 & TRN & \\
\hline CHEMBL1442835 & 688239 & 6.1362 & 5.5051 & TST & \\
\hline CHEMBL590672 & 688239 & 5.5362 & 5.3466 & TRN & \\
\hline CHEMBL1347907 & 688239 & 5.2362 & 5.5457 & TRN & \\
\hline CHEMBL1386928 & 688239 & 5.5362 & 5.6612 & TRN & \\
\hline CHEMBL1542971 & 688239 & 4.5362 & 5.6383 & TST & \\
\hline CHEMBL589734 & 688239 & 6.8861 & 5.3855 & TST & \\
\hline CHEMBL1592640 & 688239 & 8.3872 & 5.4607 & TRN & \\
\hline CHEMBL1429493 & 688239 & 6.7862 & 5.5692 & TRN & \\
\hline CHEMBL1406890 & 688239 & 5.2862 & 5.5313 & TRN & \\
\hline CHEMBL1443843 & 688239 & 5.7362 & 5.5275 & TRN & \\
\hline CHEMBL1601604 & 688239 & 4.5362 & 5.4182 & TRN & \\
\hline CHEMBL1393250 & 688239 & 8.28399 & 99999999 & 9 & 5.5508 \\
\hline CHEMBL1462442 & 688239 & 6.1862 & 5.6033 & TRN & \\
\hline CHEMBL1436556 & 688239 & 5.1862 & 5.5057 & TRN & \\
\hline CHEMBL1593460 & 688239 & 4.8362 & 5.5137 & TRN & \\
\hline CHEMBL1552802 & 688239 & 7.0862 & 5.4441 & TST & \\
\hline CHEMBL1464100 & 688239 & 6.8362 & 5.6305 & TRN & \\
\hline CHEMBL1581975 & 688239 & 7.0362 & 5.6041 & TRN & \\
\hline CHEMBL1562345 & 688239 & 4.9362 & 5.5453 & TRN & \\
\hline CHEMBL1566889 & 688239 & 6.2862 & 5.4456 & TRN & \\
\hline
\end{tabular}


Supplemental Table S2.txt

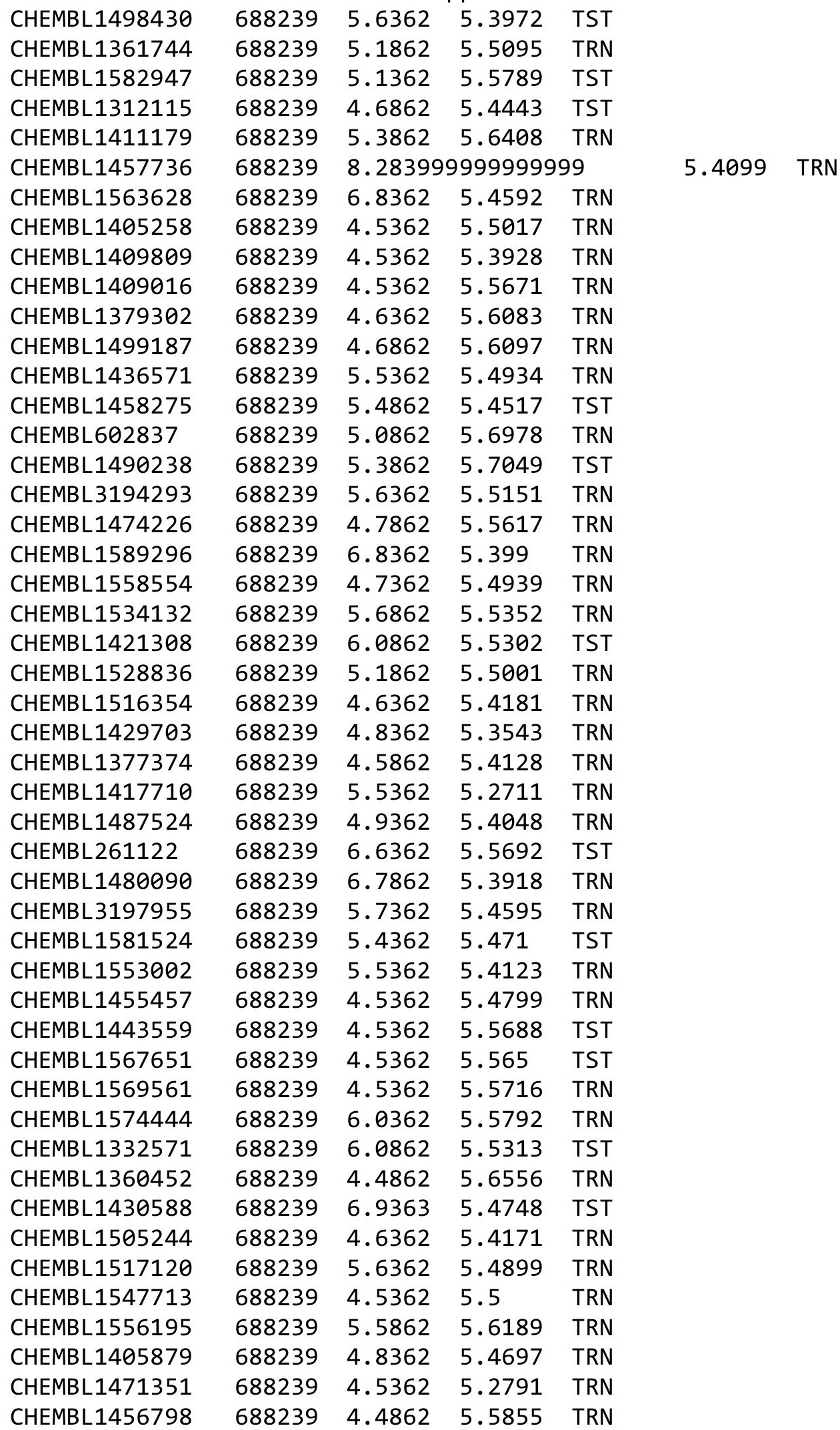


Supplemental Table S2.txt

CHEMBL1361279
CHEMBL1401081
CHEMBL3214601
CHEMBL1436905
CHEMBL1342479
CHEMBL1430211
CHEMBL1506988
CHEMBL1313532

$\begin{array}{rlll}688239 & 5.4362 & 5.4316 & \text { TRN } \\ 688239 & 6.6362 & 5.6023 & \text { TRN } \\ 688239 & 4.5362 & 5.4239999999999995 \\ 688239 & 5.1862 & 5.4408 & \text { TRN } \\ 688239 & 8.1871 & 5.455 & \text { TST } \\ 688239 & 5.2862 & 5.6299 & \text { TRN } \\ 688239 & 5.3362 & 5.4111 & \text { TRN } \\ 688239 & 5.8362 & 5.5235 & \text { TRN } \\ 688239 & 5.1862 & 5.5504 & \text { TRN } \\ 688239 & 7.1361 & 5.4098 & \text { TRN } \\ 688239 & 6.7361 & 5.4639 & \text { TST } \\ 688239 & 4.6862 & 5.3724 & \text { TST } \\ 688239 & 6.1862 & 5.4806 & \text { TRN } \\ 688239 & 8.1871 & 5.6404 & \text { TST } \\ 688239 & 6.9863 & 5.5013 & \text { TRN } \\ 688239 & 5.7362 & 5.5461 & \text { TRN } \\ 688239 & 4.6362 & 5.3747 & \text { TRN } \\ 688239 & 4.5362 & 5.6092 & \text { TRN } \\ 688239 & 4.4862 & 5.4236 & \text { TRN } \\ 688239 & 4.5362 & 5.5246 & \text { TRN } \\ 688239 & 5.0862 & 5.4307 & \text { TRN } \\ 688239 & 4.4862 & 5.3936 & \text { TST } \\ 688239 & 4.6362 & 5.2683 & \text { TRN } \\ 688239 & 6.0362 & 5.4716 & \text { TST } \\ 688239 & 4.5362 & 5.5078 & \text { TRN } \\ 688239 & 5.6862 & 5.4919 & \text { TST } \\ 688239 & 5.1862 & 5.5938 & \text { TRN } \\ 688239 & 6.1862 & 5.465 & \text { TST } \\ 688239 & 4.7362 & 5.3944 & \text { TRN } \\ 688239 & 5.0862 & 5.4273 & \text { TST } \\ 688239 & 5.3862 & 5.5972 & \text { TST } \\ 688239 & 6.6861 & 5.5017 & \text { TRN } \\ 688239 & 4.9862 & 5.3801 & \text { TRN } \\ 688239 & 5.1862 & 5.5828 & \text { TST } \\ 688239 & 5.0862 & 5.4626 & \text { TST } \\ 688239 & 5.6862 & 5.4941 & \text { TRN } \\ 688239 & 4.5362 & 5.4347 & \text { TRN } \\ 688239 & 5.6862 & 5.4751 & \text { TRN } \\ 688239 & 5.1862 & 5.5604 & \text { TST } \\ 688239 & 6.5862 & 5.4812 & \text { TRN } \\ 688239 & 5.1862 & 5.3938 & \text { TST } \\ 688239 & 4.5362 & 5.5861 & \text { TRN } \\ 688239 & 4.5362 & 5.3765 & \text { TRN } \\ 688239 & 4.5362 & 5.3906 & \text { TRN } \\ 688239 & 6.4862 & 5.5843 & \text { TRN } \\ 688239 & 5.3362 & 5.3925 & \text { TRN } \\ 688239 & 4.8862 & 5.4308 & \text { TRN } \\ & 4.5362 & 5.5442 & \text { TRN } \\ & & & \text { Page } 2638 \\ 6 & & & \end{array}$




\begin{tabular}{|c|c|c|c|c|c|c|}
\hline & & \multicolumn{5}{|c|}{ Supplemental Table S2.txt } \\
\hline CHEMBL1493415 & 688239 & 6.8861 & 5.52 & TST & & \\
\hline CHEMBL1441735 & 688239 & 5.5362 & 5.5373 & TRN & & \\
\hline CHEMBL1352091 & 688239 & 4.5362 & 5.428 & TRN & & \\
\hline CHEMBL3195880 & 688239 & 5.0862 & 5.4272 & TRN & & \\
\hline CHEMBL 1404130 & 688239 & 5.1362 & 5.3264 & TST & & \\
\hline CHEMBL1344692 & 688239 & 6.1362 & 5.6516 & TRN & & \\
\hline CHEMBL1477741 & 688239 & 4.8362 & 5.4829 & TRN & & \\
\hline CHEMBL1596727 & 688239 & 6.9863 & 5.642 & TRN & & \\
\hline CHEMBL1482628 & 688239 & 4.5862 & 5.5719 & TRN & & \\
\hline CHEMBL1302058 & 688239 & \multicolumn{3}{|c|}{8.283999999999999} & 5.5198 & TST \\
\hline CHEMBL1360940 & 688239 & 4.5362 & 5.4852 & TRN & & \\
\hline CHEMBL1489331 & 688239 & 6.1862 & 5.5686 & TRN & & \\
\hline CHEMBL1319018 & 688239 & 4.7362 & 5.3324 & TRN & & \\
\hline CHEMBL1336165 & 688239 & 5.2362 & 5.5786 & TRN & & \\
\hline CHEMBL1525598 & 688239 & 4.5362 & 5.4533 & TRN & & \\
\hline CHEMBL1492337 & 688239 & 4.7362 & 5.3741 & TRN & & \\
\hline CHEMBL1303795 & 688239 & 4.5362 & 5.5517 & TRN & & \\
\hline CHEMBL 3189541 & 688239 & 4.6362 & 5.3221 & TRN & & \\
\hline CHEMBL1490398 & 688239 & 5.1862 & 5.5649 & TRN & & \\
\hline CHEMBL1415682 & 688239 & 5.1862 & 5.52 & TRN & & \\
\hline CHEMBL1502000 & 688239 & 4.4862 & 5.3197 & TRN & & \\
\hline CHEMBL1383466 & 688239 & 6.8362 & 5.4028 & TRN & & \\
\hline CHEMBL1389685 & 688239 & 5.7862 & 5.3498 & TRN & & \\
\hline CHEMBL1488444 & 688239 & 4.5362 & 5.5094 & TRN & & \\
\hline CHEMBL1320351 & 688239 & 6.8362 & 5.4612 & TST & & \\
\hline CHEMBL1361353 & 688239 & 4.7362 & 5.4798 & TRN & & \\
\hline CHEMBL1436579 & 688239 & 4.4862 & 5.4091 & TRN & & \\
\hline CHEMBL1401848 & 688239 & \multicolumn{3}{|c|}{8.283999999999999} & 5.5758 & TST \\
\hline CHEMBL1324222 & 688239 & 5.9862 & 5.4303 & TST & & \\
\hline CHEMBL1324084 & 688239 & 5.5862 & 5.5924 & TRN & & \\
\hline CHEMBL1333954 & 688239 & 6.3863 & 5.5428 & TRN & & \\
\hline CHEMBL1378319 & 688239 & 4.5362 & 5.5057 & TRN & & \\
\hline CHEMBL3196069 & 688239 & 8.3872 & 5.4895 & TRN & & \\
\hline CHEMBL1495503 & 688239 & 5.1362 & 5.331 & TRN & & \\
\hline CHEMBL1382187 & 688239 & 5.4362 & 5.4584 & TRN & & \\
\hline CHEMBL1587422 & 688239 & 5.1862 & 5.4605 & TST & & \\
\hline CHEMBL1379253 & 688239 & 6.1862 & 5.671 & TST & & \\
\hline CHEMBL1598807 & 688239 & 4.5362 & 5.53 & TRN & & \\
\hline CHEMBL1481629 & 688239 & 4.6862 & 5.4318 & TRN & & \\
\hline CHEMBL1362976 & 688239 & 5.7862 & 5.5357 & TRN & & \\
\hline CHEMBL1537651 & 688239 & 5.3862 & 5.5706 & TRN & & \\
\hline CHEMBL 1382772 & 688239 & 4.5362 & 5.5367 & TRN & & \\
\hline CHEMBL1569323 & 688239 & 4.5362 & 5.5749 & TRN & & \\
\hline CHEMBL 1356076 & 688239 & 6.1362 & 5.4557 & TST & & \\
\hline CHEMBL1423351 & 688239 & 5.1862 & 5.4292 & TST & & \\
\hline CHEMBL1404414 & 688239 & 4.5362 & 5.5019 & TRN & & \\
\hline CHEMBL1502792 & 688239 & 5.0862 & 5.5419 & TRN & & \\
\hline CHEMBL1319512 & 688239 & 6.0862 & 5.6137 & TRN & & \\
\hline
\end{tabular}


Supplemental Table S2.txt

\begin{tabular}{|c|c|c|c|c|}
\hline CHEMBL1482144 & 688239 & 4.6362 & 5.6009 & TRN \\
\hline CHEMBL1306552 & 688239 & 5.0862 & 5.3642 & TRN \\
\hline CHEMBL 2007178 & 688239 & 5.3862 & 5.4062 & TST \\
\hline CHEMBL1479745 & 688239 & 4.7362 & 5.5134 & TRN \\
\hline CHEMBL1401454 & 688239 & 6.3362 & 5.5686 & TST \\
\hline CHEMBL1446383 & 688239 & 6.9863 & 5.4802 & TRN \\
\hline CHEMBL1481237 & 688239 & 5.0862 & 5.6517 & TRN \\
\hline CHEMBL1474605 & 688239 & 5.1862 & 5.6297 & TRN \\
\hline CHEMBL1461823 & 688239 & 4.6862 & 5.3401 & TRN \\
\hline CHEMBL1605499 & 688239 & 6.9363 & 5.5315 & TRN \\
\hline CHEMBL1400002 & 688239 & 5.6362 & 5.5145 & TRN \\
\hline CHEMBL1373162 & 688239 & 5.1362 & 5.4032 & TRN \\
\hline CHEMBL1522923 & 688239 & 6.2362 & 5.5297 & TRN \\
\hline CHEMBL1464272 & 688239 & 4.4862 & 5.5551 & TST \\
\hline CHEMBL1538295 & 688239 & 4.5362 & 5.5069 & TRN \\
\hline CHEMBL1536818 & 688239 & 5.0362 & 5.4723 & TRN \\
\hline CHEMBL1451327 & 688239 & 5.0862 & 5.4429 & TST \\
\hline CHEMBL1521653 & 688239 & 5.1862 & 5.5238 & TRN \\
\hline CHEMBL1545559 & 688239 & 4.5362 & 5.5786 & TRN \\
\hline CHEMBL1566540 & 688239 & 6.7862 & 5.4072 & TRN \\
\hline CHEMBL3198306 & 688239 & 5.7862 & 5.4824 & TST \\
\hline CHEMBL1411890 & 688239 & 4.6862 & 5.3844 & TRN \\
\hline CHEMBL1558504 & 688239 & 4.7362 & 5.4212 & TRN \\
\hline CHEMBL1309224 & 688239 & 4.5362 & 5.5265 & TRN \\
\hline CHEMBL1438714 & 688239 & 5.9362 & 5.4747 & TRN \\
\hline CHEMBL1561190 & 688239 & 4.8862 & 5.4314 & TRN \\
\hline CHEMBL1583974 & 688239 & 5.2362 & 5.5014 & TRN \\
\hline CHEMBL1543358 & 688239 & 4.7862 & 5.3658 & TST \\
\hline CHEMBL1425492 & 688239 & 4.6362 & 5.4486 & TST \\
\hline CHEMBL1453166 & 688239 & 4.8362 & 5.4441 & TRN \\
\hline CHEMBL1342133 & 688239 & 4.9862 & 5.525 & TRN \\
\hline CHEMBL388979 & 688239 & 5.3862 & 5.4608 & TRN \\
\hline CHEMBL1523004 & 688239 & 5.2362 & $5.32100 t$ & 0000000001 \\
\hline CHEMBL1476378 & 688239 & 5.7862 & 5.4607 & TRN \\
\hline CHEMBL1582973 & 688239 & 7.1361 & 5.5711 & TRN \\
\hline CHEMBL1426906 & 688239 & 4.7362 & 5.5183 & TRN \\
\hline CHEMBL1301459 & 688239 & 5.3862 & 5.4152 & TRN \\
\hline CHEMBL1458264 & 688239 & 6.5862 & 5.4486 & TRN \\
\hline CHEMBL1565756 & 688239 & 5.0362 & 5.4539 & TRN \\
\hline CHEMBL1601260 & 688239 & 4.9862 & 5.4571 & TRN \\
\hline CHEMBL1415958 & 688239 & 4.5362 & 5.5067 & TRN \\
\hline CHEMBL1317218 & 688239 & 5.0362 & 5.4679 & TRN \\
\hline CHEMBL1486370 & 688239 & 4.5362 & 5.4133 & TRN \\
\hline CHEMBL1419691 & 688239 & 5.8862 & 5.4117 & TST \\
\hline CHEMBL1431153 & 688239 & 5.8862 & 5.4862 & TST \\
\hline CHEMBL1592156 & 688239 & 5.4362 & 5.5257 & TRN \\
\hline CHEMBL1480112 & 688239 & 5.4862 & 5.3672 & TRN \\
\hline CHEMBL1581264 & 688239 & 5.9362 & 5.4269 & TRN \\
\hline
\end{tabular}




\begin{tabular}{|c|c|c|c|c|}
\hline & & & pplement & al $\mathrm{T}$ \\
\hline CHEMBL1609250 & 688239 & 8.2366 & 5.3479 & TRN \\
\hline CHEMBL1403300 & 688239 & 6.1862 & 5.5098 & TRN \\
\hline CHEMBL1609563 & 688239 & 5.5362 & 5.6079 & TRN \\
\hline CHEMBL1485712 & 688239 & 5.0862 & 5.4672 & TRN \\
\hline CHEMBL1607657 & 688239 & 5.8862 & 5.4285 & TRN \\
\hline CHEMBL1468726 & 688239 & 6.2362 & 5.5781 & TST \\
\hline CHEMBL1401623 & 688239 & 5.1862 & 5.4925 & TRN \\
\hline CHEMBL1394085 & 688239 & 6.1862 & 5.5693 & TRN \\
\hline CHEMBL1442070 & 688239 & 5.7862 & 5.5399 & TST \\
\hline CHEMBL1346662 & 688239 & 4.6362 & 5.3072 & TRN \\
\hline CHEMBL1538120 & 688239 & 5.8862 & 5.4948 & TRN \\
\hline CHEMBL1548255 & 688239 & 4.8362 & 5.4312 & TST \\
\hline CHEMBL1388540 & 688239 & 5.1862 & 5.5749 & TRN \\
\hline CHEMBL1425601 & 688239 & 4.5362 & 5.5232 & TRN \\
\hline CHEMBL1342963 & 688239 & 4.5362 & 5.4272 & TRN \\
\hline CHEMBL1476453 & 688239 & 5.6362 & 5.5092 & TRN \\
\hline CHEMBL1534170 & 688239 & 6.2362 & 5.4686 & TST \\
\hline CHEMBL1484974 & 688239 & 6.2362 & 5.5074 & TRN \\
\hline CHEMBL1520794 & 688239 & 4.4862 & 5.4524 & TRN \\
\hline CHEMBL1389861 & 688239 & 4.4862 & 5.5597 & TRN \\
\hline CHEMBL1581323 & 688239 & 4.7362 & 5.5265 & TRN \\
\hline CHEMBL1608682 & 688239 & 5.2862 & 5.3855 & TRN \\
\hline CHEMBL3212923 & 688239 & 7.9872 & 5.4942 & TST \\
\hline CHEMBL 2005895 & 688239 & 4.7362 & 5.4695 & TRN \\
\hline CHEMBL1509710 & 688239 & 7.0862 & 5.5201 & TRN \\
\hline CHEMBL1335707 & 688239 & 4.6862 & 5.4574 & TRN \\
\hline CHEMBL1478358 & 688239 & 5.6362 & 5.5437 & TRN \\
\hline CHEMBL1386334 & 688239 & 8.3372 & 5.5499 & TRN \\
\hline CHEMBL1536360 & 688239 & 6.2362 & 5.4577 & TRN \\
\hline CHEMBL1508937 & 688239 & 6.8861 & 5.4609 & TRN \\
\hline CHEMBL1344199 & 688239 & 5.1862 & 5.4596 & TRN \\
\hline CHEMBL1570287 & 688239 & 5.1862 & 5.5869 & TRN \\
\hline CHEMBL1440871 & 688239 & 6.1362 & 5.4961 & TRN \\
\hline CHEMBL1530443 & 688239 & 4.5862 & 5.5507 & TRN \\
\hline CHEMBL1430668 & 688239 & 4.7362 & 5.5161 & TST \\
\hline CHEMBL1423895 & 688239 & 6.8861 & 5.4711 & TRN \\
\hline CHEMBL1549738 & 688239 & 4.5362 & 5.4541 & TST \\
\hline CHEMBL1388476 & 688239 & 4.5362 & 5.5251 & TRN \\
\hline CHEMBL3191724 & 688239 & 5.7862 & 5.3222 & TRN \\
\hline CHEMBL1588416 & 688239 & 4.8862 & 5.6789 & TRN \\
\hline CHEMBL1370507 & 688239 & 6.2862 & 5.5093 & TRN \\
\hline CHEMBL1331274 & 688239 & 5.3862 & 5.4419 & TRN \\
\hline CHEMBL1343961 & 688239 & 6.8861 & 5.5436 & TRN \\
\hline CHEMBL1365941 & 688239 & 5.8862 & 5.626 & TRN \\
\hline CHEMBL1505142 & 688239 & 4.5362 & 5.4015 & TST \\
\hline CHEMBL1376855 & 688239 & 5.8362 & 5.4827 & TRN \\
\hline CHEMBL1608571 & 688239 & 5.7362 & 5.4257 & TRN \\
\hline CHEMBL1412728 & 688239 & 4.5362 & 5.6518 & TRN \\
\hline
\end{tabular}


Supplemental Table S2.txt

\begin{tabular}{|c|c|c|c|c|c|}
\hline CHEMBL1390033 & 688239 & 4.5362 & 5.516 & TRN & \\
\hline CHEMBL1602852 & 688239 & 6.5862 & 5.5179 & TRN & \\
\hline CHEMBL1609608 & 688239 & 5.1862 & 5.7143 & TRN & \\
\hline CHEMBL1550469 & 688239 & 4.4862 & 5.3858 & TST & \\
\hline CHEMBL3191951 & 688239 & 4.4862 & 5.455 & TRN & \\
\hline CHEMBL1337774 & 688239 & 5.8362 & 5.4615 & TRN & \\
\hline CHEMBL1502862 & 688239 & 4.5362 & 5.3802 & TRN & \\
\hline CHEMBL1332405 & 688239 & 5.8862 & 5.6401 & TRN & \\
\hline CHEMBL1334144 & 688239 & 5.1862 & 5.4675 & TRN & \\
\hline CHEMBL1447722 & 688239 & 4.5362 & 5.4882 & TRN & \\
\hline CHEMBL1582424 & 688239 & 6.2862 & 5.6334 & TRN & \\
\hline CHEMBL1474894 & 688239 & 4.5362 & 5.478 & TRN & \\
\hline CHEMBL1305642 & 688239 & 4.6862 & 5.3662 & TRN & \\
\hline CHEMBL1495535 & 688239 & 4.5862 & 5.5264 & TRN & \\
\hline CHEMBL1412025 & 688239 & 4.8862 & 5.4716 & TRN & \\
\hline CHEMBL1360895 & 688239 & 6.8861 & 5.5654 & TRN & \\
\hline CHEMBL1525604 & 688239 & 4.7862 & 5.5281 & TRN & \\
\hline CHEMBL1460435 & 688239 & 4.8862 & 5.4101 & TRN & \\
\hline CHEMBL1331572 & 688239 & 5.6362 & 5.6075 & TRN & \\
\hline CHEMBL1449028 & 688239 & 6.3362 & 5.5162 & TST & \\
\hline CHEMBL1581407 & 688239 & 4.5362 & 5.33200 & 2000000001 & TRN \\
\hline CHEMBL2269362 & 688239 & 5.2362 & 5.5481 & TST & \\
\hline CHEMBL1493996 & 688239 & 4.5362 & 5.4309 & TRN & \\
\hline CHEMBL1355253 & 688239 & 4.5362 & 5.401 & TRN & \\
\hline CHEMBL1345756 & 688239 & 4.7362 & 5.5144 & TRN & \\
\hline CHEMBL1495533 & 688239 & 4.7362 & 5.565 & TRN & \\
\hline CHEMBL1446263 & 688239 & 6.9863 & 5.6888 & TST & \\
\hline CHEMBL1605464 & 688239 & 4.5362 & 5.4474 & TRN & \\
\hline CHEMBL1537366 & 688239 & 4.5362 & 5.4963 & TRN & \\
\hline CHEMBL1388799 & 688239 & 4.6362 & 5.5415 & TRN & \\
\hline CHEMBL1321122 & 688239 & 5.3862 & 5.3944 & TST & \\
\hline CHEMBL1538934 & 688239 & 5.7862 & 5.5702 & TST & \\
\hline CHEMBL1484508 & 688239 & 5.6862 & 5.5112 & TST & \\
\hline CHEMBL1302020 & 688239 & 6.8861 & 5.4147 & TRN & \\
\hline CHEMBL1350577 & 688239 & 4.5362 & 5.4984 & TRN & \\
\hline CHEMBL1586139 & 688239 & 4.4862 & 5.2931 & TST & \\
\hline CHEMBL1457778 & 688239 & 4.5362 & 5.5344 & TRN & \\
\hline CHEMBL1475096 & 688239 & 4.4862 & 5.4933 & TRN & \\
\hline CHEMBL1513721 & 688239 & 4.9362 & 5.6094 & TST & \\
\hline CHEMBL 177122 & 688239 & 6.1362 & 5.5113 & TST & \\
\hline CHEMBL3209596 & 688239 & 5.4362 & 5.4615 & TST & \\
\hline CHEMBL1449582 & 688239 & 4.6862 & 5.5352 & TRN & \\
\hline CHEMBL1349610 & 688239 & 5.7862 & 5.4612 & TST & \\
\hline CHEMBL1369487 & 688239 & 6.6861 & 5.4283 & TRN & \\
\hline CHEMBL1556049 & 688239 & 4.5362 & 5.3463 & TRN & \\
\hline CHEMBL1332602 & 688239 & 5.2362 & 5.50299 & 9999999999 & TRN \\
\hline CHEMBL1563693 & 688239 & 4.8862 & 5.4945 & TRN & \\
\hline \multirow[t]{2}{*}{ CHEMBL1414971 } & 688239 & 5.5862 & 5.38200 & 2000000001 & TRN \\
\hline & & \multicolumn{4}{|c|}{ Page 2642} \\
\hline
\end{tabular}




\begin{tabular}{|c|c|c|c|c|c|}
\hline & & & & & \\
\hline CHEMBL1501535 & 688239 & 6.7361 & 5.5267 & TRN & \\
\hline CHEMBL1383692 & 688239 & 4.4862 & 5.5691 & TRN & \\
\hline CHEMBL1523061 & 688239 & 4.5362 & 5.6231 & TST & \\
\hline CHEMBL1308525 & 688239 & 6.8362 & 5.5157 & TRN & \\
\hline CHEMBL1438509 & 688239 & 5.0862 & 5.6809 & TRN & \\
\hline CHEMBL1577470 & 688239 & 4.7362 & 5.5475 & TST & \\
\hline CHEMBL1316680 & 688239 & 4.5362 & 5.395 & TST & \\
\hline CHEMBL1575564 & 688239 & 4.7362 & 5.5478 & TRN & \\
\hline CHEMBL1419579 & 688239 & 5.7362 & 5.3967 & TRN & \\
\hline CHEMBL1213606 & 688239 & 4.4862 & 5.6308 & TRN & \\
\hline CHEMBL1482633 & 688239 & 6.7862 & 5.4451 & TST & \\
\hline CHEMBL1514408 & 688239 & 4.8362 & 5.4837 & TRN & \\
\hline CHEMBL1591596 & 688239 & 4.5362 & 5.641 & TRN & \\
\hline CHEMBL1308518 & 688239 & 4.5362 & 5.337006 & 0000000001 & TRN \\
\hline CHEMBL602158 & 688239 & 5.0362 & 5.5981 & TRN & \\
\hline CHEMBL1495692 & 688239 & 6.2362 & 5.4473 & TRN & \\
\hline CHEMBL1360648 & 688239 & 4.7362 & 5.5298 & TRN & \\
\hline CHEMBL1601971 & 688239 & 4.8362 & 5.3847 & TRN & \\
\hline CHEMBL1349369 & 688239 & 4.8362 & 5.5772 & TST & \\
\hline CHEMBL1372766 & 688239 & 6.8861 & 5.4261 & TRN & \\
\hline CHEMBL1496015 & 688239 & 5.6362 & 5.6571 & TRN & \\
\hline CHEMBL1384319 & 688239 & 7.0362 & 5.7126 & TRN & \\
\hline CHEMBL1314896 & 688239 & 6.6861 & 5.5903 & TRN & \\
\hline CHEMBL1489889 & 688239 & 5.5362 & 5.7099 & TRN & \\
\hline CHEMBL1419652 & 688239 & 4.5362 & 5.4345 & TRN & \\
\hline CHEMBL1324017 & 688239 & 4.6362 & 5.511 & TRN & \\
\hline CHEMBL1539066 & 688239 & 6.0362 & 5.3631 & TRN & \\
\hline CHEMBL3211016 & 688239 & 6.6362 & 5.4418 & TST & \\
\hline CHEMBL1301700 & 688239 & 4.9362 & 5.49299 & 9999999999 & TRN \\
\hline CHEMBL1320718 & 688239 & 4.5362 & 5.5677 & TRN & \\
\hline CHEMBL1328076 & 688239 & 5.8862 & 5.4916 & TRN & \\
\hline CHEMBL1450942 & 688239 & 4.7862 & 5.331 & TST & \\
\hline CHEMBL1354200 & 688239 & 4.6862 & 5.465 & TST & \\
\hline CHEMBL3211642 & 688239 & 8.283999 & 99999999 & 5.4702 & TST \\
\hline CHEMBL1576814 & 688239 & 5.4862 & 5.4567 & TST & \\
\hline CHEMBL1489063 & 688239 & 6.1362 & 5.5542 & TRN & \\
\hline CHEMBL1547336 & 688239 & 5.1862 & 5.5204 & TRN & \\
\hline CHEMBL1600772 & 688239 & 4.5362 & 5.5324 & TST & \\
\hline CHEMBL3198479 & 688239 & 6.0862 & 5.46899 & 9999999999 & TRN \\
\hline CHEMBL1392114 & 688239 & 5.4862 & 5.558 & TRN & \\
\hline CHEMBL1449882 & 688239 & 5.0862 & 5.4581 & TRN & \\
\hline CHEMBL1517702 & 688239 & 8.3372 & 5.4415 & TRN & \\
\hline CHEMBL1565554 & 688239 & 5.2862 & 5.303 & TRN & \\
\hline CHEMBL1588157 & 688239 & 5.7862 & 5.4339 & TRN & \\
\hline CHEMBL3191075 & 688239 & 5.5362 & 5.5316 & TRN & \\
\hline CHEMBL1345761 & 688239 & 5.1862 & 5.5795 & TRN & \\
\hline CHEMBL1598396 & 688239 & 8.3372 & 5.5321 & TRN & \\
\hline CHEMBL1493470 & 688239 & 5.1362 & 5.5243 & TST & \\
\hline
\end{tabular}


Supplemental Table S2.txt

\begin{tabular}{|c|c|c|c|c|}
\hline CHEMBL1378569 & 688239 & 6.0862 & 5.3932 & TST \\
\hline CHEMBL1500939 & 688239 & 4.6862 & 5.5274 & TRN \\
\hline CHEMBL1483958 & 688239 & 5.2362 & 5.4728 & TRN \\
\hline CHEMBL1982984 & 688239 & 6.8861 & 5.5096 & TRN \\
\hline CHEMBL1325121 & 688239 & 5.1362 & 5.4814 & TRN \\
\hline CHEMBL1333058 & 688239 & 5.6862 & 5.4028 & TST \\
\hline CHEMBL1482517 & 688239 & 4.6362 & 5.5436 & TRN \\
\hline CHEMBL1345889 & 688239 & 5.6362 & 5.3446 & TRN \\
\hline CHEMBL1428596 & 688239 & 5.6862 & 5.494 & TRN \\
\hline CHEMBL1512209 & 688239 & 5.3362 & 5.5142 & TRN \\
\hline CHEMBL1539169 & 688239 & 5.1862 & 5.4606 & TRN \\
\hline CHEMBL1499805 & 688239 & 5.1862 & 5.5478 & TRN \\
\hline CHEMBL1411596 & 688239 & 4.9362 & 5.4369 & TRN \\
\hline CHEMBL1446508 & 688239 & 4.9862 & 5.5046 & TRN \\
\hline CHEMBL1424985 & 688239 & 5.1862 & 5.4718 & TRN \\
\hline CHEMBL1530225 & 688239 & 6.8861 & 5.4545 & TRN \\
\hline CHEMBL1476317 & 688239 & 5.4362 & 5.5613 & TRN \\
\hline CHEMBL1574529 & 688239 & 5.3862 & 5.4653 & TRN \\
\hline CHEMBL1321545 & 688239 & 6.7862 & 5.6527 & TRN \\
\hline CHEMBL1505487 & 688239 & 4.5362 & 5.5299 & TRN \\
\hline CHEMBL1611579 & 688239 & 6.1862 & 5.6005 & TRN \\
\hline CHEMBL1549112 & 688239 & 4.5362 & 5.3423 & TST \\
\hline CHEMBL1524728 & 688239 & 6.4862 & 5.5285 & TRN \\
\hline CHEMBL1344850 & 688239 & 4.4862 & 5.541 & TRN \\
\hline CHEMBL1558411 & 688239 & 5.0862 & 5.4496 & TRN \\
\hline CHEMBL1415592 & 688239 & 4.5362 & 5.3929 & TRN \\
\hline CHEMBL1445751 & 688239 & 4.4862 & 5.6084 & TRN \\
\hline CHEMBL1547352 & 688239 & 4.6362 & 5.4952 & TST \\
\hline CHEMBL1540005 & 688239 & 6.1362 & 5.5206 & TRN \\
\hline CHEMBL1521107 & 688239 & 5.1362 & 5.3119 & TRN \\
\hline CHEMBL1555769 & 688239 & 4.4862 & 5.3985 & TRN \\
\hline CHEMBL1370635 & 688239 & 4.5362 & 5.4567 & TRN \\
\hline CHEMBL1372214 & 688239 & 5.4362 & 5.675 & TRN \\
\hline CHEMBL1516826 & 688239 & 4.6862 & 5.4692 & TRN \\
\hline CHEMBL1303283 & 688239 & 5.6862 & 5.5546 & TST \\
\hline CHEMBL1338274 & 688239 & 6.1862 & 5.6088 & TST \\
\hline CHEMBL1308871 & 688239 & 5.9862 & 5.1549 & TRN \\
\hline CHEMBL1419053 & 688239 & 4.7362 & 5.5334 & TRN \\
\hline CHEMBL1460685 & 688239 & 4.8362 & 5.6407 & TRN \\
\hline CHEMBL1999960 & 688239 & 4.7862 & 5.4593 & TST \\
\hline CHEMBL1479761 & 688239 & 5.6862 & 5.6219 & TRN \\
\hline CHEMBL211481 & 688239 & 4.7862 & 5.4379 & TST \\
\hline CHEMBL1501495 & 688239 & 4.7362 & 5.25799 & 9999999999 \\
\hline CHEMBL1543908 & 688239 & 6.7361 & 5.4442 & TRN \\
\hline CHEMBL1301100 & 688239 & 5.4862 & 5.5079 & TRN \\
\hline CHEMBL1495940 & 688239 & 4.8362 & 5.5298 & TRN \\
\hline CHEMBL1970918 & 688239 & 5.4362 & 5.3687 & TRN \\
\hline CHEMBL1587974 & 688239 & 5.1862 & 5.6003 & TRN \\
\hline
\end{tabular}




\begin{tabular}{|c|c|c|c|c|}
\hline & & & & \\
\hline EMBL1518770 & בנדיסט & 4.7362 & 5.5667 & 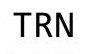 \\
\hline CHEMBL1361880 & 688239 & 5.7362 & & \\
\hline CHEMBL3207374 & 88239 & 1862 & & \\
\hline HEMBL1428663 & 88239 & .1362 & & \\
\hline CHEMBL1332840 & 88239 & 7.2865 & 796 & \\
\hline HEMBL1500390 & 88239 & .2862 & 347 & \\
\hline CHEMBL1406042 & 88239 & 6362 & & \\
\hline HEMBL1611057 & 588239 & 8862 & 37 & \\
\hline HEMBL1372460 & 88239 & 6.5363 & & \\
\hline HEMBL1542107 & 239 & 4.6862 & & \\
\hline HEMBL1 & 39 & 6.1862 & 54 & \\
\hline HEMBL1 & 39 & 4.5362 & & \\
\hline HEMBL1342542 & 688239 & 5.1862 & & \\
\hline CHEMBL1417803 & 39 & 5.2362 & & \\
\hline CHEMBL1 & 68 & 4.5862 & & \\
\hline HEMBL & 39 & 5.2362 & & \\
\hline CHEMBL: & & 6.1362 & & \\
\hline CHEMBL16e & 239 & 6.8861 & & \\
\hline HEMBL14 & 68 & 6.0362 & & \\
\hline CHEMBL1 & 68 & 5.2362 & & \\
\hline HEMBL & 39 & 4.5362 & & \\
\hline CHEMBL 1 & 39 & 862 & & \\
\hline CHEMBL 1 & 68 & 362 & & \\
\hline CHEMBL1 & 68 & 362 & & \\
\hline CHEMBL1 & 68 & 4.5362 & & \\
\hline CHEMBL? & 39 & 8862 & & \\
\hline CHEMBL: & 39 & 862 & & \\
\hline HEMBL: & 68 & 8862 & & \\
\hline CHEMBL1425153 & 688239 & 6.1362 & 68 & \\
\hline CHEMBL14 & 6882 & 5.5862 & & \\
\hline CHEMBL: & 39 & 5.4862 & & \\
\hline CHEMBL: & 68 & 362 & 02 & \\
\hline HEMBL: & & 6.9363 & & $\mathrm{R}$ \\
\hline CHEMBL1994445 & 688239 & 6.6861 & 767 & \\
\hline CHEMBL1 & & 362 & & \\
\hline CHEMBL 1 & 39 & 862 & 28 & \\
\hline CHEMBL: & 68 & 862 & & \\
\hline CHEMBL1358152 & 688239 & 4.6362 & 52 & TR \\
\hline CHEMBL1311382 & 688239 & 4.6862 & & \\
\hline $\mathrm{CH}$ & & 862 & & 15 \\
\hline CHEMBL 1 & $68 \varepsilon$ & 4.7862 & 22 & $D$ \\
\hline CHEMBL 3212244 & 688239 & 6.7862 & 5.4669 & $r R$ \\
\hline CHEMBL1543636 & 688239 & 5.1862 & 834 & $T R$ \\
\hline CHEMBL1 & 688239 & 5.1862 & & TR \\
\hline CHEMBL & & 362 & & $\mathrm{R}$ \\
\hline CHEMBL1347546 & 688239 & 4.5362 & 5.6003 & \\
\hline CHEMBL1568302 & 688239 & 6.1362 & 5.3898 & 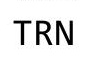 \\
\hline CHEMBL1579504 & 688239 & 5.1362 & 5.4655 & $\mathrm{R}$ \\
\hline
\end{tabular}




\begin{tabular}{|c|c|c|c|c|c|}
\hline \multicolumn{6}{|c|}{ Supplemental Table S2.txt } \\
\hline CHEMBL1301919 & 688239 & 5.4 & 5.63 & TRN & \\
\hline CHEMBL1505338 & 688239 & 6.2362 & 5.4579 & TST & \\
\hline CHEMBL1387290 & 688239 & 6.1362 & 5.4514 & TRN & \\
\hline CHEMBL1538376 & 688239 & 8.2366 & 5.5097 & TRN & \\
\hline CHEMBL1547151 & 688239 & 4.5362 & 5.3957 & TRN & \\
\hline CHEMBL1436001 & 688239 & 4.5362 & 5.3831 & TRN & \\
\hline CHEMBL1319146 & 688239 & 6.1862 & 5.3686 & TRN & \\
\hline CHEMBL1388796 & 688239 & 5.5862 & 5.4455 & TRN & \\
\hline CHEMBL1532773 & 688239 & 4.8362 & 5.2874 & TRN & \\
\hline CHEMBL1559283 & 688239 & 6.8861 & 5.4699 & TRN & \\
\hline CHEMBL1409611 & 688239 & 5.3362 & 5.4186 & TST & \\
\hline CHEMBL1514964 & 688239 & 8.28399 & 99999999 & 5.5492 & TRN \\
\hline CHEMBL1443035 & 688239 & 4.9862 & 5.4697 & TRN & \\
\hline CHEMBL1327313 & 688239 & 5.1862 & 5.5549 & TRN & \\
\hline CHEMBL1306346 & 688239 & 5.7362 & 5.4962 & TRN & \\
\hline CHEMBL1436576 & 688239 & 6.2362 & 5.6535 & TRN & \\
\hline CHEMBL1540730 & 688239 & 4.8862 & 5.2716 & TST & \\
\hline CHEMBL1416603 & 688239 & 5.6862 & 5.4294 & TRN & \\
\hline CHEMBL1584220 & 688239 & 5.1862 & 5.6375 & TRN & \\
\hline CHEMBL1480501 & 688239 & 5.1362 & 5.4876 & TRN & \\
\hline CHEMBL1483158 & 688239 & 8.3872 & 5.527 & TRN & \\
\hline CHEMBL1464418 & 688239 & 4.7362 & 5.7003 & TRN & \\
\hline CHEMBL1378994 & 688239 & 4.5362 & 5.4108 & TRN & \\
\hline CHEMBL1603691 & 688239 & 5.3362 & 5.4906 & TST & \\
\hline CHEMBL1610133 & 688239 & 6.4362 & 5.5732 & TRN & \\
\hline CHEMBL3213739 & 688239 & 5.6362 & 5.4635 & TRN & \\
\hline CHEMBL1312231 & 688239 & 4.7362 & 5.32299 & 99999999995 & TRN \\
\hline CHEMBL1377006 & 688239 & 6.1362 & 5.4773 & TST & \\
\hline CHEMBL1485366 & 688239 & 8.3872 & 5.57 & TRN & \\
\hline CHEMBL1361405 & 688239 & 8.3372 & 5.4749 & TRN & \\
\hline CHEMBL1992715 & 688239 & 7.0362 & 5.4639 & TRN & \\
\hline CHEMBL3197020 & 688239 & 5.5362 & 5.6564 & TRN & \\
\hline CHEMBL1513038 & 688239 & 4.6862 & 5.5242 & TRN & \\
\hline CHEMBL1552669 & 688239 & 5.1862 & 5.58799 & 9999999999 & TST \\
\hline CHEMBL1407577 & 688239 & 4.5862 & 5.6002 & TRN & \\
\hline CHEMBL1361243 & 688239 & 5.1862 & 5.5679 & TRN & \\
\hline CHEMBL1354994 & 688239 & 6.6362 & 5.5074 & TRN & \\
\hline CHEMBL1534662 & 688239 & 5.2862 & 5.4399 & TRN & \\
\hline CHEMBL 3211437 & 688239 & 5.7862 & 5.4208 & TRN & \\
\hline CHEMBL1359214 & 688239 & 4.5362 & 5.37200 & $\partial 000000001$ & TST \\
\hline CHEMBL1448436 & 688239 & 4.7862 & 5.5772 & TRN & \\
\hline CHEMBL1312879 & 688239 & 4.5362 & 5.5526 & TRN & \\
\hline CHEMBL1540929 & 688239 & 4.7862 & 5.3351 & TST & \\
\hline CHEMBL1440188 & 688239 & 4.7862 & 5.5439 & TRN & \\
\hline CHEMBL1316870 & 688239 & 5.0362 & 5.4232 & TRN & \\
\hline CHEMBL1308842 & 688239 & 5.1362 & 5.5163 & TRN & \\
\hline CHEMBL1432976 & 688239 & 5.6862 & 5.5742 & TRN & \\
\hline CHEMBL1416971 & 688239 & 4.9362 & 5.5326 & TRN & \\
\hline
\end{tabular}


Supplemental Table S2.txt

\begin{tabular}{|c|c|c|c|c|c|}
\hline CHEMBL1528058 & 688239 & 4.6862 & 5.6058 & TRN & \\
\hline CHEMBL1583682 & 688239 & 5.5362 & 5.4084 & TST & \\
\hline CHEMBL1306476 & 688239 & 5.7862 & 5.3948 & TST & \\
\hline CHEMBL1355957 & 688239 & 5.5362 & 5.4427 & TST & \\
\hline CHEMBL1360999 & 688239 & 4.6862 & \multicolumn{2}{|c|}{5.5520000000000005} & TST \\
\hline CHEMBL1475957 & 688239 & 4.4862 & 5.3958 & TRN & \\
\hline CHEMBL1336572 & 688239 & 6.1362 & 5.4725 & TRN & \\
\hline CHEMBL1386940 & 688239 & 4.4862 & 5.4329 & TRN & \\
\hline CHEMBL1323828 & 688239 & 5.3862 & 5.4661 & TRN & \\
\hline CHEMBL1315852 & 688239 & 6.7862 & 5.5703 & TRN & \\
\hline CHEMBL1446005 & 688239 & 4.7362 & 5.5696 & TST & \\
\hline CHEMBL1410415 & 688239 & 4.8862 & 5.4821 & TRN & \\
\hline CHEMBL1364293 & 688239 & 6.8861 & 5.4838 & TRN & \\
\hline CHEMBL1343612 & 688239 & 6.7361 & 5.5652 & TRN & \\
\hline CHEMBL1596303 & 688239 & 4.5362 & 5.5605 & TRN & \\
\hline CHEMBL1597121 & 688239 & 4.7362 & 5.5438 & TST & \\
\hline CHEMBL1414438 & 688239 & 4.6362 & 5.5422 & TRN & \\
\hline CHEMBL578928 & 688239 & 4.6862 & 5.3342 & TRN & \\
\hline CHEMBL1577199 & 688239 & 8.2366 & \multicolumn{2}{|c|}{5.577999999999999} & TRN \\
\hline CHEMBL1587259 & 688239 & 4.5362 & 5.5295 & TRN & \\
\hline CHEMBL1337271 & 688239 & 4.4862 & 5.4616 & TRN & \\
\hline CHEMBL51085 & 688239 & 4.6862 & 5.5181 & TST & \\
\hline CHEMBL1393870 & 688239 & 5.4362 & 5.5554 & TST & \\
\hline CHEMBL1458720 & 688239 & 4.6862 & 5.5891 & TRN & \\
\hline CHEMBL1431000 & 688239 & 6.7361 & 5.535 & TRN & \\
\hline CHEMBL1467500 & 688239 & 6.9363 & 5.553 & TST & \\
\hline CHEMBL1467538 & 688239 & 4.5362 & 5.391 & TST & \\
\hline CHEMBL1329640 & 688239 & 5.1362 & 5.2989 & TRN & \\
\hline CHEMBL1313479 & 688239 & 4.7362 & 5.496 & TRN & \\
\hline CHEMBL1557519 & 688239 & 4.7862 & 5.5707 & TST & \\
\hline CHEMBL1454828 & 688239 & 5.3362 & 5.4629 & TRN & \\
\hline CHEMBL1387776 & 688239 & 4.6362 & 5.511 & TRN & \\
\hline CHEMBL1471898 & 688239 & 4.9362 & 5.4606 & TST & \\
\hline CHEMBL1516268 & 688239 & 5.0362 & \multicolumn{2}{|c|}{5.367999999999999} & TRN \\
\hline CHEMBL1383217 & 688239 & 5.1862 & 5.5039 & TRN & \\
\hline CHEMBL1569060 & 688239 & 4.5362 & 5.4803 & TRN & \\
\hline CHEMBL 3197288 & 688239 & 4.5362 & 5.3293 & TRN & \\
\hline CHEMBL1323455 & 688239 & 5.1862 & 5.445 & TRN & \\
\hline CHEMBL1386769 & 688239 & 4.7862 & \multicolumn{2}{|c|}{5.372000000000001} & TRN \\
\hline CHEMBL1526679 & 688239 & 6.8362 & 5.495 & TRN & \\
\hline CHEMBL1425329 & 688239 & 4.6362 & \multicolumn{2}{|c|}{5.5329999999999995} & TRN \\
\hline CHEMBL3197970 & 688239 & 4.4862 & 5.4265 & TRN & \\
\hline CHEMBL1992104 & 688239 & 5.1862 & 5.4595 & TRN & \\
\hline CHEMBL 3211690 & 688239 & 5.1862 & 5.6708 & TRN & \\
\hline CHEMBL3214626 & 688239 & \multicolumn{3}{|c|}{8.283999999999999} & TRN \\
\hline CHEMBL1540642 & 688239 & 4.8362 & 5.4944 & TST & \\
\hline CHEMBL1503407 & 688239 & 5.7862 & 5.6905 & TRN & \\
\hline CHEMBL1318047 & 688239 & 5.1862 & 5.5156 & TRN & \\
\hline
\end{tabular}


Supplemental Table S2.txt

\begin{tabular}{|c|c|c|c|c|}
\hline CHEMBL1321455 & 688239 & 6.0862 & 5.407 & TRN \\
\hline CHEMBL1357136 & 688239 & 5.2362 & 5.4919 & TRN \\
\hline CHEMBL1333170 & 688239 & 6.1862 & 5.4887 & TRN \\
\hline CHEMBL1348081 & 688239 & 4.6862 & 5.5362 & TRN \\
\hline CHEMBL1454592 & 688239 & 5.1862 & \multicolumn{2}{|c|}{5.382999999999999} \\
\hline CHEMBL1522360 & 688239 & 4.5362 & 5.6323 & TRN \\
\hline CHEMBL1385527 & 688239 & 5.6362 & 5.4454 & TRN \\
\hline CHEMBL1460816 & 688239 & 4.7362 & 5.6059 & TRN \\
\hline CHEMBL1558020 & 688239 & 4.8362 & 5.4034 & TRN \\
\hline CHEMBL1468661 & 688239 & 4.7862 & 5.4362 & TST \\
\hline CHEMBL1420915 & 688239 & 5.1862 & 5.465 & TRN \\
\hline CHEMBL1464309 & 688239 & 5.1862 & 5.4605 & TST \\
\hline CHEMBL1388753 & 688239 & 4.5362 & 5.3868 & TRN \\
\hline CHEMBL1563360 & 688239 & 4.8862 & 5.6476 & TRN \\
\hline CHEMBL1547457 & 688239 & 5.3362 & 5.4841 & TRN \\
\hline CHEMBL1434113 & 688239 & 4.5362 & 5.4794 & TRN \\
\hline CHEMBL1477636 & 688239 & 5.4362 & 5.3332 & TRN \\
\hline CHEMBL1333876 & 688239 & 4.6862 & 5.3561 & TRN \\
\hline CHEMBL1459178 & 688239 & 5.1862 & 5.48 & TRN \\
\hline CHEMBL1612101 & 688239 & 4.5362 & 5.4524 & TRN \\
\hline CHEMBL1319595 & 688239 & 4.7362 & 5.505 & TST \\
\hline CHEMBL3189458 & 688239 & 5.7362 & 5.3538 & TRN \\
\hline CHEMBL1531696 & 688239 & 4.5362 & 5.2925 & TRN \\
\hline CHEMBL1500747 & 688239 & 6.1362 & 5.476 & TRN \\
\hline CHEMBL1344095 & 688239 & 4.4862 & \multicolumn{2}{|c|}{5.5760000000000005} \\
\hline CHEMBL1344917 & 688239 & 4.5862 & 5.6557 & TRN \\
\hline CHEMBL1374180 & 688239 & 5.0862 & 5.4178 & TRN \\
\hline CHEMBL1600330 & 688239 & 4.7862 & 5.584 & TRN \\
\hline CHEMBL1369799 & 688239 & 4.4862 & 5.4573 & TRN \\
\hline CHEMBL3209837 & 688239 & 5.4362 & 5.5108 & TRN \\
\hline CHEMBL1305493 & 688239 & 6.9363 & 5.4752 & TRN \\
\hline CHEMBL 3210218 & 688239 & 4.5362 & 5.3912 & TRN \\
\hline CHEMBL1545846 & 688239 & 4.9362 & 5.3086 & TST \\
\hline CHEMBL1533539 & 688239 & 5.2362 & 5.5525 & TST \\
\hline CHEMBL1452303 & 688239 & 6.8861 & 5.4257 & TST \\
\hline CHEMBL1341873 & 688239 & 6.3863 & 5.6917 & TRN \\
\hline CHEMBL1084625 & 688239 & 6.0 & 5.4862 & TRN \\
\hline CHEMBL1486183 & 688239 & 4.7362 & 5.4637 & TST \\
\hline CHEMBL1466945 & 688239 & 6.1862 & 5.5623 & TRN \\
\hline CHEMBL1304002 & 688239 & 6.0362 & 5.4296 & TRN \\
\hline CHEMBL1490668 & 688239 & 6.0862 & 5.4202 & TRN \\
\hline CHEMBL1612271 & 688239 & 5.2362 & 5.6025 & TRN \\
\hline CHEMBL1592005 & 688239 & 5.1862 & 5.5286 & TRN \\
\hline CHEMBL1603226 & 688239 & 5.1862 & 5.4547 & TRN \\
\hline CHEMBL1362729 & 688239 & 4.6362 & 5.4643 & TST \\
\hline CHEMBL1518719 & 688239 & 5.3862 & 5.4956 & TRN \\
\hline CHEMBL1420833 & 688239 & 4.4862 & 5.4487 & TRN \\
\hline CHEMBL1370803 & 688239 & 6.0362 & 5.4889 & TST \\
\hline
\end{tabular}


Supplemental Table S2.txt

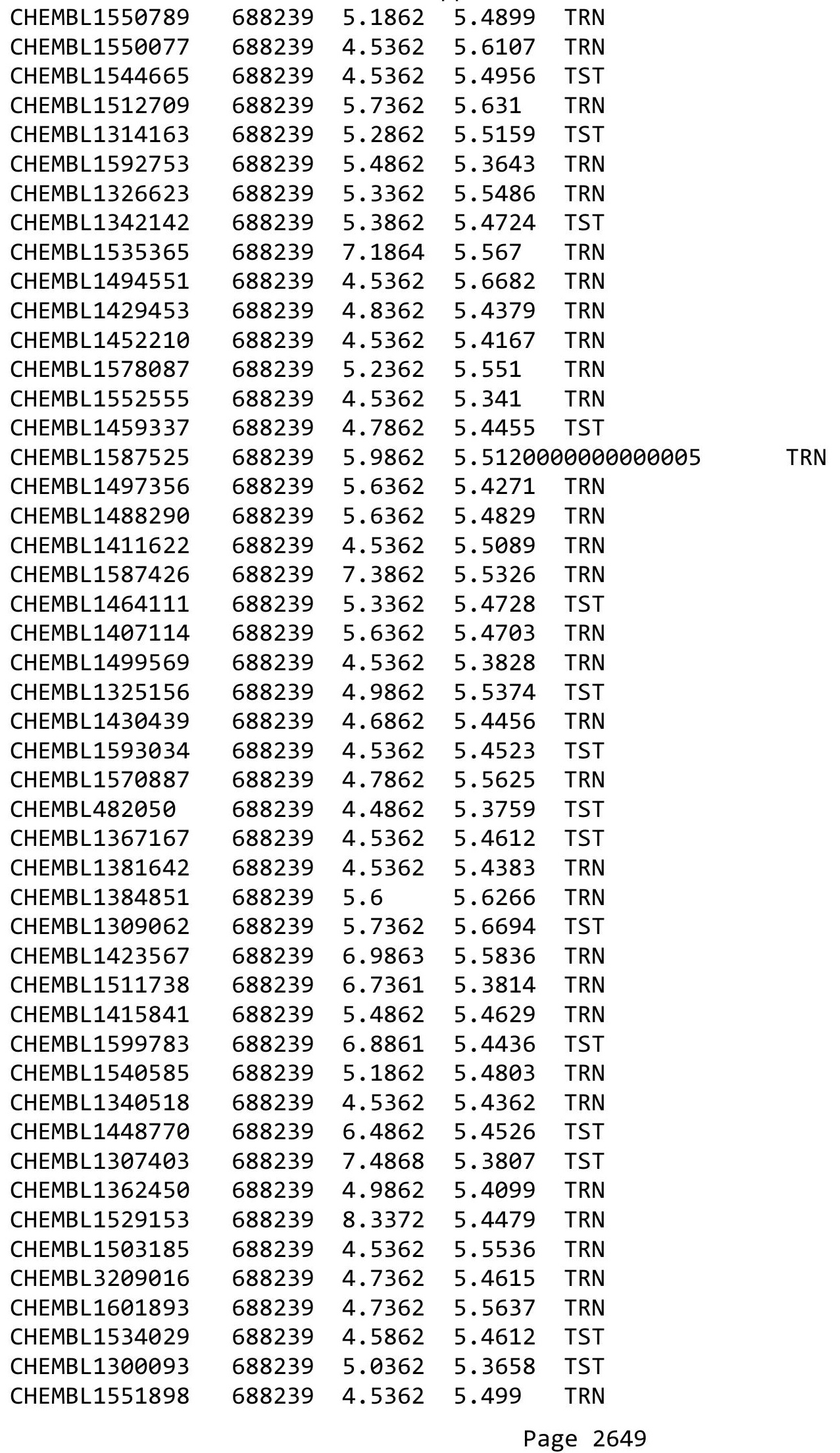


Supplemental Table S2.txt

\begin{tabular}{|c|c|c|c|c|}
\hline CHEMBL1465740 & 688239 & 5.3362 & 5.6898 & TRN \\
\hline CHEMBL1375403 & 688239 & 5.4362 & 5.4526 & TRN \\
\hline CHEMBL1507039 & 688239 & 5.0862 & 5.4396 & TRN \\
\hline CHEMBL1594697 & 688239 & 5.0862 & 5.5709 & TRN \\
\hline CHEMBL1607441 & 688239 & 4.5362 & 5.539 & TRN \\
\hline CHEMBL1550009 & 688239 & 5.7862 & 5.4568 & TST \\
\hline CHEMBL3213124 & 688239 & 6.2362 & 5.472 & TRN \\
\hline CHEMBL1378223 & 688239 & 8.2366 & 5.5656 & TST \\
\hline CHEMBL1538777 & 688239 & 5.5362 & 5.57 & TRN \\
\hline CHEMBL1558996 & 688239 & 5.3862 & 5.4897 & TRN \\
\hline CHEMBL1468496 & 688239 & 5.5862 & 5.5893 & TST \\
\hline CHEMBL1406660 & 688239 & 6.2862 & 5.5944 & TRN \\
\hline CHEMBL1385547 & 688239 & 4.5362 & 5.4816 & TRN \\
\hline CHEMBL1453127 & 688239 & 5.4362 & 5.4402 & TRN \\
\hline CHEMBL1398017 & 688239 & 6.1362 & 5.5159 & TRN \\
\hline CHEMBL1299448 & 688239 & 4.5362 & 5.3246 & TRN \\
\hline CHEMBL1556110 & 688239 & 6.7361 & 5.4772 & TRN \\
\hline CHEMBL1589799 & 688239 & 4.5362 & 5.6392 & TRN \\
\hline CHEMBL1398759 & 688239 & 7.0862 & 5.5278 & TRN \\
\hline CHEMBL1490730 & 688239 & 5.6862 & 5.6293 & TRN \\
\hline CHEMBL1540683 & 688239 & 5.6362 & 5.4301 & TST \\
\hline CHEMBL1403148 & 688239 & 4.6362 & 5.4747 & TRN \\
\hline CHEMBL1320319 & 688239 & 4.6862 & 5.5762 & TST \\
\hline CHEMBL1350252 & 688239 & 6.7862 & 5.3923 & TRN \\
\hline CHEMBL1453809 & 688239 & 4.6862 & 5.5333 & TST \\
\hline CHEMBL1414228 & 688239 & 5.3862 & 5.6378 & TRN \\
\hline CHEMBL1439578 & 688239 & 6.8362 & 5.4568 & TRN \\
\hline CHEMBL1355443 & 688239 & 4.7862 & 5.5605 & TST \\
\hline CHEMBL1604031 & 688239 & 5.3862 & 5.4562 & TRN \\
\hline CHEMBL1367385 & 688239 & 4.5362 & 5.4285 & TST \\
\hline CHEMBL1445163 & 688239 & 4.5362 & 5.4242 & TRN \\
\hline CHEMBL1334962 & 688239 & 4.6862 & 5.4294 & TST \\
\hline CHEMBL1483701 & 688239 & 4.8362 & 5.4657 & TST \\
\hline CHEMBL1484342 & 688239 & 4.9862 & 5.6141 & TRN \\
\hline CHEMBL1397841 & 688239 & 5.2362 & 5.4903 & TRN \\
\hline CHEMBL1412080 & 688239 & 5.1862 & 5.3835 & TRN \\
\hline CHEMBL1412074 & 688239 & 5.4862 & 5.483 & TRN \\
\hline CHEMBL1558717 & 688239 & 6.1362 & 5.6254 & TRN \\
\hline CHEMBL1531331 & 688239 & 5.6362 & 5.5716 & TRN \\
\hline CHEMBL3209943 & 688239 & 5.0862 & 5.4035 & TST \\
\hline CHEMBL1596349 & 688239 & 4.6862 & 5.4735 & TST \\
\hline CHEMBL1402847 & 688239 & 4.8862 & 5.5573 & TRN \\
\hline CHEMBL1543572 & 688239 & 6.2362 & 5.3959 & TRN \\
\hline CHEMBL1379570 & 688239 & 5.9362 & 5.5879 & TRN \\
\hline CHEMBL1422795 & 688239 & 4.7362 & \multicolumn{2}{|c|}{5.627999999999999} \\
\hline CHEMBL1579807 & 688239 & 5.8862 & 5.335 & TST \\
\hline CHEMBL1326483 & 688239 & 4.6862 & 5.5904 & TST \\
\hline CHEMBL1370618 & 688239 & 6.8861 & 5.5804 & TRN \\
\hline
\end{tabular}


Supplemental Table S2.txt

\begin{tabular}{|c|c|c|c|c|c|}
\hline CHEMBL1578674 & 688239 & 4.5362 & 5.5415 & TST & \\
\hline CHEMBL1499066 & 688239 & 4.4862 & 5.4384 & TRN & \\
\hline CHEMBL1434935 & 688239 & 8.3372 & 5.5108 & TRN & \\
\hline CHEMBL3199512 & 688239 & 5.3362 & 5.4002 & TRN & \\
\hline CHEMBL507237 & 688239 & 6.9863 & 5.4452 & TST & \\
\hline CHEMBL1413403 & 688239 & 6.3863 & 5.4925 & TRN & \\
\hline CHEMBL1585373 & 688239 & 6.4362 & 5.468 & TRN & \\
\hline CHEMBL1499427 & 688239 & 4.6862 & 5.5503 & TST & \\
\hline CHEMBL1388040 & 688239 & 4.5362 & 5.3644 & TRN & \\
\hline CHEMBL1511591 & 688239 & 4.9862 & 5.4207 & TRN & \\
\hline CHEMBL1385067 & 688239 & 4.9362 & 5.4032 & TST & \\
\hline CHEMBL 3213468 & 688239 & 5.2862 & 5.6444 & TRN & \\
\hline CHEMBL1409849 & 688239 & 5.1862 & 5.50799 & 9999999999 & TRN \\
\hline CHEMBL1493267 & 688239 & 5.5362 & 5.4873 & TRN & \\
\hline CHEMBL1326209 & 688239 & 6.0862 & 5.7266 & TRN & \\
\hline CHEMBL1485150 & 688239 & 6.2862 & 5.5928 & TRN & \\
\hline CHEMBL1380824 & 688239 & 5.7862 & 5.3574 & TRN & \\
\hline CHEMBL1376930 & 688239 & 4.5362 & 5.434 & TRN & \\
\hline CHEMBL1527524 & 688239 & 5.6362 & 5.5043 & TRN & \\
\hline CHEMBL1566625 & 688239 & 4.5362 & 5.5485 & TRN & \\
\hline CHEMBL1545901 & 688239 & 4.6862 & 5.5138 & TRN & \\
\hline CHEMBL1591948 & 688239 & 4.7862 & 5.5751 & TRN & \\
\hline CHEMBL1487555 & 688239 & 5.1862 & 5.44 & TST & \\
\hline CHEMBL 3193827 & 688239 & 6.2362 & 5.3586 & TRN & \\
\hline CHEMBL1488063 & 688239 & 4.5362 & 5.5176 & TST & \\
\hline CHEMBL1339900 & 688239 & 5.0862 & 5.6076 & TST & \\
\hline CHEMBL1502315 & 688239 & 5.5862 & 5.4688 & TRN & \\
\hline CHEMBL1471526 & 688239 & 4.9362 & 5.5878 & TRN & \\
\hline CHEMBL1342755 & 688239 & 5.1862 & 5.40799 & 99999999995 & TRN \\
\hline CHEMBL1597125 & 688239 & 5.3862 & 5.3303 & TRN & \\
\hline CHEMBL1600632 & 688239 & 5.0362 & 5.557 & TRN & \\
\hline CHEMBL1327957 & 688239 & 5.9862 & 5.4043 & TRN & \\
\hline CHEMBL1348427 & 688239 & 7.1864 & 5.5586 & TRN & \\
\hline CHEMBL1472008 & 688239 & 8.3372 & 5.2333 & TRN & \\
\hline CHEMBL1602734 & 688239 & 5.3362 & 5.4618 & TRN & \\
\hline CHEMBL1555186 & 688239 & 4.5362 & 5.3493 & TRN & \\
\hline CHEMBL1367861 & 688239 & 4.5362 & 5.5643 & TST & \\
\hline CHEMBL1578670 & 688239 & 6.9363 & 5.4031 & TRN & \\
\hline CHEMBL1520658 & 688239 & 6.9363 & 5.4974 & TRN & \\
\hline CHEMBL1353384 & 688239 & 8.3372 & 5.6285 & TRN & \\
\hline CHEMBL1492180 & 688239 & 5.0362 & 5.4869 & TRN & \\
\hline CHEMBL1311135 & 688239 & 4.5362 & 5.4105 & TST & \\
\hline CHEMBL1439358 & 688239 & 4.6862 & 5.5173 & TST & \\
\hline CHEMBL1407295 & 688239 & 5.4362 & 5.3733 & TST & \\
\hline CHEMBL1429074 & 688239 & 6.9363 & 5.4216 & TRN & \\
\hline CHEMBL1327676 & 688239 & 4.7362 & 5.4537 & TST & \\
\hline CHEMBL1373552 & 688239 & 4.7362 & 5.6311 & TRN & \\
\hline CHEMBL1444330 & 688239 & 5.7362 & 5.5298 & TRN & \\
\hline
\end{tabular}


Supplemental Table S2.txt

\begin{tabular}{|c|c|c|c|c|}
\hline CHEMBL1319916 & 688239 & 4.6362 & 5.5514 & TRN \\
\hline CHEMBL1363613 & 688239 & 5.1862 & 5.4908 & TRN \\
\hline CHEMBL1377226 & 688239 & 4.5862 & 5.4565 & TRN \\
\hline CHEMBL1479013 & 688239 & 4.5362 & 5.482 & TRN \\
\hline CHEMBL1345507 & 688239 & 6.2362 & 5.4804 & TRN \\
\hline CHEMBL1381386 & 688239 & 4.7862 & 5.7175 & TRN \\
\hline CHEMBL1442105 & 688239 & 4.7362 & 5.5077 & TST \\
\hline CHEMBL2001396 & 688239 & 4.5862 & 5.4957 & TST \\
\hline CHEMBL1531658 & 688239 & 4.7362 & 5.5207 & TRN \\
\hline CHEMBL1595766 & 688239 & 5.4862 & 5.416 & TRN \\
\hline CHEMBL1473154 & 688239 & 5.1862 & 5.51399 & 9999999999 \\
\hline CHEMBL1444392 & 688239 & 4.5362 & 5.4611 & TRN \\
\hline CHEMBL1309393 & 688239 & 4.7362 & 5.3868 & TRN \\
\hline CHEMBL1587078 & 688239 & 5.5362 & 5.4267 & TST \\
\hline CHEMBL1566722 & 688239 & 5.2362 & 5.42 & TRN \\
\hline CHEMBL1371079 & 688239 & 5.1862 & 5.5207 & TRN \\
\hline CHEMBL538146 & 688239 & 5.9862 & 5.5879 & TST \\
\hline CHEMBL1417992 & 688239 & 7.0362 & 5.6305 & TRN \\
\hline CHEMBL1315275 & 688239 & 5.4362 & 5.4961 & TRN \\
\hline CHEMBL1484598 & 688239 & 7.2366 & 5.4519 & TRN \\
\hline CHEMBL1499162 & 688239 & 8.3372 & 5.3823 & TST \\
\hline CHEMBL1498555 & 688239 & 5.0362 & 5.5265 & TRN \\
\hline CHEMBL1362085 & 688239 & 4.5862 & 5.5274 & TRN \\
\hline CHEMBL1374452 & 688239 & 4.7862 & 5.5981 & TRN \\
\hline CHEMBL1421147 & 688239 & 6.8362 & 5.4781 & TRN \\
\hline CHEMBL1418219 & 688239 & 4.7362 & 5.6551 & TRN \\
\hline CHEMBL1520622 & 688239 & 5.1862 & 5.7207 & TRN \\
\hline CHEMBL1536856 & 688239 & 5.6362 & 5.4872 & TRN \\
\hline CHEMBL1328659 & 688239 & 4.7362 & 5.5197 & TRN \\
\hline CHEMBL1538296 & 688239 & 4.5862 & 5.5469 & TRN \\
\hline CHEMBL1370819 & 688239 & 5.9362 & 5.4698 & TRN \\
\hline CHEMBL1464620 & 688239 & 4.7862 & 5.5656 & TRN \\
\hline CHEMBL1441540 & 688239 & 5.9862 & 5.3923 & TST \\
\hline CHEMBL1567139 & 688239 & 5.3862 & 5.2587 & TRN \\
\hline CHEMBL1304232 & 688239 & 6.0862 & 5.4282 & TRN \\
\hline CHEMBL1372548 & 688239 & 5.8862 & 5.4933 & TST \\
\hline CHEMBL1319939 & 688239 & 5.5362 & 5.3002 & TST \\
\hline CHEMBL8918 & 688239 & 5.6362 & 5.7449 & TRN \\
\hline CHEMBL1319932 & 688239 & 6.2362 & 5.4661 & TRN \\
\hline CHEMBL1606200 & 688239 & 5.2862 & 5.4091 & TRN \\
\hline CHEMBL1416512 & 688239 & 4.5362 & 5.5467 & TST \\
\hline CHEMBL1535225 & 688239 & 5.1862 & 5.443 & TST \\
\hline CHEMBL1533667 & 688239 & 5.7362 & 5.4564 & TST \\
\hline CHEMBL1357446 & 688239 & 4.5862 & 5.4622 & TRN \\
\hline CHEMBL1536120 & 688239 & 6.7862 & 5.6178 & TRN \\
\hline CHEMBL1318683 & 688239 & 4.7862 & \multicolumn{2}{|c|}{5.537999999999999} \\
\hline CHEMBL1339366 & 688239 & 5.1862 & 5.4563 & TST \\
\hline CHEMBL1415597 & 688239 & 5.0862 & 5.4489 & TRN \\
\hline
\end{tabular}


Supplemental Table S2.txt

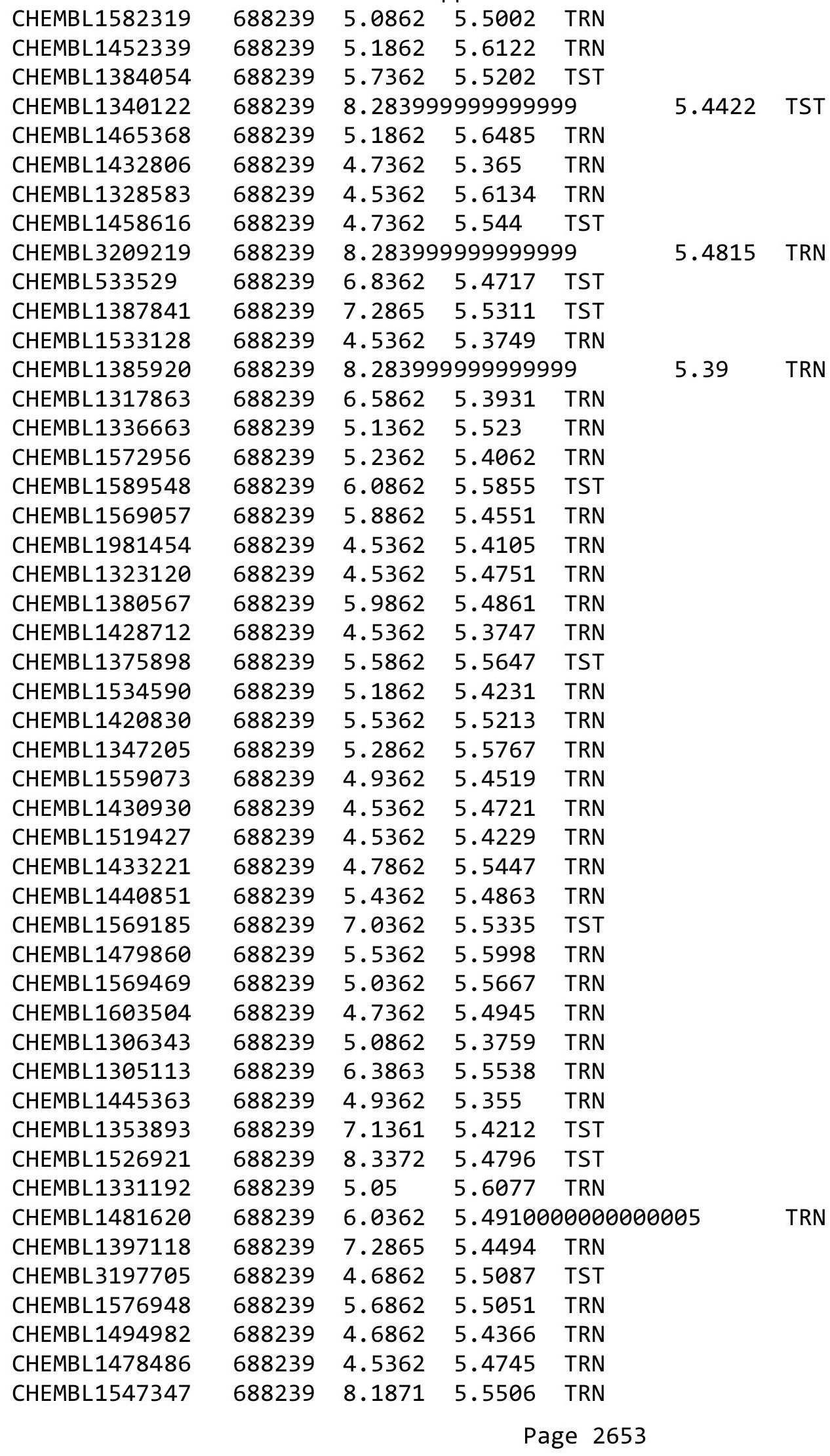




\begin{tabular}{|c|c|c|c|c|c|c|}
\hline & & \multicolumn{5}{|c|}{ Supplemental Table s2.txt } \\
\hline CHEMBL1387338 & 688239 & 6.2362 & 5.61 & TRN & & \\
\hline CHEMBL3191887 & 688239 & 5.7862 & 5.2572 & TRN & & \\
\hline CHEMBL1341977 & 688239 & 6.8362 & 5.6454 & TRN & & \\
\hline CHEMBL1524382 & 688239 & 4.6862 & 5.42 & TRN & & \\
\hline CHEMBL1511497 & 688239 & 4.7362 & 5.4897 & TRN & & \\
\hline CHEMBL1609328 & 688239 & 6.6861 & 5.5413 & TRN & & \\
\hline CHEMBL1304922 & 688239 & 4.5362 & 5.4489 & TRN & & \\
\hline CHEMBL3196708 & 688239 & 5.2362 & 5.5192 & TST & & \\
\hline CHEMBL1431556 & 688239 & 5.1362 & 5.3704 & TRN & & \\
\hline CHEMBL3190261 & 688239 & 4.7362 & 5.2395 & TRN & & \\
\hline CHEMBL1393738 & 688239 & 6.7862 & 5.5413 & TRN & & \\
\hline CHEMBL1517444 & 688239 & 5.1862 & 5.6342 & TRN & & \\
\hline CHEMBL1377992 & 688239 & 5.2862 & 5.4235 & TRN & & \\
\hline CHEMBL1493142 & 688239 & 7.2366 & 5.3458 & TRN & & \\
\hline CHEMBL1502843 & 688239 & 4.5362 & 5.4197 & TRN & & \\
\hline CHEMBL1531208 & 688239 & 8.28399 & 79999999 & 99 & 5.5002 & TRN \\
\hline CHEMBL1327906 & 688239 & 5.6862 & 5.4697 & TRN & & \\
\hline CHEMBL3213575 & 688239 & 5.0362 & 5.4627 & TRN & & \\
\hline CHEMBL1534611 & 688239 & 6.0362 & 5.5226 & TST & & \\
\hline CHEMBL1599714 & 688239 & 4.9862 & 5.4793 & TST & & \\
\hline CHEMBL1451242 & 688239 & 5.1862 & 5.57799 & 999999999 & & TST \\
\hline CHEMBL1596469 & 688239 & 5.5862 & 5.3564 & TRN & & \\
\hline CHEMBL1536860 & 688239 & 4.7362 & 5.4787 & TRN & & \\
\hline CHEMBL1314658 & 688239 & 7.5867 & 5.4963 & TRN & & \\
\hline CHEMBL1443650 & 688239 & 5.1862 & 5.4592 & TRN & & \\
\hline CHEMBL1423762 & 688239 & 4.5362 & 5.5131 & TRN & & \\
\hline CHEMBL1552041 & 688239 & 6.8362 & 5.6431 & TRN & & \\
\hline CHEMBL1382405 & 688239 & 5.2362 & 5.6045 & TRN & & \\
\hline CHEMBL1498339 & 688239 & 4.5362 & 5.7465 & TRN & & \\
\hline CHEMBL1485956 & 688239 & 5.6362 & 5.5002 & TRN & & \\
\hline CHEMBL1450126 & 688239 & 4.5362 & 5.5509 & TRN & & \\
\hline CHEMBL1540960 & 688239 & 4.4862 & 5.4239 & TST & & \\
\hline CHEMBL1469631 & 688239 & 4.5362 & 5.6138 & TRN & & \\
\hline CHEMBL1525417 & 688239 & 5.4862 & 5.5748 & TRN & & \\
\hline CHEMBL1416854 & 688239 & 5.7362 & 5.5593 & TRN & & \\
\hline CHEMBL1431280 & 688239 & 6.1862 & 5.6229 & TRN & & \\
\hline CHEMBL1376724 & 688239 & 4.4862 & 5.6663 & TRN & & \\
\hline CHEMBL1582842 & 688239 & 6.1862 & 5.4306 & TRN & & \\
\hline CHEMBL1461190 & 688239 & 6.1862 & 5.4708 & TST & & \\
\hline CHEMBL1588104 & 688239 & 5.1362 & 5.4418 & TST & & \\
\hline CHEMBL1429962 & 688239 & 8.3372 & 5.5574 & TRN & & \\
\hline CHEMBL 225354 & 688239 & 5.7362 & 5.6594 & TRN & & \\
\hline CHEMBL1333233 & 688239 & 6.3362 & 5.6403 & TRN & & \\
\hline CHEMBL1441425 & 688239 & 6.8861 & 5.4405 & TRN & & \\
\hline CHEMBL1375014 & 688239 & 5.5862 & 5.3856 & TRN & & \\
\hline CHEMBL1397715 & 688239 & 8.2366 & 5.5268 & TRN & & \\
\hline CHEMBL1508019 & 688239 & 8.28399 & 99999999 & 99 & 5.3862 & TST \\
\hline CHEMBL1358942 & 688239 & 6.1362 & 5.5091 & TRN & & \\
\hline
\end{tabular}




\begin{tabular}{|c|c|c|c|c|c|}
\hline \multicolumn{6}{|c|}{ Supplemental Table S2.txt } \\
\hline CHEMBL1381599 & 688239 & 4.95 & 5.4302 & TRN & \\
\hline CHEMBL1479496 & 688239 & 5.1862 & 5.4623 & TRN & \\
\hline CHEMBL1435761 & 688239 & 4.5362 & 5.3986 & TRN & \\
\hline CHEMBL3196119 & 688239 & 5.4362 & 5.482 & TRN & \\
\hline CHEMBL1397486 & 688239 & 6.4862 & 5.4948 & TRN & \\
\hline CHEMBL1387412 & 688239 & 4.7862 & 5.5515 & TRN & \\
\hline CHEMBL1539653 & 688239 & 5.3862 & 5.4369 & TST & \\
\hline CHEMBL1593111 & 688239 & 6.3362 & 5.6274 & TRN & \\
\hline CHEMBL1470367 & 688239 & 4.5362 & 5.4768 & TST & \\
\hline CHEMBL1346469 & 688239 & 7.0862 & 5.6054 & TRN & \\
\hline CHEMBL1502091 & 688239 & 6.8861 & 5.4717 & TRN & \\
\hline CHEMBL1313091 & 688239 & 5.1862 & 5.5134 & TRN & \\
\hline CHEMBL3192199 & 688239 & 6.2362 & 5.3948 & TRN & \\
\hline CHEMBL1315359 & 688239 & 4.5362 & 5.4761 & TRN & \\
\hline CHEMBL1532837 & 688239 & 5.0362 & 5.4039 & TRN & \\
\hline CHEMBL1479928 & 688239 & 6.0862 & 5.603 & TRN & \\
\hline CHEMBL1467862 & 688239 & 6.6861 & 5.4289 & TST & \\
\hline CHEMBL1587676 & 688239 & 4.5362 & 5.5218 & TRN & \\
\hline CHEMBL1577644 & 688239 & 8.3372 & 5.6921 & TRN & \\
\hline CHEMBL1604040 & 688239 & 4.9 & 5.5492 & TRN & \\
\hline CHEMBL1353956 & 688239 & 4.5362 & 5.3584 & TRN & \\
\hline CHEMBL1574490 & 688239 & 5.1362 & 5.4046 & TST & \\
\hline CHEMBL1470155 & 688239 & 4.6362 & 5.4797 & TRN & \\
\hline CHEMBL1484495 & 688239 & 5.2862 & 5.3745 & TST & \\
\hline CHEMBL1573733 & 688239 & 7.0362 & 5.6142 & TRN & \\
\hline CHEMBL1562577 & 688239 & 7.1361 & 5.57700 & 0000000001 & TST \\
\hline CHEMBL1382442 & 688239 & 6.8362 & 5.6299 & TRN & \\
\hline CHEMBL1372884 & 688239 & 4.6862 & 5.5319 & TST & \\
\hline CHEMBL1412297 & 688239 & 4.7862 & 5.3512 & TRN & \\
\hline CHEMBL1573505 & 688239 & 4.7362 & 5.5337 & TST & \\
\hline CHEMBL1555754 & 688239 & 6.1862 & 5.5039 & TRN & \\
\hline CHEMBL1326017 & 688239 & 6.2362 & 5.4532 & TRN & \\
\hline CHEMBL1423852 & 688239 & 4.6362 & 5.572 & TRN & \\
\hline CHEMBL1389963 & 688239 & 5.8362 & 5.6322 & TRN & \\
\hline CHEMBL1416875 & 688239 & 5.4862 & 5.5529 & TRN & \\
\hline CHEMBL1323778 & 688239 & 6.6861 & 5.5061 & TRN & \\
\hline CHEMBL1493713 & 688239 & 4.4862 & 5.553 & TRN & \\
\hline CHEMBL1597598 & 688239 & 4.7862 & 5.6739 & TRN & \\
\hline CHEMBL1412994 & 688239 & 5.5362 & 5.4973 & TRN & \\
\hline CHEMBL1449715 & 688239 & 4.5862 & 5.4284 & TST & \\
\hline CHEMBL1323315 & 688239 & 4.8862 & 5.4696 & TRN & \\
\hline CHEMBL1452783 & 688239 & 5.5862 & 5.6159 & TRN & \\
\hline CHEMBL1507472 & 688239 & 5.1862 & 5.3705 & TRN & \\
\hline CHEMBL1581618 & 688239 & 4.7362 & 5.5436 & TRN & \\
\hline CHEMBL1510345 & 688239 & 5.8862 & 5.4294 & TRN & \\
\hline CHEMBL1462573 & 688239 & 6.1362 & 5.5857 & TRN & \\
\hline CHEMBL1613366 & 688239 & 4.7362 & 5.5672 & TST & \\
\hline CHEMBL3189749 & 688239 & 4.7362 & 5.4725 & TRN & \\
\hline
\end{tabular}


Supplemental Table S2.txt

\begin{tabular}{|c|c|c|c|c|}
\hline CHEMBL1441030 & 688239 & 8.2366 & 5.3702 & TST \\
\hline CHEMBL1360283 & 688239 & 4.8362 & 5.4567 & TRN \\
\hline CHEMBL1603537 & 688239 & 5.2862 & \multicolumn{2}{|c|}{5.497999999999999} \\
\hline CHEMBL1442512 & 688239 & 4.5362 & 5.579 & TRN \\
\hline CHEMBL1305908 & 688239 & 5.8362 & 5.4364 & TRN \\
\hline CHEMBL1339547 & 688239 & 4.9362 & 5.6037 & TRN \\
\hline CHEMBL1508839 & 688239 & 4.5362 & 5.4301 & TRN \\
\hline CHEMBL1365803 & 688239 & 4.8862 & 5.6052 & TST \\
\hline CHEMBL1439941 & 688239 & 5.3362 & 5.3693 & TST \\
\hline CHEMBL1214033 & 688239 & 5.8862 & 5.4774 & TST \\
\hline CHEMBL1429429 & 688239 & 5.1862 & 5.4354 & TST \\
\hline CHEMBL1580449 & 688239 & 4.5362 & 5.5006 & TST \\
\hline CHEMBL1342770 & 688239 & 5.3362 & 5.4081 & TRN \\
\hline CHEMBL1999418 & 688239 & 6.2362 & 5.4909 & TRN \\
\hline CHEMBL1559637 & 688239 & 4.6862 & 5.5407 & TST \\
\hline CHEMBL1465555 & 688239 & 6.6861 & 5.4074 & TRN \\
\hline CHEMBL1418339 & 688239 & 8.3372 & 5.5587 & TRN \\
\hline CHEMBL1386727 & 688239 & 5.1362 & 5.4837 & TRN \\
\hline CHEMBL1389039 & 688239 & 5.1862 & 5.612 & TRN \\
\hline CHEMBL1582108 & 688239 & 5.4362 & 5.5086 & TRN \\
\hline CHEMBL1532127 & 688239 & 7.0862 & 5.4516 & TRN \\
\hline CHEMBL1577360 & 688239 & 6.0362 & 5.34 & TST \\
\hline CHEMBL1325944 & 688239 & 4.7362 & 5.3863 & TST \\
\hline CHEMBL1505046 & 688239 & 6.9363 & 5.5428 & TRN \\
\hline CHEMBL1472324 & 688239 & 4.7362 & 5.586 & TRN \\
\hline CHEMBL1312213 & 688239 & 6.1862 & 5.5265 & TST \\
\hline CHEMBL1554127 & 688239 & 6.6861 & 5.624 & TST \\
\hline CHEMBL1594040 & 688239 & 6.6861 & 5.5736 & TRN \\
\hline CHEMBL1532536 & 688239 & 4.7362 & 5.5183 & TST \\
\hline CHEMBL1505413 & 688239 & 5.2362 & 5.5198 & TRN \\
\hline CHEMBL1535410 & 688239 & 6.2362 & 5.4316 & TST \\
\hline CHEMBL1541055 & 688239 & 4.6862 & 5.5431 & TST \\
\hline CHEMBL1610157 & 688239 & 5.4362 & 5.3772 & TRN \\
\hline CHEMBL1538345 & 688239 & 4.5362 & 5.5389 & TRN \\
\hline CHEMBL1428833 & 688239 & 5.7362 & 5.4441 & TRN \\
\hline CHEMBL1374573 & 688239 & 4.5362 & 5.593999 & 9999999999 \\
\hline CHEMBL1601504 & 688239 & 7.0362 & 5.4017 & TRN \\
\hline CHEMBL1367238 & 688239 & 5.6362 & 5.5126 & TRN \\
\hline CHEMBL1608196 & 688239 & 4.6862 & 5.5185 & TST \\
\hline CHEMBL1469245 & 688239 & 5.2862 & 5.5039 & TRN \\
\hline CHEMBL1334670 & 688239 & 4.6862 & 5.41 & TRN \\
\hline CHEMBL1548028 & 688239 & 6.0862 & 5.5298 & TST \\
\hline CHEMBL1422156 & 688239 & 6.2362 & 5.547999 & 9999999999 \\
\hline CHEMBL1415802 & 688239 & 4.6362 & 5.4629 & TRN \\
\hline CHEMBL1344940 & 688239 & 4.7862 & 5.5743 & TRN \\
\hline CHEMBL1356840 & 688239 & 6.4862 & 5.4641 & TRN \\
\hline CHEMBL1442662 & 688239 & 4.5862 & 5.3981 & TRN \\
\hline CHEMBL1517148 & 688239 & 4.4862 & 5.5952 & TRN \\
\hline
\end{tabular}




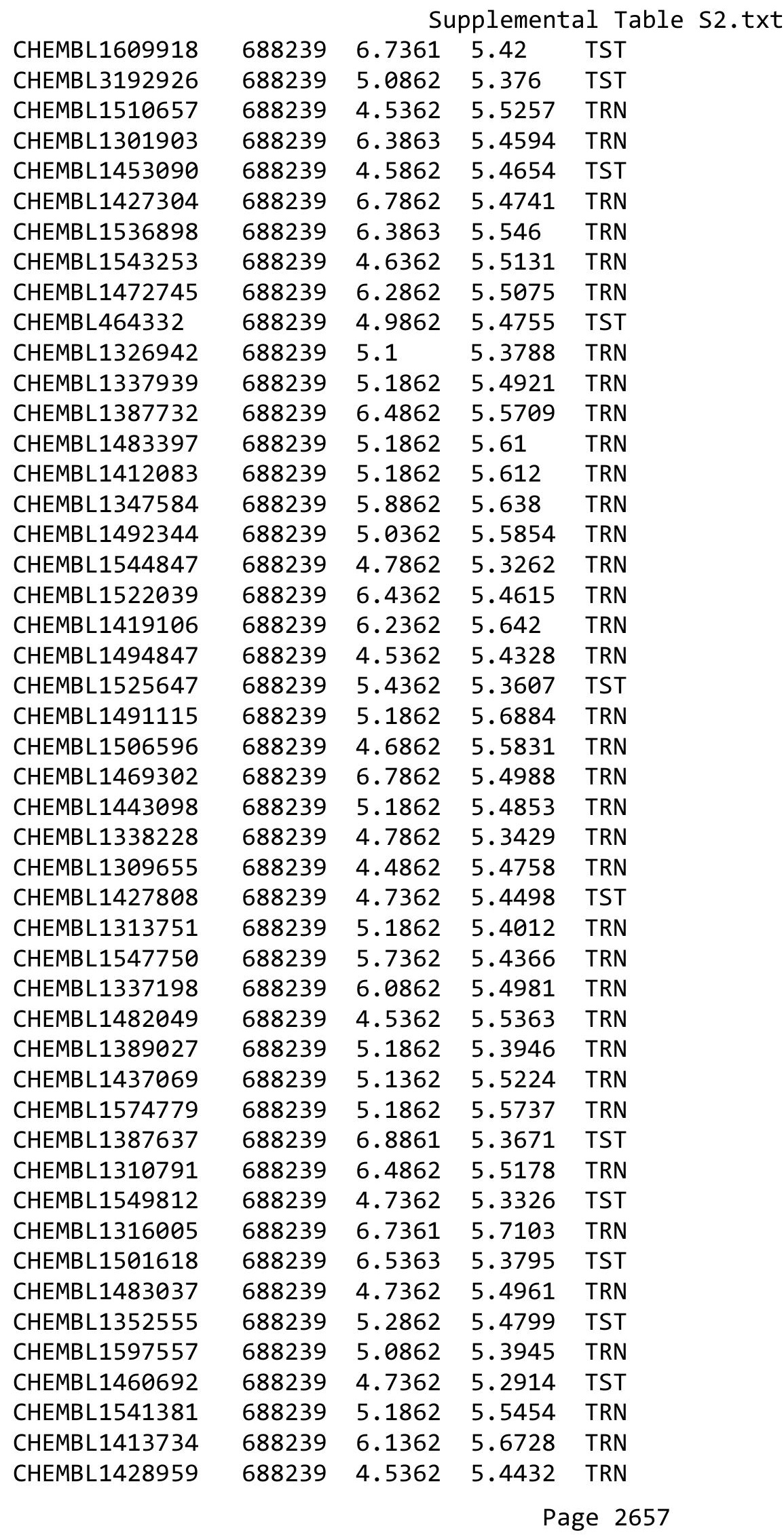


Supplemental Table S2.txt

\begin{tabular}{|c|c|c|c|c|c|}
\hline CHEMBL1550388 & 688239 & 5.9362 & 5.4772 & TST & \\
\hline CHEMBL1334836 & 688239 & 6.0862 & \multicolumn{2}{|c|}{5.5920000000000005} & TRN \\
\hline CHEMBL1389802 & 688239 & 5.4362 & 5.4447 & TRN & \\
\hline CHEMBL1549715 & 688239 & 8.2366 & 5.5319 & TRN & \\
\hline CHEMBL286013 & 688239 & 6.9363 & 5.5675 & TST & \\
\hline CHEMBL1357335 & 688239 & 5.1862 & 5.4589 & TRN & \\
\hline CHEMBL1584034 & 688239 & 4.7362 & 5.6747 & TRN & \\
\hline CHEMBL1385103 & 688239 & 5.8862 & 5.5493 & TRN & \\
\hline CHEMBL1483740 & 688239 & 4.7362 & 5.4915 & TRN & \\
\hline CHEMBL1419919 & 688239 & 4.6362 & 5.3327 & TRN & \\
\hline CHEMBL1343270 & 688239 & 5.7862 & 5.4322 & TRN & \\
\hline CHEMBL1570368 & 688239 & 4.6362 & 5.3814 & TRN & \\
\hline CHEMBL1432040 & 688239 & 6.1362 & 5.5758 & TRN & \\
\hline CHEMBL1302366 & 688239 & 6.0362 & 5.4084 & TRN & \\
\hline CHEMBL1412960 & 688239 & 4.6362 & 5.4208 & TST & \\
\hline CHEMBL1433058 & 688239 & 4.7362 & 5.4703 & TST & \\
\hline CHEMBL1501288 & 688239 & 5.6362 & 5.3872 & TST & \\
\hline CHEMBL1476015 & 688239 & 4.5362 & 5.6248 & TRN & \\
\hline CHEMBL1576519 & 688239 & 4.5862 & 5.5055 & TST & \\
\hline CHEMBL1612608 & 688239 & 4.8862 & 5.3553 & TST & \\
\hline CHEMBL1342325 & 688239 & 5.2362 & 5.4455 & TRN & \\
\hline CHEMBL1342661 & 688239 & 5.6362 & 5.5657 & TRN & \\
\hline CHEMBL1327477 & 688239 & 5.3862 & 5.5986 & TST & \\
\hline CHEMBL1522458 & 688239 & 4.6362 & 5.4334 & TRN & \\
\hline CHEMBL1306333 & 688239 & 5.0362 & 5.5116 & TRN & \\
\hline CHEMBL1517285 & 688239 & 6.3863 & 5.3895 & TRN & \\
\hline CHEMBL1307501 & 688239 & 5.1862 & 5.4351 & TRN & \\
\hline CHEMBL1399809 & 688239 & 5.1862 & 5.4437 & TST & \\
\hline CHEMBL1448152 & 688239 & 4.5362 & 5.4439 & TRN & \\
\hline CHEMBL1533211 & 688239 & 7.1361 & 5.5218 & TST & \\
\hline CHEMBL1427729 & 688239 & 5.2362 & 5.4764 & TST & \\
\hline CHEMBL501949 & 688239 & 6.1862 & 5.5385 & TST & \\
\hline CHEMBL1432936 & 688239 & 8.3372 & 5.5359 & TST & \\
\hline CHEMBL1450266 & 688239 & 4.7362 & 5.5214 & TST & \\
\hline CHEMBL1410110 & 688239 & 8.2366 & 5.46 & TRN & \\
\hline CHEMBL1442873 & 688239 & 4.7862 & 5.5481 & TST & \\
\hline CHEMBL1461297 & 688239 & 4.85 & 5.4513 & TRN & \\
\hline CHEMBL1343607 & 688239 & 5.5362 & 5.5618 & TRN & \\
\hline CHEMBL1418170 & 688239 & 5.7362 & 5.5146 & TRN & \\
\hline CHEMBL1307225 & 688239 & 5.4362 & 5.5386 & TRN & \\
\hline CHEMBL1330174 & 688239 & 5.5862 & 5.5076 & TRN & \\
\hline CHEMBL1480264 & 688239 & 4.6862 & 5.3792 & TST & \\
\hline CHEMBL1317489 & 688239 & 5.1362 & 5.4493 & TRN & \\
\hline CHEMBL1575747 & 688239 & 6.6362 & 5.5435 & TRN & \\
\hline CHEMBL3191917 & 688239 & 5.6362 & 5.3498 & TRN & \\
\hline CHEMBL1587989 & 688239 & 5.6862 & 5.5132 & TRN & \\
\hline CHEMBL1370267 & 688239 & 5.2362 & 5.5079 & TST & \\
\hline CHEMBL1542797 & 688239 & 4.7362 & 5.3627 & TRN & \\
\hline
\end{tabular}

Page 2658 
Supplemental Table S2.txt

\begin{tabular}{|c|c|c|c|c|c|}
\hline CHEMBL1436116 & 688239 & 5.4362 & 5.4819 & TRN & \\
\hline CHEMBL1417561 & 688239 & 4.5362 & 5.535 & TRN & \\
\hline CHEMBL1570392 & 688239 & 5.4362 & 5.4552 & TRN & \\
\hline CHEMBL1536270 & 688239 & 4.5362 & 5.5626 & TST & \\
\hline CHEMBL3392062 & 688239 & 8.0362 & 5.6027 & TST & \\
\hline CHEMBL1557734 & 688239 & 6.8861 & 5.4061 & TRN & \\
\hline CHEMBL1558756 & 688239 & 4.5362 & 5.6217 & TRN & \\
\hline CHEMBL1577448 & 688239 & 5.0362 & 5.5082 & TRN & \\
\hline CHEMBL1488754 & 688239 & 5.1862 & 5.3693 & TST & \\
\hline CHEMBL1521546 & 688239 & 6.3362 & 5.7008 & TRN & \\
\hline CHEMBL1535468 & 688239 & 5.9862 & 5.6565 & TRN & \\
\hline CHEMBL1353474 & 688239 & 6.0862 & 5.5452 & TRN & \\
\hline CHEMBL1373880 & 688239 & 5.7362 & 5.47 & TRN & \\
\hline CHEMBL1399541 & 688239 & 4.6362 & 5.5062 & TRN & \\
\hline CHEMBL1510871 & 688239 & 5.2862 & 5.6522 & TRN & \\
\hline CHEMBL1368720 & 688239 & 4.8362 & 5.5681 & TST & \\
\hline CHEMBL1503489 & 688239 & 5.3362 & 5.5393 & TRN & \\
\hline CHEMBL3207791 & 688239 & 4.8362 & 5.5862 & TST & \\
\hline CHEMBL1534434 & 688239 & 5.6362 & 5.4719 & TST & \\
\hline CHEMBL1447885 & 688239 & 5.0362 & 5.4799 & TST & \\
\hline CHEMBL1535754 & 688239 & 5.8362 & 5.5537 & TRN & \\
\hline CHEMBL1399998 & 688239 & 4.9362 & 5.528 & TRN & \\
\hline CHEMBL1609772 & 688239 & 5.1862 & 5.4816 & TRN & \\
\hline CHEMBL1404043 & 688239 & 4.7362 & 5.4482 & TST & \\
\hline CHEMBL1308094 & 688239 & 5.9862 & 5.487999 & 9999999995 & TR \\
\hline CHEMBL1318816 & 688239 & 4.7862 & 5.4373 & TST & \\
\hline CHEMBL1588256 & 688239 & 4.7362 & 5.3508 & TRN & \\
\hline CHEMBL1311761 & 688239 & 4.6862 & 5.5479 & TST & \\
\hline CHEMBL1426858 & 688239 & 6.8861 & 5.5563 & TST & \\
\hline CHEMBL1582036 & 688239 & 4.6362 & 5.4157 & TRN & \\
\hline CHEMBL1419206 & 688239 & 5.7362 & 5.5408 & TRN & \\
\hline CHEMBL1352064 & 688239 & 8.3372 & 5.5221 & TRN & \\
\hline CHEMBL1299707 & 688239 & 5.1862 & 5.2972 & TST & \\
\hline CHEMBL1598173 & 688239 & 5.9362 & 5.4576 & TST & \\
\hline CHEMBL1976649 & 688239 & 4.6362 & 5.3092 & TRN & \\
\hline CHEMBL1304872 & 688239 & 5.1862 & 5.5505 & TRN & \\
\hline CHEMBL1307363 & 688239 & 4.8362 & 5.502000 & 000000001 & m \\
\hline CHEMBL1548498 & 688239 & 5.2862 & 5.6245 & TST & \\
\hline CHEMBL1393316 & 688239 & 4.5862 & 5.5933 & TRN & \\
\hline CHEMBL1547348 & 688239 & 6.9363 & 5.5597 & TRN & \\
\hline CHEMBL1430325 & 688239 & 5.7362 & 5.5277 & TRN & \\
\hline CHEMBL1442801 & 688239 & 4.5362 & 5.455 & TRN & \\
\hline CHEMBL1591551 & 688239 & 5.5362 & 5.5248 & TRN & \\
\hline CHEMBL42867 & 688239 & 6.2862 & 5.4374 & TRN & \\
\hline CHEMBL1397058 & 688239 & 4.8862 & 5.5196 & TST & \\
\hline CHEMBL3199756 & 688239 & 8.28399 & 99999999 & 5.4081 & $\mathrm{TKT}$ \\
\hline CHEMBL1549744 & 688239 & 4.5362 & 5.3818 & TST & \\
\hline CHEMBL1463205 & 688239 & 6.8861 & 5.5232 & TRN & \\
\hline
\end{tabular}


Supplemental Table S2.txt

\begin{tabular}{|c|c|c|c|c|}
\hline CHEMBL1379628 & 688239 & 5.6362 & 5.5072 & TRN \\
\hline CHEMBL195693 & 688239 & 5.3862 & 5.433 & TST \\
\hline CHEMBL1306943 & 688239 & 4.6362 & 5.444 & TST \\
\hline CHEMBL1473534 & 688239 & 4.8862 & 5.4144 & TRN \\
\hline CHEMBL1557919 & 688239 & 6.0862 & 5.5837 & TRN \\
\hline CHEMBL1973328 & 688239 & 4.5862 & 5.4388 & TRN \\
\hline CHEMBL1405436 & 688239 & 4.6362 & 5.5845 & TST \\
\hline CHEMBL1438757 & 688239 & 4.5362 & 5.6199 & TST \\
\hline CHEMBL1604474 & 688239 & 5.3362 & 5.4554 & TST \\
\hline CHEMBL1373520 & 688239 & 6.9363 & 5.48799 & 9999999995 \\
\hline CHEMBL1350430 & 688239 & 4.7862 & 5.6506 & TRN \\
\hline CHEMBL1441830 & 688239 & 4.5362 & 5.4029 & TRN \\
\hline CHEMBL1423463 & 688239 & 4.6862 & 5.2869 & TRN \\
\hline CHEMBL1460213 & 688239 & 4.7862 & 5.4751 & TRN \\
\hline CHEMBL1419698 & 688239 & 4.5362 & 5.4657 & TRN \\
\hline CHEMBL1350333 & 688239 & 5.0362 & 5.74799 & 999999999 \\
\hline CHEMBL3197461 & 688239 & 6.1862 & 5.3086 & TRN \\
\hline CHEMBL1587803 & 688239 & 4.7862 & 5.5319 & TRN \\
\hline CHEMBL1349010 & 688239 & 6.1362 & 5.4745 & TST \\
\hline CHEMBL1385283 & 688239 & 4.7362 & 5.559 & TST \\
\hline CHEMBL1524892 & 688239 & 4.4862 & 5.5744 & TRN \\
\hline CHEMBL1607501 & 688239 & 6.1862 & 5.5913 & TRN \\
\hline CHEMBL1430612 & 688239 & 4.5362 & 5.4514 & TRN \\
\hline CHEMBL1583805 & 688239 & 4.5362 & 5.6893 & TRN \\
\hline CHEMBL1448262 & 688239 & 5.1862 & 5.4178 & TRN \\
\hline CHEMBL1348390 & 688239 & 4.7862 & 5.6551 & TRN \\
\hline CHEMBL1587418 & 688239 & 7.6861 & 5.5416 & TRN \\
\hline CHEMBL1432785 & 688239 & 6.1362 & 5.2807 & TRN \\
\hline CHEMBL1411564 & 688239 & 6.4 & 5.6235 & TRN \\
\hline CHEMBL1545719 & 688239 & 6.1362 & 5.4015 & TRN \\
\hline CHEMBL1317980 & 688239 & 5.5362 & 5.5132 & TRN \\
\hline CHEMBL1609415 & 688239 & 6.1362 & 5.6526 & TRN \\
\hline CHEMBL1436150 & 688239 & 6.1362 & 5.5851 & TRN \\
\hline CHEMBL1511493 & 688239 & 4.5362 & 5.4506 & TRN \\
\hline CHEMBL1377570 & 688239 & 5.4362 & 5.5022 & TRN \\
\hline CHEMBL1572276 & 688239 & 4.6862 & 5.635 & TRN \\
\hline CHEMBL1587694 & 688239 & 4.6862 & 5.4443 & TST \\
\hline CHEMBL1395814 & 688239 & 5.3362 & 5.4389 & TRN \\
\hline CHEMBL1606852 & 688239 & 5.3362 & 5.6094 & TRN \\
\hline CHEMBL1311742 & 688239 & 4.4862 & 5.2335 & TRN \\
\hline CHEMBL1547723 & 688239 & 6.7361 & 5.4534 & TRN \\
\hline CHEMBL1562889 & 688239 & 4.4862 & 5.6108 & TRN \\
\hline CHEMBL1454022 & 688239 & 5.3862 & 5.5087 & TRN \\
\hline CHEMBL1405382 & 688239 & 4.6362 & 5.563 & TRN \\
\hline CHEMBL1313805 & 688239 & 8.1367 & 5.367006 & 000000001 \\
\hline CHEMBL1416046 & 688239 & 5.8362 & 5.4743 & TRN \\
\hline CHEMBL1446529 & 688239 & 5.1862 & 5.4486 & TRN \\
\hline CHEMBL1546622 & 688239 & 6.2362 & 5.4752 & TRN \\
\hline
\end{tabular}


Supplemental Table S2.txt

\begin{tabular}{|c|c|c|c|c|c|}
\hline CHEMBL1422763 & 688239 & 6.1362 & 5.3396 & TST & \\
\hline CHEMBL1414140 & 688239 & 4.9362 & 5.4381 & TRN & \\
\hline CHEMBL1529099 & 688239 & 5.1862 & 5.5044 & TRN & \\
\hline CHEMBL1573363 & 688239 & 4.6362 & \multicolumn{2}{|c|}{5.4879999999999995} & TST \\
\hline CHEMBL3192836 & 688239 & 5.1862 & 5.4799 & TST & \\
\hline CHEMBL1484608 & 688239 & 6.6861 & \multicolumn{2}{|c|}{5.492000000000001} & TST \\
\hline CHEMBL1529492 & 688239 & 4.5362 & 5.5072 & TRN & \\
\hline CHEMBL1471481 & 688239 & 4.5362 & 5.4787 & TRN & \\
\hline CHEMBL1549379 & 688239 & 6.6362 & 5.6023 & TRN & \\
\hline CHEMBL1318156 & 688239 & 4.9862 & 5.5052 & TRN & \\
\hline CHEMBL1381226 & 688239 & 8.3372 & 5.5008 & TRN & \\
\hline CHEMBL1363629 & 688239 & 4.8362 & 5.4318 & TRN & \\
\hline CHEMBL1322336 & 688239 & 5.5862 & 5.4649 & TRN & \\
\hline CHEMBL1335955 & 688239 & 6.4862 & 5.4596 & TST & \\
\hline CHEMBL1397403 & 688239 & 4.5362 & 5.5696 & TRN & \\
\hline CHEMBL1338748 & 688239 & 5.1862 & 5.4876 & TST & \\
\hline CHEMBL1562304 & 688239 & 5.1862 & 5.349 & TST & \\
\hline CHEMBL1606158 & 688239 & 4.7362 & 5.2388 & TRN & \\
\hline CHEMBL1528612 & 688239 & 6.8861 & 5.6052 & TRN & \\
\hline CHEMBL1370897 & 688239 & 6.5862 & 5.5773 & TRN & \\
\hline CHEMBL1587416 & 688239 & 6.6362 & 5.4784 & TRN & \\
\hline CHEMBL1368345 & 688239 & 4.5362 & 5.6073 & TRN & \\
\hline CHEMBL1583196 & 688239 & 6.8861 & 5.4046 & TST & \\
\hline CHEMBL1526900 & 688239 & 6.8861 & 5.5019 & TRN & \\
\hline CHEMBL1389451 & 688239 & 6.2362 & 5.7563 & TRN & \\
\hline CHEMBL1406126 & 688239 & 5.7862 & 5.5317 & TRN & \\
\hline CHEMBL1405303 & 688239 & 4.6862 & 5.51399 & 9999999999 & TRN \\
\hline CHEMBL1503131 & 688239 & 5.0362 & 5.399 & TRN & \\
\hline CHEMBL1511217 & 688239 & 4.8362 & 5.4652 & TST & \\
\hline CHEMBL1410080 & 688239 & 7.2366 & 5.4707 & TRN & \\
\hline CHEMBL1364305 & 688239 & 4.4862 & 5.4812 & TST & \\
\hline CHEMBL1443679 & 688239 & 5.5862 & 5.3775 & TRN & \\
\hline CHEMBL1321240 & 688239 & 5.3362 & 5.446006 & 3000000001 & TRN \\
\hline CHEMBL1532034 & 688239 & 7.1864 & 5.6468 & TRN & \\
\hline CHEMBL1475696 & 688239 & 5.6362 & 5.442 & TRN & \\
\hline CHEMBL1557034 & 688239 & 5.1362 & 5.5606 & TRN & \\
\hline CHEMBL1569963 & 688239 & 4.6362 & 5.6162 & TRN & \\
\hline CHEMBL1721986 & 688239 & 6.1862 & 5.32799 & 9999999999 & TRN \\
\hline CHEMBL1502974 & 688239 & 6.9863 & 5.4439 & TRN & \\
\hline CHEMBL1585384 & 688239 & 4.5862 & 5.4653 & TST & \\
\hline CHEMBL1459197 & 688239 & 4.5862 & 5.4082 & TRN & \\
\hline CHEMBL284104 & 688239 & 7.4365 & 5.5892 & TST & \\
\hline CHEMBL1386565 & 688239 & 6.0862 & 5.4852 & TRN & \\
\hline CHEMBL1564788 & 688239 & 4.5362 & 5.5316 & TRN & \\
\hline CHEMBL1455493 & 688239 & 4.7362 & 5.5999 & TRN & \\
\hline CHEMBL1402409 & 688239 & 5.3862 & 5.6431 & TRN & \\
\hline CHEMBL1572859 & 688239 & 5.7862 & 5.4226 & TST & \\
\hline CHEMBL1460288 & 688239 & 4.9862 & 5.5765 & TRN & \\
\hline
\end{tabular}


Supplemental Table S2.txt

\begin{tabular}{|c|c|c|c|c|}
\hline HEM & & .1362 & & \\
\hline ברIMPI 19190 & & .8362 & & \\
\hline 1217 & & & & \\
\hline AEMBL1: & & & & \\
\hline AEMBL1499712 & 8239 & 862 & & \\
\hline HEMBL1413482 & 88239 & 1862 & 4094 & \\
\hline HEMBL13 & 239 & 362 & 422 & \\
\hline IFMBI 15 & & & & \\
\hline AEMBL142 & 239 & 5862 & & \\
\hline HEMBL132 & 88239 & 862 & 6314 & \\
\hline JEMBL13 & 239 & 362 & 5518 & \\
\hline IEMBL14 & 39 & 361 & 7315 & \\
\hline AEMBL14 & & & & \\
\hline HEMBL13 & & 362 & 5.535 & \\
\hline AEMBL14 & & & & \\
\hline IEMBL15 & 39 & 362 & 34 & \\
\hline HEMBL13 & & & 73 & \\
\hline HEMBL 14 & & & & \\
\hline HEMBL13 & & 362 & & \\
\hline AEMBL15 & & & & \\
\hline AEMBLIS & & 62 & & ו \\
\hline HEMBL13 & & 1 & & 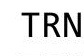 \\
\hline HEMBL15 & & & & \\
\hline AEMBL15 & & 362 & & \\
\hline AEMBL15 & & & & \\
\hline HEMBL1 & & 52 & & RN \\
\hline HEMBL1 & & & & RN \\
\hline HFMBI 1 & & 52 & & \\
\hline HEMBL13 & & & & IIT \\
\hline HEMBL13. & & & & ובו \\
\hline HEMBL1 & & & & RN \\
\hline HEMBL: & & & & RN \\
\hline$\triangle 5 \mathrm{MPI} 11$ & & & & RN \\
\hline HEMBL14 & & & & IRN \\
\hline HEMBL145 & & & 506 & $\cdots$ \\
\hline HEMBL1 & & & & | \\
\hline HFMRI 1 & & & 65 & $\Gamma \mathrm{RN}$ \\
\hline HEMBL 27 & & & & TRN \\
\hline HEMBL15 & 88239 & 362 & & TRN \\
\hline AEMBL14 & & 62 & & ГRN \\
\hline HEMBL14 & & 862 & 25 & \\
\hline CHEMBL13 & & & & Niv \\
\hline HEMBL13 & & & & RN \\
\hline AEMBL13 & 39 & 362 & 321 & TST \\
\hline HEMBL15 & & 861 & & $\pi$ \\
\hline HEMBL14 & & 4.8862 & 5.4895 & \\
\hline CHEMBL14 & & & 5.4405 & \\
\hline HEMBL1537675 & 688239 & 4.7362 & 5.4538 & \\
\hline
\end{tabular}

Page 2662 
Supplemental Table S2.txt

\begin{tabular}{|c|c|c|c|c|c|}
\hline CHEMBL1477528 & 688239 & 5.1862 & \multicolumn{2}{|c|}{5.382999999999999} & TRN \\
\hline CHEMBL1523630 & 688239 & 4.5362 & 5.3573 & TST & \\
\hline CHEMBL1512634 & 688239 & 6.9363 & 5.4341 & TRN & \\
\hline CHEMBL1495601 & 688239 & 4.7362 & 5.4312 & TRN & \\
\hline CHEMBL1495738 & 688239 & 4.6862 & 5.4685 & TRN & \\
\hline CHEMBL1332799 & 688239 & 5.4862 & 5.3481 & TST & \\
\hline CHEMBL1387578 & 688239 & 8.3372 & 5.5452 & TST & \\
\hline CHEMBL1431352 & 688239 & 5.1862 & 5.3393 & TRN & \\
\hline CHEMBL1469545 & 688239 & 5.1362 & 5.4402 & TST & \\
\hline CHEMBL1487032 & 688239 & 5.4862 & 5.6426 & TRN & \\
\hline CHEMBL1536941 & 688239 & 5.3862 & 5.5766 & TRN & \\
\hline CHEMBL1554286 & 688239 & 5.5362 & 5.5242 & TRN & \\
\hline CHEMBL1498297 & 688239 & 6.6861 & 5.5694 & TST & \\
\hline CHEMBL1492787 & 688239 & 4.5362 & 5.4254 & TST & \\
\hline CHEMBL1349618 & 688239 & 5.5362 & 5.5687 & TRN & \\
\hline CHEMBL1402782 & 688239 & 4.7362 & 5.4343 & TRN & \\
\hline CHEMBL1392729 & 688239 & 4.5362 & 5.7246 & TRN & \\
\hline CHEMBL1612477 & 688239 & 5.5362 & 5.4911 & TRN & \\
\hline CHEMBL1484086 & 688239 & 6.1862 & 5.5042 & TST & \\
\hline CHEMBL1492637 & 688239 & 4.7862 & 5.4717 & TRN & \\
\hline CHEMBL1332772 & 688239 & 5.1862 & 5.4546 & TRN & \\
\hline CHEMBL1469838 & 688239 & 5.0862 & 5.4486 & TRN & \\
\hline CHEMBL1356533 & 688239 & 6.6861 & 5.3907 & TST & \\
\hline CHEMBL1423065 & 688239 & 5.5362 & 5.5275 & TRN & \\
\hline CHEMBL1612585 & 688239 & 5.9862 & 5.5247 & TRN & \\
\hline CHEMBL1488270 & 688239 & 7.2865 & 5.4472 & TRN & \\
\hline CHEMBL3196283 & 688239 & 4.5362 & 5.3162 & TRN & \\
\hline CHEMBL 3211842 & 688239 & 4.6362 & 5.3446 & TRN & \\
\hline CHEMBL1546530 & 688239 & 6.1362 & 5.7067 & TRN & \\
\hline CHEMBL1612100 & 688239 & 5.3362 & 5.6338 & TRN & \\
\hline CHEMBL1354460 & 688239 & 4.9362 & 5.5014 & TRN & \\
\hline CHEMBL1580124 & 688239 & 5.3362 & 5.4836 & TRN & \\
\hline CHEMBL1548828 & 688239 & 5.2362 & 5.4201 & TRN & \\
\hline CHEMBL1301852 & 688239 & 4.6862 & 5.3962 & TRN & \\
\hline CHEMBL1398768 & 688239 & 5.1862 & 5.5315 & TRN & \\
\hline CHEMBL1346938 & 688239 & 5.3862 & 5.5524 & TST & \\
\hline CHEMBL1556876 & 688239 & 4.7862 & 5.3143 & TRN & \\
\hline CHEMBL1343805 & 688239 & 5.7362 & 5.6267 & TRN & \\
\hline CHEMBL1418913 & 688239 & 4.5362 & 5.4714 & TRN & \\
\hline CHEMBL1372599 & 688239 & 4.5362 & 5.4832 & TST & \\
\hline CHEMBL1477355 & 688239 & 6.9863 & 5.473 & TRN & \\
\hline CHEMBL1302391 & 688239 & 5.2862 & 5.4919 & TST & \\
\hline CHEMBL1351501 & 688239 & 6.8861 & 5.4114 & TRN & \\
\hline CHEMBL1342419 & 688239 & 4.9362 & 5.6224 & TRN & \\
\hline CHEMBL1572162 & 688239 & 5.4862 & 5.684 & TRN & \\
\hline CHEMBL1341923 & 688239 & 6.6362 & 5.5951 & TRN & \\
\hline CHEMBL1466728 & 688239 & 5.6862 & 5.6143 & TST & \\
\hline CHEMBL1312835 & 688239 & 4.5362 & 5.2974 & TRN & \\
\hline
\end{tabular}


Supplemental Table S2.txt

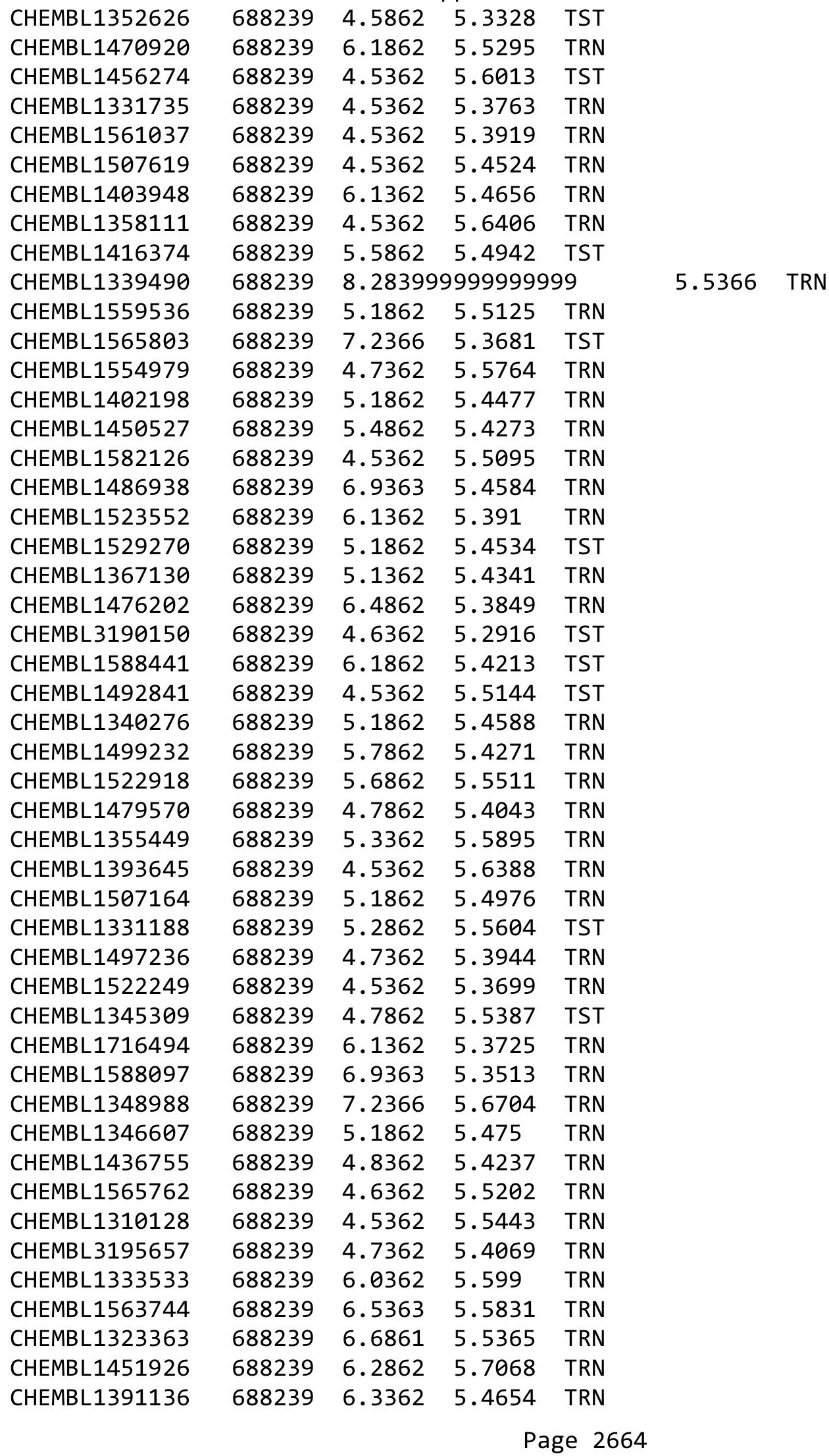




\begin{tabular}{|c|c|c|c|c|c|}
\hline & & & & & \\
\hline CHEMBL114059 & 688239 & 6.7862 & 5.4199 & TRN & \\
\hline CHEMBL1567023 & 688239 & 6.8861 & 5.5513 & TRN & \\
\hline CHEMBL1533059 & 688239 & 6.1862 & 5.5321 & TRN & \\
\hline CHEMBL1413198 & 688239 & 7.3363 & 5.5829 & TRN & \\
\hline CHEMBL1546891 & 688239 & 6.9363 & 5.4784 & TRN & \\
\hline CHEMBL1604896 & 688239 & 5.1862 & 5.557 & TST & \\
\hline CHEMBL1572581 & 688239 & 5.1862 & 5.4474 & TST & \\
\hline CHEMBL1477325 & 688239 & 4.6862 & 5.50200 & $\partial 000000001$ & TRN \\
\hline CHEMBL1508374 & 688239 & 6.3863 & 5.2744 & TRN & \\
\hline CHEMBL1608893 & 688239 & 4.7862 & 5.4468 & TRN & \\
\hline CHEMBL1546694 & 688239 & 4.5362 & 5.5114 & TRN & \\
\hline CHEMBL1605041 & 688239 & 6.1862 & 5.6571 & TST & \\
\hline CHEMBL1386734 & 688239 & 4.5862 & 5.5377 & TRN & \\
\hline CHEMBL3213501 & 688239 & 4.8362 & 5.3819 & TRN & \\
\hline CHEMBL2005302 & 688239 & 5.5362 & 5.3685 & TRN & \\
\hline CHEMBL1370240 & 688239 & 5.1862 & 5.41200 & $\partial 000000001$ & TRN \\
\hline CHEMBL1510653 & 688239 & 6.8861 & 5.6766 & TRN & \\
\hline CHEMBL1602128 & 688239 & 4.6862 & 5.459 & TST & \\
\hline CHEMBL1391613 & 688239 & 4.5362 & 5.6136 & TST & \\
\hline CHEMBL1506219 & 688239 & 5.4362 & 5.5711 & TRN & \\
\hline CHEMBL3209428 & 688239 & 4.8362 & 5.4054 & TST & \\
\hline CHEMBL1368637 & 688239 & 5.5362 & 5.5805 & TRN & \\
\hline CHEMBL1531639 & 688239 & 6.5363 & 5.579 & TRN & \\
\hline CHEMBL3208485 & 688239 & 4.6362 & 5.4414 & TST & \\
\hline CHEMBL1326694 & 688239 & 4.5362 & 5.4976 & TRN & \\
\hline CHEMBL1430900 & 688239 & 5.6862 & 5.5284 & TRN & \\
\hline CHEMBL1427947 & 688239 & 6.3863 & 5.5041 & TRN & \\
\hline CHEMBL1557973 & 688239 & 4.5862 & 5.3607 & TST & \\
\hline CHEMBL1389952 & 688239 & 4.95 & 5.4441 & TRN & \\
\hline CHEMBL1545070 & 688239 & 5.0362 & 5.4525 & TRN & \\
\hline CHEMBL1470659 & 688239 & 6.2362 & 5.3398 & TRN & \\
\hline CHEMBL1499058 & 688239 & 4.5362 & 5.5834 & TRN & \\
\hline CHEMBL1475119 & 688239 & 5.4362 & 5.5035 & TRN & \\
\hline CHEMBL1601304 & 688239 & 4.6862 & 5.4892 & TRN & \\
\hline CHEMBL3196394 & 688239 & 5.8862 & 5.54899 & 99999999995 & TRN \\
\hline CHEMBL1307763 & 688239 & 4.7862 & 5.4739 & TRN & \\
\hline CHEMBL1336698 & 688239 & 4.7862 & 5.5714 & TRN & \\
\hline CHEMBL1600681 & 688239 & 4.5362 & 5.5837 & TRN & \\
\hline CHEMBL1534465 & 688239 & 6.3362 & 5.5703 & TST & \\
\hline CHEMBL1325763 & 688239 & 7.5361 & 5.5382 & TST & \\
\hline CHEMBL1405940 & 688239 & 6.8362 & 5.4984 & TRN & \\
\hline CHEMBL3209998 & 688239 & 5.4862 & 5.4722 & TRN & \\
\hline CHEMBL1404457 & 688239 & 6.7862 & 5.5013 & TRN & \\
\hline CHEMBL1529471 & 688239 & 4.6362 & 5.341 & TRN & \\
\hline CHEMBL1386832 & 688239 & 4.6362 & 5.5219 & TRN & \\
\hline CHEMBL1503060 & 688239 & 4.5362 & 5.4709 & TRN & \\
\hline CHEMBL1328822 & 688239 & 5.4362 & 5.4551 & TRN & \\
\hline CHEMBL1974916 & 688239 & 5.3362 & 5.4547 & TRN & \\
\hline
\end{tabular}


Supplemental Table S2.txt

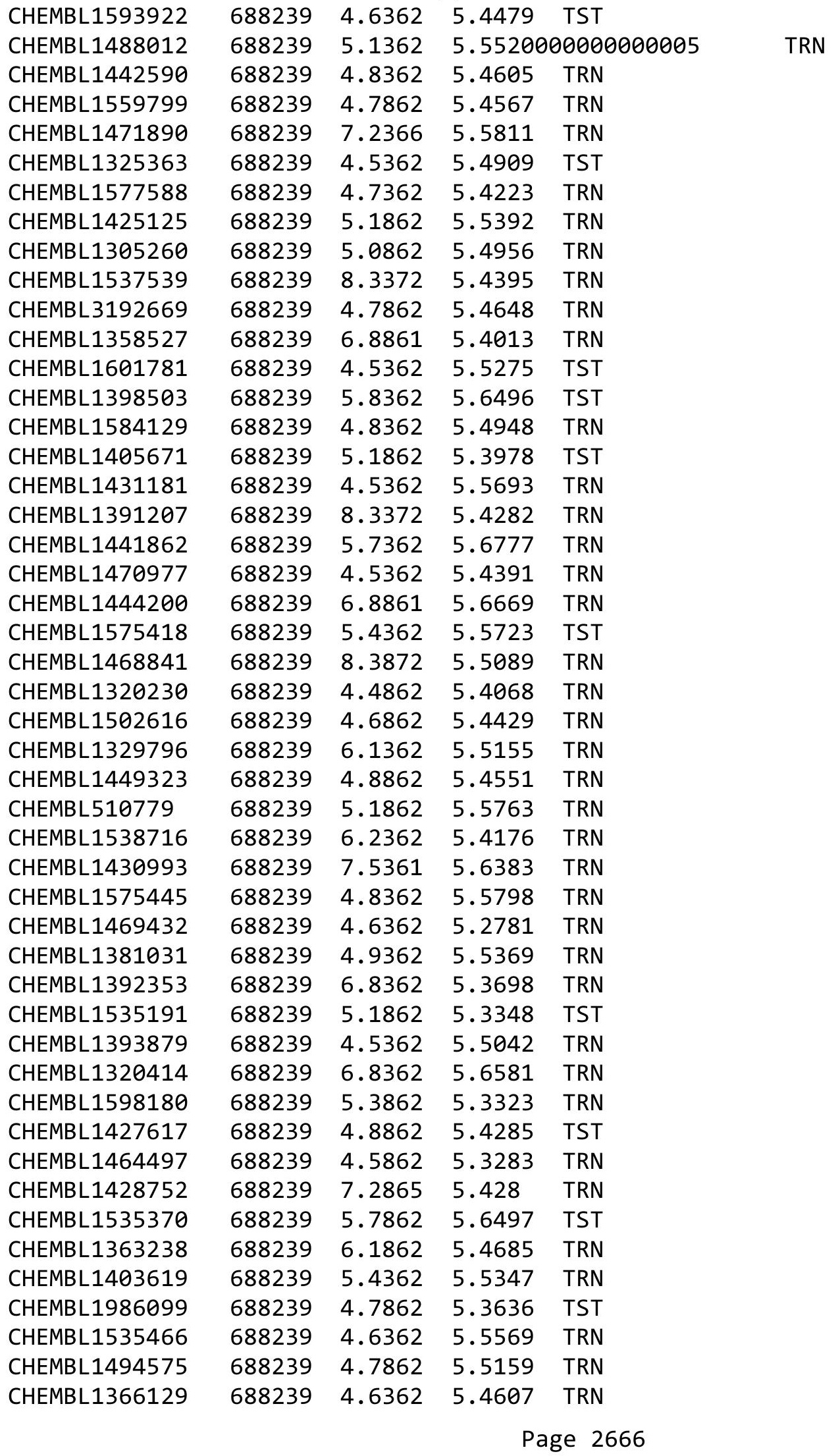


Supplemental Table S2.txt

\begin{tabular}{|c|c|c|c|c|}
\hline CHEMBL1378435 & 688239 & 5.1862 & 5.415 & TRN \\
\hline CHEMBL1576979 & 688239 & 4.7862 & 5.4562 & TRN \\
\hline CHEMBL1449432 & 688239 & 4.9362 & 5.513 & TRN \\
\hline CHEMBL1486309 & 688239 & 6.8362 & 5.5227 & TST \\
\hline CHEMBL1407153 & 688239 & 4.6362 & 5.4329 & TRN \\
\hline CHEMBL 3214425 & 688239 & 4.5362 & 5.4231 & TRN \\
\hline CHEMBL1484924 & 688239 & 4.5362 & 5.4352 & TST \\
\hline CHEMBL1534722 & 688239 & 5.1362 & 5.3899 & TRN \\
\hline CHEMBL1526802 & 688239 & 4.5362 & 5.492999 & 999999999 \\
\hline CHEMBL3196980 & 688239 & 4.5362 & 5.3437 & TRN \\
\hline CHEMBL1714669 & 688239 & 5.5862 & 5.3717 & TST \\
\hline CHEMBL1315355 & 688239 & 6.7862 & 5.5222 & TRN \\
\hline CHEMBL1332233 & 688239 & 4.5862 & 5.5732 & TRN \\
\hline CHEMBL1601341 & 688239 & 6.8861 & 5.6373 & TRN \\
\hline CHEMBL1469467 & 688239 & 6.2862 & 5.582999 & 999999999 \\
\hline CHEMBL1465208 & 688239 & 4.5362 & 5.5513 & TRN \\
\hline CHEMBL1569055 & 688239 & 4.6362 & 5.4738 & TRN \\
\hline CHEMBL1534084 & 688239 & 4.5362 & 5.403 & TRN \\
\hline CHEMBL1498232 & 688239 & 4.5362 & 5.3324 & TRN \\
\hline CHEMBL1596218 & 688239 & 5.5862 & 5.5086 & TRN \\
\hline CHEMBL561114 & 688239 & 5.4862 & 5.5468 & TRN \\
\hline CHEMBL602413 & 688239 & 4.8362 & 5.2985 & TRN \\
\hline CHEMBL1425155 & 688239 & 5.5362 & 5.447999 & 9999999995 \\
\hline CHEMBL1572870 & 688239 & 8.28399 & 99999999 & 5.3622 \\
\hline CHEMBL1476889 & 688239 & 5.1862 & 5.4097 & TRN \\
\hline CHEMBL1439216 & 688239 & 6.2862 & 5.5712 & TRN \\
\hline CHEMBL1427492 & 688239 & 4.7362 & 5.4618 & TRN \\
\hline CHEMBL3189659 & 688239 & 5.0862 & 5.4817 & TRN \\
\hline CHEMBL1521251 & 688239 & 4.8362 & 5.606 & TRN \\
\hline CHEMBL1438716 & 688239 & 5.3862 & 5.4901 & TST \\
\hline CHEMBL1461650 & 688239 & 5.3362 & 5.5194 & TRN \\
\hline CHEMBL1309280 & 688239 & 5.0862 & 5.5803 & TRN \\
\hline CHEMBL1330159 & 688239 & 6.9363 & 5.692 & TRN \\
\hline CHEMBL1415022 & 688239 & 7.9355 & 5.6334 & TRN \\
\hline CHEMBL573543 & 688239 & 5.1362 & 5.4675 & TST \\
\hline CHEMBL1485354 & 688239 & 4.8362 & 5.4024 & TRN \\
\hline CHEMBL1357978 & 688239 & 6.8861 & 5.3804 & TRN \\
\hline CHEMBL1321228 & 688239 & 6.5363 & 5.5901 & TRN \\
\hline CHEMBL1523656 & 688239 & 6.4862 & 5.518 & TST \\
\hline CHEMBL1519303 & 688239 & 5.6362 & 5.5851 & TRN \\
\hline CHEMBL1581188 & 688239 & 4.6862 & 5.4618 & TST \\
\hline CHEMBL1413419 & 688239 & 5.5362 & 5.6418 & TRN \\
\hline CHEMBL1512213 & 688239 & 5.5362 & 5.4609 & TRN \\
\hline CHEMBL 1345558 & 688239 & 4.65 & 5.4656 & TRN \\
\hline CHEMBL 3144936 & 688239 & 5.8362 & 5.5275 & TRN \\
\hline CHEMBL1364222 & 688239 & 5.6862 & 5.4322 & TST \\
\hline CHEMBL1366850 & 688239 & 6.9863 & 5.3353 & TRN \\
\hline CHEMBL1563460 & 688239 & 5.0362 & 5.3845 & TRN \\
\hline
\end{tabular}


Supplemental Table S2.txt

\begin{tabular}{|c|c|c|c|c|c|}
\hline CHEMBL1463365 & 688239 & 5.1862 & 5.4614 & TRN & \\
\hline CHEMBL1421293 & 688239 & 6.9863 & 5.6459 & TRN & \\
\hline CHEMBL1612915 & 688239 & 6.1862 & 5.4831 & TRN & \\
\hline CHEMBL1422834 & 688239 & 4.5362 & 5.4415 & TRN & \\
\hline CHEMBL1552457 & 688239 & 5.5362 & 5.4431 & TRN & \\
\hline CHEMBL1538858 & 688239 & 5.6362 & 5.4871 & TRN & \\
\hline CHEMBL3190796 & 688239 & 5.1862 & 5.5288 & TRN & \\
\hline CHEMBL1581126 & 688239 & 4.7862 & 5.416 & TST & \\
\hline CHEMBL1371215 & 688239 & 4.6362 & 5.4255 & TRN & \\
\hline CHEMBL1553343 & 688239 & 4.5362 & 5.3837 & TRN & \\
\hline CHEMBL1324282 & 688239 & 4.9362 & 5.5363 & TRN & \\
\hline CHEMBL1313654 & 688239 & 5.1862 & 5.4181 & TRN & \\
\hline CHEMBL1371690 & 688239 & 4.7362 & 5.5238 & TRN & \\
\hline CHEMBL1597620 & 688239 & 4.5362 & 5.5669 & TRN & \\
\hline CHEMBL1382592 & 688239 & 5.1862 & 5.6976 & TRN & \\
\hline CHEMBL1558545 & 688239 & 5.0862 & 5.3741 & TRN & \\
\hline CHEMBL1511323 & 688239 & 4.6862 & 5.4022 & TRN & \\
\hline CHEMBL1586230 & 688239 & 5.5862 & 5.3239 & TST & \\
\hline CHEMBL1546565 & 688239 & 4.5362 & 5.5089 & TRN & \\
\hline CHEMBL1512586 & 688239 & 4.5362 & 5.5612 & TST & \\
\hline CHEMBL1452772 & 688239 & 6.2362 & 5.5286 & TRN & \\
\hline CHEMBL1964868 & 688239 & 5.4862 & 5.3431 & TST & \\
\hline CHEMBL1542664 & 688239 & 5.7362 & 5.2807 & TRN & \\
\hline CHEMBL1460945 & 688239 & 8.3372 & 5.5184 & TST & \\
\hline CHEMBL1597286 & 688239 & 6.2362 & 5.3417 & TST & \\
\hline CHEMBL1435094 & 688239 & 6.9363 & 5.4374 & TRN & \\
\hline CHEMBL1346719 & 688239 & 4.8862 & 5.5157 & TST & \\
\hline CHEMBL1386931 & 688239 & 5.4862 & 5.5087 & TRN & \\
\hline CHEMBL1524874 & 688239 & 4.7862 & 5.4616 & TRN & \\
\hline CHEMBL1346819 & 688239 & 4.5362 & 5.5884 & TRN & \\
\hline CHEMBL1336886 & 688239 & 5.1862 & 5.3724 & TRN & \\
\hline CHEMBL1550483 & 688239 & 8.3372 & 5.5089 & TST & \\
\hline CHEMBL1348139 & 688239 & 5.7862 & 5.5625 & TRN & \\
\hline CHEMBL1543576 & 688239 & 4.7362 & 5.4118 & TRN & \\
\hline CHEMBL1324082 & 688239 & 4.6362 & 5.3436 & TST & \\
\hline CHEMBL1368449 & 688239 & 4.9362 & 5.6289 & TRN & \\
\hline CHEMBL1455782 & 688239 & 5.4362 & 5.4997 & TST & \\
\hline CHEMBL1425370 & 688239 & 8.0362 & 5.5059 & TRN & \\
\hline CHEMBL1354853 & 688239 & 8.283999 & 999999999 & 5.4208 & TRA \\
\hline CHEMBL1435061 & 688239 & 6.1862 & 5.428 & TRN & \\
\hline CHEMBL1542594 & 688239 & 4.5362 & 5.4215 & TST & \\
\hline CHEMBL1587823 & 688239 & 5.6862 & 5.4701 & TRN & \\
\hline CHEMBL1457990 & 688239 & 4.5362 & 5.491000 & 30000000005 & TST \\
\hline CHEMBL1374114 & 688239 & 5.1862 & 5.5713 & TST & \\
\hline CHEMBL1481920 & 688239 & 5.1862 & 5.5728 & TRN & \\
\hline CHEMBL1403656 & 688239 & 6.5862 & 5.5506 & TST & \\
\hline CHEMBL1518554 & 688239 & 4.5362 & 5.6591 & TRN & \\
\hline CHEMBL1463378 & 688239 & 5.4362 & 5.4535 & TST & \\
\hline
\end{tabular}


Supplemental Table S2.txt

\begin{tabular}{|c|c|c|c|c|}
\hline 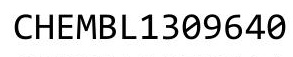 & & & & \\
\hline AEMBL1356414 & 38239 & 5362 & 1776 & \\
\hline AEMBL1410561 & 239 & 862 & 4508 & \\
\hline & 39 & 362 & & \\
\hline IEMBL1423535 & & 362 & & \\
\hline AEMBL1432878 & 88239 & 362 & 589 & \\
\hline AEMBL1373325 & 88239 & 363 & 92 & \\
\hline HEMBL1494901 & & & & \\
\hline IEMBL142 & 39 & & & \\
\hline IEMBL1555107 & & & & \\
\hline AEMBL1367876 & 39 & 862 & & \\
\hline AEMBL1390578 & 39 & 862 & & \\
\hline AEMBL1354983 & & 62 & & \\
\hline AEMBL13] & & & & \\
\hline AEMBL1451612 & & & & \\
\hline AEMBL1433985 & & 862 & 81 & \\
\hline AEMBL1506600 & & 362 & & \\
\hline IEMBL1592475 & & 62 & & \\
\hline IEMBL1316120 & & & & \\
\hline IEMBL1965138 & & 352 & & \\
\hline AEMBL1572460 & & 362 & & \\
\hline AEMBL1330298 & & & & \\
\hline IEMBL1373951 & & 62 & & \\
\hline AEMBL1612559 & & & & \\
\hline 2736 & & & & \\
\hline AEMBL1323324 & & & & \\
\hline IEMBL1328472 & & & & \\
\hline IEMBL581346 & & & & \\
\hline 37 & & & & \\
\hline 682 & & & & \\
\hline AEMBL1560431 & & & & \\
\hline IEMBL1509279 & & & & \\
\hline 56 & & & & \\
\hline 1 & & 52 & & \\
\hline & & & & -3 \\
\hline AEMBL1453739 & & & & F \\
\hline AEMBL1574006 & & 62 & & \\
\hline & & 61 & & \\
\hline 65 & & & & \\
\hline HEMBL1564443 & & & & RN \\
\hline IEMBL1508769 & & & & $\mathrm{R}$ \\
\hline EMBL1461412 & & & & \\
\hline$-\pi-7$ & & & & \\
\hline HEMBL1596590 & & & & r \\
\hline AEMBL1513566 & & & & $\lceil\mathrm{RN}$ \\
\hline IEMBL1523123 & & 362 & 58 & TR \\
\hline & & & & \\
\hline 40 & & & & \\
\hline
\end{tabular}

Page 2669 
Supplemental Table S2.txt

\begin{tabular}{|c|c|c|c|c|}
\hline 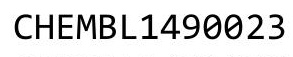 & & & & \\
\hline HEMBL1431238 & 38239 & 862 & 38 & \\
\hline AEMBL1338853 & 39 & 862 & & \\
\hline & 39 & 862 & & \\
\hline IEMBL14 & & & & \\
\hline AEMBL1359522 & 88239 & & & \\
\hline AEMBL1524014 & 88239 & 867 & 5903 & \\
\hline AEMBL3190497 & & & & \\
\hline AEMBL1469304 & 39 & 862 & & \\
\hline AEMBL134 & & 862 & & \\
\hline AEMBL1333470 & 39 & 362 & 23 & \\
\hline AEMBL3189730 & & 862 & & \\
\hline AEMBL1398270 & & & & \\
\hline HEMBL1592699 & & & & \\
\hline HEMBL134 & & & & \\
\hline AEMBL1334859 & & 862 & & \\
\hline AEMBL1312545 & & 362 & & \\
\hline IEMBL14S & & 62 & & \\
\hline AEMBL14S & & & & \\
\hline JEMBL14 & & & & \\
\hline JFMRI 15 & & 862 & & \\
\hline HEMBL140 & & 62 & & \\
\hline IEMBL145 & & 62 & & \\
\hline AFMRI 13 & & & & \\
\hline 780 & & 62 & & \\
\hline HEMBL161 & & 362 & & \\
\hline IEMBL1439645 & & & & \\
\hline IEMBL13: & & 62 & & \\
\hline IEM & & 52 & & \\
\hline 590 & & 362 & & \\
\hline AEMBL150 & & & & \\
\hline IEMBL1342824 & & 362 & & \\
\hline & & & & \\
\hline 6 & & 52 & & \\
\hline HEMBL1508830 & & & & \\
\hline AEMBL1379100 & & & & \\
\hline AEMBL1582848 & & 362 & & \\
\hline & & & & \\
\hline SIM & & & & \\
\hline HEMBL1555915 & & & & $S$ \\
\hline AEMBL1538954 & & 871 & & F \\
\hline AEMBL1340601 & & 62 & & \\
\hline & & & & \\
\hline HEMBL1436988 & & & & 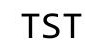 \\
\hline AEMBL1495232 & & 4.4862 & .4692 & rs \\
\hline IEMBL1384399 & & 362 & 62 & TS \\
\hline ז 19 & & & & \\
\hline HEMBL155015 & & & .4472 & \\
\hline
\end{tabular}

Page 2670 
Supplemental Table S2.txt

\begin{tabular}{|c|c|c|c|c|c|}
\hline CHEMBL1450135 & 688239 & 4.5362 & 5.4484 & TRN & \\
\hline CHEMBL1599746 & 688239 & 4.5362 & 5.4879 & TRN & \\
\hline CHEMBL3199777 & 688239 & 4.6862 & 5.5514 & TRN & \\
\hline CHEMBL1540382 & 688239 & 5.3862 & 5.5319 & TST & \\
\hline CHEMBL1325059 & 688239 & 4.5362 & 5.4455 & TRN & \\
\hline CHEMBL1441526 & 688239 & 6.6362 & 5.7094 & TRN & \\
\hline CHEMBL1437592 & 688239 & 5.4862 & 5.5464 & TRN & \\
\hline CHEMBL1554072 & 688239 & 5.4362 & 5.439 & TRN & \\
\hline CHEMBL1442316 & 688239 & 5.7862 & 5.4308 & TRN & \\
\hline CHEMBL1592956 & 688239 & 4.4362 & 5.4284 & TST & \\
\hline CHEMBL1344348 & 688239 & 5.7362 & 5.6519 & TRN & \\
\hline CHEMBL1340082 & 688239 & 4.5862 & 5.4796 & TRN & \\
\hline CHEMBL118163 & 688239 & 4.6862 & 5.5772 & TST & \\
\hline CHEMBL1368596 & 688239 & 6.1862 & 5.4901 & TRN & \\
\hline CHEMBL1427515 & 688239 & 4.9862 & 5.4878 & TRN & \\
\hline CHEMBL1606563 & 688239 & 5.0862 & 5.4802 & TRN & \\
\hline CHEMBL1423778 & 688239 & 8.28399 & 99999999 & 5.5064 & TST \\
\hline CHEMBL1307512 & 688239 & 5.4362 & 5.3689 & TRN & \\
\hline CHEMBL1505289 & 688239 & 5.3362 & 5.5978 & TST & \\
\hline CHEMBL1322470 & 688239 & 6.8861 & 5.4243 & TST & \\
\hline CHEMBL1377556 & 688239 & 4.9 & 5.5447 & TRN & \\
\hline CHEMBL1554437 & 688239 & 4.8362 & 5.4333 & TRN & \\
\hline CHEMBL1611991 & 688239 & 6.7361 & 5.3722 & TST & \\
\hline CHEMBL1608814 & 688239 & 4.5362 & 5.4769 & TRN & \\
\hline CHEMBL1355601 & 688239 & 4.7862 & 5.5634 & TRN & \\
\hline CHEMBL1446327 & 688239 & 6.8861 & 5.5288 & TRN & \\
\hline CHEMBL 2373657 & 688239 & 4.5362 & 5.4447 & TRN & \\
\hline CHEMBL1319838 & 688239 & 4.5362 & 5.4278 & TRN & \\
\hline CHEMBL1607143 & 688239 & 4.6862 & 5.5638 & TRN & \\
\hline CHEMBL1386049 & 688239 & 4.5362 & 5.4435 & TRN & \\
\hline CHEMBL1416157 & 688239 & 4.5362 & 5.5446 & TRN & \\
\hline CHEMBL3212817 & 688239 & 4.5362 & 5.3378 & TRN & \\
\hline CHEMBL1496438 & 688239 & 5.1862 & 5.4721 & TRN & \\
\hline CHEMBL1405095 & 688239 & 4.5862 & 5.4926 & TRN & \\
\hline CHEMBL1515478 & 688239 & 6.9363 & 5.4648 & TRN & \\
\hline CHEMBL1475219 & 688239 & 4.5862 & 5.4405 & TRN & \\
\hline CHEMBL1391470 & 688239 & 5.6862 & 5.55399 & 9999999999 & TRN \\
\hline CHEMBL1314631 & 688239 & 6.0362 & 5.5516 & TRN & \\
\hline CHEMBL 2001895 & 688239 & 4.7362 & 5.3938 & TST & \\
\hline CHEMBL1491756 & 688239 & 4.6362 & 5.62799 & 9999999999 & TRN \\
\hline CHEMBL1465106 & 688239 & 4.6362 & 5.3543 & TST & \\
\hline CHEMBL1393579 & 688239 & 7.6364 & 5.2934 & TST & \\
\hline CHEMBL1342072 & 688239 & 5.4862 & 5.5643 & TRN & \\
\hline CHEMBL1388875 & 688239 & 4.8862 & 5.4192 & TRN & \\
\hline CHEMBL3210029 & 688239 & 4.6862 & 5.5712 & TST & \\
\hline CHEMBL1336922 & 688239 & 4.5362 & 5.3561 & TRN & \\
\hline CHEMBL1352920 & 688239 & 6.8362 & 5.5324 & TRN & \\
\hline CHEMBL1492347 & 688239 & 8.28399 & 99999999 & 5.5619 & TRN \\
\hline
\end{tabular}


Supplemental Table S2.txt

\begin{tabular}{|c|c|c|c|c|}
\hline CHEMBL1594602 & 688239 & 5.6362 & 5.4779 & TST \\
\hline CHEMBL1377639 & 688239 & 5.1862 & 5.5611 & TRN \\
\hline CHEMBL3212100 & 688239 & 6.7361 & 5.4058 & TST \\
\hline CHEMBL1501596 & 688239 & 5.2862 & 5.4029 & TRN \\
\hline CHEMBL1532598 & 688239 & 5.6862 & 5.3917 & TRN \\
\hline CHEMBL1454444 & 688239 & 5.2362 & 5.5974 & TRN \\
\hline CHEMBL1561311 & 688239 & 5.7362 & 5.4107 & TRN \\
\hline CHEMBL1382526 & 688239 & 4.4862 & 5.4627 & TRN \\
\hline CHEMBL1549602 & 688239 & 6.3362 & 5.5486 & TRN \\
\hline CHEMBL1409928 & 688239 & 6.0362 & 5.3485 & TST \\
\hline CHEMBL1582800 & 688239 & 4.5362 & \multicolumn{2}{|c|}{5.537000000000001} \\
\hline CHEMBL1337318 & 688239 & 4.8362 & 5.5812 & TRN \\
\hline CHEMBL1539973 & 688239 & 4.6862 & 5.4727 & TST \\
\hline CHEMBL1534129 & 688239 & 6.3863 & 5.5218 & TST \\
\hline CHEMBL1606057 & 688239 & 5.8862 & 5.5095 & TRN \\
\hline CHEMBL1443058 & 688239 & 6.3362 & 5.6653 & TRN \\
\hline CHEMBL1323896 & 688239 & 5.4862 & 5.4767 & TRN \\
\hline CHEMBL1347810 & 688239 & 6.2862 & 5.4741 & TST \\
\hline CHEMBL1332423 & 688239 & 6.3362 & 5.5945 & TRN \\
\hline CHEMBL1546010 & 688239 & 4.8362 & 5.5694 & TST \\
\hline CHEMBL1502879 & 688239 & 5.3362 & 5.5923 & TRN \\
\hline CHEMBL1340392 & 688239 & 5.3862 & 5.5658 & TRN \\
\hline CHEMBL1989453 & 688239 & 5.1862 & 5.3421 & TRN \\
\hline CHEMBL1522420 & 688239 & 5.2362 & 5.5359 & TRN \\
\hline CHEMBL1532947 & 688239 & 6.5 & 5.5655 & TRN \\
\hline CHEMBL 1477770 & 688239 & 4.6362 & 5.4836 & TRN \\
\hline CHEMBL1403826 & 688239 & 6.0362 & 5.6198 & TST \\
\hline CHEMBL1531754 & 688239 & 5.6362 & 5.5281 & TRN \\
\hline CHEMBL1417454 & 688239 & 4.5362 & 5.6115 & TST \\
\hline CHEMBL1584371 & 688239 & 5.1862 & 5.3996 & TRN \\
\hline CHEMBL1446797 & 688239 & 6.6861 & 5.438 & TRN \\
\hline CHEMBL1548984 & 688239 & 8.3372 & 5.4268 & TST \\
\hline CHEMBL1588380 & 688239 & 4.5362 & 5.5274 & TRN \\
\hline CHEMBL1508778 & 688239 & 7.0862 & 5.5247 & TRN \\
\hline CHEMBL1359790 & 688239 & 6.8362 & \multicolumn{2}{|c|}{5.4479999999999995} \\
\hline CHEMBL1595768 & 688239 & 4.5862 & 5.5335 & TRN \\
\hline CHEMBL1544128 & 688239 & 5.2362 & 5.5066 & TRN \\
\hline CHEMBL1525406 & 688239 & 5.1362 & 5.5126 & TRN \\
\hline CHEMBL1547693 & 688239 & 4.6362 & 5.3471 & TRN \\
\hline CHEMBL1444410 & 688239 & 4.9362 & 5.504 & TRN \\
\hline CHEMBL1440116 & 688239 & 4.5362 & 5.4309 & TRN \\
\hline CHEMBL1593642 & 688239 & 5.4862 & 5.6423 & TRN \\
\hline CHEMBL1499919 & 688239 & 4.5362 & 5.3927 & TRN \\
\hline CHEMBL1462303 & 688239 & 5.3362 & 5.5046 & TRN \\
\hline CHEMBL1532471 & 688239 & 5.5362 & 5.5056 & TRN \\
\hline CHEMBL1507985 & 688239 & 4.5862 & 5.5198 & TRN \\
\hline CHEMBL1567609 & 688239 & 4.8362 & 5.5392 & TRN \\
\hline CHEMBL1345385 & 688239 & 5.1862 & 5.7067 & TRN \\
\hline
\end{tabular}

Page 2672 
Supplemental Table S2.txt

\begin{tabular}{|c|c|c|c|c|c|}
\hline CHEMBL1334042 & 688239 & 4.5362 & 5.4286 & TRN & \\
\hline CHEMBL1447488 & 688239 & 4.7862 & 5.5909 & TST & \\
\hline CHEMBL1609851 & 688239 & 6.2362 & 5.4855 & TRN & \\
\hline CHEMBL1303711 & 688239 & 4.7362 & 5.4625 & TRN & \\
\hline CHEMBL3214335 & 688239 & 5.1862 & 5.4066 & TRN & \\
\hline CHEMBL1396476 & 688239 & 6.0362 & 5.4426 & TRN & \\
\hline CHEMBL1353338 & 688239 & 5.1862 & 5.5762 & TST & \\
\hline CHEMBL1571254 & 688239 & 5.3862 & 5.382999 & 9999999999 & TRN \\
\hline CHEMBL1333216 & 688239 & 6.0862 & 5.394 & TRN & \\
\hline CHEMBL1363955 & 688239 & 4.7362 & 5.5545 & TRN & \\
\hline CHEMBL1390037 & 688239 & 6.0862 & 5.5823 & TRN & \\
\hline CHEMBL3211434 & 688239 & 4.5362 & 5.3796 & TRN & \\
\hline CHEMBL1501304 & 688239 & 8.28399 & 999999999 & 5.5368 & TRN \\
\hline CHEMBL1304203 & 688239 & 4.7362 & 5.5245 & TRN & \\
\hline CHEMBL1458486 & 688239 & 4.5362 & 5.6663 & TRN & \\
\hline CHEMBL1384268 & 688239 & 5.7362 & 5.6022 & TRN & \\
\hline CHEMBL1533674 & 688239 & 4.5362 & 5.4249 & TRN & \\
\hline CHEMBL1431099 & 688239 & 5.3862 & 5.5615 & TST & \\
\hline CHEMBL1400005 & 688239 & 4.4862 & 5.3907 & TST & \\
\hline CHEMBL1413124 & 688239 & 6.6362 & 5.635 & TRN & \\
\hline CHEMBL1319131 & 688239 & 5.3362 & 5.4564 & TRN & \\
\hline CHEMBL3195805 & 688239 & 4.8362 & 5.416 & TRN & \\
\hline CHEMBL1316267 & 688239 & 5.8862 & 5.6952 & TRN & \\
\hline CHEMBL1590660 & 688239 & 5.1362 & 5.3592 & TRN & \\
\hline CHEMBL1528626 & 688239 & 4.9362 & 5.4681 & TRN & \\
\hline CHEMBL1606808 & 688239 & 4.5362 & 5.5416 & TST & \\
\hline CHEMBL1500432 & 688239 & 4.7362 & 5.5651 & TRN & \\
\hline CHEMBL1500633 & 688239 & 6.6861 & 5.4868 & TST & \\
\hline CHEMBL1443619 & 688239 & 4.6362 & 5.6063 & TRN & \\
\hline CHEMBL1592025 & 688239 & 4.6862 & 5.6107 & TRN & \\
\hline CHEMBL1359418 & 688239 & 5.7362 & 5.561 & TRN & \\
\hline CHEMBL1530456 & 688239 & 5.8862 & 5.5007 & TRN & \\
\hline CHEMBL1442710 & 688239 & 5.5862 & 5.7149 & TRN & \\
\hline CHEMBL1347843 & 688239 & 4.6862 & 5.5274 & TRN & \\
\hline CHEMBL1987546 & 688239 & 4.9362 & 5.4157 & TRN & \\
\hline CHEMBL1305044 & 688239 & 4.7862 & 5.3639 & TRN & \\
\hline CHEMBL1514970 & 688239 & 7.1361 & 5.5535 & TRN & \\
\hline CHEMBL1504820 & 688239 & 5.1862 & 5.3901 & TRN & \\
\hline CHEMBL1431461 & 688239 & 6.3362 & 5.7115 & TRN & \\
\hline CHEMBL1317951 & 688239 & 6.1862 & 5.4642 & TRN & \\
\hline CHEMBL1400903 & 688239 & 4.9362 & 5.672000 & 0000000001 & \\
\hline CHEMBL1504504 & 688239 & 6.8362 & 5.513999 & 9999999999 & $\mathrm{~K}$ \\
\hline CHEMBL1461893 & 688239 & 6.2362 & 5.559 & TST & \\
\hline CHEMBL1463015 & 688239 & 6.1362 & 5.4839 & TRN & \\
\hline CHEMBL1528116 & 688239 & 6.3362 & 5.4587 & TRN & \\
\hline CHEMBL1547397 & 688239 & 6.2362 & 5.423999 & 99999999995 & $1 \mathrm{KI}$ \\
\hline CHEMBL1425466 & 688239 & 6.5363 & 5.6199 & TRN & \\
\hline CHEMBL1442382 & 688239 & 4.7862 & 5.4452 & TST & \\
\hline
\end{tabular}


Supplemental Table S2.txt

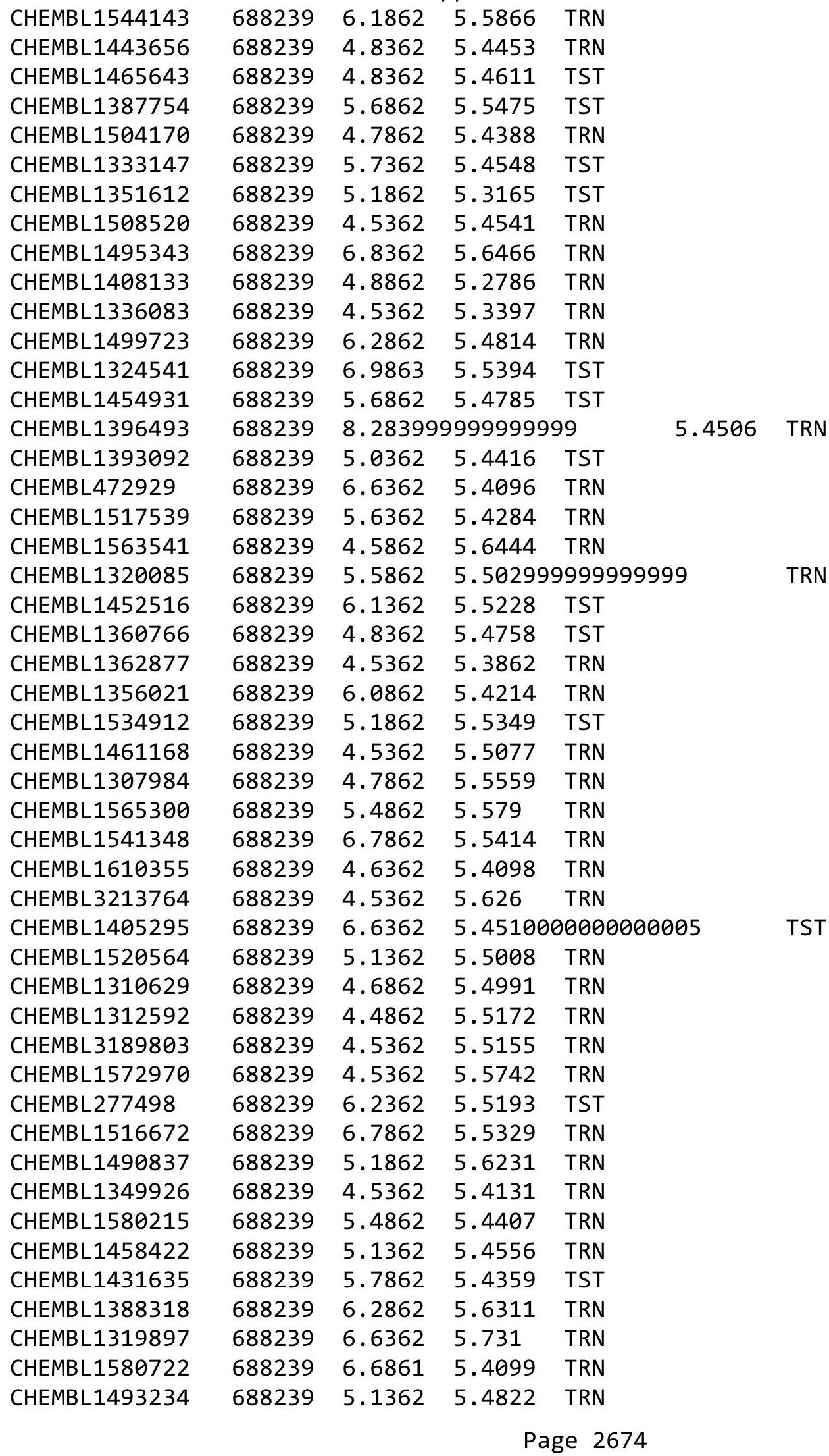


Supplemental Table S2.txt

\begin{tabular}{|c|c|c|c|c|}
\hline 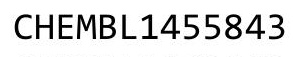 & & & & \\
\hline AEMBL1603163 & 38239 & 862 & 6148 & \\
\hline AEMBL1377616 & 239 & 62 & 673 & \\
\hline 3L1528091 & 39 & 372 & 804 & \\
\hline IEMBL1517080 & 39 & 362 & & \\
\hline AEMBL1330491 & 88239 & 362 & 532 & \\
\hline AEMBL1422461 & 88239 & 363 & 3429 & \\
\hline AEMBL1533742 & & & & \\
\hline IEMBL1430691 & 39 & 362 & & \\
\hline IEMBL3196289 & & & & \\
\hline AEMBL1574949 & 239 & 362 & 26 & \\
\hline AEMBL1359157 & 39 & 862 & & \\
\hline AEMBL1353636 & & & & \\
\hline HEMBL150 & & & & \\
\hline HEMBL1483817 & & & & \\
\hline AEMBL1325415 & & 362 & & \\
\hline HEMBL1495986 & & & & \\
\hline HEMBL154 & & & & \\
\hline AEMBL13. & & & & \\
\hline AEMBL13 & & & & \\
\hline HEMBL141 & & 62 & & \\
\hline AEMBL1539982 & & & & \\
\hline AEMBL15€ & & & & \\
\hline AFMRI 14 & & & & \\
\hline 550 & & & & \\
\hline AEMBL1523042 & & & & \\
\hline IEMBL1601573 & & & & \\
\hline AEMBL133 & & & & \\
\hline AFMRI 15 & & & & \\
\hline ר 12 & & & & \\
\hline AEMBL1518205 & & & & \\
\hline HEMBL1339616 & & & & \\
\hline & & & & \\
\hline 80 & & & & \\
\hline HEMBL1393784 & & & & RN \\
\hline AEMBL1389105 & & & & \\
\hline AEMBL1404119 & & & & \\
\hline & & & & \\
\hline 96 & & & & Trv \\
\hline HEMBL1528220 & & & & ST \\
\hline AEMBL1340932 & & & & \\
\hline AEMBL153 & & & & \\
\hline 14 & & & & \\
\hline CHEMBL1591413 & & & & \\
\hline AEMBL1376881 & & & & RN \\
\hline AEMBL1432796 & 68 & 5 . & 258 & is \\
\hline 500 & & & & \\
\hline HEMBL1337 & & & & \\
\hline
\end{tabular}


Supplemental Table S2.txt

\begin{tabular}{|c|c|c|c|c|c|}
\hline CHEMBL1324465 & 688239 & 4.5362 & 5.4423 & TRN & \\
\hline CHEMBL1300849 & 688239 & 4.7362 & 5.4304 & TRN & \\
\hline CHEMBL 3189562 & 688239 & 5.6362 & 5.4099 & TRN & \\
\hline CHEMBL1475328 & 688239 & 6.3362 & 5.4304 & TRN & \\
\hline CHEMBL1460786 & 688239 & 5.7362 & 5.5038 & TRN & \\
\hline CHEMBL1349880 & 688239 & 4.8862 & 5.4882 & TST & \\
\hline CHEMBL1477461 & 688239 & 5.7362 & 5.56 & TRN & \\
\hline CHEMBL1568254 & 688239 & 6.7862 & 5.4818 & TRN & \\
\hline CHEMBL1459347 & 688239 & 5.5362 & 5.5214 & TST & \\
\hline CHEMBL1308355 & 688239 & 5.3862 & 5.5363 & TRN & \\
\hline CHEMBL1417553 & 688239 & 5.5362 & 5.5326 & TST & \\
\hline CHEMBL1479830 & 688239 & 4.7362 & 5.3084 & TST & \\
\hline CHEMBL1400547 & 688239 & 4.4862 & 5.52 & TRN & \\
\hline CHEMBL1606544 & 688239 & 4.7862 & 5.5101 & TRN & \\
\hline CHEMBL1325722 & 688239 & 4.7362 & 5.3296 & TRN & \\
\hline CHEMBL1569951 & 688239 & 7.2366 & 5.4469 & TRN & \\
\hline CHEMBL1583826 & 688239 & 6.4362 & 5.47 & TST & \\
\hline CHEMBL1596405 & 688239 & 4.6862 & 5.4231 & TRN & \\
\hline CHEMBL1363406 & 688239 & 4.5362 & 5.4108 & TRN & \\
\hline CHEMBL1885808 & 688239 & 5.2862 & 5.5556 & TRN & \\
\hline CHEMBL1558776 & 688239 & 5.1862 & 5.6482 & TRN & \\
\hline CHEMBL1334418 & 688239 & 4.5362 & 5.3457 & TRN & \\
\hline CHEMBL1303179 & 688239 & 5.5862 & 5.5902 & TRN & \\
\hline CHEMBL1499337 & 688239 & 6.5862 & 5.6378 & TRN & \\
\hline CHEMBL1557079 & 688239 & 5.1862 & 5.5203 & TRN & \\
\hline CHEMBL1990793 & 688239 & 4.5362 & 5.3749 & TRN & \\
\hline CHEMBL 3193876 & 688239 & 6.7862 & $5.59200 e$ & 00000000005 & TRN \\
\hline CHEMBL1331917 & 688239 & 7.1864 & 5.523 & TRN & \\
\hline CHEMBL1447863 & 688239 & 4.5362 & 5.3796 & TRN & \\
\hline CHEMBL1560370 & 688239 & 5.1862 & 5.5792 & TST & \\
\hline CHEMBL1587129 & 688239 & 4.7862 & 5.3785 & TRN & \\
\hline CHEMBL1594129 & 688239 & 5.3862 & 5.5786 & TRN & \\
\hline CHEMBL1345645 & 688239 & 5.8862 & 5.3874 & TRN & \\
\hline CHEMBL1568886 & 688239 & 6.1362 & 5.3766 & TST & \\
\hline CHEMBL1587973 & 688239 & 5.0862 & 5.5195 & TST & \\
\hline CHEMBL 3190802 & 688239 & 5.0862 & 5.3339 & TRN & \\
\hline CHEMBL1518257 & 688239 & 4.5362 & 5.473 & TRN & \\
\hline CHEMBL1538109 & 688239 & 4.7362 & 5.5113 & TRN & \\
\hline CHEMBL1460230 & 688239 & 6.2862 & 5.5299 & TST & \\
\hline CHEMBL1449765 & 688239 & 5.1862 & 5.5958 & TRN & \\
\hline CHEMBL1611934 & 688239 & 8.28399 & 99999999 & 5.5035 & TST \\
\hline CHEMBL1498227 & 688239 & 6.0362 & 5.4609 & TRN & \\
\hline CHEMBL1404173 & 688239 & 4.5362 & 5.4318 & TST & \\
\hline CHEMBL1465705 & 688239 & 6.1362 & 5.4386 & TST & \\
\hline CHEMBL1449956 & 688239 & 5.4362 & 5.482 & TRN & \\
\hline CHEMBL1462555 & 688239 & 5.3362 & 5.5969 & TST & \\
\hline CHEMBL1324100 & 688239 & 4.5362 & 5.6206 & TRN & \\
\hline CHEMBL1414307 & 688239 & 6.0862 & 5.4405 & TRN & \\
\hline
\end{tabular}


Supplemental Table S2.txt

\begin{tabular}{|c|c|c|c|c|}
\hline 269 & 38239 & 5.9362 & & \\
\hline HEMBL1361106 & 88239 & 5.8862 & & \\
\hline 18 & & & & \\
\hline IEMBL148 & 3239 & & & \\
\hline AEMBL14 & 8239 & 362 & & \\
\hline HEMBL1589498 & 88239 & 0362 & 541 & \\
\hline AEMBL] & 8239 & 362 & & \\
\hline EMBL & & 3863 & & \\
\hline HEMBL146 & & 3862 & & \\
\hline HEMBL131 & 38239 & 3372 & & \\
\hline AEMBL1 & 38239 & .5862 & & \\
\hline IEMBL: & 39 & 362 & & \\
\hline IEMBL & & & & \\
\hline AEMBL. & & 5.3862 & & \\
\hline AEMBL: & & 62 & & \\
\hline AEMBL: & 39 & 362 & & \\
\hline AEMBL & & 362 & & \\
\hline AEMBL & & & & \\
\hline AEMBL & & 862 & & \\
\hline IEMBL & & & & \\
\hline AEMBL & & 68 & & \\
\hline EMBL & & 52 & & \\
\hline EMB & & 63 & & \\
\hline 83 & & 862 & & \\
\hline IEMBL: & & & & $2 \mathrm{~N}$ \\
\hline IEMBL & & 5 . & & \\
\hline EMBL & & 52 & & \\
\hline 3 & & 63 & & \\
\hline IEMBL & & & & \\
\hline AEMBL1 & & & & RN \\
\hline AEMBL: & & 52 & & \\
\hline 6 & & 52 & & \\
\hline 2 & & 62 & & RIN \\
\hline AEMBL & & 862 & & RI \\
\hline HEMBL1 & & 4.5362 & & RI \\
\hline IEMBL & & 5.4362 & & RI \\
\hline 2 & & & & \\
\hline & & & & RI \\
\hline AEMBL] & & 4.4862 & & RI \\
\hline AEMBL: & & 6.0862 & & \\
\hline AEMBL & & 6.0362 & & \\
\hline נובחים & & & & \\
\hline CHEMBL: & & 6.6861 & & ST 1 \\
\hline IEMBL: & 8239 & 6.9863 & & $\mathrm{R}$ \\
\hline MB & & 4.5362 & & \\
\hline HEMBL: & & & & \\
\hline CHEMBLI & & 7.1361 & & \\
\hline CHEMBL1553016 & 688239 & 5.4362 & 5.4586 & \\
\hline
\end{tabular}


Supplemental Table S2.txt

\begin{tabular}{|c|c|c|c|c|}
\hline 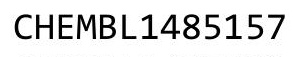 & & & & \\
\hline HEMBL1437422 & 38239 & 1862 & 88 & \\
\hline AEMBL1484753 & 239 & 362 & & \\
\hline 324 & 39 & 362 & & \\
\hline IEMBL14 & 39 & 862 & & \\
\hline AEMBL1361678 & 88239 & 362 & & \\
\hline AEMBL1346730 & 88239 & 862 & 4284 & \\
\hline AEMBL15 & & & & \\
\hline AEMBL 15 & 39 & 862 & & \\
\hline IEMBL20 & & 862 & & \\
\hline AEMBL1370271 & 39 & 862 & 98 & \\
\hline AEMBL1575374 & 39 & 362 & & \\
\hline AEMBL1531285 & & & & \\
\hline HEMBL 15 & & 362 & & \\
\hline AEMBL14 & & & & \\
\hline AEMBL15 & & 863 & & \\
\hline JEMBL13 & & 362 & & \\
\hline AEMBL15 & & 62 & & \\
\hline AEMBL13 & & & & \\
\hline AEMBL14 & & 61 & & \\
\hline AEMBL13 & & 862 & & \\
\hline AEMBL15 & & & & \\
\hline AEMBL15 & & 62 & & \\
\hline AFMBI 15 & & & & \\
\hline 96 & & & & \\
\hline ז & & 362 & & \\
\hline IEMBL31 & & & & \\
\hline IEMBL13 & & & & \\
\hline$A F M$ & & & & \\
\hline AEMBL13 & & 62 & & \\
\hline ז & & & & \\
\hline HEMBL13 & & 62 & & \\
\hline & & & & \\
\hline 9 & & & & \\
\hline HEMBL13 & & & & \\
\hline AEMBL1301880 & & & & $\mathrm{R}$ \\
\hline AEMBL1547983 & & 62 & & \\
\hline & & & & \\
\hline (2MO & & & & \\
\hline HEMBL1446280 & & & & $\mathrm{RI}$ \\
\hline AEMBL1592934 & & 62 & & $\mathrm{R}$ \\
\hline AEMBL15666 & & & & \\
\hline & & & & \\
\hline CHEMBL156 & & & & \\
\hline AEMBL1523183 & & & & RN \\
\hline IEMBL15 & & 862 & 31 & \\
\hline 120 & & & & \\
\hline HEMBL148853 & & 5.4862 & .5101 & \\
\hline
\end{tabular}

Page 2678 
Supplemental Table S2.txt

\begin{tabular}{|c|c|c|c|c|}
\hline CHEMBL1342894 & 688239 & 5.7362 & 5.3779 & TST \\
\hline CHEMBL1423023 & 688239 & 5.3862 & 5.4338 & TRN \\
\hline CHEMBL1383689 & 688239 & 6.3863 & 5.6064 & TRN \\
\hline CHEMBL1312902 & 688239 & 6.0862 & 5.4927 & TRN \\
\hline CHEMBL1574110 & 688239 & 4.7862 & 5.3897 & TST \\
\hline CHEMBL1324885 & 688239 & 4.7362 & 5.3897 & TRN \\
\hline CHEMBL3198499 & 688239 & 4.5862 & 5.375 & TST \\
\hline CHEMBL1370391 & 688239 & 4.6862 & 5.3752 & TRN \\
\hline CHEMBL1537272 & 688239 & 5.7362 & 5.4782 & TRN \\
\hline CHEMBL1570070 & 688239 & 5.7862 & 5.5763 & TRN \\
\hline CHEMBL1360888 & 688239 & 4.8362 & 5.4491 & TRN \\
\hline CHEMBL1506705 & 688239 & 8.1367 & 5.4551 & TRN \\
\hline CHEMBL1508747 & 688239 & 4.5362 & 5.5105 & TRN \\
\hline CHEMBL1384857 & 688239 & 5.5362 & 5.487999 & 9999999995 \\
\hline CHEMBL1546434 & 688239 & 5.1362 & 5.4554 & TST \\
\hline CHEMBL1608332 & 688239 & 4.4862 & 5.3983 & TST \\
\hline CHEMBL1299660 & 688239 & 5.3362 & 5.591 & TRN \\
\hline CHEMBL1400229 & 688239 & 4.8862 & 5.5307 & TRN \\
\hline CHEMBL1370658 & 688239 & 4.5362 & 5.474 & TRN \\
\hline CHEMBL1602619 & 688239 & 4.6862 & 5.5584 & TRN \\
\hline CHEMBL1320333 & 688239 & 5.0362 & 5.5224 & TST \\
\hline CHEMBL3190248 & 688239 & 5.3362 & 5.5097 & TST \\
\hline CHEMBL1391963 & 688239 & 5.6862 & 5.3644 & TST \\
\hline CHEMBL1358889 & 688239 & 5.0862 & 5.6036 & TST \\
\hline CHEMBL3189607 & 688239 & 4.7862 & 5.4762 & TRN \\
\hline CHEMBL1411120 & 688239 & 6.8362 & 5.5034 & TRN \\
\hline CHEMBL1530964 & 688239 & 4.8362 & 5.4899 & TST \\
\hline CHEMBL1420648 & 688239 & 4.7362 & 5.6756 & TRN \\
\hline CHEMBL1520547 & 688239 & 8.2366 & 5.5251 & TRN \\
\hline CHEMBL1322129 & 688239 & 6.9363 & 5.581 & TRN \\
\hline CHEMBL1435068 & 688239 & 4.8362 & 5.3289 & TRN \\
\hline CHEMBL1492060 & 688239 & 6.0362 & 5.546 & TRN \\
\hline CHEMBL1606977 & 688239 & 7.8356 & 5.4258 & TRN \\
\hline CHEMBL1339554 & 688239 & 4.6362 & 5.4012 & TRN \\
\hline CHEMBL1384712 & 688239 & 8.3372 & 5.501 & TRN \\
\hline CHEMBL1447610 & 688239 & 6.5862 & 5.4379 & TST \\
\hline CHEMBL1342010 & 688239 & 6.2362 & 5.4049 & TRN \\
\hline CHEMBL1413941 & 688239 & 4.5362 & 5.511 & TRN \\
\hline CHEMBL1492722 & 688239 & 5.9362 & 5.6196 & TRN \\
\hline CHEMBL1355636 & 688239 & 5.1862 & 5.4228 & TRN \\
\hline CHEMBL1304931 & 688239 & 5.7362 & 5.5586 & TRN \\
\hline CHEMBL1440976 & 688239 & 7.2865 & 5.5799 & TRN \\
\hline CHEMBL1536111 & 688239 & 7.2865 & 5.5056 & TRN \\
\hline CHEMBL1496850 & 688239 & 4.5362 & 5.4831 & TRN \\
\hline CHEMBL1531875 & 688239 & 4.7362 & 5.6789 & TRN \\
\hline CHEMBL1978764 & 688239 & 7.2366 & 5.365 & TRN \\
\hline CHEMBL460515 & 688239 & 4.5362 & 5.435 & TST \\
\hline CHEMBL1502571 & 688239 & 6.1362 & 5.4661 & TRN \\
\hline
\end{tabular}


Supplemental Table S2.txt

\begin{tabular}{|c|c|c|c|c|c|}
\hline CHEMBL1421817 & 688239 & 6.2362 & 5.4466 & TRN & \\
\hline CHEMBL1489950 & 688239 & 6.2362 & 5.5256 & TRN & \\
\hline CHEMBL1390377 & 688239 & 6.2362 & 5.5301 & TRN & \\
\hline CHEMBL1386761 & 688239 & 6.0862 & 5.6205 & TRN & \\
\hline CHEMBL1353302 & 688239 & 6.1862 & 5.6227 & TRN & \\
\hline CHEMBL1329042 & 688239 & 4.6862 & 5.6544 & TRN & \\
\hline CHEMBL1407993 & 688239 & 7.8861 & 5.6144 & TST & \\
\hline CHEMBL1493111 & 688239 & 5.4862 & 5.5818 & TST & \\
\hline CHEMBL1386749 & 688239 & 5.3862 & 5.4013 & TRN & \\
\hline CHEMBL1552583 & 688239 & 5.3362 & 5.5135 & TRN & \\
\hline CHEMBL1471960 & 688239 & 7.2865 & 5.6589 & TST & \\
\hline CHEMBL 29711 & 688239 & 6.6861 & 5.32299 & 99999999995 & TST \\
\hline CHEMBL1573307 & 688239 & 4.5362 & 5.37299 & 9999999999 & TRN \\
\hline CHEMBL1311452 & 688239 & 4.5362 & 5.4932 & TRN & \\
\hline CHEMBL1507199 & 688239 & 4.6862 & 5.3789 & TRN & \\
\hline CHEMBL3198774 & 688239 & 4.5362 & 5.4937 & TST & \\
\hline CHEMBL1591240 & 688239 & 6.2862 & 5.4863 & TRN & \\
\hline CHEMBL1525918 & 688239 & 4.5362 & 5.4654 & TRN & \\
\hline CHEMBL1578861 & 688239 & 4.7862 & 5.3836 & TST & \\
\hline CHEMBL1481469 & 688239 & 4.5362 & 5.5525 & TRN & \\
\hline CHEMBL1600491 & 688239 & 4.8862 & 5.5169 & TRN & \\
\hline CHEMBL1581629 & 688239 & 4.7362 & 5.3741 & TRN & \\
\hline CHEMBL1306329 & 688239 & 5.7862 & 5.5015 & TRN & \\
\hline CHEMBL1568196 & 688239 & 7.1864 & 5.5204 & TST & \\
\hline CHEMBL1610251 & 688239 & 5.8862 & 5.567 & TRN & \\
\hline CHEMBL1460918 & 688239 & 4.5362 & 5.3737 & TRN & \\
\hline CHEMBL1339017 & 688239 & 5.4362 & 5.4556 & TRN & \\
\hline CHEMBL1537582 & 688239 & 4.6362 & 5.5181 & TRN & \\
\hline CHEMBL1311284 & 688239 & 5.4362 & 5.4774 & TRN & \\
\hline CHEMBL452751 & 688239 & 6.6861 & 5.5402 & TST & \\
\hline CHEMBL1422647 & 688239 & 5.3862 & 5.4857 & TST & \\
\hline CHEMBL1453664 & 688239 & 5.1862 & 5.4287 & TRN & \\
\hline CHEMBL3193954 & 688239 & 8.3372 & 5.3584 & TRN & \\
\hline CHEMBL1390757 & 688239 & 5.1862 & 5.2698 & TRN & \\
\hline CHEMBL1539538 & 688239 & 4.5362 & 5.5147 & TRN & \\
\hline CHEMBL3213566 & 688239 & 5.1862 & 5.284 & TRN & \\
\hline CHEMBL1574600 & 688239 & 8.1871 & 5.4586 & TRN & \\
\hline CHEMBL1392839 & 688239 & 6.7862 & 5.5272 & TST & \\
\hline CHEMBL1322327 & 688239 & 4.6862 & 5.6058 & TRN & \\
\hline CHEMBL1326238 & 688239 & 4.5362 & 5.3962 & TRN & \\
\hline CHEMBL1357539 & 688239 & 4.7362 & 5.3959 & TRN & \\
\hline CHEMBL1301909 & 688239 & 5.3362 & 5.3207 & TRN & \\
\hline CHEMBL1381526 & 688239 & 6.7862 & 5.4595 & TST & \\
\hline CHEMBL1420077 & 688239 & 4.4862 & 5.6472 & TRN & \\
\hline CHEMBL1325845 & 688239 & 4.4862 & 5.4027 & TRN & \\
\hline CHEMBL1496386 & 688239 & 5.6362 & 5.4772 & TST & \\
\hline CHEMBL1405047 & 688239 & 5.2862 & 5.4512 & TRN & \\
\hline CHEMBL3210788 & 688239 & 5.1862 & 5.3813 & TST & \\
\hline
\end{tabular}


Supplemental Table S2.txt

\begin{tabular}{|c|c|c|c|c|}
\hline CHEMBL1544574 & 688239 & 5.5862 & 5.4002 & TRN \\
\hline CHEMBL1502269 & 688239 & 5.1862 & 5.4298 & TST \\
\hline CHEMBL1497949 & 688239 & 4.5362 & 5.4106 & TRN \\
\hline CHEMBL1299531 & 688239 & 4.9862 & 5.4334 & TRN \\
\hline CHEMBL 3192346 & 688239 & 5.9862 & 5.526 & TST \\
\hline CHEMBL1540731 & 688239 & 5.0862 & 5.3659 & TST \\
\hline CHEMBL1644904 & 688239 & 6.2862 & 5.5667 & TRN \\
\hline CHEMBL1506918 & 688239 & 4.5362 & 5.4065 & TRN \\
\hline CHEMBL1465803 & 688239 & 5.1362 & 5.5358 & TRN \\
\hline CHEMBL1517326 & 688239 & 4.6362 & 5.5255 & TRN \\
\hline CHEMBL1367276 & 688239 & 4.9362 & 5.5279 & TST \\
\hline CHEMBL1351198 & 688239 & 4.5362 & 5.4159 & TRN \\
\hline CHEMBL1591998 & 688239 & 4.6862 & 5.487999 & 99999999995 \\
\hline CHEMBL1522570 & 688239 & 7.2366 & 5.6009 & TRN \\
\hline CHEMBL1594481 & 688239 & 6.5862 & 5.3586 & TRN \\
\hline CHEMBL1480282 & 688239 & 4.7862 & 5.3095 & TRN \\
\hline CHEMBL1575524 & 688239 & 6.5363 & 5.6117 & TRN \\
\hline CHEMBL1506084 & 688239 & 5.2862 & 5.6612 & TRN \\
\hline CHEMBL1401488 & 688239 & 4.5362 & 5.3729 & TST \\
\hline CHEMBL1445829 & 688239 & 4.9362 & 5.5032 & TST \\
\hline CHEMBL1476115 & 688239 & 5.0862 & 5.5414 & TRN \\
\hline CHEMBL1573529 & 688239 & 6.0 & 5.4241 & TRN \\
\hline CHEMBL 3189266 & 688239 & 5.8362 & 5.4972 & TST \\
\hline CHEMBL1587904 & 688239 & 5.0362 & 5.5702 & TRN \\
\hline CHEMBL1369930 & 688239 & 5.1862 & 5.4797 & TST \\
\hline CHEMBL1557759 & 688239 & 5.1862 & 5.5078 & TRN \\
\hline CHEMBL1578668 & 688239 & 4.4862 & 5.4289 & TRN \\
\hline CHEMBL1572660 & 688239 & 5.3862 & 5.5089 & TRN \\
\hline CHEMBL 3197449 & 688239 & 5.8862 & 5.6018 & TRN \\
\hline CHEMBL1532894 & 688239 & 4.5362 & 5.4284 & TRN \\
\hline CHEMBL1363911 & 688239 & 4.6362 & 5.3628 & TRN \\
\hline CHEMBL1411370 & 688239 & 7.4868 & 5.5328 & TRN \\
\hline CHEMBL1519265 & 688239 & 4.5362 & 5.566 & TRN \\
\hline CHEMBL1373331 & 688239 & 5.2862 & 5.5107 & TRN \\
\hline CHEMBL1520705 & 688239 & 5.1362 & 5.462999 & 9999999999 \\
\hline CHEMBL1387510 & 688239 & 4.5362 & 5.324 & TRN \\
\hline CHEMBL1342591 & 688239 & 5.9362 & 5.472 & TRN \\
\hline CHEMBL1399341 & 688239 & 4.7862 & 5.5115 & TST \\
\hline CHEMBL1491268 & 688239 & 5.2862 & 5.4927 & TST \\
\hline CHEMBL1515101 & 688239 & 5.0862 & 5.4534 & TRN \\
\hline CHEMBL1555115 & 688239 & 4.5362 & 5.3509 & TRN \\
\hline CHEMBL1577747 & 688239 & 5.1862 & 5.5872 & TRN \\
\hline CHEMBL1579857 & 688239 & 7.6364 & 5.571006 & 0000000001 \\
\hline CHEMBL1556848 & 688239 & 6.8362 & 5.4844 & TST \\
\hline CHEMBL1431993 & 688239 & 5.3362 & 5.5334 & TRN \\
\hline CHEMBL1385248 & 688239 & 7.0362 & 5.6806 & TST \\
\hline CHEMBL1450982 & 688239 & 6.5862 & 5.3461 & TRN \\
\hline CHEMBL1320268 & 688239 & 5.1862 & 5.6184 & TRN \\
\hline
\end{tabular}


Supplemental Table S2.txt

\begin{tabular}{|c|c|c|c|c|}
\hline CHEMBL1504340 & 688239 & 4.5362 & 5.5492 & TRN \\
\hline CHEMBL1455234 & 688239 & 5.0862 & 5.5758 & TRN \\
\hline CHEMBL1371481 & 688239 & 4.6862 & 5.6533 & TRN \\
\hline CHEMBL1491381 & 688239 & 6.4362 & 5.3725 & TST \\
\hline CHEMBL1362394 & 688239 & 6.2862 & 5.4885 & TRN \\
\hline CHEMBL1609268 & 688239 & 4.5362 & 5.6504 & TST \\
\hline CHEMBL1342149 & 688239 & 6.8861 & \multicolumn{2}{|c|}{5.48600000000} \\
\hline CHEMBL1433074 & 688239 & 5.2862 & 5.4101 & TST \\
\hline CHEMBL1604513 & 688239 & 5.6362 & 5.5193 & TRN \\
\hline CHEMBL1389392 & 688239 & 8.3372 & 5.6295 & TST \\
\hline CHEMBL1325182 & 688239 & 4.7362 & 5.5437 & TRN \\
\hline CHEMBL1580887 & 688239 & 5.1862 & 5.3511 & TST \\
\hline CHEMBL1583213 & 688239 & 5.6362 & 5.4868 & TRN \\
\hline CHEMBL1525353 & 688239 & 4.6362 & 5.5515 & TRN \\
\hline CHEMBL1545210 & 688239 & 4.6362 & 5.5123 & TST \\
\hline CHEMBL1391372 & 688239 & 6.1362 & 5.4978 & TRN \\
\hline CHEMBL1486323 & 688239 & 5.3862 & 5.553 & TRN \\
\hline CHEMBL3197292 & 688239 & 5.5862 & 5.3987 & TRN \\
\hline CHEMBL1527581 & 688239 & 4.7362 & 5.4213 & TRN \\
\hline CHEMBL1588064 & 688239 & 6.8861 & 5.6603 & TRN \\
\hline CHEMBL1347707 & 688239 & 7.1361 & 5.5514 & TST \\
\hline CHEMBL1540381 & 688239 & 4.5362 & 5.4893 & TRN \\
\hline CHEMBL1559769 & 688239 & 5.0362 & 5.4336 & TRN \\
\hline CHEMBL3214137 & 688239 & 4.5362 & 5.4262 & TRN \\
\hline CHEMBL1431027 & 688239 & 8.3372 & 5.3578 & TRN \\
\hline CHEMBL1349468 & 688239 & 4.5362 & 5.5048 & TRN \\
\hline CHEMBL1533873 & 688239 & 6.5363 & 5.546 & TRN \\
\hline CHEMBL1446247 & 688239 & 6.8362 & 5.3563 & TST \\
\hline CHEMBL1345769 & 688239 & 5.4862 & 5.4085 & TRN \\
\hline CHEMBL1369949 & 688239 & 4.5362 & 5.4294 & TST \\
\hline CHEMBL1552594 & 688239 & 6.4862 & 5.6445 & TRN \\
\hline CHEMBL1538225 & 688239 & 5.5362 & 5.5053 & TST \\
\hline CHEMBL1321895 & 688239 & 5.1362 & 5.5729 & TST \\
\hline CHEMBL1555282 & 688239 & 5.1862 & 5.6369 & TRN \\
\hline CHEMBL1501864 & 688239 & 5.1862 & 5.4906 & TRN \\
\hline CHEMBL1372076 & 688239 & 6.0862 & 5.3655 & TRN \\
\hline CHEMBL1387524 & 688239 & 6.6362 & 5.5902 & TRN \\
\hline CHEMBL1346872 & 688239 & 4.5362 & 5.6373 & TST \\
\hline CHEMBL1498277 & 688239 & 6.7862 & 5.5691 & TRN \\
\hline CHEMBL1301896 & 688239 & 6.9363 & 5.5006 & TRN \\
\hline CHEMBL1599621 & 688239 & 4.8862 & 5.4983 & TRN \\
\hline CHEMBL1420235 & 688239 & 5.2362 & 5.6155 & TRN \\
\hline CHEMBL1379953 & 688239 & 5.3862 & 5.5454 & TRN \\
\hline CHEMBL1410438 & 688239 & 5.6862 & 5.4574 & TRN \\
\hline CHEMBL1990952 & 688239 & 5.1862 & 5.5005 & TRN \\
\hline CHEMBL1607772 & 688239 & 5.0362 & 5.4366 & TRN \\
\hline CHEMBL1597042 & 688239 & 4.6862 & 5.4778 & TRN \\
\hline CHEMBL1328888 & 688239 & 4.5362 & 5.4352 & TST \\
\hline
\end{tabular}

Page 2682 
Supplemental Table S2.txt

\begin{tabular}{|c|c|c|c|c|c|}
\hline CHEMBL1337171 & 688239 & 5.3362 & 5.4695 & TRN & \\
\hline CHEMBL1344111 & 688239 & 6.9363 & 5.5229 & TRN & \\
\hline CHEMBL1587777 & 688239 & 5.6862 & 5.4612 & TRN & \\
\hline CHEMBL1379011 & 688239 & 4.7362 & 5.4584 & TRN & \\
\hline CHEMBL1561253 & 688239 & 4.5362 & 5.6147 & TST & \\
\hline CHEMBL1407165 & 688239 & 4.5362 & 5.5299 & TST & \\
\hline CHEMBL1458490 & 688239 & 4.5362 & 5.6738 & TRN & \\
\hline CHEMBL1541644 & 688239 & 4.5362 & 5.657999 & 99999999995 & TRN \\
\hline CHEMBL1511699 & 688239 & 5.4362 & 5.4619 & TRN & \\
\hline CHEMBL1346745 & 688239 & 5.6362 & 5.3931 & TST & \\
\hline CHEMBL1426610 & 688239 & 8.28399 & 99999999 & 5.4324 & 7 \\
\hline CHEMBL1347339 & 688239 & 4.5862 & 5.2953 & TST & \\
\hline CHEMBL1494473 & 688239 & 7.1864 & 5.6141 & TRN & \\
\hline CHEMBL1449303 & 688239 & 5.4362 & 5.4892 & TST & \\
\hline CHEMBL1432718 & 688239 & 5.6862 & 5.5534 & TST & \\
\hline CHEMBL1608487 & 688239 & 5.5362 & 5.4695 & TRN & \\
\hline CHEMBL1380531 & 688239 & 4.5862 & 5.4005 & TRN & \\
\hline CHEMBL1413312 & 688239 & 4.5362 & 5.5058 & TST & \\
\hline CHEMBL1384738 & 688239 & 5.9362 & 5.4986 & TRN & \\
\hline CHEMBL1336042 & 688239 & 5.8362 & 5.4808 & TRN & \\
\hline CHEMBL1609645 & 688239 & 5.4362 & 5.5061 & TRN & \\
\hline CHEMBL1384599 & 688239 & 4.8362 & 5.4863 & TRN & \\
\hline CHEMBL1466493 & 688239 & 5.5362 & 5.4434 & TRN & \\
\hline CHEMBL1312628 & 688239 & 6.1362 & 5.5213 & TRN & \\
\hline CHEMBL1405967 & 688239 & 6.9863 & 5.4542 & TST & \\
\hline CHEMBL1511276 & 688239 & 6.0 & 5.4126 & TRN & \\
\hline CHEMBL 3213802 & 688239 & 6.8861 & 5.4713 & TRN & \\
\hline CHEMBL1465124 & 688239 & 4.8362 & 5.5102 & TRN & \\
\hline CHEMBL1431778 & 688239 & 7.6364 & 5.5296 & TRN & \\
\hline CHEMBL1567800 & 688239 & 4.5362 & 5.4676 & TST & \\
\hline CHEMBL1497571 & 688239 & 7.5361 & 5.5302 & TRN & \\
\hline CHEMBL1412521 & 688239 & 6.1362 & 5.3414 & TRN & \\
\hline CHEMBL1504746 & 688239 & 8.3872 & 5.4793 & TRN & \\
\hline CHEMBL1337568 & 688239 & 6.6861 & 5.5498 & TST & \\
\hline CHEMBL3194841 & 688239 & 4.8362 & 5.63 & TST & \\
\hline CHEMBL1966824 & 688239 & 5.1362 & 5.405 & TRN & \\
\hline CHEMBL1595251 & 688239 & 4.9862 & 5.5725 & TST & \\
\hline CHEMBL1486715 & 688239 & 4.5362 & 5.3743 & TRN & \\
\hline CHEMBL1600118 & 688239 & 5.8862 & 5.5773 & TST & \\
\hline CHEMBL1440838 & 688239 & 5.0362 & 5.6317 & TRN & \\
\hline CHEMBL1611613 & 688239 & 4.5362 & 5.507006 & 0000000001 & TST \\
\hline CHEMBL3191821 & 688239 & 4.6362 & 5.4001 & TRN & \\
\hline CHEMBL1367395 & 688239 & 4.5362 & 5.62 & TRN & \\
\hline CHEMBL1464298 & 688239 & 4.8362 & 5.3972 & TST & \\
\hline CHEMBL1528736 & 688239 & 5.6862 & 5.4679 & TRN & \\
\hline CHEMBL 3209982 & 688239 & 4.5362 & 5.4692 & TRN & \\
\hline CHEMBL1608363 & 688239 & 4.6862 & 5.5433 & TRN & \\
\hline CHEMBL1408261 & 688239 & 5.9362 & 5.4082 & TST & \\
\hline
\end{tabular}


Supplemental Table S2.txt

\begin{tabular}{|c|c|c|c|c|c|}
\hline CHEMBL1407900 & 688239 & 5.1362 & 5.7175 & TRN & \\
\hline CHEMBL1401174 & 688239 & 4.5362 & 5.419 & TRN & \\
\hline CHEMBL1444273 & 688239 & 4.6362 & 5.468 & TRN & \\
\hline CHEMBL1601708 & 688239 & 5.7862 & 5.5351 & TST & \\
\hline CHEMBL1392484 & 688239 & 4.8362 & 5.4855 & TST & \\
\hline CHEMBL1328305 & 688239 & 4.7862 & 5.3911 & TRN & \\
\hline CHEMBL1501884 & 688239 & 4.6362 & 5.2867 & TRN & \\
\hline CHEMBL1426341 & 688239 & 5.8862 & 5.631 & TRN & \\
\hline CHEMBL1528625 & 688239 & 4.5362 & 5.5896 & TRN & \\
\hline CHEMBL1429942 & 688239 & 5.1862 & 5.4206 & TRN & \\
\hline CHEMBL1539185 & 688239 & 6.9863 & 5.5704 & TRN & \\
\hline CHEMBL1602783 & 688239 & 5.5362 & 5.5882 & TST & \\
\hline CHEMBL1585948 & 688239 & 5.7862 & 5.4068 & TRN & \\
\hline CHEMBL1449471 & 688239 & 5.3362 & 5.5465 & TST & \\
\hline CHEMBL1571258 & 688239 & 4.4862 & 5.4676 & TST & \\
\hline CHEMBL1497664 & 688239 & 6.8861 & 5.6144 & TRN & \\
\hline CHEMBL1421463 & 688239 & 5.1862 & 5.4088 & TST & \\
\hline CHEMBL1393347 & 688239 & 4.7362 & 5.6983 & TRN & \\
\hline CHEMBL3189689 & 688239 & 6.4862 & 5.4274 & TST & \\
\hline CHEMBL3199341 & 688239 & 4.4862 & 5.6606 & TRN & \\
\hline CHEMBL1565819 & 688239 & 4.6362 & 5.4432 & TST & \\
\hline CHEMBL1406600 & 688239 & 5.5362 & 5.4828 & TRN & \\
\hline CHEMBL1573044 & 688239 & 6.2362 & 5.5878 & TRN & \\
\hline CHEMBL1480610 & 688239 & 5.6862 & 5.6561 & TRN & \\
\hline CHEMBL1435898 & 688239 & 5.0362 & 5.4512 & TRN & \\
\hline CHEMBL1420995 & 688239 & 6.3863 & 5.4045 & TST & \\
\hline CHEMBL1463361 & 688239 & 6.1862 & 5.4666 & TRN & \\
\hline CHEMBL1573050 & 688239 & 5.0362 & 5.4108 & TRN & \\
\hline CHEMBL1566978 & 688239 & 5.1862 & 5.5081 & TRN & \\
\hline CHEMBL1405761 & 688239 & 4.8862 & \multicolumn{2}{|c|}{5.6610000000000005} & TRN \\
\hline CHEMBL1505310 & 688239 & 6.1862 & 5.5932 & TRN & \\
\hline CHEMBL1524627 & 688239 & 6.7862 & 5.6233 & TRN & \\
\hline CHEMBL1570923 & 688239 & 6.1862 & 5.5061 & TST & \\
\hline CHEMBL144584 & 688239 & 5.3362 & 5.3594 & TRN & \\
\hline CHEMBL1530580 & 688239 & 4.8862 & 5.4902 & TRN & \\
\hline CHEMBL1367607 & 688239 & 5.1862 & 5.6508 & TRN & \\
\hline CHEMBL1463977 & 688239 & 4.6862 & 5.402 & TRN & \\
\hline CHEMBL1532439 & 688239 & 6.4862 & 5.4124 & TRN & \\
\hline CHEMBL1424530 & 688239 & 4.7862 & 5.3883 & TRN & \\
\hline CHEMBL1541656 & 688239 & 4.4862 & 5.5828 & TRN & \\
\hline CHEMBL1528451 & 688239 & 6.1362 & 5.5594 & TRN & \\
\hline CHEMBL1352760 & 688239 & 5.6862 & 5.54299 & 9999999999 & TRN \\
\hline CHEMBL1492057 & 688239 & 4.4862 & 5.5146 & TRN & \\
\hline CHEMBL1502220 & 688239 & 4.8862 & 5.3997 & TRN & \\
\hline CHEMBL1582150 & 688239 & 5.1362 & 5.4095 & TRN & \\
\hline CHEMBL1328485 & 688239 & 6.8362 & \multicolumn{2}{|c|}{5.377000000000001} & TRN \\
\hline CHEMBL1348054 & 688239 & 4.6862 & 5.4994 & TST & \\
\hline CHEMBL1398794 & 688239 & 4.9362 & 5.3632 & TRN & \\
\hline
\end{tabular}


Supplemental Table S2.txt

\begin{tabular}{|c|c|c|c|c|}
\hline 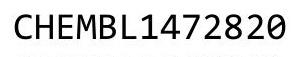 & & & & \\
\hline HEMBL1568941 & 38239 & 1862 & 2398 & \\
\hline AEMBL1404101 & 239 & 863 & & \\
\hline 399 & 39 & 862 & & \\
\hline IEMBL1484514 & 39 & 862 & & \\
\hline AEMBL1549798 & 88239 & 362 & 5039 & \\
\hline AEMBL1571611 & 88239 & 372 & 6046 & \\
\hline HEMBL1539821 & & & & \\
\hline EMBL14 & 39 & 362 & & \\
\hline IEMBL15 & & & & \\
\hline AEMBL1483256 & 39 & 362 & 5302 & \\
\hline AEMBL1393685 & & 362 & 78 & \\
\hline HEMBL157 & & & & \\
\hline AEMBL & & & & \\
\hline AEMBL15 & & & & \\
\hline HEMBL155 & & 862 & 22 & \\
\hline AEMBL1511575 & & 362 & & \\
\hline IEMBL13 & & 62 & & \\
\hline AEMBL15 & & & & \\
\hline AEMBL14 & & 61 & & \\
\hline JEMBL15 & & 862 & & \\
\hline AEMBL1387236 & & & & \\
\hline HEMBL 32 & & & & \\
\hline AFMRI 13 & & & & \\
\hline 14 & & & & \\
\hline AEMBL 14 & & & & \\
\hline IEMBL1560164 & & & & \\
\hline EMBL15 & & & & \\
\hline ALMP & & & & \\
\hline 37 & & 63 & & \\
\hline מבת נחו & & & & \\
\hline HEMBL1559530 & & & & \\
\hline & & & & \\
\hline 8 & & & & \\
\hline AEMBL15 & & & & \\
\hline AEMBL1409211 & & & & \\
\hline AEMBL1537245 & & 62 & & \\
\hline & & & & \\
\hline SIM & & & & \\
\hline HEMBL31 & & & & \\
\hline AEMBL 14 & & 62 & & \\
\hline JEMBL31\& & & & & $=$ \\
\hline & & & & \\
\hline HEMBL155 & & & & \\
\hline AEMBL1558774 & & 4.5362 & 4873 & $\mathrm{RN}$ \\
\hline IEMBL31916 & & 5.3362 & 3924 & \\
\hline 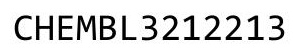 & & & & \\
\hline HEMBL140069 & & & & \\
\hline
\end{tabular}

Page 2685 
Supplemental Table S2.txt

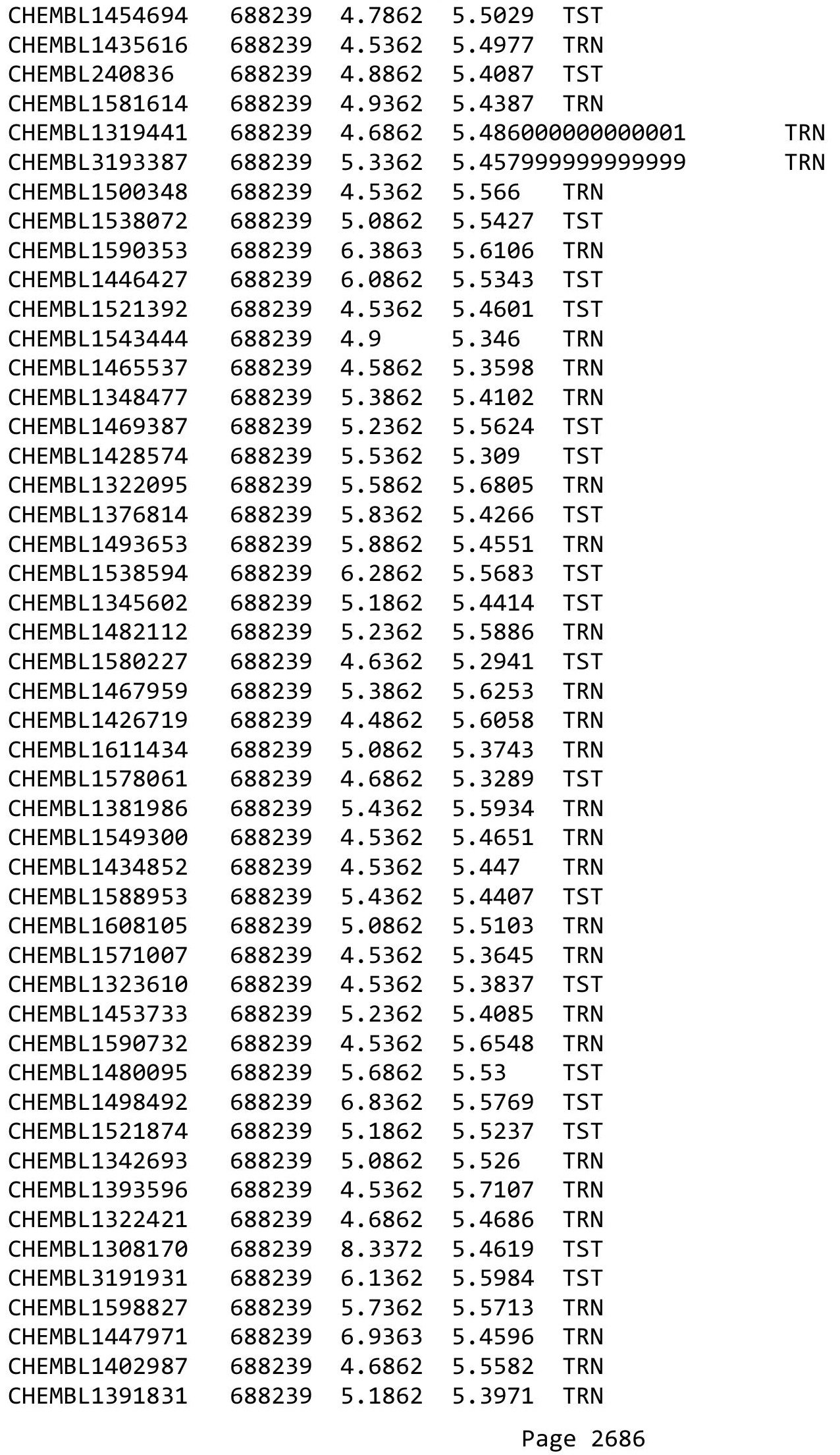


Supplemental Table S2.txt

\begin{tabular}{|c|c|c|c|c|}
\hline CHEMBL1462539 & 688239 & 5.2862 & 5.5066 & TRN \\
\hline CHEMBL1378749 & 688239 & 4.6362 & 5.5314 & TRN \\
\hline CHEMBL169662 & 688239 & 6.1362 & 5.5042 & TRN \\
\hline CHEMBL1486883 & 688239 & 6.2862 & 5.3561 & TRN \\
\hline CHEMBL1417096 & 688239 & 6.9363 & 5.3607 & TRN \\
\hline CHEMBL1610581 & 688239 & 6.2362 & 5.5123 & TRN \\
\hline CHEMBL1545781 & 688239 & 7.7352 & 5.5787 & TRN \\
\hline CHEMBL1588971 & 688239 & 4.6862 & 5.4121 & TST \\
\hline CHEMBL1366482 & 688239 & 6.7862 & 5.4003 & TST \\
\hline CHEMBL1499868 & 688239 & 5.1862 & 5.4232 & TST \\
\hline CHEMBL1389754 & 688239 & 5.5362 & 5.6187 & TRN \\
\hline CHEMBL1573298 & 688239 & 4.5362 & 5.4062 & TRN \\
\hline CHEMBL1544972 & 688239 & 8.1367 & 5.4368 & TRN \\
\hline CHEMBL1422526 & 688239 & 4.6862 & 5.4513 & TRN \\
\hline CHEMBL1541539 & 688239 & 6.8362 & 5.5832 & TRN \\
\hline CHEMBL1388625 & 688239 & 5.7862 & 5.4365 & TRN \\
\hline CHEMBL1437898 & 688239 & 5.9362 & 5.4508 & TRN \\
\hline CHEMBL1422726 & 688239 & 5.6362 & 5.5441 & TRN \\
\hline CHEMBL3196671 & 688239 & 5.2362 & 5.4757 & TRN \\
\hline CHEMBL1453175 & 688239 & 5.2862 & 5.5165 & TST \\
\hline CHEMBL1432211 & 688239 & 5.1862 & 5.5154 & TRN \\
\hline CHEMBL1538704 & 688239 & 4.4862 & 5.4806 & TRN \\
\hline CHEMBL1530302 & 688239 & 4.4862 & 5.4802 & TRN \\
\hline CHEMBL1308276 & 688239 & 4.7362 & 5.2846 & TST \\
\hline CHEMBL1540492 & 688239 & 4.7862 & 5.4809 & TST \\
\hline CHEMBL1502865 & 688239 & 6.1862 & 5.4309 & TST \\
\hline CHEMBL1492868 & 688239 & 6.9863 & 5.306 & TRN \\
\hline CHEMBL3190910 & 688239 & 5.9362 & 5.3224 & TST \\
\hline CHEMBL1344406 & 688239 & 5.3862 & 5.5485 & TRN \\
\hline CHEMBL1565380 & 688239 & 5.7862 & 5.4765 & TST \\
\hline CHEMBL1328995 & 688239 & 4.7362 & 5.4177 & TRN \\
\hline CHEMBL1451982 & 688239 & 5.0862 & 5.4747 & TRN \\
\hline CHEMBL1600058 & 688239 & 4.5362 & 5.3875 & TRN \\
\hline CHEMBL1414283 & 688239 & 5.6862 & 5.5687 & TRN \\
\hline CHEMBL1384804 & 688239 & 5.3362 & 5.4512 & TST \\
\hline CHEMBL1425257 & 688239 & 7.1864 & 5.515 & TRN \\
\hline CHEMBL1382240 & 688239 & 5.1862 & 5.4162 & TST \\
\hline CHEMBL1426311 & 688239 & 6.3362 & 5.4355 & TRN \\
\hline CHEMBL1306524 & 688239 & 4.5362 & 5.4245 & TST \\
\hline CHEMBL1358802 & 688239 & 5.5862 & 5.49100 & 00000000005 \\
\hline CHEMBL1356186 & 688239 & 6.0362 & 5.4979 & TRN \\
\hline CHEMBL1552260 & 688239 & 5.1862 & 5.4689 & TRN \\
\hline CHEMBL1510459 & 688239 & 4.7362 & 5.3431 & TRN \\
\hline CHEMBL1436732 & 688239 & 6.2862 & 5.4026 & TRN \\
\hline CHEMBL1328601 & 688239 & 5.6862 & 5.5464 & TRN \\
\hline CHEMBL1386768 & 688239 & 6.1362 & 5.3708 & TST \\
\hline CHEMBL1444340 & 688239 & 4.4862 & 5.5754 & TRN \\
\hline CHEMBL1408997 & 688239 & 6.0862 & 5.5338 & TRN \\
\hline
\end{tabular}


Supplemental Table S2.txt

\begin{tabular}{|c|c|c|c|c|}
\hline CHEMBL1583426 & 688239 & 5.6862 & 5.3614 & TRN \\
\hline CHEMBL1315778 & 688239 & 8.2366 & 5.4401 & TRN \\
\hline CHEMBL1387444 & 688239 & 7.2865 & 5.6674 & TRN \\
\hline CHEMBL1454155 & 688239 & 4.5362 & 5.5215 & TRN \\
\hline CHEMBL1407917 & 688239 & 4.6862 & 5.3961 & TRN \\
\hline CHEMBL1550732 & 688239 & 4.7862 & 5.6504 & TRN \\
\hline CHEMBL1429803 & 688239 & 5.4862 & 5.5768 & TRN \\
\hline CHEMBL1581462 & 688239 & 5.4362 & 5.5253 & TST \\
\hline CHEMBL1579791 & 688239 & 4.4862 & 5.6204 & TRN \\
\hline CHEMBL1541510 & 688239 & 7.1361 & 5.6871 & TRN \\
\hline CHEMBL1314447 & 688239 & 5.4362 & 5.4475 & TST \\
\hline CHEMBL175434 & 688239 & 4.7362 & 5.3514 & TRN \\
\hline CHEMBL1423193 & 688239 & 4.7862 & 5.5843 & TRN \\
\hline CHEMBL1383541 & 688239 & 6.8861 & 5.5686 & TRN \\
\hline CHEMBL1384057 & 688239 & 5.1862 & 5.387000 & 0000000005 \\
\hline CHEMBL1361780 & 688239 & 5.2362 & 5.5665 & TRN \\
\hline CHEMBL1600360 & 688239 & 4.5362 & 5.4929 & TRN \\
\hline CHEMBL1482121 & 688239 & 5.1862 & 5.5209 & TRN \\
\hline CHEMBL1605639 & 688239 & 6.0862 & 5.6105 & TRN \\
\hline CHEMBL1450152 & 688239 & 7.5361 & 5.4984 & TRN \\
\hline CHEMBL1460743 & 688239 & 4.4362 & 5.4157 & TRN \\
\hline CHEMBL1351968 & 688239 & 4.7862 & 5.5859 & TRN \\
\hline CHEMBL1432763 & 688239 & 5.1862 & 5.6294 & TRN \\
\hline CHEMBL1587807 & 688239 & 5.5362 & 5.5547 & TST \\
\hline CHEMBL1515580 & 688239 & 4.5362 & 5.4939 & TST \\
\hline CHEMBL1455636 & 688239 & 5.6362 & 5.6116 & TRN \\
\hline CHEMBL1409119 & 688239 & 4.6862 & 5.5665 & TRN \\
\hline CHEMBL 3191387 & 688239 & 5.6362 & 5.4888 & TST \\
\hline CHEMBL1527640 & 688239 & 6.8362 & 5.462000 & 000000001 \\
\hline CHEMBL1323564 & 688239 & 6.3362 & 5.5808 & TST \\
\hline CHEMBL1609665 & 688239 & 6.1862 & 5.5341 & TRN \\
\hline CHEMBL 3194627 & 688239 & 4.8362 & 5.3843 & TST \\
\hline CHEMBL1529527 & 688239 & 7.2865 & 5.4427 & TRN \\
\hline CHEMBL1606943 & 688239 & 4.6862 & 5.6383 & TST \\
\hline CHEMBL1992872 & 688239 & 4.7862 & 5.3843 & TST \\
\hline CHEMBL1405901 & 688239 & 4.9362 & 5.4234 & TRN \\
\hline CHEMBL1608211 & 688239 & 5.7362 & 5.7104 & TRN \\
\hline CHEMBL1587577 & 688239 & 5.4362 & 5.465 & TRN \\
\hline CHEMBL1441887 & 688239 & 6.1862 & 5.4485 & TRN \\
\hline CHEMBL1605706 & 688239 & 4.6362 & 5.487999 & 9999999995 \\
\hline CHEMBL1478001 & 688239 & 4.6362 & 5.4401 & TRN \\
\hline CHEMBL1420044 & 688239 & 5.7362 & 5.5287 & TST \\
\hline CHEMBL3197941 & 688239 & 5.8362 & 5.4643 & TRN \\
\hline CHEMBL1571307 & 688239 & 7.2366 & 5.5902 & TRN \\
\hline CHEMBL1548203 & 688239 & 4.7862 & 5.2853 & TRN \\
\hline CHEMBL1516271 & 688239 & 5.5362 & 5.5879 & TRN \\
\hline CHEMBL1380971 & 688239 & 7.2366 & 5.5401 & TRN \\
\hline CHEMBL1510343 & 688239 & 5.3362 & 5.4627 & TRN \\
\hline
\end{tabular}


Supplemental Table S2.txt

\begin{tabular}{|c|c|c|c|c|}
\hline CHEMBL1301334 & 688239 & 5.9362 & 5.5467 & TRN \\
\hline CHEMBL1494797 & 688239 & 4.9362 & 5.4168 & TRN \\
\hline CHEMBL1578689 & 688239 & 7.1864 & 5.5109 & TRN \\
\hline CHEMBL1340777 & 688239 & 4.6362 & 5.492999 & 9999999999 \\
\hline CHEMBL1384365 & 688239 & 6.2362 & 5.5279 & TRN \\
\hline CHEMBL1365833 & 688239 & 4.9362 & 5.5264 & TRN \\
\hline CHEMBL1383148 & 688239 & 5.1862 & 5.3595 & TRN \\
\hline CHEMBL1982539 & 688239 & 5.9362 & 5.2739 & TRN \\
\hline CHEMBL1386718 & 688239 & 6.2862 & 5.3364 & TRN \\
\hline CHEMBL1392578 & 688239 & 4.5862 & 5.6036 & TRN \\
\hline CHEMBL1403716 & 688239 & 6.9363 & 5.3687 & TRN \\
\hline CHEMBL1547220 & 688239 & 4.6862 & 5.5296 & TST \\
\hline CHEMBL1450703 & 688239 & 5.4362 & 5.4597 & TRN \\
\hline CHEMBL1312164 & 688239 & 6.2362 & 5.4625 & TRN \\
\hline CHEMBL 3195598 & 688239 & 6.7862 & 5.5562 & TRN \\
\hline CHEMBL 3194199 & 688239 & 5.0362 & 5.3592 & TRN \\
\hline CHEMBL1471722 & 688239 & 4.5362 & 5.4088 & TRN \\
\hline CHEMBL1357482 & 688239 & 5.9362 & 5.5267 & TRN \\
\hline CHEMBL1420546 & 688239 & 4.6862 & 5.4552 & TRN \\
\hline CHEMBL1391500 & 688239 & 4.6362 & 5.4357 & TRN \\
\hline CHEMBL1332809 & 688239 & 4.5362 & 5.4547 & TRN \\
\hline CHEMBL1383128 & 688239 & 4.7862 & 5.5182 & TST \\
\hline CHEMBL1598730 & 688239 & 5.0862 & 5.5645 & TST \\
\hline CHEMBL1382838 & 688239 & 5.7362 & 5.504 & TST \\
\hline CHEMBL1329861 & 688239 & 5.6862 & 5.4988 & TRN \\
\hline CHEMBL1354405 & 688239 & 6.6362 & 5.4018 & TRN \\
\hline CHEMBL1361257 & 688239 & 5.3862 & 5.5289 & TST \\
\hline CHEMBL1446547 & 688239 & 7.2366 & 5.423999 & 99999999995 \\
\hline CHEMBL1465451 & 688239 & 5.1362 & 5.396 & TST \\
\hline CHEMBL1326806 & 688239 & 5.6362 & 5.5747 & TRN \\
\hline CHEMBL1439381 & 688239 & 5.2362 & 5.3159 & TST \\
\hline CHEMBL1458371 & 688239 & 6.0362 & 5.4548 & TRN \\
\hline CHEMBL1375174 & 688239 & 7.0362 & 5.5997 & TST \\
\hline CHEMBL1373849 & 688239 & 5.7362 & 5.2657 & TRN \\
\hline CHEMBL 3190456 & 688239 & 4.7362 & 5.4726 & TRN \\
\hline CHEMBL1468260 & 688239 & 4.5362 & 5.3385 & TRN \\
\hline CHEMBL1461707 & 688239 & 6.2362 & 5.556 & TRN \\
\hline CHEMBL1378820 & 688239 & 6.3362 & 5.5237 & TST \\
\hline CHEMBL1597630 & 688239 & 5.3862 & 5.4468 & TRN \\
\hline CHEMBL1507599 & 688239 & 5.1362 & 5.5349 & TRN \\
\hline CHEMBL1513792 & 688239 & 5.0862 & 5.3383 & TRN \\
\hline CHEMBL1527001 & 688239 & 6.8861 & 5.7128 & TRN \\
\hline CHEMBL1407913 & 688239 & 6.3863 & 5.4846 & TST \\
\hline CHEMBL1606662 & 688239 & 6.0362 & 5.3301 & TRN \\
\hline CHEMBL1314983 & 688239 & 4.5362 & 5.3954 & TRN \\
\hline CHEMBL1561237 & 688239 & 4.8362 & 5.2301 & TRN \\
\hline CHEMBL1440489 & 688239 & 4.7362 & 5.4737 & TRN \\
\hline CHEMBL1593168 & 688239 & 4.5862 & 5.5436 & TRN \\
\hline
\end{tabular}


Supplemental Table S2.txt

\begin{tabular}{|c|c|c|c|c|c|}
\hline CHEMBL1606613 & 688239 & 6.2862 & \multicolumn{2}{|c|}{5.4239999999999995} & TRN \\
\hline CHEMBL1490208 & 688239 & 4.5362 & 5.5133 & TRN & \\
\hline CHEMBL1523501 & 688239 & 5.9362 & 5.5491 & TRN & \\
\hline CHEMBL1308881 & 688239 & 6.5363 & 5.4786 & TST & \\
\hline CHEMBL1570708 & 688239 & 5.5862 & 5.4587 & TST & \\
\hline CHEMBL1375880 & 688239 & 6.7862 & 5.2551 & TRN & \\
\hline CHEMBL1379251 & 688239 & 6.9363 & 5.5257 & TRN & \\
\hline CHEMBL1375012 & 688239 & 5.7362 & 5.4833 & TST & \\
\hline CHEMBL1366128 & 688239 & 4.4862 & 5.4586 & TRN & \\
\hline CHEMBL1511464 & 688239 & 6.8861 & 5.6274 & TRN & \\
\hline CHEMBL1595348 & 688239 & 5.2862 & 5.3947 & TRN & \\
\hline CHEMBL1404634 & 688239 & 4.5362 & 5.4182 & TST & \\
\hline CHEMBL1409098 & 688239 & 6.4862 & 5.5081 & TRN & \\
\hline CHEMBL1329015 & 688239 & 4.5362 & 5.4971 & TRN & \\
\hline CHEMBL1403343 & 688239 & 7.1864 & 5.5517 & TRN & \\
\hline CHEMBL1357822 & 688239 & 5.7862 & 5.4272 & TRN & \\
\hline CHEMBL1411741 & 688239 & 4.5362 & 5.5661 & TRN & \\
\hline CHEMBL1570528 & 688239 & 4.5362 & 5.5072 & TRN & \\
\hline CHEMBL1372869 & 688239 & 5.5862 & 5.5629 & TRN & \\
\hline CHEMBL1404862 & 688239 & 5.1862 & 5.4252 & TRN & \\
\hline CHEMBL1531662 & 688239 & 4.5362 & 5.3744 & TRN & \\
\hline CHEMBL1514123 & 688239 & 4.5362 & 5.6243 & TST & \\
\hline CHEMBL1601036 & 688239 & 5.2862 & 5.4185 & TRN & \\
\hline CHEMBL1229545 & 688239 & 4.5362 & 5.5656 & TRN & \\
\hline CHEMBL1309440 & 688239 & 5.2362 & 5.3568 & TRN & \\
\hline CHEMBL1327526 & 688239 & 6.5363 & 5.4965 & TRN & \\
\hline CHEMBL1456080 & 688239 & 4.5362 & 5.6948 & TRN & \\
\hline CHEMBL1523787 & 688239 & 4.5362 & 5.6135 & TRN & \\
\hline CHEMBL1449878 & 688239 & 4.9362 & 5.4572 & TRN & \\
\hline CHEMBL1310143 & 688239 & 4.5362 & 5.4719 & TST & \\
\hline CHEMBL1573453 & 688239 & 6.2362 & 5.4987 & TRN & \\
\hline CHEMBL1547392 & 688239 & 4.4862 & 5.4346 & TRN & \\
\hline CHEMBL1573861 & 688239 & 8.2366 & 5.5543 & TRN & \\
\hline CHEMBL66654 & 688239 & 7.0862 & 5.5548 & TST & \\
\hline CHEMBL1984639 & 688239 & 4.5362 & 5.3803 & TST & \\
\hline CHEMBL1604611 & 688239 & 4.6362 & 5.46700 & 00000000005 & \\
\hline CHEMBL1364715 & 688239 & 5.1862 & 5.5904 & TST & \\
\hline CHEMBL1591392 & 688239 & 6.2862 & 5.7279 & TRN & \\
\hline CHEMBL1966921 & 688239 & 4.8362 & 5.5733 & TRN & \\
\hline CHEMBL1526064 & 688239 & 4.5362 & 5.6001 & TST & \\
\hline CHEMBL1359445 & 688239 & 5.5362 & 5.3893 & TRN & \\
\hline CHEMBL1428486 & 688239 & 4.8362 & 5.3851 & TST & \\
\hline CHEMBL1488596 & 688239 & 5.1862 & 5.5234 & TRN & \\
\hline CHEMBL1606638 & 688239 & 4.7862 & 5.5414 & TRN & \\
\hline CHEMBL1480547 & 688239 & 6.9363 & 5.4396 & TST & \\
\hline CHEMBL1324260 & 688239 & 5.1862 & 5.5649 & TRN & \\
\hline CHEMBL1474786 & 688239 & 5.1862 & 5.3251 & TRN & \\
\hline CHEMBL1431191 & 688239 & 5.8862 & 5.5459 & TST & \\
\hline
\end{tabular}

Page 2690 


\begin{tabular}{|c|c|c|c|c|c|c|}
\hline & & \multicolumn{5}{|c|}{ Supplemental Table s2.txt } \\
\hline CHEMBL1576944 & 688239 & 4.7862 & 5.61 & TRN & & \\
\hline CHEMBL1542554 & 688239 & 5.6362 & 5.5186 & TRN & & \\
\hline CHEMBL1450087 & 688239 & 5.5862 & 5.414 & TRN & & \\
\hline CHEMBL1462457 & 688239 & 4.8362 & 5.4703 & TRN & & \\
\hline CHEMBL1575913 & 688239 & 4.6862 & 5.3661 & TRN & & \\
\hline CHEMBL1433809 & 688239 & 6.0362 & 5.4469 & TRN & & \\
\hline CHEMBL1519505 & 688239 & 5.6862 & 5.5082 & TRN & & \\
\hline CHEMBL1510321 & 688239 & 6.2362 & 5.3157 & TRN & & \\
\hline CHEMBL1547422 & 688239 & 5.4862 & 5.5336 & TST & & \\
\hline CHEMBL1338293 & 688239 & 4.9362 & 5.5985 & TRN & & \\
\hline CHEMBL1462877 & 688239 & 8.3372 & 5.4122 & TST & & \\
\hline CHEMBL1365160 & 688239 & 4.6862 & 5.5111 & TRN & & \\
\hline CHEMBL1466994 & 688239 & 5.4862 & 5.4918 & TRN & & \\
\hline CHEMBL1577845 & 688239 & 4.5362 & 5.5753 & TRN & & \\
\hline CHEMBL1364618 & 688239 & 5.1862 & 5.5308 & TRN & & \\
\hline CHEMBL1328645 & 688239 & 6.1862 & 5.5445 & TRN & & \\
\hline CHEMBL1508107 & 688239 & 6.1362 & 5.6062 & TRN & & \\
\hline CHEMBL1313437 & 688239 & 5.3862 & 5.4836 & TST & & \\
\hline CHEMBL1559056 & 688239 & 4.5362 & 5.4622 & TRN & & \\
\hline CHEMBL1547470 & 688239 & 6.3362 & 5.5076 & TRN & & \\
\hline CHEMBL1305760 & 688239 & 6.8861 & 5.2971 & TST & & \\
\hline CHEMBL1451425 & 688239 & 5.6362 & 5.6777 & TRN & & \\
\hline CHEMBL1345447 & 688239 & 4.6862 & 5.3982 & TST & & \\
\hline CHEMBL1403790 & 688239 & 4.5362 & 5.6183 & TRN & & \\
\hline CHEMBL 3196936 & 688239 & 7.1864 & 5.506 & TRN & & \\
\hline CHEMBL1451280 & 688239 & 4.6362 & 5.5228 & TRN & & \\
\hline CHEMBL1539104 & 688239 & 8.28399 & 99999999 & 99 & 5.4341 & InIv \\
\hline CHEMBL1486943 & 688239 & 4.8362 & 5.4415 & TRN & & \\
\hline CHEMBL1456502 & 688239 & 4.6862 & 5.3808 & TRN & & \\
\hline CHEMBL1422400 & 688239 & 5.1862 & 5.45 & TRN & & \\
\hline CHEMBL1343127 & 688239 & 6.2862 & 5.4372 & TST & & \\
\hline CHEMBL1580086 & 688239 & 5.1862 & 5.4409 & TRN & & \\
\hline CHEMBL1376426 & 688239 & 4.7862 & 5.483 & TRN & & \\
\hline CHEMBL1581567 & 688239 & 4.9362 & 5.4705 & TRN & & \\
\hline CHEMBL 3212991 & 688239 & 6.4862 & 5.6605 & TRN & & \\
\hline CHEMBL1353588 & 688239 & 5.1862 & 5.5148 & TST & & \\
\hline CHEMBL1609782 & 688239 & 8.28399 & 79999999 & 99 & 5.5282 & TRN \\
\hline CHEMBL1331310 & 688239 & 4.5362 & 5.4142 & TRN & & \\
\hline CHEMBL1571522 & 688239 & 4.6362 & 5.5541 & TRN & & \\
\hline CHEMBL1458840 & 688239 & 4.5362 & 5.4227 & TST & & \\
\hline CHEMBL1353479 & 688239 & 4.5362 & 5.5324 & TRN & & \\
\hline CHEMBL1610686 & 688239 & 6.8861 & 5.6009 & TRN & & \\
\hline CHEMBL1588890 & 688239 & 6.1362 & 5.5352 & TRN & & \\
\hline CHEMBL1440890 & 688239 & 5.1362 & 5.5006 & TRN & & \\
\hline CHEMBL1342054 & 688239 & 4.5862 & 5.4881 & TST & & \\
\hline CHEMBL1572892 & 688239 & 6.2862 & 5.5914 & TRN & & \\
\hline CHEMBL1471553 & 688239 & 5.9362 & 5.3269 & TRN & & \\
\hline CHEMBL1371286 & 688239 & 6.8861 & 5.51 & TRN & & \\
\hline
\end{tabular}


Supplemental Table S2.txt

\begin{tabular}{|c|c|c|c|c|c|}
\hline CHEMBL1589330 & 688239 & 6.0862 & 5.4356 & TRN & \\
\hline CHEMBL1441706 & 688239 & 4.4862 & 5.4474 & TRN & \\
\hline CHEMBL3192805 & 688239 & 4.7362 & 5.4483 & TRN & \\
\hline CHEMBL1396925 & 688239 & 4.5862 & \multicolumn{2}{|c|}{5.4270000000000005} & TRN \\
\hline CHEMBL1335842 & 688239 & 4.8862 & 5.4544 & TRN & \\
\hline CHEMBL1372994 & 688239 & 5.9362 & 5.6636 & TRN & \\
\hline CHEMBL1412244 & 688239 & 5.4362 & 5.4433 & TST & \\
\hline CHEMBL1450557 & 688239 & 5.5862 & 5.5084 & TST & \\
\hline CHEMBL1310843 & 688239 & 6.8861 & 5.4866 & TRN & \\
\hline CHEMBL1610880 & 688239 & 6.7862 & 5.534 & TRN & \\
\hline CHEMBL1307161 & 688239 & 6.5363 & 5.6182 & TST & \\
\hline CHEMBL1520572 & 688239 & 7.6364 & 5.5413 & TRN & \\
\hline CHEMBL1455974 & 688239 & 4.6862 & 5.4749 & TRN & \\
\hline CHEMBL1519338 & 688239 & 4.4862 & 5.4133 & TRN & \\
\hline CHEMBL1326447 & 688239 & 4.8862 & 5.3672 & TRN & \\
\hline CHEMBL1338588 & 688239 & 5.4362 & \multicolumn{2}{|c|}{5.4270000000000005} & TST \\
\hline CHEMBL1337217 & 688239 & 4.4862 & \multicolumn{2}{|c|}{5.587000000000001} & TRN \\
\hline CHEMBL392723 & 688239 & 5.1862 & 5.5095 & TRN & \\
\hline CHEMBL1611305 & 688239 & 5.0862 & 5.5359 & TRN & \\
\hline CHEMBL1547916 & 688239 & 5.1862 & 5.5747 & TRN & \\
\hline CHEMBL1594437 & 688239 & 6.3863 & 5.5704 & TRN & \\
\hline CHEMBL1327667 & 688239 & 4.6362 & 5.4861 & TRN & \\
\hline CHEMBL1302969 & 688239 & 7.0362 & 5.5544 & TRN & \\
\hline CHEMBL1545611 & 688239 & 6.7361 & 5.3915 & TST & \\
\hline CHEMBL1498066 & 688239 & 4.7362 & 5.5725 & TRN & \\
\hline CHEMBL1521568 & 688239 & 5.1362 & 5.5292 & TRN & \\
\hline CHEMBL1373628 & 688239 & 5.1862 & 5.5871 & TRN & \\
\hline CHEMBL1606740 & 688239 & 5.4362 & 5.4029 & TRN & \\
\hline CHEMBL1610914 & 688239 & 7.8356 & 5.5154 & TRN & \\
\hline CHEMBL1512863 & 688239 & 5.1862 & 5.5386 & TRN & \\
\hline CHEMBL1478732 & 688239 & 6.8861 & 5.4087 & TRN & \\
\hline CHEMBL1603605 & 688239 & 6.1862 & 5.6463 & TRN & \\
\hline CHEMBL1313577 & 688239 & 4.7862 & 5.4044 & TST & \\
\hline CHEMBL1419941 & 688239 & 5.4862 & 5.5879 & TRN & \\
\hline CHEMBL 1314370 & 688239 & 4.9862 & 5.4462 & TRN & \\
\hline CHEMBL3207839 & 688239 & 4.5362 & 5.5805 & TRN & \\
\hline CHEMBL1307659 & 688239 & 4.5362 & 5.3946 & TRN & \\
\hline CHEMBL1361207 & 688239 & 4.4862 & 5.5224 & TRN & \\
\hline CHEMBL1398712 & 688239 & 8.3372 & 5.5374 & TRN & \\
\hline CHEMBL1607177 & 688239 & 5.4862 & 5.5996 & TST & \\
\hline CHEMBL1582571 & 688239 & 5.6362 & 5.4228 & TST & \\
\hline CHEMBL1549568 & 688239 & 4.7862 & 5.4574 & TST & \\
\hline CHEMBL1408110 & 688239 & 6.8362 & 5.6631 & TRN & \\
\hline CHEMBL3192078 & 688239 & 4.7362 & 5.4146 & TRN & \\
\hline CHEMBL1589106 & 688239 & 4.7862 & 5.5138 & TST & \\
\hline CHEMBL1482028 & 688239 & 4.7862 & 5.53600 & 30000000005 & TST \\
\hline CHEMBL1541564 & 688239 & 4.5362 & 5.4864 & TRN & \\
\hline CHEMBL1560530 & 688239 & 4.8362 & 5.3765 & TST & \\
\hline
\end{tabular}


Supplemental Table S2.txt

\begin{tabular}{|c|c|c|c|c|c|}
\hline CHEMBL1448512 & 688239 & 8.2366 & 5.3534 & TRN & \\
\hline CHEMBL1600960 & 688239 & 6.8362 & 5.6709 & TRN & \\
\hline CHEMBL1387142 & 688239 & 5.4362 & 5.4235 & TRN & \\
\hline CHEMBL1301052 & 688239 & 5.6862 & 5.4557 & TRN & \\
\hline CHEMBL 1473848 & 688239 & 5.1862 & 5.6114 & TRN & \\
\hline CHEMBL1514114 & 688239 & 4.8862 & \multicolumn{2}{|c|}{5.3629999999999995} & TST \\
\hline CHEMBL1539816 & 688239 & 5.3862 & 5.551 & TRN & \\
\hline CHEMBL1503238 & 688239 & 4.5862 & 5.4843 & TRN & \\
\hline CHEMBL1340843 & 688239 & 4.8862 & 5.4643 & TRN & \\
\hline CHEMBL1589434 & 688239 & 5.3862 & 5.2602 & TST & \\
\hline CHEMBL3192498 & 688239 & 6.8861 & 5.4913 & TRN & \\
\hline CHEMBL1341604 & 688239 & 5.3362 & 5.4589 & TRN & \\
\hline CHEMBL1506566 & 688239 & 4.5362 & 5.4016 & TRN & \\
\hline CHEMBL1330412 & 688239 & 4.6862 & 5.4329 & TRN & \\
\hline CHEMBL1572719 & 688239 & 4.5362 & 5.4855 & TST & \\
\hline CHEMBL1594128 & 688239 & 4.9362 & 5.4133 & TRN & \\
\hline CHEMBL1578810 & 688239 & 4.6862 & 5.2884 & TST & \\
\hline CHEMBL1366231 & 688239 & 5.9362 & 5.3498 & TST & \\
\hline CHEMBL1521681 & 688239 & 4.5862 & \multicolumn{2}{|c|}{5.502000000000001} & TST \\
\hline CHEMBL1553962 & 688239 & 4.5362 & 5.3868 & TST & \\
\hline CHEMBL1604330 & 688239 & 6.1862 & 5.4168 & TRN & \\
\hline CHEMBL1417006 & 688239 & 6.1362 & 5.5898 & TRN & \\
\hline CHEMBL1431004 & 688239 & 5.5362 & 5.4188 & TRN & \\
\hline CHEMBL1315615 & 688239 & 4.7862 & 5.5638 & TRN & \\
\hline CHEMBL1350098 & 688239 & 4.5362 & 5.5039 & TRN & \\
\hline CHEMBL1602271 & 688239 & 4.5362 & 5.3477 & TRN & \\
\hline CHEMBL1300098 & 688239 & 4.5362 & 5.5624 & TRN & \\
\hline CHEMBL1567667 & 688239 & 5.6862 & 5.6211 & TST & \\
\hline CHEMBL1398748 & 688239 & 4.6862 & 5.3098 & TRN & \\
\hline CHEMBL1578917 & 688239 & 5.6362 & 5.5141 & TRN & \\
\hline CHEMBL1557399 & 688239 & 4.8362 & 5.5832 & TRN & \\
\hline CHEMBL1415694 & 688239 & 4.5862 & 5.4072 & TRN & \\
\hline CHEMBL1522089 & 688239 & 5.1862 & 5.4291 & TRN & \\
\hline CHEMBL1556531 & 688239 & 4.6862 & 5.4397 & TRN & \\
\hline CHEMBL1462533 & 688239 & 4.6862 & 5.4223 & TST & \\
\hline CHEMBL1528317 & 688239 & 4.5362 & 5.4699 & TRN & \\
\hline CHEMBL1388337 & 688239 & \multicolumn{3}{|c|}{8.283999999999999} & $\mathrm{TR}$ \\
\hline CHEMBL3193279 & 688239 & 6.2362 & 5.3197 & TRN & \\
\hline CHEMBL1599847 & 688239 & 5.8362 & 5.4189 & TRN & \\
\hline CHEMBL1378086 & 688239 & 5.2362 & 5.4737 & TRN & \\
\hline CHEMBL1303635 & 688239 & 4.7362 & 5.4903 & TRN & \\
\hline CHEMBL1376242 & 688239 & 4.9362 & 5.4612 & TRN & \\
\hline CHEMBL3195274 & 688239 & 6.1362 & 5.5305 & TRN & \\
\hline CHEMBL1412153 & 688239 & 5.8362 & 5.388999 & 9999999999 & TRN \\
\hline CHEMBL1347501 & 688239 & 6.2362 & 5.452999 & 9999999999 & 「RN \\
\hline CHEMBL1563354 & 688239 & 6.5862 & 5.4353 & TST & \\
\hline CHEMBL1364497 & 688239 & 6.1362 & 5.427000 & 00000000005 & KI \\
\hline CHEMBL1476876 & 688239 & 4.4862 & 5.58 & TRN & \\
\hline
\end{tabular}


Supplemental Table S2.txt

\begin{tabular}{|c|c|c|c|c|c|}
\hline CHEMBL1355495 & 688239 & 4.6862 & 5.6149 & TRN & \\
\hline CHEMBL1391024 & 688239 & 6.2362 & 5.5234 & TST & \\
\hline CHEMBL1428551 & 688239 & 8.3872 & 5.61 & TRN & \\
\hline CHEMBL1583255 & 688239 & 5.8362 & 5.7522 & TRN & \\
\hline CHEMBL1432178 & 688239 & 4.5362 & 5.5754 & TRN & \\
\hline CHEMBL3198909 & 688239 & 4.5362 & 5.5927 & TST & \\
\hline CHEMBL1570773 & 688239 & 5.6362 & 5.6521 & TRN & \\
\hline CHEMBL1435215 & 688239 & 4.6362 & 5.5601 & TRN & \\
\hline CHEMBL1506658 & 688239 & 6.9863 & 5.4134 & TST & \\
\hline CHEMBL1544099 & 688239 & 4.5362 & 5.4477 & TRN & \\
\hline CHEMBL1554026 & 688239 & 5.3862 & 5.4822 & TRN & \\
\hline CHEMBL1595801 & 688239 & 4.5362 & 5.4991 & TRN & \\
\hline CHEMBL1362687 & 688239 & 5.1862 & 5.3034 & TST & \\
\hline CHEMBL1423855 & 688239 & 7.1864 & 5.435 & TRN & \\
\hline CHEMBL1544113 & 688239 & 5.1862 & 5.3517 & TST & \\
\hline CHEMBL1603923 & 688239 & 6.1362 & 5.5742 & TRN & \\
\hline CHEMBL1562267 & 688239 & 5.3862 & 5.6918 & TRN & \\
\hline CHEMBL1329843 & 688239 & 6.6362 & 5.5347 & TRN & \\
\hline CHEMBL1390332 & 688239 & 6.8362 & 5.5594 & TST & \\
\hline CHEMBL1581156 & 688239 & 5.1862 & 5.3301 & TRN & \\
\hline CHEMBL1410641 & 688239 & 4.5362 & 5.4072 & TST & \\
\hline CHEMBL1321232 & 688239 & 4.9362 & 5.2997 & TRN & \\
\hline CHEMBL1338423 & 688239 & 4.5362 & 5.403 & TST & \\
\hline CHEMBL1390151 & 688239 & 6.4362 & 5.5006 & TST & \\
\hline CHEMBL1512675 & 688239 & 8.3372 & 5.4158 & TRN & \\
\hline CHEMBL1591391 & 688239 & 5.9862 & 5.5212 & TRN & \\
\hline CHEMBL1360475 & 688239 & 4.5862 & 5.6078 & TRN & \\
\hline CHEMBL1369833 & 688239 & 4.4862 & 5.46399 & 99999999995 & TRN \\
\hline CHEMBL1592369 & 688239 & 5.3362 & 5.4349 & TRN & \\
\hline CHEMBL1301558 & 688239 & 5.1362 & 5.49 & TST & \\
\hline CHEMBL1501106 & 688239 & 5.1862 & 5.4998 & TST & \\
\hline CHEMBL1364686 & 688239 & 5.0862 & 5.4606 & TRN & \\
\hline CHEMBL3211919 & 688239 & 5.7862 & 5.5025 & TRN & \\
\hline CHEMBL1479278 & 688239 & 4.5362 & 5.3233 & TRN & \\
\hline CHEMBL1412415 & 688239 & 6.7862 & 5.4838 & TRN & \\
\hline CHEMBL1381612 & 688239 & 4.5362 & 5.5422 & TST & \\
\hline CHEMBL1311407 & 688239 & 4.4862 & 5.5105 & TRN & \\
\hline CHEMBL3196457 & 688239 & 4.7362 & 5.431 & TRN & \\
\hline CHEMBL1576877 & 688239 & 4.4862 & 5.6545 & TRN & \\
\hline CHEMBL1337795 & 688239 & 4.45 & 5.5007 & TST & \\
\hline CHEMBL1612781 & 688239 & 4.6862 & 5.4104 & TRN & \\
\hline CHEMBL1417708 & 688239 & 6.1362 & 5.5366 & TRN & \\
\hline CHEMBL1570094 & 688239 & 6.3362 & 5.5179 & TRN & \\
\hline CHEMBL1327280 & 688239 & 5.3862 & 5.4597 & TRN & \\
\hline CHEMBL1454466 & 688239 & 6.2362 & 5.5368 & TST & \\
\hline CHEMBL1603495 & 688239 & 6.7862 & 5.6174 & TRN & \\
\hline CHEMBL1590505 & 688239 & 5.9862 & 5.5362 & TRN & \\
\hline CHEMBL1593458 & 688239 & 4.5362 & 5.5631 & TRN & \\
\hline
\end{tabular}


Supplemental Table S2.txt

\begin{tabular}{|c|c|c|c|c|}
\hline CHEMBL1421888 & 688239 & 5.5862 & 5.5079 & TRN \\
\hline CHEMBL1416297 & 688239 & 5.1362 & 5.4509 & TST \\
\hline CHEMBL1311260 & 688239 & 4.7862 & 5.3378 & TST \\
\hline CHEMBL1602044 & 688239 & 6.2862 & 5.3545 & TRN \\
\hline CHEMBL1394821 & 688239 & 6.1862 & 5.5662 & TRN \\
\hline CHEMBL1462280 & 688239 & 4.7862 & 5.511 & TST \\
\hline CHEMBL1554540 & 688239 & 5.2362 & 5.4898 & TRN \\
\hline CHEMBL1308277 & 688239 & 5.1862 & 5.4721 & TRN \\
\hline CHEMBL1303528 & 688239 & 8.7447 & 5.5124 & TRN \\
\hline CHEMBL1445856 & 688239 & 4.6862 & 5.6592 & TRN \\
\hline CHEMBL1604230 & 688239 & 6.8861 & 5.5353 & TRN \\
\hline CHEMBL1520899 & 688239 & 6.7361 & 5.5303 & TRN \\
\hline CHEMBL1581735 & 688239 & 7.0362 & 5.6634 & TRN \\
\hline CHEMBL1321493 & 688239 & 5.3862 & 5.4488 & TRN \\
\hline CHEMBL 3213517 & 688239 & 5.0862 & 5.5362 & TRN \\
\hline CHEMBL1300715 & 688239 & 4.8362 & 5.5909 & TRN \\
\hline CHEMBL1407597 & 688239 & 5.1862 & 5.4602 & TRN \\
\hline CHEMBL1418975 & 688239 & 6.7361 & 5.5168 & TRN \\
\hline CHEMBL1498887 & 688239 & 4.7862 & 5.4515 & TRN \\
\hline CHEMBL1461523 & 688239 & 6.9863 & 5.4695 & TRN \\
\hline CHEMBL1419150 & 688239 & 4.6862 & 5.3916 & TRN \\
\hline CHEMBL1312742 & 688239 & 6.8861 & 5.6087 & TST \\
\hline CHEMBL1577348 & 688239 & 6.8861 & 5.5525 & TRN \\
\hline CHEMBL1446668 & 688239 & 4.7362 & 5.5197 & TRN \\
\hline CHEMBL1510382 & 688239 & 6.3362 & 5.4438 & TST \\
\hline CHEMBL1589227 & 688239 & 8.283999 & \multirow{2}{*}{\multicolumn{2}{|c|}{$\begin{array}{r}9999999999 \\
5.59399999\end{array}$}} \\
\hline CHEMBL1516811 & 688239 & 5.5862 & & \\
\hline CHEMBL1396896 & 688239 & 4.6362 & 5.4248 & TRN \\
\hline CHEMBL1560064 & 688239 & 4.6862 & 5.5087 & TRN \\
\hline CHEMBL1337283 & 688239 & 5.1862 & 5.5262 & TRN \\
\hline CHEMBL2373616 & 688239 & 8.3372 & 5.4816 & TRN \\
\hline CHEMBL1320685 & 688239 & 4.9362 & 5.4395 & TRN \\
\hline CHEMBL1464329 & 688239 & 5.5862 & 5.5193 & TRN \\
\hline CHEMBL1568106 & 688239 & 5.8362 & 5.5281 & TST \\
\hline CHEMBL1409606 & 688239 & 6.0862 & 5.4335 & TST \\
\hline CHEMBL1341333 & 688239 & 4.5362 & 5.4963 & TRN \\
\hline CHEMBL3194257 & 688239 & 6.6362 & 5.4144 & TRN \\
\hline CHEMBL1548177 & 688239 & 4.5362 & 5.4452 & TRN \\
\hline CHEMBL1591457 & 688239 & 4.9362 & 5.4579 & TRN \\
\hline CHEMBL1405185 & 688239 & 5.1362 & 5.449 & TST \\
\hline CHEMBL1328630 & 688239 & 4.5362 & 5.4276 & TRN \\
\hline CHEMBL1365253 & 688239 & 5.3362 & 5.6537 & TRN \\
\hline CHEMBL1361566 & 688239 & 6.8861 & 5.5257 & TRN \\
\hline CHEMBL1331206 & 688239 & 4.6362 & 5.3562 & TRN \\
\hline CHEMBL1988289 & 688239 & 5.6362 & 5.4531 & TRN \\
\hline CHEMBL1333412 & 688239 & 4.5362 & 5.4071 & TRN \\
\hline CHEMBL3198959 & 688239 & 5.5862 & 5.4937 & TRN \\
\hline CHEMBL1602433 & 688239 & 4.5862 & 5.4102 & TRN \\
\hline
\end{tabular}


Supplemental Table S2.txt

\begin{tabular}{|c|c|c|c|c|}
\hline CHEMBL1372824 & 688239 & 6.1362 & 5.5471 & TRN \\
\hline CHEMBL1428387 & 688239 & 5.5862 & 5.6358 & TRN \\
\hline CHEMBL1412111 & 688239 & 6.9863 & 5.5517 & TRN \\
\hline CHEMBL1527621 & 688239 & 5.1862 & 5.4817 & TST \\
\hline CHEMBL1314952 & 688239 & 6.9863 & 5.5776 & TRN \\
\hline CHEMBL1354021 & 688239 & 7.1361 & 5.4876 & TRN \\
\hline CHEMBL1434680 & 688239 & 6.0362 & 5.5064 & TRN \\
\hline CHEMBL1325922 & 688239 & 4.4862 & 5.6663 & TRN \\
\hline CHEMBL1338427 & 688239 & 5.1862 & 5.5729 & TRN \\
\hline CHEMBL1522584 & 688239 & 6.5363 & 5.4065 & TST \\
\hline CHEMBL1448643 & 688239 & 5.7362 & 5.3539 & TST \\
\hline CHEMBL1604302 & 688239 & 6.6861 & 5.5356 & TRN \\
\hline CHEMBL1595023 & 688239 & 4.8862 & 5.5171 & TRN \\
\hline CHEMBL1523739 & 688239 & 6.6861 & 5.5337 & TRN \\
\hline CHEMBL1499809 & 688239 & 5.6862 & 5.5537 & TRN \\
\hline CHEMBL1313376 & 688239 & 4.6862 & 5.3803 & TRN \\
\hline CHEMBL1470591 & 688239 & 5.1862 & 5.5214 & TRN \\
\hline CHEMBL1528981 & 688239 & 5.1862 & 5.6192 & TRN \\
\hline CHEMBL406364 & 688239 & 5.0862 & 5.3578 & TRN \\
\hline CHEMBL1543412 & 688239 & 5.6362 & 5.5103 & TST \\
\hline CHEMBL1608498 & 688239 & 4.5362 & 5.4163 & TRN \\
\hline CHEMBL1491270 & 688239 & 6.9863 & 5.4491 & TRN \\
\hline CHEMBL1405063 & 688239 & 4.9862 & 5.3447 & TRN \\
\hline CHEMBL1450693 & 688239 & 5.4362 & 5.4289 & TRN \\
\hline CHEMBL1448971 & 688239 & 4.8362 & 5.6503 & TRN \\
\hline CHEMBL1360025 & 688239 & 7.2366 & 5.3751 & TRN \\
\hline CHEMBL1338720 & 688239 & 5.1862 & 5.5464 & TRN \\
\hline CHEMBL1313110 & 688239 & 4.7362 & 5.4381 & TRN \\
\hline CHEMBL1529725 & 688239 & 4.8862 & 5.5665 & TRN \\
\hline CHEMBL1300308 & 688239 & 5.1862 & 5.6132 & TRN \\
\hline CHEMBL1482843 & 688239 & 4.9862 & 5.4775 & TRN \\
\hline CHEMBL1542642 & 688239 & 8.28399 & 99999999 & 5.3896 \\
\hline CHEMBL1526910 & 688239 & 4.7862 & 5.4701 & TRN \\
\hline CHEMBL1347867 & 688239 & 5.6862 & 5.4389 & TRN \\
\hline CHEMBL1994910 & 688239 & 5.5362 & 5.3994 & TRN \\
\hline CHEMBL1506838 & 688239 & 6.8861 & 5.5793 & TRN \\
\hline CHEMBL1303630 & 688239 & 6.5862 & 5.452999 & 9999999999 \\
\hline CHEMBL1486428 & 688239 & 4.5862 & 5.4834 & TST \\
\hline CHEMBL1335464 & 688239 & 4.5362 & 5.4363 & TRN \\
\hline CHEMBL1399163 & 688239 & 4.6862 & 5.5592 & TST \\
\hline CHEMBL1328582 & 688239 & 5.7362 & 5.4334 & TRN \\
\hline CHEMBL1508922 & 688239 & 5.1862 & 5.5173 & TRN \\
\hline CHEMBL1459381 & 688239 & 6.4862 & 5.4048 & TRN \\
\hline CHEMBL1320846 & 688239 & 6.1862 & 5.4904 & TRN \\
\hline CHEMBL1419772 & 688239 & 6.2362 & 5.3865 & TST \\
\hline CHEMBL1475559 & 688239 & 5.4862 & 5.393 & TRN \\
\hline CHEMBL1399277 & 688239 & 5.5362 & 5.5456 & TRN \\
\hline CHEMBL1352003 & 688239 & 6.1362 & 5.4892 & TRN \\
\hline
\end{tabular}


Supplemental Table S2.txt

\begin{tabular}{|c|c|c|c|c|c|}
\hline CHEMBL1554957 & 688239 & 4.9362 & 5.5148 & TRN & \\
\hline CHEMBL 2000750 & 688239 & 5.7362 & 5.3229 & TRN & \\
\hline CHEMBL1469111 & 688239 & 4.6362 & 5.6276 & TRN & \\
\hline CHEMBL1408740 & 688239 & 5.4862 & 5.4337 & TRN & \\
\hline CHEMBL1521057 & 688239 & 4.8862 & 5.5177 & TRN & \\
\hline CHEMBL1623028 & 688239 & 5.4862 & 5.3306 & TRN & \\
\hline CHEMBL1380800 & 688239 & 4.7862 & 5.3781 & TRN & \\
\hline CHEMBL1550495 & 688239 & 5.7362 & 5.497000 & 000000001 & m \\
\hline CHEMBL1994163 & 688239 & 4.5362 & 5.3331 & TRN & \\
\hline CHEMBL1584329 & 688239 & 4.8362 & 5.4658 & TRN & \\
\hline CHEMBL1545589 & 688239 & 6.2862 & 5.565 & TRN & \\
\hline CHEMBL 3214094 & 688239 & 8.0862 & 5.4281 & TRN & \\
\hline CHEMBL1525136 & 688239 & 4.5362 & 5.4322 & TRN & \\
\hline CHEMBL1334066 & 688239 & 5.7362 & 5.6301 & TST & \\
\hline CHEMBL1469388 & 688239 & 5.1862 & 5.4462 & TST & \\
\hline CHEMBL3198471 & 688239 & 4.8362 & 5.4498 & TRN & \\
\hline CHEMBL1588124 & 688239 & 7.1361 & 5.5396 & TST & \\
\hline CHEMBL1417779 & 688239 & 5.1362 & 5.5443 & TST & \\
\hline CHEMBL1311527 & 688239 & 4.5362 & 5.2362 & TRN & \\
\hline CHEMBL1302816 & 688239 & 5.4362 & 5.2602 & TST & \\
\hline CHEMBL1590406 & 688239 & 5.2362 & 5.4939 & TRN & \\
\hline CHEMBL1430143 & 688239 & 4.5862 & 5.4512 & TRN & \\
\hline CHEMBL1364162 & 688239 & 4.5362 & 5.5748 & TST & \\
\hline CHEMBL 2006840 & 688239 & 4.6862 & 5.3003 & TRN & \\
\hline CHEMBL1429530 & 688239 & 5.1862 & 5.454 & TRN & \\
\hline CHEMBL1520652 & 688239 & 5.3862 & 5.6035 & TRN & \\
\hline CHEMBL3191535 & 688239 & 6.8861 & 5.4938 & TRN & \\
\hline CHEMBL1575903 & 688239 & 4.7862 & 5.5217 & TRN & \\
\hline CHEMBL1547036 & 688239 & 4.4862 & 5.5594 & TRN & \\
\hline CHEMBL1498246 & 688239 & \multicolumn{2}{|c|}{8.283999999999999} & 5.4868 & \\
\hline CHEMBL1463633 & 688239 & 4.7862 & 5.405 & TST & \\
\hline CHEMBL1342219 & 688239 & 4.7362 & 5.6187 & TRN & \\
\hline CHEMBL1522284 & 688239 & 6.9863 & 5.5094 & TRN & \\
\hline CHEMBL1373928 & 688239 & 8.3372 & 5.5279 & TRN & \\
\hline CHEMBL1335886 & 688239 & 8.3372 & 5.4161 & TRN & \\
\hline CHEMBL1328102 & 688239 & 4.5362 & 5.5458 & TRN & \\
\hline CHEMBL1504384 & 688239 & 8.1871 & 5.5193 & TRN & \\
\hline CHEMBL1423675 & 688239 & 5.8862 & 5.281000 & 000000001 & \\
\hline CHEMBL1379534 & 688239 & 4.8862 & 5.5242 & TRN & \\
\hline CHEMBL1367462 & 688239 & 8.3372 & 5.497999 & 999999999 & \\
\hline CHEMBL1516366 & 688239 & 5.0362 & 5.3969 & TRN & \\
\hline CHEMBL1512181 & 688239 & 5.4862 & 5.5795 & TRN & \\
\hline CHEMBL1338361 & 688239 & 5.1862 & 5.5188 & TST & \\
\hline CHEMBL1518230 & 688239 & 8.3872 & 5.499 & TRN & \\
\hline CHEMBL1571926 & 688239 & 6.8362 & 5.5279 & TRN & \\
\hline CHEMBL1443086 & 688239 & 5.1862 & 5.4258 & TRN & \\
\hline CHEMBL1580694 & 688239 & 6.1362 & 5.6311 & TRN & \\
\hline CHEMBL 3192554 & 688239 & 4.5362 & 5.3645 & TRN & \\
\hline
\end{tabular}


Supplemental Table S2.txt

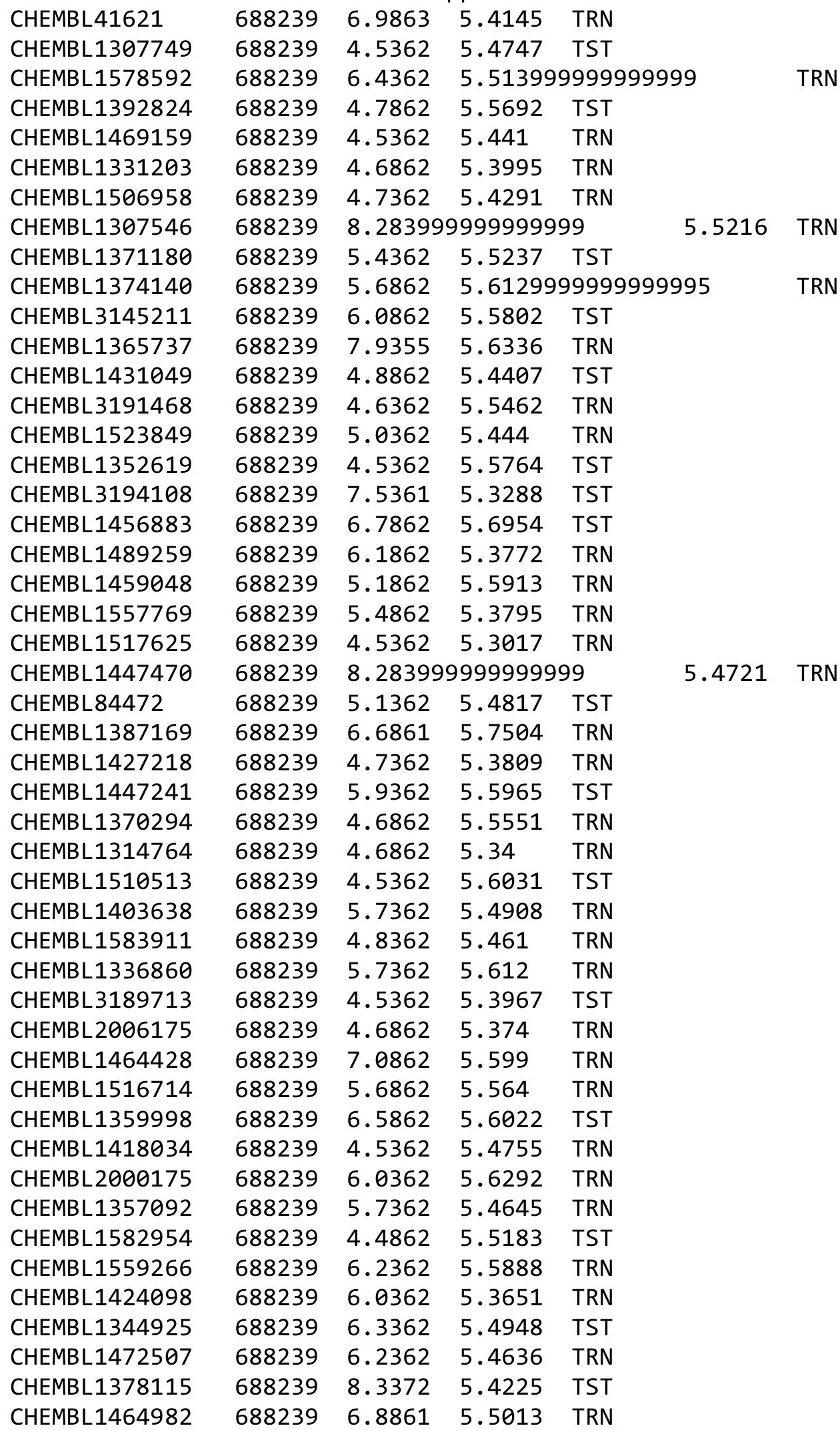

Page 2698 
Supplemental Table S2.txt

\begin{tabular}{|c|c|c|c|c|}
\hline CHEMBL1423590 & 688239 & 5.1862 & 5.4033 & TRN \\
\hline CHEMBL1603074 & 688239 & 4.6862 & 5.3777 & TRN \\
\hline CHEMBL1555811 & 688239 & 5.0362 & 5.3883 & TRN \\
\hline CHEMBL 228036 & 688239 & 4.6362 & 5.5329 & TST \\
\hline CHEMBL1611561 & 688239 & 5.2862 & 5.5984 & TRN \\
\hline CHEMBL1471690 & 688239 & 6.2862 & 5.5655 & TRN \\
\hline CHEMBL1451490 & 688239 & 4.5362 & 5.4988 & TRN \\
\hline CHEMBL1454598 & 688239 & 5.1362 & 5.596 & TRN \\
\hline CHEMBL1385146 & 688239 & 4.6362 & 5.5598 & TRN \\
\hline CHEMBL1457033 & 688239 & 5.2362 & 5.5257 & TRN \\
\hline CHEMBL1485613 & 688239 & 5.4362 & 5.5043 & TRN \\
\hline CHEMBL1527253 & 688239 & 6.0362 & 5.5015 & TRN \\
\hline CHEMBL1544402 & 688239 & 4.4862 & 5.5618 & TRN \\
\hline CHEMBL1348954 & 688239 & 5.1862 & 5.6312 & TRN \\
\hline CHEMBL1553856 & 688239 & 6.3362 & 5.5225 & TRN \\
\hline CHEMBL1470148 & 688239 & 4.6862 & 5.4233 & TRN \\
\hline CHEMBL1543939 & 688239 & 5.7362 & 5.3756 & TST \\
\hline CHEMBL1563316 & 688239 & 4.5362 & 5.4988 & TRN \\
\hline CHEMBL1577711 & 688239 & 4.5362 & 5.4954 & TRN \\
\hline CHEMBL1565466 & 688239 & 4.5362 & 5.4086 & TRN \\
\hline CHEMBL1586848 & 688239 & 6.2362 & 5.6103 & TRN \\
\hline CHEMBL1303371 & 688239 & 4.7362 & 5.4652 & TRN \\
\hline CHEMBL1346835 & 688239 & 4.5362 & 5.4078 & TRN \\
\hline CHEMBL1588166 & 688239 & 7.0362 & 5.6236 & TRN \\
\hline CHEMBL1447810 & 688239 & 5.1862 & 5.4561 & TRN \\
\hline CHEMBL1524953 & 688239 & 8.3372 & 5.6096 & TRN \\
\hline CHEMBL1501961 & 688239 & 6.1862 & 5.4479 & TRN \\
\hline CHEMBL1583247 & 688239 & 6.0862 & 5.4597 & TRN \\
\hline CHEMBL1427238 & 688239 & 5.3862 & 5.5807 & TRN \\
\hline CHEMBL1419567 & 688239 & 5.2362 & 5.4705 & TRN \\
\hline CHEMBL1302047 & 688239 & 4.5362 & 5.454 & TRN \\
\hline CHEMBL1392321 & 688239 & 4.7862 & 5.5134 & TRN \\
\hline CHEMBL1504053 & 688239 & 5.1862 & 5.4485 & TRN \\
\hline CHEMBL1458253 & 688239 & 5.0862 & 5.3332 & TRN \\
\hline CHEMBL1303889 & 688239 & 4.7362 & 5.4297 & TRN \\
\hline CHEMBL1483402 & 688239 & 6.3362 & 5.4712 & TRN \\
\hline CHEMBL1394387 & 688239 & 4.6862 & 5.3954 & TRN \\
\hline CHEMBL1381692 & 688239 & 4.6862 & 5.6567 & TRN \\
\hline CHEMBL1392660 & 688239 & 4.5362 & 5.4856 & TRN \\
\hline CHEMBL1565085 & 688239 & 4.6862 & 5.3166 & TST \\
\hline CHEMBL 3213273 & 688239 & 5.5862 & 5.4757 & TST \\
\hline CHEMBL1466364 & 688239 & 5.6362 & 5.468999 & 9999999999 \\
\hline CHEMBL1465993 & 688239 & 5.4362 & 5.4417 & TRN \\
\hline CHEMBL1335054 & 688239 & 6.8861 & 5.5739 & TRN \\
\hline CHEMBL1363743 & 688239 & 6.9363 & 5.4695 & TST \\
\hline CHEMBL1545260 & 688239 & 4.5362 & 5.5393 & TRN \\
\hline CHEMBL1528109 & 688239 & 5.3862 & 5.6341 & TRN \\
\hline CHEMBL1471465 & 688239 & 4.6862 & 5.49 & TRN \\
\hline
\end{tabular}


Supplemental Table S2.txt

\begin{tabular}{|c|c|c|c|c|}
\hline CHEMBL1332041 & 688239 & 4.4862 & 5.6448 & TRN \\
\hline CHEMBL1329566 & 688239 & 4.6362 & 5.4741 & TRN \\
\hline CHEMBL1410063 & 688239 & 4.6362 & 5.5641 & TST \\
\hline CHEMBL1346274 & 688239 & 4.7362 & 5.5072 & TST \\
\hline CHEMBL1435652 & 688239 & 4.8362 & 5.3979 & TRN \\
\hline CHEMBL502315 & 688239 & 6.1862 & 5.4587 & TRN \\
\hline CHEMBL1350980 & 688239 & 5.7362 & 5.5121 & TRN \\
\hline CHEMBL1428421 & 688239 & 4.5362 & 5.6375 & TRN \\
\hline CHEMBL1499234 & 688239 & 5.8362 & 5.4135 & TST \\
\hline CHEMBL1538697 & 688239 & 7.0362 & 5.6156 & TST \\
\hline CHEMBL1304063 & 688239 & 5.4362 & 5.5126 & TRN \\
\hline CHEMBL1389717 & 688239 & 6.9363 & 5.483 & TRN \\
\hline CHEMBL3189392 & 688239 & 6.3863 & 5.4638 & TST \\
\hline CHEMBL1346809 & 688239 & 6.0862 & 5.4671 & TST \\
\hline CHEMBL1413609 & 688239 & 5.1862 & 5.5787 & TRN \\
\hline CHEMBL1361134 & 688239 & 6.0 & 5.5741 & TRN \\
\hline CHEMBL1356688 & 688239 & 4.7362 & 5.5717 & TRN \\
\hline CHEMBL1582967 & 688239 & 5.5362 & 5.4612 & TRN \\
\hline CHEMBL1502350 & 688239 & 6.1862 & 5.6248 & TRN \\
\hline CHEMBL1457690 & 688239 & 4.5362 & 5.3826 & TRN \\
\hline CHEMBL1466316 & 688239 & 5.5862 & 5.5642 & TRN \\
\hline CHEMBL1312113 & 688239 & 4.5862 & 5.4878 & TRN \\
\hline CHEMBL1383727 & 688239 & 4.7862 & 5.3724 & TRN \\
\hline CHEMBL1526011 & 688239 & 5.7362 & 5.4503 & TRN \\
\hline CHEMBL3192175 & 688239 & 6.1362 & 5.4265 & TRN \\
\hline CHEMBL1302370 & 688239 & 7.2865 & 5.4574 & TRN \\
\hline CHEMBL1301268 & 688239 & 5.8362 & 5.3254 & TRN \\
\hline CHEMBL1376556 & 688239 & 4.6862 & 5.4589 & TRN \\
\hline CHEMBL1515780 & 688239 & 5.7362 & 5.2824 & TRN \\
\hline CHEMBL1384346 & 688239 & 6.1362 & 5.5763 & TST \\
\hline CHEMBL1552925 & 688239 & 6.1362 & 5.4279 & TRN \\
\hline CHEMBL1418342 & 688239 & 6.9363 & 5.5374 & TRN \\
\hline CHEMBL1300150 & 688239 & 4.9862 & 5.5906 & TRN \\
\hline CHEMBL1529250 & 688239 & 5.5862 & 5.5366 & TRN \\
\hline CHEMBL1493610 & 688239 & 5.1362 & 5.6129 & TRN \\
\hline CHEMBL1610091 & 688239 & 4.7362 & 5.3563 & TRN \\
\hline CHEMBL1545918 & 688239 & 5.65 & 5.5364 & TRN \\
\hline CHEMBL1561290 & 688239 & 8.3372 & 5.3847 & TRN \\
\hline CHEMBL1429681 & 688239 & 6.8861 & 5.5194 & TRN \\
\hline CHEMBL1531133 & 688239 & 4.7862 & 5.4026 & TRN \\
\hline CHEMBL1557212 & 688239 & 4.6362 & 5.58299 & 9999999999 \\
\hline CHEMBL1443945 & 688239 & 8.3872 & 5.6396 & TRN \\
\hline CHEMBL1498022 & 688239 & 4.7362 & 5.4362 & TRN \\
\hline CHEMBL1399109 & 688239 & 6.3863 & 5.5846 & TST \\
\hline CHEMBL1369919 & 688239 & 7.8861 & 5.5724 & TRN \\
\hline CHEMBL1533377 & 688239 & 4.9862 & 5.5091 & TRN \\
\hline CHEMBL3208161 & 688239 & 4.7362 & 5.5023 & TST \\
\hline CHEMBL1534325 & 688239 & 6.5862 & 5.4588 & TRN \\
\hline
\end{tabular}


Supplemental Table S2.txt

\begin{tabular}{|c|c|c|c|c|c|}
\hline CHEMBL1486025 & 688239 & 5.9362 & 5.5583 & TRN & \\
\hline CHEMBL1563627 & 688239 & 4.5362 & 5.41200 & 0000000001 & TRN \\
\hline CHEMBL1347852 & 688239 & 4.6362 & 5.4476 & TRN & \\
\hline CHEMBL 3198661 & 688239 & 5.0362 & 5.4777 & TST & \\
\hline CHEMBL1302525 & 688239 & 5.0362 & 5.4944 & TRN & \\
\hline CHEMBL1404132 & 688239 & 5.7362 & 5.5138 & TRN & \\
\hline CHEMBL1520744 & 688239 & 5.4862 & 5.269 & TRN & \\
\hline CHEMBL1584601 & 688239 & 4.5362 & 5.5178 & TST & \\
\hline CHEMBL1569333 & 688239 & 4.8362 & 5.2846 & TRN & \\
\hline CHEMBL1431158 & 688239 & 8.3372 & 5.4338 & TRN & \\
\hline CHEMBL1348613 & 688239 & 7.0862 & 5.4591 & TRN & \\
\hline CHEMBL1303682 & 688239 & 6.8861 & 5.6315 & TST & \\
\hline CHEMBL1443672 & 688239 & 4.5362 & 5.3892 & TRN & \\
\hline CHEMBL1493378 & 688239 & 7.0362 & 5.484 & TRN & \\
\hline CHEMBL1565737 & 688239 & 6.2362 & 5.3818 & TST & \\
\hline CHEMBL1304611 & 688239 & 7.0862 & 5.6621 & TRN & \\
\hline CHEMBL 3197755 & 688239 & 7.2366 & 5.4765 & TRN & \\
\hline CHEMBL1600582 & 688239 & 4.6362 & 5.6785 & TRN & \\
\hline CHEMBL1518696 & 688239 & 4.9862 & 5.414 & TRN & \\
\hline CHEMBL1540343 & 688239 & 5.9862 & 5.5795 & TST & \\
\hline CHEMBL1456760 & 688239 & 4.5362 & 5.4193 & TRN & \\
\hline CHEMBL1499869 & 688239 & 4.6362 & 5.5583 & TRN & \\
\hline CHEMBL1528267 & 688239 & 4.5362 & 5.5342 & TST & \\
\hline CHEMBL1477941 & 688239 & 4.6862 & 5.4317 & TRN & \\
\hline CHEMBL1563858 & 688239 & 5.0362 & 5.5603 & TRN & \\
\hline CHEMBL1563746 & 688239 & 6.1862 & 5.4624 & TST & \\
\hline CHEMBL1446955 & 688239 & 5.7362 & 5.5471 & TRN & \\
\hline CHEMBL1608613 & 688239 & 5.3362 & 5.5039 & TRN & \\
\hline CHEMBL1577200 & 688239 & 5.0362 & \multicolumn{2}{|c|}{5.4639999999999995} & TST \\
\hline CHEMBL1453086 & 688239 & 6.1362 & 5.4387 & TRN & \\
\hline CHEMBL1321864 & 688239 & 6.4862 & \multicolumn{2}{|c|}{5.617999999999999} & TRN \\
\hline CHEMBL1545863 & 688239 & 5.6862 & 5.5437 & TRN & \\
\hline CHEMBL1353420 & 688239 & 4.9362 & 5.6082 & TST & \\
\hline CHEMBL1584926 & 688239 & 5.0362 & 5.4681 & TRN & \\
\hline CHEMBL1418654 & 688239 & 6.8861 & 5.4863 & TST & \\
\hline CHEMBL1498963 & 688239 & 7.0362 & 5.5382 & TRN & \\
\hline CHEMBL1383182 & 688239 & 6.2862 & 5.5766 & TRN & \\
\hline CHEMBL1506618 & 688239 & 5.0362 & 5.4625 & TST & \\
\hline CHEMBL1449239 & 688239 & 5.1362 & 5.5251 & TST & \\
\hline CHEMBL1576314 & 688239 & 5.4862 & 5.4959 & TRN & \\
\hline CHEMBL1613093 & 688239 & 5.1362 & 5.4168 & TRN & \\
\hline CHEMBL1315599 & 688239 & 4.6862 & 5.6183 & TRN & \\
\hline CHEMBL1528288 & 688239 & 4.7362 & 5.505 & TRN & \\
\hline CHEMBL 2003873 & 688239 & 6.1362 & \multicolumn{2}{|c|}{5.2829999999999995} & ועו \\
\hline CHEMBL1478237 & 688239 & 5.6362 & 5.336 & TRN & \\
\hline CHEMBL1301524 & 688239 & 5.1862 & 5.4474 & TRN & \\
\hline CHEMBL1326754 & 688239 & 4.8362 & 5.6083 & TRN & \\
\hline CHEMBL1530496 & 688239 & 4.6862 & 5.5949 & TRN & \\
\hline
\end{tabular}


Supplemental Table S2.txt

\begin{tabular}{|c|c|c|c|c|}
\hline CHEMBL 3190352 & 688239 & 4.5362 & 5.3331 & TRN \\
\hline CHEMBL1515579 & 688239 & 5.4362 & 5.4423 & TRN \\
\hline CHEMBL1564248 & 688239 & 6.1862 & 5.4421 & TST \\
\hline CHEMBL1557709 & 688239 & 4.5362 & 5.4578 & TRN \\
\hline CHEMBL1572311 & 688239 & 4.9362 & 5.541 & TRN \\
\hline CHEMBL1998525 & 688239 & 4.6862 & 5.4695 & TRN \\
\hline CHEMBL1566849 & 688239 & 7.1361 & 5.4799 & TRN \\
\hline CHEMBL1349503 & 688239 & 5.7862 & 5.4493 & TRN \\
\hline CHEMBL1543879 & 688239 & 4.7362 & 5.5256 & TRN \\
\hline CHEMBL1300407 & 688239 & 4.4862 & 5.5527 & TRN \\
\hline CHEMBL1523516 & 688239 & 5.1862 & 5.6037 & TRN \\
\hline CHEMBL1564762 & 688239 & 5.8362 & 5.4628 & TRN \\
\hline CHEMBL1599045 & 688239 & 5.1862 & 5.5834 & TRN \\
\hline CHEMBL1507271 & 688239 & 4.7862 & 5.5912 & TRN \\
\hline CHEMBL1609877 & 688239 & 5.9362 & 5.3434 & TRN \\
\hline CHEMBL1416214 & 688239 & 6.8861 & 5.5343 & TRN \\
\hline CHEMBL1352968 & 688239 & 4.5862 & 5.4278 & TRN \\
\hline CHEMBL1535981 & 688239 & 5.3362 & 5.4605 & TRN \\
\hline CHEMBL1480992 & 688239 & 5.2362 & 5.3438 & TST \\
\hline CHEMBL1510095 & 688239 & 4.5862 & 5.4035 & TST \\
\hline CHEMBL1448607 & 688239 & 4.5362 & 5.4442 & TRN \\
\hline CHEMBL1450468 & 688239 & 4.5362 & 5.4233 & TRN \\
\hline CHEMBL1509714 & 688239 & 6.5363 & 5.4829 & TRN \\
\hline CHEMBL1330769 & 688239 & 5.8862 & 5.4129 & TRN \\
\hline CHEMBL1333024 & 688239 & 6.9863 & 5.4917 & TRN \\
\hline CHEMBL1346991 & 688239 & 8.3372 & 5.5072 & TST \\
\hline CHEMBL1456659 & 688239 & 4.5362 & 5.4818 & TST \\
\hline CHEMBL1575484 & 688239 & 5.1862 & 5.4314 & TRN \\
\hline CHEMBL1443236 & 688239 & 6.2362 & 5.4828 & TRN \\
\hline CHEMBL1374162 & 688239 & 4.5362 & 5.4814 & TRN \\
\hline CHEMBL1453489 & 688239 & 6.8861 & 5.508999 & 99999999995 \\
\hline CHEMBL1533151 & 688239 & 5.1862 & 5.4288 & TRN \\
\hline CHEMBL1540061 & 688239 & 4.5362 & 5.4185 & TRN \\
\hline CHEMBL1493248 & 688239 & 6.6362 & 5.3547 & TRN \\
\hline CHEMBL1402348 & 688239 & 6.1862 & 5.5427 & TRN \\
\hline CHEMBL1578855 & 688239 & 6.1362 & 5.4906 & TRN \\
\hline CHEMBL3193373 & 688239 & 6.6362 & 5.4662 & TRN \\
\hline CHEMBL1546065 & 688239 & 7.2865 & 5.4611 & TRN \\
\hline CHEMBL579498 & 688239 & 5.7862 & 5.5101 & TRN \\
\hline CHEMBL1605824 & 688239 & 5.2862 & 5.5021 & TRN \\
\hline CHEMBL1575031 & 688239 & 4.5362 & 5.4201 & TRN \\
\hline CHEMBL1320851 & 688239 & 4.5362 & 5.437 & TRN \\
\hline CHEMBL1352774 & 688239 & 4.5362 & 5.6057 & TST \\
\hline CHEMBL1430145 & 688239 & 6.0362 & 5.4182 & TRN \\
\hline CHEMBL1386844 & 688239 & 4.7362 & 5.4738 & TRN \\
\hline CHEMBL1374170 & 688239 & 6.1362 & 5.5458 & TST \\
\hline CHEMBL1470464 & 688239 & 6.7361 & 5.407999 & 99999999995 \\
\hline CHEMBL1605113 & 688239 & 6.6362 & 5.55 & TRN \\
\hline
\end{tabular}


Supplemental Table S2.txt

\begin{tabular}{|c|c|c|c|c|}
\hline CHEMBL1370773 & 688239 & 6.2862 & 5.4021 & TST \\
\hline CHEMBL275006 & 688239 & 6.2862 & 5.5523 & TST \\
\hline CHEMBL1550603 & 688239 & 6.0362 & 5.4665 & TRN \\
\hline CHEMBL1609712 & 688239 & 6.1862 & 5.566 & TST \\
\hline CHEMBL1422239 & 688239 & 4.5362 & 5.4494 & TST \\
\hline CHEMBL1550862 & 688239 & 5.0362 & 5.28 & TRN \\
\hline CHEMBL1308271 & 688239 & 6.1362 & \multicolumn{2}{|c|}{5.6370000000000005} \\
\hline CHEMBL1561565 & 688239 & 6.0862 & 5.586 & TRN \\
\hline CHEMBL1367575 & 688239 & 5.7362 & 5.433 & TST \\
\hline CHEMBL1492718 & 688239 & 5.1362 & 5.4411 & TRN \\
\hline CHEMBL1340977 & 688239 & 4.9362 & 5.3973 & TRN \\
\hline CHEMBL1304959 & 688239 & 5.9362 & 5.4593 & TRN \\
\hline CHEMBL1509035 & 688239 & 5.6362 & 5.605 & TRN \\
\hline CHEMBL 3212960 & 688239 & 6.8362 & 5.3159 & TST \\
\hline CHEMBL1409096 & 688239 & 6.2362 & 5.4048 & TRN \\
\hline CHEMBL1346061 & 688239 & 5.7862 & 5.4863 & TST \\
\hline CHEMBL1601042 & 688239 & 4.5362 & 5.4109 & TRN \\
\hline CHEMBL1546616 & 688239 & 6.7862 & 5.6718 & TRN \\
\hline CHEMBL1363713 & 688239 & 4.5362 & 5.3846 & TST \\
\hline CHEMBL1399940 & 688239 & 7.0362 & 5.4446 & TRN \\
\hline CHEMBL1583650 & 688239 & 5.6862 & 5.5596 & TRN \\
\hline CHEMBL1427396 & 688239 & 5.8362 & 5.3928 & TRN \\
\hline CHEMBL1378680 & 688239 & 6.8362 & 5.5431 & TRN \\
\hline CHEMBL1520390 & 688239 & 4.5362 & 5.4572 & TRN \\
\hline CHEMBL1427915 & 688239 & 4.4862 & 5.6175 & TRN \\
\hline CHEMBL1404327 & 688239 & 6.5363 & 5.5289 & TRN \\
\hline CHEMBL1535307 & 688239 & 6.2362 & 5.4316 & TRN \\
\hline CHEMBL1585622 & 688239 & 4.5362 & 5.5864 & TST \\
\hline CHEMBL1582896 & 688239 & 5.5362 & 5.5212 & TRN \\
\hline CHEMBL1393088 & 688239 & 4.6362 & 5.5825 & TST \\
\hline CHEMBL1464563 & 688239 & 5.7862 & 5.5655 & TRN \\
\hline CHEMBL1403571 & 688239 & 6.8362 & \multicolumn{2}{|c|}{5.457000000000001} \\
\hline CHEMBL1348499 & 688239 & 6.0362 & 5.436 & TRN \\
\hline CHEMBL1328744 & 688239 & 6.1362 & 5.5141 & TST \\
\hline CHEMBL1377963 & 688239 & 5.5362 & 5.6283 & TRN \\
\hline CHEMBL1343767 & 688239 & 4.5362 & 5.3192 & TRN \\
\hline CHEMBL1331011 & 688239 & 4.5362 & 5.3573 & TRN \\
\hline CHEMBL1539940 & 688239 & 4.5362 & 5.3945 & TST \\
\hline CHEMBL1524381 & 688239 & 4.5362 & 5.3132 & TST \\
\hline CHEMBL1581970 & 688239 & 4.6862 & 5.4144 & TRN \\
\hline CHEMBL1377643 & 688239 & 5.2362 & 5.447 & TRN \\
\hline CHEMBL1531866 & 688239 & 6.3863 & 5.5632 & TRN \\
\hline CHEMBL3213193 & 688239 & 5.2862 & 5.5926 & TST \\
\hline CHEMBL1329211 & 688239 & 4.5862 & 5.5465 & TRN \\
\hline CHEMBL1476643 & 688239 & 4.7862 & 5.3272 & TRN \\
\hline CHEMBL1530161 & 688239 & 4.5362 & 5.4377 & TRN \\
\hline CHEMBL 2007390 & 688239 & 4.5362 & 5.318 & TST \\
\hline CHEMBL1470060 & 688239 & 5.2362 & 5.6162 & TRN \\
\hline
\end{tabular}


Supplemental Table S2.txt

\begin{tabular}{|c|c|c|c|c|c|}
\hline CHEMBL1435987 & 688239 & 4.5362 & 5.4872 & TRN & \\
\hline CHEMBL1415173 & 688239 & 6.3362 & 5.4154 & TRN & \\
\hline CHEMBL1528671 & 688239 & 5.3362 & 5.6188 & TRN & \\
\hline CHEMBL1608467 & 688239 & 4.5362 & 5.4891 & TRN & \\
\hline CHEMBL1396320 & 688239 & 5.4362 & 5.5314 & TRN & \\
\hline CHEMBL1438159 & 688239 & 4.5362 & 5.3707 & TRN & \\
\hline CHEMBL1518726 & 688239 & 8.3372 & 5.4476 & TRN & \\
\hline CHEMBL1502568 & 688239 & 5.1362 & 5.4529 & TRN & \\
\hline CHEMBL1434991 & 688239 & 5.7862 & 5.359 & TRN & \\
\hline CHEMBL1520739 & 688239 & 4.5362 & 5.5433 & TRN & \\
\hline CHEMBL570399 & 688239 & 4.5362 & 5.3151 & TRN & \\
\hline CHEMBL1593950 & 688239 & 5.2862 & 5.5653 & TRN & \\
\hline CHEMBL1463137 & 688239 & 4.5362 & 5.3637 & TRN & \\
\hline CHEMBL1568544 & 688239 & 5.3862 & 5.2931 & TRN & \\
\hline CHEMBL3191498 & 688239 & 5.7862 & 5.3781 & TST & \\
\hline CHEMBL3144970 & 688239 & 4.7862 & 5.3825 & TST & \\
\hline CHEMBL1461769 & 688239 & 5.1862 & 5.642 & TST & \\
\hline CHEMBL1549597 & 688239 & 5.0362 & 5.4991 & TRN & \\
\hline CHEMBL1385343 & 688239 & 4.6362 & 5.4898 & TST & \\
\hline CHEMBL1362520 & 688239 & 6.0 & 5.3432 & TST & \\
\hline CHEMBL1380488 & 688239 & 4.5362 & 5.5532 & TRN & \\
\hline CHEMBL1423185 & 688239 & 4.5362 & 5.3287 & TRN & \\
\hline CHEMBL1494355 & 688239 & 4.7362 & 5.4077 & TRN & \\
\hline CHEMBL1437822 & 688239 & 5.0362 & 5.4421 & TST & \\
\hline CHEMBL1302931 & 688239 & 5.9862 & 5.449 & TST & \\
\hline CHEMBL1532121 & 688239 & 5.8862 & 5.4901 & TRN & \\
\hline CHEMBL1539860 & 688239 & 5.3362 & 5.4723 & TST & \\
\hline CHEMBL1572313 & 688239 & 5.1362 & 5.4469 & TRN & \\
\hline CHEMBL1396286 & 688239 & 4.5362 & 5.48 & TRN & \\
\hline CHEMBL1302125 & 688239 & 4.9862 & 5.4387 & TST & \\
\hline CHEMBL1346935 & 688239 & 4.5362 & 5.357 & TRN & \\
\hline CHEMBL1371008 & 688239 & 7.6364 & 5.4262 & TST & \\
\hline CHEMBL1583717 & 688239 & 4.6362 & 5.5566 & TRN & \\
\hline CHEMBL1377525 & 688239 & 6.6861 & 5.6886 & TRN & \\
\hline CHEMBL1530133 & 688239 & 5.8862 & \multicolumn{2}{|c|}{5.507000000000001} & TRN \\
\hline CHEMBL1582195 & 688239 & 7.1361 & 5.4036 & TST & \\
\hline CHEMBL1511168 & 688239 & 6.9363 & 5.5531 & TRN & \\
\hline CHEMBL1539131 & 688239 & 4.9362 & 5.5504 & TRN & \\
\hline CHEMBL1426679 & 688239 & 4.7362 & 5.4565 & TRN & \\
\hline CHEMBL1377399 & 688239 & 7.0362 & 5.3497 & TRN & \\
\hline CHEMBL1327038 & 688239 & 6.2362 & 5.4885 & TRN & \\
\hline CHEMBL1391149 & 688239 & 5.1862 & 5.6448 & TST & \\
\hline CHEMBL1414541 & 688239 & 4.5362 & 5.4883 & TST & \\
\hline CHEMBL1432766 & 688239 & 4.6362 & 5.309 & TRN & \\
\hline CHEMBL1523084 & 688239 & 5.5362 & 5.4503 & TST & \\
\hline CHEMBL1570564 & 688239 & 5.1862 & 5.4704 & TRN & \\
\hline CHEMBL1509748 & 688239 & 6.1862 & 5.4662 & TRN & \\
\hline CHEMBL3198622 & 688239 & 5.5862 & 5.4613 & TRN & \\
\hline
\end{tabular}




\begin{tabular}{|c|c|c|c|c|c|}
\hline \multicolumn{6}{|c|}{ Supplemental Table S2.txt } \\
\hline CHEMBL1310072 & 688239 & 6.8861 & 5.5553 & TRN & \\
\hline CHEMBL1367577 & 688239 & 6.1862 & 5.456 & TRN & \\
\hline CHEMBL1554487 & 688239 & 6.0862 & 5.5161 & TST & \\
\hline CHEMBL1491342 & 688239 & 5.0362 & 5.5772 & TRN & \\
\hline CHEMBL1410741 & 688239 & 4.6862 & 5.4038 & TST & \\
\hline CHEMBL1387180 & 688239 & 5.3862 & 5.5393 & TST & \\
\hline CHEMBL1509067 & 688239 & 6.8861 & 5.5888 & TRN & \\
\hline CHEMBL195258 & 688239 & 4.5862 & 5.4723 & TRN & \\
\hline CHEMBL3211658 & 688239 & 6.5363 & 5.5068 & TST & \\
\hline CHEMBL 1300248 & 688239 & 5.4862 & 5.6499 & TRN & \\
\hline CHEMBL1974308 & 688239 & 4.7362 & 5.4443 & TST & \\
\hline CHEMBL 3194087 & 688239 & 4.4862 & 5.3634 & TRN & \\
\hline CHEMBL1376124 & 688239 & 5.4362 & 5.6403 & TRN & \\
\hline CHEMBL1552877 & 688239 & 6.1862 & 5.4645 & TRN & \\
\hline CHEMBL1581332 & 688239 & 6.1862 & 5.5547 & TRN & \\
\hline CHEMBL1608989 & 688239 & 5.9362 & 5.3925 & TRN & \\
\hline CHEMBL1468369 & 688239 & 4.5362 & 5.3644 & TRN & \\
\hline CHEMBL1539170 & 688239 & 4.5362 & 5.48600 & 0000000001 & TRN \\
\hline CHEMBL1432298 & 688239 & 4.6862 & 5.6594 & TRN & \\
\hline CHEMBL1335165 & 688239 & 4.4862 & 5.5278 & TST & \\
\hline CHEMBL1414988 & 688239 & 4.5362 & 5.2566 & TRN & \\
\hline CHEMBL3214624 & 688239 & 6.5363 & 5.4276 & TRN & \\
\hline CHEMBL1584876 & 688239 & 5.4362 & 5.42700 & 00000000005 & TST \\
\hline CHEMBL1545289 & 688239 & 5.9362 & 5.4992 & TST & \\
\hline CHEMBL1374618 & 688239 & 4.6362 & 5.6082 & TRN & \\
\hline CHEMBL1343989 & 688239 & 4.6362 & 5.4596 & TRN & \\
\hline CHEMBL1572548 & 688239 & 4.6362 & 5.4999 & TST & \\
\hline CHEMBL1517694 & 688239 & 5.4362 & 5.5275 & TST & \\
\hline CHEMBL1523135 & 688239 & 5.3362 & 5.4034 & TRN & \\
\hline CHEMBL1463726 & 688239 & 4.6862 & 5.3941 & TRN & \\
\hline CHEMBL1352124 & 688239 & 5.7362 & 5.6869 & TRN & \\
\hline CHEMBL1442432 & 688239 & 5.4862 & 5.5076 & TRN & \\
\hline CHEMBL1495016 & 688239 & 4.5362 & 5.2741 & TRN & \\
\hline CHEMBL3197548 & 688239 & 7.2865 & 5.5858 & TRN & \\
\hline CHEMBL1510793 & 688239 & 7.4868 & 5.5087 & TRN & \\
\hline CHEMBL1476799 & 688239 & 4.6362 & 5.527 & TRN & \\
\hline CHEMBL1503168 & 688239 & 5.5362 & 5.4914 & TRN & \\
\hline CHEMBL1355445 & 688239 & 5.6362 & 5.7247 & TRN & \\
\hline CHEMBL1586819 & 688239 & 6.1862 & 5.5703 & TRN & \\
\hline CHEMBL1330864 & 688239 & 4.8362 & 5.5653 & TRN & \\
\hline CHEMBL1399266 & 688239 & 6.2362 & 5.4154 & TST & \\
\hline CHEMBL1519603 & 688239 & 5.2362 & 5.4354 & TRN & \\
\hline CHEMBL1358568 & 688239 & 4.8362 & 5.472 & TRN & \\
\hline CHEMBL1420317 & 688239 & 4.4862 & 5.4975 & TST & \\
\hline CHEMBL1453517 & 688239 & 4.7362 & 5.4163 & TRN & \\
\hline CHEMBL1545525 & 688239 & 4.6862 & 5.5336 & TST & \\
\hline CHEMBL1568840 & 688239 & 5.3362 & 5.5242 & TST & \\
\hline CHEMBL1433169 & 688239 & 4.8362 & 5.6307 & TRN & \\
\hline
\end{tabular}


Supplemental Table S2.txt

\begin{tabular}{|c|c|c|c|c|}
\hline CHEMBL1562072 & 688239 & 4.7362 & 5.4763 & TRN \\
\hline CHEMBL1581293 & 688239 & 5.5362 & 5.649 & TRN \\
\hline CHEMBL1564444 & 688239 & 4.5362 & 5.3984 & TRN \\
\hline CHEMBL1467062 & 688239 & 6.1862 & 5.5496 & TRN \\
\hline CHEMBL1325202 & 688239 & 4.5362 & 5.5667 & TST \\
\hline CHEMBL1516359 & 688239 & 5.1862 & 5.5134 & TST \\
\hline CHEMBL1553664 & 688239 & 5.6862 & 5.5133 & TRN \\
\hline CHEMBL1541823 & 688239 & 6.2362 & 5.6033 & TST \\
\hline CHEMBL1586859 & 688239 & 6.1362 & 5.7102 & TRN \\
\hline CHEMBL1461491 & 688239 & 6.9863 & 5.3531 & TST \\
\hline CHEMBL1420629 & 688239 & 4.6862 & 5.4644 & TRN \\
\hline CHEMBL1410385 & 688239 & 4.7362 & 5.5544 & TRN \\
\hline CHEMBL1538468 & 688239 & 4.8862 & 5.4712 & TRN \\
\hline CHEMBL1545801 & 688239 & 5.4362 & 5.3536 & TRN \\
\hline CHEMBL1405790 & 688239 & 5.2862 & 5.5245 & TRN \\
\hline CHEMBL1351892 & 688239 & 5.1362 & 5.4322 & TRN \\
\hline CHEMBL3189667 & 688239 & 4.8862 & 5.4671 & TST \\
\hline CHEMBL1569722 & 688239 & 8.3872 & 5.6131 & TST \\
\hline CHEMBL1358346 & 688239 & 5.0862 & 5.602 & TRN \\
\hline CHEMBL3198104 & 688239 & 6.7361 & 5.4775 & TST \\
\hline CHEMBL1401998 & 688239 & 6.9363 & 5.5028 & TST \\
\hline CHEMBL3196236 & 688239 & 5.1862 & 5.4092 & TRN \\
\hline CHEMBL1392766 & 688239 & 5.9862 & 5.4676 & TRN \\
\hline CHEMBL1305388 & 688239 & 5.2862 & 5.442 & TRN \\
\hline CHEMBL1610519 & 688239 & 6.9863 & 5.3612 & TRN \\
\hline CHEMBL1565285 & 688239 & 4.5362 & 5.2607 & TRN \\
\hline CHEMBL1318267 & 688239 & 5.0862 & 5.4977 & TRN \\
\hline CHEMBL1439845 & 688239 & 5.2862 & 5.4773 & TRN \\
\hline CHEMBL1583292 & 688239 & 4.9362 & 5.3566 & TRN \\
\hline CHEMBL1376602 & 688239 & 7.2366 & 5.3245 & TRN \\
\hline CHEMBL1326363 & 688239 & 4.6862 & 5.4794 & TST \\
\hline CHEMBL1529146 & 688239 & 4.9362 & 5.4124 & TST \\
\hline CHEMBL3213491 & 688239 & 6.1862 & 5.642 & TRN \\
\hline CHEMBL1563590 & 688239 & 5.6862 & 5.6006 & TRN \\
\hline CHEMBL1514733 & 688239 & 6.2862 & 5.342000 & 0000000005 \\
\hline CHEMBL1570485 & 688239 & 4.5362 & 5.5484 & TRN \\
\hline CHEMBL1334361 & 688239 & 8.28399 & 99999999 & 5.518 \\
\hline CHEMBL1312170 & 688239 & 6.9863 & 5.5499 & TRN \\
\hline CHEMBL1582000 & 688239 & 6.9863 & 5.371 & TST \\
\hline CHEMBL1501981 & 688239 & 6.8861 & 5.6159 & TRN \\
\hline CHEMBL1394685 & 688239 & 5.2362 & 5.5354 & TRN \\
\hline CHEMBL1561242 & 688239 & 5.1862 & 5.3933 & TRN \\
\hline CHEMBL1566901 & 688239 & 6.5862 & 5.4719 & TRN \\
\hline CHEMBL1350168 & 688239 & 5.6362 & 5.5623 & TST \\
\hline CHEMBL3195541 & 688239 & 5.1862 & 5.5089 & TRN \\
\hline CHEMBL1588914 & 688239 & 6.8362 & 5.5221 & TRN \\
\hline CHEMBL1358045 & 688239 & 6.2362 & 5.534 & TRN \\
\hline CHEMBL1446788 & 688239 & 6.4362 & 5.5974 & TRN \\
\hline
\end{tabular}


Supplemental Table S2.txt

\begin{tabular}{|c|c|c|c|c|}
\hline CHEMBL1342732 & 688239 & 4.5362 & 5.4777 & TST \\
\hline CHEMBL1418632 & 688239 & 4.7862 & 5.5097 & TRN \\
\hline CHEMBL1561909 & 688239 & 5.0862 & 5.4803 & TRN \\
\hline CHEMBL1453338 & 688239 & 5.1862 & 5.3502 & TST \\
\hline CHEMBL1613130 & 688239 & 4.5362 & 5.5314 & TST \\
\hline CHEMBL1399687 & 688239 & 4.7362 & 5.3531 & TRN \\
\hline CHEMBL1589551 & 688239 & 5.3862 & 5.596 & TRN \\
\hline CHEMBL1446104 & 688239 & 6.2862 & 5.4937 & TST \\
\hline CHEMBL1553796 & 688239 & 5.5862 & 5.4828 & TRN \\
\hline CHEMBL1377509 & 688239 & 6.1862 & $5.51200 €$ & 0000000005 \\
\hline CHEMBL1415062 & 688239 & 4.7862 & 5.4514 & TST \\
\hline CHEMBL1308467 & 688239 & 4.9862 & 5.4855 & TST \\
\hline CHEMBL1399119 & 688239 & 8.3372 & 5.5702 & TRN \\
\hline CHEMBL1484350 & 688239 & 4.4862 & 5.374 & TRN \\
\hline CHEMBL1482243 & 688239 & 5.1862 & 5.3563 & TRN \\
\hline CHEMBL1596199 & 688239 & 4.6362 & 5.482 & TRN \\
\hline CHEMBL1349965 & 688239 & 7.2366 & 5.4321 & TRN \\
\hline CHEMBL1492496 & 688239 & 4.9362 & 5.6116 & TRN \\
\hline CHEMBL1349930 & 688239 & 4.7862 & 5.5699 & TST \\
\hline CHEMBL1558270 & 688239 & 6.4862 & 5.5422 & TST \\
\hline CHEMBL1416521 & 688239 & 5.2362 & 5.4816 & TRN \\
\hline CHEMBL1576569 & 688239 & 6.4862 & 5.4917 & TRN \\
\hline CHEMBL601757 & 688239 & 5.7362 & 5.6215 & TRN \\
\hline CHEMBL1514422 & 688239 & 6.4862 & 5.529 & TRN \\
\hline CHEMBL1472931 & 688239 & 6.9363 & 5.4664 & TRN \\
\hline CHEMBL1579086 & 688239 & 6.5862 & 5.5601 & TRN \\
\hline CHEMBL1497485 & 688239 & 5.2362 & 5.2499 & TRN \\
\hline CHEMBL3198639 & 688239 & 5.4862 & 5.3837 & TST \\
\hline CHEMBL1560111 & 688239 & 4.5362 & 5.5269 & TST \\
\hline CHEMBL1965713 & 688239 & 4.6362 & 5.4906 & TRN \\
\hline CHEMBL1383821 & 688239 & 4.7862 & 5.6244 & TRN \\
\hline CHEMBL3193197 & 688239 & 7.2366 & 5.3538 & TST \\
\hline CHEMBL1492842 & 688239 & 4.5362 & 5.5704 & TRN \\
\hline CHEMBL1324093 & 688239 & 4.6362 & 5.3869 & TRN \\
\hline CHEMBL1595646 & 688239 & 4.7362 & 5.4507 & TRN \\
\hline CHEMBL1524166 & 688239 & 5.3362 & 5.4461 & TRN \\
\hline CHEMBL1470714 & 688239 & 6.0362 & 5.5204 & TRN \\
\hline CHEMBL1470332 & 688239 & 6.8861 & 5.5001 & TRN \\
\hline CHEMBL1369805 & 688239 & 5.9362 & 5.3775 & TRN \\
\hline CHEMBL 278041 & 688239 & 6.7862 & 5.4988 & TRN \\
\hline CHEMBL1323038 & 688239 & 5.7862 & 5.5923 & TST \\
\hline CHEMBL588525 & 688239 & 4.5362 & 5.4827 & TRN \\
\hline CHEMBL1510582 & 688239 & 4.5862 & 5.3461 & TRN \\
\hline CHEMBL1596566 & 688239 & 5.6862 & 5.6319 & TRN \\
\hline CHEMBL1338864 & 688239 & 5.2862 & 5.4527 & TRN \\
\hline CHEMBL1422150 & 688239 & 6.1862 & 5.5986 & TRN \\
\hline CHEMBL1488637 & 688239 & 4.7362 & 5.4869 & TRN \\
\hline CHEMBL1510156 & 688239 & 6.3863 & 5.5124 & TST \\
\hline
\end{tabular}




\begin{tabular}{|c|c|c|c|c|c|}
\hline & & \multicolumn{4}{|c|}{ Supplemental Table S2.txt } \\
\hline CHEMBL1437691 & 688239 & 4.4362 & 5.3479 & TRN & \\
\hline CHEMBL1344894 & 688239 & 5.4862 & 5.3973 & TRN & \\
\hline CHEMBL1455041 & 688239 & 5.1862 & 5.3044 & TST & \\
\hline CHEMBL1423961 & 688239 & 5.8362 & 5.3477 & TRN & \\
\hline CHEMBL1548284 & 688239 & 5.1362 & 5.3625 & TRN & \\
\hline CHEMBL1554950 & 688239 & 5.1862 & 5.5068 & TRN & \\
\hline CHEMBL1610722 & 688239 & 6.1862 & 5.5753 & TRN & \\
\hline CHEMBL1345011 & 688239 & 8.3372 & 5.4849 & TRN & \\
\hline CHEMBL1584904 & 688239 & 6.1862 & 5.5681 & TST & \\
\hline CHEMBL3208083 & 688239 & 5.0862 & 5.45799 & 9999999999 & TRN \\
\hline CHEMBL1374584 & 688239 & 5.1862 & 5.6164 & TRN & \\
\hline CHEMBL1979574 & 688239 & 5.1862 & 5.2618 & TST & \\
\hline CHEMBL1537618 & 688239 & 4.8362 & 5.3014 & TRN & \\
\hline CHEMBL1358576 & 688239 & 4.5862 & 5.4628 & TST & \\
\hline CHEMBL1510510 & 688239 & 4.8862 & 5.545 & TRN & \\
\hline CHEMBL1530021 & 688239 & 6.8861 & 5.4007 & TRN & \\
\hline CHEMBL1351862 & 688239 & 6.8362 & 5.4257 & TST & \\
\hline CHEMBL1542865 & 688239 & 5.3362 & 5.5619 & TRN & \\
\hline CHEMBL1535352 & 688239 & 6.2862 & 5.5345 & TRN & \\
\hline CHEMBL1338458 & 688239 & 4.5362 & 5.4478 & TRN & \\
\hline CHEMBL1568124 & 688239 & 4.5862 & 5.329 & TST & \\
\hline CHEMBL1362601 & 688239 & 5.6362 & 5.5633 & TRN & \\
\hline CHEMBL1520653 & 688239 & 5.1862 & 5.4812 & TST & \\
\hline CHEMBL1338617 & 688239 & 4.5362 & 5.4083 & TRN & \\
\hline CHEMBL3213518 & 688239 & 6.6362 & 5.3653 & TRN & \\
\hline CHEMBL1541155 & 688239 & 7.0362 & 5.48600 & 0000000001 & TRN \\
\hline CHEMBL491537 & 688239 & 5.4862 & 5.3763 & TRN & \\
\hline CHEMBL1607891 & 688239 & 4.5362 & 5.4551 & TST & \\
\hline CHEMBL1515593 & 688239 & 4.8362 & 5.5421 & TRN & \\
\hline CHEMBL3190817 & 688239 & 5.1862 & 5.574 & TST & \\
\hline CHEMBL1407965 & 688239 & 5.9362 & 5.4623 & TRN & \\
\hline CHEMBL1385014 & 688239 & 4.5362 & 5.4278 & TST & \\
\hline CHEMBL1383432 & 688239 & 5.9362 & 5.5264 & TRN & \\
\hline CHEMBL1323442 & 688239 & 4.7862 & 5.6438 & TRN & \\
\hline CHEMBL1422146 & 688239 & 4.7362 & 5.5402 & TRN & \\
\hline CHEMBL1542972 & 688239 & 4.8362 & 5.4873 & TRN & \\
\hline CHEMBL1481733 & 688239 & 4.8862 & 5.4134 & TST & \\
\hline CHEMBL1411462 & 688239 & 6.9863 & 5.327006 & 0000000001 & TRN \\
\hline CHEMBL1369894 & 688239 & 5.4862 & 5.5734 & TST & \\
\hline CHEMBL1574867 & 688239 & 5.7862 & 5.6852 & TRN & \\
\hline CHEMBL1329405 & 688239 & 6.0862 & 5.5034 & TRN & \\
\hline CHEMBL1574412 & 688239 & 4.9362 & 5.4236 & TRN & \\
\hline CHEMBL1566236 & 688239 & 6.9363 & 5.4935 & TST & \\
\hline CHEMBL1508227 & 688239 & 6.8362 & 5.4931 & TRN & \\
\hline CHEMBL576349 & 688239 & 6.5363 & 5.3944 & TST & \\
\hline CHEMBL1611046 & 688239 & 6.1862 & 5.477 & TRN & \\
\hline CHEMBL1485181 & 688239 & 5.3362 & 5.4771 & TRN & \\
\hline CHEMBL1403890 & 688239 & 4.6862 & 5.4598 & TRN & \\
\hline
\end{tabular}


Supplemental Table S2.txt

\begin{tabular}{|c|c|c|c|c|}
\hline J & & & & \\
\hline HEMBL1506197 & 88239 & 5362 & 3549 & \\
\hline HEMBL1490728 & 88239 & 1862 & & \\
\hline 779 & & & & \\
\hline EMBL1421944 & & 362 & & \\
\hline HEMBL1312941 & 88239 & 362 & 5471 & \\
\hline HEMBL1299973 & 88239 & .8362 & 6998 & \\
\hline HEMBL1377134 & 39 & 362 & 922 & \\
\hline IEMBL1363588 & 39 & & 435 & \\
\hline IEMBL1469410 & 39 & & & \\
\hline HEMBL1402745 & 88239 & 862 & 5784 & \\
\hline HEMBL1358601 & 39 & 3362 & .4314 & \\
\hline HEMBL1335635 & 39 & 862 & 4099 & \\
\hline 1339298 & 39 & 62 & 52 & \\
\hline HEMBL1487260 & 39 & & & \\
\hline AEMBL1471043 & 39 & 362 & & \\
\hline HEMBL1417742 & 39 & & & \\
\hline HEMBL1553 & 9 & 62 & 11 & \\
\hline HEMBL605 & & & & \\
\hline HEMBL14 & 39 & & & \\
\hline HEMBL1505589 & 39 & & & \\
\hline HEMBL1469120 & 39 & & & \\
\hline HEMBL1513 & 39 & & & \\
\hline HEMBL1492 & & & & \\
\hline 1565592 & & & & \\
\hline HEMBL1441700 & 39 & & & \\
\hline HEMBL1529934 & 39 & & & ГRN \\
\hline HEMBL130 & 9 & 62 & & \\
\hline HEM & 9 & & & \\
\hline HEME & & & & RN \\
\hline HEMBL15008 & 9 & & & ( \\
\hline HEMBL1345064 & 39 & & & TRN \\
\hline HEMBL14 & & & & וכ \\
\hline 1 & 9 & & & 「RN \\
\hline HEMBL3213240 & & & & TST \\
\hline HEMBL3197802 & 39 & & & IST \\
\hline HEMBL1311053 & 39 & & 5.4081 & TST \\
\hline 577 & 39 & & 78 & IST \\
\hline 93 & 9 & & & TRN \\
\hline HEMBL1546423 & & & & $\mathrm{RN}$ \\
\hline HEMBL1431871 & 88239 & 62 & 007 & TRN \\
\hline HEMBL13342 & 39 & & 323 & $\mathrm{~N}$ \\
\hline HEMBL1306966 & & & & \\
\hline HEMBL1500091 & & & & \\
\hline HEMBL1438524 & & & .4504 & RN \\
\hline HEMBL1593397 & 39 & 362 & 386 & $N$ \\
\hline & & & & \\
\hline 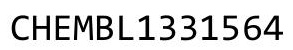 & & & & \\
\hline
\end{tabular}


Supplemental Table S2.txt

\begin{tabular}{|c|c|c|c|c|}
\hline CHEMBL1509327 & 688239 & 5.3862 & 5.4258 & TRN \\
\hline CHEMBL 3196602 & 688239 & 4.7862 & 5.347 & TRN \\
\hline CHEMBL1596409 & 688239 & 5.0362 & 5.5413 & TRN \\
\hline CHEMBL1558825 & 688239 & 4.5362 & 5.5437 & TRN \\
\hline CHEMBL1563445 & 688239 & 6.8362 & 5.6168 & TRN \\
\hline CHEMBL1389225 & 688239 & 4.5362 & 5.3863 & TRN \\
\hline CHEMBL1334710 & 688239 & 8.28399 & 99999999 & 5.4986 \\
\hline CHEMBL1597441 & 688239 & 4.5362 & 5.3956 & TST \\
\hline CHEMBL1407366 & 688239 & 6.3362 & 5.651 & TRN \\
\hline CHEMBL1378056 & 688239 & 4.7362 & 5.555 & TST \\
\hline CHEMBL1428183 & 688239 & 5.3862 & 5.6941 & TRN \\
\hline CHEMBL1566226 & 688239 & 4.7862 & $5.61100 e$ & 000000001 \\
\hline CHEMBL1378632 & 688239 & 5.4862 & 5.3546 & TST \\
\hline CHEMBL1599057 & 688239 & 4.5362 & 5.5464 & TST \\
\hline CHEMBL1555775 & 688239 & 6.0862 & 5.4977 & TST \\
\hline CHEMBL1341672 & 688239 & 6.8861 & 5.5131 & TRN \\
\hline CHEMBL1421962 & 688239 & 4.7362 & 5.5603 & TRN \\
\hline CHEMBL1990396 & 688239 & 5.5362 & 5.505 & TRN \\
\hline CHEMBL1569094 & 688239 & 4.6862 & 5.4512 & TRN \\
\hline CHEMBL1535933 & 688239 & 6.1362 & 5.399 & TRN \\
\hline CHEMBL3198485 & 688239 & 4.5362 & 5.4555 & TRN \\
\hline CHEMBL1541839 & 688239 & 4.6862 & 5.5214 & TST \\
\hline CHEMBL1574171 & 688239 & 4.5362 & 5.5266 & TRN \\
\hline CHEMBL1460208 & 688239 & 4.6362 & 5.5989 & TRN \\
\hline CHEMBL1392512 & 688239 & 5.0362 & 5.5749 & TRN \\
\hline CHEMBL1490063 & 688239 & 6.1862 & 5.5723 & TST \\
\hline CHEMBL1598002 & 688239 & 6.1362 & 5.4461 & TRN \\
\hline CHEMBL1447300 & 688239 & 6.2362 & 5.4743 & TRN \\
\hline CHEMBL1505417 & 688239 & 4.5362 & 5.4725 & TRN \\
\hline CHEMBL533602 & 688239 & 4.9362 & 5.3013 & TRN \\
\hline CHEMBL1313264 & 688239 & 4.5362 & 5.5249 & TRN \\
\hline CHEMBL1358145 & 688239 & 4.5862 & 5.4034 & TRN \\
\hline CHEMBL1407067 & 688239 & 8.3372 & 5.4446 & TST \\
\hline CHEMBL1511251 & 688239 & 6.1362 & 5.5804 & TST \\
\hline CHEMBL1331471 & 688239 & 5.5362 & 5.5503 & TRN \\
\hline CHEMBL1513932 & 688239 & 5.7862 & 5.4844 & TRN \\
\hline CHEMBL1607376 & 688239 & 4.7362 & 5.4847 & TRN \\
\hline CHEMBL1439553 & 688239 & 4.6862 & 5.4832 & TRN \\
\hline CHEMBL1549409 & 688239 & 6.1362 & 5.596 & TRN \\
\hline CHEMBL1313511 & 688239 & 4.4862 & 5.6429 & TST \\
\hline CHEMBL1553246 & 688239 & 5.1862 & 5.5309 & TRN \\
\hline CHEMBL1424835 & 688239 & 5.1862 & 5.4395 & TRN \\
\hline CHEMBL1582113 & 688239 & 4.5362 & 5.4938 & TST \\
\hline CHEMBL1968732 & 688239 & 4.8362 & 5.3481 & TRN \\
\hline CHEMBL1491686 & 688239 & 8.3872 & 5.4915 & TRN \\
\hline CHEMBL1548415 & 688239 & 5.5862 & 5.5076 & TRN \\
\hline CHEMBL 3199681 & 688239 & 6.8861 & 5.4911 & TRN \\
\hline CHEMBL1583323 & 688239 & 4.5362 & 5.6055 & TRN \\
\hline
\end{tabular}


Supplemental Table S2.txt

\begin{tabular}{|c|c|c|c|c|}
\hline CHEMBL1398830 & 688239 & 5.7362 & 5.4894 & TRN \\
\hline CHEMBL1347491 & 688239 & 4.6862 & 5.4953 & TST \\
\hline CHEMBL1497535 & 688239 & 5.7362 & 5.459 & TST \\
\hline CHEMBL1344661 & 688239 & 5.1362 & 5.55 & TRN \\
\hline CHEMBL1441119 & 688239 & 5.8362 & 5.4977 & TRN \\
\hline CHEMBL1521719 & 688239 & 4.5862 & 5.38399 & 99999999995 \\
\hline CHEMBL1462872 & 688239 & 4.5362 & 5.3517 & TRN \\
\hline CHEMBL1307148 & 688239 & 4.5362 & 5.5547 & TRN \\
\hline CHEMBL1333055 & 688239 & 6.5862 & 5.7107 & TRN \\
\hline CHEMBL1324975 & 688239 & 6.3362 & 5.4403 & TST \\
\hline CHEMBL1444704 & 688239 & 4.8862 & 5.5654 & TRN \\
\hline CHEMBL1505116 & 688239 & 4.7362 & 5.5507 & TRN \\
\hline CHEMBL1565321 & 688239 & 7.0862 & 5.563 & TRN \\
\hline CHEMBL1308068 & 688239 & 5.2862 & 5.5595 & TRN \\
\hline CHEMBL1486390 & 688239 & 4.8862 & 5.4471 & TRN \\
\hline CHEMBL1565795 & 688239 & 5.3362 & 5.4921 & TRN \\
\hline CHEMBL1343532 & 688239 & 4.6862 & 5.3694 & TRN \\
\hline CHEMBL1382331 & 688239 & 6.2362 & 5.5719 & TST \\
\hline CHEMBL1353482 & 688239 & 6.3362 & 5.5598 & TRN \\
\hline CHEMBL1378723 & 688239 & 4.7362 & 5.5349 & TRN \\
\hline CHEMBL1417549 & 688239 & 4.7362 & 5.4043 & TRN \\
\hline CHEMBL1457149 & 688239 & 5.2362 & 5.3977 & TRN \\
\hline CHEMBL1354358 & 688239 & 4.7362 & 5.5115 & TRN \\
\hline CHEMBL1299316 & 688239 & 5.7862 & 5.5016 & TST \\
\hline CHEMBL1342459 & 688239 & 4.5362 & 5.4043 & TRN \\
\hline CHEMBL1442354 & 688239 & 6.1862 & 5.5783 & TST \\
\hline CHEMBL3213677 & 688239 & 4.6362 & 5.5936 & TST \\
\hline CHEMBL1508704 & 688239 & 5.2862 & 5.4523 & TST \\
\hline CHEMBL1342842 & 688239 & 4.7862 & 5.3238 & TRN \\
\hline CHEMBL1324481 & 688239 & 5.1862 & 5.517 & TRN \\
\hline CHEMBL1323109 & 688239 & 6.7361 & 5.5849 & TRN \\
\hline CHEMBL1343092 & 688239 & 4.5362 & 5.5701 & TRN \\
\hline CHEMBL1500935 & 688239 & 5.1362 & 5.5614 & TRN \\
\hline CHEMBL1454016 & 688239 & 6.2362 & 5.5452 & TST \\
\hline CHEMBL1497422 & 688239 & 5.3362 & 5.5875 & TRN \\
\hline CHEMBL1352913 & 688239 & 5.6362 & 5.5118 & TRN \\
\hline CHEMBL1586987 & 688239 & 4.5362 & 5.5135 & TST \\
\hline CHEMBL1578690 & 688239 & 8.3372 & 5.6377 & TRN \\
\hline CHEMBL1451203 & 688239 & 6.2862 & 5.4618 & TRN \\
\hline CHEMBL1345342 & 688239 & 4.7362 & 5.5857 & TRN \\
\hline CHEMBL1424330 & 688239 & 6.1362 & 5.4444 & TST \\
\hline CHEMBL1370722 & 688239 & 4.9862 & 5.5901 & TRN \\
\hline CHEMBL1444536 & 688239 & 6.5363 & 5.5134 & TRN \\
\hline CHEMBL1991055 & 688239 & 4.4862 & 5.3596 & TST \\
\hline CHEMBL1340974 & 688239 & 6.2862 & 5.5225 & TST \\
\hline CHEMBL1416830 & 688239 & 4.5362 & 5.4793 & TRN \\
\hline CHEMBL1538624 & 688239 & 4.6362 & 5.5293 & TRN \\
\hline CHEMBL1369360 & 688239 & 6.9363 & 5.4041 & TRN \\
\hline
\end{tabular}


Supplemental Table S2.txt

\begin{tabular}{|c|c|c|c|c|c|}
\hline CHEMBL1488319 & 688239 & 6.1362 & 5.5882 & TRN & \\
\hline CHEMBL1299217 & 688239 & 4.5362 & 5.5267 & TST & \\
\hline CHEMBL1561613 & 688239 & 4.5362 & 5.3355 & TRN & \\
\hline CHEMBL1581871 & 688239 & 4.5362 & 5.5162 & TST & \\
\hline CHEMBL1381152 & 688239 & 5.1862 & 5.3691 & TST & \\
\hline CHEMBL 3190647 & 688239 & 6.5363 & 5.4512 & TRN & \\
\hline CHEMBL1369069 & 688239 & 4.5362 & 5.5056 & TRN & \\
\hline CHEMBL1579802 & 688239 & 4.5362 & 5.3266 & TST & \\
\hline CHEMBL1522178 & 688239 & 4.9362 & 5.5905 & TRN & \\
\hline CHEMBL1335812 & 688239 & 4.5362 & 5.7021 & TRN & \\
\hline CHEMBL1354752 & 688239 & 5.0862 & 5.4364 & TST & \\
\hline CHEMBL 1457503 & 688239 & 4.7362 & 5.5798 & TRN & \\
\hline CHEMBL1579478 & 688239 & 4.5862 & 5.4441 & TRN & \\
\hline CHEMBL1362332 & 688239 & 5.7862 & 5.4567 & TST & \\
\hline CHEMBL1597465 & 688239 & 5.1362 & 5.3671 & TRN & \\
\hline CHEMBL 3190092 & 688239 & 6.1362 & 5.3537 & TRN & \\
\hline CHEMBL1537077 & 688239 & 5.5862 & 5.4638 & TRN & \\
\hline CHEMBL1380123 & 688239 & 4.7862 & 5.2819 & TRN & \\
\hline CHEMBL1425752 & 688239 & 5.2862 & 5.5272 & TRN & \\
\hline CHEMBL1377917 & 688239 & 4.5362 & 5.5079 & TRN & \\
\hline CHEMBL1516414 & 688239 & 6.9363 & 5.4628 & TRN & \\
\hline CHEMBL1413558 & 688239 & 4.4862 & 5.6991 & TRN & \\
\hline CHEMBL1518376 & 688239 & 4.5362 & 5.3726 & TRN & \\
\hline CHEMBL1339152 & 688239 & 5.5362 & 5.638 & TRN & \\
\hline CHEMBL1435136 & 688239 & 6.9363 & 5.4202 & TRN & \\
\hline CHEMBL1581883 & 688239 & 4.9362 & 5.4431 & TRN & \\
\hline CHEMBL1567051 & 688239 & 4.5862 & 5.5173 & TRN & \\
\hline CHEMBL1361995 & 688239 & 4.5362 & 5.4705 & TRN & \\
\hline CHEMBL1332728 & 688239 & 4.5362 & 5.6477 & TRN & \\
\hline CHEMBL1575282 & 688239 & 5.7862 & 5.4669 & TST & \\
\hline CHEMBL1339227 & 688239 & 5.6862 & 5.527 & TRN & \\
\hline CHEMBL1529834 & 688239 & 5.7362 & 5.5083 & TRN & \\
\hline CHEMBL1473835 & 688239 & 4.5362 & 5.3353 & TRN & \\
\hline CHEMBL1317970 & 688239 & 4.5362 & 5.7017 & TRN & \\
\hline CHEMBL1547845 & 688239 & 5.9362 & 5.4332 & TRN & \\
\hline CHEMBL1431073 & 688239 & 5.1862 & 5.6418 & TRN & \\
\hline CHEMBL 3194261 & 688239 & 5.7862 & 5.5511 & TRN & \\
\hline CHEMBL1303192 & 688239 & 6.8861 & 5.5707 & TRN & \\
\hline CHEMBL1411937 & 688239 & 5.7862 & 5.6149 & TRN & \\
\hline CHEMBL1336534 & 688239 & \multicolumn{4}{|c|}{8.283999999999999} \\
\hline CHEMBL1300424 & 688239 & 7.0362 & 5.579 & TRN & \\
\hline CHEMBL1372708 & 688239 & 4.5362 & 5.592006 & 30000000005 & TRN \\
\hline CHEMBL1562755 & 688239 & 5.7862 & 5.5265 & TRN & \\
\hline CHEMBL1569833 & 688239 & 4.8862 & 5.3948 & TST & \\
\hline CHEMBL1391237 & 688239 & 5.6862 & 5.4292 & TST & \\
\hline CHEMBL1389696 & 688239 & 5.7362 & 5.7094 & TRN & \\
\hline CHEMBL1526931 & 688239 & 6.1362 & 5.3698 & TRN & \\
\hline CHEMBL1444085 & 688239 & 5.1862 & 5.6132 & TRN & \\
\hline
\end{tabular}




\begin{tabular}{|c|c|c|c|c|c|}
\hline & & & & & \\
\hline CHEMBL1510419 & 688239 & 7.4365 & 5.4668 & TST & \\
\hline CHEMBL1391104 & 688239 & 4.5362 & 5.5267 & TST & \\
\hline CHEMBL1482210 & 688239 & 6.8861 & 5.2774 & TRN & \\
\hline CHEMBL1349251 & 688239 & 6.2362 & 5.5404 & TRN & \\
\hline CHEMBL1390593 & 688239 & 5.5362 & 5.5567 & TST & \\
\hline CHEMBL1426985 & 688239 & 5.5862 & 5.4059 & TST & \\
\hline CHEMBL1428507 & 688239 & 5.1862 & 5.4405 & TRN & \\
\hline CHEMBL3211476 & 688239 & 4.7862 & 5.4341 & TST & \\
\hline CHEMBL1391691 & 688239 & 4.5362 & 5.5195 & TST & \\
\hline CHEMBL1475039 & 688239 & 5.2862 & 5.4203 & TST & \\
\hline CHEMBL1299500 & 688239 & 5.6862 & 5.367006 & 0000000001 & TRN \\
\hline CHEMBL1599805 & 688239 & 5.9362 & 5.5149 & TST & \\
\hline CHEMBL1479258 & 688239 & 6.3863 & 5.5967 & TST & \\
\hline CHEMBL1605960 & 688239 & 5.5862 & 5.3459 & TRN & \\
\hline CHEMBL1397932 & 688239 & 5.5862 & 5.4472 & TRN & \\
\hline CHEMBL1562338 & 688239 & 5.8362 & 5.6642 & TRN & \\
\hline CHEMBL1480863 & 688239 & 8.3872 & 5.4332 & TRN & \\
\hline CHEMBL1334488 & 688239 & 4.6862 & 5.5002 & TRN & \\
\hline CHEMBL1460794 & 688239 & 6.8362 & 5.6353 & TRN & \\
\hline CHEMBL1512044 & 688239 & 6.1362 & 5.4747 & TRN & \\
\hline CHEMBL1332366 & 688239 & 4.5362 & 5.4794 & TRN & \\
\hline CHEMBL1538711 & 688239 & 5.1362 & 5.5219 & TST & \\
\hline CHEMBL1336918 & 688239 & 6.8861 & 5.3708 & TST & \\
\hline CHEMBL1483681 & 688239 & 4.5362 & 5.3733 & TRN & \\
\hline CHEMBL1321500 & 688239 & 8.1871 & 5.5556 & TST & \\
\hline CHEMBL3209089 & 688239 & 5.0362 & 5.5723 & TRN & \\
\hline CHEMBL1330130 & 688239 & 7.5867 & 5.6156 & TRN & \\
\hline CHEMBL1469465 & 688239 & 5.7362 & 5.3937 & TRN & \\
\hline CHEMBL1347425 & 688239 & 6.8861 & 5.4337 & TST & \\
\hline CHEMBL1537798 & 688239 & 4.5362 & 5.4049 & TST & \\
\hline CHEMBL1612795 & 688239 & 4.7362 & 5.4011 & TRN & \\
\hline CHEMBL1455780 & 688239 & 4.6862 & 5.6174 & TST & \\
\hline CHEMBL1366820 & 688239 & 5.4362 & 5.5026 & TRN & \\
\hline CHEMBL1573674 & 688239 & 4.5362 & 5.5593 & TRN & \\
\hline CHEMBL1532033 & 688239 & 5.2362 & 5.5245 & TST & \\
\hline CHEMBL1416325 & 688239 & 4.5362 & 5.4172 & TRN & \\
\hline CHEMBL1342405 & 688239 & 5.5362 & 5.5095 & TRN & \\
\hline CHEMBL1464586 & 688239 & 5.8362 & 5.6421 & TRN & \\
\hline CHEMBL1396711 & 688239 & 6.0362 & 5.4778 & TRN & \\
\hline CHEMBL1556136 & 688239 & 4.4862 & 5.4729 & TRN & \\
\hline CHEMBL1419104 & 688239 & 5.3362 & 5.3785 & TRN & \\
\hline CHEMBL1570438 & 688239 & 6.2362 & 5.5748 & TRN & \\
\hline CHEMBL3196695 & 688239 & 5.8362 & 5.3946 & TST & \\
\hline CHEMBL1449849 & 688239 & 4.7862 & 5.3119 & TRN & \\
\hline CHEMBL1336063 & 688239 & 4.6362 & 5.5266 & TRN & \\
\hline CHEMBL3191351 & 688239 & 5.1862 & 5.4877 & TRN & \\
\hline CHEMBL1522494 & 688239 & 6.2862 & 5.4628 & TRN & \\
\hline CHEMBL1520185 & 688239 & 4.5862 & 5.559 & TRN & \\
\hline
\end{tabular}


Supplemental Table S2.txt

\begin{tabular}{|c|c|c|c|c|c|}
\hline CHEMBL1541291 & 688239 & 5.8862 & 5.5048 & TRN & \\
\hline CHEMBL1426040 & 688239 & 6.6362 & 5.5323 & TRN & \\
\hline CHEMBL3192144 & 688239 & 5.7362 & 5.3081 & TRN & \\
\hline CHEMBL1416645 & 688239 & 6.4862 & 5.6843 & TRN & \\
\hline CHEMBL1422559 & 688239 & 5.6862 & 5.5148 & TRN & \\
\hline CHEMBL1309986 & 688239 & 4.7862 & 5.3703 & TRN & \\
\hline CHEMBL1499586 & 688239 & 4.6862 & 5.461 & TRN & \\
\hline CHEMBL 3213713 & 688239 & 4.9862 & 5.32 & TRN & \\
\hline CHEMBL1574355 & 688239 & 5.6862 & 5.4767 & TRN & \\
\hline CHEMBL1600188 & 688239 & 5.1862 & 5.5351 & TST & \\
\hline CHEMBL1305299 & 688239 & 5.7362 & 5.6337 & TRN & \\
\hline CHEMBL1313087 & 688239 & 6.1862 & 5.4413 & TRN & \\
\hline CHEMBL1387786 & 688239 & 5.8362 & 5.4814 & TRN & \\
\hline CHEMBL1354912 & 688239 & 5.8362 & 5.6402 & TRN & \\
\hline CHEMBL53439 & 688239 & 5.1362 & 5.3683 & TST & \\
\hline CHEMBL1502227 & 688239 & 4.5362 & 5.466 & TST & \\
\hline CHEMBL1442999 & 688239 & 5.3862 & 5.5917 & TRN & \\
\hline CHEMBL1463204 & 688239 & 5.2862 & 5.6589 & TRN & \\
\hline CHEMBL1350167 & 688239 & 4.5862 & 5.5259 & TRN & \\
\hline CHEMBL3210450 & 688239 & 4.6862 & 5.4376 & TST & \\
\hline CHEMBL1347805 & 688239 & 6.1362 & 5.6392 & TRN & \\
\hline CHEMBL1409423 & 688239 & 4.7362 & 5.4956 & TRN & \\
\hline CHEMBL1357826 & 688239 & 4.7862 & 5.4505 & TRN & \\
\hline CHEMBL1368535 & 688239 & 6.8861 & 5.5765 & TRN & \\
\hline CHEMBL1365332 & 688239 & 6.1362 & 5.4236 & TRN & \\
\hline CHEMBL1410239 & 688239 & 4.7362 & 5.6841 & TRN & \\
\hline CHEMBL3191171 & 688239 & 5.1862 & 5.4243 & TRN & \\
\hline CHEMBL1389026 & 688239 & 4.9362 & 5.4471 & TST & \\
\hline CHEMBL1566410 & 688239 & 5.4362 & 5.5092 & TST & \\
\hline CHEMBL1572657 & 688239 & 4.7362 & 5.6262 & TST & \\
\hline CHEMBL1446729 & 688239 & 8.3372 & 5.5137 & TRN & \\
\hline CHEMBL1361940 & 688239 & 4.5362 & 5.5188 & TST & \\
\hline CHEMBL1421759 & 688239 & 5.1862 & 5.5223 & TST & \\
\hline CHEMBL1996299 & 688239 & 5.1862 & 5.472 & TRN & \\
\hline CHEMBL1556259 & 688239 & 6.8362 & 5.6327 & TRN & \\
\hline CHEMBL1349604 & 688239 & 6.5363 & 5.5146 & TRN & \\
\hline CHEMBL1361597 & 688239 & 5.7862 & 5.3448 & TRN & \\
\hline CHEMBL1342262 & 688239 & 8.28399 & 99999999 & 9 & 5.526 \\
\hline CHEMBL1574287 & 688239 & 6.1362 & 5.4795 & TRN & \\
\hline CHEMBL1536046 & 688239 & 4.8362 & 5.5013 & TRN & \\
\hline CHEMBL1593029 & 688239 & 4.5362 & 5.5157 & TST & \\
\hline CHEMBL1517031 & 688239 & 4.7862 & 5.596 & TST & \\
\hline CHEMBL1536676 & 688239 & 5.3862 & 5.6338 & TRN & \\
\hline CHEMBL1544215 & 688239 & 4.5862 & 5.4908 & TST & \\
\hline CHEMBL1381820 & 688239 & 6.1862 & 5.4901 & TST & \\
\hline CHEMBL1329602 & 688239 & 6.0362 & 5.4815 & TST & \\
\hline CHEMBL1400001 & 688239 & 5.5862 & 5.5611 & TST & \\
\hline CHEMBL1541135 & 688239 & 4.5362 & 5.5041 & TRN & \\
\hline
\end{tabular}


Supplemental Table S2.txt

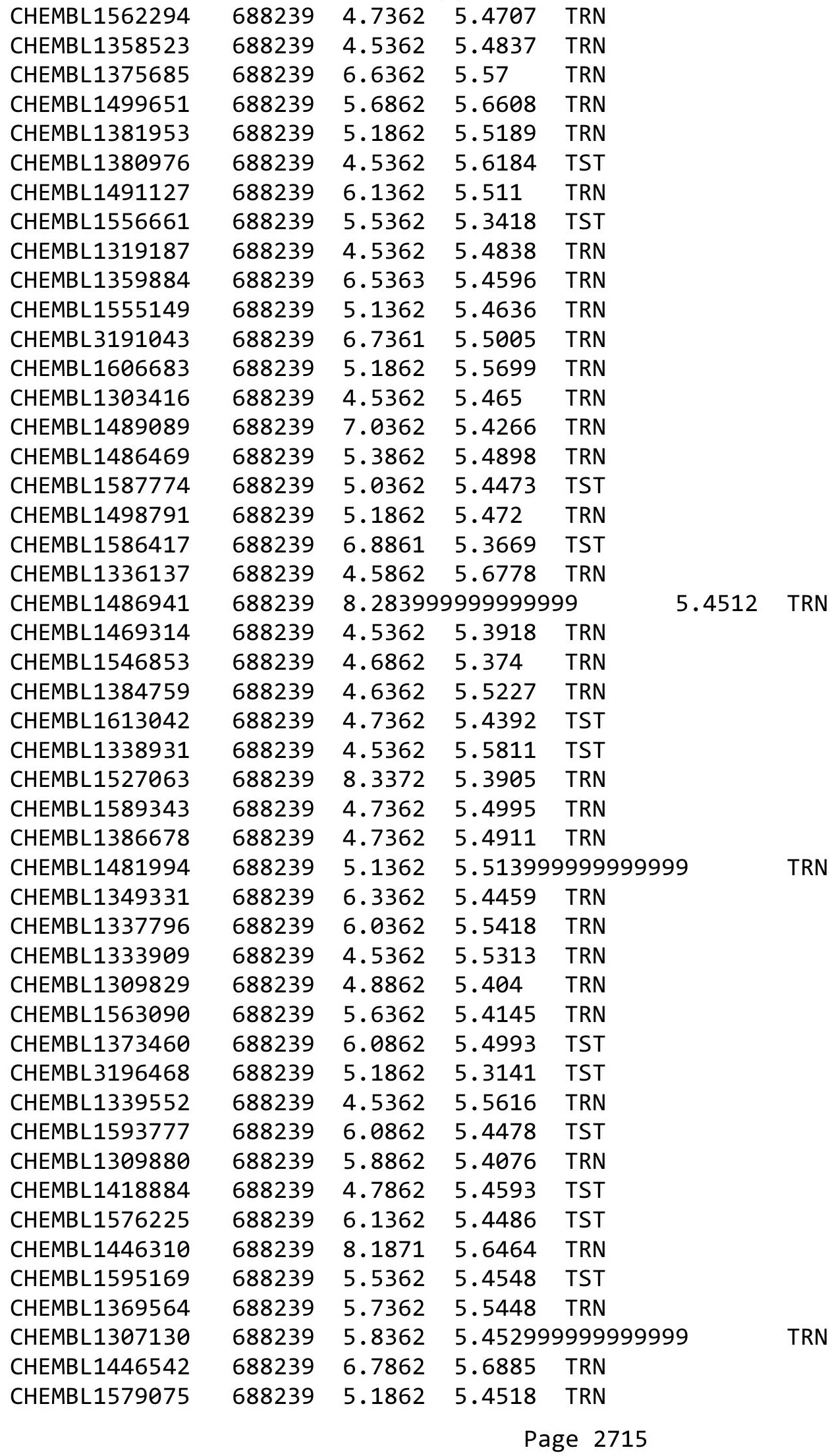


Supplemental Table S2.txt

\begin{tabular}{|c|c|c|c|c|c|}
\hline CHEMBL1338211 & 688239 & 4.5362 & 5.6285 & TRN & \\
\hline CHEMBL1332988 & 688239 & 5.5362 & 5.4972 & TRN & \\
\hline CHEMBL1532106 & 688239 & 4.4862 & \multicolumn{2}{|c|}{5.672000000000001} & TST \\
\hline CHEMBL1583061 & 688239 & 8.3372 & 5.4185 & TST & \\
\hline CHEMBL1563703 & 688239 & 4.5362 & 5.4938 & TST & \\
\hline CHEMBL1588498 & 688239 & 7.0362 & \multicolumn{2}{|c|}{5.4110000000000005} & TST \\
\hline CHEMBL1475661 & 688239 & 4.7862 & 5.5269 & TST & \\
\hline CHEMBL1525135 & 688239 & 5.5362 & 5.5064 & TRN & \\
\hline CHEMBL1324249 & 688239 & 6.2362 & 5.5856 & TRN & \\
\hline CHEMBL1460194 & 688239 & 4.5362 & 5.3862 & TST & \\
\hline CHEMBL1360292 & 688239 & 6.2362 & 5.5749 & TRN & \\
\hline CHEMBL1563422 & 688239 & 5.3862 & 5.3981 & TST & \\
\hline CHEMBL1359968 & 688239 & 4.9862 & 5.3395 & TRN & \\
\hline CHEMBL1588051 & 688239 & 4.5362 & 5.4415 & TRN & \\
\hline CHEMBL1334831 & 688239 & 4.5362 & 5.5123 & TRN & \\
\hline CHEMBL1389171 & 688239 & 4.8862 & 5.3486 & TRN & \\
\hline CHEMBL1458662 & 688239 & 5.4362 & 5.5444 & TRN & \\
\hline CHEMBL1321659 & 688239 & 4.8862 & \multicolumn{2}{|c|}{5.4110000000000005} & TRN \\
\hline CHEMBL1352236 & 688239 & 5.0862 & 5.5211 & TRN & \\
\hline CHEMBL1604650 & 688239 & 4.7862 & 5.4584 & TRN & \\
\hline CHEMBL1380714 & 688239 & 5.0862 & 5.5223 & TST & \\
\hline CHEMBL3191634 & 688239 & 5.5862 & 5.4372 & TST & \\
\hline CHEMBL1546035 & 688239 & 6.9863 & 5.6162 & TRN & \\
\hline CHEMBL1417198 & 688239 & 6.8362 & 5.5212 & TRN & \\
\hline CHEMBL1555554 & 688239 & 5.1862 & 5.4255 & TRN & \\
\hline CHEMBL1303555 & 688239 & 5.0862 & 5.5199 & TRN & \\
\hline CHEMBL1576096 & 688239 & 5.3362 & 5.4458 & TST & \\
\hline CHEMBL1417486 & 688239 & 4.6862 & 5.4195 & TRN & \\
\hline CHEMBL1378816 & 688239 & 5.5862 & 5.4449 & TRN & \\
\hline CHEMBL1551838 & 688239 & 6.8861 & 5.4585 & TRN & \\
\hline CHEMBL1413107 & 688239 & 4.5362 & 5.6069 & TRN & \\
\hline CHEMBL1337080 & 688239 & 6.3863 & 5.5568 & TRN & \\
\hline CHEMBL1467385 & 688239 & 4.7862 & 5.5768 & TRN & \\
\hline CHEMBL1495406 & 688239 & 6.4362 & 5.5586 & TRN & \\
\hline CHEMBL1590333 & 688239 & 4.5362 & 5.5167 & TRN & \\
\hline CHEMBL1565847 & 688239 & 6.0862 & 5.4717 & TST & \\
\hline CHEMBL1526757 & 688239 & 6.6861 & 5.4511 & TRN & \\
\hline CHEMBL1561621 & 688239 & 5.8362 & 5.5668 & TRN & \\
\hline CHEMBL1501166 & 688239 & 5.5362 & 5.4225 & TRN & \\
\hline CHEMBL1472173 & 688239 & 4.5362 & 5.4192 & TRN & \\
\hline CHEMBL1468410 & 688239 & 4.6362 & 5.526 & TRN & \\
\hline CHEMBL1510917 & 688239 & 4.5362 & 5.5607 & TRN & \\
\hline CHEMBL1576894 & 688239 & 6.6362 & 5.5495 & TRN & \\
\hline CHEMBL1429859 & 688239 & 4.7862 & 5.6145 & TRN & \\
\hline CHEMBL1418647 & 688239 & 5.8862 & 5.4778 & TRN & \\
\hline CHEMBL1546360 & 688239 & 5.1862 & 5.4302 & TST & \\
\hline CHEMBL1603156 & 688239 & 4.9862 & 5.5171 & TRN & \\
\hline CHEMBL1369306 & 688239 & 7.0362 & 5.6935 & TRN & \\
\hline
\end{tabular}


Supplemental Table S2.txt

\begin{tabular}{|c|c|c|c|c|c|c|}
\hline CHEMBL1412322 & 688239 & 6.9863 & 5.5061 & TST & & \\
\hline CHEMBL1316320 & 688239 & 5.9362 & 5.5127 & TRN & & \\
\hline CHEMBL1529940 & 688239 & 6.7361 & 5.6725 & TRN & & \\
\hline CHEMBL1408959 & 688239 & 5.3862 & 5.4505 & TRN & & \\
\hline CHEMBL1355843 & 688239 & 4.7362 & 5.5949 & TRN & & \\
\hline CHEMBL1526920 & 688239 & 7.2865 & 5.5366 & TST & & \\
\hline CHEMBL1486099 & 688239 & 5.5862 & 5.4239 & TRN & & \\
\hline CHEMBL1598365 & 688239 & 4.5362 & 5.3336 & TRN & & \\
\hline CHEMBL1601235 & 688239 & 4.4862 & 5.6003 & TRN & & \\
\hline CHEMBL454028 & 688239 & 4.5362 & 5.4837 & TRN & & \\
\hline CHEMBL1304661 & 688239 & 6.4362 & 5.6018 & TRN & & \\
\hline CHEMBL1534278 & 688239 & 8.28399 & 99999999 & & 5.4464 & בו \\
\hline CHEMBL1583286 & 688239 & 5.1862 & 5.4996 & TRN & & \\
\hline CHEMBL1473431 & 688239 & 4.6862 & 5.4805 & TRN & & \\
\hline CHEMBL1382745 & 688239 & 8.28399 & 99999999 & & 5.4659 & \\
\hline CHEMBL 3194767 & 688239 & 6.6362 & 5.4067 & TRN & & \\
\hline CHEMBL1556922 & 688239 & 5.3362 & 5.4686 & TRN & & \\
\hline CHEMBL1549306 & 688239 & 8.28399 & 99999999 & 99 & 5.4674 & \\
\hline CHEMBL3197406 & 688239 & 4.5362 & 5.5562 & TRN & & \\
\hline CHEMBL1303422 & 688239 & 6.0362 & 5.6162 & TRN & & \\
\hline CHEMBL1341879 & 688239 & 5.6862 & 5.3807 & TRN & & \\
\hline CHEMBL1379140 & 688239 & 4.6862 & 5.4037 & TRN & & \\
\hline CHEMBL1324437 & 688239 & 4.6862 & 5.6564 & TRN & & \\
\hline CHEMBL1409144 & 688239 & 4.5362 & 5.392 & TRN & & \\
\hline CHEMBL1319003 & 688239 & 4.5362 & 5.3473 & TRN & & \\
\hline CHEMBL1500415 & 688239 & 6.4862 & 5.5 & TRN & & \\
\hline CHEMBL1589504 & 688239 & 4.7862 & 5.5106 & TRN & & \\
\hline CHEMBL1610752 & 688239 & 4.7362 & 5.5908 & TRN & & \\
\hline CHEMBL1335168 & 688239 & 5.7362 & 5.4051 & TRN & & \\
\hline CHEMBL1541991 & 688239 & 8.1367 & 5.6322 & TRN & & \\
\hline CHEMBL2001904 & 688239 & \multicolumn{3}{|c|}{8.283999999999999} & 5.2814 & \\
\hline CHEMBL1482886 & 688239 & 6.0862 & 5.3652 & TST & & \\
\hline CHEMBL1342169 & 688239 & 5.5362 & 5.4515 & TRN & & \\
\hline CHEMBL1404807 & 688239 & 5.5862 & 5.457999 & 9999999995 & & \\
\hline CHEMBL1479099 & 688239 & 4.8362 & 5.4106 & TST & & \\
\hline CHEMBL1581167 & 688239 & 8.3372 & 5.5802 & TRN & & \\
\hline CHEMBL1468991 & 688239 & 5.0862 & 5.5299 & TRN & & \\
\hline CHEMBL1301295 & 688239 & 4.7362 & 5.5224 & TRN & & \\
\hline CHEMBL1591052 & 688239 & 6.7361 & 5.5128 & TRN & & \\
\hline CHEMBL1574413 & 688239 & 5.1862 & 5.3323 & TRN & & \\
\hline CHEMBL1376722 & 688239 & 5.9862 & 5.5115 & TRN & & \\
\hline CHEMBL1320701 & 688239 & 7.4868 & 5.5896 & TST & & \\
\hline CHEMBL1572925 & 688239 & 4.7862 & 5.507999 & 999999999 & & RN \\
\hline CHEMBL1323417 & 688239 & 5.7362 & 5.45 & TRN & & \\
\hline CHEMBL1398187 & 688239 & 8.2366 & 5.4725 & TRN & & \\
\hline CHEMBL1309262 & 688239 & 8.3372 & 5.5365 & TRN & & \\
\hline CHEMBL1493974 & 688239 & 5.6862 & 5.5372 & TRN & & \\
\hline CHEMBL1594887 & 688239 & 4.7862 & 5.5703 & TST & & \\
\hline
\end{tabular}


Supplemental Table S2.txt

\begin{tabular}{|c|c|c|c|c|c|}
\hline CHEMBL1523888 & 688239 & 5.1362 & 5.3847 & TRN & \\
\hline CHEMBL1550212 & 688239 & 8.3372 & 5.5276 & TRN & \\
\hline CHEMBL1572251 & 688239 & 6.2862 & 5.3858 & TST & \\
\hline CHEMBL1393472 & 688239 & 4.8862 & 5.5019 & TRN & \\
\hline CHEMBL1598270 & 688239 & 4.5862 & 5.5458 & TRN & \\
\hline CHEMBL1574457 & 688239 & 4.5362 & 5.3775 & TRN & \\
\hline CHEMBL1468838 & 688239 & 5.1862 & 5.4258 & TRN & \\
\hline CHEMBL1597029 & 688239 & 4.6362 & 5.5171 & TST & \\
\hline CHEMBL1299326 & 688239 & 4.7362 & 5.6321 & TRN & \\
\hline CHEMBL1381921 & 688239 & 4.8362 & 5.407 & TST & \\
\hline CHEMBL1441009 & 688239 & 5.9862 & 5.5284 & TRN & \\
\hline CHEMBL1595276 & 688239 & 4.6862 & 5.511 & TRN & \\
\hline CHEMBL1440507 & 688239 & 6.2362 & 5.4254 & TST & \\
\hline CHEMBL1423660 & 688239 & 5.5362 & 5.5305 & TRN & \\
\hline CHEMBL1566197 & 688239 & 4.6862 & 5.3872 & TRN & \\
\hline CHEMBL1450167 & 688239 & 4.5362 & 5.3531 & TST & \\
\hline CHEMBL1360507 & 688239 & 4.5362 & 5.4089 & TRN & \\
\hline CHEMBL1528939 & 688239 & 5.1862 & 5.5036 & TRN & \\
\hline CHEMBL1538453 & 688239 & 4.8362 & 5.3315 & TRN & \\
\hline CHEMBL1472545 & 688239 & 4.7362 & 5.5303 & TST & \\
\hline CHEMBL1403733 & 688239 & 4.5362 & 5.4287 & TRN & \\
\hline CHEMBL1567937 & 688239 & 4.5862 & 5.4594 & TRN & \\
\hline CHEMBL1384055 & 688239 & 4.7362 & 5.5479 & TRN & \\
\hline CHEMBL1489629 & 688239 & 4.4862 & 5.4801 & TRN & \\
\hline CHEMBL1406854 & 688239 & 5.1862 & 5.5653 & TST & \\
\hline CHEMBL1601683 & 688239 & 6.3863 & 5.5707 & TST & \\
\hline CHEMBL 3213471 & 688239 & 5.5362 & 5.50799 & 9999999999 & TRN \\
\hline CHEMBL1473041 & 688239 & 7.1864 & 5.4784 & TST & \\
\hline CHEMBL1309141 & 688239 & 5.4362 & 5.5739 & TRN & \\
\hline CHEMBL1387588 & 688239 & 4.6862 & 5.5529 & TRN & \\
\hline CHEMBL1596334 & 688239 & 4.5362 & 5.3723 & TST & \\
\hline CHEMBL1605998 & 688239 & 4.5362 & 5.5546 & TST & \\
\hline CHEMBL1490531 & 688239 & 6.8861 & 5.4423 & TRN & \\
\hline CHEMBL1399778 & 688239 & 4.5362 & 5.5714 & TRN & \\
\hline CHEMBL1300376 & 688239 & 6.9863 & 5.5541 & TST & \\
\hline CHEMBL1573408 & 688239 & 5.3862 & 5.3764 & TST & \\
\hline CHEMBL1522688 & 688239 & 5.1862 & 5.58299 & 9999999999 & TRN \\
\hline CHEMBL1610486 & 688239 & 4.7862 & 5.266 & TRN & \\
\hline CHEMBL1321972 & 688239 & 5.0362 & 5.4024 & TST & \\
\hline CHEMBL1363335 & 688239 & 6.7361 & 5.4489 & TRN & \\
\hline CHEMBL1363930 & 688239 & 6.1862 & 5.5506 & TRN & \\
\hline CHEMBL1497281 & 688239 & 4.5362 & 5.481 & TST & \\
\hline CHEMBL1442008 & 688239 & 5.4862 & 5.7067 & TRN & \\
\hline CHEMBL1511154 & 688239 & 6.0362 & 5.5373 & TRN & \\
\hline CHEMBL1502656 & 688239 & 4.5362 & 5.4063 & TRN & \\
\hline CHEMBL1524052 & 688239 & 4.5862 & 5.4006 & TST & \\
\hline CHEMBL1399839 & 688239 & 5.1362 & 5.5694 & TRN & \\
\hline CHEMBL1306763 & 688239 & 5.6862 & 5.5854 & TST & \\
\hline
\end{tabular}


Supplemental Table S2.txt

\begin{tabular}{|c|c|c|c|c|}
\hline CHEMBL1517541 & 688239 & 5.4362 & 5.358 & TST \\
\hline CHEMBL1507903 & 688239 & 4.5862 & 5.585 & TRN \\
\hline CHEMBL1347771 & 688239 & 4.4862 & 5.6363 & TRN \\
\hline CHEMBL 3198414 & 688239 & 5.1862 & 5.6126 & TRN \\
\hline CHEMBL1448069 & 688239 & 5.4862 & 5.5355 & TRN \\
\hline CHEMBL1365315 & 688239 & 7.5361 & 5.4576 & TST \\
\hline CHEMBL1388071 & 688239 & 4.5362 & 5.5216 & TRN \\
\hline CHEMBL1541769 & 688239 & 5.3862 & 5.5321 & TRN \\
\hline CHEMBL1363383 & 688239 & 5.0362 & 5.4284 & TRN \\
\hline CHEMBL1494908 & 688239 & 5.1862 & 5.603 & TRN \\
\hline CHEMBL1593260 & 688239 & 4.6862 & 5.5397 & TRN \\
\hline CHEMBL1544460 & 688239 & 4.6862 & 5.2872 & TRN \\
\hline CHEMBL1347811 & 688239 & 5.4362 & 5.481 & TRN \\
\hline CHEMBL1350696 & 688239 & 6.1362 & 5.5133 & TST \\
\hline CHEMBL1329980 & 688239 & 5.1362 & 5.4333 & TST \\
\hline CHEMBL1502414 & 688239 & 5.1862 & 5.5176 & TRN \\
\hline CHEMBL1456914 & 688239 & 5.4362 & 5.4533 & TRN \\
\hline CHEMBL1469909 & 688239 & 4.5362 & 5.6509 & TRN \\
\hline CHEMBL1602745 & 688239 & 6.4862 & 5.431 & TST \\
\hline CHEMBL1426478 & 688239 & 5.1862 & 5.4725 & TRN \\
\hline CHEMBL1397742 & 688239 & 6.1862 & 5.4922 & TRN \\
\hline CHEMBL1337310 & 688239 & 4.5362 & 5.5142 & TRN \\
\hline CHEMBL1308636 & 688239 & 5.4862 & 5.4538 & TRN \\
\hline CHEMBL1425921 & 688239 & 4.5362 & 5.5559 & TRN \\
\hline CHEMBL1540265 & 688239 & 5.1862 & 5.5787 & TRN \\
\hline CHEMBL1500973 & 688239 & 5.9362 & 5.5146 & TRN \\
\hline CHEMBL1534319 & 688239 & 4.8362 & 5.4292 & TST \\
\hline CHEMBL1544108 & 688239 & 4.7862 & 5.3644 & TRN \\
\hline CHEMBL1390338 & 688239 & 5.3862 & 5.6222 & TST \\
\hline CHEMBL1609243 & 688239 & 4.7862 & 5.5597 & TRN \\
\hline CHEMBL1527728 & 688239 & 4.7862 & 5.4425 & TRN \\
\hline CHEMBL 3195613 & 688239 & 5.9862 & 5.428999 & 9999999999 \\
\hline CHEMBL1470344 & 688239 & 4.5362 & 5.5492 & TRN \\
\hline CHEMBL1469317 & 688239 & 5.5862 & 5.4181 & TRN \\
\hline CHEMBL1596955 & 688239 & 4.8362 & 5.6252 & TRN \\
\hline CHEMBL1612696 & 688239 & 4.5362 & 5.6815 & TST \\
\hline CHEMBL1540085 & 688239 & 4.8862 & 5.4249 & TRN \\
\hline CHEMBL1093061 & 688239 & 4.7862 & 5.4546 & TST \\
\hline CHEMBL1429662 & 688239 & 4.6362 & 5.4538 & TRN \\
\hline CHEMBL1539218 & 688239 & 4.5862 & 5.445 & TRN \\
\hline CHEMBL1365850 & 688239 & 6.7361 & 5.4934 & TRN \\
\hline CHEMBL1319443 & 688239 & 4.5362 & 5.4585 & TRN \\
\hline CHEMBL1530141 & 688239 & 4.5362 & 5.3867 & TRN \\
\hline CHEMBL1523978 & 688239 & 7.5867 & 5.4484 & TRN \\
\hline CHEMBL 3189675 & 688239 & 5.3862 & 5.5662 & TRN \\
\hline CHEMBL1406281 & 688239 & 5.4862 & 5.2955 & TRN \\
\hline CHEMBL1424694 & 688239 & 5.6862 & 5.3178 & TRN \\
\hline CHEMBL1431334 & 688239 & 5.1862 & 5.6635 & TRN \\
\hline
\end{tabular}

Page 2719 
Supplemental Table S2.txt

\begin{tabular}{|c|c|c|c|c|}
\hline CHEMBL1539999 & 688239 & 5.4862 & 5.4319 & TST \\
\hline CHEMBL1526317 & 688239 & 4.5862 & 5.4538 & TRN \\
\hline CHEMBL1500312 & 688239 & 4.5362 & 5.4329 & TRN \\
\hline CHEMBL3198285 & 688239 & 8.2366 & 5.4006 & TRN \\
\hline CHEMBL1338703 & 688239 & 5.4862 & 5.6594 & TST \\
\hline CHEMBL1611657 & 688239 & 6.1862 & \multicolumn{2}{|c|}{5.4910000000000005} \\
\hline CHEMBL1439739 & 688239 & 4.6362 & 5.4991 & TRN \\
\hline CHEMBL1352276 & 688239 & 4.5362 & 5.5385 & TRN \\
\hline CHEMBL1612892 & 688239 & 4.5362 & 5.5178 & TRN \\
\hline CHEMBL1559092 & 688239 & 6.8362 & 5.6617 & TST \\
\hline CHEMBL1304191 & 688239 & 5.9862 & 5.4717 & TST \\
\hline CHEMBL1543173 & 688239 & 4.6362 & 5.5127 & TRN \\
\hline CHEMBL1503925 & 688239 & 5.1362 & 5.6536 & TST \\
\hline CHEMBL1562170 & 688239 & 4.5862 & 5.3776 & TST \\
\hline CHEMBL1539208 & 688239 & 4.6362 & 5.4588 & TRN \\
\hline CHEMBL1456482 & 688239 & 5.2362 & 5.5185 & TRN \\
\hline CHEMBL1400123 & 688239 & 6.0862 & 5.5239 & TRN \\
\hline CHEMBL1300776 & 688239 & 4.5362 & 5.3734 & TST \\
\hline CHEMBL1378683 & 688239 & 4.5362 & 5.5767 & TRN \\
\hline CHEMBL1352447 & 688239 & 4.6362 & 5.6051 & TRN \\
\hline CHEMBL1523370 & 688239 & 5.1862 & 5.4769 & TRN \\
\hline CHEMBL596633 & 688239 & 4.7862 & 5.3849 & TRN \\
\hline CHEMBL1480911 & 688239 & 5.6362 & 5.4785 & TRN \\
\hline CHEMBL1454357 & 688239 & 6.2862 & 5.6829 & TRN \\
\hline CHEMBL1469089 & 688239 & 4.6862 & 5.4427 & TRN \\
\hline CHEMBL1553693 & 688239 & 5.1862 & 5.4041 & TRN \\
\hline CHEMBL1422164 & 688239 & 4.6862 & 5.3286 & TST \\
\hline CHEMBL1345728 & 688239 & 5.1862 & 5.4988 & TST \\
\hline CHEMBL1508228 & 688239 & 5.6862 & 5.294 & TRN \\
\hline CHEMBL1497393 & 688239 & 5.1862 & 5.5159 & TRN \\
\hline CHEMBL1489151 & 688239 & 7.0362 & 5.5454 & TRN \\
\hline CHEMBL1348923 & 688239 & 4.5362 & 5.4714 & TST \\
\hline CHEMBL1365144 & 688239 & 4.6362 & 5.5654 & TRN \\
\hline CHEMBL1379792 & 688239 & 6.3863 & 5.4933 & TST \\
\hline CHEMBL1490385 & 688239 & 4.4862 & 5.6472 & TRN \\
\hline CHEMBL1521159 & 688239 & 4.5362 & 5.3706 & TRN \\
\hline CHEMBL1508126 & 688239 & 4.7362 & 5.6598 & TRN \\
\hline CHEMBL1332890 & 688239 & 6.1862 & 5.6076 & TRN \\
\hline CHEMBL1468072 & 688239 & 6.1362 & 5.3647 & TST \\
\hline CHEMBL1318556 & 688239 & 4.6362 & 5.4564 & TRN \\
\hline CHEMBL1321134 & 688239 & 5.2362 & 5.5574 & TST \\
\hline CHEMBL1375655 & 688239 & 5.3362 & 5.5046 & TRN \\
\hline CHEMBL1366894 & 688239 & 4.5862 & 5.4018 & TST \\
\hline CHEMBL1521756 & 688239 & 7.2865 & 5.524 & TST \\
\hline CHEMBL1327923 & 688239 & 4.7362 & 5.5768 & TRN \\
\hline CHEMBL1612281 & 688239 & 6.1362 & 5.515 & TRN \\
\hline CHEMBL1323338 & 688239 & 6.0862 & 5.693 & TST \\
\hline CHEMBL1395172 & 688239 & 6.1862 & 5.5123 & TRN \\
\hline
\end{tabular}


Supplemental Table S2.txt

\begin{tabular}{|c|c|c|c|c|c|}
\hline CHEMBL1501313 & 688239 & 5.2362 & 5.5253 & TRN & \\
\hline CHEMBL1478007 & 688239 & 5.1862 & 5.4061 & TST & \\
\hline CHEMBL1445387 & 688239 & 4.5362 & 5.515 & TST & \\
\hline CHEMBL1557061 & 688239 & 6.8362 & 5.4845 & TRN & \\
\hline CHEMBL1570760 & 688239 & 4.8362 & 5.484 & TRN & \\
\hline CHEMBL1528809 & 688239 & 5.4362 & 5.5372 & TST & \\
\hline CHEMBL1479005 & 688239 & 6.4362 & 5.5069 & TST & \\
\hline CHEMBL3198295 & 688239 & 5.4362 & 5.3812 & TRN & \\
\hline CHEMBL1369464 & 688239 & 5.6862 & 5.5004 & TST & \\
\hline CHEMBL1578269 & 688239 & 4.7862 & 5.276 & TRN & \\
\hline CHEMBL1312088 & 688239 & 4.5862 & 5.5862 & TRN & \\
\hline CHEMBL1589388 & 688239 & 6.2362 & 5.3513 & TST & \\
\hline CHEMBL1430173 & 688239 & 5.6362 & 5.5653 & TRN & \\
\hline CHEMBL1307880 & 688239 & 5.3862 & 5.529 & TRN & \\
\hline CHEMBL1404649 & 688239 & 5.6862 & 5.5523 & TRN & \\
\hline CHEMBL 3199644 & 688239 & 4.5362 & 5.5139 & TRN & \\
\hline CHEMBL1332672 & 688239 & 4.5362 & 5.7007 & TRN & \\
\hline CHEMBL1440372 & 688239 & 4.5362 & 5.4391 & TRN & \\
\hline CHEMBL1401457 & 688239 & 6.1362 & 5.5818 & TRN & \\
\hline CHEMBL1314214 & 688239 & 5.1862 & 5.4516 & TST & \\
\hline CHEMBL1402460 & 688239 & 6.5862 & 5.4979 & TRN & \\
\hline CHEMBL1467141 & 688239 & 6.3362 & 5.5858 & TRN & \\
\hline CHEMBL1485878 & 688239 & 5.1862 & 5.4484 & TRN & \\
\hline CHEMBL1356057 & 688239 & 4.6862 & 5.6144 & TRN & \\
\hline CHEMBL1586971 & 688239 & 4.6862 & 5.3907 & TRN & \\
\hline CHEMBL1530171 & 688239 & 4.6862 & 5.5379 & TRN & \\
\hline CHEMBL1413392 & 688239 & 4.5862 & 5.6387 & TRN & \\
\hline CHEMBL1467087 & 688239 & 8.28399 & 99999999 & 9 & 5.6131 \\
\hline CHEMBL1318491 & 688239 & 5.2362 & 5.4137 & TST & \\
\hline CHEMBL1438918 & 688239 & 6.3362 & 5.4804 & TRN & \\
\hline CHEMBL1574514 & 688239 & 4.5362 & 5.4667 & TRN & \\
\hline CHEMBL1498462 & 688239 & 7.0362 & 5.5153 & TRN & \\
\hline CHEMBL1323358 & 688239 & 5.1862 & 5.4828 & TRN & \\
\hline CHEMBL1382304 & 688239 & 4.8362 & 5.5763 & TRN & \\
\hline CHEMBL1562484 & 688239 & 6.0862 & 5.5979 & TRN & \\
\hline CHEMBL1564263 & 688239 & 5.8862 & 5.5345 & TST & \\
\hline CHEMBL1313742 & 688239 & 5.4362 & 5.4711 & TST & \\
\hline CHEMBL1506660 & 688239 & 4.7362 & 5.5835 & TST & \\
\hline CHEMBL 1403325 & 688239 & 5.1362 & 5.4757 & TRN & \\
\hline CHEMBL1570695 & 688239 & 6.7862 & 5.4834 & TRN & \\
\hline CHEMBL1575008 & 688239 & 8.3372 & 5.4928 & TRN & \\
\hline CHEMBL1353638 & 688239 & 4.6862 & 5.3446 & TRN & \\
\hline CHEMBL1504455 & 688239 & 6.3362 & 5.5072 & TST & \\
\hline CHEMBL1560936 & 688239 & 4.5362 & 5.6075 & TRN & \\
\hline CHEMBL1494277 & 688239 & 4.5362 & 5.529 & TRN & \\
\hline CHEMBL3207359 & 688239 & 5.4862 & 5.478 & TRN & \\
\hline CHEMBL1428348 & 688239 & 7.2865 & 5.4522 & TRN & \\
\hline CHEMBL1400625 & 688239 & 6.9363 & 5.5702 & TRN & \\
\hline
\end{tabular}




\begin{tabular}{|c|c|c|c|c|c|}
\hline & & \multicolumn{4}{|c|}{ Supplemental Table S2.txt } \\
\hline CHEMBL1587411 & 688239 & 7.2366 & 5.5977 & TRN & \\
\hline CHEMBL1383167 & 688239 & 6.4862 & 5.3658 & TST & \\
\hline CHEMBL1407658 & 688239 & 4.4862 & 5.4918 & TRN & \\
\hline CHEMBL1609117 & 688239 & 4.4862 & 5.2736 & TRN & \\
\hline CHEMBL1454569 & 688239 & 6.1362 & 5.4612 & TRN & \\
\hline CHEMBL1300613 & 688239 & 4.6362 & 5.5938 & TRN & \\
\hline CHEMBL1334829 & 688239 & 4.8862 & 5.528 & TRN & \\
\hline CHEMBL1386914 & 688239 & 6.3863 & 5.6243 & TRN & \\
\hline CHEMBL1570688 & 688239 & 6.2862 & 5.501 & TST & \\
\hline CHEMBL1474003 & 688239 & 6.0 & 5.3642 & TRN & \\
\hline CHEMBL1488475 & 688239 & 5.8862 & 5.5716 & TST & \\
\hline CHEMBL1321151 & 688239 & 5.5362 & 5.4878 & TRN & \\
\hline CHEMBL1607811 & 688239 & 6.7862 & 5.6318 & TRN & \\
\hline CHEMBL1382585 & 688239 & 6.8362 & 5.4967 & TRN & \\
\hline CHEMBL1389423 & 688239 & 6.7862 & 5.4033 & TRN & \\
\hline CHEMBL1486931 & 688239 & 5.7862 & 5.5128 & TRN & \\
\hline CHEMBL440394 & 688239 & 4.6362 & 5.51200 & 00000000005 & TST \\
\hline CHEMBL1469325 & 688239 & 6.9863 & 5.602 & TST & \\
\hline CHEMBL1381117 & 688239 & 4.6862 & 5.42899 & 9999999999 & TRN \\
\hline CHEMBL1316838 & 688239 & 7.0862 & 5.2925 & TST & \\
\hline CHEMBL1392628 & 688239 & 7.0362 & 5.5291 & TRN & \\
\hline CHEMBL1446394 & 688239 & 4.5862 & 5.51399 & 9999999999 & TST \\
\hline CHEMBL1532412 & 688239 & 5.4362 & 5.4005 & TRN & \\
\hline CHEMBL1452229 & 688239 & 5.3862 & 5.4851 & TST & \\
\hline CHEMBL1437206 & 688239 & 5.1862 & 5.4494 & TRN & \\
\hline CHEMBL1521643 & 688239 & 5.3862 & 5.3683 & TRN & \\
\hline CHEMBL1450960 & 688239 & 5.7862 & 5.4761 & TRN & \\
\hline CHEMBL1364069 & 688239 & 4.6862 & 5.4292 & TRN & \\
\hline CHEMBL1350311 & 688239 & 4.4862 & 5.4119 & TRN & \\
\hline CHEMBL1460564 & 688239 & 4.5362 & 5.4165 & TST & \\
\hline CHEMBL1331230 & 688239 & 6.5363 & 5.6646 & TRN & \\
\hline CHEMBL1573621 & 688239 & 6.2362 & 5.551 & TRN & \\
\hline CHEMBL1594674 & 688239 & 5.4862 & 5.4866 & TRN & \\
\hline CHEMBL1578817 & 688239 & 8.3872 & 5.4375 & TRN & \\
\hline CHEMBL1393857 & 688239 & 5.2862 & 5.4497 & TST & \\
\hline CHEMBL1552124 & 688239 & 6.3362 & 5.5346 & TST & \\
\hline CHEMBL1368762 & 688239 & 5.7362 & 5.4474 & TRN & \\
\hline CHEMBL1598999 & 688239 & 6.0862 & 5.4445 & TRN & \\
\hline CHEMBL1417815 & 688239 & 4.4862 & 5.5828 & TRN & \\
\hline CHEMBL1410969 & 688239 & 5.6862 & 5.5434 & TRN & \\
\hline CHEMBL1506712 & 688239 & 5.6362 & 5.416 & TRN & \\
\hline CHEMBL1369829 & 688239 & 5.8362 & 5.4514 & TRN & \\
\hline CHEMBL1326277 & 688239 & 6.9863 & 5.5254 & TRN & \\
\hline CHEMBL1321956 & 688239 & 6.1862 & 5.584 & TRN & \\
\hline CHEMBL1528599 & 688239 & 4.5362 & 5.4686 & TRN & \\
\hline CHEMBL1562742 & 688239 & 4.8862 & 5.3961 & TRN & \\
\hline CHEMBL1307030 & 688239 & 6.6861 & 5.5279 & TRN & \\
\hline CHEMBL1517321 & 688239 & 7.8356 & 5.4024 & TRN & \\
\hline
\end{tabular}


Supplemental Table S2.txt

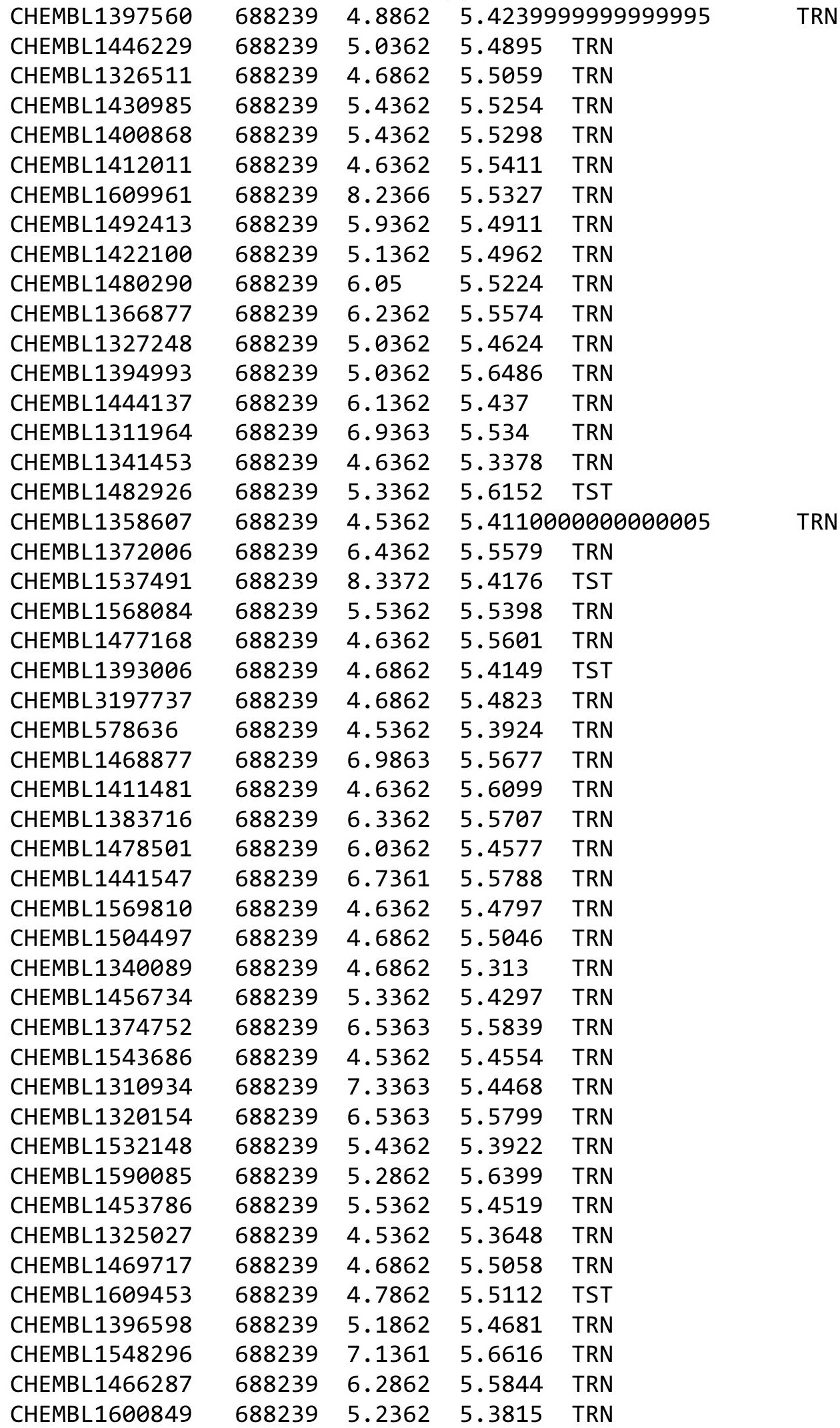


Supplemental Table S2.txt

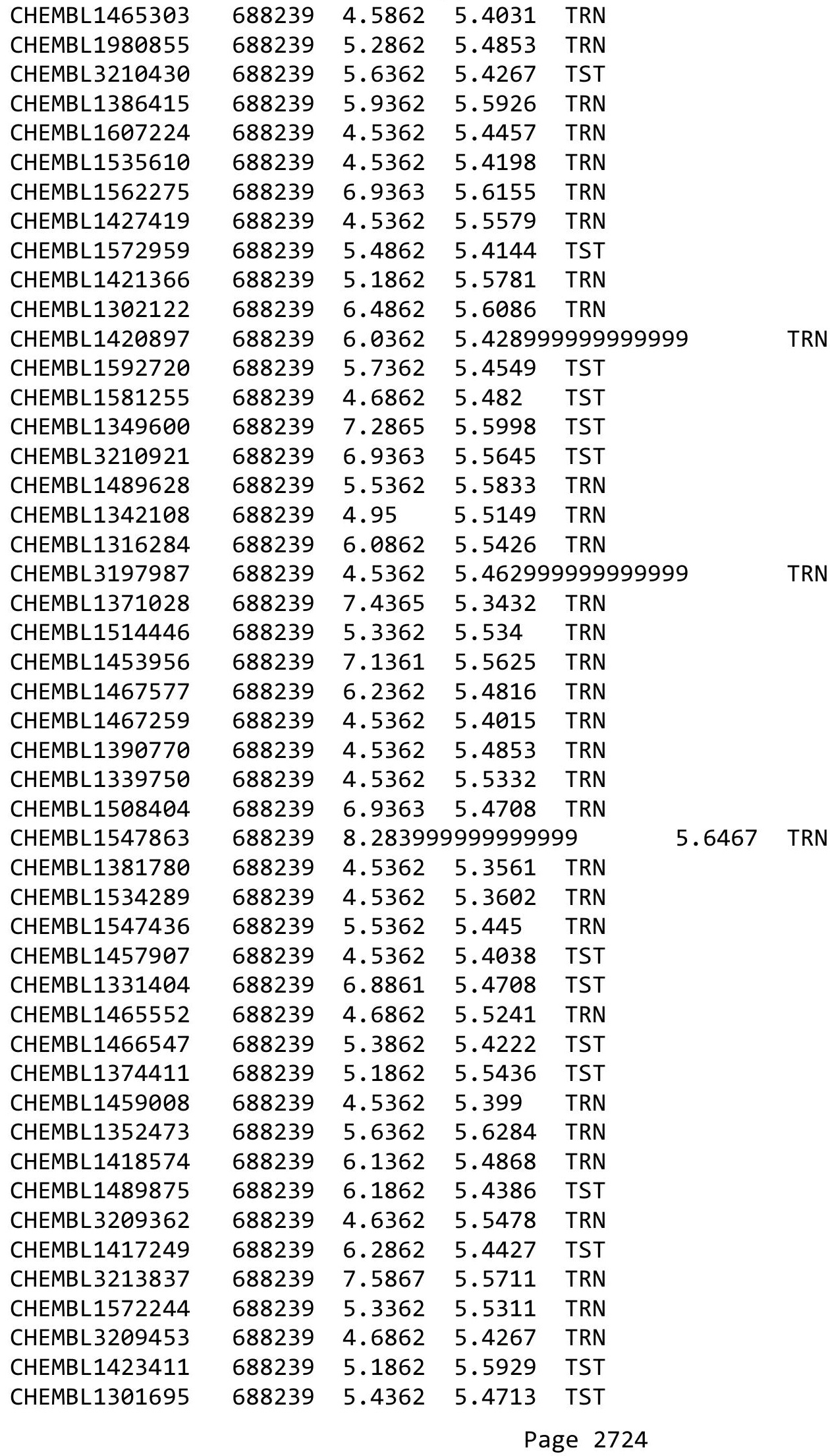


Supplemental Table S2.txt

\begin{tabular}{|c|c|c|c|c|c|}
\hline CHEMBL1344210 & 688239 & 5.3862 & 5.4105 & TRN & \\
\hline CHEMBL1537418 & 688239 & 4.6862 & 5.6048 & TST & \\
\hline CHEMBL1299260 & 688239 & 6.6861 & 5.3799 & TST & \\
\hline CHEMBL1376841 & 688239 & 6.1862 & 5.42 & TRN & \\
\hline CHEMBL1500344 & 688239 & 8.28399 & 99999999 & 99 & 5.6166 \\
\hline CHEMBL1451438 & 688239 & 4.4862 & 5.5396 & TRN & \\
\hline CHEMBL1455549 & 688239 & 4.5362 & 5.4603 & TRN & \\
\hline CHEMBL1499288 & 688239 & 5.0862 & 5.4638 & TRN & \\
\hline CHEMBL1622566 & 688239 & 4.6362 & 5.4064 & TRN & \\
\hline CHEMBL1586569 & 688239 & 4.7862 & 5.5987 & TRN & \\
\hline CHEMBL1394930 & 688239 & 5.6362 & 5.4842 & TRN & \\
\hline CHEMBL1506503 & 688239 & 4.5362 & 5.5948 & TRN & \\
\hline CHEMBL1345435 & 688239 & 4.6362 & 5.5975 & TRN & \\
\hline CHEMBL1483829 & 688239 & 4.5362 & 5.317 & TST & \\
\hline CHEMBL1440449 & 688239 & 5.7862 & 5.527 & TRN & \\
\hline CHEMBL1466705 & 688239 & 4.7862 & 5.4395 & TRN & \\
\hline CHEMBL1554625 & 688239 & 5.4862 & 5.3796 & TRN & \\
\hline CHEMBL1299313 & 688239 & 4.4862 & 5.5437 & TRN & \\
\hline CHEMBL1349011 & 688239 & 6.8861 & 5.489 & TRN & \\
\hline CHEMBL1431866 & 688239 & 5.3862 & 5.4816 & TRN & \\
\hline CHEMBL1331622 & 688239 & 4.6362 & 5.3084 & TRN & \\
\hline CHEMBL1526197 & 688239 & 6.2362 & 5.4592 & TRN & \\
\hline CHEMBL1970896 & 688239 & 5.9862 & 5.4108 & TST & \\
\hline CHEMBL1586245 & 688239 & 6.1862 & 5.4855 & TRN & \\
\hline CHEMBL 3214620 & 688239 & 5.2362 & 5.3845 & TRN & \\
\hline CHEMBL1550518 & 688239 & 8.3372 & 5.4853 & TRN & \\
\hline CHEMBL1561718 & 688239 & 5.6862 & 5.4139 & TST & \\
\hline CHEMBL1471268 & 688239 & 5.2862 & 5.5373 & TST & \\
\hline CHEMBL1562281 & 688239 & 4.5362 & 5.3546 & TST & \\
\hline CHEMBL1333525 & 688239 & 6.8861 & 5.5428 & TRN & \\
\hline CHEMBL1437941 & 688239 & 5.8862 & 5.4239 & TRN & \\
\hline CHEMBL1347836 & 688239 & 6.2862 & 5.4692 & TRN & \\
\hline CHEMBL1527483 & 688239 & 4.5362 & 5.5019 & TRN & \\
\hline CHEMBL1401239 & 688239 & 5.7862 & 5.5391 & TRN & \\
\hline CHEMBL 3192536 & 688239 & 4.5362 & 5.4059 & TRN & \\
\hline CHEMBL1324894 & 688239 & 6.0862 & 5.4921 & TRN & \\
\hline CHEMBL1578206 & 688239 & 5.9362 & 5.505 & TRN & \\
\hline CHEMBL1482791 & 688239 & 8.1871 & 5.4936 & TRN & \\
\hline CHEMBL1573473 & 688239 & 4.7362 & 5.4927 & TST & \\
\hline CHEMBL1560413 & 688239 & 4.6862 & 5.4708 & TRN & \\
\hline CHEMBL1461308 & 688239 & 6.1362 & 5.4725 & TST & \\
\hline CHEMBL1408147 & 688239 & 4.6362 & 5.3601 & TRN & \\
\hline CHEMBL1353947 & 688239 & 4.7862 & 5.5333 & TRN & \\
\hline CHEMBL1458932 & 688239 & 4.5362 & 5.4471 & TST & \\
\hline CHEMBL1512396 & 688239 & 4.5362 & 5.4354 & TRN & \\
\hline CHEMBL1519584 & 688239 & 6.2362 & 5.5247 & TST & \\
\hline CHEMBL1581965 & 688239 & 4.5362 & 5.5069 & TRN & \\
\hline CHEMBL1575397 & 688239 & 5.7362 & 5.4634 & TRN & \\
\hline
\end{tabular}


Supplemental Table S2.txt

\begin{tabular}{|c|c|c|c|c|}
\hline CHEMBL1451450 & 688239 & 6.6362 & 5.5275 & TRN \\
\hline CHEMBL1563664 & 688239 & 4.7362 & 5.3904 & TST \\
\hline CHEMBL1470732 & 688239 & 4.7362 & 5.4199 & TST \\
\hline CHEMBL175266 & 688239 & 4.4862 & 5.4751 & TST \\
\hline CHEMBL1555372 & 688239 & 5.1862 & 5.4478 & TRN \\
\hline CHEMBL1613448 & 688239 & 5.0362 & 5.6292 & TRN \\
\hline CHEMBL1580702 & 688239 & 5.0362 & 5.4165 & TRN \\
\hline CHEMBL1329945 & 688239 & 4.7362 & 5.5398 & TRN \\
\hline CHEMBL1376651 & 688239 & 4.6862 & 5.5196 & TRN \\
\hline CHEMBL1521187 & 688239 & 5.2862 & 5.5003 & TRN \\
\hline CHEMBL1353686 & 688239 & 6.9363 & 5.4636 & TST \\
\hline CHEMBL1383804 & 688239 & 4.5362 & 5.4799 & TRN \\
\hline CHEMBL1549158 & 688239 & 5.3362 & 5.5321 & TST \\
\hline CHEMBL1431913 & 688239 & 6.0862 & 5.4387 & TRN \\
\hline CHEMBL1524938 & 688239 & 6.6861 & 5.5345 & TST \\
\hline CHEMBL1505316 & 688239 & 8.2366 & 5.5231 & TRN \\
\hline CHEMBL3190917 & 688239 & 5.4362 & 5.4057 & TRN \\
\hline CHEMBL1612312 & 688239 & 5.1862 & 5.5408 & TRN \\
\hline CHEMBL1438962 & 688239 & 4.7362 & 5.4782 & TST \\
\hline CHEMBL1318188 & 688239 & 5.4862 & 5.5078 & TRN \\
\hline CHEMBL1551216 & 688239 & 4.8362 & 5.3637 & TRN \\
\hline CHEMBL3211196 & 688239 & 5.1862 & 5.476 & TRN \\
\hline CHEMBL1388850 & 688239 & 4.5362 & 5.4207 & TRN \\
\hline CHEMBL1548240 & 688239 & 7.9872 & 5.4372 & TRN \\
\hline CHEMBL1371259 & 688239 & 4.6862 & 5.46899 & 9999999999 \\
\hline CHEMBL1325910 & 688239 & 5.6362 & 5.5109 & TRN \\
\hline CHEMBL1350281 & 688239 & 5.7362 & 5.4908 & TST \\
\hline CHEMBL1451218 & 688239 & 5.9362 & 5.694 & TST \\
\hline CHEMBL1329253 & 688239 & 5.2362 & 5.4148 & TRN \\
\hline CHEMBL3193654 & 688239 & 5.1862 & 5.3855 & TRN \\
\hline CHEMBL1465731 & 688239 & 4.7862 & 5.5118 & TST \\
\hline CHEMBL1305256 & 688239 & 4.7362 & 5.3583 & TRN \\
\hline CHEMBL1555187 & 688239 & 6.2862 & 5.5611 & TST \\
\hline CHEMBL1333162 & 688239 & 4.8362 & 5.5822 & TRN \\
\hline CHEMBL1323923 & 688239 & 4.7362 & 5.5607 & TRN \\
\hline CHEMBL1561639 & 688239 & 4.6862 & 5.5589 & TRN \\
\hline CHEMBL1417778 & 688239 & 6.5363 & 5.5456 & TST \\
\hline CHEMBL1384255 & 688239 & 5.6862 & 5.4891 & TRN \\
\hline CHEMBL1349068 & 688239 & 4.5362 & 5.4232 & TRN \\
\hline CHEMBL3193688 & 688239 & 5.2362 & 5.3567 & TRN \\
\hline CHEMBL3209303 & 688239 & 6.9863 & 5.4958 & TST \\
\hline CHEMBL1330975 & 688239 & 4.5362 & 5.4738 & TRN \\
\hline CHEMBL1440187 & 688239 & 5.1862 & 5.4336 & TST \\
\hline CHEMBL1420645 & 688239 & 4.7362 & 5.5769 & TRN \\
\hline CHEMBL1574663 & 688239 & 4.7862 & 5.4995 & TRN \\
\hline CHEMBL1412913 & 688239 & 5.4362 & 5.4106 & TRN \\
\hline CHEMBL3191549 & 688239 & 5.3862 & 5.3477 & TST \\
\hline CHEMBL 377295 & 688239 & 4.9362 & 5.4502 & TST \\
\hline
\end{tabular}




\begin{tabular}{|c|c|c|c|c|c|}
\hline \multirow[b]{2}{*}{ CHEMBL1304353 } & \multicolumn{5}{|c|}{ Supplemental Table S2.txt } \\
\hline & 688239 & 4.5362 & 5.5458 & TRN & \\
\hline CHEMBL1362625 & 688239 & 6.0 & 5.3575 & TRN & \\
\hline CHEMBL1329838 & 688239 & 5.9362 & 5.5383 & TRN & \\
\hline CHEMBL1469398 & 688239 & 4.8 & \multicolumn{2}{|c|}{5.502999999999999} & TRN \\
\hline CHEMBL1406462 & 688239 & 6.3362 & 5.4771 & TRN & \\
\hline CHEMBL1373177 & 688239 & 4.6362 & 5.5308 & TST & \\
\hline CHEMBL1542182 & 688239 & 5.3862 & 5.4113 & TRN & \\
\hline CHEMBL1432501 & 688239 & 4.5362 & 5.4117 & TRN & \\
\hline CHEMBL1465920 & 688239 & 5.4862 & \multicolumn{2}{|c|}{5.4670000000000005} & TRN \\
\hline CHEMBL1552214 & 688239 & 5.0362 & 5.4961 & TRN & \\
\hline CHEMBL1321584 & 688239 & 5.7862 & 5.3243 & TST & \\
\hline CHEMBL2002522 & 688239 & 6.0862 & 5.4327 & TST & \\
\hline CHEMBL3194456 & 688239 & 4.7362 & 5.3397 & TRN & \\
\hline CHEMBL1349275 & 688239 & 4.7362 & 5.5221 & TRN & \\
\hline CHEMBL1593227 & 688239 & 4.6862 & 5.4326 & TRN & \\
\hline CHEMBL1323043 & 688239 & 5.2862 & 5.4245 & TRN & \\
\hline CHEMBL1570102 & 688239 & 5.6362 & 5.5251 & TRN & \\
\hline CHEMBL1370319 & 688239 & 5.1862 & 5.5284 & TST & \\
\hline CHEMBL1495244 & 688239 & 5.5362 & 5.6342 & TRN & \\
\hline CHEMBL1433097 & 688239 & 5.3862 & 5.3708 & TRN & \\
\hline CHEMBL1374471 & 688239 & 5.1862 & 5.5003 & TRN & \\
\hline CHEMBL1567266 & 688239 & 5.1862 & 5.5904 & TRN & \\
\hline CHEMBL1499266 & 688239 & 4.5862 & 5.5208 & TRN & \\
\hline CHEMBL1382016 & 688239 & 6.1862 & 5.526 & TRN & \\
\hline CHEMBL1437411 & 688239 & 5.4362 & 5.5434 & TST & \\
\hline CHEMBL1585020 & 688239 & 4.7362 & 5.4919 & TRN & \\
\hline CHEMBL567850 & 688239 & 5.2362 & 5.4084 & TRN & \\
\hline CHEMBL1575508 & 688239 & 5.0362 & 5.5488 & TRN & \\
\hline CHEMBL1325239 & 688239 & 5.1862 & 5.5831 & TRN & \\
\hline CHEMBL1602216 & 688239 & 6.1862 & 5.5266 & TRN & \\
\hline CHEMBL1577987 & 688239 & 6.6861 & 5.6751 & TRN & \\
\hline CHEMBL1404318 & 688239 & 4.5362 & 5.6235 & TRN & \\
\hline CHEMBL1341427 & 688239 & 5.1862 & 5.5185 & TRN & \\
\hline CHEMBL1561507 & 688239 & 4.7862 & 5.5373 & TRN & \\
\hline CHEMBL1420158 & 688239 & 5.4362 & 5.6134 & TRN & \\
\hline CHEMBL1308008 & 688239 & 6.8362 & 5.4094 & TRN & \\
\hline CHEMBL1599526 & 688239 & 5.1862 & 5.4851 & TST & \\
\hline CHEMBL1374423 & 688239 & 4.7862 & 5.5253 & TRN & \\
\hline CHEMBL1457088 & 688239 & 6.4862 & 5.5445 & TRN & \\
\hline CHEMBL1595965 & 688239 & 4.5362 & 5.4851 & TRN & \\
\hline CHEMBL1366522 & 688239 & 5.3362 & 5.5418 & TRN & \\
\hline CHEMBL1444689 & 688239 & 6.7862 & 5.5615 & TST & \\
\hline CHEMBL1499752 & 688239 & 4.6362 & 5.5189 & TRN & \\
\hline CHEMBL1373444 & 688239 & 4.8862 & 5.5674 & TRN & \\
\hline CHEMBL1483097 & 688239 & 6.4862 & 5.4837 & TRN & \\
\hline CHEMBL1410730 & 688239 & 5.3362 & 5.4729 & TRN & \\
\hline CHEMBL1575436 & 688239 & 5.2362 & 5.5441 & TST & \\
\hline CHEMBL1612514 & 688239 & 4.9862 & 5.54200 & 000000 & TST \\
\hline & & & & 2727 & \\
\hline
\end{tabular}


Supplemental Table S2.txt

\begin{tabular}{|c|c|c|c|c|c|}
\hline CHEMBL1429787 & 688239 & 4.5362 & 5.5287 & TRN & \\
\hline CHEMBL1557041 & 688239 & 5.1862 & 5.4699 & TRN & \\
\hline CHEMBL1446659 & 688239 & 4.5862 & 5.4803 & TST & \\
\hline CHEMBL3192124 & 688239 & 4.6362 & 5.6171 & TRN & \\
\hline CHEMBL1529409 & 688239 & 4.5362 & 5.4934 & TRN & \\
\hline CHEMBL1530468 & 688239 & 5.2862 & 5.6018 & TST & \\
\hline CHEMBL1362092 & 688239 & 5.3362 & 5.6078 & TRN & \\
\hline CHEMBL3212894 & 688239 & 5.5862 & 5.381 & TRN & \\
\hline CHEMBL1455464 & 688239 & 5.6862 & 5.5348 & TRN & \\
\hline CHEMBL582444 & 688239 & 4.7362 & 5.3758 & TST & \\
\hline CHEMBL1460901 & 688239 & 5.0862 & 5.3334 & TRN & \\
\hline CHEMBL1451653 & 688239 & 4.5362 & 5.4627 & TRN & \\
\hline CHEMBL1319697 & 688239 & 7.1361 & 5.5782 & TST & \\
\hline CHEMBL1988603 & 688239 & 5.6362 & 5.4265 & TRN & \\
\hline CHEMBL1577028 & 688239 & 7.4365 & 5.569 & TRN & \\
\hline CHEMBL3189555 & 688239 & 5.7362 & 5.4191 & TRN & \\
\hline CHEMBL1362288 & 688239 & 6.1862 & 5.5283 & TRN & \\
\hline CHEMBL1409718 & 688239 & 6.0362 & 5.5814 & TST & \\
\hline CHEMBL1426938 & 688239 & 8.3372 & 5.4786 & TRN & \\
\hline CHEMBL1572724 & 688239 & 5.1862 & 5.4997 & TRN & \\
\hline CHEMBL1420903 & 688239 & 5.2362 & 5.4583 & TRN & \\
\hline CHEMBL1391609 & 688239 & 4.8362 & 5.2954 & TST & \\
\hline CHEMBL1314845 & 688239 & 4.6362 & 5.595 & TRN & \\
\hline CHEMBL1345124 & 688239 & 4.6862 & 5.5585 & TRN & \\
\hline CHEMBL 2004847 & 688239 & 6.9863 & 5.4071 & TST & \\
\hline CHEMBL1401433 & 688239 & 6.8861 & 5.5928 & TRN & \\
\hline CHEMBL1373848 & 688239 & 5.1362 & 5.3477 & TRN & \\
\hline CHEMBL1495440 & 688239 & 5.1362 & \multicolumn{2}{|c|}{5.377000000000001} & TRN \\
\hline CHEMBL3212136 & 688239 & 5.4862 & 5.4917 & TRN & \\
\hline CHEMBL1399546 & 688239 & 6.1862 & 5.5176 & TRN & \\
\hline CHEMBL1473346 & 688239 & 4.5362 & 5.4181 & TST & \\
\hline CHEMBL1343551 & 688239 & 4.7362 & 5.4716 & TRN & \\
\hline CHEMBL1567455 & 688239 & 5.1362 & 5.604 & TST & \\
\hline CHEMBL1351740 & 688239 & 5.6862 & 5.7084 & TRN & \\
\hline CHEMBL1497382 & 688239 & 6.8362 & \multicolumn{2}{|c|}{5.662999999999999} & TRN \\
\hline CHEMBL1299796 & 688239 & 5.9362 & 5.6497 & TRN & \\
\hline CHEMBL1489163 & 688239 & 5.25 & 5.4126 & TRN & \\
\hline CHEMBL1431442 & 688239 & 4.6362 & 5.5911 & TRN & \\
\hline CHEMBL3198293 & 688239 & 4.5362 & 5.6598 & TST & \\
\hline CHEMBL1498802 & 688239 & 6.4862 & 5.4946 & TRN & \\
\hline CHEMBL1496189 & 688239 & 4.6862 & 5.6571 & TRN & \\
\hline CHEMBL1564965 & 688239 & 7.0862 & 5.5268 & TRN & \\
\hline CHEMBL1258904 & 688239 & 4.7862 & 5.375 & TST & \\
\hline CHEMBL1563931 & 688239 & 4.8362 & \multicolumn{2}{|c|}{5.593999999999999} & TRN \\
\hline CHEMBL1486214 & 688239 & 5.1362 & 5.4787 & TRN & \\
\hline CHEMBL1326318 & 688239 & 4.4862 & 5.3025 & TST & \\
\hline CHEMBL1313320 & 688239 & 6.1862 & 5.3483 & TRN & \\
\hline CHEMBL1398483 & 688239 & 5.6862 & 5.5022 & TRN & \\
\hline
\end{tabular}


Supplemental Table S2.txt

\begin{tabular}{|c|c|c|c|c|}
\hline CHEMBL1327848 & 688239 & 5.1862 & 5.518 & TRN \\
\hline CHEMBL1487927 & 688239 & 6.0862 & 5.5802 & TRN \\
\hline CHEMBL1504572 & 688239 & 5.3362 & 5.6018 & TRN \\
\hline CHEMBL1533457 & 688239 & 4.6862 & 5.4285 & TST \\
\hline CHEMBL1368767 & 688239 & 7.5361 & 5.3948 & TRN \\
\hline CHEMBL1499667 & 688239 & 4.6362 & 5.437 & TST \\
\hline CHEMBL1410675 & 688239 & 5.2362 & 5.6004 & TRN \\
\hline CHEMBL1564260 & 688239 & 5.2862 & 5.3714 & TRN \\
\hline CHEMBL 3191040 & 688239 & 4.9362 & 5.3389 & TRN \\
\hline CHEMBL1364965 & 688239 & 4.8362 & 5.5079 & TRN \\
\hline CHEMBL1435571 & 688239 & 5.1862 & 5.5647 & TRN \\
\hline CHEMBL1367081 & 688239 & 5.8862 & 5.4231 & TRN \\
\hline CHEMBL1542654 & 688239 & 5.5362 & 5.4579 & TST \\
\hline CHEMBL1498547 & 688239 & 4.5862 & 5.6839 & TST \\
\hline CHEMBL1432970 & 688239 & 4.5362 & 5.4018 & TRN \\
\hline CHEMBL1981990 & 688239 & 5.0862 & 5.4988 & TRN \\
\hline CHEMBL1422710 & 688239 & 5.2362 & 5.355 & TST \\
\hline CHEMBL1380331 & 688239 & 4.5362 & 5.2651 & TRN \\
\hline CHEMBL556398 & 688239 & 4.8362 & 5.3411 & TRN \\
\hline CHEMBL1381635 & 688239 & 5.5862 & 5.4563 & TRN \\
\hline CHEMBL1560737 & 688239 & 4.8362 & 5.4804 & TST \\
\hline CHEMBL1350850 & 688239 & 5.6362 & 5.5612 & TRN \\
\hline CHEMBL1389858 & 688239 & 5.1362 & 5.6117 & TST \\
\hline CHEMBL1331198 & 688239 & 5.3862 & 5.5608 & TRN \\
\hline CHEMBL 3210240 & 688239 & 7.0362 & 5.5342 & TRN \\
\hline CHEMBL1542709 & 688239 & 4.7862 & \multicolumn{2}{|c|}{5.452000000000001} \\
\hline CHEMBL1437498 & 688239 & 6.2362 & 5.7106 & TRN \\
\hline CHEMBL1464143 & 688239 & 6.4362 & 5.5872 & TRN \\
\hline CHEMBL1353252 & 688239 & 5.9362 & 5.5295 & TRN \\
\hline CHEMBL1592595 & 688239 & 5.1862 & 5.4982 & TRN \\
\hline CHEMBL1612773 & 688239 & 7.0362 & 5.5404 & TST \\
\hline CHEMBL1323022 & 688239 & 4.7362 & 5.5217 & TRN \\
\hline CHEMBL1319152 & 688239 & 6.5363 & 5.5141 & TST \\
\hline CHEMBL1397310 & 688239 & 4.7862 & 5.4005 & TRN \\
\hline CHEMBL1398470 & 688239 & 7.0362 & \multicolumn{2}{|c|}{5.377000000000001} \\
\hline CHEMBL1531328 & 688239 & 5.9362 & 5.5721 & TRN \\
\hline CHEMBL1526146 & 688239 & 4.5362 & 5.6595 & TST \\
\hline CHEMBL1608958 & 688239 & 5.1862 & 5.3707 & TRN \\
\hline CHEMBL1412999 & 688239 & 6.7361 & 5.4551 & TRN \\
\hline CHEMBL1990959 & 688239 & 5.2362 & 5.3486 & TRN \\
\hline CHEMBL1609705 & 688239 & 6.7862 & 5.4455 & TST \\
\hline CHEMBL1424176 & 688239 & 4.5362 & 5.5054 & TRN \\
\hline CHEMBL1508276 & 688239 & 4.6362 & \multicolumn{2}{|c|}{5.406000000000001} \\
\hline CHEMBL1523200 & 688239 & 6.4362 & 5.5491 & TRN \\
\hline CHEMBL1321148 & 688239 & 4.6862 & 5.7101 & TRN \\
\hline CHEMBL1382022 & 688239 & 4.7862 & 5.4023 & TRN \\
\hline CHEMBL1395257 & 688239 & 6.3863 & 5.5963 & TRN \\
\hline CHEMBL1584802 & 688239 & 5.3862 & 5.5179 & TRN \\
\hline
\end{tabular}




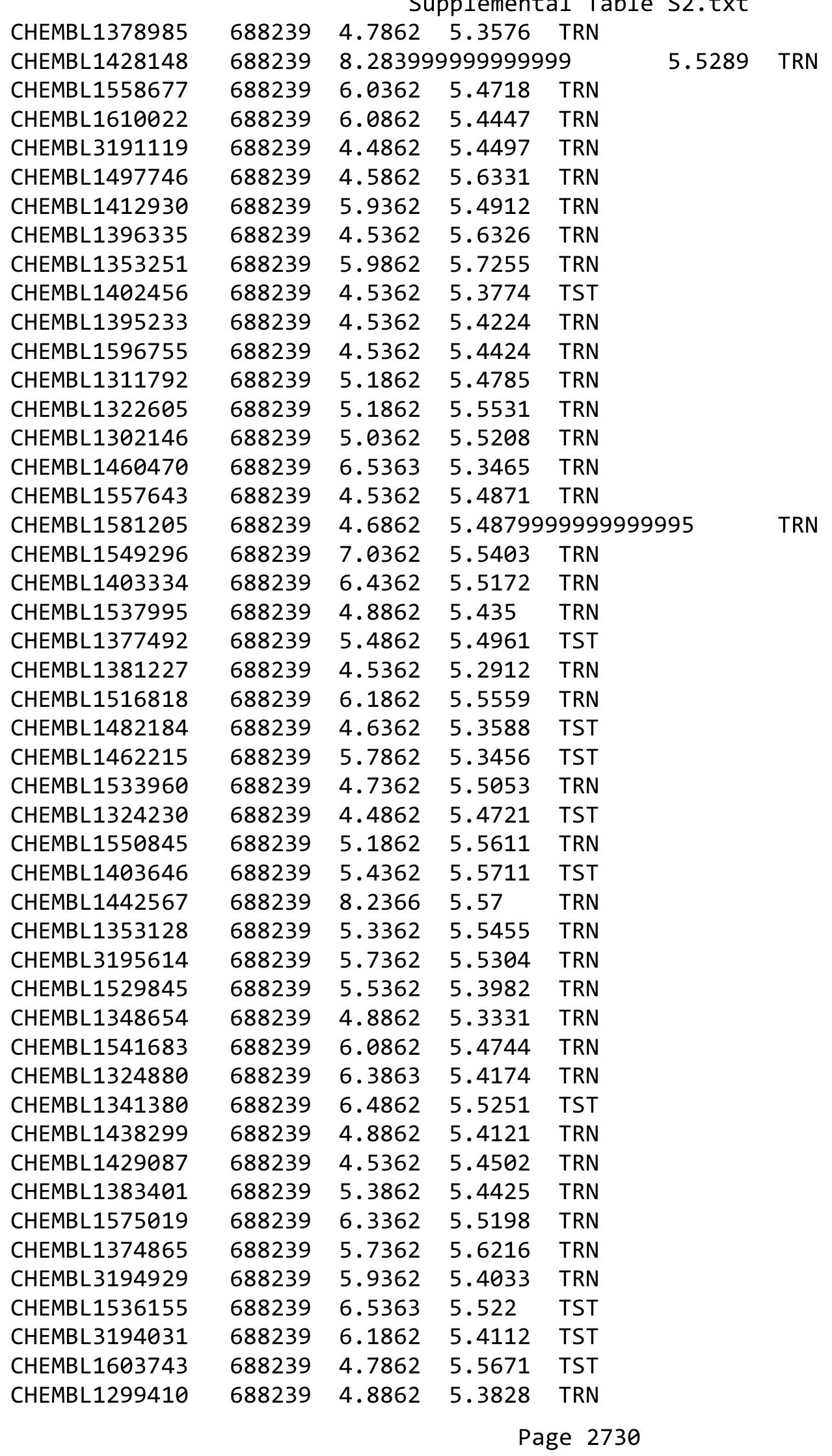


Supplemental Table S2.txt

\begin{tabular}{|c|c|c|c|c|}
\hline & & & & \\
\hline JEMBL14 & 8239 & 362 & & \\
\hline IEMBL3211124 & 8239 & 362 & 5777 & \\
\hline HEMBL1464487 & 239 & 362 & 6292 & \\
\hline & 239 & & 027 & \\
\hline FMRI 12 & 239 & & 58 & \\
\hline AEMBL1506819 & 88239 & 362 & 4642 & \\
\hline AEMBL1450105 & 88239 & 362 & 1726 & \\
\hline AEMBL1364289 & 239 & & 5241 & \\
\hline IEMBL130 & 239 & & 794 & \\
\hline IEMBL1528376 & 39 & & & \\
\hline AEMBL1555596 & 688239 & 863 & 5022 & \\
\hline AEMBL1362762 & 239 & & 45 & \\
\hline IEMBL134 & & & 38 & \\
\hline IEMBL1998984 & & & & \\
\hline AEMBL1378490 & & & & \\
\hline AEMBL1448717 & 239 & & & \\
\hline HEMBL148 & & & & \\
\hline IEMBL14: & & 52 & & \\
\hline IEMBL160 & & & & \\
\hline AEMBL 155 & & & & \\
\hline AEMBL1417302 & & & & \\
\hline AEMBL1385995 & & & & \\
\hline IEMBL13S & & & & \\
\hline HEMBL133 & & & & \\
\hline AFMRI 152 & & & & \\
\hline AEMBL1427505 & & & & \\
\hline AEMBL1564211 & & & & \\
\hline AEMBL1447458 & & & 19 & \\
\hline 931 & & & 86 & \\
\hline 63 & & & & \\
\hline HEMBL1503804 & & & & \\
\hline AEMBL1435989 & & & & \\
\hline HEMBL137 & & & 26 & \\
\hline$A F M R$ & & & 91 & \\
\hline 51 & & & & \\
\hline AEMBL1347145 & & & & \\
\hline AEMBL1363449 & & & & \\
\hline IEMBL140 & & & & \\
\hline 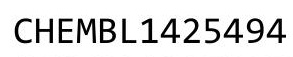 & & & & \\
\hline 597 & & & & RN \\
\hline AEMBL1482161 & 239 & & .017 & TS \\
\hline IEMBL3208128 & & & & \\
\hline HEMBL158 & & & 347 & \\
\hline HEMBL157 & & & & \\
\hline CHEMBL1342857 & & & 013 & \\
\hline AEMBL1457488 & 8239 & 4.5362 & 5.6214 & \\
\hline HFMRI 1365986 & 688239 & 4.5362 & 5.4314 & \\
\hline
\end{tabular}

Page 2731 
Supplemental Table S2.txt

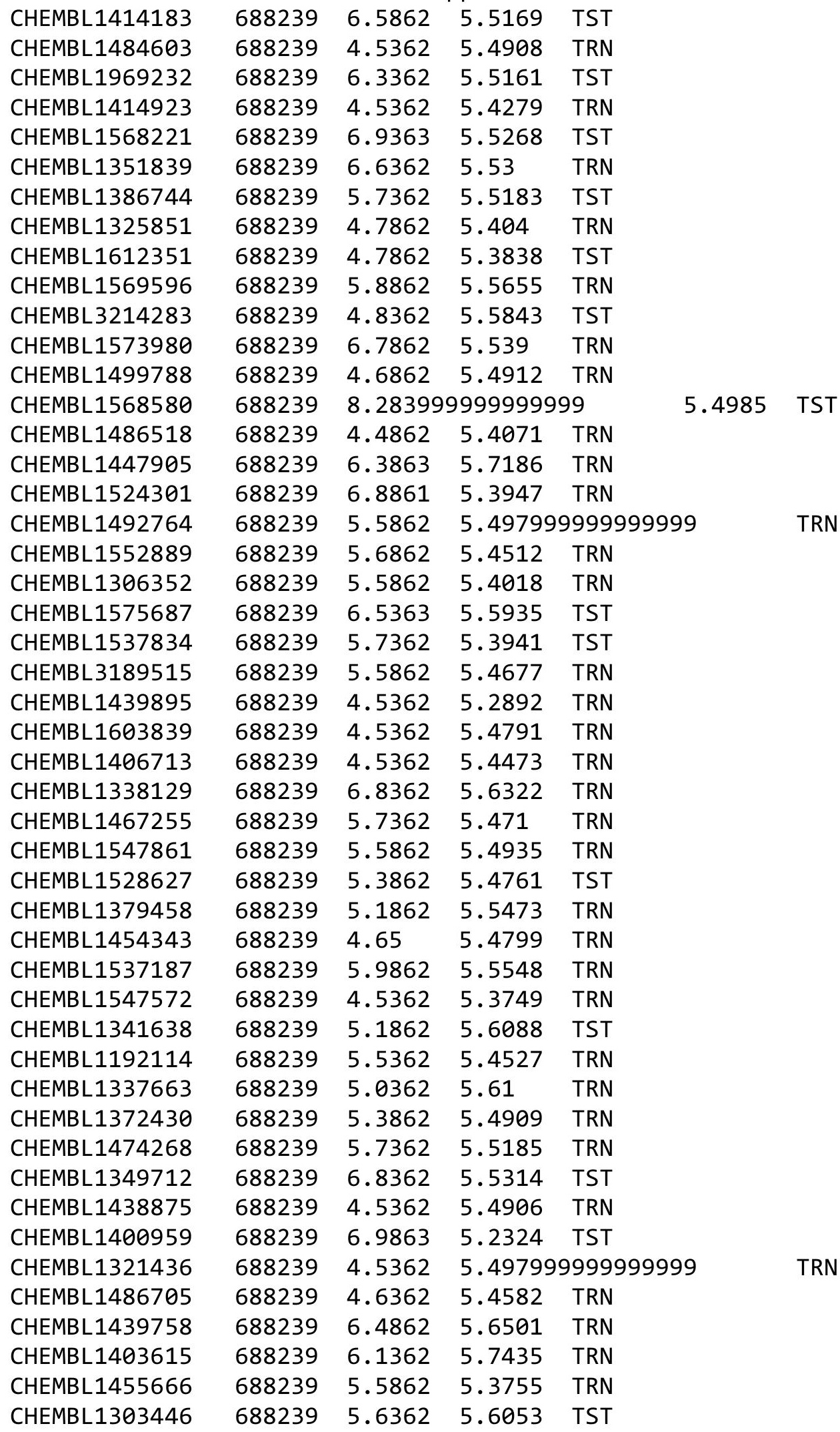


Supplemental Table S2.txt

\begin{tabular}{|c|c|c|c|c|c|}
\hline CHEMBL1541574 & 688239 & 4.5862 & 5.5785 & TRN & \\
\hline CHEMBL1301853 & 688239 & 5.5362 & 5.5714 & TRN & \\
\hline CHEMBL1303515 & 688239 & 4.6862 & 5.3503 & TRN & \\
\hline CHEMBL1400381 & 688239 & 4.5362 & 5.5486 & TRN & \\
\hline CHEMBL1560204 & 688239 & 5.3862 & 5.7621 & TRN & \\
\hline CHEMBL1469031 & 688239 & 4.5862 & 5.5852 & TRN & \\
\hline CHEMBL1520627 & 688239 & 4.9362 & 5.3519 & TRN & \\
\hline CHEMBL1445547 & 688239 & 6.45 & 5.4284 & TRN & \\
\hline CHEMBL1432758 & 688239 & 6.6362 & 5.5876 & TRN & \\
\hline CHEMBL1546309 & 688239 & 5.2862 & 5.5585 & TRN & \\
\hline CHEMBL1548317 & 688239 & 5.5362 & 5.4366 & TRN & \\
\hline CHEMBL577420 & 688239 & 6.1862 & 5.3871 & TST & \\
\hline CHEMBL1362607 & 688239 & 4.7862 & 5.6233 & TRN & \\
\hline CHEMBL1567638 & 688239 & 5.2362 & 5.3947 & TRN & \\
\hline CHEMBL1539158 & 688239 & 6.7862 & 5.5232 & TRN & \\
\hline CHEMBL1600238 & 688239 & 5.7862 & 5.4102 & TRN & \\
\hline CHEMBL1465843 & 688239 & 6.8861 & 5.7284 & TRN & \\
\hline CHEMBL 3209057 & 688239 & 6.7361 & 5.5775 & TRN & \\
\hline CHEMBL1458128 & 688239 & 5.7862 & 5.5114 & TST & \\
\hline CHEMBL1498137 & 688239 & 4.5362 & 5.5489 & TRN & \\
\hline CHEMBL1599679 & 688239 & 4.9862 & 5.5506 & TRN & \\
\hline CHEMBL1468554 & 688239 & 6.4862 & 5.4879 & TST & \\
\hline CHEMBL1471772 & 688239 & 5.4862 & 5.4812 & TRN & \\
\hline CHEMBL1561516 & 688239 & 5.0362 & 5.4932 & TRN & \\
\hline CHEMBL 3213579 & 688239 & 4.8862 & 5.5785 & TRN & \\
\hline CHEMBL1578034 & 688239 & 5.3362 & 5.5821 & TRN & \\
\hline CHEMBL1341061 & 688239 & 5.7362 & 5.4196 & TRN & \\
\hline CHEMBL1305327 & 688239 & 5.4862 & 5.5278 & TRN & \\
\hline CHEMBL1513931 & 688239 & 5.4362 & 5.6077 & TRN & \\
\hline CHEMBL1582840 & 688239 & 5.5862 & 5.4441 & TRN & \\
\hline CHEMBL1554693 & 688239 & 4.8862 & 5.3749 & TRN & \\
\hline CHEMBL1612824 & 688239 & 5.9862 & 5.5514 & TRN & \\
\hline CHEMBL1415478 & 688239 & 5.3862 & 5.5357 & TRN & \\
\hline CHEMBL1303814 & 688239 & 6.2362 & 5.3768 & TRN & \\
\hline CHEMBL1302163 & 688239 & 5.1362 & 5.5838 & TRN & \\
\hline CHEMBL1347548 & 688239 & 4.5362 & 5.4748 & TST & \\
\hline CHEMBL1566051 & 688239 & 4.6862 & 5.36299 & 99999999995 & TRN \\
\hline CHEMBL1608344 & 688239 & 6.8362 & 5.4739 & TST & \\
\hline CHEMBL1587923 & 688239 & 4.5862 & 5.5538 & TRN & \\
\hline CHEMBL1496213 & 688239 & 6.0362 & 5.6063 & TRN & \\
\hline CHEMBL1541699 & 688239 & 5.1862 & 5.5083 & TRN & \\
\hline CHEMBL1344624 & 688239 & 5.2362 & 5.5183 & TST & \\
\hline CHEMBL582507 & 688239 & 4.6362 & 5.5165 & TRN & \\
\hline CHEMBL1530592 & 688239 & 5.0362 & 5.5891 & TST & \\
\hline CHEMBL1486674 & 688239 & 6.2862 & 5.6248 & TRN & \\
\hline CHEMBL1416539 & 688239 & 5.2 & 5.504 & TRN & \\
\hline CHEMBL1369274 & 688239 & 4.5362 & 5.5252 & TRN & \\
\hline CHEMBL1508531 & 688239 & 6.0862 & 5.4534 & TRN & \\
\hline
\end{tabular}


Supplemental Table S2.txt

\begin{tabular}{|c|c|c|c|c|}
\hline CHEMBL1474535 & 688239 & 4.7862 & 5.3399 & TRN \\
\hline CHEMBL1606837 & 688239 & 4.7862 & 5.3644 & TST \\
\hline CHEMBL1573433 & 688239 & 8.2366 & 5.4863 & TRN \\
\hline CHEMBL1598886 & 688239 & 5.1862 & 5.5903 & TRN \\
\hline CHEMBL1594908 & 688239 & 5.9362 & 5.4918 & TST \\
\hline CHEMBL1527446 & 688239 & 5.1862 & 5.5775 & TRN \\
\hline CHEMBL1591393 & 688239 & 6.1362 & 5.4809 & TRN \\
\hline CHEMBL1499079 & 688239 & 6.1862 & 5.6361 & TRN \\
\hline CHEMBL1494022 & 688239 & 5.4362 & 5.6352 & TRN \\
\hline CHEMBL1566905 & 688239 & 5.4362 & 5.5015 & TST \\
\hline CHEMBL1347372 & 688239 & 5.3862 & 5.5102 & TST \\
\hline CHEMBL1585595 & 688239 & 4.5362 & 5.7211 & TRN \\
\hline CHEMBL1429729 & 688239 & 6.1862 & 5.5667 & TRN \\
\hline CHEMBL1478043 & 688239 & 6.8861 & 5.4619 & TRN \\
\hline CHEMBL3196812 & 688239 & 6.1862 & 5.4334 & TRN \\
\hline CHEMBL1449108 & 688239 & 5.4362 & 5.44 & TRN \\
\hline CHEMBL1482181 & 688239 & 4.5362 & 5.4254 & TRN \\
\hline CHEMBL1441494 & 688239 & 6.4362 & 5.6164 & TRN \\
\hline CHEMBL1379243 & 688239 & 5.1362 & 5.5071 & TRN \\
\hline CHEMBL1334930 & 688239 & 5.8862 & 5.4705 & TRN \\
\hline CHEMBL1332817 & 688239 & 6.0362 & 5.5206 & TRN \\
\hline CHEMBL1375399 & 688239 & 4.6362 & 5.5741 & TRN \\
\hline CHEMBL1529117 & 688239 & 4.5362 & 5.49200 & 0000000001 \\
\hline CHEMBL1531618 & 688239 & 5.7362 & 5.6056 & TRN \\
\hline CHEMBL1352721 & 688239 & 5.1862 & 5.3536 & TST \\
\hline CHEMBL1558576 & 688239 & 6.9863 & 5.6405 & TRN \\
\hline CHEMBL1431621 & 688239 & 5.0862 & 5.4 & TRN \\
\hline CHEMBL1401997 & 688239 & 6.7862 & 5.6277 & TRN \\
\hline CHEMBL1402751 & 688239 & 5.0862 & 5.4601 & TRN \\
\hline CHEMBL1428606 & 688239 & 4.5362 & 5.4403 & TRN \\
\hline CHEMBL1495390 & 688239 & 5.1862 & 5.5296 & TST \\
\hline CHEMBL1556143 & 688239 & 4.8362 & 5.5057 & TST \\
\hline CHEMBL1339582 & 688239 & 4.6862 & 5.5218 & TRN \\
\hline CHEMBL196605 & 688239 & 4.6362 & 5.4176 & TRN \\
\hline CHEMBL1438717 & 688239 & 5.0862 & 5.3965 & TRN \\
\hline CHEMBL1415852 & 688239 & 6.0362 & 5.4153 & TRN \\
\hline CHEMBL1455108 & 688239 & 4.5362 & 5.53100 & 0000000001 \\
\hline CHEMBL1442628 & 688239 & 7.4868 & 5.5016 & TST \\
\hline CHEMBL1487127 & 688239 & 4.5362 & 5.4534 & TRN \\
\hline CHEMBL1548838 & 688239 & 6.1362 & 5.61 & TRN \\
\hline CHEMBL1498699 & 688239 & 8.0862 & 5.4631 & TRN \\
\hline CHEMBL1363059 & 688239 & 5.9362 & 5.5131 & TRN \\
\hline CHEMBL1574548 & 688239 & 4.8362 & 5.3982 & TRN \\
\hline CHEMBL1400630 & 688239 & 6.8861 & 5.5717 & TRN \\
\hline CHEMBL1417925 & 688239 & 4.5862 & 5.4797 & TRN \\
\hline CHEMBL1406599 & 688239 & 5.6862 & 5.5913 & TRN \\
\hline CHEMBL1467438 & 688239 & 5.1862 & 5.5723 & TRN \\
\hline CHEMBL1597568 & 688239 & 5.5862 & 5.6351 & TRN \\
\hline
\end{tabular}




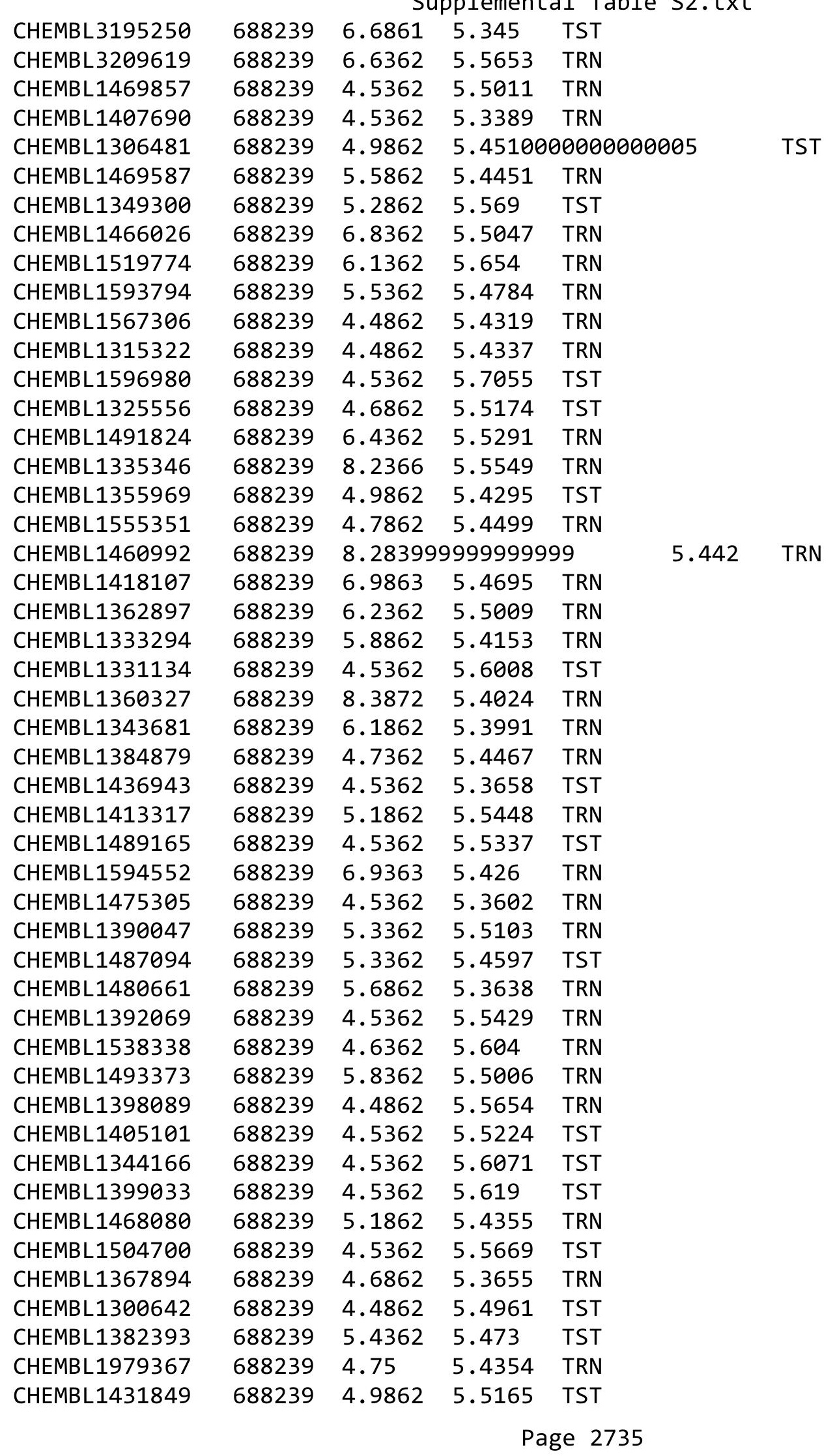


Supplemental Table S2.txt

\begin{tabular}{|c|c|c|c|c|c|}
\hline CHEMBL1339342 & 688239 & 5.2862 & 5.6092 & TST & \\
\hline CHEMBL1343393 & 688239 & 5.3862 & 5.4373 & TST & \\
\hline CHEMBL1404536 & 688239 & 6.9863 & 5.407 & TRN & \\
\hline CHEMBL1302239 & 688239 & 4.7362 & 5.5539 & TRN & \\
\hline CHEMBL1613409 & 688239 & 6.1362 & 5.6024 & TRN & \\
\hline CHEMBL1412240 & 688239 & 5.8362 & 5.4826 & TRN & \\
\hline CHEMBL3209859 & 688239 & 4.6862 & 5.4171 & TRN & \\
\hline CHEMBL1516647 & 688239 & 4.5862 & 5.4932 & TRN & \\
\hline CHEMBL3190269 & 688239 & 5.9862 & 5.5059 & TRN & \\
\hline CHEMBL1561214 & 688239 & 4.5362 & 5.4906 & TST & \\
\hline CHEMBL1385805 & 688239 & 4.5862 & 5.3229 & TRN & \\
\hline CHEMBL1408754 & 688239 & 4.6862 & 5.3043 & TRN & \\
\hline CHEMBL1465282 & 688239 & 5.7362 & 5.3941 & TST & \\
\hline CHEMBL1381862 & 688239 & 4.6362 & 5.5393 & TRN & \\
\hline CHEMBL1447050 & 688239 & 5.5362 & 5.5414 & TRN & \\
\hline CHEMBL1789999 & 688239 & 6.0362 & 5.5636 & TRN & \\
\hline CHEMBL1339252 & 688239 & 4.9862 & 5.4364 & TRN & \\
\hline CHEMBL1532714 & 688239 & 5.3862 & 5.4664 & TST & \\
\hline CHEMBL3194886 & 688239 & 5.3362 & 5.4625 & TRN & \\
\hline CHEMBL89671 & 688239 & 5.3862 & 5.5729 & TRN & \\
\hline CHEMBL1371199 & 688239 & 4.8362 & 5.5525 & TRN & \\
\hline CHEMBL1524764 & 688239 & 5.6862 & 5.4018 & TRN & \\
\hline CHEMBL1458562 & 688239 & 8.28399 & 999999999 & 5.4557 & \\
\hline CHEMBL1392059 & 688239 & 6.1862 & 5.5239 & TRN & \\
\hline CHEMBL1471804 & 688239 & 5.1362 & 5.4161 & TRN & \\
\hline CHEMBL1360432 & 688239 & 4.5862 & 5.5987 & TRN & \\
\hline CHEMBL1310735 & 688239 & 6.6362 & 5.5348 & TRN & \\
\hline CHEMBL1346250 & 688239 & 6.4862 & 5.4842 & TRN & \\
\hline CHEMBL1485220 & 688239 & 6.3362 & 5.4412 & TST & \\
\hline CHEMBL1487052 & 688239 & 6.2862 & 5.553 & TRN & \\
\hline CHEMBL1332089 & 688239 & 5.7862 & 5.6085 & TRN & \\
\hline CHEMBL1547259 & 688239 & 4.7862 & 5.3843 & TST & \\
\hline CHEMBL1438142 & 688239 & 5.3862 & 5.4378 & TST & \\
\hline CHEMBL1495273 & 688239 & 6.3362 & 5.4462 & TRN & \\
\hline CHEMBL1411170 & 688239 & 5.9362 & 5.6912 & TRN & \\
\hline CHEMBL1502949 & 688239 & 5.3862 & 5.4003 & TRN & \\
\hline CHEMBL1535826 & 688239 & 7.4365 & 5.4808 & TST & \\
\hline CHEMBL535265 & 688239 & 4.5362 & 5.4757 & TRN & \\
\hline CHEMBL1456730 & 688239 & 5.1862 & 5.4992 & TRN & \\
\hline CHEMBL1488908 & 688239 & 4.5862 & 5.36700 & 0000000001 & TST \\
\hline CHEMBL1458583 & 688239 & 5.1862 & 5.5887 & TRN & \\
\hline CHEMBL1525779 & 688239 & 5.1862 & 5.5166 & TRN & \\
\hline CHEMBL3209905 & 688239 & 4.5362 & 5.3981 & TST & \\
\hline CHEMBL1573208 & 688239 & 4.4862 & 5.4761 & TST & \\
\hline CHEMBL1499556 & 688239 & 4.9362 & 5.401 & TRN & \\
\hline CHEMBL1578303 & 688239 & 4.9362 & 5.4204 & TRN & \\
\hline CHEMBL1417203 & 688239 & 5.7362 & 5.342000 & 00000000005 & $\mathrm{~K} / \mathrm{N}$ \\
\hline CHEMBL1544247 & 688239 & 4.5862 & 5.5521 & TRN & \\
\hline
\end{tabular}


Supplemental Table S2.txt

\begin{tabular}{|c|c|c|c|c|c|c|}
\hline CHEMBL1354431 & 688239 & 4.5362 & 5.4501 & TRN & & \\
\hline CHEMBL1514592 & 688239 & 4.9362 & 5.4173 & TST & & \\
\hline CHEMBL1551974 & 688239 & 8.28399 & 99999999 & 99 & 5.501 & TRN \\
\hline CHEMBL1431599 & 688239 & 4.6362 & 5.5735 & TRN & & \\
\hline CHEMBL1587909 & 688239 & 5.5362 & 5.5631 & TRN & & \\
\hline CHEMBL1546349 & 688239 & 4.6362 & 5.459 & TRN & & \\
\hline CHEMBL1532100 & 688239 & 5.1862 & 5.3603 & TRN & & \\
\hline CHEMBL1567771 & 688239 & 4.6862 & 5.5596 & TST & & \\
\hline CHEMBL1341890 & 688239 & 4.5362 & 5.4292 & TRN & & \\
\hline CHEMBL1313493 & 688239 & 4.7362 & 5.4453 & TST & & \\
\hline CHEMBL1343434 & 688239 & 4.5362 & 5.5913 & TRN & & \\
\hline CHEMBL1348241 & 688239 & 5.1362 & 5.5545 & TRN & & \\
\hline CHEMBL1344628 & 688239 & 6.2362 & 5.5262 & TRN & & \\
\hline CHEMBL3190328 & 688239 & 4.9 & 5.4631 & TRN & & \\
\hline CHEMBL1411365 & 688239 & 6.2862 & 5.6525 & TRN & & \\
\hline CHEMBL1510703 & 688239 & 5.4862 & 5.49 & TST & & \\
\hline CHEMBL1505634 & 688239 & 5.0862 & 5.4699 & TRN & & \\
\hline CHEMBL1545143 & 688239 & 6.9363 & 5.4608 & TST & & \\
\hline CHEMBL1429372 & 688239 & 4.5362 & 5.4337 & TRN & & \\
\hline CHEMBL1399192 & 688239 & 6.2362 & 5.5329 & TRN & & \\
\hline CHEMBL1349977 & 688239 & 5.8362 & 5.6126 & TST & & \\
\hline CHEMBL1346005 & 688239 & \multicolumn{3}{|c|}{8.283999999999999} & 5.5614 & \\
\hline CHEMBL1485866 & 688239 & 4.7862 & 5.4014 & TST & & \\
\hline CHEMBL1420637 & 688239 & 4.5362 & 5.426 & TRN & & \\
\hline CHEMBL1569765 & 688239 & 4.5862 & 5.55399 & 9999999999 & & TRN \\
\hline CHEMBL1591614 & 688239 & 5.6862 & 5.5975 & TRN & & \\
\hline CHEMBL1359807 & 688239 & 6.2362 & 5.5483 & TRN & & \\
\hline CHEMBL3196632 & 688239 & 6.5862 & 5.4507 & TST & & \\
\hline CHEMBL1433266 & 688239 & 5.4362 & 5.4138 & TRN & & \\
\hline CHEMBL1536726 & 688239 & 6.4362 & 5.595 & TRN & & \\
\hline CHEMBL1358783 & 688239 & 6.4362 & 5.531006 & 0000000001 & & 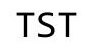 \\
\hline CHEMBL1560347 & 688239 & 4.5362 & 5.5625 & TRN & & \\
\hline CHEMBL1332522 & 688239 & 5.8862 & 5.4299 & TRN & & \\
\hline CHEMBL1329427 & 688239 & 6.2362 & 5.5339 & TRN & & \\
\hline CHEMBL1360203 & 688239 & 4.5362 & 5.3883 & TRN & & \\
\hline CHEMBL1591212 & 688239 & 4.5362 & 5.4525 & TRN & & \\
\hline CHEMBL1571600 & 688239 & 5.1862 & 5.524 & TRN & & \\
\hline CHEMBL1365929 & 688239 & 5.2362 & 5.4498 & TRN & & \\
\hline CHEMBL1326766 & 688239 & 4.5362 & 5.3731 & TRN & & \\
\hline CHEMBL1359373 & 688239 & 4.8362 & 5.3562 & TRN & & \\
\hline CHEMBL1609420 & 688239 & 5.0862 & 5.5623 & TRN & & \\
\hline CHEMBL1611253 & 688239 & 6.0362 & 5.4861 & TRN & & \\
\hline CHEMBL1452216 & 688239 & 6.7361 & 5.5174 & TRN & & \\
\hline CHEMBL3145330 & 688239 & 4.5362 & 5.4395 & TST & & \\
\hline CHEMBL1504521 & 688239 & 4.5362 & 5.4549 & TRN & & \\
\hline CHEMBL1557829 & 688239 & 4.5362 & 5.5262 & TRN & & \\
\hline CHEMBL1420906 & 688239 & 4.5362 & 5.425 & TST & & \\
\hline CHEMBL1500969 & 688239 & 5.1862 & 5.3962 & TRN & & \\
\hline
\end{tabular}


Supplemental Table S2.txt

\begin{tabular}{|c|c|c|c|c|}
\hline CHEMBL1498992 & 688239 & 5.1362 & 5.4163 & TRN \\
\hline CHEMBL1324135 & 688239 & 4.4862 & 5.5216 & TRN \\
\hline CHEMBL1465813 & 688239 & 4.5362 & 5.4191 & TRN \\
\hline CHEMBL1476551 & 688239 & 4.9862 & 5.5804 & TRN \\
\hline CHEMBL1600424 & 688239 & 5.2862 & 5.6226 & TRN \\
\hline CHEMBL1578143 & 688239 & 5.7362 & 5.5772 & TRN \\
\hline CHEMBL1546364 & 688239 & 6.1862 & 5.5868 & TRN \\
\hline CHEMBL1475888 & 688239 & 4.7362 & 5.4084 & TRN \\
\hline CHEMBL1612348 & 688239 & 4.6862 & 5.5332 & TRN \\
\hline CHEMBL 3194228 & 688239 & 5.6362 & 5.4788 & TRN \\
\hline CHEMBL1489224 & 688239 & 4.7862 & 5.4952 & TRN \\
\hline CHEMBL1606905 & 688239 & 6.3362 & 5.5299 & TST \\
\hline CHEMBL1459321 & 688239 & 5.3362 & 5.6092 & TRN \\
\hline CHEMBL1475816 & 688239 & 4.6862 & 5.5619 & TRN \\
\hline CHEMBL1385673 & 688239 & 4.5362 & 5.4719 & TST \\
\hline CHEMBL3197908 & 688239 & 4.8362 & 5.3606 & TRN \\
\hline CHEMBL1487957 & 688239 & 6.9363 & 5.46899 & Э999999999 \\
\hline CHEMBL1318517 & 688239 & 5.6862 & 5.3406 & TST \\
\hline CHEMBL1494337 & 688239 & 8.2366 & 5.4266 & TRN \\
\hline CHEMBL1423653 & 688239 & 6.2362 & 5.441 & TRN \\
\hline CHEMBL1542713 & 688239 & 5.1862 & 5.572 & TRN \\
\hline CHEMBL1353522 & 688239 & 5.2862 & 5.5125 & TRN \\
\hline CHEMBL1594688 & 688239 & 7.5867 & 5.4399 & TRN \\
\hline CHEMBL1580049 & 688239 & 4.8862 & 5.4616 & TRN \\
\hline CHEMBL1567141 & 688239 & 5.1362 & 5.612 & TRN \\
\hline CHEMBL1442627 & 688239 & 5.1862 & 5.5047 & TRN \\
\hline CHEMBL1444892 & 688239 & 8.3372 & 5.5624 & TRN \\
\hline CHEMBL1431590 & 688239 & 5.7362 & 5.3407 & TRN \\
\hline CHEMBL1570326 & 688239 & 4.5862 & 5.461 & TRN \\
\hline CHEMBL3196604 & 688239 & 5.7862 & 5.4833 & TRN \\
\hline CHEMBL1410455 & 688239 & 6.5862 & 5.46299 & 9999999999 \\
\hline CHEMBL1385055 & 688239 & 4.7362 & 5.4715 & TST \\
\hline CHEMBL1320627 & 688239 & 4.6862 & 5.601 & TST \\
\hline CHEMBL1542641 & 688239 & 4.5362 & 5.3639 & TST \\
\hline CHEMBL1416116 & 688239 & 5.1862 & 5.4352 & TRN \\
\hline CHEMBL1568349 & 688239 & 8.3872 & 5.3873 & TRN \\
\hline CHEMBL1599225 & 688239 & 6.8362 & 5.4945 & TST \\
\hline CHEMBL1536100 & 688239 & 6.2362 & 5.4895 & TRN \\
\hline CHEMBL1313722 & 688239 & 4.7362 & 5.4656 & TRN \\
\hline CHEMBL1548469 & 688239 & 5.6862 & 5.4888 & TRN \\
\hline CHEMBL1545903 & 688239 & 5.3862 & 5.5913 & TRN \\
\hline CHEMBL3189860 & 688239 & 4.6362 & 5.4563 & TRN \\
\hline CHEMBL1476543 & 688239 & 4.6862 & 5.5188 & TRN \\
\hline CHEMBL1413014 & 688239 & 5.1362 & 5.4605 & TRN \\
\hline CHEMBL1325777 & 688239 & 5.0862 & 5.4331 & TST \\
\hline CHEMBL491499 & 688239 & 4.7362 & 5.3572 & TST \\
\hline CHEMBL1421587 & 688239 & 5.8862 & 5.6622 & TRN \\
\hline CHEMBL1485169 & 688239 & 5.1862 & 5.4846 & TST \\
\hline
\end{tabular}


Supplemental Table S2.txt

\begin{tabular}{|c|c|c|c|c|}
\hline & & & & \\
\hline HEMBL1390928 & 38239 & 362 & $\partial 1$ & \\
\hline AEMBL1601002 & 239 & 362 & & \\
\hline & 39 & 862 & & \\
\hline IEMBL1327182 & 39 & 362 & & \\
\hline AEMBL1372144 & 88239 & 362 & 61 & \\
\hline AEMBL1559348 & 88239 & 362 & 4791 & \\
\hline HEMBL1458976 & & & & \\
\hline EMBL 140 & 39 & 362 & & \\
\hline IEMBL 3195483 & & & & \\
\hline AEMBL1520249 & 39 & 862 & 547 & \\
\hline AEMBL1539744 & 39 & 862 & 538 & \\
\hline AEMBL1531078 & & & & \\
\hline IEMBL1416 & & & & \\
\hline AEMBL1555790 & & & & \\
\hline AEMBL3190654 & & 862 & 17 & \\
\hline AEMBL1562213 & & 862 & & \\
\hline IEMBL1529 & & & & \\
\hline AEMBL1606790 & & & & \\
\hline 1492909 & & & & \\
\hline AEMBL1348520 & & 862 & & \\
\hline HEMBL1447 & & 62 & & \\
\hline HEMBL16e & & & & \\
\hline JᄃMD 11 & & & & \\
\hline 78 & & & & \\
\hline 1631 & & & & \\
\hline IEMBL1438139 & & & & \\
\hline EMBL13307 & & & & \\
\hline ALMP & & & & \\
\hline 85 & & 52 & & \\
\hline 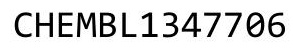 & & & & \\
\hline HEMBL1430529 & & 62 & & \\
\hline & & & & \\
\hline 4 & & & & \\
\hline & & & & \\
\hline AEMBL1537015 & & & 847 & $F$ \\
\hline AEMBL1552354 & & 362 & 521 & \\
\hline & & & 65 & \\
\hline 9 & & & 62 & \\
\hline HEMBL1528275 & & & & RN \\
\hline IEMBL1609631 & & 362 & 578 & F \\
\hline IEMBL14543 & & 62 & 596 & $s$ \\
\hline & & & & \\
\hline HEMBL1352059 & & & & \\
\hline AEMBL1569212 & & 4.8862 & 4076 & $\lceil\mathrm{RN}$ \\
\hline IEMBL1375502 & & 362 & 5171 & 17 \\
\hline 147 & & & & \\
\hline זתר & & & & \\
\hline
\end{tabular}

Page 2739 
Supplemental Table S2.txt

\begin{tabular}{|c|c|c|c|c|}
\hline & & & & \\
\hline HEMBL1425324 & 88239 & 2862 & 4847 & \\
\hline AEMBL1462351 & 39 & 51 & $\perp$ & \\
\hline & & & & \\
\hline AFMB 1 & & & & \\
\hline AEMBL1351516 & 88239 & 862 & 5134 & \\
\hline AEMBL1368609 & 88239 & 4.6362 & 4168 & \\
\hline AEMBL1314193 & & & & \\
\hline AEMBL13 & & & 557 & \\
\hline IEMBL131 & & & & \\
\hline HEMBL1533790 & 39 & & 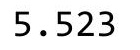 & \\
\hline HEMBL1394814 & 39 & 4. & 855 & \\
\hline HEMBL1555 & & & & \\
\hline AEMBL13ع & & & & \\
\hline AEMBL42 & & & & \\
\hline HEMBL1390726 & & & 003 & \\
\hline AEMBL1503328 & & & & \\
\hline HEMBL156 & & & 21 & \\
\hline HEMBL15 & & & & \\
\hline HEMBL14 & & & & \\
\hline AEMBL1508110 & & & & \\
\hline AEMBL1608985 & & & & \\
\hline AEMBL135 & & & 52 & \\
\hline HEMBL13 & & & & \\
\hline HFMRI 310 & & & & \\
\hline L1418079 & & & & \\
\hline HEMBL1548 & & & & \\
\hline HEMBL15637ऽ & & & & \\
\hline 6 & & & & \\
\hline 979 & & & & \\
\hline AEMBL3192770 & & & & \\
\hline HEMBL1606588 & & & & \\
\hline & & & & \\
\hline 4 & & & & \\
\hline 4 & & & & \\
\hline AEMBL462861 & & & & \\
\hline AEMBL1441063 & & & & \\
\hline & & & & \\
\hline 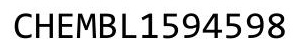 & & & 82 & \\
\hline L1339947 & & & & S \\
\hline AEMBL1518397 & & & 545 & s \\
\hline AEMBL15891 & & & & \\
\hline & & & & \\
\hline HEMBL1410074 & & & 011 & \\
\hline AEMBL1383793 & & & & RN \\
\hline MBL1566992 & & & 239 & \\
\hline 121 & & & 92 & \\
\hline 1000 & & 7.1864 & 5.5495 & \\
\hline
\end{tabular}


Supplemental Table S2.txt

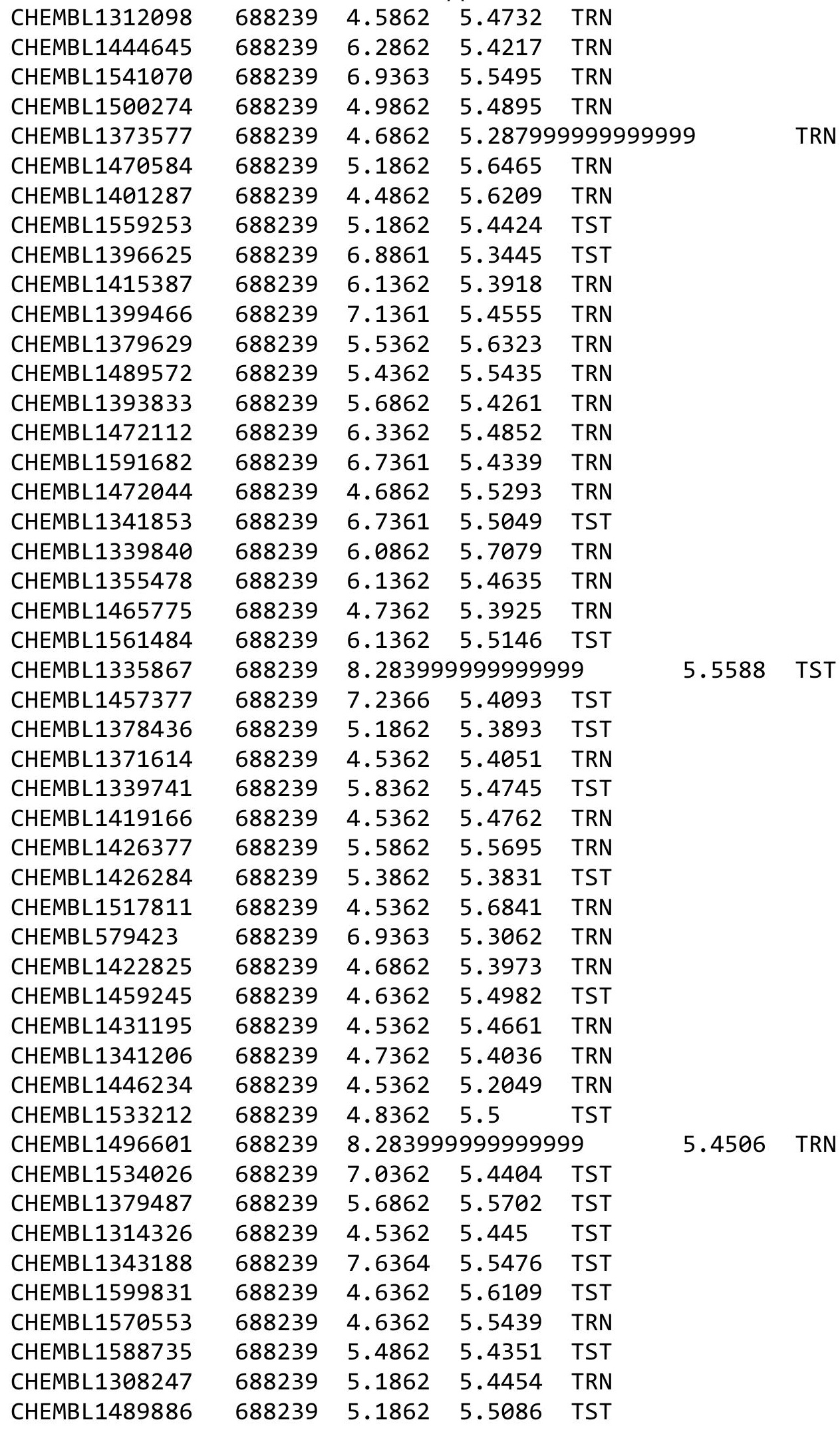


Supplemental Table S2.txt

\begin{tabular}{|c|c|c|c|c|}
\hline CHEMBL1427910 & 688239 & 5.4362 & 5.6355 & TRN \\
\hline CHEMBL1325825 & 688239 & 6.5363 & 5.5426 & TRN \\
\hline CHEMBL1574455 & 688239 & 4.5362 & 5.5546 & TRN \\
\hline CHEMBL1361976 & 688239 & 4.7862 & 5.6677 & TRN \\
\hline CHEMBL1517732 & 688239 & 5.8362 & 5.4754 & TRN \\
\hline CHEMBL1308563 & 688239 & 4.9862 & 5.3763 & TRN \\
\hline CHEMBL1372294 & 688239 & 4.8862 & 5.4468 & TRN \\
\hline CHEMBL1608904 & 688239 & 5.2862 & 5.5422 & TRN \\
\hline CHEMBL1391924 & 688239 & 4.5362 & 5.3585 & TRN \\
\hline CHEMBL1471631 & 688239 & 8.2366 & 5.4313 & TRN \\
\hline CHEMBL1352380 & 688239 & 6.2362 & 5.4363 & TRN \\
\hline CHEMBL1591353 & 688239 & 4.4862 & 5.4689 & TRN \\
\hline CHEMBL1607372 & 688239 & 5.8362 & 5.4577 & TRN \\
\hline CHEMBL1355476 & 688239 & 4.8362 & 5.4916 & TRN \\
\hline CHEMBL1480431 & 688239 & 4.4862 & 5.5026 & TRN \\
\hline CHEMBL1464047 & 688239 & 5.9362 & 5.6848 & TRN \\
\hline CHEMBL1536683 & 688239 & 4.5362 & 5.5616 & TRN \\
\hline CHEMBL1307910 & 688239 & 4.5362 & 5.5383 & TRN \\
\hline CHEMBL1572939 & 688239 & 5.1362 & 5.3896 & TST \\
\hline CHEMBL1324476 & 688239 & 4.6362 & 5.5201 & TRN \\
\hline CHEMBL1305503 & 688239 & 5.1862 & 5.5344 & TST \\
\hline CHEMBL1441962 & 688239 & 4.7362 & 5.4589 & TST \\
\hline CHEMBL1322685 & 688239 & 5.4362 & 5.3862 & TST \\
\hline CHEMBL1422038 & 688239 & 6.0 & 5.3718 & TRN \\
\hline CHEMBL1492872 & 688239 & 6.9863 & 5.4443 & TRN \\
\hline CHEMBL1464683 & 688239 & 5.2862 & 5.3592 & TST \\
\hline CHEMBL1364474 & 688239 & 4.7362 & 5.4594 & TRN \\
\hline CHEMBL1583894 & 688239 & 5.9862 & 5.4535 & TST \\
\hline CHEMBL1320682 & 688239 & 5.0362 & 5.3498 & TST \\
\hline CHEMBL1330886 & 688239 & 5.6862 & 5.465 & TST \\
\hline CHEMBL1415067 & 688239 & 4.5362 & 5.6351 & TRN \\
\hline CHEMBL1609096 & 688239 & 4.7862 & 5.4713 & TST \\
\hline CHEMBL1391661 & 688239 & 4.4862 & 5.4536 & TRN \\
\hline CHEMBL1566569 & 688239 & 5.3362 & 5.5404 & TRN \\
\hline CHEMBL3191602 & 688239 & 4.7862 & 5.3606 & TRN \\
\hline CHEMBL1433627 & 688239 & 4.8362 & 5.4951 & TRN \\
\hline CHEMBL1576841 & 688239 & 5.6362 & 5.4652 & TST \\
\hline CHEMBL1447820 & 688239 & 4.6362 & 5.6432 & TST \\
\hline CHEMBL1495394 & 688239 & 6.2862 & 5.6668 & TRN \\
\hline CHEMBL1359812 & 688239 & 5.6362 & 5.4742 & TRN \\
\hline CHEMBL1413262 & 688239 & 4.4862 & 5.41299 & 9999999999 \\
\hline CHEMBL1346768 & 688239 & 5.4862 & 5.6216 & TRN \\
\hline CHEMBL1495575 & 688239 & 4.6862 & 5.44600 & 0000000001 \\
\hline CHEMBL1486283 & 688239 & 4.7862 & 5.4222 & TST \\
\hline CHEMBL1499770 & 688239 & 6.1362 & 5.519 & TRN \\
\hline CHEMBL1612298 & 688239 & 5.1862 & 5.4093 & TRN \\
\hline CHEMBL1584973 & 688239 & 4.5362 & 5.4417 & TRN \\
\hline CHEMBL1512141 & 688239 & 4.6362 & 5.3881 & TRN \\
\hline
\end{tabular}


Supplemental Table S2.txt

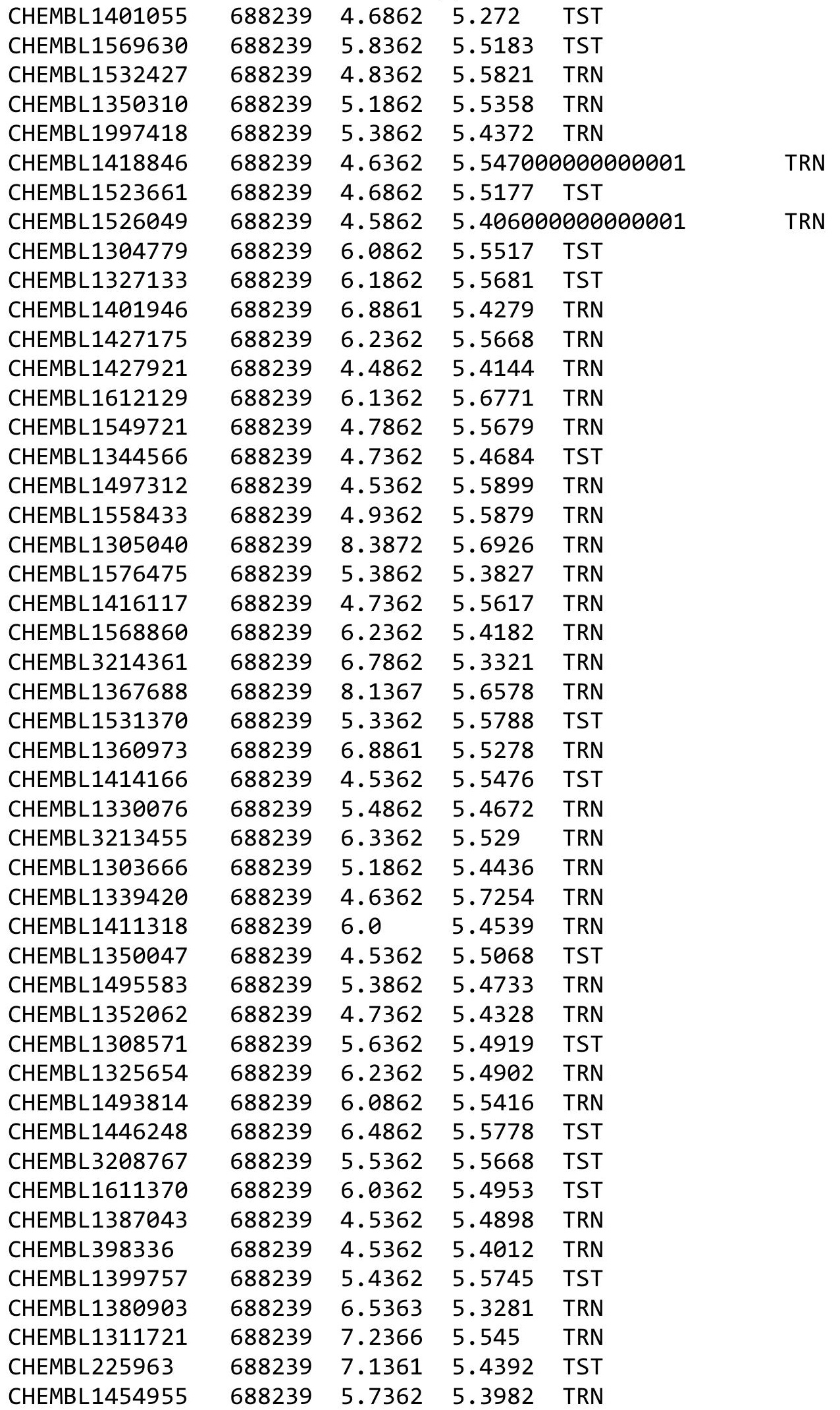




\begin{tabular}{|c|c|c|c|c|c|c|}
\hline \multicolumn{7}{|c|}{ plemental } \\
\hline CHEMBL1543207 & 688239 & 4.4862 & 5.3076 & TRN & & \\
\hline CHEMBL1501515 & 688239 & 5.0362 & 5.54799 & 9999999999 & TRN & \\
\hline CHEMBL1471595 & 688239 & 4.6362 & 5.3554 & TST & & \\
\hline CHEMBL1438324 & 688239 & 5.2862 & 5.5084 & TRN & & \\
\hline CHEMBL1365698 & 688239 & 4.5362 & 5.6732 & TST & & \\
\hline CHEMBL3191772 & 688239 & 4.4862 & 5.41299 & 9999999999 & TST & \\
\hline CHEMBL1438282 & 688239 & 5.4362 & 5.5585 & TRN & & \\
\hline CHEMBL1488846 & 688239 & 6.6362 & 5.4646 & TRN & & \\
\hline CHEMBL1547411 & 688239 & 4.5362 & 5.5143 & TRN & & \\
\hline CHEMBL1598496 & 688239 & 5.3862 & 5.5986 & TRN & & \\
\hline CHEMBL3208689 & 688239 & 6.2362 & 5.5216 & TST & & \\
\hline CHEMBL1525207 & 688239 & 5.7862 & 5.421 & TRN & & \\
\hline CHEMBL1464711 & 688239 & 5.1862 & 5.5923 & TRN & & \\
\hline CHEMBL1542323 & 688239 & 4.7862 & 5.5541 & TST & & \\
\hline CHEMBL1495376 & 688239 & 5.8862 & 5.2961 & TRN & & \\
\hline CHEMBL1328827 & 688239 & 5.2362 & 5.4668 & TRN & & \\
\hline CHEMBL1352554 & 688239 & 5.3862 & 5.5049 & TRN & & \\
\hline CHEMBL3189587 & 688239 & 4.5862 & 5.4751 & TRN & & \\
\hline CHEMBL1427266 & 688239 & 6.3362 & 5.51200 & 00000000005 & TST & \\
\hline CHEMBL1385988 & 688239 & 6.1362 & 5.5332 & TRN & & \\
\hline CHEMBL1409726 & 688239 & 5.5362 & 5.5634 & TRN & & \\
\hline CHEMBL1533703 & 688239 & 6.9863 & 5.6009 & TRN & & \\
\hline CHEMBL1554169 & 688239 & 5.1362 & 5.4284 & TST & & \\
\hline CHEMBL1394501 & 688239 & 6.0862 & 5.4113 & TRN & & \\
\hline CHEMBL1556185 & 688239 & 4.8362 & 5.432 & TRN & & \\
\hline CHEMBL1344341 & 688239 & 5.8862 & 5.4208 & TST & & \\
\hline CHEMBL1385709 & 688239 & 5.5862 & 5.4671 & TRN & & \\
\hline CHEMBL1414052 & 688239 & 5.1862 & 5.4259 & TRN & & \\
\hline CHEMBL1570419 & 688239 & 6.7361 & 5.4357 & TRN & & \\
\hline CHEMBL1417424 & 688239 & 4.6362 & 5.4995 & TST & & \\
\hline CHEMBL1439024 & 688239 & 5.1862 & 5.5337 & TRN & & \\
\hline CHEMBL1553222 & 688239 & 5.1362 & 5.4503 & TRN & & \\
\hline CHEMBL1322154 & 688239 & 4.5362 & 5.4061 & TST & & \\
\hline CHEMBL1371755 & 688239 & 5.7362 & 5.5497 & TRN & & \\
\hline CHEMBL1337436 & 688239 & 8.28399 & 99999999 & 5.5 & 00000000001 & TST \\
\hline CHEMBL1372425 & 688239 & 5.3862 & 5.4377 & TRN & & \\
\hline CHEMBL592106 & 688239 & 4.8362 & 5.3004 & TRN & & \\
\hline CHEMBL1468217 & 688239 & 6.2362 & 5.496 & TRN & & \\
\hline CHEMBL1496086 & 688239 & 5.0862 & 5.4326 & TRN & & \\
\hline CHEMBL1303954 & 688239 & 6.0362 & 5.5943 & TRN & & \\
\hline CHEMBL1449814 & 688239 & 6.8362 & 5.5902 & TRN & & \\
\hline CHEMBL1376650 & 688239 & 5.5362 & 5.5283 & TRN & & \\
\hline CHEMBL1436352 & 688239 & 5.6362 & 5.4427 & TRN & & \\
\hline CHEMBL1351692 & 688239 & 5.1862 & 5.7148 & TST & & \\
\hline CHEMBL1426208 & 688239 & 4.5362 & 5.4869 & TST & & \\
\hline CHEMBL1486823 & 688239 & 6.0862 & 5.5622 & TRN & & \\
\hline CHEMBL1315915 & 688239 & 4.7362 & 5.4136 & TRN & & \\
\hline CHEMBL1422426 & 688239 & 5.1362 & 5.4632 & TRN & & \\
\hline
\end{tabular}


Supplemental Table S2.txt

\begin{tabular}{|c|c|c|c|c|c|}
\hline CHEMBL1362575 & 688239 & 5.8862 & 5.5148 & TRN & \\
\hline CHEMBL1399402 & 688239 & 4.7362 & 5.5515 & TST & \\
\hline CHEMBL1504011 & 688239 & 5.5362 & \multicolumn{2}{|c|}{5.577000000000001} & TRN \\
\hline CHEMBL1389323 & 688239 & 4.5362 & 5.5623 & TRN & \\
\hline CHEMBL1397022 & 688239 & 6.0862 & 5.5932 & TRN & \\
\hline CHEMBL1525294 & 688239 & 4.7862 & 5.5291 & TRN & \\
\hline CHEMBL1475869 & 688239 & 6.8362 & 5.6184 & TRN & \\
\hline CHEMBL1352304 & 688239 & 4.5362 & 5.5235 & TRN & \\
\hline CHEMBL1542577 & 688239 & 5.3362 & 5.5265 & TRN & \\
\hline CHEMBL1497873 & 688239 & 4.4862 & 5.3775 & TRN & \\
\hline CHEMBL1401405 & 688239 & 5.4862 & 5.5406 & TST & \\
\hline CHEMBL1496799 & 688239 & 5.1862 & 5.6532 & TRN & \\
\hline CHEMBL1314028 & 688239 & 5.1862 & 5.5007 & TST & \\
\hline CHEMBL1464138 & 688239 & 5.1862 & 5.5157 & TST & \\
\hline CHEMBL1424444 & 688239 & 5.1862 & \multicolumn{2}{|c|}{5.382999999999999} & TST \\
\hline CHEMBL1378783 & 688239 & 7.0362 & 5.4476 & TST & \\
\hline CHEMBL3212127 & 688239 & 6.2862 & 5.4699 & TRN & \\
\hline CHEMBL1581991 & 688239 & 4.8362 & 5.6062 & TRN & \\
\hline CHEMBL1509502 & 688239 & 7.0862 & \multicolumn{2}{|c|}{5.537000000000001} & TST \\
\hline CHEMBL1387156 & 688239 & 4.5362 & 5.3904 & TST & \\
\hline CHEMBL1420271 & 688239 & 4.4862 & 5.414 & TRN & \\
\hline CHEMBL1474997 & 688239 & 4.5362 & 5.4919 & TRN & \\
\hline CHEMBL1338027 & 688239 & 4.6862 & 5.374 & TST & \\
\hline CHEMBL1443344 & 688239 & 6.1362 & \multicolumn{2}{|c|}{5.553999999999999} & TRN \\
\hline CHEMBL1506505 & 688239 & 4.7362 & 5.3954 & TST & \\
\hline CHEMBL1561101 & 688239 & 5.4362 & 5.3745 & TRN & \\
\hline CHEMBL1459415 & 688239 & 4.5362 & 5.4369 & TRN & \\
\hline CHEMBL1445198 & 688239 & 4.5362 & 5.5485 & TRN & \\
\hline CHEMBL1312498 & 688239 & 5.5362 & 5.4548 & TST & \\
\hline CHEMBL1534970 & 688239 & 5.7362 & 5.5164 & TRN & \\
\hline CHEMBL1446293 & 688239 & 5.1862 & 5.5453 & TRN & \\
\hline CHEMBL1394748 & 688239 & 5.1862 & 5.3226 & TRN & \\
\hline CHEMBL1608324 & 688239 & 5.7362 & 5.5127 & TST & \\
\hline CHEMBL1314482 & 688239 & 4.5362 & 5.3636 & TRN & \\
\hline CHEMBL3195394 & 688239 & 4.9362 & 5.4961 & TST & \\
\hline CHEMBL3210892 & 688239 & 5.7362 & 5.4419 & TRN & \\
\hline CHEMBL1366406 & 688239 & 4.4862 & 5.4737 & TRN & \\
\hline CHEMBL1550758 & 688239 & 8.3372 & 5.6336 & TST & \\
\hline CHEMBL1560021 & 688239 & 5.3862 & 5.3974 & TRN & \\
\hline CHEMBL1965184 & 688239 & 4.7862 & 5.2928 & TRN & \\
\hline CHEMBL1510421 & 688239 & 4.6862 & 5.5278 & TRN & \\
\hline CHEMBL1338494 & 688239 & 5.1362 & 5.5848 & TRN & \\
\hline CHEMBL1386747 & 688239 & 5.1862 & 5.4002 & TRN & \\
\hline CHEMBL1427503 & 688239 & 5.1862 & 5.5794 & TRN & \\
\hline CHEMBL1589639 & 688239 & 4.7862 & 5.6149 & TRN & \\
\hline CHEMBL1421175 & 688239 & 6.9363 & 5.5497 & TRN & \\
\hline CHEMBL1577691 & 688239 & 4.5362 & 5.5034 & TRN & \\
\hline CHEMBL1324710 & 688239 & 6.9363 & 5.3716 & TRN & \\
\hline
\end{tabular}


Supplemental Table S2.txt

\begin{tabular}{|c|c|c|c|c|}
\hline CHEMBL1256746 & 688239 & 4.5362 & 5.3623 & TST \\
\hline CHEMBL1306435 & 688239 & 8.3372 & 5.445 & TST \\
\hline CHEMBL3198218 & 688239 & 4.8362 & 5.5764 & TRN \\
\hline CHEMBL1441566 & 688239 & 5.8362 & 5.2421 & TST \\
\hline CHEMBL1412943 & 688239 & 6.5862 & 5.5326 & TST \\
\hline CHEMBL1466346 & 688239 & 4.5362 & 5.572 & TRN \\
\hline CHEMBL1454812 & 688239 & 6.0862 & 5.5121 & TRN \\
\hline CHEMBL 3198750 & 688239 & 6.8861 & 5.5808 & TRN \\
\hline CHEMBL1565723 & 688239 & 5.9362 & 5.4822 & TRN \\
\hline CHEMBL1576710 & 688239 & 5.3362 & 5.3719 & TRN \\
\hline CHEMBL1351424 & 688239 & 6.6861 & 5.3268 & TST \\
\hline CHEMBL1461347 & 688239 & 4.6362 & 5.4657 & TRN \\
\hline CHEMBL1579780 & 688239 & 5.8362 & 5.4675 & TST \\
\hline CHEMBL1403893 & 688239 & 4.8362 & 5.5378 & TRN \\
\hline CHEMBL1377123 & 688239 & 6.6861 & 5.6249 & TST \\
\hline CHEMBL1440024 & 688239 & 6.7862 & 5.405 & TRN \\
\hline CHEMBL3192480 & 688239 & 4.5362 & 5.3946 & TST \\
\hline CHEMBL 3210871 & 688239 & 5.1862 & 5.4829 & TST \\
\hline CHEMBL1523005 & 688239 & 4.5362 & 5.5261 & TRN \\
\hline CHEMBL1408215 & 688239 & 5.4862 & 5.401 & TRN \\
\hline CHEMBL1606040 & 688239 & 5.3362 & 5.416 & TRN \\
\hline CHEMBL1544846 & 688239 & 4.7362 & 5.4518 & TRN \\
\hline CHEMBL1563979 & 688239 & 6.7862 & 5.5682 & TRN \\
\hline CHEMBL1375670 & 688239 & 4.5362 & 5.4648 & TST \\
\hline CHEMBL1450400 & 688239 & 8.3372 & 5.3877 & TRN \\
\hline CHEMBL1308386 & 688239 & 4.6362 & 5.5629 & TRN \\
\hline CHEMBL 3214363 & 688239 & 6.2862 & 5.4835 & TRN \\
\hline CHEMBL1381969 & 688239 & 6.1862 & 5.4704 & TRN \\
\hline CHEMBL1609526 & 688239 & 6.0862 & 5.5069 & TRN \\
\hline CHEMBL1389038 & 688239 & 5.1862 & 5.4404 & TST \\
\hline CHEMBL1461101 & 688239 & 5.4362 & 5.3872 & TST \\
\hline CHEMBL1339033 & 688239 & 5.1362 & 5.4971 & TRN \\
\hline CHEMBL3191956 & 688239 & 5.3862 & 5.3244 & TRN \\
\hline CHEMBL1325274 & 688239 & 5.3862 & 5.5167 & TRN \\
\hline CHEMBL1413112 & 688239 & 4.7362 & 5.6276 & TRN \\
\hline CHEMBL1589053 & 688239 & 4.5362 & 5.5679 & TST \\
\hline CHEMBL 3194473 & 688239 & 5.4362 & 5.4743 & TRN \\
\hline CHEMBL1507694 & 688239 & 4.5362 & 5.4534 & TRN \\
\hline CHEMBL1362480 & 688239 & 8.3372 & 5.5025 & TRN \\
\hline CHEMBL1311709 & 688239 & 4.5362 & 5.4067 & TRN \\
\hline CHEMBL1497497 & 688239 & 5.0862 & 5.5463 & TST \\
\hline CHEMBL1538756 & 688239 & 6.9363 & 5.454 & TRN \\
\hline CHEMBL1304381 & 688239 & 4.8362 & 5.5728 & TRN \\
\hline CHEMBL1613136 & 688239 & 4.45 & 5.38299 & 9999999999 \\
\hline CHEMBL1531381 & 688239 & 6.8362 & 5.3918 & TRN \\
\hline CHEMBL1391236 & 688239 & 4.5362 & 5.6417 & TRN \\
\hline CHEMBL1563621 & 688239 & 4.7362 & 5.4969 & TST \\
\hline CHEMBL1309369 & 688239 & 6.1362 & 5.4304 & TRN \\
\hline
\end{tabular}


Supplemental Table S2.txt

\begin{tabular}{|c|c|c|c|c|c|}
\hline CHEMBL1541576 & 688239 & 5.8362 & 5.6039 & TRN & \\
\hline CHEMBL1356894 & 688239 & 4.5362 & 5.4352 & TRN & \\
\hline CHEMBL1397072 & 688239 & 4.7862 & 5.6043 & TRN & \\
\hline CHEMBL1389768 & 688239 & 4.5362 & 5.5091 & TRN & \\
\hline CHEMBL1309055 & 688239 & 5.1862 & 5.4781 & TRN & \\
\hline CHEMBL1308593 & 688239 & 6.9863 & 5.4107 & TRN & \\
\hline CHEMBL1336621 & 688239 & 4.5362 & 5.5078 & TRN & \\
\hline CHEMBL1585743 & 688239 & 5.7862 & 5.5687 & TRN & \\
\hline CHEMBL 3189160 & 688239 & 4.9862 & 5.3554 & TST & \\
\hline CHEMBL 3194483 & 688239 & 5.4862 & 5.6443 & TRN & \\
\hline CHEMBL1394496 & 688239 & 5.1862 & 5.4762 & TRN & \\
\hline CHEMBL1507153 & 688239 & 4.6862 & 5.4617 & TRN & \\
\hline CHEMBL1574751 & 688239 & 4.4862 & 5.3626 & TRN & \\
\hline CHEMBL1337655 & 688239 & 4.5362 & 5.4381 & TRN & \\
\hline CHEMBL1371773 & 688239 & 4.5362 & 5.428 & TRN & \\
\hline CHEMBL 3213027 & 688239 & 4.7362 & 5.3818 & TRN & \\
\hline CHEMBL1504130 & 688239 & 6.9363 & 5.4491 & TRN & \\
\hline CHEMBL3197595 & 688239 & 4.5362 & 5.5124 & TRN & \\
\hline CHEMBL1416787 & 688239 & 4.8362 & 5.5213 & TRN & \\
\hline CHEMBL1432580 & 688239 & 4.5362 & 5.6474 & TRN & \\
\hline CHEMBL1463207 & 688239 & 7.0862 & 5.5009 & TRN & \\
\hline CHEMBL1600656 & 688239 & 5.7362 & 5.5939 & TRN & \\
\hline CHEMBL1509371 & 688239 & 4.8362 & 5.3776 & TST & \\
\hline CHEMBL1344999 & 688239 & 6.9363 & 5.5264 & TRN & \\
\hline CHEMBL1429484 & 688239 & 5.2862 & 5.5495 & TRN & \\
\hline CHEMBL1516404 & 688239 & 6.1362 & 5.4833 & TST & \\
\hline CHEMBL1472126 & 688239 & 4.5362 & 5.3825 & TST & \\
\hline CHEMBL1528290 & 688239 & 4.5362 & 5.5497 & TRN & \\
\hline CHEMBL1372229 & 688239 & 5.3862 & 5.5277 & TRN & \\
\hline CHEMBL1417677 & 688239 & 4.7862 & 5.5343 & TRN & \\
\hline CHEMBL1356373 & 688239 & 5.3862 & 5.3575 & TRN & \\
\hline CHEMBL1555728 & 688239 & 4.5362 & 5.4037 & TRN & \\
\hline CHEMBL1571598 & 688239 & 7.2366 & 5.3969 & TRN & \\
\hline CHEMBL1406598 & 688239 & 4.5362 & 5.5474 & TRN & \\
\hline CHEMBL1601245 & 688239 & 4.7362 & 5.4982 & TRN & \\
\hline CHEMBL1454258 & 688239 & 8.28399 & 99999999 & 9 & 5.5071 \\
\hline CHEMBL1304049 & 688239 & 4.5362 & 5.5211 & TRN & \\
\hline CHEMBL1335331 & 688239 & 6.9363 & 5.4948 & TRN & \\
\hline CHEMBL1540206 & 688239 & 6.6362 & 5.4616 & TRN & \\
\hline CHEMBL1398557 & 688239 & 5.9362 & 5.5978 & TRN & \\
\hline CHEMBL1539956 & 688239 & 4.5362 & 5.4953 & TRN & \\
\hline CHEMBL1396330 & 688239 & 6.2862 & 5.5717 & TRN & \\
\hline CHEMBL1434839 & 688239 & 6.2862 & 5.4923 & TRN & \\
\hline CHEMBL1530694 & 688239 & 4.6862 & 5.2882 & TRN & \\
\hline CHEMBL1339495 & 688239 & 5.8362 & 5.4777 & TST & \\
\hline CHEMBL1386850 & 688239 & 8.2366 & 5.3956 & TRN & \\
\hline CHEMBL1345638 & 688239 & 6.7361 & 5.3817 & TRN & \\
\hline CHEMBL1535943 & 688239 & 5.6862 & 5.4755 & TST & \\
\hline
\end{tabular}

Page 2747 
Supplemental Table S2.txt

\begin{tabular}{|c|c|c|c|c|}
\hline CHEMBL1426799 & 688239 & 4.5362 & 5.5328 & TRN \\
\hline CHEMBL1340013 & 688239 & 8.3872 & 5.5253 & TST \\
\hline CHEMBL1320424 & 688239 & 5.4362 & 5.5631 & TRN \\
\hline CHEMBL1545028 & 688239 & 4.5862 & 5.5273 & TRN \\
\hline CHEMBL1327462 & 688239 & 5.0362 & 5.6408 & TRN \\
\hline CHEMBL1530512 & 688239 & 4.7362 & 5.5181 & TRN \\
\hline CHEMBL1587384 & 688239 & 5.4362 & 5.532 & TRN \\
\hline CHEMBL1466140 & 688239 & 4.5362 & 5.4893 & TRN \\
\hline CHEMBL1496733 & 688239 & 6.8362 & 5.4903 & TST \\
\hline CHEMBL1480101 & 688239 & 4.5862 & 5.4239 & TRN \\
\hline CHEMBL1497624 & 688239 & 6.3362 & 5.3787 & TRN \\
\hline CHEMBL1372883 & 688239 & 6.0362 & 5.7201 & TRN \\
\hline CHEMBL 3210895 & 688239 & 5.7862 & 5.3624 & TRN \\
\hline CHEMBL1391362 & 688239 & 4.5362 & 5.5361 & TRN \\
\hline CHEMBL1479412 & 688239 & 4.6862 & 5.4239 & TRN \\
\hline CHEMBL1503708 & 688239 & 5.8862 & 5.4482 & TRN \\
\hline CHEMBL1422149 & 688239 & 8.28399 & 99999999 & 5.5457 \\
\hline CHEMBL1461714 & 688239 & 4.7862 & 5.5208 & TRN \\
\hline CHEMBL1387657 & 688239 & 4.7362 & 5.3736 & TRN \\
\hline CHEMBL1459294 & 688239 & 5.0362 & 5.5485 & TST \\
\hline CHEMBL1535260 & 688239 & 6.4362 & 5.3252 & TRN \\
\hline CHEMBL1491104 & 688239 & 4.7862 & 5.3632 & TST \\
\hline CHEMBL1585035 & 688239 & 6.1862 & 5.4984 & TRN \\
\hline CHEMBL1538046 & 688239 & 4.7862 & 5.4844 & TRN \\
\hline CHEMBL1299642 & 688239 & 7.2865 & 5.4855 & TRN \\
\hline CHEMBL1511268 & 688239 & 5.5862 & 5.4466 & TRN \\
\hline CHEMBL1423475 & 688239 & 5.1862 & 5.5551 & TRN \\
\hline CHEMBL1439298 & 688239 & 6.9363 & 5.2665 & TST \\
\hline CHEMBL1605893 & 688239 & 5.1862 & 5.5706 & TRN \\
\hline CHEMBL1444109 & 688239 & 6.1362 & 5.5075 & TRN \\
\hline CHEMBL1381918 & 688239 & 6.0862 & 5.5895 & TST \\
\hline CHEMBL1376356 & 688239 & 5.8862 & 5.4485 & TST \\
\hline CHEMBL1310469 & 688239 & 6.5862 & 5.5037 & TRN \\
\hline CHEMBL1516110 & 688239 & 6.0362 & 5.5282 & TST \\
\hline CHEMBL1571587 & 688239 & 5.6862 & 5.5707 & TRN \\
\hline CHEMBL1596810 & 688239 & 4.7362 & 5.4123 & TRN \\
\hline CHEMBL1384946 & 688239 & 6.7361 & 5.407999 & 99999999995 \\
\hline CHEMBL 3191275 & 688239 & 5.1862 & 5.515 & TRN \\
\hline CHEMBL1345223 & 688239 & 5.7862 & 5.5486 & TRN \\
\hline CHEMBL1536770 & 688239 & 5.7862 & 5.5001 & TRN \\
\hline CHEMBL1392912 & 688239 & 5.0362 & 5.4342 & TRN \\
\hline CHEMBL1469573 & 688239 & 5.1362 & 5.3328 & TST \\
\hline CHEMBL1524727 & 688239 & 4.8362 & 5.4341 & TRN \\
\hline CHEMBL1492292 & 688239 & 4.4862 & 5.4722 & TRN \\
\hline CHEMBL1607874 & 688239 & 4.5362 & 5.4127 & TRN \\
\hline CHEMBL1491643 & 688239 & 5.0362 & 5.4758 & TRN \\
\hline CHEMBL1304032 & 688239 & 5.6362 & 5.46 & TRN \\
\hline CHEMBL1541466 & 688239 & 4.7862 & 5.5729 & TRN \\
\hline
\end{tabular}


Supplemental Table S2.txt

\begin{tabular}{|c|c|c|c|c|}
\hline CHEMBL1589597 & 688239 & 5.8862 & 5.4363 & TST \\
\hline CHEMBL1385178 & 688239 & 8.3872 & 5.5448 & TRN \\
\hline CHEMBL1442180 & 688239 & 5.6362 & 5.4305 & TRN \\
\hline CHEMBL1575883 & 688239 & 8.3872 & 5.5419 & TST \\
\hline CHEMBL1553091 & 688239 & 4.5862 & 5.4627 & TRN \\
\hline CHEMBL1390642 & 688239 & 5.2862 & 5.4135 & TRN \\
\hline CHEMBL1300689 & 688239 & 5.2862 & 5.7517 & TRN \\
\hline CHEMBL1558152 & 688239 & 8.3872 & 5.5824 & TRN \\
\hline CHEMBL1425789 & 688239 & 5.9862 & 5.4937 & TRN \\
\hline CHEMBL1449794 & 688239 & 6.2862 & 5.445 & TRN \\
\hline CHEMBL1390936 & 688239 & 4.5362 & 5.4678 & TRN \\
\hline CHEMBL1333988 & 688239 & 5.1862 & 5.4942 & TRN \\
\hline CHEMBL1596865 & 688239 & 8.3872 & 5.5237 & TRN \\
\hline CHEMBL1334369 & 688239 & 6.2362 & 5.5768 & TST \\
\hline CHEMBL1558753 & 688239 & 5.6362 & 5.4248 & TRN \\
\hline CHEMBL1513668 & 688239 & 5.5362 & 5.6465 & TRN \\
\hline CHEMBL1401777 & 688239 & 6.1362 & 5.6061 & TRN \\
\hline CHEMBL1459479 & 688239 & 4.5362 & 5.4543 & TST \\
\hline CHEMBL1347519 & 688239 & 5.5362 & 5.4459 & TRN \\
\hline CHEMBL1304830 & 688239 & 6.8362 & 5.5132 & TST \\
\hline CHEMBL1453462 & 688239 & 6.4862 & 5.4425 & TRN \\
\hline CHEMBL1406312 & 688239 & 4.5362 & 5.3368 & TST \\
\hline CHEMBL1434684 & 688239 & 4.5362 & 5.4551 & TRN \\
\hline CHEMBL1452930 & 688239 & 4.5362 & 5.479 & TRN \\
\hline CHEMBL1589080 & 688239 & 5.1862 & 5.3962 & TST \\
\hline CHEMBL1550697 & 688239 & 5.3362 & 5.5258 & TRN \\
\hline CHEMBL1441861 & 688239 & 6.2362 & 5.5544 & TST \\
\hline CHEMBL1608921 & 688239 & 5.1862 & 5.3887 & TRN \\
\hline CHEMBL1332705 & 688239 & 5.3362 & 5.4857 & TST \\
\hline CHEMBL438298 & 688239 & 6.1362 & 5.5763 & TRN \\
\hline CHEMBL1356645 & 688239 & 6.3362 & 5.4438 & TRN \\
\hline CHEMBL3198921 & 688239 & 4.5362 & 5.374 & TST \\
\hline CHEMBL1398106 & 688239 & 5.1862 & 5.4483 & TRN \\
\hline CHEMBL1594305 & 688239 & 5.1862 & 5.4495 & TRN \\
\hline CHEMBL1301778 & 688239 & 4.4862 & 5.5297 & TRN \\
\hline CHEMBL3197137 & 688239 & 5.1862 & 5.5534 & TST \\
\hline CHEMBL394197 & 688239 & 7.4868 & 5.3958 & TRN \\
\hline CHEMBL1435454 & 688239 & 4.6362 & 5.5755 & TRN \\
\hline CHEMBL1391695 & 688239 & 6.6362 & 5.5836 & TRN \\
\hline CHEMBL1460785 & 688239 & 5.3362 & 5.4924 & TST \\
\hline CHEMBL1418737 & 688239 & 5.9362 & 5.5509 & TRN \\
\hline CHEMBL1611330 & 688239 & 5.0362 & 5.5369 & TRN \\
\hline CHEMBL1455642 & 688239 & 5.4862 & 5.512006 & 30000000005 \\
\hline CHEMBL1319470 & 688239 & 5.7862 & 5.6136 & TRN \\
\hline CHEMBL1489296 & 688239 & 6.3863 & 5.4828 & TRN \\
\hline CHEMBL1412567 & 688239 & 6.8861 & 5.5132 & TRN \\
\hline CHEMBL1325513 & 688239 & 5.2362 & 5.4743 & TRN \\
\hline CHEMBL1590094 & 688239 & 4.7862 & 5.6181 & TRN \\
\hline
\end{tabular}


Supplemental Table S2.txt

\begin{tabular}{|c|c|c|c|c|c|}
\hline CHEMBL1421042 & 688239 & 4.9862 & 5.6324 & TST & \\
\hline CHEMBL1349614 & 688239 & 6.2362 & 5.4472 & TRN & \\
\hline CHEMBL1472851 & 688239 & 5.1862 & 5.5036 & TRN & \\
\hline CHEMBL1340801 & 688239 & 4.5362 & 5.3031 & TRN & \\
\hline CHEMBL1390147 & 688239 & 4.7362 & 5.4534 & TRN & \\
\hline CHEMBL1371788 & 688239 & 6.0862 & 5.4654 & TST & \\
\hline CHEMBL1476707 & 688239 & 5.1362 & 5.5086 & TRN & \\
\hline CHEMBL1555583 & 688239 & 8.3372 & 5.4546 & TST & \\
\hline CHEMBL1541262 & 688239 & 4.7362 & 5.6849 & TRN & \\
\hline CHEMBL1598255 & 688239 & 5.3362 & 5.6265 & TRN & \\
\hline CHEMBL1354635 & 688239 & 4.6862 & 5.4348 & TST & \\
\hline CHEMBL1427818 & 688239 & 4.7362 & 5.4582 & TRN & \\
\hline CHEMBL1599875 & 688239 & 6.4862 & 5.5176 & TST & \\
\hline CHEMBL1418885 & 688239 & 4.6862 & 5.2652 & TRN & \\
\hline CHEMBL1561348 & 688239 & 6.0862 & 5.3667 & TRN & \\
\hline CHEMBL1450864 & 688239 & 7.1864 & 5.5692 & TRN & \\
\hline CHEMBL1591331 & 688239 & 5.1862 & 5.5842 & TRN & \\
\hline CHEMBL1490363 & 688239 & 6.1862 & 5.5347 & TRN & \\
\hline CHEMBL1502630 & 688239 & 4.4862 & 5.4289 & TRN & \\
\hline CHEMBL1522930 & 688239 & 4.6862 & 5.3904 & TRN & \\
\hline CHEMBL1307551 & 688239 & 5.7362 & 5.4981 & TRN & \\
\hline CHEMBL3209367 & 688239 & 4.5362 & 5.4745 & TRN & \\
\hline CHEMBL1406807 & 688239 & 4.5362 & 5.5816 & TRN & \\
\hline CHEMBL1416952 & 688239 & 5.1862 & 5.5117 & TST & \\
\hline CHEMBL1583288 & 688239 & 4.9362 & 5.5991 & TST & \\
\hline CHEMBL1359961 & 688239 & 4.7862 & 5.4271 & TRN & \\
\hline CHEMBL1559335 & 688239 & 6.3362 & 5.4986 & TRN & \\
\hline CHEMBL1331872 & 688239 & 5.2862 & 5.5123 & TST & \\
\hline CHEMBL1344339 & 688239 & 4.7862 & 5.3419 & TST & \\
\hline CHEMBL3199275 & 688239 & 5.1862 & 5.5433 & TRN & \\
\hline CHEMBL1390304 & 688239 & 7.4868 & 5.4988 & TRN & \\
\hline CHEMBL1366501 & 688239 & 5.2862 & 5.4817 & TRN & \\
\hline CHEMBL1422753 & 688239 & 5.6362 & 5.63299 & 9999999999 & TRN \\
\hline CHEMBL1499432 & 688239 & 6.1362 & 5.4013 & TRN & \\
\hline CHEMBL1384976 & 688239 & 4.7362 & 5.5897 & TRN & \\
\hline CHEMBL1342264 & 688239 & 7.2865 & 5.3288 & TST & \\
\hline CHEMBL1986319 & 688239 & 6.3362 & 5.5647 & TRN & \\
\hline CHEMBL1408764 & 688239 & 4.6862 & 5.6576 & TRN & \\
\hline CHEMBL1492115 & 688239 & 4.7362 & 5.4749 & TRN & \\
\hline CHEMBL1604455 & 688239 & 4.5362 & 5.37299 & 9999999999 & TST \\
\hline CHEMBL1508291 & 688239 & 5.6862 & 5.6835 & TRN & \\
\hline CHEMBL1990258 & 688239 & 7.1361 & 5.566 & TST & \\
\hline CHEMBL1492251 & 688239 & 6.7361 & 5.4823 & TRN & \\
\hline CHEMBL1395053 & 688239 & 4.5362 & 5.4624 & TRN & \\
\hline CHEMBL1594964 & 688239 & 4.7362 & 5.3898 & TRN & \\
\hline CHEMBL1306086 & 688239 & 4.5362 & 5.495 & TST & \\
\hline CHEMBL1403768 & 688239 & 4.7862 & 5.4469 & TRN & \\
\hline CHEMBL1590770 & 688239 & 4.5862 & 5.3589 & TST & \\
\hline
\end{tabular}




\begin{tabular}{|c|c|c|c|c|c|}
\hline \multicolumn{6}{|c|}{ Supplemental Table S2.txt } \\
\hline CHEMBL1532196 & 688239 & 4.45 & 5.2749 & TRN & \\
\hline CHEMBL444928 & 688239 & 6.5363 & 5.4827 & TRN & \\
\hline CHEMBL1553385 & 688239 & 4.5362 & 5.5238 & TRN & \\
\hline CHEMBL1588995 & 688239 & 5.1862 & 5.5636 & TRN & \\
\hline CHEMBL1324629 & 688239 & 4.5362 & 5.6356 & TRN & \\
\hline CHEMBL1384503 & 688239 & 6.8861 & 5.5708 & TRN & \\
\hline CHEMBL1306814 & 688239 & 6.1362 & 5.5729 & TRN & \\
\hline CHEMBL1562349 & 688239 & 4.9362 & 5.4319 & TRN & \\
\hline CHEMBL1426257 & 688239 & 8.1871 & 5.6576 & TRN & \\
\hline CHEMBL1390576 & 688239 & 4.7362 & 5.6886 & TRN & \\
\hline CHEMBL1578849 & 688239 & 5.3862 & 5.4449 & TST & \\
\hline CHEMBL1490987 & 688239 & 6.1362 & 5.42399 & 99999999995 & TRN \\
\hline CHEMBL1418992 & 688239 & 4.8862 & 5.4974 & TRN & \\
\hline CHEMBL1323859 & 688239 & 5.2362 & 5.4467 & TRN & \\
\hline CHEMBL1481328 & 688239 & 5.0862 & 5.4637 & TRN & \\
\hline CHEMBL1313778 & 688239 & 4.9862 & 5.6081 & TRN & \\
\hline CHEMBL1344921 & 688239 & 4.7362 & 5.4502 & TST & \\
\hline CHEMBL1363313 & 688239 & 5.4362 & 5.5364 & TRN & \\
\hline CHEMBL1348461 & 688239 & 4.7862 & 5.48 & TRN & \\
\hline CHEMBL1342489 & 688239 & 5.7862 & 5.5702 & TRN & \\
\hline CHEMBL1586553 & 688239 & 5.7362 & 5.4463 & TST & \\
\hline CHEMBL1369563 & 688239 & 5.1862 & 5.7144 & TRN & \\
\hline CHEMBL1305819 & 688239 & 5.9862 & 5.6504 & TST & \\
\hline CHEMBL1571608 & 688239 & 4.5362 & 5.51200 & 00000000005 & TRN \\
\hline CHEMBL1450566 & 688239 & 5.8862 & 5.5527 & TRN & \\
\hline CHEMBL1582517 & 688239 & 4.8362 & 5.5624 & TST & \\
\hline CHEMBL1568497 & 688239 & 5.2862 & 5.4498 & TRN & \\
\hline CHEMBL1488482 & 688239 & 5.1862 & 5.6785 & TRN & \\
\hline CHEMBL1366824 & 688239 & 6.2862 & 5.4513 & TRN & \\
\hline CHEMBL1350130 & 688239 & 5.1862 & 5.614 & TST & \\
\hline CHEMBL1385421 & 688239 & 4.5862 & 5.4847 & TRN & \\
\hline CHEMBL81805 & 688239 & 5.1862 & 5.5172 & TRN & \\
\hline CHEMBL1339246 & 688239 & 5.7362 & 5.5277 & TST & \\
\hline CHEMBL1567046 & 688239 & 4.5362 & 5.475 & TRN & \\
\hline CHEMBL1516986 & 688239 & 4.6362 & 5.4732 & TRN & \\
\hline CHEMBL1362799 & 688239 & 5.5362 & 5.4231 & TST & \\
\hline CHEMBL1445282 & 688239 & 4.7362 & 5.3371 & TST & \\
\hline CHEMBL1339214 & 688239 & 4.5362 & 5.5298 & TRN & \\
\hline CHEMBL1576837 & 688239 & 5.0362 & 5.3933 & TST & \\
\hline CHEMBL1390443 & 688239 & 4.5362 & 5.6169 & TRN & \\
\hline CHEMBL1606193 & 688239 & 7.0362 & 5.4613 & TRN & \\
\hline CHEMBL1535183 & 688239 & 4.6362 & 5.5279 & TST & \\
\hline CHEMBL1440709 & 688239 & 6.2362 & 5.4706 & TRN & \\
\hline CHEMBL3208296 & 688239 & 5.3362 & 5.3885 & TRN & \\
\hline CHEMBL1379964 & 688239 & 5.1862 & 5.5797 & TST & \\
\hline CHEMBL1378313 & 688239 & 4.8362 & 5.4566 & TRN & \\
\hline CHEMBL1541312 & 688239 & 4.7862 & 5.3758 & TST & \\
\hline CHEMBL1543673 & 688239 & 4.5362 & 5.4735 & TST & \\
\hline
\end{tabular}


Supplemental Table S2.txt

\begin{tabular}{|c|c|c|c|c|}
\hline CHEMBL1337521 & 688239 & 7.1361 & 5.5195 & TRN \\
\hline CHEMBL1494910 & 688239 & 5.3862 & 5.5181 & TST \\
\hline CHEMBL1486891 & 688239 & 5.0862 & 5.4277 & TRN \\
\hline CHEMBL1608999 & 688239 & 4.7362 & 5.5402 & TRN \\
\hline CHEMBL1350713 & 688239 & 5.1862 & 5.5489 & TRN \\
\hline CHEMBL1361608 & 688239 & 7.2865 & 5.5599 & TRN \\
\hline CHEMBL1530996 & 688239 & 6.7862 & \multicolumn{2}{|c|}{5.547000000000001} \\
\hline CHEMBL1559975 & 688239 & 5.6862 & 5.3263 & TRN \\
\hline CHEMBL1323178 & 688239 & 4.7862 & 5.4396 & TRN \\
\hline CHEMBL1506102 & 688239 & 4.7362 & 5.4703 & TST \\
\hline CHEMBL 3397112 & 688239 & 5.9362 & 5.4482 & TRN \\
\hline CHEMBL586135 & 688239 & 5.2362 & 5.3815 & TRN \\
\hline CHEMBL1437032 & 688239 & 6.1362 & 5.7171 & TRN \\
\hline CHEMBL1390535 & 688239 & 5.4862 & 5.4022 & TRN \\
\hline CHEMBL1309458 & 688239 & 4.5362 & 5.4292 & TRN \\
\hline CHEMBL1397198 & 688239 & 6.0862 & 5.5345 & TRN \\
\hline CHEMBL1581317 & 688239 & 5.1862 & 5.4425 & TRN \\
\hline CHEMBL1574218 & 688239 & 5.1362 & 5.3392 & TRN \\
\hline CHEMBL1594865 & 688239 & 4.5862 & 5.5537 & TRN \\
\hline CHEMBL1414129 & 688239 & 5.8362 & 5.5905 & TRN \\
\hline CHEMBL1376961 & 688239 & 4.7362 & 5.3994 & TRN \\
\hline CHEMBL1544093 & 688239 & 5.0862 & 5.5826 & TST \\
\hline CHEMBL1581229 & 688239 & 5.4362 & 5.5548 & TST \\
\hline CHEMBL1593812 & 688239 & 5.8362 & 5.5479 & TRN \\
\hline CHEMBL1346797 & 688239 & 4.8362 & 5.4525 & TRN \\
\hline CHEMBL1326738 & 688239 & 4.5362 & 5.5325 & TST \\
\hline CHEMBL1436852 & 688239 & 5.5362 & 5.3973 & TRN \\
\hline CHEMBL1391672 & 688239 & 5.3362 & 5.5882 & TRN \\
\hline CHEMBL3212750 & 688239 & 5.3362 & 5.4821 & TRN \\
\hline CHEMBL1487668 & 688239 & 6.5363 & 5.6607 & TRN \\
\hline CHEMBL1598745 & 688239 & 4.4862 & 5.4369 & TRN \\
\hline CHEMBL1397159 & 688239 & 4.5362 & 5.4906 & TRN \\
\hline CHEMBL1505548 & 688239 & 6.8861 & 5.4811 & TST \\
\hline CHEMBL1482007 & 688239 & 6.0362 & 5.4571 & TRN \\
\hline CHEMBL585221 & 688239 & 4.7362 & 5.4151 & TST \\
\hline CHEMBL3197929 & 688239 & 6.3863 & 5.366006 & 0000000005 \\
\hline CHEMBL1408704 & 688239 & 5.8862 & 5.5326 & TRN \\
\hline CHEMBL1370130 & 688239 & 4.5362 & 5.4042 & TRN \\
\hline CHEMBL1462076 & 688239 & 4.7362 & 5.3585 & TST \\
\hline CHEMBL1539075 & 688239 & 4.6362 & 5.3237 & TRN \\
\hline CHEMBL1359027 & 688239 & 6.4862 & 5.5888 & TRN \\
\hline CHEMBL1504612 & 688239 & 5.2862 & 5.5407 & TRN \\
\hline CHEMBL1547796 & 688239 & 6.0862 & $5.49200 e$ & 000000001 \\
\hline CHEMBL1364568 & 688239 & 6.5363 & 5.3091 & TRN \\
\hline CHEMBL1582754 & 688239 & 5.1362 & 5.3417 & TRN \\
\hline CHEMBL1339595 & 688239 & 5.3362 & 5.4105 & TRN \\
\hline CHEMBL1391476 & 688239 & 5.1862 & 5.6031 & TST \\
\hline CHEMBL3193739 & 688239 & 4.4862 & 5.3931 & TRN \\
\hline
\end{tabular}


Supplemental Table S2.txt

\begin{tabular}{|c|c|c|c|c|}
\hline CHEMBL1534878 & 688239 & 5.1862 & 5.6733 & TST \\
\hline CHEMBL1352060 & 688239 & 5.0862 & 5.5729 & TST \\
\hline CHEMBL1492485 & 688239 & 4.6862 & 5.6073 & TRN \\
\hline CHEMBL1564482 & 688239 & 5.9862 & 5.5222 & TRN \\
\hline CHEMBL1334671 & 688239 & 4.7362 & 5.2986 & TST \\
\hline CHEMBL1336263 & 688239 & 4.5362 & 5.4344 & TST \\
\hline CHEMBL1476152 & 688239 & 5.0362 & 5.5364 & TRN \\
\hline CHEMBL1511547 & 688239 & 4.7862 & 5.4184 & TST \\
\hline CHEMBL1402010 & 688239 & 6.3863 & 5.5039 & TST \\
\hline CHEMBL1335295 & 688239 & 5.1862 & 5.4942 & TST \\
\hline CHEMBL1373090 & 688239 & 4.7362 & 5.6259 & TRN \\
\hline CHEMBL1427385 & 688239 & 8.1871 & 5.49 & TST \\
\hline CHEMBL1413378 & 688239 & 6.9363 & 5.4853 & TST \\
\hline CHEMBL1453043 & 688239 & 7.2366 & 5.3842 & TST \\
\hline CHEMBL1369917 & 688239 & 5.4862 & 5.4595 & TST \\
\hline CHEMBL1572986 & 688239 & 4.5362 & 5.5318 & TRN \\
\hline CHEMBL1517027 & 688239 & 5.8362 & 5.5673 & TRN \\
\hline CHEMBL42870 & 688239 & 4.6862 & 5.5022 & TRN \\
\hline CHEMBL1346849 & 688239 & 4.5362 & 5.6781 & TST \\
\hline CHEMBL1501394 & 688239 & 4.6862 & 5.6174 & TRN \\
\hline CHEMBL1532018 & 688239 & 5.0362 & 5.5082 & TRN \\
\hline CHEMBL1520742 & 688239 & 4.6362 & 5.4466 & TRN \\
\hline CHEMBL1370300 & 688239 & 4.5362 & 5.3327 & TRN \\
\hline CHEMBL1985680 & 688239 & 4.7862 & 5.4166 & TRN \\
\hline CHEMBL1422874 & 688239 & 4.5362 & 5.4972 & TRN \\
\hline CHEMBL1613648 & 688239 & 5.7862 & 5.6382 & TST \\
\hline CHEMBL1416339 & 688239 & 6.8861 & 5.4362 & TRN \\
\hline CHEMBL1380411 & 688239 & 5.1862 & 5.6497 & TRN \\
\hline CHEMBL1480332 & 688239 & 4.6862 & 5.4216 & TRN \\
\hline CHEMBL1585523 & 688239 & 6.1362 & 5.5758 & TST \\
\hline CHEMBL1973629 & 688239 & 4.6862 & 5.2875 & TST \\
\hline CHEMBL1399837 & 688239 & 5.7362 & 5.548999 & 99999999995 \\
\hline CHEMBL1447305 & 688239 & 5.1362 & 5.4905 & TRN \\
\hline CHEMBL1337915 & 688239 & 5.3862 & 5.4496 & TRN \\
\hline CHEMBL1492910 & 688239 & 6.3362 & 5.5868 & TST \\
\hline CHEMBL1568937 & 688239 & 4.5362 & 5.396 & TRN \\
\hline CHEMBL1601294 & 688239 & 8.3372 & 5.6546 & TRN \\
\hline CHEMBL1300340 & 688239 & 5.7862 & 5.3366 & TST \\
\hline CHEMBL1352497 & 688239 & 5.5362 & 5.5372 & TRN \\
\hline CHEMBL1378070 & 688239 & 4.5362 & 5.4905 & TRN \\
\hline CHEMBL1303498 & 688239 & 4.9362 & 5.4365 & TRN \\
\hline CHEMBL1307685 & 688239 & 7.1864 & 5.4279 & TRN \\
\hline CHEMBL1346066 & 688239 & 5.3362 & 5.3775 & TST \\
\hline CHEMBL1504178 & 688239 & 4.5362 & 5.6016 & TRN \\
\hline CHEMBL1337799 & 688239 & 4.5362 & 5.4617 & TST \\
\hline CHEMBL1603712 & 688239 & 5.2862 & 5.6178 & TRN \\
\hline CHEMBL1380432 & 688239 & 4.7862 & 5.4834 & TRN \\
\hline CHEMBL1423040 & 688239 & 5.1862 & 5.3002 & TRN \\
\hline
\end{tabular}

Page 2753 
Supplemental Table S2.txt

\begin{tabular}{|c|c|c|c|c|}
\hline CHEMBL1558544 & 688239 & 5.4862 & 5.5667 & TST \\
\hline CHEMBL1383837 & 688239 & 4.6362 & 5.6381 & TRN \\
\hline CHEMBL1336675 & 688239 & 6.1362 & 5.3533 & TST \\
\hline CHEMBL1453990 & 688239 & 5.7362 & 5.4359 & TRN \\
\hline CHEMBL1368427 & 688239 & 5.3362 & 5.6509 & TRN \\
\hline CHEMBL1381622 & 688239 & 4.7362 & 5.4068 & TST \\
\hline CHEMBL1480741 & 688239 & 5.1862 & 5.54 & TST \\
\hline CHEMBL1392581 & 688239 & 5.4862 & 5.4078 & TRN \\
\hline CHEMBL3212679 & 688239 & 6.9863 & 5.3876 & TST \\
\hline CHEMBL 2086964 & 688239 & 4.5862 & 5.4077 & TRN \\
\hline CHEMBL1401428 & 688239 & 7.2366 & 5.3945 & TST \\
\hline CHEMBL1382973 & 688239 & 4.4862 & 5.4971 & TRN \\
\hline CHEMBL1428577 & 688239 & 7.3862 & 5.6438 & TRN \\
\hline CHEMBL1492887 & 688239 & 5.2862 & 5.6357 & TRN \\
\hline CHEMBL1589187 & 688239 & 5.4862 & 5.6199 & TST \\
\hline CHEMBL1402874 & 688239 & 4.5362 & 5.5491 & TRN \\
\hline CHEMBL1528941 & 688239 & 5.9362 & 5.4844 & TRN \\
\hline CHEMBL1515069 & 688239 & 5.5862 & 5.316 & TRN \\
\hline CHEMBL1587155 & 688239 & 6.7361 & 5.6183 & TRN \\
\hline CHEMBL1442115 & 688239 & 4.6862 & 5.4824 & TRN \\
\hline CHEMBL1605528 & 688239 & 5.1362 & 5.4074 & TRN \\
\hline CHEMBL1611911 & 688239 & 6.0862 & 5.6164 & TST \\
\hline CHEMBL1397143 & 688239 & 4.6862 & 5.6346 & TRN \\
\hline CHEMBL1401255 & 688239 & 4.7362 & 5.3323 & TRN \\
\hline CHEMBL1459299 & 688239 & 5.2862 & 5.3779 & TRN \\
\hline CHEMBL1488376 & 688239 & 4.5362 & 5.5236 & TRN \\
\hline CHEMBL1358507 & 688239 & 5.3862 & 5.5693 & TRN \\
\hline CHEMBL1349271 & 688239 & 7.1864 & 5.5461 & TRN \\
\hline CHEMBL1368763 & 688239 & 4.6362 & 5.548999 & 99999999995 \\
\hline CHEMBL1550817 & 688239 & 4.9862 & 5.475 & TST \\
\hline CHEMBL1299370 & 688239 & 7.3363 & 5.4343 & TST \\
\hline CHEMBL1533887 & 688239 & 5.4862 & 5.3991 & TRN \\
\hline CHEMBL1550145 & 688239 & 5.1362 & 5.5388 & TRN \\
\hline CHEMBL1511680 & 688239 & 7.6364 & 5.5704 & TRN \\
\hline CHEMBL1499144 & 688239 & 5.8862 & 5.7361 & TRN \\
\hline CHEMBL1343032 & 688239 & 4.8362 & 5.4446 & TRN \\
\hline CHEMBL1308785 & 688239 & 5.2362 & 5.4782 & TRN \\
\hline CHEMBL1543322 & 688239 & 6.9863 & 5.5662 & TRN \\
\hline CHEMBL1321389 & 688239 & 6.7862 & 5.449 & TRN \\
\hline CHEMBL1353000 & 688239 & 5.1862 & 5.4647 & TRN \\
\hline CHEMBL1429788 & 688239 & 4.7862 & 5.4501 & TRN \\
\hline CHEMBL1478928 & 688239 & 4.7862 & 5.4435 & TRN \\
\hline CHEMBL1314070 & 688239 & 4.5362 & 5.5006 & TST \\
\hline CHEMBL1316866 & 688239 & 5.1362 & 5.4625 & TST \\
\hline CHEMBL1506122 & 688239 & 4.5362 & 5.5077 & TRN \\
\hline CHEMBL1348962 & 688239 & 4.5362 & 5.434 & TRN \\
\hline CHEMBL1480240 & 688239 & 4.7862 & 5.4399 & TST \\
\hline CHEMBL1447256 & 688239 & 8.3372 & 5.4634 & TRN \\
\hline
\end{tabular}




\begin{tabular}{|c|c|c|c|c|c|}
\hline & & & & & \\
\hline CHEMBL1335377 & 688239 & 8.7447 & 5.5727 & TRN & \\
\hline CHEMBL1384301 & 688239 & 4.5362 & 5.5297 & TRN & \\
\hline CHEMBL1355433 & 688239 & 4.5362 & 5.5504 & TRN & \\
\hline CHEMBL1365353 & 688239 & 6.1862 & 5.4754 & TST & \\
\hline CHEMBL1570465 & 688239 & 4.7862 & 5.4234 & TRN & \\
\hline CHEMBL1317299 & 688239 & 6.6362 & 5.5986 & TRN & \\
\hline CHEMBL1520362 & 688239 & 4.6362 & 5.5538 & TRN & \\
\hline CHEMBL1480036 & 688239 & 6.2362 & 5.477 & TRN & \\
\hline CHEMBL1519458 & 688239 & 4.5862 & 5.5326 & TRN & \\
\hline CHEMBL1374750 & 688239 & 4.6862 & 5.5601 & TST & \\
\hline CHEMBL1540719 & 688239 & 7.0862 & 5.3606 & TRN & \\
\hline CHEMBL1593570 & 688239 & 4.6362 & 5.4501 & TRN & \\
\hline CHEMBL1597085 & 688239 & 5.8862 & 5.5049 & TRN & \\
\hline CHEMBL1572497 & 688239 & 4.6862 & 5.4514 & TRN & \\
\hline CHEMBL1602342 & 688239 & 4.7362 & 5.3936 & TST & \\
\hline CHEMBL1598351 & 688239 & 4.5362 & 5.4679 & TRN & \\
\hline CHEMBL1385870 & 688239 & 5.1862 & 5.4242 & TRN & \\
\hline CHEMBL1429221 & 688239 & 5.4362 & 5.4998 & TRN & \\
\hline CHEMBL1492747 & 688239 & 5.2862 & 5.4794 & TRN & \\
\hline CHEMBL 3210270 & 688239 & 4.5862 & 5.5334 & TST & \\
\hline CHEMBL1441823 & 688239 & 6.0862 & 5.5207 & TRN & \\
\hline CHEMBL1504682 & 688239 & 4.6362 & 5.4306 & TRN & \\
\hline CHEMBL1485836 & 688239 & 4.9362 & 5.6236 & TST & \\
\hline CHEMBL1378568 & 688239 & 5.0862 & 5.4485 & TRN & \\
\hline CHEMBL1413744 & 688239 & 4.7862 & 5.4683 & TST & \\
\hline CHEMBL1367761 & 688239 & 4.5362 & 5.5173 & TRN & \\
\hline CHEMBL1351690 & 688239 & 4.7362 & 5.4748 & TST & \\
\hline CHEMBL1550548 & 688239 & 6.8861 & 5.7401 & TRN & \\
\hline CHEMBL1335108 & 688239 & 6.2362 & 5.4414 & TRN & \\
\hline CHEMBL1484972 & 688239 & 4.6362 & 5.6272 & TRN & \\
\hline CHEMBL1339719 & 688239 & 4.5362 & 5.665 & TRN & \\
\hline CHEMBL1407215 & 688239 & 4.7862 & 5.2956 & TRN & \\
\hline CHEMBL1469531 & 688239 & 4.7862 & 5.445 & TRN & \\
\hline CHEMBL1524756 & 688239 & 4.6862 & 5.4924 & TRN & \\
\hline CHEMBL1395391 & 688239 & 5.1862 & 5.5952 & TST & \\
\hline CHEMBL1352247 & 688239 & 6.1862 & 5.5239 & TST & \\
\hline CHEMBL1459798 & 688239 & 6.2362 & 5.54200 & 3000000001 & TST \\
\hline CHEMBL1328700 & 688239 & 4.5362 & 5.5562 & TRN & \\
\hline CHEMBL1560742 & 688239 & 5.6362 & 5.4067 & TRN & \\
\hline CHEMBL1393204 & 688239 & 6.4362 & 5.5415 & TST & \\
\hline CHEMBL1542010 & 688239 & 5.1862 & 5.50700 & 0000000001 & TRN \\
\hline CHEMBL1426573 & 688239 & 6.1362 & 5.6085 & TST & \\
\hline CHEMBL1595893 & 688239 & 4.9862 & 5.3632 & TRN & \\
\hline CHEMBL1412854 & 688239 & 6.0362 & 5.6591 & TRN & \\
\hline CHEMBL1414045 & 688239 & 6.4362 & 5.4596 & TRN & \\
\hline CHEMBL1387370 & 688239 & 5.3862 & 5.4707 & TRN & \\
\hline CHEMBL1418401 & 688239 & 5.2862 & 5.55399 & 9999999999 & TST \\
\hline CHEMBL1425437 & 688239 & 8.3372 & 5.4958 & TRN & \\
\hline
\end{tabular}


Supplemental Table S2.txt

\begin{tabular}{|c|c|c|c|c|c|}
\hline CHEMBL1580356 & 688239 & 7.0862 & 5.4669 & TRN & \\
\hline CHEMBL1570853 & 688239 & 4.8362 & 5.5368 & TRN & \\
\hline CHEMBL1497671 & 688239 & 6.7862 & 5.6647 & TRN & \\
\hline CHEMBL 3214243 & 688239 & 6.1362 & 5.5381 & TRN & \\
\hline CHEMBL1490755 & 688239 & 6.7862 & 5.4372 & TST & \\
\hline CHEMBL1386509 & 688239 & 4.5362 & 5.4519 & TRN & \\
\hline CHEMBL1548180 & 688239 & 5.0362 & 5.5574 & TST & \\
\hline CHEMBL1608194 & 688239 & 4.5362 & 5.673999 & 9999999995 & TRN \\
\hline CHEMBL1551865 & 688239 & 4.5362 & 5.6189 & TRN & \\
\hline CHEMBL1606204 & 688239 & 4.5362 & 5.481 & TST & \\
\hline CHEMBL1432695 & 688239 & 6.1862 & 5.689 & TST & \\
\hline CHEMBL1341802 & 688239 & 6.7862 & 5.4483 & TRN & \\
\hline CHEMBL1546047 & 688239 & 5.4362 & 5.4414 & TRN & \\
\hline CHEMBL1575181 & 688239 & 6.2362 & 5.5988 & TRN & \\
\hline CHEMBL528181 & 688239 & 4.5362 & 5.2493 & TRN & \\
\hline CHEMBL1418555 & 688239 & 4.6862 & 5.536006 & 0000000005 & TRN \\
\hline CHEMBL1571173 & 688239 & 5.0362 & 5.5802 & TST & \\
\hline CHEMBL 3213480 & 688239 & 8.28399 & 99999999 & 5.6105 & \\
\hline CHEMBL1365886 & 688239 & 4.5362 & 5.5248 & TRN & \\
\hline CHEMBL1485031 & 688239 & 4.5362 & 5.5548 & TRN & \\
\hline CHEMBL1373563 & 688239 & 5.1862 & 5.4752 & TRN & \\
\hline CHEMBL1478227 & 688239 & 5.1862 & 5.4359 & TST & \\
\hline CHEMBL1540117 & 688239 & 5.1862 & 5.5008 & TST & \\
\hline CHEMBL1461664 & 688239 & 5.6362 & 5.461 & TRN & \\
\hline CHEMBL1581959 & 688239 & 6.5363 & 5.4003 & TRN & \\
\hline CHEMBL1611683 & 688239 & 5.0862 & 5.5201 & TRN & \\
\hline CHEMBL1398051 & 688239 & 5.6362 & 5.5282 & TRN & \\
\hline CHEMBL1505524 & 688239 & 5.4362 & 5.442 & TRN & \\
\hline CHEMBL1428522 & 688239 & 5.6362 & 5.5545 & TRN & \\
\hline CHEMBL1415012 & 688239 & 4.7862 & 5.4182 & TRN & \\
\hline CHEMBL1467178 & 688239 & 5.5362 & 5.3647 & TST & \\
\hline CHEMBL1372373 & 688239 & 6.3863 & 5.6422 & TST & \\
\hline CHEMBL1561446 & 688239 & 5.3362 & 5.4981 & TRN & \\
\hline CHEMBL1411936 & 688239 & 5.2362 & 5.3735 & TRN & \\
\hline CHEMBL1408874 & 688239 & 4.5362 & 5.5097 & TRN & \\
\hline CHEMBL3211248 & 688239 & 5.0362 & 5.4843 & TRN & \\
\hline CHEMBL1556111 & 688239 & 4.7862 & 5.343999 & 999999999 & \\
\hline CHEMBL1404808 & 688239 & 4.4862 & 5.444 & TRN & \\
\hline CHEMBL1556491 & 688239 & 4.5362 & 5.4029 & TRN & \\
\hline CHEMBL1544703 & 688239 & 4.8362 & 5.3283 & TRN & \\
\hline CHEMBL1374813 & 688239 & 6.1362 & 5.6997 & TRN & \\
\hline CHEMBL1505571 & 688239 & 6.9863 & 5.4159 & TRN & \\
\hline CHEMBL1333826 & 688239 & 4.5362 & 5.3682 & TRN & \\
\hline CHEMBL1446819 & 688239 & 4.7862 & 5.5252 & TRN & \\
\hline CHEMBL1397333 & 688239 & 5.0862 & 5.4607 & TRN & \\
\hline CHEMBL1566112 & 688239 & 6.6861 & 5.5246 & TST & \\
\hline CHEMBL 3208855 & 688239 & 5.2862 & 5.6022 & TRN & \\
\hline CHEMBL1336084 & 688239 & 6.1362 & 5.4739 & TRN & \\
\hline
\end{tabular}

Page 2756 
Supplemental Table S2.txt

\begin{tabular}{|c|c|c|c|c|}
\hline CHEMBL1540933 & 688239 & 4.5362 & 5.5104 & TRN \\
\hline CHEMBL1511034 & 688239 & 6.8861 & 5.3239 & TRN \\
\hline CHEMBL1500089 & 688239 & 6.2362 & 5.3827 & TRN \\
\hline CHEMBL1601949 & 688239 & 5.1862 & 5.4281 & TRN \\
\hline CHEMBL1442969 & 688239 & 4.8862 & 5.5082 & TST \\
\hline CHEMBL3198633 & 688239 & 5.6862 & 5.3542 & TST \\
\hline CHEMBL3190354 & 688239 & 5.6862 & 5.354 & TRN \\
\hline CHEMBL1440331 & 688239 & 4.8362 & 5.5047 & TRN \\
\hline CHEMBL1372702 & 688239 & 5.9362 & 5.5698 & TRN \\
\hline CHEMBL1465627 & 688239 & 4.7362 & 5.4368 & TRN \\
\hline CHEMBL1405128 & 688239 & 8.3872 & 5.4436 & TRN \\
\hline CHEMBL3197577 & 688239 & 5.3862 & 5.5603 & TST \\
\hline CHEMBL1379102 & 688239 & 5.3862 & 5.415 & TRN \\
\hline CHEMBL1578866 & 688239 & 4.5362 & 5.428 & TST \\
\hline CHEMBL1419744 & 688239 & 4.5362 & 5.5316 & TRN \\
\hline CHEMBL1434931 & 688239 & 4.7362 & 5.5034 & TRN \\
\hline CHEMBL1404762 & 688239 & 7.0362 & 5.4846 & TRN \\
\hline CHEMBL1093688 & 688239 & 5.1862 & 5.4997 & TST \\
\hline CHEMBL1599723 & 688239 & 6.5862 & 5.3824 & TRN \\
\hline CHEMBL1990491 & 688239 & 4.8362 & 5.4448 & TRN \\
\hline CHEMBL1387968 & 688239 & 6.8362 & 5.5528 & TRN \\
\hline CHEMBL1385004 & 688239 & 5.0362 & 5.6286 & TRN \\
\hline CHEMBL1457911 & 688239 & 4.5362 & 5.5088 & TST \\
\hline CHEMBL1460049 & 688239 & 6.0862 & 5.5236 & TST \\
\hline CHEMBL1455998 & 688239 & 6.5363 & 5.5812 & TRN \\
\hline CHEMBL1575580 & 688239 & 4.5362 & 5.3457 & TRN \\
\hline CHEMBL1604828 & 688239 & 5.3862 & 5.526 & TST \\
\hline CHEMBL1613006 & 688239 & 6.0 & 5.4587 & TRN \\
\hline CHEMBL1405462 & 688239 & 5.0862 & 5.6054 & TRN \\
\hline CHEMBL1465422 & 688239 & 7.7852 & 5.2744 & TRN \\
\hline CHEMBL1345169 & 688239 & 6.9363 & 5.4323 & TRN \\
\hline CHEMBL1605724 & 688239 & 5.3862 & 5.5564 & TRN \\
\hline CHEMBL1503386 & 688239 & 4.5362 & 5.3929 & TST \\
\hline CHEMBL1329422 & 688239 & 5.3862 & 5.6147 & TRN \\
\hline CHEMBL1606972 & 688239 & 4.5362 & 5.4872 & TST \\
\hline CHEMBL1327880 & 688239 & 4.7362 & 5.4442 & TST \\
\hline CHEMBL1380071 & 688239 & 4.4862 & 5.5696 & TST \\
\hline CHEMBL1388239 & 688239 & 5.1362 & 5.3366 & TRN \\
\hline CHEMBL3195883 & 688239 & 4.6362 & 5.3574 & TRN \\
\hline CHEMBL1529766 & 688239 & 4.7362 & 5.4818 & TST \\
\hline CHEMBL1477568 & 688239 & 4.6862 & 5.6402 & TRN \\
\hline CHEMBL1472162 & 688239 & 5.6862 & 5.65 & TST \\
\hline CHEMBL1444030 & 688239 & 6.9863 & 5.4579 & TRN \\
\hline CHEMBL1450509 & 688239 & 4.5362 & 5.6813 & TRN \\
\hline CHEMBL1466167 & 688239 & 6.4862 & 5.5222 & TRN \\
\hline CHEMBL1378501 & 688239 & 6.2362 & 5.5037 & TRN \\
\hline CHEMBL1507487 & 688239 & 5.2362 & 5.4879 & TRN \\
\hline CHEMBL1976208 & 688239 & 4.5362 & 5.46200 & $\partial 000000001$ \\
\hline
\end{tabular}


Supplemental Table S2.txt

\begin{tabular}{|c|c|c|c|c|}
\hline CHEMBL1569520 & 688239 & 5.6362 & 5.5826 & TRN \\
\hline CHEMBL1302255 & 688239 & 8.3372 & 5.4735 & TST \\
\hline CHEMBL1309435 & 688239 & 4.4862 & 5.5281 & TST \\
\hline CHEMBL1522406 & 688239 & 5.4862 & 5.4797 & TRN \\
\hline CHEMBL1474617 & 688239 & 4.7362 & 5.4254 & TST \\
\hline CHEMBL1499474 & 688239 & 4.5362 & 5.3706 & TST \\
\hline CHEMBL1499855 & 688239 & 6.8861 & 5.5388 & TST \\
\hline CHEMBL1517212 & 688239 & 6.5363 & 5.6782 & TST \\
\hline CHEMBL1556123 & 688239 & 4.4862 & 5.4836 & TRN \\
\hline CHEMBL1438480 & 688239 & 4.5362 & 5.292006 & 000000001 \\
\hline CHEMBL1409780 & 688239 & 5.3862 & 5.4842 & TRN \\
\hline CHEMBL1386481 & 688239 & 6.1862 & 5.4614 & TST \\
\hline CHEMBL1375921 & 688239 & 4.5362 & 5.6613 & TRN \\
\hline CHEMBL1395454 & 688239 & 5.6362 & 5.4631 & TRN \\
\hline CHEMBL3197224 & 688239 & 4.6862 & 5.5314 & TST \\
\hline CHEMBL1339331 & 688239 & 6.1862 & 5.4181 & TRN \\
\hline CHEMBL1488932 & 688239 & 5.1862 & 5.3563 & TRN \\
\hline CHEMBL1449831 & 688239 & 6.1862 & 5.5543 & TRN \\
\hline CHEMBL1423956 & 688239 & 4.7362 & 5.3111 & TRN \\
\hline CHEMBL1547431 & 688239 & 4.9362 & 5.5702 & TRN \\
\hline CHEMBL1441202 & 688239 & 8.28399 & 99999999 & 5.397 \\
\hline CHEMBL1526866 & 688239 & 6.9863 & 5.5122 & TRN \\
\hline CHEMBL1456485 & 688239 & 6.1362 & 5.5126 & TRN \\
\hline CHEMBL1339489 & 688239 & 4.6362 & 5.5836 & TST \\
\hline CHEMBL1459261 & 688239 & 4.6362 & 5.5414 & TRN \\
\hline CHEMBL1579451 & 688239 & 6.9863 & 5.5239 & TRN \\
\hline CHEMBL3214209 & 688239 & 6.1862 & 5.6444 & TRN \\
\hline CHEMBL1480698 & 688239 & 4.5362 & 5.4894 & TRN \\
\hline CHEMBL1362541 & 688239 & 4.7862 & 5.5909 & TRN \\
\hline CHEMBL1334720 & 688239 & 5.2862 & 5.4044 & TRN \\
\hline CHEMBL1328998 & 688239 & 6.1362 & 5.4727 & TST \\
\hline CHEMBL1476382 & 688239 & 5.7362 & 5.4739 & TST \\
\hline CHEMBL1498279 & 688239 & 6.1362 & 5.5794 & TRN \\
\hline CHEMBL1355407 & 688239 & 5.1862 & 5.3505 & TRN \\
\hline CHEMBL1385674 & 688239 & 5.3862 & 5.4882 & TRN \\
\hline CHEMBL1360358 & 688239 & 4.7862 & 5.428999 & 999999999 \\
\hline CHEMBL1299438 & 688239 & 5.4362 & 5.5008 & TRN \\
\hline CHEMBL1529155 & 688239 & 5.4362 & 5.654 & TRN \\
\hline CHEMBL1541483 & 688239 & 5.1862 & 5.3578 & TRN \\
\hline CHEMBL1541259 & 688239 & 4.5362 & 5.3984 & TST \\
\hline CHEMBL1546397 & 688239 & 4.5362 & 5.5292 & TRN \\
\hline CHEMBL1574095 & 688239 & 6.8861 & 5.4706 & TRN \\
\hline CHEMBL1421968 & 688239 & 7.1864 & 5.5354 & TST \\
\hline CHEMBL1489581 & 688239 & 5.4862 & 5.5514 & TRN \\
\hline CHEMBL1483555 & 688239 & 5.9862 & 5.4023 & TRN \\
\hline CHEMBL1507289 & 688239 & 6.9863 & 5.4688 & TRN \\
\hline CHEMBL1407138 & 688239 & 5.1862 & 5.4149 & TRN \\
\hline CHEMBL1576068 & 688239 & 4.9862 & 5.4188 & TST \\
\hline
\end{tabular}


Supplemental Table S2.txt

CHEMBL1560319
CHEMBL1378451
CHEMBL1428953
CHEMBL1380333
CHEMBL1444166
CHEMBL2000807
CHEMBL1423888

CHEMBL1419445

CHEMBL1476225

CHEMBL1398900

CHEMBL1599775

CHEMBL1376908

CHEMBL1404701

CHEMBL1373884

CHEMBL1437316

CHEMBL1609140

CHEMBL1610899

CHEMBL1310800

CHEMBL1534776

CHEMBL1381892

CHEMBL1581483

CHEMBL1468599

CHEMBL1349902

CHEMBL 2369260

CHEMBL1576906

CHEMBL1521567

CHEMBL1420042

CHEMBL 3212766

CHEMBL1583186

CHEMBL1309830

CHEMBL1376748

CHEMBL1321364

CHEMBL1468151

CHEMBL1555376

CHEMBL1376443

CHEMBL1362696

CHEMBL1573278

CHEMBL1511924

CHEMBL1407814

CHEMBL1539954

CHEMBL1555051

CHEMBL1311322

CHEMBL1329290

CHEMBL1416543

CHEMBL1481541

CHEMBL1508265

CHEMBL 3193409

CHEMBL1490424

688239
688239
688239
688239
688239
688239
688239
688239
688239
688239
688239
688239
688239
688239
688239
688239
688239
688239
688239
688239
688239
688239
688239
688239
688239
688239
688239
688239
688239
688239
688239
688239
688239
688239
688239
688239
688239
688239
688239
688239
688239
688239
688239
688239
688239
688239
688239
688239
6

4.5362

5.5548 TRN

$\begin{array}{lll}5.3362 & 5.5619 & \text { TRN }\end{array}$

$5.2362 \quad 5.4514$ TRN

$\begin{array}{lll}4.7362 & 5.4422 & \text { TRN }\end{array}$

$\begin{array}{lll}5.3862 & 5.5779 & \text { TRN }\end{array}$

$\begin{array}{lll}4.4862 & 5.3886 & \text { TRN }\end{array}$

$\begin{array}{lll}5.9862 & 5.4898 & \text { TST }\end{array}$

$\begin{array}{lll}5.2862 & 5.5904 & \text { TRN }\end{array}$

$\begin{array}{lll}4.7362 & 5.311 & \text { TRN }\end{array}$

$\begin{array}{lll}4.6362 & 5.4179 \text { TRN }\end{array}$

$\begin{array}{lll}5.6362 & 5.6923 \text { TRN }\end{array}$

$\begin{array}{lll}7.5361 & 5.607 & \text { TRN }\end{array}$

$\begin{array}{lll}5.1362 & 5.5738 & \text { TST }\end{array}$

$\begin{array}{llll}6.0362 & 5.4467 & \text { TRN }\end{array}$

$\begin{array}{lll}5.2862 & 5.4352 & \text { TRN }\end{array}$

$\begin{array}{lll}5.2862 & 5.5175 & \text { TRN }\end{array}$

$\begin{array}{lll}5.7362 & 5.5611 & \text { TRN }\end{array}$

$\begin{array}{lll}4.5362 & 5.3511 & \text { TRN }\end{array}$

$\begin{array}{lll}5.4862 & 5.4847 & \text { TST }\end{array}$

$\begin{array}{lll}4.5362 & 5.5072 & \text { TRN }\end{array}$

$\begin{array}{lll}4.7862 & 5.4834 & \text { TRN }\end{array}$

4.53625 .5362 TRN

$\begin{array}{lll}5.4862 & 5.532 & \text { TRN }\end{array}$

$\begin{array}{lll}4.8862 & 5.4538 & \text { TST }\end{array}$

$\begin{array}{lll}4.8362 & 5.5352 & \text { TRN }\end{array}$

$\begin{array}{lll}5.1862 & 5.6217 & \text { TRN }\end{array}$

$\begin{array}{lll}4.5362 & 5.3549 & \text { TRN }\end{array}$

$\begin{array}{lll}4.9362 & 5.4004 & \text { TST }\end{array}$

$\begin{array}{lll}7.3862 & 5.4051 & \text { TRN }\end{array}$

$\begin{array}{lll}5.3862 & 5.513 & \text { TRN }\end{array}$

$\begin{array}{lll}5.7862 & 5.4682 & \text { TRN }\end{array}$

$\begin{array}{lll}6.1362 & 5.3671 & \text { TST }\end{array}$

$\begin{array}{lll}4.4862 & 5.5312 & \text { TRN }\end{array}$

$\begin{array}{lll}4.8862 & 5.3927 & \text { TRN }\end{array}$

$5.4862 \quad 5.6176$ TRN

$\begin{array}{lll}4.5362 & 5.5264 & \text { TST }\end{array}$

$\begin{array}{lll}5.8362 & 5.5287 & \text { TRN }\end{array}$

$\begin{array}{lll}4.5362 & 5.3846 & \text { TRN }\end{array}$

$\begin{array}{lll}4.7362 & 5.5159 & \text { TST }\end{array}$

$\begin{array}{lll}6.0362 & 5.561 & \text { TRN }\end{array}$

$\begin{array}{lll}5.5862 & 5.4215 & \text { TST }\end{array}$

$\begin{array}{llll}5.1862 & 5.5207 & \text { TRN }\end{array}$

$\begin{array}{lll}5.3862 & 5.5156 & \text { TRN }\end{array}$

$\begin{array}{lll}4.5362 & 5.4982 & \text { TST }\end{array}$

$\begin{array}{llll}5.3362 & 5.6304 & \text { TRN }\end{array}$

$7.7852 \quad 5.553999999999999$

TST

$\begin{array}{lll}4.4862 & 5.4747 \quad \text { TRN }\end{array}$

$4.9862 \quad 5.3455$ TST

Page 2759 


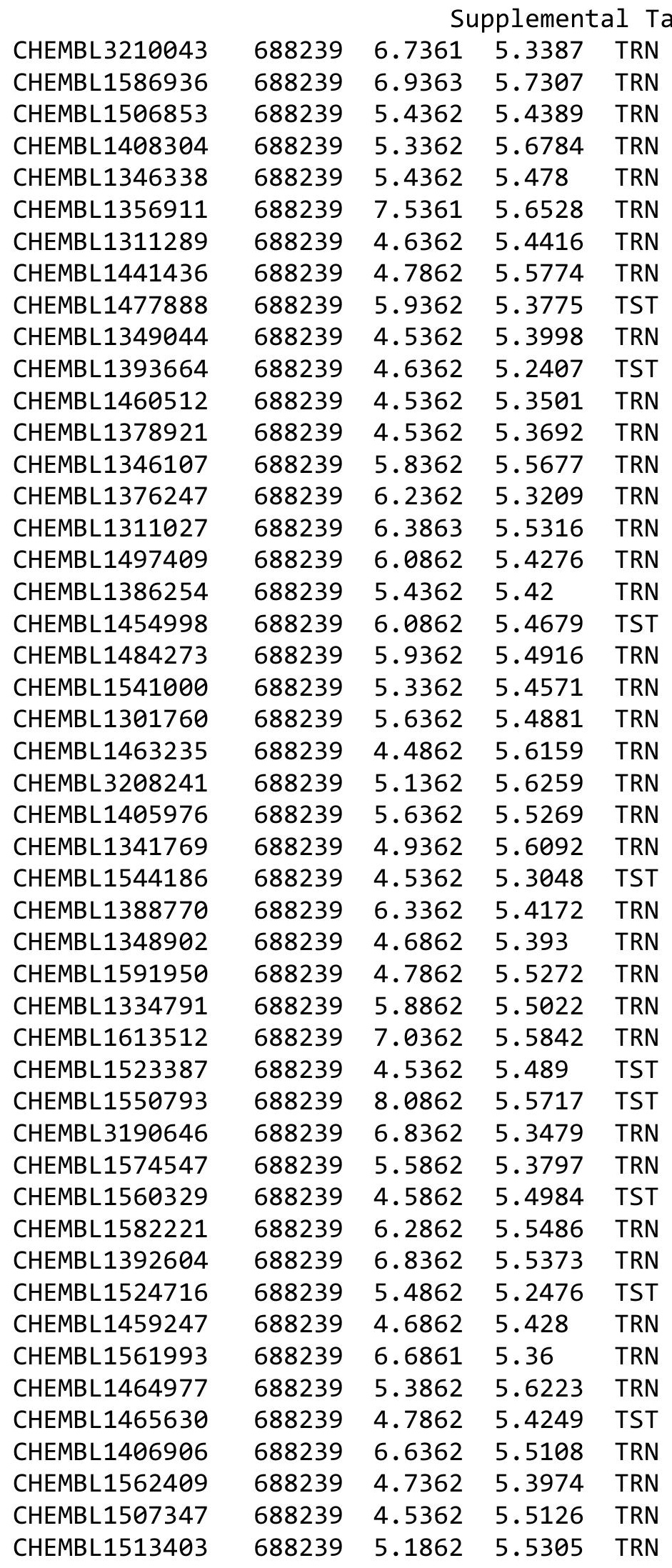




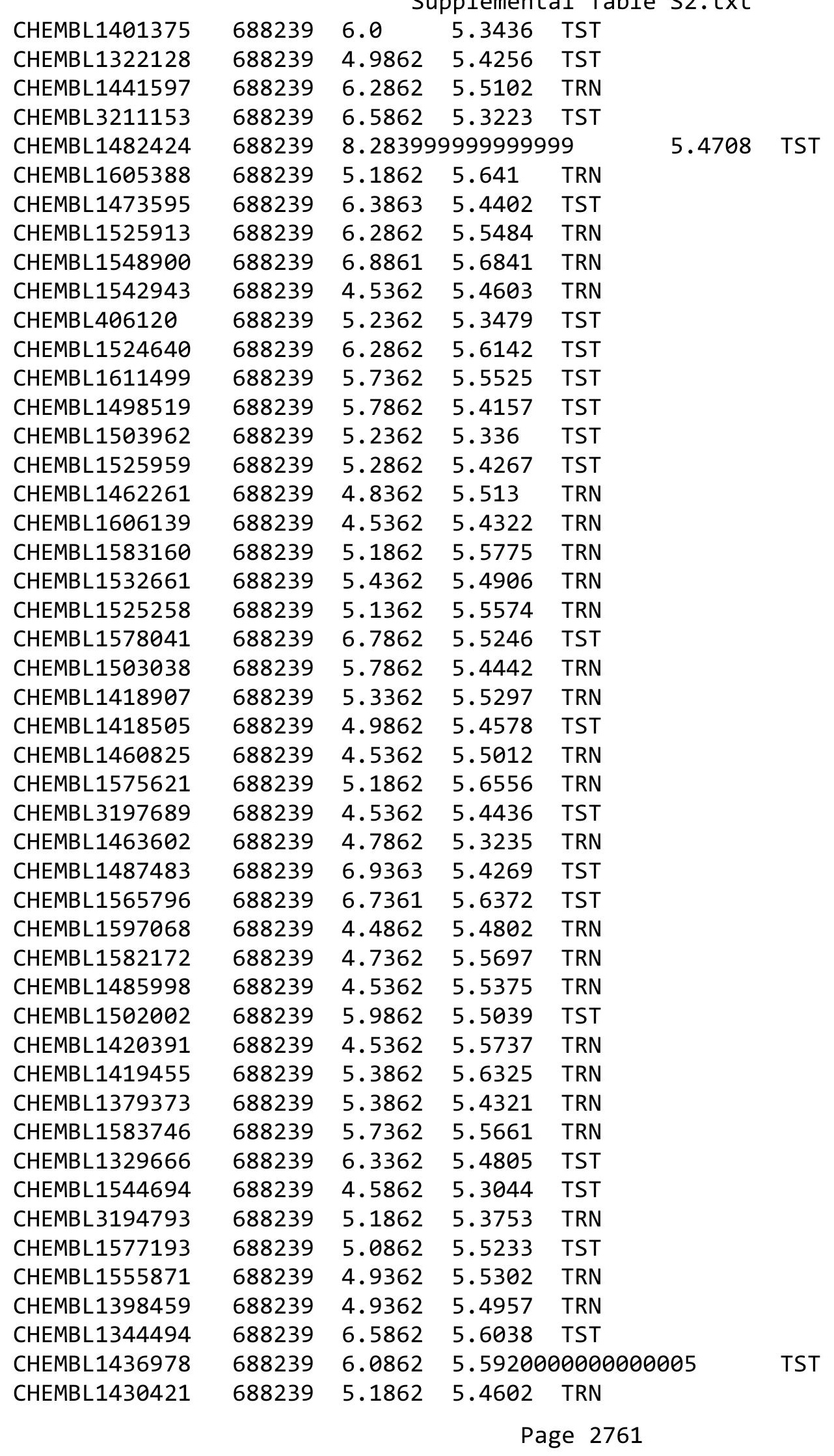


Supplemental Table S2.txt

\begin{tabular}{|c|c|c|c|c|}
\hline CHEMBL1389764 & 688239 & 6.8362 & 5.506 & TRN \\
\hline CHEMBL1530544 & 688239 & 8.3372 & 5.6752 & TST \\
\hline CHEMBL1521082 & 688239 & 4.7362 & 5.4321 & TRN \\
\hline CHEMBL1377403 & 688239 & 5.3862 & 5.5626 & TRN \\
\hline CHEMBL1340275 & 688239 & 6.0862 & 5.7067 & TST \\
\hline CHEMBL1467477 & 688239 & 4.6362 & 5.4574 & TRN \\
\hline CHEMBL1399685 & 688239 & 5.1362 & 5.7253 & TRN \\
\hline CHEMBL1457209 & 688239 & 4.5362 & 5.4934 & TRN \\
\hline CHEMBL1548583 & 688239 & 7.9872 & 5.3163 & TST \\
\hline CHEMBL3199769 & 688239 & 5.9862 & 5.6115 & TRN \\
\hline CHEMBL1311923 & 688239 & 5.0862 & 5.4523 & TRN \\
\hline CHEMBL1525949 & 688239 & 4.5362 & 5.2958 & TRN \\
\hline CHEMBL1347622 & 688239 & 5.1862 & 5.5415 & TRN \\
\hline CHEMBL1423792 & 688239 & 8.1871 & 5.4805 & TST \\
\hline CHEMBL1399027 & 688239 & 5.1862 & 5.4319 & TRN \\
\hline CHEMBL1436518 & 688239 & 4.5362 & 5.3958 & TRN \\
\hline CHEMBL1442264 & 688239 & 4.7362 & 5.462999 & 9999999999 \\
\hline CHEMBL1552046 & 688239 & 6.8861 & 5.4922 & TRN \\
\hline CHEMBL1370399 & 688239 & 5.1862 & 5.4595 & TRN \\
\hline CHEMBL1414221 & 688239 & 4.9862 & 5.5892 & TRN \\
\hline CHEMBL1435010 & 688239 & 5.5862 & 5.3903 & TRN \\
\hline CHEMBL1580416 & 688239 & 5.3862 & 5.452999 & 9999999999 \\
\hline CHEMBL1472420 & 688239 & 4.6362 & 5.4141 & TRN \\
\hline CHEMBL1559221 & 688239 & 6.9863 & 5.5178 & TRN \\
\hline CHEMBL 3208871 & 688239 & 6.8861 & 5.4703 & TST \\
\hline CHEMBL 3194331 & 688239 & 5.5362 & 5.4258 & TST \\
\hline CHEMBL1422718 & 688239 & 6.7862 & 5.3875 & TRN \\
\hline CHEMBL1468835 & 688239 & 6.8861 & 5.5599 & TRN \\
\hline CHEMBL1465702 & 688239 & 5.3362 & 5.4926 & TRN \\
\hline CHEMBL1398544 & 688239 & 5.0862 & 5.4752 & TRN \\
\hline CHEMBL1455524 & 688239 & 6.5862 & 5.3349 & TST \\
\hline CHEMBL1565954 & 688239 & 5.8362 & 5.5268 & TRN \\
\hline CHEMBL1531334 & 688239 & 4.5362 & 5.3509 & TST \\
\hline CHEMBL1344337 & 688239 & 5.1862 & 5.3699 & TST \\
\hline CHEMBL1504657 & 688239 & 5.3362 & 5.5831 & TRN \\
\hline CHEMBL1444964 & 688239 & 7.1361 & $5.74200 e$ & 0000000001 \\
\hline CHEMBL1353205 & 688239 & 5.5362 & 5.5481 & TRN \\
\hline CHEMBL1371576 & 688239 & 4.5862 & 5.4938 & TRN \\
\hline CHEMBL1384364 & 688239 & 5.6362 & 5.5348 & TRN \\
\hline CHEMBL1403620 & 688239 & 5.1362 & 5.6198 & TST \\
\hline CHEMBL1313176 & 688239 & 5.1862 & 5.6384 & TRN \\
\hline CHEMBL1604042 & 688239 & 4.6862 & 5.4703 & TST \\
\hline CHEMBL1397379 & 688239 & 5.3362 & 5.4494 & TRN \\
\hline CHEMBL1312795 & 688239 & 5.0862 & 5.5789 & TRN \\
\hline CHEMBL1348839 & 688239 & 4.4862 & 5.3489 & TST \\
\hline CHEMBL1505982 & 688239 & 5.9362 & 5.4306 & TRN \\
\hline CHEMBL16901 & 688239 & 4.7362 & 5.3555 & TST \\
\hline CHEMBL1538341 & 688239 & 6.8362 & 5.6055 & TRN \\
\hline
\end{tabular}


Supplemental Table S2.txt

\begin{tabular}{|c|c|c|c|c|}
\hline CHEMBL1607491 & 688239 & 6.2362 & 5.6033 & TST \\
\hline CHEMBL1613009 & 688239 & 5.3862 & 5.5561 & TST \\
\hline CHEMBL1512226 & 688239 & 4.5362 & 5.3816 & TST \\
\hline CHEMBL1554846 & 688239 & 5.3862 & 5.4345 & TRN \\
\hline CHEMBL1539231 & 688239 & 5.8862 & 5.4269 & TRN \\
\hline CHEMBL1327293 & 688239 & 5.3862 & 5.6422 & TRN \\
\hline CHEMBL1433484 & 688239 & 4.6362 & 5.5946 & TRN \\
\hline CHEMBL1367241 & 688239 & 4.5362 & 5.3773 & TST \\
\hline CHEMBL1301811 & 688239 & 4.4862 & 5.5547 & TST \\
\hline CHEMBL1594989 & 688239 & 4.4862 & 5.3848 & TRN \\
\hline CHEMBL1606978 & 688239 & 4.7362 & 5.4058 & TST \\
\hline CHEMBL1413849 & 688239 & 5.4862 & 5.4277 & TST \\
\hline CHEMBL1546765 & 688239 & 5.3362 & 5.5174 & TRN \\
\hline CHEMBL1534979 & 688239 & 5.3362 & 5.587006 & 000000001 \\
\hline CHEMBL1531753 & 688239 & 4.5862 & 5.5533 & TRN \\
\hline CHEMBL1370994 & 688239 & 5.5862 & 5.6442 & TST \\
\hline CHEMBL1538775 & 688239 & 4.5362 & 5.3999 & TRN \\
\hline CHEMBL1384754 & 688239 & 8.28399 & 99999999 & 5.5074 \\
\hline CHEMBL1503765 & 688239 & 5.7862 & 5.5953 & TRN \\
\hline CHEMBL1500910 & 688239 & 4.5362 & 5.4661 & TRN \\
\hline CHEMBL1304851 & 688239 & 5.5362 & $5.45700 e$ & 000000001 \\
\hline CHEMBL1584776 & 688239 & 5.0362 & 5.4415 & TRN \\
\hline CHEMBL1313044 & 688239 & 8.3372 & 5.3175 & TRN \\
\hline CHEMBL1491928 & 688239 & 4.5362 & 5.3262 & TRN \\
\hline CHEMBL1388579 & 688239 & 4.5862 & 5.5249 & TRN \\
\hline CHEMBL527870 & 688239 & 4.6862 & 5.4817 & TST \\
\hline CHEMBL1342822 & 688239 & 5.0862 & 5.4929 & TRN \\
\hline CHEMBL1423738 & 688239 & 5.2362 & 5.5496 & TRN \\
\hline CHEMBL1563862 & 688239 & 4.6362 & 5.345 & TRN \\
\hline CHEMBL1613715 & 688239 & 5.9362 & 5.3971 & TRN \\
\hline CHEMBL1567853 & 688239 & 6.1862 & 5.4977 & TST \\
\hline CHEMBL1312371 & 688239 & 4.6862 & 5.466 & TRN \\
\hline CHEMBL1575805 & 688239 & 6.7862 & 5.2812 & TRN \\
\hline CHEMBL1410981 & 688239 & 5.1862 & 5.511 & TRN \\
\hline CHEMBL1463256 & 688239 & 4.7362 & 5.5667 & TST \\
\hline CHEMBL 1457547 & 688239 & 6.0862 & 5.4992 & TRN \\
\hline CHEMBL1507131 & 688239 & 6.2362 & 5.5777 & TRN \\
\hline CHEMBL 2373575 & 688239 & 7.1361 & 5.5027 & TRN \\
\hline CHEMBL1478040 & 688239 & 6.3362 & 5.546 & TRN \\
\hline CHEMBL1387904 & 688239 & 5.6362 & 5.455 & TST \\
\hline CHEMBL 3212296 & 688239 & 5.7362 & 5.6643 & TRN \\
\hline CHEMBL1527194 & 688239 & 5.3862 & 5.5442 & TRN \\
\hline CHEMBL1547039 & 688239 & 4.6362 & 5.5905 & TRN \\
\hline CHEMBL1544829 & 688239 & 4.8362 & 5.4299 & TST \\
\hline CHEMBL3190747 & 688239 & 6.8861 & 5.4345 & TST \\
\hline CHEMBL1516053 & 688239 & 4.6362 & 5.5756 & TRN \\
\hline CHEMBL1509843 & 688239 & 4.6862 & 5.5045 & TST \\
\hline CHEMBL1409539 & 688239 & 4.6862 & 5.4013 & TRN \\
\hline
\end{tabular}

Page 2763 
Supplemental Table S2.txt

CHEMBL1537804
CHEMBL3199915
CHEMBL3211615
CHEMBL1532551
CHEMBL1569566
CHEMBL1482354
CHEMBL1342304

CHEMBL1515502

CHEMBL1564428

CHEMBL1604745

CHEMBL1540919

CHEMBL1340634

CHEMBL3212014

CHEMBL1542589

CHEMBL1587932

CHEMBL 3392035

CHEMBL1362122

CHEMBL1602466

CHEMBL1332346

CHEMBL1392530

CHEMBL3214629

CHEMBL1365385

CHEMBL1540663

CHEMBL1443593

CHEMBL1574881

CHEMBL1303754

CHEMBL1587128

CHEMBL1386382

CHEMBL1569425

CHEMBL1332278

CHEMBL1503442

CHEMBL1463569

CHEMBL1358041

CHEMBL1542147

CHEMBL1589828

CHEMBL1379589

CHEMBL1585009

CHEMBL1572608

CHEMBL1566538

CHEMBL1505065

CHEMBL1453226

CHEMBL1517393

CHEMBL1613302

CHEMBL 1495796

CHEMBL1581035

CHEMBL1587898

CHEMBL1509450

CHEMBL1340087
688239

688239

688239

688239

688239

688239

688239

688239

688239

688239

688239

688239

688239

688239

688239

688239

688239

688239

688239

688239

688239

688239

688239

688239

688239

688239

688239

688239

688239

688239

688239

688239

688239

688239

688239

688239

688239

688239

688239

688239

688239

688239

688239

688239

688239

688239

688239

688239 $\begin{array}{ll}4.9362 & 5.5254 \\ 4 R N\end{array}$

$8.3372 \quad 5.4394$ TST

$\begin{array}{lll}4.7362 & 5.4903 & \text { TST }\end{array}$

5.18625 .5946 TRN

5.48625 .406000000000001

4.73625 .4311 TRN

$\begin{array}{lll}5.4362 & 5.4009 & \text { TRN }\end{array}$

$\begin{array}{lll}4.5362 & 5.3191 & \text { TRN }\end{array}$

$5.1862 \quad 5.6046$ TST

$\begin{array}{lll}5.1862 & 5.66 \quad \text { TST }\end{array}$

$\begin{array}{lll}4.7862 & 5.2698 & \text { TST }\end{array}$

$6.9863 \quad 5.5256$ TRN

$\begin{array}{lll}4.5362 & 5.4613 & \text { TRN }\end{array}$

$\begin{array}{lll}5.7362 & 5.5873 \text { TRN }\end{array}$

$\begin{array}{lll}4.8862 & 5.6034 & \text { TST }\end{array}$

$\begin{array}{lll}6.1362 & 5.5859 & \text { TST }\end{array}$

$\begin{array}{lll}5.1862 & 5.5622 & \text { TST }\end{array}$

$\begin{array}{lll}4.7862 & 5.4977 & \text { TRN }\end{array}$

$\begin{array}{lll}5.5862 & 5.322 & \text { TRN }\end{array}$

4.73625 .5056 TRN

$\begin{array}{lll}5.8362 & 5.5044 & \text { TRN }\end{array}$

$\begin{array}{lll}4.4862 & 5.415 & \text { TRN }\end{array}$

$\begin{array}{lll}4.5362 & 5.3509 & \text { TRN }\end{array}$

$\begin{array}{lll}5.1362 & 5.5273 & \text { TRN }\end{array}$

$6.3362 \quad 5.4902$ TRN

$4.9862 \quad 5.4685$ TRN

$\begin{array}{lll}5.7862 & 5.4784 & \text { TRN }\end{array}$

$\begin{array}{lll}5.3862 & 5.4203 & \text { TST }\end{array}$

$\begin{array}{lll}4.6362 & 5.3788 & \text { TRN }\end{array}$

$\begin{array}{lll}5.9862 & 5.5566 & \text { TRN }\end{array}$

$\begin{array}{lll}5.2362 & 5.36 & \text { TST }\end{array}$

$\begin{array}{lll}4.5862 & 5.4688 & \text { TRN }\end{array}$

$5.2362 \quad 5.4561$ TRN

$5.1862 \quad 5.6126$ TRN

$4.5362 \quad 5.4239$ TRN

$\begin{array}{lll}6.9363 & 5.6174 & \text { TRN }\end{array}$

6.38635 .5165 TRN

$4.5862 \quad 5.4401$ TRN

$6.1862 \quad 5.4312$ TRN

$\begin{array}{lll}5.5362 & 5.4745 & \text { TRN }\end{array}$

$\begin{array}{lll}4.7362 & 5.3937 & \text { TRN }\end{array}$

$\begin{array}{lll}4.6362 & 5.4723 & \text { TST }\end{array}$

4.58625 .403 TRN

$\begin{array}{llll}6.4862 & 5.4538 & \text { TRN }\end{array}$

$\begin{array}{lll}5.7362 & 5.5004 & \text { TST }\end{array}$

$4.7362 \quad 5.5202$ TST

$4.5362 \quad 5.5245$ TRN

5.18625 .5748 TRN 
Supplemental Table S2.txt

\begin{tabular}{|c|c|c|c|c|}
\hline CHEMBL1489799 & 688239 & 6.1862 & 5.5567 & TRN \\
\hline CHEMBL1418453 & 688239 & 5.5862 & 5.6258 & TRN \\
\hline CHEMBL1307427 & 688239 & 6.2362 & 5.4843 & TRN \\
\hline CHEMBL1585157 & 688239 & 4.7362 & 5.5554 & TRN \\
\hline CHEMBL1494672 & 688239 & 4.7862 & 5.4614 & TST \\
\hline CHEMBL1417697 & 688239 & 5.4362 & 5.4732 & TRN \\
\hline CHEMBL1312087 & 688239 & 5.1862 & 5.2949 & TRN \\
\hline CHEMBL1600974 & 688239 & 5.6862 & 5.5611 & TST \\
\hline CHEMBL1491747 & 688239 & 5.8362 & 5.3954 & TRN \\
\hline CHEMBL1306841 & 688239 & 7.1361 & \multicolumn{2}{|c|}{5.507000000000001} \\
\hline CHEMBL1373956 & 688239 & 4.6362 & 5.606 & TRN \\
\hline CHEMBL1494838 & 688239 & 5.1862 & 5.55399 & 9999999999 \\
\hline CHEMBL1413029 & 688239 & 4.7862 & 5.5137 & TRN \\
\hline CHEMBL1542933 & 688239 & 5.8362 & 5.5257 & TRN \\
\hline CHEMBL1431971 & 688239 & 6.8362 & 5.6013 & TRN \\
\hline CHEMBL1352990 & 688239 & 6.2362 & 5.5526 & TRN \\
\hline CHEMBL1381871 & 688239 & 4.5362 & 5.4416 & TRN \\
\hline CHEMBL1604224 & 688239 & 4.7362 & 5.3194 & TRN \\
\hline CHEMBL1607844 & 688239 & 5.1362 & 5.5929 & TRN \\
\hline CHEMBL1428582 & 688239 & 5.1862 & 5.6476 & TRN \\
\hline CHEMBL1538527 & 688239 & 4.8862 & 5.3866 & TRN \\
\hline CHEMBL1349415 & 688239 & 6.0362 & 5.4382 & TRN \\
\hline CHEMBL1450639 & 688239 & 4.5862 & 5.5639 & TRN \\
\hline CHEMBL1433372 & 688239 & 6.5862 & 5.5076 & TST \\
\hline CHEMBL1530838 & 688239 & 5.1862 & 5.4606 & TRN \\
\hline CHEMBL1452942 & 688239 & 6.7862 & 5.5731 & TRN \\
\hline CHEMBL1347858 & 688239 & 4.7362 & 5.41799 & 9999999999 \\
\hline CHEMBL1555359 & 688239 & 6.0862 & 5.4488 & TRN \\
\hline CHEMBL1355648 & 688239 & 6.7862 & 5.5895 & TRN \\
\hline CHEMBL1464783 & 688239 & 5.1862 & 5.4344 & TST \\
\hline CHEMBL1998639 & 688239 & 4.8362 & 5.3945 & TRN \\
\hline CHEMBL1543107 & 688239 & 4.5362 & 5.4871 & TRN \\
\hline CHEMBL1430724 & 688239 & 5.6362 & 5.3419 & TRN \\
\hline CHEMBL1398342 & 688239 & 5.1862 & 5.3829 & TRN \\
\hline CHEMBL1314105 & 688239 & 6.3362 & 5.5052 & TRN \\
\hline CHEMBL1311637 & 688239 & 7.0862 & 5.5064 & TRN \\
\hline CHEMBL1479612 & 688239 & 5.1862 & 5.5208 & TRN \\
\hline CHEMBL1350135 & 688239 & 5.0 & 5.3983 & TRN \\
\hline CHEMBL1469000 & 688239 & 4.8862 & 5.4831 & TRN \\
\hline CHEMBL1444079 & 688239 & 6.0862 & 5.5079 & TST \\
\hline CHEMBL1378978 & 688239 & 5.4362 & 5.5331 & TRN \\
\hline CHEMBL1495292 & 688239 & 4.7862 & 5.4223 & TRN \\
\hline CHEMBL1424870 & 688239 & 5.7862 & 5.5961 & TRN \\
\hline CHEMBL3195285 & 688239 & 4.6862 & 5.4776 & TST \\
\hline CHEMBL1347983 & 688239 & 4.8362 & 5.3329 & TRN \\
\hline CHEMBL1340160 & 688239 & 4.5362 & 5.5846 & TRN \\
\hline CHEMBL1382044 & 688239 & 4.6362 & 5.5123 & TST \\
\hline CHEMBL1579817 & 688239 & 5.1862 & 5.6672 & TST \\
\hline
\end{tabular}


Supplemental Table S2.txt

\begin{tabular}{|c|c|c|c|c|}
\hline CHEMBL1299879 & 688239 & 4.6862 & 5.4856 & TRN \\
\hline CHEMBL1341191 & 688239 & 7.5361 & 5.4626 & TST \\
\hline CHEMBL1415030 & 688239 & 5.1862 & 5.2981 & TRN \\
\hline CHEMBL1483433 & 688239 & 6.0862 & 5.4406 & TRN \\
\hline CHEMBL1577941 & 688239 & 5.1862 & 5.4603 & TST \\
\hline CHEMBL1335467 & 688239 & 4.5362 & 5.5023 & TST \\
\hline CHEMBL1332214 & 688239 & 6.3362 & 5.6216 & TST \\
\hline CHEMBL1468189 & 688239 & 4.4862 & 5.4369 & TRN \\
\hline CHEMBL 3190018 & 688239 & 5.4862 & 5.4628 & TRN \\
\hline CHEMBL1495518 & 688239 & 4.7862 & 5.4492 & TST \\
\hline CHEMBL1431721 & 688239 & 6.0362 & 5.4837 & TRN \\
\hline CHEMBL1392536 & 688239 & 5.1862 & 5.46700 & 30000000005 \\
\hline CHEMBL1322644 & 688239 & 5.9362 & 5.3799 & TRN \\
\hline CHEMBL1613155 & 688239 & 6.5862 & 5.5074 & TRN \\
\hline CHEMBL1398209 & 688239 & 4.8362 & 5.3507 & TRN \\
\hline CHEMBL1410321 & 688239 & 6.8861 & 5.487 & TST \\
\hline CHEMBL1349238 & 688239 & 4.5362 & 5.4289 & TST \\
\hline CHEMBL1494786 & 688239 & 6.1862 & 5.5793 & TRN \\
\hline CHEMBL1988541 & 688239 & 4.9362 & 5.495 & TRN \\
\hline CHEMBL1371559 & 688239 & 5.1362 & 5.381 & TST \\
\hline CHEMBL1449630 & 688239 & 5.0362 & 5.3947 & TRN \\
\hline CHEMBL1505460 & 688239 & 4.5362 & 5.6462 & TST \\
\hline CHEMBL1365860 & 688239 & 6.1362 & 5.6003 & TST \\
\hline CHEMBL1347500 & 688239 & 6.6362 & 5.5932 & TRN \\
\hline CHEMBL1327186 & 688239 & 8.3372 & 5.3983 & TRN \\
\hline CHEMBL1419146 & 688239 & 4.5362 & 5.4793 & TRN \\
\hline CHEMBL1352817 & 688239 & 4.7362 & 5.4729 & TRN \\
\hline CHEMBL582478 & 688239 & 7.5361 & 5.5101 & TRN \\
\hline CHEMBL1307747 & 688239 & 4.7362 & 5.6027 & TRN \\
\hline CHEMBL1324976 & 688239 & 4.5362 & 5.5033 & TRN \\
\hline CHEMBL1605097 & 688239 & 4.4862 & 5.4283 & TRN \\
\hline CHEMBL1475222 & 688239 & 4.5362 & 5.5753 & TRN \\
\hline CHEMBL1972133 & 688239 & 4.4862 & 5.4286 & TRN \\
\hline CHEMBL1485829 & 688239 & 6.9363 & 5.4908 & TRN \\
\hline CHEMBL1532254 & 688239 & 4.5862 & 5.3993 & TRN \\
\hline CHEMBL1430433 & 688239 & 4.5362 & 5.4124 & TRN \\
\hline CHEMBL1523238 & 688239 & 5.1362 & 5.4451 & TST \\
\hline CHEMBL1474055 & 688239 & 4.7862 & 5.5284 & TRN \\
\hline CHEMBL1391723 & 688239 & 5.6362 & 5.54299 & э999999999 \\
\hline CHEMBL1490446 & 688239 & 4.6362 & 5.4618 & TRN \\
\hline CHEMBL1363788 & 688239 & 4.5362 & 5.5705 & TRN \\
\hline CHEMBL1323962 & 688239 & 6.4362 & 5.5747 & TST \\
\hline CHEMBL1542612 & 688239 & 4.5862 & 5.4236 & TRN \\
\hline CHEMBL1362266 & 688239 & 4.5362 & 5.5753 & TRN \\
\hline CHEMBL1361271 & 688239 & 4.5362 & 5.4329 & TRN \\
\hline CHEMBL1368049 & 688239 & 6.0362 & 5.5979 & TRN \\
\hline CHEMBL1304636 & 688239 & 5.6862 & 5.539 & TRN \\
\hline CHEMBL1482954 & 688239 & 4.9362 & 5.3477 & TST \\
\hline
\end{tabular}

Page 2766 
Supplemental Table S2.txt

\begin{tabular}{|c|c|c|c|c|}
\hline 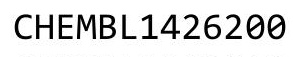 & & & & \\
\hline HEMBL1343310 & 38239 & 362 & 31 & \\
\hline AEMBL1526674 & 39 & 362 & & \\
\hline 130 & 39 & 3862 & & \\
\hline IEMBL14 & & 362 & & \\
\hline AEMBL1543714 & 88239 & 362 & 3752 & \\
\hline AEMBL1404444 & 88239 & 362 & 5592 & \\
\hline AEMBL138 & & & & \\
\hline EMBL14 & 39 & 362 & & \\
\hline IEMBL15e & & & & \\
\hline AEMBL1447331 & 39 & 862 & 5172 & \\
\hline AEMBL1522380 & & 362 & & \\
\hline HEMBL160 & & 62 & & \\
\hline IEMBL23 & & 62 & & \\
\hline AEMBL136 & & & & \\
\hline HEMBL153 & & 862 & & \\
\hline HEMBL155 & & 862 & & \\
\hline IEMBL14 & & & & \\
\hline AEMBL 15 & & & & \\
\hline JEMBL15 & & & & \\
\hline AEMPI 126 & & 862 & & \\
\hline HEMBL149 & & 61 & & \\
\hline AEMBL14 & & 4 & & \\
\hline AFMRI 15 & & & & \\
\hline 56 & & & & \\
\hline -2 12 & & 362 & & \\
\hline AEMBL136 & & & & \\
\hline AEMBL148 & & 52 & & \\
\hline AFME $-2-P A$ & & & & \\
\hline 1 & & 62 & & \\
\hline HEMBL147 & & & & \\
\hline IEMBL1479304 & & 4 & & \\
\hline & & & & \\
\hline 6 & & & & \\
\hline & & & & \\
\hline AEMBL1380346 & & & & \\
\hline AEMBL1312534 & & 362 & & \\
\hline & & & & \\
\hline 2 & & & & \\
\hline HEMBL134 & & & & RN \\
\hline AEMBL1310758 & & 362 & & s \\
\hline IEMBL14 & & 4. & & \\
\hline & & & & \\
\hline HEMBL146 & & & & \\
\hline HEMBL137574 & & 4.7362 & & $\mathrm{R}$ \\
\hline IEMBL131 & & 862 & 81 & $1 T$ \\
\hline 1571 & & & & \\
\hline HEMBL131701 & & & & \\
\hline
\end{tabular}

Page 2767 
Supplemental Table S2.txt

\begin{tabular}{|c|c|c|c|c|c|}
\hline CHEMBL1379946 & 688239 & 4.5862 & 5.522 & TST & \\
\hline CHEMBL1309278 & 688239 & 5.2362 & 5.4116 & TRN & \\
\hline CHEMBL1449279 & 688239 & 6.8362 & 5.4703 & TRN & \\
\hline CHEMBL1440369 & 688239 & 6.0362 & 5.5387 & TRN & \\
\hline CHEMBL1471263 & 688239 & 4.5362 & 5.5187 & TRN & \\
\hline CHEMBL1500709 & 688239 & 5.7862 & 5.4333 & TRN & \\
\hline CHEMBL1354774 & 688239 & 4.9362 & 5.4642 & TRN & \\
\hline CHEMBL1484310 & 688239 & 5.0862 & 5.5462 & TRN & \\
\hline CHEMBL1317888 & 688239 & 4.9862 & 5.4749 & TST & \\
\hline CHEMBL1546779 & 688239 & 5.1862 & 5.4562 & TRN & \\
\hline CHEMBL1337722 & 688239 & 6.2862 & 5.5721 & TST & \\
\hline CHEMBL1598631 & 688239 & 5.4862 & 5.4666 & TST & \\
\hline CHEMBL1588646 & 688239 & 4.6362 & 5.3707 & TRN & \\
\hline CHEMBL1610172 & 688239 & 5.3362 & 5.4336 & TST & \\
\hline CHEMBL1328722 & 688239 & 5.1862 & 5.5076 & TRN & \\
\hline CHEMBL1576094 & 688239 & 4.4862 & 5.4084 & TRN & \\
\hline CHEMBL1413527 & 688239 & 8.3872 & 5.6023 & TRN & \\
\hline CHEMBL1454642 & 688239 & 8.2366 & 5.6795 & TRN & \\
\hline CHEMBL1365264 & 688239 & 5.1862 & 5.5183 & TRN & \\
\hline CHEMBL1412421 & 688239 & 5.2362 & 5.4928 & TST & \\
\hline CHEMBL1375111 & 688239 & 4.7362 & 5.4172 & TRN & \\
\hline CHEMBL3197508 & 688239 & 4.8862 & 5.391 & TRN & \\
\hline CHEMBL1590273 & 688239 & 4.7362 & 5.4025 & TST & \\
\hline CHEMBL1466400 & 688239 & 5.5362 & 5.6027 & TRN & \\
\hline CHEMBL1547302 & 688239 & 4.5362 & 5.7559 & TRN & \\
\hline CHEMBL1445931 & 688239 & 8.3372 & 5.5354 & TRN & \\
\hline CHEMBL1329014 & 688239 & 4.7362 & 5.5702 & TRN & \\
\hline CHEMBL3197133 & 688239 & 4.5362 & 5.5049 & TST & \\
\hline CHEMBL1312458 & 688239 & 6.2362 & 5.5861 & TRN & \\
\hline CHEMBL1453106 & 688239 & 6.9363 & 5.5085 & TRN & \\
\hline CHEMBL1533839 & 688239 & 5.3862 & 5.4609 & TRN & \\
\hline CHEMBL3212886 & 688239 & 5.2362 & 5.7251 & TRN & \\
\hline CHEMBL1422711 & 688239 & 5.4862 & 5.5652 & TRN & \\
\hline CHEMBL1333289 & 688239 & 4.6862 & 5.4891 & TRN & \\
\hline CHEMBL1416442 & 688239 & 5.4362 & 5.3876 & TST & \\
\hline CHEMBL1431945 & 688239 & 4.8362 & 5.5397 & TST & \\
\hline CHEMBL3191997 & 688239 & 5.1862 & 5.5113 & TST & \\
\hline CHEMBL3214068 & 688239 & 5.9362 & 5.6074 & TST & \\
\hline CHEMBL1559424 & 688239 & 6.0862 & 5.7197 & TRN & \\
\hline CHEMBL3194008 & 688239 & 7.0862 & 5.4585 & TRN & \\
\hline CHEMBL1580606 & 688239 & 6.6861 & 5.6484 & TRN & \\
\hline CHEMBL1475300 & 688239 & 5.1862 & 5.5557 & TST & \\
\hline CHEMBL1349325 & 688239 & 8.28399 & 99999999 & 9 & 5.2892 \\
\hline CHEMBL1410710 & 688239 & 5.5362 & 5.4436 & TRN & \\
\hline CHEMBL3212972 & 688239 & 4.9362 & 5.2989 & TRN & \\
\hline CHEMBL1595723 & 688239 & 5.7362 & 5.4022 & TST & \\
\hline CHEMBL1321063 & 688239 & 5.1862 & 5.4164 & TRN & \\
\hline CHEMBL1318012 & 688239 & 5.3362 & 5.2726 & TST & \\
\hline
\end{tabular}


Supplemental Table S2.txt

\begin{tabular}{|c|c|c|c|c|}
\hline CHEMBL1529012 & 688239 & 4.7862 & 5.6637 & TST \\
\hline CHEMBL1479353 & 688239 & 5.1862 & 5.5051 & TRN \\
\hline CHEMBL1534897 & 688239 & 6.3863 & 5.5933 & TRN \\
\hline CHEMBL1377463 & 688239 & 4.5862 & 5.3807 & TRN \\
\hline CHEMBL1537312 & 688239 & 6.3362 & 5.4733 & TST \\
\hline CHEMBL1461848 & 688239 & 5.1862 & 5.5056 & TRN \\
\hline CHEMBL1369044 & 688239 & 4.7362 & 5.483 & TRN \\
\hline CHEMBL1604179 & 688239 & 6.9863 & 5.6603 & TRN \\
\hline CHEMBL1970100 & 688239 & 6.2862 & 5.4577 & TRN \\
\hline CHEMBL1310039 & 688239 & 6.1862 & 5.5964 & TST \\
\hline CHEMBL1601985 & 688239 & 5.7862 & 5.4759 & TRN \\
\hline CHEMBL1412039 & 688239 & 4.6362 & 5.1903 & TRN \\
\hline CHEMBL1327037 & 688239 & 6.0862 & 5.5862 & TRN \\
\hline CHEMBL3209328 & 688239 & 5.7362 & 5.5502 & TST \\
\hline CHEMBL1514886 & 688239 & 6.8362 & 5.4081 & TRN \\
\hline CHEMBL1517353 & 688239 & 5.5362 & 5.4187 & TRN \\
\hline CHEMBL1438285 & 688239 & 6.5862 & 5.6216 & TRN \\
\hline CHEMBL116569 & 688239 & 6.7862 & 5.5186 & TRN \\
\hline CHEMBL1344696 & 688239 & 4.5362 & 5.5725 & TRN \\
\hline CHEMBL1338315 & 688239 & 4.5362 & 5.605 & TRN \\
\hline CHEMBL1410705 & 688239 & 6.3362 & 5.4936 & TRN \\
\hline CHEMBL1609575 & 688239 & 4.5862 & 5.4786 & TST \\
\hline CHEMBL1441901 & 688239 & 6.6362 & 5.4735 & TRN \\
\hline CHEMBL1582907 & 688239 & 4.6362 & 5.4955 & TRN \\
\hline CHEMBL1368567 & 688239 & 5.4362 & 5.4662 & TRN \\
\hline CHEMBL1605458 & 688239 & 4.6862 & 5.4152 & TST \\
\hline CHEMBL1469855 & 688239 & 4.9862 & 5.4762 & TRN \\
\hline CHEMBL1392389 & 688239 & 4.7362 & 5.4821 & TST \\
\hline CHEMBL1585238 & 688239 & 5.6362 & 5.56 & TST \\
\hline CHEMBL1443521 & 688239 & 5.1862 & 5.4889 & TST \\
\hline CHEMBL1964614 & 688239 & 4.5362 & 5.391 & TRN \\
\hline CHEMBL1436793 & 688239 & 5.7862 & 5.4274 & TRN \\
\hline CHEMBL3191700 & 688239 & 6.1862 & 5.6976 & TRN \\
\hline CHEMBL1452635 & 688239 & 5.6362 & 5.398 & TRN \\
\hline CHEMBL1434693 & 688239 & 5.1862 & 5.5458 & TRN \\
\hline CHEMBL1411153 & 688239 & 4.5362 & 5.41200 & 0000000001 \\
\hline CHEMBL1524138 & 688239 & 5.1862 & 5.4399 & TRN \\
\hline CHEMBL1570749 & 688239 & 4.5362 & 5.4727 & TRN \\
\hline CHEMBL1993889 & 688239 & 5.0862 & 5.4872 & TRN \\
\hline CHEMBL1407591 & 688239 & 4.4862 & 5.4177 & TRN \\
\hline CHEMBL1599630 & 688239 & 4.9362 & 5.4733 & TRN \\
\hline CHEMBL1576375 & 688239 & 4.5862 & 5.6358 & TRN \\
\hline CHEMBL1467036 & 688239 & 5.4362 & 5.4514 & TRN \\
\hline CHEMBL1459658 & 688239 & 5.6362 & 5.4467 & TRN \\
\hline CHEMBL1456275 & 688239 & 4.8362 & 5.6199 & TRN \\
\hline CHEMBL1368612 & 688239 & 6.1862 & 5.4409 & TRN \\
\hline CHEMBL1386611 & 688239 & 4.7362 & 5.5062 & TRN \\
\hline CHEMBL1571348 & 688239 & 4.6862 & 5.3267 & TRN \\
\hline
\end{tabular}


Supplemental Table S2.txt

\begin{tabular}{|c|c|c|c|c|}
\hline CHEMBL1576611 & 688239 & 4.6862 & 5.6446 & TRN \\
\hline CHEMBL1576196 & 688239 & 6.6362 & 5.4655 & TRN \\
\hline CHEMBL1530545 & 688239 & 6.0362 & 5.5691 & TRN \\
\hline CHEMBL1384760 & 688239 & 6.2362 & 5.4617 & TST \\
\hline CHEMBL3195169 & 688239 & 6.1362 & 5.5399 & TRN \\
\hline CHEMBL1510350 & 688239 & 6.4362 & 5.4505 & TST \\
\hline CHEMBL1576812 & 688239 & 5.0862 & 5.5228 & TRN \\
\hline CHEMBL1308524 & 688239 & 5.1862 & 5.5056 & TRN \\
\hline CHEMBL1303950 & 688239 & 6.0862 & 5.6446 & TRN \\
\hline CHEMBL1578456 & 688239 & 4.6862 & 5.432 & TRN \\
\hline CHEMBL1417574 & 688239 & 6.0862 & 5.4992 & TRN \\
\hline CHEMBL1351904 & 688239 & 4.5362 & 5.5322 & TRN \\
\hline CHEMBL1323266 & 688239 & 5.3862 & 5.4157 & TRN \\
\hline CHEMBL1488723 & 688239 & 4.7362 & 5.3499 & TRN \\
\hline CHEMBL1411613 & 688239 & 4.95 & 5.4676 & TST \\
\hline CHEMBL1388481 & 688239 & 5.1862 & 5.4903 & TST \\
\hline CHEMBL1425633 & 688239 & 4.5362 & 5.4959 & TST \\
\hline CHEMBL1545209 & 688239 & 4.5362 & 5.5835 & TST \\
\hline CHEMBL1490620 & 688239 & 5.2862 & 5.5067 & TRN \\
\hline CHEMBL1442205 & 688239 & 4.4862 & 5.5275 & TRN \\
\hline CHEMBL1539818 & 688239 & 6.9363 & 5.6607 & TRN \\
\hline CHEMBL1498068 & 688239 & 6.8362 & 5.6166 & TRN \\
\hline CHEMBL1352438 & 688239 & 6.1862 & 5.4102 & TRN \\
\hline CHEMBL 2001739 & 688239 & 4.6862 & 5.3154 & TST \\
\hline CHEMBL 3195058 & 688239 & 5.3862 & 5.518 & TRN \\
\hline CHEMBL1412425 & 688239 & 4.6862 & 5.4501 & TST \\
\hline CHEMBL1378027 & 688239 & 4.9862 & 5.5935 & TRN \\
\hline CHEMBL 3196564 & 688239 & 6.2362 & 5.5634 & TRN \\
\hline CHEMBL1353815 & 688239 & 5.6362 & 5.5068 & TST \\
\hline CHEMBL1469166 & 688239 & 6.8861 & 5.4881 & TRN \\
\hline CHEMBL579583 & 688239 & 7.5361 & 5.5938 & TRN \\
\hline CHEMBL1557597 & 688239 & 6.8362 & 5.5356 & TRN \\
\hline CHEMBL1440603 & 688239 & 5.1362 & 5.4338 & TRN \\
\hline CHEMBL1530852 & 688239 & 5.6362 & 5.5165 & TRN \\
\hline CHEMBL1368827 & 688239 & 4.5362 & 5.5252 & TRN \\
\hline CHEMBL 3213727 & 688239 & 5.1862 & 5.5429 & TST \\
\hline CHEMBL391351 & 688239 & 5.5862 & 5.4374 & TRN \\
\hline CHEMBL1312690 & 688239 & 5.0362 & 5.53600 & 00000000005 \\
\hline CHEMBL1448779 & 688239 & 4.5362 & 5.4822 & TRN \\
\hline CHEMBL1499172 & 688239 & 5.0362 & 5.5761 & TST \\
\hline CHEMBL1371056 & 688239 & 4.9362 & 5.4202 & TRN \\
\hline CHEMBL1612691 & 688239 & 5.1862 & 5.4927 & TRN \\
\hline CHEMBL1429542 & 688239 & 4.5362 & 5.5662 & TRN \\
\hline CHEMBL1496981 & 688239 & 4.5362 & 5.3606 & TRN \\
\hline CHEMBL1607665 & 688239 & 5.2862 & 5.4783 & TST \\
\hline CHEMBL1382621 & 688239 & 5.1862 & 5.4922 & TRN \\
\hline CHEMBL1346042 & 688239 & 5.1862 & 5.4888 & TST \\
\hline CHEMBL1305054 & 688239 & 5.6862 & 5.5052 & TRN \\
\hline
\end{tabular}


Supplemental Table S2.txt

\begin{tabular}{|c|c|c|c|c|}
\hline CHEMBL1437183 & 688239 & 4.7862 & 5.4912 & TRN \\
\hline CHEMBL1363396 & 688239 & 5.1362 & 5.5949 & TRN \\
\hline CHEMBL1611439 & 688239 & 7.5361 & 5.5414 & TST \\
\hline CHEMBL1300722 & 688239 & 5.1862 & 5.5363 & TRN \\
\hline CHEMBL1603251 & 688239 & 5.2862 & 5.4274 & TRN \\
\hline CHEMBL1401161 & 688239 & 6.8362 & 5.3692 & TRN \\
\hline CHEMBL1449018 & 688239 & 4.4862 & 5.3633 & TRN \\
\hline CHEMBL1379472 & 688239 & 5.8862 & 5.5347 & TRN \\
\hline CHEMBL1407919 & 688239 & 4.7862 & 5.468 & TRN \\
\hline CHEMBL1594563 & 688239 & 6.8861 & 5.676 & TST \\
\hline CHEMBL1543450 & 688239 & 5.8362 & 5.4197 & TST \\
\hline CHEMBL1426197 & 688239 & 6.7862 & 5.4004 & TRN \\
\hline CHEMBL1457119 & 688239 & 5.3362 & 5.341 & TST \\
\hline CHEMBL3214098 & 688239 & 4.5862 & 5.5692 & TRN \\
\hline CHEMBL1544330 & 688239 & 4.4862 & 5.29200 & 000000001 \\
\hline CHEMBL1480758 & 688239 & 4.7362 & 5.4344 & TRN \\
\hline CHEMBL 3210190 & 688239 & 5.6862 & 5.4323 & TST \\
\hline CHEMBL1519375 & 688239 & 5.1362 & 5.5054 & TRN \\
\hline CHEMBL1377654 & 688239 & 5.7862 & 5.5163 & TST \\
\hline CHEMBL1526665 & 688239 & 4.5362 & 5.4881 & TRN \\
\hline CHEMBL1459609 & 688239 & 5.1362 & 5.6933 & TRN \\
\hline CHEMBL1595600 & 688239 & 5.4362 & 5.4105 & TRN \\
\hline CHEMBL1404121 & 688239 & 4.7862 & 5.5947 & TRN \\
\hline CHEMBL1387719 & 688239 & 6.2362 & 5.5083 & TRN \\
\hline CHEMBL1340825 & 688239 & 4.8362 & 5.4563 & TST \\
\hline CHEMBL1529111 & 688239 & 4.8862 & 5.3329 & TRN \\
\hline CHEMBL1354047 & 688239 & 4.5362 & 5.4242 & TST \\
\hline CHEMBL1589629 & 688239 & 5.6362 & 5.4883 & TRN \\
\hline CHEMBL1417294 & 688239 & 4.6862 & 5.3733 & TST \\
\hline CHEMBL1328404 & 688239 & 4.4862 & 5.4272 & TRN \\
\hline CHEMBL1369293 & 688239 & 8.3372 & 5.6567 & TRN \\
\hline CHEMBL3189414 & 688239 & 4.6362 & 5.4675 & TRN \\
\hline CHEMBL1401022 & 688239 & 5.2362 & 5.5057 & TRN \\
\hline CHEMBL346814 & 688239 & 6.5363 & 5.4724 & TST \\
\hline CHEMBL1344712 & 688239 & 6.0862 & 5.4231 & TRN \\
\hline CHEMBL1316361 & 688239 & 4.5362 & 5.4558 & TRN \\
\hline CHEMBL1436892 & 688239 & 5.3362 & 5.4155 & TRN \\
\hline CHEMBL3207903 & 688239 & 4.8862 & 5.4286 & TST \\
\hline CHEMBL1485395 & 688239 & 4.7862 & 5.5283 & TRN \\
\hline CHEMBL1484529 & 688239 & 4.5362 & 5.4342 & TST \\
\hline CHEMBL1586465 & 688239 & 5.4362 & 5.4565 & TRN \\
\hline CHEMBL1576465 & 688239 & 4.5862 & 5.4901 & TRN \\
\hline CHEMBL1407979 & 688239 & 4.7862 & 5.3438 & TRN \\
\hline CHEMBL1345349 & 688239 & 5.1862 & 5.4415 & TST \\
\hline CHEMBL1478813 & 688239 & 5.6862 & 5.5987 & TST \\
\hline CHEMBL1496193 & 688239 & 5.7362 & 5.5499 & TRN \\
\hline CHEMBL1997895 & 688239 & 4.4362 & 5.4073 & TRN \\
\hline CHEMBL1439900 & 688239 & 5.2862 & 5.6167 & TRN \\
\hline
\end{tabular}




\begin{tabular}{|c|c|c|c|c|c|}
\hline & & & oplement & al lable s & \\
\hline CHEMBL1407969 & 688239 & 4.4862 & 5.5961 & TRN & \\
\hline CHEMBL1309409 & 688239 & 5.1362 & 5.54700 & 0000000001 & TRN \\
\hline CHEMBL1587732 & 688239 & 8.3372 & 5.5169 & TST & \\
\hline CHEMBL1602850 & 688239 & 8.3372 & 5.5448 & TST & \\
\hline CHEMBL1543361 & 688239 & 4.5362 & 5.59200 & $\partial 0000000005$ & TRN \\
\hline CHEMBL1381598 & 688239 & 5.5362 & 5.5714 & TST & \\
\hline CHEMBL1459414 & 688239 & 4.5362 & 5.4562 & TRN & \\
\hline CHEMBL1323095 & 688239 & 6.0362 & 5.4433 & TRN & \\
\hline CHEMBL1528890 & 688239 & 8.4318 & 5.3289 & TST & \\
\hline CHEMBL1442304 & 688239 & 5.1362 & 5.4815 & TRN & \\
\hline CHEMBL1567069 & 688239 & 5.6862 & 5.4214 & TST & \\
\hline CHEMBL1559292 & 688239 & 4.6862 & 5.4177 & TST & \\
\hline CHEMBL3213625 & 688239 & 6.2362 & 5.4322 & TRN & \\
\hline CHEMBL1454675 & 688239 & 6.6861 & 5.6002 & TRN & \\
\hline CHEMBL1571275 & 688239 & 8.2366 & 5.4562 & TRN & \\
\hline CHEMBL1442730 & 688239 & 5.9362 & 5.4701 & TRN & \\
\hline CHEMBL1490120 & 688239 & 4.6362 & 5.444 & TST & \\
\hline CHEMBL1337399 & 688239 & 5.3362 & 5.4282 & TRN & \\
\hline CHEMBL261118 & 688239 & 6.7361 & 5.4568 & TRN & \\
\hline CHEMBL1435704 & 688239 & 4.5362 & 5.6361 & TRN & \\
\hline CHEMBL1361032 & 688239 & 5.4362 & 5.3652 & TRN & \\
\hline CHEMBL1304582 & 688239 & 5.1362 & 5.4257 & TRN & \\
\hline CHEMBL 2373561 & 688239 & 6.5862 & 5.4295 & TST & \\
\hline CHEMBL1442870 & 688239 & 8.3372 & 5.4805 & TRN & \\
\hline CHEMBL1463422 & 688239 & 5.0862 & 5.3637 & TST & \\
\hline CHEMBL1530963 & 688239 & 4.5362 & 5.419 & TRN & \\
\hline CHEMBL1418658 & 688239 & 4.4862 & 5.4337 & TRN & \\
\hline CHEMBL1457912 & 688239 & 6.5862 & 5.5546 & TRN & \\
\hline CHEMBL1589943 & 688239 & 5.5862 & 5.5569 & TRN & \\
\hline CHEMBL1602773 & 688239 & 6.5363 & 5.4539 & TRN & \\
\hline CHEMBL1546107 & 688239 & 5.6862 & 5.5608 & TRN & \\
\hline CHEMBL1608758 & 688239 & 5.6362 & 5.581 & TRN & \\
\hline CHEMBL1456709 & 688239 & 5.1862 & 5.5544 & TRN & \\
\hline CHEMBL1398347 & 688239 & 4.7362 & 5.3968 & TRN & \\
\hline CHEMBL1320048 & 688239 & 6.8861 & 5.7271 & TRN & \\
\hline CHEMBL1352442 & 688239 & 5.1862 & 5.5011 & TRN & \\
\hline CHEMBL1594740 & 688239 & 4.9362 & 5.5467 & TRN & \\
\hline CHEMBL1424193 & 688239 & 6.0862 & 5.645 & TRN & \\
\hline CHEMBL1349036 & 688239 & 8.3372 & 5.3739 & TRN & \\
\hline CHEMBL1358351 & 688239 & 4.6862 & 5.3567 & TRN & \\
\hline CHEMBL3193929 & 688239 & 4.5862 & 5.5365 & TRN & \\
\hline CHEMBL1542602 & 688239 & 6.0862 & 5.5548 & TST & \\
\hline CHEMBL1378999 & 688239 & 6.9863 & 5.607 & TST & \\
\hline CHEMBL1432406 & 688239 & 5.9862 & 5.5948 & TST & \\
\hline CHEMBL1605320 & 688239 & 4.7362 & 5.4578 & TRN & \\
\hline CHEMBL1374895 & 688239 & 5.9362 & 5.5608 & TRN & \\
\hline CHEMBL1321527 & 688239 & 4.5362 & 5.5491 & TST & \\
\hline MBL1336430 & 688239 & 362 & 5.3089 & TST & \\
\hline
\end{tabular}


Supplemental Table S2.txt

\begin{tabular}{|c|c|c|c|c|}
\hline CHEMBL1507705 & 688239 & 6.1862 & 5.4805 & TRN \\
\hline CHEMBL1608411 & 688239 & 5.0862 & 5.4021 & TRN \\
\hline CHEMBL1441775 & 688239 & 5.5362 & 5.3933 & TST \\
\hline CHEMBL1500801 & 688239 & 6.5862 & 5.4709 & TRN \\
\hline CHEMBL1513925 & 688239 & 4.5362 & 5.3384 & TRN \\
\hline CHEMBL1425714 & 688239 & 6.8861 & 5.5062 & TST \\
\hline CHEMBL1428114 & 688239 & 4.6862 & 5.5694 & TST \\
\hline CHEMBL1360842 & 688239 & 6.0862 & 5.5968 & TRN \\
\hline CHEMBL 3198760 & 688239 & 6.2362 & 5.2691 & TRN \\
\hline CHEMBL1545780 & 688239 & 4.7362 & 5.4741 & TST \\
\hline CHEMBL1364650 & 688239 & 4.5362 & 5.4864 & TRN \\
\hline CHEMBL1428870 & 688239 & 7.3363 & 5.4283 & TRN \\
\hline CHEMBL1446186 & 688239 & 5.1862 & 5.5961 & TST \\
\hline CHEMBL1599907 & 688239 & 4.5362 & \multicolumn{2}{|c|}{5.4239999999999995} \\
\hline CHEMBL1577562 & 688239 & 5.1862 & 5.4778 & TRN \\
\hline CHEMBL1521450 & 688239 & 5.7862 & 5.6669 & TRN \\
\hline CHEMBL1586500 & 688239 & 5.1862 & 5.5922 & TRN \\
\hline CHEMBL1594199 & 688239 & 4.5362 & 5.3872 & TRN \\
\hline CHEMBL1518271 & 688239 & 4.5362 & 5.5547 & TRN \\
\hline CHEMBL117108 & 688239 & 6.0862 & \multicolumn{2}{|c|}{5.417000000000001} \\
\hline CHEMBL1482935 & 688239 & 5.6862 & 5.5108 & TRN \\
\hline CHEMBL1996741 & 688239 & 4.5362 & 5.4431 & TST \\
\hline CHEMBL1529368 & 688239 & 5.0362 & 5.3816 & TRN \\
\hline CHEMBL1430029 & 688239 & 6.3362 & 5.3907 & TST \\
\hline CHEMBL1466174 & 688239 & 5.8862 & 5.4295 & TRN \\
\hline CHEMBL 3199584 & 688239 & 5.4862 & 5.3817 & TST \\
\hline CHEMBL1529043 & 688239 & 4.5362 & 5.5789 & TRN \\
\hline CHEMBL1495495 & 688239 & 5.6862 & 5.5574 & TRN \\
\hline CHEMBL1461562 & 688239 & 4.5362 & 5.5851 & TST \\
\hline CHEMBL1356404 & 688239 & 5.6362 & 5.6731 & TRN \\
\hline CHEMBL1512925 & 688239 & 4.5362 & 5.4273 & TRN \\
\hline CHEMBL1510153 & 688239 & 4.6862 & 5.3866 & TST \\
\hline CHEMBL1517192 & 688239 & 6.1862 & 5.419 & TRN \\
\hline CHEMBL1325267 & 688239 & 4.8362 & 5.2874 & TRN \\
\hline CHEMBL1382583 & 688239 & 5.3862 & 5.4064 & TRN \\
\hline CHEMBL1451499 & 688239 & 5.9362 & 5.4514 & TRN \\
\hline CHEMBL1433119 & 688239 & 4.5862 & 5.4969 & TRN \\
\hline CHEMBL1499737 & 688239 & 4.5362 & 5.4771 & TRN \\
\hline CHEMBL1387640 & 688239 & 7.0362 & 5.5996 & TRN \\
\hline CHEMBL1596252 & 688239 & 4.4862 & 5.5318 & TST \\
\hline CHEMBL1490754 & 688239 & 5.1862 & \multicolumn{2}{|c|}{5.502999999999999} \\
\hline CHEMBL1524290 & 688239 & 4.7862 & 5.442 & TST \\
\hline CHEMBL1342584 & 688239 & 6.1862 & 5.6293 & TRN \\
\hline CHEMBL1606658 & 688239 & 5.1862 & 5.4488 & TRN \\
\hline CHEMBL1343350 & 688239 & 5.1862 & 5.6679 & TRN \\
\hline CHEMBL 1427810 & 688239 & 5.1862 & 5.4524 & TRN \\
\hline CHEMBL1582968 & 688239 & 4.7362 & 5.3158 & TRN \\
\hline CHEMBL1334178 & 688239 & 4.5362 & 5.3167 & TST \\
\hline
\end{tabular}

Page 2773 
Supplemental Table S2.txt

\begin{tabular}{|c|c|c|c|c|}
\hline 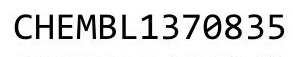 & & & & \\
\hline HEMBL1446802 & 38239 & 5362 & 6 & \\
\hline AEMBL1512204 & 239 & 362 & 5598 & \\
\hline 5280 & 39 & 852 & & \\
\hline IEMBL16 & 39 & & & \\
\hline AEMBL1382268 & 88239 & 362 & & \\
\hline AEMBL3198563 & 88239 & 362 & 2295 & \\
\hline HEMBL1491490 & & 362 & & \\
\hline EMBL14 & 39 & 862 & & \\
\hline IEMBL13 & & 862 & & \\
\hline AEMBL1495102 & 239 & 362 & 67 & \\
\hline AEMBL1515320 & 39 & 362 & & \\
\hline HEMBL1299825 & & 862 & & \\
\hline AEMBL1425635 & & 862 & & \\
\hline AEMBL1461206 & & 362 & & \\
\hline AEMBL1997797 & & 362 & & \\
\hline AEMBL1514522 & & 861 & & \\
\hline AEMBL152 & & & & \\
\hline AEMBL1583248 & & & & \\
\hline HEMBL 15 & & & & \\
\hline AEMBL1337819 & & 862 & & \\
\hline AEMBL1564804 & & 62 & & \\
\hline AEMBL150 & & 62 & & \\
\hline AFMRI 13 & & & & \\
\hline 29 & & 62 & & \\
\hline 9870 & & 862 & & \\
\hline IEMBL1572637 & & & & \\
\hline EMBL151113 & & & & \\
\hline AFMRI 13 & & 52 & & \\
\hline ILMP 12 & & 62 & & \\
\hline AEMBL1555543 & & & & \\
\hline HEMBL1404809 & & 62 & & \\
\hline 279 & & & & \\
\hline 821 & & & & \\
\hline AEMBL1311299 & & & & \\
\hline AEMBL1482010 & & & & \\
\hline AEMBL1585646 & & 62 & & \\
\hline & & 62 & & \\
\hline 314 & & & & \\
\hline HEMBL1527471 & & & & ST \\
\hline AEMBL1607327 & & 62 & & I \\
\hline AEMBL1401225 & & 62 & & \\
\hline HEMBL1417477 & & & & \\
\hline HEMBL1465679 & & & & \\
\hline HEMBL1384168 & & & & RN \\
\hline MBL1407571 & & 362 & & \\
\hline 3293 & & & & \\
\hline HEMBL158803 & & & & \\
\hline
\end{tabular}


Supplemental Table S2.txt

\begin{tabular}{|c|c|c|c|c|c|}
\hline CHEMBL1514966 & 688239 & 4.6862 & 5.4478 & TRN & \\
\hline CHEMBL1319658 & 688239 & 6.1862 & 5.5361 & TST & \\
\hline CHEMBL1473909 & 688239 & 5.9362 & 5.5358 & TRN & \\
\hline CHEMBL1363471 & 688239 & 4.6362 & 5.4809 & TRN & \\
\hline CHEMBL1479211 & 688239 & 6.9363 & 5.5851 & TRN & \\
\hline CHEMBL1372113 & 688239 & 7.4365 & 5.3957 & TST & \\
\hline CHEMBL1334112 & 688239 & 4.5362 & 5.4802 & TST & \\
\hline CHEMBL1506474 & 688239 & 4.4862 & 5.4521 & TRN & \\
\hline CHEMBL1403679 & 688239 & 5.9862 & 5.4931 & TST & \\
\hline CHEMBL1598202 & 688239 & 5.1862 & 5.4349 & TST & \\
\hline CHEMBL1507618 & 688239 & 6.6861 & 5.566 & TRN & \\
\hline CHEMBL1321444 & 688239 & 4.5362 & 5.6357 & TRN & \\
\hline CHEMBL1472233 & 688239 & 4.5362 & 5.4281 & TST & \\
\hline CHEMBL 3208997 & 688239 & 4.6362 & 5.4126 & TRN & \\
\hline CHEMBL1325930 & 688239 & 4.8862 & 5.6147 & TRN & \\
\hline CHEMBL1551627 & 688239 & 5.1862 & 5.4595 & TRN & \\
\hline CHEMBL1599208 & 688239 & 4.5362 & 5.3336 & TRN & \\
\hline CHEMBL1364122 & 688239 & 5.2862 & 5.6135 & TRN & \\
\hline CHEMBL1574535 & 688239 & 4.5362 & 5.4273 & TST & \\
\hline CHEMBL1517026 & 688239 & 4.5862 & 5.5527 & TRN & \\
\hline CHEMBL1429288 & 688239 & 6.3362 & 5.41700 & 000000001 & TST \\
\hline CHEMBL1556258 & 688239 & 4.5362 & 5.4249 & TRN & \\
\hline CHEMBL1465902 & 688239 & 6.1862 & 5.6593 & TRN & \\
\hline CHEMBL1549159 & 688239 & 4.65 & 5.3808 & TRN & \\
\hline CHEMBL1574317 & 688239 & 4.7362 & 5.4132 & TRN & \\
\hline CHEMBL1570478 & 688239 & 5.8362 & 5.6243 & TRN & \\
\hline CHEMBL1500943 & 688239 & 6.8362 & 5.5315 & TRN & \\
\hline CHEMBL1320598 & 688239 & 4.7862 & 5.5587 & TRN & \\
\hline CHEMBL1477598 & 688239 & 5.7862 & 5.6849 & TST & \\
\hline CHEMBL1605721 & 688239 & 5.1862 & 5.4713 & TRN & \\
\hline CHEMBL1571673 & 688239 & 4.7362 & 5.5653 & TST & \\
\hline CHEMBL1378028 & 688239 & 4.5862 & 5.6231 & TRN & \\
\hline CHEMBL 3212413 & 688239 & 5.3862 & 5.6042 & TST & \\
\hline CHEMBL1565777 & 688239 & 6.3362 & 5.5885 & TRN & \\
\hline CHEMBL1612243 & 688239 & 6.0362 & 5.4486 & TRN & \\
\hline CHEMBL1385616 & 688239 & 5.6862 & 5.4769 & TST & \\
\hline CHEMBL1415657 & 688239 & 5.8362 & 5.6228 & TRN & \\
\hline CHEMBL1418180 & 688239 & 5.4862 & 5.5829 & TRN & \\
\hline CHEMBL1465681 & 688239 & 6.8362 & 5.4235 & TST & \\
\hline CHEMBL1575432 & 688239 & 5.3362 & 5.4315 & TRN & \\
\hline CHEMBL1451779 & 688239 & 4.7862 & 5.5385 & TRN & \\
\hline CHEMBL1490874 & 688239 & 5.2362 & 5.5935 & TRN & \\
\hline CHEMBL1590693 & 688239 & 4.8362 & 5.4829 & TRN & \\
\hline CHEMBL1612093 & 688239 & 4.5362 & 5.642 & TRN & \\
\hline CHEMBL1403329 & 688239 & 5.7362 & 5.4977 & TRN & \\
\hline CHEMBL1368279 & 688239 & 5.1862 & 5.7067 & TRN & \\
\hline CHEMBL1427446 & 688239 & 4.5362 & 5.4464 & TST & \\
\hline CHEMBL1455696 & 688239 & 4.6862 & 5.57700 & 0000000001 & RN \\
\hline
\end{tabular}

Page 2775 


\begin{tabular}{|c|c|c|c|c|c|}
\hline \multicolumn{6}{|c|}{ Supplemental Table S2.txt } \\
\hline CHEMBL1458230 & 688239 & 7.1864 & 5.504 & TRN & \\
\hline CHEMBL1314272 & 688239 & 5.3862 & 5.4899 & TRN & \\
\hline CHEMBL1395761 & 688239 & 4.5362 & 5.4127 & TRN & \\
\hline CHEMBL1390763 & 688239 & 7.0862 & 5.5216 & TRN & \\
\hline CHEMBL1376216 & 688239 & 4.5362 & 5.6422 & TRN & \\
\hline CHEMBL1586865 & 688239 & 6.7862 & 5.5693 & TRN & \\
\hline CHEMBL1360827 & 688239 & 5.1862 & 5.5829 & TRN & \\
\hline CHEMBL1463899 & 688239 & 4.7362 & 5.5057 & TST & \\
\hline CHEMBL1497947 & 688239 & 6.8861 & 5.3628 & TST & \\
\hline CHEMBL544584 & 688239 & 4.5362 & 5.40799 & 99999999995 & TRN \\
\hline CHEMBL1612395 & 688239 & 8.3372 & 5.5538 & TRN & \\
\hline CHEMBL1432857 & 688239 & 8.1871 & 5.366006 & 00000000005 & TRN \\
\hline CHEMBL1447263 & 688239 & 6.7862 & 5.4965 & TRN & \\
\hline CHEMBL1561368 & 688239 & 6.7361 & 5.4682 & TRN & \\
\hline CHEMBL 3212613 & 688239 & 4.5362 & 5.4367 & TRN & \\
\hline CHEMBL1435866 & 688239 & 4.5362 & 5.4377 & TRN & \\
\hline CHEMBL3196650 & 688239 & 5.6862 & 5.4805 & TRN & \\
\hline CHEMBL1481141 & 688239 & 4.7362 & 5.4994 & TRN & \\
\hline CHEMBL1539566 & 688239 & 4.5362 & 5.4492 & TRN & \\
\hline CHEMBL1456852 & 688239 & 4.5362 & 5.3794 & TST & \\
\hline CHEMBL1964467 & 688239 & 5.7362 & 5.4915 & TRN & \\
\hline CHEMBL1612579 & 688239 & 8.28399 & 99999999 & 5.7154 & TST \\
\hline CHEMBL1573166 & 688239 & 6.5363 & 5.5472 & TRN & \\
\hline CHEMBL1462186 & 688239 & 4.7862 & 5.4281 & TRN & \\
\hline CHEMBL1480937 & 688239 & 4.5362 & 5.4169 & TST & \\
\hline CHEMBL1552282 & 688239 & 6.2362 & 5.5228 & TRN & \\
\hline CHEMBL1543485 & 688239 & 4.6862 & 5.4229 & TRN & \\
\hline CHEMBL1453966 & 688239 & 6.0862 & 5.505 & TRN & \\
\hline CHEMBL1341807 & 688239 & 4.5362 & 5.4545 & TRN & \\
\hline CHEMBL1309344 & 688239 & 4.9362 & 5.3578 & TRN & \\
\hline CHEMBL3193651 & 688239 & 4.5362 & 5.3098 & TRN & \\
\hline CHEMBL1431351 & 688239 & 4.7362 & 5.5523 & TRN & \\
\hline CHEMBL1463403 & 688239 & 5.0362 & 5.5042 & TRN & \\
\hline CHEMBL3192568 & 688239 & 8.2366 & 5.5473 & TST & \\
\hline CHEMBL1366153 & 688239 & 4.5362 & 5.517 & TST & \\
\hline CHEMBL1314017 & 688239 & 5.1862 & 5.3842 & TRN & \\
\hline CHEMBL1610907 & 688239 & 5.6362 & 5.6511 & TRN & \\
\hline CHEMBL1338469 & 688239 & 4.5862 & 5.4897 & TRN & \\
\hline CHEMBL1480285 & 688239 & 4.5362 & 5.5334 & TRN & \\
\hline CHEMBL1485263 & 688239 & 6.0862 & 5.4353 & TST & \\
\hline CHEMBL1454757 & 688239 & 6.2862 & 5.5562 & TRN & \\
\hline CHEMBL1363576 & 688239 & 6.1862 & 5.5309 & TRN & \\
\hline CHEMBL1493437 & 688239 & 5.1862 & 5.2726 & TRN & \\
\hline CHEMBL1477147 & 688239 & 5.2862 & 5.4542 & TRN & \\
\hline CHEMBL1414357 & 688239 & 4.5362 & 5.5666 & TRN & \\
\hline CHEMBL1487635 & 688239 & 4.6862 & 5.4636 & TRN & \\
\hline CHEMBL1410097 & 688239 & 6.3362 & 5.6178 & TRN & \\
\hline CHEMBL1335262 & 688239 & 4.7862 & 5.4697 & TRN & \\
\hline
\end{tabular}


Supplemental Table S2.txt

\begin{tabular}{|c|c|c|c|c|}
\hline CHEMBL1527705 & 688239 & 4.8862 & 5.5051 & TST \\
\hline CHEMBL1477577 & 688239 & 6.2862 & 5.5868 & TRN \\
\hline CHEMBL1592656 & 688239 & 4.5362 & 5.5486 & TRN \\
\hline CHEMBL1521482 & 688239 & 6.8861 & 5.4846 & TRN \\
\hline CHEMBL1346279 & 688239 & 6.9363 & 5.4177 & TRN \\
\hline CHEMBL1337401 & 688239 & 4.7862 & 5.5092 & TRN \\
\hline CHEMBL1488083 & 688239 & 4.8362 & 5.3925 & TST \\
\hline CHEMBL1467855 & 688239 & 5.2362 & 5.5549 & TST \\
\hline CHEMBL1364742 & 688239 & 5.6862 & 5.5049 & TRN \\
\hline CHEMBL1591559 & 688239 & 8.3372 & 5.5531 & TST \\
\hline CHEMBL1386888 & 688239 & 6.7862 & 5.4282 & TRN \\
\hline CHEMBL1589957 & 688239 & 4.8362 & 5.6099 & TRN \\
\hline CHEMBL1486914 & 688239 & 4.7862 & 5.4851 & TST \\
\hline CHEMBL1427285 & 688239 & 5.1362 & 5.5087 & TRN \\
\hline CHEMBL1493005 & 688239 & 6.7862 & 5.381 & TRN \\
\hline CHEMBL1601941 & 688239 & 4.5362 & \multicolumn{2}{|c|}{5.497999999999999} \\
\hline CHEMBL1320373 & 688239 & 4.6362 & 5.5515 & TRN \\
\hline CHEMBL1353982 & 688239 & 8.2366 & 5.5865 & TST \\
\hline CHEMBL3145315 & 688239 & 6.3863 & 5.4675 & TST \\
\hline CHEMBL3210833 & 688239 & 4.5362 & 5.4475 & TRN \\
\hline CHEMBL1300713 & 688239 & 4.7362 & 5.5034 & TRN \\
\hline CHEMBL1546595 & 688239 & 5.3362 & 5.4266 & TST \\
\hline CHEMBL1337524 & 688239 & 4.4862 & 5.5718 & TRN \\
\hline CHEMBL1580893 & 688239 & 5.3362 & 5.6514 & TRN \\
\hline CHEMBL1403294 & 688239 & 4.7862 & 5.5271 & TRN \\
\hline CHEMBL1365327 & 688239 & 4.7862 & 5.523 & TRN \\
\hline CHEMBL1589062 & 688239 & 4.8862 & 5.4047 & TRN \\
\hline CHEMBL1336923 & 688239 & 6.2362 & 5.5484 & TRN \\
\hline CHEMBL1532565 & 688239 & 7.1361 & 5.7034 & TST \\
\hline CHEMBL1964690 & 688239 & 4.7362 & 5.4232 & TRN \\
\hline CHEMBL3195413 & 688239 & 4.5362 & 5.4297 & TRN \\
\hline CHEMBL1880070 & 688239 & 4.7362 & 5.4312 & TST \\
\hline CHEMBL1604292 & 688239 & 4.5362 & 5.4263 & TRN \\
\hline CHEMBL1574077 & 688239 & 4.7862 & 5.4746 & TRN \\
\hline CHEMBL1548823 & 688239 & 4.5362 & 5.4811 & TRN \\
\hline CHEMBL1505087 & 688239 & 4.7362 & 5.7388 & TST \\
\hline CHEMBL1424258 & 688239 & 6.9363 & 5.3975 & TRN \\
\hline CHEMBL1465300 & 688239 & 4.6362 & 5.4246 & TST \\
\hline CHEMBL1384270 & 688239 & 4.5362 & 5.3917 & TRN \\
\hline CHEMBL1581058 & 688239 & 6.0862 & 5.5744 & TRN \\
\hline CHEMBL1415989 & 688239 & 4.9362 & 5.466 & TRN \\
\hline CHEMBL1608250 & 688239 & 4.6862 & 5.4846 & TRN \\
\hline CHEMBL1390738 & 688239 & 5.1862 & 5.5461 & TRN \\
\hline CHEMBL1440760 & 688239 & 5.3362 & 5.5178 & TST \\
\hline CHEMBL1553203 & 688239 & 4.7362 & 5.4968 & TRN \\
\hline CHEMBL1392355 & 688239 & 4.5362 & 5.4221 & TST \\
\hline CHEMBL1558425 & 688239 & 8.3372 & 5.5094 & TRN \\
\hline CHEMBL1379672 & 688239 & 5.1862 & 5.4186 & TRN \\
\hline
\end{tabular}


Supplemental Table S2.txt

\begin{tabular}{|c|c|c|c|c|}
\hline CHEMBL1580083 & 688239 & 5.0362 & 5.5409 & TRN \\
\hline CHEMBL1612509 & 688239 & 5.7362 & 5.5154 & TST \\
\hline CHEMBL1393355 & 688239 & 5.7362 & 5.551 & TRN \\
\hline CHEMBL1441751 & 688239 & 8.3372 & 5.4713 & TRN \\
\hline CHEMBL1359703 & 688239 & 5.5862 & 5.4864 & TRN \\
\hline CHEMBL1553957 & 688239 & 4.5862 & 5.5357 & TRN \\
\hline CHEMBL1335580 & 688239 & 4.8862 & 5.6046 & TRN \\
\hline CHEMBL 37514 & 688239 & 5.2862 & 5.511 & TRN \\
\hline CHEMBL1343935 & 688239 & 4.7862 & 5.3398 & TRN \\
\hline CHEMBL1603942 & 688239 & 6.1362 & 5.4873 & TRN \\
\hline CHEMBL1504366 & 688239 & 4.6862 & 5.5219 & TRN \\
\hline CHEMBL1519347 & 688239 & 5.8362 & 5.4464 & TRN \\
\hline CHEMBL1353808 & 688239 & 4.5362 & 5.4573 & TST \\
\hline CHEMBL1392012 & 688239 & 4.5362 & 5.329 & TRN \\
\hline CHEMBL1510625 & 688239 & 4.6862 & 5.4961 & TRN \\
\hline CHEMBL1497892 & 688239 & 5.1862 & 5.5659 & TRN \\
\hline CHEMBL3197835 & 688239 & 5.6862 & 5.5203 & TRN \\
\hline CHEMBL1434508 & 688239 & 4.5362 & 5.3987 & TRN \\
\hline CHEMBL1466276 & 688239 & 4.5362 & 5.5699 & TRN \\
\hline CHEMBL1363235 & 688239 & 6.1862 & 5.5721 & TRN \\
\hline CHEMBL1548537 & 688239 & 4.7362 & 5.5153 & TRN \\
\hline CHEMBL1325641 & 688239 & 6.3362 & 5.3617 & TRN \\
\hline CHEMBL 3144935 & 688239 & 5.4362 & 5.4431 & TRN \\
\hline CHEMBL1560358 & 688239 & 4.5362 & 5.4259 & TRN \\
\hline CHEMBL1439896 & 688239 & 4.6862 & 5.5064 & TRN \\
\hline CHEMBL1516760 & 688239 & 4.5362 & 5.67700 & 0000000005 \\
\hline CHEMBL1337004 & 688239 & 6.2362 & 5.4836 & TRN \\
\hline CHEMBL1340413 & 688239 & 5.3862 & 5.4768 & TRN \\
\hline CHEMBL1372792 & 688239 & 4.7862 & 5.289 & TRN \\
\hline CHEMBL1442540 & 688239 & 5.1362 & 5.4716 & TST \\
\hline CHEMBL1300621 & 688239 & 4.4862 & 5.4081 & TRN \\
\hline CHEMBL1397183 & 688239 & 6.2862 & 5.455 & TST \\
\hline CHEMBL1525521 & 688239 & 5.5362 & 5.3715 & TRN \\
\hline CHEMBL1462227 & 688239 & 5.3862 & 5.4167 & TST \\
\hline CHEMBL1611659 & 688239 & 6.7862 & 5.4115 & TRN \\
\hline CHEMBL1468082 & 688239 & 4.5362 & 5.3603 & TRN \\
\hline CHEMBL1610797 & 688239 & 6.4862 & 5.58700 & 000000001 \\
\hline CHEMBL1412921 & 688239 & 5.5362 & 5.5866 & TRN \\
\hline CHEMBL1360539 & 688239 & 5.0362 & 5.3974 & TST \\
\hline CHEMBL1371778 & 688239 & 5.2862 & 5.3796 & TRN \\
\hline CHEMBL1325609 & 688239 & 4.5362 & 5.5035 & TST \\
\hline CHEMBL1493676 & 688239 & 4.5362 & 5.5146 & TRN \\
\hline CHEMBL1314179 & 688239 & 5.1862 & 5.4826 & TRN \\
\hline CHEMBL1586944 & 688239 & 5.6862 & 5.4938 & TST \\
\hline CHEMBL1329679 & 688239 & 8.1871 & 5.4092 & TRN \\
\hline CHEMBL 3210769 & 688239 & 4.5862 & 5.3674 & TST \\
\hline CHEMBL1588917 & 688239 & 4.5862 & 5.5593 & TRN \\
\hline CHEMBL 3196373 & 688239 & 5.0362 & 5.4739 & TRN \\
\hline
\end{tabular}


Supplemental Table S2.txt

\begin{tabular}{|c|c|c|c|c|c|c|}
\hline CHEMBL1303670 & 688239 & 4.5362 & 5.5009 & TRN & & \\
\hline CHEMBL1505606 & 688239 & 4.5362 & 5.4594 & TRN & & \\
\hline CHEMBL1485864 & 688239 & 6.3362 & 5.5235 & TST & & \\
\hline CHEMBL1503494 & 688239 & 5.8362 & 5.6068 & TRN & & \\
\hline CHEMBL1337534 & 688239 & 5.1862 & 5.6091 & TRN & & \\
\hline CHEMBL1380425 & 688239 & 5.1862 & 5.431 & TRN & & \\
\hline CHEMBL1307093 & 688239 & 5.0862 & 5.4938 & TRN & & \\
\hline CHEMBL1477720 & 688239 & 6.1362 & 5.5058 & TST & & \\
\hline CHEMBL3208110 & 688239 & 6.3863 & 5.5882 & TRN & & \\
\hline CHEMBL1597278 & 688239 & 4.7862 & 5.5169 & TRN & & \\
\hline CHEMBL1509188 & 688239 & 4.7362 & 5.5156 & TRN & & \\
\hline CHEMBL1307591 & 688239 & 5.1362 & 5.561 & TRN & & \\
\hline CHEMBL1609681 & 688239 & 6.8861 & 5.4315 & TRN & & \\
\hline CHEMBL1443718 & 688239 & 4.7862 & 5.4602 & TRN & & \\
\hline CHEMBL3190630 & 688239 & 5.1862 & 5.4853 & TRN & & \\
\hline CHEMBL1611362 & 688239 & 5.4862 & 5.4902 & TST & & \\
\hline CHEMBL1526755 & 688239 & \multicolumn{3}{|c|}{8.283999999999999} & 5.382999999999999 & TST \\
\hline CHEMBL3211903 & 688239 & 5.1862 & 5.4114 & TRN & & \\
\hline CHEMBL1319627 & 688239 & 5.4362 & 5.505 & TRN & & \\
\hline CHEMBL1333900 & 688239 & 6.2862 & 5.4622 & TRN & & \\
\hline CHEMBL1502598 & 688239 & 5.3862 & 5.4363 & TST & & \\
\hline CHEMBL1598672 & 688239 & 6.0362 & 5.47 & TRN & & \\
\hline CHEMBL1438097 & 688239 & 5.8362 & 5.4831 & TST & & \\
\hline CHEMBL1598028 & 688239 & 6.3863 & 5.5357 & TRN & & \\
\hline CHEMBL1427548 & 688239 & 4.5362 & 5.7012 & TRN & & \\
\hline CHEMBL1443802 & 688239 & 4.8862 & 5.3137 & TRN & & \\
\hline CHEMBL1401181 & 688239 & 4.5362 & 5.5134 & TST & & \\
\hline CHEMBL1457867 & 688239 & 4.7362 & 5.5328 & TST & & \\
\hline CHEMBL1319010 & 688239 & 6.2362 & 5.5134 & TRN & & \\
\hline CHEMBL1610788 & 688239 & 6.0362 & 5.5183 & TST & & \\
\hline CHEMBL1353977 & 688239 & 5.4862 & 5.4592 & TST & & \\
\hline CHEMBL1491648 & 688239 & 5.2362 & 5.5017 & TRN & & \\
\hline CHEMBL1597889 & 688239 & 6.0862 & 5.6542 & TRN & & \\
\hline CHEMBL1432302 & 688239 & 6.4362 & 5.49700 & 0000000001 & TST & \\
\hline CHEMBL1321549 & 688239 & 4.6862 & 5.515 & TRN & & \\
\hline CHEMBL1322091 & 688239 & 4.8862 & 5.4434 & TRN & & \\
\hline CHEMBL1341792 & 688239 & 4.7362 & 5.4 & TST & & \\
\hline CHEMBL1472427 & 688239 & 4.4862 & 5.5464 & TRN & & \\
\hline CHEMBL1318396 & 688239 & 4.7862 & 5.5105 & TRN & & \\
\hline CHEMBL1410779 & 688239 & 7.0862 & 5.5015 & TRN & & \\
\hline CHEMBL1377061 & 688239 & 6.1862 & 5.3829 & TST & & \\
\hline CHEMBL1534263 & 688239 & 6.5363 & 5.4491 & TRN & & \\
\hline CHEMBL1354715 & 688239 & 5.4362 & 5.5399 & TRN & & \\
\hline CHEMBL1365642 & 688239 & 5.4862 & 5.5031 & TRN & & \\
\hline CHEMBL1511381 & 688239 & 5.1862 & 5.5054 & TST & & \\
\hline CHEMBL1364929 & 688239 & 6.1362 & 5.5038 & TRN & & \\
\hline CHEMBL1546227 & 688239 & 5.5862 & 5.5024 & TST & & \\
\hline CHEMBL1584920 & 688239 & 5.2362 & 5.6184 & TRN & & \\
\hline
\end{tabular}


Supplemental Table S2.txt

\begin{tabular}{|c|c|c|c|}
\hline CHEMBL1438749 & 688239 & 5.2362 & 5.4868 \\
\hline CHEMBL1449572 & 688239 & 5.1362 & 5.5121 \\
\hline CHEMBL 3145104 & 688239 & 5.2862 & 5.4652 \\
\hline CHEMBL1464746 & 688239 & 4.5862 & 5.5719 \\
\hline CHEMBL1485452 & 688239 & 4.5862 & 5.5235 \\
\hline CHEMBL1545256 & 688239 & 6.8362 & 5.468 \\
\hline CHEMBL3207883 & 688239 & 4.6362 & 5.461 \\
\hline CHEMBL1323547 & 688239 & 5.5862 & 5.53 \\
\hline CHEMBL3211051 & 688239 & 4.5862 & 5.4669 \\
\hline CHEMBL1310475 & 688239 & 5.8862 & 5.3829 \\
\hline CHEMBL1328629 & 688239 & 4.4862 & 5.3656 \\
\hline CHEMBL1451994 & 688239 & 4.7362 & 5.4844 \\
\hline CHEMBL1407841 & 688239 & 5.2362 & 5.483 \\
\hline CHEMBL1397082 & 688277 & 4.8 & 4.8837 \\
\hline CHEMBL1475047 & 688277 & 5.7 & 5.379 \\
\hline CHEMBL1418040 & 688277 & 4.5 & 4.88 \\
\hline CHEMBL1452048 & 688277 & 4.6 & 4.8165 \\
\hline CHEMBL1589889 & 688277 & 5.4 & 4.9999 \\
\hline CHEMBL1450973 & 688277 & 5.35 & 5.4537 \\
\hline CHEMBL1398282 & 688277 & 4.9 & 4.8807 \\
\hline CHEMBL1436403 & 688277 & 5.0 & 5.0692 \\
\hline CHEMBL1613733 & 688277 & 4.95 & 4.9473 \\
\hline CHEMBL1326785 & 688277 & 4.8 & 4.8466 \\
\hline CHEMBL1445787 & 688277 & 4.9 & 4.8485 \\
\hline CHEMBL1376571 & 688277 & 4.7 & 4.677 \\
\hline CHEMBL1399904 & 688277 & 4.5 & 4.8896 \\
\hline CHEMBL1591989 & 688277 & 4.9 & 4.8446 \\
\hline CHEMBL1475099 & 688277 & 5.35 & 4.825 \\
\hline CHEMBL1475937 & 688277 & 4.6 & 4.8901 \\
\hline CHEMBL1317538 & 688277 & 4. & 4.8099 \\
\hline CHEMBL1417736 & 688277 & 4. & 4.6406 \\
\hline CHEMBL1518946 & 688277 & 5.7 & 5.1716 \\
\hline CHEMBL1373577 & 688277 & 5 . & 4.9015 \\
\hline CHEMBL131 & 688277 & 5.3 & 4.8731 \\
\hline CHEMBL1434096 & 688277 & 4.5 & 4.873 \\
\hline CHEMBL1552723 & 688277 & 4.6 & 4.9515 \\
\hline CHEMBL1419880 & 688277 & 4.9 & 5.0252 \\
\hline CHEMBL1535880 & 68 & 4.5 & \\
\hline CHEMBL1518839 & 688277 & 5.25 & 4.9999 \\
\hline CHEMBL1434925 & 688277 & 4.9 & 5.0685 \\
\hline CHEMBL1312494 & 688277 & 5.35 & 5.0657 \\
\hline CHEMBL1612169 & 688277 & 4.45 & 4.9981 \\
\hline CHEMBL1597550 & 688277 & 5.45 & 4.8459 \\
\hline CHEMBL1356225 & 688277 & 4.9 & 4.8413 \\
\hline CHEMBL1609950 & 688277 & 4.8 & 4.7903 \\
\hline CHEMBL1514827 & 688277 & 5.25 & 5.1408 \\
\hline CHEMBL1357688 & 688277 & 5.9 & 5.4573 \\
\hline CHEMBL1420302 & 688277 & 4.45 & 5.078 \\
\hline
\end{tabular}

Page 2780 


\begin{tabular}{|c|c|c|c|c|c|}
\hline \multirow[b]{2}{*}{ CHEMBL590163 } & \\
\hline & 688277 & 4.5 & 4.9044 & TRN & \\
\hline CHEMBL1363696 & 688277 & 5.0 & 4.875 & TRN & \\
\hline CHEMBL1516908 & 688277 & 5.0 & 4.9136 & TRN & \\
\hline CHEMBL1314762 & 688277 & 4.7 & 4.859 & TRN & \\
\hline CHEMBL1518712 & 688277 & 4.5 & 4.8314 & TRN & \\
\hline CHEMBL1364983 & 688277 & 4.8 & 4.9531 & TRN & \\
\hline CHEMBL1318087 & 688277 & 5.1 & 4.9273 & TST & \\
\hline CHEMBL1433174 & 688277 & 4.75 & 4.9511 & TRN & \\
\hline CHEMBL1455025 & 688277 & 4.75 & 5.0373 & TST & \\
\hline CHEMBL1362200 & 688277 & 8.0 & 4.7571 & TRN & \\
\hline CHEMBL1559896 & 688277 & 4.5 & 4.8673 & TRN & \\
\hline CHEMBL1514593 & 688277 & 4.7 & 5.3078 & TRN & \\
\hline CHEMBL1495483 & 688277 & 4.95 & 4.6805 & TRN & \\
\hline CHEMBL1605127 & 688277 & 4.95 & 4.7699 & TRN & \\
\hline CHEMBL1347729 & 688277 & 4.5 & 4.9107 & TRN & \\
\hline CHEMBL1512010 & 688277 & 4.85 & 4.9179 & TRN & \\
\hline CHEMBL1398818 & 688277 & 5.25 & 4.9281 & TST & \\
\hline CHEMBL1333313 & 688277 & 4.45 & 4.9647 & TRN & \\
\hline CHEMBL1435113 & 688277 & 4.5 & 4.8645 & TRN & \\
\hline CHEMBL1319437 & 688277 & 4.9 & 4.8215 & TRN & \\
\hline CHEMBL1551357 & 688277 & 4.85 & 5.0387 & TRN & \\
\hline CHEMBL1396860 & 688277 & 5.4 & 5.2511 & TRN & \\
\hline CHEMBL1322100 & 688277 & 5.45 & 4.9224 & TST & \\
\hline CHEMBL1610770 & 688277 & 4.6 & 4.7008 & TST & \\
\hline CHEMBL1515065 & 688277 & 5.5 & 5.2751 & TRN & \\
\hline CHEMBL1316201 & 688277 & 4.9 & 4.8764 & TRN & \\
\hline CHEMBL1336294 & 688277 & 4.5 & 4.8048 & TRN & \\
\hline CHEMBL1473549 & 688277 & 5.1 & 4.7504 & TST & \\
\hline CHEMBL1541441 & 688277 & 4.65 & 4.838 & TST & \\
\hline CHEMBL1611559 & 688277 & 4.45 & 4.7176 & TST & \\
\hline CHEMBL1611872 & 688277 & 5.0 & 4.9319 & TRN & \\
\hline CHEMBL1513020 & 688277 & 4.9 & 4.731 & TRN & \\
\hline CHEMBL1593453 & 688277 & 4.6 & 4.75899 & 99999999995 & TRN \\
\hline CHEMBL582065 & 688277 & 5.25 & 4.9769 & TST & \\
\hline CHEMBL1356798 & 688277 & 5.4 & 4.9793 & TRN & \\
\hline CHEMBL1447292 & 688277 & 5.0 & 5.0472 & TRN & \\
\hline CHEMBL1419597 & 688277 & 4.9 & 4.9053 & TRN & \\
\hline CHEMBL1454505 & 688277 & 5.25 & 4.8594 & TRN & \\
\hline CHEMBL1524912 & 688277 & 4.8 & 4.9883 & TRN & \\
\hline CHEMBL1512184 & 688277 & 4.9 & 4.8733 & TRN & \\
\hline CHEMBL1553697 & 688277 & 4.8 & 5.0327 & TRN & \\
\hline CHEMBL1323809 & 688277 & 4.8 & 4.8486 & TST & \\
\hline CHEMBL1528536 & 688277 & 4.5 & 4.7709 & TST & \\
\hline CHEMBL1395078 & 688277 & 5.5 & 5.0101 & TST & \\
\hline CHEMBL1592234 & 688277 & 4.45 & 4.9778 & TRN & \\
\hline CHEMBL1514951 & 688277 & 5.8 & 5.4588 & TRN & \\
\hline CHEMBL1397695 & 688277 & 5.4 & 4.9197 & TRN & \\
\hline CHEMBL1317872 & 688277 & 4.7 & 4.9628 & TST & \\
\hline & & & & 278 & \\
\hline
\end{tabular}




\begin{tabular}{|c|c|c|c|c|c|}
\hline \\
\hline CHEMBL1327990 & 688277 & 4.9 & 4.8909 & TRN & \\
\hline CHEMBL1370659 & 688277 & 5.25 & 5.0789 & TRN & \\
\hline CHEMBL1396285 & 688277 & 4.5 & 4.8719 & TST & \\
\hline CHEMBL1516290 & 688277 & 4.8 & 4.7183 & TRN & \\
\hline CHEMBL1475971 & 688277 & 4.6 & 5.0213 & TRN & \\
\hline CHEMBL1322944 & 688277 & 4.6 & 4.9691 & TRN & \\
\hline CHEMBL1554400 & 688277 & 5.8 & 5.3703 & TRN & \\
\hline CHEMBL1405264 & 688277 & 6.05 & 5.0098 & TST & \\
\hline CHEMBL1485139 & 688277 & 4.45 & 4.7626 & TRN & \\
\hline CHEMBL1336110 & 688277 & 4.5 & 4.6285 & TRN & \\
\hline CHEMBL1396928 & 688277 & 5.5 & 4.881 & TST & \\
\hline CHEMBL1488285 & 688277 & 4.7 & 4.7003 & TRN & \\
\hline CHEMBL1532557 & 688277 & 5.55 & 5.0175 & TRN & \\
\hline CHEMBL1355560 & 688277 & 4.9 & 4.9417 & TRN & \\
\hline CHEMBL1398308 & 688277 & 4.5 & 4.6555 & TRN & \\
\hline CHEMBL1513968 & 688277 & 4.7 & 4.8543 & TRN & \\
\hline CHEMBL1473574 & 688277 & 5.1 & 5.239 & TRN & \\
\hline CHEMBL1565955 & 688277 & 5.3 & 4.9076 & TRN & \\
\hline CHEMBL1360786 & 688277 & 4.5 & 4.6332 & TRN & \\
\hline CHEMBL1593505 & 688277 & 5.25 & 5.1456 & TRN & \\
\hline CHEMBL1317710 & 688277 & 4.45 & $4.9060 e$ & 0000000001 & TRN \\
\hline CHEMBL1597164 & 688277 & 4.6 & 4.8214 & TRN & \\
\hline CHEMBL1396337 & 688277 & 4.7 & 5.0078 & TRN & \\
\hline CHEMBL1358556 & 688277 & 4.8 & 4.6608 & TST & \\
\hline CHEMBL1321836 & 688277 & 5.15 & 4.9573 & TRN & \\
\hline CHEMBL1410697 & 688277 & 4.95 & 4.9144 & TST & \\
\hline CHEMBL1474299 & 688277 & 4.45 & 4.933 & TRN & \\
\hline CHEMBL1447052 & 688277 & 4.5 & 4.8544 & TRN & \\
\hline CHEMBL1364753 & 688277 & 4.8 & 4.7747 & TRN & \\
\hline CHEMBL1600930 & 688277 & 5.0 & 4.9545 & TRN & \\
\hline CHEMBL1593939 & 688277 & 4.7 & 4.8917 & TRN & \\
\hline CHEMBL1556254 & 688277 & 4.9 & 4.9199 & TRN & \\
\hline CHEMBL1554584 & 688277 & 4.5 & 5.025 & TRN & \\
\hline CHEMBL1476678 & 688277 & 5.5 & 4.9279 & TRN & \\
\hline CHEMBL1407547 & 688277 & 5.5 & 4.9396 & TRN & \\
\hline CHEMBL1406583 & 688277 & 4.5 & 4.8726 & TST & \\
\hline CHEMBL1395495 & 688277 & 5.35 & 4.9996 & TRN & \\
\hline CHEMBL1485026 & 688277 & 4.8 & 4.8318 & TRN & \\
\hline CHEMBL1532744 & 688277 & 4.45 & 4.9523 & TRN & \\
\hline CHEMBL1357497 & 688277 & 4.9 & 4.8795 & TST & \\
\hline CHEMBL1490130 & 688277 & 5.25 & 4.8711 & TRN & \\
\hline CHEMBL1336746 & 688277 & 5.0 & 4.9004 & TRN & \\
\hline CHEMBL1337969 & 688277 & 4.5 & 4.9916 & TRN & \\
\hline CHEMBL1434606 & 688277 & 4.9 & 4.7901 & TRN & \\
\hline CHEMBL1483007 & 688277 & 4.8 & 4.6867 & TRN & \\
\hline CHEMBL1357853 & 688277 & 4.75 & 4.7989 & TRN & \\
\hline CHEMBL1414760 & 688277 & 4.9 & 4.7797 & TRN & \\
\hline CHEMBL1567510 & 688277 & 4.7 & 4.9573 & TRN & \\
\hline
\end{tabular}




\begin{tabular}{|c|c|c|c|c|c|}
\hline & & & & & \\
\hline CHEMBL1515468 & 688277 & 4.9 & 4.895 & TRN & \\
\hline CHEMBL1554253 & 688277 & 4.65 & 4.7864 & TRN & \\
\hline CHEMBL1478843 & 688277 & 4.6 & 6.1522 & TST & \\
\hline CHEMBL1600964 & 688277 & 4.8 & 4.9121 & TRN & \\
\hline CHEMBL1439403 & 688277 & 5.4 & 5.3169 & TRN & \\
\hline CHEMBL1590010 & 688277 & 4.5 & 4.7019 & TST & \\
\hline CHEMBL1356019 & 688277 & 5.0 & 4.8873 & TST & \\
\hline CHEMBL1372245 & 688277 & 4.65 & 5.0101 & TRN & \\
\hline CHEMBL1568958 & 688277 & 4.9 & 4.9951 & TRN & \\
\hline CHEMBL1376244 & 688277 & 4.9 & 4.9263 & TRN & \\
\hline CHEMBL1474341 & 688277 & 5.8 & 5.341 & TRN & \\
\hline CHEMBL1604305 & 688277 & 7.699 & 4.9121 & TST & \\
\hline CHEMBL1315385 & 688277 & 4.45 & 4.98300 & 00000000005 & TRN \\
\hline CHEMBL1459140 & 688277 & 4.45 & 4.7834 & TST & \\
\hline CHEMBL1320867 & 688277 & 4.95 & 4.6909 & TST & \\
\hline CHEMBL1398876 & 688277 & 4.65 & 4.9678 & TST & \\
\hline CHEMBL1489082 & 688277 & 4.7 & 4.6616 & TRN & \\
\hline CHEMBL1310637 & 688277 & 4.5 & 4.8999 & TST & \\
\hline CHEMBL1328077 & 688277 & 4.9 & 4.7724 & TRN & \\
\hline CHEMBL1317281 & 688277 & 4.9 & 4.9583 & TRN & \\
\hline CHEMBL1519969 & 688277 & 5.5 & 5.2079 & TRN & \\
\hline CHEMBL1590573 & 688277 & 4.9 & 5.0504 & TST & \\
\hline CHEMBL1474773 & 688277 & 4.9 & 4.746 & TRN & \\
\hline CHEMBL1476242 & 688277 & 4.5 & 4.8768 & TRN & \\
\hline CHEMBL1358331 & 688277 & 4.8 & 4.8107 & TRN & \\
\hline CHEMBL1527663 & 688277 & 4.45 & 4.6884 & TRN & \\
\hline CHEMBL1591115 & 688277 & 4.5 & 4.7946 & TRN & \\
\hline CHEMBL1395777 & 688277 & 4.5 & 4.9315 & TRN & \\
\hline CHEMBL1315315 & 688277 & 4.5 & 4.9161 & TST & \\
\hline CHEMBL1553783 & 688277 & 5.55 & 4.9277 & TRN & \\
\hline CHEMBL1594052 & 688277 & 4.65 & 4.8395 & TRN & \\
\hline CHEMBL1374788 & 688277 & 4.65 & 5.138 & TST & \\
\hline CHEMBL1511065 & 688277 & 4.9 & 4.8922 & TRN & \\
\hline CHEMBL1592928 & 688277 & 4.5 & 4.9077 & TRN & \\
\hline CHEMBL1533608 & 688277 & 4.5 & 4.96899 & 9999999999 & TST \\
\hline CHEMBL1452341 & 688277 & 5.45 & 4.9441 & TRN & \\
\hline CHEMBL 236614 & 688277 & 4.5 & 4.9529 & TRN & \\
\hline CHEMBL1314431 & 688277 & 4.8 & 4.7238 & TST & \\
\hline CHEMBL1514738 & 688277 & 5.5 & 4.9058 & TRN & \\
\hline CHEMBL1357800 & 688277 & 5.0 & 4.8612 & TRN & \\
\hline CHEMBL1433692 & 688277 & 5.0 & 4.8761 & TRN & \\
\hline CHEMBL1453606 & 688277 & 4.95 & 4.9446 & TST & \\
\hline CHEMBL1404129 & 688277 & 4.8 & 4.9388 & TRN & \\
\hline CHEMBL1397869 & 688277 & 5.6 & 4.9626 & TRN & \\
\hline CHEMBL1554496 & 688277 & 4.9 & 4.8301 & TST & \\
\hline CHEMBL1528838 & 688277 & 4.6 & 4.9529 & TRN & \\
\hline CHEMBL1355342 & 688277 & 4.7 & 4.745 & TRN & \\
\hline CHEMBL1430635 & 688277 & 4.8 & 5.1631 & TST & \\
\hline
\end{tabular}




\begin{tabular}{|c|c|c|c|c|}
\hline \multicolumn{5}{|c|}{ pplemental T } \\
\hline CHEMBL1592831 & 688277 & 4.5 & 4.7124 & TST \\
\hline CHEMBL1396817 & 688277 & 4.9 & 4.8937 & TRN \\
\hline CHEMBL1513509 & 688277 & 5.4 & 4.9782 & TRN \\
\hline CHEMBL1551481 & 688277 & 4.5 & 5.2793 & TRN \\
\hline CHEMBL1994902 & 688277 & 4.45 & 5.2106 & TRN \\
\hline CHEMBL1435700 & 688277 & 4.45 & 4.9162 & TRN \\
\hline CHEMBL1434810 & 688277 & 4.5 & 5.1726 & TRN \\
\hline CHEMBL1326798 & 688277 & 4.5 & 5.4424 & TRN \\
\hline CHEMBL1522332 & 688277 & 4.45 & 4.6895 & TST \\
\hline CHEMBL1553917 & 688277 & 4.5 & 4.948 & TST \\
\hline CHEMBL1397952 & 688277 & 5.5 & 5.2801 & TST \\
\hline CHEMBL1589821 & 688277 & 4.5 & 4.7996 & TRN \\
\hline CHEMBL1552057 & 688277 & 4.5 & 5.0351 & TRN \\
\hline CHEMBL 3194247 & 688277 & 4.95 & 4.9545 & TST \\
\hline CHEMBL1564096 & 688277 & 4.9 & 4.9572 & TRN \\
\hline CHEMBL1398505 & 688277 & 5.45 & 4.9438 & TRN \\
\hline CHEMBL1331074 & 688277 & 4.8 & 4.9053 & TST \\
\hline CHEMBL1593678 & 688277 & 4.5 & 4.7316 & TRN \\
\hline CHEMBL104728 & 688277 & 4.65 & 5.1367 & TST \\
\hline CHEMBL1597728 & 688277 & 4.9 & 4.958 & TRN \\
\hline CHEMBL1475403 & 688277 & 5.0 & 4.9404 & TRN \\
\hline CHEMBL1373256 & 688277 & 4.45 & 4.8842 & TRN \\
\hline CHEMBL1373521 & 688277 & 4.95 & 4.9666 & TRN \\
\hline CHEMBL1553674 & 688277 & 4.45 & 4.7745 & TRN \\
\hline CHEMBL1527186 & 688277 & 4.9 & 4.8685 & TRN \\
\hline CHEMBL1532098 & 688277 & 5.0 & 4.9866 & TRN \\
\hline CHEMBL1600425 & 688277 & 4.5 & 4.8995 & TRN \\
\hline CHEMBL1554073 & 688277 & 4.5 & 4.7304 & TRN \\
\hline CHEMBL 1405163 & 688277 & 4.9 & 4.6178 & TRN \\
\hline CHEMBL1595264 & 688277 & 5.2 & 4.9974 & TRN \\
\hline CHEMBL1481415 & 688277 & 4.8 & 4.8276 & TRN \\
\hline CHEMBL1524192 & 688277 & 5.1 & 4.9442 & TRN \\
\hline CHEMBL1554153 & 688277 & 4.9 & 5.0732 & TRN \\
\hline CHEMBL1380514 & 688277 & 4.9 & 4.8786 & TRN \\
\hline CHEMBL1333767 & 688277 & 4.9 & 4.6629 & TST \\
\hline CHEMBL1474641 & 688277 & 5.0 & 5.0164 & TRN \\
\hline CHEMBL1510389 & 688277 & 5.6 & 5.2926 & TRN \\
\hline CHEMBL1520523 & 688277 & 4.7 & 4.7127 & TRN \\
\hline CHEMBL1516425 & 688277 & 5.3 & 4.8541 & TRN \\
\hline CHEMBL1315389 & 688277 & 4.5 & 5.3601 & TRN \\
\hline CHEMBL1473009 & 688277 & 4.8 & 4.7804 & TRN \\
\hline CHEMBL1315225 & 688277 & 4.5 & 4.8986 & TST \\
\hline CHEMBL1378198 & 688277 & 4.7 & 4.6372 & TRN \\
\hline CHEMBL1395529 & 688277 & 5.0 & 4.934 & TRN \\
\hline CHEMBL1525104 & 688277 & 4.5 & 4.9098 & TRN \\
\hline CHEMBL1515371 & 688277 & 4.5 & 5.0119 & TRN \\
\hline CHEMBL1594065 & 688277 & 4.5 & 5.1751 & TRN \\
\hline CHEMBL1435894 & 688277 & 5.0 & 4.6654 & TRN \\
\hline
\end{tabular}




\begin{tabular}{|c|c|c|c|c|}
\hline & & & pplement & al $\mathrm{Ta}$ \\
\hline CHEMBL1314968 & 688277 & 4.5 & 4.9203 & TRN \\
\hline CHEMBL1394746 & 688277 & 4.5 & 4.8946 & TST \\
\hline CHEMBL1314932 & 688277 & 4.7 & 4.9265 & TRN \\
\hline CHEMBL1401545 & 688277 & 5.1 & 4.9846 & TRN \\
\hline CHEMBL1472652 & 688277 & 5.0 & 4.9709 & TRN \\
\hline CHEMBL1357087 & 688277 & 4.5 & 4.8195 & TRN \\
\hline CHEMBL1440965 & 688277 & 4.5 & 4.7749 & TRN \\
\hline CHEMBL1403829 & 688277 & 4.7 & 4.5955 & TRN \\
\hline CHEMBL1435958 & 688277 & 4.9 & 4.7131 & TST \\
\hline CHEMBL1593295 & 688277 & 5.6 & 4.8968 & TRN \\
\hline CHEMBL1515196 & 688277 & 4.5 & 4.9737 & TST \\
\hline CHEMBL1395582 & 688277 & 4.5 & 4.7632 & TRN \\
\hline CHEMBL1474187 & 688277 & 4.9 & 4.8928 & TRN \\
\hline CHEMBL1526044 & 688277 & 5.55 & 5.1558 & TRN \\
\hline CHEMBL1396641 & 688277 & 4.95 & 4.9089 & TST \\
\hline CHEMBL1435037 & 688277 & 5.1 & 4.6647 & TST \\
\hline CHEMBL 2007403 & 688277 & 5.0 & 4.9049 & TST \\
\hline CHEMBL1514829 & 688277 & 4.8 & 4.9511 & TST \\
\hline CHEMBL1558231 & 688277 & 5.4 & 4.8581 & TST \\
\hline CHEMBL1314507 & 688277 & 4.45 & 4.9332 & TRN \\
\hline CHEMBL1318437 & 688277 & 5.45 & 5.1055 & TRN \\
\hline CHEMBL1564586 & 688277 & 5.45 & 4.8543 & TRN \\
\hline CHEMBL1515962 & 688277 & 4.5 & 5.0652 & TRN \\
\hline CHEMBL1457597 & 688277 & 4.8 & 4.9611 & TST \\
\hline CHEMBL1366362 & 688277 & 4.8 & 4.8049 & TRN \\
\hline CHEMBL1463860 & 688277 & 4.45 & 5.3178 & TRN \\
\hline CHEMBL1397370 & 688277 & 4.5 & 5.0856 & TRN \\
\hline CHEMBL1592998 & 688277 & 7.4498 & 4.8739 & TRN \\
\hline CHEMBL1526982 & 688277 & 4.6 & 4.8145 & TRN \\
\hline CHEMBL1356125 & 688277 & 4.6 & 4.6952 & TRN \\
\hline CHEMBL1318246 & 688277 & 5.4 & 4.8965 & TRN \\
\hline CHEMBL1475915 & 688277 & 5.5 & 5.1088 & TST \\
\hline CHEMBL1565613 & 688277 & 4.5 & 4.6273 & TRN \\
\hline CHEMBL1357104 & 688277 & 4.6 & 4.9464 & TST \\
\hline CHEMBL1516315 & 688277 & 5.1 & 5.0428 & TRN \\
\hline CHEMBL1404575 & 688277 & 4.65 & 4.9316 & TRN \\
\hline CHEMBL1381855 & 688277 & 4.95 & 4.9288 & TRN \\
\hline CHEMBL1321036 & 688277 & 4.75 & 5.1572 & TRN \\
\hline CHEMBL1516098 & 688277 & 4.9 & 4.8784 & TRN \\
\hline CHEMBL1450676 & 688277 & 5.6 & 5.2288 & TRN \\
\hline CHEMBL1407094 & 688277 & 5.5 & 5.2092 & TST \\
\hline CHEMBL1398178 & 688277 & 5.25 & 4.9046 & TRN \\
\hline CHEMBL1514773 & 688277 & 4.6 & 5.1575 & TRN \\
\hline CHEMBL1444261 & 688277 & 4.75 & 4.9974 & TRN \\
\hline CHEMBL1357554 & 688277 & 4.6 & 4.69 & TRN \\
\hline CHEMBL1552795 & 688277 & 4.7 & 4.9551 & TST \\
\hline CHEMBL1415955 & 688277 & 4.7 & 4.8104 & TRN \\
\hline CHEMBL1376718 & 688277 & 4.5 & 4.8293 & TST \\
\hline
\end{tabular}




\begin{tabular}{|c|c|c|c|c|c|}
\hline & & & & & \\
\hline CHEMBL1434787 & 688277 & 4.8 & 4.9577 & TRN & \\
\hline CHEMBL1324142 & 688277 & 4.6 & 4.7881 & TST & \\
\hline CHEMBL1440562 & 688277 & 4.5 & 4.8551 & TST & \\
\hline CHEMBL1478802 & 688277 & 5.25 & 5.0494 & TRN & \\
\hline CHEMBL1551671 & 688277 & 4.9 & 4.8147 & TST & \\
\hline CHEMBL1439787 & 688277 & 5.2 & 5.1296 & TST & \\
\hline CHEMBL1364898 & 688277 & 4.5 & 4.8767 & TRN & \\
\hline CHEMBL1400055 & 688277 & 4.7 & 4.8782 & TRN & \\
\hline CHEMBL1485379 & 688277 & 4.6 & 4.8577 & TRN & \\
\hline CHEMBL1594926 & 688277 & 5.0 & 5.088 & TST & \\
\hline CHEMBL1356126 & 688277 & 5.0 & 4.9074 & TRN & \\
\hline CHEMBL1319892 & 688277 & 4.5 & 4.8961 & TST & \\
\hline CHEMBL1317919 & 688277 & 4.5 & 4.7523 & TRN & \\
\hline CHEMBL1540848 & 688277 & 4.8 & 4.8961 & TRN & \\
\hline CHEMBL1516258 & 688277 & 4.5 & 4.98300 & 00000000005 & TST \\
\hline CHEMBL1434245 & 688277 & 5.2 & 4.7635 & TRN & \\
\hline CHEMBL1401550 & 688277 & 4.5 & 4.9152 & TRN & \\
\hline CHEMBL239009 & 688277 & 4.5 & 4.6981 & TRN & \\
\hline CHEMBL1371746 & 688277 & 5.2 & 5.0262 & TRN & \\
\hline CHEMBL1364332 & 688277 & 4.5 & 5.0615 & TST & \\
\hline CHEMBL1415050 & 688277 & 4.5 & 4.8671 & TRN & \\
\hline CHEMBL1318141 & 688277 & 4.8 & 4.8743 & TRN & \\
\hline CHEMBL1356051 & 688277 & 6.2 & 5.51 & TRN & \\
\hline CHEMBL1528247 & 688277 & 4.9 & 4.9693 & TST & \\
\hline CHEMBL1481911 & 688277 & 4.7 & 4.8261 & TRN & \\
\hline CHEMBL1514025 & 688277 & 4.6 & 4.8113 & TST & \\
\hline CHEMBL1476683 & 688277 & 4.9 & 4.8911 & TRN & \\
\hline CHEMBL1434035 & 688277 & 4.45 & 4.8506 & TRN & \\
\hline CHEMBL1317654 & 688277 & 8.4949 & 5.0788 & TRN & \\
\hline CHEMBL1425778 & 688277 & 5.3 & 4.9516 & TST & \\
\hline CHEMBL1406802 & 688277 & 4.9 & 4.9455 & TST & \\
\hline CHEMBL1394475 & 688277 & 4.7 & 4.8102 & TRN & \\
\hline CHEMBL1551045 & 688277 & 4.8 & 4.8056 & TRN & \\
\hline CHEMBL1369018 & 688277 & 5.2 & 5.0215 & TRN & \\
\hline CHEMBL1393885 & 688277 & 4.8 & 4.9591 & TRN & \\
\hline CHEMBL1553105 & 688277 & 4.9 & 4.8741 & TRN & \\
\hline CHEMBL1445081 & 688277 & 4.5 & 4.7161 & TRN & \\
\hline CHEMBL1591941 & 688277 & 4.6 & 4.8861 & TRN & \\
\hline CHEMBL1398258 & 688277 & 5.4 & 4.8743 & TRN & \\
\hline CHEMBL1514160 & 688277 & 4.9 & 4.7712 & TRN & \\
\hline CHEMBL1322741 & 688277 & 4.6 & 4.8337 & TRN & \\
\hline CHEMBL1553227 & 688277 & 4.45 & 4.9073 & TRN & \\
\hline CHEMBL3193652 & 688277 & 5.45 & 5.2735 & TST & \\
\hline CHEMBL1397876 & 688277 & 4.9 & 4.8551 & TRN & \\
\hline CHEMBL1363355 & 688277 & 4.5 & 5.5088 & TRN & \\
\hline CHEMBL1476250 & 688277 & 6.7001 & 4.9448 & TRN & \\
\hline CHEMBL1608370 & 688277 & 5.5 & 4.9961 & TST & \\
\hline CHEMBL1477142 & 688277 & 4.5 & 4.9194 & TRN & \\
\hline
\end{tabular}




\begin{tabular}{|c|c|c|c|c|c|}
\hline \multicolumn{6}{|c|}{ Supplemental Table S2.txt } \\
\hline CHEMBL1449717 & 688277 & 5.25 & 5.0521 & TST & \\
\hline CHEMBL1590217 & 688277 & 4.5 & 4.7614 & TRN & \\
\hline CHEMBL1355768 & 688277 & 5.5 & 4.8945 & TRN & \\
\hline CHEMBL1358265 & 688277 & 4.7 & 4.9604 & TRN & \\
\hline CHEMBL1475630 & 688277 & 5.3 & 4.9269 & TRN & \\
\hline CHEMBL1592201 & 688277 & 5.4 & 5.2046 & TST & \\
\hline CHEMBL1515000 & 688277 & 4.6 & 4.945 & TRN & \\
\hline CHEMBL1356053 & 688277 & 4.5 & 4.9665 & TST & \\
\hline CHEMBL1550909 & 688277 & 5.5 & 5.1972 & TST & \\
\hline CHEMBL1481791 & 688277 & 4.7 & 4.6295 & TRN & \\
\hline CHEMBL1608062 & 688277 & 5.2 & 5.1114 & TRN & \\
\hline CHEMBL1394662 & 688277 & 4.65 & 4.9291 & TRN & \\
\hline CHEMBL1410350 & 688277 & 4.5 & 4.8063 & TST & \\
\hline CHEMBL1564573 & 688277 & 4.5 & 4.7908 & TRN & \\
\hline CHEMBL1592267 & 688277 & 4.45 & 4.9733 & TRN & \\
\hline CHEMBL1374110 & 688277 & 4.5 & 4.9509 & TRN & \\
\hline CHEMBL1514377 & 688277 & 4.85 & 4.9222 & TRN & \\
\hline CHEMBL1357448 & 688277 & 5.0 & 4.8979 & TRN & \\
\hline CHEMBL1474726 & 688277 & 5.15 & 5.037 & TST & \\
\hline CHEMBL1476520 & 688277 & 4.45 & 4.868 & TRN & \\
\hline CHEMBL1354280 & 688277 & 4.55 & 4.7073 & TRN & \\
\hline CHEMBL1404188 & 688277 & 4.6 & 4.6879 & TRN & \\
\hline CHEMBL1325261 & 688277 & 4.45 & 4.9303 & TRN & \\
\hline CHEMBL1534672 & 688277 & 5.0 & 4.7486 & TRN & \\
\hline CHEMBL1366451 & 688277 & 4.35 & 5.0232 & TST & \\
\hline CHEMBL1312208 & 688277 & 4.45 & 4.9912 & TST & \\
\hline CHEMBL1373012 & 688277 & 4.9 & 4.8772 & TRN & \\
\hline CHEMBL1359201 & 688277 & 4.5 & 4.8667 & TRN & \\
\hline CHEMBL1355042 & 688277 & 4.45 & 4.9212 & TRN & \\
\hline CHEMBL1515952 & 688277 & 5.9 & 5.4246 & TST & \\
\hline CHEMBL1595911 & 688277 & 4.7 & 4.8745 & TRN & \\
\hline CHEMBL1611952 & 688277 & 4.8 & 5.4491 & TRN & \\
\hline CHEMBL1348741 & 688277 & 4.75 & 4.9454 & TST & \\
\hline CHEMBL1405154 & 688277 & 4.5 & 4.9269 & TRN & \\
\hline CHEMBL1320320 & 688277 & 4.7 & 4.7979 & TRN & \\
\hline CHEMBL1475259 & 688277 & 4.9 & 4.9006 & TRN & \\
\hline CHEMBL1328737 & 688277 & 4.5 & 4.8637 & TRN & \\
\hline CHEMBL1523460 & 688277 & 4.95 & 4.874 & TRN & \\
\hline CHEMBL1422346 & 688277 & 5.0 & 4.92399 & 99999999995 & TRN \\
\hline CHEMBL1554039 & 688277 & 4.9 & 4.9327 & TST & \\
\hline CHEMBL1555170 & 688277 & 4.5 & 5.581 & TRN & \\
\hline CHEMBL1601644 & 688277 & 5.5 & 5.1065 & TRN & \\
\hline CHEMBL1439041 & 688277 & 4.6 & 4.8446 & TRN & \\
\hline CHEMBL1443693 & 688277 & 4.8 & 4.7606 & TRN & \\
\hline CHEMBL1571543 & 688277 & 4.5 & 4.8217 & TRN & \\
\hline CHEMBL2001739 & 688277 & 5.25 & 5.3534 & TST & \\
\hline CHEMBL1590653 & 688277 & 5.55 & 4.8886 & TRN & \\
\hline CHEMBL1555115 & 688277 & 5.25 & 4.8505 & TRN & \\
\hline
\end{tabular}




\begin{tabular}{|c|c|c|c|c|}
\hline \multicolumn{5}{|c|}{ Supplemental Table S2.txt } \\
\hline CHEMBL1363412 & 688277 & 5.25 & 4.9391 & TRN \\
\hline CHEMBL1518919 & 688277 & 5.35 & 4.9124 & TST \\
\hline CHEMBL1593320 & 688277 & 6.1 & 4.9182 & TST \\
\hline CHEMBL1573615 & 688277 & 4.45 & 4.791 & TRN \\
\hline CHEMBL1592256 & 688277 & 4.9 & 4.9233 & TRN \\
\hline CHEMBL 377583 & 688277 & 5.0 & 5.002 & TRN \\
\hline CHEMBL1355231 & 688277 & 4.7 & 4.8937 & TST \\
\hline CHEMBL1357951 & 688277 & 4.5 & 5.0493 & TRN \\
\hline CHEMBL1591689 & 688277 & 4.9 & 4.9078 & TRN \\
\hline CHEMBL1403851 & 688277 & 4.95 & 4.9737 & TRN \\
\hline CHEMBL 3192873 & 688277 & 4.9 & 5.0279 & TST \\
\hline CHEMBL1355240 & 688277 & 4.9 & 4.7053 & TRN \\
\hline CHEMBL3198440 & 688277 & 5.1 & 4.9406 & TST \\
\hline CHEMBL1590915 & 688277 & 4.5 & 4.9354 & TRN \\
\hline CHEMBL1317047 & 688277 & 5.4 & 5.1228 & TRN \\
\hline CHEMBL1494324 & 688277 & 4.5 & 4.9411 & TRN \\
\hline CHEMBL1370548 & 688277 & 4.7 & 4.9087 & TRN \\
\hline CHEMBL1367795 & 688277 & 5.6 & 5.0942 & TRN \\
\hline CHEMBL1456555 & 688277 & 5.55 & 4.9612 & TRN \\
\hline CHEMBL1552414 & 688277 & 4.5 & 4.8951 & TRN \\
\hline CHEMBL1530752 & 688277 & 4.7 & 4.9462 & TST \\
\hline CHEMBL1433544 & 688277 & 4.7 & 4.8421 & TRN \\
\hline CHEMBL1357804 & 688277 & 4.6 & 4.9305 & TRN \\
\hline CHEMBL1375694 & 688277 & 5.5 & 5.0229 & TST \\
\hline CHEMBL1547363 & 688277 & 6.35 & 4.9257 & TRN \\
\hline CHEMBL1396684 & 688277 & 5.8 & 5.5683 & TRN \\
\hline CHEMBL3213953 & 688277 & 5.0 & 5.4517 & TST \\
\hline CHEMBL1395627 & 688277 & 5.35 & 5.015 & TRN \\
\hline CHEMBL1452817 & 688277 & 5.4 & 5.2884 & TST \\
\hline CHEMBL1412832 & 688277 & 4.8 & 4.6649 & TRN \\
\hline CHEMBL1512958 & 688277 & 4.7 & 4.959 & TRN \\
\hline CHEMBL1486245 & 688277 & 4.8 & 4.9062 & TRN \\
\hline CHEMBL1327028 & 688277 & 4.8 & 4.8801 & TRN \\
\hline CHEMBL1473558 & 688277 & 5.25 & 4.8679 & TST \\
\hline CHEMBL1512137 & 688277 & 4.5 & 4.7757 & TRN \\
\hline CHEMBL1413016 & 688277 & 4.5 & 5.0724 & TRN \\
\hline CHEMBL1314550 & 688277 & 4.45 & 4.8738 & TRN \\
\hline CHEMBL1560503 & 688277 & 5.0 & 4.6296 & TST \\
\hline CHEMBL1356290 & 688277 & 4.9 & 4.8711 & TST \\
\hline CHEMBL1412987 & 688277 & 4.65 & 4.8452 & TRN \\
\hline CHEMBL1561989 & 688277 & 4.6 & 4.7177 & TRN \\
\hline CHEMBL1554162 & 688277 & 4.5 & 4.8169 & TRN \\
\hline CHEMBL1355658 & 688277 & 4.8 & 4.9719 & TRN \\
\hline CHEMBL1473551 & 688277 & 4.8 & 4.8832 & TRN \\
\hline CHEMBL1309497 & 688277 & 5.15 & 4.9217 & TRN \\
\hline CHEMBL1503002 & 688277 & 4.95 & 4.8908 & TRN \\
\hline CHEMBL1569263 & 688277 & 4.5 & 5.5598 & TRN \\
\hline CHEMBL1409391 & 688277 & 5.0 & 4.8237 & TRN \\
\hline
\end{tabular}




\begin{tabular}{|c|c|c|c|c|c|}
\hline & & & & & \\
\hline CHEMBL1407986 & 688277 & 4.5 & 4.6346 & TRN & \\
\hline CHEMBL1397035 & 688277 & 5.25 & 5.0593 & TST & \\
\hline CHEMBL1394175 & 688277 & 5.25 & 5.2134 & TST & \\
\hline CHEMBL1553829 & 688277 & 4.8 & 4.853 & TRN & \\
\hline CHEMBL1398435 & 688277 & 8.2007 & 5.1589 & TRN & \\
\hline CHEMBL1413171 & 688277 & 4.45 & 4.6705 & TRN & \\
\hline CHEMBL1702181 & 688277 & 4.9 & 4.9448 & TRN & \\
\hline CHEMBL1476763 & 688277 & 4.9 & 4.8898 & TRN & \\
\hline CHEMBL1439533 & 688277 & 4.6 & 4.7529 & TRN & \\
\hline CHEMBL1495299 & 688277 & 4.5 & 4.8784 & TRN & \\
\hline CHEMBL1484686 & 688277 & 5.0 & 4.8419 & TRN & \\
\hline CHEMBL1476900 & 688277 & 4.45 & 4.8125 & TRN & \\
\hline CHEMBL1358179 & 688277 & 4.5 & 4.6677 & TRN & \\
\hline CHEMBL1525198 & 688277 & 4.95 & 5.0377 & TRN & \\
\hline CHEMBL1356179 & 688277 & 4.6 & 4.9484 & TRN & \\
\hline CHEMBL1398485 & 688277 & 4.7 & 4.8739 & TRN & \\
\hline CHEMBL1416470 & 688277 & 4.9 & 4.8661 & TRN & \\
\hline CHEMBL1371452 & 688277 & 4.8 & 4.9025 & TRN & \\
\hline CHEMBL1484911 & 688277 & 4.6 & 4.7287 & TRN & \\
\hline CHEMBL1452502 & 688277 & 5.0 & 4.8954 & TRN & \\
\hline CHEMBL1372857 & 688277 & 4.95 & 4.9176 & TRN & \\
\hline CHEMBL1403150 & 688277 & 4.9 & 4.7299 & TST & \\
\hline CHEMBL1593214 & 688277 & 5.3 & 4.8888 & TRN & \\
\hline CHEMBL1595100 & 688277 & 4.9 & 4.8634 & TRN & \\
\hline CHEMBL1976236 & 688277 & 4.75 & 4.9534 & TST & \\
\hline CHEMBL1602735 & 688277 & 5.9 & 4.9694 & TST & \\
\hline CHEMBL1374746 & 688277 & 5.05 & 5.04899 & 99999999995 & TST \\
\hline CHEMBL1515357 & 688277 & 4.75 & 4.8632 & TRN & \\
\hline CHEMBL1603687 & 688277 & 4.5 & 4.706 & TST & \\
\hline CHEMBL1548306 & 688277 & 4.9 & 4.9069 & TST & \\
\hline CHEMBL1452896 & 688277 & 4.8 & 4.7258 & TRN & \\
\hline CHEMBL1594024 & 688277 & 4.45 & 4.8839 & TRN & \\
\hline CHEMBL1593151 & 688277 & 5.0 & 4.8434 & TRN & \\
\hline CHEMBL585999 & 688277 & 5.0 & 4.9663 & TRN & \\
\hline CHEMBL1476639 & 688277 & 4.9 & 4.9119 & TRN & \\
\hline CHEMBL1494755 & 688277 & 4.45 & 4.9322 & TRN & \\
\hline CHEMBL1592308 & 688277 & 4.55 & 4.905 & TRN & \\
\hline CHEMBL1512490 & 688277 & 4.6 & 4.8028 & TRN & \\
\hline CHEMBL1548327 & 688277 & 4.95 & 4.8969 & TST & \\
\hline CHEMBL1592292 & 688277 & 4.5 & 4.9362 & TRN & \\
\hline CHEMBL1554239 & 688277 & 4.9 & 4.8924 & TRN & \\
\hline CHEMBL1553324 & 688277 & 4.5 & 4.6568 & TRN & \\
\hline CHEMBL1445164 & 688277 & 4.45 & 4.9636 & TRN & \\
\hline CHEMBL1594868 & 688277 & 5.0 & 4.9384 & TRN & \\
\hline CHEMBL1318081 & 688277 & 4.45 & 4.9372 & TRN & \\
\hline CHEMBL1593180 & 688277 & 4.8 & 4.834 & TRN & \\
\hline CHEMBL1381270 & 688277 & 4.9 & 4.94300 & 00000000005 & TRN \\
\hline CHEMBL1366181 & 688277 & 4.6 & 4.8287 & TRN & \\
\hline
\end{tabular}




\begin{tabular}{|c|c|c|c|c|}
\hline \multicolumn{5}{|c|}{ Supplemental Table S2.txt } \\
\hline CHEMBL1317615 & 688277 & 4.5 & 4.8055 & TRN \\
\hline CHEMBL1408656 & 688277 & 4.5 & 4.7066 & TRN \\
\hline CHEMBL1562543 & 688277 & 5.25 & 4.9621 & TST \\
\hline CHEMBL1512720 & 688277 & 4.7 & 4.8766 & TRN \\
\hline CHEMBL1354621 & 688277 & 5.55 & 5.2891 & TRN \\
\hline CHEMBL1319095 & 688277 & 5.0 & 4.9323 & TRN \\
\hline CHEMBL1341870 & 688277 & 4.5 & 4.7599 & TRN \\
\hline CHEMBL1331834 & 688277 & 4.5 & 4.8152 & TRN \\
\hline CHEMBL1480801 & 688277 & 5.35 & 5.1009 & TRN \\
\hline CHEMBL1535258 & 688277 & 4.5 & 4.9303 & TRN \\
\hline CHEMBL1493139 & 688277 & 4.6 & 4.9413 & TRN \\
\hline CHEMBL1434829 & 688277 & 4.7 & 5.064 & TST \\
\hline CHEMBL1427823 & 688277 & 4.85 & 4.9657 & TRN \\
\hline CHEMBL1394550 & 688277 & 4.9 & 4.8855 & TRN \\
\hline CHEMBL1438989 & 688277 & 5.55 & 5.0426 & TRN \\
\hline CHEMBL1419071 & 688277 & 5.0 & 5.4328 & TST \\
\hline CHEMBL1582488 & 688277 & 4.95 & 4.9598 & TST \\
\hline CHEMBL1608802 & 688277 & 5.0 & 4.9059 & TRN \\
\hline CHEMBL1601695 & 688277 & 4.6 & 4.8347 & TRN \\
\hline CHEMBL1554570 & 688277 & 4.5 & 5.3212 & TRN \\
\hline CHEMBL1434260 & 688277 & 4.8 & 4.8388 & TRN \\
\hline CHEMBL1436786 & 688277 & 4.45 & 4.6972 & TST \\
\hline CHEMBL602740 & 688277 & 4.5 & 4.9016 & TRN \\
\hline CHEMBL1475174 & 688277 & 5.25 & 5.1504 & TST \\
\hline CHEMBL1443173 & 688277 & 5.0 & 5.0863 & TRN \\
\hline CHEMBL1395100 & 688277 & 4.6 & 4.8883 & TST \\
\hline CHEMBL1353194 & 688277 & 4.65 & 4.7023 & TRN \\
\hline CHEMBL1314864 & 688277 & 4.45 & 4.734 & TRN \\
\hline CHEMBL1353069 & 688277 & 4.8 & 4.7842 & TRN \\
\hline CHEMBL1518698 & 688277 & 4.6 & 4.664 & TRN \\
\hline CHEMBL1554494 & 688277 & 5.35 & 5.02 & TRN \\
\hline CHEMBL1433832 & 688277 & 4.6 & 4.731 & TRN \\
\hline CHEMBL1486098 & 688277 & 4.6 & 5.0241 & TST \\
\hline CHEMBL1497658 & 688277 & 4.45 & 5.1173 & TST \\
\hline CHEMBL1488604 & 688277 & 4.9 & 4.9424 & TRN \\
\hline CHEMBL1555159 & 688277 & 4.8 & 4.9154 & TRN \\
\hline CHEMBL1477695 & 688277 & 4.5 & 4.6447 & TRN \\
\hline CHEMBL1591901 & 688277 & 4.9 & 4.8734 & TRN \\
\hline CHEMBL1435897 & 688277 & 4.45 & 5.1093 & TRN \\
\hline CHEMBL1574638 & 688277 & 4.5 & 4.8686 & TRN \\
\hline CHEMBL1547533 & 688277 & 4.9 & 4.8861 & TST \\
\hline CHEMBL1515591 & 688277 & 4.7 & 4.8311 & TRN \\
\hline CHEMBL1553821 & 688277 & 4.45 & 5.0812 & TRN \\
\hline CHEMBL1530631 & 688277 & 4.9 & 4.928 & TST \\
\hline CHEMBL1359067 & 688277 & 5.0 & 4.9129 & TRN \\
\hline CHEMBL1395781 & 688277 & 4.5 & 4.8257 & TST \\
\hline CHEMBL1515830 & 688277 & 4.7 & 4.8315 & TST \\
\hline CHEMBL1533227 & 688277 & 5.25 & 5.5783 & TRN \\
\hline
\end{tabular}




\begin{tabular}{|c|c|c|c|c|c|}
\hline \\
\hline CHEMBL1590040 & 688277 & 4.5 & 4.9408 & TRN & \\
\hline CHEMBL1512931 & 688277 & 4.45 & 4.7658 & TRN & \\
\hline CHEMBL1395660 & 688277 & 5.3 & 4.7424 & TRN & \\
\hline CHEMBL1554931 & 688277 & 4.9 & 4.8837 & TRN & \\
\hline CHEMBL1573832 & 688277 & 4.8 & 4.8997 & TRN & \\
\hline CHEMBL1511299 & 688277 & 5.5 & 4.9845 & TST & \\
\hline CHEMBL1328834 & 688277 & 5.4 & 4.90600 & 2000000001 & TRN \\
\hline CHEMBL1394123 & 688277 & 4.7 & 4.9311 & TRN & \\
\hline CHEMBL1330767 & 688277 & 4.5 & 4.8511 & TRN & \\
\hline CHEMBL1493507 & 688277 & 4.5 & 4.8718 & TRN & \\
\hline CHEMBL1416104 & 688277 & 4.7 & 4.6525 & TST & \\
\hline CHEMBL1516642 & 688277 & 5.45 & 4.9321 & TRN & \\
\hline CHEMBL1518592 & 688277 & 4.9 & 4.8862 & TRN & \\
\hline CHEMBL1596864 & 688277 & 4.5 & 4.6662 & TST & \\
\hline CHEMBL1518001 & 688277 & 4.45 & 5.0658 & TRN & \\
\hline CHEMBL1552375 & 688277 & 4.5 & 5.0404 & TST & \\
\hline CHEMBL1355297 & 688277 & 4.9 & 4.9326 & TRN & \\
\hline CHEMBL1528373 & 688277 & 4.8 & 4.7038 & TRN & \\
\hline CHEMBL1572361 & 688277 & 4.7 & 4.9459 & TRN & \\
\hline CHEMBL1494073 & 688277 & 5.0 & 4.934 & TRN & \\
\hline CHEMBL1324329 & 688277 & 4.5 & 4.6745 & TST & \\
\hline CHEMBL1394991 & 688277 & 4.85 & 4.8569 & TST & \\
\hline CHEMBL1401579 & 688277 & 4.9 & 4.8659 & TRN & \\
\hline CHEMBL1454572 & 688277 & 4.6 & 4.9551 & TRN & \\
\hline CHEMBL1311208 & 688277 & 4.6 & 4.9774 & TRN & \\
\hline CHEMBL1595502 & 688277 & 4.5 & 5.0349 & TRN & \\
\hline CHEMBL1412672 & 688277 & 4.5 & 4.7069 & TST & \\
\hline CHEMBL1605392 & 688277 & 4.9 & 5.0348 & TRN & \\
\hline CHEMBL1394275 & 688277 & 5.55 & 4.9545 & TRN & \\
\hline CHEMBL1594066 & 688277 & 5.45 & 4.8916 & TRN & \\
\hline CHEMBL1601073 & 688277 & 4.6 & 4.9917 & TST & \\
\hline CHEMBL1445812 & 688277 & 4.5 & 4.9063 & TRN & \\
\hline CHEMBL1590072 & 688277 & 5.0 & 4.8531 & TRN & \\
\hline CHEMBL1434902 & 688277 & 4.9 & 4.96399 & 99999999995 & TST \\
\hline CHEMBL1496409 & 688277 & 4.6 & 4.8255 & TRN & \\
\hline CHEMBL1396361 & 688277 & 4.7 & 4.6282 & TRN & \\
\hline CHEMBL1447419 & 688277 & 5.2 & 5.0182 & TRN & \\
\hline CHEMBL1551354 & 688277 & 4.9 & 4.8313 & TRN & \\
\hline CHEMBL1486507 & 688277 & 4.8 & 4.8102 & TRN & \\
\hline CHEMBL1612313 & 688277 & 5.0 & 4.9356 & TRN & \\
\hline CHEMBL1372938 & 688277 & 4.6 & 4.8219 & TST & \\
\hline CHEMBL1412241 & 688277 & 4.9 & 4.9692 & TST & \\
\hline CHEMBL1318060 & 688277 & 5.7 & 5.2694 & TRN & \\
\hline CHEMBL1534295 & 688277 & 4.7 & 4.7002 & TRN & \\
\hline CHEMBL1395748 & 688277 & 4.45 & 5.0152 & TRN & \\
\hline CHEMBL1406098 & 688277 & 5.25 & 4.9216 & TRN & \\
\hline CHEMBL1475110 & 688277 & 4.7 & 4.9348 & TST & \\
\hline CHEMBL1323217 & 688277 & 4.5 & 4.7368 & TST & \\
\hline
\end{tabular}




\begin{tabular}{|c|c|c|c|c|}
\hline \multicolumn{5}{|c|}{ Supplemental Table S2.txt } \\
\hline CHEMBL1555188 & 688277 & 5.1 & 4.8986 & TRN \\
\hline CHEMBL1472809 & 688277 & 4.5 & 4.6916 & TRN \\
\hline CHEMBL1396485 & 688277 & 5.2 & 5.1201 & TRN \\
\hline CHEMBL1404482 & 688277 & 7.5003 & 4.9736 & TRN \\
\hline CHEMBL1376155 & 688277 & 4.5 & 4.8911 & TRN \\
\hline CHEMBL1513326 & 688277 & 4.85 & 4.6383 & TRN \\
\hline CHEMBL1566884 & 688277 & 4.5 & 5.2919 & TRN \\
\hline CHEMBL1358129 & 688277 & 4.5 & 4.8689 & TST \\
\hline CHEMBL1473513 & 688277 & 4.9 & 4.8242 & TRN \\
\hline CHEMBL1357015 & 688277 & 4.5 & 4.8935 & TST \\
\hline CHEMBL1382028 & 688277 & 4.95 & 5.0225 & TRN \\
\hline CHEMBL1316610 & 688277 & 4.45 & 5.1284 & TRN \\
\hline CHEMBL1434565 & 688277 & 4.5 & 4.8031 & TRN \\
\hline CHEMBL1472862 & 688277 & 5.35 & 4.8417 & TRN \\
\hline CHEMBL1528904 & 688277 & 4.5 & 4.8838 & TRN \\
\hline CHEMBL1601738 & 688277 & 4.9 & 4.9765 & TST \\
\hline CHEMBL1516585 & 688277 & 4.6 & 4.6879 & TRN \\
\hline CHEMBL1573195 & 688277 & 4.7 & 4.8329 & TRN \\
\hline CHEMBL1356931 & 688277 & 4.6 & 4.6511 & TRN \\
\hline CHEMBL1458755 & 688277 & 4.7 & 4.9581 & TRN \\
\hline CHEMBL1525158 & 688277 & 4.8 & 4.7687 & TRN \\
\hline CHEMBL1610241 & 688277 & 4.5 & 4.8091 & TRN \\
\hline CHEMBL1355837 & 688277 & 4.75 & 5.114 & TST \\
\hline CHEMBL1317472 & 688277 & 4.5 & 4.873 & TRN \\
\hline CHEMBL3145245 & 688277 & 4.95 & 4.8664 & TST \\
\hline CHEMBL1370571 & 688277 & 4.5 & 4.7374 & TRN \\
\hline CHEMBL1520224 & 688277 & 4.5 & 4.8371 & TRN \\
\hline CHEMBL1396334 & 688277 & 7.8508 & 4.8561 & TRN \\
\hline CHEMBL1327560 & 688277 & 4.95 & 5.0664 & TST \\
\hline CHEMBL1590073 & 688277 & 4.5 & 4.898 & TRN \\
\hline CHEMBL601918 & 688277 & 4.7 & 4.9282 & TRN \\
\hline CHEMBL1436633 & 688277 & 5.3 & 4.8518 & TST \\
\hline CHEMBL1434613 & 688277 & 4.5 & 4.7272 & TST \\
\hline CHEMBL1552522 & 688277 & 4.45 & 4.891 & TRN \\
\hline CHEMBL1593268 & 688277 & 4.5 & 4.8797 & TST \\
\hline CHEMBL1552509 & 688277 & 4.45 & 4.9013 & TRN \\
\hline CHEMBL1596724 & 688277 & 4.5 & 4.7251 & TRN \\
\hline CHEMBL1355453 & 688277 & 5.5 & 4.8902 & TRN \\
\hline CHEMBL1326369 & 688277 & 4.5 & 4.6858 & TRN \\
\hline CHEMBL1422097 & 688277 & 4.8 & 4.9796 & TRN \\
\hline CHEMBL1372649 & 688277 & 4.7 & 4.7765 & TRN \\
\hline CHEMBL1554430 & 688277 & 4.45 & 4.8835 & TRN \\
\hline CHEMBL1398100 & 688277 & 4.5 & 4.9618 & TST \\
\hline CHEMBL1315325 & 688277 & 4.6 & 5.0209 & TRN \\
\hline CHEMBL1477877 & 688277 & 5.4 & 5.5293 & TRN \\
\hline CHEMBL1405493 & 688277 & 4.9 & 4.8896 & TRN \\
\hline CHEMBL1371750 & 688277 & 4.9 & 4.7221 & TRN \\
\hline CHEMBL1447547 & 688277 & 4.9 & 4.8742 & TRN \\
\hline
\end{tabular}




\begin{tabular}{|c|c|c|c|c|c|}
\hline \multirow{3}{*}{$\begin{array}{l}\text { CHEMBL1455966 } \\
\text { CHEMBL } 1513762\end{array}$} & & \multicolumn{4}{|c|}{ Supplemental Table S2.txt } \\
\hline & 688277 & 5.55 & 4.8919 & 99999999995 & TRN \\
\hline & 688277 & 5.8 & 5.4047 & TRN & \\
\hline CHEMBL1316550 & 688277 & 4.9 & 4.9183 & TRN & \\
\hline CHEMBL1546767 & 688277 & 5.15 & 5.2414 & TST & \\
\hline CHEMBL1415256 & 688277 & 4.5 & 4.8203 & TRN & \\
\hline CHEMBL1513729 & 688277 & 5.2 & 4.9497 & TRN & \\
\hline CHEMBL1553370 & 688277 & 4.9 & 4.8733 & TRN & \\
\hline CHEMBL1605595 & 688277 & 4.5 & 4.6895 & TRN & \\
\hline CHEMBL1315327 & 688277 & 5.85 & 4.8725 & TRN & \\
\hline CHEMBL1355268 & 688277 & 5.0 & 4.958 & TRN & \\
\hline CHEMBL1473054 & 688277 & 7.4001 & 4.9253 & TRN & \\
\hline CHEMBL1454761 & 688277 & 4.65 & 5.4319 & TST & \\
\hline CHEMBL1450286 & 688277 & 5.0 & 4.9441 & TRN & \\
\hline CHEMBL1447966 & 688277 & 5.2 & 4.9372 & TST & \\
\hline CHEMBL1395731 & 688277 & 4.8 & 4.9279 & TST & \\
\hline CHEMBL1398144 & 688277 & 4.5 & 4.8583 & TRN & \\
\hline CHEMBL1519019 & 688277 & 4.9 & 4.9351 & TRN & \\
\hline CHEMBL1397904 & 688277 & 5.25 & 4.9016 & TRN & \\
\hline CHEMBL1374629 & 688277 & 5.0 & 4.8968 & TRN & \\
\hline CHEMBL1316827 & 688277 & 4.5 & 4.8236 & TRN & \\
\hline CHEMBL1377339 & 688277 & 5.25 & 4.8668 & TRN & \\
\hline CHEMBL1591337 & 688277 & 4.9 & 4.7555 & TRN & \\
\hline CHEMBL1318254 & 688277 & 5.1 & 5.0794 & TRN & \\
\hline CHEMBL1560549 & 688277 & 4.7 & 4.9737 & TST & \\
\hline CHEMBL602927 & 688277 & 4.8 & 5.0334 & TST & \\
\hline CHEMBL1487869 & 688277 & 4.95 & 4.872 & TRN & \\
\hline CHEMBL3199254 & 688277 & 4.75 & 5.1852 & TST & \\
\hline CHEMBL1486352 & 688277 & 4.9 & 4.8333 & TRN & \\
\hline CHEMBL1561222 & 688277 & 4.5 & 4.8511 & TRN & \\
\hline CHEMBL1476863 & 688277 & 4.7 & 4.8296 & TRN & \\
\hline CHEMBL1409574 & 688277 & 4.8 & 4.8239 & TRN & \\
\hline CHEMBL1370071 & 688277 & 5.1 & 5.126 & TRN & \\
\hline CHEMBL1320033 & 688277 & 5.55 & 5.2154 & TRN & \\
\hline CHEMBL1454437 & 688277 & 5.4 & 5.0385 & TRN & \\
\hline CHEMBL1612170 & 688277 & 4.75 & 4.9634 & TST & \\
\hline CHEMBL1555613 & 688277 & 4.45 & 4.9236 & TRN & \\
\hline CHEMBL1552437 & 688277 & 4.8 & 4.9675 & TRN & \\
\hline CHEMBL1395702 & 688277 & 5.0 & 5.0828 & TST & \\
\hline CHEMBL1330705 & 688277 & 4.7 & 5.2259 & TRN & \\
\hline CHEMBL1437583 & 688277 & 5.0 & 4.9357 & TRN & \\
\hline CHEMBL1395970 & 688277 & 4.5 & 4.6251 & TRN & \\
\hline CHEMBL1513898 & 688277 & 4.5 & 4.8946 & TRN & \\
\hline CHEMBL1493811 & 688277 & 4.5 & 4.9109 & TRN & \\
\hline CHEMBL1529641 & 688277 & 5.6 & 5.4341 & TRN & \\
\hline CHEMBL1610849 & 688277 & 4.5 & 4.9349 & TRN & \\
\hline CHEMBL1514888 & 688277 & 4.9 & 4.8538 & TRN & \\
\hline CHEMBL1518774 & 688277 & 5.0 & 4.9258 & TRN & \\
\hline CHEMBL1395520 & 688277 & 4.5 & 4.8876 & TRN & \\
\hline
\end{tabular}




\begin{tabular}{|c|c|c|c|c|c|}
\hline \multicolumn{6}{|c|}{ Supplemental Table s2.txt } \\
\hline CHEMBL1498407 & 688277 & 4.95 & 4.775 & TST & \\
\hline CHEMBL1592591 & 688277 & 4.45 & 4.6942 & TST & \\
\hline CHEMBL1342524 & 688277 & 5.05 & 4.9435 & TST & \\
\hline CHEMBL3197259 & 688277 & 5.3 & 5.7842 & TRN & \\
\hline CHEMBL1317728 & 688277 & 4.5 & 4.9106 & TRN & \\
\hline CHEMBL1598906 & 688277 & 5.8 & 5.6218 & TRN & \\
\hline CHEMBL1434798 & 688277 & 5.9 & 5.0238 & TST & \\
\hline CHEMBL1359355 & 688277 & 7.15 & 5.0829 & TRN & \\
\hline CHEMBL1561508 & 688277 & 4.45 & 4.9014 & TRN & \\
\hline CHEMBL1317831 & 688277 & 4.95 & 4.7241 & TRN & \\
\hline CHEMBL1354317 & 688277 & 4.9 & 5.0133 & TST & \\
\hline CHEMBL587620 & 688277 & 4.9 & 4.7551 & TRN & \\
\hline CHEMBL1595693 & 688277 & 5.0 & 4.6461 & TRN & \\
\hline CHEMBL1602133 & 688277 & 4.5 & 4.9499 & TST & \\
\hline CHEMBL1378286 & 688277 & 4.5 & 4.91 & TST & \\
\hline CHEMBL3198134 & 688277 & 5.55 & 5.3725 & TST & \\
\hline CHEMBL1358801 & 688277 & 5.0 & 4.8937 & TST & \\
\hline CHEMBL1322698 & 688277 & 5.0 & 4.7755 & TRN & \\
\hline CHEMBL1433556 & 688277 & 5.05 & 4.9061 & TRN & \\
\hline CHEMBL1314837 & 688277 & 4.5 & 4.6347 & TRN & \\
\hline CHEMBL1475707 & 688277 & 4.5 & 4.9733 & TRN & \\
\hline CHEMBL1364477 & 688277 & 4.5 & 4.8061 & TRN & \\
\hline CHEMBL1483444 & 688277 & 5.0 & 4.9042 & TRN & \\
\hline CHEMBL1513182 & 688277 & 4.5 & 4.9761 & TST & \\
\hline CHEMBL1590087 & 688277 & 4.6 & 4.9314 & TRN & \\
\hline CHEMBL1366676 & 688277 & 5.1 & 4.9531 & TRN & \\
\hline CHEMBL1434350 & 688277 & 4.5 & 4.8461 & TRN & \\
\hline CHEMBL1551440 & 688277 & 4.5 & 5.381 & TRN & \\
\hline CHEMBL1485054 & 688277 & 5.0 & 5.16299 & 7999999999 & TRN \\
\hline CHEMBL1315484 & 688277 & 4.9 & 4.8905 & TST & \\
\hline CHEMBL1449209 & 688277 & 4.9 & 4.7569 & TRN & \\
\hline CHEMBL1437217 & 688277 & 4.9 & 4.6278 & TRN & \\
\hline CHEMBL1318229 & 688277 & 4.7 & 4.9411 & TST & \\
\hline CHEMBL1401187 & 688277 & 4.8 & 4.9445 & TRN & \\
\hline CHEMBL1566230 & 688277 & 5.25 & 4.9594 & TST & \\
\hline CHEMBL1591601 & 688277 & 4.5 & 4.9251 & TRN & \\
\hline CHEMBL1472810 & 688277 & 5.4 & 5.0056 & TRN & \\
\hline CHEMBL1356417 & 688277 & 5.45 & 5.0151 & TRN & \\
\hline CHEMBL1514262 & 688277 & 5.0 & 4.8983 & TST & \\
\hline CHEMBL1403903 & 688277 & 4.5 & 4.8578 & TRN & \\
\hline CHEMBL1515418 & 688277 & 4.5 & 4.6967 & TST & \\
\hline CHEMBL1559377 & 688277 & 4.5 & 4.8912 & TRN & \\
\hline CHEMBL1603867 & 688277 & 4.45 & 4.9731 & TST & \\
\hline CHEMBL1362770 & 688277 & 4.9 & 4.9199 & TRN & \\
\hline CHEMBL1574951 & 688277 & 4.6 & 4.9395 & TRN & \\
\hline CHEMBL1472693 & 688277 & 4.45 & 4.8834 & TRN & \\
\hline CHEMBL1437451 & 688277 & 4.9 & 4.886 & TRN & \\
\hline CHEMBL1377304 & 688277 & 4.9 & 5.0121 & TRN & \\
\hline
\end{tabular}




\begin{tabular}{|c|c|c|c|c|}
\hline \multicolumn{5}{|c|}{ Supplemental Table S2.txt } \\
\hline CHEMBL1590383 & 688277 & 4.6 & 4.7188 & TST \\
\hline CHEMBL1551243 & 688277 & 4.6 & 4.7495 & TRN \\
\hline CHEMBL1590562 & 688277 & 8.0 & 4.8889 & TRN \\
\hline CHEMBL1551556 & 688277 & 4.5 & 4.9358 & TRN \\
\hline CHEMBL1323755 & 688277 & 4.5 & 4.6689 & TRN \\
\hline CHEMBL1601272 & 688277 & 5.35 & 4.8415 & TRN \\
\hline CHEMBL1518609 & 688277 & 4.6 & 4.7839 & TRN \\
\hline CHEMBL1434695 & 688277 & 5.3 & 5.176 & TRN \\
\hline CHEMBL1436673 & 688277 & 4.8 & 5.2238 & TRN \\
\hline CHEMBL1434090 & 688277 & 4.5 & 4.9091 & TRN \\
\hline CHEMBL1553504 & 688277 & 4.5 & 4.7085 & TRN \\
\hline CHEMBL1416251 & 688277 & 5.1 & 5.0131 & TST \\
\hline CHEMBL1603912 & 688277 & 4.8 & 4.8123 & TRN \\
\hline CHEMBL1434518 & 688277 & 4.6 & 4.8802 & TRN \\
\hline CHEMBL1474370 & 688277 & 5.0 & 4.8621 & TRN \\
\hline CHEMBL1320387 & 688277 & 4.5 & 4.8425 & TRN \\
\hline CHEMBL1315194 & 688277 & 4.5 & 4.7764 & TST \\
\hline CHEMBL1512426 & 688277 & 5.0 & 4.925 & TST \\
\hline CHEMBL1554940 & 688277 & 4.8 & 4.8292 & TRN \\
\hline CHEMBL1512211 & 688277 & 5.0 & 4.8253 & TRN \\
\hline CHEMBL1596858 & 688277 & 4.5 & 4.756 & TRN \\
\hline CHEMBL1476045 & 688277 & 5.0 & 4.8425 & TRN \\
\hline CHEMBL1435446 & 688277 & 5.35 & 4.9959 & TRN \\
\hline CHEMBL1222385 & 688277 & 4.85 & 5.0251 & TST \\
\hline CHEMBL1475308 & 688277 & 4.5 & 5.1048 & TRN \\
\hline CHEMBL1399507 & 688277 & 4.45 & 4.8287 & TST \\
\hline CHEMBL1413081 & 688277 & 4.6 & 4.6977 & TRN \\
\hline CHEMBL1590131 & 688277 & 4.9 & 4.8949 & TRN \\
\hline CHEMBL 2004809 & 688277 & 5.05 & 5.1894 & TRN \\
\hline CHEMBL1354564 & 688277 & 4.8 & 4.6272 & TRN \\
\hline CHEMBL1478339 & 688277 & 4.9 & 4.9094 & TRN \\
\hline CHEMBL1566611 & 688277 & 4.65 & 4.9625 & TST \\
\hline CHEMBL1365273 & 688277 & 8.0 & 4.8774 & TST \\
\hline CHEMBL1401745 & 688277 & 4.45 & 5.0281 & TRN \\
\hline CHEMBL1387290 & 688277 & 5.0 & 4.9718 & TRN \\
\hline CHEMBL1473703 & 688277 & 4.5 & 4.8845 & TRN \\
\hline CHEMBL1364171 & 688277 & 4.95 & 4.9465 & TST \\
\hline CHEMBL1557374 & 688277 & 4.5 & 4.8142 & TRN \\
\hline CHEMBL1378444 & 688277 & 4.9 & 4.9182 & TRN \\
\hline CHEMBL1404458 & 688277 & 5.1 & 4.9022 & TRN \\
\hline CHEMBL1407950 & 688277 & 5.0 & 4.93 & TST \\
\hline CHEMBL1357628 & 688277 & 5.0 & 4.8951 & TRN \\
\hline CHEMBL1413823 & 688277 & 5.5 & 5.3168 & TRN \\
\hline CHEMBL209149 & 688277 & 4.5 & 4.9055 & TRN \\
\hline CHEMBL1515966 & 688277 & 4.9 & 4.7356 & TST \\
\hline CHEMBL1513580 & 688277 & 4.9 & 4.8549 & TRN \\
\hline CHEMBL1483806 & 688277 & 4.5 & 4.7815 & TRN \\
\hline CHEMBL1362424 & 688277 & 5.0 & 5.1055 & TRN \\
\hline
\end{tabular}




\begin{tabular}{|c|c|c|c|c|}
\hline \multicolumn{5}{|c|}{ Supplemental Table S2.txt } \\
\hline CHEMBL1514889 & 688277 & 4.6 & 4.9294 & TRN \\
\hline CHEMBL1373404 & 688277 & 4.8 & 4.712 & TRN \\
\hline CHEMBL1376258 & 688277 & 4.8 & 4.8794 & TST \\
\hline CHEMBL1592013 & 688277 & 5.35 & 4.8334 & TRN \\
\hline CHEMBL1515988 & 688277 & 4.9 & 4.7757 & TRN \\
\hline CHEMBL1594461 & 688277 & 4.9 & 4.9322 & TRN \\
\hline CHEMBL1408108 & 688277 & 4.5 & 4.7541 & TST \\
\hline CHEMBL1494432 & 688277 & 4.9 & 4.7851 & TRN \\
\hline CHEMBL1592650 & 688277 & 4.6 & 4.7195 & TRN \\
\hline CHEMBL1317080 & 688277 & 4.8 & 4.9022 & TRN \\
\hline CHEMBL1409245 & 688277 & 5.4 & 4.9054 & TRN \\
\hline CHEMBL1574899 & 688277 & 4.5 & 4.7115 & TRN \\
\hline CHEMBL1591422 & 688277 & 5.2 & 4.9069 & TRN \\
\hline CHEMBL1322247 & 688277 & 4.5 & 5.0116 & TRN \\
\hline CHEMBL1346883 & 688277 & 4.45 & 4.797 & TRN \\
\hline CHEMBL1521403 & 688277 & 4.7 & 4.7074 & TST \\
\hline CHEMBL1494263 & 688277 & 5.0 & 4.9238 & TRN \\
\hline CHEMBL1403565 & 688277 & 4.9 & 4.8372 & TRN \\
\hline CHEMBL1324999 & 688277 & 4.7 & 4.9629 & TRN \\
\hline CHEMBL1320917 & 688277 & 5.0 & 5.124 & TRN \\
\hline CHEMBL1316037 & 688277 & 5.75 & 5.271 & TRN \\
\hline CHEMBL1592863 & 688277 & 4.45 & 5.0516 & TRN \\
\hline CHEMBL1364639 & 688277 & 5.05 & 4.9878 & TST \\
\hline CHEMBL1410928 & 688277 & 4.9 & 4.9295 & TRN \\
\hline CHEMBL1457007 & 688277 & 4.5 & 4.8234 & TRN \\
\hline CHEMBL1404816 & 688277 & 4.9 & 4.853 & TRN \\
\hline CHEMBL1356024 & 688277 & 5.55 & 4.9064 & TRN \\
\hline CHEMBL1454216 & 688277 & 5.7 & 5.2785 & TRN \\
\hline CHEMBL1554698 & 688277 & 4.6 & 4.9216 & TST \\
\hline CHEMBL1413522 & 688277 & 5.3 & 4.8874 & TST \\
\hline CHEMBL1446979 & 688277 & 4.7 & 4.8798 & TST \\
\hline CHEMBL1394691 & 688277 & 4.9 & 4.9104 & TRN \\
\hline CHEMBL 3213078 & 688277 & 4.9 & 5.0602 & TST \\
\hline CHEMBL1356112 & 688277 & 5.9 & 5.1542 & TRN \\
\hline CHEMBL1511492 & 688277 & 5.35 & 4.9162 & TST \\
\hline CHEMBL1482923 & 688277 & 4.5 & 4.8171 & TRN \\
\hline CHEMBL1435124 & 688277 & 4.5 & 4.6704 & TRN \\
\hline CHEMBL1597594 & 688277 & 4.9 & 4.9734 & TRN \\
\hline CHEMBL1319419 & 688277 & 4.8 & 4.8706 & TST \\
\hline CHEMBL1488839 & 688277 & 9.2218 & 5.0734 & TRN \\
\hline CHEMBL1412054 & 688277 & 5.0 & 4.8761 & TRN \\
\hline CHEMBL1553510 & 688277 & 4.5 & 4.6683 & TRN \\
\hline CHEMBL1338823 & 688277 & 4.75 & 4.8834 & TRN \\
\hline CHEMBL1355140 & 688277 & 5.3 & 4.9248 & TRN \\
\hline CHEMBL1436190 & 688277 & 4.5 & 4.9246 & TRN \\
\hline CHEMBL1552906 & 688277 & 5.6 & 5.1877 & TRN \\
\hline CHEMBL1402776 & 688277 & 4.5 & 4.8786 & TRN \\
\hline CHEMBL1368212 & 688277 & 4.95 & 5.0913 & TRN \\
\hline
\end{tabular}




\begin{tabular}{|c|c|c|c|c|c|}
\hline \\
\hline CHEMBL1396747 & 688277 & 4.8 & 4.9248 & TST & \\
\hline CHEMBL1475346 & 688277 & 4.5 & 4.7205 & TRN & \\
\hline CHEMBL1556139 & 688277 & 5.0 & 4.8694 & TST & \\
\hline CHEMBL1476419 & 688277 & 4.75 & 4.9092 & TRN & \\
\hline CHEMBL1355145 & 688277 & 4.8 & 4.6592 & TRN & \\
\hline CHEMBL1448584 & 688277 & 5.5 & 5.3287 & TST & \\
\hline CHEMBL1495688 & 688277 & 5.5 & 5.197 & TRN & \\
\hline CHEMBL1330184 & 688277 & 4.7 & 4.6823 & TRN & \\
\hline CHEMBL1398221 & 688277 & 4.95 & 4.9428 & TRN & \\
\hline CHEMBL1417981 & 688277 & 4.6 & 4.7355 & TST & \\
\hline CHEMBL1476813 & 688277 & 5.0 & 4.8953 & TRN & \\
\hline CHEMBL1437765 & 688277 & 4.9 & 4.9121 & TRN & \\
\hline CHEMBL1374200 & 688277 & 4.65 & 4.8824 & TST & \\
\hline CHEMBL1397745 & 688277 & 5.0 & 4.9418 & TRN & \\
\hline CHEMBL1340652 & 688277 & 5.45 & 4.8508 & TST & \\
\hline CHEMBL1520414 & 688277 & 4.5 & 5.5389 & TRN & \\
\hline CHEMBL1317115 & 688277 & 5.1 & 4.8546 & TST & \\
\hline CHEMBL1380995 & 688277 & 4.8 & 4.9698 & TST & \\
\hline CHEMBL1473209 & 688277 & 4.6 & 4.9746 & TRN & \\
\hline CHEMBL1478477 & 688277 & 5.5 & 4.8219 & TRN & \\
\hline CHEMBL1344115 & 688277 & 4.95 & 4.8865 & TST & \\
\hline CHEMBL1523584 & 688277 & 4.65 & 4.8534 & TRN & \\
\hline CHEMBL1571004 & 688277 & 4.5 & 4.854 & TRN & \\
\hline CHEMBL1483731 & 688277 & 5.95 & 4.9087 & TST & \\
\hline CHEMBL1567904 & 688277 & 4.8 & 4.628 & TRN & \\
\hline CHEMBL1476953 & 688277 & 4.5 & 4.9442 & TRN & \\
\hline CHEMBL1591793 & 688277 & 4.5 & 4.812 & TRN & \\
\hline CHEMBL1552958 & 688277 & 4.45 & 4.93199 & 99999999995 & TRN \\
\hline CHEMBL1405308 & 688277 & 4.6 & 5.0168 & TRN & \\
\hline CHEMBL1434357 & 688277 & 5.55 & 4.9241 & TRN & \\
\hline CHEMBL1304647 & 688277 & 5.25 & 5.1558 & TST & \\
\hline CHEMBL1591510 & 688277 & 4.9 & 4.8137 & TRN & \\
\hline CHEMBL1315115 & 688277 & 4.5 & 4.9373 & TRN & \\
\hline CHEMBL1338205 & 688277 & 8.0506 & 5.0299 & TST & \\
\hline CHEMBL1475327 & 688277 & 4.6 & 4.7494 & TRN & \\
\hline CHEMBL1436270 & 688277 & 5.55 & 5.0927 & TRN & \\
\hline CHEMBL1492795 & 688277 & 5.25 & 4.8436 & TRN & \\
\hline CHEMBL1593003 & 688277 & 4.5 & 4.8876 & TRN & \\
\hline CHEMBL1572909 & 688277 & 4.45 & 4.8959 & TRN & \\
\hline CHEMBL1412448 & 688277 & 4.5 & 4.6415 & TRN & \\
\hline CHEMBL1372714 & 688277 & 5.35 & 4.8724 & TRN & \\
\hline CHEMBL1523151 & 688277 & 5.1 & 5.0849 & TST & \\
\hline CHEMBL1320173 & 688277 & 4.85 & 4.6823 & TRN & \\
\hline CHEMBL1355505 & 688277 & 5.55 & 4.8729 & TRN & \\
\hline CHEMBL1365239 & 688277 & 4.95 & 4.8479 & TRN & \\
\hline CHEMBL1315177 & 688277 & 4.85 & 4.8979 & TRN & \\
\hline CHEMBL1467395 & 688277 & 5.95 & 5.0272 & TRN & \\
\hline CHEMBL1477025 & 688277 & 4.6 & 4.7691 & TST & \\
\hline
\end{tabular}




\begin{tabular}{|c|c|c|c|c|}
\hline & & & pplement & al $\mathrm{Ta}$ \\
\hline CHEMBL1364494 & 688277 & 4.8 & 4.9203 & TRN \\
\hline CHEMBL1516123 & 688277 & 5.6 & 4.9739 & TST \\
\hline CHEMBL1557788 & 688277 & 4.6 & 4.7413 & TRN \\
\hline CHEMBL3193405 & 688277 & 5.0 & 4.9327 & TST \\
\hline CHEMBL1403030 & 688277 & 5.45 & 5.1452 & TRN \\
\hline CHEMBL1512628 & 688277 & 4.45 & 4.8131 & TST \\
\hline CHEMBL1359337 & 688277 & 5.5 & 5.3168 & TRN \\
\hline CHEMBL1397550 & 688277 & 4.85 & 4.9256 & TRN \\
\hline CHEMBL1602746 & 688277 & 4.7 & 4.7296 & TRN \\
\hline CHEMBL1356939 & 688277 & 4.9 & 4.8469 & TRN \\
\hline CHEMBL1475857 & 688277 & 7.5003 & 4.9359 & TRN \\
\hline CHEMBL1565422 & 688277 & 7.2 & 4.9701 & TST \\
\hline CHEMBL1435202 & 688277 & 4.5 & 4.8461 & TRN \\
\hline CHEMBL1399640 & 688277 & 4.7 & 4.9957 & TST \\
\hline CHEMBL1449964 & 688277 & 4.7 & 4.9901 & TST \\
\hline CHEMBL1592109 & 688277 & 5.0 & 4.8887 & TRN \\
\hline CHEMBL1357897 & 688277 & 4.9 & 4.9623 & TST \\
\hline CHEMBL1512414 & 688277 & 4.5 & 4.7545 & TRN \\
\hline CHEMBL1594046 & 688277 & 4.7 & 4.9642 & TRN \\
\hline CHEMBL1434380 & 688277 & 4.8 & 4.788 & TRN \\
\hline CHEMBL1402153 & 688277 & 4.85 & 4.7716 & TST \\
\hline CHEMBL1336410 & 688277 & 4.5 & 4.9146 & TRN \\
\hline CHEMBL1524206 & 688277 & 5.25 & 5.5193 & TRN \\
\hline CHEMBL1435307 & 688277 & 4.45 & 4.8779 & TST \\
\hline CHEMBL1595237 & 688277 & 4.45 & 4.6243 & TST \\
\hline CHEMBL1370231 & 688277 & 5.25 & 4.8878 & TRN \\
\hline CHEMBL1472916 & 688277 & 5.0 & 4.9704 & TRN \\
\hline CHEMBL1566498 & 688277 & 5.7 & 5.2826 & TRN \\
\hline CHEMBL1371162 & 688277 & 5.45 & 4.9087 & TRN \\
\hline CHEMBL1514159 & 688277 & 7.6003 & 4.8428 & TST \\
\hline CHEMBL1354625 & 688277 & 4.8 & 4.8708 & TST \\
\hline CHEMBL1317610 & 688277 & 4.45 & 4.8588 & TRN \\
\hline CHEMBL1317550 & 688277 & 4.6 & 4.8804 & TRN \\
\hline CHEMBL1437518 & 688277 & 4.65 & 4.9522 & TRN \\
\hline CHEMBL1401678 & 688277 & 4.5 & 4.8816 & TST \\
\hline CHEMBL1451232 & 688277 & 4.65 & 5.2454 & TST \\
\hline CHEMBL1414371 & 688277 & 4.9 & 5.0063 & TRN \\
\hline CHEMBL1318482 & 688277 & 4.5 & 5.0421 & TRN \\
\hline CHEMBL1475309 & 688277 & 4.45 & 4.9045 & TRN \\
\hline CHEMBL1413385 & 688277 & 4.45 & 4.9265 & TRN \\
\hline CHEMBL1373857 & 688277 & 4.8 & 4.8983 & TRN \\
\hline CHEMBL1399510 & 688277 & 5.4 & 4.9031 & TRN \\
\hline CHEMBL1449173 & 688277 & 4.8 & 4.9449 & TRN \\
\hline CHEMBL1365285 & 688277 & 4.6 & 4.9751 & TRN \\
\hline CHEMBL1435491 & 688277 & 8.1024 & 4.953 & TST \\
\hline CHEMBL1520707 & 688277 & 4.5 & 4.6518 & TRN \\
\hline CHEMBL1437726 & 688277 & 4.7 & 4.976 & TRN \\
\hline CHEMBL1494950 & 688277 & 5.3 & 5.0257 & TST \\
\hline
\end{tabular}




\begin{tabular}{|c|c|c|c|c|c|}
\hline \multicolumn{6}{|c|}{ Supplemental Table S2.txt } \\
\hline CHEMBL1330759 & 688277 & 4.5 & 4.8652 & TRN & \\
\hline CHEMBL1406156 & 688277 & 4.5 & 4.6904 & TST & \\
\hline CHEMBL1516985 & 688277 & 4.7 & 4.8968 & TRN & \\
\hline CHEMBL1335173 & 688277 & 4.95 & 4.8811 & TRN & \\
\hline CHEMBL1359746 & 688277 & 4.8 & 5.018 & TRN & \\
\hline CHEMBL1354789 & 688277 & 4.9 & 4.7783 & TRN & \\
\hline CHEMBL1474836 & 688277 & 5.75 & 5.3046 & TRN & \\
\hline CHEMBL1479803 & 688277 & 4.6 & 4.8771 & TRN & \\
\hline CHEMBL1398025 & 688277 & 7.6003 & 5.1078 & TRN & \\
\hline CHEMBL1399459 & 688277 & 4.7 & 4.8389 & TST & \\
\hline CHEMBL1358376 & 688277 & 4.95 & 4.8465 & TRN & \\
\hline CHEMBL1366470 & 688277 & 5.25 & 4.94300 & 00000000005 & TRN \\
\hline CHEMBL1478785 & 688277 & 4.6 & 4.92399 & 99999999995 & TRN \\
\hline CHEMBL1555692 & 688277 & 4.9 & 4.8865 & TRN & \\
\hline CHEMBL1415444 & 688277 & 5.35 & 4.9355 & TRN & \\
\hline CHEMBL1590606 & 688277 & 5.5 & 4.8469 & TRN & \\
\hline CHEMBL1591375 & 688277 & 4.7 & 5.7634 & TRN & \\
\hline CHEMBL1396899 & 688277 & 4.8 & 4.7364 & TRN & \\
\hline CHEMBL1554015 & 688277 & 4.6 & 4.8754 & TRN & \\
\hline CHEMBL1453260 & 688277 & 4.5 & 4.7168 & TST & \\
\hline CHEMBL1554087 & 688277 & 5.9 & 5.2443 & TRN & \\
\hline CHEMBL1593468 & 688277 & 4.5 & 4.9656 & TRN & \\
\hline CHEMBL1397555 & 688277 & 4.8 & 4.9803 & TRN & \\
\hline CHEMBL1608018 & 688277 & 4.5 & 4.7141 & TRN & \\
\hline CHEMBL1445407 & 688277 & 4.5 & 4.8945 & TST & \\
\hline CHEMBL1552620 & 688277 & 5.1 & 4.8878 & TRN & \\
\hline CHEMBL1475322 & 688277 & 5.0 & 4.9547 & TRN & \\
\hline CHEMBL1604005 & 688277 & 4.6 & 5.1552 & TRN & \\
\hline CHEMBL1515896 & 688277 & 4.5 & 5.0359 & TRN & \\
\hline CHEMBL1524371 & 688277 & 4.9 & 4.7 & TRN & \\
\hline CHEMBL1538370 & 688277 & 4.9 & 5.2505 & TST & \\
\hline CHEMBL1590235 & 688277 & 4.9 & 5.1928 & TRN & \\
\hline CHEMBL1528196 & 688277 & 5.2 & 5.185 & TRN & \\
\hline CHEMBL1448432 & 688277 & 4.5 & 4.886 & TRN & \\
\hline CHEMBL1554449 & 688277 & 4.9 & 4.7766 & TRN & \\
\hline CHEMBL1471225 & 688277 & 5.2 & 5.1014 & TST & \\
\hline CHEMBL1403819 & 688277 & 5.1 & 4.9409 & TST & \\
\hline CHEMBL1477267 & 688277 & 6.5 & 5.0164 & TST & \\
\hline CHEMBL1490183 & 688277 & 5.0 & 4.9123 & TRN & \\
\hline CHEMBL1473795 & 688277 & 4.9 & 5.0252 & TRN & \\
\hline CHEMBL1593044 & 688277 & 5.45 & 5.0646 & TRN & \\
\hline CHEMBL1394612 & 688277 & 4.7 & 4.9271 & TST & \\
\hline CHEMBL1359375 & 688277 & 4.5 & 5.3506 & TRN & \\
\hline CHEMBL1472666 & 688277 & 4.9 & 4.8704 & TRN & \\
\hline CHEMBL1356105 & 688277 & 4.5 & 5.1188 & TRN & \\
\hline CHEMBL1586489 & 688277 & 5.35 & 4.7147 & TST & \\
\hline CHEMBL1412625 & 688277 & 5.4 & 4.8606 & TRN & \\
\hline CHEMBL1516902 & 688277 & 4.7 & 4.9056 & TRN & \\
\hline
\end{tabular}




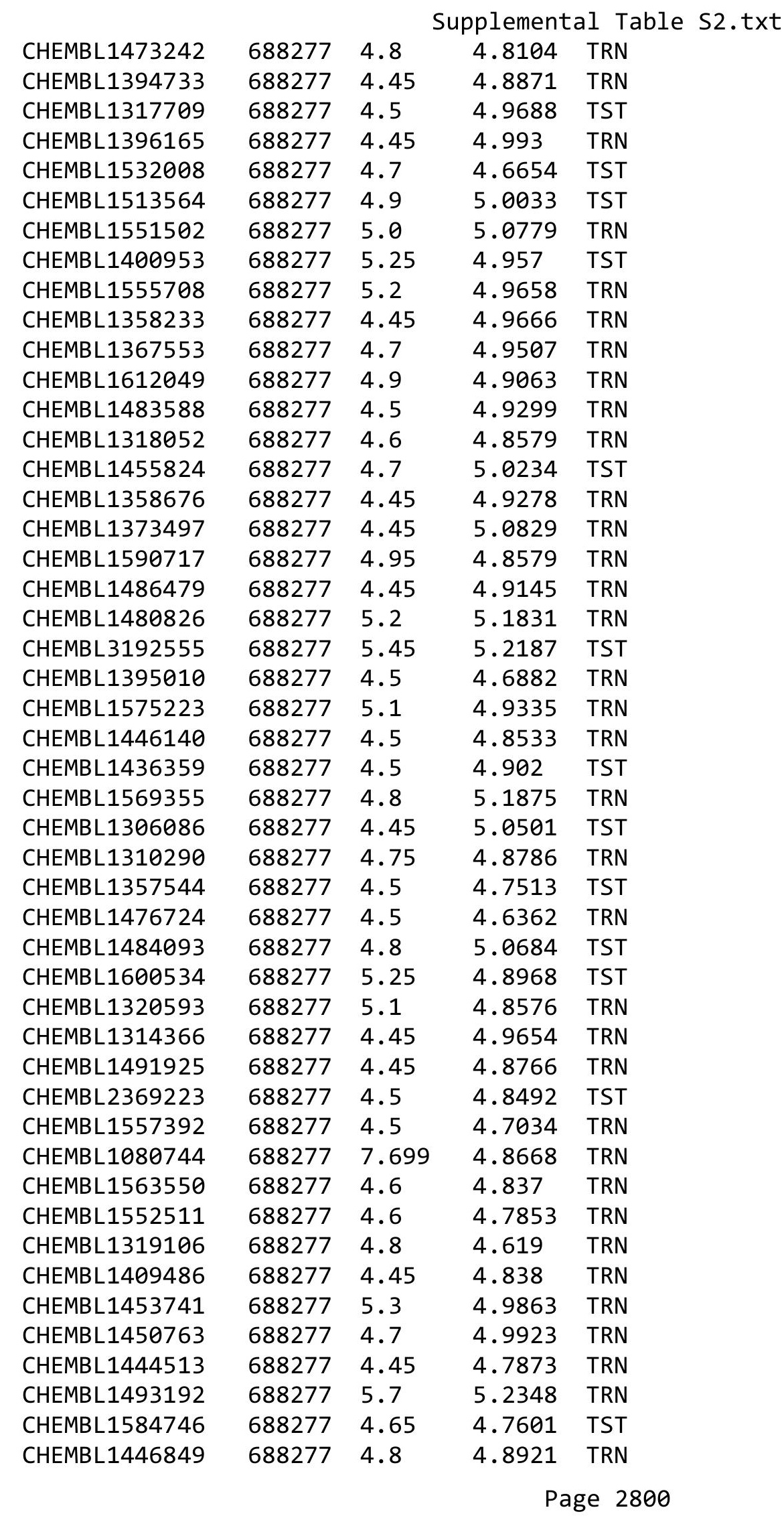




\begin{tabular}{|c|c|c|c|c|c|}
\hline & & & & & \\
\hline CHEMBL1454845 & 688277 & 5.5 & 4.6533 & TRN & \\
\hline CHEMBL1537464 & 688277 & 4.65 & 4.9769 & TST & \\
\hline CHEMBL1531582 & 688277 & 4.5 & 4.652 & TST & \\
\hline CHEMBL1514681 & 688277 & 4.9 & 4.8783 & TRN & \\
\hline CHEMBL1373914 & 688277 & 5.05 & 4.9457 & TRN & \\
\hline CHEMBL1540116 & 688277 & 5.4 & 5.0915 & TST & \\
\hline CHEMBL1521128 & 688277 & 4.7 & 4.6906 & TRN & \\
\hline CHEMBL1396810 & 688277 & 4.9 & 4.6246 & TRN & \\
\hline CHEMBL1472636 & 688277 & 4.6 & 4.7734 & TST & \\
\hline CHEMBL1475684 & 688277 & 4.9 & 4.8936 & TRN & \\
\hline CHEMBL 1370516 & 688277 & 4.5 & 4.779 & TRN & \\
\hline CHEMBL1454181 & 688277 & 5.25 & 5.0896 & TRN & \\
\hline CHEMBL1996730 & 688277 & 6.25 & 5.3779 & TST & \\
\hline CHEMBL1425250 & 688277 & 5.45 & 4.8973 & TST & \\
\hline CHEMBL1606236 & 688277 & 5.65 & 5.254 & TST & \\
\hline CHEMBL1359389 & 688277 & 4.85 & 4.92899 & 9999999999 & TRN \\
\hline CHEMBL1481050 & 688277 & 4.5 & 4.7641 & TRN & \\
\hline CHEMBL1513238 & 688277 & 4.8 & 4.6701 & TST & \\
\hline CHEMBL1396692 & 688277 & 5.2 & 4.9599 & TST & \\
\hline CHEMBL1532357 & 688277 & 4.5 & 5.1301 & TST & \\
\hline CHEMBL1515169 & 688277 & 4.85 & 4.868 & TRN & \\
\hline CHEMBL1437035 & 688277 & 5.7 & 5.2994 & TRN & \\
\hline CHEMBL592611 & 688277 & 6.2 & 4.9083 & TST & \\
\hline CHEMBL1608426 & 688277 & 4.8 & 4.9639 & TRN & \\
\hline CHEMBL1590107 & 688277 & 4.9 & 4.7762 & TST & \\
\hline CHEMBL1394649 & 688277 & 5.45 & 4.9473 & TRN & \\
\hline CHEMBL1394306 & 688277 & 4.5 & 4.8857 & TRN & \\
\hline CHEMBL1314646 & 688277 & 5.9 & 5.16100 & 00000000005 & TRN \\
\hline CHEMBL1492074 & 688277 & 4.5 & 4.7498 & TRN & \\
\hline CHEMBL1320103 & 688277 & 4.5 & 4.7144 & TRN & \\
\hline CHEMBL 1459202 & 688277 & 5.9 & 5.0049 & TRN & \\
\hline CHEMBL1395981 & 688277 & 4.6 & 5.0251 & TRN & \\
\hline CHEMBL1481012 & 688277 & 4.8 & 4.9445 & TRN & \\
\hline CHEMBL1316998 & 688277 & 4.75 & 4.9672 & TRN & \\
\hline CHEMBL1395542 & 688277 & 4.5 & 4.9014 & TRN & \\
\hline CHEMBL1476956 & 688277 & 4.5 & 4.7888 & TRN & \\
\hline CHEMBL1398099 & 688277 & 4.9 & 4.8574 & TST & \\
\hline CHEMBL1424898 & 688277 & 4.7 & 5.0479 & TST & \\
\hline CHEMBL1490017 & 688277 & 5.1 & 5.1539 & TRN & \\
\hline CHEMBL1339194 & 688277 & 4.9 & 4.7737 & TST & \\
\hline CHEMBL1397413 & 688277 & 4.7 & 4.8764 & TRN & \\
\hline CHEMBL1606753 & 688277 & 5.25 & 4.976 & TRN & \\
\hline CHEMBL1475496 & 688277 & 4.7 & 4.669 & TRN & \\
\hline CHEMBL1513976 & 688277 & 7.8508 & 4.9571 & TST & \\
\hline CHEMBL1381882 & 688277 & 4.65 & 4.8706 & TRN & \\
\hline CHEMBL1311144 & 688277 & 4.45 & 4.7916 & TST & \\
\hline CHEMBL1324000 & 688277 & 5.75 & 4.97 & TRN & \\
\hline CHEMBL1529929 & 688277 & 4.45 & 4.8976 & TST & \\
\hline
\end{tabular}




\begin{tabular}{|c|c|c|c|c|c|}
\hline \\
\hline CHEMBL602206 & 688277 & 4.5 & 4.9752 & TRN & \\
\hline CHEMBL1407071 & 688277 & 5.3 & 4.887 & TRN & \\
\hline CHEMBL1611513 & 688277 & 4.45 & 4.7651 & TRN & \\
\hline CHEMBL1357513 & 688277 & 4.7 & 4.941 & TRN & \\
\hline CHEMBL1403379 & 688277 & 4.6 & 4.7449 & TRN & \\
\hline CHEMBL1485053 & 688277 & 5.35 & 5.0281 & TST & \\
\hline CHEMBL1475766 & 688277 & 4.5 & 4.8706 & TRN & \\
\hline CHEMBL1593161 & 688277 & 4.9 & 4.8827 & TRN & \\
\hline CHEMBL1591131 & 688277 & 4.9 & 4.9305 & TRN & \\
\hline CHEMBL1436942 & 688277 & 5.0 & 4.8939 & TRN & \\
\hline CHEMBL3193102 & 688277 & 5.05 & 5.1206 & TST & \\
\hline CHEMBL1591540 & 688277 & 4.7 & 4.9723 & TRN & \\
\hline CHEMBL1481868 & 688277 & 4.8 & 5.0224 & TST & \\
\hline CHEMBL1370316 & 688277 & 5.5 & 5.17899 & 9999999999 & TRN \\
\hline CHEMBL1316850 & 688277 & 4.5 & 4.8825 & TRN & \\
\hline CHEMBL1601379 & 688277 & 4.75 & 5.113 & TRN & \\
\hline CHEMBL3210494 & 688277 & 5.1 & 4.7462 & TST & \\
\hline CHEMBL1435394 & 688277 & 4.8 & 4.8811 & TRN & \\
\hline CHEMBL1436690 & 688277 & 4.65 & 4.8892 & TST & \\
\hline CHEMBL1472817 & 688277 & 5.65 & 5.2509 & TRN & \\
\hline CHEMBL1568350 & 688277 & 4.9 & 4.8336 & TRN & \\
\hline CHEMBL1521412 & 688277 & 4.6 & 5.0823 & TST & \\
\hline CHEMBL1609985 & 688277 & 4.6 & 4.8718 & TRN & \\
\hline CHEMBL1442050 & 688277 & 4.5 & 4.8432 & TRN & \\
\hline CHEMBL1474371 & 688277 & 4.6 & 4.7378 & TRN & \\
\hline CHEMBL1434319 & 688277 & 4.5 & 4.8111 & TRN & \\
\hline CHEMBL1367834 & 688277 & 4.5 & 4.9359 & TST & \\
\hline CHEMBL1435462 & 688277 & 4.5 & 4.7502 & TRN & \\
\hline CHEMBL1410565 & 688277 & 4.5 & 4.9243 & TRN & \\
\hline CHEMBL1436415 & 688277 & 4.6 & 4.8527 & TRN & \\
\hline CHEMBL1592322 & 688277 & 5.25 & 4.9227 & TRN & \\
\hline CHEMBL1592972 & 688277 & 4.7 & 4.7759 & TST & \\
\hline CHEMBL1514320 & 688277 & 5.0 & 4.916 & TRN & \\
\hline CHEMBL1515599 & 688277 & 4.5 & 4.8253 & TRN & \\
\hline CHEMBL1397668 & 688277 & 6.1 & 5.14 & TRN & \\
\hline CHEMBL1315763 & 688277 & 4.5 & 4.9868 & TST & \\
\hline CHEMBL1402683 & 688277 & 4.7 & 4.7125 & TRN & \\
\hline CHEMBL1338463 & 688277 & 4.8 & 4.8831 & TRN & \\
\hline CHEMBL1599306 & 688277 & 5.4 & 4.949 & TRN & \\
\hline CHEMBL1476510 & 688277 & 5.55 & 5.2558 & TRN & \\
\hline CHEMBL1371559 & 688277 & 4.5 & 5.0436 & TST & \\
\hline CHEMBL1314650 & 688277 & 5.1 & 4.8871 & TST & \\
\hline CHEMBL1552079 & 688277 & 4.8 & 4.9789 & TRN & \\
\hline CHEMBL1592789 & 688277 & 4.8 & 4.84699 & 99999999995 & TST \\
\hline CHEMBL1514454 & 688277 & 4.6 & 4.9451 & TRN & \\
\hline CHEMBL1553127 & 688277 & 4.5 & 4.9697 & TRN & \\
\hline CHEMBL1493865 & 688277 & 4.9 & 4.9967 & TRN & \\
\hline CHEMBL1396715 & 688277 & 5.8 & 5.3332 & TRN & \\
\hline
\end{tabular}




\begin{tabular}{|c|c|c|c|c|c|}
\hline \multicolumn{6}{|c|}{ Supplemental Table S2.txt } \\
\hline CHEMBL1482619 & 688277 & 4.65 & 4.8955 & TRN & \\
\hline CHEMBL1385266 & 688277 & 4.75 & 4.8623 & TST & \\
\hline CHEMBL1592042 & 688277 & 4.5 & 4.9536 & TRN & \\
\hline CHEMBL1436729 & 688277 & 5.35 & 4.9847 & TRN & \\
\hline CHEMBL1590790 & 688277 & 4.7 & 5.1863 & TRN & \\
\hline CHEMBL1398092 & 688277 & 5.45 & 5.3594 & TRN & \\
\hline CHEMBL1564622 & 688277 & 4.5 & 5.0009 & TST & \\
\hline CHEMBL1358873 & 688277 & 4.7 & 4.9096 & TRN & \\
\hline CHEMBL1395894 & 688277 & 4.9 & 4.9383 & TRN & \\
\hline CHEMBL1436250 & 688277 & 5.0 & 4.8845 & TRN & \\
\hline CHEMBL1478727 & 688277 & 4.9 & 4.8767 & TRN & \\
\hline CHEMBL1395198 & 688277 & 4.8 & 4.8641 & TRN & \\
\hline CHEMBL1337084 & 688277 & 5.0 & 4.8821 & TST & \\
\hline CHEMBL1488910 & 688277 & 4.6 & 4.9347 & TRN & \\
\hline CHEMBL1416809 & 688277 & 4.95 & 4.8287 & TRN & \\
\hline CHEMBL1394568 & 688277 & 4.5 & 4.7891 & TRN & \\
\hline CHEMBL1512028 & 688277 & 4.75 & 4.827 & TRN & \\
\hline CHEMBL1571463 & 688277 & 4.7 & 4.782 & TRN & \\
\hline CHEMBL1591401 & 688277 & 4.85 & 4.872 & TRN & \\
\hline CHEMBL1317531 & 688277 & 4.6 & 4.7713 & TRN & \\
\hline CHEMBL1319537 & 688277 & 5.2 & 5.0986 & TRN & \\
\hline CHEMBL1325991 & 688277 & 4.7 & 4.8731 & TRN & \\
\hline CHEMBL 2001857 & 688277 & 5.5 & 5.2515 & TST & \\
\hline CHEMBL1346891 & 688277 & 4.95 & 4.7028 & TST & \\
\hline CHEMBL1447829 & 688277 & 4.5 & 4.6707 & TRN & \\
\hline CHEMBL1565441 & 688277 & 4.95 & 4.8689 & TRN & \\
\hline CHEMBL3197115 & 688277 & 4.95 & 4.9343 & TST & \\
\hline CHEMBL1484948 & 688277 & 4.9 & 4.9308 & TRN & \\
\hline CHEMBL1545697 & 688277 & 5.1 & 5.2555 & TST & \\
\hline CHEMBL1566838 & 688277 & 5.2 & 5.0725 & TST & \\
\hline CHEMBL1440569 & 688277 & 4.6 & 5.4481 & TST & \\
\hline CHEMBL1515690 & 688277 & 5.25 & 5.1648 & TRN & \\
\hline CHEMBL1315148 & 688277 & 4.6 & 4.7901 & TRN & \\
\hline CHEMBL1592621 & 688277 & 8.4949 & 4.8852 & TRN & \\
\hline CHEMBL1395114 & 688277 & 4.5 & 4.86600 & 00000000005 & TRN \\
\hline CHEMBL1355548 & 688277 & 4.9 & 4.8935 & TST & \\
\hline CHEMBL1356155 & 688277 & 4.6 & 4.7252 & TST & \\
\hline CHEMBL1481524 & 688277 & 8.0 & 4.965 & TST & \\
\hline CHEMBL1395184 & 688277 & 4.5 & 4.7424 & TRN & \\
\hline CHEMBL1434637 & 688277 & 5.0 & 4.721 & TRN & \\
\hline CHEMBL1479105 & 688277 & 5.3 & 4.8842 & TRN & \\
\hline CHEMBL1437275 & 688277 & 4.7 & 4.913 & TRN & \\
\hline CHEMBL1601234 & 688277 & 5.4 & 4.8864 & TRN & \\
\hline CHEMBL1434051 & 688277 & 4.9 & 4.8299 & TST & \\
\hline CHEMBL1557062 & 688277 & 5.0 & 5.1455 & TRN & \\
\hline CHEMBL1405877 & 688277 & 4.9 & 4.8416 & TRN & \\
\hline CHEMBL1491866 & 688277 & 4.5 & 4.9034 & TRN & \\
\hline CHEMBL1512431 & 688277 & 4.5 & 4.9491 & TRN & \\
\hline
\end{tabular}




\begin{tabular}{|c|c|c|c|c|}
\hline \multicolumn{5}{|c|}{ Supplemental Table S2.txt } \\
\hline CHEMBL1359129 & 688277 & 4.5 & 4.9622 & TST \\
\hline CHEMBL1356176 & 688277 & 4.5 & 4.7992 & TRN \\
\hline CHEMBL1390645 & 688277 & 4.65 & 4.8113 & TRN \\
\hline CHEMBL1480149 & 688277 & 4.9 & 4.8225 & TRN \\
\hline CHEMBL1590628 & 688277 & 4.9 & 4.9086 & TST \\
\hline CHEMBL1357624 & 688277 & 5.25 & 4.8128 & TRN \\
\hline CHEMBL1514111 & 688277 & 4.7 & 4.879 & TRN \\
\hline CHEMBL1591497 & 688277 & 4.5 & 4.7751 & TRN \\
\hline CHEMBL602234 & 688277 & 4.65 & 4.7736 & TRN \\
\hline CHEMBL1420595 & 688277 & 4.7 & 4.9014 & TST \\
\hline CHEMBL1325569 & 688277 & 4.5 & 4.9078 & TST \\
\hline CHEMBL1553505 & 688277 & 5.45 & 4.8974 & TRN \\
\hline CHEMBL1429637 & 688277 & 5.1 & 4.9779 & TST \\
\hline CHEMBL1598530 & 688277 & 4.5 & 4.9097 & TRN \\
\hline CHEMBL1540682 & 688277 & 5.05 & 5.1264 & TST \\
\hline CHEMBL1512331 & 688277 & 4.9 & 4.8399 & TRN \\
\hline CHEMBL1432762 & 688277 & 4.95 & 4.91 & TRN \\
\hline CHEMBL1551609 & 688277 & 4.5 & 4.8542 & TRN \\
\hline CHEMBL1478449 & 688277 & 5.55 & 4.9202 & TRN \\
\hline CHEMBL1593141 & 688277 & 5.1 & 4.9183 & TRN \\
\hline CHEMBL1508925 & 688277 & 4.9 & 4.9571 & TST \\
\hline CHEMBL1366731 & 688277 & 4.5 & 5.109 & TST \\
\hline CHEMBL1492169 & 688277 & 4.65 & 5.0995 & TRN \\
\hline CHEMBL1494905 & 688277 & 4.8 & 4.9463 & TRN \\
\hline CHEMBL1595411 & 688277 & 6.4 & 5.0399 & TRN \\
\hline CHEMBL1528506 & 688277 & 8.301 & 4.8818 & TRN \\
\hline CHEMBL1320008 & 688277 & 5.1 & 5.0384 & TRN \\
\hline CHEMBL1551249 & 688277 & 4.9 & 4.9333 & TST \\
\hline CHEMBL1449069 & 688277 & 5.0 & 4.6585 & TST \\
\hline CHEMBL1611263 & 688277 & 5.4 & 5.1347 & TRN \\
\hline CHEMBL1568515 & 688277 & 4.45 & 4.9415 & TST \\
\hline CHEMBL1357934 & 688277 & 4.7 & 4.8868 & TST \\
\hline CHEMBL1317719 & 688277 & 5.15 & 4.7997 & TST \\
\hline CHEMBL1455643 & 688277 & 4.8 & 4.8916 & TRN \\
\hline CHEMBL1482470 & 688277 & 5.0 & 4.7256 & TST \\
\hline CHEMBL1598888 & 688277 & 4.95 & 4.9491 & TRN \\
\hline CHEMBL1501547 & 688277 & 4.95 & 4.9337 & TRN \\
\hline CHEMBL1508694 & 688277 & 5.0 & 4.9739 & TRN \\
\hline CHEMBL1572527 & 688277 & 5.05 & 5.038 & TST \\
\hline CHEMBL1590169 & 688277 & 4.7 & 4.8739 & TRN \\
\hline CHEMBL1514491 & 688277 & 4.9 & 4.9467 & TRN \\
\hline CHEMBL1315998 & 688277 & 5.0 & 4.8999 & TRN \\
\hline CHEMBL1414363 & 688277 & 4.8 & 4.8971 & TRN \\
\hline CHEMBL1356722 & 688277 & 4.45 & 5.0734 & TRN \\
\hline CHEMBL1564360 & 688277 & 5.25 & 5.1441 & TRN \\
\hline CHEMBL1397459 & 688277 & 4.9 & 4.8564 & TST \\
\hline CHEMBL1300971 & 688277 & 5.05 & 5.0033 & TST \\
\hline CHEMBL1476773 & 688277 & 4.95 & 4.6502 & TRN \\
\hline
\end{tabular}




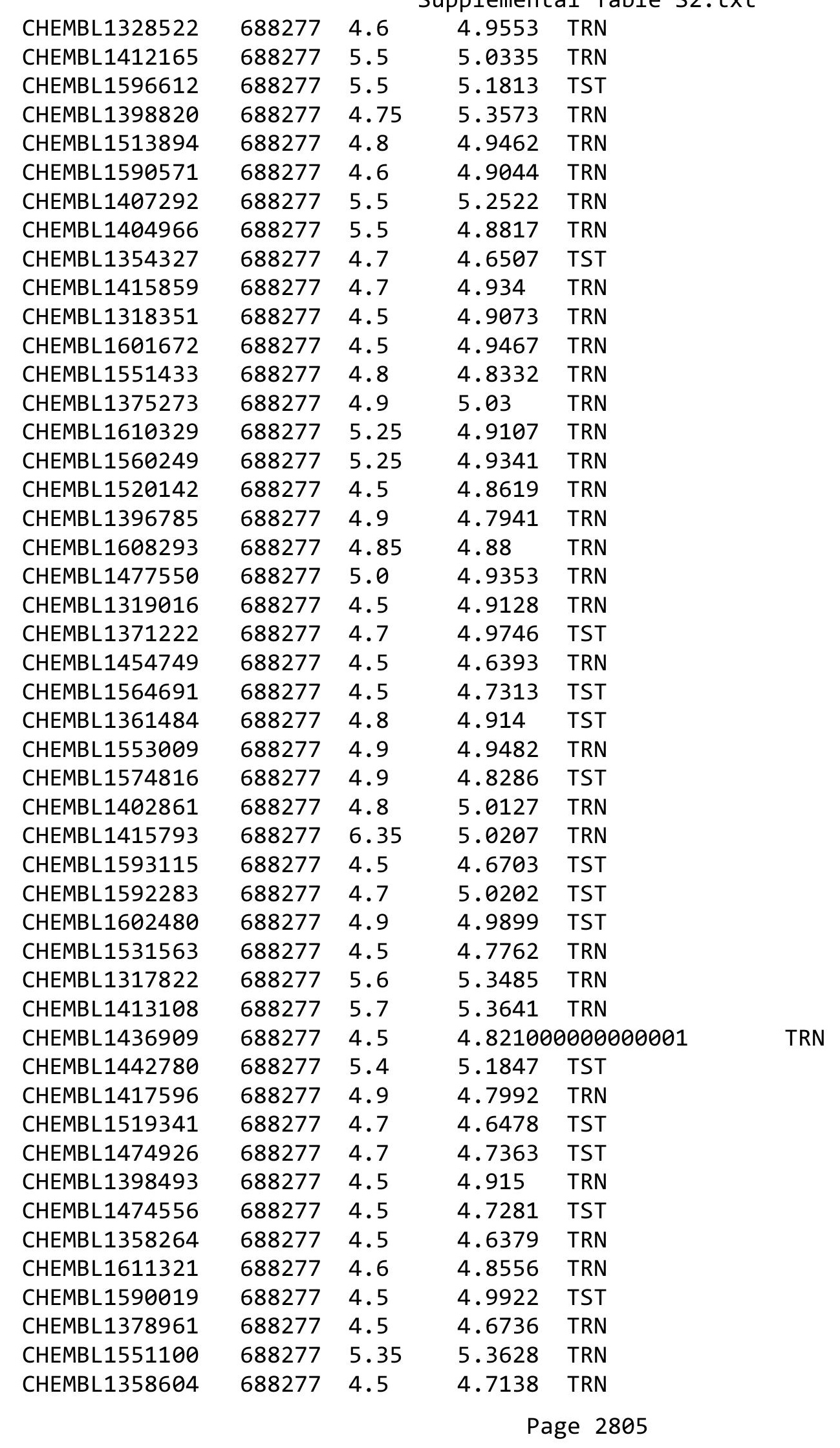




\begin{tabular}{|c|c|c|c|c|}
\hline \multicolumn{5}{|c|}{ pplemental $\mathrm{T}$} \\
\hline CHEMBL1475537 & 688277 & 5.2 & 4.9679 & TRN \\
\hline CHEMBL1318128 & 688277 & 4.9 & 5.1744 & TRN \\
\hline CHEMBL1560956 & 688277 & 5.0 & 4.8183 & TRN \\
\hline CHEMBL1592561 & 688277 & 4.9 & 4.8497 & TRN \\
\hline CHEMBL1485388 & 688277 & 4.75 & 4.84 & TRN \\
\hline CHEMBL1375376 & 688277 & 4.6 & 4.897 & TRN \\
\hline CHEMBL1596463 & 688277 & 4.5 & 4.9188 & TRN \\
\hline CHEMBL1400731 & 688277 & 4.6 & 4.7037 & TRN \\
\hline CHEMBL1316880 & 688277 & 4.7 & 4.9135 & TRN \\
\hline CHEMBL1592716 & 688277 & 5.5 & 5.1075 & TRN \\
\hline CHEMBL1593226 & 688277 & 4.9 & 4.8847 & TST \\
\hline CHEMBL1591304 & 688277 & 4.95 & 5.7545 & TRN \\
\hline CHEMBL1416275 & 688277 & 5.6 & 5.2531 & TRN \\
\hline CHEMBL1412114 & 688277 & 4.6 & 4.7263 & TST \\
\hline CHEMBL1964614 & 688277 & 5.4 & 5.0831 & TST \\
\hline CHEMBL1592338 & 688277 & 4.8 & 5.3219 & TRN \\
\hline CHEMBL1593221 & 688277 & 4.5 & 4.8842 & TRN \\
\hline CHEMBL1378321 & 688277 & 4.45 & 4.9156 & TRN \\
\hline CHEMBL1368199 & 688277 & 5.05 & 4.9159 & TRN \\
\hline CHEMBL1425943 & 688277 & 5.0 & 4.6855 & TRN \\
\hline CHEMBL1512615 & 688277 & 5.45 & 5.0374 & TRN \\
\hline CHEMBL1519352 & 688277 & 4.85 & 4.8133 & TRN \\
\hline CHEMBL1592353 & 688277 & 5.5 & 4.9531 & TST \\
\hline CHEMBL1598926 & 688277 & 4.5 & 4.9444 & TRN \\
\hline CHEMBL1418013 & 688277 & 5.0 & 4.9803 & TRN \\
\hline CHEMBL1417654 & 688277 & 4.95 & 5.0051 & TST \\
\hline CHEMBL1489449 & 688277 & 4.6 & 4.756 & TRN \\
\hline CHEMBL1376831 & 688277 & 4.9 & 4.7995 & TRN \\
\hline CHEMBL1368862 & 688277 & 4.9 & 5.0227 & TST \\
\hline CHEMBL1513105 & 688277 & 5.6 & 5.1105 & TST \\
\hline CHEMBL1516327 & 688277 & 4.5 & 5.0142 & TST \\
\hline CHEMBL1512219 & 688277 & 4.9 & 4.9805 & TRN \\
\hline CHEMBL1611769 & 688277 & 5.25 & 4.8786 & TRN \\
\hline CHEMBL1554756 & 688277 & 4.5 & 4.7284 & TRN \\
\hline CHEMBL1475985 & 688277 & 4.6 & 4.8557 & TST \\
\hline CHEMBL1446347 & 688277 & 4.7 & 5.046 & TST \\
\hline CHEMBL1527382 & 688277 & 4.9 & 4.9439 & TRN \\
\hline CHEMBL1572268 & 688277 & 5.55 & 4.8685 & TRN \\
\hline CHEMBL1362432 & 688277 & 4.9 & 4.9272 & TRN \\
\hline CHEMBL1406980 & 688277 & 5.0 & 4.8482 & TRN \\
\hline CHEMBL1561897 & 688277 & 4.6 & 4.862 & TRN \\
\hline CHEMBL1591406 & 688277 & 5.7 & 5.4588 & TRN \\
\hline CHEMBL1563695 & 688277 & 4.8 & 4.9577 & TRN \\
\hline CHEMBL1555091 & 688277 & 4.9 & 4.6206 & TRN \\
\hline CHEMBL1516339 & 688277 & 5.9 & 5.4417 & TRN \\
\hline CHEMBL1394916 & 688277 & 4.95 & 4.8812 & TST \\
\hline CHEMBL1573345 & 688277 & 4.5 & 4.6762 & TRN \\
\hline CHEMBL1536103 & 688277 & 4.8 & 4.7734 & TST \\
\hline
\end{tabular}




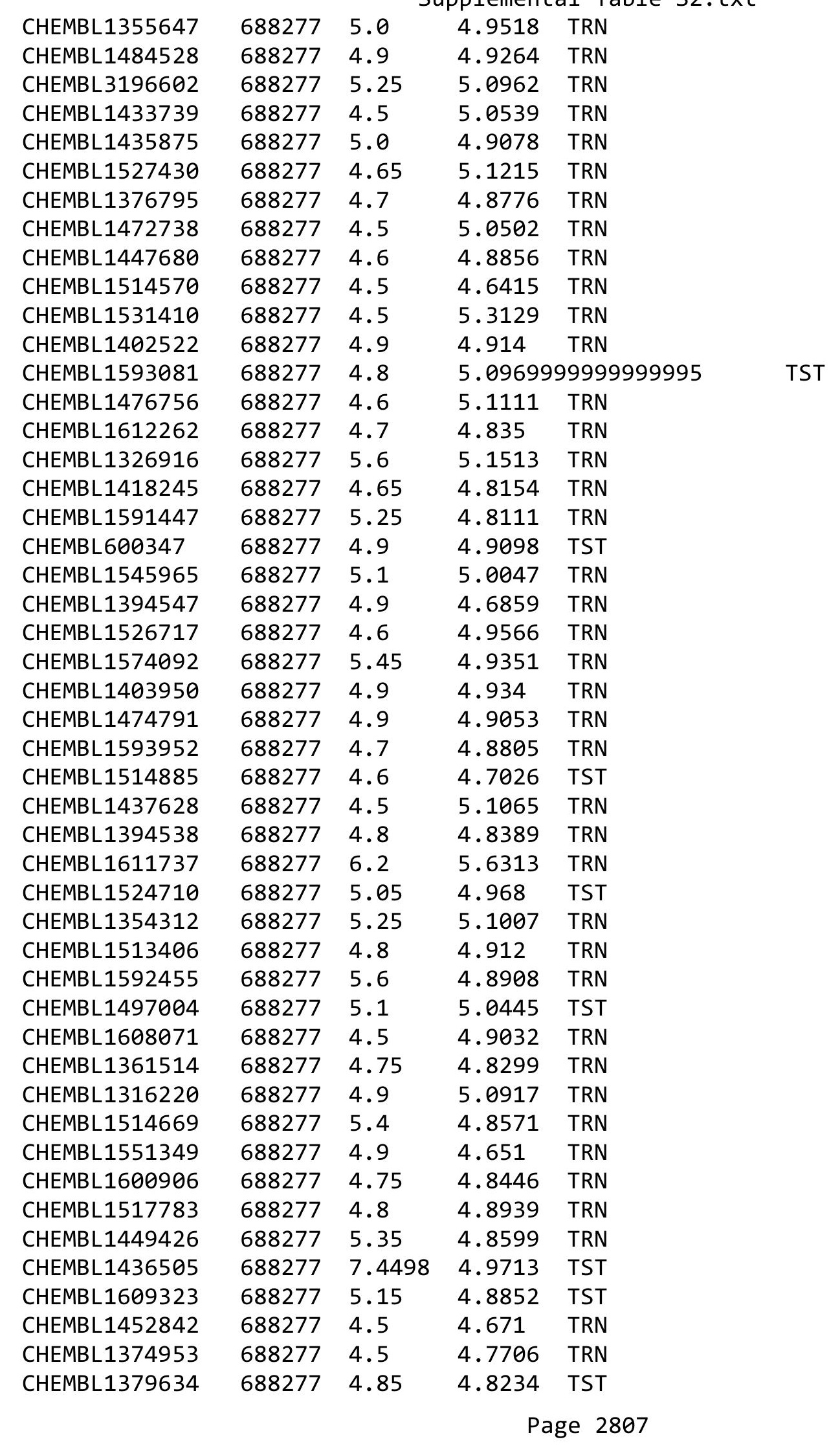




\begin{tabular}{|c|c|c|c|c|}
\hline \multicolumn{5}{|c|}{ Supplemental Table S2.txt } \\
\hline CHEMBL1375735 & 688277 & 4.5 & 5.0422 & TST \\
\hline CHEMBL1429512 & 688277 & 4.65 & 4.6932 & TST \\
\hline CHEMBL1513307 & 688277 & 4.5 & 5.0047 & TRN \\
\hline CHEMBL1515054 & 688277 & 4.7 & 5.6373 & TST \\
\hline CHEMBL 1355350 & 688277 & 5.25 & 4.8914 & TRN \\
\hline CHEMBL1337191 & 688277 & 4.8 & 4.8932 & TRN \\
\hline CHEMBL1514165 & 688277 & 4.9 & 4.9342 & TRN \\
\hline CHEMBL1437484 & 688277 & 4.9 & 4.8856 & TRN \\
\hline CHEMBL1412712 & 688277 & 4.6 & 4.7982 & TRN \\
\hline CHEMBL1530594 & 688277 & 4.5 & 4.683 & TRN \\
\hline CHEMBL1448254 & 688277 & 4.5 & 4.9977 & TRN \\
\hline CHEMBL1315812 & 688277 & 4.95 & 5.0142 & TST \\
\hline CHEMBL1483650 & 688277 & 4.5 & 4.8253 & TRN \\
\hline CHEMBL1449781 & 688277 & 4.5 & 4.9447 & TST \\
\hline CHEMBL1481939 & 688277 & 5.0 & 5.2106 & TRN \\
\hline CHEMBL1397447 & 688277 & 4.95 & 4.8847 & TRN \\
\hline CHEMBL1593037 & 688277 & 5.55 & 5.3427 & TRN \\
\hline CHEMBL1520733 & 688277 & 4.6 & 4.8668 & TRN \\
\hline CHEMBL1608441 & 688277 & 4.9 & 4.7645 & TRN \\
\hline CHEMBL1417247 & 688277 & 4.9 & 4.8256 & TRN \\
\hline CHEMBL1436672 & 688277 & 4.6 & 4.8561 & TRN \\
\hline CHEMBL1449070 & 688277 & 4.5 & 5.1318 & TRN \\
\hline CHEMBL1359678 & 688277 & 4.65 & 4.914 & TRN \\
\hline CHEMBL1554751 & 688277 & 4.9 & 4.9003 & TRN \\
\hline CHEMBL1590029 & 688277 & 4.6 & 4.9296 & TRN \\
\hline CHEMBL1528739 & 688277 & 4.65 & 5.1592 & TST \\
\hline CHEMBL1574773 & 688277 & 4.5 & 4.91 & TST \\
\hline CHEMBL1559360 & 688277 & 4.5 & 5.1104 & TRN \\
\hline CHEMBL199925 & 688277 & 4.9 & 4.9237 & TRN \\
\hline CHEMBL1521327 & 688277 & 4.9 & 4.902 & TRN \\
\hline CHEMBL3195514 & 688277 & 4.55 & 5.081 & TST \\
\hline CHEMBL1324709 & 688277 & 4.75 & 4.9512 & TST \\
\hline CHEMBL1551766 & 688277 & 4.8 & 4.9839 & TRN \\
\hline CHEMBL1555339 & 688277 & 4.5 & 4.9101 & TRN \\
\hline CHEMBL1448226 & 688277 & 4.45 & 4.9009 & TRN \\
\hline CHEMBL1356510 & 688277 & 4.9 & 4.9886 & TRN \\
\hline CHEMBL1494183 & 688277 & 4.8 & 4.9229 & TRN \\
\hline CHEMBL1600081 & 688277 & 4.7 & 4.8536 & TRN \\
\hline CHEMBL1575036 & 688277 & 4.9 & 4.9001 & TRN \\
\hline CHEMBL1356739 & 688277 & 5.45 & 5.3161 & TRN \\
\hline CHEMBL1590140 & 688277 & 5.2 & 5.2733 & TRN \\
\hline CHEMBL1479440 & 688277 & 4.8 & 4.8832 & TST \\
\hline CHEMBL1427465 & 688277 & 5.0 & 4.9598 & TST \\
\hline CHEMBL1355245 & 688277 & 4.5 & 4.8423 & TRN \\
\hline CHEMBL1373463 & 688277 & 4.5 & 4.6224 & TRN \\
\hline CHEMBL1413498 & 688277 & 4.45 & 5.0937 & TRN \\
\hline CHEMBL1553252 & 688277 & 6.25 & 5.021 & TRN \\
\hline CHEMBL1394759 & 688277 & 4.9 & 4.7982 & TRN \\
\hline
\end{tabular}




\begin{tabular}{|c|c|c|c|c|c|}
\hline & & & & & \\
\hline CHEMBL1594042 & 688277 & 5.0 & 4.9258 & TRN & \\
\hline CHEMBL1465338 & 688277 & 4.75 & 4.9289 & TRN & \\
\hline CHEMBL1512416 & 688277 & 4.9 & 4.96899 & 9999999999 & TRN \\
\hline CHEMBL1522345 & 688277 & 5.45 & 5.3236 & TRN & \\
\hline CHEMBL1365865 & 688277 & 4.9 & 4.7505 & TRN & \\
\hline CHEMBL1354862 & 688277 & 5.25 & 5.0122 & TRN & \\
\hline CHEMBL1522858 & 688277 & 5.25 & 5.0731 & TRN & \\
\hline CHEMBL1436589 & 688277 & 4.45 & 4.8821 & TRN & \\
\hline CHEMBL1558600 & 688277 & 5.95 & 4.9599 & TRN & \\
\hline CHEMBL1395734 & 688277 & 4.5 & 4.8499 & TRN & \\
\hline CHEMBL1436057 & 688277 & 4.9 & 4.8915 & TRN & \\
\hline CHEMBL1513036 & 688277 & 5.35 & 4.8777 & TRN & \\
\hline CHEMBL1309993 & 688277 & 4.6 & 4.9524 & TRN & \\
\hline CHEMBL1590279 & 688277 & 4.6 & 4.7066 & TRN & \\
\hline CHEMBL1473819 & 688277 & 5.0 & 4.99 & TRN & \\
\hline CHEMBL1397330 & 688277 & 5.05 & 4.9444 & TRN & \\
\hline CHEMBL1396547 & 688277 & 4.95 & 4.8145 & TST & \\
\hline CHEMBL1314724 & 688277 & 5.4 & 5.1215 & TRN & \\
\hline CHEMBL1519214 & 688277 & 4.5 & 4.7941 & TRN & \\
\hline CHEMBL1557075 & 688277 & 4.9 & 4.9207 & TRN & \\
\hline CHEMBL1317744 & 688277 & 4.7 & 4.8323 & TRN & \\
\hline CHEMBL1372832 & 688277 & 4.7 & 4.8335 & TRN & \\
\hline CHEMBL1573365 & 688277 & 4.9 & 4.7504 & TST & \\
\hline CHEMBL1395020 & 688277 & 5.1 & 5.0132 & TRN & \\
\hline CHEMBL1395932 & 688277 & 5.2 & 5.003 & TRN & \\
\hline CHEMBL1591340 & 688277 & 4.5 & 4.7397 & TRN & \\
\hline CHEMBL1403725 & 688277 & 5.5 & 4.8199 & TRN & \\
\hline CHEMBL1558053 & 688277 & 4.5 & 4.8125 & TST & \\
\hline CHEMBL1366018 & 688277 & 4.5 & 4.7978 & TRN & \\
\hline CHEMBL1476111 & 688277 & 4.7 & 4.9169 & TST & \\
\hline CHEMBL1590236 & 688277 & 4.5 & 4.8264 & TST & \\
\hline CHEMBL1325504 & 688277 & 4.5 & 4.6263 & TRN & \\
\hline CHEMBL1489563 & 688277 & 5.25 & 5.1055 & TRN & \\
\hline CHEMBL1354533 & 688277 & 4.8 & 4.835 & TRN & \\
\hline CHEMBL1596719 & 688277 & 4.95 & 4.8964 & TRN & \\
\hline CHEMBL1336959 & 688277 & 4.6 & 4.9181 & TST & \\
\hline CHEMBL1436170 & 688277 & 4.45 & 4.8829 & TRN & \\
\hline CHEMBL1515790 & 688277 & 4.5 & 5.1439 & TST & \\
\hline CHEMBL1377387 & 688277 & 4.65 & 4.8638 & TRN & \\
\hline CHEMBL1548075 & 688277 & 4.95 & 4.9009 & TRN & \\
\hline CHEMBL1376502 & 688277 & 4.9 & 4.8555 & TRN & \\
\hline CHEMBL1492105 & 688277 & 4.9 & 4.8351 & TRN & \\
\hline CHEMBL1553103 & 688277 & 4.5 & 5.2111 & TRN & \\
\hline CHEMBL1590765 & 688277 & 6.5 & 4.9382 & TRN & \\
\hline CHEMBL1593670 & 688277 & 5.8 & 4.9578 & TRN & \\
\hline CHEMBL1533774 & 688277 & 4.5 & 4.8638 & TRN & \\
\hline CHEMBL1504609 & 688277 & 4.9 & 4.7829 & TRN & \\
\hline CHEMBL1364048 & 688277 & 4.6 & 6.36799 & 9999999999 & TRN \\
\hline & & & & 2809 & \\
\hline
\end{tabular}




\begin{tabular}{|c|c|c|c|c|}
\hline & & & & al Table s \\
\hline CHEMBL1593377 & 688277 & 4.5 & 4.9151 & TRN \\
\hline CHEMBL1401899 & 688277 & 5.3 & 4.8387 & TRN \\
\hline CHEMBL1519385 & 688277 & 4.8 & 4.6937 & TRN \\
\hline CHEMBL1448104 & 688277 & 4.45 & 4.8552 & TRN \\
\hline CHEMBL1434937 & 688277 & 4.6 & 4.9687 & TRN \\
\hline CHEMBL1565416 & 688277 & 4.95 & 4.9282 & TRN \\
\hline CHEMBL1551795 & 688277 & 4.8 & 4.8989 & TRN \\
\hline CHEMBL1450497 & 688277 & 5.6 & 5.136 & TRN \\
\hline CHEMBL1452108 & 688277 & 5.0 & 4.8562 & TRN \\
\hline CHEMBL1436947 & 688277 & 4.75 & 4.7743 & TRN \\
\hline CHEMBL1544147 & 688277 & 4.95 & 4.9432 & TST \\
\hline CHEMBL1594015 & 688277 & 4.8 & 4.6765 & TRN \\
\hline CHEMBL1436840 & 688277 & 4.9 & 4.9089 & TRN \\
\hline CHEMBL1414391 & 688277 & 5.0 & 4.9403 & TRN \\
\hline CHEMBL1548093 & 688277 & 4.95 & 4.9212 & TRN \\
\hline CHEMBL1521694 & 688277 & 5.5 & 5.2453 & TST \\
\hline CHEMBL1412866 & 688277 & 4.7 & 4.8839 & TRN \\
\hline CHEMBL1534030 & 688277 & 5.0 & 4.9264 & TRN \\
\hline CHEMBL1339007 & 688277 & 4.7 & 4.8236 & TRN \\
\hline CHEMBL1608356 & 688277 & 5.5 & 5.33299 & 9999999999 \\
\hline CHEMBL1522944 & 688277 & 5.35 & 4.8956 & TRN \\
\hline CHEMBL1591644 & 688277 & 4.45 & 4.7829 & TRN \\
\hline CHEMBL1590626 & 688277 & 5.5 & 4.8749 & TRN \\
\hline CHEMBL1555081 & 688277 & 5.2 & 4.8649 & TRN \\
\hline CHEMBL1596673 & 688277 & 5.45 & 4.9319 & TRN \\
\hline CHEMBL1599764 & 688277 & 4.9 & 4.9404 & TRN \\
\hline CHEMBL1394726 & 688277 & 5.0 & 4.9285 & TRN \\
\hline CHEMBL1590221 & 688277 & 5.1 & 4.8379 & TRN \\
\hline CHEMBL1512257 & 688277 & 4.9 & 4.8012 & TRN \\
\hline CHEMBL1393941 & 688277 & 5.2 & 4.8775 & TRN \\
\hline CHEMBL1552986 & 688277 & 4.6 & 4.8865 & TRN \\
\hline CHEMBL1512234 & 688277 & 6.4 & 4.9477 & TST \\
\hline CHEMBL1447653 & 688277 & 5.8 & 4.7999 & TRN \\
\hline CHEMBL1394193 & 688277 & 4.8 & 4.7831 & TRN \\
\hline CHEMBL1314925 & 688277 & 4.5 & 4.8651 & TRN \\
\hline CHEMBL1491498 & 688277 & 4.5 & 4.8792 & TST \\
\hline CHEMBL1596442 & 688277 & 4.8 & 4.746 & TRN \\
\hline CHEMBL1394872 & 688277 & 4.45 & 4.8786 & TRN \\
\hline CHEMBL1566891 & 688277 & 4.65 & 4.9277 & TRN \\
\hline CHEMBL1594652 & 688277 & 4.5 & 4.698 & TRN \\
\hline CHEMBL1480883 & 688277 & 5.25 & 4.9704 & TRN \\
\hline CHEMBL1492189 & 688277 & 5.25 & 4.8832 & TRN \\
\hline CHEMBL1445067 & 688277 & 4.9 & 4.8571 & TRN \\
\hline CHEMBL1396461 & 688277 & 4.5 & 4.8463 & TRN \\
\hline CHEMBL1599340 & 688277 & 5.8 & 5.3477 & TRN \\
\hline CHEMBL1553464 & 688277 & 4.5 & 4.8456 & TRN \\
\hline CHEMBL1417702 & 688277 & 4.6 & 4.8284 & TRN \\
\hline CHEMBL1464354 & 688277 & 4.45 & 4.9283 & TRN \\
\hline
\end{tabular}




\begin{tabular}{|c|c|c|c|c|c|}
\hline \multicolumn{6}{|c|}{ Supplemental Table s2.txt } \\
\hline CHEMBL1475195 & 688277 & 5.0 & 4.8612 & TRN & \\
\hline CHEMBL1323093 & 688277 & 4.5 & 4.8205 & TRN & \\
\hline CHEMBL1484285 & 688277 & 5.4 & 4.8496 & TRN & \\
\hline CHEMBL1322995 & 688277 & 4.45 & 4.8036 & TRN & \\
\hline CHEMBL1610691 & 688277 & 5.5 & 5.271 & TRN & \\
\hline CHEMBL1358148 & 688277 & 5.0 & 4.8589 & TRN & \\
\hline CHEMBL1442632 & 688277 & 4.7 & 4.9034 & TST & \\
\hline CHEMBL1526511 & 688277 & 4.75 & 4.7674 & TST & \\
\hline CHEMBL1518345 & 688277 & 5.2 & 5.046 & TRN & \\
\hline CHEMBL1477552 & 688277 & 5.45 & 5.2129 & TST & \\
\hline CHEMBL1354701 & 688277 & 4.75 & 4.6703 & TST & \\
\hline CHEMBL1402431 & 688277 & 4.9 & 4.9607 & TRN & \\
\hline CHEMBL1526233 & 688277 & 4.6 & 4.8984 & TST & \\
\hline CHEMBL1467356 & 688277 & 4.7 & 4.96399 & 99999999995 & TST \\
\hline CHEMBL1395283 & 688277 & 4.9 & 4.9785 & TST & \\
\hline CHEMBL1436873 & 688277 & 5.0 & 5.0758 & TRN & \\
\hline CHEMBL1362608 & 688277 & 4.6 & 4.9401 & TRN & \\
\hline CHEMBL1366145 & 688277 & 4.45 & 4.9584 & TRN & \\
\hline CHEMBL1338737 & 688277 & 4.9 & 4.671 & TRN & \\
\hline CHEMBL1315150 & 688277 & 4.45 & 4.9205 & TRN & \\
\hline CHEMBL1569364 & 688277 & 5.2 & 5.0792 & TST & \\
\hline CHEMBL1591813 & 688277 & 4.5 & 4.833 & TRN & \\
\hline CHEMBL1363812 & 688277 & 4.5 & 4.9037 & TRN & \\
\hline CHEMBL1324998 & 688277 & 4.45 & 5.2942 & TRN & \\
\hline CHEMBL1475348 & 688277 & 5.0 & 4.9084 & TRN & \\
\hline CHEMBL1354925 & 688277 & 4.9 & 4.8172 & TRN & \\
\hline CHEMBL1435244 & 688277 & 4.9 & 4.7784 & TRN & \\
\hline CHEMBL1355857 & 688277 & 4.5 & 4.6427 & TST & \\
\hline CHEMBL1405646 & 688277 & 4.45 & 4.885 & TRN & \\
\hline CHEMBL1355390 & 688277 & 5.0 & 4.8921 & TRN & \\
\hline CHEMBL1557423 & 688277 & 5.0 & 5.4473 & TRN & \\
\hline CHEMBL1474452 & 688277 & 4.45 & 4.9841 & TST & \\
\hline CHEMBL1314629 & 688277 & 4.5 & 4.9849 & TRN & \\
\hline CHEMBL1487271 & 688277 & 4.5 & 4.6984 & TST & \\
\hline CHEMBL1355733 & 688277 & 5.45 & 5.0514 & TRN & \\
\hline CHEMBL1401145 & 688277 & 5.6 & 5.4937 & TRN & \\
\hline CHEMBL1531920 & 688277 & 4.5 & 4.7137 & TRN & \\
\hline CHEMBL1372212 & 688277 & 4.6 & 4.7001 & TRN & \\
\hline CHEMBL1358427 & 688277 & 4.7 & 4.9049 & TRN & \\
\hline CHEMBL1512992 & 688277 & 5.0 & 4.7421 & TRN & \\
\hline CHEMBL1314161 & 688277 & 4.9 & 4.9407 & TRN & \\
\hline CHEMBL1396087 & 688277 & 5.25 & 4.9856 & TST & \\
\hline CHEMBL1476377 & 688277 & 4.45 & 4.877 & TRN & \\
\hline CHEMBL1378347 & 688277 & 4.5 & 4.7474 & TRN & \\
\hline CHEMBL1557875 & 688277 & 5.35 & 4.9052 & TRN & \\
\hline CHEMBL1318541 & 688277 & 7.8013 & 5.0345 & TRN & \\
\hline CHEMBL1554923 & 688277 & 5.6 & 5.1805 & TRN & \\
\hline CHEMBL578420 & 688277 & 6.2 & 5.3215 & TRN & \\
\hline
\end{tabular}




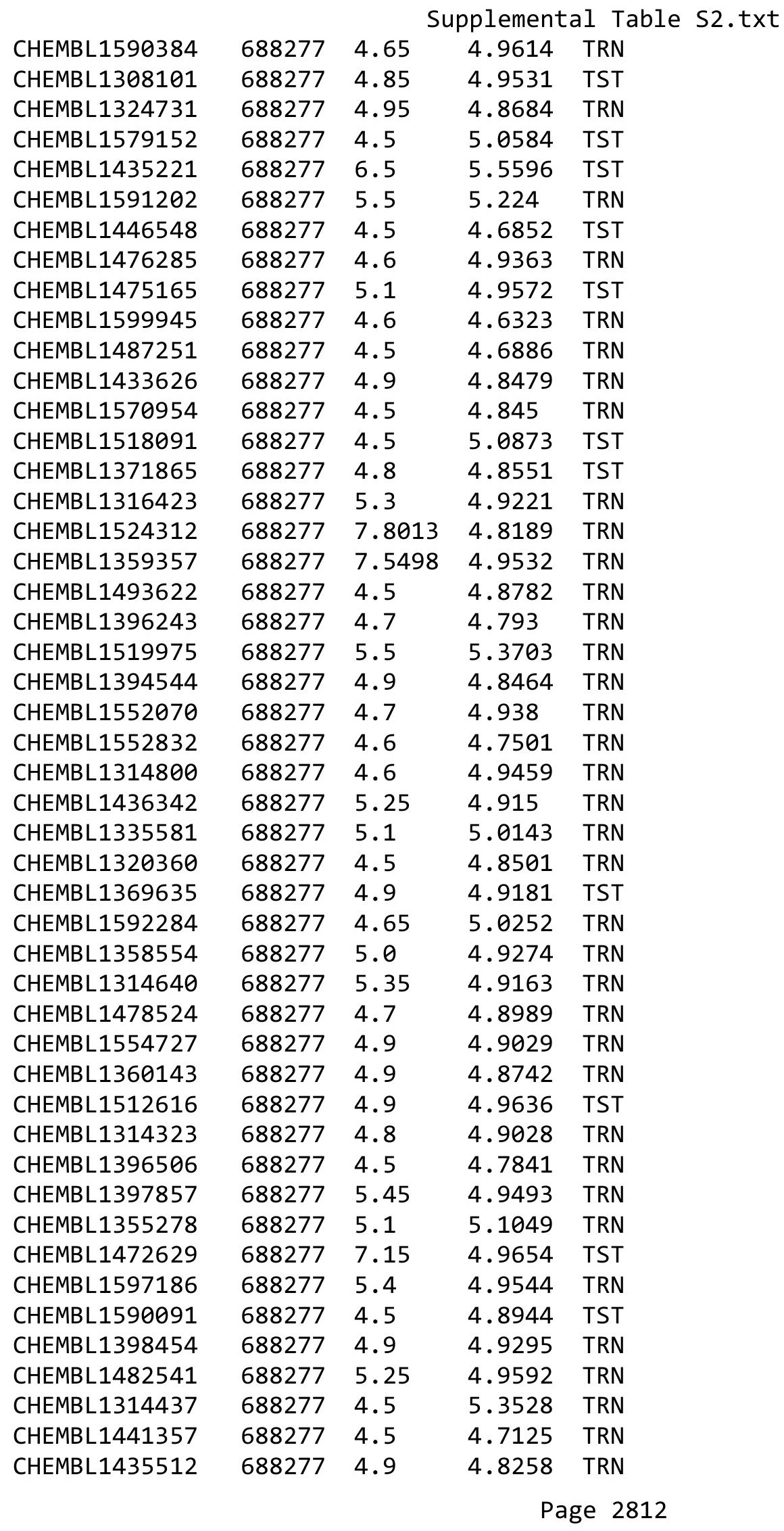




\begin{tabular}{|c|c|c|c|c|c|}
\hline & & & & & \\
\hline CHEMBL1396389 & 688277 & 4.5 & 4.8534 & TST & \\
\hline CHEMBL1300717 & 688277 & 5.25 & 5.2151 & TST & \\
\hline CHEMBL1513638 & 688277 & 4.9 & 4.8947 & TRN & \\
\hline CHEMBL1367806 & 688277 & 4.9 & 4.9536 & TRN & \\
\hline CHEMBL1435945 & 688277 & 4.8 & 4.8368 & TST & \\
\hline CHEMBL1477629 & 688277 & 4.55 & 4.63899 & 9999999999 & TRN \\
\hline CHEMBL1601128 & 688277 & 4.95 & 4.751 & TST & \\
\hline CHEMBL1325491 & 688277 & 4.9 & 4.7596 & TST & \\
\hline CHEMBL1357390 & 688277 & 4.6 & 4.936 & TRN & \\
\hline CHEMBL1552737 & 688277 & 4.5 & 4.93 & TRN & \\
\hline CHEMBL1327128 & 688277 & 4.5 & 4.6915 & TRN & \\
\hline CHEMBL1376164 & 688277 & 4.9 & 4.948 & TST & \\
\hline CHEMBL1406046 & 688277 & 4.45 & 5.1981 & TRN & \\
\hline CHEMBL1568028 & 688277 & 4.9 & 4.8917 & TRN & \\
\hline CHEMBL1356580 & 688277 & 4.95 & 4.8905 & TRN & \\
\hline CHEMBL1436966 & 688277 & 4.5 & 4.9638 & TRN & \\
\hline CHEMBL1512097 & 688277 & 4.9 & 4.9268 & TRN & \\
\hline CHEMBL1371327 & 688277 & 5.5 & 4.9349 & TRN & \\
\hline CHEMBL1611813 & 688277 & 5.55 & 4.8786 & TST & \\
\hline CHEMBL1573167 & 688277 & 5.55 & 4.8795 & TST & \\
\hline CHEMBL1590521 & 688277 & 4.9 & 5.0415 & TST & \\
\hline CHEMBL1553201 & 688277 & 4.5 & 4.8859 & TRN & \\
\hline CHEMBL1454996 & 688277 & 4.45 & 4.8803 & TRN & \\
\hline CHEMBL1396032 & 688277 & 4.9 & 4.8952 & TST & \\
\hline CHEMBL1571933 & 688277 & 5.25 & 4.9802 & TRN & \\
\hline CHEMBL1488003 & 688277 & 4.9 & 4.8433 & TST & \\
\hline CHEMBL1515266 & 688277 & 5.0 & 5.0008 & TRN & \\
\hline CHEMBL1448892 & 688277 & 4.5 & 4.8758 & TRN & \\
\hline CHEMBL1551670 & 688277 & 4.5 & 4.8559 & TRN & \\
\hline CHEMBL1613650 & 688277 & 4.6 & 4.8134 & TRN & \\
\hline CHEMBL1436989 & 688277 & 5.3 & 5.0663 & TRN & \\
\hline CHEMBL1497602 & 688277 & 6.25 & 5.5326 & TRN & \\
\hline CHEMBL1591366 & 688277 & 4.5 & 4.9278 & TRN & \\
\hline CHEMBL1525866 & 688277 & 4.5 & 4.9748 & TRN & \\
\hline CHEMBL1369899 & 688277 & 4.5 & 4.6412 & TRN & \\
\hline CHEMBL1512706 & 688277 & 5.2 & 5.1041 & TRN & \\
\hline CHEMBL1592755 & 688277 & 4.9 & 4.7372 & TRN & \\
\hline CHEMBL1555256 & 688277 & 4.5 & 4.9656 & TRN & \\
\hline CHEMBL1436027 & 688277 & 4.6 & 4.8417 & TRN & \\
\hline CHEMBL1444681 & 688277 & 4.7 & 4.891 & TRN & \\
\hline CHEMBL1338351 & 688277 & 7.699 & 5.1021 & TST & \\
\hline CHEMBL1482864 & 688277 & 4.9 & 4.732 & TRN & \\
\hline CHEMBL1433706 & 688277 & 5.35 & 4.9115 & TRN & \\
\hline CHEMBL1514267 & 688277 & 4.75 & 5.0531 & TST & \\
\hline CHEMBL1455490 & 688277 & 5.45 & 5.309 & TST & \\
\hline CHEMBL1514074 & 688277 & 4.5 & 4.8711 & TRN & \\
\hline CHEMBL1592708 & 688277 & 5.0 & 4.91100 & 00000000005 & TRN \\
\hline CHEMBL1591373 & 688277 & 5.3 & 4.8404 & TRN & \\
\hline & & & & 2813 & \\
\hline
\end{tabular}




\begin{tabular}{|c|c|c|c|c|c|}
\hline & & \multicolumn{4}{|c|}{ Supplemental Table S2.txt } \\
\hline CHEMBL1527993 & 688277 & 4.85 & 4.7868 & TST & \\
\hline CHEMBL1316622 & 688277 & 4.5 & 4.6443 & TRN & \\
\hline CHEMBL1560639 & 688277 & 5.6 & 5.1262 & TRN & \\
\hline CHEMBL1476125 & 688277 & 4.5 & 5.106 & TRN & \\
\hline CHEMBL1473541 & 688277 & 4.5 & 4.6416 & TRN & \\
\hline CHEMBL1545284 & 688277 & 5.0 & 4.9764 & TST & \\
\hline CHEMBL1397620 & 688277 & 4.5 & 4.9353 & TRN & \\
\hline CHEMBL1600154 & 688277 & 5.4 & 4.9379 & TRN & \\
\hline CHEMBL1590312 & 688277 & 4.5 & 4.9355 & TRN & \\
\hline CHEMBL1475164 & 688277 & 4.45 & 5.1187 & TRN & \\
\hline CHEMBL1601406 & 688277 & 4.85 & 5.0228 & TRN & \\
\hline CHEMBL1356761 & 688277 & 4.5 & 4.7436 & TRN & \\
\hline CHEMBL1402541 & 688277 & 5.1 & 4.9049 & TRN & \\
\hline CHEMBL1476540 & 688277 & 4.9 & 4.83899 & 99999999995 & TRN \\
\hline CHEMBL1320089 & 688277 & 4.5 & 4.7369 & TRN & \\
\hline CHEMBL1550087 & 688277 & 4.95 & 4.9236 & TRN & \\
\hline CHEMBL1417812 & 688277 & 4.8 & 4.7677 & TRN & \\
\hline CHEMBL1396540 & 688277 & 4.9 & 4.8303 & TRN & \\
\hline CHEMBL1444016 & 688277 & 5.0 & 5.0293 & TST & \\
\hline CHEMBL1368915 & 688277 & 4.5 & 5.0155 & TRN & \\
\hline CHEMBL1561928 & 688277 & 4.8 & 4.9408 & TST & \\
\hline CHEMBL1456175 & 688277 & 4.45 & 4.8039 & TRN & \\
\hline CHEMBL1476927 & 688277 & 4.9 & 4.9788 & TRN & \\
\hline CHEMBL1592694 & 688277 & 4.9 & 4.6347 & TRN & \\
\hline CHEMBL1515006 & 688277 & 4.45 & 4.7736 & TRN & \\
\hline CHEMBL1561863 & 688277 & 4.65 & 4.9295 & TRN & \\
\hline CHEMBL1609970 & 688277 & 4.9 & 4.9323 & TRN & \\
\hline CHEMBL1585078 & 688277 & 4.45 & 4.9886 & TST & \\
\hline CHEMBL1474215 & 688277 & 5.5 & 5.4609 & TRN & \\
\hline CHEMBL 233194 & 688277 & 5.55 & 5.0829 & TST & \\
\hline CHEMBL1314196 & 688277 & 4.5 & 4.883 & TRN & \\
\hline CHEMBL1399843 & 688277 & 4.5 & 4.8465 & TRN & \\
\hline CHEMBL1435433 & 688277 & 4.5 & 4.8637 & TRN & \\
\hline CHEMBL1414871 & 688277 & 4.5 & 4.8074 & TRN & \\
\hline CHEMBL1355209 & 688277 & 4.95 & 5.0271 & TRN & \\
\hline CHEMBL1399042 & 688277 & 4.9 & 4.9756 & TRN & \\
\hline CHEMBL1358237 & 688277 & 4.8 & 4.9032 & TRN & \\
\hline CHEMBL1579696 & 688277 & 4.95 & 4.8754 & TRN & \\
\hline CHEMBL1472867 & 688277 & 4.9 & 4.9933 & TRN & \\
\hline CHEMBL546137 & 688277 & 4.9 & 4.871 & TRN & \\
\hline CHEMBL1473738 & 688277 & 4.6 & 4.8139 & TST & \\
\hline CHEMBL1364321 & 688277 & 4.5 & 4.8853 & TRN & \\
\hline CHEMBL1357459 & 688277 & 4.9 & 4.6895 & TST & \\
\hline CHEMBL1423723 & 688277 & 4.45 & 5.0127 & TST & \\
\hline CHEMBL1354651 & 688277 & 4.5 & 5.1703 & TRN & \\
\hline CHEMBL1493951 & 688277 & 5.6 & 5.0658 & TRN & \\
\hline CHEMBL1553584 & 688277 & 4.6 & 4.8454 & TRN & \\
\hline CHEMBL1494639 & 688277 & 4.5 & 4.8008 & TRN & \\
\hline
\end{tabular}




\begin{tabular}{|c|c|c|c|c|c|}
\hline \\
\hline CHEMBL1477748 & 688277 & 4.45 & 5.0839 & TST & \\
\hline CHEMBL1514527 & 688277 & 5.0 & 5.0025 & TRN & \\
\hline CHEMBL1365483 & 688277 & 5.2 & 4.8465 & TRN & \\
\hline CHEMBL1356282 & 688277 & 4.8 & 4.7791 & TST & \\
\hline CHEMBL1477014 & 688277 & 4.45 & 4.7953 & TRN & \\
\hline CHEMBL1516372 & 688277 & 5.3 & 4.959 & TST & \\
\hline CHEMBL1362811 & 688277 & 4.7 & 4.7438 & TRN & \\
\hline CHEMBL1358465 & 688277 & 4.5 & 4.9169 & TRN & \\
\hline CHEMBL1560969 & 688277 & 6.3 & 5.6199 & TRN & \\
\hline CHEMBL1315510 & 688277 & 4.5 & 4.71399 & 99999999995 & TRN \\
\hline CHEMBL1332808 & 688277 & 4.95 & 4.725 & TST & \\
\hline CHEMBL1482538 & 688277 & 4.5 & 4.9881 & TST & \\
\hline CHEMBL1402846 & 688277 & 4.8 & 4.9373 & TRN & \\
\hline CHEMBL1522562 & 688277 & 4.5 & 4.8402 & TRN & \\
\hline CHEMBL1477187 & 688277 & 4.9 & 4.7474 & TST & \\
\hline CHEMBL1610097 & 688277 & 4.8 & 4.8207 & TRN & \\
\hline CHEMBL1396734 & 688277 & 4.8 & 4.8854 & TRN & \\
\hline CHEMBL1443842 & 688277 & 5.25 & 4.9958 & TRN & \\
\hline CHEMBL1592575 & 688277 & 4.5 & 4.8899 & TRN & \\
\hline CHEMBL1592483 & 688277 & 4.5 & 4.7075 & TRN & \\
\hline CHEMBL1397414 & 688277 & 4.7 & 4.8788 & TRN & \\
\hline CHEMBL1435623 & 688277 & 4.8 & 4.9644 & TRN & \\
\hline CHEMBL1605955 & 688277 & 4.9 & 5.0409 & TRN & \\
\hline CHEMBL1415141 & 688277 & 4.8 & 4.8927 & TRN & \\
\hline CHEMBL1378262 & 688277 & 4.9 & 4.8024 & TRN & \\
\hline CHEMBL1441982 & 688277 & 6.0 & 4.842 & TRN & \\
\hline CHEMBL1436312 & 688277 & 4.5 & 5.0368 & TRN & \\
\hline CHEMBL1337456 & 688277 & 4.7 & 5.1032 & TRN & \\
\hline CHEMBL1397479 & 688277 & 4.5 & 4.9284 & TRN & \\
\hline CHEMBL1513209 & 688277 & 5.0 & 4.816 & TRN & \\
\hline CHEMBL1514918 & 688277 & 4.7 & 5.0018 & TRN & \\
\hline CHEMBL1597191 & 688277 & 5.0 & 4.8494 & TRN & \\
\hline CHEMBL1514677 & 688277 & 5.55 & 5.2886 & TRN & \\
\hline CHEMBL1407870 & 688277 & 5.9 & 5.6042 & TRN & \\
\hline CHEMBL1551800 & 688277 & 6.8 & 4.9566 & TRN & \\
\hline CHEMBL1607743 & 688277 & 4.45 & 4.9274 & TST & \\
\hline CHEMBL1485418 & 688277 & 4.8 & 4.9062 & TRN & \\
\hline CHEMBL1450023 & 688277 & 4.7 & 4.7305 & TST & \\
\hline CHEMBL1317198 & 688277 & 5.45 & 5.0283 & TRN & \\
\hline CHEMBL1601222 & 688277 & 5.3 & 4.829 & TRN & \\
\hline CHEMBL1590202 & 688277 & 4.9 & 4.8909 & TRN & \\
\hline CHEMBL1493474 & 688277 & 6.5 & 4.9735 & TRN & \\
\hline CHEMBL1305188 & 688277 & 4.8 & 5.0724 & TST & \\
\hline CHEMBL1512799 & 688277 & 4.95 & 4.9751 & TRN & \\
\hline CHEMBL1476179 & 688277 & 5.0 & 4.9909 & TST & \\
\hline CHEMBL1454795 & 688277 & 4.5 & 4.9945 & TRN & \\
\hline CHEMBL1552826 & 688277 & 4.9 & 4.7347 & TST & \\
\hline CHEMBL1475132 & 688277 & 4.5 & 4.8251 & TRN & \\
\hline
\end{tabular}




\begin{tabular}{|c|c|c|c|c|}
\hline & & & pplement & $d+1$ \\
\hline CHEMBL1377384 & 688277 & 5.1 & 5.0684 & TRN \\
\hline CHEMBL1397603 & 688277 & 6.5 & 4.8637 & TRN \\
\hline CHEMBL1513342 & 688277 & 4.8 & 4.9157 & TRN \\
\hline CHEMBL1315149 & 688277 & 5.9 & 5.3827 & TRN \\
\hline CHEMBL1523446 & 688277 & 5.0 & 4.9509 & TST \\
\hline CHEMBL1338421 & 688277 & 4.9 & 4.8202 & TRN \\
\hline CHEMBL1592615 & 688277 & 4.5 & 4.6702 & TRN \\
\hline CHEMBL1358039 & 688277 & 4.65 & 4.6871 & TRN \\
\hline CHEMBL1435001 & 688277 & 4.8 & 4.941 & TRN \\
\hline CHEMBL1397127 & 688277 & 5.25 & 5.0682 & TRN \\
\hline CHEMBL1533443 & 688277 & 4.8 & 4.9461 & TRN \\
\hline CHEMBL3194115 & 688277 & 6.9 & 5.2391 & TRN \\
\hline CHEMBL1596472 & 688277 & 4.6 & 4.852 & TRN \\
\hline CHEMBL1396475 & 688277 & 4.9 & 4.8914 & TRN \\
\hline CHEMBL1572707 & 688277 & 4.9 & 4.8781 & TRN \\
\hline CHEMBL1411970 & 688277 & 4.5 & 4.9324 & TRN \\
\hline CHEMBL1598912 & 688277 & 4.8 & 4.927 & TRN \\
\hline CHEMBL1613253 & 688277 & 4.9 & 4.7257 & TRN \\
\hline CHEMBL1483489 & 688277 & 4.9 & 4.8005 & TRN \\
\hline CHEMBL1598422 & 688277 & 5.25 & 4.9261 & TRN \\
\hline CHEMBL1372680 & 688277 & 5.25 & 5.0299 & TRN \\
\hline CHEMBL365374 & 688277 & 4.5 & 4.7441 & TRN \\
\hline CHEMBL1976304 & 688277 & 4.45 & 4.8857 & TST \\
\hline CHEMBL1316301 & 688277 & 5.1 & 5.0113 & TRN \\
\hline CHEMBL1377472 & 688277 & 5.8 & 5.1748 & TRN \\
\hline CHEMBL1526089 & 688277 & 6.8 & 5.0038 & TRN \\
\hline CHEMBL1316604 & 688277 & 4.5 & 4.8992 & TRN \\
\hline CHEMBL1486073 & 688277 & 4.9 & 4.7856 & TRN \\
\hline CHEMBL1553578 & 688277 & 4.45 & 4.9857 & TRN \\
\hline CHEMBL1608213 & 688277 & 5.2 & 5.1161 & TRN \\
\hline CHEMBL1571760 & 688277 & 4.7 & 4.8624 & TST \\
\hline CHEMBL1338138 & 688277 & 4.8 & 4.888 & TST \\
\hline CHEMBL1397496 & 688277 & 4.9 & 4.6329 & TRN \\
\hline CHEMBL1452641 & 688277 & 4.8 & 4.9389 & TRN \\
\hline CHEMBL1516173 & 688277 & 5.0 & 4.9282 & TRN \\
\hline CHEMBL584894 & 688277 & 8.0 & 4.8528 & TRN \\
\hline CHEMBL 1436280 & 688277 & 5.2 & 5.2354 & TRN \\
\hline CHEMBL1574324 & 688277 & 6.35 & 5.2663 & TRN \\
\hline CHEMBL1610729 & 688277 & 5.25 & 5.1682 & TST \\
\hline CHEMBL 3209546 & 688277 & 4.85 & 5.3472 & TRN \\
\hline CHEMBL1489395 & 688277 & 4.5 & 4.6074 & TST \\
\hline CHEMBL1473984 & 688277 & 4.5 & 4.9365 & TRN \\
\hline CHEMBL1397645 & 688277 & 4.9 & 4.886 & TRN \\
\hline CHEMBL1487676 & 688277 & 4.5 & 4.7611 & TRN \\
\hline CHEMBL1315730 & 688277 & 5.0 & 4.9624 & TRN \\
\hline CHEMBL1415527 & 688277 & 4.9 & 5.053 & TRN \\
\hline CHEMBL1395125 & 688277 & 5.4 & 4.8739 & TRN \\
\hline CHEMBL1553347 & 688277 & 8.0 & 4.8759 & TRN \\
\hline
\end{tabular}




\begin{tabular}{|c|c|c|c|c|}
\hline \multicolumn{5}{|c|}{ Supplemental Table S2.txt } \\
\hline CHEMBL1368165 & 688277 & 5.5 & 4.9187 & TST \\
\hline CHEMBL1535510 & 688277 & 4.5 & 4.9897 & TRN \\
\hline CHEMBL1405806 & 688277 & 5.05 & 4.8952 & TRN \\
\hline CHEMBL1489290 & 688277 & 4.8 & 4.8569 & TRN \\
\hline CHEMBL1435751 & 688277 & 4.9 & 4.9655 & TRN \\
\hline CHEMBL1478812 & 688277 & 5.6 & 5.0002 & TRN \\
\hline CHEMBL1361815 & 688277 & 4.5 & 4.8767 & TRN \\
\hline CHEMBL1472959 & 688277 & 4.5 & 4.9649 & TST \\
\hline CHEMBL1592032 & 688277 & 4.6 & 4.7433 & TRN \\
\hline CHEMBL1611241 & 688277 & 5.2 & 5.0662 & TST \\
\hline CHEMBL1522330 & 688277 & 5.1 & 4.9234 & TRN \\
\hline CHEMBL1367869 & 688277 & 4.5 & 4.8908 & TST \\
\hline CHEMBL1522706 & 688277 & 4.5 & 4.9158 & TRN \\
\hline CHEMBL1483617 & 688277 & 4.45 & 4.8545 & TRN \\
\hline CHEMBL1395693 & 688277 & 5.0 & 5.1065 & TRN \\
\hline CHEMBL1481470 & 688277 & 4.9 & 4.9419 & TRN \\
\hline CHEMBL1594088 & 688277 & 4.5 & 4.7795 & TRN \\
\hline CHEMBL1568997 & 688277 & 4.45 & 5.0227 & TRN \\
\hline CHEMBL1320556 & 688277 & 4.9 & 4.8188 & TST \\
\hline CHEMBL1552878 & 688277 & 8.0 & 5.4762 & TST \\
\hline CHEMBL1564231 & 688277 & 5.0 & 4.8158 & TRN \\
\hline CHEMBL1381063 & 688277 & 4.9 & 4.8928 & TRN \\
\hline CHEMBL3190680 & 688277 & 4.45 & 4.9194 & TST \\
\hline CHEMBL1448144 & 688277 & 4.45 & 4.9445 & TRN \\
\hline CHEMBL1463105 & 688277 & 5.3 & 4.9152 & TST \\
\hline CHEMBL1473465 & 688277 & 5.0 & 4.8366 & TST \\
\hline CHEMBL1474426 & 688277 & 5.0 & 4.7356 & TRN \\
\hline CHEMBL1401552 & 688277 & 8.1024 & 4.8281 & TRN \\
\hline CHEMBL1511967 & 688277 & 4.5 & 4.9895 & TRN \\
\hline CHEMBL1314213 & 688277 & 4.45 & 4.9732 & TRN \\
\hline CHEMBL1595956 & 688277 & 5.4 & 4.8609 & TST \\
\hline CHEMBL1354291 & 688277 & 4.8 & 4.8261 & TRN \\
\hline CHEMBL1519623 & 688277 & 4.45 & 4.8558 & TRN \\
\hline CHEMBL1315493 & 688277 & 4.6 & 4.8732 & TRN \\
\hline CHEMBL1481309 & 688277 & 4.8 & 4.9272 & TST \\
\hline CHEMBL1595959 & 688277 & 5.2 & 5.007 & TRN \\
\hline CHEMBL1315978 & 688277 & 5.2 & 5.0289 & TRN \\
\hline CHEMBL1486128 & 688277 & 5.25 & 5.1337 & TRN \\
\hline CHEMBL1377126 & 688277 & 4.9 & 4.8353 & TRN \\
\hline CHEMBL1315331 & 688277 & 5.3 & 5.3117 & TST \\
\hline CHEMBL1437584 & 688277 & 4.7 & 4.8701 & TRN \\
\hline CHEMBL1475053 & 688277 & 4.6 & 4.8701 & TRN \\
\hline CHEMBL1593734 & 688277 & 4.5 & 4.9901 & TRN \\
\hline CHEMBL1493577 & 688277 & 4.9 & 4.9017 & TRN \\
\hline CHEMBL1319460 & 688277 & 4.5 & 5.2071 & TST \\
\hline CHEMBL1310261 & 688277 & 4.45 & 4.8489 & TRN \\
\hline CHEMBL1353630 & 688277 & 5.15 & 4.9741 & TRN \\
\hline CHEMBL1574645 & 688277 & 4.5 & 4.729 & TRN \\
\hline
\end{tabular}




\begin{tabular}{|c|c|c|c|c|c|}
\hline \\
\hline CHEMBL1594331 & 688277 & 4.5 & 5.058 & TRN & \\
\hline CHEMBL1410178 & 688277 & 4.5 & 4.9945 & TRN & \\
\hline CHEMBL1441725 & 688277 & 4.45 & 4.867 & TRN & \\
\hline CHEMBL1602114 & 688277 & 4.5 & 4.7556 & TRN & \\
\hline CHEMBL1448732 & 688277 & 4.45 & 4.9587 & TST & \\
\hline CHEMBL1380934 & 688277 & 4.85 & 4.8871 & TRN & \\
\hline CHEMBL1330033 & 688277 & 4.8 & 4.9001 & TRN & \\
\hline CHEMBL1315815 & 688277 & 7.9508 & 4.989 & TRN & \\
\hline CHEMBL1442488 & 688277 & 4.8 & 4.8824 & TRN & \\
\hline CHEMBL1591398 & 688277 & 4.5 & 5.6767 & TRN & \\
\hline CHEMBL1395531 & 688277 & 5.4 & 5.1338 & TRN & \\
\hline CHEMBL1415663 & 688277 & 4.6 & 5.1192 & TRN & \\
\hline CHEMBL601742 & 688277 & 4.7 & 4.9218 & TRN & \\
\hline CHEMBL1558119 & 688277 & 4.65 & 4.8942 & TRN & \\
\hline CHEMBL1409817 & 688277 & 4.8 & 4.8677 & TRN & \\
\hline CHEMBL1484567 & 688277 & 5.5 & 5.1919 & TRN & \\
\hline CHEMBL1454964 & 688277 & 5.45 & 5.0192 & TRN & \\
\hline CHEMBL1559605 & 688277 & 4.95 & 4.9511 & TRN & \\
\hline CHEMBL1441318 & 688277 & 5.25 & 4.9596 & TST & \\
\hline CHEMBL1409268 & 688277 & 5.1 & 4.8643 & TRN & \\
\hline CHEMBL1473287 & 688277 & 4.7 & 4.8834 & TST & \\
\hline CHEMBL1404727 & 688277 & 4.8 & 4.8763 & TRN & \\
\hline CHEMBL1591261 & 688277 & 4.9 & 4.827 & TRN & \\
\hline CHEMBL1516492 & 688277 & 5.3 & 5.1609 & TRN & \\
\hline CHEMBL1487612 & 688277 & 4.9 & 4.9368 & TRN & \\
\hline CHEMBL1597357 & 688277 & 4.5 & 4.7586 & TST & \\
\hline CHEMBL1356519 & 688277 & 5.0 & 5.34200 & 00000000005 & TRN \\
\hline CHEMBL1592910 & 688277 & 4.7 & 4.7181 & TRN & \\
\hline CHEMBL1433548 & 688277 & 4.5 & 4.7997 & TRN & \\
\hline CHEMBL1553775 & 688277 & 5.5 & 4.8977 & TRN & \\
\hline CHEMBL1474308 & 688277 & 4.95 & 4.9479 & TRN & \\
\hline CHEMBL1397822 & 688277 & 4.9 & 4.7672 & TRN & \\
\hline CHEMBL1325362 & 688277 & 4.9 & 4.7501 & TRN & \\
\hline CHEMBL1337816 & 688277 & 4.5 & 4.8157 & TRN & \\
\hline CHEMBL1405928 & 688277 & 4.5 & 4.8538 & TRN & \\
\hline CHEMBL1355134 & 688277 & 4.7 & 4.8856 & TST & \\
\hline CHEMBL1325252 & 688277 & 4.5 & 4.8046 & TRN & \\
\hline CHEMBL1593469 & 688277 & 4.6 & 4.82600 & 00000000005 & TRN \\
\hline CHEMBL1479545 & 688277 & 4.5 & 4.681 & TRN & \\
\hline CHEMBL1416511 & 688277 & 4.65 & 5.1164 & TRN & \\
\hline CHEMBL1398130 & 688277 & 5.25 & 5.1586 & TRN & \\
\hline CHEMBL1337971 & 688277 & 4.8 & 4.9894 & TRN & \\
\hline CHEMBL1474898 & 688277 & 4.5 & 4.8662 & TST & \\
\hline CHEMBL1316879 & 688277 & 4.8 & 5.2858 & TRN & \\
\hline CHEMBL1554686 & 688277 & 4.8 & 4.7915 & TRN & \\
\hline CHEMBL1513260 & 688277 & 4.8 & 4.9521 & TRN & \\
\hline CHEMBL1515852 & 688277 & 6.2 & 5.3276 & TRN & \\
\hline CHEMBL1591226 & 688277 & 4.95 & 4.8398 & TRN & \\
\hline
\end{tabular}




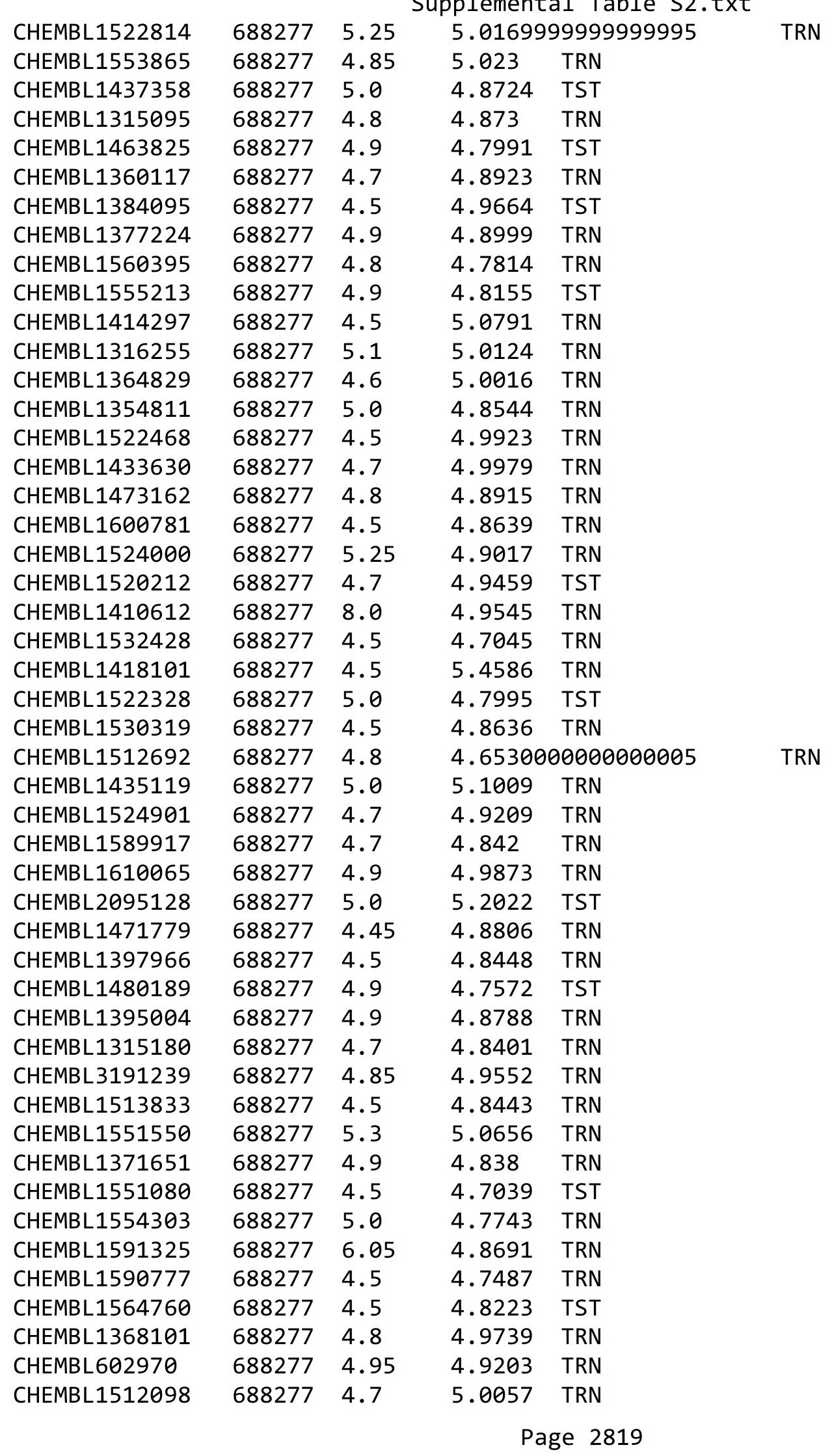




\begin{tabular}{|c|c|c|c|c|c|}
\hline \\
\hline CHEMBL1412549 & 688277 & 4.7 & 4.7038 & TRN & \\
\hline CHEMBL1315984 & 688277 & 4.9 & 5.3032 & TRN & \\
\hline CHEMBL1365615 & 688277 & 4.9 & 5.0758 & TRN & \\
\hline CHEMBL1331208 & 688277 & 5.2 & 5.0518 & TRN & \\
\hline CHEMBL1607223 & 688277 & 4.5 & 4.8786 & TRN & \\
\hline CHEMBL1440279 & 688277 & 4.6 & 4.7974 & TRN & \\
\hline CHEMBL601770 & 688277 & 5.45 & 5.0952 & TRN & \\
\hline CHEMBL1356025 & 688277 & 4.9 & 4.8816 & TRN & \\
\hline CHEMBL1444724 & 688277 & 4.8 & 4.9289 & TRN & \\
\hline CHEMBL1447168 & 688277 & 5.5 & 4.916 & TRN & \\
\hline CHEMBL1487567 & 688277 & 4.65 & 4.7088 & TRN & \\
\hline CHEMBL1593951 & 688277 & 4.5 & 4.7202 & TRN & \\
\hline CHEMBL1429821 & 688277 & 6.4 & 5.405 & TST & \\
\hline CHEMBL1437286 & 688277 & 4.5 & 4.7372 & TRN & \\
\hline CHEMBL1354671 & 688277 & 4.9 & 4.867 & TRN & \\
\hline CHEMBL1449484 & 688277 & 4.5 & 4.7915 & TRN & \\
\hline CHEMBL1590088 & 688277 & 4.45 & 4.9242 & TRN & \\
\hline CHEMBL1476769 & 688277 & 4.7 & 5.037 & TST & \\
\hline CHEMBL1437506 & 688277 & 4.9 & 4.8903 & TST & \\
\hline CHEMBL1552666 & 688277 & 4.5 & 4.9617 & TRN & \\
\hline CHEMBL1513145 & 688277 & 4.8 & 4.9473 & TST & \\
\hline CHEMBL1330510 & 688277 & 5.4 & 5.0238 & TRN & \\
\hline CHEMBL1357091 & 688277 & 4.65 & 4.9631 & TRN & \\
\hline CHEMBL1361775 & 688277 & 4.75 & 4.9672 & TRN & \\
\hline CHEMBL1513360 & 688277 & 4.7 & 4.7107 & TRN & \\
\hline CHEMBL1456079 & 688277 & 4.6 & 4.835 & TRN & \\
\hline CHEMBL1425743 & 688277 & 4.8 & 4.8656 & TST & \\
\hline CHEMBL1305968 & 688277 & 4.85 & 4.8928 & TRN & \\
\hline CHEMBL1447952 & 688277 & 4.7 & 4.836 & TRN & \\
\hline CHEMBL1532930 & 688277 & 5.2 & 4.9197 & TRN & \\
\hline CHEMBL1552177 & 688277 & 4.5 & 4.6476 & TRN & \\
\hline CHEMBL1325229 & 688277 & 5.55 & 4.93199 & 99999999995 & TRN \\
\hline CHEMBL1318880 & 688277 & 5.35 & 4.9032 & TRN & \\
\hline CHEMBL1372890 & 688277 & 4.9 & 5.0735 & TRN & \\
\hline CHEMBL1473613 & 688277 & 4.5 & 4.8945 & TRN & \\
\hline CHEMBL1354290 & 688277 & 4.8 & 4.9594 & TRN & \\
\hline CHEMBL1437252 & 688277 & 5.4 & 5.1738 & TRN & \\
\hline CHEMBL1973647 & 688277 & 4.55 & 4.811 & TST & \\
\hline CHEMBL1318033 & 688277 & 4.8 & 4.6811 & TST & \\
\hline CHEMBL1369161 & 688277 & 6.3 & 5.5504 & TRN & \\
\hline CHEMBL1356146 & 688277 & 4.5 & 4.6271 & TRN & \\
\hline CHEMBL1553494 & 688277 & 4.8 & 5.2103 & TRN & \\
\hline CHEMBL1521563 & 688277 & 5.0 & 4.8999 & TST & \\
\hline CHEMBL1396027 & 688277 & 4.7 & 4.8582 & TST & \\
\hline CHEMBL1485463 & 688277 & 4.85 & 5.0183 & TRN & \\
\hline CHEMBL1521087 & 688277 & 4.9 & 4.7537 & TRN & \\
\hline CHEMBL1464561 & 688277 & 4.9 & 5.1758 & TST & \\
\hline CHEMBL1591997 & 688277 & 5.6 & 4.8928 & TRN & \\
\hline & & & & 2820 & \\
\hline
\end{tabular}




\begin{tabular}{|c|c|c|c|c|}
\hline & & & 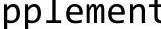 & \\
\hline CHEMBL1400556 & 688277 & 4.6 & 5.0168 & TST \\
\hline CHEMBL1337548 & 688277 & 4.6 & 4.7244 & TST \\
\hline CHEMBL1513116 & 688277 & 5.4 & 5.1026 & TST \\
\hline CHEMBL1402941 & 688277 & 4.6 & 4.9283 & TRN \\
\hline CHEMBL 3194521 & 688277 & 4.95 & 4.954 & TST \\
\hline CHEMBL1552887 & 688277 & 4.45 & 4.6757 & TST \\
\hline CHEMBL 2002008 & 688277 & 5.15 & 5.066 & TST \\
\hline CHEMBL1551280 & 688277 & 4.7 & 4.6813 & TRN \\
\hline CHEMBL1353865 & 688277 & 5.3 & 4.8925 & TRN \\
\hline CHEMBL1480988 & 688277 & 4.5 & 4.7841 & TRN \\
\hline CHEMBL1355197 & 688277 & 4.9 & 4.8942 & TRN \\
\hline CHEMBL1433827 & 688277 & 4.45 & 4.636 & TRN \\
\hline CHEMBL1557947 & 688277 & 4.5 & 4.6188 & TRN \\
\hline CHEMBL1559914 & 688277 & 5.5 & 5.2195 & TST \\
\hline CHEMBL1604206 & 688277 & 5.25 & 4.8861 & TRN \\
\hline CHEMBL1355421 & 688277 & 5.2 & 4.7263 & TST \\
\hline CHEMBL1559621 & 688277 & 4.5 & 5.0823 & TST \\
\hline CHEMBL1554336 & 688277 & 4.5 & 4.8727 & TST \\
\hline CHEMBL1559717 & 688277 & 4.9 & 4.9726 & TST \\
\hline CHEMBL1592275 & 688277 & 5.4 & 4.8775 & TRN \\
\hline CHEMBL1400053 & 688277 & 4.5 & 4.8261 & TRN \\
\hline CHEMBL1553712 & 688277 & 4.5 & 4.7303 & TRN \\
\hline CHEMBL1606605 & 688277 & 4.9 & 4.8728 & TRN \\
\hline CHEMBL1531241 & 688277 & 4.5 & 4.7344 & TRN \\
\hline CHEMBL582715 & 688277 & 5.0 & 4.9044 & TRN \\
\hline CHEMBL1437162 & 688277 & 5.0 & 4.8769 & TRN \\
\hline CHEMBL1552485 & 688277 & 4.5 & 4.7015 & TRN \\
\hline CHEMBL1488937 & 688277 & 6.0 & 5.1258 & TRN \\
\hline CHEMBL1373546 & 688277 & 4.7 & 4.9777 & TRN \\
\hline CHEMBL1356667 & 688277 & 4.7 & 4.7181 & TRN \\
\hline CHEMBL1589813 & 688277 & 5.4 & 4.8895 & TRN \\
\hline CHEMBL1496635 & 688277 & 4.8 & 4.8356 & TST \\
\hline CHEMBL1455646 & 688277 & 4.5 & 4.7572 & TRN \\
\hline CHEMBL1389630 & 688277 & 5.0 & 4.8321 & TRN \\
\hline CHEMBL1553570 & 688277 & 4.65 & 4.9565 & TRN \\
\hline CHEMBL1551835 & 688277 & 5.0 & 4.7114 & TRN \\
\hline CHEMBL1476613 & 688277 & 4.7 & 4.9556 & TRN \\
\hline CHEMBL1473582 & 688277 & 4.8 & 4.87 & TRN \\
\hline CHEMBL1474624 & 688277 & 4.5 & 4.671 & TRN \\
\hline CHEMBL1375774 & 688277 & 4.9 & 4.8232 & TRN \\
\hline CHEMBL1598581 & 688277 & 4.95 & 5.0258 & TRN \\
\hline CHEMBL1610184 & 688277 & 4.5 & 4.7084 & TST \\
\hline CHEMBL1586846 & 688277 & 4.95 & 4.9343 & TRN \\
\hline CHEMBL1479626 & 688277 & 4.5 & 4.8783 & TRN \\
\hline CHEMBL1453743 & 688277 & 4.5 & 4.6987 & TRN \\
\hline CHEMBL1485895 & 688277 & 4.7 & 4.7026 & TRN \\
\hline CHEMBL1436251 & 688277 & 5.0 & 5.0247 & TRN \\
\hline CHEMBL1559088 & 688277 & 4.65 & 4.6257 & TRN \\
\hline
\end{tabular}




\begin{tabular}{|c|c|c|c|c|c|}
\hline & & & & & \\
\hline CHEMBL1400515 & 688277 & 4.5 & 4.8978 & TRN & \\
\hline CHEMBL1997899 & 688277 & 5.2 & 5.2987 & TST & \\
\hline CHEMBL227959 & 688277 & 4.5 & 4.6795 & TRN & \\
\hline CHEMBL1436696 & 688277 & 4.5 & 4.9335 & TRN & \\
\hline CHEMBL1398864 & 688277 & 4.9 & 4.8812 & TRN & \\
\hline CHEMBL1338236 & 688277 & 4.5 & 4.7817 & TRN & \\
\hline CHEMBL1515902 & 688277 & 5.45 & 5.0435 & TST & \\
\hline CHEMBL1396127 & 688277 & 4.9 & 4.853 & TRN & \\
\hline CHEMBL1397313 & 688277 & 4.7 & 4.8769 & TST & \\
\hline CHEMBL1561016 & 688277 & 4.5 & 4.8982 & TRN & \\
\hline CHEMBL1324886 & 688277 & 4.6 & 4.8432 & TRN & \\
\hline CHEMBL1434258 & 688277 & 5.0 & 4.9183 & TST & \\
\hline CHEMBL1395440 & 688277 & 4.8 & 4.8322 & TRN & \\
\hline CHEMBL1367487 & 688277 & 4.8 & 4.9071 & TRN & \\
\hline CHEMBL1555040 & 688277 & 4.8 & 4.8332 & TST & \\
\hline CHEMBL1487476 & 688277 & 4.5 & 4.94300 & 00000000005 & TRN \\
\hline CHEMBL1488710 & 688277 & 5.95 & 5.4415 & TRN & \\
\hline CHEMBL1492968 & 688277 & 4.6 & 4.9068 & TST & \\
\hline CHEMBL1362101 & 688277 & 4.9 & 5.1647 & TST & \\
\hline CHEMBL1593778 & 688277 & 4.45 & 4.9038 & TRN & \\
\hline CHEMBL1437953 & 688277 & 8.2007 & 4.8463 & TRN & \\
\hline CHEMBL1527850 & 688277 & 5.0 & 4.8999 & TRN & \\
\hline CHEMBL1592795 & 688277 & 5.3 & 4.7691 & TRN & \\
\hline CHEMBL1475133 & 688277 & 5.2 & 4.9658 & TRN & \\
\hline CHEMBL1355470 & 688277 & 4.5 & 4.8727 & TST & \\
\hline CHEMBL1512483 & 688277 & 4.9 & 4.9397 & TRN & \\
\hline CHEMBL1591668 & 688277 & 5.5 & 4.9636 & TRN & \\
\hline CHEMBL1336808 & 688277 & 5.0 & 4.9345 & TRN & \\
\hline CHEMBL1314218 & 688277 & 4.5 & 4.7899 & TRN & \\
\hline CHEMBL1512319 & 688277 & 5.4 & 4.7662 & TRN & \\
\hline CHEMBL1329410 & 688277 & 4.9 & 4.8126 & TRN & \\
\hline CHEMBL1485604 & 688277 & 4.45 & 4.6555 & TST & \\
\hline CHEMBL1433891 & 688277 & 4.75 & 4.8589 & TRN & \\
\hline CHEMBL1362869 & 688277 & 4.5 & 4.9733 & TRN & \\
\hline CHEMBL1592927 & 688277 & 5.0 & 5.1696 & TST & \\
\hline CHEMBL1378006 & 688277 & 5.55 & 5.2672 & TRN & \\
\hline CHEMBL1519929 & 688277 & 5.0 & 4.9169 & TRN & \\
\hline CHEMBL1316895 & 688277 & 4.95 & 4.9002 & TRN & \\
\hline CHEMBL1436316 & 688277 & 5.25 & 4.9663 & TRN & \\
\hline CHEMBL1397569 & 688277 & 4.5 & 4.6376 & TRN & \\
\hline CHEMBL1518166 & 688277 & 4.5 & 4.7943 & TRN & \\
\hline CHEMBL1554305 & 688277 & 4.55 & 4.9108 & TRN & \\
\hline CHEMBL1332454 & 688277 & 4.65 & 4.6747 & TRN & \\
\hline CHEMBL1406438 & 688277 & 4.5 & 4.7283 & TRN & \\
\hline CHEMBL1402100 & 688277 & 5.2 & 4.9824 & TRN & \\
\hline CHEMBL1446615 & 688277 & 4.5 & 4.7768 & TRN & \\
\hline CHEMBL1314794 & 688277 & 5.3 & 4.9357 & TRN & \\
\hline CHEMBL601311 & 688277 & 4.5 & 4.9097 & TRN & \\
\hline
\end{tabular}




\begin{tabular}{|c|c|c|c|c|c|}
\hline \multicolumn{6}{|c|}{ Supplemental Table S2.txt } \\
\hline CHEMBL1331895 & 688277 & 5.5 & 5.0642 & TST & \\
\hline CHEMBL1602345 & 688277 & 4.8 & 4.9805 & TST & \\
\hline CHEMBL1436721 & 688277 & 4.9 & 4.8758 & TRN & \\
\hline CHEMBL1333382 & 688277 & 4.5 & 4.8536 & TRN & \\
\hline CHEMBL1475647 & 688277 & 5.25 & 4.8384 & TRN & \\
\hline CHEMBL1590646 & 688277 & 4.5 & 4.8351 & TRN & \\
\hline CHEMBL1477803 & 688277 & 4.7 & 4.6959 & TRN & \\
\hline CHEMBL1518622 & 688277 & 4.9 & 4.9429 & TRN & \\
\hline CHEMBL1438848 & 688277 & 4.8 & 4.9769 & TST & \\
\hline CHEMBL1381607 & 688277 & 4.45 & 5.0736 & TRN & \\
\hline CHEMBL1525887 & 688277 & 6.1 & 4.9243 & TRN & \\
\hline CHEMBL1553148 & 688277 & 4.9 & 5.0297 & TRN & \\
\hline CHEMBL1433703 & 688277 & 4.9 & 4.8926 & TRN & \\
\hline CHEMBL1590174 & 688277 & 4.8 & 4.9697 & TRN & \\
\hline CHEMBL1554996 & 688277 & 8.5528 & 4.9969 & TRN & \\
\hline CHEMBL1557832 & 688277 & 4.9 & 4.7177 & TRN & \\
\hline CHEMBL1521950 & 688277 & 4.9 & 4.7564 & TRN & \\
\hline CHEMBL578523 & 688277 & 4.7 & 4.8105 & TRN & \\
\hline CHEMBL1315394 & 688277 & 4.7 & 4.8371 & TRN & \\
\hline CHEMBL1446452 & 688277 & 5.6 & 5.3733 & TRN & \\
\hline CHEMBL1496933 & 688277 & 4.7 & 4.9094 & TRN & \\
\hline CHEMBL1355543 & 688277 & 4.5 & 4.9188 & TRN & \\
\hline CHEMBL1465522 & 688277 & 5.15 & 5.0511 & TRN & \\
\hline CHEMBL1590286 & 688277 & 4.9 & 4.9163 & TRN & \\
\hline CHEMBL1602652 & 688277 & 4.9 & 4.9731 & TRN & \\
\hline CHEMBL1363888 & 688277 & 5.25 & 4.8847 & TRN & \\
\hline CHEMBL1599897 & 688277 & 4.75 & 4.9536 & TRN & \\
\hline CHEMBL1439468 & 688277 & 5.0 & 5.084 & TRN & \\
\hline CHEMBL599100 & 688277 & 6.0 & 5.1716 & TRN & \\
\hline CHEMBL1358218 & 688277 & 5.7 & 4.9378 & TRN & \\
\hline CHEMBL1532790 & 688277 & 4.9 & 4.8763 & TRN & \\
\hline CHEMBL1556277 & 688277 & 6.2 & 4.91 & TST & \\
\hline CHEMBL1376485 & 688277 & 4.5 & 4.8914 & TRN & \\
\hline CHEMBL1564291 & 688277 & 4.5 & 4.8206 & TRN & \\
\hline CHEMBL1486117 & 688277 & 4.9 & 4.857 & TST & \\
\hline CHEMBL1534015 & 688277 & 4.8 & 4.9074 & TRN & \\
\hline CHEMBL1445596 & 688277 & 5.5 & 4.91 & TRN & \\
\hline CHEMBL1522810 & 688277 & 4.5 & 4.8151 & TRN & \\
\hline CHEMBL1395080 & 688277 & 4.45 & 4.9658 & TRN & \\
\hline CHEMBL1331613 & 688277 & 4.9 & 4.9273 & TRN & \\
\hline CHEMBL1492648 & 688277 & 4.45 & 4.916 & TRN & \\
\hline CHEMBL1721986 & 688277 & 5.2 & 5.0234 & TST & \\
\hline CHEMBL1574336 & 688277 & 4.45 & 4.8833 & TRN & \\
\hline CHEMBL1513023 & 688277 & 4.65 & 4.9602 & TRN & \\
\hline CHEMBL1398633 & 688277 & 4.9 & 4.8539 & TRN & \\
\hline CHEMBL1316269 & 688277 & 5.0 & 4.91 & TST & \\
\hline CHEMBL1479244 & 688277 & 5.25 & 4.965 & TST & \\
\hline CHEMBL1551719 & 688277 & 4.6 & 4.6960 & 0000000001 & TRN \\
\hline & & & & e 2823 & \\
\hline
\end{tabular}




\begin{tabular}{|c|c|c|c|c|c|}
\hline CHEMBL1441225 & 688277 & 4.5 & 4.7307 & TRN & \\
\hline CHEMBL1478691 & 688277 & 5.1 & \multicolumn{2}{|c|}{5.111000000000001} & TRN \\
\hline CHEMBL1441670 & 688277 & 5.4 & \multicolumn{2}{|c|}{5.0569999999999995} & TRN \\
\hline CHEMBL1452302 & 688277 & 4.9 & 5.1262 & TRN & \\
\hline CHEMBL1561693 & 688277 & 4.5 & 5.0088 & TRN & \\
\hline CHEMBL1604979 & 688277 & 6.15 & 5.0652 & TRN & \\
\hline CHEMBL1317325 & 688277 & 5.3 & 4.8597 & TRN & \\
\hline CHEMBL1436230 & 688277 & 5.0 & 4.9988 & TRN & \\
\hline CHEMBL1396497 & 688277 & 4.8 & 4.9687 & TRN & \\
\hline CHEMBL1606499 & 688277 & 4.7 & 5.0245 & TRN & \\
\hline CHEMBL1492924 & 688277 & 4.7 & 4.9111 & TRN & \\
\hline CHEMBL1566071 & 688277 & 4.6 & \multicolumn{2}{|c|}{4.763999999999999} & TRN \\
\hline CHEMBL1438782 & 688277 & 4.7 & 4.8842 & TRN & \\
\hline CHEMBL1364592 & 688277 & 4.5 & 4.8231 & TRN & \\
\hline CHEMBL1444446 & 688277 & 5.0 & 4.9881 & TRN & \\
\hline CHEMBL1476071 & 688277 & 5.0 & 4.9595 & TRN & \\
\hline CHEMBL1555890 & 688277 & 4.5 & 4.7197 & TRN & \\
\hline CHEMBL1554221 & 688277 & 4.9 & 4.9444 & TRN & \\
\hline CHEMBL1395822 & 688277 & 4.8 & 4.8396 & TRN & \\
\hline CHEMBL1354255 & 688277 & 5.25 & 4.9727 & TRN & \\
\hline CHEMBL1337810 & 688277 & 4.5 & 5.0986 & TRN & \\
\hline CHEMBL 3195878 & 688277 & 4.9 & 5.0959 & TST & \\
\hline CHEMBL1593233 & 688277 & 4.45 & 5.033 & TST & \\
\hline CHEMBL1449237 & 688277 & 4.5 & 4.8466 & TRN & \\
\hline CHEMBL1408443 & 688277 & 5.5 & 4.9199 & TST & \\
\hline CHEMBL1444575 & 688277 & 4.6 & 4.8187 & TRN & \\
\hline CHEMBL1571028 & 688277 & 4.5 & 5.0694 & TRN & \\
\hline CHEMBL1395424 & 688277 & 5.45 & 4.9696 & TST & \\
\hline CHEMBL1380562 & 688277 & 7.15 & 4.9148 & TRN & \\
\hline CHEMBL1610740 & 688277 & 4.9 & 4.9399 & TST & \\
\hline CHEMBL1436405 & 688277 & 4.8 & 4.8306 & TRN & \\
\hline CHEMBL1394511 & 688277 & 4.5 & 4.6331 & TRN & \\
\hline CHEMBL1436858 & 688277 & 4.9 & 4.9478 & TRN & \\
\hline CHEMBL1434842 & 688277 & 4.5 & 4.9141 & TST & \\
\hline CHEMBL1480704 & 688277 & 4.8 & 4.8661 & TRN & \\
\hline CHEMBL1574935 & 688277 & 4.9 & 4.9007 & TRN & \\
\hline CHEMBL1431429 & 688277 & 5.15 & 4.9913 & TRN & \\
\hline CHEMBL1554144 & 688277 & 4.5 & 4.8861 & TRN & \\
\hline CHEMBL1476020 & 688277 & 4.5 & 4.7388 & TRN & \\
\hline CHEMBL1514871 & 688277 & 4.75 & 4.9323 & TRN & \\
\hline CHEMBL1514321 & 688277 & 5.25 & 5.0128 & TRN & \\
\hline CHEMBL1356779 & 688277 & 5.45 & 4.8927 & TRN & \\
\hline CHEMBL1441350 & 688277 & 5.0 & 4.8989 & TST & \\
\hline CHEMBL1462207 & 688277 & 4.45 & 4.8994 & TST & \\
\hline CHEMBL1595912 & 688277 & 4.7 & 4.7733 & TRN & \\
\hline CHEMBL1594063 & 688277 & 4.6 & 4.8493 & TRN & \\
\hline CHEMBL1478389 & 688277 & 4.9 & 4.8083 & TST & \\
\hline CHEMBL1441600 & 688277 & 4.5 & 4.6571 & TRN & \\
\hline
\end{tabular}




\begin{tabular}{|c|c|c|c|c|}
\hline & & & plement & \\
\hline CHEMBL1444601 & 688277 & 8.2007 & 4.8497 & TRN \\
\hline CHEMBL1485121 & 688277 & 4.5 & 4.9178 & TRN \\
\hline CHEMBL1551853 & 688277 & 4.9 & 4.9177 & TRN \\
\hline CHEMBL1441592 & 688277 & 4.7 & 4.9011 & TST \\
\hline CHEMBL1516303 & 688277 & 5.4 & 4.8837 & TRN \\
\hline CHEMBL1568330 & 688277 & 4.5 & 4.9017 & TRN \\
\hline CHEMBL1395512 & 688277 & 4.9 & 4.8712 & TRN \\
\hline CHEMBL1474273 & 688277 & 4.8 & 4.8726 & TRN \\
\hline CHEMBL1369061 & 688277 & 4.6 & 4.8899 & TRN \\
\hline CHEMBL1528120 & 688277 & 5.5 & 4.9541 & TRN \\
\hline CHEMBL1374776 & 688277 & 4.9 & 4.975 & TRN \\
\hline CHEMBL1473570 & 688277 & 4.5 & 4.8672 & TRN \\
\hline CHEMBL1576273 & 688277 & 7.9508 & 4.9819 & TST \\
\hline CHEMBL1436234 & 688277 & 4.9 & 4.7992 & TRN \\
\hline CHEMBL1531284 & 688277 & 4.9 & 4.878 & TRN \\
\hline CHEMBL1552783 & 688277 & 4.9 & 4.9259 & TRN \\
\hline CHEMBL1472567 & 688277 & 4.8 & 4.9764 & TST \\
\hline CHEMBL1365045 & 688277 & 4.9 & 4.756 & TST \\
\hline CHEMBL1553965 & 688277 & 5.2 & 5.1679 & TRN \\
\hline CHEMBL1394243 & 688277 & 4.5 & 4.7459 & TRN \\
\hline CHEMBL1359125 & 688277 & 4.45 & 4.8738 & TRN \\
\hline CHEMBL1570025 & 688277 & 4.5 & 4.9436 & TRN \\
\hline CHEMBL1514425 & 688277 & 5.45 & 4.8949 & TRN \\
\hline CHEMBL1428415 & 688277 & 4.6 & 4.671 & TRN \\
\hline CHEMBL1515210 & 688277 & 4.5 & 4.8048 & TRN \\
\hline CHEMBL1370249 & 688277 & 4.5 & 4.9734 & TRN \\
\hline CHEMBL1400803 & 688277 & 4.45 & 4.9326 & TRN \\
\hline CHEMBL1438637 & 688277 & 4.9 & 4.7377 & TRN \\
\hline CHEMBL1412891 & 688277 & 5.0 & 4.9358 & TRN \\
\hline CHEMBL1394570 & 688277 & 4.7 & 4.7769 & TRN \\
\hline CHEMBL1326495 & 688277 & 4.45 & 5.0782 & TRN \\
\hline CHEMBL1372601 & 688277 & 4.9 & 4.925 & TRN \\
\hline CHEMBL1473004 & 688277 & 4.6 & 4.6627 & TRN \\
\hline CHEMBL1318900 & 688277 & 4.6 & 5.1529 & TST \\
\hline CHEMBL1512253 & 688277 & 4.8 & 4.8242 & TRN \\
\hline CHEMBL1525590 & 688277 & 5.4 & 4.8412 & TST \\
\hline CHEMBL1516578 & 688277 & 5.25 & 4.7922 & TRN \\
\hline CHEMBL1416008 & 688277 & 4.9 & 5.3646 & TRN \\
\hline CHEMBL1527184 & 688277 & 5.25 & 5.0306 & TRN \\
\hline CHEMBL1455349 & 688277 & 5.4 & 5.1208 & TRN \\
\hline CHEMBL1476669 & 688277 & 4.9 & 4.9444 & TRN \\
\hline CHEMBL1585988 & 688277 & 4.45 & 5.3916 & TRN \\
\hline CHEMBL1433718 & 688277 & 4.6 & 4.8073 & TRN \\
\hline CHEMBL1455717 & 688277 & 6.35 & 5.0656 & TRN \\
\hline CHEMBL1375955 & 688277 & 4.6 & 4.6754 & TST \\
\hline CHEMBL1416089 & 688277 & 4.6 & 4.6579 & TRN \\
\hline CHEMBL1412828 & 688277 & 4.9 & 4.8896 & TRN \\
\hline CHEMBL1398010 & 688277 & 4.6 & 4.8957 & TRN \\
\hline
\end{tabular}




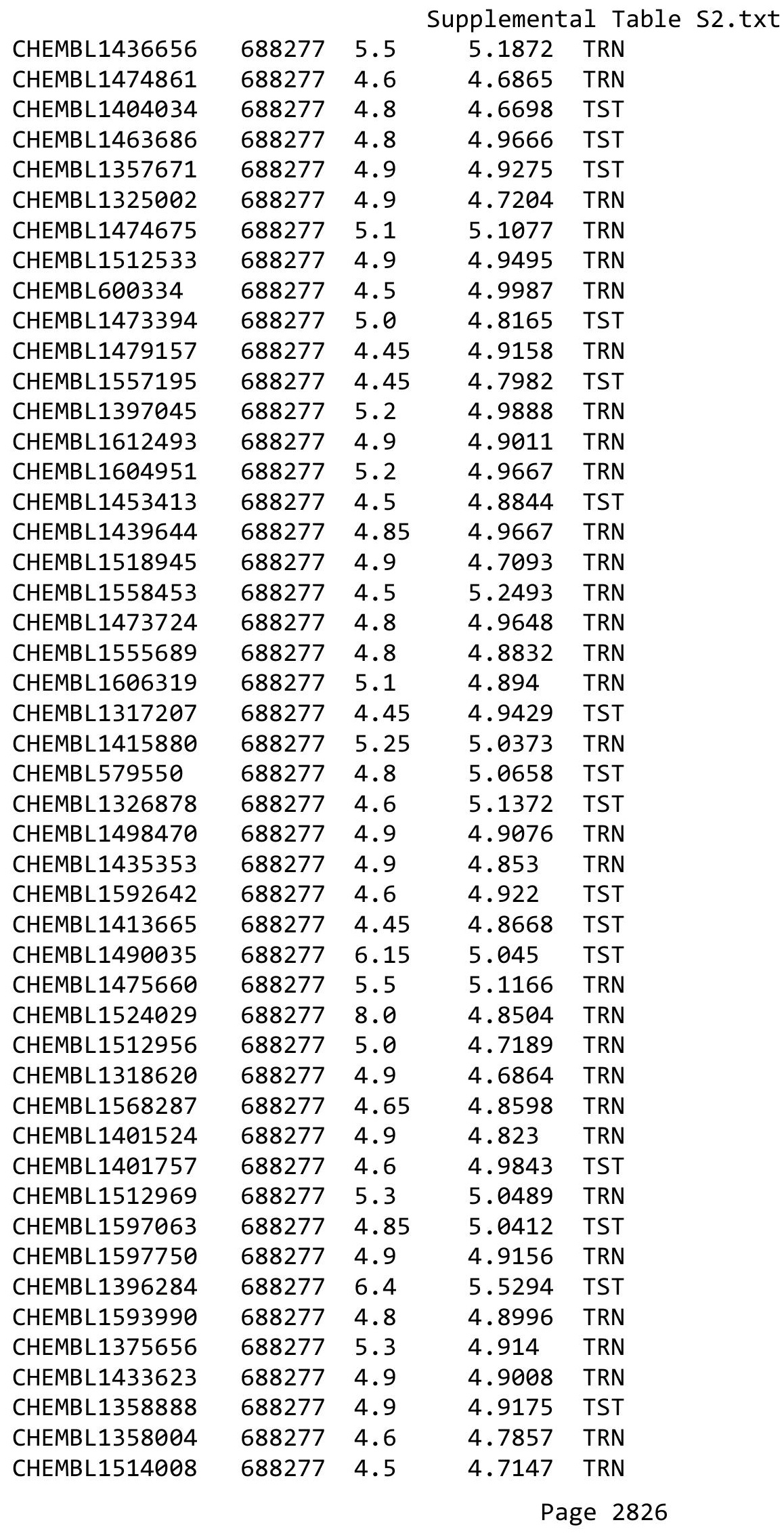




\begin{tabular}{|c|c|c|c|c|c|}
\hline \\
\hline CHEMBL1444359 & 688277 & 4.9 & 4.7756 & TRN & \\
\hline CHEMBL1558099 & 688277 & 5.5 & 4.8284 & TRN & \\
\hline CHEMBL1584663 & 688277 & 4.7 & 4.9737 & TRN & \\
\hline CHEMBL1355287 & 688277 & 4.7 & 4.8932 & TRN & \\
\hline CHEMBL1318897 & 688277 & 5.2 & 4.9306 & TST & \\
\hline CHEMBL1325060 & 688277 & 5.2 & 4.9351 & TRN & \\
\hline CHEMBL1488691 & 688277 & 5.6 & 4.9678 & TRN & \\
\hline CHEMBL1491408 & 688277 & 5.2 & 4.9765 & TRN & \\
\hline CHEMBL1368503 & 688277 & 4.5 & 4.7026 & TRN & \\
\hline CHEMBL1451213 & 688277 & 5.15 & 5.0386 & TRN & \\
\hline CHEMBL1446835 & 688277 & 4.6 & 4.8693 & TRN & \\
\hline CHEMBL1398506 & 688277 & 4.5 & 4.8083 & TRN & \\
\hline CHEMBL1595899 & 688277 & 5.0 & 4.8755 & TRN & \\
\hline CHEMBL1441244 & 688277 & 4.5 & 4.8407 & TRN & \\
\hline CHEMBL1315021 & 688277 & 4.5 & 4.6903 & TRN & \\
\hline CHEMBL1474411 & 688277 & 4.9 & 4.8949 & TRN & \\
\hline CHEMBL1355558 & 688277 & 4.5 & 5.0866 & TST & \\
\hline CHEMBL1517345 & 688277 & 4.6 & 4.6882 & TRN & \\
\hline CHEMBL1082160 & 688277 & 7.699 & 4.8937 & TRN & \\
\hline CHEMBL3194991 & 688277 & 4.9 & 4.948 & TRN & \\
\hline CHEMBL1542791 & 688277 & 4.9 & 4.9551 & TRN & \\
\hline CHEMBL1435100 & 688277 & 4.8 & 4.9362 & TRN & \\
\hline CHEMBL1593290 & 688277 & 4.9 & 4.8933 & TRN & \\
\hline CHEMBL1554561 & 688277 & 5.5 & 5.0098 & TST & \\
\hline CHEMBL1443653 & 688277 & 4.9 & 5.0751 & TRN & \\
\hline CHEMBL1437722 & 688277 & 4.5 & 4.919 & TRN & \\
\hline CHEMBL1516537 & 688277 & 4.9 & 4.8844 & TRN & \\
\hline CHEMBL1513820 & 688277 & 5.0 & 4.9663 & TRN & \\
\hline CHEMBL1322442 & 688277 & 4.7 & 4.9257 & TST & \\
\hline CHEMBL1595342 & 688277 & 4.9 & 4.9329 & TST & \\
\hline CHEMBL1320878 & 688277 & 4.6 & 4.8997 & TRN & \\
\hline CHEMBL1608433 & 688277 & 4.5 & 4.6796 & TRN & \\
\hline CHEMBL1459430 & 688277 & 4.95 & 4.9411 & TST & \\
\hline CHEMBL1321914 & 688277 & 4.5 & 4.8872 & TRN & \\
\hline CHEMBL1516887 & 688277 & 4.7 & 4.94300 & 00000000005 & TRN \\
\hline CHEMBL1406447 & 688277 & 4.5 & 4.9481 & TST & \\
\hline CHEMBL1546139 & 688277 & 4.8 & 5.0843 & TST & \\
\hline CHEMBL1479647 & 688277 & 4.5 & 4.7612 & TST & \\
\hline CHEMBL1445115 & 688277 & 4.7 & 4.9096 & TST & \\
\hline CHEMBL1320832 & 688277 & 5.25 & 4.9893 & TRN & \\
\hline CHEMBL1572761 & 688277 & 5.5 & 4.9536 & TRN & \\
\hline CHEMBL1509595 & 688277 & 5.0 & 4.9 & TRN & \\
\hline CHEMBL1318550 & 688277 & 4.6 & 4.9238 & TRN & \\
\hline CHEMBL1323878 & 688277 & 5.0 & 4.8574 & TRN & \\
\hline CHEMBL1417215 & 688277 & 4.9 & 4.8505 & TRN & \\
\hline CHEMBL1613723 & 688277 & 4.6 & 4.7284 & TST & \\
\hline CHEMBL1395601 & 688277 & 4.9 & 4.8726 & TRN & \\
\hline CHEMBL1606083 & 688277 & 4.45 & 4.8896 & TRN & \\
\hline
\end{tabular}




\begin{tabular}{|c|c|c|c|c|c|}
\hline \\
\hline CHEMBL1552027 & 688277 & 4.4 & 4.8755 & TRN & \\
\hline CHEMBL1522587 & 688277 & 5.0 & 4.8392 & TRN & \\
\hline CHEMBL1398171 & 688277 & 4.65 & 4.8003 & TRN & \\
\hline CHEMBL1398176 & 688277 & 4.45 & 5.0559 & TRN & \\
\hline CHEMBL1598809 & 688277 & 4.5 & 4.7149 & TST & \\
\hline CHEMBL1560690 & 688277 & 4.5 & 4.9781 & TST & \\
\hline CHEMBL1574676 & 688277 & 5.7 & 4.9375 & TRN & \\
\hline CHEMBL1513622 & 688277 & 4.9 & 4.8519 & TRN & \\
\hline CHEMBL1565928 & 688277 & 7.5003 & 4.9527 & TRN & \\
\hline CHEMBL1552820 & 688277 & 5.5 & 4.8623 & TST & \\
\hline CHEMBL1564109 & 688277 & 4.9 & 4.8823 & TRN & \\
\hline CHEMBL1404678 & 688277 & 4.9 & 4.9118 & TRN & \\
\hline CHEMBL1572372 & 688277 & 4.9 & 4.9063 & TRN & \\
\hline CHEMBL1339310 & 688277 & 4.95 & 4.8248 & TST & \\
\hline CHEMBL1356854 & 688277 & 5.7 & 5.1792 & TRN & \\
\hline CHEMBL1355379 & 688277 & 4.7 & 4.944 & TRN & \\
\hline CHEMBL1408045 & 688277 & 6.1 & 5.6482 & TRN & \\
\hline CHEMBL1513547 & 688277 & 5.6 & 5.13899 & 9999999999 & TRN \\
\hline CHEMBL1565394 & 688277 & 4.85 & 4.9853 & TRN & \\
\hline CHEMBL582473 & 688277 & 4.45 & 4.8603 & TRN & \\
\hline CHEMBL1519169 & 688277 & 4.45 & 5.0079 & TRN & \\
\hline CHEMBL1532569 & 688277 & 4.7 & 4.8193 & TRN & \\
\hline CHEMBL1554398 & 688277 & 5.5 & 4.9202 & TRN & \\
\hline CHEMBL1612538 & 688277 & 4.9 & 4.8548 & TRN & \\
\hline CHEMBL1418484 & 688277 & 4.8 & 4.9333 & TRN & \\
\hline CHEMBL1596986 & 688277 & 4.9 & 4.9305 & TRN & \\
\hline CHEMBL1399693 & 688277 & 4.5 & 4.7533 & TRN & \\
\hline CHEMBL1360582 & 688277 & 5.35 & 5.0138 & TRN & \\
\hline CHEMBL1329536 & 688277 & 5.25 & 4.9863 & TRN & \\
\hline CHEMBL1593766 & 688277 & 4.5 & 4.8388 & TST & \\
\hline CHEMBL1437739 & 688277 & 4.5 & 4.9347 & TST & \\
\hline CHEMBL1356312 & 688277 & 4.5 & 4.6667 & TRN & \\
\hline CHEMBL599943 & 688277 & 4.5 & 4.8481 & TRN & \\
\hline CHEMBL1553483 & 688277 & 5.0 & 4.9597 & TRN & \\
\hline CHEMBL1465114 & 688277 & 4.6 & 4.7172 & TRN & \\
\hline CHEMBL1317491 & 688277 & 4.6 & 4.9087 & TRN & \\
\hline CHEMBL1986214 & 688277 & 5.35 & 4.8981 & TST & \\
\hline CHEMBL1368684 & 688277 & 4.9 & 4.823 & TRN & \\
\hline CHEMBL1562144 & 688277 & 4.5 & 4.8208 & TRN & \\
\hline CHEMBL597874 & 688277 & 4.9 & 4.9258 & TRN & \\
\hline CHEMBL1558654 & 688277 & 4.95 & 4.8362 & TRN & \\
\hline CHEMBL1445543 & 688277 & 5.0 & 4.9402 & TST & \\
\hline CHEMBL1602456 & 688277 & 4.9 & 4.9947 & TRN & \\
\hline CHEMBL1414709 & 688277 & 4.8 & 4.9145 & TRN & \\
\hline CHEMBL1476443 & 688277 & 5.25 & 4.9225 & TST & \\
\hline CHEMBL1356978 & 688277 & 4.5 & 4.7268 & TRN & \\
\hline CHEMBL1514096 & 688277 & 5.0 & 4.9614 & TRN & \\
\hline CHEMBL1338007 & 688277 & 5.25 & 4.9476 & TRN & \\
\hline & & & & 2828 & \\
\hline
\end{tabular}




\begin{tabular}{|c|c|c|c|c|}
\hline & & & pplement & al $\mathrm{Ta}$ \\
\hline CHEMBL1515243 & 688277 & 4.9 & 5.063 & TRN \\
\hline CHEMBL1590160 & 688277 & 5.4 & 5.2237 & TRN \\
\hline CHEMBL1396478 & 688277 & 4.9 & 5.1436 & TST \\
\hline CHEMBL1572924 & 688277 & 4.95 & 5.3541 & TRN \\
\hline CHEMBL1552191 & 688277 & 4.7 & 4.874 & TST \\
\hline CHEMBL1496473 & 688277 & 4.6 & 5.07 & TST \\
\hline CHEMBL1601546 & 688277 & 4.5 & 4.8364 & TRN \\
\hline CHEMBL1405920 & 688277 & 4.5 & 4.9622 & TRN \\
\hline CHEMBL1425579 & 688277 & 5.05 & 5.0308 & TST \\
\hline CHEMBL1338319 & 688277 & 5.3 & 5.005 & TRN \\
\hline CHEMBL1562397 & 688277 & 4.7 & 4.8701 & TRN \\
\hline CHEMBL1397598 & 688277 & 5.0 & 4.8499 & TRN \\
\hline CHEMBL1593118 & 688277 & 5.1 & 4.984 & TRN \\
\hline CHEMBL1474458 & 688277 & 5.45 & 4.7199 & TRN \\
\hline CHEMBL1592923 & 688277 & 4.75 & 4.8863 & TRN \\
\hline CHEMBL1568005 & 688277 & 5.0 & 5.2952 & TRN \\
\hline CHEMBL1478586 & 688277 & 4.5 & 4.9923 & TRN \\
\hline CHEMBL1316576 & 688277 & 4.8 & 4.7235 & TST \\
\hline CHEMBL1516189 & 688277 & 4.5 & 4.8521 & TRN \\
\hline CHEMBL1396455 & 688277 & 4.45 & 4.6807 & TRN \\
\hline CHEMBL1500581 & 688277 & 4.95 & 4.9828 & TST \\
\hline CHEMBL1434884 & 688277 & 4.7 & 4.7833 & TRN \\
\hline CHEMBL1514097 & 688277 & 5.7 & 5.4173 & TRN \\
\hline CHEMBL1356364 & 688277 & 4.7 & 4.8439 & TRN \\
\hline CHEMBL1451433 & 688277 & 7.7496 & 4.8981 & TRN \\
\hline CHEMBL1320977 & 688277 & 4.6 & 4.9849 & TRN \\
\hline CHEMBL1555531 & 688277 & 5.0 & 4.9125 & TRN \\
\hline CHEMBL1398995 & 688277 & 4.45 & 4.8206 & TRN \\
\hline CHEMBL1436351 & 688277 & 4.5 & 4.8999 & TRN \\
\hline CHEMBL1418513 & 688277 & 5.3 & 4.936 & TRN \\
\hline CHEMBL1610959 & 688277 & 4.5 & 4.9004 & TRN \\
\hline CHEMBL1535951 & 688277 & 4.5 & 4.7752 & TST \\
\hline CHEMBL1422079 & 688277 & 4.9 & 4.8434 & TRN \\
\hline CHEMBL1358478 & 688277 & 4.9 & 4.9523 & TST \\
\hline CHEMBL1318438 & 688277 & 7.1002 & 4.8826 & TRN \\
\hline CHEMBL1448124 & 688277 & 4.5 & 4.9362 & TRN \\
\hline CHEMBL1481317 & 688277 & 4.6 & 4.7845 & TRN \\
\hline CHEMBL1553514 & 688277 & 4.45 & 4.9648 & TRN \\
\hline CHEMBL1366347 & 688277 & 5.4 & 5.0826 & TRN \\
\hline CHEMBL1435212 & 688277 & 5.0 & 4.9122 & TRN \\
\hline CHEMBL1455900 & 688277 & 4.9 & 4.6931 & TST \\
\hline CHEMBL1552045 & 688277 & 4.7 & 4.8744 & TRN \\
\hline CHEMBL1398430 & 688277 & 4.6 & 4.8972 & TRN \\
\hline CHEMBL1362020 & 688277 & 4.95 & 4.9854 & TST \\
\hline CHEMBL1475049 & 688277 & 6.5 & 5.4535 & TRN \\
\hline CHEMBL1326401 & 688277 & 5.5 & 5.0617 & TST \\
\hline CHEMBL1408289 & 688277 & 4.6 & 4.9606 & TRN \\
\hline CHEMBL1397028 & 688277 & 4.45 & 4.9781 & TST \\
\hline
\end{tabular}




\begin{tabular}{|c|c|c|c|c|}
\hline & & & pplement & al $\mathrm{Ta}$ \\
\hline CHEMBL1415581 & 688277 & 4.9 & 5.0571 & TRN \\
\hline CHEMBL1592962 & 688277 & 4.5 & 4.8767 & TST \\
\hline CHEMBL1396144 & 688277 & 4.5 & 4.8 & TRN \\
\hline CHEMBL1516188 & 688277 & 5.9 & 4.9645 & TRN \\
\hline CHEMBL1524637 & 688277 & 4.95 & 4.6645 & TST \\
\hline CHEMBL1515130 & 688277 & 4.9 & 4.933 & TRN \\
\hline CHEMBL1356698 & 688277 & 5.3 & 4.8959 & TRN \\
\hline CHEMBL1555114 & 688277 & 5.75 & 5.4505 & TRN \\
\hline CHEMBL1355643 & 688277 & 4.9 & 4.9067 & TRN \\
\hline CHEMBL1479295 & 688277 & 4.9 & 4.7947 & TRN \\
\hline CHEMBL1472904 & 688277 & 4.9 & 4.8773 & TRN \\
\hline CHEMBL1398139 & 688277 & 4.5 & 4.7227 & TRN \\
\hline CHEMBL1515651 & 688277 & 4.9 & 4.965 & TST \\
\hline CHEMBL1382411 & 688277 & 4.8 & 4.8207 & TRN \\
\hline CHEMBL1597836 & 688277 & 5.0 & 4.8513 & TRN \\
\hline CHEMBL1436291 & 688277 & 5.5 & 5.0366 & TRN \\
\hline CHEMBL1364359 & 688277 & 4.8 & 4.9002 & TRN \\
\hline CHEMBL1573594 & 688277 & 4.5 & 4.8441 & TRN \\
\hline CHEMBL1512279 & 688277 & 5.6 & 5.2166 & TRN \\
\hline CHEMBL1185172 & 688277 & 4.75 & 4.7747 & TRN \\
\hline CHEMBL1535245 & 688277 & 4.9 & 4.9737 & TRN \\
\hline CHEMBL1449540 & 688277 & 4.6 & 4.7129 & TRN \\
\hline CHEMBL1316911 & 688277 & 5.25 & 4.922 & TRN \\
\hline CHEMBL1597953 & 688277 & 4.5 & 5.6136 & TRN \\
\hline CHEMBL1530387 & 688277 & 4.95 & 4.9578 & TST \\
\hline CHEMBL1332494 & 688277 & 5.4 & 5.0423 & TRN \\
\hline CHEMBL1449409 & 688277 & 4.5 & 4.785 & TRN \\
\hline CHEMBL1593924 & 688277 & 4.9 & 4.9789 & TST \\
\hline CHEMBL1316696 & 688277 & 4.6 & 5.003 & TRN \\
\hline CHEMBL1374848 & 688277 & 4.9 & 5.5593 & TST \\
\hline CHEMBL1591505 & 688277 & 4.9 & 4.938 & TRN \\
\hline CHEMBL1562428 & 688277 & 5.7 & 5.0454 & TRN \\
\hline CHEMBL1442361 & 688277 & 4.8 & 4.9043 & TRN \\
\hline CHEMBL1327227 & 688277 & 4.5 & 4.6971 & TRN \\
\hline CHEMBL1558887 & 688277 & 4.9 & 4.8573 & TRN \\
\hline CHEMBL1436678 & 688277 & 4.5 & 4.9729 & TST \\
\hline CHEMBL1605182 & 688277 & 4.5 & 4.85 & TRN \\
\hline CHEMBL1394197 & 688277 & 5.25 & 5.0065 & TRN \\
\hline CHEMBL1327584 & 688277 & 4.5 & 4.7404 & TRN \\
\hline CHEMBL1598184 & 688277 & 4.85 & 4.8485 & TRN \\
\hline CHEMBL1611710 & 688277 & 4.5 & 4.7356 & TRN \\
\hline CHEMBL1335321 & 688277 & 4.45 & 5.0306 & TST \\
\hline CHEMBL1434373 & 688277 & 4.5 & 4.7045 & TST \\
\hline CHEMBL1434969 & 688277 & 4.45 & 4.9114 & TRN \\
\hline CHEMBL1396076 & 688277 & 5.1 & 5.0219 & TRN \\
\hline CHEMBL1541530 & 688277 & 4.45 & 4.7595 & TST \\
\hline CHEMBL1531869 & 688277 & 4.5 & 4.9522 & TRN \\
\hline CHEMBL1513924 & 688277 & 5.2 & 5.138 & TRN \\
\hline
\end{tabular}




\begin{tabular}{|c|c|c|c|c|}
\hline & & & pplement & al $\mathrm{Ta}$ \\
\hline CHEMBL1565001 & 688277 & 4.8 & 4.8559 & TRN \\
\hline CHEMBL1434704 & 688277 & 5.1 & 5.0413 & TRN \\
\hline CHEMBL1440408 & 688277 & 4.45 & 4.9406 & TRN \\
\hline CHEMBL1315403 & 688277 & 6.1 & 4.918 & TST \\
\hline CHEMBL1492491 & 688277 & 5.65 & 4.9417 & TST \\
\hline CHEMBL569088 & 688277 & 4.5 & 4.7463 & TRN \\
\hline CHEMBL1317669 & 688277 & 5.2 & 5.1213 & TRN \\
\hline CHEMBL1366712 & 688277 & 5.3 & 5.153 & TRN \\
\hline CHEMBL1488666 & 688277 & 4.45 & 4.926 & TRN \\
\hline CHEMBL1568306 & 688277 & 4.9 & 4.9579 & TRN \\
\hline CHEMBL1314527 & 688277 & 4.45 & 4.7248 & TRN \\
\hline CHEMBL1552671 & 688277 & 4.5 & 5.0933 & TST \\
\hline CHEMBL1572980 & 688277 & 5.35 & 5.4025 & TRN \\
\hline CHEMBL1373783 & 688277 & 4.5 & 4.8633 & TRN \\
\hline CHEMBL1463272 & 688277 & 5.0 & 4.8973 & TRN \\
\hline CHEMBL1481394 & 688277 & 4.8 & 4.9052 & TRN \\
\hline CHEMBL1328811 & 688277 & 4.9 & 4.9515 & TRN \\
\hline CHEMBL1565113 & 688277 & 4.7 & 5.0631 & TRN \\
\hline CHEMBL1373699 & 688277 & 4.7 & 4.8671 & TRN \\
\hline CHEMBL1534709 & 688277 & 6.5 & 4.7738 & TRN \\
\hline CHEMBL1434780 & 688277 & 4.9 & 4.7868 & TRN \\
\hline CHEMBL1553795 & 688277 & 4.9 & 4.8918 & TST \\
\hline CHEMBL1591135 & 688277 & 4.7 & 4.8541 & TRN \\
\hline CHEMBL1509287 & 688277 & 4.9 & 4.8844 & TRN \\
\hline CHEMBL1515104 & 688277 & 4.6 & 4.8535 & TRN \\
\hline CHEMBL1508357 & 688277 & 5.05 & 5.0793 & TRN \\
\hline CHEMBL1608080 & 688277 & 4.6 & 4.9234 & TRN \\
\hline CHEMBL1596344 & 688277 & 4.9 & 4.876 & TRN \\
\hline CHEMBL601757 & 688277 & 5.9 & 5.4603 & TST \\
\hline CHEMBL1330326 & 688277 & 4.45 & 4.6517 & TST \\
\hline CHEMBL1515745 & 688277 & 4.7 & 4.9834 & TST \\
\hline CHEMBL3196369 & 688277 & 4.65 & 4.7001 & TST \\
\hline CHEMBL1557378 & 688277 & 4.5 & 4.755 & TRN \\
\hline CHEMBL1406132 & 688277 & 5.4 & 5.1976 & TRN \\
\hline CHEMBL1305169 & 688277 & 4.9 & 4.9205 & TRN \\
\hline CHEMBL1481656 & 688277 & 4.6 & 4.9452 & TRN \\
\hline CHEMBL1316226 & 688277 & 6.1 & 5.5244 & TRN \\
\hline CHEMBL1394695 & 688277 & 4.5 & 4.8227 & TRN \\
\hline CHEMBL1357550 & 688277 & 5.2 & 4.8107 & TRN \\
\hline CHEMBL1448453 & 688277 & 5.0 & 4.9217 & TRN \\
\hline CHEMBL1552980 & 688277 & 5.0 & 4.9572 & TRN \\
\hline CHEMBL1552220 & 688277 & 4.5 & 4.8801 & TRN \\
\hline CHEMBL1598348 & 688277 & 4.9 & 4.8425 & TRN \\
\hline CHEMBL1318201 & 688277 & 4.5 & 4.916 & TRN \\
\hline CHEMBL1594558 & 688277 & 7.5003 & 5.0969 & TST \\
\hline CHEMBL1374552 & 688277 & 4.7 & 4.6705 & TST \\
\hline CHEMBL1591740 & 688277 & 4.7 & 4.8763 & TRN \\
\hline CHEMBL1593502 & 688277 & 4.8 & 5.0092 & TRN \\
\hline
\end{tabular}




\begin{tabular}{|c|c|c|c|c|}
\hline & & & $p p+e m e$ & \\
\hline CHEMBL1444885 & 688277 & 4.5 & 4.8655 & TST \\
\hline CHEMBL1417353 & 688277 & 4.9 & 4.8866 & TRN \\
\hline CHEMBL1571317 & 688277 & 4.6 & 4.8303 & TRN \\
\hline CHEMBL1438725 & 688277 & 6.4 & 5.3123 & TRN \\
\hline CHEMBL1476828 & 688277 & 4.5 & 4.9842 & TRN \\
\hline CHEMBL1590608 & 688277 & 5.9 & 5.4086 & TRN \\
\hline CHEMBL1566898 & 688277 & 4.9 & 4.856 & TRN \\
\hline CHEMBL1407819 & 688277 & 4.8 & 4.9383 & TRN \\
\hline CHEMBL1552474 & 688277 & 5.4 & 4.8438 & TRN \\
\hline CHEMBL1502502 & 688277 & 4.95 & 4.9824 & TST \\
\hline CHEMBL1419712 & 688277 & 4.95 & 5.002 & TRN \\
\hline CHEMBL1515135 & 688277 & 4.6 & 4.7626 & TRN \\
\hline CHEMBL1593184 & 688277 & 4.9 & 5.0633 & TRN \\
\hline CHEMBL1593283 & 688277 & 4.6 & 4.8712 & TST \\
\hline CHEMBL1362919 & 688277 & 4.9 & 4.9142 & TRN \\
\hline CHEMBL1602304 & 688277 & 4.85 & 4.9147 & TRN \\
\hline CHEMBL1409244 & 688277 & 4.6 & 4.7596 & TRN \\
\hline CHEMBL1516624 & 688277 & 4.9 & 4.8421 & TRN \\
\hline CHEMBL1450883 & 688277 & 5.35 & 4.9064 & TRN \\
\hline CHEMBL1526288 & 688277 & 5.45 & 4.9829 & TRN \\
\hline CHEMBL1437970 & 688277 & 5.5 & 5.0048 & TRN \\
\hline CHEMBL1593293 & 688277 & 5.2 & 4.9911 & TRN \\
\hline CHEMBL1472780 & 688277 & 4.6 & 4.9095 & TRN \\
\hline CHEMBL1474937 & 688277 & 5.0 & 4.9924 & TRN \\
\hline CHEMBL1554758 & 688277 & 4.9 & 4.9137 & TRN \\
\hline CHEMBL1317320 & 688277 & 4.5 & 4.9849 & TST \\
\hline CHEMBL1592036 & 688277 & 4.85 & 5.0355 & TRN \\
\hline CHEMBL1335028 & 688277 & 4.9 & 4.9282 & TRN \\
\hline CHEMBL1519891 & 688277 & 4.5 & 4.9172 & TRN \\
\hline CHEMBL1513746 & 688277 & 4.5 & 4.9188 & TRN \\
\hline CHEMBL1435104 & 688277 & 5.0 & 4.8683 & TRN \\
\hline CHEMBL1358301 & 688277 & 5.0 & 5.0351 & TST \\
\hline CHEMBL1397179 & 688277 & 4.8 & 4.8724 & TRN \\
\hline CHEMBL1442813 & 688277 & 4.5 & 4.9216 & TRN \\
\hline CHEMBL1316644 & 688277 & 4.9 & 5.4509 & TRN \\
\hline CHEMBL1414645 & 688277 & 4.9 & 4.8935 & TRN \\
\hline CHEMBL1433666 & 688277 & 5.0 & 4.8703 & TRN \\
\hline CHEMBL1315567 & 688277 & 4.5 & 4.6493 & TRN \\
\hline CHEMBL1334915 & 688277 & 4.8 & 4.776 & TRN \\
\hline CHEMBL1521684 & 688277 & 4.45 & 4.9243 & TRN \\
\hline CHEMBL1435458 & 688277 & 4.7 & 4.7858 & TRN \\
\hline CHEMBL1412768 & 688277 & 4.45 & 5.3674 & TRN \\
\hline CHEMBL1465410 & 688277 & 5.05 & 4.9138 & TRN \\
\hline CHEMBL1532399 & 688277 & 5.45 & 4.9862 & TRN \\
\hline CHEMBL1414582 & 688277 & 4.5 & 4.9395 & TRN \\
\hline CHEMBL1315059 & 688277 & 5.4 & 5.1907 & TRN \\
\hline CHEMBL1397657 & 688277 & 4.7 & 4.9218 & TRN \\
\hline CHEMBL1357326 & 688277 & 4.75 & 4.9116 & TRN \\
\hline
\end{tabular}




\begin{tabular}{|c|c|c|c|c|}
\hline \multicolumn{5}{|c|}{ lemental T } \\
\hline CHEMBL1593674 & 688277 & 4.6 & 4.7558 & TST \\
\hline CHEMBL1453421 & 688277 & 4.9 & 4.9645 & TRN \\
\hline CHEMBL1553845 & 688277 & 4.8 & 4.7313 & TRN \\
\hline CHEMBL1603508 & 688277 & 4.9 & 4.9445 & TRN \\
\hline CHEMBL1314250 & 688277 & 5.2 & 4.7872 & TRN \\
\hline CHEMBL1366392 & 688277 & 4.6 & 5.0202 & TRN \\
\hline CHEMBL1404815 & 688277 & 4.7 & 4.9768 & TST \\
\hline CHEMBL3193166 & 688277 & 4.45 & 4.9412 & TRN \\
\hline CHEMBL1332685 & 688277 & 5.0 & 4.8386 & TRN \\
\hline CHEMBL1496103 & 688277 & 4.5 & 4.62 & TRN \\
\hline CHEMBL1377695 & 688277 & 4.45 & 5.0116 & TST \\
\hline CHEMBL1361309 & 688277 & 5.25 & 5.078 & TRN \\
\hline CHEMBL1449496 & 688277 & 4.7 & 4.9862 & TRN \\
\hline CHEMBL1529126 & 688277 & 4.7 & 4.8964 & TRN \\
\hline CHEMBL1368392 & 688277 & 5.6 & 4.9021 & TRN \\
\hline CHEMBL1319405 & 688277 & 5.0 & 4.9721 & TST \\
\hline CHEMBL1317327 & 688277 & 4.9 & 4.6637 & TST \\
\hline CHEMBL1434738 & 688277 & 4.8 & 5.0931 & TST \\
\hline CHEMBL1361016 & 688277 & 4.5 & 4.7303 & TRN \\
\hline CHEMBL1324120 & 688277 & 5.0 & 4.8677 & TRN \\
\hline CHEMBL1565734 & 688277 & 4.45 & 4.6819 & TRN \\
\hline CHEMBL3196181 & 688277 & 5.15 & 5.291 & TRN \\
\hline CHEMBL578890 & 688277 & 4.9 & 4.692 & TRN \\
\hline CHEMBL1487634 & 688277 & 4.6 & 4.6416 & TRN \\
\hline CHEMBL1476025 & 688277 & 4.5 & 4.6798 & TRN \\
\hline CHEMBL1569635 & 688277 & 4.5 & 4.9543 & TRN \\
\hline CHEMBL1484721 & 688277 & 5.4 & 5.098 & TRN \\
\hline CHEMBL1355184 & 688277 & 4.5 & 4.8613 & TRN \\
\hline CHEMBL1476619 & 688277 & 6.4 & 4.9534 & TRN \\
\hline CHEMBL248345 & 688277 & 4.45 & 4.8871 & TRN \\
\hline CHEMBL1337279 & 688277 & 5.3 & 5.0006 & TRN \\
\hline CHEMBL1433566 & 688277 & 4.5 & 4.8261 & TRN \\
\hline CHEMBL1495164 & 688277 & 5.4 & 4.8681 & TRN \\
\hline CHEMBL1365651 & 688277 & 4.9 & 4.8632 & TRN \\
\hline CHEMBL1315281 & 688277 & 4.5 & 4.9241 & TST \\
\hline CHEMBL1567381 & 688277 & 4.7 & 5.058 & TRN \\
\hline CHEMBL1376227 & 688277 & 5.5 & 5.0594 & TRN \\
\hline CHEMBL1333459 & 688277 & 4.5 & 4.9064 & TRN \\
\hline CHEMBL1458799 & 688277 & 4.5 & 4.9799 & TRN \\
\hline CHEMBL1555145 & 688277 & 5.2 & 5.0412 & TRN \\
\hline CHEMBL1472787 & 688277 & 4.7 & 4.8638 & TRN \\
\hline CHEMBL1566256 & 688277 & 4.5 & 5.0125 & TST \\
\hline CHEMBL1436307 & 688277 & 4.6 & 4.9552 & TST \\
\hline CHEMBL1591164 & 688277 & 4.5 & 5.0365 & TRN \\
\hline CHEMBL1486620 & 688277 & 4.9 & 4.852 & TRN \\
\hline CHEMBL1453042 & 688277 & 4.45 & 4.7017 & TRN \\
\hline CHEMBL1447402 & 688277 & 4.45 & 4.7345 & TRN \\
\hline CHEMBL1358767 & 688277 & 4.5 & 4.9339 & TRN \\
\hline
\end{tabular}




\begin{tabular}{|c|c|c|c|c|}
\hline \multirow[b]{2}{*}{ CHEMBL1589873 } & \multicolumn{4}{|c|}{ Supplemental Table S2.txt } \\
\hline & 688277 & 4.5 & 4.7941 & TRN \\
\hline CHEMBL1474316 & 688277 & 7.5003 & 4.9266 & TRN \\
\hline CHEMBL1439033 & 688277 & 4.9 & 4.9502 & TRN \\
\hline CHEMBL1410173 & 688277 & 4.5 & 4.8944 & TRN \\
\hline CHEMBL1595519 & 688277 & 4.8 & 5.0213 & TRN \\
\hline CHEMBL1446073 & 688277 & 4.5 & 4.769 & TRN \\
\hline CHEMBL1354611 & 688277 & 5.4 & 4.9545 & TST \\
\hline CHEMBL1566029 & 688277 & 4.65 & 4.9457 & TRN \\
\hline CHEMBL1396074 & 688277 & 5.55 & 4.8938 & TRN \\
\hline CHEMBL1372777 & 688277 & 4.5 & 4.864 & TRN \\
\hline CHEMBL1590411 & 688277 & 4.7 & 4.8698 & TST \\
\hline CHEMBL1397566 & 688277 & 4.5 & 4.8797 & TRN \\
\hline CHEMBL1358721 & 688277 & 4.5 & 4.976 & TRN \\
\hline CHEMBL1375336 & 688277 & 4.65 & 4.7003 & TRN \\
\hline CHEMBL1371812 & 688277 & 4.7 & 5.0465 & TST \\
\hline CHEMBL1407850 & 688277 & 4.45 & 4.9143 & TRN \\
\hline CHEMBL1487628 & 688277 & 4.8 & 4.8493 & TST \\
\hline CHEMBL1456598 & 688277 & 4.9 & 4.9212 & TST \\
\hline CHEMBL1491238 & 688277 & 4.9 & 5.0297 & TRN \\
\hline CHEMBL1480233 & 688277 & 4.6 & 4.8545 & TRN \\
\hline CHEMBL1604795 & 688277 & 5.0 & 4.9212 & TRN \\
\hline CHEMBL1598545 & 688277 & 4.5 & 4.9501 & TST \\
\hline CHEMBL1611406 & 688277 & 5.25 & 4.8958 & TRN \\
\hline CHEMBL1556713 & 688277 & 4.5 & 4.8646 & TRN \\
\hline CHEMBL1341112 & 688277 & 4.95 & 4.671 & TST \\
\hline CHEMBL1327646 & 688277 & 4.5 & 5.5088 & TRN \\
\hline CHEMBL1355586 & 688277 & 4.5 & 4.8842 & TRN \\
\hline CHEMBL1609632 & 688277 & 4.75 & 4.9318 & TRN \\
\hline CHEMBL1563894 & 688277 & 4.9 & 4.9401 & TRN \\
\hline CHEMBL1403972 & 688277 & 4.65 & 4.9001 & TRN \\
\hline CHEMBL1457047 & 688277 & 4.8 & 4.7701 & TST \\
\hline CHEMBL1514575 & 688277 & 4.5 & 4.6498 & TRN \\
\hline CHEMBL1554058 & 688277 & 5.1 & 4.8805 & TRN \\
\hline CHEMBL1436130 & 688277 & 4.45 & 4.8326 & TRN \\
\hline CHEMBL1551629 & 688277 & 4.9 & 5.0029 & TST \\
\hline CHEMBL1434134 & 688277 & 5.35 & 4.9105 & TRN \\
\hline CHEMBL1472778 & 688277 & 5.0 & 4.8484 & TRN \\
\hline CHEMBL1472848 & 688277 & 4.5 & 4.8856 & TRN \\
\hline CHEMBL1474284 & 688277 & 5.0 & 4.9798 & TRN \\
\hline CHEMBL1571479 & 688277 & 4.9 & 4.9014 & TRN \\
\hline CHEMBL1356407 & 688277 & 4.8 & 4.8013 & TST \\
\hline CHEMBL1319015 & 688277 & 4.5 & 4.8684 & TRN \\
\hline CHEMBL1375575 & 688277 & 4.8 & 4.9667 & TRN \\
\hline CHEMBL1513122 & 688277 & 4.65 & 4.7689 & TRN \\
\hline CHEMBL1403048 & 688277 & 4.85 & 4.8189 & TST \\
\hline CHEMBL1598734 & 688277 & 4.9 & 4.8512 & TRN \\
\hline CHEMBL1553798 & 688277 & 4.5 & 4.7181 & TRN \\
\hline CHEMBL1369691 & 688277 & 4.8 & 4.8811 & TRN \\
\hline
\end{tabular}




\begin{tabular}{|c|c|c|c|c|c|}
\hline \multicolumn{6}{|c|}{ Supplemental Table S2.txt } \\
\hline CHEMBL1451916 & 688277 & 5.0 & 4.8739 & TRN & \\
\hline CHEMBL1512013 & 688277 & 5.25 & 5.0863 & TRN & \\
\hline CHEMBL1597910 & 688277 & 4.95 & 4.9586 & TRN & \\
\hline CHEMBL1474246 & 688277 & 4.7 & 4.7911 & TRN & \\
\hline CHEMBL1325610 & 688277 & 4.75 & 4.9173 & TRN & \\
\hline CHEMBL1554538 & 688277 & 4.6 & 4.9369 & TRN & \\
\hline CHEMBL1551417 & 688277 & 5.0 & 4.8461 & TRN & \\
\hline CHEMBL1473497 & 688277 & 5.0 & 4.9622 & TRN & \\
\hline CHEMBL1558343 & 688277 & 5.25 & 4.8949 & TST & \\
\hline CHEMBL1433850 & 688277 & 4.5 & 4.8608 & TRN & \\
\hline CHEMBL1506175 & 688277 & 4.9 & 4.8808 & TRN & \\
\hline CHEMBL1523051 & 688277 & 7.6003 & 4.8967 & TRN & \\
\hline CHEMBL596633 & 688277 & 4.85 & 4.8488 & TRN & \\
\hline CHEMBL1579060 & 688277 & 5.0 & 4.8762 & TRN & \\
\hline CHEMBL1331738 & 688277 & 5.0 & 4.8861 & TRN & \\
\hline CHEMBL1358483 & 688277 & 4.5 & 4.91100 & 00000000005 & TRN \\
\hline CHEMBL1357323 & 688277 & 4.6 & 4.7356 & TRN & \\
\hline CHEMBL1301273 & 688277 & 4.8 & 4.9125 & TST & \\
\hline CHEMBL1513494 & 688277 & 4.6 & 4.817 & TRN & \\
\hline CHEMBL1609310 & 688277 & 4.5 & 4.8907 & TST & \\
\hline CHEMBL1398497 & 688277 & 4.9 & 4.8062 & TRN & \\
\hline CHEMBL1331117 & 688277 & 5.45 & 5.1005 & TRN & \\
\hline CHEMBL3196791 & 688277 & 5.0 & 4.8638 & TST & \\
\hline CHEMBL1553050 & 688277 & 4.5 & 4.9608 & TRN & \\
\hline CHEMBL1529595 & 688277 & 4.9 & 4.7276 & TRN & \\
\hline CHEMBL1378106 & 688277 & 4.7 & 4.8761 & TRN & \\
\hline CHEMBL1610894 & 688277 & 4.85 & 4.9255 & TRN & \\
\hline CHEMBL1332116 & 688277 & 4.9 & 4.981 & TRN & \\
\hline CHEMBL524407 & 688277 & 4.9 & 4.8434 & TRN & \\
\hline CHEMBL1369778 & 688277 & 5.4 & 4.8596 & TRN & \\
\hline CHEMBL1514198 & 688277 & 4.9 & 4.8413 & TST & \\
\hline CHEMBL1513139 & 688277 & 4.5 & 4.895 & TRN & \\
\hline CHEMBL1516203 & 688277 & 4.5 & 5.0297 & TST & \\
\hline CHEMBL1365677 & 688277 & 4.8 & 4.88899 & 9999999999 & TRN \\
\hline CHEMBL1476006 & 688277 & 4.9 & 4.9102 & TST & \\
\hline CHEMBL1606131 & 688277 & 5.3 & 5.047 & TRN & \\
\hline CHEMBL1358378 & 688277 & 4.5 & 4.7416 & TRN & \\
\hline CHEMBL1476414 & 688277 & 4.6 & 4.9644 & TRN & \\
\hline CHEMBL602150 & 688277 & 4.5 & 4.9225 & TRN & \\
\hline CHEMBL1319319 & 688277 & 4.7 & 4.9291 & TRN & \\
\hline CHEMBL1567587 & 688277 & 5.0 & 4.864 & TRN & \\
\hline CHEMBL1995692 & 688277 & 5.85 & 5.3556 & TST & \\
\hline CHEMBL1609120 & 688277 & 4.5 & 4.8123 & TST & \\
\hline CHEMBL591618 & 688277 & 4.8 & 4.9055 & TST & \\
\hline CHEMBL1522302 & 688277 & 4.7 & 4.875 & TRN & \\
\hline CHEMBL1489305 & 688277 & 4.5 & 4.933 & TRN & \\
\hline CHEMBL1573866 & 688277 & 5.0 & 4.9478 & TST & \\
\hline CHEMBL1594589 & 688277 & 4.45 & 4.6297 & TRN & \\
\hline
\end{tabular}




\begin{tabular}{|c|c|c|c|c|}
\hline \multicolumn{5}{|c|}{ Supplemental Table S2.txt } \\
\hline CHEMBL1395131 & 688277 & 5.5 & 4.9105 & TST \\
\hline CHEMBL1443699 & 688277 & 4.5 & 4.9227 & TRN \\
\hline CHEMBL1434918 & 688277 & 4.5 & 4.9937 & TRN \\
\hline CHEMBL1436822 & 688277 & 5.25 & 4.8391 & TRN \\
\hline CHEMBL601140 & 688277 & 4.9 & 4.7674 & TST \\
\hline CHEMBL1593522 & 688277 & 4.6 & 4.689 & TST \\
\hline CHEMBL1519175 & 688277 & 4.6 & 4.907 & TRN \\
\hline CHEMBL1533112 & 688277 & 5.1 & 5.0773 & TST \\
\hline CHEMBL1560154 & 688277 & 4.9 & 4.6716 & TRN \\
\hline CHEMBL1436492 & 688277 & 5.8 & 4.9325 & TRN \\
\hline CHEMBL1574088 & 688277 & 4.5 & 4.7138 & TRN \\
\hline CHEMBL1371242 & 688277 & 5.0 & 4.9149 & TRN \\
\hline CHEMBL1318407 & 688277 & 4.9 & 4.8921 & TRN \\
\hline CHEMBL1359956 & 688277 & 5.3 & 5.1569 & TRN \\
\hline CHEMBL1554146 & 688277 & 4.5 & 4.7428 & TST \\
\hline CHEMBL1475763 & 688277 & 5.1 & 4.9554 & TRN \\
\hline CHEMBL1444476 & 688277 & 5.5 & 4.9096 & TRN \\
\hline CHEMBL1358128 & 688277 & 4.5 & 4.9116 & TRN \\
\hline CHEMBL1594684 & 688277 & 4.8 & 5.0024 & TRN \\
\hline CHEMBL1428003 & 688277 & 4.45 & 4.8349 & TRN \\
\hline CHEMBL1592791 & 688277 & 4.8 & 4.8203 & TRN \\
\hline CHEMBL1593099 & 688277 & 4.45 & 4.9054 & TRN \\
\hline CHEMBL1440798 & 688277 & 5.0 & 4.9754 & TRN \\
\hline CHEMBL1357767 & 688277 & 4.5 & 4.8464 & TST \\
\hline CHEMBL1553807 & 688277 & 5.35 & 5.1373 & TRN \\
\hline CHEMBL1474538 & 688277 & 4.5 & 5.1564 & TRN \\
\hline CHEMBL1474085 & 688277 & 4.5 & 4.6696 & TRN \\
\hline CHEMBL1604405 & 688277 & 4.5 & 4.5983 & TRN \\
\hline CHEMBL1520042 & 688277 & 4.8 & 4.8519 & TST \\
\hline CHEMBL1399793 & 688277 & 5.25 & 5.0622 & TRN \\
\hline CHEMBL1590533 & 688277 & 4.8 & 4.9462 & TRN \\
\hline CHEMBL1574845 & 688277 & 4.85 & 4.8058 & TRN \\
\hline CHEMBL1513957 & 688277 & 4.5 & 4.7075 & TST \\
\hline CHEMBL1317846 & 688277 & 5.7 & 5.2347 & TRN \\
\hline CHEMBL1375797 & 688277 & 4.7 & 4.6926 & TRN \\
\hline CHEMBL1600040 & 688277 & 4.55 & 4.961 & TST \\
\hline CHEMBL1351997 & 688277 & 5.1 & 4.8167 & TRN \\
\hline CHEMBL1591142 & 688277 & 4.5 & 4.8907 & TRN \\
\hline CHEMBL1373852 & 688277 & 4.8 & 4.9458 & TRN \\
\hline CHEMBL1990214 & 688277 & 4.95 & 4.961 & TRN \\
\hline CHEMBL1400938 & 688277 & 4.45 & 4.9408 & TRN \\
\hline CHEMBL1405215 & 688277 & 4.5 & 4.7646 & TRN \\
\hline CHEMBL1513288 & 688277 & 4.5 & 4.8577 & TRN \\
\hline CHEMBL1554525 & 688277 & 5.55 & 4.9122 & TRN \\
\hline CHEMBL1478953 & 688277 & 5.1 & 4.9106 & TRN \\
\hline CHEMBL1590804 & 688277 & 4.9 & 4.9766 & TRN \\
\hline CHEMBL1354776 & 688277 & 4.8 & 4.9912 & TRN \\
\hline CHEMBL1490465 & 688277 & 4.9 & 4.974 & TRN \\
\hline
\end{tabular}




\begin{tabular}{|c|c|c|c|c|}
\hline & & & pplement & al $\mathrm{Ta}$ \\
\hline CHEMBL1599457 & 688277 & 4.9 & 4.9043 & TRN \\
\hline CHEMBL1339671 & 688277 & 4.9 & 4.9089 & TST \\
\hline CHEMBL1586958 & 688277 & 4.7 & 4.947 & TST \\
\hline CHEMBL1444358 & 688277 & 4.5 & 4.8364 & TRN \\
\hline CHEMBL1474691 & 688277 & 4.45 & 4.6609 & TRN \\
\hline CHEMBL1593538 & 688277 & 5.0 & 5.2916 & TRN \\
\hline CHEMBL1395477 & 688277 & 4.9 & 4.7511 & TRN \\
\hline CHEMBL1564151 & 688277 & 4.5 & 4.8121 & TRN \\
\hline CHEMBL3210669 & 688277 & 4.95 & 4.9545 & TST \\
\hline CHEMBL1358330 & 688277 & 4.6 & 4.9784 & TRN \\
\hline CHEMBL1522726 & 688277 & 4.95 & 4.9392 & TRN \\
\hline CHEMBL1358552 & 688277 & 4.6 & 4.8123 & TRN \\
\hline CHEMBL1457898 & 688277 & 5.1 & 4.9556 & TRN \\
\hline CHEMBL1357093 & 688277 & 6.4 & 5.4984 & TST \\
\hline CHEMBL1554873 & 688277 & 5.35 & 4.9088 & TRN \\
\hline CHEMBL1398957 & 688277 & 5.0 & 4.8531 & TST \\
\hline CHEMBL1476332 & 688277 & 4.9 & 4.8131 & TRN \\
\hline CHEMBL1522993 & 688277 & 4.5 & 4.8547 & TRN \\
\hline CHEMBL3190958 & 688277 & 5.1 & 4.9884 & TST \\
\hline CHEMBL1591962 & 688277 & 4.5 & 4.8607 & TRN \\
\hline CHEMBL1595869 & 688277 & 4.6 & 4.7136 & TRN \\
\hline CHEMBL1610463 & 688277 & 4.7 & 5.1454 & TRN \\
\hline CHEMBL1988883 & 688277 & 4.45 & 5.1319 & TST \\
\hline CHEMBL1553380 & 688277 & 4.9 & 4.8735 & TRN \\
\hline CHEMBL1359251 & 688277 & 4.95 & 4.7346 & TRN \\
\hline CHEMBL1590652 & 688277 & 5.4 & 4.9474 & TRN \\
\hline CHEMBL1356030 & 688277 & 4.8 & 4.8778 & TRN \\
\hline CHEMBL1434185 & 688277 & 4.7 & 4.822 & TRN \\
\hline CHEMBL1400567 & 688277 & 5.0 & 5.1542 & TRN \\
\hline CHEMBL1488035 & 688277 & 5.45 & 5.4752 & TST \\
\hline CHEMBL1551592 & 688277 & 4.8 & 4.9083 & TRN \\
\hline CHEMBL1449165 & 688277 & 5.2 & 5.0156 & TST \\
\hline CHEMBL1514405 & 688277 & 5.25 & 4.865 & TST \\
\hline CHEMBL1354905 & 688277 & 4.9 & 4.8812 & TRN \\
\hline CHEMBL1358452 & 688277 & 5.7 & 5.3473 & TST \\
\hline CHEMBL1526054 & 688277 & 5.0 & 4.9485 & TRN \\
\hline CHEMBL1398249 & 688277 & 4.6 & 4.8901 & TRN \\
\hline CHEMBL1532286 & 688277 & 4.9 & 4.97 & TST \\
\hline CHEMBL1508255 & 688277 & 5.0 & 4.9375 & TRN \\
\hline CHEMBL1435871 & 688277 & 4.45 & 4.8792 & TRN \\
\hline CHEMBL1514150 & 688277 & 5.3 & 5.0273 & TRN \\
\hline CHEMBL1515729 & 688277 & 4.5 & 5.0644 & TST \\
\hline CHEMBL1435570 & 688277 & 4.9 & 4.8309 & TST \\
\hline CHEMBL1607281 & 688277 & 4.5 & 4.8902 & TST \\
\hline CHEMBL1482373 & 688277 & 4.8 & 4.9247 & TST \\
\hline CHEMBL1476290 & 688277 & 4.45 & 4.8612 & TRN \\
\hline CHEMBL1409293 & 688277 & 4.45 & 4.6686 & TRN \\
\hline CHEMBL1613718 & 688277 & 4.45 & 4.7967 & TRN \\
\hline
\end{tabular}




\begin{tabular}{|c|c|c|c|c|c|}
\hline \multicolumn{6}{|c|}{ Supplemental Table s2.txt } \\
\hline CHEMBL1433648 & 688277 & 5.25 & 5.0176 & TRN & \\
\hline CHEMBL1334808 & 688277 & 4.5 & 4.8559 & TRN & \\
\hline CHEMBL1410053 & 688277 & 4.45 & 4.9599 & TRN & \\
\hline CHEMBL1560065 & 688277 & 4.95 & 4.88399 & 99999999995 & TST \\
\hline CHEMBL1361793 & 688277 & 4.7 & 4.7709 & TRN & \\
\hline CHEMBL1358412 & 688277 & 5.45 & 5.1403 & TRN & \\
\hline CHEMBL1398240 & 688277 & 4.5 & 4.6867 & TRN & \\
\hline CHEMBL1610876 & 688277 & 4.5 & 4.8203 & TRN & \\
\hline CHEMBL1357964 & 688277 & 4.9 & 5.0446 & TRN & \\
\hline CHEMBL1356773 & 688277 & 4.45 & 4.6812 & TRN & \\
\hline CHEMBL1400406 & 688277 & 5.7 & 5.2038 & TRN & \\
\hline CHEMBL1608086 & 688277 & 4.9 & 4.9368 & TRN & \\
\hline CHEMBL3193515 & 688277 & 4.9 & 5.4932 & TST & \\
\hline CHEMBL1553106 & 688277 & 4.9 & 4.8349 & TRN & \\
\hline CHEMBL1551790 & 688277 & 4.7 & 4.8256 & TRN & \\
\hline CHEMBL1367449 & 688277 & 4.5 & 4.8325 & TRN & \\
\hline CHEMBL1316753 & 688277 & 4.9 & 4.9048 & TRN & \\
\hline CHEMBL1479847 & 688277 & 4.9 & 5.1345 & TRN & \\
\hline CHEMBL1344081 & 688277 & 4.95 & 5.2254 & TRN & \\
\hline CHEMBL1551933 & 688277 & 4.5 & 4.8648 & TRN & \\
\hline CHEMBL1569086 & 688277 & 4.9 & 4.8667 & TRN & \\
\hline CHEMBL1592787 & 688277 & 4.5 & 5.4535 & TRN & \\
\hline CHEMBL1554658 & 688277 & 4.8 & 4.8914 & TRN & \\
\hline CHEMBL1475918 & 688277 & 4.7 & 4.8107 & TRN & \\
\hline CHEMBL1566320 & 688277 & 4.5 & 4.8592 & TRN & \\
\hline CHEMBL1320772 & 688277 & 8.3468 & 4.9571 & TRN & \\
\hline CHEMBL1396001 & 688277 & 4.5 & 4.9449 & TRN & \\
\hline CHEMBL1587043 & 688277 & 5.5 & 5.1787 & TST & \\
\hline CHEMBL1437460 & 688277 & 6.6499 & 4.9225 & TST & \\
\hline CHEMBL1317630 & 688277 & 4.45 & 4.8863 & TST & \\
\hline CHEMBL1513844 & 688277 & 4.6 & 4.8891 & TST & \\
\hline CHEMBL1594218 & 688277 & 4.85 & 4.8773 & TRN & \\
\hline CHEMBL1377782 & 688277 & 4.45 & 4.8781 & TST & \\
\hline CHEMBL1459310 & 688277 & 4.95 & 4.8817 & TRN & \\
\hline CHEMBL1475633 & 688277 & 5.2 & 5.00899 & 99999999995 & TRN \\
\hline CHEMBL1493833 & 688277 & 4.5 & 4.8534 & TRN & \\
\hline CHEMBL1532020 & 688277 & 4.5 & 4.8842 & TRN & \\
\hline CHEMBL1475715 & 688277 & 4.8 & 4.8879 & TRN & \\
\hline CHEMBL1376919 & 688277 & 5.3 & 5.1809 & TST & \\
\hline CHEMBL1475873 & 688277 & 4.9 & 4.8769 & TRN & \\
\hline CHEMBL1475907 & 688277 & 4.6 & 4.6596 & TRN & \\
\hline CHEMBL1332880 & 688277 & 4.9 & 4.9025 & TRN & \\
\hline CHEMBL1394918 & 688277 & 4.9 & 4.8766 & TRN & \\
\hline CHEMBL1532430 & 688277 & 5.55 & 4.856 & TRN & \\
\hline CHEMBL1437230 & 688277 & 5.0 & 4.7016 & TRN & \\
\hline CHEMBL1459930 & 688277 & 5.0 & 4.9285 & TST & \\
\hline CHEMBL1398475 & 688277 & 4.9 & 5.005 & TRN & \\
\hline CHEMBL1486544 & 688277 & 5.2 & 5.2571 & TRN & \\
\hline
\end{tabular}




\begin{tabular}{|c|c|c|c|c|c|}
\hline \multicolumn{6}{|c|}{ ble Sz. } \\
\hline CHEMBL1414686 & 688277 & 4.8 & 5.0384 & TST & \\
\hline CHEMBL1316891 & 688277 & 4.8 & 4.7452 & TRN & \\
\hline CHEMBL1337527 & 688277 & 5.65 & 5.3593 & TRN & \\
\hline CHEMBL1401242 & 688277 & 4.9 & 4.9466 & TRN & \\
\hline CHEMBL1330972 & 688277 & 5.35 & 5.2877 & TRN & \\
\hline CHEMBL1436334 & 688277 & 5.3 & 5.2356 & TRN & \\
\hline CHEMBL1514672 & 688277 & 4.95 & 4.8954 & TST & \\
\hline CHEMBL1440950 & 688277 & 4.5 & 4.6407 & TRN & \\
\hline CHEMBL1394209 & 688277 & 4.9 & 4.828 & TST & \\
\hline CHEMBL1477435 & 688277 & 5.5 & 4.9152 & TRN & \\
\hline CHEMBL1407414 & 688277 & 4.45 & $4.82600 t$ & 00000000005 & TST \\
\hline CHEMBL1454073 & 688277 & 4.7 & 5.1225 & TST & \\
\hline CHEMBL1317655 & 688277 & 4.5 & 5.0138 & TRN & \\
\hline CHEMBL1407780 & 688277 & 4.5 & 5.5356 & TRN & \\
\hline CHEMBL1395966 & 688277 & 4.5 & 4.9501 & TST & \\
\hline CHEMBL3191027 & 688277 & 5.0 & 5.0593 & TST & \\
\hline CHEMBL1358681 & 688277 & 4.65 & 4.8081 & TRN & \\
\hline CHEMBL1440334 & 688277 & 4.55 & 4.8469 & TRN & \\
\hline CHEMBL1553242 & 688277 & 4.5 & 5.0302 & TRN & \\
\hline CHEMBL1602945 & 688277 & 4.6 & 4.6987 & TRN & \\
\hline CHEMBL1590482 & 688277 & 5.0 & 4.9766 & TRN & \\
\hline CHEMBL1524507 & 688277 & 5.4 & 4.9964 & TRN & \\
\hline CHEMBL1356308 & 688277 & 4.9 & 4.88899 & 9999999999 & TST \\
\hline CHEMBL1355399 & 688277 & 6.1 & 5.0285 & TRN & \\
\hline CHEMBL1403125 & 688277 & 4.7 & 4.9071 & TRN & \\
\hline CHEMBL1592872 & 688277 & 4.5 & 4.8657 & TRN & \\
\hline CHEMBL3195220 & 688277 & 4.6 & 4.875 & TST & \\
\hline CHEMBL1445710 & 688277 & 4.7 & 4.68 & TST & \\
\hline CHEMBL1437806 & 688277 & 4.8 & 4.867 & TRN & \\
\hline CHEMBL1526748 & 688277 & 4.5 & 4.6696 & TRN & \\
\hline CHEMBL1435966 & 688277 & 4.7 & 4.8917 & TST & \\
\hline CHEMBL1437029 & 688277 & 5.7 & 4.7757 & TRN & \\
\hline CHEMBL1318348 & 688277 & 5.0 & 4.8962 & TRN & \\
\hline CHEMBL1514806 & 688277 & 4.6 & 4.7285 & TRN & \\
\hline CHEMBL1317817 & 688277 & 4.9 & 4.8979 & TRN & \\
\hline CHEMBL1554040 & 688277 & 4.8 & 4.8 & TST & \\
\hline CHEMBL1475301 & 688277 & 4.9 & 4.8846 & TRN & \\
\hline CHEMBL1590587 & 688277 & 4.7 & 4.9461 & TRN & \\
\hline CHEMBL1436420 & 688277 & 4.8 & 4.8562 & TRN & \\
\hline CHEMBL1338774 & 688277 & 7.5003 & 5.3427 & TRN & \\
\hline CHEMBL1442434 & 688277 & 4.5 & 5.0256 & TRN & \\
\hline CHEMBL1534229 & 688277 & 4.9 & 4.8407 & TRN & \\
\hline CHEMBL1475672 & 688277 & 4.5 & 4.9793 & TRN & \\
\hline CHEMBL1605762 & 688277 & 4.9 & 4.9275 & TRN & \\
\hline CHEMBL1409163 & 688277 & 5.25 & 4.9335 & TRN & \\
\hline CHEMBL1325980 & 688277 & 5.6 & 4.8927 & TRN & \\
\hline CHEMBL1593342 & 688277 & 4.5 & 4.8221 & TRN & \\
\hline CHEMBL1356820 & 688277 & 4.5 & 4.9095 & TRN & \\
\hline
\end{tabular}




\begin{tabular}{|c|c|c|c|c|}
\hline \multicolumn{5}{|c|}{ Supplemental Table S2.txt } \\
\hline CHEMBL1315846 & 688277 & 4.5 & 4.8885 & TRN \\
\hline CHEMBL1593543 & 688277 & 5.5 & 5.0297 & TRN \\
\hline CHEMBL1474489 & 688277 & 4.8 & 5.1516 & TST \\
\hline CHEMBL1481190 & 688277 & 4.5 & 4.6545 & TRN \\
\hline CHEMBL1314375 & 688277 & 4.8 & 4.9038 & TST \\
\hline CHEMBL1366627 & 688277 & 5.0 & 4.9486 & TRN \\
\hline CHEMBL1357996 & 688277 & 5.0 & 4.8787 & TRN \\
\hline CHEMBL1440382 & 688277 & 4.5 & 4.8809 & TRN \\
\hline CHEMBL1611027 & 688277 & 4.7 & 4.9295 & TRN \\
\hline CHEMBL1341192 & 688277 & 4.9 & 4.8526 & TRN \\
\hline CHEMBL1402276 & 688277 & 4.7 & 4.782 & TRN \\
\hline CHEMBL267160 & 688277 & 4.9 & 4.9849 & TRN \\
\hline CHEMBL1551923 & 688277 & 4.7 & 4.8974 & TST \\
\hline CHEMBL1443639 & 688277 & 5.5 & 4.9143 & TRN \\
\hline CHEMBL1591075 & 688277 & 5.25 & 4.8765 & TRN \\
\hline CHEMBL1571730 & 688277 & 4.7 & 4.8034 & TST \\
\hline CHEMBL1493365 & 688277 & 4.7 & 4.8457 & TRN \\
\hline CHEMBL1474696 & 688277 & 5.45 & 4.8546 & TRN \\
\hline CHEMBL1610810 & 688277 & 4.95 & 4.9245 & TRN \\
\hline CHEMBL1320935 & 688277 & 4.5 & 4.8041 & TRN \\
\hline CHEMBL1398420 & 688277 & 5.15 & 5.1026 & TRN \\
\hline CHEMBL1437160 & 688277 & 5.45 & 5.0212 & TRN \\
\hline CHEMBL1476568 & 688277 & 4.5 & 4.9252 & TRN \\
\hline CHEMBL1473362 & 688277 & 5.0 & 4.9395 & TRN \\
\hline CHEMBL1316497 & 688277 & 5.55 & 4.9191 & TRN \\
\hline CHEMBL1367616 & 688277 & 4.45 & 4.8546 & TRN \\
\hline CHEMBL1403006 & 688277 & 5.15 & 4.9038 & TRN \\
\hline CHEMBL1320122 & 688277 & 5.3 & 4.7898 & TRN \\
\hline CHEMBL1367882 & 688277 & 4.6 & 4.8441 & TRN \\
\hline CHEMBL1478817 & 688277 & 5.0 & 4.827 & TRN \\
\hline CHEMBL1606585 & 688277 & 4.7 & 4.8089 & TRN \\
\hline CHEMBL1403637 & 688277 & 5.5 & 5.0131 & TRN \\
\hline CHEMBL1525495 & 688277 & 4.8 & 4.7394 & TRN \\
\hline CHEMBL1435961 & 688277 & 5.0 & 5.0007 & TRN \\
\hline CHEMBL1602484 & 688277 & 4.45 & 4.9001 & TRN \\
\hline CHEMBL1452714 & 688277 & 4.9 & 5.03 & TST \\
\hline CHEMBL1517175 & 688277 & 5.25 & 5.0399 & TRN \\
\hline CHEMBL1401707 & 688277 & 4.9 & 4.8977 & TRN \\
\hline CHEMBL1568897 & 688277 & 4.5 & 4.7992 & TRN \\
\hline CHEMBL1397186 & 688277 & 4.6 & 4.8328 & TRN \\
\hline CHEMBL1513594 & 688277 & 5.5 & 5.149 & TRN \\
\hline CHEMBL1440544 & 688277 & 4.7 & 4.8816 & TST \\
\hline CHEMBL1609743 & 688277 & 4.95 & 4.8677 & TRN \\
\hline CHEMBL1395156 & 688277 & 4.9 & 4.8982 & TRN \\
\hline CHEMBL 1358047 & 688277 & 4.6 & 5.0033 & TRN \\
\hline CHEMBL1366329 & 688277 & 4.9 & 5.0217 & TST \\
\hline CHEMBL1378033 & 688277 & 5.15 & 4.9951 & TRN \\
\hline CHEMBL1359046 & 688277 & 4.8 & 4.923 & TRN \\
\hline
\end{tabular}




\begin{tabular}{|c|c|c|c|c|c|}
\hline \\
\hline CHEMBL1375970 & 688277 & 4.5 & 4.6356 & TRN & \\
\hline CHEMBL1402249 & 688277 & 4.65 & 4.8419 & TST & \\
\hline CHEMBL1593553 & 688277 & 4.7 & 4.8852 & TRN & \\
\hline CHEMBL1513141 & 688277 & 5.5 & 4.9404 & TRN & \\
\hline CHEMBL1357453 & 688277 & 4.8 & 5.0618 & TRN & \\
\hline CHEMBL1607156 & 688277 & 6.8 & 4.9383 & TRN & \\
\hline CHEMBL1516287 & 688277 & 5.75 & 5.0278 & TRN & \\
\hline CHEMBL1514761 & 688277 & 5.35 & 5.308 & TRN & \\
\hline CHEMBL1441480 & 688277 & 4.5 & 4.6522 & TRN & \\
\hline CHEMBL1592274 & 688277 & 4.8 & 4.9345 & TRN & \\
\hline CHEMBL1394378 & 688277 & 5.0 & 4.898 & TRN & \\
\hline CHEMBL1343759 & 688277 & 4.85 & 4.9365 & TST & \\
\hline CHEMBL1470120 & 688277 & 4.45 & 4.974 & TST & \\
\hline CHEMBL1594006 & 688277 & 4.5 & 4.7841 & TRN & \\
\hline CHEMBL1368091 & 688277 & 4.9 & 4.8784 & TRN & \\
\hline CHEMBL1399642 & 688277 & 4.5 & 4.9099 & TRN & \\
\hline CHEMBL1514817 & 688277 & 4.8 & 5.125 & TST & \\
\hline CHEMBL1493332 & 688277 & 4.8 & 5.0563 & TRN & \\
\hline CHEMBL1323722 & 688277 & 4.9 & 4.98600 & 0000000001 & TRN \\
\hline CHEMBL1520778 & 688277 & 4.5 & 4.8374 & TRN & \\
\hline CHEMBL1478870 & 688277 & 4.5 & 4.6385 & TRN & \\
\hline CHEMBL1519406 & 688277 & 4.6 & 4.8346 & TST & \\
\hline CHEMBL1473454 & 688277 & 4.6 & 4.8789 & TRN & \\
\hline CHEMBL1405227 & 688277 & 5.25 & 5.0014 & TRN & \\
\hline CHEMBL1590284 & 688277 & 4.6 & 4.8435 & TRN & \\
\hline CHEMBL1444023 & 688277 & 6.4 & 5.1932 & TRN & \\
\hline CHEMBL1558930 & 688277 & 4.9 & 4.8758 & TRN & \\
\hline CHEMBL1451093 & 688277 & 4.5 & 5.0903 & TST & \\
\hline CHEMBL1398432 & 688277 & 5.0 & 5.1354 & TRN & \\
\hline CHEMBL1551691 & 688277 & 5.25 & 4.9446 & TRN & \\
\hline CHEMBL1407363 & 688277 & 4.45 & 5.0664 & TRN & \\
\hline CHEMBL1453796 & 688277 & 5.5 & 5.0336 & TRN & \\
\hline CHEMBL1395912 & 688277 & 4.5 & 4.9665 & TRN & \\
\hline CHEMBL1472981 & 688277 & 4.9 & 4.8006 & TRN & \\
\hline CHEMBL1409420 & 688277 & 5.0 & 4.8879 & TRN & \\
\hline CHEMBL1357478 & 688277 & 4.9 & 4.9326 & TRN & \\
\hline CHEMBL1416964 & 688277 & 6.15 & 4.9244 & TRN & \\
\hline CHEMBL1516105 & 688277 & 5.0 & 4.8696 & TRN & \\
\hline CHEMBL1437207 & 688277 & 4.7 & 5.1521 & TRN & \\
\hline CHEMBL1407248 & 688277 & 4.9 & 4.9614 & TRN & \\
\hline CHEMBL1591077 & 688277 & 6.1 & 4.8619 & TRN & \\
\hline CHEMBL1410576 & 688277 & 5.05 & 5.1356 & TRN & \\
\hline CHEMBL1554106 & 688277 & 4.9 & 4.8751 & TRN & \\
\hline CHEMBL1305122 & 688277 & 4.45 & 4.6745 & TRN & \\
\hline CHEMBL1574308 & 688277 & 4.6 & 4.865 & TRN & \\
\hline CHEMBL1418048 & 688277 & 4.9 & 4.9495 & TRN & \\
\hline CHEMBL1437308 & 688277 & 5.45 & 4.8258 & TRN & \\
\hline CHEMBL1337437 & 688277 & 5.0 & 4.8477 & TRN & \\
\hline
\end{tabular}




\begin{tabular}{|c|c|c|c|c|c|}
\hline \multicolumn{6}{|c|}{ Supplemental Table S2.txt } \\
\hline CHEMBL1594774 & 688277 & 5.0 & 4.9686 & TRN & \\
\hline CHEMBL1320081 & 688277 & 4.45 & 4.9169 & TST & \\
\hline CHEMBL1369733 & 688277 & 4.7 & 4.7614 & TRN & \\
\hline CHEMBL1436040 & 688277 & 4.8 & 4.8944 & TST & \\
\hline CHEMBL1355230 & 688277 & 4.5 & 4.8894 & TRN & \\
\hline CHEMBL1531041 & 688277 & 4.9 & 4.9463 & TRN & \\
\hline CHEMBL1375809 & 688277 & 7.8996 & 4.8895 & TST & \\
\hline CHEMBL1365927 & 688277 & 4.65 & 4.7036 & TRN & \\
\hline CHEMBL1513779 & 688277 & 4.5 & 4.8616 & TRN & \\
\hline CHEMBL1316412 & 688277 & 5.25 & 4.7075 & TRN & \\
\hline CHEMBL1435792 & 688277 & 4.85 & 4.8788 & TST & \\
\hline CHEMBL1450799 & 688277 & 4.5 & 4.8035 & TRN & \\
\hline CHEMBL1314398 & 688277 & 4.95 & 4.965 & TRN & \\
\hline CHEMBL1395961 & 688277 & 4.9 & 4.8729 & TRN & \\
\hline CHEMBL1342076 & 688277 & 5.6 & 5.21200 & 0000000001 & TRN \\
\hline CHEMBL1435814 & 688277 & 4.5 & 4.8816 & TRN & \\
\hline CHEMBL1594100 & 688277 & 4.8 & 4.9208 & TRN & \\
\hline CHEMBL1402959 & 688277 & 4.9 & 4.9308 & TRN & \\
\hline CHEMBL1399633 & 688277 & 4.5 & 4.9134 & TRN & \\
\hline CHEMBL1315580 & 688277 & 5.0 & 4.8973 & TRN & \\
\hline CHEMBL1554474 & 688277 & 5.4 & 4.8748 & TRN & \\
\hline CHEMBL1355854 & 688277 & 4.8 & 4.6437 & TST & \\
\hline CHEMBL1513172 & 688277 & 5.6 & 5.3176 & TST & \\
\hline CHEMBL1416927 & 688277 & 5.3 & 5.2177 & TRN & \\
\hline CHEMBL1355802 & 688277 & 6.0 & 5.7493 & TRN & \\
\hline CHEMBL1555219 & 688277 & 4.8 & 4.8863 & TST & \\
\hline CHEMBL1328538 & 688277 & 4.6 & 4.7079 & TST & \\
\hline CHEMBL1394513 & 688277 & 4.5 & 4.8772 & TRN & \\
\hline CHEMBL 1327277 & 688277 & 4.8 & 4.8685 & TST & \\
\hline CHEMBL1435287 & 688277 & 5.2 & 5.0003 & TRN & \\
\hline CHEMBL1383866 & 688277 & 4.85 & 4.9633 & TST & \\
\hline CHEMBL1552807 & 688277 & 6.0 & 5.3419 & TRN & \\
\hline CHEMBL1355392 & 688277 & 4.7 & 4.9302 & TST & \\
\hline CHEMBL1420039 & 688277 & 5.45 & 4.9748 & TRN & \\
\hline CHEMBL1457164 & 688277 & 4.5 & 5.1069 & TRN & \\
\hline CHEMBL1571438 & 688277 & 5.1 & 5.1035 & TRN & \\
\hline CHEMBL1554951 & 688277 & 5.2 & 5.0092 & TRN & \\
\hline CHEMBL1499966 & 688277 & 4.8 & 4.8296 & TST & \\
\hline CHEMBL1598947 & 688277 & 4.9 & 4.9935 & TRN & \\
\hline CHEMBL1481085 & 688277 & 4.6 & 4.7142 & TRN & \\
\hline CHEMBL1397318 & 688277 & 7.5003 & 5.0126 & TRN & \\
\hline CHEMBL1488180 & 688277 & 4.9 & 4.8505 & TRN & \\
\hline CHEMBL1308118 & 688277 & 4.9 & 4.9029 & TST & \\
\hline CHEMBL1323581 & 688277 & 4.5 & 4.9813 & TST & \\
\hline CHEMBL1482365 & 688277 & 5.1 & 4.8317 & TRN & \\
\hline CHEMBL1315927 & 688277 & 4.5 & 4.7171 & TST & \\
\hline CHEMBL1591810 & 688277 & 4.85 & 4.7356 & TRN & \\
\hline CHEMBL585820 & 688277 & 6.2 & 5.2617 & TRN & \\
\hline
\end{tabular}




\begin{tabular}{|c|c|c|c|c|}
\hline \multicolumn{5}{|c|}{ Supplemental Table S2.txt } \\
\hline CHEMBL1383967 & 688277 & 5.4 & 5.1933 & TRN \\
\hline CHEMBL1434397 & 688277 & 4.5 & 4.9378 & TRN \\
\hline CHEMBL1397149 & 688277 & 4.5 & 5.4494 & TRN \\
\hline CHEMBL1514787 & 688277 & 7.0 & 4.9025 & TRN \\
\hline CHEMBL1568115 & 688277 & 4.6 & 4.9267 & TST \\
\hline CHEMBL1407031 & 688277 & 5.25 & 5.0116 & TRN \\
\hline CHEMBL1315721 & 688277 & 4.8 & 4.9211 & TRN \\
\hline CHEMBL1594795 & 688277 & 6.4 & 4.9498 & TRN \\
\hline CHEMBL1397609 & 688277 & 4.9 & 4.7177 & TST \\
\hline CHEMBL1356208 & 688277 & 4.5 & 4.6685 & TRN \\
\hline CHEMBL1374944 & 688277 & 4.7 & 4.9026 & TRN \\
\hline CHEMBL1355422 & 688277 & 4.5 & 4.8542 & TRN \\
\hline CHEMBL1514409 & 688277 & 5.0 & 4.9346 & TRN \\
\hline CHEMBL1358317 & 688277 & 4.5 & 4.8293 & TRN \\
\hline CHEMBL1555315 & 688277 & 5.2 & 4.9406 & TRN \\
\hline CHEMBL1439717 & 688277 & 4.65 & 4.9225 & TST \\
\hline CHEMBL1472609 & 688277 & 4.9 & 4.6688 & TRN \\
\hline CHEMBL1436013 & 688277 & 4.5 & 4.7628 & TRN \\
\hline CHEMBL1407038 & 688277 & 5.0 & 4.8572 & TRN \\
\hline CHEMBL1516995 & 688277 & 4.8 & 4.7946 & TRN \\
\hline CHEMBL1473518 & 688277 & 5.25 & 5.1921 & TRN \\
\hline CHEMBL1580401 & 688277 & 5.65 & 4.9468 & TRN \\
\hline CHEMBL1438942 & 688277 & 4.7 & 5.0162 & TRN \\
\hline CHEMBL1389366 & 688277 & 5.25 & 5.1102 & TRN \\
\hline CHEMBL1476629 & 688277 & 4.6 & 4.8769 & TRN \\
\hline CHEMBL1510089 & 688277 & 4.7 & 4.9875 & TRN \\
\hline CHEMBL1316171 & 688277 & 4.7 & 4.9583 & TRN \\
\hline CHEMBL1338443 & 688277 & 5.35 & 5.0218 & TRN \\
\hline CHEMBL1434896 & 688277 & 4.5 & 4.8643 & TST \\
\hline CHEMBL1570241 & 688277 & 5.0 & 4.9367 & TRN \\
\hline CHEMBL1592622 & 688277 & 4.45 & 4.7997 & TRN \\
\hline CHEMBL1496745 & 688277 & 8.301 & 5.0317 & TRN \\
\hline CHEMBL1552892 & 688277 & 5.2 & 4.8922 & TST \\
\hline CHEMBL1333686 & 688277 & 6.0 & 5.5 & TRN \\
\hline CHEMBL1436502 & 688277 & 5.0 & 4.9029 & TRN \\
\hline CHEMBL1476692 & 688277 & 4.8 & 5.0272 & TRN \\
\hline CHEMBL1579693 & 688277 & 4.95 & 5.0781 & TST \\
\hline CHEMBL1394535 & 688277 & 4.8 & 4.8133 & TRN \\
\hline CHEMBL1590410 & 688277 & 5.9 & 5.3434 & TST \\
\hline CHEMBL1398684 & 688277 & 4.8 & 4.8328 & TRN \\
\hline CHEMBL1355148 & 688277 & 4.9 & 4.9345 & TRN \\
\hline CHEMBL1553869 & 688277 & 4.95 & 4.9065 & TST \\
\hline CHEMBL597251 & 688277 & 4.6 & 4.7231 & TST \\
\hline CHEMBL1499436 & 688277 & 4.5 & 4.8066 & TST \\
\hline CHEMBL1533813 & 688277 & 4.5 & 4.9264 & TRN \\
\hline CHEMBL1522172 & 688277 & 4.85 & 4.8782 & TRN \\
\hline CHEMBL1512629 & 688277 & 5.35 & 4.925 & TRN \\
\hline CHEMBL1487362 & 688277 & 4.5 & 4.9201 & TRN \\
\hline
\end{tabular}




\begin{tabular}{|c|c|c|c|c|c|}
\hline \\
\hline CHEMBL1417669 & 688277 & 5.4 & 4.8867 & TRN & \\
\hline CHEMBL1397338 & 688277 & 4.7 & 4.8121 & TRN & \\
\hline CHEMBL1593533 & 688277 & 4.8 & 4.8483 & TRN & \\
\hline CHEMBL1327858 & 688277 & 4.75 & 4.9635 & TST & \\
\hline CHEMBL1534173 & 688277 & 4.7 & 5.0099 & TRN & \\
\hline CHEMBL1480424 & 688277 & 5.95 & 5.0607 & TST & \\
\hline CHEMBL1577648 & 688277 & 5.0 & 4.9191 & TST & \\
\hline CHEMBL1361843 & 688277 & 5.35 & 5.0009 & TRN & \\
\hline CHEMBL1318095 & 688277 & 7.5003 & 4.8904 & TRN & \\
\hline CHEMBL1515465 & 688277 & 5.3 & 4.8448 & TRN & \\
\hline CHEMBL1520341 & 688277 & 4.9 & 4.8567 & TRN & \\
\hline CHEMBL586005 & 688277 & 4.9 & 4.8968 & TRN & \\
\hline CHEMBL1553780 & 688277 & 4.5 & 4.8442 & TRN & \\
\hline CHEMBL1365538 & 688277 & 4.5 & 4.7391 & TRN & \\
\hline CHEMBL1316795 & 688277 & 4.65 & 4.8529 & TST & \\
\hline CHEMBL1399894 & 688277 & 5.3 & 5.1597 & TRN & \\
\hline CHEMBL1533760 & 688277 & 4.7 & 4.9723 & TRN & \\
\hline CHEMBL601146 & 688277 & 5.15 & 5.2172 & TST & \\
\hline CHEMBL1473445 & 688277 & 4.5 & 4.8945 & TRN & \\
\hline CHEMBL1314331 & 688277 & 4.45 & 4.9899 & TRN & \\
\hline CHEMBL1435593 & 688277 & 4.5 & 4.6455 & TRN & \\
\hline CHEMBL1435883 & 688277 & 4.7 & 4.6844 & TST & \\
\hline CHEMBL1472866 & 688277 & 5.35 & 4.92399 & 99999999995 & TST \\
\hline CHEMBL1397897 & 688277 & 4.9 & 4.9111 & TST & \\
\hline CHEMBL1513140 & 688277 & 5.6 & 4.9143 & TRN & \\
\hline CHEMBL1348498 & 688277 & 4.6 & 4.9363 & TST & \\
\hline CHEMBL1401359 & 688277 & 5.0 & 4.8958 & TRN & \\
\hline CHEMBL1320318 & 688277 & 5.7 & 5.2656 & TRN & \\
\hline CHEMBL1314633 & 688277 & 4.9 & 5.0055 & TST & \\
\hline CHEMBL1436148 & 688277 & 4.9 & 4.8062 & TRN & \\
\hline CHEMBL1513739 & 688277 & 4.5 & 5.314 & TRN & \\
\hline CHEMBL1512119 & 688277 & 4.9 & 4.902 & TRN & \\
\hline CHEMBL1592458 & 688277 & 4.6 & 4.7682 & TRN & \\
\hline CHEMBL1438762 & 688277 & 7.0 & 4.8959 & TRN & \\
\hline CHEMBL1480522 & 688277 & 5.0 & 4.9294 & TST & \\
\hline CHEMBL1515692 & 688277 & 4.5 & 4.8467 & TRN & \\
\hline CHEMBL1605974 & 688277 & 4.5 & 4.6538 & TRN & \\
\hline CHEMBL1611117 & 688277 & 5.7 & 5.2232 & TRN & \\
\hline CHEMBL1562283 & 688277 & 6.8 & 4.849 & TRN & \\
\hline CHEMBL582699 & 688277 & 4.5 & 4.9467 & TRN & \\
\hline CHEMBL1437502 & 688277 & 5.6 & 5.32600 & 20000000005 & TST \\
\hline CHEMBL1315227 & 688277 & 4.6 & 4.8379 & TRN & \\
\hline CHEMBL1611819 & 688277 & 4.65 & 4.7295 & TRN & \\
\hline CHEMBL1427801 & 688277 & 5.35 & 5.099 & TST & \\
\hline CHEMBL1307919 & 688277 & 6.05 & 5.49100 & 00000000005 & TRN \\
\hline CHEMBL1520944 & 688277 & 4.85 & 4.9903 & TRN & \\
\hline CHEMBL1342112 & 688277 & 4.85 & 4.8965 & TST & \\
\hline CHEMBL1329145 & 688277 & 4.6 & 4.8681 & TRN & \\
\hline
\end{tabular}




\begin{tabular}{|c|c|c|c|c|}
\hline \multicolumn{5}{|c|}{ Supplemental Table S2.txt } \\
\hline CHEMBL1405638 & 688277 & 4.5 & 5.0492 & TST \\
\hline CHEMBL1607640 & 688277 & 4.5 & 5.2819 & TRN \\
\hline CHEMBL1322692 & 688277 & 5.0 & 4.9342 & TRN \\
\hline CHEMBL1325515 & 688277 & 4.7 & 4.8139 & TRN \\
\hline CHEMBL1354263 & 688277 & 5.35 & 4.8766 & TRN \\
\hline CHEMBL599307 & 688277 & 4.9 & 4.9641 & TRN \\
\hline CHEMBL1366941 & 688277 & 5.0 & 4.886 & TRN \\
\hline CHEMBL1415771 & 688277 & 4.95 & 4.9297 & TST \\
\hline CHEMBL1516076 & 688277 & 4.95 & 4.6894 & TRN \\
\hline CHEMBL1474369 & 688277 & 5.45 & 5.2622 & TRN \\
\hline CHEMBL3211651 & 688277 & 5.0 & 4.9059 & TST \\
\hline CHEMBL1593916 & 688277 & 4.5 & 4.8841 & TRN \\
\hline CHEMBL1520905 & 688277 & 4.5 & 4.694 & TRN \\
\hline CHEMBL1594699 & 688277 & 4.95 & 4.9015 & TRN \\
\hline CHEMBL1321400 & 688277 & 4.8 & 4.9587 & TRN \\
\hline CHEMBL1403123 & 688277 & 4.95 & 4.702 & TRN \\
\hline CHEMBL1323354 & 688277 & 5.1 & 4.8948 & TRN \\
\hline CHEMBL1401647 & 688277 & 6.8 & 5.1587 & TRN \\
\hline CHEMBL1333641 & 688277 & 8.0 & 4.868 & TRN \\
\hline CHEMBL1324115 & 688277 & 4.8 & 4.8654 & TRN \\
\hline CHEMBL1573196 & 688277 & 5.0 & 4.9432 & TRN \\
\hline CHEMBL1517627 & 688277 & 4.65 & 4.7086 & TRN \\
\hline CHEMBL1453589 & 688277 & 4.5 & 4.9575 & TRN \\
\hline CHEMBL1526991 & 688277 & 5.0 & 4.9532 & TRN \\
\hline CHEMBL1337118 & 688277 & 4.5 & 4.9584 & TRN \\
\hline CHEMBL1356554 & 688277 & 5.1 & 4.9581 & TST \\
\hline CHEMBL1595763 & 688277 & 4.5 & 4.9292 & TST \\
\hline CHEMBL1574597 & 688277 & 5.2 & 4.684 & TRN \\
\hline CHEMBL1589985 & 688277 & 5.5 & 4.9751 & TST \\
\hline CHEMBL1337984 & 688277 & 5.6 & 5.5057 & TRN \\
\hline CHEMBL1344582 & 688277 & 5.0 & 4.9504 & TRN \\
\hline CHEMBL1352911 & 688277 & 4.95 & 4.9494 & TST \\
\hline CHEMBL1526437 & 688277 & 5.1 & 4.9386 & TRN \\
\hline CHEMBL1368106 & 688277 & 4.9 & 4.9267 & TST \\
\hline CHEMBL1591137 & 688277 & 4.9 & 4.9479 & TRN \\
\hline CHEMBL1358070 & 688277 & 4.5 & 4.9947 & TRN \\
\hline CHEMBL1321484 & 688277 & 4.7 & 4.6772 & TRN \\
\hline CHEMBL1558969 & 688277 & 4.6 & 4.9775 & TRN \\
\hline CHEMBL1554119 & 688277 & 4.45 & 4.879 & TRN \\
\hline CHEMBL1606126 & 688277 & 4.5 & 4.9406 & TRN \\
\hline CHEMBL1369611 & 688277 & 4.9 & 4.7245 & TST \\
\hline CHEMBL1561980 & 688277 & 4.8 & 4.7481 & TST \\
\hline CHEMBL1433456 & 688277 & 4.75 & 4.949 & TRN \\
\hline CHEMBL1554254 & 688277 & 5.0 & 4.7145 & TST \\
\hline CHEMBL 1400144 & 688277 & 4.9 & 4.9217 & TRN \\
\hline CHEMBL1397944 & 688277 & 4.5 & 4.9018 & TRN \\
\hline CHEMBL1337183 & 688277 & 4.5 & 5.7439 & TRN \\
\hline CHEMBL1558691 & 688277 & 5.0 & 4.9154 & TRN \\
\hline
\end{tabular}




\begin{tabular}{|c|c|c|c|c|c|}
\hline \multirow{3}{*}{$\begin{array}{l}\text { CHEMBL1418306 } \\
\text { CHEMBL } 1512284\end{array}$} & & \multicolumn{4}{|c|}{ Supplemental Table S2.txt } \\
\hline & & 5.25 & 5.01699 & 99999999995 & TST \\
\hline & 688277 & 4.5 & 5.3479 & TRN & \\
\hline CHEMBL1373539 & 688277 & 5.7 & 4.9922 & TRN & \\
\hline CHEMBL1300608 & 688277 & 4.65 & 4.9243 & TST & \\
\hline CHEMBL1551338 & 688277 & 4.9 & 4.8761 & TST & \\
\hline CHEMBL1441988 & 688277 & 4.5 & 4.8708 & TRN & \\
\hline CHEMBL1357595 & 688277 & 4.8 & 4.6585 & TST & \\
\hline CHEMBL1477603 & 688277 & 4.45 & 4.8004 & TRN & \\
\hline CHEMBL1377262 & 688277 & 4.5 & 5.0668 & TST & \\
\hline CHEMBL1397329 & 688277 & 4.8 & 4.7631 & TST & \\
\hline CHEMBL1573376 & 688277 & 5.2 & 4.8984 & TRN & \\
\hline CHEMBL1323968 & 688277 & 5.05 & 5.0341 & TST & \\
\hline CHEMBL1439277 & 688277 & 4.9 & 4.9145 & TST & \\
\hline CHEMBL1361507 & 688277 & 4.5 & 4.7146 & TRN & \\
\hline CHEMBL1485458 & 688277 & 4.85 & 4.9844 & TRN & \\
\hline CHEMBL1434348 & 688277 & 4.7 & 4.6494 & TRN & \\
\hline CHEMBL1473833 & 688277 & 4.9 & 4.8059 & TRN & \\
\hline CHEMBL1435324 & 688277 & 4.7 & 4.8455 & TRN & \\
\hline CHEMBL1554164 & 688277 & 5.6 & 5.205 & TST & \\
\hline CHEMBL1321245 & 688277 & 4.6 & 4.8352 & TRN & \\
\hline CHEMBL1454928 & 688277 & 4.5 & 4.9265 & TST & \\
\hline CHEMBL1435455 & 688277 & 5.4 & 5.055 & TRN & \\
\hline CHEMBL1447287 & 688277 & 4.5 & 4.9121 & TRN & \\
\hline CHEMBL1605337 & 688277 & 4.9 & 5.0408 & TRN & \\
\hline CHEMBL1318029 & 688277 & 4.9 & 5.2255 & TST & \\
\hline CHEMBL1485697 & 688277 & 4.8 & 4.7791 & TRN & \\
\hline CHEMBL1454417 & 688277 & 4.6 & 4.7278 & TRN & \\
\hline CHEMBL1416354 & 688277 & 5.6 & 4.9863 & TRN & \\
\hline CHEMBL1589819 & 688277 & 4.7 & 4.9139 & TRN & \\
\hline CHEMBL1531545 & 688277 & 5.0 & 4.852 & TRN & \\
\hline CHEMBL1356322 & 688277 & 4.5 & 4.8658 & TRN & \\
\hline CHEMBL1365525 & 688277 & 4.5 & 4.6831 & TRN & \\
\hline CHEMBL1554520 & 688277 & 4.5 & 4.7732 & TRN & \\
\hline CHEMBL1435275 & 688277 & 4.5 & 4.9047 & TST & \\
\hline CHEMBL1535105 & 688277 & 5.5 & 4.894 & TRN & \\
\hline CHEMBL1316751 & 688277 & 4.9 & 4.9407 & TRN & \\
\hline CHEMBL1555009 & 688277 & 4.9 & 4.8929 & TRN & \\
\hline CHEMBL1437067 & 688277 & 4.5 & 4.7651 & TRN & \\
\hline CHEMBL1593783 & 688277 & 5.2 & 4.9233 & TRN & \\
\hline CHEMBL1337337 & 688277 & 4.6 & 4.8156 & TRN & \\
\hline CHEMBL1380508 & 688277 & 5.35 & 5.3538 & TRN & \\
\hline CHEMBL1444994 & 688277 & 4.65 & 4.9503 & TRN & \\
\hline CHEMBL1356026 & 688277 & 5.4 & 5.3741 & TRN & \\
\hline CHEMBL1596342 & 688277 & 4.5 & 4.7985 & TST & \\
\hline CHEMBL1527400 & 688277 & 5.25 & 5.1531 & TST & \\
\hline CHEMBL1488701 & 688277 & 5.2 & 4.8532 & TST & \\
\hline CHEMBL1595800 & 688277 & 4.9 & 4.7892 & TST & \\
\hline CHEMBL1397469 & 688277 & 4.6 & 4.9689 & TST & \\
\hline
\end{tabular}




\begin{tabular}{|c|c|c|c|c|c|}
\hline \multicolumn{6}{|c|}{ plemental } \\
\hline CHEMBL3198502 & 688277 & 5.2 & 5.0061 & TST & \\
\hline CHEMBL1498545 & 688277 & 5.0 & 5.0858 & TST & \\
\hline CHEMBL1311383 & 688277 & 4.75 & 5.074 & TST & \\
\hline CHEMBL1565909 & 688277 & 5.0 & 4.9642 & TST & \\
\hline CHEMBL1354416 & 688277 & 4.7 & 4.7555 & TST & \\
\hline CHEMBL1611523 & 688277 & 4.45 & 5.0692 & TST & \\
\hline CHEMBL1395883 & 688277 & 4.5 & 4.9123 & TST & \\
\hline CHEMBL1396193 & 688277 & 4.5 & 4.6936 & TST & \\
\hline CHEMBL1435533 & 688277 & 5.1 & 5.2291 & TST & \\
\hline CHEMBL1335003 & 688277 & 4.6 & 4.7338 & TST & \\
\hline CHEMBL1474068 & 688277 & 4.7 & 5.015 & TST & \\
\hline CHEMBL1488636 & 688277 & 4.9 & 4.8662 & TST & \\
\hline CHEMBL1317995 & 688277 & 5.2 & 4.9133 & TST & \\
\hline CHEMBL3198339 & 688277 & 5.45 & 4.9652 & TST & \\
\hline CHEMBL1358492 & 688277 & 4.6 & 4.8573 & TST & \\
\hline CHEMBL1514055 & 688277 & 5.5 & 4.9736 & TST & \\
\hline CHEMBL1371671 & 688277 & 4.6 & 4.6518 & TST & \\
\hline CHEMBL1486766 & 688277 & 5.0 & 4.8846 & TST & \\
\hline CHEMBL1571426 & 688277 & 4.95 & 4.9592 & TST & \\
\hline CHEMBL1467405 & 688277 & 6.15 & 5.45799 & 9999999999 & TST \\
\hline CHEMBL1455630 & 688277 & 4.9 & 4.9115 & TST & \\
\hline CHEMBL1472953 & 688277 & 4.5 & 4.6974 & TST & \\
\hline CHEMBL1563821 & 688277 & 4.95 & 4.7138 & TST & \\
\hline CHEMBL1415760 & 688277 & 4.5 & 4.7246 & TST & \\
\hline CHEMBL1338800 & 688277 & 4.9 & 4.9519 & TST & \\
\hline CHEMBL1301125 & 688277 & 5.0 & 5.0729 & TST & \\
\hline CHEMBL1449808 & 688277 & 5.6 & 5.3424 & TST & \\
\hline CHEMBL1531231 & 688277 & 4.5 & 4.6695 & TST & \\
\hline CHEMBL1395866 & 688277 & 5.55 & 4.8887 & TST & \\
\hline CHEMBL1554006 & 688277 & 4.5 & 4.7828 & TST & \\
\hline CHEMBL1314454 & 688277 & 5.9 & 5.3636 & TST & \\
\hline CHEMBL1567968 & 688277 & 5.1 & 4.7413 & TST & \\
\hline CHEMBL1325198 & 688277 & 4.7 & 4.7553 & TST & \\
\hline CHEMBL1475818 & 688277 & 5.1 & 5.1619 & TST & \\
\hline CHEMBL1437262 & 688277 & 4.6 & 4.7268 & TST & \\
\hline CHEMBL1397197 & 688277 & 5.0 & 4.922 & TST & \\
\hline CHEMBL528712 & 688277 & 4.5 & 4.86600 & 00000000005 & TST \\
\hline CHEMBL1404601 & 688277 & 4.8 & 4.9565 & TST & \\
\hline CHEMBL1592342 & 688277 & 4.9 & 4.9169 & TST & \\
\hline CHEMBL1356325 & 688277 & 5.25 & 5.0099 & TST & \\
\hline CHEMBL1397921 & 688277 & 4.6 & 4.965 & TST & \\
\hline CHEMBL1474043 & 688277 & 5.25 & 4.9955 & TST & \\
\hline CHEMBL1321262 & 688277 & 4.45 & 4.8827 & TST & \\
\hline CHEMBL1416527 & 688277 & 5.4 & 4.9798 & TST & \\
\hline CHEMBL1408099 & 688277 & 4.9 & 4.8602 & TST & \\
\hline CHEMBL1317145 & 688277 & 4.5 & 4.8172 & TST & \\
\hline CHEMBL1475835 & 688277 & 5.4 & 4.8427 & TST & \\
\hline CHEMBL1487217 & 688277 & 5.2 & 5.075 & TST & \\
\hline
\end{tabular}




\begin{tabular}{|c|c|c|c|c|c|c|}
\hline \multicolumn{7}{|c|}{ Supplemental Table S2.txt } \\
\hline CHEMBL1398263 & 688277 & 5.0 & 4.9966 & TST & & \\
\hline CHEMBL1483967 & 688277 & 4.7 & 4.7745 & TST & & \\
\hline CHEMBL1554439 & 688277 & 4.45 & 4.8642 & TST & & \\
\hline CHEMBL1434043 & 688277 & 4.5 & 5.0411 & TST & & \\
\hline CHEMBL1554101 & 688277 & 4.6 & 4.731 & TST & & \\
\hline CHEMBL1435199 & 688277 & 4.45 & 4.7665 & TST & & \\
\hline CHEMBL1354551 & 688277 & 4.7 & 4.8006 & TST & & \\
\hline CHEMBL1599294 & 688277 & 4.5 & 4.7585 & TST & & \\
\hline CHEMBL1514379 & 688277 & 5.0 & 4.9039 & TST & & \\
\hline CHEMBL1479020 & 688277 & 4.95 & 4.9101 & TST & & \\
\hline CHEMBL1495586 & 688277 & 4.5 & 4.9304 & TST & & \\
\hline CHEMBL1394244 & 688277 & 4.9 & 4.6648 & TST & & \\
\hline CHEMBL1474910 & 688277 & 4.5 & 4.837 & TST & & \\
\hline CHEMBL1475831 & 688277 & 5.45 & 5.0765 & TST & & \\
\hline CHEMBL1325661 & 688277 & 4.9 & 4.6183 & TST & & \\
\hline CHEMBL1413940 & 688277 & 4.6 & 4.6549 & TST & & \\
\hline CHEMBL1524356 & 688277 & 4.8 & 4.8941 & TST & & \\
\hline CHEMBL1354804 & 688277 & 4.7 & 4.7453 & TST & & \\
\hline CHEMBL1516550 & 688277 & 5.65 & 5.2719 & TST & & \\
\hline CHEMBL1315190 & 688277 & 6.3 & 5.0116 & TST & & \\
\hline CHEMBL1332337 & 688277 & 4.5 & 4.8374 & TST & & \\
\hline CHEMBL1476431 & 688277 & 4.9 & 4.9472 & TST & & \\
\hline CHEMBL1476909 & 688277 & 4.5 & 4.9534 & TST & & \\
\hline CHEMBL1473069 & 688277 & 4.6 & 4.9756 & TST & & \\
\hline CHEMBL1547823 & 688277 & 4.9 & 4.8515 & TST & & \\
\hline CHEMBL1435543 & 688277 & 4.7 & 4.9688 & TST & & \\
\hline CHEMBL1314220 & 688277 & 4.45 & 5.0595 & TST & & \\
\hline CHEMBL1515344 & 688277 & 4.8 & 4.9292 & TST & & \\
\hline CHEMBL1494863 & 688277 & 5.0 & 4.9108 & TST & & \\
\hline CHEMBL573107 & 954466 & 3.4024 & 3.4023 & TRN & & \\
\hline CHEMBL 2134202 & 954466 & 3.7399 & 3.7399 & TRN & & \\
\hline CHEMBL483847 & 954466 & 4.1026 & 4.1024 & TRN & & \\
\hline CHEMBL300389 & 954466 & 7.4908 & 7.4908 & TRN & & \\
\hline CHEMBL1404918 & 954466 & 3.0351 & 3.0352 & TRN & & \\
\hline CHEMBL213100 & 954466 & 4.9573 & 4.9574 & TRN & & \\
\hline CHEMBL412142 & 954466 & 4.2081 & 4.2082 & TRN & & \\
\hline CHEMBL1970879 & 954466 & 6.2422 & 6.2422 & TRN & & \\
\hline CHEMBL558642 & 954466 & 3.6231 & 3.6232 & TRN & & \\
\hline CHEMBL258844 & 954466 & 4.3699 & 4.37 & TRN & & \\
\hline CHEMBL472940 & 954466 & 3.3204 & 3.3204 & TRN & & \\
\hline CHEMBL9470 & 954466 & 5.88700 & 00000000 & 005 & 5.306 & \\
\hline CHEMBL189584 & 954466 & 4.0449 & 4.0449 & TRN & & \\
\hline CHEMBL515416 & 954466 & 4.053 & 4.0529 & TRN & & \\
\hline CHEMBL255342 & 954466 & 3.3196 & 3.3197 & TRN & & \\
\hline CHEMBL3349342 & 954466 & 5.1956 & 5.1957 & TRN & & \\
\hline CHEMBL221137 & 954466 & 5.1567 & 4.3265 & TST & & \\
\hline CHEMBL1190711 & 954466 & 5.12200 & 00000000 & & 5.1221 TRN & \\
\hline CHEMBL191334 & 954466 & 4.90600 & 00000000 & & 4.906000000000001 & TRN \\
\hline
\end{tabular}




\begin{tabular}{|c|c|c|c|c|c|c|}
\hline \\
\hline CHEMBL514499 & 954466 & 6.6866 & 6.6867 & TRN & & \\
\hline CHEMBL210618 & 954466 & 2.9139 & 2.9139 & TRN & & \\
\hline CHEMBL2363137 & 954466 & 5.005 & 5.005 & TRN & & \\
\hline CHEMBL1357247 & 954466 & 3.4195 & 3.4194 & TRN & & \\
\hline CHEMBL3392440 & 954466 & 3.7146 & 3.7147 & TRN & & \\
\hline CHEMBL3199475 & 954466 & 3.847 & 3.8471 & TRN & & \\
\hline CHEMBL379300 & 954466 & 6.0553 & 6.0554 & TRN & & \\
\hline CHEMBL180127 & 954466 & 4.7069 & 4.7068 & TRN & & \\
\hline CHEMBL1516890 & 954466 & 4.1346 & 4.1347 & TRN & & \\
\hline CHEMBL209148 & 954466 & 5.1451 & 5.1452 & TRN & & \\
\hline CHEMBL1242367 & 954466 & 4.1126 & 4.1126 & TRN & & \\
\hline CHEMBL577784 & 954466 & \multicolumn{3}{|c|}{5.1080000000000005} & 5.1081 & TRN \\
\hline CHEMBL393929 & 954466 & 3.6896 & 3.6895 & TRN & & \\
\hline CHEMBL1673039 & 954466 & 4.7106 & 4.7106 & TRN & & \\
\hline CHEMBL1909414 & 954466 & 3.9115 & 3.9114 & TRN & & \\
\hline CHEMBL 2005886 & 954466 & 5.3364 & 5.3363 & TRN & & \\
\hline CHEMBL102714 & 954466 & 4.9308 & 4.9308 & TRN & & \\
\hline CHEMBL1788116 & 954466 & 5.2135 & 5.2136 & TRN & & \\
\hline CHEMBL259181 & 954466 & 3.3633 & 3.3633 & TRN & & \\
\hline CHEMBL379975 & 954466 & 4.4137 & 4.4137 & TRN & & \\
\hline CHEMBL449158 & 954466 & 6.9794 & 6.522 & TST & & \\
\hline CHEMBL192566 & 954466 & 7.6682 & 7.3904 & TST & & \\
\hline CHEMBL585951 & 954466 & 5.9587 & 5.9586 & TRN & & \\
\hline CHEMBL1590308 & 954466 & \multicolumn{3}{|c|}{2.8360000000000003} & 3.4714 & TST \\
\hline CHEMBL1256459 & 954466 & 7.4624 & 7.4623 & TRN & & \\
\hline CHEMBL 3186408 & 954466 & 3.4534 & 3.5821 & TST & & \\
\hline CHEMBL509032 & 954466 & 6.0797 & 6.0797 & TRN & & \\
\hline CHEMBL2144069 & 954466 & 3.9187 & 3.9188 & TRN & & \\
\hline CHEMBL512504 & 954466 & 3.9689 & 3.9689 & TRN & & \\
\hline CHEMBL220241 & 954466 & 4.8222 & 4.8223 & TRN & & \\
\hline CHEMBL1643959 & 954466 & 3.2065 & 3.2064 & TRN & & \\
\hline CHEMBL65 & 954466 & 7.7029 & 7.7028 & TRN & & \\
\hline CHEMBL392695 & 954466 & 5.4684 & 5.4684 & TRN & & \\
\hline CHEMBL188678 & 954466 & 4.2166 & 4.2166 & TRN & & \\
\hline CHEMBL 373751 & 954466 & 3.3412 & 3.341 & TRN & & \\
\hline CHEMBL135561 & 954466 & 5.0284 & 4.5319 & TST & & \\
\hline CHEMBL 217354 & 954466 & 6.2971 & 5.9527 & TST & & \\
\hline CHEMBL222102 & 954466 & 3.1155 & 3.5769 & TST & & \\
\hline CHEMBL92309 & 954466 & 3.3314 & 2.6616 & TST & & \\
\hline CHEMBL 240954 & 954466 & 3.6217 & 3.3699 & TST & & \\
\hline CHEMBL399530 & 954466 & 4.3352 & 3.812 & TST & & \\
\hline CHEMBL 202721 & 954466 & 4.7958 & 4.7942 & TST & & \\
\hline CHEMBL1230020 & 954466 & 4.8994 & 3.8245 & TST & & \\
\hline CHEMBL 2137530 & 954466 & 5.0519 & 4.667 & TST & & \\
\hline CHEMBL483849 & 954466 & 1.9694 & 1.8503 & TST & & \\
\hline CHEMBL1186585 & 954466 & 3.3005 & 3.9666 & TST & & \\
\hline CHEMBL1743805 & 193333 & 8.5376 & 7.30399 & 9999999999 & & TST \\
\hline CHEMBL1743812 & 193333 & 7.0259 & 7.5903 & TRN & & \\
\hline
\end{tabular}




\begin{tabular}{|c|c|c|c|c|c|c|}
\hline & & \multicolumn{5}{|c|}{ Supplemental Table S2.txt } \\
\hline CHEMBL 285902 & 193333 & 6.6383 & 6.9343 & TRN & & \\
\hline CHEMBL1743804 & 193333 & 6.0 & 6.6141 & TRN & & \\
\hline CHEMBL286455 & 193333 & 7.4389 & 7.0972 & TST & & \\
\hline CHEMBL1743819 & 193333 & 6.0 & 6.2037 & TRN & & \\
\hline CHEMBL32720 & 193333 & 8.0555 & 6.7511 & TRN & & \\
\hline CHEMBL1743791 & 193333 & 7.5768 & 7.7975 & TRN & & \\
\hline CHEMBL1743786 & 193333 & 8.6021 & 7.7466 & TRN & & \\
\hline CHEMBL35166 & 193333 & 7.9508 & 7.6699 & TRN & & \\
\hline CHEMBL1743765 & 193333 & 7.3595 & 6.96899 & 9999999999 & & TRN \\
\hline CHEMBL35184 & 193333 & 6.0 & 6.2387 & TRN & & \\
\hline CHEMBL1743823 & 193333 & 7.4001 & 7.4283 & TRN & & \\
\hline CHEMBL1743773 & 193333 & 6.0 & 6.1959 & TRN & & \\
\hline CHEMBL1743799 & 193333 & 7.3615 & 6.976 & TRN & & \\
\hline CHEMBL32726 & 193333 & 6.0 & 6.7392 & TRN & & \\
\hline CHEMBL34990 & 193333 & 6.0 & 6.2641 & TRN & & \\
\hline CHEMBL33364 & 193333 & 6.8928 & 7.5568 & TRN & & \\
\hline CHEMBL35013 & 193333 & 6.0 & 6.6696 & TRN & & \\
\hline CHEMBL1743807 & 193333 & 8.0088 & 7.1127 & TRN & & \\
\hline CHEMBL431898 & 193333 & 6.9318 & 7.42899 & 9999999999 & & TRN \\
\hline CHEMBL 286312 & 193333 & 8.585 & 8.0598 & TRN & & \\
\hline CHEMBL35492 & 193333 & 6.0 & 6.1857 & TRN & & \\
\hline CHEMBL1743798 & 193333 & 8.1135 & 8.0752 & TRN & & \\
\hline CHEMBL1743820 & 193333 & 7.1433 & 7.3519 & TRN & & \\
\hline CHEMBL1743795 & 193333 & 6.0 & 6.254 & TRN & & \\
\hline CHEMBL1743803 & 193333 & 6.0 & 6.3533 & TRN & & \\
\hline CHEMBL1743790 & 193333 & 8.6021 & 6.6626 & TRN & & \\
\hline CHEMBL1743785 & 193333 & 8.2924 & 7.2078 & TRN & & \\
\hline CHEMBL1743822 & 193333 & 6.0 & 6.3847 & TST & & \\
\hline CHEMBL431299 & 193333 & 7.8013 & 6.2042 & TRN & & \\
\hline CHEMBL 284981 & 193333 & 6.556 & 7.7564 & TRN & & \\
\hline CHEMBL 284367 & 193333 & 6.0 & 6.093 & TRN & & \\
\hline CHEMBL1743767 & 193333 & 8.28399 & 99999999 & 99 & 7.6281 & TRN \\
\hline CHEMBL 32797 & 193333 & 8.1192 & 7.2603 & TST & & \\
\hline CHEMBL34891 & 193333 & 6.9547 & 7.2979 & TRN & & \\
\hline CHEMBL 289900 & 193333 & 6.7747 & 7.1267 & TRN & & \\
\hline CHEMBL1743778 & 193333 & 6.4437 & 6.9897 & TRN & & \\
\hline CHEMBL 32181 & 193333 & 6.4498 & 7.0211 & TRN & & \\
\hline CHEMBL32497 & 193333 & 5.0 & 6.7235 & TRN & & \\
\hline CHEMBL36030 & 193333 & 7.9101 & 6.9648 & TRN & & \\
\hline CHEMBL33769 & 193333 & 7.5969 & 7.0095 & TRN & & \\
\hline CHEMBL416959 & 193333 & 7.3979 & 6.8599 & TST & & \\
\hline CHEMBL416777 & 193333 & 6.7282 & 7.4653 & TRN & & \\
\hline CHEMBL 284513 & 193333 & 5.0 & 6.9472 & TST & & \\
\hline CHEMBL1743814 & 193333 & 6.21899 & 99999999 & 99 & 6.8534 & TST \\
\hline CHEMBL287859 & 193333 & 8.0757 & 7.7979 & TRN & & \\
\hline CHEMBL1743824 & 193333 & 8.1308 & 7.4887 & TST & & \\
\hline CHEMBL 35441 & 193333 & 7.0809 & 7.5284 & TST & & \\
\hline CHEMBL1743793 & 193333 & 6.0 & 6.1981 & TST & & \\
\hline
\end{tabular}




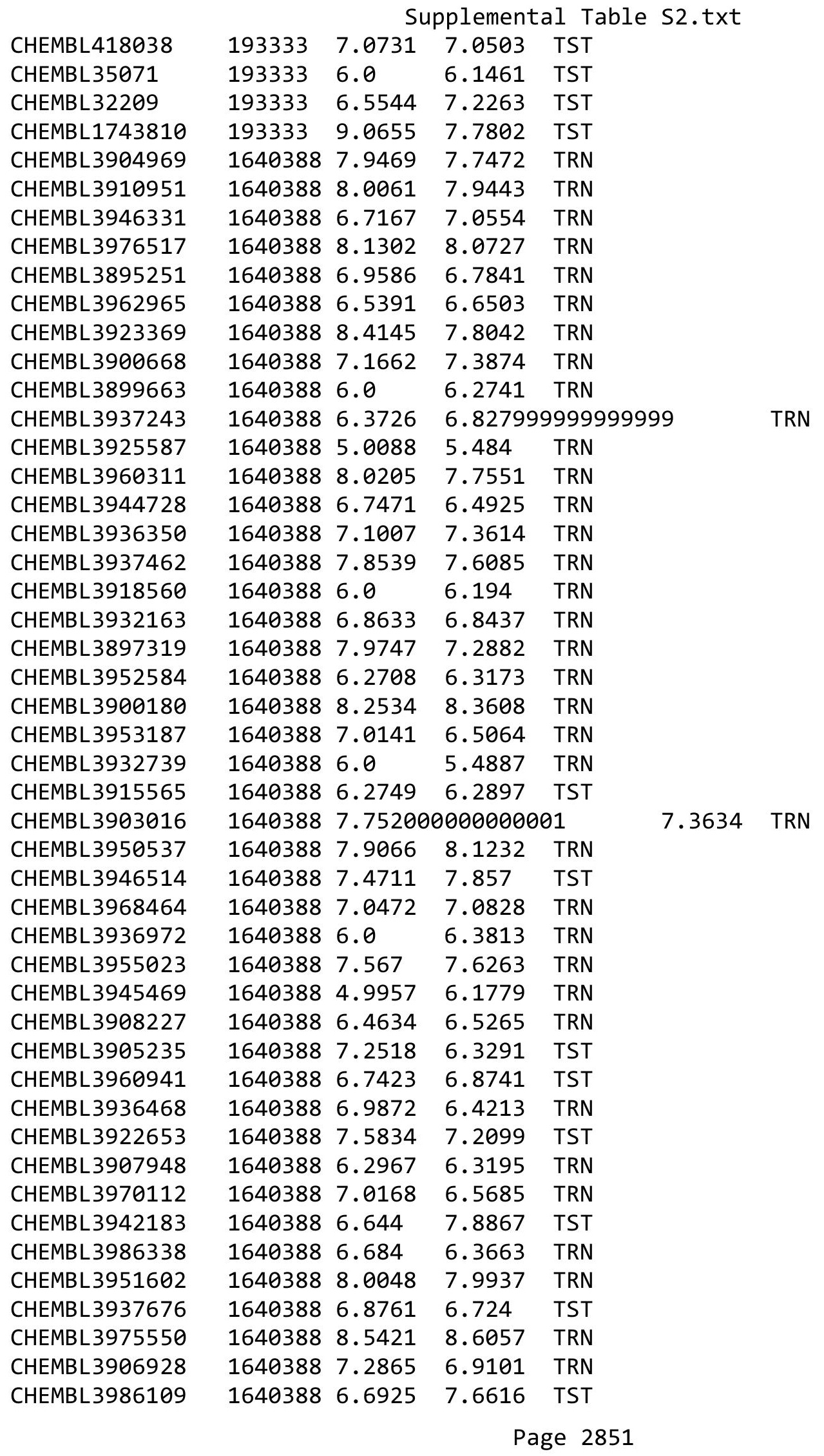


Supplemental Table S2.txt

\begin{tabular}{|c|c|c|c|c|c|}
\hline CHEMBL3921687 & 1640388 & 8.1851 & 8.15 & TRN & \\
\hline CHEMBL3923149 & 1640388 & 6.567 & 6.5206 & TRN & \\
\hline CHEMBL3947103 & 1640388 & 7.3655 & 8.1562 & TRN & \\
\hline CHEMBL3917194 & 1640388 & 7.6326 & 7.192 & TST & \\
\hline CHEMBL3924950 & 1640388 & 6.3215 & 6.4938 & TRN & \\
\hline CHEMBL3911295 & 1640388 & 6.0438 & 5.8156 & TRN & \\
\hline CHEMBL3901293 & 1640388 & 6.3893 & 6.338999 & 9999999995 & TRN \\
\hline CHEMBL3978653 & 1640388 & 8.2104 & 7.9585 & TRN & \\
\hline CHEMBL3942634 & 1640388 & 7.8761 & 7.6758 & TRN & \\
\hline CHEMBL3937136 & 1640388 & 8.1051 & 7.8497 & TRN & \\
\hline CHEMBL3923983 & 1640388 & 7.8327 & 8.0918 & TRN & \\
\hline CHEMBL3975709 & 1640388 & 7.6696 & 7.3107 & TRN & \\
\hline CHEMBL3962940 & 1640388 & 7.4815 & 8.1231 & TST & \\
\hline CHEMBL3952175 & 1640388 & 8.015 & 7.8691 & TRN & \\
\hline CHEMBL3923216 & 1640388 & 6.7545 & 6.4075 & TRN & \\
\hline CHEMBL3930459 & 1640388 & 8.2457 & 8.051 & TRN & \\
\hline CHEMBL3938133 & 1640388 & 5.4776 & 5.8082 & TRN & \\
\hline CHEMBL3909520 & 1640388 & 7.0097 & 7.2279 & TRN & \\
\hline CHEMBL3964869 & 1640388 & 7.9706 & 7.6307 & TRN & \\
\hline CHEMBL3932402 & 1640388 & 7.7399 & 7.9645 & TRN & \\
\hline CHEMBL3946777 & 1640388 & 6.7033 & 6.1922 & TRN & \\
\hline CHEMBL3906285 & 1640388 & 7.8761 & 7.3603 & TRN & \\
\hline CHEMBL3931715 & 1640388 & 6.5157 & 6.6821 & TRN & \\
\hline CHEMBL3937159 & 1640388 & 6.0061 & 6.188 & TRN & \\
\hline CHEMBL3952238 & 1640388 & 7.2865 & 7.5669 & TRN & \\
\hline CHEMBL3906413 & 1640388 & 7.6946 & 7.3339 & TRN & \\
\hline CHEMBL3935213 & 1640388 & 6.4473 & 7.1687 & TST & \\
\hline CHEMBL3917095 & 1640388 & 6.02 & 6.1352 & TRN & \\
\hline CHEMBL3954056 & 1640388 & 6.752006 & 000000000 & 7.4503 & TST \\
\hline CHEMBL3961141 & 1640388 & 7.2255 & \multicolumn{2}{|c|}{7.172000000000001} & TRN \\
\hline CHEMBL3971188 & 1640388 & 5.9136 & 5.7551 & TRN & \\
\hline CHEMBL 3954233 & 1640388 & 5.2916 & 5.8717 & TRN & \\
\hline CHEMBL3963367 & 1640388 & 6.0 & 5.9445 & TRN & \\
\hline CHEMBL3900474 & 1640388 & 5.1858 & 5.5652 & TST & \\
\hline CHEMBL3972864 & 1640388 & 5.9666 & 6.3006 & TRN & \\
\hline CHEMBL3900142 & 1640388 & 7.8601 & 8.3095 & TST & \\
\hline CHEMBL3982112 & 1640388 & 7.7077 & 7.9771 & TRN & \\
\hline CHEMBL3930913 & 1640388 & 8.0159 & 7.4911 & TRN & \\
\hline CHEMBL3975748 & 1640388 & 5.0386 & 6.0027 & TST & \\
\hline CHEMBL3978269 & 1640388 & 7.3675 & 7.7168 & TRN & \\
\hline CHEMBL3960497 & 1640388 & 6.0 & 6.0338 & TRN & \\
\hline CHEMBL3970073 & 1640388 & 6.7423 & 6.6434 & TST & \\
\hline CHEMBL3910214 & 1640388 & 6.7471 & 6.2872 & TST & \\
\hline CHEMBL3922568 & 1640388 & 7.4815 & 6.9629 & TRN & \\
\hline CHEMBL3907552 & 1640388 & 7.4001 & 7.8912 & TRN & \\
\hline CHEMBL3942429 & 1640388 & 6.9281 & 6.7337 & TST & \\
\hline CHEMBL3909734 & 1640388 & 6.7447 & 6.9328 & TRN & \\
\hline CHEMBL3915478 & 1640388 & 6.5467 & 6.407 & TRN & \\
\hline
\end{tabular}


Supplemental Table S2.txt

\begin{tabular}{|c|c|c|c|c|}
\hline HEN & 540388 & 7.2076 & & \\
\hline & & 6.0 & 5.9266 & \\
\hline 19 & 388 & & & \\
\hline HEMBL395 & 388 & 7595 & & \\
\hline AEMBL3970654 & 540388 & 6.8327 & & \\
\hline HEMBL3899253 & 640388 & 7.9469 & 0635 & \\
\hline HEMBL3890027 & 388 & 7.4425 & 47 & \\
\hline$|F M B| 389$ & & 7.5072 & & RN \\
\hline AEMBL3983102 & 388 & 6.0 & 0727 & \\
\hline HEMBL3980190 & 640388 & 8.2757 & .2408 & \\
\hline HEMBL3946332 & 388 & 7.4145 & 1917 & \\
\hline IEMBL38 & 88 & 462 & 321 & \\
\hline AEMBL3S & & & & \\
\hline HEMBL3968081 & 88 & 5.77 & 2407 & \\
\hline AEMBL397 & 88 & 8.0711 & 156 & \\
\hline AEMBL3978432 & 64 & 7.0325 & 5734 & \\
\hline HEMBL39 & 50 & 7.8601 & 312 & \\
\hline HEMBL39 & & 6 . & 361 & \\
\hline HEMBL392 & & 7.94 & 4579 & \\
\hline AEMBL39 & & 5 . & 37 & \\
\hline HEIMBLSS & 62 & 86 & 11 & 1 \\
\hline AEMBL & 38 & 56 & & RN \\
\hline AEMBL3S & & 747 & & \\
\hline HFMRI 391 & & 6.0 & & \\
\hline JEMBL 39 & 38 & 6 & & I RIV \\
\hline HEMBL3S & 62 & 7. & & RN \\
\hline HEMBL3 & 8 & & & RN \\
\hline HFMBI 36 & & 25 & 84 & \\
\hline AEMBL39 & & 6.7305 & & (5) \\
\hline HEMBL3941029 & 64 & 7.06 & & IK \\
\hline HEMBL 394 & 62 & 6 & 92 & RN \\
\hline HEMBL & & & 18 & ST \\
\hline HEMBL & & 78 & 37 & 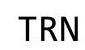 \\
\hline HEMBL392 & - & 6. & 531 & $\mathrm{IR}$ \\
\hline HEMBL3954038 & 64 & 7. & 5466 & TRN \\
\hline HEMBL 389 & $6 \Delta+2-1$ & 39 & 351 & TRN \\
\hline HFMRI 3 & & & 81 & $\Gamma \mathrm{RN}$ \\
\hline HEMBL3 & & 5 . & & ST \\
\hline HEMBL3912700 & ( & 8.2733 & 436 & TRN \\
\hline IEMBL 393 & 64 & 78 & & TST \\
\hline HEMBL 394 & 64 & 878 & 278 & ГST \\
\hline CHEMBL390 & & 5.6253 & & TRN \\
\hline HEMBL3922178 & 16 & 6.7282 & 0427 & TST \\
\hline HEMBL 3974748 & 88 & 7.4989 & & TST \\
\hline MBL3 & & & & RN \\
\hline HEMBL 391 & & .4067 & & \\
\hline CHEMBL 3899204 & 640 & 7.6536 & .1628 & \\
\hline CHEMBL3957304 & 164038 & 7.289 & 7.3889 & ГST \\
\hline
\end{tabular}

Page 2853 
Supplemental Table S2.txt

\begin{tabular}{|c|c|c|c|c|c|}
\hline CHEMBL3914428 & 1640388 & 7.6576 & 7.1951 & TST & \\
\hline CHEMBL3979609 & 1640388 & 6.0 & 6.153 & TRN & \\
\hline CHEMBL3941594 & 1640388 & 5.3098 & 5.3688 & TRN & \\
\hline CHEMBL3951076 & 1640388 & 5.5114 & 5.5947 & TST & \\
\hline CHEMBL3928158 & 1640388 & 8.1993 & 7.9625 & TRN & \\
\hline CHEMBL3953583 & 1640388 & 6.9666 & 6.5249 & TRN & \\
\hline CHEMBL3962768 & 1640388 & 7.1739 & 7.5657 & TRN & \\
\hline CHEMBL3951383 & 1640388 & 6.0 & 5.7689 & TRN & \\
\hline CHEMBL3903004 & 1640388 & 6.5719 & 6.3287 & TRN & \\
\hline CHEMBL3947947 & 1640388 & 6.1107 & 6.1133 & TRN & \\
\hline CHEMBL3891860 & 1640388 & 6.0 & 6.66100 & 00000000005 & TRN \\
\hline CHEMBL3898168 & 1640388 & 7.8928 & 7.6822 & TRN & \\
\hline CHEMBL3978851 & 1640388 & 5.4776 & 6.0934 & TRN & \\
\hline CHEMBL 3980280 & 1640388 & 7.8665 & 6.9808 & TST & \\
\hline CHEMBL3972243 & 1640388 & 5.7305 & 6.2849 & TST & \\
\hline CHEMBL3981123 & 1640388 & 7.4123 & 7.4902 & TRN & \\
\hline CHEMBL3946526 & 1640388 & 6.466 & 6.7559 & TRN & \\
\hline CHEMBL3969718 & 1640388 & 8.5346 & 7.8204 & TRN & \\
\hline CHEMBL3976583 & 1640388 & 6.0 & 6.494 & TRN & \\
\hline CHEMBL3980157 & 1640388 & 7.5243 & 6.8618 & TST & \\
\hline CHEMBL3904699 & 1640388 & 5.5114 & 5.7803 & TRN & \\
\hline CHEMBL3909933 & 1640388 & 5.8928 & 7.9026 & TST & \\
\hline CHEMBL 3957243 & 1640388 & 6.9914 & 6.7619 & TRN & \\
\hline CHEMBL3917332 & 1640388 & 5.1864 & 5.727 & TRN & \\
\hline CHEMBL3949168 & 1640388 & 6.0 & 6.1403 & TRN & \\
\hline CHEMBL3932792 & 1640388 & 5.6676 & 6.0342 & TRN & \\
\hline CHEMBL3930985 & 1640388 & 5.585 & 6.1494 & TRN & \\
\hline CHEMBL3900948 & 1640388 & 6.0 & 5.8247 & TRN & \\
\hline CHEMBL3926595 & 1640388 & 7.6904 & \multicolumn{2}{|c|}{7.3420000000000005} & TRN \\
\hline CHEMBL3932027 & 1640388 & 7.3768 & 7.2527 & TRN & \\
\hline CHEMBL 3914864 & 1640388 & 8.1798 & 8.0657 & TRN & \\
\hline CHEMBL3959171 & 1640388 & 7.2262 & 7.2343 & TRN & \\
\hline CHEMBL3918457 & 1640388 & 6.9066 & 7.1117 & TST & \\
\hline CHEMBL 3936513 & 1640388 & 5.3625 & 5.4946 & TRN & \\
\hline CHEMBL3957446 & 1640388 & 8.5072 & 8.2515 & TRN & \\
\hline CHEMBL3922708 & 1640388 & 6.0 & 6.1679 & TRN & \\
\hline CHEMBL3986848 & 1640388 & 7.5376 & 7.191 & TRN & \\
\hline CHEMBL3920229 & 1640388 & 5.0088 & 5.6974 & TRN & \\
\hline CHEMBL 3937022 & 1640388 & \multicolumn{3}{|c|}{5.7620000000000005} & TST \\
\hline CHEMBL3916577 & 1640388 & 7.0 & 6.7032 & TRN & \\
\hline CHEMBL3955622 & 1640388 & 7.3788 & 7.3748 & TRN & \\
\hline CHEMBL3958626 & 1640388 & 7.0841 & 7.7252 & TRN & \\
\hline CHEMBL3925533 & 1640388 & 6.8601 & 8.2606 & TST & \\
\hline CHEMBL3925394 & 1640388 & 6.7932 & 6.0566 & TRN & \\
\hline CHEMBL3980891 & 1640388 & 7.5834 & 7.1271 & TRN & \\
\hline CHEMBL3919312 & 1640388 & 7.6198 & 8.1693 & TRN & \\
\hline CHEMBL3970425 & 1640388 & 7.6126 & 7.9651 & TRN & \\
\hline CHEMBL3924217 & 1640388 & 5.8041 & 5.9111 & TST & \\
\hline
\end{tabular}


Supplemental Table S2.txt

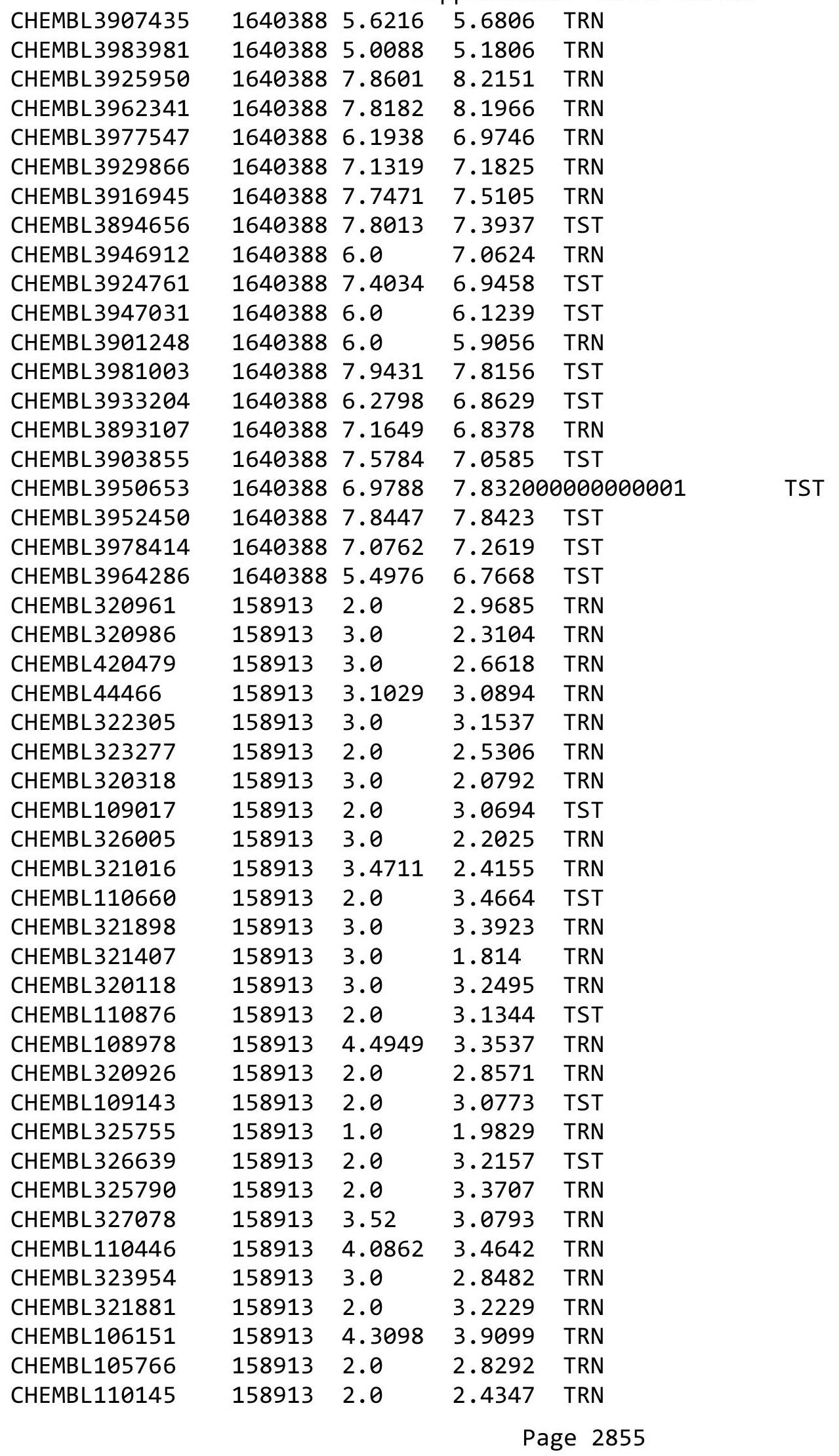




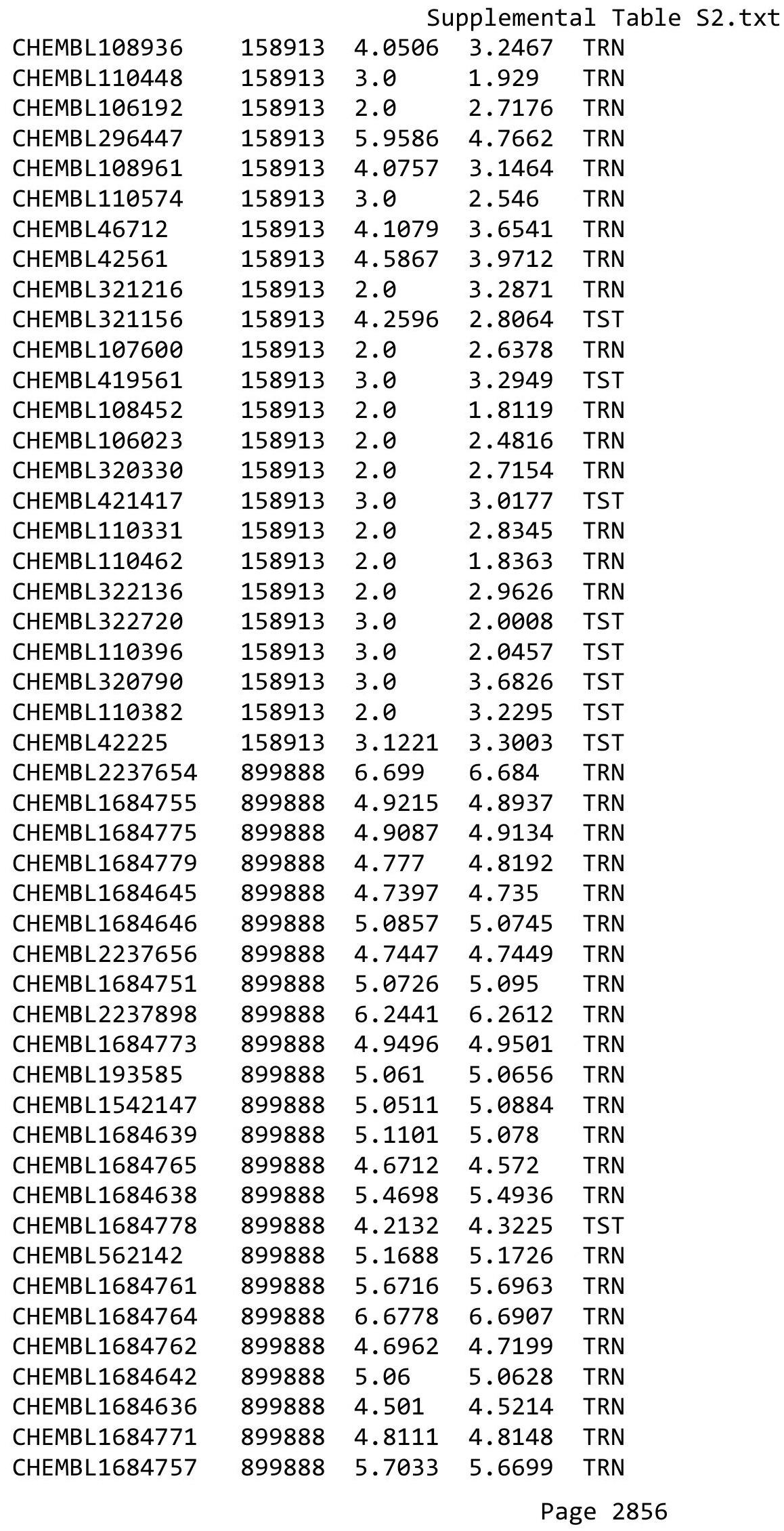


Supplemental Table S2.txt

\begin{tabular}{|c|c|c|c|c|c|}
\hline CHEMBL 2237893 & 899888 & 5.1308 & 5.6005 & TST & \\
\hline CHEMBL1684759 & 899888 & 5.9626 & 5.9111 & TRN & \\
\hline CHEMBL1209915 & 899888 & 4.7501 & 4.7888 & TRN & \\
\hline CHEMBL1684641 & 899888 & 4.9594 & 4.9795 & TRN & \\
\hline CHEMBL1449501 & 899888 & 4.3754 & 4.4014 & TRN & \\
\hline CHEMBL 2237905 & 899888 & 5.9136 & 5.9339 & TRN & \\
\hline CHEMBL 2237892 & 899888 & 4.6761 & 4.8326 & TST & \\
\hline CHEMBL1684767 & 899888 & 4.6994 & 4.7119 & TRN & \\
\hline CHEMBL1684774 & 899888 & 5.0155 & 5.0335 & TRN & \\
\hline CHEMBL1684766 & 899888 & 4.7217 & 4.6881 & TST & \\
\hline CHEMBL1684770 & 899888 & 4.4086 & 4.366006 & 30000000005 & $\mathrm{TR}$ \\
\hline CHEMBL 2237895 & 899888 & 5.7055 & 5.9787 & TST & \\
\hline CHEMBL1684777 & 899888 & 4.8884 & 4.8457 & TRN & \\
\hline CHEMBL 2237896 & 899888 & 5.5214 & 5.8893 & TST & \\
\hline CHEMBL1684776 & 899888 & 5.0467 & 5.084 & TRN & \\
\hline CHEMBL1684756 & 899888 & 5.45100 & 00000006 & 5.3955 & TST \\
\hline CHEMBL2237902 & 899888 & 5.6904 & 6.0713 & TST & \\
\hline CHEMBL1684635 & 899888 & 5.1035 & 5.0696 & TRN & \\
\hline CHEMBL1209917 & 899888 & 4.5248 & 4.5997 & TRN & \\
\hline CHEMBL 2237655 & 899888 & 4.7196 & 5.3994 & TST & \\
\hline CHEMBL1224508 & 899888 & 5.4622 & 5.4203 & TRN & \\
\hline CHEMBL 2237899 & 899888 & 6.2147 & 6.3251 & TST & \\
\hline CHEMBL1684768 & 899888 & 4.7815 & 4.7601 & TRN & \\
\hline CHEMBL 2237894 & 899888 & 5.5258 & 5.8362 & TST & \\
\hline CHEMBL 2237904 & 899888 & 4.6383 & 5.27 & TST & \\
\hline CHEMBL1684637 & 899888 & 5.1215 & 5.1737 & TRN & \\
\hline CHEMBL 2237897 & 899888 & 4.7476 & 5.2369 & TST & \\
\hline CHEMBL1684772 & 899888 & 4.7781 & 4.8233 & TRN & \\
\hline CHEMBL 2237901 & 899888 & 5.7033 & 5.9862 & TST & \\
\hline CHEMBL 2237903 & 899888 & 4.9634 & 5.2924 & TST & \\
\hline CHEMBL1684643 & 899888 & 5.1062 & 5.1179 & TRN & \\
\hline CHEMBL1684640 & 899888 & 4.4116 & 4.3688 & TRN & \\
\hline CHEMBL1684644 & 899888 & 5.1688 & 5.132999 & & \\
\hline CHEMBL1684758 & 899888 & 5.6968 & 5.7436 & TRN & \\
\hline CHEMBL1353302 & 899888 & 4.6735 & 4.6408 & TRN & \\
\hline CHEMBL1684763 & 899888 & 5.6799 & 5.6045 & TRN & \\
\hline CHEMBL1684754 & 899888 & 5.3072 & 5.3539 & TRN & \\
\hline CHEMBL1684753 & 899888 & 5.5045 & 5.4841 & TRN & \\
\hline CHEMBL1209130 & 899888 & 5.1152 & 5.0226 & TRN & \\
\hline CHEMBL2237900 & 899888 & 5.7799 & 5.8797 & TST & \\
\hline CHEMBL2237653 & 899888 & 5.3439 & 5.7384 & TST & \\
\hline CHEMBL1684769 & 899888 & 4.6708 & 4.7326 & TRN & \\
\hline CHEMBL 3975961 & 1641276 & 7.0655 & 6.8336 & TRN & \\
\hline CHEMBL 3907690 & 1641276 & 5.624 & 5.6341 & TRN & \\
\hline CHEMBL 3975964 & 1641276 & 6.3134 & 6.4316 & TRN & \\
\hline CHEMBL 3933843 & 1641276 & 6.0752 & 5.9627 & TRN & \\
\hline CHEMBL3961324 & 1641276 & 5.9382 & 6.2084 & TRN & \\
\hline CHEMBL3986625 & 1641276 & 6.3188 & 6.2751 & TRN & \\
\hline
\end{tabular}


Supplemental Table S2.txt

\begin{tabular}{|c|c|c|c|c|c|}
\hline CHEMBL3948651 & 1641276 & \multicolumn{3}{|c|}{5.6339999999999995} & 999999999 \\
\hline CHEMBL 3937638 & 1641276 & 7.0655 & 7.0461 & TRN & \\
\hline CHEMBL3956300 & 1641276 & 5.9469 & 5.9476 & TRN & \\
\hline CHEMBL 3946098 & 1641276 & 6.8827 & 6.8433 & TRN & \\
\hline CHEMBL3907301 & 1641276 & 6.1302 & 5.9929 & TRN & \\
\hline CHEMBL3962891 & 1641276 & 6.3979 & 6.664 & TRN & \\
\hline CHEMBL3957512 & 1641276 & 7.4437 & 7.2671 & TRN & \\
\hline CHEMBL 3891630 & 1641276 & 7.3279 & 7.2928 & TRN & \\
\hline CHEMBL3980389 & 1641276 & 7.284 & 7.5688 & TRN & \\
\hline CHEMBL3904894 & 1641276 & 6.2182 & 6.4056 & TRN & \\
\hline CHEMBL3893715 & 1641276 & 6.6326 & 6.8247 & TRN & \\
\hline CHEMBL3973794 & 1641276 & 7.1427 & 7.2389 & TRN & \\
\hline CHEMBL3926116 & 1641276 & 7.4089 & 7.522 & TRN & \\
\hline CHEMBL 3912702 & 1641276 & 5.0366 & 4.9565 & TRN & \\
\hline CHEMBL3932247 & 1641276 & 6.5467 & 5.9136 & TST & \\
\hline CHEMBL3961745 & 1641276 & 7.4437 & 7.3165 & TRN & \\
\hline CHEMBL3967028 & 1641276 & 7.2366 & 7.1321 & TRN & \\
\hline CHEMBL3974672 & 1641276 & 6.699 & 6.7117 & TRN & \\
\hline CHEMBL3963124 & 1641276 & 6.1568 & 5.8473 & TRN & \\
\hline CHEMBL3936491 & 1641276 & 6.2218 & 6.17299 & 7999999999 & TRN \\
\hline CHEMBL3909801 & 1641276 & 7.0969 & 6.865 & TRN & \\
\hline CHEMBL3977782 & 1641276 & 5.7027 & 5.6021 & TRN & \\
\hline CHEMBL3918012 & 1641276 & 7.1079 & 7.0633 & TRN & \\
\hline CHEMBL3919200 & 1641276 & 6.0675 & 6.0276 & TST & \\
\hline CHEMBL3951953 & 1641276 & 7.1805 & 7.1783 & TRN & \\
\hline CHEMBL3987006 & 1641276 & 7.5686 & 7.4293 & TRN & \\
\hline CHEMBL3908408 & 1641276 & 7.4949 & 7.71399 & 99999999995 & TRN \\
\hline CHEMBL3933352 & 1641276 & 6.7399 & 6.8043 & TRN & \\
\hline CHEMBL3916454 & 1641276 & 6.0 & 5.8805 & TST & \\
\hline CHEMBL3958365 & 1641276 & 6.0969 & 5.8255 & TRN & \\
\hline CHEMBL 3970532 & 1641276 & 6.5229 & 6.5788 & TRN & \\
\hline CHEMBL3940561 & 1641276 & 7.0269 & 7.0721 & TRN & \\
\hline CHEMBL3896406 & 1641276 & 6.5544 & 6.7037 & TRN & \\
\hline CHEMBL3981678 & 1641276 & 7.0706 & 7.263 & TRN & \\
\hline CHEMBL3932658 & 1641276 & 6.1586 & 6.6884 & TST & \\
\hline CHEMBL3933316 & 1641276 & 6.7212 & 6.4485 & TST & \\
\hline CHEMBL3945670 & 1641276 & 5.0305 & 5.1645 & TRN & \\
\hline CHEMBL3982663 & 1641276 & 6.3979 & 6.6729 & TRN & \\
\hline CHEMBL3967206 & 1641276 & 5.8526 & 5.8719 & TRN & \\
\hline CHEMBL3918737 & 1641276 & 7.4559 & 7.6004 & TRN & \\
\hline CHEMBL3935380 & 1641276 & 7.699 & 7.5239 & TRN & \\
\hline CHEMBL3910907 & 1641276 & 6.6216 & 6.5078 & TRN & \\
\hline CHEMBL3968223 & 1641276 & 7.2518 & 7.1679 & TRN & \\
\hline CHEMBL3977389 & 1641276 & 6.2328 & 6.2341 & TRN & \\
\hline CHEMBL3949676 & 1641276 & 6.699 & 6.6157 & TRN & \\
\hline CHEMBL3891665 & 1641276 & 7.3872 & 7.2832 & TRN & \\
\hline CHEMBL3983993 & 1641276 & 6.5017 & 6.4172 & TRN & \\
\hline CHEMBL3962351 & 1641276 & 6.341 & 6.1807 & TRN & \\
\hline
\end{tabular}


Supplemental Table S2.txt

\begin{tabular}{|c|c|c|c|c|}
\hline CHEMBL3903466 & 1641276 & 6.1451 & 6.3986 & TRN \\
\hline CHEMBL3907191 & 1641276 & 5.2379 & 5.5773 & TRN \\
\hline CHEMBL3913133 & 1641276 & 6.5952 & 6.6279 & TRN \\
\hline CHEMBL3925137 & 1641276 & 5.1578 & 5.1262 & TRN \\
\hline CHEMBL 3904771 & 1641276 & 6.0 & 6.0936 & TRN \\
\hline CHEMBL3975640 & 1641276 & 7.3872 & 7.351 & TRN \\
\hline CHEMBL3923213 & 1641276 & 6.5031 & 6.3039 & TRN \\
\hline CHEMBL3907742 & 1641276 & 6.0721 & 5.9611 & TRN \\
\hline CHEMBL3938848 & 1641276 & 6.4584 & 6.5219 & TRN \\
\hline CHEMBL3953107 & 1641276 & 5.8539 & 5.2782 & TST \\
\hline CHEMBL3909885 & 1641276 & 5.9586 & 5.5939 & TST \\
\hline CHEMBL3987199 & 1641276 & 7.3188 & 7.4421 & TRN \\
\hline CHEMBL3980806 & 1641276 & 7.3372 & 7.4389 & TRN \\
\hline CHEMBL3903543 & 1641276 & 7.4318 & 7.3745 & TRN \\
\hline CHEMBL 3960543 & 1641276 & 6.6576 & 6.6871 & TRN \\
\hline CHEMBL3979241 & 1641276 & 4.6692 & 4.5712 & TRN \\
\hline CHEMBL3907792 & 1641276 & 5.1276 & 5.1474 & TST \\
\hline CHEMBL 3947603 & 1641276 & 6.1238 & 6.5491 & TST \\
\hline CHEMBL3984296 & 1641276 & 6.2526 & 6.3151 & TRN \\
\hline CHEMBL 3890451 & 1641276 & 6.8894 & 6.8676 & TRN \\
\hline CHEMBL3929959 & 1641276 & 7.2366 & 7.2962 & TRN \\
\hline CHEMBL3895328 & 1641276 & 5.0651 & 5.4296 & TRN \\
\hline CHEMBL3954596 & 1641276 & 6.9393 & 6.8052 & TRN \\
\hline CHEMBL3892773 & 1641276 & 6.7545 & 6.6542 & TRN \\
\hline CHEMBL 3974241 & 1641276 & 5.5229 & 5.3406 & TST \\
\hline CHEMBL 3964140 & 1641276 & 6.9393 & \multicolumn{2}{|c|}{7.297000000000001} \\
\hline CHEMBL3897806 & 1641276 & 6.1851 & 6.5788 & TRN \\
\hline CHEMBL3928805 & 1641276 & 6.9172 & 7.0182 & TRN \\
\hline CHEMBL3947446 & 1641276 & 6.4802 & 6.475 & TRN \\
\hline CHEMBL3911708 & 1641276 & 7.1427 & 7.2117 & TRN \\
\hline CHEMBL3944388 & 1641276 & 5.7959 & 5.6455 & TRN \\
\hline CHEMBL3900619 & 1641276 & 6.7328 & 6.3886 & TST \\
\hline CHEMBL 3938743 & 1641276 & 7.3468 & 7.1859 & TRN \\
\hline CHEMBL3905310 & 1641276 & 7.0362 & 6.984 & TRN \\
\hline CHEMBL3898697 & 1641276 & 6.3726 & 6.3302 & TRN \\
\hline CHEMBL3930488 & 1641276 & 7.585 & 7.2181 & TRN \\
\hline CHEMBL3925220 & 1641276 & 7.0 & 6.7476 & TRN \\
\hline CHEMBL3981124 & 1641276 & 4.7959 & 5.1093 & TRN \\
\hline CHEMBL3910879 & 1641276 & 7.5086 & 7.0402 & TRN \\
\hline CHEMBL3984113 & 1641276 & 5.195 & 5.0539 & TST \\
\hline CHEMBL3939677 & 1641276 & 5.3515 & 5.1435 & TRN \\
\hline CHEMBL3912782 & 1641276 & 6.5229 & 6.5452 & TRN \\
\hline CHEMBL 3898287 & 1641276 & 4.699 & 6.81 & TST \\
\hline CHEMBL3934285 & 1641276 & 7.3098 & 7.2499 & TRN \\
\hline CHEMBL3973971 & 1641276 & 7.2676 & 7.1074 & TRN \\
\hline CHEMBL3925407 & 1641276 & 6.3979 & 6.3959 & TRN \\
\hline CHEMBL3931835 & 1641276 & 6.8297 & 6.702006 & 0000000001 \\
\hline CHEMBL3942719 & 1641276 & 7.0362 & 7.1714 & TRN \\
\hline
\end{tabular}


Supplemental Table S2.txt

\begin{tabular}{|c|c|c|c|c|}
\hline CHEMBL3975513 & 1641276 & 6.8447 & 6.8322 & TRN \\
\hline CHEMBL3934399 & 1641276 & 6.8697 & 6.9328 & TRN \\
\hline CHEMBL3919822 & 1641276 & 7.4815 & 7.3198 & TRN \\
\hline CHEMBL3983889 & 1641276 & 6.8013 & 6.7114 & TRN \\
\hline CHEMBL3908924 & 1641276 & 5.7142 & 5.4845 & TRN \\
\hline CHEMBL3901737 & 1641276 & 6.0209 & 5.8963 & TRN \\
\hline CHEMBL3934304 & 1641276 & 6.301 & \multicolumn{2}{|c|}{6.071000000000001} \\
\hline CHEMBL3969656 & 1641276 & 6.9666 & 6.8938 & TRN \\
\hline CHEMBL3927558 & 1641276 & 6.9872 & 6.8307 & TRN \\
\hline CHEMBL3969378 & 1641276 & 5.319 & 5.4586 & TRN \\
\hline CHEMBL3956667 & 1641276 & 6.4868 & 6.2714 & TRN \\
\hline CHEMBL3955671 & 1641276 & 6.0458 & 6.2206 & TRN \\
\hline CHEMBL3895935 & 1641276 & 5.9245 & 5.8317 & TRN \\
\hline CHEMBL3961801 & 1641276 & 7.2441 & 7.3091 & TRN \\
\hline CHEMBL3961784 & 1641276 & 6.3143 & 6.6913 & TRN \\
\hline CHEMBL3923298 & 1641276 & 6.0565 & 7.0402 & TRN \\
\hline CHEMBL3907070 & 1641276 & 6.7375 & 6.812 & TRN \\
\hline CHEMBL3921382 & 1641276 & 6.9469 & 6.9052 & TRN \\
\hline CHEMBL99 & 1641276 & 8.0177 & 6.4083 & TST \\
\hline CHEMBL3900617 & 1641276 & 6.8416 & 6.7657 & TRN \\
\hline CHEMBL3907307 & 1641276 & 6.5229 & 6.6844 & TRN \\
\hline CHEMBL3986003 & 1641276 & 5.7989 & 5.8722 & TRN \\
\hline CHEMBL3940441 & 1641276 & 5.6968 & 5.818 & TST \\
\hline CHEMBL3938470 & 1641276 & 5.9059 & 5.7591 & TRN \\
\hline CHEMBL 3947637 & 1641276 & 6.6003 & 6.4643 & TST \\
\hline CHEMBL3897087 & 1641276 & 6.8761 & 6.9347 & TRN \\
\hline CHEMBL3942866 & 1641276 & 7.5528 & 7.4479 & TRN \\
\hline CHEMBL3920131 & 1641276 & 5.6383 & 5.756 & TRN \\
\hline CHEMBL3921050 & 1641276 & 7.0655 & 6.7889 & TRN \\
\hline CHEMBL 3897392 & 1641276 & 6.4134 & 6.4752 & TRN \\
\hline CHEMBL3908578 & 1641276 & 6.0926 & 5.8379 & TRN \\
\hline CHEMBL3924418 & 1641276 & 6.71 & 6.9044 & TRN \\
\hline CHEMBL3910629 & 1641276 & 7.4815 & 7.3877 & TRN \\
\hline CHEMBL3938982 & 1641276 & 6.4191 & 6.6524 & TRN \\
\hline CHEMBL3973671 & 1641276 & 7.4815 & 7.211 & TST \\
\hline CHEMBL3983762 & 1641276 & 6.0092 & 6.1994 & TST \\
\hline CHEMBL3953948 & 1641276 & 6.3372 & 6.82799 & 9999999999 \\
\hline CHEMBL3960647 & 1641276 & 6.8962 & 6.5802 & TST \\
\hline CHEMBL3945418 & 1641276 & 6.399 & 6.1967 & TRN \\
\hline CHEMBL3894753 & 1641276 & 5.7122 & 6.0683 & TST \\
\hline CHEMBL3943942 & 1641276 & 6.1925 & 6.1864 & TRN \\
\hline CHEMBL3953058 & 1641276 & 6.6421 & 6.5864 & TST \\
\hline CHEMBL3964972 & 1641276 & 4.699 & 6.2558 & TST \\
\hline CHEMBL3915015 & 1641276 & 7.0044 & 6.8086 & TRN \\
\hline CHEMBL3966661 & 1641276 & 6.02 & 6.1976 & TST \\
\hline CHEMBL3923336 & 1641276 & 6.8861 & 6.9247 & TRN \\
\hline CHEMBL3948150 & 1641276 & 6.5114 & 6.4524 & TRN \\
\hline CHEMBL3901649 & 1641276 & 5.7731 & 5.7564 & TRN \\
\hline
\end{tabular}


Supplemental Table S2.txt

\begin{tabular}{|c|c|c|c|c|}
\hline 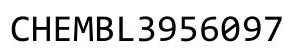 & 1276 & & & \\
\hline ב & 641276 & 6.3979 & & \\
\hline & 276 & 6 & & \\
\hline AEMBL & 1276 & 7.2218 & & \\
\hline AEMBL3910502 & 276 & 6.7423 & 3018 & \\
\hline HEMBL3940985 & 641276 & 6.0 & 1378 & \\
\hline 516 & & 965 & 439 & \\
\hline 3857 & & & 804 & \\
\hline AEMBL3969468 & & 6.1549 & 4642 & \\
\hline HEMBL3905120 & 276 & 6.5229 & 5454 & \\
\hline HEMBL3978733 & 76 & 7.699 & 4719 & \\
\hline IEMBL 3972430 & 76 & 241 & 441 & \\
\hline AEMBL39 & & 5.8854 & & \\
\hline HEMBL 39 & & 6.3546 & 1745 & \\
\hline AEMBL3930868 & 76 & 539 & 395 & \\
\hline AEMBL3985895 & 0 & 7328 & 491 & \\
\hline AEMBL39 & 6 & 47 & 771 & \\
\hline HEMBL39 & & 549 & & \\
\hline AEMBL39 & & 3505 & 663 & \\
\hline AEMBL3891628 & & 6.8327 & & ST \\
\hline HEMBL= & 0 & 3 & 463 & \\
\hline AEMBL3S & & 39 & 227 & \\
\hline AEMBL3S & & 26 & 396 & \\
\hline 252 & & 658 & 592 & \\
\hline JEMBL3920640 & & 12 & 302 & RN \\
\hline HEMBL3S & 6 & 352 & 912 & \\
\hline HEMBL3 & & 14 & 311 & \\
\hline HFMBI 3 & & 05 & 37 & \\
\hline AEMBL39 & & 6.5575 & 659 & \\
\hline HEMBL3899106 & 76 & 979 & 929 & RIN \\
\hline HEMBL 395 & 6 & & 136 & \\
\hline AFMBI 3 & & 2 & 63 & 年 \\
\hline 60 & & & 105 & ST \\
\hline HEMBL3937294 & & 7. & 035 & RN \\
\hline HEMBL3949667 & 6 & 7.2596 & 921 & ST \\
\hline JEMBL39 & & 447 & 93 & ST \\
\hline HCMDI & & 6 & & RN \\
\hline HEMBL3917862 & & 5 . & 473 & ST \\
\hline HEMBL3934253 & 76 & 6 & 506 & ST \\
\hline AEMBL39e & & 7.49 & 756 & ST \\
\hline HEMBL3895086 & 76 & 66 & & \\
\hline HEMBL3939372 & & & & RN \\
\hline HEMBL3946574 & 276 & 7.3872 & 7.4725 & $\mathrm{RN}$ \\
\hline AEMBL3961016 & 76 & 6.4711 & 7203 & TRN \\
\hline 19 & & & & \\
\hline HEMBL 3986857 & & & .5629 & \\
\hline CHEMBL 3945898 & & 7.1079 & .8556 & \\
\hline CHEMBL3933572 & 1641276 & 4.699 & 6.0204 & ГST \\
\hline
\end{tabular}

Page 2861 
Supplemental Table S2.txt

\begin{tabular}{|c|c|c|c|c|c|}
\hline CHEMBL3977839 & 1641276 & 6.0752 & 6.2814 & TRN & \\
\hline CHEMBL3935015 & 1641276 & 6.9101 & 6.8171 & TRN & \\
\hline CHEMBL3971652 & 1641276 & 7.1805 & 7.0021 & TRN & \\
\hline CHEMBL3932246 & 1641276 & 6.0814 & 5.99 & TRN & \\
\hline CHEMBL3918218 & 1641276 & 6.2328 & 6.193 & TRN & \\
\hline CHEMBL65 & 955012 & 9.2317 & 9.2812 & TRN & \\
\hline CHEMBL3349342 & 955012 & 3.5392 & 4.1067 & TRN & \\
\hline CHEMBL 2144069 & 955012 & 3.4309 & 3.798 & TRN & \\
\hline CHEMBL1970879 & 955012 & 4.1164 & 3.5782 & TRN & \\
\hline CHEMBL192566 & 955012 & 7.0299 & 8.1311 & TST & \\
\hline CHEMBL180127 & 955012 & 2.9332 & 3.9319 & TRN & \\
\hline CHEMBL213100 & 955012 & 3.1559 & 3.0019 & TRN & \\
\hline CHEMBL92309 & 955012 & 2.1915 & 2.81100 & 00000000004 & TST \\
\hline CHEMBL373751 & 955012 & 3.1219 & 3.52699 & 99999999997 & TRN \\
\hline CHEMBL449158 & 955012 & 6.3599 & 6.9065 & TST & \\
\hline CHEMBL 2363137 & 955012 & 2.7172 & 4.1593 & TRN & \\
\hline CHEMBL412142 & 955012 & 4.2247 & 3.9662 & TRN & \\
\hline CHEMBL379975 & 955012 & 6.0376 & 6.1289 & TRN & \\
\hline CHEMBL577784 & 955012 & 5.4647 & 5.5672 & TRN & \\
\hline CHEMBL 258844 & 955012 & 4.2056 & 4.363 & TRN & \\
\hline CHEMBL1230020 & 955012 & 4.6839 & 4.1582 & TRN & \\
\hline CHEMBL512504 & 955012 & 6.6361 & 6.5008 & TRN & \\
\hline CHEMBL188678 & 955012 & 5.3375 & 5.1136 & TRN & \\
\hline CHEMBL3392440 & 955012 & 4.2826 & 3.903 & TRN & \\
\hline CHEMBL1673039 & 955012 & 3.7746 & 4.4417 & TRN & \\
\hline CHEMBL3186408 & 955012 & 3.7928 & 3.8593 & TST & \\
\hline CHEMBL472940 & 955012 & 2.5482 & 3.8763 & TRN & \\
\hline CHEMBL392695 & 955012 & 5.3629 & 4.9784 & TRN & \\
\hline CHEMBL1643959 & 955012 & 3.3424 & 3.2935 & TRN & \\
\hline CHEMBL573107 & 955012 & 5.4029 & 5.4652 & TRN & \\
\hline CHEMBL209148 & 955012 & 4.7444 & 4.1371 & TRN & \\
\hline CHEMBL102714 & 955012 & 4.5083 & 4.0173 & TRN & \\
\hline CHEMBL3199475 & 955012 & 4.0829 & 4.6681 & TRN & \\
\hline CHEMBL220241 & 955012 & 5.1463 & 4.6381 & TRN & \\
\hline CHEMBL135561 & 955012 & 4.4954 & 4.2548 & TRN & \\
\hline CHEMBL1190711 & 955012 & 5.3642 & 5.38200 & 2000000001 & TRN \\
\hline CHEMBL515416 & 955012 & 5.3495 & 4.5626 & TRN & \\
\hline CHEMBL1788116 & 955012 & 4.9907 & 4.231 & TRN & \\
\hline CHEMBL585951 & 955012 & 6.2263 & 6.4432 & TRN & \\
\hline CHEMBL 1357247 & 955012 & 3.7204 & 2.9754 & TRN & \\
\hline CHEMBL191334 & 955012 & 4.1811 & 4.4258 & TRN & \\
\hline CHEMBL1590308 & 955012 & 2.4184 & 3.4378 & TST & \\
\hline CHEMBL393929 & 955012 & 3.6138 & 4.2922 & TRN & \\
\hline CHEMBL202721 & 955012 & 5.018 & 5.3173 & TRN & \\
\hline CHEMBL1404918 & 955012 & 2.6914 & 2.839 & TRN & \\
\hline CHEMBL1909414 & 955012 & 4.3825 & 4.3508 & TRN & \\
\hline CHEMBL 2005886 & 955012 & 5.7951 & 4.8751 & TRN & \\
\hline CHEMBL300389 & 955012 & \multicolumn{3}{|c|}{6.9110000000000005} & TRN \\
\hline
\end{tabular}




\begin{tabular}{|c|c|c|c|c|c|}
\hline & & \multicolumn{4}{|c|}{ Supplemental Table S2.txt } \\
\hline CHEMBL483847 & 955012 & 3.7724 & 3.9203 & TRN & \\
\hline CHEMBL483849 & 955012 & 3.0183 & 2.7034 & TRN & \\
\hline CHEMBL210618 & 955012 & 3.9086 & 3.6149 & TRN & \\
\hline CHEMBL 9470 & 955012 & 6.0917 & 5.7965 & TST & \\
\hline CHEMBL514499 & 955012 & 6.9245 & 6.8345 & TRN & \\
\hline CHEMBL259181 & 955012 & 3.4396 & 4.2249 & TRN & \\
\hline CHEMBL221137 & 955012 & 3.0302 & 4.7015 & TST & \\
\hline CHEMBL509032 & 955012 & 6.0762 & 5.1353 & TRN & \\
\hline CHEMBL1242367 & 955012 & 3.0943 & 3.9423 & TST & \\
\hline CHEMBL1516890 & 955012 & 4.4015 & 4.2297 & TST & \\
\hline CHEMBL189584 & 955012 & 4.761 & 4.9384 & TST & \\
\hline CHEMBL379300 & 955012 & 6.4403 & 6.1727 & TST & \\
\hline CHEMBL558642 & 955012 & 5.1839 & 4.0186 & TST & \\
\hline CHEMBL1256459 & 955012 & 6.2573 & 6.6286 & TST & \\
\hline CHEMBL 240954 & 955012 & 4.3694 & 4.3623 & TST & \\
\hline CHEMBL222102 & 955012 & 3.7491 & 4.3939 & TST & \\
\hline CHEMBL1190711 & 955079 & 4.7888 & 4.7605 & TRN & \\
\hline CHEMBL585951 & 955079 & 6.0402 & 5.5729 & TRN & \\
\hline CHEMBL1357247 & 955079 & 4.7581 & 3.3813 & TRN & \\
\hline CHEMBL 2144069 & 955079 & 3.9076 & 4.6271 & TRN & \\
\hline CHEMBL135561 & 955079 & 4.7036 & 4.3301 & TRN & \\
\hline CHEMBL 210618 & 955079 & 2.9683 & 3.5806 & TRN & \\
\hline CHEMBL3392440 & 955079 & 3.571 & 3.9045 & TRN & \\
\hline CHEMBL379300 & 955079 & 6.319 & 5.8165 & TRN & \\
\hline CHEMBL3186408 & 955079 & 3.4296 & 3.8746 & TST & \\
\hline CHEMBL255342 & 955079 & 3.3255 & 3.68399 & 99999999997 & TRN \\
\hline CHEMBL220241 & 955079 & 6.2283 & 4.6177 & TRN & \\
\hline CHEMBL512504 & 955079 & 4.8112 & 4.572 & TRN & \\
\hline CHEMBL188678 & 955079 & 3.65199 & (99999999 & 4.2655 & TRN \\
\hline CHEMBL514499 & 955079 & 6.8485 & 6.2892 & TRN & \\
\hline CHEMBL300389 & 955079 & 5.6336 & 6.11 & TRN & \\
\hline CHEMBL1673039 & 955079 & 3.2534 & 4.5832 & TRN & \\
\hline CHEMBL515416 & 955079 & 4.1542 & 4.4036 & TRN & \\
\hline CHEMBL1643959 & 955079 & 4.0977 & 3.8025 & TRN & \\
\hline CHEMBL412142 & 955079 & 4.1072 & 3.9956 & TRN & \\
\hline CHEMBL217354 & 955079 & 5.6045 & 5.5325 & TRN & \\
\hline CHEMBL1590308 & 955079 & 2.8284 & 3.5821 & TST & \\
\hline CHEMBL573107 & 955079 & 5.6095 & 4.8418 & TRN & \\
\hline CHEMBL1909414 & 955079 & 3.2062 & 3.915 & TRN & \\
\hline CHEMBL3199475 & 955079 & 3.552 & 4.2691 & TRN & \\
\hline CHEMBL213100 & 955079 & 5.7703 & 4.7063 & TRN & \\
\hline CHEMBL373751 & 955079 & 3.7609 & 3.8288 & TRN & \\
\hline CHEMBL1404918 & 955079 & 4.8644 & 3.1812 & TRN & \\
\hline CHEMBL1256459 & 955079 & 7.2781 & 6.3589 & TRN & \\
\hline CHEMBL65 & 955079 & 6.7382 & 6.9504 & TRN & \\
\hline CHEMBL379975 & 955079 & 5.4094 & 4.7216 & TRN & \\
\hline CHEMBL1516890 & 955079 & 4.2483 & 4.0005 & TRN & \\
\hline CHEMBL449158 & 955079 & 6.2022 & 6.0647 & TST & \\
\hline
\end{tabular}




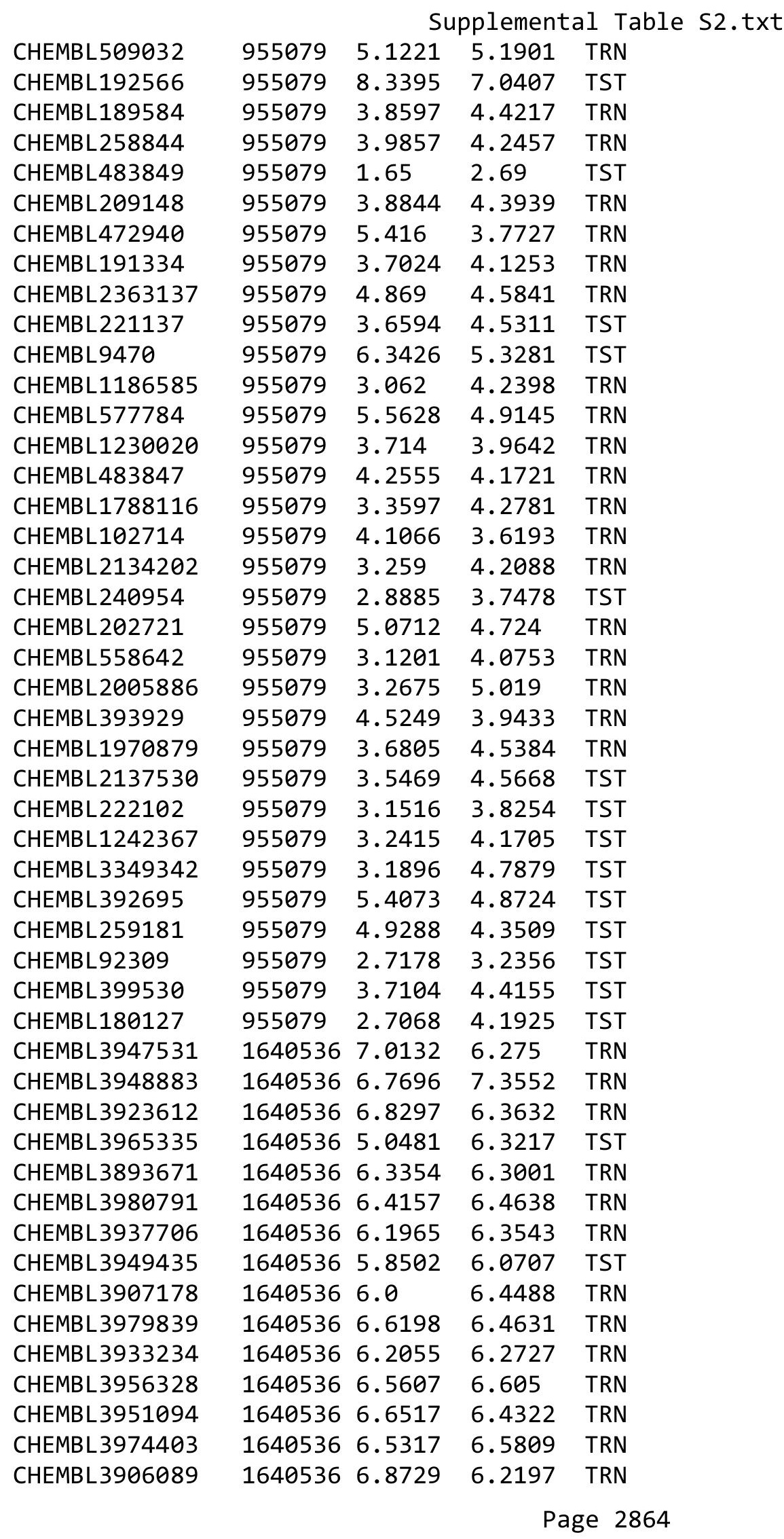


Supplemental Table S2.txt

\begin{tabular}{|c|c|c|c|c|c|c|}
\hline CHEMBL 3901814 & 1640536 & 6.0 & 6.3591 & TRN & & \\
\hline CHEMBL3914989 & 1640536 & 6.6253 & 6.2782 & TRN & & \\
\hline CHEMBL 3950174 & 1640536 & 6.4078 & 6.1301 & TST & & \\
\hline CHEMBL 3973628 & 1640536 & 7.1549 & 6.7678 & TRN & & \\
\hline CHEMBL 3903547 & 1640536 & 6.3585 & 6.3982 & TRN & & \\
\hline CHEMBL 3917876 & 1640536 & \multicolumn{3}{|c|}{6.617999999999999} & 6.4773 & TRN \\
\hline CHEMBL 3889761 & 1640536 & 5.8781 & 6.277 & TST & & \\
\hline CHEMBL 3977848 & 1640536 & 6.4214 & 6.2086 & TRN & & \\
\hline CHEMBL 3918724 & 1640536 & 6.4034 & 6.561 & TRN & & \\
\hline CHEMBL 3915473 & 1640536 & 5.3792 & 6.3964 & TRN & & \\
\hline CHEMBL 3911754 & 1640536 & 5.5181 & 5.9248 & TRN & & \\
\hline CHEMBL 3971105 & 1640536 & 6.9355 & 6.5582 & TRN & & \\
\hline CHEMBL 3943976 & 1640536 & 6.9747 & 6.176 & TRN & & \\
\hline CHEMBL 3981413 & 1640536 & 5.8986 & 6.1641 & TRN & & \\
\hline CHEMBL 3952155 & 1640536 & 6.0931 & 6.0655 & TRN & & \\
\hline CHEMBL 3899491 & 1640536 & 6.2464 & 6.0131 & TRN & & \\
\hline CHEMBL3894781 & 1640536 & 6.0 & 6.2229 & TST & & \\
\hline CHEMBL 3904103 & 1640536 & 4.0 & 5.1798 & TRN & & \\
\hline CHEMBL 3955267 & 1640536 & 6.9666 & 6.8846 & TRN & & \\
\hline CHEMBL 3931151 & 1640536 & 5.4077 & 6.4476 & TRN & & \\
\hline CHEMBL 3955514 & 1640536 & 6.341 & 6.4341 & TST & & \\
\hline CHEMBL 3983527 & 1640536 & 7.2366 & 6.7201 & TRN & & \\
\hline CHEMBL 3968362 & 1640536 & 5.9863 & 6.6163 & TRN & & \\
\hline CHEMBL 3892950 & 1640536 & 6.0 & 6.3761 & TRN & & \\
\hline CHEMBL 3949571 & 1640536 & 6.0585 & 6.2612 & TRN & & \\
\hline CHEMBL3920966 & 1640536 & 5.9614 & 6.0611 & TRN & & \\
\hline CHEMBL 3980084 & 1640536 & 6.6289 & 6.5672 & TRN & & \\
\hline CHEMBL 3896160 & 1640536 & 6.5331 & 6.3691 & TRN & & \\
\hline CHEMBL 3969440 & 1640536 & 6.0477 & 6.0506 & TRN & & \\
\hline CHEMBL 3927783 & 1640536 & 6.8041 & 6.8645 & TRN & & \\
\hline CHEMBL 3923118 & 1640536 & 4.0 & 6.7075 & TST & & \\
\hline CHEMBL 3935285 & 1640536 & 7.2366 & 6.4848 & TRN & & \\
\hline CHEMBL 3957066 & 1640536 & 5.9408 & 6.7252 & TRN & & \\
\hline CHEMBL 3939014 & 1640536 & 6.6882 & 6.3476 & TRN & & \\
\hline CHEMBL 3941390 & 1640536 & \multicolumn{3}{|c|}{6.7620000000000005} & 6.5978 & TRN \\
\hline CHEMBL3966469 & 1640536 & 6.7144 & 6.3095 & TRN & & \\
\hline CHEMBL 3979605 & 1640536 & \multicolumn{3}{|c|}{5.757000000000001} & 6.2811 & TRN \\
\hline CHEMBL 3901874 & 1640536 & \multicolumn{3}{|c|}{5.4270000000000005} & 6.8367 & TST \\
\hline CHEMBL 3898551 & 1640536 & 5.871 & 6.3012 & TST & & \\
\hline CHEMBL 3901563 & 1640536 & 6.0 & 6.4507 & TST & & \\
\hline CHEMBL 3897150 & 1640536 & \multicolumn{3}{|c|}{6.382000000000001} & 6.5334 & TRI \\
\hline CHEMBL 3920501 & 1640536 & 6.9508 & 6.5982 & TRN & & \\
\hline CHEMBL 3896383 & 1640536 & 6.0 & 6.1599 & TRN & & \\
\hline CHEMBL 3901167 & 1640536 & 6.8962 & 6.9128 & TRN & & \\
\hline CHEMBL 3906013 & 1640536 & 6.2581 & 6.5934 & TRN & & \\
\hline CHEMBL 3946528 & 1640536 & 6.4012 & 6.5913 & TRN & & \\
\hline CHEMBL 3914956 & 1640536 & \multicolumn{3}{|c|}{6.382999999999999} & 5.9475 & IS1 \\
\hline CHEMBL 3890321 & 1640536 & 6.6364 & 6.6974 & TRN & & \\
\hline
\end{tabular}


Supplemental Table S2.txt

\begin{tabular}{|c|c|c|}
\hline CHEMBL3917552 & 1640536 & 6.0 \\
\hline CHEMBL3911265 & 1640536 & 7.0 \\
\hline CHEMBL3981568 & 1640536 & 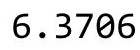 \\
\hline HEMBL3968768 & 1640536 & \\
\hline HEMBL 3984128 & 1640536 & \\
\hline HEMBL3935249 & 1640536 & \\
\hline CHEMBL3904956 & 1640536 & \\
\hline HEMBL3940831 & 1640536 & \\
\hline HEMBL 3942311 & 1640536 & \\
\hline HEMBL3932264 & 1640536 & \\
\hline CHEMBL3951150 & 1640536 & \\
\hline CHEMBL 3982393 & 1640536 & \\
\hline CHEMBL3947424 & 1640536 & \\
\hline CHEMBL3935045 & 1640536 & 6.0 \\
\hline CHEMBL3962903 & 1640536 & 6.72 \\
\hline CHEMBL3941218 & 1640536 & \\
\hline CHEMBL3929893 & 1640536 & \\
\hline CHEMBL3913898 & 164 & \\
\hline CHEMBL3968283 & 16 & 6. \\
\hline CHEMBL3943781 & 16 & 5 \\
\hline CHEMBL3934056 & 164 & 6.06 \\
\hline CHEMBL3900433 & 164 & \\
\hline CHEMBL3946567 & 164 & \\
\hline CHEMBL3892085 & 16 & \\
\hline CHEMBL3917764 & 16 & 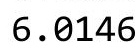 \\
\hline CHEMBL3916585 & 164 & \\
\hline CHEMBL3981612 & 164 & \\
\hline CHEMBL3910800 & 164 & \\
\hline CHEMBL396 & 16 & 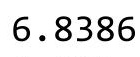 \\
\hline CHEMBL3920903 & 164 & 6.98 \\
\hline CHEMBL3946541 & 164 & 6. \\
\hline CHEMBL3907852 & 1640536 & \\
\hline CHEMBL3962398 & 16 & 6.0 \\
\hline CHEMBL3936670 & 16 & 6.0 \\
\hline CHEMBL 3938721 & 164 & 6.9 \\
\hline CHEMBL3975234 & 1640536 & 6 . \\
\hline CHEMBL 3984162 & 1640536 & \\
\hline CHEMBL3923217 & 1640536 & \\
\hline CHEMBL 3908462 & 164 & \\
\hline CHEMBL3931876 & 1640536 & 5 \\
\hline CHEMBL3891691 & 1640536 & 6.8 \\
\hline CHEMBL3985503 & 1640536 & \\
\hline CHEMBL3970172 & 1640536 & \\
\hline CHEMBL3908729 & 1640536 & 6.0 \\
\hline CHEMBL3951146 & 1640536 & 5.8 \\
\hline CHEMBL3895240 & 164053 & \\
\hline CHEMBL 3948480 & 1640536 & \\
\hline CHEMBL3944973 & & \\
\hline
\end{tabular}

6.4123 TRN

6.5191 TRN

6.1311 TRN

6.6217 TRN

6.5897 TRN

5.9431 TRN

6.3327 TRN

6.3519 TRN

6.5791 TRN

6.6206 TRN

6.5983 TST

5.9888 TRN

6.6477 TRN

6.5493 TRN

6.7068 TRN

4.8988 TRN

6.4498 TRN

6.7395 TRN

6.3742 TRN

6.5781 TRN

5.7048 TRN

6.7022 TRN

6.2948 TRN

6.3979 TRN

6.5505 TST

6.529 TRN

6.4658 TRN

5.8258 TRN

7.1906 TRN

6.3679 TRN

6.2378 TRN

6.035 TRN

6.3008 TRN

6.2888 TRN

6.2161 TRN

6.3996 TRN

6.8922 TRN

6.428999999999999 TRN

6.3382 TRN

5.3215 TST

6.9805 TRN

5.5304 TRN

6.0883 TRN

6.0055 TST

6.4351 TRN

6.7814 TST

6.3506 TRN

6.7356 TRN

Page 2866 
Supplemental Table S2.txt

\begin{tabular}{|c|c|c|c|c|}
\hline CHEMBL3976258 & 1640536 & 6.0 & 6.5004 & TRN \\
\hline CHEMBL3892506 & 1640536 & 7.2924 & 6.6154 & TRN \\
\hline CHEMBL3972704 & 1640536 & 6.9066 & 6.4629 & TRN \\
\hline CHEMBL 3922754 & 1640536 & 6.6144 & 6.3166 & TRN \\
\hline CHEMBL3929405 & 1640536 & 7.2218 & 6.6005 & TRN \\
\hline CHEMBL3976133 & 1640536 & 6.5376 & 6.2925 & TRN \\
\hline CHEMBL3910893 & 1640536 & 7.1612 & 6.5502 & TRN \\
\hline CHEMBL 3907251 & 1640536 & 6.0 & 6.1797 & TRN \\
\hline CHEMBL3937554 & 1640536 & 5.1404 & 6.2046 & TST \\
\hline CHEMBL3978218 & 1640536 & 6.0 & 6.2144 & TST \\
\hline CHEMBL3960172 & 1640536 & 6.6615 & 6.4282 & TRN \\
\hline CHEMBL3978634 & 1640536 & 6.0788 & 6.3106 & TST \\
\hline CHEMBL3963961 & 1640536 & 5.1347 & 6.6687 & TST \\
\hline CHEMBL3928761 & 1640536 & 5.8173 & 6.3164 & TRN \\
\hline CHEMBL 3961724 & 1640536 & 6.0 & 6.3249 & TRN \\
\hline CHEMBL 3898829 & 1640536 & 7.2757 & 6.7116 & TRN \\
\hline CHEMBL3931714 & 1640536 & 6.0496 & 5.9628 & TST \\
\hline CHEMBL3957279 & 1640536 & 6.3372 & 6.4928 & TRN \\
\hline CHEMBL 3927383 & 1640536 & 6.8013 & 6.7814 & TRN \\
\hline CHEMBL3933336 & 1640536 & 6.0716 & 6.4787 & TRN \\
\hline CHEMBL 3925080 & 1640536 & 6.5735 & 6.4088 & TRN \\
\hline CHEMBL 3916249 & 1640536 & 5.0597 & 6.1612 & TRN \\
\hline CHEMBL3964929 & 1640536 & 6.466 & 6.4901 & TRN \\
\hline CHEMBL3891099 & 1640536 & 7.0362 & 6.8305 & TRN \\
\hline CHEMBL 3952087 & 1640536 & 6.8729 & 6.8661 & TRN \\
\hline CHEMBL 3909767 & 1640536 & 6.0506 & 6.2183 & TRN \\
\hline CHEMBL3928264 & 1640536 & 6.6091 & 6.4183 & TRN \\
\hline CHEMBL3951942 & 1640536 & 6.6108 & 6.57299 & 9999999995 \\
\hline CHEMBL 3899768 & 1640536 & 4.0 & 6.149 & TST \\
\hline CHEMBL3941257 & 1640536 & 7.0862 & 6.886 & TRN \\
\hline CHEMBL 3914488 & 1640536 & 6.1221 & 6.4491 & TRN \\
\hline CHEMBL3916314 & 1640536 & 6.5784 & 6.7048 & TRN \\
\hline CHEMBL3961465 & 1640536 & 6.9208 & 6.6522 & TRN \\
\hline CHEMBL3905322 & 1640536 & 6.5143 & 6.73 & TRN \\
\hline CHEMBL3931941 & 1640536 & 5.8077 & 6.7073 & TST \\
\hline CHEMBL3959792 & 1640536 & 5.9469 & 6.9347 & TST \\
\hline CHEMBL3983486 & 1640536 & 6.6055 & 6.1764 & TRN \\
\hline CHEMBL3967675 & 1640536 & 4.0 & 6.7221 & TST \\
\hline CHEMBL 3897638 & 1640536 & 6.8477 & 6.6679 & TRN \\
\hline CHEMBL3957426 & 1640536 & 6.6459 & 6.5723 & TRN \\
\hline CHEMBL 3897121 & 1640536 & 6.0 & 6.3801 & TRN \\
\hline CHEMBL3944330 & 1640536 & 5.7071 & 6.6377 & TRN \\
\hline CHEMBL 3933044 & 1640536 & 6.4763 & 6.4128 & TRN \\
\hline CHEMBL3911614 & 1640536 & 6.7423 & 6.6528 & TRN \\
\hline CHEMBL3945579 & 1640536 & 6.4012 & 5.8996 & TST \\
\hline CHEMBL 3942032 & 1640536 & 7.0269 & 6.6903 & TRN \\
\hline CHEMBL3929873 & 1640536 & 6.4622 & 6.5075 & TRN \\
\hline CHEMBL 3919254 & 1640536 & 6.7122 & 6.5451 & TRN \\
\hline
\end{tabular}


Supplemental Table S2.txt

\begin{tabular}{|c|c|c|c|c|}
\hline HEMBL & 640536 & 6.0 & 6.6848 & TR \\
\hline & 640536 & 6.45 & & \\
\hline rMOP & & 77 & & \\
\hline IEMBL395587 & 536 & 8153 & & \\
\hline IEMBL3914133 & 536 & 684 & & ST \\
\hline AEMBL3939535 & 640536 & 6.3726 & 1069 & \\
\hline AEMBL & 36 & 6.0 & 384 & \\
\hline EMBL & & 1 & & RN \\
\hline HEMBL 391 & 536 & 5.1108 & 9134 & PN \\
\hline HEMBL398 & 36 & 6.0 & .2926 & $\Gamma \mathrm{RN}$ \\
\hline AEMBL393 & 64 & 7.3372 & 6637 & \\
\hline EMBL & 0 & 53 & 915 & \\
\hline EMBL & & & & RN \\
\hline AEMBL3S & 36 & 6.585 & 6.3532 & RN \\
\hline IEMBL3S & 6 & 3761 & & TST \\
\hline AEMBL3 & 64 & 6.5031 & 891 & DI \\
\hline AEMBL3 & $6<$ & 3 & & RN \\
\hline AEMBL3 & 6 & 55 & & \\
\hline AEMBL3S & 36 & 7.2076 & & RN \\
\hline EMBL3 & & & & $\cdots$ \\
\hline IEMBL & 64 & 6. & & RIV \\
\hline EMBL & 0 & & & RN \\
\hline EMBL: & 6 & 8 & & ST \\
\hline FMBI: & & 6.4609 & & RN \\
\hline EMBL3S & & & & I KIV \\
\hline IEMBL & 62 & & 321 & SI \\
\hline IEMBL & & 1 & & RN \\
\hline FMBI & 36 & 276 & & ST \\
\hline IEMBL3\& & & 6.4962 & & TRN \\
\hline AEMBL396 & 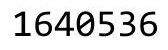 & 5.0401 & & TRN \\
\hline AEMBL3 & 64 & & 92 & 「RN \\
\hline AEMBL: & & & & RN \\
\hline IEMBL: & 6 & 5. & 31 & $\Gamma \mathrm{RN}$ \\
\hline AEMBL390 & 6 & 5.769 & 97 & TST \\
\hline AEMBL 393 & & 5.2924 & 13 & TRN \\
\hline AEMBL3 & & & & TRN \\
\hline $45 M D^{2}$ & & 1 & 58 & ГST \\
\hline & & & 5271 & $\Gamma \mathrm{RN}$ \\
\hline AEMBL39643e & & 6.9431 & 6504 & TRN \\
\hline EMBL39 & 64 & 945 & 66 & TST \\
\hline HEMBL3 & 6 & 288 & 23 & TST \\
\hline HEMBL 39 & & & & TST \\
\hline HEMBL3S & & 5.7991 & .5617 & TST \\
\hline EMBL39 & 36 & 5.9686 & .5208 & TST \\
\hline$M P I 3$ & & 5.6173 & & TST \\
\hline CHEMBL 3 & & 6.0 & .0662 & ו \\
\hline HEMBL391 & & 5.72 & 6.6696 & SI \\
\hline CHEMBL389057e & 1640536 & 6.0168 & 6.5633 & $S T$ \\
\hline
\end{tabular}

Page 2868 
Supplemental Table S2.txt

\begin{tabular}{|c|c|c|c|c|c|}
\hline CHEMBL 3959856 & 1640536 & 6.6904 & 6.2841 & TST & \\
\hline CHEMBL3890149 & 1640536 & 6.1337 & 5.9818 & TST & \\
\hline CHEMBL 3952446 & 1640536 & 6.3036 & 6.25 & TST & \\
\hline CHEMBL 3969881 & 1640536 & 6.0 & 6.6791 & TST & \\
\hline CHEMBL3981614 & 1640536 & 5.3426 & 5.9665 & TST & \\
\hline CHEMBL3980087 & 1640536 & 5.4604 & 6.5603 & TST & \\
\hline CHEMBL3926139 & 1640536 & 6.0757 & 5.8959 & TST & \\
\hline CHEMBL3980635 & 1640536 & 6.5243 & 6.8345 & TST & \\
\hline CHEMBL 3908988 & 1640536 & 6.8069 & 6.5272 & TST & \\
\hline CHEMBL3938622 & 1640536 & 6.3625 & 6.5369 & TST & \\
\hline CHEMBL3947320 & 1640536 & 7.5086 & 6.2535 & TST & \\
\hline CHEMBL3971167 & 1640536 & 6.5072 & 6.0923 & TST & \\
\hline CHEMBL 3426771 & 1478161 & 3.0 & 3.2962 & TRN & \\
\hline CHEMBL 3426738 & 1478161 & 5.7077 & 5.8015 & TRN & \\
\hline CHEMBL3426735 & 1478161 & 3.301 & 3.3132 & TRN & \\
\hline CHEMBL3426757 & 1478161 & 3.301 & 3.3826 & TRN & \\
\hline CHEMBL 3426740 & 1478161 & 2.301 & 2.1565 & TRN & \\
\hline CHEMBL 3426780 & 1478161 & 4.6925 & 4.7219 & TRN & \\
\hline CHEMBL 3426737 & 1478161 & 3.301 & 3.2139 & TRN & \\
\hline CHEMBL3426742 & 1478161 & 3.301 & 2.9704 & TRN & \\
\hline CHEMBL 3426744 & 1478161 & 3.301 & 3.24899 & 99999999997 & TRN \\
\hline CHEMBL 3426750 & 1478161 & 3.301 & 3.3809 & TRN & \\
\hline CHEMBL3426755 & 1478161 & 3.0 & 3.0563 & TRN & \\
\hline CHEMBL 3426769 & 1478161 & 2.6021 & 2.6124 & TRN & \\
\hline CHEMBL 3426772 & 1478161 & 3.0 & 2.9627 & TRN & \\
\hline CHEMBL3426762 & 1478161 & 3.0 & 3.054 & TRN & \\
\hline CHEMBL 3426752 & 1478161 & 3.301 & 3.2739 & TRN & \\
\hline CHEMBL3426747 & 1478161 & 3.301 & 3.2273 & TRN & \\
\hline CHEMBL3426736 & 1478161 & 5.0809 & 5.0635 & TRN & \\
\hline CHEMBL192013 & 1478161 & 2.301 & 2.7527 & TRN & \\
\hline CHEMBL3426749 & 1478161 & 3.301 & 3.38 & TRN & \\
\hline CHEMBL424824 & 1478161 & 2.5229 & 2.6869 & TRN & \\
\hline CHEMBL 371570 & 1478161 & 3.301 & 3.3497 & TRN & \\
\hline CHEMBL3426779 & 1478161 & 3.0 & 3.01 & TRN & \\
\hline CHEMBL 3426770 & 1478161 & 3.0 & 2.9651 & TRN & \\
\hline CHEMBL195096 & 1478161 & 2.5229 & 2.4058 & TRN & \\
\hline CHEMBL3426766 & 1478161 & 3.0 & 2.832 & TRN & \\
\hline CHEMBL3426758 & 1478161 & 3.301 & 3.0509 & TRN & \\
\hline CHEMBL 3426751 & 1478161 & 3.301 & 3.1167 & TRN & \\
\hline CHEMBL192480 & 1478161 & 2.699 & 2.7282 & TRN & \\
\hline CHEMBL3426756 & 1478161 & 3.301 & 3.2455 & TRN & \\
\hline CHEMBL 3426734 & 1478161 & 3.0 & 3.0498 & TRN & \\
\hline CHEMBL3426775 & 1478161 & 3.0 & 2.3369 & TST & \\
\hline CHEMBL3426761 & 1478161 & 3.0 & 3.5931 & TST & \\
\hline CHEMBL364456 & 1478161 & 3.0 & 3.0882 & TRN & \\
\hline CHEMBL 3426753 & 1478161 & 3.0 & 3.2084 & TRN & \\
\hline CHEMBL 371372 & 1478161 & 3.0 & 3.1039 & TRN & \\
\hline CHEMBL3426776 & 1478161 & 3.0 & 2.0829 & TST & \\
\hline
\end{tabular}




\begin{tabular}{|c|c|c|c|c|c|}
\hline \multirow[b]{2}{*}{ CHEMBL3426768 } & \multicolumn{5}{|c|}{ Supplemental Table S2.txt } \\
\hline & 1478161 & 2.301 & 2.0848 & TST & \\
\hline CHEMBL3426739 & 1478161 & 4.7967 & 4.7556 & TRN & \\
\hline CHEMBL3426778 & 1478161 & 3.0 & 4.0452 & TST & \\
\hline CHEMBL3426743 & 1478161 & 3.0 & 3.0461 & TRN & \\
\hline CHEMBL3426745 & 1478161 & 3.0 & 2.8544 & TRN & \\
\hline CHEMBL3426759 & 1478161 & 4.6038 & 3.0324 & TST & \\
\hline CHEMBL365118 & 1478161 & 2.5229 & 2.6488 & TRN & \\
\hline CHEMBL3426760 & 1478161 & 3.6021 & 3.2408 & TST & \\
\hline CHEMBL3426754 & 1478161 & 3.301 & 3.2285 & TRN & \\
\hline CHEMBL190438 & 1478161 & 3.0 & 3.0784 & TRN & \\
\hline CHEMBL3426746 & 1478161 & 3.0 & 3.1098 & TRN & \\
\hline CHEMBL3426774 & 1478161 & 3.0 & 2.1681 & TST & \\
\hline CHEMBL3426765 & 1478161 & 3.0 & 3.0133 & TST & \\
\hline CHEMBL426086 & 1478161 & 3.0 & 3.0759 & TRN & \\
\hline CHEMBL3426787 & 1478161 & 4.8539 & 3.2747 & TST & \\
\hline CHEMBL3426767 & 1478161 & 3.0 & 3.3078 & TST & \\
\hline CHEMBL3426741 & 1478161 & 3.301 & 3.2392 & TRN & \\
\hline CHEMBL 364450 & 1478161 & 4.21899 & 99999999 & 3.9035 & TRN \\
\hline CHEMBL3426785 & 1478161 & 7.0 & 4.7072 & TST & \\
\hline CHEMBL190439 & 1478161 & 3.0 & 2.9329 & TRN & \\
\hline CHEMBL3426764 & 1478161 & 3.0 & 2.6695 & TST & \\
\hline CHEMBL3426773 & 1478161 & 3.0 & 2.9672 & TST & \\
\hline CHEMBL193892 & 1478161 & 3.0 & 3.19100 & 00000000003 & TRN \\
\hline CHEMBL370286 & 1478161 & 3.0 & 2.8481 & TRN & \\
\hline CHEMBL3426777 & 1478161 & 3.0 & 1.9888 & TST & \\
\hline CHEMBL3426784 & 1478161 & 7.5528 & 3.3912 & TST & \\
\hline CHEMBL 200102 & 1478161 & 7.3665 & 4.6908 & TST & \\
\hline CHEMBL 3426748 & 1478161 & 3.301 & 3.24399 & 99999999998 & TRN \\
\hline CHEMBL3426781 & 1478161 & 4.5638 & 4.4677 & TRN & \\
\hline CHEMBL3426733 & 1478161 & 3.301 & 3.3356 & TRN & \\
\hline CHEMBL364239 & 1478161 & 2.5229 & 2.5912 & TRN & \\
\hline CHEMBL3426783 & 1478161 & 3.301 & 3.1741 & TRN & \\
\hline CHEMBL3426782 & 1478161 & 3.301 & 3.3402 & TRN & \\
\hline CHEMBL3426763 & 1478161 & 3.0 & 3.0767 & TST & \\
\hline CHEMBL3660674 & 1528025 & 7.9914 & 7.1752 & TST & \\
\hline CHEMBL3660627 & 1528025 & 6.0 & 6.9217 & TST & \\
\hline CHEMBL 3665280 & 1528025 & 7.1267 & 7.1797 & TRN & \\
\hline CHEMBL3665292 & 1528025 & 6.8431 & 7.0247 & TRN & \\
\hline CHEMBL3665243 & 1528025 & 6.8776 & 6.58200 & 0000000001 & I \\
\hline CHEMBL3660665 & 1528025 & 7.0605 & 6.8078 & TRN & \\
\hline CHEMBL3656300 & 1528025 & 5.7705 & 6.0295 & TST & \\
\hline CHEMBL 3660587 & 1528025 & 7.8019 & 8.0543 & TST & \\
\hline CHEMBL3665294 & 1528025 & 6.5648 & 6.9122 & TRN & \\
\hline CHEMBL 3660564 & 1528025 & 8.3 & 7.9627 & TRN & \\
\hline CHEMBL3656328 & 1528025 & 6.1524 & 6.3423 & TRN & \\
\hline CHEMBL3660615 & 1528025 & 6.8921 & 7.0552 & TST & \\
\hline CHEMBL 3660545 & 1528025 & 7.125 & 7.371 & TRN & \\
\hline CHEMBL3660501 & 1528025 & 6.5331 & 6.8989 & TRN & \\
\hline
\end{tabular}


Supplemental Table S2.txt

\begin{tabular}{|c|c|c|c|c|c|c|c|}
\hline CHEMBL3656308 & 1528025 & 5.0 & 5.3938 & TST & & & \\
\hline CHEMBL 3665279 & 1528025 & 7.4476 & 7.0976 & TRN & & & \\
\hline CHEMBL 3660550 & 1528025 & 7.9172 & 7.3824 & TRN & & & \\
\hline CHEMBL 3656321 & 1528025 & 6.6368 & 6.5241 & TRN & & & \\
\hline CHEMBL 3660616 & 1528025 & 6.0465 & 8.129 & TST & & & \\
\hline CHEMBL 3660605 & 1528025 & 8.699 & 7.9269 & TST & & & \\
\hline CHEMBL 3665251 & 1528025 & \multicolumn{3}{|c|}{7.242000000000001} & 7.1554 & TRN & \\
\hline CHEMBL 3660588 & 1528025 & 6.7817 & 6.9914 & TST & & & \\
\hline CHEMBL 3660486 & 1528025 & \multicolumn{3}{|c|}{7.3020000000000005} & \multicolumn{2}{|c|}{7.457000000000001} & TRN \\
\hline CHEMBL 3665295 & 1528025 & 6.5201 & 6.5054 & TRN & & & \\
\hline CHEMBL 3660503 & 1528025 & 6.9431 & 6.9697 & TRN & & & \\
\hline CHEMBL 3660620 & 1528025 & 8.1915 & 7.8057 & TST & & & \\
\hline CHEMBL 3665252 & 1528025 & 7.1056 & 6.8907 & TRN & & & \\
\hline CHEMBL 3660492 & 1528025 & 6.1117 & 6.1582 & TRN & & & \\
\hline CHEMBL 3660667 & 1528025 & 6.8447 & \multicolumn{3}{|c|}{7.0360000000000005} & TRN & \\
\hline CHEMBL 3660657 & 1528025 & 7.166 & 7.03 & TRN & & & \\
\hline CHEMBL 3660582 & 1528025 & 8.0458 & \multicolumn{3}{|c|}{7.6610000000000005} & TST & \\
\hline CHEMBL 3660528 & 1528025 & 6.2195 & 6.3584 & TRN & & & \\
\hline CHEMBL3665301 & 1528025 & 6.0 & \multicolumn{3}{|c|}{6.9670000000000005} & TST & \\
\hline CHEMBL 3665240 & 1528025 & 5.4468 & 5.0607 & TRN & & & \\
\hline CHEMBL 3660536 & 1528025 & 6.0 & 6.1127 & TRN & & & \\
\hline CHEMBL 3660666 & 1528025 & 6.9172 & 6.5883 & TRN & & & \\
\hline CHEMBL3660512 & 1528025 & 7.8289 & 7.5742 & TRN & & & \\
\hline CHEMBL 3660565 & 1528025 & 7.2486 & 7.1588 & TRN & & & \\
\hline CHEMBL 3660625 & 1528025 & 7.7484 & 7.4675 & TST & & & \\
\hline CHEMBL 3660514 & 1528025 & 7.8239 & 7.1889 & TRN & & & \\
\hline CHEMBL 3665245 & 1528025 & 7.4097 & 7.2879 & TRN & & & \\
\hline CHEMBL3660642 & 1528025 & 9.8794 & 9.5308 & TRN & & & \\
\hline CHEMBL 3665289 & 1528025 & 5.716 & 6.6367 & TST & & & \\
\hline CHEMBL 3656309 & 1528025 & 5.0 & 7.1039 & TST & & & \\
\hline CHEMBL 3660591 & 1528025 & 6.2163 & 6.4655 & TST & & & \\
\hline CHEMBL 3665258 & 1528025 & 6.1217 & 6.5203 & TRN & & & \\
\hline CHEMBL 3660661 & 1528025 & 6.0 & 6.2598 & TRN & & & \\
\hline CHEMBL 3665263 & 1528025 & 7.0352 & 6.9209 & TRN & & & \\
\hline CHEMBL 3665272 & 1528025 & 6.7053 & 6.7213 & TRN & & & \\
\hline CHEMBL 3906366 & 1528025 & 10.0088 & 9.7784 & TRN & & & \\
\hline CHEMBL 3660597 & 1528025 & 7.7959 & 7.9791 & TRN & & & \\
\hline CHEMBL 3660498 & 1528025 & 7.0565 & 7.5491 & TST & & & \\
\hline CHEMBL 3665284 & 1528025 & 7.871 & 7.0757 & TRN & & & \\
\hline CHEMBL 3660637 & 1528025 & 8.9454 & 8.7835 & TRN & & & \\
\hline CHEMBL 3665277 & 1528025 & 5.4042 & 5.8553 & TRN & & & \\
\hline CHEMBL 3660544 & 1528025 & 7.6765 & 7.6965 & TRN & & & \\
\hline CHEMBL 3660641 & 1528025 & 9.2993 & 9.514 & TRN & & & \\
\hline CHEMBL 3660694 & 1528025 & 5.4239 & 5.9666 & TRN & & & \\
\hline CHEMBL 3660506 & 1528025 & 6.82299 & 99999999 & 995 & 6.8661 & TRN & \\
\hline CHEMBL 3656299 & 1528025 & 6.1531 & 6.1196 & TST & & & \\
\hline CHEMBL 3660546 & 1528025 & 8.2684 & 8.1817 & TRN & & & \\
\hline CHEMBL3656305 & 1528025 & 5.5754 & 6.1215 & TST & & & \\
\hline
\end{tabular}


Supplemental Table S2.txt

\begin{tabular}{|c|c|c|c|c|}
\hline W & & 7.1805 & & \\
\hline & 528025 & 6.3648 & 6.085 & \\
\hline & 28025 & 6 & & \\
\hline AEMBL & 28025 & 49 & 9836 & \\
\hline AEMBL & 528025 & 29 & 5644 & \\
\hline HEMBL3656324 & 528025 & 6.2612 & 4667 & \\
\hline 72 & $\partial 25$ & 3269 & 865 & \\
\hline 614 & & & & \\
\hline AEMBL & 528025 & 6.284 & 1987 & \\
\hline HEMBL3 & 528025 & 5.6345 & 7514 & \\
\hline AEMBL3656337 & 528025 & 6.0 & 8246 & \\
\hline IEMBL & 28025 & 861 & 827 & \\
\hline AEMBL & & & & \\
\hline HEMBL3 & 528025 & 8.301 & 3089 & \\
\hline AEMBL3 & 528025 & 9.0 & 9862 & \\
\hline AEMBL3 & 528025 & 828 & 1365 & \\
\hline AEMBL & 20 & 45 & 894 & \\
\hline HEMBL; & & 74 & 384 & \\
\hline HEMBL & 528025 & 535 & 3483 & \\
\hline AEMBL: & 25 & 19 & & \\
\hline AEMIBL & 5286 & 29 & 98 & \\
\hline AEMBL & 20 & 05 & & \\
\hline AEMBL & & 44 & & \\
\hline 9641 & 8025 & 6.3978 & 526 & \\
\hline AEMBL3 & & & & I RIV \\
\hline HEMBL & 5286 & 7. & 288 & RN \\
\hline HEME & J & 21 & 626 & 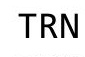 \\
\hline AFMB & 25 & 83 & 925 & \\
\hline HEMBL & & 58 & 303 & in \\
\hline HEMBL3665246 & 25 & 621 & $\partial 16$ & $\cdots$ \\
\hline HEMBL3 & 25 & 64 & 152 & SI \\
\hline HEME & J & 33 & 627 & ST \\
\hline AEMBL & 5 & 21 & 974 & ST \\
\hline HEMBL3656306 & 5286 & 5 & 302 & is \\
\hline HEMBL3665283 & 528025 & 6 & 7483 & TRN \\
\hline HEMBL & 280 & 33 & 364 & RN \\
\hline 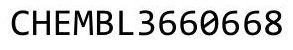 & 5 & & 138 & $\Gamma \mathrm{RN}$ \\
\hline & & & 779 & IRN \\
\hline HEMBL3665248 & 528025 & 243 & 494 & TRN \\
\hline IEMBL: & 5280 & & 622 & RN \\
\hline HEMBL3 & 5280 & 075 & 549 & ST \\
\hline HEMBL3 & & 5.6536 & & TRN \\
\hline HEMBL3 & 528025 & 7.6588 & 7.6497 & TRN \\
\hline HEMBL3660507 & 528025 & & 4908 & TS \\
\hline 1 & 528025 & & 3559 & $T_{1}$ \\
\hline HEMBL3 & תמבת & & 7386 & \\
\hline CHEMBL 3665268 & 528025 & .3037 & 2691 & \\
\hline CHEMBL3656307 & 1528025 & 5.2005 & 6.1146 & TST \\
\hline
\end{tabular}

Page 2872 


$$
\text { Supplemental Table S2.txt }
$$

\begin{tabular}{|c|c|c|c|c|c|}
\hline CHEMBL3660679 & 1528025 & 6.2628 & 6.1579 & TRN & \\
\hline CHEMBL3665269 & 1528025 & 6.1596 & 5.7439 & TST & \\
\hline CHEMBL 3660578 & 1528025 & 7.857 & 7.7607 & TRN & \\
\hline CHEMBL 3660593 & 1528025 & 8.4662 & 7.2071 & TST & \\
\hline CHEMBL3660635 & 1528025 & 8.6347 & 9.0331 & TRN & \\
\hline CHEMBL 3660634 & 1528025 & 8.699 & 8.9289 & TRN & \\
\hline CHEMBL 3665265 & 1528025 & 6.7371 & 6.5351 & TST & \\
\hline CHEMBL 3665296 & 1528025 & 6.4528 & 6.6416 & TRN & \\
\hline CHEMBL 3086089 & 1528025 & 7.4202 & 7.4388 & TRN & \\
\hline CHEMBL3660676 & 1528025 & 7.767 & 7.5551 & TRN & \\
\hline CHEMBL3665267 & 1528025 & 6.2455 & 6.2504 & TRN & \\
\hline CHEMBL 3665232 & 1528025 & 6.9248 & 6.9001 & TRN & \\
\hline CHEMBL 3665227 & 1528025 & 5.5084 & 5.9087 & TRN & \\
\hline CHEMBL 3660590 & 1528025 & 5.9052 & 6.3218 & TST & \\
\hline CHEMBL 3660482 & 1528025 & 7.107 & 7.4748 & TRN & \\
\hline CHEMBL3660499 & 1528025 & 8.7796 & 7.1084 & TRN & \\
\hline CHEMBL3665259 & 1528025 & 5.5065 & 5.4627 & TRN & \\
\hline CHEMBL 3665249 & 1528025 & 7.222 & 7.29899 & 99999999995 & TRN \\
\hline CHEMBL 3660693 & 1528025 & 6.2372 & 5.9666 & TRN & \\
\hline CHEMBL 3665226 & 1528025 & 6.9172 & 6.815 & TRN & \\
\hline CHEMBL 3660621 & 1528025 & 7.5283 & 7.0934 & TST & \\
\hline CHEMBL 3660531 & 1528025 & 6.6405 & 6.4485 & TRN & \\
\hline CHEMBL3656318 & 1528025 & 6.0302 & 6.4669 & TRN & \\
\hline CHEMBL 3639594 & 1528025 & 8.0969 & 7.6008 & TRN & \\
\hline CHEMBL 3665255 & 1528025 & 7.1325 & 7.2206 & TRN & \\
\hline CHEMBL 3660529 & 1528025 & 6.6465 & 6.3822 & TRN & \\
\hline CHEMBL3660602 & 1528025 & 8.301 & 8.0174 & TRN & \\
\hline CHEMBL3660585 & 1528025 & 8.699 & 7.5277 & TST & \\
\hline CHEMBL3660695 & 1528025 & 6.6064 & 6.7272 & TRN & \\
\hline CHEMBL 3660487 & 1528025 & 6.7126 & 6.7718 & TRN & \\
\hline CHEMBL 3665244 & 1528025 & 7.3022 & 7.2275 & TRN & \\
\hline CHEMBL 3660520 & 1528025 & 5.9541 & 6.102 & TRN & \\
\hline CHEMBL3660502 & 1528025 & 7.5157 & 7.3618 & TRN & \\
\hline CHEMBL 3660643 & 1528025 & 9.433 & 9.878 & TRN & \\
\hline CHEMBL3660638 & 1528025 & 8.6853 & 8.6564 & TST & \\
\hline CHEMBL 3665281 & 1528025 & 6.4528 & 7.0284 & TRN & \\
\hline CHEMBL 3660530 & 1528025 & 5.2738 & 5.6166 & TST & \\
\hline CHEMBL3660610 & 1528025 & 7.699 & 7.9424 & TRN & \\
\hline CHEMBL3660539 & 1528025 & 7.1249 & 7.1761 & TRN & \\
\hline CHEMBL 3660543 & 1528025 & 7.6842 & 7.9293 & TRN & \\
\hline CHEMBL 3660685 & 1528025 & 6.3481 & 5.9989 & TRN & \\
\hline CHEMBL 3660575 & 1528025 & 6.5161 & 7.1987 & TST & \\
\hline CHEMBL3660623 & 1528025 & 8.699 & 8.8862 & TST & \\
\hline CHEMBL3660681 & 1528025 & 6.0 & 6.256 & TRN & \\
\hline CHEMBL3660644 & 1528025 & 10.2596 & 10.4036 & TRN & \\
\hline CHEMBL 3656310 & 1528025 & 5.8462 & 5.6937 & TST & \\
\hline CHEMBL 3660658 & 1528025 & 6.0 & 6.9216 & TRN & \\
\hline CHEMBL 3656327 & 1528025 & 5.7258 & 5.7798 & TRN & \\
\hline
\end{tabular}


Supplemental Table S2.txt

\begin{tabular}{|c|c|c|c|c|c|}
\hline CHEMBL 3660692 & 1528025 & 7.21 & 6.9692 & TRN & \\
\hline CHEMBL 3665264 & 1528025 & 6.7263 & 6.6544 & TRN & \\
\hline CHEMBL 3660608 & 1528025 & 7.0177 & 7.5453 & TST & \\
\hline CHEMBL 3665287 & 1528025 & 6.1661 & 5.9447 & TRN & \\
\hline CHEMBL 3660697 & 1528025 & 5.7027 & 5.6089 & TRN & \\
\hline CHEMBL 3660662 & 1528025 & 6.1142 & 6.0995 & TRN & \\
\hline CHEMBL 3665253 & 1528025 & 5.5763 & 5.7565 & TRN & \\
\hline CHEMBL 3660494 & 1528025 & 6.6651 & 7.0465 & TRN & \\
\hline CHEMBL 3660629 & 1528025 & 7.9208 & 8.0241 & TRN & \\
\hline CHEMBL 3660696 & 1528025 & 6.0848 & 6.1623 & TRN & \\
\hline CHEMBL 3660688 & 1528025 & 5.5795 & 5.6544 & TRN & \\
\hline CHEMBL 3665274 & 1528025 & 6.0 & 6.0908 & TRN & \\
\hline CHEMBL 3656311 & 1528025 & 6.7344 & 8.1364 & TST & \\
\hline CHEMBL 3660569 & 1528025 & 6.914 & 7.2696 & TRN & \\
\hline CHEMBL 3660496 & 1528025 & 6.6392 & 6.6635 & TRN & \\
\hline CHEMBL 3656320 & 1528025 & 5.8321 & 5.807 & TRN & \\
\hline CHEMBL 3660622 & 1528025 & 8.5229 & 8.6739 & TST & \\
\hline CHEMBL 3656316 & 1528025 & 7.4232 & 7.5301 & TRN & \\
\hline CHEMBL 3660553 & 1528025 & 8.3059 & 8.2726 & TRN & \\
\hline CHEMBL 3660600 & 1528025 & 7.8239 & 7.542999 & 9999999999 & TRN \\
\hline CHEMBL 3660570 & 1528025 & 6.9855 & 7.2858 & TRN & \\
\hline CHEMBL 3656325 & 1528025 & 6.7235 & 6.3445 & TRN & \\
\hline CHEMBL 3660491 & 1528025 & 5.9918 & 6.3722 & TRN & \\
\hline CHEMBL 3660548 & 1528025 & 7.8908 & 7.8691 & TRN & \\
\hline CHEMBL 3660598 & 1528025 & 7.6576 & 7.5935 & TRN & \\
\hline CHEMBL 3660664 & 1528025 & 7.1163 & 6.7356 & TRN & \\
\hline CHEMBL 3660607 & 1528025 & 8.4089 & 7.5146 & TST & \\
\hline CHEMBL 3660525 & 1528025 & 7.3355 & 6.5099 & TST & \\
\hline CHEMBL 3665247 & 1528025 & 7.0882 & 7.2787 & TRN & \\
\hline CHEMBL 3665256 & 1528025 & 7.4413 & 7.0688 & TRN & \\
\hline CHEMBL 3665288 & 1528025 & 6.5361 & 6.6225 & TST & \\
\hline CHEMBL 3660504 & 1528025 & 6.0 & 6.6291 & TRN & \\
\hline CHEMBL 3656319 & 1528025 & \multicolumn{3}{|c|}{6.7860000000000005} & TRN \\
\hline CHEMBL 3660511 & 1528025 & 7.3665 & 6.9941 & TRN & \\
\hline CHEMBL 3665235 & 1528025 & 7.2318 & 7.165 & TRN & \\
\hline CHEMBL 3665250 & 1528025 & 5.2018 & 5.5145 & TRN & \\
\hline CHEMBL 3656304 & 1528025 & 5.0 & 5.9377 & TST & \\
\hline CHEMBL 3656329 & 1528025 & 6.8386 & 6.9902 & TRN & \\
\hline CHEMBL 3660547 & 1528025 & 8.1312 & 8.2158 & TRN & \\
\hline CHEMBL 3660586 & 1528025 & 8.8471 & 8.8848 & TRN & \\
\hline CHEMBL 3660596 & 1528025 & 7.7959 & 7.862999 & 99999999995 & TRN \\
\hline CHEMBL 3660516 & 1528025 & 6.081 & 5.8684 & TST & \\
\hline CHEMBL 3660626 & 1528025 & 5.8948 & 6.9833 & TST & \\
\hline CHEMBL 3665230 & 1528025 & 6.9007 & 6.7078 & TRN & \\
\hline CHEMBL 3665257 & 1528025 & 7.5025 & 7.7878 & TRN & \\
\hline CHEMBL 3656339 & 1528025 & 6.8094 & 7.0298 & TRN & \\
\hline CHEMBL 3639595 & 1528025 & 6.8156 & 6.7595 & TRN & \\
\hline CHEMBL 3660687 & 1528025 & 6.4396 & 6.8368 & TRN & \\
\hline
\end{tabular}


Supplemental Table S2.txt

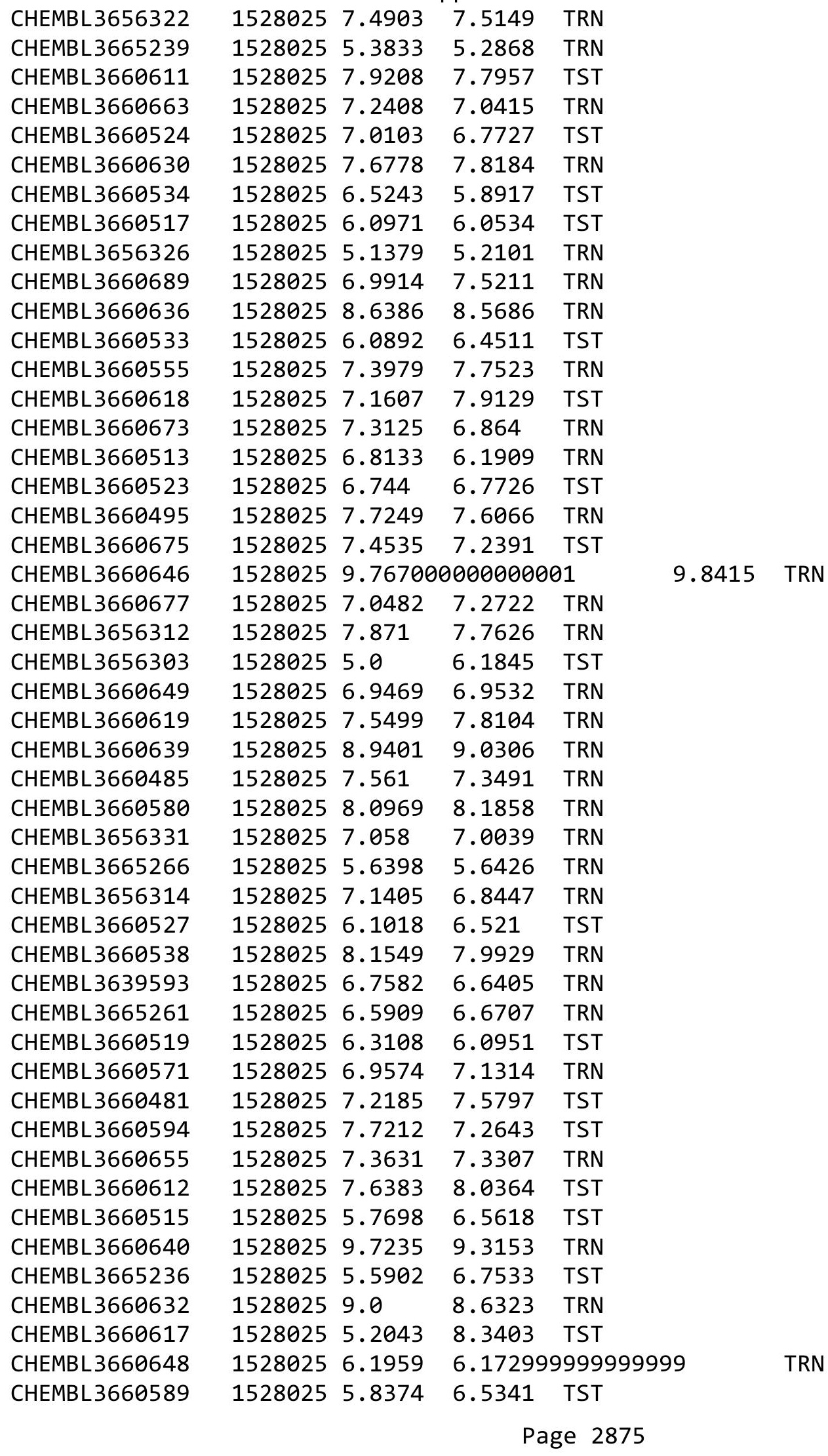


Supplemental Table S2.txt

\begin{tabular}{|c|c|c|c|c|c|c|}
\hline CHEMBL3660577 & 1528025 & 7.9698 & \multicolumn{3}{|c|}{7.882000000000001} & TRN \\
\hline CHEMBL3656330 & 1528025 & 8.0343 & 7.2591 & TRN & & \\
\hline CHEMBL3660568 & 1528025 & 7.1773 & 7.2686 & TRN & & \\
\hline CHEMBL3660483 & 1528025 & 7.0231 & 6.6312 & TRN & & \\
\hline CHEMBL3665229 & 1528025 & 6.0 & 6.4027 & TRN & & \\
\hline CHEMBL3660670 & 1528025 & 6.4353 & 6.3064 & TRN & & \\
\hline CHEMBL3665293 & 1528025 & 6.516 & 6.4681 & TRN & & \\
\hline CHEMBL2180802 & 1528025 & 10.3468 & 9.7861 & TRN & & \\
\hline CHEMBL3660680 & 1528025 & 7.0969 & 6.8646 & TRN & & \\
\hline CHEMBL3660631 & 1528025 & 6.9586 & 7.4009 & TRN & & \\
\hline CHEMBL3660574 & 1528025 & 7.4382 & 7.6663 & TST & & \\
\hline CHEMBL3660603 & 1528025 & 6.0 & 6.7611 & TRN & & \\
\hline CHEMBL3660576 & 1528025 & 7.2574 & 7.6756 & TST & & \\
\hline CHEMBL3665271 & 1528025 & 5.7368 & 5.877999 & 999999999 & & TRN \\
\hline CHEMBL3660489 & 1528025 & 7.5112 & 7.5754 & TRN & & \\
\hline CHEMBL3665234 & 1528025 & 5.3538 & 5.2343 & TRN & & \\
\hline CHEMBL3665286 & 1528025 & 6.3543 & 6.2184 & TRN & & \\
\hline CHEMBL3660671 & 1528025 & 5.9348 & 6.0685 & TRN & & \\
\hline CHEMBL3660592 & 1528025 & 6.8465 & 6.8549 & TRN & & \\
\hline CHEMBL3665238 & 1528025 & 6.2404 & 6.6684 & TRN & & \\
\hline CHEMBL3660500 & 1528025 & 7.0066 & 6.4648 & TRN & & \\
\hline CHEMBL3665260 & 1528025 & 6.2465 & 5.9934 & TRN & & \\
\hline CHEMBL3660645 & 1528025 & 10.2518 & 10.1563 & TRN & & \\
\hline CHEMBL3660522 & 1528025 & 6.5636 & 6.3889 & TST & & \\
\hline CHEMBL3665237 & 1528025 & 5.3438 & 5.2203 & TRN & & \\
\hline CHEMBL3660558 & 1528025 & 7.388 & 7.6031 & TRN & & \\
\hline CHEMBL3660556 & 1528025 & 7.8321 & 7.4684 & TRN & & \\
\hline CHEMBL3665225 & 1528025 & 7.3588 & 7.3132 & TRN & & \\
\hline CHEMBL3665228 & 1528025 & 6.21 & 6.005 & TRN & & \\
\hline CHEMBL3665299 & 1528025 & 6.0 & 7.0065 & TST & & \\
\hline CHEMBL3656323 & 1528025 & 7.1739 & 6.7325 & TRN & & \\
\hline CHEMBL3660690 & 1528025 & 6.8811 & 6.5351 & TRN & & \\
\hline CHEMBL3660604 & 1528025 & 7.7447 & 7.4635 & TRN & & \\
\hline CHEMBL3665273 & 1528025 & 7.308 & 7.013999 & 999999999 & & TST \\
\hline CHEMBL3660691 & 1528025 & 5.6568 & 5.7087 & TRN & & \\
\hline CHEMBL3665242 & 1528025 & 7.6315 & 7.7825 & TRN & & \\
\hline CHEMBL3660537 & 1528025 & 6.1765 & 6.2257 & TRN & & \\
\hline CHEMBL3660526 & 1528025 & 7.3268 & 7.0144 & TST & & \\
\hline CHEMBL3660562 & 1528025 & 7.1938 & 7.3172 & TRN & & \\
\hline CHEMBL3660656 & 1528025 & 7.2084 & 7.5361 & TRN & & \\
\hline CHEMBL3660552 & 1528025 & 7.6218 & 7.6337 & TRN & & \\
\hline CHEMBL3660653 & 1528025 & 6.0 & 6.0942 & TRN & & \\
\hline CHEMBL3665291 & 1528025 & 6.786000 & 300000000 & 205 & 7.2337 & TRN \\
\hline CHEMBL3665262 & 1528025 & 6.5919 & 7.0102 & TRN & & \\
\hline CHEMBL3660505 & 1528025 & 6.0 & 6.2425 & TRN & & \\
\hline CHEMBL3665254 & 1528025 & 6.7628 & 6.6147 & TRN & & \\
\hline CHEMBL3656332 & 1528025 & 6.0 & 6.0937 & TRN & & \\
\hline CHEMBL3660488 & 1528025 & 6.5134 & 7.2872 & TRN & & \\
\hline
\end{tabular}


Supplemental Table S2.txt

\begin{tabular}{|c|c|c|c|c|}
\hline CHEMBL 3660484 & 1528025 & 7.7537 & 6.9123 & TRN \\
\hline CHEMBL3660490 & 1528025 & 6.934 & 7.2057 & TRN \\
\hline CHEMBL3656336 & 1528025 & 6.0 & 6.4637 & TRN \\
\hline CHEMBL3660581 & 1528025 & 8.5229 & 8.7619 & TRN \\
\hline CHEMBL3660549 & 1528025 & 7.5766 & 7.4756 & TRN \\
\hline CHEMBL3660563 & 1528025 & 7.8474 & 7.9832 & TRN \\
\hline CHEMBL3660599 & 1528025 & 7.5686 & 7.614 & TRN \\
\hline CHEMBL3660583 & 1528025 & 8.301 & 8.0084 & TST \\
\hline CHEMBL3656317 & 1528025 & 6.0398 & 6.5834 & TRN \\
\hline CHEMBL3660535 & 1528025 & 7.1427 & 7.3534 & TRN \\
\hline CHEMBL3660560 & 1528025 & 8.2281 & 8.1208 & TRN \\
\hline CHEMBL3660554 & 1528025 & 8.0607 & 7.9081 & TRN \\
\hline CHEMBL3660557 & 1528025 & 7.5528 & 7.6254 & TST \\
\hline CHEMBL3660651 & 1528025 & 6.4928 & 6.4218 & TRN \\
\hline CHEMBL3665290 & 1528025 & 7.0959 & 5.1989 & TST \\
\hline CHEMBL3656315 & 1528025 & 9.0132 & 6.4938 & TST \\
\hline CHEMBL3665224 & 1528025 & 6.7755 & 6.7846 & TRN \\
\hline CHEMBL3660624 & 1528025 & 7.1803 & 6.86100 & 0000000001 \\
\hline CHEMBL3656313 & 1528025 & 7.6139 & 7.9028 & TRN \\
\hline CHEMBL3660541 & 1528025 & 6.0 & 6.4112 & TRN \\
\hline CHEMBL3660672 & 1528025 & 7.4202 & 6.8294 & TRN \\
\hline CHEMBL3660493 & 1528025 & 6.0 & 6.9538 & TST \\
\hline CHEMBL3660532 & 1528025 & 6.7875 & 6.2762 & TST \\
\hline CHEMBL 2207154 & 885155 & 6.9706 & 7.6873 & TST \\
\hline CHEMBL 2207168 & 885155 & 7.5528 & 7.5516 & TRN \\
\hline CHEMBL 2207171 & 885155 & 7.4202 & 7.4179 & TRN \\
\hline CHEMBL 2207584 & 885155 & 5.0969 & 5.0973 & TRN \\
\hline CHEMBL 2207547 & 885155 & 7.1308 & 7.1289 & TRN \\
\hline CHEMBL 2207582 & 885155 & 5.3979 & 5.3932 & TRN \\
\hline CHEMBL 2207545 & 885155 & 7.3098 & 7.3119 & TRN \\
\hline CHEMBL 2207169 & 885155 & 7.5376 & 7.5355 & TRN \\
\hline CHEMBL 2203330 & 885155 & 6.8861 & 6.8802 & TRN \\
\hline CHEMBL 2207585 & 885155 & 8.3768 & 8.3732 & TRN \\
\hline CHEMBL251327 & 885155 & 9.3979 & 3.61899 & 99999999998 \\
\hline CHEMBL 2207586 & 885155 & 8.3372 & 8.3416 & TRN \\
\hline CHEMBL 2207570 & 885155 & 9.2218 & 7.4383 & TST \\
\hline CHEMBL 2207158 & 885155 & 8.2676 & 8.2676 & TRN \\
\hline CHEMBL 2207167 & 885155 & 7.6383 & 7.6377 & TRN \\
\hline CHEMBL1236882 & 885155 & 8.8239 & 7.1143 & TST \\
\hline CHEMBL 2207558 & 885155 & 6.6778 & 6.6823 & TRN \\
\hline CHEMBL 2207159 & 885155 & 8.2441 & 8.2473 & TRN \\
\hline CHEMBL 2207569 & 885155 & 8.6383 & 8.6373 & TRN \\
\hline CHEMBL 2207583 & 885155 & 3.699 & 3.6983 & TRN \\
\hline CHEMBL 2207553 & 885155 & 6.9586 & 6.961 & TRN \\
\hline CHEMBL 2207587 & 885155 & 9.0 & 8.999 & TRN \\
\hline CHEMBL 2207592 & 885155 & 8.5086 & 8.5076 & TRN \\
\hline CHEMBL 2207577 & 885155 & 7.0315 & 7.029 & TRN \\
\hline CHEMBL 2207572 & 885155 & 7.5686 & 7.5701 & TRN \\
\hline
\end{tabular}




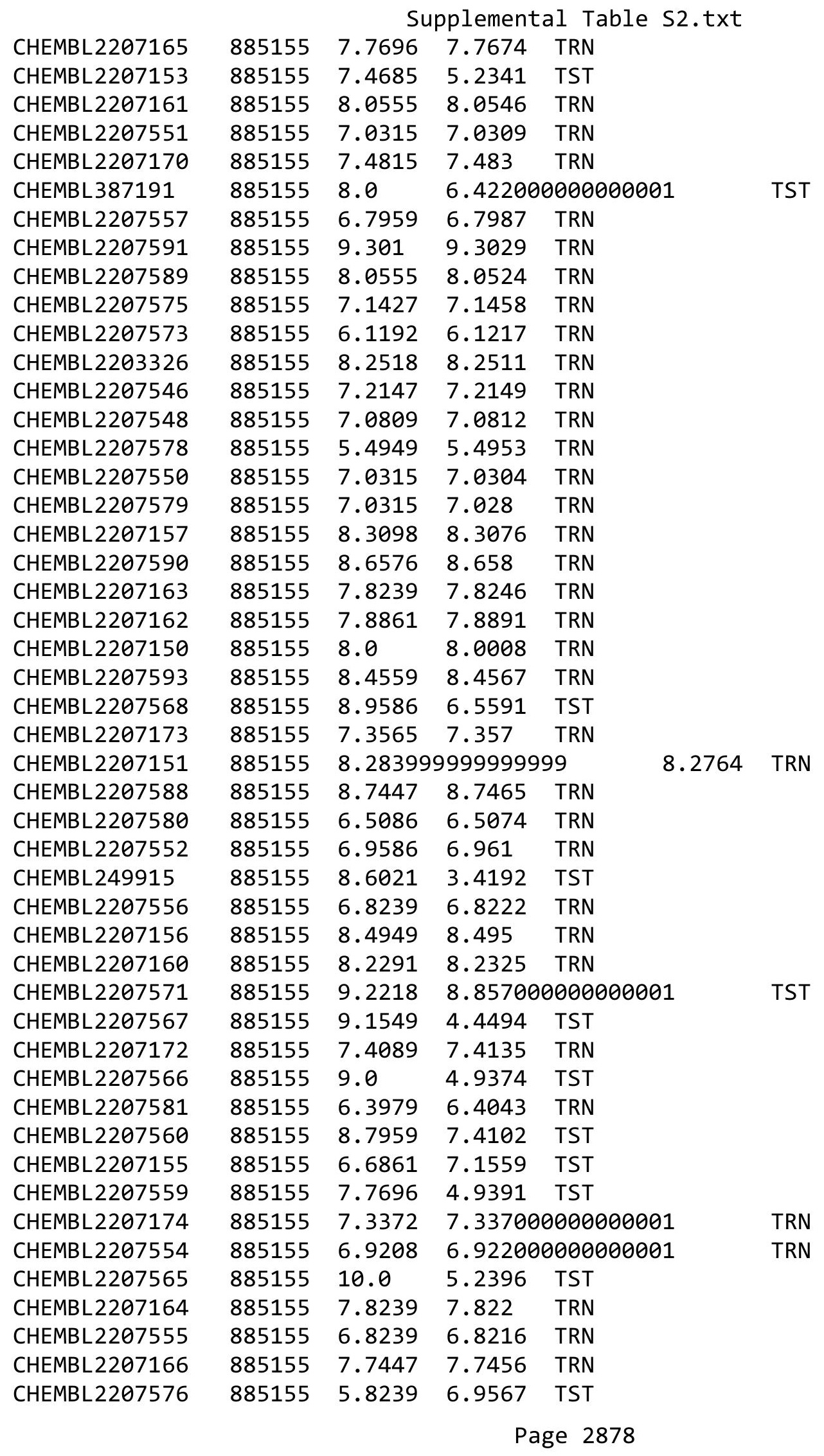


Supplemental Table S2.txt

\begin{tabular}{|c|c|c|c|c|c|c|}
\hline CHEMBL2207152 & 885155 & 7.5528 & \multicolumn{3}{|c|}{5.912999999999999} & TST \\
\hline CHEMBL2207549 & 885155 & 7.0555 & 7.1286 & TST & & \\
\hline CHEMBL2207574 & 885155 & 7.8861 & 6.265 & TST & & \\
\hline CHEMBL3684081 & 1528183 & 7.1549 & 7.2412 & TRN & & \\
\hline CHEMBL3684100 & 1528183 & 5.0 & 5.0505 & TRN & & \\
\hline CHEMBL3127540 & 1528183 & 6.0 & 5.7987 & TRN & & \\
\hline CHEMBL3684098 & 1528183 & 6.0273 & 5.9772 & TRN & & \\
\hline CHEMBL3684119 & 1528183 & 6.5901 & 6.4935 & TRN & & \\
\hline CHEMBL3127643 & 1528183 & 7.9586 & 7.8861 & TRN & & \\
\hline CHEMBL3979656 & 1528183 & 7.6576 & 7.8711 & TRN & & \\
\hline CHEMBL3894972 & 1528183 & 6.7423 & 6.6321 & TRN & & \\
\hline CHEMBL3684083 & 1528183 & 6.0 & 6.2099 & TRN & & \\
\hline CHEMBL3684114 & 1528183 & 7.2757 & 7.9774 & TRN & & \\
\hline CHEMBL3928204 & 1528183 & 6.4989 & 6.5351 & TRN & & \\
\hline CHEMBL3684091 & 1528183 & 8.1549 & 8.0033 & TRN & & \\
\hline CHEMBL3684076 & 1528183 & 7.1192 & 8.3256 & TST & & \\
\hline CHEMBL3684092 & 1528183 & 7.0223 & 6.8927 & TRN & & \\
\hline CHEMBL3949275 & 1528183 & 6.1688 & 6.0578 & TRN & & \\
\hline CHEMBL3127530 & 1528183 & 8.1549 & 7.8492 & TRN & & \\
\hline CHEMBL3127541 & 1528183 & 8.0458 & 7.0875 & TRN & & \\
\hline CHEMBL3684089 & 1528183 & 8.0458 & 8.1303 & TRN & & \\
\hline CHEMBL3893904 & 1528183 & 7.9208 & 7.2291 & TRN & & \\
\hline CHEMBL3684122 & 1528183 & 7.9208 & 7.1288 & TRN & & \\
\hline CHEMBL3684118 & 1528183 & 7.0655 & 7.9278 & TST & & \\
\hline CHEMBL3965467 & 1528183 & 7.4559 & 7.3956 & TRN & & \\
\hline CHEMBL3127664 & 1528183 & 6.3747 & 6.5622 & TRN & & \\
\hline CHEMBL3684124 & 1528183 & 7.2218 & 7.0557 & TRN & & \\
\hline CHEMBL3688829 & 1528183 & 7.2291 & 7.0069 & TST & & \\
\hline CHEMBL3684103 & 1528183 & 5.0 & 7.3552 & TST & & \\
\hline CHEMBL3127538 & 1528183 & 7.9208 & 8.0147 & TRN & & \\
\hline CHEMBL3684097 & 1528183 & 7.8239 & 8.0408 & TRN & & \\
\hline CHEMBL3684116 & 1528183 & 6.8069 & 6.8694 & TRN & & \\
\hline CHEMBL3684079 & 1528183 & 7.8539 & 8.5728 & TST & & \\
\hline CHEMBL3127661 & 1528183 & 6.0 & 6.4803 & TRN & & \\
\hline CHEMBL3949127 & 1528183 & 6.5436 & 6.4474 & TRN & & \\
\hline CHEMBL3684084 & 1528183 & 7.6778 & 7.6237 & TRN & & \\
\hline CHEMBL3127537 & 1528183 & 7.1024 & 7.5708 & TST & & \\
\hline CHEMBL3684077 & 1528183 & 7.1675 & 7.2926 & TRN & & \\
\hline CHEMBL3930420 & 1528183 & 7.7959 & 7.7231 & TRN & & \\
\hline CHEMBL3684117 & 1528183 & 7.1871 & 6.8743 & TRN & & \\
\hline CHEMBL3684108 & 1528183 & 6.8386 & 6.6477 & TRN & & \\
\hline CHEMBL3897975 & 1528183 & 6.4572 & 6.1117 & TRN & & \\
\hline CHEMBL3684096 & 1528183 & 5.0 & 4.9929 & TRN & & \\
\hline CHEMBL3908520 & 1528183 & 6.9172 & 6.7884 & TRN & & \\
\hline CHEMBL3962327 & 1528183 & 6.76200 & 00000000 & 005 & 7.0115 & TRN \\
\hline CHEMBL3684082 & 1528183 & 6.5017 & 6.2243 & TRN & & \\
\hline CHEMBL3684095 & 1528183 & 7.0362 & 7.4153 & TRN & & \\
\hline CHEMBL3684106 & 1528183 & 7.1675 & 6.8886 & TRN & & \\
\hline
\end{tabular}


Supplemental Table S2.txt

\begin{tabular}{|c|c|c|c|c|}
\hline CHEMBL 3684107 & 1528183 & 6.5607 & 7.7577 & TST \\
\hline CHEMBL 3684078 & 1528183 & 7.4685 & 8.2155 & TST \\
\hline CHEMBL3684085 & 1528183 & 6.0 & 6.4812 & TRN \\
\hline CHEMBL 3971592 & 1528183 & 7.699 & 7.6371 & TST \\
\hline CHEMBL 3684113 & 1528183 & 8.0969 & 7.8606 & TRN \\
\hline CHEMBL3684075 & 1528183 & 6.4045 & 7.7697 & TST \\
\hline CHEMBL3684099 & 1528183 & 7.5086 & \multicolumn{2}{|c|}{7.76200000000} \\
\hline CHEMBL 3127644 & 1528183 & 7.6778 & 7.9759 & TST \\
\hline CHEMBL 3684104 & 1528183 & 5.0 & 7.2782 & TST \\
\hline CHEMBL3684105 & 1528183 & 6.4123 & 7.2217 & TST \\
\hline CHEMBL3684121 & 1528183 & 6.8996 & 6.7773 & TRN \\
\hline CHEMBL 3684090 & 1528183 & 5.0 & 5.7037 & TRN \\
\hline CHEMBL 3684087 & 1528183 & 6.9547 & 6.932 & TRN \\
\hline CHEMBL 3127667 & 1528183 & 6.0 & 6.2597 & TRN \\
\hline CHEMBL 3127658 & 1528183 & 6.8996 & 6.7556 & TRN \\
\hline CHEMBL3127651 & 1528183 & 6.0 & 7.7737 & TST \\
\hline CHEMBL3684111 & 1528183 & 7.6778 & 7.6841 & TST \\
\hline CHEMBL 3127666 & 1528183 & 6.0 & 7.2019 & TST \\
\hline CHEMBL3127532 & 1528183 & 6.0 & 6.9886 & TST \\
\hline CHEMBL 3684102 & 1528183 & 7.8239 & 8.1242 & TRN \\
\hline CHEMBL 3684086 & 1528183 & 6.767 & 6.722 & TRN \\
\hline CHEMBL3684112 & 1528183 & 7.284 & 7.2377 & TRN \\
\hline CHEMBL 3895807 & 1528183 & 7.4559 & 7.1098 & TRN \\
\hline CHEMBL3684123 & 1528183 & 8.0969 & 7.9976 & TRN \\
\hline CHEMBL3933027 & 1528183 & 6.0 & 6.6921 & TRN \\
\hline CHEMBL3936465 & 1528183 & 7.6576 & 7.619 & TRN \\
\hline CHEMBL3903911 & 1528183 & 7.8239 & 7.9496 & TRN \\
\hline CHEMBL 3684115 & 1528183 & 8.2218 & 8.373 & TRN \\
\hline CHEMBL3684101 & 1528183 & 5.0 & 6.0969 & TST \\
\hline CHEMBL3982961 & 1528183 & 7.8539 & 7.7794 & TRN \\
\hline CHEMBL 3684094 & 1528183 & 7.9586 & 7.6135 & TST \\
\hline CHEMBL3684093 & 1528183 & 8.0969 & 7.5319 & TRN \\
\hline CHEMBL3684109 & 1528183 & 7.7959 & 7.909 & TRN \\
\hline CHEMBL3127649 & 1528183 & 7.7696 & 7.4119 & TST \\
\hline CHEMBL 3684080 & 1528183 & 6.7825 & 6.8938 & TRN \\
\hline CHEMBL 3684120 & 1528183 & 6.0 & 7.0522 & TRN \\
\hline CHEMBL 3684110 & 1528183 & 7.6778 & 7.9116 & TRN \\
\hline CHEMBL1817766 & 763492 & 4.0 & 4.2926 & TST \\
\hline CHEMBL1817750 & 763492 & 5.2757 & 5.0086 & TRN \\
\hline CHEMBL1817770 & 763492 & 6.0132 & 5.4863 & TRN \\
\hline CHEMBL1819550 & 763492 & 6.4815 & 6.5668 & TST \\
\hline CHEMBL1817706 & 763492 & 6.8539 & 6.7855 & TRN \\
\hline CHEMBL1819547 & 763492 & 5.6021 & 6.0233 & TST \\
\hline CHEMBL1819545 & 763492 & 4.0 & 4.0176 & TRN \\
\hline CHEMBL1819556 & 763492 & 6.4202 & 6.8825 & TST \\
\hline CHEMBL1817695 & 763492 & 4.0 & 4.0362 & TRN \\
\hline CHEMBL1817704 & 763492 & 6.5376 & 7.2766 & TRN \\
\hline CHEMBL1819541 & 763492 & 8.3872 & 8.3422 & TRN \\
\hline
\end{tabular}

Page 2880 


\begin{tabular}{|c|c|c|c|c|c|}
\hline \multicolumn{6}{|c|}{ Supplemental Table S2.txt } \\
\hline CHEMBL1819551 & 763492 & 4.0 & 3.8839 & TRN & \\
\hline CHEMBL1817708 & 763492 & 6.7212 & 6.7085 & TRN & \\
\hline CHEMBL1817764 & 763492 & 4.0 & 3.822 & TRN & \\
\hline CHEMBL1819540 & 763492 & 8.0362 & 8.0807 & TRN & \\
\hline CHEMBL1817753 & 763492 & 4.0 & 4.1153 & TRN & \\
\hline CHEMBL1819546 & 763492 & 4.0 & 5.0954 & TST & \\
\hline CHEMBL1817765 & 763492 & 4.0 & 4.2287 & TRN & \\
\hline CHEMBL1819554 & 763492 & 5.9208 & 6.1097 & TRN & \\
\hline CHEMBL1817702 & 763492 & 5.7959 & 5.7287 & TRN & \\
\hline CHEMBL1819558 & 763492 & 5.585 & 5.7844 & TRN & \\
\hline CHEMBL1817671 & 763492 & 5.9586 & 5.7814 & TRN & \\
\hline CHEMBL1819552 & 763492 & 6.3279 & 6.4487 & TRN & \\
\hline CHEMBL1817751 & 763492 & 5.7959 & 5.2414 & TRN & \\
\hline CHEMBL1817768 & 763492 & 4.0 & 3.6708 & TRN & \\
\hline CHEMBL1817772 & 763492 & 4.0 & 4.4083 & TRN & \\
\hline CHEMBL1817692 & 763492 & 4.0 & 3.95300 & 00000000003 & TRN \\
\hline CHEMBL1817771 & 763492 & 4.0 & 4.0738 & TRN & \\
\hline CHEMBL1817760 & 763492 & 4.0 & 3.4046 & TST & \\
\hline CHEMBL1819553 & 763492 & 5.9208 & 6.0205 & TRN & \\
\hline CHEMBL1819557 & 763492 & 6.6778 & 6.3393 & TRN & \\
\hline CHEMBL1817761 & 763492 & 6.4089 & 6.9302 & TST & \\
\hline CHEMBL1817754 & 763492 & 4.0 & 4.0275 & TRN & \\
\hline CHEMBL1817691 & 763492 & 6.7696 & 6.9619 & TRN & \\
\hline CHEMBL1817759 & 763492 & 4.0 & 4.3863 & TST & \\
\hline CHEMBL1819559 & 763492 & 5.5229 & 5.3918 & TRN & \\
\hline CHEMBL1817763 & 763492 & 4.0 & 4.6646 & TST & \\
\hline CHEMBL1817767 & 763492 & 4.0 & 4.6286 & TST & \\
\hline CHEMBL1817690 & 763492 & 5.9208 & 5.8773 & TRN & \\
\hline CHEMBL1817749 & 763492 & 4.0 & 4.422 & TRN & \\
\hline CHEMBL1817707 & 763492 & 6.585 & 6.5179 & TRN & \\
\hline CHEMBL1819543 & 763492 & 7.1367 & 7.0431 & TRN & \\
\hline CHEMBL1817698 & 763492 & 4.0 & 4.0144 & TRN & \\
\hline CHEMBL1817757 & 763492 & 4.0 & 3.8415 & TST & \\
\hline CHEMBL1817762 & 763492 & 4.0 & 3.8881 & TST & \\
\hline CHEMBL1817696 & 763492 & 5.585 & 5.6887 & TRN & \\
\hline CHEMBL1819441 & 763492 & 8.8539 & 8.8614 & TRN & \\
\hline CHEMBL1817693 & 763492 & 4.0 & 4.4624 & TRN & \\
\hline CHEMBL1817752 & 763492 & 5.4318 & 5.0724 & TRN & \\
\hline CHEMBL1817756 & 763492 & 6.0223 & 6.7664 & TST & \\
\hline CHEMBL1817701 & 763492 & 4.0 & 3.8703 & TRN & \\
\hline CHEMBL1819560 & 763492 & 5.7696 & 5.5784 & TRN & \\
\hline CHEMBL1817758 & 763492 & 4.0 & 4.7007 & TST & \\
\hline CHEMBL1817700 & 763492 & 4.0 & 4.0089 & TRN & \\
\hline CHEMBL1817694 & 763492 & 4.0 & 4.5636 & TRN & \\
\hline CHEMBL1817755 & 763492 & 4.0 & 4.1771 & TRN & \\
\hline CHEMBL1819542 & 763492 & 6.8097 & 6.3236 & TRN & \\
\hline CHEMBL1817697 & 763492 & 4.0 & 4.0102 & TRN & \\
\hline CHEMBL1817705 & 763492 & 6.8861 & 6.7885 & TRN & \\
\hline
\end{tabular}

Page 2881 


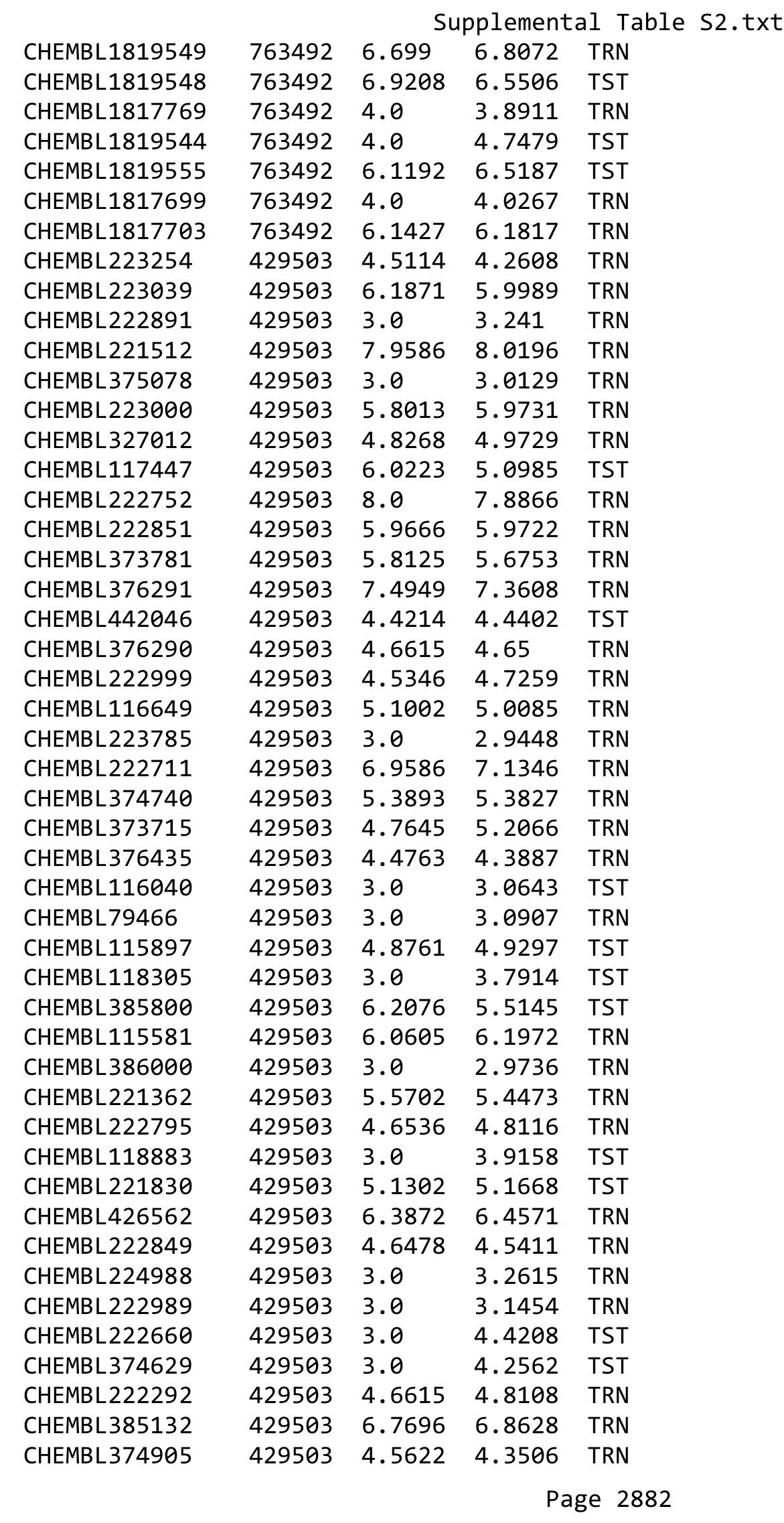




\begin{tabular}{|c|c|c|c|c|c|c|}
\hline \multicolumn{7}{|c|}{ Supplemental Table S2.txt } \\
\hline CHEMBL224884 & 429503 & 3.0 & 3.2547 & TRN & & \\
\hline CHEMBL 374331 & 429503 & 5.5406 & 5.5687 & TRN & & \\
\hline CHEMBL221669 & 429503 & 4.2716 & 4.0643 & TRN & & \\
\hline CHEMBL 375304 & 429503 & 5.2588 & 5.1041 & TRN & & \\
\hline CHEMBL 222712 & 429503 & 6.699 & 6.7757 & TRN & & \\
\hline CHEMBL225169 & 429503 & 6.5528 & 5.9035 & TST & & \\
\hline CHEMBL 376518 & 429503 & 6.1308 & 6.0267 & TRN & & \\
\hline CHEMBL 225175 & 429503 & 4.4622 & 4.1219 & TRN & & \\
\hline CHEMBL 222644 & 429503 & 8.0969 & 8.0196 & TRN & & \\
\hline CHEMBL375126 & 429503 & 7.1739 & 7.2849 & TRN & & \\
\hline CHEMBL222988 & 429503 & 4.7799 & 5.0316 & TST & & \\
\hline CHEMBL 221873 & 429503 & 3.0 & 2.8109 & TRN & & \\
\hline CHEMBL222149 & 429503 & 6.2147 & 6.2116 & TRN & & \\
\hline CHEMBL 223001 & 429503 & 3.0 & 2.9381 & TRN & & \\
\hline CHEMBL376228 & 429503 & 5.1096 & 5.0693 & TST & & \\
\hline CHEMBL 325480 & 429503 & 4.6421 & 4.7093 & TST & & \\
\hline CHEMBL 374970 & 429503 & 4.1662 & 4.1658 & TRN & & \\
\hline CHEMBL333636 & 429503 & 4.0726 & 3.9009 & TRN & & \\
\hline CHEMBL385799 & 429503 & 5.5918 & 5.7382 & TST & & \\
\hline CHEMBL 374758 & 429503 & 7.3279 & 7.2276 & TRN & & \\
\hline CHEMBL326294 & 429503 & 3.0 & 3.3372 & TST & & \\
\hline CHEMBL 222190 & 429503 & 5.02 & 4.8965 & TRN & & \\
\hline CHEMBL 224822 & 429503 & 4.5272 & 4.2036 & TST & & \\
\hline CHEMBL60569 & 429503 & 4.4179 & 4.4729 & TRN & & \\
\hline CHEMBL 2036223 & 821892 & 8.2676 & 8.3037 & TRN & & \\
\hline CHEMBL 2036224 & 821892 & 8.6576 & 8.6515 & TRN & & \\
\hline CHEMBL 2036023 & 821892 & 6.6576 & 6.6432 & TRN & & \\
\hline CHEMBL 2036205 & 821892 & 8.2518 & 8.2275 & TRN & & \\
\hline CHEMBL2036231 & 821892 & 5.0969 & 7.6023 & TST & & \\
\hline CHEMBL 2036029 & 821892 & 8.4437 & 8.4092 & TRN & & \\
\hline CHEMBL 2036198 & 821892 & 7.3468 & 7.395 & TRN & & \\
\hline CHEMBL 2036018 & 821892 & 7.4089 & 7.3836 & TRN & & \\
\hline CHEMBL 2036028 & 821892 & 8.5229 & 8.5652 & TRN & & \\
\hline CHEMBL2036027 & 821892 & 8.1192 & 8.183 & TRN & & \\
\hline CHEMBL 2036216 & 821892 & 8.28399 & 99999999 & 99 & 8.2163 & TRN \\
\hline CHEMBL 2036211 & 821892 & 8.6198 & 8.6068 & TRN & & \\
\hline CHEMBL 2036214 & 821892 & 8.1135 & 8.2287 & TRN & & \\
\hline CHEMBL 2036014 & 821892 & 6.8539 & 6.9482 & TST & & \\
\hline CHEMBL 2036025 & 821892 & 8.5229 & 8.5359 & TRN & & \\
\hline CHEMBL 2036022 & 821892 & 6.4437 & 6.5546 & TRN & & \\
\hline CHEMBL 2036204 & 821892 & 7.9586 & 7.9674 & TRN & & \\
\hline CHEMBL 2036201 & 821892 & 7.3768 & 7.4536 & TRN & & \\
\hline CHEMBL 2036035 & 821892 & 7.7447 & 7.7289 & TRN & & \\
\hline CHEMBL 2036218 & 821892 & 7.6576 & 7.6752 & TRN & & \\
\hline CHEMBL 2036034 & 821892 & 6.2366 & 6.2793 & TRN & & \\
\hline CHEMBL 2036016 & 821892 & 8.4815 & 8.4567 & TRN & & \\
\hline CHEMBL 2036215 & 821892 & 7.7212 & 7.7724 & TRN & & \\
\hline CHEMBL2036226 & 821892 & 8.6021 & 8.5754 & TRN & & \\
\hline
\end{tabular}


Supplemental Table S2.txt

\begin{tabular}{|c|c|c|c|c|}
\hline CHEMBL 2036032 & 821892 & 5.8539 & 5.8275 & TRN \\
\hline CHEMBL 2036221 & 821892 & 7.7696 & 7.7101 & TRN \\
\hline CHEMBL 2036031 & 821892 & 6.0223 & 5.9838 & TRN \\
\hline CHEMBL 2036230 & 821892 & 5.3665 & 8.01799 & э999999999 \\
\hline CHEMBL 2036208 & 821892 & 6.6576 & 6.6929 & TRN \\
\hline CHEMBL 2036024 & 821892 & 7.3565 & 7.2666 & TRN \\
\hline CHEMBL 2036200 & 821892 & 7.2518 & 8.0297 & TST \\
\hline CHEMBL 2036203 & 821892 & 8.1549 & 8.1212 & TRN \\
\hline CHEMBL 2036030 & 821892 & 8.1938 & 8.189 & TRN \\
\hline CHEMBL 2036225 & 821892 & 9.0458 & 9.0177 & TRN \\
\hline CHEMBL 2036212 & 821892 & 8.3468 & 8.3864 & TRN \\
\hline CHEMBL 2036033 & 821892 & 5.9208 & 5.8866 & TRN \\
\hline CHEMBL 2036210 & 821892 & 8.2441 & 8.2783 & TRN \\
\hline CHEMBL 2036222 & 821892 & 8.4949 & 8.5283 & TRN \\
\hline CHEMBL 2036219 & 821892 & 7.1612 & 7.1735 & TRN \\
\hline CHEMBL 2036206 & 821892 & 8.3098 & 8.2992 & TRN \\
\hline CHEMBL2036213 & 821892 & 8.1612 & 7.9341 & TRN \\
\hline CHEMBL2036017 & 821892 & 7.301 & 7.2774 & TRN \\
\hline CHEMBL 2036036 & 821892 & 8.1487 & 7.6774 & TST \\
\hline CHEMBL 2036015 & 821892 & 8.0 & 7.6836 & TST \\
\hline CHEMBL 2036229 & 821892 & 7.7696 & 7.835 & TRN \\
\hline CHEMBL 2036020 & 821892 & 6.2076 & 6.9324 & TST \\
\hline CHEMBL2036026 & 821892 & 8.0862 & 8.0644 & TRN \\
\hline CHEMBL 2036019 & 821892 & 6.4815 & 6.4653 & TRN \\
\hline CHEMBL 2036227 & 821892 & 7.5528 & 7.5727 & TRN \\
\hline CHEMBL 2036202 & 821892 & 7.9208 & 7.8632 & TST \\
\hline CHEMBL2036217 & 821892 & 7.585 & 7.6325 & TST \\
\hline CHEMBL 2036199 & 821892 & 6.8861 & 7.3145 & TST \\
\hline CHEMBL 2036220 & 821892 & 8.5086 & 8.3637 & TST \\
\hline CHEMBL 2036228 & 821892 & 8.3979 & 7.684 & TST \\
\hline CHEMBL 2036207 & 821892 & 8.699 & 9.2169 & TST \\
\hline CHEMBL 2036209 & 821892 & 6.9586 & 6.7683 & TST \\
\hline CHEMBL 2036021 & 821892 & 5.7447 & 6.6456 & TST \\
\hline CHEMBL1504701 & 688261 & 5.7788 & 5.7198 & TRN \\
\hline CHEMBL1527380 & 688261 & 6.0155 & 6.1709 & TRN \\
\hline CHEMBL1380099 & 688261 & 4.808 & 5.0314 & TST \\
\hline CHEMBL1323872 & 688261 & 5.205 & 5.715 & TRN \\
\hline CHEMBL1319113 & 688261 & 4.6072 & 4.8098 & TST \\
\hline CHEMBL1993287 & 688261 & 5.7206 & 5.2664 & TRN \\
\hline CHEMBL1584468 & 688261 & 4.5961 & 4.6595 & TRN \\
\hline CHEMBL1482760 & 688261 & 5.2763 & 5.2448 & TRN \\
\hline CHEMBL1556634 & 688261 & 4.8439 & 4.7228 & TST \\
\hline CHEMBL1342728 & 688261 & 4.9171 & 5.0686 & TRN \\
\hline CHEMBL1349063 & 688261 & 5.5725 & 5.6339 & TRN \\
\hline CHEMBL1560237 & 688261 & 6.2464 & 5.9278 & TST \\
\hline CHEMBL1328504 & 688261 & 5.2077 & 4.7952 & TRN \\
\hline CHEMBL1608535 & 688261 & 5.0044 & 4.6888 & TRN \\
\hline CHEMBL1481849 & 688261 & 5.3286 & 5.3641 & TST \\
\hline
\end{tabular}


Supplemental Table S2.txt

\begin{tabular}{|c|c|c|c|c|}
\hline 年 & & & & \\
\hline AEMBL15 & 88261 & 6484 & & \\
\hline HEMBL1302266 & 38261 & 8764 & 6141 & \\
\hline HEMBL1608727 & 88261 & .23 & 7108 & \\
\hline & 3261 & & & \\
\hline IEMBL136 & 8261 & 239 & 2086 & S \\
\hline AEMBL1521127 & 88261 & 8239 & 411 & \\
\hline HEMBL1476215 & 88261 & .9052 & .1272 & \\
\hline HEMBL1403980 & 88261 & .2904 & .5004 & \\
\hline IEMBL1451142 & 38261 & 3239 & 3862 & \\
\hline IEMBL1580075 & 38261 & 239 & .4381 & DNe \\
\hline HEMBL1378769 & 88261 & 0177 & 5.4872 & \\
\hline HEMBL1392026 & 88261 & 3742 & 0763 & \\
\hline L328834 & 88261 & & & \\
\hline EMBL1441181 & 38261 & & 1075 & \\
\hline AEMBL1315921 & 38261 & 523 & 9165 & \\
\hline HEMBL1383090 & 88261 & 3298 & 1746 & IRN \\
\hline HEMBL1308457 & 88261 & 39 & 57 & \\
\hline HBBL13be & 61 & 51 & 3609 & \\
\hline L1981 & 261 & & 2276 & \\
\hline L1488 & 261 & & 7942 & \\
\hline L1430227 & 88261 & & 5172 & \\
\hline HEMBL134 & 88261 & & & IRN \\
\hline L15 & 61 & & 25 & RN \\
\hline L14 & & & & RN \\
\hline 5 & 61 & & 94 & \\
\hline L152 & 88261 & & 5188 & $T$ \\
\hline AEMBL154 & 88261 & & & 「RN \\
\hline AEMBL1376 & 61 & & 203 & RN \\
\hline 16 & 51 & & 517 & RN \\
\hline 15 & 51 & 02 & 3866 & RN \\
\hline 3L1325 & 61 & & 542 & RN \\
\hline AEMBL1428163 & 61 & & & TRN \\
\hline AEMBL150 & 61 & & 1906 & RN \\
\hline L15 & & & 18 & RN \\
\hline 4 & & & & RN \\
\hline IEMBL1527310 & 88261 & & 91 & ST \\
\hline AEMBL1453212 & 88261 & & 2819 & TRN \\
\hline IEMBL14 & & & 2391 & RN \\
\hline 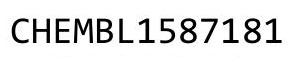 & & & 3926 & RN \\
\hline-13 & 51 & & & RN \\
\hline HEMBL1481139 & 88261 & 2.8239 & 3.5364 & RN \\
\hline IEMBL15 & 51 & & 504 & TRN \\
\hline$y$ & & & 34 & TST \\
\hline & & & 4.8161 & \\
\hline HEMBL 15 & 261 & & 5.1083 & RN \\
\hline-1602759 & 88261 & 5.3774 & 5.6382 & TRN \\
\hline CHEMBL1563712 & 688261 & 2.8239 & 4.5125 & TRN \\
\hline
\end{tabular}

Page 2885 
Supplemental Table S2.txt

\begin{tabular}{|c|c|c|c|c|c|}
\hline CHEMBL1547092 & 688261 & 5.5058 & 5.0408 & TRN & \\
\hline CHEMBL1518905 & 688261 & 6.0443 & 5.9643 & TRN & \\
\hline CHEMBL1396099 & 688261 & 5.6442 & 4.8317 & TST & \\
\hline CHEMBL1967952 & 688261 & 5.5441 & 5.4993 & TRN & \\
\hline CHEMBL1490339 & 688261 & 6.3979 & 6.3054 & TRN & \\
\hline CHEMBL1337919 & 688261 & 4.4528 & 3.4164 & TRN & \\
\hline CHEMBL1476358 & 688261 & 5.5879 & 3.5423 & TRN & \\
\hline CHEMBL1468200 & 688261 & 4.6384 & 4.513 & TST & \\
\hline CHEMBL1303916 & 688261 & 5.1013 & 4.6144 & TRN & \\
\hline CHEMBL1535055 & 688261 & 3.1249 & 4.1759 & TRN & \\
\hline CHEMBL1606557 & 688261 & 2.8239 & 3.5899 & TRN & \\
\hline CHEMBL1560590 & 688261 & 4.7571 & 4.7861 & TRN & \\
\hline CHEMBL31840 & 688261 & 5.6225 & 5.8055 & TRN & \\
\hline CHEMBL1602160 & 688261 & 4.4476 & 4.775 & TRN & \\
\hline CHEMBL1442452 & 688261 & 2.8239 & 3.5132 & TRN & \\
\hline CHEMBL1399212 & 688261 & 5.0354 & 4.4891 & TRN & \\
\hline CHEMBL1500190 & 688261 & 5.7838 & 5.3222 & TRN & \\
\hline CHEMBL3194449 & 688261 & 5.3051 & 5.1101 & TRN & \\
\hline CHEMBL1563623 & 688261 & 5.13899 & 999999999 & 4.715 & \\
\hline CHEMBL1579636 & 688261 & 5.8887 & 5.8564 & TRN & \\
\hline CHEMBL1576851 & 688261 & 5.6906 & 5.2421 & TRN & \\
\hline CHEMBL452328 & 688261 & 4.4197 & 4.4789 & TRN & \\
\hline CHEMBL1987894 & 688261 & 5.4777 & 5.689 & TRN & \\
\hline CHEMBL1453099 & 688261 & 4.4002 & 4.999 & TST & \\
\hline CHEMBL1458951 & 688261 & 2.8239 & 3.2178 & TRN & \\
\hline CHEMBL3209306 & 688261 & 5.2695 & 5.5054 & TRN & \\
\hline CHEMBL1370884 & 688261 & 5.4819 & 5.7201 & TRN & \\
\hline CHEMBL3191151 & 688261 & 5.6075 & 5.5829 & TRN & \\
\hline CHEMBL1466523 & 688261 & 5.994 & 5.5521 & TRN & \\
\hline CHEMBL585502 & 688261 & 5.647 & 6.013999 & 9999999999 & KI \\
\hline CHEMBL1471808 & 688261 & 2.8239 & 4.1401 & TRN & \\
\hline CHEMBL1544633 & 688261 & 4.5397 & 6.032 & TRN & \\
\hline CHEMBL1438717 & 688261 & 5.2634 & 5.0124 & TRN & \\
\hline CHEMBL576208 & 688261 & 4.7816 & 4.6562 & TRN & \\
\hline CHEMBL599098 & 688261 & 5.3469 & 5.0306 & TRN & \\
\hline CHEMBL1344300 & 688261 & 4.1149 & 3.8434 & TST & \\
\hline CHEMBL1588452 & 688261 & 4.71899 & 999999999 & 4.8501 & 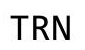 \\
\hline CHEMBL1481030 & 688261 & 6.1713 & 5.7643 & TRN & \\
\hline CHEMBL1555271 & 688261 & 5.7314 & 5.7898 & TRN & \\
\hline CHEMBL1586531 & 688261 & 5.2356 & 5.2043 & TST & \\
\hline CHEMBL1608301 & 688261 & 4.7689 & 4.6345 & TRN & \\
\hline CHEMBL3208365 & 688261 & 5.6959 & 5.8259 & TST & \\
\hline CHEMBL1611472 & 688261 & 2.8239 & 3.166000 & 30000000004 & RN \\
\hline CHEMBL1598569 & 688261 & 4.4871 & 4.7213 & TRN & \\
\hline CHEMBL1492222 & 688261 & 5.5819 & 5.3264 & TRN & \\
\hline CHEMBL3199665 & 688261 & 5.9935 & 5.8296 & TRN & \\
\hline CHEMBL1610733 & 688261 & 5.0205 & 4.6902 & TST & \\
\hline CHEMBL1382517 & 688261 & 5.0668 & 5.3742 & TST & \\
\hline
\end{tabular}




\begin{tabular}{|c|c|c|c|c|c|c|}
\hline & & & & & & \\
\hline CHEMBL546170 & 688261 & 4.7564 & 5.2139 & TRN & & \\
\hline CHEMBL604321 & 688261 & 5.189 & 5.2715 & TST & & \\
\hline CHEMBL1545099 & 688261 & 6.4191 & 6.0358 & TRN & & \\
\hline CHEMBL3199050 & 688261 & 5.2085 & 5.5642 & TRN & & \\
\hline CHEMBL1987938 & 688261 & 5.2447 & 5.3989 & TRN & & \\
\hline CHEMBL89445 & 688261 & 4.7667 & 5.4268 & TRN & & \\
\hline CHEMBL1504035 & 688261 & 4.9841 & 5.1253 & TRN & & \\
\hline CHEMBL1421396 & 688261 & 4.8016 & 5.0048 & TRN & & \\
\hline CHEMBL1380406 & 688261 & 5.0252 & 5.0031 & TRN & & \\
\hline CHEMBL1374715 & 688261 & 6.0947 & 5.7498 & TST & & \\
\hline CHEMBL1389427 & 688261 & 5.0928 & 4.8955 & TRN & & \\
\hline CHEMBL1529978 & 688261 & 5.5333 & 5.6031 & TRN & & \\
\hline CHEMBL1605372 & 688261 & 4.8273 & 5.1367 & TST & & \\
\hline CHEMBL1401327 & 688261 & 4.3833 & 4.0131 & TRN & & \\
\hline CHEMBL1404448 & 688261 & 5.6664 & 6.0345 & TRN & & \\
\hline CHEMBL405317 & 688261 & 5.4852 & 5.5519 & TRN & & \\
\hline CHEMBL1442431 & 688261 & 5.4608 & 5.3941 & TRN & & \\
\hline CHEMBL1966241 & 688261 & 5.92299 & 99999999 & 99 & 5.7062 & TRN \\
\hline CHEMBL1419779 & 688261 & 4.9023 & 5.0298 & TRN & & \\
\hline CHEMBL1346521 & 688261 & 4.6045 & 3.5242 & TRN & & \\
\hline CHEMBL1321754 & 688261 & 4.666 & 4.5277 & TRN & & \\
\hline CHEMBL1525300 & 688261 & 4.8037 & 4.5758 & TRN & & \\
\hline CHEMBL1365332 & 688261 & 4.9637 & 4.8649 & TRN & & \\
\hline CHEMBL1400319 & 688261 & 2.8239 & 3.7791 & TRN & & \\
\hline CHEMBL1999480 & 688261 & 5.7206 & 5.7975 & TST & & \\
\hline CHEMBL1514238 & 688261 & 5.9477 & 3.1906 & TRN & & \\
\hline CHEMBL1368752 & 688261 & 3.8341 & 2.7775 & TRN & & \\
\hline CHEMBL3191127 & 688261 & 5.5607 & 5.1439 & TRN & & \\
\hline CHEMBL1387436 & 688261 & 4.9855 & 4.6428 & TRN & & \\
\hline CHEMBL3193945 & 688261 & 4.4435 & 4.4042 & TRN & & \\
\hline CHEMBL1504036 & 688261 & 5.3099 & 5.0825 & TRN & & \\
\hline CHEMBL1469642 & 688261 & 5.043 & 5.1036 & TST & & \\
\hline CHEMBL1348389 & 688261 & 5.8976 & 5.9286 & TRN & & \\
\hline CHEMBL1612044 & 688261 & 5.2821 & 5.3906 & TRN & & \\
\hline CHEMBL1330780 & 688261 & 4.8074 & 4.0804 & TRN & & \\
\hline CHEMBL1519014 & 688261 & 4.9521 & 4.3618 & TRN & & \\
\hline CHEMBL1404086 & 688261 & 4.2456 & 4.6222 & TRN & & \\
\hline CHEMBL1312676 & 688261 & 4.13899 & 79999999 & 99 & 4.124 & TRN \\
\hline CHEMBL1373992 & 688261 & 4.5585 & 4.8488 & TST & & \\
\hline CHEMBL1491893 & 688261 & 6.3737 & 6.6262 & TRN & & \\
\hline CHEMBL1597628 & 688261 & 5.32299 & 99999999 & 995 & 4.9023 & TRN \\
\hline CHEMBL19954 & 688261 & 5.6005 & 5.4639 & TRN & & \\
\hline CHEMBL1302639 & 688261 & 4.918 & 4.8441 & TRN & & \\
\hline CHEMBL1602792 & 688261 & 5.2588 & 5.2348 & TST & & \\
\hline CHEMBL1989858 & 688261 & 5.2165 & 5.4978 & TST & & \\
\hline CHEMBL1471587 & 688261 & 4.7141 & 4.5645 & TRN & & \\
\hline CHEMBL1301094 & 688261 & 2.8239 & 3.5356 & TRN & & \\
\hline CHEMBL1399938 & 688261 & 5.5667 & 5.6324 & TRN & & \\
\hline
\end{tabular}


Supplemental Table S2.txt

\begin{tabular}{|c|c|c|c|c|}
\hline CHEMBL1599438 & 688261 & 5.7978 & 6.07 & TRN \\
\hline CHEMBL1584364 & 688261 & 2.8239 & 3.3859 & TRN \\
\hline CHEMBL1380239 & 688261 & 4.8401 & 4.9323 & TRN \\
\hline CHEMBL1789993 & 688261 & 5.2454 & 5.0981 & TST \\
\hline CHEMBL1346284 & 688261 & 6.2798 & 6.4283 & TRN \\
\hline CHEMBL1360194 & 688261 & 2.8239 & 2.8894 & TRN \\
\hline CHEMBL1317682 & 688261 & 2.8239 & 3.7913 & TRN \\
\hline CHEMBL1500284 & 688261 & 5.5268 & 5.1127 & TST \\
\hline CHEMBL1487460 & 688261 & 4.7091 & 4.7088 & TRN \\
\hline CHEMBL1255733 & 688261 & 6.3565 & 6.03700 & 7аaаaаa \\
\hline CHEMBL1406552 & 688261 & 4.7477 & 4.5377 & TST \\
\hline CHEMBL1462711 & 688261 & 4.1556 & 4.2312 & TRN \\
\hline CHEMBL1301125 & 688261 & 5.4407 & 5.53 & TST \\
\hline CHEMBL1506210 & 688261 & 5.1791 & 4.7364 & TRN \\
\hline CHEMBL1565600 & 688261 & 4.8196 & 4.8155 & TST \\
\hline CHEMBL 1455485 & 688261 & 4.7113 & 5.5512 & TRN \\
\hline CHEMBL1347156 & 688261 & 4.0669 & 4.365 & TRN \\
\hline CHEMBL1393944 & 688261 & 4.1021 & 4.383 & TRN \\
\hline CHEMBL1588661 & 688261 & 6.0555 & 6.0026 & TRN \\
\hline CHEMBL1371056 & 688261 & 6.1959 & 6.1681 & TRN \\
\hline CHEMBL1600963 & 688261 & 2.8239 & 3.3637 & TRN \\
\hline CHEMBL1322645 & 688261 & 5.0181 & 4.893 & TST \\
\hline CHEMBL1324319 & 688261 & 4.8894 & 5.325 & TRN \\
\hline CHEMBL1971248 & 688261 & 5.3655 & 4.9349 & TRN \\
\hline CHEMBL1403148 & 688261 & 5.58 & 5.8203 & TRN \\
\hline CHEMBL1532887 & 688261 & 4.676 & 4.3088 & TRN \\
\hline CHEMBL1334307 & 688261 & 5.0661 & 5.0655 & TRN \\
\hline CHEMBL1997659 & 688261 & 4.6233 & 4.7298 & TRN \\
\hline CHEMBL1587031 & 688261 & 5.041 & 5.1824 & TST \\
\hline CHEMBL1990919 & 688261 & 6.1871 & 6.1332 & TRN \\
\hline CHEMBL1337416 & 688261 & 5.0596 & 5.3835 & TST \\
\hline CHEMBL1987454 & 688261 & 6.1824 & 5.9297 & TRN \\
\hline CHEMBL353764 & 688261 & 4.8416 & 4.5723 & TRN \\
\hline CHEMBL1324082 & 688261 & 5.3581 & 5.2447 & TRN \\
\hline CHEMBL1563218 & 688261 & 4.9121 & 4.7597 & TRN \\
\hline CHEMBL600778 & 688261 & 6.0223 & 5.8698 & TRN \\
\hline CHEMBL257286 & 688261 & 4.4685 & 4.49 & TRN \\
\hline CHEMBL1330279 & 688261 & 5.3779 & 6.0416 & TRN \\
\hline CHEMBL1326803 & 688261 & 5.5589 & 6.0115 & TRN \\
\hline CHEMBL1558695 & 688261 & 5.8586 & 5.2702 & TRN \\
\hline CHEMBL1321240 & 688261 & 5.6087 & 5.4831 & TRN \\
\hline CHEMBL1401175 & 688261 & 5.9842 & 5.6025 & TST \\
\hline CHEMBL1447563 & 688261 & 5.631 & 5.2122 & TRN \\
\hline CHEMBL1509637 & 688261 & 2.8239 & 3.4166 & TRN \\
\hline CHEMBL1500581 & 688261 & 5.9846 & 5.7745 & TST \\
\hline CHEMBL1564670 & 688261 & 2.8239 & 3.6156 & TRN \\
\hline CHEMBL1490060 & 688261 & 4.8272 & 5.1428 & TRN \\
\hline CHEMBL1393193 & 688261 & 4.9816 & 4.3611 & TRN \\
\hline
\end{tabular}




\begin{tabular}{|c|c|c|c|c|c|c|}
\hline \multirow[b]{2}{*}{ CHEMBL37570 } & & \multicolumn{5}{|c|}{ Supplemental Table S2.txt } \\
\hline & 688261 & 5.848 & \multicolumn{3}{|c|}{5.627999999999999} & TRN \\
\hline CHEMBL1349146 & 688261 & 5.2992 & 6.019 & TRN & & \\
\hline CHEMBL 2135351 & 688261 & 6.0706 & 5.8129 & TST & & \\
\hline CHEMBL1547278 & 688261 & 4.7718 & 4.2835 & TRN & & \\
\hline CHEMBL 1447885 & 688261 & 5.0442 & 4.6942 & TRN & & \\
\hline CHEMBL1533738 & 688261 & 4.7479 & 4.7212 & TST & & \\
\hline CHEMBL1371028 & 688261 & 4.7024 & 4.2552 & TRN & & \\
\hline CHEMBL3191855 & 688261 & 5.5387 & 5.7957 & TRN & & \\
\hline CHEMBL1569667 & 688261 & 5.9739 & 5.5979 & TRN & & \\
\hline CHEMBL1483593 & 688261 & 6.6946 & 6.4072 & TRN & & \\
\hline CHEMBL603129 & 688261 & 4.9088 & 5.4375 & TRN & & \\
\hline CHEMBL1558285 & 688261 & $4.8180 e$ & 00000000 & 205 & 4.9139 & TRN \\
\hline CHEMBL1546722 & 688261 & 5.5432 & 5.6728 & TST & & \\
\hline CHEMBL1486214 & 688261 & 5.6059 & 4.667 & TRN & & \\
\hline CHEMBL1326896 & 688261 & 4.7037 & 3.7307 & TRN & & \\
\hline CHEMBL1461027 & 688261 & 2.8239 & 4.0941 & TRN & & \\
\hline CHEMBL1549738 & 688261 & 5.1118 & 5.2421 & TST & & \\
\hline CHEMBL1487218 & 688261 & 4.8005 & 4.6069 & TRN & & \\
\hline CHEMBL1366838 & 688261 & 5.8645 & 5.7523 & TRN & & \\
\hline CHEMBL1584727 & 688261 & 2.8239 & 3.1093 & TRN & & \\
\hline CHEMBL1444020 & 688261 & 6.1261 & 5.9934 & TRN & & \\
\hline CHEMBL1380592 & 688261 & 5.5144 & 4.8981 & TRN & & \\
\hline CHEMBL1576791 & 688261 & 4.7935 & 4.7293 & TRN & & \\
\hline CHEMBL1567957 & 688261 & 4.7525 & 3.9926 & TRN & & \\
\hline CHEMBL1531170 & 688261 & 5.6582 & 4.8362 & TRN & & \\
\hline CHEMBL1549611 & 688261 & 5.477 & 5.1495 & TST & & \\
\hline CHEMBL1468340 & 688261 & 5.5715 & 5.534 & TRN & & \\
\hline CHEMBL1609770 & 688261 & 6.3344 & 5.9556 & TRN & & \\
\hline CHEMBL1551000 & 688261 & 5.3636 & 4.9139 & TRN & & \\
\hline CHEMBL1329069 & 688261 & 5.374 & 5.4644 & TRN & & \\
\hline CHEMBL1546843 & 688261 & 5.5753 & 5.4108 & TRN & & \\
\hline CHEMBL 1374578 & 688261 & 2.8239 & 2.9962 & TRN & & \\
\hline CHEMBL1372199 & 688261 & 6.1959 & 5.846 & TRN & & \\
\hline CHEMBL1488760 & 688261 & 6.4437 & 5.8669 & TST & & \\
\hline CHEMBL1431587 & 688261 & 5.5139 & 5.1297 & TRN & & \\
\hline CHEMBL1311226 & 688261 & 4.6564 & 4.7982 & TST & & \\
\hline CHEMBL1383793 & 688261 & 5.2995 & 5.2809 & TRN & & \\
\hline CHEMBL 260342 & 688261 & 5.7051 & 5.5559 & TRN & & \\
\hline CHEMBL1333830 & 688261 & 5.0938 & 5.1286 & TRN & & \\
\hline CHEMBL379179 & 688261 & 5.029 & 5.2864 & TRN & & \\
\hline CHEMBL1368683 & 688261 & 5.8401 & 5.4044 & TRN & & \\
\hline CHEMBL1389728 & 688261 & 4.9049 & 4.8173 & TST & & \\
\hline CHEMBL1481328 & 688261 & 5.3181 & 4.6174 & TRN & & \\
\hline CHEMBL1576754 & 688261 & 5.0193 & 5.2859 & TRN & & \\
\hline CHEMBL1498959 & 688261 & 5.3288 & 4.9854 & TRN & & \\
\hline CHEMBL1376166 & 688261 & 6.1986 & 6.0745 & TRN & & \\
\hline CHEMBL453974 & 688261 & 5.683 & 5.1609 & TST & & \\
\hline CHEMBL1360618 & 688261 & 5.3828 & 5.05 & TRN & & \\
\hline
\end{tabular}




\begin{tabular}{|c|c|c|c|c|c|}
\hline \multicolumn{6}{|c|}{ Supplemental Table S2.txt } \\
\hline CHEMBL1413680 & 688261 & 5.2483 & 5.2309 & TST & \\
\hline CHEMBL1455137 & 688261 & 5.5277 & 5.4553 & TRN & \\
\hline CHEMBL1448503 & 688261 & 5.3018 & 5.4822 & TRN & \\
\hline CHEMBL 3196853 & 688261 & 4.5262 & 3.8144 & TRN & \\
\hline CHEMBL1384771 & 688261 & 4.7396 & 4.7128 & TST & \\
\hline CHEMBL1609900 & 688261 & 2.8239 & 2.6648 & TRN & \\
\hline CHEMBL1416693 & 688261 & 2.8239 & 3.1132 & TRN & \\
\hline CHEMBL1363437 & 688261 & 7.9208 & 6.6224 & TRN & \\
\hline CHEMBL1422429 & 688261 & 5.6857 & 6.0479 & TRN & \\
\hline CHEMBL3209269 & 688261 & 4.801 & 4.6191 & TRN & \\
\hline CHEMBL1347192 & 688261 & 4.8489 & 5.1134 & TST & \\
\hline CHEMBL1445386 & 688261 & 5.6196 & 5.1542 & TST & \\
\hline CHEMBL1492548 & 688261 & 3.9011 & 3.568 & TRN & \\
\hline CHEMBL1603293 & 688261 & 2.8239 & 3.2996 & TRN & \\
\hline CHEMBL1487345 & 688261 & 4.4289 & 4.8855 & TRN & \\
\hline CHEMBL1606861 & 688261 & 5.5339 & 4.8695 & TRN & \\
\hline CHEMBL1439210 & 688261 & 5.5207 & 5.3165 & TRN & \\
\hline CHEMBL1408708 & 688261 & 5.9488 & 5.3343 & TRN & \\
\hline CHEMBL1602637 & 688261 & 6.1415 & 6.0355 & TRN & \\
\hline CHEMBL1427709 & 688261 & 4.7482 & 4.5451 & TRN & \\
\hline CHEMBL1988660 & 688261 & 5.5369 & 5.5034 & TRN & \\
\hline CHEMBL1478237 & 688261 & 5.6509 & 3.1218 & TRN & \\
\hline CHEMBL1472773 & 688261 & 5.1354 & 5.3459 & TST & \\
\hline CHEMBL568092 & 688261 & 5.0965 & 5.1321 & TRN & \\
\hline CHEMBL1479319 & 688261 & 4.9376 & 3.6956 & TST & \\
\hline CHEMBL1480701 & 688261 & 2.8239 & 3.5791 & TRN & \\
\hline CHEMBL1424118 & 688261 & 6.5391 & 6.6533 & TRN & \\
\hline CHEMBL391123 & 688261 & 4.3064 & 4.9555 & TST & \\
\hline CHEMBL81782 & 688261 & 5.8097 & 5.92200 & 0000000001 & TRN \\
\hline CHEMBL1372924 & 688261 & 5.5217 & 5.2207 & TST & \\
\hline CHEMBL486504 & 688261 & 6.6968 & 7.0397 & TST & \\
\hline CHEMBL1420007 & 688261 & 4.6638 & 4.8277 & TRN & \\
\hline CHEMBL1549192 & 688261 & 5.4013 & 5.1031 & TRN & \\
\hline CHEMBL1372082 & 688261 & 5.8894 & 5.9673 & TRN & \\
\hline CHEMBL1369513 & 688261 & 2.8239 & 3.4884 & TRN & \\
\hline CHEMBL518292 & 688261 & 5.2769 & 5.334 & TST & \\
\hline CHEMBL199868 & 688261 & 5.5889 & 5.5851 & TRN & \\
\hline CHEMBL1527242 & 688261 & 5.3353 & 5.3043 & TRN & \\
\hline CHEMBL3199216 & 688261 & 5.5372 & 5.2533 & TRN & \\
\hline CHEMBL1388951 & 688261 & 4.7248 & 4.725 & TRN & \\
\hline CHEMBL1537106 & 688261 & 5.1218 & 5.3591 & TST & \\
\hline CHEMBL 1455421 & 688261 & 5.0681 & 5.1142 & TRN & \\
\hline CHEMBL1543337 & 688261 & 5.1995 & 5.2821 & TRN & \\
\hline CHEMBL 2354875 & 688261 & 5.0364 & 5.1663 & TRN & \\
\hline CHEMBL1455468 & 688261 & 6.0458 & 5.9695 & TRN & \\
\hline CHEMBL1967031 & 688261 & 4.9974 & 4.638 & TRN & \\
\hline CHEMBL 261114 & 688261 & 6.1904 & 5.7484 & TRN & \\
\hline CHEMBL1377164 & 688261 & 2.8239 & 4.2112 & TST & \\
\hline
\end{tabular}


Supplemental Table S2.txt

\begin{tabular}{|c|c|c|c|c|}
\hline CHEMBL1467533 & 688261 & 6.5467 & 6.3426 & TRN \\
\hline CHEMBL1576251 & 688261 & 6.2741 & 6.3653 & TRN \\
\hline CHEMBL1607187 & 688261 & 4.6584 & 4.2002 & TRN \\
\hline CHEMBL3199198 & 688261 & 2.8239 & 3.5677 & TRN \\
\hline CHEMBL1436988 & 688261 & 5.3036 & 5.7517 & TRN \\
\hline CHEMBL1540682 & 688261 & 5.4256 & \multicolumn{2}{|c|}{5.492999999999999} \\
\hline CHEMBL1588704 & 688261 & 4.5147 & 3.9067 & TRN \\
\hline CHEMBL523200 & 688261 & 5.3431 & 5.1487 & TRN \\
\hline CHEMBL1566559 & 688261 & 2.8239 & 3.3459 & TRN \\
\hline CHEMBL592600 & 688261 & 5.0871 & 5.8557 & TRN \\
\hline CHEMBL1483768 & 688261 & 5.4372 & 5.6305 & TRN \\
\hline CHEMBL583584 & 688261 & 5.8289 & 4.003 & TRN \\
\hline CHEMBL1537340 & 688261 & 2.8239 & 3.2018 & TRN \\
\hline CHEMBL1349455 & 688261 & 4.9717 & 5.0162 & TRN \\
\hline CHEMBL1443513 & 688261 & 2.8239 & 3.4373 & TRN \\
\hline CHEMBL1567896 & 688261 & 2.8239 & 3.5922 & TRN \\
\hline CHEMBL3192181 & 688261 & 5.8633 & 5.8262 & TRN \\
\hline CHEMBL1491847 & 688261 & 5.3753 & 5.43 & TST \\
\hline CHEMBL1987820 & 688261 & 5.6321 & 5.6213 & TRN \\
\hline CHEMBL1313990 & 688261 & 5.3135 & 5.5103 & TST \\
\hline CHEMBL1542833 & 688261 & 5.3741 & 5.4042 & TRN \\
\hline CHEMBL1307506 & 688261 & 4.9384 & 4.5744 & TRN \\
\hline CHEMBL1995045 & 688261 & 5.6334 & 5.6989 & TST \\
\hline CHEMBL1448625 & 688261 & 4.7348 & 4.604 & TRN \\
\hline CHEMBL512048 & 688261 & 4.9858 & 4.7757 & TRN \\
\hline CHEMBL1393671 & 688261 & 4.7433 & 5.2022 & TRN \\
\hline CHEMBL1573720 & 688261 & 5.5699 & 5.2754 & TRN \\
\hline CHEMBL1378118 & 688261 & 5.3042 & 5.5948 & TST \\
\hline CHEMBL1541779 & 688261 & 4.6623 & 5.3005 & TRN \\
\hline CHEMBL1311879 & 688261 & 5.4444 & 5.4824 & TRN \\
\hline CHEMBL2000499 & 688261 & 5.2903 & 4.6485 & TRN \\
\hline CHEMBL1393195 & 688261 & 6.2226 & 5.8388 & TRN \\
\hline CHEMBL1519655 & 688261 & 5.2248 & 5.1956 & TRN \\
\hline CHEMBL1365523 & 688261 & 2.8239 & 4.0827 & TST \\
\hline CHEMBL1464984 & 688261 & 4.7781 & 4.9815 & TRN \\
\hline CHEMBL3214583 & 688261 & 4.6193 & 4.7395 & TRN \\
\hline CHEMBL1395962 & 688261 & 5.5161 & 4.9408 & TRN \\
\hline CHEMBL1985165 & 688261 & 5.2517 & 5.2262 & TRN \\
\hline CHEMBL1588716 & 688261 & 2.8239 & 4.34 & TRN \\
\hline CHEMBL1582760 & 688261 & 6.4597 & 6.1527 & TRN \\
\hline CHEMBL1329255 & 688261 & 4.4561 & 3.4434 & TRN \\
\hline CHEMBL1491711 & 688261 & 5.3603 & 4.8401 & TRN \\
\hline CHEMBL1535161 & 688261 & 2.8239 & 3.1493 & TRN \\
\hline CHEMBL1329031 & 688261 & 2.8239 & 3.24899 & 79999999997 \\
\hline CHEMBL1520346 & 688261 & 6.7328 & 6.684 & TRN \\
\hline CHEMBL1360793 & 688261 & 5.2349 & 5.3535 & TRN \\
\hline CHEMBL1336535 & 688261 & 4.4188 & 4.3207 & TRN \\
\hline CHEMBL1533621 & 688261 & 5.5569 & 5.4865 & TRN \\
\hline
\end{tabular}

Page 2891 
Supplemental Table S2.txt

\begin{tabular}{|c|c|c|c|c|}
\hline CHEMBL1589457 & 688261 & 4.1171 & 4.5283 & TRN \\
\hline CHEMBL1405453 & 688261 & 6.4461 & 5.8162 & TRN \\
\hline CHEMBL224869 & 688261 & 4.6568 & 3.6611 & TRN \\
\hline CHEMBL1417496 & 688261 & 4.9161 & 4.6 & TRN \\
\hline CHEMBL1484195 & 688261 & 5.5941 & 5.0297 & TRN \\
\hline CHEMBL1437888 & 688261 & 5.3536 & 5.3368 & TRN \\
\hline CHEMBL1328050 & 688261 & 5.2923 & 5.1018 & TRN \\
\hline CHEMBL1586439 & 688261 & 2.8239 & 4.3552 & TRN \\
\hline CHEMBL1386838 & 688261 & 5.4204 & 5.11 & TST \\
\hline CHEMBL1500227 & 688261 & 5.9201 & 5.9723 & TRN \\
\hline CHEMBL3199311 & 688261 & 6.3344 & 5.8165 & TRN \\
\hline CHEMBL1501508 & 688261 & 4.9839 & 5.3306 & TRN \\
\hline CHEMBL1460638 & 688261 & 2.8239 & 3.7857 & TST \\
\hline CHEMBL1523845 & 688261 & 4.7514 & 4.5854 & TRN \\
\hline CHEMBL1568793 & 688261 & 2.8239 & 3.7153 & TRN \\
\hline CHEMBL1524484 & 688261 & 5.7667 & 5.6295 & TRN \\
\hline CHEMBL1393689 & 688261 & 4.7626 & 4.8946 & TRN \\
\hline CHEMBL1580848 & 688261 & 6.1057 & 5.3579 & TRN \\
\hline CHEMBL1481192 & 688261 & 5.4409 & 5.3588 & TST \\
\hline CHEMBL1613644 & 688261 & 4.504 & 4.3929 & TRN \\
\hline CHEMBL1535695 & 688261 & 4.8326 & 4.7412 & TST \\
\hline CHEMBL1347563 & 688261 & 4.8014 & 4.5221 & TRN \\
\hline CHEMBL1301647 & 688261 & 4.4152 & 4.556 & TRN \\
\hline CHEMBL1609605 & 688261 & 2.8239 & 3.5746 & TRN \\
\hline CHEMBL1588722 & 688261 & 4.5863 & 4.9849 & TST \\
\hline CHEMBL1479316 & 688261 & 5.0676 & 5.1398 & TRN \\
\hline CHEMBL473721 & 688261 & 5.165 & 5.0471 & TRN \\
\hline CHEMBL1505813 & 688261 & 5.8901 & 5.1985 & TRN \\
\hline CHEMBL1577840 & 688261 & 5.2984 & 5.3857 & TST \\
\hline CHEMBL1479010 & 688261 & 5.2648 & 4.9884 & TST \\
\hline CHEMBL533226 & 688261 & 5.3696 & 5.3998 & TRN \\
\hline CHEMBL1301313 & 688261 & 2.8239 & 3.1457 & TRN \\
\hline CHEMBL1492564 & 688261 & 5.8392 & 5.3641 & TRN \\
\hline CHEMBL1567159 & 688261 & 5.2278 & 5.42200 & 0000000001 \\
\hline CHEMBL1360484 & 688261 & 5.5768 & 5.7957 & TRN \\
\hline CHEMBL1257013 & 688261 & 4.7236 & 4.9267 & TST \\
\hline CHEMBL1333449 & 688261 & 6.1586 & 5.8264 & TRN \\
\hline CHEMBL1553717 & 688261 & 5.5294 & 5.5106 & TRN \\
\hline CHEMBL1611614 & 688261 & 6.1818 & 5.9106 & TRN \\
\hline CHEMBL1585706 & 688261 & 5.0254 & 4.6628 & TRN \\
\hline CHEMBL1311809 & 688261 & 5.4607 & 5.5368 & TST \\
\hline CHEMBL124006 & 688261 & 5.3261 & 5.4691 & TRN \\
\hline CHEMBL1505604 & 688261 & 5.7873 & 4.672 & TRN \\
\hline CHEMBL1428662 & 688261 & 4.8925 & 4.5319 & TRN \\
\hline CHEMBL1312489 & 688261 & 2.8239 & 3.4277 & TRN \\
\hline CHEMBL1501720 & 688261 & 4.5905 & 3.7772 & TST \\
\hline CHEMBL1477354 & 688261 & 4.4598 & 4.0241 & TRN \\
\hline CHEMBL1430460 & 688261 & 2.8239 & 3.5872 & TRN \\
\hline
\end{tabular}

Page 2892 
Supplemental Table S2.txt

\begin{tabular}{|c|c|c|c|c|c|}
\hline CHEMBL1305475 & 688261 & 5.1173 & 5.2752 & TRN & \\
\hline CHEMBL 2094567 & 688261 & 5.9935 & 6.0362 & TRN & \\
\hline CHEMBL1323313 & 688261 & 5.6231 & 5.4297 & TRN & \\
\hline CHEMBL1309091 & 688261 & 4.9993 & 5.3118 & TRN & \\
\hline CHEMBL1414345 & 688261 & 2.8239 & 4.5153 & TRN & \\
\hline CHEMBL1426340 & 688261 & 5.2132 & 5.2976 & TRN & \\
\hline CHEMBL1612556 & 688261 & 2.8239 & 3.5647 & TRN & \\
\hline CHEMBL1333294 & 688261 & 5.9158 & 5.8917 & TRN & \\
\hline CHEMBL1572157 & 688261 & 5.2593 & 3.6036 & TRN & \\
\hline CHEMBL1350780 & 688261 & 4.9781 & 5.3566 & TRN & \\
\hline CHEMBL1388469 & 688261 & 5.2792 & 5.8342 & TRN & \\
\hline CHEMBL1394314 & 688261 & 4.99 & 5.1632 & TRN & \\
\hline CHEMBL1369671 & 688261 & 4.7899 & 4.6279 & TRN & \\
\hline CHEMBL1530911 & 688261 & 5.6377 & 5.5293 & TRN & \\
\hline CHEMBL580955 & 688261 & 5.6295 & 5.8027 & TRN & \\
\hline CHEMBL1449669 & 688261 & 5.3862 & 5.1946 & TRN & \\
\hline CHEMBL1319676 & 688261 & 5.551 & 5.3563 & TRN & \\
\hline CHEMBL1405749 & 688261 & 4.2186 & 6.6677 & TRN & \\
\hline CHEMBL1547295 & 688261 & 4.8106 & 4.2168 & TRN & \\
\hline CHEMBL1568294 & 688261 & 4.7961 & 5.0136 & TRN & \\
\hline CHEMBL1330417 & 688261 & 4.9164 & 4.6415 & TRN & \\
\hline CHEMBL528791 & 688261 & 5.4233 & 5.4539 & TST & \\
\hline CHEMBL1502098 & 688261 & 4.9671 & 4.6656 & TRN & \\
\hline CHEMBL1446695 & 688261 & 4.7479 & 4.2799 & TRN & \\
\hline CHEMBL1483324 & 688261 & 4.6264 & 4.5928 & TRN & \\
\hline CHEMBL1366104 & 688261 & 2.8239 & 3.685 & TRN & \\
\hline CHEMBL1500188 & 688261 & 4.8378 & 5.4857 & TRN & \\
\hline CHEMBL1595952 & 688261 & 6.2083 & 6.0121 & TRN & \\
\hline CHEMBL1332139 & 688261 & 6.2882 & 6.1372 & TRN & \\
\hline CHEMBL1337130 & 688261 & 4.5489 & 3.3841 & TRN & \\
\hline CHEMBL1569783 & 688261 & 6.025 & 5.6848 & TRN & \\
\hline CHEMBL1583715 & 688261 & 5.2654 & 5.3822 & TRN & \\
\hline CHEMBL1411266 & 688261 & 2.8239 & 3.049 & TRN & \\
\hline CHEMBL1497549 & 688261 & 5.7428 & 5.7558 & TRN & \\
\hline CHEMBL1470728 & 688261 & 5.2756 & 5.475 & TST & \\
\hline CHEMBL1347152 & 688261 & 2.8239 & 4.431 & TRN & \\
\hline CHEMBL1985575 & 688261 & 5.4672 & 5.4994 & TRN & \\
\hline CHEMBL1386228 & 688261 & 6.1662 & 5.9357 & TRN & \\
\hline CHEMBL1483312 & 688261 & 5.862 & 5.1461 & TRN & \\
\hline CHEMBL3198332 & 688261 & 5.6629 & 5.3184 & TRN & \\
\hline CHEMBL3210936 & 688261 & 4.7233 & 4.6834 & TST & \\
\hline CHEMBL3196976 & 688261 & 5.3405 & 5.5606 & TRN & \\
\hline CHEMBL1520803 & 688261 & 5.1789 & 4.9886 & TRN & \\
\hline CHEMBL1569604 & 688261 & 4.7312 & 4.7492 & TRN & \\
\hline CHEMBL1386418 & 688261 & 4.7723 & 4.5658 & TRN & \\
\hline CHEMBL1506397 & 688261 & 2.8239 & 4.4709 & TST & \\
\hline CHEMBL1427287 & 688261 & 4.7156 & 4.7342 & TRN & \\
\hline CHEMBL1596609 & 688261 & 4.29899 & 99999999 & 995 & 4.015 \\
\hline
\end{tabular}




\begin{tabular}{|c|c|c|c|c|c|c|}
\hline & & \multicolumn{5}{|c|}{ Supplemental Table S2.txt } \\
\hline CHEMBL1540024 & 688261 & 5.2325 & 5.2046 & TRN & & \\
\hline CHEMBL1334919 & 688261 & 5.24 & 5.2999 & TRN & & \\
\hline CHEMBL1993934 & 688261 & 5.9404 & 5.6324 & TRN & & \\
\hline CHEMBL1462074 & 688261 & \multicolumn{3}{|c|}{6.117999999999999} & 5.9584 & TST \\
\hline CHEMBL1330058 & 688261 & 5.4023 & 5.3542 & TRN & & \\
\hline CHEMBL1567256 & 688261 & 5.34 & 4.9707 & TRN & & \\
\hline CHEMBL1569585 & 688261 & 6.1791 & 5.6824 & TST & & \\
\hline CHEMBL1301278 & 688261 & 5.2357 & 5.1945 & TST & & \\
\hline CHEMBL1577016 & 688261 & 5.8119 & 5.0035 & TST & & \\
\hline CHEMBL1566108 & 688261 & 5.6872 & 5.501 & TRN & & \\
\hline CHEMBL1993731 & 688261 & 5.6449 & 5.2265 & TRN & & \\
\hline CHEMBL1454029 & 688261 & 5.6068 & 5.7017 & TRN & & \\
\hline CHEMBL1437683 & 688261 & 5.1856 & 5.3486 & TRN & & \\
\hline CHEMBL1431376 & 688261 & 5.2972 & 5.0732 & TRN & & \\
\hline CHEMBL1523206 & 688261 & 5.5367 & 5.5237 & TST & & \\
\hline CHEMBL1302089 & 688261 & 5.5913 & 5.7231 & TRN & & \\
\hline CHEMBL1318350 & 688261 & 5.8377 & 6.0122 & TRN & & \\
\hline CHEMBL3195943 & 688261 & 4.4163 & 3.9398 & TRN & & \\
\hline CHEMBL1311094 & 688261 & 5.4454 & 5.1665 & TRN & & \\
\hline CHEMBL1977570 & 688261 & 4.9452 & 4.8992 & TRN & & \\
\hline CHEMBL1503190 & 688261 & 5.0237 & 5.0865 & TRN & & \\
\hline CHEMBL1539745 & 688261 & 2.8239 & 3.2587 & TRN & & \\
\hline CHEMBL1517325 & 688261 & 5.3143 & 5.5441 & TRN & & \\
\hline CHEMBL1327703 & 688261 & 5.1128 & 5.6634 & TRN & & \\
\hline CHEMBL1544837 & 688261 & 2.8239 & 2.9804 & TRN & & \\
\hline CHEMBL 2094484 & 688261 & 5.6194 & 5.3853 & TRN & & \\
\hline CHEMBL1491358 & 688261 & 2.8239 & 3.4425 & TRN & & \\
\hline CHEMBL1363578 & 688261 & 2.8239 & 3.4472 & TST & & \\
\hline CHEMBL1995692 & 688261 & 6.2111 & 5.9888 & TRN & & \\
\hline CHEMBL1417428 & 688261 & 5.2334 & 5.0539 & TST & & \\
\hline CHEMBL2004304 & 688261 & 5.2621 & 5.2637 & TRN & & \\
\hline CHEMBL3196518 & 688261 & 6.1481 & 6.2676 & TRN & & \\
\hline CHEMBL1466445 & 688261 & 5.4203 & 5.4833 & TRN & & \\
\hline CHEMBL1548492 & 688261 & 5.5945 & 5.7335 & TRN & & \\
\hline CHEMBL1525381 & 688261 & 4.9428 & 5.0749 & TRN & & \\
\hline CHEMBL1928491 & 688261 & 4.8741 & 5.126 & TRN & & \\
\hline CHEMBL3195477 & 688261 & 5.5882 & 5.5078 & TRN & & \\
\hline CHEMBL1547901 & 688261 & 4.7139 & 5.0599 & TST & & \\
\hline CHEMBL1572446 & 688261 & 2.8239 & 3.5361 & TST & & \\
\hline CHEMBL1584006 & 688261 & 5.3044 & 5.7652 & TRN & & \\
\hline CHEMBL1341845 & 688261 & 4.6452 & 4.704 & TRN & & \\
\hline CHEMBL1445372 & 688261 & 5.5519 & 5.3943 & TST & & \\
\hline CHEMBL1597716 & 688261 & 2.8239 & 4.1946 & TRN & & \\
\hline CHEMBL1303034 & 688261 & 6.0348 & 5.8846 & TST & & \\
\hline CHEMBL1498509 & 688261 & 5.6564 & 5.807 & TRN & & \\
\hline CHEMBL3193510 & 688261 & 5.2425 & 5.4767 & TRN & & \\
\hline CHEMBL193872 & 688261 & 5.2096 & 5.6951 & TRN & & \\
\hline CHEMBL1378385 & 688261 & 5.7029 & 6.0774 & TRN & & \\
\hline
\end{tabular}


Supplemental Table S2.txt

\begin{tabular}{|c|c|c|c|c|}
\hline & & & & \\
\hline AEMBL13 & 88261 & 4.8073 & 1938 & \\
\hline IEMBL1481538 & 38261 & 2197 & 897 & \\
\hline AEMBL1566835 & 3261 & .2169 & 2032 & \\
\hline & & & & \\
\hline AEMBL151\& & 261 & & 9516 & \\
\hline AEMBL1469827 & 88261 & 934 & 4056 & \\
\hline AEMBL1997171 & 88261 & 6.1824 & .1479 & \\
\hline AEMBL3197908 & 88261 & & 5861 & \\
\hline IEMBL146 & 261 & & & \\
\hline AEMBL581251 & 261 & & 781 & \\
\hline AEMBL1987461 & 688261 & & 3813 & \\
\hline AEMBL1587981 & 261 & & 3 & \\
\hline IEMBL1414 & 261 & & 131 & \\
\hline IEMBL1581425 & 61 & & & \\
\hline AEMBL1368103 & 61 & & & \\
\hline HEMBL1300069 & 261 & & 4116 & \\
\hline AEMBL1575588 & 261 & & 31 & \\
\hline AEMBL146 & & & & \\
\hline AEMBL15ع & & & & \\
\hline HEMBL133 & 61 & & 16 & \\
\hline AEMBL1439227 & & & 5249 & \\
\hline AEMBL1600146 & & & 34 & \\
\hline AEMBL601 & & & 853 & \\
\hline HEMBL14 & & & 22 & \\
\hline AFMRI 14 & 61 & & 893 & \\
\hline HEMBL158 & & & & \\
\hline AEMBL1566211 & & & & \\
\hline HEMBL15875 & & & 379 & \\
\hline L314 & & & 933 & \\
\hline 59 & & & 74 & \\
\hline AEMBL1982032 & & & & \\
\hline AEMBL1539572 & & & & \\
\hline AEMBL1466 & & & 763 & \\
\hline JEMBL51: & & & 927 & \\
\hline 14 & & & 55 & \\
\hline AEMBL1544402 & & & 787 & \\
\hline AEMBL1485562 & & & 991 & \\
\hline IEMBL 318 & & & 212 & \\
\hline AEMBL1484547 & & & 859 & \\
\hline HEMBL15: & & & 89 & \\
\hline AEMBL1526174 & 688261 & & 5.2095 & \\
\hline AEMBL1494636 & & & 209 & \\
\hline HEIMIBL 139 & & & & \\
\hline HEMBL1430094 & & & & \\
\hline CHEMBL1308497 & & & 944 & \\
\hline AEMBL1900055 & 8261 & 5.3273 & 4.7579 & \\
\hline HFMBI 1514474 & 688261 & 3.9228 & 3.3006 & \\
\hline
\end{tabular}

Page 2895 
Supplemental Table S2.txt

\begin{tabular}{|c|c|c|c|c|}
\hline CHEMBL1529883 & 688261 & 5.7201 & 5.8188 & TRN \\
\hline CHEMBL1408486 & 688261 & 6.1831 & 5.8233 & TRN \\
\hline CHEMBL1341518 & 688261 & 5.4546 & 4.9287 & TST \\
\hline CHEMBL1310508 & 688261 & 5.4699 & 5.57299 & 99999999995 \\
\hline CHEMBL1425008 & 688261 & 2.8239 & 3.0362 & TRN \\
\hline CHEMBL3208035 & 688261 & 2.8239 & 4.5325 & TRN \\
\hline CHEMBL3195455 & 688261 & 5.5522 & 5.396 & TRN \\
\hline CHEMBL1378489 & 688261 & 5.2886 & 5.3954 & TST \\
\hline CHEMBL1480475 & 688261 & 5.5091 & 5.2003 & TST \\
\hline CHEMBL1563136 & 688261 & 2.8239 & 3.5736 & TRN \\
\hline CHEMBL1457139 & 688261 & 4.9715 & 5.2479 & TRN \\
\hline CHEMBL1520067 & 688261 & 4.026 & 4.074 & TRN \\
\hline CHEMBL1548898 & 688261 & 4.9783 & 4.8874 & TRN \\
\hline CHEMBL1341442 & 688261 & 6.224 & 5.6178 & TRN \\
\hline CHEMBL1374957 & 688261 & 5.0256 & 4.9721 & TST \\
\hline CHEMBL1978117 & 688261 & 6.1911 & 6.0736 & TRN \\
\hline CHEMBL3190965 & 688261 & 5.5324 & 5.5958 & TRN \\
\hline CHEMBL1511179 & 688261 & 4.988 & 5.7432 & TRN \\
\hline CHEMBL3207906 & 688261 & 4.9147 & 4.9478 & TST \\
\hline CHEMBL1349067 & 688261 & 4.6793 & 4.46 & TRN \\
\hline CHEMBL1452391 & 688261 & 5.7959 & 5.7882 & TRN \\
\hline CHEMBL1491717 & 688261 & 5.5792 & 5.5209 & TRN \\
\hline CHEMBL1611922 & 688261 & 5.278 & 5.3309 & TRN \\
\hline CHEMBL 29711 & 688261 & 2.8239 & 4.5622 & TST \\
\hline CHEMBL1372356 & 688261 & 4.5277 & 4.295 & TRN \\
\hline CHEMBL1309463 & 688261 & 4.994 & 5.0031 & TRN \\
\hline CHEMBL1372163 & 688261 & 5.9809 & 6.0034 & TRN \\
\hline CHEMBL57013 & 688261 & 4.8567 & 5.2572 & TST \\
\hline CHEMBL1487099 & 688261 & 6.0209 & 6.0014 & TST \\
\hline CHEMBL1983871 & 688261 & 4.9725 & 4.8412 & TRN \\
\hline CHEMBL1982575 & 688261 & 5.0024 & 4.8799 & TRN \\
\hline CHEMBL 2359072 & 688261 & 6.4425 & 6.7131 & TRN \\
\hline CHEMBL1328069 & 688261 & 5.4299 & 5.4412 & TRN \\
\hline CHEMBL1503006 & 688261 & 4.0444 & 4.3264 & TRN \\
\hline CHEMBL1385375 & 688261 & 2.8239 & 3.5067 & TRN \\
\hline CHEMBL 6742 & 688261 & 4.8274 & 3.815 & TRN \\
\hline CHEMBL1359872 & 688261 & 6.4271 & 6.3998 & TRN \\
\hline CHEMBL1994078 & 688261 & 5.2459 & 5.2121 & TRN \\
\hline CHEMBL3198544 & 688261 & 6.3665 & 6.0374 & TRN \\
\hline CHEMBL3199512 & 688261 & 5.6343 & 5.1806 & TRN \\
\hline CHEMBL1493731 & 688261 & 5.7994 & 6.0949 & TRN \\
\hline CHEMBL1971142 & 688261 & 5.0866 & 4.9757 & TRN \\
\hline CHEMBL1365006 & 688261 & 5.2798 & 5.2646 & TRN \\
\hline CHEMBL3197070 & 688261 & 5.2958 & 5.7885 & TRN \\
\hline CHEMBL1414754 & 688261 & 4.7422 & 3.7838 & TRN \\
\hline CHEMBL1500296 & 688261 & 2.8239 & 3.9316 & TRN \\
\hline CHEMBL1611686 & 688261 & 5.1737 & 5.5227 & TRN \\
\hline CHEMBL1546005 & 688261 & 4.691 & 4.2286 & TRN \\
\hline
\end{tabular}




\begin{tabular}{|c|c|c|c|c|c|}
\hline \multirow{3}{*}{$\begin{array}{l}\text { CHEMBL1386058 } \\
\text { CHEMBL1887153 }\end{array}$} & \multirow{3}{*}{$\begin{array}{l}688261 \\
688261\end{array}$} & \multicolumn{4}{|c|}{ Supplemental Table S2.txt } \\
\hline & & 2.8239 & \multicolumn{2}{|c|}{2.9930000000000003} & \multirow[t]{2}{*}{ TRN } \\
\hline & & 5.3119 & 5.2069 & TRN & \\
\hline CHEMBL1994372 & 688261 & 5.9389 & 5.556 & TRN & \\
\hline CHEMBL1324061 & 688261 & 5.699 & 5.6012 & TRN & \\
\hline CHEMBL1392025 & 688261 & 4.5913 & 3.4159 & TRN & \\
\hline CHEMBL1421333 & 688261 & 2.8239 & 3.3827 & TRN & \\
\hline CHEMBL1550640 & 688261 & 4.2174 & 3.5938 & TRN & \\
\hline CHEMBL1411388 & 688261 & 4.9833 & 5.2235 & TRN & \\
\hline CHEMBL585591 & 688261 & 5.9809 & \multicolumn{2}{|c|}{5.797999999999999} & TRN \\
\hline CHEMBL1368526 & 688261 & 5.643 & 5.4191 & TRN & \\
\hline CHEMBL1321326 & 688261 & 5.5432 & 5.4076 & TRN & \\
\hline CHEMBL1316978 & 688261 & 5.8965 & 6.0219 & TRN & \\
\hline CHEMBL1610540 & 688261 & 5.5002 & \multicolumn{2}{|c|}{5.303999999999999} & TRN \\
\hline CHEMBL1362687 & 688261 & 5.9586 & 6.2772 & TRN & \\
\hline CHEMBL1424468 & 688261 & 6.4841 & 6.4649 & TRN & \\
\hline CHEMBL1376068 & 688261 & 2.8239 & 4.3122 & TRN & \\
\hline CHEMBL1337592 & 688261 & 6.2857 & 6.409 & TRN & \\
\hline CHEMBL3198970 & 688261 & 6.4123 & 6.0504 & TRN & \\
\hline CHEMBL1542809 & 688261 & 4.9782 & 4.7122 & TRN & \\
\hline CHEMBL1606328 & 688261 & 4.5471 & 4.577 & TST & \\
\hline CHEMBL1357063 & 688261 & 4.6716 & 5.0205 & TRN & \\
\hline CHEMBL1537417 & 688261 & 5.3722 & 5.3005 & TST & \\
\hline CHEMBL1484332 & 688261 & 5.2959 & 5.2232 & TRN & \\
\hline CHEMBL530609 & 688261 & 5.0852 & 5.231 & TRN & \\
\hline CHEMBL1335176 & 688261 & 6.0841 & 5.6926 & TST & \\
\hline CHEMBL1385516 & 688261 & 5.0033 & 4.8571 & TRN & \\
\hline CHEMBL1360530 & 688261 & 2.8239 & 3.0971 & TRN & \\
\hline CHEMBL1974506 & 688261 & 5.2942 & 5.1215 & TRN & \\
\hline CHEMBL1492289 & 688261 & 5.5488 & 5.2231 & TRN & \\
\hline CHEMBL1990093 & 688261 & 5.9492 & 5.6691 & TRN & \\
\hline CHEMBL1568243 & 688261 & 4.7833 & 4.6355 & TRN & \\
\hline CHEMBL1312644 & 688261 & 2.8239 & 2.787 & TRN & \\
\hline CHEMBL1613679 & 688261 & 3.9901 & 2.9556 & TRN & \\
\hline CHEMBL1534959 & 688261 & 5.2331 & 5.1548 & TST & \\
\hline CHEMBL1368290 & 688261 & 5.6688 & 5.3611 & TRN & \\
\hline CHEMBL1505003 & 688261 & 5.3678 & 4.8576 & TRN & \\
\hline CHEMBL1584985 & 688261 & 6.1308 & 6.016 & TRN & \\
\hline CHEMBL1352313 & 688261 & 5.479 & 5.2984 & TRN & \\
\hline CHEMBL1432727 & 688261 & 2.8239 & 3.7773 & TRN & \\
\hline CHEMBL1373096 & 688261 & 5.1856 & 5.8712 & TRN & \\
\hline CHEMBL1505209 & 688261 & 6.4168 & 6.1845 & TST & \\
\hline CHEMBL1301700 & 688261 & 5.7111 & 5.9121 & TRN & \\
\hline CHEMBL3199403 & 688261 & 5.2719 & 4.9785 & TRN & \\
\hline CHEMBL1457561 & 688261 & 5.5931 & 5.3589 & TRN & \\
\hline CHEMBL1545422 & 688261 & 2.8239 & 4.4364 & TRN & \\
\hline CHEMBL1469534 & 688261 & 2.8239 & 3.64600 & 00000000004 & TRN \\
\hline CHEMBL1502522 & 688261 & 5.3781 & 4.851 & TRN & \\
\hline CHEMBL1440293 & 688261 & 5.37799 & 79999999 & 5.479 & TST \\
\hline
\end{tabular}




\begin{tabular}{|c|c|c|c|c|c|c|}
\hline & & \multicolumn{5}{|c|}{ Supplemental Table S2.txt } \\
\hline CHEMBL1420037 & 688261 & 5.4184 & 5.4402 & TRN & & \\
\hline CHEMBL1361866 & 688261 & 4.8937 & 5.0969 & TST & & \\
\hline CHEMBL602722 & 688261 & 5.8938 & 5.6863 & TRN & & \\
\hline CHEMBL3196139 & 688261 & 5.5502 & 5.3823 & TRN & & \\
\hline CHEMBL578915 & 688261 & 4.5534 & 4.4443 & TRN & & \\
\hline CHEMBL1549450 & 688261 & 5.118 & 5.0902 & TRN & & \\
\hline CHEMBL1546134 & 688261 & 5.2738 & 5.1242 & TRN & & \\
\hline CHEMBL1522007 & 688261 & 4.5938 & 5.2817 & TRN & & \\
\hline CHEMBL1495325 & 688261 & 4.7631 & 5.3748 & TST & & \\
\hline CHEMBL1412002 & 688261 & 5.6 & 5.9011 & TRN & & \\
\hline CHEMBL1373967 & 688261 & 5.3144 & 5.8323 & TRN & & \\
\hline CHEMBL1405940 & 688261 & 5.3281 & 4.8528 & TRN & & \\
\hline CHEMBL1353737 & 688261 & 2.8239 & 4.6225 & TRN & & \\
\hline CHEMBL1419266 & 688261 & 4.34399 & 99999999 & 99 & 4.2293 & TRN \\
\hline CHEMBL1516637 & 688261 & 5.0193 & 5.1004 & TRN & & \\
\hline CHEMBL1520801 & 688261 & 5.0148 & 4.4484 & TRN & & \\
\hline CHEMBL1611182 & 688261 & 5.29 & 5.5068 & TRN & & \\
\hline CHEMBL1570706 & 688261 & 5.2891 & 5.5091 & TRN & & \\
\hline CHEMBL1460522 & 688261 & 2.8239 & 4.5054 & TST & & \\
\hline CHEMBL1197556 & 688261 & 5.4855 & 5.9237 & TRN & & \\
\hline CHEMBL1523954 & 688261 & 4.815 & 4.2736 & TRN & & \\
\hline CHEMBL 2002262 & 688261 & 5.0658 & 5.0941 & TRN & & \\
\hline CHEMBL3189712 & 688261 & 5.4564 & 5.4899 & TRN & & \\
\hline CHEMBL1332955 & 688261 & 4.9562 & 5.1678 & TRN & & \\
\hline CHEMBL1323828 & 688261 & 4.3038 & 4.1649 & TRN & & \\
\hline CHEMBL1380801 & 688261 & 5.2646 & 5.3041 & TRN & & \\
\hline CHEMBL117966 & 688261 & 5.2289 & 4.8321 & TRN & & \\
\hline CHEMBL1579277 & 688261 & 4.5264 & 4.7899 & TRN & & \\
\hline CHEMBL1373252 & 688261 & 4.8377 & 4.7503 & TRN & & \\
\hline CHEMBL1456851 & 688261 & 5.3912 & 6.1418 & TRN & & \\
\hline CHEMBL585071 & 688261 & 5.6513 & 5.7666 & TRN & & \\
\hline CHEMBL3189519 & 688261 & 5.9485 & 5.6538 & TRN & & \\
\hline CHEMBL1546374 & 688261 & 5.4551 & 5.8413 & TST & & \\
\hline CHEMBL1992918 & 688261 & 5.449 & 5.4032 & TST & & \\
\hline CHEMBL1396519 & 688261 & 5.0139 & 5.096 & TRN & & \\
\hline CHEMBL1446306 & 688261 & 6.2815 & 5.69 & TRN & & \\
\hline CHEMBL3190220 & 688261 & 5.4033 & 4.8778 & TRN & & \\
\hline CHEMBL1564519 & 688261 & 5.3719 & 5.7783 & TRN & & \\
\hline CHEMBL1528030 & 688261 & 2.8239 & 3.4637 & TRN & & \\
\hline CHEMBL1611670 & 688261 & 4.7151 & 5.1062 & TST & & \\
\hline CHEMBL1577495 & 688261 & 5.0074 & 4.9664 & TRN & & \\
\hline CHEMBL225951 & 688261 & 5.0709 & 5.0506 & TRN & & \\
\hline CHEMBL1416089 & 688261 & 5.3811 & 5.4872 & TRN & & \\
\hline CHEMBL1581233 & 688261 & 4.5056 & 4.4854 & TRN & & \\
\hline CHEMBL1414112 & 688261 & 6.1101 & 6.0124 & TRN & & \\
\hline CHEMBL1464824 & 688261 & 2.8239 & 3.9895 & TRN & & \\
\hline CHEMBL1514534 & 688261 & 5.6902 & 3.4759 & TRN & & \\
\hline CHEMBL1580774 & 688261 & 4.9808 & 4.9002 & TRN & & \\
\hline
\end{tabular}




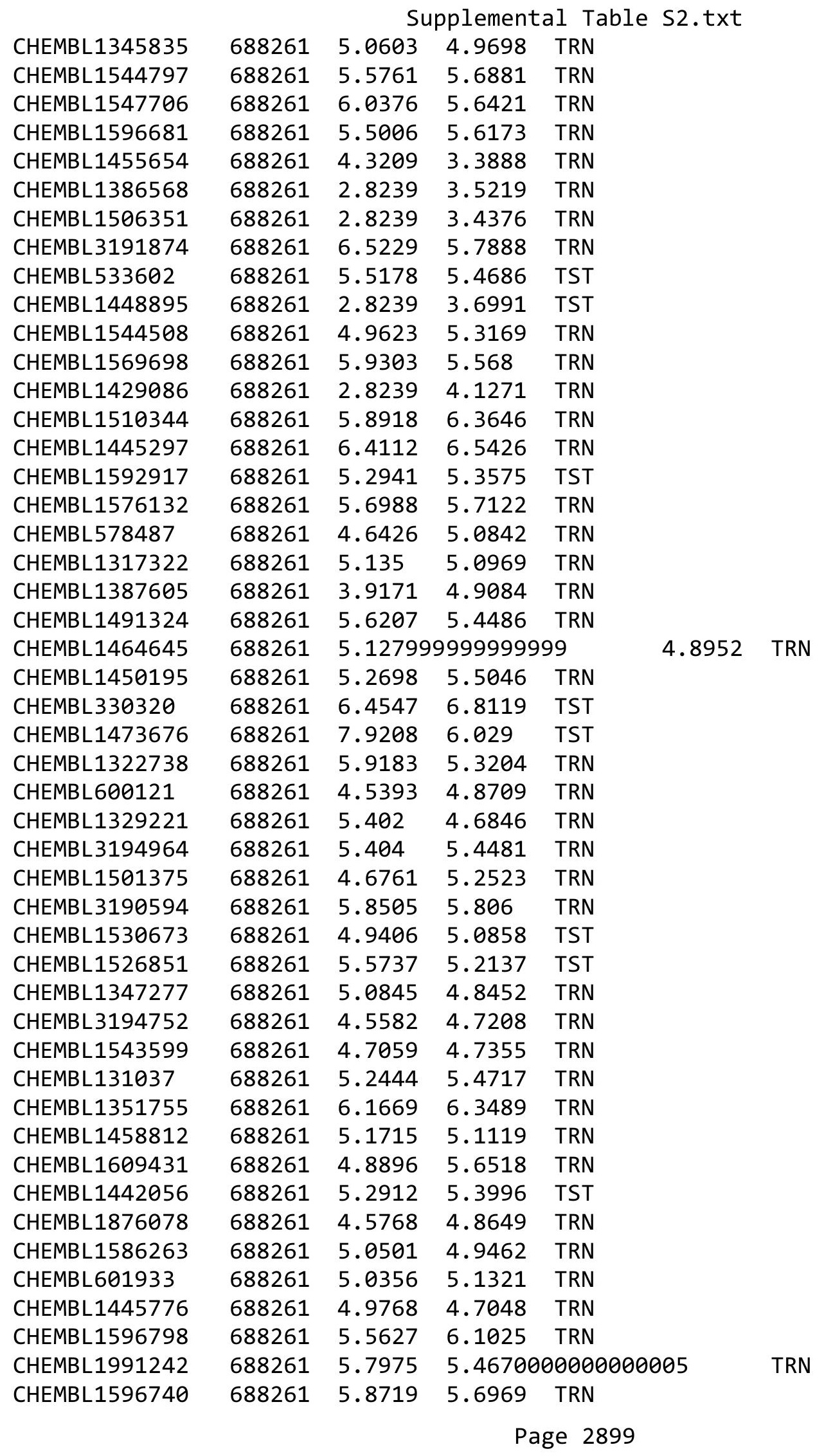




\begin{tabular}{|c|c|c|c|c|c|c|}
\hline \multirow[b]{2}{*}{ CHEMBL1996625 } & & \multicolumn{5}{|c|}{ Supplemental Table S2.txt } \\
\hline & 688261 & 4.6322 & 4.8129 & TRN & & \\
\hline CHEMBL1391582 & 688261 & 4.9317 & 5.4096 & TST & & \\
\hline CHEMBL585622 & 688261 & 5.1047 & 5.2298 & TRN & & \\
\hline CHEMBL1989225 & 688261 & 4.8011 & 4.8743 & TRN & & \\
\hline CHEMBL1544445 & 688261 & 6.20200 & 30000000 & 01 & 6.1808 & TRN \\
\hline CHEMBL1522827 & 688261 & 5.267 & 5.5048 & TRN & & \\
\hline CHEMBL1326464 & 688261 & 4.8688 & 5.0919 & TST & & \\
\hline CHEMBL1361740 & 688261 & 5.27 & 5.3234 & TST & & \\
\hline CHEMBL1497078 & 688261 & 5.0278 & 4.9052 & TRN & & \\
\hline CHEMBL1399543 & 688261 & 5.9389 & 5.8949 & TRN & & \\
\hline CHEMBL1409606 & 688261 & 5.2021 & 5.1678 & TRN & & \\
\hline CHEMBL1430068 & 688261 & 5.8983 & 5.9864 & TRN & & \\
\hline CHEMBL1550486 & 688261 & 4.8315 & 4.6843 & TRN & & \\
\hline CHEMBL1596197 & 688261 & 4.7291 & 4.5154 & TRN & & \\
\hline CHEMBL1521217 & 688261 & 6.3107 & 5.7674 & TRN & & \\
\hline CHEMBL1407996 & 688261 & 4.7679 & 4.9653 & TRN & & \\
\hline CHEMBL461579 & 688261 & 5.5183 & 5.7153 & TST & & \\
\hline CHEMBL1397089 & 688261 & 5.07100 & 00000000 & 01 & 5.5952 & TRN \\
\hline CHEMBL1392556 & 688261 & 4.7098 & 4.4751 & TRN & & \\
\hline CHEMBL1415336 & 688261 & 2.8239 & 3.3093 & TRN & & \\
\hline CHEMBL1502738 & 688261 & 5.3318 & 5.3878 & TRN & & \\
\hline CHEMBL1341399 & 688261 & 5.1626 & 5.209 & TST & & \\
\hline CHEMBL1967436 & 688261 & 5.2363 & 5.4334 & TST & & \\
\hline CHEMBL1556239 & 688261 & 6.1752 & 5.9488 & TST & & \\
\hline CHEMBL1572558 & 688261 & 5.7937 & 5.7681 & TST & & \\
\hline CHEMBL1387610 & 688261 & 5.7765 & 5.7303 & TRN & & \\
\hline CHEMBL1555066 & 688261 & 5.3662 & 5.3485 & TRN & & \\
\hline CHEMBL1489856 & 688261 & 4.0472 & 4.419 & TRN & & \\
\hline CHEMBL1460639 & 688261 & 5.6112 & 5.5956 & TST & & \\
\hline CHEMBL1461858 & 688261 & 2.8239 & 3.1458 & TRN & & \\
\hline CHEMBL1385053 & 688261 & 6.015 & 5.4898 & TRN & & \\
\hline CHEMBL1384373 & 688261 & 5.1453 & 4.9299 & TRN & & \\
\hline CHEMBL1451736 & 688261 & 6.3556 & 5.7713 & TRN & & \\
\hline CHEMBL3210428 & 688261 & 5.0849 & 5.0413 & TRN & & \\
\hline CHEMBL1583767 & 688261 & 4.8879 & 4.8686 & TRN & & \\
\hline CHEMBL1516407 & 688261 & 2.8239 & 3.4496 & TRN & & \\
\hline CHEMBL417727 & 688261 & 5.3541 & 5.544 & TRN & & \\
\hline CHEMBL1530741 & 688261 & 4.78600 & 30000000 & 005 & 4.2075 & The \\
\hline CHEMBL1462373 & 688261 & 5.2118 & 5.5 & TRN & & \\
\hline CHEMBL1308404 & 688261 & 5.5748 & 5.6462 & TRN & & \\
\hline CHEMBL3199573 & 688261 & 4.3535 & 3.5407 & TRN & & \\
\hline CHEMBL1441122 & 688261 & 5.1302 & 4.5636 & TST & & \\
\hline CHEMBL1403322 & 688261 & 5.93 & 5.5997 & TRN & & \\
\hline CHEMBL1353184 & 688261 & 2.8239 & 3.6145 & TRN & & \\
\hline CHEMBL1305972 & 688261 & 5.37 & 4.8419 & TST & & \\
\hline CHEMBL570345 & 688261 & 5.5563 & 5.7435 & TST & & \\
\hline CHEMBL1535665 & 688261 & 5.5608 & 5.3948 & TRN & & \\
\hline CHEMBL1335650 & 688261 & 4.2545 & 3.6396 & TST & & \\
\hline
\end{tabular}


Supplemental Table S2.txt

\begin{tabular}{|c|c|c|c|c|c|}
\hline CHEMBL1341680 & 688261 & 4.7079 & 4.0972 & TRN & \\
\hline CHEMBL1511219 & 688261 & 6.0315 & 6.0547 & TRN & \\
\hline CHEMBL1541771 & 688261 & 2.8239 & 3.6085 & TRN & \\
\hline CHEMBL1524608 & 688261 & 2.8239 & 3.39899 & 99999999996 & TRN \\
\hline CHEMBL1996752 & 688261 & 4.7671 & 4.6421 & TRN & \\
\hline CHEMBL1970286 & 688261 & 6.1811 & 5.7449 & TRN & \\
\hline CHEMBL1430987 & 688261 & 2.8239 & 3.1801 & TRN & \\
\hline CHEMBL1523841 & 688261 & 6.3188 & 5.6481 & TST & \\
\hline CHEMBL1507407 & 688261 & 5.3037 & 5.4514 & TRN & \\
\hline CHEMBL1997978 & 688261 & 4.7082 & 4.365 & TRN & \\
\hline CHEMBL 2007313 & 688261 & 4.569 & 4.8931 & TRN & \\
\hline CHEMBL1531500 & 688261 & 5.2296 & 5.2391 & TRN & \\
\hline CHEMBL1611744 & 688261 & 5.5522 & 5.2249 & TRN & \\
\hline CHEMBL1460991 & 688261 & 2.8239 & 3.4677 & TRN & \\
\hline CHEMBL1541554 & 688261 & 5.5646 & 5.6564 & TRN & \\
\hline CHEMBL1404792 & 688261 & 4.8678 & 6.1678 & TRN & \\
\hline CHEMBL1402096 & 688261 & 5.6306 & 5.1812 & TRN & \\
\hline CHEMBL1418818 & 688261 & 4.958 & 4.7591 & TRN & \\
\hline CHEMBL1416406 & 688261 & 4.9709 & 3.6467 & TRN & \\
\hline CHEMBL1494887 & 688261 & 4.398 & 4.955 & TST & \\
\hline CHEMBL1353341 & 688261 & 5.1236 & 5.4587 & TRN & \\
\hline CHEMBL80799 & 688261 & 5.4776 & 5.0996 & TRN & \\
\hline CHEMBL1592124 & 688261 & 6.1851 & 6.0481 & TRN & \\
\hline CHEMBL1523997 & 688261 & 5.6021 & 3.33399 & 99999999996 & TRN \\
\hline CHEMBL578944 & 688261 & 5.2502 & 5.36299 & 99999999995 & \\
\hline CHEMBL1979662 & 688261 & 2.8239 & 4.269 & TRN & \\
\hline CHEMBL1327496 & 688261 & 6.0878 & 5.5998 & TST & \\
\hline CHEMBL1342038 & 688261 & 5.1651 & 5.2174 & TRN & \\
\hline CHEMBL1395404 & 688261 & 5.4177 & 5.4619 & TRN & \\
\hline CHEMBL528694 & 688261 & 4.8161 & 5.5302 & TRN & \\
\hline CHEMBL1393820 & 688261 & 2.8239 & 4.6293 & TRN & \\
\hline CHEMBL1543268 & 688261 & 4.795 & 5.01 & TRN & \\
\hline CHEMBL1553246 & 688261 & 6.1851 & 5.5183 & TRN & \\
\hline CHEMBL590184 & 688261 & 4.7606 & 4.7379 & TRN & \\
\hline CHEMBL1419031 & 688261 & 4.9325 & 4.9317 & TRN & \\
\hline CHEMBL1353528 & 688261 & 4.516 & 4.692 & TRN & \\
\hline CHEMBL1457201 & 688261 & 5.6238 & 5.5337 & TRN & \\
\hline CHEMBL1998716 & 688261 & 6.3233 & 6.2339 & TRN & \\
\hline CHEMBL51931 & 688261 & 5.305 & 5.6582 & TRN & \\
\hline CHEMBL1986214 & 688261 & 5.1305 & 5.1459 & TRN & \\
\hline CHEMBL601757 & 688261 & 5.3574 & 5.5463 & TST & \\
\hline CHEMBL1394035 & 688261 & 2.8239 & 3.2431 & TRN & \\
\hline CHEMBL1578061 & 688261 & 5.6059 & 5.6266 & TRN & \\
\hline CHEMBL1548695 & 688261 & \multicolumn{3}{|c|}{5.2170000000000005} & \\
\hline CHEMBL1305612 & 688261 & 4.8645 & 5.0165 & TRN & \\
\hline CHEMBL 2006168 & 688261 & 5.12 & 5.1614 & TRN & \\
\hline CHEMBL1242180 & 688261 & 5.8511 & 5.6842 & TRN & \\
\hline CHEMBL1323140 & 688261 & 6.0467 & 5.3351 & TRN & \\
\hline
\end{tabular}




\begin{tabular}{|c|c|c|c|c|c|}
\hline & & \multicolumn{4}{|c|}{ Supplemental Table S2.txt } \\
\hline CHEMBL1541834 & 688261 & 5.2214 & 5.2845 & TRN & \\
\hline CHEMBL1402510 & 688261 & 5.0414 & 4.8406 & TRN & \\
\hline CHEMBL1303910 & 688261 & 5.6212 & 5.8192 & TRN & \\
\hline CHEMBL1971727 & 688261 & 5.2918 & 5.5358 & TRN & \\
\hline CHEMBL323668 & 688261 & 7.9208 & 7.385 & TST & \\
\hline CHEMBL1566610 & 688261 & 6.4789 & 5.7664 & TST & \\
\hline CHEMBL1447125 & 688261 & 6.1871 & 5.56 & TRN & \\
\hline CHEMBL1369594 & 688261 & 5.2778 & 5.3944 & TRN & \\
\hline CHEMBL1575441 & 688261 & 5.7129 & 5.227 & TST & \\
\hline CHEMBL1966751 & 688261 & 5.5471 & 4.7188 & TRN & \\
\hline CHEMBL1417620 & 688261 & 5.4316 & 5.33 & TRN & \\
\hline CHEMBL1608077 & 688261 & 5.3057 & 4.9993 & TRN & \\
\hline CHEMBL1312720 & 688261 & 4.2156 & 4.3695 & TRN & \\
\hline CHEMBL1386941 & 688261 & 2.8239 & 3.697 & TRN & \\
\hline CHEMBL1320414 & 688261 & 5.0762 & 4.8957 & TRN & \\
\hline CHEMBL1443205 & 688261 & 4.677 & 4.9402 & TRN & \\
\hline CHEMBL1372889 & 688261 & 5.169 & 5.5047 & TRN & \\
\hline CHEMBL1408307 & 688261 & 4.6801 & 4.5878 & TRN & \\
\hline CHEMBL1565526 & 688261 & 5.5522 & 5.5748 & TRN & \\
\hline CHEMBL1342029 & 688261 & 6.2464 & 6.3108 & TRN & \\
\hline CHEMBL1610036 & 688261 & 2.8239 & 4.0795 & TRN & \\
\hline CHEMBL1533067 & 688261 & 5.3729 & 5.2867 & TST & \\
\hline CHEMBL1519965 & 688261 & 5.6672 & 5.58299 & 9999999999 & TRN \\
\hline CHEMBL1459746 & 688261 & 5.8719 & 5.8953 & TRN & \\
\hline CHEMBL1390868 & 688261 & 4.9357 & 4.8231 & TRN & \\
\hline CHEMBL1423935 & 688261 & 4.8691 & 5.24200 & 0000000001 & TRN \\
\hline CHEMBL309016 & 688261 & 4.9892 & 4.8974 & TRN & \\
\hline CHEMBL1539678 & 688261 & 5.4347 & 4.9708 & TST & \\
\hline CHEMBL1307663 & 688261 & 5.1952 & 4.9277 & TRN & \\
\hline CHEMBL1424127 & 688261 & 6.0814 & 5.8949 & TRN & \\
\hline CHEMBL1419369 & 688261 & 5.6472 & 5.3714 & TRN & \\
\hline CHEMBL1528258 & 688261 & 5.4068 & 5.3925 & TRN & \\
\hline CHEMBL1582519 & 688261 & 2.8239 & 3.0814 & TRN & \\
\hline CHEMBL586135 & 688261 & 4.6503 & 5.9301 & TRN & \\
\hline CHEMBL1995769 & 688261 & 5.7742 & 5.6097 & TRN & \\
\hline CHEMBL1513325 & 688261 & 4.6991 & 6.1408 & TRN & \\
\hline CHEMBL1344025 & 688261 & 2.8239 & 3.5776 & TST & \\
\hline CHEMBL1325021 & 688261 & 5.5075 & 5.1695 & TRN & \\
\hline CHEMBL1338243 & 688261 & 4.5345 & 4.1515 & TRN & \\
\hline CHEMBL1342147 & 688261 & 5.09699 & 99999999 & 4.9963 & TRN \\
\hline CHEMBL1485865 & 688261 & 5.4304 & 5.2187 & TRN & \\
\hline CHEMBL1599070 & 688261 & 4.3749 & 4.3412 & TRN & \\
\hline CHEMBL1454183 & 688261 & 5.4173 & 4.9995 & TST & \\
\hline CHEMBL1335248 & 688261 & 3.8469 & 3.5015 & TRN & \\
\hline CHEMBL1352850 & 688261 & 5.5766 & 5.0203 & TRN & \\
\hline CHEMBL3196369 & 688261 & 2.8239 & 3.9393 & TRN & \\
\hline CHEMBL587801 & 688261 & 5.2777 & 5.1155 & TRN & \\
\hline CHEMBL1329725 & 688261 & 4.7318 & 4.433 & TRN & \\
\hline
\end{tabular}


Supplemental Table S2.txt

\begin{tabular}{|c|c|c|c|c|}
\hline IE & & & & \\
\hline & 88261 & .9208 & 6.6904 & \\
\hline$I F$ & 61 & & 028 & \\
\hline AEMBL1 & 261 & 91 & & \\
\hline AEMBL136 & 8261 & 3225 & & \\
\hline HEMBL1200512 & 88261 & 4836 & 6818 & \\
\hline HEMBL160 & 261 & & & \\
\hline IFMBI 156 & 261 & & & \\
\hline AEMBL3212 & 261 & & 3553 & \\
\hline HEMBL1583955 & 38261 & & 2801 & \\
\hline HEMBL1417929 & 88261 & & 461 & \\
\hline IEMBL319 & 261 & & 992 & \\
\hline IEMBL140 & & & & \\
\hline AEMBL1606521 & 261 & & 4394 & \\
\hline IEMBL145 & 261 & & & \\
\hline AEMBL154 & 3261 & 53 & 92 & \\
\hline AEMBL3 & 61 & & 66 & \\
\hline HEMBL1 & & & & \\
\hline AEMBL139. & 261 & 28 & 148 & \\
\hline IEMBL130 & 61 & & & RN \\
\hline HEMBLI & 51 & & 92 & \\
\hline AEMBL13 & & & 94 & \\
\hline AEMBL139 & 51 & & 28 & RN \\
\hline AEMBL199. & 61 & & 7565 & \\
\hline IEMBL133 & 51 & & & NIV \\
\hline AEMBL & & & 652 & $\mathrm{RN}$ \\
\hline AEMBLI & & & 82 & Niv \\
\hline AFMBI 1 & 1 & & 551 & RN \\
\hline AEMBL138 & & & & RIN \\
\hline HEMBL1318 & 61 & & 94 & RN \\
\hline HEMBL1608 & 61 & & 484 & $\mathrm{RN}$ \\
\hline AFMBI & & & 25 & ST \\
\hline 8 & & & 85 & RN \\
\hline HEMBL1564522 & & & 118 & RN \\
\hline HEMBL1613639 & 61 & & 5561 & TRN \\
\hline HEMBL1 & 51 & & 275 & RN \\
\hline 1 & & & 64 & TRN \\
\hline HEMBL1 & & & 033 & RN \\
\hline HEMBL1583292 & 88261 & & & ST \\
\hline AEMBL147 & & & 42 & $\mathrm{RN}$ \\
\hline HEMBL148\& & 61 & & 3093 & TRN \\
\hline HEMBL133 & & & & RN \\
\hline HEMBL15968 & & & 8123 & $\mathrm{RN}$ \\
\hline AEMBL1408268 & 261 & & 379 & TRN \\
\hline EMBL135 & & & .7414 & I \\
\hline HEMBL134 & & & .3201 & \\
\hline LHEMBL1481347 & 88261 & .4628 & 5.6173 & \\
\hline HEMBL160561 & 688261 & 4.4837 & 3.6875 & ГRN \\
\hline
\end{tabular}

Page 2903 
Supplemental Table S2.txt

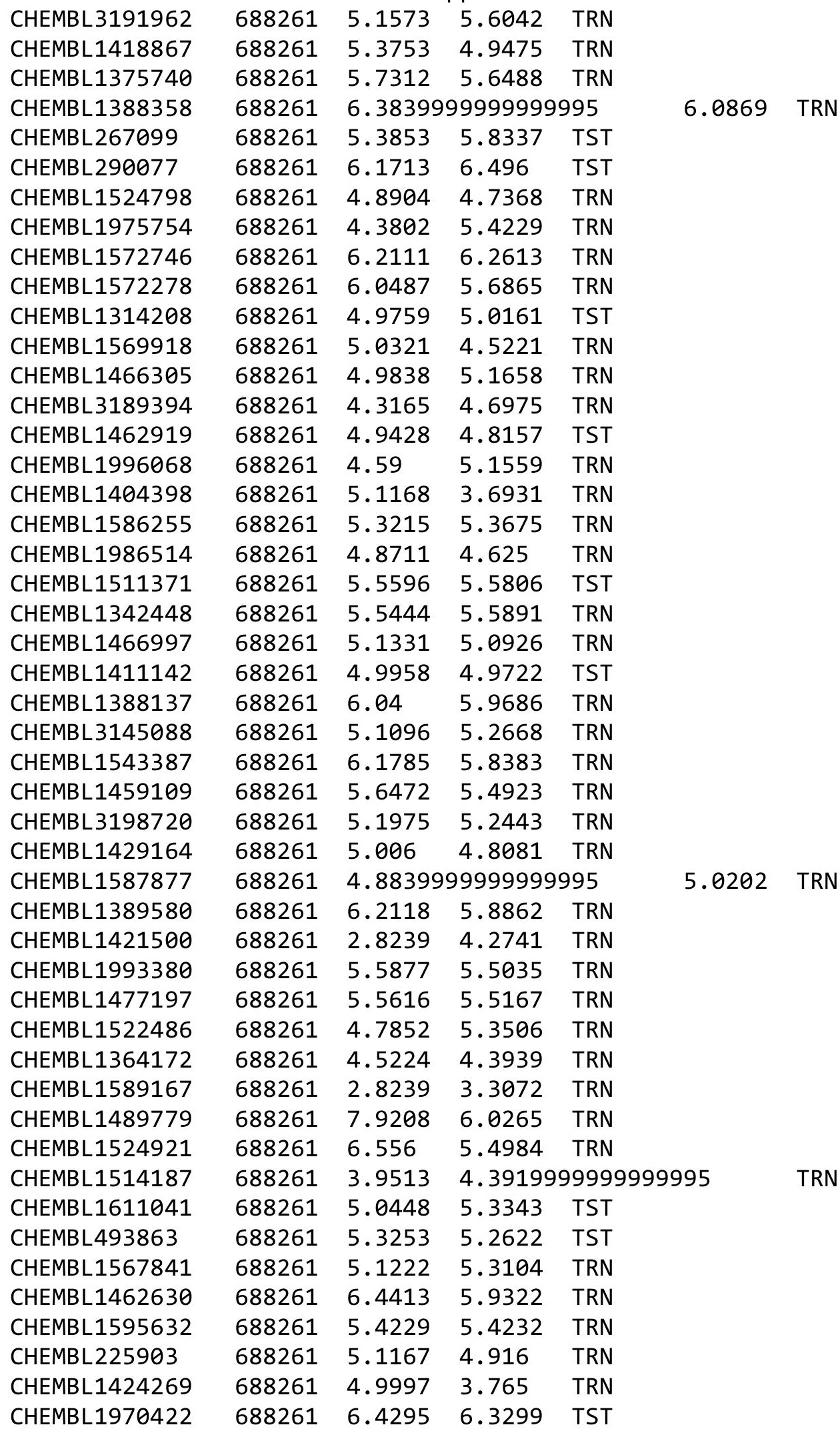

Page 2904 


\begin{tabular}{|c|c|c|c|c|c|}
\hline \multirow[b]{2}{*}{ CHEMBL3192894 } & \multicolumn{5}{|c|}{ Supplemental Table S2.txt } \\
\hline & 688261 & 4.5945 & 5.7743 & TRN & \\
\hline CHEMBL1369945 & 688261 & 4.8786 & 5.1784 & TRN & \\
\hline CHEMBL1339289 & 688261 & 5.6287 & 5.9611 & TST & \\
\hline CHEMBL1549860 & 688261 & 4.9809 & 5.1034 & TST & \\
\hline CHEMBL1489824 & 688261 & 5.5824 & 5.3919 & TST & \\
\hline CHEMBL1416671 & 688261 & 4.7441 & 4.4272 & TRN & \\
\hline CHEMBL 2004475 & 688261 & 5.2461 & 5.2752 & TST & \\
\hline CHEMBL1429789 & 688261 & 4.96 & 4.9188 & TRN & \\
\hline CHEMBL3189245 & 688261 & 4.7581 & 5.2207 & TRN & \\
\hline CHEMBL1520297 & 688261 & 2.8239 & 3.9848 & TRN & \\
\hline CHEMBL1497939 & 688261 & 5.2666 & 5.3731 & TRN & \\
\hline CHEMBL1373253 & 688261 & 4.7061 & 6.225 & TRN & \\
\hline CHEMBL1392509 & 688261 & 4.6588 & 4.3377 & TRN & \\
\hline CHEMBL1486332 & 688261 & 5.6057 & 5.6616 & TRN & \\
\hline CHEMBL1373969 & 688261 & 5.5574 & 6.001 & TRN & \\
\hline CHEMBL1544726 & 688261 & 4.485 & 5.0415 & TRN & \\
\hline CHEMBL1413355 & 688261 & 5.0645 & 5.1971 & TRN & \\
\hline CHEMBL1464686 & 688261 & 4.8497 & 4.7767 & TRN & \\
\hline CHEMBL1486176 & 688261 & 4.7877 & 5.0033 & TRN & \\
\hline CHEMBL1501238 & 688261 & 5.1264 & 4.8934 & TST & \\
\hline CHEMBL1447362 & 688261 & 2.8239 & 4.0433 & TRN & \\
\hline CHEMBL1503930 & 688261 & 5.1046 & 4.6293 & TRN & \\
\hline CHEMBL3182775 & 688261 & 6.2182 & 5.6164 & TST & \\
\hline CHEMBL1419082 & 688261 & 5.7698 & 5.4695 & TRN & \\
\hline CHEMBL1583677 & 688261 & 5.6893 & 5.4153 & TRN & \\
\hline CHEMBL602126 & 688261 & 5.7064 & 5.4751 & TRN & \\
\hline CHEMBL3209451 & 688261 & 5.0 & 4.6728 & TRN & \\
\hline CHEMBL 1457480 & 688261 & 4.9044 & 4.7197 & TRN & \\
\hline CHEMBL1550485 & 688261 & 5.2682 & 4.8856 & TST & \\
\hline CHEMBL1455689 & 688261 & 4.9589 & 4.6539 & TRN & \\
\hline CHEMBL1520080 & 688261 & 4.6075 & 4.2526 & TRN & \\
\hline CHEMBL1521348 & 688261 & 5.6472 & 5.8049 & TRN & \\
\hline CHEMBL1430060 & 688261 & 5.4332 & 5.3606 & TRN & \\
\hline CHEMBL1586371 & 688261 & 4.6872 & 3.8819 & TRN & \\
\hline CHEMBL1607906 & 688261 & 6.1506 & 5.5332 & TRN & \\
\hline CHEMBL1387238 & 688261 & 4.5452 & 4.36100 & 0000000001 & TRN \\
\hline CHEMBL1336467 & 688261 & 4.9492 & 4.0027 & TST & \\
\hline CHEMBL1335585 & 688261 & 2.8239 & 3.0344 & TRN & \\
\hline CHEMBL1450116 & 688261 & 4.8761 & 4.9879 & TRN & \\
\hline CHEMBL1487444 & 688261 & 5.2017 & 5.37700 & 2000000001 & TRN \\
\hline CHEMBL1520030 & 688261 & 4.8854 & 3.8816 & TST & \\
\hline CHEMBL1586895 & 688261 & 5.0636 & 5.3592 & TRN & \\
\hline CHEMBL1508051 & 688261 & 4.8834 & 5.1586 & TST & \\
\hline CHEMBL3191713 & 688261 & 5.6505 & 5.9558 & TST & \\
\hline CHEMBL 3145285 & 688261 & 5.5479 & 5.6676 & TST & \\
\hline CHEMBL1613188 & 688261 & 5.3124 & 5.069 & TST & \\
\hline CHEMBL1368681 & 688261 & 2.8239 & 3.7484 & TST & \\
\hline CHEMBL1487639 & 688261 & 4.7787 & 5.2201 & TST & \\
\hline
\end{tabular}


Supplemental Table S2.txt

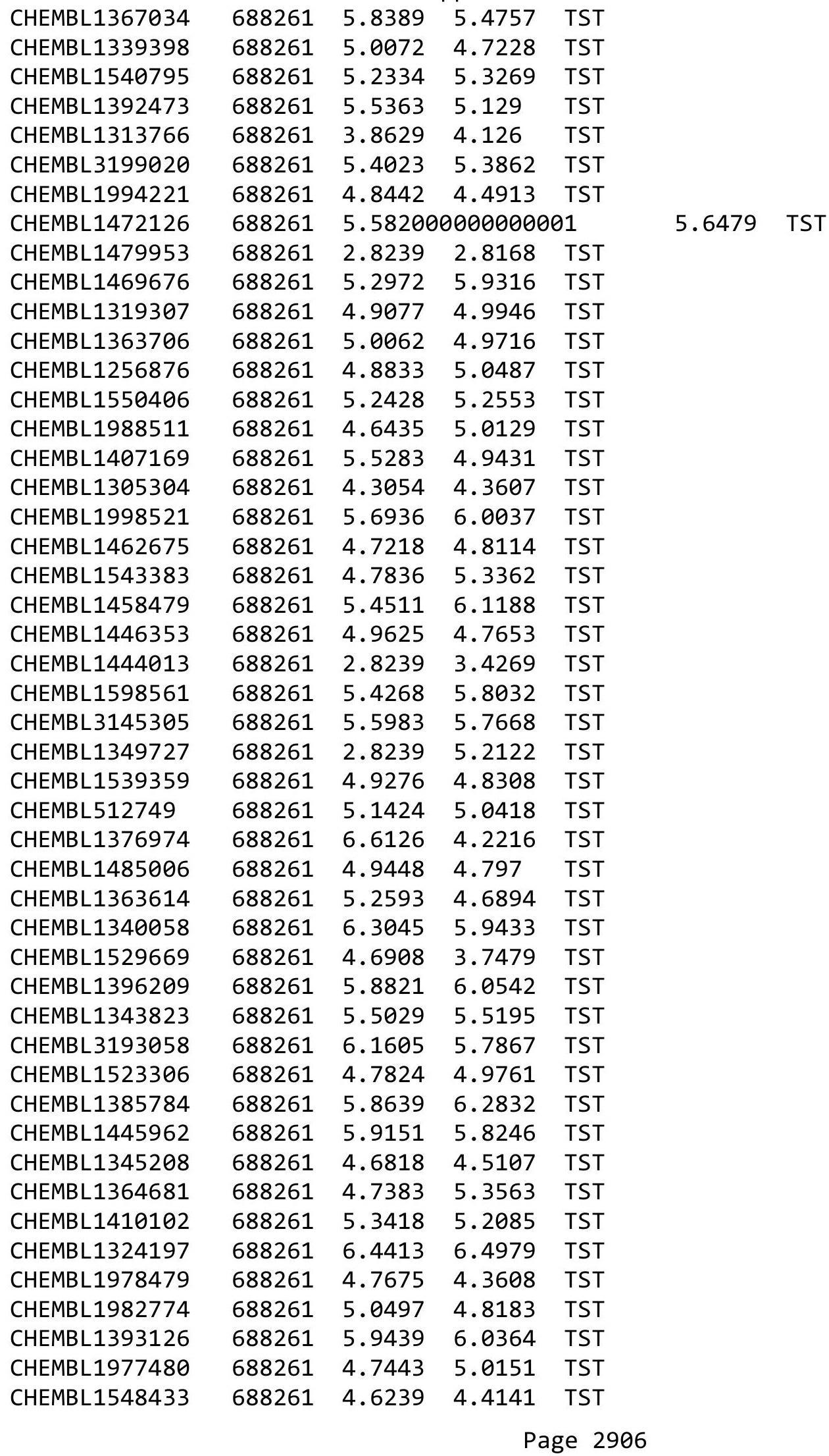


Supplemental Table S2.txt

\begin{tabular}{|c|c|c|c|c|}
\hline CHEMBL1452795 & 688261 & 5.6212 & 5.8359 & TST \\
\hline CHEMBL1444065 & 688261 & 5.3824 & 5.2057 & TST \\
\hline CHEMBL1448905 & 688261 & 5.2548 & 5.1852 & TST \\
\hline CHEMBL1967744 & 688261 & 5.0952 & 5.1103 & TST \\
\hline CHEMBL1340089 & 688261 & 5.3298 & 5.1085 & TST \\
\hline CHEMBL1469579 & 688261 & 4.1096 & 4.5138 & TST \\
\hline CHEMBL1448054 & 688261 & 6.04 & 6.0029 & TST \\
\hline CHEMBL1423192 & 688261 & 5.0933 & 4.7383 & TST \\
\hline CHEMBL1335846 & 688261 & 5.9796 & 5.8132 & TST \\
\hline CHEMBL1558993 & 688261 & 4.7975 & 4.0454 & TST \\
\hline CHEMBL600862 & 688261 & 5.2577 & 5.9556 & TST \\
\hline CHEMBL1374860 & 688261 & 5.1388 & 5.4074 & TST \\
\hline CHEMBL1524929 & 688261 & 5.2272 & 5.229 & TST \\
\hline CHEMBL1373586 & 688261 & 4.8689 & 4.9173 & TST \\
\hline CHEMBL1358473 & 688261 & 4.1471 & 4.1326 & TST \\
\hline CHEMBL1969992 & 688261 & 5.517 & 5.0174 & TST \\
\hline CHEMBL3199428 & 688261 & 5.5648 & 5.4907 & TST \\
\hline CHEMBL3210375 & 688261 & 2.8239 & 3.3806 & TST \\
\hline CHEMBL1543836 & 688261 & 2.8239 & 4.3189 & TST \\
\hline CHEMBL1341756 & 688261 & 5.2882 & 5.7735 & TST \\
\hline CHEMBL1331451 & 688261 & 2.8239 & 3.6259 & TST \\
\hline CHEMBL1581648 & 688261 & 4.8312 & 4.7814 & TST \\
\hline CHEMBL1399388 & 688261 & 5.8271 & 5.3804 & TST \\
\hline CHEMBL 86464 & 688261 & 5.5414 & 5.3152 & TST \\
\hline CHEMBL1605299 & 688261 & 4.596 & 3.4604 & TST \\
\hline CHEMBL1864040 & 688261 & 4.7866 & 5.1361 & TST \\
\hline CHEMBL1524734 & 688261 & 4.8779 & 3.7856 & TST \\
\hline CHEMBL1608333 & 688261 & 5.2713 & 5.4364 & TST \\
\hline CHEMBL1407944 & 688261 & 6.2396 & 6.1155 & TST \\
\hline CHEMBL1610510 & 688261 & 5.6876 & 5.3606 & TST \\
\hline CHEMBL1519279 & 688261 & 4.9264 & 5.2942 & TST \\
\hline CHEMBL1482663 & 688261 & 5.5481 & 5.3897 & TST \\
\hline CHEMBL1382191 & 688261 & 4.8168 & 5.1584 & TST \\
\hline CHEMBL1493225 & 688261 & 4.9107 & 4.6967 & TST \\
\hline CHEMBL1548542 & 688261 & 5.1018 & 5.1559 & TST \\
\hline CHEMBL82134 & 688261 & 4.9767 & 5.6461 & TST \\
\hline CHEMBL1379740 & 688261 & 5.522 & 5.5272 & TST \\
\hline CHEMBL1388459 & 688261 & 2.8239 & 2.7327 & TST \\
\hline CHEMBL1321538 & 688261 & 5.7162 & 5.8373 & TST \\
\hline CHEMBL607553 & 688261 & 5.2863 & \multicolumn{2}{|c|}{5.337999999999999} \\
\hline CHEMBL1335177 & 688261 & 5.5877 & 5.2876 & TST \\
\hline CHEMBL1426410 & 688261 & 4.8104 & 5.2491 & TST \\
\hline CHEMBL1528867 & 688261 & 4.8258 & 4.4437 & TST \\
\hline CHEMBL1589042 & 688261 & 4.6953 & 4.9962 & TST \\
\hline CHEMBL3212271 & 688261 & 4.2568 & 4.6612 & TST \\
\hline CHEMBL1332450 & 688261 & 4.8554 & 5.16 & TST \\
\hline CHEMBL1404547 & 688261 & 5.2039 & 5.3132 & TST \\
\hline CHEMBL1404493 & 688261 & 5.8438 & 6.0358 & TST \\
\hline
\end{tabular}


Supplemental Table S2.txt

\begin{tabular}{|c|c|c|c|c|}
\hline CHEMBL1353271 & 688261 & 4.8936 & 5.2368 & TST \\
\hline CHEMBL598883 & 688261 & 4.8993 & 3.7887 & TST \\
\hline CHEMBL1573883 & 688261 & 4.9316 & 4.9994 & TST \\
\hline CHEMBL3194563 & 688261 & 4.7009 & 5.2642 & TST \\
\hline CHEMBL1572624 & 688261 & 5.6192 & 5.5446 & TST \\
\hline CHEMBL1310355 & 688261 & 4.9282 & 4.8307 & TST \\
\hline CHEMBL1541441 & 688261 & 5.3147 & 5.4072 & TST \\
\hline CHEMBL1330879 & 688261 & 5.4495 & 5.3776 & TST \\
\hline CHEMBL 3934107 & 1641460 & 6.7645 & 6.8134 & TRN \\
\hline CHEMBL3898276 & 1641460 & 6.7721 & 6.7769 & TRN \\
\hline CHEMBL3938845 & 1641460 & 7.3768 & 7.2736 & TST \\
\hline CHEMBL3918425 & 1641460 & 5.8139 & 5.5476 & TRN \\
\hline CHEMBL3910167 & 1641460 & 7.3468 & 7.2134 & TRN \\
\hline CHEMBL3968068 & 1641460 & 7.1675 & 6.8204 & TRN \\
\hline CHEMBL3951457 & 1641460 & 7.9208 & 7.6095 & TRN \\
\hline CHEMBL3928297 & 1641460 & 7.4949 & 7.6335 & TRN \\
\hline CHEMBL3962916 & 1641460 & 7.4202 & 7.3385 & TRN \\
\hline CHEMBL 3985462 & 1641460 & 6.7258 & 7.2908 & TRN \\
\hline CHEMBL3970122 & 1641460 & 6.5719 & 6.8456 & TST \\
\hline CHEMBL3930648 & 1641460 & 6.9281 & 6.8068 & TRN \\
\hline CHEMBL3961269 & 1641460 & 7.7447 & 7.2343 & TRN \\
\hline CHEMBL3972402 & 1641460 & 7.7959 & 7.4651 & TRN \\
\hline CHEMBL3917766 & 1641460 & 7.2366 & 7.1433 & TRN \\
\hline CHEMBL3956811 & 1641460 & 6.2154 & 6.0646 & TRN \\
\hline CHEMBL3910821 & 1641460 & 7.301 & 7.1698 & TRN \\
\hline CHEMBL3979845 & 1641460 & 6.6635 & 7.0714 & TRN \\
\hline CHEMBL3983636 & 1641460 & 7.3979 & 7.4724 & TRN \\
\hline CHEMBL3906032 & 1641460 & 6.5045 & 6.7373 & TRN \\
\hline CHEMBL3986539 & 1641460 & 7.4202 & 7.2823 & TRN \\
\hline CHEMBL3960540 & 1641460 & 6.7878 & 6.9315 & TRN \\
\hline CHEMBL3890382 & 1641460 & 7.4815 & 6.8663 & TRN \\
\hline CHEMBL 3922807 & 1641460 & 6.9208 & 6.8877 & TRN \\
\hline CHEMBL3972267 & 1641460 & 7.301 & 7.4144 & TRN \\
\hline CHEMBL 3922408 & 1641460 & 6.9872 & 6.9374 & TRN \\
\hline CHEMBL3977370 & 1641460 & 6.9245 & 7.19600 & 000000001 \\
\hline CHEMBL3949043 & 1641460 & 7.3768 & 7.3007 & TRN \\
\hline CHEMBL 3907957 & 1641460 & 7.1249 & 7.2309 & TRN \\
\hline CHEMBL3901283 & 1641460 & 7.6383 & 7.7761 & TRN \\
\hline CHEMBL 3967570 & 1641460 & 6.9914 & 7.2458 & TRN \\
\hline CHEMBL3985975 & 1641460 & 7.4559 & 7.398 & TST \\
\hline CHEMBL3932909 & 1641460 & 6.1871 & 6.7059 & TRN \\
\hline CHEMBL3787279 & 1641460 & 8.0969 & 7.4933 & TST \\
\hline CHEMBL3987128 & 1641460 & 6.8665 & 6.5519 & TRN \\
\hline CHEMBL3965536 & 1641460 & 6.9788 & 6.7483 & TRN \\
\hline CHEMBL3899348 & 1641460 & 6.8928 & 7.0543 & TRN \\
\hline CHEMBL3943208 & 1641460 & 6.1568 & 6.2595 & TRN \\
\hline CHEMBL3970529 & 1641460 & 6.7799 & 6.9264 & TRN \\
\hline CHEMBL3946553 & 1641460 & 7.2676 & 7.1079 & TRN \\
\hline
\end{tabular}

Page 2908 
Supplemental Table S2.txt

\begin{tabular}{|c|c|c|c|c|c|c|}
\hline CHEMBL 3895105 & 1641460 & 6.9626 & 6.8102 & TRN & & \\
\hline CHEMBL 3909759 & 1641460 & 6.6882 & 6.7172 & TRN & & \\
\hline CHEMBL3902122 & 1641460 & 5.3179 & 6.9972 & TST & & \\
\hline CHEMBL 3970467 & 1641460 & 5.7503 & 5.5615 & TRN & & \\
\hline CHEMBL 3908404 & 1641460 & 7.2076 & 7.091 & TRN & & \\
\hline CHEMBL 3938349 & 1641460 & 7.7696 & 7.6098 & TRN & & \\
\hline CHEMBL3911269 & 1641460 & 5.9531 & 5.8514 & TRN & & \\
\hline CHEMBL 3895502 & 1641460 & 6.6968 & 6.4829 & TRN & & \\
\hline CHEMBL 3982970 & 1641460 & 7.1871 & 7.2781 & TRN & & \\
\hline CHEMBL 3959228 & 1641460 & 7.3098 & 7.4922 & TRN & & \\
\hline CHEMBL 3932656 & 1641460 & 6.8386 & 6.5724 & TST & & \\
\hline CHEMBL 3965820 & 1641460 & 7.7447 & 7.425 & TRN & & \\
\hline CHEMBL 3916224 & 1641460 & 6.699 & 6.7578 & TRN & & \\
\hline CHEMBL3966781 & 1641460 & 5.8586 & 5.8752 & TRN & & \\
\hline CHEMBL 3919765 & 1641460 & 5.9205 & 6.8545 & TRN & & \\
\hline CHEMBL 3925217 & 1641460 & 6.9666 & 7.4021 & TST & & \\
\hline CHEMBL 3926372 & 1641460 & 6.8761 & 6.9008 & TRN & & \\
\hline CHEMBL 3913097 & 1641460 & 6.9872 & 7.5513 & TST & & \\
\hline CHEMBL 3893693 & 1641460 & 6.9318 & 7.3571 & TRN & & \\
\hline CHEMBL 3974182 & 1641460 & 7.0223 & 7.066 & TRN & & \\
\hline CHEMBL 3931840 & 1641460 & 5.8697 & 6.2676 & TRN & & \\
\hline CHEMBL 3984261 & 1641460 & 7.6383 & 7.5599 & TST & & \\
\hline CHEMBL 3897551 & 1641460 & 7.4949 & 7.6066 & TST & & \\
\hline CHEMBL 3945359 & 1641460 & \multicolumn{3}{|c|}{6.2620000000000005} & 6.6443 & TRN \\
\hline CHEMBL 3986698 & 1641460 & 7.9208 & 7.7354 & TRN & & \\
\hline CHEMBL 3913403 & 1641460 & 7.1427 & 7.2582 & TRN & & \\
\hline CHEMBL 3895082 & 1641460 & 7.9208 & 7.4578 & TRN & & \\
\hline CHEMBL 3933625 & 1641460 & 6.5258 & 6.7025 & TRN & & \\
\hline CHEMBL3925215 & 1641460 & 6.6757 & 6.761 & TRN & & \\
\hline CHEMBL 3904916 & 1641460 & 6.6757 & 6.8059 & TRN & & \\
\hline CHEMBL 3924552 & 1641460 & 7.1367 & 7.1197 & TRN & & \\
\hline CHEMBL 3915723 & 1641460 & 6.6615 & 6.0695 & TST & & \\
\hline CHEMBL 3952642 & 1641460 & 6.7447 & 6.7811 & TRN & & \\
\hline CHEMBL3905296 & 1641460 & 7.3098 & 6.9959 & TRN & & \\
\hline CHEMBL 3941383 & 1641460 & 6.8928 & 7.1769 & TRN & & \\
\hline CHEMBL 3934703 & 1641460 & 6.9172 & 6.9217 & TRN & & \\
\hline CHEMBL 3906233 & 1641460 & 6.0 & 7.6355 & TST & & \\
\hline CHEMBL 3952536 & 1641460 & 7.2218 & 7.0443 & TRN & & \\
\hline CHEMBL 3979221 & 1641460 & 6.9914 & 7.0558 & TRN & & \\
\hline CHEMBL 3975261 & 1641460 & 7.2007 & 7.3043 & TST & & \\
\hline CHEMBL 3985294 & 1641460 & \multicolumn{3}{|c|}{6.757000000000001} & 7.0913 & TRN \\
\hline CHEMBL 3902662 & 1641460 & 7.3468 & 6.8053 & TRN & & \\
\hline CHEMBL 3980277 & 1641460 & 7.5229 & 7.2616 & TRN & & \\
\hline CHEMBL 3975635 & 1641460 & 6.8861 & 6.8917 & TRN & & \\
\hline CHEMBL 3890875 & 1641460 & 6.8297 & 6.9767 & TRN & & \\
\hline CHEMBL 3921176 & 1641460 & 6.6615 & 6.7214 & TRN & & \\
\hline CHEMBL 3949005 & 1641460 & 6.7167 & 6.9599 & TRN & & \\
\hline CHEMBL 3937036 & 1641460 & 7.4437 & 7.4949 & TRN & & \\
\hline
\end{tabular}

Page 2909 
Supplemental Table S2.txt

\begin{tabular}{|c|c|c|c|c|c|}
\hline CHEMBL 3950740 & 1641460 & 7.4685 & 7.0534 & TRN & \\
\hline CHEMBL3943642 & 1641460 & 7.9208 & \multicolumn{2}{|c|}{ 7.763999999999999 } & TRN \\
\hline CHEMBL 3896352 & 1641460 & 7.2007 & 6.9901 & TRN & \\
\hline CHEMBL 3897860 & 1641460 & 7.0177 & 7.1487 & TRN & \\
\hline CHEMBL 3943676 & 1641460 & 7.3565 & 7.2656 & TRN & \\
\hline CHEMBL 3898931 & 1641460 & 7.3279 & 7.6514 & TST & \\
\hline CHEMBL3980886 & 1641460 & 6.7258 & 6.7173 & TST & \\
\hline CHEMBL 3897177 & 1641460 & 6.5302 & 6.8268 & TRN & \\
\hline CHEMBL 3977964 & 1641460 & 6.2882 & 6.4316 & TST & \\
\hline CHEMBL3985976 & 1641460 & 6.6576 & 6.7483 & TST & \\
\hline CHEMBL 3981222 & 1641460 & 7.1675 & 7.3362 & TST & \\
\hline CHEMBL 3983248 & 1641460 & 6.7595 & 6.9542 & TST & \\
\hline CHEMBL 3972674 & 1641460 & 7.7212 & 7.4595 & TST & \\
\hline CHEMBL3910345 & 1641460 & 7.1549 & 7.3122 & TST & \\
\hline CHEMBL 3895164 & 1641460 & 6.7959 & 7.1885 & TST & \\
\hline CHEMBL 3971743 & 1641460 & 7.4815 & 7.1144 & TST & \\
\hline CHEMBL3963382 & 1641460 & 6.9626 & 7.0464 & TST & \\
\hline CHEMBL 3944742 & 1641460 & 7.7212 & \multicolumn{2}{|c|}{7.542000000000001} & TST \\
\hline CHEMBL 3912232 & 1641460 & 6.7212 & 7.1905 & TST & \\
\hline CHEMBL 3965053 & 1641460 & 7.2596 & 7.2081 & TST & \\
\hline CHEMBL1370719 & 737122 & 3.5017 & 3.7934 & TRN & \\
\hline CHEMBL3194040 & 737122 & 3.5017 & 3.6168 & TRN & \\
\hline CHEMBL1341190 & 737122 & 3.5017 & 3.7474 & TST & \\
\hline CHEMBL1302391 & 737122 & 4.8492 & 5.3424 & TRN & \\
\hline CHEMBL1384246 & 737122 & 4.9393 & \multicolumn{2}{|c|}{3.6630000000000003} & TRN \\
\hline CHEMBL1477197 & 737122 & 3.5017 & 3.736 & TRN & \\
\hline CHEMBL1495714 & 737122 & 4.6225 & 3.67 & TRN & \\
\hline CHEMBL1504142 & 737122 & 3.5017 & 3.5785 & TST & \\
\hline CHEMBL1491626 & 737122 & 3.5017 & 3.725 & TRN & \\
\hline CHEMBL1417204 & 737122 & 3.5017 & 3.6324 & TRN & \\
\hline CHEMBL 3193629 & 737122 & 3.5017 & 3.7809 & TRN & \\
\hline CHEMBL 3145108 & 737122 & 3.5017 & 3.6457 & TRN & \\
\hline CHEMBL3195226 & 737122 & 3.5017 & 3.77 & TRN & \\
\hline CHEMBL1384550 & 737122 & 3.5017 & 3.761 & TRN & \\
\hline CHEMBL1471189 & 737122 & 3.5017 & 3.6521 & TST & \\
\hline CHEMBL1490336 & 737122 & 3.5017 & 3.5831 & TRN & \\
\hline CHEMBL1442698 & 737122 & 5.5193 & 4.0736 & TST & \\
\hline CHEMBL1558590 & 737122 & 3.5017 & 3.6299 & TST & \\
\hline CHEMBL1546739 & 737122 & 3.5017 & 3.7048 & TRN & \\
\hline CHEMBL1976308 & 737122 & 3.5017 & 3.6386 & TRN & \\
\hline CHEMBL 3195898 & 737122 & 3.5017 & 3.7016 & TRN & \\
\hline CHEMBL256042 & 737122 & 3.5017 & 3.8572 & TRN & \\
\hline CHEMBL1445491 & 737122 & 3.5017 & 3.5399 & TRN & \\
\hline CHEMBL534353 & 737122 & 3.5017 & 3.6017 & TRN & \\
\hline CHEMBL 2373602 & 737122 & 3.5017 & 3.863 & TST & \\
\hline CHEMBL1372698 & 737122 & 3.5017 & 3.5945 & TRN & \\
\hline CHEMBL1461661 & 737122 & 3.5017 & 3.595 & TRN & \\
\hline CHEMBL1447284 & 737122 & 4.6099 & 3.7837 & TRN & \\
\hline
\end{tabular}

Page 2910 
Supplemental Table S2.txt

\begin{tabular}{|c|c|c|c|c|c|}
\hline CHEMBL 2005961 & 737122 & 3.5017 & \multicolumn{2}{|c|}{3.7289999999999996} & TRN \\
\hline CHEMBL1984876 & 737122 & 3.5017 & 3.5438 & TRN & \\
\hline CHEMBL3190827 & 737122 & 3.5017 & 4.0391 & TRN & \\
\hline CHEMBL1510156 & 737122 & 3.5017 & 3.6071 & TST & \\
\hline CHEMBL1431014 & 737122 & 3.5017 & 3.8557 & TRN & \\
\hline CHEMBL1432227 & 737122 & 3.5017 & 3.5899 & TRN & \\
\hline CHEMBL1310734 & 737122 & 3.5017 & 3.5842 & TST & \\
\hline CHEMBL1609419 & 737122 & 3.5017 & 3.7397 & TRN & \\
\hline CHEMBL1580946 & 737122 & 3.5017 & 3.7895 & TRN & \\
\hline CHEMBL1387060 & 737122 & 3.5017 & \multicolumn{2}{|c|}{3.5639999999999996} & \\
\hline CHEMBL1368523 & 737122 & 3.5017 & 3.6852 & TRN & \\
\hline CHEMBL1596609 & 737122 & 4.7786 & 3.8214 & TRN & \\
\hline CHEMBL1309573 & 737122 & 3.5017 & 3.5815 & TRN & \\
\hline CHEMBL1522851 & 737122 & 4.7411 & 3.8132 & TRN & \\
\hline CHEMBL1492017 & 737122 & 3.5017 & 3.6646 & TRN & \\
\hline CHEMBL1487635 & 737122 & 3.5017 & 3.7745 & TRN & \\
\hline CHEMBL1578607 & 737122 & 3.5017 & \multicolumn{2}{|c|}{3.6260000000000003} & \\
\hline CHEMBL1377278 & 737122 & 3.5017 & 3.5747 & TRN & \\
\hline CHEMBL1606916 & 737122 & 4.9874 & 3.6738 & TRN & \\
\hline CHEMBL1599708 & 737122 & 3.5017 & 3.5651 & TRN & \\
\hline CHEMBL455284 & 737122 & 3.5017 & 3.5967 & TRN & \\
\hline CHEMBL1323553 & 737122 & 3.5017 & 3.7865 & TRN & \\
\hline CHEMBL1493936 & 737122 & 3.5017 & 3.6923 & TRN & \\
\hline CHEMBL1529511 & 737122 & 4.8312 & 3.6748 & TST & \\
\hline CHEMBL1460585 & 737122 & 3.5017 & 3.6634 & TRN & \\
\hline CHEMBL3190555 & 737122 & 3.5017 & 3.7731 & TRN & \\
\hline CHEMBL1598011 & 737122 & 5.101 & 3.6772 & TST & \\
\hline CHEMBL1557615 & 737122 & 3.5017 & 3.6176 & TRN & \\
\hline CHEMBL1359415 & 737122 & 3.5017 & 3.5745 & TRN & \\
\hline CHEMBL1442120 & 737122 & 3.5017 & 3.5729 & TST & \\
\hline CHEMBL1497139 & 737122 & 3.5017 & 3.7836 & TST & \\
\hline CHEMBL3210072 & 737122 & 3.5017 & 3.661 & TRN & \\
\hline CHEMBL1303426 & 737122 & 3.5017 & 3.6809 & TRN & \\
\hline CHEMBL1477640 & 737122 & 4.7582 & 3.6861 & TRN & \\
\hline CHEMBL1460705 & 737122 & 3.5017 & 3.6144 & TRN & \\
\hline CHEMBL1456232 & 737122 & 4.8342 & 3.6751 & TRN & \\
\hline CHEMBL3212029 & 737122 & 3.5017 & \multicolumn{2}{|c|}{3.7319999999999998} & \\
\hline CHEMBL1310782 & 737122 & 3.5017 & \multicolumn{2}{|c|}{3.7089999999999996} & \\
\hline CHEMBL1505604 & 737122 & 3.5017 & 3.5648 & TRN & \\
\hline CHEMBL1421770 & 737122 & 3.5017 & 3.5669 & TST & \\
\hline CHEMBL1350780 & 737122 & 4.6586 & 3.8762 & TRN & \\
\hline CHEMBL1610025 & 737122 & 3.5017 & 3.8303 & TRN & \\
\hline CHEMBL1387605 & 737122 & 3.5017 & 4.0753 & TRN & \\
\hline CHEMBL1979954 & 737122 & 3.5017 & 3.5628 & TST & \\
\hline CHEMBL3199403 & 737122 & 3.5017 & 3.6421 & TRN & \\
\hline CHEMBL1332111 & 737122 & 3.5017 & 3.6193 & TRN & \\
\hline CHEMBL1302178 & 737122 & 3.5017 & 3.5841 & TRN & \\
\hline CHEMBL1981951 & 737122 & 3.5017 & 3.7052 & TST & \\
\hline
\end{tabular}

Page 2911 
Supplemental Table S2.txt

\begin{tabular}{|c|c|c|c|c|}
\hline CHEMBL1385690 & 737122 & 3.5017 & 3.6597 & TRN \\
\hline CHEMBL1377737 & 737122 & 3.5017 & 3.5918 & TRN \\
\hline CHEMBL3199851 & 737122 & 3.5017 & 3.8281 & TRN \\
\hline CHEMBL1336535 & 737122 & 3.5017 & \multicolumn{2}{|c|}{3.5860000000000003} \\
\hline CHEMBL1570958 & 737122 & 3.5017 & 3.6598 & TRN \\
\hline CHEMBL3193639 & 737122 & 3.5017 & 3.6554 & TRN \\
\hline CHEMBL1456130 & 737122 & 3.5017 & 3.5915 & TST \\
\hline CHEMBL1337227 & 737122 & 3.5017 & 3.7684 & TST \\
\hline CHEMBL1462003 & 737122 & 4.9469 & 3.6399 & TRN \\
\hline CHEMBL586135 & 737122 & 3.5017 & 3.7135 & TRN \\
\hline CHEMBL1433128 & 737122 & 4.8431 & 3.7155 & TRN \\
\hline CHEMBL1350432 & 737122 & 3.5017 & 3.5921 & TST \\
\hline CHEMBL1539016 & 737122 & 3.5017 & 3.7129 & TRN \\
\hline CHEMBL 3195760 & 737122 & 3.5017 & 3.8145 & TRN \\
\hline CHEMBL1420325 & 737122 & 3.5017 & 3.6051 & TST \\
\hline CHEMBL1998521 & 737122 & 3.5017 & 3.5899 & TRN \\
\hline CHEMBL3193056 & 737122 & 3.5017 & 3.7797 & TRN \\
\hline CHEMBL1300269 & 737122 & 5.5003 & 3.6595 & TRN \\
\hline CHEMBL1439246 & 737122 & 3.5017 & 3.5765 & TRN \\
\hline CHEMBL1976317 & 737122 & 3.5017 & 3.8697 & TRN \\
\hline CHEMBL1307050 & 737122 & 3.5017 & 3.8016 & TRN \\
\hline CHEMBL1990174 & 737122 & 3.5017 & 4.0562 & TRN \\
\hline CHEMBL1390716 & 737122 & 3.5017 & 3.5956 & TRN \\
\hline CHEMBL1578482 & 737122 & 3.5017 & 3.6064 & TRN \\
\hline CHEMBL1585944 & 737122 & 3.5017 & 3.9233 & TST \\
\hline CHEMBL1485010 & 737122 & 3.5017 & 3.6084 & TST \\
\hline CHEMBL1999049 & 737122 & 3.5017 & 3.6148 & TST \\
\hline CHEMBL1978355 & 737122 & 3.5017 & 3.6195 & TRN \\
\hline CHEMBL1964873 & 737122 & 3.5017 & 3.6256 & TRN \\
\hline CHEMBL1544221 & 737122 & 3.5017 & 3.6072 & TRN \\
\hline CHEMBL 3192432 & 737122 & 3.5017 & 3.5476 & TRN \\
\hline CHEMBL1416089 & 737122 & 3.5017 & 3.583 & TRN \\
\hline CHEMBL255067 & 737122 & 3.5017 & 3.7279 & TRN \\
\hline CHEMBL1358924 & 737122 & 3.5017 & 3.5914 & TRN \\
\hline CHEMBL1455427 & 737122 & 3.5017 & 3.6403 & TRN \\
\hline CHEMBL1545369 & 737122 & 3.5017 & 3.5485 & TRN \\
\hline CHEMBL 3197021 & 737122 & 3.5017 & 3.6944 & TRN \\
\hline CHEMBL1363376 & 737122 & 3.5017 & 3.6176 & TRN \\
\hline CHEMBL131037 & 737122 & 3.5017 & 3.5831 & TST \\
\hline CHEMBL1306723 & 737122 & 5.035 & 3.6845 & TRN \\
\hline CHEMBL1572001 & 737122 & 3.5017 & 3.5647 & TRN \\
\hline CHEMBL1539624 & 737122 & 4.5969 & 3.8499 & TRN \\
\hline CHEMBL1426792 & 737122 & 3.5017 & 3.77699 & 99999999997 \\
\hline CHEMBL1557816 & 737122 & 4.8508 & 3.6959 & TRN \\
\hline CHEMBL1455045 & 737122 & 3.5017 & 3.7741 & TRN \\
\hline CHEMBL1301723 & 737122 & 3.5017 & 3.7634 & TST \\
\hline CHEMBL528694 & 737122 & 3.5017 & 3.7185 & TRN \\
\hline CHEMBL1588411 & 737122 & 3.5017 & 3.8561 & TRN \\
\hline
\end{tabular}

Page 2912 
Supplemental Table S2.txt

\begin{tabular}{|c|c|c|c|c|}
\hline CHEMBL1400298 & 737122 & 4.5901 & 3.8356 & TRN \\
\hline CHEMBL1965132 & 737122 & 3.5017 & 3.6615 & TRN \\
\hline CHEMBL 2094567 & 737122 & 3.5017 & 3.5637 & TRN \\
\hline CHEMBL1383537 & 737122 & 3.5017 & 3.6197 & TRN \\
\hline CHEMBL1562926 & 737122 & 3.5017 & 3.5674 & TRN \\
\hline CHEMBL1553074 & 737122 & 3.5017 & 3.6103 & TRN \\
\hline CHEMBL1472570 & 737122 & 3.5017 & 3.7546 & TRN \\
\hline CHEMBL1548770 & 737122 & 4.8844 & 3.7443 & TRN \\
\hline CHEMBL1319867 & 737122 & 3.5017 & \multicolumn{2}{|c|}{3.7560000000000002} \\
\hline CHEMBL 3192010 & 737122 & 3.5017 & 3.6994 & TRN \\
\hline CHEMBL1471101 & 737122 & 3.5017 & 3.8453 & TRN \\
\hline CHEMBL1353124 & 737122 & 3.5017 & 3.5683 & TRN \\
\hline CHEMBL1448582 & 737122 & 3.5017 & 3.8367 & TRN \\
\hline CHEMBL1542074 & 737122 & 3.5017 & 3.5909 & TRN \\
\hline CHEMBL1455766 & 737122 & 3.5017 & 3.6012 & TRN \\
\hline CHEMBL1964464 & 737122 & 3.5017 & 3.5553 & TRN \\
\hline CHEMBL1351467 & 737122 & 3.5017 & 3.8082 & TRN \\
\hline CHEMBL1311826 & 737122 & 4.628 & 3.7799 & TRN \\
\hline CHEMBL1344225 & 737122 & 3.5017 & 3.5991 & TRN \\
\hline CHEMBL 3198868 & 737122 & 3.5017 & 3.7349 & TRN \\
\hline CHEMBL 3192235 & 737122 & 3.5017 & 3.7022 & TRN \\
\hline CHEMBL3199421 & 737122 & 3.5017 & 3.6952 & TRN \\
\hline CHEMBL1973773 & 737122 & 5.7786 & 5.6462 & TRN \\
\hline CHEMBL1391094 & 737122 & 3.5017 & 3.6243 & TST \\
\hline CHEMBL1311879 & 737122 & 4.8386 & 3.7917 & TRN \\
\hline CHEMBL1421427 & 737122 & 3.5017 & 3.6481 & TRN \\
\hline CHEMBL1383376 & 737122 & 3.5017 & 3.7657 & TRN \\
\hline CHEMBL1304363 & 737122 & 3.5017 & 3.5931 & TRN \\
\hline CHEMBL1463088 & 737122 & 3.5017 & 3.7467 & TRN \\
\hline CHEMBL 1979800 & 737122 & 3.5017 & 3.7684 & TRN \\
\hline CHEMBL1557648 & 737122 & 3.5017 & 3.6281 & TRN \\
\hline CHEMBL1422078 & 737122 & 4.5214 & 3.7566 & TRN \\
\hline CHEMBL1464745 & 737122 & 3.5017 & 3.5797 & TRN \\
\hline CHEMBL 3189245 & 737122 & 3.5017 & 3.5933 & TRN \\
\hline CHEMBL 3193535 & 737122 & 3.5017 & 3.6634 & TST \\
\hline CHEMBL1334809 & 737122 & 3.5017 & 3.6959 & TST \\
\hline CHEMBL1597655 & 737122 & 3.5017 & 3.761 & TRN \\
\hline CHEMBL1324005 & 737122 & 3.5017 & 3.9652 & TRN \\
\hline CHEMBL1585390 & 737122 & 3.5017 & 3.6504 & TRN \\
\hline CHEMBL546170 & 737122 & 3.5017 & 3.5874 & TRN \\
\hline CHEMBL 270605 & 737122 & 3.5017 & 4.0386 & TRN \\
\hline CHEMBL1576301 & 737122 & 7.0088 & 6.6263 & TRN \\
\hline CHEMBL 3145316 & 737122 & 3.5017 & 3.5867 & TST \\
\hline CHEMBL1586491 & 737122 & 4.6914 & 3.6315 & TRN \\
\hline CHEMBL1384726 & 737122 & 3.5017 & 3.5625 & TRN \\
\hline CHEMBL1368060 & 737122 & 3.5017 & 3.8596 & TRN \\
\hline CHEMBL 3199359 & 737122 & 3.5017 & 3.83600 & 30000000003 \\
\hline CHEMBL428064 & 737122 & 3.5017 & 3.7435 & TRN \\
\hline
\end{tabular}

Page 2913 
Supplemental Table S2.txt

\begin{tabular}{|c|c|c|c|c|}
\hline CHEMBL1423597 & 737122 & 3.5017 & 3.5666 & TRN \\
\hline CHEMBL1520214 & 737122 & 3.5017 & 3.7095 & TRN \\
\hline CHEMBL1411665 & 737122 & 3.5017 & 3.6646 & TRN \\
\hline CHEMBL1572356 & 737122 & 3.5017 & 3.6807 & TRN \\
\hline CHEMBL1458833 & 737122 & 3.5017 & 3.5914 & TRN \\
\hline CHEMBL1299526 & 737122 & 3.5017 & 3.7224 & TST \\
\hline CHEMBL1486214 & 737122 & 3.5017 & 3.7897 & TRN \\
\hline CHEMBL1565646 & 737122 & 5.0499 & 3.8765 & TRN \\
\hline CHEMBL3189289 & 737122 & 3.5017 & 3.7253 & TRN \\
\hline CHEMBL1554920 & 737122 & 3.5017 & 3.62399 & 9999999997 \\
\hline CHEMBL140425 & 737122 & 3.5017 & 3.7169 & TRN \\
\hline CHEMBL1500450 & 737122 & 3.5017 & 3.5679 & TRN \\
\hline CHEMBL1602250 & 737122 & 3.5017 & 3.7173 & TRN \\
\hline CHEMBL1987579 & 737122 & 3.5017 & 3.6863 & TST \\
\hline CHEMBL1461585 & 737122 & 3.5017 & 3.7174 & TST \\
\hline CHEMBL1608776 & 737122 & 3.5017 & 3.6357 & TST \\
\hline CHEMBL1522211 & 737122 & 3.5017 & 3.6123 & TST \\
\hline CHEMBL1343705 & 737122 & 3.5017 & 3.7797 & TST \\
\hline CHEMBL1427431 & 737122 & 3.5017 & 3.6479 & TST \\
\hline CHEMBL 3196139 & 737122 & 3.5017 & 3.5863 & TST \\
\hline CHEMBL1530899 & 737122 & 3.5017 & 3.6369 & TST \\
\hline CHEMBL1405968 & 737122 & 3.5017 & 3.6072 & TST \\
\hline CHEMBL1574879 & 737122 & 3.5017 & 3.5928 & TST \\
\hline CHEMBL1542886 & 737122 & 3.5017 & 3.6119 & TST \\
\hline CHEMBL1560839 & 737122 & 7.0088 & 6.4055 & TST \\
\hline CHEMBL1605583 & 737122 & 5.0148 & 3.7639 & TST \\
\hline CHEMBL1428935 & 737122 & 3.5017 & 3.7826 & TST \\
\hline CHEMBL 3190274 & 737122 & 3.5017 & 3.6012 & TST \\
\hline CHEMBL1311831 & 737122 & 3.5017 & 3.6703 & TST \\
\hline CHEMBL1579152 & 737122 & 3.5017 & 3.7984 & TST \\
\hline CHEMBL1375133 & 737122 & 3.5017 & 3.7102 & TST \\
\hline CHEMBL1566610 & 737122 & 3.5017 & 4.024 & TST \\
\hline CHEMBL1597627 & 737122 & 3.5017 & 3.5771 & TST \\
\hline CHEMBL 257962 & 479969 & 5.8239 & 5.8047 & TRN \\
\hline CHEMBL428429 & 479969 & 7.4318 & 6.0128 & TST \\
\hline CHEMBL404564 & 479969 & 7.0506 & 7.04799 & 999999999 \\
\hline CHEMBL428430 & 479969 & 6.3872 & 6.3772 & TRN \\
\hline CHEMBL 257753 & 479969 & 10.0 & 9.9414 & TRN \\
\hline CHEMBL404173 & 479969 & 6.8539 & 7.4736 & TST \\
\hline CHEMBL 256158 & 479969 & 8.0655 & 8.2141 & TRN \\
\hline CHEMBL401830 & 479969 & 7.3372 & 7.3666 & TRN \\
\hline CHEMBL403811 & 479969 & 7.9586 & 7.9497 & TRN \\
\hline CHEMBL404880 & 479969 & 5.8861 & 5.8325 & TRN \\
\hline CHEMBL403758 & 479969 & 8.0 & 8.001 & TRN \\
\hline CHEMBL 257779 & 479969 & 8.8861 & 8.8662 & TRN \\
\hline CHEMBL403898 & 479969 & 8.9208 & 8.795 & TRN \\
\hline CHEMBL401909 & 479969 & 8.3468 & 8.3621 & TRN \\
\hline CHEMBL428951 & 479969 & 8.0 & 8.0945 & TRN \\
\hline
\end{tabular}




\begin{tabular}{|c|c|c|c|c|c|}
\hline \multicolumn{6}{|c|}{ Supplemental Table s2.txt } \\
\hline CHEMBL403165 & 479969 & 5.8239 & 5.8438 & TRN & \\
\hline CHEMBL401988 & 479969 & 8.5376 & 8.4793 & TRN & \\
\hline CHEMBL257985 & 479969 & 7.041 & 7.1905 & TRN & \\
\hline CHEMBL403589 & 479969 & 5.5229 & 5.5086 & TRN & \\
\hline CHEMBL401883 & 479969 & 8.7212 & 7.5607 & TST & \\
\hline CHEMBL 257601 & 479969 & 8.6383 & 8.6869 & TRN & \\
\hline CHEMBL253955 & 479969 & 6.585 & 6.6166 & TRN & \\
\hline CHEMBL256298 & 479969 & 8.0969 & 8.0833 & TRN & \\
\hline CHEMBL257129 & 479969 & 8.0088 & 8.01100 & 0000000001 & TRN \\
\hline CHEMBL258388 & 479969 & 8.1487 & 8.1337 & TRN & \\
\hline CHEMBL403549 & 479969 & 6.7212 & 6.6147 & TRN & \\
\hline CHEMBL253953 & 479969 & 6.9208 & 6.8132 & TRN & \\
\hline CHEMBL403369 & 479969 & 7.8239 & 7.8568 & TRN & \\
\hline CHEMBL404743 & 479969 & 8.1938 & 8.1781 & TRN & \\
\hline CHEMBL256986 & 479969 & 7.3768 & 7.4579 & TRN & \\
\hline CHEMBL402737 & 479969 & 7.6576 & 7.6408 & TRN & \\
\hline CHEMBL254790 & 479969 & 7.9586 & 8.0465 & TRN & \\
\hline CHEMBL404638 & 479969 & 7.1487 & 7.1126 & TRN & \\
\hline CHEMBL403384 & 479969 & 7.1675 & 7.2215 & TRN & \\
\hline CHEMBL403687 & 479969 & 6.4609 & 5.8712 & TST & \\
\hline CHEMBL258217 & 479969 & 7.2676 & 7.1832 & TRN & \\
\hline CHEMBL254993 & 479969 & 8.0757 & 8.041 & TRN & \\
\hline CHEMBL258389 & 479969 & 7.6576 & 7.7471 & TRN & \\
\hline CHEMBL401975 & 479969 & 7.699 & 7.6641 & TRN & \\
\hline CHEMBL254789 & 479969 & 10.0 & 9.9596 & TRN & \\
\hline CHEMBL401884 & 479969 & 8.6383 & 8.6293 & TRN & \\
\hline CHEMBL401908 & 479969 & 7.9208 & 7.8632 & TST & \\
\hline CHEMBL429318 & 479969 & 6.0706 & 6.2407 & TST & \\
\hline CHEMBL 257752 & 479969 & 8.5528 & 7.9026 & TST & \\
\hline CHEMBL403944 & 479969 & 7.0 & 6.92299 & 9999999999 & TST \\
\hline CHEMBL258165 & 479969 & 6.8539 & 6.7686 & TST & \\
\hline CHEMBL257963 & 479969 & 8.1805 & 7.4123 & TST & \\
\hline CHEMBL402302 & 479969 & 7.7212 & 7.3693 & TST & \\
\hline CHEMBL 257754 & 479969 & 10.0 & 10.076 & TST & \\
\hline CHEMBL257364 & 479969 & 6.7447 & 6.70200 & 0000000001 & TST \\
\hline CHEMBL591412 & 752439 & 5.4012 & 5.1097 & TRN & \\
\hline CHEMBL1866926 & 752439 & 4.4835 & 4.6604 & TRN & \\
\hline CHEMBL1572920 & 752439 & 4.6572 & 4.6185 & TRN & \\
\hline CHEMBL1890613 & 752439 & 5.556 & 5.1933 & TRN & \\
\hline CHEMBL1316506 & 752439 & 4.7464 & 4.7057 & TRN & \\
\hline CHEMBL1525213 & 752439 & 4.5024 & 4.5933 & TST & \\
\hline CHEMBL1863881 & 752439 & 4.1641 & 4.0779 & TRN & \\
\hline CHEMBL1877680 & 752439 & 4.8383 & 4.8658 & TRN & \\
\hline CHEMBL1889367 & 752439 & 5.2798 & 5.4143 & TRN & \\
\hline CHEMBL1865457 & 752439 & 3.0969 & 4.0 & TST & \\
\hline CHEMBL1555271 & 752439 & 5.1524 & 5.1648 & TRN & \\
\hline CHEMBL1604735 & 752439 & 4.783 & 4.5275 & TRN & \\
\hline CHEMBL1735962 & 752439 & 4.43 & 4.5196 & TRN & \\
\hline
\end{tabular}


Supplemental Table S2.txt

\begin{tabular}{|c|c|c|c|c|c|}
\hline CHEMBL1529188 & 752439 & 4.5686 & 4.4858 & TRN & \\
\hline CHEMBL1902224 & 752439 & 5.1986 & 5.2751 & TRN & \\
\hline CHEMBL1448282 & 752439 & 5.1537 & 5.3056 & TRN & \\
\hline CHEMBL1313101 & 752439 & 4.4134 & 4.3457 & TRN & \\
\hline CHEMBL1522618 & 752439 & 3.0969 & 3.5281 & TRN & \\
\hline CHEMBL590665 & 752439 & 5.4908 & 5.3438 & TRN & \\
\hline CHEMBL1589983 & 752439 & 3.0969 & 4.7188 & TST & \\
\hline CHEMBL585827 & 752439 & 5.0645 & 5.1264 & TRN & \\
\hline CHEMBL1598785 & 752439 & 4.978 & 5.2052 & TRN & \\
\hline CHEMBL1330279 & 752439 & 5.1759 & 5.2282 & TRN & \\
\hline CHEMBL1885380 & 752439 & 5.6383 & 5.6593 & TRN & \\
\hline CHEMBL600862 & 752439 & 4.8867 & 5.0354 & TRN & \\
\hline CHEMBL1452490 & 752439 & 4.4211 & 4.3435 & TRN & \\
\hline CHEMBL1522043 & 752439 & 4.2882 & 4.3569 & TRN & \\
\hline CHEMBL1491842 & 752439 & 4.3988 & 4.3459 & TRN & \\
\hline CHEMBL592600 & 752439 & 5.2807 & 5.3964 & TRN & \\
\hline CHEMBL601768 & 752439 & 5.3737 & 5.5434 & TRN & \\
\hline CHEMBL1530766 & 752439 & 4.4103 & 4.3738 & TRN & \\
\hline CHEMBL1887169 & 752439 & 4.6882 & 4.6184 & TRN & \\
\hline CHEMBL1876834 & 752439 & 5.5834 & \multicolumn{2}{|c|}{5.452999999999999} & TRN \\
\hline CHEMBL1576870 & 752439 & 6.3188 & 6.4308 & TRN & \\
\hline CHEMBL1885580 & 752439 & 3.0969 & 3.7297 & TST & \\
\hline CHEMBL1339830 & 752439 & 4.6611 & 4.5187 & TRN & \\
\hline CHEMBL1503612 & 752439 & 3.0969 & 5.4106 & TST & \\
\hline CHEMBL602720 & 752439 & 5.1549 & 5.4678 & TRN & \\
\hline CHEMBL1879735 & 752439 & 3.0969 & 4.0224 & TST & \\
\hline CHEMBL590927 & 752439 & 5.4389 & 5.5271 & TRN & \\
\hline CHEMBL1416756 & 752439 & 5.0535 & 4.2794 & TST & \\
\hline CHEMBL1875095 & 752439 & 4.2963 & 4.3183 & TRN & \\
\hline CHEMBL1902698 & 752439 & 5.1752 & 5.6254 & TST & \\
\hline CHEMBL1864401 & 752439 & 3.0969 & 5.1655 & TST & \\
\hline CHEMBL1899890 & 752439 & 4.1215 & 4.3329 & TRN & \\
\hline CHEMBL1379163 & 752439 & 4.4695 & 4.6163 & TRN & \\
\hline CHEMBL1503124 & 752439 & 4.4688 & 5.3925 & TST & \\
\hline CHEMBL1891946 & 752439 & 4.9352 & 4.8367 & TRN & \\
\hline CHEMBL1890797 & 752439 & 3.0969 & 4.1681 & TST & \\
\hline CHEMBL 251603 & 752439 & 4.8063 & 4.7723 & TRN & \\
\hline CHEMBL1864059 & 752439 & 3.0969 & 3.7966 & TST & \\
\hline CHEMBL1903426 & 752439 & 5.1805 & 5.1817 & TRN & \\
\hline CHEMBL1578584 & 752439 & 4.5986 & 4.8157 & TST & \\
\hline CHEMBL1373096 & 752439 & 5.7258 & 5.575 & TRN & \\
\hline CHEMBL1496891 & 752439 & 4.2745 & 5.3961 & TST & \\
\hline CHEMBL1514530 & 752439 & 5.3401 & 5.3722 & TRN & \\
\hline CHEMBL1412002 & 752439 & 5.6517 & 5.3606 & TRN & \\
\hline CHEMBL1902332 & 752439 & 4.3407 & 4.3276 & TRN & \\
\hline CHEMBL1902496 & 752439 & 3.0969 & 3.1135 & TRN & \\
\hline CHEMBL1885971 & 752439 & 5.1433 & 5.0591 & TRN & \\
\hline CHEMBL1419414 & 752439 & 4.3814 & 4.3558 & TRN & \\
\hline
\end{tabular}




\begin{tabular}{|c|c|c|c|c|c|}
\hline \multirow[b]{2}{*}{ CHEMBL1393944 } & \multicolumn{5}{|c|}{ Supplemental Table S2.txt } \\
\hline & 752439 & 4.1831 & 4.7441 & TST & \\
\hline CHEMBL1430579 & 752439 & 4.3138 & 5.5444 & TST & \\
\hline CHEMBL547285 & 752439 & 5.1965 & 5.2932 & TRN & \\
\hline CHEMBL1872492 & 752439 & 4.7049 & 5.4314 & TST & \\
\hline CHEMBL1880835 & 752439 & 4.5232 & 4.2363 & TRN & \\
\hline CHEMBL1519450 & 752439 & 5.5017 & 5.5209 & TRN & \\
\hline CHEMBL580530 & 752439 & 5.3363 & 5.2051 & TRN & \\
\hline CHEMBL1443069 & 752439 & 4.6302 & 4.7305 & TRN & \\
\hline CHEMBL1906519 & 752439 & 4.3311 & 4.3438 & TRN & \\
\hline CHEMBL1878645 & 752439 & 3.0969 & 4.0492 & TST & \\
\hline CHEMBL1899180 & 752439 & 5.0991 & 5.1715 & TRN & \\
\hline CHEMBL1894788 & 752439 & 3.0969 & 4.1315 & TST & \\
\hline CHEMBL1438842 & 752439 & 3.0969 & 4.654 & TST & \\
\hline CHEMBL1906106 & 752439 & 5.1331 & 5.2042 & TRN & \\
\hline CHEMBL580955 & 752439 & 5.4248 & 5.26 & TRN & \\
\hline CHEMBL548670 & 752439 & 5.3072 & 5.1885 & TRN & \\
\hline CHEMBL 276601 & 63527 & 5.0 & 4.0585 & TST & \\
\hline CHEMBL10901 & 63527 & 5.4089 & 5.2949 & TRN & \\
\hline CHEMBL11176 & 63527 & 5.2218 & 5.3117 & TRN & \\
\hline CHEMBL11131 & 63527 & 4.5229 & 4.6619 & TRN & \\
\hline CHEMBL10834 & 63527 & 4.6021 & 5.181 & TST & \\
\hline CHEMBL 274805 & 63527 & 4.6021 & 4.6839 & TRN & \\
\hline CHEMBL 274383 & 63527 & 5.34200 & 00000000 & 005 & 5.4193 \\
\hline CHEMBL10996 & 63527 & 5.5686 & 4.6286 & TRN & \\
\hline CHEMBL10697 & 63527 & 6.0555 & 5.9668 & TRN & \\
\hline CHEMBL 274175 & 63527 & 5.699 & 5.5319 & TRN & \\
\hline CHEMBL10911 & 63527 & 4.6021 & 4.7353 & TRN & \\
\hline CHEMBL 269453 & 63527 & 4.6021 & 5.2576 & TRN & \\
\hline CHEMBL11106 & 63527 & 4.7959 & 5.6321 & TRN & \\
\hline CHEMBL10910 & 63527 & 4.6021 & 4.8037 & TRN & \\
\hline CHEMBL11341 & 63527 & 5.2676 & 4.974 & TRN & \\
\hline CHEMBL10915 & 63527 & 4.6021 & 4.9827 & TRN & \\
\hline CHEMBL10733 & 63527 & 4.6021 & 4.7737 & TRN & \\
\hline CHEMBL268754 & 63527 & 5.284 & 5.4388 & TRN & \\
\hline CHEMBL10636 & 63527 & 4.6021 & 5.4562 & TRN & \\
\hline CHEMBL269409 & 63527 & 4.6021 & 5.1526 & TRN & \\
\hline CHEMBL 269461 & 63527 & 4.6021 & 4.5343 & TST & \\
\hline CHEMBL10635 & 63527 & 5.7959 & 5.4689 & TRN & \\
\hline CHEMBL11152 & 63527 & 4.6021 & 4.6694 & TST & \\
\hline CHEMBL273948 & 63527 & 6.6478 & 5.3432 & TST & \\
\hline CHEMBL10919 & 63527 & 5.8861 & 5.3432 & TST & \\
\hline CHEMBL10644 & 63527 & 3.6021 & 5.5157 & TST & \\
\hline CHEMBL10948 & 63527 & 5.7447 & 5.3196 & TRN & \\
\hline CHEMBL10589 & 63527 & 5.3468 & 5.4933 & TRN & \\
\hline CHEMBL10744 & 63527 & 5.6021 & 5.6329 & TRN & \\
\hline CHEMBL10846 & 63527 & 4.7447 & 5.2218 & TRN & \\
\hline CHEMBL10661 & 63527 & 5.5229 & 5.6305 & TRN & \\
\hline CHEMBL11162 & 63527 & 5.0458 & 5.0588 & TST & \\
\hline
\end{tabular}




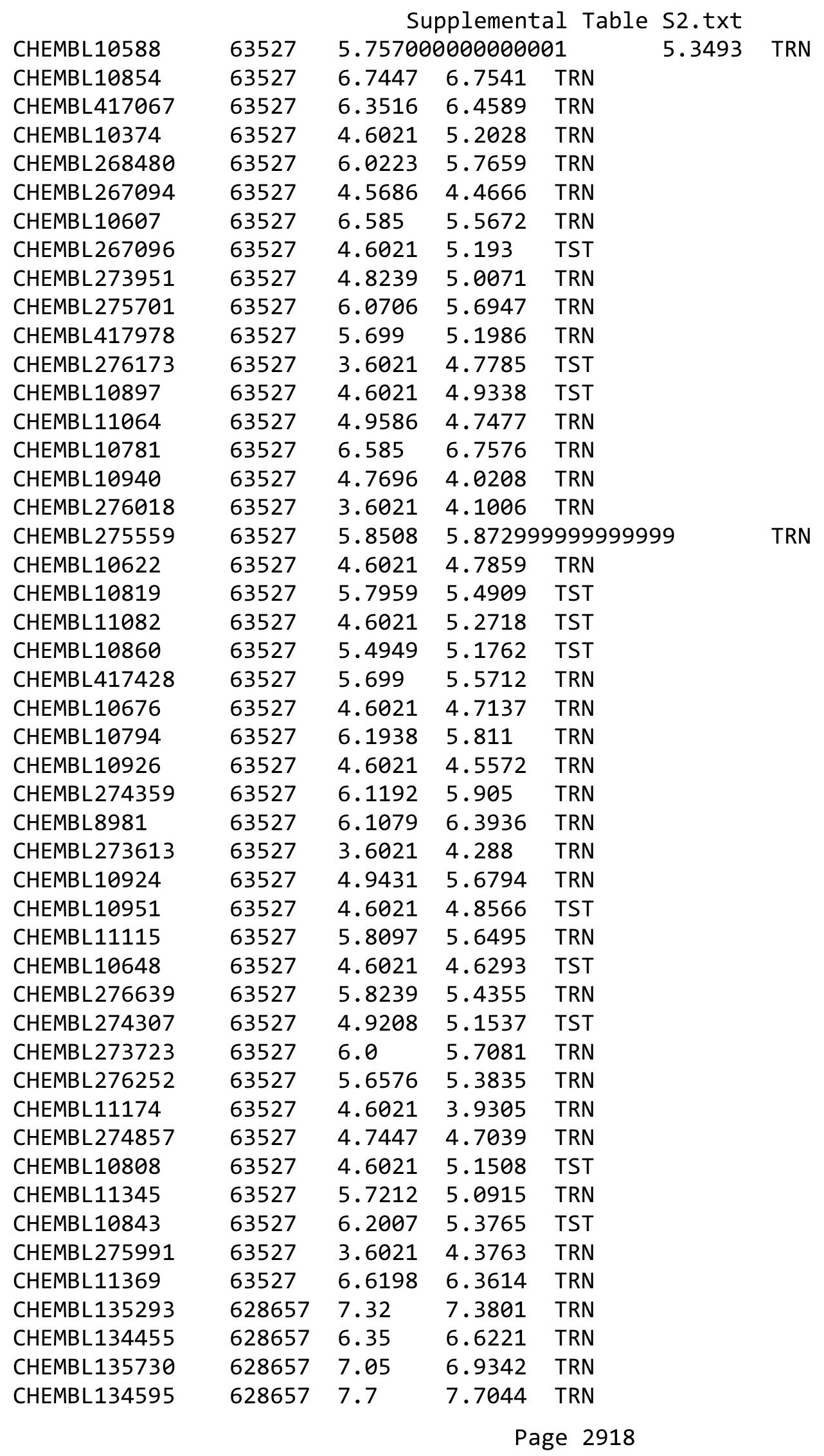




\begin{tabular}{|c|c|c|c|c|c|}
\hline \multicolumn{6}{|c|}{ Supplemental Table S2.txt } \\
\hline CHEMBL135669 & 628657 & 7.76 & 8.0602 & TRN & \\
\hline CHEMBL424470 & 628657 & 6.1 & 5.9408 & TRN & \\
\hline CHEMBL334974 & 628657 & 6.1 & 5.9403 & TRN & \\
\hline CHEMBL135586 & 628657 & 6.26 & 6.5116 & TRN & \\
\hline CHEMBL1095245 & 628657 & 5.84 & 5.6183 & TRN & \\
\hline CHEMBL135828 & 628657 & 5.3 & 5.1022 & TRN & \\
\hline CHEMBL133312 & 628657 & 5.3 & 4.9805 & TRN & \\
\hline CHEMBL133210 & 628657 & 6.92 & 6.7985 & TST & \\
\hline CHEMBL135922 & 628657 & 5.8 & 6.1042 & TRN & \\
\hline CHEMBL133138 & 628657 & 6.74 & 6.38200 & 0000000001 & TRN \\
\hline CHEMBL135554 & 628657 & 6.94 & 6.3876 & TRN & \\
\hline CHEMBL135553 & 628657 & 5.3 & 5.4198 & TRN & \\
\hline CHEMBL137725 & 628657 & 6.84 & 6.7044 & TRN & \\
\hline CHEMBL135023 & 628657 & 7.3 & 6.8458 & TST & \\
\hline CHEMBL423174 & 628657 & 5.3 & 5.6774 & TRN & \\
\hline CHEMBL137178 & 628657 & 5.3 & 5.8528 & TST & \\
\hline CHEMBL434268 & 628657 & 5.3 & 5.3435 & TRN & \\
\hline CHEMBL133309 & 628657 & 5.44 & 5.3554 & TRN & \\
\hline CHEMBL135824 & 628657 & 6.07 & 5.7819 & TRN & \\
\hline CHEMBL136022 & 628657 & 5.3 & 4.9574 & TRN & \\
\hline CHEMBL336280 & 628657 & 5.76 & 6.0746 & TRN & \\
\hline CHEMBL135272 & 628657 & 6.49 & 6.5687 & TRN & \\
\hline CHEMBL422621 & 628657 & 6.0 & 6.2122 & TRN & \\
\hline CHEMBL336504 & 628657 & 7.3 & 7.1348 & TRN & \\
\hline CHEMBL135961 & 628657 & 8.0 & 7.4954 & TRN & \\
\hline CHEMBL 337869 & 628657 & 7.3 & 7.051 & TRN & \\
\hline CHEMBL135887 & 628657 & 7.26 & 7.2972 & TRN & \\
\hline CHEMBL135785 & 628657 & 6.59 & 6.4166 & TRN & \\
\hline CHEMBL134743 & 628657 & 6.74 & 6.6765 & TRN & \\
\hline CHEMBL132764 & 628657 & 8.19 & 8.1634 & TRN & \\
\hline CHEMBL336341 & 628657 & 6.15 & 6.1268 & TRN & \\
\hline CHEMBL135295 & 628657 & 7.46 & 6.9446 & TRN & \\
\hline CHEMBL 334407 & 628657 & 7.92 & 7.2466 & TRN & \\
\hline CHEMBL132541 & 628657 & 8.12 & 7.1454 & TRN & \\
\hline CHEMBL133207 & 628657 & 7.05 & 7.4004 & TRN & \\
\hline CHEMBL341381 & 628657 & 7.89 & 7.4165 & TRN & \\
\hline CHEMBL135754 & 628657 & 6.7 & 6.435 & TRN & \\
\hline CHEMBL135379 & 628657 & 5.56 & 5.5145 & TRN & \\
\hline CHEMBL337249 & 628657 & 6.66 & 6.8683 & TRN & \\
\hline CHEMBL 336592 & 628657 & 8.0 & 7.6554 & TRN & \\
\hline CHEMBL135939 & 628657 & 7.72 & 7.6046 & TRN & \\
\hline CHEMBL132710 & 628657 & 5.3 & 5.7048 & TST & \\
\hline CHEMBL137591 & 628657 & 7.76 & 7.2181 & TRN & \\
\hline CHEMBL135585 & 628657 & 6.47 & 6.7776 & TRN & \\
\hline CHEMBL132532 & 628657 & 6.6 & 6.4681 & TRN & \\
\hline CHEMBL137326 & 628657 & 6.38 & 6.4958 & TRN & \\
\hline CHEMBL134967 & 628657 & 5.3 & 5.0821 & TRN & \\
\hline CHEMBL134806 & 628657 & 5.3 & 5.0409 & TRN & \\
\hline
\end{tabular}




\begin{tabular}{|c|c|c|c|c|c|}
\hline \multicolumn{6}{|c|}{ Supplemental Table S2.txt } \\
\hline CHEMBL337671 & 628657 & 6.0 & 6.8371 & TRN & \\
\hline CHEMBL337185 & 628657 & 6.72 & 6.8813 & TRN & \\
\hline CHEMBL136936 & 628657 & 7.7 & 7.6653 & TRN & \\
\hline CHEMBL337087 & 628657 & 5.3 & 5.7408 & TRN & \\
\hline CHEMBL132979 & 628657 & 6.96 & 7.4 & TST & \\
\hline CHEMBL135890 & 628657 & 7.74 & 7.9703 & TRN & \\
\hline CHEMBL135770 & 628657 & 6.3 & 7.1472 & TST & \\
\hline CHEMBL136029 & 628657 & 7.0 & 6.5135 & TST & \\
\hline CHEMBL133814 & 628657 & 7.18 & 7.034 & TRN & \\
\hline CHEMBL133822 & 628657 & 6.0 & 5.9225 & TRN & \\
\hline CHEMBL133335 & 628657 & 7.43 & 7.4193 & TRN & \\
\hline CHEMBL334637 & 628657 & 6.26 & 6.0024 & TST & \\
\hline CHEMBL1099255 & 628657 & 7.99 & 6.6861 & TST & \\
\hline CHEMBL337659 & 628657 & 8.72 & 7.4694 & TST & \\
\hline CHEMBL339501 & 628657 & 8.57 & 7.1845 & TST & \\
\hline CHEMBL1095256 & 628657 & 8.6 & 6.9841 & TST & \\
\hline CHEMBL336842 & 628657 & 8.22 & 7.8099 & TST & \\
\hline CHEMBL423896 & 628657 & 8.52 & 7.7443 & TST & \\
\hline CHEMBL134676 & 628657 & 7.3 & 7.2361 & TRN & \\
\hline CHEMBL444335 & 628657 & 5.3 & 5.2112 & TRN & \\
\hline CHEMBL135826 & 628657 & 5.3 & 5.2758 & TRN & \\
\hline CHEMBL 334444 & 628657 & 6.1 & 6.5061 & TRN & \\
\hline CHEMBL134656 & 628657 & 6.81 & 6.8253 & TST & \\
\hline CHEMBL133139 & 628657 & 5.8 & 6.0689 & TRN & \\
\hline CHEMBL135712 & 628657 & 6.43 & 6.7843 & TST & \\
\hline CHEMBL132916 & 628657 & 7.22 & 7.629 & TRN & \\
\hline CHEMBL135753 & 628657 & 5.3 & 5.8536 & TRN & \\
\hline CHEMBL135802 & 628657 & 5.3 & 6.7633 & TRN & \\
\hline CHEMBL441481 & 628657 & 5.3 & 5.987999 & 99999999995 & TRN \\
\hline CHEMBL1098904 & 628657 & 6.43 & 6.7577 & TRN & \\
\hline CHEMBL439978 & 628657 & 6.1 & 7.7449 & TST & \\
\hline CHEMBL423168 & 628657 & 6.3 & 6.2816 & TST & \\
\hline CHEMBL341434 & 628657 & 5.8 & 5.985 & TST & \\
\hline CHEMBL424083 & 628657 & 6.26 & 6.9107 & TST & \\
\hline CHEMBL137185 & 628657 & 5.3 & 5.2659 & TST & \\
\hline CHEMBL1096903 & 628657 & 8.03 & 8.0337 & TST & \\
\hline CHEMBL3361363 & 1459648 & 7.3152 & 7.2831 & TRN & \\
\hline CHEMBL3360787 & 1459648 & 8.1349 & 8.0224 & TRN & \\
\hline CHEMBL3361353 & 1459648 & 8.7328 & 8.7191 & TRN & \\
\hline CHEMBL3361395 & 1459648 & 8.6925 & 8.7001 & TRN & \\
\hline CHEMBL3360790 & 1459648 & 6.7959 & 6.8592 & TRN & \\
\hline CHEMBL3361351 & 1459648 & 6.2708 & 7.2298 & TST & \\
\hline CHEMBL3360788 & 1459648 & 8.4989 & 8.5118 & TRN & \\
\hline CHEMBL3361388 & 1459648 & 9.2381 & 9.1902 & TRN & \\
\hline CHEMBL3360789 & 1459648 & 7.3344 & 7.3799 & TRN & \\
\hline CHEMBL3361384 & 1459648 & 5.718999 & 999999999 & 5.6836 & TRN \\
\hline CHEMBL3360795 & 1459648 & 6.6596 & 6.6575 & TRN & \\
\hline CHEMBL3361377 & 1459648 & 7.3507 & 7.2826 & TRN & \\
\hline
\end{tabular}


Supplemental Table S2.txt

\begin{tabular}{|c|c|c|c|c|}
\hline CHEMBL3361358 & 1459648 & 7.0367 & 7.0445 & TRN \\
\hline CHEMBL3361379 & 1459648 & 8.2233 & 8.3085 & TRN \\
\hline CHEMBL3360793 & 1459648 & 6.6696 & 6.6132 & TRN \\
\hline CHEMBL3361364 & 1459648 & 7.1361 & 7.1159 & TRN \\
\hline CHEMBL3361369 & 1459648 & 6.5575 & 6.524 & TRN \\
\hline CHEMBL3361372 & 1459648 & 8.3635 & 8.2925 & TRN \\
\hline CHEMBL3361371 & 1459648 & 7.0273 & 7.0647 & TRN \\
\hline CHEMBL3361376 & 1459648 & 7.4461 & 7.593999 & \\
\hline CHEMBL3361366 & 1459648 & 7.8153 & 7.8481 & TRN \\
\hline CHEMBL3361383 & 1459648 & 6.3947 & 6.3145 & TRN \\
\hline CHEMBL3361382 & 1459648 & 7.5884 & 7.6031 & TRN \\
\hline CHEMBL3360794 & 1459648 & 6.9208 & 6.9379 & TRN \\
\hline CHEMBL3361354 & 1459648 & 6.2013 & 6.6646 & TST \\
\hline CHEMBL3361370 & 1459648 & 6.0814 & 6.1242 & TRN \\
\hline CHEMBL3361375 & 1459648 & 9.1952 & 9.1895 & TRN \\
\hline CHEMBL3361373 & 1459648 & 8.8827 & 8.8886 & TRN \\
\hline CHEMBL3361374 & 1459648 & 8.8928 & 8.9106 & TRN \\
\hline CHEMBL3361349 & 1459648 & 5.8665 & 5.8983 & TRN \\
\hline CHEMBL3361387 & 1459648 & 7.8477 & 7.9022 & TRN \\
\hline CHEMBL3361381 & 1459648 & 7.983 & 7.9383 & TRN \\
\hline CHEMBL3360786 & 1459648 & 8.3947 & 8.3924 & TRN \\
\hline CHEMBL3361360 & 1459648 & 7.9469 & 7.9423 & TRN \\
\hline CHEMBL3361359 & 1459648 & 7.4737 & 6.9623 & TST \\
\hline CHEMBL3361356 & 1459648 & 6.8601 & 7.4389 & TST \\
\hline CHEMBL3361365 & 1459648 & 7.585 & 7.5809 & TRN \\
\hline CHEMBL3361352 & 1459648 & 8.0742 & 7.7838 & TST \\
\hline CHEMBL3360792 & 1459648 & 6.9355 & 6.9296 & TRN \\
\hline CHEMBL3361394 & 1459648 & 8.9747 & 8.9921 & TRN \\
\hline CHEMBL3361391 & 1459648 & 8.7986 & 8.7513 & TRN \\
\hline CHEMBL 3361378 & 1459648 & 8.0635 & 8.0941 & TRN \\
\hline CHEMBL3361385 & 1459648 & 8.1101 & 8.021 & TRN \\
\hline CHEMBL3361355 & 1459648 & 7.0937 & 7.0831 & TRN \\
\hline CHEMBL3361350 & 1459648 & 7.0405 & 7.0237 & TRN \\
\hline CHEMBL3361368 & 1459648 & 6.3307 & 6.342000 & 30000000005 \\
\hline CHEMBL3360791 & 1459648 & 8.5735 & 8.5556 & TRN \\
\hline CHEMBL3361390 & 1459648 & 7.8182 & 7.9559 & TRN \\
\hline CHEMBL3361389 & 1459648 & 9.1898 & 9.1445 & TST \\
\hline CHEMBL3361357 & 1459648 & 7.6055 & 7.4066 & TST \\
\hline CHEMBL3361393 & 1459648 & 7.9666 & 7.8992 & TST \\
\hline CHEMBL3361392 & 1459648 & 8.8069 & 8.8828 & TST \\
\hline CHEMBL3361367 & 1459648 & 6.8182 & 7.1485 & TST \\
\hline CHEMBL3361362 & 1459648 & 4.4191 & 6.188 & TST \\
\hline CHEMBL3361361 & 1459648 & 7.8996 & 8.5107 & TST \\
\hline CHEMBL3361386 & 1459648 & 8.0931 & 8.2767 & TST \\
\hline CHEMBL3361380 & 1459648 & 6.3478 & 7.2055 & TST \\
\hline CHEMBL1257903 & 1459648 & 7.8153 & 8.0023 & TST \\
\hline CHEMBL136068 & 58198 & 5.331 & 5.487 & TRN \\
\hline CHEMBL544372 & 58198 & 5.765 & 5.3793 & TRN \\
\hline
\end{tabular}




\begin{tabular}{|c|c|c|c|c|c|}
\hline \\
\hline CHEMBL539042 & 58198 & 4.0 & 4.5481 & TRN & \\
\hline CHEMBL136064 & 58198 & 8.1549 & 7.5782 & TRN & \\
\hline CHEMBL538532 & 58198 & 5.5473 & 5.394 & TRN & \\
\hline CHEMBL440345 & 58198 & 5.3629 & 6.5009 & TRN & \\
\hline CHEMBL555975 & 58198 & 5.8033 & 5.1234 & TRN & \\
\hline CHEMBL422634 & 58198 & 6.2684 & 4.9976 & TRN & \\
\hline CHEMBL539358 & 58198 & 6.0605 & 6.0687 & TRN & \\
\hline CHEMBL555443 & 58198 & 5.2473 & 5.1123 & TRN & \\
\hline CHEMBL137159 & 58198 & 4.0 & 5.15 & TRN & \\
\hline CHEMBL136615 & 58198 & 6.7471 & 5.6818 & TST & \\
\hline CHEMBL337124 & 58198 & 4.0 & 4.4173 & TRN & \\
\hline CHEMBL554678 & 58198 & 5.3625 & 5.1667 & TRN & \\
\hline CHEMBL137776 & 58198 & 4.0 & 4.2325 & TRN & \\
\hline CHEMBL545784 & 58198 & 6.0872 & 5.87299 & 9999999999 & TRN \\
\hline CHEMBL343926 & 58198 & 4.0 & 4.194 & TST & \\
\hline CHEMBL552676 & 58198 & 4.0 & 6.3441 & TRN & \\
\hline CHEMBL138281 & 58198 & 6.71 & 6.2528 & TRN & \\
\hline CHEMBL539567 & 58198 & 6.3116 & 5.8341 & TRN & \\
\hline CHEMBL542246 & 58198 & 5.3755 & 5.4025 & TRN & \\
\hline CHEMBL545549 & 58198 & 5.7036 & 4.8887 & TRN & \\
\hline CHEMBL136702 & 58198 & 4.0 & 4.2999 & TRN & \\
\hline CHEMBL136205 & 58198 & 5.1416 & 4.6046 & TRN & \\
\hline CHEMBL344240 & 58198 & 5.8713 & 5.2783 & TRN & \\
\hline CHEMBL136642 & 58198 & 5.0915 & 5.16299 & 9999999999 & TRN \\
\hline CHEMBL539553 & 58198 & 5.1705 & 5.3422 & TST & \\
\hline CHEMBL136743 & 58198 & 6.7328 & 6.3144 & TRN & \\
\hline CHEMBL545781 & 58198 & 6.0132 & 5.4488 & TRN & \\
\hline CHEMBL134684 & 58198 & 4.0 & 4.4025 & TRN & \\
\hline CHEMBL342267 & 58198 & 5.8097 & 6.5658 & TRN & \\
\hline CHEMBL138992 & 58198 & 4.0 & 5.5806 & TRN & \\
\hline CHEMBL544146 & 58198 & 4.0 & 4.6005 & TRN & \\
\hline CHEMBL545081 & 58198 & 6.1118 & 6.2053 & TRN & \\
\hline CHEMBL136794 & 58198 & 8.0 & 6.8783 & TRN & \\
\hline CHEMBL137502 & 58198 & 5.3145 & 4.3665 & TST & \\
\hline CHEMBL337337 & 58198 & 7.2441 & 6.9899 & TRN & \\
\hline CHEMBL137658 & 58198 & 5.7328 & 5.0314 & TRN & \\
\hline CHEMBL544847 & 58198 & 4.0 & 4.4974 & TRN & \\
\hline CHEMBL543917 & 58198 & 4.0 & 4.9915 & TRN & \\
\hline CHEMBL138382 & 58198 & 4.0 & 3.7205 & TRN & \\
\hline CHEMBL343802 & 58198 & 5.8729 & 5.8894 & TRN & \\
\hline CHEMBL337810 & 58198 & 6.0762 & 5.1253 & TRN & \\
\hline CHEMBL139102 & 58198 & 4.0 & 3.2201 & TRN & \\
\hline CHEMBL337148 & 58198 & 4.0 & 5.2586 & TRN & \\
\hline CHEMBL555093 & 58198 & 5.8791 & 6.0807 & TRN & \\
\hline CHEMBL137250 & 58198 & 5.4777 & 4.7825 & TRN & \\
\hline CHEMBL136589 & 58198 & 5.4757 & 6.5426 & TST & \\
\hline CHEMBL423353 & 58198 & 6.3686 & 6.1925 & TRN & \\
\hline CHEMBL544614 & 58198 & 5.6981 & 5.3226 & TRN & \\
\hline
\end{tabular}




\begin{tabular}{|c|c|c|c|c|c|}
\hline \multicolumn{6}{|c|}{ al lable s2 } \\
\hline CHEMBL137163 & 58198 & 4.0 & 4.567 & TRN & \\
\hline CHEMBL545546 & 58198 & 6.1029 & 5.6611 & TST & \\
\hline CHEMBL422993 & 58198 & 4.0 & 5.6046 & TST & \\
\hline CHEMBL136395 & 58198 & 4.0 & 4.2405 & TRN & \\
\hline CHEMBL136963 & 58198 & 6.2518 & 6.394 & TRN & \\
\hline CHEMBL136429 & 58198 & 4.585 & 5.0878 & TRN & \\
\hline CHEMBL139578 & 58198 & 5.5281 & 5.2809 & TRN & \\
\hline CHEMBL439609 & 58198 & 5.1351 & 4.6897 & TST & \\
\hline CHEMBL136621 & 58198 & 6.0937 & 5.7636 & TRN & \\
\hline CHEMBL540578 & 58198 & 5.3579 & 4.8143 & TRN & \\
\hline CHEMBL442965 & 58198 & 5.3409 & 5.7449 & TRN & \\
\hline CHEMBL544616 & 58198 & 6.6576 & 6.706 & TRN & \\
\hline CHEMBL137085 & 58198 & 6.0246 & 5.8642 & TRN & \\
\hline CHEMBL542740 & 58198 & 6.5157 & 6.33899 & 99999999995 & TRN \\
\hline CHEMBL539302 & 58198 & 4.0 & 4.9239 & TRN & \\
\hline CHEMBL555993 & 58198 & 4.0 & 4.4759 & TRN & \\
\hline CHEMBL541603 & 58198 & 4.0 & 4.2771 & TRN & \\
\hline CHEMBL136835 & 58198 & 5.9706 & 5.8359 & TRN & \\
\hline CHEMBL136594 & 58198 & 5.1329 & 4.5221 & TRN & \\
\hline CHEMBL136789 & 58198 & 6.1457 & 5.8889 & TRN & \\
\hline CHEMBL543910 & 58198 & 5.7442 & 5.2331 & TRN & \\
\hline CHEMBL334466 & 58198 & 5.9586 & 6.0722 & TRN & \\
\hline CHEMBL136701 & 58198 & 5.7696 & 6.3203 & TST & \\
\hline CHEMBL136388 & 58198 & 4.0 & 5.2906 & TRN & \\
\hline CHEMBL344422 & 58198 & 4.0 & 4.3493 & TRN & \\
\hline CHEMBL422627 & 58198 & 5.5216 & 5.6348 & TRN & \\
\hline CHEMBL46463 & 58198 & 4.0 & 3.9774 & TRN & \\
\hline CHEMBL540585 & 58198 & 6.9431 & 6.5111 & TRN & \\
\hline CHEMBL139370 & 58198 & 5.4298 & 4.0992 & TST & \\
\hline CHEMBL545552 & 58198 & 6.6596 & 6.3247 & TRN & \\
\hline CHEMBL543437 & 58198 & 4.0 & 4.2744 & TRN & \\
\hline CHEMBL136495 & 58198 & 5.4089 & 5.7131 & TRN & \\
\hline CHEMBL136877 & 58198 & 4.0 & 4.3285 & TRN & \\
\hline CHEMBL555544 & 58198 & 4.0 & 4.3484 & TRN & \\
\hline CHEMBL555865 & 58198 & 6.4342 & 6.7538 & TRN & \\
\hline CHEMBL540066 & 58198 & 5.331 & 4.2316 & TRN & \\
\hline CHEMBL60859 & 58198 & 5.6142 & 5.6499 & TST & \\
\hline CHEMBL137768 & 58198 & 5.7144 & 5.1649 & TRN & \\
\hline CHEMBL136781 & 58198 & 7.4685 & 6.7575 & TRN & \\
\hline CHEMBL134578 & 58198 & 5.2168 & 5.853 & TRN & \\
\hline CHEMBL136509 & 58198 & 7.2596 & 6.3751 & TST & \\
\hline CHEMBL137563 & 58198 & 5.5011 & 4.6782 & TRN & \\
\hline CHEMBL543438 & 58198 & 5.2453 & 4.6794 & TST & \\
\hline CHEMBL134527 & 58198 & 7.3768 & 7.211 & TRN & \\
\hline CHEMBL544147 & 58198 & 5.5038 & 5.4549 & TRN & \\
\hline CHEMBL136381 & 58198 & 5.5602 & 4.7312 & TRN & \\
\hline CHEMBL335019 & 58198 & 4.0 & 4.7668 & TRN & \\
\hline CHEMBL543412 & 58198 & 5.7878 & 6.0227 & TRN & \\
\hline
\end{tabular}

Page 2923 


\begin{tabular}{|c|c|c|c|c|c|}
\hline & & & oplement & al Table S2. & \\
\hline CHEMBL136768 & 58198 & 6.2161 & 6.3376 & TRN & \\
\hline CHEMBL337711 & 58198 & 4.0 & 4.72199 & 99999999995 & TRN \\
\hline CHEMBL543440 & 58198 & 5.7328 & 5.1809 & TRN & \\
\hline CHEMBL543439 & 58198 & 5.782 & 4.8332 & TRN & \\
\hline CHEMBL423355 & 58198 & 5.6291 & 5.17700 & 00000000005 & TST \\
\hline CHEMBL137183 & 58198 & 4.0 & 5.2819 & TST & \\
\hline CHEMBL558819 & 58198 & 5.7033 & 6.33 & TST & \\
\hline CHEMBL539291 & 58198 & 5.3521 & 3.988 & TST & \\
\hline CHEMBL424281 & 58198 & 5.9905 & 5.6154 & TST & \\
\hline CHEMBL137339 & 58198 & 4.0 & 5.5765 & TST & \\
\hline CHEMBL540322 & 58198 & 6.9547 & 4.8864 & TST & \\
\hline CHEMBL543206 & 58198 & 4.0 & 4.8175 & TST & \\
\hline CHEMBL 335327 & 58198 & 6.4191 & 5.5493 & TST & \\
\hline CHEMBL139110 & 58198 & 5.4991 & 4.6264 & TST & \\
\hline CHEMBL543674 & 58198 & 5.2007 & 5.1082 & TST & \\
\hline CHEMBL542737 & 58198 & 5.475 & 5.3604 & TST & \\
\hline CHEMBL139963 & 58198 & 7.8539 & 7.3439 & TST & \\
\hline CHEMBL544375 & 58198 & 5.0809 & 4.5556 & TST & \\
\hline CHEMBL136622 & 58198 & 6.0458 & 6.4745 & TST & \\
\hline CHEMBL136590 & 58198 & 4.0 & 4.2474 & TST & \\
\hline CHEMBL342948 & 58198 & 4.0 & 5.2646 & TST & \\
\hline CHEMBL1396223 & 688663 & 5.0 & 4.8924 & TRN & \\
\hline CHEMBL1486329 & 688663 & 4.6 & 4.7245 & TRN & \\
\hline CHEMBL1444629 & 688663 & 4.7 & 4.5873 & TRN & \\
\hline CHEMBL1325058 & 688663 & 5.05 & 4.9632 & TRN & \\
\hline CHEMBL1407773 & 688663 & 5.0 & 4.9602 & TRN & \\
\hline CHEMBL 29711 & 688663 & 6.2 & 5.0318 & TST & \\
\hline CHEMBL417096 & 688663 & 10.6003 & 5.4058 & TST & \\
\hline CHEMBL1426021 & 688663 & 10.6003 & 5.4646 & TST & \\
\hline CHEMBL1436204 & 688663 & 4.55 & 4.7078 & TRN & \\
\hline CHEMBL1473985 & 688663 & 5.0 & 5.0067 & TRN & \\
\hline CHEMBL1538959 & 688663 & 5.0 & 4.9715 & TRN & \\
\hline CHEMBL1372952 & 688663 & 4.85 & 4.8493 & TRN & \\
\hline CHEMBL1554143 & 688663 & 4.85 & 4.8883 & TRN & \\
\hline CHEMBL1364572 & 688663 & 6.45 & 6.4292 & TRN & \\
\hline CHEMBL1473735 & 688663 & 4.45 & 4.5652 & TRN & \\
\hline CHEMBL1394653 & 688663 & 4.9 & 4.8571 & TRN & \\
\hline CHEMBL102714 & 688663 & 5.45 & 5.5702 & TRN & \\
\hline CHEMBL1600998 & 688663 & 4.8 & 4.7758 & TRN & \\
\hline CHEMBL3198756 & 688663 & 5.1 & 5.113 & TRN & \\
\hline CHEMBL1476017 & 688663 & 5.1 & 5.0156 & TRN & \\
\hline CHEMBL1396351 & 688663 & 4.9 & 4.8241 & TRN & \\
\hline CHEMBL1592304 & 688663 & 4.5 & 4.5421 & TRN & \\
\hline CHEMBL1553183 & 688663 & 4.8 & 4.8662 & TRN & \\
\hline CHEMBL1315789 & 688663 & 4.8 & 4.87 & TRN & \\
\hline CHEMBL3193997 & 688663 & 4.8 & 4.8519 & TRN & \\
\hline CHEMBL1590625 & 688663 & 4.45 & 4.4907 & TRN & \\
\hline CHEMBL1319866 & 688663 & 4.7 & 4.6974 & TRN & \\
\hline
\end{tabular}




\begin{tabular}{|c|c|c|c|c|}
\hline \multicolumn{5}{|c|}{ Supplemental Table S2.txt } \\
\hline CHEMBL1421605 & 688663 & 4.5 & 4.48 & TRN \\
\hline CHEMBL1436389 & 688663 & 5.3 & 5.1182 & TRN \\
\hline CHEMBL543467 & 688663 & 4.65 & 5.0593 & TST \\
\hline CHEMBL296586 & 688663 & 9.0 & 9.0005 & TRN \\
\hline CHEMBL1593817 & 688663 & 4.45 & 4.4539 & TRN \\
\hline CHEMBL1997993 & 688663 & 5.05 & 4.937 & TRN \\
\hline CHEMBL609027 & 688663 & 5.5 & 4.6893 & TST \\
\hline CHEMBL1490041 & 688663 & 4.85 & 4.8228 & TRN \\
\hline CHEMBL1496788 & 688663 & 4.85 & 4.9297 & TRN \\
\hline CHEMBL1531320 & 688663 & 5.45 & 5.3954 & TRN \\
\hline CHEMBL1484208 & 688663 & 5.0 & 4.9049 & TRN \\
\hline CHEMBL1371147 & 688663 & 4.6 & 4.7387 & TRN \\
\hline CHEMBL1597259 & 688663 & 4.9 & 4.9422 & TRN \\
\hline CHEMBL1399134 & 688663 & 4.9 & 4.9113 & TRN \\
\hline CHEMBL 2007422 & 688663 & 6.05 & 6.1687 & TRN \\
\hline CHEMBL1468497 & 688663 & 5.0 & 4.9866 & TRN \\
\hline CHEMBL1324313 & 688663 & 4.6 & 4.6127 & TRN \\
\hline CHEMBL1448605 & 688663 & 5.1 & 5.1577 & TRN \\
\hline CHEMBL1528672 & 688663 & 5.05 & 4.8017 & TRN \\
\hline CHEMBL1533737 & 688663 & 5.45 & 5.3341 & TRN \\
\hline CHEMBL1460810 & 688663 & 4.85 & 4.9367 & TRN \\
\hline CHEMBL1437083 & 688663 & 4.8 & 4.8842 & TRN \\
\hline CHEMBL1593156 & 688663 & 4.9 & 4.918 & TRN \\
\hline CHEMBL1358682 & 688663 & 4.45 & 4.5484 & TRN \\
\hline CHEMBL1516307 & 688663 & 4.75 & 4.7009 & TRN \\
\hline CHEMBL1359120 & 688663 & 4.65 & 4.5959 & TRN \\
\hline CHEMBL1554155 & 688663 & 4.45 & 4.8821 & TST \\
\hline CHEMBL1475514 & 688663 & 4.95 & 4.6257 & TST \\
\hline CHEMBL1328990 & 688663 & 5.0 & 4.602 & TST \\
\hline CHEMBL1526989 & 688663 & 4.5 & 4.7259 & TST \\
\hline CHEMBL1529147 & 688663 & 4.9 & 5.115 & TST \\
\hline CHEMBL1378851 & 688663 & 4.6 & 4.9034 & TST \\
\hline CHEMBL1417371 & 688663 & 10.3497 & 4.9019 & TST \\
\hline CHEMBL1435847 & 688663 & 4.85 & 4.7662 & TST \\
\hline CHEMBL1415412 & 688663 & 4.85 & 4.5504 & TST \\
\hline CHEMBL1504256 & 688663 & 5.25 & 5.3773 & TST \\
\hline CHEMBL430266 & 688663 & 6.0 & 4.8967 & TST \\
\hline CHEMBL1456711 & 688663 & 4.5 & 4.8681 & TST \\
\hline CHEMBL493960 & 562451 & 6.9586 & 6.9968 & TRN \\
\hline CHEMBL521993 & 562451 & 7.5686 & 7.3544 & TRN \\
\hline CHEMBL494552 & 562451 & 7.7447 & 7.5896 & TRN \\
\hline CHEMBL495191 & 562451 & 6.6576 & 6.6951 & TRN \\
\hline CHEMBL494168 & 562451 & 6.1249 & 6.0306 & TRN \\
\hline CHEMBL492392 & 562451 & 5.5528 & 5.6129 & TRN \\
\hline CHEMBL493139 & 562451 & 6.4437 & 6.4377 & TRN \\
\hline CHEMBL494125 & 562451 & 4.7545 & 4.8803 & TRN \\
\hline CHEMBL494032 & 562451 & 6.6861 & 6.8241 & TRN \\
\hline CHEMBL522492 & 562451 & 6.6635 & 6.6719 & TRN \\
\hline
\end{tabular}




\begin{tabular}{|c|c|c|c|c|c|}
\hline \multicolumn{6}{|c|}{ Supplemental Table S2.txt } \\
\hline CHEMBL494748 & 562451 & 9.2218 & 9.2711 & TRN & \\
\hline CHEMBL492500 & 562451 & 3.5229 & 5.051 & TST & \\
\hline CHEMBL495356 & 562451 & 8.1079 & 8.1662 & TRN & \\
\hline CHEMBL492976 & 562451 & 5.5528 & 5.5392 & TRN & \\
\hline CHEMBL494827 & 562451 & 6.5686 & 6.2546 & TST & \\
\hline CHEMBL523356 & 562451 & 7.5376 & 7.4033 & TRN & \\
\hline CHEMBL494599 & 562451 & 6.0458 & 6.0601 & TRN & \\
\hline CHEMBL495001 & 562451 & 6.8962 & 5.5641 & TST & \\
\hline CHEMBL495351 & 562451 & 6.4815 & 6.4261 & TRN & \\
\hline CHEMBL492499 & 562451 & 4.8604 & 5.8583 & TST & \\
\hline CHEMBL522883 & 562451 & 6.4647 & 6.1301 & TST & \\
\hline CHEMBL494544 & 562451 & 7.2518 & 7.2869 & TRN & \\
\hline CHEMBL494747 & 562451 & 7.585 & 7.2076 & TST & \\
\hline CHEMBL524169 & 562451 & 5.7235 & 5.625 & TRN & \\
\hline CHEMBL493108 & 562451 & 5.8297 & 5.859 & TRN & \\
\hline CHEMBL522872 & 562451 & 6.8386 & 7.0417 & TRN & \\
\hline CHEMBL494750 & 562451 & 6.6778 & 6.3985 & TRN & \\
\hline CHEMBL494127 & 562451 & 6.1192 & 6.119 & TRN & \\
\hline CHEMBL494402 & 562451 & 6.2518 & 6.2041 & TRN & \\
\hline CHEMBL493961 & 562451 & 7.0315 & 7.8712 & TST & \\
\hline CHEMBL495359 & 562451 & 6.8041 & 5.8515 & TST & \\
\hline CHEMBL494023 & 562451 & 6.4248 & 6.3387 & TRN & \\
\hline CHEMBL494359 & 562451 & 9.301 & 7.0508 & TST & \\
\hline CHEMBL494583 & 562451 & 6.3279 & 6.3586 & TRN & \\
\hline CHEMBL493333 & 562451 & 5.6882 & 5.5935 & TRN & \\
\hline CHEMBL495194 & 562451 & 6.7212 & 6.0417 & TST & \\
\hline CHEMBL494126 & 562451 & 6.0757 & 5.9875 & TRN & \\
\hline CHEMBL495170 & 562451 & 6.4776 & 5.2472 & TST & \\
\hline CHEMBL493134 & 562451 & 6.585 & 6.6239 & TRN & \\
\hline CHEMBL522329 & 562451 & 4.5229 & 4.6814 & TRN & \\
\hline CHEMBL494031 & 562451 & 6.3316 & 6.4412 & TRN & \\
\hline CHEMBL494828 & 562451 & 6.2899 & 5.4316 & TST & \\
\hline CHEMBL494598 & 562451 & 6.75200 & 000000000 & 6.8817 & TRN \\
\hline CHEMBL492498 & 562451 & 6.4815 & 6.4296 & TRN & \\
\hline CHEMBL523549 & 562451 & 6.0315 & 5.9831 & TRN & \\
\hline CHEMBL523207 & 562451 & 5.8861 & 6.0429 & TRN & \\
\hline CHEMBL495352 & 562451 & 6.8729 & 6.842000 & 30000000005 & TRN \\
\hline CHEMBL522160 & 562451 & 7.6021 & 7.3422 & TST & \\
\hline CHEMBL493929 & 562451 & 6.4202 & 6.6126 & TRN & \\
\hline CHEMBL494543 & 562451 & 6.7747 & 6.8774 & TST & \\
\hline CHEMBL493746 & 562451 & 3.5229 & 3.4529 & TRN & \\
\hline CHEMBL494185 & 562451 & 6.2604 & 6.2515 & TRN & \\
\hline CHEMBL521865 & 562451 & 5.8539 & 5.8112 & TRN & \\
\hline CHEMBL523668 & 562451 & 7.699 & 7.7056 & TRN & \\
\hline CHEMBL 3698192 & 1527704 & 6.0 & 5.8496 & TST & \\
\hline CHEMBL 3698199 & 1527704 & 6.1669 & 6.468 & TST & \\
\hline CHEMBL 3698200 & 1527704 & 6.0 & 6.4905 & TRN & \\
\hline CHEMBL 3694628 & 1527704 & 4.0 & 4.0361 & TRN & \\
\hline
\end{tabular}


Supplemental Table S2.txt

\begin{tabular}{|c|c|c|c|c|c|}
\hline CHEMBL3698195 & 1527704 & 7.1871 & 7.5735 & TRN & \\
\hline CHEMBL3698177 & 1527704 & 6.0 & 6.1093 & TRN & \\
\hline CHEMBL3698198 & 1527704 & 7.2596 & 7.2414 & TRN & \\
\hline CHEMBL3698190 & 1527704 & 6.0 & 5.4466 & TST & \\
\hline CHEMBL3698185 & 1527704 & 6.8697 & 6.8953 & TRN & \\
\hline CHEMBL3694629 & 1527704 & 4.0 & 4.4414 & TST & \\
\hline CHEMBL3694618 & 1527704 & 6.0 & \multicolumn{2}{|c|}{5.497999999999999} & TRN \\
\hline CHEMBL3698167 & 1527704 & 6.4815 & 6.4467 & TRN & \\
\hline CHEMBL 3698203 & 1527704 & 6.0 & 5.8312 & TRN & \\
\hline CHEMBL3698210 & 1527704 & 6.0 & 6.1199 & TRN & \\
\hline CHEMBL 3698214 & 1527704 & 6.6364 & 6.6308 & TRN & \\
\hline CHEMBL 3698220 & 1527704 & 6.0 & 5.6405 & TST & \\
\hline CHEMBL3698174 & 1527704 & 7.0915 & \multicolumn{2}{|c|}{7.111000000000001} & TRN \\
\hline CHEMBL3698216 & 1527704 & 6.0 & 6.0889 & TRN & \\
\hline CHEMBL3698168 & 1527704 & 6.4895 & 6.5415 & TRN & \\
\hline CHEMBL3698165 & 1527704 & 6.0 & 6.0345 & TRN & \\
\hline CHEMBL3698188 & 1527704 & 6.8447 & 6.8867 & TRN & \\
\hline CHEMBL3694625 & 1527704 & 6.4237 & 6.5799 & TST & \\
\hline CHEMBL3698196 & 1527704 & 6.5171 & 6.5836 & TRN & \\
\hline CHEMBL3694641 & 1527704 & 7.1612 & 5.8633 & TST & \\
\hline CHEMBL3698170 & 1527704 & 7.0862 & 6.9368 & TRN & \\
\hline CHEMBL3698212 & 1527704 & 6.0 & 6.0031 & TRN & \\
\hline CHEMBL3694617 & 1527704 & 6.4949 & 6.5724 & TRN & \\
\hline CHEMBL 3698215 & 1527704 & 6.0 & \multicolumn{2}{|c|}{6.156000000000001} & TRN \\
\hline CHEMBL3694621 & 1527704 & 6.0 & 6.0134 & TST & \\
\hline CHEMBL3698211 & 1527704 & 6.9872 & 6.9187 & TRN & \\
\hline CHEMBL3698219 & 1527704 & 7.0655 & 6.5768 & TST & \\
\hline CHEMBL3698194 & 1527704 & 7.5686 & 7.2677 & TRN & \\
\hline CHEMBL3698179 & 1527704 & 6.0 & 5.9945 & TRN & \\
\hline CHEMBL3932017 & 1527704 & 5.5216 & 5.2431 & TRN & \\
\hline CHEMBL3698231 & 1527704 & 6.0 & 5.8491 & TRN & \\
\hline CHEMBL3698218 & 1527704 & 6.0 & 5.7699 & TST & \\
\hline CHEMBL3694644 & 1527704 & 7.4559 & 7.2886 & TRN & \\
\hline CHEMBL 3698217 & 1527704 & 6.0 & 6.0841 & TRN & \\
\hline CHEMBL3694636 & 1527704 & 6.0 & 5.3583 & TST & \\
\hline CHEMBL3698191 & 1527704 & 7.5528 & 7.5177 & TRN & \\
\hline CHEMBL3698160 & 1527704 & 6.1818 & 6.4727 & TRN & \\
\hline CHEMBL3698176 & 1527704 & 5.6092 & 5.7641 & TRN & \\
\hline CHEMBL3698181 & 1527704 & 6.0 & 6.0397 & TRN & \\
\hline CHEMBL3694633 & 1527704 & 6.0 & 5.4059 & TST & \\
\hline CHEMBL3698163 & 1527704 & 6.0 & 6.1463 & TRN & \\
\hline CHEMBL3698173 & 1527704 & 6.0 & 5.9651 & TRN & \\
\hline CHEMBL3694620 & 1527704 & 6.0 & \multicolumn{2}{|c|}{5.957000000000001} & TRN \\
\hline CHEMBL3698187 & 1527704 & 7.6778 & 7.4503 & TRN & \\
\hline CHEMBL3698159 & 1527704 & 7.1427 & 7.0796 & TRN & \\
\hline CHEMBL3694637 & 1527704 & 6.0 & 4.9219 & TST & \\
\hline CHEMBL3698204 & 1527704 & 7.5528 & 7.2065 & TRN & \\
\hline CHEMBL3698171 & 1527704 & 6.0 & 5.7261 & TRN & \\
\hline
\end{tabular}


Supplemental Table S2.txt

\begin{tabular}{|c|c|c|c|c|c|}
\hline CHEMBL3977594 & 1527704 & 6.9066 & 7.0779 & TRN & \\
\hline CHEMBL3698175 & 1527704 & 6.0 & 5.9969 & TRN & \\
\hline CHEMBL 3698206 & 1527704 & 6.0 & 6.114 & TRN & \\
\hline CHEMBL 3698226 & 1527704 & 7.1612 & 6.1821 & TST & \\
\hline CHEMBL3694643 & 1527704 & 7.1871 & 6.8998 & TRN & \\
\hline CHEMBL 3694642 & 1527704 & 5.7104 & 5.0389 & TST & \\
\hline CHEMBL 3698241 & 1527704 & 6.4101 & 6.4896 & TRN & \\
\hline CHEMBL 3694630 & 1527704 & 6.7375 & 5.9281 & TST & \\
\hline CHEMBL 3698184 & 1527704 & 6.0 & \multicolumn{2}{|c|}{5.837999999999999} & TRN \\
\hline CHEMBL 3698164 & 1527704 & 6.0 & 6.0307 & TRN & \\
\hline CHEMBL 3698209 & 1527704 & 7.2676 & 6.9626 & TRN & \\
\hline CHEMBL 3639970 & 1527704 & 6.0 & 5.9627 & TRN & \\
\hline CHEMBL 3694631 & 1527704 & 6.7747 & 6.1573 & TST & \\
\hline CHEMBL 3694623 & 1527704 & 6.0 & 6.2907 & TRN & \\
\hline CHEMBL 3694619 & 1527704 & 6.0 & 6.1178 & TRN & \\
\hline CHEMBL3698205 & 1527704 & 7.0605 & 6.9648 & TRN & \\
\hline CHEMBL3698213 & 1527704 & 6.0 & 6.1182 & TRN & \\
\hline CHEMBL 3698197 & 1527704 & 6.4698 & 7.6413 & TST & \\
\hline CHEMBL 3698193 & 1527704 & 6.1278 & 6.4941 & TRN & \\
\hline CHEMBL3698182 & 1527704 & 6.0 & 6.1869 & TRN & \\
\hline CHEMBL 3954760 & 1527704 & 6.0 & 6.0097 & TST & \\
\hline CHEMBL 3698169 & 1527704 & 6.0 & \multicolumn{2}{|c|}{6.0520000000000005} & TRN \\
\hline CHEMBL 3694624 & 1527704 & 6.1215 & 5.9895 & TST & \\
\hline CHEMBL3698180 & 1527704 & 6.0 & 6.1393 & TRN & \\
\hline CHEMBL3698202 & 1527704 & 6.0 & 5.8626 & TRN & \\
\hline CHEMBL 3698207 & 1527704 & 6.0 & 5.8659 & TRN & \\
\hline CHEMBL3698172 & 1527704 & 7.6383 & 7.6031 & TRN & \\
\hline CHEMBL3698161 & 1527704 & 7.4089 & 7.4893 & TRN & \\
\hline CHEMBL 3698186 & 1527704 & 7.2441 & 7.1443 & TRN & \\
\hline CHEMBL3694639 & 1527704 & 6.0 & 5.6666 & TST & \\
\hline CHEMBL1423773 & 688884 & 5.0 & 5.443 & TRN & \\
\hline CHEMBL1341815 & 688884 & 4.9 & 5.2954 & TRN & \\
\hline CHEMBL1350581 & 688884 & 7.0 & 7.4721 & TRN & \\
\hline CHEMBL1387624 & 688884 & 4.9 & 4.5857 & TRN & \\
\hline CHEMBL1579418 & 688884 & 5.0 & 5.4444 & TRN & \\
\hline CHEMBL395808 & 688884 & 4.8 & 5.1304 & TRN & \\
\hline CHEMBL1455600 & 688884 & 5.8 & 5.7061 & TRN & \\
\hline CHEMBL1416062 & 688884 & 5.4 & 5.5824 & TRN & \\
\hline CHEMBL1546773 & 688884 & 4.9 & 4.5513 & TRN & \\
\hline CHEMBL1585266 & 688884 & 5.4 & 4.7612 & TRN & \\
\hline CHEMBL1441893 & 688884 & 4.8 & 5.1324 & TST & \\
\hline CHEMBL1463711 & 688884 & 4.5 & 4.7212 & TRN & \\
\hline CHEMBL1391856 & 688884 & 4.9 & 5.3544 & TST & \\
\hline CHEMBL1565991 & 688884 & 5.5 & 5.3812 & TRN & \\
\hline CHEMBL1412930 & 688884 & 5.4 & 5.4053 & TRN & \\
\hline CHEMBL1372818 & 688884 & 6.0 & 5.4312 & TRN & \\
\hline CHEMBL1391454 & 688884 & 5.1 & 5.3407 & TRN & \\
\hline CHEMBL1452841 & 688884 & 4.6 & 4.487 & TRN & \\
\hline
\end{tabular}




\begin{tabular}{|c|c|c|c|c|}
\hline & & & pplement & al $\mathrm{Ta}$ \\
\hline CHEMBL1530911 & 688884 & 5.1 & 5.4284 & TRN \\
\hline CHEMBL1602246 & 688884 & 4.9 & 5.1975 & TRN \\
\hline CHEMBL1337016 & 688884 & 4.8 & 4.619 & TRN \\
\hline CHEMBL1599589 & 688884 & 5.9 & 5.0998 & TRN \\
\hline CHEMBL3208184 & 688884 & 4.8 & 5.2059 & TRN \\
\hline CHEMBL1509321 & 688884 & 4.9 & 5.2069 & TST \\
\hline CHEMBL1537654 & 688884 & 5.5 & 4.9993 & TRN \\
\hline CHEMBL1325911 & 688884 & 5.1 & 5.4198 & TRN \\
\hline CHEMBL1550165 & 688884 & 5.9 & 5.7611 & TRN \\
\hline CHEMBL1584452 & 688884 & 4.6 & 5.3357 & TST \\
\hline CHEMBL1326366 & 688884 & 5.2 & 4.7795 & TRN \\
\hline CHEMBL1419089 & 688884 & 4.8 & 4.9122 & TRN \\
\hline CHEMBL1573401 & 688884 & 4.8 & 4.9807 & TRN \\
\hline CHEMBL1407256 & 688884 & 4.9 & 4.8875 & TRN \\
\hline CHEMBL1482555 & 688884 & 4.8 & 4.6826 & TRN \\
\hline CHEMBL1432507 & 688884 & 5.2 & 5.2387 & TRN \\
\hline CHEMBL1469621 & 688884 & 5.5 & 5.2832 & TRN \\
\hline CHEMBL1497712 & 688884 & 5.8 & 5.6957 & TRN \\
\hline CHEMBL1347130 & 688884 & 5.1 & 5.7246 & TRN \\
\hline CHEMBL251785 & 688884 & 5.8 & 5.8671 & TRN \\
\hline CHEMBL1308942 & 688884 & 4.7 & 5.1254 & TRN \\
\hline CHEMBL1550717 & 688884 & 4.9 & 5.1844 & TRN \\
\hline CHEMBL1420689 & 688884 & 5.9 & 5.6987 & TRN \\
\hline CHEMBL1524804 & 688884 & 5.3 & 4.7175 & TRN \\
\hline CHEMBL1728023 & 688884 & 4.6 & 4.7538 & TRN \\
\hline CHEMBL1344072 & 688884 & 4.9 & 5.4593 & TRN \\
\hline CHEMBL1374249 & 688884 & 4.9 & 5.1881 & TRN \\
\hline CHEMBL1304777 & 688884 & 5.9 & 5.4827 & TRN \\
\hline CHEMBL1511519 & 688884 & 4.9 & 4.9026 & TRN \\
\hline CHEMBL1577585 & 688884 & 5.9 & 6.625 & TRN \\
\hline CHEMBL1607475 & 688884 & 5.1 & 4.9194 & TRN \\
\hline CHEMBL1600958 & 688884 & 4.8 & 5.1045 & TST \\
\hline CHEMBL1360283 & 688884 & 5.4 & 5.0825 & TRN \\
\hline CHEMBL1610129 & 688884 & 7.2 & 6.2946 & TST \\
\hline CHEMBL1568610 & 688884 & 5.2 & 5.2894 & TRN \\
\hline CHEMBL1535448 & 688884 & 5.3 & 5.0129 & TRN \\
\hline CHEMBL1389117 & 688884 & 5.4 & 5.8932 & TST \\
\hline CHEMBL1973866 & 688884 & 5.4 & 5.1964 & TRN \\
\hline CHEMBL1405769 & 688884 & 5.0 & 5.6967 & TRN \\
\hline CHEMBL1595155 & 688884 & 4.6 & 5.0669 & TST \\
\hline CHEMBL1332683 & 688884 & 4.7 & 5.1458 & TRN \\
\hline CHEMBL1548490 & 688884 & 5.1 & 5.0501 & TRN \\
\hline CHEMBL1353216 & 688884 & 5.2 & 5.5523 & TRN \\
\hline CHEMBL1574971 & 688884 & 9.0969 & 7.4072 & TRN \\
\hline CHEMBL1304099 & 688884 & 4.6 & 4.6022 & TRN \\
\hline CHEMBL430893 & 688884 & 7.3002 & 6.8935 & TRN \\
\hline CHEMBL1526559 & 688884 & 6.1 & 5.5942 & TST \\
\hline CHEMBL1578026 & 688884 & 4.9 & 5.1337 & TRN \\
\hline
\end{tabular}




\begin{tabular}{|c|c|c|c|c|}
\hline \multicolumn{5}{|c|}{ Supplemental Table S2.txt } \\
\hline CHEMBL1324221 & 688884 & 5.7 & 5.5805 & TRN \\
\hline CHEMBL1305639 & 688884 & 5.3 & 5.0558 & TRN \\
\hline CHEMBL88147 & 688884 & 5.4 & 5.7592 & TRN \\
\hline CHEMBL470881 & 688884 & 6.0 & 5.8922 & TRN \\
\hline CHEMBL1527817 & 688884 & 5.5 & 5.5469 & TRN \\
\hline CHEMBL1540099 & 688884 & 6.6 & 5.7252 & TST \\
\hline CHEMBL1536015 & 688884 & 4.8 & 4.92 & TRN \\
\hline CHEMBL1502125 & 688884 & 5.6 & 5.5112 & TST \\
\hline CHEMBL1419387 & 688884 & 5.9 & 5.5727 & TRN \\
\hline CHEMBL16687 & 688884 & 5.1 & 5.0286 & TRN \\
\hline CHEMBL1360944 & 688884 & 6.3 & 6.3132 & TST \\
\hline CHEMBL1449096 & 688884 & 4.6 & 4.8652 & TST \\
\hline CHEMBL1508848 & 688884 & 5.5 & 5.3293 & TST \\
\hline CHEMBL7033 & 688884 & 4.8 & 5.0873 & TST \\
\hline CHEMBL1604912 & 688884 & 6.1 & 5.2107 & TST \\
\hline CHEMBL1479324 & 688884 & 4.8 & 4.6451 & TST \\
\hline CHEMBL1599856 & 688884 & 4.8 & 5.2541 & TST \\
\hline CHEMBL1310978 & 688884 & 5.0 & 4.8815 & TST \\
\hline CHEMBL1612870 & 688884 & 5.5 & 4.9783 & TST \\
\hline CHEMBL1561287 & 688884 & 5.5 & 4.9486 & TST \\
\hline CHEMBL1538833 & 688884 & 5.5 & 5.5533 & TST \\
\hline CHEMBL112914 & 158662 & 6.8239 & 6.7539 & TST \\
\hline CHEMBL111339 & 158662 & 5.9208 & 5.9207 & TRN \\
\hline CHEMBL113023 & 158662 & 5.8239 & 5.8239 & TRN \\
\hline CHEMBL51283 & 158662 & 6.9586 & 6.9586 & TRN \\
\hline CHEMBL 324543 & 158662 & 7.0915 & 7.0911 & TRN \\
\hline CHEMBL113521 & 158662 & 6.7212 & 6.7213 & TRN \\
\hline CHEMBL419022 & 158662 & 5.3768 & 5.3768 & TRN \\
\hline CHEMBL104779 & 158662 & 7.0 & 7.0 & TRN \\
\hline CHEMBL320339 & 158662 & 6.9208 & 6.9207 & TRN \\
\hline CHEMBL324926 & 158662 & 5.7696 & 5.7694 & TRN \\
\hline CHEMBL320705 & 158662 & 5.7447 & 5.7447 & TRN \\
\hline CHEMBL321193 & 158662 & 6.3872 & 6.3869 & TRN \\
\hline CHEMBL110905 & 158662 & 6.9208 & 6.921 & TRN \\
\hline CHEMBL113070 & 158662 & 6.9208 & 6.921 & TRN \\
\hline CHEMBL111618 & 158662 & 5.1871 & 5.1874 & TRN \\
\hline CHEMBL104153 & 158662 & 6.1675 & 6.1674 & TRN \\
\hline CHEMBL 323405 & 158662 & 6.5528 & 6.5528 & TRN \\
\hline CHEMBL111247 & 158662 & 5.585 & 5.585 & TRN \\
\hline CHEMBL332269 & 158662 & 4.9872 & 4.9875 & TRN \\
\hline CHEMBL113863 & 158662 & 6.1367 & 6.1363 & TRN \\
\hline CHEMBL104244 & 158662 & 6.0506 & 6.0491 & TRN \\
\hline CHEMBL51573 & 158662 & 3.301 & 3.8231 & TST \\
\hline CHEMBL109547 & 158662 & 5.7696 & 5.7695 & TRN \\
\hline CHEMBL50470 & 158662 & 5.0506 & 5.0504 & TRN \\
\hline CHEMBL107472 & 158662 & 5.2076 & 5.2076 & TRN \\
\hline CHEMBL112080 & 158662 & 7.0177 & 7.0177 & TRN \\
\hline CHEMBL323699 & 158662 & 5.0315 & 5.0317 & TRN \\
\hline
\end{tabular}




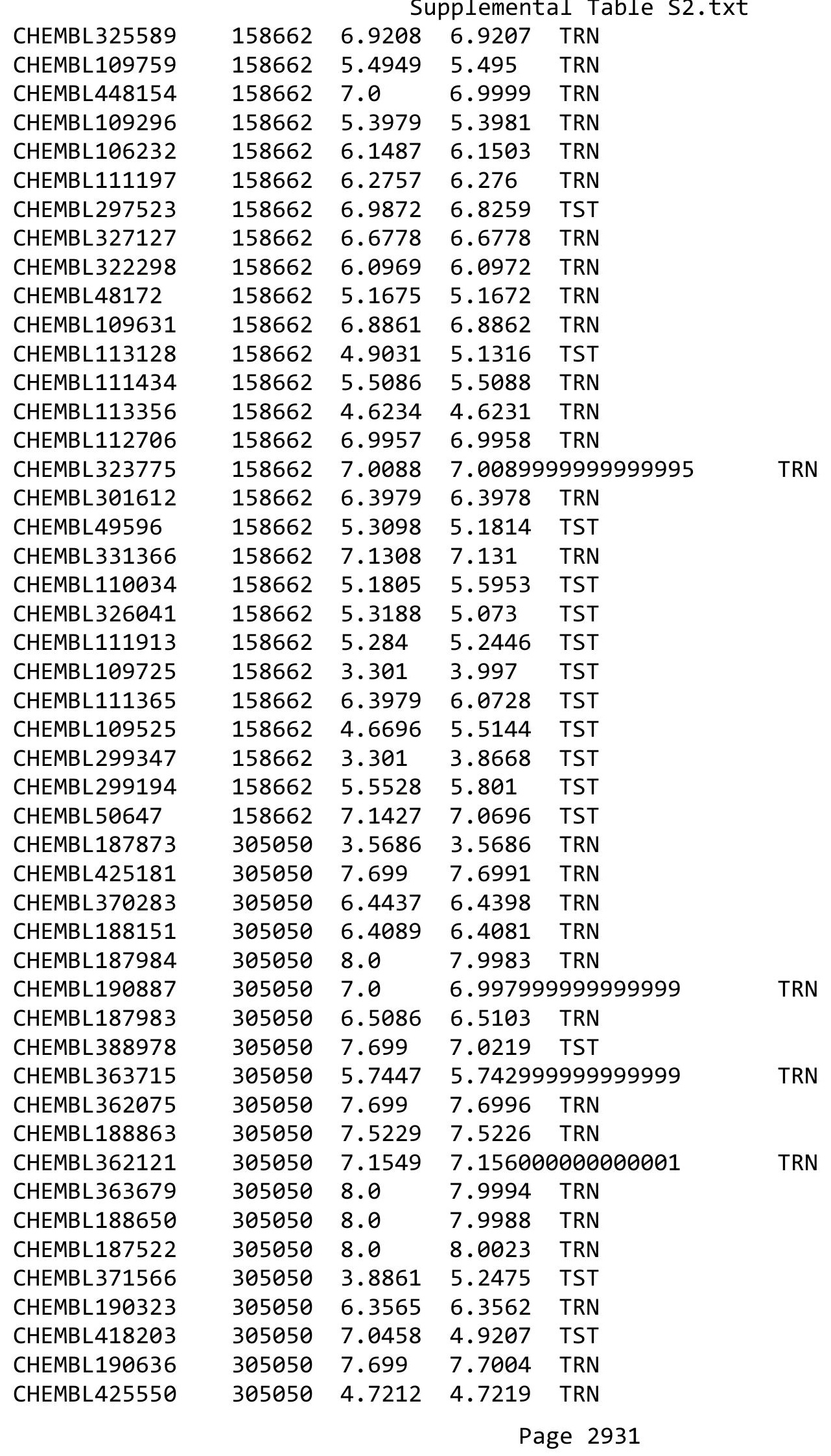




\begin{tabular}{|c|c|c|c|c|c|}
\hline \multicolumn{6}{|c|}{ Supplemental Table S2.txt } \\
\hline CHEMBL365713 & 305050 & 8.0 & 8.001 & TRN & \\
\hline CHEMBL556362 & 305050 & 5.1805 & 5.18 & TRN & \\
\hline CHEMBL363172 & 305050 & 7.0458 & 7.044 & TRN & \\
\hline CHEMBL189895 & 305050 & 5.5686 & 5.5704 & TRN & \\
\hline CHEMBL190091 & 305050 & 6.6383 & 6.6404 & TRN & \\
\hline CHEMBL188587 & 305050 & 8.0458 & 8.045 & TRN & \\
\hline CHEMBL191519 & 305050 & 6.2366 & 6.2358 & TRN & \\
\hline CHEMBL187433 & 305050 & 7.3979 & 7.3985 & TRN & \\
\hline CHEMBL188102 & 305050 & 6.2076 & 6.2084 & TRN & \\
\hline CHEMBL188812 & 305050 & 6.3768 & 6.3744 & TRN & \\
\hline CHEMBL187666 & 305050 & 7.699 & 7.6989 & TRN & \\
\hline CHEMBL361030 & 305050 & 7.301 & 7.3004 & TRN & \\
\hline CHEMBL436284 & 305050 & 8.0 & 7.9999 & TRN & \\
\hline CHEMBL365144 & 305050 & 6.8539 & 6.8558 & TRN & \\
\hline CHEMBL188251 & 305050 & 6.9208 & 6.9219 & TRN & \\
\hline CHEMBL190317 & 305050 & 6.5086 & 6.5064 & TRN & \\
\hline CHEMBL433959 & 305050 & 7.5229 & 7.5207 & TRN & \\
\hline CHEMBL1790020 & 305050 & 8.0 & 6.1635 & TST & \\
\hline CHEMBL187353 & 305050 & 6.3979 & 6.4018 & TRN & \\
\hline CHEMBL433590 & 305050 & 8.0 & 8.0007 & TRN & \\
\hline CHEMBL366209 & 305050 & 6.9586 & 6.9635 & TRN & \\
\hline CHEMBL187816 & 305050 & 7.699 & 7.6981 & TRN & \\
\hline CHEMBL190789 & 305050 & 7.699 & 7.6986 & TRN & \\
\hline CHEMBL190738 & 305050 & 6.1192 & 6.1187 & TRN & \\
\hline CHEMBL364001 & 305050 & 6.585 & 6.5843 & TRN & \\
\hline CHEMBL191312 & 305050 & 6.9586 & 7.0477 & TST & \\
\hline CHEMBL443048 & 305050 & 5.6021 & 5.19799 & 99999999995 & TST \\
\hline CHEMBL364226 & 305050 & 7.2218 & 7.2096 & TST & \\
\hline CHEMBL536272 & 305050 & 8.0 & 7.184 & TST & \\
\hline CHEMBL363174 & 305050 & 7.699 & 7.9729 & TST & \\
\hline CHEMBL364858 & 305050 & 6.9586 & 6.5355 & TST & \\
\hline CHEMBL191077 & 305050 & 6.8239 & 6.8776 & TST & \\
\hline CHEMBL186157 & 305050 & 8.0 & 7.726 & TST & \\
\hline CHEMBL364435 & 305050 & 6.6021 & 7.1378 & TST & \\
\hline CHEMBL191462 & 305050 & 5.7959 & 5.8277 & TST & \\
\hline CHEMBL3353956 & 1451727 & 7.2441 & 7.3632 & TRN & \\
\hline CHEMBL3353946 & 1451727 & 7.5229 & 7.4929 & TRN & \\
\hline CHEMBL3354588 & 1451727 & 6.8539 & 6.9071 & TRN & \\
\hline CHEMBL 3354576 & 1451727 & 7.284 & 7.3953 & TRN & \\
\hline CHEMBL3354584 & 1451727 & 5.9208 & 5.8857 & TRN & \\
\hline CHEMBL3354579 & 1451727 & 6.301 & 6.3876 & TRN & \\
\hline CHEMBL3353950 & 1451727 & 6.7447 & 6.7007 & TRN & \\
\hline CHEMBL3354577 & 1451727 & 5.9586 & 5.9964 & TRN & \\
\hline CHEMBL3353952 & 1451727 & 6.4202 & 6.4862 & TRN & \\
\hline CHEMBL3354598 & 1451727 & 7.0 & 6.9846 & TRN & \\
\hline CHEMBL3354580 & 1451727 & 6.8239 & 6.8587 & TRN & \\
\hline CHEMBL3354590 & 1451727 & 6.1427 & 6.0999 & TRN & \\
\hline CHEMBL439044 & 1451727 & 8.4559 & 7.8257 & TST & \\
\hline
\end{tabular}


Supplemental Table S2.txt

\begin{tabular}{|c|c|c|c|c|c|}
\hline CHEMBL 3353935 & 1451727 & 7.3979 & 6.3507 & TST & \\
\hline CHEMBL 3354600 & 1451727 & 6.6021 & 6.5504 & TRN & \\
\hline CHEMBL3354583 & 1451727 & 5.699 & 5.7599 & TRN & \\
\hline CHEMBL3354582 & 1451727 & 7.7447 & 7.6017 & TRN & \\
\hline CHEMBL3354581 & 1451727 & 7.1367 & 7.1428 & TRN & \\
\hline CHEMBL3354594 & 1451727 & 6.4815 & 6.4655 & TRN & \\
\hline CHEMBL3353942 & 1451727 & 7.0969 & 7.0635 & TRN & \\
\hline CHEMBL3354595 & 1451727 & 6.8539 & 6.9596 & TRN & \\
\hline CHEMBL3353939 & 1451727 & 7.9586 & 7.9919 & TRN & \\
\hline CHEMBL3354587 & 1451727 & 6.0 & 5.9439 & TRN & \\
\hline CHEMBL3353931 & 1451727 & 7.4559 & 7.5865 & TRN & \\
\hline CHEMBL3354597 & 1451727 & 6.7959 & 6.7597 & TRN & \\
\hline CHEMBL 3354574 & 1451727 & 5.8539 & 6.8078 & TST & \\
\hline CHEMBL 3353944 & 1451727 & 7.4685 & 7.4416 & TRN & \\
\hline CHEMBL 3354585 & 1451727 & 6.9586 & 6.8817 & TRN & \\
\hline CHEMBL3354570 & 1451727 & 7.2076 & 7.1667 & TRN & \\
\hline CHEMBL3353941 & 1451727 & 7.2441 & 7.26200 & 00000000005 & TRN \\
\hline CHEMBL 3353955 & 1451727 & 7.3279 & 7.2918 & TRN & \\
\hline CHEMBL3353947 & 1451727 & 7.0757 & 7.0417 & TRN & \\
\hline CHEMBL3353936 & 1451727 & 6.3468 & 5.7318 & TST & \\
\hline CHEMBL3353948 & 1451727 & 7.0862 & 7.0359 & TRN & \\
\hline CHEMBL3354572 & 1451727 & 6.6383 & 6.9613 & TST & \\
\hline CHEMBL 3354575 & 1451727 & 7.1549 & 7.0772 & TRN & \\
\hline CHEMBL3353940 & 1451727 & 7.0 & 6.9299 & TRN & \\
\hline CHEMBL3354578 & 1451727 & 5.8861 & 5.9153 & TRN & \\
\hline CHEMBL3352839 & 1451727 & 5.585 & 5.559 & TRN & \\
\hline CHEMBL3353930 & 1451727 & 8.0044 & 8.0002 & TRN & \\
\hline CHEMBL 3353934 & 1451727 & 6.1739 & 6.0763 & TST & \\
\hline CHEMBL3354601 & 1451727 & 7.5229 & 7.4571 & TRN & \\
\hline CHEMBL3353933 & 1451727 & 6.1612 & 6.2204 & TST & \\
\hline CHEMBL3353929 & 1451727 & 8.3768 & 8.2946 & TRN & \\
\hline CHEMBL3353943 & 1451727 & 7.0 & 6.9146 & TRN & \\
\hline CHEMBL3354596 & 1451727 & 5.8539 & 5.8349 & TRN & \\
\hline CHEMBL3353953 & 1451727 & 7.1805 & 7.2608 & TRN & \\
\hline CHEMBL 3353945 & 1451727 & 7.1675 & 7.1756 & TRN & \\
\hline CHEMBL3354593 & 1451727 & 5.7959 & 5.8304 & TRN & \\
\hline CHEMBL3353949 & 1451727 & 7.1079 & 7.0512 & TRN & \\
\hline CHEMBL 3354573 & 1451727 & 5.8539 & 6.9505 & TST & \\
\hline CHEMBL3354591 & 1451727 & 6.6778 & 6.6566 & TRN & \\
\hline CHEMBL3353938 & 1451727 & 7.1135 & 7.2912 & TRN & \\
\hline CHEMBL3354599 & 1451727 & 5.5229 & 5.5295 & TRN & \\
\hline CHEMBL3354592 & 1451727 & 7.2596 & 7.3368 & TRN & \\
\hline CHEMBL3353932 & 1451727 & 8.7447 & 8.2589 & TST & \\
\hline CHEMBL3353954 & 1451727 & 6.7447 & 6.9546 & TST & \\
\hline CHEMBL 3354586 & 1451727 & 5.6778 & 7.16 & TST & \\
\hline CHEMBL3354571 & 1451727 & 7.0655 & 7.1679 & TST & \\
\hline CHEMBL 3353937 & 1451727 & 6.3468 & 6.5028 & TST & \\
\hline CHEMBL3354589 & 1451727 & 7.4437 & 7.3253 & TST & \\
\hline
\end{tabular}

Page 2933 
Supplemental Table S2.txt

\begin{tabular}{|c|c|c|c|c|c|c|}
\hline CHEMBL 3354602 & 1451727 & 6.1192 & 6.1974 & TST & & \\
\hline CHEMBL3353951 & 1451727 & 6.7696 & 6.885 & TST & & \\
\hline CHEMBL3906833 & 1640801 & 5.3188 & 5.3188 & TRN & & \\
\hline CHEMBL3919581 & 1640801 & 3.7212 & 3.7231 & TRN & & \\
\hline CHEMBL 2419700 & 1640801 & 3.7212 & 3.7275 & TRN & & \\
\hline CHEMBL2419698 & 1640801 & 3.7212 & 3.7162 & TRN & & \\
\hline CHEMBL 3925030 & 1640801 & 5.041 & 5.0358 & TRN & & \\
\hline CHEMBL 3907294 & 1640801 & 3.7212 & 3.7312 & TRN & & \\
\hline CHEMBL 3943283 & 1640801 & 5.0809 & 5.0827 & TRN & & \\
\hline CHEMBL3903427 & 1640801 & 5.2366 & 5.2407 & TRN & & \\
\hline CHEMBL3933931 & 1640801 & 5.9666 & 5.9638 & TRN & & \\
\hline CHEMBL3964642 & 1640801 & 3.7212 & 3.7241 & TRN & & \\
\hline CHEMBL2419697 & 1640801 & \multicolumn{3}{|c|}{4.9830000000000005} & 4.2799 & TST \\
\hline CHEMBL2419699 & 1640801 & 3.7212 & 3.7132 & TRN & & \\
\hline CHEMBL3955207 & 1640801 & 5.1871 & 4.6122 & TST & & \\
\hline CHEMBL3902386 & 1640801 & 4.4895 & 4.9697 & TST & & \\
\hline CHEMBL2419701 & 1640801 & 3.7212 & 3.7225 & TRN & & \\
\hline CHEMBL3922251 & 1640801 & 3.7212 & 3.7315 & TRN & & \\
\hline CHEMBL3940683 & 1640801 & 3.7212 & 3.7245 & TRN & & \\
\hline CHEMBL3937250 & 1640801 & 3.7212 & 3.7269 & TRN & & \\
\hline CHEMBL3955426 & 1640801 & 4.8327 & 4.8388 & TRN & & \\
\hline CHEMBL3945618 & 1640801 & 3.7212 & 3.7192 & TRN & & \\
\hline CHEMBL3985156 & 1640801 & 3.7212 & 3.7154 & TRN & & \\
\hline CHEMBL3913243 & 1640801 & 3.7212 & 3.7328 & TRN & & \\
\hline CHEMBL3959094 & 1640801 & 3.7212 & 3.7033 & TRN & & \\
\hline CHEMBL3903965 & 1640801 & 5.1871 & 5.1842 & TRN & & \\
\hline CHEMBL3967549 & 1640801 & \multicolumn{3}{|c|}{ 4.7669999999999995 } & 4.7717 & TRN \\
\hline CHEMBL 3944401 & 1640801 & \multicolumn{3}{|c|}{5.757000000000001} & 5.7544 & TRN \\
\hline CHEMBL3940284 & 1640801 & 3.7212 & 3.7312 & TRN & & \\
\hline CHEMBL 3891789 & 1640801 & 3.7212 & 3.7109 & TRN & & \\
\hline CHEMBL3966085 & 1640801 & 5.5686 & 5.7713 & TST & & \\
\hline CHEMBL3914416 & 1640801 & 3.7212 & 3.7205 & TRN & & \\
\hline CHEMBL 3978546 & 1640801 & 5.1175 & 4.7095 & TST & & \\
\hline CHEMBL2419702 & 1640801 & 3.7212 & 3.7167 & TRN & & \\
\hline CHEMBL 3947374 & 1640801 & 5.2495 & 4.9805 & TST & & \\
\hline CHEMBL2419706 & 1640801 & 3.7212 & 3.7172 & TRN & & \\
\hline CHEMBL3928915 & 1640801 & 5.3468 & 5.4963 & TST & & \\
\hline CHEMBL3938947 & 1640801 & 3.7212 & 3.72 & TRN & & \\
\hline CHEMBL3944854 & 1640801 & 5.6882 & 5.5851 & TST & & \\
\hline CHEMBL3939009 & 1640801 & 4.7773 & 4.7806 & TST & & \\
\hline CHEMBL 2419705 & 1640801 & 3.7212 & 3.7341 & TRN & & \\
\hline CHEMBL3986804 & 1640801 & 3.7212 & 3.7241 & TRN & & \\
\hline CHEMBL3933577 & 1640801 & 3.7212 & 3.727 & TRN & & \\
\hline CHEMBL3946798 & 1640801 & 3.7212 & 3.7269 & TRN & & \\
\hline CHEMBL3956490 & 1640801 & 3.7212 & 3.718 & TRN & & \\
\hline CHEMBL3946751 & 1640801 & 5.1249 & 5.008 & TST & & \\
\hline CHEMBL3932754 & 1640801 & 4.7471 & 5.8286 & TST & & \\
\hline CHEMBL3983088 & 1640801 & 3.7212 & 3.7065 & TRN & & \\
\hline
\end{tabular}

Page 2934 
Supplemental Table S2.txt

\begin{tabular}{|c|c|c|c|c|c|}
\hline CHEMBL3956527 & 1640801 & 5.1675 & 5.2689 & TST & \\
\hline CHEMBL 3892864 & 1640801 & 3.7212 & 3.7208 & TRN & \\
\hline CHEMBL 3975140 & 1640801 & 3.7212 & 3.719 & TRN & \\
\hline CHEMBL 3941313 & 1640801 & 3.7212 & 3.7205 & TRN & \\
\hline CHEMBL 3898270 & 1640801 & 3.7212 & 3.7201 & TRN & \\
\hline CHEMBL 3987175 & 1640801 & 3.7212 & 3.7173 & TRN & \\
\hline CHEMBL 3986246 & 1640801 & 5.0 & 5.0218 & TST & \\
\hline CHEMBL3935111 & 1640801 & 3.7212 & 3.726000 & 30000000004 & TRN \\
\hline CHEMBL 3901978 & 1640801 & 3.7212 & 5.4162 & TST & \\
\hline CHEMBL 3929923 & 1640801 & 3.7212 & 3.7147 & TRN & \\
\hline CHEMBL 3961412 & 1640801 & 4.7852 & 4.8771 & TST & \\
\hline CHEMBL 3965278 & 1640801 & 3.7212 & 3.7162 & TRN & \\
\hline CHEMBL 2179879 & 877370 & 8.4202 & 8.2918 & TRN & \\
\hline CHEMBL195090 & 877370 & 8.3665 & 8.5049 & TST & \\
\hline CHEMBL 2180255 & 877370 & 7.9101 & 7.9197 & TRN & \\
\hline CHEMBL 2179850 & 877370 & 6.8239 & 6.7848 & TRN & \\
\hline CHEMBL 2179864 & 877370 & 7.1791 & 7.2054 & TRN & \\
\hline CHEMBL 365323 & 877370 & 7.8356 & 8.329 & TST & \\
\hline CHEMBL 2179841 & 877370 & 7.3372 & 7.2903 & TRN & \\
\hline CHEMBL 2179844 & 877370 & 8.1938 & 8.3864 & TRN & \\
\hline CHEMBL 2180259 & 877370 & 6.4535 & 6.3843 & TRN & \\
\hline CHEMBL 2179837 & 877370 & 6.301 & 6.1127 & TRN & \\
\hline CHEMBL 2179851 & 877370 & 7.61799 & 999999999 & 7.597 & TRN \\
\hline CHEMBL 2180261 & 877370 & 6.5867 & 6.5861 & TRN & \\
\hline CHEMBL 2179858 & 877370 & 6.6596 & 6.7744 & TRN & \\
\hline CHEMBL 2180252 & 877370 & 8.2596 & 8.4224 & TRN & \\
\hline CHEMBL 2179849 & 877370 & 7.699 & 7.7727 & TRN & \\
\hline CHEMBL 2180251 & 877370 & 8.301 & 8.2494 & TRN & \\
\hline CHEMBL 2179867 & 877370 & 6.1518 & 6.2882 & TRN & \\
\hline CHEMBL 2179859 & 877370 & 6.7747 & 6.8743 & TRN & \\
\hline CHEMBL2179854 & 877370 & 6.0173 & 5.921 & TRN & \\
\hline CHEMBL 2180263 & 877370 & 7.5376 & 7.4429 & TRN & \\
\hline CHEMBL2179883 & 877370 & 7.6556 & 7.8448 & TRN & \\
\hline CHEMBL 370523 & 877370 & 8.2076 & 8.1037 & TRN & \\
\hline CHEMBL 2179882 & 877370 & 8.2291 & 8.0553 & TRN & \\
\hline CHEMBL2179840 & 877370 & 5.6664 & 5.7613 & TRN & \\
\hline CHEMBL 2179852 & 877370 & 5.744 & 6.0319 & TRN & \\
\hline CHEMBL 2179847 & 877370 & 7.2798 & 7.3263 & TRN & \\
\hline CHEMBL 2179866 & 877370 & 7.2495 & 7.1302 & TRN & \\
\hline CHEMBL193830 & 877370 & 9.2924 & 9.5224 & TRN & \\
\hline CHEMBL365992 & 877370 & 9.0458 & 8.8429 & TRN & \\
\hline CHEMBL 2180262 & 877370 & 7.2291 & 7.3835 & TRN & \\
\hline CHEMBL 2179880 & 877370 & 7.9508 & 8.0813 & TRN & \\
\hline CHEMBL 2180250 & 877370 & 8.6576 & 8.4959 & TRN & \\
\hline CHEMBL1789658 & 877370 & 6.0092 & 7.1337 & TST & \\
\hline CHEMBL372317 & 877370 & 6.9508 & 6.853 & TRN & \\
\hline CHEMBL 2179863 & 877370 & 6.6198 & 6.6254 & TRN & \\
\hline CHEMBL2180254 & 877370 & 8.3279 & 8.238 & TRN & \\
\hline
\end{tabular}


Supplemental Table S2.txt

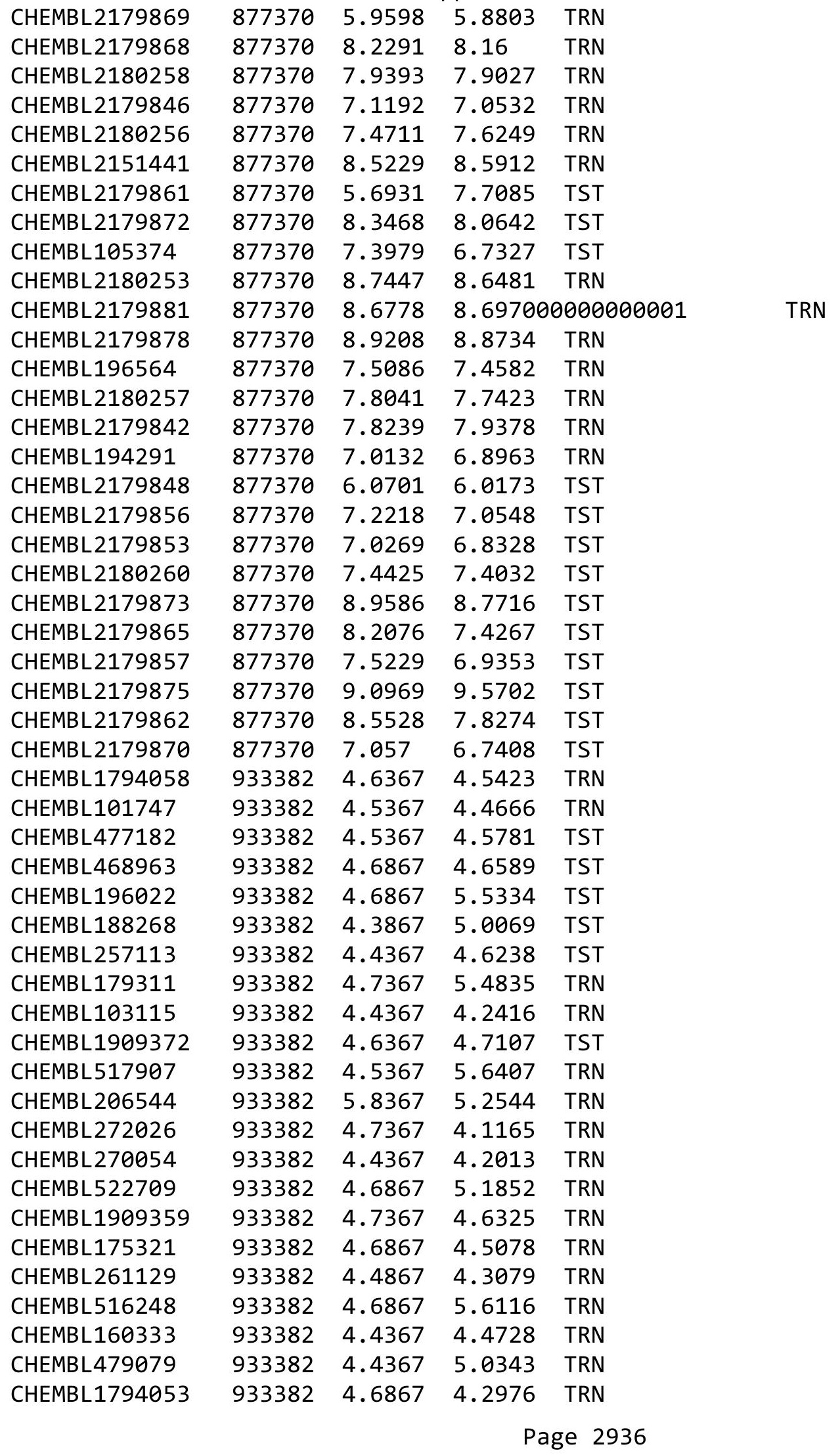


Supplemental Table S2.txt

\begin{tabular}{|c|c|c|c|c|c|}
\hline CHEMBL1956068 & 933382 & 4.5867 & 5.222 & TRN & \\
\hline CHEMBL1909365 & 933382 & 9.2218 & 4.6218 & TST & \\
\hline CHEMBL1794050 & 933382 & 4.7367 & 4.4759 & TRN & \\
\hline CHEMBL418348 & 933382 & 4.6367 & 4.922 & TST & \\
\hline CHEMBL30432 & 933382 & 4.6367 & 5.7527 & TRN & \\
\hline CHEMBL347580 & 933382 & 4.6867 & 5.2105 & TRN & \\
\hline CHEMBL222419 & 933382 & 5.4367 & 4.9447 & TRN & \\
\hline CHEMBL1909409 & 933382 & 4.6367 & 5.2881 & TRN & \\
\hline CHEMBL1794064 & 933382 & 4.6367 & 4.851 & TST & \\
\hline CHEMBL 241517 & 933382 & 4.4367 & 4.4557 & TRN & \\
\hline CHEMBL272414 & 933382 & 5.2367 & 4.1262 & TRN & \\
\hline CHEMBL407113 & 933382 & 4.4367 & 4.1269 & TRN & \\
\hline CHEMBL1909358 & 933382 & 4.4867 & 4.7608 & TRN & \\
\hline CHEMBL479038 & 933382 & 5.1367 & 4.5953 & TST & \\
\hline CHEMBL1909398 & 933382 & 4.7367 & 4.4382 & TRN & \\
\hline CHEMBL477069 & 933382 & 4.4867 & 4.3681 & TRN & \\
\hline CHEMBL1909397 & 933382 & 4.5367 & 4.2964 & TRN & \\
\hline CHEMBL1909373 & 933382 & 4.3867 & 5.1065 & TST & \\
\hline CHEMBL352222 & 933382 & 4.4867 & 4.5091 & TRN & \\
\hline CHEMBL179453 & 933382 & 4.7367 & 5.2062 & TRN & \\
\hline CHEMBL1909350 & 933382 & 4.6867 & 4.9423 & TST & \\
\hline CHEMBL15202 & 933382 & 9.1549 & 7.0203 & TRN & \\
\hline CHEMBL1794052 & 933382 & 4.8867 & 4.5256 & TRN & \\
\hline CHEMBL482326 & 933382 & 4.6367 & 5.12299 & 9999999999 & TRN \\
\hline CHEMBL65884 & 933382 & 9.301 & 6.1547 & TRN & \\
\hline CHEMBL513897 & 933382 & 4.3367 & 4.3057 & TRN & \\
\hline CHEMBL1789963 & 933382 & 4.7867 & 4.4377 & TRN & \\
\hline CHEMBL1785003 & 933382 & 4.4367 & 4.7605 & TST & \\
\hline CHEMBL458438 & 933382 & 4.7367 & 4.8949 & TRN & \\
\hline CHEMBL409892 & 933382 & 4.6367 & 4.5569 & TRN & \\
\hline CHEMBL458415 & 933382 & 4.6367 & 4.6151 & TRN & \\
\hline CHEMBL456252 & 933382 & 4.3367 & 4.4196 & TRN & \\
\hline CHEMBL476259 & 933382 & 4.7367 & 4.3838 & TRN & \\
\hline CHEMBL396107 & 933382 & 4.7867 & 4.5719 & TST & \\
\hline CHEMBL 275798 & 933382 & 4.7367 & 5.33 & TST & \\
\hline CHEMBL267228 & 933382 & 4.3867 & 4.987 & TRN & \\
\hline CHEMBL1909414 & 933382 & 4.5367 & 4.8298 & TRN & \\
\hline CHEMBL1516890 & 933382 & 4.6867 & 4.7531 & TRN & \\
\hline CHEMBL 212250 & 933382 & 4.3367 & 5.8965 & TRN & \\
\hline CHEMBL 263796 & 933382 & 4.6367 & 4.6348 & TRN & \\
\hline CHEMBL485745 & 933382 & 4.6367 & 5.1209 & TST & \\
\hline CHEMBL480382 & 933382 & 5.0367 & 5.0988 & TRN & \\
\hline CHEMBL1794068 & 933382 & 4.5867 & 4.8254 & TRN & \\
\hline CHEMBL531804 & 933382 & 4.7367 & 5.63 & TRN & \\
\hline CHEMBL483748 & 933382 & 5.2367 & 5.3888 & TRN & \\
\hline CHEMBL13868 & 933382 & 4.6867 & 5.4172 & TST & \\
\hline CHEMBL1909379 & 933382 & 4.7367 & 5.8475 & TRN & \\
\hline CHEMBL518953 & 933382 & 4.5867 & 4.9761 & TRN & \\
\hline
\end{tabular}




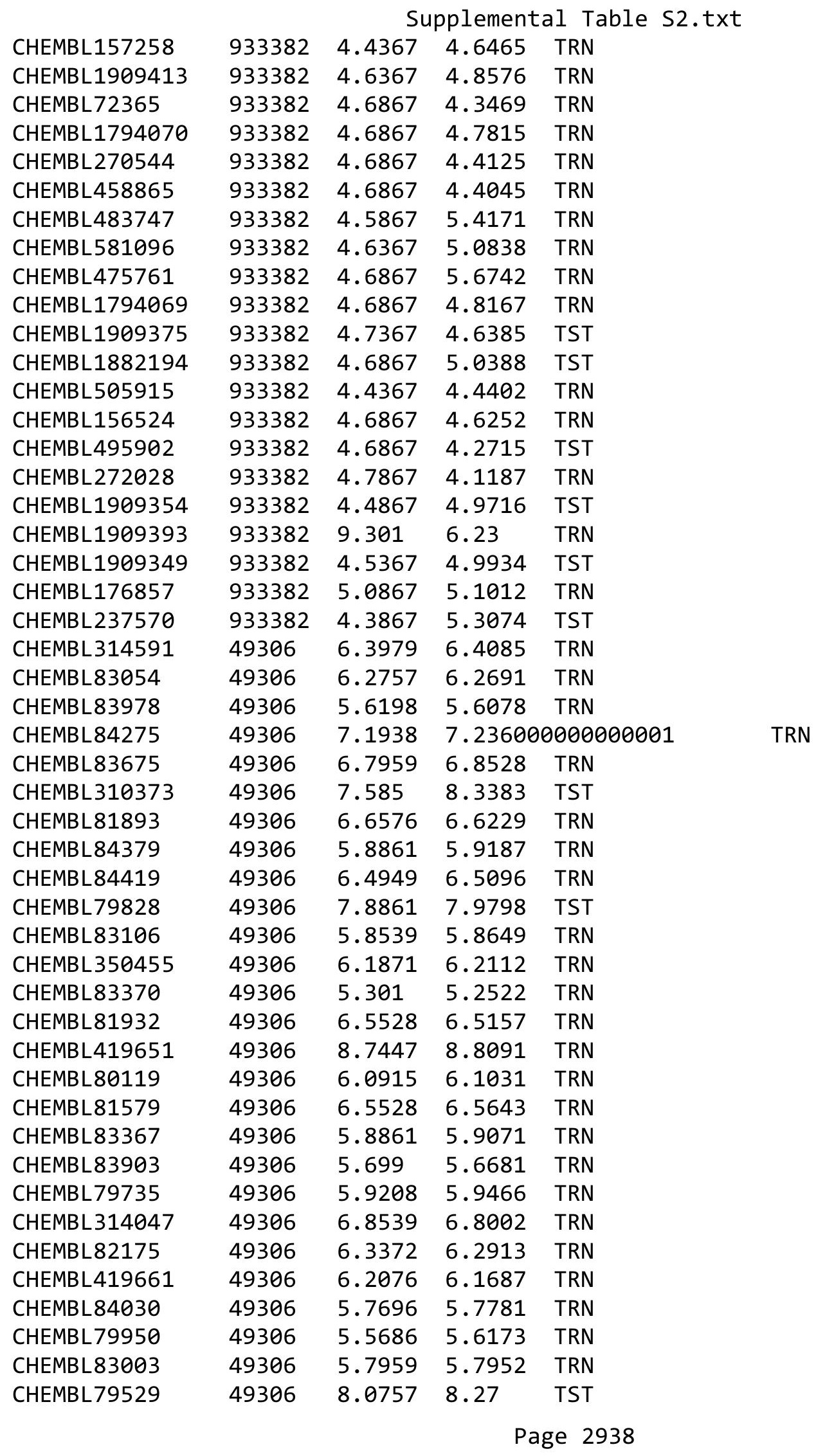




\begin{tabular}{|c|c|c|c|c|c|}
\hline \multirow[b]{2}{*}{ CHEMBL82925 } & & \multicolumn{4}{|c|}{ Supplemental Table s2.txt } \\
\hline & 49306 & 8.5229 & 8.4638 & TRN & \\
\hline CHEMBL82149 & 49306 & 5.2366 & 5.2205 & TRN & \\
\hline CHEMBL83648 & 49306 & 5.4815 & 5.4652 & TRN & \\
\hline CHEMBL312134 & 49306 & 5.6198 & 5.636 & TRN & \\
\hline CHEMBL83873 & 49306 & 5.4949 & 5.4798 & TRN & \\
\hline CHEMBL79986 & 49306 & 7.8539 & 7.82600 & 00000000005 & TRN \\
\hline CHEMBL 80017 & 49306 & 5.9208 & 5.9394 & TRN & \\
\hline CHEMBL309879 & 49306 & 8.0969 & 8.0941 & TST & \\
\hline CHEMBL83175 & 49306 & 6.7959 & 6.8015 & TRN & \\
\hline CHEMBL441450 & 49306 & 5.4198 & 5.4386 & TRN & \\
\hline CHEMBL83431 & 49306 & 5.284 & 5.2755 & TRN & \\
\hline CHEMBL 309541 & 49306 & 8.0458 & 8.2282 & TST & \\
\hline CHEMBL84410 & 49306 & 5.7447 & 5.7641 & TRN & \\
\hline CHEMBL48604 & 49306 & 7.2291 & 6.8558 & TST & \\
\hline CHEMBL79258 & 49306 & 6.7959 & 6.8614 & TRN & \\
\hline CHEMBL84502 & 49306 & 6.301 & 6.27 & TRN & \\
\hline CHEMBL157374 & 49306 & 6.0915 & 7.9898 & TST & \\
\hline CHEMBL152611 & 49306 & 5.6778 & 5.6931 & TRN & \\
\hline CHEMBL83798 & 49306 & 6.0862 & 6.099 & TRN & \\
\hline CHEMBL82040 & 49306 & 5.6021 & 5.6197 & TRN & \\
\hline CHEMBL157316 & 49306 & 5.8539 & 5.846 & TRN & \\
\hline CHEMBL315796 & 49306 & 5.8539 & 5.8064 & TRN & \\
\hline CHEMBL310575 & 49306 & 5.8697 & 5.893 & TRN & \\
\hline CHEMBL84065 & 49306 & 8.6198 & 8.4141 & TST & \\
\hline CHEMBL315014 & 49306 & 7.0706 & 7.4655 & TST & \\
\hline CHEMBL 70730 & 49306 & 7.0969 & 7.0195 & TRN & \\
\hline CHEMBL419116 & 49306 & 5.3468 & 5.3657 & TRN & \\
\hline CHEMBL311608 & 49306 & 6.1427 & 6.4526 & TST & \\
\hline CHEMBL 309717 & 49306 & 6.7447 & 5.9049 & TST & \\
\hline CHEMBL79996 & 49306 & 5.8539 & 6.1024 & TST & \\
\hline CHEMBL82456 & 49306 & 7.6383 & 7.0812 & TST & \\
\hline CHEMBL82006 & 49306 & 8.2218 & 8.4847 & TST & \\
\hline CHEMBL79501 & 49306 & 6.1612 & 6.3532 & TST & \\
\hline CHEMBL549853 & 851437 & 4.6021 & 4.2317 & TRN & \\
\hline CHEMBL2152586 & 851437 & 3.0 & 3.8925 & TST & \\
\hline CHEMBL2152609 & 851437 & 3.0 & 4.1927 & TRN & \\
\hline CHEMBL2152621 & 851437 & 6.2441 & 5.8505 & TRN & \\
\hline CHEMBL2152569 & 851437 & 3.0 & 3.6416 & TRN & \\
\hline CHEMBL2152623 & 851437 & 5.8239 & 5.5494 & TRN & \\
\hline CHEMBL2152572 & 851437 & 3.0 & 3.7134 & TRN & \\
\hline CHEMBL 2151055 & 851437 & 5.699 & 5.6368 & TRN & \\
\hline CHEMBL 2152610 & 851437 & 4.6198 & 4.9814 & TST & \\
\hline CHEMBL2152568 & 851437 & 3.0 & 3.9676 & TRN & \\
\hline CHEMBL 2152627 & 851437 & 5.4685 & 5.5848 & TRN & \\
\hline CHEMBL2152608 & 851437 & 4.1308 & 4.0831 & TRN & \\
\hline CHEMBL 2152574 & 851437 & 4.1612 & 3.6296 & TRN & \\
\hline CHEMBL560337 & 851437 & 4.1427 & 3.8714 & TRN & \\
\hline CHEMBL561194 & 851437 & 3.0 & 3.24300 & 00000000003 & TRN \\
\hline & & & & 2939 & \\
\hline
\end{tabular}




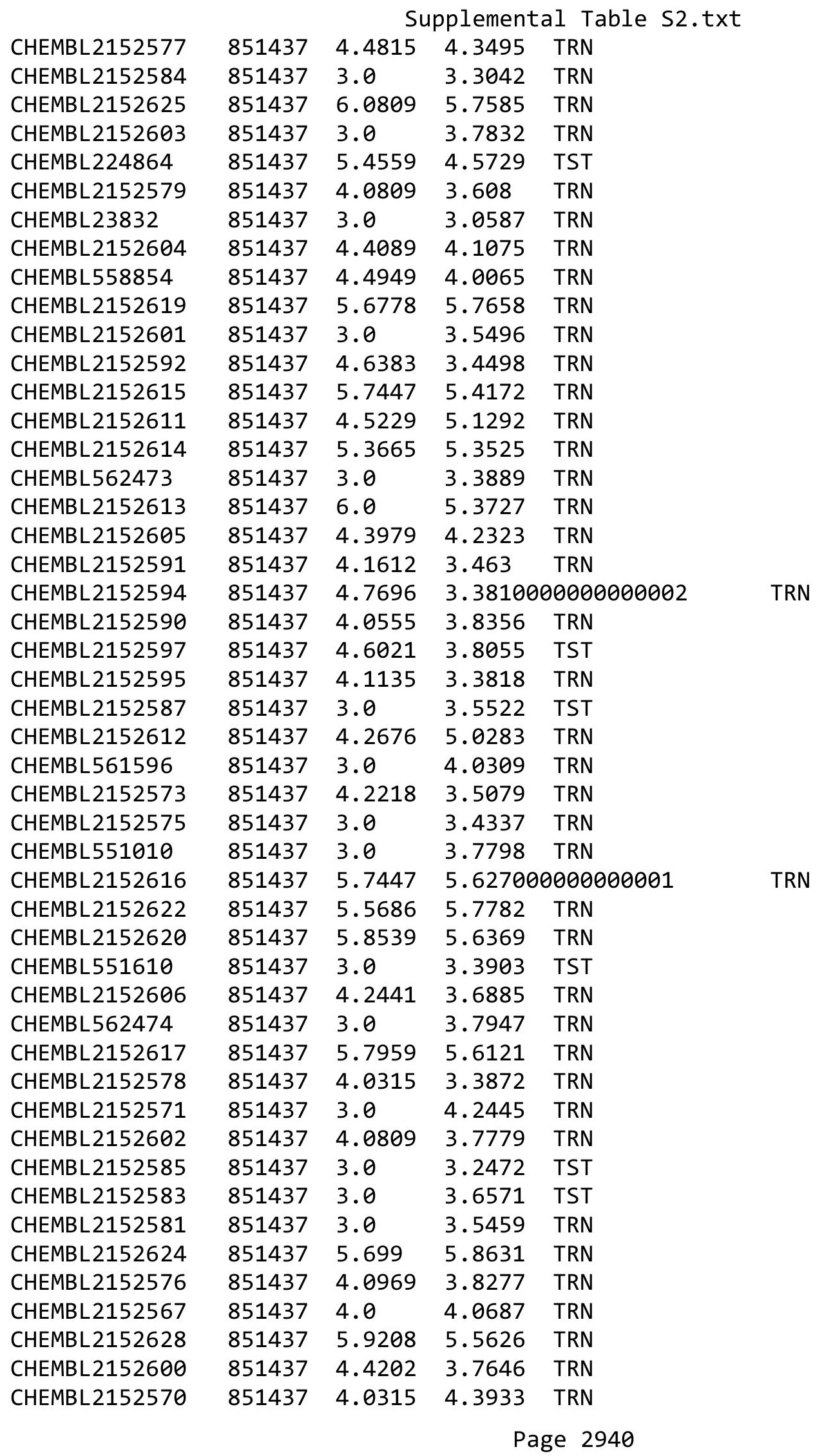




\begin{tabular}{|c|c|c|c|c|c|}
\hline \multicolumn{6}{|c|}{ Supplemental Table S2.txt } \\
\hline CHEMBL 2152596 & 851437 & 3.0 & 3.7647 & TST & \\
\hline CHEMBL 2152599 & 851437 & 3.0 & 3.83600 & 00000000003 & TST \\
\hline CHEMBL 2152618 & 851437 & 5.5086 & 5.776 & TST & \\
\hline CHEMBL 2152593 & 851437 & 2.5229 & 3.4816 & TST & \\
\hline CHEMBL572123 & 851437 & 3.0 & 4.334 & TST & \\
\hline CHEMBL 2152582 & 851437 & 3.0 & 3.7324 & TST & \\
\hline CHEMBL 2152626 & 851437 & 5.9586 & 5.351 & TST & \\
\hline CHEMBL 2152607 & 851437 & 3.0 & 3.8165 & TST & \\
\hline CHEMBL 2152580 & 851437 & 3.0 & 3.2786 & TST & \\
\hline CHEMBL 2152598 & 851437 & 4.2757 & 4.0415 & TST & \\
\hline CHEMBL540468 & 851437 & 4.4815 & 3.8266 & TST & \\
\hline CHEMBL3192138 & 688428 & 8.2218 & 7.6068 & TRN & \\
\hline CHEMBL1528660 & 688428 & 6.8069 & 6.6519 & TRN & \\
\hline CHEMBL1595169 & 688428 & 7.1367 & 6.7265 & TRN & \\
\hline CHEMBL1347346 & 688428 & 7.1427 & 7.0364 & TRN & \\
\hline CHEMBL1423927 & 688428 & 5.9996 & 5.1579 & TST & \\
\hline CHEMBL1998521 & 688428 & 6.4225 & 6.3651 & TRN & \\
\hline CHEMBL1984876 & 688428 & 6.0482 & 5.8529 & TRN & \\
\hline CHEMBL1567269 & 688428 & 5.6765 & 5.4869 & TRN & \\
\hline CHEMBL1357620 & 688428 & 7.6778 & 6.8777 & TST & \\
\hline CHEMBL1324197 & 688428 & 6.475 & 6.3159 & TST & \\
\hline CHEMBL1332139 & 688428 & 6.295 & 6.2339 & TRN & \\
\hline CHEMBL1503006 & 688428 & 3.9208 & 3.91399 & 99999999997 & TRN \\
\hline CHEMBL1372889 & 688428 & 6.857 & 6.8134 & TRN & \\
\hline CHEMBL1586862 & 688428 & 3.9208 & 5.6566 & TRN & \\
\hline CHEMBL517645 & 688428 & 6.3947 & 6.2187 & TRN & \\
\hline CHEMBL1540099 & 688428 & 6.8761 & 6.6142 & TRN & \\
\hline CHEMBL1505209 & 688428 & 5.9212 & 5.682 & TRN & \\
\hline CHEMBL1563201 & 688428 & 5.9539 & 5.9267 & TRN & \\
\hline CHEMBL1562033 & 688428 & 5.5452 & 5.8065 & TRN & \\
\hline CHEMBL1440954 & 688428 & 6.4283 & 6.414 & TRN & \\
\hline CHEMBL1386228 & 688428 & 6.0788 & 4.7591 & TRN & \\
\hline CHEMBL290077 & 688428 & 7.1549 & 6.784 & TST & \\
\hline CHEMBL1493731 & 688428 & 3.9208 & 5.7798 & TRN & \\
\hline CHEMBL3185655 & 688428 & 7.4318 & 7.0947 & TRN & \\
\hline CHEMBL1389580 & 688428 & 5.5479 & 5.2205 & TRN & \\
\hline CHEMBL1567944 & 688428 & 7.284 & 7.0622 & TST & \\
\hline CHEMBL259103 & 688428 & 6.1965 & 6.0141 & TRN & \\
\hline CHEMBL563577 & 688428 & 3.9208 & 5.5364 & TRN & \\
\hline CHEMBL1537452 & 688428 & 6.2403 & 6.4418 & TRN & \\
\hline CHEMBL1359872 & 688428 & 6.0851 & 5.9939 & TRN & \\
\hline CHEMBL267099 & 688428 & 6.6904 & 6.5617 & TST & \\
\hline CHEMBL1576870 & 688428 & 6.6925 & 6.1693 & TRN & \\
\hline CHEMBL1316831 & 688428 & 6.8041 & 6.71200 & 0000000001 & TST \\
\hline CHEMBL1368103 & 688428 & 7.3279 & 6.7863 & TRN & \\
\hline CHEMBL460601 & 688428 & 6.9281 & 6.7987 & TRN & \\
\hline CHEMBL1500581 & 688428 & 3.9208 & 5.7045 & TRN & \\
\hline CHEMBL1307091 & 688428 & 7.1549 & 6.9598 & TRN & \\
\hline
\end{tabular}


Supplemental Table S2.txt

\begin{tabular}{|c|c|c|c|c|c|}
\hline CHEMBL1355541 & 688428 & 7.0862 & 7.06 & TST & \\
\hline CHEMBL1572278 & 688428 & 5.9348 & 5.9358 & TRN & \\
\hline CHEMBL1396209 & 688428 & 6.1007 & 5.6386 & TRN & \\
\hline CHEMBL1606583 & 688428 & 3.9208 & 4.5841 & TRN & \\
\hline CHEMBL1527380 & 688428 & 6.0237 & 5.9508 & TRN & \\
\hline CHEMBL1374715 & 688428 & 5.8486 & 5.3201 & TRN & \\
\hline CHEMBL1605021 & 688428 & 5.9735 & 5.2713 & TST & \\
\hline CHEMBL1349428 & 688428 & 5.7153 & 5.5191 & TRN & \\
\hline CHEMBL1562712 & 688428 & 6.0283 & 5.122999 & 999999999 & TD \\
\hline CHEMBL1513325 & 688428 & 5.2157 & 5.6196 & TRN & \\
\hline CHEMBL1602385 & 688428 & 6.9066 & 6.7752 & TRN & \\
\hline CHEMBL1536981 & 688428 & 7.8861 & 7.4907 & TRN & \\
\hline CHEMBL1572214 & 688428 & 6.0975 & 6.0049 & TST & \\
\hline CHEMBL1567568 & 688428 & 5.9658 & 5.6341 & TRN & \\
\hline CHEMBL1358782 & 688428 & 5.8887 & 5.8414 & TRN & \\
\hline CHEMBL1524034 & 688428 & 6.4191 & 6.5099 & TRN & \\
\hline CHEMBL1567841 & 688428 & 3.9208 & 4.8607 & TRN & \\
\hline CHEMBL3199311 & 688428 & 3.9208 & 4.6463 & TRN & \\
\hline CHEMBL1300558 & 688428 & 5.8199 & 4.5248 & TRN & \\
\hline CHEMBL1562575 & 688428 & 7.7959 & 7.468 & TRN & \\
\hline CHEMBL1468323 & 688428 & 6.7055 & 6.4041 & TRN & \\
\hline CHEMBL1339289 & 688428 & 5.9129 & 4.0097 & TRN & \\
\hline CHEMBL585591 & 688428 & 6.1811 & 5.7165 & TST & \\
\hline CHEMBL1376166 & 688428 & 6.1319 & 5.9136 & TRN & \\
\hline CHEMBL1402510 & 688428 & 6.5735 & 6.6174 & TRN & \\
\hline CHEMBL1392142 & 688428 & 6.7986 & 6.7381 & TRN & \\
\hline CHEMBL1422161 & 688428 & 5.8193 & 5.4365 & TRN & \\
\hline CHEMBL1585825 & 688428 & 5.0199 & 3.9512 & TRN & \\
\hline CHEMBL1423192 & 688428 & 6.9393 & 5.5789 & TRN & \\
\hline CHEMBL598263 & 688428 & 6.983 & 6.7342 & TRN & \\
\hline CHEMBL3193098 & 688428 & 3.9208 & 5.9065 & TRN & \\
\hline CHEMBL1587117 & 688428 & 7.4202 & 7.0129 & TRN & \\
\hline CHEMBL1580848 & 688428 & 6.0035 & 5.9422 & TRN & \\
\hline CHEMBL1488760 & 688428 & 6.1451 & 6.2406 & TRN & \\
\hline CHEMBL1483593 & 688428 & 6.7471 & 6.7941 & TRN & \\
\hline CHEMBL1340058 & 688428 & 3.9208 & 5.8975 & TRN & \\
\hline CHEMBL1305287 & 688428 & 6.4921 & 5.8769 & TRN & \\
\hline CHEMBL 304291 & 688428 & 6.5544 & 6.6348 & TST & \\
\hline CHEMBL1500190 & 688428 & 5.7066 & 5.0238 & TRN & \\
\hline CHEMBL1323668 & 688428 & 6.3883 & 5.9275 & TRN & \\
\hline CHEMBL1537509 & 688428 & 7.3279 & 6.6825 & TST & \\
\hline CHEMBL1530673 & 688428 & 3.9208 & 5.8782 & TST & \\
\hline CHEMBL1543238 & 688428 & 6.0585 & 5.2773 & TRN & \\
\hline CHEMBL 222409 & 688428 & 6.4711 & 6.6605 & TRN & \\
\hline CHEMBL 261115 & 688428 & 3.9208 & 4.5509 & TRN & \\
\hline CHEMBL1329237 & 688428 & 6.0123 & 5.8542 & TRN & \\
\hline CHEMBL1321427 & 688428 & 6.45100 & 00000000 & 6.2285 & RIV \\
\hline CHEMBL1970422 & 688428 & 6.6925 & 6.6376 & TST & \\
\hline
\end{tabular}




\begin{tabular}{|c|c|c|c|c|c|}
\hline \multirow[b]{2}{*}{ CHEMBL1473676 } & \multicolumn{5}{|c|}{ Supplemental Table S2.txt } \\
\hline & 688428 & 6.9586 & 6.8803 & TST & \\
\hline CHEMBL1996189 & 688428 & 4.4202 & 5.8795 & TRN & \\
\hline CHEMBL1476264 & 688428 & 6.1871 & 5.8834 & TRN & \\
\hline CHEMBL1476215 & 688428 & 5.9278 & 5.9076 & TRN & \\
\hline CHEMBL19980 & 688428 & 7.1487 & 7.0461 & TST & \\
\hline CHEMBL373137 & 688428 & 6.9747 & 6.9862 & TRN & \\
\hline CHEMBL1333449 & 688428 & 3.9208 & 5.8324 & TRN & \\
\hline CHEMBL1537098 & 688428 & 6.9469 & 6.682 & TRN & \\
\hline CHEMBL1420319 & 688428 & 5.9784 & 5.942 & TRN & \\
\hline CHEMBL1376974 & 688428 & 7.9586 & 7.0331 & TST & \\
\hline CHEMBL1381392 & 688428 & 5.8128 & 5.0789 & TRN & \\
\hline CHEMBL1362507 & 688428 & 3.9208 & 5.843 & TRN & \\
\hline CHEMBL1327749 & 688428 & 5.8758 & 5.0368 & TRN & \\
\hline CHEMBL1447284 & 688428 & 3.9208 & 4.9854 & TRN & \\
\hline CHEMBL1560237 & 688428 & 5.9355 & 5.9888 & TST & \\
\hline CHEMBL1597778 & 688428 & 5.8368 & 5.7968 & TRN & \\
\hline CHEMBL1333930 & 688428 & 7.0458 & 6.0152 & TRN & \\
\hline CHEMBL193627 & 688428 & 3.9208 & 4.9595 & TST & \\
\hline CHEMBL579318 & 688428 & 6.8386 & 6.6554 & TRN & \\
\hline CHEMBL1371056 & 688428 & 5.845 & 5.8405 & TRN & \\
\hline CHEMBL1331514 & 688428 & 3.9208 & 4.8566 & TRN & \\
\hline CHEMBL1432420 & 688428 & 6.0329 & 4.7118 & TRN & \\
\hline CHEMBL3192855 & 688428 & 3.9208 & 6.1958 & TRN & \\
\hline CHEMBL1451935 & 688428 & 5.9931 & 5.7397 & TRN & \\
\hline CHEMBL1467877 & 688428 & 3.9208 & 5.4137 & TRN & \\
\hline CHEMBL1371507 & 688428 & 6.4056 & 6.1213 & TRN & \\
\hline CHEMBL1415899 & 688428 & 3.9208 & 3.9282 & TRN & \\
\hline CHEMBL3191808 & 688428 & 3.9208 & 5.7707 & TRN & \\
\hline CHEMBL1323774 & 688428 & 6.8928 & 7.1032 & TRN & \\
\hline CHEMBL1525789 & 688428 & 5.9492 & 5.0913 & TRN & \\
\hline CHEMBL1459109 & 688428 & 6.1669 & 6.2483 & TRN & \\
\hline CHEMBL1447219 & 688428 & 3.9208 & 5.291 & TST & \\
\hline CHEMBL1518647 & 688428 & 6.1694 & 6.0894 & TRN & \\
\hline CHEMBL1451921 & 688428 & 6.5867 & 6.2255 & TRN & \\
\hline CHEMBL300389 & 688428 & 6.7399 & 6.9151 & TST & \\
\hline CHEMBL1453996 & 688428 & 7.4089 & 6.7661 & TST & \\
\hline CHEMBL1331904 & 688428 & 6.1314 & 6.235 & TRN & \\
\hline CHEMBL1576251 & 688428 & 6.4584 & 6.4631 & TRN & \\
\hline CHEMBL1490293 & 688428 & 6.4908 & 6.3045 & TRN & \\
\hline CHEMBL1495092 & 688428 & 6.9101 & 6.7668 & TST & \\
\hline CHEMBL1379970 & 688428 & 6.6073 & 6.6104 & TRN & \\
\hline CHEMBL1360484 & 688428 & 6.5086 & 6.4903 & TRN & \\
\hline CHEMBL1462938 & 688428 & 10.0 & 7.66299 & 9999999999 & TRN \\
\hline CHEMBL1586489 & 688428 & 5.0209 & 4.084 & TRN & \\
\hline CHEMBL1994623 & 688428 & 3.9208 & 6.0012 & TRN & \\
\hline CHEMBL1428735 & 688428 & 6.4401 & 6.4727 & TRN & \\
\hline CHEMBL1521023 & 688428 & 6.7932 & 6.8248 & TRN & \\
\hline CHEMBL1305304 & 688428 & 6.3161 & 6.4981 & TRN & \\
\hline
\end{tabular}




\begin{tabular}{|c|c|c|c|c|c|c|}
\hline & & \multicolumn{5}{|c|}{ Supplemental Table S2.txt } \\
\hline CHEMBL3198912 & 688428 & 6.098 & 5.9746 & TRN & & \\
\hline CHEMBL1572139 & 688428 & 5.7277 & 5.7934 & TRN & & \\
\hline CHEMBL3189712 & 688428 & 6.0031 & 5.9188 & TRN & & \\
\hline CHEMBL1455468 & 688428 & 6.6364 & 6.2337 & TRN & & \\
\hline CHEMBL1406361 & 688428 & 6.8268 & 6.2453 & TRN & & \\
\hline CHEMBL600060 & 688428 & 6.0555 & 6.1178 & TRN & & \\
\hline CHEMBL1414112 & 688428 & 5.9948 & 5.0682 & TRN & & \\
\hline CHEMBL1472681 & 688428 & 6.1113 & 6.2475 & TRN & & \\
\hline CHEMBL1459841 & 688428 & 3.9208 & 5.0008 & TRN & & \\
\hline CHEMBL1306460 & 688428 & 5.3884 & 4.1711 & TST & & \\
\hline CHEMBL1312738 & 688428 & 6.9281 & 6.7678 & TST & & \\
\hline CHEMBL1313520 & 688428 & 6.1113 & 6.1538 & TRN & & \\
\hline CHEMBL1479301 & 688428 & 6.3958 & 6.7253 & TST & & \\
\hline CHEMBL1329221 & 688428 & 6.2055 & 5.9227 & TRN & & \\
\hline CHEMBL486504 & 688428 & 7.1427 & 6.49200 & 0000000001 & & TRN \\
\hline CHEMBL1431151 & 688428 & 5.6282 & 4.9775 & TRN & & \\
\hline CHEMBL1976786 & 688428 & 5.4874 & 5.7887 & TRN & & \\
\hline CHEMBL1579258 & 688428 & 5.7734 & 5.3082 & TRN & & \\
\hline CHEMBL1342336 & 688428 & 7.3979 & 6.9364 & TRN & & \\
\hline CHEMBL1584985 & 688428 & 6.0778 & 6.0002 & TRN & & \\
\hline CHEMBL1405749 & 688428 & 6.6819 & 6.6204 & TRN & & \\
\hline CHEMBL1372163 & 688428 & 5.8655 & 5.9313 & TRN & & \\
\hline CHEMBL1421170 & 688428 & 6.0209 & 6.0418 & TRN & & \\
\hline CHEMBL1324125 & 688428 & 6.3224 & 6.4594 & TRN & & \\
\hline CHEMBL1327496 & 688428 & 3.9208 & 5.8683 & TRN & & \\
\hline CHEMBL3191453 & 688428 & 6.0209 & 5.9473 & TRN & & \\
\hline CHEMBL1392228 & 688428 & 6.3862 & 6.0948 & TST & & \\
\hline CHEMBL1391313 & 688428 & 5.63399 & 99999999 & 995 & 5.966 & TST \\
\hline CHEMBL1384292 & 688428 & 6.82100 & 30000000 & & 6.2762 & TST \\
\hline CHEMBL3195389 & 688428 & 7.0 & 7.1669 & TST & & \\
\hline CHEMBL1324061 & 688428 & 3.9208 & 4.8328 & TST & & \\
\hline CHEMBL1541017 & 688428 & 6.2449 & 5.8477 & TST & & \\
\hline CHEMBL1321290 & 688428 & 6.6289 & 5.907 & TST & & \\
\hline CHEMBL3211308 & 688428 & 6.4012 & 6.1316 & TST & & \\
\hline CHEMBL1603960 & 688428 & 3.9208 & 4.0574 & TST & & \\
\hline CHEMBL1432507 & 688428 & 6.45100 & 20000000 & 205 & 6.4111 & ונו \\
\hline CHEMBL1408486 & 688428 & 5.8851 & 5.8547 & TST & & \\
\hline CHEMBL251785 & 688428 & 6.2588 & 6.2963 & TST & & \\
\hline CHEMBL1884996 & 688428 & 7.0362 & 6.7096 & TST & & \\
\hline CHEMBL1555935 & 688428 & 8.3979 & 7.61700 & 0000000001 & & נו \\
\hline CHEMBL1332878 & 688428 & 6.1643 & 5.9757 & TST & & \\
\hline CHEMBL1322272 & 688428 & 5.7233 & 4.8698 & TST & & \\
\hline CHEMBL1307769 & 688428 & 6.7696 & 6.6414 & TST & & \\
\hline CHEMBL310750 & 36150 & 9.0 & 5.3478 & TST & & \\
\hline CHEMBL445561 & 36150 & 8.59 & 8.6962 & TRN & & \\
\hline CHEMBL80147 & 36150 & 5.24 & 5.2958 & TRN & & \\
\hline CHEMBL420391 & 36150 & 7.92 & 7.734 & TRN & & \\
\hline CHEMBL277270 & 36150 & 8.4 & 8.3713 & TRN & & \\
\hline
\end{tabular}




\begin{tabular}{|c|c|c|c|c|c|}
\hline & & \multicolumn{4}{|c|}{ Supplemental Table S2.txt } \\
\hline CHEMBL309601 & 36150 & 8.15 & 8.2173 & TRN & \\
\hline CHEMBL80729 & 36150 & 5.62 & 3.6814 & TST & \\
\hline CHEMBL65423 & 36150 & 5.62 & 5.5578 & TRN & \\
\hline CHEMBL 312431 & 36150 & 8.54 & 8.5201 & TRN & \\
\hline CHEMBL77056 & 36150 & 2.87 & 3.1244 & TRN & \\
\hline CHEMBL 78341 & 36150 & 7.4 & 7.3935 & TRN & \\
\hline CHEMBL35561 & 36150 & 9.94 & 9.975 & TRN & \\
\hline CHEMBL80101 & 36150 & 3.26 & 3.3762 & TRN & \\
\hline CHEMBL 80240 & 36150 & 5.59 & 6.0711 & TST & \\
\hline CHEMBL311471 & 36150 & 8.19 & 8.3131 & TRN & \\
\hline CHEMBL1788150 & 36150 & 8.22 & 8.2922 & TRN & \\
\hline CHEMBL431983 & 36150 & 7.19 & 7.1933 & TRN & \\
\hline CHEMBL77446 & 36150 & 7.25 & 7.2561 & TRN & \\
\hline CHEMBL 79190 & 36150 & 7.15 & 6.8182 & TST & \\
\hline CHEMBL 284843 & 36150 & 9.05 & 9.1759 & TRN & \\
\hline CHEMBL 310841 & 36150 & 8.0 & 7.9698 & TRN & \\
\hline CHEMBL80667 & 36150 & 6.15 & 6.0542 & TRN & \\
\hline CHEMBL77556 & 36150 & 7.3 & 7.2168 & TRN & \\
\hline CHEMBL 80304 & 36150 & 3.31 & 4.4886 & TST & \\
\hline CHEMBL 78340 & 36150 & 8.59 & 8.7934 & TRN & \\
\hline CHEMBL80981 & 36150 & 4.42 & 4.2869 & TRN & \\
\hline CHEMBL 78629 & 36150 & 9.6 & 9.7342 & TRN & \\
\hline CHEMBL 284345 & 36150 & 8.97 & 8.97299 & 9999999999 & TRN \\
\hline CHEMBL80242 & 36150 & 4.11 & 4.3388 & TRN & \\
\hline CHEMBL 263556 & 36150 & 5.08 & 5.2128 & TRN & \\
\hline CHEMBL 312550 & 36150 & 4.32 & 4.3365 & TRN & \\
\hline CHEMBL 284734 & 36150 & 9.53 & 9.4515 & TRN & \\
\hline CHEMBL80665 & 36150 & 9.64 & 9.6436 & TRN & \\
\hline CHEMBL 79016 & 36150 & 5.59 & 5.7263 & TRN & \\
\hline CHEMBL80779 & 36150 & 8.96 & 8.9174 & TRN & \\
\hline CHEMBL412666 & 36150 & 7.2 & 7.2479 & TRN & \\
\hline CHEMBL 34650 & 36150 & 9.2 & 9.094 & TRN & \\
\hline CHEMBL 309333 & 36150 & 4.17 & 4.5165 & TRN & \\
\hline CHEMBL 80548 & 36150 & 3.35 & 3.366 & TRN & \\
\hline CHEMBL 79189 & 36150 & 7.7 & 7.6812 & TRN & \\
\hline CHEMBL435360 & 36150 & 7.92 & 8.0791 & TRN & \\
\hline CHEMBL 78805 & 36150 & 4.99 & 5.0419 & TRN & \\
\hline CHEMBL 78780 & 36150 & 5.31 & 5.3661 & TRN & \\
\hline CHEMBL80657 & 36150 & 4.51 & 4.5331 & TRN & \\
\hline CHEMBL80646 & 36150 & 7.29 & 7.3773 & TRN & \\
\hline CHEMBL310764 & 36150 & 2.96 & 2.8956 & TRN & \\
\hline CHEMBL 78435 & 36150 & 7.31 & 7.2677 & TRN & \\
\hline CHEMBL312120 & 36150 & 6.12 & 6.2093 & TRN & \\
\hline CHEMBL419649 & 36150 & 8.32 & 8.3053 & TRN & \\
\hline CHEMBL 78385 & 36150 & 6.36 & 6.3333 & TRN & \\
\hline CHEMBL 308267 & 36150 & 6.34 & 5.1379 & TST & \\
\hline CHEMBL 78726 & 36150 & 8.55 & 8.5551 & TRN & \\
\hline CHEMBL 78440 & 36150 & 6.07 & 5.7047 & TRN & \\
\hline
\end{tabular}




\begin{tabular}{|c|c|c|c|c|c|}
\hline & & \multicolumn{4}{|c|}{ Supplemental Table S2.txt } \\
\hline CHEMBL78998 & 36150 & 2.96 & 2.2284 & TST & \\
\hline CHEMBL311316 & 36150 & 4.41 & 4.1081 & TST & \\
\hline CHEMBL306117 & 36150 & 2.7 & 2.1569 & TST & \\
\hline CHEMBL309782 & 36150 & 3.21 & 3.1313 & TRN & \\
\hline CHEMBL285935 & 36150 & 9.53 & 9.4737 & TRN & \\
\hline CHEMBL79212 & 36150 & 6.49 & 6.3817 & TRN & \\
\hline CHEMBL1807684 & 36150 & 3.89 & 3.9442 & TRN & \\
\hline CHEMBL 311988 & 36150 & 7.28 & 6.9364 & TST & \\
\hline CHEMBL311239 & 36150 & 3.64 & 3.6775 & TRN & \\
\hline CHEMBL78443 & 36150 & 6.11 & 5.9805 & TRN & \\
\hline CHEMBL312094 & 36150 & 6.37 & 6.0446 & TRN & \\
\hline CHEMBL78346 & 36150 & 8.66 & 8.577 & TRN & \\
\hline CHEMBL78731 & 36150 & 8.28 & 8.2738 & TRN & \\
\hline CHEMBL299889 & 36150 & 3.22 & 3.24600 & 00000000004 & TRN \\
\hline CHEMBL306556 & 36150 & 6.19 & 5.3507 & TST & \\
\hline CHEMBL430630 & 36150 & 7.92 & 7.7544 & TRN & \\
\hline CHEMBL310578 & 36150 & 4.48 & 4.3901 & TRN & \\
\hline CHEMBL309308 & 36150 & 8.66 & 8.6905 & TRN & \\
\hline CHEMBL 80193 & 36150 & 4.59 & 4.4263 & TRN & \\
\hline CHEMBL78996 & 36150 & 6.41 & 6.5367 & TRN & \\
\hline CHEMBL80384 & 36150 & 4.72 & 4.4845 & TRN & \\
\hline CHEMBL 80503 & 36150 & 5.6 & 5.7278 & TRN & \\
\hline CHEMBL 79008 & 36150 & 2.98 & 2.9136 & TRN & \\
\hline CHEMBL 78971 & 36150 & 3.03 & 3.1563 & TRN & \\
\hline CHEMBL414828 & 36150 & 3.64 & 3.577 & TRN & \\
\hline CHEMBL309537 & 36150 & 3.62 & 3.5668 & TRN & \\
\hline CHEMBL311363 & 36150 & 8.52 & 8.4079 & TRN & \\
\hline CHEMBL35682 & 36150 & 9.54 & 9.5743 & TRN & \\
\hline CHEMBL439762 & 36150 & 3.38 & 3.3995 & TRN & \\
\hline CHEMBL311102 & 36150 & 3.59 & 3.6314 & TRN & \\
\hline CHEMBL442750 & 36150 & 3.19 & 3.0987 & TRN & \\
\hline CHEMBL 79131 & 36150 & 7.39 & 7.3312 & TRN & \\
\hline CHEMBL 78903 & 36150 & 7.0 & 6.606 & TST & \\
\hline CHEMBL311757 & 36150 & 8.46 & 8.5851 & TRN & \\
\hline CHEMBL 78353 & 36150 & 7.82 & 7.6562 & TRN & \\
\hline CHEMBL80939 & 36150 & 6.15 & 6.9644 & TST & \\
\hline CHEMBL311525 & 36150 & 8.05 & 5.6422 & TST & \\
\hline CHEMBL77677 & 36150 & 5.55 & 4.5862 & TST & \\
\hline CHEMBL 78812 & 36150 & 5.8 & 5.2757 & TST & \\
\hline CHEMBL309798 & 36150 & 7.14 & 8.60799 & 9999999999 & TST \\
\hline CHEMBL446407 & 36150 & 2.46 & 2.6273 & TST & \\
\hline CHEMBL312224 & 36150 & 9.22 & 8.6545 & TST & \\
\hline CHEMBL76577 & 36150 & 4.96 & 6.3298 & TST & \\
\hline CHEMBL311268 & 36150 & 8.54 & 7.9316 & TST & \\
\hline CHEMBL80906 & 36150 & 8.77 & 8.911 & TST & \\
\hline CHEMBL39538 & 36150 & 8.92 & 7.2292 & TST & \\
\hline CHEMBL309941 & 36150 & 8.52 & 7.6332 & TST & \\
\hline CHEMBL 78074 & 36150 & 5.52 & 3.4833 & TST & \\
\hline
\end{tabular}




\begin{tabular}{|c|c|c|c|c|c|c|}
\hline \multicolumn{7}{|c|}{ Supplemental Ta } \\
\hline CHEMBL310624 & 36150 & 5.6 & 9.4699 & TST & & \\
\hline CHEMBL 255342 & 955068 & 3.8753 & 3.6699 & TRN & & \\
\hline CHEMBL515416 & 955068 & 4.3662 & 4.3301 & TRN & & \\
\hline CHEMBL1186585 & 955068 & 4.2903 & 4.3762 & TRN & & \\
\hline CHEMBL1970879 & 955068 & 4.0147 & 4.1337 & TRN & & \\
\hline CHEMBL191334 & 955068 & 3.9223 & 3.8181 & TRN & & \\
\hline CHEMBL 217354 & 955068 & 5.7613 & 5.4901 & TRN & & \\
\hline CHEMBL 3199475 & 955068 & 5.5918 & 5.2952 & TRN & & \\
\hline CHEMBL2144069 & 955068 & 6.9308 & 7.1522 & TRN & & \\
\hline CHEMBL1357247 & 955068 & 3.2128 & 3.1699 & TRN & & \\
\hline CHEMBL 258844 & 955068 & 4.2276 & 4.543 & TRN & & \\
\hline CHEMBL180127 & 955068 & 3.6639 & 4.2234 & TRN & & \\
\hline CHEMBL 373751 & 955068 & 3.2037 & 3.4615 & TRN & & \\
\hline CHEMBL1242367 & 955068 & 4.9646 & 4.6047 & TRN & & \\
\hline CHEMBL1673039 & 955068 & 5.1224 & 4.748 & TRN & & \\
\hline CHEMBL412142 & 955068 & 4.0397 & 3.8396 & TRN & & \\
\hline CHEMBL393929 & 955068 & 3.4585 & 3.2507 & TRN & & \\
\hline CHEMBL92309 & 955068 & 3.7663 & 3.0366 & TST & & \\
\hline CHEMBL 220241 & 955068 & 3.5141 & 3.1033 & TRN & & \\
\hline CHEMBL189584 & 955068 & 3.6875 & 3.8924 & TRN & & \\
\hline CHEMBL 3186408 & 955068 & 4.5196 & 3.585 & TST & & \\
\hline CHEMBL483847 & 955068 & 4.122 & 4.2779 & TRN & & \\
\hline CHEMBL188678 & 955068 & 4.8208 & 4.2584 & TRN & & \\
\hline CHEMBL1788116 & 955068 & 3.9593 & 3.8819 & TRN & & \\
\hline CHEMBL1516890 & 955068 & 3.8743 & 3.9894 & TRN & & \\
\hline CHEMBL514499 & 955068 & 7.0762 & 6.9442 & TRN & & \\
\hline CHEMBL 259181 & 955068 & 5.0511 & 5.4032 & TRN & & \\
\hline CHEMBL 209148 & 955068 & 4.7719 & 4.4506 & TRN & & \\
\hline CHEMBL2005886 & 955068 & 4.7603 & 5.0119 & TRN & & \\
\hline CHEMBL1190711 & 955068 & 3.8934 & 4.1956 & TRN & & \\
\hline CHEMBL102714 & 955068 & 3.54399 & 99999999 & 996 & 3.6335 & TRN \\
\hline CHEMBL1404918 & 955068 & 3.5293 & 3.3052 & TRN & & \\
\hline CHEMBL1230020 & 955068 & 5.9394 & 5.8321 & TRN & & \\
\hline CHEMBL 379300 & 955068 & 6.2485 & 6.3217 & TRN & & \\
\hline CHEMBL577784 & 955068 & 3.4328 & 3.6548 & TRN & & \\
\hline CHEMBL65 & 955068 & 8.0649 & 7.4328 & TRN & & \\
\hline CHEMBL 240954 & 955068 & 3.3206 & 3.8374 & TST & & \\
\hline CHEMBL192566 & 955068 & 6.9697 & 7.9126 & TST & & \\
\hline CHEMBL9470 & 955068 & 6.9442 & 5.4926 & TST & & \\
\hline CHEMBL 379975 & 955068 & 3.7645 & 4.1973 & TRN & & \\
\hline CHEMBL399530 & 955068 & 4.3851 & 4.4318 & TRN & & \\
\hline CHEMBL1590308 & 955068 & 3.40100 & 00000000 & 002 & 3.2718 & TST \\
\hline CHEMBL3349342 & 955068 & 6.4261 & 6.3376 & TRN & & \\
\hline CHEMBL300389 & 955068 & 5.6787 & 5.9759 & TRN & & \\
\hline CHEMBL 210618 & 955068 & 3.2776 & 3.095 & TRN & & \\
\hline CHEMBL221137 & 955068 & 5.0098 & 4.8067 & TST & & \\
\hline CHEMBL573107 & 955068 & 3.8258 & 4.2279 & TRN & & \\
\hline CHEMBL585951 & 955068 & 5.5379 & 5.8338 & TRN & & \\
\hline
\end{tabular}




\begin{tabular}{|c|c|c|c|c|c|c|}
\hline & & \multicolumn{5}{|c|}{ Supplemental Table S2.txt } \\
\hline CHEMBL 3392440 & 955068 & 3.6084 & 3.7509 & TRN & & \\
\hline CHEMBL449158 & 955068 & 7.091 & 6.6423 & TST & & \\
\hline CHEMBL2137530 & 955068 & 5.0343 & 4.4996 & TRN & & \\
\hline CHEMBL135561 & 955068 & 4.4885 & 4.4306 & TRN & & \\
\hline CHEMBL1256459 & 955068 & 7.5835 & 7.75299 & 9999999999 & & TRN \\
\hline CHEMBL1643959 & 955068 & 3.3561 & 3.2231 & TRN & & \\
\hline CHEMBL392695 & 955068 & 5.49799 & 99999999 & 99 & 5.6548 & TRN \\
\hline CHEMBL472940 & 955068 & 2.9952 & 3.4318 & TRN & & \\
\hline CHEMBL512504 & 955068 & 4.1496 & 4.0064 & TRN & & \\
\hline CHEMBL558642 & 955068 & 4.3164 & 4.2264 & TST & & \\
\hline CHEMBL 2134202 & 955068 & 3.7501 & 4.5818 & TST & & \\
\hline CHEMBL483849 & 955068 & 2.7518 & 2.5183 & TST & & \\
\hline CHEMBL 202721 & 955068 & 3.3904 & 3.8926 & TST & & \\
\hline CHEMBL1909414 & 955068 & 5.1116 & 4.9296 & TST & & \\
\hline CHEMBL509032 & 955068 & 3.6516 & 4.8618 & TST & & \\
\hline CHEMBL 2363137 & 955068 & 5.4695 & 5.234 & TST & & \\
\hline CHEMBL 222102 & 955068 & 3.5766 & 3.5425 & TST & & \\
\hline CHEMBL 213100 & 955068 & 5.2931 & 4.1747 & TST & & \\
\hline CHEMBL514186 & 931327 & 7.0213 & 6.9291 & TRN & & \\
\hline CHEMBL1720480 & 931327 & 7.0209 & 6.79799 & 9999999999 & & TST \\
\hline CHEMBL180442 & 931327 & 6.3949 & 6.7502 & TRN & & \\
\hline CHEMBL518399 & 931327 & 6.6261 & 6.4863 & TRN & & \\
\hline CHEMBL183184 & 931327 & 6.928 & 6.8049 & TRN & & \\
\hline CHEMBL462873 & 931327 & 6.2099 & 6.3176 & TRN & & \\
\hline CHEMBL179824 & 931327 & 6.289 & 6.4992 & TRN & & \\
\hline CHEMBL187030 & 931327 & 6.0473 & 6.5376 & TST & & \\
\hline CHEMBL178152 & 931327 & 6.2648 & 6.2664 & TRN & & \\
\hline CHEMBL474578 & 931327 & 6.7931 & 6.2693 & TRN & & \\
\hline CHEMBL464427 & 931327 & 6.3438 & 6.2452 & TRN & & \\
\hline CHEMBL180640 & 931327 & 6.063 & 6.3235 & TRN & & \\
\hline CHEMBL 360570 & 931327 & 7.1583 & 6.6262 & TRN & & \\
\hline CHEMBL464024 & 931327 & 6.0364 & 6.1825 & TRN & & \\
\hline CHEMBL2297981 & 931327 & 6.8859 & 6.4097 & TST & & \\
\hline CHEMBL180437 & 931327 & 5.8729 & 6.0331 & TRN & & \\
\hline CHEMBL1711540 & 931327 & 7.2609 & 6.8336 & TST & & \\
\hline CHEMBL182252 & 931327 & 6.8613 & 6.9455 & TRN & & \\
\hline CHEMBL2297979 & 931327 & 7.3248 & 6.8167 & TST & & \\
\hline CHEMBL 362238 & 931327 & 7.4182 & 6.9815 & TRN & & \\
\hline CHEMBL472814 & 931327 & 5.983 & 6.2003 & TRN & & \\
\hline CHEMBL465028 & 931327 & 6.7023 & 6.8839 & TRN & & \\
\hline CHEMBL 361540 & 931327 & 6.6422 & 6.7264 & TRN & & \\
\hline CHEMBL 2297985 & 931327 & 5.684 & 6.5956 & TST & & \\
\hline CHEMBL463279 & 931327 & 6.62799 & 79999999 & & 6.4191 & TRN \\
\hline CHEMBL474190 & 931327 & 6.03700 & 000000006 & & 6.1318 & TRN \\
\hline CHEMBL 2297983 & 931327 & 6.5798 & 6.6908 & TST & & \\
\hline CHEMBL361309 & 931327 & 6.6633 & 6.6104 & TRN & & \\
\hline CHEMBL2297976 & 931327 & 5.6289 & 6.4342 & TST & & \\
\hline CHEMBL2297980 & 931327 & 7.6424 & 6.7167 & TST & & \\
\hline
\end{tabular}




\begin{tabular}{|c|c|c|c|c|c|}
\hline \multicolumn{6}{|c|}{ Supplemental Table S2.txt } \\
\hline CHEMBL515394 & 931327 & 7.1321 & 6.8891 & TRN & \\
\hline CHEMBL362583 & 931327 & 6.2966 & 6.9025 & TRN & \\
\hline CHEMBL465027 & 931327 & 6.8971 & 7.1198 & TRN & \\
\hline CHEMBL 264242 & 931327 & 7.2072 & 6.8644 & TRN & \\
\hline CHEMBL515891 & 931327 & 6.2952 & 6.3867 & TRN & \\
\hline CHEMBL180483 & 931327 & 6.5899 & 6.6616 & TRN & \\
\hline CHEMBL180145 & 931327 & 6.3946 & 6.705 & TRN & \\
\hline CHEMBL473767 & 931327 & 7.6521 & 7.0923 & TRN & \\
\hline CHEMBL181216 & 931327 & 6.5744 & 6.939 & TRN & \\
\hline CHEMBL2297978 & 931327 & 7.6718 & 6.7356 & TST & \\
\hline CHEMBL180413 & 931327 & 6.9736 & 6.7897 & TRN & \\
\hline CHEMBL181207 & 931327 & 7.1098 & 6.9202 & TRN & \\
\hline CHEMBL2297984 & 931327 & 7.2118 & 6.8633 & TST & \\
\hline CHEMBL180645 & 931327 & 5.7986 & 6.2774 & TRN & \\
\hline CHEMBL462872 & 931327 & 7.2059 & 6.5484 & TRN & \\
\hline CHEMBL474577 & 931327 & 6.2798 & 6.5186 & TRN & \\
\hline CHEMBL182251 & 931327 & 6.1007 & 6.7415 & TRN & \\
\hline CHEMBL181125 & 931327 & 5.8761 & 6.1296 & TRN & \\
\hline CHEMBL181310 & 931327 & 5.9983 & 6.3353 & TRN & \\
\hline CHEMBL 2297975 & 931327 & 6.2829 & 6.5261 & TST & \\
\hline CHEMBL 2297982 & 931327 & 5.5421 & 6.7193 & TST & \\
\hline CHEMBL475161 & 931327 & 7.1494 & 7.1588 & TRN & \\
\hline CHEMBL472813 & 931327 & 7.6643 & 6.4592 & TRN & \\
\hline CHEMBL435897 & 931327 & 6.6803 & 6.1055 & TRN & \\
\hline CHEMBL473962 & 931327 & 6.112 & 6.8445 & TRN & \\
\hline CHEMBL472776 & 931327 & 7.2267 & 7.1299 & TRN & \\
\hline CHEMBL 2297977 & 931327 & 6.6177 & 7.0118 & TST & \\
\hline CHEMBL541980 & 931327 & 6.3983 & 6.45100 & 00000000005 & TST \\
\hline CHEMBL 3639886 & 1528052 & 5.5376 & 6.0133 & TRN & \\
\hline CHEMBL3689832 & 1528052 & 6.7447 & 6.93 & TRN & \\
\hline CHEMBL3689781 & 1528052 & 6.8861 & 7.5991 & TRN & \\
\hline CHEMBL 3689894 & 1528052 & 7.301 & 7.3238 & TRN & \\
\hline CHEMBL3689853 & 1528052 & 6.4318 & 6.5536 & TRN & \\
\hline CHEMBL 3689778 & 1528052 & 6.2007 & 6.2404 & TRN & \\
\hline CHEMBL3689777 & 1528052 & 6.5229 & 6.7579 & TRN & \\
\hline CHEMBL3689900 & 1528052 & 6.585 & 7.2429 & TST & \\
\hline CHEMBL3689872 & 1528052 & 6.7959 & 7.3677 & TRN & \\
\hline CHEMBL3689892 & 1528052 & 7.5229 & 7.3405 & TRN & \\
\hline CHEMBL 3689834 & 1528052 & 7.2218 & 7.2049 & TRN & \\
\hline CHEMBL3689764 & 1528052 & 6.1024 & 6.5291 & TST & \\
\hline CHEMBL3689767 & 1528052 & 5.5686 & 4.3452 & TST & \\
\hline CHEMBL3689845 & 1528052 & 6.585 & 6.6439 & TRN & \\
\hline CHEMBL3689780 & 1528052 & 7.0044 & 6.9372 & TRN & \\
\hline CHEMBL 3689768 & 1528052 & 6.0 & 5.8657 & TRN & \\
\hline CHEMBL3689799 & 1528052 & 6.7959 & 6.8899 & TRN & \\
\hline CHEMBL3689804 & 1528052 & 4.0 & 4.5921 & TRN & \\
\hline CHEMBL 3689782 & 1528052 & 6.8539 & 6.8679 & TRN & \\
\hline CHEMBL3689776 & 1528052 & 4.0 & 4.9681 & TST & \\
\hline
\end{tabular}


Supplemental Table S2.txt

\begin{tabular}{|c|c|c|c|c|}
\hline HEMB & & & & \\
\hline UГM ו & 528052 & 6.0605 & & \\
\hline 3 & 28052 & & & \\
\hline AEMBL & 28052 & & 52 & \\
\hline AEMBL & 528052 & 229 & 4727 & \\
\hline HEMBL3689772 & 528052 & 4.0 & .6728 & \\
\hline מים & 528052 & 69 & 5583 & \\
\hline |FMRI & 28052 & & & \\
\hline AEMBL3689791 & 528052 & 4.0 & & \\
\hline HEMBL3689796 & 528052 & 89 & & \\
\hline HEMBL3689774 & 528052 & 686 & 85 & \\
\hline IEMBL368 & 8052 & 979 & 302 & \\
\hline IEMBL: & & & & \\
\hline HEMBL3689 & 528052 & 599 & 7.5026 & \\
\hline AEMBL368ऽ & 528052 & 208 & & \\
\hline AEMBL36898 & 528052 & 4 & .8373 & \\
\hline HEMBL36 & 8052 & & & \\
\hline HEMBL 36 & & & & \\
\hline HEMBL 3689 & 528052 & & & \\
\hline AEMBL 368 & 052 & 29 & & \\
\hline HEMBLS & 8 & 6 & & KIV \\
\hline AEMBL & 2 & & & 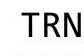 \\
\hline HEMBL; & 52 & & & \\
\hline HFMRI 3680 & & 98 & & \\
\hline HEMBL 368 & & & & N \\
\hline HEMBL36 & 8052 & & & $\cdots$ \\
\hline HEMBL; & 32 & & & RN \\
\hline HFMBI : & 052 & & & \\
\hline HEMBL3689868 & & & & iv \\
\hline HEMBL3689812 & 528052 & 6.0 & & iv \\
\hline HEMBL36898 & 8052 & & & RN \\
\hline HEMBL & 2 & & & ST \\
\hline 9 & 52 & 29 & & $\mathrm{RN}$ \\
\hline HEMBL3689786 & 528052 & & & ISI \\
\hline HEMBL 3689762 & 528052 & 6. & 69 & TST \\
\hline HEMBL 3689 & 28052 & 9 & 86 & $\mathrm{RN}$ \\
\hline HᄃMP = & 2 & & & RN \\
\hline HEMBL3 & & & & IRN \\
\hline HEMBL3689814 & 528052 & 5 & & TRN \\
\hline AEMBL 260 & 528052 & & & $\Gamma \mathrm{RN}$ \\
\hline HEMBL368s & 528052 & 58 & & \\
\hline LHEMBL3689790 & 1528052 & & & IST \\
\hline HEMBL3689822 & 528052 & 7.2924 & 7.2428 & RN \\
\hline HEMBL36898 & 528052 & 3979 & 398 & TRN \\
\hline$M B L 3$ & 528052 & & & RN \\
\hline HEMBL 3689 & 528052 & 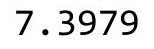 & & \\
\hline CHEMBL 368984 & 528052 & .2218 & 7.1103 & \\
\hline CHEMBL3689855 & 1528052 & 6.7212 & 6.7899 & ГRN \\
\hline
\end{tabular}

Page 2950 
Supplemental Table S2.txt

\begin{tabular}{|c|c|c|c|c|c|}
\hline CHEMBL3689797 & 1528052 & 6.2291 & 5.6474 & TST & \\
\hline CHEMBL3689883 & 1528052 & 7.699 & 7.4335 & TRN & \\
\hline CHEMBL3689890 & 1528052 & 7.3979 & 7.2383 & TRN & \\
\hline CHEMBL3689785 & 1528052 & 7.1367 & 7.7239 & TST & \\
\hline CHEMBL3689825 & 1528052 & 6.7212 & 6.7895 & TRN & \\
\hline CHEMBL3689829 & 1528052 & 7.699 & 7.3535 & TRN & \\
\hline CHEMBL3689771 & 1528052 & 5.2218 & 5.2832 & TST & \\
\hline CHEMBL3689882 & 1528052 & 7.5229 & 7.5537 & TRN & \\
\hline CHEMBL3689864 & 1528052 & 6.3872 & 6.593 & TRN & \\
\hline CHEMBL3689793 & 1528052 & 6.0809 & 5.1999 & TST & \\
\hline CHEMBL3689850 & 1528052 & 6.7212 & 6.7681 & TRN & \\
\hline CHEMBL3689854 & 1528052 & 6.4815 & 6.2457 & TRN & \\
\hline CHEMBL3689879 & 1528052 & 7.3979 & 7.5654 & TRN & \\
\hline CHEMBL 3689848 & 1528052 & 6.3279 & 6.0304 & TRN & \\
\hline CHEMBL3689843 & 1528052 & 6.2441 & 6.4742 & TRN & \\
\hline CHEMBL3689878 & 1528052 & 7.301 & 7.0573 & TRN & \\
\hline CHEMBL3689784 & 1528052 & 6.8861 & 7.2799 & TST & \\
\hline CHEMBL3689809 & 1528052 & 6.699 & 6.561 & TRN & \\
\hline CHEMBL3689831 & 1528052 & 6.699 & 6.816 & TRN & \\
\hline CHEMBL3689798 & 1528052 & 6.4437 & 5.07 & TST & \\
\hline CHEMBL3689867 & 1528052 & 6.8861 & 6.9901 & TRN & \\
\hline CHEMBL3689898 & 1528052 & 7.5229 & 7.6809 & TRN & \\
\hline CHEMBL3689875 & 1528052 & 6.699 & 6.7464 & TRN & \\
\hline CHEMBL3689889 & 1528052 & 7.301 & 7.1231 & TRN & \\
\hline CHEMBL3689820 & 1528052 & 6.5086 & 6.5387 & TRN & \\
\hline CHEMBL3689847 & 1528052 & 6.6198 & 6.5401 & TRN & \\
\hline CHEMBL3689833 & 1528052 & 7.1549 & 7.2136 & TRN & \\
\hline CHEMBL3689806 & 1528052 & 6.0 & 6.1573 & TRN & \\
\hline CHEMBL 3689862 & 1528052 & 5.1308 & 5.1585 & TRN & \\
\hline CHEMBL3689863 & 1528052 & 6.6576 & 6.7485 & TRN & \\
\hline CHEMBL3689817 & 1528052 & 6.6383 & 6.55399 & 9999999999 & TRN \\
\hline CHEMBL3689816 & 1528052 & 5.8239 & 6.9252 & TST & \\
\hline CHEMBL3689773 & 1528052 & 6.1427 & 6.1195 & TST & \\
\hline CHEMBL3689766 & 1528052 & 5.8539 & 5.5853 & TST & \\
\hline CHEMBL3689896 & 1528052 & 7.699 & 7.4654 & TRN & \\
\hline CHEMBL3689808 & 1528052 & 6.284 & 6.0853 & TRN & \\
\hline CHEMBL3689861 & 1528052 & 6.1079 & 6.8668 & TST & \\
\hline CHEMBL3689838 & 1528052 & 7.0969 & 7.4544 & TRN & \\
\hline CHEMBL 3689888 & 1528052 & 7.3979 & 7.331 & TRN & \\
\hline CHEMBL3689775 & 1528052 & 6.1192 & 4.7367 & TST & \\
\hline CHEMBL3689821 & 1528052 & 7.2007 & 7.4108 & TRN & \\
\hline CHEMBL3689836 & 1528052 & 4.0 & 4.4464 & TST & \\
\hline CHEMBL3689807 & 1528052 & 6.7959 & 6.8455 & TRN & \\
\hline CHEMBL 3689881 & 1528052 & 7.301 & 7.5538 & TRN & \\
\hline CHEMBL 3689884 & 1528052 & 7.699 & 7.6542 & TRN & \\
\hline CHEMBL3689899 & 1528052 & 7.3979 & 7.5738 & TRN & \\
\hline CHEMBL3689873 & 1528052 & 7.5229 & 7.4828 & TRN & \\
\hline CHEMBL3689857 & 1528052 & 6.2676 & 6.7279 & TRN & \\
\hline
\end{tabular}


Supplemental Table S2.txt

\begin{tabular}{|c|c|c|c|c|c|}
\hline CHEMBL 3689869 & 1528052 & 7.0458 & 6.9991 & TRN & \\
\hline CHEMBL3689827 & 1528052 & 6.8861 & 6.9121 & TRN & \\
\hline CHEMBL3689870 & 1528052 & 6.0 & 6.485 & TRN & \\
\hline CHEMBL3689789 & 1528052 & 6.4202 & 7.2141 & TST & \\
\hline CHEMBL3689769 & 1528052 & 5.8861 & 5.6718 & TST & \\
\hline CHEMBL3689792 & 1528052 & 6.6198 & 4.3655 & TST & \\
\hline CHEMBL3689830 & 1528052 & 7.699 & \multicolumn{2}{|c|}{7.656000000000001} & TRN \\
\hline CHEMBL3689815 & 1528052 & 5.3372 & 6.8004 & TST & \\
\hline CHEMBL3689824 & 1528052 & 4.0 & 4.0669 & TRN & \\
\hline CHEMBL3689842 & 1528052 & 7.2218 & 6.8339 & TRN & \\
\hline CHEMBL3689805 & 1528052 & 6.1871 & 6.1833 & TRN & \\
\hline CHEMBL3689865 & 1528052 & 6.4559 & 6.7403 & TRN & \\
\hline CHEMBL3689826 & 1528052 & 6.7959 & \multicolumn{2}{|c|}{7.122000000000001} & TRN \\
\hline CHEMBL3689823 & 1528052 & 4.0 & 4.0178 & TRN & \\
\hline CHEMBL3689765 & 1528052 & 6.4559 & 5.5119 & TST & \\
\hline CHEMBL3689770 & 1528052 & 6.4949 & 5.4523 & TST & \\
\hline CHEMBL3689887 & 1528052 & 7.5229 & 7.3758 & TRN & \\
\hline CHEMBL3689841 & 1528052 & 7.2218 & 6.943 & TRN & \\
\hline CHEMBL3689787 & 1528052 & 6.7447 & 7.1882 & TST & \\
\hline CHEMBL3689803 & 1528052 & 5.699 & 6.0469 & TRN & \\
\hline CHEMBL3689788 & 1528052 & 6.9586 & 6.685 & TST & \\
\hline CHEMBL3689840 & 1528052 & 7.3979 & 7.0224 & TRN & \\
\hline CHEMBL3689801 & 1528052 & 5.8861 & 5.5659 & TST & \\
\hline CHEMBL515416 & 954516 & 4.6809 & 4.5086 & TRN & \\
\hline CHEMBL1970879 & 954516 & 3.0677 & 3.2965 & TRN & \\
\hline CHEMBL573107 & 954516 & 4.6141 & 4.5282 & TRN & \\
\hline CHEMBL 259181 & 954516 & 3.8635 & \multicolumn{2}{|c|}{4.0280000000000005} & TRN \\
\hline CHEMBL1242367 & 954516 & 4.7557 & 4.4666 & TRN & \\
\hline CHEMBL577784 & 954516 & 4.8481 & 4.8019 & TRN & \\
\hline CHEMBL180127 & 954516 & 4.7408 & 4.8466 & TRN & \\
\hline CHEMBL392695 & 954516 & 5.8918 & 5.9631 & TRN & \\
\hline CHEMBL65 & 954516 & 7.5303 & 7.6371 & TRN & \\
\hline CHEMBL1256459 & 954516 & 8.1864 & 7.8075 & TRN & \\
\hline CHEMBL1643959 & 954516 & 2.9949 & \multicolumn{2}{|c|}{2.8539999999999996} & TRN \\
\hline CHEMBL 221137 & 954516 & 4.8622 & 4.7991 & TST & \\
\hline CHEMBL 379300 & 954516 & 6.1738 & 6.2867 & TRN & \\
\hline CHEMBL3199475 & 954516 & 5.0714 & 5.0934 & TRN & \\
\hline CHEMBL509032 & 954516 & 6.197 & 6.4193 & TRN & \\
\hline CHEMBL191334 & 954516 & 4.4023 & 4.4464 & TRN & \\
\hline CHEMBL135561 & 954516 & 3.8894 & 3.9407 & TRN & \\
\hline CHEMBL3392440 & 954516 & 3.5779 & 3.6412 & TRN & \\
\hline CHEMBL472940 & 954516 & \multicolumn{3}{|c|}{3.1630000000000003} & TRN \\
\hline CHEMBL2363137 & 954516 & 5.1833 & 5.1075 & TRN & \\
\hline CHEMBL483847 & 954516 & 3.8526 & 4.0255 & TRN & \\
\hline CHEMBL379975 & 954516 & 4.8191 & 4.9112 & TRN & \\
\hline CHEMBL1190711 & 954516 & 4.3886 & 4.3622 & TRN & \\
\hline CHEMBL 258844 & 954516 & 3.1765 & 3.3884 & TRN & \\
\hline CHEMBL1673039 & 954516 & 4.9653 & 5.0561 & TRN & \\
\hline
\end{tabular}




\begin{tabular}{|c|c|c|c|c|c|}
\hline \multicolumn{6}{|c|}{ Supplemental Table S2.txt } \\
\hline CHEMBL514499 & 954516 & 7.5508 & 7.6797 & TRN & \\
\hline CHEMBL1230020 & 954516 & 3.5641 & 3.3306 & TRN & \\
\hline CHEMBL209148 & 954516 & 4.5496 & 4.7153 & TRN & \\
\hline CHEMBL220241 & 954516 & 3.7407 & 3.7094 & TRN & \\
\hline CHEMBL202721 & 954516 & 5.0472 & 4.7563 & TRN & \\
\hline CHEMBL558642 & 954516 & 3.182 & 3.1724 & TRN & \\
\hline CHEMBL1590308 & 954516 & 3.8695 & 3.70899 & 99999999996 & TST \\
\hline CHEMBL1909414 & 954516 & 4.5389 & 4.4383 & TRN & \\
\hline CHEMBL92309 & 954516 & 3.0606 & 2.9174 & TST & \\
\hline CHEMBL3349342 & 954516 & 5.3458 & 5.1513 & TRN & \\
\hline CHEMBL393929 & 954516 & 4.4363 & 4.578 & TRN & \\
\hline CHEMBL1516890 & 954516 & 4.6861 & 4.5926 & TRN & \\
\hline CHEMBL1788116 & 954516 & 3.3968 & 3.4088 & TRN & \\
\hline CHEMBL1404918 & 954516 & 2.9104 & 2.9487 & TRN & \\
\hline CHEMBL189584 & 954516 & 5.4902 & 5.6158 & TRN & \\
\hline CHEMBL449158 & 954516 & 6.0824 & 6.8323 & TST & \\
\hline CHEMBL300389 & 954516 & 6.8904 & 6.8475 & TRN & \\
\hline CHEMBL210618 & 954516 & 4.2906 & 4.0378 & TRN & \\
\hline CHEMBL1357247 & 954516 & 2.701 & 2.6392 & TRN & \\
\hline CHEMBL483849 & 954516 & 3.2998 & 3.3276 & TRN & \\
\hline CHEMBL213100 & 954516 & 3.4105 & 3.2844 & TRN & \\
\hline CHEMBL222102 & 954516 & 3.3571 & 3.4024 & TRN & \\
\hline CHEMBL240954 & 954516 & 4.206 & 4.2154 & TST & \\
\hline CHEMBL585951 & 954516 & 5.9853 & 5.9947 & TRN & \\
\hline CHEMBL102714 & 954516 & 3.7901 & 4.0281 & TST & \\
\hline CHEMBL188678 & 954516 & 4.4095 & 4.3018 & TST & \\
\hline CHEMBL 2144069 & 954516 & 5.6079 & 4.8126 & TST & \\
\hline CHEMBL 2005886 & 954516 & 4.0785 & 5.9028 & TST & \\
\hline CHEMBL 373751 & 954516 & 4.2636 & 3.8076 & TST & \\
\hline CHEMBL512504 & 954516 & 6.6091 & 5.8933 & TST & \\
\hline CHEMBL412142 & 954516 & 3.9719 & 3.7449 & TST & \\
\hline CHEMBL 9470 & 954516 & 6.3262 & 5.697 & TST & \\
\hline CHEMBL192566 & 954516 & 7.82799 & 99999999 & 8.1999 & 1 \\
\hline CHEMBL3186408 & 954516 & 5.1567 & 3.7862 & TST & \\
\hline CHEMBL1871757 & 954267 & 5.5654 & 5.1214 & TRN & \\
\hline CHEMBL1372725 & 954267 & 4.8119 & 4.7146 & TRN & \\
\hline CHEMBL1341816 & 954267 & 5.6459 & 5.1098 & TRN & \\
\hline CHEMBL1520544 & 954267 & 4.9158 & 5.1541 & TRN & \\
\hline CHEMBL1348545 & 954267 & 5.5421 & 5.0949 & TRN & \\
\hline CHEMBL1488923 & 954267 & 6.2725 & 5.6804 & TRN & \\
\hline CHEMBL1473718 & 954267 & 5.7645 & 5.5059 & TRN & \\
\hline CHEMBL1508682 & 954267 & 4.5662 & 5.1438 & TRN & \\
\hline CHEMBL1563968 & 954267 & 5.8097 & 5.5409 & TRN & \\
\hline CHEMBL 2448464 & 954267 & 5.4789 & 5.1427 & TRN & \\
\hline CHEMBL1302274 & 954267 & 4.7678 & 5.0521 & TRN & \\
\hline CHEMBL1720969 & 954267 & 6.2612 & 6.6462 & TRN & \\
\hline CHEMBL1595687 & 954267 & 5.1367 & 5.6051 & TST & \\
\hline CHEMBL 2139616 & 954267 & 6.3757 & 6.5499 & TRN & \\
\hline
\end{tabular}

Page 2953 


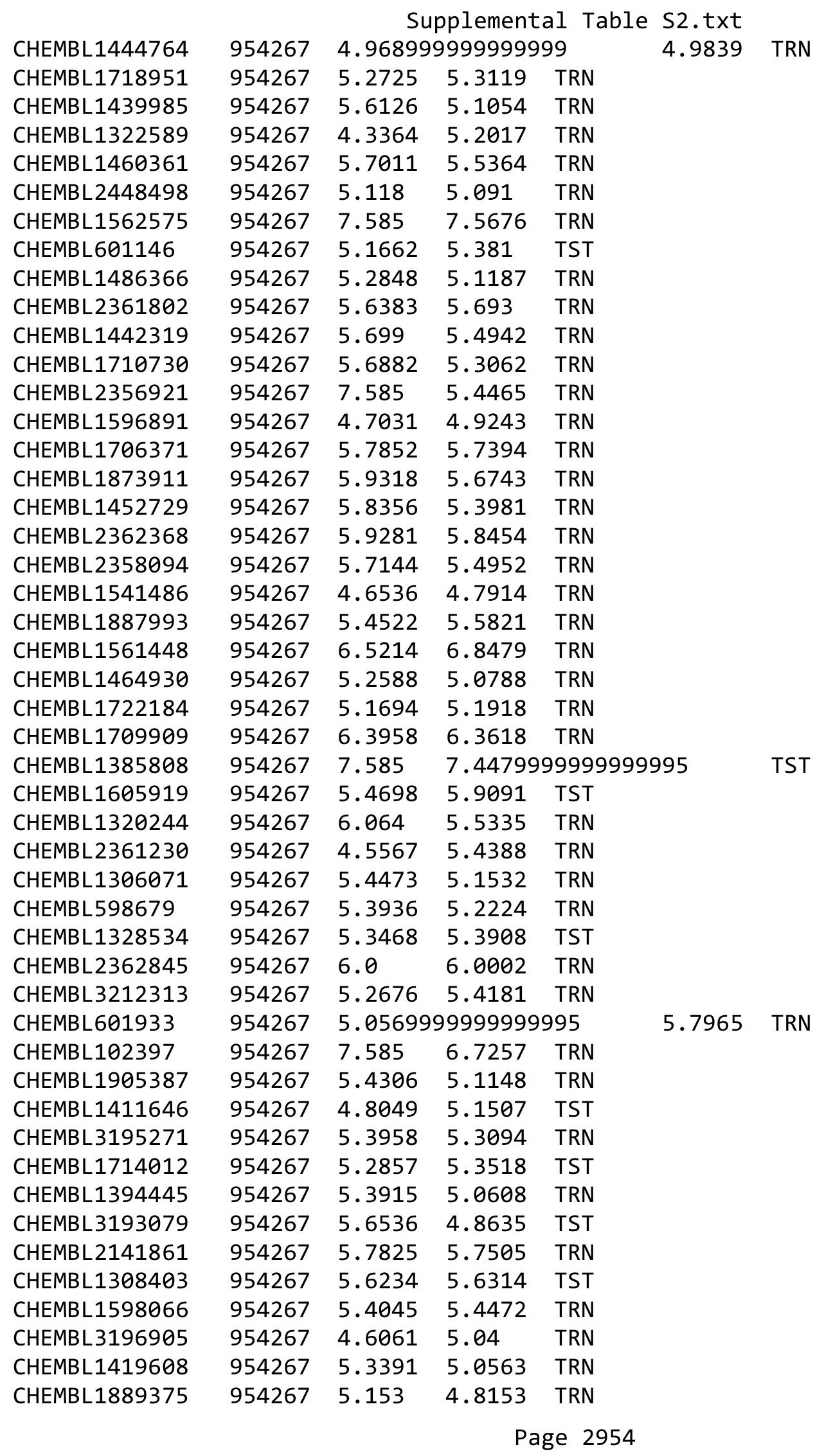




\begin{tabular}{|c|c|c|c|c|c|c|}
\hline & & \multicolumn{5}{|c|}{ Supplemental Table S2.txt } \\
\hline CHEMBL1378564 & 954267 & 5.2518 & 5.1565 & TRN & & \\
\hline CHEMBL1888955 & 954267 & 5.9469 & 6.2246 & TRN & & \\
\hline CHEMBL1886909 & 954267 & 5.644 & 5.6739 & TST & & \\
\hline CHEMBL 2136684 & 954267 & 6.3883 & 5.757999 & 999999999 & & TRN \\
\hline CHEMBL1885590 & 954267 & 6.3969 & 6.6153 & TRN & & \\
\hline CHEMBL 2361286 & 954267 & 5.3556 & 5.1957 & TRN & & \\
\hline CHEMBL1542055 & 954267 & 5.2757 & 4.5999 & TRN & & \\
\hline CHEMBL1324298 & 954267 & 5.4306 & 5.7972 & TST & & \\
\hline CHEMBL1718302 & 954267 & 5.0575 & 5.0335 & TST & & \\
\hline CHEMBL1434463 & 954267 & 7.585 & 6.6217 & TRN & & \\
\hline CHEMBL 2133076 & 954267 & 6.0 & 5.6689 & TRN & & \\
\hline CHEMBL 2362165 & 954267 & 6.0 & 6.0307 & TRN & & \\
\hline CHEMBL1540036 & 954267 & 4.7545 & 5.122999 & 9999999995 & & TRN \\
\hline CHEMBL1450612 & 954267 & 5.7825 & 4.8391 & TRN & & \\
\hline CHEMBL1884536 & 954267 & 5.3497 & 5.4989 & TRN & & \\
\hline CHEMBL1354040 & 954267 & 5.6517 & 5.0532 & TRN & & \\
\hline CHEMBL 2357851 & 954267 & 4.574 & 4.7015 & TRN & & \\
\hline CHEMBL1431378 & 954267 & 5.2557 & 5.9319 & TRN & & \\
\hline CHEMBL1327933 & 954267 & 4.6229 & 4.2988 & TRN & & \\
\hline CHEMBL 2136129 & 954267 & 5.7986 & 5.8617 & TRN & & \\
\hline CHEMBL1887850 & 954267 & 7.585 & 7.9401 & TRN & & \\
\hline CHEMBL1464202 & 954267 & 5.1255 & 5.2881 & TRN & & \\
\hline CHEMBL1905109 & 954267 & 5.7077 & 5.5001 & TRN & & \\
\hline CHEMBL1351357 & 954267 & 6.1838 & 6.3175 & TRN & & \\
\hline CHEMBL1569095 & 954267 & 4.8502 & 5.5595 & TRN & & \\
\hline CHEMBL 2356874 & 954267 & 4.9805 & 5.4263 & TRN & & \\
\hline CHEMBL1896918 & 954267 & 5.3391 & 5.1108 & TRN & & \\
\hline CHEMBL3184121 & 954267 & 4.978 & 5.2139 & TRN & & \\
\hline CHEMBL1310301 & 954267 & 5.4921 & 5.5495 & TRN & & \\
\hline CHEMBL 2360278 & 954267 & 4.3106 & 5.3822 & TRN & & \\
\hline CHEMBL1605666 & 954267 & 5.3152 & 5.233 & TST & & \\
\hline CHEMBL1526750 & 954267 & 5.5719 & 5.5322 & TRN & & \\
\hline CHEMBL 2448508 & 954267 & 5.5258 & 5.3384 & TRN & & \\
\hline CHEMBL1872984 & 954267 & 5.426 & 5.3927 & TRN & & \\
\hline CHEMBL1501091 & 954267 & 4.4874 & 5.2731 & TRN & & \\
\hline CHEMBL 2362305 & 954267 & 6.05399 & 999999999 & 99 & 5.6933 & TRN \\
\hline CHEMBL1535257 & 954267 & 4.9539 & 5.125 & TRN & & \\
\hline CHEMBL1559187 & 954267 & 5.4535 & 4.8468 & TRN & & \\
\hline CHEMBL1310739 & 954267 & 4.6817 & 4.9476 & TRN & & \\
\hline CHEMBL1510823 & 954267 & 5.2125 & 5.2248 & TST & & \\
\hline CHEMBL 2358164 & 954267 & 4.502 & 4.9832 & TRN & & \\
\hline CHEMBL 2356590 & 954267 & 6.0 & 5.7198 & TRN & & \\
\hline CHEMBL1592853 & 954267 & 5.6253 & 6.0238 & TRN & & \\
\hline CHEMBL 2360924 & 954267 & 7.585 & 6.935 & TRN & & \\
\hline CHEMBL1501242 & 954267 & 5.8297 & 5.614 & TST & & \\
\hline CHEMBL1458905 & 954267 & 4.6664 & 4.9268 & TRN & & \\
\hline CHEMBL 2355208 & 954267 & 6.0 & 6.013 & TRN & & \\
\hline CHEMBL 2360104 & 954267 & 4.673 & 5.2563 & TRN & & \\
\hline
\end{tabular}




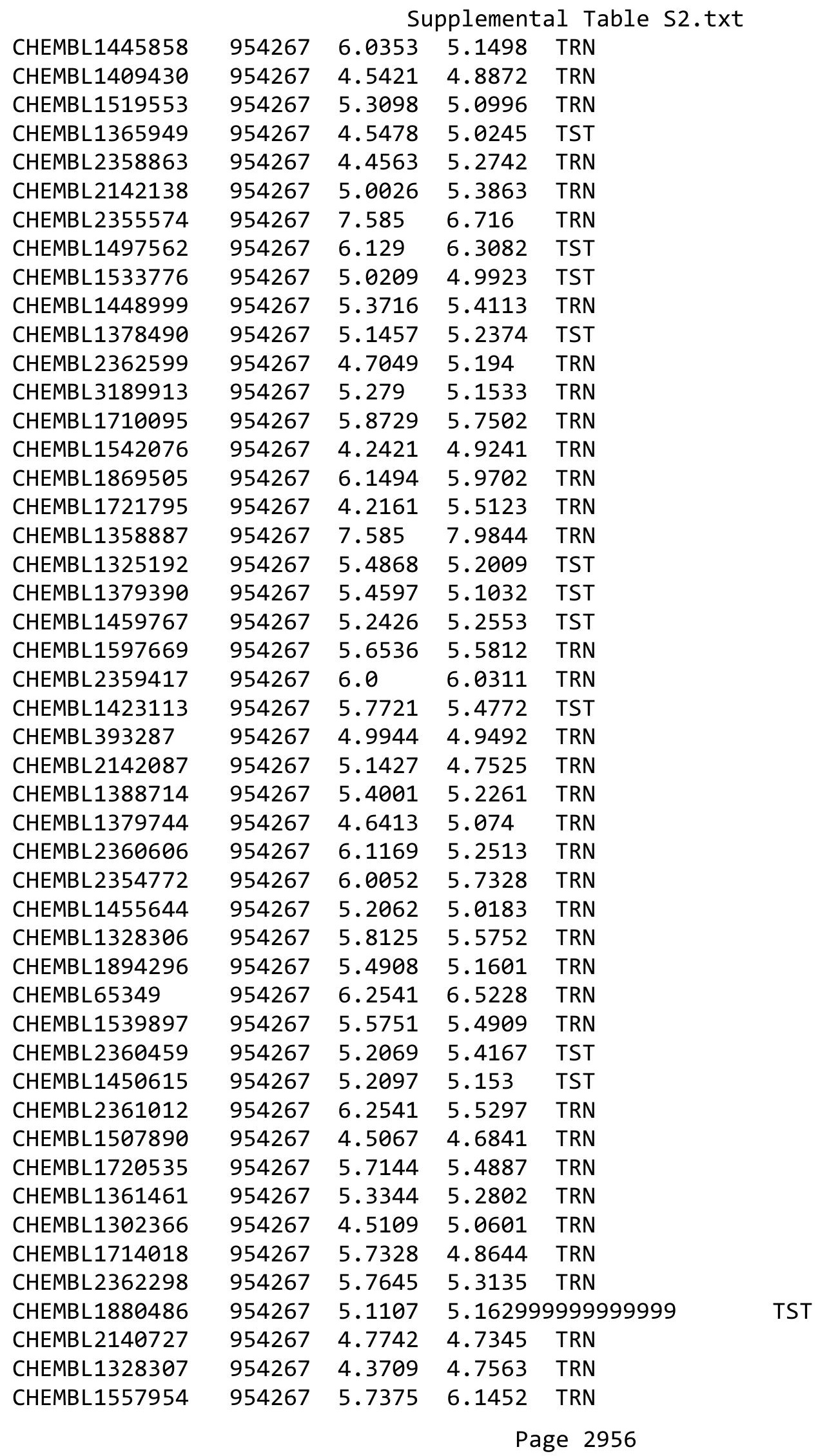




\begin{tabular}{|c|c|c|c|c|}
\hline & & & oplement & al Ta \\
\hline CHEMBL1492073 & 954267 & 5.308 & 5.1222 & TRN \\
\hline CHEMBL1599713 & 954267 & 4.2946 & 5.2085 & TRN \\
\hline CHEMBL1971142 & 954267 & 5.6126 & 5.5481 & TRN \\
\hline CHEMBL1350387 & 954267 & 5.3872 & 4.97 & TRN \\
\hline CHEMBL1380482 & 954267 & 5.6091 & 5.0546 & TST \\
\hline CHEMBL1610579 & 954267 & 6.0996 & 5.9422 & TRN \\
\hline CHEMBL3194248 & 954267 & 5.8794 & 5.9271 & TRN \\
\hline CHEMBL1974506 & 954267 & 6.3206 & 5.8647 & TRN \\
\hline CHEMBL2356909 & 954267 & 4.6511 & 5.0573 & TRN \\
\hline CHEMBL1721296 & 954267 & 5.6271 & 5.7499 & TRN \\
\hline CHEMBL1437560 & 954267 & 6.0768 & 5.6199 & TRN \\
\hline CHEMBL1432670 & 954267 & 5.5287 & 5.5186 & TRN \\
\hline CHEMBL1548549 & 954267 & 5.2596 & 5.0901 & TRN \\
\hline CHEMBL1523841 & 954267 & 5.9957 & 5.857 & TST \\
\hline CHEMBL1360946 & 954267 & 7.585 & 6.8908 & TRN \\
\hline CHEMBL1582044 & 954267 & 5.5017 & 5.626 & TRN \\
\hline CHEMBL1699920 & 954267 & 4.2971 & 6.2136 & TRN \\
\hline CHEMBL1347745 & 954267 & 5.4425 & 5.2067 & TRN \\
\hline CHEMBL1710114 & 954267 & 6.585 & 6.6799 & TRN \\
\hline CHEMBL1422378 & 954267 & 4.5594 & 4.9437 & TST \\
\hline CHEMBL 2362474 & 954267 & 5.0462 & 5.2877 & TRN \\
\hline CHEMBL 2448501 & 954267 & 5.3625 & 5.3062 & TRN \\
\hline CHEMBL1573548 & 954267 & 5.4841 & 4.961 & TST \\
\hline CHEMBL 2360772 & 954267 & 5.4449 & 5.3856 & TRN \\
\hline CHEMBL1866960 & 954267 & 6.4023 & 5.8995 & TRN \\
\hline CHEMBL2362535 & 954267 & 4.6631 & 5.3017 & TRN \\
\hline CHEMBL1998606 & 954267 & 5.8633 & 5.6045 & TST \\
\hline CHEMBL 2362103 & 954267 & 6.0132 & 6.1539 & TRN \\
\hline CHEMBL1481301 & 954267 & 4.465 & 4.3126 & TRN \\
\hline CHEMBL 2355458 & 954267 & 6.0 & 6.0838 & TRN \\
\hline CHEMBL1505743 & 954267 & 5.4034 & 5.2861 & TRN \\
\hline CHEMBL2135705 & 954267 & 4.3945 & 5.2268 & TRN \\
\hline CHEMBL1887610 & 954267 & 5.7282 & 5.9366 & TRN \\
\hline CHEMBL 2362263 & 954267 & 5.4547 & 5.3084 & TRN \\
\hline CHEMBL1604143 & 954267 & 5.301 & 5.6368 & TRN \\
\hline CHEMBL1471810 & 954267 & 5.1261 & 5.3338 & TST \\
\hline CHEMBL2361814 & 954267 & 5.1186 & 5.7167 & TRN \\
\hline CHEMBL1890313 & 954267 & 5.5452 & 5.4449 & TRN \\
\hline CHEMBL1714479 & 954267 & 6.0 & 5.4991 & TRN \\
\hline CHEMBL 2357481 & 954267 & 6.0 & 5.7832 & TRN \\
\hline CHEMBL1389871 & 954267 & 5.4449 & 5.2447 & TRN \\
\hline CHEMBL1412298 & 954267 & 4.6704 & 4.9188 & TRN \\
\hline CHEMBL1576543 & 954267 & 5.2765 & 5.4746 & TRN \\
\hline CHEMBL1600371 & 954267 & 5.4685 & 5.4082 & TRN \\
\hline CHEMBL543876 & 954267 & 5.0825 & 5.0104 & TRN \\
\hline CHEMBL1517195 & 954267 & 4.3102 & 5.2177 & TRN \\
\hline CHEMBL1353386 & 954267 & 5.5591 & 5.0001 & TRN \\
\hline CHEMBL1338601 & 954267 & 5.466 & 5.2417 & TST \\
\hline
\end{tabular}




\begin{tabular}{|c|c|c|c|c|}
\hline & & & pplement & al $\mathrm{T}$ \\
\hline CHEMBL 2354403 & 954267 & 4.7615 & 5.3623 & TRN \\
\hline CHEMBL1321083 & 954267 & 4.9914 & 5.2913 & TRN \\
\hline CHEMBL1452157 & 954267 & 4.476 & 5.0456 & TRN \\
\hline CHEMBL1339989 & 954267 & 4.3195 & 5.6702 & TST \\
\hline CHEMBL1315948 & 954267 & 4.8091 & 5.2342 & TST \\
\hline CHEMBL1699398 & 954267 & 5.2277 & 5.6378 & TST \\
\hline CHEMBL1502133 & 954267 & 5.8601 & 5.6525 & TRN \\
\hline CHEMBL1523019 & 954267 & 4.9867 & 5.3477 & TRN \\
\hline CHEMBL 2140736 & 954267 & 6.0 & 5.6805 & TRN \\
\hline CHEMBL2362196 & 954267 & 6.0 & 6.0178 & TRN \\
\hline CHEMBL 2357950 & 954267 & 5.7305 & 5.5084 & TRN \\
\hline CHEMBL578294 & 954267 & 5.0731 & 5.1103 & TRN \\
\hline CHEMBL1360319 & 954267 & 4.7289 & 5.2552 & TRN \\
\hline CHEMBL1420334 & 954267 & 5.8894 & 5.8481 & TST \\
\hline CHEMBL1519015 & 954267 & 5.2976 & 5.3622 & TRN \\
\hline CHEMBL1393891 & 954267 & 5.9508 & 5.8094 & TRN \\
\hline CHEMBL1337961 & 954267 & 5.3002 & 5.1705 & TRN \\
\hline CHEMBL1564133 & 954267 & 5.4763 & 5.4217 & TRN \\
\hline CHEMBL1707441 & 954267 & 5.0137 & 5.1458 & TRN \\
\hline CHEMBL1493367 & 954267 & 5.1278 & 5.2539 & TRN \\
\hline CHEMBL1496004 & 954267 & 5.4101 & 5.1009 & TRN \\
\hline CHEMBL 2144397 & 954267 & 5.6498 & 5.4633 & TRN \\
\hline CHEMBL 2361140 & 954267 & 6.0 & 4.8908 & TRN \\
\hline CHEMBL1597625 & 954267 & 4.6476 & 5.2735 & TRN \\
\hline CHEMBL1576075 & 954267 & 4.5333 & 4.9243 & TRN \\
\hline CHEMBL1699099 & 954267 & 4.5086 & 5.115 & TRN \\
\hline CHEMBL1451209 & 954267 & 5.7122 & 5.8671 & TRN \\
\hline CHEMBL1447479 & 954267 & 5.5272 & 5.357 & TRN \\
\hline CHEMBL1373815 & 954267 & 5.5331 & 5.3881 & TRN \\
\hline CHEMBL1730853 & 954267 & 6.0575 & 6.3201 & TRN \\
\hline CHEMBL1703435 & 954267 & 5.2418 & 5.2808 & TRN \\
\hline CHEMBL1463225 & 954267 & 7.585 & 6.5379 & TRN \\
\hline CHEMBL 2356872 & 954267 & 4.8722 & 5.3089 & TRN \\
\hline CHEMBL2360109 & 954267 & 5.8928 & 6.2131 & TRN \\
\hline CHEMBL1868229 & 954267 & 5.6364 & 5.5033 & TRN \\
\hline CHEMBL 2356745 & 954267 & 6.2013 & 5.4217 & TRN \\
\hline CHEMBL1486457 & 954267 & 5.0278 & 4.7077 & TRN \\
\hline CHEMBL1893761 & 954267 & 5.2765 & 5.3508 & TRN \\
\hline CHEMBL1567814 & 954267 & 5.6596 & 5.4712 & TRN \\
\hline CHEMBL 2356473 & 954267 & 4.7823 & 5.2748 & TRN \\
\hline CHEMBL 2360946 & 954267 & 6.0 & 5.8667 & TRN \\
\hline CHEMBL1602800 & 954267 & 4.5471 & 5.0389 & TRN \\
\hline CHEMBL566283 & 954267 & 4.5544 & 4.7021 & TRN \\
\hline CHEMBL1436393 & 954267 & 5.4056 & 5.6321 & TRN \\
\hline CHEMBL 2360993 & 954267 & 6.0 & 5.9067 & TRN \\
\hline CHEMBL 2358923 & 954267 & 5.7959 & 5.4937 & TRN \\
\hline CHEMBL1529819 & 954267 & 5.4078 & 5.5543 & TRN \\
\hline CHEMBL1312619 & 954267 & 5.4535 & 5.3757 & TRN \\
\hline
\end{tabular}




\begin{tabular}{|c|c|c|c|c|c|}
\hline & & \multicolumn{4}{|c|}{ Supplemental Table S2.txt } \\
\hline CHEMBL1333339 & 954267 & 5.5784 & 5.2956 & TRN & \\
\hline CHEMBL 2359558 & 954267 & 4.523 & 5.2829 & TRN & \\
\hline CHEMBL3185201 & 954267 & 6.0 & 5.7748 & TRN & \\
\hline CHEMBL 2358509 & 954267 & 5.2815 & 5.4196 & TRN & \\
\hline CHEMBL 2358730 & 954267 & 5.3143 & 5.216 & TRN & \\
\hline CHEMBL 2362159 & 954267 & 7.585 & 5.5403 & TRN & \\
\hline CHEMBL 2358155 & 954267 & 7.585 & 6.2483 & TRN & \\
\hline CHEMBL 2355293 & 954267 & 4.7612 & 5.2233 & TST & \\
\hline CHEMBL1537158 & 954267 & 5.284 & 5.2906 & TRN & \\
\hline CHEMBL 2360837 & 954267 & 4.2578 & 4.8679 & TRN & \\
\hline CHEMBL1388380 & 954267 & 5.1475 & 5.0509 & TRN & \\
\hline CHEMBL1460239 & 954267 & 5.466 & 5.3482 & TRN & \\
\hline CHEMBL 2359880 & 954267 & 4.4237 & 4.9397 & TRN & \\
\hline CHEMBL 2362950 & 954267 & 5.1367 & 5.2353 & TST & \\
\hline CHEMBL 2356115 & 954267 & 4.5375 & 5.65799 & 99999999995 & TRN \\
\hline CHEMBL1349146 & 954267 & 5.1656 & 5.3465 & TST & \\
\hline CHEMBL1469715 & 954267 & 5.7282 & 5.9047 & TST & \\
\hline CHEMBL 2360779 & 954267 & 7.585 & 6.6726 & TRN & \\
\hline CHEMBL 1451002 & 954267 & 5.7799 & 5.016 & TRN & \\
\hline CHEMBL1457403 & 954267 & 5.4225 & 5.8292 & TST & \\
\hline CHEMBL 2361471 & 954267 & 7.585 & 6.29200 & 0000000001 & TRN \\
\hline CHEMBL1375740 & 954267 & 5.4179 & 5.4348 & TRN & \\
\hline CHEMBL1436799 & 954267 & 7.585 & 7.0112 & TRN & \\
\hline CHEMBL 2361331 & 954267 & 4.6503 & 4.9811 & TRN & \\
\hline CHEMBL1394527 & 954267 & 5.2154 & 5.15 & TST & \\
\hline CHEMBL 2136838 & 954267 & 5.8633 & 5.6738 & TRN & \\
\hline CHEMBL1611753 & 954267 & 5.0348 & 5.1157 & TST & \\
\hline CHEMBL 2359862 & 954267 & 5.0329 & 6.2829 & TRN & \\
\hline CHEMBL1310995 & 954267 & 4.6486 & 5.3596 & TRN & \\
\hline CHEMBL1408046 & 954267 & 5.0526 & 5.052 & TRN & \\
\hline CHEMBL 2354895 & 954267 & 5.5058 & 5.1802 & TRN & \\
\hline CHEMBL1870634 & 954267 & 4.3118 & 5.4627 & TRN & \\
\hline CHEMBL 2362498 & 954267 & 4.6345 & 5.52 & TRN & \\
\hline CHEMBL 2354470 & 954267 & 4.7042 & 5.5751 & TRN & \\
\hline CHEMBL577660 & 954267 & 4.4998 & 5.3768 & TRN & \\
\hline CHEMBL1716486 & 954267 & 5.2426 & 5.3559 & TRN & \\
\hline CHEMBL1558826 & 954267 & 7.585 & 7.7036 & TST & \\
\hline CHEMBL1349451 & 954267 & 5.2774 & 5.3167 & TRN & \\
\hline CHEMBL1373252 & 954267 & 5.3851 & 5.1734 & TRN & \\
\hline CHEMBL 2135379 & 954267 & 5.0443 & 4.9452 & TRN & \\
\hline CHEMBL1425438 & 954267 & 4.471 & 5.5075 & TRN & \\
\hline CHEMBL1459657 & 954267 & 5.0711 & 4.898 & TST & \\
\hline CHEMBL1550430 & 954267 & 4.4843 & 4.7735 & TRN & \\
\hline CHEMBL 2355077 & 954267 & 6.0 & 5.7948 & TRN & \\
\hline CHEMBL1379721 & 954267 & 5.7011 & 4.876 & TRN & \\
\hline CHEMBL1469557 & 954267 & 4.7338 & 4.7943 & TST & \\
\hline CHEMBL 2357204 & 954267 & 5.9508 & 5.4524 & TRN & \\
\hline CHEMBL1429129 & 954267 & 4.6249 & 5.0194 & TST & \\
\hline
\end{tabular}




\begin{tabular}{|c|c|c|c|c|c|c|}
\hline & & \multicolumn{5}{|c|}{ Supplemental Table S2.txt } \\
\hline CHEMBL2355793 & 954267 & 4.6286 & 5.0379 & TRN & & \\
\hline CHEMBL1383554 & 954267 & 4.3326 & 4.7391 & TRN & & \\
\hline CHEMBL1402422 & 954267 & 5.475 & 4.9972 & TRN & & \\
\hline CHEMBL2359878 & 954267 & 5.9281 & 5.7653 & TRN & & \\
\hline CHEMBL1332429 & 954267 & 4.5654 & 4.9015 & TRN & & \\
\hline CHEMBL1605642 & 954267 & 4.3031 & 4.9864 & TRN & & \\
\hline CHEMBL1524746 & 954267 & 5.4202 & 5.2587 & TRN & & \\
\hline CHEMBL 2356673 & 954267 & 7.585 & 6.5423 & TRN & & \\
\hline CHEMBL2357369 & 954267 & 4.4702 & 5.2719 & TRN & & \\
\hline CHEMBL1715769 & 954267 & 5.6716 & 5.7394 & TRN & & \\
\hline CHEMBL1562296 & 954267 & 5.3788 & 5.2897 & TRN & & \\
\hline CHEMBL2357109 & 954267 & 4.6834 & 5.5731 & TRN & & \\
\hline CHEMBL 2359148 & 954267 & 4.9208 & 5.3205 & TRN & & \\
\hline CHEMBL2355909 & 954267 & 5.5607 & 5.4991 & TRN & & \\
\hline CHEMBL3189398 & 954267 & 4.3016 & 4.8771 & TST & & \\
\hline CHEMBL389390 & 954267 & 5.1612 & 5.4618 & TST & & \\
\hline CHEMBL1591875 & 954267 & 5.699 & 5.8262 & TRN & & \\
\hline CHEMBL 2448504 & 954267 & 5.289 & 5.0633 & TRN & & \\
\hline CHEMBL 1716540 & 954267 & 4.7479 & 5.2018 & TST & & \\
\hline CHEMBL1477608 & 954267 & 4.334 & 4.9478 & TRN & & \\
\hline CHEMBL 2357490 & 954267 & 5.1675 & 5.2471 & TRN & & \\
\hline CHEMBL2359890 & 954267 & 4.6838 & 5.37 & TRN & & \\
\hline CHEMBL1482680 & 954267 & 5.5157 & 5.6073 & TRN & & \\
\hline CHEMBL1551228 & 954267 & 4.9825 & 4.9527 & TRN & & \\
\hline CHEMBL1708919 & 954267 & 5.9586 & 6.3047 & TRN & & \\
\hline CHEMBL2360410 & 954267 & 4.5772 & 5.4411 & TRN & & \\
\hline CHEMBL1611723 & 954267 & 5.3526 & 6.1719 & TRN & & \\
\hline CHEMBL1435072 & 954267 & 5.82100 & 30000000 & 01 & 5.6046 & $\mathrm{TR}$ \\
\hline CHEMBL3187467 & 954267 & 5.3063 & 5.4748 & TRN & & \\
\hline CHEMBL1700115 & 954267 & 5.9957 & 6.0562 & TRN & & \\
\hline CHEMBL1503131 & 954267 & 5.224 & 5.0408 & TRN & & \\
\hline CHEMBL2361279 & 954267 & 5.2069 & 5.2365 & TRN & & \\
\hline CHEMBL2361967 & 954267 & 4.4037 & 5.6946 & TRN & & \\
\hline CHEMBL1870652 & 954267 & 5.7905 & 5.8907 & TRN & & \\
\hline CHEMBL1418437 & 954267 & 5.6038 & 5.2976 & TST & & \\
\hline CHEMBL2358913 & 954267 & 4.7817 & 5.7272 & TRN & & \\
\hline CHEMBL2355314 & 954267 & 5.9508 & 5.1258 & TRN & & \\
\hline CHEMBL1322078 & 954267 & 5.9031 & 5.7283 & TRN & & \\
\hline CHEMBL2359493 & 954267 & 4.2663 & 5.0176 & TRN & & \\
\hline CHEMBL 2357708 & 954267 & 6.0 & 5.6559 & TRN & & \\
\hline CHEMBL1897053 & 954267 & 5.3233 & 5.1567 & TRN & & \\
\hline CHEMBL 2448511 & 954267 & 5.2472 & 5.1068 & TRN & & \\
\hline CHEMBL1320042 & 954267 & 4.5253 & 5.5987 & TST & & \\
\hline CHEMBL 2361017 & 954267 & 5.2434 & 5.6114 & TRN & & \\
\hline CHEMBL1430935 & 954267 & 5.5784 & 5.4957 & TST & & \\
\hline CHEMBL1559811 & 954267 & 6.4449 & 6.9389 & TRN & & \\
\hline CHEMBL2355211 & 954267 & 5.38299 & 99999999 & 99 & 4.9349 & TRN \\
\hline CHEMBL1319691 & 954267 & 5.4377 & 5.6057 & TST & & \\
\hline
\end{tabular}




\begin{tabular}{|c|c|c|c|c|c|c|}
\hline & & \multicolumn{5}{|c|}{ Supplemental Table S2.txt } \\
\hline CHEMBL1392086 & 954267 & 5.5214 & 5.8164 & TRN & & \\
\hline CHEMBL2358606 & 954267 & 5.2083 & 5.1612 & TRN & & \\
\hline CHEMBL1499450 & 954267 & 5.433 & 5.4607 & TRN & & \\
\hline CHEMBL1410745 & 954267 & 4.9488 & 4.9595 & TST & & \\
\hline CHEMBL2355244 & 954267 & 6.08299 & 99999999 & 99 & 5.8149 & TRN \\
\hline CHEMBL1321201 & 954267 & 5.4737 & 5.8208 & TRN & & \\
\hline CHEMBL1731238 & 954267 & 5.6289 & 5.7211 & TRN & & \\
\hline CHEMBL1611601 & 954267 & 5.3458 & 5.2889 & TRN & & \\
\hline CHEMBL1886332 & 954267 & 4.9987 & 5.1386 & TRN & & \\
\hline CHEMBL1709276 & 954267 & 5.7447 & 5.3696 & TRN & & \\
\hline CHEMBL1316921 & 954267 & 5.6676 & 5.2563 & TRN & & \\
\hline CHEMBL2356184 & 954267 & 5.5544 & 5.5287 & TRN & & \\
\hline CHEMBL1712550 & 954267 & 5.2175 & 5.3959 & TRN & & \\
\hline CHEMBL1600986 & 954267 & 4.9759 & 5.0066 & TRN & & \\
\hline CHEMBL1348129 & 954267 & 5.5143 & 5.6539 & TRN & & \\
\hline CHEMBL2354969 & 954267 & 4.6362 & 5.03100 & 0000000001 & & TRN \\
\hline CHEMBL1411209 & 954267 & 5.5607 & 5.0175 & TRN & & \\
\hline CHEMBL1516708 & 954267 & 6.1046 & 5.7004 & TST & & \\
\hline CHEMBL1314738 & 954267 & 6.4868 & 7.0279 & TRN & & \\
\hline CHEMBL1489131 & 954267 & 5.556 & 5.1567 & TRN & & \\
\hline CHEMBL1360952 & 954267 & 5.34200 & 00000000 & 005 & 5.1488 & T \\
\hline CHEMBL1417294 & 954267 & 5.7959 & 6.0679 & TRN & & \\
\hline CHEMBL1303152 & 954267 & 6.466 & 6.2655 & TST & & \\
\hline CHEMBL1422386 & 954267 & 4.4501 & 4.7484 & TST & & \\
\hline CHEMBL1313978 & 954267 & 5.0146 & 5.5063 & TRN & & \\
\hline CHEMBL1420175 & 954267 & 5.0052 & 4.905 & TST & & \\
\hline CHEMBL1543358 & 954267 & 5.3107 & 5.3457 & TST & & \\
\hline CHEMBL 2354415 & 954267 & 7.585 & 5.9912 & TRN & & \\
\hline CHEMBL1698237 & 954267 & 5.58 & 5.5458 & TRN & & \\
\hline CHEMBL1898104 & 954267 & 5.6882 & 5.4485 & TRN & & \\
\hline CHEMBL1557066 & 954267 & 5.2628 & 5.2684 & TRN & & \\
\hline CHEMBL3209663 & 954267 & 5.8097 & 5.6205 & TST & & \\
\hline CHEMBL1420768 & 954267 & 5.3116 & 5.04 & TST & & \\
\hline CHEMBL1341124 & 954267 & 5.5017 & 5.8749 & TRN & & \\
\hline CHEMBL1500059 & 954267 & 5.3904 & 5.1657 & TRN & & \\
\hline CHEMBL1522331 & 954267 & 5.6716 & 5.473 & TRN & & \\
\hline CHEMBL528181 & 954267 & 5.5258 & 5.1976 & TRN & & \\
\hline CHEMBL1902683 & 954267 & 5.7545 & 5.7933 & TRN & & \\
\hline CHEMBL1420742 & 954267 & 5.0516 & 5.1569 & TRN & & \\
\hline CHEMBL1383228 & 954267 & 5.5607 & 5.5083 & TRN & & \\
\hline CHEMBL1607801 & 954267 & 6.4698 & 7.223 & TRN & & \\
\hline CHEMBL2356031 & 954267 & 6.0 & 5.91799 & 9999999999 & & R \\
\hline CHEMBL 2144544 & 954267 & 4.7833 & 5.0748 & TRN & & \\
\hline CHEMBL 2357620 & 954267 & 5.284 & 5.331 & TRN & & \\
\hline CHEMBL1547483 & 954267 & 5.129 & 5.0053 & TRN & & \\
\hline CHEMBL3197091 & 954267 & 4.9069 & 5.2732 & TRN & & \\
\hline CHEMBL1410521 & 954267 & 5.1409 & 4.9015 & TRN & & \\
\hline CHEMBL1568152 & 954267 & 5.4248 & 5.2408 & TRN & & \\
\hline
\end{tabular}




\begin{tabular}{|c|c|c|c|c|c|c|}
\hline & & \multicolumn{5}{|c|}{ Supplemental Table s2.txt } \\
\hline CHEMBL1577938 & 954267 & 5.6459 & 6.2269 & TRN & & \\
\hline CHEMBL1511219 & 954267 & 6.585 & 6.3489 & TRN & & \\
\hline CHEMBL 2139915 & 954267 & 5.059 & 5.1564 & TRN & & \\
\hline CHEMBL1581829 & 954267 & 5.1409 & 5.0562 & TRN & & \\
\hline CHEMBL1305638 & 954267 & 5.7905 & 5.4906 & TRN & & \\
\hline CHEMBL1890660 & 954267 & 5.6576 & 5.8952 & TRN & & \\
\hline CHEMBL1570769 & 954267 & 4.9194 & 5.6817 & TRN & & \\
\hline CHEMBL1401504 & 954267 & 5.2487 & 5.2723 & TRN & & \\
\hline CHEMBL1446984 & 954267 & 5.341 & 5.1916 & TRN & & \\
\hline CHEMBL1597230 & 954267 & 5.4935 & 5.1091 & TRN & & \\
\hline CHEMBL1384205 & 954267 & 5.032 & 5.2963 & TST & & \\
\hline CHEMBL1342837 & 954267 & 5.3706 & 5.4869 & TRN & & \\
\hline CHEMBL1395785 & 954267 & 4.9872 & 4.9057 & TRN & & \\
\hline CHEMBL1391059 & 954267 & 5.3757 & 5.3814 & TRN & & \\
\hline CHEMBL 2359303 & 954267 & 4.6103 & 5.0799 & TRN & & \\
\hline CHEMBL605708 & 954267 & 5.2373 & 4.7312 & TRN & & \\
\hline CHEMBL1470568 & 954267 & 5.4634 & 5.147 & TRN & & \\
\hline CHEMBL 2358028 & 954267 & 5.8729 & 5.6763 & TRN & & \\
\hline CHEMBL1430290 & 954267 & 5.2255 & 5.2537 & TRN & & \\
\hline CHEMBL1733422 & 954267 & $5.2020 e$ & 00000000 & 01 & 5.2018 & TRN \\
\hline CHEMBL1524929 & 954267 & 5.6882 & 5.7073 & TRN & & \\
\hline CHEMBL1514666 & 954267 & 5.5735 & 5.3695 & TRN & & \\
\hline CHEMBL 2144271 & 954267 & 5.5817 & 5.3618 & TRN & & \\
\hline CHEMBL1490428 & 954267 & 5.9136 & 6.0762 & TRN & & \\
\hline CHEMBL 2356339 & 954267 & 5.5287 & 5.5269 & TRN & & \\
\hline CHEMBL1528930 & 954267 & 5.3706 & 4.9797 & TRN & & \\
\hline CHEMBL585656 & 954267 & 5.6108 & 5.184 & TRN & & \\
\hline CHEMBL 2360710 & 954267 & 4.9059 & 5.1998 & TRN & & \\
\hline CHEMBL1552222 & 954267 & 5.1993 & 5.2038 & TRN & & \\
\hline CHEMBL1371382 & 954267 & 5.1463 & 5.2029 & TRN & & \\
\hline CHEMBL1875758 & 954267 & 5.6326 & 5.9686 & TRN & & \\
\hline CHEMBL1312397 & 954267 & 4.9767 & 4.9356 & TRN & & \\
\hline CHEMBL1353797 & 954267 & 4.6979 & 4.9307 & TST & & \\
\hline CHEMBL 2133122 & 954267 & 5.7077 & 5.5462 & TRN & & \\
\hline CHEMBL1521704 & 954267 & 5.3565 & 5.2488 & TRN & & \\
\hline CHEMBL3195378 & 954267 & 5.9747 & 5.7232 & TRN & & \\
\hline CHEMBL1459468 & 954267 & 6.056 & 5.806 & TRN & & \\
\hline CHEMBL1867244 & 954267 & 6.4023 & 6.1624 & TRN & & \\
\hline CHEMBL1430094 & 954267 & 6.1209 & 6.3776 & TRN & & \\
\hline CHEMBL 2361602 & 954267 & 6.0 & 6.0251 & TRN & & \\
\hline CHEMBL 2360836 & 954267 & 4.4001 & 5.5968 & TRN & & \\
\hline CHEMBL1460595 & 954267 & 5.4045 & 5.2549 & TST & & \\
\hline CHEMBL 2359362 & 954267 & 6.0768 & 5.8839 & TRN & & \\
\hline CHEMBL1515360 & 954267 & 4.5637 & 5.0504 & TRN & & \\
\hline CHEMBL1719064 & 954267 & 5.7825 & 5.6182 & TRN & & \\
\hline CHEMBL1612156 & 954267 & 5.6126 & 4.8824 & TRN & & \\
\hline CHEMBL1902622 & 954267 & 5.2644 & 5.3028 & TRN & & \\
\hline CHEMBL 2359971 & 954267 & 6.0 & 5.7654 & TRN & & \\
\hline
\end{tabular}




\begin{tabular}{|c|c|c|c|c|c|}
\hline & & & & & \\
\hline CHEMBL1474759 & 954267 & 5.1463 & 5.1845 & TST & \\
\hline CHEMBL1491601 & 954267 & 5.4698 & 5.3269 & TRN & \\
\hline CHEMBL2359472 & 954267 & 6.0 & 5.7862 & TRN & \\
\hline CHEMBL2360847 & 954267 & 6.0 & 5.461 & TRN & \\
\hline CHEMBL1723968 & 954267 & 5.4248 & 5.0119 & TST & \\
\hline CHEMBL1372936 & 954267 & 5.5622 & 5.466 & TRN & \\
\hline CHEMBL 2140460 & 954267 & 6.011 & 6.1065 & TRN & \\
\hline CHEMBL1321622 & 954267 & 5.6635 & 5.5984 & TRN & \\
\hline CHEMBL1713983 & 954267 & 5.5544 & 5.2262 & TRN & \\
\hline CHEMBL1895135 & 954267 & 4.963 & 4.8202 & TRN & \\
\hline CHEMBL2357287 & 954267 & 7.585 & 6.9405 & TRN & \\
\hline CHEMBL2141813 & 954267 & 4.9281 & 5.0918 & TST & \\
\hline CHEMBL2142640 & 954267 & 4.1876 & 5.0199 & TST & \\
\hline CHEMBL1365395 & 954267 & 4.688 & 5.0057 & TRN & \\
\hline CHEMBL2360977 & 954267 & 5.4989 & 5.059 & TRN & \\
\hline CHEMBL 2134677 & 954267 & 6.0942 & 5.5536 & TRN & \\
\hline CHEMBL1383873 & 954267 & 4.5824 & 4.7415 & TST & \\
\hline CHEMBL1301073 & 954267 & 5.3696 & 5.395 & TRN & \\
\hline CHEMBL 2358614 & 954267 & 6.0 & 5.95799 & 9999999999 & TRN \\
\hline CHEMBL2356728 & 954267 & 4.7501 & 5.0249 & TRN & \\
\hline CHEMBL1428870 & 954267 & 5.7055 & 5.6436 & TRN & \\
\hline CHEMBL1299439 & 954267 & 5.4168 & 5.2415 & TRN & \\
\hline CHEMBL2361367 & 954267 & 6.0 & 5.7811 & TRN & \\
\hline CHEMBL1306402 & 954267 & 5.0947 & 4.8161 & TRN & \\
\hline CHEMBL2355856 & 954267 & 5.6055 & 5.5562 & TRN & \\
\hline CHEMBL1458306 & 954267 & 5.1713 & 4.632 & TRN & \\
\hline CHEMBL1372292 & 954267 & 5.8665 & 5.428 & TRN & \\
\hline CHEMBL1487368 & 954267 & 6.1203 & 5.784 & TRN & \\
\hline CHEMBL1543215 & 954267 & 5.9706 & 5.6973 & TRN & \\
\hline CHEMBL2134222 & 954267 & 5.1898 & 5.0728 & TRN & \\
\hline CHEMBL2360390 & 954267 & 4.1584 & 4.8369 & TRN & \\
\hline CHEMBL1869323 & 954267 & 6.1811 & 6.1727 & TRN & \\
\hline CHEMBL1588822 & 954267 & 5.7167 & 5.2838 & TRN & \\
\hline CHEMBL464467 & 954267 & 5.9245 & 5.5941 & TST & \\
\hline CHEMBL1707564 & 954267 & 5.9172 & 5.7515 & TRN & \\
\hline CHEMBL1535227 & 954267 & 4.2747 & 5.5673 & TRN & \\
\hline CHEMBL1568497 & 954267 & 5.1871 & 5.1352 & TRN & \\
\hline CHEMBL1329535 & 954267 & 5.1858 & 5.3102 & TRN & \\
\hline CHEMBL1352181 & 954267 & 4.4499 & 5.4073 & TRN & \\
\hline CHEMBL1487901 & 954267 & 5.5768 & 5.1106 & TST & \\
\hline CHEMBL1904959 & 954267 & 5.2449 & 5.4532 & TRN & \\
\hline CHEMBL530291 & 954267 & 5.1605 & 5.796 & TRN & \\
\hline CHEMBL1482207 & 954267 & 4.5063 & 5.0698 & TRN & \\
\hline CHEMBL 2357044 & 954267 & 4.5872 & 5.115 & TRN & \\
\hline CHEMBL1404042 & 954267 & 5.4724 & 5.59 & TST & \\
\hline CHEMBL1549444 & 954267 & 5.4685 & 4.9092 & TST & \\
\hline CHEMBL1462900 & 954267 & 4.8297 & 5.1512 & TRN & \\
\hline CHEMBL2356501 & 954267 & 4.8732 & 5.1732 & TRN & \\
\hline
\end{tabular}


Supplemental Table S2.txt

\begin{tabular}{|c|c|c|c|c|c|}
\hline CHEMBL 2356600 & 954267 & 4.9952 & 5.4826 & TRN & \\
\hline CHEMBL16288 & 954267 & 6.2154 & 6.145 & TRN & \\
\hline CHEMBL1441491 & 954267 & 5.5575 & 5.6744 & TRN & \\
\hline CHEMBL3197908 & 954267 & 5.083 & 5.1888 & TRN & \\
\hline CHEMBL1698730 & 954267 & 5.4789 & 5.541 & TRN & \\
\hline CHEMBL1527251 & 954267 & 4.817 & 5.4489 & TRN & \\
\hline CHEMBL1905114 & 954267 & 5.4078 & 5.3533 & TRN & \\
\hline CHEMBL1308948 & 954267 & 4.9512 & 5.3227 & TST & \\
\hline CHEMBL1336290 & 954267 & 6.1858 & 5.8883 & TRN & \\
\hline CHEMBL1704377 & 954267 & 4.6882 & 5.1227 & TRN & \\
\hline CHEMBL1334326 & 954267 & 4.2539 & 5.1503 & TRN & \\
\hline CHEMBL1715756 & 954267 & 6.1475 & 6.0588 & TRN & \\
\hline CHEMBL1702433 & 954267 & 4.6942 & 5.4885 & TRN & \\
\hline CHEMBL1719954 & 954267 & 5.5031 & 5.4137 & TRN & \\
\hline CHEMBL1415211 & 954267 & 5.399 & 5.1101 & TRN & \\
\hline CHEMBL1434237 & 954267 & 5.4168 & 5.7446 & TRN & \\
\hline CHEMBL3560302 & 954267 & 6.0701 & 5.7376 & TRN & \\
\hline CHEMBL1427272 & 954267 & 5.1203 & 4.9099 & TRN & \\
\hline CHEMBL3561704 & 954267 & 6.0315 & 5.3268 & TRN & \\
\hline CHEMBL2357825 & 954267 & 6.5171 & 5.5795 & TST & \\
\hline CHEMBL1573963 & 954267 & 5.8069 & 5.7451 & TST & \\
\hline CHEMBL1339696 & 954267 & 5.4535 & 4.9404 & TRN & \\
\hline CHEMBL1374693 & 954267 & 4.6165 & 5.2581 & TRN & \\
\hline CHEMBL2141186 & 954267 & 5.2874 & 5.3813 & TST & \\
\hline CHEMBL2361075 & 954267 & 6.1391 & 5.7889 & TRN & \\
\hline CHEMBL1884377 & 954267 & 6.5376 & 6.144 & TRN & \\
\hline CHEMBL1579166 & 954267 & 5.4828 & 5.6091 & TRN & \\
\hline CHEMBL1705854 & 954267 & 6.3401 & 5.6972 & TST & \\
\hline CHEMBL2359218 & 954267 & 7.585 & 5.8098 & TRN & \\
\hline CHEMBL2356206 & 954267 & 5.5436 & 5.3594 & TRN & \\
\hline CHEMBL1423706 & 954267 & 5.3615 & 5.3017 & TRN & \\
\hline CHEMBL1415958 & 954267 & 6.4535 & 6.2694 & TRN & \\
\hline CHEMBL356169 & 954267 & 4.9367 & 4.8447 & TRN & \\
\hline CHEMBL1608402 & 954267 & 5.3936 & 5.5023 & TST & \\
\hline CHEMBL1370087 & 954267 & 6.5421 & 6.4304 & TRN & \\
\hline CHEMBL18115 & 954267 & 5.1355 & 5.0977 & TRN & \\
\hline CHEMBL1406556 & 954267 & 7.585 & 6.4328 & TST & \\
\hline CHEMBL 2136773 & 954267 & 5.6737 & 5.7323 & TRN & \\
\hline CHEMBL2357354 & 954267 & 5.4473 & 5.29700 & 2000000001 & TRN \\
\hline CHEMBL2360927 & 954267 & 6.0 & 5.8801 & TRN & \\
\hline CHEMBL1380862 & 954267 & 5.6635 & 6.0388 & TRN & \\
\hline CHEMBL2361810 & 954267 & 7.585 & 5.4421 & TRN & \\
\hline CHEMBL1500480 & 954267 & 5.4437 & 5.1361 & TRN & \\
\hline CHEMBL1378226 & 954267 & 6.1746 & 6.0532 & TRN & \\
\hline CHEMBL1436713 & 954267 & 4.704 & 4.6077 & TRN & \\
\hline CHEMBL2356346 & 954267 & 5.3298 & 5.124 & TRN & \\
\hline CHEMBL2359142 & 954267 & 5.9626 & 5.6449 & TRN & \\
\hline CHEMBL1451348 & 954267 & 5.224 & 5.3612 & TRN & \\
\hline
\end{tabular}




\begin{tabular}{|c|c|c|c|c|c|c|}
\hline & & \multicolumn{5}{|c|}{ Supplemental Table s2.txt } \\
\hline CHEMBL171699 & 954267 & 7.585 & 7.4476 & TRN & & \\
\hline CHEMBL517986 & 954267 & 5.7033 & 5.3364 & TST & & \\
\hline CHEMBL1453285 & 954267 & 5.3242 & 5.0459 & TRN & & \\
\hline CHEMBL1702280 & 954267 & 5.1838 & 5.2508 & TRN & & \\
\hline CHEMBL1440258 & 954267 & 4.6739 & 4.8545 & TRN & & \\
\hline CHEMBL1550670 & 954267 & 4.3701 & 5.175 & TST & & \\
\hline CHEMBL 2357977 & 954267 & 4.8489 & 5.1763 & TRN & & \\
\hline CHEMBL 2359106 & 954267 & 4.3962 & 5.3842 & TRN & & \\
\hline CHEMBL 2357535 & 954267 & 6.0 & 5.0383 & TRN & & \\
\hline CHEMBL1522937 & 954267 & 4.198 & 5.1246 & TRN & & \\
\hline CHEMBL 2362396 & 954267 & 4.8874 & 5.1829 & TRN & & \\
\hline CHEMBL1703600 & 954267 & 7.585 & 7.144 & TRN & & \\
\hline CHEMBL1345232 & 954267 & 5.7375 & 5.6778 & TRN & & \\
\hline CHEMBL 2358431 & 954267 & 4.6297 & 5.3449 & TRN & & \\
\hline CHEMBL 2354940 & 954267 & 5.6345 & 5.4332 & TRN & & \\
\hline CHEMBL 2354543 & 954267 & 6.4737 & 6.5263 & TRN & & \\
\hline CHEMBL 2137652 & 954267 & 5.3706 & 5.24299 & 9999999999 & & TRN \\
\hline CHEMBL1505224 & 954267 & 5.025 & 5.2167 & TRN & & \\
\hline CHEMBL1601830 & 954267 & 4.4048 & 4.7613 & TRN & & \\
\hline CHEMBL1385388 & 954267 & 6.4248 & 6.1346 & TRN & & \\
\hline CHEMBL1510639 & 954267 & 5.5376 & 5.5188 & TRN & & \\
\hline CHEMBL1305030 & 954267 & 6.3261 & 5.6627 & TST & & \\
\hline CHEMBL1727847 & 954267 & 6.4921 & 5.6469 & TRN & & \\
\hline CHEMBL1712719 & 954267 & 5.2495 & 5.1384 & TRN & & \\
\hline CHEMBL 2359534 & 954267 & $5.2020 e$ & 00000000 & 01 & 5.4027 & TRN \\
\hline CHEMBL1462920 & 954267 & 5.5498 & 5.7289 & TRN & & \\
\hline CHEMBL1471330 & 954267 & 5.1096 & 5.1858 & TRN & & \\
\hline CHEMBL1357092 & 954267 & 4.2431 & 5.0847 & TRN & & \\
\hline CHEMBL1524910 & 954267 & 5.21399 & 99999999 & 995 & 5.1495 & TRN \\
\hline CHEMBL1536459 & 954267 & 4.3591 & 5.0086 & TRN & & \\
\hline CHEMBL1522315 & 954267 & 5.0039 & 5.1824 & TST & & \\
\hline CHEMBL1368760 & 954267 & 4.5103 & 5.0119 & TRN & & \\
\hline CHEMBL1886120 & 954267 & 5.684 & 5.7858 & TRN & & \\
\hline CHEMBL 2136365 & 954267 & 5.4306 & 5.24299 & 9999999999 & & TRN \\
\hline CHEMBL1472420 & 954267 & 5.4895 & 5.4768 & TST & & \\
\hline CHEMBL1537098 & 954267 & 6.4067 & 7.0539 & TST & & \\
\hline CHEMBL 2138317 & 954267 & 4.8111 & 5.7106 & TRN & & \\
\hline CHEMBL1423575 & 954267 & 5.6055 & 5.1461 & TRN & & \\
\hline CHEMBL1897998 & 954267 & 5.4597 & 4.5816 & TRN & & \\
\hline CHEMBL116919 & 954267 & 4.4417 & 4.5824 & TRN & & \\
\hline CHEMBL 2361877 & 954267 & 4.584 & 4.9995 & TRN & & \\
\hline CHEMBL193627 & 954267 & 5.7305 & 5.5564 & TST & & \\
\hline CHEMBL1323505 & 954267 & 4.6041 & 5.1819 & TRN & & \\
\hline CHEMBL1516583 & 954267 & 5.4413 & 4.8997 & TST & & \\
\hline CHEMBL3211736 & 954267 & 5.4089 & 5.3626 & TRN & & \\
\hline CHEMBL1375894 & 954267 & 5.0101 & 5.1074 & TRN & & \\
\hline CHEMBL1559529 & 954267 & 6.2182 & 5.6731 & TRN & & \\
\hline CHEMBL2359169 & 954267 & 5.4711 & 5.7546 & TRN & & \\
\hline
\end{tabular}




\begin{tabular}{|c|c|c|c|c|c|c|}
\hline & & \multicolumn{5}{|c|}{ Supplemental Table S2.txt } \\
\hline CHEMBL3195410 & 954267 & 5.056 & 5.6096 & TRN & & \\
\hline CHEMBL 2358514 & 954267 & 5.0429 & 5.0911 & TRN & & \\
\hline CHEMBL1602454 & 954267 & 6.1024 & 6.306 & TRN & & \\
\hline CHEMBL1503659 & 954267 & 5.5935 & 5.0737 & TST & & \\
\hline CHEMBL1706987 & 954267 & 5.3585 & 5.0148 & TST & & \\
\hline CHEMBL1727214 & 954267 & 5.3261 & 5.4296 & TRN & & \\
\hline CHEMBL1871362 & 954267 & 6.1255 & 6.0596 & TRN & & \\
\hline CHEMBL1441773 & 954267 & 5.4318 & 5.1164 & TRN & & \\
\hline CHEMBL1531646 & 954267 & 4.5253 & 4.7882 & TRN & & \\
\hline CHEMBL 2069955 & 954267 & 5.1506 & 5.0886 & TST & & \\
\hline CHEMBL1438308 & 954267 & \multicolumn{3}{|c|}{5.327000000000001} & 5.1552 & TRN \\
\hline CHEMBL1300237 & 954267 & 5.7905 & 5.3802 & TST & & \\
\hline CHEMBL1317554 & 954267 & 6.1325 & 6.3986 & TRN & & \\
\hline CHEMBL1569668 & 954267 & 5.3788 & 5.2003 & TRN & & \\
\hline CHEMBL1430416 & 954267 & 5.4271 & 4.5574 & TRN & & \\
\hline CHEMBL 2354821 & 954267 & 5.1851 & 5.0763 & TST & & \\
\hline CHEMBL37430 & 954267 & 4.7873 & 5.0906 & TRN & & \\
\hline CHEMBL1448198 & 954267 & 5.5528 & 5.2175 & TRN & & \\
\hline CHEMBL 2361956 & 954267 & 6.0 & 5.6956 & TRN & & \\
\hline CHEMBL1869587 & 954267 & 5.7033 & 5.5615 & TRN & & \\
\hline CHEMBL 2359661 & 954267 & 4.8063 & 6.0162 & TRN & & \\
\hline CHEMBL1981570 & 954267 & 5.4271 & 5.1356 & TRN & & \\
\hline CHEMBL 2355799 & 954267 & 5.2823 & 5.6432 & TST & & \\
\hline CHEMBL 2357719 & 954267 & 6.1343 & 5.7852 & TRN & & \\
\hline CHEMBL2358117 & 954267 & 6.0 & 4.8977 & TRN & & \\
\hline CHEMBL1579968 & 954267 & 6.295 & 5.9923 & TRN & & \\
\hline CHEMBL1460011 & 954267 & \multicolumn{3}{|c|}{5.162999999999999} & 5.0657 & TRN \\
\hline CHEMBL1976507 & 954267 & 6.1643 & 5.7123 & TRN & & \\
\hline CHEMBL 2359943 & 954267 & 4.2721 & 5.2524 & TRN & & \\
\hline CHEMBL1428181 & 954267 & 5.2083 & 5.2561 & TST & & \\
\hline CHEMBL1710523 & 954267 & 5.5346 & 5.5583 & TRN & & \\
\hline CHEMBL 2358381 & 954267 & 6.0 & 5.5897 & TRN & & \\
\hline CHEMBL1349315 & 954267 & 5.475 & 5.3128 & TRN & & \\
\hline CHEMBL1329135 & 954267 & 4.9531 & 4.6773 & TST & & \\
\hline CHEMBL 2362338 & 954267 & 7.585 & 6.3512 & TRN & & \\
\hline CHEMBL 2134576 & 954267 & 6.0 & 5.6803 & TRN & & \\
\hline CHEMBL1901570 & 954267 & 4.8897 & 5.5623 & TST & & \\
\hline CHEMBL 2357524 & 954267 & 5.4881 & 5.211 & TRN & & \\
\hline CHEMBL1355253 & 954267 & 4.7918 & 4.9162 & TRN & & \\
\hline CHEMBL1299470 & 954267 & 5.0467 & 5.039 & TRN & & \\
\hline CHEMBL1567488 & 954267 & 5.8794 & 5.4713 & TST & & \\
\hline CHEMBL1726645 & 954267 & 5.5735 & 5.5981 & TRN & & \\
\hline CHEMBL1462457 & 954267 & 5.2807 & 5.3273 & TRN & & \\
\hline CHEMBL1600736 & 954267 & 5.1325 & 5.3361 & TRN & & \\
\hline CHEMBL3198899 & 954267 & 5.6635 & 5.2642 & TRN & & \\
\hline CHEMBL1382244 & 954267 & 5.284 & 5.1705 & TRN & & \\
\hline CHEMBL 2359884 & 954267 & 6.0 & 5.3164 & TRN & & \\
\hline CHEMBL1867339 & 954267 & 5.9318 & 5.8607 & TRN & & \\
\hline
\end{tabular}




\begin{tabular}{|c|c|c|c|c|c|c|}
\hline & & \multicolumn{5}{|c|}{ Supplemental Table S2.txt } \\
\hline CHEMBL1396779 & 954267 & 4.5188 & 4.8965 & TRN & & \\
\hline CHEMBL1370423 & 954267 & 4.5002 & 4.6989 & TRN & & \\
\hline CHEMBL1730354 & 954267 & 5.8861 & 6.0476 & TRN & & \\
\hline CHEMBL1325003 & 954267 & 6.3335 & 6.3132 & TRN & & \\
\hline CHEMBL1609759 & 954267 & 5.7033 & 5.1871 & TRN & & \\
\hline CHEMBL1466453 & 954267 & 5.3206 & 5.3445 & TRN & & \\
\hline CHEMBL1573351 & 954267 & 5.1518 & 4.8832 & TRN & & \\
\hline CHEMBL1332776 & 954267 & 5.2373 & 5.1548 & TRN & & \\
\hline CHEMBL1346079 & 954267 & 5.7033 & 5.4734 & TRN & & \\
\hline CHEMBL1891205 & 954267 & 5.5346 & 5.9458 & TRN & & \\
\hline CHEMBL2133625 & 954267 & 4.6498 & 5.499 & TRN & & \\
\hline CHEMBL1541153 & 954267 & 6.0424 & 5.9079 & TST & & \\
\hline CHEMBL1380943 & 954267 & 5.2069 & 4.9036 & TRN & & \\
\hline CHEMBL1570706 & 954267 & 5.1911 & 5.3113 & TRN & & \\
\hline CHEMBL1324188 & 954267 & 5.6716 & 5.3757 & TRN & & \\
\hline CHEMBL1339433 & 954267 & 6.266 & 5.6896 & TRN & & \\
\hline CHEMBL1515941 & 954267 & 5.0472 & 5.0169 & TRN & & \\
\hline CHEMBL 2355783 & 954267 & 4.6078 & 5.2363 & TRN & & \\
\hline CHEMBL1600400 & 954267 & 5.5157 & 5.4508 & TRN & & \\
\hline CHEMBL 2357773 & 954267 & 6.1361 & 5.8983 & TRN & & \\
\hline CHEMBL1388829 & 954267 & 5.8861 & 5.8287 & TST & & \\
\hline CHEMBL1491097 & 954267 & 5.0752 & 5.1533 & TRN & & \\
\hline CHEMBL1429793 & 954267 & 5.5317 & 5.3432 & TST & & \\
\hline CHEMBL1585652 & 954267 & 5.6757 & 4.6218 & TRN & & \\
\hline CHEMBL1506016 & 954267 & 4.6026 & 5.3143 & TST & & \\
\hline CHEMBL1906549 & 954267 & 7.585 & 6.3242 & TRN & & \\
\hline CHEMBL1349753 & 954267 & 5.38299 & 99999999 & 99 & 5.388 & TRN \\
\hline CHEMBL1384292 & 954267 & 5.6696 & 5.7077 & TRN & & \\
\hline CHEMBL441618 & 954267 & 4.5921 & 4.854 & TRN & & \\
\hline CHEMBL1319336 & 954267 & 5.7905 & 5.7178 & TST & & \\
\hline CHEMBL1728514 & 954267 & 5.6234 & 5.5291 & TST & & \\
\hline CHEMBL1409464 & 954267 & 5.3516 & 5.2292 & TRN & & \\
\hline CHEMBL1721043 & 954267 & 5.2062 & 5.2306 & TST & & \\
\hline CHEMBL 2357474 & 954267 & 5.9626 & 5.8603 & TRN & & \\
\hline CHEMBL1332417 & 954267 & 5.5498 & 4.9944 & TRN & & \\
\hline CHEMBL3184689 & 954267 & 4.6289 & 4.8713 & TRN & & \\
\hline CHEMBL1577804 & 954267 & 5.5361 & 5.4048 & TST & & \\
\hline CHEMBL1595792 & 954267 & 6.4815 & 5.8464 & TRN & & \\
\hline CHEMBL1497138 & 954267 & 5.4895 & 5.2145 & TST & & \\
\hline CHEMBL1374399 & 954267 & 4.5117 & 4.7453 & TRN & & \\
\hline CHEMBL1445386 & 954267 & 6.209 & 6.1474 & TST & & \\
\hline CHEMBL1427279 & 954267 & 5.6402 & 5.2923 & TRN & & \\
\hline CHEMBL2359156 & 954267 & 6.0 & 5.0412 & TRN & & \\
\hline CHEMBL1407998 & 954267 & 5.5058 & 5.3593 & TRN & & \\
\hline CHEMBL2361077 & 954267 & 5.3288 & 5.1903 & TRN & & \\
\hline CHEMBL1387035 & 954267 & 5.3595 & 5.2167 & TST & & \\
\hline CHEMBL1594160 & 954267 & 5.38399 & 99999999 & 995 & 4.8822 & TRN \\
\hline CHEMBL2360148 & 954267 & 5.7905 & 5.4204 & TRN & & \\
\hline
\end{tabular}




\begin{tabular}{|c|c|c|c|c|}
\hline \multicolumn{5}{|c|}{ Supplemental Table S2.txt } \\
\hline CHEMBL2134088 & 954267 & 6.0 & 5.9498 & TRN \\
\hline CHEMBL1388405 & 954267 & 5.2366 & 5.0068 & TRN \\
\hline CHEMBL1573994 & 954267 & 6.5302 & 6.2894 & TST \\
\hline CHEMBL1505232 & 954267 & 5.301 & 4.9966 & TRN \\
\hline CHEMBL1346449 & 954267 & 4.9923 & 4.9264 & TRN \\
\hline CHEMBL1531675 & 954267 & 5.8928 & 5.8122 & TST \\
\hline CHEMBL1699402 & 954267 & 5.7496 & 5.6317 & TRN \\
\hline CHEMBL1303580 & 954267 & 5.0883 & 4.9322 & TRN \\
\hline CHEMBL530499 & 954267 & 5.3098 & 5.1098 & TST \\
\hline CHEMBL3213599 & 954267 & 5.2441 & 5.5156 & TRN \\
\hline CHEMBL1425552 & 954267 & 5.6635 & 5.4859 & TRN \\
\hline CHEMBL1442067 & 954267 & 4.9367 & 5.1244 & TST \\
\hline CHEMBL2355889 & 954267 & 6.0 & 5.624 & TRN \\
\hline CHEMBL1551755 & 954267 & 5.3363 & 5.5264 & TRN \\
\hline CHEMBL1440892 & 954267 & 4.8847 & 5.0322 & TRN \\
\hline CHEMBL1535490 & 954267 & 5.6799 & 5.9939 & TRN \\
\hline CHEMBL1310617 & 954267 & 6.3799 & 6.2185 & TST \\
\hline CHEMBL1520831 & 954267 & 6.3188 & 6.2958 & TRN \\
\hline CHEMBL1610523 & 954267 & 5.3757 & 5.3326 & TST \\
\hline CHEMBL 2356497 & 954267 & 5.1068 & 5.4124 & TRN \\
\hline CHEMBL290077 & 954267 & 6.4672 & 6.1452 & TRN \\
\hline CHEMBL1434227 & 954267 & 4.1789 & 4.9815 & TRN \\
\hline CHEMBL1536958 & 954267 & 5.7077 & 5.4233 & TRN \\
\hline CHEMBL1554917 & 954267 & 5.5686 & 5.6937 & TRN \\
\hline CHEMBL1550584 & 954267 & 4.9215 & 5.3314 & TRN \\
\hline CHEMBL1349832 & 954267 & 4.7883 & 4.9921 & TST \\
\hline CHEMBL1405122 & 954267 & 6.0975 & 6.8817 & TST \\
\hline CHEMBL 2356987 & 954267 & 6.0809 & 6.0131 & TRN \\
\hline CHEMBL 2360293 & 954267 & 4.3405 & 5.1643 & TRN \\
\hline CHEMBL1469736 & 954267 & 5.6757 & 5.7232 & TRN \\
\hline CHEMBL1717409 & 954267 & 5.7905 & 6.0917 & TRN \\
\hline CHEMBL1364572 & 954267 & 5.8633 & 6.5545 & TST \\
\hline CHEMBL1551207 & 954267 & 7.585 & 8.1503 & TRN \\
\hline CHEMBL1440954 & 954267 & 7.585 & 6.8508 & TRN \\
\hline CHEMBL1877280 & 954267 & 4.4965 & 4.9711 & TRN \\
\hline CHEMBL1310099 & 954267 & 5.6946 & 6.3454 & TRN \\
\hline CHEMBL1570857 & 954267 & 5.1675 & 5.2237 & TRN \\
\hline CHEMBL 2362799 & 954267 & 6.0 & 5.5798 & TRN \\
\hline CHEMBL536166 & 954267 & 5.4522 & 5.5488 & TRN \\
\hline CHEMBL1458209 & 954267 & 5.8761 & 5.3189 & TRN \\
\hline CHEMBL1880788 & 954267 & 5.2725 & 5.1145 & TST \\
\hline CHEMBL1522458 & 954267 & 4.5017 & 4.6664 & TRN \\
\hline CHEMBL 2356045 & 954267 & 4.7862 & 5.4176 & TRN \\
\hline CHEMBL1354163 & 954267 & 6.1249 & 6.1503 & TRN \\
\hline CHEMBL1724732 & 954267 & 5.0691 & 5.2678 & TRN \\
\hline CHEMBL1384853 & 954267 & 5.1952 & 5.1965 & TRN \\
\hline CHEMBL1519965 & 954267 & 6.0223 & 5.7079 & TST \\
\hline CHEMBL1700596 & 954267 & 5.3045 & 5.46 & TRN \\
\hline
\end{tabular}




\begin{tabular}{|c|c|c|c|c|c|c|}
\hline & & & & & & \\
\hline CHEMBL1418276 & 954267 & 5.2565 & 5.3183 & TRN & & \\
\hline CHEMBL1576870 & 954267 & 6.4634 & 7.5738 & TRN & & \\
\hline CHEMBL2362947 & 954267 & 7.585 & 6.4369 & TRN & & \\
\hline CHEMBL1344875 & 954267 & 5.2984 & 5.2059 & TRN & & \\
\hline CHEMBL1442388 & 954267 & 5.4498 & 5.5806 & TST & & \\
\hline CHEMBL1546353 & 954267 & 5.1612 & 5.12299 & 999999999 & & TRN \\
\hline CHEMBL2360733 & 954267 & 5.9245 & 5.5529 & TRN & & \\
\hline CHEMBL2356419 & 954267 & 6.0 & 5.7322 & TRN & & \\
\hline CHEMBL585591 & 954267 & 5.9393 & 5.5433 & TST & & \\
\hline CHEMBL3193168 & 954267 & 5.5719 & 5.1098 & TST & & \\
\hline CHEMBL1536763 & 954267 & 5.5045 & 5.557 & TRN & & \\
\hline CHEMBL1578679 & 954267 & 4.3677 & 5.0194 & TST & & \\
\hline CHEMBL1605795 & 954267 & 6.5467 & 5.8107 & TRN & & \\
\hline CHEMBL 2362014 & 954267 & 4.8684 & 5.4961 & TRN & & \\
\hline CHEMBL494325 & 954267 & 5.3439 & 5.0755 & TRN & & \\
\hline CHEMBL1452795 & 954267 & 5.3556 & 5.6917 & TST & & \\
\hline CHEMBL1347664 & 954267 & 5.1107 & 4.9798 & TRN & & \\
\hline CHEMBL2357208 & 954267 & 6.2388 & 5.70299 & 999999999 & & TRN \\
\hline CHEMBL1322972 & 954267 & 4.5209 & 4.5107 & TRN & & \\
\hline CHEMBL1522721 & 954267 & 4.3163 & 4.765 & TRN & & \\
\hline CHEMBL 2357036 & 954267 & 6.0 & 6.1258 & TRN & & \\
\hline CHEMBL2362917 & 954267 & 4.3824 & 5.5674 & TST & & \\
\hline CHEMBL2360102 & 954267 & 4.7739 & 5.1224 & TRN & & \\
\hline CHEMBL 2136594 & 954267 & 6.0 & 5.62299 & 999999999 & & TRN \\
\hline CHEMBL3192873 & 954267 & 6.4547 & 5.9354 & TRN & & \\
\hline CHEMBL1333750 & 954267 & 5.4547 & 5.2499 & TRN & & \\
\hline CHEMBL1892704 & 954267 & 5.3251 & 4.8772 & TRN & & \\
\hline CHEMBL1468011 & 954267 & 5.9872 & 5.9093 & TRN & & \\
\hline CHEMBL1528960 & 954267 & 5.6126 & 5.559 & TRN & & \\
\hline CHEMBL 2357774 & 954267 & 5.6108 & 5.6792 & TRN & & \\
\hline CHEMBL1545631 & 954267 & 5.3872 & 5.6957 & TRN & & \\
\hline CHEMBL2355186 & 954267 & 4.6872 & 5.1732 & TRN & & \\
\hline CHEMBL1505283 & 954267 & 4.3766 & 5.0456 & TST & & \\
\hline CHEMBL1706322 & 954267 & 5.4389 & 5.4798 & TRN & & \\
\hline CHEMBL1375402 & 954267 & 5.2941 & 5.1462 & TRN & & \\
\hline CHEMBL3561832 & 954267 & 6.0 & 5.4113 & TRN & & \\
\hline CHEMBL1867711 & 954267 & 5.3546 & 5.7192 & TRN & & \\
\hline CHEMBL2357813 & 954267 & 5.7545 & 5.7222 & TRN & & \\
\hline CHEMBL1597864 & 954267 & 4.4532 & 5.5098 & TRN & & \\
\hline CHEMBL 2357014 & 954267 & 4.4439 & 5.2243 & TRN & & \\
\hline CHEMBL1528004 & 954267 & 4.937 & 5.2207 & TRN & & \\
\hline CHEMBL 2139889 & 954267 & 6.0348 & 5.9807 & TRN & & \\
\hline CHEMBL2361197 & 954267 & 5.2248 & 4.9761 & TRN & & \\
\hline CHEMBL 2354781 & 954267 & 5.9245 & 5.7863 & TRN & & \\
\hline CHEMBL1599566 & 954267 & 4.7095 & 5.1255 & TST & & \\
\hline CHEMBL1323459 & 954267 & 5.75200 & 300000006 & $\partial 1$ & 5.5655 & TRN \\
\hline CHEMBL1580426 & 954267 & 4.8955 & 5.0233 & TRN & & \\
\hline CHEMBL2357917 & 954267 & 5.2388 & 5.3561 & TRN & & \\
\hline
\end{tabular}


Supplemental Table S2.txt

\begin{tabular}{|c|c|c|c|c|c|}
\hline CHEMBL2357859 & 954267 & 5.5331 & 5.3868 & TRN & \\
\hline CHEMBL1349063 & 954267 & 6.1367 & \multicolumn{2}{|c|}{5.952000000000001} & TRN \\
\hline CHEMBL1390450 & 954267 & 5.6556 & 5.7626 & TRN & \\
\hline CHEMBL1877605 & 954267 & 4.9252 & 4.8667 & TRN & \\
\hline CHEMBL1730810 & 954267 & 4.8173 & 5.2097 & TRN & \\
\hline CHEMBL1411872 & 954267 & 4.5972 & 5.0085 & TRN & \\
\hline CHEMBL1299835 & 954267 & 6.3028 & 5.9734 & TST & \\
\hline CHEMBL 2354897 & 954267 & 5.9586 & 6.0063 & TRN & \\
\hline CHEMBL1385727 & 954267 & 4.7622 & 4.5273 & TRN & \\
\hline CHEMBL1612755 & 954267 & 4.9855 & 5.6402 & TRN & \\
\hline CHEMBL1488082 & 954267 & 5.2565 & 4.901 & TST & \\
\hline CHEMBL1877044 & 954267 & 5.2418 & 4.9116 & TRN & \\
\hline CHEMBL2360990 & 954267 & 5.5045 & 5.2753 & TRN & \\
\hline CHEMBL 2356833 & 954267 & 5.065 & 5.2723 & TRN & \\
\hline CHEMBL1605995 & 954267 & 5.0851 & 5.1055 & TST & \\
\hline CHEMBL 2357938 & 954267 & 6.0 & 5.8096 & TRN & \\
\hline CHEMBL1482541 & 954267 & 5.556 & 5.1957 & TRN & \\
\hline CHEMBL2360603 & 954267 & 4.5167 & 5.3306 & TRN & \\
\hline CHEMBL1567308 & 954267 & 5.5638 & 5.215 & TRN & \\
\hline CHEMBL2355499 & 954267 & 5.6038 & 5.6151 & TRN & \\
\hline CHEMBL1470152 & 954267 & 5.2676 & 5.3096 & TRN & \\
\hline CHEMBL2359567 & 954267 & 6.4976 & 6.1255 & TRN & \\
\hline CHEMBL1874105 & 954267 & 5.9508 & 5.7135 & TRN & \\
\hline CHEMBL1329693 & 954267 & 5.2503 & 5.3663 & TRN & \\
\hline CHEMBL1315617 & 954267 & 4.62 & 5.4303 & TRN & \\
\hline CHEMBL1541314 & 954267 & 4.957 & 5.0994 & TRN & \\
\hline CHEMBL1870719 & 954267 & 5.3179 & 5.4526 & TRN & \\
\hline CHEMBL1412006 & 954267 & 6.0173 & 6.1918 & TRN & \\
\hline CHEMBL3126906 & 954267 & 5.3458 & 5.855 & TRN & \\
\hline CHEMBL1581715 & 954267 & 5.1904 & 5.0051 & TRN & \\
\hline CHEMBL1312953 & 954267 & 4.58 & 5.0773 & TST & \\
\hline CHEMBL1342825 & 954267 & 4.6377 & 4.9609 & TRN & \\
\hline CHEMBL1428735 & 954267 & 5.7423 & 5.5767 & TRN & \\
\hline CHEMBL 2360357 & 954267 & 4.9642 & 5.8037 & TRN & \\
\hline CHEMBL 2135670 & 954267 & 5.2782 & 5.4499 & TRN & \\
\hline CHEMBL1458403 & 954267 & 5.4622 & 5.0027 & TST & \\
\hline CHEMBL1460004 & 954267 & 5.0004 & 4.9994 & TST & \\
\hline CHEMBL2362759 & 954267 & 4.8368 & 5.335 & TST & \\
\hline CHEMBL1488010 & 954267 & 5.2573 & 5.3255 & TST & \\
\hline CHEMBL1486585 & 954267 & 5.8477 & 6.0777 & TST & \\
\hline CHEMBL1508450 & 954267 & 5.1656 & 4.9998 & TST & \\
\hline CHEMBL 2358725 & 954267 & 6.0 & 5.0943 & TST & \\
\hline CHEMBL1716006 & 954267 & 5.04 & 5.0696 & TST & \\
\hline CHEMBL1475289 & 954267 & 5.5638 & 5.7485 & TST & \\
\hline CHEMBL1736440 & 954267 & 5.2269 & 5.4094 & TST & \\
\hline CHEMBL1881663 & 954267 & 6.0841 & 5.6287 & TST & \\
\hline CHEMBL1736950 & 954267 & 5.4318 & 5.4096 & TST & \\
\hline CHEMBL1562110 & 954267 & 4.8111 & 4.9091 & TST & \\
\hline
\end{tabular}


Supplemental Table S2.txt

\begin{tabular}{|c|c|c|c|c|}
\hline CHEMBL1436659 & 954267 & 7.585 & 7.5461 & TST \\
\hline CHEMBL 2357126 & 954267 & 5.6799 & 5.9469 & TST \\
\hline CHEMBL 2361094 & 954267 & 6.1765 & 5.2522 & TST \\
\hline CHEMBL1721373 & 954267 & 6.2472 & \multicolumn{2}{|c|}{6.3839999999999995} \\
\hline CHEMBL1346904 & 954267 & 5.3675 & 5.2859 & TST \\
\hline CHEMBL3109486 & 954267 & 5.1367 & 5.1953 & TST \\
\hline CHEMBL 2362678 & 954267 & 5.0716 & 5.3924 & TST \\
\hline CHEMBL 2361245 & 954267 & 4.7328 & 4.8946 & TST \\
\hline CHEMBL 2356196 & 954267 & 5.5467 & 5.4123 & TST \\
\hline CHEMBL1380049 & 954267 & 5.3862 & 5.0952 & TST \\
\hline CHEMBL 2354532 & 954267 & 5.0164 & 5.1439 & TST \\
\hline CHEMBL1444205 & 954267 & 5.3439 & 5.2832 & TST \\
\hline CHEMBL1329817 & 954267 & 4.6794 & 4.8098 & TST \\
\hline CHEMBL1863833 & 954267 & 5.8633 & 5.9218 & TST \\
\hline CHEMBL1369460 & 954267 & 5.1858 & 4.8616 & TST \\
\hline CHEMBL1542018 & 954267 & 5.1537 & 4.9468 & TST \\
\hline CHEMBL3194195 & 954267 & 4.4062 & 4.8781 & TST \\
\hline CHEMBL 2358039 & 954267 & 6.0 & 5.9881 & TST \\
\hline CHEMBL1419188 & 954267 & 5.4976 & 5.5207 & TST \\
\hline CHEMBL1594806 & 954267 & 5.4271 & 5.1547 & TST \\
\hline CHEMBL1366706 & 954267 & 5.3344 & 5.6171 & TST \\
\hline CHEMBL 2362241 & 954267 & 4.2289 & 5.2358 & TST \\
\hline CHEMBL1872446 & 954267 & 4.3662 & 5.4278 & TST \\
\hline CHEMBL1898843 & 954267 & 5.0376 & 5.2605 & TST \\
\hline CHEMBL1435670 & 954267 & 4.6207 & 4.2771 & TST \\
\hline CHEMBL3559848 & 954267 & 5.5751 & 5.3233 & TST \\
\hline CHEMBL1368493 & 954267 & 4.1842 & 4.7912 & TST \\
\hline CHEMBL1371507 & 954267 & 6.466 & 5.899 & TST \\
\hline CHEMBL1594360 & 954267 & 5.5935 & 4.9771 & TST \\
\hline CHEMBL 2355448 & 954267 & 4.2034 & 5.3602 & TST \\
\hline CHEMBL1561002 & 954267 & 4.4726 & 5.0877 & TST \\
\hline CHEMBL1894184 & 954267 & 5.6144 & 5.9132 & TST \\
\hline CHEMBL 2362244 & 954267 & 5.5391 & 5.2613 & TST \\
\hline CHEMBL51931 & 954267 & 5.3439 & 5.4921 & TST \\
\hline CHEMBL 2360583 & 954267 & 5.5129 & 5.8219 & TST \\
\hline CHEMBL1392611 & 954267 & 5.767 & 6.0169 & TST \\
\hline CHEMBL1429297 & 954267 & 5.4168 & 4.835 & TST \\
\hline CHEMBL1358759 & 954267 & 4.587 & 5.1023 & TST \\
\hline CHEMBL1501402 & 954267 & 4.2248 & 5.3298 & TST \\
\hline CHEMBL1403324 & 954267 & 5.5391 & 5.6217 & TST \\
\hline CHEMBL1440643 & 954267 & 5.3757 & 5.2844 & TST \\
\hline CHEMBL 2357823 & 954267 & 6.3526 & 5.86700 & 0000000001 \\
\hline CHEMBL1366114 & 954267 & 4.9311 & 4.9556 & TST \\
\hline CHEMBL1359848 & 954267 & 5.0625 & 4.95100 & 30000000005 \\
\hline CHEMBL 2361264 & 954267 & 4.8219 & 5.1224 & TST \\
\hline CHEMBL1468323 & 954267 & 6.1649 & 5.8875 & TST \\
\hline CHEMBL1436699 & 954267 & 5.1096 & 5.1439 & TST \\
\hline CHEMBL1506451 & 954267 & 5.5884 & 5.4216 & TST \\
\hline
\end{tabular}




\begin{tabular}{|c|c|c|c|c|c|}
\hline & & & & & \\
\hline CHEMBL1895081 & 954267 & 5.4353 & 5.0693 & TST & \\
\hline CHEMBL1491001 & 954267 & 4.7486 & 4.7301 & TST & \\
\hline CHEMBL1712299 & 954267 & 5.3595 & 5.1393 & TST & \\
\hline CHEMBL1491453 & 954267 & 5.5214 & 5.1556 & TST & \\
\hline CHEMBL2361151 & 954267 & 6.3605 & 5.6107 & TST & \\
\hline CHEMBL1448592 & 954267 & 4.6568 & 5.3569 & TST & \\
\hline CHEMBL1375648 & 954267 & 5.7447 & 5.5752 & TST & \\
\hline CHEMBL3194760 & 954267 & 5.4535 & 5.8749 & TST & \\
\hline CHEMBL1583846 & 954267 & 5.1871 & 5.6989 & TST & \\
\hline CHEMBL2355447 & 954267 & 6.0 & 5.7804 & TST & \\
\hline CHEMBL1706712 & 954267 & 5.4763 & 5.7561 & TST & \\
\hline CHEMBL1899185 & 954267 & 5.1798 & 5.1748 & TST & \\
\hline CHEMBL2359062 & 954267 & 6.0061 & 5.622006 & 3000000001 & TST \\
\hline CHEMBL1500372 & 954267 & 5.2733 & 5.2909 & TST & \\
\hline CHEMBL 3210088 & 954267 & 5.6383 & 5.9303 & TST & \\
\hline CHEMBL1724034 & 954267 & 4.6635 & 4.8664 & TST & \\
\hline CHEMBL1606743 & 954267 & 5.6126 & 5.1733 & TST & \\
\hline CHEMBL1492399 & 954267 & 5.6882 & 5.5336 & TST & \\
\hline CHEMBL1374384 & 954267 & 5.6655 & 5.4961 & TST & \\
\hline CHEMBL2356526 & 954267 & 4.7438 & 5.0847 & TST & \\
\hline CHEMBL1541329 & 954267 & 4.3502 & 4.9937 & TST & \\
\hline CHEMBL1424453 & 954267 & 4.3022 & 5.1032 & TST & \\
\hline CHEMBL2361351 & 954267 & 5.4202 & 5.6049 & TST & \\
\hline CHEMBL1455730 & 954267 & 5.475 & 5.3359 & TST & \\
\hline CHEMBL1603932 & 954267 & 5.1726 & 4.88899 & 9999999999 & TST \\
\hline CHEMBL1327046 & 954267 & 4.6919 & 4.1099 & TST & \\
\hline CHEMBL2362398 & 954267 & 4.6426 & 5.0587 & TST & \\
\hline CHEMBL1605033 & 954267 & 4.9821 & 5.3234 & TST & \\
\hline CHEMBL1717761 & 954267 & 4.2741 & 5.0662 & TST & \\
\hline CHEMBL1610477 & 954267 & 5.3925 & 5.1738 & TST & \\
\hline CHEMBL3210608 & 954267 & 5.6021 & 5.3684 & TST & \\
\hline CHEMBL1376629 & 954267 & 5.1726 & 5.2976 & TST & \\
\hline CHEMBL102210 & 158524 & 3.5229 & 3.42100 & 00000000003 & TRN \\
\hline CHEMBL107901 & 158524 & 6.6383 & 6.3812 & TRN & \\
\hline CHEMBL102908 & 158524 & 7.0 & 7.0038 & TRN & \\
\hline CHEMBL105702 & 158524 & 6.3565 & 6.2591 & TRN & \\
\hline CHEMBL102686 & 158524 & 6.9586 & 6.7627 & TRN & \\
\hline CHEMBL105032 & 158524 & 5.8508 & 5.8728 & TRN & \\
\hline CHEMBL 316770 & 158524 & 4.9547 & 5.4782 & TRN & \\
\hline CHEMBL104896 & 158524 & 6.4318 & 6.2422 & TRN & \\
\hline CHEMBL106332 & 158524 & 5.2708 & 5.1906 & TRN & \\
\hline CHEMBL104964 & 158524 & 5.9208 & 6.1519 & TRN & \\
\hline CHEMBL104090 & 158524 & 4.0 & 5.5671 & TST & \\
\hline CHEMBL104862 & 158524 & 5.0357 & 4.7927 & TRN & \\
\hline CHEMBL318581 & 158524 & 5.6861 & 5.9256 & TRN & \\
\hline CHEMBL105227 & 158524 & 7.699 & 6.6784 & TRN & \\
\hline CHEMBL105259 & 158524 & 6.1427 & 6.5205 & TRN & \\
\hline CHEMBL323336 & 158524 & 6.2757 & 6.9474 & TRN & \\
\hline
\end{tabular}


Supplemental Table S2.txt

\begin{tabular}{|c|c|c|c|c|}
\hline CHEMBL450338 & .58524 & 6.6778 & 6.6377 & TRN \\
\hline CHEMBL 322464 & 58524 & 4.6655 & 4.1789 & TRN \\
\hline HEMBL321990 & 58524 & 0969 & 6.8036 & [RN \\
\hline HEMBL103690 & 58524 & 7.2218 & 7.2861 & RN \\
\hline HEMBL105239 & 58524 & 6.6576 & 6.6406 & RN \\
\hline HEMBL99743 & 58524 & 6.1549 & 4.5892 & \\
\hline HEMBL 105280 & 58524 & 7.5229 & 7.5627 & RN \\
\hline HEMBL421404 & 58524 & 5.8327 & 5.6532 & TRN \\
\hline HEMBL103012 & 58524 & 6.3565 & 6.2273 & CT \\
\hline HEMBL104339 & 58524 & 6.5376 & 6.5852 & Siv \\
\hline HEMBL319235 & .58524 & 3.5229 & 5.0793 & \\
\hline HEMBL104924 & 58524 & 3.5229 & 4.3238 & ST \\
\hline HEMBL319024 & 58524 & 6.7959 & 5.1969 & \\
\hline HEMBL105689 & .58524 & 3.5229 & 3.4522 & TST \\
\hline HEMBL104067 & 58524 & 7.0969 & 7.0189 & 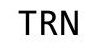 \\
\hline HEMBL 319242 & .58524 & 5.4976 & 5.5975 & ונו \\
\hline HEMBL104206 & .58524 & 5.1726 & 5.2579 & RIV \\
\hline HEMBL105622 & 58524 & 7.0 & 6.8204 & RN \\
\hline HEMBL321286 & 58524 & 5.8996 & 5.6938 & \\
\hline HEMBL103870 & 58524 & 6.1024 & 507 & TST \\
\hline HEMBL103066 & 58524 & 6.3188 & 142 & RIV \\
\hline HEMBL1e & 58524 & 29 & 37 & ST \\
\hline HEMBL10 & 58524 & 5.5901 & 98 & TRN \\
\hline HEMBL104922 & 58524 & 6.3565 & 5.7612 & TST \\
\hline CHEMBL441272 & 58524 & 6.5376 & 93 & TRN \\
\hline HEMBL105409 & 58524 & 76 & 069 & ISI \\
\hline HEMBL1C & 58524 & $\partial 66$ & 077 & TST \\
\hline CHEMBL103861 & 58524 & 7.301 & 7.425 & TRN \\
\hline CHEMBL102554 & 58524 & 6.8239 & 4844 & TRN \\
\hline CHEMBL 321504 & 58524 & 3.5229 & 3.4085 & TRN \\
\hline CHEMBL102330 & 58524 & & 354 & ГRN \\
\hline HEMBL 32 & 58524 & 212 & 4.9341 & ГST \\
\hline EHEMBL1e & 58524 & 6.585 & 6.6127 & TRN \\
\hline CHEMBL102427 & 58524 & 5.6364 & 5.4599 & TRN \\
\hline CHEMBL106966 & 58524 & 6.0706 & 6.2933 & TRN \\
\hline CHEMBL1e & 58524 & .2924 & 6.5608 & TRN \\
\hline CHEMBL1C & 58524 & 3.5229 & 4.3276 & TRN \\
\hline CHEMBL320645 & 58524 & 5.9172 & 6.3238 & TRN \\
\hline CHEMBL102346 & 58524 & 7.0969 & 6.8017 & TRN \\
\hline CHEMBL103003 & 58524 & 5.9431 & 5.3297 & TST \\
\hline CHEMBL105183 & 158524 & 7.699 & 6.9957 & TRN \\
\hline CHEMBL104427 & 158524 & 3.5229 & 3.9776 & TRN \\
\hline CHEMBL104094 & 158524 & 4.7399 & 5.3989 & TST \\
\hline CHEMBL321323 & 58524 & 5.0259 & 4.9993 & TR \\
\hline CHEMBL 320864 & 58524 & 5.0017 & 6.0305 & TRN \\
\hline CHEMBL317401 & 158524 & 6.1308 & 6.1442 & \\
\hline CHEMBL318358 & 158524 & 5.699 & 4.9834 & \\
\hline CHEMBL106494 & 158524 & 6.4815 & 4.0753 & TST \\
\hline
\end{tabular}

Page 2973 


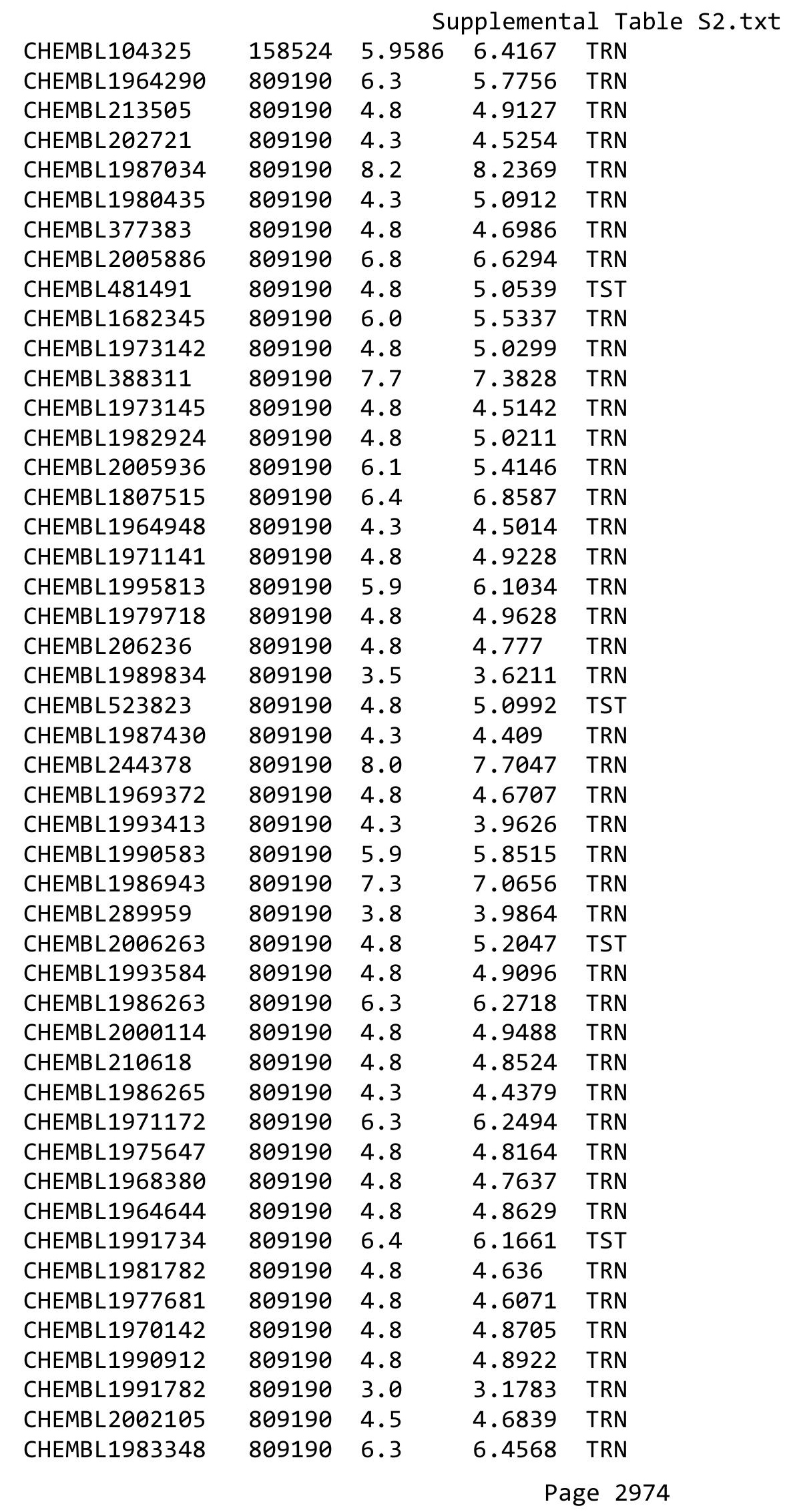




\begin{tabular}{|c|c|c|c|c|c|}
\hline \\
\hline CHEMBL1988163 & 809190 & 7.7 & 7.8811 & TRN & \\
\hline CHEMBL1995592 & 809190 & 5.9 & 5.2257 & TST & \\
\hline CHEMBL1974480 & 809190 & 5.5 & 5.1756 & TRN & \\
\hline CHEMBL 2000934 & 809190 & 4.3 & 4.2874 & TRN & \\
\hline CHEMBL 2006493 & 809190 & 4.8 & 4.9424 & TST & \\
\hline CHEMBL1986177 & 809190 & 4.3 & 4.3351 & TRN & \\
\hline CHEMBL1983449 & 809190 & 4.8 & 4.7271 & TRN & \\
\hline CHEMBL1992323 & 809190 & 4.8 & 4.7021 & TRN & \\
\hline CHEMBL 2003524 & 809190 & 4.8 & 4.8639 & TST & \\
\hline CHEMBL 2002649 & 809190 & 6.3 & 6.3694 & TRN & \\
\hline CHEMBL1983589 & 809190 & 6.2 & 6.5848 & TRN & \\
\hline CHEMBL1989423 & 809190 & 3.8 & 3.7742 & TST & \\
\hline CHEMBL1985367 & 809190 & 4.3 & 4.46399 & 99999999995 & TST \\
\hline CHEMBL1996510 & 809190 & 5.9 & 5.9092 & TST & \\
\hline CHEMBL437747 & 809190 & 4.8 & 4.7631 & TRN & \\
\hline CHEMBL 2005718 & 809190 & 5.9 & 6.1607 & TRN & \\
\hline CHEMBL1995172 & 809190 & 4.3 & 4.0012 & TST & \\
\hline CHEMBL 2001584 & 809190 & 4.3 & 4.5343 & TRN & \\
\hline CHEMBL507936 & 809190 & 4.8 & 4.6739 & TRN & \\
\hline CHEMBL104264 & 809190 & 4.8 & 5.2456 & TST & \\
\hline CHEMBL1967998 & 809190 & 7.2 & 7.5329 & TRN & \\
\hline CHEMBL1994321 & 809190 & 4.8 & 4.8728 & TRN & \\
\hline CHEMBL1978562 & 809190 & 5.6 & 5.3911 & TST & \\
\hline CHEMBL1997129 & 809190 & 6.3 & 6.4765 & TRN & \\
\hline CHEMBL451964 & 809190 & 4.8 & 4.9543 & TRN & \\
\hline CHEMBL1964307 & 809190 & 6.0 & 5.5328 & TRN & \\
\hline CHEMBL1989471 & 809190 & 4.3 & 5.40799 & 99999999995 & TST \\
\hline CHEMBL 2000508 & 809190 & 4.8 & 4.9362 & TRN & \\
\hline CHEMBL 2001547 & 809190 & 4.8 & 4.6935 & TRN & \\
\hline CHEMBL210928 & 809190 & 4.8 & 4.739 & TRN & \\
\hline CHEMBL1978195 & 809190 & 4.3 & 4.6508 & TRN & \\
\hline CHEMBL1994361 & 809190 & 4.8 & 4.5828 & TRN & \\
\hline CHEMBL1986603 & 809190 & 4.8 & 4.5402 & TST & \\
\hline CHEMBL1972840 & 809190 & 4.8 & 4.8191 & TRN & \\
\hline CHEMBL 2003286 & 809190 & 4.8 & 4.6495 & TRN & \\
\hline CHEMBL1992306 & 809190 & 4.8 & 5.0464 & TRN & \\
\hline CHEMBL 206382 & 809190 & 4.8 & 4.7991 & TRN & \\
\hline CHEMBL1998585 & 809190 & 4.8 & 6.0161 & TRN & \\
\hline CHEMBL519697 & 809190 & 4.8 & 4.6946 & TRN & \\
\hline CHEMBL 2004934 & 809190 & 4.8 & 4.4823 & TRN & \\
\hline CHEMBL1987261 & 809190 & 5.3 & 6.2555 & TRN & \\
\hline CHEMBL1977619 & 809190 & 3.8 & 3.7897 & TST & \\
\hline CHEMBL1996345 & 809190 & 4.3 & 4.7994 & TST & \\
\hline CHEMBL1975128 & 809190 & 6.5 & 7.2045 & TRN & \\
\hline CHEMBL 2004025 & 809190 & 4.3 & 4.9115 & TRN & \\
\hline CHEMBL1996048 & 809190 & 4.3 & 5.1804 & TST & \\
\hline CHEMBL1976158 & 809190 & 4.6 & 4.9141 & TST & \\
\hline CHEMBL461876 & 809190 & 4.3 & 4.4554 & TRN & \\
\hline & & & & 2975 & \\
\hline
\end{tabular}




\begin{tabular}{|c|c|c|c|c|c|}
\hline \multirow{3}{*}{$\begin{array}{l}\text { CHEMBL1965033 } \\
\text { CHEMBL } 2001485\end{array}$} & \multirow{3}{*}{$\begin{array}{l}809190 \\
809190\end{array}$} & \multicolumn{4}{|c|}{ Supplemental Table S2.txt } \\
\hline & & 4.3 & \multicolumn{2}{|c|}{3.9819999999999998} & TRN \\
\hline & & 4.8 & 4.6651 & TRN & \\
\hline CHEMBL504950 & 809190 & 4.8 & 4.6208 & TRN & \\
\hline CHEMBL1997335 & 809190 & 6.6 & 5.9067 & TRN & \\
\hline CHEMBL1984363 & 809190 & 4.8 & 4.7594 & TRN & \\
\hline CHEMBL1978099 & 809190 & 6.5 & 6.7591 & TRN & \\
\hline CHEMBL1977041 & 809190 & 4.8 & 5.1907 & TRN & \\
\hline CHEMBL1968070 & 809190 & 4.8 & 4.9674 & TRN & \\
\hline CHEMBL1988608 & 809190 & 4.8 & 5.4573 & TRN & \\
\hline CHEMBL184847 & 809190 & 4.8 & 4.5338 & TRN & \\
\hline CHEMBL1971132 & 809190 & 4.3 & 4.3059 & TRN & \\
\hline CHEMBL1984367 & 809190 & 4.8 & 4.9337 & TRN & \\
\hline CHEMBL1985723 & 809190 & 6.3 & 6.2646 & TRN & \\
\hline CHEMBL226898 & 809190 & 5.9 & 5.6468 & TRN & \\
\hline CHEMBL1991377 & 809190 & 4.3 & 4.3366 & TRN & \\
\hline CHEMBL539474 & 809190 & 4.8 & 5.5427 & TST & \\
\hline CHEMBL575824 & 809190 & 4.8 & 4.8531 & TRN & \\
\hline CHEMBL1988387 & 809190 & 6.8 & 5.3515 & TRN & \\
\hline CHEMBL1973868 & 809190 & 4.3 & 4.1863 & TRN & \\
\hline CHEMBL1972462 & 809190 & 4.3 & 4.4551 & TRN & \\
\hline CHEMBL1977128 & 809190 & 4.3 & 4.9422 & TRN & \\
\hline CHEMBL1990288 & 809190 & 4.8 & 4.4982 & TRN & \\
\hline CHEMBL1970074 & 809190 & 4.8 & 5.2505 & TRN & \\
\hline CHEMBL1965702 & 809190 & 5.7 & 6.2187 & TRN & \\
\hline CHEMBL1986970 & 809190 & 4.8 & 5.3667 & TRN & \\
\hline CHEMBL1958401 & 809190 & 4.8 & 4.1535 & TRN & \\
\hline CHEMBL 2003456 & 809190 & 4.8 & 4.695 & TRN & \\
\hline CHEMBL1966816 & 809190 & 4.8 & 5.0565 & TRN & \\
\hline CHEMBL1972584 & 809190 & 4.8 & 4.8348 & TRN & \\
\hline CHEMBL 2002992 & 809190 & 4.4 & 4.6231 & TRN & \\
\hline CHEMBL560813 & 809190 & 4.8 & 4.6273 & TRN & \\
\hline CHEMBL1982700 & 809190 & 4.3 & 4.4709 & TST & \\
\hline CHEMBL1968791 & 809190 & 4.8 & 4.8376 & TRN & \\
\hline CHEMBL326282 & 809190 & 4.8 & 4.4713 & TST & \\
\hline CHEMBL1977634 & 809190 & 4.3 & 4.2939 & TRN & \\
\hline CHEMBL1992732 & 809190 & 4.8 & 4.7791 & TST & \\
\hline CHEMBL1971186 & 809190 & 4.8 & 4.6197 & TRN & \\
\hline CHEMBL 2003482 & 809190 & 4.8 & 4.6244 & TRN & \\
\hline CHEMBL1976872 & 809190 & 3.8 & 4.3098 & TST & \\
\hline CHEMBL 2006456 & 809190 & 6.0 & 6.3248 & TRN & \\
\hline CHEMBL1969156 & 809190 & 3.8 & 4.2043 & TST & \\
\hline CHEMBL1973211 & 809190 & 4.8 & 5.0161 & TRN & \\
\hline CHEMBL 2007151 & 809190 & 4.8 & 4.8259 & TRN & \\
\hline CHEMBL1998953 & 809190 & 4.3 & 4.9864 & TRN & \\
\hline CHEMBL1971606 & 809190 & 4.3 & 4.3337 & TRN & \\
\hline CHEMBL1972125 & 809190 & 4.8 & 4.7622 & TRN & \\
\hline CHEMBL1976134 & 809190 & 6.0 & 5.8558 & TRN & \\
\hline CHEMBL1965131 & 809190 & 4.8 & 4.7232 & TRN & \\
\hline
\end{tabular}




\begin{tabular}{|c|c|c|c|c|}
\hline \multicolumn{5}{|c|}{ lemental T } \\
\hline CHEMBL1972158 & 809190 & 6.5 & 6.2869 & TRN \\
\hline CHEMBL1981215 & 809190 & 4.3 & 4.2153 & TRN \\
\hline CHEMBL1974457 & 809190 & 4.8 & 5.268 & TRN \\
\hline CHEMBL1999414 & 809190 & 4.3 & 5.7297 & TRN \\
\hline CHEMBL1967336 & 809190 & 4.3 & 4.2373 & TRN \\
\hline CHEMBL 2006581 & 809190 & 4.8 & 4.8866 & TRN \\
\hline CHEMBL1970340 & 809190 & 4.8 & 4.3381 & TRN \\
\hline CHEMBL1967992 & 809190 & 4.3 & 4.5598 & TRN \\
\hline CHEMBL 2005186 & 809190 & 4.8 & 4.6504 & TRN \\
\hline CHEMBL1981671 & 809190 & 4.3 & 4.6962 & TRN \\
\hline CHEMBL 2006450 & 809190 & 4.3 & 3.9579 & TRN \\
\hline CHEMBL1975534 & 809190 & 4.8 & 4.4651 & TRN \\
\hline CHEMBL1993424 & 809190 & 8.1 & 8.1283 & TRN \\
\hline CHEMBL1966703 & 809190 & 4.8 & 4.4748 & TST \\
\hline CHEMBL 2001987 & 809190 & 4.3 & 4.3561 & TRN \\
\hline CHEMBL1969561 & 809190 & 5.9 & 5.3117 & TRN \\
\hline CHEMBL1994555 & 809190 & 4.3 & 4.9411 & TST \\
\hline CHEMBL1975121 & 809190 & 4.3 & 4.5455 & TRN \\
\hline CHEMBL1983640 & 809190 & 4.3 & 4.4429 & TRN \\
\hline CHEMBL1997023 & 809190 & 4.8 & 5.0168 & TST \\
\hline CHEMBL1964687 & 809190 & 4.8 & 4.6561 & TRN \\
\hline CHEMBL1971943 & 809190 & 4.4 & 4.3799 & TRN \\
\hline CHEMBL1999918 & 809190 & 5.9 & 5.1915 & TRN \\
\hline CHEMBL1988537 & 809190 & 4.8 & 4.7528 & TST \\
\hline CHEMBL1969049 & 809190 & 4.8 & 4.7716 & TRN \\
\hline CHEMBL 2005828 & 809190 & 4.8 & 4.8332 & TRN \\
\hline CHEMBL1980178 & 809190 & 5.9 & 6.2351 & TRN \\
\hline CHEMBL1998611 & 809190 & 4.8 & 4.7147 & TRN \\
\hline CHEMBL485556 & 809190 & 4.8 & 4.802 & TRN \\
\hline CHEMBL1975900 & 809190 & 4.8 & 4.5284 & TRN \\
\hline CHEMBL 255822 & 809190 & 4.8 & 4.7685 & TRN \\
\hline CHEMBL1972221 & 809190 & 6.6 & 6.8357 & TRN \\
\hline CHEMBL 2006778 & 809190 & 6.6 & 6.2136 & TRN \\
\hline CHEMBL378627 & 809190 & 4.8 & 4.4943 & TRN \\
\hline CHEMBL1996979 & 809190 & 4.8 & 5.2842 & TRN \\
\hline CHEMBL1968406 & 809190 & 4.8 & 4.6572 & TRN \\
\hline CHEMBL1982476 & 809190 & 7.1 & 7.1152 & TRN \\
\hline CHEMBL1998545 & 809190 & 4.8 & 4.7018 & TRN \\
\hline CHEMBL1986869 & 809190 & 4.8 & 4.6934 & TRN \\
\hline CHEMBL1975923 & 809190 & 5.7 & 5.0878 & TST \\
\hline CHEMBL 2005449 & 809190 & 7.0 & 6.9885 & TRN \\
\hline CHEMBL1987998 & 809190 & 4.3 & 4.3237 & TRN \\
\hline CHEMBL1682558 & 809190 & 4.8 & 5.0763 & TRN \\
\hline CHEMBL1990496 & 809190 & 4.5 & 4.5121 & TRN \\
\hline CHEMBL 242865 & 809190 & 6.1 & 6.0011 & TRN \\
\hline CHEMBL1997623 & 809190 & 6.2 & 5.4734 & TRN \\
\hline CHEMBL1983884 & 809190 & 3.0 & 4.4926 & TST \\
\hline CHEMBL1967094 & 809190 & 4.8 & 4.6202 & TRN \\
\hline
\end{tabular}




\begin{tabular}{|c|c|c|c|c|c|}
\hline & & & & & \\
\hline CHEMBL1982992 & 809190 & 4.8 & 4.7585 & TRN & \\
\hline CHEMBL1998110 & 809190 & 4.3 & 4.4328 & TRN & \\
\hline CHEMBL1999590 & 809190 & 4.8 & 5.3789 & TST & \\
\hline CHEMBL1981079 & 809190 & 4.5 & 5.3125 & TRN & \\
\hline CHEMBL1978166 & 809190 & 5.8 & 5.2298 & TRN & \\
\hline CHEMBL1980489 & 809190 & 4.8 & 4.4815 & TRN & \\
\hline CHEMBL 2000832 & 809190 & 6.4 & 5.8161 & TRN & \\
\hline CHEMBL1967116 & 809190 & 6.9 & 6.3823 & TRN & \\
\hline CHEMBL1990590 & 809190 & 4.3 & 4.103 & TRN & \\
\hline CHEMBL1977814 & 809190 & 4.5 & 4.4828 & TST & \\
\hline CHEMBL1970709 & 809190 & 4.8 & 4.6489 & TRN & \\
\hline CHEMBL1974617 & 809190 & 4.0 & 4.2953 & TRN & \\
\hline CHEMBL1965660 & 809190 & 6.0 & 5.6517 & TRN & \\
\hline CHEMBL1992125 & 809190 & 6.1 & 5.9078 & TRN & \\
\hline CHEMBL1998112 & 809190 & 4.8 & 5.1898 & TRN & \\
\hline CHEMBL1972290 & 809190 & 6.0 & 6.1773 & TRN & \\
\hline CHEMBL1969126 & 809190 & 4.8 & 4.4659 & TRN & \\
\hline CHEMBL1980896 & 809190 & 4.8 & 4.49100 & 00000000005 & TRN \\
\hline CHEMBL1970104 & 809190 & 6.4 & 6.7227 & TRN & \\
\hline CHEMBL1991429 & 809190 & 6.0 & 5.8826 & TRN & \\
\hline CHEMBL1971149 & 809190 & 4.8 & 4.6303 & TRN & \\
\hline CHEMBL1999714 & 809190 & 4.8 & 4.5868 & TRN & \\
\hline CHEMBL1994040 & 809190 & 4.8 & 4.7399 & TRN & \\
\hline CHEMBL388978 & 809190 & 8.7 & 9.1039 & TST & \\
\hline CHEMBL579246 & 809190 & 4.8 & 4.8319 & TRN & \\
\hline CHEMBL398951 & 809190 & 4.4 & 4.7192 & TST & \\
\hline CHEMBL1982506 & 809190 & 4.8 & 4.6331 & TST & \\
\hline CHEMBL2004716 & 809190 & 6.4 & 6.3144 & TRN & \\
\hline CHEMBL1968127 & 809190 & 4.8 & 4.8661 & TRN & \\
\hline CHEMBL1975233 & 809190 & 4.8 & 4.5163 & TRN & \\
\hline CHEMBL1985406 & 809190 & 4.8 & 4.8709 & TRN & \\
\hline CHEMBL 2007603 & 809190 & 4.3 & 4.1547 & TRN & \\
\hline CHEMBL 207400 & 809190 & 4.8 & 4.6008 & TST & \\
\hline CHEMBL1421720 & 809190 & 4.3 & 4.7135 & TRN & \\
\hline CHEMBL1968130 & 809190 & 4.7 & 4.3823 & TST & \\
\hline CHEMBL1982135 & 809190 & 4.8 & 4.66100 & 00000000005 & TRN \\
\hline CHEMBL1976090 & 809190 & 4.8 & 4.6377 & TRN & \\
\hline CHEMBL1993243 & 809190 & 4.8 & 5.4451 & TRN & \\
\hline CHEMBL1992922 & 809190 & 6.4 & 6.0028 & TRN & \\
\hline CHEMBL399021 & 809190 & 4.8 & 4.4955 & TRN & \\
\hline CHEMBL1997597 & 809190 & 6.8 & 7.0626 & TRN & \\
\hline CHEMBL1969537 & 809190 & 4.8 & 4.8629 & TST & \\
\hline CHEMBL576113 & 809190 & 4.3 & 4.6409 & TRN & \\
\hline CHEMBL1976093 & 809190 & 4.8 & 4.7897 & TRN & \\
\hline CHEMBL1975256 & 809190 & 4.8 & 5.0545 & TST & \\
\hline CHEMBL508928 & 809190 & 5.0 & 5.092 & TRN & \\
\hline CHEMBL1991356 & 809190 & 4.8 & 4.6431 & TST & \\
\hline CHEMBL2004892 & 809190 & 6.7 & 6.6039 & TRN & \\
\hline
\end{tabular}




\begin{tabular}{|c|c|c|c|c|}
\hline & & & pplement & al Tá \\
\hline CHEMBL1949855 & 809190 & 5.0 & 4.6487 & TRN \\
\hline CHEMBL1972339 & 809190 & 6.7 & 6.5896 & TRN \\
\hline CHEMBL116070 & 809190 & 4.8 & 4.7001 & TRN \\
\hline CHEMBL1970314 & 809190 & 4.8 & 4.7341 & TRN \\
\hline CHEMBL 2004871 & 809190 & 4.8 & 5.0634 & TRN \\
\hline CHEMBL 2004872 & 809190 & 4.8 & 4.6421 & TRN \\
\hline CHEMBL1727312 & 809190 & 4.0 & 3.8531 & TRN \\
\hline CHEMBL1990223 & 809190 & 4.3 & 4.4519 & TRN \\
\hline CHEMBL1969879 & 809190 & 7.5 & 7.5021 & TRN \\
\hline CHEMBL1964382 & 809190 & 4.3 & 4.6477 & TST \\
\hline CHEMBL101311 & 809190 & 5.6 & 5.4813 & TRN \\
\hline CHEMBL1981720 & 809190 & 4.8 & 4.6207 & TRN \\
\hline CHEMBL262433 & 809190 & 4.8 & 4.6762 & TRN \\
\hline CHEMBL 306380 & 809190 & 4.8 & 4.4475 & TRN \\
\hline CHEMBL1966722 & 809190 & 4.8 & 4.7765 & TST \\
\hline CHEMBL1983595 & 809190 & 4.3 & 4.7863 & TRN \\
\hline CHEMBL1988581 & 809190 & 6.7 & 7.0045 & TST \\
\hline CHEMBL 2005699 & 809190 & 4.3 & 4.3636 & TRN \\
\hline CHEMBL1975500 & 809190 & 4.8 & 5.1583 & TRN \\
\hline CHEMBL1976328 & 809190 & 4.8 & 4.5298 & TRN \\
\hline CHEMBL394619 & 809190 & 4.8 & 4.9655 & TRN \\
\hline CHEMBL 2006564 & 809190 & 6.5 & 6.806 & TRN \\
\hline CHEMBL1964399 & 809190 & 4.8 & 4.8234 & TRN \\
\hline CHEMBL1996831 & 809190 & 4.8 & 4.7481 & TST \\
\hline CHEMBL411903 & 809190 & 6.1 & 6.0091 & TRN \\
\hline CHEMBL1980253 & 809190 & 7.0 & 6.4559 & TRN \\
\hline CHEMBL1978167 & 809190 & 4.3 & 4.9355 & TST \\
\hline CHEMBL1965988 & 809190 & 6.2 & 5.6182 & TRN \\
\hline CHEMBL418203 & 809190 & 4.4 & 5.1318 & TST \\
\hline CHEMBL1989646 & 809190 & 6.1 & 6.518 & TRN \\
\hline CHEMBL1682357 & 809190 & 4.8 & 5.4545 & TRN \\
\hline CHEMBL225519 & 809190 & 5.6 & 5.1084 & TRN \\
\hline CHEMBL 209534 & 809190 & 4.8 & 4.7167 & TRN \\
\hline CHEMBL1978200 & 809190 & 4.8 & 4.7188 & TRN \\
\hline CHEMBL1970522 & 809190 & 4.8 & 4.8458 & TRN \\
\hline CHEMBL402846 & 809190 & 4.8 & 4.6148 & TRN \\
\hline CHEMBL1996931 & 809190 & 4.8 & 4.5214 & TRN \\
\hline CHEMBL1964692 & 809190 & 5.9 & 5.7178 & TRN \\
\hline CHEMBL1971223 & 809190 & 4.3 & 4.9419 & TRN \\
\hline CHEMBL1964413 & 809190 & 4.8 & 4.5698 & TRN \\
\hline CHEMBL1973483 & 809190 & 4.8 & 5.0032 & TRN \\
\hline CHEMBL1998470 & 809190 & 4.3 & 4.282 & TRN \\
\hline CHEMBL1996980 & 809190 & 7.2 & 6.7323 & TRN \\
\hline CHEMBL1984432 & 809190 & 4.8 & 4.8405 & TRN \\
\hline CHEMBL 219722 & 809190 & 5.9 & 5.5803 & TRN \\
\hline CHEMBL1975903 & 809190 & 4.3 & 4.4972 & TRN \\
\hline CHEMBL1994669 & 809190 & 8.5 & 8.5333 & TRN \\
\hline CHEMBL1997340 & 809190 & 4.8 & 5.0527 & TRN \\
\hline
\end{tabular}




\begin{tabular}{|c|c|c|c|c|}
\hline \multicolumn{5}{|c|}{ Supplemental Table S2.txt } \\
\hline CHEMBL1522508 & 809190 & 4.8 & 4.282 & TRN \\
\hline CHEMBL1989474 & 809190 & 4.8 & 4.7924 & TRN \\
\hline CHEMBL1090360 & 809190 & 4.8 & 5.2149 & TRN \\
\hline CHEMBL 210887 & 809190 & 4.8 & 4.9009 & TRN \\
\hline CHEMBL1988805 & 809190 & 4.3 & 4.6974 & TST \\
\hline CHEMBL458997 & 809190 & 4.6 & 4.6816 & TRN \\
\hline CHEMBL1971021 & 809190 & 4.8 & 4.6381 & TRN \\
\hline CHEMBL227271 & 809190 & 4.8 & 5.1561 & TRN \\
\hline CHEMBL583144 & 809190 & 4.8 & 4.6093 & TRN \\
\hline CHEMBL1974310 & 809190 & 4.8 & 4.9357 & TRN \\
\hline CHEMBL1969942 & 809190 & 4.3 & 4.4884 & TRN \\
\hline CHEMBL1978567 & 809190 & 4.3 & 4.4328 & TRN \\
\hline CHEMBL1982660 & 809190 & 4.8 & 4.9486 & TRN \\
\hline CHEMBL1994693 & 809190 & 4.8 & 4.9315 & TRN \\
\hline CHEMBL1982957 & 809190 & 6.9 & 5.6966 & TRN \\
\hline CHEMBL 2002346 & 809190 & 7.5 & 6.9296 & TRN \\
\hline CHEMBL1975138 & 809190 & 4.8 & 4.7928 & TST \\
\hline CHEMBL424872 & 809190 & 4.4 & 4.6082 & TRN \\
\hline CHEMBL1971947 & 809190 & 4.8 & 5.2584 & TRN \\
\hline CHEMBL412142 & 809190 & 4.8 & 4.6834 & TST \\
\hline CHEMBL1980704 & 809190 & 4.8 & 4.7499 & TST \\
\hline CHEMBL 2003271 & 809190 & 4.8 & 4.6994 & TRN \\
\hline CHEMBL1972365 & 809190 & 3.8 & 4.8628 & TST \\
\hline CHEMBL1966808 & 809190 & 4.8 & 4.5233 & TST \\
\hline CHEMBL 2004447 & 809190 & 4.8 & 4.8302 & TRN \\
\hline CHEMBL1992231 & 809190 & 4.3 & 5.1875 & TRN \\
\hline CHEMBL1983111 & 809190 & 7.6 & 7.4592 & TRN \\
\hline CHEMBL1973860 & 809190 & 4.8 & 5.065 & TRN \\
\hline CHEMBL260135 & 809190 & 4.8 & 4.7993 & TRN \\
\hline CHEMBL220241 & 809190 & 4.8 & 4.5931 & TRN \\
\hline CHEMBL1988141 & 809190 & 6.2 & 6.1547 & TST \\
\hline CHEMBL1982610 & 809190 & 4.8 & 4.8091 & TST \\
\hline CHEMBL1977134 & 809190 & 4.3 & 4.4208 & TRN \\
\hline CHEMBL1999496 & 809190 & 4.8 & 5.0299 & TRN \\
\hline CHEMBL 2006933 & 809190 & 4.8 & 5.0629 & TST \\
\hline CHEMBL1985206 & 809190 & 4.3 & 4.1171 & TST \\
\hline CHEMBL1988300 & 809190 & 4.8 & 5.0202 & TRN \\
\hline CHEMBL1991078 & 809190 & 6.0 & 5.8815 & TRN \\
\hline CHEMBL1977749 & 809190 & 4.3 & 5.1872 & TST \\
\hline CHEMBL 2000685 & 809190 & 6.7 & 6.4821 & TRN \\
\hline CHEMBL2001613 & 809190 & 4.6 & 4.3289 & TRN \\
\hline CHEMBL1997275 & 809190 & 4.3 & 4.2171 & TRN \\
\hline CHEMBL1993904 & 809190 & 4.3 & 4.4794 & TRN \\
\hline CHEMBL1994438 & 809190 & 6.0 & 5.699 & TRN \\
\hline CHEMBL1967513 & 809190 & 4.3 & 4.2125 & TRN \\
\hline CHEMBL 2000724 & 809190 & 4.3 & 4.3149 & TRN \\
\hline CHEMBL1985311 & 809190 & 4.8 & 4.9042 & TRN \\
\hline CHEMBL1982413 & 809190 & 5.9 & 5.2622 & TRN \\
\hline
\end{tabular}




\begin{tabular}{|c|c|c|c|c|}
\hline & & & pplement & al $\mathrm{Ta}$ \\
\hline CHEMBL1969502 & 809190 & 6.7 & 6.6312 & TST \\
\hline CHEMBL1965910 & 809190 & 4.8 & 4.4473 & TRN \\
\hline CHEMBL1682553 & 809190 & 4.8 & 4.6336 & TRN \\
\hline CHEMBL1983963 & 809190 & 4.8 & 5.529 & TRN \\
\hline CHEMBL1997764 & 809190 & 4.8 & 5.0343 & TRN \\
\hline CHEMBL 2000271 & 809190 & 4.8 & 5.3484 & TRN \\
\hline CHEMBL562488 & 809190 & 3.8 & 4.282 & TRN \\
\hline CHEMBL1981792 & 809190 & 5.4 & 4.7842 & TRN \\
\hline CHEMBL1987535 & 809190 & 4.3 & 4.8037 & TRN \\
\hline CHEMBL1985092 & 809190 & 4.8 & 4.8515 & TRN \\
\hline CHEMBL1981410 & 809190 & 4.8 & 4.9604 & TRN \\
\hline CHEMBL 2002586 & 809190 & 4.3 & 4.4821 & TRN \\
\hline CHEMBL1996234 & 809190 & 4.8 & 4.5965 & TRN \\
\hline CHEMBL 383264 & 809190 & 4.3 & 4.5593 & TRN \\
\hline CHEMBL 2007421 & 809190 & 5.7 & 5.4375 & TST \\
\hline CHEMBL1991434 & 809190 & 4.8 & 4.9409 & TST \\
\hline CHEMBL1967544 & 809190 & 4.8 & 4.7527 & TRN \\
\hline CHEMBL1973138 & 809190 & 4.3 & 4.4864 & TRN \\
\hline CHEMBL 223367 & 809190 & 4.8 & 5.4844 & TST \\
\hline CHEMBL1992673 & 809190 & 4.4 & 3.9469 & TRN \\
\hline CHEMBL1969151 & 809190 & 5.8 & 6.3509 & TRN \\
\hline CHEMBL1996587 & 809190 & 4.8 & 4.5744 & TRN \\
\hline CHEMBL1993335 & 809190 & 5.7 & 5.3041 & TST \\
\hline CHEMBL1988692 & 809190 & 4.3 & 4.3336 & TRN \\
\hline CHEMBL 2007574 & 809190 & 4.3 & 4.9722 & TRN \\
\hline CHEMBL1964804 & 809190 & 4.8 & 4.3806 & TRN \\
\hline CHEMBL443962 & 809190 & 4.8 & 4.582 & TST \\
\hline CHEMBL 2000354 & 809190 & 4.8 & 4.9143 & TRN \\
\hline CHEMBL1965507 & 809190 & 6.3 & 5.6311 & TRN \\
\hline CHEMBL 274064 & 809190 & 4.8 & 4.6668 & TRN \\
\hline CHEMBL1998680 & 809190 & 4.3 & 4.3844 & TRN \\
\hline CHEMBL1967564 & 809190 & 4.8 & 4.654 & TRN \\
\hline CHEMBL592030 & 809190 & 4.4 & 5.2604 & TST \\
\hline CHEMBL 2000071 & 809190 & 6.3 & 5.7549 & TRN \\
\hline CHEMBL1979176 & 809190 & 4.8 & 4.7668 & TRN \\
\hline CHEMBL1970317 & 809190 & 4.3 & 5.1765 & TRN \\
\hline CHEMBL 2002613 & 809190 & 4.3 & 4.5844 & TRN \\
\hline CHEMBL 248757 & 809190 & 4.8 & 5.4246 & TST \\
\hline CHEMBL1978014 & 809190 & 4.8 & 4.7425 & TRN \\
\hline CHEMBL 2002736 & 809190 & 4.3 & 4.4856 & TRN \\
\hline CHEMBL1997007 & 809190 & 5.5 & 5.2625 & TRN \\
\hline CHEMBL1994538 & 809190 & 4.8 & 5.0126 & TRN \\
\hline CHEMBL1964444 & 809190 & 4.5 & 4.4482 & TRN \\
\hline CHEMBL 2002690 & 809190 & 4.3 & 4.2718 & TRN \\
\hline CHEMBL 2006567 & 809190 & 4.8 & 4.9001 & TRN \\
\hline CHEMBL1986139 & 809190 & 4.8 & 4.3938 & TRN \\
\hline CHEMBL 383527 & 809190 & 4.8 & 4.815 & TRN \\
\hline CHEMBL1980540 & 809190 & 4.8 & 4.8182 & TRN \\
\hline
\end{tabular}




\begin{tabular}{|c|c|c|c|c|c|}
\hline \multicolumn{6}{|c|}{ Supplemental Table S2.txt } \\
\hline CHEMBL 278041 & 809190 & 4.3 & 4.3265 & TRN & \\
\hline CHEMBL1979883 & 809190 & 4.9 & 4.9252 & TRN & \\
\hline CHEMBL1984162 & 809190 & 8.0 & 7.4368 & TRN & \\
\hline CHEMBL1998432 & 809190 & 7.4 & 6.7647 & TRN & \\
\hline CHEMBL491758 & 809190 & 6.5 & 6.4276 & TRN & \\
\hline CHEMBL1986590 & 809190 & 4.3 & 4.4571 & TRN & \\
\hline CHEMBL549730 & 809190 & 4.8 & 4.5597 & TRN & \\
\hline CHEMBL1970189 & 809190 & 4.8 & 4.6347 & TRN & \\
\hline CHEMBL1870106 & 809190 & 4.3 & 4.7301 & TRN & \\
\hline CHEMBL1996791 & 809190 & 4.8 & 5.0106 & TRN & \\
\hline CHEMBL371206 & 809190 & 4.8 & 4.7576 & TRN & \\
\hline CHEMBL1974664 & 809190 & 4.8 & 5.391 & TST & \\
\hline CHEMBL406845 & 809190 & 4.3 & 3.9925 & TRN & \\
\hline CHEMBL482538 & 809190 & 4.7 & 4.8899 & TRN & \\
\hline CHEMBL1974288 & 809190 & 4.8 & 4.9 & TRN & \\
\hline CHEMBL1984296 & 809190 & 4.3 & 5.2946 & TST & \\
\hline CHEMBL196363 & 809190 & 6.2 & 5.6891 & TRN & \\
\hline CHEMBL1996837 & 809190 & 3.8 & 3.6175 & TRN & \\
\hline CHEMBL1190711 & 809190 & 4.8 & 4.9747 & TRN & \\
\hline CHEMBL1990346 & 809190 & 4.8 & 4.8468 & TRN & \\
\hline CHEMBL1968705 & 809190 & 4.3 & 4.566 & TRN & \\
\hline CHEMBL1991410 & 809190 & 4.3 & 3.7411 & TRN & \\
\hline CHEMBL1964441 & 809190 & 4.3 & 4.7141 & TRN & \\
\hline CHEMBL546797 & 809190 & 4.3 & 4.7285 & TRN & \\
\hline CHEMBL404367 & 809190 & 4.8 & 4.9631 & TRN & \\
\hline CHEMBL1966343 & 809190 & 6.5 & 6.0087 & TRN & \\
\hline CHEMBL1978271 & 809190 & 4.3 & 4.7222 & TRN & \\
\hline CHEMBL1967887 & 809190 & 4.8 & 5.197 & TRN & \\
\hline CHEMBL 2007266 & 809190 & 4.3 & 4.0804 & TRN & \\
\hline CHEMBL1985469 & 809190 & 4.3 & 4.6632 & TST & \\
\hline CHEMBL 2000568 & 809190 & 4.5 & 4.76699 & 99999999995 & TRN \\
\hline CHEMBL1994308 & 809190 & 4.3 & 4.4637 & TST & \\
\hline CHEMBL 2000335 & 809190 & 4.8 & 5.2353 & TRN & \\
\hline CHEMBL1988717 & 809190 & 6.0 & 5.8946 & TRN & \\
\hline CHEMBL1974328 & 809190 & 6.0 & 5.3682 & TRN & \\
\hline CHEMBL509032 & 809190 & 6.7 & 5.7733 & TRN & \\
\hline CHEMBL 243298 & 809190 & 7.1 & 6.6641 & TRN & \\
\hline CHEMBL1973808 & 809190 & 4.8 & 4.3496 & TRN & \\
\hline CHEMBL1972576 & 809190 & 4.8 & 5.4147 & TRN & \\
\hline CHEMBL1992342 & 809190 & 7.2 & 7.7419 & TRN & \\
\hline CHEMBL1988173 & 809190 & 4.8 & 4.7231 & TST & \\
\hline CHEMBL1973013 & 809190 & 4.3 & 4.5857 & TST & \\
\hline CHEMBL1966204 & 809190 & 6.0 & 5.5301 & TRN & \\
\hline CHEMBL1965423 & 809190 & 4.8 & 4.8674 & TRN & \\
\hline CHEMBL1983025 & 809190 & 4.8 & 5.2878 & TRN & \\
\hline CHEMBL1975927 & 809190 & 6.4 & 6.5969 & TRN & \\
\hline CHEMBL205415 & 809190 & 4.5 & 4.9045 & TRN & \\
\hline CHEMBL2001920 & 809190 & 4.8 & 4.8476 & TRN & \\
\hline
\end{tabular}




\begin{tabular}{|c|c|c|c|c|}
\hline \multicolumn{5}{|c|}{ emental T } \\
\hline CHEMBL 2002322 & 809190 & 4.8 & 4.9762 & TRN \\
\hline CHEMBL1977138 & 809190 & 6.8 & 6.2149 & TST \\
\hline CHEMBL 2002323 & 809190 & 4.8 & 4.6581 & TST \\
\hline CHEMBL1241473 & 809190 & 7.2 & 7.2069 & TRN \\
\hline CHEMBL1978448 & 809190 & 4.6 & 4.4648 & TST \\
\hline CHEMBL1980329 & 809190 & 7.7 & 7.4356 & TRN \\
\hline CHEMBL 2004515 & 809190 & 5.4 & 5.1953 & TRN \\
\hline CHEMBL 2001257 & 809190 & 4.8 & 4.7613 & TRN \\
\hline CHEMBL1992042 & 809190 & 4.3 & 5.2417 & TST \\
\hline CHEMBL 2005548 & 809190 & 4.8 & 4.377 & TRN \\
\hline CHEMBL1992536 & 809190 & 4.8 & 4.7771 & TRN \\
\hline CHEMBL21156 & 809190 & 7.4 & 6.6881 & TST \\
\hline CHEMBL1992740 & 809190 & 4.8 & 4.8218 & TRN \\
\hline CHEMBL1994724 & 809190 & 4.3 & 4.5167 & TRN \\
\hline CHEMBL1989267 & 809190 & 5.3 & 5.0554 & TRN \\
\hline CHEMBL439340 & 809190 & 4.8 & 4.5573 & TRN \\
\hline CHEMBL1974574 & 809190 & 4.3 & 5.0398 & TST \\
\hline CHEMBL 2006188 & 809190 & 4.8 & 4.7596 & TRN \\
\hline CHEMBL1970290 & 809190 & 5.7 & 5.6368 & TRN \\
\hline CHEMBL1967531 & 809190 & 4.8 & 4.8768 & TRN \\
\hline CHEMBL1970913 & 809190 & 4.8 & 4.9357 & TRN \\
\hline CHEMBL1973893 & 809190 & 7.3 & 7.2408 & TRN \\
\hline CHEMBL1997534 & 809190 & 5.9 & 5.7952 & TRN \\
\hline CHEMBL1993877 & 809190 & 4.3 & 4.1034 & TRN \\
\hline CHEMBL1996500 & 809190 & 4.4 & 4.4949 & TRN \\
\hline CHEMBL1985095 & 809190 & 4.8 & 5.716 & TST \\
\hline CHEMBL1965469 & 809190 & 5.3 & 4.95 & TRN \\
\hline CHEMBL1991180 & 809190 & 6.1 & 5.5644 & TST \\
\hline CHEMBL1989708 & 809190 & 4.6 & 5.0988 & TRN \\
\hline CHEMBL1682540 & 809190 & 4.8 & 4.9631 & TRN \\
\hline CHEMBL1976420 & 809190 & 4.5 & 5.7799 & TST \\
\hline CHEMBL1998253 & 809190 & 4.3 & 4.8519 & TST \\
\hline CHEMBL413779 & 809190 & 4.8 & 5.1864 & TST \\
\hline CHEMBL1981744 & 809190 & 5.4 & 4.8688 & TRN \\
\hline CHEMBL1994864 & 809190 & 4.8 & 4.6836 & TRN \\
\hline CHEMBL 2002446 & 809190 & 4.8 & 4.9328 & TST \\
\hline CHEMBL497151 & 809190 & 4.8 & 4.8719 & TRN \\
\hline CHEMBL 2000029 & 809190 & 6.9 & 6.4937 & TRN \\
\hline CHEMBL1973961 & 809190 & 4.3 & 4.1291 & TRN \\
\hline CHEMBL 246970 & 809190 & 4.8 & 4.997 & TRN \\
\hline CHEMBL340921 & 809190 & 4.8 & 5.2778 & TST \\
\hline CHEMBL1994977 & 809190 & 4.3 & 4.9071 & TRN \\
\hline CHEMBL373598 & 809190 & 4.8 & 5.1219 & TST \\
\hline CHEMBL 2001149 & 809190 & 4.3 & 4.4395 & TRN \\
\hline CHEMBL1999718 & 809190 & 4.8 & 4.6868 & TRN \\
\hline CHEMBL1987073 & 809190 & 4.3 & 4.9272 & TRN \\
\hline CHEMBL 2005478 & 809190 & 4.3 & 4.9216 & TST \\
\hline CHEMBL1276446 & 809190 & 7.6 & 6.8772 & TST \\
\hline
\end{tabular}




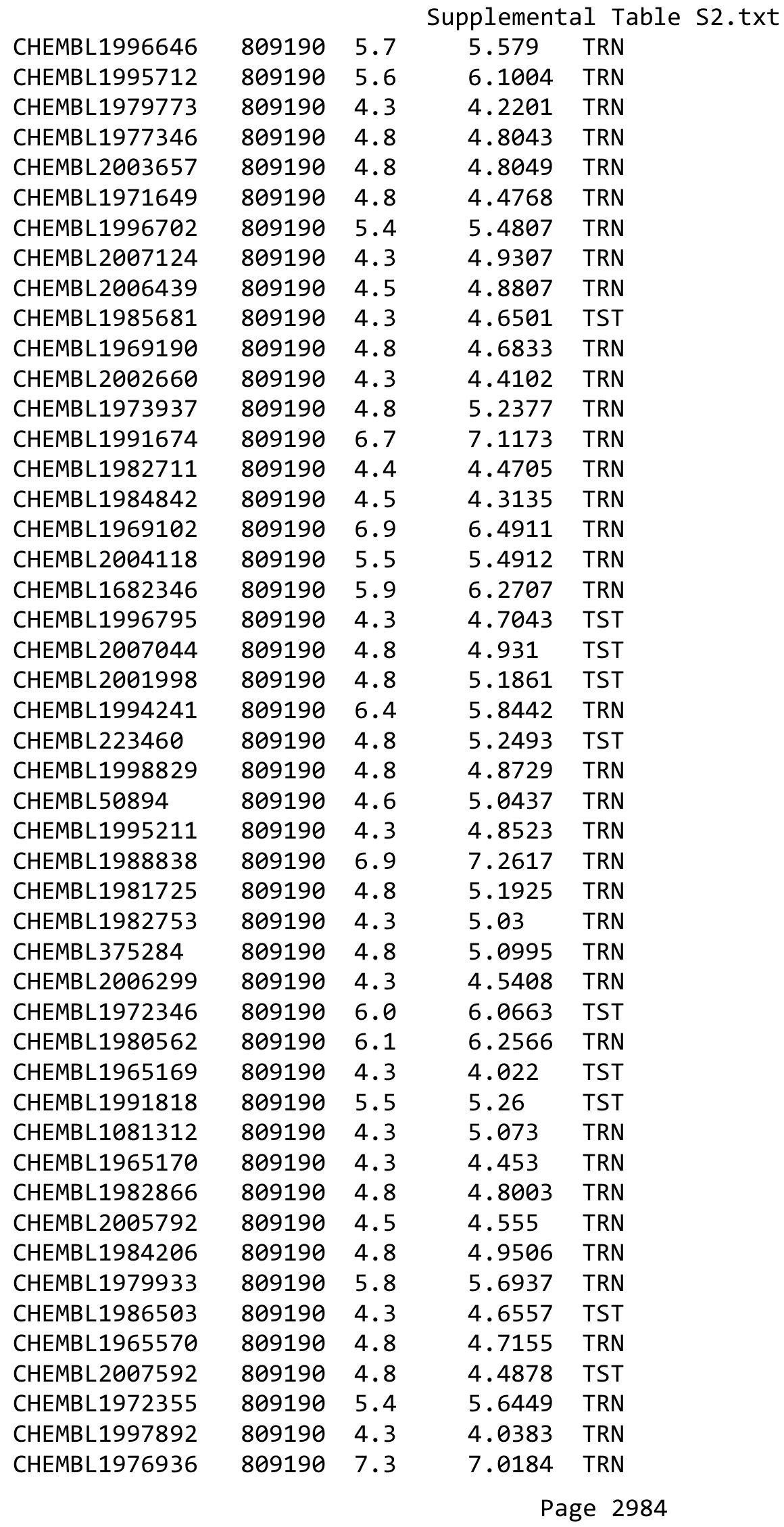




\begin{tabular}{|c|c|c|c|c|}
\hline & & & 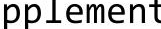 & al \\
\hline CHEMBL1997193 & 809190 & 4.3 & 5.4085 & TST \\
\hline CHEMBL210963 & 809190 & 4.8 & 4.731 & TRN \\
\hline CHEMBL1964902 & 809190 & 4.3 & 4.4068 & TRN \\
\hline CHEMBL1082440 & 809190 & 4.9 & 5.5789 & TST \\
\hline CHEMBL1614705 & 809190 & 4.8 & 4.7993 & TRN \\
\hline CHEMBL1972362 & 809190 & 4.8 & 4.5924 & TRN \\
\hline CHEMBL1984633 & 809190 & 4.8 & 4.7122 & TRN \\
\hline CHEMBL1972988 & 809190 & 4.3 & 5.0931 & TRN \\
\hline CHEMBL1965845 & 809190 & 4.8 & 5.4432 & TRN \\
\hline CHEMBL1983715 & 809190 & 6.5 & 6.6731 & TRN \\
\hline CHEMBL1971017 & 809190 & 5.8 & 5.3791 & TRN \\
\hline CHEMBL 2006715 & 809190 & 6.3 & 5.729 & TRN \\
\hline CHEMBL1990482 & 809190 & 4.8 & 4.4442 & TRN \\
\hline CHEMBL1990904 & 809190 & 4.8 & 4.5699 & TRN \\
\hline CHEMBL 2000104 & 809190 & 4.8 & 4.5632 & TRN \\
\hline CHEMBL 2005475 & 809190 & 4.8 & 4.7992 & TRN \\
\hline CHEMBL1987448 & 809190 & 5.5 & 5.5559 & TRN \\
\hline CHEMBL183844 & 809190 & 4.8 & 4.6355 & TRN \\
\hline CHEMBL220057 & 809190 & 4.9 & 5.426 & TRN \\
\hline CHEMBL1682545 & 809190 & 4.8 & 4.6505 & TRN \\
\hline CHEMBL 383541 & 809190 & 4.8 & 4.9731 & TRN \\
\hline CHEMBL 2001224 & 809190 & 4.8 & 4.4787 & TRN \\
\hline CHEMBL10 & 809190 & 4.3 & 4.2901 & TRN \\
\hline CHEMBL1976732 & 809190 & 4.8 & 4.7555 & TRN \\
\hline CHEMBL 2005216 & 809190 & 6.8 & 6.5613 & TRN \\
\hline CHEMBL1969506 & 809190 & 4.8 & 4.9655 & TRN \\
\hline CHEMBL1980763 & 809190 & 5.7 & 5.3571 & TRN \\
\hline CHEMBL1964937 & 809190 & 5.8 & 5.4437 & TRN \\
\hline CHEMBL1980163 & 809190 & 4.8 & 4.5913 & TRN \\
\hline CHEMBL590109 & 809190 & 6.0 & 5.4763 & TST \\
\hline CHEMBL1977931 & 809190 & 4.1 & 4.3477 & TRN \\
\hline CHEMBL1970879 & 809190 & 4.8 & 4.1627 & TRN \\
\hline CHEMBL1989856 & 809190 & 7.0 & 5.0549 & TST \\
\hline CHEMBL 2005899 & 809190 & 4.8 & 4.5992 & TRN \\
\hline CHEMBL1682552 & 809190 & 4.8 & 4.4814 & TRN \\
\hline CHEMBL259850 & 809190 & 4.8 & 4.6361 & TRN \\
\hline CHEMBL 2007479 & 809190 & 4.3 & 4.7107 & TRN \\
\hline CHEMBL229799 & 809190 & 6.1 & 5.8557 & TRN \\
\hline CHEMBL105739 & 809190 & 6.2 & 6.0549 & TRN \\
\hline CHEMBL1682359 & 809190 & 4.8 & 4.8788 & TRN \\
\hline CHEMBL1972220 & 809190 & 4.3 & 4.7299 & TRN \\
\hline CHEMBL379300 & 809190 & 6.5 & 5.7358 & TRN \\
\hline CHEMBL203673 & 809190 & 4.8 & 4.6948 & TRN \\
\hline CHEMBL 2003785 & 809190 & 4.2 & 4.5995 & TST \\
\hline CHEMBL1973720 & 809190 & 6.8 & 6.5364 & TRN \\
\hline CHEMBL1969523 & 809190 & 4.8 & 5.1712 & TRN \\
\hline CHEMBL207995 & 809190 & 4.8 & 4.6483 & TRN \\
\hline CHEMBL2001923 & 809190 & 4.5 & 4.4393 & TRN \\
\hline
\end{tabular}




\begin{tabular}{|c|c|c|c|c|}
\hline & & & pplement & \\
\hline CHEMBL1986781 & 809190 & 4.8 & 4.8131 & TRN \\
\hline CHEMBL1983070 & 809190 & 4.3 & 4.1135 & TRN \\
\hline CHEMBL526133 & 809190 & 4.8 & 4.7613 & TRN \\
\hline CHEMBL 2003514 & 809190 & 4.3 & 4.4235 & TRN \\
\hline CHEMBL1989043 & 809190 & 4.3 & 4.2501 & TRN \\
\hline CHEMBL1979057 & 809190 & 4.8 & 4.8014 & TRN \\
\hline CHEMBL1981045 & 809190 & 4.8 & 4.9308 & TRN \\
\hline CHEMBL387971 & 809190 & 4.8 & 4.9677 & TST \\
\hline CHEMBL1975418 & 809190 & 4.8 & 5.8558 & TRN \\
\hline CHEMBL1992796 & 809190 & 4.8 & 4.7314 & TRN \\
\hline CHEMBL1164180 & 809190 & 6.3 & 6.2214 & TST \\
\hline CHEMBL223257 & 809190 & 4.8 & 5.0525 & TST \\
\hline CHEMBL1967560 & 809190 & 4.8 & 4.7661 & TRN \\
\hline CHEMBL1997611 & 809190 & 4.3 & 4.8114 & TST \\
\hline CHEMBL1516890 & 809190 & 4.8 & 5.1433 & TRN \\
\hline CHEMBL211378 & 809190 & 4.8 & 4.7644 & TRN \\
\hline CHEMBL1982465 & 809190 & 5.9 & 5.4845 & TRN \\
\hline CHEMBL 2001751 & 809190 & 7.3 & 6.6594 & TRN \\
\hline CHEMBL1984586 & 809190 & 4.8 & 4.8182 & TRN \\
\hline CHEMBL1999774 & 809190 & 4.8 & 4.8182 & TST \\
\hline CHEMBL1972659 & 809190 & 4.8 & 5.1887 & TST \\
\hline CHEMBL 2002723 & 809190 & 5.7 & 5.2194 & TST \\
\hline CHEMBL1973395 & 809190 & 7.2 & 6.4581 & TRN \\
\hline CHEMBL 272453 & 809190 & 4.8 & 4.9473 & TRN \\
\hline CHEMBL1970217 & 809190 & 4.8 & 4.852 & TRN \\
\hline CHEMBL1968850 & 809190 & 4.8 & 4.5921 & TRN \\
\hline CHEMBL 2005528 & 809190 & 4.8 & 5.2723 & TST \\
\hline CHEMBL1984686 & 809190 & 4.3 & 4.4277 & TRN \\
\hline CHEMBL185569 & 809190 & 4.8 & 5.1252 & TRN \\
\hline CHEMBL1969843 & 809190 & 4.8 & 4.6491 & TRN \\
\hline CHEMBL 2007002 & 809190 & 4.8 & 5.0031 & TRN \\
\hline CHEMBL1987007 & 809190 & 4.8 & 5.0918 & TRN \\
\hline CHEMBL1973793 & 809190 & 4.3 & 4.5433 & TST \\
\hline CHEMBL1969588 & 809190 & 8.1 & 7.7649 & TRN \\
\hline CHEMBL1984711 & 809190 & 4.8 & 5.2786 & TRN \\
\hline CHEMBL1992073 & 809190 & 8.4 & 8.0921 & TRN \\
\hline CHEMBL484390 & 809190 & 4.8 & 4.962 & TRN \\
\hline CHEMBL1979252 & 809190 & 4.8 & 4.8156 & TRN \\
\hline CHEMBL1986143 & 809190 & 4.3 & 4.5101 & TRN \\
\hline CHEMBL1972934 & 809190 & 4.1 & 4.1539 & TRN \\
\hline CHEMBL2007559 & 809190 & 4.3 & 4.2549 & TRN \\
\hline CHEMBL1992581 & 809190 & 4.3 & 4.1783 & TRN \\
\hline CHEMBL1682341 & 809190 & 4.8 & 5.3477 & TRN \\
\hline CHEMBL 2004290 & 809190 & 4.3 & 4.662 & TRN \\
\hline CHEMBL1986499 & 809190 & 6.5 & 6.5986 & TRN \\
\hline CHEMBL1972937 & 809190 & 4.8 & 4.8897 & TRN \\
\hline CHEMBL1972250 & 809190 & 4.8 & 4.9746 & TST \\
\hline CHEMBL 2000393 & 809190 & 8.3 & 6.608 & TST \\
\hline
\end{tabular}




\begin{tabular}{|c|c|c|c|c|c|}
\hline \multicolumn{6}{|c|}{ Supplemental Table S2.txt } \\
\hline CHEMBL2004311 & 809190 & 4.8 & 4.7763 & TRN & \\
\hline CHEMBL1992634 & 809190 & 6.3 & 6.0757 & TRN & \\
\hline CHEMBL1242373 & 809190 & 4.8 & 4.6583 & TRN & \\
\hline CHEMBL1984847 & 809190 & 4.3 & 4.1317 & TRN & \\
\hline CHEMBL 316264 & 809190 & 4.8 & 4.4537 & TRN & \\
\hline CHEMBL1988075 & 809190 & 4.8 & 5.2677 & TRN & \\
\hline CHEMBL1996576 & 809190 & 4.3 & 4.6763 & TST & \\
\hline CHEMBL1991678 & 809190 & 4.3 & 4.4899 & TRN & \\
\hline CHEMBL2001239 & 809190 & 4.8 & 5.095 & TRN & \\
\hline CHEMBL1988594 & 809190 & 6.0 & 5.3383 & TRN & \\
\hline CHEMBL 2001288 & 809190 & 4.8 & 4.6731 & TRN & \\
\hline CHEMBL1992363 & 809190 & 6.3 & 6.1068 & TRN & \\
\hline CHEMBL 260092 & 809190 & 6.3 & 6.1365 & TRN & \\
\hline CHEMBL1999811 & 809190 & 4.8 & 4.6716 & TRN & \\
\hline CHEMBL1965495 & 809190 & 5.8 & 5.2462 & TRN & \\
\hline CHEMBL 235157 & 809190 & 4.3 & 4.636 & TST & \\
\hline CHEMBL1985074 & 809190 & 4.8 & 4.9366 & TST & \\
\hline CHEMBL 2000481 & 809190 & 4.8 & 4.6687 & TRN & \\
\hline CHEMBL1982874 & 809190 & 4.8 & 5.0181 & TRN & \\
\hline CHEMBL1991725 & 809190 & 4.8 & 4.4777 & TRN & \\
\hline CHEMBL1992242 & 809190 & 4.8 & 4.6201 & TRN & \\
\hline CHEMBL1982271 & 809190 & 7.0 & 6.50799 & 9999999999 & TRN \\
\hline CHEMBL 2007296 & 809190 & 4.8 & 4.6059 & TRN & \\
\hline CHEMBL2004159 & 809190 & 4.3 & 4.466 & TRN & \\
\hline CHEMBL396523 & 809190 & 7.7 & 7.579 & TRN & \\
\hline CHEMBL1978371 & 809190 & 4.3 & 4.7367 & TST & \\
\hline CHEMBL1970203 & 809190 & 4.8 & 5.4669 & TRN & \\
\hline CHEMBL1986530 & 809190 & 4.8 & 4.8623 & TST & \\
\hline CHEMBL440084 & 809190 & 4.3 & 3.923 & TRN & \\
\hline CHEMBL1968590 & 809190 & 4.8 & 5.2541 & TRN & \\
\hline CHEMBL385478 & 809190 & 6.8 & 6.0682 & TRN & \\
\hline CHEMBL1999749 & 809190 & 4.8 & 4.6221 & TRN & \\
\hline CHEMBL 2005375 & 809190 & 4.8 & 4.6001 & TRN & \\
\hline CHEMBL1984191 & 809190 & 4.8 & 4.6708 & TRN & \\
\hline CHEMBL1983006 & 809190 & 4.8 & 4.8501 & TRN & \\
\hline CHEMBL1966501 & 809190 & 5.6 & 4.6064 & TRN & \\
\hline CHEMBL1971029 & 809190 & 7.9 & 7.6152 & TRN & \\
\hline CHEMBL394790 & 809190 & 4.8 & 4.7108 & TRN & \\
\hline CHEMBL226471 & 809190 & 4.8 & 4.6194 & TRN & \\
\hline CHEMBL1974702 & 809190 & 4.8 & 4.9221 & TRN & \\
\hline CHEMBL1996111 & 809190 & 6.0 & 5.3653 & TRN & \\
\hline CHEMBL1966175 & 809190 & 8.5 & 8.3717 & TRN & \\
\hline CHEMBL1965589 & 809190 & 4.8 & 4.8275 & TRN & \\
\hline CHEMBL 2007375 & 809190 & 4.3 & 4.2324 & TRN & \\
\hline CHEMBL 379975 & 809190 & 6.6 & 6.1071 & TST & \\
\hline CHEMBL474432 & 809190 & 6.4 & 6.6241 & TST & \\
\hline CHEMBL1973016 & 809190 & 4.3 & 4.5793 & TRN & \\
\hline CHEMBL1965387 & 809190 & 4.3 & 4.1839 & TRN & \\
\hline
\end{tabular}




\begin{tabular}{|c|c|c|c|c|c|}
\hline & & & & & \\
\hline CHEMBL2001539 & 809190 & 3.8 & 3.739 & TST & \\
\hline CHEMBL1997041 & 809190 & 5.4 & 4.9126 & TRN & \\
\hline CHEMBL1988153 & 809190 & 4.8 & 5.0486 & TRN & \\
\hline CHEMBL550418 & 809190 & 4.3 & 4.3954 & TRN & \\
\hline CHEMBL1986666 & 809190 & 6.0 & 6.3474 & TRN & \\
\hline CHEMBL1971289 & 809190 & 4.3 & 4.4086 & TRN & \\
\hline CHEMBL1999556 & 809190 & 6.0 & 5.2508 & TRN & \\
\hline CHEMBL1988437 & 809190 & 4.6 & 5.5608 & TST & \\
\hline CHEMBL1968245 & 809190 & 4.8 & 4.9631 & TRN & \\
\hline CHEMBL1979577 & 809190 & 4.8 & 5.0792 & TRN & \\
\hline CHEMBL1998121 & 809190 & 4.8 & 4.6088 & TRN & \\
\hline CHEMBL1233887 & 809190 & 4.3 & 4.8453 & TST & \\
\hline CHEMBL1991800 & 809190 & 4.8 & 4.7203 & TRN & \\
\hline CHEMBL 2003689 & 809190 & 4.3 & 4.477 & TRN & \\
\hline CHEMBL379835 & 809190 & 4.8 & 4.4931 & TST & \\
\hline CHEMBL1979357 & 809190 & 4.8 & 4.9892 & TRN & \\
\hline CHEMBL1980802 & 809190 & 4.8 & 4.7152 & TST & \\
\hline CHEMBL1996649 & 809190 & 7.3 & 5.35 & TRN & \\
\hline CHEMBL1996817 & 809190 & 5.2 & 5.8429 & TRN & \\
\hline CHEMBL1979554 & 809190 & 4.8 & 5.0602 & TRN & \\
\hline CHEMBL1986756 & 809190 & 4.3 & 4.4667 & TRN & \\
\hline CHEMBL 2004355 & 809190 & 4.8 & 4.9513 & TRN & \\
\hline CHEMBL468280 & 809190 & 4.8 & 4.4721 & TST & \\
\hline CHEMBL1990884 & 809190 & 4.8 & 4.6451 & TRN & \\
\hline CHEMBL 3109278 & 809190 & 4.4 & 4.6374 & TRN & \\
\hline CHEMBL 256835 & 809190 & 4.8 & 5.0343 & TRN & \\
\hline CHEMBL1974998 & 809190 & 4.3 & 4.8157 & TRN & \\
\hline CHEMBL1980142 & 809190 & 4.8 & 5.0668 & TRN & \\
\hline CHEMBL41783 & 809190 & 4.8 & 4.8487 & TRN & \\
\hline CHEMBL 2004438 & 809190 & 4.5 & 4.3882 & TRN & \\
\hline CHEMBL1940137 & 809190 & 5.5 & 5.0593 & TRN & \\
\hline CHEMBL 2006276 & 809190 & 4.8 & 4.81800 & 00000000005 & TRN \\
\hline CHEMBL191003 & 809190 & 6.7 & 6.08299 & 9999999999 & TRN \\
\hline CHEMBL 271381 & 809190 & 5.9 & 5.4773 & TRN & \\
\hline CHEMBL 2006785 & 809190 & 4.8 & 4.6961 & TRN & \\
\hline CHEMBL1982466 & 809190 & 4.8 & 5.1664 & TRN & \\
\hline CHEMBL1973359 & 809190 & 6.1 & 5.9206 & TST & \\
\hline CHEMBL1995740 & 809190 & 4.8 & 4.9271 & TRN & \\
\hline CHEMBL1996390 & 809190 & 4.8 & 5.1998 & TRN & \\
\hline CHEMBL1990162 & 809190 & 5.4 & 5.3007 & TRN & \\
\hline CHEMBL1992220 & 809190 & 7.1 & 6.9047 & TRN & \\
\hline CHEMBL1979690 & 809190 & 7.7 & 7.5405 & TRN & \\
\hline CHEMBL 234085 & 809190 & 8.3 & 8.4508 & TRN & \\
\hline CHEMBL1969042 & 809190 & 4.8 & 4.8186 & TRN & \\
\hline CHEMBL 2000345 & 809190 & 6.1 & 5.9444 & TRN & \\
\hline CHEMBL1999931 & 809190 & 7.1 & 5.88700 & 00000000005 & TRN \\
\hline CHEMBL1976376 & 809190 & 4.3 & 3.9069 & TRN & \\
\hline CHEMBL1991640 & 809190 & 4.8 & 5.1996 & TST & \\
\hline
\end{tabular}




\begin{tabular}{|c|c|c|c|c|}
\hline & & & 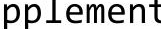 & al Ta \\
\hline CHEMBL1983575 & 809190 & 6.1 & 5.8493 & TRN \\
\hline CHEMBL302449 & 809190 & 9.2 & 6.2868 & TST \\
\hline CHEMBL 2007064 & 809190 & 6.5 & 6.254 & TRN \\
\hline CHEMBL1981047 & 809190 & 6.3 & 6.2826 & TRN \\
\hline CHEMBL229968 & 809190 & 5.9 & 5.2878 & TRN \\
\hline CHEMBL1976196 & 809190 & 4.3 & 5.0097 & TST \\
\hline CHEMBL1976240 & 809190 & 4.8 & 4.7802 & TRN \\
\hline CHEMBL1987948 & 809190 & 5.6 & 6.0266 & TRN \\
\hline CHEMBL1997197 & 809190 & 4.3 & 4.2609 & TRN \\
\hline CHEMBL1979093 & 809190 & 4.8 & 4.6971 & TRN \\
\hline CHEMBL1968151 & 809190 & 4.8 & 4.843 & TST \\
\hline CHEMBL1381197 & 809190 & 4.8 & 5.1295 & TRN \\
\hline CHEMBL1987009 & 809190 & 4.8 & 5.2285 & TRN \\
\hline CHEMBL 379218 & 809190 & 4.8 & 5.7204 & TRN \\
\hline CHEMBL 2003817 & 809190 & 4.8 & 4.6216 & TRN \\
\hline CHEMBL336961 & 809190 & 4.8 & 4.9445 & TRN \\
\hline CHEMBL1994830 & 809190 & 4.8 & 4.7976 & TRN \\
\hline CHEMBL1987054 & 809190 & 7.2 & 7.3372 & TRN \\
\hline CHEMBL1970083 & 809190 & 6.8 & 6.3827 & TRN \\
\hline CHEMBL 226403 & 809190 & 4.8 & 4.785 & TRN \\
\hline CHEMBL 2005631 & 809190 & 6.5 & 6.4813 & TRN \\
\hline CHEMBL1994938 & 809190 & 4.8 & 5.1575 & TRN \\
\hline CHEMBL1977223 & 809190 & 4.8 & 5.2424 & TRN \\
\hline CHEMBL1966279 & 809190 & 4.8 & 4.6312 & TRN \\
\hline CHEMBL1236126 & 809190 & 4.8 & 4.8712 & TRN \\
\hline CHEMBL1997846 & 809190 & 4.7 & 5.1714 & TRN \\
\hline CHEMBL1984760 & 809190 & 5.6 & 5.5258 & TRN \\
\hline CHEMBL 2004419 & 809190 & 4.8 & 5.1749 & TRN \\
\hline CHEMBL1991728 & 809190 & 6.0 & 6.1657 & TRN \\
\hline CHEMBL360847 & 809190 & 5.7 & 5.1253 & TST \\
\hline CHEMBL 2007073 & 809190 & 4.3 & 4.8256 & TRN \\
\hline CHEMBL1995811 & 809190 & 4.3 & 4.1607 & TRN \\
\hline CHEMBL1975787 & 809190 & 4.8 & 4.9895 & TRN \\
\hline CHEMBL 2002407 & 809190 & 5.8 & 5.3946 & TRN \\
\hline CHEMBL1972489 & 809190 & 4.8 & 4.5462 & TRN \\
\hline CHEMBL1994074 & 809190 & 4.8 & 4.9005 & TRN \\
\hline CHEMBL1992937 & 809190 & 4.4 & 4.3949 & TST \\
\hline CHEMBL451401 & 809190 & 3.8 & 3.7489 & TRN \\
\hline CHEMBL1968930 & 809190 & 6.6 & 6.3788 & TRN \\
\hline CHEMBL1985566 & 809190 & 4.8 & 5.2032 & TRN \\
\hline CHEMBL1972119 & 809190 & 4.8 & 5.0321 & TRN \\
\hline CHEMBL1986328 & 809190 & 4.8 & 4.66 & TST \\
\hline CHEMBL95692 & 809190 & 4.8 & 4.8208 & TRN \\
\hline CHEMBL1090356 & 809190 & 4.8 & 4.9678 & TRN \\
\hline CHEMBL1976455 & 809190 & 4.8 & 4.4739 & TST \\
\hline CHEMBL261849 & 809190 & 4.3 & 4.6387 & TST \\
\hline CHEMBL1983923 & 809190 & 6.5 & 7.0448 & TST \\
\hline CHEMBL1983534 & 809190 & 4.8 & 4.891 & TST \\
\hline
\end{tabular}




\begin{tabular}{|c|c|c|c|c|c|}
\hline & & \multicolumn{4}{|c|}{ plemental Table S2 } \\
\hline CHEMBL1982361 & 809190 & 4.8 & 4.762 & TST & \\
\hline CHEMBL1999112 & 809190 & 4.8 & 5.21299 & 9999999999 & TST \\
\hline CHEMBL1982122 & 809190 & 4.8 & 4.4033 & TST & \\
\hline CHEMBL 2000801 & 809190 & 4.8 & 4.422 & TST & \\
\hline CHEMBL1682546 & 809190 & 4.8 & 5.1248 & TST & \\
\hline CHEMBL1988872 & 809190 & 4.3 & 5.8383 & TST & \\
\hline CHEMBL1991395 & 809190 & 4.8 & 4.686 & TST & \\
\hline CHEMBL1971245 & 809190 & 4.8 & 5.0234 & TST & \\
\hline CHEMBL1987648 & 809190 & 4.8 & 4.7275 & TST & \\
\hline CHEMBL1996780 & 809190 & 4.8 & 5.027 & TST & \\
\hline CHEMBL1972142 & 809190 & 4.8 & 6.0525 & TST & \\
\hline CHEMBL1966514 & 809190 & 6.2 & 5.5515 & TST & \\
\hline CHEMBL 2003638 & 809190 & 4.6 & 5.5233 & TST & \\
\hline CHEMBL296586 & 809190 & 4.8 & 4.9503 & TST & \\
\hline CHEMBL1996066 & 809190 & 4.8 & 5.4961 & TST & \\
\hline CHEMBL1983393 & 809190 & 4.3 & 4.5584 & TST & \\
\hline CHEMBL516429 & 809190 & 4.8 & 5.471 & TST & \\
\hline CHEMBL1993722 & 809190 & 5.8 & 5.4836 & TST & \\
\hline CHEMBL 2006674 & 809190 & 4.3 & 4.1515 & TST & \\
\hline CHEMBL1984236 & 809190 & 4.3 & 4.5239 & TST & \\
\hline CHEMBL1992371 & 809190 & 4.3 & 4.6528 & TST & \\
\hline CHEMBL1375640 & 809190 & 4.8 & 4.6873 & TST & \\
\hline CHEMBL1979970 & 809190 & 4.8 & 4.3074 & TST & \\
\hline CHEMBL249282 & 809190 & 4.8 & 4.8959 & TST & \\
\hline CHEMBL1967252 & 809190 & 4.2 & 4.7218 & TST & \\
\hline CHEMBL 2004637 & 809190 & 5.5 & 5.0599 & TST & \\
\hline CHEMBL1993374 & 809190 & 4.3 & 3.98199 & 99999999998 & TST \\
\hline CHEMBL1969264 & 809190 & 5.8 & 5.0274 & TST & \\
\hline CHEMBL1994318 & 809190 & 4.3 & 4.3834 & TST & \\
\hline CHEMBL1973711 & 809190 & 4.8 & 5.2624 & TST & \\
\hline CHEMBL 2006237 & 809190 & 4.8 & 4.8819 & TST & \\
\hline CHEMBL1999506 & 809190 & 4.3 & 4.9712 & TST & \\
\hline CHEMBL 2005509 & 809190 & 7.2 & 6.7003 & TST & \\
\hline CHEMBL1991138 & 809190 & 4.8 & 4.6834 & TST & \\
\hline CHEMBL1979516 & 809190 & 6.6 & 6.0905 & TST & \\
\hline CHEMBL1969755 & 809190 & 4.8 & 4.3579 & TST & \\
\hline CHEMBL1605605 & 809190 & 4.3 & 4.4275 & TST & \\
\hline CHEMBL1996208 & 809190 & 4.3 & 5.0849 & TST & \\
\hline CHEMBL1989029 & 809190 & 4.8 & 4.6463 & TST & \\
\hline CHEMBL392642 & 809190 & 4.8 & 4.9526 & TST & \\
\hline CHEMBL514499 & 809190 & 6.7 & 5.6434 & TST & \\
\hline CHEMBL1970352 & 809190 & 5.7 & 4.6909 & TST & \\
\hline CHEMBL1965631 & 809190 & 4.8 & 4.7347 & TST & \\
\hline CHEMBL1980144 & 809190 & 4.8 & 5.1979 & TST & \\
\hline CHEMBL1991188 & 809190 & 4.8 & 4.7795 & TST & \\
\hline CHEMBL1980167 & 809190 & 4.3 & 5.6262 & TST & \\
\hline CHEMBL1972849 & 809190 & 4.8 & 4.4294 & TST & \\
\hline CHEMBL 377408 & 809190 & 4.3 & 4.7535 & TST & \\
\hline
\end{tabular}




\begin{tabular}{|c|c|c|c|c|}
\hline \multicolumn{5}{|c|}{ Supplemental Table S2.txt } \\
\hline CHEMBL1986855 & 809190 & 6.6 & 7.0058 & TST \\
\hline CHEMBL215152 & 809190 & 4.4 & 4.9837 & TST \\
\hline CHEMBL231209 & 809190 & 4.8 & 4.7752 & TST \\
\hline CHEMBL1976220 & 809190 & 4.8 & 4.7171 & TST \\
\hline CHEMBL2006765 & 809190 & 6.4 & 6.2169 & TST \\
\hline CHEMBL 259922 & 809190 & 4.8 & 4.6108 & TST \\
\hline CHEMBL1997617 & 809190 & 4.8 & 4.7114 & TST \\
\hline CHEMBL1969301 & 809190 & 4.8 & 5.077 & TST \\
\hline CHEMBL17370 & 809190 & 4.8 & 4.4277 & TST \\
\hline CHEMBL1980246 & 809190 & 4.3 & 4.5522 & TST \\
\hline CHEMBL1987910 & 809190 & 4.8 & 4.4313 & TST \\
\hline CHEMBL1983932 & 809190 & 4.8 & 4.8664 & TST \\
\hline CHEMBL1983980 & 809190 & 5.3 & 5.4815 & TST \\
\hline CHEMBL1999484 & 809190 & 6.5 & 6.6911 & TST \\
\hline CHEMBL1966069 & 809190 & 4.8 & 4.9418 & TST \\
\hline CHEMBL1986899 & 809190 & 4.3 & 4.7436 & TST \\
\hline CHEMBL1991285 & 809190 & 4.8 & 4.7935 & TST \\
\hline CHEMBL1997822 & 809190 & 4.8 & 5.0688 & TST \\
\hline CHEMBL 243088 & 809190 & 7.6 & 7.4697 & TST \\
\hline CHEMBL1984038 & 809190 & 4.4 & 4.2636 & TST \\
\hline CHEMBL1974416 & 809190 & 4.8 & 5.2074 & TST \\
\hline CHEMBL1993661 & 809190 & 8.2 & 7.5778 & TST \\
\hline CHEMBL1997872 & 809190 & 4.8 & 5.5704 & TST \\
\hline CHEMBL538094 & 446136 & 8.301 & 8.3017 & TRN \\
\hline CHEMBL541135 & 446136 & 8.5229 & 8.5317 & TRN \\
\hline CHEMBL535185 & 446136 & 8.5229 & 7.9238 & TST \\
\hline CHEMBL536519 & 446136 & 7.7959 & 7.7969 & TRN \\
\hline CHEMBL557838 & 446136 & 8.699 & 8.6996 & TRN \\
\hline CHEMBL558790 & 446136 & 8.2218 & 8.2266 & TRN \\
\hline CHEMBL540112 & 446136 & 8.3979 & 8.3985 & TRN \\
\hline CHEMBL538092 & 446136 & 8.0 & 8.0013 & TRN \\
\hline CHEMBL536296 & 446136 & 8.3979 & 8.4047 & TRN \\
\hline CHEMBL557016 & 446136 & 8.2218 & 8.2256 & TRN \\
\hline CHEMBL536294 & 446136 & 7.9208 & 7.9054 & TRN \\
\hline CHEMBL556165 & 446136 & 8.3979 & 8.3913 & TRN \\
\hline CHEMBL534739 & 446136 & 8.2218 & 8.2147 & TRN \\
\hline CHEMBL534728 & 446136 & 8.699 & 8.7025 & TRN \\
\hline CHEMBL537656 & 446136 & 7.7212 & 7.7182 & TRN \\
\hline CHEMBL541392 & 446136 & 7.0362 & 7.0284 & TRN \\
\hline CHEMBL534729 & 446136 & 9.3979 & 9.4001 & TRN \\
\hline CHEMBL553558 & 446136 & 8.699 & 8.7081 & TRN \\
\hline CHEMBL536521 & 446136 & 8.699 & 8.6962 & TRN \\
\hline CHEMBL536083 & 446136 & 8.301 & 8.3031 & TRN \\
\hline CHEMBL536981 & 446136 & 7.9586 & 7.9618 & TRN \\
\hline CHEMBL536522 & 446136 & 7.6576 & 7.6561 & TRN \\
\hline CHEMBL536749 & 446136 & 8.699 & 8.4287 & TST \\
\hline CHEMBL558370 & 446136 & 8.2218 & 8.218 & TRN \\
\hline CHEMBL556766 & 446136 & 7.699 & 7.7084 & TRN \\
\hline
\end{tabular}




\begin{tabular}{|c|c|c|c|c|c|}
\hline \multicolumn{6}{|c|}{ Supplemental Table S2.txt } \\
\hline CHEMBL537667 & 446136 & 9.0 & 8.9862 & TRN & \\
\hline CHEMBL535633 & 446136 & 7.301 & 7.3038 & TRN & \\
\hline CHEMBL537666 & 446136 & 8.1549 & 8.1702 & TRN & \\
\hline CHEMBL537886 & 446136 & 8.699 & 8.7061 & TRN & \\
\hline CHEMBL556348 & 446136 & 8.3979 & 7.9962 & TST & \\
\hline CHEMBL536295 & 446136 & 9.0969 & 9.0882 & TRN & \\
\hline CHEMBL558184 & 446136 & 7.7447 & 7.7475 & TRN & \\
\hline CHEMBL535853 & 446136 & 7.585 & 7.5816 & TRN & \\
\hline CHEMBL537668 & 446136 & 8.5229 & 8.5235 & TRN & \\
\hline CHEMBL534738 & 446136 & 8.3979 & 8.3906 & TRN & \\
\hline CHEMBL537433 & 446136 & 7.9586 & 7.9539 & TRN & \\
\hline CHEMBL557788 & 446136 & 8.699 & 8.6997 & TRN & \\
\hline CHEMBL556976 & 446136 & 8.699 & 8.695 & TRN & \\
\hline CHEMBL537888 & 446136 & 9.5229 & 9.5181 & TRN & \\
\hline CHEMBL537655 & 446136 & 8.5229 & 8.5242 & TRN & \\
\hline CHEMBL557977 & 446136 & 8.0969 & 8.0022 & TST & \\
\hline CHEMBL556343 & 446136 & 8.699 & 8.7055 & TRN & \\
\hline CHEMBL536982 & 446136 & 8.699 & 8.4625 & TST & \\
\hline CHEMBL536748 & 446136 & 8.699 & 8.0971 & TST & \\
\hline CHEMBL558212 & 446136 & 8.699 & 8.6433 & TST & \\
\hline CHEMBL540886 & 446136 & 9.2218 & 7.9184 & TST & \\
\hline CHEMBL535408 & 446136 & 8.3979 & 8.1124 & TST & \\
\hline CHEMBL535632 & 446136 & 9.0 & 9.2914 & TST & \\
\hline CHEMBL537446 & 446136 & 9.0 & 8.9715 & TST & \\
\hline CHEMBL557369 & 446136 & 7.8861 & 7.1427 & TST & \\
\hline CHEMBL536085 & 446136 & 7.3768 & 7.3383 & TST & \\
\hline CHEMBL 246620 & 457662 & 5.289 & 7.3257 & TST & \\
\hline CHEMBL248225 & 457662 & 5.862 & 6.7498 & TRN & \\
\hline CHEMBL245603 & 457662 & 5.206 & 5.5435 & TRN & \\
\hline CHEMBL397132 & 457662 & 7.1135 & 8.03399 & 9999999999 & TRN \\
\hline CHEMBL248396 & 457662 & 8.301 & 7.9814 & TRN & \\
\hline CHEMBL248394 & 457662 & 5.4307 & 6.5915 & TRN & \\
\hline CHEMBL 247028 & 457662 & 7.7959 & 8.0717 & TRN & \\
\hline CHEMBL398728 & 457662 & 7.1135 & 6.9683 & TRN & \\
\hline CHEMBL 245401 & 457662 & 8.5229 & 6.7729 & TST & \\
\hline CHEMBL245802 & 457662 & 9.301 & 8.4977 & TRN & \\
\hline CHEMBL401326 & 457662 & 8.2218 & 6.0815 & TST & \\
\hline CHEMBL401274 & 457662 & 7.6021 & 8.1124 & TRN & \\
\hline CHEMBL440959 & 457662 & 7.8239 & 7.0306 & TRN & \\
\hline CHEMBL400689 & 457662 & 8.5229 & 7.7164 & TRN & \\
\hline CHEMBL398912 & 457662 & 5.8901 & 6.0327 & TRN & \\
\hline CHEMBL247026 & 457662 & 8.699 & 7.7629 & TRN & \\
\hline CHEMBL247394 & 457662 & 8.0458 & 8.1074 & TRN & \\
\hline CHEMBL 248668 & 457662 & 7.699 & 8.3877 & TRN & \\
\hline CHEMBL247199 & 457662 & 7.3565 & 7.9877 & TRN & \\
\hline CHEMBL245796 & 457662 & 8.699 & 8.1032 & TRN & \\
\hline CHEMBL248395 & 457662 & 7.7212 & 8.2958 & TRN & \\
\hline CHEMBL399255 & 457662 & 6.5406 & 6.9571 & TRN & \\
\hline
\end{tabular}




\begin{tabular}{|c|c|c|c|c|c|}
\hline \multirow{2}{*}{ CHEMBL 247611} & \\
\hline & 457662 & 7.1367 & 7.1537 & TRN & \\
\hline CHEMBL247588 & 457662 & 8.5229 & 8.3671 & TRN & \\
\hline CHEMBL399253 & 457662 & 5.7587 & 4.3126 & TRN & \\
\hline CHEMBL247193 & 457662 & 8.0 & 8.1839 & TRN & \\
\hline CHEMBL245604 & 457662 & 5.3392 & 5.1769 & TRN & \\
\hline CHEMBL 247237 & 457662 & 7.6021 & 7.1414 & TRN & \\
\hline CHEMBL247396 & 457662 & 8.699 & 7.6439 & TST & \\
\hline CHEMBL445410 & 457662 & 7.7696 & 7.8028 & TST & \\
\hline CHEMBL400688 & 457662 & 7.0506 & 6.8468 & TRN & \\
\hline CHEMBL398913 & 457662 & 7.3279 & 7.1759 & TRN & \\
\hline CHEMBL247200 & 457662 & 7.3565 & 7.1812 & TRN & \\
\hline CHEMBL247427 & 457662 & 6.4498 & 5.7432 & TRN & \\
\hline CHEMBL 248667 & 457662 & 7.8539 & 8.2934 & TRN & \\
\hline CHEMBL400893 & 457662 & 8.5229 & 7.9915 & TRN & \\
\hline CHEMBL401075 & 457662 & 5.5224 & 5.7218 & TRN & \\
\hline CHEMBL395894 & 457662 & 8.1549 & 8.0985 & TRN & \\
\hline CHEMBL399532 & 457662 & 8.2218 & 7.985 & TRN & \\
\hline CHEMBL399254 & 457662 & 8.3979 & 7.96299 & 9999999999 & TRN \\
\hline CHEMBL247652 & 457662 & 5.8996 & 7.0631 & TRN & \\
\hline CHEMBL247201 & 457662 & 8.3979 & 8.4368 & TRN & \\
\hline CHEMBL245801 & 457662 & 4.0 & 4.2754 & TRN & \\
\hline CHEMBL247029 & 457662 & 4.0 & 7.2124 & TST & \\
\hline CHEMBL 247222 & 457662 & 8.699 & 8.7917 & TRN & \\
\hline CHEMBL396372 & 457662 & 9.0 & 8.1107 & TRN & \\
\hline CHEMBL247610 & 457662 & 4.0 & 4.9931 & TRN & \\
\hline CHEMBL245605 & 457662 & 7.9586 & 6.5196 & TST & \\
\hline CHEMBL397313 & 457662 & 8.699 & 5.6686 & TST & \\
\hline CHEMBL 247426 & 457662 & 6.1085 & 6.1826 & TST & \\
\hline CHEMBL245773 & 457662 & 4.0 & 8.0559 & TST & \\
\hline CHEMBL247027 & 457662 & 6.5406 & 7.355 & TST & \\
\hline CHEMBL247590 & 457662 & 8.699 & 8.0178 & TST & \\
\hline CHEMBL247246 & 457662 & 4.0 & 6.8152 & TST & \\
\hline CHEMBL398750 & 457662 & 9.0969 & 7.4919 & TST & \\
\hline CHEMBL3970704 & 1527742 & 7.0706 & 7.1178 & TRN & \\
\hline CHEMBL3918030 & 1527742 & 6.0 & 6.8825 & TRN & \\
\hline CHEMBL3911936 & 1527742 & 7.2676 & 6.95200 & 2000000001 & TST \\
\hline CHEMBL3933009 & 1527742 & 6.0 & 6.6053 & TRN & \\
\hline CHEMBL3932610 & 1527742 & 6.1805 & 6.5161 & TRN & \\
\hline CHEMBL3956247 & 1527742 & 6.0 & 6.6043 & TRN & \\
\hline CHEMBL3956371 & 1527742 & 7.7447 & 6.5408 & TRN & \\
\hline CHEMBL3895474 & 1527742 & 5.7959 & 6.7682 & TRN & \\
\hline CHEMBL3932417 & 1527742 & 7.1427 & 7.1667 & TST & \\
\hline CHEMBL3981837 & 1527742 & 7.6198 & 7.2305 & TRN & \\
\hline CHEMBL3908919 & 1527742 & 6.0 & 6.4458 & TRN & \\
\hline CHEMBL3934106 & 1527742 & 7.5528 & 7.2465 & TRN & \\
\hline CHEMBL3112755 & 1527742 & 8.0458 & 6.5736 & TRN & \\
\hline CHEMBL3922601 & 1527742 & 6.0 & 6.3512 & TRN & \\
\hline CHEMBL3112743 & 1527742 & 5.3665 & 6.2005 & TRN & \\
\hline
\end{tabular}

Page 2993 
Supplemental Table S2.txt

\begin{tabular}{|c|c|c|c|c|c|}
\hline CHEMBL3941396 & 1527742 & 6.9626 & 7.2523 & TRN & \\
\hline CHEMBL3906670 & 1527742 & 6.0 & 6.4588 & TRN & \\
\hline CHEMBL3112757 & 1527742 & 6.6478 & 6.4657 & TRN & \\
\hline CHEMBL3951105 & 1527742 & 6.0 & 6.395 & TRN & \\
\hline CHEMBL3896225 & 1527742 & 7.4089 & 6.9578 & TST & \\
\hline CHEMBL3960469 & 1527742 & 6.4949 & 6.6529 & TRN & \\
\hline CHEMBL3925213 & 1527742 & 6.0 & 6.2373 & TRN & \\
\hline CHEMBL3944458 & 1527742 & 7.8861 & 6.8461 & TRN & \\
\hline CHEMBL3895019 & 1527742 & 7.5229 & 7.1278 & TST & \\
\hline CHEMBL3899991 & 1527742 & 6.0 & 6.3463 & TRN & \\
\hline CHEMBL3961606 & 1527742 & 8.0 & 6.8073 & TRN & \\
\hline CHEMBL3981884 & 1527742 & 8.0969 & 7.6281 & TRN & \\
\hline CHEMBL3910341 & 1527742 & 7.1079 & 7.2524 & TRN & \\
\hline CHEMBL3913452 & 1527742 & 6.284 & 6.5668 & TRN & \\
\hline CHEMBL3967936 & 1527742 & 7.2596 & 7.6076 & TRN & \\
\hline CHEMBL3902510 & 1527742 & 7.585 & 7.3383 & TRN & \\
\hline CHEMBL3941136 & 1527742 & 8.0969 & 6.8576 & TRN & \\
\hline CHEMBL3112754 & 1527742 & 5.6021 & 6.4537 & TRN & \\
\hline CHEMBL3892741 & 1527742 & 8.7959 & 7.5869 & TRN & \\
\hline CHEMBL3971925 & 1527742 & 7.2218 & 6.7334 & TST & \\
\hline CHEMBL3916954 & 1527742 & 7.2518 & 7.0439 & TST & \\
\hline CHEMBL3112591 & 1527742 & 7.9586 & 7.3211 & TST & \\
\hline CHEMBL3971570 & 1527742 & 6.7212 & 6.6851 & TST & \\
\hline CHEMBL3947548 & 1527742 & 7.9208 & 7.1241 & TST & \\
\hline CHEMBL3931678 & 1527742 & 7.4815 & 6.5343 & TRN & \\
\hline CHEMBL3970865 & 1527742 & 6.8239 & 6.9593 & TRN & \\
\hline CHEMBL3935623 & 1527742 & 8.699 & 7.2103 & TST & \\
\hline CHEMBL3889864 & 1527742 & 6.0757 & 7.041 & TST & \\
\hline CHEMBL3903047 & 1527742 & 6.8861 & 7.2048 & TRN & \\
\hline CHEMBL3922994 & 1527742 & 7.6576 & 7.0874 & TST & \\
\hline CHEMBL3932306 & 1527742 & 7.0177 & 6.8008 & TRN & \\
\hline CHEMBL3961665 & 1527742 & 7.4437 & 7.41299 & 9999999999 & TRN \\
\hline CHEMBL3962320 & 1527742 & 6.6819 & 6.5337 & TRN & \\
\hline CHEMBL3659511 & 1527742 & 6.6198 & 6.3155 & TRN & \\
\hline CHEMBL3112747 & 1527742 & 7.3768 & 7.4073 & TST & \\
\hline CHEMBL3984624 & 1527742 & 6.0 & 6.1634 & TRN & \\
\hline CHEMBL3963657 & 1527742 & 7.8239 & 7.5802 & TRN & \\
\hline CHEMBL3926592 & 1527742 & 6.5376 & 6.4249 & TRN & \\
\hline CHEMBL3921900 & 1527742 & 6.3188 & 6.3896 & TRN & \\
\hline CHEMBL3112745 & 1527742 & 6.8239 & 6.7644 & TRN & \\
\hline CHEMBL3974207 & 1527742 & 7.3468 & 6.7641 & TRN & \\
\hline CHEMBL3931511 & 1527742 & 6.0 & 6.5058 & TRN & \\
\hline CHEMBL3955696 & 1527742 & 7.2366 & 7.516 & TRN & \\
\hline CHEMBL3957507 & 1527742 & 6.3279 & 7.2724 & TRN & \\
\hline CHEMBL3976550 & 1527742 & 6.9208 & 6.7428 & TST & \\
\hline CHEMBL3947285 & 1527742 & 6.9208 & 6.6447 & TST & \\
\hline CHEMBL3964136 & 1527742 & 7.7696 & 7.8947 & TRN & \\
\hline CHEMBL3959809 & 1527742 & 5.0 & 6.4417 & TRN & \\
\hline
\end{tabular}


Supplemental Table S2.txt

\begin{tabular}{|c|c|c|c|c|c|}
\hline CHEMBL 3900778 & 1527742 & 7.3872 & 6.8368 & TST & \\
\hline CHEMBL3958442 & 1527742 & 7.2076 & 6.6196 & TRN & \\
\hline CHEMBL3929994 & 1527742 & 6.0 & 6.5578 & TRN & \\
\hline CHEMBL3919215 & 1527742 & 7.7696 & \multicolumn{2}{|c|}{6.452000000000001} & TRN \\
\hline CHEMBL3112748 & 1527742 & 7.4437 & 7.5226 & TST & \\
\hline CHEMBL3910351 & 1527742 & 6.3872 & \multicolumn{2}{|c|}{ 7.452999999999999 } & TRN \\
\hline CHEMBL3984986 & 1527742 & 7.2676 & 7.0409 & TST & \\
\hline CHEMBL3934406 & 1527742 & 7.5229 & 6.9285 & TRN & \\
\hline CHEMBL 3112753 & 1527742 & 7.1135 & 6.6824 & TRN & \\
\hline CHEMBL3112744 & 1527742 & 6.6198 & 6.7374 & TRN & \\
\hline CHEMBL3939469 & 1527742 & 7.699 & 7.2162 & TST & \\
\hline CHEMBL3922005 & 1527742 & 7.699 & 7.0542 & TRN & \\
\hline CHEMBL3963057 & 1527742 & 7.9586 & 6.7318 & TRN & \\
\hline CHEMBL 3112751 & 1527742 & 8.0 & 7.0672 & TST & \\
\hline CHEMBL3968922 & 1527742 & 6.6108 & 6.5128 & TRN & \\
\hline CHEMBL3112749 & 1527742 & 7.3768 & 7.4305 & TST & \\
\hline CHEMBL3983979 & 1527742 & 6.1079 & 6.9371 & TST & \\
\hline CHEMBL 3977380 & 1527742 & 5.8861 & 7.6046 & TRN & \\
\hline CHEMBL 3944847 & 1527742 & 6.8697 & 7.2679 & TRN & \\
\hline CHEMBL3946631 & 1527742 & 8.0969 & 6.9273 & TRN & \\
\hline CHEMBL3958929 & 1527742 & 6.0 & 6.2667 & TRN & \\
\hline CHEMBL3938105 & 1527742 & 6.0 & 6.4955 & TRN & \\
\hline CHEMBL3987101 & 1527742 & 7.1427 & 7.477 & TRN & \\
\hline CHEMBL 3904412 & 1527742 & 6.983 & 7.3492 & TRN & \\
\hline CHEMBL 3953568 & 1527742 & 8.0 & 7.7706 & TRN & \\
\hline CHEMBL3937542 & 1642261 & 6.301 & 6.4684 & TRN & \\
\hline CHEMBL3983825 & 1642261 & 5.1024 & 4.7972 & TRN & \\
\hline CHEMBL3961294 & 1642261 & 6.5528 & 6.5499 & TRN & \\
\hline CHEMBL3916988 & 1642261 & 6.4949 & 6.4411 & TRN & \\
\hline CHEMBL3939548 & 1642261 & 5.8239 & 5.9005 & TRN & \\
\hline CHEMBL3952772 & 1642261 & 5.6778 & 5.6531 & TRN & \\
\hline CHEMBL3950181 & 1642261 & 5.0862 & 5.3751 & TRN & \\
\hline CHEMBL3916480 & 1642261 & 6.585 & 6.2191 & TRN & \\
\hline CHEMBL 3979310 & 1642261 & 6.5086 & 6.4186 & TRN & \\
\hline CHEMBL3910295 & 1642261 & 5.8539 & 5.874 & TRN & \\
\hline CHEMBL 3953243 & 1642261 & 5.6576 & 5.8668 & TRN & \\
\hline CHEMBL 3975454 & 1642261 & 5.9208 & 5.7286 & TRN & \\
\hline CHEMBL3923002 & 1642261 & 5.1024 & 5.4181 & TRN & \\
\hline CHEMBL3956515 & 1642261 & 6.3372 & 6.5066 & TRN & \\
\hline CHEMBL 3891424 & 1642261 & 5.6576 & 5.5209 & TRN & \\
\hline CHEMBL3982473 & 1642261 & 6.6778 & 6.2778 & TRN & \\
\hline CHEMBL3984671 & 1642261 & 5.9586 & 6.0177 & TRN & \\
\hline CHEMBL3913619 & 1642261 & 6.284 & 5.9756 & TRN & \\
\hline CHEMBL3961377 & 1642261 & 6.0506 & 6.2811 & TRN & \\
\hline CHEMBL 3946847 & 1642261 & 5.3665 & 5.689 & TRN & \\
\hline CHEMBL3944913 & 1642261 & 4.5376 & 4.7613 & TRN & \\
\hline CHEMBL3986372 & 1642261 & 6.4559 & 6.4275 & TRN & \\
\hline CHEMBL 3967080 & 1642261 & 5.3098 & 5.0303 & TRN & \\
\hline
\end{tabular}

Page 2995 
Supplemental Table S2.txt

\begin{tabular}{|c|c|c|c|}
\hline HEMBL3931540 & 1642261 & 4.7447 & 5.0098 \\
\hline CHEMBL 3966723 & 1642261 & 5.8239 & 5.5113 \\
\hline HEMBL3967225 & 642261 & 5.1192 & 41 \\
\hline CHEMBL 3907871 & 1642261 & 5.2441 & 9955 \\
\hline HEMBL3934879 & 642261 & 5.7447 & 5487 \\
\hline CHEMBL3924528 & 1642261 & 6.699 & 6.4767 \\
\hline HEMBL3895881 & 642261 & 5.9586 & . 3764 \\
\hline AEMBL3910396 & 261 & 6.7696 & 6.3481 \\
\hline HEMBL3958885 & 1642261 & 6.0757 & 5.3757 \\
\hline HEMBL3983644 & 1642261 & 5.0706 & 5.6731 \\
\hline HEMBL3937361 & 1642261 & 5.9208 & 6.0409 \\
\hline HEMBL3956055 & 261 & 6.1249 & 6.0119 \\
\hline HEMBL3920297 & 164 & 5.7696 & 5.9392 \\
\hline HEMBL3920323 & 1642261 & 6.5686 & 6.2429 \\
\hline HEMBL3977662 & 164 & 6.0555 & 6.1635 \\
\hline HEMBL3902568 & 164 & 5.5376 & 5.8479 \\
\hline HEMBL3922458 & 164 & 5.5528 & 993 \\
\hline HEMBL3933100 & 164 & 5.9208 & 343 \\
\hline HEMBL3983174 & 164 & 5.4202 & 5.7664 \\
\hline HEMBL3907560 & 164 & 6.1805 & 529 \\
\hline HEMBL3947279 & 164 & 6.7959 & 6.3881 \\
\hline HEMBL3937418 & 164 & 6 . & 5 . \\
\hline HEMBL397 & 164 & 75 & 62 \\
\hline AEMBL3964686 & 164 & 7.284 & 6.4984 \\
\hline HEMBL3912968 & 164 & 6.699 & \\
\hline CHEMBL 3923844 & 164 & 5 . & 187 \\
\hline HEMBL3904008 & 164 & 6.6021 & 19 \\
\hline HEMBL3913624 & 164 & 32 & 5.9485 \\
\hline HEMBL3938221 & 164 & 5.4949 & 5.23 \\
\hline HEMBL3949340 & 164 & 6.4318 & 6.6557 \\
\hline CHEMBL 3927036 & 164 & 6.2147 & 6.1256 \\
\hline CHEMBL 3 & 164 & 6.9586 & 6.3243 \\
\hline CHEMBL1439938 & 688 & 5.1 & 5.2705 \\
\hline CHEMBL1510118 & 688 & 5. & 5.6879 \\
\hline CHEMBL578512 & 688405 & 9.5229 & 6.0153 \\
\hline CHEMBL1511885 & 688 & 6.1583 & 5.9737 \\
\hline CHEMBL & 5 & 83 & 94 \\
\hline CHEMBL1981951 & 688 & 5.35 & 5.3859 \\
\hline CHEMBL1446949 & 688405 & 7.5498 & 7.5842 \\
\hline CHEMBL1302894 & 688405 & 8.3979 & 8.2604 \\
\hline CHEMBL1476356 & 688405 & 4.2592 & 4.3245 \\
\hline CHEMBL1433345 & 688 & 5.4583 & 5.4222 \\
\hline CHEMBL1330510 & 688405 & 6.5 & 6.5349 \\
\hline CHEMBL1499411 & 688405 & 6.05 & 6.2049 \\
\hline CHEMBL1433323 & 688 & 7.2581 & 7.0559 \\
\hline CHEMBL1433980 & 688405 & 5.2583 & 5.5898 \\
\hline CHEMBL1537850 & 688405 & 4.95 & 5.0227 \\
\hline CHEMBL1505818 & 688405 & 5.45 & 5.3931 \\
\hline
\end{tabular}

Page 2996 


\begin{tabular}{|c|c|c|c|c|c|}
\hline \multicolumn{6}{|c|}{ Supplemental Table s2.txt } \\
\hline CHEMBL1476170 & 688405 & 6.3 & 5.6597 & TST & \\
\hline CHEMBL1314086 & 688405 & 6.2583 & 5.8983 & TRN & \\
\hline CHEMBL1335099 & 688405 & 5.95 & 5.9832 & TRN & \\
\hline CHEMBL1358834 & 688405 & 5.8583 & 5.9253 & TRN & \\
\hline CHEMBL1371924 & 688405 & 6.45 & 6.2655 & TRN & \\
\hline CHEMBL1514777 & 688405 & 5.0092 & 5.2549 & TRN & \\
\hline CHEMBL1314118 & 688405 & 6.3583 & 5.9784 & TRN & \\
\hline CHEMBL112597 & 688405 & 6.7501 & 6.8676 & TRN & \\
\hline CHEMBL1354227 & 688405 & 5.2583 & 5.2765 & TRN & \\
\hline CHEMBL1541339 & 688405 & 7.8508 & 7.9091 & TRN & \\
\hline CHEMBL1354177 & 688405 & 4.2592 & 4.2081 & TRN & \\
\hline CHEMBL1317927 & 688405 & 5.2583 & 5.2433 & TRN & \\
\hline CHEMBL1301335 & 688405 & 6.8499 & 6.6686 & TST & \\
\hline CHEMBL1566610 & 688405 & 7.0501 & 6.9986 & TRN & \\
\hline CHEMBL1550871 & 688405 & 5.2583 & 5.6675 & TRN & \\
\hline CHEMBL546170 & 688405 & 5.5 & 5.8619 & TRN & \\
\hline CHEMBL1575588 & 688405 & 6.2 & 6.3806 & TRN & \\
\hline CHEMBL1385840 & 688405 & 8.0 & 5.70799 & 9999999999 & TST \\
\hline CHEMBL1511821 & 688405 & 5.3583 & 5.4029 & TRN & \\
\hline CHEMBL1354215 & 688405 & 4.1592 & 4.2111 & TRN & \\
\hline CHEMBL1354113 & 688405 & 5.2583 & 5.7421 & TRN & \\
\hline CHEMBL1354094 & 688405 & 6.6584 & 6.1716 & TRN & \\
\hline CHEMBL1435225 & 688405 & 5.2583 & 5.0196 & TRN & \\
\hline CHEMBL1368548 & 688405 & 6.8582 & 6.9167 & TRN & \\
\hline CHEMBL1323851 & 688405 & 6.45 & 6.1681 & TRN & \\
\hline CHEMBL1255837 & 688405 & 5.0 & 5.5205 & TST & \\
\hline CHEMBL1436634 & 688405 & 5.3583 & 5.36100 & 0000000001 & TRN \\
\hline CHEMBL1392791 & 688405 & 4.95 & 4.7846 & TRN & \\
\hline CHEMBL1316872 & 688405 & 4.3592 & 4.3312 & TRN & \\
\hline CHEMBL 3210867 & 688405 & 6.3 & 6.4213 & TRN & \\
\hline CHEMBL1467893 & 688405 & 5.65 & 5.7002 & TST & \\
\hline CHEMBL1340359 & 688405 & 5.1 & 5.5773 & TST & \\
\hline CHEMBL1511856 & 688405 & 5.1592 & 5.0063 & TRN & \\
\hline CHEMBL1433769 & 688405 & 5.3583 & 5.2275 & TRN & \\
\hline CHEMBL111750 & 688405 & 6.5501 & 6.3803 & TRN & \\
\hline CHEMBL1511892 & 688405 & 5.2583 & 5.5044 & TRN & \\
\hline CHEMBL1443332 & 688405 & 5.5 & 5.5456 & TRN & \\
\hline CHEMBL1396709 & 688405 & 4.0592 & 4.32100 & 0000000001 & TRN \\
\hline CHEMBL1341889 & 688405 & 5.0583 & 4.8664 & TRN & \\
\hline CHEMBL1316198 & 688405 & 5.3583 & 5.6177 & TRN & \\
\hline CHEMBL1472459 & 688405 & 4.9583 & 5.7225 & TRN & \\
\hline CHEMBL1435265 & 688405 & 5.4583 & 5.5572 & TRN & \\
\hline CHEMBL1550915 & 688405 & 5.3583 & 5.4093 & TRN & \\
\hline CHEMBL1256686 & 688405 & 7.8013 & 6.1642 & TST & \\
\hline CHEMBL1445748 & 688405 & 5.45 & 5.4561 & TRN & \\
\hline CHEMBL1354214 & 688405 & 5.9583 & 5.3997 & TRN & \\
\hline CHEMBL1393978 & 688405 & 5.4583 & 5.5744 & TRN & \\
\hline CHEMBL1314059 & 688405 & 5.0583 & 5.0909 & TRN & \\
\hline
\end{tabular}




\begin{tabular}{|c|c|c|c|c|c|}
\hline \multicolumn{6}{|c|}{ Supplemental Table S2.txt } \\
\hline CHEMBL3195226 & 688405 & 5.65 & 5.8645 & TRN & \\
\hline CHEMBL3192616 & 688405 & 8.3979 & 8.0476 & TRN & \\
\hline CHEMBL1589783 & 688405 & 4.3592 & 4.0041 & TRN & \\
\hline CHEMBL534353 & 688405 & 5.45 & 6.4003 & TST & \\
\hline CHEMBL 1448627 & 688405 & 6.3 & 6.1967 & TRN & \\
\hline CHEMBL1162415 & 688405 & 6.7001 & 6.5406 & TRN & \\
\hline CHEMBL1472458 & 688405 & 4.1592 & 4.1439 & TRN & \\
\hline CHEMBL1305540 & 688405 & 5.85 & 5.5604 & TST & \\
\hline CHEMBL1965415 & 688405 & 5.95 & 6.2777 & TRN & \\
\hline CHEMBL1543597 & 688405 & 6.9 & 7.0924 & TRN & \\
\hline CHEMBL1210313 & 688405 & 6.9582 & 7.2293 & TRN & \\
\hline CHEMBL1315412 & 688405 & 5.5583 & 5.4039 & TRN & \\
\hline CHEMBL1393909 & 688405 & 4.9092 & 4.6678 & TRN & \\
\hline CHEMBL1527869 & 688405 & 8.3979 & 8.418 & TRN & \\
\hline CHEMBL1569585 & 688405 & 5.95 & 5.9077 & TRN & \\
\hline CHEMBL1976308 & 688405 & 5.6 & 5.6585 & TRN & \\
\hline CHEMBL1555096 & 688405 & 5.3583 & 5.2879 & TRN & \\
\hline CHEMBL1550914 & 688405 & 5.7592 & 6.4752 & TRN & \\
\hline CHEMBL1533351 & 688405 & 5.7 & 5.7707 & TRN & \\
\hline CHEMBL1456412 & 688405 & 6.8 & 5.147 & TST & \\
\hline CHEMBL1350719 & 688405 & 10.0 & 10.1681 & TRN & \\
\hline CHEMBL1358647 & 688405 & 4.9592 & 4.9331 & TRN & \\
\hline CHEMBL1448732 & 688405 & 4.95 & 5.0032 & TRN & \\
\hline CHEMBL1474387 & 688405 & 7.3585 & 7.0163 & TRN & \\
\hline CHEMBL428064 & 688405 & 5.65 & 5.5689 & TST & \\
\hline CHEMBL1468672 & 688405 & 5.55 & 5.4577 & TRN & \\
\hline CHEMBL 2002150 & 688405 & 6.7001 & 6.502999 & 9999999999 & TRN \\
\hline CHEMBL1522836 & 688405 & 6.5501 & 6.1858 & TST & \\
\hline CHEMBL1341782 & 688405 & 5.55 & 5.2751 & TRN & \\
\hline CHEMBL528694 & 688405 & 8.3468 & 7.8406 & TRN & \\
\hline CHEMBL1485168 & 688405 & 5.5 & 5.5008 & TRN & \\
\hline CHEMBL1433364 & 688405 & 5.2583 & 5.126 & TRN & \\
\hline CHEMBL1331050 & 688405 & 4.95 & 6.5122 & TST & \\
\hline CHEMBL1335176 & 688405 & 5.7 & 5.7599 & TRN & \\
\hline CHEMBL1403026 & 688405 & 5.15 & 5.5174 & TST & \\
\hline CHEMBL1604790 & 688405 & 6.05 & 6.1109 & TST & \\
\hline CHEMBL1571839 & 688405 & 7.8996 & 6.0932 & TST & \\
\hline CHEMBL1474508 & 688405 & 4.2592 & 5.8183 & TST & \\
\hline CHEMBL1475745 & 688405 & 5.5592 & 6.5823 & TST & \\
\hline CHEMBL1334291 & 688405 & 5.7 & 5.8176 & TST & \\
\hline CHEMBL1537810 & 688405 & 6.5 & 6.5175 & TST & \\
\hline CHEMBL1433279 & 688405 & 5.5583 & 5.1212 & TST & \\
\hline CHEMBL1358475 & 688405 & 5.5583 & 5.1677 & TST & \\
\hline CHEMBL1433350 & 688405 & 5.2583 & 5.3716 & TST & \\
\hline CHEMBL1472536 & 688405 & 4.4592 & 4.7272 & TST & \\
\hline CHEMBL1978331 & 688405 & 9.0 & 6.1823 & TST & \\
\hline CHEMBL1315807 & 688405 & 5.8592 & 6.6412 & TST & \\
\hline CHEMBL1492922 & 688405 & 7.6498 & 6.2764 & TST & \\
\hline
\end{tabular}




\begin{tabular}{|c|c|c|c|c|c|}
\hline & & \multicolumn{4}{|c|}{ Supplemental Table s2.txt } \\
\hline CHEMBL57347 & 70610 & 7.2924 & 7.3406 & TRN & \\
\hline CHEMBL432708 & 70610 & 7.1427 & 7.1386 & TRN & \\
\hline CHEMBL292701 & 70610 & 5.2596 & 5.2684 & TRN & \\
\hline CHEMBL293132 & 70610 & 7.3665 & 7.3553 & TRN & \\
\hline CHEMBL299026 & 70610 & 7.0862 & 7.0096 & TRN & \\
\hline CHEMBL58684 & 70610 & 6.6778 & 6.6702 & TRN & \\
\hline CHEMBL56380 & 70610 & 5.699 & \multicolumn{2}{|c|}{5.702000000000001} & TRN \\
\hline CHEMBL418111 & 70610 & 7.0757 & 7.0786 & TRN & \\
\hline CHEMBL57585 & 70610 & 6.9208 & 6.9106 & TRN & \\
\hline CHEMBL57323 & 70610 & 6.3979 & 5.8451 & TST & \\
\hline CHEMBL57531 & 70610 & 4.8861 & 4.9311 & TST & \\
\hline CHEMBL298620 & 70610 & 6.3468 & 6.3426 & TRN & \\
\hline CHEMBL300171 & 70610 & 6.5376 & 5.7848 & TST & \\
\hline CHEMBL416501 & 70610 & 6.3768 & 6.3763 & TRN & \\
\hline CHEMBL58937 & 70610 & 5.5686 & 5.5574 & TRN & \\
\hline CHEMBL58628 & 70610 & 4.8861 & 5.0211 & TST & \\
\hline CHEMBL293592 & 70610 & 3.301 & 4.0919 & TST & \\
\hline CHEMBL299687 & 70610 & 6.2218 & 6.2203 & TRN & \\
\hline CHEMBL294711 & 70610 & 6.2147 & 6.2177 & TRN & \\
\hline CHEMBL294438 & 70610 & 7.1249 & 7.1317 & TRN & \\
\hline CHEMBL417961 & 70610 & 7.1249 & 7.1241 & TRN & \\
\hline CHEMBL418284 & 70610 & 7.2218 & 7.2159 & TRN & \\
\hline CHEMBL292146 & 70610 & 7.4559 & 7.4585 & TRN & \\
\hline CHEMBL 301483 & 70610 & 7.3098 & 7.3258 & TRN & \\
\hline CHEMBL57207 & 70610 & 7.4685 & 7.4747 & TRN & \\
\hline CHEMBL291777 & 70610 & 6.4685 & 6.4614 & TRN & \\
\hline CHEMBL 301273 & 70610 & 6.8861 & 6.9337 & TRN & \\
\hline CHEMBL299763 & 70610 & 7.3188 & 4.5285 & TST & \\
\hline CHEMBL57229 & 70610 & 4.7447 & 5.5983 & TST & \\
\hline CHEMBL56983 & 70610 & 6.9586 & 6.9651 & TRN & \\
\hline CHEMBL301641 & 70610 & 7.1739 & 7.1766 & TRN & \\
\hline CHEMBL57035 & 70610 & 5.0 & 5.8965 & TST & \\
\hline CHEMBL58627 & 70610 & 5.5229 & 5.4596 & TST & \\
\hline CHEMBL60635 & 70610 & 5.0969 & 5.0756 & TRN & \\
\hline CHEMBL299270 & 70610 & 5.6021 & 5.6014 & TRN & \\
\hline CHEMBL431942 & 70610 & 7.4559 & 7.4339 & TRN & \\
\hline CHEMBL444829 & 70610 & 6.9586 & 6.9541 & TRN & \\
\hline CHEMBL58936 & 70610 & 5.1675 & 5.1789 & TRN & \\
\hline CHEMBL60979 & 70610 & 7.2007 & 7.1932 & TRN & \\
\hline CHEMBL56236 & 70610 & 6.1487 & 4.3436 & TST & \\
\hline CHEMBL417950 & 70610 & 4.5686 & 4.5861 & TRN & \\
\hline CHEMBL417208 & 70610 & 6.4949 & 6.4877 & TRN & \\
\hline CHEMBL58652 & 70610 & 6.9208 & 6.9127 & TRN & \\
\hline CHEMBL56942 & 70610 & 6.6383 & 4.296 & TST & \\
\hline CHEMBL300335 & 70610 & 5.5528 & 5.5586 & TRN & \\
\hline CHEMBL300992 & 70610 & 5.4318 & 5.4268 & TRN & \\
\hline CHEMBL45827 & 70610 & 7.3188 & 7.332999 & 9999999999 & TRN \\
\hline CHEMBL60690 & 70610 & 6.585 & 6.599 & TRN & \\
\hline
\end{tabular}




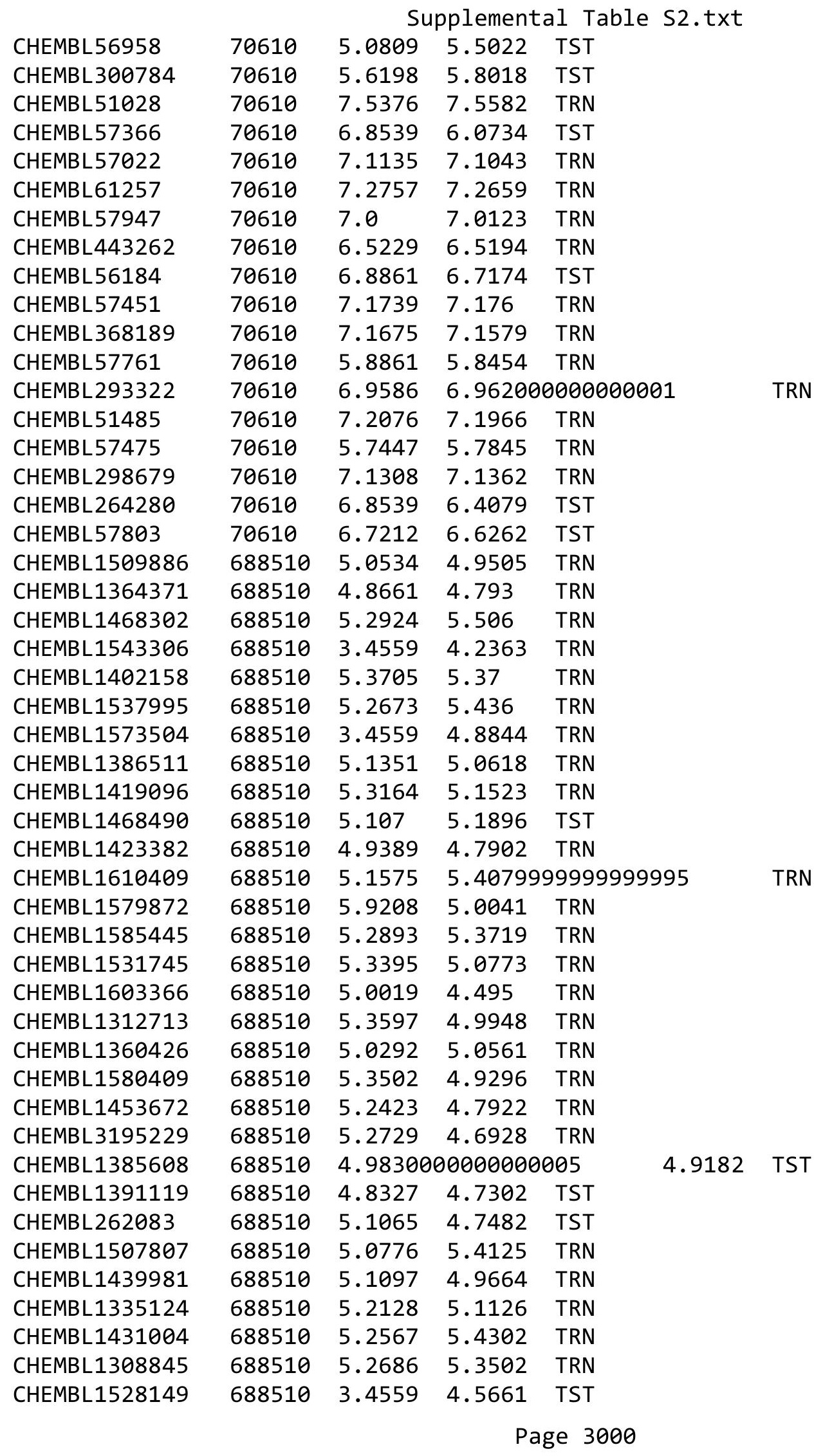




\begin{tabular}{|c|c|c|c|c|c|}
\hline \multicolumn{6}{|c|}{ Supplemental Table S2.txt } \\
\hline CHEMBL1559259 & 688510 & 5.2832 & 5.5571 & TRN & \\
\hline CHEMBL3211272 & 688510 & 5.2991 & 5.0393 & TRN & \\
\hline CHEMBL1366620 & 688510 & 5.1157 & 4.7341 & TRN & \\
\hline CHEMBL3199632 & 688510 & 3.4559 & 4.0955 & TRN & \\
\hline CHEMBL1427860 & 688510 & 3.4559 & 4.4118 & TRN & \\
\hline CHEMBL1499276 & 688510 & 5.3002 & 4.7894 & TRN & \\
\hline CHEMBL1319576 & 688510 & 4.5728 & 4.8484 & TRN & \\
\hline CHEMBL1342128 & 688510 & 4.945 & 5.0471 & TRN & \\
\hline CHEMBL1453776 & 688510 & 3.9208 & 4.2217 & TRN & \\
\hline CHEMBL1370128 & 688510 & 3.4559 & 4.4406 & TRN & \\
\hline CHEMBL1455508 & 688510 & 3.4559 & 4.2969 & TRN & \\
\hline CHEMBL1471779 & 688510 & 5.3153 & 4.8352 & TRN & \\
\hline CHEMBL1393538 & 688510 & 5.1916 & 4.6068 & TRN & \\
\hline CHEMBL1527817 & 688510 & 5.0089 & 5.2611 & TST & \\
\hline CHEMBL1341841 & 688510 & 4.6934 & 4.7514 & TRN & \\
\hline CHEMBL1389702 & 688510 & 3.4559 & 4.6314 & TST & \\
\hline CHEMBL1379143 & 688510 & 5.199 & 5.0021 & TST & \\
\hline CHEMBL1457093 & 688510 & 5.2873 & 4.6663 & TRN & \\
\hline CHEMBL1483730 & 688510 & 5.0794 & 5.0997 & TRN & \\
\hline CHEMBL1329549 & 688510 & 5.1176 & 5.1455 & TRN & \\
\hline CHEMBL1426896 & 688510 & 5.2326 & 4.8859 & TST & \\
\hline CHEMBL1487131 & 688510 & 5.2457 & 5.2474 & TRN & \\
\hline CHEMBL1312703 & 688510 & 5.2752 & 4.7844 & TRN & \\
\hline CHEMBL1310577 & 688510 & 5.2196 & 5.3436 & TRN & \\
\hline CHEMBL1446166 & 688510 & 5.1585 & 5.0553 & TRN & \\
\hline CHEMBL3197426 & 688510 & 5.0505 & 4.6012 & TRN & \\
\hline CHEMBL3194054 & 688510 & 4.9834 & 4.1636 & TRN & \\
\hline CHEMBL1311646 & 688510 & 3.4559 & 4.2891 & TRN & \\
\hline CHEMBL1973629 & 688510 & 3.4559 & 3.6785 & TRN & \\
\hline CHEMBL1426022 & 688510 & 4.9927 & 4.9596 & TRN & \\
\hline CHEMBL1351633 & 688510 & 4.8748 & 5.1117 & TRN & \\
\hline CHEMBL1327690 & 688510 & 5.1763 & 5.2428 & TRN & \\
\hline CHEMBL1342925 & 688510 & 5.1133 & 5.0362 & TRN & \\
\hline CHEMBL1389982 & 688510 & 5.1145 & 5.1739 & TRN & \\
\hline CHEMBL1383592 & 688510 & 5.1315 & 4.8811 & TRN & \\
\hline CHEMBL1511420 & 688510 & 4.6776 & 4.1565 & TRN & \\
\hline CHEMBL1300782 & 688510 & 4.8804 & 4.76699 & 99999999995 & TRN \\
\hline CHEMBL1423799 & 688510 & 5.2451 & 5.644 & TRN & \\
\hline CHEMBL3208997 & 688510 & 5.1498 & 4.9152 & TRN & \\
\hline CHEMBL1311570 & 688510 & 5.1282 & 5.0816 & TRN & \\
\hline CHEMBL1502859 & 688510 & 5.3585 & 5.0695 & TRN & \\
\hline CHEMBL1427745 & 688510 & 5.2786 & 4.8154 & TST & \\
\hline CHEMBL1600727 & 688510 & 4.8938 & 5.23 & TRN & \\
\hline CHEMBL3214137 & 688510 & 5.0808 & 5.0059 & TRN & \\
\hline CHEMBL1404069 & 688510 & 3.4559 & 4.3728 & TRN & \\
\hline CHEMBL1456185 & 688510 & 4.9278 & 4.9205 & TRN & \\
\hline CHEMBL1353075 & 688510 & 4.8639 & 3.935 & TRN & \\
\hline CHEMBL1870697 & 688510 & 3.4559 & 3.9923 & TRN & \\
\hline
\end{tabular}




\begin{tabular}{|c|c|c|c|c|c|c|}
\hline & & \multicolumn{5}{|c|}{ Supplemental Table S2.txt } \\
\hline CHEMBL1428935 & 688510 & 5.3894 & 4.9322 & TST & & \\
\hline CHEMBL1574689 & 688510 & 5.1579 & 5.0644 & TRN & & \\
\hline CHEMBL1308461 & 688510 & 5.1409 & 4.9347 & TRN & & \\
\hline CHEMBL1493500 & 688510 & 5.2389 & 5.1006 & TRN & & \\
\hline CHEMBL417727 & 688510 & 5.3428 & 5.0483 & TST & & \\
\hline CHEMBL1365319 & 688510 & 4.8655 & 4.8842 & TRN & & \\
\hline CHEMBL1427504 & 688510 & 5.2451 & 5.2269 & TRN & & \\
\hline CHEMBL1570844 & 688510 & \multicolumn{3}{|c|}{5.1080000000000005} & 4.8925 & TRN \\
\hline CHEMBL1539256 & 688510 & 5.1179 & 4.8049 & TRN & & \\
\hline CHEMBL3213775 & 688510 & 4.573 & 3.8681 & TRN & & \\
\hline CHEMBL1608982 & 688510 & 3.4559 & 4.7435 & TST & & \\
\hline CHEMBL1585652 & 688510 & 5.0434 & 4.973 & TRN & & \\
\hline CHEMBL1348426 & 688510 & 5.256 & \multicolumn{3}{|c|}{4.7780000000000005} & TRN \\
\hline CHEMBL1480648 & 688510 & 5.1453 & 4.7423 & TRN & & \\
\hline CHEMBL1462447 & 688510 & 3.4559 & 4.7179 & TRN & & \\
\hline CHEMBL1350415 & 688510 & 4.71899 & 99999999 & 99 & 4.5304 & TRN \\
\hline CHEMBL1439255 & 688510 & 4.8729 & 5.3756 & TRN & & \\
\hline CHEMBL1560529 & 688510 & 3.4559 & 4.0936 & TRN & & \\
\hline CHEMBL1493277 & 688510 & 4.9872 & 5.1165 & TRN & & \\
\hline CHEMBL564979 & 688510 & 5.1383 & 5.2235 & TRN & & \\
\hline CHEMBL1377743 & 688510 & 5.0436 & 5.142 & TRN & & \\
\hline CHEMBL1387309 & 688510 & 5.0456 & 4.9724 & TRN & & \\
\hline CHEMBL1359694 & 688510 & 4.8788 & 5.2924 & TST & & \\
\hline CHEMBL1568243 & 688510 & \multicolumn{3}{|c|}{5.2620000000000005} & 5.0753 & TST \\
\hline CHEMBL3190644 & 688510 & 5.1898 & 4.9696 & TST & & \\
\hline CHEMBL1432676 & 688510 & 5.9208 & 5.0527 & TST & & \\
\hline CHEMBL3195213 & 688510 & 3.4559 & 4.6196 & TST & & \\
\hline CHEMBL1398754 & 688510 & 3.4559 & 4.7392 & TST & & \\
\hline CHEMBL1353428 & 688510 & 5.3889 & 4.654 & TST & & \\
\hline CHEMBL1599610 & 688510 & 5.1137 & 5.2338 & TST & & \\
\hline CHEMBL1545971 & 688510 & 5.1472 & 4.9252 & TST & & \\
\hline CHEMBL1453832 & 688510 & 5.0242 & 4.5607 & TST & & \\
\hline CHEMBL1522356 & 688510 & 5.2785 & 5.5223 & TST & & \\
\hline CHEMBL1990096 & 688510 & 5.1497 & 4.5602 & TST & & \\
\hline CHEMBL1345334 & 688510 & 5.3957 & 5.1519 & TST & & \\
\hline CHEMBL1563162 & 688510 & 5.0664 & 4.9172 & TST & & \\
\hline CHEMBL1534058 & 688510 & 3.4559 & 4.5798 & TST & & \\
\hline CHEMBL1467233 & 688510 & 3.4559 & 4.5306 & TST & & \\
\hline CHEMBL1349920 & 688510 & 4.9527 & 5.0183 & TST & & \\
\hline CHEMBL3646013 & 1528071 & 8.0 & 6.7207 & TST & & \\
\hline CHEMBL 3646084 & 1528071 & 6.0 & 7.2048 & TRN & & \\
\hline CHEMBL3643468 & 1528071 & 6.0 & 6.9914 & TRN & & \\
\hline CHEMBL3646104 & 1528071 & 5.0 & 6.4603 & TRN & & \\
\hline CHEMBL3646078 & 1528071 & 7.0 & 6.7001 & TRN & & \\
\hline CHEMBL3646081 & 1528071 & 6.0 & 6.9139 & TRN & & \\
\hline CHEMBL3646074 & 1528071 & 7.0 & 6.9781 & TRN & & \\
\hline CHEMBL3646073 & 1528071 & 7.0 & 6.9108 & TRN & & \\
\hline CHEMBL3646060 & 1528071 & 8.0 & 7.0388 & TRN & & \\
\hline
\end{tabular}




\begin{tabular}{|c|c|c|c|}
\hline \multicolumn{4}{|c|}{$\begin{array}{c}5 \\
\end{array}$} \\
\hline CHEMBL3646023 & 15280718.0 & 6.7444 & TST \\
\hline CHEMBL3646089 & 15280716.0 & 6.3761 & TRN \\
\hline CHEMBL3646063 & 15280718.0 & 6.8439 & TRN \\
\hline CHEMBL 3646100 & 15280716.0 & 6.886 & TRN \\
\hline CHEMBL 3646066 & 15280718.0 & 6.876 & TRN \\
\hline CHEMBL3646098 & 15280716.0 & 6.4936 & TRN \\
\hline CHEMBL3646103 & 15280715.0 & 5.7721 & TRN \\
\hline CHEMBL 3643463 & 15280717.0 & 7.0067 & TRN \\
\hline CHEMBL3646049 & 15280716.0 & 5.853 & TRN \\
\hline CHEMBL3646027 & 15280717.0 & 6.3616 & TST \\
\hline CHEMBL 3643464 & 15280716.0 & 6.9515 & TRN \\
\hline CHEMBL3646008 & 15280718.0 & 7.1508 & TRN \\
\hline CHEMBL3646012 & 15280718.0 & 6.181 & TST \\
\hline CHEMBL3646018 & 15280718.0 & 7.6325 & TRN \\
\hline CHEMBL3646029 & 15280717.0 & 6.2113 & TRN \\
\hline CHEMBL 3646061 & 15280718.0 & 6.8309 & TRN \\
\hline CHEMBL3646068 & 15280718.0 & 7.1552 & TRN \\
\hline CHEMBL 3646045 & 15280716.0 & 6.8654 & TRN \\
\hline CHEMBL3643455 & 15280718.0 & 7.7315 & TRN \\
\hline CHEMBL3646051 & 15280716.0 & 6.2389 & TRN \\
\hline CHEMBL3646082 & 15280716.0 & 6.6345 & TST \\
\hline CHEMBL3646094 & 15280716.0 & 6.7715 & TRN \\
\hline CHEMBL3646086 & 15280716.0 & 6.0779 & TRN \\
\hline CHEMBL3646046 & 15280716.0 & 6.1004 & TRN \\
\hline CHEMBL3646076 & 15280717.0 & 7.3532 & TRN \\
\hline CHEMBL 3643475 & 15280715.0 & 7.2439 & TRN \\
\hline CHEMBL3646017 & 15280718.0 & 6.9132 & TRN \\
\hline CHEMBL3646019 & 15280718.0 & 7.7332 & TRN \\
\hline CHEMBL 3646058 & 15280718.0 & 6.4062 & TRN \\
\hline CHEMBL 3646077 & 15280717.0 & 6.4965 & TST \\
\hline CHEMBL3646092 & 15280716.0 & 6.4659 & TRN \\
\hline CHEMBL3646009 & 15280718.0 & 6.9294 & TRN \\
\hline CHEMBL3643469 & 15280717.0 & 6.9751 & TRN \\
\hline CHEMBL3646034 & 15280717.0 & 6.8932 & TRN \\
\hline CHEMBL 3646024 & 15280718.0 & 7.3303 & TRN \\
\hline CHEMBL3646079 & 15280717.0 & 7.016 & TRN \\
\hline CHEMBL 3646057 & 15280718.0 & 7.0614 & TST \\
\hline CHEMBL3646010 & 15280718.0 & 6.6904 & TRN \\
\hline CHEMBL3646106 & 15280716.0 & 6.5051 & TRN \\
\hline CHEMBL 3646035 & 15280717.0 & 6.0398 & TRN \\
\hline CHEMBL3643466 & 15280718.0 & 7.6681 & TRN \\
\hline CHEMBL 3646031 & 15280717.0 & 6.5759 & TST \\
\hline CHEMBL 3643442 & 15280716.0 & 6.2201 & TST \\
\hline CHEMBL 3643470 & 15280716.0 & 6.5904 & TRN \\
\hline CHEMBL 3646044 & 15280716.0 & 6.1427 & TRN \\
\hline CHEMBL3646062 & 15280718.0 & 7.4965 & TST \\
\hline CHEMBL 3646014 & 15280718.0 & 6.2111 & TRN \\
\hline CHEMBL3643498 & 15280717.0 & 7.0143 & TRN \\
\hline
\end{tabular}




\begin{tabular}{|c|c|c|c|c|}
\hline CHEMBL3646102 & 15280715.0 & 6.1358 & TRN & \\
\hline CHEMBL3646021 & 15280718.0 & 6.8278 & TST & \\
\hline CHEMBL3646037 & 15280717.0 & 6.1799 & TRN & \\
\hline CHEMBL3646040 & 15280716.0 & 6.7829 & TRN & \\
\hline CHEMBL3646048 & 15280716.0 & 6.3167 & TST & \\
\hline CHEMBL3646088 & 15280716.0 & 6.3346 & TRN & \\
\hline CHEMBL3643453 & 15280717.0 & 7.2821 & TRN & \\
\hline CHEMBL3646083 & 15280716.0 & 6.6524 & TST & \\
\hline CHEMBL3646096 & 15280716.0 & 7.6123 & TRN & \\
\hline CHEMBL3646069 & 15280718.0 & 6.7349 & TRN & \\
\hline CHEMBL3646095 & 15280716.0 & 6.8017 & TRN & \\
\hline CHEMBL3643456 & 15280718.0 & 7.3892 & TRN & \\
\hline CHEMBL3646093 & 15280716.0 & 6.4047 & TRN & \\
\hline CHEMBL3643452 & 15280717.0 & 7.7805 & TRN & \\
\hline CHEMBL 3643448 & 15280718.0 & 7.5899 & TRN & \\
\hline CHEMBL3643467 & 15280717.0 & 6.9373 & TRN & \\
\hline CHEMBL3646039 & 15280716.0 & 6.6196 & TRN & \\
\hline CHEMBL3646015 & 15280718.0 & 7.7873 & TRN & \\
\hline CHEMBL3646022 & 15280718.0 & 7.271 & TRN & \\
\hline CHEMBL3643462 & 15280716.0 & 6.9632 & TRN & \\
\hline CHEMBL 3643457 & 15280717.0 & 7.3212 & TRN & \\
\hline CHEMBL 3643443 & 15280718.0 & \multicolumn{2}{|c|}{7.537999999999999} & TRN \\
\hline CHEMBL3646087 & 15280716.0 & 7.0453 & TRN & \\
\hline CHEMBL3646099 & 15280716.0 & 5.9137 & TRN & \\
\hline CHEMBL3639449 & 15280716.0 & 6.2193 & TRN & \\
\hline CHEMBL 3643461 & 15280716.0 & 6.5938 & TRN & \\
\hline CHEMBL3646030 & 15280717.0 & 7.0014 & TRN & \\
\hline CHEMBL 3646020 & 15280718.0 & 6.5691 & TRN & \\
\hline CHEMBL3646042 & 15280716.0 & 6.2602 & TRN & \\
\hline CHEMBL 3646080 & 15280716.0 & 6.4939 & TST & \\
\hline CHEMBL 3646043 & 15280716.0 & 5.7832 & TST & \\
\hline CHEMBL3646097 & 15280716.0 & 6.6767 & TRN & \\
\hline CHEMBL3646004 & 15280716.0 & 5.8353 & TST & \\
\hline CHEMBL3646026 & 15280717.0 & 6.7763 & TRN & \\
\hline CHEMBL 3643451 & 15280716.0 & 6.5202 & TRN & \\
\hline CHEMBL 3643454 & 15280718.0 & 7.7351 & TRN & \\
\hline CHEMBL3646041 & 15280716.0 & 6.2239 & TRN & \\
\hline CHEMBL 3643458 & 15280716.0 & 7.0085 & TRN & \\
\hline CHEMBL3646091 & 15280716.0 & 6.9003 & TRN & \\
\hline CHEMBL3646036 & 15280717.0 & 5.8644 & TRN & \\
\hline CHEMBL3645993 & 15280716.0 & 6.9445 & TST & \\
\hline CHEMBL3646011 & 15280718.0 & 6.7878 & TST & \\
\hline CHEMBL3646059 & 15280718.0 & 7.7456 & TRN & \\
\hline CHEMBL3646050 & 15280716.0 & \multicolumn{2}{|c|}{6.4910000000000005} & TRN \\
\hline CHEMBL3646070 & 15280718.0 & 6.9828 & TRN & \\
\hline CHEMBL 3643449 & 15280718.0 & \multicolumn{2}{|c|}{7.462999999999999} & TRN \\
\hline CHEMBL 3646038 & 15280717.0 & 6.2456 & TRN & \\
\hline CHEMBL 3643465 & 15280717.0 & 7.0061 & TRN & \\
\hline
\end{tabular}




\begin{tabular}{|c|c|c|c|c|c|}
\hline \multicolumn{6}{|c|}{ Supplemental Table S2.txt } \\
\hline CHEMBL3646028 & 1528071 & 7.0 & 6.393 & TST & \\
\hline CHEMBL3646055 & 1528071 & 6.0 & 6.3662 & TRN & \\
\hline CHEMBL3646056 & 1528071 & 6.0 & 6.0364 & TRN & \\
\hline CHEMBL 3646052 & 1528071 & 6.0 & 6.2731 & TST & \\
\hline CHEMBL3646090 & 1528071 & 6.0 & 6.2722 & TRN & \\
\hline CHEMBL3646033 & 1528071 & 7.0 & 6.7131 & TST & \\
\hline CHEMBL3646025 & 1528071 & 8.0 & 6.6905 & TRN & \\
\hline CHEMBL3643445 & 1528071 & 8.0 & 7.6225 & TRN & \\
\hline CHEMBL3643499 & 1528071 & 8.0 & 7.8003 & TRN & \\
\hline CHEMBL3643459 & 1528071 & 6.0 & 6.6511 & TRN & \\
\hline CHEMBL3646067 & 1528071 & 8.0 & 7.0893 & TRN & \\
\hline CHEMBL3646047 & 1528071 & 6.0 & 6.6183 & TRN & \\
\hline CHEMBL3646085 & 1528071 & 6.0 & 6.4586 & TST & \\
\hline CHEMBL3646053 & 1528071 & 6.0 & 6.5964 & TST & \\
\hline CHEMBL3646032 & 1528071 & 7.0 & 6.1491 & TST & \\
\hline CHEMBL3646071 & 1528071 & 8.0 & 6.7395 & TST & \\
\hline CHEMBL3646072 & 1528071 & 7.0 & 6.46 & TST & \\
\hline CHEMBL3646064 & 1528071 & 8.0 & 6.8475 & TST & \\
\hline CHEMBL3646105 & 1528071 & 5.0 & 6.9455 & TST & \\
\hline CHEMBL 3643460 & 1528071 & 5.0 & 6.5108 & TST & \\
\hline CHEMBL3646016 & 1528071 & 8.0 & 6.6121 & TST & \\
\hline CHEMBL3646075 & 1528071 & 7.0 & 6.5898 & TST & \\
\hline CHEMBL 3646054 & 1528071 & 6.0 & 5.9255 & TST & \\
\hline CHEMBL 3785603 & 1566412 & 4.58 & 4.5689 & TRN & \\
\hline CHEMBL3329517 & 1566412 & 5.8697 & 5.9216 & TRN & \\
\hline CHEMBL3787052 & 1566412 & 5.7496 & 5.7397 & TRN & \\
\hline CHEMBL3329510 & 1566412 & 5.7305 & 5.7302 & TRN & \\
\hline CHEMBL3329509 & 1566412 & 5.5702 & 5.5596 & TRN & \\
\hline CHEMBL3787696 & 1566412 & 5.1898 & 5.1529 & TRN & \\
\hline CHEMBL3786871 & 1566412 & 5.5901 & 5.5597 & TRN & \\
\hline CHEMBL3329505 & 1566412 & 5.58 & 5.6213 & TRN & \\
\hline CHEMBL3329506 & 1566412 & 5.6498 & 5.6994 & TRN & \\
\hline CHEMBL3329523 & 1566412 & 5.8996 & 5.5166 & TRN & \\
\hline CHEMBL3329507 & 1566412 & 5.8601 & 5.7867 & TRN & \\
\hline CHEMBL 3787001 & 1566412 & 5.4698 & 5.6649 & TRN & \\
\hline CHEMBL3329522 & 1566412 & 6.0506 & 6.0507 & TRN & \\
\hline CHEMBL3787599 & 1566412 & 5.2299 & 5.1858 & TRN & \\
\hline CHEMBL3786510 & 1566412 & 5.4895 & 5.5698 & TRN & \\
\hline CHEMBL3785305 & 1566412 & 5.6799 & 5.3991 & TST & \\
\hline CHEMBL3329512 & 1566412 & 6.1024 & 5.9446 & TRN & \\
\hline CHEMBL3629565 & 1566412 & 3.3 & 5.0674 & TST & \\
\hline CHEMBL1276197 & 1566412 & 5.0301 & 5.4017 & TST & \\
\hline CHEMBL3785430 & 1566412 & 4.7399 & 4.70100 & 00000000005 & TRN \\
\hline CHEMBL3785309 & 1566412 & 4.76 & 5.1642 & TST & \\
\hline CHEMBL3329519 & 1566412 & 5.6498 & 5.746 & TRN & \\
\hline CHEMBL 3787543 & 1566412 & 4.6099 & 4.6398 & TRN & \\
\hline CHEMBL3786279 & 1566412 & 4.7899 & 4.8376 & TRN & \\
\hline CHEMBL90512 & 1566412 & 6.2007 & 5.1067 & TST & \\
\hline
\end{tabular}


Supplemental Table S2.txt

\begin{tabular}{|c|c|c|c|c|}
\hline 580 & 566412 & 5.9788 & 9296 & \\
\hline & 566412 & 4.7701 & 5.2178 & \\
\hline CMO1. & 66412 & 4.9602 & & \\
\hline AEMBL3629564 & 566412 & 3.3 & 923 & \\
\hline AEMBL 3785855 & 566412 & 4.7701 & 7645 & \\
\hline AEMBL: & 566412 & 5.7696 & 3373 & \\
\hline 388 & 12 & 5.4895 & 423 & \\
\hline AEMBL & 12 & 5.8794 & & \\
\hline 87039 & 1566412 & 5.3098 & 276 & \\
\hline HEMBL3329513 & 566412 & 5.7905 & 522 & \\
\hline 9511 & 156 & & & \\
\hline 101 & 2 & 15 & 287 & \\
\hline AEMB & 2 & & & \\
\hline AEMBL3 & 1566412 & 3.3 & 5.0783 & \\
\hline AEMBL. & 1566412 & & 811 & \\
\hline 508 & 156 & & & \\
\hline 16 & 156 & 6 . & & \\
\hline 20 & 156 & & & \\
\hline 7688 & 1566412 & 4.64 & & \\
\hline 588 & & & & \\
\hline 542 & 156 & & & \\
\hline 1 & 2 & & & \\
\hline 34 & $15 \epsilon$ & 96 & 19 & \\
\hline 627 & 12 & 4. & & \\
\hline CHEMBL & 156 & 5 . & & \\
\hline $\mathrm{CHE}$ & 209 & & & \\
\hline 3 & 209 & & & \\
\hline 19 & 209 & 51 & 23 & \\
\hline (9игми & 209 & & & \\
\hline CHEMBL 3 & 209 & & & \\
\hline $\mathrm{CHE}$ & 2092 & & & \\
\hline $\mathrm{CHE}$ & 09 & & 32 & \\
\hline $\mathrm{CHE}$ & 209 & & 21 & \\
\hline CHEMBL & 2092 & & & 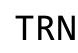 \\
\hline CHEMBL 1 & 209245 & & 56 & \\
\hline & 209 & & & \\
\hline $\mathrm{CH}$ & 09 & 2. & 59 & \\
\hline $\mathrm{CHE}$ & 209 & 3. & 536 & TR \\
\hline CHEMBL & 209245 & 5.0969 & 7.1977 & TS \\
\hline - & 2092 & 969 & & \\
\hline CHEMB & 2092 & 69 & & \\
\hline CHEMBL & 209245 & 5.699 & 7.0219 & \\
\hline CHEMBL & 209245 & 6.8861 & 6.1008 & K \\
\hline CHEMBL & 209245 & 3.4559 & 2.8124 & TR \\
\hline 1746 & 20924 & 6.5 & 7.1228 & \\
\hline CHEMBL & 2092 & 08 & 6.0235 & \\
\hline CHEMBL & 209245 & 4.3979 & 6.1008 & \\
\hline CHEMBL433847 & 209245 & 2.0969 & 1.9096 & \\
\hline
\end{tabular}

Page 3006 


\begin{tabular}{|c|c|c|c|c|c|c|}
\hline & & \multicolumn{5}{|c|}{ Supplemental Table S2.txt } \\
\hline CHEMBL130147 & 209245 & 4.8239 & 5.7323 & TRN & & \\
\hline CHEMBL133808 & 209245 & 4.4559 & 4.2493 & TRN & & \\
\hline CHEMBL407378 & 209245 & 4.9872 & 6.0371 & TST & & \\
\hline CHEMBL129730 & 209245 & 3.2218 & 4.551 & TST & & \\
\hline CHEMBL1556461 & 209245 & 6.7959 & 6.6192 & TRN & & \\
\hline CHEMBL334510 & 209245 & 8.0 & 8.14200 & 000000000 & & TRN \\
\hline CHEMBL338639 & 209245 & 1.9208 & 3.3236 & TRN & & \\
\hline CHEMBL130058 & 209245 & 4.1549 & 5.5357 & TST & & \\
\hline CHEMBL132307 & 209245 & 3.3979 & 2.5331 & TRN & & \\
\hline CHEMBL335915 & 209245 & 2.0969 & 2.1878 & TRN & & \\
\hline CHEMBL133837 & 209245 & 6.3979 & 6.2838 & TRN & & \\
\hline CHEMBL131738 & 209245 & 2.0969 & 2.2318 & TRN & & \\
\hline CHEMBL337502 & 209245 & 4.6696 & 4.8063 & TRN & & \\
\hline CHEMBL445632 & 209245 & 3.699 & 3.3871 & TRN & & \\
\hline CHEMBL134081 & 209245 & 4.7212 & 5.2929 & TRN & & \\
\hline CHEMBL33473 & 209245 & 6.699 & 6.1982 & TRN & & \\
\hline CHEMBL337852 & 209245 & 3.6289 & 3.7711 & TRN & & \\
\hline CHEMBL337394 & 209245 & 2.0969 & 3.5751 & TST & & \\
\hline CHEMBL 337674 & 209245 & 3.38199 & 99999999 & 997 & 3.1522 & TRN \\
\hline CHEMBL434623 & 209245 & 4.5086 & 4.9191 & TST & & \\
\hline CHEMBL133449 & 209245 & 6.1549 & 5.8733 & TRN & & \\
\hline CHEMBL264249 & 209245 & 5.4815 & 7.2205 & TST & & \\
\hline CHEMBL132939 & 209245 & 3.7328 & 4.6856 & TST & & \\
\hline CHEMBL337273 & 209245 & 3.1367 & 4.1074 & TRN & & \\
\hline CHEMBL130930 & 209245 & 4.5528 & 3.5601 & TRN & & \\
\hline CHEMBL130307 & 209245 & 2.0969 & 3.2591 & TRN & & \\
\hline CHEMBL 2370701 & 209245 & 6.301 & 6.5706 & TST & & \\
\hline CHEMBL1258761 & 664672 & 7.8665 & 7.8827 & TRN & & \\
\hline CHEMBL1257734 & 664672 & 8.3497 & 7.6029 & TST & & \\
\hline CHEMBL1258534 & 664672 & 9.057 & 8.5497 & TRN & & \\
\hline CHEMBL1257969 & 664672 & 7.8601 & 7.7446 & TRN & & \\
\hline CHEMBL1258084 & 664672 & 7.6517 & 7.8652 & TRN & & \\
\hline CHEMBL1258426 & 664672 & 7.6073 & 7.6434 & TST & & \\
\hline CHEMBL1257382 & 664672 & 10.2403 & 7.7886 & TST & & \\
\hline CHEMBL1257262 & 664672 & 9.52 & 7.6543 & TST & & \\
\hline CHEMBL1257145 & 664672 & 7.9914 & 7.904 & TRN & & \\
\hline CHEMBL 1257383 & 664672 & 7.9172 & 7.6228 & TST & & \\
\hline CHEMBL1258427 & 664672 & 7.8013 & 8.0334 & TRN & & \\
\hline CHEMBL1258200 & 664672 & 7.9872 & 7.8188 & TRN & & \\
\hline CHEMBL1257857 & 664672 & 7.6517 & 7.6499 & TST & & \\
\hline CHEMBL1257384 & 664672 & 7.6108 & 7.8804 & TRN & & \\
\hline CHEMBL1258535 & 664672 & 8.0205 & 8.4767 & TRN & & \\
\hline CHEMBL1257968 & 664672 & 7.9393 & 7.7076 & TST & & \\
\hline CHEMBL1257492 & 664672 & 8.6819 & 7.7603 & TST & & \\
\hline CHEMBL1257615 & 664672 & 7.8665 & 8.1633 & TRN & & \\
\hline CHEMBL1257385 & 664672 & 8.2284 & 8.0211 & TRN & & \\
\hline CHEMBL1257261 & 664672 & 8.0846 & 8.0288 & TRN & & \\
\hline CHEMBL1257970 & 664672 & 7.7799 & 8.4272 & TRN & & \\
\hline
\end{tabular}


Supplemental Table S2.txt

\begin{tabular}{|c|c|c|c|c|c|}
\hline CHEMBL1258882 & 664672 & 7.9747 & 7.666 & TRN & \\
\hline CHEMBL1258087 & 664672 & 9.0904 & 8.5024 & TRN & \\
\hline CHEMBL1257495 & 664672 & 7.8827 & 8.009 & TRN & \\
\hline CHEMBL1258650 & 664672 & 8.2358 & 8.4052 & TRN & \\
\hline CHEMBL1257616 & 664672 & 8.5186 & 8.2922 & TRN & \\
\hline CHEMBL1258880 & 664672 & 7.3516 & 7.7677 & TRN & \\
\hline CHEMBL1258313 & 664672 & 8.2403 & 7.9416 & TRN & \\
\hline CHEMBL1257858 & 664672 & 7.6615 & 8.184 & TRN & \\
\hline CHEMBL1258086 & 664672 & 8.4191 & 8.3501 & TRN & \\
\hline CHEMBL1257736 & 664672 & 8.7696 & 8.0929 & TRN & \\
\hline CHEMBL1258762 & 664672 & 7.9508 & 8.5607 & TRN & \\
\hline CHEMBL1258085 & 664672 & 8.2604 & 7.9791 & TRN & \\
\hline CHEMBL1257146 & 664672 & 8.0453 & 7.9859 & TRN & \\
\hline CHEMBL1258647 & 664672 & 8.1314 & 7.7366 & TRN & \\
\hline CHEMBL1257614 & 664672 & 8.8125 & 7.7878 & TST & \\
\hline CHEMBL1257493 & 664672 & 9.2403 & 7.6805 & TST & \\
\hline CHEMBL1258314 & 664672 & 8.066 & 7.9076 & TRN & \\
\hline CHEMBL1258312 & 664672 & 7.4685 & 7.57100 & 0000000001 & TST \\
\hline CHEMBL1257147 & 664672 & 8.0061 & 8.1108 & TRN & \\
\hline CHEMBL1257737 & 664672 & 8.025 & 8.2246 & TRN & \\
\hline CHEMBL1257856 & 664672 & 6.5376 & 7.5031 & TST & \\
\hline CHEMBL1258649 & 664672 & 8.8508 & 8.6267 & TRN & \\
\hline CHEMBL1257494 & 664672 & 8.1669 & 7.8704 & TRN & \\
\hline CHEMBL1258199 & 664672 & 7.4535 & 8.1089 & TRN & \\
\hline CHEMBL1258648 & 664672 & 7.556 & 7.6777 & TRN & \\
\hline CHEMBL1258532 & 664672 & 7.0931 & 7.7604 & TST & \\
\hline CHEMBL1257613 & 664672 & 8.58 & 7.6531 & TST & \\
\hline CHEMBL1258428 & 664672 & 8.0496 & 8.4007 & TRN & \\
\hline CHEMBL1258763 & 664672 & 8.7305 & 8.4924 & TRN & \\
\hline CHEMBL1258879 & 664672 & 8.4976 & 8.0117 & TRN & \\
\hline CHEMBL1258881 & 664672 & 9.0501 & 8.6568 & TRN & \\
\hline CHEMBL1258425 & 664672 & 7.3904 & 7.6882 & TST & \\
\hline CHEMBL1257263 & 664672 & 7.2874 & 7.5762 & TRN & \\
\hline CHEMBL1257144 & 664672 & 7.2366 & 7.8905 & TRN & \\
\hline CHEMBL1258760 & 664672 & 7.4711 & 7.7956 & TRN & \\
\hline CHEMBL1258533 & 664672 & 7.7878 & 7.61600 & 00000000005 & TRN \\
\hline CHEMBL1257971 & 664672 & 8.6308 & 8.5731 & TRN & \\
\hline CHEMBL1257859 & 664672 & 8.6091 & 8.3269 & TRN & \\
\hline CHEMBL1257264 & 664672 & 8.0311 & 7.7081 & TRN & \\
\hline CHEMBL1257735 & 664672 & 9.2396 & 7.7343 & TST & \\
\hline CHEMBL449158 & 954911 & 6.3318 & 6.9148 & TST & \\
\hline CHEMBL577784 & 954911 & 4.3651 & 4.3651 & TRN & \\
\hline CHEMBL180127 & 954911 & 5.0486 & 5.0486 & TRN & \\
\hline CHEMBL1190711 & 954911 & 5.206 & 5.206 & TRN & \\
\hline CHEMBL1404918 & 954911 & 2.7633 & 2.7633 & TRN & \\
\hline CHEMBL 3199475 & 954911 & 5.1672 & 5.1672 & TRN & \\
\hline CHEMBL220241 & 954911 & 5.3523 & 5.3523 & TRN & \\
\hline CHEMBL135561 & 954911 & $3.7260 e$ & 30000000 & 004 & 30000000004 \\
\hline
\end{tabular}


Supplemental Table S2.txt

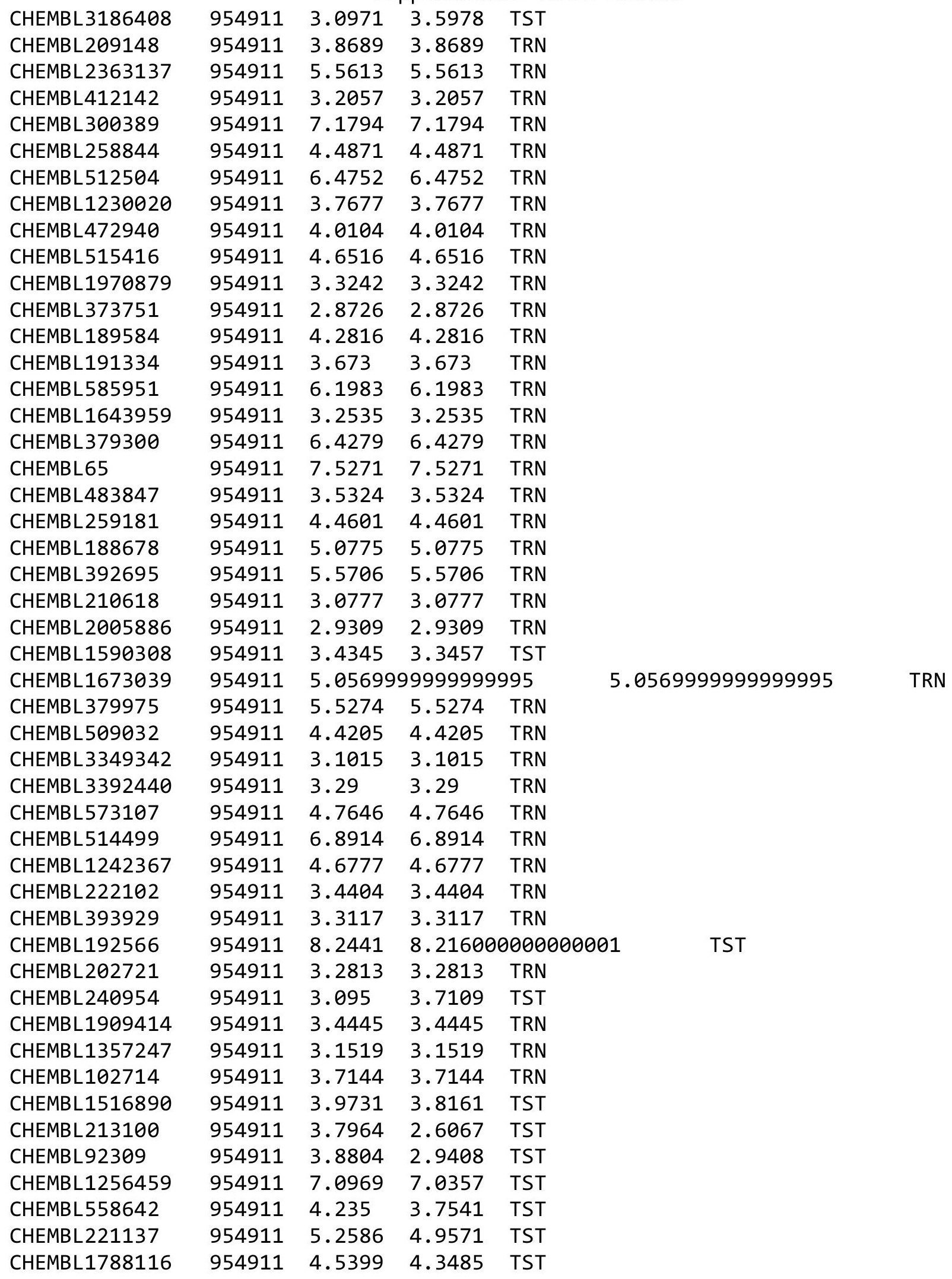

Page 3009 
Supplemental Table S2.txt

\begin{tabular}{|c|c|c|c|c|}
\hline CHEMBL 2144069 & 954911 & 2.9833 & 3.4943 & TST \\
\hline CHEMBL483849 & 954911 & 3.0021 & 1.8387 & TST \\
\hline CHEMBL 9470 & 954911 & 5.9636 & 5.895 & TST \\
\hline CHEMBL51641 & 154333 & 6.1805 & 6.1075 & TRN \\
\hline CHEMBL420484 & 154333 & 7.0223 & 7.2059 & TRN \\
\hline CHEMBL109633 & 154333 & 5.6383 & 6.4365 & TRN \\
\hline CHEMBL108342 & 154333 & 7.2218 & 7.3967 & TRN \\
\hline CHEMBL326257 & 154333 & 6.7959 & 5.8007 & TST \\
\hline CHEMBL108450 & 154333 & 6.6021 & 6.7526 & TRN \\
\hline CHEMBL108132 & 154333 & 5.699 & 5.8289 & TRN \\
\hline CHEMBL109093 & 154333 & 6.699 & 5.8059 & TST \\
\hline CHEMBL108390 & 154333 & 6.3979 & 5.2466 & TRN \\
\hline CHEMBL320041 & 154333 & 5.2218 & 5.1135 & TRN \\
\hline CHEMBL326681 & 154333 & 7.2218 & 7.2603 & TRN \\
\hline CHEMBL324400 & 154333 & 6.699 & 7.1647 & TRN \\
\hline CHEMBL111349 & 154333 & 7.2596 & 6.9324 & TRN \\
\hline CHEMBL321392 & 154333 & 5.699 & 5.0554 & TRN \\
\hline CHEMBL109278 & 154333 & 6.6383 & 6.5112 & TST \\
\hline CHEMBL324679 & 154333 & 5.699 & 4.8618 & TRN \\
\hline CHEMBL111587 & 154333 & 6.0 & 6.0942 & TRN \\
\hline CHEMBL110992 & 154333 & 8.0 & 7.0301 & TRN \\
\hline CHEMBL299152 & 154333 & 7.9208 & 7.7591 & TRN \\
\hline CHEMBL110207 & 154333 & 6.0 & 6.7618 & TRN \\
\hline CHEMBL108664 & 154333 & 8.0458 & 7.8295 & TRN \\
\hline CHEMBL107972 & 154333 & 7.6383 & 7.3464 & TRN \\
\hline CHEMBL108247 & 154333 & 6.7825 & 7.2524 & TRN \\
\hline CHEMBL108718 & 154333 & 6.4815 & 7.1482 & TRN \\
\hline CHEMBL108236 & 154333 & 8.0458 & 7.4817 & TRN \\
\hline CHEMBL 320494 & 154333 & 3.1367 & 4.6704 & TST \\
\hline CHEMBL108985 & 154333 & 6.3872 & 6.29299 & 9999999999 \\
\hline CHEMBL108806 & 154333 & 3.7959 & 4.1411 & TRN \\
\hline CHEMBL108385 & 154333 & 5.0458 & 5.11600 & 00000000005 \\
\hline CHEMBL321637 & 154333 & 8.0 & 7.1264 & TRN \\
\hline CHEMBL 323171 & 154333 & 4.7959 & 6.0259 & TRN \\
\hline CHEMBL326426 & 154333 & 6.699 & 6.8616 & TRN \\
\hline CHEMBL105865 & 154333 & 6.5229 & 5.529 & TRN \\
\hline CHEMBL106701 & 154333 & 4.6383 & 4.6508 & TST \\
\hline CHEMBL108665 & 154333 & 6.6021 & 7.1057 & TRN \\
\hline CHEMBL109134 & 154333 & 7.4559 & 7.4262 & TRN \\
\hline CHEMBL109208 & 154333 & 4.699 & 5.121 & TRN \\
\hline CHEMBL322087 & 154333 & 7.1549 & 7.3795 & TRN \\
\hline CHEMBL109298 & 154333 & 5.0969 & 5.0296 & TRN \\
\hline CHEMBL49964 & 154333 & 6.9586 & 6.9811 & TRN \\
\hline CHEMBL108751 & 154333 & 3.7447 & 4.379 & TRN \\
\hline CHEMBL107698 & 154333 & 6.7305 & 6.8256 & TRN \\
\hline CHEMBL108192 & 154333 & 5.7959 & 4.9557 & TRN \\
\hline CHEMBL107603 & 154333 & 3.7696 & 4.8017 & TRN \\
\hline CHEMBL 300040 & 154333 & 7.5686 & 6.931 & TRN \\
\hline
\end{tabular}




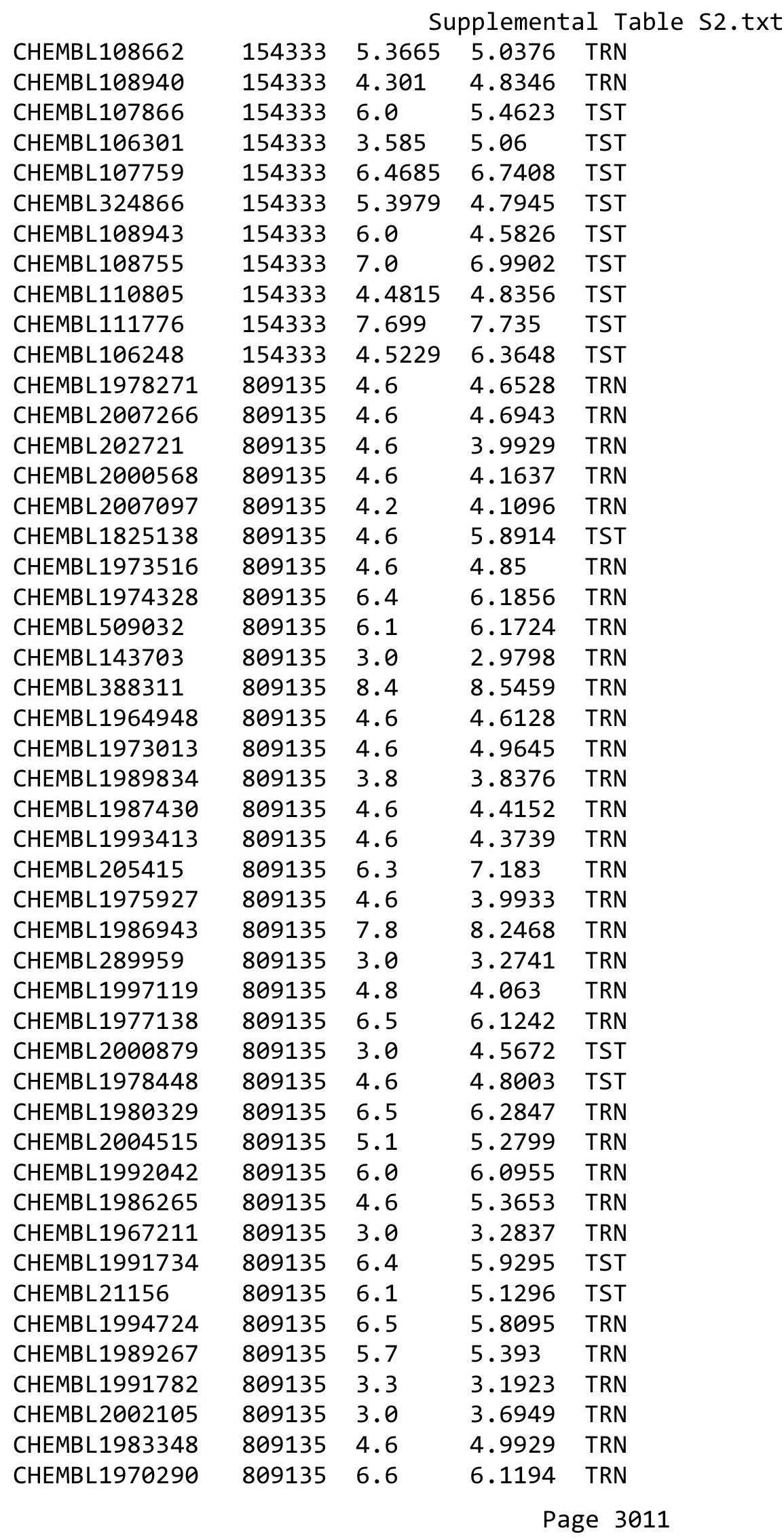




\begin{tabular}{|c|c|c|c|c|c|}
\hline & & & & & \\
\hline CHEMBL1968394 & 809135 & 3.0 & 3.0802 & TRN & \\
\hline CHEMBL1993877 & 809135 & 4.6 & 5.7357 & TRN & \\
\hline CHEMBL1996500 & 809135 & 4.6 & 4.32100 & 3000000001 & TRN \\
\hline CHEMBL1980671 & 809135 & 3.0 & 3.5115 & TRN & \\
\hline CHEMBL1973363 & 809135 & 5.7 & 6.0387 & TRN & \\
\hline CHEMBL1986177 & 809135 & 4.6 & 4.7756 & TRN & \\
\hline CHEMBL1989708 & 809135 & 4.6 & 4.8942 & TRN & \\
\hline CHEMBL1976420 & 809135 & 4.6 & 4.0862 & TRN & \\
\hline CHEMBL1981744 & 809135 & 4.6 & 4.4534 & TRN & \\
\hline CHEMBL1989423 & 809135 & 3.0 & 3.6573 & TST & \\
\hline CHEMBL1985367 & 809135 & 4.6 & 4.3622 & TRN & \\
\hline CHEMBL1996510 & 809135 & 9.5 & 8.3474 & TRN & \\
\hline CHEMBL 2000029 & 809135 & 7.9 & 7.3661 & TRN & \\
\hline CHEMBL1995172 & 809135 & 3.3 & 3.80899 & 99999999997 & TST \\
\hline CHEMBL 2001584 & 809135 & 4.6 & 4.657 & TRN & \\
\hline CHEMBL1973961 & 809135 & 4.6 & 4.4133 & TRN & \\
\hline CHEMBL1971227 & 809135 & 5.7 & 6.1955 & TST & \\
\hline CHEMBL1967998 & 809135 & 5.9 & 5.7099 & TRN & \\
\hline CHEMBL1978562 & 809135 & 4.6 & 5.4545 & TRN & \\
\hline CHEMBL1994977 & 809135 & 4.6 & 4.6731 & TRN & \\
\hline CHEMBL2001149 & 809135 & 5.9 & 5.5291 & TRN & \\
\hline CHEMBL1974875 & 809135 & 4.1 & 3.9031 & TRN & \\
\hline CHEMBL 2005478 & 809135 & 4.6 & 5.2542 & TRN & \\
\hline CHEMBL1996646 & 809135 & 6.0 & 6.2585 & TRN & \\
\hline CHEMBL1979773 & 809135 & 4.6 & 4.6468 & TRN & \\
\hline CHEMBL1989471 & 809135 & 4.6 & 5.0439 & TST & \\
\hline CHEMBL 2002099 & 809135 & 4.6 & 5.5472 & TRN & \\
\hline CHEMBL1992723 & 809135 & 3.0 & 3.6692 & TRN & \\
\hline CHEMBL1996702 & 809135 & 4.6 & 4.8146 & TRN & \\
\hline CHEMBL 2007124 & 809135 & 4.6 & 4.4589 & TRN & \\
\hline CHEMBL1978195 & 809135 & 6.2 & 6.0644 & TRN & \\
\hline CHEMBL1985681 & 809135 & 4.6 & 5.4245 & TRN & \\
\hline CHEMBL1991674 & 809135 & 7.0 & 7.1753 & TRN & \\
\hline CHEMBL1982711 & 809135 & 6.8 & 6.6576 & TRN & \\
\hline CHEMBL 262623 & 809135 & 4.4 & 4.1422 & TRN & \\
\hline CHEMBL1984842 & 809135 & 4.6 & 4.7111 & TRN & \\
\hline CHEMBL 2004118 & 809135 & 4.6 & 4.3445 & TRN & \\
\hline CHEMBL1996345 & 809135 & 4.6 & 4.3037 & TRN & \\
\hline CHEMBL 2004025 & 809135 & 5.9 & 5.9726 & TRN & \\
\hline CHEMBL1996048 & 809135 & 4.6 & 5.5459 & TRN & \\
\hline CHEMBL50894 & 809135 & 4.6 & 5.1247 & TRN & \\
\hline CHEMBL1995211 & 809135 & 6.2 & 5.5373 & TRN & \\
\hline CHEMBL1965033 & 809135 & 4.6 & 4.6163 & TRN & \\
\hline CHEMBL461876 & 809135 & 4.6 & 5.0856 & TRN & \\
\hline CHEMBL1982753 & 809135 & 5.8 & 6.097 & TRN & \\
\hline CHEMBL2006299 & 809135 & 6.7 & 5.7258 & TRN & \\
\hline CHEMBL1972346 & 809135 & 6.1 & 5.5142 & TST & \\
\hline CHEMBL1971519 & 809135 & 4.7 & 4.7575 & TRN & \\
\hline & & & & 3012 & \\
\hline
\end{tabular}




\begin{tabular}{|c|c|c|c|c|}
\hline \multicolumn{5}{|c|}{ semental } \\
\hline CHEMBL1997335 & 809135 & 5.8 & 4.9943 & TRN \\
\hline CHEMBL1965169 & 809135 & 4.6 & 4.0776 & TRN \\
\hline CHEMBL1081312 & 809135 & 6.3 & 5.7059 & TRN \\
\hline CHEMBL1965170 & 809135 & 4.6 & \multicolumn{2}{|c|}{5.0760000000000005} \\
\hline CHEMBL1994808 & 809135 & 4.1 & 4.0047 & TST \\
\hline CHEMBL 2005792 & 809135 & 4.6 & 4.6975 & TRN \\
\hline CHEMBL1991867 & 809135 & 4.1 & 3.8695 & TRN \\
\hline CHEMBL1972355 & 809135 & 6.4 & 6.6466 & TRN \\
\hline CHEMBL1997892 & 809135 & 4.6 & 4.9827 & TRN \\
\hline CHEMBL 2001641 & 809135 & 4.4 & 4.4532 & TRN \\
\hline CHEMBL1964902 & 809135 & 4.6 & 4.5167 & TRN \\
\hline CHEMBL1973868 & 809135 & 4.6 & 4.9449 & TRN \\
\hline CHEMBL1983715 & 809135 & 4.6 & 4.9726 & TRN \\
\hline CHEMBL 2002992 & 809135 & 8.1 & 7.3356 & TRN \\
\hline CHEMBL1982700 & 809135 & 4.6 & 4.1768 & TRN \\
\hline CHEMBL10 & 809135 & 4.6 & 4.5551 & TRN \\
\hline CHEMBL1980763 & 809135 & 4.6 & 4.7022 & TRN \\
\hline CHEMBL1977931 & 809135 & 4.1 & 4.5138 & TRN \\
\hline CHEMBL1976872 & 809135 & 3.0 & 3.1837 & TRN \\
\hline CHEMBL 2004887 & 809135 & 4.3 & 4.0329 & TRN \\
\hline CHEMBL1969156 & 809135 & 3.0 & 3.3419 & TRN \\
\hline CHEMBL 2007479 & 809135 & 4.6 & 4.631 & TRN \\
\hline CHEMBL1998953 & 809135 & 4.6 & 4.6404 & TRN \\
\hline CHEMBL1971606 & 809135 & 5.7 & 5.4339 & TRN \\
\hline CHEMBL1999120 & 809135 & 3.0 & 3.7411 & TST \\
\hline CHEMBL1972220 & 809135 & 4.6 & 5.0405 & TRN \\
\hline CHEMBL1972583 & 809135 & 3.0 & 3.4528 & TRN \\
\hline CHEMBL1981215 & 809135 & 4.6 & 4.3806 & TRN \\
\hline CHEMBL 2003785 & 809135 & 4.3 & 4.3518 & TRN \\
\hline CHEMBL1973720 & 809135 & 9.1 & 8.8044 & TRN \\
\hline CHEMBL1999414 & 809135 & 4.6 & 4.2986 & TRN \\
\hline CHEMBL1967336 & 809135 & 4.6 & 4.5447 & TRN \\
\hline CHEMBL 2001923 & 809135 & 4.6 & 4.257 & TRN \\
\hline CHEMBL 2003514 & 809135 & 6.2 & 6.1533 & TRN \\
\hline CHEMBL1970340 & 809135 & 4.7 & 4.8652 & TRN \\
\hline CHEMBL1967992 & 809135 & 6.1 & 5.6642 & TRN \\
\hline CHEMBL1989043 & 809135 & 6.5 & 5.2817 & TRN \\
\hline CHEMBL 2006450 & 809135 & 4.6 & 5.2533 & TRN \\
\hline CHEMBL1967538 & 809135 & 4.1 & 4.4631 & TRN \\
\hline CHEMBL 2001987 & 809135 & 4.6 & 4.3595 & TRN \\
\hline CHEMBL1994555 & 809135 & 4.6 & 4.575 & TRN \\
\hline CHEMBL1968515 & 809135 & 5.4 & 4.2267 & TST \\
\hline CHEMBL1164180 & 809135 & 6.1 & 5.5305 & TST \\
\hline CHEMBL1975121 & 809135 & 6.9 & 6.2103 & TRN \\
\hline CHEMBL1983640 & 809135 & 4.6 & 4.7719 & TRN \\
\hline CHEMBL1971943 & 809135 & 4.6 & 5.1163 & TRN \\
\hline CHEMBL1984686 & 809135 & 4.6 & 4.0623 & TST \\
\hline CHEMBL1973793 & 809135 & 4.6 & 4.8535 & TRN \\
\hline
\end{tabular}




\begin{tabular}{|c|c|c|c|c|}
\hline \multicolumn{5}{|c|}{ lemental Ta } \\
\hline CHEMBL1992073 & 809135 & 6.7 & 6.0089 & TRN \\
\hline CHEMBL1990254 & 809135 & 7.2 & 7.1923 & TRN \\
\hline CHEMBL1986143 & 809135 & 5.8 & 6.6331 & TRN \\
\hline CHEMBL1972934 & 809135 & 4.2 & 4.0709 & TRN \\
\hline CHEMBL 2007559 & 809135 & 4.6 & 4.0296 & TRN \\
\hline CHEMBL1992581 & 809135 & 4.6 & 4.4812 & TRN \\
\hline CHEMBL 2004290 & 809135 & 4.6 & 4.1926 & TRN \\
\hline CHEMBL1975921 & 809135 & 4.5 & 3.6878 & TRN \\
\hline CHEMBL1983573 & 809135 & 3.0 & 3.5502 & TRN \\
\hline CHEMBL1975923 & 809135 & 4.9 & 5.3084 & TST \\
\hline CHEMBL 1984402 & 809135 & 4.3 & 3.4122 & TRN \\
\hline CHEMBL 2005449 & 809135 & 4.6 & 4.6969 & TRN \\
\hline CHEMBL1996576 & 809135 & 4.6 & 5.2452 & TST \\
\hline CHEMBL1991678 & 809135 & 4.6 & 4.513 & TRN \\
\hline CHEMBL1987998 & 809135 & 4.6 & 4.7553 & TRN \\
\hline CHEMBL1971534 & 809135 & 5.5 & 4.977 & TRN \\
\hline CHEMBL1990496 & 809135 & 4.6 & 5.2618 & TRN \\
\hline CHEMBL242865 & 809135 & 4.6 & 5.1612 & TRN \\
\hline CHEMBL235157 & 809135 & 4.6 & 4.6744 & TRN \\
\hline CHEMBL 2004159 & 809135 & 6.0 & 5.3096 & TRN \\
\hline CHEMBL1978371 & 809135 & 5.8 & 5.9795 & TST \\
\hline CHEMBL440084 & 809135 & 4.6 & 5.0679 & TRN \\
\hline CHEMBL1998110 & 809135 & 4.6 & 4.9481 & TRN \\
\hline CHEMBL1978166 & 809135 & 6.0 & 6.5316 & TRN \\
\hline CHEMBL1972454 & 809135 & 3.0 & 3.3876 & TST \\
\hline CHEMBL1974617 & 809135 & 4.9 & 4.5865 & TRN \\
\hline CHEMBL86755 & 809135 & 4.6 & 4.7003 & TRN \\
\hline CHEMBL1965660 & 809135 & 7.2 & 7.7225 & TRN \\
\hline CHEMBL1992125 & 809135 & 6.0 & 5.4644 & TRN \\
\hline CHEMBL1966175 & 809135 & 4.9 & 5.731 & TRN \\
\hline CHEMBL 2007375 & 809135 & 4.6 & 4.4786 & TRN \\
\hline CHEMBL379975 & 809135 & 6.2 & 6.7983 & TST \\
\hline CHEMBL1965387 & 809135 & 4.6 & 4.9507 & TRN \\
\hline CHEMBL 2001539 & 809135 & 3.0 & 4.63 & TST \\
\hline CHEMBL 388978 & 809135 & 8.7 & 8.458 & TST \\
\hline CHEMBL1997041 & 809135 & 5.0 & 4.6539 & TRN \\
\hline CHEMBL550418 & 809135 & 4.6 & 4.8412 & TRN \\
\hline CHEMBL398951 & 809135 & 4.6 & 4.1914 & TST \\
\hline CHEMBL1971289 & 809135 & 4.6 & 5.0903 & TST \\
\hline CHEMBL1988437 & 809135 & 4.6 & 4.492 & TRN \\
\hline CHEMBL1421720 & 809135 & 5.8 & 5.6082 & TRN \\
\hline CHEMBL1233887 & 809135 & 4.6 & 4.5922 & TRN \\
\hline CHEMBL1968130 & 809135 & 4.6 & 3.8015 & TRN \\
\hline CHEMBL1996649 & 809135 & 4.6 & 4.3823 & TRN \\
\hline CHEMBL1986756 & 809135 & 4.6 & 4.4671 & TRN \\
\hline CHEMBL1949855 & 809135 & 5.1 & 5.2688 & TRN \\
\hline CHEMBL3109278 & 809135 & 4.6 & 4.6748 & TRN \\
\hline CHEMBL1727312 & 809135 & 3.0 & 2.9581 & TRN \\
\hline
\end{tabular}




\begin{tabular}{|c|c|c|c|c|c|}
\hline \multicolumn{6}{|c|}{ Supplemental Table S2.txt } \\
\hline CHEMBL1990223 & 809135 & 4.6 & 4.8237 & TRN & \\
\hline CHEMBL 2004438 & 809135 & 4.6 & 4.5154 & TRN & \\
\hline CHEMBL1964382 & 809135 & 4.6 & 4.8064 & TST & \\
\hline CHEMBL101311 & 809135 & 4.6 & 4.9463 & TRN & \\
\hline CHEMBL191003 & 809135 & 4.6 & 4.9544 & TRN & \\
\hline CHEMBL1973359 & 809135 & 6.6 & 6.2006 & TST & \\
\hline CHEMBL1988581 & 809135 & 6.9 & 7.1165 & TST & \\
\hline CHEMBL2005699 & 809135 & 4.6 & 4.4397 & TRN & \\
\hline CHEMBL 2006564 & 809135 & 5.7 & 5.12299 & 7999999999 & TRN \\
\hline CHEMBL1979690 & 809135 & 5.7 & 5.7697 & TRN & \\
\hline CHEMBL234085 & 809135 & 4.7 & 5.0351 & TRN & \\
\hline CHEMBL1978167 & 809135 & 4.6 & 4.5844 & TRN & \\
\hline CHEMBL418203 & 809135 & 7.1 & 6.7039 & TST & \\
\hline CHEMBL225519 & 809135 & 7.4 & 6.6303 & TRN & \\
\hline CHEMBL1994159 & 809135 & 4.2 & 3.7592 & TRN & \\
\hline CHEMBL1976376 & 809135 & 4.6 & 4.4132 & TRN & \\
\hline CHEMBL1988622 & 809135 & 3.0 & 3.7342 & TRN & \\
\hline CHEMBL1983575 & 809135 & 5.7 & 5.5542 & TRN & \\
\hline CHEMBL1968868 & 809135 & 4.6 & 4.3429 & TRN & \\
\hline CHEMBL1981047 & 809135 & 4.6 & 4.4422 & TRN & \\
\hline CHEMBL1998470 & 809135 & 5.9 & 5.5624 & TRN & \\
\hline CHEMBL1976196 & 809135 & 4.6 & 5.1187 & TRN & \\
\hline CHEMBL1997197 & 809135 & 4.6 & 4.7892 & TRN & \\
\hline CHEMBL1975903 & 809135 & 4.6 & 4.6173 & TRN & \\
\hline CHEMBL1983630 & 809135 & 4.2 & 3.9207 & TRN & \\
\hline CHEMBL1522508 & 809135 & 3.0 & 2.7487 & TRN & \\
\hline CHEMBL1973795 & 809135 & 3.0 & 3.2865 & TRN & \\
\hline CHEMBL1988805 & 809135 & 4.6 & 4.8175 & TRN & \\
\hline CHEMBL458997 & 809135 & 4.6 & 4.5953 & TRN & \\
\hline CHEMBL1969942 & 809135 & 4.6 & 4.5844 & TRN & \\
\hline CHEMBL1982660 & 809135 & 4.6 & 4.1754 & TRN & \\
\hline CHEMBL1978567 & 809135 & 4.6 & 4.9481 & TRN & \\
\hline CHEMBL1976290 & 809135 & 3.0 & 3.2997 & TRN & \\
\hline CHEMBL1995765 & 809135 & 4.7 & 4.7755 & TRN & \\
\hline CHEMBL1984760 & 809135 & 4.6 & 4.449 & TRN & \\
\hline CHEMBL424872 & 809135 & 4.6 & 4.29 & TST & \\
\hline CHEMBL360847 & 809135 & 8.8 & 7.261 & TRN & \\
\hline CHEMBL1995811 & 809135 & 5.8 & 5.2685 & TRN & \\
\hline CHEMBL1983111 & 809135 & 5.9 & 5.5059 & TRN & \\
\hline CHEMBL1995916 & 809135 & 3.0 & 2.9643 & TRN & \\
\hline CHEMBL1988141 & 809135 & 6.1 & 7.347 & TST & \\
\hline CHEMBL1992937 & 809135 & 4.6 & 4.5707 & TRN & \\
\hline CHEMBL451401 & 809135 & 3.0 & 3.2266 & TRN & \\
\hline CHEMBL1977134 & 809135 & 4.6 & 4.7593 & TRN & \\
\hline CHEMBL1970873 & 809135 & 3.0 & 2.8922 & TRN & \\
\hline CHEMBL1985206 & 809135 & 4.6 & 4.7507 & TRN & \\
\hline CHEMBL1977749 & 809135 & 4.6 & 4.8063 & TST & \\
\hline CHEMBL 2002450 & 809135 & 3.1 & 3.2178 & TRN & \\
\hline
\end{tabular}




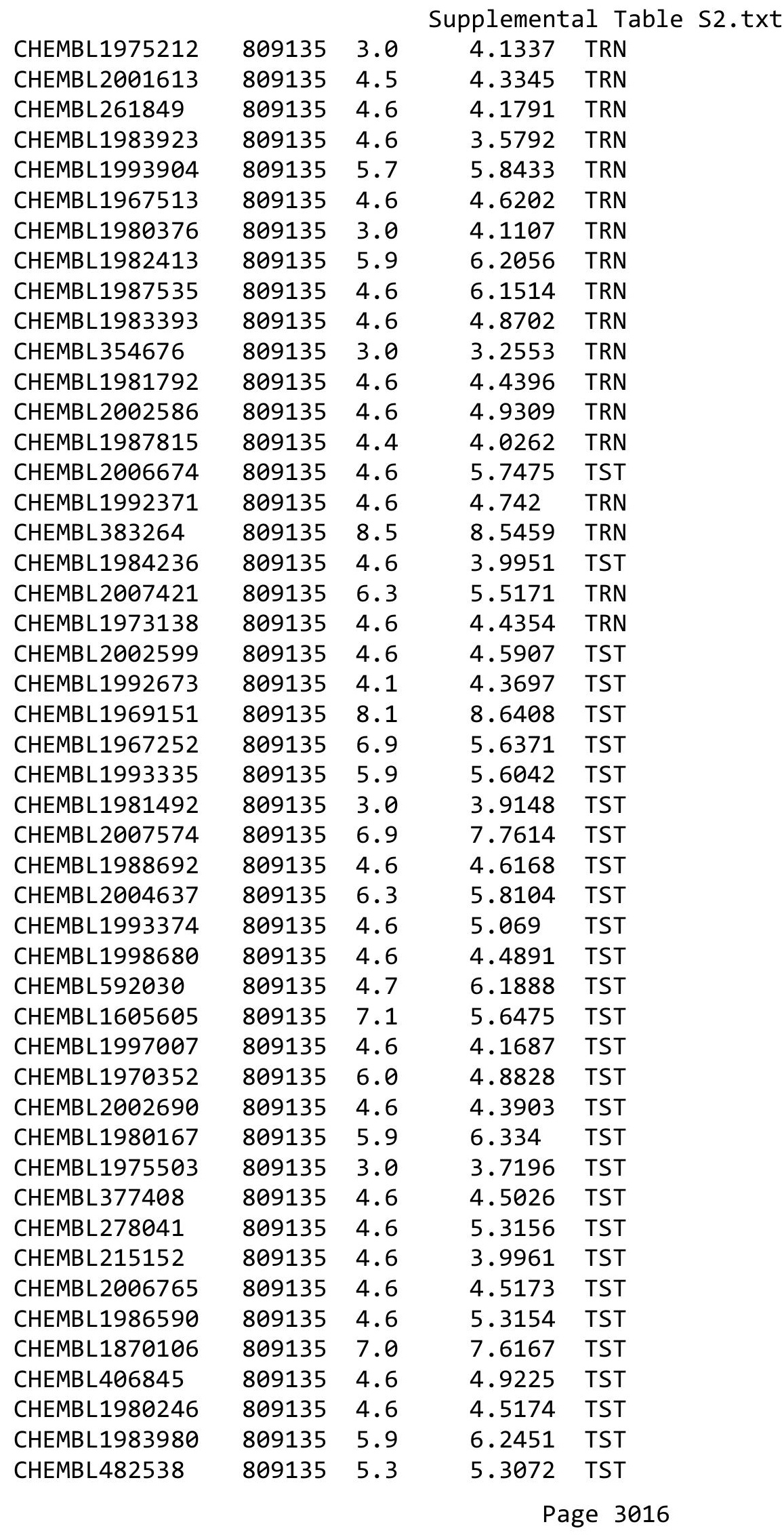




\begin{tabular}{|c|c|c|c|c|c|c|}
\hline \multicolumn{7}{|c|}{ Supplemental Table S2.txt } \\
\hline CHEMBL1999484 & 809135 & 4.6 & 5.6864 & TST & & \\
\hline CHEMBL1973399 & 809135 & 3.0 & 3.5953 & TST & & \\
\hline CHEMBL1986899 & 809135 & 4.6 & 4.3226 & TST & & \\
\hline CHEMBL1996837 & 809135 & 4.2 & 4.152 & TST & & \\
\hline CHEMBL1984038 & 809135 & 4.6 & 4.3674 & TST & & \\
\hline CHEMBL1964718 & 809135 & 3.0 & 3.5206 & TST & & \\
\hline CHEMBL1993661 & 809135 & 7.2 & 6.3724 & TST & & \\
\hline CHEMBL1968705 & 809135 & 6.2 & 4.3641 & TST & & \\
\hline CHEMBL1991410 & 809135 & 4.6 & 4.3317 & TST & & \\
\hline CHEMBL1964441 & 809135 & 4.6 & 5.0522 & TST & & \\
\hline CHEMBL1986684 & 809135 & 3.0 & 3.0899 & TST & & \\
\hline CHEMBL546797 & 809135 & 5.7 & 5.7984 & TST & & \\
\hline CHEMBL577445 & 817941 & 3.4948 & 4.3118 & TRN & & \\
\hline CHEMBL601814 & 817941 & 3.4948 & 4.2208 & TRN & & \\
\hline CHEMBL601156 & 817941 & 4.8399 & 4.2872 & TST & & \\
\hline CHEMBL531060 & 817941 & 4.7342 & 4.3109 & TRN & & \\
\hline CHEMBL527131 & 817941 & 3.4948 & 3.7419 & TRN & & \\
\hline CHEMBL531290 & 817941 & 4.7928 & 4.6639 & TST & & \\
\hline CHEMBL600549 & 817941 & 3.4948 & 3.3592 & TRN & & \\
\hline CHEMBL 2028064 & 817941 & 6.3178 & 5.7264 & TST & & \\
\hline CHEMBL585839 & 817941 & 3.4948 & 3.4293 & TRN & & \\
\hline CHEMBL598881 & 817941 & 4.78 & 4.3541 & TST & & \\
\hline CHEMBL 2028050 & 817941 & 5.3668 & 5.4914 & TRN & & \\
\hline CHEMBL586026 & 817941 & 5.4241 & 5.4736 & TST & & \\
\hline CHEMBL585622 & 817941 & 5.9842 & 5.7921 & TRN & & \\
\hline CHEMBL601771 & 817941 & 3.4948 & 4.2672 & TST & & \\
\hline CHEMBL582547 & 817941 & 5.2563 & 5.5838 & TRN & & \\
\hline CHEMBL579443 & 817941 & 4.7928 & 4.8068 & TRN & & \\
\hline CHEMBL586031 & 817941 & 5.99706 & 30000000 & 01 & 5.7754 & TST \\
\hline CHEMBL601348 & 817941 & 3.4948 & 3.6528 & TST & & \\
\hline CHEMBL584655 & 817941 & 5.3918 & 4.9412 & TRN & & \\
\hline CHEMBL529732 & 817941 & 3.4948 & 3.135 & TRN & & \\
\hline CHEMBL586344 & 817941 & 3.4948 & 3.5839 & TST & & \\
\hline CHEMBL577011 & 817941 & 3.4948 & 3.6098 & TRN & & \\
\hline CHEMBL1459149 & 817941 & 3.4948 & 3.7588 & TST & & \\
\hline CHEMBL606531 & 817941 & 5.4156 & 5.301 & TRN & & \\
\hline CHEMBL602366 & 817941 & 3.4948 & 3.4479 & TRN & & \\
\hline CHEMBL532155 & 817941 & 3.4948 & 4.578 & TRN & & \\
\hline CHEMBL590212 & 817941 & 5.9907 & 5.5646 & TRN & & \\
\hline CHEMBL546799 & 817941 & 5.3918 & 5.2486 & TRN & & \\
\hline CHEMBL1545915 & 817941 & 3.4948 & 3.7155 & TRN & & \\
\hline CHEMBL534612 & 817941 & 4.9262 & 5.3233 & TRN & & \\
\hline CHEMBL535730 & 817941 & 5.515 & 5.3079 & TST & & \\
\hline CHEMBL338094 & 817941 & 3.4948 & 3.4734 & TRN & & \\
\hline CHEMBL582486 & 817941 & 3.4948 & 3.5367 & TST & & \\
\hline CHEMBL586468 & 817941 & 3.4948 & 3.1628 & TRN & & \\
\hline CHEMBL527541 & 817941 & 3.4948 & 3.4704 & TRN & & \\
\hline CHEMBL459199 & 817941 & 5.3979 & 5.2609 & TRN & & \\
\hline
\end{tabular}




\begin{tabular}{|c|c|c|c|c|c|}
\hline \multicolumn{6}{|c|}{ Supplemental Table S2.txt } \\
\hline CHEMBL602946 & 817941 & 5.4211 & 5.4563 & TRN & \\
\hline CHEMBL532141 & 817941 & 5.4712 & 5.3115 & TRN & \\
\hline CHEMBL591637 & 817941 & 6.0311 & 6.335 & TRN & \\
\hline CHEMBL601612 & 817941 & 4.7928 & 4.461 & TST & \\
\hline CHEMBL581187 & 817941 & 4.8546 & 5.0582 & TRN & \\
\hline CHEMBL592123 & 817941 & 5.9907 & 5.9862 & TRN & \\
\hline CHEMBL547193 & 817941 & 3.4948 & 4.4815 & TRN & \\
\hline CHEMBL582070 & 817941 & 4.9631 & 4.8169 & TRN & \\
\hline CHEMBL581175 & 817941 & 3.4948 & 4.5578 & TRN & \\
\hline CHEMBL587989 & 817941 & 3.4948 & 3.6481 & TRN & \\
\hline CHEMBL583844 & 817941 & 3.4948 & 3.3934 & TST & \\
\hline CHEMBL607688 & 817941 & 4.7866 & 4.5748 & TRN & \\
\hline CHEMBL592332 & 817941 & 5.1548 & 4.4866 & TRN & \\
\hline CHEMBL601567 & 817941 & 5.0217 & 4.9265 & TRN & \\
\hline CHEMBL606159 & 817941 & 4.8054 & 4.4414 & TRN & \\
\hline CHEMBL532079 & 817941 & 5.4222 & 5.062 & TRN & \\
\hline CHEMBL530531 & 817941 & 6.7325 & 7.1267 & TST & \\
\hline CHEMBL581240 & 817941 & 4.9631 & 4.6899 & TRN & \\
\hline CHEMBL591183 & 817941 & 6.0 & 6.3566 & TRN & \\
\hline CHEMBL600174 & 817941 & 5.3682 & 4.68199 & 99999999995 & TRN \\
\hline CHEMBL600444 & 817941 & 3.4948 & 4.6685 & TRN & \\
\hline CHEMBL524784 & 817941 & 3.4948 & 4.1437 & TRN & \\
\hline CHEMBL609156 & 817941 & 3.4948 & 3.2746 & TRN & \\
\hline CHEMBL579300 & 817941 & 4.8239 & 5.0195 & TRN & \\
\hline CHEMBL549210 & 817941 & 4.8641 & 4.6538 & TRN & \\
\hline CHEMBL528734 & 817941 & 3.4948 & 3.61899 & 99999999998 & TRN \\
\hline CHEMBL537071 & 817941 & 5.2976 & 5.0031 & TRN & \\
\hline CHEMBL 2028055 & 817941 & 5.3886 & 5.0359 & TRN & \\
\hline CHEMBL580388 & 817941 & 3.4948 & 3.7179 & TST & \\
\hline CHEMBL584015 & 817941 & 5.9907 & 5.3937 & TRN & \\
\hline CHEMBL586442 & 817941 & 3.4948 & 3.148 & TRN & \\
\hline CHEMBL602764 & 817941 & 3.4948 & 3.3206 & TRN & \\
\hline CHEMBL529640 & 817941 & 5.3876 & 5.1111 & TRN & \\
\hline CHEMBL 95606 & 817941 & 3.4948 & 3.7084 & TST & \\
\hline CHEMBL592305 & 817941 & 3.4948 & 3.585 & TST & \\
\hline CHEMBL597857 & 817941 & 3.4948 & 4.7437 & TRN & \\
\hline CHEMBL579105 & 817941 & 5.1201 & 5.2299 & TRN & \\
\hline CHEMBL 2028046 & 817941 & 5.1991 & 4.7432 & TRN & \\
\hline CHEMBL533999 & 817941 & 3.4948 & 3.4644 & TRN & \\
\hline CHEMBL578933 & 817941 & 5.4721 & 5.2163 & TRN & \\
\hline CHEMBL579294 & 817941 & 3.4948 & 3.6231 & TRN & \\
\hline CHEMBL601786 & 817941 & 3.4948 & 4.4367 & TRN & \\
\hline CHEMBL601825 & 817941 & 3.4948 & 3.4895 & TRN & \\
\hline CHEMBL531611 & 817941 & 4.937 & 5.0712 & TRN & \\
\hline CHEMBL548374 & 817941 & 5.4043 & 5.1596 & TRN & \\
\hline CHEMBL586000 & 817941 & 3.4948 & 4.4318 & TRN & \\
\hline CHEMBL602409 & 817941 & 3.4948 & 3.4839 & TRN & \\
\hline CHEMBL602234 & 817941 & 6.035 & 5.9963 & TRN & \\
\hline
\end{tabular}




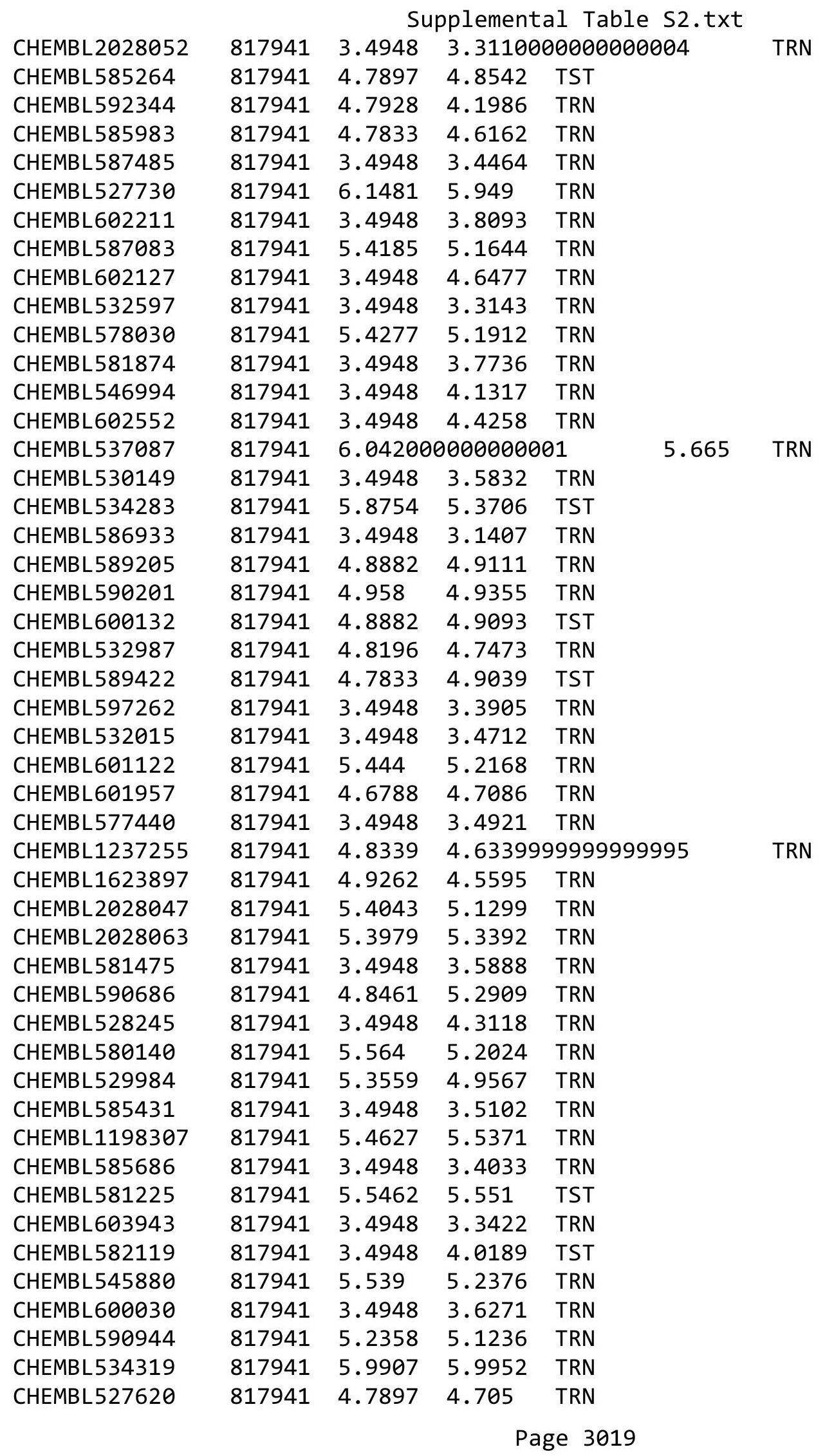


Supplemental Table S2.txt

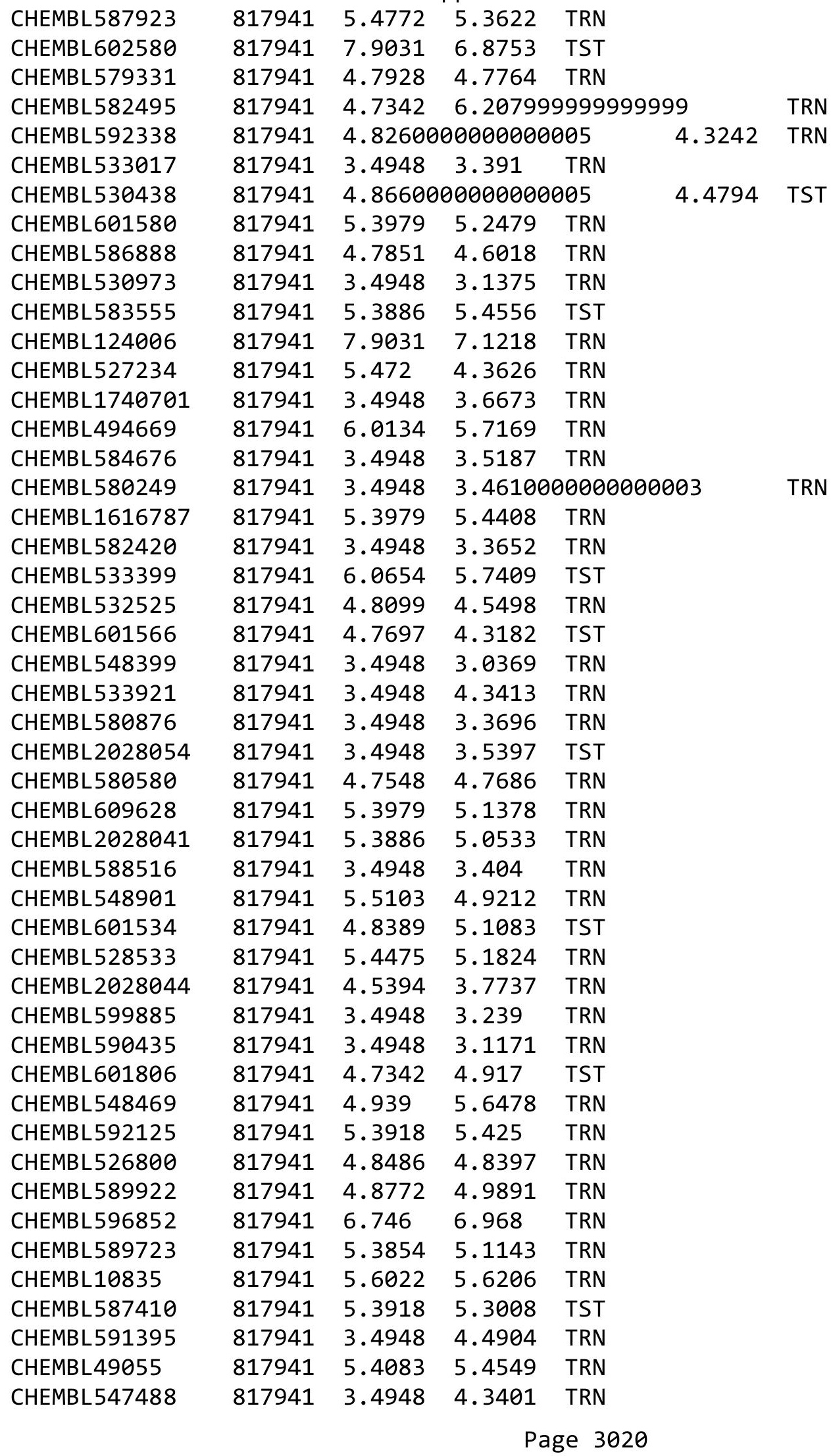


Supplemental Table S2.txt

\begin{tabular}{|c|c|c|c|c|}
\hline CHEMBL584237 & 941 & 4.9587 & 4.3405 & TRN \\
\hline HFMBI 585966 & 17941 & 5.3886 & 5.2296 & TPN \\
\hline HEMBL604982 & 17941 & 7928 & 6581 & \\
\hline HEMBL579459 & 17941 & 3.4948 & .4618 & ST \\
\hline HEMBL577014 & 17941 & 4.9249 & 5.1212 & \\
\hline HEMBL 600488 & 17941 & .4948 & 3.3532 & \\
\hline HEMBL591641 & 7941 & 4.7928 & 4.5249 & $\mathrm{RN}$ \\
\hline HEMBL589224 & 17941 & 4948 & 4.3088 & ST \\
\hline HEMBL603686 & 17941 & .9984 & 4.9077 & \\
\hline HEMBL529385 & 17941 & .0422 & 4.745 & \\
\hline HEMBL526587 & 17941 & 3.4948 & 3.5104 & \\
\hline HEMBL12 & 7941 & 3.4948 & 3.4766 & $\mathrm{RN}$ \\
\hline HEMBL 54 & 17941 & 5.8829 & 5.5561 & RN \\
\hline HEMBL 600439 & 17941 & 8997 & 8369 & \\
\hline HEMBL532510 & 17941 & 3.4948 & 4.1822 & TIV \\
\hline HEMBL592 & 7941 & 966 & 7222 & NIV \\
\hline HEMBL6 & 941 & & & $\mathrm{RN}$ \\
\hline HEMBL589 & 941 & 6. & 5.5595 & RN \\
\hline HEMBL60e & 941 & 787 & 5336 & \\
\hline HEMBL596652 & 941 & 48 & 3143 & RIN \\
\hline HEMBL 5 & 941 & 56 & 959 & RN \\
\hline HEMBL & & & 14 & $\mathrm{RN}$ \\
\hline HEMBL 536 & 941 & 959 & 5314 & RN \\
\hline HEMBL 202 & & 928 & 187 & 「RN \\
\hline HEMBL 600706 & 7941 & 948 & 5155 & RN \\
\hline JEMBL589 & 941 & 948 & 527 & RN \\
\hline HEMBLS & & 48 & 569 & RN \\
\hline HEMBL5 & & 48 & 7284 & RN \\
\hline HEMBL 601 & & 97 & 518 & IRN \\
\hline HEMBL 589236 & .7941 & 948 & 5002 & TRN \\
\hline HEMBL59 & 941 & 948 & 274 & 「RN \\
\hline HEMBI & & 01 & 627 & ГRN \\
\hline HEMBL 58 & & & 5914 & 「RN \\
\hline HEMBL533598 & 7941 & 42 & 972 & TRN \\
\hline HEMBL531222 & 7941 & 948 & 2894 & TRN \\
\hline HEMBL16 & 7941 & 928 & 694 & TST \\
\hline CHEMBL5 & & 79 & 74 & TRN \\
\hline HEMBL578952 & & 3.4948 & 3.2776 & TRN \\
\hline HEMBL 2028066 & 7941 & 4.7959 & 5678 & TST \\
\hline HEMBL 586 & 941 & 948 & 882 & TRN \\
\hline CHEMBL584235 & 7941 & 311 & 5.771 & 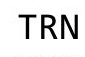 \\
\hline CHEMBL549208 & & 4.7897 & 4.4361 & 「RN \\
\hline CHEMBL582286 & 7941 & 5.4046 & 4.7589 & TRN \\
\hline HEMBL586 & 7941 & 4.7959 & 5693 & $\mathrm{TR}$ \\
\hline EBL5 5 & 1 & 1948 & 1494 & I KIV \\
\hline CHEMBL532560 & 17941 & 5.2032 & 4.9402 & \\
\hline CHEMBL582478 & 17941 & 4.4949 & 4.7922 & $R N$ \\
\hline CHEMBL608855 & 817941 & 5.3718 & 5.3072 & 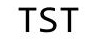 \\
\hline
\end{tabular}

Page 3021 


\begin{tabular}{|c|c|c|c|c|c|}
\hline \multicolumn{6}{|c|}{ Supplemental Table S2.txt } \\
\hline CHEMBL611070 & 817941 & 3.4948 & 4.0806 & TRN & \\
\hline CHEMBL535079 & 817941 & 3.4948 & 3.4322 & TRN & \\
\hline CHEMBL598369 & 817941 & 3.4948 & 3.3473 & TRN & \\
\hline CHEMBL580819 & 817941 & 3.4948 & 3.3581 & TRN & \\
\hline CHEMBL580516 & 817941 & 5.5556 & 5.711 & TRN & \\
\hline CHEMBL601158 & 817941 & 3.4948 & 3.3794 & TRN & \\
\hline CHEMBL 2028057 & 817941 & 4.7662 & 4.5673 & TRN & \\
\hline CHEMBL591887 & 817941 & 4.7767 & 4.3666 & TRN & \\
\hline CHEMBL1485159 & 817941 & 4.8546 & 4.82 & TRN & \\
\hline CHEMBL 2021322 & 817941 & 4.7833 & 5.0388 & TRN & \\
\hline CHEMBL597855 & 817941 & 3.4948 & 3.7328 & TRN & \\
\hline CHEMBL590683 & 817941 & 5.4566 & 5.1598 & TRN & \\
\hline CHEMBL602179 & 817941 & 3.4948 & 3.5955 & TRN & \\
\hline CHEMBL601378 & 817941 & 5.3886 & 5.3588 & TRN & \\
\hline CHEMBL527593 & 817941 & 3.4948 & 3.5642 & TST & \\
\hline CHEMBL586178 & 817941 & 3.4948 & 3.3499 & TRN & \\
\hline CHEMBL535514 & 817941 & 3.4948 & 4.1094 & TRN & \\
\hline CHEMBL533563 & 817941 & 5.3918 & 4.9197 & TST & \\
\hline CHEMBL525519 & 817941 & 5.3735 & 5.2673 & TRN & \\
\hline CHEMBL317364 & 817941 & 4.9894 & 4.9502 & TRN & \\
\hline CHEMBL602940 & 817941 & 4.7833 & 4.5444 & TST & \\
\hline CHEMBL602586 & 817941 & 4.8759 & 5.0443 & TST & \\
\hline CHEMBL607975 & 817941 & 3.4948 & 3.299 & TRN & \\
\hline CHEMBL590933 & 817941 & 5.9939 & 5.9702 & TRN & \\
\hline CHEMBL 2028062 & 817941 & 3.4948 & 4.4237 & TRN & \\
\hline CHEMBL582767 & 817941 & 7.9031 & 7.1395 & TST & \\
\hline CHEMBL590159 & 817941 & 3.4948 & 3.8215 & TRN & \\
\hline CHEMBL261095 & 817941 & 3.4948 & 3.5681 & TRN & \\
\hline CHEMBL548334 & 817941 & 3.4948 & 3.5601 & TST & \\
\hline CHEMBL591623 & 817941 & 4.8026 & 4.6899 & TRN & \\
\hline CHEMBL579315 & 817941 & 3.4948 & 3.6419 & TRN & \\
\hline CHEMBL590674 & 817941 & 4.9129 & 4.8688 & TRN & \\
\hline CHEMBL 2028049 & 817941 & 3.4948 & 3.6686 & TRN & \\
\hline CHEMBL536421 & 817941 & 3.4948 & 3.3783 & TRN & \\
\hline CHEMBL586033 & 817941 & 5.9939 & 6.2118 & TRN & \\
\hline CHEMBL606252 & 817941 & 3.4948 & 4.3265 & TRN & \\
\hline CHEMBL 2028061 & 817941 & 3.4948 & 3.7686 & TRN & \\
\hline CHEMBL581349 & 817941 & 3.4948 & 3.6835 & TRN & \\
\hline CHEMBL605281 & 817941 & 4.7928 & 4.3737 & TRN & \\
\hline CHEMBL 206540 & 817941 & 3.4948 & 3.3813 & TRN & \\
\hline CHEMBL589920 & 817941 & 4.5688 & 4.90600 & 0000000001 & TRN \\
\hline CHEMBL588155 & 817941 & 4.8221 & 4.5659 & TRN & \\
\hline CHEMBL600374 & 817941 & 6.0701 & 6.1026 & TRN & \\
\hline CHEMBL530308 & 817941 & 5.3787 & 5.2336 & TST & \\
\hline CHEMBL529603 & 817941 & 3.4948 & 3.6054 & TRN & \\
\hline CHEMBL1594640 & 817941 & 3.4948 & 3.2283 & TRN & \\
\hline CHEMBL597248 & 817941 & 5.4732 & 5.4037 & TRN & \\
\hline CHEMBL582666 & 817941 & 6.4791 & 5.5761 & TRN & \\
\hline
\end{tabular}




\begin{tabular}{|c|c|c|c|c|c|}
\hline & & \multicolumn{4}{|c|}{ Supplemental Table S2.txt } \\
\hline CHEMBL536393 & 817941 & 3.4948 & 3.3074 & TRN & \\
\hline CHEMBL 2028067 & 817941 & 4.8084 & 5.5996 & TRN & \\
\hline CHEMBL533917 & 817941 & 7.9031 & 7.3889 & TRN & \\
\hline CHEMBL599886 & 817941 & 3.4948 & 4.0339 & TST & \\
\hline CHEMBL535556 & 817941 & 3.4948 & 4.6488 & TRN & \\
\hline CHEMBL602413 & 817941 & 5.0851 & 5.1933 & TRN & \\
\hline CHEMBL533855 & 817941 & 5.4537 & 5.6109 & TRN & \\
\hline CHEMBL579760 & 817941 & 5.4296 & 5.2499 & TST & \\
\hline CHEMBL600305 & 817941 & 3.4948 & 3.2685 & TRN & \\
\hline CHEMBL1619026 & 817941 & 4.9394 & 4.9183 & TRN & \\
\hline CHEMBL601528 & 817941 & 4.7959 & 4.3066 & TRN & \\
\hline CHEMBL580757 & 817941 & 3.4948 & 3.5143 & TRN & \\
\hline CHEMBL601492 & 817941 & 4.8369 & 4.6198 & TRN & \\
\hline CHEMBL529874 & 817941 & 3.4948 & 3.57800 & 00000000003 & TST \\
\hline CHEMBL598279 & 817941 & 5.4161 & 5.2785 & TRN & \\
\hline CHEMBL580381 & 817941 & 4.809 & 4.8369 & TRN & \\
\hline CHEMBL580353 & 817941 & 3.4948 & 4.1491 & TRN & \\
\hline CHEMBL587371 & 817941 & 4.8355 & 4.4813 & TRN & \\
\hline CHEMBL600904 & 817941 & 4.8935 & 4.8389 & TRN & \\
\hline CHEMBL596643 & 817941 & 3.4948 & 4.1801 & TRN & \\
\hline CHEMBL609036 & 817941 & 5.3285 & 5.25899 & 99999999995 & TRN \\
\hline CHEMBL604323 & 817941 & 3.4948 & 3.2747 & TRN & \\
\hline CHEMBL524973 & 817941 & 5.3821 & 5.3694 & TRN & \\
\hline CHEMBL607308 & 817941 & 4.7529 & 4.5423 & TRN & \\
\hline CHEMBL581194 & 817941 & 5.4428 & 4.8907 & TRN & \\
\hline CHEMBL588732 & 817941 & 3.4948 & 3.6367 & TRN & \\
\hline CHEMBL587104 & 817941 & 4.9262 & 5.0245 & TRN & \\
\hline CHEMBL530223 & 817941 & 5.3645 & 4.995 & TRN & \\
\hline CHEMBL592808 & 817941 & 5.4081 & 5.1073 & TRN & \\
\hline CHEMBL1437888 & 817941 & 6.5866 & 6.3301 & TRN & \\
\hline CHEMBL 2028045 & 817941 & 3.4948 & 3.9064 & TRN & \\
\hline CHEMBL 2028058 & 817941 & 5.3979 & 5.0377 & TRN & \\
\hline CHEMBL1744512 & 817941 & 3.4948 & 4.2333 & TRN & \\
\hline CHEMBL583682 & 817941 & 4.8232 & 5.0281 & TRN & \\
\hline CHEMBL528492 & 817941 & 3.4948 & 3.4173 & TRN & \\
\hline CHEMBL589951 & 817941 & 4.7927 & 3.5077 & TRN & \\
\hline CHEMBL537505 & 817941 & 3.4948 & 4.0572 & TRN & \\
\hline CHEMBL587825 & 817941 & 3.4948 & 3.8682 & TRN & \\
\hline CHEMBL 2028053 & 817941 & 3.4948 & 3.2605 & TRN & \\
\hline CHEMBL580654 & 817941 & 3.4948 & 3.2834 & TRN & \\
\hline CHEMBL534190 & 817941 & 3.4948 & 4.5995 & TRN & \\
\hline CHEMBL588855 & 817941 & 5.8517 & 5.9189 & TRN & \\
\hline CHEMBL592786 & 817941 & 4.8239 & 4.6768 & TRN & \\
\hline CHEMBL580188 & 817941 & 3.4948 & 3.346 & TRN & \\
\hline CHEMBL587288 & 817941 & 3.4948 & 3.2127 & TRN & \\
\hline CHEMBL 2028068 & 817941 & 4.7828 & 4.9302 & TST & \\
\hline CHEMBL529348 & 817941 & 5.3948 & 5.2618 & TRN & \\
\hline CHEMBL547266 & 817941 & 5.92 & 6.2114 & TRN & \\
\hline
\end{tabular}




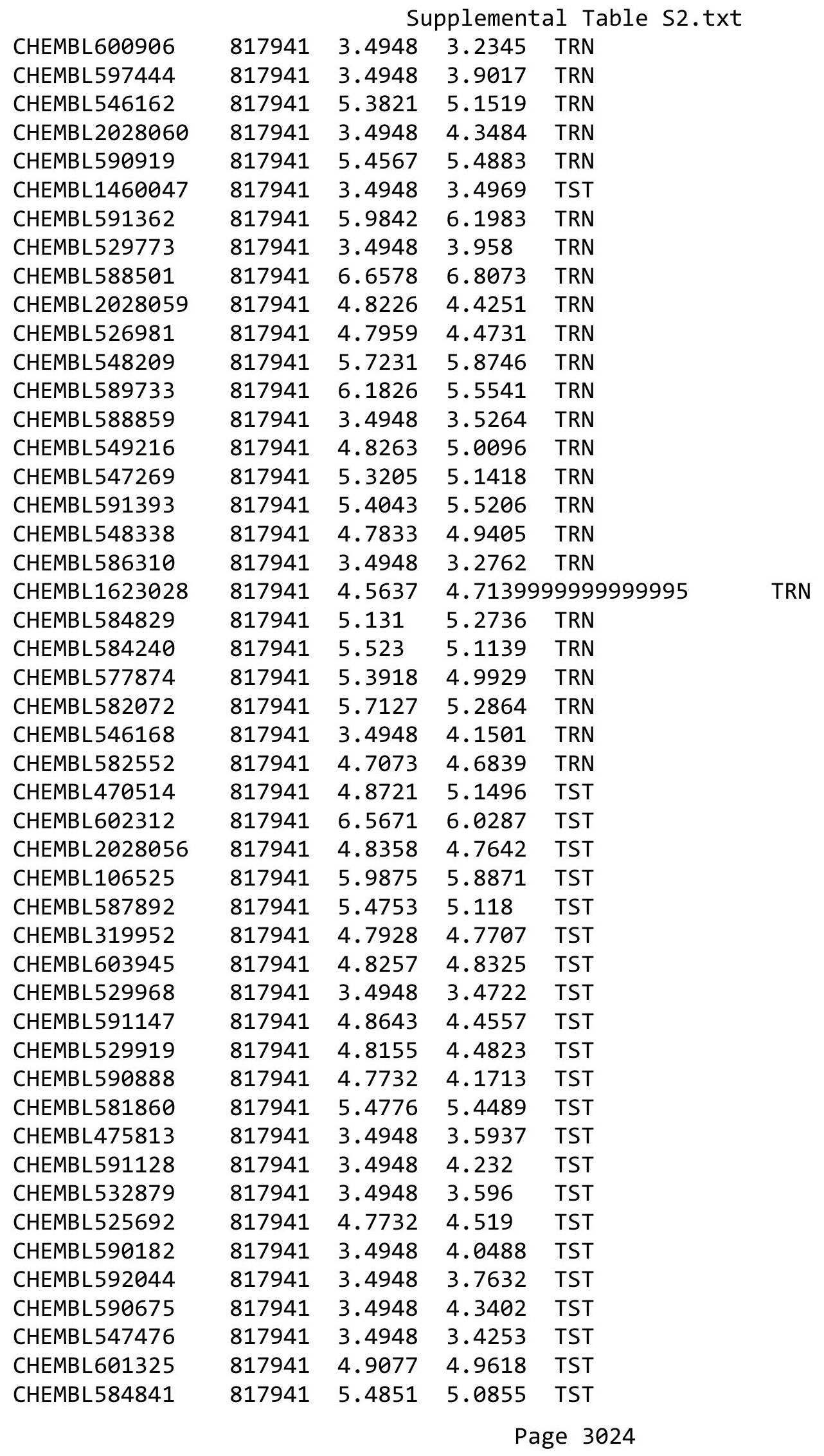


Supplemental Table S2.txt

\begin{tabular}{|c|c|c|c|c|}
\hline CHEMBL587022 & 817941 & 4.8054 & 4.4164 & TST \\
\hline CHEMBL525826 & 817941 & 4.8461 & 4.9006 & TST \\
\hline CHEMBL534288 & 817941 & 4.8058 & 4.7162 & TST \\
\hline CHEMBL590914 & 817941 & 5.4145 & 5.2602 & TST \\
\hline CHEMBL590680 & 817941 & 3.4948 & 3.4003 & TST \\
\hline CHEMBL 2028048 & 817941 & 4.7897 & 4.4247 & TST \\
\hline CHEMBL1738986 & 817941 & 5.0002 & 5.0287 & TST \\
\hline CHEMBL525486 & 817941 & 5.4227 & 5.79899 & 99999999995 \\
\hline CHEMBL 2028042 & 817941 & 3.4948 & 3.2163 & TST \\
\hline CHEMBL537778 & 817941 & 5.3886 & 5.3395 & TST \\
\hline CHEMBL577012 & 817941 & 3.4948 & 4.5496 & TST \\
\hline CHEMBL582079 & 817941 & 4.7866 & 4.6482 & TST \\
\hline CHEMBL525106 & 817941 & 5.5579 & 5.4941 & TST \\
\hline CHEMBL578294 & 817941 & 5.5307 & 5.2528 & TST \\
\hline CHEMBL585243 & 817941 & 4.78 & 4.3933 & TST \\
\hline CHEMBL 2028043 & 817941 & 6.5531 & 5.5287 & TST \\
\hline CHEMBL581489 & 817941 & 3.4948 & 3.2173 & TST \\
\hline CHEMBL605751 & 817941 & 6.0557 & 6.24700 & 0000000001 \\
\hline CHEMBL546531 & 817941 & 6.0944 & 5.5612 & TST \\
\hline CHEMBL261693 & 817941 & 3.4948 & 3.9349 & TST \\
\hline CHEMBL588481 & 817941 & 6.0572 & 5.682 & TST \\
\hline CHEMBL547614 & 817941 & 3.4948 & 3.2789 & TST \\
\hline CHEMBL589916 & 817941 & 3.4948 & 3.3759 & TST \\
\hline CHEMBL528437 & 817941 & 5.4222 & 5.1835 & TST \\
\hline CHEMBL591890 & 817941 & 3.4948 & 4.6714 & TST \\
\hline CHEMBL596856 & 817941 & 3.4948 & 4.3548 & TST \\
\hline CHEMBL3086567 & 1276235 & 7.4145 & 7.7395 & TRN \\
\hline CHEMBL3086393 & 1276235 & 7.4584 & 7.229 & TRN \\
\hline CHEMBL3086435 & 1276235 & 5.0 & 5.8024 & TRN \\
\hline CHEMBL3086378 & 1276235 & 6.6979 & 6.6272 & TRN \\
\hline CHEMBL3086419 & 1276235 & 6.8761 & 6.6125 & TRN \\
\hline CHEMBL3086426 & 1276235 & 6.5186 & 4.84699 & 99999999995 \\
\hline CHEMBL 3086416 & 1276235 & 6.9055 & 6.9403 & TRN \\
\hline CHEMBL3086398 & 1276235 & 6.8333 & 6.9496 & TRN \\
\hline CHEMBL3086411 & 1276235 & 7.7167 & 7.8249 & TRN \\
\hline CHEMBL 3086424 & 1276235 & 5.0 & 5.3299 & TST \\
\hline CHEMBL3086402 & 1276235 & 6.9062 & 7.0537 & TRN \\
\hline CHEMBL3086423 & 1276235 & 6.9792 & 7.3201 & TRN \\
\hline CHEMBL3086391 & 1276235 & 7.4067 & 7.5129 & TRN \\
\hline CHEMBL3086414 & 1276235 & 7.4559 & 6.9579 & TRN \\
\hline CHEMBL3086569 & 1276235 & 6.6407 & 6.7825 & TRN \\
\hline CHEMBL3086386 & 1276235 & 6.8173 & 7.49 & TST \\
\hline CHEMBL3086412 & 1276235 & 6.9978 & 6.2187 & TST \\
\hline CHEMBL 3086440 & 1276235 & 7.2832 & 7.3364 & TRN \\
\hline CHEMBL3086573 & 1276235 & 7.3969 & 6.9858 & TRN \\
\hline CHEMBL3086568 & 1276235 & 6.73 & 7.0722 & TRN \\
\hline CHEMBL 3086425 & 1276235 & 7.066 & 7.7661 & TST \\
\hline CHEMBL 3086434 & 1276235 & 6.6899 & 5.7632 & TST \\
\hline
\end{tabular}




\begin{tabular}{|c|c|c|c|c|c|c|}
\hline \multicolumn{7}{|c|}{ Supplemental Table S2.txt } \\
\hline CHEMBL3086399 & 1276235 & 5.0 & 5.1484 & TRN & & \\
\hline CHEMBL3086413 & 1276235 & 7.3665 & 6.6184 & TRN & & \\
\hline CHEMBL3086409 & 1276235 & 6.6003 & 5.4836 & TST & & \\
\hline CHEMBL3086438 & 1276235 & 7.2204 & 7.347 & TRN & & \\
\hline CHEMBL 3086394 & 1276235 & $6.8210 e$ & 00000000 & & 6.9342 & TRN \\
\hline CHEMBL3086436 & 1276235 & 6.4619 & 5.9752 & TST & & \\
\hline CHEMBL3086381 & 1276235 & 6.0523 & 5.7907 & TRN & & \\
\hline CHEMBL 3086428 & 1276235 & 6.6819 & 6.6092 & TRN & & \\
\hline CHEMBL3086396 & 1276235 & 5.0 & 5.80399 & 9999999999 & & TRN \\
\hline CHEMBL 3086582 & 1276235 & 6.4985 & 6.4917 & TRN & & \\
\hline CHEMBL3086566 & 1276235 & 7.5498 & 7.74 & TRN & & \\
\hline CHEMBL 3086578 & 1276235 & 6.8576 & 6.6737 & TRN & & \\
\hline CHEMBL3086403 & 1276235 & 5.0 & 5.1416 & TRN & & \\
\hline CHEMBL3086384 & 1276235 & 7.0141 & 7.81 & TST & & \\
\hline CHEMBL3086401 & 1276235 & 6.9226 & 6.3247 & TRN & & \\
\hline CHEMBL3086382 & 1276235 & 6.3866 & 5.8948 & TRN & & \\
\hline CHEMBL3086389 & 1276235 & 6.32299 & 99999999 & 995 & 6.7395 & TST \\
\hline CHEMBL3086579 & 1276235 & 5.0 & 5.166 & TRN & & \\
\hline CHEMBL 3086404 & 1276235 & 6.4828 & 6.7029 & TRN & & \\
\hline CHEMBL3086377 & 1276235 & $6.2170 e$ & 00000000 & 005 & 6.7956 & TRN \\
\hline CHEMBL3086572 & 1276235 & 7.4724 & 7.3427 & TRN & & \\
\hline CHEMBL 3086570 & 1276235 & 6.8156 & 7.2024 & TRN & & \\
\hline CHEMBL 3085784 & 1276235 & 6.4963 & 5.9158 & TRN & & \\
\hline CHEMBL 3086584 & 1276235 & 6.7734 & 6.0578 & TRN & & \\
\hline CHEMBL3086586 & 1276235 & 7.0048 & 6.8504 & TRN & & \\
\hline CHEMBL3086575 & 1276235 & 7.251 & 7.3774 & TRN & & \\
\hline CHEMBL3086400 & 1276235 & 6.8156 & 6.7218 & TRN & & \\
\hline CHEMBL3086385 & 1276235 & 6.8047 & 7.1889 & TST & & \\
\hline CHEMBL 3086415 & 1276235 & 7.5045 & 6.1425 & TST & & \\
\hline CHEMBL3086390 & 1276235 & 6.7181 & 6.8518 & TST & & \\
\hline CHEMBL 3086441 & 1276235 & 7.9872 & 7.8231 & TRN & & \\
\hline CHEMBL 3086571 & 1276235 & 7.4045 & 7.27 & TRN & & \\
\hline CHEMBL 3086387 & 1276235 & 6.7817 & 7.3764 & TST & & \\
\hline CHEMBL 3086577 & 1276235 & 6.9496 & 6.75700 & 0000000001 & & TRN \\
\hline CHEMBL 3086574 & 1276235 & 6.8781 & 7.059 & TRN & & \\
\hline CHEMBL3086397 & 1276235 & 7.3468 & 7.3554 & TRN & & \\
\hline CHEMBL3086388 & 1276235 & 6.8184 & 7.0457 & TST & & \\
\hline CHEMBL3086418 & 1276235 & 7.3788 & 7.5352 & TRN & & \\
\hline CHEMBL3086392 & 1276235 & 7.4078 & 7.1726 & TRN & & \\
\hline CHEMBL 3086417 & 1276235 & 7.4622 & 7.0182 & TRN & & \\
\hline CHEMBL3086588 & 1276235 & 5.0 & 6.0755 & TRN & & \\
\hline CHEMBL3086410 & 1276235 & 6.8353 & 6.5231 & TRN & & \\
\hline CHEMBL3086408 & 1276235 & 7.1487 & 7.2597 & TRN & & \\
\hline CHEMBL 3086439 & 1276235 & 7.3799 & 7.3194 & TRN & & \\
\hline CHEMBL3086395 & 1276235 & 7.4023 & 6.1359 & TST & & \\
\hline CHEMBL3086432 & 1276235 & 6.4461 & 5.6559 & TST & & \\
\hline CHEMBL334947 & 68483 & 5.9208 & 5.4772 & TRN & & \\
\hline CHEMBL336597 & 68483 & 6.0269 & 6.1495 & TRN & & \\
\hline
\end{tabular}




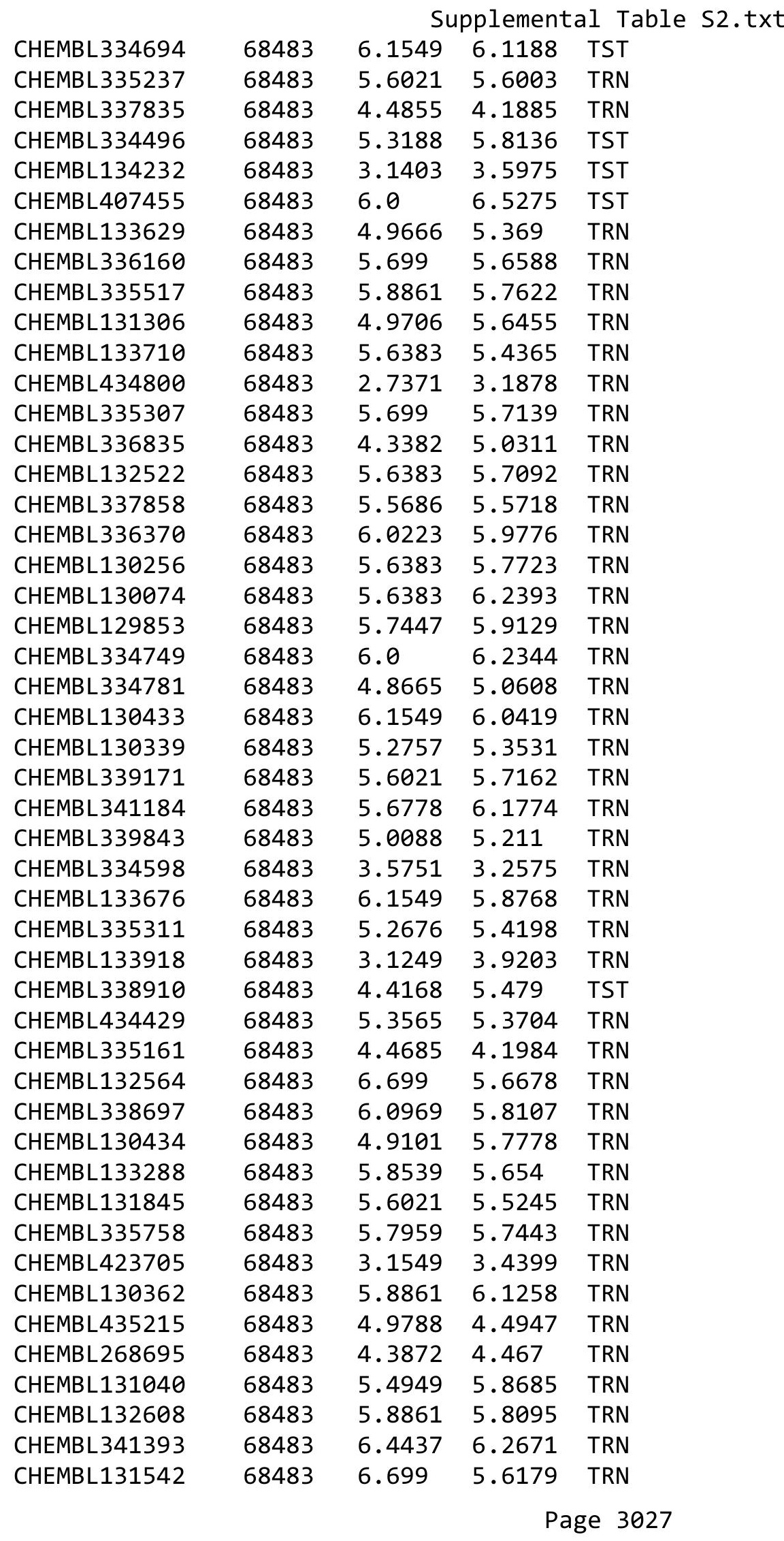




\begin{tabular}{|c|c|c|c|c|c|}
\hline \multicolumn{6}{|c|}{ Supplemental Table S2.txt } \\
\hline CHEMBL442406 & 68483 & 5.7447 & 4.7756 & TST & \\
\hline CHEMBL133908 & 68483 & 5.9586 & 5.3305 & TRN & \\
\hline CHEMBL131155 & 68483 & 4.2518 & 3.8838 & TRN & \\
\hline CHEMBL289404 & 68483 & 6.6021 & 6.0659 & TRN & \\
\hline CHEMBL130515 & 68483 & 4.6819 & 5.0432 & TRN & \\
\hline CHEMBL334390 & 68483 & 4.7959 & 5.251 & TRN & \\
\hline CHEMBL63804 & 68483 & 6.2757 & 5.1752 & TST & \\
\hline CHEMBL336572 & 68483 & 5.0706 & 4.8009 & TRN & \\
\hline CHEMBL341181 & 68483 & 5.301 & 5.2156 & TST & \\
\hline CHEMBL334409 & 68483 & 5.0362 & 6.6892 & TST & \\
\hline CHEMBL131701 & 68483 & 4.9706 & 5.0065 & TRN & \\
\hline CHEMBL334635 & 68483 & 7.2218 & 6.0943 & TST & \\
\hline CHEMBL133121 & 68483 & 6.7959 & 6.3307 & TST & \\
\hline CHEMBL335101 & 68483 & 5.9431 & 5.3565 & TST & \\
\hline CHEMBL133625 & 68483 & 5.8239 & 5.678 & TRN & \\
\hline CHEMBL335685 & 68483 & 6.2218 & 5.7171 & TST & \\
\hline CHEMBL130594 & 68483 & 5.8539 & 5.5864 & TRN & \\
\hline CHEMBL130284 & 68483 & 5.9586 & 5.6432 & TRN & \\
\hline CHEMBL132572 & 68483 & 5.6021 & 6.0426 & TRN & \\
\hline CHEMBL129959 & 68483 & 4.8268 & 6.0067 & TST & \\
\hline CHEMBL340678 & 68483 & 4.3152 & 5.2256 & TST & \\
\hline CHEMBL131739 & 68483 & 6.0605 & 5.7351 & TST & \\
\hline CHEMBL130258 & 68483 & 4.1024 & 4.1011 & TST & \\
\hline CHEMBL445906 & 68483 & 5.8861 & 5.5604 & TRN & \\
\hline CHEMBL 334942 & 68483 & 5.2218 & 5.4294 & TRN & \\
\hline CHEMBL334772 & 68483 & 5.699 & 5.1859 & TRN & \\
\hline CHEMBL339276 & 68483 & 5.2757 & 4.8526 & TST & \\
\hline CHEMBL130548 & 68483 & 5.2366 & 6.4414 & TST & \\
\hline CHEMBL335871 & 68483 & 5.5686 & 6.3726 & TST & \\
\hline CHEMBL92309 & 954423 & 2.53 & 2.5491 & TST & \\
\hline CHEMBL102714 & 954423 & 3.1428 & 3.0983 & TRN & \\
\hline CHEMBL1590308 & 954423 & 2.5503 & 2.96100 & 00000000003 & TST \\
\hline CHEMBL202721 & 954423 & 4.5664 & 4.5702 & TRN & \\
\hline CHEMBL 2144069 & 954423 & 4.832 & 4.8142 & TRN & \\
\hline CHEMBL577784 & 954423 & 4.7889 & 4.7722 & TRN & \\
\hline CHEMBL399530 & 954423 & 5.2095 & 5.1963 & TRN & \\
\hline CHEMBL1190711 & 954423 & 4.2834 & 4.2714 & TRN & \\
\hline CHEMBL 2134202 & 954423 & 3.5565 & 3.6539 & TRN & \\
\hline CHEMBL 2005886 & 954423 & 4.7373 & 4.7136 & TRN & \\
\hline CHEMBL 258844 & 954423 & 3.2262 & 3.2119 & TRN & \\
\hline CHEMBL3392440 & 954423 & 3.7421 & 3.75699 & 99999999997 & TRN \\
\hline CHEMBL9470 & 954423 & 4.4561 & 5.6449 & TST & \\
\hline CHEMBL509032 & 954423 & 5.3123 & 5.3347 & TRN & \\
\hline CHEMBL259181 & 954423 & 2.9492 & 2.9224 & TRN & \\
\hline CHEMBL 209148 & 954423 & 4.4554 & 4.4373 & TRN & \\
\hline CHEMBL 217354 & 954423 & 6.4586 & 6.4932 & TRN & \\
\hline CHEMBL 220241 & 954423 & 3.8897 & 3.9049 & TRN & \\
\hline CHEMBL189584 & 954423 & 3.6847 & 3.6802 & TRN & \\
\hline
\end{tabular}




\begin{tabular}{|c|c|c|c|c|c|c|c|}
\hline \multicolumn{8}{|c|}{ Supplemental Table S2.txt } \\
\hline CHEMBL3199475 & 954423 & 3.84 & 3.8765 & TRN & & & \\
\hline CHEMBL1970879 & 954423 & 3.9928 & 4.022 & TRN & & & \\
\hline CHEMBL1516890 & 954423 & 3.8695 & 3.8883 & TRN & & & \\
\hline CHEMBL1673039 & 954423 & 4.4353 & 4.4951 & TRN & & & \\
\hline CHEMBL1788116 & 954423 & 3.4212 & 3.3964 & TRN & & & \\
\hline CHEMBL1404918 & 954423 & 2.79600 & 00000000 & 003 & 2.79100 & 00000000004 & TRN \\
\hline CHEMBL188678 & 954423 & 4.0131 & 4.0567 & TRN & & & \\
\hline CHEMBL180127 & 954423 & 3.1627 & 3.1492 & TRN & & & \\
\hline CHEMBL1256459 & 954423 & 7.0737 & 7.0732 & TRN & & & \\
\hline CHEMBL191334 & 954423 & 3.917 & 3.92199 & 999999999 & 97 & TRN & \\
\hline CHEMBL1909414 & 954423 & 3.8925 & 3.8892 & TRN & & & \\
\hline CHEMBL393929 & 954423 & 4.90600 & 00000000 & 01 & 4.8937 & TRN & \\
\hline CHEMBL 2137530 & 954423 & 5.0267 & 4.9674 & TRN & & & \\
\hline CHEMBL483849 & 954423 & 1.7016 & 1.9038 & TST & & & \\
\hline CHEMBL412142 & 954423 & 3.9651 & 3.9941 & TRN & & & \\
\hline CHEMBL558642 & 954423 & 2.6304 & 2.6184 & TRN & & & \\
\hline CHEMBL515416 & 954423 & 5.1356 & 5.1013 & TRN & & & \\
\hline CHEMBL1242367 & 954423 & 3.05 & 3.0555 & TRN & & & \\
\hline CHEMBL300389 & 954423 & 6.6116 & 6.6116 & TRN & & & \\
\hline CHEMBL210618 & 954423 & 4.0603 & 4.0739 & TRN & & & \\
\hline CHEMBL65 & 954423 & 7.3905 & 7.399 & TRN & & & \\
\hline CHEMBL2363137 & 954423 & 3.9944 & 3.9622 & TRN & & & \\
\hline CHEMBL1643959 & 954423 & 2.8878 & 2.92 & TRN & & & \\
\hline CHEMBL573107 & 954423 & 4.9097 & 4.8956 & TRN & & & \\
\hline CHEMBL1186585 & 954423 & 4.0676 & 4.0174 & TRN & & & \\
\hline CHEMBL483847 & 954423 & 3.6998 & 3.7251 & TRN & & & \\
\hline CHEMBL1230020 & 954423 & 3.4935 & 3.4948 & TRN & & & \\
\hline CHEMBL3349342 & 954423 & 5.1585 & 5.1621 & TRN & & & \\
\hline CHEMBL472940 & 954423 & 2.7011 & 2.7028 & TRN & & & \\
\hline CHEMBL373751 & 954423 & 3.1103 & 3.1094 & TRN & & & \\
\hline CHEMBL135561 & 954423 & 4.1547 & 4.1418 & TRN & & & \\
\hline CHEMBL1357247 & 954423 & 2.5897 & 2.5782 & TRN & & & \\
\hline CHEMBL 379300 & 954423 & 5.9304 & 5.907 & TRN & & & \\
\hline CHEMBL 221137 & 954423 & 3.8329 & 4.2836 & TST & & & \\
\hline CHEMBL392695 & 954423 & 3.8864 & 4.7801 & TST & & & \\
\hline CHEMBL3186408 & 954423 & 2.9502 & 3.7002 & TST & & & \\
\hline CHEMBL449158 & 954423 & 6.2018 & 6.4387 & TST & & & \\
\hline CHEMBL240954 & 954423 & 3.7795 & 3.5181 & TST & & & \\
\hline CHEMBL379975 & 954423 & 5.6342 & 5.4065 & TST & & & \\
\hline CHEMBL514499 & 954423 & 5.5294 & 6.7726 & TST & & & \\
\hline CHEMBL 255342 & 954423 & 3.3088 & 3.4292 & TST & & & \\
\hline CHEMBL213100 & 954423 & 3.1468 & 3.8636 & TST & & & \\
\hline CHEMBL192566 & 954423 & 6.1927 & 7.4491 & TST & & & \\
\hline CHEMBL512504 & 954423 & 4.0827 & 5.0073 & TST & & & \\
\hline CHEMBL585951 & 954423 & 3.9572 & 5.5594 & TST & & & \\
\hline CHEMBL222102 & 954423 & 3.6127 & 3.2665 & TST & & & \\
\hline CHEMBL341112 & 623655 & 3.0 & 3.5531 & TRN & & & \\
\hline CHEMBL1093873 & 623655 & 3.0 & 3.7311 & TRN & & & \\
\hline
\end{tabular}




\begin{tabular}{|c|c|c|c|c|}
\hline \multicolumn{5}{|c|}{ Supplemental Table S2.txt } \\
\hline CHEMBL1093220 & 623655 & 3.0 & 2.9485 & TST \\
\hline CHEMBL1092984 & 623655 & 3.0 & 2.9066 & TST \\
\hline CHEMBL1093508 & 623655 & 4.7959 & 4.0558 & TRN \\
\hline CHEMBL1090902 & 623655 & 4.301 & 3.9176 & TRN \\
\hline CHEMBL1092746 & 623655 & 3.7447 & 3.4088 & TRN \\
\hline CHEMBL1092937 & 623655 & 3.0 & 3.6251 & TST \\
\hline CHEMBL1093492 & 623655 & 3.0 & 3.122 & TRN \\
\hline CHEMBL1092966 & 623655 & 3.6021 & 3.4842 & TRN \\
\hline CHEMBL1089234 & 623655 & 4.699 & 3.8411 & TRN \\
\hline CHEMBL1095562 & 623655 & 4.4559 & 3.6972 & TRN \\
\hline CHEMBL1092978 & 623655 & 3.6021 & 3.8633 & TRN \\
\hline CHEMBL1092979 & 623655 & 3.2218 & 3.9846 & TRN \\
\hline CHEMBL1093263 & 623655 & 4.4559 & 3.9198 & TRN \\
\hline CHEMBL1094254 & 623655 & 3.0 & 3.0114 & TRN \\
\hline CHEMBL1090692 & 623655 & 3.0 & 3.1363 & TRN \\
\hline CHEMBL1090903 & 623655 & 3.0 & 3.8243 & TRN \\
\hline CHEMBL1092702 & 623655 & 4.5229 & 3.9735 & TRN \\
\hline CHEMBL1093875 & 623655 & 5.699 & 4.1186 & TRN \\
\hline CHEMBL1091257 & 623655 & 4.7447 & 4.0301 & TRN \\
\hline CHEMBL1092947 & 623655 & 3.3468 & 3.1232 & TRN \\
\hline CHEMBL1091652 & 623655 & 3.0 & 4.2587 & TRN \\
\hline CHEMBL1092967 & 623655 & 3.0 & 2.8953 & TST \\
\hline CHEMBL1092613 & 623655 & 4.0458 & 3.9184 & TRN \\
\hline CHEMBL1093493 & 623655 & 3.5086 & 3.7123 & TRN \\
\hline CHEMBL1091037 & 623655 & 4.8539 & 4.1412 & TRN \\
\hline CHEMBL564201 & 623655 & 3.699 & 3.4115 & TST \\
\hline CHEMBL1090936 & 623655 & 3.5376 & 4.0439 & TRN \\
\hline CHEMBL1090901 & 623655 & 3.0 & 2.8663 & TRN \\
\hline CHEMBL159895 & 623655 & 3.0 & 2.9736 & TST \\
\hline CHEMBL1091736 & 623655 & 4.6198 & 4.0938 & TRN \\
\hline CHEMBL1089893 & 623655 & 3.0 & 3.5046 & TRN \\
\hline CHEMBL1093512 & 623655 & 4.6021 & 3.9635 & TRN \\
\hline CHEMBL1092674 & 623655 & 3.0969 & 2.9499 & TRN \\
\hline CHEMBL1092614 & 623655 & 3.0 & 3.8489 & TRN \\
\hline CHEMBL1092935 & 623655 & 3.1249 & 3.2319 & TRN \\
\hline CHEMBL1095561 & 623655 & 3.0 & 3.2279 & TRN \\
\hline CHEMBL1088991 & 623655 & 3.0 & 2.9298 & TST \\
\hline CHEMBL1093853 & 623655 & 3.0 & 3.0539 & TRN \\
\hline CHEMBL1091258 & 623655 & 3.3468 & 3.7666 & TRN \\
\hline CHEMBL1092701 & 623655 & 3.5229 & 4.01 & TRN \\
\hline CHEMBL1092938 & 623655 & 3.0 & 3.1361 & TRN \\
\hline CHEMBL1093907 & 623655 & 4.0506 & 3.1016 & TRN \\
\hline CHEMBL1093876 & 623655 & 3.0 & 3.1954 & TRN \\
\hline CHEMBL1093874 & 623655 & 4.3872 & 3.8119 & TRN \\
\hline CHEMBL418899 & 623655 & 3.0 & 3.7546 & TST \\
\hline CHEMBL1092673 & 623655 & 3.5229 & 3.8159 & TRN \\
\hline CHEMBL1091653 & 623655 & 4.3768 & 3.8421 & TRN \\
\hline CHEMBL1093233 & 623655 & 3.6198 & 3.4284 & TRN \\
\hline
\end{tabular}




\begin{tabular}{|c|c|c|c|c|c|}
\hline & & \multicolumn{4}{|c|}{ Supplemental Table S2.txt } \\
\hline CHEMBL1092095 & 623655 & 3.699 & 3.4205 & TRN & \\
\hline CHEMBL1090566 & 623655 & 3.0 & 2.9119 & TRN & \\
\hline CHEMBL1090678 & 623655 & 3.0 & 3.5625 & TRN & \\
\hline CHEMBL1093827 & 623655 & 3.4559 & 3.6713 & TRN & \\
\hline CHEMBL209918 & 623655 & 3.0 & 3.0801 & TRN & \\
\hline CHEMBL111951 & 623655 & 3.0 & 3.8424 & TST & \\
\hline CHEMBL1093511 & 623655 & 3.0 & 3.0808 & TRN & \\
\hline CHEMBL1093988 & 623655 & 4.3279 & 3.9469 & TRN & \\
\hline CHEMBL1093520 & 623655 & 3.0 & 2.9474 & TRN & \\
\hline CHEMBL1093553 & 623655 & 3.0 & 3.79699 & 99999999997 & TRN \\
\hline CHEMBL1091953 & 623655 & 3.0 & 3.0892 & TRN & \\
\hline CHEMBL1093507 & 623655 & 3.0 & 3.0316 & TRN & \\
\hline CHEMBL1092703 & 623655 & 3.2218 & 3.6324 & TRN & \\
\hline CHEMBL1089907 & 623655 & 3.0 & 2.9578 & TRN & \\
\hline CHEMBL1093920 & 623655 & 3.0 & 4.2089 & TRN & \\
\hline CHEMBL1092936 & 623655 & 3.0 & 2.9376 & TST & \\
\hline CHEMBL1094255 & 623655 & 3.0 & 3.0555 & TRN & \\
\hline CHEMBL1093513 & 623655 & 3.0 & 3.2743 & TST & \\
\hline CHEMBL1091651 & 623655 & 3.0 & 3.7766 & TST & \\
\hline CHEMBL1093919 & 623655 & 3.8239 & 4.1564 & TST & \\
\hline CHEMBL1090567 & 623655 & 3.0 & 2.9727 & TST & \\
\hline CHEMBL1089235 & 623655 & 3.0 & 3.4605 & TST & \\
\hline CHEMBL98778 & 623655 & 4.6383 & 3.7505 & TST & \\
\hline CHEMBL1093826 & 623655 & 3.0 & 3.9827 & TST & \\
\hline CHEMBL1092985 & 623655 & 3.0 & 2.9619 & TST & \\
\hline CHEMBL1093906 & 623655 & 3.0 & 3.1243 & TST & \\
\hline CHEMBL 2000685 & 809216 & 4.3 & 4.7004 & TRN & \\
\hline CHEMBL1985311 & 809216 & 4.3 & 4.6982 & TRN & \\
\hline CHEMBL1965660 & 809216 & 4.7 & 4.9923 & TST & \\
\hline CHEMBL1969502 & 809216 & 7.5 & 6.576006 & 00000000005 & TRN \\
\hline CHEMBL1965910 & 809216 & 4.5 & 6.2445 & TST & \\
\hline CHEMBL1682553 & 809216 & 4.7 & 4.8348 & TRN & \\
\hline CHEMBL1971430 & 809216 & 4.7 & 5.0163 & TRN & \\
\hline CHEMBL1997764 & 809216 & 4.7 & 4.6728 & TRN & \\
\hline CHEMBL1983963 & 809216 & 6.2 & 5.6683 & TRN & \\
\hline CHEMBL 2000271 & 809216 & 7.7 & 5.5902 & TRN & \\
\hline CHEMBL1985092 & 809216 & 4.7 & 4.7157 & TRN & \\
\hline CHEMBL 2004692 & 809216 & 4.3 & 4.4887 & TST & \\
\hline CHEMBL1981410 & 809216 & 4.7 & 4.0848 & TRN & \\
\hline CHEMBL1996234 & 809216 & 4.7 & 5.6637 & TST & \\
\hline CHEMBL1991434 & 809216 & 4.3 & 4.9321 & TST & \\
\hline CHEMBL1967544 & 809216 & 4.7 & 4.7917 & TRN & \\
\hline CHEMBL223367 & 809216 & 4.3 & 4.6113 & TST & \\
\hline CHEMBL340384 & 809216 & 4.7 & 5.159 & TST & \\
\hline CHEMBL1996587 & 809216 & 4.7 & 4.8671 & TRN & \\
\hline CHEMBL1964804 & 809216 & 4.7 & 4.4919 & TRN & \\
\hline CHEMBL443962 & 809216 & 4.3 & 4.7061 & TST & \\
\hline CHEMBL2000354 & 809216 & 4.7 & 4.8454 & TRN & \\
\hline
\end{tabular}




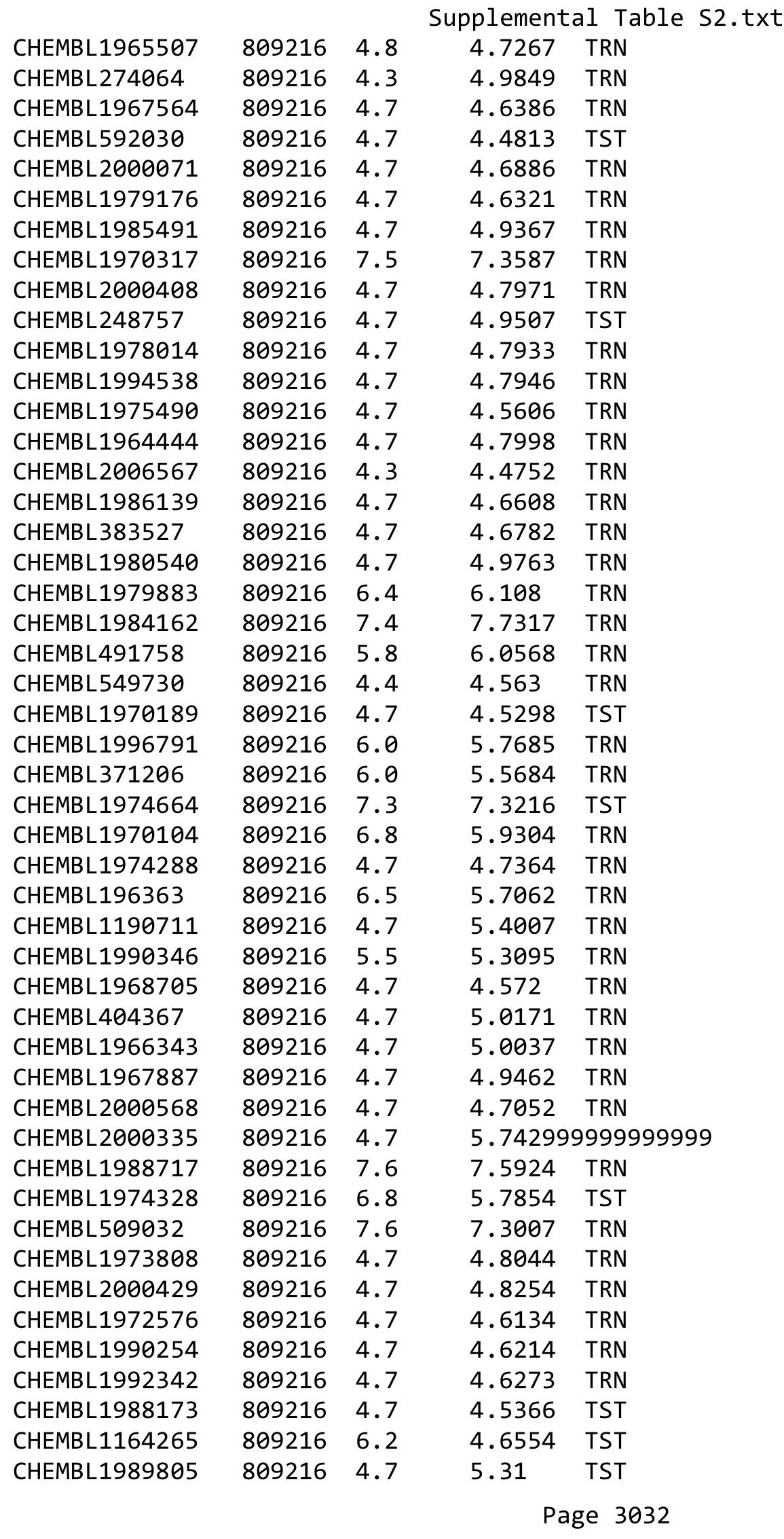




\begin{tabular}{|c|c|c|c|c|c|}
\hline \multicolumn{6}{|c|}{ Supplemental Table S2.txt } \\
\hline CHEMBL1965423 & 809216 & 4.7 & 4.79 & TRN & \\
\hline CHEMBL1983025 & 809216 & 5.9 & 5.4584 & TRN & \\
\hline CHEMBL205415 & 809216 & 4.7 & 4.5858 & TRN & \\
\hline CHEMBL1977135 & 809216 & 4.7 & 4.5259 & TRN & \\
\hline CHEMBL 2001920 & 809216 & 4.7 & 4.4114 & TST & \\
\hline CHEMBL 2002322 & 809216 & 4.3 & 4.2218 & TRN & \\
\hline CHEMBL1980904 & 809216 & 6.8 & 6.6698 & TRN & \\
\hline CHEMBL1241473 & 809216 & 7.5 & 7.394 & TRN & \\
\hline CHEMBL 2002323 & 809216 & 7.8 & 4.601 & TST & \\
\hline CHEMBL1978448 & 809216 & 5.9 & 4.8983 & TST & \\
\hline CHEMBL 2001257 & 809216 & 4.9 & 5.5875 & TRN & \\
\hline CHEMBL 2005548 & 809216 & 4.7 & 4.6734 & TRN & \\
\hline CHEMBL271441 & 809216 & 6.4 & 6.1786 & TRN & \\
\hline CHEMBL1992536 & 809216 & 4.7 & 4.6032 & TRN & \\
\hline CHEMBL1992740 & 809216 & 4.7 & 4.917 & TRN & \\
\hline CHEMBL 2002373 & 809216 & 4.7 & 4.5637 & TRN & \\
\hline CHEMBL439340 & 809216 & 4.7 & 4.7173 & TRN & \\
\hline CHEMBL 2006188 & 809216 & 4.7 & 4.7987 & TRN & \\
\hline CHEMBL1967531 & 809216 & 4.7 & 4.9789 & TRN & \\
\hline CHEMBL1970913 & 809216 & 4.3 & 4.765 & TRN & \\
\hline CHEMBL1973893 & 809216 & 4.7 & 4.4557 & TRN & \\
\hline CHEMBL1997534 & 809216 & 4.7 & 4.69300 & 00000000005 & TRN \\
\hline CHEMBL1996500 & 809216 & 4.7 & 4.445 & TRN & \\
\hline CHEMBL1985095 & 809216 & 4.7 & 4.4556 & TST & \\
\hline CHEMBL 273187 & 809216 & 6.6 & 6.4582 & TRN & \\
\hline CHEMBL1991180 & 809216 & 4.6 & 4.9022 & TST & \\
\hline CHEMBL1682540 & 809216 & 4.7 & 4.6849 & TRN & \\
\hline CHEMBL1986979 & 809216 & 6.0 & 5.9154 & TRN & \\
\hline CHEMBL1976420 & 809216 & 6.6 & 5.8998 & TST & \\
\hline CHEMBL1994864 & 809216 & 4.7 & 4.7151 & TRN & \\
\hline CHEMBL413779 & 809216 & 4.3 & 4.7427 & TST & \\
\hline CHEMBL 2002446 & 809216 & 4.9 & 5.7085 & TST & \\
\hline CHEMBL497151 & 809216 & 4.7 & 4.5915 & TRN & \\
\hline CHEMBL1973961 & 809216 & 4.7 & 4.7592 & TRN & \\
\hline CHEMBL 246970 & 809216 & 4.7 & 4.5806 & TRN & \\
\hline CHEMBL340921 & 809216 & 4.5 & 4.8185 & TST & \\
\hline CHEMBL373598 & 809216 & 4.3 & 4.6588 & TST & \\
\hline CHEMBL1999718 & 809216 & 4.7 & 4.5313 & TRN & \\
\hline CHEMBL1276446 & 809216 & 6.8 & 5.9855 & TST & \\
\hline CHEMBL1977346 & 809216 & 4.7 & 4.3988 & TRN & \\
\hline CHEMBL1971649 & 809216 & 4.7 & 4.2918 & TRN & \\
\hline CHEMBL 2003657 & 809216 & 4.7 & 5.2578 & TRN & \\
\hline CHEMBL 2006439 & 809216 & 4.7 & 4.7682 & TRN & \\
\hline CHEMBL2006156 & 809216 & 4.3 & 4.6952 & TST & \\
\hline CHEMBL1969190 & 809216 & 5.7 & 5.4082 & TRN & \\
\hline CHEMBL1973937 & 809216 & 4.8 & 4.9795 & TRN & \\
\hline CHEMBL1991674 & 809216 & 4.7 & 4.6523 & TRN & \\
\hline CHEMBL1982711 & 809216 & 4.7 & 4.6092 & TRN & \\
\hline
\end{tabular}




\begin{tabular}{|c|c|c|c|c|}
\hline \multicolumn{5}{|c|}{ Supplemental Table S2.txt } \\
\hline CHEMBL1984842 & 809216 & 4.7 & 4.6025 & TRN \\
\hline CHEMBL1969102 & 809216 & 7.9 & 7.6995 & TRN \\
\hline CHEMBL1682346 & 809216 & 4.7 & 4.985 & TRN \\
\hline CHEMBL 2007044 & 809216 & 4.3 & 4.6729 & TST \\
\hline CHEMBL 2001998 & 809216 & 4.7 & 4.9964 & TST \\
\hline CHEMBL1994241 & 809216 & 4.8 & 4.8123 & TRN \\
\hline CHEMBL 223460 & 809216 & 4.3 & 4.758 & TST \\
\hline CHEMBL1998829 & 809216 & 4.7 & 5.2424 & TRN \\
\hline CHEMBL50894 & 809216 & 6.4 & 5.7178 & TRN \\
\hline CHEMBL1988838 & 809216 & 6.6 & 6.8205 & TRN \\
\hline CHEMBL1981725 & 809216 & 8.1 & 7.8889 & TRN \\
\hline CHEMBL375284 & 809216 & 4.3 & 4.2083 & TRN \\
\hline CHEMBL1982866 & 809216 & 4.7 & 4.6898 & TRN \\
\hline CHEMBL 2005792 & 809216 & 4.7 & 4.5774 & TRN \\
\hline CHEMBL462120 & 809216 & 4.3 & 5.0062 & TST \\
\hline CHEMBL1984206 & 809216 & 4.3 & 4.3899 & TRN \\
\hline CHEMBL1991577 & 809216 & 4.7 & 4.5922 & TRN \\
\hline CHEMBL1965570 & 809216 & 6.4 & 6.5287 & TRN \\
\hline CHEMBL 2007592 & 809216 & 4.7 & 4.5051 & TST \\
\hline CHEMBL 210963 & 809216 & 4.7 & 4.2995 & TRN \\
\hline CHEMBL1082440 & 809216 & 4.4 & 5.0309 & TST \\
\hline CHEMBL1614705 & 809216 & 4.7 & 4.7915 & TST \\
\hline CHEMBL1972362 & 809216 & 4.7 & 4.2335 & TRN \\
\hline CHEMBL1984633 & 809216 & 4.7 & 4.6793 & TRN \\
\hline CHEMBL1965845 & 809216 & 4.7 & 4.6974 & TRN \\
\hline CHEMBL 2006715 & 809216 & 7.9 & 6.8651 & TRN \\
\hline CHEMBL1986597 & 809216 & 4.7 & 4.7061 & TRN \\
\hline CHEMBL1971017 & 809216 & 4.3 & 4.4106 & TRN \\
\hline CHEMBL1990482 & 809216 & 4.7 & 4.7615 & TRN \\
\hline CHEMBL1990904 & 809216 & 4.7 & 4.8407 & TRN \\
\hline CHEMBL 2005475 & 809216 & 4.7 & 4.5166 & TRN \\
\hline CHEMBL 2000104 & 809216 & 4.7 & 4.2197 & TRN \\
\hline CHEMBL183844 & 809216 & 4.7 & 4.6671 & TRN \\
\hline CHEMBL 220057 & 809216 & 4.9 & 5.0493 & TRN \\
\hline CHEMBL1682545 & 809216 & 4.7 & 4.6438 & TRN \\
\hline CHEMBL 383541 & 809216 & 4.7 & 4.7504 & TRN \\
\hline CHEMBL 2001224 & 809216 & 4.7 & 4.6192 & TRN \\
\hline CHEMBL10 & 809216 & 4.7 & 4.4582 & TRN \\
\hline CHEMBL1976732 & 809216 & 4.7 & 5.0014 & TRN \\
\hline CHEMBL1969506 & 809216 & 4.7 & 4.6714 & TRN \\
\hline CHEMBL1964937 & 809216 & 4.7 & 4.5982 & TRN \\
\hline CHEMBL1980163 & 809216 & 4.7 & 4.6687 & TRN \\
\hline CHEMBL590109 & 809216 & 4.5 & 4.7679 & TST \\
\hline CHEMBL1970879 & 809216 & 8.5 & 7.7306 & TRN \\
\hline CHEMBL1989856 & 809216 & 5.8 & 5.1976 & TST \\
\hline CHEMBL 2005899 & 809216 & 4.7 & 4.6382 & TRN \\
\hline CHEMBL1682552 & 809216 & 4.7 & 4.6363 & TRN \\
\hline CHEMBL 259850 & 809216 & 4.3 & 4.4409 & TRN \\
\hline
\end{tabular}




\begin{tabular}{|c|c|c|c|c|c|}
\hline \multicolumn{6}{|c|}{ Supplemental Table S2.txt } \\
\hline CHEMBL229799 & 809216 & 4.7 & 5.171 & TRN & \\
\hline CHEMBL1682359 & 809216 & 4.7 & 4.6697 & TRN & \\
\hline CHEMBL105739 & 809216 & 5.7 & 5.5462 & TRN & \\
\hline CHEMBL379300 & 809216 & 4.7 & 5.1468 & TRN & \\
\hline CHEMBL203673 & 809216 & 4.7 & 4.67899 & 9999999999 & TRN \\
\hline CHEMBL1969523 & 809216 & 5.4 & 4.8113 & TRN & \\
\hline CHEMBL207995 & 809216 & 4.7 & 4.502 & TRN & \\
\hline CHEMBL 2001923 & 809216 & 4.7 & 4.1921 & TRN & \\
\hline CHEMBL1986781 & 809216 & 4.7 & 4.7271 & TRN & \\
\hline CHEMBL526133 & 809216 & 4.7 & 4.7478 & TRN & \\
\hline CHEMBL1966836 & 809216 & 5.9 & 5.9106 & TRN & \\
\hline CHEMBL1979057 & 809216 & 4.7 & 4.2281 & TRN & \\
\hline CHEMBL1981045 & 809216 & 4.3 & 4.6497 & TRN & \\
\hline CHEMBL387971 & 809216 & 4.8 & 5.3266 & TST & \\
\hline CHEMBL1975418 & 809216 & 4.7 & 4.865 & TRN & \\
\hline CHEMBL1992796 & 809216 & 4.3 & 4.9111 & TST & \\
\hline CHEMBL1999428 & 809216 & 4.7 & 4.4738 & TRN & \\
\hline CHEMBL223257 & 809216 & 4.3 & 4.6481 & TST & \\
\hline CHEMBL1967560 & 809216 & 4.7 & 4.77800 & 00000000005 & TRN \\
\hline CHEMBL1516890 & 809216 & 6.3 & 5.3999 & TRN & \\
\hline CHEMBL211378 & 809216 & 4.3 & 5.169 & TRN & \\
\hline CHEMBL1982465 & 809216 & 6.2 & 5.9886 & TRN & \\
\hline CHEMBL 2001751 & 809216 & 6.4 & 5.95 & TRN & \\
\hline CHEMBL 2003420 & 809216 & 4.7 & 4.5133 & TRN & \\
\hline CHEMBL1984586 & 809216 & 4.7 & 4.6586 & TRN & \\
\hline CHEMBL272938 & 809216 & 6.6 & 6.1677 & TRN & \\
\hline CHEMBL1972659 & 809216 & 4.3 & 4.5912 & TST & \\
\hline CHEMBL1973395 & 809216 & 4.4 & 5.0182 & TRN & \\
\hline CHEMBL272453 & 809216 & 4.7 & 5.3361 & TRN & \\
\hline CHEMBL1970217 & 809216 & 4.7 & 4.7377 & TRN & \\
\hline CHEMBL1971801 & 809216 & 4.3 & 4.8557 & TRN & \\
\hline CHEMBL1968850 & 809216 & 4.3 & 4.3494 & TRN & \\
\hline CHEMBL 2005528 & 809216 & 4.7 & 4.6335 & TST & \\
\hline CHEMBL185569 & 809216 & 4.4 & 4.4829 & TRN & \\
\hline CHEMBL1969843 & 809216 & 4.7 & 4.7204 & TRN & \\
\hline CHEMBL 2007002 & 809216 & 4.7 & 4.6943 & TRN & \\
\hline CHEMBL1990288 & 809216 & 4.7 & 4.8258 & TRN & \\
\hline CHEMBL1987007 & 809216 & 4.7 & 4.4762 & TRN & \\
\hline CHEMBL1969588 & 809216 & 7.1 & 6.2274 & TRN & \\
\hline CHEMBL1984711 & 809216 & 7.3 & 7.2753 & TRN & \\
\hline CHEMBL484390 & 809216 & 4.7 & 4.4052 & TST & \\
\hline CHEMBL1979252 & 809216 & 4.7 & 4.8746 & TRN & \\
\hline CHEMBL1682341 & 809216 & 4.7 & 4.8346 & TRN & \\
\hline CHEMBL 2004290 & 809216 & 7.2 & 7.1714 & TRN & \\
\hline CHEMBL1986499 & 809216 & 4.7 & 4.9289 & TRN & \\
\hline CHEMBL1972937 & 809216 & 4.7 & 4.5755 & TRN & \\
\hline CHEMBL1972250 & 809216 & 4.3 & 4.6848 & TST & \\
\hline CHEMBL2000393 & 809216 & 5.7 & 5.857 & TST & \\
\hline
\end{tabular}




\begin{tabular}{|c|c|c|c|c|}
\hline \multicolumn{5}{|c|}{ Supplemental Table S2.txt } \\
\hline CHEMBL403402 & 809216 & 6.5 & 6.2791 & TRN \\
\hline CHEMBL 2004311 & 809216 & 4.7 & 4.8518 & TRN \\
\hline CHEMBL1992634 & 809216 & 4.7 & 4.5887 & TRN \\
\hline CHEMBL1242373 & 809216 & 4.7 & 4.7694 & TRN \\
\hline CHEMBL1988075 & 809216 & 4.7 & 5.9987 & TRN \\
\hline CHEMBL316264 & 809216 & 4.7 & 4.5492 & TRN \\
\hline CHEMBL1991678 & 809216 & 4.7 & 4.5367 & TRN \\
\hline CHEMBL 2001239 & 809216 & 4.3 & 5.1008 & TST \\
\hline CHEMBL1988594 & 809216 & 4.7 & 4.7346 & TRN \\
\hline CHEMBL 2001288 & 809216 & 4.7 & 4.5635 & TRN \\
\hline CHEMBL 260092 & 809216 & 4.3 & 4.9428 & TRN \\
\hline CHEMBL1999811 & 809216 & 4.7 & 5.5819 & TST \\
\hline CHEMBL1965495 & 809216 & 4.3 & 4.7959 & TRN \\
\hline CHEMBL1985074 & 809216 & 4.7 & 4.8562 & TST \\
\hline CHEMBL1982874 & 809216 & 4.7 & 4.848 & TRN \\
\hline CHEMBL 2000481 & 809216 & 4.7 & 4.4505 & TRN \\
\hline CHEMBL1991725 & 809216 & 4.7 & 5.0186 & TRN \\
\hline CHEMBL1992242 & 809216 & 4.3 & 4.3648 & TRN \\
\hline CHEMBL 2007296 & 809216 & 4.7 & 4.6403 & TRN \\
\hline CHEMBL396523 & 809216 & 5.9 & 5.9594 & TRN \\
\hline CHEMBL208637 & 809216 & 4.3 & 4.1911 & TRN \\
\hline CHEMBL1970203 & 809216 & 4.7 & 4.6412 & TRN \\
\hline CHEMBL1986530 & 809216 & 4.7 & 4.515 & TST \\
\hline CHEMBL1999321 & 809216 & 4.7 & 4.6894 & TRN \\
\hline CHEMBL1968590 & 809216 & 6.2 & 7.7734 & TRN \\
\hline CHEMBL1999749 & 809216 & 6.4 & 6.4121 & TRN \\
\hline CHEMBL 2005375 & 809216 & 4.7 & 4.4274 & TRN \\
\hline CHEMBL1984191 & 809216 & 4.7 & 4.5481 & TRN \\
\hline CHEMBL1983006 & 809216 & 4.7 & 4.5453 & TRN \\
\hline CHEMBL1971029 & 809216 & 7.1 & 7.1766 & TRN \\
\hline CHEMBL394790 & 809216 & 4.7 & 4.5632 & TRN \\
\hline CHEMBL226471 & 809216 & 4.3 & 4.5542 & TRN \\
\hline CHEMBL1974702 & 809216 & 4.7 & 4.787 & TST \\
\hline CHEMBL1996111 & 809216 & 4.7 & 4.5417 & TRN \\
\hline CHEMBL1965589 & 809216 & 4.7 & 4.7303 & TRN \\
\hline CHEMBL1998193 & 809216 & 4.7 & 4.2874 & TRN \\
\hline CHEMBL474432 & 809216 & 5.8 & 5.524 & TST \\
\hline CHEMBL1988153 & 809216 & 4.7 & 4.5693 & TRN \\
\hline CHEMBL1972584 & 809216 & 6.7 & 6.6229 & TRN \\
\hline CHEMBL1999556 & 809216 & 4.3 & 4.2643 & TRN \\
\hline CHEMBL1988437 & 809216 & 4.7 & 5.8345 & TST \\
\hline CHEMBL1968245 & 809216 & 4.7 & 5.1907 & TRN \\
\hline CHEMBL1998121 & 809216 & 6.4 & 5.6809 & TRN \\
\hline CHEMBL1979577 & 809216 & 6.4 & 5.8983 & TRN \\
\hline CHEMBL1991800 & 809216 & 4.7 & 4.6276 & TRN \\
\hline CHEMBL52387 & 809216 & 4.4 & 5.1451 & TST \\
\hline CHEMBL379835 & 809216 & 4.3 & 4.7401 & TST \\
\hline CHEMBL1979357 & 809216 & 4.7 & 4.765 & TRN \\
\hline
\end{tabular}




\begin{tabular}{|c|c|c|c|c|}
\hline & & & pplement & al $\mathrm{Ta}$ \\
\hline CHEMBL1980802 & 809216 & 4.3 & 4.6305 & TST \\
\hline CHEMBL1979554 & 809216 & 4.7 & 4.8159 & TRN \\
\hline CHEMBL1996817 & 809216 & 5.0 & 5.6043 & TRN \\
\hline CHEMBL409349 & 809216 & 6.4 & 5.9829 & TRN \\
\hline CHEMBL 2004355 & 809216 & 4.3 & 4.4347 & TRN \\
\hline CHEMBL468280 & 809216 & 4.7 & 4.6571 & TST \\
\hline CHEMBL1990884 & 809216 & 6.8 & 6.2303 & TRN \\
\hline CHEMBL 3109278 & 809216 & 6.2 & 5.8796 & TRN \\
\hline CHEMBL 256835 & 809216 & 4.7 & 4.7803 & TRN \\
\hline CHEMBL1980142 & 809216 & 4.7 & 4.7834 & TRN \\
\hline CHEMBL41783 & 809216 & 4.7 & 4.6544 & TRN \\
\hline CHEMBL 2004438 & 809216 & 4.3 & 4.7272 & TRN \\
\hline CHEMBL 2006276 & 809216 & 4.7 & 4.5491 & TRN \\
\hline CHEMBL 271381 & 809216 & 4.8 & 5.6691 & TRN \\
\hline CHEMBL 2006785 & 809216 & 4.7 & 4.7486 & TST \\
\hline CHEMBL1982466 & 809216 & 7.6 & 7.7588 & TRN \\
\hline CHEMBL1994638 & 809216 & 6.0 & 6.0384 & TRN \\
\hline CHEMBL1995740 & 809216 & 4.7 & 4.533 & TRN \\
\hline CHEMBL1985888 & 809216 & 6.1 & 5.9922 & TRN \\
\hline CHEMBL1996390 & 809216 & 4.3 & 4.2429 & TRN \\
\hline CHEMBL1986943 & 809216 & 4.7 & 5.1993 & TRN \\
\hline CHEMBL 234085 & 809216 & 4.7 & 4.1457 & TRN \\
\hline CHEMBL1995832 & 809216 & 4.7 & 4.742 & TRN \\
\hline CHEMBL1969042 & 809216 & 4.7 & 4.533 & TRN \\
\hline CHEMBL 2000345 & 809216 & 4.7 & 4.8069 & TRN \\
\hline CHEMBL1999931 & 809216 & 6.2 & 5.7116 & TRN \\
\hline CHEMBL1991640 & 809216 & 4.7 & 4.8342 & TST \\
\hline CHEMBL1375418 & 809216 & 4.7 & 5.2645 & TRN \\
\hline CHEMBL 302449 & 809216 & 4.3 & 5.909 & TST \\
\hline CHEMBL 2007064 & 809216 & 4.3 & 5.3084 & TRN \\
\hline CHEMBL1981047 & 809216 & 8.3 & 7.6341 & TRN \\
\hline CHEMBL229968 & 809216 & 4.7 & 5.0883 & TRN \\
\hline CHEMBL1976240 & 809216 & 4.7 & 4.7266 & TRN \\
\hline CHEMBL1979093 & 809216 & 5.7 & 5.5565 & TRN \\
\hline CHEMBL1968151 & 809216 & 4.7 & 4.5553 & TST \\
\hline CHEMBL1381197 & 809216 & 6.4 & 5.5638 & TRN \\
\hline CHEMBL1987009 & 809216 & 4.7 & 4.5759 & TRN \\
\hline CHEMBL379218 & 809216 & 4.7 & 5.056 & TRN \\
\hline CHEMBL 2003817 & 809216 & 4.3 & 4.6546 & TRN \\
\hline CHEMBL336961 & 809216 & 4.7 & 5.7544 & TRN \\
\hline CHEMBL1994830 & 809216 & 4.7 & 4.6445 & TRN \\
\hline CHEMBL1987054 & 809216 & 7.2 & 7.5884 & TRN \\
\hline CHEMBL1970083 & 809216 & 7.2 & 6.8862 & TRN \\
\hline CHEMBL 226403 & 809216 & 4.4 & 4.6928 & TRN \\
\hline CHEMBL 2005631 & 809216 & 7.6 & 7.0197 & TRN \\
\hline CHEMBL1994938 & 809216 & 9.1 & 8.9242 & TRN \\
\hline CHEMBL1977223 & 809216 & 4.7 & 4.8993 & TRN \\
\hline CHEMBL1236126 & 809216 & 4.3 & 4.9973 & TST \\
\hline
\end{tabular}




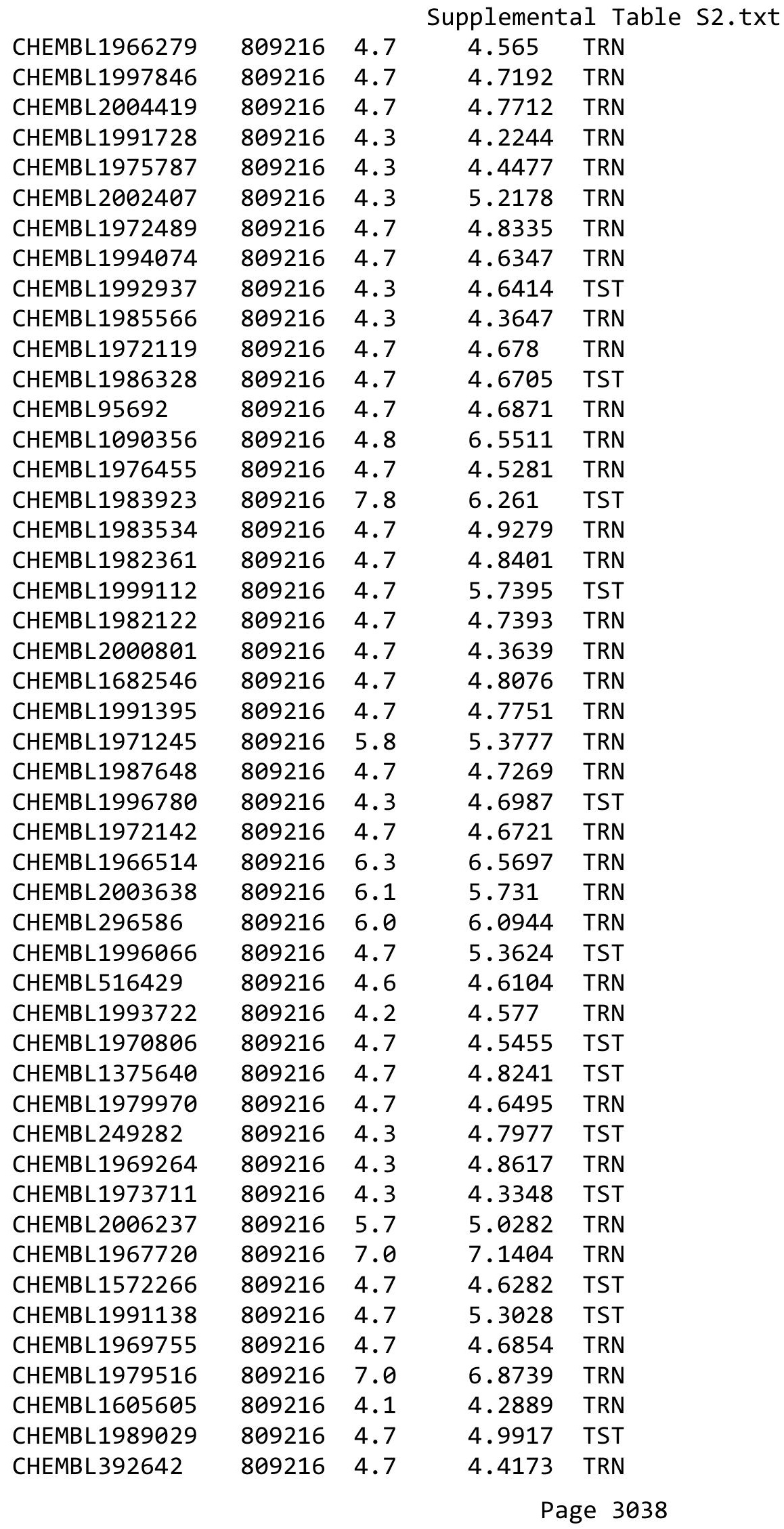




\begin{tabular}{|c|c|c|c|c|c|}
\hline & & & & & \\
\hline CHEMBL2000652 & 809216 & 6.3 & 6.5327 & TRN & \\
\hline CHEMBL514499 & 809216 & 5.3 & 4.7141 & TST & \\
\hline CHEMBL1965631 & 809216 & 4.7 & 4.8662 & TRN & \\
\hline CHEMBL1980144 & 809216 & 4.7 & 4.6825 & TRN & \\
\hline CHEMBL1991188 & 809216 & 4.7 & 4.6929 & TRN & \\
\hline CHEMBL1972849 & 809216 & 4.7 & 4.937 & TRN & \\
\hline CHEMBL 377408 & 809216 & 4.7 & 4.7087 & TRN & \\
\hline CHEMBL215152 & 809216 & 4.7 & 4.77800 & 00000000005 & TRN \\
\hline CHEMBL231209 & 809216 & 4.7 & 4.15 & TRN & \\
\hline CHEMBL1976220 & 809216 & 4.7 & 4.5916 & TRN & \\
\hline CHEMBL259922 & 809216 & 4.7 & 6.1217 & TST & \\
\hline CHEMBL1982383 & 809216 & 4.7 & 4.5446 & TRN & \\
\hline CHEMBL1969301 & 809216 & 4.7 & 4.6662 & TST & \\
\hline CHEMBL17370 & 809216 & 4.7 & 4.7305 & TRN & \\
\hline CHEMBL1987910 & 809216 & 4.7 & 4.369 & TRN & \\
\hline CHEMBL374044 & 809216 & 6.5 & 6.0074 & TRN & \\
\hline CHEMBL1983932 & 809216 & 4.7 & 4.8726 & TRN & \\
\hline CHEMBL404366 & 809216 & 4.7 & 5.6372 & TRN & \\
\hline CHEMBL1966069 & 809216 & 4.7 & 4.7167 & TRN & \\
\hline CHEMBL1997822 & 809216 & 4.7 & 6.0898 & TRN & \\
\hline CHEMBL1991285 & 809216 & 4.7 & 4.6897 & TRN & \\
\hline CHEMBL 243088 & 809216 & 6.2 & 5.9248 & TRN & \\
\hline CHEMBL1984038 & 809216 & 4.7 & 4.1186 & TRN & \\
\hline CHEMBL1974416 & 809216 & 6.5 & 6.3558 & TRN & \\
\hline CHEMBL1997872 & 809216 & 4.7 & 4.7074 & TRN & \\
\hline CHEMBL1964290 & 809216 & 4.7 & 4.9945 & TST & \\
\hline CHEMBL 213505 & 809216 & 4.7 & 4.7596 & TRN & \\
\hline CHEMBL1987034 & 809216 & 6.8 & 6.8645 & TRN & \\
\hline CHEMBL1993941 & 809216 & 7.5 & 7.5649 & TRN & \\
\hline CHEMBL 377383 & 809216 & 4.7 & 4.4545 & TRN & \\
\hline CHEMBL 2005886 & 809216 & 8.1 & 7.5289 & TRN & \\
\hline CHEMBL481491 & 809216 & 4.7 & 4.4919 & TST & \\
\hline CHEMBL1682345 & 809216 & 4.3 & 4.9119 & TRN & \\
\hline CHEMBL1973142 & 809216 & 4.7 & 4.9761 & TST & \\
\hline CHEMBL1973145 & 809216 & 4.4 & 4.4765 & TRN & \\
\hline CHEMBL1982924 & 809216 & 4.7 & 4.8824 & TRN & \\
\hline CHEMBL 2005936 & 809216 & 4.7 & 4.7634 & TRN & \\
\hline CHEMBL1807515 & 809216 & 4.7 & 5.0118 & TRN & \\
\hline CHEMBL1971141 & 809216 & 4.7 & 4.1932 & TRN & \\
\hline CHEMBL1995813 & 809216 & 4.7 & 4.9508 & TRN & \\
\hline CHEMBL1979718 & 809216 & 4.3 & 4.8244 & TRN & \\
\hline CHEMBL523823 & 809216 & 4.7 & 4.578 & TST & \\
\hline CHEMBL1973178 & 809216 & 6.9 & 6.16799 & 9999999999 & TRN \\
\hline CHEMBL 244378 & 809216 & 6.1 & 5.8971 & TRN & \\
\hline CHEMBL1988778 & 809216 & 6.3 & 6.1736 & TRN & \\
\hline CHEMBL2001957 & 809216 & 4.7 & 4.7047 & TRN & \\
\hline CHEMBL1969372 & 809216 & 4.7 & 4.8604 & TRN & \\
\hline CHEMBL1990583 & 809216 & 4.7 & 5.5791 & TRN & \\
\hline
\end{tabular}




\begin{tabular}{|c|c|c|c|c|c|}
\hline \multicolumn{6}{|c|}{ Supplemental Table S2.txt } \\
\hline CHEMBL 2006263 & 809216 & 4.7 & 4.6082 & TST & \\
\hline CHEMBL1993584 & 809216 & 4.7 & 4.8676 & TRN & \\
\hline CHEMBL1986263 & 809216 & 4.7 & 4.8929 & TRN & \\
\hline CHEMBL 2000114 & 809216 & 4.7 & 4.4132 & TRN & \\
\hline CHEMBL 210618 & 809216 & 4.3 & 4.2654 & TRN & \\
\hline CHEMBL1975647 & 809216 & 4.7 & 4.9136 & TRN & \\
\hline CHEMBL1968380 & 809216 & 4.7 & 4.4533 & TRN & \\
\hline CHEMBL1964644 & 809216 & 4.7 & 4.5177 & TRN & \\
\hline CHEMBL1981782 & 809216 & 4.7 & 4.6298 & TRN & \\
\hline CHEMBL1977681 & 809216 & 4.7 & 4.7974 & TRN & \\
\hline CHEMBL1970142 & 809216 & 7.8 & 7.3853 & TRN & \\
\hline CHEMBL1990912 & 809216 & 4.7 & 4.6477 & TRN & \\
\hline CHEMBL1988163 & 809216 & 6.9 & 6.5498 & TRN & \\
\hline CHEMBL1995592 & 809216 & 4.3 & 5.3113 & TST & \\
\hline CHEMBL 2006493 & 809216 & 4.7 & 4.56800 & 00000000005 & TST \\
\hline CHEMBL1996923 & 809216 & 4.3 & 4.582 & TST & \\
\hline CHEMBL1983449 & 809216 & 4.7 & 4.8052 & TRN & \\
\hline CHEMBL1992323 & 809216 & 4.7 & 4.6183 & TST & \\
\hline CHEMBL1969735 & 809216 & 4.7 & 4.748 & TRN & \\
\hline CHEMBL 2003524 & 809216 & 4.3 & 4.7178 & TST & \\
\hline CHEMBL 2002649 & 809216 & 4.7 & 4.6332 & TRN & \\
\hline CHEMBL437747 & 809216 & 4.7 & 4.9846 & TRN & \\
\hline CHEMBL507936 & 809216 & 4.3 & 4.4945 & TRN & \\
\hline CHEMBL104264 & 809216 & 4.3 & 4.8756 & TST & \\
\hline CHEMBL1994321 & 809216 & 6.4 & 5.9749 & TRN & \\
\hline CHEMBL1997129 & 809216 & 4.5 & 4.7582 & TRN & \\
\hline CHEMBL451964 & 809216 & 4.7 & 4.5926 & TRN & \\
\hline CHEMBL1964307 & 809216 & 4.5 & 4.6998 & TRN & \\
\hline CHEMBL 2000508 & 809216 & 4.7 & 4.7697 & TRN & \\
\hline CHEMBL1971694 & 809216 & 4.7 & 4.6902 & TST & \\
\hline CHEMBL 2001547 & 809216 & 4.7 & 4.6823 & TRN & \\
\hline CHEMBL210928 & 809216 & 4.7 & 4.4688 & TRN & \\
\hline CHEMBL1994361 & 809216 & 4.7 & 4.7685 & TRN & \\
\hline CHEMBL1986603 & 809216 & 4.7 & 4.8927 & TST & \\
\hline CHEMBL1972840 & 809216 & 4.3 & 4.4346 & TRN & \\
\hline CHEMBL1977148 & 809216 & 8.1 & 7.8075 & TRN & \\
\hline CHEMBL 2003286 & 809216 & 4.7 & 4.6134 & TRN & \\
\hline CHEMBL1992306 & 809216 & 6.0 & 6.0271 & TRN & \\
\hline CHEMBL 2002165 & 809216 & 7.3 & 7.4195 & TRN & \\
\hline CHEMBL 206382 & 809216 & 4.7 & 4.6007 & TRN & \\
\hline CHEMBL1998585 & 809216 & 4.7 & 5.8517 & TRN & \\
\hline CHEMBL127898 & 809216 & 4.7 & 4.713 & TST & \\
\hline CHEMBL519697 & 809216 & 4.7 & 4.3334 & TST & \\
\hline CHEMBL 2004934 & 809216 & 4.7 & 4.7317 & TRN & \\
\hline CHEMBL1975128 & 809216 & 4.7 & 5.0664 & TRN & \\
\hline CHEMBL1996048 & 809216 & 6.0 & 5.1607 & TST & \\
\hline CHEMBL461876 & 809216 & 4.7 & 4.6896 & TST & \\
\hline CHEMBL 2001485 & 809216 & 6.7 & 6.8427 & TRN & \\
\hline
\end{tabular}




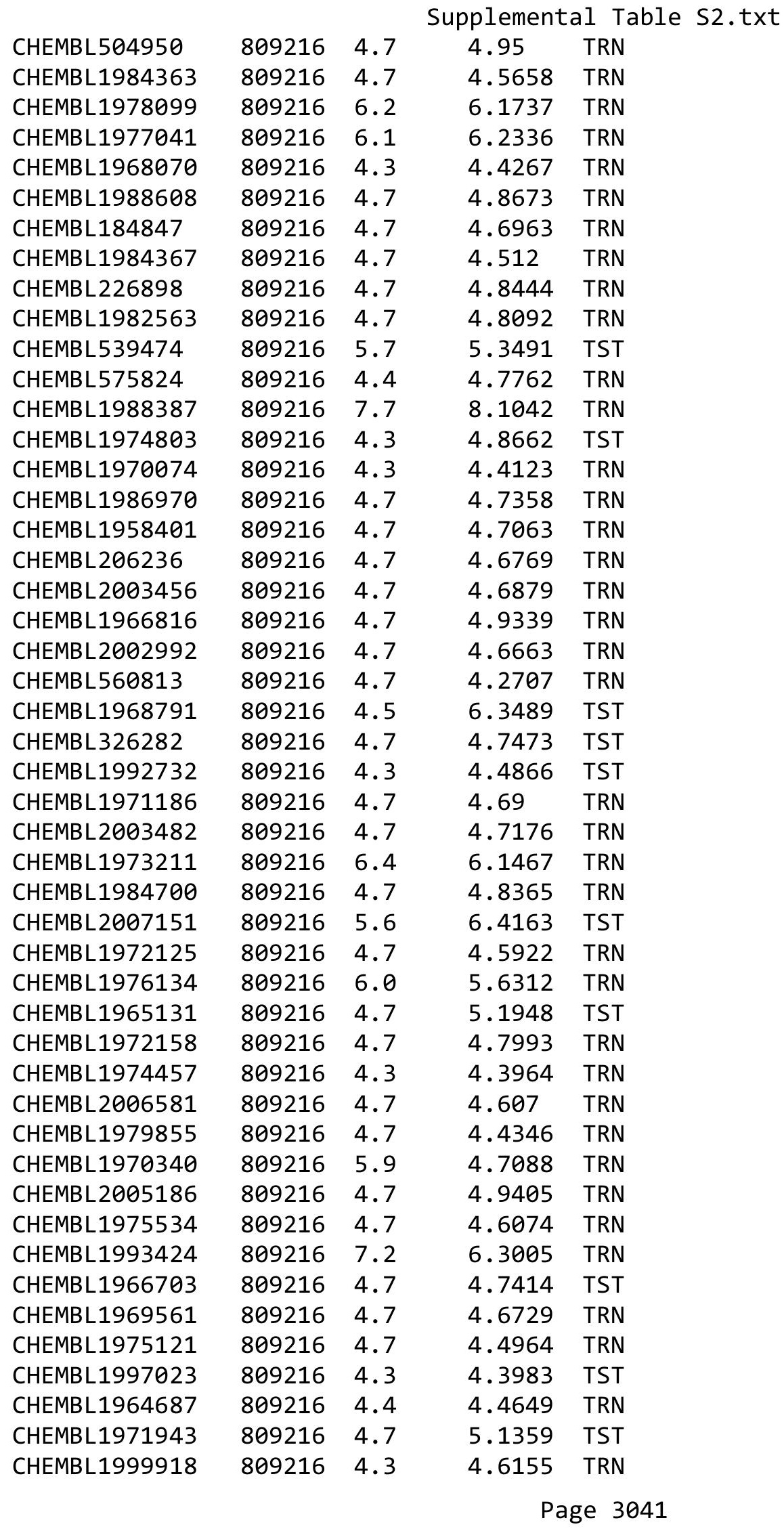




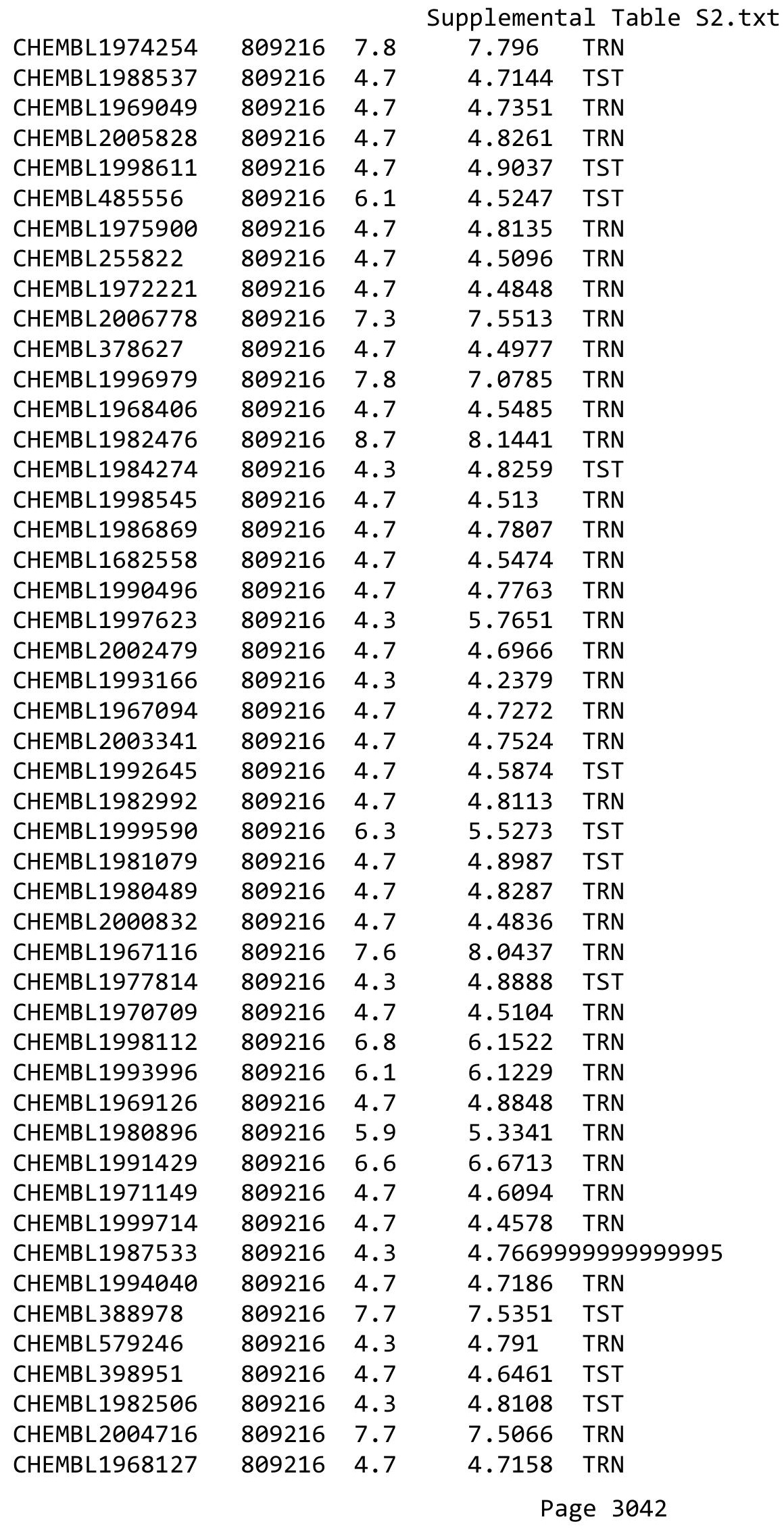




\begin{tabular}{|c|c|c|c|c|c|}
\hline \multicolumn{6}{|c|}{ Supplemental Table S2.txt } \\
\hline CHEMBL1975233 & 809216 & 4.7 & 4.586 & TRN & \\
\hline CHEMBL1985406 & 809216 & 4.7 & 4.7313 & TRN & \\
\hline CHEMBL207400 & 809216 & 4.3 & 4.6224 & TST & \\
\hline CHEMBL 2000894 & 809216 & 4.7 & 4.8797 & TST & \\
\hline CHEMBL1982135 & 809216 & 4.7 & 4.5126 & TRN & \\
\hline CHEMBL1976090 & 809216 & 4.7 & 4.6285 & TRN & \\
\hline CHEMBL1993243 & 809216 & 8.1 & 8.1923 & TRN & \\
\hline CHEMBL1992922 & 809216 & 4.3 & 4.878 & TRN & \\
\hline CHEMBL 2004771 & 809216 & 4.7 & 4.6452 & TRN & \\
\hline CHEMBL 399021 & 809216 & 5.7 & 6.2176 & TST & \\
\hline CHEMBL1997597 & 809216 & 4.7 & 4.6086 & TRN & \\
\hline CHEMBL1969537 & 809216 & 4.7 & 5.2962 & TST & \\
\hline CHEMBL1976093 & 809216 & 4.7 & 4.7111 & TRN & \\
\hline CHEMBL1975256 & 809216 & 4.7 & 4.5498 & TST & \\
\hline CHEMBL508928 & 809216 & 7.7 & 7.7414 & TRN & \\
\hline CHEMBL1991356 & 809216 & 4.7 & 4.9592 & TST & \\
\hline CHEMBL 2004892 & 809216 & 4.7 & 4.497 & TRN & \\
\hline CHEMBL116070 & 809216 & 4.7 & 4.5519 & TRN & \\
\hline CHEMBL1990821 & 809216 & 4.7 & 4.9127 & TST & \\
\hline CHEMBL1970314 & 809216 & 4.7 & 4.5024 & TRN & \\
\hline CHEMBL 2004871 & 809216 & 4.7 & 4.5291 & TRN & \\
\hline CHEMBL 2004872 & 809216 & 4.7 & 4.5988 & TRN & \\
\hline CHEMBL1727312 & 809216 & 4.3 & 4.1655 & TRN & \\
\hline CHEMBL1969879 & 809216 & 4.7 & 4.4204 & TRN & \\
\hline CHEMBL1981720 & 809216 & 4.7 & 4.8057 & TRN & \\
\hline CHEMBL419932 & 809216 & 4.7 & 4.7868 & TRN & \\
\hline CHEMBL262433 & 809216 & 4.7 & 5.1127 & TRN & \\
\hline CHEMBL 373798 & 809216 & 6.2 & 5.86799 & 9999999999 & TRN \\
\hline CHEMBL 306380 & 809216 & 7.4 & 7.9606 & TRN & \\
\hline CHEMBL1966722 & 809216 & 4.7 & 4.2385 & TST & \\
\hline CHEMBL1975500 & 809216 & 4.7 & 5.0527 & TRN & \\
\hline CHEMBL1976328 & 809216 & 4.7 & 4.4571 & TRN & \\
\hline CHEMBL394619 & 809216 & 4.7 & 4.8099 & TRN & \\
\hline CHEMBL1964399 & 809216 & 4.3 & 4.8612 & TRN & \\
\hline CHEMBL1996831 & 809216 & 4.7 & 4.6093 & TST & \\
\hline CHEMBL411903 & 809216 & 4.7 & 4.4069 & TRN & \\
\hline CHEMBL1965988 & 809216 & 6.4 & 5.9302 & TRN & \\
\hline CHEMBL418203 & 809216 & 4.7 & 4.5857 & TST & \\
\hline CHEMBL1989646 & 809216 & 4.7 & 5.0694 & TRN & \\
\hline CHEMBL1682357 & 809216 & 4.7 & 4.7585 & TRN & \\
\hline CHEMBL225519 & 809216 & 4.7 & 4.2958 & TRN & \\
\hline CHEMBL 209534 & 809216 & 4.3 & 4.4733 & TRN & \\
\hline CHEMBL1978200 & 809216 & 4.7 & 4.8507 & TRN & \\
\hline CHEMBL1970522 & 809216 & 4.7 & 4.8225 & TRN & \\
\hline CHEMBL402846 & 809216 & 4.7 & 5.2842 & TRN & \\
\hline CHEMBL1964692 & 809216 & 6.1 & 5.5757 & TRN & \\
\hline CHEMBL1996931 & 809216 & 4.7 & 4.6323 & TRN & \\
\hline CHEMBL1964413 & 809216 & 4.7 & 4.6927 & TRN & \\
\hline
\end{tabular}




\begin{tabular}{|c|c|c|c|c|}
\hline \multicolumn{5}{|c|}{ Supplemental Table S2.txt } \\
\hline CHEMBL1973483 & 809216 & 4.7 & 4.7115 & TRN \\
\hline CHEMBL1984432 & 809216 & 4.7 & 4.5995 & TRN \\
\hline CHEMBL 219722 & 809216 & 5.8 & 5.1528 & TRN \\
\hline CHEMBL1997340 & 809216 & 4.7 & 4.5871 & TST \\
\hline CHEMBL1522508 & 809216 & 4.7 & 4.8479 & TST \\
\hline CHEMBL1989474 & 809216 & 4.7 & 4.6175 & TST \\
\hline CHEMBL1090360 & 809216 & 7.2 & 6.5897 & TST \\
\hline CHEMBL 210887 & 809216 & 4.7 & 4.8291 & TST \\
\hline CHEMBL458997 & 809216 & 4.7 & 5.8379 & TST \\
\hline CHEMBL1971021 & 809216 & 4.7 & 4.3566 & TST \\
\hline CHEMBL227271 & 809216 & 4.7 & 5.0827 & TST \\
\hline CHEMBL583144 & 809216 & 4.7 & 4.7264 & TST \\
\hline CHEMBL1974310 & 809216 & 4.7 & 4.0932 & TST \\
\hline CHEMBL1982660 & 809216 & 4.7 & 5.0109 & TST \\
\hline CHEMBL1994693 & 809216 & 4.7 & 4.5407 & TST \\
\hline CHEMBL1982957 & 809216 & 4.7 & 5.3945 & TST \\
\hline CHEMBL1725279 & 809216 & 4.7 & 5.5325 & TST \\
\hline CHEMBL1975138 & 809216 & 4.7 & 4.0633 & TST \\
\hline CHEMBL424872 & 809216 & 4.2 & 4.4241 & TST \\
\hline CHEMBL 2006836 & 809216 & 4.4 & 4.8812 & TST \\
\hline CHEMBL1971947 & 809216 & 6.8 & 6.0038 & TST \\
\hline CHEMBL412142 & 809216 & 4.3 & 4.7179 & TST \\
\hline CHEMBL1980704 & 809216 & 4.7 & 4.6969 & TST \\
\hline CHEMBL 2003271 & 809216 & 4.7 & 5.0739 & TST \\
\hline CHEMBL1966808 & 809216 & 4.7 & 4.5415 & TST \\
\hline CHEMBL1996255 & 809216 & 6.3 & 5.955 & TST \\
\hline CHEMBL 2004447 & 809216 & 4.4 & 4.5336 & TST \\
\hline CHEMBL1983111 & 809216 & 7.2 & 6.0222 & TST \\
\hline CHEMBL1973860 & 809216 & 4.7 & 4.697 & TST \\
\hline CHEMBL260135 & 809216 & 4.3 & 4.5733 & TST \\
\hline CHEMBL 220241 & 809216 & 4.7 & 5.0149 & TST \\
\hline CHEMBL1982610 & 809216 & 5.7 & 5.2121 & TST \\
\hline CHEMBL1999496 & 809216 & 4.7 & 4.5511 & TST \\
\hline CHEMBL2006933 & 809216 & 4.3 & 4.8174 & TST \\
\hline CHEMBL1988300 & 809216 & 6.2 & 6.7395 & TST \\
\hline CHEMBL1991078 & 809216 & 6.5 & 6.2874 & TST \\
\hline CHEMBL1987359 & 809216 & 4.7 & 4.7639 & TST \\
\hline CHEMBL3969664 & 1642517 & 5.971 & 5.8058 & TRN \\
\hline CHEMBL3931652 & 1642517 & 7.317 & 7.2112 & TRN \\
\hline CHEMBL3890552 & 1642517 & 6.228 & 5.8212 & TRN \\
\hline CHEMBL3922208 & 1642517 & 6.5 & 6.6909 & TRN \\
\hline CHEMBL 3983427 & 1642517 & 8.0506 & 8.4739 & TRN \\
\hline CHEMBL3959416 & 1642517 & 7.8416 & 6.3167 & TRN \\
\hline CHEMBL 3928889 & 1642517 & 6.0 & 6.1225 & TRN \\
\hline CHEMBL3936355 & 1642517 & 4.0 & 5.9569 & TST \\
\hline CHEMBL3950911 & 1642517 & 6.0 & 5.978 & TRN \\
\hline CHEMBL3889556 & 1642517 & 8.4815 & 8.42 & TRN \\
\hline CHEMBL3909675 & 1642517 & 7.9066 & 7.6743 & TRN \\
\hline
\end{tabular}


Supplemental Table S2.txt

\begin{tabular}{|c|c|c|c|c|c|c|}
\hline CHEMBL3935995 & 1642517 & 8.6021 & 7.7129 & TST & & \\
\hline CHEMBL3980931 & 1642517 & 6.0 & 5.9582 & TRN & & \\
\hline CHEMBL3946989 & 1642517 & 6.0 & 6.412999 & 9999999999 & & TRN \\
\hline CHEMBL3906769 & 1642517 & 8.2147 & 7.0959 & TRN & & \\
\hline CHEMBL3951030 & 1642517 & 6.0 & 6.2141 & TRN & & \\
\hline CHEMBL3925568 & 1642517 & 6.0 & 5.9248 & TRN & & \\
\hline CHEMBL3914669 & 1642517 & 4.0 & 5.8986 & TRN & & \\
\hline CHEMBL3970209 & 1642517 & 7.2541 & 7.1289 & TRN & & \\
\hline CHEMBL3922442 & 1642517 & 6.6 & 6.3002 & TRN & & \\
\hline CHEMBL3896213 & 1642517 & 7.3288 & 7.3841 & TST & & \\
\hline CHEMBL3970054 & 1642517 & 8.0 & 6.8353 & TST & & \\
\hline CHEMBL3963279 & 1642517 & 8.0315 & 8.1071 & TRN & & \\
\hline CHEMBL3978440 & 1642517 & 6.0 & 5.9858 & TRN & & \\
\hline CHEMBL3984318 & 1642517 & 7.9393 & 7.4416 & TST & & \\
\hline CHEMBL3891750 & 1642517 & 7.1002 & 6.4518 & TRN & & \\
\hline CHEMBL3899349 & 1642517 & 5.25200 & 000000000 & & 5.4117 & TRN \\
\hline CHEMBL3974838 & 1642517 & 8.4949 & 8.429 & TRN & & \\
\hline CHEMBL 3954147 & 1642517 & 6.0 & 7.0731 & TRN & & \\
\hline CHEMBL3964899 & 1642517 & 8.4949 & 7.5473 & TRN & & \\
\hline CHEMBL3891830 & 1642517 & 6.42200 & 000000000 & & 6.9201 & TRN \\
\hline CHEMBL3891197 & 1642517 & 6.246 & 7.1769 & TRN & & \\
\hline CHEMBL 3899300 & 1642517 & 4.0 & 5.0538 & TRN & & \\
\hline CHEMBL3937576 & 1642517 & 6.0 & 6.8592 & TRN & & \\
\hline CHEMBL3936551 & 1642517 & 6.0 & 6.2239 & TRN & & \\
\hline CHEMBL3947197 & 1642517 & 7.9666 & 8.3038 & TRN & & \\
\hline CHEMBL3894510 & 1642517 & 5.62200 & 000000000 & & 5.8348 & TRN \\
\hline CHEMBL 3897182 & 1642517 & 8.2596 & 7.3339 & TST & & \\
\hline CHEMBL3942735 & 1642517 & 8.1805 & 7.6382 & TST & & \\
\hline CHEMBL3920897 & 1642517 & 8.4815 & 7.7077 & TRN & & \\
\hline CHEMBL3941856 & 1642517 & 7.2 & 6.5684 & TST & & \\
\hline CHEMBL3904138 & 1642517 & 8.2076 & 8.0338 & TRN & & \\
\hline CHEMBL3891835 & 1642517 & 7.3002 & 7.3377 & TRN & & \\
\hline CHEMBL3938002 & 1642517 & 7.4271 & 6.6834 & TST & & \\
\hline CHEMBL3942250 & 1642517 & 7.567 & 6.3728 & TRN & & \\
\hline CHEMBL3950348 & 1642517 & 6.745 & 6.0299 & TRN & & \\
\hline CHEMBL 3924464 & 1642517 & 8.5376 & 7.5043 & TRN & & \\
\hline CHEMBL3947638 & 1642517 & \multicolumn{3}{|c|}{5.6370000000000005} & 6.1834 & TRN \\
\hline CHEMBL3936619 & 1642517 & 6.0 & 6.1944 & TRN & & \\
\hline CHEMBL3898513 & 1642517 & 8.1192 & 7.9884 & TRN & & \\
\hline CHEMBL3929261 & 1642517 & \multicolumn{3}{|c|}{5.547999999999999} & 5.9882 & TRN \\
\hline CHEMBL3955511 & 1642517 & 7.8447 & 7.282 & TST & & \\
\hline CHEMBL3919823 & 1642517 & 5.976 & 5.8584 & TRN & & \\
\hline CHEMBL3904840 & 1642517 & 6.0 & 6.4141 & TRN & & \\
\hline CHEMBL3946826 & 1642517 & 7.7932 & 6.7262 & TRN & & \\
\hline CHEMBL3898553 & 1642517 & 7.8996 & 7.2412 & TRN & & \\
\hline CHEMBL3923816 & 1642517 & 8.0655 & 7.0475 & TRN & & \\
\hline CHEMBL3961280 & 1642517 & 8.3279 & 7.8895 & TST & & \\
\hline CHEMBL3973480 & 1642517 & 8.0088 & 7.3042 & TRN & & \\
\hline
\end{tabular}




\begin{tabular}{|c|c|c|c|c|c|c|}
\hline \multirow{3}{*}{$\begin{array}{l}\text { CHEMBL } 3986774 \\
\text { CHEMBL3896451 }\end{array}$} & \multicolumn{6}{|c|}{ Supplemental Table S2.txt } \\
\hline & 1642517 & 4.0 & \multicolumn{3}{|c|}{5.781000000000001} & TST \\
\hline & 1642517 & \multicolumn{3}{|c|}{5.162999999999999} & 6.0217 & TST \\
\hline CHEMBL 3932188 & 1642517 & 6.0 & 7.095 & TRN & & \\
\hline CHEMBL3967445 & 1642517 & 8.1938 & 7.9704 & TRN & & \\
\hline CHEMBL3948827 & 1642517 & \multicolumn{3}{|c|}{5.587999999999999} & 5.0355 & TRN \\
\hline CHEMBL3966375 & 1642517 & 7.1278 & 7.1051 & TST & & \\
\hline CHEMBL3915589 & 1642517 & 6.0 & \multicolumn{3}{|c|}{7.912000000000001} & TST \\
\hline CHEMBL 3934526 & 1642517 & 5.926 & 5.7056 & TST & & \\
\hline CHEMBL3981846 & 1642517 & 4.0 & 5.4646 & TRN & & \\
\hline CHEMBL3906194 & 1642517 & 7.3098 & 6.6258 & TRN & & \\
\hline CHEMBL3950699 & 1642517 & 6.0 & 6.1013 & TRN & & \\
\hline CHEMBL3914354 & 1642517 & 7.9706 & 6.985 & TST & & \\
\hline CHEMBL 3943500 & 1642517 & 6.7001 & 6.7594 & TST & & \\
\hline CHEMBL3957535 & 1642517 & 8.2291 & 8.0088 & TRN & & \\
\hline CHEMBL3935159 & 1642517 & 7.6021 & 6.7179 & TST & & \\
\hline CHEMBL3948603 & 1642517 & 6.803 & 6.6364 & TRN & & \\
\hline CHEMBL 3934050 & 1642517 & 6.8 & 6.5587 & TRN & & \\
\hline CHEMBL 3916556 & 1642517 & 6.186 & 7.2979 & TRN & & \\
\hline CHEMBL3905914 & 1642517 & 8.5229 & 8.5191 & TRN & & \\
\hline CHEMBL 3966695 & 1642517 & 6.0 & 6.1443 & TRN & & \\
\hline CHEMBL3938026 & 1642517 & 7.7122 & 6.8451 & TRN & & \\
\hline CHEMBL3929472 & 1642517 & 4.0 & 5.6514 & TRN & & \\
\hline CHEMBL 3961849 & 1642517 & 7.3325 & 7.21 & TRN & & \\
\hline CHEMBL3946841 & 1642517 & 7.8894 & 7.6144 & TST & & \\
\hline CHEMBL 3947089 & 1642517 & 8.0269 & 7.1632 & TRN & & \\
\hline CHEMBL3932769 & 1642517 & 5.63299 & 999999999 & & 6.3181 & TST \\
\hline CHEMBL3953197 & 1642517 & 7.5686 & 6.5032 & TRN & & \\
\hline CHEMBL 3921656 & 1642517 & 8.4437 & 7.7355 & TRN & & \\
\hline CHEMBL3915054 & 1642517 & 6.8 & 6.6609 & TRN & & \\
\hline CHEMBL 3897781 & 1642517 & 8.2076 & 7.6631 & TST & & \\
\hline CHEMBL 3904743 & 1642517 & 6.0 & 6.4716 & TRN & & \\
\hline CHEMBL3936758 & 1642517 & 8.3279 & 7.2733 & TRN & & \\
\hline CHEMBL 3906207 & 1642517 & 8.0915 & 8.3289 & TST & & \\
\hline CHEMBL3964916 & 1642517 & 7.6003 & 7.1092 & TST & & \\
\hline CHEMBL 3975636 & 1642517 & 7.058 & 7.1341 & TRN & & \\
\hline CHEMBL3895558 & 1642517 & 7.8601 & 7.8757 & TRN & & \\
\hline CHEMBL3967077 & 1642517 & 8.3768 & 7.5761 & TST & & \\
\hline CHEMBL3911481 & 1642517 & 6.9755 & 7.5815 & TRN & & \\
\hline CHEMBL3928215 & 1642517 & 7.0241 & 7.2715 & TRN & & \\
\hline CHEMBL 3906045 & 1642517 & 6.9751 & 6.3098 & TST & & \\
\hline CHEMBL3953783 & 1642517 & 7.0809 & 7.4151 & TRN & & \\
\hline CHEMBL3917725 & 1642517 & 8.4089 & 8.574 & TRN & & \\
\hline CHEMBL3907767 & 1642517 & 4.0 & 5.2321 & TRN & & \\
\hline CHEMBL3909983 & 1642517 & 7.4559 & 7.5612 & TRN & & \\
\hline CHEMBL 3933252 & 1642517 & 7.9872 & 7.2313 & TST & & \\
\hline CHEMBL3951416 & 1642517 & 6.03100 & 000000000 & & 6.2298 & TRN \\
\hline CHEMBL3933125 & 1642517 & 6.0 & 6.1174 & TRN & & \\
\hline CHEMBL3945189 & 1642517 & 6.794 & 6.4312 & TST & & \\
\hline
\end{tabular}




\begin{tabular}{|c|c|c|c|c|c|}
\hline CHEMBL3911143 & 1642517 & 6.0 & \multicolumn{2}{|c|}{6.1339999999999995} & TRN \\
\hline CHEMBL3923168 & 1642517 & 6.0 & 7.0861 & TRN & \\
\hline CHEMBL 3945387 & 1642517 & 6.0 & 6.0394 & TRN & \\
\hline CHEMBL3928620 & 1642517 & 6.9 & 6.307 & TRN & \\
\hline CHEMBL 3964243 & 1642517 & 7.1062 & 7.0333 & TRN & \\
\hline CHEMBL3965629 & 1642517 & 7.8996 & 6.8423 & TRN & \\
\hline CHEMBL 3976763 & 1642517 & 7.6904 & 7.8076 & TRN & \\
\hline CHEMBL 3958089 & 1642517 & 6.436 & 6.8609 & TRN & \\
\hline CHEMBL3954936 & 1642517 & 7.8962 & 8.7624 & TRN & \\
\hline CHEMBL3976605 & 1642517 & 7.2 & 6.9763 & TST & \\
\hline CHEMBL3924602 & 1642517 & 6.011 & 5.9469 & TST & \\
\hline CHEMBL 3919300 & 1642517 & 7.4001 & 7.0675 & TRN & \\
\hline CHEMBL 3962858 & 1642517 & 6.0 & 6.1077 & TRN & \\
\hline CHEMBL3913899 & 1642517 & 7.1051 & 6.4955 & TRN & \\
\hline CHEMBL3984595 & 1642517 & 7.7721 & 6.7304 & TRN & \\
\hline CHEMBL3965486 & 1642517 & 6.222 & 7.3792 & TST & \\
\hline CHEMBL3911891 & 1642517 & 6.0 & 6.6528 & TRN & \\
\hline CHEMBL3976490 & 1642517 & 6.7469 & 6.9725 & TRN & \\
\hline CHEMBL 3947652 & 1642517 & 6.806 & 6.9268 & TRN & \\
\hline CHEMBL3943013 & 1642517 & 7.068 & 7.2087 & TRN & \\
\hline CHEMBL3890005 & 1642517 & 7.9914 & 8.548 & TRN & \\
\hline CHEMBL3920065 & 1642517 & 7.098 & 7.0311 & TRN & \\
\hline CHEMBL3936866 & 1642517 & 7.3507 & 6.9021 & TRN & \\
\hline CHEMBL 3978377 & 1642517 & 6.407 & 6.1642 & TRN & \\
\hline CHEMBL3964565 & 1642517 & 4.0 & 6.0484 & TRN & \\
\hline CHEMBL3910372 & 1642517 & 7.4634 & 7.2895 & TRN & \\
\hline CHEMBL 3902545 & 1642517 & 6.9531 & 6.706 & TRN & \\
\hline CHEMBL3980975 & 1642517 & 6.144 & 6.8971 & TST & \\
\hline CHEMBL 3945829 & 1642517 & 5.16 & 6.2613 & TST & \\
\hline CHEMBL3935464 & 1642517 & 6.8 & 6.604 & TRN & \\
\hline CHEMBL3903983 & 1642517 & 7.8962 & 7.9792 & TST & \\
\hline CHEMBL3960396 & 1642517 & 5.925 & 6.1999 & TST & \\
\hline CHEMBL 3897237 & 1642517 & 6.0 & 5.9097 & TRN & \\
\hline CHEMBL 3914720 & 1642517 & 7.7773 & 7.0526 & TST & \\
\hline CHEMBL3916735 & 1642517 & 6.767 & 5.5775 & TRN & \\
\hline CHEMBL3930601 & 1642517 & 5.676 & 6.4911 & TRN & \\
\hline CHEMBL3933222 & 1642517 & 4.0 & 5.37799 & 9999999999 & TRN \\
\hline CHEMBL3936653 & 1642517 & 8.1427 & 7.829 & TRN & \\
\hline CHEMBL 3946102 & 1642517 & 6.0 & 6.3619 & TRN & \\
\hline CHEMBL3971321 & 1642517 & 5.942 & 6.2933 & TST & \\
\hline CHEMBL3961941 & 1642517 & 6.8941 & 6.7564 & TRN & \\
\hline CHEMBL 3952765 & 1642517 & 7.6517 & 6.7248 & TRN & \\
\hline CHEMBL3890699 & 1642517 & 8.5086 & 8.5735 & TRN & \\
\hline CHEMBL 3967670 & 1642517 & 5.511 & 6.0955 & TRN & \\
\hline CHEMBL3960245 & 1642517 & 6.638999 & 79999999 & 6.3058 & TST \\
\hline CHEMBL3934656 & 1642517 & 8.2007 & 8.7535 & TRN & \\
\hline CHEMBL3981471 & 1642517 & 8.1249 & 7.7565 & TRN & \\
\hline CHEMBL 3956614 & 1642517 & 6.9 & 7.5799 & TRN & \\
\hline
\end{tabular}




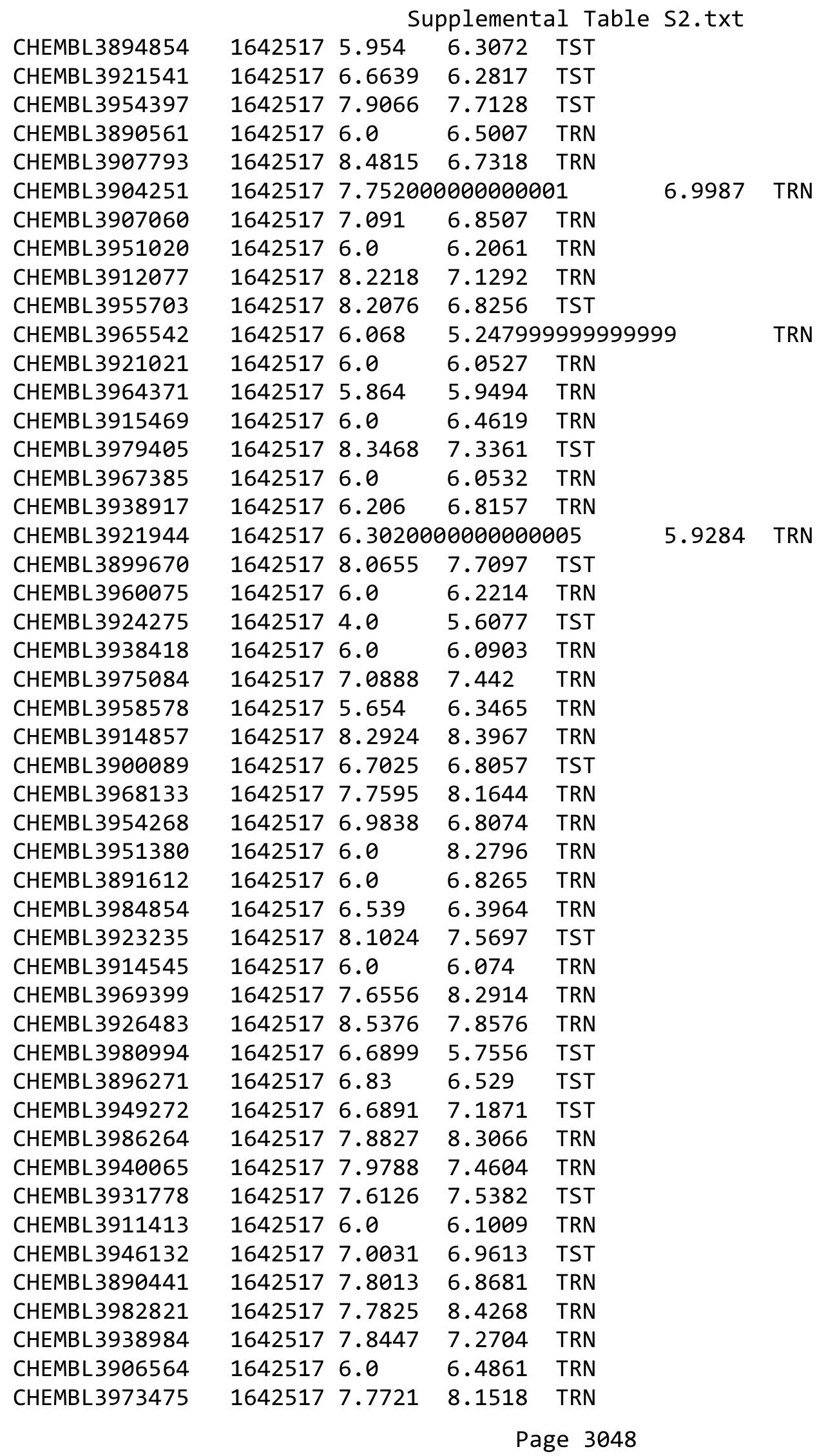




\begin{tabular}{|c|c|c|c|c|c|c|}
\hline \multicolumn{7}{|c|}{ Supplemental Table S2.txt } \\
\hline CHEMBL 3981370 & 1642517 & 6.0 & 7.1445 & TRN & & \\
\hline CHEMBL 3923377 & 1642517 & 6.9481 & 6.1895 & TRN & & \\
\hline CHEMBL3952152 & 1642517 & 8.2676 & 7.1869 & TRN & & \\
\hline CHEMBL3919664 & 1642517 & 6.0 & 6.4276 & TRN & & \\
\hline CHEMBL3928756 & 1642517 & 6.8 & 7.0004 & TRN & & \\
\hline CHEMBL 3956010 & 1642517 & 7.7352 & 6.9286 & TRN & & \\
\hline CHEMBL 3952160 & 1642517 & 7.1337 & 7.3706 & TST & & \\
\hline CHEMBL3918171 & 1642517 & 6.0 & 6.0396 & TRN & & \\
\hline CHEMBL 3928785 & 1642517 & 7.11799 & 99999999 & 99 & 7.0908 & TRN \\
\hline CHEMBL3901310 & 1642517 & 8.2147 & 6.5011 & TRN & & \\
\hline CHEMBL 3901985 & 1642517 & 7.76200 & 00000000 & 005 & 7.3855 & TST \\
\hline CHEMBL 3946254 & 1642517 & 6.9076 & 5.8987 & TRN & & \\
\hline CHEMBL181740 & 304672 & 6.1192 & 5.3336 & TST & & \\
\hline CHEMBL185184 & 304672 & 6.0 & 6.8594 & TST & & \\
\hline CHEMBL184083 & 304672 & 6.699 & 7.54 & TRN & & \\
\hline CHEMBL183192 & 304672 & 6.8268 & 7.3394 & TRN & & \\
\hline CHEMBL183327 & 304672 & 7.4377 & 7.3468 & TRN & & \\
\hline CHEMBL184502 & 304672 & 7.5768 & 7.42399 & 99999999 & 995 & TRN \\
\hline CHEMBL427322 & 304672 & 5.0706 & 6.2058 & TRN & & \\
\hline CHEMBL361669 & 304672 & 7.1871 & 7.1376 & TRN & & \\
\hline CHEMBL182601 & 304672 & 7.7212 & 7.0183 & TRN & & \\
\hline CHEMBL182445 & 304672 & 5.8239 & 5.2908 & TRN & & \\
\hline CHEMBL183422 & 304672 & 7.8386 & 7.5721 & TRN & & \\
\hline CHEMBL184992 & 304672 & 6.0 & 5.8169 & TRN & & \\
\hline CHEMBL183003 & 304672 & 8.3595 & 7.6945 & TRN & & \\
\hline CHEMBL183743 & 304672 & 6.0 & 5.7602 & TRN & & \\
\hline CHEMBL441120 & 304672 & 6.0 & 6.5677 & TST & & \\
\hline CHEMBL425701 & 304672 & 5.585 & 5.2621 & TRN & & \\
\hline CHEMBL184908 & 304672 & 6.8239 & 7.595 & TRN & & \\
\hline CHEMBL362021 & 304672 & 7.4318 & 7.4702 & TRN & & \\
\hline CHEMBL363109 & 304672 & 7.3036 & 7.4231 & TRN & & \\
\hline CHEMBL182630 & 304672 & 6.0177 & 5.6791 & TRN & & \\
\hline CHEMBL182292 & 304672 & 7.7696 & 6.6742 & TRN & & \\
\hline CHEMBL184765 & 304672 & 7.9208 & 7.0065 & TRN & & \\
\hline CHEMBL184608 & 304672 & 7.699 & 7.6729 & TRN & & \\
\hline CHEMBL 362173 & 304672 & 8.2441 & 6.0253 & TRN & & \\
\hline CHEMBL183505 & 304672 & 5.7825 & 6.275 & TRN & & \\
\hline CHEMBL366267 & 304672 & 7.34200 & 00000000 & 005 & 7.6124 & \\
\hline CHEMBL185213 & 304672 & 5.9031 & 6.2223 & TRN & & \\
\hline CHEMBL183013 & 304672 & 4.0 & 5.0251 & TRN & & \\
\hline CHEMBL369117 & 304672 & 5.7696 & 6.6742 & TRN & & \\
\hline CHEMBL361042 & 304672 & 7.3625 & 7.5147 & TRN & & \\
\hline CHEMBL362105 & 304672 & 6.0 & 5.5943 & TRN & & \\
\hline CHEMBL184033 & 304672 & 7.6402 & 7.4619 & TRN & & \\
\hline CHEMBL359656 & 304672 & 8.1192 & 7.4929 & TRN & & \\
\hline CHEMBL184621 & 304672 & 6.8861 & 7.3927 & TST & & \\
\hline CHEMBL184386 & 304672 & 6.3546 & 7.1219 & TRN & & \\
\hline CHEMBL366065 & 304672 & 6.0 & 5.9727 & TRN & & \\
\hline
\end{tabular}




\begin{tabular}{|c|c|c|c|c|c|}
\hline \multicolumn{6}{|c|}{ Supplemental Table S2.txt } \\
\hline CHEMBL185183 & 304672 & 6.8386 & 7.1821 & TRN & \\
\hline CHEMBL184969 & 304672 & 4.0 & 4.8854 & TRN & \\
\hline CHEMBL183471 & 304672 & 7.7595 & 7.6527 & TRN & \\
\hline CHEMBL185428 & 304672 & 6.0 & 5.5243 & TRN & \\
\hline CHEMBL181951 & 304672 & 5.0315 & 5.3024 & TST & \\
\hline CHEMBL184868 & 304672 & 8.0862 & 6.7451 & TST & \\
\hline CHEMBL184420 & 304672 & 6.0 & 6.5869 & TST & \\
\hline CHEMBL184030 & 304672 & 7.3585 & 7.7144 & TRN & \\
\hline CHEMBL363284 & 304672 & 5.2218 & 5.9656 & TRN & \\
\hline CHEMBL360991 & 304672 & 6.0942 & 6.2725 & TRN & \\
\hline CHEMBL184232 & 304672 & 8.4815 & 7.8857 & TRN & \\
\hline CHEMBL425884 & 304672 & 7.3261 & 7.6122 & TRN & \\
\hline CHEMBL362104 & 304672 & 8.3028 & 7.4929 & TRN & \\
\hline CHEMBL184664 & 304672 & 6.7399 & 7.2726 & TRN & \\
\hline CHEMBL181952 & 304672 & 8.3372 & 6.8708 & TST & \\
\hline CHEMBL183164 & 304672 & 7.6073 & 7.6031 & TRN & \\
\hline CHEMBL426429 & 304672 & 5.9626 & 5.7791 & TST & \\
\hline CHEMBL363993 & 304672 & 6.6676 & 7.2271 & TRN & \\
\hline CHEMBL185225 & 304672 & 6.7122 & 7.2599 & TRN & \\
\hline CHEMBL173877 & 304672 & 7.9208 & 7.2356 & TRN & \\
\hline CHEMBL185260 & 304672 & 7.7986 & 7.5416 & TRN & \\
\hline CHEMBL439661 & 304672 & 6.0 & 5.8087 & TRN & \\
\hline CHEMBL184595 & 304672 & 7.0414 & 7.4225 & TRN & \\
\hline CHEMBL184881 & 304672 & 7.5768 & 7.5851 & TST & \\
\hline CHEMBL185300 & 304672 & 7.5376 & 6.8248 & TST & \\
\hline CHEMBL183472 & 304672 & 7.4318 & 7.2223 & TST & \\
\hline CHEMBL185105 & 304672 & 6.0 & 5.6065 & TST & \\
\hline CHEMBL182182 & 304672 & 5.7212 & 5.2415 & TST & \\
\hline CHEMBL362698 & 304672 & 5.9045 & 6.3447 & TST & \\
\hline CHEMBL360502 & 304672 & 7.3969 & 7.7432 & TST & \\
\hline CHEMBL182311 & 304672 & 6.0757 & 5.4379 & TST & \\
\hline CHEMBL337683 & 158975 & 5.4685 & 5.4876 & TRN & \\
\hline CHEMBL130664 & 158975 & 4.9586 & 4.6707 & TRN & \\
\hline CHEMBL131909 & 158975 & 6.2218 & 6.5007 & TST & \\
\hline CHEMBL337383 & 158975 & 6.8539 & 6.812 & TRN & \\
\hline CHEMBL337524 & 158975 & 6.9586 & 6.6126 & TRN & \\
\hline CHEMBL132475 & 158975 & 2.5229 & 4.3101 & TRN & \\
\hline CHEMBL424452 & 158975 & 6.2218 & 6.0516 & TST & \\
\hline CHEMBL 334303 & 158975 & 6.1805 & 6.5373 & TST & \\
\hline CHEMBL435000 & 158975 & 5.699 & 4.8923 & TRN & \\
\hline CHEMBL131097 & 158975 & 4.2147 & 4.2687 & TRN & \\
\hline CHEMBL422084 & 158975 & 5.5229 & 4.3858 & TRN & \\
\hline CHEMBL424081 & 158975 & 5.0458 & 4.40300 & 00000000005 & TRN \\
\hline CHEMBL133187 & 158975 & 5.7447 & 4.7163 & TRN & \\
\hline CHEMBL133895 & 158975 & 4.6198 & 4.6375 & TRN & \\
\hline CHEMBL133016 & 158975 & 4.9586 & 6.2998 & TST & \\
\hline CHEMBL133638 & 158975 & 6.0458 & 6.3459 & TST & \\
\hline CHEMBL130671 & 158975 & 4.7212 & 4.5476 & TRN & \\
\hline
\end{tabular}




\begin{tabular}{|c|c|c|c|c|c|}
\hline \multicolumn{6}{|c|}{ Supplemental Table S2.txt } \\
\hline CHEMBL132823 & 158975 & 4.9208 & 4.9732 & TRN & \\
\hline CHEMBL 2370698 & 158975 & 5.9586 & 5.5257 & TRN & \\
\hline CHEMBL132567 & 158975 & 5.585 & 5.2563 & TST & \\
\hline CHEMBL130432 & 158975 & 5.4437 & 5.0145 & TRN & \\
\hline CHEMBL132772 & 158975 & 4.8239 & 5.2869 & TRN & \\
\hline CHEMBL424444 & 158975 & 4.284 & 4.463 & TRN & \\
\hline CHEMBL132476 & 158975 & 4.699 & 5.0613 & TRN & \\
\hline CHEMBL133854 & 158975 & 6.2218 & 6.0458 & TST & \\
\hline CHEMBL335061 & 158975 & 5.9586 & 5.7025 & TRN & \\
\hline CHEMBL334742 & 158975 & 6.6778 & 6.7979 & TRN & \\
\hline CHEMBL132310 & 158975 & 5.6198 & 5.3562 & TRN & \\
\hline CHEMBL133852 & 158975 & 5.5528 & 5.2156 & TRN & \\
\hline CHEMBL131964 & 158975 & 4.2441 & 5.0861 & TRN & \\
\hline CHEMBL133803 & 158975 & 5.9586 & 6.5991 & TST & \\
\hline CHEMBL132421 & 158975 & 6.0 & 5.9607 & TRN & \\
\hline CHEMBL130155 & 158975 & 2.5229 & 4.1778 & TRN & \\
\hline CHEMBL131760 & 158975 & 4.4815 & 6.55399 & 9999999999 & TST \\
\hline CHEMBL341195 & 158975 & 5.301 & 5.5617 & TRN & \\
\hline CHEMBL134222 & 158975 & 5.7959 & 5.6034 & TRN & \\
\hline CHEMBL130763 & 158975 & 5.2218 & 5.1227 & TRN & \\
\hline CHEMBL422440 & 158975 & 6.699 & 6.8 & TRN & \\
\hline CHEMBL133392 & 158975 & 5.0458 & 4.3653 & TRN & \\
\hline CHEMBL133346 & 158975 & 5.2218 & 5.4491 & TRN & \\
\hline CHEMBL131633 & 158975 & 5.3565 & 4.9655 & TRN & \\
\hline CHEMBL134131 & 158975 & 5.5528 & 6.3234 & TST & \\
\hline CHEMBL335100 & 158975 & 5.8539 & 5.46200 & 0000000001 & TRN \\
\hline CHEMBL 338958 & 158975 & 5.2218 & 4.949 & TST & \\
\hline CHEMBL135193 & 158975 & 5.4949 & 5.3047 & TRN & \\
\hline CHEMBL335309 & 158975 & 6.3372 & 6.6895 & TRN & \\
\hline CHEMBL134167 & 158975 & 6.9586 & 5.6172 & TRN & \\
\hline CHEMBL334807 & 158975 & 2.5229 & 5.5393 & TRN & \\
\hline CHEMBL133870 & 158975 & 5.9586 & 5.2414 & TST & \\
\hline CHEMBL334884 & 158975 & 7.0 & 6.2525 & TST & \\
\hline CHEMBL3655937 & 1535401 & 5.8047 & 5.8382 & TRN & \\
\hline CHEMBL3655955 & 1535401 & 5.8771 & 5.8787 & TRN & \\
\hline CHEMBL3655993 & 1535401 & 8.0969 & 8.1127 & TRN & \\
\hline CHEMBL 3655998 & 1535401 & 6.9066 & 6.9173 & TRN & \\
\hline CHEMBL3652241 & 1535401 & 6.3152 & 6.29799 & 9999999999 & TRN \\
\hline CHEMBL 3655987 & 1535401 & 5.4609 & 5.3729 & TST & \\
\hline CHEMBL3652236 & 1535401 & 6.2218 & 5.9882 & TST & \\
\hline CHEMBL3655916 & 1535401 & 6.7721 & 6.7368 & TRN & \\
\hline CHEMBL3655918 & 1535401 & 6.8928 & 6.9414 & TRN & \\
\hline CHEMBL3656024 & 1535401 & 5.914 & 5.7981 & TRN & \\
\hline CHEMBL 3656016 & 1535401 & 6.7235 & 6.6802 & TRN & \\
\hline CHEMBL3655996 & 1535401 & 6.9245 & 6.9359 & TRN & \\
\hline CHEMBL3655974 & 1535401 & 7.4318 & 7.474 & TRN & \\
\hline CHEMBL3655936 & 1535401 & 7.3665 & 7.3795 & TRN & \\
\hline CHEMBL3656008 & 1535401 & 6.1068 & 6.1335 & TRN & \\
\hline
\end{tabular}


Supplemental Table S2.txt

\begin{tabular}{|c|c|c|c|c|c|}
\hline CHEMBL 3656023 & 1535401 & 5.473 & 5.5067 & TRN & \\
\hline CHEMBL3655960 & 1535401 & 6.0325 & 6.0079 & TRN & \\
\hline CHEMBL3652231 & 1535401 & 6.2175 & 6.2311 & TRN & \\
\hline CHEMBL3656019 & 1535401 & 5.7503 & 5.8044 & TRN & \\
\hline CHEMBL 3655984 & 1535401 & 7.7212 & 7.6944 & TRN & \\
\hline CHEMBL 3656007 & 1535401 & 6.9469 & 6.9142 & TRN & \\
\hline CHEMBL3655988 & 1535401 & 5.8771 & 5.8895 & TST & \\
\hline CHEMBL3655929 & 1535401 & 7.2366 & 7.3353 & TST & \\
\hline CHEMBL3655946 & 1535401 & 6.5243 & 6.54 & TRN & \\
\hline CHEMBL3655927 & 1535401 & 6.5129 & 6.5956 & TRN & \\
\hline CHEMBL 3655908 & 1535401 & 6.0809 & 6.0482 & TRN & \\
\hline CHEMBL3655977 & 1535401 & 4.8705 & 4.9108 & TRN & \\
\hline CHEMBL 3652239 & 1535401 & 6.4962 & 6.4947 & TRN & \\
\hline CHEMBL3655910 & 1535401 & 6.1278 & 6.1641 & TRN & \\
\hline CHEMBL 3655942 & 1535401 & 6.6253 & 6.4947 & TST & \\
\hline CHEMBL3655969 & 1535401 & 5.3544 & 5.3495 & TRN & \\
\hline CHEMBL3656020 & 1535401 & 5.8623 & 5.6635 & TRN & \\
\hline CHEMBL 3655989 & 1535401 & 6.8928 & 6.8755 & TRN & \\
\hline CHEMBL 3655970 & 1535401 & 6.8041 & 6.7918 & TRN & \\
\hline CHEMBL 3655979 & 1535401 & 7.4815 & 7.4857 & TRN & \\
\hline CHEMBL3655956 & 1535401 & 5.3301 & 5.3319 & TRN & \\
\hline CHEMBL3656015 & 1535401 & 7.2441 & 7.2622 & TRN & \\
\hline CHEMBL 3655982 & 1535401 & 6.4425 & 6.4227 & TST & \\
\hline CHEMBL 3655966 & 1535401 & 6.2604 & 6.2439 & TST & \\
\hline CHEMBL3655972 & 1535401 & 5.6436 & 5.6985 & TRN & \\
\hline CHEMBL 3656014 & 1535401 & 6.4157 & 6.3748 & TRN & \\
\hline CHEMBL3655953 & 1535401 & 5.9755 & 5.9094 & TRN & \\
\hline CHEMBL 3655981 & 1535401 & 5.9311 & 5.4812 & TST & \\
\hline CHEMBL3655994 & 1535401 & 7.2441 & 7.2426 & TRN & \\
\hline CHEMBL3655961 & 1535401 & 5.3453 & 5.2207 & TRN & \\
\hline CHEMBL 3655924 & 1535401 & 6.4868 & 6.4314 & TRN & \\
\hline CHEMBL 3652230 & 1535401 & 6.5751 & 6.5287 & TRN & \\
\hline CHEMBL 3655932 & 1535401 & 6.5186 & 6.5198 & TRN & \\
\hline CHEMBL3655951 & 1535401 & 5.6242 & 5.6845 & TRN & \\
\hline CHEMBL3655928 & 1535401 & 6.2958 & 6.3362 & TRN & \\
\hline CHEMBL3655940 & 1535401 & 5.9646 & 6.025 & TST & \\
\hline CHEMBL3655911 & 1535401 & 6.7423 & 6.8334 & TRN & \\
\hline CHEMBL 3655962 & 1535401 & 6.8697 & 6.6637 & TST & \\
\hline CHEMBL 3655958 & 1535401 & 6.9208 & 6.7326 & TRN & \\
\hline CHEMBL3652240 & 1535401 & 4.7871 & 4.7692 & TRN & \\
\hline CHEMBL 3655921 & 1535401 & 6.0501 & 5.9853 & TRN & \\
\hline CHEMBL3656009 & 1535401 & 6.8928 & 6.8768 & TRN & \\
\hline CHEMBL3655990 & 1535401 & 7.0044 & 7.017 & TRN & \\
\hline CHEMBL 3652238 & 1535401 & $6.7520 e$ & 000000000 & & 6.7651 \\
\hline CHEMBL 3655941 & 1535401 & 6.059 & 6.0041 & TRN & \\
\hline CHEMBL3655933 & 1535401 & 5.6548 & 5.7153 & TRN & \\
\hline CHEMBL3655923 & 1535401 & 7.1549 & 7.1361 & TRN & \\
\hline CHEMBL3655939 & 1535401 & 6.0453 & 6.0665 & TRN & \\
\hline
\end{tabular}

Page 3052 
Supplemental Table S2.txt

\begin{tabular}{|c|c|c|c|c|c|}
\hline CHEMBL 3656002 & 1535401 & 6.1385 & 6.0832 & TRN & \\
\hline CHEMBL 3655963 & 1535401 & 5.539 & 5.6332 & TRN & \\
\hline CHEMBL3655992 & 1535401 & 7.585 & 7.6944 & TRN & \\
\hline CHEMBL3655912 & 1535401 & 6.284 & 5.5718 & TST & \\
\hline CHEMBL 3655967 & 1535401 & 7.3872 & 7.3493 & TRN & \\
\hline CHEMBL 3656001 & 1535401 & 6.5003 & 6.5796 & TRN & \\
\hline CHEMBL 3655980 & 1535401 & 5.9594 & 5.6808 & TST & \\
\hline CHEMBL3655926 & 1535401 & 6.9706 & 6.7076 & TST & \\
\hline CHEMBL3655934 & 1535401 & 6.4179 & 6.4116 & TRN & \\
\hline CHEMBL3655930 & 1535401 & 6.5229 & 6.4904 & TRN & \\
\hline CHEMBL3655913 & 1535401 & 6.8508 & 6.7988 & TRN & \\
\hline CHEMBL 3656003 & 1535401 & 7.0044 & 7.0071 & TRN & \\
\hline CHEMBL3655954 & 1535401 & 6.3625 & 6.42 & TRN & \\
\hline CHEMBL3655957 & 1535401 & 6.6737 & 6.6254 & TRN & \\
\hline CHEMBL3655976 & 1535401 & 6.4622 & 6.4726 & TRN & \\
\hline CHEMBL 3656010 & 1535401 & 7.2676 & 7.307 & TRN & \\
\hline CHEMBL3655964 & 1535401 & 6.6326 & 6.6193 & TRN & \\
\hline CHEMBL 3655925 & 1535401 & 6.8861 & 6.8226 & TRN & \\
\hline CHEMBL3655919 & 1535401 & 7.1249 & 7.1497 & TRN & \\
\hline CHEMBL3652235 & 1535401 & 5.7324 & 5.774 & TRN & \\
\hline CHEMBL 3656022 & 1535401 & 5.9014 & 5.9932 & TRN & \\
\hline CHEMBL3639548 & 1535401 & 5.8297 & 5.8289 & TRN & \\
\hline CHEMBL 3655978 & 1535401 & 4.9499 & 5.1399 & TRN & \\
\hline CHEMBL 3655922 & 1535401 & 6.3054 & 6.3046 & TRN & \\
\hline CHEMBL3655959 & 1535401 & 7.6576 & 7.6522 & TRN & \\
\hline CHEMBL 3655947 & 1535401 & 5.8817 & 5.8364 & TRN & \\
\hline CHEMBL 3655920 & 1535401 & 6.8268 & 6.86100 & 0000000001 & TRN \\
\hline CHEMBL 3655983 & 1535401 & 6.7595 & 6.752006 & 3000000001 & TRN \\
\hline CHEMBL 3656004 & 1535401 & 6.4634 & 6.5096 & TRN & \\
\hline CHEMBL3652229 & 1535401 & 6.3757 & 6.4148 & TRN & \\
\hline CHEMBL 3656021 & 1535401 & 6.1878 & 6.1028 & TST & \\
\hline CHEMBL 3652237 & 1535401 & 6.7033 & 6.7168 & TRN & \\
\hline CHEMBL 3652232 & 1535401 & 6.6596 & 6.7223 & TST & \\
\hline CHEMBL3655909 & 1535401 & 6.5686 & 6.496 & TRN & \\
\hline CHEMBL 3655971 & 1535401 & 7.301 & 7.1382 & TST & \\
\hline CHEMBL3656018 & 1535401 & 5.8781 & 5.7972 & TST & \\
\hline CHEMBL3655995 & 1535401 & 7.6576 & 7.7537 & TST & \\
\hline CHEMBL 3655997 & 1535401 & 7.3098 & 7.3448 & TST & \\
\hline CHEMBL 3655935 & 1535401 & 6.5952 & 6.6513 & TRN & \\
\hline CHEMBL 3656011 & 1535401 & 7.1938 & 7.1631 & TST & \\
\hline CHEMBL3655965 & 1535401 & 5.6492 & 5.7249 & TST & \\
\hline CHEMBL 3656017 & 1535401 & 5.6662 & 5.6193 & TST & \\
\hline CHEMBL3655999 & 1535401 & 6.2832 & 6.3554 & TST & \\
\hline CHEMBL 3652234 & 1535401 & 6.4535 & 6.4309 & TRN & \\
\hline CHEMBL3655986 & 1535401 & 6.0742 & 6.3495 & TST & \\
\hline CHEMBL3656012 & 1535401 & 7.5376 & 7.8405 & TST & \\
\hline CHEMBL3655907 & 1535401 & 6.7144 & 6.7006 & TRN & \\
\hline CHEMBL3655952 & 1535401 & 5.7254 & 5.7724 & TRN & \\
\hline
\end{tabular}


Supplemental Table S2.txt

\begin{tabular}{|c|c|c|c|c|c|}
\hline CHEMBL 3652242 & 1535401 & 6.5045 & 6.4572 & TRN & \\
\hline CHEMBL 3656006 & 1535401 & 7.1549 & 7.1315 & TST & \\
\hline CHEMBL 3652243 & 1535401 & 6.5901 & 6.6338 & TRN & \\
\hline CHEMBL 3656013 & 1535401 & 7.2366 & 7.4202 & TST & \\
\hline CHEMBL 3652227 & 1535401 & 6.45100 & 000000000 & 6.4981 & TRN \\
\hline CHEMBL3655985 & 1535401 & 6.4498 & 6.4376 & TRN & \\
\hline CHEMBL 3655917 & 1535401 & 7.4685 & 7.4598 & TRN & \\
\hline CHEMBL 3655950 & 1535401 & 6.6596 & 6.6552 & TST & \\
\hline CHEMBL 3656000 & 1535401 & 7.2076 & \multicolumn{2}{|c|}{7.2589999999999995} & TST \\
\hline CHEMBL 3655945 & 1535401 & 5.75799 & 999999999 & 5.7524 & TRN \\
\hline CHEMBL 3655968 & 1535401 & 6.4271 & \multicolumn{2}{|c|}{6.6339999999999995} & TST \\
\hline CHEMBL 3652233 & 1535401 & 6.3665 & 6.2336 & TST & \\
\hline CHEMBL 3655991 & 1535401 & 5.4041 & 5.5902 & TST & \\
\hline CHEMBL 3656005 & 1535401 & 6.9706 & 7.0683 & TST & \\
\hline CHEMBL 3655975 & 1535401 & 5.3714 & 6.5122 & TST & \\
\hline CHEMBL3655973 & 1535401 & 5.2434 & 5.2311 & TRN & \\
\hline CHEMBL3655949 & 1535401 & 4.9102 & 4.923 & TRN & \\
\hline CHEMBL 3655914 & 1535401 & 6.6556 & 6.6205 & TRN & \\
\hline CHEMBL 3655948 & 1535401 & 5.8996 & 5.9327 & TRN & \\
\hline CHEMBL 3655931 & 1535401 & 6.3969 & 6.2794 & TRN & \\
\hline CHEMBL 3655938 & 1535401 & 6.2 & 6.2296 & TRN & \\
\hline CHEMBL 3652228 & 1535401 & 6.5361 & 6.57 & TRN & \\
\hline CHEMBL 3652226 & 1535401 & 6.5243 & 6.4633 & TRN & \\
\hline CHEMBL 3126868 & 1294971 & 3.699 & 3.7123 & TRN & \\
\hline CHEMBL 3126885 & 1294971 & 3.699 & 3.7712 & TRN & \\
\hline CHEMBL 3127060 & 1294971 & 3.699 & 3.7124 & TRN & \\
\hline CHEMBL3126912 & 1294971 & 3.699 & 3.7299 & TRN & \\
\hline CHEMBL 3126900 & 1294971 & 3.699 & 3.6358 & TRN & \\
\hline CHEMBL3126879 & 1294971 & 3.699 & 3.9882 & TRN & \\
\hline CHEMBL 3126888 & 1294971 & 3.699 & 3.7667 & TRN & \\
\hline CHEMBL 3126874 & 1294971 & 4.8239 & 4.8549 & TRN & \\
\hline CHEMBL 3127047 & 1294971 & 5.4572 & 5.0789 & TST & \\
\hline CHEMBL 3127045 & 1294971 & 3.699 & 3.6875 & TRN & \\
\hline CHEMBL 3127055 & 1294971 & 6.9586 & 5.9264 & TST & \\
\hline CHEMBL 3127052 & 1294971 & 3.699 & 3.6842 & TRN & \\
\hline CHEMBL 3126887 & 1294971 & 3.699 & 4.0087 & TRN & \\
\hline CHEMBL 3127051 & 1294971 & 3.699 & 3.8102 & TRN & \\
\hline CHEMBL1814767 & 1294971 & 6.6778 & 6.6609 & TRN & \\
\hline CHEMBL3126899 & 1294971 & 5.5031 & 5.3142 & TRN & \\
\hline CHEMBL 3126869 & 1294971 & 3.699 & 3.626000 & 30000000003 & $T$ \\
\hline CHEMBL 3126884 & 1294971 & 3.699 & 3.5716 & TRN & \\
\hline CHEMBL 3124960 & 1294971 & 3.699 & 3.8556 & TRN & \\
\hline CHEMBL3126907 & 1294971 & 7.0 & 5.7598 & TST & \\
\hline CHEMBL3126876 & 1294971 & 3.699 & 3.8659 & TRN & \\
\hline CHEMBL 3126875 & 1294971 & 3.699 & 3.7514 & TRN & \\
\hline CHEMBL 3127048 & 1294971 & 3.699 & 4.0644 & TST & \\
\hline CHEMBL 3127062 & 1294971 & 3.699 & 3.6315 & TRN & \\
\hline CHEMBL 3126872 & 1294971 & 3.699 & 3.9101 & TST & \\
\hline
\end{tabular}


Supplemental Table S2.txt

\begin{tabular}{|c|c|c|c|c|c|}
\hline CHEMBL3126896 & 1294971 & 4.8996 & 4.7375 & TST & \\
\hline CHEMBL3127068 & 1294971 & 5.1169 & 4.9152 & TRN & \\
\hline CHEMBL3126883 & 1294971 & 3.699 & 3.6659 & TRN & \\
\hline CHEMBL3126906 & 1294971 & 5.585 & \multicolumn{2}{|c|}{ 5.367999999999999 } & TST \\
\hline CHEMBL3127059 & 1294971 & 3.699 & 3.4064 & TRN & \\
\hline CHEMBL319177 & 1294971 & 3.699 & 3.4498 & TST & \\
\hline CHEMBL403715 & 1294971 & 3.699 & 3.8983 & TST & \\
\hline CHEMBL3127066 & 1294971 & 3.699 & 4.1631 & TRN & \\
\hline CHEMBL3127057 & 1294971 & 3.699 & 3.8461 & TST & \\
\hline CHEMBL3126871 & 1294971 & 4.7773 & 5.1179 & TRN & \\
\hline CHEMBL1269812 & 1294971 & 7.301 & \multicolumn{2}{|c|}{6.712000000000001} & TST \\
\hline CHEMBL3126898 & 1294971 & 5.3107 & 5.0 & TST & \\
\hline CHEMBL3126886 & 1294971 & 3.699 & 3.5577 & TRN & \\
\hline CHEMBL 3127054 & 1294971 & 3.699 & 3.6612 & TRN & \\
\hline CHEMBL3126903 & 1294971 & 3.699 & 3.7792 & TRN & \\
\hline CHEMBL1814768 & 1294971 & 6.7696 & 6.5495 & TRN & \\
\hline CHEMBL3127049 & 1294971 & 6.6383 & 6.6476 & TRN & \\
\hline CHEMBL3126891 & 1294971 & 3.699 & 3.7279 & TRN & \\
\hline CHEMBL3126865 & 1294971 & 5.4584 & 4.7337 & TST & \\
\hline CHEMBL3126867 & 1294971 & 3.699 & \multicolumn{2}{|c|}{3.2769999999999997} & TRN \\
\hline CHEMBL3126904 & 1294971 & 3.699 & 3.5495 & TRN & \\
\hline CHEMBL 3127044 & 1294971 & 3.699 & 4.0576 & TST & \\
\hline CHEMBL3126910 & 1294971 & 3.699 & 3.6956 & TRN & \\
\hline CHEMBL3126915 & 1294971 & 4.8996 & 3.7696 & TST & \\
\hline CHEMBL3126895 & 1294971 & 5.2 & 5.0246 & TRN & \\
\hline CHEMBL3126873 & 1294971 & 3.699 & 3.3234 & TRN & \\
\hline CHEMBL3126901 & 1294971 & 3.699 & 3.7926 & TRN & \\
\hline CHEMBL 3127058 & 1294971 & 3.699 & 4.0041 & TRN & \\
\hline CHEMBL3126908 & 1294971 & 7.1549 & 7.1761 & TRN & \\
\hline CHEMBL3127050 & 1294971 & 3.699 & 3.9702 & TRN & \\
\hline CHEMBL3126892 & 1294971 & 3.699 & 3.6232 & TRN & \\
\hline CHEMBL3126893 & 1294971 & 3.699 & 3.8489 & TRN & \\
\hline CHEMBL3126914 & 1294971 & 6.7959 & 6.8893 & TST & \\
\hline CHEMBL 3127064 & 1294971 & 4.7328 & 5.1509 & TST & \\
\hline CHEMBL3127061 & 1294971 & 3.699 & 4.0236 & TRN & \\
\hline CHEMBL3127063 & 1294971 & 3.699 & 3.5724 & TRN & \\
\hline CHEMBL3126902 & 1294971 & 3.699 & 3.6315 & TRN & \\
\hline CHEMBL3127056 & 1294971 & 5.4425 & 4.971 & TST & \\
\hline CHEMBL3126909 & 1294971 & 3.699 & 3.6571 & TRN & \\
\hline CHEMBL3126911 & 1294971 & 5.0675 & 4.7153 & TRN & \\
\hline CHEMBL3126870 & 1294971 & 3.699 & 3.6393 & TRN & \\
\hline CHEMBL3126877 & 1294971 & 3.699 & 3.681 & TRN & \\
\hline CHEMBL3126878 & 1294971 & 3.699 & 3.4513 & TRN & \\
\hline CHEMBL3127046 & 1294971 & 4.9666 & 4.9244 & TRN & \\
\hline CHEMBL3127065 & 1294971 & 6.7959 & 6.6994 & TRN & \\
\hline CHEMBL3126913 & 1294971 & 3.699 & 3.8435 & TRN & \\
\hline CHEMBL3126905 & 1294971 & 6.6198 & 6.6991 & TST & \\
\hline CHEMBL3126889 & 1294971 & 3.699 & 4.0085 & TRN & \\
\hline
\end{tabular}


Supplemental Table S2.txt

\begin{tabular}{|c|c|c|c|c|}
\hline CHEMBL 3126894 & 1294971 & 3.699 & 3.7811 & TRN \\
\hline CHEMBL 3127053 & 1294971 & 3.699 & 3.5696 & TRN \\
\hline CHEMBL3126882 & 1294971 & 3.699 & 3.8271 & TRN \\
\hline CHEMBL 3127067 & 1294971 & 4.9172 & 4.876 & TRN \\
\hline CHEMBL 3126890 & 1294971 & 3.699 & 3.7373 & TRN \\
\hline CHEMBL 3126881 & 1294971 & 3.699 & 3.4394 & TRN \\
\hline CHEMBL 3126866 & 1294971 & 3.699 & 3.7657 & TRN \\
\hline CHEMBL 3126880 & 1294971 & 3.699 & 3.7503 & TST \\
\hline CHEMBL 3126897 & 1294971 & 3.699 & 3.8546 & TST \\
\hline CHEMBL2036596 & 822962 & 8.1805 & 7.5489 & TRN \\
\hline CHEMBL 2036580 & 822962 & 6.9208 & \multicolumn{2}{|c|}{7.656000000000001} \\
\hline CHEMBL 2036744 & 822962 & 5.8861 & 6.5544 & TST \\
\hline CHEMBL 2036577 & 822962 & 6.2676 & 6.4339 & TRN \\
\hline CHEMBL 2036571 & 822962 & 6.8861 & \multicolumn{2}{|c|}{6.178999999999999} \\
\hline CHEMBL 2036743 & 822962 & 7.0969 & 7.5367 & TRN \\
\hline CHEMBL 2036574 & 822962 & 7.6383 & 6.2798 & TRN \\
\hline CHEMBL2036590 & 822962 & 6.4685 & 6.4634 & TRN \\
\hline CHEMBL 2036592 & 822962 & 7.0362 & 6.5582 & TRN \\
\hline CHEMBL 2036736 & 822962 & 6.4318 & 5.8237 & TRN \\
\hline CHEMBL 2036581 & 822962 & 5.0969 & 6.7491 & TST \\
\hline CHEMBL 2036573 & 822962 & 6.7212 & 6.152 & TRN \\
\hline CHEMBL2036569 & 822962 & 6.4559 & 6.0816 & TRN \\
\hline CHEMBL 2036732 & 822962 & 5.6778 & 6.6659 & TRN \\
\hline CHEMBL 2036589 & 822962 & 6.0757 & 6.3304 & TRN \\
\hline CHEMBL2036729 & 822962 & 7.4559 & 6.8378 & TST \\
\hline CHEMBL2036593 & 822962 & 6.7212 & \multicolumn{2}{|c|}{6.736000000000001} \\
\hline CHEMBL 2036579 & 822962 & 6.5086 & 7.0706 & TST \\
\hline CHEMBL 2036730 & 822962 & 9.2218 & 7.4991 & TST \\
\hline CHEMBL 2036739 & 822962 & 6.7447 & 6.5029 & TST \\
\hline CHEMBL 2036737 & 822962 & 6.284 & 6.4115 & TRN \\
\hline CHEMBL2036597 & 822962 & 7.8861 & 7.4855 & TRN \\
\hline CHEMBL2036746 & 822962 & 6.5229 & 6.7774 & TRN \\
\hline CHEMBL 2036575 & 822962 & 5.4318 & 6.2106 & TRN \\
\hline CHEMBL 2036568 & 822962 & 6.3372 & 5.9784 & TRN \\
\hline CHEMBL 2036583 & 822962 & 8.1739 & 7.3786 & TST \\
\hline CHEMBL2036747 & 822962 & 5.284 & 5.1849 & TRN \\
\hline CHEMBL2036733 & 822962 & 6.7696 & 6.269 & TRN \\
\hline CHEMBL 2036745 & 822962 & 8.3565 & 7.276 & TST \\
\hline CHEMBL 2036570 & 822962 & 3.5229 & 5.0731 & TRN \\
\hline CHEMBL 2036578 & 822962 & 6.2076 & 7.1249 & TRN \\
\hline CHEMBL2036594 & 822962 & 6.1367 & 7.2161 & TRN \\
\hline CHEMBL2036576 & 822962 & 6.3372 & 6.3515 & TRN \\
\hline CHEMBL2036582 & 822962 & 7.2218 & 7.0933 & TST \\
\hline CHEMBL 2036742 & 822962 & 7.1549 & 7.7579 & TRN \\
\hline CHEMBL 2036734 & 822962 & 8.2441 & 7.294 & TRN \\
\hline CHEMBL2036584 & 822962 & 6.3872 & 6.5998 & TST \\
\hline CHEMBL2036738 & 822962 & 6.4949 & 6.5006 & TST \\
\hline CHEMBL 2036741 & 822962 & 6.6778 & 5.7678 & TRN \\
\hline
\end{tabular}


Supplemental Table S2.txt

\begin{tabular}{|c|c|c|c|c|c|}
\hline CHEMBL2036735 & 822962 & 3.5229 & 3.985 & TRN & \\
\hline CHEMBL 2036585 & 822962 & 7.2218 & 6.4608 & TST & \\
\hline CHEMBL2036595 & 822962 & 7.4949 & 7.2064 & TRN & \\
\hline CHEMBL 2036586 & 822962 & 7.7959 & 7.2241 & TRN & \\
\hline CHEMBL 2036591 & 822962 & 5.8861 & 5.6538 & TRN & \\
\hline CHEMBL2036567 & 822962 & 6.284 & 6.1671 & TRN & \\
\hline CHEMBL 2036740 & 822962 & 5.4815 & 7.1505 & TST & \\
\hline CHEMBL 2036572 & 822962 & 4.9586 & 5.306 & TRN & \\
\hline CHEMBL 2036731 & 822962 & 6.2676 & 6.5997 & TRN & \\
\hline CHEMBL 2036588 & 822962 & 6.8239 & 6.3488 & TRN & \\
\hline CHEMBL 2036587 & 822962 & 6.2076 & 6.7776 & TRN & \\
\hline CHEMBL1203044 & 155502 & 10.3188 & 9.7149 & TRN & \\
\hline CHEMBL1203042 & 155502 & 11.0458 & 10.9707 & TRN & \\
\hline CHEMBL1203031 & 155502 & 10.4089 & 10.5961 & TRN & \\
\hline CHEMBL1203072 & 155502 & 8.0061 & 9.4814 & TST & \\
\hline CHEMBL1203069 & 155502 & 9.9586 & 9.9855 & TRN & \\
\hline CHEMBL1203090 & 155502 & 7.8097 & 7.5897 & TRN & \\
\hline CHEMBL1203064 & 155502 & 8.0888 & 7.9872 & TRN & \\
\hline CHEMBL1203027 & 155502 & 11.0458 & 10.7483 & TRN & \\
\hline CHEMBL112418 & 155502 & 9.3872 & 9.5217 & TST & \\
\hline CHEMBL1203077 & 155502 & 9.3372 & 9.5304 & TRN & \\
\hline CHEMBL1203045 & 155502 & 8.2733 & 8.1569 & TRN & \\
\hline CHEMBL 322340 & 155502 & 7.8844 & 8.1491 & TRN & \\
\hline CHEMBL1203067 & 155502 & 6.1805 & 7.8283 & TST & \\
\hline CHEMBL1203086 & 155502 & 10.4089 & 10.4873 & TRN & \\
\hline CHEMBL 1203050 & 155502 & 10.6778 & 10.5395 & TRN & \\
\hline CHEMBL1203020 & 155502 & 10.0269 & 10.2836 & TST & \\
\hline CHEMBL1203056 & 155502 & 9.4949 & 9.2793 & TRN & \\
\hline CHEMBL1203055 & 155502 & \multicolumn{3}{|c|}{10.699000000000002} & 10.9681 TRN \\
\hline CHEMBL1203070 & 155502 & 7.8303 & 7.8645 & TST & \\
\hline CHEMBL1203053 & 155502 & 10.7959 & 10.8694 & TRN & \\
\hline CHEMBL1203041 & 155502 & 10.0862 & 10.1565 & TRN & \\
\hline CHEMBL1203083 & 155502 & 9.5086 & 10.0214 & TRN & \\
\hline CHEMBL1203051 & 155502 & 10.0809 & 9.9974 & TRN & \\
\hline CHEMBL 2447997 & 155502 & 9.2757 & 9.4331 & TRN & \\
\hline CHEMBL1203084 & 155502 & \multicolumn{3}{|c|}{10.699000000000002} & 10.2796 TRN \\
\hline CHEMBL1203085 & 155502 & 10.3768 & 10.4165 & TRN & \\
\hline CHEMBL1203062 & 155502 & 9.5528 & 9.6698 & TRN & \\
\hline CHEMBL1203073 & 155502 & 8.618 & 9.2793 & TST & \\
\hline CHEMBL1203089 & 155502 & 9.4949 & 9.5647 & TRN & \\
\hline CHEMBL1203075 & 155502 & 8.3116 & 8.9724 & TST & \\
\hline CHEMBL109445 & 155502 & 10.0 & 9.7473 & TRN & \\
\hline CHEMBL1203019 & 155502 & 10.1427 & 10.4146 & TST & \\
\hline CHEMBL1203017 & 155502 & 10.2676 & 10.4146 & TST & \\
\hline CHEMBL1203066 & 155502 & 9.1612 & 9.1651 & TRN & \\
\hline CHEMBL1203029 & 155502 & 10.4202 & 10.2995 & TRN & \\
\hline CHEMBL1203052 & 155502 & 10.1427 & 9.6221 & TST & \\
\hline CHEMBL1203063 & 155502 & 10.3768 & 10.1655 & TRN & \\
\hline
\end{tabular}

Page 3057 
Supplemental Table S2.txt

\begin{tabular}{|c|c|c|c|c|c|}
\hline CHEMBL109240 & 155502 & 9.1871 & 9.4908 & TST & \\
\hline CHEMBL1203040 & 155502 & 10.2924 & 10.5414 & TRN & \\
\hline CHEMBL1203082 & 155502 & 10.1487 & 10.3865 & TRN & \\
\hline CHEMBL1203054 & 155502 & 9.7959 & 9.78 & TRN & \\
\hline CHEMBL1203046 & 155502 & 7.9374 & 8.0493 & TRN & \\
\hline CHEMBL1203068 & 155502 & 9.7959 & 9.7221 & TRN & \\
\hline CHEMBL113499 & 155502 & 9.3768 & 9.6454 & TRN & \\
\hline CHEMBL1203091 & 155502 & 9.5528 & 9.5229 & TRN & \\
\hline CHEMBL1203078 & 155502 & 11.0269 & 10.8748 & TRN & \\
\hline CHEMBL1203074 & 155502 & 9.7447 & 10.2826 & TST & \\
\hline CHEMBL1203034 & 155502 & 10.4949 & 10.4572 & TRN & \\
\hline CHEMBL1203039 & 155502 & 10.9208 & 10.7411 & TRN & \\
\hline CHEMBL1203028 & 155502 & 9.8861 & 9.785 & TRN & \\
\hline CHEMBL1203065 & 155502 & 8.6904 & 9.1598 & TRN & \\
\hline CHEMBL1203035 & 155502 & 8.98299 & 99999999 & 99 & 9.0115 \\
\hline CHEMBL1203061 & 155502 & 9.7959 & 9.4829 & TST & \\
\hline CHEMBL1203030 & 155502 & 10.1739 & 10.3158 & TRN & \\
\hline CHEMBL1203021 & 155502 & 10.4685 & 10.2137 & TRN & \\
\hline CHEMBL1203032 & 155502 & 10.6021 & 10.3911 & TRN & \\
\hline CHEMBL1203092 & 155502 & 9.8861 & 9.6434 & TRN & \\
\hline CHEMBL1203081 & 155502 & 9.6383 & 9.9041 & TRN & \\
\hline CHEMBL1203087 & 155502 & 10.5686 & 10.6317 & TRN & \\
\hline CHEMBL1203038 & 155502 & 10.9208 & 10.8343 & TRN & \\
\hline CHEMBL1203057 & 155502 & 9.4559 & 9.8896 & TST & \\
\hline CHEMBL1203071 & 155502 & 9.8861 & 9.5863 & TST & \\
\hline CHEMBL1203036 & 155502 & 10.5086 & 10.6816 & TRN & \\
\hline CHEMBL1203018 & 155502 & 10.5229 & 10.585 & TRN & \\
\hline CHEMBL1203058 & 155502 & 9.7959 & 9.9529 & TST & \\
\hline CHEMBL1203060 & 155502 & 9.5229 & 9.408 & TST & \\
\hline CHEMBL 2447996 & 155502 & 9.5376 & 9.8166 & TST & \\
\hline CHEMBL1203024 & 155502 & 10.5229 & 10.5285 & TRN & \\
\hline CHEMBL1203033 & 155502 & 10.7696 & 10.8694 & TRN & \\
\hline CHEMBL 240954 & 954741 & 2.9595 & 3.4849 & TST & \\
\hline CHEMBL 3186408 & 954741 & 4.4134 & 3.6726 & TST & \\
\hline CHEMBL 2144069 & 954741 & 4.7505 & 4.9067 & TRN & \\
\hline CHEMBL191334 & 954741 & 3.1335 & 3.4713 & TRN & \\
\hline CHEMBL 210618 & 954741 & 3.4668 & 3.281 & TRN & \\
\hline CHEMBL 213100 & 954741 & 5.3563 & 5.6472 & TRN & \\
\hline CHEMBL585951 & 954741 & 5.651 & 6.1264 & TRN & \\
\hline CHEMBL 255342 & 954741 & 3.4719 & 3.2039 & TRN & \\
\hline CHEMBL 217354 & 954741 & 5.556 & 5.5313 & TRN & \\
\hline CHEMBL1673039 & 954741 & 4.8773 & 4.909 & TRN & \\
\hline CHEMBL1404918 & 954741 & 2.7572 & 2.5152 & TRN & \\
\hline CHEMBL512504 & 954741 & 6.7143 & 6.5285 & TRN & \\
\hline CHEMBL221137 & 954741 & 4.8159 & 4.2338 & TST & \\
\hline CHEMBL 379300 & 954741 & 5.5534 & 5.6902 & TRN & \\
\hline CHEMBL449158 & 954741 & 7.2053 & 6.4471 & TST & \\
\hline CHEMBL192566 & 954741 & 6.9284 & 6.6381 & TST & \\
\hline
\end{tabular}


Supplemental Table S2.txt

\begin{tabular}{|c|c|c|c|c|c|}
\hline CHEMBL1788116 & 954741 & 4.819 & 5.0717 & TRN & \\
\hline CHEMBL1970879 & 954741 & 3.6742 & 4.1915 & TRN & \\
\hline CHEMBL2137530 & 954741 & 5.1222 & 4.731 & TRN & \\
\hline CHEMBL1242367 & 954741 & 3.4676 & 3.7269 & TRN & \\
\hline CHEMBL1230020 & 954741 & 3.4473 & 3.1484 & TRN & \\
\hline CHEMBL509032 & 954741 & 5.7027 & 5.8456 & TRN & \\
\hline CHEMBL220241 & 954741 & 6.0721 & 6.1856 & TRN & \\
\hline CHEMBL393929 & 954741 & 3.2977 & 3.4803 & TRN & \\
\hline CHEMBL92309 & 954741 & 3.5777 & 2.3952 & TST & \\
\hline CHEMBL3392440 & 954741 & 3.5894 & 3.8845 & TRN & \\
\hline CHEMBL1909414 & 954741 & 3.2135 & 3.0752 & TRN & \\
\hline CHEMBL514499 & 954741 & 5.1755 & 5.1116 & TRN & \\
\hline CHEMBL65 & 954741 & 6.914 & 6.5765 & TRN & \\
\hline CHEMBL373751 & 954741 & 4.0925 & 3.95399 & 99999999997 & TRN \\
\hline CHEMBL515416 & 954741 & 4.538 & 4.0027 & TRN & \\
\hline CHEMBL 202721 & 954741 & 4.1893 & 4.4914 & TRN & \\
\hline CHEMBL1256459 & 954741 & 5.1489 & 4.9467 & TRN & \\
\hline CHEMBL209148 & 954741 & 3.4422 & 3.6241 & TRN & \\
\hline CHEMBL180127 & 954741 & 3.6062 & 3.8728 & TRN & \\
\hline CHEMBL472940 & 954741 & 2.5314 & 2.5788 & TRN & \\
\hline CHEMBL258844 & 954741 & 4.1894 & 4.2556 & TRN & \\
\hline CHEMBL2134202 & 954741 & 3.4488 & 3.6948 & TRN & \\
\hline CHEMBL1186585 & 954741 & \multicolumn{3}{|c|}{5.372999999999999} & TRN \\
\hline CHEMBL1357247 & 954741 & 2.9404 & 3.0386 & TRN & \\
\hline CHEMBL399530 & 954741 & 3.9919 & 4.1935 & TRN & \\
\hline CHEMBL3199475 & 954741 & 4.9728 & 4.6069 & TRN & \\
\hline CHEMBL222102 & 954741 & 3.2413 & 3.4333 & TRN & \\
\hline CHEMBL 2005886 & 954741 & 4.711 & 4.7561 & TRN & \\
\hline CHEMBL259181 & 954741 & 3.5076 & 3.6934 & TRN & \\
\hline CHEMBL573107 & 954741 & 3.7909 & 4.2012 & TRN & \\
\hline CHEMBL2363137 & 954741 & 5.0517 & 4.5295 & TRN & \\
\hline CHEMBL1190711 & 954741 & 5.3468 & 5.3051 & TRN & \\
\hline CHEMBL483847 & 954741 & 4.1091 & 4.2506 & TRN & \\
\hline CHEMBL1590308 & 954741 & 3.326 & 3.6402 & TST & \\
\hline CHEMBL412142 & 954741 & 4.498 & 4.7122 & TRN & \\
\hline CHEMBL9470 & 954741 & 6.3353 & 5.0264 & TST & \\
\hline CHEMBL3349342 & 954741 & 4.4505 & 4.3381 & TRN & \\
\hline CHEMBL102714 & 954741 & 3.1867 & 3.1592 & TRN & \\
\hline CHEMBL558642 & 954741 & 4.9602 & 4.5792 & TRN & \\
\hline CHEMBL483849 & 954741 & 2.3673 & 1.8414 & TST & \\
\hline CHEMBL577784 & 954741 & 5.5206 & 5.1829 & TRN & \\
\hline CHEMBL379975 & 954741 & 4.8335 & 4.4021 & TST & \\
\hline CHEMBL1643959 & 954741 & 4.1564 & 3.7662 & TST & \\
\hline CHEMBL392695 & 954741 & 3.3757 & 3.824 & TST & \\
\hline CHEMBL188678 & 954741 & 4.3556 & 4.1609 & TST & \\
\hline CHEMBL189584 & 954741 & 5.001 & 4.2712 & TST & \\
\hline CHEMBL135561 & 954741 & 4.617 & 4.433 & TST & \\
\hline CHEMBL1516890 & 954741 & 3.6906 & 4.0087 & TST & \\
\hline
\end{tabular}


Supplemental Table S2.txt

\begin{tabular}{|c|c|c|c|c|}
\hline & & 376 & 4 & TST \\
\hline HFMBI 1612106 & 301720 & & & \\
\hline IEMBL533082 & 720 & & & \\
\hline EMBL1403085 & 301720 & 4 & 6029 & \\
\hline AEMBL1386568 & 301720 & 4.5242 & 1441 & \\
\hline AEMBL1612809 & 720 & & 041 & \\
\hline 9317 & 720 & & 348 & \\
\hline IEMBL1442864 & 720 & & 3997 & \\
\hline AEMBL1473916 & 301720 & 284 & .0228 & \\
\hline HEMBL1591647 & 301720 & 3.284 & 3.5 & \\
\hline 8072 & 720 & 84 & 558 & \\
\hline 1938 & & & & \\
\hline HEMBL & 720 & 84 & 186 & \\
\hline IEMBL 243861 & 720 & 4.5758 & .7208 & \\
\hline AEMBL1513630 & 720 & 84 & 1252 & \\
\hline 429 & 20 & 37 & 817 & \\
\hline 893 & 20 & & 702 & \\
\hline IEMBL: & 20 & 722 & 5788 & \\
\hline 2335 & 20 & & 087 & \\
\hline IEMBL] & 20 & 4. & 4.3859 & \\
\hline 850 & 20 & & 051 & \\
\hline 860 & 20 & & 48 & \\
\hline 7704 & 20 & 3 & 3.4983 & \\
\hline 136 & & & & \\
\hline EMBL: & 20 & 3 & 755 & \\
\hline 790 & 20 & & 769 & \\
\hline 772 & 0 & & & $\cdots$ \\
\hline 524 & & & 252 & \\
\hline 016 & & & & \\
\hline 1626 & 20 & 3. & 671 & \\
\hline 215 & 20 & & 885 & \\
\hline 901 & & & & \\
\hline & & & 832 & \\
\hline 5434 & & & & \\
\hline 5497 & 20 & & 311 & \\
\hline 617 & 20 & & 023 & \\
\hline & & & & m \\
\hline & & & & RN \\
\hline 1026 & 20 & & 854 & \\
\hline 60 & 20 & & & \\
\hline 4145 & 20 & & 202 & \\
\hline & & & 4.2853 & RI \\
\hline IEMBL] & & & 2316 & RN \\
\hline 3857 & 20 & & 1472 & \\
\hline 239 & & & & \\
\hline HEMBL1448680 & & & 3.5264 & \\
\hline HEMBL1487689 & 720 & 4.3156 & 4.0977 & \\
\hline CHEMBL1343775 & 1301720 & 3.284 & 3.7134 & \\
\hline
\end{tabular}

Page 3060 


$$
\text { Supplemental Table S2.txt }
$$

\begin{tabular}{|c|c|c|c|c|c|}
\hline CHEMBL1339989 & 1301720 & 3.284 & 3.7904 & TST & \\
\hline CHEMBL525098 & 1301720 & 4.4139 & 3.3523 & TRN & \\
\hline CHEMBL1493415 & 1301720 & 3.284 & 3.5943 & TRN & \\
\hline CHEMBL1563784 & 1301720 & 3.284 & 3.088 & TRN & \\
\hline CHEMBL1576924 & 1301720 & 3.284 & 3.0137 & TRN & \\
\hline CHEMBL1890802 & 1301720 & 3.284 & 3.4301 & TRN & \\
\hline CHEMBL1574003 & 1301720 & 3.284 & 3.7425 & TRN & \\
\hline CHEMBL1698675 & 1301720 & 3.284 & 3.4737 & TRN & \\
\hline CHEMBL1995197 & 1301720 & 4.3963 & 4.2219 & TRN & \\
\hline CHEMBL1457400 & 1301720 & 3.284 & 3.5059 & TRN & \\
\hline CHEMBL1451888 & 1301720 & 4.3746 & 3.8849 & TRN & \\
\hline CHEMBL1436017 & 1301720 & 4.4728 & 3.9559 & TRN & \\
\hline CHEMBL1324944 & 1301720 & 5.3279 & 4.4332 & TRN & \\
\hline CHEMBL3190993 & 1301720 & 3.284 & 3.5008 & TRN & \\
\hline CHEMBL1466410 & 1301720 & 3.6198 & 4.0661 & TRN & \\
\hline CHEMBL1338805 & 1301720 & 4.8486 & 4.0057 & TRN & \\
\hline CHEMBL1975547 & 1301720 & 3.284 & 3.5075 & TRN & \\
\hline CHEMBL 2355419 & 1301720 & 3.284 & 3.4935 & TST & \\
\hline CHEMBL1306033 & 1301720 & 4.9066 & 3.8104 & TST & \\
\hline CHEMBL1489057 & 1301720 & 4.2986 & 3.2989 & TST & \\
\hline CHEMBL1301758 & 1301720 & 3.284 & 3.8109 & TST & \\
\hline CHEMBL1349892 & 1301720 & 3.284 & 3.2562 & TST & \\
\hline CHEMBL1970965 & 1301720 & 3.284 & 3.7485 & TST & \\
\hline CHEMBL1577186 & 1301720 & 3.284 & 3.4729 & TST & \\
\hline CHEMBL1531133 & 1301720 & 4.8184 & 4.1495 & TST & \\
\hline CHEMBL1330625 & 1301720 & 3.284 & 3.5403 & TST & \\
\hline CHEMBL1379522 & 1301720 & 3.284 & 3.4262 & TST & \\
\hline CHEMBL221045 & 428114 & 6.2027 & 6.5022 & TRN & \\
\hline CHEMBL220611 & 428114 & 8.9208 & 8.9162 & TRN & \\
\hline CHEMBL221108 & 428114 & 6.9547 & 6.7399 & TRN & \\
\hline CHEMBL426731 & 428114 & 6.9706 & 6.4035 & TRN & \\
\hline CHEMBL339570 & 428114 & 6.058 & 6.3623 & TRN & \\
\hline CHEMBL373907 & 428114 & 6.4841 & 6.4301 & TRN & \\
\hline CHEMBL333936 & 428114 & 7.7447 & \multicolumn{2}{|c|}{6.877000000000001} & TRN \\
\hline CHEMBL221107 & 428114 & 6.1284 & 6.2012 & TRN & \\
\hline CHEMBL222457 & 428114 & 6.2 & 7.2905 & TRN & \\
\hline CHEMBL373403 & 428114 & 5.2386 & 6.142 & TST & \\
\hline CHEMBL373977 & 428114 & 8.3665 & 7.6269 & TRN & \\
\hline CHEMBL222197 & 428114 & 7.5229 & 7.0532 & TRN & \\
\hline CHEMBL219986 & 428114 & 8.9586 & 8.8444 & TRN & \\
\hline CHEMBL374012 & 428114 & 7.3979 & 7.7311 & TRN & \\
\hline CHEMBL424752 & 428114 & 8.8861 & 8.0674 & TRN & \\
\hline CHEMBL220441 & 428114 & 6.9245 & 7.5303 & TRN & \\
\hline CHEMBL 219742 & 428114 & 4.0969 & 3.9452 & TRN & \\
\hline CHEMBL374433 & 428114 & 5.2508 & 6.1182 & TST & \\
\hline CHEMBL123908 & 428114 & 6.7825 & 7.0695 & TRN & \\
\hline CHEMBL222615 & 428114 & 8.6198 & 8.8133 & TRN & \\
\hline CHEMBL375805 & 428114 & 6.2248 & 6.7068 & TRN & \\
\hline
\end{tabular}




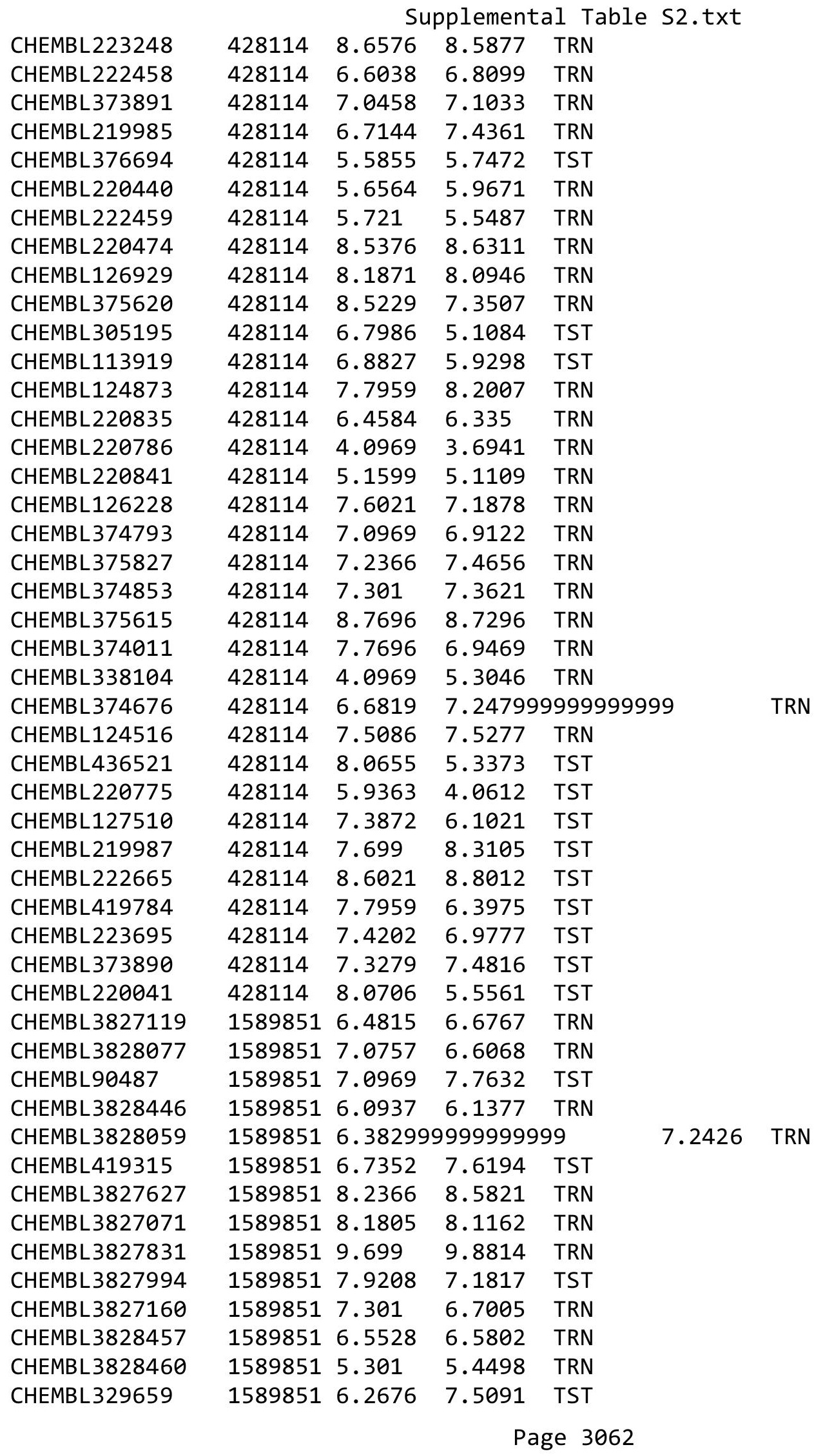


Supplemental Table S2.txt

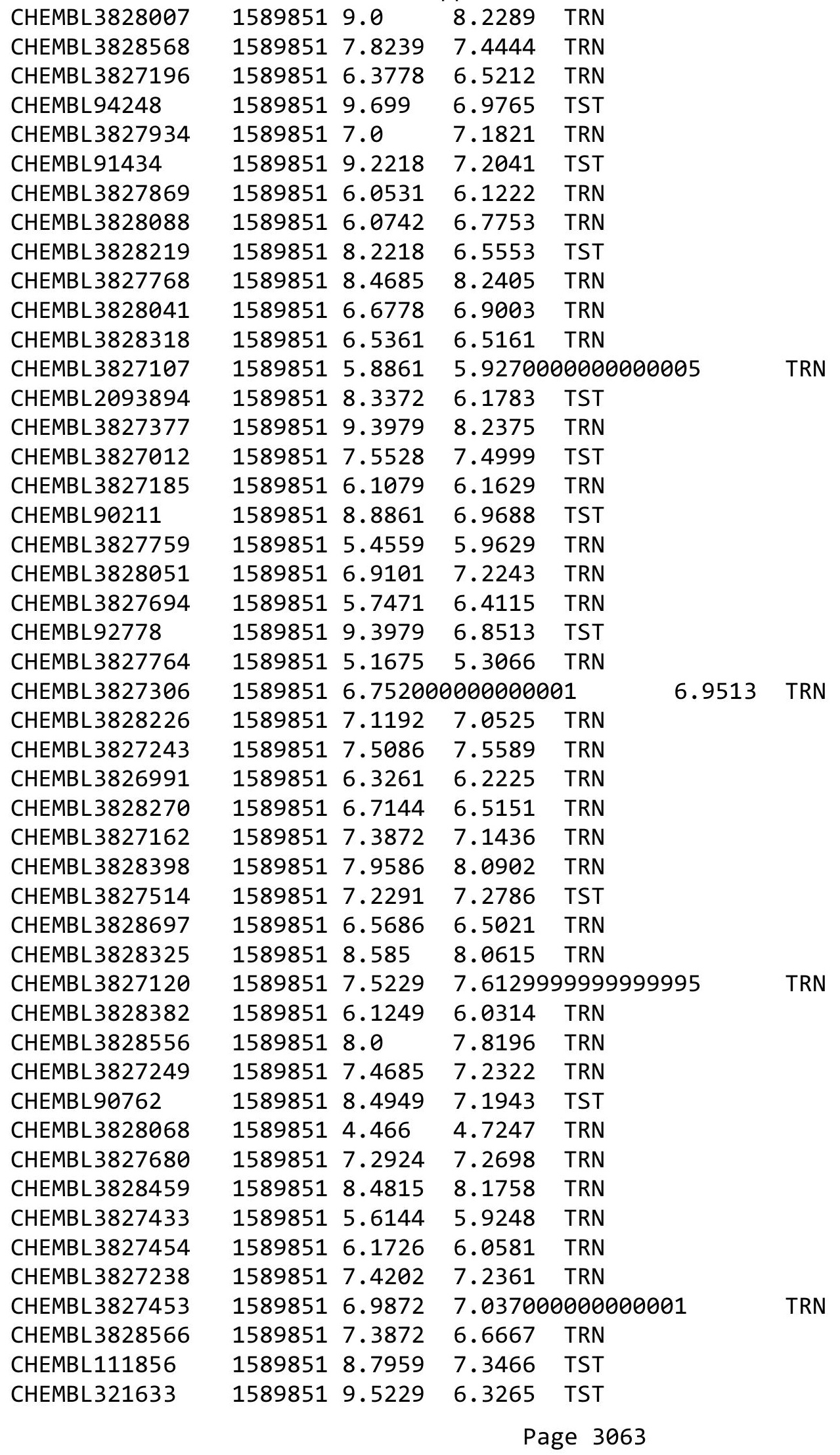


Supplemental Table S2.txt

\begin{tabular}{|c|c|c|c|c|}
\hline CHEMBL3828753 & 1589851 & 7.585 & 7.3692 & TRN \\
\hline CHEMBL3828521 & 1589851 & 8.8861 & 8.8941 & TRN \\
\hline CHEMBL3828216 & 1589851 & 6.475 & 7.2793 & TRN \\
\hline CHEMBL3828455 & 1589851 & 9.3979 & 9.554 & TRN \\
\hline CHEMBL 3827566 & 1589851 & 8.7959 & 9.1951 & TRN \\
\hline CHEMBL93231 & 1589851 & 9.699 & 7.1685 & TST \\
\hline CHEMBL 3827250 & 1589851 & 7.3502 & 7.3823 & TRN \\
\hline CHEMBL 3827024 & 1589851 & 6.58 & 7.0356 & TRN \\
\hline CHEMBL 3828527 & 1589851 & 6.7305 & \multicolumn{2}{|c|}{6.877000000000001} \\
\hline CHEMBL91124 & 1589851 & 9.699 & 7.3202 & TST \\
\hline CHEMBL 3828305 & 1589851 & 6.0362 & 5.8323 & TRN \\
\hline CHEMBL3827212 & 1589851 & 5.7696 & 5.6165 & TRN \\
\hline CHEMBL 3828338 & 1589851 & 7.4089 & 6.3619 & TST \\
\hline CHEMBL 3827224 & 1589851 & 5.301 & 5.0543 & TRN \\
\hline CHEMBL92327 & 1589851 & 7.3979 & 7.4979 & TST \\
\hline CHEMBL 3828531 & 1589851 & 9.1549 & 6.3236 & TST \\
\hline CHEMBL 3827735 & 1589851 & 7.1024 & 7.1189 & TRN \\
\hline CHEMBL 3828582 & 1589851 & 4.284 & 4.2263 & TRN \\
\hline CHEMBL 3828437 & 1589851 & 7.0655 & 6.8926 & TRN \\
\hline CHEMBL433171 & 1589851 & 8.8861 & 7.7439 & TST \\
\hline CHEMBL92899 & 1589851 & 7.7144 & 6.9784 & TST \\
\hline CHEMBL 3828712 & 1589851 & 8.1938 & 8.1902 & TRN \\
\hline CHEMBL92923 & 1589851 & 9.301 & 7.0722 & TST \\
\hline CHEMBL 3828314 & 1589851 & 6.5086 & 6.3426 & TRN \\
\hline CHEMBL 3827073 & 1589851 & 7.6198 & 7.1345 & TRN \\
\hline CHEMBL328346 & 1589851 & 8.301 & 6.9122 & TST \\
\hline CHEMBL 3827615 & 1589851 & 7.5229 & 7.0473 & TRN \\
\hline CHEMBL 3827321 & 1589851 & 9.301 & 6.6039 & TST \\
\hline CHEMBL 3827937 & 1589851 & 8.1805 & 8.01799 & 9999999999 \\
\hline CHEMBL 3828359 & 1589851 & 6.9586 & 7.79299 & 9999999999 \\
\hline CHEMBL 3827117 & 1589851 & 7.2676 & 7.1704 & TRN \\
\hline CHEMBL 3827781 & 1589851 & 6.6819 & 6.5149 & TRN \\
\hline CHEMBL 3827703 & 1589851 & 7.9586 & 8.4141 & TRN \\
\hline CHEMBL3828315 & 1589851 & 6.6925 & 6.7463 & TRN \\
\hline CHEMBL 3827640 & 1589851 & 7.0088 & 6.8452 & TRN \\
\hline CHEMBL 3827521 & 1589851 & 9.0 & 9.2303 & TRN \\
\hline CHEMBL3664758 & 1527878 & 8.1487 & 8.1783 & TRN \\
\hline CHEMBL1950759 & 1527878 & 8.3188 & 7.854 & TRN \\
\hline CHEMBL3664792 & 1527878 & 8.3565 & 7.3444 & TST \\
\hline CHEMBL3669676 & 1527878 & 6.0 & 6.2678 & TRN \\
\hline CHEMBL 3664763 & 1527878 & 6.0 & 7.1642 & TRN \\
\hline CHEMBL3669677 & 1527878 & 6.0 & 6.3563 & TRN \\
\hline CHEMBL3664766 & 1527878 & 7.6576 & 7.5669 & TRN \\
\hline CHEMBL 3664740 & 1527878 & 8.8539 & 7.9359 & TRN \\
\hline CHEMBL 3664733 & 1527878 & 8.2366 & 8.326 & TRN \\
\hline CHEMBL 3664764 & 1527878 & 7.7696 & 7.4595 & TRN \\
\hline CHEMBL3669665 & 1527878 & 8.9208 & 7.9593 & TRN \\
\hline CHEMBL1950767 & 1527878 & 6.7144 & 6.8839 & TRN \\
\hline
\end{tabular}


Supplemental Table S2.txt

\begin{tabular}{|c|c|c|c|c|c|}
\hline CHEMBL3669637 & 1527878 & 8.7212 & 9.1361 & TRN & \\
\hline CHEMBL 3669645 & 1527878 & 8.5686 & 8.4455 & TRN & \\
\hline CHEMBL1950775 & 1527878 & 6.0 & 8.0047 & TRN & \\
\hline CHEMBL3669660 & 1527878 & 7.6778 & 6.7581 & TST & \\
\hline CHEMBL3669689 & 1527878 & 6.0 & 5.6515 & TRN & \\
\hline CHEMBL3664778 & 1527878 & 8.9208 & 8.3862 & TRN & \\
\hline CHEMBL3669685 & 1527878 & 6.0 & 7.2021 & TST & \\
\hline CHEMBL 3664781 & 1527878 & 8.0315 & 8.2304 & TRN & \\
\hline CHEMBL3664751 & 1527878 & 6.0 & 5.8896 & TRN & \\
\hline CHEMBL3669638 & 1527878 & 7.3188 & 6.8446 & TRN & \\
\hline CHEMBL3664767 & 1527878 & 6.0 & 6.5221 & TRN & \\
\hline CHEMBL3664793 & 1527878 & 6.0 & 7.7087 & TST & \\
\hline CHEMBL3669657 & 1527878 & 9.5376 & 8.2593 & TST & \\
\hline CHEMBL3664774 & 1527878 & 8.2366 & 8.0611 & TRN & \\
\hline CHEMBL3669668 & 1527878 & 6.0 & 6.1693 & TRN & \\
\hline CHEMBL3664779 & 1527878 & 8.5376 & 8.5199 & TRN & \\
\hline CHEMBL3669693 & 1527878 & 6.0 & 7.2505 & TST & \\
\hline CHEMBL 3669641 & 1527878 & 6.6126 & 7.5473 & TRN & \\
\hline CHEMBL 3664745 & 1527878 & 8.0706 & 8.04 & TRN & \\
\hline CHEMBL3947690 & 1527878 & 8.5229 & 7.2528 & TRN & \\
\hline CHEMBL3664761 & 1527878 & 8.3098 & 8.2414 & TRN & \\
\hline CHEMBL3664795 & 1527878 & 7.1938 & 7.2081 & TST & \\
\hline CHEMBL3669662 & 1527878 & 8.6383 & 7.1066 & TRN & \\
\hline CHEMBL1950764 & 1527878 & 8.2007 & 8.1514 & TRN & \\
\hline CHEMBL3664759 & 1527878 & 8.4437 & 7.2981 & TRN & \\
\hline CHEMBL3664736 & 1527878 & 7.8539 & 7.6239 & TRN & \\
\hline CHEMBL 3664743 & 1527878 & 7.8861 & 7.86700 & 0000000001 & TRN \\
\hline CHEMBL3664775 & 1527878 & 6.4672 & 6.7327 & TRN & \\
\hline CHEMBL3664771 & 1527878 & 6.4559 & 6.1474 & TRN & \\
\hline CHEMBL1950763 & 1527878 & 8.4202 & 8.3192 & TRN & \\
\hline CHEMBL3669669 & 1527878 & 6.2358 & 6.1323 & TRN & \\
\hline CHEMBL3639636 & 1527878 & 8.0915 & 7.79299 & 9999999999 & TRN \\
\hline CHEMBL3669661 & 1527878 & 9.5086 & 7.4603 & TST & \\
\hline CHEMBL3664749 & 1527878 & 6.0 & 6.5618 & TRN & \\
\hline CHEMBL3669690 & 1527878 & 6.0 & 6.3195 & TRN & \\
\hline CHEMBL3664738 & 1527878 & 7.9586 & 8.6812 & TRN & \\
\hline CHEMBL3664777 & 1527878 & 8.3468 & 8.9481 & TRN & \\
\hline CHEMBL1950760 & 1527878 & 6.0 & 7.4068 & TRN & \\
\hline CHEMBL 3664739 & 1527878 & 8.699 & 8.4399 & TRN & \\
\hline CHEMBL3669643 & 1527878 & 6.0 & 6.2928 & TRN & \\
\hline CHEMBL 3664734 & 1527878 & 7.7696 & 8.2081 & TRN & \\
\hline CHEMBL3664794 & 1527878 & 6.6421 & 7.8659 & TST & \\
\hline CHEMBL3664747 & 1527878 & 7.3565 & 7.1129 & TRN & \\
\hline CHEMBL1950773 & 1527878 & 6.0 & 6.6316 & TRN & \\
\hline CHEMBL3669674 & 1527878 & 6.0 & \multicolumn{2}{|c|}{6.1979999999999995} & TRN \\
\hline CHEMBL3669642 & 1527878 & 8.1427 & 7.4292 & TST & \\
\hline CHEMBL3669663 & 1527878 & 8.8539 & 8.6277 & TRN & \\
\hline CHEMBL 3664744 & 1527878 & 8.0 & 7.5986 & TRN & \\
\hline
\end{tabular}


Supplemental Table S2.txt

\begin{tabular}{|c|c|c|c|c|}
\hline CHEMBL3669649 & 1527878 & 7.9586 & 8.3952 & TRN \\
\hline CHEMBL 3664746 & 1527878 & 8.585 & 7.4102 & TRN \\
\hline CHEMBL 3664731 & 1527878 & 8.3188 & 8.2637 & TRN \\
\hline CHEMBL 3669652 & 1527878 & 8.8539 & 7.9469 & TST \\
\hline CHEMBL3664732 & 1527878 & 8.4318 & 7.9567 & TRN \\
\hline CHEMBL 3664728 & 1527878 & 7.3565 & 7.4633 & TRN \\
\hline CHEMBL 3669654 & 1527878 & 8.9208 & 8.6899 & TST \\
\hline CHEMBL 3669673 & 1527878 & 6.0 & 8.4904 & TST \\
\hline CHEMBL 3664789 & 1527878 & 7.6576 & 7.4481 & TRN \\
\hline CHEMBL3669656 & 1527878 & 9.2518 & 9.2646 & TRN \\
\hline CHEMBL 3664750 & 1527878 & 8.2518 & 8.2218 & TRN \\
\hline CHEMBL1950757 & 1527878 & 8.3768 & 7.425 & TRN \\
\hline CHEMBL 3664752 & 1527878 & 7.7447 & 7.3815 & TRN \\
\hline CHEMBL 3669651 & 1527878 & 8.4949 & 8.2758 & TST \\
\hline CHEMBL1950755 & 1527878 & 6.0 & 6.5684 & TRN \\
\hline CHEMBL 3669639 & 1527878 & 9.3279 & 9.0242 & TRN \\
\hline CHEMBL 3664790 & 1527878 & 6.0 & 6.3158 & TRN \\
\hline CHEMBL1950761 & 1527878 & 7.4318 & 7.3695 & TRN \\
\hline CHEMBL1950776 & 1527878 & 6.0 & 7.8247 & TST \\
\hline CHEMBL3664768 & 1527878 & 6.0 & 6.5804 & TRN \\
\hline CHEMBL 3669650 & 1527878 & 6.0 & 8.2672 & TST \\
\hline CHEMBL1950750 & 1527878 & 8.1079 & 7.0869 & TRN \\
\hline CHEMBL 3669667 & 1527878 & 7.3565 & 6.9642 & TRN \\
\hline CHEMBL 3664786 & 1527878 & 7.8239 & 6.6046 & TRN \\
\hline CHEMBL 3664755 & 1527878 & 8.0862 & 8.1114 & TST \\
\hline CHEMBL 3664769 & 1527878 & 7.8539 & 7.1059 & TRN \\
\hline CHEMBL 3664753 & 1527878 & 8.3872 & 8.1433 & TRN \\
\hline CHEMBL 3669687 & 1527878 & 6.0 & 7.5422 & TRN \\
\hline CHEMBL 3664773 & 1527878 & 6.8239 & 6.9297 & TRN \\
\hline CHEMBL 3669647 & 1527878 & 7.8861 & 7.7013 & TRN \\
\hline CHEMBL1950754 & 1527878 & 7.284 & 6.5822 & TRN \\
\hline CHEMBL3669686 & 1527878 & 9.1675 & 6.8234 & TST \\
\hline CHEMBL 3669670 & 1527878 & 7.0969 & 7.0348 & TRN \\
\hline CHEMBL 3664780 & 1527878 & 9.1487 & 9.3808 & TRN \\
\hline CHEMBL 3669679 & 1527878 & 6.0 & 6.6108 & TRN \\
\hline CHEMBL 3664762 & 1527878 & 6.1002 & 7.2279 & TST \\
\hline CHEMBL1950749 & 1527878 & 6.9393 & 6.7957 & TRN \\
\hline CHEMBL 3669675 & 1527878 & 6.0 & 6.6462 & TRN \\
\hline CHEMBL 3669655 & 1527878 & 9.3279 & 8.2274 & TST \\
\hline CHEMBL 3669648 & 1527878 & 7.4089 & 7.1217 & TRN \\
\hline CHEMBL3664791 & 1527878 & 7.699 & 7.3278 & TST \\
\hline CHEMBL 3664726 & 1527878 & 6.0 & 6.4438 & TRN \\
\hline CHEMBL 3669659 & 1527878 & 6.0 & 5.9519 & TRN \\
\hline CHEMBL 3664772 & 1527878 & 6.3645 & 6.5754 & TRN \\
\hline CHEMBL1950770 & 1527878 & 7.2924 & 7.7834 & TRN \\
\hline CHEMBL 3664770 & 1527878 & 7.8539 & 7.5693 & TRN \\
\hline CHEMBL3664776 & 1527878 & 6.983 & 7.0125 & TRN \\
\hline CHEMBL3669692 & 1527878 & 6.0 & 7.7526 & TST \\
\hline
\end{tabular}


Supplemental Table S2.txt

\begin{tabular}{lllll} 
CHEMBL1950762 & 1527878 & 6.0 & 6.855 & TRN \\
CHEMBL3664760 & 1527878 & 8.1612 & 8.7517 & TRN \\
CHEMBL3669644 & 1527878 & 7.6198 & 8.2102 & TST \\
CHEMBL3669688 & 1527878 & 6.0 & 6.5174 & TST \\
CHEMBL3669671 & 1527878 & 6.8894 & 7.3402 & TRN \\
CHEMBL3664735 & 1527878 & 7.4559 & 7.4416 & TRN \\
CHEMBL3669666 & 1527878 & 7.1549 & 7.0667 & TRN \\
CHEMBL3669646 & 1527878 & 6.0 & 7.0799 & TRN \\
CHEMBL1950751 & 1527878 & 8.1079 & 7.3851 & TST \\
CHEMBL3669672 & 1527878 & 7.284 & 7.4776 & TRN \\
CHEMBL3664756 & 1527878 & 8.4815 & 7.4925 & TRN \\
CHEMBL3664737 & 1527878 & 8.1871 & 8.4322 & TRN \\
CHEMBL3669640 & 1527878 & 9.4815 & 9.3407 & TRN \\
CHEMBL3664729 & 1527878 & 7.9586 & 7.3059 & TRN \\
CHEMBL3664782 & 1527878 & 6.0 & 7.5151 & TST \\
CHEMBL3664787 & 1527878 & 9.1427 & 8.8693 & TRN \\
CHEMBL3669678 & 1527878 & 6.0 & 5.8016 & TRN \\
CHEMBL3664765 & 1527878 & 7.8861 & 7.4892 & TRN \\
CHEMBL3669683 & 1527878 & 6.0 & 6.8151 & TRN \\
CHEMBL3664754 & 1527878 & 6.0 & 7.7809 & TRN \\
CHEMBL3664748 & 1527878 & 6.857 & 7.3787 & TRN \\
CHEMBL3664757 & 1527878 & 8.5229 & 7.871 & TRN \\
CHEMBL3669681 & 1527878 & 6.0 & 7.1907 & TRN \\
CHEMBL3669658 & 1527878 & 6.9393 & 6.9197 & TRN \\
CHEMBL3669664 & 1527878 & 8.8861 & 7.0894 & TRN \\
CHEMBL1950756 & 1527878 & 8.3372 & 7.7826 & TRN \\
CHEMBL3669691 & 1527878 & 6.0 & 6.0142 & TRN \\
CHEMBL3664785 & 1527878 & 7.1079 & 6.7394 & TRN \\
CHEMBL3664742 & 1527878 & 7.9586 & 8.0507 & TRN \\
CHEMBL3669653 & 1527878 & 8.9208 & 8.9183 & TST \\
CHEMBL3664727 & 1527878 & 6.0 & 7.6059 & TST \\
CHEMBL1950758 & 1527878 & 7.2218 & 7.0725 & TST \\
CHEMBL1415156 & 1301449 & 4.5362 & 4.0122 & TRN \\
CHEMBL3664741 & 1527878 & 7.4318 & 7.5203 & TST \\
CHEMB1470357 & 1301449 & 2.8916 & 3.9269 & TRN \\
CHEMBL1950765 & 1527878 & 7.9586 & 7.6253 & TST \\
CHEMBEM 1996376 & 1301449 & 4.4235 & 4.6274 & TRN \\
CHEMBL3664783 & 1527878 & 7.0 & 7.0765 & TST \\
CHEMBL3664784 & 1527878 & 6.0 & 6.5231 & TST \\
CHEMBL1950777 & 1527878 & 6.0 & 8.8543 & TST \\
CHEMBL3664788 & 1527878 & 6.8297 & 7.0732 & TST \\
CHEMB 1969684 & 1527878 & 6.0 & 8.411 & TST \\
\hline
\end{tabular}

Page 3067 
Supplemental Table S2.txt

\begin{tabular}{|c|c|c|c|c|c|c|}
\hline CHEMBL1334670 & 1301449 & 2.8917 & 2.7499 & TRN & & \\
\hline CHEMBL1403970 & 1301449 & 4.5788 & 4.2031 & TRN & & \\
\hline CHEMBL1605867 & 1301449 & 4.9384 & 5.4009 & TRN & & \\
\hline CHEMBL1570497 & 1301449 & 3.9458 & 3.702 & TRN & & \\
\hline CHEMBL1503634 & 1301449 & 4.4731 & 3.7379 & TRN & & \\
\hline CHEMBL1590287 & 1301449 & 4.4363 & 4.2422 & TRN & & \\
\hline CHEMBL1523317 & 1301449 & 4.5651 & 4.2998 & TRN & & \\
\hline CHEMBL1445776 & 1301449 & 4.9982 & 4.9426 & TRN & & \\
\hline CHEMBL1997668 & 1301449 & 2.8916 & 3.1866 & TST & & \\
\hline CHEMBL1527008 & 1301449 & 4.1825 & 4.5584 & TRN & & \\
\hline CHEMBL1601789 & 1301449 & 2.8917 & 3.0394 & TRN & & \\
\hline CHEMBL1472327 & 1301449 & 4.6399 & 4.7577 & TST & & \\
\hline CHEMBL1510959 & 1301449 & 4.0578 & 3.5054 & TRN & & \\
\hline CHEMBL1734083 & 1301449 & \multicolumn{3}{|c|}{5.968999999999999} & .8994 & TRN \\
\hline CHEMBL1392310 & 1301449 & 4.1719 & 2.7881 & TST & & \\
\hline CHEMBL1392627 & 1301449 & \multicolumn{3}{|c|}{4.7010000000000005} & .6523 & TRN \\
\hline CHEMBL1325945 & 1301449 & 6.7929 & 4.853 & TST & & \\
\hline CHEMBL1422481 & 1301449 & 2.8918 & 3.5895 & TRN & & \\
\hline CHEMBL1969046 & 1301449 & 5.5892 & \multicolumn{3}{|c|}{5.5329999999999995} & TRN \\
\hline CHEMBL1598762 & 1301449 & 5.4528 & 4.6172 & TRN & & \\
\hline CHEMBL 2000517 & 1301449 & 6.1564 & 5.4735 & TRN & & \\
\hline CHEMBL1541408 & 1301449 & 2.8916 & 3.4942 & TRN & & \\
\hline CHEMBL1383058 & 1301449 & 4.2908 & 3.9497 & TRN & & \\
\hline CHEMBL1429228 & 1301449 & 2.8917 & 2.9952 & TRN & & \\
\hline CHEMBL3190218 & 1301449 & 4.0903 & 3.3439 & TST & & \\
\hline CHEMBL1466196 & 1301449 & 2.8917 & 3.1824 & TRN & & \\
\hline CHEMBL1432707 & 1301449 & 5.8775 & 5.5809 & TRN & & \\
\hline CHEMBL1473955 & 1301449 & 4.3164 & 4.3513 & TRN & & \\
\hline CHEMBL1589837 & 1301449 & 3.3691 & 3.5795 & TRN & & \\
\hline CHEMBL1463829 & 1301449 & 2.8918 & 2.6888 & TRN & & \\
\hline CHEMBL1458444 & 1301449 & 4.4919 & 3.9628 & TRN & & \\
\hline CHEMBL1331211 & 1301449 & 4.4289 & 4.308 & TRN & & \\
\hline CHEMBL1522941 & 1301449 & 5.1159 & 4.8022 & TRN & & \\
\hline CHEMBL1877709 & 1301449 & 6.0879 & 5.8121 & TRN & & \\
\hline CHEMBL1497838 & 1301449 & 2.8916 & 3.0733 & TRN & & \\
\hline CHEMBL1163377 & 1301449 & 6.2358 & 5.5036 & TRN & & \\
\hline CHEMBL235504 & 1301449 & 4.9036 & 4.9694 & TRN & & \\
\hline CHEMBL171632 & 1301449 & 5.8952 & 3.984 & TST & & \\
\hline CHEMBL1719244 & 1301449 & 4.9717 & 4.7755 & TRN & & \\
\hline CHEMBL1347897 & 1301449 & 3.9905 & 3.5225 & TRN & & \\
\hline CHEMBL417727 & 1301449 & 5.8745 & 5.5442 & TRN & & \\
\hline CHEMBL1403154 & 1301449 & 4.6268 & 4.3549 & TRN & & \\
\hline CHEMBL1460342 & 1301449 & 4.8388 & 4.0293 & TST & & \\
\hline CHEMBL1484234 & 1301449 & 4.3009 & 4.2209 & TRN & & \\
\hline CHEMBL1347107 & 1301449 & 4.1291 & 3.4719 & TRN & & \\
\hline CHEMBL1458321 & 1301449 & 5.3765 & 5.552006 & 00000000005 & & TRN \\
\hline CHEMBL1528308 & 1301449 & 4.3618 & 3.1918 & TST & & \\
\hline CHEMBL1720594 & 1301449 & 2.8924 & 4.5113 & TST & & \\
\hline
\end{tabular}


Supplemental Table S2.txt

\begin{tabular}{|c|c|c|c|c|c|c|}
\hline CHEMBL1705326 & 1301449 & 2.8917 & 3.7786 & TRN & & \\
\hline CHEMBL1735482 & 1301449 & 5.575 & 5.4174 & TRN & & \\
\hline CHEMBL1704261 & 1301449 & 4.9266 & 4.6825 & TRN & & \\
\hline CHEMBL1899721 & 1301449 & 4.0974 & 4.4696 & TRN & & \\
\hline CHEMBL1419015 & 1301449 & 2.8915 & 2.8777 & TRN & & \\
\hline CHEMBL1303255 & 1301449 & 2.8917 & 4.6712 & TST & & \\
\hline CHEMBL1506031 & 1301449 & 4.0984 & 3.1519 & TRN & & \\
\hline CHEMBL1409603 & 1301449 & 2.8917 & 2.642 & TRN & & \\
\hline CHEMBL1379918 & 1301449 & 4.1862 & 3.8577 & TRN & & \\
\hline CHEMBL1400512 & 1301449 & 4.3855 & 5.3615 & TST & & \\
\hline CHEMBL3144961 & 1301449 & 2.8921 & 3.5821 & TRN & & \\
\hline CHEMBL1417929 & 1301449 & 4.5477 & 4.0354 & TRN & & \\
\hline CHEMBL1716155 & 1301449 & 2.8919 & 2.5814 & TRN & & \\
\hline CHEMBL1421377 & 1301449 & 2.8916 & 4.6311 & TST & & \\
\hline CHEMBL1986381 & 1301449 & 4.0943 & 3.3948 & TST & & \\
\hline CHEMBL1998302 & 1301449 & 5.7268 & 6.1158 & TRN & & \\
\hline CHEMBL1585740 & 1301449 & 5.0409 & 4.787 & TRN & & \\
\hline CHEMBL1587422 & 1301449 & 2.8917 & 2.75 & TRN & & \\
\hline CHEMBL1454614 & 1301449 & 5.5941 & 5.5178 & TRN & & \\
\hline CHEMBL1388012 & 1301449 & 4.1704 & 4.7818 & TRN & & \\
\hline CHEMBL1906345 & 1301449 & 4.865 & 4.4349 & TST & & \\
\hline CHEMBL1698715 & 1301449 & 5.0618 & 4.508 & TRN & & \\
\hline CHEMBL1709883 & 1301449 & 4.9789 & 4.9977 & TRN & & \\
\hline CHEMBL3144858 & 1301449 & 2.8918 & 3.1268 & TRN & & \\
\hline CHEMBL 3144974 & 1301449 & \multicolumn{3}{|c|}{4.6080000000000005} & 5.0737 & TRN \\
\hline CHEMBL3190880 & 1301449 & \multicolumn{3}{|c|}{5.6579999999999995} & 6.005 & TRN \\
\hline CHEMBL1580345 & 1301449 & 2.8917 & 2.9292 & TRN & & \\
\hline CHEMBL1988648 & 1301449 & 4.9221 & 4.0962 & TST & & \\
\hline CHEMBL1384253 & 1301449 & 6.0386 & 5.6036 & TRN & & \\
\hline CHEMBL1450897 & 1301449 & 5.2946 & 5.096 & TRN & & \\
\hline CHEMBL1328567 & 1301449 & 4.7141 & 4.8018 & TRN & & \\
\hline CHEMBL1717890 & 1301449 & 4.933 & 5.0275 & TRN & & \\
\hline CHEMBL1465938 & 1301449 & 4.12 & 4.6314 & TRN & & \\
\hline CHEMBL3193897 & 1301449 & 2.8916 & 3.2107 & TST & & \\
\hline CHEMBL1504710 & 1301449 & 3.8856 & 4.3372 & TST & & \\
\hline CHEMBL1508839 & 1301449 & 2.8917 & 3.4253 & TRN & & \\
\hline CHEMBL1458194 & 1301449 & 2.8917 & 2.4205 & TRN & & \\
\hline CHEMBL1478825 & 1301449 & 2.892 & 3.3697 & TRN & & \\
\hline CHEMBL1725485 & 1301449 & 5.3949 & 5.3406 & TRN & & \\
\hline CHEMBL604321 & 1301449 & 4.323 & 3.8521 & TRN & & \\
\hline CHEMBL1698802 & 1301449 & 5.2634 & 5.4623 & TRN & & \\
\hline CHEMBL3195461 & 1301449 & 2.8918 & 3.4946 & TST & & \\
\hline CHEMBL3187596 & 1301449 & 2.8917 & 2.8191 & TRN & & \\
\hline CHEMBL1325440 & 1301449 & 2.8917 & 2.8345 & TRN & & \\
\hline CHEMBL1460491 & 1301449 & 2.8917 & 3.5642 & TST & & \\
\hline CHEMBL1562466 & 1301449 & 5.1238 & 5.033 & TRN & & \\
\hline CHEMBL1342041 & 1301449 & 2.8911 & 3.4215 & TRN & & \\
\hline CHEMBL1463659 & 1301449 & 6.6777 & 4.9352 & TST & & \\
\hline
\end{tabular}


Supplemental Table S2.txt

\begin{tabular}{|c|c|c|c|c|c|c|}
\hline CHEMBL 2142396 & 1301449 & 2.8916 & 3.3447 & TRN & & \\
\hline CHEMBL 3145001 & 1301449 & 5.2774 & 4.8726 & TRN & & \\
\hline CHEMBL1874279 & 1301449 & 2.8914 & 2.8826 & TRN & & \\
\hline CHEMBL1732657 & 1301449 & 2.8915 & 2.7924 & TRN & & \\
\hline CHEMBL1591913 & 1301449 & \multicolumn{3}{|c|}{4.0680000000000005} & 3.8774 & TRN \\
\hline CHEMBL1878046 & 1301449 & 4.8657 & 3.4842 & TST & & \\
\hline CHEMBL1304979 & 1301449 & 2.8917 & 3.7616 & TRN & & \\
\hline CHEMBL1736254 & 1301449 & 5.2978 & 4.8728 & TRN & & \\
\hline CHEMBL1420189 & 1301449 & 2.8917 & 3.3527 & TRN & & \\
\hline CHEMBL339561 & 1301449 & 4.4949 & 4.8484 & TRN & & \\
\hline CHEMBL1473428 & 1301449 & 4.6159 & 4.4047 & TRN & & \\
\hline CHEMBL 2145123 & 1301449 & 2.8917 & 3.138 & TRN & & \\
\hline CHEMBL1535503 & 1301449 & 5.0477 & 4.4479 & TRN & & \\
\hline CHEMBL1577193 & 1301449 & 5.3858 & 5.1147 & TRN & & \\
\hline CHEMBL1733422 & 1301449 & 5.3208 & 5.061 & TRN & & \\
\hline CHEMBL1475961 & 1301449 & 4.1925 & 3.9401 & TRN & & \\
\hline CHEMBL1392911 & 1301449 & 5.0028 & 4.2759 & TRN & & \\
\hline CHEMBL1388300 & 1301449 & 2.8917 & 3.8137 & TRN & & \\
\hline CHEMBL1378634 & 1301449 & 5.4149 & 5.1523 & TRN & & \\
\hline CHEMBL1362935 & 1301449 & 2.8917 & 4.0843 & TST & & \\
\hline CHEMBL1362933 & 1301449 & 5.0044 & 4.85 & TRN & & \\
\hline CHEMBL3144987 & 1301449 & 2.8916 & 3.4253 & TRN & & \\
\hline CHEMBL3144896 & 1301449 & 4.6157 & 4.7619 & TRN & & \\
\hline CHEMBL3189487 & 1301449 & 4.3031 & 4.4393 & TRN & & \\
\hline CHEMBL1729804 & 1301449 & 4.1686 & 4.2709 & TRN & & \\
\hline CHEMBL1555938 & 1301449 & 2.8916 & 3.1681 & TRN & & \\
\hline CHEMBL3191236 & 1301449 & 2.8918 & 3.1563 & TST & & \\
\hline CHEMBL1354019 & 1301449 & 2.8918 & 3.2305 & TRN & & \\
\hline CHEMBL1302170 & 1301449 & 3.8461 & 4.3125 & TRN & & \\
\hline CHEMBL1607263 & 1301449 & 4.0659 & 4.2025 & TRN & & \\
\hline CHEMBL3189071 & 1301449 & 2.891 & 3.6858 & TRN & & \\
\hline CHEMBL1453503 & 1301449 & 4.4923 & 4.765 & TRN & & \\
\hline CHEMBL1882729 & 1301449 & 5.0254 & 4.1101 & TRN & & \\
\hline CHEMBL1727228 & 1301449 & 2.892 & 2.6197 & TRN & & \\
\hline CHEMBL1344648 & 1301449 & 4.7888 & 3.8561 & TST & & \\
\hline CHEMBL1310865 & 1301449 & 4.1623 & 4.2926 & TRN & & \\
\hline CHEMBL1982305 & 1301449 & 5.49700 & t00000006 & $\partial 1$ & 6.0393 & TRN \\
\hline CHEMBL1438722 & 1301449 & 4.9497 & 4.5732 & TRN & & \\
\hline CHEMBL1430005 & 1301449 & 4.2219 & 4.0221 & TRN & & \\
\hline CHEMBL1502394 & 1301449 & 5.0964 & 4.9158 & TRN & & \\
\hline CHEMBL1709354 & 1301449 & 4.0968 & 4.2835 & TRN & & \\
\hline CHEMBL527336 & 1301449 & 2.8917 & 2.7421 & TRN & & \\
\hline CHEMBL1698877 & 1301449 & 2.8917 & 2.9843 & TRN & & \\
\hline CHEMBL1321941 & 1301449 & 2.8916 & 3.5643 & TRN & & \\
\hline CHEMBL1355280 & 1301449 & 4.28 & 4.4104 & TRN & & \\
\hline CHEMBL478754 & 1301449 & 5.1063 & 3.9945 & TST & & \\
\hline CHEMBL1329974 & 1301449 & 4.8906 & 4.3588 & TRN & & \\
\hline CHEMBL1470135 & 1301449 & 4.8479 & 4.7279 & TRN & & \\
\hline
\end{tabular}


Supplemental Table S2.txt

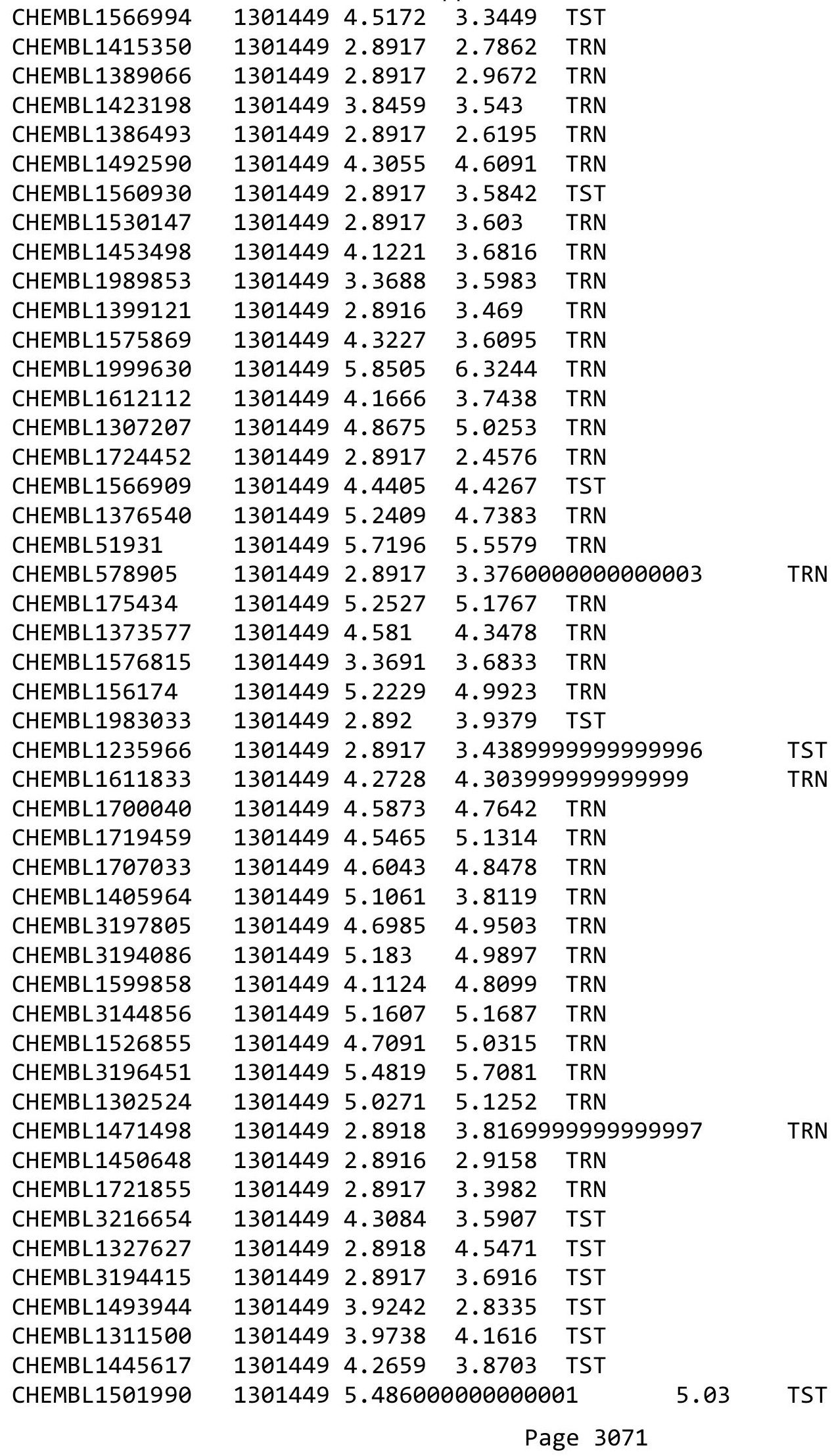


Supplemental Table S2.txt

\begin{tabular}{|c|c|c|c|c|c|}
\hline CHEMBL1441739 & 1301449 & 4.8784 & 4.8401 & TST & \\
\hline CHEMBL1706438 & 1301449 & 5.4533 & 4.9414 & TST & \\
\hline CHEMBL1726134 & 1301449 & 5.0814 & 5.1663 & TST & \\
\hline CHEMBL 2000196 & 1301449 & 5.1155 & 4.9788 & TST & \\
\hline CHEMBL1391527 & 1301449 & 4.052 & 4.3279 & TST & \\
\hline CHEMBL 2141749 & 1301449 & 2.8909 & 4.1501 & TST & \\
\hline CHEMBL 3144940 & 1301449 & 2.8917 & 3.2771 & TST & \\
\hline CHEMBL1380801 & 1301449 & 4.0026 & 4.3962 & TST & \\
\hline CHEMBL1389025 & 1301449 & 4.0337 & 4.9969 & TST & \\
\hline CHEMBL3145187 & 1301449 & 4.8977 & 4.3045 & TST & \\
\hline CHEMBL71466 & 1301449 & 5.3502 & 5.1199 & TST & \\
\hline CHEMBL592115 & 1301449 & 4.3967 & 3.7475 & TST & \\
\hline CHEMBL1494979 & 1301449 & 5.2708 & 3.83100 & 00000000004 & TST \\
\hline CHEMBL1395907 & 1301449 & 5.2741 & 4.5782 & TST & \\
\hline CHEMBL1728280 & 1301449 & 6.0744 & 4.5238 & TST & \\
\hline CHEMBL1711166 & 1301449 & 2.8912 & 4.4359 & TST & \\
\hline CHEMBL3931629 & 1641720 & 8.2218 & 8.2259 & TRN & \\
\hline CHEMBL 3928003 & 1641720 & 7.4318 & 6.2789 & TST & \\
\hline CHEMBL3965221 & 1641720 & 7.7959 & 7.8239 & TRN & \\
\hline CHEMBL 3974666 & 1641720 & 7.2147 & 7.2257 & TRN & \\
\hline CHEMBL 3975630 & 1641720 & 7.1427 & 7.2534 & TRN & \\
\hline CHEMBL3928489 & 1641720 & 7.0132 & 7.063 & TRN & \\
\hline CHEMBL3911455 & 1641720 & 7.8239 & 7.8814 & TRN & \\
\hline CHEMBL 3933673 & 1641720 & 7.699 & 7.5261 & TRN & \\
\hline CHEMBL3943081 & 1641720 & 6.0 & 6.1 & TRN & \\
\hline CHEMBL 3957881 & 1641720 & 7.2076 & 7.2101 & TRN & \\
\hline CHEMBL 3953085 & 1641720 & 7.7447 & 7.3796 & TST & \\
\hline CHEMBL3903598 & 1641720 & 7.9208 & 7.858 & TRN & \\
\hline CHEMBL3902195 & 1641720 & 7.5229 & 7.4507 & TRN & \\
\hline CHEMBL3961398 & 1641720 & 7.3372 & 7.3907 & TRN & \\
\hline CHEMBL3896708 & 1641720 & 7.4202 & 7.3615 & TST & \\
\hline CHEMBL 3962480 & 1641720 & 6.0 & 5.8792 & TRN & \\
\hline CHEMBL3916137 & 1641720 & 8.1549 & 8.2661 & TRN & \\
\hline CHEMBL3926922 & 1641720 & \multicolumn{3}{|c|}{8.283999999999999} & TRN \\
\hline CHEMBL3960189 & 1641720 & 7.041 & 7.0572 & TRN & \\
\hline CHEMBL3928673 & 1641720 & 7.5686 & 7.6954 & TRN & \\
\hline CHEMBL 3897098 & 1641720 & 7.4949 & 7.4188 & TRN & \\
\hline CHEMBL3977719 & 1641720 & 7.4815 & 7.4644 & TRN & \\
\hline CHEMBL3906862 & 1641720 & 7.3768 & 7.3955 & TRN & \\
\hline CHEMBL3942993 & 1641720 & 7.2596 & 7.3078 & TST & \\
\hline CHEMBL 3956637 & 1641720 & 8.3979 & 7.7783 & TST & \\
\hline CHEMBL3910623 & 1641720 & 7.585 & 7.6693 & TRN & \\
\hline CHEMBL3891639 & 1641720 & 7.8239 & 7.6102 & TRN & \\
\hline CHEMBL3959165 & 1641720 & 7.3979 & 7.3577 & TRN & \\
\hline CHEMBL3943992 & 1641720 & 7.5686 & 7.5782 & TRN & \\
\hline CHEMBL 3923661 & 1641720 & 7.1135 & 7.2686 & TRN & \\
\hline CHEMBL3955739 & 1641720 & 7.7447 & 7.7318 & TRN & \\
\hline CHEMBL3945759 & 1641720 & 7.5686 & 7.6448 & TRN & \\
\hline
\end{tabular}


Supplemental Table S2.txt

\begin{tabular}{|c|c|c|c|c|}
\hline & & & & \\
\hline CHEMBL 3947955 & 641720 & 7.5229 & & \\
\hline HEMBL3965540 & 720 & 6.0 & & \\
\hline & 720 & 2218 & & \\
\hline EMBL39 & 720 & 6.0 & & \\
\hline AEMBL3902454 & 641720 & 6.0 & 285 & \\
\hline HEMBL3934114 & 641720 & 7.5528 & .7796 & \\
\hline HEMBL; & & & 2542 & \\
\hline EMBL & 720 & 7212 & 279 & \\
\hline EMBL 3921487 & 720 & 8861 & & \\
\hline AEMBL3951587 & 720 & 7.3665 & 7.2822 & \\
\hline AEMBL3896941 & 720 & 7.3665 & & \\
\hline AEMBL 3950387 & 720 & 8 & 56 & \\
\hline IEMBL 3985197 & 720 & 229 & & \\
\hline IEMBL 39 & 720 & & & \\
\hline IEMBL 3957087 & 720 & 7.5686 & & \\
\hline IEMBL 3922622 & & 7 & & \\
\hline AEMBL: & 20 & 9 & & \\
\hline IEMBL: & 20 & 41 & & \\
\hline 15 & 20 & 7.2 & & \\
\hline EMBL: & 20 & 2 & & \\
\hline IEMBL 3984703 & & 9 & & \\
\hline IEMBL: & 20 & & & \\
\hline 85 & 20 & & & \\
\hline 92 & & & & \\
\hline IEMBL39 & 20 & & & \\
\hline IEMBL 3939345 & 20 & 8 & & \\
\hline$\partial 1$ & 20 & & & \\
\hline 01 & 20 & & & TIV \\
\hline & & & & \\
\hline & 20 & & & \\
\hline IEMBL 3907166 & 20 & 7.56 & & $\mathrm{RI}$ \\
\hline & & & & RN \\
\hline 31 & 20 & 4 & 16 & \\
\hline & 20 & & & $\Gamma \mathrm{RN}$ \\
\hline IEMBL 3890414 & 20 & & & \\
\hline IEMBL 3898871 & 20 & 7.9 & & $\mathrm{R}$ \\
\hline 4942 & 20 & 8 & 99 & RI \\
\hline 32 & 20 & & & RN \\
\hline & & & & ST \\
\hline EMBL39 & 20 & 36 & 891 & \\
\hline 84 & 16 & & & $\mathrm{~K}$ \\
\hline 0104 & 16 & & & \\
\hline HEMBL3946268 & & 7.5686 & 7.4055 & \\
\hline AEMBL 3914884 & 720 & 7.6198 & 7.6161 & $\mathrm{R}$ \\
\hline HEMBL3941831 & 720 & 59 & 7.5 & $F$ \\
\hline & & & & \\
\hline Сиг् & חברד & -1 & 7.5405 & \\
\hline
\end{tabular}

Page 3073 
Supplemental Table S2.txt

\begin{tabular}{|c|c|c|c|c|c|}
\hline CHEMBL3923691 & 1641720 & 7.9586 & 7.7952 & TRN & \\
\hline CHEMBL3899195 & 1641720 & 7.699 & 8.0508 & TST & \\
\hline CHEMBL3894701 & 1641720 & 8.301 & 7.9693 & TRN & \\
\hline CHEMBL 3896787 & 1641720 & 6.0 & 6.5326 & TRN & \\
\hline CHEMBL3895190 & 1641720 & 7.4685 & 7.444 & TRN & \\
\hline CHEMBL 3942003 & 1641720 & 7.5528 & 7.7194 & TRN & \\
\hline CHEMBL3903829 & 1641720 & 7.1938 & 7.2015 & TRN & \\
\hline CHEMBL 3889941 & 1641720 & 7.8239 & 7.1311 & TST & \\
\hline CHEMBL 3950337 & 1641720 & 8.0 & 7.9676 & TRN & \\
\hline CHEMBL3972662 & 1641720 & 7.5086 & 7.7872 & TST & \\
\hline CHEMBL 3906041 & 1641720 & 8.0969 & 8.1786 & TRN & \\
\hline CHEMBL3967350 & 1641720 & 8.2757 & 7.5694 & TST & \\
\hline CHEMBL3904553 & 1641720 & 7.3768 & 7.3366 & TRN & \\
\hline CHEMBL 3918380 & 1641720 & 7.1427 & 7.6126 & TST & \\
\hline CHEMBL3985743 & 1641720 & 7.9208 & 7.9428 & TRN & \\
\hline CHEMBL 3978556 & 1641720 & 7.2007 & 7.1022 & TRN & \\
\hline CHEMBL3971407 & 1641720 & 7.1871 & 7.6245 & TST & \\
\hline CHEMBL3985196 & 1641720 & 7.0088 & 7.3393 & TST & \\
\hline CHEMBL 3895906 & 1641720 & 7.4202 & 7.3978 & TRN & \\
\hline CHEMBL3660775 & 1527625 & 7.2218 & 5.9507 & TST & \\
\hline CHEMBL 3660804 & 1527625 & 7.1024 & 6.8241 & TST & \\
\hline CHEMBL 3086318 & 1527625 & 8.7212 & 8.90299 & 9999999999 & TRN \\
\hline CHEMBL 3660762 & 1527625 & 8.9586 & 8.9394 & TRN & \\
\hline CHEMBL3660769 & 1527625 & 7.2218 & 6.26399 & & TST \\
\hline CHEMBL 3660761 & 1527625 & 8.0315 & 8.2757 & TRN & \\
\hline CHEMBL 3660784 & 1527625 & 7.585 & 7.7002 & TST & \\
\hline CHEMBL 3660791 & 1527625 & 8.8861 & 8.8582 & TRN & \\
\hline CHEMBL 3660786 & 1527625 & 7.4413 & 7.2574 & TST & \\
\hline CHEMBL 3660754 & 1527625 & 8.2147 & 8.1561 & TRN & \\
\hline CHEMBL 3085827 & 1527625 & 7.7212 & 7.8198 & TRN & \\
\hline CHEMBL 3660764 & 1527625 & 8.1113 & 8.0347 & TRN & \\
\hline CHEMBL3660771 & 1527625 & 6.301 & 4.7573 & TST & \\
\hline CHEMBL 3660790 & 1527625 & 8.4089 & 8.2367 & TRN & \\
\hline CHEMBL3660763 & 1527625 & 8.8539 & 8.796 & TRN & \\
\hline CHEMBL3660803 & 1527625 & 7.4828 & 7.7598 & TRN & \\
\hline CHEMBL 3086323 & 1527625 & 8.1427 & 7.6733 & TRN & \\
\hline CHEMBL3085980 & 1527625 & 8.5686 & 8.4545 & TRN & \\
\hline CHEMBL3086316 & 1527625 & 6.0 & 6.2118 & TRN & \\
\hline CHEMBL3639596 & 1527625 & 8.8861 & 8.8907 & TRN & \\
\hline CHEMBL3660781 & 1527625 & 8.6021 & 8.7685 & TRN & \\
\hline CHEMBL3660788 & 1527625 & 7.301 & 7.2966 & TST & \\
\hline CHEMBL3660795 & 1527625 & 8.0555 & 8.0859 & TRN & \\
\hline CHEMBL 3660756 & 1527625 & 7.4989 & 7.575 & TRN & \\
\hline CHEMBL3085981 & 1527625 & 8.7696 & 8.8623 & TRN & \\
\hline CHEMBL3660779 & 1527625 & 8.3372 & 6.9097 & TST & \\
\hline CHEMBL 3660780 & 1527625 & 9.2218 & 8.825 & TRN & \\
\hline CHEMBL3660797 & 1527625 & 7.0 & 6.1896 & TRN & \\
\hline CHEMBL 3085984 & 1527625 & 9.1249 & 9.3116 & TRN & \\
\hline
\end{tabular}


Supplemental Table S2.txt

\begin{tabular}{|c|c|c|c|}
\hline HEMBL3086317 & 1527625 & 8.9208 & 8.8695 \\
\hline CHEMBL 3660772 & 1527625 & 6.301 & 4.8748 \\
\hline HEMBL3660796 & 527625 & 8.699 & \\
\hline HEMBL3660760 & 527625 & 8.0969 & \\
\hline HEMBL3085970 & 527625 & 8.0969 & 325 \\
\hline HEMBL 3085830 & .527625 & 6.0 & 6.6278 \\
\hline HEMBL3660778 & 527625 & 8.8447 & 1157 \\
\hline AEMBL 3085832 & 527625 & 8.7696 & \\
\hline HEMBL3660768 & 1527625 & 8.585 & 7303 \\
\hline HEMBL3660802 & 1527625 & 9.0862 & 9.2288 \\
\hline HEMBL 3085831 & 1527625 & 8.8239 & 8.831 \\
\hline HEMBL3660782 & 1527625 & 8.8239 & 8.8447 \\
\hline AEMBL3660766 & 1527625 & 8.5376 & \\
\hline HEMBL3660759 & 1527625 & 8.3565 & 7.9945 \\
\hline HEMBL3660773 & 1527625 & 6.5229 & 6.2749 \\
\hline HEMBL3660755 & 1527625 & 7.9066 & 7.9732 \\
\hline HEMBL3660800 & 1527625 & 8.7696 & 78 \\
\hline HEMBL3086320 & 1527625 & 6.0 & 732 \\
\hline HEMBL3085972 & 1527625 & 8.4559 & 8.4766 \\
\hline HEMBL3660789 & 1527625 & 9.0315 & 563 \\
\hline HEMBL3086322 & 1527625 & 8.7447 & 8 . \\
\hline HEMBL3660765 & 1527625 & 8.0269 & 66 \\
\hline HEMBL3085979 & 1527625 & 8.2291 & 198 \\
\hline AEMBL3660793 & 1527625 & 6.8539 & 126 \\
\hline HEMBL3086314 & 1527625 & 8.3468 & 8.2861 \\
\hline HEMBL3660758 & 1527625 & 7.2218 & 6.4812 \\
\hline AEMBL: & 1527625 & 7.4437 & 337 \\
\hline HEMBL3085977 & 1527625 & 9.1675 & 883 \\
\hline HEMBL3086179 & 1527625 & 6.0 & 558 \\
\hline HEMBL3660757 & 1527625 & 8.0655 & 433 \\
\hline HEMBL3660785 & 1527625 & 7.2218 & 59 \\
\hline HEMBL & 1527625 & 8.7959 & 941 \\
\hline HEMBL & 1527625 & 9.0269 & 524 \\
\hline CHEMBL3660777 & 1527625 & 8.0862 & 7.0545 \\
\hline HEMBL3085973 & 1527625 & 9.1938 & 8.8064 \\
\hline HEMBL3660770 & 1527625 & 6.4283 & 136 \\
\hline CHEMBL: & 1527625 & 7.2218 & 89 \\
\hline CHEMBL 3085834 & 1527625 & 8.8861 & 8.7218 \\
\hline CHEMBL3660776 & 1527625 & 7.5544 & 6.8882 \\
\hline CHEMBL 3660794 & 1527625 & 7.4815 & 7.7076 \\
\hline CHEMBL 3085829 & 1527625 & 8.4815 & 8.4003 \\
\hline CHEMBL3660753 & 1527625 & 8.3279 & 8.3184 \\
\hline CHEMBL3660792 & 1527625 & 8.7959 & 8.7624 \\
\hline CHEMBL 3660767 & 1527625 & 8.2518 & 8.2326 \\
\hline CHEMBL 3086172 & 1527625 & 8.6198 & 8.7986 \\
\hline CHEMBL 3085976 & 1527625 & 8.9208 & 8.9688 \\
\hline CHEMBL3660798 & 1527625 & 7.7447 & 7.7206 \\
\hline CHEMBL3086321 & 1527625 & 6.0 & 6.1276 \\
\hline
\end{tabular}


Supplemental Table S2.txt

\begin{tabular}{|c|c|c|c|c|}
\hline CHEMBL 3085975 & 1527625 & 8.699 & 8.8074 & 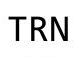 \\
\hline CHEMBL3085971 & 1527625 & 8.2441 & 8.4261 & \\
\hline HEMBL3085985 & 527625 & 7.8928 & 7.5818 & \\
\hline AEMBL3660787 & 527625 & 8.5376 & 733 & \\
\hline AEMBL3660801 & .527625 & 8.8239 & 8.7927 & \\
\hline AEMBL3085978 & 527625 & 9.0969 & 9.2024 & \\
\hline HEMBL1542752 & 688660 & 4.7 & 4.558 & \\
\hline CHEMBL1558758 & 688660 & & 134 & \\
\hline HEMBL1581845 & 88660 & 4.55 & 4.71 & \\
\hline HEMBL1498375 & 88660 & 4.75 & 4.8198 & \\
\hline HEMBL1560511 & 588660 & 4.55 & 4.6291 & \\
\hline HEMBL3194367 & 688660 & 4.4 & 5.0814 & \\
\hline CHEMBL1996271 & 688660 & & 4.8265 & \\
\hline HEMBL1603169 & 88660 & 4.6 & 181 & \\
\hline AEMBL1514812 & 588660 & 4.6 & 326 & \\
\hline AEMBL1509713 & 688660 & 5. & 25 & \\
\hline AEMBL1299778 & 688660 & & & \\
\hline CHEMBL1588049 & 688660 & 5 . & 42 & \\
\hline AEMBL1467892 & 688660 & 4.75 & & \\
\hline AEMBL1531258 & 688660 & 4. & 95 & \\
\hline AEMBL1439113 & 688660 & & & \\
\hline HEMBL3195460 & 688660 & & & \\
\hline CHEMBL1525084 & 688660 & & 77 & \\
\hline CHEMBL1492786 & 688660 & 5 . & 28 & \\
\hline CHEMBL3197145 & 688660 & 4. & 87 & \\
\hline HEMBL 260876 & 688 & & & \\
\hline CHEMBL1480530 & 688660 & 4. & 317 & \\
\hline CHEMBL1370884 & 688660 & & 74 & \\
\hline CHEMBL1542674 & 60 & 4. & 87 & \\
\hline CHEMBL1373002 & 688 & 4. & 4. & \\
\hline CHEMBL1426136 & 688 & & & \\
\hline CHEMBL1358939 & 688660 & 4. & 064 & \\
\hline CHEMB & 60 & & & \\
\hline CHEMI & 50 & 6. & 25 & \\
\hline CHEMBL1537553 & 688660 & 5.4 & 88 & TR \\
\hline CHEMBL1571125 & 688660 & 5 . & & \\
\hline CHEMBL1520754 & 688660 & 6. & 87 & TR \\
\hline 13463 & 688 & 4. & & \\
\hline CHEMBL1382167 & 688 & 5.25 & 98 & \\
\hline CHEMBL1611288 & 688660 & 5.0 & 5.1061 & 10 \\
\hline CHEMBL1507252 & 688660 & 4.65 & 369 & $\mathrm{TR}$ \\
\hline CHEMBL3208375 & 688660 & 4. & 28 & R \\
\hline CHEMBL1484653 & 688660 & 4. & & \\
\hline CHEMBL1354035 & 688660 & 4.45 & 4.7354 & \\
\hline CHEMBL3196519 & 688660 & 4.55 & 5.1043 & $\mathrm{TR}$ \\
\hline CHEMBL1420489 & 688660 & 4.4 & 5.0767 & 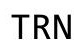 \\
\hline CHEMBL1491243 & 688660 & & 4.6325 & \\
\hline CHEMBL1385055 & 688660 & 4.55 & 4.8663 & \\
\hline
\end{tabular}

Page 3076 


\begin{tabular}{|c|c|c|c|c|c|}
\hline & & \multicolumn{4}{|c|}{ Supplemental Table S2.txt } \\
\hline CHEMBL1422352 & 688660 & 4.55 & 4.7758 & TRN & \\
\hline CHEMBL1496534 & 688660 & 5.4 & 5.0088 & TRN & \\
\hline CHEMBL1447788 & 688660 & 4.45 & 5.2244 & TRN & \\
\hline CHEMBL1399957 & 688660 & 4.65 & 4.5499 & TRN & \\
\hline CHEMBL1606963 & 688660 & 5.0 & 4.6071 & TRN & \\
\hline CHEMBL1449161 & 688660 & 6.2 & 5.2328 & TRN & \\
\hline CHEMBL1385245 & 688660 & 4.4 & 4.7832 & TST & \\
\hline CHEMBL1499441 & 688660 & 4.4 & 4.7845 & TST & \\
\hline CHEMBL1325360 & 688660 & 5.2 & 5.1282 & TRN & \\
\hline CHEMBL1571596 & 688660 & 5.45 & 5.2239 & TRN & \\
\hline CHEMBL1401382 & 688660 & 5.5 & 5.0993 & TST & \\
\hline CHEMBL1320822 & 688660 & 4.4 & 5.0971 & TRN & \\
\hline CHEMBL1447922 & 688660 & 4.45 & 4.6408 & TRN & \\
\hline CHEMBL1980369 & 688660 & 4.55 & 4.8137 & TRN & \\
\hline CHEMBL1428598 & 688660 & 5.0 & 4.9949 & TRN & \\
\hline CHEMBL1483394 & 688660 & 6.2 & 4.958 & TRN & \\
\hline CHEMBL1548626 & 688660 & 4.4 & 5.1504 & TRN & \\
\hline CHEMBL1391223 & 688660 & 5.45 & 4.8533 & TST & \\
\hline CHEMBL1336949 & 688660 & 4.4 & 4.8343 & TST & \\
\hline CHEMBL1520859 & 688660 & 4.6 & 4.8699 & TRN & \\
\hline CHEMBL1366171 & 688660 & 5.35 & 5.41799 & 9999999999 & TRN \\
\hline CHEMBL1407845 & 688660 & 6.2 & 5.0402 & TST & \\
\hline CHEMBL1564263 & 688660 & 4.4 & 4.8601 & TRN & \\
\hline CHEMBL1383566 & 688660 & 4.7 & 5.2602 & TRN & \\
\hline CHEMBL1419114 & 688660 & 5.15 & 5.0342 & TRN & \\
\hline CHEMBL1457472 & 688660 & 4.85 & 4.7579 & TRN & \\
\hline CHEMBL1498461 & 688660 & 5.5 & 4.7849 & TRN & \\
\hline CHEMBL1331651 & 688660 & 4.85 & 5.0615 & TRN & \\
\hline CHEMBL1422439 & 688660 & 4.45 & 4.7722 & TST & \\
\hline CHEMBL1478517 & 688660 & 5.95 & 4.9514 & TRN & \\
\hline CHEMBL1383270 & 688660 & 4.55 & 4.853 & TRN & \\
\hline CHEMBL1498483 & 688660 & 4.4 & 4.7065 & TRN & \\
\hline CHEMBL1476643 & 688660 & 4.4 & 4.6599 & TRN & \\
\hline CHEMBL1568611 & 688660 & 4.4 & 5.0131 & TRN & \\
\hline CHEMBL3195463 & 688660 & 4.4 & 4.7942 & TST & \\
\hline CHEMBL1608727 & 688660 & 4.8 & 4.848 & TST & \\
\hline CHEMBL1437859 & 688660 & 4.45 & 4.9801 & TRN & \\
\hline CHEMBL1525047 & 688660 & 4.7 & 4.6132 & TST & \\
\hline CHEMBL1437393 & 688660 & 5.5 & 4.6435 & TRN & \\
\hline CHEMBL1410681 & 688660 & 5.4 & 4.6352 & TRN & \\
\hline CHEMBL 2001904 & 688660 & 5.1 & 4.8458 & TST & \\
\hline CHEMBL1413984 & 688660 & 4.65 & 5.2575 & TRN & \\
\hline CHEMBL1481047 & 688660 & 4.6 & 4.6887 & TRN & \\
\hline CHEMBL1521831 & 688660 & 5.55 & 4.5827 & TST & \\
\hline CHEMBL1572112 & 688660 & 4.4 & 4.8223 & TRN & \\
\hline CHEMBL1563118 & 688660 & 4.45 & 4.5878 & TRN & \\
\hline CHEMBL1435726 & 688660 & 5.2 & 5.0598 & TRN & \\
\hline CHEMBL1478182 & 688660 & 4.5 & 5.0767 & TST & \\
\hline
\end{tabular}




\begin{tabular}{|c|c|c|c|c|}
\hline \multicolumn{5}{|c|}{ Supplemental Table S2.txt } \\
\hline CHEMBL1595057 & 688660 & 4.45 & 4.7266 & TRN \\
\hline CHEMBL1359837 & 688660 & 4.65 & 4.6963 & TST \\
\hline CHEMBL1596070 & 688660 & 5.15 & 5.1153 & TRN \\
\hline CHEMBL1461107 & 688660 & 6.15 & 5.1717 & TRN \\
\hline CHEMBL1312648 & 688660 & 6.2 & 4.6245 & TST \\
\hline CHEMBL1374827 & 688660 & 4.55 & 4.5361 & TRN \\
\hline CHEMBL1818881 & 688660 & 6.15 & 4.9727 & TRN \\
\hline CHEMBL576353 & 688660 & 6.2 & 4.9346 & TRN \\
\hline CHEMBL1500688 & 688660 & 6.2 & 5.2861 & TRN \\
\hline CHEMBL1306888 & 688660 & 5.45 & 4.7398 & TRN \\
\hline CHEMBL2373661 & 688660 & 4.4 & 4.4323 & TST \\
\hline CHEMBL1556881 & 688660 & 6.1 & 5.066 & TRN \\
\hline CHEMBL1388829 & 688660 & 5.05 & 4.7269 & TST \\
\hline CHEMBL1502068 & 688660 & 5.25 & 4.6894 & TST \\
\hline CHEMBL1425909 & 688660 & 4.4 & 4.5324 & TST \\
\hline CHEMBL1371180 & 688660 & 5.9 & 4.9438 & TRN \\
\hline CHEMBL1568600 & 688660 & 5.35 & 4.7158 & TRN \\
\hline CHEMBL1311574 & 688660 & 5.5 & 5.1904 & TRN \\
\hline CHEMBL1327351 & 688660 & 4.5 & 4.7385 & TRN \\
\hline CHEMBL1583316 & 688660 & 5.1 & 5.0111 & TRN \\
\hline CHEMBL1470135 & 688660 & 5.4 & 4.8814 & TRN \\
\hline CHEMBL1519374 & 688660 & 5.45 & 4.8761 & TRN \\
\hline CHEMBL1471773 & 688660 & 5.5 & 4.7949 & TRN \\
\hline CHEMBL1430449 & 688660 & 4.55 & 4.7544 & TRN \\
\hline CHEMBL1603356 & 688660 & 4.4 & 4.6867 & TRN \\
\hline CHEMBL1612554 & 688660 & 5.85 & 4.9293 & TRN \\
\hline CHEMBL1474672 & 688660 & 5.15 & 4.7611 & TRN \\
\hline CHEMBL1526461 & 688660 & 4.4 & 4.8502 & TRN \\
\hline CHEMBL1305077 & 688660 & 4.5 & 5.1403 & TRN \\
\hline CHEMBL1532837 & 688660 & 5.45 & 4.896 & TRN \\
\hline CHEMBL1445962 & 688660 & 4.4 & 4.9638 & TRN \\
\hline CHEMBL1421066 & 688660 & 6.2 & 4.8734 & TRN \\
\hline CHEMBL1501375 & 688660 & 5.4 & 4.9687 & TRN \\
\hline CHEMBL1573346 & 688660 & 5.0 & 5.1144 & TRN \\
\hline CHEMBL1602925 & 688660 & 5.05 & 5.1546 & TRN \\
\hline CHEMBL1331612 & 688660 & 5.05 & 4.63 & TRN \\
\hline CHEMBL1372900 & 688660 & 4.65 & 4.6801 & TST \\
\hline CHEMBL1557869 & 688660 & 6.0 & 4.6876 & TRN \\
\hline CHEMBL1391551 & 688660 & 4.4 & 4.7995 & TRN \\
\hline CHEMBL1315134 & 688660 & 4.45 & 5.0524 & TRN \\
\hline CHEMBL1458017 & 688660 & 4.55 & 5.1116 & TRN \\
\hline CHEMBL1566871 & 688660 & 4.4 & 4.8082 & TRN \\
\hline CHEMBL1446475 & 688660 & 5.7 & 4.9075 & TRN \\
\hline CHEMBL1332241 & 688660 & 5.05 & 4.8925 & TST \\
\hline CHEMBL3190015 & 688660 & 4.95 & 4.629 & TRN \\
\hline CHEMBL3211368 & 688660 & 6.15 & 4.8948 & TST \\
\hline CHEMBL 1607877 & 688660 & 4.55 & 5.0331 & TRN \\
\hline CHEMBL1355210 & 688660 & 4.4 & 4.644 & TRN \\
\hline
\end{tabular}




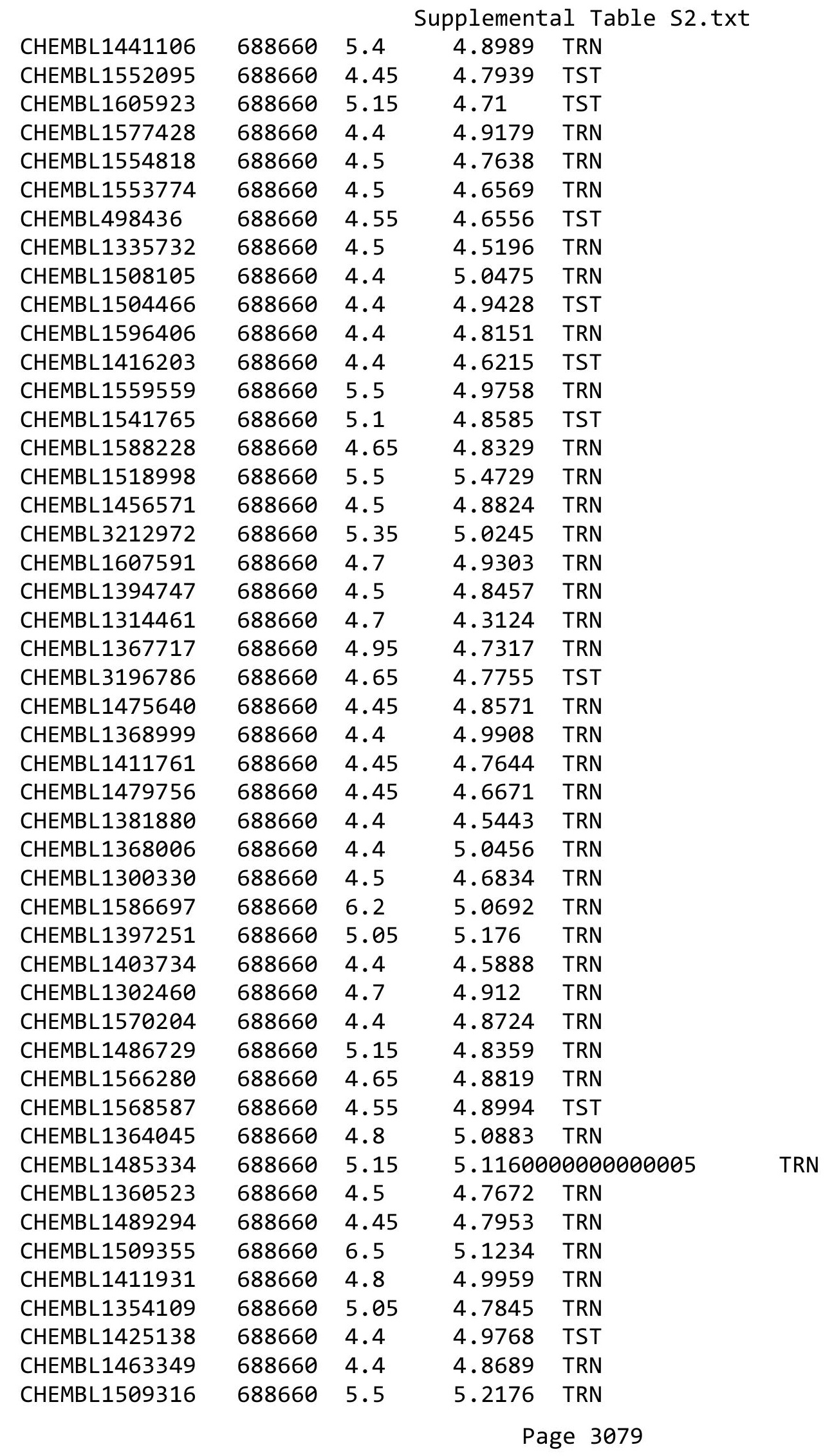




\begin{tabular}{|c|c|c|c|c|c|}
\hline \multicolumn{6}{|c|}{ Supplemental Table S2.txt } \\
\hline CHEMBL1504738 & 688660 & 4.4 & 4.6083 & TRN & \\
\hline CHEMBL1531633 & 688660 & 5.15 & 4.8773 & TRN & \\
\hline CHEMBL1394484 & 688660 & 4.5 & 4.6785 & TRN & \\
\hline CHEMBL1424729 & 688660 & 4.4 & 4.73300 & 00000000005 & TRN \\
\hline CHEMBL1472540 & 688660 & 4.6 & 4.9034 & TRN & \\
\hline CHEMBL1434806 & 688660 & 4.65 & 4.9097 & TRN & \\
\hline CHEMBL1507472 & 688660 & 5.05 & 4.8399 & TST & \\
\hline CHEMBL1331884 & 688660 & 4.4 & 4.8891 & TRN & \\
\hline CHEMBL1527050 & 688660 & 4.7 & 4.9609 & TRN & \\
\hline CHEMBL1524613 & 688660 & 4.9 & 4.6898 & TST & \\
\hline CHEMBL1340315 & 688660 & 4.6 & 4.9122 & TRN & \\
\hline CHEMBL1398721 & 688660 & 5.0 & 4.8503 & TRN & \\
\hline CHEMBL1420688 & 688660 & 4.65 & 5.0574 & TRN & \\
\hline CHEMBL1336606 & 688660 & 4.7 & 4.9596 & TRN & \\
\hline CHEMBL1461600 & 688660 & 6.15 & 4.6569 & TRN & \\
\hline CHEMBL1520464 & 688660 & 4.4 & 4.7978 & TRN & \\
\hline CHEMBL1548417 & 688660 & 6.2 & 4.9369 & TRN & \\
\hline CHEMBL1611167 & 688660 & 4.4 & 4.8533 & TRN & \\
\hline CHEMBL1459638 & 688660 & 6.0 & 4.8706 & TRN & \\
\hline CHEMBL1332755 & 688660 & 4.65 & 5.0701 & TRN & \\
\hline CHEMBL1611717 & 688660 & 4.5 & 4.8575 & TRN & \\
\hline CHEMBL1485377 & 688660 & 5.35 & 5.2115 & TRN & \\
\hline CHEMBL1454171 & 688660 & 4.6 & 4.7665 & TST & \\
\hline CHEMBL3196251 & 688660 & 6.2 & 4.805 & TRN & \\
\hline CHEMBL1526642 & 688660 & 6.15 & 5.2333 & TRN & \\
\hline CHEMBL1359144 & 688660 & 6.15 & 4.9006 & TRN & \\
\hline CHEMBL1363015 & 688660 & 4.4 & 4.8708 & TRN & \\
\hline CHEMBL1350338 & 688660 & 6.15 & 4.8309 & TRN & \\
\hline CHEMBL1378870 & 688660 & 4.4 & 4.996 & TRN & \\
\hline CHEMBL1494524 & 688660 & 4.55 & 4.8218 & TRN & \\
\hline CHEMBL1523423 & 688660 & 6.2 & 4.8836 & TRN & \\
\hline CHEMBL1409791 & 688660 & 4.5 & 4.9872 & TRN & \\
\hline CHEMBL1477158 & 688660 & 5.45 & 5.2562 & TRN & \\
\hline CHEMBL1422418 & 688660 & 5.2 & 4.945 & TST & \\
\hline CHEMBL1528062 & 688660 & 4.8 & 4.7751 & TRN & \\
\hline CHEMBL1532809 & 688660 & 4.75 & 5.2037 & TRN & \\
\hline CHEMBL1555941 & 688660 & 5.05 & 4.8903 & TRN & \\
\hline CHEMBL1401237 & 688660 & 4.4 & 4.6865 & TRN & \\
\hline CHEMBL1419900 & 688660 & 4.55 & 4.5116 & TRN & \\
\hline CHEMBL1320019 & 688660 & 4.4 & 5.1167 & TRN & \\
\hline CHEMBL1365240 & 688660 & 4.4 & 4.8928 & TRN & \\
\hline CHEMBL1319104 & 688660 & 4.4 & 4.63399 & 99999999995 & TRN \\
\hline CHEMBL1439102 & 688660 & 4.4 & 4.5285 & TST & \\
\hline CHEMBL1473151 & 688660 & 4.85 & 4.9116 & TRN & \\
\hline CHEMBL1461782 & 688660 & 5.3 & 4.9145 & TRN & \\
\hline CHEMBL1389920 & 688660 & 5.9 & 4.9798 & TRN & \\
\hline CHEMBL1384955 & 688660 & 4.45 & 4.9263 & TRN & \\
\hline CHEMBL3197897 & 688660 & 4.4 & 4.6236 & TST & \\
\hline
\end{tabular}




\begin{tabular}{|c|c|c|c|c|}
\hline \multicolumn{5}{|c|}{ Supplemental Table S2.txt } \\
\hline CHEMBL1330905 & 688660 & 4.4 & 4.7964 & TRN \\
\hline CHEMBL1467266 & 688660 & 5.5 & 4.9125 & TRN \\
\hline CHEMBL1320327 & 688660 & 5.5 & 4.8828 & TRN \\
\hline CHEMBL1591211 & 688660 & 4.45 & 4.8691 & TRN \\
\hline CHEMBL1475226 & 688660 & 4.45 & 4.6555 & TRN \\
\hline CHEMBL1543673 & 688660 & 4.9 & 4.7741 & TST \\
\hline CHEMBL1318484 & 688660 & 5.15 & 4.9358 & TRN \\
\hline CHEMBL1572642 & 688660 & 4.7 & 4.9807 & TRN \\
\hline CHEMBL1566928 & 688660 & 5.4 & 4.6663 & TRN \\
\hline CHEMBL1539472 & 688660 & 5.35 & 5.1824 & TRN \\
\hline CHEMBL1347294 & 688660 & 5.5 & 5.1062 & TRN \\
\hline CHEMBL1503699 & 688660 & 6.15 & 4.8972 & TRN \\
\hline CHEMBL1400868 & 688660 & 4.4 & 4.8829 & TRN \\
\hline CHEMBL1465648 & 688660 & 4.8 & 4.8767 & TST \\
\hline CHEMBL1610430 & 688660 & 4.4 & 4.8327 & TRN \\
\hline CHEMBL1562592 & 688660 & 5.35 & 5.2313 & TRN \\
\hline CHEMBL1363122 & 688660 & 6.0 & 4.5227 & TST \\
\hline CHEMBL1556305 & 688660 & 5.0 & 4.90600 & 0000000001 \\
\hline CHEMBL1546005 & 688660 & 4.4 & 5.032 & TRN \\
\hline CHEMBL1490427 & 688660 & 5.45 & 5.0618 & TRN \\
\hline CHEMBL3196928 & 688660 & 5.0 & 5.0683 & TRN \\
\hline CHEMBL1532055 & 688660 & 6.15 & 4.863 & TRN \\
\hline CHEMBL1321911 & 688660 & 4.4 & 4.8686 & TRN \\
\hline CHEMBL 3208838 & 688660 & 6.05 & 4.8721 & TRN \\
\hline CHEMBL1603844 & 688660 & 4.4 & 4.7978 & TRN \\
\hline CHEMBL1488255 & 688660 & 4.5 & 4.7908 & TRN \\
\hline CHEMBL1386304 & 688660 & 4.45 & 4.5949 & TRN \\
\hline CHEMBL1311729 & 688660 & 4.4 & 4.9332 & TRN \\
\hline CHEMBL1338205 & 688660 & 4.7 & 5.0438 & TRN \\
\hline CHEMBL1432430 & 688660 & 5.5 & 4.8953 & TRN \\
\hline CHEMBL1391978 & 688660 & 4.9 & 5.0535 & TRN \\
\hline CHEMBL1424708 & 688660 & 5.2 & 4.9443 & TRN \\
\hline CHEMBL1496606 & 688660 & 6.15 & 4.8093 & TRN \\
\hline CHEMBL1409054 & 688660 & 4.4 & 4.9883 & TRN \\
\hline CHEMBL1403564 & 688660 & 4.55 & 4.6581 & TRN \\
\hline CHEMBL1510317 & 688660 & 4.75 & 4.9144 & TST \\
\hline CHEMBL1537907 & 688660 & 4.65 & 4.7918 & TRN \\
\hline CHEMBL1583391 & 688660 & 4.5 & 4.9591 & TRN \\
\hline CHEMBL1438771 & 688660 & 4.75 & 4.6976 & TRN \\
\hline CHEMBL1300164 & 688660 & 5.45 & 5.0754 & TRN \\
\hline CHEMBL1609177 & 688660 & 5.45 & 4.85 & TST \\
\hline CHEMBL1526443 & 688660 & 6.2 & 4.9831 & TRN \\
\hline CHEMBL1456055 & 688660 & 4.4 & 4.9398 & TRN \\
\hline CHEMBL1414989 & 688660 & 4.6 & 4.8505 & TRN \\
\hline CHEMBL1451593 & 688660 & 6.15 & 5.1817 & TRN \\
\hline CHEMBL1465525 & 688660 & 5.55 & 4.8396 & TRN \\
\hline CHEMBL1524113 & 688660 & 4.5 & 4.4996 & TRN \\
\hline CHEMBL1991601 & 688660 & 4.55 & 4.5436 & TRN \\
\hline
\end{tabular}




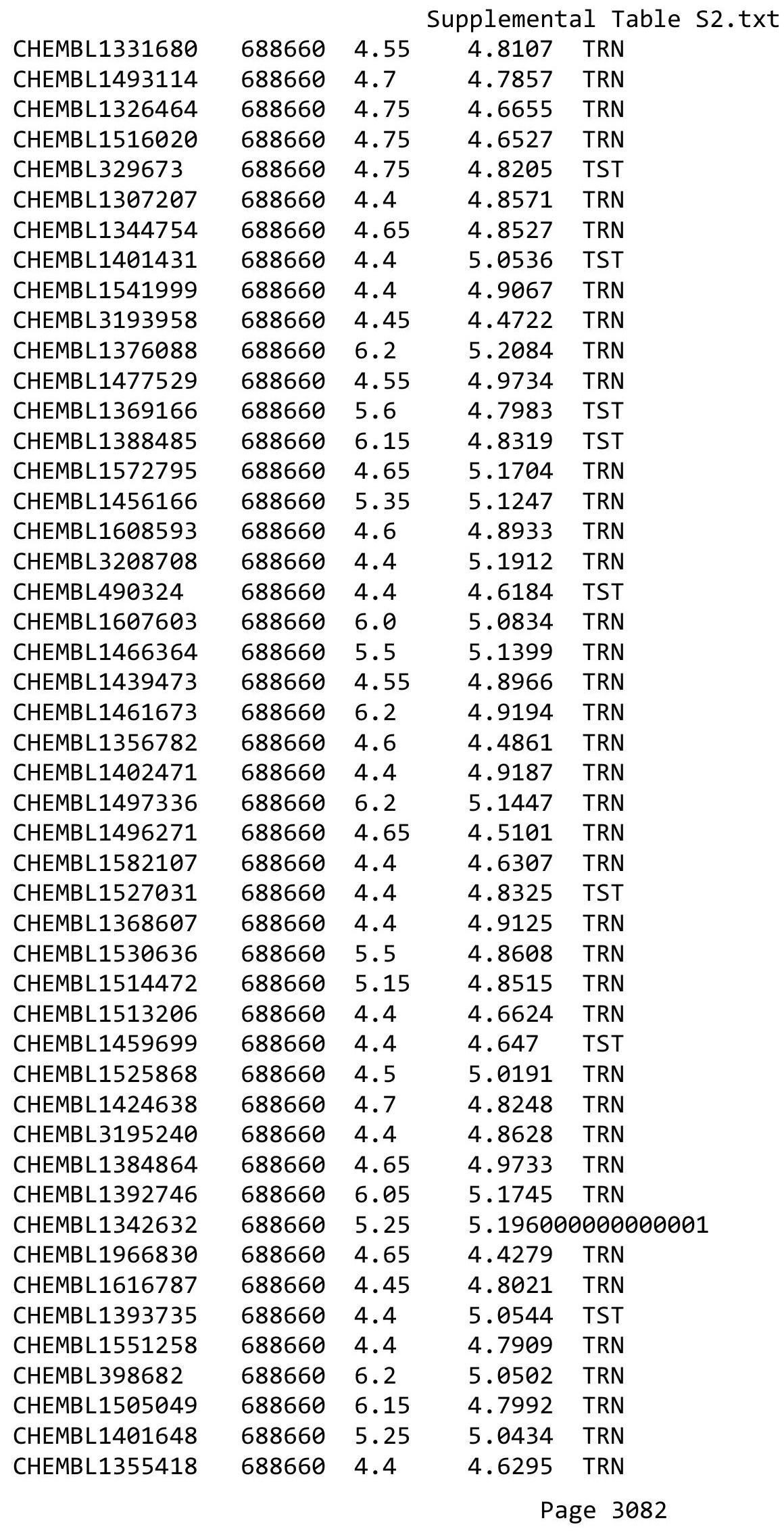




\begin{tabular}{|c|c|c|c|c|}
\hline \multicolumn{5}{|c|}{ Supplemental Table S2.tx } \\
\hline CHEMBL1370116 & 688660 & 4.4 & 4.7886 & TST \\
\hline CHEMBL1611919 & 688660 & 5.25 & 4.838 & TRN \\
\hline CHEMBL1492639 & 688660 & 4.4 & 4.713 & TRN \\
\hline CHEMBL1586606 & 688660 & 4.4 & 4.7857 & TRN \\
\hline CHEMBL1594200 & 688660 & 4.55 & 5.3862 & TRN \\
\hline CHEMBL1996024 & 688660 & 4.4 & 5.1312 & TRN \\
\hline CHEMBL1542773 & 688660 & 5.85 & 4.82600 & 00000000005 \\
\hline CHEMBL1564060 & 688660 & 5.5 & 4.7241 & TRN \\
\hline CHEMBL1411779 & 688660 & 4.65 & 4.9372 & TRN \\
\hline CHEMBL3195430 & 688660 & 5.2 & 4.8186 & TRN \\
\hline CHEMBL1361431 & 688660 & 4.75 & 4.8106 & TRN \\
\hline CHEMBL1561784 & 688660 & 5.5 & 5.0639 & TRN \\
\hline CHEMBL1589777 & 688660 & 4.4 & 4.7554 & TRN \\
\hline CHEMBL1399848 & 688660 & 4.4 & 4.9822 & TST \\
\hline CHEMBL1387242 & 688660 & 5.55 & 5.4285 & TRN \\
\hline CHEMBL1491264 & 688660 & 4.4 & 4.6058 & TRN \\
\hline CHEMBL1441419 & 688660 & 4.4 & 4.6311 & TST \\
\hline CHEMBL1570879 & 688660 & 5.0 & 4.8405 & TRN \\
\hline CHEMBL1419304 & 688660 & 5.0 & 4.9274 & TRN \\
\hline CHEMBL1488237 & 688660 & 5.1 & 4.7369 & TRN \\
\hline CHEMBL1550894 & 688660 & 4.6 & 4.6469 & TST \\
\hline CHEMBL1613681 & 688660 & 5.5 & 4.827 & TRN \\
\hline CHEMBL1440134 & 688660 & 4.4 & 4.6387 & TST \\
\hline CHEMBL1425280 & 688660 & 6.2 & 5.2965 & TRN \\
\hline CHEMBL1389066 & 688660 & 4.5 & 4.8933 & TST \\
\hline CHEMBL436589 & 688660 & 4.75 & 4.9754 & TRN \\
\hline CHEMBL1335941 & 688660 & 6.15 & 4.8264 & TRN \\
\hline CHEMBL1388198 & 688660 & 4.55 & 4.7677 & TRN \\
\hline CHEMBL1424929 & 688660 & 4.8 & 4.8127 & TST \\
\hline CHEMBL 1400375 & 688660 & 4.4 & 4.8838 & TRN \\
\hline CHEMBL1432126 & 688660 & 5.2 & 4.7353 & TST \\
\hline CHEMBL1346127 & 688660 & 5.45 & 5.2361 & TRN \\
\hline CHEMBL1502148 & 688660 & 5.75 & 5.1837 & TRN \\
\hline CHEMBL1419340 & 688660 & 5.05 & 4.9853 & TRN \\
\hline CHEMBL1495845 & 688660 & 4.45 & 4.668 & TRN \\
\hline CHEMBL1424273 & 688660 & 4.55 & 4.8481 & TRN \\
\hline CHEMBL1373383 & 688660 & 5.05 & 4.8461 & TST \\
\hline CHEMBL1377337 & 688660 & 5.0 & 5.0828 & TRN \\
\hline CHEMBL1459368 & 688660 & 4.85 & 4.6985 & TRN \\
\hline CHEMBL1403732 & 688660 & 4.95 & 4.9017 & TRN \\
\hline CHEMBL1417772 & 688660 & 4.45 & 5.0001 & TST \\
\hline CHEMBL1376522 & 688660 & 6.15 & 4.869 & TRN \\
\hline CHEMBL1597561 & 688660 & 4.35 & 4.5509 & TRN \\
\hline CHEMBL1378500 & 688660 & 5.45 & 5.0177 & TRN \\
\hline CHEMBL1533020 & 688660 & 5.9 & 5.1241 & TRN \\
\hline CHEMBL1417410 & 688660 & 4.4 & 5.2221 & TRN \\
\hline CHEMBL1461473 & 688660 & 4.7 & 4.7294 & TST \\
\hline CHEMBL1379685 & 688660 & 5.5 & 5.0183 & TRN \\
\hline
\end{tabular}




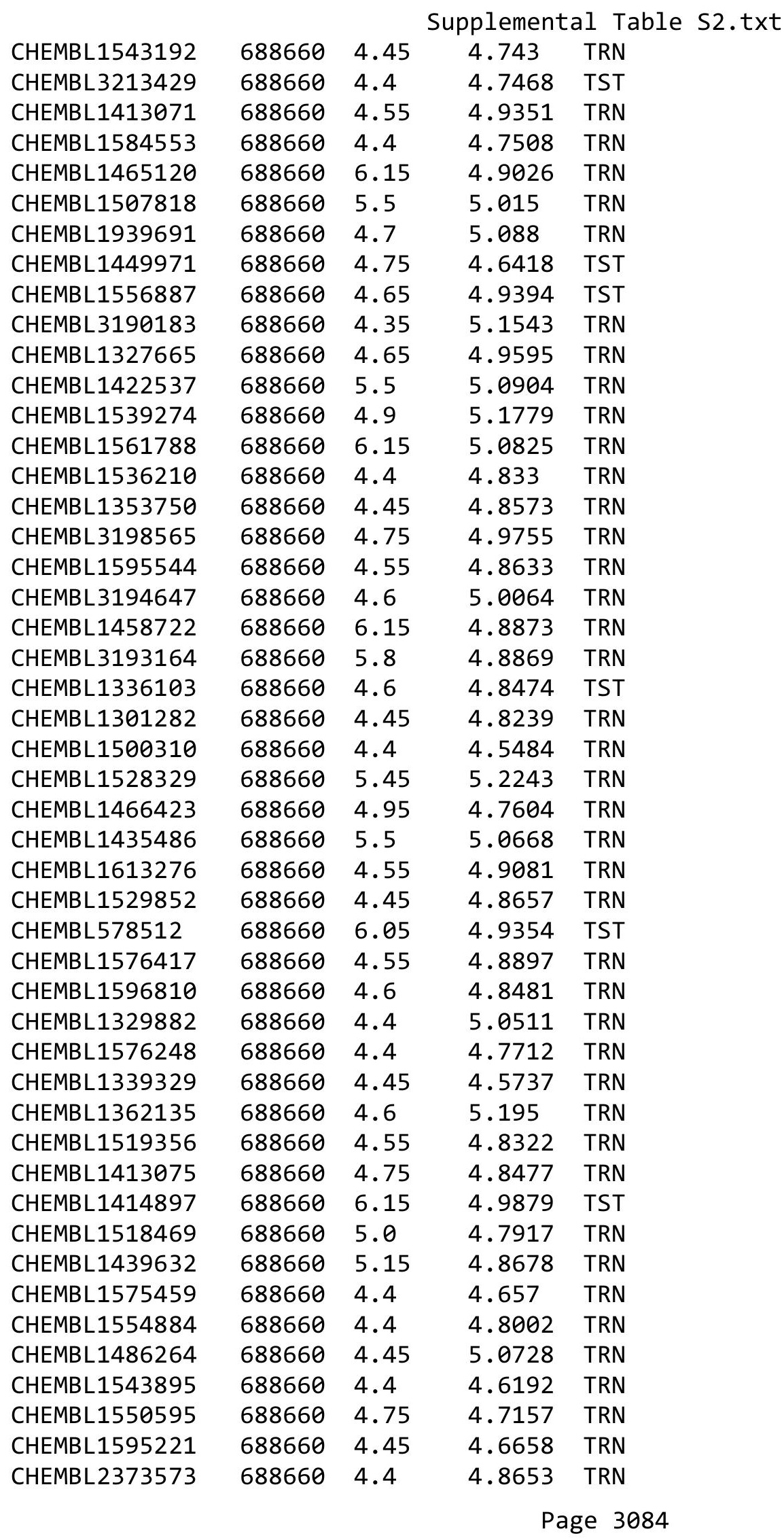




\begin{tabular}{|c|c|c|c|c|c|}
\hline \multicolumn{6}{|c|}{ Supplemental Table S2.txt } \\
\hline CHEMBL365161 & 688660 & 5.2 & 4.8273 & TRN & \\
\hline CHEMBL1388870 & 688660 & 6.15 & 4.7119 & TST & \\
\hline CHEMBL1698464 & 688660 & 4.5 & 4.8566 & TRN & \\
\hline CHEMBL1361707 & 688660 & 5.25 & 4.93199 & 99999999995 & TRN \\
\hline CHEMBL1563251 & 688660 & 4.85 & 4.7124 & TRN & \\
\hline CHEMBL479898 & 688660 & 4.7 & 4.876 & TRN & \\
\hline CHEMBL1472156 & 688660 & 5.15 & 4.9111 & TRN & \\
\hline CHEMBL1463707 & 688660 & 4.4 & 4.7207 & TRN & \\
\hline CHEMBL1394760 & 688660 & 5.55 & 5.2015 & TRN & \\
\hline CHEMBL1556661 & 688660 & 5.35 & 4.7175 & TRN & \\
\hline CHEMBL1575843 & 688660 & 4.7 & 5.0038 & TRN & \\
\hline CHEMBL1301080 & 688660 & 5.45 & 5.1798 & TRN & \\
\hline CHEMBL1432243 & 688660 & 4.6 & 4.761 & TRN & \\
\hline CHEMBL1545721 & 688660 & 4.4 & 4.5983 & TRN & \\
\hline CHEMBL1483166 & 688660 & 5.5 & 4.8714 & TST & \\
\hline CHEMBL3194499 & 688660 & 4.35 & 4.9347 & TRN & \\
\hline CHEMBL1517502 & 688660 & 4.65 & 5.0863 & TRN & \\
\hline CHEMBL1451398 & 688660 & 4.65 & 4.7211 & TRN & \\
\hline CHEMBL1331872 & 688660 & 4.55 & 4.7431 & TST & \\
\hline CHEMBL1375518 & 688660 & 5.15 & 5.2619 & TRN & \\
\hline CHEMBL1480967 & 688660 & 4.7 & 5.0379 & TRN & \\
\hline CHEMBL1517752 & 688660 & 5.45 & 4.9841 & TRN & \\
\hline CHEMBL1504383 & 688660 & 4.4 & 4.9103 & TRN & \\
\hline CHEMBL 3199250 & 688660 & 5.05 & 5.142 & TRN & \\
\hline CHEMBL1561194 & 688660 & 5.4 & 4.5354 & TST & \\
\hline CHEMBL3207333 & 688660 & 4.4 & 4.8798 & TRN & \\
\hline CHEMBL3210567 & 688660 & 4.4 & 5.1351 & TRN & \\
\hline CHEMBL1605463 & 688660 & 4.6 & 4.7707 & TRN & \\
\hline CHEMBL1534402 & 688660 & 4.4 & 4.7971 & TST & \\
\hline CHEMBL3190976 & 688660 & 4.7 & 4.9958 & TRN & \\
\hline CHEMBL1314060 & 688660 & 4.65 & 4.5692 & TRN & \\
\hline CHEMBL1495095 & 688660 & 5.5 & 5.0928 & TRN & \\
\hline CHEMBL1398363 & 688660 & 4.55 & 4.9949 & TRN & \\
\hline CHEMBL1599023 & 688660 & 4.8 & 4.8902 & TST & \\
\hline CHEMBL1573877 & 688660 & 4.85 & 4.7893 & TRN & \\
\hline CHEMBL1426864 & 688660 & 4.4 & 4.9783 & TRN & \\
\hline CHEMBL1444765 & 688660 & 4.4 & 4.8244 & TRN & \\
\hline CHEMBL1607204 & 688660 & 4.4 & 5.0253 & TRN & \\
\hline CHEMBL1556054 & 688660 & 4.5 & 4.8271 & TRN & \\
\hline CHEMBL1424398 & 688660 & 4.4 & 4.8114 & TRN & \\
\hline CHEMBL1510214 & 688660 & 6.15 & 4.8106 & TRN & \\
\hline CHEMBL1305980 & 688660 & 4.4 & 4.7105 & TRN & \\
\hline CHEMBL1305207 & 688660 & 6.2 & 4.8593 & TRN & \\
\hline CHEMBL1497595 & 688660 & 5.4 & 5.1671 & TRN & \\
\hline CHEMBL1354492 & 688660 & 4.65 & 4.7689 & TST & \\
\hline CHEMBL1473903 & 688660 & 5.4 & 4.80399 & 9999999999 & TRN \\
\hline CHEMBL1323475 & 688660 & 4.45 & 4.8571 & TRN & \\
\hline CHEMBL1577818 & 688660 & 4.4 & 4.8234 & TRN & \\
\hline
\end{tabular}




\begin{tabular}{|c|c|c|c|c|c|}
\hline & & \multicolumn{4}{|c|}{ Supplemental Table S2.txt } \\
\hline CHEMBL1473194 & 688660 & 4.75 & 4.7093 & TRN & \\
\hline CHEMBL1375375 & 688660 & 4.55 & 4.7666 & TRN & \\
\hline CHEMBL1591445 & 688660 & 4.45 & 4.4406 & TRN & \\
\hline CHEMBL3197625 & 688660 & 5.4 & 4.9577 & TRN & \\
\hline CHEMBL1321514 & 688660 & 5.45 & 4.7322 & TRN & \\
\hline CHEMBL1452132 & 688660 & 4.5 & 4.71 & TRN & \\
\hline CHEMBL1347293 & 688660 & 4.7 & 4.9512 & TRN & \\
\hline CHEMBL1374062 & 688660 & 4.8 & 4.8777 & TRN & \\
\hline CHEMBL1397123 & 688660 & 5.0 & 4.9146 & TRN & \\
\hline CHEMBL375673 & 688660 & 4.4 & 4.9979 & TST & \\
\hline CHEMBL487603 & 688660 & 5.0 & 4.773 & TRN & \\
\hline CHEMBL1552330 & 688660 & 4.45 & 4.8501 & TRN & \\
\hline CHEMBL1562690 & 688660 & 5.75 & 5.0452 & TRN & \\
\hline CHEMBL1454418 & 688660 & 5.05 & 4.9987 & TRN & \\
\hline CHEMBL1462705 & 688660 & 4.65 & 4.9033 & TRN & \\
\hline CHEMBL1446577 & 688660 & 5.35 & 5.1921 & TRN & \\
\hline CHEMBL1326650 & 688660 & 4.95 & 4.9778 & TRN & \\
\hline CHEMBL1396632 & 688660 & 4.4 & 4.8479 & TRN & \\
\hline CHEMBL1466117 & 688660 & 4.4 & 4.8725 & TRN & \\
\hline CHEMBL1457501 & 688660 & 4.65 & 4.5614 & TRN & \\
\hline CHEMBL1336047 & 688660 & 4.65 & 4.7088 & TRN & \\
\hline CHEMBL1354960 & 688660 & 4.55 & 4.7867 & TST & \\
\hline CHEMBL1530137 & 688660 & 4.4 & 4.7988 & TRN & \\
\hline CHEMBL1603070 & 688660 & 5.3 & 4.7213 & TST & \\
\hline CHEMBL1316802 & 688660 & 4.55 & 5.0028 & TRN & \\
\hline CHEMBL1412252 & 688660 & 4.4 & 4.646 & TST & \\
\hline CHEMBL1476104 & 688660 & 4.65 & 4.7843 & TRN & \\
\hline CHEMBL1612428 & 688660 & 6.5 & 4.842 & TRN & \\
\hline CHEMBL1327952 & 688660 & 4.4 & 4.8582 & TRN & \\
\hline CHEMBL1339261 & 688660 & 4.8 & 4.6792 & TRN & \\
\hline CHEMBL1539510 & 688660 & 4.4 & 4.875 & TRN & \\
\hline CHEMBL1459746 & 688660 & 4.65 & 5.0464 & TRN & \\
\hline CHEMBL1407484 & 688660 & 4.65 & 4.88899 & 9999999999 & TRN \\
\hline CHEMBL1596084 & 688660 & 4.6 & 4.9473 & TRN & \\
\hline CHEMBL3212256 & 688660 & 4.4 & 4.9192 & TRN & \\
\hline CHEMBL1487232 & 688660 & 4.4 & 4.7161 & TRN & \\
\hline CHEMBL1544434 & 688660 & 4.4 & 4.7078 & TRN & \\
\hline CHEMBL1342460 & 688660 & 6.1 & 5.0821 & TRN & \\
\hline CHEMBL1512670 & 688660 & 4.55 & 4.8603 & TRN & \\
\hline CHEMBL1319565 & 688660 & 5.6 & 4.9511 & TST & \\
\hline CHEMBL1428664 & 688660 & 4.4 & 5.012 & TRN & \\
\hline CHEMBL1349617 & 688660 & 4.9 & 4.934 & TRN & \\
\hline CHEMBL1256181 & 688660 & 4.4 & 4.9161 & TST & \\
\hline CHEMBL1359416 & 688660 & 4.4 & 4.7674 & TRN & \\
\hline CHEMBL1509340 & 688660 & 5.5 & 4.9995 & TRN & \\
\hline CHEMBL1489574 & 688660 & 4.65 & 4.8052 & TRN & \\
\hline CHEMBL1476196 & 688660 & 4.4 & 4.6553 & TRN & \\
\hline CHEMBL1432648 & 688660 & 4.5 & 4.9631 & TRN & \\
\hline
\end{tabular}




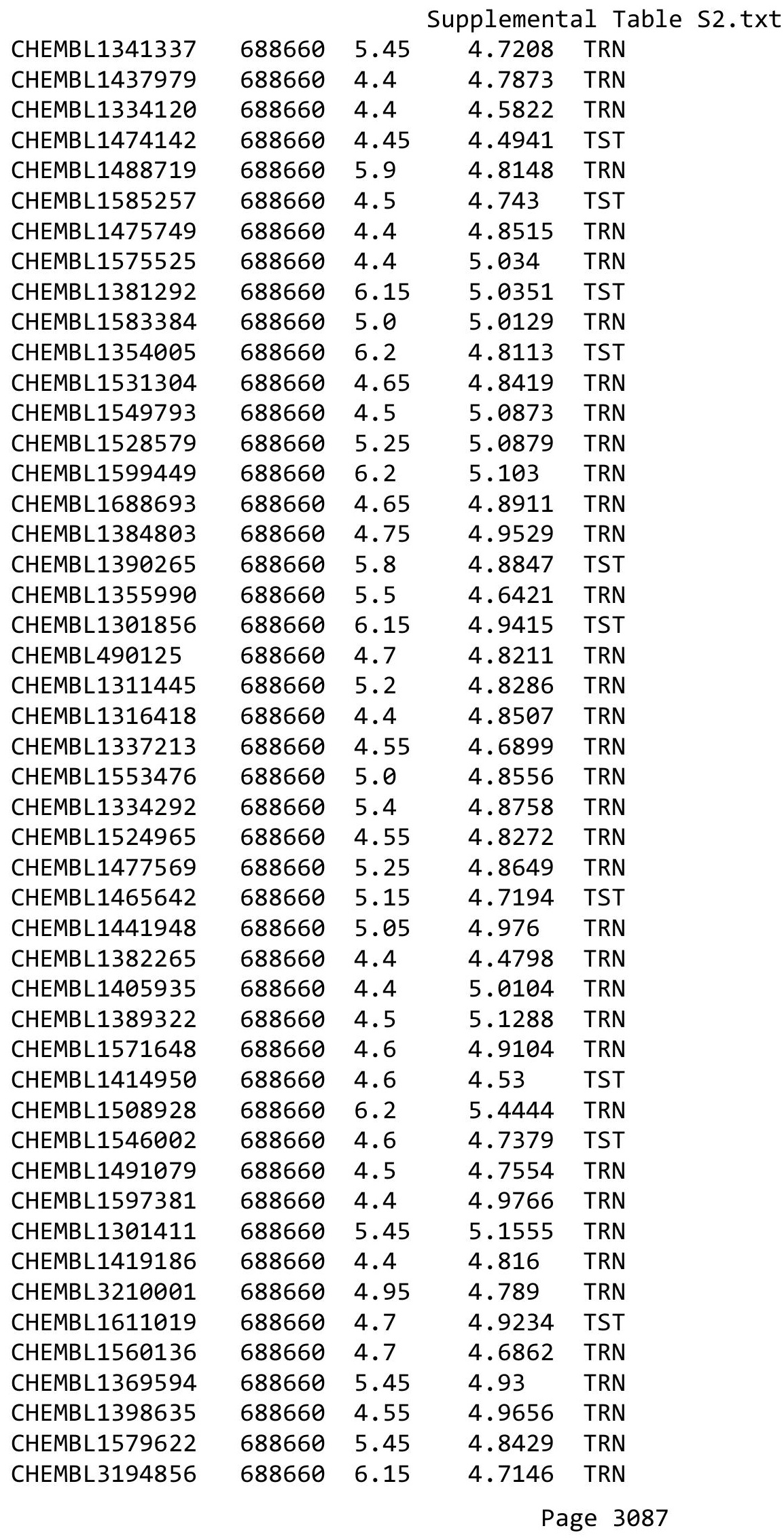




\begin{tabular}{|c|c|c|c|c|}
\hline \multicolumn{5}{|c|}{ Supplemental Table S2.txt } \\
\hline CHEMBL1299864 & 688660 & 5.0 & 4.7077 & TST \\
\hline CHEMBL1584389 & 688660 & 4.55 & 4.7519 & TRN \\
\hline CHEMBL3197218 & 688660 & 4.5 & 4.8326 & TRN \\
\hline CHEMBL1385428 & 688660 & 4.4 & 4.8596 & TRN \\
\hline CHEMBL1299205 & 688660 & 5.95 & 5.0591 & TRN \\
\hline CHEMBL1337057 & 688660 & 4.45 & 5.0654 & TRN \\
\hline CHEMBL1488073 & 688660 & 4.4 & 4.7949 & TRN \\
\hline CHEMBL 3195748 & 688660 & 5.85 & 5.476 & TRN \\
\hline CHEMBL1506854 & 688660 & 4.4 & 4.8132 & TRN \\
\hline CHEMBL1359796 & 688660 & 4.55 & 4.8291 & TRN \\
\hline CHEMBL1537602 & 688660 & 4.7 & 5.2357 & TRN \\
\hline CHEMBL1497525 & 688660 & 5.35 & 4.8934 & TRN \\
\hline CHEMBL1562963 & 688660 & 5.0 & 4.9294 & TRN \\
\hline CHEMBL1427517 & 688660 & 4.45 & 4.9145 & TRN \\
\hline CHEMBL1447255 & 688660 & 4.4 & 5.0134 & TRN \\
\hline CHEMBL1517662 & 688660 & 5.55 & 4.7001 & TST \\
\hline CHEMBL1534303 & 688660 & 4.45 & 5.1389 & TRN \\
\hline CHEMBL1350778 & 688660 & 4.55 & 4.8254 & TRN \\
\hline CHEMBL1522530 & 688660 & 5.25 & 4.992 & TRN \\
\hline CHEMBL1387258 & 688660 & 6.15 & 4.8587 & TST \\
\hline CHEMBL1501640 & 688660 & 5.5 & 4.9437 & TRN \\
\hline CHEMBL1605321 & 688660 & 4.4 & 4.859 & TRN \\
\hline CHEMBL1526017 & 688660 & 6.15 & 4.8472 & TRN \\
\hline CHEMBL1302289 & 688660 & 6.2 & 5.1151 & TRN \\
\hline CHEMBL1406716 & 688660 & 4.4 & 4.8142 & TRN \\
\hline CHEMBL1472501 & 688660 & 5.5 & 4.7768 & TST \\
\hline CHEMBL1487786 & 688660 & 4.4 & 4.7779 & TRN \\
\hline CHEMBL1509555 & 688660 & 5.4 & 4.6816 & TRN \\
\hline CHEMBL1511549 & 688660 & 4.4 & 4.6092 & TRN \\
\hline CHEMBL1368038 & 688660 & 4.65 & 4.631 & TRN \\
\hline CHEMBL1490893 & 688660 & 5.15 & 4.7349 & TRN \\
\hline CHEMBL1470210 & 688660 & 4.6 & 4.8633 & TRN \\
\hline CHEMBL1392861 & 688660 & 4.45 & 4.7206 & TRN \\
\hline CHEMBL1450088 & 688660 & 5.8 & 4.9361 & TST \\
\hline CHEMBL1528877 & 688660 & 4.4 & 4.7888 & TRN \\
\hline CHEMBL1548253 & 688660 & 4.6 & 4.968 & TST \\
\hline CHEMBL1357665 & 688660 & 4.45 & 5.0096 & TRN \\
\hline CHEMBL 3209306 & 688660 & 4.4 & 5.0421 & TRN \\
\hline CHEMBL551883 & 688660 & 4.5 & 4.6666 & TRN \\
\hline CHEMBL1339075 & 688660 & 4.4 & 5.0744 & TRN \\
\hline CHEMBL1348962 & 688660 & 6.2 & 4.8063 & TRN \\
\hline CHEMBL1500967 & 688660 & 6.5 & 5.1158 & TRN \\
\hline CHEMBL507237 & 688660 & 4.7 & 4.5335 & TST \\
\hline CHEMBL1355487 & 688660 & 4.4 & 4.8564 & TRN \\
\hline CHEMBL1533771 & 688660 & 4.4 & 5.1017 & TRN \\
\hline CHEMBL3194916 & 688660 & 4.4 & 4.7969 & TST \\
\hline CHEMBL1327340 & 688660 & 6.15 & 5.044 & TRN \\
\hline CHEMBL1405316 & 688660 & 4.55 & 4.7544 & TRN \\
\hline
\end{tabular}




\begin{tabular}{|c|c|c|c|c|}
\hline \multicolumn{5}{|c|}{ Supplemental Table S2.txt } \\
\hline CHEMBL1513500 & 688660 & 5.4 & 5.0184 & TRN \\
\hline CHEMBL1355823 & 688660 & 4.6 & 4.7185 & TRN \\
\hline CHEMBL1426968 & 688660 & 4.75 & 5.2467 & TRN \\
\hline CHEMBL1539635 & 688660 & 6.2 & 5.0934 & TRN \\
\hline CHEMBL1597632 & 688660 & 5.2 & 5.0494 & TRN \\
\hline CHEMBL3186541 & 688660 & 6.15 & 4.9169 & TRN \\
\hline CHEMBL1581991 & 688660 & 4.7 & 4.9655 & TST \\
\hline CHEMBL1310389 & 688660 & 5.05 & 5.0682 & TST \\
\hline CHEMBL1465527 & 688660 & 5.5 & 5.0552 & TST \\
\hline CHEMBL1589739 & 688660 & 4.4 & 4.7554 & TRN \\
\hline CHEMBL1339905 & 688660 & 4.65 & 4.802 & TRN \\
\hline CHEMBL1540721 & 688660 & 5.35 & 5.1211 & TRN \\
\hline CHEMBL1351677 & 688660 & 4.4 & 4.6645 & TST \\
\hline CHEMBL1321975 & 688660 & 4.6 & 4.6902 & TST \\
\hline CHEMBL1557474 & 688660 & 5.0 & 4.7652 & TRN \\
\hline CHEMBL 254071 & 688660 & 4.45 & 5.0087 & TRN \\
\hline CHEMBL1395256 & 688660 & 4.55 & 4.846 & TRN \\
\hline CHEMBL1418016 & 688660 & 5.0 & 4.6992 & TRN \\
\hline CHEMBL1397651 & 688660 & 4.55 & 4.6123 & TRN \\
\hline CHEMBL1316828 & 688660 & 4.45 & 4.6479 & TST \\
\hline CHEMBL1361883 & 688660 & 4.45 & 4.7315 & TRN \\
\hline CHEMBL1456972 & 688660 & 5.4 & 4.9915 & TRN \\
\hline CHEMBL1390711 & 688660 & 4.75 & 4.8423 & TRN \\
\hline CHEMBL1453144 & 688660 & 4.5 & 4.6324 & TRN \\
\hline CHEMBL331372 & 688660 & 4.4 & 4.7398 & TST \\
\hline CHEMBL1301251 & 688660 & 5.45 & 4.8972 & TRN \\
\hline CHEMBL1566316 & 688660 & 6.2 & 4.9552 & TST \\
\hline CHEMBL1600619 & 688660 & 4.4 & 4.6496 & TRN \\
\hline CHEMBL1437782 & 688660 & 5.3 & 4.7267 & TST \\
\hline CHEMBL1526681 & 688660 & 4.4 & 4.7314 & TRN \\
\hline CHEMBL1438761 & 688660 & 4.4 & 4.7587 & TRN \\
\hline CHEMBL1569232 & 688660 & 4.65 & 4.9336 & TRN \\
\hline CHEMBL1414491 & 688660 & 4.9 & 5.0499 & TRN \\
\hline CHEMBL1548105 & 688660 & 4.4 & 5.0241 & TRN \\
\hline CHEMBL1496187 & 688660 & 4.4 & 4.6214 & TST \\
\hline CHEMBL3213216 & 688660 & 5.15 & 4.8837 & TRN \\
\hline CHEMBL1400881 & 688660 & 5.5 & 5.0225 & TRN \\
\hline CHEMBL1319862 & 688660 & 6.15 & 4.7781 & TRN \\
\hline CHEMBL1509795 & 688660 & 4.8 & 4.6675 & TRN \\
\hline CHEMBL1338285 & 688660 & 4.95 & 4.9418 & TST \\
\hline CHEMBL1329514 & 688660 & 4.7 & 4.6085 & TRN \\
\hline CHEMBL1493051 & 688660 & 4.35 & 4.859 & TRN \\
\hline CHEMBL1430040 & 688660 & 4.65 & 4.952 & TRN \\
\hline CHEMBL1591260 & 688660 & 4.65 & 4.9691 & TRN \\
\hline CHEMBL189584 & 688660 & 4.4 & 4.6676 & TST \\
\hline CHEMBL1381191 & 688660 & 4.4 & 4.8526 & TRN \\
\hline CHEMBL1307701 & 688660 & 5.1 & 5.2138 & TRN \\
\hline CHEMBL1540665 & 688660 & 5.45 & 4.8405 & TRN \\
\hline
\end{tabular}




\begin{tabular}{|c|c|c|c|c|c|}
\hline \multicolumn{6}{|c|}{ Supplemental Table S2.txt } \\
\hline CHEMBL1347664 & 688660 & 4.4 & 5.1255 & TRN & \\
\hline CHEMBL1463427 & 688660 & 6.2 & 4.784 & TRN & \\
\hline CHEMBL1569946 & 688660 & 4.35 & 5.1591 & TRN & \\
\hline CHEMBL1549261 & 688660 & 4.4 & 4.7954 & TRN & \\
\hline CHEMBL1554991 & 688660 & 4.4 & 4.7811 & TRN & \\
\hline CHEMBL1501076 & 688660 & 4.4 & 4.9678 & TRN & \\
\hline CHEMBL1606371 & 688660 & 5.5 & 5.0883 & TRN & \\
\hline CHEMBL1515407 & 688660 & 4.4 & 4.6979 & TRN & \\
\hline CHEMBL379350 & 688660 & 4.7 & 4.7537 & TRN & \\
\hline CHEMBL1325427 & 688660 & 4.8 & 4.7113 & TST & \\
\hline CHEMBL3193190 & 688660 & 4.4 & 5.1454 & TRN & \\
\hline CHEMBL1348796 & 688660 & 6.2 & 5.1564 & TRN & \\
\hline CHEMBL1402175 & 688660 & 5.6 & 4.9114 & TRN & \\
\hline CHEMBL1444507 & 688660 & 4.55 & 4.8978 & TRN & \\
\hline CHEMBL1603228 & 688660 & 5.15 & 4.8743 & TRN & \\
\hline CHEMBL1556832 & 688660 & 5.5 & 4.5851 & TRN & \\
\hline CHEMBL1587459 & 688660 & 5.75 & 4.7255 & TRN & \\
\hline CHEMBL1489737 & 688660 & 5.45 & 4.9606 & TST & \\
\hline CHEMBL3193059 & 688660 & 6.15 & 5.1492 & TRN & \\
\hline CHEMBL1328075 & 688660 & 4.8 & 4.9351 & TRN & \\
\hline CHEMBL1588191 & 688660 & 5.4 & 4.9793 & TRN & \\
\hline CHEMBL1362886 & 688660 & 4.5 & 4.9623 & TRN & \\
\hline CHEMBL1384158 & 688660 & 6.15 & 4.97199 & 99999999995 & TRN \\
\hline CHEMBL1488866 & 688660 & 4.4 & 5.0625 & TRN & \\
\hline CHEMBL1612978 & 688660 & 5.45 & 4.4073 & TRN & \\
\hline CHEMBL1533933 & 688660 & 4.55 & 4.9485 & TRN & \\
\hline CHEMBL1361889 & 688660 & 4.5 & 4.7798 & TRN & \\
\hline CHEMBL1224757 & 688660 & 4.5 & 5.1027 & TRN & \\
\hline CHEMBL1453311 & 688660 & 5.45 & 4.6789 & TST & \\
\hline CHEMBL3213899 & 688660 & 5.4 & 4.9161 & TRN & \\
\hline CHEMBL3210368 & 688660 & 5.25 & 5.0241 & TRN & \\
\hline CHEMBL233531 & 688660 & 4.4 & 4.7209 & TRN & \\
\hline CHEMBL1487781 & 688660 & 4.6 & 4.9489 & TRN & \\
\hline CHEMBL99408 & 688660 & 5.5 & 4.9222 & TRN & \\
\hline CHEMBL1353650 & 688660 & 4.75 & 5.0816 & TRN & \\
\hline CHEMBL469036 & 688660 & 4.5 & 4.6369 & TST & \\
\hline CHEMBL1398061 & 688660 & 4.55 & 4.7094 & TRN & \\
\hline CHEMBL1334083 & 688660 & 4.4 & 4.8142 & TRN & \\
\hline CHEMBL1323237 & 688660 & 5.3 & 4.8929 & TRN & \\
\hline CHEMBL1528821 & 688660 & 4.4 & 4.8112 & TRN & \\
\hline CHEMBL1376137 & 688660 & 4.45 & 4.6561 & TRN & \\
\hline CHEMBL1583030 & 688660 & 4.55 & 5.0037 & TRN & \\
\hline CHEMBL3196111 & 688660 & 5.5 & 5.0636 & TRN & \\
\hline CHEMBL3193378 & 688660 & 5.35 & 5.1205 & TRN & \\
\hline CHEMBL1488867 & 688660 & 6.15 & 5.0227 & TRN & \\
\hline CHEMBL1413822 & 688660 & 4.4 & 4.8768 & TRN & \\
\hline CHEMBL1429321 & 688660 & 6.2 & 5.1509 & TRN & \\
\hline CHEMBL1507523 & 688660 & 4.8 & 4.895 & TRN & \\
\hline
\end{tabular}




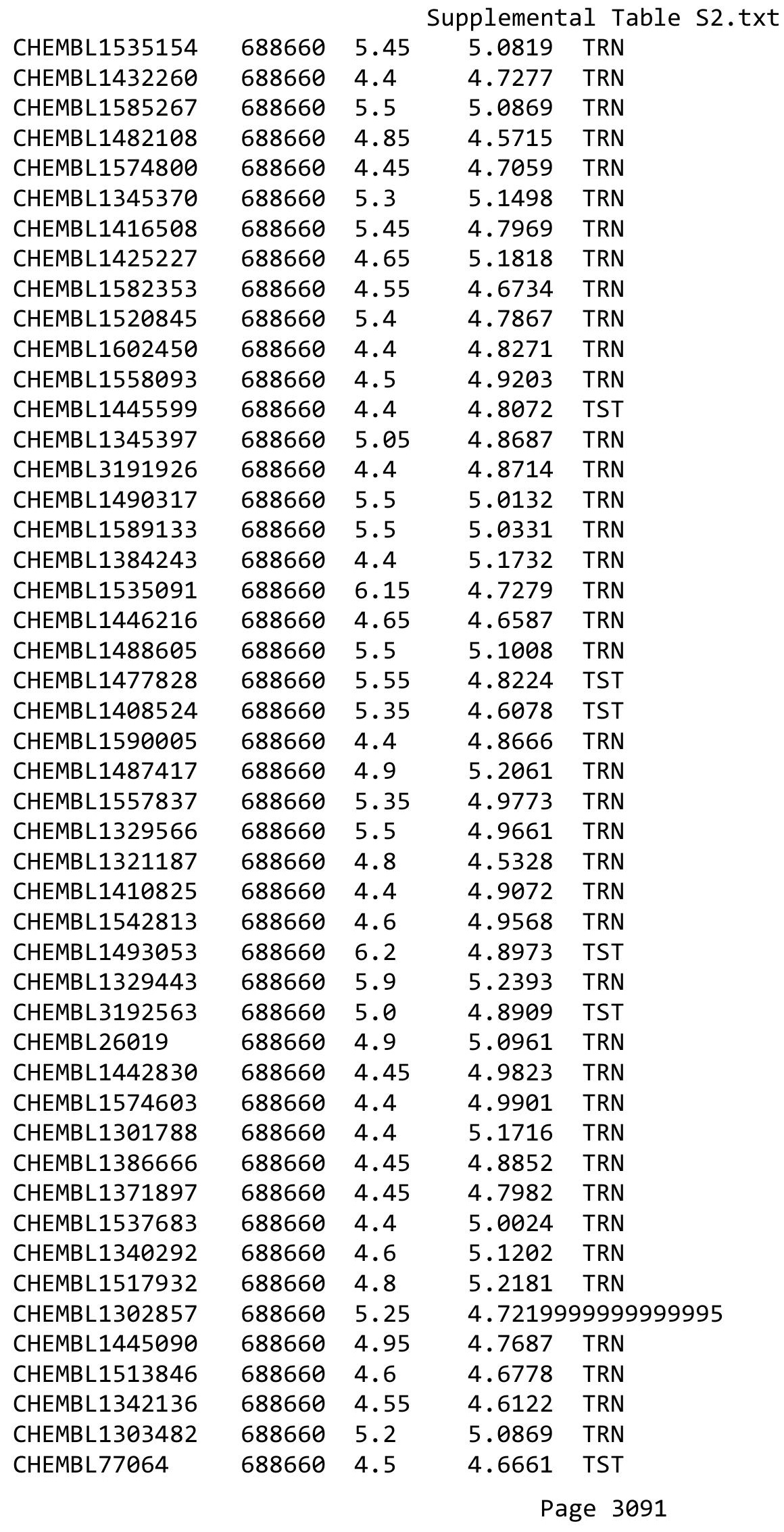

TRN 


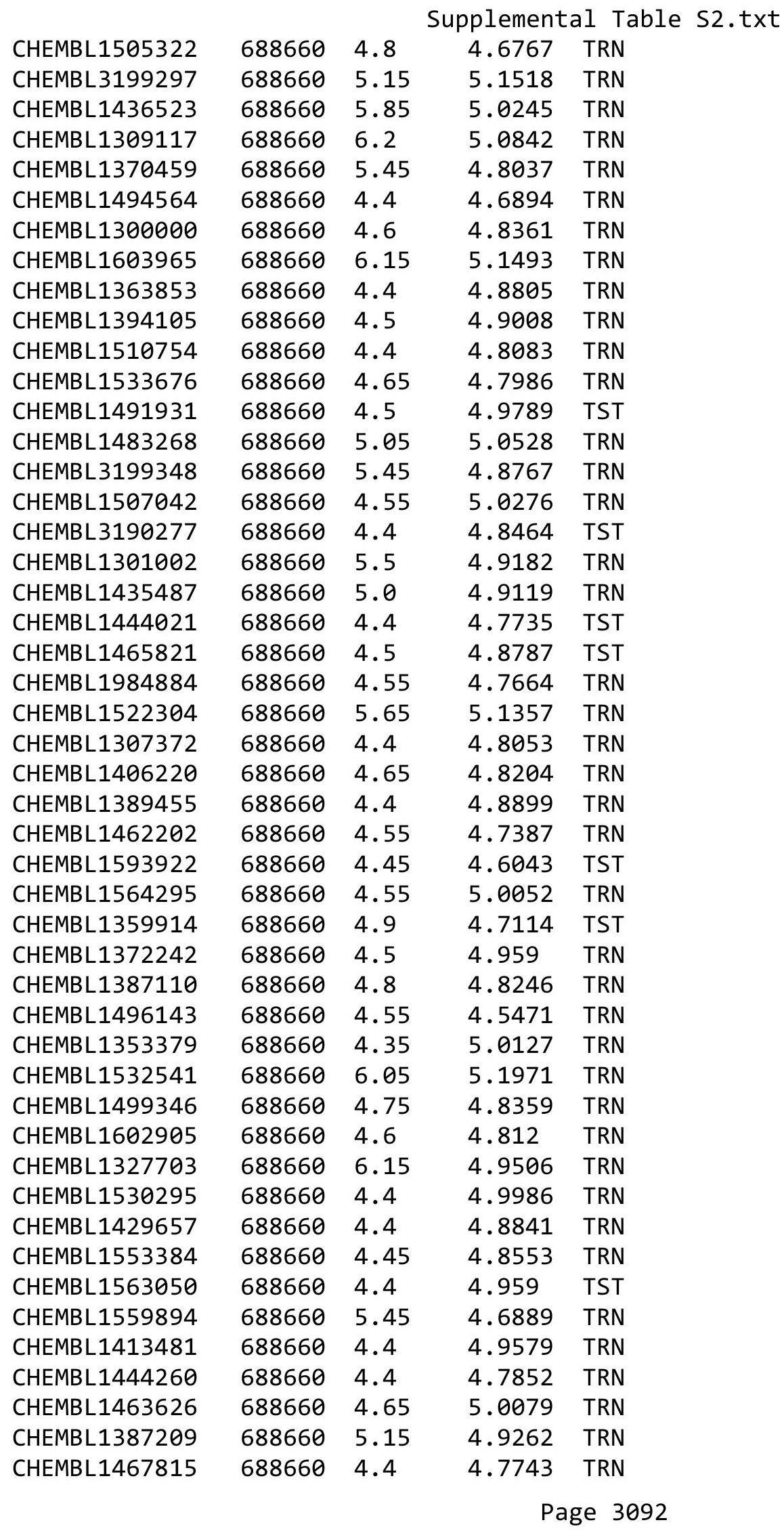




\begin{tabular}{|c|c|c|c|c|c|}
\hline \multicolumn{6}{|c|}{ Supplemental Table S2.txt } \\
\hline CHEMBL3209821 & 688660 & 6.0 & 5.1789 & TRN & \\
\hline CHEMBL1550788 & 688660 & 4.4 & 4.6892 & TRN & \\
\hline CHEMBL1352072 & 688660 & 4.4 & 5.0855 & TRN & \\
\hline CHEMBL1417212 & 688660 & 4.8 & 4.9879 & TRN & \\
\hline CHEMBL1545382 & 688660 & 5.4 & 4.9392 & TRN & \\
\hline CHEMBL1515422 & 688660 & 4.35 & 4.8241 & TRN & \\
\hline CHEMBL1455075 & 688660 & 4.55 & 5.1392 & TRN & \\
\hline CHEMBL1313638 & 688660 & 5.55 & 4.8239 & TRN & \\
\hline CHEMBL1414458 & 688660 & 5.55 & 5.0549 & TRN & \\
\hline CHEMBL1555642 & 688660 & 4.7 & 4.787 & TRN & \\
\hline CHEMBL1588339 & 688660 & 4.4 & 4.4526 & TRN & \\
\hline CHEMBL1572539 & 688660 & 5.3 & 5.2012 & TRN & \\
\hline CHEMBL1399970 & 688660 & 5.45 & 5.1331 & TRN & \\
\hline CHEMBL1580910 & 688660 & 4.75 & 4.8967 & TRN & \\
\hline CHEMBL1502063 & 688660 & 5.45 & 4.6826 & TRN & \\
\hline CHEMBL1417635 & 688660 & 6.2 & 5.013 & TRN & \\
\hline CHEMBL1334837 & 688660 & 4.5 & 4.5675 & TRN & \\
\hline CHEMBL1401317 & 688660 & 4.55 & 4.8923 & TRN & \\
\hline CHEMBL1551259 & 688660 & 4.4 & 5.0224 & TRN & \\
\hline CHEMBL1462267 & 688660 & 4.55 & 4.9441 & TRN & \\
\hline CHEMBL 3213560 & 688660 & 5.5 & 4.73300 & 00000000005 & TST \\
\hline CHEMBL1576702 & 688660 & 6.1 & 4.957 & TRN & \\
\hline CHEMBL1200938 & 688660 & 4.4 & 4.8635 & TST & \\
\hline CHEMBL1429723 & 688660 & 5.45 & 5.1583 & TRN & \\
\hline CHEMBL1525781 & 688660 & 5.0 & 4.9736 & TRN & \\
\hline CHEMBL1348088 & 688660 & 4.4 & 5.1411 & TRN & \\
\hline CHEMBL1332843 & 688660 & 4.45 & 4.8351 & TRN & \\
\hline CHEMBL1572168 & 688660 & 6.2 & 4.9821 & TRN & \\
\hline CHEMBL1581312 & 688660 & 6.15 & 5.0448 & TRN & \\
\hline CHEMBL1431669 & 688660 & 4.65 & 4.8249 & TRN & \\
\hline CHEMBL1355723 & 688660 & 5.2 & 4.621 & TRN & \\
\hline CHEMBL1427264 & 688660 & 4.7 & 5.0071 & TRN & \\
\hline CHEMBL1551638 & 688660 & 4.4 & 4.6358 & TRN & \\
\hline CHEMBL3211443 & 688660 & 5.15 & 4.7358 & TRN & \\
\hline CHEMBL3189747 & 688660 & 4.4 & 4.6634 & TRN & \\
\hline CHEMBL1470752 & 688660 & 5.4 & 5.1024 & TRN & \\
\hline CHEMBL3195364 & 688660 & 5.3 & 5.1826 & TRN & \\
\hline CHEMBL1527473 & 688660 & 5.35 & 4.7125 & TRN & \\
\hline CHEMBL1529996 & 688660 & 4.4 & 5.0357 & TRN & \\
\hline CHEMBL1393654 & 688660 & 5.15 & 5.1825 & TRN & \\
\hline CHEMBL1447284 & 688660 & 4.6 & 4.8863 & TRN & \\
\hline CHEMBL3190283 & 688660 & 4.9 & 5.05699 & 99999999995 & TST \\
\hline CHEMBL241858 & 688660 & 4.35 & 4.9311 & TRN & \\
\hline CHEMBL1443887 & 688660 & 6.2 & 5.2858 & TRN & \\
\hline CHEMBL1359249 & 688660 & 5.65 & 4.9237 & TRN & \\
\hline CHEMBL1471184 & 688660 & 4.75 & 4.9442 & TRN & \\
\hline CHEMBL1554942 & 688660 & 4.6 & 4.7939 & TRN & \\
\hline CHEMBL1583002 & 688660 & 6.15 & 5.0023 & TRN & \\
\hline
\end{tabular}




\begin{tabular}{|c|c|c|c|c|}
\hline \multicolumn{5}{|c|}{ Supplemental Table s2.txt } \\
\hline CHEMBL3191104 & 688660 & 4.5 & 4.9853 & TRN \\
\hline CHEMBL1425512 & 688660 & 6.15 & 5.12200 & 0000000001 \\
\hline CHEMBL1517390 & 688660 & 4.8 & 4.8543 & TRN \\
\hline CHEMBL1487196 & 688660 & 4.6 & 5.0739 & TRN \\
\hline CHEMBL1503395 & 688660 & 5.45 & 5.1524 & TRN \\
\hline CHEMBL1368325 & 688660 & 5.05 & 4.7273 & TRN \\
\hline CHEMBL1487117 & 688660 & 6.05 & 4.7394 & TRN \\
\hline CHEMBL1360273 & 688660 & 4.6 & 5.0053 & TRN \\
\hline CHEMBL1520155 & 688660 & 4.4 & 5.0915 & TRN \\
\hline CHEMBL1517256 & 688660 & 6.15 & 5.0752 & TRN \\
\hline CHEMBL1606008 & 688660 & 4.4 & 4.8264 & TRN \\
\hline CHEMBL1321862 & 688660 & 4.7 & 4.5464 & TRN \\
\hline CHEMBL1563784 & 688660 & 4.4 & 4.9722 & TRN \\
\hline CHEMBL1428943 & 688660 & 5.1 & 5.1 & TRN \\
\hline CHEMBL1566702 & 688660 & 4.9 & 5.044 & TRN \\
\hline CHEMBL1560481 & 688660 & 4.7 & 5.1791 & TRN \\
\hline CHEMBL1302545 & 688660 & 4.6 & 4.7486 & TRN \\
\hline CHEMBL1568046 & 688660 & 6.2 & 5.1605 & TRN \\
\hline CHEMBL1361493 & 688660 & 4.7 & 5.0025 & TRN \\
\hline CHEMBL1323832 & 688660 & 4.85 & 4.6702 & TRN \\
\hline CHEMBL1256686 & 688660 & 4.4 & 4.5904 & TST \\
\hline CHEMBL1341561 & 688660 & 4.65 & 4.6684 & TRN \\
\hline CHEMBL1561741 & 688660 & 4.95 & 5.2 & TRN \\
\hline CHEMBL1586560 & 688660 & 4.4 & 4.9121 & TST \\
\hline CHEMBL472437 & 688660 & 4.6 & 4.6813 & TST \\
\hline CHEMBL1352086 & 688660 & 4.55 & 4.7544 & TRN \\
\hline CHEMBL578061 & 688660 & 4.7 & 4.9096 & TRN \\
\hline CHEMBL 2003806 & 688660 & 5.15 & 5.0443 & TRN \\
\hline CHEMBL1421922 & 688660 & 4.5 & 5.2053 & TRN \\
\hline CHEMBL1601056 & 688660 & 5.0 & 5.0767 & TRN \\
\hline CHEMBL1406323 & 688660 & 5.45 & 4.9864 & TRN \\
\hline CHEMBL1323042 & 688660 & 4.5 & 4.8259 & TRN \\
\hline CHEMBL1385784 & 688660 & 4.4 & 4.8864 & TST \\
\hline CHEMBL1509211 & 688660 & 4.85 & 4.7195 & TST \\
\hline CHEMBL1425272 & 688660 & 4.4 & 4.6833 & TRN \\
\hline CHEMBL1512940 & 688660 & 4.5 & 4.6118 & TRN \\
\hline CHEMBL1502653 & 688660 & 4.45 & 4.9427 & TRN \\
\hline CHEMBL1527992 & 688660 & 4.4 & 4.6992 & TST \\
\hline CHEMBL1485137 & 688660 & 4.55 & 4.7434 & TRN \\
\hline CHEMBL411666 & 688660 & 4.9 & 4.8068 & TRN \\
\hline CHEMBL3196983 & 688660 & 5.3 & 5.1118 & TRN \\
\hline CHEMBL1321759 & 688660 & 5.05 & 5.3137 & TRN \\
\hline CHEMBL1356438 & 688660 & 5.0 & 4.9119 & TRN \\
\hline CHEMBL3207339 & 688660 & 4.75 & 4.8891 & TRN \\
\hline CHEMBL1328213 & 688660 & 6.15 & 4.8152 & TST \\
\hline CHEMBL1336974 & 688660 & 4.4 & 4.7126 & TRN \\
\hline CHEMBL1507043 & 688660 & 5.5 & 4.9713 & TRN \\
\hline CHEMBL1984065 & 688660 & 5.05 & 5.0399 & TRN \\
\hline
\end{tabular}

TRN 


\begin{tabular}{|c|c|c|c|c|}
\hline \multicolumn{5}{|c|}{ Supplemental Table S2.txt } \\
\hline CHEMBL1371613 & 688660 & 4.55 & 4.9443 & TRN \\
\hline CHEMBL1313830 & 688660 & 4.4 & 4.4267 & TRN \\
\hline CHEMBL1462609 & 688660 & 4.4 & 5.0677 & TRN \\
\hline CHEMBL1609461 & 688660 & 4.45 & 4.7358 & TRN \\
\hline CHEMBL1405947 & 688660 & 4.4 & 4.689 & TRN \\
\hline CHEMBL1589103 & 688660 & 4.4 & 4.829 & TRN \\
\hline CHEMBL1526672 & 688660 & 5.45 & 4.7031 & TRN \\
\hline CHEMBL1355259 & 688660 & 6.2 & 5.1219 & TRN \\
\hline CHEMBL1474058 & 688660 & 4.5 & 4.6411 & TRN \\
\hline CHEMBL1304384 & 688660 & 4.6 & 4.9957 & TRN \\
\hline CHEMBL1384253 & 688660 & 5.75 & 4.8341 & TRN \\
\hline CHEMBL1406792 & 688660 & 4.7 & 5.0079 & TRN \\
\hline CHEMBL1523417 & 688660 & 4.4 & 5.2599 & TRN \\
\hline CHEMBL1578798 & 688660 & 4.45 & 4.74 & TRN \\
\hline CHEMBL1324351 & 688660 & 6.15 & 4.8713 & TRN \\
\hline CHEMBL1570750 & 688660 & 4.4 & 4.5099 & TRN \\
\hline CHEMBL1483683 & 688660 & 4.4 & 4.7586 & TST \\
\hline CHEMBL1547631 & 688660 & 4.65 & 4.9194 & TRN \\
\hline CHEMBL1721986 & 688660 & 5.45 & 5.0525 & TRN \\
\hline CHEMBL1524542 & 688660 & 6.0 & 4.8609 & TRN \\
\hline CHEMBL1601494 & 688660 & 5.45 & 5.0005 & TRN \\
\hline CHEMBL1398209 & 688660 & 4.4 & 4.4023 & TRN \\
\hline CHEMBL1311773 & 688660 & 4.4 & 4.6614 & TRN \\
\hline CHEMBL1982658 & 688660 & 5.2 & 5.0746 & TRN \\
\hline CHEMBL2373602 & 688660 & 6.0 & 4.6215 & TST \\
\hline CHEMBL1347154 & 688660 & 6.2 & 4.9409 & TST \\
\hline CHEMBL1388927 & 688660 & 4.7 & 4.8026 & TRN \\
\hline CHEMBL1347726 & 688660 & 4.65 & 4.8299 & TRN \\
\hline CHEMBL1301377 & 688660 & 5.2 & 5.0296 & TRN \\
\hline CHEMBL1498344 & 688660 & 5.05 & 4.6188 & TST \\
\hline CHEMBL1328795 & 688660 & 4.55 & 5.0998 & TRN \\
\hline CHEMBL1580619 & 688660 & 4.7 & 4.6905 & TRN \\
\hline CHEMBL1470047 & 688660 & 4.45 & 4.7855 & TRN \\
\hline CHEMBL1562867 & 688660 & 4.5 & 4.6842 & TST \\
\hline CHEMBL1458181 & 688660 & 6.2 & 5.1199 & TRN \\
\hline CHEMBL1318333 & 688660 & 6.45 & 5.0499 & TRN \\
\hline CHEMBL1584579 & 688660 & 4.75 & 4.8135 & TRN \\
\hline CHEMBL1316721 & 688660 & 5.35 & 4.7689 & TRN \\
\hline CHEMBL1478186 & 688660 & 6.0 & 5.1337 & TRN \\
\hline CHEMBL1371962 & 688660 & 6.2 & 5.0414 & TRN \\
\hline CHEMBL1542462 & 688660 & 4.9 & 4.6846 & TRN \\
\hline CHEMBL1441973 & 688660 & 5.4 & 5.1558 & TRN \\
\hline CHEMBL1432300 & 688660 & 4.4 & 4.6732 & TRN \\
\hline CHEMBL1325956 & 688660 & 4.4 & 5.0377 & TRN \\
\hline CHEMBL1322445 & 688660 & 4.4 & 5.2929 & TRN \\
\hline CHEMBL1556020 & 688660 & 4.65 & 4.82100 & 0000000001 \\
\hline CHEMBL1472472 & 688660 & 4.45 & 4.6653 & TRN \\
\hline CHEMBL1362255 & 688660 & 5.4 & 5.2928 & TRN \\
\hline
\end{tabular}




\begin{tabular}{|c|c|c|c|c|c|}
\hline \multicolumn{6}{|c|}{ Supplemental Table S2.txt } \\
\hline CHEMBL3191688 & 688660 & 4.55 & 4.9042 & TST & \\
\hline CHEMBL1489005 & 688660 & 4.55 & 5.0365 & TRN & \\
\hline CHEMBL1392981 & 688660 & 6.15 & 5.1376 & TRN & \\
\hline CHEMBL3210594 & 688660 & 4.4 & 4.7567 & TRN & \\
\hline CHEMBL1538846 & 688660 & 6.2 & 4.9608 & TST & \\
\hline CHEMBL1569269 & 688660 & 6.5 & 4.7443 & TST & \\
\hline CHEMBL1348216 & 688660 & 4.55 & 4.7817 & TRN & \\
\hline CHEMBL1500830 & 688660 & 4.4 & 4.5787 & TRN & \\
\hline CHEMBL1517465 & 688660 & 4.5 & 4.8527 & TRN & \\
\hline CHEMBL1343448 & 688660 & 4.4 & 4.6254 & TRN & \\
\hline CHEMBL1565290 & 688660 & 4.55 & 4.8691 & TRN & \\
\hline CHEMBL3209497 & 688660 & 4.5 & 4.7413 & TRN & \\
\hline CHEMBL1493016 & 688660 & 4.4 & 4.65600 & 3000000001 & TRN \\
\hline CHEMBL1597465 & 688660 & 4.4 & 4.9397 & TRN & \\
\hline CHEMBL1506930 & 688660 & 5.45 & 4.8861 & TRN & \\
\hline CHEMBL1584523 & 688660 & 4.55 & 4.931 & TRN & \\
\hline CHEMBL1471428 & 688660 & 5.5 & 4.8551 & TST & \\
\hline CHEMBL1547092 & 688660 & 4.5 & 5.0118 & TRN & \\
\hline CHEMBL1421457 & 688660 & 5.5 & 4.6918 & TST & \\
\hline CHEMBL1419718 & 688660 & 5.7 & 4.8913 & TST & \\
\hline CHEMBL1321407 & 688660 & 4.5 & 4.8626 & TRN & \\
\hline CHEMBL1467356 & 688660 & 4.5 & 4.7117 & TRN & \\
\hline CHEMBL1578269 & 688660 & 4.4 & 5.1158 & TRN & \\
\hline CHEMBL1423286 & 688660 & 6.2 & 4.9792 & TRN & \\
\hline CHEMBL1510925 & 688660 & 4.5 & 4.9279 & TRN & \\
\hline CHEMBL1356315 & 688660 & 4.5 & 5.2012 & TRN & \\
\hline CHEMBL1384299 & 688660 & 5.2 & 5.0787 & TRN & \\
\hline CHEMBL1464675 & 688660 & 4.5 & 4.7483 & TRN & \\
\hline CHEMBL1427566 & 688660 & 5.5 & 4.8801 & TRN & \\
\hline CHEMBL1406272 & 688660 & 4.85 & 4.8304 & TRN & \\
\hline CHEMBL1464721 & 688660 & 5.35 & 4.8904 & TRN & \\
\hline CHEMBL1389933 & 688660 & 4.45 & 4.7551 & TRN & \\
\hline CHEMBL1303814 & 688660 & 4.4 & 4.9456 & TRN & \\
\hline CHEMBL1421900 & 688660 & 4.4 & 4.8951 & TRN & \\
\hline CHEMBL1448599 & 688660 & 4.4 & 4.8271 & TRN & \\
\hline CHEMBL261782 & 688660 & 4.55 & 4.78 & TRN & \\
\hline CHEMBL1562664 & 688660 & 4.45 & 4.5644 & TRN & \\
\hline CHEMBL1373590 & 688660 & 4.4 & 4.8658 & TRN & \\
\hline CHEMBL1309736 & 688660 & 5.45 & 4.8923 & TRN & \\
\hline CHEMBL1581250 & 688660 & 4.55 & 4.83899 & 99999999995 & TRN \\
\hline CHEMBL1303653 & 688660 & 4.4 & 4.8952 & TRN & \\
\hline CHEMBL104255 & 688660 & 4.55 & 5.0077 & TRN & \\
\hline CHEMBL1503156 & 688660 & 6.15 & 5.2109 & TRN & \\
\hline CHEMBL1300391 & 688660 & 4.4 & 4.9225 & TRN & \\
\hline CHEMBL1564040 & 688660 & 4.4 & 4.6376 & TRN & \\
\hline CHEMBL1605033 & 688660 & 6.2 & 4.7488 & TRN & \\
\hline CHEMBL1351028 & 688660 & 6.15 & 5.0989 & TRN & \\
\hline CHEMBL246657 & 688660 & 4.9 & 4.8647 & TRN & \\
\hline
\end{tabular}




\begin{tabular}{|c|c|c|c|c|c|}
\hline & & & & & \\
\hline CHEMBL1476017 & 688660 & 4.4 & 4.9172 & TST & \\
\hline CHEMBL1393265 & 688660 & 4.7 & 4.8752 & TST & \\
\hline CHEMBL1544782 & 688660 & 4.4 & 4.7615 & TRN & \\
\hline CHEMBL1498509 & 688660 & 5.35 & 4.7497 & TRN & \\
\hline CHEMBL1599946 & 688660 & 4.6 & 4.6145 & TRN & \\
\hline CHEMBL1551351 & 688660 & 4.4 & 4.7283 & TRN & \\
\hline CHEMBL1535261 & 688660 & 4.45 & 4.8538 & TRN & \\
\hline CHEMBL1403929 & 688660 & 4.4 & 4.8142 & TRN & \\
\hline CHEMBL1302213 & 688660 & 4.4 & 5.1294 & TRN & \\
\hline CHEMBL1525207 & 688660 & 4.4 & 4.7036 & TRN & \\
\hline CHEMBL1378093 & 688660 & 6.15 & 4.7568 & TRN & \\
\hline CHEMBL1609720 & 688660 & 4.5 & 4.6509 & TRN & \\
\hline CHEMBL1494023 & 688660 & 5.5 & 4.88899 & 9999999999 & TRN \\
\hline CHEMBL1361601 & 688660 & 4.4 & 4.7416 & TRN & \\
\hline CHEMBL407864 & 688660 & 4.4 & 4.6607 & TRN & \\
\hline CHEMBL1420872 & 688660 & 4.5 & 4.9526 & TRN & \\
\hline CHEMBL1348732 & 688660 & 4.5 & 4.8618 & TRN & \\
\hline CHEMBL59026 & 688660 & 4.45 & 5.1643 & TRN & \\
\hline CHEMBL1580255 & 688660 & 5.8 & 5.1527 & TRN & \\
\hline CHEMBL1568122 & 688660 & 4.95 & 4.7242 & TRN & \\
\hline CHEMBL1351459 & 688660 & 4.8 & 4.7539 & TRN & \\
\hline CHEMBL1456622 & 688660 & 4.6 & 4.9214 & TRN & \\
\hline CHEMBL3198972 & 688660 & 5.55 & 4.8153 & TRN & \\
\hline CHEMBL1441161 & 688660 & 4.45 & 4.8996 & TRN & \\
\hline CHEMBL1471025 & 688660 & 6.2 & 4.8184 & TST & \\
\hline CHEMBL1603500 & 688660 & 4.5 & 4.9519 & TRN & \\
\hline CHEMBL1413527 & 688660 & 4.7 & 5.1822 & TRN & \\
\hline CHEMBL1452031 & 688660 & 4.4 & 4.718 & TST & \\
\hline CHEMBL1453670 & 688660 & 4.4 & 4.7194 & TRN & \\
\hline CHEMBL1375491 & 688660 & 5.0 & 5.0764 & TRN & \\
\hline CHEMBL1309635 & 688660 & 4.6 & 5.0616 & TRN & \\
\hline CHEMBL1336688 & 688660 & 4.4 & 4.7996 & TRN & \\
\hline CHEMBL1532436 & 688660 & 4.5 & 5.0191 & TRN & \\
\hline CHEMBL1425525 & 688660 & 4.4 & 4.7553 & TST & \\
\hline CHEMBL1400705 & 688660 & 5.5 & 5.0184 & TRN & \\
\hline CHEMBL1433095 & 688660 & 4.45 & 4.6385 & TRN & \\
\hline CHEMBL1302785 & 688660 & 4.95 & 4.7821 & TRN & \\
\hline CHEMBL1428197 & 688660 & 4.45 & 4.7942 & TRN & \\
\hline CHEMBL1329634 & 688660 & 4.75 & 4.7283 & TRN & \\
\hline CHEMBL1412015 & 688660 & 4.45 & 4.6842 & TRN & \\
\hline CHEMBL1606625 & 688660 & 4.4 & 4.7207 & TRN & \\
\hline CHEMBL1425167 & 688660 & 5.55 & 4.8492 & TRN & \\
\hline CHEMBL1982577 & 688660 & 4.4 & 4.9638 & TST & \\
\hline CHEMBL1600953 & 688660 & 5.45 & 4.8703 & TST & \\
\hline CHEMBL539027 & 688660 & 4.4 & 4.82100 & 3000000001 & TRN \\
\hline CHEMBL1493085 & 688660 & 4.4 & 4.8974 & TRN & \\
\hline CHEMBL1609354 & 688660 & 4.4 & 5.0581 & TRN & \\
\hline CHEMBL1574275 & 688660 & 4.6 & 5.0161 & TRN & \\
\hline
\end{tabular}




\begin{tabular}{|c|c|c|c|c|}
\hline \multicolumn{5}{|c|}{ Supplemental Table S2.txt } \\
\hline CHEMBL1346288 & 688660 & 4.4 & 5.0819 & TST \\
\hline CHEMBL1534168 & 688660 & 4.4 & 4.7392 & TRN \\
\hline CHEMBL1605353 & 688660 & 4.4 & 4.8769 & TRN \\
\hline CHEMBL1434611 & 688660 & 4.45 & 4.8235 & TRN \\
\hline CHEMBL1471656 & 688660 & 5.1 & 5.0241 & TRN \\
\hline CHEMBL1322322 & 688660 & 5.5 & 4.8759 & TST \\
\hline CHEMBL1426867 & 688660 & 4.65 & 5.0321 & TRN \\
\hline CHEMBL1608376 & 688660 & 5.5 & 4.9646 & TRN \\
\hline CHEMBL1473233 & 688660 & 4.85 & 4.7304 & TRN \\
\hline CHEMBL1365251 & 688660 & 4.5 & 5.1487 & TRN \\
\hline CHEMBL1547423 & 688660 & 4.85 & 4.7241 & TRN \\
\hline CHEMBL1593507 & 688660 & 4.4 & 4.8338 & TST \\
\hline CHEMBL1472473 & 688660 & 4.55 & 4.6284 & TST \\
\hline CHEMBL1439019 & 688660 & 4.4 & 4.6456 & TRN \\
\hline CHEMBL1367501 & 688660 & 5.45 & 4.7826 & TRN \\
\hline CHEMBL1591836 & 688660 & 4.55 & 4.8414 & TRN \\
\hline CHEMBL1429514 & 688660 & 4.35 & 4.935 & TRN \\
\hline CHEMBL1438441 & 688660 & 4.5 & 4.6255 & TST \\
\hline CHEMBL1350749 & 688660 & 4.45 & 4.9023 & TRN \\
\hline CHEMBL1377432 & 688660 & 5.15 & 5.1685 & TRN \\
\hline CHEMBL1490813 & 688660 & 5.0 & 5.3556 & TRN \\
\hline CHEMBL3392027 & 688660 & 4.85 & 4.9371 & TRN \\
\hline CHEMBL1302256 & 688660 & 6.15 & 5.0396 & TRN \\
\hline CHEMBL1441897 & 688660 & 4.7 & 4.9895 & TRN \\
\hline CHEMBL 1608572 & 688660 & 4.65 & 5.1463 & TRN \\
\hline CHEMBL31425 & 688660 & 5.0 & 4.9858 & TST \\
\hline CHEMBL1394492 & 688660 & 4.4 & 4.8784 & TRN \\
\hline CHEMBL1530292 & 688660 & 4.65 & 4.6977 & TRN \\
\hline CHEMBL3189285 & 688660 & 4.4 & 5.2751 & TRN \\
\hline CHEMBL3208675 & 688660 & 5.3 & 5.0021 & TRN \\
\hline CHEMBL1310218 & 688660 & 4.95 & 4.6599 & TST \\
\hline CHEMBL1339797 & 688660 & 4.5 & 4.6923 & TST \\
\hline CHEMBL1508492 & 688660 & 6.15 & 5.0516 & TRN \\
\hline CHEMBL1484327 & 688660 & 4.55 & 4.9447 & TRN \\
\hline CHEMBL1606297 & 688660 & 5.45 & 4.9089 & TRN \\
\hline CHEMBL1442207 & 688660 & 4.55 & 5.0429 & TRN \\
\hline CHEMBL1500393 & 688660 & 5.0 & 5.2676 & TRN \\
\hline CHEMBL1300046 & 688660 & 5.85 & 5.129 & TRN \\
\hline CHEMBL 307341 & 688660 & 4.65 & 4.6772 & TRN \\
\hline CHEMBL1503595 & 688660 & 6.15 & 5.0155 & TRN \\
\hline CHEMBL1444634 & 688660 & 5.05 & 5.2771 & TRN \\
\hline CHEMBL1408980 & 688660 & 4.55 & 4.7052 & TST \\
\hline CHEMBL1999835 & 688660 & 5.3 & 4.9949 & TRN \\
\hline CHEMBL 3195827 & 688660 & 4.4 & 5.1089 & TRN \\
\hline CHEMBL1978908 & 688660 & 5.45 & 4.8638 & TRN \\
\hline CHEMBL1481995 & 688660 & 4.4 & 5.1689 & TRN \\
\hline CHEMBL1553027 & 688660 & 4.65 & 4.7551 & TRN \\
\hline CHEMBL1305695 & 688660 & 4.45 & 4.7065 & TRN \\
\hline
\end{tabular}




\begin{tabular}{|c|c|c|c|c|}
\hline & & & oplement & al \\
\hline CHEMBL1477748 & 688660 & 4.7 & 4.8063 & TRN \\
\hline CHEMBL1409895 & 688660 & 4.4 & 4.7223 & TRN \\
\hline CHEMBL1309099 & 688660 & 4.6 & 5.039 & TRN \\
\hline CHEMBL1477383 & 688660 & 4.4 & 4.8842 & TRN \\
\hline CHEMBL1582444 & 688660 & 6.15 & 4.9595 & TST \\
\hline CHEMBL1364856 & 688660 & 4.6 & 4.6152 & TRN \\
\hline CHEMBL1539838 & 688660 & 4.55 & 4.5557 & TRN \\
\hline CHEMBL1462351 & 688660 & 4.9 & 4.6059 & TRN \\
\hline CHEMBL1447668 & 688660 & 4.4 & 4.8883 & TST \\
\hline CHEMBL1515687 & 688660 & 4.6 & 4.9905 & TST \\
\hline CHEMBL1433158 & 688660 & 4.6 & 4.6373 & TRN \\
\hline CHEMBL3194704 & 688660 & 6.15 & 5.2023 & TRN \\
\hline CHEMBL1516556 & 688660 & 4.65 & 5.121 & TRN \\
\hline CHEMBL1300803 & 688660 & 4.65 & 4.9126 & TRN \\
\hline CHEMBL1600712 & 688660 & 4.45 & 4.5799 & TRN \\
\hline CHEMBL1411971 & 688660 & 4.4 & 4.598 & TST \\
\hline CHEMBL1492520 & 688660 & 5.4 & 5.1446 & TRN \\
\hline CHEMBL45068 & 688660 & 4.55 & 5.0882 & TRN \\
\hline CHEMBL1469259 & 688660 & 5.95 & 4.7794 & TRN \\
\hline CHEMBL1505787 & 688660 & 5.0 & 4.8246 & TRN \\
\hline CHEMBL1517450 & 688660 & 5.5 & 5.1059 & TRN \\
\hline CHEMBL1546745 & 688660 & 4.5 & 4.6777 & TRN \\
\hline CHEMBL1315819 & 688660 & 5.0 & 4.8399 & TRN \\
\hline CHEMBL1422544 & 688660 & 4.45 & 4.8726 & TRN \\
\hline CHEMBL1595511 & 688660 & 4.6 & 5.0484 & TST \\
\hline CHEMBL1300297 & 688660 & 4.4 & 4.8888 & TRN \\
\hline CHEMBL1540504 & 688660 & 5.45 & 4.8205 & TRN \\
\hline CHEMBL1328307 & 688660 & 4.4 & 5.0615 & TST \\
\hline CHEMBL1366651 & 688660 & 5.45 & 4.9341 & TRN \\
\hline CHEMBL1561768 & 688660 & 6.2 & 4.9689 & TRN \\
\hline CHEMBL1499437 & 688660 & 4.4 & 4.8942 & TRN \\
\hline CHEMBL1523249 & 688660 & 6.2 & 4.6661 & TST \\
\hline CHEMBL1256697 & 688660 & 4.4 & 4.704 & TST \\
\hline CHEMBL1537961 & 688660 & 4.4 & 5.2386 & TRN \\
\hline CHEMBL1543392 & 688660 & 4.4 & 4.9842 & TRN \\
\hline CHEMBL1385191 & 688660 & 6.2 & 5.2018 & TRN \\
\hline CHEMBL1585304 & 688660 & 4.4 & 5.2598 & TRN \\
\hline CHEMBL1384404 & 688660 & 5.4 & 4.6884 & TRN \\
\hline CHEMBL1454636 & 688660 & 6.1 & 5.053 & TRN \\
\hline CHEMBL1583125 & 688660 & 5.55 & 4.9842 & TRN \\
\hline CHEMBL1594349 & 688660 & 4.5 & 4.8832 & TRN \\
\hline CHEMBL1494520 & 688660 & 4.45 & 4.8041 & TRN \\
\hline CHEMBL1524562 & 688660 & 4.6 & 4.904 & TRN \\
\hline CHEMBL1598044 & 688660 & 4.95 & 5.1268 & TRN \\
\hline CHEMBL1444267 & 688660 & 4.5 & 4.6949 & TRN \\
\hline CHEMBL1549446 & 688660 & 6.15 & 5.1021 & TRN \\
\hline CHEMBL1462381 & 688660 & 5.0 & 4.6798 & TRN \\
\hline CHEMBL1312794 & 688660 & 5.95 & 4.9545 & TRN \\
\hline
\end{tabular}




\begin{tabular}{|c|c|c|c|c|}
\hline \multicolumn{5}{|c|}{ Supplemental Table S2.txt } \\
\hline CHEMBL1549175 & 688660 & 5.5 & 4.8257 & TRN \\
\hline CHEMBL1579722 & 688660 & 4.65 & 4.7865 & TST \\
\hline CHEMBL1484514 & 688660 & 5.85 & 5.1264 & TRN \\
\hline CHEMBL3194775 & 688660 & 4.95 & 4.6107 & TRN \\
\hline CHEMBL1333447 & 688660 & 5.0 & 5.3191 & TRN \\
\hline CHEMBL1478601 & 688660 & 4.4 & 5.0672 & TRN \\
\hline CHEMBL1511760 & 688660 & 5.5 & 4.8545 & TRN \\
\hline CHEMBL1315952 & 688660 & 4.45 & 4.8783 & TRN \\
\hline CHEMBL1442225 & 688660 & 5.45 & 5.1325 & TRN \\
\hline CHEMBL 3190786 & 688660 & 5.3 & 4.8842 & TRN \\
\hline CHEMBL1333982 & 688660 & 5.8 & 4.8519 & TRN \\
\hline CHEMBL1383283 & 688660 & 4.6 & 5.0561 & TRN \\
\hline CHEMBL1461460 & 688660 & 5.95 & 5.1245 & TRN \\
\hline CHEMBL1423419 & 688660 & 5.55 & 4.655 & TST \\
\hline CHEMBL1515031 & 688660 & 6.2 & 4.8274 & TRN \\
\hline CHEMBL1457603 & 688660 & 5.45 & 4.7916 & TRN \\
\hline CHEMBL1448387 & 688660 & 4.45 & 4.718 & TST \\
\hline CHEMBL1491468 & 688660 & 4.4 & 4.9972 & TRN \\
\hline CHEMBL1522232 & 688660 & 4.35 & 4.8674 & TST \\
\hline CHEMBL1412067 & 688660 & 4.75 & 4.9032 & TRN \\
\hline CHEMBL1533518 & 688660 & 5.4 & 5.037 & TRN \\
\hline CHEMBL1521342 & 688660 & 5.35 & 4.8307 & TST \\
\hline CHEMBL1446929 & 688660 & 5.45 & 4.985 & TRN \\
\hline CHEMBL1549456 & 688660 & 5.05 & 5.1281 & TRN \\
\hline CHEMBL1317560 & 688660 & 4.85 & 4.8726 & TRN \\
\hline CHEMBL1493528 & 688660 & 4.4 & 4.7967 & TRN \\
\hline CHEMBL1594408 & 688660 & 5.45 & 5.2348 & TRN \\
\hline CHEMBL1488029 & 688660 & 4.4 & 4.9845 & TRN \\
\hline CHEMBL1412969 & 688660 & 5.15 & 4.8961 & TRN \\
\hline CHEMBL1554138 & 688660 & 4.4 & 4.442 & TRN \\
\hline CHEMBL1560219 & 688660 & 4.65 & 4.591 & TRN \\
\hline CHEMBL1549894 & 688660 & 5.35 & 4.6369 & TRN \\
\hline CHEMBL1495768 & 688660 & 4.4 & 4.6488 & TRN \\
\hline CHEMBL405110 & 688660 & 4.95 & 4.6903 & TST \\
\hline CHEMBL1592394 & 688660 & 4.85 & 4.9971 & TRN \\
\hline CHEMBL315348 & 688660 & 4.5 & 4.7718 & TRN \\
\hline CHEMBL1537205 & 688660 & 5.0 & 4.9757 & TRN \\
\hline CHEMBL1417932 & 688660 & 4.4 & 4.9839 & TRN \\
\hline CHEMBL1513240 & 688660 & 4.5 & 4.4895 & TRN \\
\hline CHEMBL1312056 & 688660 & 6.15 & 4.8862 & TRN \\
\hline CHEMBL1556095 & 688660 & 6.2 & 4.9383 & TST \\
\hline CHEMBL1542132 & 688660 & 5.55 & 5.0049 & TRN \\
\hline CHEMBL1343383 & 688660 & 5.95 & 4.9952 & TRN \\
\hline CHEMBL1449886 & 688660 & 5.9 & 5.0286 & TST \\
\hline CHEMBL1572368 & 688660 & 5.05 & 5.2385 & TRN \\
\hline CHEMBL1383971 & 688660 & 4.4 & 4.8066 & TRN \\
\hline CHEMBL1457689 & 688660 & 5.95 & 5.0327 & TRN \\
\hline CHEMBL1413612 & 688660 & 4.6 & 4.7473 & TRN \\
\hline
\end{tabular}




\begin{tabular}{|c|c|c|c|c|}
\hline \multicolumn{5}{|c|}{ pplemental $\mathrm{T}$} \\
\hline CHEMBL1353655 & 688660 & 4.4 & 4.4911 & TST \\
\hline CHEMBL1603308 & 688660 & 4.4 & 5.032 & TRN \\
\hline CHEMBL1352786 & 688660 & 4.5 & 4.7657 & TRN \\
\hline CHEMBL1465953 & 688660 & 4.4 & 4.5925 & TST \\
\hline CHEMBL1531588 & 688660 & 5.45 & 4.671 & TST \\
\hline CHEMBL1444680 & 688660 & 6.15 & 5.1012 & TRN \\
\hline CHEMBL329836 & 688660 & 4.55 & 4.9415 & TST \\
\hline CHEMBL1423310 & 688660 & 4.4 & 4.9185 & TRN \\
\hline CHEMBL1998940 & 688660 & 5.15 & 4.8483 & TST \\
\hline CHEMBL1611069 & 688660 & 4.5 & 5.0794 & TRN \\
\hline CHEMBL1556596 & 688660 & 5.0 & 5.0277 & TRN \\
\hline CHEMBL1596319 & 688660 & 5.0 & 4.9066 & TRN \\
\hline CHEMBL1349450 & 688660 & 5.05 & 4.9665 & TRN \\
\hline CHEMBL1424161 & 688660 & 5.15 & 5.0316 & TRN \\
\hline CHEMBL1357899 & 688660 & 4.45 & 4.8328 & TRN \\
\hline CHEMBL1442219 & 688660 & 4.6 & 4.8053 & TRN \\
\hline CHEMBL1353100 & 688660 & 4.4 & 5.1218 & TRN \\
\hline CHEMBL1378489 & 688660 & 4.7 & 4.9463 & TRN \\
\hline CHEMBL1527263 & 688660 & 5.05 & 4.9528 & TRN \\
\hline CHEMBL1360704 & 688660 & 5.45 & 5.0928 & TRN \\
\hline CHEMBL1517697 & 688660 & 4.4 & 4.6652 & TRN \\
\hline CHEMBL1376185 & 688660 & 4.4 & 4.7531 & TRN \\
\hline CHEMBL1381105 & 688660 & 4.45 & 4.883 & TRN \\
\hline CHEMBL1420221 & 688660 & 5.0 & 4.8181 & TST \\
\hline CHEMBL1975935 & 688660 & 4.45 & 4.4545 & TRN \\
\hline CHEMBL1417377 & 688660 & 4.4 & 4.9055 & TRN \\
\hline CHEMBL1504715 & 688660 & 5.45 & 4.8543 & TRN \\
\hline CHEMBL1394876 & 688660 & 4.4 & 4.713 & TST \\
\hline CHEMBL1422092 & 688660 & 4.4 & 4.6959 & TRN \\
\hline CHEMBL1405750 & 688660 & 4.7 & 4.9038 & TRN \\
\hline CHEMBL1605094 & 688660 & 4.65 & 4.6476 & TRN \\
\hline CHEMBL1326797 & 688660 & 4.75 & 4.9251 & TRN \\
\hline CHEMBL1564961 & 688660 & 6.2 & 5.0754 & TRN \\
\hline CHEMBL1409679 & 688660 & 4.9 & 4.6494 & TST \\
\hline CHEMBL1519568 & 688660 & 6.05 & 4.8971 & TRN \\
\hline CHEMBL3197615 & 688660 & 4.65 & 5.2471 & TRN \\
\hline CHEMBL1324303 & 688660 & 4.65 & 4.8884 & TRN \\
\hline CHEMBL1327106 & 688660 & 6.5 & 4.7351 & TRN \\
\hline CHEMBL1301177 & 688660 & 4.45 & 4.7474 & TST \\
\hline CHEMBL1429741 & 688660 & 4.4 & 5.0041 & TRN \\
\hline CHEMBL1473229 & 688660 & 4.55 & 5.1467 & TST \\
\hline CHEMBL1366544 & 688660 & 4.4 & 4.7466 & TRN \\
\hline CHEMBL1369887 & 688660 & 5.4 & 5.1959 & TRN \\
\hline CHEMBL1336070 & 688660 & 4.4 & 4.5351 & TRN \\
\hline CHEMBL1347778 & 688660 & 4.5 & 5.0049 & TRN \\
\hline CHEMBL1554625 & 688660 & 4.4 & 4.5415 & TST \\
\hline CHEMBL1555629 & 688660 & 5.45 & 4.8562 & TRN \\
\hline CHEMBL1415425 & 688660 & 4.5 & 4.7459 & TRN \\
\hline
\end{tabular}




\begin{tabular}{|c|c|c|c|c|c|}
\hline \multicolumn{6}{|c|}{ Supplemental Table S2.txt } \\
\hline CHEMBL1322375 & 688660 & 6.15 & 5.0484 & TRN & \\
\hline CHEMBL1449688 & 688660 & 4.65 & 4.871 & TRN & \\
\hline CHEMBL1357421 & 688660 & 4.4 & 4.93199 & 99999999995 & TRN \\
\hline CHEMBL1504587 & 688660 & 6.15 & 5.0346 & TST & \\
\hline CHEMBL1489748 & 688660 & 6.15 & 4.912 & TRN & \\
\hline CHEMBL1460676 & 688660 & 4.6 & 5.0348 & TRN & \\
\hline CHEMBL1312321 & 688660 & 4.4 & 4.8858 & TRN & \\
\hline CHEMBL1451294 & 688660 & 4.4 & 4.7957 & TRN & \\
\hline CHEMBL1343982 & 688660 & 5.35 & 5.3198 & TRN & \\
\hline CHEMBL1540543 & 688660 & 4.4 & 5.0919 & TRN & \\
\hline CHEMBL1566143 & 688660 & 4.8 & 4.9252 & TRN & \\
\hline CHEMBL 2369260 & 688660 & 6.15 & 4.9268 & TRN & \\
\hline CHEMBL1345465 & 688660 & 4.6 & 4.7377 & TST & \\
\hline CHEMBL1573118 & 688660 & 4.4 & 4.9014 & TRN & \\
\hline CHEMBL1324475 & 688660 & 4.45 & 4.5609 & TRN & \\
\hline CHEMBL1997990 & 688660 & 5.15 & 4.9499 & TRN & \\
\hline CHEMBL1543654 & 688660 & 4.4 & 4.9136 & TRN & \\
\hline CHEMBL1369231 & 688660 & 4.55 & 4.8298 & TRN & \\
\hline CHEMBL1371149 & 688660 & 5.05 & 4.8824 & TRN & \\
\hline CHEMBL1408251 & 688660 & 4.7 & 5.0605 & TRN & \\
\hline CHEMBL1437954 & 688660 & 4.6 & 4.7609 & TRN & \\
\hline CHEMBL1606132 & 688660 & 5.0 & 4.9991 & TRN & \\
\hline CHEMBL1446166 & 688660 & 4.75 & 5.0111 & TRN & \\
\hline CHEMBL1507682 & 688660 & 5.0 & 4.9545 & TRN & \\
\hline CHEMBL1395871 & 688660 & 4.5 & 5.0219 & TRN & \\
\hline CHEMBL1578015 & 688660 & 4.55 & 4.5424 & TRN & \\
\hline CHEMBL1326058 & 688660 & 4.7 & 4.5696 & TRN & \\
\hline CHEMBL1441731 & 688660 & 4.4 & 5.03100 & 0000000001 & TRN \\
\hline CHEMBL1443454 & 688660 & 4.6 & 4.9252 & TRN & \\
\hline CHEMBL1490054 & 688660 & 4.4 & 5.034 & TST & \\
\hline CHEMBL1444318 & 688660 & 4.4 & 4.7869 & TRN & \\
\hline CHEMBL1329423 & 688660 & 4.4 & 5.4541 & TRN & \\
\hline CHEMBL1608333 & 688660 & 4.45 & 5.0619 & TRN & \\
\hline CHEMBL1486615 & 688660 & 6.15 & 5.0017 & TRN & \\
\hline CHEMBL1488131 & 688660 & 5.45 & 4.8657 & TST & \\
\hline CHEMBL1410895 & 688660 & 4.4 & 4.8809 & TRN & \\
\hline CHEMBL1464256 & 688660 & 5.45 & 5.114 & TRN & \\
\hline CHEMBL1580586 & 688660 & 4.6 & 4.8551 & TRN & \\
\hline CHEMBL1299265 & 688660 & 5.05 & 5.0036 & TRN & \\
\hline CHEMBL 3213936 & 688660 & 4.4 & 5.1101 & TRN & \\
\hline CHEMBL596674 & 688660 & 5.2 & 4.7375 & TRN & \\
\hline CHEMBL1482287 & 688660 & 5.4 & 5.0634 & TRN & \\
\hline CHEMBL1997978 & 688660 & 4.65 & 5.0498 & TRN & \\
\hline CHEMBL1340424 & 688660 & 6.2 & 4.8125 & TRN & \\
\hline CHEMBL1611800 & 688660 & 4.4 & 4.7683 & TST & \\
\hline CHEMBL1518899 & 688660 & 4.7 & 4.7063 & TRN & \\
\hline CHEMBL1995496 & 688660 & 4.5 & 4.9967 & TRN & \\
\hline CHEMBL 3191345 & 688660 & 6.15 & 4.8927 & TRN & \\
\hline
\end{tabular}




\begin{tabular}{|c|c|c|c|c|}
\hline \multicolumn{5}{|c|}{ Supplemental Table S2.txt } \\
\hline CHEMBL1506500 & 688660 & 5.85 & 5.0168 & TRN \\
\hline CHEMBL1328904 & 688660 & 4.85 & 5.0028 & TRN \\
\hline CHEMBL1329049 & 688660 & 4.4 & 5.1142 & TRN \\
\hline CHEMBL1448838 & 688660 & 5.5 & 5.0228 & TRN \\
\hline CHEMBL1421239 & 688660 & 5.15 & 4.9459 & TRN \\
\hline CHEMBL1526980 & 688660 & 4.65 & 5.0013 & TRN \\
\hline CHEMBL1423202 & 688660 & 4.4 & 4.8726 & TRN \\
\hline CHEMBL1512090 & 688660 & 5.1 & 4.8758 & TRN \\
\hline CHEMBL1482263 & 688660 & 4.4 & 4.7168 & TRN \\
\hline CHEMBL607309 & 688660 & 4.55 & 4.8447 & TRN \\
\hline CHEMBL1547184 & 688660 & 4.6 & 4.7816 & TST \\
\hline CHEMBL1490677 & 688660 & 4.4 & 4.9637 & TRN \\
\hline CHEMBL1467995 & 688660 & 5.5 & 4.8164 & TST \\
\hline CHEMBL1986725 & 688660 & 4.9 & 4.9408 & TRN \\
\hline CHEMBL1555397 & 688660 & 4.4 & 4.9318 & TRN \\
\hline CHEMBL3190311 & 688660 & 4.55 & 4.7392 & TRN \\
\hline CHEMBL1560176 & 688660 & 4.4 & 4.7672 & TRN \\
\hline CHEMBL1392747 & 688660 & 4.65 & 4.8573 & TRN \\
\hline CHEMBL1437706 & 688660 & 5.45 & 4.8741 & TST \\
\hline CHEMBL1364266 & 688660 & 6.45 & 4.7777 & TST \\
\hline CHEMBL1398789 & 688660 & 4.4 & 4.9194 & TST \\
\hline CHEMBL1562359 & 688660 & 4.45 & 5.0669 & TRN \\
\hline CHEMBL1380724 & 688660 & 5.5 & 4.8624 & TRN \\
\hline CHEMBL1429181 & 688660 & 4.6 & 5.0109 & TRN \\
\hline CHEMBL1301551 & 688660 & 5.15 & 4.9161 & TST \\
\hline CHEMBL1327980 & 688660 & 5.95 & 5.3971 & TRN \\
\hline CHEMBL1432736 & 688660 & 4.4 & 4.8367 & TRN \\
\hline CHEMBL1302722 & 688660 & 4.4 & 4.5695 & TRN \\
\hline CHEMBL3192155 & 688660 & 4.4 & 4.8609 & TRN \\
\hline CHEMBL1305366 & 688660 & 5.5 & 5.0004 & TRN \\
\hline CHEMBL1554761 & 688660 & 5.05 & 4.9151 & TST \\
\hline CHEMBL1555066 & 688660 & 4.4 & 5.0448 & TRN \\
\hline CHEMBL1413374 & 688660 & 5.5 & 5.1244 & TRN \\
\hline CHEMBL1471045 & 688660 & 6.15 & 5.1461 & TRN \\
\hline CHEMBL1398345 & 688660 & 4.4 & 4.8111 & TRN \\
\hline CHEMBL1451344 & 688660 & 4.45 & 4.9223 & TRN \\
\hline CHEMBL3191430 & 688660 & 4.5 & 4.6269 & TRN \\
\hline CHEMBL1540268 & 688660 & 4.4 & 4.5579 & TRN \\
\hline CHEMBL1602082 & 688660 & 4.4 & 4.7309 & TRN \\
\hline CHEMBL1394930 & 688660 & 5.4 & 4.8715 & TRN \\
\hline CHEMBL1404131 & 688660 & 4.4 & 4.9192 & TRN \\
\hline CHEMBL1549745 & 688660 & 4.6 & 4.7906 & TRN \\
\hline CHEMBL1525975 & 688660 & 6.15 & 4.5849 & TST \\
\hline CHEMBL1575688 & 688660 & 4.35 & 5.1796 & TRN \\
\hline CHEMBL1392434 & 688660 & 4.4 & 4.8253 & TRN \\
\hline CHEMBL1496366 & 688660 & 4.5 & 4.7017 & TST \\
\hline CHEMBL 1347186 & 688660 & 4.4 & 4.8481 & TRN \\
\hline CHEMBL1526126 & 688660 & 6.15 & 4.8962 & TRN \\
\hline
\end{tabular}




\begin{tabular}{|c|c|c|c|c|c|}
\hline & & \multicolumn{4}{|c|}{ Supplemental Table S2.txt } \\
\hline CHEMBL1460184 & 688660 & 5.05 & 4.7864 & TRN & \\
\hline CHEMBL1573441 & 688660 & 4.55 & 4.6646 & TRN & \\
\hline CHEMBL1553064 & 688660 & 4.4 & 4.8132 & TRN & \\
\hline CHEMBL1392391 & 688660 & 5.5 & 5.0245 & TRN & \\
\hline CHEMBL1465730 & 688660 & 5.05 & 5.1135 & TRN & \\
\hline CHEMBL1381724 & 688660 & 4.4 & 4.7852 & TST & \\
\hline CHEMBL1391241 & 688660 & 4.75 & 4.8557 & TRN & \\
\hline CHEMBL1337287 & 688660 & 6.15 & 5.3936 & TRN & \\
\hline CHEMBL1334238 & 688660 & 5.4 & 4.9887 & TRN & \\
\hline CHEMBL 2001024 & 688660 & 4.5 & 4.8192 & TRN & \\
\hline CHEMBL1403919 & 688660 & 4.5 & 4.717 & TRN & \\
\hline CHEMBL1504513 & 688660 & 5.5 & 4.9255 & TRN & \\
\hline CHEMBL1364801 & 688660 & 5.3 & 4.7347 & TRN & \\
\hline CHEMBL1458420 & 688660 & 4.4 & 5.0361 & TRN & \\
\hline CHEMBL1302664 & 688660 & 4.35 & 4.6619 & TRN & \\
\hline CHEMBL1439136 & 688660 & 4.4 & 4.742 & TRN & \\
\hline CHEMBL1487834 & 688660 & 4.45 & 4.7771 & TRN & \\
\hline CHEMBL1440743 & 688660 & 4.4 & 4.6085 & TST & \\
\hline CHEMBL 3212783 & 688660 & 5.4 & 4.704 & TST & \\
\hline CHEMBL1517295 & 688660 & 4.5 & 5.2244 & TRN & \\
\hline CHEMBL3196392 & 688660 & 4.85 & 5.0848 & TRN & \\
\hline CHEMBL1489498 & 688660 & 4.4 & 4.8913 & TRN & \\
\hline CHEMBL1379663 & 688660 & 4.45 & 4.8773 & TRN & \\
\hline CHEMBL1568101 & 688660 & 5.2 & 4.659 & TST & \\
\hline CHEMBL1329055 & 688660 & 5.3 & 4.8058 & TRN & \\
\hline CHEMBL3197099 & 688660 & 4.4 & 4.8086 & TRN & \\
\hline CHEMBL1486874 & 688660 & 4.4 & 4.7039 & TRN & \\
\hline CHEMBL1593112 & 688660 & 4.55 & 5.0615 & TRN & \\
\hline CHEMBL1984244 & 688660 & 4.8 & 4.4329 & TRN & \\
\hline CHEMBL3199926 & 688660 & 4.4 & 4.7296 & TRN & \\
\hline CHEMBL1417515 & 688660 & 4.4 & 4.649 & TRN & \\
\hline CHEMBL1575123 & 688660 & 4.5 & 5.0864 & TRN & \\
\hline CHEMBL1424550 & 688660 & 4.4 & 4.8234 & TRN & \\
\hline CHEMBL1525115 & 688660 & 5.0 & 4.9432 & TRN & \\
\hline CHEMBL1307971 & 688660 & 4.4 & 4.7669 & TST & \\
\hline CHEMBL1495010 & 688660 & 6.15 & 4.7591 & TST & \\
\hline CHEMBL1458873 & 688660 & 4.4 & 4.7708 & TRN & \\
\hline CHEMBL1608996 & 688660 & 5.15 & 4.8171 & TRN & \\
\hline CHEMBL1501508 & 688660 & 4.4 & 5.13899 & 7999999999 & TRN \\
\hline CHEMBL1371711 & 688660 & 6.2 & 5.2398 & TRN & \\
\hline CHEMBL1403154 & 688660 & 5.6 & 4.971 & TST & \\
\hline CHEMBL1561666 & 688660 & 4.4 & 4.8299 & TST & \\
\hline CHEMBL1310572 & 688660 & 5.5 & 4.7533 & TRN & \\
\hline CHEMBL1300430 & 688660 & 4.4 & 4.8719 & TRN & \\
\hline CHEMBL1605229 & 688660 & 5.15 & 4.8297 & TRN & \\
\hline CHEMBL1512996 & 688660 & 5.15 & 4.7717 & TRN & \\
\hline CHEMBL1416095 & 688660 & 4.55 & 4.8248 & TRN & \\
\hline CHEMBL1313064 & 688660 & 4.45 & 4.7549 & TRN & \\
\hline
\end{tabular}




\begin{tabular}{|c|c|c|c|c|}
\hline \multicolumn{5}{|c|}{ Supplemental Table S2.txt } \\
\hline CHEMBL1432444 & 688660 & 5.0 & 5.0074 & TST \\
\hline CHEMBL3191983 & 688660 & 4.65 & 4.8726 & TRN \\
\hline CHEMBL1982521 & 688660 & 4.5 & 4.8959 & TRN \\
\hline CHEMBL1589536 & 688660 & 5.4 & 5.2208 & TRN \\
\hline CHEMBL1396391 & 688660 & 6.2 & 4.8274 & TST \\
\hline CHEMBL1483420 & 688660 & 4.4 & 4.793 & TRN \\
\hline CHEMBL1304815 & 688660 & 4.4 & 5.1869 & TRN \\
\hline CHEMBL1570845 & 688660 & 5.35 & 4.7972 & TRN \\
\hline CHEMBL1450135 & 688660 & 4.4 & 4.865 & TRN \\
\hline CHEMBL1332361 & 688660 & 4.3 & 5.2056 & TRN \\
\hline CHEMBL1416490 & 688660 & 4.4 & 4.8114 & TRN \\
\hline CHEMBL1418815 & 688660 & 6.15 & 4.8956 & TRN \\
\hline CHEMBL1325392 & 688660 & 4.45 & 4.7618 & TRN \\
\hline CHEMBL1452379 & 688660 & 5.05 & 4.8956 & TRN \\
\hline CHEMBL1388724 & 688660 & 6.2 & 4.9323 & TRN \\
\hline CHEMBL1504829 & 688660 & 5.45 & 4.9764 & TST \\
\hline CHEMBL1449354 & 688660 & 4.55 & 4.8453 & TRN \\
\hline CHEMBL1542944 & 688660 & 6.2 & 4.9114 & TST \\
\hline CHEMBL1510514 & 688660 & 4.6 & 5.1727 & TRN \\
\hline CHEMBL1536332 & 688660 & 4.8 & 4.8054 & TST \\
\hline CHEMBL1308049 & 688660 & 4.9 & 4.7795 & TRN \\
\hline CHEMBL1350815 & 688660 & 5.55 & 5.1332 & TRN \\
\hline CHEMBL1384536 & 688660 & 4.4 & 4.9059 & TRN \\
\hline CHEMBL1579289 & 688660 & 5.05 & 4.7283 & TST \\
\hline CHEMBL1599210 & 688660 & 5.5 & 5.0257 & TRN \\
\hline CHEMBL1348076 & 688660 & 5.15 & 4.9403 & TRN \\
\hline CHEMBL1402442 & 688660 & 4.45 & 4.7559 & TST \\
\hline CHEMBL1582179 & 688660 & 4.55 & 4.8964 & TRN \\
\hline CHEMBL1373880 & 688660 & 4.45 & 5.1394 & TST \\
\hline CHEMBL1465279 & 688660 & 4.4 & 4.8759 & TRN \\
\hline CHEMBL1373364 & 688660 & 4.6 & 4.9133 & TRN \\
\hline CHEMBL1448489 & 688660 & 4.4 & 4.5471 & TST \\
\hline CHEMBL1445138 & 688660 & 5.5 & 5.0388 & TRN \\
\hline CHEMBL1533963 & 688660 & 4.5 & 4.8725 & TRN \\
\hline CHEMBL3191352 & 688660 & 4.4 & 5.1273 & TRN \\
\hline CHEMBL1385348 & 688660 & 4.4 & 4.7345 & TRN \\
\hline CHEMBL1568842 & 688660 & 4.5 & 4.721 & TRN \\
\hline CHEMBL1404738 & 688660 & 4.6 & 4.6375 & TRN \\
\hline CHEMBL1384304 & 688660 & 4.65 & 4.7774 & TRN \\
\hline CHEMBL1306384 & 688660 & 5.2 & 5.0524 & TRN \\
\hline CHEMBL1256746 & 688660 & 4.4 & 4.6987 & TST \\
\hline CHEMBL3144987 & 688660 & 4.4 & 4.935 & TST \\
\hline CHEMBL1370828 & 688660 & 4.4 & 4.836 & TST \\
\hline CHEMBL1354523 & 688660 & 5.55 & 5.2126 & TRN \\
\hline CHEMBL1382939 & 688660 & 5.2 & 4.756 & TST \\
\hline CHEMBL1303924 & 688660 & 4.4 & 4.7732 & TRN \\
\hline CHEMBL1323116 & 688660 & 4.65 & 4.4768 & TRN \\
\hline CHEMBL1320569 & 688660 & 4.4 & 5.0436 & TST \\
\hline
\end{tabular}




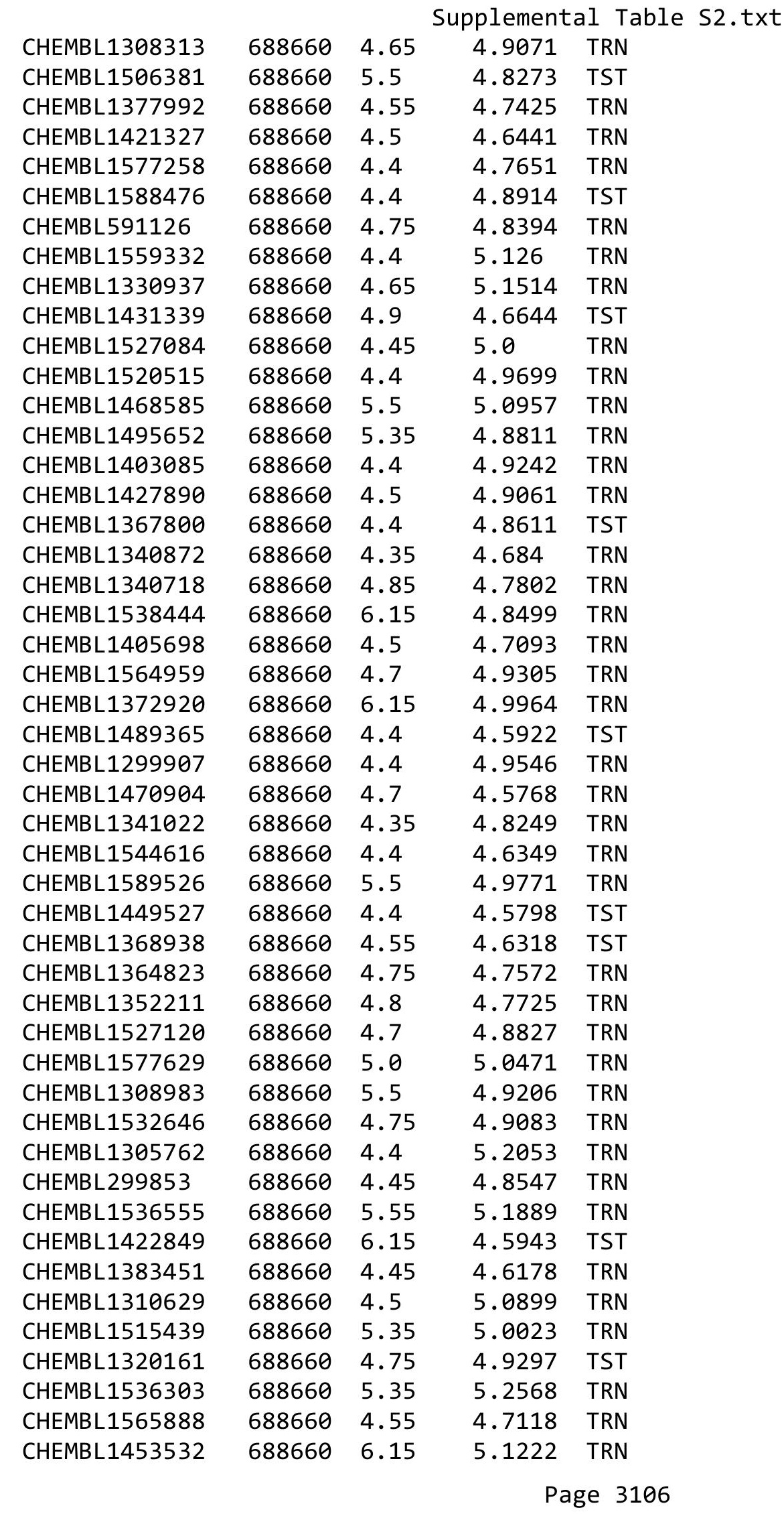




\begin{tabular}{|c|c|c|c|c|}
\hline \multicolumn{5}{|c|}{ Supplemental Table S2.txt } \\
\hline CHEMBL1329225 & 688660 & 4.4 & 4.5341 & TRN \\
\hline CHEMBL 1434476 & 688660 & 5.15 & 5.0133 & TRN \\
\hline CHEMBL1563712 & 688660 & 5.65 & 4.9498 & TST \\
\hline CHEMBL1455977 & 688660 & 4.8 & 5.0421 & TRN \\
\hline CHEMBL1491787 & 688660 & 5.45 & 5.1942 & TRN \\
\hline CHEMBL1441408 & 688660 & 4.4 & 4.9673 & TST \\
\hline CHEMBL1481103 & 688660 & 4.95 & 5.2403 & TRN \\
\hline CHEMBL1708067 & 688660 & 4.6 & 4.606 & TRN \\
\hline CHEMBL1327291 & 688660 & 4.4 & 4.6662 & TRN \\
\hline CHEMBL1488521 & 688660 & 4.4 & 4.6849 & TST \\
\hline CHEMBL1344417 & 688660 & 4.45 & 4.6303 & TRN \\
\hline CHEMBL1599628 & 688660 & 4.6 & 4.8378 & TRN \\
\hline CHEMBL1398181 & 688660 & 5.45 & 4.9152 & TRN \\
\hline CHEMBL1488858 & 688660 & 5.5 & 5.0183 & TRN \\
\hline CHEMBL1393768 & 688660 & 5.8 & 5.0682 & TRN \\
\hline CHEMBL1596068 & 688660 & 4.55 & 5.0621 & TRN \\
\hline CHEMBL1483146 & 688660 & 4.5 & 4.6226 & TRN \\
\hline CHEMBL1406406 & 688660 & 4.7 & 4.8991 & TRN \\
\hline CHEMBL1473339 & 688660 & 4.65 & 4.9753 & TRN \\
\hline CHEMBL1322387 & 688660 & 4.65 & 4.8344 & TRN \\
\hline CHEMBL1342473 & 688660 & 4.5 & 4.904 & TST \\
\hline CHEMBL1546193 & 688660 & 4.75 & 4.8219 & TST \\
\hline CHEMBL1487421 & 688660 & 5.5 & 4.9102 & TRN \\
\hline CHEMBL1421559 & 688660 & 5.1 & 4.8098 & TRN \\
\hline CHEMBL1476801 & 688660 & 4.45 & 4.8023 & TRN \\
\hline CHEMBL1430760 & 688660 & 4.4 & 4.7083 & TST \\
\hline CHEMBL1583711 & 688660 & 4.4 & 4.8902 & TST \\
\hline CHEMBL1997668 & 688660 & 4.45 & 4.8763 & TRN \\
\hline CHEMBL1463091 & 688660 & 4.65 & 4.8265 & TRN \\
\hline CHEMBL1409730 & 688660 & 4.4 & 4.7634 & TRN \\
\hline CHEMBL1532755 & 688660 & 4.45 & 4.834 & TRN \\
\hline CHEMBL1352675 & 688660 & 4.4 & 4.9992 & TRN \\
\hline CHEMBL1328817 & 688660 & 4.5 & 4.6857 & TRN \\
\hline CHEMBL357625 & 688660 & 4.6 & 4.7787 & TRN \\
\hline CHEMBL1604647 & 688660 & 5.6 & 4.9837 & TST \\
\hline CHEMBL1355862 & 688660 & 4.4 & 4.7621 & TST \\
\hline CHEMBL 3197788 & 688660 & 4.4 & 5.0133 & TRN \\
\hline CHEMBL1533731 & 688660 & 4.6 & 4.9301 & TRN \\
\hline CHEMBL1588863 & 688660 & 5.2 & 4.6285 & TRN \\
\hline CHEMBL1457009 & 688660 & 5.4 & 5.2733 & TRN \\
\hline CHEMBL1534040 & 688660 & 4.35 & 4.6516 & TST \\
\hline CHEMBL1594755 & 688660 & 4.6 & 4.9015 & TRN \\
\hline CHEMBL1361531 & 688660 & 4.4 & 5.0716 & TRN \\
\hline CHEMBL1432581 & 688660 & 4.45 & 4.8112 & TRN \\
\hline CHEMBL1466826 & 688660 & 4.5 & 4.5215 & TST \\
\hline CHEMBL1430610 & 688660 & 6.2 & 4.9323 & TRN \\
\hline CHEMBL3208394 & 688660 & 4.7 & 5.0445 & TRN \\
\hline CHEMBL1459189 & 688660 & 6.2 & 4.8702 & TRN \\
\hline
\end{tabular}




\begin{tabular}{|c|c|c|c|c|}
\hline \multicolumn{5}{|c|}{ Supplemental Table S2.txt } \\
\hline CHEMBL1317726 & 688660 & 4.65 & 4.8835 & TST \\
\hline CHEMBL1437490 & 688660 & 4.45 & 4.7295 & TRN \\
\hline CHEMBL1417036 & 688660 & 4.4 & 5.0258 & TRN \\
\hline CHEMBL1528742 & 688660 & 5.5 & 5.3245 & TRN \\
\hline CHEMBL1481002 & 688660 & 4.85 & 4.8973 & TRN \\
\hline CHEMBL1567984 & 688660 & 4.4 & 4.9664 & TRN \\
\hline CHEMBL1442500 & 688660 & 5.45 & 5.1421 & TRN \\
\hline CHEMBL1542991 & 688660 & 4.85 & 4.9061 & TRN \\
\hline CHEMBL1563978 & 688660 & 4.95 & 4.8286 & TRN \\
\hline CHEMBL1577177 & 688660 & 5.5 & 5.0506 & TRN \\
\hline CHEMBL1575560 & 688660 & 5.15 & 5.3778 & TRN \\
\hline CHEMBL1423978 & 688660 & 4.45 & 4.7147 & TRN \\
\hline CHEMBL1603457 & 688660 & 4.6 & 5.0322 & TRN \\
\hline CHEMBL1511548 & 688660 & 6.15 & 5.1819 & TRN \\
\hline CHEMBL1586019 & 688660 & 4.4 & 4.4547 & TRN \\
\hline CHEMBL1601329 & 688660 & 4.95 & 5.2924 & TRN \\
\hline CHEMBL1592780 & 688660 & 4.5 & 4.8913 & TRN \\
\hline CHEMBL1478237 & 688660 & 5.15 & 4.9153 & TRN \\
\hline CHEMBL1596236 & 688660 & 5.15 & 4.9707 & TRN \\
\hline CHEMBL1514990 & 688660 & 4.9 & 4.9115 & TRN \\
\hline CHEMBL1438964 & 688660 & 5.3 & 4.8174 & TST \\
\hline CHEMBL1426796 & 688660 & 5.95 & 4.7881 & TRN \\
\hline CHEMBL1599029 & 688660 & 5.45 & 5.2474 & TRN \\
\hline CHEMBL1366610 & 688660 & 4.4 & 4.9854 & TRN \\
\hline CHEMBL1426381 & 688660 & 5.55 & 4.7621 & TST \\
\hline CHEMBL1440685 & 688660 & 5.2 & 4.6492 & TRN \\
\hline CHEMBL1449901 & 688660 & 5.45 & 5.0501 & TRN \\
\hline CHEMBL1335912 & 688660 & 6.15 & 5.1116 & TRN \\
\hline CHEMBL1481468 & 688660 & 4.6 & 4.7659 & TST \\
\hline CHEMBL1331013 & 688660 & 4.8 & 4.7256 & TRN \\
\hline CHEMBL1608382 & 688660 & 5.15 & 5.2208 & TRN \\
\hline CHEMBL1390168 & 688660 & 4.5 & 5.1634 & TRN \\
\hline CHEMBL1594143 & 688660 & 6.15 & 5.2794 & TRN \\
\hline CHEMBL3191375 & 688660 & 5.05 & 4.7525 & TRN \\
\hline CHEMBL1490688 & 688660 & 5.2 & 5.3468 & TRN \\
\hline CHEMBL1531549 & 688660 & 4.65 & 5.3434 & TRN \\
\hline CHEMBL1454289 & 688660 & 6.2 & 4.977 & TRN \\
\hline CHEMBL3196706 & 688660 & 5.5 & 5.0473 & TRN \\
\hline CHEMBL1417302 & 688660 & 4.6 & 4.5792 & TRN \\
\hline CHEMBL1504353 & 688660 & 4.4 & 5.0216 & TRN \\
\hline CHEMBL1965860 & 688660 & 4.5 & 4.9152 & TRN \\
\hline CHEMBL1421851 & 688660 & 5.15 & 4.9058 & TRN \\
\hline CHEMBL1480022 & 688660 & 5.35 & 4.9428 & TRN \\
\hline CHEMBL1369704 & 688660 & 4.9 & 4.7722 & TRN \\
\hline CHEMBL1537964 & 688660 & 6.2 & 5.3615 & TRN \\
\hline CHEMBL1303197 & 688660 & 5.5 & 5.3571 & TRN \\
\hline CHEMBL1604435 & 688660 & 4.5 & 4.5818 & TRN \\
\hline CHEMBL1451505 & 688660 & 4.45 & 4.9157 & TRN \\
\hline
\end{tabular}




\begin{tabular}{|c|c|c|c|c|}
\hline & & & ient & al Ta \\
\hline CHEMBL428784 & 688660 & 5.5 & 4.7243 & TRN \\
\hline CHEMBL1529509 & 688660 & 4.4 & 4.9226 & TRN \\
\hline CHEMBL1472327 & 688660 & 4.45 & 4.9231 & TRN \\
\hline CHEMBL1353477 & 688660 & 5.5 & 4.7802 & TST \\
\hline CHEMBL1397158 & 688660 & 4.6 & 4.604 & TRN \\
\hline CHEMBL1498296 & 688660 & 5.55 & 4.6731 & TST \\
\hline CHEMBL1305643 & 688660 & 4.5 & 4.8428 & TRN \\
\hline CHEMBL1483764 & 688660 & 5.2 & 4.9842 & TRN \\
\hline CHEMBL1553644 & 688660 & 4.55 & 4.9615 & TRN \\
\hline CHEMBL1508933 & 688660 & 4.65 & 5.1781 & TST \\
\hline CHEMBL1307703 & 688660 & 4.55 & 5.1734 & TRN \\
\hline CHEMBL518292 & 688660 & 5.45 & 4.6206 & TST \\
\hline CHEMBL1456923 & 688660 & 4.4 & 4.627 & TST \\
\hline CHEMBL1319389 & 688660 & 4.65 & 4.6459 & TRN \\
\hline CHEMBL1455178 & 688660 & 4.45 & 4.6993 & TRN \\
\hline CHEMBL1543695 & 688660 & 5.55 & 4.9262 & TRN \\
\hline CHEMBL1346926 & 688660 & 5.65 & 5.0407 & TRN \\
\hline CHEMBL1536628 & 688660 & 4.45 & 5.2486 & TRN \\
\hline CHEMBL1346359 & 688660 & 4.4 & 4.7418 & TRN \\
\hline CHEMBL1596938 & 688660 & 5.45 & 5.0765 & TRN \\
\hline CHEMBL 1560072 & 688660 & 4.55 & 4.8305 & TRN \\
\hline CHEMBL1416136 & 688660 & 5.05 & 4.9043 & TRN \\
\hline CHEMBL1306139 & 688660 & 5.75 & 5.2213 & TRN \\
\hline CHEMBL1356435 & 688660 & 4.4 & 4.8169 & TRN \\
\hline CHEMBL1486042 & 688660 & 5.45 & 4.928 & TRN \\
\hline CHEMBL1609089 & 688660 & 4.6 & 4.7555 & TRN \\
\hline CHEMBL1352800 & 688660 & 4.8 & 4.7372 & TRN \\
\hline CHEMBL29542 & 688660 & 4.4 & 4.8362 & TRN \\
\hline CHEMBL1364028 & 688660 & 4.4 & 4.9696 & TRN \\
\hline CHEMBL3209647 & 688660 & 6.15 & 5.0341 & TST \\
\hline CHEMBL1367925 & 688660 & 4.8 & 4.8181 & TRN \\
\hline CHEMBL1347020 & 688660 & 5.5 & 5.1222 & TRN \\
\hline CHEMBL588965 & 688660 & 4.4 & 4.5708 & TRN \\
\hline CHEMBL1596168 & 688660 & 5.5 & 4.8729 & TRN \\
\hline CHEMBL1310863 & 688660 & 5.5 & 4.5726 & TST \\
\hline CHEMBL1504221 & 688660 & 4.6 & 4.7961 & TRN \\
\hline CHEMBL1387514 & 688660 & 4.65 & 4.8695 & TST \\
\hline CHEMBL1558826 & 688660 & 5.75 & 4.5685 & TST \\
\hline CHEMBL1541918 & 688660 & 4.6 & 4.74 & TRN \\
\hline CHEMBL1416350 & 688660 & 6.15 & 4.9622 & TST \\
\hline CHEMBL1582405 & 688660 & 6.15 & 4.8082 & TRN \\
\hline CHEMBL1561248 & 688660 & 5.15 & 4.9504 & TRN \\
\hline CHEMBL1971033 & 688660 & 4.4 & 5.1031 & TRN \\
\hline CHEMBL1528751 & 688660 & 5.6 & 5.1228 & TRN \\
\hline CHEMBL3145001 & 688660 & 4.4 & 5.0107 & TST \\
\hline CHEMBL1524160 & 688660 & 5.45 & 5.0746 & TRN \\
\hline CHEMBL1549079 & 688660 & 4.5 & 4.9133 & TRN \\
\hline CHEMBL1577139 & 688660 & 4.55 & 4.9206 & TRN \\
\hline
\end{tabular}




\begin{tabular}{|c|c|c|c|c|c|}
\hline & & \multicolumn{4}{|c|}{ Supplemental Table s2.txt } \\
\hline CHEMBL1316155 & 688660 & 4.75 & 4.9775 & TRN & \\
\hline CHEMBL1438199 & 688660 & 4.4 & 4.6618 & TRN & \\
\hline CHEMBL1335351 & 688660 & 5.95 & 4.9278 & TRN & \\
\hline CHEMBL1520131 & 688660 & 4.7 & 4.8986 & TRN & \\
\hline CHEMBL3190372 & 688660 & 6.05 & 4.9895 & TRN & \\
\hline CHEMBL1469505 & 688660 & 4.9 & 4.8679 & TRN & \\
\hline CHEMBL1407070 & 688660 & 5.85 & 5.0269 & TRN & \\
\hline CHEMBL1579800 & 688660 & 4.65 & 4.7368 & TRN & \\
\hline CHEMBL1400973 & 688660 & 4.75 & 4.8182 & TRN & \\
\hline CHEMBL 2369228 & 688660 & 4.9 & 4.8082 & TRN & \\
\hline CHEMBL1520346 & 688660 & 4.75 & 4.7722 & TRN & \\
\hline CHEMBL1502191 & 688660 & 5.9 & 4.9463 & TRN & \\
\hline CHEMBL1466984 & 688660 & 4.4 & 4.8514 & TRN & \\
\hline CHEMBL1447865 & 688660 & 4.4 & 4.9431 & TRN & \\
\hline CHEMBL1521820 & 688660 & 4.45 & 4.8186 & TRN & \\
\hline CHEMBL34137 & 688660 & 5.05 & 4.9981 & TST & \\
\hline CHEMBL1713905 & 688660 & 4.55 & 4.9839 & TRN & \\
\hline CHEMBL1531830 & 688660 & 5.9 & 5.2473 & TRN & \\
\hline CHEMBL1403652 & 688660 & 5.35 & 4.9699 & TRN & \\
\hline CHEMBL1613062 & 688660 & 5.5 & 5.0149 & TST & \\
\hline CHEMBL1449018 & 688660 & 4.6 & 4.74100 & 00000000005 & TRN \\
\hline CHEMBL1416334 & 688660 & 4.4 & 5.1471 & TRN & \\
\hline CHEMBL1583471 & 688660 & 4.5 & 4.9304 & TRN & \\
\hline CHEMBL1459795 & 688660 & 5.15 & 4.9071 & TRN & \\
\hline CHEMBL1559374 & 688660 & 5.1 & 4.8847 & TRN & \\
\hline CHEMBL1460910 & 688660 & 4.7 & 4.6481 & TRN & \\
\hline CHEMBL1324440 & 688660 & 4.4 & 4.6724 & TRN & \\
\hline CHEMBL1479511 & 688660 & 5.55 & 5.5761 & TRN & \\
\hline CHEMBL1417999 & 688660 & 4.4 & 4.8228 & TRN & \\
\hline CHEMBL1585171 & 688660 & 4.6 & 4.7782 & TRN & \\
\hline CHEMBL1582822 & 688660 & 5.45 & 4.6217 & TST & \\
\hline CHEMBL1422447 & 688660 & 5.15 & 5.087 & TRN & \\
\hline CHEMBL1383762 & 688660 & 4.4 & 4.6839 & TRN & \\
\hline CHEMBL1448314 & 688660 & 4.4 & 4.9004 & TRN & \\
\hline CHEMBL1409238 & 688660 & 4.4 & 4.7073 & TST & \\
\hline CHEMBL1436922 & 688660 & 5.65 & 5.2099 & TRN & \\
\hline CHEMBL1581648 & 688660 & 4.65 & 4.5907 & TST & \\
\hline CHEMBL1314819 & 688660 & 4.4 & 4.6838 & TRN & \\
\hline CHEMBL1607246 & 688660 & 4.55 & 4.8252 & TRN & \\
\hline CHEMBL1526854 & 688660 & 5.15 & 5.1534 & TRN & \\
\hline CHEMBL1594682 & 688660 & 6.2 & 5.184 & TST & \\
\hline CHEMBL1328079 & 688660 & 4.4 & 5.0052 & TRN & \\
\hline CHEMBL3213740 & 688660 & 4.6 & 4.9431 & TRN & \\
\hline CHEMBL1443979 & 688660 & 5.4 & 4.7736 & TRN & \\
\hline CHEMBL1320661 & 688660 & 4.45 & 4.7689 & TRN & \\
\hline CHEMBL1490239 & 688660 & 5.45 & 4.9744 & TRN & \\
\hline CHEMBL1359550 & 688660 & 4.4 & 4.6758 & TRN & \\
\hline CHEMBL1347668 & 688660 & 5.35 & 4.9273 & TRN & \\
\hline
\end{tabular}




\begin{tabular}{|c|c|c|c|c|c|}
\hline \multirow[b]{2}{*}{ CHEMBL177987 } & & \multicolumn{4}{|c|}{ Supplemental Table S2.txt } \\
\hline & 688660 & 4.95 & 4.80399 & 9999999999 & TST \\
\hline CHEMBL1459326 & 688660 & 4.4 & 4.64199 & 99999999995 & TRN \\
\hline CHEMBL1384027 & 688660 & 4.8 & 4.9709 & TRN & \\
\hline CHEMBL10284 & 688660 & 4.65 & 4.7023 & TRN & \\
\hline CHEMBL1535294 & 688660 & 4.8 & 5.1304 & TRN & \\
\hline CHEMBL3195536 & 688660 & 4.4 & 4.7623 & TRN & \\
\hline CHEMBL1329648 & 688660 & 4.8 & 4.7352 & TRN & \\
\hline CHEMBL1548939 & 688660 & 5.2 & 4.7472 & TST & \\
\hline CHEMBL1476213 & 688660 & 4.4 & 4.7472 & TRN & \\
\hline CHEMBL1545838 & 688660 & 5.05 & 4.6679 & TRN & \\
\hline CHEMBL1590615 & 688660 & 4.7 & 4.7053 & TRN & \\
\hline CHEMBL1369755 & 688660 & 4.45 & 4.6522 & TRN & \\
\hline CHEMBL1575689 & 688660 & 4.5 & 4.6883 & TRN & \\
\hline CHEMBL1473847 & 688660 & 4.45 & 4.6391 & TRN & \\
\hline CHEMBL1444617 & 688660 & 4.7 & 4.6681 & TRN & \\
\hline CHEMBL1455358 & 688660 & 5.35 & 5.3215 & TRN & \\
\hline CHEMBL1418421 & 688660 & 4.8 & 5.1371 & TRN & \\
\hline CHEMBL3209695 & 688660 & 4.4 & 4.9541 & TRN & \\
\hline CHEMBL1455730 & 688660 & 4.4 & 4.7432 & TRN & \\
\hline CHEMBL1545264 & 688660 & 4.8 & 4.6551 & TRN & \\
\hline CHEMBL1547667 & 688660 & 5.4 & 4.8645 & TRN & \\
\hline CHEMBL1430296 & 688660 & 5.55 & 4.9012 & TRN & \\
\hline CHEMBL1603664 & 688660 & 5.55 & 5.0128 & TRN & \\
\hline CHEMBL1542862 & 688660 & 5.2 & 4.8139 & TRN & \\
\hline CHEMBL1608610 & 688660 & 4.5 & 4.7328 & TRN & \\
\hline CHEMBL1589124 & 688660 & 4.0 & 4.9809 & TRN & \\
\hline CHEMBL1536211 & 688660 & 4.85 & 4.9821 & TRN & \\
\hline CHEMBL1561861 & 688660 & 4.5 & 4.5956 & TST & \\
\hline CHEMBL1545798 & 688660 & 4.55 & 4.7686 & TST & \\
\hline CHEMBL1381878 & 688660 & 4.6 & 4.7941 & TRN & \\
\hline CHEMBL1359572 & 688660 & 4.4 & 5.0347 & TRN & \\
\hline CHEMBL1399595 & 688660 & 4.4 & 4.7757 & TRN & \\
\hline CHEMBL1435732 & 688660 & 4.45 & 4.8641 & TRN & \\
\hline CHEMBL1530189 & 688660 & 4.4 & 4.7598 & TRN & \\
\hline CHEMBL1595875 & 688660 & 4.4 & 4.6665 & TST & \\
\hline CHEMBL1574176 & 688660 & 4.55 & 4.8424 & TRN & \\
\hline CHEMBL1474130 & 688660 & 4.35 & 4.7154 & TRN & \\
\hline CHEMBL1477527 & 688660 & 4.4 & 5.1649 & TRN & \\
\hline CHEMBL1477573 & 688660 & 4.55 & 5.0297 & TRN & \\
\hline CHEMBL1307320 & 688660 & 5.0 & 4.7059 & TRN & \\
\hline CHEMBL1335043 & 688660 & 5.55 & 4.9738 & TRN & \\
\hline CHEMBL1513550 & 688660 & 5.15 & 4.7989 & TRN & \\
\hline CHEMBL 2001294 & 688660 & 4.95 & 4.7458 & TRN & \\
\hline CHEMBL1509054 & 688660 & 4.95 & 5.1166 & TRN & \\
\hline CHEMBL3196211 & 688660 & 4.4 & 5.0594 & TRN & \\
\hline CHEMBL1302170 & 688660 & 4.6 & 5.0648 & TRN & \\
\hline CHEMBL1420707 & 688660 & 4.4 & 4.7867 & TRN & \\
\hline CHEMBL1360146 & 688660 & 4.4 & 4.8046 & TRN & \\
\hline
\end{tabular}




\begin{tabular}{|c|c|c|c|c|}
\hline & & & upplement & $\mathrm{d} \perp$ \\
\hline CHEMBL1561254 & 688660 & 5.9 & 4.7743 & TST \\
\hline CHEMBL1371416 & 688660 & 5.55 & 4.8449 & TRN \\
\hline CHEMBL1424545 & 688660 & 4.45 & 4.7978 & TRN \\
\hline CHEMBL1538339 & 688660 & 4.4 & 5.0626 & TRN \\
\hline CHEMBL1411115 & 688660 & 5.0 & 4.9501 & TRN \\
\hline CHEMBL1608353 & 688660 & 5.05 & 5.0662 & TST \\
\hline CHEMBL1394812 & 688660 & 5.45 & 4.9742 & TRN \\
\hline CHEMBL1389755 & 688660 & 4.7 & 4.6967 & TRN \\
\hline CHEMBL1564804 & 688660 & 5.05 & 5.0538 & TRN \\
\hline CHEMBL1453782 & 688660 & 4.55 & 4.8154 & TRN \\
\hline CHEMBL1304471 & 688660 & 5.45 & 5.0593 & TRN \\
\hline CHEMBL1494973 & 688660 & 5.4 & 4.8491 & TRN \\
\hline CHEMBL1416998 & 688660 & 4.5 & 4.9343 & TRN \\
\hline CHEMBL1581073 & 688660 & 5.65 & 4.8257 & TRN \\
\hline CHEMBL1309676 & 688660 & 6.15 & 5.0111 & TRN \\
\hline CHEMBL1569074 & 688660 & 4.5 & 4.7225 & TRN \\
\hline CHEMBL1312607 & 688660 & 4.4 & 5.0475 & TRN \\
\hline CHEMBL13790 & 688660 & 4.4 & 4.8943 & TRN \\
\hline CHEMBL1610505 & 688660 & 5.15 & 4.9009 & TRN \\
\hline CHEMBL1552909 & 688660 & 4.7 & 4.7701 & TRN \\
\hline CHEMBL1530525 & 688660 & 4.4 & 4.9061 & TST \\
\hline CHEMBL1592668 & 688660 & 4.5 & 4.6178 & TRN \\
\hline CHEMBL1399735 & 688660 & 4.4 & 5.2188 & TRN \\
\hline CHEMBL1313167 & 688660 & 5.5 & 5.0243 & TRN \\
\hline CHEMBL1414103 & 688660 & 5.15 & 4.8667 & TRN \\
\hline CHEMBL1518732 & 688660 & 4.55 & 4.7478 & TRN \\
\hline CHEMBL1427794 & 688660 & 5.45 & 4.7493 & TST \\
\hline CHEMBL1572400 & 688660 & 5.15 & 4.9312 & TRN \\
\hline CHEMBL3209896 & 688660 & 4.5 & 4.7633 & TST \\
\hline CHEMBL1348789 & 688660 & 4.7 & 4.8465 & TRN \\
\hline CHEMBL1405192 & 688660 & 5.45 & 5.1354 & TRN \\
\hline CHEMBL1454267 & 688660 & 4.45 & 4.7156 & TRN \\
\hline CHEMBL1389884 & 688660 & 4.5 & 4.7402 & TRN \\
\hline CHEMBL1583190 & 688660 & 4.5 & 4.814 & TRN \\
\hline CHEMBL1569154 & 688660 & 4.55 & 4.6776 & TRN \\
\hline CHEMBL1300632 & 688660 & 5.5 & 4.8958 & TRN \\
\hline CHEMBL1560871 & 688660 & 6.2 & 5.1304 & TRN \\
\hline CHEMBL1577013 & 688660 & 6.2 & 4.907 & TRN \\
\hline CHEMBL1525189 & 688660 & 4.45 & 4.9761 & TRN \\
\hline CHEMBL1370452 & 688660 & 4.65 & 5.0498 & TST \\
\hline CHEMBL1386129 & 688660 & 4.35 & 4.923 & TRN \\
\hline CHEMBL1373925 & 688660 & 4.5 & 4.6723 & TRN \\
\hline CHEMBL1515274 & 688660 & 4.4 & 4.7273 & TRN \\
\hline CHEMBL1344856 & 688660 & 6.1 & 5.029 & TRN \\
\hline CHEMBL1990694 & 688660 & 4.45 & 4.7904 & TRN \\
\hline CHEMBL1552939 & 688660 & 4.6 & 4.6732 & TRN \\
\hline CHEMBL1530257 & 688660 & 4.45 & 4.7284 & TRN \\
\hline CHEMBL1510351 & 688660 & 6.15 & 4.5537 & TRN \\
\hline
\end{tabular}




\begin{tabular}{|c|c|c|c|c|c|}
\hline \multirow[b]{2}{*}{ CHEMBL1476358 } & \multicolumn{5}{|c|}{ Supplemental Table s2.txt } \\
\hline & 688660 & 5.15 & 5.1247 & TRN & \\
\hline CHEMBL1400769 & 688660 & 5.0 & 5.0142 & TRN & \\
\hline CHEMBL1400553 & 688660 & 5.15 & 4.6363 & TST & \\
\hline CHEMBL1537093 & 688660 & 6.0 & 4.6911 & TST & \\
\hline CHEMBL1384748 & 688660 & 4.4 & 4.7644 & TRN & \\
\hline CHEMBL1480532 & 688660 & 4.55 & 4.86600 & 00000000005 & TRN \\
\hline CHEMBL1569791 & 688660 & 5.2 & 4.958 & TRN & \\
\hline CHEMBL1302202 & 688660 & 5.3 & 4.9588 & TRN & \\
\hline CHEMBL1349105 & 688660 & 5.15 & 4.9639 & TST & \\
\hline CHEMBL1326371 & 688660 & 4.55 & 4.7792 & TST & \\
\hline CHEMBL1389132 & 688660 & 5.0 & 4.9043 & TRN & \\
\hline CHEMBL1595927 & 688660 & 4.55 & 4.7887 & TRN & \\
\hline CHEMBL1589034 & 688660 & 5.0 & 5.0291 & TRN & \\
\hline CHEMBL1493793 & 688660 & 6.15 & 4.9476 & TRN & \\
\hline CHEMBL1346056 & 688660 & 4.75 & 4.8453 & TRN & \\
\hline CHEMBL1363861 & 688660 & 4.6 & 4.5449 & TRN & \\
\hline CHEMBL1357867 & 688660 & 4.4 & 4.5776 & TST & \\
\hline CHEMBL1313553 & 688660 & 4.6 & 4.88 & TRN & \\
\hline CHEMBL1982010 & 688660 & 4.4 & 4.6942 & TST & \\
\hline CHEMBL1486301 & 688660 & 4.4 & 5.1001 & TRN & \\
\hline CHEMBL1575129 & 688660 & 4.75 & 4.937 & TST & \\
\hline CHEMBL1302390 & 688660 & 5.5 & 4.8319 & TRN & \\
\hline CHEMBL1583742 & 688660 & 5.5 & 5.2445 & TRN & \\
\hline CHEMBL1420866 & 688660 & 4.5 & 4.4862 & TRN & \\
\hline CHEMBL1436991 & 688660 & 6.5501 & 5.0916 & TRN & \\
\hline CHEMBL1332017 & 688660 & 4.4 & 4.6671 & TST & \\
\hline CHEMBL1377765 & 688660 & 4.4 & 5.0216 & TRN & \\
\hline CHEMBL1564701 & 688660 & 6.2 & 5.1433 & TRN & \\
\hline CHEMBL1379613 & 688660 & 4.95 & 5.2632 & TRN & \\
\hline CHEMBL3194707 & 688660 & 4.4 & 4.6984 & TRN & \\
\hline CHEMBL1603085 & 688660 & 4.45 & 4.5773 & TRN & \\
\hline CHEMBL1398187 & 688660 & 4.45 & 4.8324 & TRN & \\
\hline CHEMBL3209649 & 688660 & 4.4 & 4.9825 & TRN & \\
\hline CHEMBL1404379 & 688660 & 4.55 & 4.8161 & TRN & \\
\hline CHEMBL379099 & 688660 & 6.2 & 5.0785 & TRN & \\
\hline CHEMBL1531919 & 688660 & 4.5 & 4.7436 & TRN & \\
\hline CHEMBL1505531 & 688660 & 5.6 & 4.5877 & TRN & \\
\hline CHEMBL1495818 & 688660 & 4.4 & 4.8817 & TRN & \\
\hline CHEMBL1504685 & 688660 & 4.4 & 4.6637 & TST & \\
\hline CHEMBL1535845 & 688660 & 5.15 & 4.9414 & TST & \\
\hline CHEMBL1453007 & 688660 & 4.7 & 4.8059 & TRN & \\
\hline CHEMBL1382469 & 688660 & 4.35 & 4.8602 & TRN & \\
\hline CHEMBL1343748 & 688660 & 4.5 & 4.5285 & TST & \\
\hline CHEMBL1448878 & 688660 & 4.8 & 5.005 & TRN & \\
\hline CHEMBL1513455 & 688660 & 5.85 & 5.2221 & TRN & \\
\hline CHEMBL1547876 & 688660 & 4.4 & 5.2366 & TRN & \\
\hline CHEMBL1367820 & 688660 & 4.6 & 4.6883 & TRN & \\
\hline CHEMBL 31840 & 688660 & 4.4 & 5.0063 & TRN & \\
\hline & & & & 3113 & \\
\hline
\end{tabular}




\begin{tabular}{|c|c|c|c|c|}
\hline \multicolumn{5}{|c|}{ Supplemental Table S2.txt } \\
\hline CHEMBL1531758 & 688660 & 5.15 & 4.8775 & TRN \\
\hline CHEMBL1372748 & 688660 & 4.55 & 4.9441 & TST \\
\hline CHEMBL1508948 & 688660 & 4.4 & 4.7855 & TRN \\
\hline CHEMBL1323869 & 688660 & 4.4 & 4.7148 & TST \\
\hline CHEMBL1440384 & 688660 & 4.4 & 4.849 & TRN \\
\hline CHEMBL1559831 & 688660 & 4.4 & 4.8298 & TRN \\
\hline CHEMBL1314045 & 688660 & 4.4 & 4.7449 & TRN \\
\hline CHEMBL1401720 & 688660 & 5.5 & 4.8701 & TRN \\
\hline CHEMBL1354110 & 688660 & 6.15 & 4.992 & TRN \\
\hline CHEMBL1404636 & 688660 & 4.5 & 4.8543 & TRN \\
\hline CHEMBL95770 & 688660 & 4.35 & 4.8377 & TRN \\
\hline CHEMBL1585637 & 688660 & 5.15 & 4.7739 & TRN \\
\hline CHEMBL1418628 & 688660 & 6.2 & 4.92 & TST \\
\hline CHEMBL1356174 & 688660 & 4.5 & 4.9387 & TRN \\
\hline CHEMBL1432801 & 688660 & 4.4 & 5.0352 & TRN \\
\hline CHEMBL1407984 & 688660 & 6.15 & 4.8762 & TST \\
\hline CHEMBL1356182 & 688660 & 4.4 & 4.5884 & TRN \\
\hline CHEMBL1323978 & 688660 & 4.45 & 4.6772 & TRN \\
\hline CHEMBL1592417 & 688660 & 4.4 & 4.6493 & TRN \\
\hline CHEMBL1575276 & 688660 & 4.45 & 4.7457 & TRN \\
\hline CHEMBL1560513 & 688660 & 5.3 & 5.1166 & TRN \\
\hline CHEMBL1601975 & 688660 & 4.4 & 4.7462 & TST \\
\hline CHEMBL1376863 & 688660 & 4.5 & 4.5209 & TRN \\
\hline CHEMBL1308025 & 688660 & 6.2 & 5.1324 & TRN \\
\hline CHEMBL1585877 & 688660 & 6.15 & 5.1766 & TRN \\
\hline CHEMBL1315855 & 688660 & 4.4 & 4.7311 & TST \\
\hline CHEMBL3212566 & 688660 & 6.2 & 5.0312 & TRN \\
\hline CHEMBL1573238 & 688660 & 5.65 & 5.0669 & TRN \\
\hline CHEMBL1484779 & 688660 & 4.45 & 4.8167 & TRN \\
\hline CHEMBL1401987 & 688660 & 5.25 & 4.8262 & TRN \\
\hline CHEMBL1602852 & 688660 & 4.95 & 5.1815 & TRN \\
\hline CHEMBL1310683 & 688660 & 4.4 & 4.6375 & TRN \\
\hline CHEMBL1374915 & 688660 & 4.65 & 4.9455 & TRN \\
\hline CHEMBL1443321 & 688660 & 4.3 & 4.7728 & TRN \\
\hline CHEMBL1326110 & 688660 & 5.2 & 4.8166 & TRN \\
\hline CHEMBL1474719 & 688660 & 4.4 & 5.2239 & TRN \\
\hline CHEMBL1545831 & 688660 & 4.4 & 4.8049 & TRN \\
\hline CHEMBL1449731 & 688660 & 4.55 & 4.7625 & TRN \\
\hline CHEMBL1311261 & 688660 & 4.7 & 4.6992 & TRN \\
\hline CHEMBL1519722 & 688660 & 4.4 & 4.6352 & TRN \\
\hline CHEMBL1486440 & 688660 & 6.15 & 4.8649 & TST \\
\hline CHEMBL589062 & 688660 & 4.4 & 4.8482 & TRN \\
\hline CHEMBL1469185 & 688660 & 4.4 & 4.9611 & TRN \\
\hline CHEMBL1610297 & 688660 & 5.15 & 5.0247 & TRN \\
\hline CHEMBL1396575 & 688660 & 4.6 & 4.9834 & TRN \\
\hline CHEMBL1337436 & 688660 & 6.15 & 4.97 & TST \\
\hline CHEMBL 3856092 & 688660 & 5.6 & 4.9772 & TST \\
\hline CHEMBL1359083 & 688660 & 5.25 & 5.1917 & TRN \\
\hline
\end{tabular}




\begin{tabular}{|c|c|c|c|c|c|}
\hline \multicolumn{6}{|c|}{ Supplemental Table S2.txt } \\
\hline CHEMBL1425177 & 688660 & 5.85 & 5.0896 & TRN & \\
\hline CHEMBL1420837 & 688660 & 4.55 & 4.8451 & TRN & \\
\hline CHEMBL1379675 & 688660 & 4.4 & 4.9934 & TRN & \\
\hline CHEMBL1391113 & 688660 & 6.15 & 5.0817 & TST & \\
\hline CHEMBL1517192 & 688660 & 4.45 & 4.7325 & TRN & \\
\hline CHEMBL1453108 & 688660 & 6.0 & 5.1592 & TRN & \\
\hline CHEMBL1341707 & 688660 & 4.65 & 4.6322 & TRN & \\
\hline CHEMBL1323309 & 688660 & 4.6 & 4.8955 & TRN & \\
\hline CHEMBL1491309 & 688660 & 4.65 & 4.6041 & TRN & \\
\hline CHEMBL1481770 & 688660 & 6.15 & 4.9198 & TRN & \\
\hline CHEMBL1422690 & 688660 & 4.45 & 4.9895 & TRN & \\
\hline CHEMBL1968732 & 688660 & 5.5 & 5.12200 & 0000000001 & TRN \\
\hline CHEMBL1457334 & 688660 & 5.55 & 5.3724 & TRN & \\
\hline CHEMBL1385598 & 688660 & 4.65 & 4.6087 & TRN & \\
\hline CHEMBL1359306 & 688660 & 5.45 & 4.9287 & TRN & \\
\hline CHEMBL1534469 & 688660 & 4.65 & 4.8988 & TRN & \\
\hline CHEMBL1578393 & 688660 & 4.75 & 4.8614 & TRN & \\
\hline CHEMBL1612112 & 688660 & 4.65 & 4.9533 & TRN & \\
\hline CHEMBL1416316 & 688660 & 4.6 & 4.6673 & TRN & \\
\hline CHEMBL1583715 & 688660 & 4.4 & 4.9246 & TRN & \\
\hline CHEMBL1407596 & 688660 & 4.6 & 4.8377 & TRN & \\
\hline CHEMBL1307236 & 688660 & 6.15 & 5.2444 & TRN & \\
\hline CHEMBL1574857 & 688660 & 5.4 & 4.9094 & TRN & \\
\hline CHEMBL1349408 & 688660 & 6.2 & 4.8928 & TST & \\
\hline CHEMBL1378294 & 688660 & 4.75 & 4.7597 & TRN & \\
\hline CHEMBL1318099 & 688660 & 4.6 & 4.5797 & TRN & \\
\hline CHEMBL1488743 & 688660 & 4.4 & 4.8302 & TRN & \\
\hline CHEMBL1406639 & 688660 & 5.35 & 4.92399 & 99999999995 & TRN \\
\hline CHEMBL1315413 & 688660 & 4.65 & 5.0113 & TST & \\
\hline CHEMBL1384204 & 688660 & 4.4 & 4.9948 & TRN & \\
\hline CHEMBL1480859 & 688660 & 6.2 & 5.2353 & TRN & \\
\hline CHEMBL1415081 & 688660 & 4.85 & 4.9622 & TRN & \\
\hline CHEMBL3208609 & 688660 & 6.0 & 4.7691 & TRN & \\
\hline CHEMBL1559422 & 688660 & 4.65 & 5.1465 & TRN & \\
\hline CHEMBL1423795 & 688660 & 4.75 & 5.0212 & TRN & \\
\hline CHEMBL1551809 & 688660 & 5.15 & 4.5634 & TRN & \\
\hline CHEMBL1504409 & 688660 & 4.4 & 4.7117 & TRN & \\
\hline CHEMBL1491891 & 688660 & 4.7 & 4.8206 & TRN & \\
\hline CHEMBL1370630 & 688660 & 4.6 & 4.8347 & TRN & \\
\hline CHEMBL1974613 & 688660 & 4.4 & 4.9307 & TRN & \\
\hline CHEMBL1391175 & 688660 & 4.4 & 4.7638 & TRN & \\
\hline CHEMBL1331501 & 688660 & 4.55 & 4.8347 & TRN & \\
\hline CHEMBL1468224 & 688660 & 5.5 & 5.2505 & TRN & \\
\hline CHEMBL1383015 & 688660 & 4.4 & 4.5899 & TST & \\
\hline CHEMBL1547504 & 688660 & 6.2 & 5.1996 & TRN & \\
\hline CHEMBL3192195 & 688660 & 4.4 & 4.8543 & TRN & \\
\hline CHEMBL1496591 & 688660 & 4.5 & 4.6512 & TRN & \\
\hline CHEMBL1509813 & 688660 & 6.15 & 4.8762 & TRN & \\
\hline
\end{tabular}




\begin{tabular}{|c|c|c|c|c|c|}
\hline \multicolumn{6}{|c|}{ Supplemental Table S2.txt } \\
\hline CHEMBL1330442 & 688660 & 4.5 & 4.8166 & TRN & \\
\hline CHEMBL1415572 & 688660 & 5.15 & 5.2614 & TRN & \\
\hline CHEMBL1457131 & 688660 & 4.95 & 4.7627 & TST & \\
\hline CHEMBL1470571 & 688660 & 4.75 & 5.0926 & TRN & \\
\hline CHEMBL1326997 & 688660 & 4.75 & 4.8048 & TRN & \\
\hline CHEMBL1532351 & 688660 & 5.45 & 5.013 & TRN & \\
\hline CHEMBL1594952 & 688660 & 5.0 & 4.9467 & TRN & \\
\hline CHEMBL1313996 & 688660 & 4.4 & 4.6207 & TRN & \\
\hline CHEMBL1479794 & 688660 & 4.4 & 5.0485 & TRN & \\
\hline CHEMBL1346592 & 688660 & 5.4 & \multicolumn{2}{|c|}{5.093999999999999} & TRN \\
\hline CHEMBL363207 & 688660 & 4.4 & 4.7775 & TST & \\
\hline CHEMBL 1438580 & 688660 & 4.45 & 4.744 & TRN & \\
\hline CHEMBL1393171 & 688660 & 5.15 & 4.7879 & TRN & \\
\hline CHEMBL1557704 & 688660 & 4.6 & \multicolumn{2}{|c|}{4.736000000000001} & TRN \\
\hline CHEMBL1346760 & 688660 & 5.0 & 4.7427 & TRN & \\
\hline CHEMBL1333027 & 688660 & 5.1 & 4.9551 & TRN & \\
\hline CHEMBL1412307 & 688660 & 4.4 & 4.6962 & TST & \\
\hline CHEMBL1349733 & 688660 & 5.35 & \multicolumn{2}{|c|}{4.8919999999999995} & TRN \\
\hline CHEMBL1488044 & 688660 & 4.45 & 4.7129 & TRN & \\
\hline CHEMBL1407917 & 688660 & 4.45 & 4.6739 & TRN & \\
\hline CHEMBL1575297 & 688660 & 5.95 & \multicolumn{2}{|c|}{5.132000000000001} & TRN \\
\hline CHEMBL1532390 & 688660 & 4.55 & 4.6396 & TRN & \\
\hline CHEMBL1608923 & 688660 & 6.5 & 4.9932 & TRN & \\
\hline CHEMBL1412575 & 688660 & 4.9 & 4.9192 & TRN & \\
\hline CHEMBL1483496 & 688660 & 5.3 & \multicolumn{2}{|c|}{4.781000000000001} & TRN \\
\hline CHEMBL1426085 & 688660 & 5.3 & 5.0477 & TRN & \\
\hline CHEMBL1453519 & 688660 & 4.6 & 4.7988 & TRN & \\
\hline CHEMBL1329238 & 688660 & 4.75 & 4.7492 & TRN & \\
\hline CHEMBL3192131 & 688660 & 5.5 & 4.7368 & TRN & \\
\hline CHEMBL1386743 & 688660 & 6.15 & 4.9092 & TRN & \\
\hline CHEMBL1460355 & 688660 & 5.45 & 4.8166 & TRN & \\
\hline CHEMBL1343516 & 688660 & 5.05 & 4.7673 & TRN & \\
\hline CHEMBL1363654 & 688660 & 4.8 & 4.8765 & TRN & \\
\hline CHEMBL1555468 & 688660 & 4.4 & 4.8188 & TRN & \\
\hline CHEMBL1385322 & 688660 & 4.75 & 4.7756 & TRN & \\
\hline CHEMBL1425176 & 688660 & 4.35 & 4.6795 & TST & \\
\hline CHEMBL1332067 & 688660 & 5.25 & 5.0936 & TRN & \\
\hline CHEMBL1608624 & 688660 & 4.4 & 4.7995 & TRN & \\
\hline CHEMBL1318681 & 688660 & 5.3 & 4.961 & TRN & \\
\hline CHEMBL1560825 & 688660 & 5.5 & 4.9044 & TRN & \\
\hline CHEMBL1328835 & 688660 & 4.5 & 5.0939 & TRN & \\
\hline CHEMBL1361870 & 688660 & 4.5 & 4.6893 & TST & \\
\hline CHEMBL1497862 & 688660 & 5.8 & 5.0604 & TRN & \\
\hline CHEMBL1410092 & 688660 & 4.55 & 4.9068 & TRN & \\
\hline CHEMBL1517728 & 688660 & 4.4 & 5.1062 & TRN & \\
\hline CHEMBL1370289 & 688660 & 4.4 & 4.8273 & TST & \\
\hline CHEMBL1501104 & 688660 & 5.5 & 5.1602 & TRN & \\
\hline CHEMBL57171 & 688660 & 4.4 & 4.8429 & TRN & \\
\hline
\end{tabular}




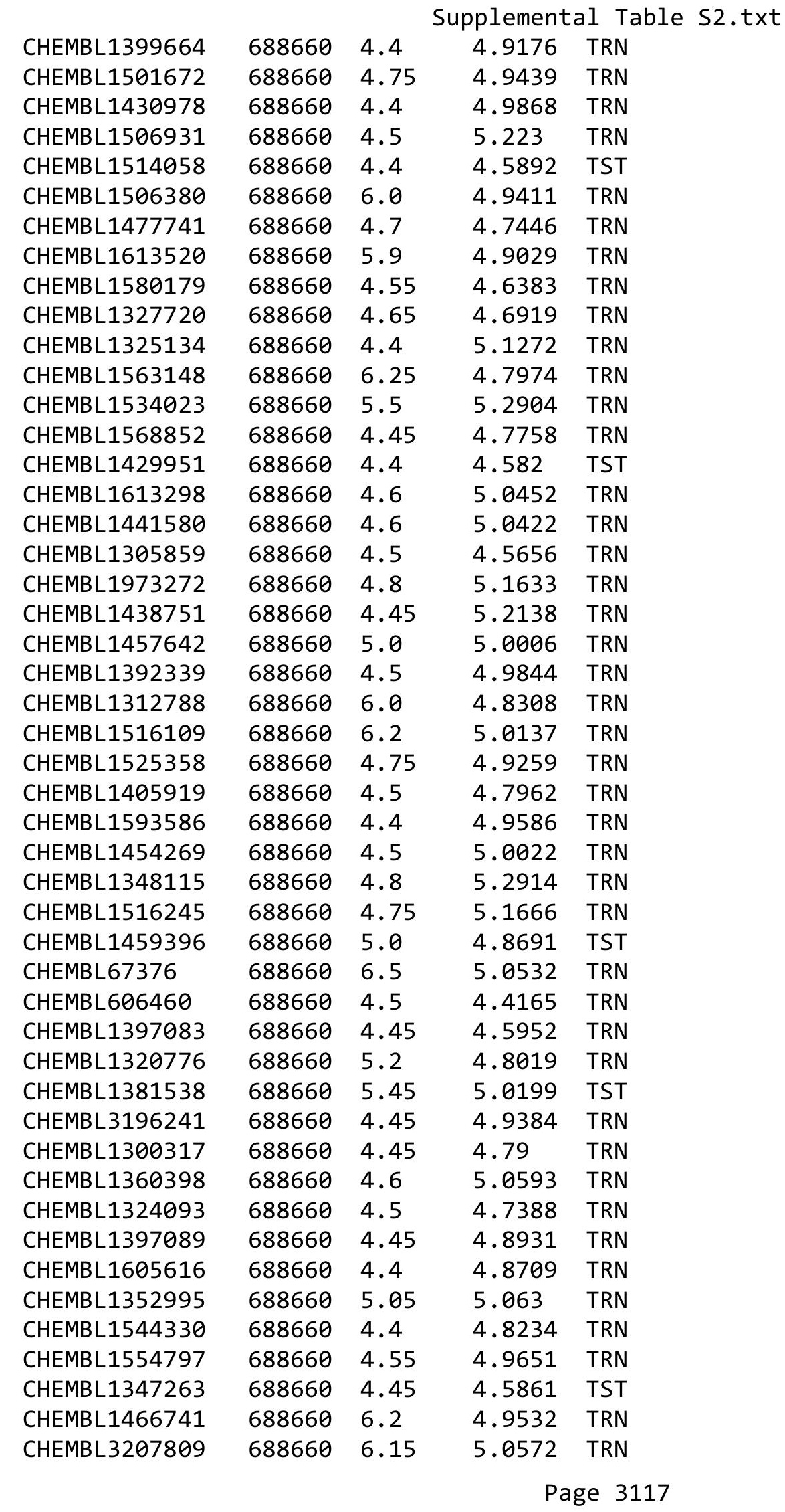




\begin{tabular}{|c|c|c|c|c|}
\hline \multicolumn{5}{|c|}{ Supplemental Table S2.txt } \\
\hline CHEMBL1344176 & 688660 & 4.4 & 5.2279 & TRN \\
\hline CHEMBL1481384 & 688660 & 5.2 & 5.1084 & TRN \\
\hline CHEMBL1578411 & 688660 & 4.6 & 4.8838 & TRN \\
\hline CHEMBL1479621 & 688660 & 4.45 & 4.7531 & TRN \\
\hline CHEMBL1550732 & 688660 & 5.05 & 4.6258 & TRN \\
\hline CHEMBL1335308 & 688660 & 6.15 & 5.3315 & TRN \\
\hline CHEMBL1312301 & 688660 & 5.35 & 4.894 & TRN \\
\hline CHEMBL1446949 & 688660 & 5.0 & 4.6843 & TST \\
\hline CHEMBL1385727 & 688660 & 4.45 & 4.8522 & TRN \\
\hline CHEMBL1352904 & 688660 & 4.4 & 4.5092 & TRN \\
\hline CHEMBL1496585 & 688660 & 4.55 & 4.8362 & TRN \\
\hline CHEMBL1304373 & 688660 & 6.2 & 5.0682 & TRN \\
\hline CHEMBL1417133 & 688660 & 4.85 & 4.9258 & TRN \\
\hline CHEMBL1394128 & 688660 & 5.1 & 5.2169 & TRN \\
\hline CHEMBL1402212 & 688660 & 5.65 & 5.2417 & TRN \\
\hline CHEMBL1524438 & 688660 & 4.65 & 4.935 & TRN \\
\hline CHEMBL1368383 & 688660 & 4.85 & 5.1144 & TRN \\
\hline CHEMBL1463594 & 688660 & 4.4 & 4.8998 & TRN \\
\hline CHEMBL1534864 & 688660 & 5.45 & 5.138 & TRN \\
\hline CHEMBL1366791 & 688660 & 5.25 & 4.8614 & TST \\
\hline CHEMBL1470548 & 688660 & 4.4 & 4.8557 & TRN \\
\hline CHEMBL3210324 & 688660 & 4.4 & 5.2774 & TRN \\
\hline CHEMBL1349162 & 688660 & 4.4 & 4.915 & TRN \\
\hline CHEMBL1360386 & 688660 & 4.45 & 4.5823 & TRN \\
\hline CHEMBL1484644 & 688660 & 4.4 & 4.7422 & TRN \\
\hline CHEMBL3214009 & 688660 & 4.4 & 4.8246 & TRN \\
\hline CHEMBL3190203 & 688660 & 5.15 & 4.9851 & TRN \\
\hline CHEMBL1445943 & 688660 & 5.0 & 5.0544 & TRN \\
\hline CHEMBL1443568 & 688660 & 5.2 & 4.9982 & TRN \\
\hline CHEMBL1317465 & 688660 & 5.5 & 4.8013 & TRN \\
\hline CHEMBL170190 & 688660 & 4.4 & 4.811 & TST \\
\hline CHEMBL1441348 & 688660 & 4.65 & 4.7589 & TRN \\
\hline CHEMBL1477341 & 688660 & 4.4 & 5.0165 & TRN \\
\hline CHEMBL1566701 & 688660 & 4.75 & 4.5749 & TRN \\
\hline CHEMBL1553753 & 688660 & 6.2 & 4.8991 & TRN \\
\hline CHEMBL1527357 & 688660 & 5.15 & 4.8848 & TRN \\
\hline CHEMBL1334135 & 688660 & 5.8 & 4.9796 & TRN \\
\hline CHEMBL1479122 & 688660 & 4.95 & 5.1658 & TRN \\
\hline CHEMBL1503840 & 688660 & 4.4 & 4.609 & TRN \\
\hline CHEMBL1508583 & 688660 & 4.4 & 4.9588 & TRN \\
\hline CHEMBL1561942 & 688660 & 4.55 & 4.9326 & TST \\
\hline CHEMBL 1455485 & 688660 & 5.0 & 4.9046 & TRN \\
\hline CHEMBL1410321 & 688660 & 4.5 & 4.7302 & TRN \\
\hline CHEMBL1565719 & 688660 & 5.45 & 5.001 & TRN \\
\hline CHEMBL1462007 & 688660 & 4.5 & 4.8665 & TRN \\
\hline CHEMBL1308309 & 688660 & 4.6 & 5.0688 & TRN \\
\hline CHEMBL1496880 & 688660 & 4.8 & 5.0208 & TRN \\
\hline CHEMBL1366279 & 688660 & 4.7 & 4.7476 & TRN \\
\hline
\end{tabular}




\begin{tabular}{|c|c|c|c|c|}
\hline \multicolumn{5}{|c|}{ Supplemental Tab } \\
\hline CHEMBL1366822 & 688660 & 4.4 & 4.7449 & TST \\
\hline CHEMBL1540844 & 688660 & 6.2 & 4.8229 & TRN \\
\hline CHEMBL1304923 & 688660 & 4.35 & 5.003 & TRN \\
\hline CHEMBL1309608 & 688660 & 4.45 & 4.735 & TRN \\
\hline CHEMBL1316691 & 688660 & 4.75 & 4.6371 & TRN \\
\hline CHEMBL1542161 & 688660 & 4.55 & 4.7383 & TRN \\
\hline CHEMBL1339102 & 688660 & 6.25 & 5.2093 & TRN \\
\hline CHEMBL1309290 & 688660 & 4.75 & 4.8099 & TRN \\
\hline CHEMBL1480372 & 688660 & 5.1 & 4.6494 & TRN \\
\hline CHEMBL1442064 & 688660 & 4.4 & 4.7971 & TST \\
\hline CHEMBL1565934 & 688660 & 4.7 & 4.5677 & TRN \\
\hline CHEMBL1482749 & 688660 & 4.4 & 4.8988 & TRN \\
\hline CHEMBL1530764 & 688660 & 4.4 & 4.7062 & TRN \\
\hline CHEMBL1612818 & 688660 & 4.7 & 4.8143 & TRN \\
\hline CHEMBL1342493 & 688660 & 4.6 & 5.0644 & TRN \\
\hline CHEMBL1467871 & 688660 & 4.8 & 4.8101 & TST \\
\hline CHEMBL1523275 & 688660 & 4.4 & 4.7667 & TRN \\
\hline CHEMBL1494806 & 688660 & 4.4 & 4.6947 & TRN \\
\hline CHEMBL1454315 & 688660 & 5.55 & 5.1913 & TRN \\
\hline CHEMBL1315186 & 688660 & 5.15 & 4.6761 & TRN \\
\hline CHEMBL1513654 & 688660 & 4.6 & 4.7431 & TST \\
\hline CHEMBL1555914 & 688660 & 4.55 & 5.0575 & TST \\
\hline CHEMBL1421566 & 688660 & 4.65 & 4.598 & TST \\
\hline CHEMBL1379239 & 688660 & 4.4 & 4.7124 & TRN \\
\hline CHEMBL1454296 & 688660 & 4.65 & 5.0206 & TRN \\
\hline CHEMBL1589264 & 688660 & 5.6 & 4.8923 & TRN \\
\hline CHEMBL 2002162 & 688660 & 4.4 & 4.7726 & TST \\
\hline CHEMBL1517813 & 688660 & 5.05 & 4.9548 & TRN \\
\hline CHEMBL1342924 & 688660 & 6.15 & 5.1983 & TRN \\
\hline CHEMBL1344834 & 688660 & 4.65 & 4.7224 & TRN \\
\hline CHEMBL1582014 & 688660 & 4.55 & 4.7864 & TRN \\
\hline CHEMBL1327840 & 688660 & 4.6 & 4.6647 & TST \\
\hline CHEMBL1352142 & 688660 & 6.2 & 5.022 & TST \\
\hline CHEMBL1540766 & 688660 & 5.55 & 4.9082 & TRN \\
\hline CHEMBL1366998 & 688660 & 4.4 & 4.7827 & TRN \\
\hline CHEMBL1483432 & 688660 & 5.75 & 5.0229 & TRN \\
\hline CHEMBL1344808 & 688660 & 4.4 & 4.948 & TRN \\
\hline CHEMBL1537141 & 688660 & 5.45 & 5.0231 & TRN \\
\hline CHEMBL1579807 & 688660 & 4.7 & 4.7626 & TRN \\
\hline CHEMBL1413042 & 688660 & 4.4 & 4.9701 & TRN \\
\hline CHEMBL1401337 & 688660 & 4.65 & 4.8787 & TRN \\
\hline CHEMBL1573266 & 688660 & 4.7 & 5.0131 & TST \\
\hline CHEMBL1328718 & 688660 & 4.45 & 5.2044 & TRN \\
\hline CHEMBL1604129 & 688660 & 5.45 & 5.033 & TRN \\
\hline CHEMBL1359568 & 688660 & 4.45 & 4.7353 & TRN \\
\hline CHEMBL1380783 & 688660 & 5.5 & 5.0209 & TRN \\
\hline CHEMBL1518313 & 688660 & 6.15 & 4.798 & TST \\
\hline CHEMBL1540340 & 688660 & 4.6 & 4.985 & TST \\
\hline
\end{tabular}




\begin{tabular}{|c|c|c|c|c|}
\hline \multicolumn{5}{|c|}{ Supplemental Table S2.txt } \\
\hline CHEMBL1605869 & 688660 & 4.7 & 4.9718 & TRN \\
\hline CHEMBL1529624 & 688660 & 4.7 & 4.7702 & TRN \\
\hline CHEMBL1475023 & 688660 & 5.8 & 5.1295 & TST \\
\hline CHEMBL1401818 & 688660 & 4.4 & 4.7215 & TRN \\
\hline CHEMBL1422984 & 688660 & 5.15 & 5.4187 & TRN \\
\hline CHEMBL1431703 & 688660 & 4.4 & 4.7561 & TST \\
\hline CHEMBL1589983 & 688660 & 4.45 & 5.0057 & TRN \\
\hline CHEMBL1480910 & 688660 & 4.85 & 4.9228 & TRN \\
\hline CHEMBL1476798 & 688660 & 5.15 & 4.7717 & TRN \\
\hline CHEMBL1396381 & 688660 & 4.4 & 5.0053 & TST \\
\hline CHEMBL1505000 & 688660 & 4.75 & 4.987 & TRN \\
\hline CHEMBL1378535 & 688660 & 6.15 & 5.0733 & TRN \\
\hline CHEMBL1336821 & 688660 & 4.75 & 4.9461 & TRN \\
\hline CHEMBL1418096 & 688660 & 4.4 & 4.918 & TRN \\
\hline CHEMBL1516069 & 688660 & 4.4 & 4.8746 & TRN \\
\hline CHEMBL3209718 & 688660 & 5.5 & 5.0518 & TRN \\
\hline CHEMBL1520356 & 688660 & 4.65 & 4.8092 & TRN \\
\hline CHEMBL1599090 & 688660 & 6.15 & 5.019 & TRN \\
\hline CHEMBL1570438 & 688660 & 4.9 & 5.0287 & TRN \\
\hline CHEMBL1444425 & 688660 & 4.75 & 4.9172 & TRN \\
\hline CHEMBL1538795 & 688660 & 4.35 & 4.8395 & TST \\
\hline CHEMBL1375110 & 688660 & 5.4 & 4.7839 & TRN \\
\hline CHEMBL303579 & 688660 & 4.95 & 4.8139 & TRN \\
\hline CHEMBL1540556 & 688660 & 4.4 & 4.708 & TST \\
\hline CHEMBL1529652 & 688660 & 4.65 & 4.9677 & TRN \\
\hline CHEMBL1458055 & 688660 & 5.45 & 4.8797 & TRN \\
\hline CHEMBL1613116 & 688660 & 4.4 & 4.7365 & TRN \\
\hline CHEMBL1338712 & 688660 & 5.15 & 5.1106 & TRN \\
\hline CHEMBL1325482 & 688660 & 5.8 & 4.954 & TRN \\
\hline CHEMBL1358587 & 688660 & 4.55 & 4.9123 & TRN \\
\hline CHEMBL3191568 & 688660 & 4.5 & 4.9181 & TRN \\
\hline CHEMBL1461360 & 688660 & 4.65 & 4.7676 & TRN \\
\hline CHEMBL1584502 & 688660 & 4.5 & 4.909 & TRN \\
\hline CHEMBL1875040 & 688660 & 5.6 & 4.8597 & TRN \\
\hline CHEMBL1400432 & 688660 & 4.4 & 4.4896 & TRN \\
\hline CHEMBL1565512 & 688660 & 5.15 & 4.9649 & TRN \\
\hline CHEMBL1481222 & 688660 & 4.6 & 4.6352 & TRN \\
\hline CHEMBL1537481 & 688660 & 4.65 & 4.8384 & TRN \\
\hline CHEMBL1402610 & 688660 & 5.4 & 4.7376 & TRN \\
\hline CHEMBL1447844 & 688660 & 4.4 & 4.7549 & TRN \\
\hline CHEMBL1527812 & 688660 & 4.65 & 4.9663 & TRN \\
\hline CHEMBL1347731 & 688660 & 5.2 & 5.0276 & TST \\
\hline CHEMBL1362948 & 688660 & 4.35 & 4.5722 & TRN \\
\hline CHEMBL1407187 & 688660 & 4.7 & 4.9973 & TRN \\
\hline CHEMBL1437106 & 688660 & 4.4 & 4.5616 & TRN \\
\hline CHEMBL1322950 & 688660 & 4.65 & 4.9898 & TRN \\
\hline CHEMBL3196435 & 688660 & 5.5 & 4.8755 & TRN \\
\hline CHEMBL1510813 & 688660 & 5.45 & 5.0542 & TRN \\
\hline
\end{tabular}




\begin{tabular}{|c|c|c|c|c|c|}
\hline \multirow{2}{*}{\multicolumn{2}{|c|}{ CHEMBL1572376 }} & \\
\hline & & 4.5 & 5.0092 & TRN & \\
\hline CHEMBL1537118 & 688660 & 6.15 & 4.8124 & TST & \\
\hline CHEMBL1532452 & 688660 & 4.7 & 4.9046 & TRN & \\
\hline CHEMBL3199307 & 688660 & 5.55 & 4.9158 & TRN & \\
\hline CHEMBL1320423 & 688660 & 4.4 & 4.7038 & TRN & \\
\hline CHEMBL1590730 & 688660 & 4.7 & 4.4731 & TRN & \\
\hline CHEMBL1311505 & 688660 & 4.5 & 4.8001 & TRN & \\
\hline CHEMBL1306117 & 688660 & 6.2 & 5.1462 & TRN & \\
\hline CHEMBL1542059 & 688660 & 5.05 & 4.9176 & TRN & \\
\hline CHEMBL1521434 & 688660 & 5.35 & 4.9796 & TRN & \\
\hline CHEMBL1326661 & 688660 & 5.15 & 4.8083 & TST & \\
\hline CHEMBL1549199 & 688660 & 5.45 & 5.0468 & TRN & \\
\hline CHEMBL1311678 & 688660 & 4.4 & 4.90300 & 00000000005 & TRN \\
\hline CHEMBL1504565 & 688660 & 5.55 & 4.9336 & TRN & \\
\hline CHEMBL1370379 & 688660 & 4.4 & 4.9992 & TRN & \\
\hline CHEMBL1461290 & 688660 & 4.4 & 5.0717 & TRN & \\
\hline CHEMBL1476176 & 688660 & 4.9 & 4.9687 & TRN & \\
\hline CHEMBL1335944 & 688660 & 4.45 & 4.8854 & TRN & \\
\hline CHEMBL1307573 & 688660 & 4.4 & 4.7441 & TRN & \\
\hline CHEMBL1554604 & 688660 & 4.6 & 4.7828 & TRN & \\
\hline CHEMBL1537846 & 688660 & 4.45 & 4.8535 & TST & \\
\hline CHEMBL1556794 & 688660 & 4.4 & 4.8675 & TRN & \\
\hline CHEMBL1559339 & 688660 & 4.45 & 4.7096 & TRN & \\
\hline CHEMBL1334612 & 688660 & 4.3 & 4.6229 & TRN & \\
\hline CHEMBL1386108 & 688660 & 4.45 & 5.0262 & TRN & \\
\hline CHEMBL1498852 & 688660 & 5.85 & 5.1755 & TRN & \\
\hline CHEMBL1992234 & 688660 & 6.2 & 4.7191 & TST & \\
\hline CHEMBL1455912 & 688660 & 5.0 & 4.9444 & TRN & \\
\hline CHEMBL3191694 & 688660 & 4.5 & 5.0638 & TRN & \\
\hline CHEMBL482050 & 688660 & 4.4 & 4.6546 & TST & \\
\hline CHEMBL1383511 & 688660 & 4.4 & 4.61600 & 30000000005 & TRN \\
\hline CHEMBL1454614 & 688660 & 5.15 & 4.7732 & TRN & \\
\hline CHEMBL1360842 & 688660 & 5.45 & 4.8956 & TRN & \\
\hline CHEMBL1419714 & 688660 & 5.7 & 4.7821 & TRN & \\
\hline CHEMBL1579523 & 688660 & 4.4 & 4.6333 & TST & \\
\hline CHEMBL1608800 & 688660 & 4.55 & 5.0428 & TRN & \\
\hline CHEMBL1547422 & 688660 & 4.5 & 4.7609 & TRN & \\
\hline CHEMBL1358226 & 688660 & 4.4 & 4.5847 & TRN & \\
\hline CHEMBL1329005 & 688660 & 6.15 & 4.949 & TST & \\
\hline CHEMBL1351764 & 688660 & 5.05 & 4.9654 & TRN & \\
\hline CHEMBL1397507 & 688660 & 5.05 & 4.8057 & TST & \\
\hline CHEMBL1443312 & 688660 & 4.85 & 4.4067 & TRN & \\
\hline CHEMBL1388522 & 688660 & 4.35 & 5.3103 & TRN & \\
\hline CHEMBL1305519 & 688660 & 5.8 & 5.2075 & TRN & \\
\hline CHEMBL1530797 & 688660 & 4.45 & 4.9633 & TRN & \\
\hline CHEMBL1578022 & 688660 & 6.0 & 5.0998 & TRN & \\
\hline CHEMBL1499210 & 688660 & 4.4 & 4.9268 & TRN & \\
\hline CHEMBL1360170 & 688660 & 4.4 & 4.8013 & TRN & \\
\hline
\end{tabular}




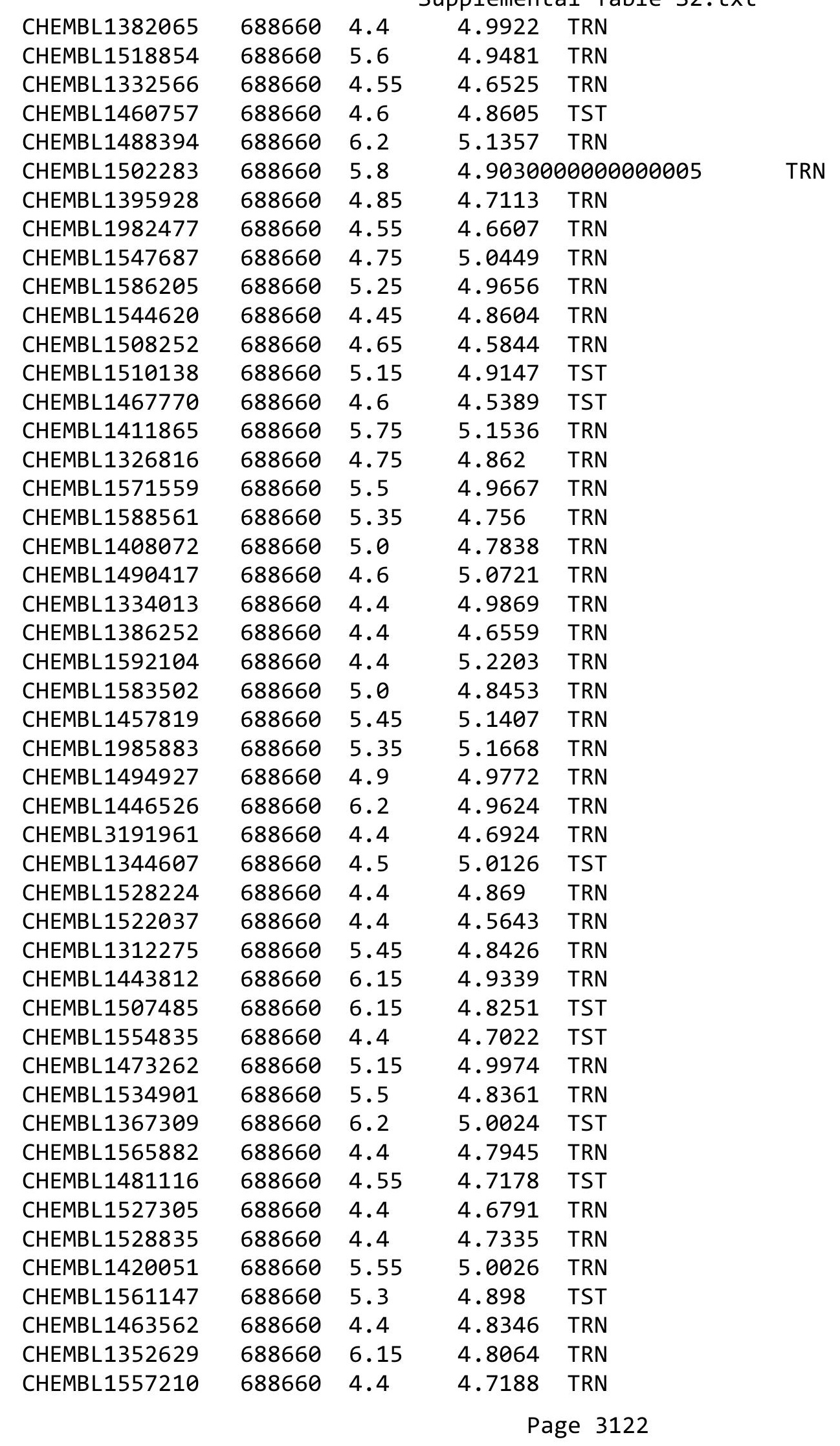




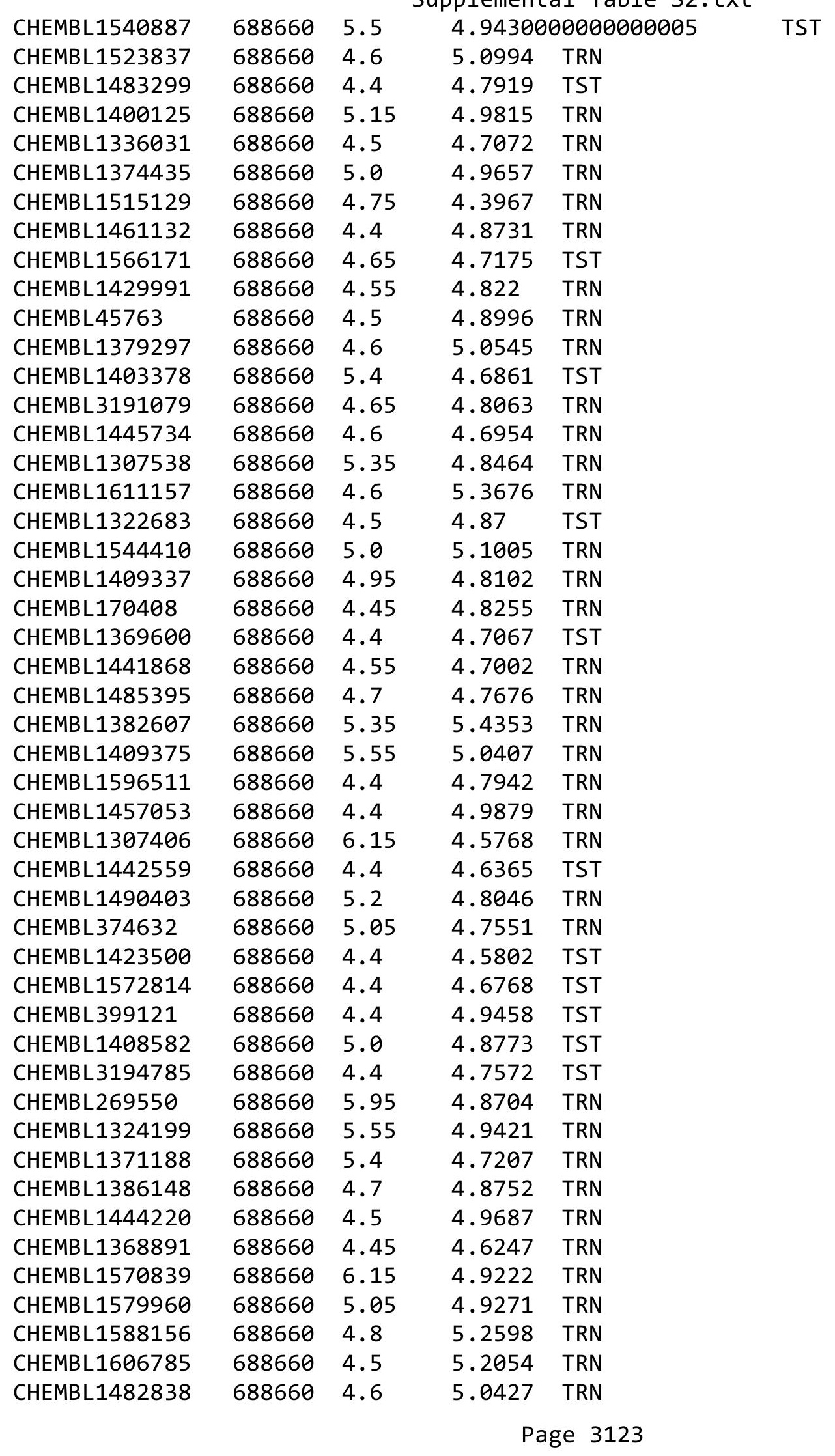




\begin{tabular}{|c|c|c|c|c|}
\hline & & & upplement & al $\mathrm{Ta}$ \\
\hline CHEMBL1451030 & 688660 & 5.45 & 5.0917 & TRN \\
\hline CHEMBL1366999 & 688660 & 4.5 & 4.77 & TST \\
\hline CHEMBL1336428 & 688660 & 4.4 & 4.6294 & TRN \\
\hline CHEMBL1476929 & 688660 & 4.9 & 5.0274 & TRN \\
\hline CHEMBL1359918 & 688660 & 4.45 & 4.9712 & TRN \\
\hline CHEMBL3195959 & 688660 & 4.4 & 4.6868 & TRN \\
\hline CHEMBL1556145 & 688660 & 4.45 & 4.7997 & TRN \\
\hline CHEMBL1446748 & 688660 & 4.6 & 4.8861 & TRN \\
\hline CHEMBL1611954 & 688660 & 5.05 & 4.9458 & TRN \\
\hline CHEMBL1557950 & 688660 & 5.45 & 5.1221 & TRN \\
\hline CHEMBL1440163 & 688660 & 5.55 & 4.6453 & TRN \\
\hline CHEMBL1367823 & 688660 & 4.4 & 4.7051 & TRN \\
\hline CHEMBL1502004 & 688660 & 4.6 & 4.7303 & TRN \\
\hline CHEMBL1563513 & 688660 & 4.4 & 4.6963 & TRN \\
\hline CHEMBL1336866 & 688660 & 4.55 & 4.7837 & TRN \\
\hline CHEMBL1588448 & 688660 & 6.15 & 4.8103 & TRN \\
\hline CHEMBL1363446 & 688660 & 4.4 & 4.8977 & TST \\
\hline CHEMBL1481192 & 688660 & 5.4 & 4.902 & TRN \\
\hline CHEMBL1483490 & 688660 & 4.4 & 5.0473 & TRN \\
\hline CHEMBL1450156 & 688660 & 4.4 & 4.8342 & TRN \\
\hline CHEMBL1459140 & 688660 & 5.4 & 4.9893 & TRN \\
\hline CHEMBL1372955 & 688660 & 5.15 & 5.0997 & TRN \\
\hline CHEMBL1429902 & 688660 & 4.4 & 4.7691 & TST \\
\hline CHEMBL1385617 & 688660 & 4.4 & 4.9918 & TST \\
\hline CHEMBL1459740 & 688660 & 4.65 & 5.0033 & TRN \\
\hline CHEMBL1489077 & 688660 & 4.55 & 4.7746 & TRN \\
\hline CHEMBL1324299 & 688660 & 4.4 & 5.0111 & TRN \\
\hline CHEMBL1483727 & 688660 & 5.05 & 4.8363 & TRN \\
\hline CHEMBL3190218 & 688660 & 4.4 & 4.931 & TRN \\
\hline CHEMBL1401587 & 688660 & 4.4 & 4.8663 & TRN \\
\hline CHEMBL1359376 & 688660 & 4.95 & 4.9437 & TST \\
\hline CHEMBL1608763 & 688660 & 5.4 & 4.9249 & TRN \\
\hline CHEMBL1457190 & 688660 & 4.4 & 5.1501 & TRN \\
\hline CHEMBL1468405 & 688660 & 6.15 & 5.0666 & TRN \\
\hline CHEMBL1449968 & 688660 & 4.55 & 4.7107 & TST \\
\hline CHEMBL1564313 & 688660 & 4.8 & 4.8507 & TRN \\
\hline CHEMBL1349724 & 688660 & 4.55 & 4.9344 & TRN \\
\hline CHEMBL1589430 & 688660 & 5.6 & 4.8948 & TRN \\
\hline CHEMBL1598246 & 688660 & 4.65 & 4.8296 & TRN \\
\hline CHEMBL1497302 & 688660 & 4.4 & 5.1136 & TRN \\
\hline CHEMBL1378757 & 688660 & 4.4 & 5.0889 & TRN \\
\hline CHEMBL1376618 & 688660 & 5.0 & 4.8634 & TRN \\
\hline CHEMBL1304368 & 688660 & 4.9 & 4.9017 & TRN \\
\hline CHEMBL1329726 & 688660 & 5.0 & 4.5813 & TST \\
\hline CHEMBL1460209 & 688660 & 4.55 & 4.8644 & TST \\
\hline CHEMBL1300731 & 688660 & 5.2 & 5.1619 & TRN \\
\hline CHEMBL1505620 & 688660 & 4.4 & 4.7017 & TRN \\
\hline CHEMBL1562304 & 688660 & 4.6 & 4.8755 & TRN \\
\hline
\end{tabular}




\begin{tabular}{|c|c|c|c|c|c|}
\hline & & \multicolumn{4}{|c|}{ Supplemental Table s2.txt } \\
\hline CHEMBL1343357 & 688660 & 4.45 & 4.6169 & TRN & \\
\hline CHEMBL1373272 & 688660 & 4.45 & 5.1763 & TRN & \\
\hline CHEMBL1400196 & 688660 & 4.7 & 4.6428 & TRN & \\
\hline CHEMBL1591591 & 688660 & 4.5 & 4.7471 & TST & \\
\hline CHEMBL1391624 & 688660 & 4.5 & 4.8266 & TST & \\
\hline CHEMBL3194953 & 688660 & 5.65 & 4.9381 & TRN & \\
\hline CHEMBL1537304 & 688660 & 5.45 & 5.1738 & TRN & \\
\hline CHEMBL1407370 & 688660 & 5.45 & 5.0053 & TRN & \\
\hline CHEMBL1568261 & 688660 & 5.5 & 4.9169 & TRN & \\
\hline CHEMBL1601300 & 688660 & 5.35 & 4.6755 & TRN & \\
\hline CHEMBL1604602 & 688660 & 4.8 & 4.754 & TRN & \\
\hline CHEMBL1605147 & 688660 & 5.5 & 4.9845 & TRN & \\
\hline CHEMBL1575824 & 688660 & 4.55 & 4.9807 & TRN & \\
\hline CHEMBL1324622 & 688660 & 5.05 & 4.842 & TRN & \\
\hline CHEMBL1601936 & 688660 & 4.6 & 4.9135 & TRN & \\
\hline CHEMBL1418902 & 688660 & 4.4 & 4.8915 & TRN & \\
\hline CHEMBL1437138 & 688660 & 4.4 & 4.9494 & TRN & \\
\hline CHEMBL1572008 & 688660 & 4.45 & 5.0778 & TRN & \\
\hline CHEMBL1420823 & 688660 & 4.4 & 4.7354 & TST & \\
\hline CHEMBL1508628 & 688660 & 5.9 & 5.06800 & 00000000005 & TRN \\
\hline CHEMBL1395700 & 688660 & 4.55 & 5.2186 & TRN & \\
\hline CHEMBL1541427 & 688660 & 4.4 & 4.6552 & TRN & \\
\hline CHEMBL1430464 & 688660 & 4.65 & 4.925 & TRN & \\
\hline CHEMBL1609072 & 688660 & 5.3 & 5.1024 & TRN & \\
\hline CHEMBL1466840 & 688660 & 4.5 & 4.572 & TRN & \\
\hline CHEMBL1470944 & 688660 & 4.7 & 4.9403 & TRN & \\
\hline CHEMBL1609490 & 688660 & 5.15 & 4.9666 & TRN & \\
\hline CHEMBL1303531 & 688660 & 4.4 & 4.6685 & TRN & \\
\hline CHEMBL 246656 & 688660 & 4.45 & 4.7655 & TRN & \\
\hline CHEMBL1413474 & 688660 & 5.3 & 4.7669 & TRN & \\
\hline CHEMBL1455245 & 688660 & 5.5 & 4.907 & TRN & \\
\hline CHEMBL1396741 & 688660 & 4.4 & 5.0023 & TRN & \\
\hline CHEMBL3213365 & 688660 & 4.8 & 5.0318 & TRN & \\
\hline CHEMBL1478757 & 688660 & 6.15 & 4.949 & TRN & \\
\hline CHEMBL1312358 & 688660 & 4.4 & 4.6773 & TRN & \\
\hline CHEMBL1409623 & 688660 & 4.5 & 4.5182 & TRN & \\
\hline CHEMBL1548170 & 688660 & 4.4 & 4.9688 & TST & \\
\hline CHEMBL1403132 & 688660 & 4.4 & 5.0006 & TRN & \\
\hline CHEMBL1499320 & 688660 & 4.4 & 4.874 & TRN & \\
\hline CHEMBL1543851 & 688660 & 4.75 & 4.7521 & TRN & \\
\hline CHEMBL1393197 & 688660 & 4.4 & 4.8499 & TRN & \\
\hline CHEMBL1426020 & 688660 & 4.4 & 4.7131 & TRN & \\
\hline CHEMBL1465302 & 688660 & 4.7 & 4.8559 & TST & \\
\hline CHEMBL1436017 & 688660 & 4.4 & 4.752 & TRN & \\
\hline CHEMBL317469 & 688660 & 4.7 & 4.8637 & TRN & \\
\hline CHEMBL340807 & 688660 & 4.45 & 4.7715 & TRN & \\
\hline CHEMBL1328734 & 688660 & 6.0 & 5.1688 & TRN & \\
\hline CHEMBL1304303 & 688660 & 6.2 & 4.9418 & TRN & \\
\hline
\end{tabular}




\begin{tabular}{|c|c|c|c|c|c|}
\hline & & \multicolumn{4}{|c|}{ Supplemental Table S2.txt } \\
\hline CHEMBL1401645 & 688660 & 4.5 & 4.689 & TRN & \\
\hline CHEMBL443510 & 688660 & 4.65 & 4.9049 & TST & \\
\hline CHEMBL1426378 & 688660 & 4.4 & 4.7866 & TRN & \\
\hline CHEMBL 3209236 & 688660 & 5.35 & 4.7372 & TST & \\
\hline CHEMBL3196656 & 688660 & 4.5 & 4.8563 & TRN & \\
\hline CHEMBL1574869 & 688660 & 4.45 & 4.794 & TRN & \\
\hline CHEMBL1447071 & 688660 & 4.4 & 4.8582 & TRN & \\
\hline CHEMBL1370760 & 688660 & 4.55 & 4.909 & TRN & \\
\hline CHEMBL1470235 & 688660 & 4.8 & 4.9033 & TRN & \\
\hline CHEMBL3193247 & 688660 & 5.15 & 4.8327 & TRN & \\
\hline CHEMBL1381066 & 688660 & 4.4 & 4.7849 & TST & \\
\hline CHEMBL1601696 & 688660 & 5.0 & 5.0972 & TRN & \\
\hline CHEMBL1383525 & 688660 & 5.15 & 5.2271 & TRN & \\
\hline CHEMBL1430074 & 688660 & 4.5 & 4.5725 & TRN & \\
\hline CHEMBL1414915 & 688660 & 4.45 & 4.966 & TRN & \\
\hline CHEMBL1555359 & 688660 & 5.45 & 4.9462 & TRN & \\
\hline CHEMBL1547626 & 688660 & 4.4 & 4.9654 & TRN & \\
\hline CHEMBL1312126 & 688660 & 4.45 & 5.1796 & TRN & \\
\hline CHEMBL1304647 & 688660 & 4.45 & 5.03100 & 0000000001 & TRN \\
\hline CHEMBL 2005602 & 688660 & 4.4 & 4.8957 & TRN & \\
\hline CHEMBL1554856 & 688660 & 4.5 & 4.9724 & TRN & \\
\hline CHEMBL3194683 & 688660 & 4.4 & 4.802 & TRN & \\
\hline CHEMBL1554811 & 688660 & 4.45 & 4.7201 & TST & \\
\hline CHEMBL1432151 & 688660 & 4.6 & 4.9648 & TRN & \\
\hline CHEMBL1504842 & 688660 & 4.8 & 4.8584 & TRN & \\
\hline CHEMBL1431521 & 688660 & 4.55 & 4.725 & TRN & \\
\hline CHEMBL1424718 & 688660 & 5.55 & 4.907 & TRN & \\
\hline CHEMBL1381339 & 688660 & 4.5 & 5.0435 & TRN & \\
\hline CHEMBL1591207 & 688660 & 4.55 & 5.1639 & TRN & \\
\hline CHEMBL1318785 & 688660 & 4.55 & 5.1469 & TRN & \\
\hline CHEMBL1541695 & 688660 & 4.55 & 4.8294 & TST & \\
\hline CHEMBL1463957 & 688660 & 5.3 & 5.1769 & TRN & \\
\hline CHEMBL1973435 & 688660 & 4.6 & 4.8041 & TST & \\
\hline CHEMBL1507302 & 688660 & 4.7 & 4.7966 & TRN & \\
\hline CHEMBL1459686 & 688660 & 5.5 & 4.8274 & TRN & \\
\hline CHEMBL1311046 & 688660 & 5.45 & 5.0015 & TST & \\
\hline CHEMBL1413669 & 688660 & 4.55 & 4.6979 & TRN & \\
\hline CHEMBL1589205 & 688660 & 4.45 & 4.6104 & TRN & \\
\hline CHEMBL1597459 & 688660 & 4.4 & 4.7351 & TRN & \\
\hline CHEMBL1508930 & 688660 & 4.45 & 4.5552 & TST & \\
\hline CHEMBL1454640 & 688660 & 4.5 & 4.5101 & TRN & \\
\hline CHEMBL1510149 & 688660 & 4.4 & 4.62 & TRN & \\
\hline CHEMBL1323910 & 688660 & 6.2 & 4.7887 & TST & \\
\hline CHEMBL1498254 & 688660 & 6.2 & 4.9097 & TST & \\
\hline CHEMBL1469075 & 688660 & 4.5 & 4.5711 & TRN & \\
\hline CHEMBL1390511 & 688660 & 4.4 & 4.8347 & TST & \\
\hline CHEMBL1456979 & 688660 & 4.65 & 4.6928 & TRN & \\
\hline CHEMBL1486057 & 688660 & 5.5 & 4.7744 & TRN & \\
\hline
\end{tabular}




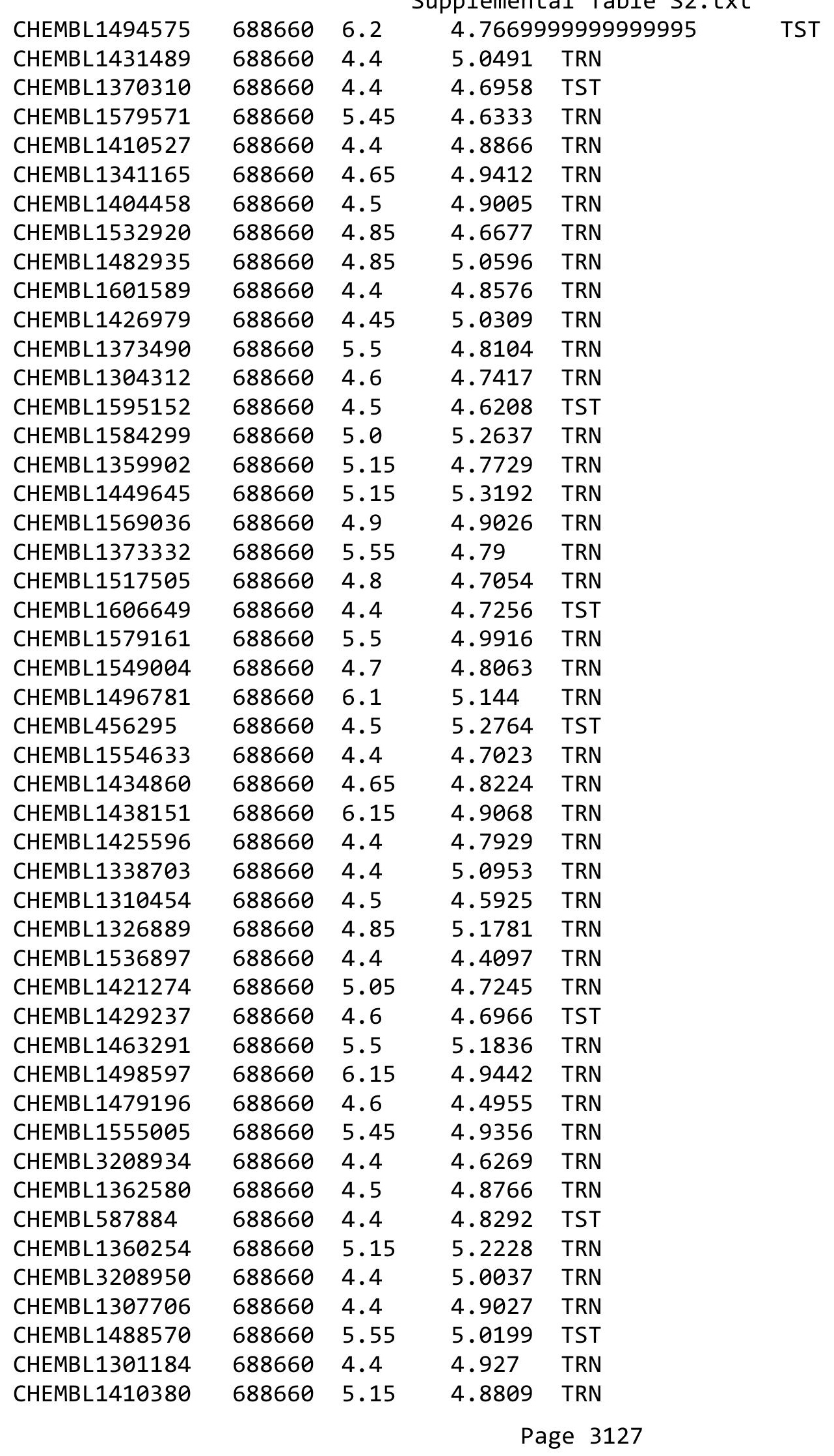




\begin{tabular}{|c|c|c|c|c|c|}
\hline & & & & & \\
\hline CHEMBL1553098 & 688660 & 4.4 & 4.794 & TRN & \\
\hline CHEMBL1418493 & 688660 & 4.45 & 4.6976 & TRN & \\
\hline CHEMBL1345592 & 688660 & 4.7 & 4.7443 & TRN & \\
\hline CHEMBL1462574 & 688660 & 4.4 & 4.7484 & TRN & \\
\hline CHEMBL1347777 & 688660 & 4.75 & 4.72199 & 99999999995 & TRN \\
\hline CHEMBL1568598 & 688660 & 4.4 & 4.8717 & TRN & \\
\hline CHEMBL1604007 & 688660 & 5.45 & 4.9989 & TRN & \\
\hline CHEMBL1505292 & 688660 & 4.6 & 4.6458 & TST & \\
\hline CHEMBL1591082 & 688660 & 4.65 & 4.6391 & TRN & \\
\hline CHEMBL1526129 & 688660 & 4.45 & 4.9635 & TRN & \\
\hline CHEMBL1541255 & 688660 & 4.6 & 4.6593 & TRN & \\
\hline CHEMBL1404365 & 688660 & 4.7 & 4.944 & TRN & \\
\hline CHEMBL1356283 & 688660 & 4.4 & 5.1519 & TRN & \\
\hline CHEMBL1475607 & 688660 & 4.4 & 4.9837 & TRN & \\
\hline CHEMBL1570584 & 688660 & 5.5 & 5.0029 & TRN & \\
\hline CHEMBL1562493 & 688660 & 4.4 & 4.8044 & TRN & \\
\hline CHEMBL1336914 & 688660 & 4.5 & 4.7467 & TRN & \\
\hline CHEMBL1584469 & 688660 & 4.5 & 4.7749 & TRN & \\
\hline CHEMBL1385842 & 688660 & 4.5 & 4.9734 & TRN & \\
\hline CHEMBL1383022 & 688660 & 4.55 & 4.6795 & TRN & \\
\hline CHEMBL1380967 & 688660 & 6.2 & 4.8096 & TST & \\
\hline CHEMBL1384377 & 688660 & 4.4 & 4.8501 & TRN & \\
\hline CHEMBL1335206 & 688660 & 5.25 & 4.8123 & TRN & \\
\hline CHEMBL3190644 & 688660 & 4.4 & 4.7807 & TST & \\
\hline CHEMBL1570587 & 688660 & 5.2 & 5.0902 & TRN & \\
\hline CHEMBL1392642 & 688660 & 5.45 & 5.1848 & TRN & \\
\hline CHEMBL 2138770 & 688660 & 5.95 & 4.8589 & TRN & \\
\hline CHEMBL1403683 & 688660 & 5.3 & 4.9382 & TRN & \\
\hline CHEMBL1472131 & 688660 & 4.55 & 4.6813 & TRN & \\
\hline CHEMBL1308179 & 688660 & 4.45 & 4.8359 & TST & \\
\hline CHEMBL1410581 & 688660 & 4.45 & 5.3463 & TRN & \\
\hline CHEMBL1412019 & 688660 & 5.0 & 4.8579 & TRN & \\
\hline CHEMBL3197940 & 688660 & 5.0 & 4.76399 & 9999999999 & TRN \\
\hline CHEMBL1373847 & 688660 & 4.4 & 4.5939 & TRN & \\
\hline CHEMBL1522005 & 688660 & 4.95 & 4.9042 & TST & \\
\hline CHEMBL1547335 & 688660 & 5.15 & 4.9293 & TRN & \\
\hline CHEMBL1517513 & 688660 & 5.15 & 5.0507 & TST & \\
\hline CHEMBL1349941 & 688660 & 4.45 & 5.1437 & TRN & \\
\hline CHEMBL1341642 & 688660 & 5.15 & 4.8526 & TRN & \\
\hline CHEMBL194400 & 688660 & 4.4 & 4.7858 & TST & \\
\hline CHEMBL1450715 & 688660 & 5.05 & 4.684 & TRN & \\
\hline CHEMBL1345202 & 688660 & 4.5 & 5.0158 & TRN & \\
\hline CHEMBL1426041 & 688660 & 5.45 & 5.1586 & TRN & \\
\hline CHEMBL1411171 & 688660 & 4.4 & 4.8243 & TRN & \\
\hline CHEMBL1402777 & 688660 & 5.45 & 4.9606 & TRN & \\
\hline CHEMBL1369482 & 688660 & 4.5 & 4.6673 & TST & \\
\hline CHEMBL1403784 & 688660 & 4.4 & 4.9452 & TRN & \\
\hline CHEMBL1339581 & 688660 & 5.5 & 5.0794 & TRN & \\
\hline
\end{tabular}




\begin{tabular}{|c|c|c|c|c|c|}
\hline \multicolumn{6}{|c|}{ Supplemental Table S2.txt } \\
\hline CHEMBL1549985 & 688660 & 4.5 & 4.8124 & TRN & \\
\hline CHEMBL1427549 & 688660 & 4.6 & 4.7825 & TRN & \\
\hline CHEMBL1570685 & 688660 & 4.85 & 4.9054 & TRN & \\
\hline CHEMBL1580604 & 688660 & 4.7 & 4.8345 & TRN & \\
\hline CHEMBL1459449 & 688660 & 4.7 & 4.7302 & TST & \\
\hline CHEMBL1319701 & 688660 & 6.15 & 4.7004 & TST & \\
\hline CHEMBL1348630 & 688660 & 4.5 & 4.9376 & TRN & \\
\hline CHEMBL1409155 & 688660 & 4.5 & 5.0363 & TRN & \\
\hline CHEMBL1464198 & 688660 & 6.15 & 5.0214 & TRN & \\
\hline CHEMBL1454102 & 688660 & 4.65 & 4.8806 & TRN & \\
\hline CHEMBL1552505 & 688660 & 4.65 & 4.7622 & TRN & \\
\hline CHEMBL1587388 & 688660 & 4.85 & 4.937 & TST & \\
\hline CHEMBL1524251 & 688660 & 4.75 & 4.7602 & TRN & \\
\hline CHEMBL1576064 & 688660 & 6.2 & 4.9803 & TRN & \\
\hline CHEMBL1417231 & 688660 & 4.6 & 4.8306 & TRN & \\
\hline CHEMBL3210758 & 688660 & 4.4 & 4.8989 & TRN & \\
\hline CHEMBL1372788 & 688660 & 4.4 & 4.8328 & TST & \\
\hline CHEMBL3190502 & 688660 & 5.25 & 5.0071 & TRN & \\
\hline CHEMBL373492 & 688660 & 5.05 & 4.8588 & TRN & \\
\hline CHEMBL1334707 & 688660 & 4.4 & 4.6737 & TRN & \\
\hline CHEMBL1515828 & 688660 & 5.1 & 5.1424 & TRN & \\
\hline CHEMBL1401295 & 688660 & 4.7 & 5.03100 & 2000000001 & TRN \\
\hline CHEMBL 3190456 & 688660 & 5.05 & 4.7635 & TST & \\
\hline CHEMBL1477246 & 688660 & 5.15 & 5.2969 & TRN & \\
\hline CHEMBL1547975 & 688660 & 4.4 & 4.9391 & TRN & \\
\hline CHEMBL 1556160 & 688660 & 6.15 & 4.7885 & TST & \\
\hline CHEMBL1416819 & 688660 & 4.4 & 4.8066 & TRN & \\
\hline CHEMBL1453454 & 688660 & 4.4 & 4.8617 & TRN & \\
\hline CHEMBL3199139 & 688660 & 4.4 & 4.7984 & TRN & \\
\hline CHEMBL1539224 & 688660 & 4.5 & 4.3214 & TRN & \\
\hline CHEMBL1588721 & 688660 & 4.4 & 4.6834 & TST & \\
\hline CHEMBL1530025 & 688660 & 4.4 & 4.9123 & TRN & \\
\hline CHEMBL1584455 & 688660 & 6.5 & 5.0517 & TRN & \\
\hline CHEMBL1389433 & 688660 & 4.5 & 4.6268 & TRN & \\
\hline CHEMBL1341575 & 688660 & 4.45 & 4.7226 & TST & \\
\hline CHEMBL1340039 & 688660 & 4.6 & 4.8979 & TRN & \\
\hline CHEMBL1436748 & 688660 & 4.5 & 4.6401 & TRN & \\
\hline CHEMBL1304195 & 688660 & 4.55 & 4.9478 & TRN & \\
\hline CHEMBL1543579 & 688660 & 4.4 & 5.0126 & TRN & \\
\hline CHEMBL1513228 & 688660 & 4.7 & 4.6336 & TRN & \\
\hline CHEMBL355014 & 688660 & 4.45 & 4.7837 & TRN & \\
\hline CHEMBL1322914 & 688660 & 4.4 & 4.7528 & TRN & \\
\hline CHEMBL1548185 & 688660 & 4.7 & 4.6545 & TRN & \\
\hline CHEMBL1421402 & 688660 & 4.4 & 4.7197 & TRN & \\
\hline CHEMBL1333688 & 688660 & 4.45 & 4.7387 & TRN & \\
\hline CHEMBL1327768 & 688660 & 5.15 & 5.04899 & 99999999995 & TRN \\
\hline CHEMBL1329244 & 688660 & 5.85 & 4.9244 & TRN & \\
\hline CHEMBL1312061 & 688660 & 5.0 & 4.8277 & TRN & \\
\hline
\end{tabular}




\begin{tabular}{|c|c|c|c|c|}
\hline \multicolumn{5}{|c|}{ Supplemental Table S2.txt } \\
\hline CHEMBL1514456 & 688660 & 4.6 & 4.9779 & TRN \\
\hline CHEMBL1345480 & 688660 & 6.45 & 4.8956 & TST \\
\hline CHEMBL1549338 & 688660 & 4.65 & 4.9931 & TRN \\
\hline CHEMBL1468371 & 688660 & 5.4 & 5.0796 & TRN \\
\hline CHEMBL1547869 & 688660 & 5.45 & 4.9757 & TRN \\
\hline CHEMBL1478061 & 688660 & 5.35 & 4.7842 & TRN \\
\hline CHEMBL1362566 & 688660 & 4.45 & 4.7254 & TRN \\
\hline CHEMBL1372879 & 688660 & 5.8 & 4.9009 & TRN \\
\hline CHEMBL1500679 & 688660 & 4.4 & 4.7559 & TRN \\
\hline CHEMBL1491932 & 688660 & 5.1 & 4.9648 & TRN \\
\hline CHEMBL1460522 & 688660 & 5.5 & 4.6791 & TST \\
\hline CHEMBL 3207728 & 688660 & 4.45 & 4.9935 & TRN \\
\hline CHEMBL3213362 & 688660 & 5.1 & 4.9266 & TST \\
\hline CHEMBL1605304 & 688660 & 4.45 & 4.5718 & TRN \\
\hline CHEMBL1364119 & 688660 & 4.4 & 4.7303 & TRN \\
\hline CHEMBL1306374 & 688660 & 5.5 & 4.6654 & TRN \\
\hline CHEMBL1541932 & 688660 & 5.5 & 5.0691 & TRN \\
\hline CHEMBL1383919 & 688660 & 4.4 & 4.5983 & TRN \\
\hline CHEMBL1311042 & 688660 & 4.4 & 4.788 & TST \\
\hline CHEMBL1315844 & 688660 & 4.7 & 4.8351 & TRN \\
\hline CHEMBL3209983 & 688660 & 4.4 & 5.0868 & TRN \\
\hline CHEMBL3194191 & 688660 & 4.5 & 4.9833 & TRN \\
\hline CHEMBL1576574 & 688660 & 4.45 & 5.2632 & TRN \\
\hline CHEMBL1439318 & 688660 & 4.4 & 4.8416 & TRN \\
\hline CHEMBL1609107 & 688660 & 5.45 & 4.6894 & TST \\
\hline CHEMBL1500975 & 688660 & 5.15 & 4.7684 & TRN \\
\hline CHEMBL1477805 & 688660 & 4.4 & 4.687 & TRN \\
\hline CHEMBL1304220 & 688660 & 4.4 & 4.9551 & TRN \\
\hline CHEMBL1391831 & 688660 & 5.4 & 5.2163 & TRN \\
\hline CHEMBL1600220 & 688660 & 5.0 & 5.0887 & TRN \\
\hline CHEMBL1460148 & 688660 & 4.5 & 5.0215 & TRN \\
\hline CHEMBL1341404 & 688660 & 4.6 & 5.0528 & TRN \\
\hline CHEMBL1576149 & 688660 & 5.15 & 4.8666 & TRN \\
\hline CHEMBL1382511 & 688660 & 4.4 & 4.9048 & TRN \\
\hline CHEMBL1365663 & 688660 & 4.65 & 4.8474 & TRN \\
\hline CHEMBL1561275 & 688660 & 5.5 & 4.9178 & TRN \\
\hline CHEMBL1305818 & 688660 & 4.4 & 5.0229 & TRN \\
\hline CHEMBL1404846 & 688660 & 4.4 & 4.9429 & TRN \\
\hline CHEMBL1560229 & 688660 & 4.4 & 4.7363 & TST \\
\hline CHEMBL1535503 & 688660 & 4.5 & 4.953 & TST \\
\hline CHEMBL1304422 & 688660 & 5.4 & 4.8886 & TRN \\
\hline CHEMBL1517337 & 688660 & 4.4 & 4.9748 & TST \\
\hline CHEMBL1544608 & 688660 & 5.0 & 4.8297 & TST \\
\hline CHEMBL1444047 & 688660 & 5.45 & 5.1262 & TRN \\
\hline CHEMBL1585654 & 688660 & 4.45 & 4.746 & TRN \\
\hline CHEMBL1361913 & 688660 & 5.15 & 5.0919 & TRN \\
\hline CHEMBL1461193 & 688660 & 4.4 & 4.6256 & TST \\
\hline CHEMBL1971913 & 688660 & 4.55 & 4.6961 & TRN \\
\hline
\end{tabular}




\begin{tabular}{|c|c|c|c|c|c|}
\hline \\
\hline CHEMBL1424264 & 688660 & 4.6 & 4.9398 & TRN & \\
\hline CHEMBL1431350 & 688660 & 5.5 & 4.8715 & TRN & \\
\hline CHEMBL1455549 & 688660 & 4.6 & 4.7517 & TRN & \\
\hline CHEMBL1459918 & 688660 & 4.45 & 4.8926 & TRN & \\
\hline CHEMBL1583232 & 688660 & 5.55 & 4.8874 & TRN & \\
\hline CHEMBL1424140 & 688660 & 4.55 & 5.1816 & TRN & \\
\hline CHEMBL1379235 & 688660 & 4.4 & 5.1271 & TRN & \\
\hline CHEMBL1415033 & 688660 & 5.05 & 5.0355 & TRN & \\
\hline CHEMBL1478532 & 688660 & 6.15 & 5.0375 & TRN & \\
\hline CHEMBL1504586 & 688660 & 5.15 & 5.0376 & TST & \\
\hline CHEMBL1577547 & 688660 & 5.5 & 4.6542 & TRN & \\
\hline CHEMBL1533401 & 688660 & 4.5 & 4.9932 & TRN & \\
\hline CHEMBL1453739 & 688660 & 4.45 & 5.0588 & TRN & \\
\hline CHEMBL1336876 & 688660 & 4.4 & 4.5701 & TRN & \\
\hline CHEMBL1608622 & 688660 & 6.15 & 5.0131 & TRN & \\
\hline CHEMBL1451299 & 688660 & 5.05 & 5.1918 & TRN & \\
\hline CHEMBL3189365 & 688660 & 4.45 & 5.3035 & TRN & \\
\hline CHEMBL1473005 & 688660 & 5.15 & 4.8648 & TRN & \\
\hline CHEMBL1447725 & 688660 & 5.15 & 5.0359 & TRN & \\
\hline CHEMBL1437614 & 688660 & 4.4 & 5.2205 & TST & \\
\hline CHEMBL1596380 & 688660 & 4.4 & 4.7273 & TRN & \\
\hline CHEMBL1556286 & 688660 & 6.2 & 5.1667 & TRN & \\
\hline CHEMBL1367594 & 688660 & 6.2 & 4.7503 & TRN & \\
\hline CHEMBL112115 & 688660 & 5.35 & 4.6329 & TRN & \\
\hline CHEMBL1567711 & 688660 & 6.15 & 4.967 & TRN & \\
\hline CHEMBL1533626 & 688660 & 4.4 & 4.6304 & TRN & \\
\hline CHEMBL1981200 & 688660 & 5.4 & 5.0106 & TRN & \\
\hline CHEMBL601933 & 688660 & 5.5 & 4.5644 & TRN & \\
\hline CHEMBL1329793 & 688660 & 4.45 & 4.9306 & TRN & \\
\hline CHEMBL1375998 & 688660 & 4.6 & 4.812 & TRN & \\
\hline CHEMBL1587181 & 688660 & 4.4 & 4.6156 & TRN & \\
\hline CHEMBL1471612 & 688660 & 4.55 & 4.9938 & TST & \\
\hline CHEMBL1398163 & 688660 & 4.4 & 4.6556 & TRN & \\
\hline CHEMBL1447076 & 688660 & 4.4 & 4.8465 & TRN & \\
\hline CHEMBL1577452 & 688660 & 4.8 & 4.8653 & TRN & \\
\hline CHEMBL1375603 & 688660 & 5.4 & $5.1110 e$ & 0000000001 & TRN \\
\hline CHEMBL1578780 & 688660 & 4.5 & 5.1711 & TRN & \\
\hline CHEMBL1569086 & 688660 & 4.4 & 5.0335 & TRN & \\
\hline CHEMBL1361053 & 688660 & 4.55 & 4.8872 & TRN & \\
\hline CHEMBL1553368 & 688660 & 4.55 & 4.7066 & TRN & \\
\hline CHEMBL1580191 & 688660 & 4.7 & 4.9276 & TRN & \\
\hline CHEMBL1421128 & 688660 & 4.4 & 4.7037 & TRN & \\
\hline CHEMBL1499220 & 688660 & 4.4 & 4.725 & TRN & \\
\hline CHEMBL1531341 & 688660 & 6.1 & 4.8498 & TRN & \\
\hline CHEMBL1479519 & 688660 & 4.6 & 4.9967 & TRN & \\
\hline CHEMBL1573891 & 688660 & 5.0 & 4.9086 & TRN & \\
\hline CHEMBL1370844 & 688660 & 4.4 & 4.9172 & TRN & \\
\hline CHEMBL1566524 & 688660 & 5.05 & 5.0901 & TRN & \\
\hline
\end{tabular}




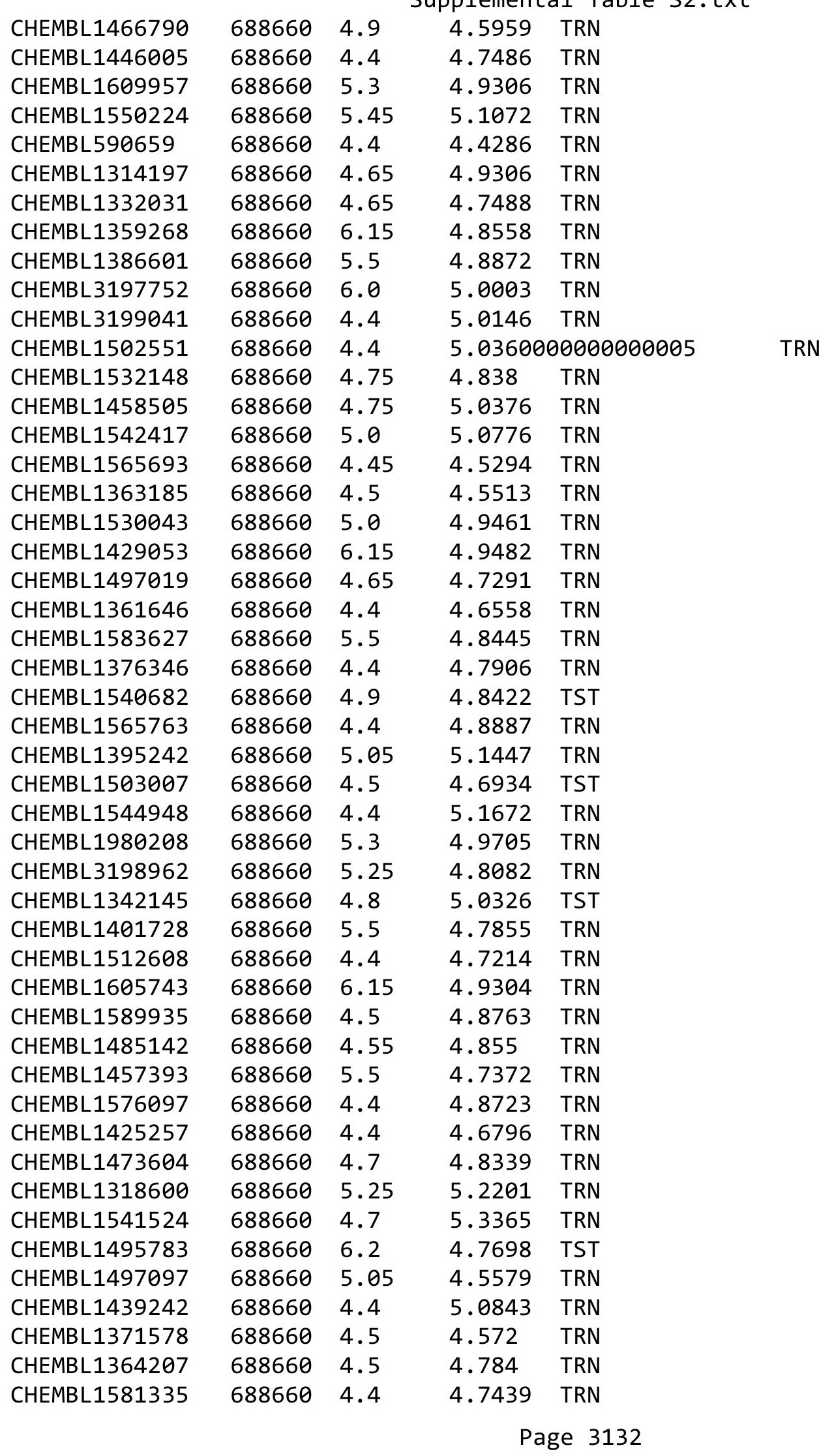




\begin{tabular}{|c|c|c|c|c|}
\hline \multicolumn{5}{|c|}{ Supplemental Table s2.txt } \\
\hline CHEMBL1599551 & 688660 & 5.1 & 5.1503 & TRN \\
\hline CHEMBL1362867 & 688660 & 4.5 & 4.7084 & TRN \\
\hline CHEMBL1396387 & 688660 & 4.55 & 4.735 & TRN \\
\hline CHEMBL1449456 & 688660 & 4.4 & 4.7126 & TST \\
\hline CHEMBL1530455 & 688660 & 4.65 & 5.0172 & TST \\
\hline CHEMBL1353565 & 688660 & 5.05 & 4.9294 & TST \\
\hline CHEMBL1598910 & 688660 & 4.6 & 4.7172 & TST \\
\hline CHEMBL1433662 & 688660 & 4.65 & 4.4021 & TST \\
\hline CHEMBL1578736 & 688660 & 5.9 & 4.8073 & TST \\
\hline CHEMBL1368512 & 688660 & 4.4 & 4.81800 & 00000000005 \\
\hline CHEMBL1330155 & 688660 & 4.9 & 5.1349 & TST \\
\hline CHEMBL1435035 & 688660 & 6.2 & 4.9125 & TST \\
\hline CHEMBL1442438 & 688660 & 4.5 & 4.7808 & TST \\
\hline CHEMBL3209549 & 688660 & 4.4 & 4.7316 & TST \\
\hline CHEMBL1549418 & 688660 & 4.5 & 4.7621 & TST \\
\hline CHEMBL1575446 & 688660 & 6.2 & 5.0349 & TST \\
\hline CHEMBL1438405 & 688660 & 4.45 & 5.3641 & TST \\
\hline CHEMBL 74852 & 688660 & 4.4 & 4.7535 & TST \\
\hline CHEMBL1608745 & 688660 & 4.8 & 5.1554 & TST \\
\hline CHEMBL1328165 & 688660 & 5.15 & 5.0354 & TST \\
\hline CHEMBL1305537 & 688660 & 4.4 & 4.7209 & TST \\
\hline CHEMBL1440929 & 688660 & 4.65 & 4.8727 & TST \\
\hline CHEMBL3193368 & 688660 & 6.0 & 5.1811 & TST \\
\hline CHEMBL1544136 & 688660 & 4.6 & 4.8073 & TST \\
\hline CHEMBL1395315 & 688660 & 4.45 & 4.5877 & TST \\
\hline CHEMBL1446911 & 688660 & 5.45 & 5.0063 & TST \\
\hline CHEMBL1382269 & 688660 & 4.7 & 5.0167 & TST \\
\hline CHEMBL1595306 & 688660 & 4.4 & 4.774 & TST \\
\hline CHEMBL1429461 & 688660 & 4.4 & 4.6581 & TST \\
\hline CHEMBL1467161 & 688660 & 4.55 & 4.6709 & TST \\
\hline CHEMBL1524106 & 688660 & 6.15 & 5.1025 & TST \\
\hline CHEMBL1424269 & 688660 & 5.5 & 5.0415 & TST \\
\hline CHEMBL155563 & 688660 & 5.3 & 4.8755 & TST \\
\hline CHEMBL1546284 & 688660 & 4.4 & 4.7341 & TST \\
\hline CHEMBL1405015 & 688660 & 4.8 & 4.8017 & TST \\
\hline CHEMBL1322540 & 688660 & 5.45 & 5.2494 & TST \\
\hline CHEMBL1584597 & 688660 & 4.45 & 4.9467 & TST \\
\hline CHEMBL1385060 & 688660 & 4.4 & 4.9338 & TST \\
\hline CHEMBL1435502 & 688660 & 5.0 & 4.8558 & TST \\
\hline CHEMBL 293776 & 688660 & 4.6 & 4.8345 & TST \\
\hline CHEMBL1329268 & 688660 & 4.4 & 5.2004 & TST \\
\hline CHEMBL1302138 & 688660 & 6.1 & 5.2638 & TST \\
\hline CHEMBL1331822 & 688660 & 5.05 & 5.0178 & TST \\
\hline CHEMBL1481408 & 688660 & 5.5 & 5.4227 & TST \\
\hline CHEMBL1335208 & 688660 & 4.4 & 4.5376 & TST \\
\hline CHEMBL1550035 & 688660 & 4.7 & 4.7184 & TST \\
\hline CHEMBL1525238 & 688660 & 4.4 & 5.1156 & TST \\
\hline CHEMBL1415885 & 688660 & 4.5 & 5.032 & TST \\
\hline
\end{tabular}




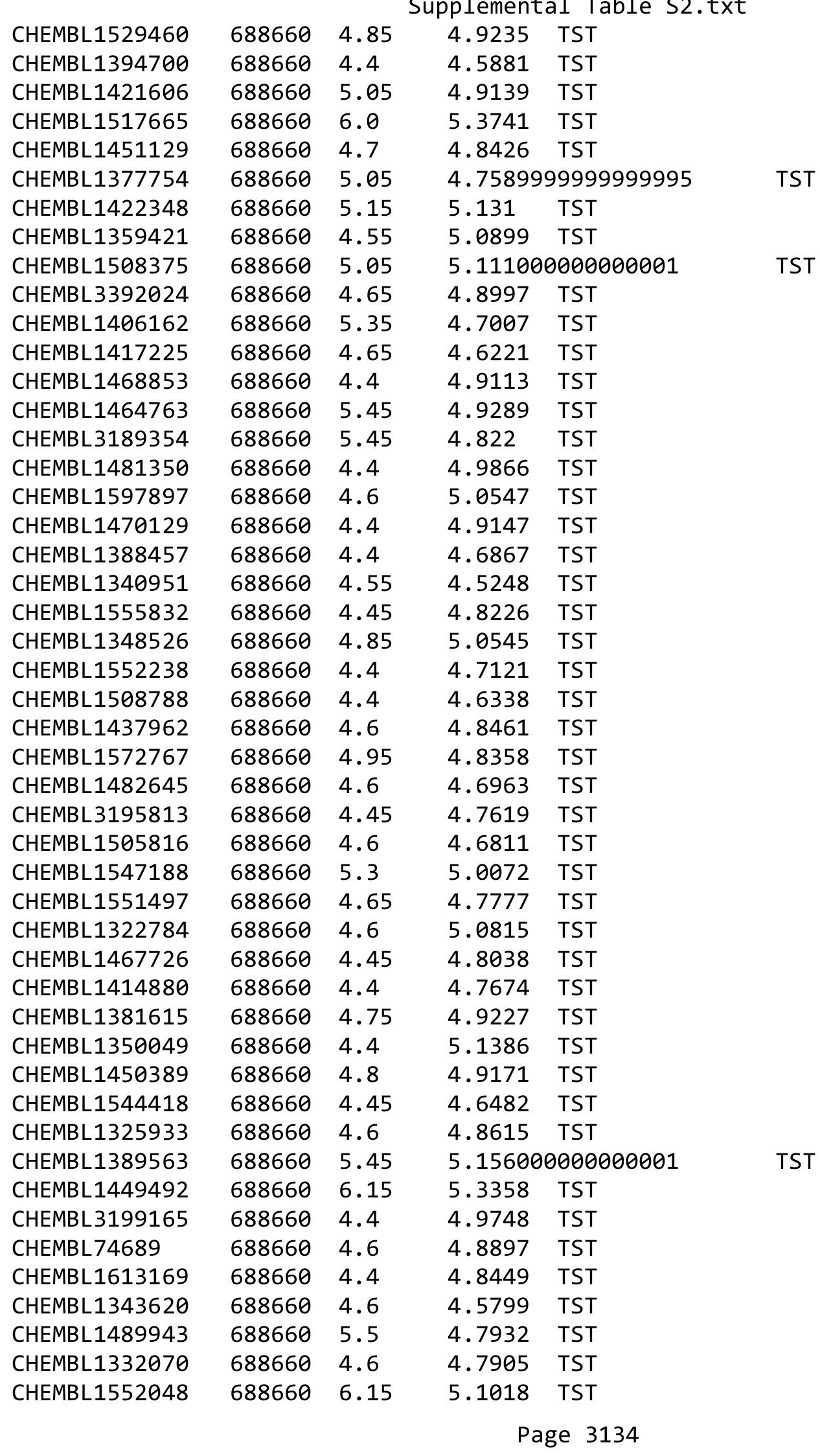




\begin{tabular}{|c|c|c|c|c|c|}
\hline & & \multicolumn{4}{|c|}{ Supplemental Table S2.txt } \\
\hline CHEMBL1536636 & 688660 & 4.4 & 4.6756 & TST & \\
\hline CHEMBL1327366 & 688660 & 4.55 & 4.461 & TST & \\
\hline CHEMBL1999802 & 688660 & 4.4 & 4.854 & TST & \\
\hline CHEMBL1580233 & 688660 & 4.6 & 4.9276 & TST & \\
\hline CHEMBL1559554 & 688660 & 4.35 & 4.80699 & 99999999995 & TST \\
\hline CHEMBL1984098 & 688660 & 5.5 & 4.6604 & TST & \\
\hline CHEMBL1319928 & 688660 & 4.65 & 4.9775 & TST & \\
\hline CHEMBL1342407 & 688660 & 4.55 & 5.0121 & TST & \\
\hline CHEMBL1376349 & 688660 & 5.5 & 5.1988 & TST & \\
\hline CHEMBL1330791 & 688660 & 4.55 & 5.1799 & TST & \\
\hline CHEMBL1521159 & 688660 & 4.55 & 5.0956 & TST & \\
\hline CHEMBL1500536 & 688660 & 5.05 & 4.9017 & TST & \\
\hline CHEMBL1534203 & 688660 & 5.0 & 4.5468 & TST & \\
\hline CHEMBL2004475 & 688660 & 4.4 & 4.7161 & TST & \\
\hline CHEMBL1318912 & 688660 & 4.4 & 5.3592 & TST & \\
\hline CHEMBL1403244 & 688660 & 4.6 & 4.595 & TST & \\
\hline CHEMBL3189893 & 688660 & 5.6 & 4.9243 & TST & \\
\hline CHEMBL1416992 & 688660 & 6.2 & 4.9376 & TST & \\
\hline CHEMBL1359707 & 688660 & 4.4 & 4.7947 & TST & \\
\hline CHEMBL1393883 & 688660 & 4.4 & 4.7327 & TST & \\
\hline CHEMBL1456395 & 688660 & 5.35 & 4.88899 & 9999999999 & TST \\
\hline CHEMBL1553590 & 688660 & 4.6 & 4.7691 & TST & \\
\hline CHEMBL1552558 & 688660 & 4.75 & 4.8266 & TST & \\
\hline CHEMBL3210809 & 688660 & 5.5 & 5.0057 & TST & \\
\hline CHEMBL1501274 & 688660 & 5.7 & 4.9188 & TST & \\
\hline CHEMBL1349908 & 688660 & 4.55 & 4.6817 & TST & \\
\hline CHEMBL1375254 & 688660 & 5.9 & 5.1268 & TST & \\
\hline CHEMBL1531133 & 688660 & 4.6 & 4.8186 & TST & \\
\hline CHEMBL1561625 & 688660 & 4.4 & 4.9824 & TST & \\
\hline CHEMBL1454195 & 688660 & 4.55 & 4.7612 & TST & \\
\hline CHEMBL1598232 & 688660 & 4.4 & 4.7409 & TST & \\
\hline CHEMBL1543663 & 688660 & 4.6 & 4.9282 & TST & \\
\hline CHEMBL1346392 & 688660 & 4.85 & 4.7307 & TST & \\
\hline CHEMBL1439938 & 688660 & 5.3 & 5.0047 & TST & \\
\hline CHEMBL1426712 & 688660 & 6.2 & 5.0248 & TST & \\
\hline CHEMBL1304687 & 688660 & 4.7 & 5.0537 & TST & \\
\hline CHEMBL1565289 & 688660 & 5.05 & 5.183 & TST & \\
\hline CHEMBL3196451 & 688660 & 5.4 & 4.8566 & TST & \\
\hline CHEMBL1498916 & 688660 & 4.35 & 4.8961 & TST & \\
\hline CHEMBL1489625 & 688660 & 4.4 & 4.6355 & TST & \\
\hline CHEMBL1509040 & 688660 & 5.55 & 4.9752 & TST & \\
\hline CHEMBL1412237 & 688660 & 4.6 & 5.03 & TST & \\
\hline CHEMBL1589028 & 688660 & 5.5 & 4.7983 & TST & \\
\hline CHEMBL1589790 & 688660 & 4.55 & 4.8894 & TST & \\
\hline CHEMBL1443903 & 688660 & 4.65 & 4.9123 & TST & \\
\hline CHEMBL1382170 & 688660 & 6.2 & 5.1235 & TST & \\
\hline CHEMBL3211648 & 688660 & 4.4 & 4.8294 & TST & \\
\hline CHEMBL1550221 & 688660 & 4.4 & 4.8491 & TST & \\
\hline
\end{tabular}




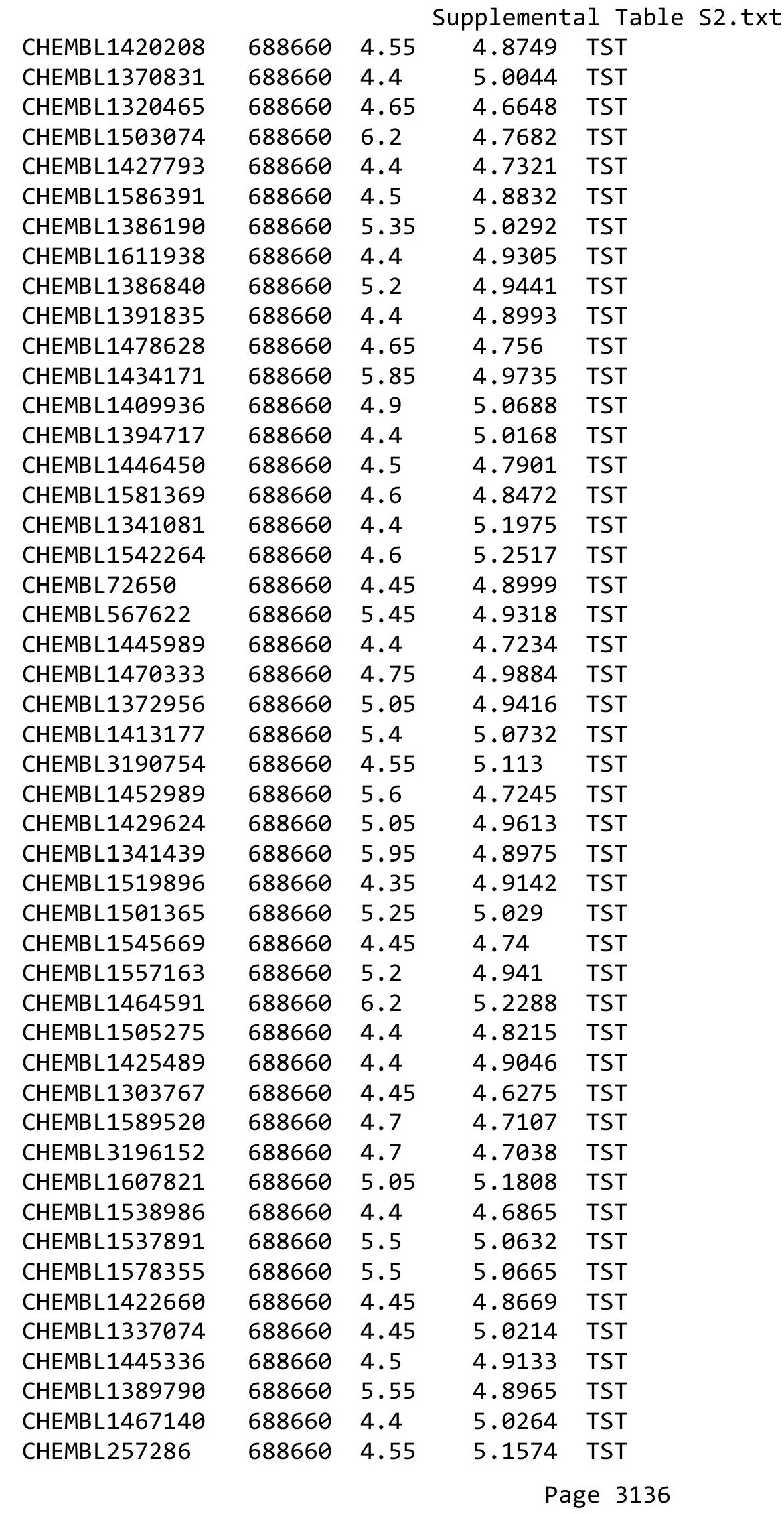




\begin{tabular}{|c|c|c|c|c|}
\hline \multicolumn{5}{|c|}{ Supplemental Table S2.txt } \\
\hline CHEMBL2139269 & 688660 & 4.65 & 4.5946 & TST \\
\hline CHEMBL1449416 & 688660 & 5.95 & 5.1416 & TST \\
\hline CHEMBL1517276 & 688660 & 4.45 & 4.9489 & TST \\
\hline CHEMBL1484390 & 688660 & 4.45 & 4.755 & TST \\
\hline CHEMBL1383301 & 688660 & 6.15 & 5.2041 & TST \\
\hline CHEMBL1427915 & 688660 & 4.4 & 4.8009 & TST \\
\hline CHEMBL1544339 & 688660 & 5.4 & 5.0538 & TST \\
\hline CHEMBL1477120 & 688660 & 4.5 & 4.9413 & TST \\
\hline CHEMBL1520872 & 688660 & 5.45 & 5.3349 & TST \\
\hline CHEMBL3214578 & 688660 & 5.4 & 4.8946 & TST \\
\hline CHEMBL1565789 & 688660 & 4.7 & 5.0641 & TST \\
\hline CHEMBL1606656 & 688660 & 4.4 & 4.9217 & TST \\
\hline CHEMBL1381742 & 688660 & 5.15 & 4.8034 & TST \\
\hline CHEMBL 3191870 & 688660 & 4.4 & 4.7774 & TST \\
\hline CHEMBL1404381 & 688660 & 4.4 & 5.1352 & TST \\
\hline CHEMBL1301731 & 688660 & 4.75 & 4.577 & TST \\
\hline CHEMBL1442988 & 688660 & 4.5 & 4.7791 & TST \\
\hline CHEMBL1439871 & 688660 & 4.4 & 4.9395 & TST \\
\hline CHEMBL 3211508 & 688660 & 5.45 & 4.9226 & TST \\
\hline CHEMBL1374202 & 688660 & 4.65 & 4.7637 & TST \\
\hline CHEMBL1461821 & 688660 & 4.7 & 4.9523 & TST \\
\hline CHEMBL1337195 & 688660 & 5.25 & 5.004 & TST \\
\hline CHEMBL1396496 & 688660 & 4.4 & 4.6503 & TST \\
\hline CHEMBL1551540 & 688660 & 5.4 & 5.2216 & TST \\
\hline CHEMBL1565319 & 688660 & 5.45 & 4.9249 & TST \\
\hline CHEMBL1378088 & 688660 & 4.4 & 4.6616 & TST \\
\hline CHEMBL1360987 & 688660 & 4.4 & 4.7413 & TST \\
\hline CHEMBL1465133 & 688660 & 4.4 & 4.9877 & TST \\
\hline CHEMBL 2000529 & 688660 & 5.15 & 4.8567 & TST \\
\hline CHEMBL1429838 & 688660 & 4.4 & 5.0344 & TST \\
\hline CHEMBL1493873 & 688660 & 4.85 & 5.0014 & TST \\
\hline CHEMBL1427447 & 688660 & 5.4 & 4.7745 & TST \\
\hline CHEMBL1369684 & 688660 & 5.35 & 5.0802 & TST \\
\hline CHEMBL1378459 & 688660 & 6.2 & 4.8398 & TST \\
\hline CHEMBL1387156 & 688660 & 4.45 & 4.8214 & TST \\
\hline CHEMBL1524233 & 688660 & 4.4 & 5.1576 & TST \\
\hline CHEMBL1350070 & 688660 & 5.45 & 5.0871 & TST \\
\hline CHEMBL1555050 & 688660 & 4.85 & 4.6479 & TST \\
\hline CHEMBL1601320 & 688660 & 5.05 & 5.0717 & TST \\
\hline CHEMBL1440433 & 688660 & 5.7 & 4.7901 & TST \\
\hline CHEMBL1373316 & 688660 & 5.25 & 4.8761 & TST \\
\hline CHEMBL1432867 & 688660 & 4.75 & 4.9121 & TST \\
\hline CHEMBL1486451 & 688660 & 5.5 & 4.9693 & TST \\
\hline CHEMBL1548510 & 688660 & 5.7 & 4.7572 & TST \\
\hline CHEMBL1457208 & 688660 & 4.55 & 4.6192 & TST \\
\hline CHEMBL1492819 & 688660 & 4.4 & 4.6695 & TST \\
\hline CHEMBL1342211 & 688660 & 4.95 & 4.5097 & TST \\
\hline CHEMBL1377032 & 688660 & 5.5 & 4.9207 & TST \\
\hline
\end{tabular}




\begin{tabular}{|c|c|c|c|c|c|}
\hline \multicolumn{6}{|c|}{ Supplemental Table s2.txt } \\
\hline CHEMBL1384311 & 688660 & 4.45 & 4.6992 & TST & \\
\hline CHEMBL1346534 & 688660 & 4.6 & 4.8675 & TST & \\
\hline CHEMBL1300977 & 688660 & 4.7 & 4.6941 & TST & \\
\hline CHEMBL1484757 & 688660 & 6.5 & 4.9868 & TST & \\
\hline CHEMBL1353663 & 688660 & 4.4 & 4.7895 & TST & \\
\hline CHEMBL1485063 & 688660 & 5.0 & 4.9734 & TST & \\
\hline CHEMBL3194983 & 688660 & 5.2 & 5.2424 & TST & \\
\hline CHEMBL1579767 & 688660 & 6.1 & 5.3971 & TST & \\
\hline CHEMBL1380216 & 688660 & 6.15 & 5.0474 & TST & \\
\hline CHEMBL375107 & 688660 & 4.65 & 4.5748 & TST & \\
\hline CHEMBL1305665 & 688660 & 4.7 & 4.6458 & TST & \\
\hline CHEMBL1587630 & 688660 & 5.5 & 5.1276 & TST & \\
\hline CHEMBL1372592 & 688660 & 4.8 & 4.9787 & TST & \\
\hline CHEMBL1547737 & 688660 & 5.0 & 4.7438 & TST & \\
\hline CHEMBL1456234 & 688660 & 6.15 & 5.0946 & TST & \\
\hline CHEMBL1507117 & 688660 & 4.7 & 5.0875 & TST & \\
\hline CHEMBL1363764 & 688660 & 4.7 & 4.5981 & TST & \\
\hline CHEMBL1343458 & 688660 & 4.5 & 4.6633 & TST & \\
\hline CHEMBL1421698 & 688660 & 4.4 & 5.0745 & TST & \\
\hline CHEMBL1579719 & 688660 & 5.55 & 5.0584 & TST & \\
\hline CHEMBL1440458 & 688660 & 4.4 & 5.0338 & TST & \\
\hline CHEMBL1551369 & 688660 & 4.4 & 5.3033 & TST & \\
\hline CHEMBL 254576 & 688660 & 4.4 & 4.7527 & TST & \\
\hline CHEMBL1414278 & 688660 & 4.4 & 4.7686 & TST & \\
\hline CHEMBL1508686 & 688660 & 6.5501 & 4.9842 & TST & \\
\hline CHEMBL1531686 & 688660 & 5.0 & 5.0084 & TST & \\
\hline CHEMBL1529115 & 688660 & 5.15 & 4.9374 & TST & \\
\hline CHEMBL1359446 & 688660 & 5.45 & 5.1669 & TST & \\
\hline CHEMBL1440128 & 688660 & 5.45 & 4.8363 & TST & \\
\hline CHEMBL1359708 & 688660 & 4.9 & 4.8818 & TST & \\
\hline CHEMBL3192609 & 688660 & 4.4 & 4.7243 & TST & \\
\hline CHEMBL66675 & 688660 & 4.4 & 4.6904 & TST & \\
\hline CHEMBL1321982 & 688660 & 5.25 & 4.71899 & 9999999999 & TST \\
\hline CHEMBL1331063 & 688660 & 4.4 & 4.7928 & TST & \\
\hline CHEMBL1597899 & 688660 & 4.35 & 4.8066 & TST & \\
\hline CHEMBL1312467 & 688660 & 6.15 & 4.6503 & TST & \\
\hline CHEMBL1459093 & 688660 & 4.5 & 4.8781 & TST & \\
\hline CHEMBL1544473 & 688660 & 4.9 & 5.0366 & TST & \\
\hline CHEMBL3195505 & 688660 & 4.5 & 4.8356 & TST & \\
\hline CHEMBL1411392 & 688660 & 4.5 & 4.9846 & TST & \\
\hline CHEMBL1322279 & 688660 & 5.0 & 4.7857 & TST & \\
\hline CHEMBL1547311 & 688660 & 4.4 & 4.7833 & TST & \\
\hline CHEMBL1307962 & 688660 & 4.4 & 4.9834 & TST & \\
\hline CHEMBL1571090 & 688660 & 6.15 & 5.0211 & TST & \\
\hline CHEMBL1505513 & 688660 & 5.05 & 4.8601 & TST & \\
\hline CHEMBL1497238 & 688660 & 4.5 & 4.80399 & 9999999999 & TST \\
\hline CHEMBL1320891 & 688660 & 6.15 & 5.2284 & TST & \\
\hline CHEMBL1415175 & 688660 & 4.4 & 4.7356 & TST & \\
\hline
\end{tabular}




\begin{tabular}{|c|c|c|c|c|}
\hline \multicolumn{5}{|c|}{ Supplemental Table S2.txt } \\
\hline CHEMBL1578034 & 688660 & 4.4 & 5.3132 & TST \\
\hline CHEMBL1404419 & 688660 & 4.85 & 4.6215 & TST \\
\hline CHEMBL1583534 & 688660 & 4.5 & 4.6403 & TST \\
\hline CHEMBL1381087 & 688660 & 4.4 & 4.7257 & TST \\
\hline CHEMBL3197991 & 688660 & 4.65 & 5.0117 & TST \\
\hline CHEMBL1351807 & 688660 & 4.4 & 4.4999 & TST \\
\hline CHEMBL1462198 & 688660 & 5.15 & 4.8337 & TST \\
\hline CHEMBL1572113 & 688660 & 4.65 & 4.9675 & TST \\
\hline CHEMBL1497535 & 688660 & 4.4 & 4.7555 & TST \\
\hline CHEMBL3145201 & 688660 & 4.4 & 5.0604 & TST \\
\hline CHEMBL1489984 & 688660 & 4.4 & 4.7576 & TST \\
\hline CHEMBL1536456 & 688660 & 4.65 & 4.6789 & TST \\
\hline CHEMBL1561237 & 688660 & 4.7 & 4.7153 & TST \\
\hline CHEMBL 3207557 & 688660 & 5.5 & 4.645 & TST \\
\hline CHEMBL1582621 & 688660 & 5.55 & 4.8021 & TST \\
\hline CHEMBL474786 & 688660 & 5.5 & 4.8575 & TST \\
\hline CHEMBL1587261 & 688660 & 5.55 & 4.8749 & TST \\
\hline CHEMBL1534682 & 688660 & 4.5 & 5.1869 & TST \\
\hline CHEMBL1355270 & 688660 & 4.6 & 4.614 & TST \\
\hline CHEMBL1501479 & 688660 & 4.4 & 5.3157 & TST \\
\hline CHEMBL1404870 & 688660 & 6.1 & 5.0819 & TST \\
\hline CHEMBL1567517 & 688660 & 4.4 & 5.2278 & TST \\
\hline CHEMBL1393915 & 688660 & 4.5 & 4.5933 & TST \\
\hline CHEMBL1409188 & 688660 & 6.15 & 4.6995 & TST \\
\hline CHEMBL1386089 & 688660 & 4.5 & 4.7317 & TST \\
\hline CHEMBL1308434 & 688660 & 6.15 & 5.1663 & TST \\
\hline CHEMBL1389894 & 688660 & 5.45 & 5.0602 & TST \\
\hline CHEMBL1499057 & 688660 & 4.55 & 4.7303 & TST \\
\hline CHEMBL1375446 & 688660 & 4.45 & 4.9049 & TST \\
\hline CHEMBL1484235 & 688660 & 5.5 & 4.9201 & TST \\
\hline CHEMBL1301070 & 688660 & 4.55 & 4.7123 & TST \\
\hline CHEMBL1410260 & 688660 & 4.4 & 4.5012 & TST \\
\hline CHEMBL1464412 & 688660 & 4.65 & 5.0707 & TST \\
\hline CHEMBL1483315 & 688660 & 4.4 & 4.8378 & TST \\
\hline CHEMBL1309990 & 688660 & 6.0 & 5.0599 & TST \\
\hline CHEMBL1523203 & 688660 & 4.85 & 4.9785 & TST \\
\hline CHEMBL1576141 & 688660 & 5.45 & 5.0292 & TST \\
\hline CHEMBL428644 & 63357 & 6.4559 & 6.5993 & TRN \\
\hline CHEMBL417971 & 63357 & 5.9066 & 6.0379 & TST \\
\hline CHEMBL 273476 & 63357 & 7.2993 & 7.2939 & TRN \\
\hline CHEMBL 269140 & 63357 & 5.2823 & 4.6284 & TST \\
\hline CHEMBL 266337 & 63357 & 8.0862 & 7.9965 & TRN \\
\hline CHEMBL9189 & 63357 & 6.284 & 6.4242 & TRN \\
\hline CHEMBL 268864 & 63357 & 7.7905 & 7.8708 & TRN \\
\hline CHEMBL9012 & 63357 & 5.3645 & 5.8645 & TST \\
\hline CHEMBL9502 & 63357 & 9.0706 & 9.226 & TRN \\
\hline CHEMBL417972 & 63357 & 7.3565 & 7.2766 & TRN \\
\hline CHEMBL 266144 & 63357 & 6.1163 & 6.1525 & TRN \\
\hline
\end{tabular}




\begin{tabular}{|c|c|c|c|c|c|}
\hline \multicolumn{6}{|c|}{ Supplemental Table S2.txt } \\
\hline CHEMBL9313 & 63357 & 9.2518 & 8.8552 & TRN & \\
\hline CHEMBL427935 & 63357 & 5.6925 & 5.4435 & TRN & \\
\hline CHEMBL269141 & 63357 & 9.3665 & 9.4091 & TRN & \\
\hline CHEMBL266336 & 63357 & 5.6144 & 5.7978 & TRN & \\
\hline CHEMBL8736 & 63357 & 7.6234 & 7.6725 & TRN & \\
\hline CHEMBL8776 & 63357 & 5.9666 & 5.9663 & TST & \\
\hline CHEMBL8671 & 63357 & 6.1073 & 6.0051 & TRN & \\
\hline CHEMBL266594 & 63357 & 8.1785 & 8.1705 & TRN & \\
\hline CHEMBL 9050 & 63357 & 8.2381 & 8.4739 & TRN & \\
\hline CHEMBL8925 & 63357 & 6.4023 & 6.6191 & TRN & \\
\hline CHEMBL267695 & 63357 & 8.327 & 8.1353 & TRN & \\
\hline CHEMBL267761 & 63357 & 7.3665 & 7.3607 & TRN & \\
\hline CHEMBL266143 & 63357 & 6.0458 & 6.1098 & TRN & \\
\hline CHEMBL 275306 & 63357 & 6.9666 & 6.8599 & TRN & \\
\hline CHEMBL 268902 & 63357 & 6.3595 & 6.3115 & TRN & \\
\hline CHEMBL 266354 & 63357 & 7.7905 & 7.8663 & TRN & \\
\hline CHEMBL9283 & 63357 & 9.0915 & 9.208 & TRN & \\
\hline CHEMBL 9040 & 63357 & 6.9747 & 6.9258 & TRN & \\
\hline CHEMBL9119 & 63357 & 8.7258 & 8.4765 & TRN & \\
\hline CHEMBL266996 & 63357 & 5.5421 & 5.5429 & TRN & \\
\hline CHEMBL 268432 & 63357 & 6.1002 & 6.1641 & TRN & \\
\hline CHEMBL8911 & 63357 & 7.4318 & 7.2579 & TRN & \\
\hline CHEMBL9147 & 63357 & 6.7496 & 6.8018 & TRN & \\
\hline CHEMBL430084 & 63357 & 7.2366 & 7.3804 & TRN & \\
\hline CHEMBL 9084 & 63357 & 4.8508 & 5.4682 & TST & \\
\hline CHEMBL8677 & 63357 & 6.0531 & 6.0047 & TRN & \\
\hline CHEMBL 9082 & 63357 & 6.7878 & 6.7639 & TRN & \\
\hline CHEMBL9228 & 63357 & 5.1669 & 4.9703 & TRN & \\
\hline CHEMBL 9334 & 63357 & 9.6576 & 9.5523 & TRN & \\
\hline CHEMBL267279 & 63357 & 8.1186 & 8.3782 & TRN & \\
\hline CHEMBL 9342 & 63357 & 7.466 & 7.4451 & TRN & \\
\hline CHEMBL 9488 & 63357 & 9.3372 & 9.2494 & TRN & \\
\hline CHEMBL 8878 & 63357 & 6.6576 & 6.803 & TRN & \\
\hline CHEMBL 269108 & 63357 & 6.1141 & 6.16200 & 0000000001 & TRN \\
\hline CHEMBL9495 & 63357 & 6.9508 & 6.9358 & TRN & \\
\hline CHEMBL 9212 & 63357 & 7.4828 & 7.7831 & TST & \\
\hline CHEMBL9183 & 63357 & 6.1662 & 6.1154 & TST & \\
\hline CHEMBL9132 & 63357 & 6.9172 & 7.5381 & TST & \\
\hline CHEMBL 9223 & 63357 & 8.3516 & 7.5977 & TST & \\
\hline CHEMBL268433 & 63357 & 7.0706 & 8.2099 & TST & \\
\hline CHEMBL 267483 & 63357 & 6.1649 & 5.6344 & TST & \\
\hline CHEMBL9141 & 63357 & 7.7645 & 7.6822 & TST & \\
\hline CHEMBL9139 & 63357 & 8.9101 & 8.7718 & TST & \\
\hline CHEMBL9168 & 63357 & 5.7878 & 6.1734 & TST & \\
\hline CHEMBL1431490 & 737333 & 4.8145 & 4.7181 & TRN & \\
\hline CHEMBL1337575 & 737333 & 4.7819 & 4.7673 & TRN & \\
\hline CHEMBL1448466 & 737333 & 4.6635 & 4.2301 & TRN & \\
\hline CHEMBL1342851 & 737333 & 4.7393 & 3.8979 & TRN & \\
\hline
\end{tabular}




\begin{tabular}{|c|c|c|c|c|c|}
\hline \multicolumn{6}{|c|}{ Supplemental Table S2.txt } \\
\hline CHEMBL1441145 & 737333 & 3.0 & 4.2173 & TRN & \\
\hline CHEMBL1970117 & 737333 & 4.6519 & 4.1223 & TRN & \\
\hline CHEMBL1320239 & 737333 & 4.3436 & 4.0728 & TRN & \\
\hline CHEMBL1578546 & 737333 & 4.9012 & 4.3688 & TRN & \\
\hline CHEMBL1433062 & 737333 & 4.8281 & 4.5043 & TST & \\
\hline CHEMBL1979849 & 737333 & 5.9705 & 3.7875 & TRN & \\
\hline CHEMBL1578543 & 737333 & 3.6021 & 3.7249 & TRN & \\
\hline CHEMBL1301906 & 737333 & 4.0556 & 3.85399 & 99999999996 & TRN \\
\hline CHEMBL1539235 & 737333 & 4.4683 & 4.9039 & TRN & \\
\hline CHEMBL198666 & 737333 & 3.0 & 4.0126 & TRN & \\
\hline CHEMBL1613004 & 737333 & 4.1021 & 3.9993 & TST & \\
\hline CHEMBL1566266 & 737333 & 4.5645 & 4.664 & TRN & \\
\hline CHEMBL1429363 & 737333 & 4.2041 & 3.8582 & TRN & \\
\hline CHEMBL1500600 & 737333 & 4.8353 & 4.7863 & TRN & \\
\hline CHEMBL408994 & 737333 & 5.159 & 4.1373 & TRN & \\
\hline CHEMBL1518374 & 737333 & 4.9192 & 4.5026 & TRN & \\
\hline CHEMBL1375487 & 737333 & 4.2109 & 3.9797 & TRN & \\
\hline CHEMBL358546 & 737333 & 4.5022 & 4.0863 & TRN & \\
\hline CHEMBL1506123 & 737333 & 4.07 & 3.9449 & TRN & \\
\hline CHEMBL1322274 & 737333 & 4.5283 & 4.2362 & TRN & \\
\hline CHEMBL1361703 & 737333 & 4.9701 & 4.481 & TRN & \\
\hline CHEMBL1548516 & 737333 & 3.0 & 4.099 & TST & \\
\hline CHEMBL1334684 & 737333 & 5.6994 & 5.6023 & TRN & \\
\hline CHEMBL1368385 & 737333 & 3.0 & 3.8418 & TRN & \\
\hline CHEMBL1353146 & 737333 & 3.0 & 3.9023 & TRN & \\
\hline CHEMBL1426027 & 737333 & 4.7826 & 4.2521 & TST & \\
\hline CHEMBL1447311 & 737333 & 4.4367 & 3.8828 & TRN & \\
\hline CHEMBL1469246 & 737333 & 5.1239 & 3.9673 & TRN & \\
\hline CHEMBL1375161 & 737333 & 4.4707 & 4.1665 & TRN & \\
\hline CHEMBL3209128 & 737333 & 3.0 & 3.9914 & TST & \\
\hline CHEMBL1545787 & 737333 & 3.301 & 4.0184 & TST & \\
\hline CHEMBL1564253 & 737333 & 4.9848 & 4.2225 & TRN & \\
\hline CHEMBL1329230 & 737333 & 4.2083 & 3.804 & TRN & \\
\hline CHEMBL1329271 & 737333 & 4.2039 & 3.7682 & TRN & \\
\hline CHEMBL1432963 & 737333 & 6.0162 & 4.2243 & TRN & \\
\hline CHEMBL1448598 & 737333 & 3.6021 & 3.8746 & TRN & \\
\hline CHEMBL1565196 & 737333 & 4.5574 & 3.7899 & TRN & \\
\hline CHEMBL1510830 & 737333 & 3.0 & 3.8917 & TST & \\
\hline CHEMBL1419252 & 737333 & 3.301 & 3.9382 & TRN & \\
\hline CHEMBL1382866 & 737333 & 3.0 & 3.9154 & TRN & \\
\hline CHEMBL1389035 & 737333 & 3.0 & 3.9179 & TRN & \\
\hline CHEMBL1377510 & 737333 & 4.3784 & 3.9066 & TRN & \\
\hline CHEMBL1452430 & 737333 & 3.0 & 3.6731 & TRN & \\
\hline CHEMBL1448942 & 737333 & 3.0 & 4.4069 & TRN & \\
\hline CHEMBL1450165 & 737333 & 4.3683 & 4.5967 & TRN & \\
\hline CHEMBL1981657 & 737333 & 5.5496 & 4.2565 & TRN & \\
\hline CHEMBL1485842 & 737333 & 4.1484 & 3.8009 & TRN & \\
\hline CHEMBL1546750 & 737333 & 4.0169 & 3.6812 & TRN & \\
\hline
\end{tabular}




\begin{tabular}{|c|c|c|c|c|c|}
\hline \multirow[b]{2}{*}{ CHEMBL1346172 } & \multicolumn{5}{|c|}{ Supplemental Table S2.txt } \\
\hline & 737333 & 5.0037 & 4.4762 & TRN & \\
\hline CHEMBL1528906 & 737333 & 3.0 & 3.64600 & 00000000004 & TRN \\
\hline CHEMBL1416591 & 737333 & 4.0175 & 3.7664 & TRN & \\
\hline CHEMBL1509057 & 737333 & 4.3822 & 3.8045 & TRN & \\
\hline CHEMBL1518838 & 737333 & 4.4402 & 4.5608 & TRN & \\
\hline CHEMBL1421864 & 737333 & 4.4224 & 4.0836 & TRN & \\
\hline CHEMBL1350226 & 737333 & 4.4117 & 4.2699 & TRN & \\
\hline CHEMBL1444769 & 737333 & 3.0 & 3.9245 & TRN & \\
\hline CHEMBL1510817 & 737333 & 4.1397 & 3.6849 & TRN & \\
\hline CHEMBL1430364 & 737333 & 3.0 & 4.251 & TST & \\
\hline CHEMBL259355 & 737333 & 7.71 & 5.1398 & TRN & \\
\hline CHEMBL1412556 & 737333 & 4.2018 & 3.8493 & TRN & \\
\hline CHEMBL1307528 & 737333 & 3.0 & 4.0193 & TRN & \\
\hline CHEMBL1976046 & 737333 & 4.0142 & 4.6193 & TRN & \\
\hline CHEMBL1500691 & 737333 & 3.0 & 4.0359 & TRN & \\
\hline CHEMBL1469796 & 737333 & 4.0386 & 3.7694 & TRN & \\
\hline CHEMBL1995948 & 737333 & 4.7367 & 5.1248 & TRN & \\
\hline CHEMBL1459296 & 737333 & 3.301 & 4.1199 & TRN & \\
\hline CHEMBL1535180 & 737333 & 4.1346 & 4.0044 & TRN & \\
\hline CHEMBL1360879 & 737333 & 3.0 & 3.6892 & TRN & \\
\hline CHEMBL606116 & 737333 & 3.0 & 3.6903 & TST & \\
\hline CHEMBL1526624 & 737333 & 3.0 & 4.2151 & TRN & \\
\hline CHEMBL1381306 & 737333 & 4.4972 & 3.946 & TRN & \\
\hline CHEMBL1586461 & 737333 & 3.0 & 3.7695 & TRN & \\
\hline CHEMBL1377070 & 737333 & 4.2041 & 4.252 & TRN & \\
\hline CHEMBL1391342 & 737333 & 4.1059 & 3.9686 & TRN & \\
\hline CHEMBL1377708 & 737333 & 4.4609 & 3.9897 & TRN & \\
\hline CHEMBL1489356 & 737333 & 4.5051 & 3.6044 & TRN & \\
\hline CHEMBL1424125 & 737333 & 4.2606 & 4.4829 & TRN & \\
\hline CHEMBL1449293 & 737333 & 4.133 & 4.7048 & TRN & \\
\hline CHEMBL1589313 & 737333 & 3.0 & 3.8875 & TST & \\
\hline CHEMBL 3145073 & 737333 & 4.1476 & 4.3617 & TRN & \\
\hline CHEMBL1588288 & 737333 & 3.0 & 3.7304 & TRN & \\
\hline CHEMBL1409120 & 737333 & 4.8062 & 4.4566 & TRN & \\
\hline CHEMBL1342384 & 737333 & 4.6625 & 3.7458 & TRN & \\
\hline CHEMBL1412123 & 737333 & 4.9003 & 4.4185 & TRN & \\
\hline CHEMBL1303417 & 737333 & 4.3352 & 4.0074 & TRN & \\
\hline CHEMBL1329285 & 737333 & 3.301 & 3.9087 & TRN & \\
\hline CHEMBL1421862 & 737333 & 3.301 & 4.2674 & TRN & \\
\hline CHEMBL3196191 & 737333 & 3.0 & 4.125 & TRN & \\
\hline CHEMBL1525853 & 737333 & 4.3192 & 4.05399 & 9999999999 & TRN \\
\hline CHEMBL1541779 & 737333 & 4.6239 & 4.1874 & TRN & \\
\hline CHEMBL1412226 & 737333 & 4.1522 & 4.1431 & TRN & \\
\hline CHEMBL1612543 & 737333 & 4.6118 & 4.1319 & TRN & \\
\hline CHEMBL1496995 & 737333 & 4.063 & 4.5476 & TRN & \\
\hline CHEMBL1345363 & 737333 & 4.6245 & 3.8939 & TRN & \\
\hline CHEMBL1386015 & 737333 & 4.7217 & 4.4096 & TRN & \\
\hline CHEMBL1373377 & 737333 & 3.0 & 3.8429 & TRN & \\
\hline
\end{tabular}




\begin{tabular}{|c|c|c|c|c|c|}
\hline & & \multicolumn{4}{|c|}{ Supplemental Table S2.txt } \\
\hline CHEMBL1372855 & 737333 & 4.5061 & 3.7959 & TRN & \\
\hline CHEMBL1426947 & 737333 & 5.3919 & 5.0257 & TRN & \\
\hline CHEMBL1413020 & 737333 & 3.0 & 4.7098 & TRN & \\
\hline CHEMBL1392628 & 737333 & 4.1598 & 3.7165 & TRN & \\
\hline CHEMBL1587620 & 737333 & 4.7865 & 4.8388 & TRN & \\
\hline CHEMBL1381627 & 737333 & 6.3075 & 4.19600 & 0000000001 & TRN \\
\hline CHEMBL1470855 & 737333 & 3.0 & 3.6724 & TRN & \\
\hline CHEMBL1577661 & 737333 & 4.5754 & 5.0239 & TRN & \\
\hline CHEMBL1459742 & 737333 & 3.301 & 3.7431 & TRN & \\
\hline CHEMBL1328182 & 737333 & 4.1752 & 4.0732 & TRN & \\
\hline CHEMBL1367408 & 737333 & 3.0 & 4.1807 & TRN & \\
\hline CHEMBL1324399 & 737333 & 4.2041 & 3.9597 & TST & \\
\hline CHEMBL1360564 & 737333 & 4.3779 & 3.9445 & TRN & \\
\hline CHEMBL1479248 & 737333 & 4.1606 & 4.0314 & TRN & \\
\hline CHEMBL1564105 & 737333 & 3.0 & 4.2775 & TST & \\
\hline CHEMBL1305391 & 737333 & 5.0706 & 5.1935 & TRN & \\
\hline CHEMBL1521410 & 737333 & 3.0 & 4.1015 & TRN & \\
\hline CHEMBL3216654 & 737333 & 5.0722 & 3.9599 & TST & \\
\hline CHEMBL1971613 & 737333 & 4.1334 & 3.9215 & TST & \\
\hline CHEMBL1462120 & 737333 & 3.0 & 3.9681 & TRN & \\
\hline CHEMBL3194979 & 737333 & 5.5187 & 4.1304 & TST & \\
\hline CHEMBL1541229 & 737333 & 4.5453 & 3.8748 & TRN & \\
\hline CHEMBL1349382 & 737333 & 4.234 & 4.1471 & TRN & \\
\hline CHEMBL1560288 & 737333 & 4.1177 & 3.7273 & TRN & \\
\hline CHEMBL1579787 & 737333 & 3.9031 & 4.0719 & TRN & \\
\hline CHEMBL1461254 & 737333 & 4.3001 & 3.8646 & TRN & \\
\hline CHEMBL1468488 & 737333 & 3.0 & 4.3139 & TRN & \\
\hline CHEMBL1549371 & 737333 & 3.0 & 3.7325 & TRN & \\
\hline CHEMBL1547238 & 737333 & 3.0 & 4.4077 & TRN & \\
\hline CHEMBL1455030 & 737333 & 3.301 & 3.9321 & TRN & \\
\hline CHEMBL1331729 & 737333 & 4.2453 & 4.33899 & 99999999995 & TRN \\
\hline CHEMBL1566165 & 737333 & 6.1395 & 4.9348 & TRN & \\
\hline CHEMBL3193997 & 737333 & 3.0 & 3.9504 & TRN & \\
\hline CHEMBL1305221 & 737333 & 4.227 & 3.8659 & TRN & \\
\hline CHEMBL1439324 & 737333 & 3.9031 & 4.0026 & TRN & \\
\hline CHEMBL1408073 & 737333 & 3.0 & 3.8043 & TRN & \\
\hline CHEMBL1389163 & 737333 & 4.5261 & 4.0844 & TRN & \\
\hline CHEMBL1494360 & 737333 & 4.268 & 4.2147 & TRN & \\
\hline CHEMBL1338518 & 737333 & 3.0 & 3.8594 & TRN & \\
\hline CHEMBL1452830 & 737333 & 3.0 & 4.1912 & TST & \\
\hline CHEMBL1389629 & 737333 & 3.6021 & 3.7124 & TRN & \\
\hline CHEMBL1575787 & 737333 & 6.2533 & 3.9982 & TRN & \\
\hline CHEMBL1446626 & 737333 & 3.0 & 4.76399 & 9999999999 & TRN \\
\hline CHEMBL1570005 & 737333 & $4.5360 e$ & 00000000 & 3.7452 & TRN \\
\hline CHEMBL1370919 & 737333 & 4.175 & 4.3671 & TRN & \\
\hline CHEMBL1303367 & 737333 & 3.0 & 3.6223 & TRN & \\
\hline CHEMBL1442697 & 737333 & 4.4363 & 4.3095 & TRN & \\
\hline CHEMBL1431591 & 737333 & 4.0983 & 4.3329 & TRN & \\
\hline
\end{tabular}




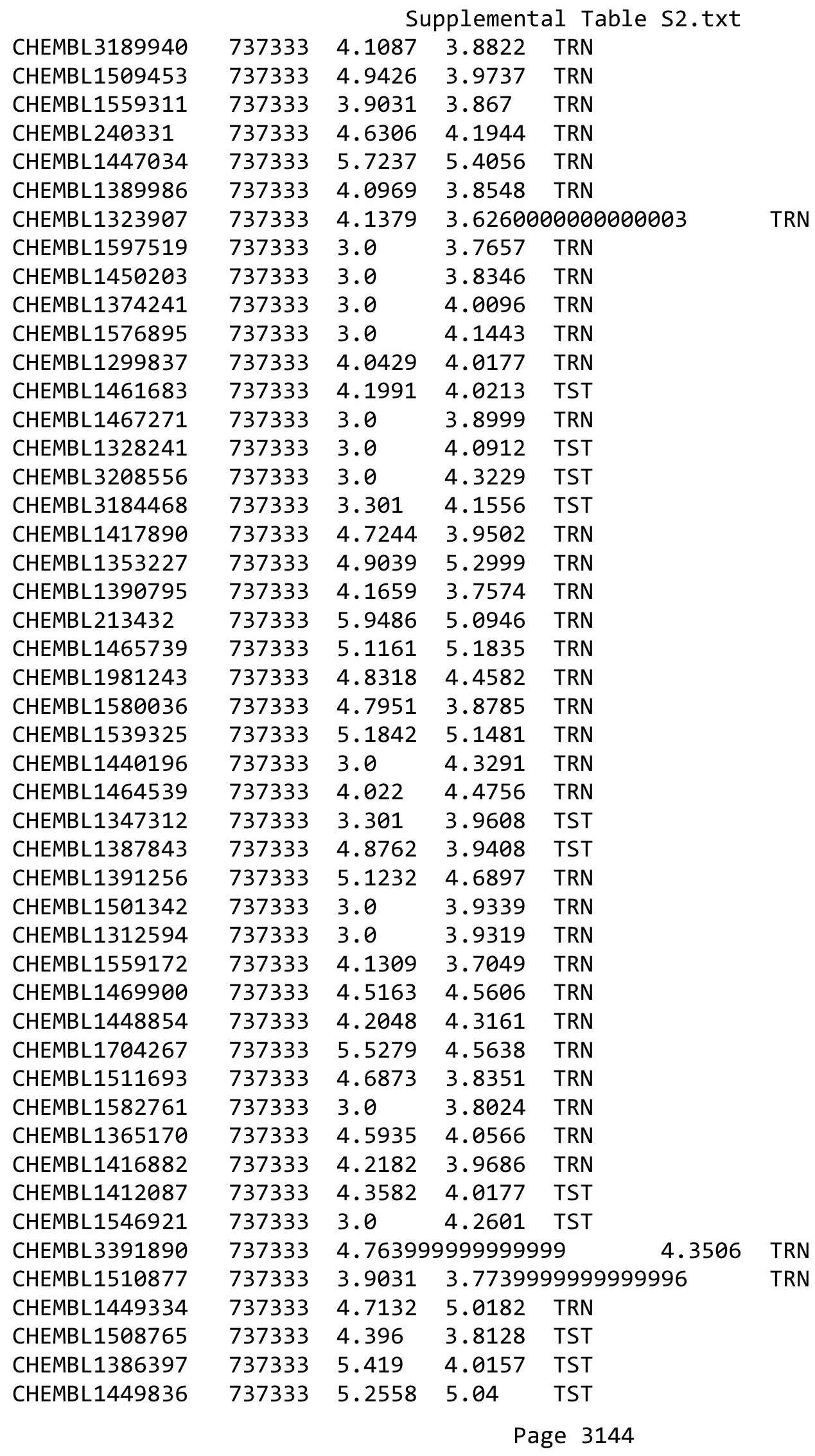




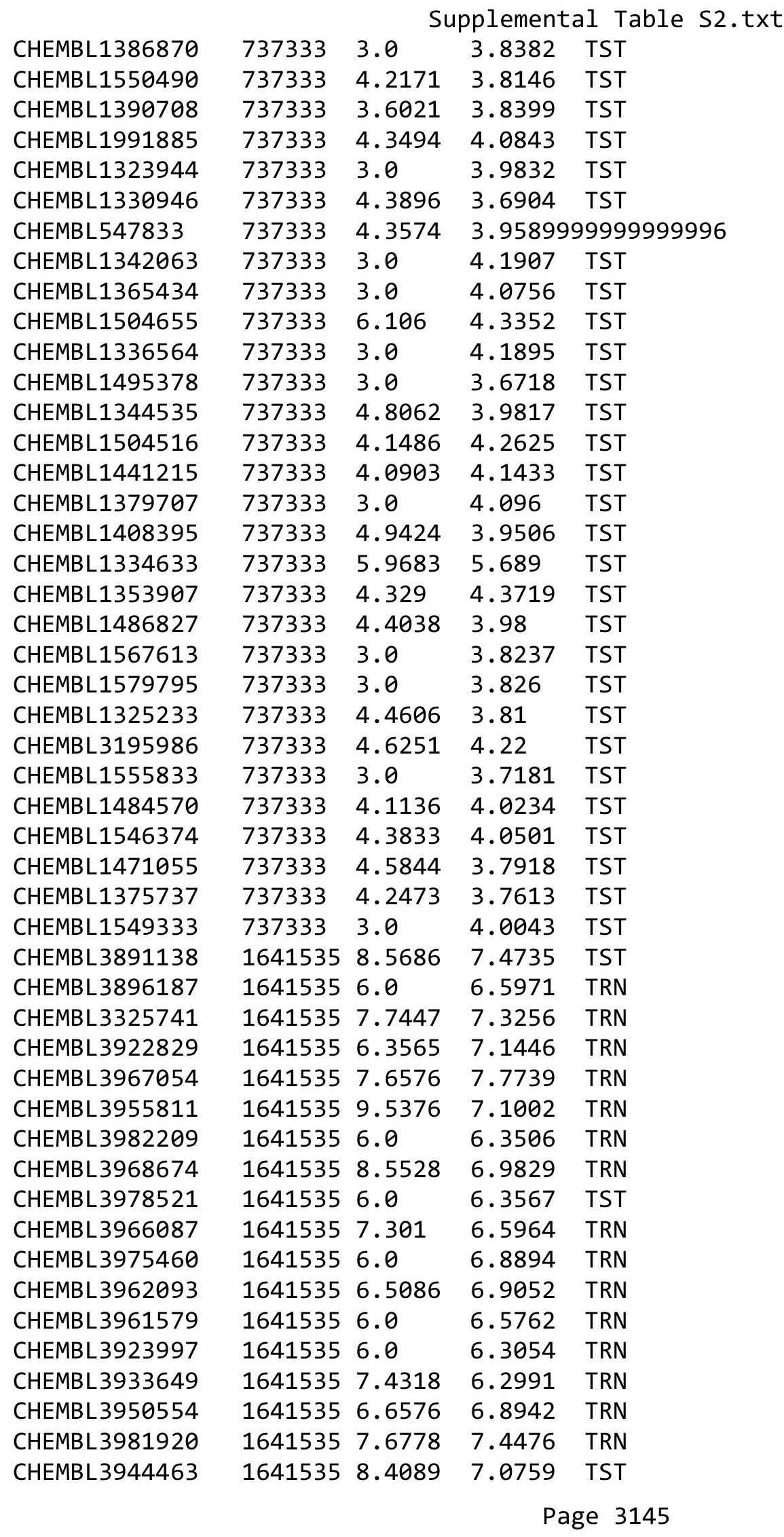




$$
\text { Supplemental Table S2.txt }
$$

\begin{tabular}{|c|c|c|c|c|c|}
\hline CHEMBL3953581 & 1641535 & 8.6576 & 7.4256 & TRN & \\
\hline CHEMBL3937236 & 1641535 & 6.0 & 6.3493 & TRN & \\
\hline CHEMBL3958147 & 1641535 & 6.4949 & 7.0673 & TRN & \\
\hline CHEMBL3926280 & 1641535 & 7.4815 & 8.0945 & TRN & \\
\hline CHEMBL3894064 & 1641535 & 8.2147 & 7.1977 & TRN & \\
\hline CHEMBL3904720 & 1641535 & 6.8539 & 7.6469 & TRN & \\
\hline CHEMBL3912618 & 1641535 & 6.0 & 6.8518 & TST & \\
\hline CHEMBL3959344 & 1641535 & 7.8239 & 7.5672 & TRN & \\
\hline CHEMBL3952340 & 1641535 & 6.0 & 6.2819 & TRN & \\
\hline CHEMBL3892661 & 1641535 & 8.3665 & 7.3871 & TRN & \\
\hline CHEMBL3947232 & 1641535 & 6.0 & 6.6374 & TRN & \\
\hline CHEMBL3927166 & 1641535 & 8.3979 & 6.6319 & TRN & \\
\hline CHEMBL3927010 & 1641535 & 8.0757 & 6.7618 & TRN & \\
\hline CHEMBL3925105 & 1641535 & 7.7447 & 6.7829 & TRN & \\
\hline CHEMBL3963013 & 1641535 & 7.7959 & 7.2327 & TRN & \\
\hline CHEMBL3325743 & 1641535 & 6.0 & 5.8472 & TRN & \\
\hline CHEMBL3916757 & 1641535 & 7.0044 & 7.848 & TST & \\
\hline CHEMBL3914096 & 1641535 & 7.041 & 7.0321 & TRN & \\
\hline CHEMBL3972220 & 1641535 & 6.0 & 6.895 & TST & \\
\hline CHEMBL3936717 & 1641535 & 8.1805 & 7.1007 & TRN & \\
\hline CHEMBL3931712 & 1641535 & 6.0 & 6.6568 & TST & \\
\hline CHEMBL3970538 & 1641535 & 6.0 & 5.8715 & TRN & \\
\hline CHEMBL3954755 & 1641535 & 7.1249 & 7.2385 & TRN & \\
\hline CHEMBL3964680 & 1641535 & 6.0 & 7.1271 & TST & \\
\hline CHEMBL3957370 & 1641535 & 6.0 & 5.8689 & TRN & \\
\hline CHEMBL3953392 & 1641535 & 6.6021 & 6.9168 & TRN & \\
\hline CHEMBL3900207 & 1641535 & 6.0 & 6.2981 & TRN & \\
\hline CHEMBL3945586 & 1641535 & 7.7696 & 8.128 & TRN & \\
\hline CHEMBL3913419 & 1641535 & 7.4949 & 8.0694 & TRN & \\
\hline CHEMBL3928743 & 1641535 & 7.3979 & 7.757006 & 0000000001 & TRN \\
\hline CHEMBL3963646 & 1641535 & 7.1675 & 7.813 & TRN & \\
\hline CHEMBL3949376 & 1641535 & 6.0 & 6.1027 & TRN & \\
\hline CHEMBL3890280 & 1641535 & 7.3098 & 7.0187 & TRN & \\
\hline CHEMBL3969813 & 1641535 & 5.7212 & 7.1598 & TST & \\
\hline CHEMBL3898872 & 1641535 & 7.9586 & 7.9365 & TRN & \\
\hline CHEMBL3892267 & 1641535 & 9.0809 & 8.0008 & TRN & \\
\hline CHEMBL3974597 & 1641535 & 6.0 & 6.34 & TRN & \\
\hline CHEMBL3922753 & 1641535 & 9.1135 & 6.814 & TST & \\
\hline CHEMBL3959062 & 1641535 & 6.0 & 5.8699 & TRN & \\
\hline CHEMBL3929357 & 1641535 & 10.7696 & 7.0363 & TST & \\
\hline CHEMBL3980600 & 1641535 & 6.0 & 6.3679 & TST & \\
\hline CHEMBL3973915 & 1641535 & 6.0 & 6.4129 & TRN & \\
\hline CHEMBL3927301 & 1641535 & 6.0 & 6.858 & TRN & \\
\hline CHEMBL3901630 & 1641535 & 7.3665 & 7.5966 & TRN & \\
\hline CHEMBL3963239 & 1641535 & 6.0 & 5.817 & TRN & \\
\hline CHEMBL3921489 & 1641535 & 8.1135 & 8.1622 & TRN & \\
\hline CHEMBL3898532 & 1641535 & 7.5086 & 7.0317 & TRN & \\
\hline CHEMBL3921394 & 1641535 & 6.0 & 7.3311 & TRN & \\
\hline
\end{tabular}




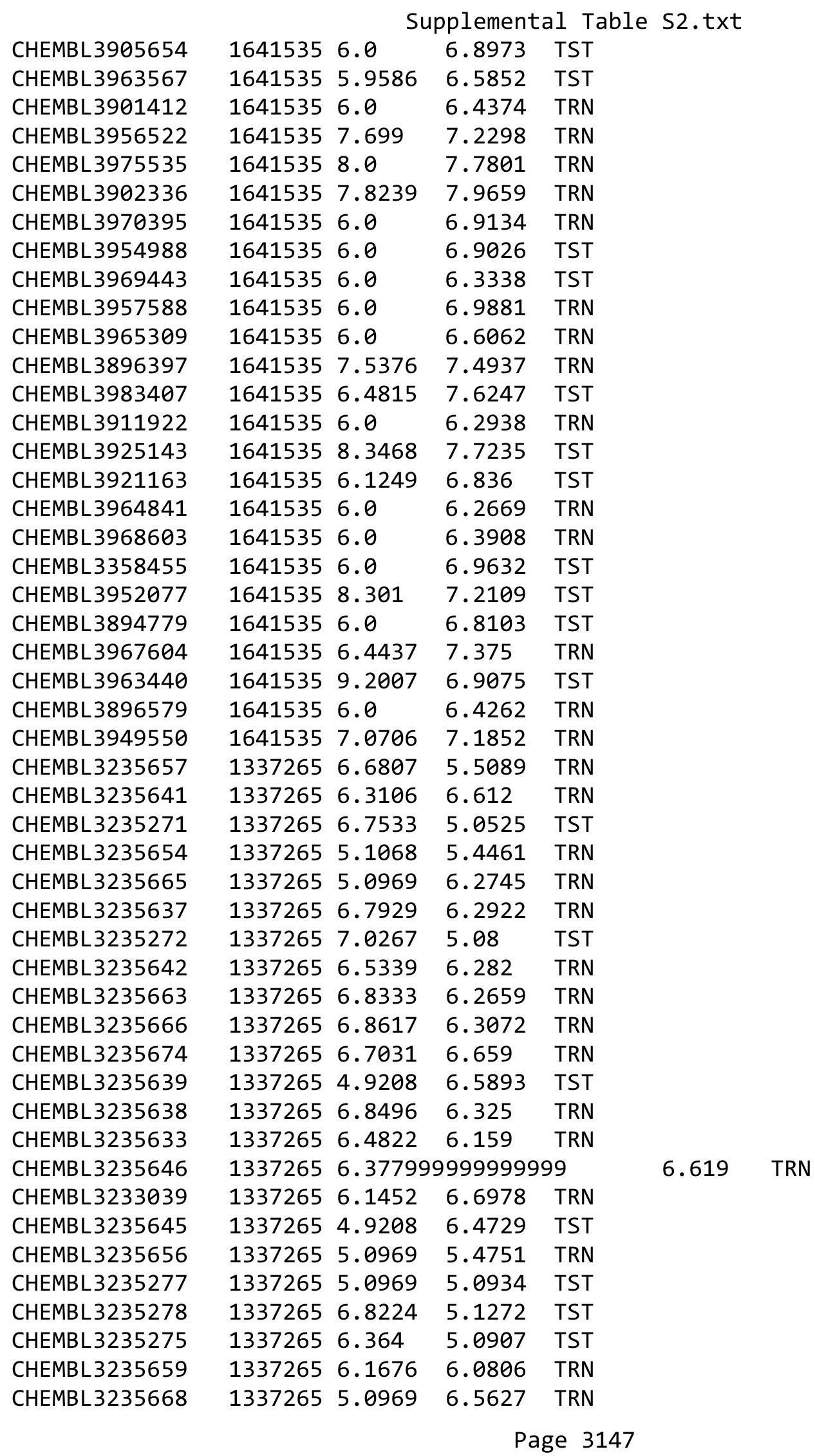


Supplemental Table S2.txt

\begin{tabular}{|c|c|c|c|c|}
\hline CHEMBL3235671 & 1337265 & 7.1461 & 6.6537 & TRN \\
\hline CHEMBL3235672 & 1337265 & 7.1755 & 6.6967 & TRN \\
\hline CHEMBL3235655 & 1337265 & 7.2671 & 5.8495 & TRN \\
\hline CHEMBL 3235636 & 1337265 & 6.7734 & 6.6142 & TRN \\
\hline CHEMBL3235634 & 1337265 & 5.0969 & 5.7846 & TRN \\
\hline CHEMBL3235276 & 1337265 & 5.0969 & 5.4592 & TST \\
\hline CHEMBL 3235274 & 1337265 & 7.1095 & 5.0562 & TST \\
\hline CHEMBL 3235649 & 1337265 & 5.0625 & 5.6407 & TRN \\
\hline CHEMBL 3235627 & 1337265 & 6.7137 & \multicolumn{2}{|c|}{6.0920000000000005} \\
\hline CHEMBL3235658 & 1337265 & 6.1974 & 6.4453 & TRN \\
\hline CHEMBL3235648 & 1337265 & 7.3847 & 6.3195 & TRN \\
\hline CHEMBL3235650 & 1337265 & 5.0726 & 5.2721 & TRN \\
\hline CHEMBL3235629 & 1337265 & 5.0 & 5.7532 & TRN \\
\hline CHEMBL3235667 & 1337265 & 7.1813 & 6.8895 & TRN \\
\hline CHEMBL3235643 & 1337265 & 5.0969 & 6.3217 & TRN \\
\hline CHEMBL3235669 & 1337265 & 7.1151 & 6.5979 & TRN \\
\hline CHEMBL3235630 & 1337265 & 6.6972 & 6.1033 & TRN \\
\hline CHEMBL 3235644 & 1337265 & 4.9208 & 6.5368 & TST \\
\hline CHEMBL3235670 & 1337265 & 6.9094 & 6.9701 & TRN \\
\hline CHEMBL3235660 & 1337265 & 7.0358 & 6.1095 & TRN \\
\hline CHEMBL3235273 & 1337265 & 6.375 & 5.4084 & TST \\
\hline CHEMBL3235635 & 1337265 & 5.0969 & 5.8128 & TRN \\
\hline CHEMBL3235653 & 1337265 & 5.0969 & 5.4079 & TRN \\
\hline CHEMBL3235662 & 1337265 & 6.6275 & 6.2267 & TRN \\
\hline CHEMBL3235664 & 1337265 & 6.9788 & 6.6483 & TRN \\
\hline CHEMBL3235640 & 1337265 & 4.9208 & 6.5094 & TST \\
\hline CHEMBL3235632 & 1337265 & 5.0 & 5.7675 & TRN \\
\hline CHEMBL3235647 & 1337265 & 6.5804 & 6.2803 & TRN \\
\hline CHEMBL3235270 & 1337265 & 7.0185 & 5.4007 & TST \\
\hline CHEMBL3235651 & 1337265 & 5.083 & 5.3034 & TRN \\
\hline CHEMBL3235661 & 1337265 & 7.0794 & 6.5887 & TRN \\
\hline CHEMBL3235673 & 1337265 & 5.0969 & 6.9854 & TRN \\
\hline CHEMBL3235652 & 1337265 & 5.0878 & 5.7673 & TST \\
\hline CHEMBL1398190 & 752389 & 3.0044 & 3.1244 & TRN \\
\hline CHEMBL1421207 & 752389 & 5.0004 & 3.4375 & TRN \\
\hline CHEMBL1409207 & 752389 & 3.0044 & 3.5892 & TRN \\
\hline CHEMBL1727519 & 752389 & 3.0044 & 3.1299 & TRN \\
\hline CHEMBL1523192 & 752389 & 3.0044 & 2.9745 & TRN \\
\hline CHEMBL1996363 & 752389 & 3.0044 & 3.3186 & TRN \\
\hline CHEMBL1569865 & 752389 & 3.0044 & 3.3292 & TRN \\
\hline CHEMBL1432696 & 752389 & 3.0044 & 3.4503 & TRN \\
\hline CHEMBL1439958 & 752389 & 3.0044 & 3.6025 & TST \\
\hline CHEMBL1723854 & 752389 & 3.0044 & 3.4052 & TRN \\
\hline CHEMBL1505608 & 752389 & 3.0044 & 3.1211 & TRN \\
\hline CHEMBL1573198 & 752389 & 3.0044 & 3.3847 & TRN \\
\hline CHEMBL1446410 & 752389 & 3.0044 & 2.9417 & TRN \\
\hline CHEMBL505670 & 752389 & 3.0044 & 3.2303 & TRN \\
\hline CHEMBL1372792 & 752389 & 4.7471 & 3.6843 & TRN \\
\hline
\end{tabular}




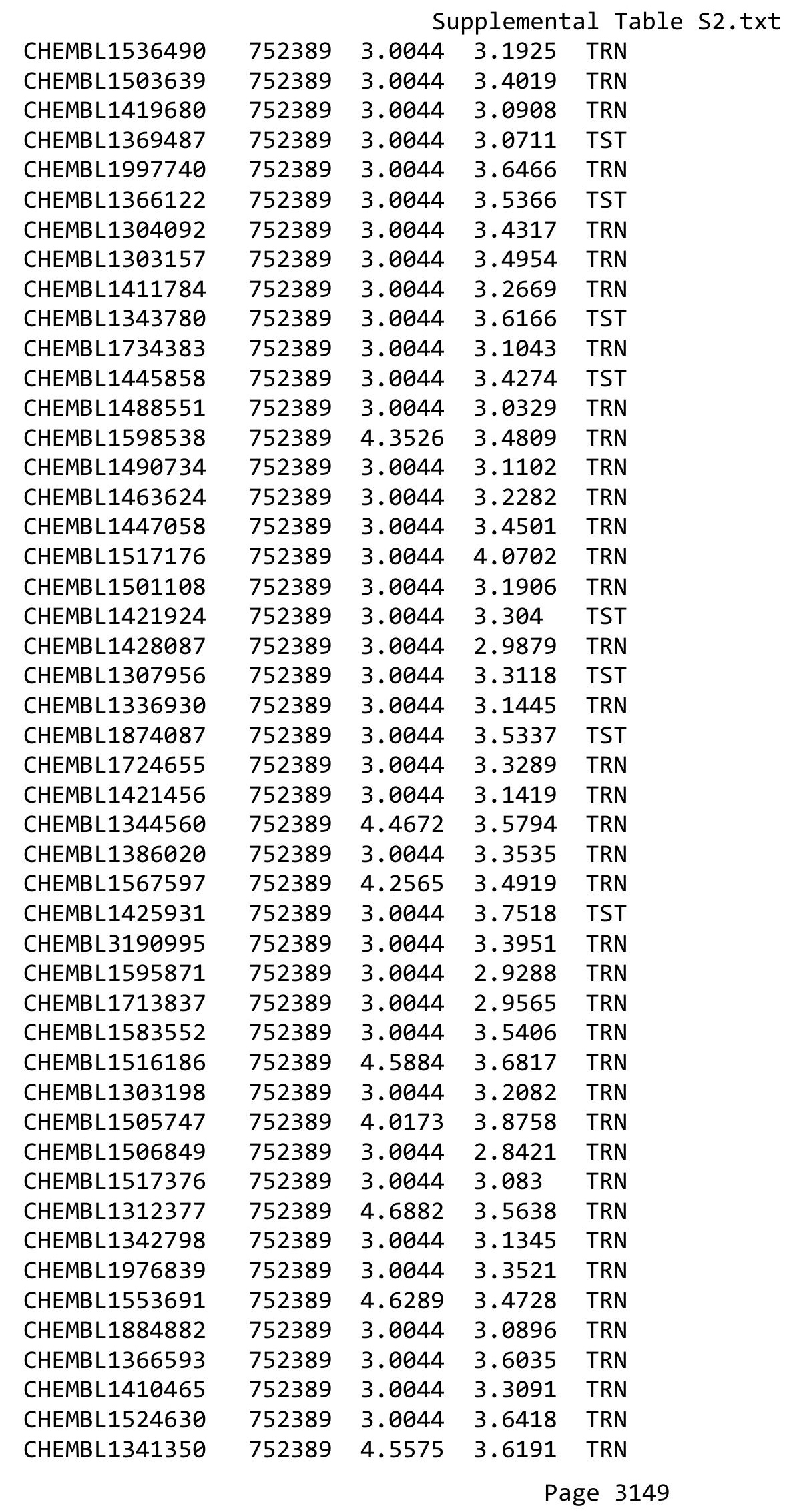




\begin{tabular}{|c|c|c|c|c|c|}
\hline \multirow[b]{2}{*}{ CHEMBL1300464 } & & \multicolumn{4}{|c|}{ Supplemental Table s2.txt } \\
\hline & 752389 & 3.0044 & 2.8819 & 99999999997 & TRN \\
\hline CHEMBL1481938 & 752389 & 3.0044 & 3.1462 & TRN & \\
\hline CHEMBL1540094 & 752389 & 3.0044 & 3.2179 & TRN & \\
\hline CHEMBL1522724 & 752389 & 3.0044 & 3.51 & TRN & \\
\hline CHEMBL1330698 & 752389 & 3.0044 & 3.3552 & TRN & \\
\hline CHEMBL1429367 & 752389 & 3.0044 & 2.9061 & TRN & \\
\hline CHEMBL1499248 & 752389 & 3.0044 & 3.3828 & TST & \\
\hline CHEMBL1393310 & 752389 & 3.0044 & 3.016 & TRN & \\
\hline CHEMBL1967726 & 752389 & 3.0044 & 3.7504 & TRN & \\
\hline CHEMBL1576646 & 752389 & 3.0044 & 3.2575 & TRN & \\
\hline CHEMBL3195708 & 752389 & 3.0044 & 3.1127 & TRN & \\
\hline CHEMBL1972014 & 752389 & 4.2716 & 3.7297 & TRN & \\
\hline CHEMBL1572627 & 752389 & 3.0044 & 3.2448 & TRN & \\
\hline CHEMBL1492158 & 752389 & 4.317 & 3.1221 & TRN & \\
\hline CHEMBL1339166 & 752389 & 4.5361 & 3.4716 & TRN & \\
\hline CHEMBL1364211 & 752389 & 4.279 & 3.6557 & TRN & \\
\hline CHEMBL1580407 & 752389 & 3.0044 & 3.5057 & TRN & \\
\hline CHEMBL1964868 & 752389 & 3.0044 & 3.3204 & TRN & \\
\hline CHEMBL1480157 & 752389 & 3.0044 & 3.3497 & TRN & \\
\hline CHEMBL1971324 & 752389 & 3.0044 & 2.9645 & TRN & \\
\hline CHEMBL1580198 & 752389 & 3.0044 & 3.605 & TRN & \\
\hline CHEMBL1512498 & 752389 & 3.0044 & 2.8222 & TRN & \\
\hline CHEMBL 2007056 & 752389 & 3.0044 & 3.4395 & TST & \\
\hline CHEMBL1572588 & 752389 & 5.1494 & 4.1569 & TRN & \\
\hline CHEMBL1385897 & 752389 & 3.0044 & 3.5339 & TRN & \\
\hline CHEMBL1532783 & 752389 & 3.0044 & 3.3923 & TRN & \\
\hline CHEMBL1543229 & 752389 & 3.0044 & 3.3956 & TRN & \\
\hline CHEMBL1454807 & 752389 & 4.757 & 3.4299 & TRN & \\
\hline CHEMBL1892727 & 752389 & 3.0044 & 3.4474 & TST & \\
\hline CHEMBL1722129 & 752389 & 3.0044 & 3.2244 & TRN & \\
\hline CHEMBL1319447 & 752389 & 3.0044 & 3.7192 & TRN & \\
\hline CHEMBL1599761 & 752389 & 3.0044 & 3.2955 & TRN & \\
\hline CHEMBL1978330 & 752389 & 3.0044 & 3.3388 & TRN & \\
\hline CHEMBL1416556 & 752389 & 3.0044 & 2.7007 & TRN & \\
\hline CHEMBL1542591 & 752389 & 3.0044 & 3.2405 & TRN & \\
\hline CHEMBL457679 & 752389 & 4.8539 & 3.4717 & TRN & \\
\hline CHEMBL1491210 & 752389 & 3.0044 & 3.228 & TRN & \\
\hline CHEMBL 3209848 & 752389 & 3.0044 & 3.5958 & TST & \\
\hline CHEMBL1333238 & 752389 & 3.0044 & 3.3104 & TRN & \\
\hline CHEMBL495991 & 752389 & 3.0044 & 3.2031 & TRN & \\
\hline CHEMBL1506476 & 752389 & 3.0044 & 3.2406 & TRN & \\
\hline CHEMBL1723047 & 752389 & 3.0044 & 3.4406 & TRN & \\
\hline CHEMBL1984796 & 752389 & 3.0044 & 3.4583 & TRN & \\
\hline CHEMBL1539384 & 752389 & 3.0044 & 3.1822 & TRN & \\
\hline CHEMBL1381831 & 752389 & 3.0044 & 3.3048 & TRN & \\
\hline CHEMBL1465106 & 752389 & 3.0044 & 3.2592 & TRN & \\
\hline CHEMBL1579898 & 752389 & 3.0044 & 3.2362 & TRN & \\
\hline CHEMBL1368671 & 752389 & 4.2277 & 3.2371 & TST & \\
\hline
\end{tabular}




\begin{tabular}{|c|c|c|c|c|c|c|}
\hline & & \multicolumn{5}{|c|}{ Supplemental Table S2.txt } \\
\hline CHEMBL1582416 & 752389 & 3.0044 & 3.3009 & TRN & & \\
\hline CHEMBL1582996 & 752389 & 4.5287 & 3.4063 & TRN & & \\
\hline CHEMBL1448387 & 752389 & 4.5214 & 3.5622 & TST & & \\
\hline CHEMBL1576943 & 752389 & 3.0044 & 3.4907 & TRN & & \\
\hline CHEMBL1398060 & 752389 & 3.0044 & 4.0312 & TST & & \\
\hline CHEMBL1710856 & 752389 & 4.3925 & 3.5477 & TRN & & \\
\hline CHEMBL1390551 & 752389 & 3.0044 & 3.0839 & TRN & & \\
\hline CHEMBL1459317 & 752389 & 3.0044 & 3.1143 & TRN & & \\
\hline CHEMBL1337221 & 752389 & 3.0044 & 3.2637 & TRN & & \\
\hline CHEMBL1317867 & 752389 & 3.0044 & 3.6691 & TST & & \\
\hline CHEMBL1462803 & 752389 & 4.6253 & 3.1557 & TRN & & \\
\hline CHEMBL481577 & 752389 & 4.4202 & 3.5067 & TRN & & \\
\hline CHEMBL1714498 & 752389 & 5.4168 & 3.7253 & TST & & \\
\hline CHEMBL1983116 & 752389 & 3.0044 & 3.1221 & TRN & & \\
\hline CHEMBL1578643 & 752389 & 3.0044 & 3.821 & TRN & & \\
\hline CHEMBL1487921 & 752389 & 3.0044 & 3.0997 & TRN & & \\
\hline CHEMBL1610433 & 752389 & 4.7959 & 3.6878 & TRN & & \\
\hline CHEMBL1338930 & 752389 & 3.0044 & 3.0241 & TRN & & \\
\hline CHEMBL1352343 & 752389 & 3.0044 & 3.3801 & TRN & & \\
\hline CHEMBL1389963 & 752389 & 3.0044 & 3.4854 & TRN & & \\
\hline CHEMBL1868381 & 752389 & 4.5114 & 4.0725 & TST & & \\
\hline CHEMBL1408828 & 752389 & 3.0044 & 3.1676 & TRN & & \\
\hline CHEMBL1558977 & 752389 & 3.0044 & 3.0878 & TRN & & \\
\hline CHEMBL1728023 & 752389 & 3.0044 & 3.3036 & TRN & & \\
\hline CHEMBL1303150 & 752389 & 4.3516 & 3.2251 & TRN & & \\
\hline CHEMBL1533337 & 752389 & 4.0472 & 3.3168 & TRN & & \\
\hline CHEMBL1533083 & 752389 & 3.0044 & 3.516 & TRN & & \\
\hline CHEMBL3193499 & 752389 & 3.0044 & 3.2881 & TRN & & \\
\hline CHEMBL1531495 & 752389 & 3.0044 & 3.0019 & TRN & & \\
\hline CHEMBL1556750 & 752389 & 4.2132 & 3.1133 & TST & & \\
\hline CHEMBL1468444 & 752389 & 3.0044 & 3.5525 & TRN & & \\
\hline CHEMBL3208853 & 752389 & 3.0044 & 3.1756 & TRN & & \\
\hline CHEMBL1610395 & 752389 & $4.9830 e$ & 0000000 & 205 & 3.4919 & TRN \\
\hline CHEMBL1422748 & 752389 & 3.0044 & 3.1113 & TRN & & \\
\hline CHEMBL1566130 & 752389 & 3.0044 & 3.193 & TRN & & \\
\hline CHEMBL1405900 & 752389 & 3.0044 & 3.6802 & TRN & & \\
\hline CHEMBL3191182 & 752389 & 3.0044 & 3.2691 & TRN & & \\
\hline CHEMBL1981303 & 752389 & 3.0044 & 3.34 & TRN & & \\
\hline CHEMBL1551560 & 752389 & 4.7986 & 4.2369 & TRN & & \\
\hline CHEMBL1430935 & 752389 & 3.0044 & 3.1119 & TRN & & \\
\hline CHEMBL1611002 & 752389 & 3.0044 & 2.9321 & TRN & & \\
\hline CHEMBL1612672 & 752389 & 3.0044 & 3.517 & TRN & & \\
\hline CHEMBL1473591 & 752389 & 3.0044 & 2.9415 & TRN & & \\
\hline CHEMBL1394008 & 752389 & 3.0044 & 3.5682 & TRN & & \\
\hline CHEMBL1477656 & 752389 & 4.7932 & 3.6583 & TST & & \\
\hline CHEMBL1431909 & 752389 & 3.0044 & 3.0841 & TRN & & \\
\hline CHEMBL1362667 & 752389 & 4.3197 & 3.5174 & TST & & \\
\hline CHEMBL1371472 & 752389 & 4.27 & 3.1605 & TST & & \\
\hline
\end{tabular}


Supplemental Table S2.txt

\begin{tabular}{|c|c|c|c|c|c|}
\hline CHEMBL1423797 & 752389 & 4.7595 & 3.7462 & TRN & \\
\hline CHEMBL1423836 & 752389 & 3.0044 & 3.3257 & TRN & \\
\hline CHEMBL1406911 & 752389 & 3.0044 & 3.2481 & TRN & \\
\hline CHEMBL1452945 & 752389 & 4.7721 & 3.6249 & TRN & \\
\hline CHEMBL1720248 & 752389 & 3.0044 & 3.4749 & TRN & \\
\hline CHEMBL1442704 & 752389 & 5.3335 & 3.4903 & TRN & \\
\hline CHEMBL1303193 & 752389 & 3.0044 & 3.133 & TRN & \\
\hline CHEMBL1460092 & 752389 & 4.2984 & 3.5225 & TRN & \\
\hline CHEMBL1577981 & 752389 & 3.0044 & 3.2385 & TRN & \\
\hline CHEMBL1609003 & 752389 & 3.0044 & 3.3181 & TRN & \\
\hline CHEMBL1462918 & 752389 & 3.0044 & 3.3028 & TRN & \\
\hline CHEMBL1984348 & 752389 & 3.0044 & 3.5796 & TST & \\
\hline CHEMBL521762 & 752389 & 3.0044 & 3.3138 & TRN & \\
\hline CHEMBL1559256 & 752389 & 4.7077 & 3.4491 & TRN & \\
\hline CHEMBL512216 & 752389 & 4.4711 & 3.1959 & TRN & \\
\hline CHEMBL1200847 & 752389 & 5.3215 & 3.4464 & TRN & \\
\hline CHEMBL1492819 & 752389 & 3.0044 & 2.7336 & TRN & \\
\hline CHEMBL1577333 & 752389 & 3.0044 & 3.3811 & TRN & \\
\hline CHEMBL1365068 & 752389 & 3.0044 & 3.2231 & TST & \\
\hline CHEMBL1605363 & 752389 & 4.684 & 3.1177 & TRN & \\
\hline CHEMBL1417553 & 752389 & 3.0044 & 3.1733 & TST & \\
\hline CHEMBL3195935 & 752389 & 3.0044 & 3.5178 & TST & \\
\hline CHEMBL1878187 & 752389 & 5.9431 & 3.4732 & TST & \\
\hline CHEMBL1583067 & 752389 & 3.0044 & 3.2941 & TRN & \\
\hline CHEMBL518575 & 752389 & 3.0044 & 3.1887 & TRN & \\
\hline CHEMBL1482959 & 752389 & 3.0044 & 3.1681 & TRN & \\
\hline CHEMBL1420548 & 752389 & 3.0044 & 3.46 & TRN & \\
\hline CHEMBL1444979 & 752389 & 3.0044 & 3.2481 & TRN & \\
\hline CHEMBL1374557 & 752389 & 3.0044 & 3.21 & TRN & \\
\hline CHEMBL1333548 & 752389 & 3.0044 & 3.2528 & TRN & \\
\hline CHEMBL1488420 & 752389 & 3.0044 & 3.0941 & TRN & \\
\hline CHEMBL1528991 & 752389 & 3.0044 & 3.2522 & TRN & \\
\hline CHEMBL1416570 & 752389 & 3.0044 & 3.5289 & TRN & \\
\hline CHEMBL1339921 & 752389 & 5.0057 & 3.5151 & TRN & \\
\hline CHEMBL1561287 & 752389 & 3.0044 & 3.6201 & TRN & \\
\hline CHEMBL1574438 & 752389 & 3.0044 & 3.4539 & TRN & \\
\hline CHEMBL1465435 & 752389 & 3.0044 & 3.333999 & 99999999996 & TRN \\
\hline CHEMBL1375292 & 752389 & 3.0044 & 3.0 & TRN & \\
\hline CHEMBL1863847 & 752389 & 3.0044 & 3.7154 & TST & \\
\hline CHEMBL1375034 & 752389 & 3.0044 & 3.4108 & TRN & \\
\hline CHEMBL3199198 & 752389 & 4.3893 & 3.5497 & TRN & \\
\hline CHEMBL3192243 & 752389 & 3.0044 & 3.2944 & TRN & \\
\hline CHEMBL1326748 & 752389 & 3.0044 & 3.3436 & TST & \\
\hline CHEMBL1583907 & 752389 & 3.0044 & 3.3286 & TST & \\
\hline CHEMBL1447988 & 752389 & 3.0044 & 3.6285 & TRN & \\
\hline CHEMBL538104 & 752389 & 4.5186 & 3.363 & TST & \\
\hline CHEMBL1380676 & 752389 & 4.71899 & 999999999 & 3.3743 & TRN \\
\hline CHEMBL1483453 & 752389 & 3.0044 & 3.5091 & TRN & \\
\hline
\end{tabular}


Supplemental Table S2.txt

\begin{tabular}{|c|c|c|c|c|}
\hline CHEMBL1407873 & 752389 & 5.0255 & 4.0907 & TRN \\
\hline CHEMBL1863914 & 752389 & 4.2857 & 3.2597 & TRN \\
\hline CHEMBL3194691 & 752389 & 3.0044 & 3.5184 & TST \\
\hline CHEMBL1381340 & 752389 & 3.0044 & 3.2693 & TRN \\
\hline CHEMBL1423165 & 752389 & 3.0044 & 3.4175 & TRN \\
\hline CHEMBL1359137 & 752389 & 3.0044 & 3.6757 & TRN \\
\hline CHEMBL1370456 & 752389 & 3.0044 & 3.5376 & TST \\
\hline CHEMBL1419027 & 752389 & 3.0044 & 3.5568 & TRN \\
\hline CHEMBL1457252 & 752389 & 4.9706 & 3.3572 & TRN \\
\hline CHEMBL1477749 & 752389 & 4.0482 & 3.5836 & TRN \\
\hline CHEMBL 3195184 & 752389 & 4.3862 & 3.7345 & TRN \\
\hline CHEMBL1325286 & 752389 & 5.279 & 3.7172 & TST \\
\hline CHEMBL1322281 & 752389 & 4.9172 & 3.6609 & TST \\
\hline CHEMBL1897572 & 752389 & 5.1543 & 4.1252 & TRN \\
\hline CHEMBL3194152 & 752389 & 3.0044 & 3.6538 & TRN \\
\hline CHEMBL1523044 & 752389 & 3.0044 & 3.8044 & TST \\
\hline CHEMBL1883085 & 752389 & 3.0044 & 3.6133 & TRN \\
\hline CHEMBL1427044 & 752389 & 3.0044 & 3.284 & TRN \\
\hline CHEMBL1484508 & 752389 & 3.0044 & 3.5116 & TST \\
\hline CHEMBL1578806 & 752389 & 3.0044 & 3.236 & TRN \\
\hline CHEMBL1379877 & 752389 & 4.9469 & 3.4152 & TRN \\
\hline CHEMBL1608989 & 752389 & 3.0044 & 3.2069 & TRN \\
\hline CHEMBL1583844 & 752389 & 3.0044 & 3.5274 & TRN \\
\hline CHEMBL1463714 & 752389 & 3.0044 & 3.3602 & TST \\
\hline CHEMBL1558403 & 752389 & 3.0044 & 3.9841 & TRN \\
\hline CHEMBL1414655 & 752389 & 3.0044 & 3.2361 & TRN \\
\hline CHEMBL1521250 & 752389 & 3.0044 & 3.3376 & TRN \\
\hline CHEMBL3214439 & 752389 & 3.0044 & 3.538999 & 99999999997 \\
\hline CHEMBL1523597 & 752389 & 3.0044 & 3.3323 & TRN \\
\hline CHEMBL1514705 & 752389 & 3.0044 & 3.1662 & TRN \\
\hline CHEMBL1428271 & 752389 & 3.0044 & 3.3986 & TRN \\
\hline CHEMBL 268584 & 752389 & 3.0044 & 3.1256 & TST \\
\hline CHEMBL1386791 & 752389 & 3.0044 & 3.2188 & TRN \\
\hline CHEMBL1578612 & 752389 & 4.9031 & 3.4508 & TRN \\
\hline CHEMBL1311260 & 752389 & 3.0044 & 3.3417 & TRN \\
\hline CHEMBL1896512 & 752389 & 3.0044 & 3.3491 & TRN \\
\hline CHEMBL1416018 & 752389 & 3.0044 & 3.4799 & TRN \\
\hline CHEMBL1567518 & 752389 & 3.0044 & 3.2375 & TRN \\
\hline CHEMBL1382089 & 752389 & 3.0044 & 3.2644 & TRN \\
\hline CHEMBL1601846 & 752389 & 4.0942 & 3.4487 & TST \\
\hline CHEMBL1342485 & 752389 & 3.0044 & 3.0606 & TST \\
\hline CHEMBL1328741 & 752389 & 3.0044 & 3.2052 & TRN \\
\hline CHEMBL428496 & 752389 & 3.0044 & 3.6762 & TST \\
\hline CHEMBL1333151 & 752389 & 4.6925 & 3.8749 & TRN \\
\hline CHEMBL1463189 & 752389 & 4.284 & 3.9005 & TRN \\
\hline CHEMBL1459316 & 752389 & 3.0044 & 3.228 & TRN \\
\hline CHEMBL1441958 & 752389 & 3.0044 & 3.1462 & TRN \\
\hline CHEMBL3191091 & 752389 & 3.0044 & 3.5579 & TRN \\
\hline
\end{tabular}




\begin{tabular}{|c|c|c|c|c|}
\hline \multicolumn{5}{|c|}{ Supplemental Table S2.txt } \\
\hline CHEMBL1598441 & 752389 & 3.0044 & 3.5958 & TRN \\
\hline CHEMBL1985338 & 752389 & 3.0044 & 3.6551 & TRN \\
\hline CHEMBL1428589 & 752389 & 3.0044 & 3.5675 & TRN \\
\hline CHEMBL 3191571 & 752389 & 5.1475 & 3.3253 & TRN \\
\hline CHEMBL1558832 & 752389 & 3.0044 & 3.1072 & TST \\
\hline CHEMBL1407274 & 752389 & 3.0044 & 3.3406 & TRN \\
\hline CHEMBL1885471 & 752389 & 3.0044 & 3.6582 & TST \\
\hline CHEMBL1503442 & 752389 & 3.0044 & 3.33 & TRN \\
\hline CHEMBL240332 & 752389 & 4.3487 & 3.3409 & TRN \\
\hline CHEMBL1352376 & 752389 & 3.0044 & 3.8493 & TRN \\
\hline CHEMBL1873191 & 752389 & 3.0044 & 3.4834 & TST \\
\hline CHEMBL1351618 & 752389 & 3.0044 & 3.0759 & TRN \\
\hline CHEMBL1601348 & 752389 & 3.0044 & 3.0671 & TRN \\
\hline CHEMBL1393284 & 752389 & 3.0044 & 3.545 & TRN \\
\hline CHEMBL1513083 & 752389 & 3.0044 & 3.3799 & TST \\
\hline CHEMBL1605813 & 752389 & 3.0044 & 3.0386 & TRN \\
\hline CHEMBL1402149 & 752389 & 3.0044 & 3.0028 & TRN \\
\hline CHEMBL1446234 & 752389 & 3.0044 & 3.85 & TRN \\
\hline CHEMBL1606773 & 752389 & 3.0044 & 3.5884 & TST \\
\hline CHEMBL1559324 & 752389 & 3.0044 & 3.5067 & TST \\
\hline CHEMBL1585764 & 752389 & 3.0044 & 3.3786 & TRN \\
\hline CHEMBL1548789 & 752389 & 3.0044 & 3.4088 & TRN \\
\hline CHEMBL1457774 & 752389 & 3.0044 & 2.7722 & TRN \\
\hline CHEMBL1401048 & 752389 & 3.0044 & 3.5317 & TRN \\
\hline CHEMBL1431919 & 752389 & 3.0044 & 3.8385 & TRN \\
\hline CHEMBL1972346 & 752389 & 3.0044 & 3.3717 & TRN \\
\hline CHEMBL1300370 & 752389 & 3.0044 & 3.2507 & TST \\
\hline CHEMBL1598493 & 752389 & 3.0044 & 3.2945 & TST \\
\hline CHEMBL1307648 & 752389 & 3.0044 & 3.1874 & TRN \\
\hline CHEMBL1501146 & 752389 & 3.0044 & 3.2311 & TRN \\
\hline CHEMBL1327721 & 752389 & 3.0044 & 3.5801 & TRN \\
\hline CHEMBL1973694 & 752389 & 3.0044 & 3.3541 & TRN \\
\hline CHEMBL1504624 & 752389 & 3.0044 & 3.3489 & TST \\
\hline CHEMBL1573707 & 752389 & 4.3316 & 3.1393 & TRN \\
\hline CHEMBL1605468 & 752389 & 3.0044 & 3.3145 & TRN \\
\hline CHEMBL1323268 & 752389 & 4.7447 & 3.2826 & TRN \\
\hline CHEMBL1497357 & 752389 & 4.8297 & 3.656 & TST \\
\hline CHEMBL1500423 & 752389 & 3.0044 & 3.3351 & TRN \\
\hline CHEMBL1421166 & 752389 & 3.0044 & 3.4326 & TRN \\
\hline CHEMBL1339765 & 752389 & 3.0044 & 3.3542 & TRN \\
\hline CHEMBL1537639 & 752389 & 5.1662 & 3.4349 & TST \\
\hline CHEMBL1360606 & 752389 & 3.0044 & 3.8462 & TST \\
\hline CHEMBL1379898 & 752389 & 3.0044 & 3.195 & TRN \\
\hline CHEMBL1555050 & 752389 & 4.3478 & 3.0821 & TRN \\
\hline CHEMBL1484293 & 752389 & 3.0044 & 3.2872 & TRN \\
\hline CHEMBL1995385 & 752389 & 4.1701 & 3.2451 & TRN \\
\hline CHEMBL 3145254 & 752389 & 4.4437 & 3.4967 & TRN \\
\hline CHEMBL1995922 & 752389 & 3.0044 & 3.2714 & TRN \\
\hline
\end{tabular}




\begin{tabular}{|c|c|c|c|c|c|}
\hline & & \multicolumn{4}{|c|}{ Supplemental Table S2.txt } \\
\hline CHEMBL1402103 & 752389 & 3.0044 & 3.1205 & TRN & \\
\hline CHEMBL1422285 & 752389 & 3.0044 & 2.9467 & TRN & \\
\hline CHEMBL1313936 & 752389 & 3.0044 & 3.0985 & TRN & \\
\hline CHEMBL1340895 & 752389 & 4.618 & 3.4207 & TRN & \\
\hline CHEMBL1482878 & 752389 & 4.6882 & 3.4915 & TST & \\
\hline CHEMBL1465727 & 752389 & 3.0044 & 3.583 & TRN & \\
\hline CHEMBL1372505 & 752389 & 3.0044 & 3.17 & TRN & \\
\hline CHEMBL1604510 & 752389 & 3.0044 & 3.1891 & TRN & \\
\hline CHEMBL1587434 & 752389 & 3.0044 & 3.11800 & 00000000003 & TRN \\
\hline CHEMBL600034 & 752389 & 3.0044 & 3.3198 & TRN & \\
\hline CHEMBL1702248 & 752389 & 3.0044 & 3.2851 & TRN & \\
\hline CHEMBL 2003840 & 752389 & 3.0044 & 3.1413 & TRN & \\
\hline CHEMBL1325819 & 752389 & 4.9431 & 3.6546 & TRN & \\
\hline CHEMBL1705345 & 752389 & 3.0044 & 3.355 & TRN & \\
\hline CHEMBL3196160 & 752389 & 3.0044 & 3.1908 & TRN & \\
\hline CHEMBL1538590 & 752389 & 3.0044 & 3.5292 & TRN & \\
\hline CHEMBL1529418 & 752389 & 3.0044 & 3.4167 & TST & \\
\hline CHEMBL1898065 & 752389 & 3.0044 & 3.6517 & TST & \\
\hline CHEMBL1325293 & 752389 & 3.0044 & 3.0024 & TRN & \\
\hline CHEMBL3190691 & 752389 & 3.0044 & 3.532 & TST & \\
\hline CHEMBL1486531 & 752389 & 5.0306 & 3.2661 & TRN & \\
\hline CHEMBL1523652 & 752389 & 3.0044 & 3.4372 & TRN & \\
\hline CHEMBL 3212018 & 752389 & 3.0044 & 3.8563 & TST & \\
\hline CHEMBL1594756 & 752389 & 3.0044 & 3.3706 & TST & \\
\hline CHEMBL 2001481 & 752389 & 4.3307 & 2.9816 & TRN & \\
\hline CHEMBL1613256 & 752389 & 3.0044 & 3.4896 & TRN & \\
\hline CHEMBL1578039 & 752389 & 3.0044 & 3.1922 & TRN & \\
\hline CHEMBL1386658 & 752389 & 3.0044 & 3.3813 & TRN & \\
\hline CHEMBL1569794 & 752389 & 3.0044 & 3.3132 & TRN & \\
\hline CHEMBL1602261 & 752389 & 3.0044 & 3.0802 & TRN & \\
\hline CHEMBL584246 & 752389 & 3.0044 & 3.2482 & TST & \\
\hline CHEMBL1991136 & 752389 & 3.0044 & 3.0826 & TRN & \\
\hline CHEMBL1595909 & 752389 & 3.0044 & 3.2932 & TRN & \\
\hline CHEMBL3209076 & 752389 & 4.3449 & 3.7123 & TRN & \\
\hline CHEMBL1597246 & 752389 & 3.0044 & 3.4488 & TRN & \\
\hline CHEMBL1497581 & 752389 & 3.0044 & 3.3194 & TRN & \\
\hline CHEMBL1543005 & 752389 & 3.0044 & 3.1283 & TRN & \\
\hline CHEMBL1432052 & 752389 & 3.0044 & 3.0583 & TST & \\
\hline CHEMBL1866444 & 752389 & 3.0044 & 3.5259 & TRN & \\
\hline CHEMBL1867926 & 752389 & 3.0044 & 3.4179 & TRN & \\
\hline CHEMBL1881583 & 752389 & 4.4672 & 3.1809 & TRN & \\
\hline CHEMBL66953 & 752389 & 4.0953 & 3.2948 & TST & \\
\hline CHEMBL1611662 & 752389 & 3.0044 & 2.9688 & TRN & \\
\hline CHEMBL1349690 & 752389 & 3.0044 & 3.1897 & TRN & \\
\hline CHEMBL3211284 & 752389 & 3.0044 & 3.2803 & TRN & \\
\hline CHEMBL3195223 & 752389 & 3.0044 & 3.5224 & TST & \\
\hline CHEMBL1360793 & 752389 & 3.0044 & 3.2315 & TRN & \\
\hline CHEMBL1408986 & 752389 & 3.0044 & 3.4493 & TRN & \\
\hline
\end{tabular}




\begin{tabular}{|c|c|c|c|c|c|c|}
\hline \multirow{3}{*}{$\begin{array}{l}\text { CHEMBL1721095 } \\
\text { CHFMBI } 1584115\end{array}$} & & \multicolumn{5}{|c|}{ Supplemental Table S2.txt } \\
\hline & 752389 & 5.1361 & 3.328000 & 30000000 & 203 & TRN \\
\hline & 752389 & 3.0044 & 3.5433 & TST & & \\
\hline CHEMBL1521461 & 752389 & 3.0044 & 2.9691 & TRN & & \\
\hline CHEMBL1975523 & 752389 & 3.0044 & 3.3594 & TRN & & \\
\hline CHEMBL1518508 & 752389 & 3.0044 & 2.9574 & TRN & & \\
\hline CHEMBL1487625 & 752389 & 4.4802 & 3.4647 & TST & & \\
\hline CHEMBL1454397 & 752389 & 3.0044 & 3.1932 & TRN & & \\
\hline CHEMBL 2003831 & 752389 & 3.0044 & 3.4946 & TRN & & \\
\hline CHEMBL1469032 & 752389 & 3.0044 & 3.216 & TRN & & \\
\hline CHEMBL1998893 & 752389 & 3.0044 & 3.3126 & TRN & & \\
\hline CHEMBL1576642 & 752389 & 3.0044 & 3.6232 & TST & & \\
\hline CHEMBL1377943 & 752389 & 4.284 & 3.415 & TRN & & \\
\hline CHEMBL1393520 & 752389 & 3.0044 & 3.2794 & TRN & & \\
\hline CHEMBL1499508 & 752389 & 3.0044 & 3.1223 & TRN & & \\
\hline CHEMBL3194876 & 752389 & 3.0044 & 3.4118 & TRN & & \\
\hline CHEMBL1403913 & 752389 & 3.0044 & 3.3129 & TST & & \\
\hline CHEMBL1466606 & 752389 & 3.0044 & 2.8725 & TRN & & \\
\hline CHEMBL1318179 & 752389 & 3.0044 & 3.6787 & TRN & & \\
\hline CHEMBL1324227 & 752389 & 4.82100 & 300000000 & & 3.2663 & TST \\
\hline CHEMBL1405729 & 752389 & 3.0044 & 3.5194 & TRN & & \\
\hline CHEMBL1868444 & 752389 & 3.0044 & 3.4654 & TST & & \\
\hline CHEMBL3197965 & 752389 & 4.8268 & 3.5388 & TRN & & \\
\hline CHEMBL1476029 & 752389 & 3.0044 & 3.0879 & TRN & & \\
\hline CHEMBL1382001 & 752389 & 3.0044 & 2.9013 & TRN & & \\
\hline CHEMBL1375904 & 752389 & 3.0044 & 3.0981 & TRN & & \\
\hline CHEMBL1885064 & 752389 & 5.3261 & 3.6891 & TST & & \\
\hline CHEMBL1970711 & 752389 & 3.0044 & 3.2143 & TRN & & \\
\hline CHEMBL1598745 & 752389 & 3.0044 & 3.2623 & TST & & \\
\hline CHEMBL1453623 & 752389 & 4.2373 & 3.5208 & TRN & & \\
\hline CHEMBL1573304 & 752389 & 4.0862 & 3.7787 & TRN & & \\
\hline CHEMBL1440463 & 752389 & 3.0044 & 2.8887 & TRN & & \\
\hline CHEMBL1343099 & 752389 & 3.0044 & 3.2098 & TRN & & \\
\hline CHEMBL1313945 & 752389 & 4.4123 & 3.4741 & TRN & & \\
\hline CHEMBL1579116 & 752389 & 3.0044 & 3.4103 & TRN & & \\
\hline CHEMBL1987483 & 752389 & 3.0044 & 3.3414 & TRN & & \\
\hline CHEMBL1309911 & 752389 & 4.4962 & 3.5863 & TRN & & \\
\hline CHEMBL1534294 & 752389 & 3.0044 & 3.1637 & TRN & & \\
\hline CHEMBL1522986 & 752389 & 3.0044 & 3.5523 & TST & & \\
\hline CHEMBL1421105 & 752389 & 3.0044 & 3.3133 & TRN & & \\
\hline CHEMBL1497574 & 752389 & 3.0044 & 3.2672 & TRN & & \\
\hline CHEMBL1408741 & 752389 & 3.0044 & 3.1744 & TRN & & \\
\hline CHEMBL1594826 & 752389 & 3.0044 & 2.9597 & TRN & & \\
\hline CHEMBL1546791 & 752389 & 3.0044 & 3.3324 & TRN & & \\
\hline CHEMBL1582131 & 752389 & 4.2549 & 3.4005 & TRN & & \\
\hline CHEMBL1483095 & 752389 & 3.0044 & 2.8418 & TRN & & \\
\hline CHEMBL1444791 & 752389 & 4.8069 & 3.2564 & TRN & & \\
\hline CHEMBL1310631 & 752389 & 3.0044 & 3.3716 & TRN & & \\
\hline CHEMBL1393396 & 752389 & 3.0044 & 3.5543 & TRN & & \\
\hline
\end{tabular}




\begin{tabular}{|c|c|c|c|c|c|}
\hline & & \multicolumn{4}{|c|}{ Supplemental Table S2.txt } \\
\hline CHEMBL1499390 & 752389 & 3.0044 & 3.3244 & TRN & \\
\hline CHEMBL1469894 & 752389 & 3.0044 & 3.3447 & TRN & \\
\hline CHEMBL1420252 & 752389 & 3.0044 & 3.3661 & TRN & \\
\hline CHEMBL1572785 & 752389 & 3.0044 & 3.2125 & TST & \\
\hline CHEMBL 1456545 & 752389 & 4.2351 & 3.6433 & TRN & \\
\hline CHEMBL1445617 & 752389 & 3.0044 & 3.3835 & TRN & \\
\hline CHEMBL1431810 & 752389 & 4.9586 & 3.1027 & TST & \\
\hline CHEMBL1309404 & 752389 & 4.684 & 3.5328 & TRN & \\
\hline CHEMBL1346297 & 752389 & 3.0044 & 3.3634 & TRN & \\
\hline CHEMBL1580472 & 752389 & 3.0044 & 3.0468 & TRN & \\
\hline CHEMBL1502526 & 752389 & 3.0044 & 3.1684 & TRN & \\
\hline CHEMBL1386952 & 752389 & 3.0044 & 3.6976 & TRN & \\
\hline CHEMBL1400989 & 752389 & 3.0044 & 3.4186 & TRN & \\
\hline CHEMBL1698604 & 752389 & 3.0044 & 3.4714 & TRN & \\
\hline CHEMBL1350845 & 752389 & 3.0044 & 3.2228 & TRN & \\
\hline CHEMBL1487380 & 752389 & 3.0044 & 3.4413 & TRN & \\
\hline CHEMBL1411354 & 752389 & 3.0044 & 2.9596 & TRN & \\
\hline CHEMBL3211738 & 752389 & 3.0044 & 3.4518 & TRN & \\
\hline CHEMBL1328405 & 752389 & 3.0044 & 3.43300 & 00000000003 & TST \\
\hline CHEMBL1370184 & 752389 & 3.0044 & 2.9549 & TST & \\
\hline CHEMBL1486503 & 752389 & 3.0044 & 3.4172 & TST & \\
\hline CHEMBL1539653 & 752389 & 3.0044 & 3.153 & TST & \\
\hline CHEMBL3196874 & 752389 & 3.0044 & 3.3098 & TST & \\
\hline CHEMBL1545489 & 752389 & 3.0044 & 3.6897 & TST & \\
\hline CHEMBL3211804 & 752389 & 3.0044 & 3.6899 & TST & \\
\hline CHEMBL1309683 & 752389 & 3.0044 & 3.1073 & TST & \\
\hline CHEMBL1546706 & 752389 & 3.0044 & 3.4104 & TST & \\
\hline CHEMBL1540841 & 752389 & 3.0044 & 3.4747 & TST & \\
\hline CHEMBL1310269 & 752389 & 3.0044 & 3.2423 & TST & \\
\hline CHEMBL1578141 & 752389 & 3.0044 & 3.2457 & TST & \\
\hline CHEMBL1535241 & 752389 & 4.4045 & 3.2178 & TST & \\
\hline CHEMBL1480971 & 752389 & 3.0044 & 3.4576 & TST & \\
\hline CHEMBL1459196 & 752389 & 3.0044 & 2.9985 & TST & \\
\hline CHEMBL1461287 & 752389 & 3.0044 & 3.2245 & TST & \\
\hline CHEMBL1462078 & 752389 & 4.9208 & 3.572 & TST & \\
\hline CHEMBL1499361 & 752389 & 3.0044 & 3.6374 & TST & \\
\hline CHEMBL3191412 & 752389 & 3.0044 & 3.4561 & TST & \\
\hline CHEMBL1419935 & 752389 & 3.0044 & 3.0343 & TST & \\
\hline CHEMBL3214600 & 752389 & 3.0044 & 3.6035 & TST & \\
\hline CHEMBL1864111 & 752389 & 3.0044 & 3.7689 & TST & \\
\hline CHEMBL1557186 & 752389 & 3.0044 & 3.365 & TST & \\
\hline CHEMBL1338689 & 752389 & 4.6326 & 3.2792 & TST & \\
\hline CHEMBL1456548 & 752389 & 5.2526 & 3.4707 & TST & \\
\hline CHEMBL 1380580 & 752389 & 3.0044 & 3.2223 & TST & \\
\hline CHEMBL1604953 & 752389 & 3.0044 & 3.8977 & TST & \\
\hline CHEMBL1481671 & 752389 & 3.0044 & 2.9191 & TST & \\
\hline CHEMBL1405274 & 752389 & 3.0044 & 3.5825 & TST & \\
\hline CHEMBL1500904 & 752389 & 3.0044 & 3.3067 & TST & \\
\hline
\end{tabular}




\begin{tabular}{|c|c|c|c|c|c|}
\hline \multicolumn{6}{|c|}{ Supplemental Table S2.txt } \\
\hline CHEMBL1323828 & 752389 & 3.0044 & 3.4725 & TST & \\
\hline CHEMBL1981833 & 752389 & 3.0044 & 3.4641 & TST & \\
\hline CHEMBL1901790 & 752389 & 3.0044 & 3.7959 & TST & \\
\hline CHEMBL1992719 & 752389 & 4.5817 & 3.5902 & TST & \\
\hline CHEMBL1432585 & 752389 & 3.0044 & 3.4869 & TST & \\
\hline CHEMBL1578178 & 752389 & 3.0044 & 3.77100 & 00000000004 & TST \\
\hline CHEMBL1361805 & 752389 & 3.0044 & 3.2245 & TST & \\
\hline CHEMBL1389733 & 752389 & 3.0044 & 3.1895 & TST & \\
\hline CHEMBL423638 & 612154 & 8.5229 & 7.84200 & 00000000005 & TRN \\
\hline CHEMBL193856 & 612154 & 6.0 & 6.0479 & TRN & \\
\hline CHEMBL128663 & 612154 & 4.8239 & 4.604 & TRN & \\
\hline CHEMBL299794 & 612154 & 6.1135 & 5.4014 & TST & \\
\hline CHEMBL126672 & 612154 & 5.5686 & 4.8028 & TRN & \\
\hline CHEMBL491477 & 612154 & 5.0458 & 5.3951 & TRN & \\
\hline CHEMBL305076 & 612154 & 5.6021 & 6.1363 & TST & \\
\hline CHEMBL605776 & 612154 & 6.8239 & 7.0682 & TST & \\
\hline CHEMBL598297 & 612154 & 6.0223 & 6.4861 & TRN & \\
\hline CHEMBL596691 & 612154 & 5.3098 & 4.9102 & TRN & \\
\hline CHEMBL597090 & 612154 & 4.5229 & 4.7114 & TRN & \\
\hline CHEMBL340341 & 612154 & 4.6778 & 4.1562 & TRN & \\
\hline CHEMBL597274 & 612154 & 6.5686 & 6.2235 & TRN & \\
\hline CHEMBL338350 & 612154 & 4.9208 & 4.47199 & 99999999995 & TRN \\
\hline CHEMBL596894 & 612154 & 5.0862 & 4.5976 & TRN & \\
\hline CHEMBL599379 & 612154 & 6.2441 & 6.9475 & TRN & \\
\hline CHEMBL117615 & 612154 & 4.6576 & 6.4261 & TST & \\
\hline CHEMBL129523 & 612154 & 7.3979 & 6.9446 & TRN & \\
\hline CHEMBL195309 & 612154 & 6.8539 & 6.6205 & TRN & \\
\hline CHEMBL590485 & 612154 & 6.8861 & 5.6153 & TST & \\
\hline CHEMBL298672 & 612154 & 6.1135 & 5.6573 & TST & \\
\hline CHEMBL447148 & 612154 & 5.4559 & 5.0374 & TRN & \\
\hline CHEMBL462224 & 612154 & 5.3098 & 5.58200 & 2000000001 & TRN \\
\hline CHEMBL450838 & 612154 & 4.9914 & 5.1779 & TRN & \\
\hline CHEMBL390665 & 612154 & 6.0706 & 6.4252 & TRN & \\
\hline CHEMBL521440 & 612154 & 5.4685 & 5.556 & TRN & \\
\hline CHEMBL129260 & 612154 & 5.6198 & 5.0737 & TRN & \\
\hline CHEMBL338785 & 612154 & 5.2596 & 5.1339 & TRN & \\
\hline CHEMBL483677 & 612154 & 6.8239 & 6.4948 & TRN & \\
\hline CHEMBL485243 & 612154 & 6.5229 & 6.1089 & TRN & \\
\hline CHEMBL590144 & 612154 & 7.7959 & 6.8653 & TRN & \\
\hline CHEMBL88084 & 612154 & 8.0 & 7.2527 & TRN & \\
\hline CHEMBL610783 & 612154 & 6.5229 & 7.0458 & TRN & \\
\hline CHEMBL445386 & 612154 & 6.3979 & 6.7199 & TST & \\
\hline CHEMBL127107 & 612154 & 4.585 & 4.4672 & TRN & \\
\hline CHEMBL596701 & 612154 & 6.4318 & 6.6851 & TRN & \\
\hline CHEMBL611993 & 612154 & 6.9586 & 6.7194 & TRN & \\
\hline CHEMBL129819 & 612154 & 3.7496 & 4.4443 & TRN & \\
\hline CHEMBL607846 & 612154 & 5.6861 & 5.8644 & TRN & \\
\hline CHEMBL13623 & 612154 & 4.1675 & 6.4172 & TST & \\
\hline
\end{tabular}




\begin{tabular}{|c|c|c|c|c|c|}
\hline \multirow[b]{2}{*}{ CHEMBL20403 } & \multicolumn{5}{|c|}{ ellitas } \\
\hline & 612154 & 6.4815 & 7.3161 & TRN & \\
\hline CHEMBL340896 & 612154 & 5.8239 & 5.1804 & TRN & \\
\hline CHEMBL127719 & 612154 & 4.8539 & 4.8735 & TRN & \\
\hline CHEMBL512897 & 612154 & 4.1675 & 4.8504 & TRN & \\
\hline CHEMBL 145 & 612154 & 5.3979 & 5.9872 & TRN & \\
\hline CHEMBL599704 & 612154 & 5.2218 & 6.6102 & TST & \\
\hline CHEMBL99217 & 612154 & 7.8239 & 7.6217 & TRN & \\
\hline CHEMBL482206 & 612154 & 5.4949 & 5.7276 & TRN & \\
\hline CHEMBL 292239 & 612154 & 5.8239 & 5.9486 & TRN & \\
\hline CHEMBL483684 & 612154 & 5.9208 & 5.9781 & TRN & \\
\hline CHEMBL486432 & 612154 & 5.0 & 5.0704 & TRN & \\
\hline CHEMBL598960 & 612154 & 5.1249 & 5.7862 & TST & \\
\hline CHEMBL508183 & 612154 & 5.699 & 6.0622 & TRN & \\
\hline CHEMBL129292 & 612154 & 7.8539 & 7.7676 & TRN & \\
\hline CHEMBL590152 & 612154 & 7.4437 & 7.6949 & TRN & \\
\hline CHEMBL13980 & 612154 & 5.0706 & 6.3488 & TST & \\
\hline CHEMBL22789 & 612154 & 7.5686 & 7.6227 & TRN & \\
\hline CHEMBL473946 & 612154 & 4.699 & 5.2314 & TRN & \\
\hline CHEMBL481613 & 612154 & 5.4815 & 5.5686 & TRN & \\
\hline CHEMBL141645 & 612154 & 7.6383 & 7.6921 & TRN & \\
\hline CHEMBL7162 & 612154 & 5.0 & 5.726 & TST & \\
\hline CHEMBL489899 & 612154 & 5.0 & 5.3298 & TRN & \\
\hline CHEMBL609907 & 612154 & 4.1675 & 5.8752 & TST & \\
\hline CHEMBL597240 & 612154 & 7.699 & 7.3387 & TRN & \\
\hline CHEMBL600479 & 612154 & 6.4815 & 6.6099 & TRN & \\
\hline CHEMBL471939 & 612154 & 4.8239 & 5.2048 & TRN & \\
\hline CHEMBL364739 & 612154 & 6.5229 & 6.8158 & TRN & \\
\hline CHEMBL128869 & 612154 & 4.8539 & 5.5579 & TST & \\
\hline CHEMBL605132 & 612154 & 6.8861 & 7.4219 & TST & \\
\hline CHEMBL597070 & 612154 & 6.1308 & 6.07700 & 0000000001 & TST \\
\hline CHEMBL126326 & 612154 & 4.3098 & 4.8306 & TST & \\
\hline CHEMBL597733 & 612154 & 5.0 & 5.4071 & TRN & \\
\hline CHEMBL126910 & 612154 & 4.7212 & 4.6376 & TST & \\
\hline CHEMBL258986 & 612154 & 4.3872 & 4.8341 & TRN & \\
\hline CHEMBL514950 & 612154 & 5.0969 & 5.2467 & TRN & \\
\hline CHEMBL294159 & 612154 & 5.7959 & 5.4886 & TRN & \\
\hline CHEMBL598296 & 612154 & 6.0605 & 6.2106 & TST & \\
\hline CHEMBL15058 & 612154 & 5.0969 & 6.609 & TST & \\
\hline CHEMBL452605 & 612154 & 6.4559 & 6.0888 & TRN & \\
\hline CHEMBL 2315090 & 934509 & 4.0 & 5.3325 & TRN & \\
\hline CHEMBL 2315101 & 934509 & 7.7447 & 7.4383 & TRN & \\
\hline CHEMBL 2315117 & 934509 & 5.0 & 6.5612 & TRN & \\
\hline CHEMBL2315118 & 934509 & 6.9469 & 5.9589 & TST & \\
\hline CHEMBL2315135 & 934509 & 7.4685 & 6.1142 & TRN & \\
\hline CHEMBL 229254 & 934509 & 5.2924 & 5.4724 & TST & \\
\hline CHEMBL 2315092 & 934509 & 5.9208 & 6.4951 & TST & \\
\hline CHEMBL 2315128 & 934509 & 4.0 & 4.819 & TRN & \\
\hline CHEMBL 2315121 & 934509 & 6.1675 & 5.70299 & 9999999999 & TST \\
\hline & & & & e 3159 & \\
\hline
\end{tabular}


Supplemental Table S2.txt

\begin{tabular}{|c|c|c|c|c|c|}
\hline CHEMBL2315113 & 934509 & 6.5654 & 6.7335 & TRN & \\
\hline CHEMBL2315116 & 934509 & 7.5086 & 7.3929 & TRN & \\
\hline CHEMBL2315133 & 934509 & 6.0259 & 5.3209 & TRN & \\
\hline CHEMBL2315124 & 934509 & 7.1427 & 6.7337 & TRN & \\
\hline CHEMBL2315123 & 934509 & 6.4935 & 6.6313 & TRN & \\
\hline CHEMBL2315412 & 934509 & 7.6778 & 7.4163 & TRN & \\
\hline CHEMBL2315119 & 934509 & 4.0 & 6.2275 & TST & \\
\hline CHEMBL2315107 & 934509 & 7.3768 & 7.0857 & TRN & \\
\hline CHEMBL2315103 & 934509 & 7.0809 & 7.8639 & TRN & \\
\hline CHEMBL2311575 & 934509 & 5.0 & 5.7119 & TRN & \\
\hline CHEMBL2315127 & 934509 & 6.0362 & 4.7152 & TRN & \\
\hline CHEMBL2315110 & 934509 & 7.9586 & 7.7598 & TRN & \\
\hline CHEMBL2315093 & 934509 & 6.6576 & 5.682 & TRN & \\
\hline CHEMBL2315094 & 934509 & 5.061 & 6.5493 & TRN & \\
\hline CHEMBL2315115 & 934509 & 7.8239 & 7.2975 & TRN & \\
\hline CHEMBL2315102 & 934509 & 8.1549 & 8.2239 & TRN & \\
\hline CHEMBL2315105 & 934509 & 7.1612 & 7.7538 & TRN & \\
\hline CHEMBL2315104 & 934509 & 8.2218 & 7.4531 & TRN & \\
\hline CHEMBL572098 & 934509 & 7.6021 & 6.8496 & TRN & \\
\hline CHEMBL2315137 & 934509 & 7.2366 & 6.7996 & TRN & \\
\hline CHEMBL2315125 & 934509 & 5.0 & 5.20200 & 0000000001 & TRN \\
\hline CHEMBL2315130 & 934509 & 7.8539 & 7.4207 & TRN & \\
\hline CHEMBL2315100 & 934509 & 7.6778 & 7.4383 & TRN & \\
\hline CHEMBL2315098 & 934509 & 5.9031 & 6.6105 & TRN & \\
\hline CHEMBL2315097 & 934509 & 5.0 & 6.6177 & TRN & \\
\hline CHEMBL2315131 & 934509 & 6.1487 & 5.5756 & TRN & \\
\hline CHEMBL2315136 & 934509 & 6.8268 & 7.6308 & TRN & \\
\hline CHEMBL2315108 & 934509 & 5.8523 & 6.8981 & TRN & \\
\hline CHEMBL2315096 & 934509 & 8.0 & 7.1002 & TRN & \\
\hline CHEMBL2315134 & 934509 & 5.5067 & 6.2128 & TRN & \\
\hline CHEMBL2315099 & 934509 & 7.6021 & 7.4144 & TRN & \\
\hline CHEMBL2315120 & 934509 & 5.0 & 6.1275 & TST & \\
\hline CHEMBL2315089 & 934509 & 7.1079 & 5.7814 & TRN & \\
\hline CHEMBL2315111 & 934509 & 7.4815 & 6.6317 & TRN & \\
\hline CHEMBL229212 & 934509 & 7.585 & 6.4675 & TRN & \\
\hline CHEMBL2315132 & 934509 & 7.9208 & 7.7968 & TRN & \\
\hline CHEMBL2315122 & 934509 & 6.585 & 6.5519 & TRN & \\
\hline CHEMBL2315091 & 934509 & 4.0 & 5.4611 & TRN & \\
\hline CHEMBL2315126 & 934509 & 4.0 & 5.3149 & TST & \\
\hline CHEMBL2315109 & 934509 & 6.4535 & 6.5524 & TST & \\
\hline CHEMBL2315112 & 934509 & 7.4949 & 6.7619 & TST & \\
\hline CHEMBL2315106 & 934509 & 6.8239 & 6.9391 & TST & \\
\hline CHEMBL2315129 & 934509 & 7.2076 & 6.1643 & TST & \\
\hline CHEMBL591796 & 934509 & 7.7447 & 7.6157 & TST & \\
\hline CHEMBL2315095 & 934509 & 7.4685 & 7.0091 & TST & \\
\hline CHEMBL2315114 & 934509 & 6.301 & 6.6762 & TST & \\
\hline CHEMBL3696656 & 1528225 & 7.7696 & 7.5094 & TRN & \\
\hline CHEMBL3696593 & 1528225 & 8.8861 & 7.9019 & TRN & \\
\hline
\end{tabular}

Page 3160 


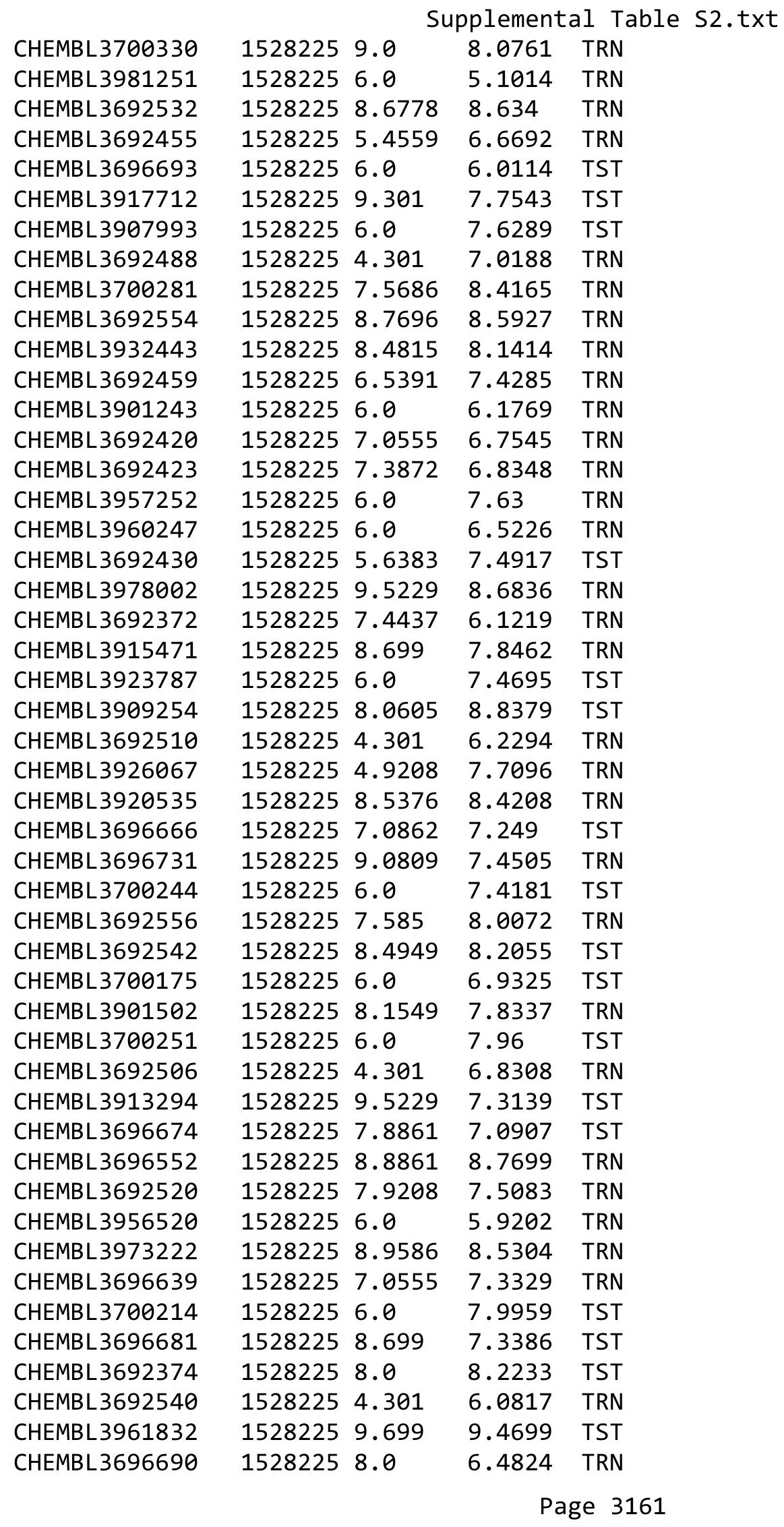


Supplemental Table S2.txt

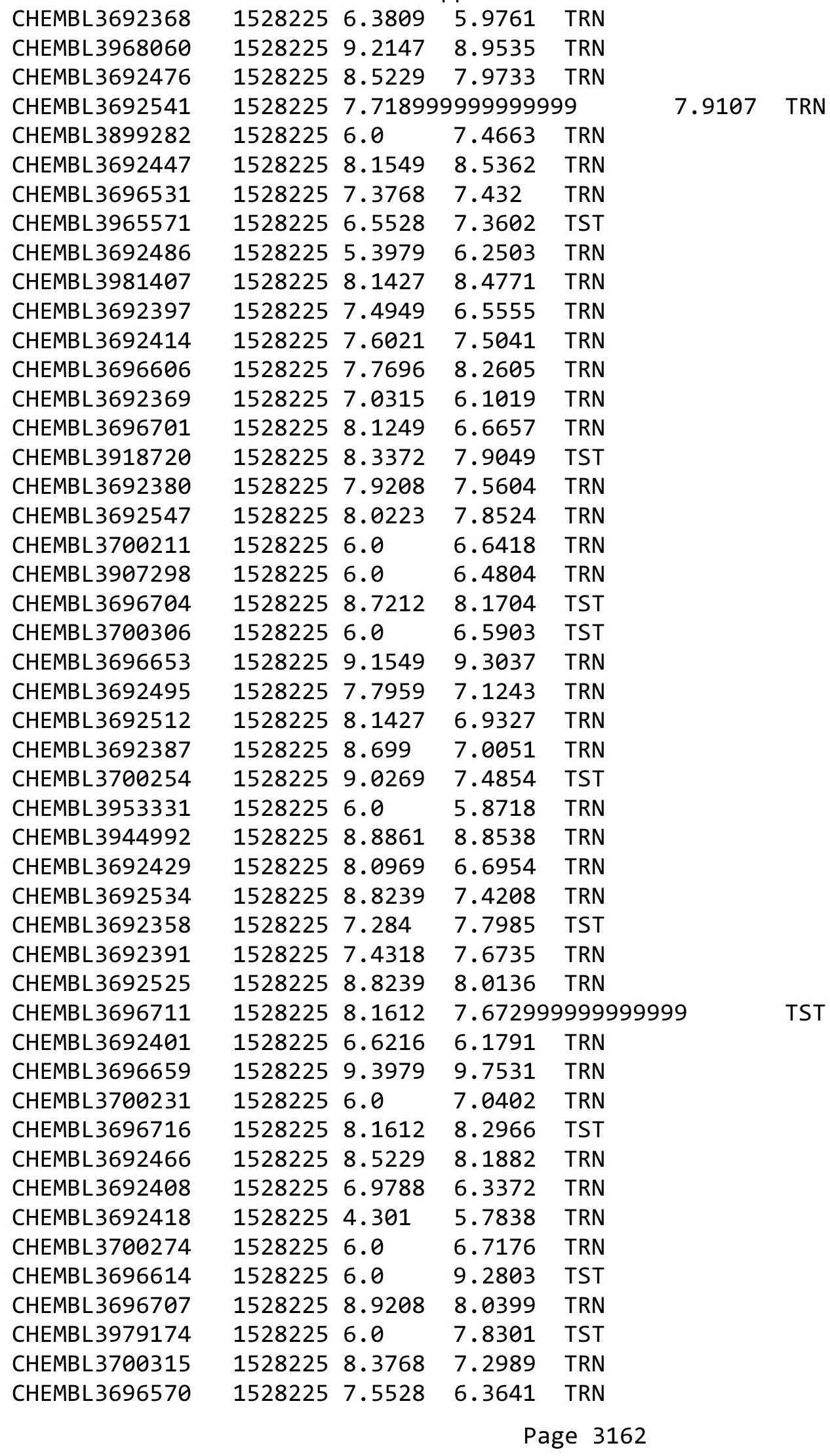


Supplemental Table S2.txt

\begin{tabular}{|c|c|c|c|c|}
\hline CHEMBL3696680 & 1528225 & 8.5229 & \multicolumn{2}{|c|}{7.867999999999999} \\
\hline CHEMBL3696527 & 1528225 & 8.1427 & 7.7655 & TRN \\
\hline CHEMBL3700216 & 1528225 & 6.0 & 7.4741 & TRN \\
\hline CHEMBL3700202 & 1528225 & 6.0 & 6.8235 & TRN \\
\hline CHEMBL3914383 & 1528225 & 6.0 & 6.6683 & TST \\
\hline CHEMBL3930804 & 1528225 & 6.0 & \multicolumn{2}{|c|}{7.0760000000000005} \\
\hline CHEMBL3957301 & 1528225 & 5.7959 & 7.309 & TST \\
\hline CHEMBL3905398 & 1528225 & 6.0 & 6.6963 & TST \\
\hline CHEMBL3696695 & 1528225 & 11.0 & 7.4872 & TRN \\
\hline CHEMBL3692487 & 1528225 & 6.4237 & 5.8683 & TRN \\
\hline CHEMBL3963295 & 1528225 & 8.585 & 8.8837 & TST \\
\hline CHEMBL3692523 & 1528225 & 7.0088 & 7.6204 & TRN \\
\hline CHEMBL3692472 & 1528225 & 7.4559 & 7.0684 & TRN \\
\hline CHEMBL3700188 & 1528225 & 6.0 & 6.6009 & TRN \\
\hline CHEMBL3692438 & 1528225 & 8.2218 & 7.7763 & TRN \\
\hline CHEMBL3960015 & 1528225 & 8.3468 & 8.0474 & TRN \\
\hline CHEMBL3696533 & 1528225 & 9.2757 & 8.5315 & TRN \\
\hline CHEMBL3700288 & 1528225 & 9.1079 & 8.3103 & TRN \\
\hline CHEMBL3919456 & 1528225 & 9.0 & 8.0065 & TRN \\
\hline CHEMBL3696709 & 1528225 & 8.9586 & 8.2373 & TRN \\
\hline CHEMBL3692528 & 1528225 & 7.4318 & 7.9463 & TRN \\
\hline CHEMBL3901547 & 1528225 & 8.1549 & 7.846 & TRN \\
\hline CHEMBL3692456 & 1528225 & 4.301 & 5.4341 & TRN \\
\hline CHEMBL3700204 & 1528225 & 6.0 & 5.8786 & TRN \\
\hline CHEMBL3696594 & 1528225 & 6.6778 & 6.5167 & TRN \\
\hline CHEMBL3700319 & 1528225 & 6.0 & 6.0508 & TRN \\
\hline CHEMBL3692511 & 1528225 & 8.1675 & 8.0257 & TRN \\
\hline CHEMBL3909337 & 1528225 & 6.0 & 7.4433 & TST \\
\hline CHEMBL3893593 & 1528225 & 6.6778 & 8.3303 & TST \\
\hline CHEMBL3696727 & 1528225 & 6.0 & 6.1915 & TRN \\
\hline CHEMBL3696651 & 1528225 & 8.0757 & 7.7894 & TRN \\
\hline CHEMBL3692376 & 1528225 & 6.1129 & 6.4435 & TRN \\
\hline CHEMBL3700310 & 1528225 & 4.9208 & 6.3622 & TRN \\
\hline CHEMBL3947410 & 1528225 & 6.0 & 5.9405 & TRN \\
\hline CHEMBL3692400 & 1528225 & 8.2676 & 8.2085 & TRN \\
\hline CHEMBL3696679 & 1528225 & 6.699 & 6.3525 & TRN \\
\hline CHEMBL3700197 & 1528225 & 6.0 & 6.9814 & TST \\
\hline CHEMBL3696692 & 1528225 & 8.5229 & 6.8817 & TST \\
\hline CHEMBL3696643 & 1528225 & 6.0 & 7.7992 & TST \\
\hline CHEMBL3958175 & 1528225 & 6.0 & 6.608 & TST \\
\hline CHEMBL3944211 & 1528225 & 8.9208 & 9.0759 & TRN \\
\hline CHEMBL3692383 & 1528225 & 4.301 & 6.1369 & TRN \\
\hline CHEMBL3936593 & 1528225 & 6.0 & 6.7992 & TST \\
\hline CHEMBL3956118 & 1528225 & 8.7696 & 7.711 & TRN \\
\hline CHEMBL3692428 & 1528225 & 8.0 & 6.9951 & TRN \\
\hline CHEMBL3922541 & 1528225 & 9.699 & 9.2907 & TRN \\
\hline CHEMBL3696682 & 1528225 & 8.4437 & 6.45799 & 99999 \\
\hline CHEMBL3700314 & 1528225 & 9.2676 & 6.9596 & TRN \\
\hline & & & & 3163 \\
\hline
\end{tabular}


Supplemental Table S2.txt

\begin{tabular}{|c|c|c|c|c|c|}
\hline CHEMBL3700193 & 1528225 & 8.9208 & 8.7114 & TRN & \\
\hline CHEMBL3907146 & 1528225 & 9.1487 & 9.135 & TRN & \\
\hline CHEMBL3700309 & 1528225 & 6.0 & 7.1192 & TST & \\
\hline CHEMBL3692473 & 1528225 & 4.301 & 5.7116 & TRN & \\
\hline CHEMBL3692445 & 1528225 & 8.3979 & 7.561 & TRN & \\
\hline CHEMBL3696537 & 1528225 & 4.301 & 5.8773 & TRN & \\
\hline CHEMBL3692536 & 1528225 & 4.301 & 5.4163 & TRN & \\
\hline CHEMBL3692465 & 1528225 & 8.1549 & 8.0295 & TRN & \\
\hline CHEMBL3692443 & 1528225 & 8.5229 & 8.1348 & TRN & \\
\hline CHEMBL3692378 & 1528225 & 4.301 & 7.0478 & TST & \\
\hline CHEMBL3692375 & 1528225 & 4.301 & 6.7514 & TRN & \\
\hline CHEMBL3940931 & 1528225 & 9.0 & 7.4224 & TRN & \\
\hline CHEMBL3916982 & 1528225 & 8.8539 & 8.5009 & TST & \\
\hline CHEMBL3692392 & 1528225 & 8.5229 & 9.127 & TST & \\
\hline CHEMBL3889488 & 1528225 & 8.585 & 7.7204 & TRN & \\
\hline CHEMBL3692462 & 1528225 & 8.3979 & 8.0014 & TRN & \\
\hline CHEMBL3696576 & 1528225 & 9.9208 & 9.5947 & TRN & \\
\hline CHEMBL3692388 & 1528225 & 6.7645 & 7.372006 & 0000000001 & TRN \\
\hline CHEMBL3692422 & 1528225 & 6.056 & 6.676 & TRN & \\
\hline CHEMBL3982646 & 1528225 & 6.0 & $6.20100 t$ & 00000000005 & TRN \\
\hline CHEMBL 3700311 & 1528225 & 6.0 & 6.789 & TRN & \\
\hline CHEMBL3692448 & 1528225 & 6.0685 & 5.9846 & TRN & \\
\hline CHEMBL3692407 & 1528225 & 5.4437 & 6.4723 & TRN & \\
\hline CHEMBL3692424 & 1528225 & 7.8539 & 7.9192 & TRN & \\
\hline CHEMBL3696714 & 1528225 & 4.9208 & 6.4037 & TST & \\
\hline CHEMBL3696554 & 1528225 & 8.6778 & 7.3395 & TST & \\
\hline CHEMBL3972473 & 1528225 & 7.6198 & 8.3396 & TRN & \\
\hline CHEMBL3692458 & 1528225 & 7.6576 & 8.206 & TRN & \\
\hline CHEMBL3696657 & 1528225 & 8.3372 & 7.6049 & TRN & \\
\hline CHEMBL3696671 & 1528225 & 6.0 & 7.7118 & TST & \\
\hline CHEMBL3696557 & 1528225 & 7.6021 & 6.2362 & TRN & \\
\hline CHEMBL3696585 & 1528225 & 8.1079 & 7.3797 & TST & \\
\hline CHEMBL3639954 & 1528225 & 5.6021 & 7.2277 & TRN & \\
\hline CHEMBL3692421 & 1528225 & 7.3188 & 7.8718 & TRN & \\
\hline CHEMBL3696708 & 1528225 & 9.1367 & 7.6954 & TRN & \\
\hline CHEMBL3692389 & 1528225 & 7.6021 & 7.5317 & TRN & \\
\hline CHEMBL3692546 & 1528225 & 8.1871 & 8.7324 & TRN & \\
\hline CHEMBL3696581 & 1528225 & 6.0 & 6.6174 & TRN & \\
\hline CHEMBL3696663 & 1528225 & 4.9208 & 6.3217 & TRN & \\
\hline CHEMBL3915188 & 1528225 & 9.0 & 8.3433 & TRN & \\
\hline CHEMBL3696573 & 1528225 & 8.1079 & 7.7977 & TRN & \\
\hline CHEMBL3696610 & 1528225 & 7.8861 & 9.1835 & TRN & \\
\hline CHEMBL3929470 & 1528225 & 7.5229 & 7.6424 & TRN & \\
\hline CHEMBL3692384 & 1528225 & 4.301 & 7.9424 & TST & \\
\hline CHEMBL3696661 & 1528225 & 8.6576 & 9.2386 & TRN & \\
\hline CHEMBL3958256 & 1528225 & 6.0 & 6.7344 & TRN & \\
\hline CHEMBL3692564 & 1528225 & 6.2218 & 6.6898 & TRN & \\
\hline CHEMBL3692548 & 1528225 & 6.2676 & 7.0506 & TRN & \\
\hline
\end{tabular}


Supplemental Table S2.txt

\begin{tabular}{|c|c|c|c|c|c|}
\hline CHEMBL 3692433 & 1528225 & 6.3439 & 7.1294 & TRN & \\
\hline CHEMBL 3692399 & 1528225 & 8.0 & 7.5275 & TRN & \\
\hline CHEMBL 3700308 & 1528225 & 6.0 & 7.6187 & TST & \\
\hline CHEMBL 3953616 & 1528225 & 6.0 & 6.718 & TRN & \\
\hline CHEMBL 3700282 & 1528225 & 7.8239 & 9.0287 & TRN & \\
\hline CHEMBL 3696732 & 1528225 & 6.0 & 6.7335 & TRN & \\
\hline CHEMBL 3933920 & 1528225 & 9.5229 & 8.0328 & TRN & \\
\hline CHEMBL 3952578 & 1528225 & 7.3468 & 7.6546 & TST & \\
\hline CHEMBL 3692493 & 1528225 & 8.301 & 7.1014 & TST & \\
\hline CHEMBL 3700283 & 1528225 & 6.0 & 6.6459 & TRN & \\
\hline CHEMBL 3692385 & 1528225 & 4.301 & 6.37799 & 9999999999 & TST \\
\hline CHEMBL 3696662 & 1528225 & 8.6021 & 6.5871 & TRN & \\
\hline CHEMBL 3700289 & 1528225 & 6.0 & 7.8634 & TST & \\
\hline CHEMBL 3700226 & 1528225 & 6.0 & 7.4135 & TST & \\
\hline CHEMBL 3700328 & 1528225 & 9.5229 & 8.6424 & TRN & \\
\hline CHEMBL 3692524 & 1528225 & 8.1487 & 8.1858 & TRN & \\
\hline CHEMBL 3692379 & 1528225 & 7.9586 & 7.4187 & TRN & \\
\hline CHEMBL 3700280 & 1528225 & 7.7959 & 8.0376 & TRN & \\
\hline CHEMBL 3696685 & 1528225 & 6.7696 & 6.4901 & TRN & \\
\hline CHEMBL 3954689 & 1528225 & 8.3098 & 8.0505 & TRN & \\
\hline CHEMBL 3891421 & 1528225 & 8.6198 & 7.6556 & TST & \\
\hline CHEMBL 3692507 & 1528225 & 6.8097 & 6.2483 & TRN & \\
\hline CHEMBL 3894766 & 1528225 & 8.1675 & 7.9772 & TRN & \\
\hline CHEMBL 3692494 & 1528225 & 6.0 & 6.0178 & TRN & \\
\hline CHEMBL 3692482 & 1528225 & 6.2993 & 7.0068 & TST & \\
\hline CHEMBL 3902145 & 1528225 & 8.699 & 8.0294 & TRN & \\
\hline CHEMBL 3700327 & 1528225 & 9.301 & 8.0458 & TRN & \\
\hline CHEMBL 3692468 & 1528225 & 7.1367 & 7.3801 & TRN & \\
\hline CHEMBL3692426 & 1528225 & \multicolumn{3}{|c|}{6.4510000000000005} & TRN \\
\hline CHEMBL 3692366 & 1528225 & 6.6655 & 7.6978 & TST & \\
\hline CHEMBL 3696668 & 1528225 & 6.8539 & 6.4994 & TRN & \\
\hline CHEMBL 3896516 & 1528225 & 6.0 & 7.1438 & TST & \\
\hline CHEMBL 3696556 & 1528225 & 8.9706 & 9.8612 & TRN & \\
\hline CHEMBL 3987133 & 1528225 & 8.1805 & 8.0227 & TST & \\
\hline CHEMBL 3957258 & 1528225 & 6.0 & 6.862 & TRN & \\
\hline CHEMBL 3700174 & 1528225 & 8.7212 & 6.8573 & TST & \\
\hline CHEMBL3968441 & 1528225 & 9.7959 & 7.2781 & TST & \\
\hline CHEMBL 3700218 & 1528225 & 6.0 & 7.1085 & TRN & \\
\hline CHEMBL3696622 & 1528225 & 8.0506 & 8.5464 & TST & \\
\hline CHEMBL 3692417 & 1528225 & 4.301 & 7.5449 & TST & \\
\hline CHEMBL 3972121 & 1528225 & 7.2076 & 6.9785 & TST & \\
\hline CHEMBL 3692440 & 1528225 & 6.8477 & 7.20100 & 00000000005 & RN \\
\hline CHEMBL 3966127 & 1528225 & 6.0 & 6.1463 & TRN & \\
\hline CHEMBL 3692442 & 1528225 & 7.1675 & 6.6782 & TRN & \\
\hline CHEMBL 3910371 & 1528225 & 7.9208 & 8.1014 & TRN & \\
\hline CHEMBL 3696673 & 1528225 & 6.9586 & 7.6048 & TST & \\
\hline CHEMBL 3692377 & 1528225 & 7.0269 & 6.8463 & TST & \\
\hline CHEMBL 3692544 & 1528225 & 7.8539 & 7.8092 & TRN & \\
\hline
\end{tabular}

Page 3165 
Supplemental Table S2.txt

\begin{tabular}{|c|c|c|c|c|c|}
\hline CHEMBL3696655 & 1528225 & 9.2757 & 9.2335 & TST & \\
\hline CHEMBL3936677 & 1528225 & 9.301 & 8.8755 & TRN & \\
\hline CHEMBL 3907246 & 1528225 & 8.7447 & 8.1104 & TST & \\
\hline CHEMBL3903929 & 1528225 & 6.0 & 6.7466 & TRN & \\
\hline CHEMBL3700291 & 1528225 & 6.0 & 6.8214 & TST & \\
\hline CHEMBL3984136 & 1528225 & 6.0 & \multicolumn{2}{|c|}{6.486000000000001} & TRN \\
\hline CHEMBL3932757 & 1528225 & 6.0 & 7.4453 & TRN & \\
\hline CHEMBL 3974860 & 1528225 & 8.1427 & 8.703 & TST & \\
\hline CHEMBL 3696530 & 1528225 & 6.7959 & 6.7331 & TRN & \\
\hline CHEMBL3696717 & 1528225 & 6.0 & 6.7366 & TRN & \\
\hline CHEMBL3692390 & 1528225 & 8.5229 & 8.4001 & TRN & \\
\hline CHEMBL 3696544 & 1528225 & 8.6778 & \multicolumn{2}{|c|}{7.763999999999999} & TRN \\
\hline CHEMBL3696549 & 1528225 & 6.0 & \multicolumn{2}{|c|}{6.292999999999999} & TST \\
\hline CHEMBL3911179 & 1528225 & 7.9208 & 8.474 & TRN & \\
\hline CHEMBL3700185 & 1528225 & 8.9208 & 6.5733 & TST & \\
\hline CHEMBL3696621 & 1528225 & 7.5622 & 8.4297 & TRN & \\
\hline CHEMBL3696688 & 1528225 & 8.2147 & 7.6691 & TST & \\
\hline CHEMBL 3984490 & 1528225 & 7.4089 & 6.5153 & TST & \\
\hline CHEMBL 3953840 & 1528225 & 6.6383 & 5.6413 & TST & \\
\hline CHEMBL 3696562 & 1528225 & 8.1805 & 7.9725 & TRN & \\
\hline CHEMBL 3692552 & 1528225 & 8.0809 & 7.9378 & TRN & \\
\hline CHEMBL 3696551 & 1528225 & 8.6198 & 8.3744 & TRN & \\
\hline CHEMBL3692454 & 1528225 & 6.8297 & 6.8556 & TRN & \\
\hline CHEMBL 3692411 & 1528225 & 7.3098 & 6.5406 & TRN & \\
\hline CHEMBL 3696684 & 1528225 & 6.7447 & 6.2182 & TRN & \\
\hline CHEMBL 3696660 & 1528225 & 8.4318 & 9.3739 & TST & \\
\hline CHEMBL 3982610 & 1528225 & 6.0 & 7.3443 & TST & \\
\hline CHEMBL 3977820 & 1528225 & 9.2291 & 9.2965 & TRN & \\
\hline CHEMBL 3692444 & 1528225 & 8.301 & 8.2196 & TRN & \\
\hline CHEMBL 3692381 & 1528225 & 6.6778 & 6.94 & TRN & \\
\hline CHEMBL3918016 & 1528225 & 6.0 & 5.6181 & TRN & \\
\hline CHEMBL3963166 & 1528225 & 9.1549 & 8.4217 & TRN & \\
\hline CHEMBL3696601 & 1528225 & 6.5686 & 7.0191 & TRN & \\
\hline CHEMBL3696555 & 1528225 & 9.9208 & 9.0784 & TRN & \\
\hline CHEMBL 3978293 & 1528225 & 6.0 & 6.5757 & TRN & \\
\hline CHEMBL3700186 & 1528225 & 6.0 & 6.3375 & TST & \\
\hline CHEMBL 3692509 & 1528225 & 8.2291 & 6.9102 & TST & \\
\hline CHEMBL3700297 & 1528225 & 6.0 & 7.6119 & TRN & \\
\hline CHEMBL 3696545 & 1528225 & 6.6383 & 6.3772 & TRN & \\
\hline CHEMBL 3692478 & 1528225 & 8.699 & 8.3907 & TRN & \\
\hline CHEMBL 3700222 & 1528225 & 6.0 & 6.0646 & TRN & \\
\hline CHEMBL 3692558 & 1528225 & 8.585 & 8.3501 & TRN & \\
\hline CHEMBL3692519 & 1528225 & 7.6383 & 6.6091 & TRN & \\
\hline CHEMBL 3913384 & 1528225 & 6.0 & 8.5538 & TRN & \\
\hline CHEMBL3692497 & 1528225 & 5.8861 & 6.5572 & TRN & \\
\hline CHEMBL3905989 & 1528225 & 8.2441 & 8.7931 & TRN & \\
\hline CHEMBL 3940206 & 1528225 & 9.0 & 8.5533 & TRN & \\
\hline CHEMBL 3700273 & 1528225 & 9.0132 & 9.2032 & TRN & \\
\hline
\end{tabular}


Supplemental Table S2.txt

\begin{tabular}{|c|c|c|c|c|}
\hline 502 & 528225 & 8.5086 & 7.8501 & \\
\hline HEMBL3700325 & 528225 & 7.0 & 8.5572 & \\
\hline & 528225 & 6 & & \\
\hline IEMBL 3692496 & 528225 & 599 & & \\
\hline AEMBL3 & 528225 & 4815 & & \\
\hline AEMBL3922832 & 528225 & 8.0969 & 8.4566 & \\
\hline AEMBL: & 528225 & 3098 & & \\
\hline EMBL & 528225 & & & \\
\hline AEMBL37 & 528225 & 6.0 & & \\
\hline AEMBL3700182 & 528225 & 6.0 & & $S$ \\
\hline AEMBL36 & 528225 & 8.5229 & 67 & \\
\hline IEMBL: & 528225 & .4318 & 89 & \\
\hline EMBL & 225 & & & \\
\hline HEMBL3 & 528225 & 7.017 & & \\
\hline AEMBL36 & 528225 & 21 & & \\
\hline AEMBL3 & 25 & F & 8.2 & \\
\hline AEMBL: & 225 & 4.301 & 39 & \\
\hline IEMBL: & 225 & & & \\
\hline AEMBL & 225 & 6.0 & & גח \\
\hline IEMBL: & 25 & 8 & & \\
\hline IEMBL & 25 & ה & 8 . & \\
\hline EMBL & 25 & & & \\
\hline IEMBL & 25 & & & \\
\hline IEMBL & 225 & & & \\
\hline IEMBL3 & 25 & & & ST \\
\hline IEMBL & 25 & 5 & 8 . & $\mathrm{RI}$ \\
\hline EMBL & 25 & & & 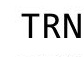 \\
\hline IEMB & 25 & 58 & & RN \\
\hline IEMBL: & 225 & 506 & & RN \\
\hline IEMBL3 & 25 & & & ST \\
\hline AEMBL: & 25 & 7.2924 & & RI \\
\hline 21 & 25 & & 6. & 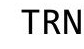 \\
\hline AEMBL: & 25 & 458 & 41 & 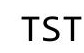 \\
\hline AEMBL3 & 25 & 539 & & RI \\
\hline AEMBL 394 & 25 & 8.2118 & 8 . & RI \\
\hline EMBL: & & & 37 & 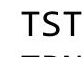 \\
\hline 3 & 25 & & 13 & NIV \\
\hline & & 8 . & & RN \\
\hline AEMBL 3696677 & 528225 & 8.5229 & & RI \\
\hline IEMBL3 & 25 & $4<1$ & & \\
\hline AEMBL: & 25 & & & \\
\hline HEMBL & 1528225 & & & RI \\
\hline HEMBL3 & 528225 & & & $\mathrm{RI}$ \\
\hline IEMBL3696658 & 225 & 8.5086 & 29 & RI \\
\hline 13 & 25 & 979 & & \\
\hline CHEMBL369 & 528225 & & 7.8846 & \\
\hline CHEMBL3692522 & 528225 & 9. 3979 & 8.0867 & \\
\hline CHEMBL3692396 & 1528225 & 8.5229 & 7.9931 & 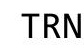 \\
\hline
\end{tabular}

Page 3167 
Supplemental Table S2.txt

\begin{tabular}{|c|c|c|c|c|c|}
\hline CHEMBL 3692382 & 1528225 & 7.2441 & 7.6574 & TRN & \\
\hline CHEMBL 3692521 & 1528225 & 4.301 & 6.0039 & TRN & \\
\hline CHEMBL 3692403 & 1528225 & 7.7447 & 7.202000 & 0000000001 & TRN \\
\hline CHEMBL 3692449 & 1528225 & 6.5171 & 6.1529 & TRN & \\
\hline CHEMBL 3957042 & 1528225 & 8.6778 & 8.7139 & TRN & \\
\hline CHEMBL3692484 & 1528225 & 5.6383 & 6.6518 & TRN & \\
\hline CHEMBL3692432 & 1528225 & 7.2218 & 7.11 & TRN & \\
\hline CHEMBL 3692553 & 1528225 & 8.1612 & 7.6731 & TRN & \\
\hline CHEMBL 3692463 & 1528225 & 8.699 & 8.1376 & TRN & \\
\hline CHEMBL 3700183 & 1528225 & 8.6778 & 6.9432 & TRN & \\
\hline CHEMBL 3931913 & 1528225 & 7.585 & 7.0678 & TRN & \\
\hline CHEMBL3692404 & 1528225 & 7.6383 & 6.3986 & TRN & \\
\hline CHEMBL 3696703 & 1528225 & 9.1487 & 8.4511 & TST & \\
\hline CHEMBL3696524 & 1528225 & 9.1675 & 8.6752 & TST & \\
\hline CHEMBL 3692471 & 1528225 & 8.301 & 8.359 & TRN & \\
\hline CHEMBL 3700276 & 1528225 & 6.0 & 6.0462 & TRN & \\
\hline CHEMBL3969692 & 1528225 & 8.3279 & 8.8858 & TST & \\
\hline CHEMBL 3696604 & 1528225 & 8.3468 & 8.4134 & TRN & \\
\hline CHEMBL3692469 & 1528225 & 7.6576 & 7.1236 & TRN & \\
\hline CHEMBL 3696602 & 1528225 & 8.2218 & 8.7652 & TRN & \\
\hline CHEMBL 3692437 & 1528225 & 6.9626 & 7.1002 & TRN & \\
\hline CHEMBL3692491 & 1528225 & 8.0 & 8.594 & TRN & \\
\hline CHEMBL 3696641 & 1528225 & 6.0 & 7.0291 & TST & \\
\hline CHEMBL3696636 & 1528225 & \multicolumn{3}{|c|}{8.283999999999999} & TRN \\
\hline CHEMBL 3928898 & 1528225 & 6.0 & 7.7086 & TST & \\
\hline CHEMBL 3696608 & 1528225 & 6.0 & 7.5683 & TRN & \\
\hline CHEMBL3692436 & 1528225 & 6.8013 & 7.052000 & 0000000005 & TRN \\
\hline CHEMBL 3931084 & 1528225 & 6.0 & 6.2639 & TRN & \\
\hline CHEMBL3700272 & 1528225 & 9.699 & 7.8189 & TRN & \\
\hline CHEMBL 3696611 & 1528225 & 7.7959 & 7.0813 & TRN & \\
\hline CHEMBL 3692359 & 1528225 & 6.4962 & 6.3477 & TRN & \\
\hline CHEMBL 3927132 & 1528225 & 8.9586 & 7.8725 & TST & \\
\hline CHEMBL3980316 & 1528225 & 8.0969 & 8.7435 & TRN & \\
\hline CHEMBL3696534 & 1528225 & 6.0 & 8.2865 & TRN & \\
\hline CHEMBL 3696542 & 1528225 & 7.2518 & 7.4948 & TRN & \\
\hline CHEMBL3961128 & 1528225 & 8.9208 & 8.4781 & TRN & \\
\hline CHEMBL 3696553 & 1528225 & 9.301 & 7.9392 & TRN & \\
\hline CHEMBL 3895454 & 1528225 & 6.0 & 8.468 & TRN & \\
\hline CHEMBL3700302 & 1528225 & 9.0862 & 8.0635 & TRN & \\
\hline CHEMBL 3692543 & 1528225 & 8.1135 & 6.9189 & TRN & \\
\hline CHEMBL 3914831 & 1528225 & 7.3768 & 8.4617 & TST & \\
\hline CHEMBL 3696565 & 1528225 & 8.6576 & 8.6693 & TRN & \\
\hline CHEMBL 3692565 & 1528225 & 6.9208 & 7.1738 & TRN & \\
\hline CHEMBL3692402 & 1528225 & 6.6737 & 7.7383 & TST & \\
\hline CHEMBL 3696609 & 1528225 & 7.6576 & 8.2274 & TRN & \\
\hline CHEMBL 3696699 & 1528225 & 9.5229 & 7.6205 & TST & \\
\hline CHEMBL 3692413 & 1528225 & 8.2218 & 7.5747 & TRN & \\
\hline CHEMBL3919415 & 1528225 & 6.0 & 6.8089 & TST & \\
\hline
\end{tabular}


Supplemental Table S2.txt

\begin{tabular}{|c|c|c|c|c|c|}
\hline CHEMBL3986417 & 1528225 & 6.0 & 7.0826 & TST & \\
\hline CHEMBL3696638 & 1528225 & 5.8539 & 6.1571 & TRN & \\
\hline CHEMBL3692370 & 1528225 & 6.0706 & 6.6383 & TRN & \\
\hline CHEMBL3692479 & 1528225 & 6.1972 & 7.3025 & TST & \\
\hline CHEMBL 3639990 & 1528225 & 6.0 & 7.3574 & TST & \\
\hline CHEMBL3696535 & 1528225 & 6.0 & 6.9859 & TST & \\
\hline CHEMBL3692435 & 1528225 & 8.0969 & 7.4045 & TRN & \\
\hline CHEMBL3987096 & 1528225 & 6.0 & 6.805 & TST & \\
\hline CHEMBL3692530 & 1528225 & 6.0 & 8.3251 & TRN & \\
\hline CHEMBL3692431 & 1528225 & 5.9208 & 6.3659 & TST & \\
\hline CHEMBL3692386 & 1528225 & 4.301 & 7.3767 & TST & \\
\hline CHEMBL3692483 & 1528225 & 7.0809 & 6.9183 & TRN & \\
\hline CHEMBL3903545 & 1528225 & 6.0 & 7.0474 & TRN & \\
\hline CHEMBL3692464 & 1528225 & 7.6383 & 8.2185 & TRN & \\
\hline CHEMBL3925510 & 1528225 & 8.5229 & 8.5589 & TRN & \\
\hline CHEMBL3696644 & 1528225 & 6.9208 & 6.9809 & TRN & \\
\hline CHEMBL3692439 & 1528225 & 9.3979 & 7.4355 & TRN & \\
\hline CHEMBL3692405 & 1528225 & 5.699 & 7.1682 & TRN & \\
\hline CHEMBL3692505 & 1528225 & 5.4089 & 7.119 & TRN & \\
\hline CHEMBL3913086 & 1528225 & 8.7212 & 8.2006 & TRN & \\
\hline CHEMBL3927889 & 1528225 & 6.0 & 5.9526 & TRN & \\
\hline CHEMBL3904058 & 1528225 & 6.0 & 7.4945 & TRN & \\
\hline CHEMBL3895628 & 1528225 & 8.5229 & 8.2981 & TRN & \\
\hline CHEMBL3692373 & 1528225 & 7.6021 & 6.4822 & TRN & \\
\hline CHEMBL3692492 & 1528225 & 8.699 & 8.6928 & TRN & \\
\hline CHEMBL3696637 & 1528225 & 6.0 & 7.0187 & TRN & \\
\hline CHEMBL3911003 & 1528225 & 8.1549 & 7.9856 & TRN & \\
\hline CHEMBL3700293 & 1528225 & 6.1024 & 7.3663 & TST & \\
\hline CHEMBL3696603 & 1528225 & 8.2147 & 8.6251 & TRN & \\
\hline CHEMBL3696652 & 1528225 & 9.699 & 10.0979 & TRN & \\
\hline CHEMBL3696696 & 1528225 & 7.7696 & 7.08899 & 99999999995 & TRN \\
\hline CHEMBL3692508 & 1528225 & 8.5376 & 8.4508 & TRN & \\
\hline CHEMBL3696569 & 1528225 & 8.3979 & 6.79899 & 99999999995 & TST \\
\hline CHEMBL3899915 & 1528225 & 7.585 & 7.7784 & TRN & \\
\hline CHEMBL3700318 & 1528225 & 6.0 & 7.71899 & 9999999999 & TST \\
\hline CHEMBL3700329 & 1528225 & 9.3979 & 7.0384 & TRN & \\
\hline CHEMBL3696541 & 1528225 & 8.2441 & 9.02799 & 9999999999 & TRN \\
\hline CHEMBL3700227 & 1528225 & 6.0 & 5.3755 & TRN & \\
\hline CHEMBL3700267 & 1528225 & 6.0 & 7.3421 & TST & \\
\hline CHEMBL3700286 & 1528225 & 6.0 & 7.2508 & TRN & \\
\hline CHEMBL3696592 & 1528225 & 9.0 & 7.0195 & TRN & \\
\hline CHEMBL3696646 & 1528225 & 6.0 & 6.3108 & TRN & \\
\hline CHEMBL3982685 & 1528225 & 8.8861 & 8.6977 & TRN & \\
\hline CHEMBL3692557 & 1528225 & 9.1135 & 8.7209 & TST & \\
\hline CHEMBL3700269 & 1528225 & 6.0 & 7.665 & TRN & \\
\hline CHEMBL 3692441 & 1528225 & 7.4318 & 7.2591 & TRN & \\
\hline CHEMBL3905404 & 1528225 & 9.2218 & 8.7585 & TRN & \\
\hline CHEMBL 3692410 & 1528225 & 7.7447 & 7.0775 & TRN & \\
\hline
\end{tabular}




\begin{tabular}{|c|c|c|c|c|}
\hline \multicolumn{5}{|c|}{ Supplemental Table S2.txt } \\
\hline CHEMBL3916548 & 1528225 & 6.0 & 6.4636 & TRN \\
\hline CHEMBL3943879 & 1528225 & 6.0 & 6.7559 & TST \\
\hline CHEMBL3912653 & 1528225 & 8.4815 & 8.2236 & TRN \\
\hline CHEMBL3934616 & 1528225 & 9.5086 & 8.5727 & TRN \\
\hline CHEMBL3700331 & 1528225 & 5.699 & 6.26 & TRN \\
\hline CHEMBL3692362 & 1528225 & 7.4685 & 6.517 & TRN \\
\hline CHEMBL3692531 & 1528225 & 7.4437 & 7.9627 & TRN \\
\hline CHEMBL 3692513 & 1528225 & 7.5686 & 8.2497 & TRN \\
\hline CHEMBL 3692485 & 1528225 & 8.3979 & 6.7666 & TRN \\
\hline CHEMBL3696532 & 1528225 & 7.585 & 7.0486 & TRN \\
\hline CHEMBL 3692504 & 1528225 & 7.6778 & 7.5933 & TRN \\
\hline CHEMBL3696705 & 1528225 & 9.301 & 8.3971 & TRN \\
\hline CHEMBL 3692477 & 1528225 & 8.5229 & 7.266 & TRN \\
\hline CHEMBL3696667 & 1528225 & 7.699 & 8.1104 & TRN \\
\hline CHEMBL 3692395 & 1528225 & 9.699 & 9.5979 & TRN \\
\hline CHEMBL 3692498 & 1528225 & 7.7212 & 6.4704 & TRN \\
\hline CHEMBL3696665 & 1528225 & 7.0315 & 6.7386 & TRN \\
\hline CHEMBL 3949046 & 1528225 & 8.8962 & 8.729 & TST \\
\hline CHEMBL 3968053 & 1528225 & 8.7447 & 8.0096 & TST \\
\hline CHEMBL 3696546 & 1528225 & 7.3665 & 6.1146 & TRN \\
\hline CHEMBL 3692500 & 1528225 & 7.8539 & 7.7163 & TRN \\
\hline CHEMBL3692527 & 1528225 & 8.0132 & 7.9263 & TRN \\
\hline CHEMBL3696697 & 1528225 & 6.0 & 7.3257 & TST \\
\hline CHEMBL 3692434 & 1528225 & 8.301 & 7.5203 & TRN \\
\hline CHEMBL 3692360 & 1528225 & 7.4815 & 8.2838 & TRN \\
\hline CHEMBL3692361 & 1528225 & 8.3979 & 9.6696 & TRN \\
\hline CHEMBL3966470 & 1528225 & 8.8861 & 8.6371 & TRN \\
\hline CHEMBL 3890849 & 1528225 & 8.9586 & 8.9643 & TRN \\
\hline CHEMBL 3692412 & 1528225 & 5.4437 & 7.9962 & TST \\
\hline CHEMBL3696595 & 1528225 & 6.0223 & 6.7339 & TRN \\
\hline CHEMBL 3696564 & 1528225 & 7.6198 & 8.4701 & TRN \\
\hline CHEMBL3696529 & 1528225 & 7.5686 & 7.4986 & TRN \\
\hline CHEMBL3692427 & 1528225 & 5.9586 & 6.9249 & TRN \\
\hline CHEMBL 3692560 & 1528225 & 7.7447 & 8.5923 & TRN \\
\hline CHEMBL3692503 & 1528225 & 8.2924 & 7.8699 & TST \\
\hline CHEMBL3700324 & 1528225 & 8.4815 & 7.4029 & TRN \\
\hline CHEMBL3692538 & 1528225 & 6.7212 & 7.4563 & TRN \\
\hline CHEMBL3696591 & 1528225 & 8.3372 & 8.204 & TST \\
\hline CHEMBL 3692398 & 1528225 & 6.3947 & 6.0154 & TRN \\
\hline CHEMBL3929878 & 1528225 & 9.0 & 8.0587 & TRN \\
\hline CHEMBL3700316 & 1528225 & 6.0 & 7.2933 & TST \\
\hline CHEMBL 3696664 & 1528225 & 6.3279 & 7.3356 & TRN \\
\hline CHEMBL3692539 & 1528225 & 8.6198 & 8.0356 & TRN \\
\hline CHEMBL 3692467 & 1528225 & 7.699 & 7.6271 & TRN \\
\hline CHEMBL 3700230 & 1528225 & 8.585 & 7.3963 & TRN \\
\hline CHEMBL3956499 & 1528225 & 6.0 & 7.6241 & TST \\
\hline CHEMBL3983289 & 1528225 & 8.6778 & 8.5841 & TRN \\
\hline CHEMBL3920653 & 1528225 & 6.0 & 5.7766 & TRN \\
\hline
\end{tabular}


Supplemental Table S2.txt

\begin{tabular}{|c|c|c|c|c|c|}
\hline CHEMBL3692409 & 1528225 & 7.6198 & 6.9101 & TRN & \\
\hline CHEMBL412582 & 34106 & 7.3188 & 5.32 & TST & \\
\hline CHEMBL304785 & 34106 & 4.9586 & 4.9419 & TRN & \\
\hline CHEMBL67054 & 34106 & 5.9586 & 5.4197 & TRN & \\
\hline CHEMBL69677 & 34106 & 5.7447 & 5.3921 & TRN & \\
\hline CHEMBL69714 & 34106 & 3.0 & 4.522 & TRN & \\
\hline CHEMBL69991 & 34106 & 5.9586 & 5.4275 & TRN & \\
\hline CHEMBL70061 & 34106 & 5.1938 & 4.7682 & TRN & \\
\hline CHEMBL69849 & 34106 & 3.0 & 3.8525 & TRN & \\
\hline CHEMBL69969 & 34106 & 6.699 & 4.8843 & TRN & \\
\hline CHEMBL68946 & 34106 & 4.8239 & 5.8048 & TRN & \\
\hline CHEMBL69564 & 34106 & 5.8539 & 5.4372 & TRN & \\
\hline CHEMBL443008 & 34106 & 4.3665 & 4.2086 & TRN & \\
\hline CHEMBL68428 & 34106 & 5.8539 & 5.0527 & TRN & \\
\hline CHEMBL412452 & 34106 & 5.9208 & 5.5249 & TRN & \\
\hline CHEMBL303871 & 34106 & 3.0 & \multicolumn{2}{|c|}{5.422000000000001} & TRN \\
\hline CHEMBL69096 & 34106 & 4.4089 & 4.9144 & TRN & \\
\hline CHEMBL 70068 & 34106 & 5.2366 & 5.1048 & TRN & \\
\hline CHEMBL305175 & 34106 & 6.301 & 4.7107 & TRN & \\
\hline CHEMBL 304838 & 34106 & 5.7696 & 5.4239 & TRN & \\
\hline CHEMBL305296 & 34106 & 6.6383 & 5.0022 & TST & \\
\hline CHEMBL431187 & 34106 & 6.1367 & 5.7292 & TRN & \\
\hline CHEMBL69553 & 34106 & 4.4318 & 4.5936 & TRN & \\
\hline CHEMBL304729 & 34106 & 5.4202 & 5.7189 & TRN & \\
\hline CHEMBL 308215 & 34106 & 5.699 & 5.431 & TRN & \\
\hline CHEMBL305066 & 34106 & 5.6198 & 5.7028 & TRN & \\
\hline CHEMBL302046 & 34106 & 4.3768 & 3.5758 & TRN & \\
\hline CHEMBL442366 & 34106 & 4.2007 & 4.1717 & TRN & \\
\hline CHEMBL 305800 & 34106 & 5.3979 & 4.3356 & TRN & \\
\hline CHEMBL439755 & 34106 & 5.4318 & 4.795 & TRN & \\
\hline CHEMBL304154 & 34106 & 4.3565 & 5.2681 & TRN & \\
\hline CHEMBL68915 & 34106 & 3.0 & 2.7754 & TRN & \\
\hline CHEMBL303908 & 34106 & 4.1367 & 4.4355 & TRN & \\
\hline CHEMBL69611 & 34106 & 4.699 & 5.0092 & TRN & \\
\hline CHEMBL69009 & 34106 & 5.0969 & 5.4322 & TRN & \\
\hline CHEMBL303431 & 34106 & 3.0 & 4.2207 & TRN & \\
\hline CHEMBL67393 & 34106 & 4.284 & 4.4045 & TRN & \\
\hline CHEMBL 71757 & 34106 & 3.0 & 4.3013 & TST & \\
\hline CHEMBL68585 & 34106 & 5.8539 & 5.5851 & TRN & \\
\hline CHEMBL 67334 & 34106 & 3.0 & 3.4805 & TRN & \\
\hline CHEMBL68431 & 34106 & 4.5229 & 4.1112 & TST & \\
\hline CHEMBL 68162 & 34106 & 3.0 & 3.3321 & TRN & \\
\hline CHEMBL66504 & 34106 & 5.0706 & 5.4516 & TRN & \\
\hline CHEMBL68637 & 34106 & 3.0 & 4.7973 & TST & \\
\hline CHEMBL65936 & 34106 & 5.4318 & 5.0365 & TST & \\
\hline CHEMBL273334 & 34106 & 5.0969 & 5.4014 & TST & \\
\hline CHEMBL67947 & 34106 & 5.1549 & 5.2346 & TST & \\
\hline CHEMBL 304544 & 34106 & 3.0 & 3.9308 & TST & \\
\hline
\end{tabular}




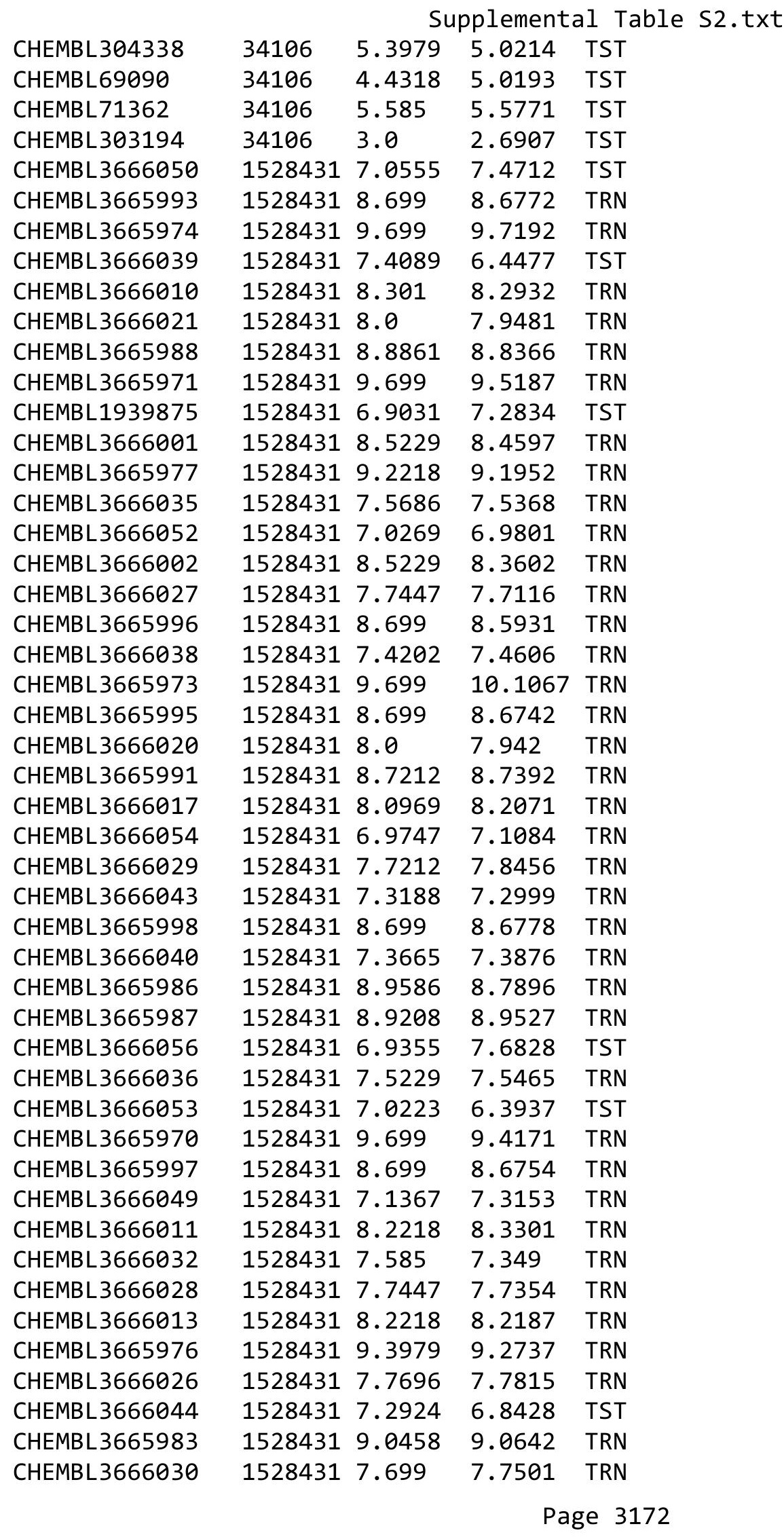


Supplemental Table S2.txt

\begin{tabular}{|c|c|c|c|c|}
\hline W & 528431 & & & \\
\hline & & 7.585 & 7.409 & \\
\hline & & & & \\
\hline IEMBL & & 284 & & \\
\hline AEMBL & 528431 & 3861 & & \\
\hline HEMBL3666016 & 528431 & 8.1549 & 8002 & \\
\hline 241 & 31 & 565 & & \\
\hline 047 & & & & \\
\hline HEMBL & 528431 & 9.2218 & & \\
\hline HEMBL3666006 & 528431 & 8.3979 & 4277 & \\
\hline AEMBL3666018 & 528431 & 8.0 & & \\
\hline IEMBL] & 51 & 229 & 178 & \\
\hline IEMBL: & & & & \\
\hline HEMBL3 & 528431 & 223 & 9.0889 & \\
\hline AEMBL3 & 31 & 69 & & \\
\hline AEMBL3 & $\angle 0$ & 49 & 19 & \\
\hline HEMBLI & 31 & 997 & & \\
\hline HEMBL & 31 & & & \\
\hline AEMBL3 & 31 & 458 & 93 & \\
\hline AEMBL & & 8. & & \\
\hline HEMBL & 528 & 8 & 45 & Niv \\
\hline AEMBL & 1 & 2 & & וזנה \\
\hline AEMBL & 31 & 58 & & \\
\hline 6003 & & 8 . & & \\
\hline AEMBL3 & & & & I RIV \\
\hline HEMBL; & 52 & 8 . & & | \\
\hline AEMBL & 1 & & & RN \\
\hline HFMRI & 31 & 69 & & \\
\hline AEMBL3 & & & & I \\
\hline HEMBL3666009 & - & & & IK \\
\hline HEMBL3 & 31 & & & RN \\
\hline HEMB & 1 & & & ST \\
\hline 14 & 31 & 18 & 37 & Pח \\
\hline HEMBL3 & & 8. & & 15 \\
\hline HEMBL1939874 & 528 & 7.0132 & 27 & TST \\
\hline HEMBL & 52 & & 82 & TRN \\
\hline HCMPI & 31 & 8 & & $\Gamma \mathrm{RN}$ \\
\hline HEMBL & & & 746 & IST \\
\hline HEMBL3666037 & 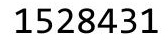 & 59 & 6725 & TST \\
\hline EMBL & 52 & 39 & 782 & IRN \\
\hline HEMBL3 & - & 39 & 3374 & RN \\
\hline HEMBL3 & & & 8.2623 & TRN \\
\hline HEMBL3 & 31 & 7.8539 & 784 & RN \\
\hline AEMBL3665981 & 528 & 9.0969 & 2377 & TR \\
\hline 022 & $=0$ & & & IRN \\
\hline HEMBL3 & & (5) & 9867 & \\
\hline CHEMBL 3666048 & 528 & .1938 & 7.099 & \\
\hline HEMBL3666031 & 1528431 & 7.6198 & 7.8361 & ГST \\
\hline
\end{tabular}

Page 3173 
Supplemental Table S2.txt

\begin{tabular}{|c|c|c|c|c|c|}
\hline CHEMBL3665999 & 1528431 & 8.5229 & 8.5489 & TST & \\
\hline CHEMBL3665972 & 1528431 & 9.699 & 8.9021 & TST & \\
\hline CHEMBL3716160 & 1536719 & 8.7212 & 9.0937 & TRN & \\
\hline CHEMBL 3715600 & 1536719 & 8.4437 & 7.8989 & TRN & \\
\hline CHEMBL3714842 & 1536719 & 7.6198 & 7.9456 & TRN & \\
\hline CHEMBL3715685 & 1536719 & 7.5528 & 6.8919 & TRN & \\
\hline CHEMBL3714991 & 1536719 & 5.6273 & 5.9471 & TRN & \\
\hline CHEMBL3715516 & 1536719 & 8.7959 & 8.4715 & TRN & \\
\hline CHEMBL3716687 & 1536719 & 4.5229 & 3.9585 & TRN & \\
\hline CHEMBL3718695 & 1536719 & 4.5229 & 6.3589 & TRN & \\
\hline CHEMBL3717956 & 1536719 & 8.7959 & 8.5198 & TRN & \\
\hline CHEMBL3716372 & 1536719 & 7.585 & 7.7039 & TRN & \\
\hline CHEMBL3718626 & 1536719 & 7.5528 & 7.8693 & TRN & \\
\hline CHEMBL3718639 & 1536719 & 7.5528 & 7.3065 & TST & \\
\hline CHEMBL3717885 & 1536719 & 8.7212 & 7.6004 & TST & \\
\hline CHEMBL3718893 & 1536719 & 4.5229 & 4.8031 & TRN & \\
\hline CHEMBL3716726 & 1536719 & 8.1192 & 7.8554 & TRN & \\
\hline CHEMBL3718707 & 1536719 & 7.5686 & \multicolumn{2}{|c|}{7.867000000000001} & TRN \\
\hline CHEMBL3717633 & 1536719 & 4.5229 & 5.9667 & TST & \\
\hline CHEMBL3719223 & 1536719 & 7.5686 & 7.9124 & TRN & \\
\hline CHEMBL3717970 & 1536719 & 4.5229 & 4.8845 & TST & \\
\hline CHEMBL 3718360 & 1536719 & 8.7212 & 8.3676 & TRN & \\
\hline CHEMBL3717529 & 1536719 & 5.5042 & 5.5803 & TST & \\
\hline CHEMBL3715367 & 1536719 & 9.0269 & 9.0917 & TRN & \\
\hline CHEMBL 3716644 & 1536719 & 7.6021 & 7.81 & TRN & \\
\hline CHEMBL3716173 & 1536719 & 4.5229 & 4.5794 & TRN & \\
\hline CHEMBL3715728 & 1536719 & 5.5686 & 4.9934 & TRN & \\
\hline CHEMBL 3716623 & 1536719 & 7.6021 & 7.7464 & TRN & \\
\hline CHEMBL3715025 & 1536719 & 8.699 & 8.9132 & TRN & \\
\hline CHEMBL3715312 & 1536719 & 4.5229 & 4.2588 & TRN & \\
\hline CHEMBL3715042 & 1536719 & 4.5229 & 4.752 & TRN & \\
\hline CHEMBL 3718248 & 1536719 & 4.5229 & 4.2682 & TRN & \\
\hline CHEMBL 3716027 & 1536719 & 4.5229 & 5.0965 & TRN & \\
\hline CHEMBL3716904 & 1536719 & 8.7212 & 8.2251 & TRN & \\
\hline CHEMBL3718433 & 1536719 & 8.6778 & 8.7827 & TRN & \\
\hline CHEMBL3716524 & 1536719 & 4.5229 & 5.0205 & TST & \\
\hline CHEMBL 3717972 & 1536719 & 7.5686 & 7.5604 & TRN & \\
\hline CHEMBL3715374 & 1536719 & 4.5229 & 5.3344 & TST & \\
\hline CHEMBL3718657 & 1536719 & 7.3098 & 7.0462 & TRN & \\
\hline CHEMBL3717199 & 1536719 & 4.5229 & 3.9393 & TST & \\
\hline CHEMBL3718382 & 1536719 & 6.8069 & 6.4969 & TST & \\
\hline CHEMBL3715336 & 1536719 & 4.5229 & 3.4465 & TST & \\
\hline CHEMBL3717259 & 1536719 & 7.6383 & 7.1728 & TRN & \\
\hline CHEMBL 3715848 & 1536719 & 8.3279 & 7.5134 & TRN & \\
\hline CHEMBL3716037 & 1536719 & 4.5229 & 4.9729 & TST & \\
\hline CHEMBL3718927 & 1536719 & 8.2441 & 7.777 & TRN & \\
\hline CHEMBL3716552 & 1536719 & 8.6778 & 8.9988 & TRN & \\
\hline CHEMBL3716197 & 1536719 & 7.6198 & 7.2436 & TRN & \\
\hline
\end{tabular}


Supplemental Table S2.txt

\begin{tabular}{|c|c|c|c|c|c|}
\hline CHEMBL3719253 & 1536719 & 8.699 & 8.4614 & TRN & \\
\hline CHEMBL3719133 & 1536719 & 4.5229 & 4.6459 & TRN & \\
\hline CHEMBL3717746 & 1536719 & 9.0177 & 9.021 & TRN & \\
\hline CHEMBL3718733 & 1536719 & 4.5229 & 3.3664 & TST & \\
\hline CHEMBL3715391 & 1536719 & 7.5376 & 7.8936 & TRN & \\
\hline CHEMBL3715692 & 1536719 & 5.6312 & 5.8846 & TST & \\
\hline CHEMBL3716230 & 1536719 & 7.6383 & 7.8682 & TRN & \\
\hline CHEMBL3718116 & 1536719 & 5.6916 & 6.0262 & TRN & \\
\hline CHEMBL3719256 & 1536719 & 9.0 & 8.9803 & TRN & \\
\hline CHEMBL3717527 & 1536719 & 4.5229 & 4.6407 & TST & \\
\hline CHEMBL 3716754 & 1536719 & 7.6383 & 7.3532 & TST & \\
\hline CHEMBL3715578 & 1536719 & 7.4202 & 7.4089 & TRN & \\
\hline CHEMBL 3718490 & 1536719 & 7.585 & 7.8144 & TRN & \\
\hline CHEMBL3715686 & 1536719 & 5.6231 & 4.797 & TST & \\
\hline CHEMBL3719385 & 1536719 & 4.5229 & 4.9104 & TST & \\
\hline CHEMBL3717789 & 1536719 & 5.6338 & 5.6308 & TRN & \\
\hline CHEMBL3719018 & 1536719 & 4.5229 & 4.5487 & TRN & \\
\hline CHEMBL3719060 & 1536719 & 8.699 & 8.3066 & TRN & \\
\hline CHEMBL3716096 & 1536719 & 8.9208 & 8.9676 & TRN & \\
\hline CHEMBL3714941 & 1536719 & 8.6576 & 8.8174 & TRN & \\
\hline CHEMBL307232 & 155185 & 5.5376 & 5.5368 & TRN & \\
\hline CHEMBL305617 & 155185 & 7.585 & 6.8444 & TST & \\
\hline CHEMBL409425 & 155185 & 6.2518 & 6.2516 & TRN & \\
\hline CHEMBL304161 & 155185 & 7.9586 & 7.9722 & TRN & \\
\hline CHEMBL431377 & 155185 & 6.699 & 6.6851 & TRN & \\
\hline CHEMBL422235 & 155185 & 5.4815 & 5.4818 & TRN & \\
\hline CHEMBL68706 & 155185 & 5.3468 & 5.3468 & TRN & \\
\hline CHEMBL278644 & 155185 & 5.6198 & 5.6199 & TRN & \\
\hline CHEMBL306426 & 155185 & 5.9208 & 5.9246 & TRN & \\
\hline CHEMBL303154 & 155185 & 7.3665 & 7.3819 & TRN & \\
\hline CHEMBL 71768 & 155185 & 6.6478 & 6.6467 & TRN & \\
\hline CHEMBL307639 & 155185 & 5.0 & 5.5937 & TST & \\
\hline CHEMBL419447 & 155185 & 6.6198 & 6.6155 & TRN & \\
\hline CHEMBL70569 & 155185 & 8.3979 & 5.3989 & TST & \\
\hline CHEMBL308828 & 155185 & 7.7212 & 7.7125 & TRN & \\
\hline CHEMBL305618 & 155185 & 8.3979 & 8.3974 & TRN & \\
\hline CHEMBL 71204 & 155185 & 6.9208 & 6.9359 & TRN & \\
\hline CHEMBL18744 & 155185 & 7.301 & 6.3351 & TST & \\
\hline CHEMBL430802 & 155185 & 6.5607 & 6.57 & TRN & \\
\hline CHEMBL 70951 & 155185 & 4.585 & 4.58899 & 99999999995 & TRN \\
\hline CHEMBL18745 & 155185 & 8.0 & 6.0803 & TST & \\
\hline CHEMBL308747 & 155185 & 4.7959 & 4.7937 & TRN & \\
\hline CHEMBL305237 & 155185 & 6.7447 & 6.7439 & TRN & \\
\hline CHEMBL69324 & 155185 & 5.2518 & 5.2476 & TRN & \\
\hline CHEMBL303385 & 155185 & 6.0969 & 6.0975 & TRN & \\
\hline CHEMBL308199 & 155185 & 6.0 & 6.0003 & TRN & \\
\hline CHEMBL308249 & 155185 & 6.5157 & 6.5104 & TRN & \\
\hline CHEMBL303010 & 155185 & 5.3979 & 5.3917 & TRN & \\
\hline
\end{tabular}




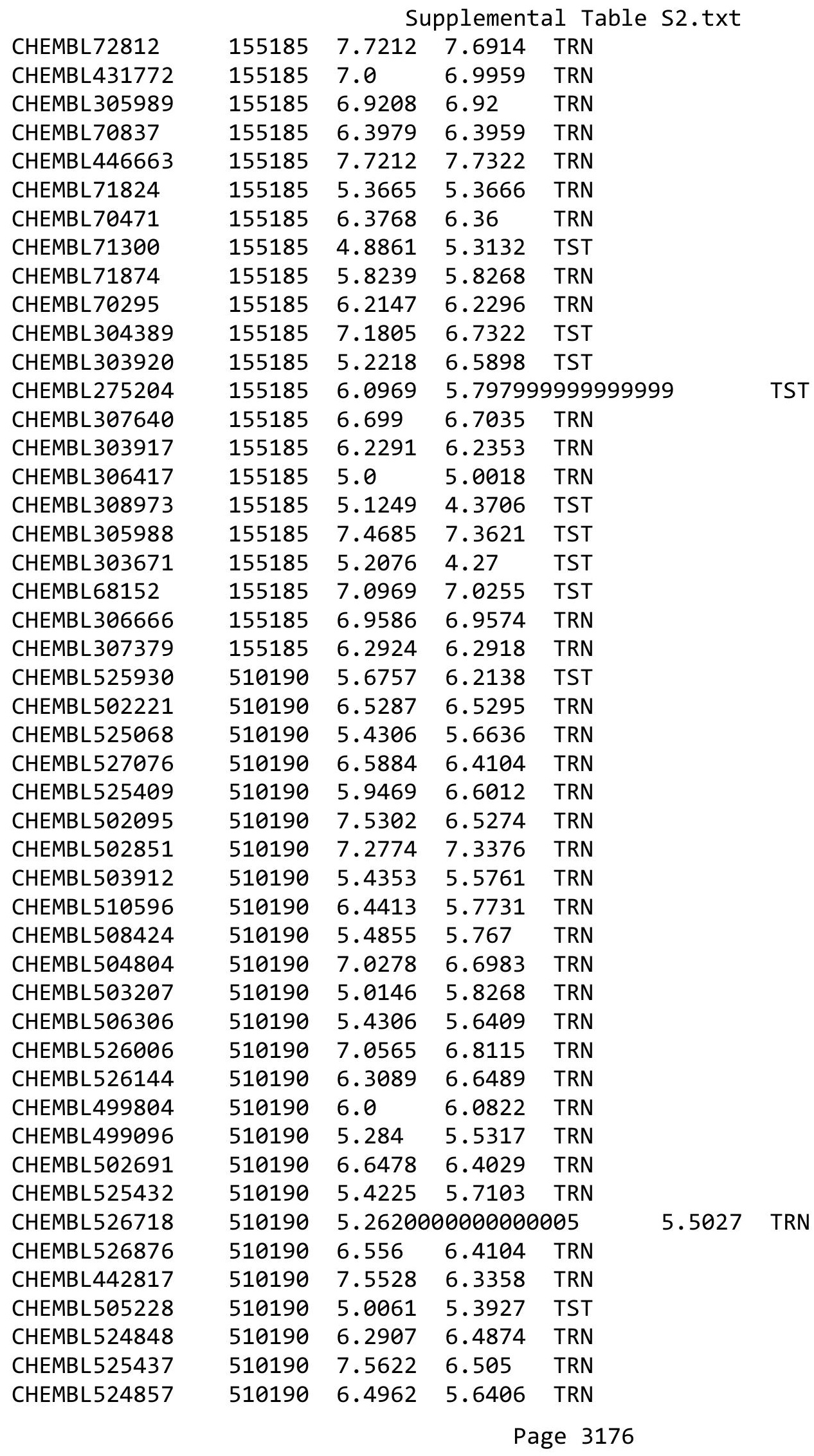




\begin{tabular}{|c|c|c|c|c|c|}
\hline & & \\
\hline CHEMBL503485 & 510190 & 5.7122 & 5.8228 & TRN & \\
\hline CHEMBL445007 & 510190 & 6.4776 & 6.311 & TRN & \\
\hline CHEMBL500793 & 510190 & 6.75700 & 00000000 & 6.4104 & TRN \\
\hline CHEMBL526159 & 510190 & 6.9245 & 6.9532 & TST & \\
\hline CHEMBL508154 & 510190 & 7.0137 & 6.8622 & TST & \\
\hline CHEMBL527047 & 510190 & 5.7773 & 5.768 & TRN & \\
\hline CHEMBL502573 & 510190 & 6.6073 & 5.8399 & TRN & \\
\hline CHEMBL506820 & 510190 & 5.6615 & 6.5836 & TST & \\
\hline CHEMBL526878 & 510190 & 5.27 & 5.7438 & TRN & \\
\hline CHEMBL526129 & 510190 & 5.0061 & $5.46200 t$ & 0000000001 & TST \\
\hline CHEMBL501519 & 510190 & 6.5918 & 6.3693 & TRN & \\
\hline CHEMBL525450 & 510190 & 6.8729 & 6.6372 & TRN & \\
\hline CHEMBL507277 & 510190 & 5.7258 & 5.7434 & TRN & \\
\hline CHEMBL507118 & 510190 & 6.6234 & 7.108 & TRN & \\
\hline CHEMBL526184 & 510190 & 4.295 & 6.3484 & TRN & \\
\hline CHEMBL446909 & 510190 & 7.4365 & 6.3201 & TRN & \\
\hline CHEMBL500259 & 510190 & 6.4157 & 6.0063 & TST & \\
\hline CHEMBL451621 & 510190 & 6.5143 & 6.3143 & TRN & \\
\hline CHEMBL500622 & 510190 & 5.4449 & 6.0142 & TRN & \\
\hline CHEMBL526490 & 510190 & 5.7595 & 6.1533 & TRN & \\
\hline CHEMBL508595 & 510190 & 6.6799 & 6.4626 & TRN & \\
\hline CHEMBL500011 & 510190 & 6.6289 & 6.2525 & TRN & \\
\hline CHEMBL451315 & 510190 & 6.5768 & 6.4104 & TRN & \\
\hline CHEMBL502191 & 510190 & 6.2782 & 5.8774 & TST & \\
\hline CHEMBL506104 & 510190 & 6.4685 & 6.8607 & TRN & \\
\hline CHEMBL507091 & 510190 & 6.3152 & 5.83899 & 99999999995 & TRN \\
\hline CHEMBL510043 & 510190 & 6.5467 & 6.3774 & TRN & \\
\hline CHEMBL509567 & 510190 & 6.5421 & 6.6141 & TRN & \\
\hline CHEMBL501008 & 510190 & 6.341 & 5.7296 & TRN & \\
\hline CHEMBL448982 & 510190 & 6.5287 & 6.2558 & TRN & \\
\hline CHEMBL500358 & 510190 & 6.4056 & 5.9841 & TRN & \\
\hline CHEMBL504270 & 510190 & 6.8297 & 7.2446 & TRN & \\
\hline CHEMBL527044 & 510190 & 6.5376 & 6.1349 & TRN & \\
\hline CHEMBL500102 & 510190 & 5.4145 & 6.0572 & TRN & \\
\hline CHEMBL453948 & 510190 & 5.9066 & 6.291 & TRN & \\
\hline CHEMBL502360 & 510190 & 5.8327 & 6.0574 & TRN & \\
\hline CHEMBL526853 & 510190 & 5.6635 & 5.9424 & TRN & \\
\hline CHEMBL503286 & 510190 & 5.4724 & 6.2207 & TRN & \\
\hline CHEMBL525787 & 510190 & 5.8539 & 6.4893 & TRN & \\
\hline CHEMBL510064 & 510190 & 5.7328 & 5.7426 & TRN & \\
\hline CHEMBL499657 & 510190 & 6.5986 & 6.4441 & TRN & \\
\hline CHEMBL526486 & 510190 & 5.7496 & 6.1683 & TST & \\
\hline CHEMBL525430 & 510190 & 5.6144 & 5.7569 & TRN & \\
\hline CHEMBL509654 & 510190 & 6.5317 & 6.311 & TRN & \\
\hline CHEMBL525024 & 510190 & 5.5498 & 5.8101 & TRN & \\
\hline CHEMBL455317 & 510190 & 5.7696 & 6.1693 & TRN & \\
\hline CHEMBL508546 & 510190 & 5.7399 & 5.7832 & TST & \\
\hline CHEMBL526681 & 510190 & 7.0701 & 6.7247 & TST & \\
\hline
\end{tabular}




\begin{tabular}{|c|c|c|c|c|c|}
\hline \multicolumn{6}{|c|}{ Supplemental Table S } \\
\hline CHEMBL511043 & 510190 & 6.6757 & 6.1236 & TST & \\
\hline CHEMBL506034 & 510190 & 6.4802 & 5.8101 & TST & \\
\hline CHEMBL503296 & 510190 & 6.6364 & 7.3484 & TST & \\
\hline CHEMBL455565 & 510190 & 6.4584 & 6.2283 & TST & \\
\hline CHEMBL505745 & 510190 & 6.4685 & 7.1023 & TST & \\
\hline CHEMBL508820 & 510190 & 6.5157 & 6.2294 & TST & \\
\hline CHEMBL524340 & 510190 & 7.1013 & 6.7854 & TST & \\
\hline CHEMBL499419 & 510190 & 6.4271 & 6.3676 & TST & \\
\hline CHEMBL500116 & 510190 & 5.2336 & 5.7021 & TST & \\
\hline CHEMBL501245 & 510190 & 6.0 & 6.3341 & TST & \\
\hline CHEMBL498834 & 510190 & 6.4023 & \multicolumn{2}{|c|}{5.7410000000000005} & TST \\
\hline CHEMBL201604 & 330651 & 6.8416 & 6.1935 & TRN & \\
\hline CHEMBL201435 & 330651 & 4.0 & 4.7112 & TRN & \\
\hline CHEMBL202317 & 330651 & 7.699 & 7.3962 & TRN & \\
\hline CHEMBL202319 & 330651 & 7.8861 & 6.7069 & TRN & \\
\hline CHEMBL201815 & 330651 & 6.5376 & 6.1191 & TRN & \\
\hline CHEMBL202261 & 330651 & 4.0 & 6.4352 & TRN & \\
\hline CHEMBL426302 & 330651 & 7.2076 & 6.2133 & TRN & \\
\hline CHEMBL439511 & 330651 & 6.1574 & 6.7 & TST & \\
\hline CHEMBL201456 & 330651 & 7.2757 & 5.7854 & TRN & \\
\hline CHEMBL380442 & 330651 & 6.8794 & 7.2868 & TRN & \\
\hline CHEMBL202595 & 330651 & 7.3188 & \multicolumn{2}{|c|}{6.337000000000001} & TRN \\
\hline CHEMBL377075 & 330651 & 4.0 & 5.2396 & TST & \\
\hline CHEMBL202191 & 330651 & 6.1079 & 5.8132 & TST & \\
\hline CHEMBL201385 & 330651 & 7.3098 & 7.2835 & TRN & \\
\hline CHEMBL201634 & 330651 & 4.0 & 5.6283 & TRN & \\
\hline CHEMBL201606 & 330651 & 4.0 & 4.4387 & TRN & \\
\hline CHEMBL201814 & 330651 & 7.0458 & 5.505 & TRN & \\
\hline CHEMBL203254 & 330651 & 7.3872 & \multicolumn{2}{|c|}{6.718999999999999} & TRN \\
\hline CHEMBL201558 & 330651 & 7.4815 & 7.0855 & TRN & \\
\hline CHEMBL380686 & 330651 & 7.6198 & 5.978 & TRN & \\
\hline CHEMBL201350 & 330651 & 4.0 & 6.2019 & TRN & \\
\hline CHEMBL202448 & 330651 & 4.0 & 6.5117 & TST & \\
\hline CHEMBL201600 & 330651 & 7.3279 & 6.6708 & TRN & \\
\hline CHEMBL 383418 & 330651 & 4.0 & 4.1329 & TRN & \\
\hline CHEMBL381497 & 330651 & 5.6123 & 5.8009 & TRN & \\
\hline CHEMBL201601 & 330651 & 4.0 & 6.3391 & TRN & \\
\hline CHEMBL202581 & 330651 & 6.2565 & 7.0266 & TRN & \\
\hline CHEMBL 202514 & 330651 & 6.5003 & 5.836 & TRN & \\
\hline CHEMBL 371635 & 330651 & 7.1079 & 7.1007 & TRN & \\
\hline CHEMBL 201040 & 330651 & 5.5505 & 5.2164 & TRN & \\
\hline CHEMBL 201635 & 330651 & 4.0 & 4.4466 & TRN & \\
\hline CHEMBL 202195 & 330651 & 4.0 & 5.2757 & TST & \\
\hline CHEMBL 201360 & 330651 & 4.0 & 5.4564 & TRN & \\
\hline CHEMBL 202513 & 330651 & 6.4685 & 7.2289 & TRN & \\
\hline CHEMBL 381010 & 330651 & 7.0969 & 5.065 & TRN & \\
\hline CHEMBL 201406 & 330651 & 7.3665 & 6.8568 & TRN & \\
\hline CHEMBL202326 & 330651 & 4.0 & 6.3689 & TRN & \\
\hline
\end{tabular}




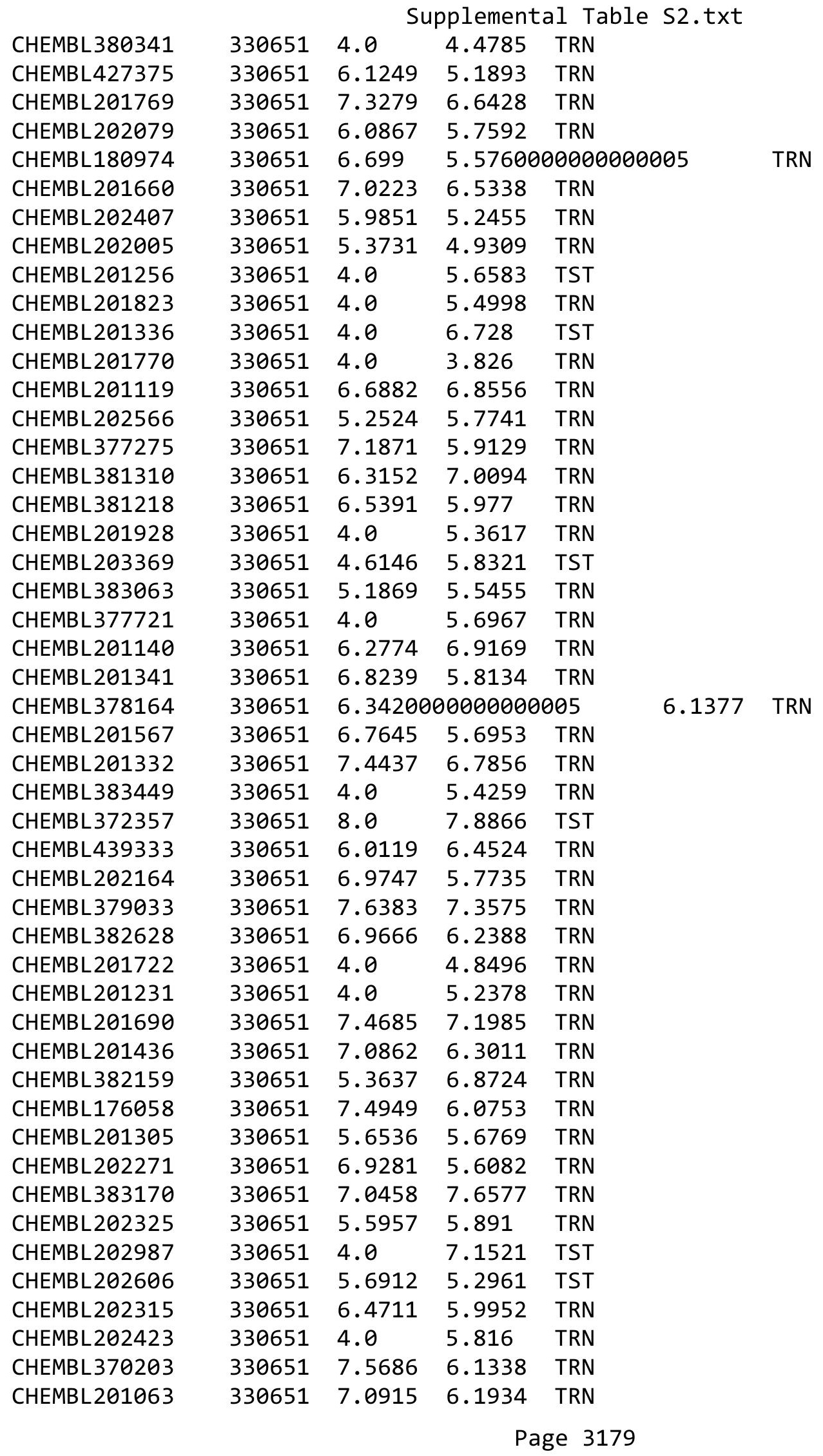




\begin{tabular}{|c|c|c|c|c|c|}
\hline \multicolumn{6}{|c|}{ Supplemental Table s2.txt } \\
\hline CHEMBL202062 & 330651 & 6.7033 & 6.5401 & TRN & \\
\hline CHEMBL425757 & 330651 & 5.7592 & 6.4658 & TRN & \\
\hline CHEMBL201088 & 330651 & 7.0862 & 5.7585 & TRN & \\
\hline CHEMBL201873 & 330651 & 6.5171 & 5.7181 & TST & \\
\hline CHEMBL201555 & 330651 & 4.0 & 5.7357 & TRN & \\
\hline CHEMBL201457 & 330651 & 4.0 & 4.5897 & TRN & \\
\hline CHEMBL 204401 & 330651 & 5.2362 & 5.2691 & TRN & \\
\hline CHEMBL201927 & 330651 & 5.8857 & 4.7526 & TRN & \\
\hline CHEMBL381699 & 330651 & 5.6341 & 5.305 & TRN & \\
\hline CHEMBL202375 & 330651 & 4.0 & 4.6832 & TRN & \\
\hline CHEMBL 200985 & 330651 & 5.5696 & 5.8607 & TRN & \\
\hline CHEMBL 202310 & 330651 & 6.9393 & 5.2994 & TST & \\
\hline CHEMBL202304 & 330651 & 4.0 & 5.944 & TST & \\
\hline CHEMBL202539 & 330651 & 6.4353 & 7.3786 & TST & \\
\hline CHEMBL202405 & 330651 & 7.6778 & 5.888 & TST & \\
\hline CHEMBL381529 & 330651 & 6.9788 & 6.8617 & TST & \\
\hline CHEMBL202587 & 330651 & 4.0 & 4.8586 & TST & \\
\hline CHEMBL 203312 & 330651 & 6.7471 & 5.36600 & 00000000005 & TST \\
\hline CHEMBL203426 & 330651 & 7.4949 & 6.796 & TST & \\
\hline CHEMBL202449 & 330651 & 4.0 & 6.0653 & TST & \\
\hline CHEMBL201912 & 330651 & 4.0 & 5.0452 & TST & \\
\hline CHEMBL201337 & 330651 & 7.2147 & 5.6761 & TST & \\
\hline CHEMBL201876 & 330651 & 5.0026 & 6.5641 & TST & \\
\hline CHEMBL202165 & 330651 & 7.3565 & 6.3848 & TST & \\
\hline CHEMBL202250 & 330651 & 5.8097 & 5.8003 & TST & \\
\hline CHEMBL 201603 & 330651 & 6.6861 & 6.5674 & TST & \\
\hline CHEMBL201034 & 330651 & 5.4034 & 6.505 & TST & \\
\hline CHEMBL425221 & 330651 & 7.6778 & 5.124 & TST & \\
\hline CHEMBL1367787 & 737056 & 2.699 & 2.79600 & 00000000003 & TRN \\
\hline CHEMBL1303641 & 737056 & 2.699 & 3.1899 & TRN & \\
\hline CHEMBL1564363 & 737056 & 4.8572 & 3.3814 & TRN & \\
\hline CHEMBL1334149 & 737056 & 5.2056 & 3.635 & TRN & \\
\hline CHEMBL1568206 & 737056 & 2.699 & 3.1281 & TRN & \\
\hline CHEMBL1344330 & 737056 & 2.699 & 2.9928 & TRN & \\
\hline CHEMBL1411702 & 737056 & 2.699 & 2.5584 & TRN & \\
\hline CHEMBL418068 & 737056 & 4.4934 & 3.7547 & TRN & \\
\hline CHEMBL1368362 & 737056 & 2.699 & 2.8817 & TRN & \\
\hline CHEMBL1585746 & 737056 & 2.699 & 3.0756 & TRN & \\
\hline CHEMBL1602055 & 737056 & 2.699 & 3.0916 & TRN & \\
\hline CHEMBL1379737 & 737056 & 2.699 & 2.5869 & TRN & \\
\hline CHEMBL1548333 & 737056 & 2.699 & 2.9827 & TRN & \\
\hline CHEMBL1343560 & 737056 & 2.699 & 2.8604 & TRN & \\
\hline CHEMBL1578893 & 737056 & 2.699 & 3.2441 & TST & \\
\hline CHEMBL3208613 & 737056 & 2.699 & 2.81699 & 99999999997 & TST \\
\hline CHEMBL1351543 & 737056 & 2.699 & 2.3847 & TRN & \\
\hline CHEMBL1304114 & 737056 & 2.699 & 2.4102 & TRN & \\
\hline CHEMBL1998038 & 737056 & 2.699 & 2.5865 & TRN & \\
\hline CHEMBL1469472 & 737056 & 2.699 & 2.7246 & TRN & \\
\hline
\end{tabular}


Supplemental Table S2.txt

\begin{tabular}{|c|c|c|c|c|}
\hline AEMBL1420123 & 056 & & & . \\
\hline HEMBL1447803 & 37056 & 2.699 & & \\
\hline 375 & & 99 & & \\
\hline EMBL1985649 & 7056 & 599 & & \\
\hline IEMBL14 & 7056 & 699 & 3105 & \\
\hline AEMBL1451931 & 37056 & 699 & .258 & \\
\hline AEMBL145 & 37056 & 699 & 5555 & \\
\hline 63 & $\partial 56$ & 699 & & \\
\hline IEMBL13 & 7056 & .699 & .7957 & \\
\hline IEMBL1469444 & 7056 & .2671 & .0072 & \\
\hline AEMBL1503962 & 7056 & .699 & 9334 & \\
\hline AEMBL1462687 & 56 & .699 & .7108 & \\
\hline IEMBL14 & & 99 & .7138 & RN \\
\hline AEMBL1 & 356 & 699 & 2.4079 & \\
\hline HEMBL136 & $\partial 56$ & .699 & .7615 & RN \\
\hline IEMBL131 & 56 & 599 & 7 & 5T \\
\hline IEMBL14C & 56 & 699 & .1618 & RN \\
\hline AEMBL15 & & .699 & 26 & RN \\
\hline AEMBL1 & 56 & 2.699 & 2.7631 & \\
\hline IEMBL16 & & 699 & 8781 & $\mathrm{~T}$ \\
\hline IEMBL142 & 6 & 2.699 & 34 & RN \\
\hline IEMBL146 & 66 & .130 & 2.7038 & ST \\
\hline IEMBL14 & & 2.699 & 2.2104 & \\
\hline 43 & & 699 & .438 & \\
\hline IEMBL19ऽ & & 99 & & N \\
\hline IEMBL31 & 6 & 2.699 & 97 & RN \\
\hline IEMBL1: & 56 & .699 & 74 & RN \\
\hline 70 & & .699 & 3.1736 & \\
\hline 86 & & 2.699 & & 1 \\
\hline IEMBL13 & & 99 & & $\pi$ \\
\hline IEMBL13 & 56 & 4.815 & 64 & RN \\
\hline EMBLI & & 99 & 41 & ST \\
\hline 43 & & 2.699 & & TRN \\
\hline IEMBL15e & & & 3.2021 & TST \\
\hline IEMBL1300769 & 56 & 2.699 & .7821 & TRN \\
\hline IEMBL] & 56 & 99 & .4745 & RN \\
\hline 41 & & 99 & 58 & RN \\
\hline & & 99 & & RN \\
\hline AEMBL1466263 & 56 & 2.699 & 2.7094 & TRN \\
\hline IEMBL13e & & 2.699 & .7825 & TRN \\
\hline AEMBL16 & 56 & .699 & 2.3518 & RN \\
\hline 211 & & & 3.2372 & SI \\
\hline 25 & 056 & 2.699 & 2.9639 & ГST \\
\hline EMBL1445259 & 7056 & 2.699 & 3.4077 & TRN \\
\hline 23 & & 2.699 & 2.4766 & RIV \\
\hline CHEMBL1505642 & & 2.699 & 3.2554 & RIV \\
\hline CHEMBL3211983 & & 2.699 & 2.9729 & SI \\
\hline CHEMBL1545384 & 737056 & 2.699 & 2.8407 & ГRN \\
\hline
\end{tabular}

Page 3181 
Supplemental Table S2.txt

\begin{tabular}{|c|c|c|c|c|c|}
\hline CHEMBL1521960 & 737056 & 2.699 & 2.9871 & TRN & \\
\hline CHEMBL1459861 & 737056 & 2.699 & 3.4369 & TST & \\
\hline CHEMBL1360708 & 737056 & 2.699 & 2.4604 & TRN & \\
\hline CHEMBL1369492 & 737056 & 2.699 & 2.9243 & TRN & \\
\hline CHEMBL1300876 & 737056 & 2.699 & 2.7546 & TRN & \\
\hline CHEMBL1344245 & 737056 & 2.699 & 2.61899 & 99999999998 & TRN \\
\hline CHEMBL1502870 & 737056 & 2.699 & 2.6365 & TRN & \\
\hline CHEMBL1320537 & 737056 & 2.699 & 2.9757 & TRN & \\
\hline CHEMBL1527903 & 737056 & 2.699 & 2.8556 & TRN & \\
\hline CHEMBL1346753 & 737056 & 3.8757 & 3.32899 & 99999999997 & TRN \\
\hline CHEMBL1320481 & 737056 & 2.699 & 2.6394 & TRN & \\
\hline CHEMBL1457702 & 737056 & 2.699 & 2.7033 & TRN & \\
\hline CHEMBL1323252 & 737056 & 2.699 & 2.7727 & TRN & \\
\hline CHEMBL1478085 & 737056 & 2.699 & 2.9276 & TRN & \\
\hline CHEMBL1323674 & 737056 & 2.699 & 3.2532 & TRN & \\
\hline CHEMBL1990694 & 737056 & 2.699 & 3.5309 & TRN & \\
\hline CHEMBL88326 & 737056 & 5.2401 & 4.1592 & TRN & \\
\hline CHEMBL1993173 & 737056 & 2.699 & 2.4241 & TRN & \\
\hline CHEMBL1446738 & 737056 & 2.699 & 2.9651 & TRN & \\
\hline CHEMBL1454269 & 737056 & 2.699 & 3.2285 & TRN & \\
\hline CHEMBL3195851 & 737056 & 2.699 & 2.5575 & TRN & \\
\hline CHEMBL1462636 & 737056 & 2.699 & 3.0905 & TRN & \\
\hline CHEMBL1352196 & 737056 & 2.699 & 3.1946 & TST & \\
\hline CHEMBL3195461 & 737056 & 2.699 & 2.9715 & TRN & \\
\hline CHEMBL1354019 & 737056 & 2.699 & 2.5 & TRN & \\
\hline CHEMBL1365210 & 737056 & 2.699 & 2.4822 & TRN & \\
\hline CHEMBL1388952 & 737056 & 2.699 & 3.2957 & TST & \\
\hline CHEMBL1563488 & 737056 & 2.699 & 2.9219 & TRN & \\
\hline CHEMBL1964978 & 737056 & 2.699 & 2.3632 & TRN & \\
\hline CHEMBL1379309 & 737056 & 2.699 & 2.6548 & TRN & \\
\hline CHEMBL1348090 & 737056 & 2.699 & 2.97 & TRN & \\
\hline CHEMBL1999473 & 737056 & 2.699 & 2.5838 & TRN & \\
\hline CHEMBL1612112 & 737056 & 2.699 & 2.6354 & TRN & \\
\hline CHEMBL1527528 & 737056 & 2.699 & 2.5365 & TRN & \\
\hline CHEMBL1529584 & 737056 & 2.699 & 2.9426 & TRN & \\
\hline CHEMBL3192206 & 737056 & 5.3026 & 3.2818 & TRN & \\
\hline CHEMBL1310325 & 737056 & 2.699 & 2.8388 & TRN & \\
\hline CHEMBL1512862 & 737056 & 2.699 & 2.9686 & TRN & \\
\hline CHEMBL1389315 & 737056 & 2.699 & 2.9466 & TRN & \\
\hline CHEMBL1309682 & 737056 & 2.699 & 3.2903 & TST & \\
\hline CHEMBL1416360 & 737056 & 2.699 & 2.4996 & TRN & \\
\hline CHEMBL1598597 & 737056 & 2.699 & 2.6262 & TRN & \\
\hline CHEMBL1340316 & 737056 & 2.699 & 2.4041 & TRN & \\
\hline CHEMBL1384253 & 737056 & 2.699 & 3.1796 & TRN & \\
\hline CHEMBL1526865 & 737056 & 2.699 & 2.3718 & TRN & \\
\hline CHEMBL1360857 & 737056 & 2.699 & 2.7649 & TRN & \\
\hline CHEMBL3193946 & 737056 & 2.699 & 3.3867 & TRN & \\
\hline CHEMBL1433585 & 737056 & 2.699 & 3.0407 & TRN & \\
\hline
\end{tabular}


Supplemental Table S2.txt

\begin{tabular}{|c|c|c|c|c|}
\hline CHEMBL1511181 & 737056 & 2.699 & 3.123 & TRN \\
\hline CHEMBL1480087 & 737056 & 2.699 & 2.3858 & TRN \\
\hline CHEMBL1415156 & 737056 & 2.699 & 2.6691 & TRN \\
\hline CHEMBL1334670 & 737056 & 4.9621 & 3.7685 & TRN \\
\hline CHEMBL3210910 & 737056 & 2.699 & 2.6194 & TRN \\
\hline CHEMBL1302539 & 737056 & 2.699 & 2.5797 & TRN \\
\hline CHEMBL1455832 & 737056 & 2.699 & 2.8262 & TRN \\
\hline CHEMBL1503523 & 737056 & 2.699 & 2.9387 & TRN \\
\hline CHEMBL1302170 & 737056 & 2.699 & 2.51 & TRN \\
\hline CHEMBL1427838 & 737056 & 2.699 & 2.6271 & TRN \\
\hline CHEMBL1603305 & 737056 & 2.699 & 2.6789 & TRN \\
\hline CHEMBL1351935 & 737056 & 2.699 & 2.4749 & TRN \\
\hline CHEMBL1390860 & 737056 & 2.699 & 2.6262 & TRN \\
\hline CHEMBL1405964 & 737056 & 2.699 & 2.6077 & TRN \\
\hline CHEMBL2003304 & 737056 & 2.699 & 3.4236 & TRN \\
\hline CHEMBL1575065 & 737056 & 2.699 & 3.0171 & TST \\
\hline CHEMBL1363428 & 737056 & 2.699 & 2.3792 & TST \\
\hline CHEMBL1594257 & 737056 & 2.699 & 3.0597 & TST \\
\hline CHEMBL1587842 & 737056 & 2.699 & 3.0536 & TST \\
\hline CHEMBL1438567 & 737056 & 2.699 & 2.9903 & TST \\
\hline CHEMBL1300620 & 737056 & 2.699 & 2.8754 & TST \\
\hline CHEMBL1536144 & 737056 & 2.699 & 2.7212 & TST \\
\hline CHEMBL1440953 & 737056 & 2.699 & 2.575 & TST \\
\hline CHEMBL269122 & 737056 & 2.699 & 3.3225 & TST \\
\hline CHEMBL1548790 & 737056 & 2.699 & 2.5964 & TST \\
\hline CHEMBL1550672 & 737056 & 2.699 & 2.6538 & TST \\
\hline CHEMBL1440277 & 737056 & 2.699 & 2.5853 & TST \\
\hline CHEMBL1559707 & 737056 & 5.2468 & 2.806 & TST \\
\hline CHEMBL1380232 & 737056 & 4.3595 & 2.7099 & TST \\
\hline CHEMBL1443623 & 737056 & 2.699 & 3.1585 & TST \\
\hline CHEMBL1308037 & 737056 & 2.699 & 2.4567 & TST \\
\hline CHEMBL1447326 & 737056 & 2.699 & 2.575 & TST \\
\hline CHEMBL1569997 & 737056 & 2.699 & 2.7756 & TST \\
\hline CHEMBL1533336 & 737056 & 2.699 & 3.0426 & TST \\
\hline CHEMBL1458402 & 737056 & 2.699 & 2.2975 & TST \\
\hline CHEMBL1572208 & 737056 & 4.4002 & 3.2915 & TST \\
\hline CHEMBL340831 & 202115 & 6.9586 & 7.8931 & TST \\
\hline CHEMBL131119 & 202115 & 8.0555 & 8.0449 & TRN \\
\hline CHEMBL133352 & 202115 & 8.0362 & 8.0161 & TRN \\
\hline CHEMBL337475 & 202115 & 8.9208 & 8.9999 & TRN \\
\hline CHEMBL336593 & 202115 & 8.0132 & 7.9937 & TRN \\
\hline CHEMBL337266 & 202115 & 9.6198 & \multicolumn{2}{|c|}{9.056000000000001} \\
\hline CHEMBL423151 & 202115 & 8.0969 & 8.0966 & TRN \\
\hline CHEMBL131560 & 202115 & 8.3665 & 8.3911 & TRN \\
\hline CHEMBL132100 & 202115 & 9.0969 & 9.318 & TRN \\
\hline CHEMBL130218 & 202115 & 9.0969 & 9.0748 & TRN \\
\hline CHEMBL335456 & 202115 & 9.6778 & 9.6136 & TRN \\
\hline CHEMBL307753 & 202115 & 7.5229 & 7.5427 & TRN \\
\hline
\end{tabular}




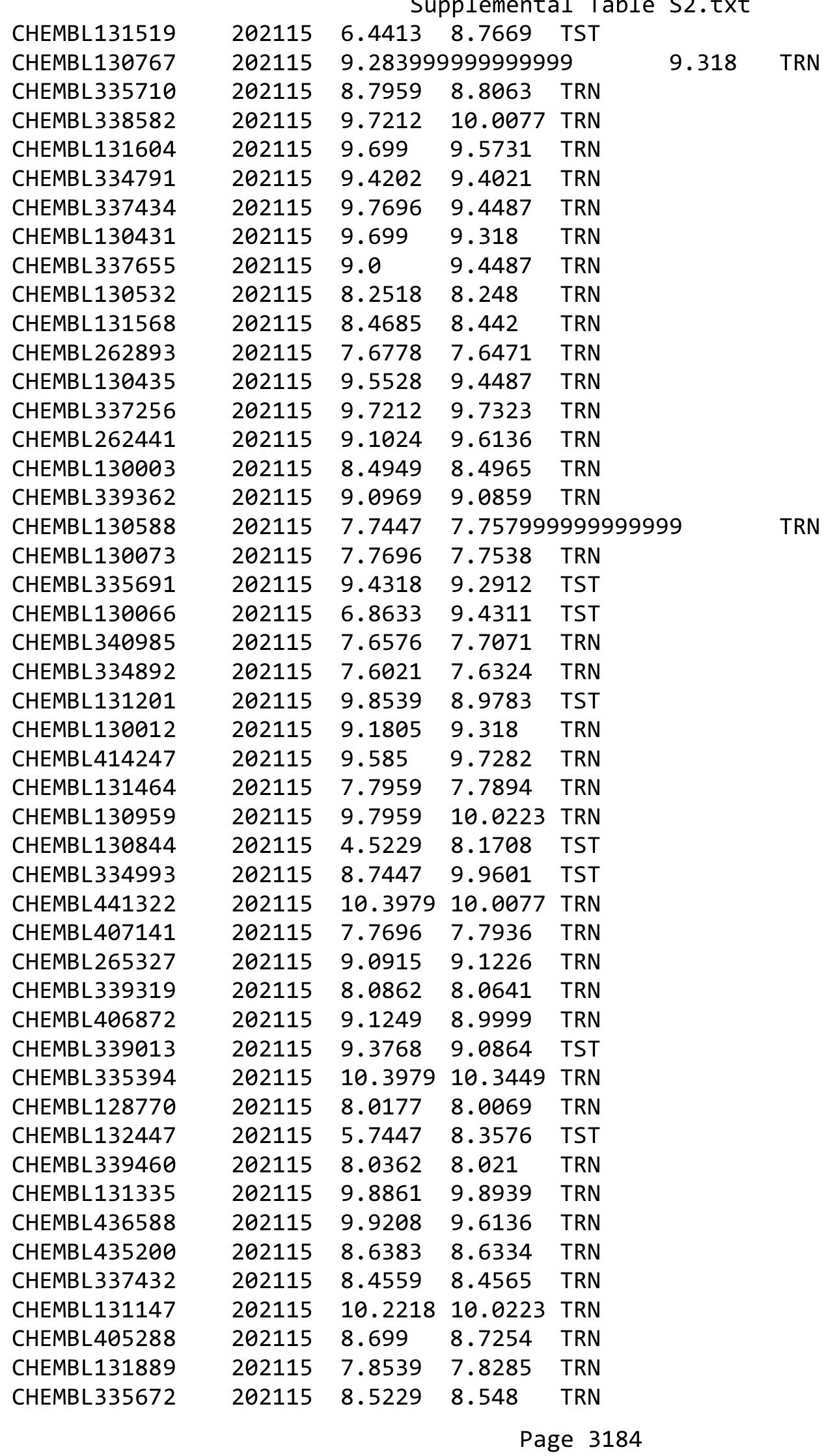


Supplemental Table S2.txt

\begin{tabular}{|c|c|c|c|c|}
\hline CHEMBL336755 & 202115 & 8.699 & 8.67 & TRN \\
\hline CHEMBL40991 & 202115 & 9.6383 & 9.1067 & TST \\
\hline CHEMBL262677 & 202115 & 8.9586 & 9.1226 & TST \\
\hline CHEMBL414430 & 202115 & 10.0458 & 9.6136 & TST \\
\hline CHEMBL131651 & 202115 & 7.8539 & 9.0973 & TST \\
\hline CHEMBL336939 & 202115 & 10.1549 & 9.9868 & TST \\
\hline CHEMBL130553 & 202115 & 7.9586 & 8.0443 & TST \\
\hline CHEMBL336406 & 202115 & 8.0 & 8.3812 & TST \\
\hline CHEMBL132738 & 202115 & 7.4425 & 8.0668 & TST \\
\hline CHEMBL1935048 & 794418 & 3.0 & 3.3563 & TRN \\
\hline CHEMBL1935040 & 794418 & 3.0 & 2.9622 & TRN \\
\hline CHEMBL1935169 & 794418 & 4.4517 & 3.1641 & TST \\
\hline CHEMBL1935061 & 794418 & 3.0 & 3.3663 & TRN \\
\hline CHEMBL1935069 & 794418 & 3.0 & 3.0941 & TST \\
\hline CHEMBL1935047 & 794418 & 3.0 & 3.2409 & TRN \\
\hline CHEMBL1935168 & 794418 & 4.9889 & 3.228 & TST \\
\hline CHEMBL1935021 & 794418 & 3.0 & 2.8789 & TRN \\
\hline CHEMBL1935063 & 794418 & 3.0 & 3.3036 & TRN \\
\hline CHEMBL1935023 & 794418 & 3.0 & 3.0028 & TRN \\
\hline CHEMBL1935039 & 794418 & 3.0 & 2.9064 & TRN \\
\hline CHEMBL1935026 & 794418 & 3.0 & 2.905 & TRN \\
\hline CHEMBL1935035 & 794418 & 3.0 & 2.9982 & TRN \\
\hline CHEMBL1935036 & 794418 & 3.0 & 3.0879 & TRN \\
\hline CHEMBL1935034 & 794418 & 3.0 & 2.9405 & TST \\
\hline CHEMBL1935033 & 794418 & 3.0 & 3.0212 & TRN \\
\hline CHEMBL1935024 & 794418 & 3.0 & 2.947 & TRN \\
\hline CHEMBL1935065 & 794418 & 3.0 & 3.0287 & TRN \\
\hline CHEMBL1935068 & 794418 & 3.0 & 2.9752 & TRN \\
\hline CHEMBL1935032 & 794418 & 3.0 & 2.8232 & TRN \\
\hline CHEMBL1935059 & 794418 & 3.0 & 3.1964 & TRN \\
\hline CHEMBL1935055 & 794418 & 3.0 & 3.1798 & TRN \\
\hline CHEMBL1935022 & 794418 & 3.0 & 2.9123 & TRN \\
\hline CHEMBL1933087 & 794418 & 3.0 & 2.8059 & TRN \\
\hline CHEMBL1935049 & 794418 & 3.0 & 3.1817 & TRN \\
\hline CHEMBL1935017 & 794418 & 3.0 & 2.839 & TST \\
\hline CHEMBL1935042 & 794418 & 3.0 & 3.0326 & TRN \\
\hline CHEMBL1935056 & 794418 & 3.0 & 3.1517 & TRN \\
\hline CHEMBL1935050 & 794418 & 4.7557 & 3.5714 & TRN \\
\hline CHEMBL1935171 & 794418 & 5.0804 & 3.1731 & TST \\
\hline CHEMBL1935045 & 794418 & 3.0 & 2.948 & TST \\
\hline CHEMBL1935067 & 794418 & 3.0 & 3.0293 & TRN \\
\hline CHEMBL1935072 & 794418 & 4.6847 & 3.2254 & TST \\
\hline CHEMBL1935029 & 794418 & 3.0 & 2.8399 & TRN \\
\hline CHEMBL1935028 & 794418 & 3.0 & 2.8355 & TRN \\
\hline CHEMBL1935038 & 794418 & 3.0 & 2.9103 & TST \\
\hline CHEMBL1935054 & 794418 & 3.0 & 3.1572 & TRN \\
\hline CHEMBL1935046 & 794418 & 3.0 & 3.2437 & TRN \\
\hline CHEMBL1935018 & 794418 & 3.0 & 2.8706 & TST \\
\hline
\end{tabular}




\begin{tabular}{|c|c|c|c|c|c|}
\hline \multicolumn{6}{|c|}{ Supplemental Table S2.txt } \\
\hline CHEMBL1935051 & 794418 & 3.0 & 3.1661 & TRN & \\
\hline CHEMBL1935060 & 794418 & 3.0 & 3.3252 & TST & \\
\hline CHEMBL1935020 & 794418 & 3.0 & 2.9987 & TRN & \\
\hline CHEMBL1935062 & 794418 & 4.4379 & 3.4465 & TRN & \\
\hline CHEMBL1935027 & 794418 & 3.0 & 2.945 & TRN & \\
\hline CHEMBL1935043 & 794418 & 3.0 & 3.1178 & TRN & \\
\hline CHEMBL1935066 & 794418 & 3.0 & 2.9545 & TRN & \\
\hline CHEMBL1935057 & 794418 & 3.0 & 3.1501 & TRN & \\
\hline CHEMBL1935030 & 794418 & 3.0 & 2.8729 & TRN & \\
\hline CHEMBL1935053 & 794418 & 3.0 & 3.2007 & TRN & \\
\hline CHEMBL1935170 & 794418 & 4.5714 & 3.1682 & TST & \\
\hline CHEMBL1935172 & 794418 & 5.0526 & 3.1774 & TST & \\
\hline CHEMBL1935031 & 794418 & 3.0 & \multicolumn{2}{|c|}{2.8810000000000002} & TRN \\
\hline CHEMBL1935071 & 794418 & \multicolumn{3}{|c|}{$4.638999999999999 \quad 3.1719$} & TST \\
\hline CHEMBL1935070 & 794418 & 3.0 & 3.1329 & TRN & \\
\hline CHEMBL1935058 & 794418 & 3.0 & 3.1236 & TRN & \\
\hline CHEMBL1935037 & 794418 & 3.0 & 2.9404 & TRN & \\
\hline CHEMBL1935064 & 794418 & 3.0 & 3.2772 & TST & \\
\hline CHEMBL1935052 & 794418 & 3.0 & 3.2523 & TRN & \\
\hline CHEMBL1935019 & 794418 & 3.0 & 3.2314 & TRN & \\
\hline CHEMBL1935041 & 794418 & 3.0 & 2.8383 & TRN & \\
\hline CHEMBL1935044 & 794418 & 3.0 & \multicolumn{2}{|c|}{2.9760000000000004} & TST \\
\hline CHEMBL 3657021 & 1528690 & 6.0 & 8.1112 & TRN & \\
\hline CHEMBL3653222 & 1528690 & 9.6383 & 8.4573 & TRN & \\
\hline CHEMBL3657110 & 1528690 & 8.4916 & 9.006 & TST & \\
\hline CHEMBL3653208 & 1528690 & 9.7696 & 9.1673 & TRN & \\
\hline CHEMBL3653249 & 1528690 & 9.4437 & 9.1509 & TRN & \\
\hline CHEMBL3657055 & 1528690 & 7.6676 & 8.9474 & TST & \\
\hline CHEMBL 3653214 & 1528690 & 9.699 & 8.823 & TRN & \\
\hline CHEMBL3657001 & 1528690 & 9.5686 & 9.5412 & TRN & \\
\hline CHEMBL3653273 & 1528690 & 9.2441 & 8.4727 & TRN & \\
\hline CHEMBL3653244 & 1528690 & 8.4437 & 8.423 & TST & \\
\hline CHEMBL 3657106 & 1528690 & 9.6904 & 8.3989 & TST & \\
\hline CHEMBL 3653220 & 1528690 & 9.3872 & 9.5032 & TRN & \\
\hline CHEMBL3656991 & 1528690 & 9.9586 & 9.3261 & TRN & \\
\hline CHEMBL3656987 & 1528690 & 9.7959 & 8.9727 & TST & \\
\hline CHEMBL3653267 & 1528690 & 9.9586 & 8.4607 & TRN & \\
\hline CHEMBL3656994 & 1528690 & 8.1656 & 8.0306 & TRN & \\
\hline CHEMBL3653230 & 1528690 & 9.4685 & 9.4161 & TRN & \\
\hline CHEMBL3653262 & 1528690 & 8.9586 & 8.6329 & TRN & \\
\hline CHEMBL3657024 & 1528690 & 10.0458 & 9.3328 & TRN & \\
\hline CHEMBL3653212 & 1528690 & 8.9172 & 8.3992 & TRN & \\
\hline CHEMBL3653188 & 1528690 & 9.7212 & 9.0592 & TRN & \\
\hline CHEMBL3653231 & 1528690 & 6.0 & 8.7483 & TRN & \\
\hline CHEMBL3657123 & 1528690 & 6.0 & 7.8573 & TRN & \\
\hline CHEMBL3653194 & 1528690 & 9.7212 & 8.8672 & TRN & \\
\hline CHEMBL3653290 & 1528690 & 8.7905 & 8.7183 & TRN & \\
\hline CHEMBL3653215 & 1528690 & 9.699 & 9.023 & TRN & \\
\hline
\end{tabular}


Supplemental Table S2.txt

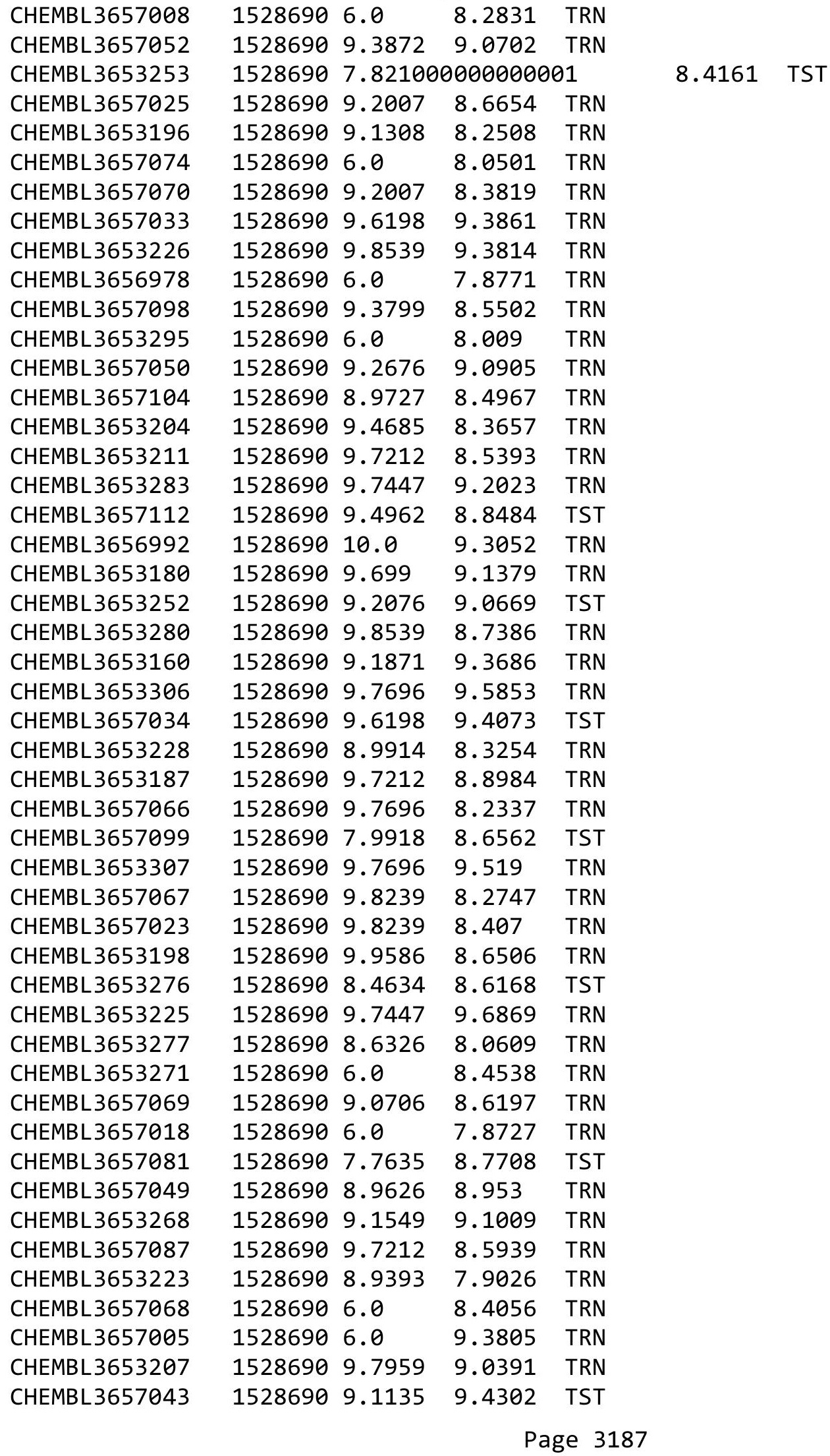


Supplemental Table S2.txt

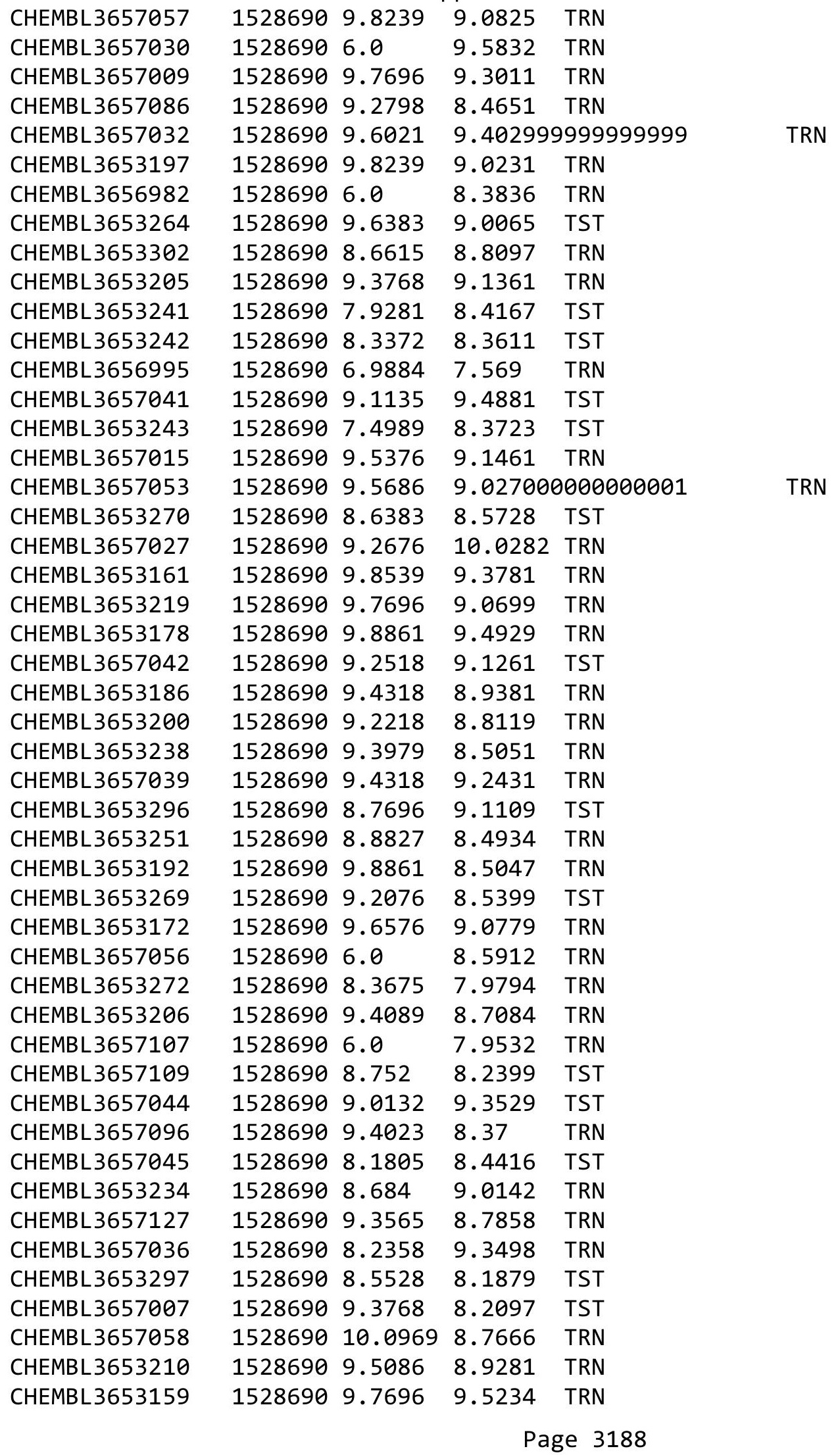


Supplemental Table S2.txt

\begin{tabular}{|c|c|c|c|c|}
\hline HEMBL: & & & 74 & \\
\hline HFMBI 3657093 & & 9.4815 & 8.6822 & \\
\hline HEMBL & 8690 & & & \\
\hline AEMBL: & 528690 & 6.0 & 3205 & \\
\hline HEMBL3653278 & 528690 & 8.3019 & .6093 & \\
\hline HEMBL & 528690 & & & \\
\hline IFMBI & 690 & 9.6778 & & \\
\hline HEMBL365 & 528690 & 6.0 & & \\
\hline HEMBL3653176 & 528690 & 9.7696 & 16 & \\
\hline HEMBL3653303 & 528690 & 8.71 & 8.9788 & \\
\hline HEMBL365 & 528690 & 9.3768 & 32 & \\
\hline AEMBL & & 686 & & RN \\
\hline HEMBL3 & 528690 & 9.301 & & \\
\hline AEMBL3 & 690 & 536 & & \\
\hline AEMBL3653165 & 528690 & 8.644 & & \\
\hline IEMBL: & 690 & 6 & 32 & \\
\hline AEMBL & & 21 & & \\
\hline HEMBL & 690 & 7959 & & RN \\
\hline AEMBL3 & 590 & 7.1161 & & \\
\hline AEMBL3653304 & 590 & 957 & 38 & NIV \\
\hline EMBL & 90 & 686 & & RN \\
\hline IEMBL & & 52 & & \\
\hline HEMBL; & 90 & 076 & & $\mathrm{RN}$ \\
\hline AEMBL3 & 90 & 6.0 & & \\
\hline AEMBL 36 & 690 & 9.7447 & 69 & RN \\
\hline EMBL: & 90 & 9 & & $R N$ \\
\hline FM & & 32 & & $\mathrm{RN}$ \\
\hline 89 & & 18 & & RN \\
\hline IEMBL3 & & & & IRN \\
\hline IEMBL 365 & 690 & 9.5986 & 79 & RN \\
\hline EMBL & 90 & 87 & & $\mathrm{RN}$ \\
\hline 1 & & 17 & & RN \\
\hline & & 9. & & ST \\
\hline AEMBL 36 & & & & ГST \\
\hline HEMBL 365 & 690 & 8.8794 & & ГST \\
\hline СMO1- & 90 & 76 & & 「RN \\
\hline & & & & $\mathrm{RN}$ \\
\hline HEMBL3 & & 10.0969 & & RN \\
\hline HEMBL 365 & 528690 & 6. & & $\Gamma R$ \\
\hline EMBL3 & 590 & 9. & & 「RN \\
\hline HEMBL36 & 590 & 9.8861 & & \\
\hline HEMBL36 & & 10.0969 & & $\mathrm{RN}$ \\
\hline HEMBL36 & & 9.4949 & & 「RN \\
\hline HEMBL365 & 690 & 7.0329 & & TS \\
\hline 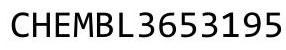 & & 9.7696 & & \\
\hline HEMBL 365 & 528690 & & & \\
\hline HEMBL 365 & 528690 & 9.5086 & 8.4444 & \\
\hline CHEMBL3653166 & 1528690 & 6.0 & 9.5544 & \\
\hline
\end{tabular}

Page 3189 
Supplemental Table S2.txt

\begin{tabular}{|c|c|c|c|c|}
\hline CHEMBL3653158 & 1528690 & 9.7696 & 9.5291 & TRN \\
\hline CHEMBL3657094 & 1528690 & 8.9355 & 8.1126 & TRN \\
\hline CHEMBL3653281 & 1528690 & 8.4214 & 7.8878 & TST \\
\hline CHEMBL3657076 & 1528690 & 8.9281 & 9.2017 & TRN \\
\hline CHEMBL3657105 & 1528690 & 9.5045 & 8.602 & TRN \\
\hline CHEMBL3657013 & 1528690 & 9.699 & 8.5528 & TRN \\
\hline CHEMBL 3657113 & 1528690 & 9.4306 & 8.119 & TRN \\
\hline CHEMBL 3653177 & 1528690 & 9.9208 & 9.2986 & TRN \\
\hline CHEMBL3653218 & 1528690 & 9.6778 & 9.2277 & TRN \\
\hline CHEMBL3653305 & 1528690 & 9.4202 & 8.3111 & TST \\
\hline CHEMBL 3653175 & 1528690 & 9.8239 & 9.3168 & TRN \\
\hline CHEMBL 3657128 & 1528690 & 7.3625 & 7.8225 & TRN \\
\hline CHEMBL 3653237 & 1528690 & 9.4559 & 9.398 & TRN \\
\hline CHEMBL 3657061 & 1528690 & 6.0 & 8.7257 & TRN \\
\hline CHEMBL 3657051 & 1528690 & 8.9208 & 8.9282 & TRN \\
\hline CHEMBL 3653282 & 1528690 & 9.3872 & 8.3135 & TST \\
\hline CHEMBL 3653213 & 1528690 & 9.5528 & 9.115 & TRN \\
\hline CHEMBL 3657102 & 1528690 & 8.8969 & 8.3583 & TRN \\
\hline CHEMBL 3653266 & 1528690 & 9.2518 & 9.3798 & TRN \\
\hline CHEMBL3656980 & 1528690 & 9.4949 & 9.4852 & TRN \\
\hline CHEMBL 3657012 & 1528690 & 9.9586 & 9.4722 & TRN \\
\hline CHEMBL 3657016 & 1528690 & 9.585 & 8.7731 & TRN \\
\hline CHEMBL 3653286 & 1528690 & 9.1871 & 8.8512 & TRN \\
\hline CHEMBL 3657126 & 1528690 & 8.3242 & 8.8974 & TRN \\
\hline CHEMBL 3653258 & 1528690 & 8.251 & 8.55299 & э999999999 \\
\hline CHEMBL3653309 & 1528690 & 9.5686 & 9.6131 & TRN \\
\hline CHEMBL3653203 & 1528690 & 9.3979 & 9.3629 & TRN \\
\hline CHEMBL 3653247 & 1528690 & 9.3468 & 8.3995 & TST \\
\hline CHEMBL 3653233 & 1528690 & 9.7212 & 9.26799 & 9999999999 \\
\hline CHEMBL3657101 & 1528690 & 9.6144 & 8.1731 & TRN \\
\hline CHEMBL 3653191 & 1528690 & 9.7959 & 8.7316 & TRN \\
\hline CHEMBL 3657091 & 1528690 & 6.0 & 8.5678 & TRN \\
\hline CHEMBL 3653201 & 1528690 & 8.5302 & 8.0832 & TRN \\
\hline CHEMBL 3657022 & 1528690 & 8.9788 & 9.17799 & 9999999999 \\
\hline CHEMBL3653263 & 1528690 & 9.4559 & 9.0654 & TRN \\
\hline CHEMBL3656997 & 1528690 & 9.7447 & 8.6864 & TRN \\
\hline CHEMBL 3653285 & 1528690 & 8.7144 & 8.7315 & TRN \\
\hline CHEMBL 3657077 & 1528690 & 8.9355 & 8.8503 & TST \\
\hline CHEMBL3653308 & 1528690 & 6.0 & 8.3583 & TRN \\
\hline CHEMBL 3657078 & 1528690 & 8.5508 & 8.5553 & TRN \\
\hline CHEMBL 3656983 & 1528690 & 9.4949 & 9.5953 & TRN \\
\hline CHEMBL 3653260 & 1528690 & 9.5528 & 9.1226 & TRN \\
\hline CHEMBL 3653254 & 1528690 & 7.9281 & 8.5166 & TST \\
\hline CHEMBL 3653174 & 1528690 & 6.0 & 9.5124 & TRN \\
\hline CHEMBL3653167 & 1528690 & 9.699 & 9.5232 & TRN \\
\hline CHEMBL3653209 & 1528690 & 8.9872 & 8.1806 & TRN \\
\hline CHEMBL 3653284 & 1528690 & 8.7825 & 8.6577 & TRN \\
\hline CHEMBL3653299 & 1528690 & 9.1805 & 9.1561 & TRN \\
\hline
\end{tabular}


Supplemental Table S2.txt

\begin{tabular}{|c|c|c|c|c|c|}
\hline CHEMBL3657088 & 1528690 & 9.1487 & 8.1321 & TST & \\
\hline CHEMBL3653239 & 1528690 & 8.8327 & 9.1238 & TST & \\
\hline CHEMBL3653261 & 1528690 & 9.4949 & 8.904 & TRN & \\
\hline CHEMBL3653298 & 1528690 & 8.6198 & 8.8371 & TRN & \\
\hline CHEMBL3657095 & 1528690 & 9.5969 & 8.272 & TRN & \\
\hline CHEMBL3657017 & 1528690 & 9.7212 & 8.6042 & TRN & \\
\hline CHEMBL3653274 & 1528690 & 9.585 & 9.1829 & TRN & \\
\hline CHEMBL3657115 & 1528690 & 6.0 & 8.3416 & TRN & \\
\hline CHEMBL3657054 & 1528690 & 6.0 & 8.8973 & TST & \\
\hline CHEMBL3653279 & 1528690 & 9.6198 & 9.2549 & TRN & \\
\hline CHEMBL3653250 & 1528690 & 9.4949 & 8.56 & TRN & \\
\hline CHEMBL3653202 & 1528690 & 9.7959 & 9.1129 & TRN & \\
\hline CHEMBL3653190 & 1528690 & 9.1871 & 8.9134 & TRN & \\
\hline CHEMBL3656988 & 1528690 & 6.0 & 8.7663 & TRN & \\
\hline CHEMBL 3657060 & 1528690 & 6.0 & 8.9604 & TRN & \\
\hline CHEMBL3639520 & 1528690 & 10.1549 & 9.634 & TST & \\
\hline CHEMBL3657026 & 1528690 & 9.4089 & 9.382 & TST & \\
\hline CHEMBL 3653199 & 1528690 & 9.5686 & 8.5606 & TST & \\
\hline CHEMBL3653300 & 1528690 & 8.7375 & 9.0519 & TST & \\
\hline CHEMBL3653173 & 1528690 & 10.0458 & 9.3069 & TST & \\
\hline CHEMBL 3657000 & 1528690 & 9.4437 & 8.7115 & TST & \\
\hline CHEMBL3656989 & 1528690 & 9.5376 & 8.8063 & TST & \\
\hline CHEMBL3653240 & 1528690 & 8.8125 & 8.2208 & TST & \\
\hline CHEMBL3657093 & 1528690 & 8.6187 & 8.3082 & TST & \\
\hline CHEMBL3657065 & 1528690 & 9.5528 & 8.1968 & TST & \\
\hline CHEMBL3639521 & 1528690 & 8.3036 & 8.3548 & TST & \\
\hline CHEMBL 3657114 & 1528690 & 9.6716 & 7.9783 & TST & \\
\hline CHEMBL3657103 & 1528690 & 9.4535 & 8.7187 & TST & \\
\hline CHEMBL3657029 & 1528690 & 9.3665 & 9.5818 & TST & \\
\hline CHEMBL3653256 & 1528690 & 6.0 & 8.1973 & TST & \\
\hline CHEMBL3657046 & 1528690 & 9.5376 & 9.4351 & TST & \\
\hline CHEMBL3653189 & 1528690 & 9.3279 & 9.1408 & TST & \\
\hline CHEMBL3653291 & 1528690 & 9.1805 & 8.9862 & TST & \\
\hline CHEMBL3653292 & 1528690 & 8.8794 & 9.009 & TST & \\
\hline CHEMBL3657100 & 1528690 & 8.2272 & 8.2964 & TST & \\
\hline CHEMBL1969873 & 1457664 & 4.3372 & 3.2615 & TST & \\
\hline CHEMBL 3325837 & 1457664 & 3.0 & 2.961999 & 99999999997 & TRN \\
\hline CHEMBL3325941 & 1457664 & 4.7696 & 4.6386 & TRN & \\
\hline CHEMBL418899 & 1457664 & 5.7696 & 3.7324 & TST & \\
\hline CHEMBL3325686 & 1457664 & 4.1192 & 3.8625 & TRN & \\
\hline CHEMBL3325668 & 1457664 & 3.0 & 3.0362 & TRN & \\
\hline CHEMBL3325951 & 1457664 & 3.0 & 3.0307 & TRN & \\
\hline CHEMBL3325944 & 1457664 & 3.0 & 2.6673 & TRN & \\
\hline CHEMBL3325950 & 1457664 & 3.0 & 3.1417 & TRN & \\
\hline CHEMBL3325833 & 1457664 & 3.0 & 2.8567 & TRN & \\
\hline CHEMBL3325680 & 1457664 & 3.0 & 2.9017 & TRN & \\
\hline CHEMBL3325955 & 1457664 & 3.0 & 2.9244 & TRN & \\
\hline CHEMBL1989547 & 1457664 & 3.0 & 3.0619 & TRN & \\
\hline
\end{tabular}


Supplemental Table S2.txt

\begin{tabular}{|c|c|c|c|c|c|}
\hline CHEMBL3325953 & 1457664 & 3.0 & 3.1398 & TRN & \\
\hline CHEMBL3327379 & 1457664 & 3.0 & 2.9047 & TRN & \\
\hline CHEMBL3325827 & 1457664 & 3.0 & 2.9863 & TRN & \\
\hline CHEMBL3325840 & 1457664 & 3.0 & 3.0199 & TRN & \\
\hline CHEMBL3325935 & 1457664 & 4.6576 & 4.0914 & TRN & \\
\hline CHEMBL3325839 & 1457664 & 3.0 & 3.17 & TRN & \\
\hline CHEMBL3325689 & 1457664 & 3.0 & 2.9279 & TRN & \\
\hline CHEMBL573352 & 1457664 & 4.4202 & 3.7224 & TST & \\
\hline CHEMBL1995839 & 1457664 & 3.0 & 3.1032 & TRN & \\
\hline CHEMBL3325823 & 1457664 & 3.0 & 3.0829 & TRN & \\
\hline CHEMBL 2009615 & 1457664 & 3.0 & 3.1175 & TRN & \\
\hline CHEMBL3325948 & 1457664 & 3.0 & 3.0496 & TRN & \\
\hline CHEMBL1989039 & 1457664 & 3.0 & 2.7995 & TRN & \\
\hline CHEMBL3325677 & 1457664 & 3.0 & 3.012 & TRN & \\
\hline CHEMBL3325943 & 1457664 & 3.0 & 3.2038 & TRN & \\
\hline CHEMBL3325954 & 1457664 & 3.0 & 2.9866 & TRN & \\
\hline CHEMBL 2005128 & 1457664 & 3.0 & 2.9651 & TST & \\
\hline CHEMBL 3325682 & 1457664 & 3.0 & 3.0983 & TRN & \\
\hline CHEMBL3325669 & 1457664 & 3.0 & \multicolumn{2}{|c|}{2.8680000000000003} & TRN \\
\hline CHEMBL3325836 & 1457664 & 3.0 & 2.9661 & TRN & \\
\hline CHEMBL3325956 & 1457664 & 3.0 & 3.3443 & TRN & \\
\hline CHEMBL3325936 & 1457664 & 3.0 & 3.0921 & TRN & \\
\hline CHEMBL 2112432 & 1457664 & 4.7696 & 3.7458 & TST & \\
\hline CHEMBL3325681 & 1457664 & 3.0 & 2.9467 & TRN & \\
\hline CHEMBL3325675 & 1457664 & 3.0 & 2.9905 & TRN & \\
\hline CHEMBL3325667 & 1457664 & 3.0 & 3.1156 & TRN & \\
\hline CHEMBL3325451 & 1457664 & 3.0 & 2.9267 & TRN & \\
\hline CHEMBL3325945 & 1457664 & 3.0 & 3.1632 & TRN & \\
\hline CHEMBL3325821 & 1457664 & 3.0 & 2.9125 & TRN & \\
\hline CHEMBL3325674 & 1457664 & 3.0 & 2.9587 & TRN & \\
\hline CHEMBL3325832 & 1457664 & 3.0 & 3.5839 & TRN & \\
\hline CHEMBL3325946 & 1457664 & 4.0269 & 4.1169 & TRN & \\
\hline CHEMBL564201 & 1457664 & 3.0 & 2.9882 & TST & \\
\hline CHEMBL3325938 & 1457664 & 3.0 & 3.0205 & TRN & \\
\hline CHEMBL3325952 & 1457664 & 3.0 & 2.9259 & TRN & \\
\hline CHEMBL3325820 & 1457664 & 3.0 & 3.1288 & TRN & \\
\hline CHEMBL3325949 & 1457664 & 3.0 & 3.1431 & TRN & \\
\hline CHEMBL3325687 & 1457664 & 3.0 & 3.3948 & TRN & \\
\hline CHEMBL3325685 & 1457664 & 4.0706 & 3.7698 & TRN & \\
\hline CHEMBL3325939 & 1457664 & 3.0 & 2.9823 & TRN & \\
\hline CHEMBL351569 & 1457664 & 3.0 & 2.9869 & TRN & \\
\hline CHEMBL3325822 & 1457664 & 3.0 & 2.9635 & TRN & \\
\hline CHEMBL1996660 & 1457664 & 3.0 & 3.1014 & TST & \\
\hline CHEMBL3325683 & 1457664 & 3.0 & 2.9018 & TST & \\
\hline CHEMBL3325688 & 1457664 & 3.0 & 2.949 & TRN & \\
\hline CHEMBL3325690 & 1457664 & 3.0 & 2.8318 & TRN & \\
\hline CHEMBL1526476 & 1457664 & 3.0 & 2.7853 & TRN & \\
\hline CHEMBL3325947 & 1457664 & 3.0 & 4.4635 & TST & \\
\hline
\end{tabular}




\begin{tabular}{|c|c|c|c|c|c|}
\hline \\
\hline CHEMBL3325835 & 1457664 & 3.0 & 3.7544 & TST & \\
\hline CHEMBL3325838 & 1457664 & 3.0 & 3.0543 & TST & \\
\hline CHEMBL3325825 & 1457664 & 3.0 & 2.9334 & TST & \\
\hline CHEMBL 2008653 & 1457664 & 3.0 & 3.1419 & TST & \\
\hline CHEMBL3325684 & 1457664 & 3.0 & 2.9047 & TST & \\
\hline CHEMBL1922082 & 1457664 & 3.0 & 2.9349 & TST & \\
\hline CHEMBL3325834 & 1457664 & 3.0 & 2.8726 & TST & \\
\hline CHEMBL3325676 & 1457664 & 3.0 & 3.19199 & 99999999997 & TST \\
\hline CHEMBL3325937 & 1457664 & 3.0 & 2.8863 & TST & \\
\hline CHEMBL213525 & 379936 & 4.5686 & 4.1844 & TRN & \\
\hline CHEMBL 380048 & 379936 & 6.2076 & 5.7949 & TRN & \\
\hline CHEMBL 379732 & 379936 & 6.1024 & 5.8284 & TRN & \\
\hline CHEMBL378472 & 379936 & 6.1024 & 6.4569 & TRN & \\
\hline CHEMBL384477 & 379936 & 6.6198 & 6.5988 & TRN & \\
\hline CHEMBL379347 & 379936 & 5.0 & 4.1113 & TRN & \\
\hline CHEMBL379825 & 379936 & 6.9208 & 5.1971 & TST & \\
\hline CHEMBL 213075 & 379936 & 6.6383 & 6.1454 & TRN & \\
\hline CHEMBL384103 & 379936 & 5.6198 & 6.365 & TRN & \\
\hline CHEMBL 212494 & 379936 & 7.1367 & 7.0032 & TRN & \\
\hline CHEMBL384089 & 379936 & 5.3279 & 5.3242 & TRN & \\
\hline CHEMBL424888 & 379936 & 4.0 & 4.6201 & TRN & \\
\hline CHEMBL378066 & 379936 & 6.6576 & 6.4944 & TRN & \\
\hline CHEMBL386199 & 379936 & 5.2757 & 5.8171 & TRN & \\
\hline CHEMBL209786 & 379936 & 5.3979 & 5.4091 & TRN & \\
\hline CHEMBL212495 & 379936 & 6.4815 & 5.71200 & 0000000001 & TRN \\
\hline CHEMBL 209894 & 379936 & 5.3372 & 5.1011 & TRN & \\
\hline CHEMBL 385047 & 379936 & 6.4318 & 5.8741 & TST & \\
\hline CHEMBL 211878 & 379936 & 5.4949 & 5.4376 & TRN & \\
\hline CHEMBL379392 & 379936 & 5.8861 & 5.7422 & TRN & \\
\hline CHEMBL378766 & 379936 & 7.1308 & 5.5217 & TST & \\
\hline CHEMBL 214090 & 379936 & 6.1487 & 5.697 & TRN & \\
\hline CHEMBL 377839 & 379936 & 7.7696 & 7.9084 & TRN & \\
\hline CHEMBL383920 & 379936 & 4.0 & 4.943006 & 00000000005 & TST \\
\hline CHEMBL 209785 & 379936 & 3.301 & 3.8396 & TRN & \\
\hline CHEMBL 213475 & 379936 & 5.6576 & 5.4588 & TRN & \\
\hline CHEMBL210056 & 379936 & 7.4202 & 6.6886 & TRN & \\
\hline CHEMBL 377456 & 379936 & 4.0 & 4.3893 & TRN & \\
\hline CHEMBL214137 & 379936 & 4.3565 & 4.4046 & TST & \\
\hline CHEMBL386398 & 379936 & 4.0 & 6.3767 & TST & \\
\hline CHEMBL 385194 & 379936 & 4.0 & 5.0056 & TRN & \\
\hline CHEMBL 213422 & 379936 & 7.585 & 7.4291 & TRN & \\
\hline CHEMBL 209448 & 379936 & 7.4949 & 7.0285 & TRN & \\
\hline CHEMBL215677 & 379936 & 6.8239 & 6.8981 & TRN & \\
\hline CHEMBL386979 & 379936 & 4.0 & 5.143 & TST & \\
\hline CHEMBL 209594 & 379936 & 6.301 & 6.0354 & TRN & \\
\hline CHEMBL 213313 & 379936 & 6.3188 & 5.8788 & TRN & \\
\hline CHEMBL 215506 & 379936 & 3.301 & 3.6725 & TRN & \\
\hline CHEMBL212846 & 379936 & 5.5528 & 5.615 & TRN & \\
\hline
\end{tabular}




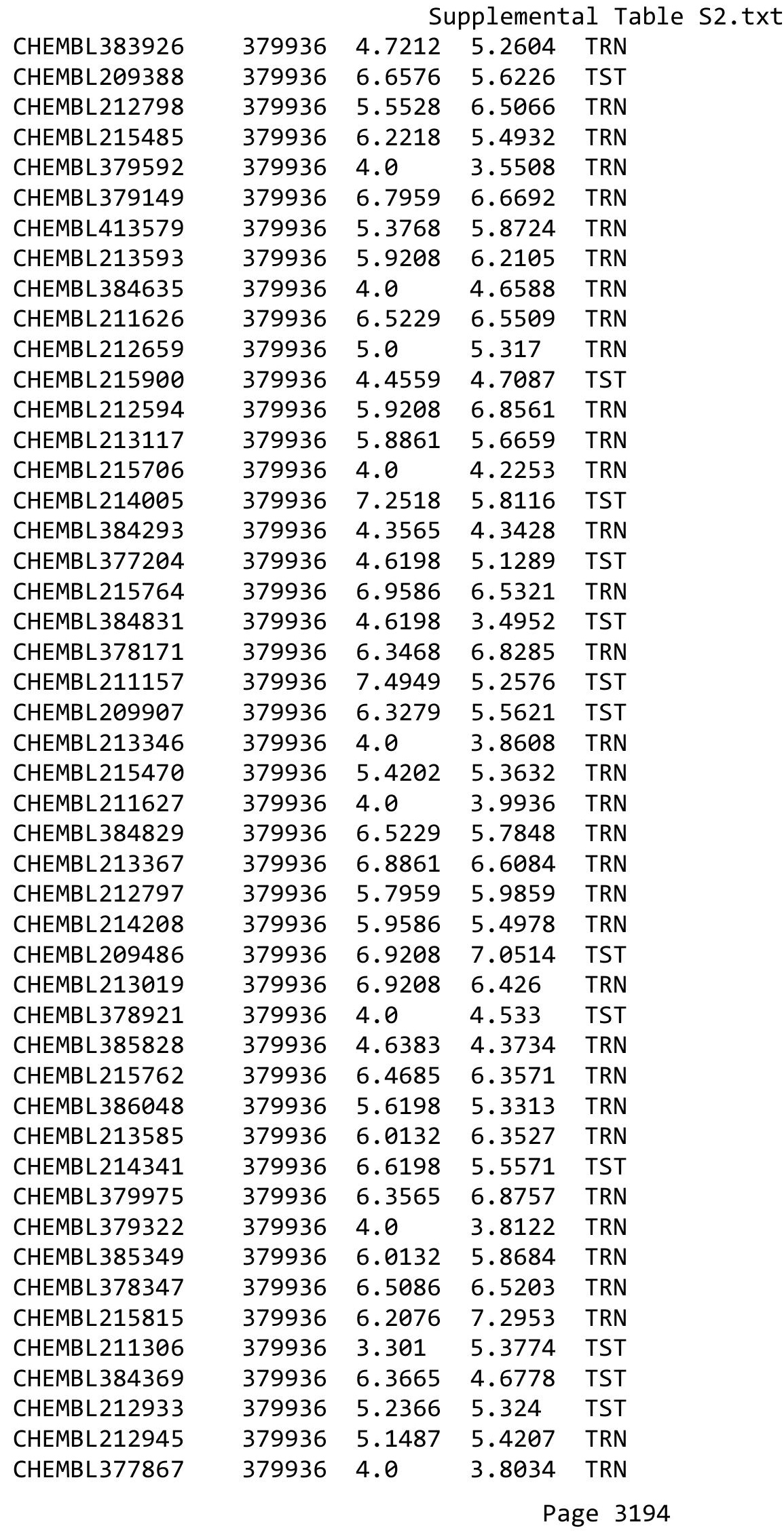




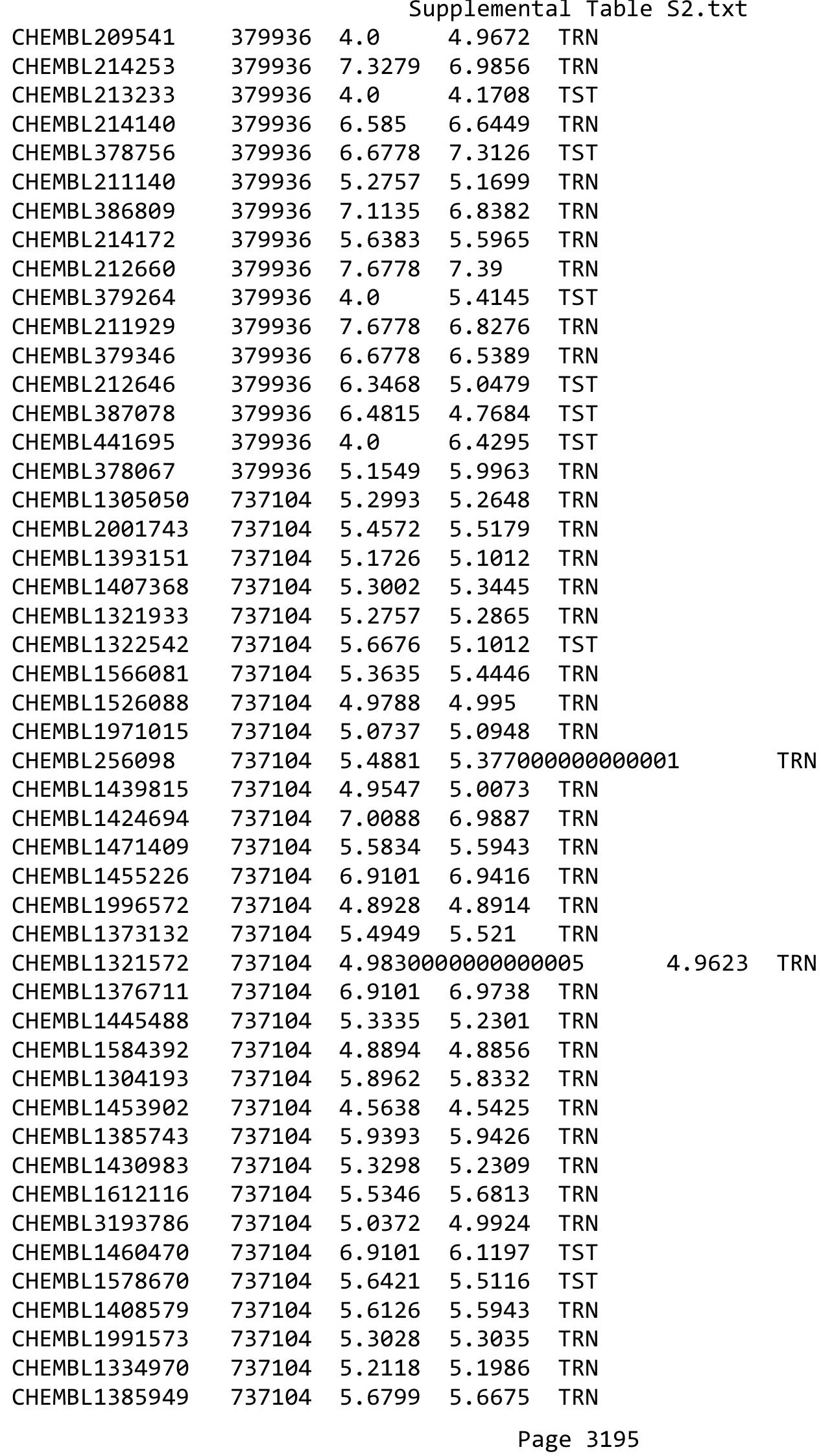




\begin{tabular}{|c|c|c|c|c|c|}
\hline \multicolumn{6}{|c|}{ Supplemental Table S2.txt } \\
\hline CHEMBL1548812 & 737104 & 5.2924 & 5.7917 & TST & \\
\hline CHEMBL1384370 & 737104 & 6.9101 & 6.9115 & TRN & \\
\hline CHEMBL1478587 & 737104 & 5.2958 & 5.27 & TRN & \\
\hline CHEMBL1608642 & 737104 & 5.7747 & 5.7849 & TRN & \\
\hline CHEMBL1463659 & 737104 & 6.9101 & 6.9137 & TRN & \\
\hline CHEMBL1988133 & 737104 & 3.9101 & 3.9362 & TRN & \\
\hline CHEMBL1372387 & 737104 & 4.7212 & 4.7536 & TRN & \\
\hline CHEMBL1390703 & 737104 & 4.857 & 4.9174 & TRN & \\
\hline CHEMBL1467623 & 737104 & 4.7595 & 4.7776 & TRN & \\
\hline CHEMBL3191015 & 737104 & 6.9101 & 5.831 & TST & \\
\hline CHEMBL1504939 & 737104 & 5.3979 & 5.3838 & TRN & \\
\hline CHEMBL1313807 & 737104 & 4.9547 & 5.04899 & 99999999995 & TRN \\
\hline CHEMBL1580684 & 737104 & 5.4377 & 5.4585 & TRN & \\
\hline CHEMBL3192879 & 737104 & 5.3716 & 5.3911 & TRN & \\
\hline CHEMBL1605172 & 737104 & 5.6326 & 5.6405 & TRN & \\
\hline CHEMBL3199879 & 737104 & 5.4012 & 5.3132 & TRN & \\
\hline CHEMBL1537922 & 737104 & 5.7305 & 5.7786 & TST & \\
\hline CHEMBL1701224 & 737104 & 5.5986 & 5.5792 & TRN & \\
\hline CHEMBL1325664 & 737104 & 5.224 & 5.1804 & TRN & \\
\hline CHEMBL1982888 & 737104 & 5.2321 & 5.3021 & TRN & \\
\hline CHEMBL1329141 & 737104 & 6.9101 & 6.8466 & TRN & \\
\hline CHEMBL1672292 & 737104 & 4.9469 & 5.0213 & TRN & \\
\hline CHEMBL1421970 & 737104 & 5.7212 & 5.6949 & TST & \\
\hline CHEMBL1441794 & 737104 & 5.5186 & 5.4568 & TRN & \\
\hline CHEMBL1966168 & 737104 & 4.7905 & 4.7827 & TRN & \\
\hline CHEMBL3145364 & 737104 & 5.4724 & 5.4376 & TRN & \\
\hline CHEMBL1981200 & 737104 & 4.5986 & 4.5867 & TRN & \\
\hline CHEMBL599924 & 737104 & 5.6498 & 6.3769 & TST & \\
\hline CHEMBL570345 & 737104 & 7.0088 & 5.5108 & TST & \\
\hline CHEMBL3212539 & 737104 & 5.3098 & 5.5244 & TST & \\
\hline CHEMBL1407203 & 737104 & 5.4012 & 5.3751 & TST & \\
\hline CHEMBL1536896 & 737104 & 5.3125 & 5.2556 & TST & \\
\hline CHEMBL66953 & 737104 & 7.0088 & 6.0251 & TST & \\
\hline CHEMBL1324382 & 737104 & 5.4698 & 5.9545 & TST & \\
\hline CHEMBL1325945 & 737104 & 7.0088 & 6.6517 & TST & \\
\hline CHEMBL578512 & 737104 & 7.0088 & 6.9729 & TST & \\
\hline CHEMBL1981446 & 737104 & 5.3224 & 5.2049 & TST & \\
\hline CHEMBL1387693 & 737104 & 5.1772 & 5.5463 & TST & \\
\hline CHEMBL3690625 & 1528801 & 6.6576 & 5.9303 & TST & \\
\hline CHEMBL3694965 & 1528801 & 6.6576 & 6.5919 & TRN & \\
\hline CHEMBL3698535 & 1528801 & 5.5086 & 5.8115 & TRN & \\
\hline CHEMBL3695052 & 1528801 & 5.9208 & 5.8735 & TRN & \\
\hline CHEMBL3694988 & 1528801 & 6.301 & 5.9962 & TRN & \\
\hline CHEMBL 3694944 & 1528801 & 6.7696 & 6.5833 & TRN & \\
\hline CHEMBL3695045 & 1528801 & 5.5086 & 5.7938 & TRN & \\
\hline CHEMBL3694910 & 1528801 & 6.2757 & 6.4433 & TRN & \\
\hline CHEMBL3690684 & 1528801 & 6.0044 & 6.1851 & TST & \\
\hline CHEMBL3690793 & 1528801 & 6.1938 & 6.6068 & TST & \\
\hline
\end{tabular}


Supplemental Table S2.txt

\begin{tabular}{|c|c|c|c|c|}
\hline W & 528801 & & & \\
\hline HЕMPI 2606217 & 528801 & 7.0 & 5.0896 & \\
\hline & 28801 & 76 & & \\
\hline AEMBL & 8801 & & & $\mathrm{MI}$ \\
\hline 590685 & 528801 & 75 & & \\
\hline HEMBL3690639 & 528801 & 5.8539 & 8929 & \\
\hline 50 & 3801 & 86 & & \\
\hline 597 & 28801 & & & RN \\
\hline 586225 & 528801 & & 5155 & \\
\hline HEMBL3694883 & 528801 & 76 & 6672 & \\
\hline HEMBL3686198 & 528801 & 5.65 & 48 & \\
\hline IEMBL & 8801 & & 835 & \\
\hline IEMBL: & 8801 & & & \\
\hline HEMBL3 & 528801 & & .1227 & \\
\hline AEMBL3 & 528801 & & 78 & \\
\hline AEMBL3686233 & 528801 & 6. & 5571 & \\
\hline AEMBL3 & 528801 & & & \\
\hline HEMBL & 8801 & & & \\
\hline AEMBL3694877 & 528801 & & 6.1603 & \\
\hline IEMBL3 & 801 & & & \\
\hline AEMBL: & 01 & & 47 & RIV \\
\hline AEMBL & 3801 & & & RN \\
\hline AEMBL & 801 & & & \\
\hline 61 & 8801 & & & \\
\hline HEMBL 369 & & & & T- \\
\hline AEMBL: & 801 & & 16 & 1 \\
\hline HEM & 01 & & & RN \\
\hline AFMRI & 801 & & 73 & \\
\hline AEMBL & 801 & & & IRIV \\
\hline AEMBL36906 & 01 & & & IK \\
\hline HEMBL $36862 €$ & 801 & & 352 & RN \\
\hline HEME & & & 51 & RN \\
\hline 6 & 01 & 4 & & 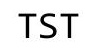 \\
\hline HEMBL3686194 & 528801 & & 6.7961 & IRN \\
\hline HEMBL3698606 & 528801 & & 5.7801 & TST \\
\hline HEMBL3686221 & 3801 & & 971 & TST \\
\hline HᄃMD - & 01 & & 75 & ST \\
\hline HEMBL3690809 & & & 971 & ГRN \\
\hline HEMBL3686230 & 528801 & & 5.8517 & TRN \\
\hline AEMBL36906 & 528801 & 4 & 16 & 「RN \\
\hline HEMBL 3695 & 528801 & 6 & 631 & \\
\hline HEMBL 3695056 & 1528801 & & 5.0917 & ГST \\
\hline HEMBL369 & 528801 & & 6844 & RN \\
\hline AEMBL3690604 & 528801 & 66 & 6.1056 & TR \\
\hline HEMBL36948 & 301 & & & RN \\
\hline HEMBL 3686 & 528801 & & .9928 & \\
\hline HEMBL 36 & & .2924 & 5.8554 & \\
\hline LHEMBL3694955 & 1528801 & 5.4089 & 5.9978 & ГRN \\
\hline
\end{tabular}


Supplemental Table S2.txt

\begin{tabular}{|c|c|c|c|c|}
\hline CHEMBL3695040 & 1528801 & 6.7212 & 6.0833 & TRN \\
\hline CHEMBL3694869 & 1528801 & 6.4202 & 6.1577 & TRN \\
\hline CHEMBL3698602 & 1528801 & 6.699 & 6.9767 & TRN \\
\hline CHEMBL3690605 & 1528801 & 6.301 & 6.3369 & TST \\
\hline CHEMBL3686206 & 1528801 & 6.0315 & 6.0168 & TRN \\
\hline CHEMBL 3686178 & 1528801 & 5.6778 & 5.9019 & TRN \\
\hline CHEMBL 3694908 & 1528801 & 5.1487 & 5.5009 & TRN \\
\hline CHEMBL 3690781 & 1528801 & 5.6778 & 6.0052 & TST \\
\hline CHEMBL3690607 & 1528801 & 6.0315 & 5.584 & TST \\
\hline CHEMBL3698553 & 1528801 & 5.9586 & 6.6567 & TRN \\
\hline CHEMBL3695038 & 1528801 & 6.4815 & 6.4122 & TRN \\
\hline CHEMBL 3686237 & 1528801 & 6.2441 & 5.6643 & TRN \\
\hline CHEMBL 3695041 & 1528801 & 6.0 & 6.3427 & TRN \\
\hline CHEMBL3695046 & 1528801 & 6.0 & 6.2291 & TRN \\
\hline CHEMBL 3690707 & 1528801 & 5.1427 & 6.3499 & TST \\
\hline CHEMBL 3690786 & 1528801 & 7.0969 & \multicolumn{2}{|c|}{6.611000000000001} \\
\hline CHEMBL 3639974 & 1528801 & 6.7959 & \multicolumn{2}{|c|}{6.792999999999999} \\
\hline CHEMBL 3698560 & 1528801 & 6.6778 & 6.0446 & TRN \\
\hline CHEMBL 3690785 & 1528801 & 6.5528 & 6.435 & TRN \\
\hline CHEMBL3690806 & 1528801 & 6.301 & 6.0898 & TST \\
\hline CHEMBL 3690787 & 1528801 & 7.2218 & 6.7097 & TRN \\
\hline CHEMBL3690699 & 1528801 & 5.5528 & 5.9801 & TRN \\
\hline CHEMBL3690795 & 1528801 & 6.6383 & 6.2893 & TRN \\
\hline CHEMBL3694942 & 1528801 & 6.3665 & 6.2995 & TRN \\
\hline CHEMBL 3686214 & 1528801 & 6.7447 & 6.3988 & TST \\
\hline CHEMBL 3698607 & 1528801 & 6.5086 & 5.9691 & TRN \\
\hline CHEMBL 3690745 & 1528801 & 5.5528 & 5.142 & TRN \\
\hline CHEMBL 3690651 & 1528801 & 6.5086 & 6.2183 & TRN \\
\hline CHEMBL 3686190 & 1528801 & 5.1249 & 5.8406 & TRN \\
\hline CHEMBL3694925 & 1528801 & 5.6383 & 5.6904 & TRN \\
\hline CHEMBL 3686257 & 1528801 & 6.1249 & 6.2741 & TRN \\
\hline CHEMBL 3639895 & 1528801 & 6.3468 & 5.9647 & TRN \\
\hline CHEMBL3695062 & 1528801 & 6.8861 & 7.1955 & TRN \\
\hline CHEMBL 3690704 & 1528801 & 6.7959 & 6.6287 & TRN \\
\hline CHEMBL 3686270 & 1528801 & 6.3979 & 6.3791 & TRN \\
\hline CHEMBL 3686204 & 1528801 & 6.1192 & 5.8417 & TRN \\
\hline CHEMBL 3690634 & 1528801 & 6.0132 & 6.0152 & TRN \\
\hline CHEMBL3694920 & 1528801 & 6.7212 & 6.7381 & TRN \\
\hline CHEMBL3694873 & 1528801 & 6.4559 & 5.8372 & TRN \\
\hline CHEMBL3690681 & 1528801 & 4.5229 & 5.8543 & TST \\
\hline CHEMBL 3690763 & 1528801 & 5.2076 & 5.4165 & TRN \\
\hline CHEMBL3694917 & 1528801 & 6.0655 & 6.1504 & TRN \\
\hline CHEMBL3690741 & 1528801 & 5.8239 & 5.8111 & TRN \\
\hline CHEMBL3686163 & 1528801 & 5.7447 & 6.1974 & TRN \\
\hline CHEMBL3686170 & 1528801 & 6.5376 & 5.9813 & TRN \\
\hline CHEMBL 3686247 & 1528801 & 6.6021 & 6.5189 & TRN \\
\hline CHEMBL 3694943 & 1528801 & 5.0458 & 5.9639 & TRN \\
\hline CHEMBL3690656 & 1528801 & 6.1024 & 6.2445 & TRN \\
\hline
\end{tabular}


Supplemental Table S2.txt

\begin{tabular}{|c|c|c|c|c|}
\hline 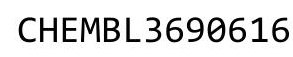 & 801 & & & \\
\hline HEMBL3 & 528801 & 6.5686 & 6.0217 & \\
\hline & & & & \\
\hline 791 & 28801 & 021 & 531 & \\
\hline IEMBL3690630 & 528801 & 7212 & 4051 & \\
\hline HEMBL3694913 & 528801 & 5.9586 & 2797 & \\
\hline HEMBL; & 528801 & 686 & 2905 & \\
\hline 612 & 28801 & 979 & & \\
\hline 94868 & 528801 & 979 & $\partial 624$ & \\
\hline AEMBL3690614 & 528801 & 5.8861 & 8799 & \\
\hline HEMBL3686197 & 528801 & 6.0 & 4028 & \\
\hline IEMBL36 & 528801 & 249 & 8288 & \\
\hline 48 & 28801 & & & \\
\hline AEMBL & 528801 & 528 & 904 & \\
\hline IEMBL3 & 528801 & & 5842 & \\
\hline AEMBL3690759 & 528801 & 556 & & \\
\hline HEMBL & 28801 & 383 & 182 & \\
\hline HEMBL & 28801 & & & \\
\hline 654 & 528801 & 383 & 228 & \\
\hline AEMBL36 & 528801 & & & RN \\
\hline AEMBL3698590 & 28801 & 539 & 141 & \\
\hline HEMBL3C & 28801 & 91 & 961 & \\
\hline HEMBL3 & 28801 & 86 & & RN \\
\hline 700 & 528801 & 125 & & DS > \\
\hline AEMBL3694951 & 28801 & 98 & 71 & RN \\
\hline L3690804 & 28801 & 47 & 506 & RN \\
\hline 702 & 528801 & 72 & 85 & Niv \\
\hline 99 & 801 & & & \\
\hline 0631 & 528801 & & & RN \\
\hline AEMBL3694940 & 528801 & 57 & 86 & RN \\
\hline AEMBL3686177 & 528801 & & 709 & RN \\
\hline 49 & 28801 & & & RN \\
\hline 90 & 01 & & & RN \\
\hline HEMBL3686256 & & & 308 & RN \\
\hline AEMBL3698577 & 528801 & 47 & 276 & ST \\
\hline AEMBL3690766 & 28801 & 03 & 389 & RN \\
\hline 774 & $\partial 1$ & 15 & & RN \\
\hline & 528801 & 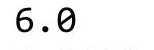 & 415 & RN \\
\hline HEMBL3694882 & 528801 & 5 & 3785 & RN \\
\hline AEMBL3698614 & 528801 & 915 & 779 & RN \\
\hline HEMBL3686169 & 528801 & 979 & 743 & 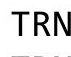 \\
\hline HEMBL3694969 & & & 677 & RN \\
\hline HEMBL3694866 & 528801 & 5.7447 & 4255 & RN \\
\hline AEMBL3694893 & 528801 & 5.8861 & 6.0139 & RN \\
\hline EMBL3690615 & 52880 & 518 & & \\
\hline HEMBL3690757 & 1528801 & 229 & 9835 & \\
\hline HEMBL3694902 & 1020001 & 7.0458 & 6.9076 & \\
\hline LHEMBL 369489 & 1528801 & 5.3665 & 6.317 & RN \\
\hline
\end{tabular}

Page 3199 
Supplemental Table S2.txt

\begin{tabular}{|c|c|c|c|c|}
\hline CHEMBL3690778 & 1528801 & 6.7959 & 6.4767 & TRN \\
\hline CHEMBL3698576 & 1528801 & 5.3565 & 6.4751 & TST \\
\hline CHEMBL3690762 & 1528801 & 4.9172 & 5.0533 & TST \\
\hline CHEMBL3698585 & 1528801 & 6.0 & 5.9398 & TRN \\
\hline CHEMBL3694889 & 1528801 & 4.9872 & 5.3909 & TRN \\
\hline CHEMBL3690726 & 1528801 & 4.7799 & 4.7235 & TRN \\
\hline CHEMBL3695030 & 1528801 & 6.5528 & 6.7177 & TRN \\
\hline CHEMBL3690694 & 1528801 & 7.1549 & 5.9874 & TST \\
\hline CHEMBL3695047 & 1528801 & 6.0177 & \multicolumn{2}{|c|}{5.912000000000001} \\
\hline CHEMBL3690690 & 1528801 & 6.0362 & 6.1744 & TRN \\
\hline CHEMBL3690708 & 1528801 & 5.9208 & 6.4112 & TST \\
\hline CHEMBL3690783 & 1528801 & 6.2147 & 6.5378 & TST \\
\hline CHEMBL3690664 & 1528801 & 6.0655 & 6.3333 & TST \\
\hline CHEMBL3686193 & 1528801 & 5.2757 & 5.6165 & TST \\
\hline CHEMBL3694949 & 1528801 & 6.2676 & 6.2788 & TRN \\
\hline CHEMBL3695059 & 1528801 & 5.8861 & 6.1803 & TRN \\
\hline CHEMBL3690780 & 1528801 & 5.7959 & 5.9065 & TST \\
\hline CHEMBL3694959 & 1528801 & 6.6778 & 6.4268 & TRN \\
\hline CHEMBL3690731 & 1528801 & 5.7212 & 5.6266 & TRN \\
\hline CHEMBL3686215 & 1528801 & 6.8861 & 6.0835 & TST \\
\hline CHEMBL3686192 & 1528801 & 5.1739 & 6.0636 & TST \\
\hline CHEMBL3690663 & 1528801 & 6.4202 & 5.9683 & TRN \\
\hline CHEMBL3690643 & 1528801 & 6.1079 & 6.0884 & TRN \\
\hline CHEMBL3686262 & 1528801 & 4.752 & 5.4108 & TST \\
\hline CHEMBL3690640 & 1528801 & 6.2518 & 6.3264 & TRN \\
\hline CHEMBL3694985 & 1528801 & 5.4685 & 5.3413 & TRN \\
\hline CHEMBL 3690754 & 1528801 & 4.8729 & 5.029 & TRN \\
\hline CHEMBL3690622 & 1528801 & 5.3665 & 5.9904 & TRN \\
\hline CHEMBL3694926 & 1528801 & 5.8239 & 5.8516 & TST \\
\hline CHEMBL3690740 & 1528801 & 5.6198 & 5.7 & TRN \\
\hline CHEMBL3690784 & 1528801 & 4.8268 & 6.2183 & TRN \\
\hline CHEMBL3695044 & 1528801 & 6.0 & 6.2019 & TRN \\
\hline CHEMBL3698595 & 1528801 & 6.1871 & 6.2717 & TST \\
\hline CHEMBL3694979 & 1528801 & 6.1367 & 6.3105 & TRN \\
\hline CHEMBL3698618 & 1528801 & 6.7696 & 6.2712 & TRN \\
\hline CHEMBL3698548 & 1528801 & 6.2218 & 6.2838 & TST \\
\hline CHEMBL3690709 & 1528801 & 6.4815 & 6.48799 & 99999999995 \\
\hline CHEMBL 3690728 & 1528801 & 5.6198 & 5.9476 & TRN \\
\hline CHEMBL 3694914 & 1528801 & 6.2291 & 6.346 & TRN \\
\hline CHEMBL3690772 & 1528801 & 5.0269 & 6.1053 & TST \\
\hline CHEMBL3695042 & 1528801 & 7.0969 & 6.3205 & TRN \\
\hline CHEMBL3695023 & 1528801 & 6.8239 & 6.4897 & TRN \\
\hline CHEMBL3698531 & 1528801 & 6.2924 & 6.0963 & TRN \\
\hline CHEMBL3698542 & 1528801 & 5.4685 & 5.6381 & TRN \\
\hline CHEMBL3686175 & 1528801 & 6.2596 & 6.0439 & TRN \\
\hline CHEMBL3690608 & 1528801 & 5.0862 & 5.9848 & TST \\
\hline CHEMBL3694962 & 1528801 & 5.8539 & 5.6845 & TRN \\
\hline CHEMBL 3694974 & 1528801 & 6.7447 & 6.4967 & TRN \\
\hline
\end{tabular}

Page 3200 
Supplemental Table S2.txt

\begin{tabular}{|c|c|c|c|c|c|}
\hline CHEMBL3690689 & 1528801 & 5.4318 & 5.6069 & TRN & \\
\hline CHEMBL 3686207 & 1528801 & 6.5528 & 6.5782 & TRN & \\
\hline CHEMBL3698603 & 1528801 & 5.9208 & 6.1951 & TRN & \\
\hline CHEMBL 3694964 & 1528801 & 6.585 & 6.7263 & TRN & \\
\hline CHEMBL 3690718 & 1528801 & 5.2518 & 5.1674 & TST & \\
\hline CHEMBL 3695043 & 1528801 & 6.9208 & 6.1297 & TRN & \\
\hline CHEMBL 3690715 & 1528801 & 6.7212 & 6.6295 & TRN & \\
\hline CHEMBL3695039 & 1528801 & 5.9208 & 5.8728 & TRN & \\
\hline CHEMBL 3694856 & 1528801 & 6.4815 & 5.8598 & TRN & \\
\hline CHEMBL 3694897 & 1528801 & 5.4437 & 5.7505 & TRN & \\
\hline CHEMBL 3698619 & 1528801 & 7.1549 & 6.9994 & TST & \\
\hline CHEMBL3690596 & 1528801 & 6.585 & 6.3012 & TRN & \\
\hline CHEMBL3694931 & 1528801 & 6.284 & 6.23600 & 0000000001 & TRN \\
\hline CHEMBL3690679 & 1528801 & 5.2924 & 6.1517 & TST & \\
\hline CHEMBL 3690676 & 1528801 & 5.0605 & 6.152 & TRN & \\
\hline CHEMBL 3686226 & 1528801 & 6.3872 & 6.1917 & TST & \\
\hline CHEMBL3686236 & 1528801 & 6.0177 & 5.6029 & TRN & \\
\hline CHEMBL 3686208 & 1528801 & 6.0 & 6.3996 & TRN & \\
\hline CHEMBL 3690792 & 1528801 & 6.6021 & 6.3016 & TST & \\
\hline CHEMBL 3686171 & 1528801 & 6.0 & 5.5793 & TRN & \\
\hline CHEMBL3694971 & 1528801 & 5.7212 & 5.994 & TRN & \\
\hline CHEMBL 3698611 & 1528801 & 7.1549 & 6.597 & TST & \\
\hline CHEMBL 3695025 & 1528801 & 6.6383 & 6.6129 & TRN & \\
\hline CHEMBL 3698558 & 1528801 & 6.4437 & 6.4688 & TRN & \\
\hline CHEMBL 3686249 & 1528801 & 6.0969 & 6.274 & TRN & \\
\hline CHEMBL 3694847 & 1528801 & 5.1427 & 5.0141 & TRN & \\
\hline CHEMBL3698589 & 1528801 & 6.7447 & 6.7353 & TRN & \\
\hline CHEMBL3694916 & 1528801 & 6.0 & 6.0906 & TRN & \\
\hline CHEMBL3690636 & 1528801 & 6.3372 & 6.1096 & TRN & \\
\hline CHEMBL 3694864 & 1528801 & 6.4318 & 6.3266 & TRN & \\
\hline CHEMBL 3686201 & 1528801 & 6.6198 & 6.1685 & TRN & \\
\hline CHEMBL 3690662 & 1528801 & 6.2218 & 5.9009 & TRN & \\
\hline CHEMBL 3690771 & 1528801 & 4.6556 & 6.4067 & TST & \\
\hline CHEMBL3698568 & 1528801 & 6.6198 & 7.1224 & TRN & \\
\hline CHEMBL3698566 & 1528801 & 5.4202 & 5.972 & TRN & \\
\hline CHEMBL3690687 & 1528801 & 6.0 & 6.2873 & TST & \\
\hline CHEMBL 3695033 & 1528801 & 6.2218 & 6.5101 & TRN & \\
\hline CHEMBL 3694912 & 1528801 & 6.1938 & 6.4357 & TRN & \\
\hline CHEMBL 3690603 & 1528801 & 6.4559 & 5.7402 & TST & \\
\hline CHEMBL 3690775 & 1528801 & 5.0362 & 6.1963 & TST & \\
\hline CHEMBL3694863 & 1528801 & 5.0915 & 5.6785 & TRN & \\
\hline CHEMBL 3690794 & 1528801 & 6.7212 & 6.5648 & TRN & \\
\hline CHEMBL 3698547 & 1528801 & 5.7959 & 6.0177 & TRN & \\
\hline CHEMBL3686158 & 1528801 & 5.2596 & 5.1384 & TRN & \\
\hline CHEMBL3694911 & 1528801 & 6.4202 & \multicolumn{2}{|c|}{6.2139999999999995} & TRN \\
\hline CHEMBL 3694870 & 1528801 & 5.3468 & 5.5332 & TRN & \\
\hline CHEMBL 3694930 & 1528801 & 6.2007 & 6.0734 & TRN & \\
\hline CHEMBL 3690789 & 1528801 & 6.3979 & 6.2791 & TRN & \\
\hline
\end{tabular}


Supplemental Table S2.txt

\begin{tabular}{|c|c|c|c|c|}
\hline The & 528801 & & & \\
\hline & & 5.5686 & & \\
\hline & 801 & & & \\
\hline AEMBL & 8801 & & & 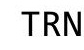 \\
\hline AEMBL & 528801 & & & \\
\hline HEMBL3690686 & 528801 & 6.9586 & 1704 & \\
\hline 90736 & 528801 & & & \\
\hline 586251 & 528801 & & & \\
\hline AEMBL3686245 & 528801 & & & \\
\hline HEMBL3695032 & 528801 & & & \\
\hline HEMBL3698546 & 528801 & & & \\
\hline IEMBL & 28801 & & & \\
\hline IEMBL: & 8801 & & & RN \\
\hline HEMBL3694991 & 528801 & & & \\
\hline AEMBL3694871 & 528801 & & & \\
\hline AEMBL3695016 & 528801 & 37 & 43 & \\
\hline AEMBL3 & 528801 & & & \\
\hline HEMBL36 & 528801 & & & \\
\hline AEMBL3694886 & 528801 & & & \\
\hline AEMBL3686210 & 3801 & & & \\
\hline HEMBL= & 801 & & 7 & - \\
\hline AEMBL: & 3801 & & & 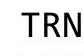 \\
\hline HEMBL; & 801 & & & \\
\hline 90698 & 8801 & & & \\
\hline AEMBL3686216 & 01 & & & $\mathrm{~T}$ \\
\hline AEMBL & 801 & & & SN \\
\hline HEM & 01 & & & RN \\
\hline AFMRI : & 3801 & & & \\
\hline HEMBL3698620 & 3801 & & & 1 \\
\hline AEMBL3686155 & 01 & & & 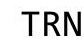 \\
\hline HEMBL3690730 & 3801 & & & RN \\
\hline HEMBL & 01 & & & RN \\
\hline AEMBL: & 01 & & & RN \\
\hline HEMBL3694872 & 528801 & & & IRN \\
\hline HEMBL3695034 & 528801 & & & TRN \\
\hline HEMBL3690758 & 3801 & & 44 & RN \\
\hline HFMRI & 01 & & & RN \\
\hline HEMBL & & & & RN \\
\hline HEMBL3694905 & 528801 & 6. & & $\Gamma \mathrm{RN}$ \\
\hline AEMBL3690632 & 528801 & & & $\Gamma \mathrm{RN}$ \\
\hline HEMBL3686196 & 528801 & & 06 & \\
\hline HEMBL3686153 & 1528801 & & & RIV \\
\hline HEMBL3694878 & 528801 & 4. & 5.2059 & RN \\
\hline AEMBL3686223 & 528801 & 5.3468 & 386 & TRN \\
\hline $\mathrm{MPI}=$ & 801 & & & \\
\hline HEMBL3695006 & 528801 & & - & \\
\hline HEMBL3686164 & 528801 & .9208 & .7 & \\
\hline LHEMBL3690734 & 1528801 & 5.3372 & 5.4585 & RN \\
\hline
\end{tabular}

Page 3202 
Supplemental Table S2.txt

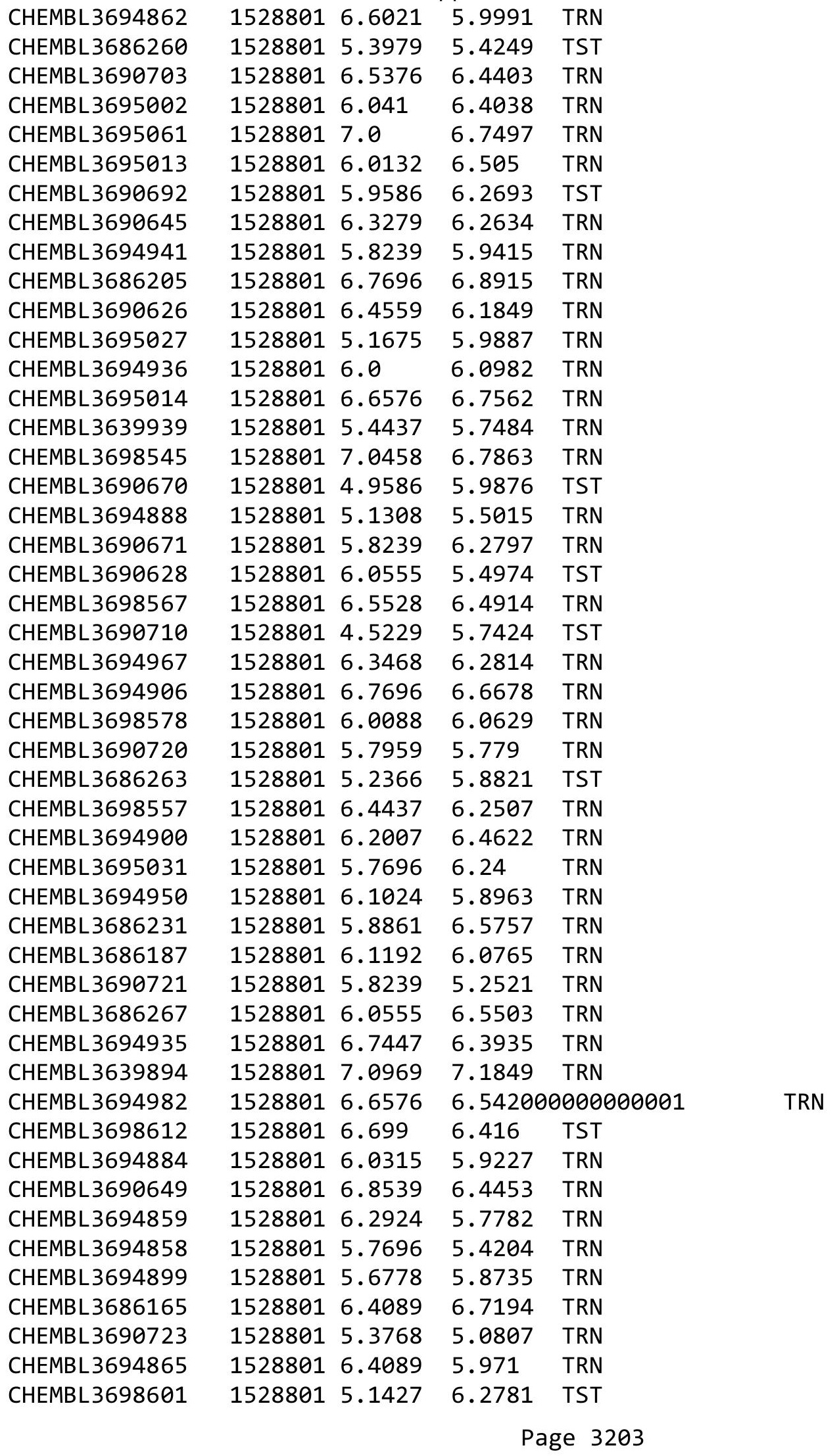


Supplemental Table S2.txt

\begin{tabular}{|c|c|c|c|c|}
\hline CHEMBL 3694984 & 1528801 & 6.9208 & 6.6997 & TRN \\
\hline CHEMBL3698543 & 1528801 & 6.1675 & 6.4103 & TRN \\
\hline CHEMBL3690652 & 1528801 & 6.0 & 6.0947 & TRN \\
\hline CHEMBL 3690683 & 1528801 & 5.2518 & 6.1833 & TST \\
\hline CHEMBL 3686246 & 1528801 & 5.1427 & 5.6953 & TST \\
\hline CHEMBL3690595 & 1528801 & 6.7696 & 6.7743 & TRN \\
\hline CHEMBL3698564 & 1528801 & 5.8239 & 6.0789 & TRN \\
\hline CHEMBL 3690768 & 1528801 & 7.0 & 6.9354 & TRN \\
\hline CHEMBL 3694909 & 1528801 & 5.9208 & 6.1636 & TRN \\
\hline CHEMBL3690669 & 1528801 & 6.0 & 5.8733 & TRN \\
\hline CHEMBL 3694946 & 1528801 & 5.7447 & \multicolumn{2}{|c|}{5.8229999999999995} \\
\hline CHEMBL 3690722 & 1528801 & 4.58 & 5.2168 & TRN \\
\hline CHEMBL 3694972 & 1528801 & 6.7959 & 6.6037 & TRN \\
\hline CHEMBL 3694851 & 1528801 & 5.3979 & 5.8441 & TRN \\
\hline CHEMBL 3690641 & 1528801 & 6.1675 & 6.0076 & TRN \\
\hline CHEMBL 3690765 & 1528801 & 4.5229 & 4.7779 & TRN \\
\hline CHEMBL3690812 & 1528801 & 4.5229 & 5.608 & TRN \\
\hline CHEMBL3690635 & 1528801 & 6.9208 & 6.3096 & TRN \\
\hline CHEMBL 3698613 & 1528801 & 7.1549 & 6.5616 & TRN \\
\hline CHEMBL 3698552 & 1528801 & 5.8539 & 6.4027 & TST \\
\hline CHEMBL 3698541 & 1528801 & 5.4318 & 5.7741 & TRN \\
\hline CHEMBL3698570 & 1528801 & 6.7959 & 6.4061 & TRN \\
\hline CHEMBL 3686152 & 1528801 & 5.699 & 6.0373 & TST \\
\hline CHEMBL 3694867 & 1528801 & 6.3665 & 6.1778 & TRN \\
\hline CHEMBL 3686181 & 1528801 & 6.3372 & 5.902 & TST \\
\hline CHEMBL 3694968 & 1528801 & 6.6383 & 6.3656 & TRN \\
\hline CHEMBL3690779 & 1528801 & 6.2007 & 6.1055 & TRN \\
\hline CHEMBL 3694970 & 1528801 & 6.6383 & \multicolumn{2}{|c|}{6.2620000000000005} \\
\hline CHEMBL 3694874 & 1528801 & 6.1675 & 5.9269 & TRN \\
\hline CHEMBL 3686259 & 1528801 & 6.1308 & 6.1554 & TST \\
\hline CHEMBL 3686151 & 1528801 & 6.1612 & 6.1687 & TRN \\
\hline CHEMBL 3694997 & 1528801 & 5.6576 & 6.0213 & TRN \\
\hline CHEMBL3698596 & 1528801 & 4.6676 & 6.6181 & TST \\
\hline CHEMBL 3686159 & 1528801 & 5.7696 & 5.0709 & TRN \\
\hline CHEMBL 3694915 & 1528801 & 5.6198 & 5.8915 & TRN \\
\hline CHEMBL 3694879 & 1528801 & 6.3665 & 6.0612 & TRN \\
\hline CHEMBL 3698574 & 1528801 & 5.7212 & 6.0663 & TRN \\
\hline CHEMBL 3639851 & 1528801 & 6.1612 & 6.0711 & TRN \\
\hline CHEMBL 3694853 & 1528801 & 5.2518 & 5.9137 & TRN \\
\hline CHEMBL 3690711 & 1528801 & 5.6576 & 5.5009 & TST \\
\hline CHEMBL 3690814 & 1528801 & 6.2757 & 6.0591 & TRN \\
\hline CHEMBL 3686176 & 1528801 & 6.0 & 6.4943 & TRN \\
\hline CHEMBL 3698562 & 1528801 & 6.2366 & 5.8374 & TRN \\
\hline CHEMBL3694977 & 1528801 & 6.585 & 6.1931 & TRN \\
\hline CHEMBL 3690813 & 1528801 & 5.6383 & 5.6561 & TRN \\
\hline CHEMBL 3694921 & 1528801 & 5.9586 & 6.057 & TRN \\
\hline CHEMBL 3694989 & 1528801 & 6.3872 & 6.1516 & TRN \\
\hline CHEMBL3698555 & 1528801 & 6.3565 & 5.9667 & TRN \\
\hline
\end{tabular}


Supplemental Table S2.txt

\begin{tabular}{|c|c|c|c|c|}
\hline - & 801 & & & \\
\hline HEMBL3694998 & 528801 & 5.6198 & 5.7022 & \\
\hline & & & & \\
\hline 706 & 28801 & 021 & & \\
\hline AEMBL3694855 & 528801 & 4.8601 & & \\
\hline AEMBL3698587 & 528801 & 6.0 & 9497 & \\
\hline HEMBL; & 528801 & tכ & 8723 & \\
\hline 593 & 28801 & & 23 & \\
\hline EMBL & 528801 & 83 & .3579 & \\
\hline AEMBL3694901 & 528801 & 6.1739 & . 2972 & \\
\hline HEMBL3690717 & 528801 & 6.301 & 6157 & \\
\hline AEMBL & 528801 & 315 & 7686 & \\
\hline 80 & 28801 & & & \\
\hline AEMBL & 528801 & 15 & & \\
\hline JEMBL3690748 & 528801 & 99 & 9501 & \\
\hline AEMBL3690808 & 528801 & 7212 & 3553 & \\
\hline HEMBL3 & 28801 & 37 & 337 & \\
\hline HEMBL3 & 28801 & & 995 & \\
\hline HEMBL & 528801 & & .7705 & \\
\hline IEMBL 3694 & 528801 & 76 & 1277 & N \\
\hline 753 & 8801 & 17 & 693 & IRN \\
\hline HEMBL3 & 28801 & 8 & 95 & \\
\hline 81 & 28801 & & & \\
\hline 352 & 528801 & 73 & 5843 & \\
\hline IEMBL3 & 8801 & 7 & 85 & RIV \\
\hline 29 & 28801 & 2 & 15 & RN \\
\hline 96 & 528801 & 6 & 53 & RN \\
\hline 17 & 528801 & & & RN \\
\hline 73 & 801 & 5 & & ST \\
\hline AEMBL36 & 28801 & 9 & 85 & RN \\
\hline IEMBL 3690624 & 28801 & 6 & 32 & \\
\hline 212 & 01 & & & \\
\hline & 301 & & 162 & RN \\
\hline HEMBL3695048 & & 5 . & & RN \\
\hline AEMBL3690602 & 528801 & 208 & 098 & RN \\
\hline AEMBL3 & 28801 & 9 & 06 & \\
\hline 92 & $\partial 1$ & & & RIV \\
\hline & 528801 & & 5.6229 & RN \\
\hline HEMBL3698573 & 528801 & 6.3665 & 6.3788 & ST \\
\hline AEMBL3690693 & 528801 & 9 & 838 & ST \\
\hline HEMBL3694923 & 528801 & 49 & 6. & 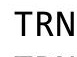 \\
\hline & & & & RN \\
\hline HEMBL3690782 & 528801 & & 2963 & ST \\
\hline IEMBL3690742 & 528801 & 4.9547 & 4.7427 & RN \\
\hline & 52880 & & 604 & \\
\hline HEMBL3690642 & 1528801 & 208 & . 9974 & \\
\hline S & 1528801 & 3372 & 6.0604 & \\
\hline SHEMBL3686203 & 1528801 & 6.4949 & 6.2818 & \\
\hline
\end{tabular}

Page 3205 
Supplemental Table S2.txt

\begin{tabular}{|c|c|c|c|c|c|}
\hline CHEMBL 3690797 & 1528801 & 7.0 & 6.5578 & TRN & \\
\hline CHEMBL3686219 & 1528801 & 4.6655 & 5.8698 & TST & \\
\hline CHEMBL3686240 & 1528801 & 5.699 & 5.8712 & TRN & \\
\hline CHEMBL3694857 & 1528801 & 6.1675 & 6.0262 & TRN & \\
\hline CHEMBL 3698608 & 1528801 & 6.4815 & 6.2338 & TRN & \\
\hline CHEMBL 3690623 & 1528801 & 5.9208 & 5.7904 & TRN & \\
\hline CHEMBL3695004 & 1528801 & 6.2218 & 6.129 & TRN & \\
\hline CHEMBL3690729 & 1528801 & 4.9393 & 5.0807 & TRN & \\
\hline CHEMBL3698605 & 1528801 & 4.6126 & 5.2469 & TST & \\
\hline CHEMBL3690713 & 1528801 & 5.0177 & 5.9441 & TST & \\
\hline CHEMBL 3690610 & 1528801 & 6.5229 & 5.8285 & TST & \\
\hline CHEMBL3690739 & 1528801 & 4.5229 & 4.6156 & TRN & \\
\hline CHEMBL3690677 & 1528801 & 5.2007 & 5.9188 & TRN & \\
\hline CHEMBL3686255 & 1528801 & 5.2366 & 5.9627 & TST & \\
\hline CHEMBL3694992 & 1528801 & 6.5376 & 6.0236 & TRN & \\
\hline CHEMBL 3695000 & 1528801 & 6.2366 & 6.2947 & TRN & \\
\hline CHEMBL3686224 & 1528801 & 6.3768 & 5.8684 & TRN & \\
\hline CHEMBL3686253 & 1528801 & 5.9586 & 5.8083 & TST & \\
\hline CHEMBL3686266 & 1528801 & 4.8894 & 5.9887 & TST & \\
\hline CHEMBL3690668 & 1528801 & 5.4318 & 6.0231 & TST & \\
\hline CHEMBL 3690647 & 1528801 & 5.5528 & 5.9675 & TRN & \\
\hline CHEMBL3698615 & 1528801 & 6.8861 & 6.75899 & 99999999995 & TRN \\
\hline CHEMBL3694973 & 1528801 & 6.7212 & 6.7958 & TRN & \\
\hline CHEMBL3690629 & 1528801 & 6.6778 & 6.5735 & TRN & \\
\hline CHEMBL3695036 & 1528801 & 6.9586 & 6.7781 & TRN & \\
\hline CHEMBL3698610 & 1528801 & 6.699 & 6.3474 & TRN & \\
\hline CHEMBL3694932 & 1528801 & 6.4559 & 6.3213 & TRN & \\
\hline CHEMBL 3690743 & 1528801 & 5.301 & 5.2899 & TRN & \\
\hline CHEMBL3686261 & 1528801 & 5.7959 & 5.9835 & TST & \\
\hline CHEMBL3639896 & 1528801 & 6.1612 & 6.2285 & TST & \\
\hline CHEMBL3690802 & 1528801 & 6.284 & 5.6894 & TST & \\
\hline CHEMBL3690696 & 1528801 & 5.8861 & 5.9421 & TRN & \\
\hline CHEMBL3690617 & 1528801 & 5.6383 & 5.9685 & TST & \\
\hline CHEMBL3695026 & 1528801 & 5.301 & 6.1264 & TST & \\
\hline CHEMBL3686199 & 1528801 & 5.4437 & 5.6516 & TRN & \\
\hline CHEMBL3698561 & 1528801 & 7.0969 & 6.48600 & 0000000001 & TRN \\
\hline CHEMBL3698550 & 1528801 & 5.6383 & 6.109 & TST & \\
\hline CHEMBL3686232 & 1528801 & 6.7212 & 6.6335 & TRN & \\
\hline CHEMBL3686167 & 1528801 & 5.8239 & 6.0692 & TRN & \\
\hline CHEMBL3694957 & 1528801 & 5.585 & 5.9799 & TRN & \\
\hline CHEMBL3694939 & 1528801 & 6.6383 & 6.9801 & TRN & \\
\hline CHEMBL3690619 & 1528801 & 6.1612 & 6.0082 & TRN & \\
\hline CHEMBL 3690620 & 1528801 & 6.585 & 6.6243 & TRN & \\
\hline CHEMBL3690811 & 1528801 & 5.9208 & 5.4199 & TRN & \\
\hline CHEMBL3694996 & 1528801 & 6.1938 & 5.841 & TRN & \\
\hline CHEMBL3695024 & 1528801 & 6.1805 & 6.3539 & TRN & \\
\hline CHEMBL3695065 & 1528801 & 6.7959 & 7.148 & TRN & \\
\hline CHEMBL 3686189 & 1528801 & 5.8239 & 5.81 & TST & \\
\hline
\end{tabular}


Supplemental Table S2.txt

\begin{tabular}{|c|c|c|c|c|}
\hline W & 528801 & .6576 & & \\
\hline & & 5.3565 & & \\
\hline & 801 & & & \\
\hline AEMBL & 801 & & & \\
\hline AEMBL & 528801 & 372 & 1966 & \\
\hline HEMBL3690655 & 528801 & 4.8761 & 9691 & \\
\hline 64 & 801 & & 652 & \\
\hline EM & 8801 & & & \\
\hline AEMBL3690714 & 528801 & & 3173 & \\
\hline HEMBL3686202 & 528801 & 27 & 9398 & \\
\hline HEMBL3686234 & 528801 & & 2955 & \\
\hline EMBL: & 8801 & & 245 & \\
\hline IEMBL & 8801 & & & \\
\hline HEMBL3698532 & 528801 & & .1412 & \\
\hline AEMBL3694963 & 528801 & 7. & 5153 & \\
\hline AEMBL3690747 & 528801 & 78 & 5559 & \\
\hline AEMBL & 8801 & & 66 & \\
\hline AEMBL & 8801 & & & \\
\hline 94999 & 528801 & & & \\
\hline AEMBL: & 801 & & & \\
\hline AEMBL: & OI & & 96 & RIN \\
\hline AEMBL & 3801 & & & RN \\
\hline AEMBL & 801 & & & \\
\hline 98604 & 8801 & & 541 & \\
\hline AEMBL3698616 & & & & I RIV \\
\hline HEMBL; & 801 & & 59 & RN \\
\hline HEM & 01 & & & 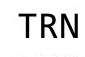 \\
\hline AFMRI & 301 & & 23 & \\
\hline AEMBL3 & 801 & & & in \\
\hline HEMBL3694933 & 01 & & 06 & IK \\
\hline HEMBL 369 & 3801 & & 947 & RN \\
\hline AEME & $\partial 1$ & & 24 & RN \\
\hline AEMBL & $\partial 1$ & & 96 & 3 \\
\hline AEMBL3690697 & 528801 & & 6. & 15 \\
\hline HEMBL3690680 & 528801 & & & TST \\
\hline HEMBL3 & 3801 & & 779 & TST \\
\hline 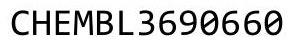 & 1 & & 22 & RN \\
\hline & & & 5.6825 & 「RN \\
\hline HEMBL3694880 & 528801 & 6 . & 5.8573 & TRN \\
\hline AEMBL3686 & 528801 & & 105 & TST \\
\hline HEMBL 3690 & 528801 & & 5.473 & DN \\
\hline HEMBL3686182 & 528801 & & & TRN \\
\hline HEMBL3694947 & 528801 & & 6695 & $R$ \\
\hline AEMBL3690800 & 528801 & 05 & 5.9078 & TR \\
\hline MOL- & 801 & 5 & & $\mathrm{~N}$ \\
\hline HEMBL 36862 & 528801 & & .1356 & \\
\hline HEMBL3686218 & 528801 & 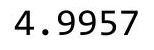 & .0157 & \\
\hline CHEMBL3686154 & 1528801 & 6.0555 & 6.2185 & ГST \\
\hline
\end{tabular}

Page 3207 
Supplemental Table S2.txt

\begin{tabular}{|c|c|c|c|c|}
\hline CHEMBL3686185 & 1528801 & 6.0862 & 6.3418 & TST \\
\hline CHEMBL3694904 & 1528801 & 5.6021 & 6.3985 & TST \\
\hline CHEMBL3686179 & 1528801 & 6.3468 & 6.4042 & TRN \\
\hline CHEMBL3695022 & 1528801 & 5.7959 & 5.9118 & TRN \\
\hline CHEMBL 3686220 & 1528801 & 4.9281 & 6.6131 & TST \\
\hline CHEMBL3686195 & 1528801 & 6.2518 & 6.0335 & TRN \\
\hline CHEMBL3686174 & 1528801 & 6.4949 & 6.2249 & TRN \\
\hline CHEMBL3686200 & 1528801 & 6.5229 & 6.4096 & TRN \\
\hline CHEMBL3690600 & 1528801 & 6.8239 & 6.7733 & TRN \\
\hline CHEMBL3698554 & 1528801 & 7.0969 & 6.6099 & TRN \\
\hline CHEMBL3690621 & 1528801 & 5.3468 & 6.0249 & TRN \\
\hline CHEMBL3694958 & 1528801 & 5.4949 & 5.8122 & TRN \\
\hline CHEMBL3690752 & 1528801 & 5.7959 & 5.5702 & TRN \\
\hline CHEMBL3690653 & 1528801 & 6.2676 & 6.7207 & TRN \\
\hline CHEMBL3690667 & 1528801 & 6.1487 & 5.8563 & TST \\
\hline CHEMBL3690744 & 1528801 & 5.3468 & 5.2425 & TRN \\
\hline CHEMBL3690803 & 1528801 & 5.585 & 6.19600 & 0000000001 \\
\hline CHEMBL3686235 & 1528801 & 7.1549 & 6.2949 & TRN \\
\hline CHEMBL3690770 & 1528801 & 6.2147 & 6.1991 & TRN \\
\hline CHEMBL3695063 & 1528801 & 6.7696 & 6.8416 & TRN \\
\hline CHEMBL3690761 & 1528801 & 4.9469 & 4.7029 & TRN \\
\hline CHEMBL3690807 & 1528801 & 6.2007 & 6.1197 & TRN \\
\hline CHEMBL3695009 & 1528801 & 5.284 & 5.9481 & TRN \\
\hline CHEMBL3686161 & 1528801 & 5.9586 & 6.0514 & TRN \\
\hline CHEMBL3690633 & 1528801 & 5.8239 & 6.2812 & TRN \\
\hline CHEMBL3686168 & 1528801 & 6.2147 & 6.275 & TRN \\
\hline CHEMBL3698559 & 1528801 & 6.0 & 5.65799 & 99999999995 \\
\hline CHEMBL3695060 & 1528801 & 6.7447 & 6.5187 & TRN \\
\hline CHEMBL3694960 & 1528801 & 6.0 & 6.4949 & TRN \\
\hline CHEMBL3690658 & 1528801 & 5.7696 & 6.2394 & TRN \\
\hline CHEMBL3694975 & 1528801 & 6.8861 & 6.7699 & TRN \\
\hline CHEMBL3698575 & 1528801 & 4.8633 & 6.61299 & 99999999995 \\
\hline CHEMBL3694875 & 1528801 & 4.857 & 5.4454 & TRN \\
\hline CHEMBL 3690755 & 1528801 & 5.1739 & 5.4794 & TRN \\
\hline CHEMBL3698572 & 1528801 & 5.4949 & 6.7404 & TST \\
\hline CHEMBL3686186 & 1528801 & 5.8539 & 5.7249 & TST \\
\hline CHEMBL 3686150 & 1528801 & 6.0915 & 6.5351 & TRN \\
\hline CHEMBL3686258 & 1528801 & 6.3468 & 5.9062 & TST \\
\hline CHEMBL 3698571 & 1528801 & 5.9586 & 6.1466 & TST \\
\hline CHEMBL3686183 & 1528801 & 5.8539 & 5.9473 & TRN \\
\hline CHEMBL 3686241 & 1528801 & 6.1308 & 5.50299 & 9999999999 \\
\hline CHEMBL3686238 & 1528801 & 5.4318 & 5.5866 & TST \\
\hline CHEMBL3694903 & 1528801 & 6.3665 & 6.3667 & TRN \\
\hline CHEMBL3694849 & 1528801 & 4.8962 & 5.6038 & TRN \\
\hline CHEMBL3695051 & 1528801 & 5.5528 & 5.9434 & TRN \\
\hline CHEMBL3698569 & 1528801 & 6.9208 & 6.0991 & TST \\
\hline CHEMBL3690665 & 1528801 & 6.0458 & 6.0698 & TRN \\
\hline CHEMBL 3686252 & 1528801 & 6.1938 & 5.8783 & TRN \\
\hline
\end{tabular}


Supplemental Table S2.txt

\begin{tabular}{|c|c|c|c|c|}
\hline CHEMBL3690682 & 1528801 & 6.4815 & 5.9777 & TRN \\
\hline CHEMBL3686227 & 1528801 & 6.0 & 5.934 & TRN \\
\hline CHEMBL3698609 & 1528801 & 5.7696 & \multicolumn{2}{|c|}{6.031000000000001} \\
\hline CHEMBL 3690801 & 1528801 & 6.3768 & 6.665 & TRN \\
\hline CHEMBL3690598 & 1528801 & 6.8861 & 7.0889 & TRN \\
\hline CHEMBL3686269 & 1528801 & 5.284 & 6.5751 & TRN \\
\hline CHEMBL3686264 & 1528801 & 5.9586 & 6.3011 & TST \\
\hline CHEMBL3695021 & 1528801 & 6.0969 & 6.1134 & TRN \\
\hline CHEMBL3695037 & 1528801 & 6.3188 & 5.9683 & TRN \\
\hline CHEMBL3690637 & 1528801 & 6.3979 & 5.9915 & TRN \\
\hline CHEMBL3698551 & 1528801 & 6.7696 & 6.8453 & TST \\
\hline CHEMBL3694928 & 1528801 & 6.585 & 6.4274 & TRN \\
\hline CHEMBL 3690724 & 1528801 & 5.4318 & 5.4887 & TRN \\
\hline CHEMBL3690609 & 1528801 & 5.3098 & 5.5651 & TRN \\
\hline CHEMBL3694861 & 1528801 & 5.0044 & 5.2997 & TRN \\
\hline CHEMBL3686166 & 1528801 & 6.0044 & 5.8229 & TRN \\
\hline CHEMBL3695012 & 1528801 & 6.8861 & 6.2797 & TRN \\
\hline CHEMBL3694983 & 1528801 & 6.699 & 6.4146 & TRN \\
\hline CHEMBL3698621 & 1528801 & 4.5702 & 6.1017 & TST \\
\hline CHEMBL3690727 & 1528801 & 5.8239 & 5.0011 & TST \\
\hline CHEMBL3686254 & 1528801 & 7.0 & 6.1748 & TST \\
\hline CHEMBL3694954 & 1528801 & 5.6778 & 5.6741 & TST \\
\hline CHEMBL3686250 & 1528801 & 5.4685 & 5.485 & TST \\
\hline CHEMBL 3690732 & 1528801 & 5.3565 & 5.2168 & TST \\
\hline CHEMBL 3690788 & 1528801 & 6.6198 & 6.2871 & TST \\
\hline CHEMBL3686188 & 1528801 & 6.1367 & 5.8265 & TST \\
\hline CHEMBL3690751 & 1528801 & 5.6778 & 5.407 & TST \\
\hline CHEMBL3694995 & 1528801 & 6.1612 & 5.8083 & TST \\
\hline CHEMBL 3698579 & 1528801 & 6.2218 & 6.5148 & TST \\
\hline CHEMBL3690674 & 1528801 & 5.5686 & 5.8024 & TST \\
\hline CHEMBL3690810 & 1528801 & 5.7447 & 5.9853 & TST \\
\hline CHEMBL3690750 & 1528801 & 5.6198 & 5.5427 & TST \\
\hline CHEMBL 3690737 & 1528801 & 5.1871 & 5.3841 & TST \\
\hline CHEMBL3698556 & 1528801 & 6.0809 & 5.9405 & TST \\
\hline CHEMBL3695008 & 1528801 & 5.6576 & 6.2286 & TST \\
\hline CHEMBL3695001 & 1528801 & 6.4949 & 6.1037 & TST \\
\hline CHEMBL3690725 & 1528801 & 5.9586 & 5.7028 & TST \\
\hline CHEMBL3690627 & 1528801 & 5.3279 & 5.9391 & TST \\
\hline CHEMBL3694876 & 1528801 & 5.6198 & 5.5196 & TST \\
\hline CHEMBL3698580 & 1528801 & 6.8861 & 6.572 & TST \\
\hline CHEMBL3694956 & 1528801 & 6.0088 & 6.3135 & TST \\
\hline CHEMBL3694896 & 1528801 & 5.9586 & 6.2403 & TST \\
\hline CHEMBL3690648 & 1528801 & 6.7447 & 6.3744 & TST \\
\hline CHEMBL3695055 & 1528801 & 5.8239 & 5.7972 & TST \\
\hline CHEMBL3690618 & 1528801 & 4.9747 & 5.8428 & TST \\
\hline CHEMBL3686248 & 1528801 & 5.699 & 5.9884 & TST \\
\hline CHEMBL3690666 & 1528801 & 6.7696 & 6.0803 & TST \\
\hline CHEMBL3690638 & 1528801 & 5.9586 & 6.1083 & TST \\
\hline
\end{tabular}


Supplemental Table S2.txt

\begin{tabular}{|c|c|c|c|c|c|c|}
\hline CHEMBL 3690661 & 1528801 & 6.3098 & 6.1451 & TST & & \\
\hline CHEMBL 3690798 & 1528801 & 6.4685 & 6.33299 & 999999999 & & TST \\
\hline CHEMBL 3690777 & 1528801 & 6.7447 & 6.4948 & TST & & \\
\hline CHEMBL 3690733 & 1528801 & 5.1135 & 5.1362 & TST & & \\
\hline CHEMBL3698594 & 1528801 & 6.3468 & 6.2944 & TST & & \\
\hline CHEMBL3694934 & 1528801 & 6.0 & 6.11100 & 000000000 & & TST \\
\hline CHEMBL 3686229 & 1528801 & 6.0 & 6.67200 & 000000000 & & \\
\hline CHEMBL 3694929 & 1528801 & 5.4949 & 6.4984 & TST & & \\
\hline CHEMBL 3922879 & 1641260 & 8.301 & 8.2113 & TRN & & \\
\hline CHEMBL3975222 & 1641260 & 9.0 & 9.0623 & TRN & & \\
\hline CHEMBL3947789 & 1641260 & 7.7212 & 8.1863 & TST & & \\
\hline CHEMBL 3901800 & 1641260 & 7.5686 & 7.5404 & TRN & & \\
\hline CHEMBL3981935 & 1641260 & 9.0 & 9.1481 & TRN & & \\
\hline CHEMBL 3955492 & 1641260 & 6.9101 & 6.7922 & TRN & & \\
\hline CHEMBL3942390 & 1641260 & 9.0 & 8.7997 & TRN & & \\
\hline CHEMBL3980938 & 1641260 & 6.4698 & 6.569 & TST & & \\
\hline CHEMBL3977495 & 1641260 & 7.7959 & 7.761 & TST & & \\
\hline CHEMBL 3898325 & 1641260 & 7.8239 & 8.2909 & TST & & \\
\hline CHEMBL 3925735 & 1641260 & 8.0969 & 8.0272 & TRN & & \\
\hline CHEMBL3929964 & 1641260 & 7.699 & 7.9243 & TRN & & \\
\hline CHEMBL3931305 & 1641260 & 7.4318 & 8.0807 & TRN & & \\
\hline CHEMBL 3955838 & 1641260 & 8.699 & 8.9059 & TRN & & \\
\hline CHEMBL 3896923 & 1641260 & 6.9393 & 7.9868 & TRN & & \\
\hline CHEMBL 3924887 & 1641260 & 7.8239 & 7.0501 & TRN & & \\
\hline CHEMBL 3927965 & 1641260 & 6.2503 & 5.9789 & TRN & & \\
\hline CHEMBL3962243 & 1641260 & 7.4815 & 8.3176 & TRN & & \\
\hline CHEMBL 3972867 & 1641260 & 6.0 & 6.3799 & TRN & & \\
\hline CHEMBL3927199 & 1641260 & \multicolumn{3}{|c|}{6.821000000000001} & 6.5767 & \\
\hline CHEMBL 3937948 & 1641260 & 7.9208 & 8.2527 & TRN & & \\
\hline CHEMBL 3957009 & 1641260 & 8.5229 & 8.672 & TRN & & \\
\hline CHEMBL 3896469 & 1641260 & 6.06 & 5.8756 & TRN & & \\
\hline CHEMBL 3947108 & 1641260 & 7.041 & 6.7229 & TRN & & \\
\hline CHEMBL 3936255 & 1641260 & 10.0 & 8.5127 & TRN & & \\
\hline CHEMBL3914636 & 1641260 & 7.7959 & 7.8443 & TST & & \\
\hline CHEMBL 3983380 & 1641260 & 8.0458 & 8.3997 & TST & & \\
\hline CHEMBL 3914724 & 1641260 & 7.8239 & 7.4792 & TRN & & \\
\hline CHEMBL3895615 & 1641260 & 7.4949 & 7.3343 & TRN & & \\
\hline CHEMBL 3920926 & 1641260 & 9.0 & 8.8078 & TST & & \\
\hline CHEMBL 3948257 & 1641260 & 8.3979 & 8.4036 & TRN & & \\
\hline CHEMBL 3929436 & 1641260 & 8.0969 & 8.2256 & TRN & & \\
\hline CHEMBL3973554 & 1641260 & 8.5229 & 9.2092 & TRN & & \\
\hline CHEMBL3952268 & 1641260 & 7.3979 & 7.9067 & TRN & & \\
\hline CHEMBL3973393 & 1641260 & 10.0 & 9.2122 & TRN & & \\
\hline CHEMBL 3918768 & 1641260 & 7.3188 & 7.5685 & TRN & & \\
\hline CHEMBL3911309 & 1641260 & 6.0 & 5.5744 & TRN & & \\
\hline CHEMBL 3956847 & 1641260 & 7.699 & 7.6519 & TRN & & \\
\hline CHEMBL3924579 & 1641260 & 7.7959 & 8.1733 & TRN & & \\
\hline CHEMBL3974411 & 1641260 & 8.5229 & 8.3121 & TRN & & \\
\hline
\end{tabular}


Supplemental Table S2.txt

\begin{tabular}{|c|c|c|c|c|}
\hline HEN & 541260 & 8.699 & 6445 & \\
\hline HFMRI 3923577 & 641260 & 7.8861 & 7.9891 & \\
\hline$A F A$ & 260 & & & \\
\hline AEMBL & 260 & 5229 & 3557 & \\
\hline AEMBL3951214 & 260 & 2809 & & \\
\hline HEMBL3956839 & 641260 & 10.0 & 6425 & \\
\hline 94 & 260 & 6.8794 & 204 & \\
\hline IFMRI 39 & & 969 & 68 & \\
\hline AEMBL3890997 & 260 & 5.44 & 5.5298 & \\
\hline HEMBL3971913 & 260 & 7.9586 & 2524 & \\
\hline HEMBL3957064 & 260 & 6.0 & 5195 & \\
\hline IEMBL39e & 60 & 208 & 639 & \\
\hline AEMBL39 & & & & \\
\hline HEMBL 39 & 260 & 7.6576 & 8.0956 & \\
\hline AEMBL393 & 260 & 778 & 543 & \\
\hline HEMBL 390982 & 50 & 8 & 5084 & \\
\hline HEMBL39 & 60 & 979 & 871 & \\
\hline HEMBL39 & & 84 & & \\
\hline HEMBL 398 & & 7.3979 & 7.0655 & \\
\hline AEMBL39 & & 7.8239 & 3059 & \\
\hline HEIMBLSS & 0 & 097 & 524 & \\
\hline AEMBL39 & & 979 & 167 & \\
\hline HEMBL39 & & 16 & 842 & \\
\hline HEMBL 39 & & 7.0223 & 1997 & \\
\hline HEMBL392 & 50 & 6. & 301 & RN \\
\hline HEMBL398 & & 72 & 834 & \\
\hline HEMBL39 & & & 112 & \\
\hline HFMBI 30 & 60 & 01 & 398 & RN \\
\hline HEMBL394 & & 7.2218 & & RN \\
\hline HEMBL 3892243 & 50 & 1503 & 7468 & RN \\
\hline HEMBL 389 & & 576 & 5128 & RN \\
\hline HFMBI $3 C^{-}$ & & 33 & 06 & RN \\
\hline 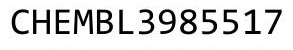 & & 202 & 713 & RN \\
\hline HEMBL3972464 & 60 & & 7083 & I \\
\hline AEMBL394509 & 60 & 969 & 9342 & RN \\
\hline HEMBL389 & 60 & 549 & 205 & ST \\
\hline HCMDI ? & & & & RN \\
\hline HEMBL3943877 & & & 1922 & RN \\
\hline HEMBL3974519 & 60 & 086 & 5144 & TRN \\
\hline IEMBL39 & & & 272 & RN \\
\hline HEMBL396 & 60 & & 391 & \\
\hline CHEMBL390 & & 58 & 8.4866 & RN \\
\hline HEMBL3934757 & 260 & 10.0 & 2123 & $\mathrm{RN}$ \\
\hline AEMBL3980914 & 260 & 7.2924 & 7086 & ГRN \\
\hline EBL39 & & 0 & 5455 & \\
\hline CHEMBL 390107 & & & .3529 & \\
\hline HEN & ש & & .8135 & \\
\hline THEMBL3916892 & 1641260 & .795 & 7.5238 & ГRN \\
\hline
\end{tabular}

Page 3211 
Supplemental Table S2.txt

\begin{tabular}{|c|c|c|c|c|}
\hline CHEMBL3958759 & 1641260 & 8.0458 & 7.6481 & TRN \\
\hline CHEMBL3962449 & 1641260 & 8.699 & 8.5036 & TRN \\
\hline CHEMBL3917963 & 1641260 & 6.6904 & 6.8137 & TRN \\
\hline CHEMBL3933407 & 1641260 & 7.0605 & 6.9283 & TRN \\
\hline CHEMBL3907350 & 1641260 & 7.2007 & 7.4375 & TRN \\
\hline CHEMBL3912749 & 1641260 & 7.9586 & 7.1845 & TRN \\
\hline CHEMBL 3900411 & 1641260 & 8.699 & 8.648 & TRN \\
\hline CHEMBL3923489 & 1641260 & 7.585 & 7.5117 & TRN \\
\hline CHEMBL3924684 & 1641260 & 7.7696 & 7.754 & TRN \\
\hline CHEMBL 3893224 & 1641260 & 7.9586 & 8.1359 & TRN \\
\hline CHEMBL3911138 & 1641260 & 8.699 & 8.9877 & TST \\
\hline CHEMBL3972197 & 1641260 & 7.699 & 7.5123 & TST \\
\hline CHEMBL3925219 & 1641260 & 7.5229 & 7.1899 & TST \\
\hline CHEMBL3948184 & 1641260 & 7.8239 & 7.8893 & TST \\
\hline CHEMBL3905403 & 1641260 & 6.5406 & 5.9599 & TST \\
\hline CHEMBL3928917 & 1641260 & 7.1675 & 7.09 & TST \\
\hline CHEMBL3967869 & 1641260 & 7.6383 & 7.699 & TST \\
\hline CHEMBL3949061 & 1641260 & 7.8539 & 8.1787 & TST \\
\hline CHEMBL3935376 & 1641260 & 7.5229 & 7.1949 & TST \\
\hline CHEMBL 3949138 & 1641260 & 8.2218 & \multicolumn{2}{|c|}{8.152000000000001} \\
\hline CHEMBL 3894650 & 1641260 & 7.585 & 8.7429 & TST \\
\hline CHEMBL 3966628 & 1641260 & 7.7696 & 7.4997 & TST \\
\hline CHEMBL3984459 & 1641260 & 7.6383 & 7.4809 & TST \\
\hline CHEMBL 3948193 & 1641260 & 8.5229 & 7.6402 & TST \\
\hline CHEMBL 3894249 & 1641260 & 8.5229 & 8.9747 & TST \\
\hline CHEMBL 3656525 & 1527622 & 9.2218 & 8.7653 & TST \\
\hline CHEMBL3656499 & 1527622 & 9.0969 & 9.1914 & TRN \\
\hline CHEMBL 3656511 & 1527622 & 9.1549 & 8.7696 & TRN \\
\hline CHEMBL3656476 & 1527622 & 9.699 & 9.363 & TRN \\
\hline CHEMBL3656509 & 1527622 & 9.3979 & 8.8299 & TST \\
\hline CHEMBL 3656503 & 1527622 & 8.0809 & 8.3988 & TRN \\
\hline CHEMBL 3656482 & 1527622 & 9.699 & \multicolumn{2}{|c|}{9.472999999999999} \\
\hline CHEMBL3656496 & 1527622 & 9.699 & 9.6139 & TRN \\
\hline CHEMBL3656489 & 1527622 & 9.3979 & 9.0716 & TRN \\
\hline CHEMBL3656506 & 1527622 & 8.6383 & 8.8883 & TRN \\
\hline CHEMBL 3656533 & 1527622 & 9.699 & 9.6357 & TRN \\
\hline CHEMBL3656532 & 1527622 & 9.0969 & 8.7604 & TRN \\
\hline CHEMBL3656491 & 1527622 & 9.699 & 9.3522 & TRN \\
\hline CHEMBL 3656490 & 1527622 & 8.9208 & 8.9437 & TRN \\
\hline CHEMBL3656475 & 1527622 & 10.0 & 9.9146 & TRN \\
\hline CHEMBL 3656501 & 1527622 & 9.301 & 9.3264 & TRN \\
\hline CHEMBL 3656498 & 1527622 & 9.1549 & 9.1682 & TRN \\
\hline CHEMBL3656522 & 1527622 & 9.2218 & 9.3292 & TRN \\
\hline CHEMBL 3656508 & 1527622 & 8.6383 & 8.6973 & TST \\
\hline CHEMBL 3656493 & 1527622 & 8.3979 & 8.9247 & TRN \\
\hline CHEMBL 3660707 & 1527622 & 9.1549 & 8.873 & TRN \\
\hline CHEMBL 3656477 & 1527622 & 9.2218 & 9.1326 & TRN \\
\hline CHEMBL 3656497 & 1527622 & 8.8861 & 8.8801 & TRN \\
\hline
\end{tabular}


Supplemental Table S2.txt

\begin{tabular}{|c|c|c|c|c|}
\hline The & 527622 & & & 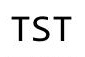 \\
\hline & 527622 & 8.0809 & 3.6656 & \\
\hline & 622 & & & \\
\hline AEMBL & 7622 & & & \\
\hline AEMBL & 527622 & 10.0 & & \\
\hline HEMBL3656520 & 527622 & 8.6198 & 3559 & \\
\hline 08 & 622 & & 94 & \\
\hline 519 & 622 & & & \\
\hline AEMBL36 & 527622 & 9208 & 2053 & \\
\hline HEMBL3656488 & 527622 & 10.0 & 5056 & \\
\hline AEMBL3656523 & 622 & 9.2218 & 271 & \\
\hline IEMBL & 622 & 9. & 5889 & \\
\hline IEMBL: & & & & \\
\hline HEMBL3 & 622 & 7959 & 8.9892 & \\
\hline AEMBL36 & 622 & 10.0 & & \\
\hline AEMBL366 & 622 & 8.0757 & 41 & \\
\hline AEMBL3 & 22 & 24 & 25 & \\
\hline HEMBL3 & & & & \\
\hline AEMBL3 & 622 & & .7348 & \\
\hline AEMBL3 & 522 & & & \\
\hline HEMBL= & 22 & 291 & 91 & NIV \\
\hline IEMBL & 22 & & & זים \\
\hline AEMBL & 22 & & & \\
\hline 710 & 622 & & & \\
\hline AEMBL36 & & & & וSו \\
\hline HEMBL3 & 22 & 7. & 7 & SI \\
\hline HEMBL & 22 & & & ST \\
\hline AFMRI : & 22 & 9. & 46 & RN \\
\hline HEMBL3 & & & & TST \\
\hline HEMBL3656530 & & & & IR \\
\hline HEMBL36 & 22 & 9 & .04 & ST \\
\hline HEMBL & 22 & & 94 & RN \\
\hline AEMBL: & 22 & & 99 & RN \\
\hline HEMBL3656507 & & & 206 & $\Gamma \mathrm{RN}$ \\
\hline HEMBL3656487 & 622 & 10.0 & 59 & RN \\
\hline HEMBL3 & 22 & & 393 & ST \\
\hline HCMP - & & 8 & 77 & RN \\
\hline HEMBL & & 10.0 & . 3659 & TRN \\
\hline HEMBL3656484 & 622 & 9. & 5189 & TRN \\
\hline AEMBL3 & 522 & 9. & 83 & RN \\
\hline HEMBL36 & 22 & 16 & 4206 & RN \\
\hline HEMBL 3 & & & & TST \\
\hline HEMBL36 & 622 & & 9.3661 & TST \\
\hline AEMBL3660703 & 622 & 7.5768 & 5839 & TST \\
\hline $1=$ & & & 7842 & ST \\
\hline HEMBL3 & 622 & & & -1 \\
\hline CHEMBL 3656524 & 527622 & 9.3979 & 9.4006 & SI \\
\hline CHEMBL3656500 & 1527622 & 8.3979 & 8.4614 & ST \\
\hline
\end{tabular}

Page 3213 


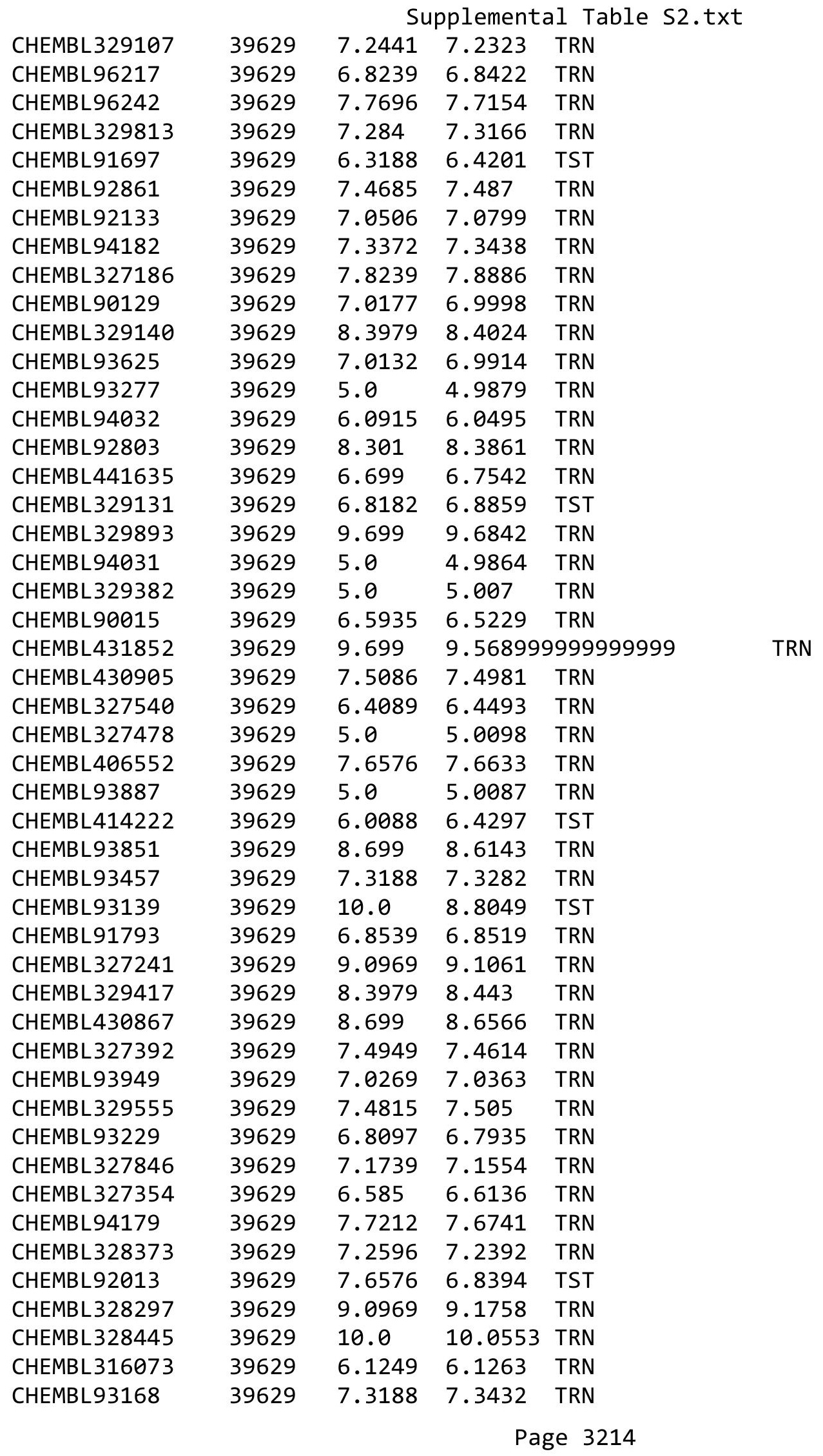




\begin{tabular}{|c|c|c|c|c|c|}
\hline \multicolumn{6}{|c|}{ Supplemental Table S2.txt } \\
\hline CHEMBL327800 & 39629 & 6.8539 & 6.8397 & TRN & \\
\hline CHEMBL93644 & 39629 & 6.2147 & 6.2216 & TRN & \\
\hline CHEMBL328260 & 39629 & 9.0969 & 9.4482 & TST & \\
\hline CHEMBL327898 & 39629 & 7.3372 & 7.7928 & TST & \\
\hline CHEMBL315159 & 39629 & 7.7212 & 7.2865 & TST & \\
\hline CHEMBL330065 & 39629 & 6.6576 & 6.601 & TST & \\
\hline CHEMBL327801 & 39629 & 8.0458 & 8.8782 & TST & \\
\hline CHEMBL91339 & 39629 & 5.0 & 6.3874 & TST & \\
\hline CHEMBL93961 & 39629 & 7.9208 & 7.7583 & TST & \\
\hline CHEMBL330528 & 39629 & 7.585 & 6.9003 & TST & \\
\hline CHEMBL85086 & 39629 & 8.1549 & 7.6903 & TST & \\
\hline CHEMBL330285 & 39629 & 5.0 & 7.0941 & TST & \\
\hline CHEMBL93691 & 39629 & 5.0 & 6.2126 & TST & \\
\hline CHEMBL 2420644 & 978888 & 4.0 & 5.5099 & TST & \\
\hline CHEMBL 2420668 & 978888 & 4.0 & 4.1393 & TRN & \\
\hline CHEMBL 2420622 & 978888 & 9.0 & 8.7428 & TRN & \\
\hline CHEMBL2420659 & 978888 & 7.8539 & 7.8572 & TRN & \\
\hline CHEMBL 2420637 & 978888 & 6.8861 & 7.2425 & TRN & \\
\hline CHEMBL 2420642 & 978888 & 4.0 & 4.7057 & TRN & \\
\hline CHEMBL 2420628 & 978888 & 9.0 & 9.1923 & TRN & \\
\hline CHEMBL 2420658 & 978888 & 8.2218 & 7.605 & TRN & \\
\hline CHEMBL 2420641 & 978888 & 4.0 & 3.9285 & TRN & \\
\hline CHEMBL17289 & 978888 & 8.301 & 5.6081 & TST & \\
\hline CHEMBL 2420651 & 978888 & 7.9586 & 7.9679 & TRN & \\
\hline CHEMBL 2420660 & 978888 & 5.7959 & 5.9407 & TRN & \\
\hline CHEMBL 2420661 & 978888 & 4.0 & 3.8418 & TRN & \\
\hline CHEMBL 2420640 & 978888 & 4.0 & 4.2555 & TRN & \\
\hline CHEMBL 2420670 & 978888 & 8.0 & 7.1574 & TRN & \\
\hline CHEMBL 2420619 & 978888 & 7.8539 & 7.7489 & TRN & \\
\hline CHEMBL 2420652 & 978888 & 5.2676 & 5.0515 & TRN & \\
\hline CHEMBL 2420621 & 978888 & 7.3188 & 7.6431 & TRN & \\
\hline CHEMBL 2420671 & 978888 & 4.0 & 4.1672 & TRN & \\
\hline CHEMBL 2420626 & 978888 & 8.699 & 9.0521 & TRN & \\
\hline CHEMBL 2419503 & 978888 & 7.7447 & 7.2362 & TRN & \\
\hline CHEMBL 2420635 & 978888 & 4.0 & 3.92199 & 99999999997 & TRN \\
\hline CHEMBL 2420665 & 978888 & 4.0 & 4.0331 & TST & \\
\hline CHEMBL 2420629 & 978888 & 8.699 & 7.9482 & TRN & \\
\hline CHEMBL 2420656 & 978888 & 5.8239 & 6.2392 & TRN & \\
\hline CHEMBL 2420643 & 978888 & 4.0 & 3.7662 & TRN & \\
\hline CHEMBL 2420632 & 978888 & 8.5229 & 8.7438 & TRN & \\
\hline CHEMBL566757 & 978888 & 9.0 & 4.9659 & TST & \\
\hline CHEMBL 2420646 & 978888 & 7.8861 & 8.0621 & TRN & \\
\hline CHEMBL 2420638 & 978888 & 7.1675 & 7.4541 & TRN & \\
\hline CHEMBL 2420673 & 978888 & 5.7696 & 6.2107 & TRN & \\
\hline CHEMBL 2420654 & 978888 & 4.0 & 4.3828 & TRN & \\
\hline CHEMBL 2420631 & 978888 & 9.0 & 7.9491 & TST & \\
\hline CHEMBL 2420649 & 978888 & 8.5229 & 8.3307 & TRN & \\
\hline CHEMBL 2420634 & 978888 & 8.699 & 8.8886 & TST & \\
\hline
\end{tabular}




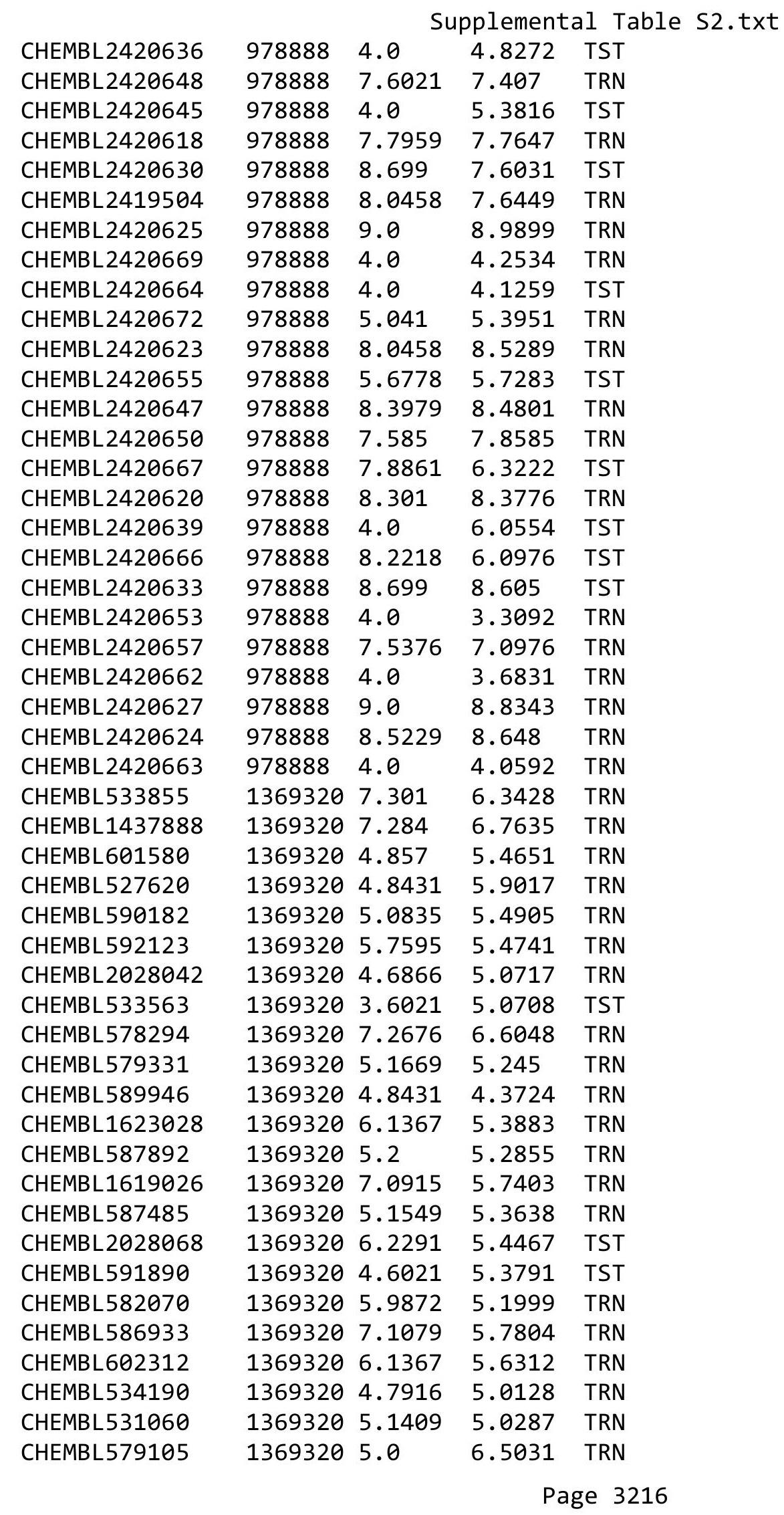


Supplemental Table S2.txt

\begin{tabular}{|c|c|c|c|c|}
\hline CHEMBL526587 & & & 5.4794 & 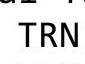 \\
\hline CHEMBI 585966 & 369320 & 4.8775 & 5.0218 & TRN \\
\hline HEMBLS & 99320 & 6.3768 & 3866 & \\
\hline HEMBL 592332 & 369320 & 6.585 & 0435 & \\
\hline HEMBL 589733 & 369320 & 6.0862 & 3462 & \\
\hline HEMBL5 & 69320 & 5086 & 3977 & \\
\hline HEMBL 534319 & 369320 & 6.0044 & 6711 & PN \\
\hline HEMBL 2028048 & 369320 & 4.73 & .1484 & \\
\hline HEMBL534612 & 369320 & 7.0 & 5.5815 & \\
\hline HEMBL6 & 320 & 5 . & 26 & \\
\hline HEMBL6 & 320 & 4.8861 & .1347 & \\
\hline HEMBL 5 & 320 & 7.0 & 3088 & \\
\hline HEMBL537778 & 369320 & 5.67 & 5.4317 & 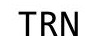 \\
\hline HEMBL 607688 & 320 & 75 & 5.8163 & \\
\hline HEMBL5 & 20 & 4. & 5.472 & \\
\hline HEMBL: & 20 & 12 & 35 & RN \\
\hline HEMBL: & & & & \\
\hline HEMBL1 & 320 & 4.6021 & 25 & $\mathrm{RN}$ \\
\hline HEMBL5 & 320 & 4. & & \\
\hline HEMBLS & 20 & 6.0 & 71 & RN \\
\hline HEMBL & & 3. & & RN \\
\hline HEMBL & & & & RN \\
\hline HEMBL3 & 320 & & & TRN \\
\hline HEMBL5 & & & & TRN \\
\hline HEMBL 2 & & 5 . & 312 & TRN \\
\hline HEMBL & & & & ST \\
\hline HEMBL & & & & I T \\
\hline HEMBL5 & & 4. & & TST \\
\hline HEMBL601 & 20 & & 977 & TRN \\
\hline CHEMBL5 & 20 & 4. & 5.2004 & RN \\
\hline HEMBL & 20 & & 67 & $\mathrm{RN}$ \\
\hline HEMBL & & 7. & 67 & TRN \\
\hline HEMBL532 & 20 & 7.301 & 3612 & TRN \\
\hline HEMBL 202 & 320 & 4. & 5.1801 & TRN \\
\hline HEMBL5 & & & 544 & TRN \\
\hline HEMBL & & & 61 & 「RN \\
\hline CHEMBL5 & & 6. & 792 & TST \\
\hline HEMBL 20 & 369320 & 3.6021 & $\partial 209$ & TRN \\
\hline CHEMBL596643 & 369320 & 4.8431 & 3297 & TR \\
\hline CHEMBL & & & & TRN \\
\hline CHEMBL5 & & 5 & 74 & TRN \\
\hline CHEMBL 5 & 369320 & 4.8768 & 5.1616 & TRN \\
\hline CHEMBL589205 & 369320 & 6 . & 8134 & $T R$ \\
\hline CHEMBL529348 & 320 & 5 . & 5.2409 & ח \\
\hline CHEMBL 5 & & & & $T$ \\
\hline HEMBL 2 & 320 & 5.9788 & 5.9719 & \\
\hline CHEMBL602413 & 1369320 & 5.4401 & 5.3632 & rRN \\
\hline CHEMBL2028054 & 1369320 & 4.7457 & 5.3226 & 15 \\
\hline
\end{tabular}

Page 3217 
Supplemental Table S2.txt

\begin{tabular}{|c|c|c|c|c|c|}
\hline CHEMBL530531 & 1369320 & 5.6108 & 5.4174 & TST & \\
\hline CHEMBL 2028045 & 1369320 & 5.8477 & \multicolumn{2}{|c|}{6.452000000000001} & TRN \\
\hline CHEMBL601743 & 1369320 & 5.58 & \multicolumn{2}{|c|}{5.446000000000001} & TRN \\
\hline CHEMBL577011 & 1369320 & 5.0804 & 5.2151 & TRN & \\
\hline CHEMBL585839 & 1369320 & 5.0915 & 5.0981 & TRN & \\
\hline CHEMBL582478 & 1369320 & 7.2147 & 5.77 & TRN & \\
\hline CHEMBL537087 & 1369320 & 4.9978 & 5.2043 & TRN & \\
\hline CHEMBL581860 & 1369320 & 6.284 & 5.4747 & TRN & \\
\hline CHEMBL 2028043 & 1369320 & 4.8925 & 5.4018 & TRN & \\
\hline CHEMBL606531 & 1369320 & 7.0 & 5.4127 & TRN & \\
\hline CHEMBL600374 & 1369320 & 5.4881 & 5.0191 & TRN & \\
\hline CHEMBL580516 & 1369320 & 5.4306 & 5.1708 & TRN & \\
\hline CHEMBL546168 & 1369320 & 4.8248 & 5.0397 & TRN & \\
\hline CHEMBL580757 & 1369320 & 4.8431 & 5.0781 & TRN & \\
\hline CHEMBL577445 & 1369320 & 5.4283 & 5.1756 & TRN & \\
\hline CHEMBL584237 & 1369320 & 4.6078 & 6.0416 & TRN & \\
\hline CHEMBL532079 & 1369320 & 4.7387 & 5.0027 & TRN & \\
\hline CHEMBL580353 & 1369320 & 4.7627 & 5.1704 & TRN & \\
\hline CHEMBL546531 & 1369320 & 6.0 & 6.2207 & TRN & \\
\hline CHEMBL527234 & 1369320 & 4.8775 & 5.7933 & TRN & \\
\hline CHEMBL547266 & 1369320 & 5.7212 & 5.2162 & TRN & \\
\hline CHEMBL586468 & 1369320 & 6.6198 & 5.1698 & TRN & \\
\hline CHEMBL547443 & 1369320 & 6.8861 & 6.584 & TRN & \\
\hline CHEMBL579294 & 1369320 & 5.2596 & 5.941 & TRN & \\
\hline CHEMBL547269 & 1369320 & 5.1746 & 5.4502 & TRN & \\
\hline CHEMBL591183 & 1369320 & 6.2291 & 5.8182 & TRN & \\
\hline CHEMBL546799 & 1369320 & 7.2218 & 6.3339 & TRN & \\
\hline CHEMBL597855 & 1369320 & 3.6021 & 5.1017 & TRN & \\
\hline CHEMBL532510 & 1369320 & 5.0555 & 5.2253 & TRN & \\
\hline CHEMBL586442 & 1369320 & 4.9983 & 5.2854 & TRN & \\
\hline CHEMBL1616787 & 1369320 & 7.1135 & 6.5374 & TRN & \\
\hline CHEMBL601825 & 1369320 & 4.6021 & 4.3339 & TRN & \\
\hline CHEMBL583682 & 1369320 & 4.6499 & 5.0216 & TRN & \\
\hline CHEMBL588481 & 1369320 & 5.8861 & 5.1308 & TRN & \\
\hline CHEMBL537505 & 1369320 & 4.6021 & 5.215 & TRN & \\
\hline CHEMBL2028049 & 1369320 & 5.5114 & 5.3858 & TRN & \\
\hline CHEMBL587104 & 1369320 & 5.0953 & 5.3869 & TRN & \\
\hline CHEMBL530438 & 1369320 & 5.2277 & 5.02800 & 00000000005 & TST \\
\hline CHEMBL529385 & 1369320 & 6.9208 & 6.3522 & TRN & \\
\hline CHEMBL531222 & 1369320 & 5.0438 & 5.1765 & TRN & \\
\hline CHEMBL2028058 & 1369320 & 5.2291 & 5.8675 & TRN & \\
\hline CHEMBL589916 & 1369320 & 5.1549 & 5.2071 & TRN & \\
\hline CHEMBL599885 & 1369320 & 4.7706 & 4.9564 & TRN & \\
\hline CHEMBL590675 & 1369320 & 6.1024 & 6.2932 & TRN & \\
\hline CHEMBL525106 & 1369320 & 5.4191 & 5.9009 & TRN & \\
\hline CHEMBL607308 & 1369320 & 5.3595 & 5.5876 & TRN & \\
\hline CHEMBL596852 & 1369320 & 5.2534 & 5.2226 & TRN & \\
\hline CHEMBL548338 & 1369320 & 6.1135 & 5.0305 & TRN & \\
\hline
\end{tabular}


Supplemental Table S2.txt

\begin{tabular}{|c|c|c|c|c|c|}
\hline CHEMBL528533 & 1369320 & 5.6198 & 5.2954 & TRN & \\
\hline CHEMBL580249 & 1369320 & 3.6021 & 5.3653 & TRN & \\
\hline CHEMBL602179 & 1369320 & 5.224 & 5.2521 & TRN & \\
\hline CHEMBL530308 & 1369320 & 7.2007 & 6.3278 & TST & \\
\hline CHEMBL 2028060 & 1369320 & 4.7929 & 5.0079 & TRN & \\
\hline CHEMBL588732 & 1369320 & 4.752 & 5.3954 & TRN & \\
\hline CHEMBL580388 & 1369320 & 4.7828 & 5.3752 & TST & \\
\hline CHEMBL588501 & 1369320 & 5.5622 & 5.5758 & TRN & \\
\hline CHEMBL535556 & 1369320 & 4.8536 & 5.1 & TRN & \\
\hline CHEMBL602211 & 1369320 & 6.1249 & 6.4169 & TRN & \\
\hline CHEMBL601492 & 1369320 & 6.6198 & 5.9432 & TRN & \\
\hline CHEMBL584240 & 1369320 & 5.9747 & 4.984 & TRN & \\
\hline CHEMBL601528 & 1369320 & 5.1494 & 5.2804 & TRN & \\
\hline CHEMBL577874 & 1369320 & 5.1124 & 5.5604 & TRN & \\
\hline CHEMBL528492 & 1369320 & 4.8176 & \multicolumn{2}{|c|}{5.3660000000000005} & TRN \\
\hline CHEMBL532015 & 1369320 & 6.0655 & 5.2716 & TRN & \\
\hline CHEMBL583844 & 1369320 & 4.9234 & 5.0281 & TST & \\
\hline CHEMBL601158 & 1369320 & 5.0 & 5.0821 & TRN & \\
\hline CHEMBL533921 & 1369320 & 6.5686 & 5.7834 & TRN & \\
\hline CHEMBL591128 & 1369320 & 6.0 & 5.3188 & TRN & \\
\hline CHEMBL581194 & 1369320 & 5.1152 & 5.2455 & TRN & \\
\hline CHEMBL602552 & 1369320 & 4.8633 & 5.2585 & TRN & \\
\hline CHEMBL533999 & 1369320 & 5.8894 & 5.1691 & TRN & \\
\hline CHEMBL529874 & 1369320 & 7.1549 & 6.5095 & TST & \\
\hline CHEMBL524973 & 1369320 & 7.0 & \multicolumn{2}{|c|}{5.8229999999999995} & TRN \\
\hline CHEMBL459199 & 1369320 & 5.1158 & 5.1594 & TRN & \\
\hline CHEMBL589236 & 1369320 & 4.7129 & 4.3074 & TRN & \\
\hline CHEMBL590680 & 1369320 & 5.3215 & \multicolumn{2}{|c|}{5.7170000000000005} & TRN \\
\hline CHEMBL 2028047 & 1369320 & 7.0655 & 6.52 & TRN & \\
\hline CHEMBL579459 & 1369320 & 3.6021 & 4.9936 & TST & \\
\hline CHEMBL536421 & 1369320 & 5.0 & 4.95 & TRN & \\
\hline CHEMBL600549 & 1369320 & 6.0 & 6.2618 & TRN & \\
\hline CHEMBL587410 & 1369320 & 3.6021 & 5.0838 & TST & \\
\hline CHEMBL580188 & 1369320 & 4.7335 & 5.4641 & TRN & \\
\hline CHEMBL533017 & 1369320 & 3.6021 & 4.9624 & TRN & \\
\hline CHEMBL533399 & 1369320 & 6.0605 & 5.5369 & TST & \\
\hline CHEMBL587288 & 1369320 & 5.0491 & 5.8703 & TRN & \\
\hline CHEMBL533917 & 1369320 & 6.0 & \multicolumn{2}{|c|}{5.787000000000001} & TRN \\
\hline CHEMBL589951 & 1369320 & 5.3757 & 5.7419 & TRN & \\
\hline CHEMBL1744512 & 1369320 & 5.3089 & 5.7877 & TST & \\
\hline CHEMBL588855 & 1369320 & 5.02 & 5.1333 & TRN & \\
\hline CHEMBL590201 & 1369320 & 4.6194 & 4.266 & TRN & \\
\hline CHEMBL607975 & 1369320 & 5.2154 & 5.4756 & TRN & \\
\hline CHEMBL589723 & 1369320 & 5.2 & 5.0242 & TRN & \\
\hline CHEMBL600305 & 1369320 & 4.7572 & 4.9945 & TRN & \\
\hline CHEMBL 2028059 & 1369320 & 4.8579 & 4.8997 & TRN & \\
\hline CHEMBL578952 & 1369320 & 5.5017 & 5.4476 & TRN & \\
\hline \multirow[t]{2}{*}{ CHEMBL608855 } & 1369320 & 4.6686 & \multicolumn{2}{|c|}{ 5.367999999999999 } & TST \\
\hline & & & & 3219 & \\
\hline
\end{tabular}




\begin{tabular}{|c|c|c|c|c|c|}
\hline \multicolumn{6}{|c|}{ Supplemental Table S2.txt } \\
\hline CHEMBL589422 & 1369320 & 5.02 & 5.1847 & TST & \\
\hline CHEMBL586033 & 1369320 & 5.1726 & 5.4643 & TRN & \\
\hline CHEMBL597248 & 1369320 & 5.3915 & 5.2917 & TRN & \\
\hline CHEMBL602940 & 1369320 & 5.1439 & 5.8006 & TST & \\
\hline CHEMBL602580 & 1369320 & 6.2366 & 5.5956 & TST & \\
\hline CHEMBL 2028051 & 1369320 & 4.7404 & 5.221 & TRN & \\
\hline CHEMBL591641 & 1369320 & 4.8768 & 5.8118 & TRN & \\
\hline CHEMBL578030 & 1369320 & 7.2518 & 6.5113 & TRN & \\
\hline CHEMBL586704 & 1369320 & 4.9007 & 5.5302 & TRN & \\
\hline CHEMBL580876 & 1369320 & 5.4522 & 5.78299 & 99999999995 & TRN \\
\hline CHEMBL526981 & 1369320 & 4.7462 & 5.1069 & TRN & \\
\hline CHEMBL590933 & 1369320 & 7.0809 & 5.8114 & TRN & \\
\hline CHEMBL590212 & 1369320 & 6.0 & 4.94600 & 0000000001 & TRN \\
\hline CHEMBL586178 & 1369320 & 4.7077 & 4.4078 & TRN & \\
\hline CHEMBL10835 & 1369320 & 6.2291 & 5.4398 & TRN & \\
\hline CHEMBL601566 & 1369320 & 4.7066 & 5.0182 & TST & \\
\hline CHEMBL581349 & 1369320 & 5.0991 & 5.2139 & TRN & \\
\hline CHEMBL536393 & 1369320 & 4.9431 & 5.9128 & TRN & \\
\hline CHEMBL548901 & 1369320 & 7.0 & 5.7712 & TRN & \\
\hline CHEMBL596652 & 1369320 & 4.7693 & 4.3535 & TRN & \\
\hline CHEMBL534283 & 1369320 & 6.1871 & 5.8689 & TST & \\
\hline CHEMBL599886 & 1369320 & 4.9961 & 5.6756 & TST & \\
\hline CHEMBL 2028055 & 1369320 & 4.7542 & 5.1473 & TRN & \\
\hline CHEMBL591887 & 1369320 & 5.9208 & 5.0737 & TRN & \\
\hline CHEMBL532141 & 1369320 & 7.2291 & 5.614 & TRN & \\
\hline CHEMBL601156 & 1369320 & 6.4437 & 6.0749 & TST & \\
\hline CHEMBL586078 & 1369320 & 6.0458 & 6.1554 & TRN & \\
\hline CHEMBL606159 & 1369320 & 7.041 & 6.5306 & TRN & \\
\hline CHEMBL529984 & 1369320 & 4.8735 & 4.9396 & TRN & \\
\hline CHEMBL597444 & 1369320 & 7.2518 & 6.6455 & TRN & \\
\hline CHEMBL529640 & 1369320 & 4.6021 & 5.6949 & TRN & \\
\hline CHEMBL592044 & 1369320 & 7.284 & 6.2791 & TST & \\
\hline CHEMBL537071 & 1369320 & 5.2596 & 5.7618 & TRN & \\
\hline CHEMBL603943 & 1369320 & 4.87 & 5.159 & TRN & \\
\hline CHEMBL338094 & 1369320 & 6.0655 & 5.6987 & TRN & \\
\hline CHEMBL609156 & 1369320 & 5.0173 & 5.2846 & TRN & \\
\hline CHEMBL601786 & 1369320 & 7.2218 & 5.2973 & TRN & \\
\hline CHEMBL600444 & 1369320 & 5.065 & 4.7531 & TRN & \\
\hline CHEMBL532155 & 1369320 & 5.0 & 5.3147 & TRN & \\
\hline CHEMBL600904 & 1369320 & 5.2596 & 4.3095 & TRN & \\
\hline CHEMBL592550 & 1369320 & 4.7823 & 4.4663 & TRN & \\
\hline CHEMBL 2028050 & 1369320 & 4.8099 & 5.2648 & TRN & \\
\hline CHEMBL582547 & 1369320 & 7.1079 & 6.4373 & TRN & \\
\hline CHEMBL577014 & 1369320 & 6.7696 & 5.5904 & TRN & \\
\hline CHEMBL534288 & 1369320 & 4.8147 & 4.868 & TRN & \\
\hline CHEMBL592344 & 1369320 & 6.0809 & 6.269 & TRN & \\
\hline CHEMBL589224 & 1369320 & 3.6021 & 5.0005 & TST & \\
\hline CHEMBL590686 & 1369320 & 5.0 & 5.2248 & TRN & \\
\hline
\end{tabular}


Supplemental Table S2.txt

\begin{tabular}{|c|c|c|c|c|}
\hline CHEMBL598881 & 1369320 & 5.0 & 5.0306 & TST \\
\hline CHEMBL531290 & 1369320 & 4.7298 & 5.1038 & TST \\
\hline CHEMBL600488 & 1369320 & 4.7825 & 5.1778 & TRN \\
\hline CHEMBL 2028057 & 1369320 & 4.8617 & 5.1679 & TRN \\
\hline CHEMBL598279 & 1369320 & 7.2218 & 5.6668 & TRN \\
\hline CHEMBL587923 & 1369320 & 5.2596 & 5.4325 & TRN \\
\hline CHEMBL528245 & 1369320 & 4.6043 & 5.4094 & TRN \\
\hline CHEMBL600906 & 1369320 & 4.8147 & 5.4633 & TRN \\
\hline CHEMBL579300 & 1369320 & 4.7395 & 5.2743 & TRN \\
\hline CHEMBL528437 & 1369320 & 6.8539 & 5.4347 & TRN \\
\hline CHEMBL579760 & 1369320 & 4.9179 & 5.1664 & TST \\
\hline CHEMBL529919 & 1369320 & 3.6021 & 5.3007 & TRN \\
\hline CHEMBL603945 & 1369320 & 6.1427 & 5.8133 & TRN \\
\hline CHEMBL581225 & 1369320 & 6.2218 & 5.4793 & TST \\
\hline CHEMBL586026 & 1369320 & 5.2291 & 5.405 & TST \\
\hline CHEMBL 2028053 & 1369320 & 4.6662 & 4.9974 & TRN \\
\hline CHEMBL582180 & 1369320 & 6.8861 & 6.2968 & TRN \\
\hline CHEMBL592305 & 1369320 & 4.7981 & 4.3953 & TST \\
\hline CHEMBL592125 & 1369320 & 6.0 & 5.1003 & TRN \\
\hline CHEMBL591393 & 1369320 & 5.4522 & 5.4754 & TRN \\
\hline CHEMBL547193 & 1369320 & 5.1675 & 5.48 & TRN \\
\hline CHEMBL585622 & 1369320 & 6.1487 & 5.8329 & TRN \\
\hline CHEMBL530149 & 1369320 & 6.0655 & 5.1262 & TRN \\
\hline CHEMBL581874 & 1369320 & 7.0 & 5.67899 & 9999999999 \\
\hline CHEMBL527730 & 1369320 & 3.6021 & 5.6261 & TRN \\
\hline CHEMBL580140 & 1369320 & 4.8063 & 6.0262 & TRN \\
\hline CHEMBL584655 & 1369320 & 5.0 & 6.1433 & TRN \\
\hline CHEMBL530978 & 1369320 & 4.8147 & 4.9818 & TRN \\
\hline CHEMBL590914 & 1369320 & 7.041 & 6.5918 & TRN \\
\hline CHEMBL589060 & 1369320 & 5.0 & 5.0592 & TRN \\
\hline CHEMBL590944 & 1369320 & 4.9566 & 5.1673 & TRN \\
\hline CHEMBL585983 & 1369320 & 5.5686 & 5.7808 & TRN \\
\hline CHEMBL582072 & 1369320 & 5.0 & 5.008 & TRN \\
\hline CHEMBL582486 & 1369320 & 4.7881 & 5.7357 & TST \\
\hline CHEMBL583555 & 1369320 & 5.58 & 5.4197 & TST \\
\hline CHEMBL529603 & 1369320 & 4.6021 & 5.1644 & TRN \\
\hline CHEMBL592808 & 1369320 & 4.9255 & 6.5023 & TRN \\
\hline CHEMBL589920 & 1369320 & 4.6021 & 5.0421 & TRN \\
\hline CHEMBL597857 & 1369320 & 5.1107 & 5.6759 & TRN \\
\hline CHEMBL547614 & 1369320 & 3.6021 & 5.2182 & TST \\
\hline CHEMBL601348 & 1369320 & 3.6021 & 5.025 & TST \\
\hline CHEMBL1738986 & 1369320 & 4.6753 & 5.8233 & TRN \\
\hline CHEMBL582552 & 1369320 & 7.0809 & 5.7081 & TRN \\
\hline CHEMBL581489 & 1369320 & 4.7091 & 5.4968 & TRN \\
\hline CHEMBL527131 & 1369320 & 3.6021 & 4.8201 & TRN \\
\hline CHEMBL1237255 & 1369320 & 7.0915 & 6.6059 & TRN \\
\hline CHEMBL600030 & 1369320 & 5.0851 & 5.0357 & TRN \\
\hline CHEMBL581240 & 1369320 & 4.7395 & 4.8694 & TRN \\
\hline
\end{tabular}


Supplemental Table S2.txt

\begin{tabular}{|c|c|c|c|c|c|}
\hline CHEMBL529968 & 1369320 & 6.6778 & 4.988 & TRN & \\
\hline CHEMBL531611 & 1369320 & 4.782 & 5.233 & TRN & \\
\hline CHEMBL582286 & 1369320 & 5.1073 & 5.5582 & TRN & \\
\hline CHEMBL597262 & 1369320 & 6.0 & 5.2493 & TRN & \\
\hline CHEMBL585431 & 1369320 & 4.6021 & 5.1626 & TRN & \\
\hline CHEMBL585686 & 1369320 & 7.2291 & 6.4066 & TRN & \\
\hline CHEMBL1594640 & 1369320 & 4.9872 & 5.2269 & TRN & \\
\hline CHEMBL524930 & 1369320 & 4.8431 & 5.7204 & TRN & \\
\hline CHEMBL580381 & 1369320 & 5.1361 & 4.7447 & TRN & \\
\hline CHEMBL609036 & 1369320 & 4.7737 & 5.1895 & TRN & \\
\hline CHEMBL611070 & 1369320 & 5.0 & 4.9468 & TRN & \\
\hline CHEMBL49055 & 1369320 & 5.3325 & 5.4667 & TRN & \\
\hline CHEMBL527541 & 1369320 & 5.3696 & 5.1606 & TRN & \\
\hline CHEMBL601325 & 1369320 & 5.8508 & 5.7295 & TST & \\
\hline CHEMBL546994 & 1369320 & 3.6021 & 4.9545 & TRN & \\
\hline CHEMBL547825 & 1369320 & 5.5186 & 5.6259 & TRN & \\
\hline CHEMBL604389 & 1369320 & 4.9234 & 5.1824 & TRN & \\
\hline CHEMBL609628 & 1369320 & 7.0605 & 6.5233 & TRN & \\
\hline CHEMBL532525 & 1369320 & 7.0 & 6.2454 & TRN & \\
\hline CHEMBL548209 & 1369320 & 7.0655 & 5.2086 & TRN & \\
\hline CHEMBL 2028067 & 1369320 & 5.2007 & 6.6772 & TRN & \\
\hline CHEMBL591623 & 1369320 & 5.5302 & 5.9939 & TRN & \\
\hline CHEMBL587825 & 1369320 & 5.1469 & 5.79899 & 99999999995 & TRN \\
\hline CHEMBL587022 & 1369320 & 4.8321 & 4.9934 & TST & \\
\hline CHEMBL584235 & 1369320 & 7.0915 & 5.8482 & TRN & \\
\hline CHEMBL587371 & 1369320 & 5.7282 & 5.1849 & TRN & \\
\hline CHEMBL590683 & 1369320 & 5.3298 & 5.6267 & TRN & \\
\hline CHEMBL1615697 & 1369320 & 4.7357 & 5.1528 & TST & \\
\hline CHEMBL1623897 & 1369320 & 5.1675 & 4.9328 & TRN & \\
\hline CHEMBL 549208 & 1369320 & 4.6021 & 5.1407 & TRN & \\
\hline CHEMBL586888 & 1369320 & 6.4949 & 6.4628 & TRN & \\
\hline CHEMBL601534 & 1369320 & 7.1675 & 5.2924 & TST & \\
\hline CHEMBL578933 & 1369320 & 5.1226 & 5.1587 & TRN & \\
\hline CHEMBL604982 & 1369320 & 5.2441 & 5.4224 & TRN & \\
\hline CHEMBL95606 & 1369320 & 5.1361 & 5.0554 & TST & \\
\hline CHEMBL525519 & 1369320 & 5.6108 & 5.2401 & TRN & \\
\hline CHEMBL1198307 & 1369320 & 6.1427 & 6.45 & TRN & \\
\hline CHEMBL534589 & 1369320 & 4.8136 & 5.0313 & TRN & \\
\hline CHEMBL601567 & 1369320 & 5.7235 & 5.358 & TRN & \\
\hline CHEMBL529773 & 1369320 & 4.7357 & 5.6345 & TRN & \\
\hline CHEMBL546162 & 1369320 & 4.7627 & 4.9555 & TRN & \\
\hline CHEMBL 581475 & 1369320 & 4.7696 & 5.4187 & TRN & \\
\hline CHEMBL547488 & 1369320 & 4.7055 & 5.1796 & TRN & \\
\hline CHEMBL601612 & 1369320 & 3.6021 & 4.9818 & TST & \\
\hline CHEMBL578508 & 1369320 & 4.8239 & 5.1756 & TRN & \\
\hline CHEMBL600706 & 1369320 & 4.7298 & 5.2641 & TRN & \\
\hline CHEMBL603686 & 1369320 & 4.7296 & 5.2496 & TST & \\
\hline CHEMBL592338 & 1369320 & 5.3487 & 5.1995 & TRN & \\
\hline
\end{tabular}


Supplemental Table S2.txt

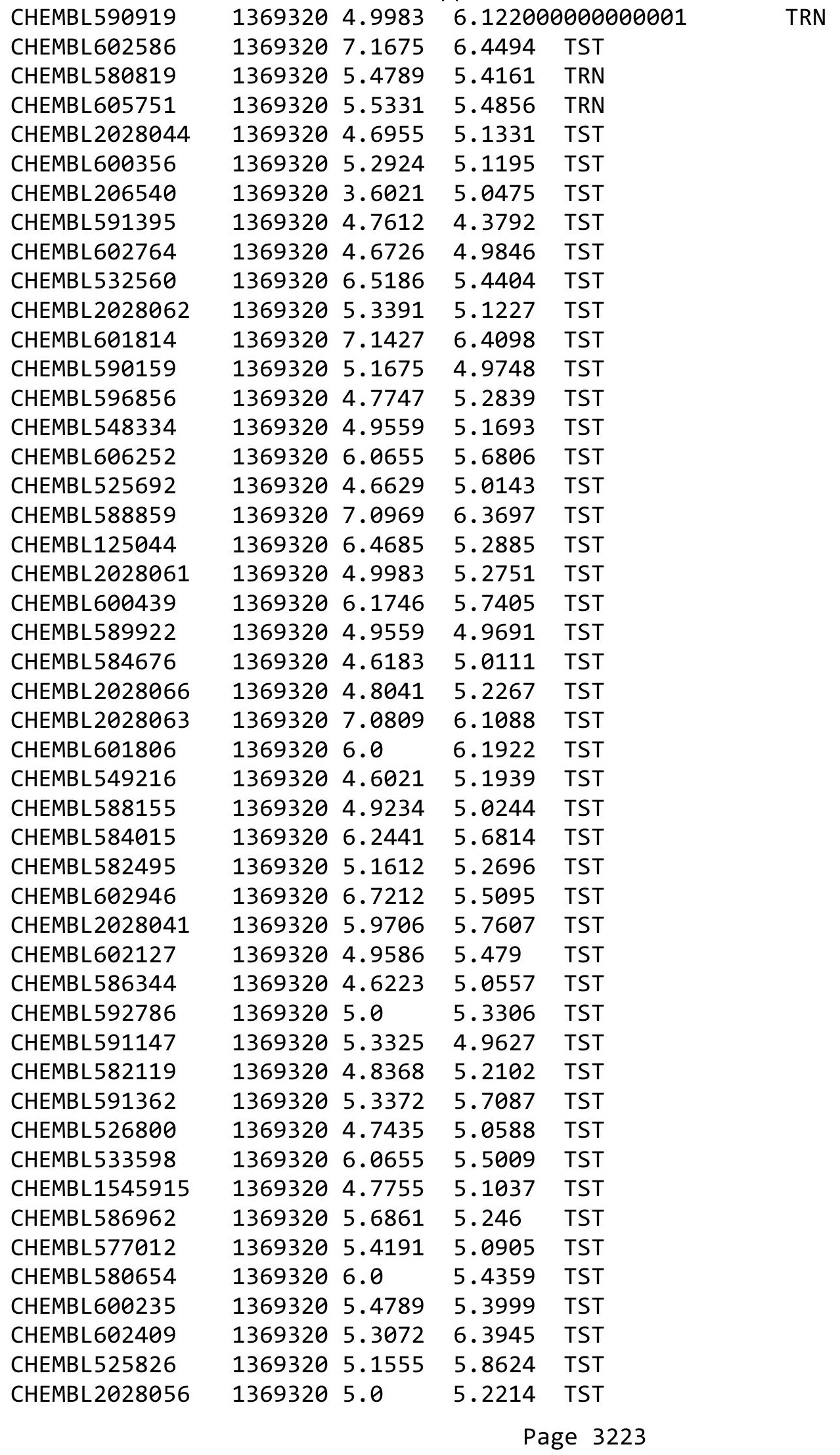




\begin{tabular}{|c|c|c|c|c|c|}
\hline \multicolumn{6}{|c|}{ Supplemental Table S2.txt } \\
\hline CHEMBL 3823133 & 1586857 & 5.0 & 5.1451 & TRN & \\
\hline CHEMBL 3822701 & 1586857 & 8.0506 & 7.3517 & TST & \\
\hline CHEMBL3823126 & 1586857 & 5.0 & 4.9221 & TRN & \\
\hline CHEMBL 3823893 & 1586857 & 5.0 & 4.9684 & TRN & \\
\hline CHEMBL3822459 & 1586857 & 5.0 & 5.1451 & TRN & \\
\hline CHEMBL 3824179 & 1586857 & 5.0 & 5.3058 & TRN & \\
\hline CHEMBL 3823878 & 1586857 & 6.9586 & 5.59 & TRN & \\
\hline CHEMBL3823671 & 1586857 & 5.0 & 5.244 & TRN & \\
\hline CHEMBL 3823088 & 1586857 & 5.0 & 4.9928 & TRN & \\
\hline CHEMBL3823221 & 1586857 & 7.0809 & 7.0401 & TRN & \\
\hline CHEMBL 3823334 & 1586857 & 7.1549 & 7.0467 & TST & \\
\hline CHEMBL 3824272 & 1586857 & 5.0 & 5.0366 & TRN & \\
\hline CHEMBL 2177395 & 1586857 & 6.284 & 5.9387 & TRN & \\
\hline CHEMBL3823291 & 1586857 & 5.0 & 6.1868 & TST & \\
\hline CHEMBL3824232 & 1586857 & 5.0 & 4.5689 & TRN & \\
\hline CHEMBL 3824332 & 1586857 & 5.0 & 5.4892 & TRN & \\
\hline CHEMBL3824241 & 1586857 & 5.0 & 6.1868 & TST & \\
\hline CHEMBL 3822774 & 1586857 & 8.0 & 8.1592 & TRN & \\
\hline CHEMBL3822981 & 1586857 & 6.0 & 5.59 & TRN & \\
\hline CHEMBL 3824227 & 1586857 & 5.0 & 4.9949 & TRN & \\
\hline CHEMBL 3823327 & 1586857 & 5.0 & 5.03100 & 0000000001 & TRN \\
\hline CHEMBL 3823994 & 1586857 & 5.0 & 5.59 & TRN & \\
\hline CHEMBL3822792 & 1586857 & 5.0 & 4.8791 & TRN & \\
\hline CHEMBL 3823043 & 1586857 & 5.0 & 5.4892 & TRN & \\
\hline CHEMBL 3823643 & 1586857 & 5.0 & 5.59 & TRN & \\
\hline CHEMBL 3822727 & 1586857 & 5.0 & 5.59 & TRN & \\
\hline CHEMBL3823755 & 1586857 & 7.4949 & 6.50700 & 0000000001 & TRN \\
\hline CHEMBL 3824226 & 1586857 & 5.0 & 4.9857 & TRN & \\
\hline CHEMBL 3822975 & 1586857 & 7.0 & 6.9394 & TRN & \\
\hline CHEMBL 3823421 & 1586857 & 7.0458 & 6.50700 & 0000000001 & TRN \\
\hline CHEMBL 3822809 & 1586857 & 5.0 & 5.0156 & TRN & \\
\hline CHEMBL3822636 & 1586857 & 5.0 & 6.50700 & 0000000001 & TRN \\
\hline CHEMBL 3824136 & 1586857 & 5.0 & 4.9398 & TST & \\
\hline CHEMBL3823835 & 1586857 & 6.8861 & 5.59 & TRN & \\
\hline CHEMBL 3823225 & 1586857 & 5.0 & 5.1259 & TRN & \\
\hline CHEMBL 3822928 & 1586857 & 5.0 & 5.21899 & 9999999999 & TST \\
\hline CHEMBL3823117 & 1586857 & 5.0 & 5.0193 & TST & \\
\hline CHEMBL 3823985 & 1586857 & 5.0 & 4.9107 & TRN & \\
\hline CHEMBL3823541 & 1586857 & 5.0 & 4.5689 & TRN & \\
\hline CHEMBL3823976 & 1586857 & 5.0 & 5.228 & TST & \\
\hline CHEMBL 3823722 & 1586857 & 5.0 & 5.59 & TRN & \\
\hline CHEMBL 3823082 & 1586857 & 5.0 & 5.59 & TRN & \\
\hline CHEMBL 3824278 & 1586857 & 5.0 & 6.1868 & TST & \\
\hline CHEMBL3822569 & 1586857 & 6.0 & 5.4811 & TRN & \\
\hline CHEMBL3823818 & 1586857 & 5.0 & 5.0015 & TRN & \\
\hline CHEMBL 3823889 & 1586857 & 7.0969 & 6.1868 & TST & \\
\hline CHEMBL3823681 & 1586857 & 5.0 & 5.3752 & TST & \\
\hline CHEMBL 3823144 & 1586857 & 5.0 & 4.9616 & TRN & \\
\hline
\end{tabular}


Supplemental Table S2.txt

\begin{tabular}{|c|c|c|c|c|}
\hline CHEMBL3823411 & 1586857 & 7.3468 & 6.4502 & TRN \\
\hline CHEMBL3823847 & 1586857 & 5.0 & 5.2933 & TST \\
\hline CHEMBL3824079 & 1586857 & 5.0 & 5.2933 & TST \\
\hline CHEMBL 3824197 & 1586857 & 5.0 & 5.4811 & TRN \\
\hline CHEMBL3823936 & 1586857 & 5.0 & 4.9938 & TRN \\
\hline CHEMBL 3822888 & 1586857 & 5.0 & 5.59 & TRN \\
\hline CHEMBL3823786 & 1586857 & 5.0 & 7.3517 & TST \\
\hline CHEMBL 2313904 & 934298 & 4.0 & 4.2649 & TRN \\
\hline CHEMBL 2313914 & 934298 & 4.0 & 4.1667 & TRN \\
\hline CHEMBL 2313894 & 934298 & 4.0 & 4.5059 & TRN \\
\hline CHEMBL 2313892 & 934298 & 4.0 & 3.9327 & TRN \\
\hline CHEMBL 2313923 & 934298 & 5.7959 & 5.3767 & TRN \\
\hline CHEMBL 2313903 & 934298 & 4.0 & 4.2898 & TST \\
\hline CHEMBL 2313888 & 934298 & 4.0 & 3.9709 & TRN \\
\hline CHEMBL 2313905 & 934298 & 4.0 & 4.0966 & TRN \\
\hline CHEMBL 2313890 & 934298 & 4.0 & 3.5943 & TRN \\
\hline CHEMBL 2313926 & 934298 & 5.1675 & 4.9203 & TRN \\
\hline CHEMBL 2313901 & 934298 & 4.0 & 3.7267 & TRN \\
\hline CHEMBL 2313922 & 934298 & 4.0 & 4.3737 & TRN \\
\hline CHEMBL 2313895 & 934298 & 4.0 & 3.7212 & TRN \\
\hline CHEMBL 2313896 & 934298 & 4.0 & 3.7641 & TRN \\
\hline CHEMBL 2313887 & 934298 & 4.0 & 4.0064 & TRN \\
\hline CHEMBL 2314169 & 934298 & 4.0 & 4.1104 & TST \\
\hline CHEMBL 2313902 & 934298 & 4.0 & 4.2574 & TRN \\
\hline CHEMBL 2314167 & 934298 & 5.8239 & 4.9123 & TRN \\
\hline CHEMBL 2313927 & 934298 & 4.0 & 4.0178 & TRN \\
\hline CHEMBL 2314164 & 934298 & 4.0 & 4.0208 & TRN \\
\hline CHEMBL 2314165 & 934298 & 4.0 & 4.05699 & 99999999995 \\
\hline CHEMBL 2313884 & 934298 & 6.1024 & 5.364 & TRN \\
\hline CHEMBL 2313916 & 934298 & 4.0 & 3.9352 & TRN \\
\hline CHEMBL 2313912 & 934298 & 6.1675 & 5.2546 & TRN \\
\hline CHEMBL 2313906 & 934298 & 4.0 & 4.5052 & TRN \\
\hline CHEMBL 2313918 & 934298 & 5.2147 & 4.9066 & TRN \\
\hline CHEMBL2313919 & 934298 & 4.0 & 4.5085 & TRN \\
\hline CHEMBL 2314163 & 934298 & 6.3872 & 4.7175 & TST \\
\hline CHEMBL 2313897 & 934298 & 4.0 & 3.8685 & TRN \\
\hline CHEMBL 2314170 & 934298 & 4.0 & 3.9388 & TRN \\
\hline CHEMBL 2314166 & 934298 & 4.0 & 3.7369 & TRN \\
\hline CHEMBL 2313907 & 934298 & 4.0 & 4.7225 & TRN \\
\hline CHEMBL 2313908 & 934298 & 5.5528 & 5.195 & TRN \\
\hline CHEMBL2313915 & 934298 & 4.0 & 4.1377 & TRN \\
\hline CHEMBL 2313891 & 934298 & 5.3768 & 4.8444 & TRN \\
\hline CHEMBL 2313917 & 934298 & 5.5086 & 5.4831 & TRN \\
\hline CHEMBL 2313921 & 934298 & 4.0 & 4.0605 & TRN \\
\hline CHEMBL1593867 & 934298 & 7.585 & 5.8788 & TST \\
\hline CHEMBL2313886 & 934298 & 4.0 & 4.2098 & TRN \\
\hline CHEMBL 2313913 & 934298 & 4.0 & 4.2282 & TRN \\
\hline CHEMBL 2313920 & 934298 & 4.0 & 4.9059 & TRN \\
\hline
\end{tabular}




\begin{tabular}{|c|c|c|c|c|c|}
\hline \multicolumn{6}{|c|}{ Supplemental Table S2.txt } \\
\hline CHEMBL2313900 & 934298 & 4.0 & 4.0686 & TRN & \\
\hline CHEMBL 2313898 & 934298 & 4.0 & 3.8183 & TRN & \\
\hline CHEMBL2313925 & 934298 & 4.0 & 5.3884 & TRN & \\
\hline CHEMBL2313893 & 934298 & 4.0 & 3.6891 & TST & \\
\hline CHEMBL2313911 & 934298 & 4.0 & 4.5797 & TST & \\
\hline CHEMBL2313924 & 934298 & 5.6383 & 5.2927 & TST & \\
\hline CHEMBL2314168 & 934298 & 4.0 & 4.1249 & TST & \\
\hline CHEMBL 2313910 & 934298 & 4.0 & 4.3808 & TST & \\
\hline CHEMBL2313889 & 934298 & 4.0 & 3.8402 & TST & \\
\hline CHEMBL2313909 & 934298 & 5.2924 & 4.8029 & TST & \\
\hline CHEMBL2313899 & 934298 & 4.0 & 3.8618 & TST & \\
\hline CHEMBL2313885 & 934298 & 5.699 & 4.6572 & TST & \\
\hline CHEMBL1214647 & 650211 & 4.2757 & 4.5663 & TRN & \\
\hline CHEMBL1214798 & 650211 & 2.5229 & 2.3469 & TRN & \\
\hline CHEMBL1214866 & 650211 & 2.5229 & 2.6441 & TRN & \\
\hline CHEMBL1215367 & 650211 & 3.5229 & 3.2257 & TRN & \\
\hline CHEMBL1212961 & 650211 & 2.5229 & 2.812 & TRN & \\
\hline CHEMBL1214867 & 650211 & 2.5229 & 2.6874 & TRN & \\
\hline CHEMBL1215156 & 650211 & 4.4949 & 4.4719 & TRN & \\
\hline CHEMBL1214797 & 650211 & 2.5229 & 2.2925 & TRN & \\
\hline CHEMBL1214793 & 650211 & 2.5229 & 2.9438 & TRN & \\
\hline CHEMBL1214868 & 650211 & 2.5229 & 3.7074 & TST & \\
\hline CHEMBL1214938 & 650211 & 2.5229 & 2.5808 & TRN & \\
\hline CHEMBL1215291 & 650211 & 4.9208 & 4.774 & TRN & \\
\hline CHEMBL1214864 & 650211 & 2.5229 & 2.8891 & TST & \\
\hline CHEMBL1215796 & 650211 & 4.1938 & 3.5863 & TRN & \\
\hline CHEMBL1215801 & 650211 & 5.0969 & 4.852 & TRN & \\
\hline CHEMBL1214719 & 650211 & 4.6021 & 4.393 & TRN & \\
\hline CHEMBL1215081 & 650211 & 4.6778 & 4.2224 & TRN & \\
\hline CHEMBL1214935 & 650211 & 4.0 & 3.6145 & TRN & \\
\hline CHEMBL1214941 & 650211 & 4.3468 & 4.3067 & TRN & \\
\hline CHEMBL1214940 & 650211 & 4.585 & 4.4293 & TRN & \\
\hline CHEMBL1214649 & 650211 & 2.5229 & 3.56399 & 99999999996 & TST \\
\hline CHEMBL1214863 & 650211 & 2.5229 & 3.3151 & TST & \\
\hline CHEMBL1215079 & 650211 & 4.284 & 4.4738 & TRN & \\
\hline CHEMBL1215439 & 650211 & 3.9508 & 3.6017 & TRN & \\
\hline CHEMBL1215440 & 650211 & 3.9957 & 4.3913 & TRN & \\
\hline CHEMBL1215718 & 650211 & 2.5229 & 3.0088 & TRN & \\
\hline CHEMBL1215224 & 650211 & 3.6498 & 3.9301 & TRN & \\
\hline CHEMBL1215512 & 650211 & 2.5229 & 3.0852 & TRN & \\
\hline CHEMBL1215717 & 650211 & 2.5229 & 2.5643 & TRN & \\
\hline CHEMBL1214865 & 650211 & 4.5086 & 3.8991 & TST & \\
\hline CHEMBL1215225 & 650211 & 2.5229 & 3.2627 & TRN & \\
\hline CHEMBL1215005 & 650211 & 3.5229 & 3.6761 & TRN & \\
\hline CHEMBL1215649 & 650211 & 4.0269 & 3.3426 & TRN & \\
\hline CHEMBL1215292 & 650211 & 3.6402 & 3.5 & TRN & \\
\hline CHEMBL1215798 & 650211 & 2.5229 & 2.9039 & TST & \\
\hline CHEMBL1214792 & 650211 & 2.5229 & 2.5937 & TST & \\
\hline
\end{tabular}


Supplemental Table S2.txt

\begin{tabular}{|c|c|c|c|c|}
\hline CHEMBL1215511 & 650211 & 2.5229 & 2.3672 & TRN \\
\hline CHEMBL1215650 & 650211 & 2.5229 & 2.9034 & TRN \\
\hline CHEMBL1215082 & 650211 & 4.0655 & 4.0946 & TRN \\
\hline CHEMBL1215007 & 650211 & 5.3979 & 4.228 & TST \\
\hline CHEMBL1215290 & 650211 & 4.7447 & 5.0337 & TRN \\
\hline CHEMBL1215006 & 650211 & 4.4202 & 3.7687 & TRN \\
\hline CHEMBL1215578 & 650211 & 4.1367 & 3.8163 & TRN \\
\hline CHEMBL1214714 & 650211 & 2.5229 & 3.2996 & TST \\
\hline CHEMBL1214716 & 650211 & 4.7696 & 4.7859 & TRN \\
\hline CHEMBL1214646 & 650211 & 2.5229 & 3.0341 & TST \\
\hline CHEMBL1214718 & 650211 & 4.2007 & 4.0579 & TRN \\
\hline CHEMBL1214939 & 650211 & 3.6861 & 3.6402 & TST \\
\hline CHEMBL1214713 & 650211 & 4.0 & 4.387 & TRN \\
\hline CHEMBL1215226 & 650211 & 4.4437 & 4.8067 & TRN \\
\hline CHEMBL1215648 & 650211 & 3.6757 & 3.7128 & TRN \\
\hline CHEMBL1214791 & 650211 & 2.5229 & 2.5159 & TRN \\
\hline CHEMBL1215004 & 650211 & 4.8861 & 4.6463 & TRN \\
\hline CHEMBL1214715 & 650211 & 4.9586 & 4.8351 & TRN \\
\hline CHEMBL1215003 & 650211 & 4.2147 & 3.9018 & TRN \\
\hline CHEMBL1214645 & 650211 & 3.6819 & 3.48199 & 99999999998 \\
\hline CHEMBL1215579 & 650211 & 2.5229 & 3.1547 & TRN \\
\hline CHEMBL1215364 & 650211 & 3.6253 & 4.0549 & TRN \\
\hline CHEMBL1215651 & 650211 & 4.1367 & 3.661 & TRN \\
\hline CHEMBL1215580 & 650211 & 4.0969 & 4.0458 & TRN \\
\hline CHEMBL1214934 & 650211 & 4.0757 & 4.0554 & TRN \\
\hline CHEMBL1214869 & 650211 & 2.5229 & 2.7106 & TRN \\
\hline CHEMBL1215716 & 650211 & 2.5229 & 3.0989 & TRN \\
\hline CHEMBL1214862 & 650211 & 2.5229 & 2.8693 & TST \\
\hline CHEMBL1215510 & 650211 & 4.7212 & 4.5692 & TRN \\
\hline CHEMBL1215513 & 650211 & 3.6615 & 3.66600 & 00000000004 \\
\hline CHEMBL1215442 & 650211 & 3.8041 & 4.4683 & TRN \\
\hline CHEMBL1215155 & 650211 & 4.7959 & 4.8887 & TRN \\
\hline CHEMBL1215800 & 650211 & 2.5229 & 3.7061 & TRN \\
\hline CHEMBL1214648 & 650211 & 4.4089 & 4.5065 & TRN \\
\hline CHEMBL1214796 & 650211 & 3.8794 & 2.8738 & TRN \\
\hline CHEMBL1215080 & 650211 & 4.3872 & 3.6184 & TRN \\
\hline CHEMBL1214794 & 650211 & 2.5229 & 3.5251 & TST \\
\hline CHEMBL1215799 & 650211 & 4.6778 & 4.5535 & TRN \\
\hline CHEMBL1214937 & 650211 & 4.0555 & 4.2785 & TRN \\
\hline CHEMBL1214795 & 650211 & 4.3979 & 3.5764 & TST \\
\hline CHEMBL1215366 & 650211 & 4.9586 & 5.0468 & TRN \\
\hline CHEMBL1214717 & 650211 & 4.6778 & 3.9936 & TRN \\
\hline CHEMBL1214861 & 650211 & 2.5229 & 2.8682 & TRN \\
\hline CHEMBL1215797 & 650211 & 3.8697 & 3.6489 & TRN \\
\hline CHEMBL400566 & 650211 & 4.699 & 4.4204 & TRN \\
\hline CHEMBL1215227 & 650211 & 4.7696 & 4.9905 & TRN \\
\hline CHEMBL1215803 & 650211 & 3.6234 & 3.2634 & TRN \\
\hline CHEMBL1214720 & 650211 & 2.5229 & 3.2104 & TST \\
\hline
\end{tabular}


Supplemental Table S2.txt

\begin{tabular}{|c|c|c|c|c|c|}
\hline CHEMBL1215157 & 650211 & 4.2518 & 4.1707 & TST & \\
\hline CHEMBL1215365 & 650211 & 4.9586 & 5.0672 & TST & \\
\hline CHEMBL1215802 & 650211 & 3.7055 & 3.3141 & TST & \\
\hline CHEMBL1215581 & 650211 & 2.5229 & 3.196 & TST & \\
\hline CHEMBL1214936 & 650211 & 4.6198 & 4.4089 & TST & \\
\hline CHEMBL1214790 & 650211 & 2.5229 & 2.7728 & TST & \\
\hline CHEMBL1215154 & 650211 & 2.5229 & 3.9128 & TST & \\
\hline CHEMBL1215441 & 650211 & 4.5528 & 4.6115 & TST & \\
\hline CHEMBL1215719 & 650211 & 2.5229 & 3.6119 & TST & \\
\hline CHEMBL259181 & 954859 & 5.2796 & 5.4555 & TRN & \\
\hline CHEMBL373751 & 954859 & 3.3357 & 3.4304 & TRN & \\
\hline CHEMBL1230020 & 954859 & 4.1371 & 4.1935 & TRN & \\
\hline CHEMBL392695 & 954859 & 4.2576 & 4.5158 & TRN & \\
\hline CHEMBL222102 & 954859 & 4.2847 & 4.0571 & TRN & \\
\hline CHEMBL449158 & 954859 & 6.1958 & 7.0596 & TST & \\
\hline CHEMBL577784 & 954859 & 5.3332 & 5.5085 & TRN & \\
\hline CHEMBL379300 & 954859 & 6.7009 & 6.6904 & TRN & \\
\hline CHEMBL 2005886 & 954859 & 6.3051 & 6.4093 & TRN & \\
\hline CHEMBL379975 & 954859 & 5.5529 & 5.5142 & TRN & \\
\hline CHEMBL220241 & 954859 & 3.9854 & 3.523 & TRN & \\
\hline CHEMBL399530 & 954859 & 5.0306 & 4.8726 & TRN & \\
\hline CHEMBL1590308 & 954859 & 3.8259 & 3.0447 & TST & \\
\hline CHEMBL 213100 & 954859 & 5.9353 & 5.7603 & TRN & \\
\hline CHEMBL 240954 & 954859 & 3.4498 & 3.61 & TST & \\
\hline CHEMBL393929 & 954859 & 4.8938 & 4.4408 & TRN & \\
\hline CHEMBL483849 & 954859 & 2.0094 & 2.1498 & TST & \\
\hline CHEMBL102714 & 954859 & 4.3149 & 3.8165 & TRN & \\
\hline CHEMBL300389 & 954859 & 7.4204 & 6.947 & TRN & \\
\hline CHEMBL1357247 & 954859 & 3.2348 & 3.2498 & TRN & \\
\hline CHEMBL135561 & 954859 & 4.2021 & 4.6817 & TRN & \\
\hline CHEMBL1190711 & 954859 & 5.5478 & 5.8504 & TRN & \\
\hline CHEMBL191334 & 954859 & 3.8845 & 3.8869 & TRN & \\
\hline CHEMBL1186585 & 954859 & 3.1357 & 3.3587 & TRN & \\
\hline CHEMBL483847 & 954859 & 4.5032 & 4.6114 & TRN & \\
\hline CHEMBL1970879 & 954859 & 6.1688 & 6.11100 & 0000000001 & TRN \\
\hline CHEMBL1404918 & 954859 & 3.2239 & 3.0731 & TRN & \\
\hline CHEMBL65 & 954859 & 8.33 & 8.2521 & TRN & \\
\hline CHEMBL92309 & 954859 & 4.0266 & 3.0424 & TST & \\
\hline CHEMBL412142 & 954859 & 3.6286 & 3.6291 & TRN & \\
\hline CHEMBL3392440 & 954859 & 4.0976 & 4.2184 & TRN & \\
\hline CHEMBL1242367 & 954859 & 5.0331 & 4.6797 & TRN & \\
\hline CHEMBL509032 & 954859 & 6.4104 & 6.2409 & TRN & \\
\hline CHEMBL573107 & 954859 & 5.2204 & 5.3179 & TRN & \\
\hline CHEMBL202721 & 954859 & 4.8829 & 4.7406 & TRN & \\
\hline CHEMBL 2363137 & 954859 & 5.659 & 5.4913 & TRN & \\
\hline CHEMBL1643959 & 954859 & 4.2383 & 4.1374 & TRN & \\
\hline CHEMBL3199475 & 954859 & 4.9384 & 5.0168 & TRN & \\
\hline \multirow[t]{2}{*}{ CHEMBL 2137530} & 954859 & 3.7071 & 4.65300 & $\partial 0000 €$ & TRN \\
\hline & & \multicolumn{4}{|c|}{ Page 3228} \\
\hline
\end{tabular}




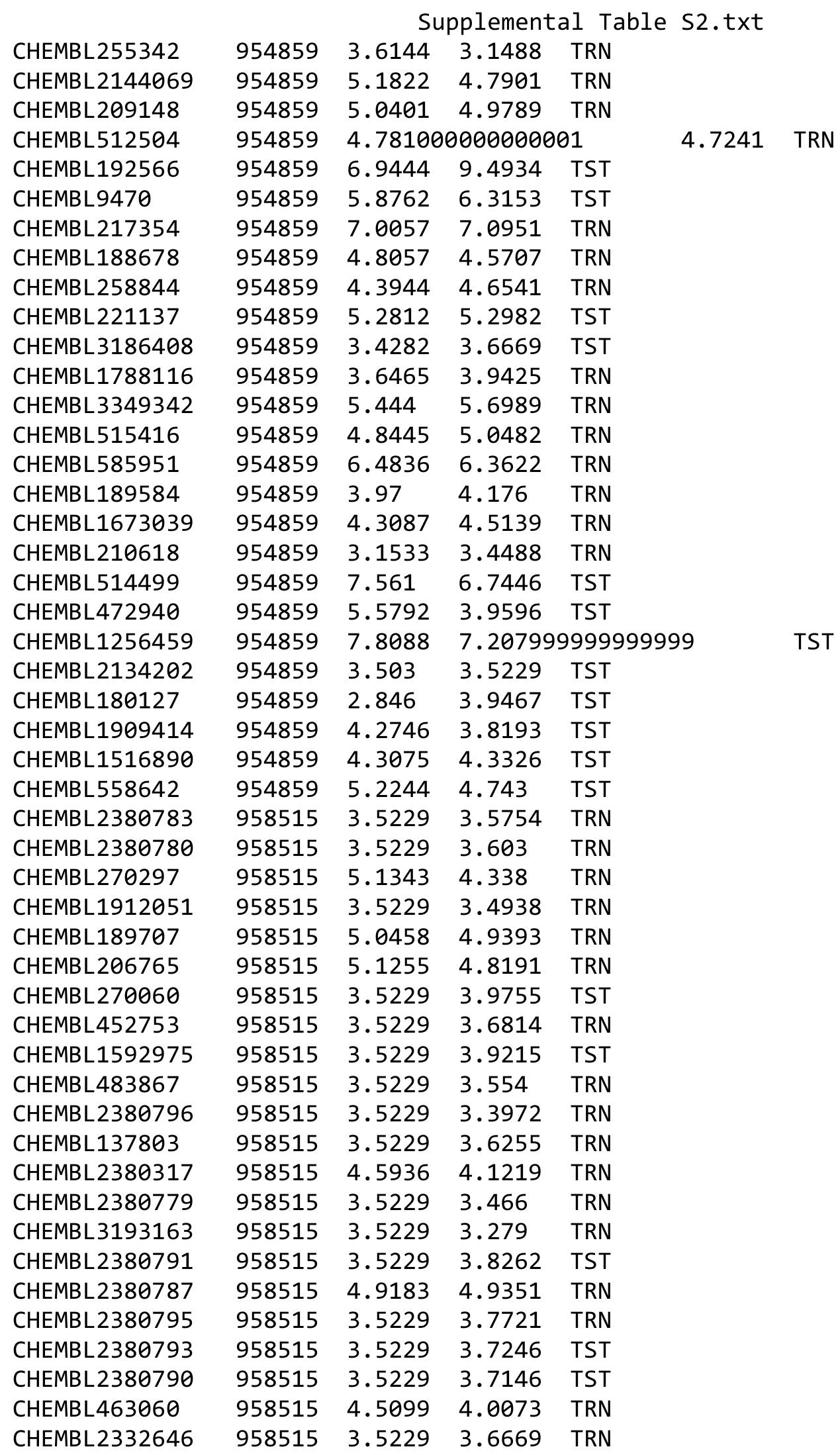

Page 3229 
Supplemental Table S2.txt

\begin{tabular}{|c|c|c|c|c|}
\hline CHEMBL 2380800 & 958515 & 3.5229 & 3.5377 & TRN \\
\hline CHEMBL 2380785 & 958515 & 4.5986 & 4.904 & TRN \\
\hline CHEMBL1644108 & 958515 & 3.5229 & 3.5494 & TRN \\
\hline CHEMBL453279 & 958515 & 3.5229 & 3.6239 & TRN \\
\hline CHEMBL2380801 & 958515 & 3.5229 & 3.4378 & TRN \\
\hline CHEMBL 2380782 & 958515 & 4.5528 & 4.7887 & TRN \\
\hline CHEMBL2206431 & 958515 & 3.5229 & 3.5725 & TST \\
\hline CHEMBL3186408 & 958515 & 3.5229 & 3.6553 & TRN \\
\hline CHEMBL 371358 & 958515 & 4.9978 & 5.1622 & TRN \\
\hline CHEMBL2380792 & 958515 & 3.5229 & 3.6516 & TRN \\
\hline CHEMBL2380789 & 958515 & 3.5229 & 3.7372 & TST \\
\hline CHEMBL364038 & 958515 & 3.5229 & 4.1519 & TRN \\
\hline CHEMBL88985 & 958515 & 3.5229 & 3.7859 & TST \\
\hline CHEMBL520363 & 958515 & 3.5229 & 3.6831 & TRN \\
\hline CHEMBL2380794 & 958515 & 4.6527 & 3.9972 & TRN \\
\hline CHEMBL 2380798 & 958515 & 3.5229 & 3.4259 & TRN \\
\hline CHEMBL2380781 & 958515 & 4.6052 & 4.3128 & TRN \\
\hline CHEMBL359555 & 958515 & 3.5229 & 3.4994 & TRN \\
\hline CHEMBL 2380786 & 958515 & 4.9838 & 5.1393 & TRN \\
\hline CHEMBL1276311 & 958515 & 3.5229 & 3.6628 & TRN \\
\hline CHEMBL1644102 & 958515 & 3.5229 & 3.7192 & TST \\
\hline CHEMBL89311 & 958515 & 3.5229 & 3.6278 & TST \\
\hline CHEMBL510842 & 958515 & 3.5229 & 3.6966 & TRN \\
\hline CHEMBL2380799 & 958515 & 3.5229 & 3.7181 & TRN \\
\hline CHEMBL2380797 & 958515 & 3.5229 & 3.8931 & TRN \\
\hline CHEMBL1257707 & 958515 & 3.5229 & 3.2679 & TRN \\
\hline CHEMBL452752 & 958515 & 3.5229 & $4.02800 t$ & 00000000005 \\
\hline CHEMBL522604 & 958515 & 3.5229 & 3.4867 & TRN \\
\hline CHEMBL372877 & 958515 & 3.5229 & 3.6167 & TRN \\
\hline CHEMBL425554 & 958515 & 4.677 & 4.3935 & TRN \\
\hline CHEMBL453565 & 958515 & 3.5229 & 3.6886 & TST \\
\hline CHEMBL 2380788 & 958515 & 3.5229 & 3.548 & TST \\
\hline CHEMBL519381 & 958515 & 3.5229 & 3.5482 & TST \\
\hline CHEMBL429762 & 958515 & 3.5229 & 3.6968 & TST \\
\hline CHEMBL 2380784 & 958515 & 4.9423 & 4.3165 & TST \\
\hline CHEMBL3685696 & 1527674 & 5.4318 & 5.7072 & TRN \\
\hline CHEMBL3685649 & 1527674 & 5.6198 & 5.8729 & TRN \\
\hline CHEMBL3685660 & 1527674 & 6.5229 & 6.9953 & TRN \\
\hline CHEMBL 3681012 & 1527674 & 6.5229 & 6.3536 & TRN \\
\hline CHEMBL 3685633 & 1527674 & 5.4559 & 5.848 & TST \\
\hline CHEMBL3685647 & 1527674 & 5.6383 & 5.8318 & TRN \\
\hline CHEMBL3685698 & 1527674 & 5.6021 & 6.1317 & TRN \\
\hline CHEMBL3639798 & 1527674 & 7.699 & 7.7324 & TRN \\
\hline CHEMBL 3685722 & 1527674 & 6.3979 & 6.3389 & TRN \\
\hline CHEMBL3681001 & 1527674 & 6.0458 & 6.2516 & TRN \\
\hline CHEMBL3680994 & 1527674 & 7.2218 & 6.7319 & TRN \\
\hline CHEMBL3685667 & 1527674 & 6.2218 & 6.859 & TRN \\
\hline CHEMBL3685697 & 1527674 & 6.0458 & 6.2316 & TRN \\
\hline
\end{tabular}


Supplemental Table S2.txt

\begin{tabular}{|c|c|c|c|c|c|}
\hline CHEMBL3681013 & 1527674 & 8.0 & 7.2931 & TRN & \\
\hline CHEMBL3685657 & 1527674 & 6.699 & 7.0274 & TRN & \\
\hline CHEMBL3680995 & 1527674 & 7.3979 & 7.2374 & TRN & \\
\hline CHEMBL3685691 & 1527674 & 6.0458 & 6.086 & TRN & \\
\hline CHEMBL 3685656 & 1527674 & 7.1549 & 7.0913 & TRN & \\
\hline CHEMBL 3685670 & 1527674 & 6.3979 & 6.1838 & TRN & \\
\hline CHEMBL 3681018 & 1527674 & 6.0458 & 5.985 & TRN & \\
\hline CHEMBL 3685713 & 1527674 & 7.0 & 6.1272 & TRN & \\
\hline CHEMBL3685709 & 1527674 & 5.7696 & 5.9461 & TST & \\
\hline CHEMBL 3685682 & 1527674 & 7.699 & 6.807 & TRN & \\
\hline CHEMBL 3685732 & 1527674 & 6.1549 & 6.2428 & TRN & \\
\hline CHEMBL3680992 & 1527674 & 6.301 & 7.25799 & 9999999999 & TST \\
\hline CHEMBL 3681021 & 1527674 & 6.0969 & 5.6886 & TRN & \\
\hline CHEMBL 3685692 & 1527674 & 6.7212 & 6.8098 & TRN & \\
\hline CHEMBL 3685701 & 1527674 & 6.8239 & 6.4407 & TRN & \\
\hline CHEMBL3681015 & 1527674 & 6.2218 & 6.1712 & TRN & \\
\hline CHEMBL3685725 & 1527674 & 6.1549 & 6.16299 & 9999999999 & TRN \\
\hline CHEMBL 3685644 & 1527674 & 5.3665 & 5.7181 & TRN & \\
\hline CHEMBL 3685694 & 1527674 & 6.2218 & 6.8046 & TRN & \\
\hline CHEMBL 3685714 & 1527674 & 6.0 & 6.6627 & TRN & \\
\hline CHEMBL 3685678 & 1527674 & 5.5376 & 5.7867 & TRN & \\
\hline CHEMBL 3685628 & 1527674 & 6.5229 & 6.5146 & TRN & \\
\hline CHEMBL 3685661 & 1527674 & 7.3979 & 6.4261 & TRN & \\
\hline CHEMBL 3680989 & 1527674 & 5.4318 & 5.9783 & TRN & \\
\hline CHEMBL 3681019 & 1527674 & 6.0 & 5.7685 & TRN & \\
\hline CHEMBL 3685662 & 1527674 & 5.4318 & 6.2116 & TRN & \\
\hline CHEMBL 3685668 & 1527674 & 6.699 & 6.4162 & TRN & \\
\hline CHEMBL 3681026 & 1527674 & 6.2218 & 6.119 & TRN & \\
\hline CHEMBL 3685723 & 1527674 & 5.9586 & 6.0457 & TRN & \\
\hline CHEMBL 3680988 & 1527674 & 7.0 & 6.7169 & TRN & \\
\hline CHEMBL 3681022 & 1527674 & 6.699 & 6.0836 & TRN & \\
\hline CHEMBL3685679 & 1527674 & 6.5229 & 6.6065 & TRN & \\
\hline CHEMBL 3685643 & 1527674 & 5.7696 & 5.8833 & TRN & \\
\hline CHEMBL 3685675 & 1527674 & 6.0 & 6.3089 & TST & \\
\hline CHEMBL 3685652 & 1527674 & 7.3979 & 6.6419 & TRN & \\
\hline CHEMBL3685733 & 1527674 & 6.1549 & 6.1132 & TRN & \\
\hline CHEMBL 3685664 & 1527674 & 6.699 & 7.0963 & TRN & \\
\hline CHEMBL 3685654 & 1527674 & 7.2218 & 6.6329 & TRN & \\
\hline CHEMBL 3680990 & 1527674 & 6.0458 & 6.0745 & TRN & \\
\hline CHEMBL 3685702 & 1527674 & 6.1549 & 6.0202 & TRN & \\
\hline CHEMBL 3685683 & 1527674 & 6.3979 & 6.8042 & TRN & \\
\hline CHEMBL 3685638 & 1527674 & 6.0969 & 6.4469 & TRN & \\
\hline CHEMBL3681005 & 1527674 & 7.3979 & 7.505 & TRN & \\
\hline CHEMBL 3685642 & 1527674 & 6.0 & 6.3984 & TRN & \\
\hline CHEMBL 3685716 & 1527674 & 5.5528 & 5.5091 & TRN & \\
\hline CHEMBL 3680998 & 1527674 & 7.1549 & 6.8634 & TRN & \\
\hline CHEMBL3685650 & 1527674 & 5.699 & 5.9613 & TRN & \\
\hline CHEMBL 3681010 & 1527674 & 6.699 & 6.5343 & TRN & \\
\hline
\end{tabular}


Supplemental Table S2.txt

\begin{tabular}{|c|c|c|c|c|c|}
\hline CHEMBL3685639 & 1527674 & 5.7212 & 5.9468 & TST & \\
\hline CHEMBL3681016 & 1527674 & 5.3188 & 5.8736 & TRN & \\
\hline CHEMBL3685731 & 1527674 & 6.2218 & 6.2645 & TRN & \\
\hline CHEMBL 3680993 & 1527674 & 7.1549 & 7.3559 & TST & \\
\hline CHEMBL3681020 & 1527674 & 6.0969 & 5.6821 & TRN & \\
\hline CHEMBL3685686 & 1527674 & 6.2218 & 6.38899 & 9999999999 & TRN \\
\hline CHEMBL 3685706 & 1527674 & 5.4815 & 5.8072 & TRN & \\
\hline CHEMBL 3685719 & 1527674 & 6.0458 & 5.683 & TRN & \\
\hline CHEMBL3681009 & 1527674 & 6.8861 & 7.20799 & 9999999999 & TRN \\
\hline CHEMBL3685674 & 1527674 & 5.4685 & 6.1786 & TRN & \\
\hline CHEMBL3685693 & 1527674 & 7.2218 & 7.1395 & TRN & \\
\hline CHEMBL3685695 & 1527674 & 7.0 & 7.0358 & TRN & \\
\hline CHEMBL 3685635 & 1527674 & 6.699 & 6.4646 & TRN & \\
\hline CHEMBL 3685634 & 1527674 & 7.0 & 6.2114 & TRN & \\
\hline CHEMBL3685637 & 1527674 & 6.301 & 6.21700 & 00000000005 & TRN \\
\hline CHEMBL3685641 & 1527674 & 6.3979 & 6.5535 & TRN & \\
\hline CHEMBL3680999 & 1527674 & 5.585 & 6.1786 & TRN & \\
\hline CHEMBL 3685717 & 1527674 & 6.301 & 6.4339 & TRN & \\
\hline CHEMBL 3681027 & 1527674 & 7.3979 & 6.9975 & TRN & \\
\hline CHEMBL3685728 & 1527674 & 6.5229 & 6.6285 & TRN & \\
\hline CHEMBL3685715 & 1527674 & 6.699 & 7.1537 & TRN & \\
\hline CHEMBL3685666 & 1527674 & 6.5229 & 6.585 & TRN & \\
\hline CHEMBL3685705 & 1527674 & 6.301 & 6.4729 & TRN & \\
\hline CHEMBL3685690 & 1527674 & 5.9586 & 6.2269 & TRN & \\
\hline CHEMBL 3685730 & 1527674 & 5.301 & 6.0873 & TST & \\
\hline CHEMBL3685707 & 1527674 & 5.5686 & 6.6485 & TST & \\
\hline CHEMBL 3685700 & 1527674 & 6.301 & 6.3996 & TRN & \\
\hline CHEMBL3681023 & 1527674 & 5.5229 & 5.7442 & TRN & \\
\hline CHEMBL3680986 & 1527674 & 6.699 & 6.3634 & TST & \\
\hline CHEMBL 3681017 & 1527674 & 5.7696 & 6.1809 & TRN & \\
\hline CHEMBL3685727 & 1527674 & 7.699 & 6.5641 & TRN & \\
\hline CHEMBL3681004 & 1527674 & 7.2218 & 7.0983 & TRN & \\
\hline CHEMBL3685718 & 1527674 & 6.301 & 5.643 & TRN & \\
\hline CHEMBL3685681 & 1527674 & 6.699 & 6.7777 & TRN & \\
\hline CHEMBL3685640 & 1527674 & 5.4685 & 5.9726 & TST & \\
\hline CHEMBL3685665 & 1527674 & 6.3979 & 6.4755 & TRN & \\
\hline CHEMBL3685651 & 1527674 & 6.5229 & 6.1921 & TRN & \\
\hline CHEMBL 3685631 & 1527674 & 7.301 & 7.9156 & TRN & \\
\hline CHEMBL 3681014 & 1527674 & 6.699 & 6.471 & TRN & \\
\hline CHEMBL3685646 & 1527674 & 5.6778 & 5.9449 & TRN & \\
\hline CHEMBL3685659 & 1527674 & 7.301 & 7.1182 & TRN & \\
\hline CHEMBL3685689 & 1527674 & 6.5229 & 6.444 & TRN & \\
\hline CHEMBL3685712 & 1527674 & 8.0 & 7.2106 & TRN & \\
\hline CHEMBL3685630 & 1527674 & 6.0458 & 5.8596 & TRN & \\
\hline CHEMBL3685726 & 1527674 & 5.7447 & 6.3464 & TRN & \\
\hline CHEMBL3685687 & 1527674 & 6.0969 & 6.2633 & TRN & \\
\hline CHEMBL3685724 & 1527674 & 5.7959 & 5.7684 & TRN & \\
\hline CHEMBL3685632 & 1527674 & 6.3979 & 6.0529 & TRN & \\
\hline
\end{tabular}


Supplemental Table S2.txt

\begin{tabular}{|c|c|c|c|c|c|}
\hline CHEMBL3685671 & 1527674 & 6.301 & \multicolumn{2}{|c|}{6.7860000000000005} & TRN \\
\hline CHEMBL3685708 & 1527674 & 5.8239 & 5.6924 & TST & \\
\hline CHEMBL3685685 & 1527674 & 5.3979 & 5.5078 & TRN & \\
\hline CHEMBL3685629 & 1527674 & 5.4949 & 6.3693 & TRN & \\
\hline CHEMBL 3681006 & 1527674 & 6.8239 & 6.5302 & TRN & \\
\hline CHEMBL3681000 & 1527674 & 6.1549 & 5.9835 & TST & \\
\hline CHEMBL3685655 & 1527674 & 5.6383 & 5.8654 & TRN & \\
\hline CHEMBL3680991 & 1527674 & 5.7959 & 6.2899 & TST & \\
\hline CHEMBL 3681024 & 1527674 & 7.0458 & 6.2728 & TRN & \\
\hline CHEMBL3685669 & 1527674 & 6.699 & 6.4356 & TRN & \\
\hline CHEMBL3681002 & 1527674 & 5.3372 & 6.2159 & TST & \\
\hline CHEMBL1368744 & 1527674 & 5.4815 & 6.46399 & 99999999995 & TST \\
\hline CHEMBL3685680 & 1527674 & 6.1549 & 6.3764 & TRN & \\
\hline CHEMBL3685677 & 1527674 & 5.5376 & 6.3682 & TST & \\
\hline CHEMBL 3685673 & 1527674 & 6.699 & 6.7234 & TRN & \\
\hline CHEMBL3639845 & 1527674 & 5.3979 & 6.1035 & TRN & \\
\hline CHEMBL3685636 & 1527674 & 6.3979 & 5.936 & TRN & \\
\hline CHEMBL3685729 & 1527674 & 6.699 & 6.5613 & TRN & \\
\hline CHEMBL3685645 & 1527674 & 5.4559 & 6.1395 & TST & \\
\hline CHEMBL 3685653 & 1527674 & 7.0 & 6.6474 & TRN & \\
\hline CHEMBL3685663 & 1527674 & 5.9586 & 5.70700 & 2000000001 & TRN \\
\hline CHEMBL3685684 & 1527674 & 7.0 & 6.7102 & TST & \\
\hline CHEMBL3924347 & 1527674 & 6.0 & 6.5634 & TST & \\
\hline CHEMBL3685676 & 1527674 & 6.3979 & 6.5436 & TST & \\
\hline CHEMBL 3681011 & 1527674 & 5.7212 & 6.8069 & TST & \\
\hline CHEMBL3685711 & 1527674 & 5.4685 & 6.5125 & TST & \\
\hline CHEMBL3685658 & 1527674 & 6.699 & 6.6331 & TST & \\
\hline CHEMBL3681007 & 1527674 & 8.1549 & 7.454 & TST & \\
\hline CHEMBL3680996 & 1527674 & 5.9586 & 6.3114 & TST & \\
\hline CHEMBL 3680987 & 1527674 & 5.7696 & 6.7003 & TST & \\
\hline CHEMBL3685672 & 1527674 & 6.4685 & 6.3333 & TST & \\
\hline CHEMBL 3685648 & 1527674 & 6.0458 & 5.39 & TST & \\
\hline CHEMBL3681008 & 1527674 & 7.301 & 6.9453 & TST & \\
\hline CHEMBL 3681003 & 1527674 & 6.301 & 6.8281 & TST & \\
\hline CHEMBL3685688 & 1527674 & 7.0 & 6.7069 & TST & \\
\hline CHEMBL3685721 & 1527674 & 5.3098 & 6.3636 & TST & \\
\hline CHEMBL3680997 & 1527674 & 6.5229 & 6.2221 & TST & \\
\hline CHEMBL3685710 & 1527674 & 5.5376 & 6.425 & TST & \\
\hline CHEMBL3685703 & 1527674 & 5.7212 & 5.7544 & TST & \\
\hline CHEMBL3681025 & 1527674 & 6.699 & 6.5345 & TST & \\
\hline CHEMBL 3685720 & 1527674 & 5.301 & 5.6893 & TST & \\
\hline CHEMBL3685704 & 1527674 & 6.5229 & 6.3083 & TST & \\
\hline CHEMBL1270716 & 674074 & 7.4202 & 6.2737 & TST & \\
\hline CHEMBL1270122 & 674074 & 7.8539 & 7.692 & TRN & \\
\hline CHEMBL1271232 & 674074 & 6.1818 & 6.4287 & TRN & \\
\hline CHEMBL1271128 & 674074 & 6.4881 & 6.6462 & TRN & \\
\hline CHEMBL1270923 & 674074 & 6.8539 & 6.2035 & TST & \\
\hline CHEMBL1269092 & 674074 & 6.5528 & 6.602 & TST & \\
\hline
\end{tabular}


Supplemental Table S2.txt

\begin{tabular}{|c|c|c|c|c|c|}
\hline CHEMBL1269089 & 674074 & 6.699 & 7.3556 & TRN & \\
\hline CHEMBL1269055 & 674074 & 5.3188 & 6.228 & TRN & \\
\hline CHEMBL1270325 & 674074 & 6.8996 & 7.1929 & TRN & \\
\hline CHEMBL1271442 & 674074 & 8.301 & 7.857 & TRN & \\
\hline CHEMBL1271334 & 674074 & 7.7447 & 8.1634 & TRN & \\
\hline CHEMBL1270124 & 674074 & 7.1367 & 7.1263 & TRN & \\
\hline CHEMBL1270821 & 674074 & 4.0 & 3.8691 & TRN & \\
\hline CHEMBL1269783 & 674074 & 6.317 & 5.9926 & TRN & \\
\hline CHEMBL1269910 & 674074 & 6.066 & 5.6416 & TRN & \\
\hline CHEMBL1270326 & 674074 & 7.2366 & 6.9894 & TRN & \\
\hline CHEMBL1270123 & 674074 & 7.2518 & 7.3222 & TRN & \\
\hline CHEMBL1269056 & 674074 & 6.5331 & 6.2146 & TRN & \\
\hline CHEMBL1269908 & 674074 & 6.1938 & 6.5999 & TST & \\
\hline CHEMBL1270822 & 674074 & 4.0 & 3.3828 & TRN & \\
\hline CHEMBL1270424 & 674074 & 7.6383 & 7.1005 & TRN & \\
\hline CHEMBL1270016 & 674074 & 7.6383 & 7.7474 & TRN & \\
\hline CHEMBL1271129 & 674074 & 6.5702 & 7.1262 & TRN & \\
\hline CHEMBL1269784 & 674074 & 6.3344 & 6.2545 & TRN & \\
\hline CHEMBL1270014 & 674074 & 4.0 & 4.6482 & TRN & \\
\hline CHEMBL1269909 & 674074 & 6.3872 & 6.8708 & TST & \\
\hline CHEMBL1270228 & 674074 & 6.7905 & 6.9429 & TRN & \\
\hline CHEMBL1270230 & 674074 & 7.6576 & 7.108 & TRN & \\
\hline CHEMBL1270518 & 674074 & 6.9318 & 7.1935 & TRN & \\
\hline CHEMBL1270520 & 674074 & 6.6655 & 6.8018 & TRN & \\
\hline CHEMBL1271127 & 674074 & 6.3851 & 6.6608 & TRN & \\
\hline CHEMBL1269729 & 674074 & 7.4089 & 6.8254 & TRN & \\
\hline CHEMBL1270425 & 674074 & 7.4089 & 7.5014 & TRN & \\
\hline CHEMBL1271233 & 674074 & 6.9431 & 7.0834 & TRN & \\
\hline CHEMBL1270324 & 674074 & 7.2757 & 6.9157 & TRN & \\
\hline CHEMBL1271441 & 674074 & 8.0969 & 8.1238 & TRN & \\
\hline CHEMBL1269728 & 674074 & 7.6576 & 7.3498 & TRN & \\
\hline CHEMBL1269782 & 674074 & 6.2874 & 6.5657 & TRN & \\
\hline CHEMBL1270229 & 674074 & 7.2218 & 7.0663 & TRN & \\
\hline CHEMBL1269090 & 674074 & 5.8861 & 6.2346 & TRN & \\
\hline CHEMBL1271234 & 674074 & 7.1675 & 7.026 & TRN & \\
\hline CHEMBL1271335 & 674074 & 6.8665 & 7.3184 & TRN & \\
\hline CHEMBL1271022 & 674074 & 6.341 & 5.9626 & TST & \\
\hline CHEMBL1270519 & 674074 & 6.8827 & 7.2646 & TRN & \\
\hline CHEMBL1270618 & 674074 & 7.0458 & 6.5697 & TRN & \\
\hline CHEMBL1270426 & 674074 & 7.3565 & \multicolumn{2}{|c|}{ 7.257999999999999 } & TRN \\
\hline CHEMBL1271023 & 674074 & 6.2757 & 6.0205 & TST & \\
\hline CHEMBL1270717 & 674074 & 4.0 & 4.3812 & TRN & \\
\hline CHEMBL225519 & 674074 & 8.0 & 5.7118 & TST & \\
\hline CHEMBL1271024 & 674074 & 6.1007 & 6.0469 & TST & \\
\hline CHEMBL1270924 & 674074 & 7.3979 & 5.726 & TST & \\
\hline CHEMBL1270015 & 674074 & 8.0969 & 8.1324 & TRN & \\
\hline CHEMBL1271443 & 674074 & 8.699 & 7.8687 & TRN & \\
\hline CHEMBL1269057 & 674074 & 8.0458 & 7.5138 & TRN & \\
\hline
\end{tabular}


Supplemental Table S2.txt

\begin{tabular}{|c|c|c|c|c|}
\hline 12 & 74 & 62 & 377 & TRN \\
\hline CHEMBL1269091 & 674074 & 6.7055 & 6.8971 & \\
\hline CHEMBL1270925 & 674074 & 7.4437 & 5.9676 & \\
\hline CHEMBL1270619 & 674074 & 7.1675 & 6.2768 & \\
\hline CHEMBL1270715 & 674074 & 5.9408 & 6.336 & \\
\hline CHEMBL1270620 & 674074 & 7.284 & 6.4475 & \\
\hline CHEMBL421450 & 88770 & 4.15 & 4.0379 & \\
\hline CHEMBL129120 & 88770 & 5.05 & 4.9458 & \\
\hline CHEMBL338373 & 88770 & 4.75 & 4.7988 & \\
\hline CHEMBL128249 & 8770 & 4.97 & 4.8703 & \\
\hline CHEMBL129286 & 8770 & 4.73 & 4.5308 & \\
\hline CHEMBL433666 & 8770 & 5.01 & 5.1469 & \\
\hline CHEMBL340865 & 88770 & 3.92 & 4.4909 & \\
\hline CHEMBL128231 & 8770 & 4.43 & & \\
\hline CHEMBL13 & 88770 & & & \\
\hline CHEMBL128 & 8770 & & 5.0668 & \\
\hline CHEMBL128376 & 3770 & 5.22 & 5.124 & \\
\hline CHEMBL129055 & 8770 & 3.71 & 3.6799 & TRN \\
\hline CHEMB & 8770 & 4.22 & 209 & \\
\hline CHEMBL12 & 8770 & 5.26 & 5.2475 & \\
\hline CHEME & 8770 & $5.4-2 \cdot x-3$ & 5.4176 & \\
\hline CHEMBL128868 & 8770 & & & \\
\hline CHEME & 8770 & 4.41 & 4.3159 & TR \\
\hline CHEME & 8770 & 5. & 35 & $\mathrm{TH}$ \\
\hline CHEMB & 8770 & 5.09 & 42 & TST \\
\hline CHEMBL12 & 8770 & 4.5 & 4.9249 & \\
\hline CHEMBL33 & 8770 & & & \\
\hline CHEM & 8770 & 4.81 & 4.9638 & $T R$ \\
\hline CHEMBL3 & 8770 & 5.44 & 5.3546 & TR \\
\hline CHEM & 8770 & 3. & 49 & \\
\hline CHEMBL337606 & 8770 & 4.89 & 4.8578 & $T R$ \\
\hline CHEMBL127330 & 8770 & 5.22 & 5.0595 & \\
\hline CHEME & 8770 & 4.2 & 4.2882 & \\
\hline CHEMBL129462 & 88770 & 3.91 & 3.885 & TR \\
\hline CHEME & מברס & 4,11 & 4.3205 & \\
\hline CHEMBL & 8770 & 4.6 & .7671 & TR \\
\hline CHEME & 8770 & 4. & 355 & TR \\
\hline CHEM & 8770 & 4.3 & 06 & \\
\hline CHEMBL338144 & 88770 & 4.63 & 4.5995 & TR \\
\hline CHEMBL & & 5.45 & & \\
\hline CHEMBL128556 & 3770 & 3.85 & 3.9258 & \\
\hline CHEMBL127388 & 8770 & 3.87 & 4.0712 & \\
\hline CHEME & 8770 & 3.83 & & \\
\hline CHEMBL420148 & 88770 & 3.7 & - 0177 & \\
\hline & & & & \\
\hline CHEMBL128927 & 88770 & 4.54 & 4.441 & TR \\
\hline CHEMBL12 & & & 4.1213 & \\
\hline CHEMBL129119 & 88770 & 4.79 & 4.9251 & \\
\hline
\end{tabular}

Page 3235 


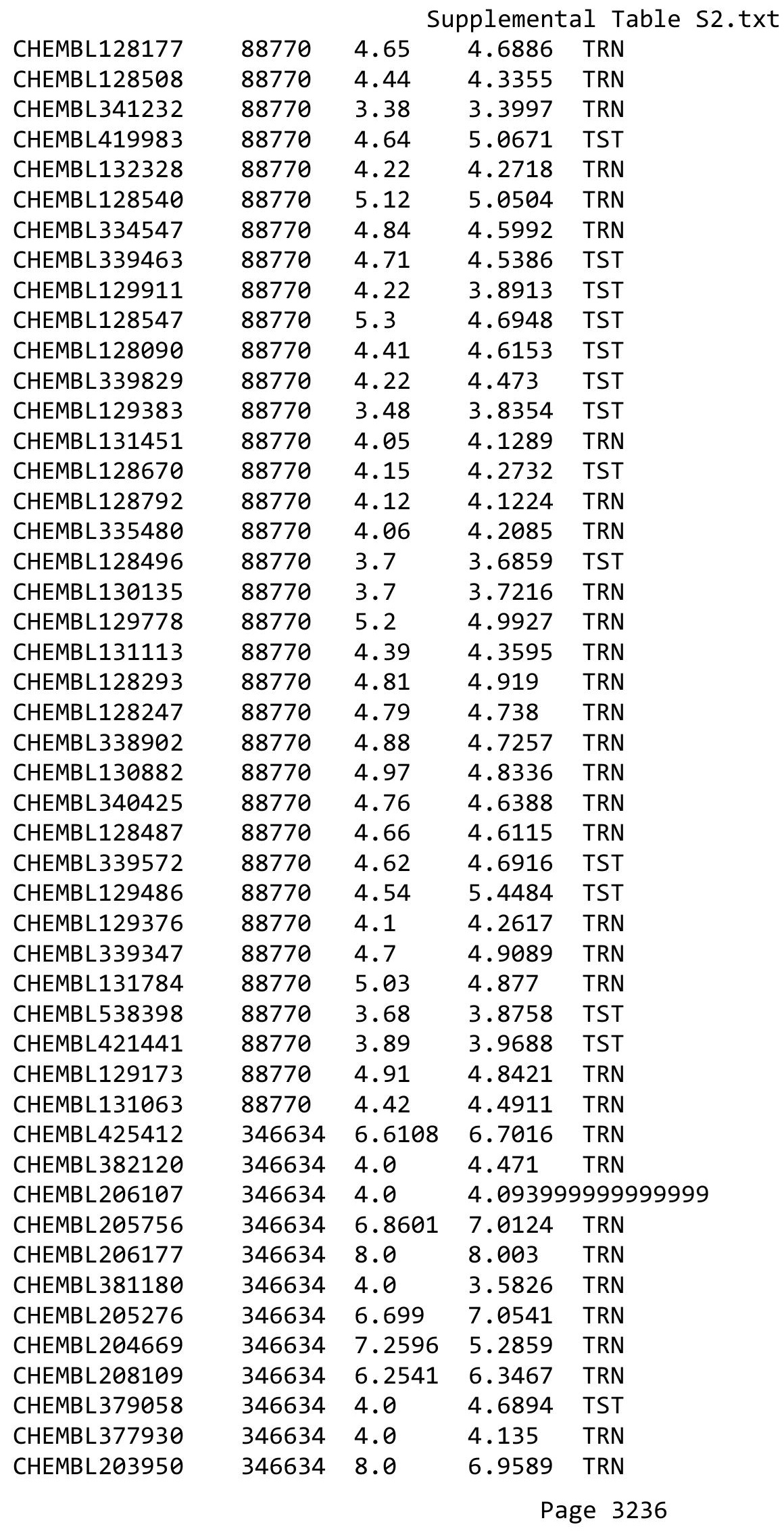




\begin{tabular}{|c|c|c|c|c|}
\hline & & Sup & oplement & al Table S2 \\
\hline CHEMBL203241 & 346634 & 4.0 & 3.4379 & TRN \\
\hline CHEMBL204422 & 346634 & 8.0969 & 8.4229 & TRN \\
\hline CHEMBL437297 & 346634 & 7.7959 & 6.6359 & TRN \\
\hline CHEMBL207793 & 346634 & 5.2554 & 6.6383 & TST \\
\hline CHEMBL382216 & 346634 & 7.4089 & 7.3457 & TRN \\
\hline CHEMBL383302 & 346634 & 7.5686 & 7.6784 & TRN \\
\hline CHEMBL207149 & 346634 & 6.1884 & 6.5137 & TRN \\
\hline CHEMBL203464 & 346634 & 8.301 & 7.3898 & TRN \\
\hline CHEMBL206959 & 346634 & 4.0 & 4.4932 & TRN \\
\hline CHEMBL382446 & 346634 & 4.0 & 5.1095 & TRN \\
\hline CHEMBL378966 & 346634 & 6.2976 & 6.9105 & TRN \\
\hline CHEMBL377145 & 346634 & 6.0737 & 5.7549 & TRN \\
\hline CHEMBL207581 & 346634 & 7.7447 & 7.6753 & TRN \\
\hline CHEMBL207974 & 346634 & 4.0 & 4.8474 & TRN \\
\hline CHEMBL207310 & 346634 & 4.0 & 5.3869 & TRN \\
\hline CHEMBL379455 & 346634 & 6.7447 & 5.5892 & TST \\
\hline CHEMBL203527 & 346634 & 6.2314 & 6.4768 & TRN \\
\hline CHEMBL382195 & 346634 & 7.0655 & 7.6329 & TRN \\
\hline CHEMBL208498 & 346634 & 5.7433 & 6.6689 & TRN \\
\hline CHEMBL378311 & 346634 & 7.5528 & 7.5881 & TRN \\
\hline CHEMBL203465 & 346634 & 6.3605 & 5.9215 & TRN \\
\hline CHEMBL205713 & 346634 & 6.6655 & 7.2293 & TRN \\
\hline CHEMBL205210 & 346634 & 8.0969 & 6.5304 & TRN \\
\hline CHEMBL204983 & 346634 & 7.1367 & 7.2121 & TRN \\
\hline CHEMBL203294 & 346634 & 6.6126 & 5.092 & TRN \\
\hline CHEMBL437324 & 346634 & 4.0 & 4.6756 & TRN \\
\hline CHEMBL383622 & 346634 & 6.7773 & 4.2212 & TST \\
\hline CHEMBL208237 & 346634 & 5.3039 & 5.3504 & TRN \\
\hline CHEMBL426491 & 346634 & 4.0 & 4.3036 & TRN \\
\hline CHEMBL427209 & 346634 & 6.7959 & 5.5789 & TST \\
\hline CHEMBL205882 & 346634 & 5.8972 & 4.7289 & TST \\
\hline CHEMBL381924 & 346634 & 4.0 & 5.4046 & TST \\
\hline CHEMBL378071 & 346634 & 6.3344 & 5.9643 & TST \\
\hline CHEMBL205889 & 346634 & 7.6383 & 6.4779 & TST \\
\hline CHEMBL203242 & 346634 & 5.1694 & 4.9528 & TST \\
\hline CHEMBL208313 & 346634 & 7.6383 & 5.6526 & TST \\
\hline CHEMBL206882 & 346634 & 7.8239 & 6.14 & TST \\
\hline CHEMBL205315 & 346634 & 8.2218 & 4.7609 & TST \\
\hline CHEMBL172048 & 213372 & 7.0915 & 7.04899 & 99999999995 \\
\hline CHEMBL170707 & 213372 & 9.3279 & 9.2927 & TRN \\
\hline CHEMBL168419 & 213372 & 6.1337 & 6.1077 & TRN \\
\hline CHEMBL352778 & 213372 & 10.0 & 9.9024 & TRN \\
\hline CHEMBL171481 & 213372 & 8.8239 & 8.6522 & TRN \\
\hline CHEMBL355215 & 213372 & 9.7959 & 9.9657 & TRN \\
\hline CHEMBL355240 & 213372 & 10.1549 & 10.2337 & TRN \\
\hline CHEMBL352656 & 213372 & 7.5086 & 7.596 & TRN \\
\hline CHEMBL355508 & 213372 & 6.8239 & 7.1011 & TST \\
\hline CHEMBL171929 & 213372 & 9.2757 & 9.1138 & TRN \\
\hline
\end{tabular}


Supplemental Table S2.txt

\begin{tabular}{|c|c|c|c|c|}
\hline AEMBL17 & 372 & 249 & 2675 & TRN \\
\hline CHEMBL169343 & 13372 & 7.5528 & 7.7584 & \\
\hline HEMBL422901 & 3372 & 3565 & 4467 & \\
\hline HEMBL424584 & 13372 & 9.9586 & 10.0344 & DN \\
\hline HEMBL355183 & 13372 & .1675 & .129 & \\
\hline HEMBL169530 & 13372 & 8.1805 & 8.4207 & \\
\hline HEMBL169377 & 13372 & .9586 & .9833 & \\
\hline HEMBL169210 & 13372 & 5528 & 7.4714 & RN \\
\hline HEMBL171735 & 213372 & 9.2596 & 9.1925 & \\
\hline HEMBL169147 & 13372 & .5686 & 9.3696 & \\
\hline HEMBL170198 & 13372 & 8.1549 & 7.7645 & \\
\hline HEMBL 355501 & 13372 & 815 & 9.2417 & \\
\hline HEMBL1 & 3372 & 212 & 7.5469 & ST \\
\hline HEMBL169640 & 213372 & 9.3372 & 9.2981 & RN \\
\hline HEMBL170126 & 13372 & 9.1135 & 2683 & \\
\hline HEMBL172470 & 13372 & 9.7212 & 9.8365 & NIV \\
\hline HEMBL3 & 13372 & 686 & 8.5888 & RIN \\
\hline HEMBL3 & 13372 & 576 & 7.566 & \\
\hline HEMBL170515 & 13372 & 9.8239 & 9.7439 & RN \\
\hline HEMBL446690 & 372 & 9.7212 & 9297 & $\mathrm{~N}$ \\
\hline HEMBL1 & 372 & 9.4437 & 9.2782 & RIV \\
\hline HEMBL1 & 372 & 65 & 8.4249 & RN \\
\hline HEMBL169444 & 3372 & 539 & 9.8693 & RN \\
\hline HEMBL352809 & 13372 & 7.8239 & 7.7682 & 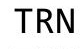 \\
\hline HEMBL170620 & 13372 & 68 & 399 & I RIN \\
\hline HEMBL353244 & 13372 & 9.6778 & 129 & SI \\
\hline HEMBL1 & 3372 & 132 & 064 & TRN \\
\hline HEMBL1 & 13372 & 8.9208 & 9.0853 & TRN \\
\hline IHEMBL444087 & 13372 & 9.8861 & 9.7881 & TRIV \\
\hline CHEMBL352299 & 13372 & 8.8861 & 8.8691 & TRN \\
\hline HEMBL171284 & 3372 & .5229 & 2396 & RN \\
\hline CHEMBL1 & 372 & 607 & 699 & TRN \\
\hline CHEMBL3 & 372 & 7.2757 & 3919 & TRN \\
\hline CHEMBL 368085 & 13372 & 7.6383 & 7.7119 & TRN \\
\hline HEMBL171389 & 13372 & 10.0458 & 10.0991 & TRN \\
\hline HEMBL171546 & 3372 & 8.3872 & 8.639 & TRN \\
\hline CHEMBL3 & 372 & 586 & 025 & RN \\
\hline CHEMBL170374 & 3372 & 9.4089 & 9.3947 & TRN \\
\hline CHEMBL171139 & 13372 & 9.6576 & 9.439 & TRN \\
\hline HEMBL169600 & 13372 & 7.6383 & 7.5194 & TRN \\
\hline CHEMBL353589 & 13372 & 9.3188 & 9.3268 & TRN \\
\hline CHEMBL172396 & 213372 & 9.4318 & 9.5636 & IS \\
\hline CHEMBL171032 & 13372 & 9.1739 & 9.6025 & TST \\
\hline CHEMBL171663 & 13372 & 9.1135 & 9.1355 & $\mathrm{TR}$ \\
\hline CHEMBL355242 & 13372 & 7.1871 & 6.982 & ונד \\
\hline CHEMBL353459 & 213372 & 7.2518 & 7.3243 & niv \\
\hline CHEMBL439838 & 13372 & 9.7212 & 9.9717 & ST \\
\hline CHEMBL353594 & 213372 & 7.2924 & 7.6312 & ГST \\
\hline
\end{tabular}

Page 3238 


\begin{tabular}{|c|c|c|c|c|c|c|}
\hline & & \multicolumn{5}{|c|}{ Supplemental Table S2.txt } \\
\hline CHEMBL172169 & 213372 & 6.9788 & 7.5047 & TST & & \\
\hline CHEMBL355536 & 213372 & 9.7696 & 9.7664 & TST & & \\
\hline CHEMBL423443 & 213372 & 9.0 & 8.5695 & TST & & \\
\hline CHEMBL170252 & 213372 & 7.699 & 8.8102 & TST & & \\
\hline CHEMBL168939 & 213372 & 7.8539 & 7.7645 & TST & & \\
\hline CHEMBL171111 & 213372 & 8.9208 & 8.9739 & TST & & \\
\hline CHEMBL171613 & 213372 & 8.9586 & 9.0398 & TST & & \\
\hline CHEMBL 2312346 & 936414 & 5.6498 & 4.8471 & TRN & & \\
\hline CHEMBL 2312348 & 936414 & 3.0 & 3.1156 & TST & & \\
\hline CHEMBL2312367 & 936414 & 6.7212 & 6.7794 & TRN & & \\
\hline CHEMBL2311978 & 936414 & 3.0 & 2.9304 & TRN & & \\
\hline CHEMBL2312357 & 936414 & 3.0 & 3.2273 & TRN & & \\
\hline CHEMBL123099 & 936414 & 6.3768 & 6.9898 & TRN & & \\
\hline CHEMBL 2312358 & 936414 & 7.5229 & 7.7039 & TRN & & \\
\hline CHEMBL2312365 & 936414 & 3.0 & 3.8454 & TRN & & \\
\hline CHEMBL 2312385 & 936414 & 3.0 & 3.3586 & TRN & & \\
\hline CHEMBL 2312384 & 936414 & 6.7212 & 6.572 & TRN & & \\
\hline CHEMBL2311976 & 936414 & 3.0 & 2.7434 & TRN & & \\
\hline CHEMBL 2312388 & 936414 & 5.4425 & 5.6161 & TRN & & \\
\hline CHEMBL2312355 & 936414 & 3.0 & 3.1046 & TRN & & \\
\hline CHEMBL 2312390 & 936414 & 3.0 & 3.2493 & TST & & \\
\hline CHEMBL2312370 & 936414 & 7.0969 & 6.2483 & TRN & & \\
\hline CHEMBL 2312392 & 936414 & 6.7212 & 7.0464 & TRN & & \\
\hline CHEMBL2311977 & 936414 & 3.0 & 2.8481 & TRN & & \\
\hline CHEMBL2312350 & 936414 & 5.6289 & 5.8392 & TRN & & \\
\hline CHEMBL2312375 & 936414 & 3.0 & 4.1311 & TRN & & \\
\hline CHEMBL2312389 & 936414 & 6.3279 & 6.1293 & TRN & & \\
\hline CHEMBL2312351 & 936414 & 3.0 & 3.8801 & TRN & & \\
\hline CHEMBL2312354 & 936414 & \multicolumn{3}{|c|}{5.617999999999999} & .4776 & TRN \\
\hline CHEMBL 2311981 & 936414 & 3.0 & 2.9618 & TST & & \\
\hline CHEMBL 2311547 & 936414 & 5.4763 & 4.515 & TRN & & \\
\hline CHEMBL2312345 & 936414 & 3.0 & 3.1056 & TST & & \\
\hline CHEMBL2312344 & 936414 & 5.9431 & 6.9523 & TRN & & \\
\hline CHEMBL2312369 & 936414 & 6.5528 & 6.0628 & TRN & & \\
\hline CHEMBL2311979 & 936414 & 3.0 & 2.9793 & TRN & & \\
\hline CHEMBL2312366 & 936414 & 6.2007 & 6.4528 & TRN & & \\
\hline CHEMBL 2312352 & 936414 & 6.1308 & 5.5786 & TRN & & \\
\hline CHEMBL2312374 & 936414 & 6.3565 & 6.3568 & TRN & & \\
\hline CHEMBL 2312371 & 936414 & 6.1308 & 5.8638 & TRN & & \\
\hline CHEMBL 2312349 & 936414 & 5.5129 & 5.8298 & TRN & & \\
\hline CHEMBL2311982 & 936414 & 3.0 & 3.0962 & TST & & \\
\hline CHEMBL 2312386 & 936414 & 5.9031 & 5.9223 & TRN & & \\
\hline CHEMBL2312387 & 936414 & 6.8239 & 6.4397 & TRN & & \\
\hline CHEMBL 2312347 & 936414 & 5.2976 & 4.5697 & TST & & \\
\hline CHEMBL2312359 & 936414 & 3.0 & 2.8321 & TRN & & \\
\hline CHEMBL2312356 & 936414 & 3.0 & 3.39600 & 00000000004 & & TRN \\
\hline CHEMBL 2312377 & 936414 & 6.5528 & 6.7542 & TRN & & \\
\hline CHEMBL2312381 & 936414 & 3.0 & 2.77 & TRN & & \\
\hline
\end{tabular}


Supplemental Table S2.txt

\begin{tabular}{|c|c|c|c|c|c|}
\hline CHEMBL 2312368 & 936414 & 6.9586 & 6.8741 & TRN & \\
\hline CHEMBL 2312378 & 936414 & 6.9208 & 6.7611 & TRN & \\
\hline CHEMBL2312361 & 936414 & 7.2218 & 6.8448 & TRN & \\
\hline CHEMBL2311980 & 936414 & 3.0 & 2.6879 & TST & \\
\hline CHEMBL2312380 & 936414 & 3.0 & 2.9856 & TRN & \\
\hline CHEMBL2312391 & 936414 & 6.5376 & 6.7381 & TRN & \\
\hline CHEMBL 2312373 & 936414 & 6.4318 & 6.6137 & TRN & \\
\hline CHEMBL2312376 & 936414 & 6.6383 & 5.9702 & TRN & \\
\hline CHEMBL2312360 & 936414 & 3.0 & 2.6269 & TRN & \\
\hline CHEMBL2311983 & 936414 & 5.5817 & 5.2638 & TRN & \\
\hline CHEMBL 2312382 & 936414 & 6.1192 & 6.3915 & TST & \\
\hline CHEMBL2312353 & 936414 & 5.5719 & 5.8301 & TST & \\
\hline CHEMBL2312363 & 936414 & 3.0 & 2.8222 & TST & \\
\hline CHEMBL2312362 & 936414 & 3.0 & 3.0643 & TST & \\
\hline CHEMBL2312379 & 936414 & 5.6091 & 4.999 & TST & \\
\hline CHEMBL 2312383 & 936414 & 6.8539 & 6.8165 & TST & \\
\hline CHEMBL2312364 & 936414 & 5.9355 & 5.8256 & TST & \\
\hline CHEMBL2312372 & 936414 & 6.3872 & 6.1096 & TST & \\
\hline CHEMBL435005 & 198910 & 6.2218 & 7.0467 & TRN & \\
\hline CHEMBL126401 & 198910 & 5.4815 & 5.5863 & TST & \\
\hline CHEMBL124652 & 198910 & 4.4089 & 4.9076 & TRN & \\
\hline CHEMBL340748 & 198910 & 6.585 & 6.21399 & 99999999995 & TRN \\
\hline CHEMBL124327 & 198910 & 6.8539 & 7.5476 & TRN & \\
\hline CHEMBL126696 & 198910 & 5.4949 & 6.3756 & TST & \\
\hline CHEMBL338831 & 198910 & 6.0969 & 5.9123 & TRN & \\
\hline CHEMBL406612 & 198910 & 6.6383 & 7.2848 & TRN & \\
\hline CHEMBL436390 & 198910 & 5.4815 & 5.3013 & TST & \\
\hline CHEMBL124510 & 198910 & 7.0969 & 7.268 & TRN & \\
\hline CHEMBL420522 & 198910 & 5.4318 & 5.0843 & TST & \\
\hline CHEMBL333723 & 198910 & 5.7696 & 5.5652 & TRN & \\
\hline CHEMBL127608 & 198910 & 6.699 & 7.0559 & TST & \\
\hline CHEMBL339025 & 198910 & 5.9208 & 7.0145 & TST & \\
\hline CHEMBL341342 & 198910 & 7.4685 & 7.1901 & TRN & \\
\hline CHEMBL278315 & 198910 & 7.1549 & 6.8427 & TRN & \\
\hline CHEMBL338685 & 198910 & 6.5229 & 6.84399 & 9999999999 & TST \\
\hline CHEMBL127765 & 198910 & 5.8894 & 5.2993 & TRN & \\
\hline CHEMBL340549 & 198910 & 5.9208 & 6.2959 & TRN & \\
\hline CHEMBL339533 & 198910 & 6.8539 & 7.0891 & TRN & \\
\hline CHEMBL334128 & 198910 & 7.0458 & 6.7885 & TRN & \\
\hline CHEMBL341122 & 198910 & 5.7212 & 7.7215 & TST & \\
\hline CHEMBL 340000 & 198910 & 5.9706 & 6.3172 & TRN & \\
\hline CHEMBL127769 & 198910 & 6.8539 & 6.6019 & TRN & \\
\hline CHEMBL127189 & 198910 & 6.5229 & 6.9017 & TRN & \\
\hline CHEMBL435606 & 198910 & 7.301 & 7.0377 & TRN & \\
\hline CHEMBL339975 & 198910 & 7.8539 & 7.3135 & TRN & \\
\hline CHEMBL433669 & 198910 & 5.585 & 5.4196 & TRN & \\
\hline CHEMBL125045 & 198910 & 7.4685 & 6.8032 & TRN & \\
\hline CHEMBL340038 & 198910 & 7.4318 & 6.9126 & TRN & \\
\hline
\end{tabular}




\begin{tabular}{|c|c|c|c|c|c|}
\hline \multicolumn{6}{|c|}{ Supplemental Table s2.txt } \\
\hline CHEMBL340456 & 198910 & 6.0809 & 7.0377 & TST & \\
\hline CHEMBL341345 & 198910 & 7.1549 & 6.8635 & TST & \\
\hline CHEMBL127932 & 198910 & 4.6021 & 5.6938 & TRN & \\
\hline CHEMBL127372 & 198910 & 6.0 & 6.0365 & TRN & \\
\hline CHEMBL435007 & 198910 & 6.5686 & 6.6692 & TRN & \\
\hline CHEMBL338305 & 198910 & 6.7696 & 7.0139 & TRN & \\
\hline CHEMBL339891 & 198910 & 7.3979 & 7.0993 & TRN & \\
\hline CHEMBL125088 & 198910 & 6.6576 & 6.3644 & TRN & \\
\hline CHEMBL443547 & 198910 & 7.1549 & 7.146 & TRN & \\
\hline CHEMBL333934 & 198910 & 7.0458 & 7.0164 & TST & \\
\hline CHEMBL338819 & 198910 & 4.5086 & 7.1125 & TST & \\
\hline CHEMBL436386 & 198910 & 5.9586 & 6.9125 & TRN & \\
\hline CHEMBL339231 & 198910 & 7.4318 & 6.7647 & TRN & \\
\hline CHEMBL126989 & 198910 & 6.699 & 7.1196 & TST & \\
\hline CHEMBL331914 & 198910 & 6.301 & 6.4652 & TRN & \\
\hline CHEMBL419613 & 198910 & 6.0706 & 6.2043 & TRN & \\
\hline CHEMBL331273 & 198910 & 7.2218 & 6.9321 & TRN & \\
\hline CHEMBL444070 & 198910 & 6.0 & 6.1333 & TRN & \\
\hline CHEMBL123564 & 198910 & 7.2924 & 6.5383 & TRN & \\
\hline CHEMBL433670 & 198910 & 7.6383 & 7.1658 & TRN & \\
\hline CHEMBL124387 & 198910 & 6.7212 & 6.7263 & TRN & \\
\hline CHEMBL340169 & 198910 & 6.6383 & 6.9921 & TRN & \\
\hline CHEMBL16361 & 157530 & 8.585 & 8.0 & TST & \\
\hline CHEMBL279192 & 157530 & 8.5528 & 8.3088 & TRN & \\
\hline CHEMBL16629 & 157530 & 8.4089 & 8.3256 & TRN & \\
\hline CHEMBL276737 & 157530 & 7.3279 & 7.5882 & TRN & \\
\hline CHEMBL280104 & 157530 & 8.3872 & 8.1943 & TRN & \\
\hline CHEMBL16536 & 157530 & 9.3979 & 7.7928 & TST & \\
\hline CHEMBL16566 & 157530 & 7.699 & 8.6686 & TST & \\
\hline CHEMBL278970 & 157530 & 7.8861 & 8.1328 & TRN & \\
\hline CHEMBL16351 & 157530 & 8.5086 & 8.0806 & TRN & \\
\hline CHEMBL16427 & 157530 & 8.3979 & 8.01 & TRN & \\
\hline CHEMBL16421 & 157530 & 7.4437 & 8.1201 & TRN & \\
\hline CHEMBL278477 & 157530 & 8.2076 & 7.5426 & TRN & \\
\hline CHEMBL430323 & 157530 & 8.3872 & 8.0117 & TRN & \\
\hline CHEMBL276592 & 157530 & 9.0 & 8.5157 & TRN & \\
\hline CHEMBL16340 & 157530 & 8.5229 & 7.9272 & TRN & \\
\hline CHEMBL16777 & 157530 & 8.3279 & 8.1518 & TRN & \\
\hline CHEMBL16694 & 157530 & 9.0969 & 8.4337 & TST & \\
\hline CHEMBL276055 & 157530 & 7.4815 & 7.8461 & TRN & \\
\hline CHEMBL16832 & 157530 & 8.1675 & 8.2857 & TRN & \\
\hline CHEMBL16473 & 157530 & 7.7447 & 7.5647 & TRN & \\
\hline CHEMBL16337 & 157530 & 6.0 & 7.6147 & TRN & \\
\hline CHEMBL16551 & 157530 & 8.5686 & 8.122 & TRN & \\
\hline CHEMBL16266 & 157530 & 7.7447 & 8.3026 & TRN & \\
\hline CHEMBL16875 & 157530 & 8.8539 & 8.299 & TRN & \\
\hline CHEMBL16238 & 157530 & 8.6576 & 9.07200 & 0000000001 & TST \\
\hline CHEMBL16856 & 157530 & 9.301 & 8.3822 & TST & \\
\hline
\end{tabular}




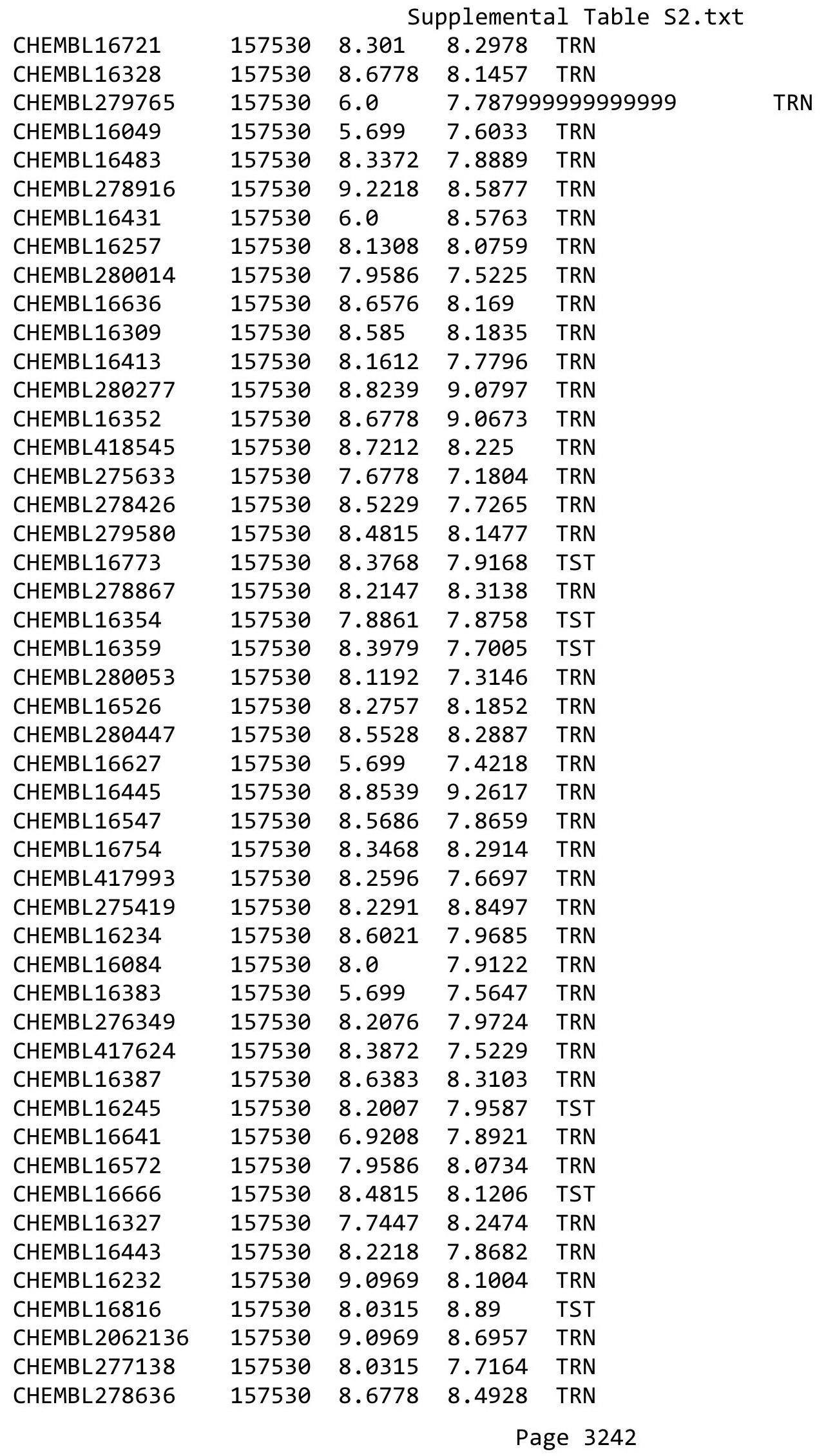




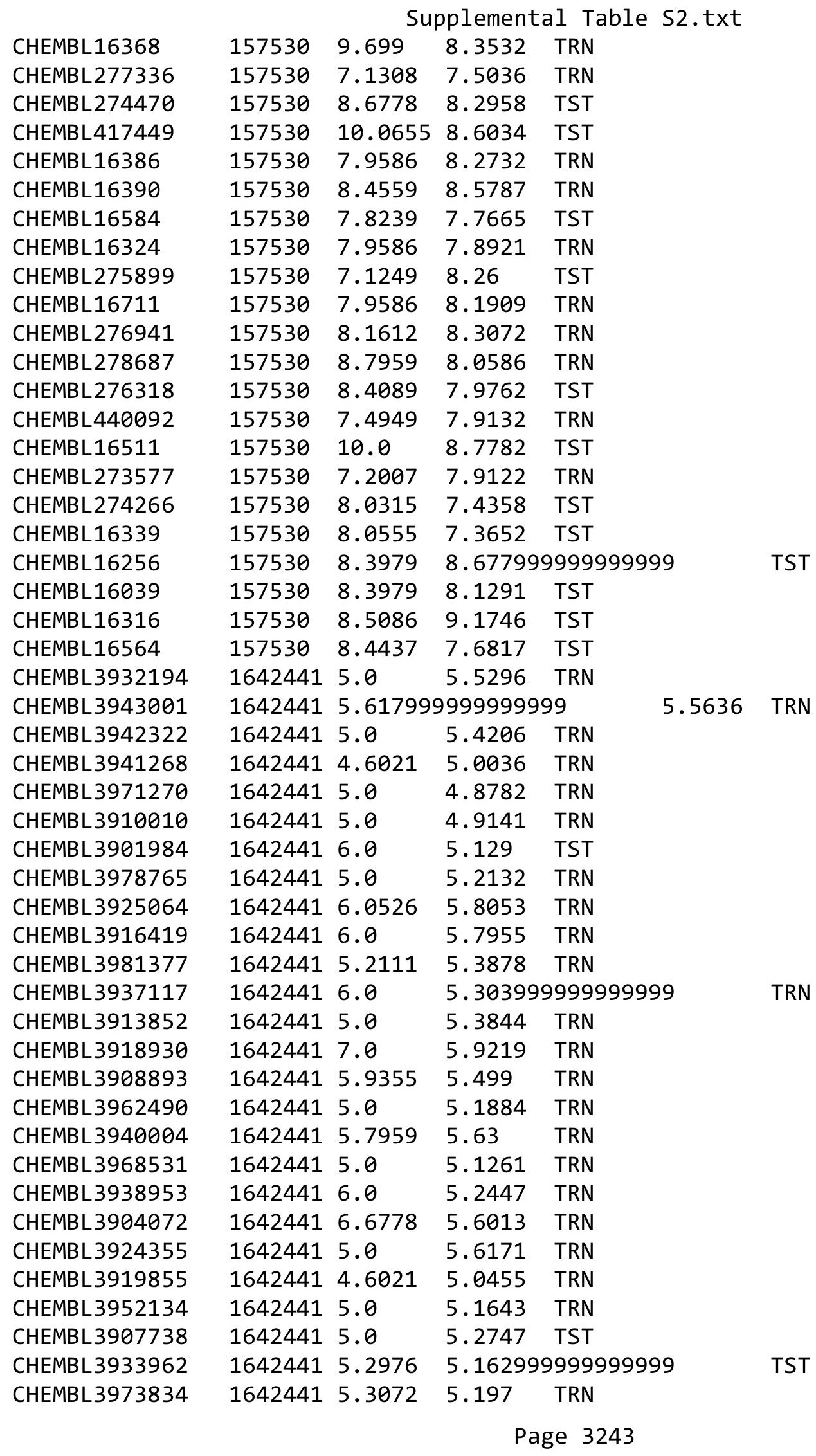


Supplemental Table S2.txt

\begin{tabular}{|c|c|c|c|c|c|c|}
\hline CHEMBL 3897015 & 1642441 & 5.5498 & 5.7875 & TRN & & \\
\hline CHEMBL 3943875 & 1642441 & 5.0 & 5.4978 & TRN & & \\
\hline CHEMBL 3957443 & 1642441 & 5.0 & 5.7577 & TRN & & \\
\hline CHEMBL 3933294 & 1642441 & \multicolumn{3}{|c|}{5.757000000000001} & 5.0471 & TRN \\
\hline CHEMBL 3907358 & 1642441 & 5.0 & 5.1642 & TRN & & \\
\hline CHEMBL 3909202 & 1642441 & 4.6021 & 5.4119 & TST & & \\
\hline CHEMBL 3912605 & 1642441 & 5.0 & 5.4119 & TRN & & \\
\hline CHEMBL 3894733 & 1642441 & 4.6021 & 4.9465 & TRN & & \\
\hline CHEMBL 3928856 & 1642441 & 5.5498 & 5.5271 & TST & & \\
\hline CHEMBL3930790 & 1642441 & 5.0 & 4.8579 & TRN & & \\
\hline CHEMBL 3983971 & 1642441 & 5.0 & \multicolumn{3}{|c|}{5.672000000000001} & TRI \\
\hline CHEMBL 3968026 & 1642441 & 5.0 & 5.6623 & TST & & \\
\hline CHEMBL 3985140 & 1642441 & 5.0 & 5.3146 & TRN & & \\
\hline CHEMBL 3898993 & 1642441 & 5.1675 & 5.2476 & TRN & & \\
\hline CHEMBL3931669 & 1642441 & 6.0 & 5.7615 & TRN & & \\
\hline CHEMBL 3956323 & 1642441 & 4.6021 & 5.1163 & TRN & & \\
\hline CHEMBL3914324 & 1642441 & 5.4976 & 5.9126 & TST & & \\
\hline CHEMBL 3936804 & 1642441 & 4.6021 & 5.0228 & TRN & & \\
\hline CHEMBL 3945123 & 1642441 & 5.0 & 5.4226 & TST & & \\
\hline CHEMBL3951056 & 1642441 & 6.0 & 5.7453 & TRN & & \\
\hline CHEMBL 3980140 & 1642441 & 5.0 & 5.1416 & TRN & & \\
\hline CHEMBL 3897391 & 1642441 & 5.0 & 5.0709 & TRN & & \\
\hline CHEMBL 3941839 & 1642441 & 6.0 & 4.9477 & TRN & & \\
\hline CHEMBL 3973389 & 1642441 & 5.0 & 5.5684 & TST & & \\
\hline CHEMBL 3944360 & 1642441 & 5.0 & 5.3945 & TRN & & \\
\hline CHEMBL 3944878 & 1642441 & 6.0 & 5.5798 & TRN & & \\
\hline CHEMBL 3958563 & 1642441 & 5.0 & 5.4391 & TRN & & \\
\hline CHEMBL 3928755 & 1642441 & 5.0 & 5.3275 & TST & & \\
\hline CHEMBL 3944712 & 1642441 & 5.3665 & 5.7644 & TST & & \\
\hline CHEMBL 3951757 & 1642441 & 6.7077 & 5.7474 & TST & & \\
\hline CHEMBL 3907457 & 1642441 & 4.6021 & 4.7273 & TRN & & \\
\hline CHEMBL 3912026 & 1642441 & 5.0 & 5.6451 & TRN & & \\
\hline CHEMBL3969134 & 1642441 & 5.1772 & 5.7005 & TST & & \\
\hline CHEMBL 3950397 & 1642441 & 5.5072 & 5.6035 & TST & & \\
\hline CHEMBL 3929932 & 1642441 & 6.0 & 5.2471 & TRN & & \\
\hline CHEMBL 3893482 & 1642441 & 5.0 & 5.3194 & TST & & \\
\hline CHEMBL 3931062 & 1642441 & 5.7375 & 5.3731 & TRN & & \\
\hline CHEMBL 3955986 & 1642441 & 5.0 & 4.69 & TRN & & \\
\hline CHEMBL 3910925 & 1642441 & \multicolumn{3}{|c|}{5.382000000000001} & 5.3929 & . \\
\hline CHEMBL 3908347 & 1642441 & 6.0 & 5.5595 & TST & & \\
\hline CHEMBL 3900163 & 1642441 & 5.0 & 5.3466 & TST & & \\
\hline CHEMBL 3948778 & 1642441 & 6.0048 & 5.3737 & TRN & & \\
\hline CHEMBL110716 & 88045 & 8.2218 & 7.9176 & TRN & & \\
\hline CHEMBL110864 & 88045 & 5.0 & 5.5554 & TRN & & \\
\hline CHEMBL 317480 & 88045 & 5.0 & 5.7701 & TST & & \\
\hline CHEMBL110322 & 88045 & 7.8539 & 8.0404 & TRN & & \\
\hline CHEMBL110651 & 88045 & 5.0 & 5.6668 & TST & & \\
\hline CHEMBL325369 & 88045 & 7.1427 & 7.2588 & TRN & & \\
\hline
\end{tabular}




\begin{tabular}{|c|c|c|c|c|}
\hline & & & prement & able \\
\hline CHEMBL110428 & 88045 & 7.2596 & 6.7804 & TRN \\
\hline CHEMBL109182 & 88045 & 8.0 & 7.97 & TRN \\
\hline CHEMBL323419 & 88045 & 7.9586 & 7.9626 & TRN \\
\hline CHEMBL324436 & 88045 & 8.0969 & 7.4393 & TRN \\
\hline CHEMBL419557 & 88045 & 5.0 & 4.7932 & TRN \\
\hline CHEMBL107352 & 88045 & 6.5031 & 6.4914 & TRN \\
\hline CHEMBL110935 & 88045 & 6.3893 & 6.1885 & TST \\
\hline CHEMBL105996 & 88045 & 6.6198 & 5.5548 & TST \\
\hline CHEMBL106420 & 88045 & 6.9547 & 5.2103 & TST \\
\hline CHEMBL105834 & 88045 & 8.3979 & 7.3127 & TST \\
\hline CHEMBL109163 & 88045 & 5.0 & 6.3792 & TST \\
\hline CHEMBL320525 & 88045 & 7.8239 & 7.8749 & TRN \\
\hline CHEMBL106045 & 88045 & 8.301 & 8.4387 & TRN \\
\hline CHEMBL322780 & 88045 & 7.8861 & 7.8316 & TRN \\
\hline CHEMBL105994 & 88045 & 6.7959 & 6.8824 & TRN \\
\hline CHEMBL110731 & 88045 & 6.4868 & 6.7633 & TRN \\
\hline CHEMBL317407 & 88045 & 7.6383 & 7.8063 & TRN \\
\hline CHEMBL106729 & 88045 & 7.2076 & 7.6567 & TRN \\
\hline CHEMBL108568 & 88045 & 7.1871 & 7.1092 & TRN \\
\hline CHEMBL105774 & 88045 & 7.7447 & 7.1462 & TRN \\
\hline CHEMBL419197 & 88045 & 9.0 & 9.0749 & TRN \\
\hline CHEMBL322794 & 88045 & 9.0 & 8.7791 & TRN \\
\hline CHEMBL109116 & 88045 & 8.699 & 7.6567 & TRN \\
\hline CHEMBL110706 & 88045 & 7.1427 & 6.73600 & 0000000001 \\
\hline CHEMBL106892 & 88045 & 6.0458 & 7.6567 & TRN \\
\hline CHEMBL106503 & 88045 & 7.1487 & 7.6709 & TRN \\
\hline CHEMBL108207 & 88045 & 8.1549 & 8.4352 & TRN \\
\hline CHEMBL110166 & 88045 & 7.1739 & 7.4741 & TRN \\
\hline CHEMBL106375 & 88045 & 7.699 & 8.0469 & TRN \\
\hline CHEMBL110653 & 88045 & 8.301 & 8.2914 & TRN \\
\hline CHEMBL316549 & 88045 & 8.2218 & 7.9528 & TRN \\
\hline CHEMBL105888 & 88045 & 5.0 & 6.0874 & TST \\
\hline CHEMBL110388 & 88045 & 7.284 & 7.1418 & TRN \\
\hline CHEMBL317242 & 88045 & 6.7447 & 7.1025 & TST \\
\hline CHEMBL106784 & 88045 & 8.0 & 7.8538 & TRN \\
\hline CHEMBL320249 & 88045 & 7.9586 & 7.6905 & TRN \\
\hline CHEMBL324633 & 88045 & 5.0 & 6.5733 & TST \\
\hline CHEMBL323173 & 88045 & 7.7696 & 4.958 & TST \\
\hline CHEMBL106504 & 88045 & 7.9208 & 7.2986 & TRN \\
\hline CHEMBL108519 & 88045 & 8.2218 & 8.0093 & TRN \\
\hline CHEMBL110655 & 88045 & 8.2218 & 8.2665 & TRN \\
\hline CHEMBL320700 & 88045 & 7.0315 & 7.2268 & TRN \\
\hline CHEMBL107235 & 88045 & 7.7696 & 6.0617 & TST \\
\hline CHEMBL110717 & 88045 & 6.699 & 6.9872 & TRN \\
\hline CHEMBL323458 & 88045 & 7.9586 & 8.1547 & TRN \\
\hline CHEMBL106581 & 88045 & 8.5229 & 8.6479 & TRN \\
\hline CHEMBL110763 & 88045 & 8.3979 & 8.2847 & TRN \\
\hline CHEMBL323761 & 88045 & 6.7799 & 6.8995 & TRN \\
\hline
\end{tabular}




\begin{tabular}{|c|c|c|c|c|c|}
\hline \multicolumn{6}{|c|}{ Supplemental Table S2.txt } \\
\hline CHEMBL322536 & 88045 & 6.3372 & 6.1067 & TRN & \\
\hline CHEMBL110343 & 88045 & 8.3979 & 8.5615 & TRN & \\
\hline CHEMBL321483 & 88045 & 8.1549 & 7.5005 & TRN & \\
\hline CHEMBL107365 & 88045 & 8.301 & 6.7579 & TST & \\
\hline CHEMBL317643 & 88045 & 7.5528 & 7.3856 & TRN & \\
\hline CHEMBL320327 & 88045 & 6.9914 & 7.0007 & TRN & \\
\hline CHEMBL320813 & 88045 & 8.5229 & 8.6625 & TRN & \\
\hline CHEMBL107412 & 88045 & 6.3188 & 6.6302 & TRN & \\
\hline CHEMBL110596 & 88045 & 6.7447 & 6.5933 & TRN & \\
\hline CHEMBL324434 & 88045 & 5.0 & 5.5066 & TRN & \\
\hline CHEMBL106314 & 88045 & 8.301 & 6.5242 & TST & \\
\hline CHEMBL106756 & 88045 & 8.3979 & 7.2565 & TST & \\
\hline CHEMBL320297 & 88045 & 5.0 & 4.9962 & TRN & \\
\hline CHEMBL106987 & 88045 & 7.5528 & 7.7913 & TRN & \\
\hline CHEMBL322051 & 88045 & 8.0458 & 6.11700 & 0000000001 & TST \\
\hline CHEMBL320708 & 88045 & 7.6198 & 7.7727 & TRN & \\
\hline CHEMBL321640 & 88045 & 7.2218 & 5.8628 & TST & \\
\hline CHEMBL106927 & 88045 & 6.6021 & 6.7766 & TRN & \\
\hline CHEMBL108325 & 88045 & 8.2218 & 8.2265 & TRN & \\
\hline CHEMBL106200 & 88045 & 8.2218 & 7.6445 & TRN & \\
\hline CHEMBL107197 & 88045 & 8.699 & 8.1303 & TST & \\
\hline CHEMBL108523 & 88045 & 7.9208 & 7.665 & TRN & \\
\hline CHEMBL108326 & 88045 & 7.4559 & 7.4688 & TRN & \\
\hline CHEMBL106319 & 88045 & 7.4318 & 7.3049 & TRN & \\
\hline CHEMBL 321433 & 88045 & 7.5229 & 7.0658 & TRN & \\
\hline CHEMBL321903 & 88045 & 8.2218 & 8.1547 & TRN & \\
\hline CHEMBL324015 & 88045 & 5.0 & 5.0198 & TRN & \\
\hline CHEMBL107712 & 88045 & 7.8539 & 8.1422 & TRN & \\
\hline CHEMBL108600 & 88045 & 5.0 & 5.165 & TST & \\
\hline CHEMBL423140 & 88045 & 5.8539 & 5.9327 & TST & \\
\hline CHEMBL110597 & 88045 & 8.1549 & 6.4567 & TST & \\
\hline CHEMBL2016729 & 814483 & 7.8239 & 7.8255 & TRN & \\
\hline CHEMBL 2016703 & 814483 & 7.3468 & 7.3401 & TRN & \\
\hline CHEMBL2016728 & 814483 & 7.6576 & 7.6567 & TRN & \\
\hline CHEMBL2016778 & 814483 & 6.6819 & 6.6831 & TRN & \\
\hline CHEMBL2016775 & 814483 & 8.2218 & 8.227 & TRN & \\
\hline CHEMBL 2016702 & 814483 & 7.0177 & 7.0187 & TRN & \\
\hline CHEMBL2016772 & 814483 & 6.5884 & 8.0517 & TST & \\
\hline CHEMBL 2016782 & 814483 & 6.4855 & 6.4857 & TRN & \\
\hline CHEMBL2016785 & 814483 & 6.1972 & 6.2033 & TRN & \\
\hline CHEMBL 2016777 & 814483 & 6.6253 & 6.6246 & TRN & \\
\hline CHEMBL2016706 & 814483 & 6.6478 & 6.3775 & TST & \\
\hline CHEMBL2016786 & 814483 & 6.6716 & 6.6652 & TRN & \\
\hline CHEMBL 2016722 & 814483 & 7.7696 & 7.7444 & TRN & \\
\hline CHEMBL2016716 & 814483 & 5.1367 & 5.7843 & TST & \\
\hline CHEMBL 2016711 & 814483 & 7.3098 & 7.3215 & TRN & \\
\hline CHEMBL 2016710 & 814483 & 6.6003 & 6.5857 & TRN & \\
\hline CHEMBL 2016580 & 814483 & 6.1965 & 6.2074 & TRN & \\
\hline
\end{tabular}




\begin{tabular}{|c|c|c|c|c|c|}
\hline \multirow[b]{2}{*}{ CHEMBL198361 } & \multicolumn{5}{|c|}{ Supplemental Table S2.txt } \\
\hline & 814483 & 7.301 & 7.8034 & TST & \\
\hline CHEMBL 2016725 & 814483 & 7.6383 & 7.6431 & TRN & \\
\hline CHEMBL 2016731 & 814483 & 7.699 & 7.6754 & TRN & \\
\hline CHEMBL 2016705 & 814483 & 4.0 & 3.9991 & TRN & \\
\hline CHEMBL 2016781 & 814483 & 7.1024 & 7.0972 & TRN & \\
\hline CHEMBL 2016730 & 814483 & 8.1549 & 8.1566 & TRN & \\
\hline CHEMBL 2016784 & 814483 & 6.8239 & 6.8213 & TRN & \\
\hline CHEMBL 2016701 & 814483 & 6.5686 & 6.5817 & TRN & \\
\hline CHEMBL 2016709 & 814483 & 6.6676 & 6.2007 & TST & \\
\hline CHEMBL 2016718 & 814483 & 6.8239 & 6.8138 & TRN & \\
\hline CHEMBL 2016717 & 814483 & 6.7447 & 6.7393 & TRN & \\
\hline CHEMBL 2016707 & 814483 & 7.4437 & 6.8406 & TST & \\
\hline CHEMBL 2016704 & 814483 & 8.1549 & 8.1527 & TRN & \\
\hline CHEMBL 2016713 & 814483 & 7.0757 & 7.063 & TRN & \\
\hline CHEMBL 2016774 & 814483 & 7.5086 & 7.532 & TRN & \\
\hline CHEMBL 2016712 & 814483 & 6.4881 & 6.4977 & TRN & \\
\hline CHEMBL 2016700 & 814483 & 6.1068 & 6.1069 & TRN & \\
\hline CHEMBL 2016779 & 814483 & 6.9355 & 6.9364 & TRN & \\
\hline CHEMBL 2016719 & 814483 & 6.6716 & 6.6643 & TRN & \\
\hline CHEMBL 2016708 & 814483 & 6.8508 & 6.3927 & TST & \\
\hline CHEMBL 2016783 & 814483 & $6.4510 e$ & 00000000 & 6.447 & TRN \\
\hline CHEMBL 2016720 & 814483 & 4.0 & 7.0866 & TST & \\
\hline CHEMBL 2016724 & 814483 & 8.0458 & 8.0415 & TRN & \\
\hline CHEMBL184084 & 814483 & 7.301 & 7.115 & TST & \\
\hline CHEMBL 2016773 & 814483 & 4.0 & 7.7829 & TST & \\
\hline CHEMBL 2016726 & 814483 & 8.0 & 8.0066 & TRN & \\
\hline CHEMBL 2016727 & 814483 & 6.8239 & 6.8258 & TRN & \\
\hline CHEMBL 2016721 & 814483 & 7.8239 & 7.8518 & TRN & \\
\hline CHEMBL 2016776 & 814483 & 7.7212 & 7.7191 & TRN & \\
\hline CHEMBL 2016714 & 814483 & 6.5157 & 6.5243 & TRN & \\
\hline CHEMBL 2016698 & 814483 & 6.6576 & 6.66100 & 00000000005 & TRN \\
\hline CHEMBL 2016723 & 814483 & 7.3279 & 7.3229 & TRN & \\
\hline CHEMBL 2016699 & 814483 & 6.1612 & 6.3615 & TST & \\
\hline CHEMBL 2016715 & 814483 & 6.9355 & 6.0718 & TST & \\
\hline CHEMBL 2016780 & 814483 & 6.9957 & 7.0007 & TST & \\
\hline CHEMBL510354 & 560527 & 4.585 & 4.4376 & TRN & \\
\hline CHEMBL467238 & 560527 & 3.0 & 3.2545 & TRN & \\
\hline CHEMBL475281 & 560527 & 3.0 & 3.9499 & TST & \\
\hline CHEMBL517101 & 560527 & 3.0 & 3.1266 & TRN & \\
\hline CHEMBL460792 & 560527 & 3.0 & 3.1333 & TRN & \\
\hline CHEMBL459743 & 560527 & 3.0 & 2.8686 & TST & \\
\hline CHEMBL448868 & 560527 & 3.0 & 3.1362 & TRN & \\
\hline CHEMBL461633 & 560527 & 4.5229 & 4.2329 & TRN & \\
\hline CHEMBL459727 & 560527 & 3.0 & 2.7574 & TRN & \\
\hline CHEMBL461850 & 560527 & 3.0 & 3.1002 & TRN & \\
\hline CHEMBL516612 & 560527 & 3.0 & 3.284 & TRN & \\
\hline CHEMBL506724 & 560527 & 3.0 & 2.8924 & TRN & \\
\hline CHEMBL460993 & 560527 & 3.0 & 2.8898 & TRN & \\
\hline
\end{tabular}




\begin{tabular}{|c|c|c|c|c|c|}
\hline & & & & & \\
\hline CHEMBL462260 & 560527 & 5.0458 & 4.9841 & TRN & \\
\hline CHEMBL511379 & 560527 & 4.301 & 4.2787 & TRN & \\
\hline CHEMBL468481 & 560527 & 3.0 & 3.1041 & TRN & \\
\hline CHEMBL468891 & 560527 & 4.0 & 4.0541 & TRN & \\
\hline CHEMBL460353 & 560527 & 4.4559 & 4.6047 & TRN & \\
\hline CHEMBL467217 & 560527 & 3.0 & 3.2395 & TRN & \\
\hline CHEMBL459940 & 560527 & 3.0 & 2.8163 & TRN & \\
\hline CHEMBL460982 & 560527 & 4.8239 & 4.3179 & TST & \\
\hline CHEMBL453929 & 560527 & 3.0 & 3.2456 & TRN & \\
\hline CHEMBL510282 & 560527 & 4.699 & 4.8646 & TRN & \\
\hline CHEMBL500760 & 560527 & 4.4949 & 4.7897 & TRN & \\
\hline CHEMBL460593 & 560527 & 3.0 & 3.1834 & TRN & \\
\hline CHEMBL518634 & 560527 & 3.0 & 2.845 & TRN & \\
\hline CHEMBL513348 & 560527 & 3.0 & 2.8968 & TRN & \\
\hline CHEMBL448847 & 560527 & 3.0 & 3.1719 & TRN & \\
\hline CHEMBL459529 & 560527 & 3.0 & 2.81600 & 00000000003 & TRN \\
\hline CHEMBL460782 & 560527 & 5.0969 & 4.1582 & TST & \\
\hline CHEMBL460803 & 560527 & 3.0 & 4.0375 & TST & \\
\hline CHEMBL448958 & 560527 & 4.6576 & 4.7121 & TRN & \\
\hline CHEMBL448408 & 560527 & 3.0 & 3.0245 & TRN & \\
\hline CHEMBL518797 & 560527 & 3.0 & 3.2833 & TRN & \\
\hline CHEMBL442876 & 560527 & 4.0969 & 4.3789 & TRN & \\
\hline CHEMBL462689 & 560527 & 4.5229 & 4.4539 & TRN & \\
\hline CHEMBL459939 & 560527 & 4.0 & 3.4962 & TRN & \\
\hline CHEMBL509918 & 560527 & 4.3979 & 4.4914 & TRN & \\
\hline CHEMBL466179 & 560527 & 3.0 & 3.2934 & TST & \\
\hline CHEMBL511372 & 560527 & 3.0 & 4.1363 & TRN & \\
\hline CHEMBL459744 & 560527 & 3.0 & 3.032 & TRN & \\
\hline CHEMBL462261 & 560527 & 4.9208 & 4.9364 & TRN & \\
\hline CHEMBL459300 & 560527 & 3.0 & 3.0297 & TRN & \\
\hline CHEMBL460563 & 560527 & 4.8239 & 4.8962 & TRN & \\
\hline CHEMBL500986 & 560527 & 3.0 & 2.931 & TRN & \\
\hline CHEMBL512561 & 560527 & 3.0 & 2.8767 & TRN & \\
\hline CHEMBL517894 & 560527 & 3.0 & 2.6636 & TRN & \\
\hline CHEMBL461839 & 560527 & 3.0 & 3.26800 & 00000000002 & TRN \\
\hline CHEMBL468072 & 560527 & 4.301 & 3.9338 & TRN & \\
\hline CHEMBL466401 & 560527 & 5.0458 & 5.28 & TRN & \\
\hline CHEMBL516484 & 560527 & 3.0 & 2.795 & TRN & \\
\hline CHEMBL469118 & 560527 & 3.0 & 3.6996 & TST & \\
\hline CHEMBL461634 & 560527 & 3.0 & 3.1893 & TRN & \\
\hline CHEMBL461010 & 560527 & 3.0 & 2.7054 & TRN & \\
\hline CHEMBL461842 & 560527 & 4.0969 & 3.9395 & TRN & \\
\hline CHEMBL511935 & 560527 & 3.0 & 2.9866 & TRN & \\
\hline CHEMBL517724 & 560527 & 5.3979 & 5.3357 & TRN & \\
\hline CHEMBL467849 & 560527 & 3.0 & 3.265 & TRN & \\
\hline CHEMBL459728 & 560527 & 3.0 & 3.011 & TRN & \\
\hline CHEMBL516778 & 560527 & 3.0 & 2.8836 & TRN & \\
\hline CHEMBL462049 & 560527 & 4.4815 & 4.0938 & TRN & \\
\hline
\end{tabular}




\begin{tabular}{|c|c|c|c|c|}
\hline & & & $p p+c$ & \\
\hline CHEMBL511180 & 560527 & 3.0 & 3.2505 & TRN \\
\hline CHEMBL145352 & 560527 & 4.5686 & 4.0291 & TRN \\
\hline CHEMBL512048 & 560527 & 3.0 & 2.9715 & TRN \\
\hline CHEMBL512761 & 560527 & 4.699 & 4.5544 & TRN \\
\hline CHEMBL460995 & 560527 & 3.0 & 4.4522 & TST \\
\hline CHEMBL468490 & 560527 & 3.0 & 2.7795 & TRN \\
\hline CHEMBL498855 & 560527 & 4.3979 & 4.5271 & TRN \\
\hline CHEMBL461208 & 560527 & 3.0 & 3.0954 & TRN \\
\hline CHEMBL512049 & 560527 & 5.2218 & 4.698 & TRN \\
\hline CHEMBL504500 & 560527 & 5.0458 & 4.9534 & TRN \\
\hline CHEMBL518673 & 560527 & 3.0 & 3.3886 & TST \\
\hline CHEMBL506221 & 560527 & 3.0 & 2.7585 & TST \\
\hline CHEMBL512214 & 560527 & 4.0969 & 3.5312 & TRN \\
\hline CHEMBL502103 & 560527 & 3.0 & 3.2768 & TRN \\
\hline CHEMBL466206 & 560527 & 4.0 & 4.0296 & TRN \\
\hline CHEMBL460570 & 560527 & 4.0605 & 4.0798 & TRN \\
\hline CHEMBL462059 & 560527 & 3.0 & 2.862 & TRN \\
\hline CHEMBL449985 & 560527 & 5.0969 & 4.7039 & TRN \\
\hline CHEMBL460354 & 560527 & 3.0 & 3.4534 & TST \\
\hline CHEMBL513144 & 560527 & 3.0 & 3.56399 & 99999999996 \\
\hline CHEMBL459501 & 560527 & 5.2218 & 5.0661 & TRN \\
\hline CHEMBL455496 & 560527 & 4.7696 & 4.9856 & TRN \\
\hline CHEMBL459302 & 560527 & 3.0 & 3.1935 & TRN \\
\hline CHEMBL461209 & 560527 & 3.0 & 3.3392 & TRN \\
\hline CHEMBL513482 & 560527 & 3.0 & 3.063 & TRN \\
\hline CHEMBL518188 & 560527 & 3.0 & 3.0001 & TRN \\
\hline CHEMBL447111 & 560527 & 4.9586 & 4.9159 & TRN \\
\hline CHEMBL467863 & 560527 & 4.2218 & 3.9407 & TRN \\
\hline CHEMBL466004 & 560527 & 3.0 & 3.1621 & TRN \\
\hline CHEMBL452994 & 560527 & 3.0 & 2.9622 & TRN \\
\hline CHEMBL504860 & 560527 & 3.0 & 3.036 & TRN \\
\hline CHEMBL467646 & 560527 & 3.0 & 2.8116 & TRN \\
\hline CHEMBL468905 & 560527 & 4.301 & 3.9709 & TRN \\
\hline CHEMBL468073 & 560527 & 4.4559 & 4.4619 & TRN \\
\hline CHEMBL460581 & 560527 & 3.0 & 3.0324 & TRN \\
\hline CHEMBL468491 & 560527 & 3.0 & 3.161 & TRN \\
\hline CHEMBL461009 & 560527 & 3.0 & 2.9146 & TRN \\
\hline CHEMBL459938 & 560527 & 3.0 & 3.0364 & TST \\
\hline CHEMBL469109 & 560527 & 4.0 & 3.9108 & TRN \\
\hline CHEMBL466003 & 560527 & 3.0 & 3.2894 & TRN \\
\hline CHEMBL468683 & 560527 & 3.0 & 3.2654 & TST \\
\hline CHEMBL517107 & 560527 & 4.8861 & 5.0229 & TRN \\
\hline CHEMBL448142 & 560527 & 3.0 & 3.1361 & TRN \\
\hline CHEMBL460783 & 560527 & 4.9586 & 4.2233 & TST \\
\hline CHEMBL462690 & 560527 & 5.2218 & 5.1595 & TRN \\
\hline CHEMBL517857 & 560527 & 4.9586 & 4.7482 & TRN \\
\hline CHEMBL509657 & 560527 & 4.7959 & 4.728 & TRN \\
\hline CHEMBL512260 & 560527 & 5.2218 & 5.04899 & 99999999995 \\
\hline & & & $\mathrm{a}$ & 3249 \\
\hline
\end{tabular}




\begin{tabular}{|c|c|c|c|c|c|}
\hline \multicolumn{6}{|c|}{ Supplemental Table S2.txt } \\
\hline CHEMBL448841 & 560527 & 4.5686 & 4.2314 & TST & \\
\hline CHEMBL505863 & 560527 & 4.7959 & 4.5448 & TRN & \\
\hline CHEMBL469106 & 560527 & 4.4815 & 4.3903 & TRN & \\
\hline CHEMBL508178 & 560527 & 3.0 & 2.8831 & TRN & \\
\hline CHEMBL461841 & 560527 & 4.301 & 3.9114 & TST & \\
\hline CHEMBL500208 & 560527 & 4.4815 & 4.7611 & TRN & \\
\hline CHEMBL 80101 & 560527 & 4.3979 & 4.6962 & TRN & \\
\hline CHEMBL460801 & 560527 & 3.0 & 3.0933 & TRN & \\
\hline CHEMBL467645 & 560527 & 3.0 & 2.9178 & TRN & \\
\hline CHEMBL468480 & 560527 & 3.0 & 3.0541 & TRN & \\
\hline CHEMBL467423 & 560527 & 3.0 & 3.1405 & TRN & \\
\hline CHEMBL447958 & 560527 & 3.0 & 2.9485 & TRN & \\
\hline CHEMBL460784 & 560527 & 4.7212 & 4.4343 & TRN & \\
\hline CHEMBL468074 & 560527 & 4.2596 & 4.1838 & TRN & \\
\hline CHEMBL467436 & 560527 & 5.2218 & 5.41200 & 0000000001 & TRN \\
\hline CHEMBL461424 & 560527 & 3.0 & 2.8838 & TRN & \\
\hline CHEMBL460347 & 560527 & 5.0 & 4.9637 & TRN & \\
\hline CHEMBL511207 & 560527 & 3.0 & 4.0061 & TST & \\
\hline CHEMBL460582 & 560527 & 3.0 & 3.3788 & TST & \\
\hline CHEMBL467237 & 560527 & 4.5229 & 4.4059 & TRN & \\
\hline CHEMBL468890 & 560527 & 3.0 & 2.9017 & TRN & \\
\hline CHEMBL450862 & 560527 & 4.0969 & 3.9801 & TRN & \\
\hline CHEMBL511913 & 560527 & 3.0 & 3.0771 & TRN & \\
\hline CHEMBL541931 & 560527 & 3.0 & 3.2589 & TRN & \\
\hline CHEMBL468471 & 560527 & 3.0 & 2.7522 & TRN & \\
\hline CHEMBL503254 & 560527 & 5.3979 & 5.3159 & TRN & \\
\hline CHEMBL447590 & 560527 & 3.0 & 4.1095 & TST & \\
\hline CHEMBL460804 & 560527 & 4.5686 & 4.6537 & TRN & \\
\hline CHEMBL460802 & 560527 & 4.0 & 3.8391 & TRN & \\
\hline CHEMBL517260 & 560527 & 3.0 & 2.9673 & TRN & \\
\hline CHEMBL467858 & 560527 & 3.0 & 2.8591 & TST & \\
\hline CHEMBL505114 & 560527 & 3.0 & 3.77 & TST & \\
\hline CHEMBL459310 & 560527 & 3.0 & 3.1108 & TRN & \\
\hline CHEMBL462051 & 560527 & 3.0 & 3.0487 & TRN & \\
\hline CHEMBL503504 & 560527 & 4.3979 & 4.6234 & TRN & \\
\hline CHEMBL513531 & 560527 & 3.0 & 3.0282 & TRN & \\
\hline CHEMBL468691 & 560527 & 3.0 & 2.9388 & TRN & \\
\hline CHEMBL452114 & 560527 & 3.0 & 3.2113 & TRN & \\
\hline CHEMBL460348 & 560527 & 5.2218 & 5.1462 & TRN & \\
\hline CHEMBL460571 & 560527 & 4.3979 & 4.3101 & TRN & \\
\hline CHEMBL461851 & 560527 & 3.0 & 3.3834 & TST & \\
\hline CHEMBL467435 & 560527 & 5.3979 & 3.8558 & TST & \\
\hline CHEMBL459311 & 560527 & 3.0 & 3.3198 & TST & \\
\hline CHEMBL459301 & 560527 & 3.0 & 3.5346 & TST & \\
\hline CHEMBL461635 & 560527 & 3.0 & 4.17 & TST & \\
\hline CHEMBL409315 & 560527 & 5.5229 & 4.9241 & TST & \\
\hline CHEMBL467239 & 560527 & 3.0 & 3.7335 & TST & \\
\hline CHEMBL512985 & 560527 & 3.0 & 3.058006 & 00000000003 & TST \\
\hline & & & & 3250 & \\
\hline
\end{tabular}




\begin{tabular}{|c|c|c|c|c|c|}
\hline \multirow[b]{2}{*}{ CHEMBL460994 } & \multicolumn{5}{|c|}{ Supplemental Table S2.txt } \\
\hline & 560527 & 4.0 & 4.3342 & TST & \\
\hline CHEMBL512261 & 560527 & 4.9208 & 5.2943 & TST & \\
\hline CHEMBL466002 & 560527 & 3.0 & 2.7351 & TST & \\
\hline CHEMBL461840 & 560527 & 5.301 & 4.5536 & TST & \\
\hline CHEMBL518027 & 560527 & 3.0 & 3.37100 & 00000000004 & TST \\
\hline CHEMBL468059 & 560527 & 3.0 & 2.6963 & TST & \\
\hline CHEMBL466178 & 560527 & 3.0 & 3.4079 & TST & \\
\hline CHEMBL467848 & 560527 & 3.0 & 3.2914 & TST & \\
\hline CHEMBL468909 & 560527 & 3.0 & 3.3349 & TST & \\
\hline CHEMBL467859 & 560527 & 3.0 & 2.8531 & TST & \\
\hline CHEMBL461852 & 560527 & 3.0 & 3.0001 & TST & \\
\hline CHEMBL448036 & 560527 & 4.699 & 4.5604 & TST & \\
\hline CHEMBL462696 & 560527 & 3.0 & 3.2599 & TST & \\
\hline CHEMBL460572 & 560527 & 3.0 & 3.569 & TST & \\
\hline CHEMBL122651 & 45421 & 6.8539 & 6.8509 & TRN & \\
\hline CHEMBL121501 & 45421 & 7.8861 & 7.3962 & TST & \\
\hline CHEMBL122950 & 45421 & 6.8665 & 6.9073 & TRN & \\
\hline CHEMBL 82868 & 45421 & 6.8386 & 6.7977 & TRN & \\
\hline CHEMBL316169 & 45421 & 6.8665 & 6.96 & TRN & \\
\hline CHEMBL83508 & 45421 & 7.5376 & 7.5123 & TRN & \\
\hline CHEMBL123382 & 45421 & 7.4089 & 7.4076 & TRN & \\
\hline CHEMBL123064 & 45421 & 6.8069 & 7.3312 & TST & \\
\hline CHEMBL331669 & 45421 & 8.0 & 8.0066 & TRN & \\
\hline CHEMBL311336 & 45421 & 6.7328 & 6.7511 & TRN & \\
\hline CHEMBL121559 & 45421 & 6.8962 & 6.8827 & TRN & \\
\hline CHEMBL331308 & 45421 & 7.7959 & 7.4933 & TST & \\
\hline CHEMBL332406 & 45421 & 7.8861 & 7.892 & TRN & \\
\hline CHEMBL332362 & 45421 & 7.7959 & 7.8288 & TRN & \\
\hline CHEMBL120049 & 45421 & 7.7212 & 7.7146 & TRN & \\
\hline CHEMBL123041 & 45421 & 6.9706 & 6.9658 & TRN & \\
\hline CHEMBL123463 & 45421 & 7.3665 & 7.2344 & TRN & \\
\hline CHEMBL121729 & 45421 & 7.1549 & 7.2495 & TRN & \\
\hline CHEMBL123233 & 45421 & 7.3979 & 7.4211 & TRN & \\
\hline CHEMBL262676 & 45421 & 7.3768 & 7.3993 & TRN & \\
\hline CHEMBL122868 & 45421 & 6.9586 & 6.9509 & TRN & \\
\hline CHEMBL330950 & 45421 & 6.5376 & 7.1861 & TST & \\
\hline CHEMBL 333248 & 45421 & 7.699 & 7.4549 & TST & \\
\hline CHEMBL340461 & 45421 & 7.1249 & 7.1697 & TRN & \\
\hline CHEMBL124237 & 45421 & 6.6778 & 7.3281 & TST & \\
\hline CHEMBL293774 & 45421 & 5.699 & 5.7598 & TRN & \\
\hline CHEMBL122711 & 45421 & 7.3098 & 7.3678 & TRN & \\
\hline CHEMBL333532 & 45421 & 7.9208 & 7.8964 & TRN & \\
\hline CHEMBL123105 & 45421 & 7.2596 & 7.2271 & TRN & \\
\hline CHEMBL450327 & 45421 & 5.699 & 5.7283 & TRN & \\
\hline CHEMBL304281 & 45421 & 5.699 & 5.5712 & TRN & \\
\hline CHEMBL122836 & 45421 & 5.699 & 5.8337 & TRN & \\
\hline CHEMBL331114 & 45421 & 7.9208 & 7.8882 & TRN & \\
\hline CHEMBL122109 & 45421 & 7.6778 & 7.5234 & TST & \\
\hline
\end{tabular}




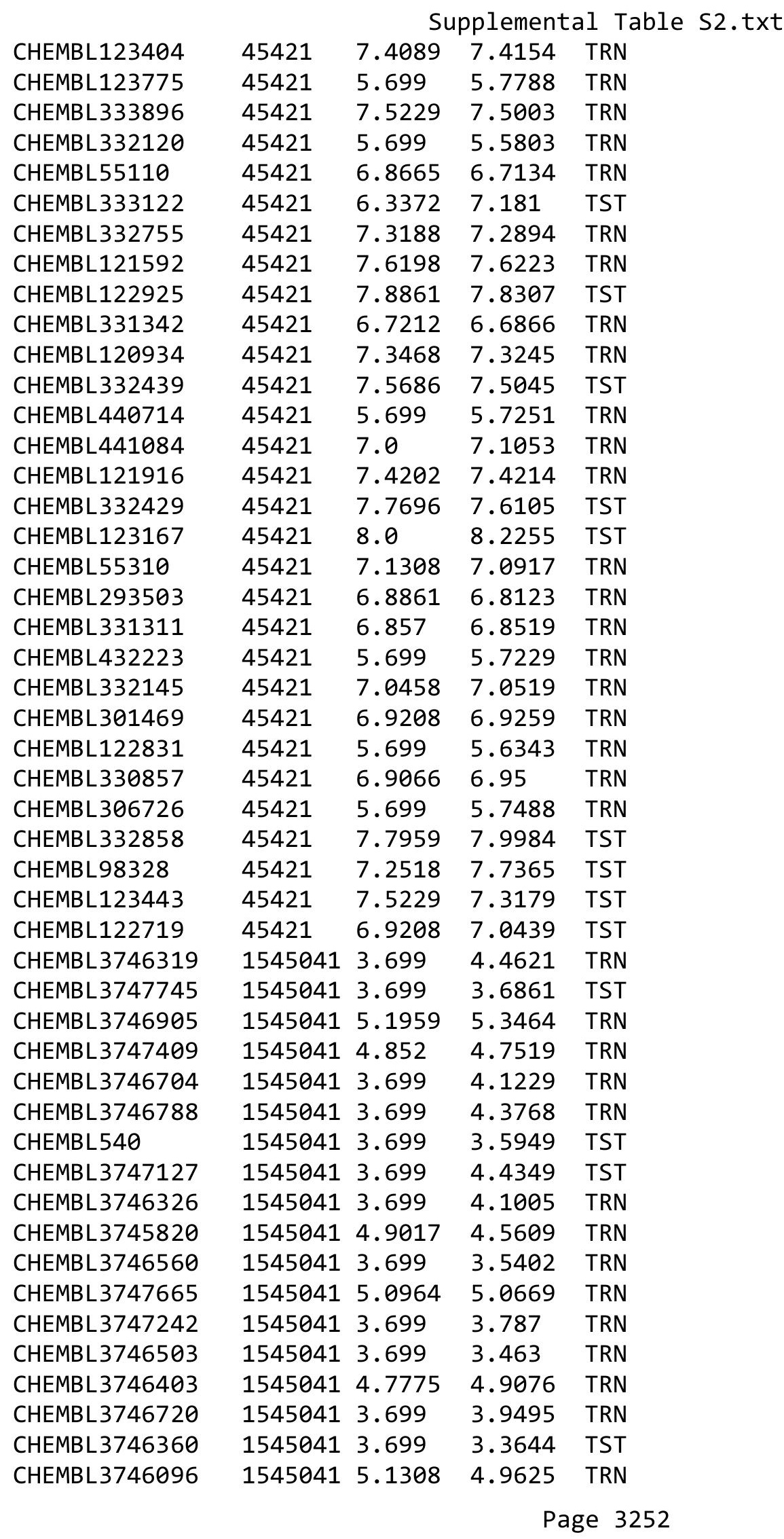


Supplemental Table S2.txt

\begin{tabular}{|c|c|c|c|c|c|}
\hline CHEMBL 3747598 & 1545041 & 5.1343 & 4.9717 & TRN & \\
\hline CHEMBL3745972 & 1545041 & 3.699 & 3.9453 & TST & \\
\hline CHEMBL3746813 & 1545041 & 5.1844 & 4.944 & TRN & \\
\hline CHEMBL3746937 & 1545041 & 5.3152 & 5.3155 & TRN & \\
\hline CHEMBL 3747251 & 1545041 & 3.699 & 3.987 & TRN & \\
\hline CHEMBL3747725 & 1545041 & 5.2055 & 4.8686 & TRN & \\
\hline CHEMBL3746668 & 1545041 & 4.8339 & 4.5983 & TRN & \\
\hline CHEMBL3746903 & 1545041 & 3.699 & 4.1383 & TST & \\
\hline CHEMBL3746500 & 1545041 & 3.699 & 3.4474 & TST & \\
\hline CHEMBL3746718 & 1545041 & 3.699 & 3.623 & TRN & \\
\hline CHEMBL3746020 & 1545041 & 3.699 & 3.4699 & TRN & \\
\hline CHEMBL 3747101 & 1545041 & 5.1701 & 4.8941 & TRN & \\
\hline CHEMBL3747627 & 1545041 & 3.699 & 4.0085 & TRN & \\
\hline CHEMBL3746628 & 1545041 & 5.1198 & 4.842 & TRN & \\
\hline CHEMBL3747658 & 1545041 & 3.699 & 3.5514 & TST & \\
\hline CHEMBL3746744 & 1545041 & 3.699 & 4.4555 & TRN & \\
\hline CHEMBL3746698 & 1545041 & 4.9496 & 4.613 & TRN & \\
\hline CHEMBL3747163 & 1545041 & 3.699 & 4.2317 & TST & \\
\hline CHEMBL3747142 & 1545041 & 5.2034 & 5.4717 & TRN & \\
\hline CHEMBL3746933 & 1545041 & 5.3188 & 5.6005 & TRN & \\
\hline CHEMBL3746767 & 1545041 & 3.699 & 3.8794 & TRN & \\
\hline CHEMBL 3747202 & 1545041 & 3.699 & 3.7665 & TRN & \\
\hline CHEMBL3746005 & 1545041 & 3.699 & 3.5862 & TRN & \\
\hline CHEMBL3746684 & 1545041 & 5.5719 & 5.3687 & TRN & \\
\hline CHEMBL3747635 & 1545041 & 3.699 & 3.5112 & TST & \\
\hline CHEMBL3746641 & 1545041 & 3.699 & 3.9437 & TST & \\
\hline CHEMBL3746811 & 1545041 & 5.1308 & 5.026 & TRN & \\
\hline CHEMBL3746216 & 1545041 & 3.699 & 4.2973 & TRN & \\
\hline CHEMBL3746061 & 1545041 & 4.8976 & 4.7121 & TRN & \\
\hline CHEMBL3747335 & 1545041 & 4.9796 & 4.721 & TRN & \\
\hline CHEMBL3746688 & 1545041 & 5.0931 & 4.5704 & TRN & \\
\hline CHEMBL 3746970 & 1545041 & 5.0057 & 4.67899 & 9999999999 & TRN \\
\hline CHEMBL3747731 & 1545041 & 3.699 & 4.0949 & TST & \\
\hline CHEMBL3746987 & 1545041 & 3.699 & 3.5767 & TRN & \\
\hline CHEMBL3747572 & 1545041 & 3.699 & 3.6947 & TST & \\
\hline CHEMBL3747176 & 1545041 & 3.699 & 4.1874 & TRN & \\
\hline CHEMBL 3747200 & 1545041 & 3.699 & 3.6732 & TRN & \\
\hline CHEMBL3747686 & 1545041 & 5.1018 & 4.9773 & TRN & \\
\hline CHEMBL3745971 & 1545041 & 3.699 & 3.2003 & TRN & \\
\hline CHEMBL3745869 & 1545041 & 5.1169 & 4.4972 & TRN & \\
\hline CHEMBL3746790 & 1545041 & 3.699 & 3.1867 & TRN & \\
\hline CHEMBL 3747384 & 1545041 & 3.699 & 4.3109 & TST & \\
\hline CHEMBL3746132 & 1545041 & 3.699 & 4.3975 & TRN & \\
\hline CHEMBL3747232 & 1545041 & 4.7605 & 4.779 & TRN & \\
\hline CHEMBL3747035 & 1545041 & 5.1891 & 4.7912 & TRN & \\
\hline CHEMBL3747671 & 1545041 & 3.699 & 3.5507 & TRN & \\
\hline CHEMBL3747564 & 1545041 & 3.699 & 4.2895 & TRN & \\
\hline CHEMBL3746023 & 1545041 & 3.699 & 3.6058 & TST & \\
\hline
\end{tabular}


Supplemental Table S2.txt

\begin{tabular}{|c|c|c|c|c|}
\hline CHEMBL 3747164 & 1545041 & 5.1785 & 5.003 & TRN \\
\hline CHEMBL 3745908 & 1545041 & 5.209 & 5.1377 & TRN \\
\hline CHEMBL3746194 & 1545041 & 3.699 & 3.3868 & TST \\
\hline CHEMBL 3746501 & 1545041 & 3.699 & 3.8815 & TRN \\
\hline CHEMBL 3747374 & 1545041 & 3.699 & 3.7806 & TST \\
\hline CHEMBL 3746367 & 1545041 & 3.699 & 3.2654 & TST \\
\hline CHEMBL 86464 & 737003 & 5.523 & 5.1349 & TRN \\
\hline CHEMBL1588275 & 737003 & 4.9238 & 4.48 & TRN \\
\hline CHEMBL1540627 & 737003 & 5.3667 & 5.5681 & TRN \\
\hline CHEMBL1455530 & 737003 & 5.0079 & 4.5516 & TST \\
\hline CHEMBL1366082 & 737003 & 5.1598 & 4.8762 & TRN \\
\hline CHEMBL1387554 & 737003 & 4.9813 & 4.5259 & TRN \\
\hline CHEMBL157351 & 737003 & 5.3391 & 5.1168 & TRN \\
\hline CHEMBL3391727 & 737003 & 4.9296 & 4.7849 & TST \\
\hline CHEMBL1982108 & 737003 & 5.1798 & 5.1897 & TRN \\
\hline CHEMBL1710079 & 737003 & 5.5047 & 5.54 & TRN \\
\hline CHEMBL1729758 & 737003 & 5.0695 & 4.57 & TRN \\
\hline CHEMBL 1457602 & 737003 & 5.7247 & 5.3049 & TRN \\
\hline CHEMBL1533093 & 737003 & 5.7488 & 5.7447 & TRN \\
\hline CHEMBL1511432 & 737003 & 5.8742 & 5.6952 & TRN \\
\hline CHEMBL1527341 & 737003 & 4.822 & 4.5577 & TRN \\
\hline CHEMBL1328510 & 737003 & 4.9589 & 4.748 & TRN \\
\hline CHEMBL1698838 & 737003 & 4.9913 & 4.8974 & TRN \\
\hline CHEMBL 2369258 & 737003 & 5.3582 & 4.6511 & TRN \\
\hline CHEMBL1428166 & 737003 & 5.3748 & 4.6732 & TRN \\
\hline CHEMBL1410019 & 737003 & 3.699 & 4.6026 & TRN \\
\hline CHEMBL1407381 & 737003 & 5.129 & 4.8207 & TRN \\
\hline CHEMBL1565576 & 737003 & 3.699 & 4.5977 & TRN \\
\hline CHEMBL1535363 & 737003 & 4.749 & 4.8163 & TRN \\
\hline CHEMBL1391818 & 737003 & 5.309 & 5.07100 & 0000000001 \\
\hline CHEMBL1460676 & 737003 & 5.1409 & 5.115 & TRN \\
\hline CHEMBL1467505 & 737003 & 4.9678 & 4.4502 & TRN \\
\hline CHEMBL1523981 & 737003 & 5.0894 & 4.9609 & TRN \\
\hline CHEMBL1565285 & 737003 & 5.636 & 5.4884 & TRN \\
\hline CHEMBL1507187 & 737003 & 4.8168 & 4.5876 & TRN \\
\hline CHEMBL1457115 & 737003 & 3.699 & 4.8891 & TST \\
\hline CHEMBL2369209 & 737003 & 3.699 & 4.6618 & TRN \\
\hline CHEMBL1576266 & 737003 & 4.7588 & 4.7334 & TRN \\
\hline CHEMBL1330103 & 737003 & 5.3375 & 4.8744 & TRN \\
\hline CHEMBL532452 & 737003 & 3.699 & 4.6621 & TRN \\
\hline CHEMBL1414734 & 737003 & 3.699 & 4.8559 & TST \\
\hline CHEMBL 3211947 & 737003 & 4.985 & 4.6981 & TRN \\
\hline CHEMBL1724877 & 737003 & 5.1953 & 4.9645 & TRN \\
\hline CHEMBL1347600 & 737003 & 3.699 & 4.5881 & TST \\
\hline CHEMBL1587829 & 737003 & 3.699 & 4.6789 & TRN \\
\hline CHEMBL1376371 & 737003 & 5.4558 & 5.0174 & TST \\
\hline CHEMBL1443947 & 737003 & 4.9026 & 4.5467 & TRN \\
\hline CHEMBL1322017 & 737003 & 5.0544 & 4.8867 & TRN \\
\hline
\end{tabular}

Page 3254 
Supplemental Table S2.txt

\begin{tabular}{|c|c|c|c|c|}
\hline CHEMBL1503520 & 737003 & 5.1276 & 5.2655 & TRN \\
\hline CHEMBL1980281 & 737003 & 5.3371 & 5.4664 & TRN \\
\hline CHEMBL1548182 & 737003 & 4.7095 & 4.6496 & TST \\
\hline CHEMBL1728596 & 737003 & 5.4302 & 5.4775 & TRN \\
\hline CHEMBL1467095 & 737003 & 3.699 & 4.5784 & TRN \\
\hline CHEMBL 2369230 & 737003 & 5.3198 & 5.1073 & TRN \\
\hline CHEMBL1604861 & 737003 & 3.699 & 5.1026 & TRN \\
\hline CHEMBL 2369219 & 737003 & 5.3407 & 4.8434 & TRN \\
\hline CHEMBL1535340 & 737003 & 5.2733 & 4.8508 & TST \\
\hline CHEMBL1715631 & 737003 & 4.8534 & 4.6823 & TRN \\
\hline CHEMBL1413902 & 737003 & 5.2436 & 4.8393 & TRN \\
\hline CHEMBL1319248 & 737003 & 5.5262 & 5.2862 & TRN \\
\hline CHEMBL1591182 & 737003 & 5.0681 & 4.9985 & TST \\
\hline CHEMBL1698828 & 737003 & 5.0005 & 4.71 & TRN \\
\hline CHEMBL1343853 & 737003 & 5.2947 & 5.4705 & TRN \\
\hline CHEMBL1520667 & 737003 & 5.0819 & 4.9012 & TST \\
\hline CHEMBL1200792 & 737003 & 4.7611 & 4.5481 & TST \\
\hline CHEMBL1532262 & 737003 & 4.7487 & 4.9867 & TRN \\
\hline CHEMBL1724950 & 737003 & 5.0975 & 4.8743 & TRN \\
\hline CHEMBL1978733 & 737003 & 5.1944 & 4.7172 & TRN \\
\hline CHEMBL1596428 & 737003 & 5.4384 & 5.0457 & TRN \\
\hline CHEMBL1435164 & 737003 & 3.699 & 4.4192 & TRN \\
\hline CHEMBL1509569 & 737003 & 6.251 & 5.2062 & TRN \\
\hline CHEMBL1316978 & 737003 & 5.8948 & 5.7343 & TRN \\
\hline CHEMBL1300583 & 737003 & 4.8428 & 4.9781 & TRN \\
\hline CHEMBL1561727 & 737003 & 5.3518 & 4.8847 & TRN \\
\hline CHEMBL461579 & 737003 & 5.1294 & 4.8531 & TST \\
\hline CHEMBL1708056 & 737003 & 4.9313 & 4.7342 & TRN \\
\hline CHEMBL1315701 & 737003 & 4.9754 & 4.8439 & TRN \\
\hline CHEMBL1443214 & 737003 & 5.3383 & 4.4662 & TRN \\
\hline CHEMBL1425512 & 737003 & 5.28799 & 999999999 & 5.0368 \\
\hline CHEMBL1709129 & 737003 & 3.699 & 4.6137 & TRN \\
\hline CHEMBL1409350 & 737003 & 6.0146 & 5.7381 & TRN \\
\hline CHEMBL3197908 & 737003 & 4.9943 & 4.702 & TRN \\
\hline CHEMBL1503928 & 737003 & 3.699 & 4.3927 & TRN \\
\hline CHEMBL1534034 & 737003 & 5.6645 & 5.5925 & TRN \\
\hline CHEMBL1542113 & 737003 & 5.0298 & 4.8563 & TRN \\
\hline CHEMBL1593484 & 737003 & 4.9534 & 4.7975 & TRN \\
\hline CHEMBL1344491 & 737003 & 3.699 & 5.1213 & TRN \\
\hline CHEMBL1388253 & 737003 & 5.0865 & 5.1555 & TRN \\
\hline CHEMBL1705481 & 737003 & 4.7074 & 4.6411 & TST \\
\hline CHEMBL1427545 & 737003 & 5.3671 & 4.9946 & TRN \\
\hline CHEMBL448741 & 737003 & 4.8736 & 4.7841 & TST \\
\hline CHEMBL1290361 & 737003 & 3.699 & 4.85800 & 30000000005 \\
\hline CHEMBL1483598 & 737003 & 3.699 & 4.5861 & TRN \\
\hline CHEMBL1427763 & 737003 & 5.5206 & 5.6649 & TRN \\
\hline CHEMBL23194 & 737003 & 4.8066 & 4.5395 & TST \\
\hline CHEMBL1434585 & 737003 & 5.0806 & 4.5931 & TRN \\
\hline
\end{tabular}




\begin{tabular}{|c|c|c|c|c|}
\hline \multicolumn{5}{|c|}{ Supplemental Table } \\
\hline CHEMBL1304615 & 737003 & 4.8815 & 4.6686 & TRN \\
\hline CHEMBL1356525 & 737003 & 5.0348 & 5.0574 & TST \\
\hline CHEMBL1435941 & 737003 & 3.699 & 4.8602 & TRN \\
\hline CHEMBL1548334 & 737003 & 5.1521 & 5.0426 & TRN \\
\hline CHEMBL1554781 & 737003 & 4.9649 & 4.6679 & TRN \\
\hline CHEMBL1989158 & 737003 & 5.4187 & 5.4981 & TRN \\
\hline CHEMBL1344488 & 737003 & 5.0693 & 5.0876 & TRN \\
\hline CHEMBL1571934 & 737003 & 5.0336 & 4.7551 & TRN \\
\hline CHEMBL1351737 & 737003 & 5.1782 & 5.0298 & TRN \\
\hline CHEMBL1490987 & 737003 & 4.8309 & 5.157 & TRN \\
\hline CHEMBL1528513 & 737003 & 5.1141 & 5.0004 & TRN \\
\hline CHEMBL1487183 & 737003 & 5.7632 & 5.4875 & TST \\
\hline CHEMBL1717208 & 737003 & 3.699 & 4.7224 & TST \\
\hline CHEMBL1721463 & 737003 & 4.8537 & 4.7123 & TRN \\
\hline CHEMBL1384172 & 737003 & 5.0712 & 5.2105 & TST \\
\hline CHEMBL1346179 & 737003 & 5.3796 & 5.1381 & TRN \\
\hline CHEMBL1466441 & 737003 & 5.817 & 5.1494 & TRN \\
\hline CHEMBL1408841 & 737003 & 3.699 & 4.7116 & TRN \\
\hline CHEMBL1299925 & 737003 & 5.8693 & 4.6138 & TRN \\
\hline CHEMBL1402707 & 737003 & 4.7249 & 4.7021 & TST \\
\hline CHEMBL1380969 & 737003 & 5.114 & 4.874 & TRN \\
\hline CHEMBL1589425 & 737003 & 5.4237 & 5.3621 & TST \\
\hline CHEMBL1408030 & 737003 & 4.8587 & 4.7351 & TST \\
\hline CHEMBL1564990 & 737003 & 5.0853 & 4.6586 & TRN \\
\hline CHEMBL1532679 & 737003 & 3.699 & 4.5321 & TRN \\
\hline CHEMBL1452283 & 737003 & 5.4073 & 5.0804 & TRN \\
\hline CHEMBL1418255 & 737003 & 4.957 & 4.7224 & TST \\
\hline CHEMBL1464020 & 737003 & 5.0554 & 4.7965 & TRN \\
\hline CHEMBL1454967 & 737003 & 4.9875 & 4.8463 & TRN \\
\hline CHEMBL1532960 & 737003 & 5.4465 & 5.0497 & TRN \\
\hline CHEMBL1732411 & 737003 & 5.1917 & 5.2898 & TRN \\
\hline CHEMBL1328113 & 737003 & 5.2541 & 5.0237 & TRN \\
\hline CHEMBL1715362 & 737003 & 4.9614 & 4.7761 & TRN \\
\hline CHEMBL1507137 & 737003 & 5.4483 & 4.845 & TRN \\
\hline CHEMBL1336152 & 737003 & 3.699 & 4.4117 & TST \\
\hline CHEMBL3213394 & 737003 & 4.8891 & 4.7381 & TRN \\
\hline CHEMBL1447539 & 737003 & 5.279 & 4.3936 & TRN \\
\hline CHEMBL1444501 & 737003 & 4.9667 & 5.1457 & TRN \\
\hline CHEMBL1522211 & 737003 & 5.1047 & 4.8812 & TRN \\
\hline CHEMBL1726406 & 737003 & 3.699 & 5.1013 & TRN \\
\hline CHEMBL581880 & 737003 & 3.699 & 4.8682 & TST \\
\hline CHEMBL591404 & 737003 & 5.2239 & 5.0552 & TRN \\
\hline CHEMBL1534719 & 737003 & 5.8342 & 5.0205 & TRN \\
\hline CHEMBL1374245 & 737003 & 4.9667 & 4.8136 & TRN \\
\hline CHEMBL1704033 & 737003 & 5.0739 & 4.9788 & TRN \\
\hline CHEMBL3191507 & 737003 & 6.0237 & 6.3376 & TRN \\
\hline CHEMBL1995152 & 737003 & 5.9531 & 4.9401 & TRN \\
\hline CHEMBL3199272 & 737003 & 3.699 & 4.8659 & TRN \\
\hline
\end{tabular}




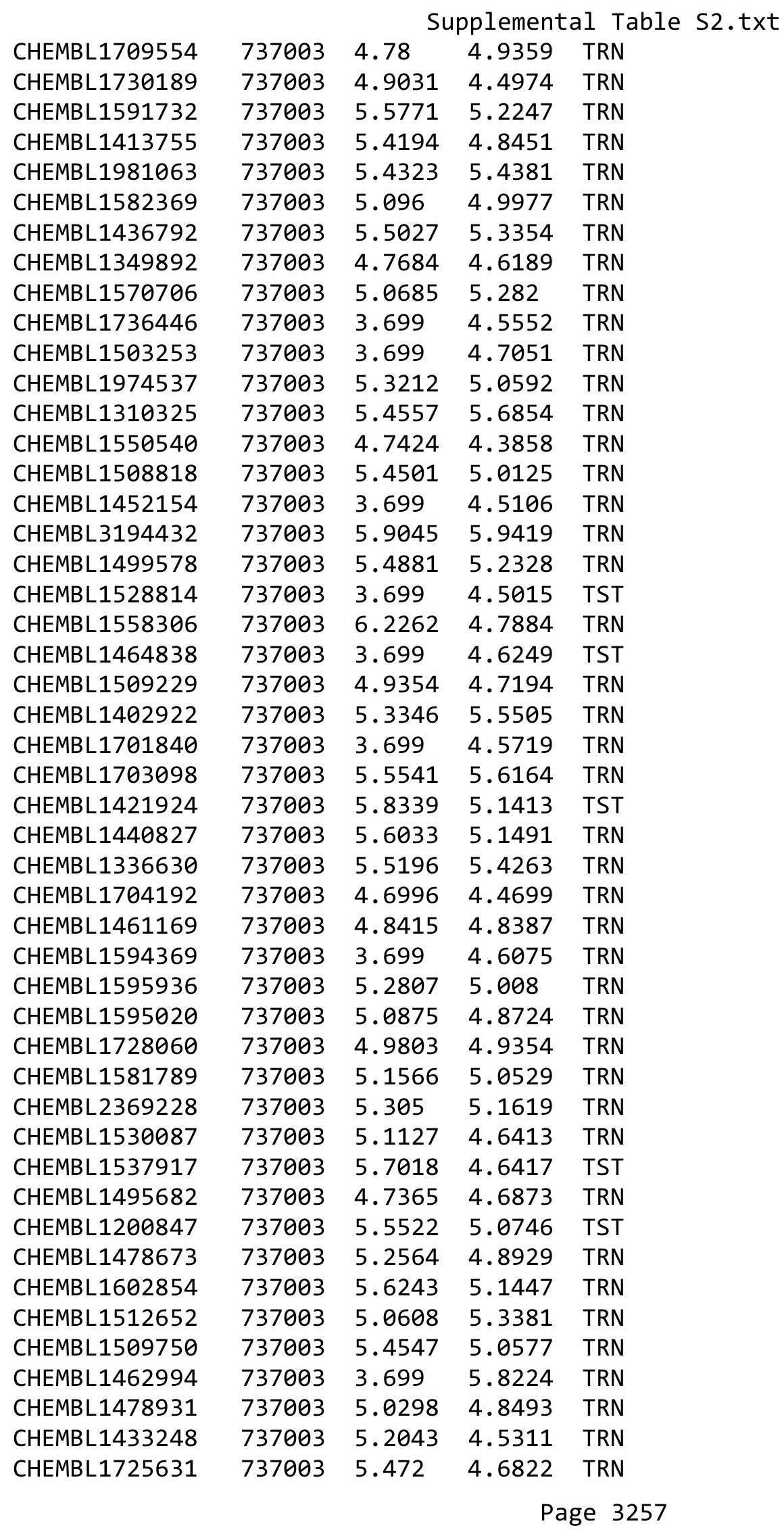




\begin{tabular}{|c|c|c|c|c|c|c|}
\hline & & \multicolumn{5}{|c|}{ Supplemental Table s2.txt } \\
\hline CHEMBL1599465 & 737003 & 3.699 & 4.8431 & TRN & & \\
\hline CHEMBL1428095 & 737003 & 3.699 & 5.0192 & TRN & & \\
\hline CHEMBL1454777 & 737003 & 5.3979 & 4.9745 & TST & & \\
\hline CHEMBL 3192765 & 737003 & 5.1514 & 5.3075 & TRN & & \\
\hline CHEMBL1450522 & 737003 & 3.699 & 4.6657 & TST & & \\
\hline CHEMBL1518668 & 737003 & 5.1674 & 4.6887 & TRN & & \\
\hline CHEMBL1368012 & 737003 & 5.8814 & 5.6903 & TRN & & \\
\hline CHEMBL1470791 & 737003 & 5.3913 & 5.3462 & TRN & & \\
\hline CHEMBL3197529 & 737003 & 5.3095 & 4.9255 & TRN & & \\
\hline CHEMBL1326930 & 737003 & 6.1778 & 4.7973 & TRN & & \\
\hline CHEMBL1548086 & 737003 & 5.3214 & 5.3621 & TST & & \\
\hline CHEMBL1429422 & 737003 & 3.699 & 4.4581 & TRN & & \\
\hline CHEMBL1368514 & 737003 & 5.2246 & 5.1439 & TRN & & \\
\hline CHEMBL 1226 & 737003 & 6.059 & 5.5614 & TRN & & \\
\hline CHEMBL1208858 & 737003 & \multicolumn{3}{|c|}{5.252000000000001} & 4.8362 & TRN \\
\hline CHEMBL1706626 & 737003 & 3.699 & 4.5565 & TRN & & \\
\hline CHEMBL503363 & 737003 & 4.9142 & 4.6508 & TST & & \\
\hline CHEMBL1554625 & 737003 & 5.3761 & 5.0807 & TST & & \\
\hline CHEMBL 1370042 & 737003 & 5.0961 & 4.8825 & TRN & & \\
\hline CHEMBL1543529 & 737003 & 3.699 & 4.6862 & TST & & \\
\hline CHEMBL1702693 & 737003 & 3.699 & 4.6804 & TRN & & \\
\hline CHEMBL1704417 & 737003 & 5.1957 & 4.9421 & TRN & & \\
\hline CHEMBL1509380 & 737003 & 5.1733 & 4.9536 & TRN & & \\
\hline CHEMBL1613394 & 737003 & 5.1611 & 4.9306 & TRN & & \\
\hline CHEMBL1448793 & 737003 & 5.7696 & 5.5518 & TRN & & \\
\hline CHEMBL1406738 & 737003 & 3.699 & 4.7024 & TRN & & \\
\hline CHEMBL1513972 & 737003 & 4.9376 & 4.4952 & TST & & \\
\hline CHEMBL3192124 & 737003 & 6.2612 & 6.3803 & TRN & & \\
\hline CHEMBL 1575772 & 737003 & 3.699 & 4.6268 & TRN & & \\
\hline CHEMBL1336154 & 737003 & 5.8811 & 5.57 & TRN & & \\
\hline CHEMBL1346693 & 737003 & 5.6696 & 5.0452 & TRN & & \\
\hline CHEMBL1306824 & 737003 & 5.2104 & 4.8003 & TRN & & \\
\hline CHEMBL1496572 & 737003 & 4.9374 & 4.6732 & TRN & & \\
\hline CHEMBL1403654 & 737003 & 5.0002 & 4.8646 & TRN & & \\
\hline CHEMBL1734073 & 737003 & 4.9455 & 4.5281 & TRN & & \\
\hline CHEMBL1735976 & 737003 & 5.1812 & 5.091 & TRN & & \\
\hline CHEMBL1986183 & 737003 & 5.8401 & 5.7899 & TRN & & \\
\hline CHEMBL1421282 & 737003 & 3.699 & 4.5332 & TST & & \\
\hline CHEMBL1320017 & 737003 & 4.9092 & 4.7148 & TRN & & \\
\hline CHEMBL1322772 & 737003 & 5.2866 & 5.19600 & 0000000001 & & TRI \\
\hline CHEMBL1348428 & 737003 & 5.0093 & 4.8668 & TRN & & \\
\hline CHEMBL1599339 & 737003 & 3.699 & 4.6578 & TRN & & \\
\hline CHEMBL1533968 & 737003 & 4.9613 & 4.732 & TST & & \\
\hline CHEMBL548017 & 737003 & 3.699 & 4.9577 & TRN & & \\
\hline CHEMBL1591106 & 737003 & 5.5324 & 5.3866 & TRN & & \\
\hline CHEMBL1383214 & 737003 & 4.916 & 4.8027 & TRN & & \\
\hline CHEMBL1595575 & 737003 & 4.7035 & 4.9463 & TRN & & \\
\hline CHEMBL1318088 & 737003 & 5.3336 & 5.3235 & TRN & & \\
\hline
\end{tabular}




\begin{tabular}{|c|c|c|c|c|c|}
\hline & & \multicolumn{4}{|c|}{ Supplemental Table S2.txt } \\
\hline CHEMBL1604350 & 737003 & 3.699 & 5.1023 & TRN & \\
\hline CHEMBL1996133 & 737003 & 5.1792 & 5.1374 & TRN & \\
\hline CHEMBL1729624 & 737003 & 4.9015 & 4.7667 & TRN & \\
\hline CHEMBL1525327 & 737003 & 3.699 & 4.6896 & TRN & \\
\hline CHEMBL1468776 & 737003 & 5.1321 & 5.3074 & TRN & \\
\hline CHEMBL 2369277 & 737003 & 4.9069 & 4.828 & TRN & \\
\hline CHEMBL1538277 & 737003 & 5.2432 & 4.7753 & TRN & \\
\hline CHEMBL1394750 & 737003 & 4.9007 & 4.5516 & TRN & \\
\hline CHEMBL1477355 & 737003 & 4.8062 & 4.7823 & TRN & \\
\hline CHEMBL 2369172 & 737003 & 5.2964 & 4.9478 & TRN & \\
\hline CHEMBL1708596 & 737003 & 5.1003 & 5.199 & TRN & \\
\hline CHEMBL1516412 & 737003 & 3.699 & 4.7961 & TST & \\
\hline CHEMBL1454899 & 737003 & 3.699 & 4.6849 & TRN & \\
\hline CHEMBL1448027 & 737003 & 5.2621 & 5.1971 & TRN & \\
\hline CHEMBL1550225 & 737003 & 5.2847 & 5.41700 & 0000000001 & TRN \\
\hline CHEMBL1319374 & 737003 & 3.699 & 4.5907 & TRN & \\
\hline CHEMBL1734113 & 737003 & 4.7342 & 4.8364 & TRN & \\
\hline CHEMBL1547025 & 737003 & 4.9599 & 4.2973 & TRN & \\
\hline CHEMBL1995720 & 737003 & 5.5782 & 5.263 & TRN & \\
\hline CHEMBL1981002 & 737003 & 4.9567 & 4.8824 & TST & \\
\hline CHEMBL1577297 & 737003 & 4.7527 & 4.6661 & TRN & \\
\hline CHEMBL1613445 & 737003 & 5.3482 & 5.4419 & TRN & \\
\hline CHEMBL1453208 & 737003 & 5.2076 & 5.0877 & TST & \\
\hline CHEMBL3213571 & 737003 & 4.9641 & 5.148 & TRN & \\
\hline CHEMBL1705612 & 737003 & 5.1052 & 4.8058 & TRN & \\
\hline CHEMBL1377868 & 737003 & 3.699 & 4.6054 & TRN & \\
\hline CHEMBL1318210 & 737003 & 3.699 & 4.431 & TRN & \\
\hline CHEMBL1337235 & 737003 & 3.699 & 4.8548 & TRN & \\
\hline CHEMBL 3212707 & 737003 & 5.6419 & 5.2865 & TRN & \\
\hline CHEMBL1487035 & 737003 & 4.7623 & 4.4732 & TRN & \\
\hline CHEMBL1495340 & 737003 & 5.0854 & 4.9787 & TRN & \\
\hline CHEMBL1509316 & 737003 & 4.7426 & 4.5125 & TRN & \\
\hline CHEMBL1494737 & 737003 & 5.9905 & 5.3386 & TST & \\
\hline CHEMBL1729974 & 737003 & 5.2884 & 5.5036 & TRN & \\
\hline CHEMBL1592706 & 737003 & 5.5016 & 5.2647 & TRN & \\
\hline CHEMBL1409219 & 737003 & 4.9977 & 4.7693 & TRN & \\
\hline CHEMBL1505944 & 737003 & 4.9497 & 4.7441 & TRN & \\
\hline CHEMBL1550174 & 737003 & 3.699 & 4.9155 & TRN & \\
\hline CHEMBL1518077 & 737003 & 3.699 & 5.0446 & TRN & \\
\hline CHEMBL1992490 & 737003 & 5.3921 & 5.4095 & TRN & \\
\hline CHEMBL1423463 & 737003 & 4.7615 & 4.6893 & TST & \\
\hline CHEMBL1510761 & 737003 & 5.2769 & 5.0601 & TRN & \\
\hline CHEMBL1521485 & 737003 & 6.2933 & 4.9888 & TRN & \\
\hline CHEMBL1603662 & 737003 & 3.699 & 4.5199 & TRN & \\
\hline CHEMBL584444 & 737003 & 4.9183 & 4.7538 & TRN & \\
\hline CHEMBL1432123 & 737003 & 5.2418 & 4.6349 & TRN & \\
\hline CHEMBL1973159 & 737003 & 5.5314 & 5.6758 & TST & \\
\hline CHEMBL1325858 & 737003 & 5.4289 & 5.2249 & TST & \\
\hline
\end{tabular}




\begin{tabular}{|c|c|c|c|c|c|}
\hline \multicolumn{6}{|c|}{ Supplemental Table S2.txt } \\
\hline CHEMBL3192949 & 737003 & 6.4134 & 6.5617 & TST & \\
\hline CHEMBL1517599 & 737003 & 5.2741 & 4.71 & TST & \\
\hline CHEMBL1585763 & 737003 & 4.9854 & 4.6746 & TST & \\
\hline CHEMBL1349480 & 737003 & 5.8 & 5.5815 & TST & \\
\hline CHEMBL1390705 & 737003 & 5.0504 & 4.7999 & TST & \\
\hline CHEMBL 2004487 & 737003 & 5.3451 & $5.24100 e$ & 00000000005 & TST \\
\hline CHEMBL1400908 & 737003 & 4.9898 & 4.7621 & TST & \\
\hline CHEMBL1414380 & 737003 & 4.9504 & 4.637 & TST & \\
\hline CHEMBL1540419 & 737003 & 5.1462 & 5.0245 & TST & \\
\hline CHEMBL1381940 & 737003 & 6.1494 & 5.7149 & TST & \\
\hline CHEMBL1402791 & 737003 & 5.0421 & 4.6441 & TST & \\
\hline CHEMBL1549666 & 737003 & 5.25799 & 999999999 & 5.351 & TST \\
\hline CHEMBL1981290 & 737003 & 5.5184 & 5.6442 & TST & \\
\hline CHEMBL1583807 & 737003 & 5.1112 & 5.0133 & TST & \\
\hline CHEMBL1410483 & 737003 & 5.5435 & 5.1303 & TST & \\
\hline CHEMBL1609296 & 737003 & 5.1521 & 4.5595 & TST & \\
\hline CHEMBL3198118 & 737003 & 5.7228 & 6.0181 & TST & \\
\hline CHEMBL1418004 & 737003 & 6.1175 & $5.36100 e$ & 0000000001 & T \\
\hline CHEMBL1305066 & 737003 & 5.4314 & 4.5898 & TST & \\
\hline CHEMBL1494987 & 737003 & 4.9643 & 4.6997 & TST & \\
\hline CHEMBL1487895 & 737003 & 3.699 & 4.6597 & TST & \\
\hline CHEMBL1407747 & 737003 & 5.0341 & 4.649 & TST & \\
\hline CHEMBL1393812 & 737003 & 5.0906 & 4.848 & TST & \\
\hline CHEMBL1543903 & 737003 & 3.699 & 4.4565 & TST & \\
\hline CHEMBL1334739 & 737003 & 5.0113 & 4.8319 & TST & \\
\hline CHEMBL1889837 & 737003 & 5.1745 & 4.7367 & TST & \\
\hline CHEMBL3211086 & 737003 & 5.0578 & 4.5451 & TST & \\
\hline CHEMBL1984581 & 737003 & 5.5719 & 5.7317 & TST & \\
\hline CHEMBL3209319 & 737003 & 4.9941 & 4.6429 & TST & \\
\hline CHEMBL1577443 & 737003 & 5.1575 & 4.6497 & TST & \\
\hline CHEMBL1730952 & 737003 & 5.6619 & 5.3047 & TST & \\
\hline CHEMBL1440558 & 737003 & 4.7997 & 4.6813 & TST & \\
\hline CHEMBL1321398 & 737003 & 5.0226 & 4.8522 & TST & \\
\hline CHEMBL1507250 & 736962 & 6.0088 & 6.2513 & TRN & \\
\hline CHEMBL1448054 & 736962 & 3.0969 & 3.6671 & TRN & \\
\hline CHEMBL1382884 & 736962 & 5.52 & 5.2411 & TRN & \\
\hline CHEMBL1542868 & 736962 & 3.0969 & 4.5863 & TRN & \\
\hline CHEMBL1563483 & 736962 & 6.1427 & 5.332999 & 9999999999 & G \\
\hline CHEMBL578487 & 736962 & 3.0969 & 3.8882 & TRN & \\
\hline CHEMBL1407572 & 736962 & 3.0969 & 3.9312 & TST & \\
\hline CHEMBL455284 & 736962 & 5.9626 & 5.6115 & TRN & \\
\hline CHEMBL1445650 & 736962 & 5.6737 & 5.2419 & TRN & \\
\hline CHEMBL1418095 & 736962 & 3.0969 & 3.9008 & TRN & \\
\hline CHEMBL222409 & 736962 & 4.2993 & 3.7654 & TRN & \\
\hline CHEMBL1411912 & 736962 & 4.8962 & 3.7526 & TRN & \\
\hline CHEMBL1442155 & 736962 & 3.0969 & 4.1081 & TST & \\
\hline CHEMBL1307769 & 736962 & 4.6904 & 3.7524 & TRN & \\
\hline CHEMBL1577016 & 736962 & 3.0969 & 4.0272 & TST & \\
\hline
\end{tabular}


Supplemental Table S2.txt

\begin{tabular}{|c|c|c|c|c|c|}
\hline CHEMBL1605536 & 736962 & 6.1612 & 4.9737 & TRN & \\
\hline CHEMBL 2003909 & 736962 & 3.0969 & 4.6402 & TRN & \\
\hline CHEMBL1426542 & 736962 & 3.0969 & 3.6309 & TRN & \\
\hline CHEMBL1448282 & 736962 & 4.9355 & 3.6985 & TRN & \\
\hline CHEMBL1452379 & 736962 & 5.9469 & 5.0507 & TST & \\
\hline CHEMBL1484195 & 736962 & 4.382 & 3.7186 & TRN & \\
\hline CHEMBL1325943 & 736962 & 6.4949 & 5.4196 & TRN & \\
\hline CHEMBL1301125 & 736962 & 6.1367 & 5.1655 & TST & \\
\hline CHEMBL1364681 & 736962 & 3.0969 & 3.6912 & TRN & \\
\hline CHEMBL1392776 & 736962 & 6.2007 & 5.4871 & TRN & \\
\hline CHEMBL1510984 & 736962 & 5.3307 & 3.8771 & TRN & \\
\hline CHEMBL1334514 & 736962 & 6.1739 & 5.3072 & TRN & \\
\hline CHEMBL1305054 & 736962 & 3.0969 & 3.9612 & TRN & \\
\hline CHEMBL1300558 & 736962 & 3.0969 & 3.6164 & TRN & \\
\hline CHEMBL1489779 & 736962 & 4.6234 & 3.8036 & TRN & \\
\hline CHEMBL603129 & 736962 & 3.0969 & 3.698 & TRN & \\
\hline CHEMBL1380507 & 736962 & 7.7959 & 4.3003 & TRN & \\
\hline CHEMBL1432638 & 736962 & 4.1898 & 3.6479 & TRN & \\
\hline CHEMBL1486253 & 736962 & 5.2848 & 3.9835 & TST & \\
\hline CHEMBL1348108 & 736962 & 3.0969 & 3.778 & TRN & \\
\hline CHEMBL1515023 & 736962 & 4.5017 & 3.6894 & TRN & \\
\hline CHEMBL1513046 & 736962 & 3.0969 & 4.82100 & 0000000001 & TRN \\
\hline CHEMBL1551000 & 736962 & 3.0969 & 4.0285 & TRN & \\
\hline CHEMBL1493942 & 736962 & 4.5735 & 4.419 & TRN & \\
\hline CHEMBL1385053 & 736962 & 4.4318 & 3.6484 & TRN & \\
\hline CHEMBL1459187 & 736962 & 4.1415 & 3.8227 & TRN & \\
\hline CHEMBL1577966 & 736962 & 3.0969 & 4.0263 & TST & \\
\hline CHEMBL1484623 & 736962 & 3.0969 & 3.7439 & TRN & \\
\hline CHEMBL1364793 & 736962 & 3.0969 & 3.967 & TRN & \\
\hline CHEMBL1976638 & 736962 & 7.7959 & 3.9072 & TST & \\
\hline CHEMBL1497999 & 736962 & 3.0969 & 4.6137 & TRN & \\
\hline CHEMBL1533161 & 736962 & 3.0969 & 3.8442 & TRN & \\
\hline CHEMBL1339678 & 736962 & 6.3372 & 5.5644 & TRN & \\
\hline CHEMBL1391582 & 736962 & 3.0969 & 3.7073 & TST & \\
\hline CHEMBL1565526 & 736962 & 3.0969 & 3.8387 & TRN & \\
\hline CHEMBL1571901 & 736962 & 5.6946 & 5.0645 & TRN & \\
\hline CHEMBL 2359467 & 736962 & 3.0969 & 4.8186 & TRN & \\
\hline CHEMBL1491637 & 736962 & 5.1221 & 4.1571 & TRN & \\
\hline CHEMBL1593286 & 736962 & 6.2076 & 5.2042 & TRN & \\
\hline CHEMBL1544486 & 736962 & 5.1694 & 3.8128 & TRN & \\
\hline CHEMBL1309059 & 736962 & 5.5751 & 4.8844 & TRN & \\
\hline CHEMBL1481122 & 736962 & 3.0969 & 3.8419 & TST & \\
\hline CHEMBL1347071 & 736962 & 5.063 & 5.3701 & TRN & \\
\hline CHEMBL1964614 & 736962 & 4.2255 & 4.5272 & TRN & \\
\hline CHEMBL1362402 & 736962 & 3.0969 & 3.7655 & TRN & \\
\hline CHEMBL1700777 & 736962 & 4.7033 & 4.4359 & TRN & \\
\hline CHEMBL1359872 & 736962 & 3.0969 & 3.6802 & TRN & \\
\hline CHEMBL1494120 & 736962 & 6.5686 & 6.3273 & TRN & \\
\hline
\end{tabular}




\begin{tabular}{|c|c|c|c|c|c|}
\hline & & \multicolumn{4}{|c|}{ Supplemental Table S2.txt } \\
\hline CHEMBL1344025 & 736962 & 3.0969 & 5.1697 & TST & \\
\hline CHEMBL1371264 & 736962 & 3.0969 & 3.6183 & TRN & \\
\hline CHEMBL1729978 & 736962 & 5.1457 & 3.7675 & TRN & \\
\hline CHEMBL1469247 & 736962 & 4.4815 & 3.8129 & TRN & \\
\hline CHEMBL1331541 & 736962 & 3.0969 & 4.0088 & TRN & \\
\hline CHEMBL1547232 & 736962 & 3.0969 & 4.7724 & TST & \\
\hline CHEMBL3196134 & 736962 & 4.7852 & 4.4661 & TRN & \\
\hline CHEMBL1995045 & 736962 & 4.3206 & 5.5346 & TST & \\
\hline CHEMBL1412002 & 736962 & 3.0969 & 3.6013 & TRN & \\
\hline CHEMBL1329237 & 736962 & 4.327 & 3.89 & TRN & \\
\hline CHEMBL1316247 & 736962 & 3.0969 & 3.7488 & TRN & \\
\hline CHEMBL1555271 & 736962 & 5.5513 & 3.6422 & TRN & \\
\hline CHEMBL1590553 & 736962 & 4.1439 & 3.6901 & TRN & \\
\hline CHEMBL1978733 & 736962 & 5.6198 & 5.1521 & TRN & \\
\hline CHEMBL1332916 & 736962 & 3.0969 & 3.9721 & TRN & \\
\hline CHEMBL78150 & 736962 & 3.0969 & 4.21399 & 99999999995 & TST \\
\hline CHEMBL1367034 & 736962 & 3.0969 & 3.7747 & TRN & \\
\hline CHEMBL1419096 & 736962 & 4.3605 & 3.6716 & TRN & \\
\hline CHEMBL1367311 & 736962 & 3.0969 & 3.8357 & TRN & \\
\hline CHEMBL1332878 & 736962 & 3.0969 & 3.6794 & TRN & \\
\hline CHEMBL1535161 & 736962 & 3.0969 & 3.867 & TRN & \\
\hline CHEMBL1342029 & 736962 & 3.0969 & 4.5626 & TST & \\
\hline CHEMBL1349116 & 736962 & 4.3098 & 3.8184 & TRN & \\
\hline CHEMBL1200512 & 736962 & 5.9747 & 4.011 & TST & \\
\hline CHEMBL1357620 & 736962 & 3.0969 & 3.6207 & TST & \\
\hline CHEMBL1515368 & 736962 & 3.0969 & 4.0604 & TRN & \\
\hline CHEMBL1438667 & 736962 & 4.5702 & 3.7762 & TRN & \\
\hline CHEMBL1986418 & 736962 & 3.0969 & 3.949 & TRN & \\
\hline CHEMBL1993194 & 736962 & 6.0088 & 3.7638 & TRN & \\
\hline CHEMBL1393671 & 736962 & 3.0969 & 3.6084 & TRN & \\
\hline CHEMBL1376759 & 736962 & 4.6498 & 4.5069 & TRN & \\
\hline CHEMBL467987 & 736962 & 5.3224 & 4.7134 & TST & \\
\hline CHEMBL1461730 & 736962 & 6.0915 & 5.3105 & TRN & \\
\hline CHEMBL1400459 & 736962 & 3.0969 & 3.7244 & TRN & \\
\hline CHEMBL590927 & 736962 & 5.5482 & 3.634 & TRN & \\
\hline CHEMBL1309091 & 736962 & 5.3054 & 5.0468 & TRN & \\
\hline CHEMBL1371989 & 736962 & 3.0969 & 3.7058 & TRN & \\
\hline CHEMBL1536342 & 736962 & 4.5686 & 3.7318 & TRN & \\
\hline CHEMBL1354093 & 736962 & 7.7959 & 3.7918 & TRN & \\
\hline CHEMBL1504565 & 736962 & 3.0969 & 4.5365 & TST & \\
\hline CHEMBL1720152 & 736962 & 3.0969 & 4.4788 & TST & \\
\hline CHEMBL147514 & 736962 & 5.0101 & 5.4209 & TRN & \\
\hline CHEMBL1439227 & 736962 & 3.0969 & 4.2387 & TRN & \\
\hline CHEMBL1505088 & 736962 & 3.0969 & 3.7737 & TRN & \\
\hline CHEMBL1396619 & 736962 & 6.0 & 5.3103 & TRN & \\
\hline CHEMBL1562664 & 736962 & 5.4157 & 5.0482 & TRN & \\
\hline CHEMBL1304383 & 736962 & 3.0969 & 3.7703 & TRN & \\
\hline CHEMBL1998531 & 736962 & 3.0969 & 3.8595 & TRN & \\
\hline
\end{tabular}




\begin{tabular}{|c|c|c|c|c|c|c|}
\hline \multirow[b]{2}{*}{ CHEMBL1573050 } & \multicolumn{5}{|c|}{ Supplemental Table S2.txt } & \\
\hline & 736962 & 3.0969 & 3.7842 & TRN & & \\
\hline CHEMBL1501242 & 736962 & 4.2328 & 3.7822 & TST & & \\
\hline CHEMBL1454000 & 736962 & 3.0969 & 3.7948 & TRN & & \\
\hline CHEMBL1405288 & 736962 & 5.1945 & 3.807 & TRN & & \\
\hline CHEMBL1422513 & 736962 & 5.3925 & 3.9067 & TRN & & \\
\hline CHEMBL1970422 & 736962 & 3.0969 & 5.474 & TST & & \\
\hline CHEMBL1716112 & 736962 & 5.3125 & 6.2772 & TST & & \\
\hline CHEMBL1990582 & 736962 & 3.0969 & 5.6396 & TRN & & \\
\hline CHEMBL1613639 & 736962 & 3.0969 & 3.6668 & TRN & & \\
\hline CHEMBL1418818 & 736962 & 4.9586 & 5.2865 & TRN & & \\
\hline CHEMBL1372889 & 736962 & 6.284 & 6.5439 & TRN & & \\
\hline CHEMBL1424468 & 736962 & 3.0969 & 3.6046 & TRN & & \\
\hline CHEMBL1381439 & 736962 & 5.5952 & 4.9683 & TST & & \\
\hline CHEMBL1403322 & 736962 & 3.0969 & 3.7068 & TRN & & \\
\hline CHEMBL1588217 & 736962 & 3.0969 & 3.8494 & TRN & & \\
\hline CHEMBL1321754 & 736962 & 6.0088 & 5.2126 & TRN & & \\
\hline CHEMBL1535490 & 736962 & 5.7747 & 5.48 & TST & & \\
\hline CHEMBL1565007 & 736962 & 4.6383 & 3.9996 & TRN & & \\
\hline CHEMBL1491981 & 736962 & 4.1062 & 3.6625 & TRN & & \\
\hline CHEMBL1375045 & 736962 & 5.4045 & 5.3157 & TRN & & \\
\hline CHEMBL1525220 & 736962 & 3.0969 & 3.9619 & TRN & & \\
\hline CHEMBL1309521 & 736962 & 3.0969 & 3.7021 & TRN & & \\
\hline CHEMBL1568294 & 736962 & 5.1273 & 3.7842 & TRN & & \\
\hline CHEMBL1455137 & 736962 & 5.7696 & 5.2362 & TRN & & \\
\hline CHEMBL1540682 & 736962 & 6.0458 & 5.2281 & TST & & \\
\hline CHEMBL1331836 & 736962 & 3.0969 & 3.6779 & TRN & & \\
\hline CHEMBL1445297 & 736962 & 3.0969 & 3.6596 & TRN & & \\
\hline CHEMBL1416089 & 736962 & 6.0969 & 5.1773 & TRN & & \\
\hline CHEMBL1435226 & 736962 & 3.0969 & 4.9356 & TRN & & \\
\hline CHEMBL1445707 & 736962 & 4.8069 & 3.7865 & TRN & & \\
\hline CHEMBL1464071 & 736962 & 3.0969 & 3.6729 & TRN & & \\
\hline CHEMBL547285 & 736962 & 5.064 & 3.6391 & TRN & & \\
\hline CHEMBL578257 & 736962 & 3.0969 & 5.1326 & TST & & \\
\hline CHEMBL1372082 & 736962 & 3.0969 & 3.6197 & TRN & & \\
\hline CHEMBL1170485 & 736962 & 6.7696 & 5.2573 & TST & & \\
\hline CHEMBL1708144 & 736962 & 5.1986 & 5.1765 & TRN & & \\
\hline CHEMBL1599776 & 736962 & 6.3372 & 5.0205 & TRN & & \\
\hline CHEMBL3198633 & 736962 & 5.6799 & 5.4349 & TST & & \\
\hline CHEMBL1492399 & 736962 & 5.7852 & 5.3487 & TRN & & \\
\hline CHEMBL1553738 & 736962 & 5.5952 & 4.4436 & TRN & & \\
\hline CHEMBL1998940 & 736962 & 4.7375 & 4.8529 & TST & & \\
\hline CHEMBL1432251 & 736962 & 6.3468 & 5.3566 & TRN & & \\
\hline CHEMBL1610510 & 736962 & 3.0969 & 3.9645 & TST & & \\
\hline CHEMBL1519651 & 736962 & 3.0969 & 3.8641 & TRN & & \\
\hline CHEMBL1566108 & 736962 & 4.2426 & 3.6938 & TRN & & \\
\hline CHEMBL1517461 & 736962 & 3.0969 & 4.0274 & TRN & & \\
\hline CHEMBL265686 & 736962 & 6.3372 & 5.687 & TRN & & \\
\hline CHEMBL1370513 & 736962 & 4.21899 & 9999999 & 99 & 3.7228 & TRN \\
\hline
\end{tabular}


Supplemental Table S2.txt

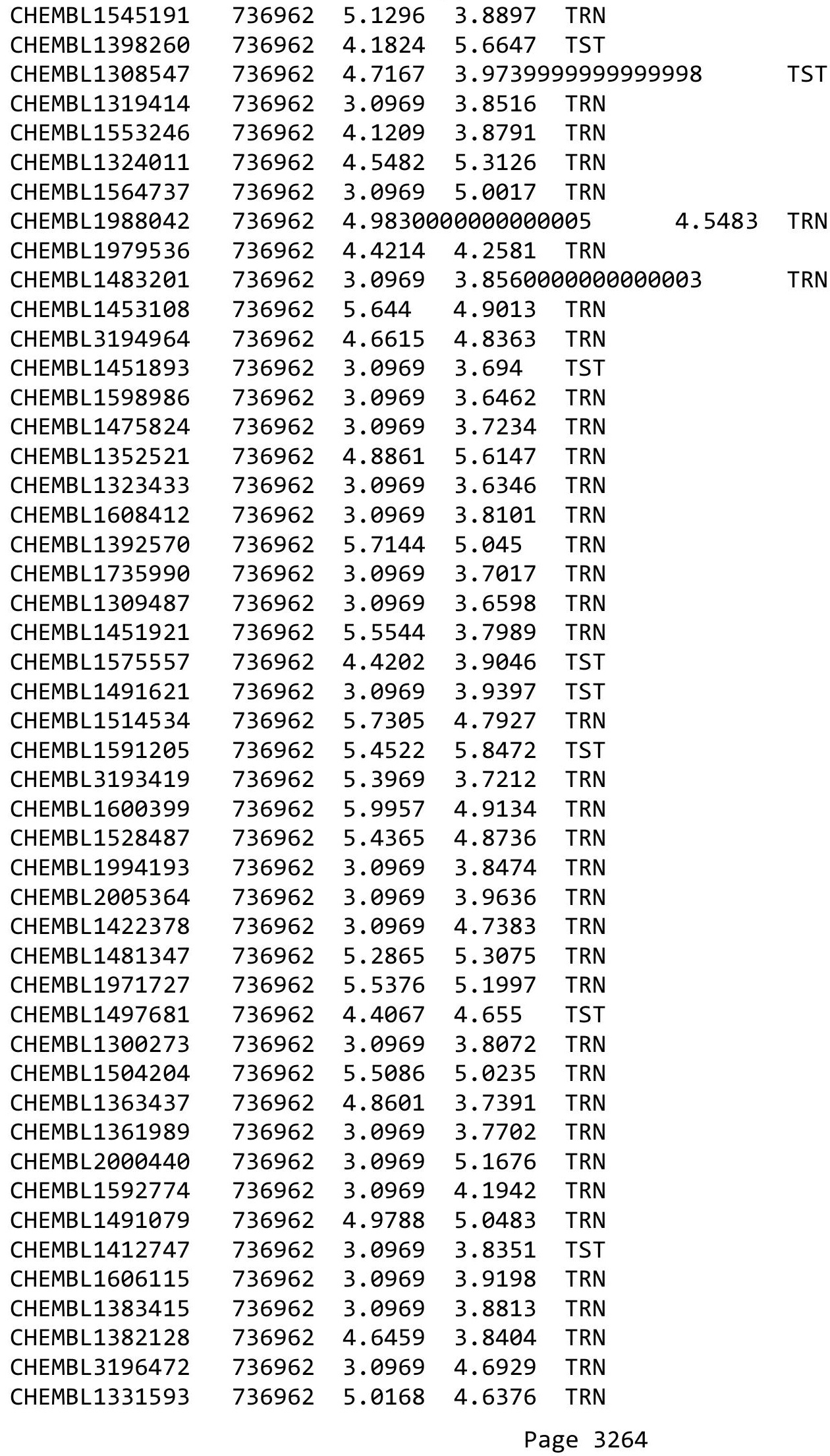




\begin{tabular}{|c|c|c|c|c|c|}
\hline & & \multicolumn{4}{|c|}{ Supplemental Table S2.txt } \\
\hline CHEMBL1711969 & 736962 & 3.0969 & 4.6092 & TST & \\
\hline CHEMBL1486664 & 736962 & 4.3925 & 4.4139 & TRN & \\
\hline CHEMBL1317996 & 736962 & 3.0969 & 3.9192 & TRN & \\
\hline CHEMBL1506503 & 736962 & 6.1249 & 6.1664 & TRN & \\
\hline CHEMBL1346112 & 736962 & 3.0969 & 3.8578 & TRN & \\
\hline CHEMBL1387172 & 736962 & 4.295 & 3.9007 & TRN & \\
\hline CHEMBL1497989 & 736962 & 3.0969 & 3.8059 & TRN & \\
\hline CHEMBL1538246 & 736962 & 4.6162 & 4.83 & TST & \\
\hline CHEMBL1595952 & 736962 & 3.0969 & 3.6377 & TRN & \\
\hline CHEMBL1335177 & 736962 & 3.0969 & 3.6933 & TRN & \\
\hline CHEMBL551783 & 736962 & 4.7986 & 4.6543 & TRN & \\
\hline CHEMBL1407659 & 736962 & 5.3098 & 5.106 & TRN & \\
\hline CHEMBL1578527 & 736962 & 5.2899 & 4.6792 & TRN & \\
\hline CHEMBL585071 & 736962 & 5.857 & 4.984 & TST & \\
\hline CHEMBL1590016 & 736962 & 5.2628 & 3.7751 & TRN & \\
\hline CHEMBL1374527 & 736962 & 4.7282 & 3.9102 & TRN & \\
\hline CHEMBL316589 & 736962 & 4.8894 & 4.9484 & TRN & \\
\hline CHEMBL1326803 & 736962 & 3.0969 & 3.6333 & TRN & \\
\hline CHEMBL1461400 & 736962 & 5.9508 & 5.2951 & TRN & \\
\hline CHEMBL1363043 & 736962 & 3.0969 & 3.8904 & TRN & \\
\hline CHEMBL1514530 & 736962 & 5.0762 & 3.5952 & TRN & \\
\hline CHEMBL1457201 & 736962 & 4.9747 & 4.5639 & TRN & \\
\hline CHEMBL1459746 & 736962 & 4.6478 & 4.6402 & TRN & \\
\hline CHEMBL1460612 & 736962 & 3.0969 & 3.8786 & TST & \\
\hline CHEMBL1427457 & 736962 & 3.0969 & 3.8854 & TRN & \\
\hline CHEMBL1377737 & 736962 & 6.2676 & 5.7671 & TRN & \\
\hline CHEMBL1400298 & 736962 & 5.7077 & 5.3084 & TRN & \\
\hline CHEMBL1580219 & 736962 & 3.0969 & 3.7761 & TRN & \\
\hline CHEMBL1538267 & 736962 & 3.0969 & 4.5766 & TRN & \\
\hline CHEMBL1304363 & 736962 & 5.5784 & 6.4313 & TRN & \\
\hline CHEMBL1432507 & 736962 & 3.0969 & 4.6182 & TRN & \\
\hline CHEMBL1322272 & 736962 & 3.0969 & 3.7378 & TRN & \\
\hline CHEMBL1391377 & 736962 & 4.5751 & 3.6652 & TRN & \\
\hline CHEMBL1565338 & 736962 & 4.5918 & 3.8104 & TRN & \\
\hline CHEMBL1324319 & 736962 & 3.0969 & 3.6916 & TRN & \\
\hline CHEMBL1491324 & 736962 & 4.8665 & 4.5451 & TRN & \\
\hline CHEMBL1300193 & 736962 & 3.0969 & 3.8129 & TRN & \\
\hline CHEMBL1570647 & 736962 & 3.0969 & 3.7904 & TRN & \\
\hline CHEMBL1393625 & 736962 & 5.7282 & 5.0736 & TRN & \\
\hline CHEMBL1537481 & 736962 & 4.2708 & 4.39199 & 99999999995 & TRN \\
\hline CHEMBL1602385 & 736962 & 7.7959 & 4.0305 & TRN & \\
\hline CHEMBL1466542 & 736962 & 3.0969 & 3.7519 & TRN & \\
\hline CHEMBL1532525 & 736962 & 4.9031 & 3.843 & TRN & \\
\hline CHEMBL1540099 & 736962 & 3.0969 & 3.6409 & TRN & \\
\hline CHEMBL1481849 & 736962 & 5.301 & 5.1096 & TST & \\
\hline CHEMBL1337659 & 736962 & 4.3893 & 3.9024 & TRN & \\
\hline CHEMBL1370884 & 736962 & 6.585 & 5.9721 & TRN & \\
\hline CHEMBL1369033 & 736962 & 3.0969 & 3.7671 & TRN & \\
\hline
\end{tabular}


Supplemental Table S2.txt

\begin{tabular}{|c|c|c|c|c|}
\hline CHEMBL1507347 & 736962 & 3.0969 & 3.8052 & TRN \\
\hline CHEMBL1456851 & 736962 & 3.0969 & 3.6678 & TRN \\
\hline CHEMBL1401965 & 736962 & 5.1175 & 3.8073 & TST \\
\hline CHEMBL1509896 & 736962 & 3.0969 & 3.7598 & TRN \\
\hline CHEMBL1417726 & 736962 & 4.2125 & 3.9821 & TRN \\
\hline CHEMBL374107 & 736962 & 3.0969 & 5.284 & TST \\
\hline CHEMBL1454029 & 736962 & 3.0969 & 3.8902 & TRN \\
\hline CHEMBL1524095 & 736962 & 3.0969 & 3.7848 & TRN \\
\hline CHEMBL1594114 & 736962 & 4.6655 & 3.8252 & TRN \\
\hline CHEMBL1357385 & 736962 & 4.5969 & 3.7032 & TRN \\
\hline CHEMBL1989603 & 736962 & 3.0969 & 3.9341 & TRN \\
\hline CHEMBL1572746 & 736962 & 4.4935 & 3.6174 & TRN \\
\hline CHEMBL1447442 & 736962 & 3.0969 & 3.87 & TRN \\
\hline CHEMBL1542955 & 736962 & 3.0969 & 4.6502 & TRN \\
\hline CHEMBL154358 & 736962 & 3.0969 & 3.8491 & TRN \\
\hline CHEMBL1306816 & 736962 & 5.9031 & 5.0501 & TST \\
\hline CHEMBL586135 & 736962 & 6.0362 & 5.5097 & TRN \\
\hline CHEMBL1556278 & 736962 & 3.0969 & 3.6858 & TRN \\
\hline CHEMBL1372199 & 736962 & 4.2636 & 3.6988 & TRN \\
\hline CHEMBL577662 & 736962 & 4.9101 & 5.3955 & TRN \\
\hline CHEMBL1319502 & 736962 & 4.5302 & 4.3955 & TRN \\
\hline CHEMBL 1457403 & 736962 & 5.5817 & 4.5477 & TRN \\
\hline CHEMBL1518625 & 736962 & 5.4647 & 5.3955 & TRN \\
\hline CHEMBL1491534 & 736962 & 3.0969 & 3.6477 & TRN \\
\hline CHEMBL1713509 & 736962 & 3.0969 & 3.6643 & TRN \\
\hline CHEMBL1500188 & 736962 & 3.0969 & 4.5234 & TRN \\
\hline CHEMBL1430060 & 736962 & 3.0969 & 4.1395 & TRN \\
\hline CHEMBL1520424 & 736962 & 4.5114 & 3.8228 & TRN \\
\hline CHEMBL1574879 & 736962 & 6.585 & 6.0884 & TRN \\
\hline CHEMBL1712891 & 736962 & 3.0969 & 3.78800 & 0000000003 \\
\hline CHEMBL1600688 & 736962 & 3.0969 & 3.7704 & TRN \\
\hline CHEMBL579318 & 736962 & 5.9586 & 4.8812 & TRN \\
\hline CHEMBL1318350 & 736962 & 5.5086 & 4.9756 & TST \\
\hline CHEMBL1609686 & 736962 & 3.0969 & 3.8911 & TRN \\
\hline CHEMBL1392611 & 736962 & 6.4089 & 4.9393 & TRN \\
\hline CHEMBL3189714 & 736962 & 5.9031 & 5.0843 & TRN \\
\hline CHEMBL1484459 & 736962 & 3.0969 & 3.8459 & TRN \\
\hline CHEMBL1432186 & 736962 & 4.5751 & 3.798 & TRN \\
\hline CHEMBL1583768 & 736962 & 4.3401 & 3.9848 & TRN \\
\hline CHEMBL131037 & 736962 & 5.7825 & 4.8824 & TRN \\
\hline CHEMBL1303623 & 736962 & 4.1226 & 4.7012 & TRN \\
\hline CHEMBL1411639 & 736962 & 3.0969 & 3.7305 & TRN \\
\hline CHEMBL1544465 & 736962 & 3.0969 & 3.6158 & TRN \\
\hline CHEMBL1547706 & 736962 & 4.8697 & 3.8139 & TRN \\
\hline CHEMBL1467999 & 736962 & 4.3224 & 4.8471 & TRN \\
\hline CHEMBL1465527 & 736962 & 6.1135 & 5.6649 & TST \\
\hline CHEMBL1310995 & 736962 & 4.7645 & 3.9959 & TRN \\
\hline CHEMBL1422161 & 736962 & 5.1701 & 4.7635 & TRN \\
\hline
\end{tabular}

Page 3266 


\begin{tabular}{|c|c|c|c|c|c|c|}
\hline & & \multicolumn{5}{|c|}{ Supplemental Table S2.txt } \\
\hline CHEMBL1734695 & 736962 & 4.4815 & 3.9192 & TRN & & \\
\hline CHEMBL1606309 & 736962 & 4.1113 & 4.8028 & TRN & & \\
\hline CHEMBL578512 & 736962 & 6.2924 & 5.2622 & TRN & & \\
\hline CHEMBL 3196351 & 736962 & 5.0214 & 4.7099 & TRN & & \\
\hline CHEMBL1565636 & 736962 & 3.0969 & 4.3599 & TRN & & \\
\hline CHEMBL15968 & 736962 & 4.7258 & 3.725 & TRN & & \\
\hline CHEMBL1346284 & 736962 & 4.6882 & 4.2676 & TRN & & \\
\hline CHEMBL1327496 & 736962 & 4.8041 & 3.8734 & TRN & & \\
\hline CHEMBL1511029 & 736962 & 3.0969 & 3.9487 & TRN & & \\
\hline CHEMBL1450086 & 736962 & 5.8268 & 5.1066 & TRN & & \\
\hline CHEMBL1300908 & 736962 & 6.2291 & 5.4753 & TRN & & \\
\hline CHEMBL1396209 & 736962 & 5.6289 & 5.7019 & TRN & & \\
\hline CHEMBL1544634 & 736962 & 3.0969 & 3.8119 & TST & & \\
\hline CHEMBL1459767 & 736962 & 5.9431 & 4.9702 & TRN & & \\
\hline CHEMBL1444542 & 736962 & 4.4776 & 4.1101 & TST & & \\
\hline CHEMBL1531170 & 736962 & 4.9393 & 4.0026 & TRN & & \\
\hline CHEMBL3195389 & 736962 & 7.7959 & 6.496 & TRN & & \\
\hline CHEMBL1525381 & 736962 & 3.0969 & 3.7308 & TRN & & \\
\hline CHEMBL1469102 & 736962 & 3.0969 & 4.1145 & TST & & \\
\hline CHEMBL600862 & 736962 & 5.0511 & 3.6168 & TRN & & \\
\hline CHEMBL1460007 & 736962 & 3.0969 & 3.8338 & TRN & & \\
\hline CHEMBL1393480 & 736962 & 5.129 & 4.5138 & TRN & & \\
\hline CHEMBL1579258 & 736962 & 4.1918 & 4.8263 & TST & & \\
\hline CHEMBL428064 & 736962 & 5.6635 & 5.8049 & TRN & & \\
\hline CHEMBL 297323 & 736962 & 3.0969 & 4.3145 & TRN & & \\
\hline CHEMBL1343568 & 736962 & 5.8356 & 5.4812 & TRN & & \\
\hline CHEMBL1344225 & 736962 & 6.4949 & 6.6805 & TRN & & \\
\hline CHEMBL1612997 & 736962 & 3.0969 & 3.8937 & TRN & & \\
\hline CHEMBL1440300 & 736962 & 5.75200 & 0000000 & $\partial 1$ & 5.7495 & TRN \\
\hline CHEMBL1299946 & 736962 & 3.0969 & 3.7292 & TRN & & \\
\hline CHEMBL1463659 & 736962 & 4.9066 & 5.2968 & TRN & & \\
\hline CHEMBL1526339 & 736962 & 3.0969 & 3.7648 & TRN & & \\
\hline CHEMBL1418432 & 736962 & 3.0969 & 6.2891 & TRN & & \\
\hline CHEMBL1482145 & 736962 & 3.0969 & 3.7506 & TRN & & \\
\hline CHEMBL1456060 & 736962 & 3.0969 & 4.0117 & TST & & \\
\hline CHEMBL1327693 & 736962 & 3.0969 & 3.8579 & TRN & & \\
\hline CHEMBL1397445 & 736962 & 4.4112 & 3.9416 & TRN & & \\
\hline CHEMBL1714557 & 736962 & 3.0969 & 3.8074 & TRN & & \\
\hline CHEMBL408702 & 736962 & 5.0052 & 3.7008 & TRN & & \\
\hline CHEMBL1509493 & 736962 & 3.0969 & 4.7474 & TRN & & \\
\hline CHEMBL1703925 & 736962 & 3.0969 & 3.6962 & TRN & & \\
\hline CHEMBL1479301 & 736962 & 4.4908 & 3.6406 & TST & & \\
\hline CHEMBL1479240 & 736962 & 4.1945 & 4.3611 & TRN & & \\
\hline CHEMBL482116 & 736962 & 5.8996 & 5.0719 & TRN & & \\
\hline CHEMBL1568923 & 736962 & 3.0969 & 3.6989 & TRN & & \\
\hline CHEMBL1486874 & 736962 & 4.9788 & 6.3525 & TRN & & \\
\hline CHEMBL1350673 & 736962 & 4.7077 & 3.6813 & TRN & & \\
\hline CHEMBL1531851 & 736962 & 3.0969 & 3.9113 & TRN & & \\
\hline
\end{tabular}




\begin{tabular}{|c|c|c|c|c|c|}
\hline \multicolumn{6}{|c|}{ Supplemental Table S2.txt } \\
\hline CHEMBL1532328 & 736962 & 3.0969 & 3.7532 & TRN & \\
\hline CHEMBL1468134 & 736962 & 5.3686 & 4.904 & TRN & \\
\hline CHEMBL1576251 & 736962 & 5.1681 & 3.7683 & TRN & \\
\hline CHEMBL1467599 & 736962 & 3.0969 & 3.9024 & TST & \\
\hline CHEMBL1497939 & 736962 & 5.6308 & 5.3951 & TRN & \\
\hline CHEMBL1989858 & 736962 & 5.2588 & 4.53600 & 00000000005 & TST \\
\hline CHEMBL1502133 & 736962 & 5.5186 & 5.3467 & TRN & \\
\hline CHEMBL1582099 & 736962 & 5.7721 & 4.5032 & TST & \\
\hline CHEMBL279539 & 736962 & 3.0969 & 3.6579 & TRN & \\
\hline CHEMBL1412127 & 736962 & 5.2007 & 3.7422 & TRN & \\
\hline CHEMBL 2002162 & 736962 & 5.6861 & 5.4023 & TST & \\
\hline CHEMBL1344838 & 736962 & 5.2676 & 4.7397 & TRN & \\
\hline CHEMBL1558755 & 736962 & 3.0969 & 4.0021 & TRN & \\
\hline CHEMBL592600 & 736962 & 5.5143 & 3.7583 & TRN & \\
\hline CHEMBL 2007135 & 736962 & 3.0969 & 4.7023 & TRN & \\
\hline CHEMBL1336485 & 736962 & 7.7959 & 3.7312 & TRN & \\
\hline CHEMBL1714537 & 736962 & 4.2941 & 4.9966 & TST & \\
\hline CHEMBL1346432 & 736962 & 5.2104 & 3.6887 & TRN & \\
\hline CHEMBL1409606 & 736962 & 5.2823 & 5.4417 & TST & \\
\hline CHEMBL1450116 & 736962 & 4.8013 & 4.255 & TRN & \\
\hline CHEMBL1458747 & 736962 & 3.0969 & 3.8855 & TRN & \\
\hline CHEMBL1490339 & 736962 & 3.0969 & 3.77100 & 00000000004 & TRN \\
\hline CHEMBL1335846 & 736962 & 5.2125 & 5.7084 & TRN & \\
\hline CHEMBL1537124 & 736962 & 3.0969 & 5.353 & TRN & \\
\hline CHEMBL1339830 & 736962 & 6.0223 & 4.825 & TRN & \\
\hline CHEMBL1736070 & 736962 & 3.0969 & 3.7064 & TRN & \\
\hline CHEMBL1987894 & 736962 & 5.5884 & 5.2212 & TRN & \\
\hline CHEMBL1526767 & 736962 & 3.0969 & 3.8546 & TRN & \\
\hline CHEMBL1702373 & 736962 & 3.0969 & 3.7236 & TRN & \\
\hline CHEMBL1467533 & 736962 & 4.118 & 4.504 & TRN & \\
\hline CHEMBL1374718 & 736962 & 3.0969 & 3.8123 & TRN & \\
\hline CHEMBL1571885 & 736962 & 4.7375 & 4.8637 & TRN & \\
\hline CHEMBL1343823 & 736962 & 5.0991 & 5.4781 & TRN & \\
\hline CHEMBL532160 & 736962 & 5.4547 & 4.9688 & TRN & \\
\hline CHEMBL1519279 & 736962 & 3.0969 & 3.6343 & TRN & \\
\hline CHEMBL1380723 & 736962 & 3.0969 & 3.7665 & TRN & \\
\hline CHEMBL1368007 & 736962 & 3.0969 & 3.7622 & TRN & \\
\hline CHEMBL1547979 & 736962 & 4.2299 & 4.0174 & TST & \\
\hline CHEMBL1569543 & 736962 & 3.0969 & 5.2604 & TRN & \\
\hline CHEMBL414890 & 736962 & 5.6556 & 5.4166 & TST & \\
\hline CHEMBL 261114 & 736962 & 3.0969 & 3.6126 & TRN & \\
\hline CHEMBL562566 & 736962 & 4.8153 & 5.0698 & TRN & \\
\hline CHEMBL1441701 & 736962 & 3.0969 & 3.7574 & TST & \\
\hline CHEMBL1576851 & 736962 & 3.0969 & 3.6643 & TRN & \\
\hline CHEMBL3191453 & 736962 & 3.0969 & 4.4531 & TRN & \\
\hline CHEMBL1501091 & 736962 & 3.0969 & 4.1527 & TRN & \\
\hline CHEMBL1483112 & 736962 & 5.6799 & 4.9692 & TRN & \\
\hline CHEMBL1536981 & 736962 & 4.6091 & 3.8523 & TRN & \\
\hline
\end{tabular}




\begin{tabular}{|c|c|c|c|c|c|}
\hline \multicolumn{6}{|c|}{ Supplemental Table S2.txt } \\
\hline CHEMBL274070 & 736962 & 7.7959 & 5.4347 & TST & \\
\hline CHEMBL3196124 & 736962 & 5.4724 & 5.1189 & TRN & \\
\hline CHEMBL1365398 & 736962 & 4.5346 & 3.6963 & TRN & \\
\hline CHEMBL1368418 & 736962 & 3.0969 & 3.7429 & TRN & \\
\hline CHEMBL1387610 & 736962 & 6.2596 & 5.6092 & TRN & \\
\hline CHEMBL1391387 & 736962 & 4.8297 & 3.7502 & TRN & \\
\hline CHEMBL1499792 & 736962 & 5.8041 & 5.0465 & TRN & \\
\hline CHEMBL1338667 & 736962 & 5.6162 & 4.9591 & TRN & \\
\hline CHEMBL3189873 & 736962 & 6.1871 & 5.607 & TRN & \\
\hline CHEMBL486504 & 736962 & 3.0969 & 3.7708 & TRN & \\
\hline CHEMBL1417428 & 736962 & 6.4202 & 5.1461 & TST & \\
\hline CHEMBL578502 & 736962 & 5.0057 & 4.8254 & TRN & \\
\hline CHEMBL1995692 & 736962 & 5.2027 & 3.7909 & TRN & \\
\hline CHEMBL1488472 & 736962 & 4.5045 & 3.6525 & TRN & \\
\hline CHEMBL1486214 & 736962 & 5.4935 & 5.3887 & TRN & \\
\hline CHEMBL1469224 & 736962 & 4.2636 & 4.8162 & TRN & \\
\hline CHEMBL1441122 & 736962 & 6.4949 & 5.1541 & TRN & \\
\hline CHEMBL1481543 & 736962 & 6.3768 & 5.7747 & TRN & \\
\hline CHEMBL1410008 & 736962 & 3.0969 & 3.7439 & TRN & \\
\hline CHEMBL1705098 & 736962 & 4.7144 & 4.3168 & TRN & \\
\hline CHEMBL1563899 & 736962 & 3.0969 & 3.7768 & TRN & \\
\hline CHEMBL579322 & 736962 & 3.0969 & 3.74899 & 999999 & TRN \\
\hline CHEMBL3209306 & 736962 & 5.9281 & 5.4767 & TRN & \\
\hline CHEMBL1326180 & 736962 & 5.6799 & 5.2239 & TRN & \\
\hline CHEMBL1341270 & 736962 & 3.0969 & 5.3052 & TST & \\
\hline CHEMBL600100 & 736962 & 3.0969 & 3.7598 & TRN & \\
\hline CHEMBL193872 & 736962 & 5.3344 & 5.1962 & TST & \\
\hline CHEMBL1448945 & 736962 & 3.0969 & 3.7748 & TRN & \\
\hline CHEMBL 2135351 & 736962 & 3.0969 & 4.1012 & TRN & \\
\hline CHEMBL1341442 & 736962 & 3.0969 & 3.7545 & TRN & \\
\hline CHEMBL1600855 & 736962 & 5.8041 & 5.19799 & 99999999995 & TRN \\
\hline CHEMBL1197556 & 736962 & 4.9508 & 5.2542 & TST & \\
\hline CHEMBL1383397 & 736962 & 3.0969 & 4.4367 & TST & \\
\hline CHEMBL590665 & 736962 & 5.0057 & 3.6607 & TRN & \\
\hline CHEMBL 2002169 & 736962 & 3.0969 & 3.884 & TRN & \\
\hline CHEMBL1331290 & 736962 & 3.0969 & 3.9084 & TRN & \\
\hline CHEMBL 1302238 & 736962 & 4.9747 & 4.6253 & TRN & \\
\hline CHEMBL1379970 & 736962 & 5.9872 & 5.8014 & TRN & \\
\hline CHEMBL577635 & 736962 & 6.0757 & 5.2139 & TST & \\
\hline CHEMBL1966865 & 736962 & 3.0969 & 4.9746 & TRN & \\
\hline CHEMBL1570491 & 736962 & 4.2815 & 3.9048 & TRN & \\
\hline CHEMBL1333294 & 736962 & 3.0969 & 3.6829 & TRN & \\
\hline CHEMBL1596798 & 736962 & 4.5591 & 4.3894 & TRN & \\
\hline CHEMBL1723033 & 736962 & 4.5751 & 3.8555 & TRN & \\
\hline CHEMBL1983939 & 736962 & 4.2168 & 3.7281 & TRN & \\
\hline CHEMBL494255 & 736962 & 5.8996 & 5.5261 & TST & \\
\hline CHEMBL3199286 & 736962 & 5.6946 & 5.2986 & TRN & \\
\hline CHEMBL1567899 & 736962 & 5.7986 & 5.3303 & TRN & \\
\hline
\end{tabular}




\begin{tabular}{|c|c|c|c|c|c|}
\hline \multicolumn{6}{|c|}{ Supplemental Table S2 } \\
\hline CHEMBL89445 & 736962 & 5.7932 & 5.2775 & TRN & \\
\hline CHEMBL1410857 & 736962 & 3.0969 & 3.8826 & TST & \\
\hline CHEMBL1380996 & 736962 & 3.0969 & 4.2182 & TRN & \\
\hline CHEMBL 2360527 & 736962 & 4.6459 & 3.8475 & TRN & \\
\hline CHEMBL 3145303 & 736962 & 5.4789 & 3.9529 & TRN & \\
\hline CHEMBL1312935 & 736962 & 4.4672 & 3.7572 & TRN & \\
\hline CHEMBL1498959 & 736962 & 3.0969 & 3.8232 & TRN & \\
\hline CHEMBL1362055 & 736962 & 4.699 & 3.8259 & TRN & \\
\hline CHEMBL1368103 & 736962 & 3.0969 & 3.8523 & TRN & \\
\hline CHEMBL3199403 & 736962 & 5.2757 & 5.0639 & TRN & \\
\hline CHEMBL600060 & 736962 & 3.0969 & 3.71199 & 99999999997 & TRN \\
\hline CHEMBL1306460 & 736962 & 4.5186 & 4.1085 & TST & \\
\hline CHEMBL1459140 & 736962 & 6.1249 & 5.124 & TRN & \\
\hline CHEMBL1468786 & 736962 & 4.5544 & 4.649 & TST & \\
\hline CHEMBL1420393 & 736962 & 5.2373 & 5.1481 & TRN & \\
\hline CHEMBL1597772 & 736962 & 4.4895 & 3.7657 & TRN & \\
\hline CHEMBL1339245 & 736962 & 5.0926 & 3.8219 & TRN & \\
\hline CHEMBL1427279 & 736962 & 6.4318 & 5.0304 & TRN & \\
\hline CHEMBL252387 & 736962 & 5.0052 & 4.4644 & TRN & \\
\hline CHEMBL 3197908 & 736962 & 5.6289 & 5.2407 & TRN & \\
\hline CHEMBL1462064 & 736962 & 3.0969 & 4.1845 & TRN & \\
\hline CHEMBL1511424 & 736962 & 6.1024 & 5.6561 & TRN & \\
\hline CHEMBL1473701 & 736962 & 3.0969 & 3.8271 & TST & \\
\hline CHEMBL1487720 & 736962 & 3.0969 & 3.7657 & TRN & \\
\hline CHEMBL1515116 & 736962 & 3.0969 & 3.7519 & TRN & \\
\hline CHEMBL1402010 & 736962 & 6.585 & 5.7735 & TRN & \\
\hline CHEMBL1359789 & 736962 & 7.7959 & 3.6743 & TRN & \\
\hline CHEMBL1390968 & 736962 & 3.0969 & 3.861 & TRN & \\
\hline CHEMBL1495527 & 736962 & 3.0969 & 3.73 & TRN & \\
\hline CHEMBL1480238 & 736962 & 4.2765 & 4.8529 & TRN & \\
\hline CHEMBL518292 & 736962 & 5.0376 & 5.0278 & TST & \\
\hline CHEMBL1409398 & 736962 & 5.1079 & 4.511 & TRN & \\
\hline CHEMBL1330459 & 736962 & 6.0177 & 5.2243 & TST & \\
\hline CHEMBL1464206 & 736962 & 4.5467 & 3.8209 & TRN & \\
\hline CHEMBL1332955 & 736962 & 5.0985 & 4.7923 & TST & \\
\hline CHEMBL1586489 & 736962 & 3.0969 & 3.7876 & TRN & \\
\hline CHEMBL3190965 & 736962 & 4.4547 & 5.3302 & TRN & \\
\hline CHEMBL1491847 & 736962 & 5.6162 & 5.0059 & TST & \\
\hline CHEMBL1451284 & 736962 & 3.0969 & 3.714 & TRN & \\
\hline CHEMBL1537680 & 736962 & 3.0969 & 4.67899 & 9999999999 & TRN \\
\hline CHEMBL1483593 & 736962 & 3.0969 & 3.7372 & TRN & \\
\hline CHEMBL1310479 & 736962 & 3.0969 & 4.6783 & TRN & \\
\hline CHEMBL1448627 & 736962 & 5.857 & 5.5069 & TST & \\
\hline CHEMBL1558285 & 736962 & 4.9066 & 4.6437 & TRN & \\
\hline CHEMBL1310753 & 736962 & 3.0969 & 3.844 & TRN & \\
\hline CHEMBL1339270 & 736962 & 5.2118 & 5.5429 & TRN & \\
\hline CHEMBL1535665 & 736962 & 5.7258 & 5.1239 & TRN & \\
\hline CHEMBL1476734 & 736962 & 3.0969 & 3.8956 & TRN & \\
\hline
\end{tabular}




\begin{tabular}{|c|c|c|c|c|c|}
\hline \multicolumn{6}{|c|}{ Supplemental Table S2.txt } \\
\hline CHEMBL1971142 & 736962 & 5.556 & 5.5252 & TRN & \\
\hline CHEMBL586602 & 736962 & 5.4685 & 5.4513 & TRN & \\
\hline CHEMBL1497812 & 736962 & 5.341 & 4.8229 & TRN & \\
\hline CHEMBL1587218 & 736962 & 3.0969 & 3.9225 & TRN & \\
\hline CHEMBL1343705 & 736962 & 6.0506 & 5.5919 & TRN & \\
\hline CHEMBL1529161 & 736962 & 4.8697 & 4.8387 & TRN & \\
\hline CHEMBL1333930 & 736962 & 5.9788 & 6.3747 & TRN & \\
\hline CHEMBL1562712 & 736962 & 6.2596 & 4.831 & TRN & \\
\hline CHEMBL1492096 & 736962 & 3.0969 & 5.2763 & TRN & \\
\hline CHEMBL1611985 & 736962 & 3.0969 & 3.6503 & TRN & \\
\hline CHEMBL1411388 & 736962 & 4.6126 & 3.7277 & TRN & \\
\hline CHEMBL1452130 & 736962 & 3.0969 & 5.5246 & TRN & \\
\hline CHEMBL1369930 & 736962 & 3.0969 & 3.6523 & TRN & \\
\hline CHEMBL1720876 & 736962 & 6.5376 & 5.1915 & TST & \\
\hline CHEMBL1362490 & 736962 & 4.2588 & 3.77 & TST & \\
\hline CHEMBL602722 & 736962 & 5.3809 & 3.7098 & TRN & \\
\hline CHEMBL 303579 & 736962 & 6.2676 & 5.1283 & TRN & \\
\hline CHEMBL1392527 & 736962 & 5.2464 & 3.8375 & TST & \\
\hline CHEMBL1530673 & 736962 & 3.0969 & 4.0718 & TST & \\
\hline CHEMBL 299613 & 736962 & 3.0969 & 3.9678 & TST & \\
\hline CHEMBL578944 & 736962 & 5.3224 & 4.7497 & TRN & \\
\hline CHEMBL1610821 & 736962 & 3.0969 & 4.8964 & TRN & \\
\hline CHEMBL1529115 & 736962 & 5.7932 & 5.7183 & TRN & \\
\hline CHEMBL1469379 & 736962 & 3.0969 & 3.7873 & TRN & \\
\hline CHEMBL1533321 & 736962 & 3.0969 & 3.8989 & TST & \\
\hline CHEMBL1550278 & 736962 & 3.0969 & 4.1576 & TST & \\
\hline CHEMBL1346034 & 736962 & 4.3757 & 3.9684 & TRN & \\
\hline CHEMBL1704858 & 736962 & 3.0969 & 3.8825 & TRN & \\
\hline CHEMBL1393195 & 736962 & 5.2062 & 3.807 & TRN & \\
\hline CHEMBL1610875 & 736962 & 4.6576 & 5.51399 & 9999999999 & TRN \\
\hline CHEMBL1486690 & 736962 & 3.0969 & 4.7325 & TST & \\
\hline CHEMBL1470568 & 736962 & 5.9547 & 5.8 & TRN & \\
\hline CHEMBL1522289 & 736962 & 5.6038 & 4.0232 & TRN & \\
\hline CHEMBL1569988 & 736962 & 5.6364 & 6.0334 & TRN & \\
\hline CHEMBL1524929 & 736962 & 6.1135 & 5.4832 & TRN & \\
\hline CHEMBL1314757 & 736962 & 3.0969 & 4.3733 & TRN & \\
\hline CHEMBL 2004141 & 736962 & 6.0757 & 5.9383 & TRN & \\
\hline CHEMBL1482052 & 736962 & 3.0969 & 3.6095 & TRN & \\
\hline CHEMBL1437139 & 736962 & 4.1618 & 5.6758 & TST & \\
\hline CHEMBL1415844 & 736962 & 3.0969 & 3.6943 & TRN & \\
\hline CHEMBL1519450 & 736962 & 5.2248 & 3.7919 & TRN & \\
\hline CHEMBL1465720 & 736962 & 3.0969 & 4.9721 & TRN & \\
\hline CHEMBL1452795 & 736962 & 6.1367 & 5.0117 & TRN & \\
\hline CHEMBL1612042 & 736962 & 6.0044 & 5.4125 & TRN & \\
\hline CHEMBL1489149 & 736962 & 3.0969 & 3.7704 & TRN & \\
\hline CHEMBL1360484 & 736962 & 3.0969 & 3.6749 & TRN & \\
\hline CHEMBL 1585715 & 736962 & 3.0969 & 3.8082 & TRN & \\
\hline CHEMBL1505209 & 736962 & 4.2147 & 3.9551 & TST & \\
\hline
\end{tabular}


Supplemental Table S2.txt

\begin{tabular}{|c|c|c|c|c|c|}
\hline CHEMBL1387181 & 736962 & 4.6925 & 3.7639 & TST & \\
\hline CHEMBL1521172 & 736962 & 3.0969 & 4.4107 & TRN & \\
\hline CHEMBL1300302 & 736962 & 4.5784 & 4.4367 & TRN & \\
\hline CHEMBL3195749 & 736962 & 5.5361 & 5.1748 & TRN & \\
\hline CHEMBL1531073 & 736962 & 7.7959 & 5.8697 & TRN & \\
\hline CHEMBL1429850 & 736962 & 3.0969 & 4.4098 & TST & \\
\hline CHEMBL1400322 & 736962 & 3.0969 & 3.8013 & TST & \\
\hline CHEMBL1608078 & 736962 & 5.9508 & 5.4747 & TRN & \\
\hline CHEMBL1353271 & 736962 & 3.0969 & 3.884 & TRN & \\
\hline CHEMBL1332139 & 736962 & 6.0862 & 5.1195 & TRN & \\
\hline CHEMBL1424127 & 736962 & 5.4023 & 3.6854 & TRN & \\
\hline CHEMBL1558156 & 736962 & 4.4609 & 4.2719 & TRN & \\
\hline CHEMBL3198970 & 736962 & 5.0287 & 3.8358 & TRN & \\
\hline CHEMBL1566488 & 736962 & 6.3279 & 5.4242 & TRN & \\
\hline CHEMBL1504701 & 736962 & 3.0969 & 5.4807 & TRN & \\
\hline CHEMBL580918 & 736962 & 5.3344 & 5.4513 & TRN & \\
\hline CHEMBL1546843 & 736962 & 5.7471 & 4.1067 & TRN & \\
\hline CHEMBL1457561 & 736962 & 4.1918 & 4.233006 & 0000000005 & TRN \\
\hline CHEMBL1595169 & 736962 & 4.556 & 3.8364 & TRN & \\
\hline CHEMBL1420037 & 736962 & 4.7986 & 5.3289 & TST & \\
\hline CHEMBL1475884 & 736962 & 3.0969 & 3.6708 & TST & \\
\hline CHEMBL1732859 & 736962 & 3.0969 & 4.0229 & TRN & \\
\hline CHEMBL1455279 & 736962 & 4.2993 & 4.4776 & TRN & \\
\hline CHEMBL1476264 & 736962 & 4.2676 & 3.9707 & TST & \\
\hline CHEMBL1303161 & 736962 & 3.0969 & 3.6906 & TRN & \\
\hline CHEMBL1561596 & 736962 & 3.0969 & 3.7755 & TRN & \\
\hline CHEMBL3195657 & 736962 & 5.3344 & 5.068006 & 0000000005 & TRN \\
\hline CHEMBL1437715 & 736962 & 3.0969 & 3.6962 & TRN & \\
\hline CHEMBL1548492 & 736962 & 5.1818 & 3.6067 & TRN & \\
\hline CHEMBL1328466 & 736962 & 3.0969 & 4.2493 & TRN & \\
\hline CHEMBL1444020 & 736962 & 6.4815 & 6.1029 & TRN & \\
\hline CHEMBL1499414 & 736962 & 3.0969 & 3.7373 & TRN & \\
\hline CHEMBL580955 & 736962 & \multicolumn{3}{|c|}{5.382000000000001} & тा \\
\hline CHEMBL1332565 & 736962 & 3.0969 & 3.6689 & TRN & \\
\hline CHEMBL1465706 & 736962 & 3.0969 & 3.6888 & TRN & \\
\hline CHEMBL1717082 & 736962 & 3.0969 & 3.9509 & TRN & \\
\hline CHEMBL1332347 & 736962 & 3.0969 & 3.7282 & TRN & \\
\hline CHEMBL1373096 & 736962 & 5.1415 & 3.8868 & TRN & \\
\hline CHEMBL1966890 & 736962 & 4.8861 & 4.9309 & TRN & \\
\hline CHEMBL1584985 & 736962 & 4.6198 & 3.8035 & TST & \\
\hline CHEMBL1533166 & 736962 & 3.0969 & 3.6165 & TRN & \\
\hline CHEMBL1348332 & 736962 & 3.0969 & 3.9553 & TST & \\
\hline CHEMBL1595790 & 736962 & 5.1752 & 5.5652 & TST & \\
\hline CHEMBL576349 & 736962 & 4.7352 & 4.3423 & TRN & \\
\hline CHEMBL1491238 & 736962 & 6.0506 & 5.6704 & TRN & \\
\hline CHEMBL1468181 & 736962 & 5.0246 & 5.8945 & TRN & \\
\hline CHEMBL1399125 & 736962 & 7.7959 & 3.9737 & TRN & \\
\hline CHEMBL 277148 & 736962 & 3.0969 & 3.7803 & TRN & \\
\hline
\end{tabular}




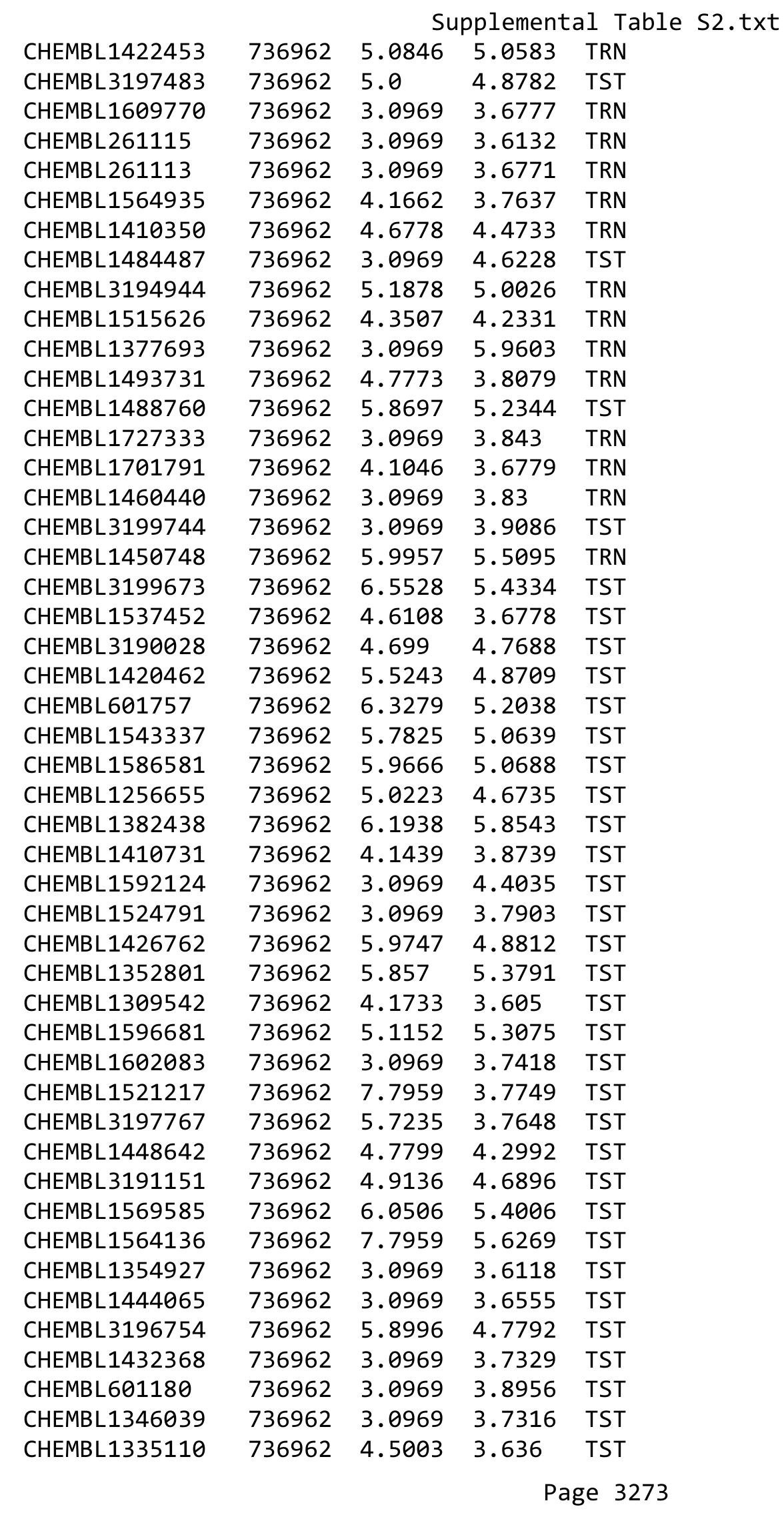


Supplemental Table S2.txt

\begin{tabular}{|c|c|c|c|c|}
\hline HEMBL1401272 & 36962 & 6.0757 & 5.3556 & \\
\hline HEMBL1321427 & 36962 & 3.0969 & 4.1409 & \\
\hline HEMBL 373137 & 6962 & 3969 & 3.7016 & \\
\hline HEMBL2359072 & 36962 & 5.7852 & 3.8001 & \\
\hline HEMBL1723154 & 36962 & 3.0969 & . 6998 & \\
\hline HEMBL1560061 & 36962 & 3.0969 & 3.8829 & \\
\hline HEMBL1318526 & 36962 & .7471 & .1549 & \\
\hline HEMBL1333314 & 36962 & .0969 & .7779 & \\
\hline AEMBL1714459 & 36962 & 3.0969 & 3.7163 & \\
\hline HEMBL1425889 & 36962 & 4.6757 & 4.4744 & \\
\hline HEMBL1596740 & 36962 & 3.0969 & 3.6984 & \\
\hline AEMBL1331733 & 36962 & 3.0969 & .8249 & \\
\hline HEMBL1587868 & 36962 & 3.0969 & .865 & \\
\hline HEMBL1528469 & 36962 & 5.4895 & 5.0424 & \\
\hline HEMBL1602808 & 36962 & 5.0747 & 3.7547 & \\
\hline AEMBL1322738 & 36962 & 3.0969 & 4.1054 & \\
\hline HEMBL1524014 & 36962 & 3.0969 & 3.7514 & \\
\hline HEMBL1542713 & 36962 & 3.0969 & 3.9718 & \\
\hline HEMBL1468435 & 36962 & 4.7696 & 3.7829 & \\
\hline HEMBL1482542 & 36962 & 7.7959 & 83 & \\
\hline HEMBL1397089 & 36962 & 675 & 4.9556 & \\
\hline HEMBL2094567 & 36962 & 5.8861 & .6769 & \\
\hline HEMBL1538784 & 36962 & 969 & 5.3414 & \\
\hline HEMBL1602086 & 36962 & 6.4318 & 6.108 & \\
\hline HEMBL1548471 & 36962 & 5 . & 199 & \\
\hline AEMBL1450653 & 6962 & 69 & 3.7186 & \\
\hline HEMBL1387338 & 36962 & 59 & 4.3256 & \\
\hline HEMBL157 & 36962 & 97 & 4.9285 & \\
\hline HEMBL1528118 & 36962 & 69 & 3.6298 & \\
\hline HEMBL1573994 & 36962 & 59 & 6. & \\
\hline HEMBL1408150 & 36962 & 36 & 3.7364 & \\
\hline HEMBL1429782 & 36962 & 69 & 26 & \\
\hline CHEMBL3191 & 962 & & 422 & \\
\hline CHEMBL585502 & 36962 & 4.2848 & 4 & \\
\hline HEMBL303879 & 1148 & 3 & 3.5004 & \\
\hline HEMBL 302490 & 148 & 7 & 7.4001 & \\
\hline CHEMBL69757 & 148 & 8 & 03 & \\
\hline HEMBL304172 & 1148 & 7. & 7.8994 & \\
\hline CHEMBL306865 & 1148 & 8. & 8.2004 & \\
\hline HEMBL 67374 & 148 & 7 & 7.8006 & \\
\hline CHEMBL66780 & 71148 & 4 & 2.6523 & \\
\hline CHEMBL67241 & 71148 & & 5.3995 & \\
\hline CHEMBL410319 & 1148 & 6.2 & 6.2003 & \\
\hline HEMBL65884 & 1148 & 8 . & 8.1003 & \\
\hline CHEMBL67733 & 1148 & 0 & 6.8002 & \\
\hline CHEMBL67855 & 71148 & 3 . & 3. & \\
\hline CHEMBL294595 & 71148 & 5. & 5.6002 & \\
\hline CHEMBL63915 & 71148 & 8.3 & 8.3 & \\
\hline
\end{tabular}

Page 3274 


\begin{tabular}{|c|c|c|c|c|c|}
\hline & & & & & \\
\hline CHEMBL66543 & 71148 & 7.8 & 7.7989 & TRN & \\
\hline CHEMBL63414 & 71148 & 7.5 & 6.5281 & TST & \\
\hline CHEMBL68944 & 71148 & 3.5 & 3.5002 & TRN & \\
\hline CHEMBL66900 & 71148 & 7.9 & 6.3311 & TST & \\
\hline CHEMBL308455 & 71148 & 8.0 & 6.1315 & TST & \\
\hline CHEMBL63595 & 71148 & 5.6 & 5.5992 & TRN & \\
\hline CHEMBL66292 & 71148 & 8.6 & 8.6022 & TRN & \\
\hline CHEMBL309152 & 71148 & 8.3 & 8.3 & TRN & \\
\hline CHEMBL308454 & 71148 & 8.5 & 8.499 & TRN & \\
\hline CHEMBL303433 & 71148 & 7.8 & 7.8001 & TRN & \\
\hline CHEMBL68063 & 71148 & 4.0 & 3.7441 & TST & \\
\hline CHEMBL63728 & 71148 & 5.6 & 5.3822 & TST & \\
\hline CHEMBL65945 & 71148 & 4.0 & 4.8486 & TST & \\
\hline CHEMBL63348 & 71148 & 6.8 & 6.8 & TRN & \\
\hline CHEMBL66003 & 71148 & 4.0 & 4.3934 & TST & \\
\hline CHEMBL294592 & 71148 & 6.8 & 6.7995 & TRN & \\
\hline CHEMBL68242 & 71148 & 6.0 & 6.0008 & TRN & \\
\hline CHEMBL66510 & 71148 & 7.0 & 6.9996 & TRN & \\
\hline CHEMBL307311 & 71148 & 6.9 & 6.8997 & TRN & \\
\hline CHEMBL 291425 & 71148 & 6.8 & 6.8 & TRN & \\
\hline CHEMBL67310 & 71148 & 6.6 & 6.601 & TRN & \\
\hline CHEMBL65538 & 71148 & 3.5 & 3.49899 & 99999999997 & TRN \\
\hline CHEMBL302048 & 71148 & 7.5 & 7.4996 & TRN & \\
\hline CHEMBL68450 & 71148 & 8.0 & 6.1781 & TST & \\
\hline CHEMBL63727 & 71148 & 7.0 & 6.9991 & TRN & \\
\hline CHEMBL69588 & 71148 & 8.0 & 8.0004 & TRN & \\
\hline CHEMBL67799 & 71148 & 7.8 & 7.7996 & TRN & \\
\hline CHEMBL303321 & 71148 & 8.2 & 8.1997 & TRN & \\
\hline CHEMBL68397 & 71148 & 7.4 & 7.4 & TRN & \\
\hline CHEMBL69526 & 71148 & 5.7 & 5.7005 & TRN & \\
\hline CHEMBL308430 & 71148 & 7.9 & 7.8998 & TRN & \\
\hline CHEMBL66004 & 71148 & 5.5 & 5.2389 & TST & \\
\hline CHEMBL66910 & 71148 & 7.5 & 7.5 & TRN & \\
\hline CHEMBL66791 & 71148 & 8.4 & 8.4005 & TRN & \\
\hline CHEMBL418690 & 71148 & 8.0 & 7.9994 & TRN & \\
\hline CHEMBL442363 & 71148 & 5.2 & 4.8732 & TST & \\
\hline CHEMBL66170 & 71148 & 8.0 & 8.0021 & TRN & \\
\hline CHEMBL65988 & 71148 & 7.5 & 7.4998 & TRN & \\
\hline CHEMBL293191 & 71148 & 5.6 & 5.6001 & TRN & \\
\hline CHEMBL303687 & 71148 & 3.5 & 3.5002 & TRN & \\
\hline CHEMBL63803 & 71148 & 7.0 & 4.9468 & TST & \\
\hline CHEMBL306692 & 71148 & 6.5 & 6.4995 & TRN & \\
\hline CHEMBL66453 & 71148 & 8.4 & 8.398 & TRN & \\
\hline CHEMBL304339 & 71148 & 5.9 & 5.9009 & TRN & \\
\hline CHEMBL65987 & 71148 & 8.1 & 8.0999 & TRN & \\
\hline CHEMBL302969 & 71148 & 7.2 & 6.181 & TST & \\
\hline CHEMBL67562 & 71148 & 6.5 & 8.1432 & TST & \\
\hline CHEMBL305477 & 71148 & 7.6 & 8.17799 & 9999999999 & TST \\
\hline & & & & ge 3275 & \\
\hline
\end{tabular}




\begin{tabular}{|c|c|c|c|c|c|}
\hline \multicolumn{6}{|c|}{ Supplemental Table S2.txt } \\
\hline CHEMBL 303630 & 71148 & 8.6 & 8.1209 & TST & \\
\hline CHEMBL1407164 & 744201 & 7.4685 & 7.4677 & TRN & \\
\hline CHEMBL1397614 & 744201 & 6.9208 & 6.8866 & TRN & \\
\hline CHEMBL566900 & 744201 & 7.4202 & 7.4282 & TRN & \\
\hline CHEMBL1354134 & 744201 & 7.0458 & 7.0272 & TRN & \\
\hline CHEMBL1410859 & 744201 & 6.6038 & 6.6004 & TRN & \\
\hline CHEMBL1515144 & 744201 & 7.8539 & 7.8618 & TRN & \\
\hline CHEMBL1513850 & 744201 & 5.4347 & 5.4471 & TRN & \\
\hline CHEMBL1515868 & 744201 & 6.7932 & 7.1632 & TST & \\
\hline CHEMBL1476609 & 744201 & 7.0915 & 6.9188 & TST & \\
\hline CHEMBL1705549 & 744201 & 7.301 & 7.28799 & 9999999999 & TRN \\
\hline CHEMBL1329627 & 744201 & 6.6402 & 6.6711 & TRN & \\
\hline CHEMBL1476499 & 744201 & 7.3279 & 7.3329 & TRN & \\
\hline CHEMBL1599314 & 744201 & 6.9318 & 6.9242 & TRN & \\
\hline CHEMBL1474834 & 744201 & 7.9586 & 7.9637 & TRN & \\
\hline CHEMBL1433941 & 744201 & 5.1 & 5.1109 & TRN & \\
\hline CHEMBL565654 & 744201 & 5.9784 & 5.9802 & TRN & \\
\hline CHEMBL1405981 & 744201 & 5.1 & 5.1068 & TRN & \\
\hline CHEMBL1495595 & 744201 & 4.0 & 3.984 & TRN & \\
\hline CHEMBL1707127 & 744201 & 6.7011 & 6.7102 & TRN & \\
\hline CHEMBL1396483 & 744201 & 7.699 & 7.6955 & TRN & \\
\hline CHEMBL1725513 & 744201 & 7.1024 & 7.0753 & TRN & \\
\hline CHEMBL1436585 & 744201 & 6.8508 & 6.875 & TRN & \\
\hline CHEMBL1704879 & 744201 & 7.4318 & 7.4339 & TRN & \\
\hline CHEMBL1320749 & 744201 & 4.0 & 3.9971 & TRN & \\
\hline CHEMBL1591577 & 744201 & 7.9208 & 7.9443 & TRN & \\
\hline CHEMBL1329116 & 744201 & 4.0 & 4.0177 & TRN & \\
\hline CHEMBL1770624 & 744201 & 5.7783 & 6.3065 & TST & \\
\hline CHEMBL1397997 & 744201 & 5.7846 & 5.8165 & TST & \\
\hline CHEMBL1396654 & 744201 & 7.4559 & 7.47 & TRN & \\
\hline CHEMBL1604618 & 744201 & 6.8665 & 6.848 & TRN & \\
\hline CHEMBL1555138 & 744201 & 6.8928 & 6.8966 & TRN & \\
\hline CHEMBL1535925 & 744201 & 7.0555 & 7.011 & TRN & \\
\hline CHEMBL1612677 & 744201 & 6.5702 & 6.5686 & TRN & \\
\hline CHEMBL1551169 & 744201 & 7.1549 & 7.1471 & TRN & \\
\hline CHEMBL1394132 & 744201 & 4.0 & 6.2423 & TST & \\
\hline CHEMBL1733003 & 744201 & 6.61799 & 99999999 & 6.6476 & TRN \\
\hline CHEMBL1396306 & 744201 & 4.0 & 3.9937 & TRN & \\
\hline CHEMBL1609579 & 744201 & 5.4 & 5.4022 & TRN & \\
\hline CHEMBL1437638 & 744201 & 7.3468 & 7.5237 & TST & \\
\hline CHEMBL1724489 & 744201 & 6.983 & 6.9753 & TRN & \\
\hline CHEMBL1435542 & 744201 & 7.3979 & 7.4093 & TRN & \\
\hline CHEMBL567331 & 744201 & 7.4089 & 7.3787 & TRN & \\
\hline CHEMBL1357975 & 744201 & 7.3768 & 7.4228 & TRN & \\
\hline CHEMBL566687 & 744201 & 6.8996 & 6.871 & TRN & \\
\hline CHEMBL1734733 & 744201 & 6.5901 & 6.9412 & TST & \\
\hline CHEMBL1374544 & 744201 & 7.4437 & 7.3421 & TST & \\
\hline CHEMBL1315944 & 744201 & 6.4802 & 6.1259 & TST & \\
\hline
\end{tabular}


Supplemental Table S2.txt

\begin{tabular}{|c|c|c|c|c|c|c|}
\hline CHEMBL1552755 & 744201 & 7.5376 & 7.31 & TST & & \\
\hline CHEMBL1318637 & 744201 & 7.5376 & 7.3256 & TST & & \\
\hline CHEMBL1473127 & 744201 & 7.8239 & 7.6496 & TST & & \\
\hline CHEMBL566062 & 744201 & 5.9626 & 6.6819 & TST & & \\
\hline CHEMBL1519015 & 954359 & 5.15799 & 99999999 & 995 & 4.9946 & TRN \\
\hline CHEMBL1516708 & 954359 & 5.7077 & 5.3644 & TST & & \\
\hline CHEMBL1898104 & 954359 & 5.3595 & 5.4053 & TRN & & \\
\hline CHEMBL2354543 & 954359 & 6.1308 & 6.3969 & TRN & & \\
\hline CHEMBL 2357354 & 954359 & 5.1169 & 4.8526 & TRN & & \\
\hline CHEMBL1704377 & 954359 & 4.5921 & 4.4844 & TRN & & \\
\hline CHEMBL1374500 & 954359 & 4.5396 & 4.7386 & TRN & & \\
\hline CHEMBL 2356206 & 954359 & 4.1872 & 4.7702 & TRN & & \\
\hline CHEMBL2357950 & 954359 & 5.4698 & 5.432 & TRN & & \\
\hline CHEMBL1405122 & 954359 & 7.585 & 5.7187 & TST & & \\
\hline CHEMBL1310739 & 954359 & 4.3594 & 4.4985 & TRN & & \\
\hline CHEMBL1491097 & 954359 & 5.0164 & 4.7532 & TRN & & \\
\hline CHEMBL1884845 & 954359 & 5.6198 & 6.273 & TRN & & \\
\hline CHEMBL1531675 & 954359 & 5.7399 & 5.2048 & TST & & \\
\hline CHEMBL1600371 & 954359 & 5.3206 & 4.9663 & TRN & & \\
\hline CHEMBL1432670 & 954359 & 5.3468 & 5.1623 & TRN & & \\
\hline CHEMBL1456751 & 954359 & 4.2566 & 5.2101 & TRN & & \\
\hline CHEMBL1488010 & 954359 & 4.9842 & 4.9926 & TST & & \\
\hline CHEMBL1581715 & 954359 & 3.1549 & 4.7863 & TRN & & \\
\hline CHEMBL1339433 & 954359 & 5.1267 & 5.3565 & TRN & & \\
\hline CHEMBL1491601 & 954359 & 5.3279 & 4.7118 & TRN & & \\
\hline CHEMBL1522458 & 954359 & 4.2503 & 4.0011 & TRN & & \\
\hline CHEMBL1869587 & 954359 & 5.4191 & 5.3641 & TRN & & \\
\hline CHEMBL1325192 & 954359 & 5.1746 & 4.8718 & TST & & \\
\hline CHEMBL1611601 & 954359 & 4.971 & 4.6916 & TRN & & \\
\hline CHEMBL1610523 & 954359 & 5.1192 & 4.756 & TRN & & \\
\hline CHEMBL1721296 & 954359 & 5.4685 & 5.4085 & TRN & & \\
\hline CHEMBL1719954 & 954359 & 4.9062 & 5.1473 & TRN & & \\
\hline CHEMBL1328307 & 954359 & 4.5272 & 4.1781 & TRN & & \\
\hline CHEMBL1529819 & 954359 & 5.2027 & 4.8335 & TRN & & \\
\hline CHEMBL1712719 & 954359 & 5.0991 & 4.6553 & TRN & & \\
\hline CHEMBL1440892 & 954359 & 5.0985 & 4.7033 & TST & & \\
\hline CHEMBL1417294 & 954359 & 5.4202 & 5.8454 & TRN & & \\
\hline CHEMBL 2357774 & 954359 & 5.4342 & 5.2072 & TRN & & \\
\hline CHEMBL2359534 & 954359 & 4.813 & 5.2065 & TRN & & \\
\hline CHEMBL1378564 & 954359 & 4.95 & 4.6811 & TRN & & \\
\hline CHEMBL1698730 & 954359 & 4.5527 & 5.3811 & TRN & & \\
\hline CHEMBL585656 & 954359 & 5.2832 & 5.1051 & TRN & & \\
\hline CHEMBL 2448501 & 954359 & 5.1113 & 5.0607 & TRN & & \\
\hline CHEMBL1519553 & 954359 & 4.5549 & 4.7834 & TRN & & \\
\hline CHEMBL1388380 & 954359 & 4.228 & 4.8396 & TRN & & \\
\hline CHEMBL1415211 & 954359 & 4.8167 & 5.0234 & TRN & & \\
\hline CHEMBL1388405 & 954359 & 4.9978 & 4.8446 & TRN & & \\
\hline CHEMBL1436713 & 954359 & 3.1549 & 4.0762 & TRN & & \\
\hline
\end{tabular}


Supplemental Table S2.txt

\begin{tabular}{|c|c|c|c|c|c|c|}
\hline CHEMBL1329817 & 954359 & 4.9978 & 4.1226 & TRN & & \\
\hline CHEMBL1546353 & 954359 & 4.4145 & 4.8228 & TRN & & \\
\hline CHEMBL1349206 & 954359 & 4.3888 & 5.2105 & TST & & \\
\hline CHEMBL1579968 & 954359 & 5.7959 & 5.678999 & 999999999 & & TRN \\
\hline CHEMBL1510639 & 954359 & 5.2441 & 4.9587 & TRN & & \\
\hline CHEMBL1528960 & 954359 & 4.7557 & 5.5209 & TRN & & \\
\hline CHEMBL1906549 & 954359 & 6.4191 & 6.781006 & 000000000 & & TRN \\
\hline CHEMBL1708919 & 954359 & 5.8356 & 6.0793 & TRN & & \\
\hline CHEMBL1402422 & 954359 & 5.2612 & 4.912 & TRN & & \\
\hline CHEMBL1300237 & 954359 & 5.5017 & 5.3454 & TST & & \\
\hline CHEMBL1392611 & 954359 & 5.7375 & 5.6003 & TRN & & \\
\hline CHEMBL1379721 & 954359 & 4.2151 & 4.8165 & TRN & & \\
\hline CHEMBL1310617 & 954359 & 5.8697 & 5.8057 & TRN & & \\
\hline CHEMBL 2357126 & 954359 & 5.5834 & 5.5012 & TRN & & \\
\hline CHEMBL 2448511 & 954359 & 4.9654 & 5.0412 & TRN & & \\
\hline CHEMBL1890313 & 954359 & 5.5045 & 5.2425 & TRN & & \\
\hline CHEMBL1391059 & 954359 & 5.2048 & 4.7713 & TST & & \\
\hline CHEMBL 290077 & 954359 & 5.8539 & 5.9426 & TRN & & \\
\hline CHEMBL1599621 & 954359 & 3.4948 & 4.5883 & TRN & & \\
\hline CHEMBL1542312 & 954359 & 5.104 & 4.7667 & TST & & \\
\hline CHEMBL1305030 & 954359 & 5.9172 & 5.3685 & TST & & \\
\hline CHEMBL1500480 & 954359 & 5.266 & 4.5506 & TRN & & \\
\hline CHEMBL1569668 & 954359 & 5.1118 & 4.9423 & TRN & & \\
\hline CHEMBL1506451 & 954359 & 5.4067 & 4.9613 & TRN & & \\
\hline CHEMBL1543358 & 954359 & 5.2211 & 4.9682 & TST & & \\
\hline CHEMBL1612755 & 954359 & 4.9367 & 5.0392 & TRN & & \\
\hline CHEMBL1596891 & 954359 & 4.2997 & 4.5638 & TRN & & \\
\hline CHEMBL1612194 & 954359 & 4.2469 & 4.6218 & TRN & & \\
\hline CHEMBL1602800 & 954359 & 5.2069 & 4.1684 & TRN & & \\
\hline CHEMBL1430290 & 954359 & 5.0292 & 4.727 & TRN & & \\
\hline CHEMBL1407998 & 954359 & 5.3862 & 4.7855 & TRN & & \\
\hline CHEMBL1310301 & 954359 & 5.4012 & 5.0837 & TRN & & \\
\hline CHEMBL601933 & 954359 & 5.6216 & 4.7345 & TRN & & \\
\hline CHEMBL1383554 & 954359 & 3.1549 & 4.0826 & TRN & & \\
\hline CHEMBL1699398 & 954359 & 5.3716 & 5.1976 & TST & & \\
\hline CHEMBL1469557 & 954359 & 3.1549 & 4.1874 & TST & & \\
\hline CHEMBL1486585 & 954359 & 5.5498 & 5.4582 & TRN & & \\
\hline CHEMBL 2069955 & 954359 & 4.5068 & 4.833 & TST & & \\
\hline CHEMBL1562110 & 954359 & 4.6191 & 4.4687 & TRN & & \\
\hline CHEMBL1444764 & 954359 & 4.8233 & 4.5134 & TRN & & \\
\hline CHEMBL1389871 & 954359 & 5.1186 & 4.9313 & TRN & & \\
\hline CHEMBL1412298 & 954359 & 4.2297 & 4.0822 & TRN & & \\
\hline CHEMBL1610477 & 954359 & 5.1568 & 5.0002 & TRN & & \\
\hline CHEMBL1393891 & 954359 & 5.5751 & 5.5744 & TRN & & \\
\hline CHEMBL1611723 & 954359 & \multicolumn{3}{|c|}{5.218999999999999} & 5.6885 & $1 \mathrm{~K}$ \\
\hline CHEMBL1312953 & 954359 & 4.8874 & 4.6379 & TST & & \\
\hline CHEMBL 2357917 & 954359 & 4.8128 & 5.1884 & TRN & & \\
\hline CHEMBL1522331 & 954359 & 5.3288 & 5.1825 & TRN & & \\
\hline
\end{tabular}




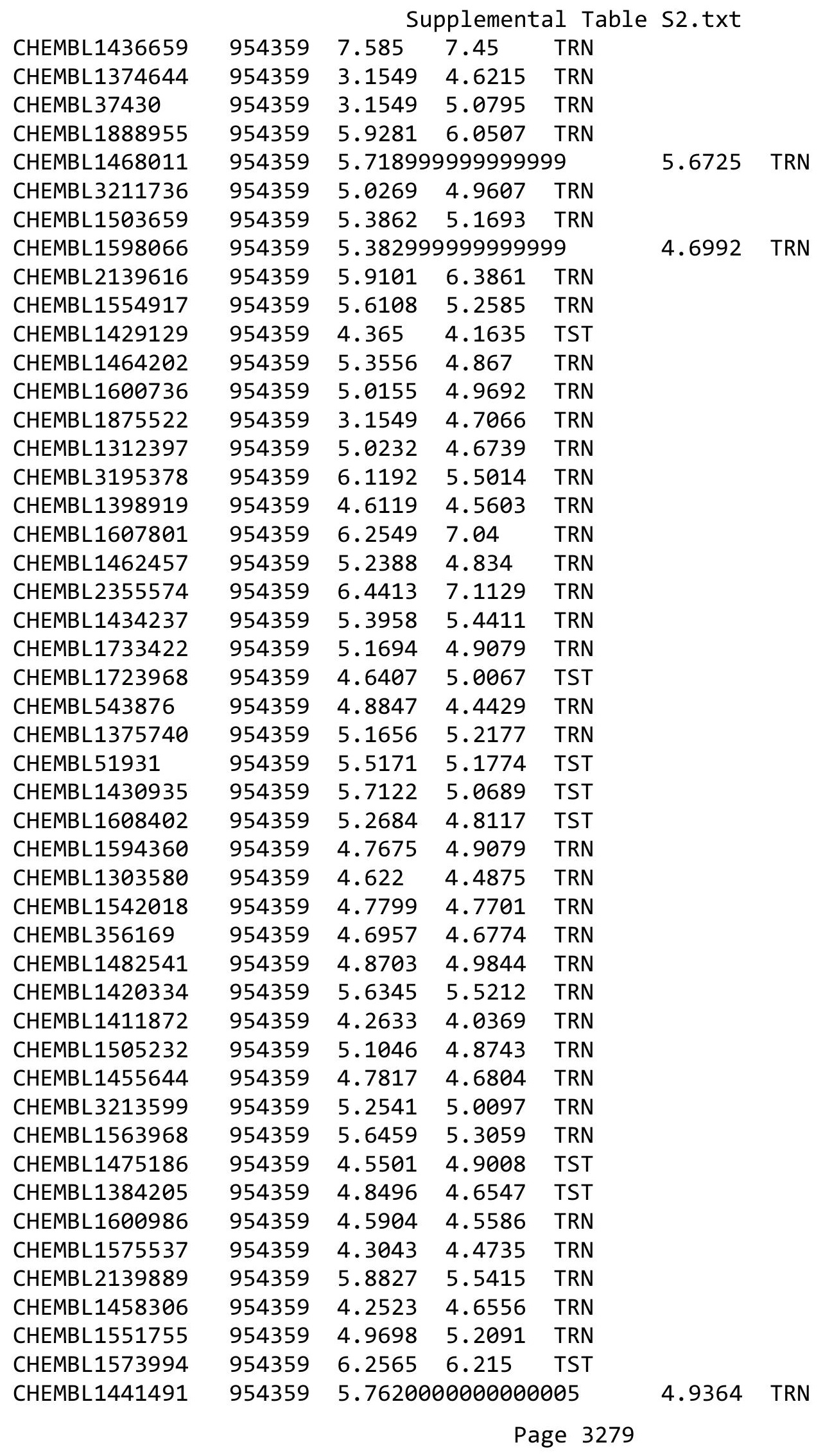




\begin{tabular}{|c|c|c|c|c|c|}
\hline \multicolumn{6}{|c|}{ Supplemental Table S2.txt } \\
\hline CHEMBL1347745 & 954359 & 5.2104 & 4.687 & TRN & \\
\hline CHEMBL1605795 & 954359 & 6.2396 & 5.7016 & TRN & \\
\hline CHEMBL1501402 & 954359 & 5.4685 & 4.3845 & TST & \\
\hline CHEMBL1379390 & 954359 & 5.0177 & 5.1408 & TRN & \\
\hline CHEMBL1481301 & 954359 & 3.1549 & 4.1093 & TRN & \\
\hline CHEMBL 2354821 & 954359 & 4.7886 & 4.6231 & TST & \\
\hline CHEMBL1727214 & 954359 & 5.2549 & 5.0374 & TRN & \\
\hline CHEMBL1444205 & 954359 & 5.0904 & 4.7924 & TRN & \\
\hline CHEMBL1451002 & 954359 & 4.5809 & 4.72199 & 99999999995 & TRN \\
\hline CHEMBL1490428 & 954359 & 5.5719 & 6.0675 & TRN & \\
\hline CHEMBL1609759 & 954359 & 4.586 & 4.7578 & TRN & \\
\hline CHEMBL1402883 & 954359 & 4.3117 & 4.7614 & TRN & \\
\hline CHEMBL1341816 & 954359 & 5.1163 & 5.3773 & TRN & \\
\hline CHEMBL1579153 & 954359 & 7.585 & 5.2891 & TRN & \\
\hline CHEMBL1384292 & 954359 & 5.4935 & 5.5399 & TRN & \\
\hline CHEMBL1890660 & 954359 & 5.3768 & 5.5066 & TRN & \\
\hline CHEMBL1415958 & 954359 & 6.2907 & 6.0469 & TRN & \\
\hline CHEMBL1458905 & 954359 & 4.3255 & 4.3184 & TRN & \\
\hline CHEMBL578294 & 954359 & 4.6735 & 4.7434 & TRN & \\
\hline CHEMBL1710730 & 954359 & 5.3251 & 4.7758 & TRN & \\
\hline CHEMBL1392086 & 954359 & 5.3526 & 5.1784 & TRN & \\
\hline CHEMBL1301073 & 954359 & 5.2967 & 4.9147 & TRN & \\
\hline CHEMBL1514666 & 954359 & 5.1993 & 5.1257 & TRN & \\
\hline CHEMBL1383873 & 954359 & 4.6312 & 4.4598 & TST & \\
\hline CHEMBL3194248 & 954359 & 5.6108 & 5.6144 & TRN & \\
\hline CHEMBL1573112 & 954359 & 3.1549 & 5.1121 & TST & \\
\hline CHEMBL 1455730 & 954359 & 5.2449 & 4.9925 & TRN & \\
\hline CHEMBL1548205 & 954359 & 3.1549 & 4.5559 & TRN & \\
\hline CHEMBL1873911 & 954359 & 5.7447 & 5.4606 & TRN & \\
\hline CHEMBL1370087 & 954359 & 6.3904 & 6.2165 & TRN & \\
\hline CHEMBL1594160 & 954359 & 4.756 & 4.9146 & TRN & \\
\hline CHEMBL1719064 & 954359 & 5.644 & 5.2673 & TRN & \\
\hline CHEMBL1582044 & 954359 & 5.1475 & 5.2355 & TRN & \\
\hline CHEMBL 2359878 & 954359 & 5.7645 & 5.2813 & TRN & \\
\hline CHEMBL1430094 & 954359 & 7.585 & 5.9461 & TRN & \\
\hline CHEMBL1867244 & 954359 & 5.983 & 5.8734 & TRN & \\
\hline CHEMBL 1418276 & 954359 & 4.9212 & 4.7718 & TRN & \\
\hline CHEMBL3210608 & 954359 & 5.4976 & 5.3063 & TRN & \\
\hline CHEMBL1457403 & 954359 & 5.8508 & 5.194 & TST & \\
\hline CHEMBL1887610 & 954359 & 5.7799 & 5.5361 & TRN & \\
\hline CHEMBL1373252 & 954359 & 4.7708 & 5.1338 & TRN & \\
\hline CHEMBL1349832 & 954359 & 4.4318 & 4.2402 & TST & \\
\hline CHEMBL1321622 & 954359 & 5.8182 & 5.4415 & TRN & \\
\hline CHEMBL1736950 & 954359 & 5.2388 & 5.1012 & TRN & \\
\hline CHEMBL1699920 & 954359 & 7.585 & 4.1408 & TRN & \\
\hline CHEMBL1299835 & 954359 & 6.1232 & 5.5091 & TRN & \\
\hline CHEMBL1420768 & 954359 & 4.8821 & 4.789 & TRN & \\
\hline CHEMBL1332417 & 954359 & 4.6114 & 4.67 & TST & \\
\hline
\end{tabular}


Supplemental Table S2.txt

\begin{tabular}{|c|c|c|c|c|c|}
\hline CHEMBL1710114 & 954359 & 6.4179 & 6.4884 & TRN & \\
\hline CHEMBL1435670 & 954359 & 3.1549 & 4.0803 & TRN & \\
\hline CHEMBL1419608 & 954359 & 3.1549 & 4.5088 & TRN & \\
\hline CHEMBL1460361 & 954359 & 5.2832 & 5.2761 & TRN & \\
\hline CHEMBL1322972 & 954359 & 3.1549 & 3.9003 & TRN & \\
\hline CHEMBL2357719 & 954359 & 5.7696 & 5.4729 & TRN & \\
\hline CHEMBL1353797 & 954359 & 4.4087 & 4.6075 & TST & \\
\hline CHEMBL1347664 & 954359 & 4.8374 & 4.5256 & TRN & \\
\hline CHEMBL1324298 & 954359 & 5.2426 & 5.2479 & TRN & \\
\hline CHEMBL1434227 & 954359 & 4.3748 & 3.8188 & TRN & \\
\hline CHEMBL1429297 & 954359 & 3.4948 & 4.8082 & TRN & \\
\hline CHEMBL1976507 & 954359 & 5.5272 & 5.8424 & TRN & \\
\hline CHEMBL1520831 & 954359 & 6.0287 & 6.3866 & TRN & \\
\hline CHEMBL3197091 & 954359 & 4.7645 & 4.7352 & TRN & \\
\hline CHEMBL1711360 & 954359 & 4.5643 & 4.6305 & TRN & \\
\hline CHEMBL1422386 & 954359 & 4.5664 & 3.9388 & TST & \\
\hline CHEMBL1568497 & 954359 & 5.0132 & 4.7595 & TRN & \\
\hline CHEMBL1390450 & 954359 & 5.3536 & 5.2439 & TRN & \\
\hline CHEMBL1347246 & 954359 & 4.9884 & 4.3916 & TRN & \\
\hline CHEMBL1716486 & 954359 & 5.2 & 4.9064 & TRN & \\
\hline CHEMBL1341124 & 954359 & 5.7077 & 5.2836 & TRN & \\
\hline CHEMBL1423113 & 954359 & 5.4248 & 5.1245 & TST & \\
\hline CHEMBL1541153 & 954359 & 5.8601 & 5.7631 & TST & \\
\hline CHEMBL1319304 & 954359 & 3.1549 & 4.5702 & TRN & \\
\hline CHEMBL1310099 & 954359 & 5.6308 & 5.4119 & TRN & \\
\hline CHEMBL1602454 & 954359 & 5.8962 & 5.5522 & TRN & \\
\hline CHEMBL1597669 & 954359 & 5.5302 & 5.4091 & TRN & \\
\hline CHEMBL1588822 & 954359 & 5.1746 & 5.0608 & TRN & \\
\hline CHEMBL1594806 & 954359 & 5.1439 & 5.0684 & TRN & \\
\hline CHEMBL1362520 & 954359 & 3.1549 & 4.6665 & TRN & \\
\hline CHEMBL1372936 & 954359 & 5.3107 & 4.9021 & TRN & \\
\hline CHEMBL1722184 & 954359 & 4.8339 & 4.7048 & TRN & \\
\hline CHEMBL1475289 & 954359 & 5.45100 & 00000006 & 205 & 5.5159 \\
\hline CHEMBL1446497 & 954359 & 4.3351 & 4.8883 & TRN & \\
\hline CHEMBL1430416 & 954359 & 3.1549 & 4.2883 & TRN & \\
\hline CHEMBL1328534 & 954359 & 5.5287 & 4.7135 & TRN & \\
\hline CHEMBL 2360459 & 954359 & 5.2441 & 4.9501 & TST & \\
\hline CHEMBL3210088 & 954359 & 5.8356 & 5.3767 & TRN & \\
\hline CHEMBL1729978 & 954359 & 3.1549 & 4.5017 & TRN & \\
\hline CHEMBL1488923 & 954359 & 5.8665 & 5.7397 & TRN & \\
\hline CHEMBL1437560 & 954359 & 5.767 & 5.4932 & TRN & \\
\hline CHEMBL1552222 & 954359 & 5.1986 & 4.9251 & TRN & \\
\hline CHEMBL1569095 & 954359 & 4.8687 & 4.5084 & TRN & \\
\hline CHEMBL1500372 & 954359 & 5.0521 & 4.7467 & TRN & \\
\hline CHEMBL1387035 & 954359 & 5.1337 & 4.7136 & TST & \\
\hline CHEMBL1874105 & 954359 & 6.0424 & 5.3028 & TRN & \\
\hline CHEMBL1573963 & 954359 & 5.4089 & 5.6281 & TST & \\
\hline CHEMBL 3195410 & 954359 & 5.8894 & 4.9081 & TRN & \\
\hline
\end{tabular}




\begin{tabular}{|c|c|c|c|c|c|}
\hline \multicolumn{6}{|c|}{ Supplemental Table S2.txt } \\
\hline CHEMBL1706987 & 954359 & 5.1186 & 4.8251 & TST & \\
\hline CHEMBL1520544 & 954359 & 5.065 & 4.5413 & TST & \\
\hline CHEMBL2357474 & 954359 & 5.5969 & 5.6154 & TRN & \\
\hline CHEMBL1885590 & 954359 & 6.1284 & 6.2714 & TRN & \\
\hline CHEMBL1561448 & 954359 & 6.2526 & 6.3888 & TRN & \\
\hline CHEMBL1541486 & 954359 & 4.3166 & 3.9568 & TRN & \\
\hline CHEMBL2358614 & 954359 & 6.0 & 5.5514 & TRN & \\
\hline CHEMBL1419629 & 954359 & 3.1549 & 4.82600 & 00000000005 & TRN \\
\hline CHEMBL1577804 & 954359 & 5.3625 & 4.9518 & TRN & \\
\hline CHEMBL1345232 & 954359 & 5.4949 & 5.2838 & TRN & \\
\hline CHEMBL1605033 & 954359 & 4.967 & 4.6424 & TRN & \\
\hline CHEMBL1877605 & 954359 & 4.5318 & 4.7571 & TRN & \\
\hline CHEMBL1899185 & 954359 & 5.4921 & 4.8688 & TRN & \\
\hline CHEMBL1573351 & 954359 & 3.1549 & 4.5488 & TRN & \\
\hline CHEMBL1542055 & 954359 & 3.1549 & 4.61 & TRN & \\
\hline CHEMBL530291 & 954359 & 3.1549 & 4.8374 & TRN & \\
\hline CHEMBL1435072 & 954359 & 5.4318 & 5.3132 & TRN & \\
\hline CHEMBL116919 & 954359 & 3.1549 & 4.2725 & TRN & \\
\hline CHEMBL1424901 & 954359 & 5.5086 & 4.6611 & TRN & \\
\hline CHEMBL1715756 & 954359 & 5.983 & 5.817 & TRN & \\
\hline CHEMBL1699099 & 954359 & 4.5862 & 3.6783 & TRN & \\
\hline CHEMBL1508682 & 954359 & 4.5664 & 4.1206 & TRN & \\
\hline CHEMBL1431378 & 954359 & 5.7258 & 5.0445 & TRN & \\
\hline CHEMBL1869323 & 954359 & 5.8239 & 5.9145 & TRN & \\
\hline CHEMBL1312619 & 954359 & 5.2612 & 4.9272 & TRN & \\
\hline CHEMBL1519965 & 954359 & 5.6326 & 5.6171 & TRN & \\
\hline CHEMBL1533776 & 954359 & 4.7314 & 4.5868 & TST & \\
\hline CHEMBL1404042 & 954359 & 5.6289 & 5.1619 & TST & \\
\hline CHEMBL1332429 & 954359 & 4.4921 & 4.24 & TRN & \\
\hline CHEMBL2355499 & 954359 & 5.3757 & 5.05 & TRN & \\
\hline CHEMBL1703435 & 954359 & 5.0146 & 4.8243 & TRN & \\
\hline CHEMBL2357813 & 954359 & 5.5607 & 5.3278 & TRN & \\
\hline CHEMBL1715769 & 954359 & 5.5302 & 5.4412 & TRN & \\
\hline CHEMBL 2142087 & 954359 & 4.1777 & 4.3984 & TRN & \\
\hline CHEMBL 2141186 & 954359 & 4.8827 & 4.9171 & TST & \\
\hline CHEMBL1375648 & 954359 & 5.6757 & 5.53799 & 9999999999 & TRN \\
\hline CHEMBL1526750 & 954359 & 5.1681 & 5.0474 & TRN & \\
\hline CHEMBL1731238 & 954359 & 5.5768 & 5.2609 & TRN & \\
\hline CHEMBL1880486 & 954359 & 4.8703 & 4.7373 & TRN & \\
\hline CHEMBL1438308 & 954359 & 5.2676 & 4.9368 & TRN & \\
\hline CHEMBL1507890 & 954359 & 3.1549 & 4.2649 & TRN & \\
\hline CHEMBL1458209 & 954359 & 5.4306 & 5.0762 & TRN & \\
\hline CHEMBL 2135670 & 954359 & 5.3947 & 5.12799 & 9999999999 & TRN \\
\hline CHEMBL1728514 & 954359 & 5.4225 & 5.2414 & TST & \\
\hline CHEMBL1537158 & 954359 & 4.6061 & 4.98600 & 0000000001 & TRN \\
\hline CHEMBL2355211 & 954359 & 4.9991 & 4.7599 & TRN & \\
\hline CHEMBL1388829 & 954359 & 5.6108 & 5.7135 & TST & \\
\hline CHEMBL1459767 & 954359 & 5.5129 & 4.829 & TST & \\
\hline
\end{tabular}




\begin{tabular}{|c|c|c|c|c|c|}
\hline \multicolumn{6}{|c|}{ Supplemental Table S2.txt } \\
\hline CHEMBL1474759 & 954359 & 4.95 & 4.7486 & TST & \\
\hline CHEMBL1401504 & 954359 & 5.1838 & 4.8661 & TRN & \\
\hline CHEMBL1321201 & 954359 & 5.4112 & 5.3973 & TRN & \\
\hline CHEMBL2133122 & 954359 & 5.1746 & 5.3606 & TRN & \\
\hline CHEMBL389390 & 954359 & 5.4191 & 4.9916 & TST & \\
\hline CHEMBL1328306 & 954359 & 5.8041 & 5.4144 & TRN & \\
\hline CHEMBL1333750 & 954359 & 5.3072 & 5.0609 & TRN & \\
\hline CHEMBL3126906 & 954359 & 5.7212 & 5.3814 & TRN & \\
\hline CHEMBL 2361777 & 954359 & 4.7491 & 4.9627 & TST & \\
\hline CHEMBL1880788 & 954359 & 5.1013 & 4.5953 & TRN & \\
\hline CHEMBL1541314 & 954359 & 4.4481 & 4.8602 & TRN & \\
\hline CHEMBL1592853 & 954359 & 5.3063 & 5.8128 & TRN & \\
\hline CHEMBL1706322 & 954359 & 5.3487 & 4.8638 & TRN & \\
\hline CHEMBL1368039 & 954359 & 4.9698 & 4.745 & TRN & \\
\hline CHEMBL1718951 & 954359 & 4.9897 & 5.0033 & TRN & \\
\hline CHEMBL1524929 & 954359 & 5.5867 & 5.5476 & TRN & \\
\hline CHEMBL102397 & 954359 & 5.857 & 6.858 & TRN & \\
\hline CHEMBL3197908 & 954359 & 5.2154 & 4.7776 & TRN & \\
\hline CHEMBL494325 & 954359 & 5.2291 & 4.9399 & TRN & \\
\hline CHEMBL2356987 & 954359 & 5.7932 & 5.7245 & TRN & \\
\hline CHEMBL1576075 & 954359 & 4.22 & 3.9509 & TRN & \\
\hline CHEMBL1605995 & 954359 & 4.9126 & 4.6399 & TST & \\
\hline CHEMBL1881663 & 954359 & 5.7825 & 5.6168 & TRN & \\
\hline CHEMBL1436699 & 954359 & 4.5696 & 4.8474 & TRN & \\
\hline CHEMBL1306071 & 954359 & 5.6596 & 5.0609 & TRN & \\
\hline CHEMBL1529294 & 954359 & 3.1549 & 4.3464 & TRN & \\
\hline CHEMBL1904959 & 954359 & 4.5702 & 5.1653 & TRN & \\
\hline CHEMBL1562575 & 954359 & 7.585 & 7.5757 & TRN & \\
\hline CHEMBL1700115 & 954359 & 5.8097 & 5.7287 & TRN & \\
\hline CHEMBL1448198 & 954359 & 4.9062 & 5.1578 & TRN & \\
\hline CHEMBL1709909 & 954359 & 6.057 & 5.7418 & TRN & \\
\hline CHEMBL1902683 & 954359 & 5.4547 & 5.65 & TRN & \\
\hline CHEMBL1716540 & 954359 & 4.4516 & 4.5455 & TST & \\
\hline CHEMBL1329135 & 954359 & 3.1549 & 4.6277 & TRN & \\
\hline CHEMBL1895135 & 954359 & 4.8324 & 4.4177 & TRN & \\
\hline CHEMBL1447479 & 954359 & 5.2182 & 5.1245 & TRN & \\
\hline CHEMBL1448999 & 954359 & 5.3726 & 4.9236 & TRN & \\
\hline CHEMBL464467 & 954359 & 5.6289 & 5.5546 & TST & \\
\hline CHEMBL1303152 & 954359 & 6.3449 & 6.0917 & TST & \\
\hline CHEMBL1434463 & 954359 & 6.3904 & 6.8713 & TRN & \\
\hline CHEMBL1570857 & 954359 & 5.0888 & 4.8889 & TRN & \\
\hline CHEMBL1410521 & 954359 & 4.2297 & 4.24 & TRN & \\
\hline CHEMBL1867339 & 954359 & 5.7645 & 5.919 & TRN & \\
\hline CHEMBL1486457 & 954359 & 4.6655 & 4.6565 & TRN & \\
\hline CHEMBL1884377 & 954359 & 6.4012 & 6.0081 & TRN & \\
\hline CHEMBL1342825 & 954359 & 4.4324 & 4.3683 & TRN & \\
\hline CHEMBL 2448498 & 954359 & 4.4533 & 4.93199 & 99999999995 & TRN \\
\hline CHEMBL1493367 & 954359 & 5.1463 & 4.9121 & TRN & \\
\hline
\end{tabular}


Supplemental Table S2.txt

\begin{tabular}{|c|c|c|c|c|c|c|}
\hline CHEMBL1875758 & 954359 & 5.4001 & 5.6064 & TRN & & \\
\hline CHEMBL 2448464 & 954359 & 5.2204 & 5.0574 & TRN & & \\
\hline CHEMBL1699402 & 954359 & 5.4123 & 5.1606 & TRN & & \\
\hline CHEMBL1385808 & 954359 & 7.585 & 6.9947 & TST & & \\
\hline CHEMBL1892704 & 954359 & 5.0942 & 4.6592 & TST & & \\
\hline CHEMBL1337961 & 954359 & 5.1397 & 4.8442 & TRN & & \\
\hline CHEMBL1460239 & 954359 & 5.1739 & 4.6704 & TRN & & \\
\hline CHEMBL1299439 & 954359 & 5.4271 & 5.1005 & TRN & & \\
\hline CHEMBL1368493 & 954359 & 3.1549 & 3.9235 & TRN & & \\
\hline CHEMBL1698237 & 954359 & 5.3478 & 5.2459 & TRN & & \\
\hline CHEMBL1425552 & 954359 & \multicolumn{3}{|c|}{5.757000000000001} & 4.7523 & TRN \\
\hline CHEMBL 2141861 & 954359 & 5.4868 & 5.4832 & TRN & & \\
\hline CHEMBL1349063 & 954359 & 6.1152 & 5.4599 & TRN & & \\
\hline CHEMBL1459657 & 954359 & 4.5588 & 4.5817 & TST & & \\
\hline CHEMBL 2360772 & 954359 & 4.744 & 5.2695 & TRN & & \\
\hline CHEMBL1606743 & 954359 & 5.2612 & 5.0931 & TRN & & \\
\hline CHEMBL1510823 & 954359 & 5.2226 & 4.9385 & TST & & \\
\hline CHEMBL1581829 & 954359 & 4.5194 & 4.6943 & TRN & & \\
\hline CHEMBL1580452 & 954359 & 3.1549 & 4.4919 & TRN & & \\
\hline CHEMBL1508450 & 954359 & 4.6287 & 4.7681 & TST & & \\
\hline CHEMBL1348129 & 954359 & 5.5467 & 4.9573 & TRN & & \\
\hline CHEMBL1870719 & 954359 & 5.1649 & 4.8772 & TRN & & \\
\hline CHEMBL1460595 & 954359 & 4.9578 & 4.9917 & TST & & \\
\hline CHEMBL 2359286 & 954359 & 4.3632 & 4.7943 & TST & & \\
\hline CHEMBL1396779 & 954359 & 4.3147 & 4.0832 & TRN & & \\
\hline CHEMBL1440643 & 954359 & 5.1135 & 4.7415 & TRN & & \\
\hline CHEMBL1346904 & 954359 & \multicolumn{3}{|c|}{5.2139999999999995} & 4.8334 & TRN \\
\hline CHEMBL1385388 & 954359 & 6.032 & 6.0124 & TRN & & \\
\hline CHEMBL1420742 & 954359 & 5.1524 & 4.7306 & TRN & & \\
\hline CHEMBL1314738 & 954359 & 6.2933 & 6.8027 & TRN & & \\
\hline CHEMBL1463225 & 954359 & 6.4584 & 6.9716 & TRN & & \\
\hline CHEMBL1482207 & 954359 & 4.66 & 3.9284 & TRN & & \\
\hline CHEMBL1460011 & 954359 & 4.3719 & 4.8314 & TRN & & \\
\hline CHEMBL528181 & 954359 & 5.3925 & 4.9473 & TRN & & \\
\hline CHEMBL1469736 & 954359 & 5.4763 & 5.546 & TRN & & \\
\hline CHEMBL1360952 & 954359 & 5.0996 & 4.8438 & TRN & & \\
\hline CHEMBL1322078 & 954359 & 5.5302 & 5.5802 & TRN & & \\
\hline CHEMBL1372725 & 954359 & 4.3912 & 4.4805 & TRN & & \\
\hline CHEMBL1866960 & 954359 & 5.9208 & 5.8197 & TRN & & \\
\hline CHEMBL1303750 & 954359 & 3.1549 & 4.7775 & TRN & & \\
\hline CHEMBL1497562 & 954359 & 5.7773 & 5.5557 & TST & & \\
\hline CHEMBL1380482 & 954359 & 5.5817 & 4.731 & TST & & \\
\hline CHEMBL1497138 & 954359 & 5.295 & 4.9468 & TST & & \\
\hline CHEMBL1474888 & 954359 & 3.1549 & 4.546 & TRN & & \\
\hline CHEMBL1364572 & 954359 & 5.6737 & 5.8306 & TST & & \\
\hline CHEMBL1442067 & 954359 & 4.6156 & 4.6145 & TRN & & \\
\hline CHEMBL1561002 & 954359 & 4.6119 & 3.9551 & TRN & & \\
\hline CHEMBL1886332 & 954359 & 5.0424 & 4.7799 & TRN & & \\
\hline
\end{tabular}




\begin{tabular}{|c|c|c|c|c|c|}
\hline & & \multicolumn{4}{|c|}{ Supplemental Table S2.txt } \\
\hline CHEMBL1416342 & 954359 & 4.3999 & 4.9381 & TRN & \\
\hline CHEMBL1886909 & 954359 & 5.6126 & 5.2723 & TST & \\
\hline CHEMBL3209663 & 954359 & 6.1296 & 5.5549 & TST & \\
\hline CHEMBL2140460 & 954359 & 5.8153 & 5.9277 & TRN & \\
\hline CHEMBL1424453 & 954359 & 4.2189 & 4.4038 & TRN & \\
\hline CHEMBL1519955 & 954359 & 3.1549 & 4.6225 & TRN & \\
\hline CHEMBL1716006 & 954359 & 4.3079 & 4.4891 & TRN & \\
\hline CHEMBL1707564 & 954359 & 5.6459 & 5.6154 & TRN & \\
\hline CHEMBL1887850 & 954359 & 7.585 & 7.7435 & TRN & \\
\hline CHEMBL1302274 & 954359 & 3.1549 & 4.7111 & TRN & \\
\hline CHEMBL1607407 & 954359 & 3.1549 & 4.0665 & TRN & \\
\hline CHEMBL2139915 & 954359 & 3.1549 & 4.7512 & TRN & \\
\hline CHEMBL1375402 & 954359 & 4.9957 & 4.8038 & TRN & \\
\hline CHEMBL1730354 & 954359 & 5.7471 & 5.6737 & TRN & \\
\hline CHEMBL1583846 & 954359 & 5.556 & 4.8234 & TST & \\
\hline CHEMBL3198899 & 954359 & 5.2358 & 5.4379 & TRN & \\
\hline CHEMBL2362474 & 954359 & 4.6068 & 5.0595 & TRN & \\
\hline CHEMBL 2134677 & 954359 & 5.6615 & 5.4811 & TRN & \\
\hline CHEMBL1319691 & 954359 & 5.1733 & 5.1842 & TST & \\
\hline CHEMBL1471330 & 954359 & 4.9017 & 4.5961 & TRN & \\
\hline CHEMBL1570537 & 954359 & 3.1549 & 4.7531 & TRN & \\
\hline CHEMBL1473718 & 954359 & 5.4237 & 5.3625 & TRN & \\
\hline CHEMBL441618 & 954359 & 3.1549 & 4.284 & TRN & \\
\hline CHEMBL1439985 & 954359 & 5.0292 & 5.3907 & TRN & \\
\hline CHEMBL1974506 & 954359 & 5.3585 & 5.6353 & TRN & \\
\hline CHEMBL2361077 & 954359 & 4.7222 & 5.0051 & TRN & \\
\hline CHEMBL1445386 & 954359 & 6.0477 & 5.2794 & TST & \\
\hline CHEMBL1394527 & 954359 & 4.8589 & 4.7661 & TST & \\
\hline CHEMBL1610504 & 954359 & 3.1549 & 5.0124 & TST & \\
\hline CHEMBL1492399 & 954359 & 5.3458 & 5.438 & TRN & \\
\hline CHEMBL1451348 & 954359 & 5.4486 & 5.0168 & TRN & \\
\hline CHEMBL1329693 & 954359 & 5.0273 & 4.7726 & TRN & \\
\hline CHEMBL1537730 & 954359 & 3.1549 & 5.0564 & TST & \\
\hline CHEMBL1710523 & 954359 & 5.2565 & 5.169 & TRN & \\
\hline CHEMBL1371382 & 954359 & 4.9303 & 4.8268 & TRN & \\
\hline CHEMBL2136129 & 954359 & 5.6968 & 5.5346 & TRN & \\
\hline CHEMBL1897998 & 954359 & 3.1549 & 4.8246 & TRN & \\
\hline CHEMBL1527341 & 954359 & 4.9101 & 5.0254 & TST & \\
\hline CHEMBL3194760 & 954359 & 5.5607 & 5.4771 & TST & \\
\hline CHEMBL1867711 & 954359 & 5.1051 & 4.6753 & TRN & \\
\hline CHEMBL1359616 & 954359 & 5.7423 & 4.9118 & TRN & \\
\hline CHEMBL1380049 & 954359 & 5.1694 & 4.73600 & 0000000001 & TRN \\
\hline CHEMBL1566146 & 954359 & 5.1124 & 5.0151 & TST & \\
\hline CHEMBL1486366 & 954359 & 4.4431 & 4.8138 & TRN & \\
\hline CHEMBL 2360109 & 954359 & 5.767 & 5.2446 & TRN & \\
\hline CHEMBL530499 & 954359 & 5.2154 & 4.9123 & TST & \\
\hline CHEMBL1394445 & 954359 & 4.8047 & 4.9656 & TRN & \\
\hline CHEMBL1481347 & 954359 & 6.3726 & 4.8374 & TRN & \\
\hline
\end{tabular}




\begin{tabular}{|c|c|c|c|c|c|c|}
\hline & & \multicolumn{5}{|c|}{ Supplemental Table S2.txt } \\
\hline CHEMBL1462900 & 954359 & 5.3439 & 4.6639 & TRN & & \\
\hline CHEMBL1349315 & 954359 & 5.1331 & 5.037 & TRN & & \\
\hline CHEMBL1323505 & 954359 & 4.776 & 4.4164 & TRN & & \\
\hline CHEMBL1448592 & 954359 & 5.1101 & 4.6197 & TRN & & \\
\hline CHEMBL1523841 & 954359 & 5.8996 & 5.4151 & TST & & \\
\hline CHEMBL1536958 & 954359 & 5.279 & 5.38899 & 9999999 & 99 & TRN \\
\hline CHEMBL1568152 & 954359 & 4.9539 & 4.9095 & TST & & \\
\hline CHEMBL1550670 & 954359 & 4.5378 & 4.1903 & TRN & & \\
\hline CHEMBL1557954 & 954359 & 5.7496 & 5.5664 & TRN & & \\
\hline CHEMBL1720969 & 954359 & 5.9469 & 6.0268 & TRN & & \\
\hline CHEMBL 2373481 & 954359 & 4.436 & 4.9366 & TST & & \\
\hline CHEMBL1597230 & 954359 & 5.4365 & 4.7779 & TRN & & \\
\hline CHEMBL1905387 & 954359 & 5.153 & 4.7226 & TRN & & \\
\hline CHEMBL1872984 & 954359 & 5.3288 & 5.0718 & TRN & & \\
\hline CHEMBL1358887 & 954359 & 7.585 & 7.6517 & TRN & & \\
\hline CHEMBL1371507 & 954359 & 6.0218 & 5.9528 & TRN & & \\
\hline CHEMBL1491001 & 954359 & 3.1549 & 4.4305 & TRN & & \\
\hline CHEMBL1548549 & 954359 & 4.7296 & 5.0311 & TRN & & \\
\hline CHEMBL1316921 & 954359 & 5.2933 & 5.1796 & TRN & & \\
\hline CHEMBL1713983 & 954359 & 5.4295 & 4.7552 & TRN & & \\
\hline CHEMBL1446984 & 954359 & 5.5768 & 4.7378 & TRN & & \\
\hline CHEMBL 2136773 & 954359 & 5.3947 & 5.2311 & TRN & & \\
\hline CHEMBL1559529 & 954359 & 5.7423 & 5.729 & TRN & & \\
\hline CHEMBL1730853 & 954359 & 5.983 & 5.8596 & TRN & & \\
\hline CHEMBL1902622 & 954359 & 5.295 & 4.794 & TRN & & \\
\hline CHEMBL598679 & 954359 & 5.3215 & 4.9657 & TRN & & \\
\hline CHEMBL1905109 & 954359 & 5.4724 & 5.3176 & TRN & & \\
\hline CHEMBL1317554 & 954359 & 6.1355 & 6.334 & TRN & & \\
\hline CHEMBL1451209 & 954359 & 5.5129 & 5.59 & TRN & & \\
\hline CHEMBL1346079 & 954359 & 5.567 & 5.0547 & TRN & & \\
\hline CHEMBL18115 & 954359 & 4.4338 & 4.9818 & TRN & & \\
\hline CHEMBL1901570 & 954359 & 5.7235 & 4.3558 & TST & & \\
\hline CHEMBL1706371 & 954359 & 5.7235 & 5.5187 & TRN & & \\
\hline CHEMBL1320244 & 954359 & 5.6615 & 5.1969 & TRN & & \\
\hline CHEMBL1567814 & 954359 & 5.6073 & 5.3649 & TRN & & \\
\hline CHEMBL1571397 & 954359 & 5.15799 & 99999999 & 995 & 4.3199 & $1 \mathrm{nI}$ \\
\hline CHEMBL1380862 & 954359 & 5.4535 & 5.5535 & TRN & & \\
\hline CHEMBL 2137652 & 954359 & 5.0496 & 4.8966 & TRN & & \\
\hline CHEMBL1441773 & 954359 & 4.6992 & 5.2756 & TRN & & \\
\hline CHEMBL 2448504 & 954359 & 5.1831 & 4.8154 & TRN & & \\
\hline CHEMBL1452795 & 954359 & 5.4486 & 5.1137 & TST & & \\
\hline CHEMBL1428735 & 954359 & 5.5072 & 5.6363 & TRN & & \\
\hline CHEMBL1709276 & 954359 & 5.2541 & 4.8989 & TRN & & \\
\hline CHEMBL1472420 & 954359 & 5.3019 & 5.0292 & TST & & \\
\hline CHEMBL1464930 & 954359 & 5.0814 & 4.8473 & TRN & & \\
\hline CHEMBL1492073 & 954359 & 4.6944 & 4.8371 & TRN & & \\
\hline CHEMBL1868229 & 954359 & 5.3904 & 4.9134 & TRN & & \\
\hline CHEMBL1460004 & 954359 & 4.765 & 4.5824 & TST & & \\
\hline
\end{tabular}




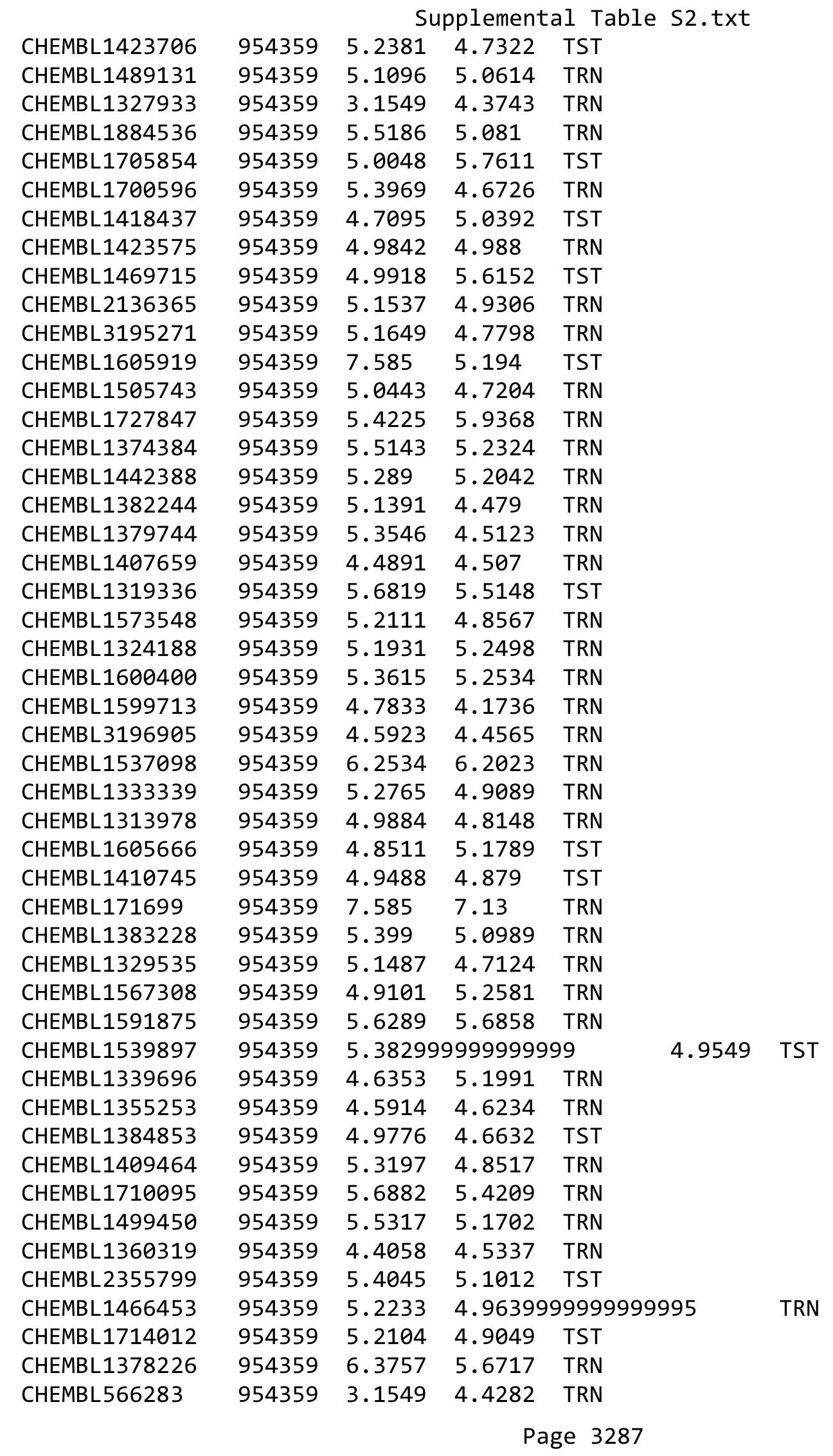




\begin{tabular}{|c|c|c|c|c|c|}
\hline & & \multicolumn{4}{|c|}{ Supplemental Table S2.txt } \\
\hline CHEMBL1999906 & 954359 & 3.1549 & 5.309 & TST & \\
\hline CHEMBL3189398 & 954359 & 3.1549 & 4.3241 & TRN & \\
\hline CHEMBL1354040 & 954359 & 5.1574 & 5.1833 & TRN & \\
\hline CHEMBL1419188 & 954359 & 5.2403 & 5.1412 & TRN & \\
\hline CHEMBL1511219 & 954359 & 6.2899 & 6.2624 & TRN & \\
\hline CHEMBL1595687 & 954359 & 5.15 & 4.6739 & TST & \\
\hline CHEMBL1487368 & 954359 & 5.9626 & 5.5541 & TRN & \\
\hline CHEMBL1305638 & 954359 & 5.5243 & 5.3128 & TRN & \\
\hline CHEMBL1470152 & 954359 & 5.2104 & 4.6449 & TRN & \\
\hline CHEMBL 2357524 & 954359 & 5.2441 & 4.8215 & TRN & \\
\hline CHEMBL1389657 & 954359 & 3.1549 & 4.7151 & TRN & \\
\hline CHEMBL1736440 & 954359 & 5.0996 & 4.9877 & TRN & \\
\hline CHEMBL1453285 & 954359 & 5.0985 & 4.5608 & TRN & \\
\hline CHEMBL1570706 & 954359 & 5.0809 & 4.8632 & TRN & \\
\hline CHEMBL1422378 & 954359 & 3.1549 & 4.5927 & TST & \\
\hline CHEMBL3194195 & 954359 & 4.3765 & 4.1922 & TRN & \\
\hline CHEMBL1712550 & 954359 & 4.7378 & 5.19799 & 99999999995 & TRN \\
\hline CHEMBL605708 & 954359 & 4.6243 & 4.3885 & TRN & \\
\hline CHEMBL 2361197 & 954359 & 4.7991 & 4.6909 & TRN & \\
\hline CHEMBL 2355112 & 954359 & 3.1549 & 5.1385 & TRN & \\
\hline CHEMBL1376629 & 954359 & 4.3172 & 4.8931 & TRN & \\
\hline CHEMBL1549444 & 954359 & 3.4948 & 4.8468 & TST & \\
\hline CHEMBL1408046 & 954359 & 4.6778 & 4.7895 & TRN & \\
\hline CHEMBL1585652 & 954359 & 3.1549 & 5.1916 & TRN & \\
\hline CHEMBL1337733 & 954359 & 3.1549 & 4.6159 & TRN & \\
\hline CHEMBL193627 & 954359 & 5.0453 & 5.3326 & TST & \\
\hline CHEMBL 2135379 & 954359 & 4.9442 & 4.4017 & TRN & \\
\hline CHEMBL 2134222 & 954359 & 4.9133 & 4.6305 & TRN & \\
\hline CHEMBL 1450615 & 954359 & 5.0376 & 4.7707 & TST & \\
\hline CHEMBL1346449 & 954359 & 4.8187 & 4.4224 & TRN & \\
\hline CHEMBL1891205 & 954359 & 5.4191 & 5.5018 & TRN & \\
\hline CHEMBL1428870 & 954359 & 5.7167 & 5.1851 & TRN & \\
\hline CHEMBL1503131 & 954359 & 4.3377 & 4.898 & TRN & \\
\hline CHEMBL 2360990 & 954359 & 5.0752 & 5.1713 & TRN & \\
\hline CHEMBL1557066 & 954359 & 5.0716 & 4.8322 & TRN & \\
\hline CHEMBL1336290 & 954359 & 4.4332 & 5.6269 & TRN & \\
\hline CHEMBL1576870 & 954359 & 7.585 & 6.4659 & TRN & \\
\hline CHEMBL65349 & 954359 & 6.3565 & 5.8267 & TRN & \\
\hline CHEMBL1327034 & 954359 & 4.6874 & 4.4745 & TRN & \\
\hline CHEMBL1567488 & 954359 & 5.8962 & 5.2894 & TRN & \\
\hline CHEMBL1428181 & 954359 & 5.5686 & 4.8076 & TRN & \\
\hline CHEMBL1971142 & 954359 & $5.3820 e$ & 00000000 & 5.3529 & TRN \\
\hline CHEMBL1342837 & 954359 & 5.4401 & 5.0832 & TRN & \\
\hline CHEMBL1604143 & 954359 & 4.9755 & 5.1289 & TRN & \\
\hline CHEMBL1380943 & 954359 & 4.8392 & 4.824 & TRN & \\
\hline CHEMBL1350387 & 954359 & 4.67 & 4.7191 & TRN & \\
\hline CHEMBL 2448508 & 954359 & 5.5157 & 5.1447 & TRN & \\
\hline CHEMBL1610579 & 954359 & 5.7986 & 5.5691 & TRN & \\
\hline
\end{tabular}




\begin{tabular}{|c|c|c|c|c|c|c|}
\hline & & \multicolumn{5}{|c|}{ Supplemental Table S2.txt } \\
\hline CHEMBL1577938 & 954359 & 5.7986 & 5.5819 & TRN & & \\
\hline CHEMBL1732521 & 954359 & 7.585 & 5.351 & TRN & & \\
\hline CHEMBL 2354532 & 954359 & 5.1035 & 4.3383 & TRN & & \\
\hline CHEMBL1717409 & 954359 & 5.7645 & 5.45 & TRN & & \\
\hline CHEMBL1349753 & 954359 & 4.9855 & 4.9883 & TRN & & \\
\hline CHEMBL1365395 & 954359 & 4.5967 & 4.4507 & TRN & & \\
\hline CHEMBL1468323 & 954359 & 5.7747 & 5.739 & TRN & & \\
\hline CHEMBL1535490 & 954359 & \multicolumn{3}{|c|}{5.327000000000001} & 5.7399 & TRN \\
\hline CHEMBL1338601 & 954359 & 5.1574 & 4.9773 & TRN & & \\
\hline CHEMBL1427272 & 954359 & 4.7625 & 4.6824 & TRN & & \\
\hline CHEMBL1385727 & 954359 & 3.1549 & 4.0963 & TRN & & \\
\hline CHEMBL1702280 & 954359 & 5.1013 & 4.7847 & TRN & & \\
\hline CHEMBL1308403 & 954359 & 5.2441 & 5.0383 & TST & & \\
\hline CHEMBL1870652 & 954359 & 5.6144 & 5.7536 & TRN & & \\
\hline CHEMBL1894296 & 954359 & 5.1986 & 4.6817 & TRN & & \\
\hline CHEMBL1981570 & 954359 & 4.8706 & 5.2004 & TRN & & \\
\hline CHEMBL 2144397 & 954359 & 5.4056 & 5.2064 & TRN & & \\
\hline CHEMBL1366706 & 954359 & 5.3261 & 5.0784 & TRN & & \\
\hline CHEMBL1442319 & 954359 & 5.3516 & 5.3393 & TRN & & \\
\hline CHEMBL1721043 & 954359 & 4.9274 & 4.806 & TST & & \\
\hline CHEMBL1905114 & 954359 & 5.1643 & 4.95100 & 000000 & & TRN \\
\hline CHEMBL1869505 & 954359 & 5.8386 & 5.6898 & TRN & & \\
\hline CHEMBL1505224 & 954359 & 4.3846 & 4.5472 & TRN & & \\
\hline CHEMBL1726645 & 954359 & 5.4283 & 5.1756 & TRN & & \\
\hline CHEMBL1412006 & 954359 & 5.7905 & 5.6575 & TRN & & \\
\hline CHEMBL1425675 & 954359 & 4.7535 & 4.9704 & TRN & & \\
\hline CHEMBL 2358514 & 954359 & 4.8321 & 4.4794 & TST & & \\
\hline CHEMBL1524746 & 954359 & 5.0123 & 5.0721 & TST & & \\
\hline CHEMBL 1458403 & 954359 & 5.1593 & 5.0027 & TRN & & \\
\hline CHEMBL1459468 & 954359 & 5.5901 & 5.7651 & TRN & & \\
\hline CHEMBL3193079 & 954359 & 3.1549 & 5.0886 & TST & & \\
\hline CHEMBL1863833 & 954359 & 5.7799 & 5.4786 & TRN & & \\
\hline CHEMBL1372292 & 954359 & 3.1549 & 5.0544 & TRN & & \\
\hline CHEMBL1366606 & 954359 & 4.2325 & 4.7344 & TRN & & \\
\hline CHEMBL1597625 & 954359 & 4.6821 & 4.0141 & TRN & & \\
\hline CHEMBL1877044 & 954359 & 4.6698 & 4.7968 & TRN & & \\
\hline CHEMBL1368760 & 954359 & 4.2152 & 4.4748 & TRN & & \\
\hline CHEMBL1325003 & 954359 & 6.0742 & 6.3169 & TRN & & \\
\hline CHEMBL1706712 & 954359 & 5.4449 & 5.2201 & TRN & & \\
\hline CHEMBL1570769 & 954359 & 4.7731 & 4.5538 & TRN & & \\
\hline CHEMBL1348545 & 954359 & 3.1549 & 4.8863 & TRN & & \\
\hline CHEMBL1998606 & 954359 & 4.75899 & 99999999 & 995 & 5.3844 & TRN \\
\hline CHEMBL1871362 & 954359 & 5.9706 & 5.6797 & TRN & & \\
\hline CHEMBL1535257 & 954359 & 4.7967 & 4.5252 & TRN & & \\
\hline CHEMBL1887993 & 954359 & 5.2848 & 4.7322 & TRN & & \\
\hline CHEMBL1528004 & 954359 & 4.7359 & 4.8205 & TRN & & \\
\hline CHEMBL1897053 & 954359 & 5.1707 & 4.921 & TRN & & \\
\hline CHEMBL1391167 & 954359 & 3.1549 & 4.6869 & TRN & & \\
\hline
\end{tabular}


Supplemental Table S2.txt

\begin{tabular}{|c|c|c|c|c|}
\hline 年 & & & & \\
\hline HEMBL2144271 & & 5.3979 & 4.9398 & \\
\hline 41 & & & & \\
\hline FMRI 17 & & & 48 & \\
\hline IEMBL1712299 & 59 & 18 & 864 & \\
\hline AEMBL1586355 & 54359 & 1549 & .8213 & \\
\hline HEMBL15 & 59 & 188 & .8211 & \\
\hline AEMBL14 & & & 43 & \\
\hline AEMBL14 & & & 5859 & \\
\hline AEMBL1482680 & 59 & 91 & 9805 & \\
\hline HEMBL1521704 & 59 & 1965 & 9171 & \\
\hline AEMBL135 & 59 & & 8071 & \\
\hline JEMBL18 & & & & \\
\hline HEMBL 318 & & & & \\
\hline AEMBL1359848 & 99 & & 4522 & \\
\hline AEMBL134 & 59 & 88 & & \\
\hline HEMBL15 & & & 146 & \\
\hline HEMBL14 & & & & \\
\hline AEMBL 13 & & & & \\
\hline AEMBL17 & & & & ST \\
\hline AEMBL1547483 & 9 & & 3656 & I \\
\hline HEMBL14. & & & 364 & \\
\hline HEMBL132 & & & 977 & \\
\hline AFMRI 131 & & & & \\
\hline JEMBL14 & & & & 151 \\
\hline L31S & & & 53 & ISI \\
\hline JEMBL15 & & & 67 & \\
\hline 441 & & & 72 & ST \\
\hline HEMBL155 & & & & \\
\hline HEMBL150 & & & 35 & SI \\
\hline HEMBL161 & & & & \\
\hline AFMRI 13 & & & 32 & ST \\
\hline 68 & & & 51 & ST \\
\hline HEMBL1562296 & & & & SI \\
\hline HEMBL1721795 & & & 861 & ГST \\
\hline AEMBL14 & & & 98 & \\
\hline 4 MDI 50 & & & & \\
\hline HEMBL1595792 & & & 854 & ST \\
\hline HEMBL1429793 & & & & ST \\
\hline HEMBL13 & & & 851 & ST \\
\hline HEMBL17 & & & 866 & \\
\hline תר 1 & & & & \\
\hline HEMBL1462920 & & & 298 & ST \\
\hline HEMBL1536763 & 59 & 35 & 3576 & TST \\
\hline EMBL14 & & & 232 & $s$ \\
\hline CHEMBL1403324 & & & .2404 & \\
\hline CHEMBL3212313 & & 5.1209 & 9776 & \\
\hline CHEMBL 2362368 & 954359 & 5.7328 & 5.3729 & ГST \\
\hline
\end{tabular}

Page 3290 


\begin{tabular}{|c|c|c|c|c|c|c|}
\hline & & \multicolumn{5}{|c|}{ Supplemental Table S2.txt } \\
\hline CHEMBL1718302 & 954359 & 4.3651 & 4.6691 & TST & & \\
\hline CHEMBL1603932 & 954359 & 4.6784 & 4.8061 & TST & & \\
\hline CHEMBL1436393 & 954359 & 5.426 & 5.2199 & TST & & \\
\hline CHEMBL1309164 & 954359 & 5.3862 & 4.73 & TST & & \\
\hline CHEMBL1894184 & 954359 & 5.5031 & 5.4727 & TST & & \\
\hline CHEMBL1411209 & 954359 & 4.3537 & 4.7283 & TST & & \\
\hline CHEMBL 2136838 & 954359 & 5.6055 & 5.4883 & TST & & \\
\hline CHEMBL1889375 & 954359 & 4.8517 & 4.1232 & TST & & \\
\hline CHEMBL1543215 & 954359 & 5.6655 & 5.8041 & TST & & \\
\hline CHEMBL1321083 & 954359 & 4.6461 & 4.8722 & TST & & \\
\hline CHEMBL1345115 & 954359 & 4.5267 & 4.2999 & TST & & \\
\hline CHEMBL3193168 & 954359 & 4.4492 & 5.0677 & TST & & \\
\hline CHEMBL1522315 & 954359 & 4.9586 & 4.5641 & TST & & \\
\hline CHEMBL1871757 & 954359 & \multicolumn{3}{|c|}{4.9830000000000005} & 4.8291 & TST \\
\hline CHEMBL1436799 & 954359 & 6.4353 & 7.1375 & TST & & \\
\hline CHEMBL1450612 & 954359 & 3.1549 & 4.7309 & TST & & \\
\hline CHEMBL1516583 & 954359 & 4.2582 & 4.7759 & TST & & \\
\hline CHEMBL1558826 & 954359 & 7.585 & 7.0644 & TST & & \\
\hline CHEMBL1578406 & 954359 & 4.4177 & 4.857 & TST & & \\
\hline CHEMBL1351357 & 954359 & 5.9747 & 5.6668 & TST & & \\
\hline CHEMBL1528930 & 954359 & 4.4014 & 4.9305 & TST & & \\
\hline CHEMBL1327046 & 954359 & 3.1549 & 3.9655 & TST & & \\
\hline CHEMBL1524910 & 954359 & 4.9101 & 4.7155 & TST & & \\
\hline CHEMBL1579166 & 954359 & 5.3298 & 5.0823 & TST & & \\
\hline CHEMBL1531646 & 954359 & 4.2711 & 4.0746 & TST & & \\
\hline CHEMBL1332776 & 954359 & 4.8365 & 4.6736 & TST & & \\
\hline CHEMBL16288 & 954359 & 6.1785 & 5.8736 & TST & & \\
\hline CHEMBL1427279 & 954359 & 5.0311 & 5.2537 & TST & & \\
\hline CHEMBL3702312 & 1528144 & 6.5031 & 6.5129 & TRN & & \\
\hline CHEMBL3702353 & 1528144 & 7.585 & 7.6693 & TRN & & \\
\hline CHEMBL3702266 & 1528144 & 7.2441 & 7.2266 & TRN & & \\
\hline CHEMBL3698913 & 1528144 & 7.3872 & 7.4801 & TRN & & \\
\hline CHEMBL3698952 & 1528144 & 7.699 & 7.5524 & TRN & & \\
\hline CHEMBL3702299 & 1528144 & 7.2076 & 7.1163 & TRN & & \\
\hline CHEMBL3698919 & 1528144 & 6.5834 & 6.6134 & TRN & & \\
\hline CHEMBL3698953 & 1528144 & 6.5287 & 6.561 & TRN & & \\
\hline CHEMBL3702317 & 1528144 & 7.7696 & 7.7054 & TRN & & \\
\hline CHEMBL1323994 & 1528144 & 8.5229 & 6.3108 & TST & & \\
\hline CHEMBL3702293 & 1528144 & 7.6576 & 7.6644 & TRN & & \\
\hline CHEMBL 244683 & 1528144 & 7.1805 & 7.5582 & TST & & \\
\hline CHEMBL3702328 & 1528144 & 8.2218 & 8.2352 & TRN & & \\
\hline CHEMBL 3702260 & 1528144 & 7.0315 & 6.9961 & TRN & & \\
\hline CHEMBL3702316 & 1528144 & 7.4318 & 7.4166 & TRN & & \\
\hline CHEMBL1519408 & 1528144 & 6.0 & 6.6643 & TST & & \\
\hline CHEMBL 3702257 & 1528144 & 7.1367 & 7.1565 & TRN & & \\
\hline CHEMBL3698925 & 1528144 & 7.8539 & 7.8938 & TRN & & \\
\hline CHEMBL3702271 & 1528144 & 7.699 & 7.569 & TRN & & \\
\hline CHEMBL3702289 & 1528144 & 7.5086 & 7.5676 & TRN & & \\
\hline
\end{tabular}

Page 3291 
Supplemental Table S2.txt

\begin{tabular}{|c|c|c|c|c|c|}
\hline CHEMBL3702280 & 1528144 & 7.585 & 7.5 & TRN & \\
\hline CHEMBL3702307 & 1528144 & 8.0 & 8.0563 & TRN & \\
\hline CHEMBL3702279 & 1528144 & 7.3768 & 7.3661 & TRN & \\
\hline CHEMBL3640011 & 1528144 & 7.5376 & 7.4458 & TRN & \\
\hline CHEMBL 3698924 & 1528144 & 7.0458 & 7.1683 & TRN & \\
\hline CHEMBL3698946 & 1528144 & 7.8239 & 7.9379 & TRN & \\
\hline CHEMBL 3702324 & 1528144 & 7.7447 & 7.8034 & TRN & \\
\hline CHEMBL3702315 & 1528144 & 7.5376 & 7.4899 & TRN & \\
\hline CHEMBL3702301 & 1528144 & 7.699 & 7.6626 & TRN & \\
\hline CHEMBL3698942 & 1528144 & 5.9333 & 5.9454 & TRN & \\
\hline CHEMBL 3702296 & 1528144 & 7.8539 & 7.8624 & TRN & \\
\hline CHEMBL3209562 & 1528144 & 6.0 & 4.8172 & TST & \\
\hline CHEMBL 3702303 & 1528144 & 6.9031 & 6.8541 & TRN & \\
\hline CHEMBL3698916 & 1528144 & 7.3872 & 7.4204 & TRN & \\
\hline CHEMBL 3702288 & 1528144 & 7.3468 & 7.3361 & TRN & \\
\hline CHEMBL3698930 & 1528144 & 7.284 & 7.28299 & 99999999995 & TRN \\
\hline CHEMBL3702291 & 1528144 & 7.1938 & 6.4423 & TST & \\
\hline CHEMBL 3702349 & 1528144 & 7.1612 & 7.1665 & TRN & \\
\hline CHEMBL3698939 & 1528144 & 7.3565 & 7.3176 & TRN & \\
\hline CHEMBL 3702294 & 1528144 & 7.3372 & 7.3335 & TRN & \\
\hline CHEMBL 3702297 & 1528144 & 7.5086 & 7.6229 & TRN & \\
\hline CHEMBL427876 & 1528144 & 7.5229 & 7.1391 & TST & \\
\hline CHEMBL 3702264 & 1528144 & 7.7447 & 7.7246 & TRN & \\
\hline CHEMBL3702306 & 1528144 & 7.8861 & 7.8247 & TRN & \\
\hline CHEMBL 3698937 & 1528144 & 8.0969 & 7.9129 & TRN & \\
\hline CHEMBL 3698928 & 1528144 & 6.6402 & 6.6422 & TRN & \\
\hline CHEMBL3702273 & 1528144 & 7.3279 & 5.7691 & TST & \\
\hline CHEMBL 3702292 & 1528144 & 7.6198 & 7.6506 & TRN & \\
\hline CHEMBL 3702286 & 1528144 & 7.2007 & 7.1946 & TRN & \\
\hline CHEMBL 3702277 & 1528144 & 7.9208 & 7.8233 & TRN & \\
\hline CHEMBL 3702269 & 1528144 & 7.9586 & 7.9074 & TRN & \\
\hline CHEMBL3702268 & 1528144 & 7.7212 & 7.8809 & TRN & \\
\hline CHEMBL 3702302 & 1528144 & 7.0757 & 7.0963 & TRN & \\
\hline CHEMBL3698957 & 1528144 & 8.0969 & 8.1039 & TRN & \\
\hline CHEMBL3698955 & 1528144 & 8.2218 & 8.2752 & TRN & \\
\hline CHEMBL3702290 & 1528144 & 7.2676 & 7.3208 & TRN & \\
\hline CHEMBL3698935 & 1528144 & 5.9927 & 5.999 & TRN & \\
\hline CHEMBL 3702327 & 1528144 & 7.9208 & 7.91700 & 0000000001 & TRN \\
\hline CHEMBL 3915325 & 1528144 & 7.9208 & 6.8487 & TST & \\
\hline CHEMBL3702313 & 1528144 & 6.9586 & 6.8932 & TRN & \\
\hline CHEMBL 3702249 & 1528144 & 8.0969 & 8.0946 & TRN & \\
\hline CHEMBL3698947 & 1528144 & 7.9586 & 8.0141 & TRN & \\
\hline CHEMBL3702308 & 1528144 & 7.6021 & 7.7202 & TRN & \\
\hline CHEMBL1490677 & 1528144 & 6.0 & 6.7943 & TST & \\
\hline CHEMBL3702319 & 1528144 & 7.8861 & 7.8829 & TRN & \\
\hline CHEMBL 3702274 & 1528144 & 7.7959 & 6.7866 & TST & \\
\hline CHEMBL3698948 & 1528144 & 7.2676 & 7.2542 & TRN & \\
\hline CHEMBL3698938 & 1528144 & 7.1308 & 7.1416 & TRN & \\
\hline
\end{tabular}


Supplemental Table S2.txt

\begin{tabular}{|c|c|c|c|c|c|}
\hline CHEMBL3702256 & 1528144 & 7.2366 & 7.256 & TRN & \\
\hline CHEMBL3702283 & 1528144 & 7.2596 & 7.2629 & TRN & \\
\hline CHEMBL3698927 & 1528144 & 6.2388 & 6.1964 & TRN & \\
\hline CHEMBL 3702314 & 1528144 & 6.9245 & 7.0182 & TRN & \\
\hline CHEMBL 3702258 & 1528144 & 7.585 & 7.6607 & TRN & \\
\hline CHEMBL 3702254 & 1528144 & 6.1024 & 6.16 & TRN & \\
\hline CHEMBL3702250 & 1528144 & 8.1549 & 8.0981 & TRN & \\
\hline CHEMBL3702281 & 1528144 & 7.3565 & 7.3927 & TRN & \\
\hline CHEMBL1372231 & 1528144 & 6.7696 & 6.2685 & TST & \\
\hline CHEMBL3702354 & 1528144 & 7.4559 & 7.5362 & TRN & \\
\hline CHEMBL3698941 & 1528144 & 5.8164 & 5.7301 & TRN & \\
\hline CHEMBL3632739 & 1528144 & 8.3979 & 8.2654 & TRN & \\
\hline CHEMBL3698910 & 1528144 & 6.466 & 6.5809 & TRN & \\
\hline CHEMBL 3702285 & 1528144 & 7.7212 & 7.7225 & TRN & \\
\hline CHEMBL 3702263 & 1528144 & 7.699 & 7.7067 & TRN & \\
\hline CHEMBL3702261 & 1528144 & 7.0655 & 7.0435 & TRN & \\
\hline CHEMBL3702265 & 1528144 & 7.3188 & 7.3665 & TRN & \\
\hline CHEMBL3698934 & 1528144 & 6.0467 & 6.0567 & TRN & \\
\hline CHEMBL3698933 & 1528144 & 6.1694 & 6.1664 & TRN & \\
\hline CHEMBL3698951 & 1528144 & 7.6198 & 7.5805 & TRN & \\
\hline CHEMBL3698931 & 1528144 & 7.0458 & 7.0247 & TRN & \\
\hline CHEMBL3698950 & 1528144 & 7.9208 & 7.9045 & TRN & \\
\hline CHEMBL3702255 & 1528144 & 7.4815 & 7.5175 & TRN & \\
\hline CHEMBL3702329 & 1528144 & 7.9586 & 7.941 & TRN & \\
\hline CHEMBL3702304 & 1528144 & 7.9208 & 7.9647 & TRN & \\
\hline CHEMBL3698915 & 1528144 & 7.6383 & 7.5922 & TRN & \\
\hline CHEMBL3932333 & 1528144 & 7.8861 & 5.6935 & TST & \\
\hline CHEMBL3698944 & 1528144 & 7.6021 & 7.6533 & TRN & \\
\hline CHEMBL 3702326 & 1528144 & 7.9208 & 7.82299 & 99999999995 & TRN \\
\hline CHEMBL3702320 & 1528144 & 8.0969 & 8.0698 & TRN & \\
\hline CHEMBL3698920 & 1528144 & 6.3536 & 6.3297 & TRN & \\
\hline CHEMBL3698959 & 1528144 & 8.0 & 8.0266 & TRN & \\
\hline CHEMBL1236081 & 1528144 & 7.6021 & 6.4793 & TST & \\
\hline CHEMBL3702282 & 1528144 & 7.6021 & 6.5459 & TST & \\
\hline CHEMBL3659491 & 1528144 & 8.2218 & 8.3342 & TRN & \\
\hline CHEMBL3702305 & 1528144 & 8.0969 & 7.9928 & TRN & \\
\hline CHEMBL3698911 & 1528144 & 6.5317 & 6.5031 & TRN & \\
\hline CHEMBL 3702321 & 1528144 & 7.6383 & 7.6403 & TRN & \\
\hline CHEMBL3698956 & 1528144 & 8.3979 & 8.334 & TRN & \\
\hline CHEMBL3698945 & 1528144 & 7.2291 & 7.2074 & TRN & \\
\hline CHEMBL3702267 & 1528144 & 7.1135 & 7.1423 & TRN & \\
\hline CHEMBL3702284 & 1528144 & 7.5686 & 7.5819 & TRN & \\
\hline CHEMBL1609317 & 1528144 & 7.1079 & 6.8522 & TST & \\
\hline CHEMBL3698936 & 1528144 & 6.7595 & 7.0459 & TRN & \\
\hline CHEMBL3698954 & 1528144 & 7.1079 & 7.2373 & TRN & \\
\hline CHEMBL3698917 & 1528144 & 6.6904 & 6.6398 & TRN & \\
\hline CHEMBL3702295 & 1528144 & 7.585 & 7.6591 & TRN & \\
\hline CHEMBL 3702323 & 1528144 & 7.8861 & 7.7952 & TRN & \\
\hline
\end{tabular}


Supplemental Table S2.txt

\begin{tabular}{|c|c|c|c|c|c|}
\hline CHEMBL 3702318 & 1528144 & 7.7212 & 7.2995 & TST & \\
\hline CHEMBL3698960 & 1528144 & 7.7696 & 7.6487 & TRN & \\
\hline CHEMBL3702311 & 1528144 & 5.2674 & 5.2468 & TRN & \\
\hline CHEMBL3698926 & 1528144 & 7.1938 & 7.1207 & TRN & \\
\hline CHEMBL3698949 & 1528144 & 7.3768 & 7.4341 & TRN & \\
\hline CHEMBL1303465 & 1528144 & 7.1871 & 7.3127 & TST & \\
\hline CHEMBL3702262 & 1528144 & 6.5406 & 6.484 & TRN & \\
\hline CHEMBL3702350 & 1528144 & 7.4559 & 7.4662 & TRN & \\
\hline CHEMBL3702322 & 1528144 & 8.301 & 8.315 & TRN & \\
\hline CHEMBL3698912 & 1528144 & 7.1549 & 6.9862 & TRN & \\
\hline CHEMBL3702275 & 1528144 & 7.2676 & 6.5363 & TST & \\
\hline CHEMBL3698921 & 1528144 & 5.5025 & 5.5456 & TRN & \\
\hline CHEMBL 3702351 & 1528144 & 7.6021 & 7.5853 & TRN & \\
\hline CHEMBL3639977 & 1528144 & 6.3382 & 6.4213 & TRN & \\
\hline CHEMBL 3702310 & 1528144 & 7.9586 & 8.082 & TRN & \\
\hline CHEMBL3702270 & 1528144 & 7.8861 & 7.7884 & TRN & \\
\hline CHEMBL3698909 & 1528144 & 7.284 & 7.1009 & TRN & \\
\hline CHEMBL 3702272 & 1528144 & 6.5735 & 6.0961 & TST & \\
\hline CHEMBL3702325 & 1528144 & 7.8539 & 7.8129 & TST & \\
\hline CHEMBL 3702252 & 1528144 & 8.1549 & 7.4905 & TST & \\
\hline CHEMBL 3702287 & 1528144 & 7.4949 & 7.4817 & TST & \\
\hline CHEMBL3698943 & 1528144 & 6.8477 & 6.6875 & TST & \\
\hline CHEMBL3702309 & 1528144 & 8.1549 & 7.749 & TST & \\
\hline CHEMBL191003 & 1528144 & 7.1871 & 9.8508 & TST & \\
\hline CHEMBL3702251 & 1528144 & 8.1549 & 8.1363 & TST & \\
\hline CHEMBL 3702352 & 1528144 & 8.0969 & 7.7692 & TST & \\
\hline CHEMBL3702259 & 1528144 & 7.1079 & 7.1685 & TST & \\
\hline CHEMBL3698929 & 1528144 & 6.3788 & 7.0198 & TST & \\
\hline CHEMBL3698940 & 1528144 & 6.1605 & 6.4576 & TST & \\
\hline CHEMBL3702300 & 1528144 & 7.6198 & 7.7389 & TST & \\
\hline CHEMBL3918041 & 1528144 & 7.7959 & 6.08799 & 9999999999 & TST \\
\hline CHEMBL3702276 & 1528144 & 7.8239 & 7.3676 & TST & \\
\hline CHEMBL 3698914 & 1528144 & 7.301 & 7.5011 & TST & \\
\hline CHEMBL1419943 & 1528144 & 7.6383 & 5.9467 & TST & \\
\hline CHEMBL3702298 & 1528144 & 7.1549 & 7.2277 & TST & \\
\hline CHEMBL3702278 & 1528144 & 7.4559 & 7.7008 & TST & \\
\hline CHEMBL3698918 & 1528144 & 7.7447 & 7.9399 & TST & \\
\hline CHEMBL3698932 & 1528144 & \multicolumn{3}{|c|}{6.327000000000001} & TST \\
\hline CHEMBL3963453 & 1528648 & 9.0 & 8.9025 & TRN & \\
\hline CHEMBL3937904 & 1528648 & 9.0 & 8.9545 & TRN & \\
\hline CHEMBL3969688 & 1528648 & 9.3979 & 9.4188 & TRN & \\
\hline CHEMBL3931100 & 1528648 & 8.7696 & 8.2907 & TST & \\
\hline CHEMBL3945064 & 1528648 & 8.2596 & 8.2222 & TRN & \\
\hline CHEMBL3671821 & 1528648 & 8.2924 & 8.0478 & TST & \\
\hline CHEMBL 3937803 & 1528648 & 9.5229 & 9.4807 & TRN & \\
\hline CHEMBL3984096 & 1528648 & 7.3546 & 8.2219 & TST & \\
\hline CHEMBL 3944694 & 1528648 & 7.6556 & 7.6408 & TRN & \\
\hline CHEMBL 3671797 & 1528648 & 8.7959 & 8.7271 & TRN & \\
\hline
\end{tabular}


Supplemental Table S2.txt

\begin{tabular}{|c|c|c|c|c|}
\hline S & & 9959 & 781 & \\
\hline & & 9.0969 & 9.1045 & \\
\hline & & & & \\
\hline IEMBL & & & & \\
\hline AEMBL3936572 & 528648 & 8.7696 & 8586 & \\
\hline HEMBL3957553 & 528648 & 8.1675 & 8347 & \\
\hline 33 & 548 & 212 & 7564 & \\
\hline |FMRI & & & 4384 & \\
\hline AEMBL3967051 & 528648 & 8.2518 & 2353 & \\
\hline HEMBL3920681 & 528648 & 9.699 & 7374 & \\
\hline HEMBL3930712 & 528648 & 9.5229 & 5332 & \\
\hline IEMBL36 & 48 & 67 & 461 & \\
\hline IEMBL: & & & & \\
\hline HEMBL36 & 528648 & 586 & 9521 & \\
\hline AEMBL39 & 528648 & & 272 & \\
\hline HEMBL390 & 8648 & 7. & 537 & \\
\hline AEMBL39 & +8 & 8 & 266 & . \\
\hline HEMBL39 & & & & \\
\hline AEMBL36 & 528648 & 67 & 5984 & \\
\hline AEMBL39 & 48 & & & \\
\hline HEIMBL3t & 528648 & 7. & 904 & Niv \\
\hline AEMBL3S & 48 & 7. & 903 & RN \\
\hline HEMBL3S & 18 & & 386 & \\
\hline 997 & & & 018 & \\
\hline AEMBL3S & & 6 . & & I RIV \\
\hline HEMBL3 & 8648 & 8. & & RN \\
\hline AEMBL & & 9. & 53 & 然 \\
\hline$H F M B I=$ & 48 & 9 . & 94 & \\
\hline HEMBL36 & & 506 & 539 & in \\
\hline HEMBL 367 & 48 & & 951 & IRN \\
\hline HEMBL3S & 8648 & & 361 & SI \\
\hline HEMBL & & 8 & 541 & ST \\
\hline 41 & 48 & 7. & 383 & TRN \\
\hline HEMBL397 & & 8 . & 104 & IRN \\
\hline HEMBL3982862 & 528648 & 8.1487 & 3596 & TST \\
\hline HEMBL3 & 3648 & 5 & 5997 & ГST \\
\hline HᄃMD - & & & 821 & $\Gamma \mathrm{RN}$ \\
\hline & & & 867 & ГST \\
\hline HEMBL3671803 & 528648 & 8. & 638 & TST \\
\hline EMBL3 & 528648 & & 811 & IRN \\
\hline HEMBL36 & 3648 & & 3423 & \\
\hline HEMBL 36 & & & 041 & ST \\
\hline HEMBL36 & 528310 & & 3999 & ГST \\
\hline AEMBL3676562 & 528310 & 6.4622 & 081 & RN \\
\hline 1. & 3310 & & 476 & |S| \\
\hline HEMBL36 & & & & \\
\hline HEMBL3681793 & 528310 & 7.3468 & 733 & \\
\hline HEMBL3671598 & 1528310 & 4.7993 & 4.3026 & 2 \\
\hline
\end{tabular}

Page 3295 
Supplemental Table S2.txt

\begin{tabular}{|c|c|c|c|c|c|}
\hline CHEMBL3681809 & 1528310 & 7.8539 & 7.4217 & TRN & \\
\hline CHEMBL3681824 & 1528310 & 6.2924 & 6.3356 & TST & \\
\hline CHEMBL3681697 & 1528310 & 7.4949 & 7.1195 & TRN & \\
\hline CHEMBL3671677 & 1528310 & 6.3925 & 5.8027 & TST & \\
\hline CHEMBL3681685 & 1528310 & 7.284 & 6.9969 & TRN & \\
\hline CHEMBL3676619 & 1528310 & 7.2518 & 7.6677 & TST & \\
\hline CHEMBL3681795 & 1528310 & 5.0 & 5.0767 & TRN & \\
\hline CHEMBL3671780 & 1528310 & 6.8996 & 6.666 & TRN & \\
\hline CHEMBL3676676 & 1528310 & 7.1805 & 7.7803 & TRN & \\
\hline CHEMBL3681706 & 1528310 & 7.2518 & 7.26 & TRN & \\
\hline CHEMBL3681792 & 1528310 & 7.5528 & 7.5924 & TRN & \\
\hline CHEMBL3671665 & 1528310 & 5.0838 & 4.8591 & TST & \\
\hline CHEMBL3681663 & 1528310 & 5.2234 & 4.958 & TRN & \\
\hline CHEMBL3681789 & 1528310 & 5.0 & 5.4854 & TRN & \\
\hline CHEMBL3681762 & 1528310 & 7.284 & 6.9513 & TRN & \\
\hline CHEMBL3676711 & 1528310 & 6.7496 & 6.9528 & TRN & \\
\hline CHEMBL3671740 & 1528310 & 6.6556 & 6.111006 & 0000000001 & TRN \\
\hline CHEMBL 3676740 & 1528310 & 7.2366 & 7.0207 & TRN & \\
\hline CHEMBL3681702 & 1528310 & 6.0 & 6.8473 & TRN & \\
\hline CHEMBL3676616 & 1528310 & 4.0 & 4.7384 & TST & \\
\hline CHEMBL3676594 & 1528310 & 6.0921 & 5.9478 & TRN & \\
\hline CHEMBL3671775 & 1528310 & 6.2518 & 6.0458 & TRN & \\
\hline CHEMBL3676581 & 1528310 & 6.8477 & 7.4525 & TRN & \\
\hline CHEMBL3671689 & 1528310 & 6.5867 & 6.4292 & TRN & \\
\hline CHEMBL3671603 & 1528310 & 6.3401 & 5.6311 & TRN & \\
\hline CHEMBL3681653 & 1528310 & 6.0 & 5.8335 & TRN & \\
\hline CHEMBL3676737 & 1528310 & 6.3143 & 6.5382 & TST & \\
\hline CHEMBL3671604 & 1528310 & 3.0 & 5.2219 & TST & \\
\hline CHEMBL 3676704 & 1528310 & 5.7124 & 5.1601 & TRN & \\
\hline CHEMBL3676580 & 1528310 & 5.7016 & 5.477 & TST & \\
\hline CHEMBL 3676748 & 1528310 & 4.0 & 4.4323 & TST & \\
\hline CHEMBL3676607 & 1528310 & 5.8582 & 5.5081 & TST & \\
\hline CHEMBL3681825 & 1528310 & 5.0 & 6.5371 & TST & \\
\hline CHEMBL3681817 & 1528310 & 7.0 & 6.5117 & TRN & \\
\hline CHEMBL3676670 & 1528310 & 6.4413 & 6.0033 & TRN & \\
\hline CHEMBL3676712 & 1528310 & 5.8771 & 5.39 & TRN & \\
\hline CHEMBL3681705 & 1528310 & 6.0 & 7.1281 & TRN & \\
\hline CHEMBL3671722 & 1528310 & 5.6194 & 5.6102 & TST & \\
\hline CHEMBL3681693 & 1528310 & 7.5086 & 7.519 & TRN & \\
\hline CHEMBL3681676 & 1528310 & 7.7447 & 7.4902 & TRN & \\
\hline CHEMBL3676570 & 1528310 & 5.2683 & 5.0884 & TST & \\
\hline CHEMBL3681853 & 1528310 & 7.5229 & 7.5007 & TRN & \\
\hline CHEMBL3676751 & 1528310 & 5.1954 & 5.546 & TRN & \\
\hline CHEMBL3671731 & 1528310 & 5.9136 & 5.0452 & TRN & \\
\hline CHEMBL3671692 & 1528310 & 6.3354 & \multicolumn{2}{|c|}{6.047999999999999} & TRN \\
\hline CHEMBL3671636 & 1528310 & 5.5867 & 4.6739 & TRN & \\
\hline CHEMBL3676597 & 1528310 & 6.1433 & 6.4404 & TRN & \\
\hline CHEMBL3676656 & 1528310 & 4.0 & 5.5572 & TST & \\
\hline
\end{tabular}


Supplemental Table S2.txt

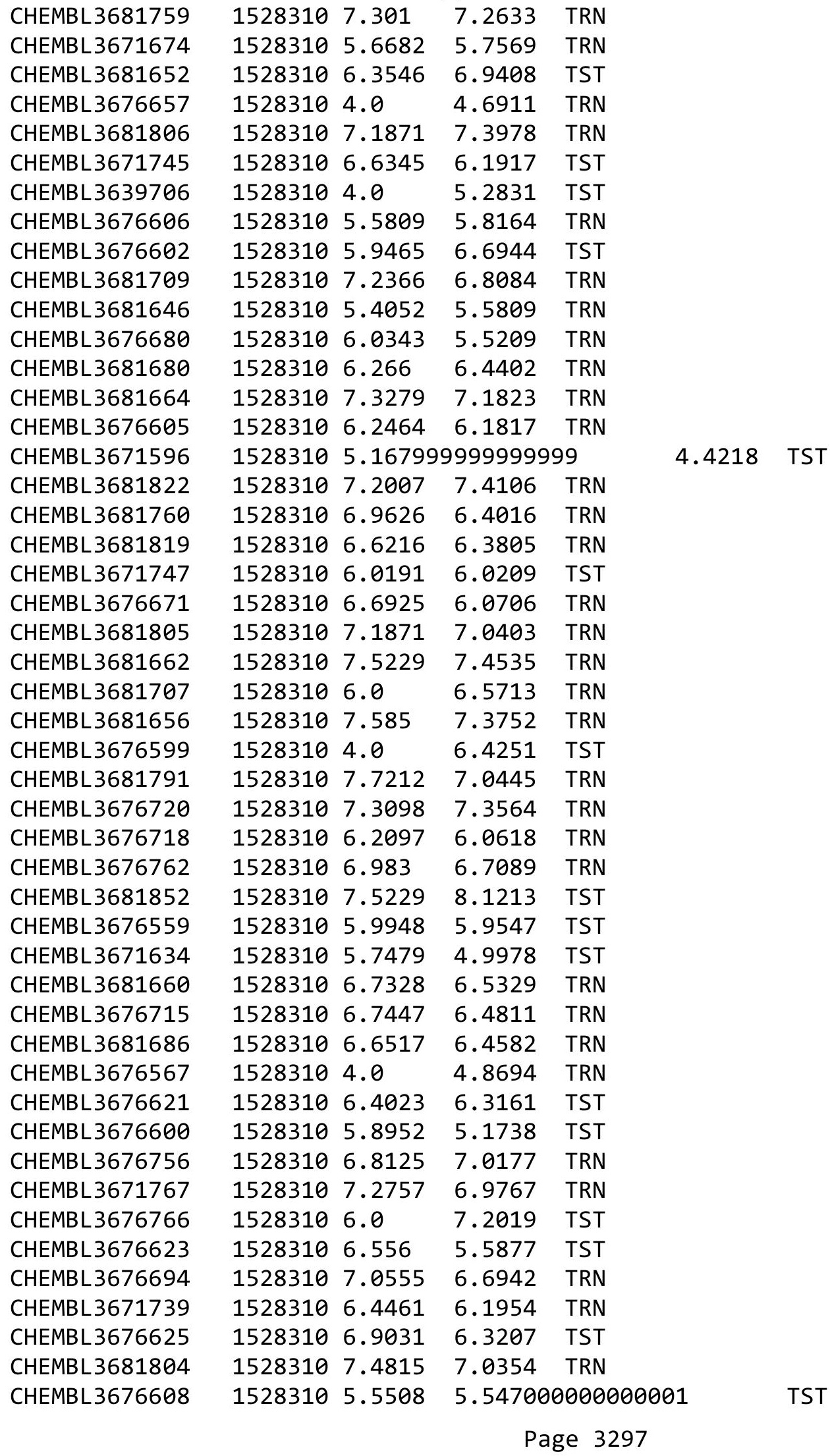


Supplemental Table S2.txt

\begin{tabular}{|c|c|c|c|c|}
\hline CHEMBL 3681772 & 1528310 & 7.1135 & 6.4624 & TRN \\
\hline CHEMBL 3671625 & 1528310 & 5.6075 & 5.3549 & TRN \\
\hline CHEMBL 3671742 & 1528310 & 5.5955 & 5.8761 & TST \\
\hline CHEMBL 3671612 & 1528310 & 6.0716 & 4.9504 & TRN \\
\hline CHEMBL3671787 & 1528310 & 5.6498 & 6.0057 & TRN \\
\hline CHEMBL3671668 & 1528310 & 5.9427 & 4.4026 & TST \\
\hline CHEMBL 3681846 & 1528310 & 5.8407 & 5.6265 & TRN \\
\hline CHEMBL 3676706 & 1528310 & 6.7282 & 6.5424 & TRN \\
\hline CHEMBL 3681673 & 1528310 & 6.0 & 6.6973 & TRN \\
\hline CHEMBL3676662 & 1528310 & 5.1958 & 5.3037 & TRN \\
\hline CHEMBL3671635 & 1528310 & 7.0 & 6.5205 & TRN \\
\hline CHEMBL 3676683 & 1528310 & 4.0 & 4.2761 & TRN \\
\hline CHEMBL 3676758 & 1528310 & 7.6576 & 7.3407 & TRN \\
\hline CHEMBL 3671590 & 1528310 & 5.9322 & 5.7108 & TRN \\
\hline CHEMBL3681714 & 1528310 & 6.0 & 6.4029 & TRN \\
\hline CHEMBL3681659 & 1528310 & 7.4089 & 6.966 & TRN \\
\hline CHEMBL3676705 & 1528310 & 6.0 & 6.9474 & TRN \\
\hline CHEMBL 3671617 & 1528310 & 3.0 & 4.0373 & TRN \\
\hline CHEMBL3681641 & 1528310 & 6.0 & 7.3507 & TRN \\
\hline CHEMBL3681639 & 1528310 & 7.2218 & 6.7461 & TST \\
\hline CHEMBL3671611 & 1528310 & 4.7546 & 4.5738 & TRN \\
\hline CHEMBL3681679 & 1528310 & 7.3979 & 7.4563 & TRN \\
\hline CHEMBL 3676679 & 1528310 & 6.04 & 6.154 & TRN \\
\hline CHEMBL 3676578 & 1528310 & 5.4304 & 5.6309 & TST \\
\hline CHEMBL 3681794 & 1528310 & 5.0 & 4.6581 & TRN \\
\hline CHEMBL3681776 & 1528310 & 7.5376 & 7.1548 & TRN \\
\hline CHEMBL 3676732 & 1528310 & 6.6308 & 7.0002 & TRN \\
\hline CHEMBL 3676640 & 1528310 & 5.3057 & 5.8408 & TST \\
\hline CHEMBL3681683 & 1528310 & 7.2596 & 7.0133 & TRN \\
\hline CHEMBL 3676618 & 1528310 & 6.2733 & 6.1262 & TRN \\
\hline CHEMBL 3671786 & 1528310 & 6.1506 & 6.50799 & 9999999999 \\
\hline CHEMBL 3676753 & 1528310 & 7.5086 & 7.9342 & TRN \\
\hline CHEMBL 3681849 & 1528310 & 7.1024 & 6.6105 & TST \\
\hline CHEMBL 3676703 & 1528310 & 7.2757 & 7.2635 & TRN \\
\hline CHEMBL 3681750 & 1528310 & 7.2291 & 7.1359 & TRN \\
\hline CHEMBL3681687 & 1528310 & 7.699 & 7.6697 & TRN \\
\hline CHEMBL3681803 & 1528310 & 6.0 & 6.6813 & TRN \\
\hline CHEMBL 3671772 & 1528310 & 4.0 & 5.7855 & TST \\
\hline CHEMBL3671672 & 1528310 & 6.1746 & 6.3858 & TRN \\
\hline CHEMBL 3676725 & 1528310 & 6.153 & 6.477 & TST \\
\hline CHEMBL3681681 & 1528310 & 7.6198 & 7.7163 & TRN \\
\hline CHEMBL3671688 & 1528310 & 6.5544 & 6.4525 & TRN \\
\hline CHEMBL 3671627 & 1528310 & 5.2546 & 5.349 & TRN \\
\hline CHEMBL3676628 & 1528310 & 5.8199 & 5.9987 & TRN \\
\hline CHEMBL 3676775 & 1528310 & 7.7212 & 7.3701 & TRN \\
\hline CHEMBL3671637 & 1528310 & 5.3969 & 5.8615 & TRN \\
\hline CHEMBL3671608 & 1528310 & 6.2434 & 5.885 & TRN \\
\hline CHEMBL3676586 & 1528310 & 6.5986 & 5.7705 & TRN \\
\hline
\end{tabular}


Supplemental Table S2.txt

\begin{tabular}{|c|c|c|c|c|}
\hline CHEMBL 3671621 & 1528310 & 6.2034 & 7.1615 & TST \\
\hline CHEMBL 3676777 & 1528310 & 6.6021 & 7.897 & TST \\
\hline CHEMBL3671711 & 1528310 & 4.0 & \multicolumn{2}{|c|}{4.8180000000000005} \\
\hline CHEMBL 3681645 & 1528310 & 5.9385 & 6.6828 & TRN \\
\hline CHEMBL 3681810 & 1528310 & 5.0 & 5.2949 & TRN \\
\hline CHEMBL3676684 & 1528310 & 6.3019 & 6.2771 & TRN \\
\hline CHEMBL 3681780 & 1528310 & 5.0 & 5.6554 & TRN \\
\hline CHEMBL 3676747 & 1528310 & 6.2565 & 6.8503 & TRN \\
\hline CHEMBL3671616 & 1528310 & 5.8687 & 5.0154 & TRN \\
\hline CHEMBL 3676611 & 1528310 & 6.8761 & 7.0719 & TRN \\
\hline CHEMBL3676557 & 1528310 & 6.5513 & 6.551 & TST \\
\hline CHEMBL 3671724 & 1528310 & 6.2652 & 5.3089 & TST \\
\hline CHEMBL3671733 & 1528310 & 5.2829 & 5.584 & TRN \\
\hline CHEMBL 3676576 & 1528310 & 5.6592 & 5.4182 & TRN \\
\hline CHEMBL 3671683 & 1528310 & 5.6156 & 5.3881 & TRN \\
\hline CHEMBL3671710 & 1528310 & 4.0 & 4.5176 & TRN \\
\hline CHEMBL3681739 & 1528310 & 6.9626 & 6.5464 & TRN \\
\hline CHEMBL 3671620 & 1528310 & 3.0 & 4.498 & TRN \\
\hline CHEMBL 3671651 & 1528310 & 4.1785 & 4.7595 & TST \\
\hline CHEMBL 3671750 & 1528310 & 4.0 & 4.3177 & TRN \\
\hline CHEMBL 3681655 & 1528310 & 7.1938 & 7.334 & TRN \\
\hline CHEMBL 3676575 & 1528310 & 5.9796 & 5.5481 & TRN \\
\hline CHEMBL3676577 & 1528310 & 6.2581 & 5.8405 & TRN \\
\hline CHEMBL 3671610 & 1528310 & 4.5106 & 4.8054 & TRN \\
\hline CHEMBL 3681736 & 1528310 & 7.7959 & 7.7159 & TRN \\
\hline CHEMBL3681816 & 1528310 & 6.2518 & 6.433 & TRN \\
\hline CHEMBL 3681678 & 1528310 & 6.0 & 6.195 & TRN \\
\hline CHEMBL 3671624 & 1528310 & 5.3447 & 5.5103 & TRN \\
\hline CHEMBL 3681717 & 1528310 & 7.3188 & 7.3244 & TRN \\
\hline CHEMBL 3671693 & 1528310 & 5.8804 & 5.8291 & TST \\
\hline CHEMBL 3681802 & 1528310 & 6.0 & 6.6239 & TRN \\
\hline CHEMBL 3676776 & 1528310 & 7.1938 & 6.7473 & TRN \\
\hline CHEMBL3671628 & 1528310 & 5.4067 & 4.763 & TRN \\
\hline CHEMBL 3671785 & 1528310 & 6.3737 & 6.3662 & TRN \\
\hline CHEMBL 3681713 & 1528310 & 7.2676 & 6.7248 & TRN \\
\hline CHEMBL3671716 & 1528310 & 6.1586 & 5.9511 & TRN \\
\hline CHEMBL 3671644 & 1528310 & 6.1124 & 5.5118 & TRN \\
\hline CHEMBL3681787 & 1528310 & 5.0 & 5.4329 & TRN \\
\hline CHEMBL 3681642 & 1528310 & 7.4949 & 7.1124 & TRN \\
\hline CHEMBL 3676693 & 1528310 & 6.699 & 6.8462 & TRN \\
\hline CHEMBL3676636 & 1528310 & 6.1972 & 5.9124 & TRN \\
\hline CHEMBL 3671642 & 1528310 & 5.2502 & 5.1884 & TRN \\
\hline CHEMBL3681747 & 1528310 & 5.0 & 6.0907 & TST \\
\hline CHEMBL 3676678 & 1528310 & 5.8492 & 5.3371 & TRN \\
\hline CHEMBL 3676755 & 1528310 & 7.1739 & 6.9475 & TRN \\
\hline CHEMBL3681769 & 1528310 & 7.7212 & 7.3277 & TRN \\
\hline CHEMBL 3676689 & 1528310 & 7.3279 & 6.8762 & TST \\
\hline CHEMBL3681854 & 1528310 & 7.699 & 7.8015 & TRN \\
\hline
\end{tabular}


Supplemental Table S2.txt

\begin{tabular}{|c|c|c|c|c|c|}
\hline CHEMBL3681834 & 1528310 & 7.4437 & 7.3629 & TRN & \\
\hline CHEMBL3676765 & 1528310 & 6.0 & 6.8508 & TST & \\
\hline CHEMBL3671609 & 1528310 & 3.0 & 4.3121 & TRN & \\
\hline CHEMBL 3671758 & 1528310 & 5.0962 & 5.5299 & TRN & \\
\hline CHEMBL 3671737 & 1528310 & 6.0942 & 5.2247 & TRN & \\
\hline CHEMBL3676589 & 1528310 & 7.0088 & 6.1986 & TRN & \\
\hline CHEMBL 3676643 & 1528310 & 6.7447 & 6.4266 & TRN & \\
\hline CHEMBL 3676655 & 1528310 & 5.5741 & 5.9594 & TRN & \\
\hline CHEMBL 3676604 & 1528310 & 5.9987 & 6.3909 & TST & \\
\hline CHEMBL 3681745 & 1528310 & 7.1135 & 7.0698 & TRN & \\
\hline CHEMBL 3671706 & 1528310 & 7.3098 & 7.705 & TRN & \\
\hline CHEMBL3681712 & 1528310 & 7.2441 & 7.2364 & TRN & \\
\hline CHEMBL 3676750 & 1528310 & 6.71 & 6.1619 & TRN & \\
\hline CHEMBL 3676733 & 1528310 & 7.0506 & 7.3019 & TRN & \\
\hline CHEMBL 3671761 & 1528310 & 5.8729 & 6.3965 & TRN & \\
\hline CHEMBL 3681811 & 1528310 & 6.1713 & 6.1386 & TRN & \\
\hline CHEMBL 3676653 & 1528310 & 6.3439 & 6.19 & TRN & \\
\hline CHEMBL 3671641 & 1528310 & 3.0 & 3.6111 & TRN & \\
\hline CHEMBL 3681654 & 1528310 & 7.5528 & 7.5524 & TRN & \\
\hline CHEMBL3671666 & 1528310 & 5.5588 & 4.5927 & TRN & \\
\hline CHEMBL3676669 & 1528310 & 5.6015 & 5.9036 & TRN & \\
\hline CHEMBL 3676646 & 1528310 & 6.6289 & 6.4128 & TRN & \\
\hline CHEMBL 3676664 & 1528310 & 5.6358 & 5.3621 & TRN & \\
\hline CHEMBL 3681727 & 1528310 & 7.5686 & 7.4233 & TRN & \\
\hline CHEMBL3681796 & 1528310 & 7.3872 & 7.4359 & TRN & \\
\hline CHEMBL 3676709 & 1528310 & 5.9678 & 5.3721 & TST & \\
\hline CHEMBL3681692 & 1528310 & 7.6383 & 7.7986 & TRN & \\
\hline CHEMBL3676569 & 1528310 & 4.0 & 4.9578 & TRN & \\
\hline CHEMBL 3676622 & 1528310 & 5.1257 & 5.4635 & TST & \\
\hline CHEMBL3671687 & 1528310 & 6.82100 & 10000000 & 1 & 6.2778 \\
\hline CHEMBL 3676727 & 1528310 & 5.8268 & 5.5804 & TST & \\
\hline CHEMBL 3671680 & 1528310 & 5.1062 & 5.1922 & TST & \\
\hline CHEMBL 3676565 & 1528310 & 5.2734 & 4.989 & TRN & \\
\hline CHEMBL3681770 & 1528310 & 7.6778 & 7.4757 & TRN & \\
\hline CHEMBL3681779 & 1528310 & 5.0 & 5.7524 & TRN & \\
\hline CHEMBL 3681721 & 1528310 & 7.3098 & 7.4315 & TRN & \\
\hline CHEMBL 3681840 & 1528310 & 7.2291 & 6.5431 & TRN & \\
\hline CHEMBL 3681800 & 1528310 & 7.4318 & 7.3226 & TRN & \\
\hline CHEMBL3681768 & 1528310 & 7.6778 & 6.9351 & TRN & \\
\hline CHEMBL3686491 & 1528310 & 7.5086 & 7.568 & TRN & \\
\hline CHEMBL 3681722 & 1528310 & 6.0 & 6.5178 & TRN & \\
\hline CHEMBL 3671647 & 1528310 & 4.8033 & 4.9494 & TRN & \\
\hline CHEMBL 3676741 & 1528310 & 6.1555 & 6.6645 & TRN & \\
\hline CHEMBL3676598 & 1528310 & 5.7934 & 5.9546 & TST & \\
\hline CHEMBL 3671658 & 1528310 & 5.3175 & 4.7905 & TRN & \\
\hline CHEMBL 3676638 & 1528310 & 5.2346 & 5.4583 & TRN & \\
\hline CHEMBL 3671643 & 1528310 & 6.71 & 5.9995 & TRN & \\
\hline CHEMBL3681665 & 1528310 & 7.3768 & 7.2925 & TRN & \\
\hline
\end{tabular}

Page 3300 
Supplemental Table S2.txt

\begin{tabular}{|c|c|c|c|c|c|c|}
\hline CHEMBL 3671697 & 1528310 & 5.9535 & 4.8924 & TST & & \\
\hline CHEMBL3671671 & 1528310 & 6.4225 & \multicolumn{3}{|c|}{6.502000000000001} & TRN \\
\hline CHEMBL3681726 & 1528310 & 7.585 & 7.2257 & TRN & & \\
\hline CHEMBL 3671770 & 1528310 & 6.4168 & 5.5311 & TRN & & \\
\hline CHEMBL3671707 & 1528310 & 6.057 & 6.718 & TRN & & \\
\hline CHEMBL 3671788 & 1528310 & 6.0009 & 5.9601 & TST & & \\
\hline CHEMBL 3681774 & 1528310 & 6.2899 & 5.9191 & TRN & & \\
\hline CHEMBL3671638 & 1528310 & 6.2464 & 5.9057 & TRN & & \\
\hline CHEMBL3681674 & 1528310 & 7.699 & 7.4038 & TRN & & \\
\hline CHEMBL3671663 & 1528310 & 5.8671 & 5.4731 & TRN & & \\
\hline CHEMBL3681797 & 1528310 & 6.4828 & 6.6832 & TRN & & \\
\hline CHEMBL3671784 & 1528310 & 6.6073 & 6.6078 & TRN & & \\
\hline CHEMBL3681742 & 1528310 & 7.699 & 7.36 & TRN & & \\
\hline CHEMBL3676652 & 1528310 & 6.2503 & 6.5457 & TRN & & \\
\hline CHEMBL3671730 & 1528310 & 5.0731 & 5.83299 & 9999999999 & & TST \\
\hline CHEMBL3676588 & 1528310 & 6.8268 & 6.3121 & TRN & & \\
\hline CHEMBL3639755 & 1528310 & 6.1931 & 5.9122 & TRN & & \\
\hline CHEMBL 3676561 & 1528310 & \multicolumn{3}{|c|}{6.7620000000000005} & 7.1304 & TRN \\
\hline CHEMBL3671605 & 1528310 & 5.4563 & 4.072 & TST & & \\
\hline CHEMBL3671639 & 1528310 & 4.6593 & 5.0266 & TRN & & \\
\hline CHEMBL3681710 & 1528310 & 6.0 & 6.7299 & TRN & & \\
\hline CHEMBL 3671622 & 1528310 & 5.4024 & 5.2846 & TRN & & \\
\hline CHEMBL3681845 & 1528310 & 7.7696 & 6.8381 & TRN & & \\
\hline CHEMBL3676768 & 1528310 & 7.6383 & 7.4344 & TRN & & \\
\hline CHEMBL3671776 & 1528310 & 6.4342 & 6.4746 & TRN & & \\
\hline CHEMBL3676639 & 1528310 & 5.5899 & 5.5724 & TRN & & \\
\hline CHEMBL3671678 & 1528310 & 4.5301 & 4.5747 & TRN & & \\
\hline CHEMBL3671587 & 1528310 & \multicolumn{3}{|c|}{5.656000000000001} & 6.2399 & TST \\
\hline CHEMBL 3676745 & 1528310 & 6.8268 & 7.1642 & TRN & & \\
\hline CHEMBL3676754 & 1528310 & 7.1871 & 6.9446 & TRN & & \\
\hline CHEMBL 3681829 & 1528310 & 6.0 & 6.9089 & TRN & & \\
\hline CHEMBL 3681767 & 1528310 & 7.7212 & 7.2265 & TRN & & \\
\hline CHEMBL 3676752 & 1528310 & 7.6021 & 7.6816 & TRN & & \\
\hline CHEMBL3676730 & 1528310 & 6.0 & 5.2819 & TST & & \\
\hline CHEMBL3676686 & 1528310 & \multicolumn{3}{|c|}{6.752000000000001} & 7.2814 & TRN \\
\hline CHEMBL3681711 & 1528310 & 6.9586 & 6.4379 & TRN & & \\
\hline CHEMBL3681698 & 1528310 & 7.3188 & 6.8288 & TRN & & \\
\hline CHEMBL3676677 & 1528310 & 6.9031 & 7.3952 & TRN & & \\
\hline CHEMBL3681830 & 1528310 & 6.0 & 7.2595 & TRN & & \\
\hline CHEMBL3676764 & 1528310 & 5.2172 & 5.6288 & TST & & \\
\hline CHEMBL3681807 & 1528310 & 7.4815 & 7.8884 & TRN & & \\
\hline CHEMBL3681838 & 1528310 & 6.7645 & 7.0371 & TRN & & \\
\hline CHEMBL3676773 & 1528310 & 7.699 & 7.6168 & TRN & & \\
\hline CHEMBL3671694 & 1528310 & 5.6041 & 5.8172 & TRN & & \\
\hline CHEMBL3671588 & 1528310 & 5.8049 & 5.4094 & TRN & & \\
\hline CHEMBL3676651 & 1528310 & 6.1409 & 5.7856 & TRN & & \\
\hline CHEMBL3681735 & 1528310 & 7.2076 & 7.364 & TST & & \\
\hline CHEMBL3671705 & 1528310 & 5.4346 & 5.4616 & TRN & & \\
\hline
\end{tabular}




$$
\text { Supplemental Table S2.txt }
$$

\begin{tabular}{|c|c|c|c|c|c|}
\hline CHEMBL3681704 & 1528310 & 7.2924 & 8.074 & TRN & \\
\hline CHEMBL3676635 & 1528310 & 4.0 & 4.8916 & TRN & \\
\hline CHEMBL3671661 & 1528310 & 5.756 & 5.8445 & TRN & \\
\hline CHEMBL3681643 & 1528310 & 7.4437 & 7.7231 & TRN & \\
\hline CHEMBL3676749 & 1528310 & 4.0 & 5.2935 & TST & \\
\hline CHEMBL3676583 & 1528310 & 6.0953 & 6.3529 & TST & \\
\hline CHEMBL3671606 & 1528310 & 6.52 & 6.3254 & TRN & \\
\hline CHEMBL3671764 & 1528310 & 4.0 & 4.7277 & TRN & \\
\hline CHEMBL3676629 & 1528310 & 6.0 & 6.3758 & TRN & \\
\hline CHEMBL3681823 & 1528310 & 6.1355 & 6.2953 & TRN & \\
\hline CHEMBL3676572 & 1528310 & 6.6696 & 6.655 & TRN & \\
\hline CHEMBL3681818 & 1528310 & 6.2882 & 6.12 & TRN & \\
\hline CHEMBL3671615 & 1528310 & 5.065 & 5.2594 & TRN & \\
\hline CHEMBL3676685 & 1528310 & 5.0 & 5.5993 & TRN & \\
\hline CHEMBL3681766 & 1528310 & 7.1079 & 7.0601 & TRN & \\
\hline CHEMBL3671757 & 1528310 & 6.2865 & 6.3781 & TRN & \\
\hline CHEMBL3671650 & 1528310 & 3.0 & 4.1364 & TRN & \\
\hline CHEMBL3676632 & 1528310 & 5.9326 & 6.0131 & TRN & \\
\hline CHEMBL3671685 & 1528310 & 5.2113 & 4.9596 & TST & \\
\hline CHEMBL3671728 & 1528310 & 6.6716 & 6.4896 & TRN & \\
\hline CHEMBL3681737 & 1528310 & 7.5686 & 7.6047 & TRN & \\
\hline CHEMBL3681798 & 1528310 & 7.3279 & 7.1997 & TRN & \\
\hline CHEMBL3671600 & 1528310 & 4.7875 & 4.8726 & TST & \\
\hline CHEMBL3681785 & 1528310 & 6.1851 & 6.1152 & TRN & \\
\hline CHEMBL3671653 & 1528310 & 6.2048 & 5.4095 & TRN & \\
\hline CHEMBL3671594 & 1528310 & 4.6981 & 5.419 & TRN & \\
\hline CHEMBL3676593 & 1528310 & 6.7212 & 6.0392 & TST & \\
\hline CHEMBL3676667 & 1528310 & 5.0572 & 5.3933 & TRN & \\
\hline CHEMBL3681675 & 1528310 & 6.0 & 7.407999 & 99999999995 & TRN \\
\hline CHEMBL3676585 & 1528310 & 5.6992 & 6.6486 & TST & \\
\hline CHEMBL3676610 & 1528310 & 5.8649 & 5.798999 & 99999999995 & TRN \\
\hline CHEMBL3676613 & 1528310 & 5.9003 & 6.2001 & TRN & \\
\hline CHEMBL3671631 & 1528310 & 5.188 & 4.2644 & TST & \\
\hline CHEMBL3681731 & 1528310 & 7.4437 & 7.1851 & TRN & \\
\hline CHEMBL3681778 & 1528310 & 5.2275 & 5.1927 & TRN & \\
\hline CHEMBL 3676564 & 1528310 & 5.5909 & 5.6203 & TRN & \\
\hline CHEMBL3676719 & 1528310 & 6.2487 & 6.5945 & TRN & \\
\hline CHEMBL3676673 & 1528310 & 6.5186 & 6.1411 & TRN & \\
\hline CHEMBL3671682 & 1528310 & 6.0711 & 6.3218 & TRN & \\
\hline CHEMBL3676697 & 1528310 & 6.8182 & 6.6922 & TRN & \\
\hline CHEMBL3671662 & 1528310 & 5.6026 & 5.6059 & TRN & \\
\hline CHEMBL3681716 & 1528310 & 7.2147 & 7.5232 & TST & \\
\hline CHEMBL3681661 & 1528310 & 7.5229 & 7.3438 & TRN & \\
\hline CHEMBL3671659 & 1528310 & 5.4793 & 4.6484 & TRN & \\
\hline CHEMBL3671777 & 1528310 & 5.2608 & 4.8974 & TRN & \\
\hline CHEMBL3671719 & 1528310 & 5.99700 & 00000006 & 5.3333 & TRN \\
\hline CHEMBL3676710 & 1528310 & 7.3279 & 6.8411 & TRN & \\
\hline CHEMBL3676591 & 1528310 & 7.1249 & 7.0361 & TRN & \\
\hline
\end{tabular}


Supplemental Table S2.txt

\begin{tabular}{|c|c|c|c|c|}
\hline HEMBL: & & & & TS \\
\hline HFMRI 3671681 & 528310 & 6.1439 & & \\
\hline HEMBL & & & 6664 & \\
\hline HEMBL3676627 & 528310 & 7331 & 5272 & \\
\hline HEMBL3676631 & 528310 & 6.2434 & .3395 & \\
\hline HEMBL3671597 & 528310 & 5.26 & 763 & \\
\hline AEMBL3681773 & 310 & & 5568 & \\
\hline HEMBL3671646 & 310 & 6.0 & & \\
\hline HEMBL3671771 & 528310 & 5.2218 & 152 & \\
\hline HEMBL3681694 & 528310 & 7.3279 & .2995 & \\
\hline HEMBL36 & 528310 & 05 & & \\
\hline HEMBL & 310 & & & \\
\hline HEMBL3 & 310 & 905 & & \\
\hline HEMBL36 & 310 & 829 & & \\
\hline HEMBL36 & 310 & 79 & & \\
\hline AEMBL & 310 & 74 & & \\
\hline AEMBL & 310 & & & \\
\hline HEMBL; & 310 & 73 & & \\
\hline HEMBL3 & 310 & 76 & & \\
\hline AEMBL36 & 310 & 5 . & 07 & \\
\hline AEMBL: & 310 & & & \\
\hline AEMBL & 10 & & & \\
\hline HEMBL & 310 & 6. & & \\
\hline HEMBL3 & 10 & & & \\
\hline AEMBL36 & 10 & 21 & & RIV \\
\hline AEMBL: & 10 & 6 & & \\
\hline AEMBL & 10 & & & \\
\hline ALMP & & 4. & & \\
\hline AEMBL & & & & RIN \\
\hline AEMBL3671654 & 310 & 4. & & RN \\
\hline AEMBL: & 10 & & & $\mathrm{RN}$ \\
\hline 9 & & & & \\
\hline & & & & 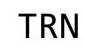 \\
\hline AEMBL36 & & & & ГRN \\
\hline HEMBL3676637 & 310 & & & RN \\
\hline AFMRI : & 10 & & & 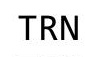 \\
\hline & & & & \\
\hline HEMBL3 & & & & ST \\
\hline AEMBL36 & 310 & & & $\Gamma R$ \\
\hline EMBL 3 & 10 & & & RN \\
\hline HEMBL36 & & 7.3872 & & \\
\hline & & & & ST \\
\hline HEMBL3676641 & & & & RN \\
\hline AEMBL36 & 10 & & 32 & $\mathrm{R}$ \\
\hline MBL3 & & & & \\
\hline HEMBL 3681636 & 1528310 & & & \\
\hline CHEMBL3681669 & .528310 & & & \\
\hline CHEMBL3676687 & 1528310 & 5.7975 & 6.2461 & \\
\hline
\end{tabular}

Page 3303 
Supplemental Table S2.txt

\begin{tabular}{|c|c|c|c|c|c|}
\hline CHEMBL 3671713 & 1528310 & 6.0635 & 6.1936 & TRN & \\
\hline CHEMBL 3676665 & 1528310 & 6.2573 & 6.3273 & TRN & \\
\hline CHEMBL 3676666 & 1528310 & 5.5106 & 5.8217 & TRN & \\
\hline CHEMBL 3681691 & 1528310 & 6.9245 & 6.6656 & TRN & \\
\hline CHEMBL 3681715 & 1528310 & 7.4437 & 7.3063 & TRN & \\
\hline CHEMBL 3671626 & 1528310 & 4.1637 & 3.9179 & TRN & \\
\hline CHEMBL 3681728 & 1528310 & 7.7959 & 7.6374 & TRN & \\
\hline CHEMBL 3676774 & 1528310 & 7.6021 & 7.3187 & TRN & \\
\hline CHEMBL 3671592 & 1528310 & 5.8431 & 5.5408 & TST & \\
\hline CHEMBL 3671760 & 1528310 & 4.0 & 5.0266 & TRN & \\
\hline CHEMBL 3676612 & 1528310 & 5.9322 & 5.9928 & TRN & \\
\hline CHEMBL 3671704 & 1528310 & 6.7595 & 6.6993 & TRN & \\
\hline CHEMBL 3681738 & 1528310 & 7.1612 & 6.5393 & TRN & \\
\hline CHEMBL3681837 & 1528310 & 7.1367 & 6.957999 & 9999999999 & TRN \\
\hline CHEMBL 3681851 & 1528310 & 7.2924 & 7.7477 & TRN & \\
\hline CHEMBL 3671714 & 1528310 & 4.0 & 4.6073 & TST & \\
\hline CHEMBL 3676728 & 1528310 & 6.3054 & 5.6436 & TST & \\
\hline CHEMBL 3671782 & 1528310 & 6.6271 & 6.1841 & TRN & \\
\hline CHEMBL 3676739 & 1528310 & 6.0 & 6.3365 & TRN & \\
\hline CHEMBL 3681729 & 1528310 & 7.8239 & 7.7802 & TRN & \\
\hline CHEMBL 3676615 & 1528310 & 5.9219 & 5.8886 & TST & \\
\hline CHEMBL 3676617 & 1528310 & 5.8735 & 5.9752 & TST & \\
\hline CHEMBL 3671726 & 1528310 & 5.95 & 6.1116 & TST & \\
\hline CHEMBL 3676558 & 1528310 & 5.8771 & 5.7568 & TST & \\
\hline CHEMBL 3671751 & 1528310 & 5.132999 & 999999999 & 5.6153 & TST \\
\hline CHEMBL 3681814 & 1528310 & 7.2076 & 6.9163 & TRN & \\
\hline CHEMBL 3676672 & 1528310 & 5.9666 & 6.1455 & TRN & \\
\hline CHEMBL 3681690 & 1528310 & 7.3565 & 6.5913 & TRN & \\
\hline CHEMBL 3676721 & 1528310 & 7.3098 & 7.3099 & TRN & \\
\hline CHEMBL 3681801 & 1528310 & 6.9788 & 6.6481 & TRN & \\
\hline CHEMBL 3676714 & 1528310 & 5.0 & 5.6164 & TRN & \\
\hline CHEMBL 3671769 & 1528310 & 5.6059 & 5.4462 & TRN & \\
\hline CHEMBL 3671752 & 1528310 & 5.1717 & 4.9766 & TRN & \\
\hline CHEMBL3681670 & 1528310 & 6.7144 & 6.4406 & TRN & \\
\hline CHEMBL 3676574 & 1528310 & 5.9423 & 6.0904 & TRN & \\
\hline CHEMBL 3671744 & 1528310 & 5.5397 & 6.5192 & TST & \\
\hline CHEMBL 3681782 & 1528310 & 7.3188 & 7.6199 & TRN & \\
\hline CHEMBL 3671738 & 1528310 & 6.3335 & 6.5569 & TRN & \\
\hline CHEMBL 3671756 & 1528310 & 7.1805 & 6.9797 & TRN & \\
\hline CHEMBL 3681821 & 1528310 & 6.8962 & 7.0576 & TRN & \\
\hline CHEMBL 3676761 & 1528310 & 5.0367 & 5.3092 & TRN & \\
\hline CHEMBL 3681725 & 1528310 & 7.4559 & 7.4522 & TRN & \\
\hline CHEMBL 3671652 & 1528310 & 5.3769 & 5.5871 & TRN & \\
\hline CHEMBL3681812 & 1528310 & 5.0 & 5.8723 & TST & \\
\hline CHEMBL 3671591 & 1528310 & 5.6394 & 5.3106 & TRN & \\
\hline CHEMBL 3676601 & 1528310 & 5.7106 & 6.773 & TST & \\
\hline CHEMBL 3676746 & 1528310 & 5.1502 & 5.5123 & TRN & \\
\hline CHEMBL 3681684 & 1528310 & 7.1938 & 7.3603 & TRN & \\
\hline
\end{tabular}

Page 3304 
Supplemental Table S2.txt

\begin{tabular}{|c|c|c|c|c|c|}
\hline CHEMBL 3676698 & 1528310 & 6.7747 & 6.8085 & TRN & \\
\hline CHEMBL3676590 & 1528310 & 7.0655 & 7.29799 & 7999999999 & TRN \\
\hline CHEMBL 3681790 & 1528310 & 6.6421 & 6.4231 & TRN & \\
\hline CHEMBL3681708 & 1528310 & 7.4949 & 6.9131 & TRN & \\
\hline CHEMBL 3681635 & 1528310 & 6.6073 & 7.2681 & TST & \\
\hline CHEMBL 3681734 & 1528310 & 7.8239 & 7.5415 & TRN & \\
\hline CHEMBL 3676563 & 1528310 & 5.3373 & 5.6585 & TRN & \\
\hline CHEMBL 3671648 & 1528310 & 5.0714 & 4.5476 & TST & \\
\hline CHEMBL3676568 & 1528310 & 6.3116 & 5.329 & TRN & \\
\hline CHEMBL3676566 & 1528310 & 5.7359 & 5.6931 & TST & \\
\hline CHEMBL 3671686 & 1528310 & 4.9873 & 5.2028 & TST & \\
\hline CHEMBL 3676647 & 1528310 & 6.9431 & 6.2126 & TRN & \\
\hline CHEMBL 3671695 & 1528310 & 4.0 & 4.6876 & TRN & \\
\hline CHEMBL3681765 & 1528310 & 7.6383 & 7.1682 & TRN & \\
\hline CHEMBL3681696 & 1528310 & 6.0 & 7.0353 & TRN & \\
\hline CHEMBL 3676722 & 1528310 & 7.301 & 7.2038 & TRN & \\
\hline CHEMBL3681832 & 1528310 & 6.0 & 6.8723 & TRN & \\
\hline CHEMBL 3681848 & 1528310 & 7.5229 & 6.8789 & TRN & \\
\hline CHEMBL 3676724 & 1528310 & 6.7235 & 6.8572 & TRN & \\
\hline CHEMBL 3671593 & 1528310 & 4.3406 & 5.4963 & TST & \\
\hline CHEMBL 3671675 & 1528310 & 6.3242 & 5.9338 & TRN & \\
\hline CHEMBL 3671700 & 1528310 & 6.2211 & 6.0008 & TRN & \\
\hline CHEMBL 3681638 & 1528310 & 7.1871 & 7.1796 & TRN & \\
\hline CHEMBL3681839 & 1528310 & 7.1487 & 7.0976 & TST & \\
\hline CHEMBL 3676701 & 1528310 & 7.1487 & 6.8682 & TRN & \\
\hline CHEMBL3681843 & 1528310 & 7.8239 & 7.7734 & TRN & \\
\hline CHEMBL3681799 & 1528310 & 7.1192 & 7.093 & TRN & \\
\hline CHEMBL 3676663 & 1528310 & 5.3487 & 4.9062 & TRN & \\
\hline CHEMBL3676731 & 1528310 & 6.6596 & 6.9996 & TRN & \\
\hline CHEMBL 3681841 & 1528310 & 6.0 & 6.6594 & TRN & \\
\hline CHEMBL 3676688 & 1528310 & 7.1024 & 7.7869 & TST & \\
\hline CHEMBL3681699 & 1528310 & 7.3468 & 7.2285 & TRN & \\
\hline CHEMBL3681831 & 1528310 & 7.4318 & 7.2202 & TRN & \\
\hline CHEMBL 3681746 & 1528310 & 7.0915 & 7.1001 & TRN & \\
\hline CHEMBL 3671649 & 1528310 & 4.7456 & 4.8446 & TST & \\
\hline CHEMBL3681749 & 1528310 & 7.301 & 7.4286 & TRN & \\
\hline CHEMBL3681718 & 1528310 & 7.0605 & 6.8716 & TRN & \\
\hline CHEMBL 3676691 & 1528310 & 5.0 & 6.3253 & TRN & \\
\hline CHEMBL3671679 & 1528310 & 7.3098 & 7.0953 & TRN & \\
\hline CHEMBL 3671703 & 1528310 & 5.9978 & 5.6627 & TST & \\
\hline CHEMBL3681813 & 1528310 & 7.2366 & 7.3247 & TRN & \\
\hline CHEMBL3681730 & 1528310 & 7.8239 & 7.7996 & TRN & \\
\hline CHEMBL 3676587 & 1528310 & 6.7496 & 6.6469 & TRN & \\
\hline CHEMBL3676659 & 1528310 & 5.739 & 5.0574 & TRN & \\
\hline CHEMBL 3671602 & 1528310 & 4.8579 & 4.0538 & TST & \\
\hline CHEMBL 3676668 & 1528310 & 5.2688 & 5.7294 & TRN & \\
\hline CHEMBL 3671763 & 1528310 & 5.8199 & 6.3809 & TRN & \\
\hline CHEMBL3676660 & 1528310 & 4.0 & 5.2085 & TST & \\
\hline
\end{tabular}


Supplemental Table S2.txt

\begin{tabular}{|c|c|c|c|c|c|}
\hline CHEMBL3671773 & 1528310 & 6.6655 & 6.2506 & TRN & \\
\hline CHEMBL3671762 & 1528310 & 4.0 & 4.1103 & TRN & \\
\hline CHEMBL 3681740 & 1528310 & 7.7696 & 7.7058 & TRN & \\
\hline CHEMBL 3671781 & 1528310 & 6.7399 & 6.5967 & TRN & \\
\hline CHEMBL3681723 & 1528310 & 6.7055 & 7.021 & TRN & \\
\hline CHEMBL3671754 & 1528310 & 6.1085 & 6.4028 & TRN & \\
\hline CHEMBL3681827 & 1528310 & 6.8861 & 6.6376 & TRN & \\
\hline CHEMBL 3671749 & 1528310 & 5.7106 & 5.6169 & TRN & \\
\hline CHEMBL3676603 & 1528310 & 5.9674 & 6.4499 & TST & \\
\hline CHEMBL3676695 & 1528310 & 6.1979 & 6.1108 & TRN & \\
\hline CHEMBL3671702 & 1528310 & 6.0762 & 6.0589 & TRN & \\
\hline CHEMBL3681741 & 1528310 & 7.7447 & 7.9158 & TRN & \\
\hline CHEMBL3676708 & 1528310 & 6.3605 & 6.4104 & TST & \\
\hline CHEMBL 3671645 & 1528310 & 5.691 & 5.4902 & TRN & \\
\hline CHEMBL3671789 & 1528310 & 6.1694 & 5.7033 & TST & \\
\hline CHEMBL3676760 & 1528310 & 7.4949 & 6.7595 & TRN & \\
\hline CHEMBL3671709 & 1528310 & 6.644 & 6.5939 & TRN & \\
\hline CHEMBL3681764 & 1528310 & 7.5229 & 7.319 & TRN & \\
\hline CHEMBL3671595 & 1528310 & 4.5115 & 5.0921 & TRN & \\
\hline CHEMBL3676596 & 1528310 & 5.9918 & 5.5727 & TST & \\
\hline CHEMBL3676735 & 1528310 & 7.2007 & 7.0541 & TRN & \\
\hline CHEMBL 3671768 & 1528310 & 5.2287 & 4.633 & TST & \\
\hline CHEMBL3681833 & 1528310 & 7.6021 & 7.3635 & TRN & \\
\hline CHEMBL3676674 & 1528310 & 5.5315 & 5.4099 & TRN & \\
\hline CHEMBL 3676717 & 1528310 & 6.9431 & 7.0508 & TRN & \\
\hline CHEMBL3681751 & 1528310 & 7.2007 & 7.1742 & TRN & \\
\hline CHEMBL3639704 & 1528310 & 5.6409 & 4.4477 & TST & \\
\hline CHEMBL3671708 & 1528310 & 6.1331 & 6.148 & TRN & \\
\hline CHEMBL3671717 & 1528310 & 5.6024 & 5.9381 & TRN & \\
\hline CHEMBL 3671614 & 1528310 & 5.2412 & 5.8833 & TRN & \\
\hline CHEMBL 3671748 & 1528310 & 5.2292 & 5.3158 & TST & \\
\hline CHEMBL3639806 & 1528310 & 5.0 & 5.0376 & TRN & \\
\hline CHEMBL3681733 & 1528310 & 7.7696 & 7.6488 & TRN & \\
\hline CHEMBL 3681748 & 1528310 & 6.0132 & 6.7161 & TST & \\
\hline CHEMBL3676699 & 1528310 & 6.9626 & 6.2529 & TRN & \\
\hline CHEMBL3676772 & 1528310 & 7.6198 & 7.6234 & TRN & \\
\hline CHEMBL3676757 & 1528310 & 7.1805 & 6.9467 & TRN & \\
\hline CHEMBL3681703 & 1528310 & 7.3188 & 7.8563 & TRN & \\
\hline CHEMBL3676620 & 1528310 & 6.466 & 6.63700 & 00000000005 & TRN \\
\hline CHEMBL3681842 & 1528310 & 7.7447 & 7.3814 & TRN & \\
\hline CHEMBL3681847 & 1528310 & 7.6576 & 7.6778 & TRN & \\
\hline CHEMBL3671589 & 1528310 & 5.6398 & 5.6548 & TRN & \\
\hline CHEMBL3671774 & 1528310 & 6.7399 & 6.7618 & TRN & \\
\hline CHEMBL3681761 & 1528310 & 7.7447 & 7.9478 & TRN & \\
\hline CHEMBL3671696 & 1528310 & 5.9101 & 6.8336 & TST & \\
\hline CHEMBL3676579 & 1528310 & 5.4429 & 5.3688 & TST & \\
\hline CHEMBL3676692 & 1528310 & 6.9172 & 6.426 & TRN & \\
\hline CHEMBL3676634 & 1528310 & 7.7696 & 7.5783 & TRN & \\
\hline
\end{tabular}




\begin{tabular}{|c|c|c|c|c|c|c|}
\hline \multicolumn{7}{|c|}{ Supplemental Table S2.txt } \\
\hline CHEMBL3639756 & 1528310 & 6.0 & 5.6599 & TST & & \\
\hline CHEMBL 3671765 & 1528310 & 4.0 & 4.4249 & TRN & & \\
\hline CHEMBL3676573 & 1528310 & 6.2083 & 5.9093 & TRN & & \\
\hline CHEMBL3676702 & 1528310 & 7.3979 & 7.3167 & TRN & & \\
\hline CHEMBL3671715 & 1528310 & 4.0 & 5.8254 & TST & & \\
\hline CHEMBL3681844 & 1528310 & 6.0 & 7.0048 & TRN & & \\
\hline CHEMBL3671657 & 1528310 & 5.3542 & 4.7982 & TRN & & \\
\hline CHEMBL3681688 & 1528310 & 6.0 & 6.9755 & TRN & & \\
\hline CHEMBL3681771 & 1528310 & 7.1938 & 6.716 & TRN & & \\
\hline CHEMBL3676642 & 1528310 & 6.065 & 5.9985 & TRN & & \\
\hline CHEMBL3681786 & 1528310 & 7.4815 & 7.6751 & TRN & & \\
\hline CHEMBL 3681644 & 1528310 & 7.3979 & 7.2449 & TRN & & \\
\hline CHEMBL 3676644 & 1528310 & 5.518 & 4.9809 & TRN & & \\
\hline CHEMBL 3676648 & 1528310 & 5.7997 & 5.6417 & TRN & & \\
\hline CHEMBL3681657 & 1528310 & 7.3468 & 7.3886 & TRN & & \\
\hline CHEMBL3671670 & 1528310 & 4.6364 & 4.2432 & TST & & \\
\hline CHEMBL3676649 & 1528310 & 5.9329 & 5.9889 & TRN & & \\
\hline CHEMBL3671667 & 1528310 & 4.1717 & 4.4498 & TRN & & \\
\hline CHEMBL3676759 & 1528310 & 5.9101 & 5.5157 & TRN & & \\
\hline CHEMBL3681671 & 1528310 & 6.7747 & 6.8602 & TRN & & \\
\hline CHEMBL3681783 & 1528310 & 7.6576 & 6.9255 & TRN & & \\
\hline CHEMBL3676661 & 1528310 & 4.0 & 4.4985 & TRN & & \\
\hline CHEMBL3671727 & 1528310 & 5.8595 & 6.0091 & TST & & \\
\hline CHEMBL 3676743 & 1528310 & 6.3726 & 5.8766 & TST & & \\
\hline CHEMBL3671735 & 1528310 & 7.4437 & 7.0143 & TRN & & \\
\hline CHEMBL3676734 & 1528310 & 7.2007 & 7.319 & TRN & & \\
\hline CHEMBL3681836 & 1528310 & 7.2596 & 7.0427 & TRN & & \\
\hline CHEMBL3681820 & 1528310 & 5.0 & 6.1685 & TRN & & \\
\hline CHEMBL3671712 & 1528310 & 5.6207 & 5.3891 & TST & & \\
\hline CHEMBL3676630 & 1528310 & 6.6459 & 6.239 & TRN & & \\
\hline CHEMBL3676682 & 1528310 & 7.0969 & 6.8477 & TRN & & \\
\hline CHEMBL 3671778 & 1528310 & 6.3233 & 6.2789 & TST & & \\
\hline CHEMBL3681689 & 1528310 & 7.4089 & 6.6313 & TRN & & \\
\hline CHEMBL3681667 & 1528310 & 7.2596 & 7.2075 & TRN & & \\
\hline CHEMBL3671741 & 1528310 & 6.4976 & 6.7908 & TRN & & \\
\hline CHEMBL3676769 & 1528310 & 7.6778 & 7.5753 & TRN & & \\
\hline CHEMBL3671629 & 1528310 & 3.0 & 4.5674 & TRN & & \\
\hline CHEMBL 3676614 & 1528310 & 5.808 & 5.6415 & TRN & & \\
\hline CHEMBL3671669 & 1528310 & 4.3761 & 3.9776 & TST & & \\
\hline CHEMBL 3676700 & 1528310 & 5.1309 & 5.3138 & TST & & \\
\hline CHEMBL3676645 & 1528310 & 6.75200 & 00000000 & 01 & 6.4266 & TRN \\
\hline CHEMBL3681788 & 1528310 & 5.0 & 5.3609 & TRN & & \\
\hline CHEMBL3681775 & 1528310 & 7.6778 & 7.3338 & TRN & & \\
\hline CHEMBL3676742 & 1528310 & 6.2027 & 5.7948 & TST & & \\
\hline CHEMBL3676592 & 1528310 & 5.5333 & 5.5308 & TST & & \\
\hline CHEMBL3671701 & 1528310 & 6.0414 & 6.2024 & TRN & & \\
\hline CHEMBL3681828 & 1528310 & 7.4318 & 7.1318 & TRN & & \\
\hline CHEMBL3676681 & 1528310 & 6.1713 & 6.2928 & TRN & & \\
\hline
\end{tabular}


Supplemental Table S2.txt

\begin{tabular}{|c|c|c|c|c|c|}
\hline CHEMBL 3671607 & 1528310 & 4.7775 & 5.8159 & TST & \\
\hline CHEMBL 3676658 & 1528310 & 5.1456 & 4.9729 & TRN & \\
\hline CHEMBL3671599 & 1528310 & 4.2474 & 4.1901 & TRN & \\
\hline CHEMBL 3676716 & 1528310 & 7.0915 & 7.1041 & TRN & \\
\hline CHEMBL 3681756 & 1528310 & 7.0809 & 7.0888 & TRN & \\
\hline CHEMBL 3681724 & 1528310 & 7.2676 & 6.64 & TRN & \\
\hline CHEMBL 3676654 & 1528310 & 5.4951 & 5.1052 & TRN & \\
\hline CHEMBL 3639705 & 1528310 & 6.4908 & 7.2887 & TRN & \\
\hline CHEMBL 3676582 & 1528310 & 7.2366 & \multicolumn{2}{|c|}{6.5520000000000005} & TRN \\
\hline CHEMBL 3681640 & 1528310 & 6.9508 & 6.4293 & TRN & \\
\hline CHEMBL 3671759 & 1528310 & 5.0367 & 4.9725 & TRN & \\
\hline CHEMBL 3671632 & 1528310 & 5.309 & 5.1769 & TRN & \\
\hline CHEMBL 3671718 & 1528310 & 4.0 & 5.7285 & TST & \\
\hline CHEMBL 3681744 & 1528310 & 7.2757 & 6.5198 & TRN & \\
\hline CHEMBL 3686492 & 1528310 & 7.7212 & 7.6666 & TRN & \\
\hline CHEMBL 3676633 & 1528310 & 7.699 & \multicolumn{2}{|c|}{7.787000000000001} & TST \\
\hline CHEMBL 3671618 & 1528310 & 5.7414 & 4.9052 & TRN & \\
\hline CHEMBL 3676713 & 1528310 & 5.6635 & 5.7132 & TRN & \\
\hline CHEMBL 3671623 & 1528310 & 4.92 & 5.0634 & TRN & \\
\hline CHEMBL 3681850 & 1528310 & 6.4711 & 6.5152 & TST & \\
\hline CHEMBL 3676763 & 1528310 & 5.0 & 5.3413 & TRN & \\
\hline CHEMBL3676571 & 1528310 & 5.6332 & 5.0473 & TST & \\
\hline CHEMBL 3681777 & 1528310 & 7.6021 & 7.385 & TRN & \\
\hline CHEMBL 3676726 & 1528310 & 6.4547 & 6.6697 & TRN & \\
\hline CHEMBL 3681700 & 1528310 & 6.0 & 7.0947 & TRN & \\
\hline CHEMBL 3681815 & 1528310 & 6.71 & 6.555 & TRN & \\
\hline CHEMBL 3676767 & 1528310 & 6.6326 & 7.2227 & TST & \\
\hline CHEMBL 3671766 & 1528310 & 4.0 & 4.6027 & TST & \\
\hline CHEMBL3671633 & 1528310 & 6.1945 & 4.9569 & TST & \\
\hline CHEMBL 3681826 & 1528310 & 6.7352 & 6.5086 & TST & \\
\hline CHEMBL 3681637 & 1528310 & 7.4089 & 7.4169 & TST & \\
\hline CHEMBL 3676707 & 1528310 & 6.2612 & 6.4199 & TST & \\
\hline CHEMBL 3671743 & 1528310 & 5.6751 & 4.8652 & TST & \\
\hline CHEMBL3671755 & 1528310 & 4.0 & 5.1709 & TST & \\
\hline CHEMBL 3671753 & 1528310 & 6.0218 & 6.8397 & TST & \\
\hline CHEMBL 3676560 & 1528310 & 6.1643 & 6.5296 & TST & \\
\hline CHEMBL 3671698 & 1528310 & 7.2924 & 6.6471 & TST & \\
\hline CHEMBL 3681757 & 1528310 & 7.3565 & 6.5623 & TST & \\
\hline CHEMBL3681666 & 1528310 & 7.2147 & 7.6623 & TST & \\
\hline CHEMBL 3681808 & 1528310 & 6.8761 & 7.484 & TST & \\
\hline CHEMBL 3681720 & 1528310 & 7.1024 & 7.0294 & TST & \\
\hline CHEMBL 3671613 & 1528310 & 5.5505 & 5.2898 & TST & \\
\hline CHEMBL 3676595 & 1528310 & 6.26200 & 30000000 & 6.0083 & TST \\
\hline CHEMBL 3676624 & 1528310 & 5.9944 & 6.1159 & TST & \\
\hline CHEMBL 3681781 & 1528310 & 5.0 & 5.8521 & TST & \\
\hline CHEMBL 3676744 & 1528310 & 6.9245 & 7.2239 & TST & \\
\hline CHEMBL 3681701 & 1528310 & 7.5229 & 7.1505 & TST & \\
\hline CHEMBL 3681682 & 1528310 & 6.9318 & 7.1393 & TST & \\
\hline
\end{tabular}

Page 3308 
Supplemental Table S2.txt

\begin{tabular}{|c|c|c|c|c|}
\hline CHEMBL3671725 & 528310 & 4.0 & 4.8028 & 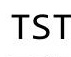 \\
\hline CHEMBL3671723 & 1528310 & 7.1135 & 6.2747 & \\
\hline HEMBL3676770 & 528310 & 7.6383 & 7.2924 & \\
\hline HEMBL3681743 & 528310 & 5.0 & 5.7678 & \\
\hline HEMBL3676723 & 528310 & 7.0706 & 6.7571 & \\
\hline HEMBL3671681 & 528310 & 5.1826 & 5.011 & \\
\hline HEMBL3671690 & .528310 & 6.3363 & 6.2485 & \\
\hline HEMBL3671734 & 528310 & 7.2676 & 6.4107 & \\
\hline HEMBL3671619 & 528310 & 4.4791 & 4.2965 & \\
\hline HEMBL3676771 & 528310 & 7.6778 & 7.5614 & \\
\hline HEMBL557535 & 85134 & 4.5702 & 4.5232 & \\
\hline HEMBL562546 & 85134 & 3.0 & 3.3069 & \\
\hline HEMBL557062 & 85134 & 4.1487 & 3.4562 & \\
\hline HEMBL552022 & 85134 & 4.8539 & 4.891 & \\
\hline HEMBL552973 & 85134 & 5.0044 & 5.1578 & \\
\hline HEMBL560882 & 85134 & 4.4089 & 4.4888 & \\
\hline HEMBL553856 & 85134 & 4.8508 & 4.8232 & \\
\hline CHEMBL561 & 85 & 5.2366 & 5.3147 & \\
\hline HEMBL 54 & 34 & 3.301 & 3.3386 & \\
\hline HEMBL556493 & 34 & 4.757 & 4.8216 & RN \\
\hline HEMBL561810 & 34 & 4.4437 & 4.587 & $2 \mathrm{~N}$ \\
\hline HEMBL540736 & 85134 & 4.2381 & 2237 & 10 \\
\hline HEMBL 56 & 85134 & 4.2518 & 133 & \\
\hline HEMBL56 & 34 & 5.1192 & 574 & \\
\hline HEMBL560009 & 34 & 239 & 4.623 & RN \\
\hline HEMBL552972 & 85134 & 6.2596 & 37 & RN \\
\hline HEMBL555342 & 85134 & 5.3565 & 5.3067 & RN \\
\hline HEMBL550206 & 34 & 4.4698 & 4.3904 & $\mathrm{R}$ \\
\hline HEMBL 53 & 34 & 5.1938 & 5.3082 & RN \\
\hline THEMBL551 & 34 & 4.3468 & 457 & RN \\
\hline HEMBL561406 & 85 & 4.0 & 101 & RN \\
\hline HEMBL554782 & 85134 & 4.5086 & 4.4405 & RN \\
\hline HEMBL561007 & 34 & 5.7212 & 538 & RN \\
\hline CHEMBL55 & 34 & 5 . & 79 & RN \\
\hline CHEMBL552921 & 85 & 3.0 & 3.3262 & ST \\
\hline CHEMBL559259 & 85134 & 5.0915 & 3935 & RN \\
\hline CHEMBL553572 & 585134 & 4.0915 & 4.1177 & RN \\
\hline HEMBL556522 & 34 & 5.6198 & 3936 & RN \\
\hline CHEMBL564150 & 34 & 3.0 & 33 & RN \\
\hline CHEMBL562405 & 85134 & 5.1079 & 5.0531 & RN \\
\hline CHEMBL556142 & 585134 & 5.3872 & 5.0524 & RN \\
\hline CHEMBL538645 & 585 & 5.1192 & 68 & RN \\
\hline CHEMBL564552 & 585134 & 4.7212 & 4.133 & 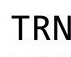 \\
\hline CHEMBL551619 & 585134 & 5.4202 & 5.364 & RN \\
\hline CHEMBL563183 & 585134 & 5.0088 & 4.9047 & RN \\
\hline CHEMBL549307 & 585134 & 3.0 & 3.2444 & ST \\
\hline CHEMBL540672 & 585 & 5.9586 & 6.0116 & RN \\
\hline CHEMBL563041 & 585134 & 4.2076 & 4.1425 & \\
\hline
\end{tabular}

Page 3309 


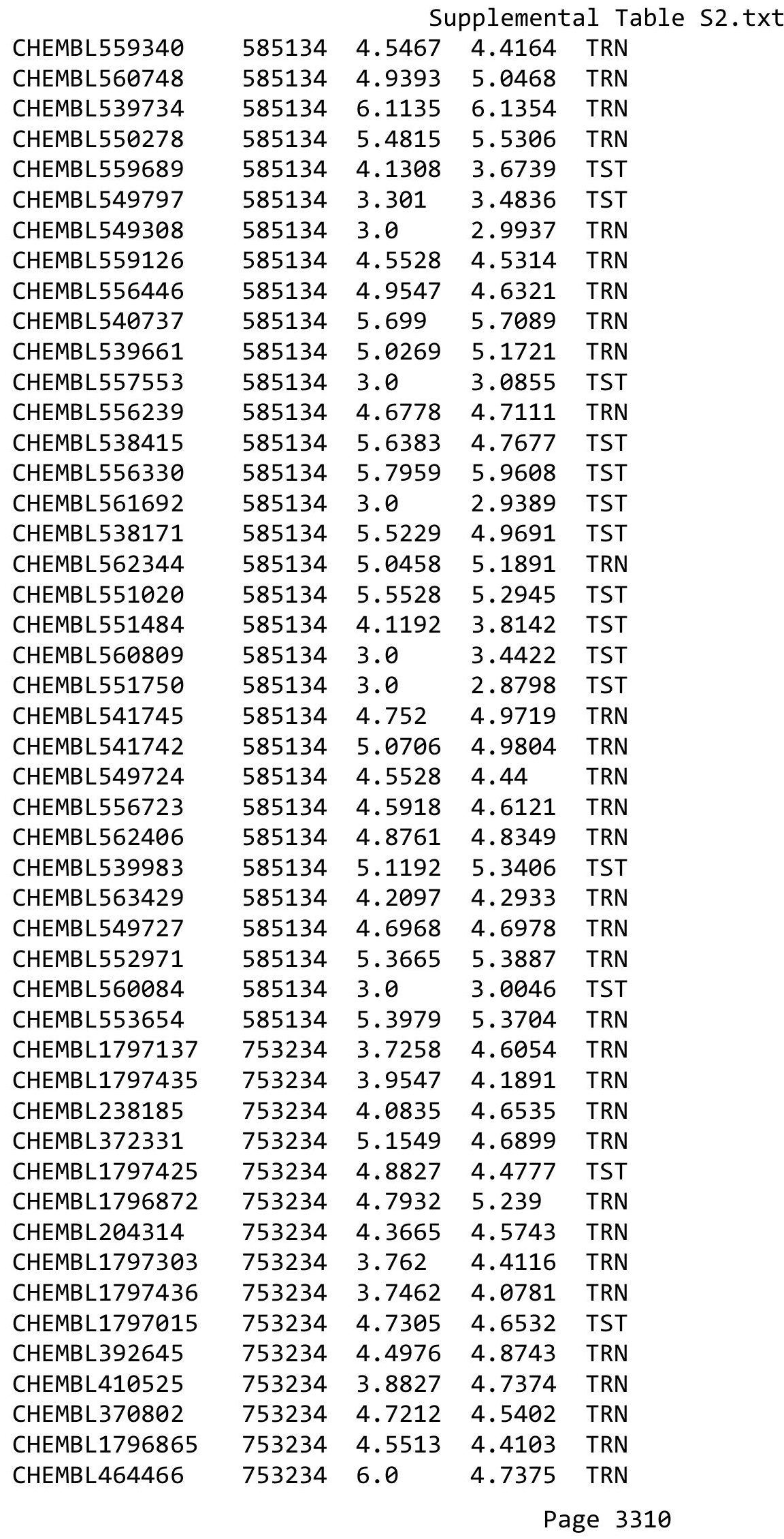


Supplemental Table S2.txt

\begin{tabular}{|c|c|c|c|c|}
\hline CHEMBL397365 & 753234 & 4.1325 & 4.5672 & TRN \\
\hline CHEMBL445145 & 753234 & 3.9172 & 4.5743 & TRN \\
\hline CHEMBL470029 & 753234 & 4.7471 & 4.8322 & TRN \\
\hline CHEMBL1796879 & 753234 & 5.4881 & 4.3757 & TST \\
\hline CHEMBL1797312 & 753234 & 4.5834 & 3.9817 & TRN \\
\hline CHEMBL508934 & 753234 & 4.5591 & 4.6191 & TRN \\
\hline CHEMBL1797026 & 753234 & 4.2741 & 4.3534 & TRN \\
\hline CHEMBL1797311 & 753234 & 3.7471 & 4.2329 & TRN \\
\hline CHEMBL1077973 & 753234 & 4.8153 & 4.7453 & TRN \\
\hline CHEMBL1797017 & 753234 & 4.5986 & 4.5422 & TRN \\
\hline CHEMBL23236 & 753234 & 4.7696 & 4.8598 & TST \\
\hline CHEMBL1797420 & 753234 & 3.6167 & 4.1412 & TST \\
\hline CHEMBL1077758 & 753234 & 4.8601 & 4.6689 & TRN \\
\hline CHEMBL1797314 & 753234 & 4.0814 & 4.1203 & TRN \\
\hline CHEMBL202456 & 753234 & 4.1805 & 4.4469 & TRN \\
\hline CHEMBL1797432 & 753234 & 4.6882 & 4.3072 & TRN \\
\hline CHEMBL1796878 & 753234 & 5.6517 & 4.7106 & TST \\
\hline CHEMBL397935 & 753234 & 4.158 & 5.0477 & TRN \\
\hline CHEMBL508614 & 753234 & 4.8761 & 4.7481 & TRN \\
\hline CHEMBL439220 & 753234 & 4.1085 & 4.4429 & TRN \\
\hline CHEMBL 238219 & 753234 & 5.4868 & 4.5156 & TRN \\
\hline CHEMBL 236943 & 753234 & 3.9914 & 4.474 & TRN \\
\hline CHEMBL1077974 & 753234 & 4.5638 & 4.8604 & TRN \\
\hline CHEMBL1797305 & 753234 & 4.4815 & 4.4963 & TRN \\
\hline CHEMBL1077660 & 753234 & 4.6946 & 4.6763 & TRN \\
\hline CHEMBL1078409 & 753234 & 4.7878 & 4.7479 & TRN \\
\hline CHEMBL1797421 & 753234 & 4.3288 & 4.1605 & TST \\
\hline CHEMBL 251308 & 753234 & 4.7959 & 4.6882 & TST \\
\hline CHEMBL 383749 & 753234 & 6.0 & 4.8662 & TRN \\
\hline CHEMBL1797316 & 753234 & 4.2125 & 4.5588 & TRN \\
\hline CHEMBL381895 & 753234 & 4.5376 & 4.9529 & TRN \\
\hline CHEMBL 202579 & 753234 & 4.301 & 4.83899 & 99999999995 \\
\hline CHEMBL1797317 & 753234 & 5.0969 & 4.2822 & TRN \\
\hline CHEMBL 269277 & 753234 & 4.3665 & 4.7845 & TST \\
\hline CHEMBL1797309 & 753234 & 4.2765 & 4.7031 & TRN \\
\hline CHEMBL1797427 & 753234 & 4.6073 & 4.3662 & TST \\
\hline CHEMBL487933 & 753234 & 4.0862 & 4.7709 & TST \\
\hline CHEMBL1797020 & 753234 & 4.9508 & 4.6576 & TST \\
\hline CHEMBL1081877 & 753234 & 4.5391 & 4.3975 & TRN \\
\hline CHEMBL437113 & 753234 & 4.2924 & 4.4423 & TRN \\
\hline CHEMBL1797430 & 753234 & 3.7258 & 4.234 & TRN \\
\hline CHEMBL1797318 & 753234 & 4.8962 & 4.4873 & TRN \\
\hline CHEMBL1797429 & 753234 & 4.1373 & 4.6535 & TRN \\
\hline CHEMBL1797437 & 753234 & 4.2692 & 4.0234 & TST \\
\hline CHEMBL1797016 & 753234 & 4.9788 & 4.6808 & TRN \\
\hline CHEMBL1797428 & 753234 & 4.3936 & 4.2975 & TRN \\
\hline CHEMBL1797025 & 753234 & 4.1152 & 4.8312 & TRN \\
\hline CHEMBL1797304 & 753234 & 4.3625 & 4.9873 & TRN \\
\hline
\end{tabular}

Page 3311 
Supplemental Table S2.txt

\begin{tabular}{|c|c|c|c|c|}
\hline CHEMBL 238186 & 753234 & 4.0357 & 4.4583 & TRN \\
\hline CHEMBL1797021 & 753234 & 5.5129 & 4.7346 & TST \\
\hline CHEMBL1796870 & 753234 & 4.8962 & 4.8654 & TRN \\
\hline CHEMBL1796875 & 753234 & 4.5575 & 4.7646 & TRN \\
\hline CHEMBL1078171 & 753234 & 4.5952 & 4.9626 & TRN \\
\hline CHEMBL1077661 & 753234 & 5.3768 & 5.237 & TRN \\
\hline CHEMBL541940 & 753234 & 4.8539 & 4.4759 & TST \\
\hline CHEMBL1797315 & 753234 & 4.6517 & 4.6857 & TRN \\
\hline CHEMBL1797019 & 753234 & 4.6216 & 4.7999 & TST \\
\hline CHEMBL562059 & 753234 & 4.6003 & 3.95399 & 99999999997 \\
\hline CHEMBL1078508 & 753234 & 4.6478 & 4.63 & TRN \\
\hline CHEMBL1078407 & 753234 & 5.4949 & 4.7491 & TRN \\
\hline CHEMBL1797424 & 753234 & 4.9508 & 4.4807 & TST \\
\hline CHEMBL1796867 & 753234 & 4.9101 & 4.7016 & TRN \\
\hline CHEMBL1796866 & 753234 & 5.9431 & 4.6101 & TST \\
\hline CHEMBL 235667 & 753234 & 4.4237 & 4.7292 & TRN \\
\hline CHEMBL391948 & 753234 & 4.3307 & 4.563 & TRN \\
\hline CHEMBL390727 & 753234 & 6.0 & 5.0738 & TRN \\
\hline CHEMBL1796876 & 753234 & 5.1101 & 4.8877 & TRN \\
\hline CHEMBL1797434 & 753234 & 3.8996 & 4.1976 & TRN \\
\hline CHEMBL1797140 & 753234 & 4.7721 & 4.7079 & TST \\
\hline CHEMBL446073 & 753234 & 4.4647 & 4.7336 & TRN \\
\hline CHEMBL372990 & 753234 & 6.0 & 5.145 & TRN \\
\hline CHEMBL1796863 & 753234 & 4.8508 & 4.6886 & TRN \\
\hline CHEMBL1797143 & 753234 & 4.6819 & 4.8899 & TRN \\
\hline CHEMBL1797423 & 753234 & 3.9747 & 4.5809 & TST \\
\hline CHEMBL1797010 & 753234 & 5.8153 & 4.575 & TST \\
\hline CHEMBL1797320 & 753234 & 4.9508 & 4.252 & TST \\
\hline CHEMBL 236090 & 753234 & 4.104 & 4.428 & TRN \\
\hline CHEMBL1797306 & 753234 & 5.0 & 4.5145 & TRN \\
\hline CHEMBL1797012 & 753234 & 5.5867 & 4.4235 & TST \\
\hline CHEMBL1797301 & 753234 & 4.04 & 4.5716 & TRN \\
\hline CHEMBL1796880 & 753234 & 4.9893 & 4.7624 & TRN \\
\hline CHEMBL574391 & 753234 & 5.1079 & 4.44 & TST \\
\hline CHEMBL1080965 & 753234 & 6.0 & 4.9675 & TRN \\
\hline CHEMBL1796873 & 753234 & 5.6716 & 4.9106 & TRN \\
\hline CHEMBL1797310 & 753234 & 4.5498 & 3.9678 & TRN \\
\hline CHEMBL1797139 & 753234 & 5.4815 & 4.7316 & TST \\
\hline CHEMBL1796861 & 753234 & 4.6364 & 4.7778 & TRN \\
\hline CHEMBL383331 & 753234 & 4.5229 & 4.9747 & TST \\
\hline CHEMBL169 & 753234 & 6.0 & 4.7905 & TRN \\
\hline CHEMBL1796864 & 753234 & 4.8996 & 4.4069 & TRN \\
\hline CHEMBL572899 & 753234 & 4.4547 & 4.6501 & TST \\
\hline CHEMBL392670 & 753234 & 5.1361 & 4.8968 & TST \\
\hline CHEMBL 236932 & 753234 & 4.2069 & 4.3086 & TRN \\
\hline CHEMBL1797024 & 753234 & 4.2034 & 4.7091 & TRN \\
\hline CHEMBL1796874 & 753234 & 5.2684 & 5.1198 & TRN \\
\hline CHEMBL487887 & 753234 & 4.2441 & 4.7379 & TST \\
\hline
\end{tabular}




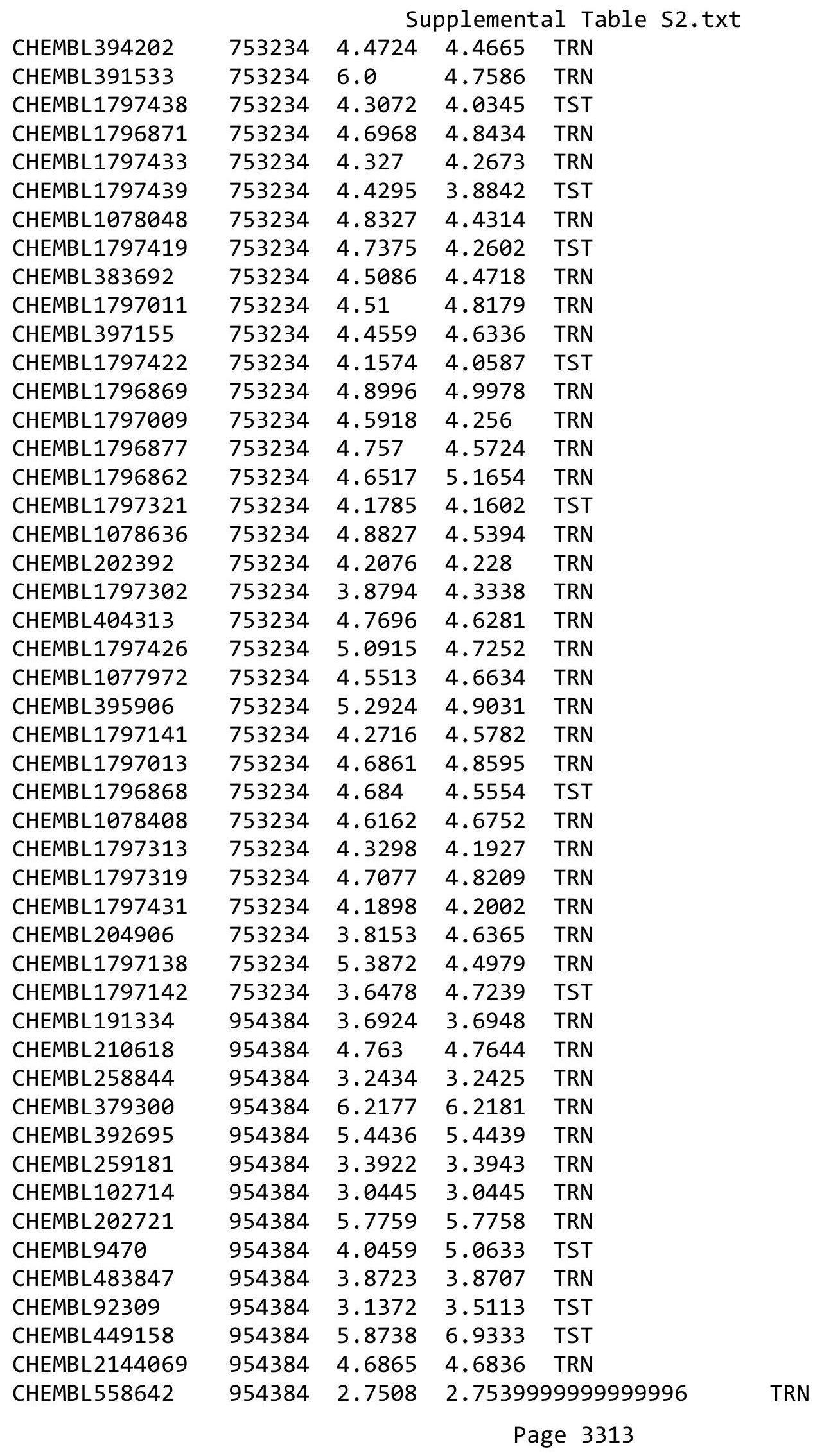


Supplemental Table S2.txt

\begin{tabular}{|c|c|c|c|c|c|}
\hline CHEMBL1256459 & 954384 & 6.5274 & 6.5277 & TRN & \\
\hline CHEMBL1230020 & 954384 & 4.2144 & 4.2129 & TRN & \\
\hline CHEMBL 222102 & 954384 & 4.2332 & 4.229 & TRN & \\
\hline CHEMBL 209148 & 954384 & 4.5182 & 4.5185 & TRN & \\
\hline CHEMBL3392440 & 954384 & 3.4796 & 3.4804 & TRN & \\
\hline CHEMBL188678 & 954384 & 4.1905 & 4.1936 & TRN & \\
\hline CHEMBL393929 & 954384 & 4.5459 & 4.5463 & TRN & \\
\hline CHEMBL 255342 & 954384 & 3.6174 & 3.6166 & TRN & \\
\hline CHEMBL1909414 & 954384 & 5.0589 & 5.0592 & TRN & \\
\hline CHEMBL180127 & 954384 & 4.6097 & 4.6094 & TRN & \\
\hline CHEMBL1516890 & 954384 & 4.0911 & 4.08899 & 99999999995 & TRN \\
\hline CHEMBL472940 & 954384 & 2.4446 & 2.4438 & TRN & \\
\hline CHEMBL509032 & 954384 & 5.6746 & 5.6752 & TRN & \\
\hline CHEMBL 220241 & 954384 & 4.7245 & 4.7225 & TRN & \\
\hline CHEMBL135561 & 954384 & 3.5524 & 3.551 & TRN & \\
\hline CHEMBL 2005886 & 954384 & 4.8939 & 4.8919 & TRN & \\
\hline CHEMBL240954 & 954384 & 3.9459 & 3.5883 & TST & \\
\hline CHEMBL 3186408 & 954384 & 3.1204 & 3.5296 & TST & \\
\hline CHEMBL 300389 & 954384 & 6.2309 & 6.2301 & TRN & \\
\hline CHEMBL2137530 & 954384 & 4.6588 & 4.6605 & TRN & \\
\hline CHEMBL1404918 & 954384 & 2.9451 & 2.943 & TRN & \\
\hline CHEMBL379975 & 954384 & 5.5578 & 5.5578 & TRN & \\
\hline CHEMBL1788116 & 954384 & 3.2147 & 3.2145 & TRN & \\
\hline CHEMBL189584 & 954384 & 7.9119 & 7.9132 & TRN & \\
\hline CHEMBL412142 & 954384 & 3.0456 & 3.0486 & TRN & \\
\hline CHEMBL1357247 & 954384 & 3.2384 & 3.2397 & TRN & \\
\hline CHEMBL399530 & 954384 & 3.2127 & 3.2148 & TRN & \\
\hline CHEMBL 221137 & 954384 & 4.4236 & 4.6634 & TST & \\
\hline CHEMBL1190711 & 954384 & 4.7945 & 4.7931 & TRN & \\
\hline CHEMBL 3199475 & 954384 & 3.3555 & \multicolumn{2}{|c|}{3.3560000000000003} & TRN \\
\hline CHEMBL1590308 & 954384 & 3.2689 & 3.0552 & TST & \\
\hline CHEMBL577784 & 954384 & 5.0047 & 5.001 & TRN & \\
\hline CHEMBL1970879 & 954384 & 3.1121 & 3.114 & TRN & \\
\hline CHEMBL514499 & 954384 & 7.5154 & 7.5185 & TRN & \\
\hline CHEMBL1186585 & 954384 & 4.684 & 4.6846 & TRN & \\
\hline CHEMBL585951 & 954384 & 5.8719 & 5.8709 & TRN & \\
\hline CHEMBL1673039 & 954384 & 3.2606 & 3.2585 & TRN & \\
\hline CHEMBL 2363137 & 954384 & 5.0282 & 5.0279 & TRN & \\
\hline CHEMBL483849 & 954384 & 2.4691 & 2.918 & TST & \\
\hline CHEMBL1643959 & 954384 & 4.4588 & 4.4605 & TRN & \\
\hline CHEMBL3349342 & 954384 & 4.8114 & 4.8112 & TRN & \\
\hline CHEMBL65 & 954384 & 7.475 & 7.4746 & TRN & \\
\hline CHEMBL 213100 & 954384 & 4.9856 & 3.8598 & TST & \\
\hline CHEMBL192566 & 954384 & 9.2598 & 8.4988 & TST & \\
\hline CHEMBL512504 & 954384 & 5.8416 & 4.5012 & TST & \\
\hline CHEMBL 2134202 & 954384 & 3.7909 & 4.5107 & TST & \\
\hline CHEMBL 373751 & 954384 & 3.8305 & 4.0164 & TST & \\
\hline CHEMBL217354 & 954384 & 7.1698 & 5.7245 & TST & \\
\hline
\end{tabular}


Supplemental Table S2.txt

\begin{tabular}{|c|c|c|c|c|}
\hline CHEMBL573107 & 954384 & 4.9107 & 5.1599 & TST \\
\hline CHEMBL515416 & 954384 & 4.9668 & 4.0333 & TST \\
\hline CHEMBL1242367 & 954384 & 3.5941 & 3.6596 & TST \\
\hline CHEMBL3956995 & 1638893 & 7.0 & 7.3489 & TRN \\
\hline CHEMBL3905131 & 1638893 & 7.0 & 8.5338 & TRN \\
\hline CHEMBL3916600 & 1638893 & 7.0 & 6.8169 & TRN \\
\hline CHEMBL3956211 & 1638893 & 6.0 & 5.2522 & TRN \\
\hline CHEMBL3907624 & 1638893 & 7.0 & 7.5814 & TRN \\
\hline CHEMBL3969644 & 1638893 & 7.0 & 6.9264 & TST \\
\hline CHEMBL598610 & 1638893 & 8.0 & 7.6724 & TRN \\
\hline CHEMBL3956652 & 1638893 & 8.0 & 6.856 & TRN \\
\hline CHEMBL596736 & 1638893 & 7.0 & 7.0113 & TRN \\
\hline CHEMBL3892687 & 1638893 & 7.0 & 7.9839 & TST \\
\hline CHEMBL3977601 & 1638893 & 6.0 & 7.305 & TRN \\
\hline CHEMBL3910975 & 1638893 & 8.0 & 7.3817 & TRN \\
\hline CHEMBL3914310 & 1638893 & 7.0 & 7.3489 & TRN \\
\hline CHEMBL3984477 & 1638893 & 7.0 & 6.7726 & TRN \\
\hline CHEMBL3966861 & 1638893 & 6.0 & 5.7836 & TRN \\
\hline CHEMBL3931476 & 1638893 & 8.0 & 6.544 & TRN \\
\hline CHEMBL3945421 & 1638893 & 4.0 & 4.9077 & TRN \\
\hline CHEMBL3917951 & 1638893 & 8.0 & 7.5906 & TRN \\
\hline CHEMBL3975990 & 1638893 & 8.0 & 7.9899 & TRN \\
\hline CHEMBL3959043 & 1638893 & 8.0 & 7.6364 & TRN \\
\hline CHEMBL3901629 & 1638893 & 8.0 & 8.208 & TRN \\
\hline CHEMBL596761 & 1638893 & 8.0 & 8.2446 & TRN \\
\hline CHEMBL3929290 & 1638893 & 7.0 & 7.562 & TRN \\
\hline CHEMBL3897602 & 1638893 & 4.0 & 5.9337 & TST \\
\hline CHEMBL 3938265 & 1638893 & 7.0 & 6.8169 & TRN \\
\hline CHEMBL 3964750 & 1638893 & 6.0 & 6.8118 & TRN \\
\hline CHEMBL 3928172 & 1638893 & 8.0 & 8.8624 & TST \\
\hline CHEMBL3952709 & 1638893 & 8.0 & 7.6011 & TRN \\
\hline CHEMBL3973930 & 1638893 & 8.0 & 8.4006 & TRN \\
\hline CHEMBL 3922768 & 1638893 & 8.0 & 7.9487 & TRN \\
\hline CHEMBL3968380 & 1638893 & 7.0 & 6.2903 & TRN \\
\hline CHEMBL 3945007 & 1638893 & 4.0 & 4.7321 & TRN \\
\hline CHEMBL 3893470 & 1638893 & 4.0 & 5.1354 & TRN \\
\hline CHEMBL3914322 & 1638893 & 8.0 & 8.122 & TRN \\
\hline CHEMBL 3972249 & 1638893 & 6.0 & 6.2356 & TRN \\
\hline CHEMBL598799 & 1638893 & 8.0 & 7.8781 & TRN \\
\hline CHEMBL 3890062 & 1638893 & 4.0 & 4.8967 & TRN \\
\hline CHEMBL 3925604 & 1638893 & 7.0 & 7.2403 & TRN \\
\hline CHEMBL 3927080 & 1638893 & 8.0 & 7.7525 & TRN \\
\hline CHEMBL 3896110 & 1638893 & 4.0 & 4.3796 & TRN \\
\hline CHEMBL3915573 & 1638893 & 6.0 & 5.5228 & TRN \\
\hline CHEMBL596754 & 1638893 & 8.0 & 7.9194 & TRN \\
\hline CHEMBL 3900967 & 1638893 & 8.0 & 5.2251 & TRN \\
\hline CHEMBL3924346 & 1638893 & 8.0 & 7.0412 & TRN \\
\hline CHEMBL3939269 & 1638893 & 4.0 & 5.4142 & TST \\
\hline
\end{tabular}




\begin{tabular}{|c|c|c|c|c|}
\hline & & & & \\
\hline CHEMBL 3949983 & 1638893 & 7.0 & 7.2008 & TRN \\
\hline CHEMBL3894186 & 1638893 & 7.0 & 7.305 & TRN \\
\hline CHEMBL3939306 & 1638893 & 8.0 & 8.5338 & TRN \\
\hline CHEMBL 3914607 & 1638893 & 8.0 & 8.5879 & TRN \\
\hline CHEMBL 3930226 & 1638893 & 6.0 & 5.3153 & TRN \\
\hline CHEMBL 3943406 & 1638893 & 7.0 & 6.856 & TRN \\
\hline CHEMBL596964 & 1638893 & 8.0 & 8.4699 & TRN \\
\hline CHEMBL3976426 & 1638893 & 8.0 & 7.7735 & TRN \\
\hline CHEMBL 3895707 & 1638893 & 7.0 & 7.4588 & TST \\
\hline CHEMBL3953980 & 1638893 & 7.0 & 7.4583 & TST \\
\hline CHEMBL 3982861 & 1638893 & 7.0 & 6.3655 & TRN \\
\hline CHEMBL3921290 & 1638893 & 6.0 & 6.9255 & TST \\
\hline CHEMBL 3909900 & 1638893 & 8.0 & 8.1901 & TRN \\
\hline CHEMBL 3920254 & 1638893 & 8.0 & 7.6608 & TST \\
\hline CHEMBL3939723 & 1638893 & 4.0 & 6.5568 & TST \\
\hline CHEMBL3971412 & 1638893 & 7.0 & 5.7096 & TRN \\
\hline CHEMBL3925515 & 1638893 & 7.0 & 8.2131 & TST \\
\hline CHEMBL3894461 & 1638893 & 8.0 & 6.7781 & TRN \\
\hline CHEMBL 3963327 & 1638893 & 7.0 & 6.7726 & TRN \\
\hline CHEMBL3966711 & 1638893 & 8.0 & 8.0275 & TRN \\
\hline CHEMBL597773 & 1638893 & 8.0 & 7.9585 & TRN \\
\hline CHEMBL3913135 & 1638893 & 7.0 & 7.7525 & TRN \\
\hline CHEMBL 3974474 & 1638893 & 6.0 & 6.4899 & TRN \\
\hline CHEMBL 3915273 & 1638893 & 8.0 & 7.2998 & TRN \\
\hline CHEMBL 3926697 & 1638893 & 6.0 & 6.7781 & TRN \\
\hline CHEMBL3905089 & 1638893 & 7.0 & 5.9595 & TRN \\
\hline CHEMBL597569 & 1638893 & 8.0 & 8.1842 & TRN \\
\hline CHEMBL3980861 & 1638893 & 7.0 & 5.831 & TRN \\
\hline CHEMBL 3967834 & 1638893 & 6.0 & 7.3708 & TST \\
\hline CHEMBL3903506 & 1638893 & 6.0 & 5.5518 & TRN \\
\hline CHEMBL3912995 & 1638893 & 7.0 & 7.0615 & TST \\
\hline CHEMBL 3977186 & 1638893 & 7.0 & 6.4872 & TRN \\
\hline CHEMBL3906273 & 1638893 & 7.0 & 5.8454 & TST \\
\hline CHEMBL3951191 & 1638893 & 7.0 & 6.3068 & TRN \\
\hline CHEMBL 3957562 & 1638893 & 7.0 & 7.1845 & TRN \\
\hline CHEMBL3941197 & 1638893 & 7.0 & 5.8483 & TRN \\
\hline CHEMBL 3920405 & 1638893 & 7.0 & 7.7348 & TST \\
\hline CHEMBL598377 & 1638893 & 8.1308 & 7.6724 & TRN \\
\hline CHEMBL 3984055 & 1638893 & 7.0 & 7.0375 & TRN \\
\hline CHEMBL 3944861 & 1638893 & 7.0 & 7.2536 & TRN \\
\hline CHEMBL3913571 & 1638893 & 7.0 & 6.4135 & TST \\
\hline CHEMBL 3947615 & 1638893 & 6.0 & 5.6131 & TRN \\
\hline CHEMBL3953871 & 1638893 & 5.0 & 6.1814 & TST \\
\hline CHEMBL 3928746 & 1638893 & 6.0 & 6.2903 & TRN \\
\hline CHEMBL 3909214 & 1638893 & 8.0 & 6.4391 & TRN \\
\hline CHEMBL 2309506 & 1638893 & 7.0 & 8.0031 & TST \\
\hline CHEMBL 3922068 & 1638893 & 4.0 & 4.4722 & TRN \\
\hline CHEMBL3912102 & 1638893 & 4.0 & 5.3817 & TRN \\
\hline
\end{tabular}




\begin{tabular}{|c|c|c|c|c|}
\hline & & & ient & $a \perp 1 a$ \\
\hline CHEMBL 3985245 & 1638893 & 8.0 & 7.3682 & TRN \\
\hline CHEMBL3960271 & 1638893 & 4.0 & 4.005 & TRN \\
\hline CHEMBL3922584 & 1638893 & 4.0 & 4.8111 & TRN \\
\hline CHEMBL3901236 & 1638893 & 8.0 & 7.2805 & TRN \\
\hline CHEMBL599398 & 1638893 & 7.0 & 6.9236 & TRN \\
\hline CHEMBL3935462 & 1638893 & 8.0 & 8.377 & TRN \\
\hline CHEMBL3930003 & 1638893 & 8.0 & 8.3389 & TRN \\
\hline CHEMBL3945209 & 1638893 & 6.0 & 5.8388 & TRN \\
\hline CHEMBL 3940740 & 1638893 & 6.0 & 6.0 & TRN \\
\hline CHEMBL3984522 & 1638893 & 7.0 & 6.6632 & TRN \\
\hline CHEMBL3948925 & 1638893 & 8.0 & 8.8624 & TST \\
\hline CHEMBL3943878 & 1638893 & 8.0 & 7.2403 & TRN \\
\hline CHEMBL3982179 & 1638893 & 8.0 & 6.8301 & TRN \\
\hline CHEMBL 3916142 & 1638893 & 6.0 & 5.5045 & TRN \\
\hline CHEMBL3913421 & 1638893 & 8.0 & 8.1735 & TRN \\
\hline CHEMBL 3924787 & 1638893 & 7.0 & 8.0147 & TST \\
\hline CHEMBL3902161 & 1638893 & 8.0 & 7.9331 & TRN \\
\hline CHEMBL3923619 & 1638893 & 6.0 & 6.2816 & TRN \\
\hline CHEMBL 3910297 & 1638893 & 6.0 & 4.7857 & TRN \\
\hline CHEMBL3946860 & 1638893 & 7.0 & 7.4344 & TRN \\
\hline CHEMBL 3912598 & 1638893 & 8.0 & 7.9899 & TRN \\
\hline CHEMBL3909453 & 1638893 & 6.0 & 4.8636 & TRN \\
\hline CHEMBL3889939 & 1638893 & 8.0 & 7.8504 & TRN \\
\hline CHEMBL3960127 & 1638893 & 7.0 & 5.2238 & TRN \\
\hline CHEMBL3890703 & 1638893 & 6.0 & 5.886 & TRN \\
\hline CHEMBL 3901144 & 1638893 & 8.0 & 7.6515 & TRN \\
\hline CHEMBL 2309507 & 1638893 & 7.0 & 7.7004 & TST \\
\hline CHEMBL3952852 & 1638893 & 4.0 & 4.5451 & TRN \\
\hline CHEMBL 3897288 & 1638893 & 7.0 & 6.7445 & TRN \\
\hline CHEMBL3918126 & 1638893 & 8.0 & 6.6865 & TRN \\
\hline CHEMBL3943273 & 1638893 & 6.0 & 5.6656 & TST \\
\hline CHEMBL3913614 & 1638893 & 7.0 & 6.6238 & TRN \\
\hline CHEMBL3909637 & 1638893 & 8.0 & 5.9288 & TST \\
\hline CHEMBL598163 & 1638893 & 8.0 & 7.6724 & TRN \\
\hline CHEMBL3922737 & 1638893 & 7.0 & 6.5172 & TST \\
\hline CHEMBL3921652 & 1638893 & 7.0 & 6.3353 & TRN \\
\hline CHEMBL3976389 & 1638893 & 8.0 & 8.2257 & TRN \\
\hline CHEMBL3893547 & 1638893 & 6.0 & 7.8281 & TST \\
\hline CHEMBL 3890344 & 1638893 & 6.0 & 6.5198 & TRN \\
\hline CHEMBL3909619 & 1638893 & 8.0 & 6.856 & TRN \\
\hline CHEMBL 3949397 & 1638893 & 4.0 & 5.1789 & TRN \\
\hline CHEMBL3919147 & 1638893 & 7.0 & 6.6415 & TST \\
\hline CHEMBL3985004 & 1638893 & 8.0 & 8.4773 & TST \\
\hline CHEMBL 3899708 & 1638893 & 6.0 & 6.4633 & TST \\
\hline CHEMBL3931061 & 1638893 & 6.0 & 6.5404 & TST \\
\hline CHEMBL 3889947 & 1638893 & 8.0 & 7.9839 & TST \\
\hline CHEMBL3933560 & 1638893 & 8.0 & 7.4588 & TST \\
\hline CHEMBL3928197 & 1638893 & 8.0 & 7.5603 & TRN \\
\hline
\end{tabular}




\begin{tabular}{|c|c|c|c|c|c|}
\hline & & & & & \\
\hline CHEMBL3942950 & 1638893 & 7.0 & 7.1407 & TST & \\
\hline CHEMBL3899385 & 1638893 & 7.0 & 7.3206 & TRN & \\
\hline CHEMBL3976436 & 1638893 & 4.0 & 4.7103 & TRN & \\
\hline CHEMBL3949197 & 1638893 & 4.0 & 4.5539 & TRN & \\
\hline CHEMBL 3907592 & 1638893 & 7.0 & 6.8301 & TRN & \\
\hline CHEMBL3943805 & 1638893 & 7.0 & 6.8698 & TRN & \\
\hline CHEMBL3893111 & 1638893 & 8.0 & 8.0754 & TRN & \\
\hline CHEMBL 3898427 & 1638893 & 6.0 & 5.2585 & TST & \\
\hline CHEMBL3971713 & 1638893 & 8.0 & 7.0028 & TRN & \\
\hline CHEMBL 3946801 & 1638893 & 7.0 & 7.6126 & TRN & \\
\hline CHEMBL3937516 & 1638893 & 8.0 & 7.6608 & TST & \\
\hline CHEMBL3939256 & 1638893 & 6.0 & 5.8302 & TRN & \\
\hline CHEMBL3976961 & 1638893 & 8.0 & 7.9815 & TRN & \\
\hline CHEMBL3970892 & 1638893 & 8.0 & 8.2777 & TRN & \\
\hline CHEMBL3916309 & 1638893 & 7.0 & 5.9342 & TST & \\
\hline CHEMBL3950023 & 1638893 & 4.0 & 4.6264 & TRN & \\
\hline CHEMBL3953109 & 1638893 & 7.0 & 6.7886 & TRN & \\
\hline CHEMBL 3943474 & 1638893 & 7.0 & 7.2884 & TST & \\
\hline CHEMBL3936496 & 1638893 & 7.0 & 5.8681 & TST & \\
\hline CHEMBL3901210 & 1638893 & 8.0 & 8.1842 & TRN & \\
\hline CHEMBL3965755 & 1638893 & 8.0 & 7.6491 & TRN & \\
\hline CHEMBL3978889 & 1638893 & 8.0 & 7.5557 & TST & \\
\hline CHEMBL3973966 & 1638893 & 6.0 & 6.7445 & TRN & \\
\hline CHEMBL3967081 & 1638893 & 7.0 & 7.12200 & 0000000001 & TST \\
\hline CHEMBL3980019 & 1638893 & 7.0 & 7.0562 & TST & \\
\hline CHEMBL3932057 & 1638893 & 7.0 & 7.6384 & TRN & \\
\hline CHEMBL3947855 & 1638893 & 6.0 & 6.1753 & TRN & \\
\hline CHEMBL3891395 & 1638893 & 4.0 & 4.935 & TRN & \\
\hline CHEMBL3959855 & 1638893 & 4.0 & 4.691 & TRN & \\
\hline CHEMBL 3959884 & 1638893 & 8.0 & 8.0413 & TRN & \\
\hline CHEMBL 3898480 & 1638893 & 7.0 & 7.2805 & TRN & \\
\hline CHEMBL3917105 & 1638893 & 7.0 & 7.3766 & TRN & \\
\hline CHEMBL3931285 & 1638893 & 6.0 & 7.0615 & TST & \\
\hline CHEMBL598164 & 1638893 & 8.0 & 7.54299 & 9999999999 & TRN \\
\hline CHEMBL3986849 & 1638893 & 4.0 & 5.4029 & TRN & \\
\hline CHEMBL3966521 & 1638893 & 4.0 & 5.1632 & TRN & \\
\hline CHEMBL3917093 & 1638893 & 7.0 & 8.0912 & TRN & \\
\hline CHEMBL3904339 & 1638893 & 7.0 & 8.208 & TRN & \\
\hline CHEMBL3979482 & 1638893 & 6.0 & 6.3118 & TRN & \\
\hline CHEMBL 3967810 & 1638893 & 4.0 & 5.2712 & TST & \\
\hline CHEMBL3936337 & 1638893 & 4.0 & 6.1353 & TST & \\
\hline CHEMBL604094 & 1638893 & 8.0 & 8.0864 & TRN & \\
\hline CHEMBL 3906200 & 1638893 & 8.0 & 8.26799 & 9999999999 & TRN \\
\hline CHEMBL3982819 & 1638893 & 7.0 & 7.9886 & TST & \\
\hline CHEMBL 3907094 & 1638893 & 8.0 & 7.8489 & TST & \\
\hline CHEMBL3936547 & 1638893 & 7.0 & 7.2805 & TRN & \\
\hline CHEMBL 3948072 & 1638893 & 4.0 & 4.4186 & TRN & \\
\hline CHEMBL3952020 & 1638893 & 7.0 & 5.8833 & TRN & \\
\hline
\end{tabular}




\begin{tabular}{|c|c|c|c|c|c|}
\hline \multirow{3}{*}{ CHEMBL 3940017} & \multirow{2}{*}{1638893} & \multirow[b]{2}{*}{7.0} & & & \\
\hline & & & 4.9914 & TST & \\
\hline & 1638893 & 6.0 & 4.5037 & TST & \\
\hline CHEMBL597752 & 1638893 & 4.0 & 5.9938 & TRN & \\
\hline CHEMBL3898444 & 1638893 & 8.0 & 8.0754 & TRN & \\
\hline CHEMBL3944171 & 1638893 & 6.0 & 6.8434 & TRN & \\
\hline CHEMBL3976428 & 1638893 & 4.0 & 6.5842 & TST & \\
\hline CHEMBL598611 & 1638893 & 8.0 & \multicolumn{2}{|c|}{7.542999999999999} & TRN \\
\hline CHEMBL3912163 & 1638893 & 6.0 & 5.7654 & TRN & \\
\hline CHEMBL3981584 & 1638893 & 7.0 & 7.3047 & TST & \\
\hline CHEMBL3968968 & 1638893 & 7.0 & 7.1208 & TRN & \\
\hline CHEMBL3967530 & 1638893 & 8.0 & 8.1886 & TRN & \\
\hline CHEMBL3972561 & 1638893 & 8.0 & 6.6865 & TRN & \\
\hline CHEMBL3986286 & 1638893 & 8.0 & 7.5603 & TRN & \\
\hline CHEMBL3904673 & 1638893 & 6.0 & 7.3667 & TRN & \\
\hline CHEMBL3954393 & 1638893 & 7.0 & 7.3489 & TRN & \\
\hline CHEMBL3907491 & 1638893 & 4.0 & 5.4689 & TRN & \\
\hline CHEMBL597551 & 1638893 & 4.0 & 4.7443 & TRN & \\
\hline CHEMBL3939206 & 1638893 & 7.0 & 6.2452 & TRN & \\
\hline CHEMBL3909969 & 1638893 & 6.0 & 6.7317 & TRN & \\
\hline CHEMBL3955436 & 1638893 & 8.0 & 7.9506 & TST & \\
\hline CHEMBL3961102 & 1638893 & 4.0 & 5.6164 & TRN & \\
\hline CHEMBL3984008 & 1638893 & 8.0 & 8.0147 & TST & \\
\hline CHEMBL3987181 & 1638893 & 7.0 & 6.7726 & TRN & \\
\hline CHEMBL3936512 & 1638893 & 7.0 & \multicolumn{2}{|c|}{7.122000000000001} & TST \\
\hline CHEMBL3912308 & 1638893 & 8.0 & 6.6865 & TRN & \\
\hline CHEMBL 3966166 & 1638893 & 4.0 & 4.149 & TRN & \\
\hline CHEMBL3948777 & 1638893 & 6.0 & 6.3803 & TRN & \\
\hline CHEMBL 3947208 & 1638893 & 7.0 & 6.5195 & TST & \\
\hline CHEMBL3897865 & 1638893 & 8.0 & 7.8977 & TST & \\
\hline CHEMBL3964433 & 1638893 & 4.0 & 4.4706 & TRN & \\
\hline CHEMBL 3901188 & 1638893 & 7.0 & 5.8681 & TST & \\
\hline CHEMBL3962938 & 1638893 & 8.0 & 7.9839 & TST & \\
\hline CHEMBL3965255 & 1638893 & 4.0 & 5.8101 & TST & \\
\hline CHEMBL3898372 & 1638893 & 7.0 & 7.0469 & TRN & \\
\hline CHEMBL3899973 & 1638893 & 7.0 & 6.1615 & TRN & \\
\hline CHEMBL3937246 & 1638893 & 8.0 & 6.2625 & TST & \\
\hline CHEMBL3917670 & 1638893 & 7.0 & 6.9977 & TRN & \\
\hline CHEMBL3933777 & 1638893 & 4.0 & 4.7499 & TST & \\
\hline CHEMBL3905086 & 1638893 & 7.0 & 7.3988 & TRN & \\
\hline CHEMBL3951620 & 1638893 & 8.0 & 7.9331 & TRN & \\
\hline CHEMBL3924396 & 1638893 & 6.0 & 6.2903 & TRN & \\
\hline CHEMBL3960592 & 1638893 & 4.0 & 5.0166 & TRN & \\
\hline CHEMBL3946124 & 1638893 & 7.0 & 6.9938 & TRN & \\
\hline CHEMBL3984972 & 1638893 & 8.0 & 7.8504 & TRN & \\
\hline CHEMBL3980430 & 1638893 & 7.0 & 7.12200 & 0000000001 & TST \\
\hline CHEMBL 3975711 & 1638893 & 6.0 & 6.0741 & TRN & \\
\hline CHEMBL3956162 & 1638893 & 7.0 & 7.7348 & TST & \\
\hline \multirow[t]{2}{*}{ CHEMBL3928963 } & 1638893 & 8.0 & 8.0864 & TRN & \\
\hline & & & \multicolumn{2}{|c|}{ Page 3319} & \\
\hline
\end{tabular}




\begin{tabular}{|c|c|c|c|c|c|}
\hline & & & & & \\
\hline CHEMBL3968341 & 1638893 & 7.0 & 6.6952 & TRN & \\
\hline CHEMBL3984573 & 1638893 & 8.0 & 6.9234 & TRN & \\
\hline CHEMBL3975710 & 1638893 & 7.0 & 7.1277 & TRN & \\
\hline CHEMBL3934468 & 1638893 & 7.0 & 6.7445 & TRN & \\
\hline CHEMBL3684807 & 1527947 & 8.1367 & 7.4909 & TRN & \\
\hline CHEMBL3684850 & 1527947 & 9.2218 & 8.9648 & TRN & \\
\hline CHEMBL3684909 & 1527947 & 8.1675 & 8.273 & TRN & \\
\hline CHEMBL 3684903 & 1527947 & 8.1938 & 7.1129 & TRN & \\
\hline CHEMBL3684895 & 1527947 & 6.0 & 6.53799 & 9999999999 & TRN \\
\hline CHEMBL3680145 & 1527947 & 6.0 & 8.1052 & TST & \\
\hline CHEMBL 3684770 & 1527947 & 8.5686 & 8.0774 & TRN & \\
\hline CHEMBL3684889 & 1527947 & 6.0 & 6.03299 & 99999999995 & TRN \\
\hline CHEMBL 3684899 & 1527947 & 8.5528 & 7.9074 & TST & \\
\hline CHEMBL 3684859 & 1527947 & 8.8861 & 7.1368 & TRN & \\
\hline CHEMBL3684916 & 1527947 & 8.4318 & 8.1619 & TST & \\
\hline CHEMBL3684836 & 1527947 & 6.0 & 7.4357 & TRN & \\
\hline CHEMBL3680154 & 1527947 & 6.0 & 6.2658 & TRN & \\
\hline CHEMBL3680159 & 1527947 & 6.0 & 7.4713 & TRN & \\
\hline CHEMBL3684769 & 1527947 & 9.0 & 9.1636 & TRN & \\
\hline CHEMBL3684858 & 1527947 & 6.0 & 8.1439 & TRN & \\
\hline CHEMBL3684767 & 1527947 & 8.6021 & 8.7289 & TRN & \\
\hline CHEMBL3684779 & 1527947 & 9.0 & 8.5019 & TRN & \\
\hline CHEMBL3680150 & 1527947 & 8.9586 & 9.4163 & TRN & \\
\hline CHEMBL3680143 & 1527947 & 8.0655 & 8.2178 & TRN & \\
\hline CHEMBL3680136 & 1527947 & 6.0 & 6.3433 & TRN & \\
\hline CHEMBL3680149 & 1527947 & 8.7696 & 6.8721 & TST & \\
\hline CHEMBL3684868 & 1527947 & 9.0969 & 6.9065 & TRN & \\
\hline CHEMBL 3684774 & 1527947 & 8.585 & 8.7925 & TRN & \\
\hline CHEMBL3684917 & 1527947 & 8.0177 & 7.2462 & TRN & \\
\hline CHEMBL3684778 & 1527947 & 9.0458 & 8.2468 & TRN & \\
\hline CHEMBL3684799 & 1527947 & 6.0 & 6.8257 & TRN & \\
\hline CHEMBL3680118 & 1527947 & 6.0 & 6.351 & TRN & \\
\hline CHEMBL 3684781 & 1527947 & 8.4685 & 6.6168 & TST & \\
\hline CHEMBL 3684848 & 1527947 & 8.0969 & 6.8822 & TRN & \\
\hline CHEMBL3684818 & 1527947 & 8.5229 & 8.1879 & TST & \\
\hline CHEMBL3684786 & 1527947 & 8.2076 & 8.2089 & TRN & \\
\hline CHEMBL3684764 & 1527947 & 8.6576 & 8.9578 & TRN & \\
\hline CHEMBL 3680155 & 1527947 & 6.0 & 7.4107 & TRN & \\
\hline CHEMBL3684765 & 1527947 & 9.0458 & 7.9926 & TRN & \\
\hline CHEMBL 3684825 & 1527947 & 8.3188 & 7.3852 & TRN & \\
\hline CHEMBL3684875 & 1527947 & 8.6383 & 7.6169 & TRN & \\
\hline CHEMBL3684780 & 1527947 & 8.0809 & 6.5962 & TRN & \\
\hline CHEMBL3684902 & 1527947 & 6.0 & 7.2972 & TRN & \\
\hline CHEMBL3684766 & 1527947 & 8.4202 & 8.5004 & TRN & \\
\hline CHEMBL 3684827 & 1527947 & 6.0 & 6.9183 & TRN & \\
\hline CHEMBL 3684762 & 1527947 & 6.0 & 6.1634 & TRN & \\
\hline CHEMBL 3684846 & 1527947 & 8.6576 & 7.0615 & TRN & \\
\hline CHEMBL3680144 & 1527947 & 8.0506 & 9.01700 & 2000000001 & TST \\
\hline & & & & 3320 & \\
\hline
\end{tabular}


Supplemental Table S2.txt

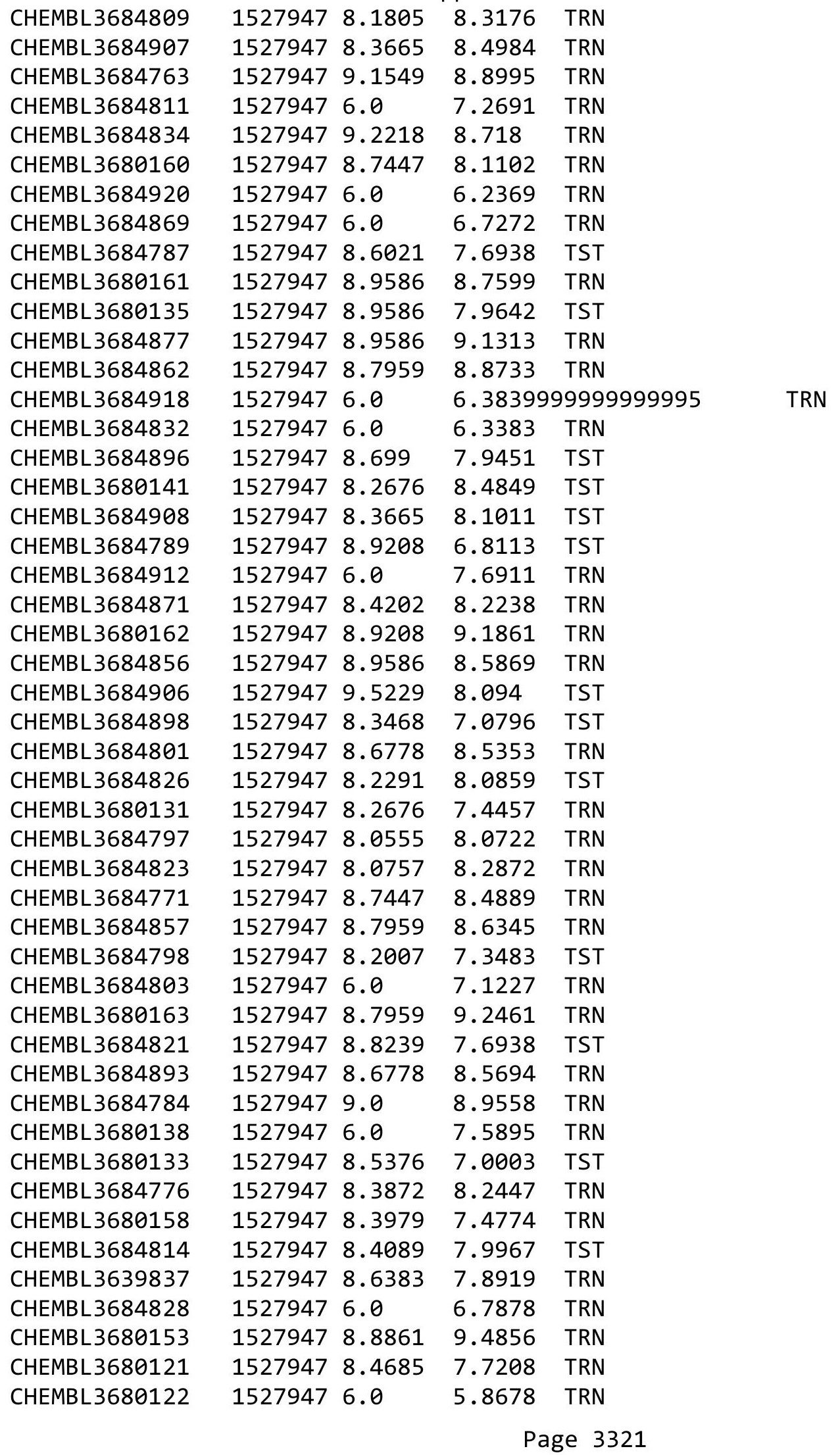


Supplemental Table S2.txt

\begin{tabular}{|c|c|c|c|c|c|}
\hline CHEMBL3684829 & 1527947 & 6.0 & 7.1846 & TRN & \\
\hline CHEMBL3684833 & 1527947 & 8.6021 & 7.7381 & TRN & \\
\hline CHEMBL 3684830 & 1527947 & 8.0915 & 8.7358 & TST & \\
\hline CHEMBL 3680168 & 1527947 & 8.585 & 8.724 & TRN & \\
\hline CHEMBL 3680127 & 1527947 & 6.0 & 7.3562 & TRN & \\
\hline CHEMBL 3680132 & 1527947 & 8.6576 & 7.3832 & TRN & \\
\hline CHEMBL 3684835 & 1527947 & 6.0 & 6.4013 & TRN & \\
\hline CHEMBL 3680166 & 1527947 & 8.9208 & 8.8081 & TRN & \\
\hline CHEMBL 3684785 & 1527947 & 8.5528 & 8.1628 & TRN & \\
\hline CHEMBL3684905 & 1527947 & 8.8539 & 8.3054 & TST & \\
\hline CHEMBL 3684837 & 1527947 & 8.699 & 8.6374 & TRN & \\
\hline CHEMBL 3680117 & 1527947 & 6.0 & 7.2987 & TRN & \\
\hline CHEMBL 3684796 & 1527947 & 9.3979 & 7.95200 & 0000000001 & TRN \\
\hline CHEMBL 3684768 & 1527947 & 8.9208 & 8.6234 & TRN & \\
\hline CHEMBL 3684795 & 1527947 & 8.699 & 7.6605 & TRN & \\
\hline CHEMBL 3684772 & 1527947 & 9.1549 & 8.4065 & TRN & \\
\hline CHEMBL3680146 & 1527947 & 6.0 & 7.9665 & TRN & \\
\hline CHEMBL 3684794 & 1527947 & 8.7212 & 7.1903 & TRN & \\
\hline CHEMBL 3684806 & 1527947 & 8.3665 & 6.9437 & TST & \\
\hline CHEMBL 3684775 & 1527947 & 8.3872 & 8.6306 & TRN & \\
\hline CHEMBL 3684855 & 1527947 & 8.7959 & 9.1577 & TRN & \\
\hline CHEMBL 3684782 & 1527947 & 8.1938 & 8.9534 & TRN & \\
\hline CHEMBL 3684849 & 1527947 & 8.1308 & 9.4332 & TST & \\
\hline CHEMBL 3684842 & 1527947 & 8.2441 & 9.1822 & TST & \\
\hline CHEMBL 3684824 & 1527947 & 8.6576 & 6.7262 & TST & \\
\hline CHEMBL 3684879 & 1527947 & 6.0 & 8.3048 & TRN & \\
\hline CHEMBL 3684783 & 1527947 & 8.1675 & 8.8226 & TRN & \\
\hline CHEMBL 3684878 & 1527947 & 8.4815 & 8.8493 & TST & \\
\hline CHEMBL3684759 & 1527947 & 6.0 & 8.3433 & TRN & \\
\hline CHEMBL 3684854 & 1527947 & 6.0 & 6.6116 & TRN & \\
\hline CHEMBL 3680165 & 1527947 & 10.0 & 8.7586 & TRN & \\
\hline CHEMBL 3684773 & 1527947 & 8.9208 & 8.2788 & TRN & \\
\hline CHEMBL 3684892 & 1527947 & 8.2147 & 7.7754 & TST & \\
\hline CHEMBL 3684820 & 1527947 & 8.699 & 7.6863 & TST & \\
\hline CHEMBL 3684880 & 1527947 & 6.0 & 8.2271 & TRN & \\
\hline CHEMBL3680151 & 1527947 & 9.0969 & 8.5919 & TRN & \\
\hline CHEMBL3684777 & 1527947 & 8.7212 & 9.0022 & TRN & \\
\hline CHEMBL3684813 & 1527947 & 8.7696 & 7.3961 & TST & \\
\hline CHEMBL 3684815 & 1527947 & 8.4949 & 8.3692 & TRN & \\
\hline CHEMBL3680169 & 1527947 & 8.8539 & 8.5323 & TRN & \\
\hline CHEMBL3684790 & 1527947 & 8.3279 & 7.4402 & TRN & \\
\hline CHEMBL 3684853 & 1527947 & 6.0 & 6.9725 & TRN & \\
\hline CHEMBL3684808 & 1527947 & 8.7447 & 7.188 & TST & \\
\hline CHEMBL 3680164 & 1527947 & 8.6778 & 8.2111 & TRN & \\
\hline CHEMBL 3680142 & 1527947 & 8.3279 & 8.2448 & TRN & \\
\hline CHEMBL 3684831 & 1527947 & 8.3979 & 8.5346 & TST & \\
\hline CHEMBL 3684793 & 1527947 & 8.9586 & 7.2795 & TRN & \\
\hline CHEMBL 3684910 & 1527947 & 8.0757 & 8.3814 & TST & \\
\hline
\end{tabular}


Supplemental Table S2.txt

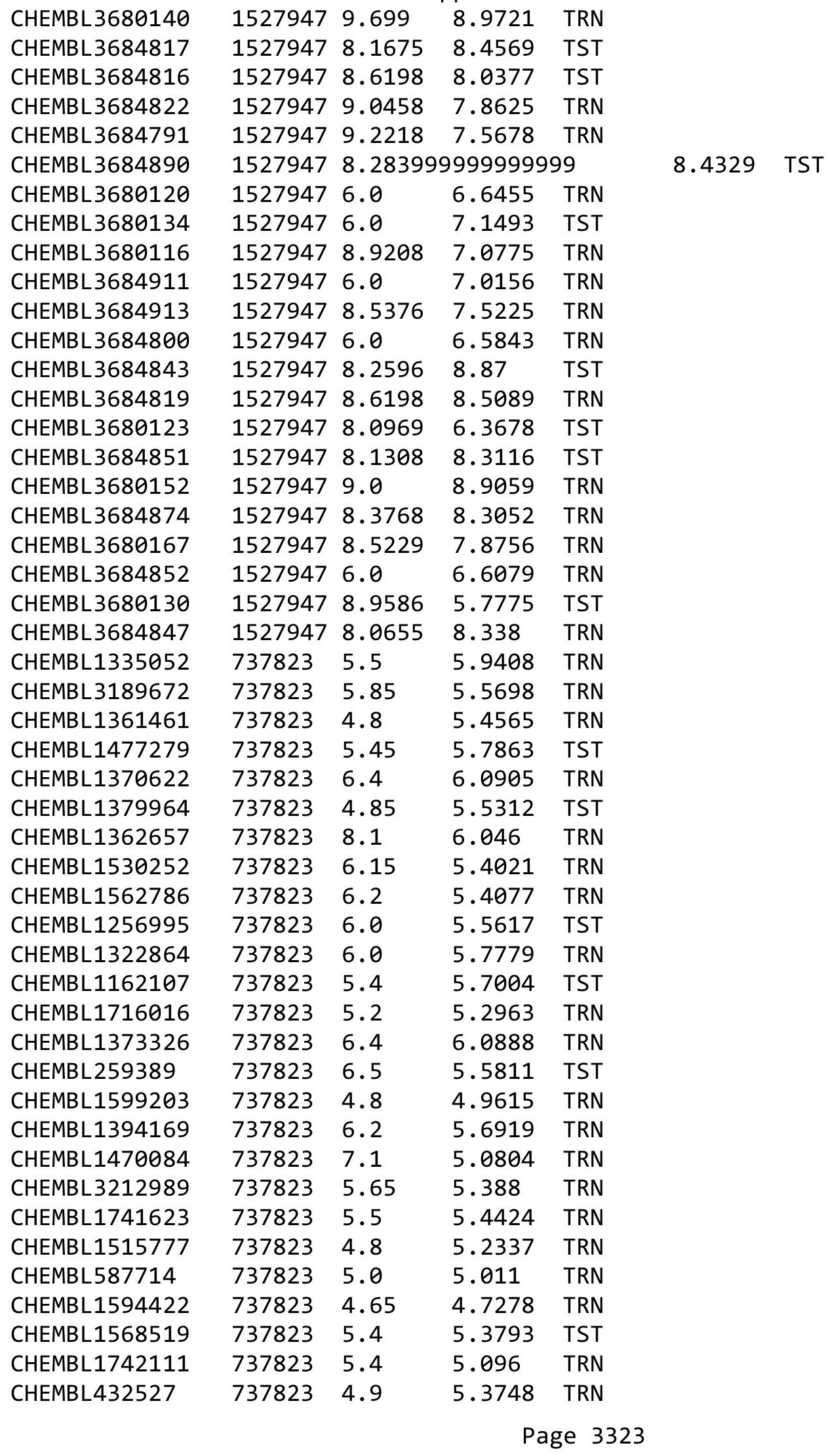




\begin{tabular}{|c|c|c|c|c|c|}
\hline \multicolumn{6}{|c|}{ ble S2 } \\
\hline CHEMBL269550 & 737823 & 6.0 & 4.885 & TRN & \\
\hline CHEMBL1531291 & 737823 & 4.6 & 5.1477 & TRN & \\
\hline CHEMBL1591107 & 737823 & 6.0 & 6.3253 & TRN & \\
\hline CHEMBL88147 & 737823 & 6.7 & 5.78600 & 00000000005 & TRN \\
\hline CHEMBL1551834 & 737823 & 4.7 & 4.7851 & TRN & \\
\hline CHEMBL3196775 & 737823 & 5.85 & 5.3282 & TRN & \\
\hline CHEMBL1317802 & 737823 & 5.3 & 4.5161 & TRN & \\
\hline CHEMBL1702111 & 737823 & 5.7 & 5.3892 & TRN & \\
\hline CHEMBL1701329 & 737823 & 5.7 & 5.6203 & TRN & \\
\hline CHEMBL1455641 & 737823 & 5.1 & 5.051 & TRN & \\
\hline CHEMBL1732053 & 737823 & 4.95 & 4.7774 & TRN & \\
\hline CHEMBL1467227 & 737823 & 4.8 & 5.6215 & TST & \\
\hline CHEMBL1565536 & 737823 & 5.8 & 5.1789 & TRN & \\
\hline CHEMBL1590550 & 737823 & 4.7 & 5.2134 & TRN & \\
\hline CHEMBL1723309 & 737823 & 5.35 & 5.2848 & TRN & \\
\hline CHEMBL1479506 & 737823 & 5.0 & 4.98 & TRN & \\
\hline CHEMBL1527565 & 737823 & 5.4 & 5.5116 & TST & \\
\hline CHEMBL375629 & 737823 & 4.5 & 4.9576 & TST & \\
\hline CHEMBL 1407440 & 737823 & 5.4 & 5.8644 & TRN & \\
\hline CHEMBL1496663 & 737823 & 4.4 & 5.2979 & TST & \\
\hline CHEMBL1508951 & 737823 & 6.85 & 5.5093 & TRN & \\
\hline CHEMBL1350587 & 737823 & 6.5 & 5.5912 & TRN & \\
\hline CHEMBL1552854 & 737823 & 6.5 & 6.5598 & TRN & \\
\hline CHEMBL1302827 & 737823 & 5.8 & 5.5091 & TST & \\
\hline CHEMBL1495506 & 737823 & 4.7 & 5.1567 & TRN & \\
\hline CHEMBL1553422 & 737823 & 4.5 & 4.9536 & TST & \\
\hline CHEMBL1396577 & 737823 & 4.7 & 4.9606 & TRN & \\
\hline CHEMBL1722356 & 737823 & 8.2 & 5.039 & TST & \\
\hline CHEMBL1233250 & 737823 & 4.5 & 4.7838 & TST & \\
\hline CHEMBL3214277 & 737823 & 5.1 & 5.2136 & TRN & \\
\hline CHEMBL1256687 & 737823 & 7.0 & 6.2054 & TST & \\
\hline CHEMBL1514149 & 737823 & 5.6 & 5.7736 & TRN & \\
\hline CHEMBL1312936 & 737823 & 4.8 & 5.0143 & TRN & \\
\hline CHEMBL1475657 & 737823 & 5.5 & 5.4494 & TRN & \\
\hline CHEMBL909 & 737823 & 6.2 & 5.465 & TRN & \\
\hline CHEMBL1395862 & 737823 & 5.5 & 5.4344 & TRN & \\
\hline CHEMBL1534347 & 737823 & 4.8 & 5.2577 & TRN & \\
\hline CHEMBL1320172 & 737823 & 4.8 & 5.0101 & TRN & \\
\hline CHEMBL1462156 & 737823 & 4.9 & 4.8144 & TRN & \\
\hline CHEMBL1575145 & 737823 & 4.85 & 5.1865 & TRN & \\
\hline CHEMBL1443086 & 737823 & 4.55 & 4.9749 & TRN & \\
\hline CHEMBL1493099 & 737823 & 4.9 & 5.3824 & TST & \\
\hline CHEMBL1392767 & 737823 & 5.55 & 5.1938 & TRN & \\
\hline CHEMBL1305253 & 737823 & 5.75 & 6.0365 & TRN & \\
\hline CHEMBL1318553 & 737823 & 5.0 & 5.1384 & TST & \\
\hline CHEMBL1466015 & 737823 & 4.8 & 5.2155 & TST & \\
\hline CHEMBL1467355 & 737823 & 4.8 & 5.3688 & TST & \\
\hline CHEMBL1349241 & 737823 & 5.4 & 4.9283 & TRN & \\
\hline
\end{tabular}




\begin{tabular}{|c|c|c|c|c|c|}
\hline \\
\hline CHEMBL1329940 & 737823 & 5.4 & 5.113 & TST & \\
\hline CHEMBL1392952 & 737823 & 6.05 & 5.5134 & TRN & \\
\hline CHEMBL1592571 & 737823 & 6.0 & 6.26399 & 9999999999 & TRN \\
\hline CHEMBL1513633 & 737823 & 4.6 & 4.8066 & TRN & \\
\hline CHEMBL1351200 & 737823 & 5.5 & 5.6184 & TST & \\
\hline CHEMBL1317885 & 737823 & 5.9 & 5.4764 & TRN & \\
\hline CHEMBL1425169 & 737823 & 5.8 & 5.352 & TRN & \\
\hline CHEMBL1323434 & 737823 & 5.65 & 5.7242 & TRN & \\
\hline CHEMBL1531342 & 737823 & 5.4 & 5.5524 & TRN & \\
\hline CHEMBL1703300 & 737823 & 4.75 & 4.8696 & TRN & \\
\hline CHEMBL1435409 & 737823 & 6.1 & 6.4318 & TRN & \\
\hline CHEMBL1489182 & 737823 & 6.9 & 6.1567 & TRN & \\
\hline CHEMBL1600685 & 737823 & 4.8 & 5.7211 & TRN & \\
\hline CHEMBL1394474 & 737823 & -0.0 & 4.8879 & TRN & \\
\hline CHEMBL 279841 & 737823 & 4.4 & 5.1008 & TRN & \\
\hline CHEMBL1563398 & 737823 & 5.0 & 4.9544 & TRN & \\
\hline CHEMBL1418522 & 737823 & 4.8 & 5.7607 & TST & \\
\hline CHEMBL1499077 & 737823 & 6.3 & 6.107 & TRN & \\
\hline CHEMBL1552095 & 737823 & 4.4 & 5.26 & TST & \\
\hline CHEMBL1386277 & 737823 & 5.5 & 5.3671 & TRN & \\
\hline CHEMBL3209517 & 737823 & 4.85 & 5.3082 & TRN & \\
\hline CHEMBL1317300 & 737823 & 5.0 & 5.5192 & TRN & \\
\hline CHEMBL168276 & 737823 & 4.4 & 5.2937 & TRN & \\
\hline CHEMBL1606425 & 737823 & 4.8 & 5.17 & TRN & \\
\hline CHEMBL1406800 & 737823 & 4.85 & 5.0533 & TRN & \\
\hline CHEMBL1586390 & 737823 & 4.65 & 5.2289 & TST & \\
\hline CHEMBL1395247 & 737823 & 5.4 & 5.475 & TRN & \\
\hline CHEMBL301707 & 737823 & 4.4 & 5.3051 & TRN & \\
\hline CHEMBL1964464 & 737823 & 5.35 & 5.0148 & TRN & \\
\hline CHEMBL1525320 & 737823 & 5.2 & 5.5259 & TRN & \\
\hline CHEMBL1599905 & 737823 & 5.6 & 5.7656 & TST & \\
\hline CHEMBL1366453 & 737823 & 4.5 & 5.0199 & TST & \\
\hline CHEMBL1554465 & 737823 & 4.8 & 4.5214 & TRN & \\
\hline CHEMBL1742131 & 737823 & 4.75 & 4.9915 & TST & \\
\hline CHEMBL510009 & 737823 & 6.4 & 6.1473 & TRN & \\
\hline CHEMBL1323465 & 737823 & 5.0 & 5.1252 & TRN & \\
\hline CHEMBL1436488 & 737823 & 4.8 & 4.2556 & TRN & \\
\hline CHEMBL1240673 & 737823 & 5.1 & 5.4948 & TRN & \\
\hline CHEMBL1734583 & 737823 & 8.0 & 5.1522 & TRN & \\
\hline CHEMBL1255655 & 737823 & 6.6 & 5.271 & TRN & \\
\hline CHEMBL1483773 & 737823 & 4.9 & 5.2793 & TST & \\
\hline CHEMBL1462421 & 737823 & 5.05 & 5.3071 & TRN & \\
\hline CHEMBL1385309 & 737823 & 4.8 & 5.3834 & TRN & \\
\hline CHEMBL 7463 & 737823 & 5.1 & 5.0629 & TST & \\
\hline CHEMBL1528993 & 737823 & 4.6 & 4.8727 & TRN & \\
\hline CHEMBL1509383 & 737823 & 4.8 & 5.0911 & TRN & \\
\hline CHEMBL1462878 & 737823 & 6.2 & 5.6575 & TRN & \\
\hline CHEMBL1314516 & 737823 & 5.3 & 5.7947 & TRN & \\
\hline
\end{tabular}




\begin{tabular}{|c|c|c|c|c|c|}
\hline \\
\hline CHEMBL1565333 & 737823 & 5.3 & 5.5285 & TST & \\
\hline CHEMBL1564977 & 737823 & 5.9 & 5.5462 & TRN & \\
\hline CHEMBL1478541 & 737823 & 5.3 & 5.2996 & TST & \\
\hline CHEMBL1539796 & 737823 & 5.0 & 4.8821 & TRN & \\
\hline CHEMBL1484864 & 737823 & 6.05 & 5.6237 & TRN & \\
\hline CHEMBL1509598 & 737823 & 5.05 & 4.9185 & TRN & \\
\hline CHEMBL1382502 & 737823 & 4.9 & 4.6617 & TRN & \\
\hline CHEMBL1567913 & 737823 & 6.3 & 5.8789 & TRN & \\
\hline CHEMBL1451238 & 737823 & 4.8 & 5.5321 & TRN & \\
\hline CHEMBL1555014 & 737823 & 6.4 & 6.24100 & 00000000005 & TRN \\
\hline CHEMBL1358560 & 737823 & 4.6 & 4.5029 & TRN & \\
\hline CHEMBL1533335 & 737823 & 5.6 & 5.7618 & TRN & \\
\hline CHEMBL3209931 & 737823 & 6.0 & 5.8027 & TRN & \\
\hline CHEMBL1571264 & 737823 & 6.0 & 5.4608 & TRN & \\
\hline CHEMBL1352766 & 737823 & 5.7 & 5.3526 & TRN & \\
\hline CHEMBL1558929 & 737823 & 6.0 & 4.7451 & TRN & \\
\hline CHEMBL1500134 & 737823 & 5.0 & 5.3394 & TRN & \\
\hline CHEMBL1526768 & 737823 & 6.2 & 6.0782 & TST & \\
\hline CHEMBL88272 & 737823 & 4.9 & 5.6106 & TST & \\
\hline CHEMBL3213479 & 737823 & 5.85 & 5.4147 & TRN & \\
\hline CHEMBL1508906 & 737823 & 4.8 & 5.4488 & TRN & \\
\hline CHEMBL1462816 & 737823 & 5.65 & 5.5126 & TRN & \\
\hline CHEMBL1716715 & 737823 & 5.75 & 5.3139 & TRN & \\
\hline CHEMBL 227298 & 737823 & 5.4 & 5.3219 & TRN & \\
\hline CHEMBL1491965 & 737823 & 4.6 & 5.6349 & TRN & \\
\hline CHEMBL1315794 & 737823 & 5.6 & 5.5196 & TRN & \\
\hline CHEMBL1438615 & 737823 & 4.65 & 5.0144 & TRN & \\
\hline CHEMBL 228792 & 737823 & 5.1 & 5.593 & TRN & \\
\hline CHEMBL85139 & 737823 & 6.5 & 5.6271 & TRN & \\
\hline CHEMBL1608397 & 737823 & 5.75 & 5.4104 & TRN & \\
\hline CHEMBL1606866 & 737823 & 6.0 & 5.1895 & TRN & \\
\hline CHEMBL1393461 & 737823 & 4.9 & 4.7896 & TRN & \\
\hline CHEMBL1383537 & 737823 & 6.2 & 5.6693 & TRN & \\
\hline CHEMBL 1447520 & 737823 & 5.2 & 5.6863 & TST & \\
\hline CHEMBL1533214 & 737823 & 4.8 & 5.3785 & TRN & \\
\hline CHEMBL1445026 & 737823 & 5.8 & 5.4107 & TRN & \\
\hline CHEMBL1325701 & 737823 & 5.3 & 5.6538 & TRN & \\
\hline CHEMBL1518338 & 737823 & 6.4 & 5.6138 & TRN & \\
\hline CHEMBL1378545 & 737823 & 5.6 & 5.374 & TRN & \\
\hline CHEMBL1394923 & 737823 & 5.0 & 5.1901 & TRN & \\
\hline CHEMBL1340272 & 737823 & 4.85 & 4.9293 & TRN & \\
\hline CHEMBL1557821 & 737823 & 4.7 & 5.0458 & TRN & \\
\hline CHEMBL1409320 & 737823 & 4.8 & 4.8391 & TRN & \\
\hline CHEMBL1437448 & 737823 & 4.7 & 5.0727 & TST & \\
\hline CHEMBL1526964 & 737823 & 5.9 & 5.8803 & TST & \\
\hline CHEMBL1436475 & 737823 & 4.7 & 4.3092 & TRN & \\
\hline CHEMBL1591965 & 737823 & 5.2 & 5.2375 & TRN & \\
\hline CHEMBL1397821 & 737823 & 5.5 & 5.7774 & TRN & \\
\hline
\end{tabular}




\begin{tabular}{|c|c|c|c|c|c|}
\hline & & \multicolumn{4}{|c|}{ Supplemental Table S2.txt } \\
\hline CHEMBL3198793 & 737823 & 4.85 & 5.2959 & TST & \\
\hline CHEMBL1440943 & 737823 & 4.6 & 5.1469 & TRN & \\
\hline CHEMBL1453899 & 737823 & 5.15 & 5.1882 & TRN & \\
\hline CHEMBL1515826 & 737823 & 5.5 & 5.2804 & TST & \\
\hline CHEMBL1524920 & 737823 & 6.0 & 5.4066 & TRN & \\
\hline CHEMBL1538611 & 737823 & 5.45 & 5.4478 & TRN & \\
\hline CHEMBL 277525 & 737823 & 6.6 & 5.871 & TRN & \\
\hline CHEMBL1358568 & 737823 & 6.0 & 5.1848 & TRN & \\
\hline CHEMBL1318104 & 737823 & 5.3 & 5.5213 & TRN & \\
\hline CHEMBL1514161 & 737823 & 6.2 & 4.8139 & TRN & \\
\hline CHEMBL1580474 & 737823 & 4.8 & 4.8483 & TRN & \\
\hline CHEMBL1303741 & 737823 & 5.25 & 5.3217 & TRN & \\
\hline CHEMBL1602394 & 737823 & 5.7 & 5.7974 & TRN & \\
\hline CHEMBL1551729 & 737823 & 4.8 & 5.5946 & TRN & \\
\hline CHEMBL1326308 & 737823 & 4.8 & 5.2216 & TRN & \\
\hline CHEMBL1358341 & 737823 & 5.4 & 5.21899 & 9999999999 & TRN \\
\hline CHEMBL3199738 & 737823 & 5.9 & 5.6608 & TRN & \\
\hline CHEMBL1586835 & 737823 & 4.6 & 5.0511 & TRN & \\
\hline CHEMBL 26138 & 737823 & 6.6 & 5.489 & TRN & \\
\hline CHEMBL1605449 & 737823 & 5.7 & 4.848 & TRN & \\
\hline CHEMBL3192267 & 737823 & 4.8 & 5.7529 & TRN & \\
\hline CHEMBL1469862 & 737823 & 5.35 & 5.483 & TRN & \\
\hline CHEMBL1532426 & 737823 & 5.4 & 5.4559 & TRN & \\
\hline CHEMBL1578011 & 737823 & 4.95 & 5.522 & TRN & \\
\hline CHEMBL 271023 & 737823 & 4.9 & 5.1298 & TST & \\
\hline CHEMBL1395415 & 737823 & 4.9 & 5.1286 & TRN & \\
\hline CHEMBL1533467 & 737823 & 5.9 & 5.6826 & TRN & \\
\hline CHEMBL1513247 & 737823 & 4.6 & 4.1562 & TRN & \\
\hline CHEMBL1501744 & 737823 & 6.05 & 5.1532 & TRN & \\
\hline CHEMBL1347469 & 737823 & 5.8 & 5.7579 & TRN & \\
\hline CHEMBL1472233 & 737823 & 5.05 & 5.3238 & TRN & \\
\hline CHEMBL1412390 & 737823 & 6.2 & 6.2079 & TRN & \\
\hline CHEMBL24983 & 737823 & 6.0 & 5.5728 & TST & \\
\hline CHEMBL1408647 & 737823 & 5.7 & 5.4797 & TRN & \\
\hline CHEMBL1449103 & 737823 & 4.95 & 5.4512 & TRN & \\
\hline CHEMBL1353181 & 737823 & 5.4 & 4.5261 & TRN & \\
\hline CHEMBL1581616 & 737823 & 5.3 & 5.151 & TRN & \\
\hline CHEMBL1374962 & 737823 & 7.35 & 5.6476 & TRN & \\
\hline CHEMBL1515246 & 737823 & 5.4 & 5.2913 & TRN & \\
\hline CHEMBL428496 & 737823 & 4.5 & 5.3456 & TST & \\
\hline CHEMBL1323124 & 737823 & 4.9 & 4.5368 & TRN & \\
\hline CHEMBL1378959 & 737823 & 4.95 & 4.9331 & TRN & \\
\hline CHEMBL90769 & 737823 & 7.0 & 5.4889 & TRN & \\
\hline CHEMBL1377710 & 737823 & 4.65 & 5.3903 & TRN & \\
\hline CHEMBL1430918 & 737823 & 5.0 & 5.4013 & TRN & \\
\hline CHEMBL1414688 & 737823 & 5.2 & 5.3415 & TRN & \\
\hline CHEMBL1476897 & 737823 & 6.2 & 5.1645 & TST & \\
\hline CHEMBL411502 & 737823 & 4.7 & 4.7373 & TST & \\
\hline
\end{tabular}




\begin{tabular}{|c|c|c|c|c|}
\hline \multicolumn{5}{|c|}{ Supplemental Table S2.txt } \\
\hline CHEMBL1565961 & 737823 & 4.85 & 4.6748 & TRN \\
\hline CHEMBL1517172 & 737823 & 4.5 & 5.1108 & TRN \\
\hline CHEMBL1545653 & 737823 & 5.05 & 5.7223 & TRN \\
\hline CHEMBL1423250 & 737823 & 4.8 & 5.0418 & TRN \\
\hline CHEMBL1463609 & 737823 & 4.95 & 5.0572 & TRN \\
\hline CHEMBL1519649 & 737823 & 6.2 & 6.396 & TRN \\
\hline CHEMBL14690 & 737823 & 4.8 & 5.3678 & TST \\
\hline CHEMBL1454270 & 737823 & 4.7 & 4.6689 & TRN \\
\hline CHEMBL1460531 & 737823 & 5.9 & 5.7113 & TST \\
\hline CHEMBL1469535 & 737823 & 4.8 & 5.1397 & TRN \\
\hline CHEMBL1612691 & 737823 & 5.4 & 4.7638 & TRN \\
\hline CHEMBL3198365 & 737823 & 4.95 & 5.5552 & TRN \\
\hline CHEMBL1441347 & 737823 & 4.75 & 5.1726 & TST \\
\hline CHEMBL1982520 & 737823 & 5.55 & 5.5855 & TST \\
\hline CHEMBL1425746 & 737823 & 5.2 & 5.3752 & TRN \\
\hline CHEMBL1564740 & 737823 & 4.8 & 4.9826 & TRN \\
\hline CHEMBL1441222 & 737823 & 5.3 & 5.669 & TRN \\
\hline CHEMBL1563819 & 737823 & 5.8 & 5.8167 & TST \\
\hline CHEMBL1488679 & 737823 & 5.9 & 6.0078 & TST \\
\hline CHEMBL1513928 & 737823 & 4.8 & 5.063 & TRN \\
\hline CHEMBL1562987 & 737823 & 4.5 & 5.2237 & TRN \\
\hline CHEMBL1517935 & 737823 & 4.9 & 5.2815 & TRN \\
\hline CHEMBL 72365 & 737823 & 6.1 & 5.4783 & TST \\
\hline CHEMBL1593128 & 737823 & 5.4 & 5.3508 & TRN \\
\hline CHEMBL1605713 & 737823 & 4.8 & 5.102 & TRN \\
\hline CHEMBL1331690 & 737823 & 4.8 & 4.9018 & TRN \\
\hline CHEMBL1626274 & 737823 & 6.0 & 5.1228 & TST \\
\hline CHEMBL1410926 & 737823 & 5.1 & 5.1577 & TRN \\
\hline CHEMBL1533645 & 737823 & 5.9 & 5.8999 & TRN \\
\hline CHEMBL1315184 & 737823 & 6.1 & 5.8231 & TRN \\
\hline CHEMBL1446324 & 737823 & 4.8 & 5.13 & TRN \\
\hline CHEMBL102714 & 737823 & 5.5 & 5.5739 & TST \\
\hline CHEMBL1405325 & 737823 & 6.2 & 5.8712 & TRN \\
\hline CHEMBL1583276 & 737823 & 4.8 & 5.2583 & TRN \\
\hline CHEMBL1549240 & 737823 & 4.7 & 5.2135 & TRN \\
\hline CHEMBL1494592 & 737823 & 4.8 & 5.2228 & TRN \\
\hline CHEMBL1368566 & 737823 & 5.0 & 5.1687 & TRN \\
\hline CHEMBL1532991 & 737823 & 4.9 & 5.0247 & TRN \\
\hline CHEMBL1383364 & 737823 & 4.9 & 4.6449 & TRN \\
\hline CHEMBL1550048 & 737823 & 5.55 & 5.4873 & TRN \\
\hline CHEMBL1447550 & 737823 & 5.4 & 5.3331 & TRN \\
\hline CHEMBL1612410 & 737823 & 4.8 & 5.3143 & TRN \\
\hline CHEMBL1327555 & 737823 & 5.4 & 5.0472 & TRN \\
\hline CHEMBL1393348 & 737823 & 4.85 & 5.3855 & TRN \\
\hline CHEMBL1451037 & 737823 & 4.7 & 5.6727 & TST \\
\hline CHEMBL1540475 & 737823 & 4.75 & 4.9381 & TRN \\
\hline CHEMBL1554308 & 737823 & 5.5 & 5.4079 & TRN \\
\hline CHEMBL1443425 & 737823 & 4.5 & 5.0016 & TRN \\
\hline
\end{tabular}




\begin{tabular}{|c|c|c|c|c|}
\hline & & & ement & al Ta \\
\hline CHEMBL1708951 & 737823 & 4.8 & 5.0846 & TRN \\
\hline CHEMBL1591451 & 737823 & 4.9 & 4.9629 & TRN \\
\hline CHEMBL1389687 & 737823 & 4.6 & 5.5204 & TST \\
\hline CHEMBL1409568 & 737823 & 4.75 & 4.864 & TRN \\
\hline CHEMBL1411396 & 737823 & 5.05 & 5.3987 & TST \\
\hline CHEMBL1355589 & 737823 & 5.0 & 4.7748 & TRN \\
\hline CHEMBL1421523 & 737823 & 4.7 & 5.2387 & TST \\
\hline CHEMBL1593645 & 737823 & 5.3 & 5.4812 & TRN \\
\hline CHEMBL1356485 & 737823 & 5.7 & 5.6351 & TRN \\
\hline CHEMBL1330067 & 737823 & 5.9 & 5.1336 & TRN \\
\hline CHEMBL1524985 & 737823 & 5.65 & 5.5286 & TRN \\
\hline CHEMBL1439040 & 737823 & 5.9 & 5.106 & TST \\
\hline CHEMBL1494481 & 737823 & 6.5 & 5.665 & TRN \\
\hline CHEMBL1315504 & 737823 & 5.7 & 6.0973 & TRN \\
\hline CHEMBL475376 & 737823 & 6.0 & 5.5516 & TRN \\
\hline CHEMBL3198027 & 737823 & 5.35 & 5.4605 & TST \\
\hline CHEMBL1318847 & 737823 & 4.9 & 5.5758 & TRN \\
\hline CHEMBL1575476 & 737823 & 5.95 & 5.3371 & TST \\
\hline CHEMBL1499485 & 737823 & 4.85 & 5.0185 & TRN \\
\hline CHEMBL1454951 & 737823 & 5.45 & 5.4764 & TRN \\
\hline CHEMBL1256775 & 737823 & 4.9 & 5.0771 & TRN \\
\hline CHEMBL1333968 & 737823 & 5.9 & 5.6254 & TRN \\
\hline CHEMBL 3214445 & 737823 & 4.9 & 5.1581 & TRN \\
\hline CHEMBL1600294 & 737823 & 5.8 & 5.4682 & TRN \\
\hline CHEMBL3351080 & 737823 & 6.1 & 5.898 & TRN \\
\hline CHEMBL1597037 & 737823 & 6.9 & 5.9686 & TRN \\
\hline CHEMBL1539061 & 737823 & 4.85 & 5.2567 & TRN \\
\hline CHEMBL1474876 & 737823 & 4.7 & 4.3995 & TRN \\
\hline CHEMBL315268 & 737823 & 4.4 & 4.6358 & TST \\
\hline CHEMBL1483625 & 737823 & 4.8 & 4.9837 & TRN \\
\hline CHEMBL1413343 & 737823 & 4.6 & 5.131 & TRN \\
\hline CHEMBL1433762 & 737823 & 4.5 & 4.9624 & TRN \\
\hline CHEMBL3199708 & 737823 & 5.6 & 5.5351 & TRN \\
\hline CHEMBL1366361 & 737823 & 4.75 & 4.9626 & TRN \\
\hline CHEMBL1593096 & 737823 & 4.5 & 4.6417 & TRN \\
\hline CHEMBL1361050 & 737823 & 5.4 & 5.0608 & TRN \\
\hline CHEMBL1306942 & 737823 & 4.9 & 5.0584 & TRN \\
\hline CHEMBL1402633 & 737823 & 7.25 & 6.3859 & TRN \\
\hline CHEMBL1407530 & 737823 & 5.4 & 5.1636 & TRN \\
\hline CHEMBL1472036 & 737823 & 4.7 & 4.7056 & TRN \\
\hline CHEMBL1472572 & 737823 & 4.55 & 5.0938 & TRN \\
\hline CHEMBL1397914 & 737823 & 4.8 & 5.0032 & TRN \\
\hline CHEMBL1609270 & 737823 & 6.0 & 4.919 & TRN \\
\hline CHEMBL1607623 & 737823 & 6.7 & 5.6312 & TRN \\
\hline CHEMBL1570350 & 737823 & 5.2 & 5.205 & TRN \\
\hline CHEMBL1382823 & 737823 & 5.0 & 5.3009 & TRN \\
\hline CHEMBL3211462 & 737823 & 4.85 & 5.6176 & TST \\
\hline CHEMBL1582272 & 737823 & 4.9 & 5.1993 & TST \\
\hline
\end{tabular}




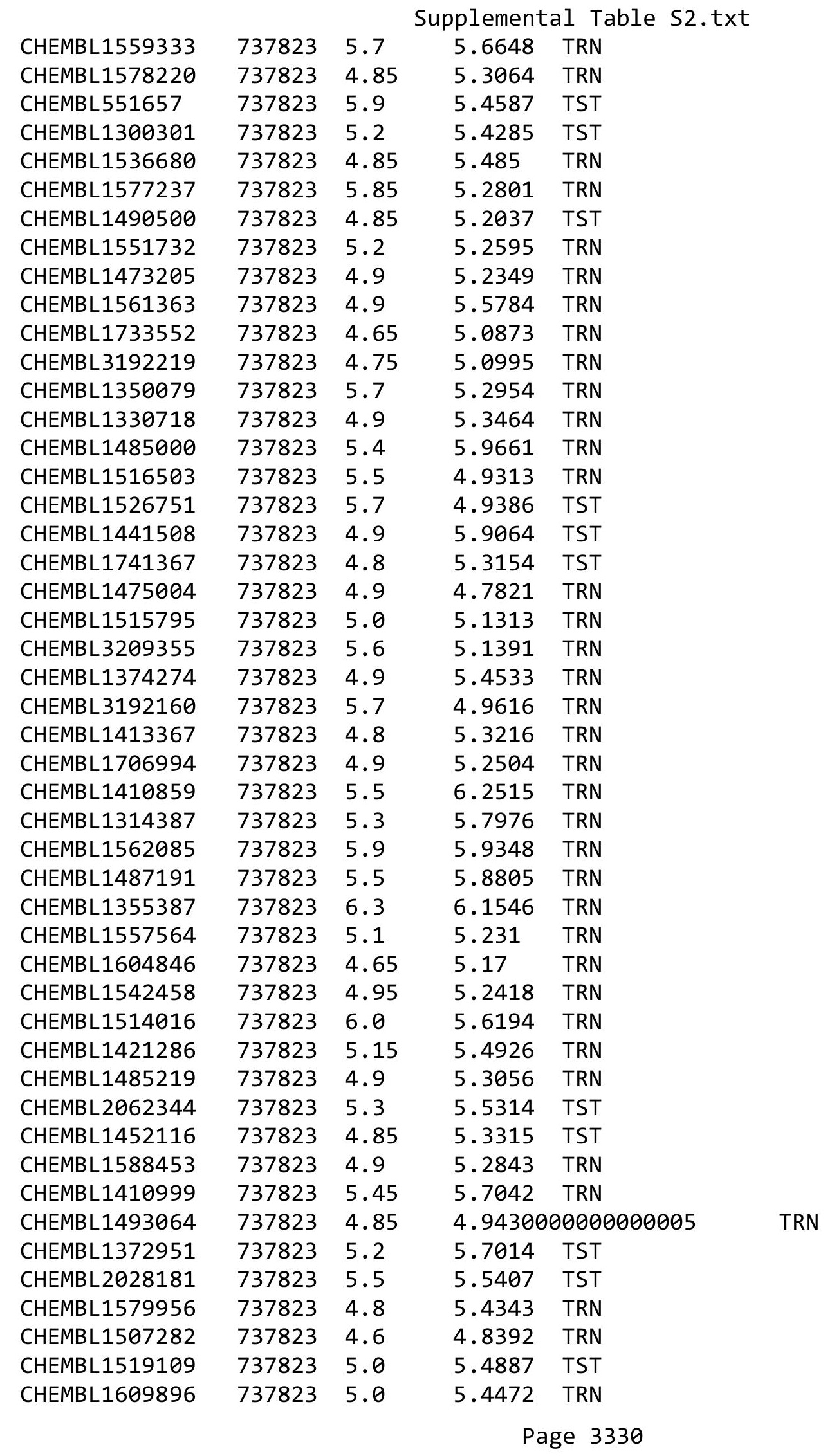




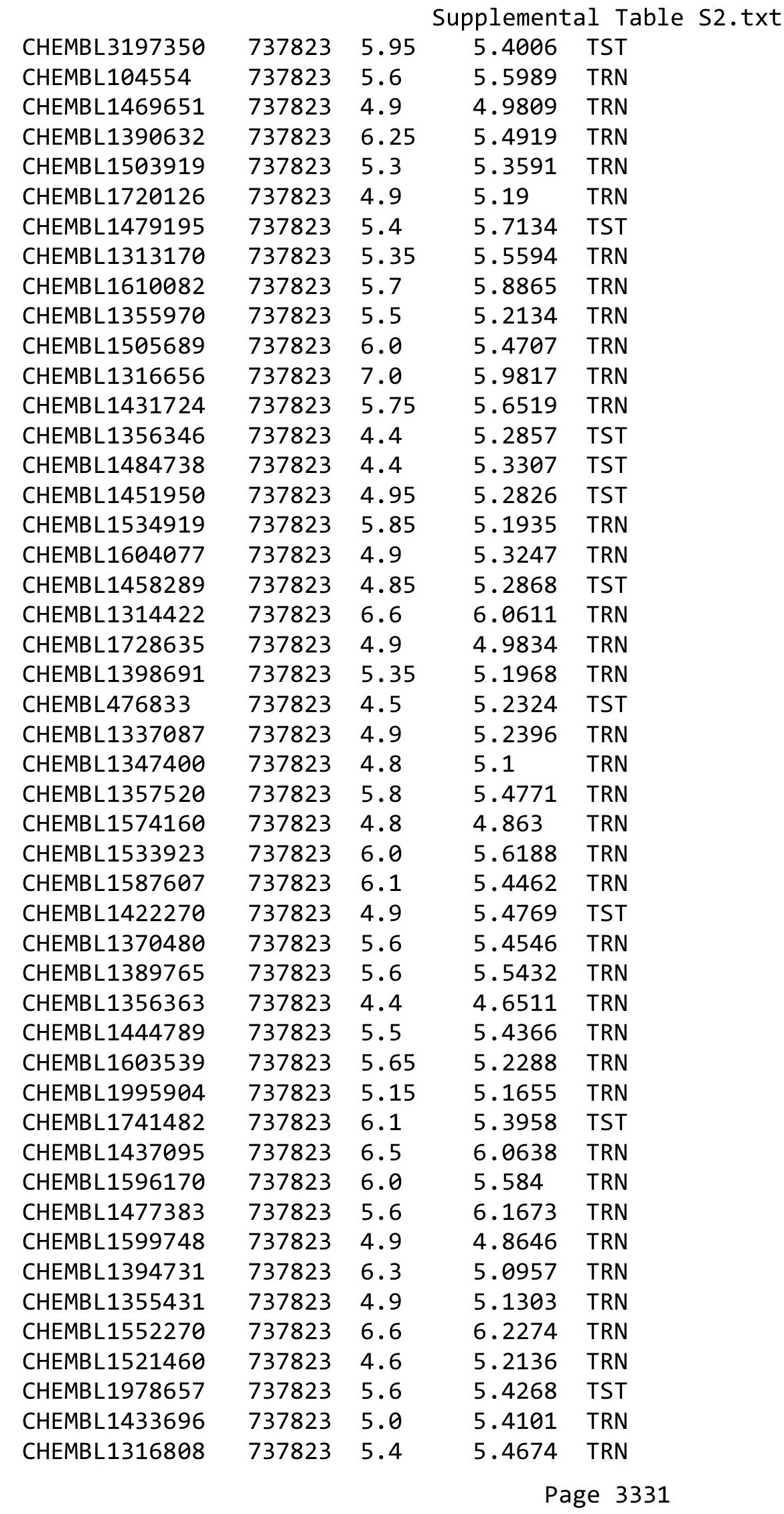




\begin{tabular}{|c|c|c|c|c|c|}
\hline \multicolumn{6}{|c|}{ Supplemental Table S2.txt } \\
\hline CHEMBL1342714 & 737823 & 4.85 & 5.2376 & TRN & \\
\hline CHEMBL1494609 & 737823 & 5.3 & 5.1118 & TRN & \\
\hline CHEMBL1565236 & 737823 & 5.4 & 5.5333 & TRN & \\
\hline CHEMBL1525975 & 737823 & 6.1 & 5.3481 & TST & \\
\hline CHEMBL1574720 & 737823 & 4.9 & 5.3674 & TRN & \\
\hline CHEMBL1420689 & 737823 & 6.0 & 5.6976 & TRN & \\
\hline CHEMBL1300519 & 737823 & 5.5 & 5.0855 & TRN & \\
\hline CHEMBL1741907 & 737823 & 4.8 & 5.0172 & TRN & \\
\hline CHEMBL1554791 & 737823 & 5.7 & 5.6376 & TRN & \\
\hline CHEMBL1529925 & 737823 & 4.55 & 5.41799 & 9999999999 & TRN \\
\hline CHEMBL1537367 & 737823 & 5.05 & 5.4428 & TRN & \\
\hline CHEMBL1516005 & 737823 & 6.4 & 5.9049 & TRN & \\
\hline CHEMBL1475338 & 737823 & 5.7 & 6.1993 & TRN & \\
\hline CHEMBL1600325 & 737823 & 4.4 & 4.4837 & TRN & \\
\hline CHEMBL1340482 & 737823 & 4.95 & 5.4169 & TRN & \\
\hline CHEMBL3210380 & 737823 & 4.85 & 5.4139 & TRN & \\
\hline CHEMBL1341687 & 737823 & 6.9 & 6.2379 & TST & \\
\hline CHEMBL1435374 & 737823 & 5.7 & 5.7744 & TRN & \\
\hline CHEMBL1530272 & 737823 & 6.1 & 5.865 & TST & \\
\hline CHEMBL1435450 & 737823 & 6.1 & 6.2595 & TRN & \\
\hline CHEMBL1422703 & 737823 & 4.55 & 5.1681 & TRN & \\
\hline CHEMBL1307989 & 737823 & 5.9 & 5.6684 & TST & \\
\hline CHEMBL1515526 & 737823 & 5.4 & 5.7338 & TRN & \\
\hline CHEMBL1321892 & 737823 & 5.95 & 5.4679 & TRN & \\
\hline CHEMBL1405581 & 737823 & 5.7 & 5.1929 & TRN & \\
\hline CHEMBL1336149 & 737823 & 5.4 & 5.29299 & 9999999999 & TRN \\
\hline CHEMBL1428926 & 737823 & 4.85 & 5.7851 & TST & \\
\hline CHEMBL3199536 & 737823 & 6.85 & 5.5559 & TRN & \\
\hline CHEMBL1599378 & 737823 & 5.5 & 5.9831 & TRN & \\
\hline CHEMBL1741647 & 737823 & 5.85 & 5.2174 & TRN & \\
\hline CHEMBL1468264 & 737823 & 5.65 & 5.4361 & TST & \\
\hline CHEMBL1338094 & 737823 & 5.45 & 4.7317 & TRN & \\
\hline CHEMBL1337320 & 737823 & 4.95 & 5.2258 & TRN & \\
\hline CHEMBL1304319 & 737823 & 5.05 & 5.5934 & TRN & \\
\hline CHEMBL1316368 & 737823 & 4.9 & 5.2332 & TRN & \\
\hline CHEMBL 29811 & 737823 & 4.6 & 4.9868 & TRN & \\
\hline CHEMBL1402965 & 737823 & 4.9 & 4.6446 & TRN & \\
\hline CHEMBL1482035 & 737823 & 5.7 & 5.1891 & TRN & \\
\hline CHEMBL1483550 & 737823 & 5.55 & 5.4662 & TRN & \\
\hline CHEMBL587259 & 737823 & 5.6 & 5.3228 & TRN & \\
\hline CHEMBL1574576 & 737823 & 5.7 & 5.7619 & TRN & \\
\hline CHEMBL1256873 & 737823 & 4.5 & 4.9977 & TRN & \\
\hline CHEMBL1536543 & 737823 & 5.55 & 5.3405 & TRN & \\
\hline CHEMBL1348996 & 737823 & 5.35 & 5.0162 & TRN & \\
\hline CHEMBL507122 & 737823 & 6.1 & 5.4993 & TST & \\
\hline CHEMBL444309 & 737823 & 4.6 & 5.5403 & TRN & \\
\hline CHEMBL1403793 & 737823 & 5.6 & 5.7449 & TRN & \\
\hline CHEMBL1569843 & 737823 & 5.45 & 5.8575 & TRN & \\
\hline
\end{tabular}




\begin{tabular}{|c|c|c|c|c|c|}
\hline & & & & & \\
\hline CHEMBL1398608 & 737823 & 5.4 & 5.7202 & TRN & \\
\hline CHEMBL1513347 & 737823 & 6.1 & 5.6022 & TRN & \\
\hline CHEMBL1583320 & 737823 & 4.8 & 4.9976 & TRN & \\
\hline CHEMBL1490330 & 737823 & 5.4 & 5.3556 & TRN & \\
\hline CHEMBL1333810 & 737823 & 6.3 & 5.3714 & TRN & \\
\hline CHEMBL1594704 & 737823 & 4.5 & 5.2095 & TRN & \\
\hline CHEMBL1498402 & 737823 & 4.85 & 5.4499 & TST & \\
\hline CHEMBL1423337 & 737823 & 4.95 & 4.8858 & TRN & \\
\hline CHEMBL1352421 & 737823 & 4.6 & 5.6604 & TRN & \\
\hline CHEMBL1387431 & 737823 & 5.0 & 4.9794 & TRN & \\
\hline CHEMBL1555316 & 737823 & 6.9 & 6.08799 & 9999999999 & TRN \\
\hline CHEMBL28862 & 737823 & 6.0 & 4.9204 & TRN & \\
\hline CHEMBL1488179 & 737823 & 4.8 & 5.0379 & TRN & \\
\hline CHEMBL1475207 & 737823 & 4.9 & 5.3352 & TRN & \\
\hline CHEMBL32503 & 737823 & 4.3 & 5.3807 & TST & \\
\hline CHEMBL1538039 & 737823 & 5.4 & 5.7575 & TRN & \\
\hline CHEMBL1602695 & 737823 & 5.3 & 5.1959 & TRN & \\
\hline CHEMBL1410865 & 737823 & 6.0 & 5.5434 & TRN & \\
\hline CHEMBL1438916 & 737823 & 5.8 & 5.6827 & TST & \\
\hline CHEMBL3212521 & 737823 & 5.05 & 5.1329 & TRN & \\
\hline CHEMBL1499314 & 737823 & 5.5 & 5.37299 & 9999999999 & TST \\
\hline CHEMBL1741709 & 737823 & 4.8 & 5.1802 & TRN & \\
\hline CHEMBL1546034 & 737823 & 5.45 & 5.3497 & TST & \\
\hline CHEMBL1980198 & 737823 & 5.3 & 5.0278 & TRN & \\
\hline CHEMBL1741523 & 737823 & 4.6 & 4.9798 & TRN & \\
\hline CHEMBL1319093 & 737823 & 4.6 & 5.5781 & TRN & \\
\hline CHEMBL1430994 & 737823 & 4.8 & 5.3181 & TRN & \\
\hline CHEMBL1997220 & 737823 & 6.05 & 5.6177 & TRN & \\
\hline CHEMBL1592470 & 737823 & 5.5 & 5.7702 & TRN & \\
\hline CHEMBL1742184 & 737823 & 6.2 & 4.7425 & TST & \\
\hline CHEMBL1539263 & 737823 & 5.7 & 5.28600 & 00000000005 & TRN \\
\hline CHEMBL1460922 & 737823 & 5.35 & 5.0709 & TRN & \\
\hline CHEMBL1443124 & 737823 & 6.0 & 5.38700 & 00000000005 & TRN \\
\hline CHEMBL1406851 & 737823 & 4.9 & 5.2932 & TRN & \\
\hline CHEMBL1353342 & 737823 & 5.6 & 5.1659 & TST & \\
\hline CHEMBL1364637 & 737823 & 5.9 & 5.4904 & TST & \\
\hline CHEMBL1533099 & 737823 & 4.85 & 5.8139 & TRN & \\
\hline CHEMBL1374050 & 737823 & 5.0 & 5.0459 & TRN & \\
\hline CHEMBL1439866 & 737823 & 4.9 & 5.2415 & TST & \\
\hline CHEMBL1502107 & 737823 & 4.8 & 5.3894 & TRN & \\
\hline CHEMBL1513121 & 737823 & 4.8 & 5.1063 & TRN & \\
\hline CHEMBL1331634 & 737823 & 6.0 & 5.2808 & TRN & \\
\hline CHEMBL1477307 & 737823 & 4.75 & 5.5495 & TRN & \\
\hline CHEMBL1430579 & 737823 & 5.2 & 5.2409 & TRN & \\
\hline CHEMBL1569893 & 737823 & 5.9 & 5.3272 & TRN & \\
\hline CHEMBL1299810 & 737823 & 5.05 & 5.483 & TRN & \\
\hline CHEMBL1317950 & 737823 & 5.4 & 6.2631 & TRN & \\
\hline CHEMBL 3304020 & 737823 & 5.1 & 5.2432 & TST & \\
\hline & & & & 3333 & \\
\hline
\end{tabular}




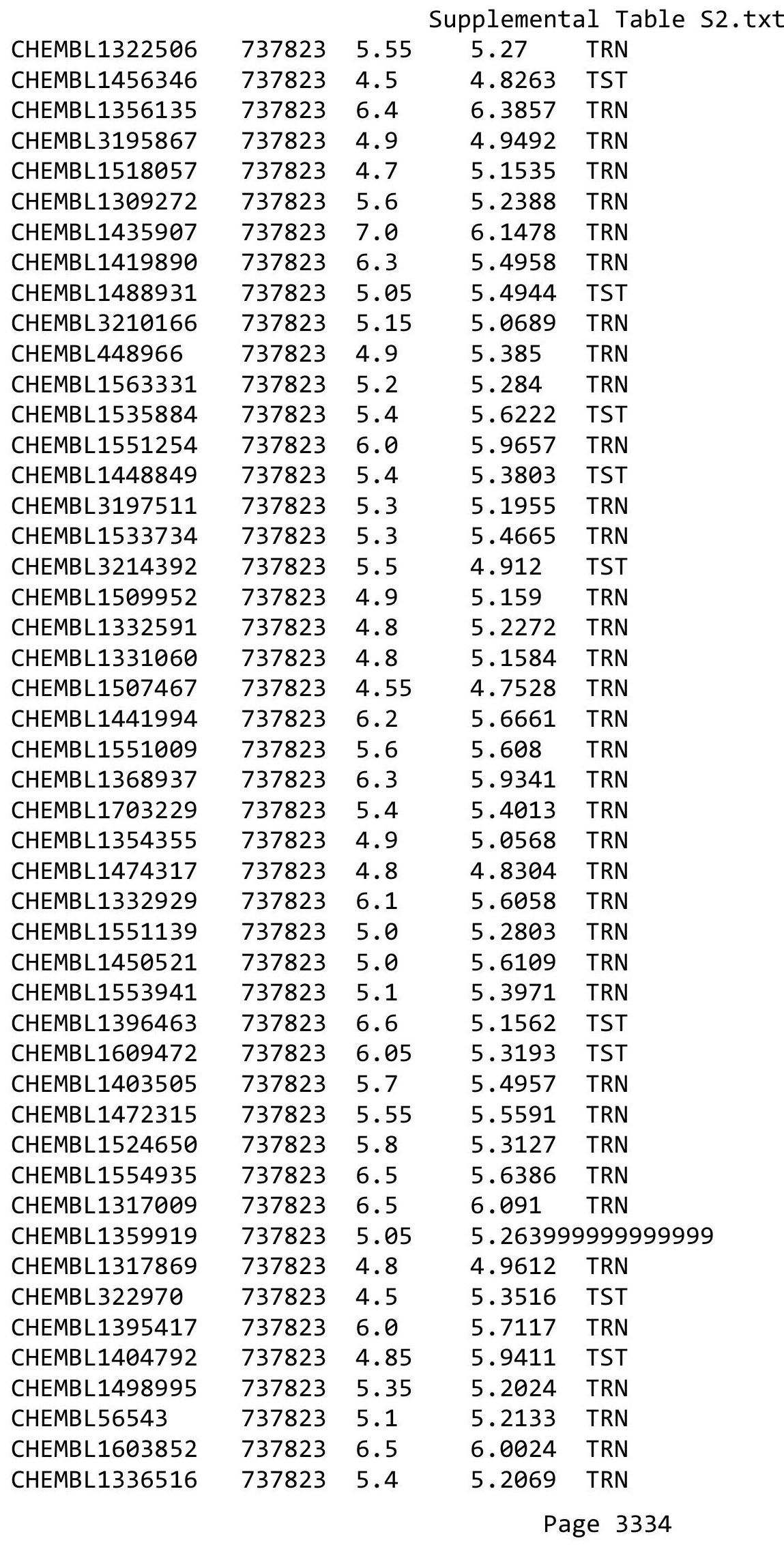




\begin{tabular}{|c|c|c|c|c|}
\hline & & & & al Table \\
\hline CHEMBL1552551 & 737823 & 4.8 & 5.4089 & TRN \\
\hline CHEMBL3207571 & 737823 & 4.85 & 5.27 & TRN \\
\hline CHEMBL10 & 737823 & 6.0 & 6.0172 & TRN \\
\hline CHEMBL1321655 & 737823 & 4.6 & 5.5568 & TRN \\
\hline CHEMBL1398319 & 737823 & 6.3 & 5.2923 & TRN \\
\hline CHEMBL1520971 & 737823 & 4.85 & 5.1555 & TST \\
\hline CHEMBL1585320 & 737823 & 5.15 & 4.9812 & TRN \\
\hline CHEMBL1591543 & 737823 & 6.5 & 5.9506 & TRN \\
\hline CHEMBL1469798 & 737823 & 5.2 & 5.7576 & TRN \\
\hline CHEMBL1998893 & 737823 & 5.8 & 5.7925 & TRN \\
\hline CHEMBL3210111 & 737823 & 5.6 & 5.1523 & TRN \\
\hline CHEMBL1457305 & 737823 & 5.8 & 5.4197 & TRN \\
\hline CHEMBL1344685 & 737823 & 4.8 & 5.3422 & TRN \\
\hline CHEMBL1437718 & 737823 & 4.9 & 5.2157 & TRN \\
\hline CHEMBL1392455 & 737823 & 5.5 & 5.9579 & TRN \\
\hline CHEMBL1430949 & 737823 & 4.4 & 4.9453 & TRN \\
\hline CHEMBL1399699 & 737823 & 5.7 & 4.9629 & TRN \\
\hline CHEMBL1370690 & 737823 & 4.75 & 4.9632 & TST \\
\hline CHEMBL1351344 & 737823 & 4.9 & 5.4249 & TST \\
\hline CHEMBL239439 & 737823 & 5.5 & 5.7455 & TST \\
\hline CHEMBL1595521 & 737823 & 4.9 & 5.066 & TST \\
\hline CHEMBL1546843 & 737823 & 5.15 & 5.2866 & TRN \\
\hline CHEMBL1491858 & 737823 & 4.95 & 5.53700 & 0000000001 \\
\hline CHEMBL1427932 & 737823 & 5.3 & 4.9407 & TRN \\
\hline CHEMBL1492266 & 737823 & 5.4 & 5.8361 & TST \\
\hline CHEMBL1435045 & 737823 & 6.1 & 5.6875 & TRN \\
\hline CHEMBL1568723 & 737823 & 4.9 & 5.7814 & TRN \\
\hline CHEMBL1466628 & 737823 & 5.4 & 5.0285 & TRN \\
\hline CHEMBL1559728 & 737823 & 6.1 & 5.2391 & TRN \\
\hline CHEMBL1449218 & 737823 & 6.1 & 5.6525 & TRN \\
\hline CHEMBL1577593 & 737823 & 4.9 & 5.1727 & TRN \\
\hline CHEMBL1508113 & 737823 & 5.15 & 5.5814 & TRN \\
\hline CHEMBL1482790 & 737823 & 6.1 & 5.6177 & TRN \\
\hline CHEMBL1409686 & 737823 & 5.5 & 5.6518 & TRN \\
\hline CHEMBL1315530 & 737823 & 4.9 & 5.2792 & TRN \\
\hline CHEMBL1393431 & 737823 & 4.85 & 5.3226 & TRN \\
\hline CHEMBL1520374 & 737823 & 5.1 & 5.6016 & TRN \\
\hline CHEMBL3199347 & 737823 & 5.15 & 5.2631 & TRN \\
\hline CHEMBL1408522 & 737823 & 5.4 & 5.5247 & TST \\
\hline CHEMBL1551231 & 737823 & 4.7 & 4.7233 & TRN \\
\hline CHEMBL1407217 & 737823 & 5.5 & 5.521 & TRN \\
\hline CHEMBL1384399 & 737823 & 5.45 & 5.5188 & TRN \\
\hline CHEMBL1356844 & 737823 & 5.3 & 5.3093 & TRN \\
\hline CHEMBL1473260 & 737823 & 5.5 & 5.3054 & TRN \\
\hline CHEMBL1345018 & 737823 & 5.9 & 5.5794 & TRN \\
\hline CHEMBL3213228 & 737823 & 4.6 & 4.885 & TST \\
\hline CHEMBL1371710 & 737823 & 5.0 & 5.1801 & TRN \\
\hline CHEMBL1441676 & 737823 & 4.6 & 5.0733 & TRN \\
\hline
\end{tabular}




\begin{tabular}{|c|c|c|c|c|c|}
\hline \multicolumn{6}{|c|}{ Supplemental Table S2.txt } \\
\hline CHEMBL1475589 & 737823 & 5.2 & 5.3303 & TRN & \\
\hline CHEMBL1466055 & 737823 & 5.65 & 5.4105 & TRN & \\
\hline CHEMBL1451875 & 737823 & 4.85 & 5.0165 & TRN & \\
\hline CHEMBL1380712 & 737823 & 4.75 & 5.3562 & TST & \\
\hline CHEMBL1342700 & 737823 & 4.75 & 5.0152 & TRN & \\
\hline CHEMBL1557567 & 737823 & 4.9 & 4.9673 & TRN & \\
\hline CHEMBL596674 & 737823 & 6.0 & 5.4513 & TRN & \\
\hline CHEMBL491910 & 737823 & 4.8 & 5.0306 & TRN & \\
\hline CHEMBL1422614 & 737823 & 5.15 & 5.5389 & TRN & \\
\hline CHEMBL1367020 & 737823 & 6.3 & 5.7613 & TRN & \\
\hline CHEMBL1232596 & 737823 & 5.6 & 5.3163 & TRN & \\
\hline CHEMBL3196421 & 737823 & 5.2 & 5.178 & TRN & \\
\hline CHEMBL1372401 & 737823 & 5.15 & 5.42200 & 0000000001 & TRN \\
\hline CHEMBL1555713 & 737823 & 6.0 & 5.5758 & TRN & \\
\hline CHEMBL 2373602 & 737823 & 4.4 & 5.5341 & TST & \\
\hline CHEMBL1302425 & 737823 & 5.45 & 5.8275 & TST & \\
\hline CHEMBL1575569 & 737823 & 5.6 & 5.2684 & TRN & \\
\hline CHEMBL1339627 & 737823 & 5.0 & 5.1865 & TRN & \\
\hline CHEMBL1396211 & 737823 & 6.1 & 5.9341 & TRN & \\
\hline CHEMBL1317386 & 737823 & 5.4 & 5.2509 & TRN & \\
\hline CHEMBL1531070 & 737823 & 5.1 & 5.0972 & TRN & \\
\hline CHEMBL1526486 & 737823 & 4.8 & 5.025 & TST & \\
\hline CHEMBL1467157 & 737823 & 5.55 & 5.52 & TRN & \\
\hline CHEMBL1406274 & 737823 & 6.0 & 5.4532 & TST & \\
\hline CHEMBL1514547 & 737823 & 5.5 & 5.4253 & TST & \\
\hline CHEMBL1345104 & 737823 & 4.9 & 5.3957 & TRN & \\
\hline CHEMBL1741508 & 737823 & 4.55 & 5.3968 & TST & \\
\hline CHEMBL1405203 & 737823 & 4.8 & 5.2498 & TRN & \\
\hline CHEMBL384903 & 737823 & 5.4 & 5.9317 & TST & \\
\hline CHEMBL1358738 & 737823 & 5.4 & 5.4956 & TRN & \\
\hline CHEMBL1417263 & 737823 & 5.15 & 5.436 & TRN & \\
\hline CHEMBL1317504 & 737823 & 5.6 & 4.9172 & TRN & \\
\hline CHEMBL1399384 & 737823 & 5.3 & 5.37299 & & TRN \\
\hline CHEMBL1559127 & 737823 & 5.1 & 5.0332 & TRN & \\
\hline CHEMBL1327466 & 737823 & 5.7 & 5.6155 & TRN & \\
\hline CHEMBL1411578 & 737823 & 4.8 & 4.6085 & TST & \\
\hline CHEMBL1584758 & 737823 & 6.1 & 5.3341 & TRN & \\
\hline CHEMBL1396377 & 737823 & 5.4 & 5.5143 & TRN & \\
\hline CHEMBL1741826 & 737823 & 5.5 & 5.3381 & TST & \\
\hline CHEMBL1307447 & 737823 & 4.85 & 5.4594 & TRN & \\
\hline CHEMBL1513300 & 737823 & 5.5 & 5.6367 & TRN & \\
\hline CHEMBL1544821 & 737823 & 5.95 & 5.7674 & TRN & \\
\hline CHEMBL1437273 & 737823 & 6.0 & 5.3541 & TRN & \\
\hline CHEMBL1472029 & 737823 & 5.3 & 5.3833 & TRN & \\
\hline CHEMBL1371017 & 737823 & 4.65 & 5.3618 & TRN & \\
\hline CHEMBL1391936 & 737823 & 5.9 & 5.5593 & TRN & \\
\hline CHEMBL1483427 & 737823 & 5.4 & 5.3617 & TRN & \\
\hline CHEMBL1359379 & 737823 & 4.8 & 5.0434 & TRN & \\
\hline
\end{tabular}




\begin{tabular}{|c|c|c|c|c|}
\hline \multicolumn{5}{|c|}{ Supplemental Table S2.txt } \\
\hline CHEMBL1530213 & 737823 & 5.2 & 5.223 & TRN \\
\hline CHEMBL1385130 & 737823 & 5.05 & 5.3672 & TRN \\
\hline CHEMBL1554854 & 737823 & 5.3 & 5.6163 & TRN \\
\hline CHEMBL1305738 & 737823 & 4.6 & 5.1228 & TRN \\
\hline CHEMBL1345404 & 737823 & 5.5 & 5.4639 & TRN \\
\hline CHEMBL1741797 & 737823 & 5.3 & 4.7471 & TRN \\
\hline CHEMBL1433593 & 737823 & 4.9 & 5.007 & TST \\
\hline CHEMBL1568990 & 737823 & 4.65 & 5.1397 & TRN \\
\hline CHEMBL1256740 & 737823 & 6.0 & 5.6967 & TST \\
\hline CHEMBL1536043 & 737823 & 5.4 & 5.3219 & TRN \\
\hline CHEMBL1395792 & 737823 & 6.1 & 6.053 & TRN \\
\hline CHEMBL1566556 & 737823 & 5.4 & 4.9668 & TRN \\
\hline CHEMBL1546584 & 737823 & 4.6 & 6.0842 & TRN \\
\hline CHEMBL1501395 & 737823 & 4.85 & 5.4094 & TST \\
\hline CHEMBL1350860 & 737823 & 5.65 & 4.9758 & TRN \\
\hline CHEMBL1408703 & 737823 & 4.9 & 4.7677 & TRN \\
\hline CHEMBL1364255 & 737823 & 4.95 & 4.8834 & TRN \\
\hline CHEMBL1733672 & 737823 & 5.4 & 5.2034 & TRN \\
\hline CHEMBL1742150 & 737823 & 5.1 & 5.5278 & TST \\
\hline CHEMBL1551919 & 737823 & 7.1 & 6.2717 & TRN \\
\hline CHEMBL1516103 & 737823 & 6.4 & 5.7973 & TRN \\
\hline CHEMBL1450373 & 737823 & 5.2 & 5.3446 & TRN \\
\hline CHEMBL1376879 & 737823 & 4.8 & 5.1851 & TRN \\
\hline CHEMBL153 & 737823 & 4.7 & 5.166 & TST \\
\hline CHEMBL 1403902 & 737823 & 5.0 & 5.0614 & TRN \\
\hline CHEMBL1461795 & 737823 & 4.55 & 5.4476 & TRN \\
\hline CHEMBL1609406 & 737823 & 5.3 & 5.2967 & TRN \\
\hline CHEMBL1486808 & 737823 & 5.3 & 5.2563 & TRN \\
\hline CHEMBL 3189630 & 737823 & 4.75 & 5.5255 & TST \\
\hline CHEMBL 1742290 & 737823 & 4.8 & 5.455 & TRN \\
\hline CHEMBL1475146 & 737823 & 5.4 & 5.7609 & TRN \\
\hline CHEMBL1449082 & 737823 & 4.6 & 4.8991 & TRN \\
\hline CHEMBL1354961 & 737823 & 5.2 & 5.4775 & TRN \\
\hline CHEMBL1506687 & 737823 & 4.7 & 5.0855 & TRN \\
\hline CHEMBL1478504 & 737823 & 6.0 & 5.9155 & TRN \\
\hline CHEMBL1400744 & 737823 & 5.55 & 5.2491 & TRN \\
\hline CHEMBL1742349 & 737823 & 5.1 & 5.6338 & TST \\
\hline CHEMBL 3199344 & 737823 & 5.45 & 5.2158 & TRN \\
\hline CHEMBL1701169 & 737823 & 4.85 & 5.1691 & TRN \\
\hline CHEMBL1444164 & 737823 & 5.15 & 5.5427 & TRN \\
\hline CHEMBL1365404 & 737823 & 4.65 & 5.0459 & TRN \\
\hline CHEMBL1376554 & 737823 & 5.35 & 5.4585 & TRN \\
\hline CHEMBL1357445 & 737823 & 6.4 & 5.869 & TRN \\
\hline CHEMBL1569529 & 737823 & 5.8 & 5.7773 & TRN \\
\hline CHEMBL1733013 & 737823 & 5.6 & 5.4813 & TRN \\
\hline CHEMBL1396080 & 737823 & 4.5 & 4.6705 & TRN \\
\hline CHEMBL1330626 & 737823 & 5.4 & 5.2838 & TRN \\
\hline CHEMBL1552517 & 737823 & 4.7 & 5.5567 & TRN \\
\hline
\end{tabular}




\begin{tabular}{|c|c|c|c|c|c|}
\hline & & & & & \\
\hline CHEMBL1452159 & 737823 & 5.0 & 5.104 & TRN & \\
\hline CHEMBL1442537 & 737823 & 5.9 & 5.3744 & TRN & \\
\hline CHEMBL1596796 & 737823 & 5.8 & 5.4463 & TRN & \\
\hline CHEMBL1358276 & 737823 & 4.7 & 4.4862 & TRN & \\
\hline CHEMBL1376005 & 737823 & 5.4 & 5.1188 & TST & \\
\hline CHEMBL1414240 & 737823 & 5.25 & 5.45799 & & TST \\
\hline CHEMBL1471962 & 737823 & 5.1 & 5.2697 & TRN & \\
\hline CHEMBL1398790 & 737823 & 5.55 & 5.5263 & TRN & \\
\hline CHEMBL1609497 & 737823 & 5.75 & 5.1651 & TST & \\
\hline CHEMBL3199868 & 737823 & 5.65 & 5.7238 & TRN & \\
\hline CHEMBL1301305 & 737823 & 4.75 & 5.0298 & TRN & \\
\hline CHEMBL1504999 & 737823 & 4.9 & 4.9259 & TST & \\
\hline CHEMBL448741 & 737823 & 4.6 & 4.8592 & TRN & \\
\hline CHEMBL 3194238 & 737823 & 4.8 & 5.0431 & TRN & \\
\hline CHEMBL1603542 & 737823 & 5.5 & 5.5246 & TRN & \\
\hline CHEMBL1470386 & 737823 & 4.85 & 5.3353 & TRN & \\
\hline CHEMBL3212563 & 737823 & 6.25 & 5.6795 & TRN & \\
\hline CHEMBL1741796 & 737823 & 4.9 & 4.7695 & TRN & \\
\hline CHEMBL1396142 & 737823 & 4.9 & 4.9736 & TRN & \\
\hline CHEMBL1607197 & 737823 & 5.15 & 5.1439 & TRN & \\
\hline CHEMBL1711282 & 737823 & 4.85 & 5.2707 & TRN & \\
\hline CHEMBL1373954 & 737823 & 5.5 & 4.9531 & TRN & \\
\hline CHEMBL1461327 & 737823 & 5.6 & 5.3679 & TRN & \\
\hline CHEMBL45244 & 737823 & 6.0 & 4.6943 & TRN & \\
\hline CHEMBL1413306 & 737823 & 6.2 & 5.1909 & TRN & \\
\hline CHEMBL1562277 & 737823 & 6.5 & 5.285 & TRN & \\
\hline CHEMBL1513643 & 737823 & 5.4 & 5.9151 & TRN & \\
\hline CHEMBL1470796 & 737823 & 5.25 & 5.3006 & TRN & \\
\hline CHEMBL1398669 & 737823 & 5.1 & 5.6092 & TRN & \\
\hline CHEMBL1604088 & 737823 & 5.3 & 5.0517 & TRN & \\
\hline CHEMBL523283 & 737823 & 5.6 & 5.4585 & TRN & \\
\hline CHEMBL1304907 & 737823 & 4.5 & 5.2597 & TRN & \\
\hline CHEMBL1525073 & 737823 & 4.8 & 5.4132 & TRN & \\
\hline CHEMBL3211162 & 737823 & 5.1 & 5.36799 & 9999999999 & TRN \\
\hline CHEMBL518430 & 737823 & 5.8 & 5.3655 & TRN & \\
\hline CHEMBL1402908 & 737823 & 5.45 & 5.5403 & TRN & \\
\hline CHEMBL1368337 & 737823 & 4.6 & 5.5275 & TRN & \\
\hline CHEMBL1741794 & 737823 & 5.6 & 6.0175 & TRN & \\
\hline CHEMBL1377580 & 737823 & 6.1 & 5.6385 & TRN & \\
\hline CHEMBL1541518 & 737823 & 5.6 & 5.2765 & TRN & \\
\hline CHEMBL 287327 & 737823 & 4.4 & 5.3302 & TST & \\
\hline CHEMBL1369036 & 737823 & 5.1 & 5.0944 & TRN & \\
\hline CHEMBL1742173 & 737823 & 5.4 & 5.3091 & TST & \\
\hline CHEMBL1553751 & 737823 & 4.9 & 5.4708 & TRN & \\
\hline CHEMBL1578210 & 737823 & 4.9 & 5.3235 & TRN & \\
\hline CHEMBL1422368 & 737823 & 5.8 & 5.61700 & 0000000001 & TRN \\
\hline CHEMBL1361468 & 737823 & 4.8 & 4.7381 & TRN & \\
\hline CHEMBL1565965 & 737823 & 4.7 & 4.8017 & TRN & \\
\hline & & & & 3338 & \\
\hline
\end{tabular}




\begin{tabular}{|c|c|c|c|c|c|}
\hline CHEMBL1741957 & 737823 & 5.1 & \multicolumn{2}{|c|}{ 5.093999999999999 } & TRN \\
\hline CHEMBL1372133 & 737823 & 5.3 & 5.2981 & TRN & \\
\hline CHEMBL325238 & 737823 & 4.8 & 4.9852 & TRN & \\
\hline CHEMBL1256749 & 737823 & 6.0 & 5.487 & TST & \\
\hline CHEMBL1550537 & 737823 & 4.8 & 5.4334 & TRN & \\
\hline CHEMBL1308897 & 737823 & 4.6 & 5.0759 & TST & \\
\hline CHEMBL1473133 & 737823 & 6.9 & 6.345 & TRN & \\
\hline CHEMBL1397438 & 737823 & 5.3 & 5.6151 & TRN & \\
\hline CHEMBL1323897 & 737823 & 5.9 & 5.3081 & TRN & \\
\hline CHEMBL1582527 & 737823 & 5.8 & \multicolumn{2}{|c|}{5.361000000000001} & TRN \\
\hline CHEMBL1322091 & 737823 & 5.3 & 5.3892 & TRN & \\
\hline CHEMBL1610056 & 737823 & 5.55 & 5.1804 & TST & \\
\hline CHEMBL 3207715 & 737823 & 4.65 & 5.5836 & TRN & \\
\hline CHEMBL 3436365 & 737823 & 4.9 & 5.3403 & TRN & \\
\hline CHEMBL1479296 & 737823 & 5.6 & 5.501 & TRN & \\
\hline CHEMBL1399055 & 737823 & 5.1 & 4.633 & TRN & \\
\hline CHEMBL45245 & 737823 & 6.6 & 5.9252 & TRN & \\
\hline CHEMBL1301326 & 737823 & 4.9 & 5.5189 & TRN & \\
\hline CHEMBL1490477 & 737823 & 6.7 & 5.6621 & TRN & \\
\hline CHEMBL3190830 & 737823 & 5.35 & 5.6607 & TRN & \\
\hline CHEMBL1607885 & 737823 & 5.4 & 5.9927 & TRN & \\
\hline CHEMBL1491710 & 737823 & 5.5 & 5.3428 & TST & \\
\hline CHEMBL1371311 & 737823 & 5.6 & 5.5083 & TRN & \\
\hline CHEMBL1354287 & 737823 & 5.8 & 5.8132 & TRN & \\
\hline CHEMBL1436992 & 737823 & 5.0 & 4.8647 & TST & \\
\hline CHEMBL1444914 & 737823 & 5.0 & 5.3931 & TRN & \\
\hline CHEMBL1304670 & 737823 & 5.6 & 5.6039 & TRN & \\
\hline CHEMBL1517187 & 737823 & 4.4 & 4.5545 & TST & \\
\hline CHEMBL1340383 & 737823 & 5.1 & 5.3854 & TST & \\
\hline CHEMBL491952 & 737823 & 4.9 & 4.7889 & TRN & \\
\hline CHEMBL66105 & 737823 & 4.5 & 5.2296 & TRN & \\
\hline CHEMBL1234930 & 737823 & 4.5 & 4.7639 & TST & \\
\hline CHEMBL1517176 & 737823 & 4.85 & 5.1633 & TRN & \\
\hline CHEMBL1523400 & 737823 & 4.95 & 5.109 & TRN & \\
\hline CHEMBL3207808 & 737823 & 6.25 & 5.8907 & TRN & \\
\hline CHEMBL1515867 & 737823 & 4.8 & 5.226 & TRN & \\
\hline CHEMBL 3213682 & 737823 & 5.9 & 5.6523 & TRN & \\
\hline CHEMBL 3208295 & 737823 & 5.6 & 5.7974 & TST & \\
\hline CHEMBL1361214 & 737823 & 4.95 & 4.8888 & TRN & \\
\hline CHEMBL1608811 & 737823 & 5.55 & 5.2714 & TRN & \\
\hline CHEMBL1346159 & 737823 & 5.35 & 5.5358 & TST & \\
\hline CHEMBL1543084 & 737823 & 5.35 & 5.30200 & 00000000005 & TRN \\
\hline CHEMBL3214398 & 737823 & 6.3 & 5.6072 & TRN & \\
\hline CHEMBL1316492 & 737823 & 4.8 & 4.9425 & TRN & \\
\hline CHEMBL1437905 & 737823 & 4.4 & 4.8643 & TRN & \\
\hline CHEMBL1341070 & 737823 & 5.15 & 5.3302 & TRN & \\
\hline CHEMBL1528708 & 737823 & 4.9 & 4.8701 & TRN & \\
\hline \multirow[t]{2}{*}{ CHEMBL1404071 } & 737823 & 5.75 & 5.6876 & TRN & \\
\hline & & \multicolumn{4}{|c|}{ Page 3339} \\
\hline
\end{tabular}




\begin{tabular}{|c|c|c|c|c|}
\hline \multicolumn{5}{|c|}{ Supplemental Table S2.txt } \\
\hline CHEMBL1485060 & 737823 & 5.5 & 5.6753 & TRN \\
\hline CHEMBL1335760 & 737823 & 5.0 & 5.0303 & TRN \\
\hline CHEMBL510275 & 737823 & 4.4 & 4.6517 & TST \\
\hline CHEMBL1428398 & 737823 & 5.45 & 4.9155 & TRN \\
\hline CHEMBL1415500 & 737823 & 6.05 & 5.6619 & TRN \\
\hline CHEMBL1450586 & 737823 & 5.5 & 5.6931 & TRN \\
\hline CHEMBL1587782 & 737823 & 7.0 & 4.8801 & TST \\
\hline CHEMBL288591 & 737823 & 6.0 & 5.4322 & TRN \\
\hline CHEMBL149463 & 737823 & 6.7 & 5.8143 & TRN \\
\hline CHEMBL1603418 & 737823 & 6.0 & 6.3399 & TRN \\
\hline CHEMBL336467 & 737823 & 6.4 & 5.8024 & TRN \\
\hline CHEMBL1605085 & 737823 & 5.0 & 5.1204 & TRN \\
\hline CHEMBL1423676 & 737823 & 5.5 & 5.7269 & TRN \\
\hline CHEMBL1558939 & 737823 & 5.7 & 5.4782 & TRN \\
\hline CHEMBL1466402 & 737823 & 5.4 & 4.9477 & TRN \\
\hline CHEMBL1541179 & 737823 & 4.6 & 4.837 & TST \\
\hline CHEMBL1592679 & 737823 & 5.4 & 5.4279 & TRN \\
\hline CHEMBL1306897 & 737823 & 5.8 & 4.9216 & TRN \\
\hline CHEMBL1473760 & 737823 & 7.0 & 6.2132 & TRN \\
\hline CHEMBL1562792 & 737823 & 4.95 & 5.3064 & TRN \\
\hline CHEMBL1742133 & 737823 & 5.1 & 5.3191 & TRN \\
\hline CHEMBL269733 & 737823 & 4.5 & 4.88899 & 9999999999 \\
\hline CHEMBL1526673 & 737823 & 5.35 & 5.5476 & TRN \\
\hline CHEMBL1570733 & 737823 & 4.6 & 5.0132 & TST \\
\hline CHEMBL1561151 & 737823 & 4.9 & 5.3589 & TRN \\
\hline CHEMBL1363867 & 737823 & 4.85 & 5.1945 & TRN \\
\hline CHEMBL 26320 & 737823 & 5.0 & 5.1238 & TRN \\
\hline CHEMBL1335414 & 737823 & 6.5 & 5.8855 & TRN \\
\hline CHEMBL1364995 & 737823 & 7.6 & 5.6662 & TRN \\
\hline CHEMBL1307425 & 737823 & 5.3 & 5.4404 & TRN \\
\hline CHEMBL1343084 & 737823 & 5.55 & 5.3544 & TRN \\
\hline CHEMBL1395899 & 737823 & 4.9 & 4.9379 & TRN \\
\hline CHEMBL1490863 & 737823 & 4.7 & 4.9057 & TRN \\
\hline CHEMBL1320272 & 737823 & 4.55 & 5.5084 & TRN \\
\hline CHEMBL1539358 & 737823 & 4.55 & 4.9877 & TRN \\
\hline CHEMBL3211795 & 737823 & 5.15 & 5.1188 & TRN \\
\hline CHEMBL1348414 & 737823 & 4.55 & 5.0492 & TST \\
\hline CHEMBL1373202 & 737823 & 4.8 & 5.0868 & TRN \\
\hline CHEMBL1351212 & 737823 & 4.8 & 4.7836 & TRN \\
\hline CHEMBL202752 & 737823 & 6.4 & 5.6555 & TRN \\
\hline CHEMBL1332471 & 737823 & 4.7 & 4.8904 & TRN \\
\hline CHEMBL38576 & 737823 & 4.5 & 5.0597 & TRN \\
\hline CHEMBL1444489 & 737823 & 4.6 & 4.5272 & TRN \\
\hline CHEMBL1526824 & 737823 & 4.8 & 5.6996 & TRN \\
\hline CHEMBL1365235 & 737823 & 5.2 & 5.1014 & TRN \\
\hline CHEMBL1378755 & 737823 & 6.8 & 6.2148 & TRN \\
\hline CHEMBL1566647 & 737823 & 5.1 & 5.2364 & TRN \\
\hline CHEMBL 228862 & 737823 & 5.3 & 5.4403 & TRN \\
\hline
\end{tabular}




\begin{tabular}{|c|c|c|c|c|c|}
\hline \multicolumn{6}{|c|}{ Supplemental Table s2.txt } \\
\hline CHEMBL1410101 & 737823 & 6.7 & 5.3033 & TRN & \\
\hline CHEMBL1483498 & 737823 & 4.6 & 4.8368 & TRN & \\
\hline CHEMBL1415861 & 737823 & 5.35 & 5.4546 & TST & \\
\hline CHEMBL1567704 & 737823 & 5.8 & 4.9155 & TST & \\
\hline CHEMBL1306015 & 737823 & 6.85 & 6.0483 & TRN & \\
\hline CHEMBL1607611 & 737823 & 5.5 & 5.409 & TRN & \\
\hline CHEMBL3189237 & 737823 & 5.65 & 5.0171 & TST & \\
\hline CHEMBL63102 & 737823 & 4.8 & 5.2695 & TST & \\
\hline CHEMBL1339696 & 737823 & 5.4 & 5.2067 & TRN & \\
\hline CHEMBL3192169 & 737823 & 5.1 & 5.4227 & TRN & \\
\hline CHEMBL1474927 & 737823 & 5.4 & 5.6739 & TRN & \\
\hline CHEMBL1315091 & 737823 & 5.5 & 5.5869 & TRN & \\
\hline CHEMBL1985310 & 737823 & 4.65 & 5.2956 & TST & \\
\hline CHEMBL1438695 & 737823 & 5.6 & $5.4270 e$ & 00000000005 & TRN \\
\hline CHEMBL1741558 & 737823 & 4.95 & 5.0383 & TRN & \\
\hline CHEMBL1305666 & 737823 & 5.1 & 4.8152 & TRN & \\
\hline CHEMBL1742246 & 737823 & 4.75 & 4.8621 & TRN & \\
\hline CHEMBL1607206 & 737823 & 7.3 & 5.4059 & TRN & \\
\hline CHEMBL1356132 & 737823 & 4.6 & 4.9621 & TRN & \\
\hline CHEMBL1347660 & 737823 & 5.45 & 5.6154 & TST & \\
\hline CHEMBL1563219 & 737823 & 4.5 & 5.3404 & TRN & \\
\hline CHEMBL1317344 & 737823 & 5.4 & 5.2373 & TRN & \\
\hline CHEMBL1256737 & 737823 & 6.0 & 5.2651 & TRN & \\
\hline CHEMBL1556022 & 737823 & 4.85 & 5.3874 & TRN & \\
\hline CHEMBL1505836 & 737823 & 5.15 & 5.1063 & TRN & \\
\hline CHEMBL1376191 & 737823 & 5.6 & 5.7689 & TRN & \\
\hline CHEMBL1333565 & 737823 & 5.0 & 5.3847 & TRN & \\
\hline CHEMBL1528911 & 737823 & 5.45 & 5.5254 & TRN & \\
\hline CHEMBL1438688 & 737823 & 4.8 & 5.6593 & TRN & \\
\hline CHEMBL313163 & 737823 & 5.2 & 5.7917 & TRN & \\
\hline CHEMBL1532921 & 737823 & 5.5 & 5.7093 & TRN & \\
\hline CHEMBL1310018 & 737823 & 4.9 & 5.0017 & TRN & \\
\hline CHEMBL60718 & 737823 & 4.9 & 4.8798 & TRN & \\
\hline CHEMBL1317769 & 737823 & 4.9 & 5.6643 & TRN & \\
\hline CHEMBL1543676 & 737823 & 4.6 & 4.8845 & TST & \\
\hline CHEMBL1395196 & 737823 & 5.3 & 4.8537 & TST & \\
\hline CHEMBL1523570 & 737823 & 5.45 & 5.4645 & TRN & \\
\hline CHEMBL1515858 & 737823 & 5.4 & 5.1608 & TRN & \\
\hline CHEMBL1977734 & 737823 & 4.95 & 5.562 & TRN & \\
\hline CHEMBL1581408 & 737823 & 4.6 & 5.4358 & TST & \\
\hline CHEMBL1742231 & 737823 & 4.6 & 5.1938 & TRN & \\
\hline CHEMBL1593370 & 737823 & 4.9 & 4.5907 & TRN & \\
\hline CHEMBL1426036 & 737823 & 5.1 & 5.3754 & TRN & \\
\hline CHEMBL1597203 & 737823 & 4.75 & 4.92399 & 99999999995 & TRN \\
\hline CHEMBL1442011 & 737823 & 4.9 & 5.5179 & TRN & \\
\hline CHEMBL1484896 & 737823 & 4.6 & 4.5788 & TRN & \\
\hline CHEMBL1705804 & 737823 & 4.6 & 5.4932 & TRN & \\
\hline CHEMBL1606094 & 737823 & 5.7 & 5.4015 & TST & \\
\hline
\end{tabular}




\begin{tabular}{|c|c|c|c|c|c|}
\hline \\
\hline CHEMBL1424275 & 737823 & 4.8 & 5.0205 & TRN & \\
\hline CHEMBL1398540 & 737823 & 5.4 & 5.5272 & TRN & \\
\hline CHEMBL1372421 & 737823 & 5.1 & 5.3566 & TRN & \\
\hline CHEMBL1389843 & 737823 & 5.9 & 5.9318 & TRN & \\
\hline CHEMBL1460356 & 737823 & 4.9 & 5.2768 & TRN & \\
\hline CHEMBL1564194 & 737823 & 6.2 & 5.9943 & TRN & \\
\hline CHEMBL33884 & 737823 & 4.8 & 5.0912 & TST & \\
\hline CHEMBL1319789 & 737823 & 6.0 & 5.2228 & TRN & \\
\hline CHEMBL1552957 & 737823 & 5.0 & 4.9887 & TRN & \\
\hline CHEMBL1589925 & 737823 & 6.0 & 5.8256 & TRN & \\
\hline CHEMBL1539506 & 737823 & 6.5 & 5.7478 & TRN & \\
\hline CHEMBL1572855 & 737823 & 4.7 & 5.9467 & TRN & \\
\hline CHEMBL86537 & 737823 & 6.3 & 6.3239 & TST & \\
\hline CHEMBL1399528 & 737823 & 5.9 & 6.0568 & TRN & \\
\hline CHEMBL103469 & 737823 & 5.6 & 5.1614 & TRN & \\
\hline CHEMBL1345906 & 737823 & 4.85 & 5.0102 & TRN & \\
\hline CHEMBL1468831 & 737823 & 4.7 & 5.2484 & TRN & \\
\hline CHEMBL1315965 & 737823 & 4.7 & 5.0941 & TRN & \\
\hline CHEMBL1519330 & 737823 & 4.8 & 5.1064 & TRN & \\
\hline CHEMBL1529571 & 737823 & 5.6 & 5.4048 & TRN & \\
\hline CHEMBL1409446 & 737823 & 5.3 & 5.1302 & TRN & \\
\hline CHEMBL1544520 & 737823 & 5.25 & 5.4723 & TST & \\
\hline CHEMBL53206 & 737823 & 5.9 & 5.4636 & TRN & \\
\hline CHEMBL1382870 & 737823 & 5.0 & 5.348 & TRN & \\
\hline CHEMBL1307882 & 737823 & 5.85 & 5.8004 & TRN & \\
\hline CHEMBL1451128 & 737823 & 4.85 & 5.2055 & TRN & \\
\hline CHEMBL 1474272 & 737823 & 6.9 & 6.1702 & TRN & \\
\hline CHEMBL1514953 & 737823 & 5.7 & 5.7939 & TRN & \\
\hline CHEMBL265177 & 737823 & 5.3 & 5.5235 & TST & \\
\hline CHEMBL13791 & 737823 & 6.0 & 5.4205 & TRN & \\
\hline CHEMBL1346685 & 737823 & 5.6 & 5.4475 & TRN & \\
\hline CHEMBL400875 & 737823 & 4.9 & 5.075 & TRN & \\
\hline CHEMBL1412842 & 737823 & 4.6 & 5.6055 & TRN & \\
\hline CHEMBL1496243 & 737823 & 5.4 & 5.1926 & TRN & \\
\hline CHEMBL1382909 & 737823 & 5.3 & 5.5843 & TRN & \\
\hline CHEMBL1455043 & 737823 & 4.55 & 5.33799 & 9999999999 & TRN \\
\hline CHEMBL1536326 & 737823 & 4.9 & 5.308 & TRN & \\
\hline CHEMBL1514719 & 737823 & 5.3 & 5.3726 & TRN & \\
\hline CHEMBL3192772 & 737823 & 4.75 & 4.8666 & TRN & \\
\hline CHEMBL1554763 & 737823 & 5.6 & 5.5885 & TRN & \\
\hline CHEMBL1269022 & 737823 & 6.9 & 5.9069 & TST & \\
\hline CHEMBL1426928 & 737823 & 4.6 & 5.2608 & TST & \\
\hline CHEMBL1313862 & 737823 & 5.65 & 5.2939 & TRN & \\
\hline CHEMBL1564734 & 737823 & 5.2 & 5.4321 & TRN & \\
\hline CHEMBL1327945 & 737823 & 5.5 & 5.3109 & TRN & \\
\hline CHEMBL1500945 & 737823 & 4.4 & 4.7758 & TRN & \\
\hline CHEMBL1370467 & 737823 & 6.0 & 5.3447 & TRN & \\
\hline CHEMBL1378758 & 737823 & 6.5 & 5.8134 & TRN & \\
\hline & & & & 3342 & \\
\hline
\end{tabular}




\begin{tabular}{|c|c|c|c|c|c|}
\hline & & \multicolumn{4}{|c|}{ Supplemental Table S2.txt } \\
\hline CHEMBL1436865 & 737823 & 4.8 & 4.9146 & TRN & \\
\hline CHEMBL1481746 & 737823 & 6.1 & 5.6753 & TST & \\
\hline CHEMBL1448728 & 737823 & 5.3 & 5.6379 & TRN & \\
\hline CHEMBL 3210786 & 737823 & 5.55 & 5.3652 & TST & \\
\hline CHEMBL1437661 & 737823 & 5.3 & 5.2259 & TRN & \\
\hline CHEMBL1408854 & 737823 & 4.9 & 5.0441 & TRN & \\
\hline CHEMBL1521273 & 737823 & 4.9 & 5.4788 & TRN & \\
\hline CHEMBL517986 & 737823 & 5.7 & 4.7273 & TRN & \\
\hline CHEMBL1498141 & 737823 & 5.25 & 5.2881 & TRN & \\
\hline CHEMBL1562974 & 737823 & 6.1 & 5.7802 & TRN & \\
\hline CHEMBL1409341 & 737823 & 6.1 & 5.7484 & TRN & \\
\hline CHEMBL3210188 & 737823 & 5.5 & 5.6011 & TRN & \\
\hline CHEMBL1495665 & 737823 & 6.3 & 5.7548 & TRN & \\
\hline CHEMBL1329108 & 737823 & 5.7 & 6.00700 & 0000000001 & TRN \\
\hline CHEMBL1427238 & 737823 & 4.8 & 5.2466 & TRN & \\
\hline CHEMBL1256392 & 737823 & 4.4 & 5.66100 & 00000000005 & TRN \\
\hline CHEMBL1408954 & 737823 & 6.1 & 5.3324 & TRN & \\
\hline CHEMBL1367387 & 737823 & 4.85 & 4.9042 & TRN & \\
\hline CHEMBL1969464 & 737823 & 5.5 & 5.1274 & TRN & \\
\hline CHEMBL1466684 & 737823 & 4.85 & 5.1798 & TRN & \\
\hline CHEMBL1493039 & 737823 & 6.5 & 5.5953 & TST & \\
\hline CHEMBL1555519 & 737823 & 5.0 & 5.3278 & TRN & \\
\hline CHEMBL1433489 & 737823 & 4.5 & 5.0909 & TRN & \\
\hline CHEMBL1427095 & 737823 & 4.55 & 5.3353 & TRN & \\
\hline CHEMBL1557951 & 737823 & 4.65 & 5.5189 & TRN & \\
\hline CHEMBL1557696 & 737823 & 6.4 & 6.2829 & TRN & \\
\hline CHEMBL1592212 & 737823 & 5.1 & 5.2958 & TRN & \\
\hline CHEMBL1595827 & 737823 & 4.6 & 5.2462 & TRN & \\
\hline CHEMBL1354112 & 737823 & 5.4 & 5.3638 & TRN & \\
\hline CHEMBL1513654 & 737823 & 4.9 & 5.2999 & TST & \\
\hline CHEMBL1575404 & 737823 & 4.55 & 5.0736 & TRN & \\
\hline CHEMBL1565409 & 737823 & 4.5 & 4.7326 & TRN & \\
\hline CHEMBL1407471 & 737823 & 5.3 & 5.1046 & TST & \\
\hline CHEMBL1355835 & 737823 & 6.3 & 6.0565 & TRN & \\
\hline CHEMBL1371959 & 737823 & 5.05 & 5.6126 & TRN & \\
\hline CHEMBL3214608 & 737823 & 4.6 & 5.2659 & TRN & \\
\hline CHEMBL1399994 & 737823 & 5.5 & 5.3311 & TRN & \\
\hline CHEMBL1574567 & 737823 & 5.8 & 5.2116 & TST & \\
\hline CHEMBL405374 & 737823 & 5.4 & 5.2341 & TST & \\
\hline CHEMBL1521041 & 737823 & 4.95 & 5.3544 & TRN & \\
\hline CHEMBL1515717 & 737823 & 6.2 & 5.8859 & TRN & \\
\hline CHEMBL1361182 & 737823 & 5.5 & 5.3512 & TRN & \\
\hline CHEMBL3199291 & 737823 & 4.85 & 5.3016 & TST & \\
\hline CHEMBL1594799 & 737823 & 6.15 & 5.1196 & TRN & \\
\hline CHEMBL1612127 & 737823 & 4.4 & 4.8586 & TRN & \\
\hline CHEMBL 244743 & 737823 & 4.8 & 5.6578 & TST & \\
\hline CHEMBL1314897 & 737823 & 5.0 & 4.8653 & TRN & \\
\hline CHEMBL1302204 & 737823 & 4.8 & 5.3566 & TRN & \\
\hline
\end{tabular}




\begin{tabular}{|c|c|c|c|c|c|}
\hline \\
\hline CHEMBL1489512 & 737823 & 4.9 & 5.148 & TRN & \\
\hline CHEMBL1605233 & 737823 & 6.3 & 5.1569 & TRN & \\
\hline CHEMBL1330763 & 737823 & 6.1 & 5.8277 & TRN & \\
\hline CHEMBL1582666 & 737823 & 4.7 & 4.7884 & TRN & \\
\hline CHEMBL1354341 & 737823 & 4.9 & 4.572 & TRN & \\
\hline CHEMBL1341400 & 737823 & 7.6 & 5.3161 & TRN & \\
\hline CHEMBL3208265 & 737823 & 5.35 & 5.38399 & 99999999995 & TRN \\
\hline CHEMBL1494832 & 737823 & 6.7 & 5.7736 & TRN & \\
\hline CHEMBL1512385 & 737823 & 5.1 & 5.1868 & TRN & \\
\hline CHEMBL1548012 & 737823 & 5.8 & 5.7795 & TRN & \\
\hline CHEMBL1510139 & 737823 & 5.55 & 5.4576 & TRN & \\
\hline CHEMBL1327566 & 737823 & 4.6 & 5.1977 & TRN & \\
\hline CHEMBL1438771 & 737823 & 5.8 & 5.5839 & TRN & \\
\hline CHEMBL1557213 & 737823 & 5.4 & 5.5748 & TST & \\
\hline CHEMBL1330087 & 737823 & 6.0 & 5.1794 & TRN & \\
\hline CHEMBL1399844 & 737823 & 5.1 & 5.8528 & TST & \\
\hline CHEMBL1530789 & 737823 & 5.35 & 5.3899 & TRN & \\
\hline CHEMBL1330183 & 737823 & 5.7 & 5.399 & TST & \\
\hline CHEMBL1732802 & 737823 & 6.9 & 5.1101 & TRN & \\
\hline CHEMBL1590645 & 737823 & 5.5 & 5.5 & TRN & \\
\hline CHEMBL1444367 & 737823 & 4.5 & 4.7389 & TRN & \\
\hline CHEMBL1355909 & 737823 & 5.6 & 5.0288 & TRN & \\
\hline CHEMBL1611225 & 737823 & 5.4 & 5.6716 & TRN & \\
\hline CHEMBL1305545 & 737823 & 4.95 & 5.2029 & TRN & \\
\hline CHEMBL1480350 & 737823 & 5.5 & 5.5342 & TRN & \\
\hline CHEMBL1351231 & 737823 & 4.75 & 5.2408 & TST & \\
\hline CHEMBL1602633 & 737823 & 4.7 & 4.8058 & TRN & \\
\hline CHEMBL1255657 & 737823 & 4.4 & 5.2388 & TRN & \\
\hline CHEMBL1334122 & 737823 & 4.85 & 5.4592 & TRN & \\
\hline CHEMBL1526635 & 737823 & 6.6 & 5.6828 & TRN & \\
\hline CHEMBL1534738 & 737823 & 4.6 & 4.9602 & TRN & \\
\hline CHEMBL1543887 & 737823 & 6.3 & 5.3551 & TRN & \\
\hline CHEMBL1403134 & 737823 & 5.5 & 5.745 & TRN & \\
\hline CHEMBL1425498 & 737823 & 4.9 & 5.3411 & TRN & \\
\hline CHEMBL1741597 & 737823 & 5.5 & 5.5275 & TRN & \\
\hline CHEMBL48278 & 737823 & 4.9 & 5.1257 & TRN & \\
\hline CHEMBL1591508 & 737823 & 4.4 & 4.8198 & TST & \\
\hline CHEMBL1308838 & 737823 & 5.35 & 5.059 & TRN & \\
\hline CHEMBL1568370 & 737823 & 4.9 & 5.0312 & TRN & \\
\hline CHEMBL1604244 & 737823 & 4.9 & 5.1188 & TRN & \\
\hline CHEMBL1437054 & 737823 & 5.5 & 5.7966 & TST & \\
\hline CHEMBL1534376 & 737823 & 4.9 & 4.607 & TRN & \\
\hline CHEMBL3198125 & 737823 & 4.6 & 4.9044 & TRN & \\
\hline CHEMBL 247129 & 737823 & 5.55 & 5.5517 & TRN & \\
\hline CHEMBL1383824 & 737823 & 5.85 & 5.7441 & TRN & \\
\hline CHEMBL1568767 & 737823 & 6.2 & 5.8452 & TRN & \\
\hline CHEMBL1442459 & 737823 & 5.3 & 5.0321 & TST & \\
\hline CHEMBL1437075 & 737823 & 4.8 & 5.2628 & TRN & \\
\hline
\end{tabular}




\begin{tabular}{|c|c|c|c|c|c|}
\hline \multicolumn{6}{|c|}{ Supplemental Table S2.txt } \\
\hline CHEMBL1531681 & 737823 & 4.55 & 5.1591 & TRN & \\
\hline CHEMBL363332 & 737823 & 6.0 & 5.4437 & TST & \\
\hline CHEMBL1443168 & 737823 & 6.2 & 5.324 & TRN & \\
\hline CHEMBL1476021 & 737823 & 4.9 & 5.7829 & TRN & \\
\hline CHEMBL1499237 & 737823 & 6.05 & 5.273 & TST & \\
\hline CHEMBL1475951 & 737823 & 6.1 & 5.8811 & TRN & \\
\hline CHEMBL1480742 & 737823 & 4.7 & 4.7226 & TRN & \\
\hline CHEMBL1407743 & 737823 & 4.55 & 4.9768 & TRN & \\
\hline CHEMBL1416639 & 737823 & 4.7 & 4.9711 & TRN & \\
\hline CHEMBL1574148 & 737823 & 6.15 & 5.75899 & 99999999995 & TRN \\
\hline CHEMBL1300069 & 737823 & 7.0 & 5.4412 & TST & \\
\hline CHEMBL1520187 & 737823 & 4.9 & 5.2326 & TST & \\
\hline CHEMBL1536139 & 737823 & 5.45 & 6.0308 & TRN & \\
\hline CHEMBL1609446 & 737823 & 5.5 & 5.5004 & TST & \\
\hline CHEMBL1362249 & 737823 & 5.55 & 5.4049 & TRN & \\
\hline CHEMBL115225 & 737823 & 7.1 & 5.9782 & TRN & \\
\hline CHEMBL1460362 & 737823 & 5.3 & 5.3705 & TRN & \\
\hline CHEMBL1377410 & 737823 & 4.9 & 5.1356 & TRN & \\
\hline CHEMBL1535980 & 737823 & 4.5 & 5.3868 & TRN & \\
\hline CHEMBL1496566 & 737823 & 4.9 & 5.2434 & TRN & \\
\hline CHEMBL1463543 & 737823 & 5.4 & 5.5284 & TRN & \\
\hline CHEMBL1741806 & 737823 & 5.45 & 5.2779 & TRN & \\
\hline CHEMBL1534196 & 737823 & 5.45 & 5.2645 & TRN & \\
\hline CHEMBL1505786 & 737823 & 4.9 & 5.0977 & TRN & \\
\hline CHEMBL11458 & 737823 & 4.9 & 5.254 & TST & \\
\hline CHEMBL1317461 & 737823 & 6.9 & 6.306 & TRN & \\
\hline CHEMBL472994 & 737823 & 5.5 & 5.8582 & TST & \\
\hline CHEMBL1447410 & 737823 & 4.85 & 4.7613 & TRN & \\
\hline CHEMBL3190163 & 737823 & 6.55 & 5.598 & TRN & \\
\hline CHEMBL1572770 & 737823 & 6.7 & 5.5635 & TST & \\
\hline CHEMBL1496623 & 737823 & 5.8 & 5.6779 & TRN & \\
\hline CHEMBL1526852 & 737823 & 4.8 & 4.9732 & TRN & \\
\hline CHEMBL1416438 & 737823 & 5.85 & 6.42200 & 0000000001 & TRN \\
\hline CHEMBL1611902 & 737823 & 5.7 & 5.3775 & TST & \\
\hline CHEMBL1256998 & 737823 & 4.9 & 5.0935 & TST & \\
\hline CHEMBL1592966 & 737823 & 5.5 & 5.6074 & TRN & \\
\hline CHEMBL1357130 & 737823 & 5.0 & 4.8605 & TST & \\
\hline CHEMBL10347 & 737823 & 6.0 & 5.2589 & TRN & \\
\hline CHEMBL1386418 & 737823 & 5.05 & 5.04 & TRN & \\
\hline CHEMBL1378037 & 737823 & 4.65 & 4.9011 & TST & \\
\hline CHEMBL3198788 & 737823 & 4.85 & 5.0417 & TRN & \\
\hline CHEMBL1515315 & 737823 & 5.7 & 5.6151 & TRN & \\
\hline CHEMBL1598818 & 737823 & 5.6 & 5.3364 & TST & \\
\hline CHEMBL1461021 & 737823 & 6.5 & 5.6259 & TRN & \\
\hline CHEMBL1443360 & 737823 & 5.0 & 5.1419 & TRN & \\
\hline CHEMBL1699708 & 737823 & 6.1 & 4.9816 & TRN & \\
\hline CHEMBL1421692 & 737823 & 4.85 & 5.0807 & TRN & \\
\hline CHEMBL1409605 & 737823 & 4.95 & 4.8555 & TRN & \\
\hline
\end{tabular}




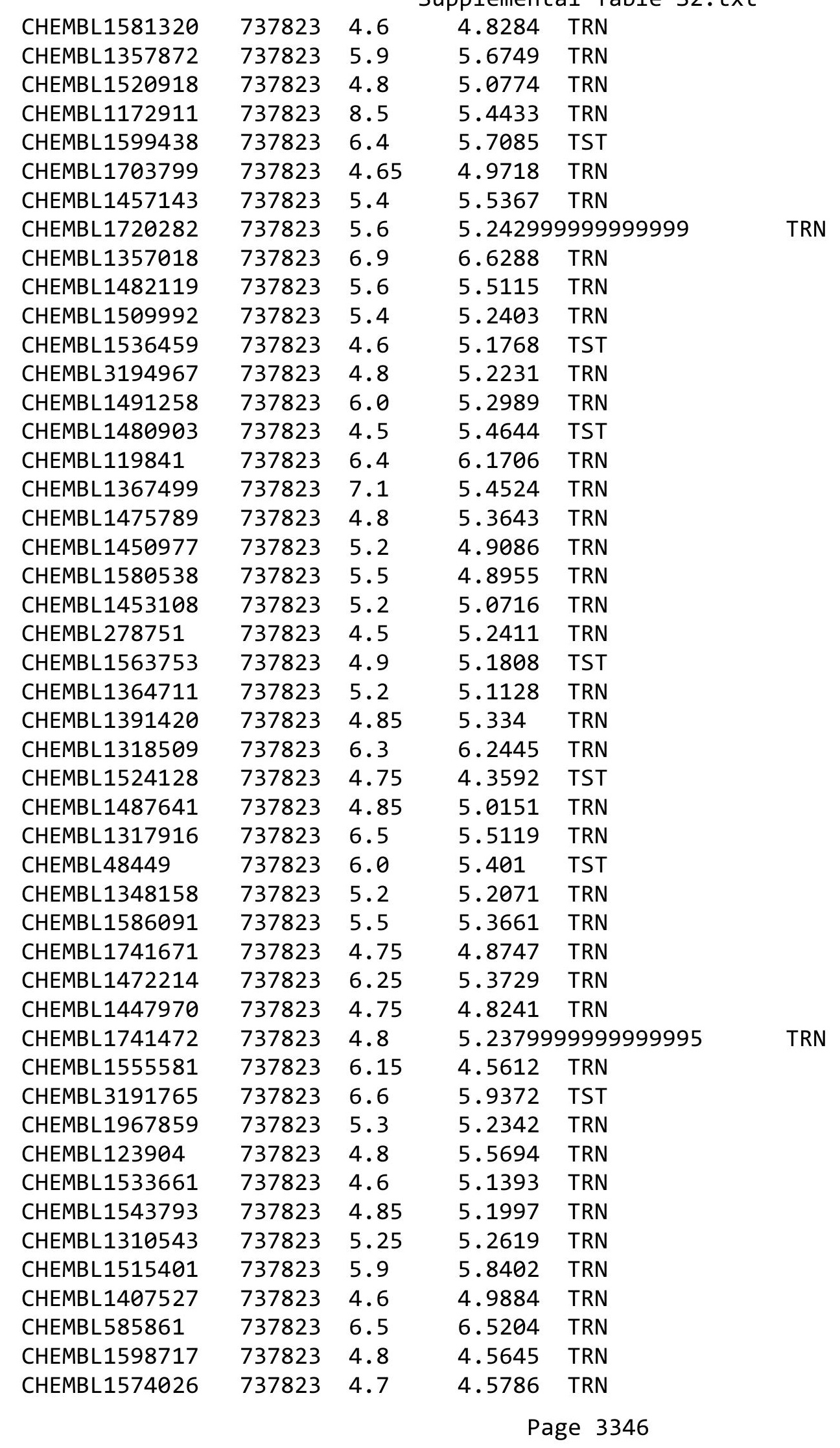




\begin{tabular}{|c|c|c|c|c|c|}
\hline \multirow[b]{2}{*}{ CHEMBL1422116 } & & \multicolumn{4}{|c|}{ Supplemental Table S2.txt } \\
\hline & 737823 & 5.95 & 5.5274 & TRN & \\
\hline CHEMBL3197212 & 737823 & 5.0 & 5.2079 & 9999999999 & TRN \\
\hline CHEMBL1315145 & 737823 & 6.1 & 5.602 & TRN & \\
\hline CHEMBL1358816 & 737823 & 5.4 & 5.54 & TST & \\
\hline CHEMBL1393076 & 737823 & 5.35 & 5.4544 & TRN & \\
\hline CHEMBL1474483 & 737823 & 4.7 & 5.0168 & TRN & \\
\hline CHEMBL1492953 & 737823 & 4.9 & 5.4186 & TRN & \\
\hline CHEMBL1456034 & 737823 & 5.9 & 5.2591 & TST & \\
\hline CHEMBL1378653 & 737823 & 5.85 & 5.2962 & TRN & \\
\hline CHEMBL1515961 & 737823 & 5.5 & 5.2345 & TRN & \\
\hline CHEMBL1394113 & 737823 & 6.2 & 6.0916 & TRN & \\
\hline CHEMBL1613725 & 737823 & 6.2 & 6.1595 & TRN & \\
\hline CHEMBL1570405 & 737823 & 4.6 & 5.2692 & TST & \\
\hline CHEMBL1603268 & 737823 & 4.95 & 5.7646 & TST & \\
\hline CHEMBL1318166 & 737823 & 4.9 & 4.94 & TST & \\
\hline CHEMBL1593889 & 737823 & 6.0 & 5.6668 & TRN & \\
\hline CHEMBL1332696 & 737823 & 4.65 & 5.1651 & TRN & \\
\hline CHEMBL1439665 & 737823 & 4.9 & 5.0848 & TRN & \\
\hline CHEMBL 3208450 & 737823 & 4.85 & 5.2661 & TRN & \\
\hline CHEMBL1316557 & 737823 & 4.9 & 5.0646 & TRN & \\
\hline CHEMBL1546161 & 737823 & 5.65 & 5.7316 & TST & \\
\hline CHEMBL1579407 & 737823 & 4.85 & 5.6536 & TST & \\
\hline CHEMBL1501924 & 737823 & 5.9 & 5.5048 & TRN & \\
\hline CHEMBL1598334 & 737823 & 4.8 & 5.0292 & TRN & \\
\hline CHEMBL1378901 & 737823 & 5.4 & 5.2998 & TRN & \\
\hline CHEMBL1566670 & 737823 & 4.9 & 5.0918 & TRN & \\
\hline CHEMBL1452065 & 737823 & 5.4 & 4.8242 & TRN & \\
\hline CHEMBL1411137 & 737823 & 5.4 & 5.8733 & TRN & \\
\hline CHEMBL1314185 & 737823 & 5.8 & 5.4937 & TRN & \\
\hline CHEMBL1324871 & 737823 & 5.4 & 4.9817 & TST & \\
\hline CHEMBL1567472 & 737823 & 5.7 & 5.7732 & TRN & \\
\hline CHEMBL1447425 & 737823 & 6.4 & 5.6716 & TRN & \\
\hline CHEMBL1610400 & 737823 & 5.2 & 4.6669 & TRN & \\
\hline CHEMBL1566015 & 737823 & 6.25 & 6.0323 & TRN & \\
\hline CHEMBL1415414 & 737823 & 6.0 & 5.4570 & 3000000001 & TRN \\
\hline CHEMBL1605148 & 737823 & 4.85 & 4.8799 & TRN & \\
\hline CHEMBL1567238 & 737823 & 5.5 & 5.7015 & TRN & \\
\hline CHEMBL1361757 & 737823 & 5.7 & 5.2861 & TRN & \\
\hline CHEMBL1608942 & 737823 & 4.8 & 5.0801 & TRN & \\
\hline CHEMBL1590831 & 737823 & 4.5 & 5.6586 & TRN & \\
\hline CHEMBL1454931 & 737823 & 5.8 & 5.5701 & TRN & \\
\hline CHEMBL3197818 & 737823 & 4.9 & 4.865 & TRN & \\
\hline CHEMBL3211758 & 737823 & 4.9 & 4.8071 & TRN & \\
\hline CHEMBL1548181 & 737823 & 4.8 & 5.0396 & TST & \\
\hline CHEMBL1317998 & 737823 & 4.6 & 4.7803 & TRN & \\
\hline CHEMBL1522681 & 737823 & 5.1 & 4.8777 & TRN & \\
\hline CHEMBL1332726 & 737823 & 5.1 & 5.1515 & TRN & \\
\hline CHEMBL1303042 & 737823 & 4.85 & 5.5988 & TRN & \\
\hline
\end{tabular}




\begin{tabular}{|c|c|c|c|c|c|}
\hline \multicolumn{6}{|c|}{ Supplemental Table S2.txt } \\
\hline CHEMBL1408013 & 737823 & 5.1 & 5.4916 & TRN & \\
\hline CHEMBL1597843 & 737823 & 5.65 & 5.6096 & TRN & \\
\hline CHEMBL1575261 & 737823 & 5.9 & 5.9779 & TRN & \\
\hline CHEMBL1340380 & 737823 & 7.5 & 5.1959 & TRN & \\
\hline CHEMBL1598705 & 737823 & 5.3 & 4.8874 & TRN & \\
\hline CHEMBL1435886 & 737823 & 5.2 & 4.8535 & TRN & \\
\hline CHEMBL1377868 & 737823 & 5.4 & 5.5512 & TRN & \\
\hline CHEMBL1558538 & 737823 & 4.8 & 5.0403 & TRN & \\
\hline CHEMBL1372615 & 737823 & 6.0 & 5.5115 & TRN & \\
\hline CHEMBL1411045 & 737823 & 5.4 & 5.4211 & TST & \\
\hline CHEMBL1427243 & 737823 & 5.8 & 5.2237 & TRN & \\
\hline CHEMBL1361505 & 737823 & 5.2 & 6.0975 & TST & \\
\hline CHEMBL1442612 & 737823 & 5.4 & 5.4241 & TRN & \\
\hline CHEMBL1570854 & 737823 & 5.6 & 5.9732 & TRN & \\
\hline CHEMBL1489663 & 737823 & 5.4 & 5.7411 & TRN & \\
\hline CHEMBL1511006 & 737823 & 4.6 & 5.7618 & TRN & \\
\hline CHEMBL1408904 & 737823 & 6.05 & 5.6331 & TRN & \\
\hline CHEMBL3192578 & 737823 & 5.55 & 5.4111 & TST & \\
\hline CHEMBL1518718 & 737823 & 5.6 & 5.7384 & TRN & \\
\hline CHEMBL1515559 & 737823 & 5.1 & 4.9432 & TRN & \\
\hline CHEMBL1366094 & 737823 & 4.8 & 5.2291 & TRN & \\
\hline CHEMBL1575429 & 737823 & 4.9 & 5.1038 & TST & \\
\hline CHEMBL3211431 & 737823 & 5.95 & 5.4502 & TRN & \\
\hline CHEMBL1485654 & 737823 & 4.7 & 4.824 & TRN & \\
\hline CHEMBL177809 & 737823 & 4.9 & 4.8527 & TRN & \\
\hline CHEMBL1584418 & 737823 & 5.15 & 5.6021 & TRN & \\
\hline CHEMBL1443859 & 737823 & 5.5 & 5.419 & TRN & \\
\hline CHEMBL1370855 & 737823 & 5.8 & 5.7462 & TRN & \\
\hline CHEMBL3209417 & 737823 & 5.55 & 5.4011 & TST & \\
\hline CHEMBL1592213 & 737823 & 5.3 & 5.4916 & TRN & \\
\hline CHEMBL1413165 & 737823 & 4.6 & 5.2971 & TRN & \\
\hline CHEMBL328710 & 737823 & 7.0 & 5.9508 & TRN & \\
\hline CHEMBL1592209 & 737823 & 4.8 & 5.5151 & TRN & \\
\hline CHEMBL1320190 & 737823 & 4.6 & 5.044 & TRN & \\
\hline CHEMBL1445828 & 737823 & 4.85 & 5.2463 & TRN & \\
\hline CHEMBL1476430 & 737823 & 4.8 & 5.69 & TRN & \\
\hline CHEMBL1301059 & 737823 & 6.1 & 5.603 & TST & \\
\hline CHEMBL1507076 & 737823 & 6.15 & 5.6257 & TRN & \\
\hline CHEMBL1443643 & 737823 & 5.45 & 5.1426 & TRN & \\
\hline CHEMBL1373818 & 737823 & 4.5 & 4.4301 & TST & \\
\hline CHEMBL1231330 & 737823 & 4.4 & 5.0744 & TRN & \\
\hline CHEMBL1547832 & 737823 & 6.1 & 5.3776 & TRN & \\
\hline CHEMBL1592651 & 737823 & 4.9 & 4.8934 & TRN & \\
\hline CHEMBL112816 & 737823 & 4.5 & 5.2864 & TRN & \\
\hline CHEMBL528080 & 737823 & 6.2 & 5.79700 & 0000000001 & TRN \\
\hline CHEMBL1506622 & 737823 & 5.25 & 5.4745 & TRN & \\
\hline CHEMBL1446774 & 737823 & 5.6 & 5.3786 & TRN & \\
\hline CHEMBL1371564 & 737823 & 4.9 & 5.1993 & TRN & \\
\hline
\end{tabular}




\begin{tabular}{|c|c|c|c|c|c|}
\hline \multicolumn{6}{|c|}{ Supplemental Table S2.txt } \\
\hline CHEMBL1476298 & 737823 & 4.7 & 4.7298 & TRN & \\
\hline CHEMBL1513800 & 737823 & 5.4 & 5.1292 & TRN & \\
\hline CHEMBL1508362 & 737823 & 4.85 & 5.5069 & TRN & \\
\hline CHEMBL3192875 & 737823 & 5.6 & 5.2696 & TRN & \\
\hline CHEMBL1370229 & 737823 & 5.4 & 6.0493 & TRN & \\
\hline CHEMBL286721 & 737823 & 6.3 & 5.5324 & TRN & \\
\hline CHEMBL1595376 & 737823 & 5.15 & 5.1767 & TST & \\
\hline CHEMBL1235551 & 737823 & 5.0 & 4.8767 & TRN & \\
\hline CHEMBL1360799 & 737823 & 5.7 & 5.705 & TRN & \\
\hline CHEMBL1525058 & 737823 & 5.15 & 5.21899 & 9999999999 & TRN \\
\hline CHEMBL1577213 & 737823 & 5.8 & 5.037 & TRN & \\
\hline CHEMBL1565645 & 737823 & 6.3 & 5.3507 & TRN & \\
\hline CHEMBL1720268 & 737823 & 4.85 & 4.9811 & TRN & \\
\hline CHEMBL1591556 & 737823 & 4.7 & 5.3848 & TST & \\
\hline CHEMBL1404703 & 737823 & 5.8 & 5.4092 & TRN & \\
\hline CHEMBL1395661 & 737823 & 6.0 & 5.2297 & TRN & \\
\hline CHEMBL1456872 & 737823 & 4.8 & 5.3186 & TRN & \\
\hline CHEMBL23194 & 737823 & 4.8 & 5.1539 & TST & \\
\hline CHEMBL1371031 & 737823 & 4.65 & 5.1367 & TRN & \\
\hline CHEMBL1449458 & 737823 & 4.8 & 4.8354 & TRN & \\
\hline CHEMBL3191366 & 737823 & 4.85 & 4.7702 & TRN & \\
\hline CHEMBL1337387 & 737823 & 4.4 & 4.6695 & TRN & \\
\hline CHEMBL601135 & 737823 & 4.85 & 5.4425 & TRN & \\
\hline CHEMBL1338245 & 737823 & 5.2 & 5.0961 & TRN & \\
\hline CHEMBL1354626 & 737823 & 6.8 & 5.808 & TRN & \\
\hline CHEMBL21241 & 737823 & 4.4 & 4.7796 & TRN & \\
\hline CHEMBL1328340 & 737823 & 5.15 & 4.665 & TST & \\
\hline CHEMBL1378030 & 737823 & 5.7 & 5.466 & TRN & \\
\hline CHEMBL1506343 & 737823 & 5.1 & 5.1955 & TRN & \\
\hline CHEMBL1433002 & 737823 & 4.55 & 4.743 & TRN & \\
\hline CHEMBL1365983 & 737823 & 4.6 & 5.0982 & TRN & \\
\hline CHEMBL1434085 & 737823 & 4.9 & 4.4843 & TRN & \\
\hline CHEMBL1325093 & 737823 & 5.2 & 5.4016 & TST & \\
\hline CHEMBL1567160 & 737823 & 6.1 & 5.2904 & TRN & \\
\hline CHEMBL1352069 & 737823 & 5.2 & 5.5596 & TST & \\
\hline CHEMBL1596762 & 737823 & 4.8 & 5.1825 & TRN & \\
\hline CHEMBL1377908 & 737823 & 4.8 & 4.7464 & TRN & \\
\hline CHEMBL1571504 & 737823 & 4.4 & 4.9574 & TST & \\
\hline CHEMBL3190602 & 737823 & 5.85 & 4.8218 & TRN & \\
\hline CHEMBL1369125 & 737823 & 4.85 & 5.3799 & TRN & \\
\hline CHEMBL1597572 & 737823 & 5.8 & 5.2408 & TRN & \\
\hline CHEMBL78150 & 737823 & 5.0 & 5.6283 & TRN & \\
\hline CHEMBL1598297 & 737823 & 4.85 & 5.606 & TRN & \\
\hline CHEMBL 38832 & 737823 & 4.8 & 5.1874 & TST & \\
\hline CHEMBL1547055 & 737823 & 4.6 & 5.2678 & TRN & \\
\hline CHEMBL1396203 & 737823 & 5.6 & 5.9492 & TRN & \\
\hline CHEMBL1473379 & 737823 & 4.7 & 5.0601 & TRN & \\
\hline CHEMBL1396539 & 737823 & 4.8 & 4.8697 & TRN & \\
\hline
\end{tabular}




\begin{tabular}{|c|c|c|c|c|c|}
\hline \multicolumn{6}{|c|}{ Supplemental Table S2.txt } \\
\hline CHEMBL1382389 & 737823 & 5.75 & 5.1418 & TRN & \\
\hline CHEMBL1603446 & 737823 & 5.7 & 5.2947 & TRN & \\
\hline CHEMBL1356744 & 737823 & 7.0 & 6.2064 & TRN & \\
\hline CHEMBL1742251 & 737823 & 6.3 & 5.4326 & TRN & \\
\hline CHEMBL489935 & 737823 & 5.1 & 5.33299 & 9999999999 & TRN \\
\hline CHEMBL1340705 & 737823 & 5.4 & 5.5155 & TRN & \\
\hline CHEMBL1316482 & 737823 & 5.0 & 5.1861 & TRN & \\
\hline CHEMBL1345927 & 737823 & 4.6 & 5.4389 & TRN & \\
\hline CHEMBL20377 & 737823 & 4.5 & 4.8884 & TRN & \\
\hline CHEMBL1972346 & 737823 & 5.3 & 5.4019 & TRN & \\
\hline CHEMBL1482381 & 737823 & 5.8 & 5.7606 & TST & \\
\hline CHEMBL1606547 & 737823 & 6.35 & 5.2837 & TRN & \\
\hline CHEMBL1413654 & 737823 & 5.4 & 4.9902 & TRN & \\
\hline CHEMBL1469385 & 737823 & 5.9 & 6.1625 & TST & \\
\hline CHEMBL1369444 & 737823 & 4.9 & 5.23 & TRN & \\
\hline CHEMBL1395997 & 737823 & 4.9 & 5.4504 & TRN & \\
\hline CHEMBL1389184 & 737823 & 4.6 & 4.7504 & TRN & \\
\hline CHEMBL1366732 & 737823 & 5.9 & 5.8036 & TRN & \\
\hline CHEMBL1365455 & 737823 & 4.5 & 5.4913 & TRN & \\
\hline CHEMBL1317358 & 737823 & 6.1 & 5.6117 & TRN & \\
\hline CHEMBL 23832 & 737823 & 4.8 & 5.2197 & TRN & \\
\hline CHEMBL1585681 & 737823 & 5.6 & 5.3846 & TRN & \\
\hline CHEMBL1397913 & 737823 & 5.2 & 5.322 & TRN & \\
\hline CHEMBL44297 & 737823 & 4.7 & 4.968 & TST & \\
\hline CHEMBL1474211 & 737823 & 5.3 & 5.2306 & TRN & \\
\hline CHEMBL1404884 & 737823 & 5.6 & 5.3443 & TRN & \\
\hline CHEMBL179763 & 737823 & 4.8 & 5.6859 & TRN & \\
\hline CHEMBL3351064 & 737823 & 6.4 & 5.2004 & TRN & \\
\hline CHEMBL12129 & 737823 & 4.1 & 5.0099 & TRN & \\
\hline CHEMBL1491137 & 737823 & 4.6 & 4.9611 & TRN & \\
\hline CHEMBL1425402 & 737823 & 4.85 & 4.7891 & TRN & \\
\hline CHEMBL1473752 & 737823 & 5.4 & 5.3891 & TRN & \\
\hline CHEMBL1409825 & 737823 & 4.9 & 4.7358 & TRN & \\
\hline CHEMBL94631 & 737823 & 4.5 & 5.0338 & TRN & \\
\hline CHEMBL1398810 & 737823 & 4.8 & 5.268 & TRN & \\
\hline CHEMBL1482233 & 737823 & 4.65 & 5.4322 & TRN & \\
\hline CHEMBL1524904 & 737823 & 5.35 & 5.3967 & TRN & \\
\hline CHEMBL1428167 & 737823 & 5.0 & 4.8041 & TRN & \\
\hline CHEMBL1256971 & 737823 & 4.5 & 5.20700 & 0000000001 & TST \\
\hline CHEMBL45068 & 737823 & 5.2 & 5.17700 & 00000000005 & TST \\
\hline CHEMBL1472651 & 737823 & 4.9 & 5.0517 & TRN & \\
\hline CHEMBL1343857 & 737823 & 5.7 & 5.7979 & TRN & \\
\hline CHEMBL1355718 & 737823 & 4.6 & 5.1102 & TRN & \\
\hline CHEMBL1475924 & 737823 & 4.9 & 5.3321 & TRN & \\
\hline CHEMBL 3212233 & 737823 & 5.3 & 5.2126 & TST & \\
\hline CHEMBL1399273 & 737823 & 5.1 & 5.3427 & TST & \\
\hline CHEMBL1256484 & 737823 & 5.4 & 4.7911 & TRN & \\
\hline CHEMBL1343632 & 737823 & 5.4 & 5.454 & TRN & \\
\hline
\end{tabular}




\begin{tabular}{|c|c|c|c|c|c|}
\hline CHEMBL1493869 & 737823 & 5.8 & 5.87799 & • & TRN \\
\hline CHEMBL 1476049 & 737823 & 6.4 & 5.9851 & TRN & \\
\hline CHEMBL1558916 & 737823 & 4.8 & 5.5625 & TRN & \\
\hline CHEMBL1450573 & 737823 & 6.6 & 5.73799 & 99999999995 & TRN \\
\hline CHEMBL1332265 & 737823 & 5.4 & 5.3477 & TST & \\
\hline CHEMBL1315268 & 737823 & 5.4 & 4.8422 & TRN & \\
\hline CHEMBL1315802 & 737823 & 4.7 & 5.1245 & TRN & \\
\hline CHEMBL1464940 & 737823 & 4.9 & 5.5368 & TRN & \\
\hline CHEMBL1699601 & 737823 & 5.5 & 5.6025 & TRN & \\
\hline CHEMBL1407445 & 737823 & 5.4 & 4.9539 & TRN & \\
\hline CHEMBL1574626 & 737823 & 5.4 & 4.7579 & TRN & \\
\hline CHEMBL1555255 & 737823 & 5.3 & 5.0668 & TST & \\
\hline CHEMBL1476009 & 737823 & 6.0 & 5.3967 & TRN & \\
\hline CHEMBL1332453 & 737823 & 5.1 & 5.3509 & TRN & \\
\hline CHEMBL1467931 & 737823 & 6.25 & 5.8282 & TRN & \\
\hline CHEMBL 1331120 & 737823 & 6.05 & 5.7687 & TRN & \\
\hline CHEMBL1379480 & 737823 & 5.0 & 5.4939 & TST & \\
\hline CHEMBL1303309 & 737823 & 5.4 & 4.9072 & TRN & \\
\hline CHEMBL1408323 & 737823 & 4.85 & 5.1265 & TRN & \\
\hline CHEMBL1529694 & 737823 & 5.5 & 5.3046 & TRN & \\
\hline CHEMBL1492339 & 737823 & 5.9 & 5.24299 & 9999999999 & TRN \\
\hline CHEMBL1446323 & 737823 & 5.9 & 5.71299 & 9999999999 & TRN \\
\hline CHEMBL1741631 & 737823 & 5.3 & 5.6768 & TST & \\
\hline CHEMBL1256693 & 737823 & 5.0 & 5.0245 & TRN & \\
\hline CHEMBL1314286 & 737823 & 6.0 & 5.5002 & TST & \\
\hline CHEMBL1610312 & 737823 & 4.95 & 5.8814 & TST & \\
\hline CHEMBL1328390 & 737823 & 5.5 & 5.2472 & TRN & \\
\hline CHEMBL1601416 & 737823 & 5.0 & 5.7002 & TRN & \\
\hline CHEMBL1356085 & 737823 & 5.4 & 5.3062 & TRN & \\
\hline CHEMBL1551444 & 737823 & 4.6 & 4.7169 & TRN & \\
\hline CHEMBL1364804 & 737823 & 4.9 & 4.6216 & TRN & \\
\hline CHEMBL1605510 & 737823 & 5.1 & 5.6668 & TRN & \\
\hline CHEMBL1308151 & 737823 & 6.05 & 5.5071 & TRN & \\
\hline CHEMBL502044 & 737823 & -0.0 & 4.7 & TST & \\
\hline CHEMBL1304293 & 737823 & 4.85 & 5.4928 & TRN & \\
\hline CHEMBL1319554 & 737823 & 4.8 & 5.5151 & TRN & \\
\hline CHEMBL41221 & 737823 & 4.5 & 4.9496 & TRN & \\
\hline CHEMBL1381730 & 737823 & 5.1 & 5.1594 & TRN & \\
\hline CHEMBL1982308 & 737823 & 5.0 & 5.2407 & TRN & \\
\hline CHEMBL1530672 & 737823 & 5.2 & 5.3466 & TRN & \\
\hline CHEMBL1361552 & 737823 & 5.5 & 5.7821 & TRN & \\
\hline CHEMBL1731530 & 737823 & 5.4 & 5.1214 & TRN & \\
\hline CHEMBL1538146 & 737823 & 5.1 & 5.0226 & TRN & \\
\hline CHEMBL 23731 & 737823 & 6.0 & 5.0481 & TRN & \\
\hline CHEMBL1375340 & 737823 & 4.8 & 5.4846 & TST & \\
\hline CHEMBL1530209 & 737823 & 4.65 & 5.279 & TRN & \\
\hline CHEMBL1606337 & 737823 & 5.1 & 5.3179 & TRN & \\
\hline CHEMBL453066 & 737823 & 6.2 & 5.5004 & TRN & \\
\hline
\end{tabular}




\begin{tabular}{|c|c|c|c|c|c|}
\hline \multirow[b]{2}{*}{ CHEMBL1331419 } & \multirow[b]{2}{*}{737823} & \\
\hline & & 5.6 & 5.4146 & TST & \\
\hline CHEMBL1397965 & 737823 & 5.1 & 5.3215 & TRN & \\
\hline CHEMBL1742242 & 737823 & 4.4 & 4.637 & TRN & \\
\hline CHEMBL1547352 & 737823 & 4.6 & 5.2693 & TRN & \\
\hline CHEMBL1515355 & 737823 & 6.4 & 5.9464 & TRN & \\
\hline CHEMBL1309363 & 737823 & 4.9 & 5.7046 & TRN & \\
\hline CHEMBL1349496 & 737823 & 4.6 & 5.1216 & TRN & \\
\hline CHEMBL1373007 & 737823 & 4.8 & \multicolumn{2}{|c|}{5.172000000000001} & TST \\
\hline CHEMBL1256109 & 737823 & 4.6 & 6.0577 & TRN & \\
\hline CHEMBL1343091 & 737823 & 4.4 & 4.6532 & TRN & \\
\hline CHEMBL1973886 & 737823 & 5.15 & 5.3333 & TRN & \\
\hline CHEMBL1333061 & 737823 & 4.7 & 5.01 & TRN & \\
\hline CHEMBL1483978 & 737823 & 5.15 & 5.3045 & TRN & \\
\hline CHEMBL1256359 & 737823 & 6.2 & 5.0148 & TRN & \\
\hline CHEMBL1331754 & 737823 & 7.2 & 5.6692 & TST & \\
\hline CHEMBL1604095 & 737823 & 5.2 & 5.5794 & TRN & \\
\hline CHEMBL1375428 & 737823 & 6.5 & 5.6388 & TRN & \\
\hline CHEMBL1430383 & 737823 & 4.8 & \multicolumn{2}{|c|}{5.196000000000001} & TRN \\
\hline CHEMBL 317757 & 737823 & 4.4 & 5.4614 & TRN & \\
\hline CHEMBL1486647 & 737823 & 4.9 & 5.3385 & TRN & \\
\hline CHEMBL1367789 & 737823 & 5.7 & 5.7333 & TRN & \\
\hline CHEMBL1544733 & 737823 & 5.2 & 5.3297 & TRN & \\
\hline CHEMBL1496345 & 737823 & 5.0 & 5.4137 & TRN & \\
\hline CHEMBL1523175 & 737823 & 5.35 & 5.6257 & TRN & \\
\hline CHEMBL1601305 & 737823 & 4.7 & 4.7492 & TRN & \\
\hline CHEMBL8747 & 737823 & 6.1 & 5.3981 & TRN & \\
\hline CHEMBL1369796 & 737823 & 5.6 & 6.022 & TRN & \\
\hline CHEMBL1564066 & 737823 & 5.5 & 5.523 & TRN & \\
\hline CHEMBL1318114 & 737823 & 6.7 & 6.2633 & TRN & \\
\hline CHEMBL1604074 & 737823 & 6.0 & 5.4211 & TRN & \\
\hline CHEMBL1372043 & 737823 & 6.1 & 5.8522 & TST & \\
\hline CHEMBL136906 & 737823 & 5.4 & 5.4596 & TRN & \\
\hline CHEMBL1605334 & 737823 & 4.85 & 5.4107 & TRN & \\
\hline CHEMBL1316408 & 737823 & 6.5 & 5.9843 & TRN & \\
\hline CHEMBL1235001 & 737823 & 9.0 & 5.1704 & TRN & \\
\hline CHEMBL1425367 & 737823 & 5.2 & 5.4739 & TRN & \\
\hline CHEMBL1396862 & 737823 & 4.9 & 5.0399 & TRN & \\
\hline CHEMBL1334357 & 737823 & 5.9 & 5.6076 & TST & \\
\hline CHEMBL39878 & 737823 & 4.7 & 4.9183 & TRN & \\
\hline CHEMBL1519110 & 737823 & 6.25 & 5.4405 & TST & \\
\hline CHEMBL1592465 & 737823 & 5.1 & 5.5059 & TRN & \\
\hline CHEMBL1457332 & 737823 & 5.0 & 4.9114 & TRN & \\
\hline CHEMBL1512027 & 737823 & 5.7 & 5.4877 & TRN & \\
\hline CHEMBL1414185 & 737823 & 6.1 & 5.6034 & TST & \\
\hline CHEMBL1542592 & 737823 & 5.9 & 5.8683 & TST & \\
\hline CHEMBL601616 & 737823 & 5.3 & 5.5793 & TRN & \\
\hline CHEMBL1437831 & 737823 & 4.5 & 5.1833 & TST & \\
\hline \multirow[t]{2}{*}{ CHEMBL1315991 } & 737823 & 4.8 & 4.9426 & TRN & \\
\hline & & \multicolumn{4}{|c|}{ Page 3352} \\
\hline
\end{tabular}




\begin{tabular}{|c|c|c|c|c|c|}
\hline \multicolumn{6}{|c|}{ Supplemental Table S2.txt } \\
\hline CHEMBL1563936 & 737823 & 4.8 & 5.5679 & TRN & \\
\hline CHEMBL 3196345 & 737823 & 5.65 & 5.6919 & TRN & \\
\hline CHEMBL1370525 & 737823 & 5.55 & 5.0508 & TRN & \\
\hline CHEMBL1406879 & 737823 & 4.8 & 4.6722 & TRN & \\
\hline CHEMBL1579761 & 737823 & 4.85 & 5.2281 & TRN & \\
\hline CHEMBL1300958 & 737823 & 5.1 & 5.4288 & TRN & \\
\hline CHEMBL1565564 & 737823 & 6.0 & 5.4654 & TRN & \\
\hline CHEMBL1320225 & 737823 & 4.45 & 4.859 & TST & \\
\hline CHEMBL1502064 & 737823 & 4.75 & 5.4412 & TST & \\
\hline CHEMBL1474169 & 737823 & 5.0 & 5.3443 & TRN & \\
\hline CHEMBL66 & 737823 & 4.8 & 5.2387 & TST & \\
\hline CHEMBL1416685 & 737823 & 5.0 & 5.1039 & TRN & \\
\hline CHEMBL1576215 & 737823 & 5.8 & 4.8732 & TRN & \\
\hline CHEMBL1583920 & 737823 & 4.85 & 5.2301 & TRN & \\
\hline CHEMBL1712760 & 737823 & 4.8 & 5.3402 & TRN & \\
\hline CHEMBL1559654 & 737823 & 6.7 & 6.6914 & TRN & \\
\hline CHEMBL1397406 & 737823 & 4.7 & 4.783 & TRN & \\
\hline CHEMBL1544132 & 737823 & 5.1 & 5.5993 & TRN & \\
\hline CHEMBL1478194 & 737823 & 5.05 & 5.3935 & TRN & \\
\hline CHEMBL1330614 & 737823 & 5.4 & 6.1441 & TRN & \\
\hline CHEMBL1727680 & 737823 & 5.4 & 6.0328 & TRN & \\
\hline CHEMBL1375008 & 737823 & 7.5 & 5.3006 & TST & \\
\hline CHEMBL1590857 & 737823 & 6.3 & 5.721 & TRN & \\
\hline CHEMBL 3211776 & 737823 & 6.1 & 5.5646 & TRN & \\
\hline CHEMBL1558951 & 737823 & 4.6 & 4.9912 & TRN & \\
\hline CHEMBL1301464 & 737823 & 6.05 & 5.8486 & TST & \\
\hline CHEMBL1439210 & 737823 & 4.7 & 5.2544 & TRN & \\
\hline CHEMBL1329419 & 737823 & 5.4 & 5.1605 & TRN & \\
\hline CHEMBL1161936 & 737823 & 5.5 & 4.9694 & TST & \\
\hline CHEMBL 3084891 & 737823 & 4.8 & 4.9244 & TRN & \\
\hline CHEMBL1535431 & 737823 & 5.7 & 5.4586 & TRN & \\
\hline CHEMBL1612675 & 737823 & 4.9 & 4.8848 & TST & \\
\hline CHEMBL 3193830 & 737823 & 4.85 & 4.6939 & TRN & \\
\hline CHEMBL1408475 & 737823 & 4.8 & 5.2961 & TRN & \\
\hline CHEMBL3195166 & 737823 & 5.55 & 5.7701 & TRN & \\
\hline CHEMBL1398022 & 737823 & 5.4 & 5.7877 & TRN & \\
\hline CHEMBL 275938 & 737823 & 5.0 & 5.3069 & TST & \\
\hline CHEMBL310310 & 737823 & 4.5 & 5.4524 & TRN & \\
\hline CHEMBL1529232 & 737823 & 4.9 & 5.5586 & TRN & \\
\hline CHEMBL1989683 & 737823 & 5.9 & 5.4606 & TRN & \\
\hline CHEMBL1708935 & 737823 & 4.8 & 5.4731 & TRN & \\
\hline CHEMBL1545539 & 737823 & 5.6 & 5.2147 & TST & \\
\hline CHEMBL1603627 & 737823 & 5.0 & 4.9574 & TRN & \\
\hline CHEMBL1516163 & 737823 & 6.2 & 5.6824 & TRN & \\
\hline CHEMBL1441254 & 737823 & 5.15 & 5.5216 & TRN & \\
\hline CHEMBL1453438 & 737823 & 4.9 & 5.5624 & TRN & \\
\hline CHEMBL1395107 & 737823 & 5.9 & 6.0572 & TRN & \\
\hline CHEMBL1448138 & 737823 & 5.8 & $5.6620 e$ & 0000000001 & TRN \\
\hline & & & & e 3353 & \\
\hline
\end{tabular}




\begin{tabular}{|c|c|c|c|c|c|}
\hline & & \multicolumn{4}{|c|}{ Supplemental Table S2.txt } \\
\hline CHEMBL1371655 & 737823 & 4.95 & 5.1132 & TRN & \\
\hline CHEMBL588859 & 737823 & 5.5 & 5.4275 & TRN & \\
\hline CHEMBL18840 & 737823 & 6.0 & 5.3241 & TRN & \\
\hline CHEMBL3207419 & 737823 & 4.95 & 5.4311 & TRN & \\
\hline CHEMBL 1366020 & 737823 & 6.0 & 6.2276 & TRN & \\
\hline CHEMBL1453970 & 737823 & 4.85 & 5.4291 & TRN & \\
\hline CHEMBL1256844 & 737823 & 4.4 & 4.8191 & TST & \\
\hline CHEMBL 2000120 & 737823 & 5.35 & 5.2759 & TRN & \\
\hline CHEMBL1396407 & 737823 & 6.4 & \multicolumn{2}{|c|}{5.622000000000001} & TRN \\
\hline CHEMBL1366479 & 737823 & 4.55 & 5.2665 & TRN & \\
\hline CHEMBL1448147 & 737823 & 5.3 & 5.4245 & TST & \\
\hline CHEMBL3213904 & 737823 & 4.8 & 5.2528 & TST & \\
\hline CHEMBL1300933 & 737823 & 5.05 & 5.2821 & TRN & \\
\hline CHEMBL1557048 & 737823 & 6.7 & 6.0244 & TRN & \\
\hline CHEMBL1331489 & 737823 & 5.1 & 6.0808 & TRN & \\
\hline CHEMBL1424582 & 737823 & 6.05 & 5.3358 & TRN & \\
\hline CHEMBL1575911 & 737823 & 5.9 & 5.4778 & TST & \\
\hline CHEMBL1441981 & 737823 & 4.8 & 4.9235 & TRN & \\
\hline CHEMBL1503387 & 737823 & 4.9 & \multicolumn{2}{|c|}{5.667999999999999} & TRN \\
\hline CHEMBL1329119 & 737823 & 5.35 & 5.1932 & TRN & \\
\hline CHEMBL1891843 & 737823 & 5.35 & 5.5463 & TST & \\
\hline CHEMBL1554158 & 737823 & 6.2 & 6.0254 & TRN & \\
\hline CHEMBL1502536 & 737823 & 4.4 & 5.1171 & TRN & \\
\hline CHEMBL1527851 & 737823 & 6.5 & 5.246 & TRN & \\
\hline CHEMBL1404647 & 737823 & 4.8 & 4.7417 & TRN & \\
\hline CHEMBL1314416 & 737823 & 6.4 & 5.7048 & TRN & \\
\hline CHEMBL1544606 & 737823 & 4.8 & 5.25 & TRN & \\
\hline CHEMBL1319195 & 737823 & 4.9 & 5.3466 & TRN & \\
\hline CHEMBL1553136 & 737823 & 5.5 & 5.7194 & TRN & \\
\hline CHEMBL1443393 & 737823 & 6.2 & 5.6276 & TRN & \\
\hline CHEMBL 9843 & 737823 & 5.5 & 5.5608 & TRN & \\
\hline CHEMBL1498977 & 737823 & 4.95 & 5.2728 & TRN & \\
\hline CHEMBL1349528 & 737823 & 6.2 & 5.3834 & TRN & \\
\hline CHEMBL1374334 & 737823 & 7.1 & 5.4201 & TST & \\
\hline CHEMBL1488845 & 737823 & 4.8 & 5.0397 & TST & \\
\hline CHEMBL1424371 & 737823 & 5.05 & 5.5154 & TST & \\
\hline CHEMBL1353281 & 737823 & 5.2 & 4.8628 & TRN & \\
\hline CHEMBL1574504 & 737823 & 5.85 & 5.678 & TRN & \\
\hline CHEMBL1521352 & 737823 & 4.85 & 5.131 & TRN & \\
\hline CHEMBL1557841 & 737823 & 5.0 & 5.5791 & TRN & \\
\hline CHEMBL1470247 & 737823 & 5.9 & 5.231 & TRN & \\
\hline CHEMBL1571883 & 737823 & 5.9 & 5.5959 & TRN & \\
\hline CHEMBL1317712 & 737823 & 5.1 & 4.5237 & TRN & \\
\hline CHEMBL1496722 & 737823 & 6.75 & 5.5669 & TRN & \\
\hline CHEMBL1470037 & 737823 & 6.75 & 5.5133 & TST & \\
\hline CHEMBL1326359 & 737823 & 6.0 & 5.4303 & TRN & \\
\hline CHEMBL1390245 & 737823 & 4.85 & 5.7304 & TST & \\
\hline CHEMBL1334465 & 737823 & 6.9 & 5.7487 & TRN & \\
\hline
\end{tabular}




\begin{tabular}{|c|c|c|c|c|c|}
\hline \multirow[b]{2}{*}{ CHEMBL1387585 } & \multirow{2}{*}{737823} & \multicolumn{4}{|c|}{ at lable se } \\
\hline & & 4.8 & 5.2336 & TST & \\
\hline CHEMBL1474151 & 737823 & 4.8 & \multicolumn{2}{|c|}{5.617999999999999} & TRN \\
\hline CHEMBL1368681 & 737823 & 5.1 & 5.8229 & TRN & \\
\hline CHEMBL1434895 & 737823 & 5.3 & 4.8599 & TRN & \\
\hline CHEMBL1485865 & 737823 & 4.6 & 5.0665 & TST & \\
\hline CHEMBL1553185 & 737823 & 5.1 & 5.7848 & TRN & \\
\hline CHEMBL1447682 & 737823 & 5.85 & \multicolumn{2}{|c|}{5.297999999999999} & TRN \\
\hline CHEMBL1473834 & 737823 & 6.2 & 5.5421 & TRN & \\
\hline CHEMBL1437281 & 737823 & 5.1 & 4.6047 & TRN & \\
\hline CHEMBL1340579 & 737823 & 5.65 & 5.7668 & TRN & \\
\hline CHEMBL1595037 & 737823 & 5.75 & 5.806 & TST & \\
\hline CHEMBL1593707 & 737823 & 4.9 & 5.078 & TRN & \\
\hline CHEMBL1522136 & 737823 & 5.3 & 5.2027 & TRN & \\
\hline CHEMBL1418803 & 737823 & 4.95 & 5.1358 & TRN & \\
\hline CHEMBL1398580 & 737823 & 5.3 & 5.2865 & TRN & \\
\hline CHEMBL47940 & 737823 & 4.8 & 5.0579 & TRN & \\
\hline CHEMBL1350071 & 737823 & 5.5 & 5.3252 & TRN & \\
\hline CHEMBL1486399 & 737823 & 5.7 & 5.1591 & TRN & \\
\hline CHEMBL1610687 & 737823 & 5.1 & 5.7163 & TST & \\
\hline CHEMBL20730 & 737823 & 4.9 & 5.0609 & TRN & \\
\hline CHEMBL1492946 & 737823 & 6.0 & 5.61 & TRN & \\
\hline CHEMBL1439063 & 737823 & 5.5 & 5.3721 & TRN & \\
\hline CHEMBL1573935 & 737823 & 5.3 & 5.0688 & TRN & \\
\hline CHEMBL1590639 & 737823 & 4.6 & 4.837 & TRN & \\
\hline CHEMBL1372404 & 737823 & 6.5 & 5.4378 & TRN & \\
\hline CHEMBL1356242 & 737823 & 4.4 & 5.1536 & TRN & \\
\hline CHEMBL1462914 & 737823 & 5.4 & 5.3885 & TRN & \\
\hline CHEMBL1591992 & 737823 & 5.8 & \multicolumn{2}{|c|}{5.292999999999999} & TRN \\
\hline CHEMBL1551051 & 737823 & 6.4 & 5.7984 & TRN & \\
\hline CHEMBL1256797 & 737823 & 4.5 & 4.9495 & TRN & \\
\hline CHEMBL1398931 & 737823 & 5.5 & 5.4189 & TRN & \\
\hline CHEMBL1584932 & 737823 & 5.2 & 4.9194 & TRN & \\
\hline CHEMBL1437159 & 737823 & 5.6 & 5.6072 & TRN & \\
\hline CHEMBL1356196 & 737823 & 4.6 & 4.6211 & TRN & \\
\hline CHEMBL1410759 & 737823 & 6.0 & 5.5124 & TST & \\
\hline CHEMBL1591336 & 737823 & 4.9 & 5.2982 & TRN & \\
\hline CHEMBL1601589 & 737823 & 5.35 & 5.4087 & TRN & \\
\hline CHEMBL1460432 & 737823 & 5.6 & 5.4421 & TRN & \\
\hline CHEMBL1542131 & 737823 & 4.9 & 5.4403 & TRN & \\
\hline CHEMBL1420005 & 737823 & 4.5 & 5.2801 & TRN & \\
\hline CHEMBL1331913 & 737823 & 6.3 & 5.722 & TRN & \\
\hline CHEMBL1515417 & 737823 & 5.6 & 5.7707 & TRN & \\
\hline CHEMBL1611012 & 737823 & 6.9 & 5.4106 & TRN & \\
\hline CHEMBL1358297 & 737823 & 4.9 & 4.5649 & TST & \\
\hline CHEMBL171064 & 737823 & 4.4 & 4.9315 & TST & \\
\hline CHEMBL1452722 & 737823 & 6.1 & 5.7514 & TRN & \\
\hline CHEMBL67212 & 737823 & 5.9 & 5.8364 & TRN & \\
\hline \multirow[t]{2}{*}{ CHEMBL60859 } & 737823 & 4.5 & 4.9335 & TST & \\
\hline & & \multicolumn{4}{|c|}{ Page 3355} \\
\hline
\end{tabular}




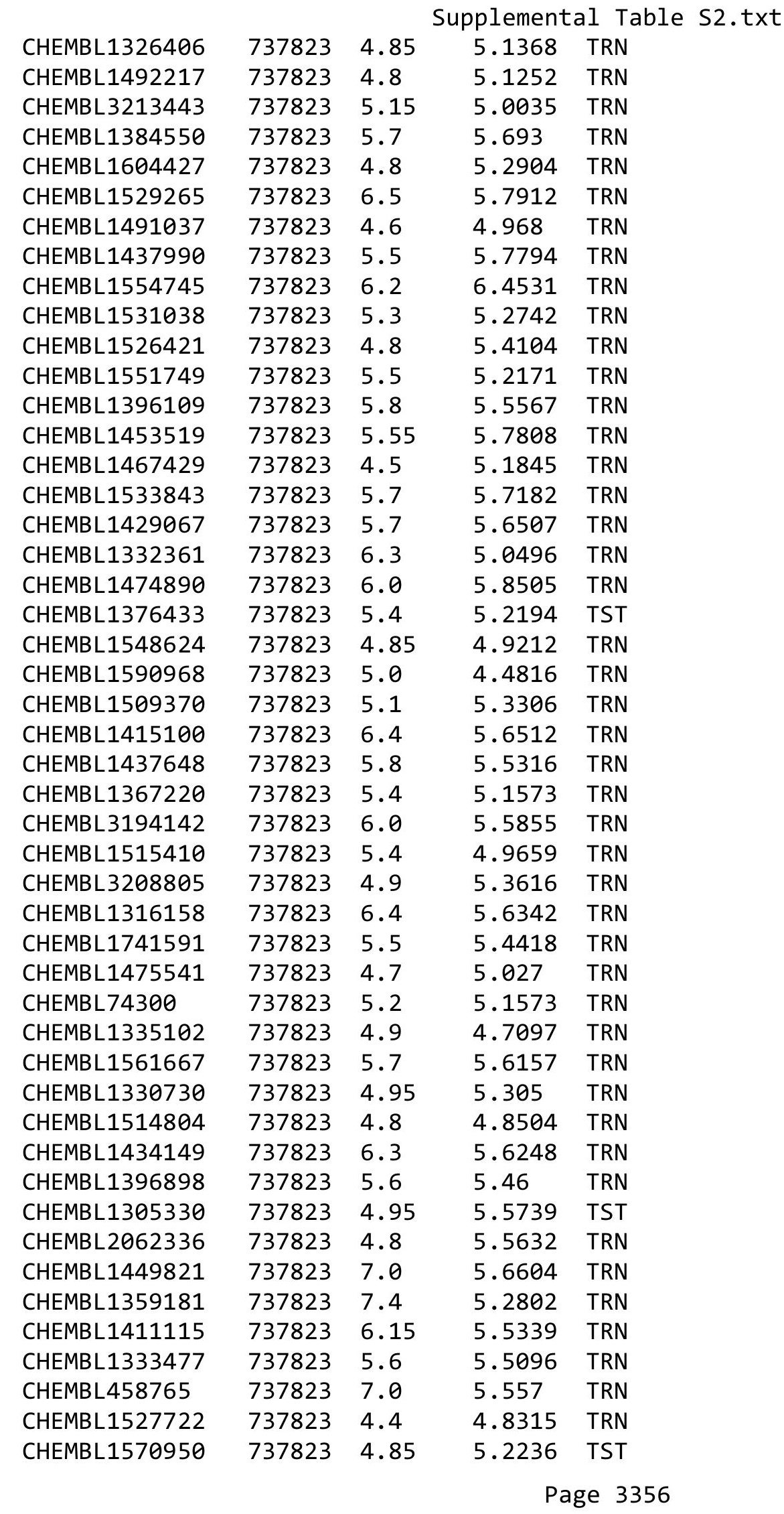




\begin{tabular}{|c|c|c|c|c|c|}
\hline \multicolumn{6}{|c|}{ Supplemental Table S2.txt } \\
\hline CHEMBL3197172 & 737823 & 5.45 & 4.8778 & TRN & \\
\hline CHEMBL1515287 & 737823 & 4.8 & 5.2401 & TRN & \\
\hline CHEMBL1312616 & 737823 & 5.2 & 5.3918 & TRN & \\
\hline CHEMBL1515829 & 737823 & 4.9 & 5.1233 & TRN & \\
\hline CHEMBL1591503 & 737823 & 4.6 & 4.9761 & TRN & \\
\hline CHEMBL3196659 & 737823 & 5.0 & 5.1978 & TRN & \\
\hline CHEMBL1358628 & 737823 & 4.6 & 5.1018 & TST & \\
\hline CHEMBL3210395 & 737823 & 5.4 & 5.4346 & TRN & \\
\hline CHEMBL1360740 & 737823 & 4.9 & 4.7526 & TRN & \\
\hline CHEMBL1390586 & 737823 & 4.65 & 4.9848 & TRN & \\
\hline CHEMBL 3192627 & 737823 & 5.1 & 5.4178 & TRN & \\
\hline CHEMBL1574915 & 737823 & 6.15 & 5.7738 & TRN & \\
\hline CHEMBL164269 & 737823 & 5.5 & 5.5309 & TRN & \\
\hline CHEMBL 3198587 & 737823 & 5.65 & 5.2816 & TRN & \\
\hline CHEMBL1459606 & 737823 & 4.95 & 5.3043 & TRN & \\
\hline CHEMBL1569583 & 737823 & 5.4 & 5.3747 & TRN & \\
\hline CHEMBL 74121 & 737823 & 4.5 & 5.1302 & TST & \\
\hline CHEMBL1388994 & 737823 & 4.5 & 4.95100 & 00000000005 & TRN \\
\hline CHEMBL1361656 & 737823 & 6.8 & 6.2695 & TRN & \\
\hline CHEMBL1594612 & 737823 & 6.5 & 6.3212 & TRN & \\
\hline CHEMBL1512740 & 737823 & 6.7 & 6.0447 & TRN & \\
\hline CHEMBL1553034 & 737823 & 4.8 & 4.5505 & TRN & \\
\hline CHEMBL1607512 & 737823 & 5.25 & 5.5237 & TRN & \\
\hline CHEMBL1602117 & 737823 & 4.85 & 5.1067 & TRN & \\
\hline CHEMBL3197636 & 737823 & 4.6 & 5.0501 & TRN & \\
\hline CHEMBL1485976 & 737823 & 5.4 & 5.1895 & TRN & \\
\hline CHEMBL1975888 & 737823 & 5.7 & 5.6032 & TRN & \\
\hline CHEMBL1449856 & 737823 & 4.9 & 5.0201 & TRN & \\
\hline CHEMBL1588955 & 737823 & 5.9 & 5.5509 & TRN & \\
\hline CHEMBL1578193 & 737823 & 4.8 & 5.379 & TST & \\
\hline CHEMBL1454793 & 737823 & 4.9 & 5.0001 & TRN & \\
\hline CHEMBL1360026 & 737823 & 5.35 & 5.3452 & TRN & \\
\hline CHEMBL1323714 & 737823 & 6.2 & 5.2288 & TRN & \\
\hline CHEMBL1515698 & 737823 & 5.7 & 5.2802 & TRN & \\
\hline CHEMBL 3193293 & 737823 & 5.2 & 4.8582 & TST & \\
\hline CHEMBL1370314 & 737823 & 8.2 & 5.0495 & TRN & \\
\hline CHEMBL1571705 & 737823 & 5.5 & 5.5729 & TRN & \\
\hline CHEMBL534084 & 737823 & 6.0 & 5.3105 & TRN & \\
\hline CHEMBL1200462 & 737823 & 6.0 & 5.2591 & TST & \\
\hline CHEMBL1490786 & 737823 & 4.6 & 4.5865 & TRN & \\
\hline CHEMBL1324697 & 737823 & 4.6 & 4.9473 & TST & \\
\hline CHEMBL421215 & 737823 & 6.1 & 6.4237 & TST & \\
\hline CHEMBL1589340 & 737823 & 5.05 & 5.4439 & TRN & \\
\hline CHEMBL1391723 & 737823 & 4.8 & 5.027 & TRN & \\
\hline CHEMBL1311139 & 737823 & 4.8 & 4.8516 & TRN & \\
\hline CHEMBL1526358 & 737823 & 5.4 & 4.8371 & TST & \\
\hline CHEMBL1403809 & 737823 & 4.7 & 4.7862 & TRN & \\
\hline CHEMBL1316944 & 737823 & 5.3 & 5.2929 & TRN & \\
\hline
\end{tabular}




\begin{tabular}{|c|c|c|c|c|c|}
\hline \\
\hline CHEMBL1449042 & 737823 & 5.0 & 5.0236 & TRN & \\
\hline CHEMBL1512988 & 737823 & 6.0 & 5.3843 & TRN & \\
\hline CHEMBL1385673 & 737823 & 5.4 & 5.0074 & TST & \\
\hline CHEMBL1609209 & 737823 & 4.9 & 5.3176 & TRN & \\
\hline CHEMBL1601285 & 737823 & 5.85 & 5.3391 & TRN & \\
\hline CHEMBL1330388 & 737823 & 5.4 & 5.6912 & TST & \\
\hline CHEMBL1373948 & 737823 & 5.7 & 5.0772 & TRN & \\
\hline CHEMBL1312774 & 737823 & 4.6 & 4.7316 & TRN & \\
\hline CHEMBL111545 & 737823 & 5.0 & 5.4665 & TST & \\
\hline CHEMBL1452398 & 737823 & 5.45 & 5.2269 & TRN & \\
\hline CHEMBL1424249 & 737823 & 4.4 & 5.8092 & TST & \\
\hline CHEMBL1355263 & 737823 & 4.8 & 4.6576 & TRN & \\
\hline CHEMBL1504240 & 737823 & 4.6 & 5.3045 & TRN & \\
\hline CHEMBL1467491 & 737823 & 6.05 & 5.359 & TRN & \\
\hline CHEMBL3193407 & 737823 & 5.3 & 5.0659 & TRN & \\
\hline CHEMBL1327772 & 737823 & 5.8 & 5.9652 & TRN & \\
\hline CHEMBL1593375 & 737823 & 5.1 & 5.2082 & TRN & \\
\hline CHEMBL1213187 & 737823 & 4.4 & 5.1313 & TST & \\
\hline CHEMBL1394520 & 737823 & 5.0 & 5.2097 & TRN & \\
\hline CHEMBL1440715 & 737823 & 5.1 & 5.5134 & TRN & \\
\hline CHEMBL1434369 & 737823 & 4.9 & 4.8272 & TRN & \\
\hline CHEMBL1602549 & 737823 & 5.9 & 5.1793 & TST & \\
\hline CHEMBL1256746 & 737823 & 4.6 & 5.1474 & TRN & \\
\hline CHEMBL1461759 & 737823 & 4.75 & 4.9605 & TRN & \\
\hline CHEMBL1417125 & 737823 & 4.85 & 5.9059 & TRN & \\
\hline CHEMBL3208526 & 737823 & 4.9 & 5.3279 & TRN & \\
\hline CHEMBL1478279 & 737823 & 4.8 & 4.4883 & TRN & \\
\hline CHEMBL1596088 & 737823 & 5.7 & 5.6906 & TRN & \\
\hline CHEMBL1741480 & 737823 & 4.9 & 5.1518 & TRN & \\
\hline CHEMBL1475685 & 737823 & 4.5 & 4.5992 & TRN & \\
\hline CHEMBL1519435 & 737823 & 6.1 & 6.16700 & 0000000001 & TRN \\
\hline CHEMBL1325879 & 737823 & 5.2 & 5.4284 & TRN & \\
\hline CHEMBL1440867 & 737823 & 4.9 & 4.7977 & TRN & \\
\hline CHEMBL1595377 & 737823 & 5.6 & 5.4748 & TRN & \\
\hline CHEMBL1159900 & 737823 & 4.5 & 5.0561 & TRN & \\
\hline CHEMBL1499209 & 737823 & 4.6 & 5.471 & TST & \\
\hline CHEMBL3212717 & 737823 & 4.8 & 5.1688 & TRN & \\
\hline CHEMBL3209986 & 737823 & 5.8 & 5.3723 & TRN & \\
\hline CHEMBL285932 & 737823 & 4.8 & 5.3927 & TST & \\
\hline CHEMBL1611449 & 737823 & 5.0 & 5.3738 & TRN & \\
\hline CHEMBL1357857 & 737823 & 5.3 & 5.2985 & TRN & \\
\hline CHEMBL1403333 & 737823 & 6.4 & 5.5634 & TRN & \\
\hline CHEMBL1318668 & 737823 & 5.2 & 5.3036 & TRN & \\
\hline CHEMBL482116 & 737823 & 5.55 & 5.2477 & TRN & \\
\hline CHEMBL261011 & 737823 & 4.8 & 4.8172 & TST & \\
\hline CHEMBL1514375 & 737823 & 4.5 & 5.0225 & TST & \\
\hline CHEMBL1545634 & 737823 & 5.4 & 6.1222 & TST & \\
\hline CHEMBL1514143 & 737823 & 5.2 & 5.0043 & TRN & \\
\hline
\end{tabular}




\begin{tabular}{|c|c|c|c|c|c|}
\hline & & & ipplement & al Table S2 & \\
\hline CHEMBL1605237 & 737823 & 4.85 & 4.8491 & TRN & \\
\hline CHEMBL284028 & 737823 & 5.3 & 5.50700 & 0000000001 & TRN \\
\hline CHEMBL3211204 & 737823 & 5.05 & 5.8633 & TRN & \\
\hline CHEMBL1372282 & 737823 & 6.0 & 6.274 & TST & \\
\hline CHEMBL1306876 & 737823 & 5.2 & 5.2159 & TST & \\
\hline CHEMBL1536668 & 737823 & 4.9 & 5.2412 & TRN & \\
\hline CHEMBL1576865 & 737823 & 4.75 & 5.284 & TRN & \\
\hline CHEMBL1472011 & 737823 & 4.85 & 5.1687 & TRN & \\
\hline CHEMBL1602710 & 737823 & 4.8 & 5.3778 & TRN & \\
\hline CHEMBL1529327 & 737823 & 6.45 & 5.479 & TRN & \\
\hline CHEMBL3190415 & 737823 & 5.3 & 5.34399 & 9999999999 & TRN \\
\hline CHEMBL1717253 & 737823 & 4.6 & 4.995 & TRN & \\
\hline CHEMBL352396 & 737823 & 4.4 & 4.664 & TST & \\
\hline CHEMBL1326093 & 737823 & 5.5 & 5.4732 & TRN & \\
\hline CHEMBL1575531 & 737823 & 5.35 & 5.294 & TRN & \\
\hline CHEMBL1256760 & 737823 & 4.6 & 4.6796 & TST & \\
\hline CHEMBL1471546 & 737823 & 5.35 & 5.4232 & TST & \\
\hline CHEMBL3190213 & 737823 & 4.7 & 5.4913 & TRN & \\
\hline CHEMBL1417002 & 737823 & 4.85 & 5.2439 & TRN & \\
\hline CHEMBL1380396 & 737823 & 6.5 & 6.07299 & 99999999995 & TRN \\
\hline CHEMBL 3211784 & 737823 & 5.1 & 5.0825 & TRN & \\
\hline CHEMBL1391744 & 737823 & 5.0 & 5.5866 & TRN & \\
\hline CHEMBL1964667 & 737823 & 5.7 & 5.8912 & TRN & \\
\hline CHEMBL1539526 & 737823 & 4.9 & 5.7898 & TST & \\
\hline CHEMBL1406491 & 737823 & 5.4 & 5.5941 & TST & \\
\hline CHEMBL1399489 & 737823 & 5.1 & 5.0485 & TRN & \\
\hline CHEMBL1604914 & 737823 & 5.4 & 5.7295 & TRN & \\
\hline CHEMBL1423135 & 737823 & 5.5 & 5.9827 & TRN & \\
\hline CHEMBL1598462 & 737823 & 5.5 & 4.9307 & TRN & \\
\hline CHEMBL1578591 & 737823 & 4.9 & 4.9912 & TST & \\
\hline CHEMBL1376629 & 737823 & 4.7 & 5.0258 & TRN & \\
\hline CHEMBL1473965 & 737823 & 5.7 & 5.36 & TRN & \\
\hline CHEMBL1742374 & 737823 & 5.6 & 5.808 & TRN & \\
\hline CHEMBL1514071 & 737823 & 6.2 & 6.3867 & TRN & \\
\hline CHEMBL1378132 & 737823 & 5.0 & 4.7487 & TRN & \\
\hline CHEMBL1525571 & 737823 & 5.35 & 5.1189 & TRN & \\
\hline CHEMBL1407857 & 737823 & 5.9 & 5.4832 & TRN & \\
\hline CHEMBL1358810 & 737823 & 5.5 & 5.3785 & TRN & \\
\hline CHEMBL1587467 & 737823 & 5.65 & 5.5565 & TRN & \\
\hline CHEMBL1409292 & 737823 & 4.65 & 5.14 & TRN & \\
\hline CHEMBL258405 & 737823 & 4.5 & 5.405 & TST & \\
\hline CHEMBL1428519 & 737823 & 5.95 & 5.5367 & TRN & \\
\hline CHEMBL1580384 & 737823 & 4.8 & 5.0223 & TRN & \\
\hline CHEMBL598952 & 737823 & 5.6 & 5.21 & TST & \\
\hline CHEMBL1404803 & 737823 & 5.3 & 5.3638 & TRN & \\
\hline CHEMBL1256173 & 737823 & 5.5 & 5.09699 & 99999999995 & TRN \\
\hline CHEMBL1361500 & 737823 & 5.7 & 5.4896 & TRN & \\
\hline CHEMBL275006 & 737823 & 4.5 & 5.3282 & TST & \\
\hline
\end{tabular}




\begin{tabular}{|c|c|c|c|c|c|}
\hline & & & & & \\
\hline CHEMBL1523594 & 737823 & 6.2 & 5.4412 & TRN & \\
\hline CHEMBL1452221 & 737823 & 4.6 & 4.9533 & TRN & \\
\hline CHEMBL1380069 & 737823 & 4.9 & 5.5727 & TRN & \\
\hline CHEMBL1590259 & 737823 & 4.9 & 5.1565 & TRN & \\
\hline CHEMBL1571639 & 737823 & 6.0 & 5.9848 & TRN & \\
\hline CHEMBL1603047 & 737823 & 6.65 & 6.2705 & TRN & \\
\hline CHEMBL1570633 & 737823 & 6.2 & 5.7741 & TRN & \\
\hline CHEMBL1559362 & 737823 & 6.85 & 5.5607 & TRN & \\
\hline CHEMBL122270 & 737823 & 6.0 & 4.3441 & TRN & \\
\hline CHEMBL1524401 & 737823 & 4.7 & 5.32799 & 9999999999 & TRN \\
\hline CHEMBL1362872 & 737823 & 5.35 & 5.51 & TRN & \\
\hline CHEMBL1417503 & 737823 & 4.4 & 5.4893 & TST & \\
\hline CHEMBL1508431 & 737823 & 4.85 & 6.0449 & TST & \\
\hline CHEMBL77387 & 737823 & 4.5 & 5.6167 & TRN & \\
\hline CHEMBL1351254 & 737823 & 4.8 & 5.1998 & TRN & \\
\hline CHEMBL1561888 & 737823 & 4.6 & 5.1125 & TRN & \\
\hline CHEMBL1323164 & 737823 & 5.3 & 4.8872 & TRN & \\
\hline CHEMBL1360725 & 737823 & 4.4 & 4.9046 & TST & \\
\hline CHEMBL1529478 & 737823 & 5.7 & 5.8664 & TRN & \\
\hline CHEMBL1584779 & 737823 & 5.95 & 5.7499 & TRN & \\
\hline CHEMBL1582419 & 737823 & 4.7 & 5.0418 & TRN & \\
\hline CHEMBL1470632 & 737823 & 4.85 & 5.0487 & TRN & \\
\hline CHEMBL1376927 & 737823 & 5.4 & 5.4371 & TRN & \\
\hline CHEMBL1313121 & 737823 & 6.8 & 5.5551 & TRN & \\
\hline CHEMBL1441408 & 737823 & 4.85 & 5.2 & TST & \\
\hline CHEMBL1514465 & 737823 & 4.9 & 5.6222 & TRN & \\
\hline CHEMBL1323488 & 737823 & 4.8 & 4.574 & TRN & \\
\hline CHEMBL522311 & 737823 & 5.3 & 5.4706 & TRN & \\
\hline CHEMBL1302492 & 737823 & 4.85 & 5.1582 & TRN & \\
\hline CHEMBL1517718 & 737823 & 6.0 & 5.5725 & TRN & \\
\hline CHEMBL1523557 & 737823 & 5.0 & 5.2712 & TRN & \\
\hline CHEMBL1463824 & 737823 & 5.2 & 4.9599 & TRN & \\
\hline CHEMBL33103 & 737823 & 4.8 & 4.9682 & TRN & \\
\hline CHEMBL1583880 & 737823 & 5.1 & 4.77 & TRN & \\
\hline CHEMBL1312952 & 737823 & 5.4 & 5.4741 & TRN & \\
\hline CHEMBL1473123 & 737823 & 6.0 & 5.3391 & TRN & \\
\hline CHEMBL1590038 & 737823 & 4.8 & 4.8438 & TRN & \\
\hline CHEMBL1517584 & 737823 & 5.15 & 5.2334 & TRN & \\
\hline CHEMBL1331351 & 737823 & 6.1 & 5.4564 & TRN & \\
\hline CHEMBL1319426 & 737823 & 4.95 & 5.8186 & TRN & \\
\hline CHEMBL1450919 & 737823 & 5.9 & 5.4741 & TRN & \\
\hline CHEMBL1403554 & 737823 & 5.4 & 5.9606 & TRN & \\
\hline CHEMBL1320469 & 737823 & 6.3 & 6.2714 & TRN & \\
\hline CHEMBL1473317 & 737823 & 6.2 & 5.6973 & TRN & \\
\hline CHEMBL1434006 & 737823 & 5.2 & 5.2782 & TRN & \\
\hline CHEMBL1342307 & 737823 & 4.9 & 4.7364 & TRN & \\
\hline CHEMBL1510205 & 737823 & 4.9 & 5.0308 & TRN & \\
\hline CHEMBL1457730 & 737823 & 4.65 & 4.578 & TST & \\
\hline
\end{tabular}




\begin{tabular}{|c|c|c|c|c|}
\hline & & & & \\
\hline CHEMBL 2374062 & 737823 & 4.4 & 5.0488 & TST \\
\hline CHEMBL1534512 & 737823 & 5.8 & 4.6927 & TRN \\
\hline CHEMBL1741943 & 737823 & 4.9 & 5.1227 & TRN \\
\hline CHEMBL1329033 & 737823 & 5.0 & 5.1904 & TST \\
\hline CHEMBL1354751 & 737823 & 4.8 & 5.0053 & TRN \\
\hline CHEMBL1430202 & 737823 & 7.0 & 5.6611 & TRN \\
\hline CHEMBL1554411 & 737823 & 5.8 & 5.5795 & TRN \\
\hline CHEMBL1483257 & 737823 & 5.1 & 5.0027 & TRN \\
\hline CHEMBL1415957 & 737823 & 5.0 & 5.2325 & TRN \\
\hline CHEMBL1567159 & 737823 & 4.85 & 5.6 & TRN \\
\hline CHEMBL1485948 & 737823 & 4.75 & 5.2598 & TRN \\
\hline CHEMBL1512742 & 737823 & 6.1 & 5.3976 & TST \\
\hline CHEMBL1467630 & 737823 & 4.95 & 5.0381 & TRN \\
\hline CHEMBL1257123 & 737823 & 5.1 & 5.2379 & TRN \\
\hline CHEMBL 256835 & 737823 & 4.5 & 5.8096 & TRN \\
\hline CHEMBL1327459 & 737823 & 6.2 & 4.985 & TRN \\
\hline CHEMBL523167 & 737823 & 4.8 & 4.6403 & TRN \\
\hline CHEMBL1544498 & 737823 & 5.4 & 5.4896 & TRN \\
\hline CHEMBL3211292 & 737823 & 5.55 & 5.4874 & TRN \\
\hline CHEMBL1404598 & 737823 & 5.3 & 5.6819 & TRN \\
\hline CHEMBL294590 & 737823 & 4.7 & 5.7376 & TRN \\
\hline CHEMBL1327708 & 737823 & 5.4 & 4.935 & TRN \\
\hline CHEMBL1559990 & 737823 & 5.3 & 5.3155 & TRN \\
\hline CHEMBL 3212828 & 737823 & 4.6 & 5.1041 & TRN \\
\hline CHEMBL1409758 & 737823 & 5.4 & 5.6074 & TRN \\
\hline CHEMBL1399058 & 737823 & 4.8 & 5.2113 & TRN \\
\hline CHEMBL1449707 & 737823 & 6.1 & 5.6979 & TRN \\
\hline CHEMBL1307309 & 737823 & 4.7 & 4.9689 & TRN \\
\hline CHEMBL1355783 & 737823 & 6.7 & 5.8184 & TST \\
\hline CHEMBL1374456 & 737823 & 5.8 & 5.1331 & TRN \\
\hline CHEMBL1607650 & 737823 & 5.2 & 5.3956 & TST \\
\hline CHEMBL1547564 & 737823 & 5.2 & 5.0946 & TRN \\
\hline CHEMBL1351544 & 737823 & 5.6 & 5.7665 & TST \\
\hline CHEMBL1982394 & 737823 & 5.4 & 4.9915 & TRN \\
\hline CHEMBL1314453 & 737823 & 4.8 & 4.7295 & TRN \\
\hline CHEMBL1563566 & 737823 & 5.6 & 6.0114 & TRN \\
\hline CHEMBL1553218 & 737823 & 5.4 & 5.6362 & TRN \\
\hline CHEMBL1479741 & 737823 & 6.2 & 6.0672 & TRN \\
\hline CHEMBL1477727 & 737823 & 4.8 & 5.0088 & TRN \\
\hline CHEMBL 1357553 & 737823 & 5.4 & 6.0219 & TRN \\
\hline CHEMBL1602770 & 737823 & 6.1 & 4.8236 & TRN \\
\hline CHEMBL1370029 & 737823 & 4.9 & 5.0381 & TRN \\
\hline CHEMBL1517696 & 737823 & 4.55 & 4.9805 & TRN \\
\hline CHEMBL1568805 & 737823 & 4.9 & 5.476 & TRN \\
\hline CHEMBL1349471 & 737823 & 5.3 & 5.3907 & TRN \\
\hline CHEMBL1467631 & 737823 & 4.85 & 5.2581 & TRN \\
\hline CHEMBL1507026 & 737823 & 4.85 & 4.8396 & TRN \\
\hline CHEMBL1735211 & 737823 & 4.4 & 5.3263 & TRN \\
\hline
\end{tabular}




\begin{tabular}{|c|c|c|c|c|c|}
\hline \multicolumn{6}{|c|}{ Supplemental Table S2.txt } \\
\hline CHEMBL1595363 & 737823 & 5.75 & 5.2856 & TRN & \\
\hline CHEMBL1699751 & 737823 & 4.6 & 5.2634 & TRN & \\
\hline CHEMBL1475255 & 737823 & 6.5 & 7.0703 & TRN & \\
\hline CHEMBL1429915 & 737823 & 4.6 & 5.1949 & TRN & \\
\hline CHEMBL1503178 & 737823 & 5.0 & 4.8754 & TRN & \\
\hline CHEMBL1374043 & 737823 & 5.2 & 5.0814 & TRN & \\
\hline CHEMBL1421107 & 737823 & 4.95 & 5.744 & TRN & \\
\hline CHEMBL1311630 & 737823 & 5.95 & \multicolumn{2}{|c|}{5.867999999999999} & TRN \\
\hline CHEMBL1430657 & 737823 & 5.2 & 4.8424 & TRN & \\
\hline CHEMBL1498495 & 737823 & 4.4 & 4.7186 & TRN & \\
\hline CHEMBL3193159 & 737823 & 5.3 & 4.7835 & TRN & \\
\hline CHEMBL1580108 & 737823 & 5.8 & 5.2607 & TRN & \\
\hline CHEMBL1532878 & 737823 & 5.55 & 5.5929 & TRN & \\
\hline CHEMBL1358583 & 737823 & 4.9 & 4.8921 & TRN & \\
\hline CHEMBL1496571 & 737823 & 4.7 & 5.2997 & TRN & \\
\hline CHEMBL1987514 & 737823 & 4.8 & 5.4463 & TRN & \\
\hline CHEMBL1540956 & 737823 & 5.35 & 5.1657 & TRN & \\
\hline CHEMBL1429056 & 737823 & 4.4 & 5.1166 & TST & \\
\hline CHEMBL1369940 & 737823 & 5.5 & 5.1156 & TRN & \\
\hline CHEMBL1304696 & 737823 & 6.1 & 5.4382 & TRN & \\
\hline CHEMBL1328324 & 737823 & 5.4 & 4.8751 & TST & \\
\hline CHEMBL1400667 & 737823 & 4.7 & 4.9871 & TST & \\
\hline CHEMBL1406944 & 737823 & 4.65 & 5.3462 & TRN & \\
\hline CHEMBL1374810 & 737823 & 6.3 & 5.5718 & TRN & \\
\hline CHEMBL1407257 & 737823 & 6.1 & 5.9021 & TRN & \\
\hline CHEMBL416657 & 737823 & 4.6 & 5.0169 & TRN & \\
\hline CHEMBL3194695 & 737823 & 5.6 & 4.5906 & TRN & \\
\hline CHEMBL41680 & 737823 & 4.5 & 5.2919 & TST & \\
\hline CHEMBL1461075 & 737823 & 5.7 & 5.0802 & TRN & \\
\hline CHEMBL1384675 & 737823 & 5.5 & 5.348 & TRN & \\
\hline CHEMBL3190658 & 737823 & 4.9 & 5.4816 & TRN & \\
\hline CHEMBL1742157 & 737823 & 4.65 & 5.19799 & 99999999995 & TRN \\
\hline CHEMBL3208809 & 737823 & 4.5 & 5.3363 & TRN & \\
\hline CHEMBL1483285 & 737823 & 4.5 & 4.7779 & TRN & \\
\hline CHEMBL1510192 & 737823 & 6.05 & 5.9637 & TRN & \\
\hline CHEMBL1328307 & 737823 & 4.75 & 5.0366 & TST & \\
\hline CHEMBL1557167 & 737823 & 5.2 & 5.4284 & TST & \\
\hline CHEMBL478501 & 737823 & 4.5 & 5.114 & TRN & \\
\hline CHEMBL1440039 & 737823 & 4.95 & 5.2152 & TRN & \\
\hline CHEMBL1432327 & 737823 & 5.3 & 5.3751 & TST & \\
\hline CHEMBL1594648 & 737823 & 4.9 & 5.2304 & TRN & \\
\hline CHEMBL1371781 & 737823 & 4.5 & 4.9191 & TRN & \\
\hline CHEMBL1442173 & 737823 & 4.8 & 4.7513 & TRN & \\
\hline CHEMBL1507563 & 737823 & 4.85 & 4.6739 & TRN & \\
\hline CHEMBL1587759 & 737823 & 4.8 & 5.0781 & TST & \\
\hline CHEMBL1481347 & 737823 & 4.85 & 5.1642 & TST & \\
\hline CHEMBL2003798 & 737823 & 5.05 & 5.4105 & TRN & \\
\hline \multirow[t]{2}{*}{ CHEMBL1626177 } & 737823 & 4.5 & 5.4858 & TST & \\
\hline & & \multicolumn{4}{|c|}{ Page 3362} \\
\hline
\end{tabular}




\begin{tabular}{|c|c|c|c|c|}
\hline & & & pplement & al $\mathrm{Ta}$ \\
\hline CHEMBL1408259 & 737823 & 6.0 & 5.3657 & TRN \\
\hline CHEMBL1328386 & 737823 & 4.8 & 5.1071 & TRN \\
\hline CHEMBL1477247 & 737823 & 5.3 & 5.3112 & TRN \\
\hline CHEMBL1569352 & 737823 & 4.6 & 5.521 & TRN \\
\hline CHEMBL1323270 & 737823 & 4.5 & 4.745 & TRN \\
\hline CHEMBL1344541 & 737823 & 5.1 & 5.5356 & TRN \\
\hline CHEMBL1433052 & 737823 & 4.8 & 4.9775 & TST \\
\hline CHEMBL1593930 & 737823 & 4.6 & 4.8752 & TST \\
\hline CHEMBL1376289 & 737823 & 5.45 & 5.5697 & TRN \\
\hline CHEMBL1552066 & 737823 & 5.4 & 5.166 & TRN \\
\hline CHEMBL1405262 & 737823 & 5.25 & 5.6505 & TRN \\
\hline CHEMBL1481781 & 737823 & 4.8 & 4.6879 & TRN \\
\hline CHEMBL1459758 & 737823 & 4.8 & 4.7338 & TRN \\
\hline CHEMBL1326322 & 737823 & 6.5 & 5.466 & TRN \\
\hline CHEMBL1092376 & 737823 & 4.55 & 5.405 & TRN \\
\hline CHEMBL1371824 & 737823 & 5.5 & 5.5824 & TRN \\
\hline CHEMBL1591374 & 737823 & 4.9 & 5.1883 & TRN \\
\hline CHEMBL1358019 & 737823 & 4.5 & 4.9354 & TRN \\
\hline CHEMBL1425640 & 737823 & 4.85 & 5.5319 & TRN \\
\hline CHEMBL44 & 737823 & 5.3 & 5.709 & TRN \\
\hline CHEMBL1379481 & 737823 & 5.45 & 5.3555 & TRN \\
\hline CHEMBL521970 & 737823 & 6.1 & 5.8004 & TRN \\
\hline CHEMBL1429162 & 737823 & 4.8 & 5.2827 & TRN \\
\hline CHEMBL1461471 & 737823 & 4.6 & 4.8679 & TST \\
\hline CHEMBL8260 & 737823 & 6.3 & 5.6686 & TRN \\
\hline CHEMBL1536844 & 737823 & 6.0 & 5.0858 & TST \\
\hline CHEMBL1597366 & 737823 & 4.8 & 4.7459 & TRN \\
\hline CHEMBL1529774 & 737823 & 4.85 & 4.9137 & TRN \\
\hline CHEMBL1320948 & 737823 & 5.1 & 5.1924 & TRN \\
\hline CHEMBL1352528 & 737823 & 5.8 & 5.4074 & TRN \\
\hline CHEMBL1437690 & 737823 & 4.6 & 5.3215 & TRN \\
\hline CHEMBL1355644 & 737823 & 7.1 & 6.5879 & TRN \\
\hline CHEMBL1365701 & 737823 & 6.0 & 5.9374 & TRN \\
\hline CHEMBL 296586 & 737823 & 6.8 & 6.0383 & TST \\
\hline CHEMBL1351229 & 737823 & 5.5 & 5.6465 & TRN \\
\hline CHEMBL1479131 & 737823 & 5.5 & 5.0943 & TRN \\
\hline CHEMBL1607419 & 737823 & 4.85 & 5.3893 & TRN \\
\hline CHEMBL1425715 & 737823 & 5.35 & 5.6169 & TRN \\
\hline CHEMBL1597105 & 737823 & 4.5 & 5.0359 & TST \\
\hline CHEMBL1333410 & 737823 & 5.35 & 5.7593 & TRN \\
\hline CHEMBL1330954 & 737823 & 5.55 & 4.9487 & TRN \\
\hline CHEMBL1742382 & 737823 & 4.9 & 4.5815 & TRN \\
\hline CHEMBL1319691 & 737823 & 4.85 & 5.4726 & TRN \\
\hline CHEMBL1329110 & 737823 & 6.0 & 5.2193 & TRN \\
\hline CHEMBL1576355 & 737823 & 4.65 & 5.2272 & TST \\
\hline CHEMBL1447143 & 737823 & 5.1 & 5.3634 & TRN \\
\hline CHEMBL1427572 & 737823 & 5.7 & 5.0411 & TRN \\
\hline CHEMBL1375424 & 737823 & 6.55 & 5.4352 & TRN \\
\hline
\end{tabular}




\begin{tabular}{|c|c|c|c|c|c|}
\hline \\
\hline CHEMBL1400773 & 737823 & 5.3 & 4.9354 & TRN & \\
\hline CHEMBL 1442380 & 737823 & 5.4 & 4.9329 & TRN & \\
\hline CHEMBL1395527 & 737823 & 4.9 & 4.9519 & TRN & \\
\hline CHEMBL1487236 & 737823 & 4.55 & 5.2636 & TRN & \\
\hline CHEMBL1305322 & 737823 & 5.6 & 5.5222 & TRN & \\
\hline CHEMBL1348883 & 737823 & 4.8 & 5.4795 & TRN & \\
\hline CHEMBL1405744 & 737823 & 6.0 & 5.3603 & TRN & \\
\hline CHEMBL1493861 & 737823 & 4.75 & 5.1157 & TRN & \\
\hline CHEMBL1423999 & 737823 & 4.85 & 5.0642 & TRN & \\
\hline CHEMBL1496177 & 737823 & 6.6 & 5.4256 & TRN & \\
\hline CHEMBL3196672 & 737823 & 6.35 & 5.7041 & TRN & \\
\hline CHEMBL1607962 & 737823 & 5.0 & 5.0969 & TRN & \\
\hline CHEMBL15060 & 737823 & 5.9 & 5.1117 & TRN & \\
\hline CHEMBL1565578 & 737823 & 6.0 & 5.4537 & TRN & \\
\hline CHEMBL1587070 & 737823 & 6.0 & 5.7506 & TRN & \\
\hline CHEMBL1512802 & 737823 & 4.6 & 4.9456 & TRN & \\
\hline CHEMBL1480984 & 737823 & 5.0 & 5.3797 & TRN & \\
\hline CHEMBL1527442 & 737823 & 4.8 & 5.29799 & 9999999999 & TST \\
\hline CHEMBL1554348 & 737823 & 5.9 & 5.4339 & TRN & \\
\hline CHEMBL1399313 & 737823 & 5.9 & 5.6734 & TRN & \\
\hline CHEMBL1401073 & 737823 & 4.9 & 5.0353 & TRN & \\
\hline CHEMBL1566217 & 737823 & 4.75 & 5.1397 & TRN & \\
\hline CHEMBL1432284 & 737823 & 5.0 & 4.8493 & TRN & \\
\hline CHEMBL1731078 & 737823 & 5.7 & 5.2653 & TRN & \\
\hline CHEMBL1472955 & 737823 & 6.2 & 5.9412 & TRN & \\
\hline CHEMBL1381787 & 737823 & 5.0 & 5.222 & TRN & \\
\hline CHEMBL1552154 & 737823 & 5.1 & 5.0754 & TRN & \\
\hline CHEMBL1469557 & 737823 & 5.2 & 5.2952 & TRN & \\
\hline CHEMBL1492063 & 737823 & 5.3 & 5.2895 & TRN & \\
\hline CHEMBL1345724 & 737823 & 4.95 & 5.2477 & TRN & \\
\hline CHEMBL1446743 & 737823 & 4.9 & 5.3308 & TST & \\
\hline CHEMBL1718851 & 737823 & 5.05 & 5.5926 & TRN & \\
\hline CHEMBL1527392 & 737823 & 5.35 & 5.1124 & TRN & \\
\hline CHEMBL1604396 & 737823 & 4.7 & 5.4402 & TRN & \\
\hline CHEMBL491578 & 737823 & 5.1 & 5.3977 & TRN & \\
\hline CHEMBL1479340 & 737823 & 4.55 & 5.0616 & TRN & \\
\hline CHEMBL1597343 & 737823 & 5.55 & 5.3313 & TRN & \\
\hline CHEMBL1417491 & 737823 & 4.85 & 5.2526 & TST & \\
\hline CHEMBL1596756 & 737823 & 5.0 & 5.5445 & TRN & \\
\hline CHEMBL1581244 & 737823 & 5.45 & 5.4717 & TRN & \\
\hline CHEMBL1432651 & 737823 & 5.3 & 5.5673 & TRN & \\
\hline CHEMBL1415310 & 737823 & 5.7 & 5.4377 & TRN & \\
\hline CHEMBL1496101 & 737823 & 5.1 & 5.0302 & TRN & \\
\hline CHEMBL1302757 & 737823 & 6.25 & 5.6315 & TRN & \\
\hline CHEMBL1492220 & 737823 & 7.8 & 5.1258 & TRN & \\
\hline CHEMBL 3195544 & 737823 & 6.5 & 5.5823 & TRN & \\
\hline CHEMBL1516068 & 737823 & 4.9 & 5.3693 & TRN & \\
\hline CHEMBL1303328 & 737823 & 4.75 & 5.3604 & TRN & \\
\hline
\end{tabular}




\begin{tabular}{|c|c|c|c|c|}
\hline \multicolumn{5}{|c|}{ Supplemental Table S2.txt } \\
\hline CHEMBL1329109 & 737823 & 4.75 & 4.6782 & TRN \\
\hline CHEMBL1436682 & 737823 & 6.7 & 5.9259 & TRN \\
\hline CHEMBL1334657 & 737823 & 4.8 & 4.6806 & TRN \\
\hline CHEMBL1524520 & 737823 & 6.2 & 6.0999 & TRN \\
\hline CHEMBL1440487 & 737823 & 5.8 & 5.6766 & TRN \\
\hline CHEMBL1447768 & 737823 & 5.2 & 5.25700 & 0000000001 \\
\hline CHEMBL362051 & 737823 & 4.4 & 4.8548 & TRN \\
\hline CHEMBL1554622 & 737823 & 5.6 & 5.6971 & TRN \\
\hline CHEMBL1442538 & 737823 & 5.1 & 5.2124 & TRN \\
\hline CHEMBL1742239 & 737823 & 5.2 & 5.7745 & TRN \\
\hline CHEMBL1474987 & 737823 & 5.4 & 4.6578 & TRN \\
\hline CHEMBL1368788 & 737823 & 5.55 & 5.256 & TRN \\
\hline CHEMBL1442458 & 737823 & 5.3 & 5.2441 & TRN \\
\hline CHEMBL1361406 & 737823 & 6.0 & 5.3361 & TRN \\
\hline CHEMBL1329507 & 737823 & 5.9 & 5.8925 & TRN \\
\hline CHEMBL1575025 & 737823 & 4.9 & 5.3521 & TST \\
\hline CHEMBL1391308 & 737823 & 5.1 & 5.0895 & TRN \\
\hline CHEMBL1558569 & 737823 & 5.4 & 5.4669 & TRN \\
\hline CHEMBL1475366 & 737823 & 5.4 & 6.0142 & TRN \\
\hline CHEMBL1486231 & 737823 & 4.8 & 5.2007 & TRN \\
\hline CHEMBL1256984 & 737823 & 5.3 & 5.3961 & TST \\
\hline CHEMBL1491874 & 737823 & 5.55 & 5.8028 & TRN \\
\hline CHEMBL1453240 & 737823 & 5.3 & 5.4367 & TRN \\
\hline CHEMBL1486506 & 737823 & 5.2 & 5.2035 & TST \\
\hline CHEMBL1741917 & 737823 & 4.9 & 5.0607 & TRN \\
\hline CHEMBL1417140 & 737823 & 5.0 & 5.1378 & TRN \\
\hline CHEMBL1497812 & 737823 & 4.9 & 5.3285 & TRN \\
\hline CHEMBL3196379 & 737823 & 5.75 & 5.6845 & TRN \\
\hline CHEMBL 3190590 & 737823 & 5.5 & 5.5662 & TST \\
\hline CHEMBL1257130 & 737823 & 4.6 & 5.7425 & TRN \\
\hline CHEMBL3213666 & 737823 & 5.0 & 5.5938 & TRN \\
\hline CHEMBL1501148 & 737823 & 6.1 & 5.5285 & TRN \\
\hline CHEMBL1257002 & 737823 & 4.4 & 5.1111 & TRN \\
\hline CHEMBL1416531 & 737823 & 6.45 & 5.5648 & TRN \\
\hline CHEMBL1741925 & 737823 & 5.5 & 5.6506 & TRN \\
\hline CHEMBL1539331 & 737823 & 5.3 & 5.4108 & TRN \\
\hline CHEMBL1350898 & 737823 & 6.05 & 5.2845 & TRN \\
\hline CHEMBL1742330 & 737823 & 5.0 & 5.2491 & TRN \\
\hline CHEMBL1462730 & 737823 & 5.25 & 5.6584 & TST \\
\hline CHEMBL1372635 & 737823 & 4.8 & 5.1124 & TRN \\
\hline CHEMBL1515956 & 737823 & 5.1 & 4.8598 & TRN \\
\hline CHEMBL602418 & 737823 & 4.7 & 5.3344 & TRN \\
\hline CHEMBL1451317 & 737823 & 4.8 & 5.4741 & TST \\
\hline CHEMBL1330357 & 737823 & 4.5 & 4.9689 & TST \\
\hline CHEMBL1362079 & 737823 & 4.9 & 4.7851 & TRN \\
\hline CHEMBL1442986 & 737823 & 5.3 & 4.9788 & TRN \\
\hline CHEMBL1255659 & 737823 & 4.5 & 6.0507 & TST \\
\hline CHEMBL1487748 & 737823 & 6.0 & 5.1737 & TRN \\
\hline
\end{tabular}




\begin{tabular}{|c|c|c|c|c|c|}
\hline \multicolumn{6}{|c|}{ Supplemental Table S2.txt } \\
\hline CHEMBL1502796 & 737823 & 5.9 & 4.9206 & TRN & \\
\hline CHEMBL1379839 & 737823 & 5.45 & 4.9436 & TST & \\
\hline CHEMBL1603186 & 737823 & 5.6 & 5.1037 & TRN & \\
\hline CHEMBL3211113 & 737823 & 5.0 & 5.6448 & TRN & \\
\hline CHEMBL1416351 & 737823 & 6.2 & 5.9044 & TRN & \\
\hline CHEMBL1301415 & 737823 & 5.1 & 4.9776 & TRN & \\
\hline CHEMBL1513669 & 737823 & 6.5 & 6.3695 & TRN & \\
\hline CHEMBL313938 & 737823 & -0.0 & 4.6076 & TRN & \\
\hline CHEMBL1492346 & 737823 & 6.7 & 5.0454 & TRN & \\
\hline CHEMBL1504481 & 737823 & 5.05 & 5.4537 & TRN & \\
\hline CHEMBL1400015 & 737823 & 4.75 & 5.0835 & TRN & \\
\hline CHEMBL1396358 & 737823 & 5.3 & 5.0769 & TRN & \\
\hline CHEMBL1448354 & 737823 & 4.6 & 4.7178 & TRN & \\
\hline CHEMBL1483013 & 737823 & 5.8 & 5.4447 & TRN & \\
\hline CHEMBL3212912 & 737823 & 6.4 & 5.21299 & 9999999999 & TST \\
\hline CHEMBL1553404 & 737823 & 5.3 & $4.9110 e$ & 00000000005 & TRN \\
\hline CHEMBL1435077 & 737823 & 6.8 & 6.2579 & TRN & \\
\hline CHEMBL1530501 & 737823 & 5.6 & 5.8289 & TST & \\
\hline CHEMBL1356771 & 737823 & 4.8 & 5.0481 & TRN & \\
\hline CHEMBL1564071 & 737823 & 4.55 & 5.2886 & TRN & \\
\hline CHEMBL1525674 & 737823 & 4.5 & 5.2736 & TRN & \\
\hline CHEMBL452887 & 737823 & 4.5 & 5.3095 & TRN & \\
\hline CHEMBL1305452 & 737823 & 5.4 & 5.5273 & TRN & \\
\hline CHEMBL1498873 & 737823 & 5.3 & 5.4331 & TRN & \\
\hline CHEMBL1302090 & 737823 & 5.9 & 4.6349 & TRN & \\
\hline CHEMBL1349786 & 737823 & 4.5 & 4.9026 & TRN & \\
\hline CHEMBL1571108 & 737823 & 5.8 & 5.56 & TRN & \\
\hline CHEMBL478 & 737823 & 4.8 & 5.3613 & TRN & \\
\hline CHEMBL1429119 & 737823 & 5.7 & 5.32299 & 99999999995 & TRN \\
\hline CHEMBL1473753 & 737823 & 4.9 & 5.0846 & TRN & \\
\hline CHEMBL1491888 & 737823 & 5.7 & 5.4331 & TST & \\
\hline CHEMBL157351 & 737823 & 5.2 & 5.8997 & TST & \\
\hline CHEMBL1464306 & 737823 & 5.95 & 5.397 & TRN & \\
\hline CHEMBL1565927 & 737823 & 5.6 & 5.7669 & TRN & \\
\hline CHEMBL1741827 & 737823 & 5.5 & 5.7213 & TRN & \\
\hline CHEMBL1449160 & 737823 & 4.85 & 5.3118 & TRN & \\
\hline CHEMBL1567886 & 737823 & 4.7 & 5.0126 & TRN & \\
\hline CHEMBL3194442 & 737823 & 5.4 & 5.3841 & TRN & \\
\hline CHEMBL1473429 & 737823 & 4.5 & 5.1165 & TST & \\
\hline CHEMBL1452079 & 737823 & 5.05 & 5.3777 & TRN & \\
\hline CHEMBL1529625 & 737823 & 4.5 & 4.747 & TST & \\
\hline CHEMBL1511739 & 737823 & 5.45 & 5.7304 & TRN & \\
\hline CHEMBL1474471 & 737823 & 4.9 & 5.8965 & TRN & \\
\hline CHEMBL1528076 & 737823 & 5.1 & 5.3006 & TRN & \\
\hline CHEMBL1725279 & 737823 & 7.8 & 5.6191 & TST & \\
\hline CHEMBL1741567 & 737823 & 4.6 & 4.5209 & TRN & \\
\hline CHEMBL1476939 & 737823 & 6.8 & 5.7116 & TRN & \\
\hline CHEMBL1368493 & 737823 & 5.5 & 5.2016 & TRN & \\
\hline
\end{tabular}




\begin{tabular}{|c|c|c|c|c|c|}
\hline \multicolumn{6}{|c|}{ Supplemental Table S2.txt } \\
\hline CHEMBL 278332 & 737823 & 5.1 & 4.9565 & TRN & \\
\hline CHEMBL1402656 & 737823 & 4.8 & 5.1158 & TRN & \\
\hline CHEMBL3196035 & 737823 & 4.9 & 5.1552 & TRN & \\
\hline CHEMBL489737 & 737823 & 6.2 & 5.6759 & TRN & \\
\hline CHEMBL3212534 & 737823 & 4.9 & 5.2939 & TRN & \\
\hline CHEMBL1503135 & 737823 & 6.1 & 5.3282 & TRN & \\
\hline CHEMBL1701700 & 737823 & 6.3 & 5.58200 & 0000000001 & TRN \\
\hline CHEMBL1358313 & 737823 & 4.7 & 5.3215 & TRN & \\
\hline CHEMBL1520445 & 737823 & 5.1 & 5.625 & TRN & \\
\hline CHEMBL1575131 & 737823 & 4.75 & 4.9892 & TRN & \\
\hline CHEMBL1599334 & 737823 & 5.0 & 4.7786 & TRN & \\
\hline CHEMBL1534263 & 737823 & 4.75 & 5.5045 & TRN & \\
\hline CHEMBL1480012 & 737823 & 7.0 & 5.2227 & TRN & \\
\hline CHEMBL1612296 & 737823 & 5.7 & 5.3112 & TRN & \\
\hline CHEMBL1402957 & 737823 & 5.5 & 5.19 & TST & \\
\hline CHEMBL1345025 & 737823 & 4.75 & 5.2524 & TRN & \\
\hline CHEMBL1525916 & 737823 & 4.9 & 5.0205 & TRN & \\
\hline CHEMBL1490414 & 737823 & 5.15 & 5.5376 & TRN & \\
\hline CHEMBL1569491 & 737823 & 5.1 & 5.2939 & TRN & \\
\hline CHEMBL1547486 & 737823 & 4.8 & 4.9117 & TRN & \\
\hline CHEMBL541847 & 737823 & 6.5 & 6.4671 & TRN & \\
\hline CHEMBL1573692 & 737823 & 5.15 & 5.1889 & TRN & \\
\hline CHEMBL1514748 & 737823 & 5.3 & 5.755 & TRN & \\
\hline CHEMBL3213131 & 737823 & 5.95 & 5.4401 & TST & \\
\hline CHEMBL 278041 & 737823 & 4.8 & 5.6655 & TRN & \\
\hline CHEMBL1491271 & 737823 & 5.45 & 5.6046 & TRN & \\
\hline CHEMBL1741675 & 737823 & 5.4 & 5.0303 & TST & \\
\hline CHEMBL1380994 & 737823 & 5.75 & 5.4631 & TRN & \\
\hline CHEMBL1474402 & 737823 & 6.3 & 5.8519 & TRN & \\
\hline CHEMBL1563772 & 737823 & 5.25 & 5.495 & TRN & \\
\hline CHEMBL1338060 & 737823 & 5.0 & 5.0259 & TST & \\
\hline CHEMBL1329327 & 737823 & 4.85 & 5.0487 & TRN & \\
\hline CHEMBL1409802 & 737823 & 5.7 & 5.4859 & TRN & \\
\hline CHEMBL1518301 & 737823 & 4.5 & 4.743 & TRN & \\
\hline CHEMBL1394469 & 737823 & 4.9 & 5.8672 & TRN & \\
\hline CHEMBL1371221 & 737823 & 6.4 & 5.9582 & TRN & \\
\hline CHEMBL1600552 & 737823 & 4.9 & 5.3344 & TRN & \\
\hline CHEMBL1494771 & 737823 & 4.9 & 5.5574 & TRN & \\
\hline CHEMBL1424763 & 737823 & 5.5 & 4.8569 & TRN & \\
\hline CHEMBL1502594 & 737823 & 5.3 & 5.4408 & TST & \\
\hline CHEMBL1396936 & 737823 & 5.6 & 5.8632 & TRN & \\
\hline CHEMBL3193196 & 737823 & 5.35 & 5.3707 & TST & \\
\hline CHEMBL1741991 & 737823 & 5.3 & 4.9629 & TST & \\
\hline CHEMBL1527251 & 737823 & 5.5 & 5.2047 & TRN & \\
\hline CHEMBL1483344 & 737823 & 5.45 & 5.2118 & TRN & \\
\hline CHEMBL1570792 & 737823 & 6.1 & 5.2237 & TRN & \\
\hline CHEMBL1446716 & 737823 & 6.7 & 6.6438 & TRN & \\
\hline CHEMBL1496569 & 737823 & 5.3 & 5.7983 & TRN & \\
\hline
\end{tabular}




\begin{tabular}{|c|c|c|c|c|c|}
\hline \\
\hline CHEMBL1255941 & 737823 & 4.4 & 5.3444 & TST & \\
\hline CHEMBL1719582 & 737823 & 4.5 & 4.635 & TRN & \\
\hline CHEMBL1489778 & 737823 & 4.85 & 5.0537 & TRN & \\
\hline CHEMBL1452199 & 737823 & 4.8 & 5.2698 & TRN & \\
\hline CHEMBL1442105 & 737823 & 4.95 & 4.8756 & TRN & \\
\hline CHEMBL1742271 & 737823 & 8.3 & 5.2683 & TRN & \\
\hline CHEMBL1345648 & 737823 & 6.75 & 5.8815 & TRN & \\
\hline CHEMBL1361731 & 737823 & 4.8 & 5.0371 & TRN & \\
\hline CHEMBL1575580 & 737823 & 5.2 & 5.2526 & TRN & \\
\hline CHEMBL1410547 & 737823 & 5.05 & 5.0178 & TRN & \\
\hline CHEMBL1396664 & 737823 & 4.8 & 4.9649 & TRN & \\
\hline CHEMBL1312235 & 737823 & 4.8 & 5.598 & TRN & \\
\hline CHEMBL1537303 & 737823 & 4.6 & 5.2156 & TST & \\
\hline CHEMBL1410039 & 737823 & 6.4 & 5.5118 & TRN & \\
\hline CHEMBL1480917 & 737823 & 4.85 & 4.8522 & TST & \\
\hline CHEMBL1398067 & 737823 & 5.3 & 5.2082 & TRN & \\
\hline CHEMBL1412872 & 737823 & 5.5 & 5.4731 & TRN & \\
\hline CHEMBL1331525 & 737823 & 6.4 & 6.1576 & TRN & \\
\hline CHEMBL1412305 & 737823 & 6.1 & 5.5271 & TRN & \\
\hline CHEMBL332122 & 737823 & 5.8 & 5.5652 & TRN & \\
\hline CHEMBL1594359 & 737823 & 7.4 & 6.6211 & TRN & \\
\hline CHEMBL1489435 & 737823 & 5.6 & 5.41299 & 9999999999 & TRN \\
\hline CHEMBL1411314 & 737823 & 5.8 & 5.6643 & TRN & \\
\hline CHEMBL1423713 & 737823 & 4.55 & 4.9479 & TRN & \\
\hline CHEMBL1333144 & 737823 & 5.85 & 5.1247 & TRN & \\
\hline CHEMBL1398543 & 737823 & 5.8 & 5.2674 & TRN & \\
\hline CHEMBL1363376 & 737823 & 6.95 & 6.1435 & TRN & \\
\hline CHEMBL1554433 & 737823 & 5.2 & 5.6996 & TRN & \\
\hline CHEMBL1384353 & 737823 & 4.8 & 5.3821 & TRN & \\
\hline CHEMBL1408604 & 737823 & 5.4 & 5.7442 & TST & \\
\hline CHEMBL1482426 & 737823 & 5.7 & 5.5036 & TRN & \\
\hline CHEMBL1525169 & 737823 & 6.3 & 5.3101 & TRN & \\
\hline CHEMBL1552839 & 737823 & 6.1 & 5.6767 & TRN & \\
\hline CHEMBL1574390 & 737823 & 4.9 & 5.3214 & TRN & \\
\hline CHEMBL1397257 & 737823 & 5.0 & 5.1689 & TRN & \\
\hline CHEMBL1458544 & 737823 & 5.65 & 5.4431 & TRN & \\
\hline CHEMBL1593019 & 737823 & 4.8 & 4.9825 & TRN & \\
\hline CHEMBL27441 & 737823 & 4.5 & 5.1701 & TRN & \\
\hline CHEMBL1317232 & 737823 & 4.7 & 4.7819 & TRN & \\
\hline CHEMBL1381005 & 737823 & 4.85 & 5.6322 & TST & \\
\hline CHEMBL1425687 & 737823 & 4.95 & 4.9064 & TRN & \\
\hline CHEMBL1540708 & 737823 & 6.1 & 5.9827 & TRN & \\
\hline CHEMBL1359877 & 737823 & 4.4 & 4.8476 & TRN & \\
\hline CHEMBL1729853 & 737823 & 4.6 & 4.9916 & TRN & \\
\hline CHEMBL1698217 & 737823 & 4.9 & 5.4946 & TRN & \\
\hline CHEMBL1528482 & 737823 & 5.7 & 5.2945 & TRN & \\
\hline CHEMBL1502885 & 737823 & 4.8 & 4.8437 & TRN & \\
\hline CHEMBL1526369 & 737823 & 5.7 & 5.4339 & TRN & \\
\hline & & & & 3368 & \\
\hline
\end{tabular}




\begin{tabular}{|c|c|c|c|c|}
\hline \multicolumn{5}{|c|}{ Supplemental Table S2.txt } \\
\hline CHEMBL1551925 & 737823 & 5.3 & 5.2836 & TRN \\
\hline CHEMBL3191606 & 737823 & 5.65 & 5.4715 & TRN \\
\hline CHEMBL1409109 & 737823 & 4.9 & 4.7802 & TST \\
\hline CHEMBL1403626 & 737823 & 5.2 & 5.277 & TRN \\
\hline CHEMBL1424121 & 737823 & 5.8 & 5.1435 & TRN \\
\hline CHEMBL1487894 & 737823 & 4.85 & 5.459 & TRN \\
\hline CHEMBL1540663 & 737823 & 5.8 & 5.8764 & TRN \\
\hline CHEMBL 3189794 & 737823 & 5.85 & 5.6746 & TRN \\
\hline CHEMBL1551477 & 737823 & 4.9 & 5.0444 & TRN \\
\hline CHEMBL 210945 & 737823 & 5.5 & 5.1361 & TRN \\
\hline CHEMBL1504272 & 737823 & 5.35 & 5.4951 & TRN \\
\hline CHEMBL1542169 & 737823 & 6.0 & 5.1089 & TST \\
\hline CHEMBL1305982 & 737823 & 5.65 & 5.5334 & TRN \\
\hline CHEMBL1476981 & 737823 & 4.6 & 4.7159 & TRN \\
\hline CHEMBL1435276 & 737823 & 4.8 & 4.8038 & TRN \\
\hline CHEMBL1611463 & 737823 & 4.8 & 5.1395 & TRN \\
\hline CHEMBL1466831 & 737823 & 4.9 & 5.5648 & TRN \\
\hline CHEMBL1480880 & 737823 & 5.8 & 5.8523 & TST \\
\hline CHEMBL1585534 & 737823 & 6.0 & 5.6879 & TRN \\
\hline CHEMBL1316775 & 737823 & 4.9 & 5.2431 & TRN \\
\hline CHEMBL3199652 & 737823 & 4.8 & 5.3703 & TRN \\
\hline CHEMBL1475851 & 737823 & 4.6 & 4.9047 & TRN \\
\hline CHEMBL1379951 & 737823 & 5.35 & 5.5662 & TRN \\
\hline CHEMBL1322050 & 737823 & 5.5 & 5.532 & TRN \\
\hline CHEMBL441618 & 737823 & 4.5 & 5.4804 & TRN \\
\hline CHEMBL1318448 & 737823 & 5.3 & 5.1463 & TRN \\
\hline CHEMBL1365092 & 737823 & 4.85 & 5.0548 & TRN \\
\hline CHEMBL1531837 & 737823 & 4.8 & 5.0739 & TRN \\
\hline CHEMBL1349535 & 737823 & 5.7 & 5.2482 & TRN \\
\hline CHEMBL1331037 & 737823 & 6.3 & 6.5602 & TRN \\
\hline CHEMBL1432279 & 737823 & 4.6 & 5.0245 & TRN \\
\hline CHEMBL1410635 & 737823 & 4.5 & 4.7161 & TRN \\
\hline CHEMBL1434535 & 737823 & 4.7 & 5.8424 & TRN \\
\hline CHEMBL1456204 & 737823 & 6.4 & 5.64 & TRN \\
\hline CHEMBL1527775 & 737823 & 4.6 & 4.9722 & TRN \\
\hline CHEMBL1467364 & 737823 & 4.85 & 5.0443 & TRN \\
\hline CHEMBL1386709 & 737823 & 6.4 & 5.039 & TRN \\
\hline CHEMBL1490333 & 737823 & 5.7 & 4.7985 & TRN \\
\hline CHEMBL1331137 & 737823 & 4.7 & 5.1165 & TRN \\
\hline CHEMBL1363364 & 737823 & 4.65 & 5.0626 & TST \\
\hline CHEMBL1577187 & 737823 & 5.6 & 5.591 & TRN \\
\hline CHEMBL1378505 & 737823 & 5.3 & 5.3127 & TST \\
\hline CHEMBL1568870 & 737823 & 4.85 & 5.1353 & TRN \\
\hline CHEMBL1448542 & 737823 & 4.8 & 4.5226 & TRN \\
\hline CHEMBL1973707 & 737823 & 5.35 & 5.3529 & TRN \\
\hline CHEMBL1326282 & 737823 & 4.95 & 5.0378 & TRN \\
\hline CHEMBL1360337 & 737823 & 5.55 & 5.4649 & TRN \\
\hline CHEMBL1456323 & 737823 & 5.2 & 5.6952 & TRN \\
\hline
\end{tabular}




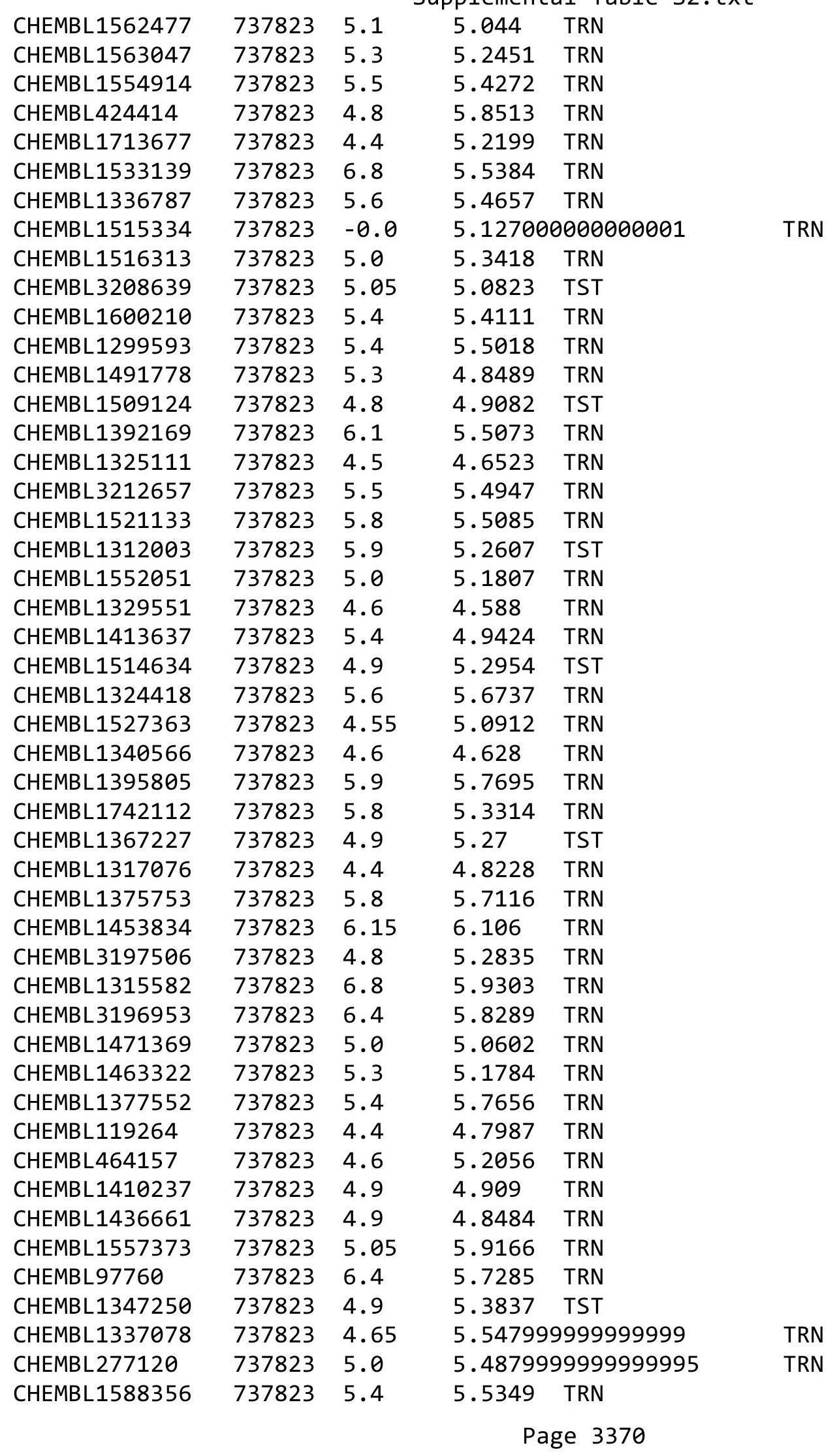




\begin{tabular}{|c|c|c|c|c|c|}
\hline \multicolumn{6}{|c|}{ Supplemental Table S2.txt } \\
\hline CHEMBL1606727 & 737823 & 5.6 & 5.8629 & TRN & \\
\hline CHEMBL1474125 & 737823 & 4.6 & 4.643 & TRN & \\
\hline CHEMBL1409809 & 737823 & 5.65 & 5.9528 & TRN & \\
\hline CHEMBL1365427 & 737823 & 4.6 & 4.6926 & TRN & \\
\hline CHEMBL1320518 & 737823 & 5.4 & 5.1374 & TRN & \\
\hline CHEMBL1307715 & 737823 & 4.6 & 5.2463 & TRN & \\
\hline CHEMBL1393480 & 737823 & 4.8 & 5.2375 & TRN & \\
\hline CHEMBL1322584 & 737823 & 4.9 & 5.58 & TRN & \\
\hline CHEMBL1377201 & 737823 & 5.4 & 5.0523 & TRN & \\
\hline CHEMBL1361794 & 737823 & 4.65 & 5.1413 & TRN & \\
\hline CHEMBL1432644 & 737823 & 4.6 & 5.0609 & TRN & \\
\hline CHEMBL1483133 & 737823 & 4.9 & 4.9581 & TRN & \\
\hline CHEMBL1504920 & 737823 & 4.9 & 5.3288 & TRN & \\
\hline CHEMBL1516006 & 737823 & 5.0 & 5.1608 & TRN & \\
\hline CHEMBL1506066 & 737823 & 5.25 & 5.4041 & TRN & \\
\hline CHEMBL1372627 & 737823 & 5.8 & 5.0252 & TRN & \\
\hline CHEMBL1425933 & 737823 & 5.5 & 5.0806 & TRN & \\
\hline CHEMBL164 & 737823 & 6.0 & 5.9483 & TRN & \\
\hline CHEMBL3192769 & 737823 & 4.95 & 5.2405 & TRN & \\
\hline CHEMBL1416727 & 737823 & 5.2 & 5.1656 & TRN & \\
\hline CHEMBL1409396 & 737823 & 5.4 & 5.5704 & TRN & \\
\hline CHEMBL1518305 & 737823 & 4.7 & 5.7773 & TRN & \\
\hline CHEMBL1539830 & 737823 & 5.95 & 5.4629 & TRN & \\
\hline CHEMBL1572589 & 737823 & 5.55 & 5.32799 & 9999999999 & TRN \\
\hline CHEMBL1318635 & 737823 & 5.8 & 5.4946 & TRN & \\
\hline CHEMBL3195361 & 737823 & 6.3 & 5.4302 & TRN & \\
\hline CHEMBL1334104 & 737823 & 5.9 & 5.2766 & TRN & \\
\hline CHEMBL1606199 & 737823 & 5.6 & 6.2674 & TRN & \\
\hline CHEMBL1366635 & 737823 & 4.8 & 5.0526 & TST & \\
\hline CHEMBL1401859 & 737823 & 6.1 & 6.0417 & TRN & \\
\hline CHEMBL1388180 & 737823 & 6.05 & 5.0919 & TST & \\
\hline CHEMBL402468 & 737823 & 5.4 & 5.3281 & TST & \\
\hline CHEMBL1308013 & 737823 & 5.65 & 5.401 & TRN & \\
\hline CHEMBL1366573 & 737823 & 4.55 & 4.8115 & TRN & \\
\hline CHEMBL1529570 & 737823 & 5.65 & 5.8412 & TRN & \\
\hline CHEMBL1553689 & 737823 & 4.7 & 4.8186 & TRN & \\
\hline CHEMBL1441011 & 737823 & 8.2 & 5.3683 & TRN & \\
\hline CHEMBL1742035 & 737823 & 5.4 & 5.5162 & TRN & \\
\hline CHEMBL1581696 & 737823 & 4.85 & 5.2569 & TRN & \\
\hline CHEMBL1404928 & 737823 & 5.35 & 4.8476 & TRN & \\
\hline CHEMBL1363077 & 737823 & 4.8 & 5.5129 & TRN & \\
\hline CHEMBL1415305 & 737823 & 5.75 & 5.5474 & TST & \\
\hline CHEMBL1710203 & 737823 & 4.8 & 4.9704 & TRN & \\
\hline CHEMBL1505071 & 737823 & 6.3 & 5.7016 & TST & \\
\hline CHEMBL259103 & 737823 & 5.5 & 6.2938 & TRN & \\
\hline CHEMBL1433783 & 737823 & 4.8 & 4.7739 & TRN & \\
\hline CHEMBL1480219 & 737823 & 4.9 & 5.7094 & TRN & \\
\hline CHEMBL1505738 & 737823 & 4.55 & $5.0360 e$ & 00000000005 & TRN \\
\hline & & & & 3371 & \\
\hline
\end{tabular}




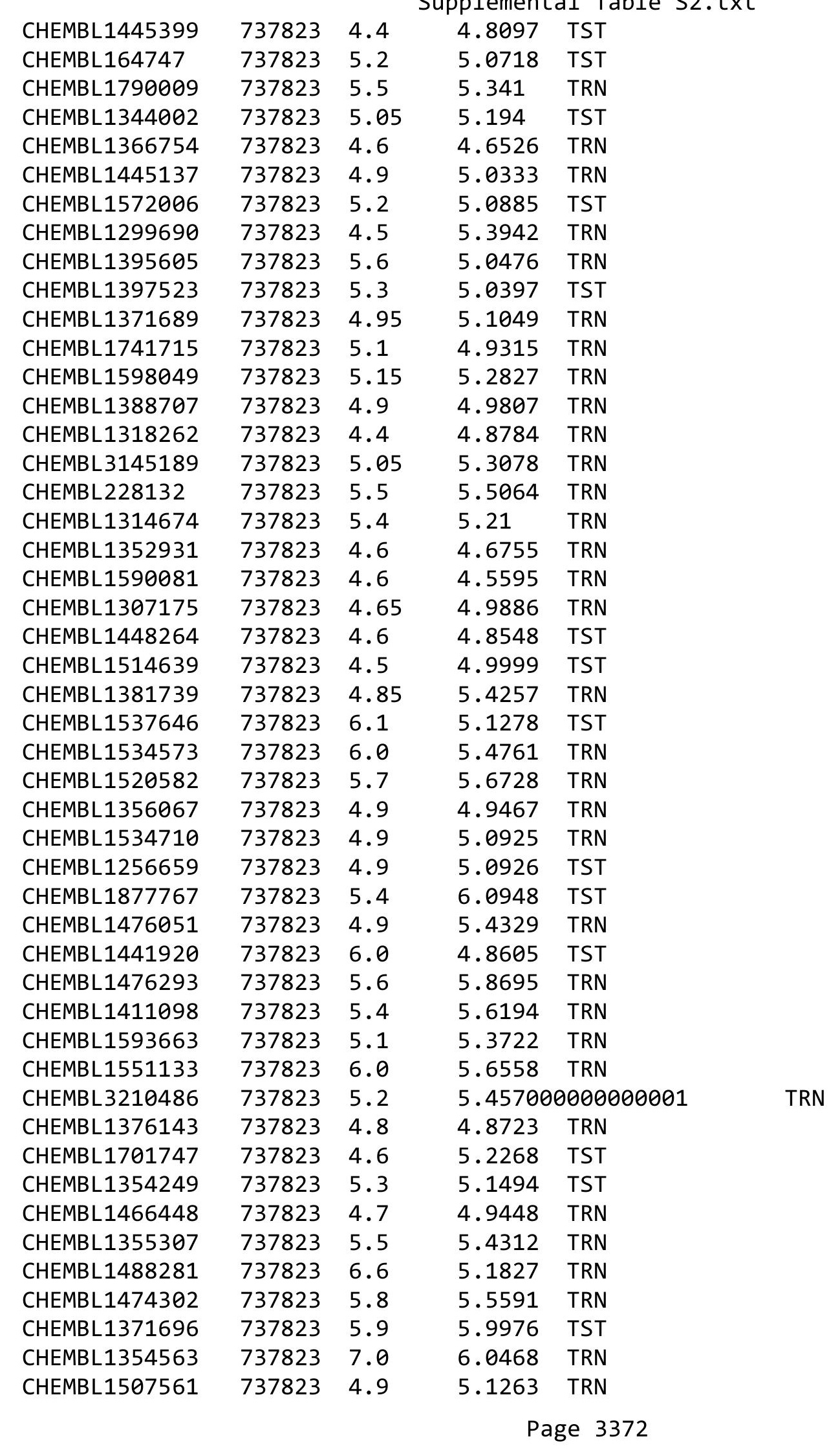




\begin{tabular}{|c|c|c|c|c|c|}
\hline & & & & & \\
\hline CHEMBL1466551 & 737823 & 5.6 & 5.4245 & TRN & \\
\hline CHEMBL1448005 & 737823 & 5.4 & 5.2012 & TST & \\
\hline CHEMBL1742209 & 737823 & 4.5 & 5.4544 & TRN & \\
\hline CHEMBL1742040 & 737823 & 5.3 & 5.2168 & TRN & \\
\hline CHEMBL1449870 & 737823 & 5.1 & 5.6213 & TRN & \\
\hline CHEMBL3145111 & 737823 & 4.65 & 5.5623 & TRN & \\
\hline CHEMBL1515691 & 737823 & 4.7 & 5.3026 & TST & \\
\hline CHEMBL1710092 & 737823 & 5.25 & 5.4979 & TRN & \\
\hline CHEMBL1438041 & 737823 & 4.9 & 5.0677 & TRN & \\
\hline CHEMBL1501813 & 737823 & 4.75 & 5.1425 & TRN & \\
\hline CHEMBL1410910 & 737823 & 5.5 & 5.6161 & TRN & \\
\hline CHEMBL1526043 & 737823 & 5.6 & 5.5529 & TRN & \\
\hline CHEMBL1395089 & 737823 & 4.7 & 5.05699 & 99999999995 & TRN \\
\hline CHEMBL 3197456 & 737823 & 5.95 & 5.2459 & TRN & \\
\hline CHEMBL1332504 & 737823 & 7.5 & 6.2095 & TRN & \\
\hline CHEMBL1414577 & 737823 & 5.3 & 5.2516 & TRN & \\
\hline CHEMBL1375431 & 737823 & 4.9 & 5.4653 & TRN & \\
\hline CHEMBL1372645 & 737823 & 5.4 & 4.9897 & TRN & \\
\hline CHEMBL1594421 & 737823 & 4.9 & 5.1579 & TRN & \\
\hline CHEMBL1612976 & 737823 & 5.4 & 5.1967 & TRN & \\
\hline CHEMBL1996020 & 737823 & 5.6 & 5.0812 & TRN & \\
\hline CHEMBL522121 & 737823 & 5.2 & 5.6389 & TRN & \\
\hline CHEMBL3213318 & 737823 & 5.3 & 5.3387 & TRN & \\
\hline CHEMBL1492229 & 737823 & 5.3 & 5.1448 & TRN & \\
\hline CHEMBL1521909 & 737823 & 5.95 & 5.8881 & TRN & \\
\hline CHEMBL1314434 & 737823 & 4.6 & 4.9299 & TRN & \\
\hline CHEMBL1414493 & 737823 & 5.75 & 5.3674 & TRN & \\
\hline CHEMBL1401455 & 737823 & 5.3 & 5.3922 & TRN & \\
\hline CHEMBL1352082 & 737823 & 4.6 & 5.225 & TST & \\
\hline CHEMBL66998 & 737823 & 5.3 & 6.0094 & TRN & \\
\hline CHEMBL1595002 & 737823 & 5.4 & 5.6002 & TRN & \\
\hline CHEMBL 1425720 & 737823 & 6.0 & 5.26 & TRN & \\
\hline CHEMBL1568113 & 737823 & 5.95 & 5.4938 & TRN & \\
\hline CHEMBL523318 & 737823 & 6.2 & 5.6981 & TRN & \\
\hline CHEMBL575239 & 737823 & 4.5 & 4.5241 & TRN & \\
\hline CHEMBL495068 & 737823 & 5.4 & 5.164 & TRN & \\
\hline CHEMBL1485069 & 737823 & 5.1 & 5.6784 & TST & \\
\hline CHEMBL1389304 & 737823 & 5.5 & 5.2668 & TRN & \\
\hline CHEMBL1558083 & 737823 & 5.4 & 5.6617 & TRN & \\
\hline CHEMBL1381498 & 737823 & 4.9 & 5.25200 & 2000000001 & TST \\
\hline CHEMBL1491168 & 737823 & 4.85 & 4.8971 & TRN & \\
\hline CHEMBL1989625 & 737823 & 5.05 & 5.255 & TRN & \\
\hline CHEMBL1335890 & 737823 & 6.0 & 5.5781 & TRN & \\
\hline CHEMBL1547741 & 737823 & 4.85 & 4.6671 & TRN & \\
\hline CHEMBL1346628 & 737823 & 5.5 & 6.0478 & TRN & \\
\hline CHEMBL1316796 & 737823 & 5.8 & 5.595 & TRN & \\
\hline CHEMBL1580492 & 737823 & 4.9 & 5.2502 & TRN & \\
\hline CHEMBL1516622 & 737823 & 5.5 & 4.9676 & TRN & \\
\hline & & & & 3373 & \\
\hline
\end{tabular}




\begin{tabular}{|c|c|c|c|c|c|}
\hline \multicolumn{6}{|c|}{ Supplemental Table S2.txt } \\
\hline CHEMBL1489535 & 737823 & 5.0 & 5.1159 & TST & \\
\hline CHEMBL1328688 & 737823 & 5.45 & 5.1381 & TRN & \\
\hline CHEMBL6640 & 737823 & 5.5 & 5.4256 & TRN & \\
\hline CHEMBL1592964 & 737823 & 4.9 & 5.2631 & TRN & \\
\hline CHEMBL1444983 & 737823 & 4.7 & 4.9087 & TRN & \\
\hline CHEMBL1371975 & 737823 & 6.25 & 5.5215 & TST & \\
\hline CHEMBL1440617 & 737823 & 4.9 & 4.7602 & TRN & \\
\hline CHEMBL1359613 & 737823 & 4.7 & 4.6104 & TRN & \\
\hline CHEMBL1529665 & 737823 & 5.7 & 5.2296 & TST & \\
\hline CHEMBL1571970 & 737823 & 5.4 & 5.2453 & TRN & \\
\hline CHEMBL1481741 & 737823 & 4.9 & 4.8554 & TRN & \\
\hline CHEMBL1579123 & 737823 & 4.8 & 5.1445 & TRN & \\
\hline CHEMBL1387889 & 737823 & 4.8 & 5.2648 & TRN & \\
\hline CHEMBL1304606 & 737823 & 4.9 & 5.2016 & TRN & \\
\hline CHEMBL 3209784 & 737823 & 5.0 & 5.4573 & TST & \\
\hline CHEMBL306764 & 737823 & 5.7 & 5.504 & TRN & \\
\hline CHEMBL1613268 & 737823 & 5.4 & 5.4432 & TRN & \\
\hline CHEMBL3212699 & 737823 & 6.25 & 5.3099 & TRN & \\
\hline CHEMBL1331647 & 737823 & 4.8 & 5.5179 & TRN & \\
\hline CHEMBL1550052 & 737823 & 4.4 & 5.1414 & TRN & \\
\hline CHEMBL1520998 & 737823 & 8.1 & 5.2047 & TRN & \\
\hline CHEMBL1475737 & 737823 & 5.4 & 5.7056 & TRN & \\
\hline CHEMBL1428349 & 737823 & 5.7 & 5.3519 & TRN & \\
\hline CHEMBL1431831 & 737823 & 5.45 & 5.3389 & TRN & \\
\hline CHEMBL1734974 & 737823 & 5.15 & 5.1182 & TRN & \\
\hline CHEMBL1598317 & 737823 & 6.55 & 5.2668 & TST & \\
\hline CHEMBL1522017 & 737823 & 5.0 & 5.6903 & TRN & \\
\hline CHEMBL1451315 & 737823 & 5.4 & 5.2585 & TRN & \\
\hline CHEMBL3210333 & 737823 & 4.8 & $5.0280 e$ & 00000000005 & TRN \\
\hline CHEMBL1302946 & 737823 & 4.6 & 4.9736 & TST & \\
\hline CHEMBL1397427 & 737823 & 6.1 & 5.4459 & TRN & \\
\hline CHEMBL1437011 & 737823 & 6.0 & 6.108 & TRN & \\
\hline CHEMBL1448291 & 737823 & 4.9 & 5.7535 & TRN & \\
\hline CHEMBL1368892 & 737823 & 6.0 & 5.3792 & TRN & \\
\hline CHEMBL1420741 & 737823 & 5.1 & 5.3041 & TRN & \\
\hline CHEMBL1741330 & 737823 & 7.2 & 5.6697 & TRN & \\
\hline CHEMBL1428339 & 737823 & 4.6 & 5.2605 & TRN & \\
\hline CHEMBL338314 & 737823 & 4.8 & 5.5757 & TST & \\
\hline CHEMBL1335680 & 737823 & 4.85 & 5.3674 & TRN & \\
\hline CHEMBL1430037 & 737823 & 4.8 & 4.856 & TRN & \\
\hline CHEMBL1611856 & 737823 & 4.9 & 5.7089 & TRN & \\
\hline CHEMBL1317177 & 737823 & 6.2 & 6.0169 & TRN & \\
\hline CHEMBL1408874 & 737823 & 4.9 & 5.3611 & TRN & \\
\hline CHEMBL1373723 & 737823 & 4.9 & 5.0205 & TRN & \\
\hline CHEMBL1486915 & 737823 & 4.5 & 4.72 & TRN & \\
\hline CHEMBL3209485 & 737823 & 5.1 & 5.1552 & TRN & \\
\hline CHEMBL1392924 & 737823 & 5.5 & 5.4346 & TRN & \\
\hline CHEMBL1458583 & 737823 & 5.4 & 5.0087 & TRN & \\
\hline
\end{tabular}




\begin{tabular}{|c|c|c|c|c|}
\hline \multicolumn{5}{|c|}{ pplemental T } \\
\hline CHEMBL1742016 & 737823 & 5.4 & 5.1531 & TST \\
\hline CHEMBL1256943 & 737823 & 4.9 & 5.1278 & TRN \\
\hline CHEMBL1394499 & 737823 & 5.4 & 5.6377 & TRN \\
\hline CHEMBL1440921 & 737823 & 4.8 & 5.4951 & TRN \\
\hline CHEMBL1555396 & 737823 & 6.1 & 5.7986 & TRN \\
\hline CHEMBL1347208 & 737823 & 5.4 & 5.5201 & TST \\
\hline CHEMBL1505565 & 737823 & 4.85 & 4.9217 & TRN \\
\hline CHEMBL1518620 & 737823 & 6.85 & 5.8103 & TST \\
\hline CHEMBL1374718 & 737823 & 4.6 & 5.4769 & TST \\
\hline CHEMBL92708 & 737823 & 4.5 & 5.0135 & TRN \\
\hline CHEMBL1088657 & 737823 & 4.65 & 5.2074 & TRN \\
\hline CHEMBL1579754 & 737823 & 6.4 & 5.6858 & TRN \\
\hline CHEMBL1574956 & 737823 & 5.6 & 5.5381 & TRN \\
\hline CHEMBL1703665 & 737823 & 4.55 & 5.1068 & TRN \\
\hline CHEMBL1337787 & 737823 & 5.1 & 5.2249 & TRN \\
\hline CHEMBL 2110371 & 737823 & 5.3 & 5.6599 & TRN \\
\hline CHEMBL3208532 & 737823 & 5.4 & 6.0512 & TRN \\
\hline CHEMBL491960 & 737823 & 6.0 & 6.1639 & TRN \\
\hline CHEMBL1192187 & 737823 & 6.0 & 4.8868 & TRN \\
\hline CHEMBL1789998 & 737823 & 4.5 & 5.5315 & TST \\
\hline CHEMBL1562791 & 737823 & 5.0 & 5.3005 & TRN \\
\hline CHEMBL311226 & 737823 & 4.5 & 4.8986 & TST \\
\hline CHEMBL1550414 & 737823 & 5.1 & 5.4861 & TRN \\
\hline CHEMBL1305118 & 737823 & 5.1 & 4.8906 & TRN \\
\hline CHEMBL1479912 & 737823 & 5.4 & 5.5795 & TRN \\
\hline CHEMBL1388783 & 737823 & 4.85 & 5.7589 & TRN \\
\hline CHEMBL1611550 & 737823 & 5.3 & 5.8289 & TRN \\
\hline CHEMBL1379319 & 737823 & 5.4 & 5.2242 & TRN \\
\hline CHEMBL1530525 & 737823 & 5.0 & 5.2283 & TST \\
\hline CHEMBL1355840 & 737823 & 5.3 & 5.4455 & TRN \\
\hline CHEMBL1604045 & 737823 & 5.3 & 5.2933 & TRN \\
\hline CHEMBL1556701 & 737823 & 5.9 & 5.6051 & TRN \\
\hline CHEMBL1393508 & 737823 & 5.8 & 5.3636 & TRN \\
\hline CHEMBL1348933 & 737823 & 5.5 & 5.431 & TRN \\
\hline CHEMBL1448691 & 737823 & 4.8 & 4.9684 & TRN \\
\hline CHEMBL1398456 & 737823 & 6.2 & 5.8366 & TRN \\
\hline CHEMBL1488574 & 737823 & 4.5 & 5.3254 & TRN \\
\hline CHEMBL1315072 & 737823 & 6.0 & 5.7217 & TRN \\
\hline CHEMBL1372577 & 737823 & 5.45 & 5.3606 & TRN \\
\hline CHEMBL1470840 & 737823 & 5.4 & 5.5127 & TRN \\
\hline CHEMBL1313335 & 737823 & 6.45 & 6.0506 & TRN \\
\hline CHEMBL3196906 & 737823 & 5.45 & 5.2943 & TRN \\
\hline CHEMBL1475358 & 737823 & 4.6 & 4.7954 & TRN \\
\hline CHEMBL1343750 & 737823 & 6.2 & 5.1957 & TRN \\
\hline CHEMBL1466220 & 737823 & 4.85 & 5.3731 & TRN \\
\hline CHEMBL1377301 & 737823 & 6.3 & 5.817 & TRN \\
\hline CHEMBL1397454 & 737823 & 5.1 & 4.8459 & TRN \\
\hline CHEMBL1562221 & 737823 & 5.1 & 5.1793 & TRN \\
\hline
\end{tabular}




\begin{tabular}{|c|c|c|c|c|c|}
\hline & & \multicolumn{4}{|c|}{ Supplemental Table S2.txt } \\
\hline CHEMBL1304396 & 737823 & 4.55 & 5.2162 & TST & \\
\hline CHEMBL1515194 & 737823 & 4.8 & 4.4922 & TRN & \\
\hline CHEMBL1477964 & 737823 & 5.4 & 5.0607 & TRN & \\
\hline CHEMBL1463649 & 737823 & 6.15 & 5.6952 & TRN & \\
\hline CHEMBL1434789 & 737823 & 4.7 & 4.7569 & TRN & \\
\hline CHEMBL3192271 & 737823 & 5.3 & 5.0258 & TRN & \\
\hline CHEMBL1418227 & 737823 & -0.0 & 4.2888 & TRN & \\
\hline CHEMBL1340013 & 737823 & 4.5 & 5.7007 & TRN & \\
\hline CHEMBL1605255 & 737823 & 4.9 & 5.0277 & TRN & \\
\hline CHEMBL1396146 & 737823 & 5.4 & 5.3443 & TRN & \\
\hline CHEMBL1256878 & 737823 & 6.0 & 5.2109 & TRN & \\
\hline CHEMBL 296407 & 737823 & 4.4 & 5.2439 & TRN & \\
\hline CHEMBL1330594 & 737823 & 5.7 & 5.6184 & TRN & \\
\hline CHEMBL1441572 & 737823 & 5.3 & 5.4526 & TST & \\
\hline CHEMBL1318708 & 737823 & 4.9 & 5.3639 & TRN & \\
\hline CHEMBL338790 & 737823 & 6.0 & 5.5988 & TST & \\
\hline CHEMBL1488197 & 737823 & 6.0 & 5.2873 & TRN & \\
\hline CHEMBL1326152 & 737823 & 4.8 & 5.1014 & TRN & \\
\hline CHEMBL1507862 & 737823 & 5.2 & 5.6985 & TST & \\
\hline CHEMBL1605814 & 737823 & 4.6 & 5.0653 & TRN & \\
\hline CHEMBL3208355 & 737823 & 4.85 & 5.1551 & TRN & \\
\hline CHEMBL1379083 & 737823 & 5.9 & 5.0541 & TST & \\
\hline CHEMBL76904 & 737823 & 5.3 & 5.4584 & TRN & \\
\hline CHEMBL1319962 & 737823 & 4.8 & 5.2651 & TRN & \\
\hline CHEMBL1741515 & 737823 & 4.9 & 4.905 & TRN & \\
\hline CHEMBL1317458 & 737823 & 6.0 & 5.6014 & TST & \\
\hline CHEMBL 288174 & 737823 & 4.5 & 4.8398 & TST & \\
\hline CHEMBL545050 & 737823 & 4.4 & 5.2337 & TST & \\
\hline CHEMBL1406556 & 737823 & 5.1 & 5.3974 & TRN & \\
\hline CHEMBL1565139 & 737823 & 5.3 & 4.90600 & 0000000001 & TRN \\
\hline CHEMBL1452567 & 737823 & 5.9 & 5.1964 & TRN & \\
\hline CHEMBL1413137 & 737823 & 5.3 & 5.8089 & TRN & \\
\hline CHEMBL1317943 & 737823 & 5.0 & 4.0852 & TRN & \\
\hline CHEMBL1446922 & 737823 & 4.6 & 4.6601 & TRN & \\
\hline CHEMBL1432275 & 737823 & 5.2 & 4.9915 & TRN & \\
\hline CHEMBL1603906 & 737823 & 5.75 & 5.5735 & TRN & \\
\hline CHEMBL56393 & 737823 & 4.5 & 5.0672 & TRN & \\
\hline CHEMBL1365609 & 737823 & 4.6 & 4.6932 & TRN & \\
\hline CHEMBL1394579 & 737823 & 4.8 & 5.3206 & TRN & \\
\hline CHEMBL1318937 & 737823 & 5.35 & 4.7864 & TRN & \\
\hline CHEMBL1375112 & 737823 & 5.0 & 5.1686 & TRN & \\
\hline CHEMBL1348252 & 737823 & 5.4 & 5.2198 & TRN & \\
\hline CHEMBL1735134 & 737823 & 5.7 & 5.8571 & TRN & \\
\hline CHEMBL1312751 & 737823 & 5.2 & 4.8068 & TRN & \\
\hline CHEMBL1420370 & 737823 & 5.2 & 5.9019 & TRN & \\
\hline CHEMBL1337163 & 737823 & 4.8 & 5.3635 & TRN & \\
\hline CHEMBL1742070 & 737823 & 4.55 & 4.8243 & TRN & \\
\hline CHEMBL1496752 & 737823 & 6.9 & 5.8226 & TRN & \\
\hline
\end{tabular}




\begin{tabular}{|c|c|c|c|c|}
\hline \multicolumn{5}{|c|}{ Supplemental Table S2.txt } \\
\hline CHEMBL311158 & 737823 & 4.9 & 4.9001 & TRN \\
\hline CHEMBL1315527 & 737823 & 5.7 & 5.6775 & TRN \\
\hline CHEMBL1454711 & 737823 & 7.15 & 6.0245 & TRN \\
\hline CHEMBL1559472 & 737823 & 5.95 & 5.6446 & TRN \\
\hline CHEMBL1432306 & 737823 & 5.1 & 5.2255 & TRN \\
\hline CHEMBL1583020 & 737823 & 5.75 & 5.3867 & TRN \\
\hline CHEMBL1452049 & 737823 & 4.6 & 5.1231 & TRN \\
\hline CHEMBL1600490 & 737823 & 5.35 & 5.4272 & TRN \\
\hline CHEMBL18794 & 737823 & 4.5 & \multicolumn{2}{|c|}{5.257000000000001} \\
\hline CHEMBL1547886 & 737823 & 5.75 & 5.1889 & TRN \\
\hline CHEMBL1518689 & 737823 & 4.8 & 5.0683 & TRN \\
\hline CHEMBL1256573 & 737823 & 4.5 & 5.3548 & TST \\
\hline CHEMBL1380300 & 737823 & 5.6 & 5.6851 & TRN \\
\hline CHEMBL1995254 & 737823 & 5.65 & 6.0343 & TRN \\
\hline CHEMBL1550370 & 737823 & 4.7 & 5.0823 & TRN \\
\hline CHEMBL1481465 & 737823 & 5.3 & 5.0402 & TRN \\
\hline CHEMBL1518285 & 737823 & 4.8 & 5.5568 & TST \\
\hline CHEMBL1593199 & 737823 & 5.6 & 5.2934 & TRN \\
\hline CHEMBL3145061 & 737823 & 4.8 & 5.3331 & TRN \\
\hline CHEMBL1433039 & 737823 & 5.4 & 5.4579 & TST \\
\hline CHEMBL423429 & 737823 & 4.9 & 5.5224 & TRN \\
\hline CHEMBL1588059 & 737823 & 5.5 & 5.0888 & TRN \\
\hline CHEMBL1408096 & 737823 & 4.8 & 5.9808 & TST \\
\hline CHEMBL1598887 & 737823 & 5.5 & 5.3775 & TRN \\
\hline CHEMBL1600524 & 737823 & 5.25 & 5.9134 & TRN \\
\hline CHEMBL1354262 & 737823 & 4.8 & 5.0282 & TRN \\
\hline CHEMBL1400159 & 737823 & 4.5 & 5.3494 & TRN \\
\hline CHEMBL1389823 & 737823 & 5.8 & 5.506 & TST \\
\hline CHEMBL1484898 & 737823 & 4.85 & 4.9412 & TST \\
\hline CHEMBL1561515 & 737823 & 4.45 & 5.2726 & TST \\
\hline CHEMBL1557466 & 737823 & 5.5 & 4.86 & TRN \\
\hline CHEMBL1496203 & 737823 & 6.4 & 5.5357 & TRN \\
\hline CHEMBL1569655 & 737823 & 4.6 & 4.9901 & TRN \\
\hline CHEMBL1970527 & 737823 & 6.6 & 5.4172 & TRN \\
\hline CHEMBL1542230 & 737823 & 4.75 & 4.4458 & TRN \\
\hline CHEMBL1257014 & 737823 & 4.9 & 5.0217 & TRN \\
\hline CHEMBL 28140 & 737823 & 4.5 & 4.8328 & TRN \\
\hline CHEMBL1420680 & 737823 & 5.15 & 4.944 & TRN \\
\hline CHEMBL1613160 & 737823 & 5.4 & 5.3711 & TST \\
\hline CHEMBL3196704 & 737823 & 5.2 & 5.2971 & TST \\
\hline CHEMBL1322233 & 737823 & 6.2 & 6.0059 & TRN \\
\hline CHEMBL1502052 & 737823 & 5.95 & 5.6524 & TRN \\
\hline CHEMBL1532985 & 737823 & 5.1 & 5.2113 & TRN \\
\hline CHEMBL1487111 & 737823 & 4.8 & 4.7897 & TRN \\
\hline CHEMBL1316222 & 737823 & 6.0 & 5.2727 & TST \\
\hline CHEMBL1742085 & 737823 & 5.5 & 5.3967 & TST \\
\hline CHEMBL1611644 & 737823 & 4.85 & 5.3643 & TRN \\
\hline CHEMBL1466869 & 737823 & 4.9 & 5.2356 & TRN \\
\hline
\end{tabular}




\begin{tabular}{|c|c|c|c|c|c|}
\hline \\
\hline CHEMBL1314891 & 737823 & 5.6 & 5.2549 & TRN & \\
\hline CHEMBL1407848 & 737823 & 5.35 & 5.3753 & TRN & \\
\hline CHEMBL22075 & 737823 & 5.7 & 5.726 & TRN & \\
\hline CHEMBL3195972 & 737823 & 5.3 & 5.1373 & TRN & \\
\hline CHEMBL1554183 & 737823 & 4.5 & 4.9059 & TST & \\
\hline CHEMBL544115 & 737823 & 4.7 & 4.9777 & TST & \\
\hline CHEMBL1573473 & 737823 & 5.55 & 5.2128 & TRN & \\
\hline CHEMBL1422230 & 737823 & 5.45 & 6.0263 & TST & \\
\hline CHEMBL1518571 & 737823 & 5.3 & 5.0185 & TST & \\
\hline CHEMBL1547205 & 737823 & 5.8 & 5.718 & TRN & \\
\hline CHEMBL1401813 & 737823 & 5.6 & 5.5828 & TRN & \\
\hline CHEMBL3198098 & 737823 & 6.45 & 6.0048 & TRN & \\
\hline CHEMBL1331231 & 737823 & 4.85 & 5.3191 & TST & \\
\hline CHEMBL1331004 & 737823 & 4.5 & 4.8047 & TRN & \\
\hline CHEMBL1608337 & 737823 & 5.9 & 5.5086 & TRN & \\
\hline CHEMBL1434848 & 737823 & 4.8 & 5.3721 & TRN & \\
\hline CHEMBL1551418 & 737823 & 5.0 & 4.9388 & TRN & \\
\hline CHEMBL1418471 & 737823 & 4.8 & 4.9944 & TRN & \\
\hline CHEMBL1485581 & 737823 & 5.1 & 5.0382 & TRN & \\
\hline CHEMBL587849 & 737823 & 5.4 & 5.5266 & TRN & \\
\hline CHEMBL1590334 & 737823 & 6.5 & 5.5392 & TRN & \\
\hline CHEMBL3195405 & 737823 & 5.45 & 5.7703 & TRN & \\
\hline CHEMBL3192068 & 737823 & 4.55 & 4.9611 & TRN & \\
\hline CHEMBL1319120 & 737823 & 5.3 & 5.4545 & TRN & \\
\hline CHEMBL3214295 & 737823 & 5.2 & 5.4303 & TRN & \\
\hline CHEMBL1320042 & 737823 & 4.85 & 4.8175 & TST & \\
\hline CHEMBL1601104 & 737823 & 6.55 & 5.6092 & TRN & \\
\hline CHEMBL1376158 & 737823 & 6.5 & 5.6953 & TRN & \\
\hline CHEMBL1365785 & 737823 & 5.1 & 5.1989 & TRN & \\
\hline CHEMBL1332362 & 737823 & 5.1 & 5.2235 & TRN & \\
\hline CHEMBL1471244 & 737823 & 5.1 & 5.499 & TRN & \\
\hline CHEMBL539027 & 737823 & 6.0 & 5.4871 & TRN & \\
\hline CHEMBL1334959 & 737823 & 6.5 & 5.7536 & TRN & \\
\hline CHEMBL1379149 & 737823 & 5.75 & 5.4778 & TRN & \\
\hline CHEMBL1317510 & 737823 & 5.2 & 5.6043 & TRN & \\
\hline CHEMBL1500771 & 737823 & 5.0 & 5.1973 & TRN & \\
\hline CHEMBL1404831 & 737823 & 5.65 & 5.2805 & TRN & \\
\hline CHEMBL1427220 & 737823 & 5.2 & 4.9719 & TST & \\
\hline CHEMBL1435916 & 737823 & 4.5 & 4.6754 & TRN & \\
\hline CHEMBL472656 & 737823 & 6.0 & 5.4809 & TST & \\
\hline CHEMBL1436195 & 737823 & 4.9 & 4.9405 & TRN & \\
\hline CHEMBL 21396 & 737823 & 7.1 & 5.8744 & TRN & \\
\hline CHEMBL1415854 & 737823 & 5.45 & 5.7929 & TST & \\
\hline CHEMBL1320903 & 737823 & 5.6 & 5.6237 & TRN & \\
\hline CHEMBL1315820 & 737823 & 5.6 & 5.42399 & 99999999995 & TRN \\
\hline CHEMBL1741836 & 737823 & 8.0 & 5.0434 & TRN & \\
\hline CHEMBL1435079 & 737823 & 4.6 & 4.9787 & TRN & \\
\hline CHEMBL1367935 & 737823 & 6.7 & 5.6233 & TRN & \\
\hline
\end{tabular}




\begin{tabular}{|c|c|c|c|c|}
\hline \multicolumn{5}{|c|}{ Supplemental Table S2.txt } \\
\hline CHEMBL3191636 & 737823 & 5.35 & 5.0636 & TST \\
\hline CHEMBL1561206 & 737823 & 5.3 & 5.1775 & TRN \\
\hline CHEMBL1385652 & 737823 & 5.1 & 5.7423 & TRN \\
\hline CHEMBL1514110 & 737823 & 4.7 & 4.4299 & TRN \\
\hline CHEMBL1332630 & 737823 & 5.65 & 5.5171 & TRN \\
\hline CHEMBL1463576 & 737823 & 5.4 & 5.2301 & TRN \\
\hline CHEMBL1580880 & 737823 & 5.4 & 5.2766 & TRN \\
\hline CHEMBL1257075 & 737823 & 6.0 & 5.2581 & TRN \\
\hline CHEMBL1332456 & 737823 & 5.7 & 5.526 & TRN \\
\hline CHEMBL 250711 & 737823 & 4.7 & 4.8752 & TRN \\
\hline CHEMBL1552329 & 737823 & 5.7 & 5.7448 & TRN \\
\hline CHEMBL1480192 & 737823 & 4.95 & 5.4167 & TRN \\
\hline CHEMBL1256776 & 737823 & 4.9 & 5.4035 & TRN \\
\hline CHEMBL1404882 & 737823 & 4.6 & 5.1375 & TRN \\
\hline CHEMBL1438061 & 737823 & 5.35 & 5.3625 & TRN \\
\hline CHEMBL1544037 & 737823 & 5.55 & 5.3077 & TRN \\
\hline CHEMBL1491759 & 737823 & 5.2 & 4.6928 & TST \\
\hline CHEMBL1311432 & 737823 & 5.05 & 5.4033 & TRN \\
\hline CHEMBL1368113 & 737823 & 4.7 & 5.1839 & TRN \\
\hline CHEMBL1588249 & 737823 & 4.95 & 5.1033 & TRN \\
\hline CHEMBL3189338 & 737823 & 5.5 & 5.3555 & TRN \\
\hline CHEMBL1326753 & 737823 & 4.75 & 5.1788 & TRN \\
\hline CHEMBL1575136 & 737823 & 4.75 & 5.092 & TRN \\
\hline CHEMBL1446649 & 737823 & 4.7 & 5.2564 & TRN \\
\hline CHEMBL1505597 & 737823 & 4.85 & 5.4895 & TRN \\
\hline CHEMBL1373907 & 737823 & 4.8 & 4.7225 & TRN \\
\hline CHEMBL1583076 & 737823 & 4.85 & 5.5182 & TST \\
\hline CHEMBL1560068 & 737823 & 4.6 & 5.0811 & TST \\
\hline CHEMBL3190650 & 737823 & 5.65 & 5.3818 & TRN \\
\hline CHEMBL1554088 & 737823 & 5.8 & 5.6438 & TRN \\
\hline CHEMBL1405546 & 737823 & 5.9 & 5.4701 & TRN \\
\hline CHEMBL1552540 & 737823 & 5.4 & 5.3377 & TRN \\
\hline CHEMBL1353037 & 737823 & 4.85 & 5.0694 & TRN \\
\hline CHEMBL1581081 & 737823 & 4.8 & 5.0845 & TRN \\
\hline CHEMBL1516362 & 737823 & 4.4 & 5.8028 & TST \\
\hline CHEMBL1570435 & 737823 & 4.6 & 5.2331 & TRN \\
\hline CHEMBL1505091 & 737823 & 5.3 & 5.0356 & TST \\
\hline CHEMBL1375095 & 737823 & 5.2 & 5.4649 & TRN \\
\hline CHEMBL1514307 & 737823 & 5.5 & 5.6281 & TRN \\
\hline CHEMBL1371634 & 737823 & 6.1 & 5.5092 & TST \\
\hline CHEMBL1363275 & 737823 & 4.8 & 5.1723 & TRN \\
\hline CHEMBL1568277 & 737823 & 5.3 & 5.6921 & TRN \\
\hline CHEMBL1742368 & 737823 & 7.4 & 5.2597 & TST \\
\hline CHEMBL1315920 & 737823 & 6.6 & 6.3257 & TRN \\
\hline CHEMBL1413605 & 737823 & 6.05 & 5.7532 & TRN \\
\hline CHEMBL1422112 & 737823 & 4.4 & 5.3741 & TRN \\
\hline CHEMBL1335644 & 737823 & 5.4 & 5.7816 & TRN \\
\hline CHEMBL3186408 & 737823 & 6.0 & 5.2047 & TST \\
\hline
\end{tabular}




\begin{tabular}{|c|c|c|c|c|c|}
\hline \multicolumn{6}{|c|}{ Supplemental Table S2.txt } \\
\hline CHEMBL1470395 & 737823 & 5.45 & 5.3232 & TRN & \\
\hline CHEMBL1592517 & 737823 & 4.6 & 4.6135 & TRN & \\
\hline CHEMBL1400637 & 737823 & 6.4 & 5.3074 & TRN & \\
\hline CHEMBL1301709 & 737823 & 5.65 & 5.631 & TRN & \\
\hline CHEMBL1336469 & 737823 & 4.7 & 4.9298 & TRN & \\
\hline CHEMBL1363873 & 737823 & 4.9 & 5.2085 & TRN & \\
\hline CHEMBL1492178 & 737823 & 6.0 & 5.3752 & TRN & \\
\hline CHEMBL1741449 & 737823 & 4.85 & 5.1134 & TST & \\
\hline CHEMBL1449777 & 737823 & 5.4 & 5.9403 & TST & \\
\hline CHEMBL1320750 & 737823 & 5.45 & 5.635 & TRN & \\
\hline CHEMBL1355463 & 737823 & 6.4 & 6.2033 & TRN & \\
\hline CHEMBL1256243 & 737823 & 4.5 & 4.9474 & TST & \\
\hline CHEMBL1442987 & 737823 & 5.3 & 5.2693 & TRN & \\
\hline CHEMBL1366157 & 737823 & 5.4 & 5.3113 & TRN & \\
\hline CHEMBL1489446 & 737823 & 4.6 & 4.7866 & TRN & \\
\hline CHEMBL1417771 & 737823 & 6.5 & 6.15 & TRN & \\
\hline CHEMBL1741936 & 737823 & 5.0 & 5.2244 & TST & \\
\hline CHEMBL1329488 & 737823 & 5.3 & 5.2919 & TRN & \\
\hline CHEMBL1733514 & 737823 & 5.7 & 5.2621 & TRN & \\
\hline CHEMBL1429076 & 737823 & 4.95 & 5.12200 & 0000000001 & TRN \\
\hline CHEMBL1447663 & 737823 & 4.9 & 5.3279 & TRN & \\
\hline CHEMBL1351822 & 737823 & 4.9 & 5.025 & TRN & \\
\hline CHEMBL1358272 & 737823 & 6.2 & 5.9322 & TRN & \\
\hline CHEMBL1594044 & 737823 & 5.0 & 5.4356 & TRN & \\
\hline CHEMBL3191786 & 737823 & 5.55 & 5.8514 & TST & \\
\hline CHEMBL1302086 & 737823 & 5.0 & 5.3573 & TST & \\
\hline CHEMBL1450926 & 737823 & 4.5 & 4.8605 & TRN & \\
\hline CHEMBL1380969 & 737823 & 6.25 & 5.50299 & 9999999999 & TRN \\
\hline CHEMBL1497410 & 737823 & 5.05 & 5.7872 & TRN & \\
\hline CHEMBL1564032 & 737823 & 5.1 & 5.2382 & TRN & \\
\hline CHEMBL1472223 & 737823 & 4.85 & 4.9029 & TRN & \\
\hline CHEMBL457665 & 737823 & 4.4 & 4.6701 & TRN & \\
\hline CHEMBL1347071 & 737823 & 4.8 & 6.0252 & TST & \\
\hline CHEMBL 3209548 & 737823 & 4.9 & 4.6669 & TRN & \\
\hline CHEMBL1314446 & 737823 & 6.8 & 5.8303 & TRN & \\
\hline CHEMBL1422586 & 737823 & 5.2 & 5.2074 & TRN & \\
\hline CHEMBL1604264 & 737823 & 5.4 & 5.6785 & TRN & \\
\hline CHEMBL1476348 & 737823 & 5.3 & 5.0663 & TRN & \\
\hline CHEMBL1350809 & 737823 & 5.6 & 5.1117 & TRN & \\
\hline CHEMBL1451363 & 737823 & 4.75 & 5.419 & TRN & \\
\hline CHEMBL1497183 & 737823 & 4.75 & 5.1309 & TRN & \\
\hline CHEMBL1399677 & 737823 & 4.6 & 5.3312 & TST & \\
\hline CHEMBL1570971 & 737823 & 5.5 & 5.5304 & TRN & \\
\hline CHEMBL 30024 & 737823 & 4.4 & 4.878 & TST & \\
\hline CHEMBL1308249 & 737823 & 4.55 & 5.0316 & TST & \\
\hline CHEMBL1590982 & 737823 & 6.4 & 5.5398 & TRN & \\
\hline CHEMBL 1465386 & 737823 & 4.8 & 5.0642 & TRN & \\
\hline CHEMBL1372199 & 737823 & 4.55 & 5.215 & TRN & \\
\hline
\end{tabular}




\begin{tabular}{|c|c|c|c|c|}
\hline \multicolumn{5}{|c|}{ Supplemental T } \\
\hline CHEMBL1534773 & 737823 & 6.2 & 5.7896 & TRN \\
\hline CHEMBL1359691 & 737823 & 6.0 & 5.5208 & TRN \\
\hline CHEMBL1609528 & 737823 & 5.1 & 5.1836 & TRN \\
\hline CHEMBL1466200 & 737823 & 4.75 & 4.7191 & TRN \\
\hline CHEMBL1331734 & 737823 & 7.2 & 5.8845 & TST \\
\hline CHEMBL3197624 & 737823 & 5.2 & 5.0433 & TRN \\
\hline CHEMBL1970734 & 737823 & 5.55 & 5.4111 & TRN \\
\hline CHEMBL1544439 & 737823 & 4.75 & 4.7085 & TRN \\
\hline CHEMBL1446600 & 737823 & 4.6 & 4.7469 & TRN \\
\hline CHEMBL1570769 & 737823 & 5.5 & 5.5807 & TRN \\
\hline CHEMBL1741616 & 737823 & 5.2 & 5.7068 & TRN \\
\hline CHEMBL1475487 & 737823 & 6.7 & 6.0738 & TRN \\
\hline CHEMBL429095 & 737823 & 6.2 & 5.5041 & TST \\
\hline CHEMBL1344097 & 737823 & 4.55 & 5.574 & TST \\
\hline CHEMBL1415180 & 737823 & 4.6 & 4.3479 & TRN \\
\hline CHEMBL1585542 & 737823 & 4.6 & 5.2371 & TRN \\
\hline CHEMBL1580932 & 737823 & 5.6 & 5.6031 & TRN \\
\hline CHEMBL1322136 & 737823 & 6.0 & 5.3123 & TRN \\
\hline CHEMBL 268490 & 737823 & -0.0 & 5.1474 & TRN \\
\hline CHEMBL1437119 & 737823 & 5.5 & 5.1923 & TRN \\
\hline CHEMBL1530995 & 737823 & 6.25 & 5.5324 & TST \\
\hline CHEMBL1391282 & 737823 & 4.85 & 4.8218 & TRN \\
\hline CHEMBL 1476670 & 737823 & 5.6 & 5.4614 & TRN \\
\hline CHEMBL1480293 & 737823 & 5.3 & 5.2342 & TRN \\
\hline CHEMBL1493284 & 737823 & 4.9 & 4.8662 & TRN \\
\hline CHEMBL1742011 & 737823 & 4.8 & 5.2381 & TRN \\
\hline CHEMBL1593337 & 737823 & 4.8 & 4.6396 & TRN \\
\hline CHEMBL1433013 & 737823 & 5.0 & 5.1759 & TRN \\
\hline CHEMBL1386594 & 737823 & 4.8 & 5.2609 & TRN \\
\hline CHEMBL1371957 & 737823 & 5.7 & 5.2476 & TRN \\
\hline CHEMBL1440390 & 737823 & 5.5 & 5.5806 & TRN \\
\hline CHEMBL1324493 & 737823 & 5.1 & 5.231 & TRN \\
\hline CHEMBL1369948 & 737823 & 5.5 & 5.4074 & TST \\
\hline CHEMBL1349783 & 737823 & 6.45 & 5.7105 & TRN \\
\hline CHEMBL1540051 & 737823 & 6.2 & 5.6391 & TRN \\
\hline CHEMBL1485494 & 737823 & 6.1 & 5.7027 & TRN \\
\hline CHEMBL1486716 & 737823 & 4.6 & 5.0306 & TRN \\
\hline CHEMBL 77456 & 737823 & 5.4 & 5.6316 & TRN \\
\hline CHEMBL1359027 & 737823 & 5.5 & 5.3534 & TRN \\
\hline CHEMBL1409078 & 737823 & 4.75 & 5.3201 & TRN \\
\hline CHEMBL1395499 & 737823 & 5.7 & 5.3012 & TRN \\
\hline CHEMBL1329562 & 737823 & 5.45 & 5.7061 & TRN \\
\hline CHEMBL3208086 & 737823 & 5.6 & 5.4343 & TRN \\
\hline CHEMBL1433155 & 737823 & 5.7 & 5.8091 & TST \\
\hline CHEMBL 3210000 & 737823 & 4.85 & 5.2689 & TRN \\
\hline CHEMBL1586704 & 737823 & 6.4 & 5.2854 & TRN \\
\hline CHEMBL1555348 & 737823 & 6.1 & 5.978 & TRN \\
\hline CHEMBL58033 & 737823 & 6.0 & 5.0354 & TRN \\
\hline
\end{tabular}




\begin{tabular}{|c|c|c|c|c|c|}
\hline \multicolumn{6}{|c|}{ Supplemental Table S2.txt } \\
\hline CHEMBL1256720 & 737823 & 4.8 & 5.2377 & TRN & \\
\hline CHEMBL1523565 & 737823 & 5.6 & 5.6801 & TRN & \\
\hline CHEMBL1351531 & 737823 & 5.8 & 4.9651 & TRN & \\
\hline CHEMBL1398800 & 737823 & 4.8 & 5.2779 & TRN & \\
\hline CHEMBL1548739 & 737823 & 4.6 & 5.2376 & TRN & \\
\hline CHEMBL1360310 & 737823 & 6.0 & 5.7359 & TRN & \\
\hline CHEMBL1537212 & 737823 & 4.8 & 5.2621 & TST & \\
\hline CHEMBL1565437 & 737823 & 4.85 & 5.5091 & TRN & \\
\hline CHEMBL64569 & 737823 & 5.3 & 5.3761 & TRN & \\
\hline CHEMBL1610514 & 737823 & 5.05 & 4.8074 & TRN & \\
\hline CHEMBL1472390 & 737823 & 5.15 & 5.3112 & TRN & \\
\hline CHEMBL 3192752 & 737823 & 4.55 & 4.8454 & TRN & \\
\hline CHEMBL1458453 & 737823 & 5.4 & 5.2237 & TRN & \\
\hline CHEMBL 3198745 & 737823 & 4.5 & 5.2453 & TRN & \\
\hline CHEMBL1507058 & 737823 & 5.5 & 5.0497 & TRN & \\
\hline CHEMBL1402562 & 737823 & 5.1 & 5.2595 & TRN & \\
\hline CHEMBL271165 & 737823 & 5.4 & 5.3497 & TRN & \\
\hline CHEMBL1603589 & 737823 & 5.05 & 5.3295 & TRN & \\
\hline CHEMBL1474578 & 737823 & 5.3 & 5.0307 & TRN & \\
\hline CHEMBL1993788 & 737823 & 5.85 & 5.4014 & TRN & \\
\hline CHEMBL1315373 & 737823 & 6.3 & 5.9071 & TRN & \\
\hline CHEMBL1703263 & 737823 & 6.1 & 4.9463 & TRN & \\
\hline CHEMBL1398138 & 737823 & 6.1 & 6.03299 & 99999999995 & TRN \\
\hline CHEMBL1495854 & 737823 & 6.7 & 6.0275 & TRN & \\
\hline CHEMBL1315833 & 737823 & 6.0 & 5.4656 & TRN & \\
\hline CHEMBL1571975 & 737823 & 6.3 & 5.4726 & TRN & \\
\hline CHEMBL 2369288 & 737823 & 4.85 & 5.2313 & TRN & \\
\hline CHEMBL1328536 & 737823 & 7.6 & 5.8609 & TRN & \\
\hline CHEMBL1397902 & 737823 & 5.4 & 5.822 & TRN & \\
\hline CHEMBL1395219 & 737823 & 4.6 & 4.8723 & TRN & \\
\hline CHEMBL1358462 & 737823 & 4.8 & 5.1144 & TST & \\
\hline CHEMBL 3211761 & 737823 & 5.55 & 5.5341 & TST & \\
\hline CHEMBL3196226 & 737823 & 5.75 & 5.3545 & TRN & \\
\hline CHEMBL1736619 & 737823 & 4.6 & 4.7634 & TRN & \\
\hline CHEMBL1413611 & 737823 & 5.05 & 4.841 & TRN & \\
\hline CHEMBL1542902 & 737823 & 5.7 & 5.4748 & TRN & \\
\hline CHEMBL1401991 & 737823 & 4.8 & 5.0846 & TRN & \\
\hline CHEMBL1415221 & 737823 & 6.45 & 5.3852 & TRN & \\
\hline CHEMBL3209592 & 737823 & 4.8 & 5.1568 & TRN & \\
\hline CHEMBL1568250 & 737823 & 6.6 & 6.3537 & TRN & \\
\hline CHEMBL1400491 & 737823 & 6.4 & 5.7642 & TRN & \\
\hline CHEMBL1355002 & 737823 & 6.2 & 5.5669 & TRN & \\
\hline CHEMBL1546137 & 737823 & 4.4 & 5.0353 & TRN & \\
\hline CHEMBL1393740 & 737823 & 5.45 & 5.6456 & TRN & \\
\hline CHEMBL1592356 & 737823 & 5.3 & 5.2857 & TST & \\
\hline CHEMBL3193042 & 737823 & 4.85 & 5.2296 & TRN & \\
\hline CHEMBL1573735 & 737823 & 5.6 & 5.8673 & TST & \\
\hline CHEMBL1364880 & 737823 & 5.6 & 5.1019 & TRN & \\
\hline
\end{tabular}




\begin{tabular}{|c|c|c|c|c|}
\hline \multicolumn{5}{|c|}{ Supplemental Table s2.txt } \\
\hline CHEMBL1309646 & 737823 & 5.2 & 5.1709 & TRN \\
\hline CHEMBL1434111 & 737823 & 4.5 & 4.8461 & TRN \\
\hline CHEMBL1322545 & 737823 & 4.5 & 5.5394 & TRN \\
\hline CHEMBL1574103 & 737823 & 5.2 & 5.0803 & TRN \\
\hline CHEMBL1376134 & 737823 & 5.15 & 5.0164 & TRN \\
\hline CHEMBL1332143 & 737823 & 4.85 & 5.3187 & TST \\
\hline CHEMBL1741678 & 737823 & 5.3 & 4.6583 & TST \\
\hline CHEMBL1406485 & 737823 & 6.0 & 5.6774 & TRN \\
\hline CHEMBL1518067 & 737823 & 6.0 & 5.5125 & TRN \\
\hline CHEMBL1730467 & 737823 & 4.85 & 4.7001 & TRN \\
\hline CHEMBL1511085 & 737823 & 4.85 & 5.313 & TRN \\
\hline CHEMBL1606541 & 737823 & 5.7 & 5.5998 & TST \\
\hline CHEMBL602314 & 737823 & 5.4 & 5.4391 & TRN \\
\hline CHEMBL1492558 & 737823 & 4.6 & 4.7466 & TRN \\
\hline CHEMBL1330114 & 737823 & 5.5 & 5.4791 & TRN \\
\hline CHEMBL3209589 & 737823 & 4.8 & 5.3258 & TRN \\
\hline CHEMBL1550597 & 737823 & 5.65 & 5.0831 & TRN \\
\hline CHEMBL3197815 & 737823 & 5.45 & 5.4336 & TRN \\
\hline CHEMBL1590106 & 737823 & 5.1 & 6.0842 & TRN \\
\hline CHEMBL1594150 & 737823 & 5.9 & 5.9576 & TST \\
\hline CHEMBL1530645 & 737823 & 5.2 & 5.4727 & TRN \\
\hline CHEMBL1357968 & 737823 & 4.8 & 4.5099 & TRN \\
\hline CHEMBL1270168 & 737823 & 6.6 & 5.5887 & TRN \\
\hline CHEMBL1612346 & 737823 & 5.4 & 5.2294 & TST \\
\hline CHEMBL1329218 & 737823 & 4.4 & 4.9534 & TST \\
\hline CHEMBL1330926 & 737823 & 5.5 & 5.6243 & TRN \\
\hline CHEMBL1433687 & 737823 & 5.0 & 5.676 & TRN \\
\hline CHEMBL1457138 & 737823 & 5.3 & 5.5604 & TRN \\
\hline CHEMBL1524388 & 737823 & 5.0 & 5.1896 & TRN \\
\hline CHEMBL 203187 & 737823 & 5.4 & 4.7946 & TRN \\
\hline CHEMBL1501014 & 737823 & 5.15 & 5.3401 & TRN \\
\hline CHEMBL1578191 & 737823 & -0.0 & 4.89 & TRN \\
\hline CHEMBL1479420 & 737823 & 4.7 & 4.9771 & TRN \\
\hline CHEMBL1377111 & 737823 & 6.0 & 5.3462 & TST \\
\hline CHEMBL1452742 & 737823 & 5.05 & 5.1088 & TRN \\
\hline CHEMBL1579818 & 737823 & 4.9 & 5.2563 & TST \\
\hline CHEMBL1378246 & 737823 & 5.4 & 5.3533 & TRN \\
\hline CHEMBL1398537 & 737823 & 5.8 & $5.2810 e$ & 0000000001 \\
\hline CHEMBL1367355 & 737823 & 4.55 & 5.2097 & TRN \\
\hline CHEMBL3196561 & 737823 & 5.15 & 5.7465 & TRN \\
\hline CHEMBL1411496 & 737823 & 4.85 & 5.7464 & TST \\
\hline CHEMBL1356029 & 737823 & 4.8 & 5.5531 & TRN \\
\hline CHEMBL1316165 & 737823 & 5.0 & 4.9117 & TRN \\
\hline CHEMBL1609748 & 737823 & 4.9 & 5.5147 & TRN \\
\hline CHEMBL1591893 & 737823 & 6.4 & 6.2576 & TRN \\
\hline CHEMBL1394187 & 737823 & 4.7 & 4.8862 & TRN \\
\hline CHEMBL1475689 & 737823 & 5.3 & 5.2154 & TRN \\
\hline CHEMBL1399760 & 737823 & 4.4 & 4.8348 & TRN \\
\hline
\end{tabular}




\begin{tabular}{|c|c|c|c|c|c|}
\hline \multicolumn{6}{|c|}{ Supplemental Table S2.txt } \\
\hline CHEMBL1353815 & 737823 & 4.85 & 5.0728 & TRN & \\
\hline CHEMBL1587369 & 737823 & 4.85 & 5.0343 & TST & \\
\hline CHEMBL251904 & 737823 & 6.0 & 5.4961 & TRN & \\
\hline CHEMBL1590261 & 737823 & 5.8 & 5.4696 & TRN & \\
\hline CHEMBL1437133 & 737823 & 5.3 & 4.7899 & TRN & \\
\hline CHEMBL3199224 & 737823 & 5.45 & 5.3205 & TRN & \\
\hline CHEMBL1314745 & 737823 & 4.9 & 5.0893 & TRN & \\
\hline CHEMBL1408372 & 737823 & 4.85 & 4.9853 & TRN & \\
\hline CHEMBL 7162 & 737823 & 5.4 & 5.5346 & TST & \\
\hline CHEMBL1559187 & 737823 & 4.8 & 4.959 & TRN & \\
\hline CHEMBL1384971 & 737823 & 5.1 & 4.7915 & TRN & \\
\hline CHEMBL1436355 & 737823 & 6.7 & 6.346 & TRN & \\
\hline CHEMBL399121 & 737823 & 5.5 & 5.1693 & TST & \\
\hline CHEMBL1742107 & 737823 & 5.15 & 5.0108 & TST & \\
\hline CHEMBL1567431 & 737823 & 4.75 & 5.0034 & TRN & \\
\hline CHEMBL1418178 & 737823 & 5.25 & 5.5656 & TRN & \\
\hline CHEMBL1358796 & 737823 & 6.7 & 6.3099 & TRN & \\
\hline CHEMBL1591140 & 737823 & 5.8 & 5.5783 & TRN & \\
\hline CHEMBL1539239 & 737823 & 4.7 & 5.3272 & TRN & \\
\hline CHEMBL1570285 & 737823 & 5.6 & 5.4841 & TRN & \\
\hline CHEMBL1307784 & 737823 & 4.55 & 5.4087 & TST & \\
\hline CHEMBL3210104 & 737823 & 4.95 & 5.1442 & TRN & \\
\hline CHEMBL1407380 & 737823 & 4.8 & 4.9115 & TRN & \\
\hline CHEMBL1561310 & 737823 & 4.55 & 5.1135 & TST & \\
\hline CHEMBL1362068 & 737823 & 4.6 & 5.2514 & TRN & \\
\hline CHEMBL3208470 & 737823 & 4.6 & 5.4224 & TRN & \\
\hline CHEMBL1403482 & 737823 & 4.55 & 5.011 & TRN & \\
\hline CHEMBL1433486 & 737823 & 4.9 & 5.2512 & TRN & \\
\hline CHEMBL56731 & 737823 & 6.3 & 5.331 & TRN & \\
\hline CHEMBL1565219 & 737823 & 5.3 & 4.8912 & TST & \\
\hline CHEMBL1476722 & 737823 & 6.6 & 5.05399 & 9999999999 & TRN \\
\hline CHEMBL1448379 & 737823 & 5.7 & 5.4923 & TRN & \\
\hline CHEMBL3208819 & 737823 & 4.95 & 5.1526 & TRN & \\
\hline CHEMBL1576119 & 737823 & 5.75 & 5.47 & TRN & \\
\hline CHEMBL1173475 & 737823 & 6.0 & 5.9112 & TRN & \\
\hline CHEMBL3191841 & 737823 & 4.9 & 5.2296 & TST & \\
\hline CHEMBL1612133 & 737823 & 5.5 & 5.6668 & TRN & \\
\hline CHEMBL1425173 & 737823 & 5.65 & 5.7615 & TRN & \\
\hline CHEMBL1329806 & 737823 & 5.55 & 5.6411 & TRN & \\
\hline CHEMBL489525 & 737823 & 5.0 & 5.2565 & TRN & \\
\hline CHEMBL1574831 & 737823 & 5.9 & 5.4928 & TRN & \\
\hline CHEMBL1513241 & 737823 & 5.3 & 5.4879 & TRN & \\
\hline CHEMBL1741632 & 737823 & 7.5 & 5.2888 & TST & \\
\hline CHEMBL1334255 & 737823 & 6.2 & 5.4553 & TRN & \\
\hline CHEMBL1314663 & 737823 & 4.7 & 4.7877 & TRN & \\
\hline CHEMBL1479862 & 737823 & 5.45 & 5.3374 & TST & \\
\hline CHEMBL1369964 & 737823 & 6.5 & 5.7443 & TRN & \\
\hline CHEMBL1593867 & 737823 & 6.4 & 6.0068 & TRN & \\
\hline
\end{tabular}




\begin{tabular}{|c|c|c|c|c|c|}
\hline \\
\hline CHEMBL1356439 & 737823 & 5.8 & 5.5901 & TRN & \\
\hline CHEMBL1436761 & 737823 & 5.0 & 4.0854 & TRN & \\
\hline CHEMBL3199356 & 737823 & 4.85 & 5.3953 & TST & \\
\hline CHEMBL1522803 & 737823 & 4.55 & 5.2993 & TST & \\
\hline CHEMBL1307687 & 737823 & 4.9 & 4.9718 & TRN & \\
\hline CHEMBL1443307 & 737823 & 5.7 & 5.4993 & TRN & \\
\hline CHEMBL1592327 & 737823 & 6.2 & 5.9742 & TRN & \\
\hline CHEMBL1558201 & 737823 & 5.9 & 5.9061 & TRN & \\
\hline CHEMBL1742121 & 737823 & 5.3 & 5.4422 & TRN & \\
\hline CHEMBL1707644 & 737823 & 5.4 & 5.0469 & TRN & \\
\hline CHEMBL1557851 & 737823 & 5.95 & 5.2932 & TST & \\
\hline CHEMBL1559404 & 737823 & 5.1 & 5.012 & TRN & \\
\hline CHEMBL69367 & 737823 & 4.5 & 4.5453 & TRN & \\
\hline CHEMBL1365504 & 737823 & 4.65 & 5.1671 & TRN & \\
\hline CHEMBL1437597 & 737823 & 5.4 & 5.1392 & TRN & \\
\hline CHEMBL1471701 & 737823 & 5.05 & 5.1791 & TRN & \\
\hline CHEMBL1470727 & 737823 & 4.95 & 5.41700 & $\partial 000000001$ & TRN \\
\hline CHEMBL1417349 & 737823 & 4.9 & 4.335 & TRN & \\
\hline CHEMBL1334179 & 737823 & 4.8 & 5.0671 & TST & \\
\hline CHEMBL1472971 & 737823 & 5.2 & 5.084 & TRN & \\
\hline CHEMBL1484261 & 737823 & 5.7 & 5.9029 & TRN & \\
\hline CHEMBL471005 & 737823 & 6.3 & 5.6414 & TST & \\
\hline CHEMBL1573134 & 737823 & 6.5 & 6.0191 & TRN & \\
\hline CHEMBL1333076 & 737823 & 5.7 & 5.6339 & TRN & \\
\hline CHEMBL1392490 & 737823 & 4.4 & 4.8838 & TST & \\
\hline CHEMBL1506462 & 737823 & 5.5 & 5.5249 & TRN & \\
\hline CHEMBL1742042 & 737823 & 4.65 & 5.5041 & TRN & \\
\hline CHEMBL1349604 & 737823 & 5.9 & 5.6584 & TRN & \\
\hline CHEMBL476189 & 737823 & 5.2 & 5.2891 & TRN & \\
\hline CHEMBL1613049 & 737823 & 5.5 & 5.0442 & TRN & \\
\hline CHEMBL1465072 & 737823 & 4.9 & 5.0809 & TRN & \\
\hline CHEMBL1527157 & 737823 & 6.0 & 4.8467 & TST & \\
\hline CHEMBL1553740 & 737823 & 6.6 & 6.0436 & TRN & \\
\hline CHEMBL1301162 & 737823 & 5.1 & 5.0419 & TST & \\
\hline CHEMBL1480754 & 737823 & 5.4 & 5.147 & TST & \\
\hline CHEMBL606167 & 737823 & 5.85 & 5.7264 & TST & \\
\hline CHEMBL1583793 & 737823 & 4.95 & 5.2459 & TRN & \\
\hline CHEMBL1383146 & 737823 & 5.55 & 5.1318 & TRN & \\
\hline CHEMBL1558771 & 737823 & 5.8 & 5.2576 & TRN & \\
\hline CHEMBL1403214 & 737823 & 5.15 & 5.4437 & TRN & \\
\hline CHEMBL1590262 & 737823 & 5.3 & 5.442 & TRN & \\
\hline CHEMBL1572972 & 737823 & 4.9 & 5.2931 & TST & \\
\hline CHEMBL1437523 & 737823 & 5.3 & 5.94799 & 99999999995 & TRN \\
\hline CHEMBL1548495 & 737823 & 5.6 & 5.2835 & TRN & \\
\hline CHEMBL1560252 & 737823 & 5.7 & 5.1948 & TRN & \\
\hline CHEMBL1741727 & 737823 & 5.4 & 5.317 & TRN & \\
\hline CHEMBL1537880 & 737823 & 5.35 & 5.5296 & TST & \\
\hline CHEMBL63426 & 737823 & 5.8 & 5.0092 & TST & \\
\hline & & & & 3385 & \\
\hline
\end{tabular}




\begin{tabular}{|c|c|c|c|c|}
\hline & & & pplement & al $\mathrm{Ta}$ \\
\hline CHEMBL286615 & 737823 & 4.9 & 5.1527 & TRN \\
\hline CHEMBL1416184 & 737823 & 6.0 & 5.6897 & TRN \\
\hline CHEMBL1414251 & 737823 & 6.4 & 6.2703 & TRN \\
\hline CHEMBL1415115 & 737823 & 4.85 & 5.5242 & TRN \\
\hline CHEMBL3214452 & 737823 & 6.2 & 5.7606 & TRN \\
\hline CHEMBL1571138 & 737823 & -0.0 & 5.2518 & TST \\
\hline CHEMBL1356166 & 737823 & 4.6 & 4.9462 & TRN \\
\hline CHEMBL1529656 & 737823 & 5.4 & 5.3003 & TRN \\
\hline CHEMBL1523126 & 737823 & 4.45 & 4.9865 & TRN \\
\hline CHEMBL3211592 & 737823 & 5.35 & 5.8617 & TRN \\
\hline CHEMBL1742245 & 737823 & 6.0 & 5.5285 & TST \\
\hline CHEMBL1374355 & 737823 & 6.1 & 6.1208 & TRN \\
\hline CHEMBL1526199 & 737823 & 6.7 & 5.8688 & TRN \\
\hline CHEMBL1464912 & 737823 & 5.6 & 5.1978 & TRN \\
\hline CHEMBL1467911 & 737823 & 5.15 & 5.3872 & TRN \\
\hline CHEMBL1450096 & 737823 & 6.3 & 5.767 & TST \\
\hline CHEMBL1451330 & 737823 & 5.15 & 4.942 & TST \\
\hline CHEMBL1413161 & 737823 & 8.1 & 4.8173 & TRN \\
\hline CHEMBL1593232 & 737823 & 6.0 & 5.625 & TST \\
\hline CHEMBL1410057 & 737823 & 5.4 & 5.4789 & TST \\
\hline CHEMBL1548959 & 737823 & 4.85 & 5.3524 & TRN \\
\hline CHEMBL1724554 & 737823 & 5.6 & 5.7693 & TRN \\
\hline CHEMBL1497637 & 737823 & 4.65 & 5.2862 & TRN \\
\hline CHEMBL1418916 & 737823 & 5.5 & 5.4716 & TRN \\
\hline CHEMBL3193466 & 737823 & 5.1 & 5.2939 & TRN \\
\hline CHEMBL 279218 & 737823 & 4.4 & 5.2222 & TST \\
\hline CHEMBL1447745 & 737823 & 5.6 & 5.3729 & TRN \\
\hline CHEMBL1302930 & 737823 & 5.6 & 5.0567 & TRN \\
\hline CHEMBL1554723 & 737823 & 4.8 & 4.6401 & TRN \\
\hline CHEMBL1505285 & 737823 & 5.2 & 5.0659 & TRN \\
\hline CHEMBL1611549 & 737823 & 5.0 & 5.0006 & TRN \\
\hline CHEMBL1742155 & 737823 & 5.6 & 5.5095 & TRN \\
\hline CHEMBL1366446 & 737823 & 4.75 & 5.2201 & TST \\
\hline CHEMBL1520238 & 737823 & 6.4 & 5.7052 & TRN \\
\hline CHEMBL1540572 & 737823 & 5.3 & 5.1354 & TRN \\
\hline CHEMBL1357293 & 737823 & 6.9 & 6.165 & TRN \\
\hline CHEMBL1578679 & 737823 & 4.8 & 5.2789 & TRN \\
\hline CHEMBL1458392 & 737823 & 5.8 & 5.4949 & TRN \\
\hline CHEMBL1450936 & 737823 & 4.8 & 5.267 & TRN \\
\hline CHEMBL1411055 & 737823 & 6.4 & 5.0556 & TST \\
\hline CHEMBL1531021 & 737823 & 5.0 & 4.9793 & TRN \\
\hline CHEMBL1566984 & 737823 & 5.5 & 4.8439 & TRN \\
\hline CHEMBL1397636 & 737823 & 6.5 & 6.0692 & TRN \\
\hline CHEMBL1408520 & 737823 & 4.8 & 5.1509 & TRN \\
\hline CHEMBL1479805 & 737823 & 4.9 & 4.8329 & TRN \\
\hline CHEMBL1375286 & 737823 & 5.4 & 5.2531 & TRN \\
\hline CHEMBL3189154 & 737823 & 5.1 & 5.9413 & TRN \\
\hline CHEMBL1358402 & 737823 & 4.5 & 5.2898 & TST \\
\hline
\end{tabular}




\begin{tabular}{|c|c|c|c|c|}
\hline & & & pplement & al Ta \\
\hline CHEMBL1370189 & 737823 & 6.3 & 6.0582 & TRN \\
\hline CHEMBL1445647 & 737823 & 4.75 & 5.0378 & TRN \\
\hline CHEMBL1554983 & 737823 & 5.6 & 5.6471 & TRN \\
\hline CHEMBL492130 & 737823 & 4.8 & 5.1964 & TRN \\
\hline CHEMBL1436042 & 737823 & 4.8 & 4.8969 & TRN \\
\hline CHEMBL1494452 & 737823 & 4.9 & 5.5212 & TRN \\
\hline CHEMBL543467 & 737823 & 4.5 & 5.2132 & TRN \\
\hline CHEMBL1473191 & 737823 & 6.5 & 5.2488 & TST \\
\hline CHEMBL1551981 & 737823 & 4.4 & 5.0447 & TRN \\
\hline CHEMBL1384975 & 737823 & 5.6 & 5.7125 & TST \\
\hline CHEMBL1534714 & 737823 & 6.0 & 5.3138 & TRN \\
\hline CHEMBL 280828 & 737823 & 4.4 & 5.1061 & TST \\
\hline CHEMBL1741927 & 737823 & 5.95 & 5.5567 & TRN \\
\hline CHEMBL1512210 & 737823 & 4.7 & 5.1056 & TRN \\
\hline CHEMBL1511621 & 737823 & 5.75 & 5.5217 & TRN \\
\hline CHEMBL1377637 & 737823 & 5.05 & 5.1177 & TRN \\
\hline CHEMBL1460429 & 737823 & 5.15 & 4.9582 & TRN \\
\hline CHEMBL1416681 & 737823 & 4.75 & 5.0265 & TRN \\
\hline CHEMBL1491976 & 737823 & 5.8 & 6.1469 & TRN \\
\hline CHEMBL1417610 & 737823 & 5.2 & 5.7305 & TST \\
\hline CHEMBL1437213 & 737823 & 4.6 & 4.7093 & TRN \\
\hline CHEMBL1382247 & 737823 & 5.5 & 5.1883 & TRN \\
\hline CHEMBL1377140 & 737823 & 5.4 & 5.312 & TRN \\
\hline CHEMBL1371346 & 737823 & 5.5 & 5.5427 & TST \\
\hline CHEMBL153057 & 737823 & 4.5 & 5.1646 & TST \\
\hline CHEMBL1549333 & 737823 & 4.8 & 5.8 & TRN \\
\hline CHEMBL491771 & 737823 & 5.3 & 5.4831 & TRN \\
\hline CHEMBL1461894 & 737823 & 5.0 & 5.0795 & TRN \\
\hline CHEMBL1741979 & 737823 & 4.6 & 5.7146 & TRN \\
\hline CHEMBL1470330 & 737823 & 5.4 & 5.4688 & TRN \\
\hline CHEMBL1565060 & 737823 & 5.3 & 5.2406 & TRN \\
\hline CHEMBL1551643 & 737823 & 4.9 & 4.9018 & TRN \\
\hline CHEMBL1516154 & 737823 & 4.6 & 4.8492 & TRN \\
\hline CHEMBL1507424 & 737823 & 5.8 & 5.5701 & TRN \\
\hline CHEMBL1536389 & 737823 & 4.9 & 5.4576 & TST \\
\hline CHEMBL1400520 & 737823 & 5.2 & 5.3403 & TRN \\
\hline CHEMBL1590598 & 737823 & 6.6 & 6.2452 & TRN \\
\hline CHEMBL1498884 & 737823 & 5.9 & 5.9363 & TRN \\
\hline CHEMBL1429733 & 737823 & 5.6 & 5.7252 & TRN \\
\hline CHEMBL1612814 & 737823 & 5.1 & 5.3415 & TST \\
\hline CHEMBL1520792 & 737823 & 5.5 & 5.124 & TRN \\
\hline CHEMBL1557121 & 737823 & 4.6 & 5.3927 & TST \\
\hline CHEMBL1318293 & 737823 & 5.5 & 5.595 & TRN \\
\hline CHEMBL365739 & 737823 & 6.0 & 5.983 & TST \\
\hline CHEMBL1323051 & 737823 & 5.2 & 5.3494 & TRN \\
\hline CHEMBL1450689 & 737823 & 5.25 & 5.4055 & TRN \\
\hline CHEMBL1396326 & 737823 & 5.0 & 5.3081 & TRN \\
\hline CHEMBL1591533 & 737823 & 5.5 & 5.1963 & TRN \\
\hline
\end{tabular}




\begin{tabular}{|c|c|c|c|c|c|}
\hline \multicolumn{6}{|c|}{ Supplemental Table S2.txt } \\
\hline CHEMBL1385305 & 737823 & 6.05 & 5.5521 & TRN & \\
\hline CHEMBL1411123 & 737823 & 5.15 & 4.9469 & TRN & \\
\hline CHEMBL1609561 & 737823 & 4.65 & 5.1725 & TRN & \\
\hline CHEMBL1547788 & 737823 & 5.5 & 5.956 & TRN & \\
\hline CHEMBL1540034 & 737823 & 4.8 & 4.8368 & TRN & \\
\hline CHEMBL1704206 & 737823 & 4.65 & 4.7113 & TST & \\
\hline CHEMBL1399249 & 737823 & 5.4 & 5.1444 & TST & \\
\hline CHEMBL158507 & 737823 & 7.1 & 5.7607 & TRN & \\
\hline CHEMBL1529359 & 737823 & 5.1 & 5.3612 & TRN & \\
\hline CHEMBL1357558 & 737823 & 6.0 & 5.6625 & TRN & \\
\hline CHEMBL 3213731 & 737823 & 4.85 & 5.2916 & TRN & \\
\hline CHEMBL1507864 & 737823 & 4.95 & 4.8793 & TST & \\
\hline CHEMBL1356923 & 737823 & 4.6 & 5.0719 & TRN & \\
\hline CHEMBL1384157 & 737823 & 4.55 & 4.8549 & TST & \\
\hline CHEMBL1471411 & 737823 & 5.05 & 5.3684 & TRN & \\
\hline CHEMBL1478530 & 737823 & 4.4 & 5.3448 & TST & \\
\hline CHEMBL1533853 & 737823 & 6.3 & 6.0612 & TRN & \\
\hline CHEMBL1732035 & 737823 & 5.15 & 5.4318 & TRN & \\
\hline CHEMBL1421520 & 737823 & 5.65 & 5.2336 & TRN & \\
\hline CHEMBL1376954 & 737823 & 6.3 & 5.852 & TRN & \\
\hline CHEMBL1495077 & 737823 & 4.8 & 4.67899 & 9999999999 & TRN \\
\hline CHEMBL1357231 & 737823 & 5.8 & 6.0022 & TRN & \\
\hline CHEMBL1580156 & 737823 & 6.2 & 5.4584 & TRN & \\
\hline CHEMBL 3189243 & 737823 & 4.8 & 5.0907 & TRN & \\
\hline CHEMBL1601095 & 737823 & 4.6 & 4.8352 & TRN & \\
\hline CHEMBL203722 & 737823 & 5.5 & 5.5388 & TST & \\
\hline CHEMBL1603394 & 737823 & 5.5 & 5.3485 & TRN & \\
\hline CHEMBL1320893 & 737823 & 4.7 & 5.3374 & TRN & \\
\hline CHEMBL1435447 & 737823 & 5.4 & 5.0777 & TRN & \\
\hline CHEMBL1573171 & 737823 & 6.3 & 6.0187 & TRN & \\
\hline CHEMBL1551122 & 737823 & 4.8 & 4.7217 & TRN & \\
\hline CHEMBL1406406 & 737823 & 4.85 & 5.4112 & TRN & \\
\hline CHEMBL1315335 & 737823 & 5.4 & 5.2991 & TRN & \\
\hline CHEMBL1363130 & 737823 & 5.6 & 5.2195 & TRN & \\
\hline CHEMBL536950 & 737823 & 5.3 & 5.4916 & TST & \\
\hline CHEMBL73310 & 737823 & 4.8 & 4.9923 & TRN & \\
\hline CHEMBL1742264 & 737823 & 4.55 & 5.0603 & TRN & \\
\hline CHEMBL1425995 & 737823 & 6.1 & 5.4972 & TRN & \\
\hline CHEMBL1357289 & 737823 & 5.2 & 5.506 & TRN & \\
\hline CHEMBL1358654 & 737823 & 4.7 & 5.1969 & TRN & \\
\hline CHEMBL1600239 & 737823 & 5.5 & 5.5859 & TRN & \\
\hline CHEMBL1363413 & 737823 & -0.0 & 5.1541 & TRN & \\
\hline CHEMBL1543356 & 737823 & 4.75 & 5.2157 & TRN & \\
\hline CHEMBL1309281 & 737823 & 5.55 & 5.3222 & TRN & \\
\hline CHEMBL1468265 & 737823 & 6.35 & 5.5139 & TRN & \\
\hline CHEMBL1529089 & 737823 & 5.9 & 5.8187 & TRN & \\
\hline CHEMBL1487944 & 737823 & 5.2 & 5.3761 & TST & \\
\hline CHEMBL1322026 & 737823 & 6.3 & 5.6581 & TST & \\
\hline
\end{tabular}




\begin{tabular}{|c|c|c|c|c|c|}
\hline \multicolumn{6}{|c|}{ Supplemental Table S2.txt } \\
\hline CHEMBL 3212689 & 737823 & 6.05 & 5.5845 & TRN & \\
\hline CHEMBL1337408 & 737823 & 5.6 & 5.2924 & TRN & \\
\hline CHEMBL1555637 & 737823 & 5.05 & 5.0476 & TRN & \\
\hline CHEMBL1435994 & 737823 & 4.7 & 5.4218 & TRN & \\
\hline CHEMBL1368563 & 737823 & 5.5 & 5.1901 & TRN & \\
\hline CHEMBL1714881 & 737823 & 6.15 & 5.4493 & TRN & \\
\hline CHEMBL71851 & 737823 & 5.3 & 5.6096 & TST & \\
\hline CHEMBL1396679 & 737823 & 4.6 & 4.6252 & TRN & \\
\hline CHEMBL1447149 & 737823 & 4.8 & 4.7695 & TRN & \\
\hline CHEMBL1449224 & 737823 & 5.2 & 5.5165 & TRN & \\
\hline CHEMBL 3193279 & 737823 & 4.85 & 5.165 & TRN & \\
\hline CHEMBL1394854 & 737823 & 5.3 & 5.2973 & TRN & \\
\hline CHEMBL1605399 & 737823 & 5.1 & 5.5174 & TRN & \\
\hline CHEMBL1530370 & 737823 & 6.8 & 5.6958 & TRN & \\
\hline CHEMBL1565160 & 737823 & 5.7 & 5.3613 & TST & \\
\hline CHEMBL1326546 & 737823 & 6.0 & 5.5443 & TRN & \\
\hline CHEMBL1335655 & 737823 & 5.9 & 5.5717 & TRN & \\
\hline CHEMBL1330957 & 737823 & 6.0 & 5.1978 & TRN & \\
\hline CHEMBL 2004183 & 737823 & 6.15 & 5.5752 & TRN & \\
\hline CHEMBL1421173 & 737823 & 4.7 & 4.6245 & TRN & \\
\hline CHEMBL1466281 & 737823 & 5.0 & 5.1885 & TRN & \\
\hline CHEMBL1471467 & 737823 & 4.8 & 5.1244 & TRN & \\
\hline CHEMBL1317415 & 737823 & 5.4 & 5.1626 & TST & \\
\hline CHEMBL1256750 & 737823 & 4.4 & 4.6681 & TRN & \\
\hline CHEMBL1339710 & 737823 & 4.85 & 5.1792 & TRN & \\
\hline CHEMBL1321686 & 737823 & 5.8 & 5.3751 & TRN & \\
\hline CHEMBL1440842 & 737823 & 5.3 & 5.5101 & TST & \\
\hline CHEMBL1316337 & 737823 & 4.9 & 5.2632 & TRN & \\
\hline CHEMBL1554612 & 737823 & 5.4 & 5.4659 & TRN & \\
\hline CHEMBL1488727 & 737823 & 4.8 & 5.2396 & TRN & \\
\hline CHEMBL1531056 & 737823 & 5.3 & 5.42200 & 0000000001 & TRN \\
\hline CHEMBL1426718 & 737823 & 5.05 & 5.385 & TRN & \\
\hline CHEMBL1516054 & 737823 & 6.1 & 6.157 & TRN & \\
\hline CHEMBL153648 & 737823 & 4.5 & 5.0513 & TST & \\
\hline CHEMBL117405 & 737823 & 6.0 & 5.4718 & TRN & \\
\hline CHEMBL1591712 & 737823 & 4.9 & 4.9464 & TRN & \\
\hline CHEMBL1584983 & 737823 & 5.85 & 5.5479 & TST & \\
\hline CHEMBL1434308 & 737823 & 4.9 & 5.607 & TRN & \\
\hline CHEMBL1437012 & 737823 & 5.1 & 5.3855 & TRN & \\
\hline CHEMBL1412139 & 737823 & 5.8 & 5.2246 & TRN & \\
\hline CHEMBL1317579 & 737823 & 4.8 & 4.9469 & TRN & \\
\hline CHEMBL1433939 & 737823 & 5.0 & 4.7517 & TST & \\
\hline CHEMBL1392839 & 737823 & 4.65 & 5.3568 & TST & \\
\hline CHEMBL 395446 & 737823 & 5.1 & 5.4318 & TRN & \\
\hline CHEMBL1567251 & 737823 & 4.8 & 5.012 & TRN & \\
\hline CHEMBL1364220 & 737823 & 4.7 & 4.6498 & TRN & \\
\hline CHEMBL1701448 & 737823 & 6.1 & 5.5461 & TRN & \\
\hline CHEMBL1315236 & 737823 & 4.9 & 5.1435 & TRN & \\
\hline
\end{tabular}




\begin{tabular}{|c|c|c|c|c|c|}
\hline \multicolumn{6}{|c|}{ Supplemental Table S2.txt } \\
\hline CHEMBL1438323 & 737823 & 7.1 & 5.9502 & TRN & \\
\hline CHEMBL1561341 & 737823 & 5.7 & 5.4764 & TRN & \\
\hline CHEMBL1601191 & 737823 & 5.85 & 5.0961 & TRN & \\
\hline CHEMBL291536 & 737823 & 6.0 & 5.2936 & TST & \\
\hline CHEMBL1445795 & 737823 & 5.35 & 5.4382 & TRN & \\
\hline CHEMBL1394472 & 737823 & 6.0 & 5.4548 & TRN & \\
\hline CHEMBL1434801 & 737823 & 5.3 & 5.2045 & TRN & \\
\hline CHEMBL1562612 & 737823 & 5.9 & 5.7313 & TRN & \\
\hline CHEMBL1568744 & 737823 & 6.0 & 5.3308 & TRN & \\
\hline CHEMBL1472753 & 737823 & 4.9 & 4.8314 & TRN & \\
\hline CHEMBL1214274 & 737823 & 5.5 & 5.2428 & TST & \\
\hline CHEMBL1374713 & 737823 & 4.95 & 5.1555 & TRN & \\
\hline CHEMBL1516015 & 737823 & 4.5 & 5.2822 & TRN & \\
\hline CHEMBL1464956 & 737823 & 5.4 & 4.922 & TRN & \\
\hline CHEMBL1469541 & 737823 & 5.1 & 5.0826 & TRN & \\
\hline CHEMBL50112 & 737823 & 4.4 & 4.6746 & TRN & \\
\hline CHEMBL1517644 & 737823 & 5.3 & 5.0008 & TST & \\
\hline CHEMBL1457494 & 737823 & 4.6 & 4.8242 & TRN & \\
\hline CHEMBL1593592 & 737823 & 4.8 & 4.6669 & TRN & \\
\hline CHEMBL1526210 & 737823 & 4.9 & 5.6006 & TST & \\
\hline CHEMBL1447964 & 737823 & 7.2 & 5.6629 & TRN & \\
\hline CHEMBL1543489 & 737823 & 5.3 & 4.8539 & TRN & \\
\hline CHEMBL1610991 & 737823 & 5.6 & 5.50799 & 9999999999 & TRN \\
\hline CHEMBL1742147 & 737823 & 4.85 & 4.668 & TRN & \\
\hline CHEMBL1534601 & 737823 & 5.3 & 5.3581 & TRN & \\
\hline CHEMBL1329648 & 737823 & 5.7 & 6.0456 & TRN & \\
\hline CHEMBL1549097 & 737823 & 4.9 & 5.1244 & TRN & \\
\hline CHEMBL1316956 & 737823 & 5.6 & 5.79299 & 9999999999 & TRN \\
\hline CHEMBL1526648 & 737823 & 6.2 & 5.5771 & TRN & \\
\hline CHEMBL1420257 & 737823 & 5.9 & $5.4860 e$ & $\partial 000000001$ & TRN \\
\hline CHEMBL1317163 & 737823 & 4.8 & 4.7368 & TRN & \\
\hline CHEMBL1173453 & 737823 & 5.4 & 5.2423 & TRN & \\
\hline CHEMBL1369318 & 737823 & 4.9 & 5.2075 & TRN & \\
\hline CHEMBL3193076 & 737823 & 5.7 & 5.5876 & TRN & \\
\hline CHEMBL1315129 & 737823 & 6.1 & 5.6074 & TRN & \\
\hline CHEMBL1540313 & 737823 & 6.5 & 5.8255 & TST & \\
\hline CHEMBL1438458 & 737823 & 4.9 & 5.2564 & TRN & \\
\hline CHEMBL1437263 & 737823 & 5.5 & 5.53 & TRN & \\
\hline CHEMBL1741983 & 737823 & 6.2 & 5.2081 & TST & \\
\hline CHEMBL1316711 & 737823 & 6.0 & 5.3932 & TST & \\
\hline CHEMBL1537075 & 737823 & 6.55 & 5.6883 & TRN & \\
\hline CHEMBL1483608 & 737823 & 6.95 & 5.4664 & TST & \\
\hline CHEMBL1562921 & 737823 & 6.25 & 5.7671 & TRN & \\
\hline CHEMBL1397325 & 737823 & 4.5 & 4.9001 & TRN & \\
\hline CHEMBL 8145 & 737823 & 4.8 & 5.5179 & TRN & \\
\hline CHEMBL221300 & 737823 & 6.1 & 5.4444 & TRN & \\
\hline CHEMBL1467717 & 737823 & 5.7 & 5.7915 & TRN & \\
\hline CHEMBL1580265 & 737823 & 7.15 & 5.561 & TRN & \\
\hline
\end{tabular}




\begin{tabular}{|c|c|c|c|c|c|}
\hline \multicolumn{6}{|c|}{ Supplemental Table S2.txt } \\
\hline CHEMBL1349639 & 737823 & 5.8 & 5.3742 & TRN & \\
\hline CHEMBL1537500 & 737823 & 4.7 & 4.8692 & TRN & \\
\hline CHEMBL1471206 & 737823 & 4.8 & 5.2045 & TRN & \\
\hline CHEMBL1415521 & 737823 & 7.1 & 6.3223 & TRN & \\
\hline CHEMBL1303557 & 737823 & 4.8 & 5.3753 & TST & \\
\hline CHEMBL1524851 & 737823 & 5.6 & 5.2964 & TRN & \\
\hline CHEMBL1436441 & 737823 & 5.1 & 5.3706 & TST & \\
\hline CHEMBL1552707 & 737823 & 6.1 & 5.6401 & TRN & \\
\hline CHEMBL1335654 & 737823 & 5.7 & 5.4358 & TRN & \\
\hline CHEMBL1368395 & 737823 & 4.8 & 5.1312 & TRN & \\
\hline CHEMBL1741574 & 737823 & 5.4 & 5.8136 & TST & \\
\hline CHEMBL1418094 & 737823 & 5.5 & 5.36299 & 99999999995 & TST \\
\hline CHEMBL1340140 & 737823 & 5.1 & 5.3382 & TRN & \\
\hline CHEMBL1479936 & 737823 & 4.85 & 5.4298 & TRN & \\
\hline CHEMBL1403562 & 737823 & 5.6 & 5.5959 & TRN & \\
\hline CHEMBL1450507 & 737823 & 4.7 & 4.8023 & TRN & \\
\hline CHEMBL1403023 & 737823 & 5.35 & 5.0524 & TRN & \\
\hline CHEMBL1301957 & 737823 & 4.7 & 5.2021 & TST & \\
\hline CHEMBL3196390 & 737823 & 5.85 & 5.8643 & TRN & \\
\hline CHEMBL1612479 & 737823 & 5.0 & 5.398 & TST & \\
\hline CHEMBL1359473 & 737823 & 4.6 & 4.9767 & TRN & \\
\hline CHEMBL1313698 & 737823 & 5.05 & 5.2401 & TRN & \\
\hline CHEMBL1388293 & 737823 & 5.0 & 4.9122 & TRN & \\
\hline CHEMBL1314477 & 737823 & -0.0 & 4.9239 & TRN & \\
\hline CHEMBL1599132 & 737823 & 4.95 & 5.3183 & TRN & \\
\hline CHEMBL1591956 & 737823 & 6.2 & 6.25799 & 9999999999 & TRN \\
\hline CHEMBL93403 & 737823 & 4.9 & 4.9886 & TRN & \\
\hline CHEMBL3196691 & 737823 & 6.3 & 5.6052 & TRN & \\
\hline CHEMBL1333449 & 737823 & 5.7 & 5.8328 & TRN & \\
\hline CHEMBL1518415 & 737823 & 7.0 & 6.5865 & TRN & \\
\hline CHEMBL1590855 & 737823 & 6.0 & 5.7129 & TRN & \\
\hline CHEMBL3196157 & 737823 & 4.9 & 5.2388 & TRN & \\
\hline CHEMBL1741547 & 737823 & 4.95 & 4.9958 & TST & \\
\hline CHEMBL1611670 & 737823 & 5.4 & 5.5202 & TST & \\
\hline CHEMBL1323438 & 737823 & 4.9 & 5.3693 & TRN & \\
\hline CHEMBL1348385 & 737823 & 4.55 & 5.1644 & TRN & \\
\hline CHEMBL1719114 & 737823 & 5.5 & 4.9797 & TRN & \\
\hline CHEMBL1234042 & 737823 & 4.5 & 4.8156 & TRN & \\
\hline CHEMBL1579324 & 737823 & 4.85 & 5.0284 & TRN & \\
\hline CHEMBL1892270 & 737823 & 5.25 & 5.7115 & TRN & \\
\hline CHEMBL1421029 & 737823 & 6.1 & 5.3955 & TRN & \\
\hline CHEMBL1351426 & 737823 & 5.6 & 5.37299 & 9999999999 & TST \\
\hline CHEMBL1369871 & 737823 & 4.8 & 5.2762 & TRN & \\
\hline CHEMBL1451176 & 737823 & 5.1 & 5.6992 & TST & \\
\hline CHEMBL1362203 & 737823 & 5.85 & 5.1296 & TRN & \\
\hline CHEMBL1556533 & 737823 & 5.1 & 5.3667 & TRN & \\
\hline CHEMBL1507098 & 737823 & 5.05 & 5.9038 & TRN & \\
\hline CHEMBL1498835 & 737823 & 4.95 & 5.3567 & TRN & \\
\hline
\end{tabular}




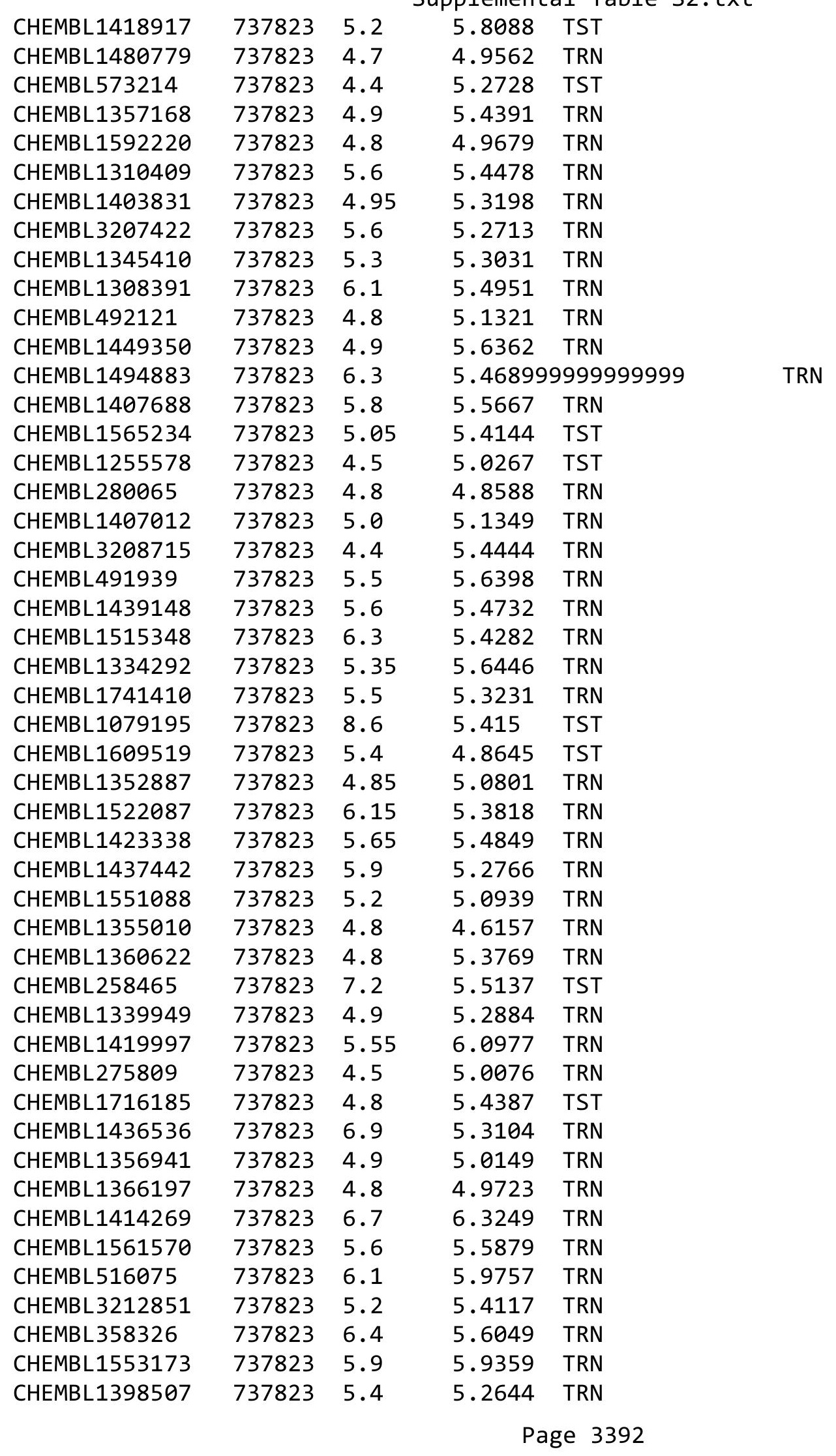




\begin{tabular}{|c|c|c|c|c|c|}
\hline & & & & & \\
\hline CHEMBL1495801 & 737823 & 5.1 & 5.2482 & TRN & \\
\hline CHEMBL1301881 & 737823 & 6.0 & 5.8125 & TRN & \\
\hline CHEMBL1542383 & 737823 & 5.1 & 5.0942 & TRN & \\
\hline CHEMBL3197876 & 737823 & 5.8 & 5.7917 & TRN & \\
\hline CHEMBL1374028 & 737823 & 5.3 & 5.1411 & TST & \\
\hline CHEMBL1480575 & 737823 & 5.55 & 5.7559 & TRN & \\
\hline CHEMBL1484181 & 737823 & 4.95 & 4.8985 & TRN & \\
\hline CHEMBL1364185 & 737823 & 4.9 & 5.0565 & TRN & \\
\hline CHEMBL1547530 & 737823 & 5.0 & 4.8037 & TRN & \\
\hline CHEMBL1511687 & 737823 & 4.85 & 5.12 & TRN & \\
\hline CHEMBL1408022 & 737823 & 4.6 & 5.1294 & TRN & \\
\hline CHEMBL1505411 & 737823 & 4.95 & 5.7635 & TST & \\
\hline CHEMBL1398066 & 737823 & 5.6 & 5.1465 & TRN & \\
\hline CHEMBL1411360 & 737823 & 6.9 & 5.7453 & TST & \\
\hline CHEMBL1436059 & 737823 & 5.1 & 5.2225 & TRN & \\
\hline CHEMBL1466675 & 737823 & 5.0 & 5.0793 & TRN & \\
\hline CHEMBL1492687 & 737823 & 4.95 & 5.4454 & TRN & \\
\hline CHEMBL3209977 & 737823 & 4.55 & 5.006 & TRN & \\
\hline CHEMBL1613623 & 737823 & 4.9 & 5.1826 & TRN & \\
\hline CHEMBL1375216 & 737823 & 5.1 & 5.3847 & TRN & \\
\hline CHEMBL1488084 & 737823 & 4.75 & 5.3462 & TRN & \\
\hline CHEMBL1492095 & 737823 & 5.55 & 5.3086 & TRN & \\
\hline CHEMBL491940 & 737823 & 6.1 & 5.6677 & TRN & \\
\hline CHEMBL1300098 & 737823 & 5.6 & 5.2646 & TRN & \\
\hline CHEMBL1329102 & 737823 & 6.3 & 5.5109 & TST & \\
\hline CHEMBL1352808 & 737823 & 4.8 & 5.5781 & TST & \\
\hline CHEMBL1318316 & 737823 & 5.9 & 5.9108 & TRN & \\
\hline CHEMBL1396298 & 737823 & 4.5 & 5.2672 & TST & \\
\hline CHEMBL1454954 & 737823 & 5.2 & 5.4711 & TRN & \\
\hline CHEMBL85194 & 737823 & 7.9 & 5.6164 & TRN & \\
\hline CHEMBL1554243 & 737823 & 4.6 & 4.7679 & TRN & \\
\hline CHEMBL1572187 & 737823 & 4.7 & 4.8993 & TRN & \\
\hline CHEMBL1368282 & 737823 & 5.5 & 5.2587 & TST & \\
\hline CHEMBL1367772 & 737823 & 4.5 & 5.4519 & TRN & \\
\hline CHEMBL1475750 & 737823 & 4.9 & 5.6514 & TRN & \\
\hline CHEMBL1549000 & 737823 & 5.45 & 5.1123 & TRN & \\
\hline CHEMBL1396583 & 737823 & 5.0 & 5.0126 & TRN & \\
\hline CHEMBL1582945 & 737823 & 6.7 & 5.2699 & TRN & \\
\hline CHEMBL1590123 & 737823 & 6.7 & 6.1716 & TRN & \\
\hline CHEMBL1437174 & 737823 & 5.7 & 5.2854 & TRN & \\
\hline CHEMBL489943 & 737823 & 4.8 & 5.0334 & TRN & \\
\hline CHEMBL15927 & 737823 & 5.2 & 4.7529 & TRN & \\
\hline CHEMBL1366433 & 737823 & 6.1 & 5.5781 & TRN & \\
\hline CHEMBL1722408 & 737823 & 4.8 & 4.9739 & TRN & \\
\hline CHEMBL1516476 & 737823 & 6.0 & 5.61600 & 20000000005 & TRN \\
\hline CHEMBL1359917 & 737823 & 4.9 & 5.6053 & TRN & \\
\hline CHEMBL1362587 & 737823 & 5.1 & 5.011 & TST & \\
\hline CHEMBL498770 & 737823 & 4.8 & 5.1298 & TST & \\
\hline & & & & e 3393 & \\
\hline
\end{tabular}




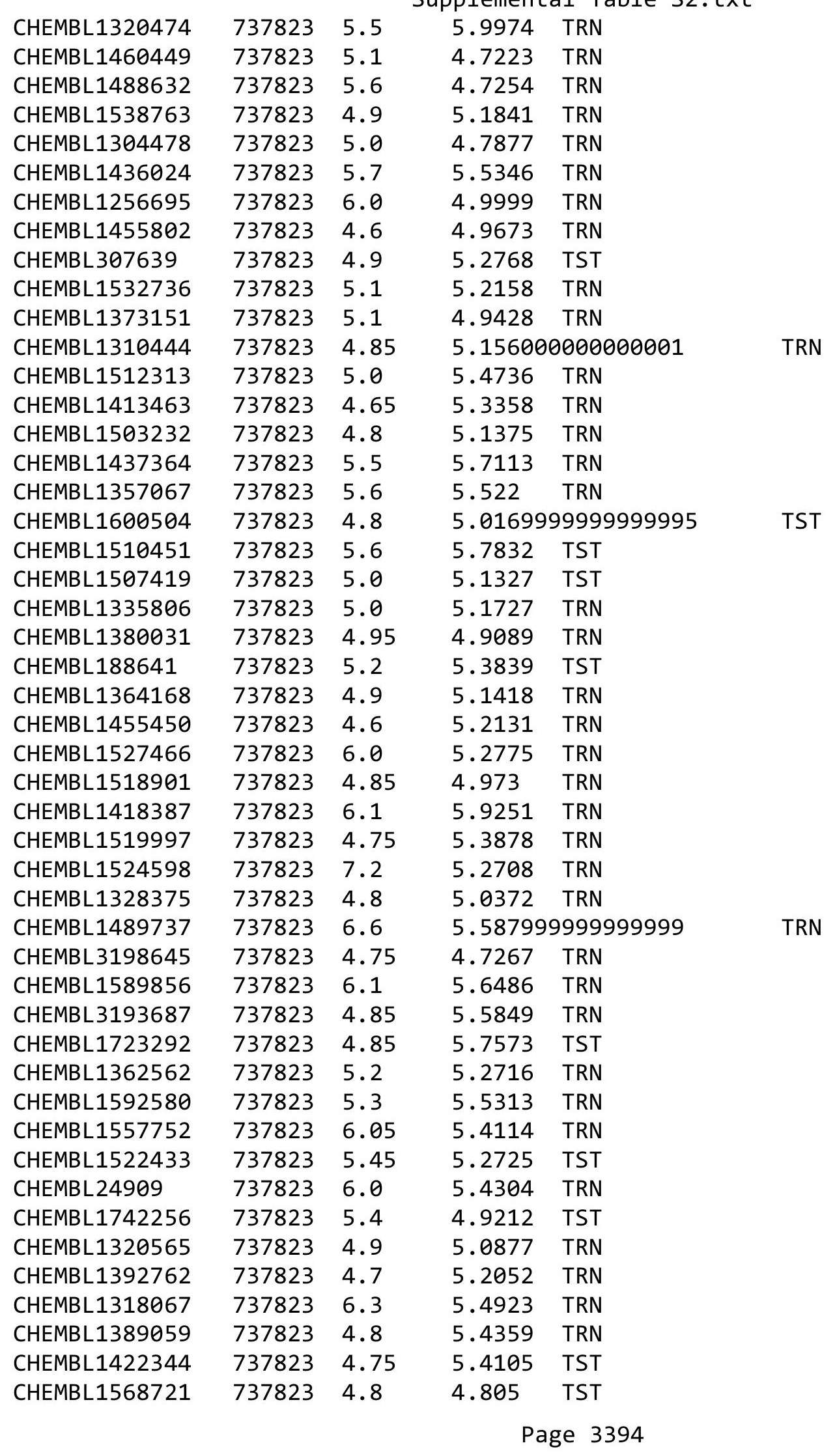




\begin{tabular}{|c|c|c|c|c|}
\hline & & & ient & al Ta \\
\hline CHEMBL1604398 & 737823 & 6.3 & 4.9562 & TRN \\
\hline CHEMBL1322216 & 737823 & 5.1 & 5.3101 & TRN \\
\hline CHEMBL1330569 & 737823 & 5.1 & 5.4536 & TST \\
\hline CHEMBL1323029 & 737823 & 5.7 & 5.2641 & TRN \\
\hline CHEMBL1369939 & 737823 & 5.9 & 5.6094 & TRN \\
\hline CHEMBL1333282 & 737823 & 5.35 & 5.3819 & TRN \\
\hline CHEMBL1516629 & 737823 & 5.0 & 5.7376 & TRN \\
\hline CHEMBL1392042 & 737823 & 5.7 & 5.5979 & TRN \\
\hline CHEMBL1475562 & 737823 & 6.6 & 6.4023 & TRN \\
\hline CHEMBL3208032 & 737823 & 4.9 & 5.3716 & TRN \\
\hline CHEMBL1894909 & 737823 & 5.1 & 5.3788 & TRN \\
\hline CHEMBL1434251 & 737823 & 5.2 & 4.9555 & TST \\
\hline CHEMBL3199416 & 737823 & 5.95 & 5.5519 & TRN \\
\hline CHEMBL1481573 & 737823 & 4.7 & 5.4676 & TST \\
\hline CHEMBL1591209 & 737823 & 5.6 & 5.5653 & TRN \\
\hline CHEMBL1473754 & 737823 & 4.9 & 4.8473 & TRN \\
\hline CHEMBL1509649 & 737823 & 5.8 & 6.0754 & TRN \\
\hline CHEMBL1440329 & 737823 & 4.75 & 5.4203 & TRN \\
\hline CHEMBL3207984 & 737823 & 6.25 & 5.4421 & TST \\
\hline CHEMBL1480944 & 737823 & 4.55 & 4.8919 & TRN \\
\hline CHEMBL3209598 & 737823 & 6.25 & 5.6611 & TRN \\
\hline CHEMBL1509145 & 737823 & 4.85 & 5.2253 & TRN \\
\hline CHEMBL1594227 & 737823 & 4.5 & 4.7708 & TRN \\
\hline CHEMBL1355537 & 737823 & 6.3 & 5.5239 & TRN \\
\hline CHEMBL1551534 & 737823 & 4.6 & 4.5833 & TRN \\
\hline CHEMBL1590818 & 737823 & 5.6 & 5.5106 & TRN \\
\hline CHEMBL1364006 & 737823 & 5.0 & 4.8551 & TRN \\
\hline CHEMBL490745 & 737823 & 4.7 & 4.6032 & TRN \\
\hline CHEMBL1524497 & 737823 & 8.3 & 5.0428 & TRN \\
\hline CHEMBL31599 & 737823 & 4.5 & 5.432 & TRN \\
\hline CHEMBL1490139 & 737823 & 4.9 & 5.5821 & TRN \\
\hline CHEMBL1526524 & 737823 & 5.5 & 5.403 & TRN \\
\hline CHEMBL1316616 & 737823 & 4.8 & 5.8673 & TRN \\
\hline CHEMBL1444135 & 737823 & 5.15 & 5.1933 & TRN \\
\hline CHEMBL1612586 & 737823 & 4.85 & 5.3272 & TST \\
\hline CHEMBL3194842 & 737823 & 5.15 & 5.6129 & TRN \\
\hline CHEMBL1377706 & 737823 & 4.8 & 5.2772 & TRN \\
\hline CHEMBL1480788 & 737823 & 5.7 & 5.3121 & TRN \\
\hline CHEMBL1585731 & 737823 & 6.3 & 5.1117 & TRN \\
\hline CHEMBL1356501 & 737823 & 6.7 & 5.6278 & TRN \\
\hline CHEMBL1396822 & 737823 & 4.7 & 4.6362 & TST \\
\hline CHEMBL1401202 & 737823 & 5.0 & 5.2251 & TRN \\
\hline CHEMBL554041 & 737823 & 4.8 & 5.0135 & TST \\
\hline CHEMBL1584828 & 737823 & 4.5 & 5.349 & TRN \\
\hline CHEMBL1405459 & 737823 & 4.95 & 5.2243 & TRN \\
\hline CHEMBL1592452 & 737823 & 4.8 & 5.1636 & TRN \\
\hline CHEMBL1395007 & 737823 & 4.9 & 4.8934 & TRN \\
\hline CHEMBL1526697 & 737823 & 5.8 & 5.7497 & TRN \\
\hline
\end{tabular}




\begin{tabular}{|c|c|c|c|c|c|}
\hline \multicolumn{6}{|c|}{ Supplemental Table S2.txt } \\
\hline CHEMBL1357180 & 737823 & 5.9 & 5.4799 & TRN & \\
\hline CHEMBL1560706 & 737823 & 4.6 & 5.2595 & TST & \\
\hline CHEMBL1589202 & 737823 & 5.85 & 5.4847 & TRN & \\
\hline CHEMBL1318480 & 737823 & 5.6 & 5.0517 & TRN & \\
\hline CHEMBL1529151 & 737823 & 5.3 & 5.1798 & TRN & \\
\hline CHEMBL1417448 & 737823 & 5.1 & 5.725 & TRN & \\
\hline CHEMBL1376394 & 737823 & 4.75 & 5.5187 & TRN & \\
\hline CHEMBL1486496 & 737823 & 4.95 & 5.7451 & TRN & \\
\hline CHEMBL1565125 & 737823 & 5.3 & 5.4272 & TRN & \\
\hline CHEMBL1412477 & 737823 & 5.2 & 6.3248 & TST & \\
\hline CHEMBL321820 & 737823 & 4.6 & 4.7245 & TST & \\
\hline CHEMBL1324889 & 737823 & 5.3 & 5.6995 & TRN & \\
\hline CHEMBL1358263 & 737823 & 4.7 & 5.2851 & TRN & \\
\hline CHEMBL1598666 & 737823 & 5.7 & 6.0162 & TRN & \\
\hline CHEMBL 235453 & 737823 & 5.25 & 5.1208 & TRN & \\
\hline CHEMBL1323391 & 737823 & 4.8 & 5.1369 & TRN & \\
\hline CHEMBL491909 & 737823 & 4.9 & 5.1704 & TRN & \\
\hline CHEMBL25236 & 737823 & 4.7 & 5.2606 & TRN & \\
\hline CHEMBL1493592 & 737823 & 5.05 & 5.5529 & TRN & \\
\hline CHEMBL1496237 & 737823 & 5.1 & 5.2092 & TRN & \\
\hline CHEMBL1522566 & 737823 & 4.95 & 5.4217 & TRN & \\
\hline CHEMBL1563722 & 737823 & 4.6 & 5.2697 & TRN & \\
\hline CHEMBL1537973 & 737823 & 4.7 & 5.3904 & TRN & \\
\hline CHEMBL1348828 & 737823 & 5.7 & 5.1254 & TRN & \\
\hline CHEMBL1555944 & 737823 & 4.8 & 5.0464 & TRN & \\
\hline CHEMBL441282 & 737823 & 4.7 & 5.4533 & TST & \\
\hline CHEMBL3190824 & 737823 & 5.8 & 5.5387 & TRN & \\
\hline CHEMBL1514819 & 737823 & 4.8 & 5.8809 & TRN & \\
\hline CHEMBL1314273 & 737823 & 6.2 & 5.7195 & TRN & \\
\hline CHEMBL1446539 & 737823 & 4.8 & 5.4178 & TRN & \\
\hline CHEMBL426123 & 737823 & 4.7 & 5.3521 & TST & \\
\hline CHEMBL1382385 & 737823 & 5.35 & 4.7707 & TRN & \\
\hline CHEMBL1354325 & 737823 & 6.8 & 4.9484 & TST & \\
\hline CHEMBL1469707 & 737823 & 4.6 & 5.2006 & TST & \\
\hline CHEMBL1361837 & 737823 & 5.0 & 5.6311 & TRN & \\
\hline CHEMBL1310938 & 737823 & 5.0 & 5.2391 & TRN & \\
\hline CHEMBL1741866 & 737823 & 6.1 & 5.8263 & TRN & \\
\hline CHEMBL1309312 & 737823 & 4.65 & 5.3559 & TRN & \\
\hline CHEMBL1416207 & 737823 & 6.1 & $5.5470 e$ & 0000000001 & TRN \\
\hline CHEMBL1474625 & 737823 & 5.7 & 5.9587 & TRN & \\
\hline CHEMBL1742292 & 737823 & 5.5 & 5.2835 & TRN & \\
\hline CHEMBL1320315 & 737823 & 6.0 & 4.9842 & TST & \\
\hline CHEMBL1442392 & 737823 & 4.6 & 5.0102 & TRN & \\
\hline CHEMBL1608930 & 737823 & 5.1 & 5.1423 & TRN & \\
\hline CHEMBL1571005 & 737823 & 4.8 & 5.2887 & TRN & \\
\hline CHEMBL3194069 & 737823 & 5.75 & 5.2159 & TRN & \\
\hline CHEMBL1602112 & 737823 & 4.9 & 4.5911 & TRN & \\
\hline CHEMBL490913 & 737823 & 4.9 & 5.1372 & TRN & \\
\hline
\end{tabular}




\begin{tabular}{|c|c|c|c|c|c|}
\hline \\
\hline CHEMBL1331410 & 737823 & 4.7 & 4.6792 & TRN & \\
\hline CHEMBL491742 & 737823 & 4.5 & 5.1557 & TRN & \\
\hline CHEMBL1443281 & 737823 & 4.5 & 5.0069 & TRN & \\
\hline CHEMBL1322743 & 737823 & 5.7 & 5.6205 & TRN & \\
\hline CHEMBL1371337 & 737823 & 5.55 & 5.4543 & TST & \\
\hline CHEMBL1611715 & 737823 & 4.6 & 5.0619 & TRN & \\
\hline CHEMBL 293762 & 737823 & 4.5 & 5.3257 & TST & \\
\hline CHEMBL1531277 & 737823 & 5.4 & 5.7293 & TRN & \\
\hline CHEMBL1504600 & 737823 & 7.25 & 6.2209 & TST & \\
\hline CHEMBL512908 & 737823 & 6.6 & 5.9558 & TST & \\
\hline CHEMBL1354547 & 737823 & 4.9 & 5.1479 & TRN & \\
\hline CHEMBL1356299 & 737823 & 4.6 & 5.3971 & TRN & \\
\hline CHEMBL1327203 & 737823 & 6.6 & 6.5583 & TRN & \\
\hline CHEMBL 9225 & 737823 & 4.9 & 5.0342 & TRN & \\
\hline CHEMBL1576725 & 737823 & 5.7 & 5.9948 & TRN & \\
\hline CHEMBL1489605 & 737823 & 5.8 & 5.7916 & TRN & \\
\hline CHEMBL1489541 & 737823 & 5.0 & 5.0281 & TRN & \\
\hline CHEMBL3191729 & 737823 & 5.0 & 5.5246 & TRN & \\
\hline CHEMBL1520940 & 737823 & 5.5 & 5.4864 & TRN & \\
\hline CHEMBL1405627 & 737823 & 5.6 & 4.5825 & TRN & \\
\hline CHEMBL1454660 & 737823 & 6.25 & 5.3757 & TRN & \\
\hline CHEMBL1333056 & 737823 & 4.7 & 4.9509 & TST & \\
\hline CHEMBL1561402 & 737823 & 4.5 & 5.0045 & TRN & \\
\hline CHEMBL1561506 & 737823 & 5.3 & 5.2803 & TRN & \\
\hline CHEMBL454761 & 737823 & 4.5 & 4.9441 & TST & \\
\hline CHEMBL1356842 & 737823 & 4.9 & 5.0526 & TRN & \\
\hline CHEMBL1331572 & 737823 & 4.8 & 5.558 & TRN & \\
\hline CHEMBL1417861 & 737823 & 5.6 & 6.1858 & TRN & \\
\hline CHEMBL1420830 & 737823 & 6.7 & 5.5206 & TST & \\
\hline CHEMBL1594881 & 737823 & 6.4 & 6.1296 & TRN & \\
\hline CHEMBL1318083 & 737823 & 6.0 & 5.79299 & 9999999999 & TRN \\
\hline CHEMBL1450864 & 737823 & 5.2 & 5.1096 & TRN & \\
\hline CHEMBL1545452 & 737823 & 5.6 & 5.1718 & TRN & \\
\hline CHEMBL1714814 & 737823 & 4.6 & 5.2266 & TST & \\
\hline CHEMBL1590975 & 737823 & 6.2 & 5.5958 & TRN & \\
\hline CHEMBL1591380 & 737823 & 5.0 & 5.3544 & TRN & \\
\hline CHEMBL1400275 & 737823 & 4.8 & 5.4466 & TRN & \\
\hline CHEMBL1612623 & 737823 & 5.5 & 5.072 & TRN & \\
\hline CHEMBL1403294 & 737823 & 4.9 & 5.478 & TRN & \\
\hline CHEMBL1318004 & 737823 & 5.4 & 5.0013 & TRN & \\
\hline CHEMBL1436925 & 737823 & 6.3 & 6.3956 & TRN & \\
\hline CHEMBL1518546 & 737823 & 5.55 & 5.3028 & TRN & \\
\hline CHEMBL1317537 & 737823 & 6.3 & 6.0131 & TRN & \\
\hline CHEMBL1513920 & 737823 & 5.4 & 5.8235 & TRN & \\
\hline CHEMBL1490857 & 737823 & 5.65 & 5.1946 & TRN & \\
\hline CHEMBL 302783 & 737823 & 4.4 & 4.8449 & TRN & \\
\hline CHEMBL1484866 & 737823 & 6.8 & 6.3416 & TRN & \\
\hline CHEMBL1436361 & 737823 & 5.3 & 4.6281 & TRN & \\
\hline & & & & 3397 & \\
\hline
\end{tabular}




\begin{tabular}{|c|c|c|c|c|}
\hline & & & ment & al Ta \\
\hline CHEMBL1506017 & 737823 & 4.8 & 5.2578 & TRN \\
\hline CHEMBL1358631 & 737823 & 5.2 & 4.938 & TRN \\
\hline CHEMBL1358652 & 737823 & 4.8 & 5.2697 & TRN \\
\hline CHEMBL1448223 & 737823 & 5.4 & 5.5959 & TRN \\
\hline CHEMBL1335290 & 737823 & 4.7 & 5.4833 & TRN \\
\hline CHEMBL1498144 & 737823 & 4.8 & 5.5635 & TRN \\
\hline CHEMBL1528124 & 737823 & 4.6 & 4.8184 & TRN \\
\hline CHEMBL1340572 & 737823 & 5.35 & 5.1337 & TRN \\
\hline CHEMBL1371572 & 737823 & 5.2 & 5.1464 & TRN \\
\hline CHEMBL1726157 & 737823 & 5.15 & 4.9082 & TRN \\
\hline CHEMBL1528565 & 737823 & 4.6 & 4.7328 & TST \\
\hline CHEMBL1972348 & 737823 & 5.45 & 5.2297 & TRN \\
\hline CHEMBL1433752 & 737823 & 6.5 & 6.1671 & TRN \\
\hline CHEMBL1551064 & 737823 & 4.8 & 4.6841 & TRN \\
\hline CHEMBL1459535 & 737823 & 4.85 & 5.0772 & TRN \\
\hline CHEMBL1374501 & 737823 & 5.5 & 5.3216 & TRN \\
\hline CHEMBL1468283 & 737823 & 5.4 & 5.6219 & TRN \\
\hline CHEMBL1327059 & 737823 & 5.1 & 5.1386 & TRN \\
\hline CHEMBL1559560 & 737823 & 4.4 & 4.9718 & TST \\
\hline CHEMBL1591635 & 737823 & 5.5 & 5.5011 & TRN \\
\hline CHEMBL1478249 & 737823 & 6.2 & 5.6057 & TRN \\
\hline CHEMBL1551200 & 737823 & 6.1 & 5.9505 & TRN \\
\hline CHEMBL1256660 & 737823 & 4.9 & 5.1883 & TRN \\
\hline CHEMBL1361742 & 737823 & 6.3 & 5.3958 & TRN \\
\hline CHEMBL1487502 & 737823 & 4.9 & 5.1237 & TRN \\
\hline CHEMBL1451768 & 737823 & 4.7 & 4.8846 & TRN \\
\hline CHEMBL1346080 & 737823 & 4.9 & 5.34 & TRN \\
\hline CHEMBL1555896 & 737823 & 4.85 & 4.7783 & TRN \\
\hline CHEMBL1315109 & 737823 & 5.5 & 5.1377 & TRN \\
\hline CHEMBL1428510 & 737823 & 5.5 & 5.2261 & TRN \\
\hline CHEMBL1354388 & 737823 & 5.0 & 5.3452 & TRN \\
\hline CHEMBL1357157 & 737823 & 5.6 & 4.9159 & TRN \\
\hline CHEMBL3214056 & 737823 & 6.45 & 6.0167 & TRN \\
\hline CHEMBL1573418 & 737823 & 4.9 & 5.0762 & TRN \\
\hline CHEMBL1548190 & 737823 & 4.8 & 5.4432 & TRN \\
\hline CHEMBL1495760 & 737823 & 4.65 & 5.1832 & TRN \\
\hline CHEMBL1370601 & 737823 & 6.05 & 5.3455 & TRN \\
\hline CHEMBL1397225 & 737823 & 4.8 & 4.5645 & TRN \\
\hline CHEMBL1357491 & 737823 & 4.9 & 5.6656 & TRN \\
\hline CHEMBL1316453 & 737823 & 4.8 & 5.2712 & TRN \\
\hline CHEMBL1990383 & 737823 & 5.35 & 5.1684 & TRN \\
\hline CHEMBL1572747 & 737823 & 5.5 & 5.6064 & TRN \\
\hline CHEMBL1504991 & 737823 & 7.3 & 5.5776 & TRN \\
\hline CHEMBL1364298 & 737823 & 6.55 & 5.2528 & TRN \\
\hline CHEMBL1698315 & 737823 & 4.85 & 5.5395 & TST \\
\hline CHEMBL1462161 & 737823 & 4.6 & 4.8541 & TRN \\
\hline CHEMBL266459 & 737823 & 4.9 & 5.3063 & TST \\
\hline CHEMBL1542047 & 737823 & 5.4 & 5.4646 & TRN \\
\hline
\end{tabular}




\begin{tabular}{|c|c|c|c|c|}
\hline \multicolumn{5}{|c|}{ Supplemental Table S2.txt } \\
\hline CHEMBL1532517 & 737823 & 5.4 & 5.3946 & TRN \\
\hline CHEMBL289233 & 737823 & 6.4 & 5.2136 & TRN \\
\hline CHEMBL1523486 & 737823 & 4.65 & 4.8939 & TRN \\
\hline CHEMBL1372099 & 737823 & 5.15 & 4.9901 & TRN \\
\hline CHEMBL 2007212 & 737823 & 6.0 & 4.9837 & TRN \\
\hline CHEMBL1578982 & 737823 & 5.75 & 4.8449 & TRN \\
\hline CHEMBL1308884 & 737823 & 5.55 & 5.2696 & TRN \\
\hline CHEMBL409902 & 737823 & 4.6 & 5.003 & TST \\
\hline CHEMBL1407160 & 737823 & 5.95 & 5.5859 & TRN \\
\hline CHEMBL1333382 & 737823 & 5.5 & 5.6051 & TRN \\
\hline CHEMBL1529705 & 737823 & 4.75 & 5.4274 & TST \\
\hline CHEMBL1515804 & 737823 & 5.3 & 5.4899 & TRN \\
\hline CHEMBL1486304 & 737823 & 6.2 & 5.9855 & TRN \\
\hline CHEMBL1555369 & 737823 & 5.5 & 5.2338 & TRN \\
\hline CHEMBL1574071 & 737823 & 5.7 & 5.0143 & TST \\
\hline CHEMBL1409258 & 737823 & 5.8 & 5.3519 & TRN \\
\hline CHEMBL1306864 & 737823 & 5.6 & 4.8464 & TRN \\
\hline CHEMBL1500199 & 737823 & 4.85 & 5.2711 & TRN \\
\hline CHEMBL1393830 & 737823 & 5.05 & 5.8612 & TST \\
\hline CHEMBL1389497 & 737823 & 6.0 & 5.7931 & TRN \\
\hline CHEMBL1403168 & 737823 & 5.9 & 5.0465 & TRN \\
\hline CHEMBL1331618 & 737823 & 5.3 & 5.0461 & TRN \\
\hline CHEMBL1530091 & 737823 & 4.7 & 4.8686 & TRN \\
\hline CHEMBL1980031 & 737823 & 5.9 & 5.0079 & TRN \\
\hline CHEMBL1337951 & 737823 & 5.5 & 5.6016 & TRN \\
\hline CHEMBL1417604 & 737823 & 5.2 & 5.4968 & TST \\
\hline CHEMBL1410599 & 737823 & 5.1 & 4.8668 & TRN \\
\hline CHEMBL1587168 & 737823 & 4.8 & 5.0188 & TRN \\
\hline CHEMBL1326411 & 737823 & 4.5 & 4.7403 & TRN \\
\hline CHEMBL1515034 & 737823 & 5.3 & 5.567 & TRN \\
\hline CHEMBL1194310 & 737823 & 4.5 & 4.9275 & TST \\
\hline CHEMBL1591879 & 737823 & 6.3 & 5.358 & TRN \\
\hline CHEMBL1705400 & 737823 & 5.5 & 5.3034 & TRN \\
\hline CHEMBL1256697 & 737823 & 4.6 & 5.1441 & TRN \\
\hline CHEMBL1400900 & 737823 & 4.9 & 5.2939 & TRN \\
\hline CHEMBL1377369 & 737823 & 5.1 & 5.4004 & TST \\
\hline CHEMBL1508610 & 737823 & 5.4 & 5.3302 & TRN \\
\hline CHEMBL1602161 & 737823 & 4.9 & 4.9538 & TRN \\
\hline CHEMBL1490214 & 737823 & 4.9 & 5.1921 & TST \\
\hline CHEMBL1613702 & 737823 & 4.4 & 4.5583 & TST \\
\hline CHEMBL1461188 & 737823 & 5.4 & 5.481 & TRN \\
\hline CHEMBL1583365 & 737823 & 6.6 & 5.5423 & TRN \\
\hline CHEMBL1355663 & 737823 & 6.0 & 5.4463 & TRN \\
\hline CHEMBL1511350 & 737823 & 5.45 & 5.6852 & TRN \\
\hline CHEMBL1371022 & 737823 & 5.0 & 5.3754 & TRN \\
\hline CHEMBL1490573 & 737823 & 5.6 & 5.6736 & TRN \\
\hline CHEMBL1558223 & 737823 & 4.8 & 5.1333 & TRN \\
\hline CHEMBL13662 & 737823 & 7.1 & 5.4204 & TRN \\
\hline
\end{tabular}




\begin{tabular}{|c|c|c|c|c|}
\hline & & & pplement & al $\mathrm{Ta}$ \\
\hline CHEMBL51697 & 737823 & 6.0 & 5.0483 & TST \\
\hline CHEMBL1304098 & 737823 & 4.8 & 4.8154 & TST \\
\hline CHEMBL1714198 & 737823 & 6.7 & 5.1767 & TRN \\
\hline CHEMBL1499066 & 737823 & 4.6 & 5.0629 & TRN \\
\hline CHEMBL1542467 & 737823 & 4.8 & 4.9196 & TST \\
\hline CHEMBL1419702 & 737823 & 4.5 & 4.9039 & TRN \\
\hline CHEMBL1309731 & 737823 & 5.45 & 4.9499 & TRN \\
\hline CHEMBL3196162 & 737823 & 6.25 & 5.6653 & TRN \\
\hline CHEMBL1741952 & 737823 & 6.6 & 5.2181 & TRN \\
\hline CHEMBL1329604 & 737823 & 6.95 & 5.8612 & TST \\
\hline CHEMBL1595142 & 737823 & 6.4 & 5.8771 & TRN \\
\hline CHEMBL1578674 & 737823 & 5.4 & 5.2089 & TRN \\
\hline CHEMBL1414232 & 737823 & 5.0 & 5.2645 & TRN \\
\hline CHEMBL1394706 & 737823 & 4.6 & 5.6091 & TRN \\
\hline CHEMBL1590909 & 737823 & 6.4 & 6.1442 & TRN \\
\hline CHEMBL1395165 & 737823 & 4.7 & 4.5937 & TRN \\
\hline CHEMBL265698 & 737823 & 5.9 & 5.8181 & TRN \\
\hline CHEMBL1362544 & 737823 & 4.8 & 4.506 & TRN \\
\hline CHEMBL1398786 & 737823 & 4.9 & 4.4784 & TST \\
\hline CHEMBL1526480 & 737823 & 4.55 & 5.1918 & TRN \\
\hline CHEMBL313339 & 737823 & 5.45 & 5.7896 & TST \\
\hline CHEMBL88621 & 737823 & 4.5 & 4.8542 & TRN \\
\hline CHEMBL1370296 & 737823 & 5.4 & 5.9051 & TRN \\
\hline CHEMBL1354693 & 737823 & 4.8 & 4.8942 & TRN \\
\hline CHEMBL1516211 & 737823 & 6.0 & 6.1133 & TRN \\
\hline CHEMBL1407287 & 737823 & 5.35 & 5.2209 & TRN \\
\hline CHEMBL1483332 & 737823 & 4.55 & 5.0981 & TRN \\
\hline CHEMBL1611646 & 737823 & 5.5 & 5.5544 & TRN \\
\hline CHEMBL1453217 & 737823 & 5.4 & 4.9212 & TRN \\
\hline CHEMBL1518559 & 737823 & 4.75 & 4.8988 & TRN \\
\hline CHEMBL1445799 & 737823 & 5.7 & 5.519 & TRN \\
\hline CHEMBL1515565 & 737823 & 6.1 & 5.4098 & TRN \\
\hline CHEMBL101168 & 737823 & 4.9 & 5.1518 & TST \\
\hline CHEMBL2369279 & 737823 & 5.8 & 5.2243 & TRN \\
\hline CHEMBL1354600 & 737823 & 5.9 & 5.4932 & TRN \\
\hline CHEMBL 3210878 & 737823 & 4.9 & 5.2114 & TRN \\
\hline CHEMBL1742145 & 737823 & 5.2 & 4.9613 & TST \\
\hline CHEMBL1394783 & 737823 & 5.6 & 5.275 & TRN \\
\hline CHEMBL3211898 & 737823 & 4.65 & 5.5904 & TRN \\
\hline CHEMBL1511998 & 737823 & 6.4 & 5.5595 & TST \\
\hline CHEMBL1552984 & 737823 & 5.3 & 4.9784 & TRN \\
\hline CHEMBL1605426 & 737823 & 4.8 & 4.8377 & TST \\
\hline CHEMBL1396757 & 737823 & 6.4 & 5.8695 & TRN \\
\hline CHEMBL1516170 & 737823 & 5.0 & 5.55 & TRN \\
\hline CHEMBL1569846 & 737823 & 4.95 & 4.9976 & TST \\
\hline CHEMBL3197340 & 737823 & 5.65 & 5.5491 & TRN \\
\hline CHEMBL1447904 & 737823 & 4.6 & 5.0045 & TRN \\
\hline CHEMBL1314386 & 737823 & 7.0 & 5.9357 & TRN \\
\hline
\end{tabular}




\begin{tabular}{|c|c|c|c|c|c|}
\hline \\
\hline CHEMBL1484398 & 737823 & 4.9 & 5.4399 & TRN & \\
\hline CHEMBL1528906 & 737823 & 5.3 & 5.4661 & TRN & \\
\hline CHEMBL1585324 & 737823 & 5.45 & 5.4949 & TRN & \\
\hline CHEMBL1310810 & 737823 & 6.7 & 5.5969 & TRN & \\
\hline CHEMBL1256835 & 737823 & 4.4 & 4.9393 & TRN & \\
\hline CHEMBL276727 & 737823 & 4.5 & 5.0219 & TST & \\
\hline CHEMBL512832 & 737823 & 5.9 & 5.9769 & TRN & \\
\hline CHEMBL1314291 & 737823 & 4.5 & 5.1024 & TRN & \\
\hline CHEMBL1508867 & 737823 & 4.95 & 5.3824 & TRN & \\
\hline CHEMBL1570292 & 737823 & 5.4 & 5.6653 & TST & \\
\hline CHEMBL1414666 & 737823 & 4.55 & 4.9504 & TRN & \\
\hline CHEMBL3212838 & 737823 & 5.85 & 5.2184 & TRN & \\
\hline CHEMBL1449575 & 737823 & 6.4 & 5.6456 & TRN & \\
\hline CHEMBL1574446 & 737823 & 5.6 & 5.1785 & TRN & \\
\hline CHEMBL3211591 & 737823 & 4.75 & 5.232 & TST & \\
\hline CHEMBL1482806 & 737823 & 4.85 & 5.29899 & 99999999995 & TRN \\
\hline CHEMBL1530194 & 737823 & 6.0 & 5.8776 & TRN & \\
\hline CHEMBL1488997 & 737823 & 5.0 & 5.3018 & TRN & \\
\hline CHEMBL1516388 & 737823 & 6.0 & 5.3225 & TST & \\
\hline CHEMBL1593717 & 737823 & 4.4 & 4.9067 & TST & \\
\hline CHEMBL1741697 & 737823 & 4.55 & 5.4112 & TRN & \\
\hline CHEMBL1473420 & 737823 & 4.9 & 5.4321 & TRN & \\
\hline CHEMBL1569985 & 737823 & 5.0 & 5.1777 & TRN & \\
\hline CHEMBL1409996 & 737823 & 4.5 & 5.0572 & TRN & \\
\hline CHEMBL1603926 & 737823 & 6.0 & 5.3825 & TRN & \\
\hline CHEMBL1304249 & 737823 & 4.55 & 5.0974 & TRN & \\
\hline CHEMBL66693 & 737823 & 4.5 & 4.7813 & TRN & \\
\hline CHEMBL1395137 & 737823 & 4.8 & 4.9729 & TRN & \\
\hline CHEMBL1404954 & 737823 & 5.4 & 5.9581 & TRN & \\
\hline CHEMBL1442250 & 737823 & 5.2 & 5.1716 & TRN & \\
\hline CHEMBL1333564 & 737823 & 5.8 & 5.6859 & TRN & \\
\hline CHEMBL1484692 & 737823 & 5.45 & 5.3827 & TST & \\
\hline CHEMBL1421262 & 737823 & 4.9 & 5.3662 & TRN & \\
\hline CHEMBL1741790 & 737823 & 4.4 & 5.1352 & TST & \\
\hline CHEMBL1358983 & 737823 & 6.0 & 6.17 & TRN & \\
\hline CHEMBL1534143 & 737823 & 5.05 & 5.5521 & TRN & \\
\hline CHEMBL1587623 & 737823 & 5.2 & 4.8043 & TRN & \\
\hline CHEMBL1434950 & 737823 & 4.4 & 4.9804 & TST & \\
\hline CHEMBL1699539 & 737823 & 5.2 & 5.2498 & TRN & \\
\hline CHEMBL1520347 & 737823 & 5.1 & 4.8042 & TRN & \\
\hline CHEMBL1515295 & 737823 & 4.7 & 4.7441 & TRN & \\
\hline CHEMBL1473472 & 737823 & 4.8 & 5.2543 & TRN & \\
\hline CHEMBL1523107 & 737823 & 4.8 & 5.0395 & TRN & \\
\hline CHEMBL1494100 & 737823 & 5.55 & 5.1927 & TRN & \\
\hline CHEMBL1312830 & 737823 & 4.85 & 5.4241 & TRN & \\
\hline CHEMBL1513990 & 737823 & 6.7 & 6.5725 & TRN & \\
\hline CHEMBL1413443 & 737823 & 4.7 & 5.0061 & TRN & \\
\hline CHEMBL1552277 & 737823 & 6.4 & 5.8506 & TRN & \\
\hline & & & & 3401 & \\
\hline
\end{tabular}




\begin{tabular}{|c|c|c|c|c|c|}
\hline \multicolumn{6}{|c|}{ Supplemental Table S2.txt } \\
\hline CHEMBL1589335 & 737823 & 5.6 & 5.2458 & TST & \\
\hline CHEMBL1402334 & 737823 & 4.8 & 5.4508 & TRN & \\
\hline CHEMBL1565311 & 737823 & 6.5 & 6.0354 & TRN & \\
\hline CHEMBL491976 & 737823 & 5.0 & 5.1511 & TRN & \\
\hline CHEMBL1343568 & 737823 & 5.2 & 5.1487 & TRN & \\
\hline CHEMBL1357338 & 737823 & 6.0 & 5.7267 & TRN & \\
\hline CHEMBL1408236 & 737823 & 5.45 & 5.6499 & TRN & \\
\hline CHEMBL1568465 & 737823 & 5.3 & 5.49 & TRN & \\
\hline CHEMBL1490528 & 737823 & 5.4 & 5.1246 & TRN & \\
\hline CHEMBL1587518 & 737823 & 4.75 & 5.4851 & TST & \\
\hline CHEMBL1518920 & 737823 & 5.6 & $5.6270 e$ & 0000000001 & TRN \\
\hline CHEMBL1377781 & 737823 & 4.6 & 4.9937 & TRN & \\
\hline CHEMBL1400050 & 737823 & 6.0 & 5.7962 & TRN & \\
\hline CHEMBL1330272 & 737823 & 5.1 & 4.6632 & TRN & \\
\hline CHEMBL1609103 & 737823 & 4.65 & 4.8973 & TRN & \\
\hline CHEMBL1452098 & 737823 & 5.5 & 5.7863 & TRN & \\
\hline CHEMBL1965559 & 737823 & 5.2 & 5.6822 & TRN & \\
\hline CHEMBL1382735 & 737823 & 5.35 & 5.2412 & TRN & \\
\hline CHEMBL1733088 & 737823 & 5.1 & 5.5157 & TRN & \\
\hline CHEMBL1526113 & 737823 & 5.4 & 5.5492 & TRN & \\
\hline CHEMBL1303031 & 737823 & 4.8 & 5.4943 & TST & \\
\hline CHEMBL369142 & 737823 & 4.5 & 5.5077 & TST & \\
\hline CHEMBL36121 & 737823 & 6.35 & 5.2179 & TST & \\
\hline CHEMBL1450860 & 737823 & 5.3 & 5.8892 & TRN & \\
\hline CHEMBL1398216 & 737823 & 5.1 & 5.0492 & TST & \\
\hline CHEMBL1335726 & 737823 & 4.5 & 5.2772 & TRN & \\
\hline CHEMBL333985 & 737823 & 5.8 & 5.3476 & TST & \\
\hline CHEMBL1408609 & 737823 & 4.8 & 5.5201 & TST & \\
\hline CHEMBL1439144 & 737823 & 5.5 & 5.3751 & TST & \\
\hline CHEMBL1304054 & 737823 & 5.65 & 5.6109 & TRN & \\
\hline CHEMBL1602926 & 737823 & 6.3 & 5.8392 & TRN & \\
\hline CHEMBL1524866 & 737823 & 5.3 & 5.2535 & TST & \\
\hline CHEMBL3191056 & 737823 & 5.05 & 5.7539 & TST & \\
\hline CHEMBL1332964 & 737823 & 4.8 & 4.4342 & TRN & \\
\hline CHEMBL1395412 & 737823 & 4.8 & 4.6322 & TST & \\
\hline CHEMBL479014 & 737823 & 6.9 & 5.8686 & TST & \\
\hline CHEMBL1390616 & 737823 & 4.9 & 5.0389 & TRN & \\
\hline CHEMBL1605138 & 737823 & 5.05 & 5.393 & TRN & \\
\hline CHEMBL1587575 & 737823 & 4.9 & 4.8337 & TRN & \\
\hline CHEMBL68423 & 737823 & 6.7 & 5.7826 & TST & \\
\hline CHEMBL1359803 & 737823 & 4.7 & 5.5539 & TRN & \\
\hline CHEMBL1513280 & 737823 & 5.6 & 5.083 & TRN & \\
\hline CHEMBL1704202 & 737823 & 4.75 & 5.135 & TRN & \\
\hline CHEMBL1372657 & 737823 & 6.0 & 5.6609 & TST & \\
\hline CHEMBL1568684 & 737823 & 6.0 & 5.5636 & TST & \\
\hline CHEMBL1358807 & 737823 & 4.9 & 5.1406 & TRN & \\
\hline CHEMBL1256866 & 737823 & 4.9 & 4.832 & TRN & \\
\hline CHEMBL76589 & 737823 & 5.4 & 5.3706 & TRN & \\
\hline
\end{tabular}




\begin{tabular}{|c|c|c|c|c|c|}
\hline CHEMBL1424743 & 737823 & 4.8 & 4.6898 & TRN & \\
\hline CHEMBL1430113 & 737823 & 4.6 & 4.8994 & TRN & \\
\hline CHEMBL1413230 & 737823 & 5.45 & 5.2371 & TST & \\
\hline CHEMBL1432603 & 737823 & 4.8 & 5.7531 & TRN & \\
\hline CHEMBL1557015 & 737823 & 4.55 & 5.2844 & TRN & \\
\hline CHEMBL1719804 & 737823 & 5.45 & \multicolumn{2}{|c|}{5.202999999999999} & TRN \\
\hline CHEMBL1483263 & 737823 & 5.1 & 4.9215 & TST & \\
\hline CHEMBL1591677 & 737823 & 4.6 & 4.9815 & TRN & \\
\hline CHEMBL1471612 & 737823 & 5.45 & 5.4772 & TRN & \\
\hline CHEMBL1355146 & 737823 & 4.5 & 4.5864 & TRN & \\
\hline CHEMBL1318447 & 737823 & 6.3 & 6.086 & TRN & \\
\hline CHEMBL1448870 & 737823 & 5.0 & \multicolumn{2}{|c|}{5.0360000000000005} & TRN \\
\hline CHEMBL1434082 & 737823 & 5.1 & 5.5182 & TRN & \\
\hline CHEMBL1316219 & 737823 & 5.3 & 5.5708 & TRN & \\
\hline CHEMBL1509337 & 737823 & 5.1 & 5.3306 & TRN & \\
\hline CHEMBL1461511 & 737823 & 4.9 & 4.7399 & TRN & \\
\hline CHEMBL1380944 & 737823 & 4.65 & 4.8236 & TST & \\
\hline CHEMBL1486820 & 737823 & 5.1 & 5.131 & TRN & \\
\hline CHEMBL1480136 & 737823 & 4.9 & 5.3849 & TST & \\
\hline CHEMBL1491709 & 737823 & 5.1 & 5.0027 & TRN & \\
\hline CHEMBL1607586 & 737823 & 4.85 & 5.0025 & TRN & \\
\hline CHEMBL 273807 & 737823 & 4.5 & 5.2272 & TRN & \\
\hline CHEMBL1329174 & 737823 & 4.4 & 4.6061 & TRN & \\
\hline CHEMBL1512708 & 737823 & 6.3 & 5.9545 & TRN & \\
\hline CHEMBL1310193 & 737823 & 5.9 & 5.5741 & TRN & \\
\hline CHEMBL1462462 & 737823 & 6.05 & 5.8362 & TST & \\
\hline CHEMBL3198657 & 737823 & 5.1 & 4.8781 & TST & \\
\hline CHEMBL1416795 & 737823 & 4.6 & 4.9413 & TRN & \\
\hline CHEMBL1567569 & 737823 & 5.4 & 5.3304 & TRN & \\
\hline CHEMBL1374288 & 737823 & 4.65 & 4.8477 & TRN & \\
\hline CHEMBL584860 & 737823 & 6.05 & 5.2855 & TRN & \\
\hline CHEMBL1442060 & 737823 & 5.65 & 5.3338 & TRN & \\
\hline CHEMBL81753 & 737823 & 5.6 & 5.079 & TST & \\
\hline CHEMBL 1478350 & 737823 & 6.0 & 5.9369 & TRN & \\
\hline CHEMBL1487070 & 737823 & 4.5 & 4.6219 & TRN & \\
\hline CHEMBL1403448 & 737823 & 5.95 & 5.8232 & TRN & \\
\hline CHEMBL1487421 & 737823 & 4.6 & 5.6439 & TRN & \\
\hline CHEMBL1741713 & 737823 & 5.4 & 4.9312 & TRN & \\
\hline CHEMBL582507 & 737823 & 4.9 & 5.3705 & TRN & \\
\hline CHEMBL1569972 & 737823 & 4.9 & 4.6287 & TRN & \\
\hline CHEMBL1708182 & 737823 & 4.4 & 5.0698 & TRN & \\
\hline CHEMBL580421 & 737823 & 5.5 & 4.7969 & TST & \\
\hline CHEMBL1486796 & 737823 & 5.45 & 5.4511 & TRN & \\
\hline CHEMBL1309131 & 737823 & 4.85 & 5.5657 & TRN & \\
\hline CHEMBL1316265 & 737823 & 4.6 & 4.7217 & TRN & \\
\hline CHEMBL1601121 & 737823 & 4.8 & 4.8447 & TRN & \\
\hline CHEMBL1386134 & 737823 & 4.6 & 4.9495 & TST & \\
\hline CHEMBL1552181 & 737823 & 5.6 & 5.2478 & TRN & \\
\hline
\end{tabular}




\begin{tabular}{|c|c|c|c|c|c|}
\hline & & & & & \\
\hline CHEMBL1398713 & 737823 & 6.3 & 5.3556 & TST & \\
\hline CHEMBL1344883 & 737823 & 4.4 & 4.8215 & TRN & \\
\hline CHEMBL1439455 & 737823 & 5.8 & 5.2992 & TRN & \\
\hline CHEMBL1321846 & 737823 & 4.8 & 5.0752 & TRN & \\
\hline CHEMBL1489033 & 737823 & 5.3 & 5.2294 & TST & \\
\hline CHEMBL1561383 & 737823 & 5.1 & 5.2902 & TRN & \\
\hline CHEMBL1310481 & 737823 & 5.7 & 5.4537 & TST & \\
\hline CHEMBL1362420 & 737823 & 6.6 & 5.7277 & TRN & \\
\hline CHEMBL1524363 & 737823 & 4.65 & 5.71899 & 9999999999 & TST \\
\hline CHEMBL1348232 & 737823 & 4.7 & 5.1994 & TRN & \\
\hline CHEMBL1530495 & 737823 & 5.2 & 5.2969 & TRN & \\
\hline CHEMBL1517418 & 737823 & 5.6 & 5.2019 & TRN & \\
\hline CHEMBL1329194 & 737823 & 8.0 & 5.1873 & TST & \\
\hline CHEMBL1551982 & 737823 & 4.8 & 5.0274 & TRN & \\
\hline CHEMBL1475990 & 737823 & 6.1 & 5.62799 & 9999999999 & TRN \\
\hline CHEMBL1571144 & 737823 & 4.6 & 5.8504 & TST & \\
\hline CHEMBL1411555 & 737823 & 5.7 & 5.6072 & TRN & \\
\hline CHEMBL19259 & 737823 & 4.5 & 5.3743 & TRN & \\
\hline CHEMBL1288013 & 737823 & 6.2 & 5.7877 & TRN & \\
\hline CHEMBL1593432 & 737823 & 4.9 & 5.0825 & TRN & \\
\hline CHEMBL1515374 & 737823 & 5.7 & 5.7518 & TRN & \\
\hline CHEMBL1567516 & 737823 & 5.4 & 5.2459 & TST & \\
\hline CHEMBL1317400 & 737823 & 5.7 & 5.4938 & TRN & \\
\hline CHEMBL1531863 & 737823 & 4.7 & 5.0584 & TRN & \\
\hline CHEMBL1591876 & 737823 & 5.0 & 5.1845 & TRN & \\
\hline CHEMBL1551633 & 737823 & 4.8 & 5.4386 & TRN & \\
\hline CHEMBL1449517 & 737823 & 6.0 & 5.3252 & TRN & \\
\hline CHEMBL1371836 & 737823 & 6.1 & 4.9567 & TRN & \\
\hline CHEMBL1602123 & 737823 & 5.0 & 4.7199 & TRN & \\
\hline CHEMBL1741524 & 737823 & 6.9 & 4.6934 & TRN & \\
\hline CHEMBL1374260 & 737823 & 5.2 & 5.2963 & TST & \\
\hline CHEMBL1565914 & 737823 & 5.7 & 5.3739 & TRN & \\
\hline CHEMBL1473405 & 737823 & 5.1 & 5.75700 & 0000000001 & TRN \\
\hline CHEMBL1389041 & 737823 & 5.65 & 5.6253 & TRN & \\
\hline CHEMBL1600620 & 737823 & 5.9 & 5.5011 & TRN & \\
\hline CHEMBL150 & 737823 & 7.1 & 6.0561 & TRN & \\
\hline CHEMBL1706828 & 737823 & 4.5 & 5.2174 & TRN & \\
\hline CHEMBL1546010 & 737823 & 6.65 & 5.0347 & TST & \\
\hline CHEMBL1556431 & 737823 & 4.6 & 4.8132 & TRN & \\
\hline CHEMBL1443979 & 737823 & 6.8 & 5.7094 & TRN & \\
\hline CHEMBL1367104 & 737823 & 4.5 & 5.0276 & TRN & \\
\hline CHEMBL1360821 & 737823 & 4.5 & 4.8915 & TRN & \\
\hline CHEMBL1579133 & 737823 & 4.6 & 4.9243 & TRN & \\
\hline CHEMBL1530280 & 737823 & 6.05 & 5.3987 & TRN & \\
\hline CHEMBL1326132 & 737823 & 4.9 & 5.0693 & TRN & \\
\hline CHEMBL1341727 & 737823 & 4.8 & 4.9975 & TRN & \\
\hline CHEMBL1426363 & 737823 & 5.8 & 4.9673 & TRN & \\
\hline CHEMBL1591238 & 737823 & 4.9 & 5.1203 & TRN & \\
\hline
\end{tabular}




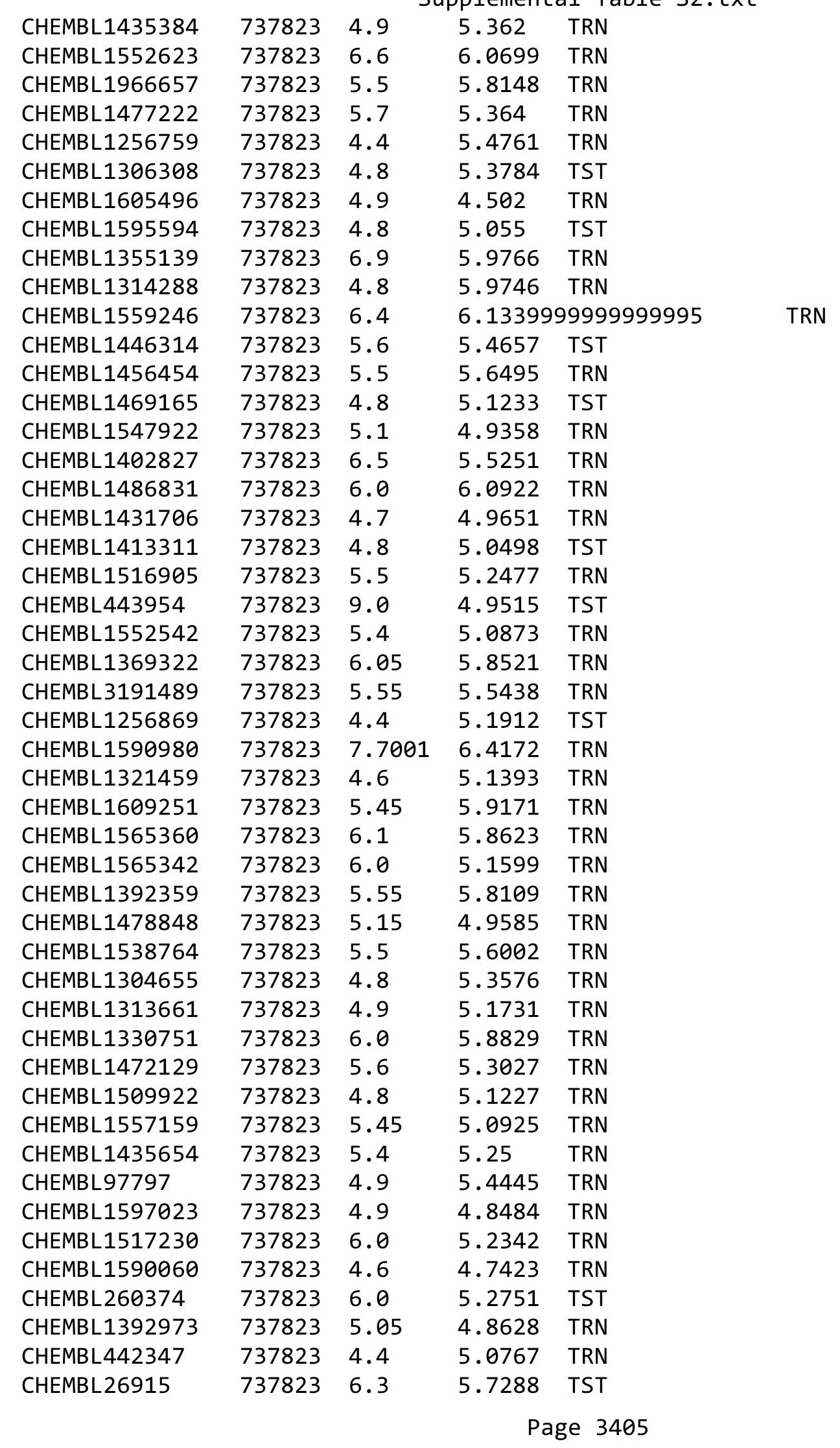




\begin{tabular}{|c|c|c|c|c|c|}
\hline & & & & & \\
\hline CHEMBL1445817 & 737823 & 6.7 & 5.2845 & TST & \\
\hline CHEMBL1591384 & 737823 & 4.8 & 4.9813 & TRN & \\
\hline CHEMBL1519165 & 737823 & 5.1 & 5.2142 & TRN & \\
\hline CHEMBL1469402 & 737823 & 4.9 & 5.4457 & TRN & \\
\hline CHEMBL3208361 & 737823 & 5.7 & 5.2339 & TRN & \\
\hline CHEMBL1507284 & 737823 & 4.6 & 4.435 & TRN & \\
\hline CHEMBL1312749 & 737823 & 6.35 & 5.9879 & TRN & \\
\hline CHEMBL1513223 & 737823 & 5.6 & 5.5017 & TRN & \\
\hline CHEMBL1399898 & 737823 & 5.45 & 5.7824 & TRN & \\
\hline CHEMBL1972133 & 737823 & 6.85 & 6.2873 & TRN & \\
\hline CHEMBL1319292 & 737823 & 4.8 & 4.7643 & TRN & \\
\hline CHEMBL1510151 & 737823 & 4.9 & 5.3455 & TRN & \\
\hline CHEMBL1510776 & 737823 & 4.9 & 4.90300 & 00000000005 & TRN \\
\hline CHEMBL1554693 & 737823 & 4.7 & 5.0736 & TRN & \\
\hline CHEMBL1320242 & 737823 & 5.45 & 5.1969 & TRN & \\
\hline CHEMBL1374061 & 737823 & 6.75 & 5.61100 & 0000000001 & TST \\
\hline CHEMBL1566684 & 737823 & 6.15 & 5.6249 & TST & \\
\hline CHEMBL1346407 & 737823 & 4.8 & 5.1201 & TRN & \\
\hline CHEMBL1356094 & 737823 & 6.7 & 5.6188 & TRN & \\
\hline CHEMBL1421390 & 737823 & 5.3 & 5.0884 & TRN & \\
\hline CHEMBL1336812 & 737823 & 4.8 & 5.2567 & TST & \\
\hline CHEMBL1317306 & 737823 & 6.2 & 5.7794 & TRN & \\
\hline CHEMBL1474977 & 737823 & 8.9 & 4.9186 & TRN & \\
\hline CHEMBL1516249 & 737823 & 5.0 & 4.8575 & TRN & \\
\hline CHEMBL3214526 & 737823 & 4.65 & 4.8935 & TST & \\
\hline CHEMBL1367917 & 737823 & 5.3 & 5.3384 & TRN & \\
\hline CHEMBL1443628 & 737823 & 7.0 & 5.3968 & TRN & \\
\hline CHEMBL1444269 & 737823 & 5.1 & 5.268 & TRN & \\
\hline CHEMBL1427943 & 737823 & 5.05 & 5.1569 & TRN & \\
\hline CHEMBL1359184 & 737823 & 6.0 & 5.1686 & TRN & \\
\hline CHEMBL1336557 & 737823 & 4.7 & 5.267 & TRN & \\
\hline CHEMBL1594030 & 737823 & 5.3 & 5.1875 & TRN & \\
\hline CHEMBL1451346 & 737823 & 5.55 & 5.1817 & TRN & \\
\hline CHEMBL3198450 & 737823 & 5.6 & 5.6004 & TST & \\
\hline CHEMBL1519291 & 737823 & 5.3 & 5.1009 & TRN & \\
\hline CHEMBL3212789 & 737823 & 5.15 & 5.2359 & TRN & \\
\hline CHEMBL1461239 & 737823 & 5.1 & 5.0808 & TST & \\
\hline CHEMBL1329446 & 737823 & 4.9 & 4.9847 & TRN & \\
\hline CHEMBL1337960 & 737823 & 6.1 & 5.644 & TRN & \\
\hline CHEMBL1405151 & 737823 & 5.75 & 5.5728 & TRN & \\
\hline CHEMBL1590974 & 737823 & 6.0 & 5.6883 & TRN & \\
\hline CHEMBL1512702 & 737823 & 5.1 & 4.6642 & TRN & \\
\hline CHEMBL1358007 & 737823 & 5.8 & 5.4753 & TST & \\
\hline CHEMBL1448533 & 737823 & 4.6 & 5.438 & TRN & \\
\hline CHEMBL1346358 & 737823 & 4.9 & 4.8254 & TRN & \\
\hline CHEMBL1439401 & 737823 & 6.8 & 6.1074 & TRN & \\
\hline CHEMBL1517999 & 737823 & 5.5 & 5.5504 & TRN & \\
\hline CHEMBL1354455 & 737823 & 5.6 & 6.0516 & TRN & \\
\hline
\end{tabular}




\begin{tabular}{|c|c|c|c|c|c|}
\hline \multicolumn{6}{|c|}{ Supplemental Table S2.txt } \\
\hline CHEMBL1342890 & 737823 & 5.0 & 5.5548 & TRN & \\
\hline CHEMBL1607133 & 737823 & 4.9 & 4.8194 & TRN & \\
\hline CHEMBL1386793 & 737823 & 5.05 & 5.5284 & TRN & \\
\hline CHEMBL1742323 & 737823 & 5.0 & 4.7926 & TRN & \\
\hline CHEMBL1541405 & 737823 & 5.85 & 5.8959 & TRN & \\
\hline CHEMBL1370770 & 737823 & 5.9 & 5.4757 & TRN & \\
\hline CHEMBL1469167 & 737823 & 5.05 & 5.4595 & TRN & \\
\hline CHEMBL1319243 & 737823 & 4.6 & 5.4396 & TRN & \\
\hline CHEMBL1583603 & 737823 & 4.9 & 5.171 & TRN & \\
\hline CHEMBL1409713 & 737823 & 4.55 & 5.3558 & TST & \\
\hline CHEMBL1565751 & 737823 & 5.3 & 5.1541 & TRN & \\
\hline CHEMBL1572174 & 737823 & 5.9 & 5.2897 & TRN & \\
\hline CHEMBL1386168 & 737823 & 4.6 & 5.44799 & 99999999995 & TRN \\
\hline CHEMBL 3211432 & 737823 & 5.7 & 5.6818 & TRN & \\
\hline CHEMBL1334334 & 737823 & 5.5 & 5.7181 & TRN & \\
\hline CHEMBL1453542 & 737823 & 4.5 & 4.9597 & TST & \\
\hline CHEMBL1480840 & 737823 & 4.85 & 5.1511 & TRN & \\
\hline CHEMBL1561791 & 737823 & 5.4 & 5.1132 & TRN & \\
\hline CHEMBL1520928 & 737823 & 5.85 & 5.8114 & TRN & \\
\hline CHEMBL1369693 & 737823 & 4.85 & 5.7847 & TRN & \\
\hline CHEMBL1301722 & 737823 & 4.6 & 5.077 & TST & \\
\hline CHEMBL1432007 & 737823 & 5.6 & 5.8941 & TRN & \\
\hline CHEMBL1516530 & 737823 & 6.1 & 5.4088 & TRN & \\
\hline CHEMBL480626 & 737823 & 5.0 & 5.056 & TRN & \\
\hline CHEMBL1376755 & 737823 & 4.85 & 5.1335 & TRN & \\
\hline CHEMBL1594078 & 737823 & 4.7 & 4.5698 & TRN & \\
\hline CHEMBL1513077 & 737823 & 4.9 & 5.0639 & TRN & \\
\hline CHEMBL1341809 & 737823 & 5.05 & 5.2925 & TST & \\
\hline CHEMBL3213699 & 737823 & 5.4 & 5.1262 & TRN & \\
\hline CHEMBL1554888 & 737823 & 5.8 & 5.6964 & TRN & \\
\hline CHEMBL1383394 & 737823 & 4.75 & 5.1843 & TRN & \\
\hline CHEMBL1514390 & 737823 & 4.9 & 4.6591 & TRN & \\
\hline CHEMBL3197064 & 737823 & 4.9 & 4.9099 & TRN & \\
\hline CHEMBL 68500 & 737823 & 4.9 & 5.6214 & TST & \\
\hline CHEMBL1360327 & 737823 & 4.85 & 5.3517 & TST & \\
\hline CHEMBL1533033 & 737823 & 5.1 & 5.4197 & TRN & \\
\hline CHEMBL1578807 & 737823 & 5.4 & 5.1375 & TRN & \\
\hline CHEMBL1542604 & 737823 & 5.4 & 5.5838 & TST & \\
\hline CHEMBL1408424 & 737823 & 5.15 & 4.9669 & TRN & \\
\hline CHEMBL1389262 & 737823 & 4.9 & 4.5246 & TRN & \\
\hline CHEMBL1969457 & 737823 & 4.8 & 5.5307 & TRN & \\
\hline CHEMBL1497099 & 737823 & 4.8 & 4.7955 & TRN & \\
\hline CHEMBL1465936 & 737823 & 4.6 & 5.143 & TRN & \\
\hline CHEMBL1380635 & 737823 & 4.8 & 4.8152 & TRN & \\
\hline CHEMBL1554588 & 737823 & 4.8 & 5.381 & TRN & \\
\hline CHEMBL3214412 & 737823 & 5.6 & 5.5201 & TRN & \\
\hline CHEMBL 1741745 & 737823 & 5.3 & 5.2782 & TRN & \\
\hline CHEMBL1409830 & 737823 & 5.3 & 5.5199 & TRN & \\
\hline
\end{tabular}




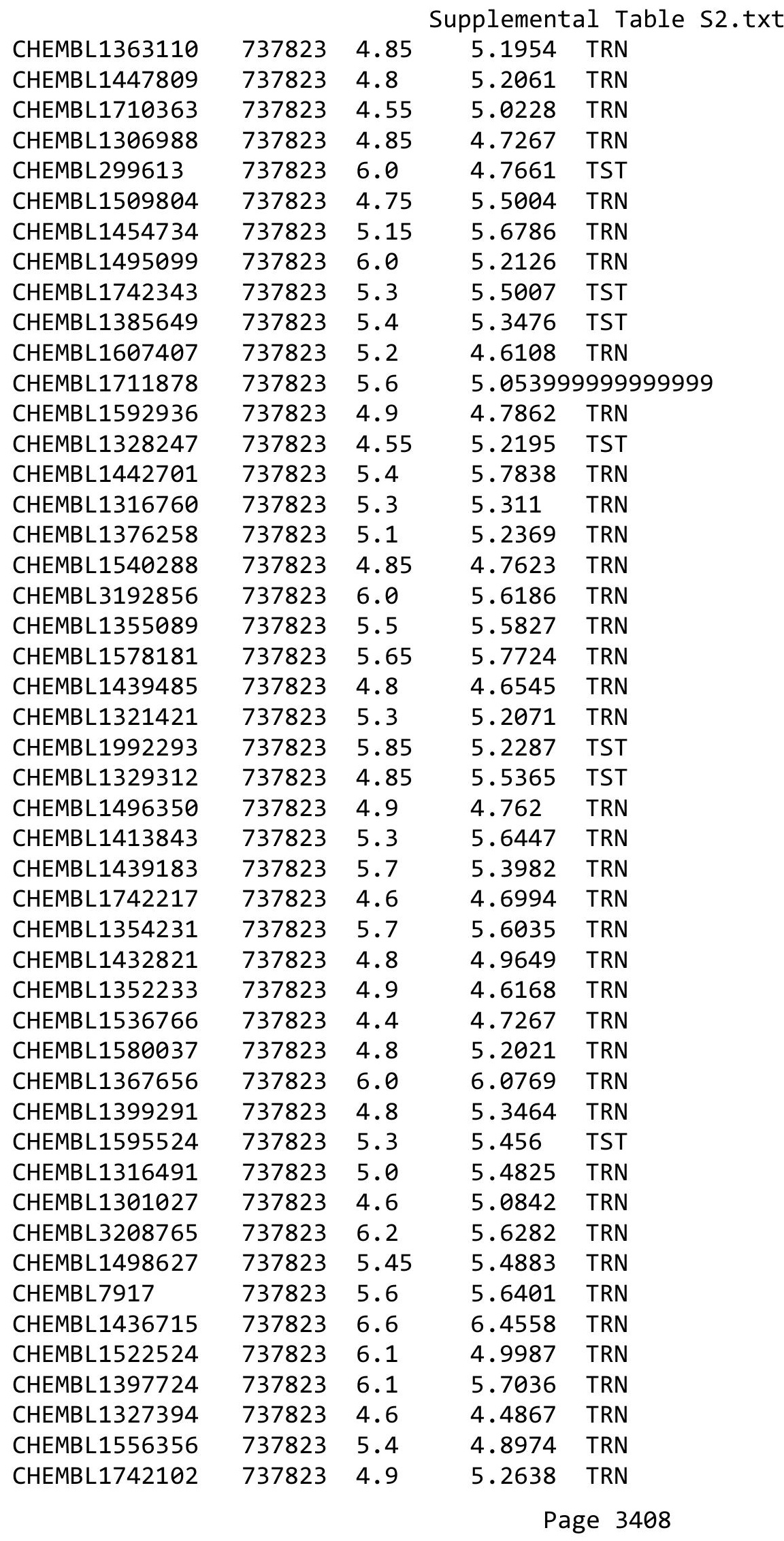




\begin{tabular}{|c|c|c|c|c|c|}
\hline \multicolumn{6}{|c|}{ Supplemental Table S2.txt } \\
\hline CHEMBL1501874 & 737823 & 5.65 & 5.528 & TRN & \\
\hline CHEMBL1562895 & 737823 & 5.9 & 5.5414 & TRN & \\
\hline CHEMBL1455816 & 737823 & 5.3 & 5.526 & TST & \\
\hline CHEMBL1477982 & 737823 & 5.1 & 5.8111 & TRN & \\
\hline CHEMBL1313321 & 737823 & 5.35 & 5.6146 & TST & \\
\hline CHEMBL1477140 & 737823 & 5.4 & 5.481 & TRN & \\
\hline CHEMBL1572430 & 737823 & 5.5 & 5.4276 & TRN & \\
\hline CHEMBL1500866 & 737823 & 4.9 & 5.2444 & TRN & \\
\hline CHEMBL1493944 & 737823 & 4.65 & 5.2596 & TRN & \\
\hline CHEMBL490717 & 737823 & 4.9 & 4.6574 & TRN & \\
\hline CHEMBL1542520 & 737823 & 4.8 & 5.0849 & TRN & \\
\hline CHEMBL1450537 & 737823 & 5.1 & 5.6716 & TST & \\
\hline CHEMBL1590341 & 737823 & 6.0 & 6.0251 & TRN & \\
\hline CHEMBL1478351 & 737823 & 5.25 & 5.7554 & TRN & \\
\hline CHEMBL1445057 & 737823 & 6.5 & 5.2236 & TRN & \\
\hline CHEMBL1552985 & 737823 & 5.8 & 5.4386 & TRN & \\
\hline CHEMBL1584624 & 737823 & 5.6 & 5.6225 & TRN & \\
\hline CHEMBL3196801 & 737823 & 5.45 & 4.9094 & TRN & \\
\hline CHEMBL1591548 & 737823 & 5.0 & 4.7794 & TRN & \\
\hline CHEMBL1416194 & 737823 & 4.8 & 4.8031 & TRN & \\
\hline CHEMBL1546073 & 737823 & 5.4 & 5.1676 & TRN & \\
\hline CHEMBL1594405 & 737823 & 4.7 & 5.3441 & TRN & \\
\hline CHEMBL1403121 & 737823 & 5.3 & 5.6323 & TRN & \\
\hline CHEMBL1538593 & 737823 & 4.8 & 4.5441 & TRN & \\
\hline CHEMBL3191557 & 737823 & 5.3 & 5.37799 & 9999999999 & TRN \\
\hline CHEMBL1442996 & 737823 & 5.2 & 5.1606 & TRN & \\
\hline CHEMBL1589133 & 737823 & 4.85 & 5.2036 & TRN & \\
\hline CHEMBL1538481 & 737823 & 6.15 & 5.2624 & TRN & \\
\hline CHEMBL1256754 & 737823 & 4.9 & 4.9536 & TRN & \\
\hline CHEMBL1317066 & 737823 & 6.1 & 5.8013 & TRN & \\
\hline CHEMBL1482158 & 737823 & 5.1 & 5.6603 & TST & \\
\hline CHEMBL1352043 & 737823 & 4.8 & 5.5664 & TRN & \\
\hline CHEMBL523464 & 737823 & 4.8 & 4.6016 & TRN & \\
\hline CHEMBL1372528 & 737823 & 6.5 & 4.6927 & TRN & \\
\hline CHEMBL1456931 & 737823 & 5.7 & 5.4771 & TRN & \\
\hline CHEMBL1332450 & 737823 & 5.9 & 5.7178 & TRN & \\
\hline CHEMBL1577959 & 737823 & 6.0 & 5.5796 & TRN & \\
\hline CHEMBL1320201 & 737823 & 4.4 & 5.0738 & TST & \\
\hline CHEMBL1416009 & 737823 & 5.4 & 5.6487 & TST & \\
\hline CHEMBL3196233 & 737823 & 5.45 & 5.2502 & TRN & \\
\hline CHEMBL1410452 & 737823 & 4.95 & 4.651 & TRN & \\
\hline CHEMBL1536762 & 737823 & 5.4 & 5.1247 & TRN & \\
\hline CHEMBL1497777 & 737823 & 6.0 & 4.8155 & TRN & \\
\hline CHEMBL 38288 & 737823 & 6.2 & 4.8724 & TRN & \\
\hline CHEMBL1313894 & 737823 & 5.45 & 4.7625 & TRN & \\
\hline CHEMBL1559126 & 737823 & 4.8 & 5.3195 & TRN & \\
\hline CHEMBL1592557 & 737823 & 5.2 & 5.57799 & 9999999999 & TRN \\
\hline CHEMBL1385123 & 737823 & 4.6 & 5.2415 & TST & \\
\hline
\end{tabular}




\begin{tabular}{|c|c|c|c|c|c|}
\hline CHEMBL1526543 & 737823 & 6.0 & 5.1233 & TST & \\
\hline CHEMBL1392232 & 737823 & 4.9 & 5.57700 & 3000000001 & TRN \\
\hline CHEMBL1411094 & 737823 & 4.9 & 5.3209 & TRN & \\
\hline CHEMBL13647 & 737823 & 4.5 & 4.9095 & TRN & \\
\hline CHEMBL 76897 & 737823 & 5.0 & 4.9592 & TRN & \\
\hline CHEMBL1396698 & 737823 & 5.7 & 5.5886 & TRN & \\
\hline CHEMBL1300005 & 737823 & 6.75 & 5.8732 & TST & \\
\hline CHEMBL452861 & 737823 & 6.7 & 5.7623 & TRN & \\
\hline CHEMBL1451492 & 737823 & 5.1 & 5.2226 & TRN & \\
\hline CHEMBL1601844 & 737823 & 4.7 & 4.8173 & TRN & \\
\hline CHEMBL1602780 & 737823 & 4.8 & 5.2948 & TRN & \\
\hline CHEMBL1601630 & 737823 & 4.9 & 5.4298 & TRN & \\
\hline CHEMBL1728735 & 737823 & 4.8 & 5.3098 & TRN & \\
\hline CHEMBL1576777 & 737823 & 5.6 & 5.4949 & TRN & \\
\hline CHEMBL1601482 & 737823 & 4.55 & 4.71399 & 99999999995 & TRN \\
\hline CHEMBL1607837 & 737823 & 5.8 & 5.7344 & TRN & \\
\hline CHEMBL1451307 & 737823 & 5.45 & 5.2697 & TRN & \\
\hline CHEMBL1474681 & 737823 & 5.4 & 5.7857 & TRN & \\
\hline CHEMBL1496949 & 737823 & 4.8 & 5.4152 & TST & \\
\hline CHEMBL1496986 & 737823 & 4.95 & 5.5451 & TRN & \\
\hline CHEMBL3198283 & 737823 & 4.9 & 5.0967 & TRN & \\
\hline CHEMBL1330692 & 737823 & 6.0 & 5.8098 & TRN & \\
\hline CHEMBL1528626 & 737823 & 5.2 & 5.6399 & TRN & \\
\hline CHEMBL1498788 & 737823 & 5.95 & 5.8225 & TRN & \\
\hline CHEMBL1394135 & 737823 & 4.4 & 5.0729 & TRN & \\
\hline CHEMBL1419252 & 737823 & 5.55 & 5.1087 & TST & \\
\hline CHEMBL1733899 & 737823 & 6.35 & 5.5578 & TRN & \\
\hline CHEMBL1514765 & 737823 & 5.6 & 5.3722 & TRN & \\
\hline CHEMBL1380811 & 737823 & 4.9 & 5.1107 & TRN & \\
\hline CHEMBL1420206 & 737823 & 5.1 & 5.3655 & TRN & \\
\hline CHEMBL3213672 & 737823 & 4.9 & 5.2432 & TRN & \\
\hline CHEMBL1535635 & 737823 & 5.7 & 5.3343 & TRN & \\
\hline CHEMBL1519567 & 737823 & 4.9 & 4.8973 & TRN & \\
\hline CHEMBL58353 & 737823 & 4.9 & 4.8832 & TST & \\
\hline CHEMBL1405909 & 737823 & 5.9 & 5.614 & TRN & \\
\hline CHEMBL1316285 & 737823 & 5.1 & 5.2649 & TRN & \\
\hline CHEMBL1427131 & 737823 & 5.45 & 5.2113 & TRN & \\
\hline CHEMBL3208403 & 737823 & 5.9 & 6.0281 & TRN & \\
\hline CHEMBL1527958 & 737823 & 5.5 & 5.645 & TRN & \\
\hline CHEMBL1458077 & 737823 & 4.9 & 5.4314 & TRN & \\
\hline CHEMBL1363193 & 737823 & 4.8 & 5.0057 & TST & \\
\hline CHEMBL1548763 & 737823 & 4.6 & 5.1103 & TRN & \\
\hline CHEMBL3194183 & 737823 & 5.1 & 5.314 & TRN & \\
\hline CHEMBL1487898 & 737823 & 4.6 & 4.8451 & TRN & \\
\hline CHEMBL1478808 & 737823 & 5.2 & 4.9087 & TRN & \\
\hline CHEMBL1359326 & 737823 & 4.55 & 5.3359 & TRN & \\
\hline CHEMBL3207645 & 737823 & 6.05 & 5.4054 & TRN & \\
\hline CHEMBL3189225 & 737823 & 5.5 & 5.6434 & TRN & \\
\hline
\end{tabular}




\begin{tabular}{|c|c|c|c|c|c|}
\hline \multicolumn{6}{|c|}{ Supplemental Table S2.txt } \\
\hline CHEMBL1393667 & 737823 & 5.35 & 5.2771 & TRN & \\
\hline CHEMBL1544930 & 737823 & 4.85 & 4.9028 & TRN & \\
\hline CHEMBL3195211 & 737823 & 5.55 & 5.584 & TRN & \\
\hline CHEMBL1474854 & 737823 & 4.8 & 5.1355 & TRN & \\
\hline CHEMBL1489589 & 737823 & 5.8 & 5.5586 & TRN & \\
\hline CHEMBL1586705 & 737823 & 6.75 & 6.2319 & TRN & \\
\hline CHEMBL1405461 & 737823 & 5.9 & 6.0891 & TRN & \\
\hline CHEMBL1508220 & 737823 & 5.95 & 5.3928 & TRN & \\
\hline CHEMBL1491554 & 737823 & 5.6 & 5.8158 & TST & \\
\hline CHEMBL1503273 & 737823 & 5.05 & 5.2331 & TRN & \\
\hline CHEMBL1742362 & 737823 & 5.2 & 5.5288 & TRN & \\
\hline CHEMBL1437447 & 737823 & 4.6 & 5.4102 & TRN & \\
\hline CHEMBL1362892 & 737823 & 5.7 & 5.4329 & TRN & \\
\hline CHEMBL1522767 & 737823 & 4.85 & 4.9576 & TRN & \\
\hline CHEMBL1322537 & 737823 & 6.55 & 5.5355 & TRN & \\
\hline CHEMBL1376767 & 737823 & 5.95 & 5.7663 & TRN & \\
\hline CHEMBL1355090 & 737823 & 4.4 & 5.1561 & TRN & \\
\hline CHEMBL1376572 & 737823 & 5.4 & 5.4245 & TRN & \\
\hline CHEMBL1453601 & 737823 & 5.3 & 5.2964 & TRN & \\
\hline CHEMBL1568555 & 737823 & 6.3 & 6.2193 & TST & \\
\hline CHEMBL1398636 & 737823 & 5.8 & 5.61700 & 0000000001 & TRN \\
\hline CHEMBL1476139 & 737823 & 5.5 & 5.4868 & TRN & \\
\hline CHEMBL1405016 & 737823 & 4.55 & 5.3585 & TRN & \\
\hline CHEMBL1373772 & 737823 & 5.3 & 5.1323 & TRN & \\
\hline CHEMBL1530130 & 737823 & 5.0 & 4.9759 & TRN & \\
\hline CHEMBL183 & 737823 & 6.6 & 5.1498 & TRN & \\
\hline CHEMBL1512835 & 737823 & 5.6 & 5.296 & TRN & \\
\hline CHEMBL1422722 & 737823 & 7.2 & 5.0096 & TRN & \\
\hline CHEMBL1312648 & 737823 & 5.8 & 5.9335 & TRN & \\
\hline CHEMBL1338358 & 737823 & 5.2 & 5.7474 & TRN & \\
\hline CHEMBL428814 & 737823 & 5.6 & 5.5368 & TRN & \\
\hline CHEMBL1554976 & 737823 & 5.0 & 5.9692 & TRN & \\
\hline CHEMBL600287 & 737823 & 5.0 & 5.7483 & TRN & \\
\hline CHEMBL1162521 & 737823 & 7.2 & 5.6849 & TRN & \\
\hline CHEMBL1385182 & 737823 & 4.9 & 5.7384 & TRN & \\
\hline CHEMBL1462945 & 737823 & 5.7 & 5.2407 & TRN & \\
\hline CHEMBL305881 & 737823 & 4.5 & 4.9222 & TRN & \\
\hline CHEMBL1572157 & 737823 & 5.4 & 5.1046 & TRN & \\
\hline CHEMBL1348253 & 737823 & 4.85 & 5.3576 & TRN & \\
\hline CHEMBL1579467 & 737823 & 4.85 & 5.3782 & TRN & \\
\hline CHEMBL1394765 & 737823 & 5.5 & 5.5681 & TRN & \\
\hline CHEMBL1495694 & 737823 & 6.4 & 5.6537 & TRN & \\
\hline CHEMBL3195971 & 737823 & 5.1 & 5.1488 & TRN & \\
\hline CHEMBL1502803 & 737823 & 5.0 & 5.0912 & TRN & \\
\hline CHEMBL1438661 & 737823 & 5.0 & 5.3166 & TRN & \\
\hline CHEMBL1455353 & 737823 & 5.3 & 5.5839 & TRN & \\
\hline CHEMBL1567163 & 737823 & 4.5 & 5.3533 & TST & \\
\hline CHEMBL1486217 & 737823 & 5.6 & 4.925 & TRN & \\
\hline
\end{tabular}




\begin{tabular}{|c|c|c|c|c|c|}
\hline \multicolumn{6}{|c|}{ Supplemental Table S2.txt } \\
\hline CHEMBL1350235 & 737823 & 4.7 & 5.2463 & TRN & \\
\hline CHEMBL1447544 & 737823 & 5.7 & 5.3324 & TRN & \\
\hline CHEMBL 275097 & 737823 & 5.8 & 5.6707 & TRN & \\
\hline CHEMBL1511066 & 737823 & 4.8 & 4.9402 & TRN & \\
\hline CHEMBL3195251 & 737823 & 5.0 & 5.6556 & TRN & \\
\hline CHEMBL1302300 & 737823 & 6.3 & 5.8118 & TRN & \\
\hline CHEMBL1573125 & 737823 & 5.85 & 6.096 & TRN & \\
\hline CHEMBL1590397 & 737823 & 5.8 & 5.6917 & TRN & \\
\hline CHEMBL1445999 & 737823 & 5.2 & 5.1766 & TST & \\
\hline CHEMBL1330404 & 737823 & 5.3 & 5.1369 & TRN & \\
\hline CHEMBL1588603 & 737823 & 5.1 & 5.3686 & TRN & \\
\hline CHEMBL1709113 & 737823 & 8.0 & 4.9799 & TRN & \\
\hline CHEMBL1333287 & 737823 & 5.6 & 5.5986 & TRN & \\
\hline CHEMBL1408735 & 737823 & 4.6 & 4.7193 & TRN & \\
\hline CHEMBL1525602 & 737823 & 6.4 & 6.1401 & TRN & \\
\hline CHEMBL3210017 & 737823 & 4.8 & 5.28600 & 00000000005 & TRN \\
\hline CHEMBL1529538 & 737823 & 4.6 & 4.7135 & TRN & \\
\hline CHEMBL1532441 & 737823 & 5.6 & 5.2174 & TRN & \\
\hline CHEMBL1510212 & 737823 & 5.55 & 5.6373 & TRN & \\
\hline CHEMBL 2373582 & 737823 & 5.4 & 4.9848 & TST & \\
\hline CHEMBL1479730 & 737823 & 5.0 & 4.9977 & TRN & \\
\hline CHEMBL1440619 & 737823 & 5.7 & 5.4406 & TRN & \\
\hline CHEMBL1435823 & 737823 & 4.9 & 5.2128 & TRN & \\
\hline CHEMBL1349246 & 737823 & 5.4 & 5.6734 & TST & \\
\hline CHEMBL1601908 & 737823 & 4.7 & 5.7446 & TRN & \\
\hline CHEMBL1543685 & 737823 & 5.65 & 5.5365 & TST & \\
\hline CHEMBL1432791 & 737823 & 6.4 & 5.5315 & TRN & \\
\hline CHEMBL1361847 & 737823 & 5.4 & 5.95799 & 9999999999 & TRN \\
\hline CHEMBL425403 & 737823 & 6.6 & 5.8581 & TRN & \\
\hline CHEMBL1492136 & 737823 & 4.75 & 5.0004 & TRN & \\
\hline CHEMBL1352270 & 737823 & 5.05 & 5.5232 & TRN & \\
\hline CHEMBL1390531 & 737823 & 5.4 & 5.3549 & TRN & \\
\hline CHEMBL1337108 & 737823 & 4.8 & 4.683 & TRN & \\
\hline CHEMBL1537907 & 737823 & 5.55 & 5.6322 & TST & \\
\hline CHEMBL1455200 & 737823 & 5.2 & 5.2133 & TRN & \\
\hline CHEMBL1611496 & 737823 & 6.2 & 6.4157 & TRN & \\
\hline CHEMBL1320841 & 737823 & 5.6 & 5.6539 & TRN & \\
\hline CHEMBL1594988 & 737823 & 4.95 & 5.3584 & TST & \\
\hline CHEMBL1432354 & 737823 & 5.2 & 5.3293 & TRN & \\
\hline CHEMBL1313465 & 737823 & 5.3 & 5.1935 & TRN & \\
\hline CHEMBL1981379 & 737823 & 5.75 & 5.6586 & TST & \\
\hline CHEMBL1451411 & 737823 & 4.6 & 5.0845 & TRN & \\
\hline CHEMBL1742199 & 737823 & 4.9 & 5.0824 & TRN & \\
\hline CHEMBL1368511 & 737823 & 6.4 & 5.5195 & TST & \\
\hline CHEMBL1562088 & 737823 & 5.3 & 5.3333 & TST & \\
\hline CHEMBL1437906 & 737823 & 4.8 & 4.5801 & TRN & \\
\hline CHEMBL1490740 & 737823 & 6.1 & 5.8777 & TRN & \\
\hline CHEMBL1489424 & 737823 & 5.3 & 5.6895 & TRN & \\
\hline
\end{tabular}




\begin{tabular}{|c|c|c|c|c|}
\hline \multicolumn{5}{|c|}{ Supplemental Table S2.txt } \\
\hline CHEMBL1582428 & 737823 & 4.85 & 5.0387 & TRN \\
\hline CHEMBL1359291 & 737823 & 4.8 & 4.7792 & TRN \\
\hline CHEMBL1729271 & 737823 & 4.4 & 5.1163 & TRN \\
\hline CHEMBL1527611 & 737823 & 5.0 & 5.4706 & TRN \\
\hline CHEMBL1538177 & 737823 & 4.65 & 4.9016 & TRN \\
\hline CHEMBL1611348 & 737823 & 4.7 & 4.8284 & TRN \\
\hline CHEMBL1566120 & 737823 & 4.65 & 4.9165 & TRN \\
\hline CHEMBL1516953 & 737823 & 5.1 & 5.9494 & TRN \\
\hline CHEMBL1392699 & 737823 & 4.8 & 5.4206 & TRN \\
\hline CHEMBL1594134 & 737823 & 5.2 & 5.8998 & TRN \\
\hline CHEMBL1592804 & 737823 & 6.2 & 5.5202 & TRN \\
\hline CHEMBL279731 & 737823 & 4.6 & 5.0193 & TST \\
\hline CHEMBL1400995 & 737823 & 5.05 & 5.0969 & TRN \\
\hline CHEMBL586 & 737823 & 5.3 & 4.8172 & TRN \\
\hline CHEMBL1401243 & 737823 & 5.2 & 5.2661 & TRN \\
\hline CHEMBL1418789 & 737823 & 5.45 & 5.4327 & TRN \\
\hline CHEMBL1698533 & 737823 & 4.65 & 5.0417 & TRN \\
\hline CHEMBL1587637 & 737823 & 5.5 & 5.619 & TRN \\
\hline CHEMBL1334106 & 737823 & 5.0 & 5.1797 & TRN \\
\hline CHEMBL1324402 & 737823 & 5.9 & 5.6426 & TRN \\
\hline CHEMBL1391756 & 737823 & 4.9 & 5.5008 & TRN \\
\hline CHEMBL1339570 & 737823 & 4.8 & 5.0276 & TRN \\
\hline CHEMBL1551913 & 737823 & 6.3 & 5.8841 & TRN \\
\hline CHEMBL1329402 & 737823 & 5.35 & 5.2421 & TRN \\
\hline CHEMBL 259325 & 737823 & 5.7 & 6.1017 & TRN \\
\hline CHEMBL1345892 & 737823 & 5.5 & 5.3682 & TRN \\
\hline CHEMBL1609624 & 737823 & 4.7 & 4.8215 & TRN \\
\hline CHEMBL1396171 & 737823 & 5.2 & 5.7897 & TRN \\
\hline CHEMBL1563513 & 737823 & 5.45 & 5.8217 & TRN \\
\hline CHEMBL1354901 & 737823 & 5.9 & 5.6315 & TRN \\
\hline CHEMBL1299997 & 737823 & 5.85 & 5.7599 & TRN \\
\hline CHEMBL1503047 & 737823 & 6.25 & 5.8242 & TRN \\
\hline CHEMBL1301960 & 737823 & 6.4 & 5.2612 & TRN \\
\hline CHEMBL1519173 & 737823 & 5.5 & 5.2271 & TST \\
\hline CHEMBL3208773 & 737823 & 4.7 & 5.2323 & TST \\
\hline CHEMBL1424948 & 737823 & 4.85 & 5.2351 & TRN \\
\hline CHEMBL1523323 & 737823 & 5.7 & 5.2087 & TRN \\
\hline CHEMBL1444394 & 737823 & 6.55 & 6.5842 & TRN \\
\hline CHEMBL3191564 & 737823 & 5.4 & 5.6054 & TST \\
\hline CHEMBL1562333 & 737823 & 6.1 & 5.6238 & TRN \\
\hline CHEMBL1350835 & 737823 & 4.8 & 5.0126 & TRN \\
\hline CHEMBL1602964 & 737823 & 5.0 & 5.6095 & TST \\
\hline CHEMBL1490198 & 737823 & 5.15 & 5.0283 & TRN \\
\hline CHEMBL1370701 & 737823 & 4.85 & 5.0482 & TRN \\
\hline CHEMBL611494 & 737823 & 4.5 & 5.3547 & TST \\
\hline CHEMBL1096400 & 737823 & 4.5 & 5.3702 & TST \\
\hline CHEMBL1552779 & 737823 & 4.4 & 5.1548 & TRN \\
\hline CHEMBL1742077 & 737823 & 6.3 & 5.5408 & TST \\
\hline
\end{tabular}




\begin{tabular}{|c|c|c|c|c|c|}
\hline & & & 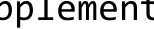 & & \\
\hline CHEMBL345124 & 737823 & 4.9 & 5.3414 & TST & \\
\hline CHEMBL1741622 & 737823 & 5.55 & 5.495 & TRN & \\
\hline CHEMBL1525540 & 737823 & 4.95 & 5.0003 & TRN & \\
\hline CHEMBL1350293 & 737823 & 4.85 & 5.3689 & TRN & \\
\hline CHEMBL1399634 & 737823 & 5.2 & 5.4812 & TRN & \\
\hline CHEMBL1341642 & 737823 & 4.65 & 5.0135 & TRN & \\
\hline CHEMBL1419723 & 737823 & 5.7 & 5.379 & TRN & \\
\hline CHEMBL1324528 & 737823 & 5.7 & 5.5494 & TRN & \\
\hline CHEMBL1727631 & 737823 & 4.9 & 5.3278 & TRN & \\
\hline CHEMBL1418866 & 737823 & 6.35 & 6.3612 & TRN & \\
\hline CHEMBL1371547 & 737823 & 6.1 & 4.9314 & TRN & \\
\hline CHEMBL1557929 & 737823 & 6.1 & 5.5605 & TST & \\
\hline CHEMBL1396773 & 737823 & 5.1 & 5.1093 & TRN & \\
\hline CHEMBL1548154 & 737823 & 5.3 & 5.655 & TRN & \\
\hline CHEMBL1595929 & 737823 & 4.9 & 5.2997 & TST & \\
\hline CHEMBL1603113 & 737823 & 4.8 & 4.8351 & TRN & \\
\hline CHEMBL1257041 & 737823 & 4.9 & 5.4171 & TRN & \\
\hline CHEMBL1306964 & 737823 & 5.2 & 5.1658 & TRN & \\
\hline CHEMBL1474695 & 737823 & 4.8 & 4.9895 & TRN & \\
\hline CHEMBL1409626 & 737823 & 5.6 & 5.1351 & TRN & \\
\hline CHEMBL1496934 & 737823 & 5.4 & 5.5597 & TRN & \\
\hline CHEMBL1435248 & 737823 & 4.9 & 5.1809 & TRN & \\
\hline CHEMBL1377215 & 737823 & 6.3 & 5.7366 & TRN & \\
\hline CHEMBL1397548 & 737823 & 4.6 & 4.9227 & TRN & \\
\hline CHEMBL1452057 & 737823 & 4.8 & 5.0506 & TRN & \\
\hline CHEMBL 379350 & 737823 & 6.05 & 5.9594 & TRN & \\
\hline CHEMBL1473554 & 737823 & 6.3 & 5.66 & TRN & \\
\hline CHEMBL1468227 & 737823 & 7.3 & 4.9702 & TRN & \\
\hline CHEMBL1344701 & 737823 & 5.7 & 5.70299 & 9999999999 & TRN \\
\hline CHEMBL1532597 & 737823 & 4.6 & 4.7014 & TRN & \\
\hline CHEMBL1599163 & 737823 & 6.9 & 6.1543 & TRN & \\
\hline CHEMBL3209650 & 737823 & 4.65 & 5.3441 & TST & \\
\hline CHEMBL1475788 & 737823 & 4.8 & 4.7707 & TRN & \\
\hline CHEMBL1323927 & 737823 & 5.8 & 5.50799 & 9999999999 & TRN \\
\hline CHEMBL107528 & 737823 & 4.5 & 4.7784 & TRN & \\
\hline CHEMBL1491974 & 737823 & 5.4 & 5.3189 & TRN & \\
\hline CHEMBL1728559 & 737823 & 4.7 & 5.0262 & TRN & \\
\hline CHEMBL1356256 & 737823 & 5.3 & 5.0737 & TRN & \\
\hline CHEMBL1457635 & 737823 & 5.85 & 5.4546 & TRN & \\
\hline CHEMBL3195422 & 737823 & 4.8 & 5.1126 & TST & \\
\hline CHEMBL1572530 & 737823 & 5.3 & 5.1809 & TRN & \\
\hline CHEMBL1257003 & 737823 & 4.8 & 5.2008 & TRN & \\
\hline CHEMBL1574548 & 737823 & 5.8 & 6.4277 & TST & \\
\hline CHEMBL1569975 & 737823 & 5.05 & 5.042 & TRN & \\
\hline CHEMBL1306585 & 737823 & 5.1 & 5.3871 & TST & \\
\hline CHEMBL1567295 & 737823 & 5.1 & 5.4142 & TRN & \\
\hline CHEMBL1329326 & 737823 & 5.5 & 5.6507 & TRN & \\
\hline CHEMBL1476129 & 737823 & 5.5 & 5.4719 & TRN & \\
\hline
\end{tabular}




\begin{tabular}{|c|c|c|c|c|c|}
\hline \multicolumn{6}{|c|}{ Supplemental Table S2.txt } \\
\hline CHEMBL1390056 & 737823 & 5.5 & 5.5468 & TRN & \\
\hline CHEMBL1395402 & 737823 & 5.8 & 5.4633 & TRN & \\
\hline CHEMBL1741894 & 737823 & 5.3 & 5.468 & TST & \\
\hline CHEMBL1390396 & 737823 & 6.7 & 5.5896 & TRN & \\
\hline CHEMBL1618718 & 737823 & 4.7 & 4.9152 & TRN & \\
\hline CHEMBL1311260 & 737823 & 6.05 & 5.1883 & TRN & \\
\hline CHEMBL1306927 & 737823 & 4.6 & 5.1988 & TRN & \\
\hline CHEMBL1596030 & 737823 & 7.0 & 5.4298 & TRN & \\
\hline CHEMBL1331579 & 737823 & 6.1 & 5.50200 & $\partial 000000001$ & TRN \\
\hline CHEMBL1568735 & 737823 & 5.9 & 5.8919 & TRN & \\
\hline CHEMBL1396611 & 737823 & 5.7 & 5.6907 & TRN & \\
\hline CHEMBL1341789 & 737823 & 4.8 & 4.8026 & TRN & \\
\hline CHEMBL1528540 & 737823 & 7.4 & 5.1127 & TST & \\
\hline CHEMBL1364366 & 737823 & 5.3 & 5.3674 & TRN & \\
\hline CHEMBL1555610 & 737823 & 4.9 & 5.4786 & TRN & \\
\hline CHEMBL1552635 & 737823 & 4.6 & 4.9205 & TRN & \\
\hline CHEMBL1357770 & 737823 & 7.6 & 5.4456 & TST & \\
\hline CHEMBL1480190 & 737823 & 4.85 & 5.358 & TRN & \\
\hline CHEMBL1432751 & 737823 & 4.85 & 5.166 & TRN & \\
\hline CHEMBL1433798 & 737823 & 5.2 & 5.6848 & TRN & \\
\hline CHEMBL1434411 & 737823 & 5.3 & 4.9339 & TRN & \\
\hline CHEMBL1513324 & 737823 & 6.2 & 5.9757 & TRN & \\
\hline CHEMBL1411457 & 737823 & 4.85 & 5.2798 & TRN & \\
\hline CHEMBL37081 & 737823 & 6.6 & 5.5867 & TRN & \\
\hline CHEMBL1742204 & 737823 & 5.55 & 5.1513 & TRN & \\
\hline CHEMBL 243664 & 737823 & 7.2 & 6.0548 & TRN & \\
\hline CHEMBL1256667 & 737823 & 7.6 & 5.308 & TST & \\
\hline CHEMBL1379391 & 737823 & 6.85 & 5.9233 & TRN & \\
\hline CHEMBL1432016 & 737823 & 4.55 & 4.966 & TST & \\
\hline CHEMBL1453311 & 737823 & 4.8 & 5.5017 & TST & \\
\hline CHEMBL1490656 & 737823 & 5.5 & 5.2276 & TRN & \\
\hline CHEMBL1469597 & 737823 & 4.55 & 4.7458 & TRN & \\
\hline CHEMBL1437747 & 737823 & 5.8 & 5.5734 & TRN & \\
\hline CHEMBL1453369 & 737823 & 4.6 & 4.9985 & TRN & \\
\hline CHEMBL1356134 & 737823 & 4.8 & 5.5612 & TRN & \\
\hline CHEMBL22870 & 737823 & 4.5 & 5.1657 & TRN & \\
\hline CHEMBL1350707 & 737823 & 5.45 & 5.7253 & TRN & \\
\hline CHEMBL1333759 & 737823 & 4.85 & 5.6109 & TRN & \\
\hline CHEMBL1577130 & 737823 & 4.6 & 5.1759 & TRN & \\
\hline CHEMBL1415728 & 737823 & 4.8 & 5.1371 & TRN & \\
\hline CHEMBL1572734 & 737823 & 4.85 & 5.3906 & TRN & \\
\hline CHEMBL1314975 & 737823 & 4.9 & 5.1973 & TST & \\
\hline CHEMBL259073 & 737823 & 4.7 & 5.2175 & TST & \\
\hline CHEMBL1454368 & 737823 & 6.35 & 5.276 & TRN & \\
\hline CHEMBL1355135 & 737823 & 5.6 & 5.4667 & TRN & \\
\hline CHEMBL1438371 & 737823 & 6.5 & 6.3035 & TRN & \\
\hline CHEMBL1514027 & 737823 & 6.3 & 5.9062 & TRN & \\
\hline CHEMBL1507984 & 737823 & 4.55 & 4.6473 & TST & \\
\hline
\end{tabular}




\begin{tabular}{|c|c|c|c|c|c|}
\hline \multicolumn{6}{|c|}{ Supplemental Table S2.txt } \\
\hline CHEMBL1328490 & 737823 & 5.1 & 4.9695 & TST & \\
\hline CHEMBL1422487 & 737823 & 4.85 & 5.4002 & TRN & \\
\hline CHEMBL1351562 & 737823 & 5.0 & 5.6134 & TRN & \\
\hline CHEMBL1515789 & 737823 & 5.4 & 5.1492 & TRN & \\
\hline CHEMBL1334321 & 737823 & 4.9 & 5.5059 & TRN & \\
\hline CHEMBL1742049 & 737823 & 5.5 & 5.0443 & TST & \\
\hline CHEMBL1574278 & 737823 & 5.8 & 5.4933 & TRN & \\
\hline CHEMBL1324640 & 737823 & 5.5 & 5.5375 & TST & \\
\hline CHEMBL1562915 & 737823 & 6.55 & 5.4513 & TRN & \\
\hline CHEMBL1610228 & 737823 & 5.7 & 5.4534 & TRN & \\
\hline CHEMBL1160730 & 737823 & 6.0 & 5.69799 & 99999999995 & TRN \\
\hline CHEMBL1741716 & 737823 & 4.85 & 5.0489 & TRN & \\
\hline CHEMBL1551962 & 737823 & 4.8 & 5.4198 & TRN & \\
\hline CHEMBL1443323 & 737823 & 7.3 & 6.2939 & TRN & \\
\hline CHEMBL1446687 & 737823 & 5.6 & 5.4134 & TRN & \\
\hline CHEMBL1569400 & 737823 & 4.6 & 4.8552 & TRN & \\
\hline CHEMBL1495004 & 737823 & 4.8 & 5.401 & TRN & \\
\hline CHEMBL1531672 & 737823 & 5.3 & 5.4264 & TRN & \\
\hline CHEMBL1388465 & 737823 & 4.55 & 5.2318 & TRN & \\
\hline CHEMBL1590223 & 737823 & 4.4 & 5.1356 & TRN & \\
\hline CHEMBL1445702 & 737823 & 5.75 & 5.3606 & TRN & \\
\hline CHEMBL1714628 & 737823 & 4.75 & 4.6847 & TRN & \\
\hline CHEMBL1554637 & 737823 & 4.8 & 5.2998 & TRN & \\
\hline CHEMBL1506638 & 737823 & 5.5 & 5.3754 & TRN & \\
\hline CHEMBL1590919 & 737823 & 4.8 & 4.8597 & TRN & \\
\hline CHEMBL1353921 & 737823 & 5.15 & 5.6055 & TRN & \\
\hline CHEMBL1436526 & 737823 & 4.7 & 4.8773 & TRN & \\
\hline CHEMBL1612050 & 737823 & 5.1 & 5.3129 & TST & \\
\hline CHEMBL1446448 & 737823 & 5.0 & 5.0872 & TRN & \\
\hline CHEMBL1413489 & 737823 & 6.0 & 5.5223 & TRN & \\
\hline CHEMBL1545407 & 737823 & 5.15 & 5.4252 & TRN & \\
\hline CHEMBL1590156 & 737823 & 5.2 & 5.6176 & TRN & \\
\hline CHEMBL1414375 & 737823 & 5.65 & 5.0023 & TRN & \\
\hline CHEMBL1520388 & 737823 & 5.25 & 5.2085 & TRN & \\
\hline CHEMBL1481160 & 737823 & 5.5 & 5.3544 & TST & \\
\hline CHEMBL1496611 & 737823 & 5.55 & 5.6835 & TRN & \\
\hline CHEMBL1474468 & 737823 & 5.8 & 6.3627 & TRN & \\
\hline CHEMBL1371202 & 737823 & 5.2 & 5.6841 & TRN & \\
\hline CHEMBL1304570 & 737823 & 5.2 & 5.3996 & TRN & \\
\hline CHEMBL1437128 & 737823 & 6.0 & 5.2499 & TRN & \\
\hline CHEMBL1730483 & 737823 & 4.85 & 4.9911 & TRN & \\
\hline CHEMBL3210057 & 737823 & 5.6 & 5.3832 & TRN & \\
\hline CHEMBL1331587 & 737823 & 5.4 & 5.2384 & TRN & \\
\hline CHEMBL1527622 & 737823 & 5.3 & 5.5811 & TRN & \\
\hline CHEMBL3192809 & 737823 & 4.8 & 5.4069 & TRN & \\
\hline CHEMBL1523040 & 737823 & 5.4 & 5.6126 & TRN & \\
\hline CHEMBL1584359 & 737823 & 5.45 & 5.2068 & TST & \\
\hline CHEMBL1536210 & 737823 & 4.95 & 5.4407 & TRN & \\
\hline
\end{tabular}




\begin{tabular}{|c|c|c|c|c|}
\hline & & & ipplement & al Table S \\
\hline CHEMBL1532912 & 737823 & 4.9 & 5.4915 & TRN \\
\hline CHEMBL1606796 & 737823 & 4.9 & 4.7136 & TRN \\
\hline CHEMBL1314799 & 737823 & 5.7 & 5.3567 & TRN \\
\hline CHEMBL1539107 & 737823 & 4.8 & 5.5401 & TRN \\
\hline CHEMBL1474326 & 737823 & 5.5 & 5.5694 & TRN \\
\hline CHEMBL1317498 & 737823 & 5.2 & 4.9664 & TRN \\
\hline CHEMBL 275854 & 737823 & 4.5 & 4.9608 & TRN \\
\hline CHEMBL1466129 & 737823 & 4.5 & 5.0144 & TRN \\
\hline CHEMBL1602084 & 737823 & 4.65 & 4.9003 & TRN \\
\hline CHEMBL1534202 & 737823 & 5.3 & 5.3001 & TST \\
\hline CHEMBL1303356 & 737823 & 4.6 & 5.1179 & TST \\
\hline CHEMBL1320000 & 737823 & 5.45 & 5.7054 & TRN \\
\hline CHEMBL1718423 & 737823 & 6.95 & 6.0265 & TRN \\
\hline CHEMBL1443376 & 737823 & 4.7 & 4.859 & TRN \\
\hline CHEMBL1558388 & 737823 & 6.3 & 5.489 & TRN \\
\hline CHEMBL1230276 & 737823 & 6.0 & 5.6077 & TRN \\
\hline CHEMBL1376070 & 737823 & 5.3 & 5.2406 & TRN \\
\hline CHEMBL1564137 & 737823 & 4.55 & 4.9954 & TRN \\
\hline CHEMBL1530692 & 737823 & 4.8 & 5.2201 & TRN \\
\hline CHEMBL1478226 & 737823 & 4.9 & 5.6128 & TRN \\
\hline CHEMBL1598281 & 737823 & 5.25 & 5.5208 & TRN \\
\hline CHEMBL1342562 & 737823 & 5.2 & 5.0711 & TRN \\
\hline CHEMBL1318758 & 737823 & 5.7 & 5.2099 & TRN \\
\hline CHEMBL1742280 & 737823 & 5.45 & 5.8131 & TRN \\
\hline CHEMBL1558777 & 737823 & 5.9 & 5.3369 & TRN \\
\hline CHEMBL1565378 & 737823 & 5.0 & 5.0794 & TRN \\
\hline CHEMBL1421737 & 737823 & 4.85 & 5.1467 & TRN \\
\hline CHEMBL1725598 & 737823 & 5.5 & 5.079 & TRN \\
\hline CHEMBL3192008 & 737823 & 5.5 & 5.5613 & TST \\
\hline CHEMBL1606673 & 737823 & 4.9 & 4.8213 & TRN \\
\hline CHEMBL1496528 & 737823 & 4.8 & 5.3683 & TRN \\
\hline CHEMBL338115 & 737823 & 5.8 & 5.5601 & TRN \\
\hline CHEMBL1317913 & 737823 & 5.0 & 5.0901 & TRN \\
\hline CHEMBL1401732 & 737823 & 5.7 & 5.6538 & TST \\
\hline CHEMBL1332463 & 737823 & 6.5 & 5.9268 & TRN \\
\hline CHEMBL1526526 & 737823 & 6.0 & 5.4803 & TRN \\
\hline CHEMBL1465401 & 737823 & 5.55 & 5.6304 & TRN \\
\hline CHEMBL1356794 & 737823 & 6.7 & 6.312 & TRN \\
\hline CHEMBL1311749 & 737823 & 4.85 & 5.7504 & TST \\
\hline CHEMBL1488301 & 737823 & 4.85 & 5.078 & TRN \\
\hline CHEMBL1399944 & 737823 & 5.5 & 5.05399 & 9999999999 \\
\hline CHEMBL1524194 & 737823 & 5.4 & 5.0595 & TRN \\
\hline CHEMBL1337524 & 737823 & 4.85 & 5.0209 & TRN \\
\hline CHEMBL98350 & 737823 & 6.0 & 5.7673 & TST \\
\hline CHEMBL1547276 & 737823 & 4.65 & 5.4286 & TRN \\
\hline CHEMBL1299214 & 737823 & 4.85 & 4.754 & TST \\
\hline CHEMBL1416912 & 737823 & 4.8 & 4.9365 & TRN \\
\hline CHEMBL1437711 & 737823 & 4.5 & 4.9177 & TST \\
\hline
\end{tabular}




\begin{tabular}{|c|c|c|c|c|}
\hline & & & pplement & al $\mathrm{Ta}$ \\
\hline CHEMBL1434747 & 737823 & 7.0 & 6.1512 & TRN \\
\hline CHEMBL1313701 & 737823 & 4.85 & 4.9679 & TRN \\
\hline CHEMBL1466277 & 737823 & 5.8 & 6.1615 & TST \\
\hline CHEMBL1495150 & 737823 & 5.3 & 5.6702 & TRN \\
\hline CHEMBL1356775 & 737823 & 4.9 & 5.1776 & TST \\
\hline CHEMBL1706520 & 737823 & 4.85 & 5.0926 & TRN \\
\hline CHEMBL1548924 & 737823 & 5.6 & 5.7719 & TST \\
\hline CHEMBL1353174 & 737823 & 5.3 & 5.3994 & TRN \\
\hline CHEMBL1412937 & 737823 & 4.65 & 5.2193 & TRN \\
\hline CHEMBL1322078 & 737823 & 5.55 & 5.3774 & TRN \\
\hline CHEMBL1475131 & 737823 & 6.9 & 6.6311 & TRN \\
\hline CHEMBL1465060 & 737823 & 4.85 & 5.3441 & TST \\
\hline CHEMBL1382296 & 737823 & 4.9 & 5.7144 & TRN \\
\hline CHEMBL1315700 & 737823 & 4.9 & 5.0064 & TRN \\
\hline CHEMBL1331702 & 737823 & 5.65 & 5.8687 & TRN \\
\hline CHEMBL1190214 & 737823 & 5.8 & 5.5542 & TST \\
\hline CHEMBL1255866 & 737823 & 5.2 & 5.119 & TST \\
\hline CHEMBL1495091 & 737823 & 5.7 & 5.1584 & TRN \\
\hline CHEMBL1463032 & 737823 & 5.9 & 5.4575 & TRN \\
\hline CHEMBL1557790 & 737823 & 5.65 & 5.1852 & TRN \\
\hline CHEMBL1306724 & 737823 & 4.85 & 5.0155 & TRN \\
\hline CHEMBL1606076 & 737823 & 5.05 & 5.2707 & TRN \\
\hline CHEMBL1437158 & 737823 & 4.9 & 5.8128 & TRN \\
\hline CHEMBL33171 & 737823 & 4.8 & 5.1438 & TRN \\
\hline CHEMBL1318064 & 737823 & 4.8 & 5.3249 & TRN \\
\hline CHEMBL 29097 & 737823 & 4.5 & 4.9261 & TRN \\
\hline CHEMBL1321535 & 737823 & 5.8 & 5.5181 & TRN \\
\hline CHEMBL1741773 & 737823 & 7.8 & 4.8522 & TST \\
\hline CHEMBL1424229 & 737823 & 4.9 & 5.0791 & TST \\
\hline CHEMBL1592211 & 737823 & 5.6 & 5.8781 & TRN \\
\hline CHEMBL1499774 & 737823 & 5.6 & 5.1024 & TST \\
\hline CHEMBL1424178 & 737823 & 4.9 & 5.388 & TRN \\
\hline CHEMBL1408128 & 737823 & 6.15 & 5.4518 & TRN \\
\hline CHEMBL1478769 & 737823 & 5.3 & 5.2465 & TRN \\
\hline CHEMBL1326159 & 737823 & 5.45 & 5.2544 & TRN \\
\hline CHEMBL1571146 & 737823 & 4.9 & 5.2117 & TRN \\
\hline CHEMBL1485984 & 737823 & 5.1 & 4.3883 & TST \\
\hline CHEMBL1580701 & 737823 & 4.9 & 5.2093 & TRN \\
\hline CHEMBL1256913 & 737823 & 5.7 & 5.3252 & TRN \\
\hline CHEMBL1554721 & 737823 & 7.2 & 6.52 & TRN \\
\hline CHEMBL1508815 & 737823 & 4.75 & 5.3369 & TRN \\
\hline CHEMBL1741495 & 737823 & 5.4 & 5.394 & TRN \\
\hline CHEMBL1437056 & 737823 & 5.9 & 5.558 & TRN \\
\hline CHEMBL1967673 & 737823 & 4.75 & 5.4884 & TRN \\
\hline CHEMBL1331066 & 737823 & 6.8 & 6.1424 & TST \\
\hline CHEMBL1326100 & 737823 & 5.4 & 5.5051 & TRN \\
\hline CHEMBL1550234 & 737823 & 5.3 & 5.7656 & TRN \\
\hline CHEMBL1454544 & 737823 & 5.9 & 6.2296 & TRN \\
\hline
\end{tabular}




\begin{tabular}{|c|c|c|c|c|c|}
\hline \multicolumn{6}{|c|}{ Supplemental Table S2.txt } \\
\hline CHEMBL1329761 & 737823 & 5.0 & 5.2159 & TRN & \\
\hline CHEMBL1318042 & 737823 & 6.7 & 5.9373 & TRN & \\
\hline CHEMBL1389803 & 737823 & 5.8 & 5.4753 & TRN & \\
\hline CHEMBL1476871 & 737823 & 4.6 & 5.1422 & TRN & \\
\hline CHEMBL1410388 & 737823 & 4.65 & 4.998 & TRN & \\
\hline CHEMBL1537220 & 737823 & 5.0 & 5.6555 & TRN & \\
\hline CHEMBL1334840 & 737823 & 5.1 & 5.2528 & TRN & \\
\hline CHEMBL1307904 & 737823 & 4.6 & 5.2201 & TST & \\
\hline CHEMBL1469083 & 737823 & 4.85 & 4.896 & TRN & \\
\hline CHEMBL1403781 & 737823 & 6.35 & 5.3952 & TRN & \\
\hline CHEMBL1358395 & 737823 & 6.7 & 6.0508 & TRN & \\
\hline CHEMBL1987784 & 737823 & 5.35 & 5.6487 & TRN & \\
\hline CHEMBL1417999 & 737823 & 5.6 & 5.3367 & TRN & \\
\hline CHEMBL1468432 & 737823 & 5.5 & 5.1932 & TRN & \\
\hline CHEMBL1433559 & 737823 & 5.6 & 5.5287 & TRN & \\
\hline CHEMBL1388860 & 737823 & 6.3 & 5.8797 & TRN & \\
\hline CHEMBL1555823 & 737823 & 6.1 & 5.886 & TRN & \\
\hline CHEMBL1363513 & 737823 & 6.4 & 5.4151 & TRN & \\
\hline CHEMBL3208849 & 737823 & 5.15 & 5.1417 & TRN & \\
\hline CHEMBL1513063 & 737823 & 5.5 & 5.396 & TRN & \\
\hline CHEMBL340807 & 737823 & 6.1 & 5.608 & TRN & \\
\hline CHEMBL476672 & 737823 & 5.3 & 5.3874 & TST & \\
\hline CHEMBL1543109 & 737823 & 6.25 & 5.3725 & TRN & \\
\hline CHEMBL1466372 & 737823 & 5.65 & 5.1266 & TST & \\
\hline CHEMBL3144985 & 737823 & 4.7 & 5.7204 & TST & \\
\hline CHEMBL1569147 & 737823 & 4.85 & 5.0561 & TRN & \\
\hline CHEMBL1361675 & 737823 & 5.5 & 5.4456 & TST & \\
\hline CHEMBL3191906 & 737823 & 4.85 & 5.1996 & TRN & \\
\hline CHEMBL1379308 & 737823 & 4.9 & 5.1057 & TRN & \\
\hline CHEMBL1323759 & 737823 & 6.4 & 5.3409 & TRN & \\
\hline CHEMBL1235966 & 737823 & 4.8 & $5.2420 e$ & 2000000001 & TRN \\
\hline CHEMBL1398578 & 737823 & 5.3 & 4.9286 & TST & \\
\hline CHEMBL1602211 & 737823 & 5.0 & 5.067 & TRN & \\
\hline CHEMBL1340864 & 737823 & 4.9 & 5.2968 & TRN & \\
\hline CHEMBL1605699 & 737823 & 4.8 & 5.0257 & TRN & \\
\hline CHEMBL1479152 & 737823 & 4.9 & 4.955 & TRN & \\
\hline CHEMBL1477447 & 737823 & 4.8 & 5.4414 & TRN & \\
\hline CHEMBL1495832 & 737823 & 5.55 & 5.3883 & TRN & \\
\hline CHEMBL1405758 & 737823 & 4.8 & 4.9789 & TST & \\
\hline CHEMBL1353871 & 737823 & 5.6 & 5.5957 & TRN & \\
\hline CHEMBL1343385 & 737823 & 4.9 & 4.3249 & TRN & \\
\hline CHEMBL1398528 & 737823 & 5.7 & 5.4668 & TRN & \\
\hline CHEMBL1356834 & 737823 & 4.9 & 5.2567 & TRN & \\
\hline CHEMBL1403154 & 737823 & 6.3 & 5.5419 & TST & \\
\hline CHEMBL1507611 & 737823 & 5.75 & 5.3909 & TRN & \\
\hline CHEMBL1446854 & 737823 & 4.55 & 4.8946 & TRN & \\
\hline CHEMBL1322285 & 737823 & 5.6 & 5.7975 & TRN & \\
\hline CHEMBL1317747 & 737823 & 5.0 & 5.1299 & TRN & \\
\hline
\end{tabular}




\begin{tabular}{|c|c|c|c|c|c|}
\hline \multicolumn{6}{|c|}{ Supplemental Table S2.txt } \\
\hline CHEMBL1421060 & 737823 & 5.55 & 5.2021 & TRN & \\
\hline CHEMBL1588349 & 737823 & 5.6 & 5.3343 & TRN & \\
\hline CHEMBL1576649 & 737823 & 5.95 & 5.567 & TRN & \\
\hline CHEMBL1494802 & 737823 & 5.15 & 5.7491 & TRN & \\
\hline CHEMBL533542 & 737823 & 6.9 & 5.5036 & TRN & \\
\hline CHEMBL1402381 & 737823 & 4.8 & 4.633 & TRN & \\
\hline CHEMBL1390555 & 737823 & 5.2 & 5.6639 & TRN & \\
\hline CHEMBL1457123 & 737823 & 5.4 & 5.6933 & TRN & \\
\hline CHEMBL1414993 & 737823 & 5.4 & 5.3821 & TRN & \\
\hline CHEMBL1431673 & 737823 & 4.8 & 5.4798 & TRN & \\
\hline CHEMBL1336155 & 737823 & 5.5 & 4.901 & TST & \\
\hline CHEMBL1515635 & 737823 & 5.1 & 5.1777 & TRN & \\
\hline CHEMBL1464417 & 737823 & 4.95 & 5.3392 & TRN & \\
\hline CHEMBL1414073 & 737823 & 5.4 & 5.5845 & TRN & \\
\hline CHEMBL1412594 & 737823 & 5.15 & 5.309 & TRN & \\
\hline CHEMBL1448646 & 737823 & 5.3 & 5.5623 & TRN & \\
\hline CHEMBL1316353 & 737823 & 5.8 & 5.61 & TRN & \\
\hline CHEMBL47529 & 737823 & 6.4 & 5.8935 & TRN & \\
\hline CHEMBL1434156 & 737823 & 4.9 & 4.4219 & TRN & \\
\hline CHEMBL332898 & 737823 & 5.9 & 6.03700 & 0000000001 & TRN \\
\hline CHEMBL1413770 & 737823 & 5.8 & 5.7237 & TRN & \\
\hline CHEMBL 3208462 & 737823 & 6.35 & 5.4352 & TRN & \\
\hline CHEMBL1474532 & 737823 & 5.6 & 4.8169 & TRN & \\
\hline CHEMBL1428605 & 737823 & 5.35 & 5.0685 & TRN & \\
\hline CHEMBL1363622 & 737823 & 4.6 & 5.1575 & TRN & \\
\hline CHEMBL1383931 & 737823 & 5.4 & 5.568 & TRN & \\
\hline CHEMBL1503191 & 737823 & 4.85 & 5.1928 & TRN & \\
\hline CHEMBL1406460 & 737823 & 5.95 & 5.4018 & TRN & \\
\hline CHEMBL1541799 & 737823 & 5.35 & 5.3424 & TRN & \\
\hline CHEMBL1527221 & 737823 & 5.7 & 5.5908 & TRN & \\
\hline CHEMBL1590230 & 737823 & 5.2 & 5.4712 & TRN & \\
\hline CHEMBL 2369218 & 737823 & 5.7 & 5.7248 & TST & \\
\hline CHEMBL3145176 & 737823 & 4.6 & 5.1554 & TST & \\
\hline CHEMBL1422579 & 737823 & 5.75 & 5.4597 & TST & \\
\hline CHEMBL1396010 & 737823 & 4.7 & 4.7366 & TRN & \\
\hline CHEMBL1590886 & 737823 & 4.8 & 5.16100 & 00000000005 & TRN \\
\hline CHEMBL1310796 & 737823 & 5.3 & 5.2697 & TRN & \\
\hline CHEMBL1362547 & 737823 & 5.4 & 5.4196 & TRN & \\
\hline CHEMBL1543421 & 737823 & 4.8 & 5.2382 & TRN & \\
\hline CHEMBL 72410 & 737823 & 4.4 & 4.6129 & TRN & \\
\hline CHEMBL1524503 & 737823 & 4.4 & 4.9277 & TRN & \\
\hline CHEMBL1338159 & 737823 & 6.2 & 6.0102 & TRN & \\
\hline CHEMBL3189280 & 737823 & 6.9 & 5.7834 & TRN & \\
\hline CHEMBL1394353 & 737823 & 4.8 & 5.3022 & TRN & \\
\hline CHEMBL1559538 & 737823 & 4.6 & 4.9758 & TRN & \\
\hline CHEMBL1557234 & 737823 & 5.0 & 4.8375 & TRN & \\
\hline CHEMBL1585050 & 737823 & 6.0 & 5.8052 & TRN & \\
\hline CHEMBL1446009 & 737823 & 5.0 & 5.3076 & TRN & \\
\hline
\end{tabular}




\begin{tabular}{|c|c|c|c|c|c|}
\hline \multicolumn{6}{|c|}{ Supplemental Table S2.txt } \\
\hline CHEMBL1592556 & 737823 & 5.9 & 5.6684 & TRN & \\
\hline CHEMBL1373796 & 737823 & 5.3 & 5.8996 & TRN & \\
\hline CHEMBL1304517 & 737823 & 4.5 & 5.7114 & TRN & \\
\hline CHEMBL1558371 & 737823 & 4.6 & 5.2436 & TRN & \\
\hline CHEMBL542700 & 737823 & -0.0 & 4.9067 & TST & \\
\hline CHEMBL 259140 & 737823 & 6.6 & 6.3629 & TRN & \\
\hline CHEMBL1595205 & 737823 & 4.9 & 4.7971 & TRN & \\
\hline CHEMBL1591190 & 737823 & 5.8 & 5.4749 & TRN & \\
\hline CHEMBL1507704 & 737823 & 6.6 & 5.3722 & TRN & \\
\hline CHEMBL1408238 & 737823 & 6.3 & 5.5405 & TRN & \\
\hline CHEMBL1533516 & 737823 & 5.4 & 5.4445 & TRN & \\
\hline CHEMBL1593589 & 737823 & 4.9 & 5.2179 & TRN & \\
\hline CHEMBL1342476 & 737823 & 5.9 & 5.4905 & TRN & \\
\hline CHEMBL1323355 & 737823 & 4.8 & 5.532 & TRN & \\
\hline CHEMBL1561692 & 737823 & 5.75 & 5.6066 & TRN & \\
\hline CHEMBL1405922 & 737823 & 5.4 & 5.3704 & TRN & \\
\hline CHEMBL1516856 & 737823 & 7.2 & 5.3632 & TRN & \\
\hline CHEMBL1433897 & 737823 & 4.8 & 5.1386 & TRN & \\
\hline CHEMBL1741502 & 737823 & 5.0 & 5.1755 & TST & \\
\hline CHEMBL1445893 & 737823 & 5.6 & 5.6279 & TRN & \\
\hline CHEMBL1741552 & 737823 & 8.2 & 5.2885 & TRN & \\
\hline CHEMBL1373591 & 737823 & 4.85 & 5.5753 & TRN & \\
\hline CHEMBL1413193 & 737823 & 4.65 & 5.1229 & TRN & \\
\hline CHEMBL1577515 & 737823 & 4.6 & 5.3146 & TRN & \\
\hline CHEMBL1318766 & 737823 & 5.7 & 5.535 & TST & \\
\hline CHEMBL1423903 & 737823 & 4.95 & 5.2879 & TRN & \\
\hline CHEMBL1344112 & 737823 & 4.8 & 5.0082 & TRN & \\
\hline CHEMBL3214238 & 737823 & 6.65 & 5.5297 & TRN & \\
\hline CHEMBL 230056 & 737823 & 4.6 & 5.1152 & TRN & \\
\hline CHEMBL1323317 & 737823 & 5.3 & 5.5685 & TST & \\
\hline CHEMBL1374205 & 737823 & 5.9 & 5.5451 & TRN & \\
\hline CHEMBL1403270 & 737823 & 5.65 & 5.24 & TST & \\
\hline CHEMBL3194933 & 737823 & 5.05 & 5.5185 & TST & \\
\hline CHEMBL1498583 & 737823 & 5.65 & 5.0708 & TST & \\
\hline CHEMBL1441394 & 737823 & 5.55 & 5.4041 & TRN & \\
\hline CHEMBL1368572 & 737823 & 6.2 & 5.4646 & TRN & \\
\hline CHEMBL1496514 & 737823 & 6.0 & 5.0003 & TST & \\
\hline CHEMBL1456755 & 737823 & 6.3 & 6.2578 & TRN & \\
\hline CHEMBL1592982 & 737823 & 6.2 & 6.316 & TRN & \\
\hline CHEMBL489934 & 737823 & 5.3 & 5.6929 & TRN & \\
\hline CHEMBL1320424 & 737823 & 5.1 & 5.4213 & TRN & \\
\hline CHEMBL1552588 & 737823 & 5.6 & 5.5912 & TRN & \\
\hline CHEMBL1611170 & 737823 & 5.5 & 5.3022 & TRN & \\
\hline CHEMBL1412900 & 737823 & 4.8 & 4.8747 & TRN & \\
\hline CHEMBL1572383 & 737823 & 4.7 & 4.8091 & TRN & \\
\hline CHEMBL1595282 & 737823 & 5.9 & 5.4829 & TRN & \\
\hline CHEMBL1592506 & 737823 & 6.1 & 5.59399 & 9999999999 & TRN \\
\hline CHEMBL1742259 & 737823 & 5.1 & 4.79 & TRN & \\
\hline & & & $P$ & 3421 & \\
\hline
\end{tabular}




\begin{tabular}{|c|c|c|c|c|c|}
\hline \\
\hline CHEMBL1347390 & 737823 & 6.4 & 5.5151 & TRN & \\
\hline CHEMBL1552396 & 737823 & 5.5 & 5.8373 & TRN & \\
\hline CHEMBL1447894 & 737823 & 5.4 & 5.1307 & TRN & \\
\hline CHEMBL1376290 & 737823 & 5.3 & 5.3358 & TRN & \\
\hline CHEMBL1356733 & 737823 & 5.6 & 5.5136 & TRN & \\
\hline CHEMBL1517817 & 737823 & 4.9 & 5.0727 & TRN & \\
\hline CHEMBL1729257 & 737823 & 4.85 & 4.6362 & TRN & \\
\hline CHEMBL1458664 & 737823 & 5.2 & 5.5354 & TRN & \\
\hline CHEMBL3198070 & 737823 & 6.2 & 5.5329 & TRN & \\
\hline CHEMBL1590059 & 737823 & 4.6 & 4.7597 & TRN & \\
\hline CHEMBL1365833 & 737823 & 4.45 & 5.4385 & TRN & \\
\hline CHEMBL1458145 & 737823 & 5.65 & 4.9902 & TRN & \\
\hline CHEMBL1444527 & 737823 & 5.0 & 5.3408 & TST & \\
\hline CHEMBL1439673 & 737823 & 5.0 & 5.4427 & TRN & \\
\hline CHEMBL1611192 & 737823 & 4.8 & 5.1867 & TRN & \\
\hline CHEMBL1318597 & 737823 & 4.8 & 4.4714 & TRN & \\
\hline CHEMBL1374585 & 737823 & 5.4 & 5.2565 & TRN & \\
\hline CHEMBL1321118 & 737823 & 5.3 & 5.5077 & TRN & \\
\hline CHEMBL1551818 & 737823 & 4.7 & 4.7124 & TRN & \\
\hline CHEMBL1383401 & 737823 & 5.7 & 5.2 & TRN & \\
\hline CHEMBL1593661 & 737823 & 4.9 & 5.0977 & TRN & \\
\hline CHEMBL1742180 & 737823 & 6.15 & 5.5135 & TRN & \\
\hline CHEMBL1318307 & 737823 & 4.6 & 4.8134 & TST & \\
\hline CHEMBL1437709 & 737823 & 6.2 & 5.0889 & TST & \\
\hline CHEMBL1600921 & 737823 & 6.2 & 5.4749 & TRN & \\
\hline CHEMBL1464103 & 737823 & 5.1 & 5.45 & TST & \\
\hline CHEMBL1488990 & 737823 & 5.2 & 5.3926 & TRN & \\
\hline CHEMBL1400312 & 737823 & 5.45 & 5.21299 & 9999999999 & TRN \\
\hline CHEMBL1454949 & 737823 & 5.4 & 5.4949 & TST & \\
\hline CHEMBL1570083 & 737823 & 6.1 & 5.8801 & TRN & \\
\hline CHEMBL1502072 & 737823 & 6.35 & 5.5465 & TRN & \\
\hline CHEMBL1545573 & 737823 & 4.5 & 5.0177 & TST & \\
\hline CHEMBL1741382 & 737823 & 5.5 & 5.3026 & TST & \\
\hline CHEMBL1742202 & 737823 & 4.85 & 5.443 & TST & \\
\hline CHEMBL1479144 & 737823 & 5.9 & 6.0696 & TRN & \\
\hline CHEMBL1243269 & 737823 & 4.6 & 4.8939 & TST & \\
\hline CHEMBL1323563 & 737823 & 4.8 & 5.2363 & TRN & \\
\hline CHEMBL1351886 & 737823 & 4.9 & 5.0174 & TST & \\
\hline CHEMBL1360601 & 737823 & 4.85 & 5.0605 & TRN & \\
\hline CHEMBL1404858 & 737823 & 4.85 & 5.1451 & TRN & \\
\hline CHEMBL1500523 & 737823 & 4.9 & 5.1436 & TRN & \\
\hline CHEMBL1589897 & 737823 & 4.6 & 4.9048 & TRN & \\
\hline CHEMBL1410012 & 737823 & 4.6 & 4.8829 & TRN & \\
\hline CHEMBL1722818 & 737823 & 7.0 & 5.0871 & TST & \\
\hline CHEMBL1607968 & 737823 & 5.6 & 5.3137 & TRN & \\
\hline CHEMBL1353354 & 737823 & 5.8 & 5.4244 & TRN & \\
\hline CHEMBL1329117 & 737823 & 5.5 & 4.9062 & TST & \\
\hline CHEMBL3213877 & 737823 & 6.25 & 5.2867 & TRN & \\
\hline
\end{tabular}




\begin{tabular}{|c|c|c|c|c|c|}
\hline \multicolumn{6}{|c|}{ Supplemental Table S2.txt } \\
\hline CHEMBL1493877 & 737823 & 4.75 & 5.3961 & TRN & \\
\hline CHEMBL1465342 & 737823 & 5.25 & 5.4728 & TRN & \\
\hline CHEMBL1371458 & 737823 & 5.5 & 5.1783 & TRN & \\
\hline CHEMBL1406865 & 737823 & 4.6 & 4.3182 & TRN & \\
\hline CHEMBL1453817 & 737823 & 5.85 & 6.0947 & TRN & \\
\hline CHEMBL1610581 & 737823 & 5.9 & 5.2496 & TRN & \\
\hline CHEMBL258767 & 737823 & 6.0 & 5.5289 & TRN & \\
\hline CHEMBL1419070 & 737823 & 4.95 & 5.0227 & TRN & \\
\hline CHEMBL1741421 & 737823 & 4.4 & 5.3166 & TRN & \\
\hline CHEMBL1365934 & 737823 & 5.4 & 5.432 & TRN & \\
\hline CHEMBL1307366 & 737823 & 5.65 & 5.266 & TRN & \\
\hline CHEMBL1516342 & 737823 & 4.8 & 5.1381 & TRN & \\
\hline CHEMBL222334 & 737823 & 5.0 & 5.374 & TRN & \\
\hline CHEMBL1563254 & 737823 & 4.85 & 5.5425 & TST & \\
\hline CHEMBL1382877 & 737823 & 4.85 & 5.234 & TRN & \\
\hline CHEMBL1585650 & 737823 & 4.85 & 4.913 & TRN & \\
\hline CHEMBL1397654 & 737823 & 4.9 & 6.0633 & TRN & \\
\hline CHEMBL 76232 & 737823 & 4.5 & 4.7487 & TRN & \\
\hline CHEMBL1503381 & 737823 & 5.7 & 5.5671 & TRN & \\
\hline CHEMBL1417540 & 737823 & 5.35 & 5.3649 & TRN & \\
\hline CHEMBL1565888 & 737823 & 5.65 & 5.147 & TRN & \\
\hline CHEMBL1484573 & 737823 & 4.65 & 5.3913 & TST & \\
\hline CHEMBL1433232 & 737823 & 5.5 & 5.3886 & TRN & \\
\hline CHEMBL2369261 & 737823 & 5.55 & 5.425 & TST & \\
\hline CHEMBL1574460 & 737823 & 4.9 & 5.1731 & TRN & \\
\hline CHEMBL3213016 & 737823 & 5.0 & 5.42200 & 0000000001 & TRN \\
\hline CHEMBL1413296 & 737823 & 5.4 & 4.8562 & TRN & \\
\hline CHEMBL1579870 & 737823 & 5.05 & 5.1208 & TRN & \\
\hline CHEMBL1406712 & 737823 & 4.9 & 5.2719 & TRN & \\
\hline CHEMBL1361984 & 737823 & 6.05 & 5.1433 & TRN & \\
\hline CHEMBL1332209 & 737823 & 4.7 & 5.3228 & TRN & \\
\hline CHEMBL1358252 & 737823 & 6.5 & 5.6518 & TRN & \\
\hline CHEMBL1478853 & 737823 & 5.4 & 4.7837 & TST & \\
\hline CHEMBL1567191 & 737823 & 5.6 & 5.2874 & TRN & \\
\hline CHEMBL1609880 & 737823 & 5.95 & 5.9309 & TST & \\
\hline CHEMBL1500692 & 737823 & 4.85 & 4.9481 & TRN & \\
\hline CHEMBL491943 & 737823 & 4.8 & 4.8795 & TRN & \\
\hline CHEMBL1365347 & 737823 & 4.9 & 5.0017 & TRN & \\
\hline CHEMBL1514455 & 737823 & 6.2 & 4.9353 & TRN & \\
\hline CHEMBL1395850 & 737823 & 5.9 & 5.4032 & TRN & \\
\hline CHEMBL1324022 & 737823 & 4.9 & 4.9 & TRN & \\
\hline CHEMBL1482153 & 737823 & 6.7 & 5.4216 & TRN & \\
\hline CHEMBL1493183 & 737823 & 5.55 & 5.5224 & TRN & \\
\hline CHEMBL1514440 & 737823 & 6.0 & 5.3182 & TRN & \\
\hline CHEMBL1357444 & 737823 & 6.2 & 6.5698 & TRN & \\
\hline CHEMBL1553577 & 737823 & 5.5 & 5.0945 & TRN & \\
\hline CHEMBL1742076 & 737823 & -0.0 & 5.4988 & TST & \\
\hline CHEMBL1723812 & 737823 & 4.85 & 5.5581 & TRN & \\
\hline
\end{tabular}




\begin{tabular}{|c|c|c|c|c|c|}
\hline \\
\hline CHEMBL1393664 & 737823 & 5.4 & 5.7917 & TST & \\
\hline CHEMBL1358161 & 737823 & 4.7 & 5.1214 & TRN & \\
\hline CHEMBL1555677 & 737823 & 4.8 & 5.0389 & TRN & \\
\hline CHEMBL1321887 & 737823 & 5.2 & 5.5829 & TRN & \\
\hline CHEMBL1548421 & 737823 & 4.9 & 5.1349 & TRN & \\
\hline CHEMBL1454052 & 737823 & 4.6 & 5.0685 & TRN & \\
\hline CHEMBL1390261 & 737823 & 6.9 & 5.6275 & TRN & \\
\hline CHEMBL1565164 & 737823 & 5.1 & 5.7427 & TST & \\
\hline CHEMBL1598704 & 737823 & 4.95 & 5.0709 & TST & \\
\hline CHEMBL1437428 & 737823 & 5.4 & 5.2952 & TST & \\
\hline CHEMBL1518709 & 737823 & 4.9 & 5.374 & TRN & \\
\hline CHEMBL1418619 & 737823 & 5.6 & 5.2771 & TRN & \\
\hline CHEMBL1602002 & 737823 & 4.65 & 5.008 & TRN & \\
\hline CHEMBL1604232 & 737823 & 6.25 & 5.3332 & TRN & \\
\hline CHEMBL1313226 & 737823 & 5.5 & 5.0697 & TRN & \\
\hline CHEMBL1409689 & 737823 & 6.8 & 6.7974 & TRN & \\
\hline CHEMBL3195612 & 737823 & 5.55 & 5.4865 & TRN & \\
\hline CHEMBL1580282 & 737823 & 4.7 & 5.2956 & TRN & \\
\hline CHEMBL1538161 & 737823 & 4.75 & 4.8028 & TRN & \\
\hline CHEMBL1568026 & 737823 & 5.85 & 5.5488 & TRN & \\
\hline CHEMBL1523314 & 737823 & 5.7 & 5.471 & TRN & \\
\hline CHEMBL1502201 & 737823 & 5.35 & 5.6774 & TST & \\
\hline CHEMBL592561 & 737823 & 5.5 & 5.416 & TRN & \\
\hline CHEMBL1492493 & 737823 & 4.75 & 5.1711 & TRN & \\
\hline CHEMBL1398762 & 737823 & 5.35 & 5.0142 & TRN & \\
\hline CHEMBL495069 & 737823 & 4.7 & 5.0818 & TRN & \\
\hline CHEMBL1413982 & 737823 & 7.4 & 5.16799 & 9999999999 & TRN \\
\hline CHEMBL1579887 & 737823 & 4.6 & 5.3581 & TRN & \\
\hline CHEMBL1437007 & 737823 & 4.8 & 4.7921 & TRN & \\
\hline CHEMBL1485152 & 737823 & 4.9 & 4.6658 & TRN & \\
\hline CHEMBL1407215 & 737823 & 4.5 & 4.6595 & TST & \\
\hline CHEMBL1735424 & 737823 & 4.85 & 5.1023 & TRN & \\
\hline CHEMBL3193992 & 737823 & 5.1 & 4.9824 & TRN & \\
\hline CHEMBL1596499 & 737823 & 5.6 & 5.5936 & TRN & \\
\hline CHEMBL1352779 & 737823 & 5.1 & 5.1862 & TRN & \\
\hline CHEMBL9352 & 737823 & 5.5 & 5.1634 & TST & \\
\hline CHEMBL3190499 & 737823 & 6.6 & 5.6837 & TST & \\
\hline CHEMBL1356101 & 737823 & 5.2 & 5.1218 & TRN & \\
\hline CHEMBL1561457 & 737823 & 5.1 & 5.5118 & TRN & \\
\hline CHEMBL3198189 & 737823 & 5.7 & 5.2781 & TST & \\
\hline CHEMBL3189354 & 737823 & 4.7 & 5.4079 & TRN & \\
\hline CHEMBL3210667 & 737823 & 5.45 & 5.1087 & TRN & \\
\hline CHEMBL1437046 & 737823 & 4.9 & 5.3247 & TRN & \\
\hline CHEMBL1445913 & 737823 & 6.3 & 5.0108 & TRN & \\
\hline CHEMBL1323549 & 737823 & 6.0 & 5.8962 & TRN & \\
\hline CHEMBL1591971 & 737823 & 5.5 & 5.6203 & TRN & \\
\hline CHEMBL543557 & 737823 & 4.5 & 4.898 & TRN & \\
\hline CHEMBL1522556 & 737823 & 5.1 & 4.7501 & TRN & \\
\hline & & & & 424 & \\
\hline
\end{tabular}




\begin{tabular}{|c|c|c|c|c|c|}
\hline \multicolumn{6}{|c|}{ Supplemental Table S2.txt } \\
\hline CHEMBL1523959 & 737823 & 5.0 & 5.191 & TRN & \\
\hline CHEMBL1426500 & 737823 & 6.15 & 5.2433 & TRN & \\
\hline CHEMBL1610350 & 737823 & 5.5 & 6.0513 & TRN & \\
\hline CHEMBL1409613 & 737823 & 7.0 & 6.2902 & TRN & \\
\hline CHEMBL1355262 & 737823 & 4.8 & 4.9259 & TRN & \\
\hline CHEMBL1435254 & 737823 & 4.6 & 4.7724 & TRN & \\
\hline CHEMBL1412769 & 737823 & 5.5 & 5.0102 & TRN & \\
\hline CHEMBL1560502 & 737823 & 4.8 & 5.0071 & TRN & \\
\hline CHEMBL1609585 & 737823 & 4.85 & 5.2262 & TRN & \\
\hline CHEMBL1436817 & 737823 & 4.8 & 4.7051 & TRN & \\
\hline CHEMBL1368286 & 737823 & 6.6 & 5.7359 & TRN & \\
\hline CHEMBL1383447 & 737823 & 4.65 & 5.7469 & TST & \\
\hline CHEMBL371811 & 737823 & 6.7 & 5.71700 & 00000000005 & TRN \\
\hline CHEMBL39879 & 737823 & 4.6 & 5.3861 & TRN & \\
\hline CHEMBL1605678 & 737823 & 6.9 & 4.865 & TRN & \\
\hline CHEMBL1303049 & 737823 & 5.65 & 5.3717 & TRN & \\
\hline CHEMBL1545141 & 737823 & 5.45 & 5.3075 & TST & \\
\hline CHEMBL3189991 & 737823 & 5.35 & 4.7301 & TRN & \\
\hline CHEMBL36060 & 737823 & 4.5 & 5.0708 & TRN & \\
\hline CHEMBL1422932 & 737823 & 4.85 & 5.2468 & TRN & \\
\hline CHEMBL1487092 & 737823 & 4.5 & 4.8936 & TRN & \\
\hline CHEMBL1590132 & 737823 & 5.9 & 5.5696 & TRN & \\
\hline CHEMBL1320982 & 737823 & 4.9 & 5.2093 & TRN & \\
\hline CHEMBL1322311 & 737823 & 4.75 & 4.9857 & TRN & \\
\hline CHEMBL1512833 & 737823 & 5.7 & 5.6407 & TRN & \\
\hline CHEMBL1527926 & 737823 & 4.6 & 5.2818 & TRN & \\
\hline CHEMBL1323101 & 737823 & 6.4 & 5.9718 & TRN & \\
\hline CHEMBL1512317 & 737823 & 4.9 & 4.8055 & TRN & \\
\hline CHEMBL60518 & 737823 & 4.9 & 5.2354 & TRN & \\
\hline CHEMBL1343101 & 737823 & 4.9 & 5.3007 & TST & \\
\hline CHEMBL1331301 & 737823 & 6.9 & 5.6156 & TRN & \\
\hline CHEMBL3197859 & 737823 & 4.95 & 5.2112 & TRN & \\
\hline CHEMBL1406640 & 737823 & 4.6 & 5.2034 & TRN & \\
\hline CHEMBL1435713 & 737823 & 4.8 & 4.9508 & TRN & \\
\hline CHEMBL1411210 & 737823 & 5.85 & 5.6916 & TRN & \\
\hline CHEMBL1702153 & 737823 & 4.6 & 5.1163 & TST & \\
\hline CHEMBL1331444 & 737823 & 5.7 & 4.6545 & TRN & \\
\hline CHEMBL1475902 & 737823 & 6.0 & 6.0953 & TRN & \\
\hline CHEMBL1256727 & 737823 & 6.0 & 5.4004 & TRN & \\
\hline CHEMBL3196296 & 737823 & 5.0 & 5.2517 & TST & \\
\hline CHEMBL1326272 & 737823 & 6.15 & 5.5212 & TRN & \\
\hline CHEMBL1396374 & 737823 & 6.2 & 6.2626 & TRN & \\
\hline CHEMBL3192797 & 737823 & 4.8 & 5.2511 & TRN & \\
\hline CHEMBL1742187 & 737823 & 4.8 & 5.1034 & TRN & \\
\hline CHEMBL1358234 & 737823 & 5.9 & 5.3882 & TRN & \\
\hline CHEMBL1566017 & 737823 & 4.7 & 4.8075 & TRN & \\
\hline CHEMBL1571840 & 737823 & 4.8 & 4.626 & TRN & \\
\hline CHEMBL1445578 & 737823 & 5.7 & 5.5535 & TRN & \\
\hline
\end{tabular}




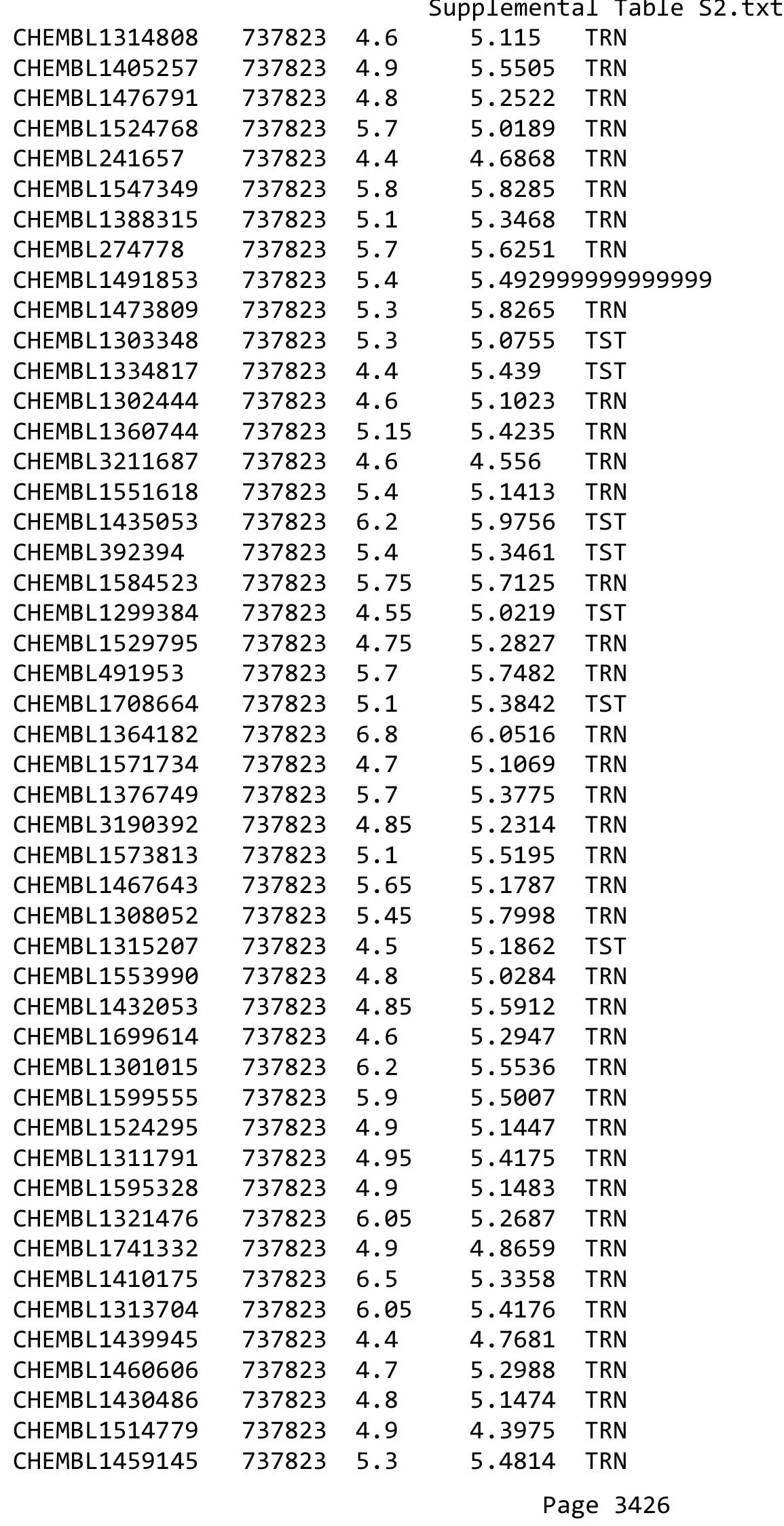




\begin{tabular}{|c|c|c|c|c|c|}
\hline \\
\hline CHEMBL1379744 & 737823 & 4.8 & 5.1517 & TRN & \\
\hline CHEMBL1476604 & 737823 & 4.8 & 4.7569 & TRN & \\
\hline CHEMBL1522755 & 737823 & 5.65 & 5.4631 & TRN & \\
\hline CHEMBL1613397 & 737823 & 4.8 & 5.0777 & TRN & \\
\hline CHEMBL1602661 & 737823 & 5.55 & 5.0168 & TST & \\
\hline CHEMBL1363185 & 737823 & 5.7 & 5.4176 & TRN & \\
\hline CHEMBL3198545 & 737823 & 5.85 & 6.0723 & TRN & \\
\hline CHEMBL1322914 & 737823 & 4.95 & 5.3024 & TST & \\
\hline CHEMBL1327681 & 737823 & 6.4 & 6.1629 & TRN & \\
\hline CHEMBL1466017 & 737823 & 6.45 & 5.6011 & TRN & \\
\hline CHEMBL1384711 & 737823 & 4.8 & 4.9072 & TRN & \\
\hline CHEMBL3199510 & 737823 & 5.75 & 4.9846 & TRN & \\
\hline CHEMBL1470129 & 737823 & 4.95 & 5.2908 & TRN & \\
\hline CHEMBL321691 & 737823 & 4.4 & 4.9994 & TST & \\
\hline CHEMBL1441650 & 737823 & 4.65 & 5.1178 & TRN & \\
\hline CHEMBL1707011 & 737823 & 5.7 & 5.2827 & TRN & \\
\hline CHEMBL1981840 & 737823 & 5.9 & 5.8085 & TST & \\
\hline CHEMBL1523946 & 737823 & 4.65 & 5.3278 & TRN & \\
\hline CHEMBL1544250 & 737823 & 5.0 & 5.3611 & TRN & \\
\hline CHEMBL1603692 & 737823 & 5.0 & 5.06800 & 00000000005 & TRN \\
\hline CHEMBL1520653 & 737823 & 4.75 & 5.1876 & TST & \\
\hline CHEMBL1361501 & 737823 & 4.95 & 5.3699 & TRN & \\
\hline CHEMBL1493118 & 737823 & 6.2 & 5.3694 & TRN & \\
\hline CHEMBL1445255 & 737823 & 4.8 & 4.9953 & TRN & \\
\hline CHEMBL 504585 & 737823 & 6.5 & 5.2191 & TRN & \\
\hline CHEMBL1456420 & 737823 & 5.6 & 5.0608 & TRN & \\
\hline CHEMBL1546319 & 737823 & 5.25 & 4.8624 & TST & \\
\hline CHEMBL1581512 & 737823 & 5.8 & 5.6946 & TRN & \\
\hline CHEMBL1353756 & 737823 & 6.5 & 5.3767 & TRN & \\
\hline CHEMBL1440219 & 737823 & 5.4 & 5.8493 & TRN & \\
\hline CHEMBL1457798 & 737823 & 5.05 & 5.4771 & TRN & \\
\hline CHEMBL 375672 & 737823 & 5.4 & 5.6492 & TRN & \\
\hline CHEMBL153036 & 737823 & 6.0 & 5.2905 & TRN & \\
\hline CHEMBL1547186 & 737823 & 5.4 & 5.2699 & TST & \\
\hline CHEMBL1355712 & 737823 & 6.2 & 6.1799 & TRN & \\
\hline CHEMBL1741481 & 737823 & 4.8 & 5.0609 & TRN & \\
\hline CHEMBL1573058 & 737823 & 5.8 & 5.6071 & TRN & \\
\hline CHEMBL1574218 & 737823 & 5.0 & 5.3498 & TRN & \\
\hline CHEMBL1556561 & 737823 & 5.55 & 4.9487 & TRN & \\
\hline CHEMBL105739 & 737823 & 6.1 & 5.6973 & TRN & \\
\hline CHEMBL1485598 & 737823 & 6.2 & 5.6831 & TRN & \\
\hline CHEMBL1337620 & 737823 & 5.9 & 5.16100 & $\partial 0000000005$ & TRN \\
\hline CHEMBL1349158 & 737823 & 5.9 & 5.6603 & TRN & \\
\hline CHEMBL1318400 & 737823 & 6.0 & 5.3711 & TRN & \\
\hline CHEMBL1424426 & 737823 & 4.7 & 4.8089 & TRN & \\
\hline CHEMBL1435647 & 737823 & 4.8 & 4.8931 & TST & \\
\hline CHEMBL1429565 & 737823 & 5.0 & 5.1996 & TRN & \\
\hline CHEMBL1607010 & 737823 & 5.2 & 4.8733 & TRN & \\
\hline & & & & 427 & \\
\hline
\end{tabular}




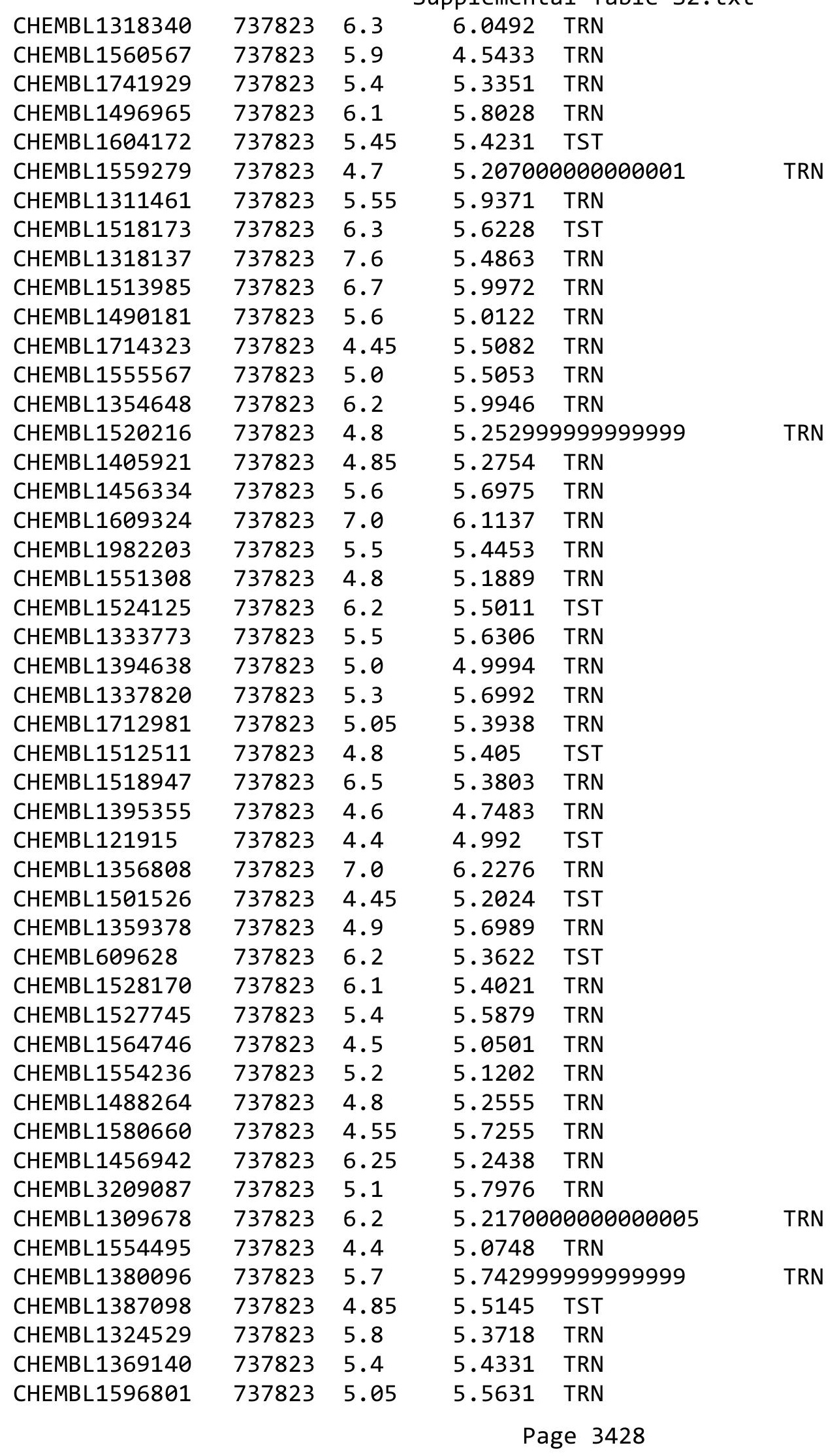




\begin{tabular}{|c|c|c|c|c|c|}
\hline \multicolumn{6}{|c|}{ Supplemental Table S2.txt } \\
\hline CHEMBL3195954 & 737823 & 5.6 & 5.2859 & TRN & \\
\hline CHEMBL1601443 & 737823 & 4.9 & 4.9221 & TRN & \\
\hline CHEMBL1256996 & 737823 & 6.0 & 5.2077 & TRN & \\
\hline CHEMBL1562337 & 737823 & 5.6 & 5.2754 & TRN & \\
\hline CHEMBL1413388 & 737823 & 5.0 & 5.0918 & TRN & \\
\hline CHEMBL1435698 & 737823 & 4.9 & 5.0256 & TRN & \\
\hline CHEMBL1364931 & 737823 & 5.2 & 6.0374 & TRN & \\
\hline CHEMBL3193500 & 737823 & 5.4 & 5.29299 & 9999999999 & TRN \\
\hline CHEMBL1454855 & 737823 & 4.8 & 5.3742 & TRN & \\
\hline CHEMBL1333768 & 737823 & 5.4 & 5.0862 & TRN & \\
\hline CHEMBL1720716 & 737823 & 4.55 & 4.7653 & TRN & \\
\hline CHEMBL1509477 & 737823 & 4.95 & 5.1697 & TRN & \\
\hline CHEMBL1355665 & 737823 & 5.1 & 4.824 & TRN & \\
\hline CHEMBL1472926 & 737823 & 6.7 & 6.1801 & TRN & \\
\hline CHEMBL1326836 & 737823 & 4.65 & 4.871 & TST & \\
\hline CHEMBL1456015 & 737823 & 5.7 & 5.6508 & TRN & \\
\hline CHEMBL1450556 & 737823 & 5.55 & 5.2813 & TRN & \\
\hline CHEMBL287689 & 737823 & 5.4 & 5.5901 & TRN & \\
\hline CHEMBL429711 & 737823 & 7.3 & 5.7682 & TRN & \\
\hline CHEMBL1453758 & 737823 & 6.2 & 5.7683 & TRN & \\
\hline CHEMBL1611718 & 737823 & 4.8 & 5.1309 & TRN & \\
\hline CHEMBL3195204 & 737823 & 4.75 & 5.2148 & TRN & \\
\hline CHEMBL1497006 & 737823 & 4.8 & 4.6847 & TRN & \\
\hline CHEMBL1502195 & 737823 & 6.05 & 5.4045 & TRN & \\
\hline CHEMBL3211478 & 737823 & 5.4 & 5.4287 & TRN & \\
\hline CHEMBL444810 & 737823 & 5.55 & 5.6244 & TRN & \\
\hline CHEMBL491547 & 737823 & 5.1 & 5.1847 & TRN & \\
\hline CHEMBL1595178 & 737823 & 5.4 & 5.6567 & TRN & \\
\hline CHEMBL1411467 & 737823 & 6.15 & 5.6778 & TRN & \\
\hline CHEMBL1422725 & 737823 & 5.0 & 5.0937 & TRN & \\
\hline CHEMBL1325869 & 737823 & 5.9 & 5.6377 & TRN & \\
\hline CHEMBL490743 & 737823 & 4.9 & 4.7609 & TRN & \\
\hline CHEMBL1604366 & 737823 & 5.4 & 5.3056 & TST & \\
\hline CHEMBL1472765 & 737823 & 6.1 & 6.0895 & TRN & \\
\hline CHEMBL1741757 & 737823 & 5.8 & 4.9945 & TST & \\
\hline CHEMBL1379706 & 737823 & 4.9 & 5.4088 & TRN & \\
\hline CHEMBL1474795 & 737823 & 4.9 & 4.5879 & TRN & \\
\hline CHEMBL1576337 & 737823 & 4.55 & 5.6762 & TRN & \\
\hline CHEMBL1741361 & 737823 & 6.0 & 6.1589 & TRN & \\
\hline CHEMBL429023 & 737823 & 4.8 & 5.5578 & TST & \\
\hline CHEMBL1416252 & 737823 & 5.7 & 5.4127 & TRN & \\
\hline CHEMBL1323204 & 737823 & 6.2 & 5.3 & TRN & \\
\hline CHEMBL1581948 & 737823 & 6.4 & 5.3464 & TST & \\
\hline CHEMBL1404656 & 737823 & 5.35 & 5.5094 & TST & \\
\hline CHEMBL 2002813 & 737823 & 5.2 & 4.3094 & TST & \\
\hline CHEMBL1503625 & 737823 & 4.9 & 5.3884 & TRN & \\
\hline CHEMBL3212090 & 737823 & 4.85 & 5.2536 & TRN & \\
\hline CHEMBL431998 & 737823 & 4.5 & 4.8126 & TST & \\
\hline
\end{tabular}




\begin{tabular}{|c|c|c|c|c|c|}
\hline \multicolumn{6}{|c|}{ Supplemental Table S2.txt } \\
\hline CHEMBL1256916 & 737823 & 4.5 & 4.9955 & TRN & \\
\hline CHEMBL 3192647 & 737823 & 6.25 & 5.4947 & TRN & \\
\hline CHEMBL1409866 & 737823 & 4.75 & 5.0459 & TRN & \\
\hline CHEMBL3193269 & 737823 & 4.95 & 5.5809 & TRN & \\
\hline CHEMBL1472845 & 737823 & 4.7 & 4.9349 & TRN & \\
\hline CHEMBL1569088 & 737823 & 5.0 & 5.61 & TST & \\
\hline CHEMBL1434783 & 737823 & 5.0 & 5.2106 & TRN & \\
\hline CHEMBL1312953 & 737823 & 5.35 & 5.67 & TST & \\
\hline CHEMBL1382099 & 737823 & 4.8 & 4.6852 & TST & \\
\hline CHEMBL1339209 & 737823 & 6.3 & 6.3088 & TRN & \\
\hline CHEMBL1606345 & 737823 & 5.65 & 5.2568 & TRN & \\
\hline CHEMBL1335409 & 737823 & 6.8 & 5.3489 & TRN & \\
\hline CHEMBL1592864 & 737823 & 4.8 & 4.9422 & TRN & \\
\hline CHEMBL1493402 & 737823 & 5.45 & 5.4568 & TRN & \\
\hline CHEMBL1476280 & 737823 & 4.8 & 4.9593 & TRN & \\
\hline CHEMBL1549510 & 737823 & 6.45 & 5.6812 & TRN & \\
\hline CHEMBL1437013 & 737823 & 6.2 & 5.83299 & 9999999999 & TRN \\
\hline CHEMBL1551518 & 737823 & 6.5 & 5.8175 & TRN & \\
\hline CHEMBL1742304 & 737823 & 6.4 & 5.68 & TRN & \\
\hline CHEMBL3212613 & 737823 & 4.85 & 4.9052 & TRN & \\
\hline CHEMBL3199056 & 737823 & 5.65 & 5.475 & TRN & \\
\hline CHEMBL11471 & 737823 & -0.0 & 4.5452 & TRN & \\
\hline CHEMBL1521414 & 737823 & 5.4 & 4.8154 & TRN & \\
\hline CHEMBL1414071 & 737823 & 7.6 & 5.9094 & TRN & \\
\hline CHEMBL1447959 & 737823 & 6.1 & 5.5407 & TRN & \\
\hline CHEMBL1566978 & 737823 & 4.85 & 5.8298 & TRN & \\
\hline CHEMBL1735112 & 737823 & 4.8 & 5.2333 & TST & \\
\hline CHEMBL1386135 & 737823 & 4.85 & 5.4108 & TST & \\
\hline CHEMBL1359716 & 737823 & 5.0 & 5.3547 & TRN & \\
\hline CHEMBL1741546 & 737823 & 6.0 & 4.7822 & TRN & \\
\hline CHEMBL1436917 & 737823 & 5.5 & 5.215 & TRN & \\
\hline CHEMBL1327497 & 737823 & 5.3 & 5.4095 & TST & \\
\hline CHEMBL1317378 & 737823 & 5.0 & 5.1428 & TRN & \\
\hline CHEMBL1461491 & 737823 & 6.0 & 5.0809 & TST & \\
\hline CHEMBL106437 & 737823 & 4.5 & 5.0843 & TRN & \\
\hline CHEMBL1379187 & 737823 & 4.6 & 5.3728 & TRN & \\
\hline CHEMBL1741433 & 737823 & 4.8 & 5.6214 & TRN & \\
\hline CHEMBL1375090 & 737823 & 6.0 & 5.1273 & TRN & \\
\hline CHEMBL1529948 & 737823 & 5.3 & 5.2274 & TRN & \\
\hline CHEMBL1519798 & 737823 & 5.5 & 5.3135 & TRN & \\
\hline CHEMBL1535796 & 737823 & 5.3 & 5.2953 & TRN & \\
\hline CHEMBL1435028 & 737823 & 5.2 & 5.4049 & TRN & \\
\hline CHEMBL517040 & 737823 & 5.0 & 5.086 & TST & \\
\hline CHEMBL1547900 & 737823 & 5.2 & 4.9874 & TRN & \\
\hline CHEMBL1487013 & 737823 & 5.4 & 5.3937 & TRN & \\
\hline CHEMBL1573165 & 737823 & 4.4 & 5.6906 & TST & \\
\hline CHEMBL1321899 & 737823 & 5.3 & 5.2465 & TRN & \\
\hline CHEMBL3209359 & 737823 & 5.5 & 5.4545 & TRN & \\
\hline
\end{tabular}




\begin{tabular}{|c|c|c|c|c|c|}
\hline \multicolumn{6}{|c|}{ Supplemental Table S2.txt } \\
\hline CHEMBL1349366 & 737823 & 6.35 & 5.8744 & TRN & \\
\hline CHEMBL1447738 & 737823 & 5.2 & 5.0749 & TRN & \\
\hline CHEMBL1430976 & 737823 & 4.85 & 5.3669 & TRN & \\
\hline CHEMBL1588849 & 737823 & 5.3 & 5.2916 & TRN & \\
\hline CHEMBL1460723 & 737823 & 5.4 & 5.5368 & TRN & \\
\hline CHEMBL1334293 & 737823 & 5.4 & 5.2627 & TRN & \\
\hline CHEMBL1333616 & 737823 & 4.85 & 5.2819 & TRN & \\
\hline CHEMBL1529543 & 737823 & 5.6 & 5.2736 & TRN & \\
\hline CHEMBL1593511 & 737823 & 4.9 & 4.9787 & TRN & \\
\hline CHEMBL1414213 & 737823 & 4.9 & 5.0385 & TRN & \\
\hline CHEMBL 2000196 & 737823 & 4.85 & 5.5025 & TRN & \\
\hline CHEMBL1401672 & 737823 & 5.4 & 4.8378 & TRN & \\
\hline CHEMBL1388651 & 737823 & 6.2 & 5.7054 & TRN & \\
\hline CHEMBL 39317 & 737823 & 7.5 & 5.2438 & TRN & \\
\hline CHEMBL1370889 & 737823 & 4.85 & 5.2201 & TRN & \\
\hline CHEMBL125569 & 737823 & 4.8 & 5.4242 & TRN & \\
\hline CHEMBL1299778 & 737823 & 5.65 & 5.7785 & TRN & \\
\hline CHEMBL1424437 & 737823 & 5.8 & 5.5096 & TRN & \\
\hline CHEMBL1434072 & 737823 & 5.7 & 5.9483 & TRN & \\
\hline CHEMBL1552727 & 737823 & 6.8 & 5.6764 & TRN & \\
\hline CHEMBL1319049 & 737823 & 4.8 & 5.1987 & TRN & \\
\hline CHEMBL1460770 & 737823 & 5.85 & 5.2758 & TRN & \\
\hline CHEMBL 276140 & 737823 & 9.1 & 5.3513 & TRN & \\
\hline CHEMBL1327411 & 737823 & 5.3 & 5.8742 & TST & \\
\hline CHEMBL 3190938 & 737823 & 6.5 & 5.3612 & TRN & \\
\hline CHEMBL1362464 & 737823 & 4.95 & 5.0888 & TRN & \\
\hline CHEMBL1457550 & 737823 & 6.0 & 5.016 & TRN & \\
\hline CHEMBL1504465 & 737823 & 4.65 & 5.648 & TRN & \\
\hline CHEMBL1425423 & 737823 & 5.25 & 5.5054 & TRN & \\
\hline CHEMBL1559828 & 737823 & 5.3 & 5.1279 & TRN & \\
\hline CHEMBL1498966 & 737823 & 5.6 & 5.2202 & TRN & \\
\hline CHEMBL1323732 & 737823 & 5.5 & 5.3777 & TRN & \\
\hline CHEMBL1493707 & 737823 & 5.1 & 5.5906 & TRN & \\
\hline CHEMBL1514683 & 737823 & 5.3 & 5.3508 & TRN & \\
\hline CHEMBL1571483 & 737823 & 5.4 & 5.7237 & TRN & \\
\hline CHEMBL1612492 & 737823 & 5.25 & 4.9325 & TRN & \\
\hline CHEMBL1596230 & 737823 & 5.55 & 4.9953 & TRN & \\
\hline CHEMBL1451815 & 737823 & 5.05 & 4.9879 & TRN & \\
\hline CHEMBL1315690 & 737823 & 5.0 & 5.16700 & 0000000001 & TRN \\
\hline CHEMBL1332357 & 737823 & 4.85 & 5.2002 & TRN & \\
\hline CHEMBL1429320 & 737823 & 4.85 & 5.5122 & TST & \\
\hline CHEMBL90882 & 737823 & 4.7 & 5.2898 & TRN & \\
\hline CHEMBL1552249 & 737823 & 4.6 & 5.0401 & TRN & \\
\hline CHEMBL1323524 & 737823 & 4.9 & 4.6735 & TRN & \\
\hline CHEMBL1991234 & 737823 & 4.8 & 5.396 & TST & \\
\hline CHEMBL18701 & 737823 & 5.0 & 5.1484 & TRN & \\
\hline CHEMBL1506416 & 737823 & 5.35 & 5.2375 & TRN & \\
\hline CHEMBL1454748 & 737823 & 5.3 & 5.5351 & TRN & \\
\hline
\end{tabular}




\begin{tabular}{|c|c|c|c|c|c|}
\hline & & \multicolumn{4}{|c|}{ Supplemental Table S2.txt } \\
\hline CHEMBL1373930 & 737823 & 5.05 & 5.4606 & TRN & \\
\hline CHEMBL1741343 & 737823 & 4.7 & 5.2012 & TRN & \\
\hline CHEMBL1567934 & 737823 & 4.6 & 4.8655 & TRN & \\
\hline CHEMBL1553741 & 737823 & 5.2 & 5.2256 & TRN & \\
\hline CHEMBL1519953 & 737823 & 4.95 & 5.1678 & TRN & \\
\hline CHEMBL1568012 & 737823 & 6.6 & 5.7717 & TRN & \\
\hline CHEMBL1395303 & 737823 & 5.4 & 5.1382 & TRN & \\
\hline CHEMBL1593547 & 737823 & 5.7 & 5.5717 & TRN & \\
\hline CHEMBL1560365 & 737823 & 5.45 & 5.6525 & TST & \\
\hline CHEMBL1487532 & 737823 & -0.0 & 5.0865 & TST & \\
\hline CHEMBL491977 & 737823 & 4.8 & 4.7768 & TRN & \\
\hline CHEMBL1567229 & 737823 & 5.8 & 5.0396 & TRN & \\
\hline CHEMBL3207405 & 737823 & 5.7 & 5.5146 & TRN & \\
\hline CHEMBL3195193 & 737823 & 5.45 & 5.4679 & TRN & \\
\hline CHEMBL1569923 & 737823 & 5.05 & 5.3584 & TRN & \\
\hline CHEMBL1601997 & 737823 & 5.7 & 5.7666 & TST & \\
\hline CHEMBL1324866 & 737823 & 4.55 & 5.2601 & TRN & \\
\hline CHEMBL1555008 & 737823 & 5.9 & 5.4728 & TRN & \\
\hline CHEMBL547407 & 737823 & 4.85 & 5.012 & TRN & \\
\hline CHEMBL1533537 & 737823 & 5.0 & 5.0045 & TRN & \\
\hline CHEMBL1565525 & 737823 & 6.0 & 6.2445 & TRN & \\
\hline CHEMBL1600497 & 737823 & 6.0 & 5.724 & TRN & \\
\hline CHEMBL1324334 & 737823 & 5.4 & 5.033 & TRN & \\
\hline CHEMBL463783 & 737823 & 5.4 & 5.0036 & TRN & \\
\hline CHEMBL1565258 & 737823 & 7.4 & 5.23 & TRN & \\
\hline CHEMBL1573063 & 737823 & 5.8 & 5.6503 & TRN & \\
\hline CHEMBL1741522 & 737823 & 5.3 & 4.8328 & TRN & \\
\hline CHEMBL375126 & 737823 & 4.9 & 5.2019 & TRN & \\
\hline CHEMBL1509863 & 737823 & 4.4 & 5.1335 & TST & \\
\hline CHEMBL1356943 & 737823 & 5.3 & 5.1322 & TRN & \\
\hline CHEMBL1396559 & 737823 & 4.9 & 4.9415 & TRN & \\
\hline CHEMBL1395049 & 737823 & 5.4 & 5.4464 & TRN & \\
\hline CHEMBL1412954 & 737823 & 5.25 & 5.1607 & TRN & \\
\hline CHEMBL1576031 & 737823 & 5.45 & 5.5409 & TST & \\
\hline CHEMBL1353190 & 737823 & 6.6 & 5.55399 & 9999999999 & TRN \\
\hline CHEMBL3193750 & 737823 & 4.55 & 5.0444 & TST & \\
\hline CHEMBL3189742 & 737823 & 5.3 & 5.5111 & TRN & \\
\hline CHEMBL1530189 & 737823 & 4.8 & 5.1364 & TST & \\
\hline CHEMBL1609404 & 737823 & 5.7 & 5.2957 & TRN & \\
\hline CHEMBL596728 & 737823 & 5.1 & 5.6419 & TRN & \\
\hline CHEMBL24510 & 737823 & 4.5 & 4.8385 & TST & \\
\hline CHEMBL2001481 & 737823 & 6.4 & 5.9267 & TRN & \\
\hline CHEMBL3208389 & 737823 & 5.4 & 5.4775 & TRN & \\
\hline CHEMBL1481810 & 737823 & 4.85 & 5.3084 & TRN & \\
\hline CHEMBL1440650 & 737823 & 5.0 & 5.6002 & TRN & \\
\hline CHEMBL1712617 & 737823 & 4.6 & 4.9821 & TST & \\
\hline CHEMBL1513740 & 737823 & 4.8 & 5.0748 & TRN & \\
\hline CHEMBL1309630 & 737823 & 5.35 & 4.89 & TST & \\
\hline & & & & 3432 & \\
\hline
\end{tabular}




\begin{tabular}{|c|c|c|c|c|}
\hline \multicolumn{5}{|r|}{ al Table s } \\
\hline CHEMBL1308019 & 737823 & 5.1 & 5.3004 & TRN \\
\hline CHEMBL1492056 & 737823 & 4.7 & 5.1566 & TRN \\
\hline CHEMBL1557784 & 737823 & 5.3 & 5.4751 & TST \\
\hline CHEMBL1396791 & 737823 & 5.4 & 5.4068 & TRN \\
\hline CHEMBL1346774 & 737823 & 5.55 & 5.9904 & TRN \\
\hline CHEMBL1430479 & 737823 & 5.85 & 5.7398 & TRN \\
\hline CHEMBL1392330 & 737823 & 4.85 & 5.5835 & TRN \\
\hline CHEMBL1377809 & 737823 & 4.85 & 5.1935 & TRN \\
\hline CHEMBL1577408 & 737823 & 4.6 & 5.1377 & TRN \\
\hline CHEMBL1477076 & 737823 & 6.0 & 5.5582 & TRN \\
\hline CHEMBL 1408879 & 737823 & 5.6 & 5.0512 & TRN \\
\hline CHEMBL1544377 & 737823 & 5.5 & 5.4531 & TRN \\
\hline CHEMBL1562229 & 737823 & 8.2 & 5.0486 & TRN \\
\hline CHEMBL1461461 & 737823 & 5.1 & 5.3041 & TRN \\
\hline CHEMBL3199340 & 737823 & 4.8 & 5.0304 & TRN \\
\hline CHEMBL 30432 & 737823 & 5.1 & 5.21299 & 9999999999 \\
\hline CHEMBL1329499 & 737823 & 5.4 & 5.9257 & TRN \\
\hline CHEMBL1481608 & 737823 & 5.7 & 5.6032 & TRN \\
\hline CHEMBL1603718 & 737823 & 5.7 & 5.414 & TRN \\
\hline CHEMBL1478734 & 737823 & 4.85 & 5.315 & TRN \\
\hline CHEMBL 1460842 & 737823 & 6.55 & 5.9573 & TRN \\
\hline CHEMBL1306582 & 737823 & 5.6 & 5.5542 & TRN \\
\hline CHEMBL 273386 & 737823 & 6.6 & 5.4522 & TRN \\
\hline CHEMBL1519391 & 737823 & 5.3 & 6.0619 & TRN \\
\hline CHEMBL303516 & 737823 & 7.0 & 5.1288 & TST \\
\hline CHEMBL1587532 & 737823 & 4.85 & 5.3276 & TRN \\
\hline CHEMBL1590813 & 737823 & 4.9 & 4.6634 & TRN \\
\hline CHEMBL1255650 & 737823 & 4.8 & 5.1289 & TST \\
\hline CHEMBL1563147 & 737823 & 5.5 & 5.2419 & TRN \\
\hline CHEMBL3208619 & 737823 & 4.7 & 4.9073 & TRN \\
\hline CHEMBL1512683 & 737823 & 4.7 & 4.928 & TRN \\
\hline CHEMBL1609078 & 737823 & 6.2 & 5.9808 & TRN \\
\hline CHEMBL1568392 & 737823 & 4.85 & 4.9981 & TST \\
\hline CHEMBL1599025 & 737823 & 5.1 & 4.9436 & TRN \\
\hline CHEMBL1395026 & 737823 & 5.7 & 5.5133 & TRN \\
\hline CHEMBL3213185 & 737823 & 5.65 & 5.6165 & TRN \\
\hline CHEMBL1424953 & 737823 & 6.05 & 5.7506 & TRN \\
\hline CHEMBL552439 & 737823 & 5.4 & 5.9535 & TST \\
\hline CHEMBL3208267 & 737823 & 4.8 & 5.356 & TRN \\
\hline CHEMBL1444408 & 737823 & 5.5 & 4.8514 & TST \\
\hline CHEMBL3209936 & 737823 & 5.15 & 5.176 & TRN \\
\hline CHEMBL1563190 & 737823 & 5.05 & 5.5868 & TRN \\
\hline CHEMBL1742258 & 737823 & 5.5 & 5.0518 & TRN \\
\hline CHEMBL1357676 & 737823 & 4.8 & 5.0159 & TRN \\
\hline CHEMBL1593134 & 737823 & 5.5 & 5.6364 & TRN \\
\hline CHEMBL1593765 & 737823 & 6.0 & 5.5774 & TRN \\
\hline CHEMBL1398351 & 737823 & 4.9 & 5.0215 & TST \\
\hline CHEMBL1461573 & 737823 & 5.95 & 5.6321 & TST \\
\hline
\end{tabular}




\begin{tabular}{|c|c|c|c|c|c|}
\hline \\
\hline CHEMBL1463060 & 737823 & 5.0 & 4.902 & TRN & \\
\hline CHEMBL1374335 & 737823 & 5.4 & 5.8645 & TRN & \\
\hline CHEMBL1573858 & 737823 & 4.9 & 5.474 & TRN & \\
\hline CHEMBL1367030 & 737823 & 6.2 & 5.7435 & TRN & \\
\hline CHEMBL1521204 & 737823 & 5.45 & 5.7247 & TRN & \\
\hline CHEMBL1577436 & 737823 & 5.4 & 5.565 & TST & \\
\hline CHEMBL 267548 & 737823 & 5.2 & 5.3711 & TST & \\
\hline CHEMBL1444632 & 737823 & 4.8 & 4.9461 & TST & \\
\hline CHEMBL1607115 & 737823 & 4.8 & 5.2604 & TRN & \\
\hline CHEMBL1741429 & 737823 & 4.85 & 5.1368 & TRN & \\
\hline CHEMBL1456686 & 737823 & 5.65 & 5.79200 & 0000000001 & TRN \\
\hline CHEMBL3194986 & 737823 & 4.45 & 5.7612 & TST & \\
\hline CHEMBL1377727 & 737823 & 6.0 & 5.5469 & TRN & \\
\hline CHEMBL1402435 & 737823 & 4.8 & 4.7504 & TRN & \\
\hline CHEMBL16687 & 737823 & 7.2 & 5.9348 & TRN & \\
\hline CHEMBL1470566 & 737823 & 7.2 & 5.4725 & TRN & \\
\hline CHEMBL123132 & 737823 & 4.5 & 5.2219 & TST & \\
\hline CHEMBL1475695 & 737823 & 4.9 & 5.2375 & TRN & \\
\hline CHEMBL509150 & 737823 & 5.6 & 5.5724 & TRN & \\
\hline CHEMBL1713992 & 737823 & 6.0 & 5.5775 & TST & \\
\hline CHEMBL1494296 & 737823 & 5.25 & 5.2606 & TRN & \\
\hline CHEMBL1603750 & 737823 & 6.7 & 5.0373 & TST & \\
\hline CHEMBL1338333 & 737823 & 4.6 & 4.9973 & TRN & \\
\hline CHEMBL1591896 & 737823 & 6.8 & 6.4206 & TRN & \\
\hline CHEMBL1530832 & 737823 & 6.0 & 5.6603 & TRN & \\
\hline CHEMBL1394031 & 737823 & 5.35 & 5.5929 & TRN & \\
\hline CHEMBL1349183 & 737823 & 4.75 & 4.9525 & TRN & \\
\hline CHEMBL1308401 & 737823 & 4.8 & 5.4603 & TST & \\
\hline CHEMBL1478772 & 737823 & 5.7 & 5.3604 & TRN & \\
\hline CHEMBL1583174 & 737823 & 4.9 & 5.1677 & TRN & \\
\hline CHEMBL1512454 & 737823 & 6.2 & 5.2573 & TRN & \\
\hline CHEMBL1609178 & 737823 & 6.3 & 5.7154 & TRN & \\
\hline CHEMBL1570079 & 737823 & 5.15 & 5.1859 & TRN & \\
\hline CHEMBL1495160 & 737823 & 4.9 & 4.9917 & TRN & \\
\hline CHEMBL1741625 & 737823 & 5.0 & 4.9916 & TRN & \\
\hline CHEMBL1313459 & 737823 & 5.45 & 5.3007 & TRN & \\
\hline CHEMBL1613349 & 737823 & 5.85 & 4.8315 & TRN & \\
\hline CHEMBL3209319 & 737823 & 5.15 & 5.0188 & TRN & \\
\hline CHEMBL1322757 & 737823 & 4.9 & 5.2595 & TRN & \\
\hline CHEMBL1365902 & 737823 & 5.5 & 5.4131 & TRN & \\
\hline CHEMBL1581055 & 737823 & 6.25 & 5.6771 & TRN & \\
\hline CHEMBL1452910 & 737823 & 4.9 & 5.1964 & TRN & \\
\hline CHEMBL3192865 & 737823 & 5.45 & 5.4529 & TRN & \\
\hline CHEMBL1564927 & 737823 & 5.5 & 5.5425 & TST & \\
\hline CHEMBL1338985 & 737823 & 5.0 & 5.4753 & TRN & \\
\hline CHEMBL1533852 & 737823 & 5.8 & 4.7346 & TRN & \\
\hline CHEMBL1447317 & 737823 & 4.5 & 5.0274 & TST & \\
\hline CHEMBL1458191 & 737823 & 6.35 & 5.5709 & TRN & \\
\hline
\end{tabular}




\begin{tabular}{|c|c|c|c|c|c|}
\hline & & \multicolumn{4}{|c|}{ Supplemental Table S2.txt } \\
\hline CHEMBL476513 & 737823 & 5.85 & 5.0722 & TRN & \\
\hline CHEMBL1454730 & 737823 & 5.2 & 5.4706 & TRN & \\
\hline CHEMBL1435086 & 737823 & 5.3 & \multicolumn{2}{|c|}{5.5760000000000005} & TRN \\
\hline CHEMBL1520405 & 737823 & 4.8 & 5.42 & TRN & \\
\hline CHEMBL1343392 & 737823 & 5.4 & 4.9851 & TRN & \\
\hline CHEMBL1079374 & 737823 & 6.25 & 5.8225 & TRN & \\
\hline CHEMBL1546475 & 737823 & 5.35 & 5.4521 & TRN & \\
\hline CHEMBL1523579 & 737823 & 6.4 & 5.2629 & TRN & \\
\hline CHEMBL3198813 & 737823 & 6.05 & 5.5196 & TRN & \\
\hline CHEMBL1378322 & 737823 & 5.2 & 5.2135 & TRN & \\
\hline CHEMBL1339651 & 737823 & 4.6 & 4.9717 & TRN & \\
\hline CHEMBL1611806 & 737823 & 4.7 & 4.7342 & TRN & \\
\hline CHEMBL1319232 & 737823 & 5.6 & 5.5301 & TST & \\
\hline CHEMBL1358359 & 737823 & 5.5 & \multicolumn{2}{|c|}{5.492000000000001} & TST \\
\hline CHEMBL234978 & 737823 & 4.95 & 5.8269 & TRN & \\
\hline CHEMBL1564477 & 737823 & 4.8 & 4.7944 & TRN & \\
\hline CHEMBL1314367 & 737823 & 5.8 & 5.9811 & TRN & \\
\hline CHEMBL1502711 & 737823 & 4.85 & 5.2693 & TRN & \\
\hline CHEMBL1596872 & 737823 & 4.8 & 5.2061 & TRN & \\
\hline CHEMBL1592376 & 737823 & 4.7 & 5.0639 & TRN & \\
\hline CHEMBL1741471 & 737823 & 6.5 & 5.3281 & TRN & \\
\hline CHEMBL1513665 & 737823 & 4.9 & 5.5363 & TRN & \\
\hline CHEMBL1515280 & 737823 & 4.8 & 4.6619 & TRN & \\
\hline CHEMBL1431735 & 737823 & 4.8 & 5.0682 & TRN & \\
\hline CHEMBL1381200 & 737823 & 4.9 & 5.0785 & TRN & \\
\hline CHEMBL1315380 & 737823 & 6.2 & 5.8431 & TRN & \\
\hline CHEMBL1411881 & 737823 & 4.9 & 5.4017 & TRN & \\
\hline CHEMBL3213493 & 737823 & 4.85 & 5.3737 & TRN & \\
\hline CHEMBL 275311 & 737823 & 4.5 & 5.1111 & TRN & \\
\hline CHEMBL1454153 & 737823 & 6.3 & 5.7794 & TRN & \\
\hline CHEMBL501701 & 737823 & 6.0 & 5.1029 & TRN & \\
\hline CHEMBL1329823 & 737823 & 6.0 & 5.7245 & TRN & \\
\hline CHEMBL1600150 & 737823 & 5.0 & 5.1301 & TRN & \\
\hline CHEMBL52460 & 737823 & 4.9 & 5.5526 & TST & \\
\hline CHEMBL1553825 & 737823 & 6.3 & 5.7825 & TRN & \\
\hline CHEMBL1554360 & 737823 & 5.4 & 5.3532 & TRN & \\
\hline CHEMBL3193129 & 737823 & 4.9 & 5.3605 & TRN & \\
\hline CHEMBL1399207 & 737823 & 4.75 & 4.7378 & TRN & \\
\hline CHEMBL1308605 & 737823 & 5.45 & 5.0914 & TRN & \\
\hline CHEMBL1417789 & 737823 & 5.7 & 5.5777 & TRN & \\
\hline CHEMBL1467110 & 737823 & 6.3 & \multicolumn{2}{|c|}{5.627000000000001} & TRN \\
\hline CHEMBL903 & 737823 & 4.4 & 4.8238 & TST & \\
\hline CHEMBL1589124 & 737823 & 5.95 & 5.5925 & TST & \\
\hline CHEMBL1537962 & 737823 & 6.15 & 5.1332 & TRN & \\
\hline CHEMBL1593158 & 737823 & 5.7 & 5.6965 & TRN & \\
\hline CHEMBL1521391 & 737823 & 4.7 & 4.9026 & TRN & \\
\hline CHEMBL1322527 & 737823 & 5.5 & 5.7221 & TST & \\
\hline CHEMBL1565577 & 737823 & 4.6 & 4.8679 & TST & \\
\hline
\end{tabular}




\begin{tabular}{|c|c|c|c|c|c|}
\hline \multicolumn{6}{|c|}{ Supplemental Table S2.txt } \\
\hline CHEMBL1362931 & 737823 & 5.7 & 4.9581 & TRN & \\
\hline CHEMBL1443703 & 737823 & 5.5 & 4.9842 & TRN & \\
\hline CHEMBL1437962 & 737823 & 6.3 & 5.3195 & TST & \\
\hline CHEMBL1574219 & 737823 & 4.65 & 5.0546 & TST & \\
\hline CHEMBL3207544 & 737823 & 4.9 & 5.2089 & TRN & \\
\hline CHEMBL1570413 & 737823 & 4.8 & 5.1867 & TRN & \\
\hline CHEMBL1709998 & 737823 & 6.2 & 5.37 & TST & \\
\hline CHEMBL1315257 & 737823 & 5.8 & 6.1437 & TRN & \\
\hline CHEMBL1463191 & 737823 & 4.85 & 5.0009 & TRN & \\
\hline CHEMBL1439231 & 737823 & 6.2 & \multicolumn{2}{|c|}{5.797000000000001} & TRN \\
\hline CHEMBL1407304 & 737823 & 5.25 & 5.3757 & TRN & \\
\hline CHEMBL1358005 & 737823 & 4.5 & 4.87 & TST & \\
\hline CHEMBL1453216 & 737823 & 4.6 & 5.0598 & TRN & \\
\hline CHEMBL1447719 & 737823 & 6.45 & 6.1251 & TRN & \\
\hline CHEMBL1441052 & 737823 & 5.4 & 5.5712 & TRN & \\
\hline CHEMBL1601955 & 737823 & 5.1 & 4.8991 & TRN & \\
\hline CHEMBL1551479 & 737823 & 6.1 & 5.2855 & TRN & \\
\hline CHEMBL1551567 & 737823 & 4.5 & 5.2015 & TRN & \\
\hline CHEMBL3189663 & 737823 & 5.8 & 5.8238 & TRN & \\
\hline CHEMBL1488784 & 737823 & 4.4 & 4.8731 & TRN & \\
\hline CHEMBL1373587 & 737823 & 6.9 & 5.1731 & TST & \\
\hline CHEMBL1591573 & 737823 & 4.6 & 4.6898 & TRN & \\
\hline CHEMBL1525716 & 737823 & 5.4 & 4.9332 & TRN & \\
\hline CHEMBL1487735 & 737823 & 4.9 & 5.3552 & TRN & \\
\hline CHEMBL405912 & 737823 & 7.5 & 6.6407 & TRN & \\
\hline CHEMBL1387287 & 737823 & 5.35 & 5.4466 & TRN & \\
\hline CHEMBL1397532 & 737823 & 4.7 & 5.6961 & TRN & \\
\hline CHEMBL1416235 & 737823 & 5.4 & \multicolumn{2}{|c|}{5.742000000000001} & TRN \\
\hline CHEMBL3214365 & 737823 & 5.55 & 5.6096 & TRN & \\
\hline CHEMBL1589230 & 737823 & 5.15 & 5.4654 & TRN & \\
\hline CHEMBL1509329 & 737823 & 7.1 & 4.9105 & TRN & \\
\hline CHEMBL591613 & 737823 & 5.35 & \multicolumn{2}{|c|}{5.622999999999999} & TRN \\
\hline CHEMBL1452675 & 737823 & 5.4 & 5.2697 & TRN & \\
\hline CHEMBL1520442 & 737823 & 4.8 & 5.0239 & TRN & \\
\hline CHEMBL1441891 & 737823 & 5.9 & 5.6794 & TRN & \\
\hline CHEMBL1494444 & 737823 & 4.55 & 5.1154 & TST & \\
\hline CHEMBL197027 & 737823 & 4.5 & 5.5361 & TST & \\
\hline CHEMBL1505957 & 737823 & 5.15 & 5.4429 & TRN & \\
\hline CHEMBL450493 & 737823 & 4.9 & 5.4246 & TRN & \\
\hline CHEMBL1742375 & 737823 & 6.2 & 5.7818 & TST & \\
\hline CHEMBL1335967 & 737823 & 4.6 & 5.559 & TRN & \\
\hline CHEMBL1362189 & 737823 & 5.7 & 5.7762 & TRN & \\
\hline CHEMBL1546136 & 737823 & 4.6 & 5.1461 & TRN & \\
\hline CHEMBL1392755 & 737823 & 5.2 & 5.2974 & TRN & \\
\hline CHEMBL1555028 & 737823 & 4.8 & 5.1609 & TRN & \\
\hline CHEMBL1604924 & 737823 & 5.3 & 5.5643 & TRN & \\
\hline CHEMBL1496194 & 737823 & 5.4 & 4.9882 & TRN & \\
\hline CHEMBL1708288 & 737823 & 5.35 & 5.0035 & TRN & \\
\hline
\end{tabular}




\begin{tabular}{|c|c|c|c|c|}
\hline & & & ient & al Ta \\
\hline CHEMBL1512250 & 737823 & 6.3 & 6.0096 & TRN \\
\hline CHEMBL1385489 & 737823 & 5.3 & 5.6437 & TST \\
\hline CHEMBL1437488 & 737823 & 5.1 & 5.558 & TRN \\
\hline CHEMBL3191940 & 737823 & 6.2 & 5.5219 & TST \\
\hline CHEMBL1532319 & 737823 & 6.2 & 5.0321 & TRN \\
\hline CHEMBL1359731 & 737823 & 5.2 & 5.8185 & TRN \\
\hline CHEMBL1370214 & 737823 & 6.3 & 5.682 & TRN \\
\hline CHEMBL1429297 & 737823 & 4.8 & 4.9889 & TST \\
\hline CHEMBL1306134 & 737823 & 4.85 & 5.3089 & TRN \\
\hline CHEMBL3210689 & 737823 & 4.65 & 4.9088 & TST \\
\hline CHEMBL1569058 & 737823 & 6.75 & 5.8635 & TRN \\
\hline CHEMBL1364717 & 737823 & 4.6 & 4.9837 & TRN \\
\hline CHEMBL1364980 & 737823 & 4.8 & 4.8163 & TRN \\
\hline CHEMBL3198312 & 737823 & 5.5 & 5.0543 & TRN \\
\hline CHEMBL1385992 & 737823 & 4.9 & 4.7647 & TST \\
\hline CHEMBL1490894 & 737823 & 4.6 & 5.218 & TRN \\
\hline CHEMBL1506831 & 737823 & 4.75 & 5.4006 & TRN \\
\hline CHEMBL61605 & 737823 & 4.5 & 4.8153 & TST \\
\hline CHEMBL1366371 & 737823 & 4.8 & 4.8701 & TRN \\
\hline CHEMBL1609808 & 737823 & 5.3 & 5.2021 & TRN \\
\hline CHEMBL1555037 & 737823 & 5.3 & 4.9119 & TRN \\
\hline CHEMBL1317335 & 737823 & 4.7 & 5.2643 & TRN \\
\hline CHEMBL476135 & 737823 & 6.2 & 5.6983 & TRN \\
\hline CHEMBL1366070 & 737823 & 4.9 & 5.4462 & TST \\
\hline CHEMBL1489211 & 737823 & 4.7 & 4.8324 & TRN \\
\hline CHEMBL1404630 & 737823 & 6.4 & 5.4273 & TRN \\
\hline CHEMBL1553963 & 737823 & 5.5 & 5.4117 & TRN \\
\hline CHEMBL1565546 & 737823 & 4.8 & 5.164 & TRN \\
\hline CHEMBL1410496 & 737823 & 4.5 & 4.7669 & TRN \\
\hline CHEMBL1704069 & 737823 & 4.6 & 5.0064 & TRN \\
\hline CHEMBL 1433785 & 737823 & 5.5 & 5.376 & TRN \\
\hline CHEMBL1338083 & 737823 & 5.1 & 5.5012 & TRN \\
\hline CHEMBL 3213793 & 737823 & 5.7 & 5.5188 & TRN \\
\hline CHEMBL1450602 & 737823 & 5.4 & 5.4132 & TRN \\
\hline CHEMBL1355701 & 737823 & 6.1 & 6.0979 & TRN \\
\hline CHEMBL1323118 & 737823 & 5.3 & 5.1433 & TRN \\
\hline CHEMBL1405410 & 737823 & 4.6 & 5.145 & TRN \\
\hline CHEMBL1439882 & 737823 & 5.6 & 5.6276 & TRN \\
\hline CHEMBL1387681 & 737823 & 6.05 & 5.3673 & TRN \\
\hline CHEMBL1540031 & 737823 & 4.75 & 5.0743 & TRN \\
\hline CHEMBL137267 & 737823 & 6.1 & 5.875 & TRN \\
\hline CHEMBL1361855 & 737823 & 6.2 & 5.6675 & TST \\
\hline CHEMBL1510699 & 737823 & 5.0 & 5.4188 & TRN \\
\hline CHEMBL1582789 & 737823 & 4.85 & 4.9687 & TRN \\
\hline CHEMBL1323529 & 737823 & 4.4 & 4.83 & TRN \\
\hline CHEMBL1456312 & 737823 & 4.9 & 5.1001 & TRN \\
\hline CHEMBL1491699 & 737823 & -0.0 & 4.5876 & TRN \\
\hline CHEMBL1527840 & 737823 & 4.6 & 5.2675 & TRN \\
\hline
\end{tabular}




\begin{tabular}{|c|c|c|c|c|}
\hline & & & pplement & al $\mathrm{Ta}$ \\
\hline CHEMBL1382292 & 737823 & 5.1 & 4.9993 & TRN \\
\hline CHEMBL1590321 & 737823 & 5.2 & 5.7296 & TRN \\
\hline CHEMBL1592438 & 737823 & 5.2 & 5.4118 & TRN \\
\hline CHEMBL3195945 & 737823 & 5.7 & 5.7286 & TRN \\
\hline CHEMBL79140 & 737823 & 4.5 & 5.0825 & TRN \\
\hline CHEMBL1331674 & 737823 & 5.0 & 5.4148 & TRN \\
\hline CHEMBL1608233 & 737823 & 5.45 & 5.4414 & TRN \\
\hline CHEMBL1363953 & 737823 & 4.65 & 4.678 & TST \\
\hline CHEMBL1594075 & 737823 & 4.8 & 5.1924 & TRN \\
\hline CHEMBL1326533 & 737823 & 5.65 & 5.7872 & TRN \\
\hline CHEMBL1595826 & 737823 & 4.85 & 5.1494 & TRN \\
\hline CHEMBL1552747 & 737823 & 4.5 & 4.5854 & TRN \\
\hline CHEMBL1577418 & 737823 & 5.05 & 5.7812 & TRN \\
\hline CHEMBL1350723 & 737823 & 5.25 & 5.3528 & TRN \\
\hline CHEMBL1343285 & 737823 & 5.7 & 5.5884 & TRN \\
\hline CHEMBL1491065 & 737823 & 5.0 & 4.8564 & TRN \\
\hline CHEMBL1433776 & 737823 & 5.1 & 5.0062 & TRN \\
\hline CHEMBL1386579 & 737823 & 4.65 & 5.3222 & TST \\
\hline CHEMBL1495875 & 737823 & 4.4 & 4.4288 & TRN \\
\hline CHEMBL1397704 & 737823 & 4.6 & 4.5175 & TRN \\
\hline CHEMBL1476640 & 737823 & 4.9 & 4.8954 & TRN \\
\hline CHEMBL1420885 & 737823 & 4.8 & 5.3761 & TST \\
\hline CHEMBL1434824 & 737823 & 6.3 & 5.6046 & TST \\
\hline CHEMBL1492087 & 737823 & 4.6 & 4.6081 & TRN \\
\hline CHEMBL1519603 & 737823 & 5.15 & 6.1373 & TRN \\
\hline CHEMBL1698063 & 737823 & 4.85 & 5.0815 & TRN \\
\hline CHEMBL1501500 & 737823 & 4.9 & 5.5294 & TRN \\
\hline CHEMBL1741700 & 737823 & 4.85 & 5.403 & TST \\
\hline CHEMBL1725507 & 737823 & 5.7 & 5.2501 & TRN \\
\hline CHEMBL1493910 & 737823 & 5.3 & 5.3509 & TRN \\
\hline CHEMBL1310477 & 737823 & 5.75 & 5.2395 & TRN \\
\hline CHEMBL1571361 & 737823 & 4.9 & 5.22 & TRN \\
\hline CHEMBL1374763 & 737823 & 6.9 & 5.5624 & TRN \\
\hline CHEMBL1309266 & 737823 & 5.75 & 5.4318 & TRN \\
\hline CHEMBL1307437 & 737823 & 5.45 & 5.7304 & TRN \\
\hline CHEMBL1601536 & 737823 & 4.6 & 4.8776 & TRN \\
\hline CHEMBL1301953 & 737823 & 5.5 & 5.5375 & TRN \\
\hline CHEMBL1378704 & 737823 & 4.8 & 4.6036 & TRN \\
\hline CHEMBL1607616 & 737823 & 5.0 & 5.0042 & TRN \\
\hline CHEMBL1356505 & 737823 & 6.5 & 6.5777 & TRN \\
\hline CHEMBL1529777 & 737823 & 5.3 & 5.7236 & TRN \\
\hline CHEMBL1502739 & 737823 & 5.05 & 5.3305 & TRN \\
\hline CHEMBL1334282 & 737823 & 5.4 & 5.2601 & TRN \\
\hline CHEMBL1469742 & 737823 & 4.65 & 5.2344 & TRN \\
\hline CHEMBL1559556 & 737823 & 4.85 & 4.7126 & TRN \\
\hline CHEMBL1440302 & 737823 & 5.4 & 5.7756 & TRN \\
\hline CHEMBL1379830 & 737823 & 5.25 & 5.3743 & TRN \\
\hline CHEMBL1558843 & 737823 & 6.5 & 6.559 & TRN \\
\hline
\end{tabular}




\begin{tabular}{|c|c|c|c|c|c|}
\hline \multicolumn{6}{|c|}{ Supplemental Table S2.txt } \\
\hline CHEMBL1597695 & 737823 & 6.0 & 5.6707 & TST & \\
\hline CHEMBL1476206 & 737823 & 4.5 & 4.8773 & TRN & \\
\hline CHEMBL1416225 & 737823 & 4.55 & 5.2069 & TRN & \\
\hline CHEMBL1422472 & 737823 & 5.45 & 5.5645 & TRN & \\
\hline CHEMBL1553498 & 737823 & 4.5 & 5.5262 & TRN & \\
\hline CHEMBL1419628 & 737823 & 8.2 & 5.2217 & TRN & \\
\hline CHEMBL3209815 & 737823 & 4.85 & 5.55399 & 9999999999 & TRN \\
\hline CHEMBL1589976 & 737823 & 4.9 & 4.8494 & TRN & \\
\hline CHEMBL1596241 & 737823 & 5.1 & 5.6148 & TRN & \\
\hline CHEMBL1437325 & 737823 & 5.0 & 4.9179 & TRN & \\
\hline CHEMBL 3214130 & 737823 & 5.95 & 5.5011 & TRN & \\
\hline CHEMBL3191409 & 737823 & 5.6 & 5.4626 & TRN & \\
\hline CHEMBL1519472 & 737823 & 5.8 & 5.9764 & TRN & \\
\hline CHEMBL291278 & 737823 & 4.4 & 4.8137 & TRN & \\
\hline CHEMBL1535983 & 737823 & 5.9 & 5.6954 & TRN & \\
\hline CHEMBL1352188 & 737823 & 4.4 & 4.9794 & TST & \\
\hline CHEMBL1586735 & 737823 & 5.7 & 5.4616 & TRN & \\
\hline CHEMBL1387012 & 737823 & 4.8 & 5.2671 & TRN & \\
\hline CHEMBL1592835 & 737823 & 6.2 & 5.7536 & TRN & \\
\hline CHEMBL1398834 & 737823 & 5.2 & 4.91 & TRN & \\
\hline CHEMBL1452643 & 737823 & 5.2 & 4.9049 & TRN & \\
\hline CHEMBL1380910 & 737823 & 4.85 & 4.96 & TRN & \\
\hline CHEMBL1428733 & 737823 & 4.9 & 5.0285 & TRN & \\
\hline CHEMBL1396108 & 737823 & 4.9 & 4.9223 & TRN & \\
\hline CHEMBL1357724 & 737823 & 5.1 & 5.7783 & TRN & \\
\hline CHEMBL 2006154 & 737823 & 4.9 & 5.2817 & TRN & \\
\hline CHEMBL1580790 & 737823 & 4.9 & 5.273 & TRN & \\
\hline CHEMBL1316463 & 737823 & 4.6 & 5.7547 & TRN & \\
\hline CHEMBL1469018 & 737823 & 4.65 & 5.2702 & TRN & \\
\hline CHEMBL1519647 & 737823 & 4.85 & 5.4054 & TRN & \\
\hline CHEMBL1539317 & 737823 & 4.65 & 5.1459 & TRN & \\
\hline CHEMBL1396737 & 737823 & 4.6 & 4.3797 & TRN & \\
\hline CHEMBL1436763 & 737823 & 4.8 & 5.1076 & TRN & \\
\hline CHEMBL1351663 & 737823 & 5.25 & 5.4389 & TRN & \\
\hline CHEMBL1269845 & 737823 & 5.5 & 5.6868 & TRN & \\
\hline CHEMBL1378629 & 737823 & 4.9 & 4.9509 & TRN & \\
\hline CHEMBL1725148 & 737823 & 4.95 & 4.8678 & TRN & \\
\hline CHEMBL1354433 & 737823 & 5.5 & 5.3938 & TRN & \\
\hline CHEMBL1596066 & 737823 & 4.85 & 5.2685 & TRN & \\
\hline CHEMBL1322549 & 737823 & 5.5 & 5.3858 & TST & \\
\hline CHEMBL1479817 & 737823 & 5.2 & 5.4372 & TRN & \\
\hline CHEMBL1341368 & 737823 & 4.4 & 5.2242 & TRN & \\
\hline CHEMBL1488095 & 737823 & 4.9 & 5.4736 & TRN & \\
\hline CHEMBL1557089 & 737823 & 4.85 & 5.7161 & TRN & \\
\hline CHEMBL1525226 & 737823 & 5.65 & 5.9077 & TRN & \\
\hline CHEMBL1322940 & 737823 & 6.1 & 5.6126 & TRN & \\
\hline CHEMBL 280074 & 737823 & 5.3 & 5.7032 & TRN & \\
\hline CHEMBL1421887 & 737823 & 4.55 & 4.9351 & TRN & \\
\hline
\end{tabular}




\begin{tabular}{|c|c|c|c|c|}
\hline \multicolumn{5}{|c|}{ Supplemental Table S2.txt } \\
\hline CHEMBL181633 & 737823 & 4.8 & 5.1243 & TRN \\
\hline CHEMBL1566101 & 737823 & 4.6 & 5.1517 & TRN \\
\hline CHEMBL1449737 & 737823 & 5.5 & 5.2678 & TST \\
\hline CHEMBL1556045 & 737823 & 7.2 & 5.8103 & TRN \\
\hline CHEMBL1584704 & 737823 & 5.0 & 5.2888 & TRN \\
\hline CHEMBL1706307 & 737823 & 5.0 & 5.3585 & TRN \\
\hline CHEMBL1369854 & 737823 & 5.4 & 4.9401 & TRN \\
\hline CHEMBL1312104 & 737823 & 4.4 & 5.2492 & TRN \\
\hline CHEMBL1334935 & 737823 & 6.4 & 5.936 & TRN \\
\hline CHEMBL1256686 & 737823 & 4.5 & 5.1388 & TST \\
\hline CHEMBL1256180 & 737823 & 6.1 & 4.8403 & TRN \\
\hline CHEMBL1334477 & 737823 & 5.6 & 6.02 & TRN \\
\hline CHEMBL1255940 & 737823 & 5.5 & 5.3064 & TRN \\
\hline CHEMBL1378731 & 737823 & 6.1 & 5.4877 & TRN \\
\hline CHEMBL1597762 & 737823 & 5.65 & 5.4454 & TRN \\
\hline CHEMBL1489354 & 737823 & 5.35 & 5.0267 & TRN \\
\hline CHEMBL1358090 & 737823 & 6.2 & 5.7185 & TRN \\
\hline CHEMBL1304990 & 737823 & 4.6 & 5.121 & TST \\
\hline CHEMBL1450026 & 737823 & 5.3 & 5.4086 & TRN \\
\hline CHEMBL1560276 & 737823 & 4.8 & 5.1357 & TST \\
\hline CHEMBL1482847 & 737823 & 6.6 & 5.8865 & TRN \\
\hline CHEMBL1485319 & 737823 & 4.7 & 5.525 & TRN \\
\hline CHEMBL1467331 & 737823 & 6.95 & 5.8976 & TRN \\
\hline CHEMBL1597812 & 737823 & 4.5 & 4.7543 & TST \\
\hline CHEMBL1514431 & 737823 & 4.7 & 4.8723 & TRN \\
\hline CHEMBL1580710 & 737823 & 5.1 & 5.1285 & TRN \\
\hline CHEMBL490744 & 737823 & 4.9 & 4.365 & TRN \\
\hline CHEMBL1584461 & 737823 & 5.8 & 4.9497 & TRN \\
\hline CHEMBL1596513 & 737823 & 4.8 & 5.1011 & TRN \\
\hline CHEMBL1318041 & 737823 & 5.7 & 5.6953 & TRN \\
\hline CHEMBL1467857 & 737823 & 4.5 & 5.1945 & TST \\
\hline CHEMBL1589130 & 737823 & 5.65 & 5.5475 & TRN \\
\hline CHEMBL1357850 & 737823 & 6.3 & 6.4442 & TRN \\
\hline CHEMBL1559062 & 737823 & 5.1 & 5.2019 & TRN \\
\hline CHEMBL1487396 & 737823 & 4.9 & 5.1056 & TRN \\
\hline CHEMBL227988 & 737823 & 5.3 & 5.3844 & TRN \\
\hline CHEMBL1097940 & 737823 & 4.5 & 5.1149 & TST \\
\hline CHEMBL1510930 & 737823 & 5.5 & 5.2654 & TRN \\
\hline CHEMBL456881 & 737823 & 5.2 & 5.528 & TRN \\
\hline CHEMBL1537062 & 737823 & 5.2 & 4.8798 & TST \\
\hline CHEMBL1514219 & 737823 & 4.4 & 5.1558 & TRN \\
\hline CHEMBL1558480 & 737823 & 5.0 & 4.8034 & TRN \\
\hline CHEMBL1302009 & 737823 & 5.05 & 5.6981 & TRN \\
\hline CHEMBL1401499 & 737823 & 4.8 & 5.3496 & TRN \\
\hline CHEMBL1357199 & 737823 & 5.6 & 5.7598 & TRN \\
\hline CHEMBL 3192412 & 737823 & 4.95 & 5.6037 & TRN \\
\hline CHEMBL1983266 & 737823 & 6.4 & 5.6767 & TST \\
\hline CHEMBL1405676 & 737823 & 4.7 & 5.4852 & TRN \\
\hline
\end{tabular}




\begin{tabular}{|c|c|c|c|c|c|}
\hline \multicolumn{6}{|c|}{ Supplemental Table S2.txt } \\
\hline CHEMBL20562 & 737823 & 4.4 & 4.8985 & TST & \\
\hline CHEMBL1368786 & 737823 & 4.9 & 4.9709 & TRN & \\
\hline CHEMBL1557870 & 737823 & 5.15 & 5.6924 & TRN & \\
\hline CHEMBL1476043 & 737823 & 6.9 & 5.7873 & TRN & \\
\hline CHEMBL1256839 & 737823 & 4.5 & 5.1242 & TRN & \\
\hline CHEMBL1598543 & 737823 & 4.8 & 4.7389 & TRN & \\
\hline CHEMBL23327 & 737823 & 6.5 & 5.5408 & TRN & \\
\hline CHEMBL1605363 & 737823 & 6.8 & 6.1169 & TRN & \\
\hline CHEMBL1536205 & 737823 & 5.4 & 4.8055 & TRN & \\
\hline CHEMBL1552643 & 737823 & 4.9 & 5.4124 & TRN & \\
\hline CHEMBL1442243 & 737823 & 4.8 & 5.351 & TRN & \\
\hline CHEMBL1567887 & 737823 & 5.65 & 5.5088 & TRN & \\
\hline CHEMBL1304797 & 737823 & 4.9 & 5.4235 & TRN & \\
\hline CHEMBL1548111 & 737823 & 4.5 & 5.49 & TST & \\
\hline CHEMBL1358284 & 737823 & 4.5 & 5.0699 & TST & \\
\hline CHEMBL1508044 & 737823 & 5.35 & 5.2134 & TST & \\
\hline CHEMBL3191893 & 737823 & 5.3 & 5.46299 & 9999999999 & TRN \\
\hline CHEMBL1317626 & 737823 & 5.0 & 5.1907 & TRN & \\
\hline CHEMBL1609142 & 737823 & 5.9 & 5.3631 & TRN & \\
\hline CHEMBL1453185 & 737823 & 4.7 & 4.8082 & TRN & \\
\hline CHEMBL2369181 & 737823 & 5.6 & 5.4504 & TRN & \\
\hline CHEMBL1474016 & 737823 & 5.3 & 5.865 & TRN & \\
\hline CHEMBL1460951 & 737823 & 8.2 & 4.8313 & TRN & \\
\hline CHEMBL1996902 & 737823 & 5.8 & 5.2703 & TRN & \\
\hline CHEMBL362863 & 737823 & 6.5 & 5.40600 & 0000000001 & TST \\
\hline CHEMBL1551548 & 737823 & 4.9 & 5.0406 & TRN & \\
\hline CHEMBL1484422 & 737823 & 5.3 & 5.7324 & TRN & \\
\hline CHEMBL1587410 & 737823 & 4.9 & 5.0043 & TRN & \\
\hline CHEMBL1382729 & 737823 & 4.95 & 5.0893 & TRN & \\
\hline CHEMBL1358012 & 737823 & 4.7 & 5.0855 & TRN & \\
\hline CHEMBL1375115 & 737823 & 5.55 & 5.3484 & TST & \\
\hline CHEMBL1371014 & 737823 & 4.95 & 5.4501 & TRN & \\
\hline CHEMBL1559387 & 737823 & 5.5 & 5.4535 & TST & \\
\hline CHEMBL1412893 & 737823 & 6.2 & 5.9204 & TRN & \\
\hline CHEMBL1367367 & 737823 & 5.4 & 5.29200 & 0000000001 & TRN \\
\hline CHEMBL3195224 & 737823 & 5.65 & 5.4631 & TRN & \\
\hline CHEMBL1378710 & 737823 & 5.55 & 5.7241 & TRN & \\
\hline CHEMBL1453872 & 737823 & 5.1 & 5.8667 & TST & \\
\hline CHEMBL1470888 & 737823 & 5.5 & 5.3311 & TRN & \\
\hline CHEMBL1571550 & 737823 & 6.8 & 4.8833 & TST & \\
\hline CHEMBL1320722 & 737823 & 5.5 & 5.4837 & TRN & \\
\hline CHEMBL1482155 & 737823 & 5.6 & 5.1076 & TRN & \\
\hline CHEMBL 274438 & 737823 & 5.6 & 5.3049 & TRN & \\
\hline CHEMBL1424424 & 737823 & 5.4 & 5.0743 & TRN & \\
\hline CHEMBL492122 & 737823 & 4.8 & 5.0241 & TRN & \\
\hline CHEMBL172064 & 737823 & 5.3 & 5.5747 & TST & \\
\hline CHEMBL1314906 & 737823 & 4.7 & 4.6691 & TRN & \\
\hline CHEMBL1345307 & 737823 & 4.9 & 4.997 & TRN & \\
\hline
\end{tabular}




\begin{tabular}{|c|c|c|c|c|c|}
\hline \multicolumn{6}{|c|}{ Supplemental Table s2.txt } \\
\hline CHEMBL1470578 & 737823 & 4.85 & 5.1296 & TRN & \\
\hline CHEMBL1373994 & 737823 & 4.9 & 4.9202 & TRN & \\
\hline CHEMBL1390454 & 737823 & 4.95 & 5.1885 & TRN & \\
\hline CHEMBL1315508 & 737823 & 5.8 & 5.69 & TRN & \\
\hline CHEMBL1410311 & 737823 & 4.75 & 5.3049 & TRN & \\
\hline CHEMBL192566 & 737823 & 4.4 & 4.9621 & TST & \\
\hline CHEMBL1330580 & 737823 & 5.45 & 5.4218 & TRN & \\
\hline CHEMBL1741812 & 737823 & 6.0 & 6.0939 & TRN & \\
\hline CHEMBL1312757 & 737823 & 5.45 & 5.6505 & TRN & \\
\hline CHEMBL1395915 & 737823 & 6.7 & \multicolumn{2}{|c|}{6.252000000000001} & TRN \\
\hline CHEMBL1420061 & 737823 & 4.85 & 4.9388 & TRN & \\
\hline CHEMBL1344451 & 737823 & 5.6 & 5.5543 & TST & \\
\hline CHEMBL1497338 & 737823 & 5.35 & 5.3208 & TRN & \\
\hline CHEMBL 285843 & 737823 & 6.0 & 4.9656 & TRN & \\
\hline CHEMBL1598994 & 737823 & 5.0 & 5.0175 & TRN & \\
\hline CHEMBL1550866 & 737823 & 4.85 & 5.3431 & TST & \\
\hline CHEMBL1466951 & 737823 & 4.7 & 5.1315 & TRN & \\
\hline CHEMBL1374863 & 737823 & 5.1 & 5.3081 & TRN & \\
\hline CHEMBL445102 & 737823 & 4.5 & 5.1778 & TRN & \\
\hline CHEMBL1488115 & 737823 & 5.65 & 5.2259 & TRN & \\
\hline CHEMBL1473116 & 737823 & 5.3 & \multicolumn{2}{|c|}{4.9510000000000005} & TRN \\
\hline CHEMBL1492215 & 737823 & 5.6 & 5.4653 & TRN & \\
\hline CHEMBL1436956 & 737823 & 6.0 & 5.4794 & TRN & \\
\hline CHEMBL1349872 & 737823 & 5.3 & 5.3374 & TRN & \\
\hline CHEMBL1342399 & 737823 & 4.9 & 5.0233 & TRN & \\
\hline CHEMBL1576730 & 737823 & 4.75 & 5.3949 & TRN & \\
\hline CHEMBL266500 & 737823 & 4.6 & 5.3206 & TRN & \\
\hline CHEMBL1579455 & 737823 & 5.2 & 5.3311 & TST & \\
\hline CHEMBL1340002 & 737823 & 4.95 & 5.2169 & TRN & \\
\hline CHEMBL1517335 & 737823 & 4.65 & 4.9676 & TRN & \\
\hline CHEMBL1476504 & 737823 & 5.3 & 5.6401 & TRN & \\
\hline CHEMBL1582663 & 737823 & 4.75 & 5.2463 & TRN & \\
\hline CHEMBL1333637 & 737823 & 5.15 & 5.5091 & TRN & \\
\hline CHEMBL1307620 & 737823 & 5.95 & 5.5939 & TRN & \\
\hline CHEMBL1613444 & 737823 & 6.35 & 5.6214 & TRN & \\
\hline CHEMBL1467219 & 737823 & 5.35 & 5.3893 & TRN & \\
\hline CHEMBL1430823 & 737823 & 5.8 & 5.483 & TRN & \\
\hline CHEMBL1363569 & 737823 & 5.8 & 5.6463 & TRN & \\
\hline CHEMBL3211853 & 737823 & 4.7 & 4.9268 & TRN & \\
\hline CHEMBL1584987 & 737823 & 4.95 & 5.2115 & TRN & \\
\hline CHEMBL1327673 & 737823 & 4.5 & 4.82600 & 00000000005 & TRN \\
\hline CHEMBL1426944 & 737823 & 5.6 & 5.6189 & TRN & \\
\hline CHEMBL1433153 & 737823 & 5.8 & 5.5331 & TRN & \\
\hline CHEMBL1515024 & 737823 & 4.7 & 4.6894 & TRN & \\
\hline CHEMBL407874 & 737823 & 6.0 & 5.6784 & TRN & \\
\hline CHEMBL1395029 & 737823 & 5.1 & 4.67899 & 9999999999 & TRN \\
\hline CHEMBL1416829 & 737823 & 5.3 & 5.2008 & TRN & \\
\hline CHEMBL3195513 & 737823 & 6.55 & 5.5624 & TRN & \\
\hline
\end{tabular}




\begin{tabular}{|c|c|c|c|c|c|}
\hline \multicolumn{6}{|c|}{ Supplemental Table S2.txt } \\
\hline CHEMBL52 & 737823 & 4.6 & 5.1817 & TRN & \\
\hline CHEMBL1538230 & 737823 & 4.8 & 5.8471 & TST & \\
\hline CHEMBL59532 & 737823 & 4.8 & 5.3404 & TST & \\
\hline CHEMBL350343 & 737823 & 4.9 & 5.1395 & TRN & \\
\hline CHEMBL1213137 & 737823 & 4.9 & 4.8588 & TRN & \\
\hline CHEMBL1318066 & 737823 & 5.4 & 5.1851 & TRN & \\
\hline CHEMBL1552187 & 737823 & 4.6 & 4.8647 & TRN & \\
\hline CHEMBL1607888 & 737823 & 4.8 & 5.1839 & TST & \\
\hline CHEMBL1409167 & 737823 & 6.0 & 5.7229 & TRN & \\
\hline CHEMBL1380794 & 737823 & 4.8 & 5.3138 & TRN & \\
\hline CHEMBL1439334 & 737823 & 5.1 & 4.7821 & TRN & \\
\hline CHEMBL1389326 & 737823 & 5.0 & 5.8137 & TRN & \\
\hline CHEMBL1366699 & 737823 & 4.6 & 5.1073 & TRN & \\
\hline CHEMBL1434550 & 737823 & 4.7 & 5.1997 & TRN & \\
\hline CHEMBL1320989 & 737823 & 5.0 & 5.1691 & TRN & \\
\hline CHEMBL1335579 & 737823 & 4.55 & 5.0407 & TRN & \\
\hline CHEMBL18879 & 737823 & 4.6 & 5.4625 & TST & \\
\hline CHEMBL545523 & 737823 & 6.5 & 6.1809 & TRN & \\
\hline CHEMBL1487003 & 737823 & 5.4 & 5.1553 & TRN & \\
\hline CHEMBL1570869 & 737823 & 6.55 & 5.3737 & TRN & \\
\hline CHEMBL1397833 & 737823 & 5.1 & 5.4392 & TST & \\
\hline CHEMBL1552150 & 737823 & 5.5 & 5.1875 & TRN & \\
\hline CHEMBL3190247 & 737823 & 5.35 & 5.1456 & TRN & \\
\hline CHEMBL1330317 & 737823 & 5.7 & 6.0173 & TRN & \\
\hline CHEMBL1472732 & 737823 & 4.8 & 5.0814 & TRN & \\
\hline CHEMBL1558537 & 737823 & 5.5 & 5.0805 & TST & \\
\hline CHEMBL1454463 & 737823 & 4.6 & 4.6765 & TRN & \\
\hline CHEMBL1394477 & 737823 & 4.8 & 5.45200 & 0000000001 & TRN \\
\hline CHEMBL1308821 & 737823 & 4.5 & 4.8937 & TRN & \\
\hline CHEMBL1487063 & 737823 & 5.35 & 5.7422 & TRN & \\
\hline CHEMBL1559248 & 737823 & 4.75 & 5.2395 & TRN & \\
\hline CHEMBL1467087 & 737823 & 6.7 & 5.0723 & TRN & \\
\hline CHEMBL1351689 & 737823 & 4.8 & 4.8058 & TRN & \\
\hline CHEMBL1451548 & 737823 & 5.4 & 5.3424 & TRN & \\
\hline CHEMBL1992166 & 737823 & 4.85 & 5.3685 & TRN & \\
\hline CHEMBL3213165 & 737823 & 5.9 & 5.4165 & TRN & \\
\hline CHEMBL1319632 & 737823 & 6.05 & 5.0944 & TRN & \\
\hline CHEMBL1554569 & 737823 & 4.9 & 5.0932 & TRN & \\
\hline CHEMBL1569009 & 737823 & 5.1 & 5.317 & TRN & \\
\hline CHEMBL1381111 & 737823 & 5.45 & 4.8401 & TRN & \\
\hline CHEMBL1380717 & 737823 & 4.85 & 4.9394 & TRN & \\
\hline CHEMBL62350 & 737823 & 5.7 & 5.8408 & TRN & \\
\hline CHEMBL1447909 & 737823 & 4.9 & 5.5085 & TRN & \\
\hline CHEMBL1381655 & 737823 & 5.2 & 4.9827 & TRN & \\
\hline CHEMBL1256959 & 737823 & 4.5 & 4.7447 & TST & \\
\hline CHEMBL1346997 & 737823 & 4.75 & 5.3504 & TRN & \\
\hline CHEMBL1443695 & 737823 & 4.6 & 4.8174 & TRN & \\
\hline CHEMBL1498170 & 737823 & 4.75 & 5.5492 & TRN & \\
\hline
\end{tabular}




\begin{tabular}{|c|c|c|c|c|}
\hline \multicolumn{5}{|c|}{ Supplemental Table S2.txt } \\
\hline CHEMBL1589728 & 737823 & 4.2 & 4.7639 & TST \\
\hline CHEMBL1356628 & 737823 & 4.8 & 5.4294 & TRN \\
\hline CHEMBL1596455 & 737823 & 5.45 & 5.125 & TRN \\
\hline CHEMBL1573480 & 737823 & 4.9 & 5.341 & TRN \\
\hline CHEMBL1318518 & 737823 & 4.9 & 4.7559 & TRN \\
\hline CHEMBL1605666 & 737823 & 5.45 & 5.8787 & TST \\
\hline CHEMBL1528915 & 737823 & 5.9 & 5.2922 & TST \\
\hline CHEMBL1741940 & 737823 & 5.0 & 4.8998 & TRN \\
\hline CHEMBL 3214477 & 737823 & 4.6 & 5.018 & TRN \\
\hline CHEMBL1472152 & 737823 & 5.4 & 5.2907 & TRN \\
\hline CHEMBL1511721 & 737823 & 4.95 & 5.2789 & TST \\
\hline CHEMBL1384608 & 737823 & 5.2 & 4.9475 & TRN \\
\hline CHEMBL1563501 & 737823 & 4.9 & 5.5263 & TRN \\
\hline CHEMBL1404737 & 737823 & 5.1 & 5.1943 & TRN \\
\hline CHEMBL1536942 & 737823 & 4.9 & 5.0283 & TRN \\
\hline CHEMBL1362959 & 737823 & 6.2 & 5.8204 & TST \\
\hline CHEMBL1318573 & 737823 & 5.4 & 5.6713 & TRN \\
\hline CHEMBL1367608 & 737823 & 5.5 & 5.9294 & TRN \\
\hline CHEMBL1607228 & 737823 & 6.0 & 5.5093 & TRN \\
\hline CHEMBL1547372 & 737823 & 5.75 & 5.7513 & TRN \\
\hline CHEMBL1533882 & 737823 & 4.55 & 5.2565 & TRN \\
\hline CHEMBL1355677 & 737823 & 4.9 & 5.6421 & TRN \\
\hline CHEMBL1999906 & 737823 & 5.95 & 5.6623 & TST \\
\hline CHEMBL1558135 & 737823 & 5.0 & 5.2944 & TRN \\
\hline CHEMBL1596347 & 737823 & 4.9 & 5.7825 & TST \\
\hline CHEMBL1524591 & 737823 & 5.6 & 5.2881 & TRN \\
\hline CHEMBL1358570 & 737823 & 5.6 & 5.1614 & TST \\
\hline CHEMBL1741926 & 737823 & 4.5 & 4.652 & TST \\
\hline CHEMBL 388054 & 737823 & 6.0 & 4.9209 & TRN \\
\hline CHEMBL1480847 & 737823 & 5.7 & 5.3231 & TRN \\
\hline CHEMBL1538117 & 737823 & 5.15 & 5.4066 & TRN \\
\hline CHEMBL118109 & 737823 & 5.9 & 5.5464 & TRN \\
\hline CHEMBL1582197 & 737823 & 4.9 & 4.8923 & TST \\
\hline CHEMBL1414259 & 737823 & 5.3 & 5.2447 & TRN \\
\hline CHEMBL1400884 & 737823 & 6.0 & 5.2913 & TST \\
\hline CHEMBL1717325 & 737823 & 5.05 & 5.4169 & TRN \\
\hline CHEMBL1397177 & 737823 & 5.4 & 5.3331 & TRN \\
\hline CHEMBL1723345 & 737823 & 5.0 & 4.9937 & TRN \\
\hline CHEMBL1384961 & 737823 & 4.5 & 5.0139 & TRN \\
\hline CHEMBL1383753 & 737823 & 5.25 & 5.3826 & TRN \\
\hline CHEMBL1256364 & 737823 & 6.1 & 5.5054 & TRN \\
\hline CHEMBL3211748 & 737823 & 6.05 & 5.5112 & TRN \\
\hline CHEMBL1439336 & 737823 & 5.05 & 4.9204 & TRN \\
\hline CHEMBL1573688 & 737823 & 4.85 & 4.8579 & TRN \\
\hline CHEMBL1742378 & 737823 & 4.7 & 5.0096 & TRN \\
\hline CHEMBL1440032 & 737823 & 5.2 & 4.9692 & TRN \\
\hline CHEMBL1568802 & 737823 & 5.55 & 5.1793 & TST \\
\hline CHEMBL491555 & 737823 & 5.4 & 5.3233 & TRN \\
\hline
\end{tabular}




\begin{tabular}{|c|c|c|c|c|c|}
\hline \\
\hline CHEMBL1483207 & 737823 & 5.4 & 5.0799 & TRN & \\
\hline CHEMBL1572988 & 737823 & 5.8 & 4.2947 & TRN & \\
\hline CHEMBL1547257 & 737823 & 5.15 & 5.9417 & TRN & \\
\hline CHEMBL1403388 & 737823 & 6.0 & 5.8721 & TST & \\
\hline CHEMBL1437226 & 737823 & 6.0 & 5.9144 & TRN & \\
\hline CHEMBL1354596 & 737823 & 5.7 & 5.6818 & TRN & \\
\hline CHEMBL1568413 & 737823 & 5.65 & 5.4466 & TRN & \\
\hline CHEMBL1370100 & 737823 & 6.3 & 5.6528 & TRN & \\
\hline CHEMBL1456100 & 737823 & 5.3 & 5.8796 & TRN & \\
\hline CHEMBL1538008 & 737823 & 8.2 & 5.0191 & TRN & \\
\hline CHEMBL 3194463 & 737823 & 4.85 & 5.4899 & TST & \\
\hline CHEMBL1430904 & 737823 & 5.1 & 5.2069 & TRN & \\
\hline CHEMBL1561738 & 737823 & 5.05 & 5.9247 & TRN & \\
\hline CHEMBL1436644 & 737823 & 6.1 & 5.7895 & TRN & \\
\hline CHEMBL1511729 & 737823 & 5.3 & 5.4911 & TRN & \\
\hline CHEMBL1255749 & 737823 & 5.9 & 5.1536 & TST & \\
\hline CHEMBL1535931 & 737823 & 4.9 & $5.0680 e$ & 00000000005 & TRN \\
\hline CHEMBL1602382 & 737823 & 4.6 & 5.0651 & TST & \\
\hline CHEMBL1500365 & 737823 & 4.8 & 4.8771 & TRN & \\
\hline CHEMBL1434482 & 737823 & 5.0 & 4.7847 & TRN & \\
\hline CHEMBL3208377 & 737823 & 6.15 & 5.7048 & TST & \\
\hline CHEMBL1353886 & 737823 & 4.8 & 5.4597 & TRN & \\
\hline CHEMBL1362159 & 737823 & 4.8 & 4.7638 & TRN & \\
\hline CHEMBL1494099 & 737823 & 5.1 & 5.0068 & TRN & \\
\hline CHEMBL1591674 & 737823 & 4.8 & 4.5653 & TRN & \\
\hline CHEMBL1256186 & 737823 & 4.9 & 5.3595 & TST & \\
\hline CHEMBL1556027 & 737823 & 4.8 & 5.4423 & TRN & \\
\hline CHEMBL1577056 & 737823 & 6.35 & 5.4031 & TRN & \\
\hline CHEMBL1557212 & 737823 & 5.4 & $5.9570 e$ & 0000000001 & TST \\
\hline CHEMBL1308386 & 737823 & 5.5 & 5.3897 & TRN & \\
\hline CHEMBL1460680 & 737823 & 4.6 & 5.2444 & TRN & \\
\hline CHEMBL1482527 & 737823 & 6.4 & 5.1473 & TRN & \\
\hline CHEMBL1741610 & 737823 & 5.35 & 5.0107 & TRN & \\
\hline CHEMBL1587519 & 737823 & 4.8 & 5.2628 & TRN & \\
\hline CHEMBL1428282 & 737823 & 5.5 & 4.8613 & TRN & \\
\hline CHEMBL1595253 & 737823 & 5.9 & 5.7347 & TRN & \\
\hline CHEMBL269521 & 737823 & 5.7 & 5.0526 & TST & \\
\hline CHEMBL1407667 & 737823 & 6.35 & 5.6943 & TRN & \\
\hline CHEMBL1462826 & 737823 & 4.6 & 4.7788 & TST & \\
\hline CHEMBL1575899 & 737823 & 4.55 & 4.8707 & TRN & \\
\hline CHEMBL1571290 & 737823 & 4.6 & 5.2161 & TRN & \\
\hline CHEMBL1537864 & 737823 & 5.0 & 5.5953 & TRN & \\
\hline CHEMBL1531607 & 737823 & 5.7 & 5.5647 & TRN & \\
\hline CHEMBL1531899 & 737823 & 6.9 & 5.402 & TRN & \\
\hline CHEMBL1593371 & 737823 & 4.6 & 5.0705 & TRN & \\
\hline CHEMBL1361149 & 737823 & 4.6 & 4.978 & TRN & \\
\hline CHEMBL491978 & 737823 & 4.8 & 4.5721 & TRN & \\
\hline CHEMBL1540570 & 737823 & 5.15 & 5.5712 & TST & \\
\hline
\end{tabular}




\begin{tabular}{|c|c|c|c|c|c|}
\hline \multicolumn{6}{|c|}{ Supplemental Table S2.txt } \\
\hline CHEMBL1498906 & 737823 & 4.7 & 5.3648 & TRN & \\
\hline CHEMBL 1400320 & 737823 & 4.4 & 5.2098 & TRN & \\
\hline CHEMBL1470219 & 737823 & 4.85 & 5.33 & TRN & \\
\hline CHEMBL1573949 & 737823 & 4.9 & 5.3196 & TRN & \\
\hline CHEMBL1404451 & 737823 & 6.6 & 6.4296 & TRN & \\
\hline CHEMBL1441453 & 737823 & 5.5 & 5.5441 & TRN & \\
\hline CHEMBL1380899 & 737823 & 4.95 & 5.1486 & TRN & \\
\hline CHEMBL1490809 & 737823 & 5.5 & 5.206 & TRN & \\
\hline CHEMBL1352020 & 737823 & 5.9 & 5.474 & TRN & \\
\hline CHEMBL1317314 & 737823 & 5.3 & 5.4552 & TRN & \\
\hline CHEMBL1432973 & 737823 & 5.1 & 5.2235 & TRN & \\
\hline CHEMBL1476108 & 737823 & 5.6 & 4.8572 & TRN & \\
\hline CHEMBL1309244 & 737823 & 5.5 & 5.6068 & TST & \\
\hline CHEMBL1483032 & 737823 & 4.9 & $5.1960 e$ & 2000000001 & TRN \\
\hline CHEMBL1486909 & 737823 & 4.8 & 4.84399 & 9999999999 & TST \\
\hline CHEMBL17468 & 737823 & 6.1 & 5.5758 & TST & \\
\hline CHEMBL1438164 & 737823 & 4.8 & 5.2608 & TRN & \\
\hline CHEMBL1336102 & 737823 & 5.55 & 4.8519 & TRN & \\
\hline CHEMBL1523982 & 737823 & 5.5 & 5.4567 & TRN & \\
\hline CHEMBL1478806 & 737823 & 5.5 & 5.4404 & TRN & \\
\hline CHEMBL1566012 & 737823 & 6.8 & 5.74 & TST & \\
\hline CHEMBL1408303 & 737823 & 5.75 & 5.9238 & TRN & \\
\hline CHEMBL1596743 & 737823 & 6.1 & 5.3751 & TRN & \\
\hline CHEMBL1610944 & 737823 & 4.9 & 4.9918 & TRN & \\
\hline CHEMBL3208514 & 737823 & 5.1 & 5.4519 & TRN & \\
\hline CHEMBL1427330 & 737823 & 5.3 & 5.3296 & TST & \\
\hline CHEMBL1399905 & 737823 & 4.85 & 4.6796 & TRN & \\
\hline CHEMBL1523957 & 737823 & 5.0 & 5.5381 & TRN & \\
\hline CHEMBL1529609 & 737823 & 5.4 & $5.3770 e$ & 2000000001 & TRN \\
\hline CHEMBL1356395 & 737823 & 6.1 & 5.6533 & TRN & \\
\hline CHEMBL 1475642 & 737823 & 4.5 & 5.4346 & TRN & \\
\hline CHEMBL1596221 & 737823 & 4.85 & 5.1977 & TRN & \\
\hline CHEMBL168279 & 737823 & 4.4 & 5.1577 & TST & \\
\hline CHEMBL1741347 & 737823 & 4.7 & 5.1313 & TRN & \\
\hline CHEMBL 3198835 & 737823 & 4.85 & 5.1745 & TRN & \\
\hline CHEMBL1741506 & 737823 & 5.6 & 5.0573 & TRN & \\
\hline CHEMBL1415465 & 737823 & 5.5 & 4.7312 & TRN & \\
\hline CHEMBL1411164 & 737823 & 5.0 & 5.1434 & TRN & \\
\hline CHEMBL1573964 & 737823 & 6.1 & 5.1435 & TRN & \\
\hline CHEMBL1306142 & 737823 & 5.8 & 5.6572 & TRN & \\
\hline CHEMBL1473331 & 737823 & 5.6 & 5.5121 & TRN & \\
\hline CHEMBL1566928 & 737823 & 6.2 & 6.0258 & TRN & \\
\hline CHEMBL1473543 & 737823 & 5.4 & 5.8684 & TST & \\
\hline CHEMBL1503678 & 737823 & 4.5 & 4.8419 & TRN & \\
\hline CHEMBL1476712 & 737823 & 5.5 & 5.3688 & TRN & \\
\hline CHEMBL1513485 & 737823 & 5.1 & 5.6644 & TRN & \\
\hline CHEMBL1345861 & 737823 & 4.6 & 5.4019 & TRN & \\
\hline CHEMBL1330032 & 737823 & 5.3 & 5.20299 & 9999999999 & TRN \\
\hline & & & & 3446 & \\
\hline
\end{tabular}




\begin{tabular}{|c|c|c|c|c|}
\hline \multicolumn{5}{|c|}{ Supplemental Table s2.txt } \\
\hline CHEMBL1350415 & 737823 & 5.65 & 5.6692 & TRN \\
\hline CHEMBL1470528 & 737823 & 4.8 & 5.2155 & TST \\
\hline CHEMBL1591272 & 737823 & 5.6 & 5.7444 & TRN \\
\hline CHEMBL1324842 & 737823 & 5.5 & 5.3851 & TRN \\
\hline CHEMBL1486876 & 737823 & 6.3 & 5.6957 & TST \\
\hline CHEMBL1530558 & 737823 & 5.25 & 5.7134 & TRN \\
\hline CHEMBL1533024 & 737823 & 4.9 & 5.3013 & TRN \\
\hline CHEMBL1533616 & 737823 & 5.5 & 5.3228 & TRN \\
\hline CHEMBL1385038 & 737823 & 4.8 & 5.2408 & TST \\
\hline CHEMBL1459336 & 737823 & 4.9 & 5.1107 & TRN \\
\hline CHEMBL1512919 & 737823 & 6.0 & 5.7595 & TRN \\
\hline CHEMBL1491288 & 737823 & 5.1 & 4.9317 & TRN \\
\hline CHEMBL1549419 & 737823 & 6.05 & 5.9903 & TRN \\
\hline CHEMBL1435520 & 737823 & 5.2 & 5.2816 & TRN \\
\hline CHEMBL1335233 & 737823 & 4.6 & 4.4009 & TRN \\
\hline CHEMBL1579482 & 737823 & 4.6 & 5.1154 & TRN \\
\hline CHEMBL1330811 & 737823 & 5.7 & 5.2713 & TRN \\
\hline CHEMBL16671 & 737823 & 4.4 & 5.3182 & TST \\
\hline CHEMBL1458309 & 737823 & 4.85 & 5.3558 & TST \\
\hline CHEMBL1405762 & 737823 & 5.4 & 5.356 & TST \\
\hline CHEMBL1437667 & 737823 & 6.5 & 5.7633 & TRN \\
\hline CHEMBL1325634 & 737823 & 5.6 & 5.2128 & TRN \\
\hline CHEMBL1368856 & 737823 & 5.3 & 5.0586 & TRN \\
\hline CHEMBL1360218 & 737823 & 6.3 & 5.2167 & TRN \\
\hline CHEMBL1352774 & 737823 & 4.75 & 5.2147 & TST \\
\hline CHEMBL1597107 & 737823 & 5.0 & 5.3419 & TRN \\
\hline CHEMBL1432283 & 737823 & 5.5 & 5.61100 & 0000000001 \\
\hline CHEMBL1741822 & 737823 & 6.2 & 4.7432 & TST \\
\hline CHEMBL1720193 & 737823 & 5.25 & 4.8977 & TRN \\
\hline CHEMBL1555122 & 737823 & 4.6 & 4.9105 & TRN \\
\hline CHEMBL1533144 & 737823 & 5.1 & 5.1322 & TRN \\
\hline CHEMBL1445889 & 737823 & 6.3 & 5.6572 & TRN \\
\hline CHEMBL1408386 & 737823 & 4.65 & 5.1661 & TRN \\
\hline CHEMBL1482582 & 737823 & 5.3 & 5.6912 & TRN \\
\hline CHEMBL1417375 & 737823 & 5.9 & 5.4768 & TRN \\
\hline CHEMBL1375321 & 737823 & 5.5 & 5.6863 & TRN \\
\hline CHEMBL1407670 & 737823 & 5.8 & 6.0433 & TRN \\
\hline CHEMBL1333080 & 737823 & 4.85 & 5.1315 & TRN \\
\hline CHEMBL1388771 & 737823 & 5.6 & 5.5256 & TRN \\
\hline CHEMBL1406437 & 737823 & 4.8 & 5.224 & TRN \\
\hline CHEMBL1585753 & 737823 & 4.8 & 4.9231 & TRN \\
\hline CHEMBL1386703 & 737823 & 4.65 & 5.0044 & TRN \\
\hline CHEMBL1307320 & 737823 & 5.0 & 5.5247 & TRN \\
\hline CHEMBL 274844 & 737823 & 4.8 & 4.8267 & TRN \\
\hline CHEMBL1446665 & 737823 & 5.4 & 5.5033 & TST \\
\hline CHEMBL1562685 & 737823 & 5.6 & 5.5125 & TRN \\
\hline CHEMBL1448044 & 737823 & 5.3 & 5.5692 & TRN \\
\hline CHEMBL1425061 & 737823 & 5.6 & 5.1717 & TRN \\
\hline
\end{tabular}




\begin{tabular}{|c|c|c|c|c|}
\hline \multicolumn{5}{|c|}{ Supplemental Table S2.txt } \\
\hline CHEMBL1353775 & 737823 & 5.6 & 5.1437 & TRN \\
\hline CHEMBL1536220 & 737823 & 5.6 & 4.9331 & TRN \\
\hline CHEMBL1361585 & 737823 & 4.95 & 5.2301 & TRN \\
\hline CHEMBL1490108 & 737823 & 4.9 & 4.9249 & TRN \\
\hline CHEMBL1380806 & 737823 & 4.4 & 4.8496 & TRN \\
\hline CHEMBL1741568 & 737823 & 4.65 & 5.0889 & TST \\
\hline CHEMBL1394964 & 737823 & 5.8 & 5.3442 & TRN \\
\hline CHEMBL1314388 & 737823 & 6.1 & 6.5062 & TRN \\
\hline CHEMBL 3210074 & 737823 & 5.65 & 5.25 & TRN \\
\hline CHEMBL1388203 & 737823 & 7.2 & 6.0898 & TST \\
\hline CHEMBL1472356 & 737823 & 4.9 & 5.2214 & TRN \\
\hline CHEMBL1588389 & 737823 & 6.0 & 5.7529 & TRN \\
\hline CHEMBL1585369 & 737823 & 5.15 & 5.3341 & TRN \\
\hline CHEMBL14276 & 737823 & 6.5 & 5.3827 & TRN \\
\hline CHEMBL1452716 & 737823 & 4.8 & 5.1741 & TRN \\
\hline CHEMBL1558384 & 737823 & 5.2 & 5.289 & TRN \\
\hline CHEMBL1456911 & 737823 & 5.95 & 5.4881 & TRN \\
\hline CHEMBL3210522 & 737823 & 5.1 & 5.2998 & TST \\
\hline CHEMBL1401933 & 737823 & 6.1 & 5.6311 & TRN \\
\hline CHEMBL1369642 & 737823 & 4.9 & 4.9225 & TRN \\
\hline CHEMBL1396989 & 737823 & 5.4 & 5.5235 & TRN \\
\hline CHEMBL1410399 & 737823 & 5.1 & 5.2263 & TRN \\
\hline CHEMBL1466542 & 737823 & 4.7 & 5.2925 & TRN \\
\hline CHEMBL1406854 & 737823 & 4.8 & 5.2723 & TST \\
\hline CHEMBL1454224 & 737823 & 5.0 & 4.5586 & TRN \\
\hline CHEMBL1358244 & 737823 & 5.4 & 5.3043 & TRN \\
\hline CHEMBL1329104 & 737823 & 5.3 & 5.221 & TRN \\
\hline CHEMBL3192501 & 737823 & 4.85 & 5.0708 & TRN \\
\hline CHEMBL1609726 & 737823 & 5.9 & 5.0433 & TRN \\
\hline CHEMBL1590556 & 737823 & 4.8 & 4.6243 & TRN \\
\hline CHEMBL1316893 & 737823 & 6.6 & 6.0612 & TRN \\
\hline CHEMBL1538898 & 737823 & 4.8 & 5.0887 & TRN \\
\hline CHEMBL1409986 & 737823 & 6.0 & 5.4757 & TRN \\
\hline CHEMBL1502523 & 737823 & 5.5 & 5.251 & TRN \\
\hline CHEMBL3196744 & 737823 & 6.35 & 5.3905 & TRN \\
\hline CHEMBL1611820 & 737823 & 4.9 & 4.5744 & TRN \\
\hline CHEMBL1451733 & 737823 & 6.2 & 5.1525 & TST \\
\hline CHEMBL1526229 & 737823 & 5.3 & 5.2946 & TST \\
\hline CHEMBL1434643 & 737823 & 4.9 & 4.6001 & TRN \\
\hline CHEMBL1406782 & 737823 & 4.8 & 5.5335 & TRN \\
\hline CHEMBL1527813 & 737823 & 4.9 & 5.0855 & TRN \\
\hline CHEMBL1344860 & 737823 & 5.9 & 6.1058 & TST \\
\hline CHEMBL1402493 & 737823 & 6.05 & 5.1207 & TRN \\
\hline CHEMBL1373004 & 737823 & 7.1 & 6.0856 & TRN \\
\hline CHEMBL1515985 & 737823 & 4.6 & 5.1575 & TRN \\
\hline CHEMBL1594020 & 737823 & 5.7 & 5.5145 & TRN \\
\hline CHEMBL3193903 & 737823 & 5.05 & 4.9604 & TRN \\
\hline CHEMBL1496664 & 737823 & 5.7 & 5.3792 & TRN \\
\hline
\end{tabular}




\begin{tabular}{|c|c|c|c|c|c|}
\hline \multicolumn{6}{|c|}{ Supplemental Table S2.txt } \\
\hline CHEMBL446774 & 737823 & 4.4 & 5.224 & TRN & \\
\hline CHEMBL1604505 & 737823 & 4.9 & 5.2611 & TRN & \\
\hline CHEMBL1489708 & 737823 & 4.6 & 4.9854 & TRN & \\
\hline CHEMBL1515764 & 737823 & 5.8 & 5.6612 & TRN & \\
\hline CHEMBL1602568 & 737823 & 4.8 & 5.3573 & TRN & \\
\hline CHEMBL1433336 & 737823 & 5.3 & 4.9009 & TRN & \\
\hline CHEMBL1589893 & 737823 & 4.8 & 5.0593 & TRN & \\
\hline CHEMBL1452408 & 737823 & 5.2 & 5.4824 & TRN & \\
\hline CHEMBL1564845 & 737823 & 4.8 & 6.0361 & TRN & \\
\hline CHEMBL3209279 & 737823 & 4.65 & 5.1475 & TRN & \\
\hline CHEMBL1353478 & 737823 & 4.6 & 4.9198 & TST & \\
\hline CHEMBL1392986 & 737823 & 4.9 & 5.2621 & TST & \\
\hline CHEMBL24850 & 737823 & 5.2 & 5.5522 & TRN & \\
\hline CHEMBL1729474 & 737823 & 5.0 & 5.2042 & TRN & \\
\hline CHEMBL104264 & 737823 & 5.7 & 5.0769 & TRN & \\
\hline CHEMBL1358342 & 737823 & 4.9 & 4.7776 & TRN & \\
\hline CHEMBL1607455 & 737823 & 5.35 & 5.686 & TRN & \\
\hline CHEMBL1501507 & 737823 & 4.6 & 4.8334 & TRN & \\
\hline CHEMBL1405464 & 737823 & 5.3 & 5.5424 & TRN & \\
\hline CHEMBL1404209 & 737823 & 5.55 & 5.4834 & TRN & \\
\hline CHEMBL1396792 & 737823 & 5.1 & 5.1794 & TRN & \\
\hline CHEMBL3194323 & 737823 & 5.5 & 5.1329 & TRN & \\
\hline CHEMBL99344 & 737823 & 4.5 & 5.0369 & TRN & \\
\hline CHEMBL1490012 & 737823 & 5.35 & 5.2398 & TRN & \\
\hline CHEMBL1512895 & 737823 & 5.6 & 4.8972 & TRN & \\
\hline CHEMBL1517040 & 737823 & 4.9 & 5.5126 & TRN & \\
\hline CHEMBL3196358 & 737823 & 5.2 & 5.1183 & TRN & \\
\hline CHEMBL1365271 & 737823 & 4.7 & 4.6801 & TRN & \\
\hline CHEMBL1500867 & 737823 & 6.4 & 5.7488 & TRN & \\
\hline CHEMBL1454249 & 737823 & 6.35 & 5.2194 & TRN & \\
\hline CHEMBL1402049 & 737823 & 6.5 & 5.8398 & TRN & \\
\hline CHEMBL1398013 & 737823 & 6.7 & 5.4588 & TRN & \\
\hline CHEMBL491748 & 737823 & 6.6 & 5.6560 & 0000000001 & TRN \\
\hline CHEMBL1594217 & 737823 & 4.5 & 5.256 & TST & \\
\hline CHEMBL1424596 & 737823 & 4.45 & 5.8522 & TST & \\
\hline CHEMBL1369483 & 737823 & 5.1 & 5.1798 & TRN & \\
\hline CHEMBL1593775 & 737823 & 4.5 & 5.3179 & TRN & \\
\hline CHEMBL1578254 & 737823 & 5.5 & 5.3994 & TRN & \\
\hline CHEMBL1396997 & 737823 & 5.6 & 5.4657 & TRN & \\
\hline CHEMBL1606193 & 737823 & 5.5 & 5.2907 & TRN & \\
\hline CHEMBL1526205 & 737823 & 4.9 & 5.0539 & TRN & \\
\hline CHEMBL1434833 & 737823 & 5.9 & 5.7526 & TRN & \\
\hline CHEMBL1523520 & 737823 & 5.0 & 5.2493 & TST & \\
\hline CHEMBL 3189288 & 737823 & 5.65 & 5.3018 & TRN & \\
\hline CHEMBL1317647 & 737823 & 5.1 & 5.3316 & TRN & \\
\hline CHEMBL1552071 & 737823 & 5.3 & 5.3318 & TRN & \\
\hline CHEMBL1458255 & 737823 & 5.2 & 5.2895 & TRN & \\
\hline CHEMBL1741965 & 737823 & 4.9 & 5.3629 & TST & \\
\hline
\end{tabular}




\begin{tabular}{|c|c|c|c|c|}
\hline & & & pplement & al $\mathrm{Ta}$ \\
\hline CHEMBL518923 & 737823 & 5.0 & 5.3338 & TRN \\
\hline CHEMBL1478627 & 737823 & 6.6 & 5.6615 & TRN \\
\hline CHEMBL1319038 & 737823 & 4.8 & 5.5051 & TST \\
\hline CHEMBL1323684 & 737823 & 5.2 & 4.9575 & TRN \\
\hline CHEMBL1413280 & 737823 & 6.8 & 5.5081 & TRN \\
\hline CHEMBL3196565 & 737823 & 5.4 & 5.8581 & TRN \\
\hline CHEMBL1395429 & 737823 & 4.8 & 4.8784 & TRN \\
\hline CHEMBL1330951 & 737823 & 6.3 & 5.5258 & TRN \\
\hline CHEMBL1505390 & 737823 & 5.6 & 5.7543 & TRN \\
\hline CHEMBL1357982 & 737823 & 4.8 & 4.702 & TRN \\
\hline CHEMBL50378 & 737823 & 4.8 & 5.2678 & TST \\
\hline CHEMBL1530895 & 737823 & 6.15 & 5.2418 & TRN \\
\hline CHEMBL1577306 & 737823 & 4.5 & 5.2642 & TRN \\
\hline CHEMBL1522579 & 737823 & 5.5 & 5.1501 & TRN \\
\hline CHEMBL1599388 & 737823 & 5.4 & 5.2246 & TST \\
\hline CHEMBL1592549 & 737823 & 5.3 & 5.1787 & TRN \\
\hline CHEMBL1392763 & 737823 & 4.8 & 4.9721 & TST \\
\hline CHEMBL1741956 & 737823 & 4.4 & 5.1046 & TRN \\
\hline CHEMBL1401196 & 737823 & 4.85 & 5.4221 & TRN \\
\hline CHEMBL1316828 & 737823 & 4.5 & 4.9852 & TST \\
\hline CHEMBL1373767 & 737823 & 4.6 & 4.7628 & TRN \\
\hline CHEMBL1512049 & 737823 & 5.2 & 5.5522 & TRN \\
\hline CHEMBL1303217 & 737823 & 5.2 & 5.1833 & TRN \\
\hline CHEMBL1707752 & 737823 & 4.95 & 5.0792 & TRN \\
\hline CHEMBL1473498 & 737823 & 4.7 & 5.0918 & TRN \\
\hline CHEMBL1373428 & 737823 & 4.8 & 5.5501 & TRN \\
\hline CHEMBL1336932 & 737823 & 6.3 & 5.745 & TRN \\
\hline CHEMBL1488305 & 737823 & 4.8 & 4.9185 & TRN \\
\hline CHEMBL1511553 & 737823 & 4.85 & 5.1489 & TRN \\
\hline CHEMBL1303074 & 737823 & 5.95 & 5.5501 & TST \\
\hline CHEMBL1517884 & 737823 & 4.9 & 4.9515 & TRN \\
\hline CHEMBL1589352 & 737823 & 5.1 & 5.69 & TRN \\
\hline CHEMBL1358525 & 737823 & 6.9 & 5.7439 & TRN \\
\hline CHEMBL1742255 & 737823 & 4.85 & 4.8675 & TRN \\
\hline CHEMBL1742306 & 737823 & 5.9 & 5.2877 & TRN \\
\hline CHEMBL1330385 & 737823 & 5.3 & 4.8025 & TRN \\
\hline CHEMBL1325709 & 737823 & 5.65 & 5.5951 & TRN \\
\hline CHEMBL1541487 & 737823 & 4.8 & 4.7754 & TRN \\
\hline CHEMBL1332569 & 737823 & 4.85 & 4.9663 & TRN \\
\hline CHEMBL1465487 & 737823 & 4.8 & 4.7296 & TRN \\
\hline CHEMBL1570134 & 737823 & 5.4 & 5.2412 & TRN \\
\hline CHEMBL1473919 & 737823 & 5.7 & 5.9467 & TRN \\
\hline CHEMBL1593219 & 737823 & 5.2 & 5.2403 & TRN \\
\hline CHEMBL1554851 & 737823 & 4.9 & 5.2554 & TRN \\
\hline CHEMBL1588025 & 737823 & 5.0 & 5.2162 & TST \\
\hline CHEMBL1374605 & 737823 & 5.2 & 5.2001 & TRN \\
\hline CHEMBL1319718 & 737823 & 5.0 & 5.1298 & TRN \\
\hline CHEMBL1393716 & 737823 & 6.4 & 5.355 & TRN \\
\hline
\end{tabular}




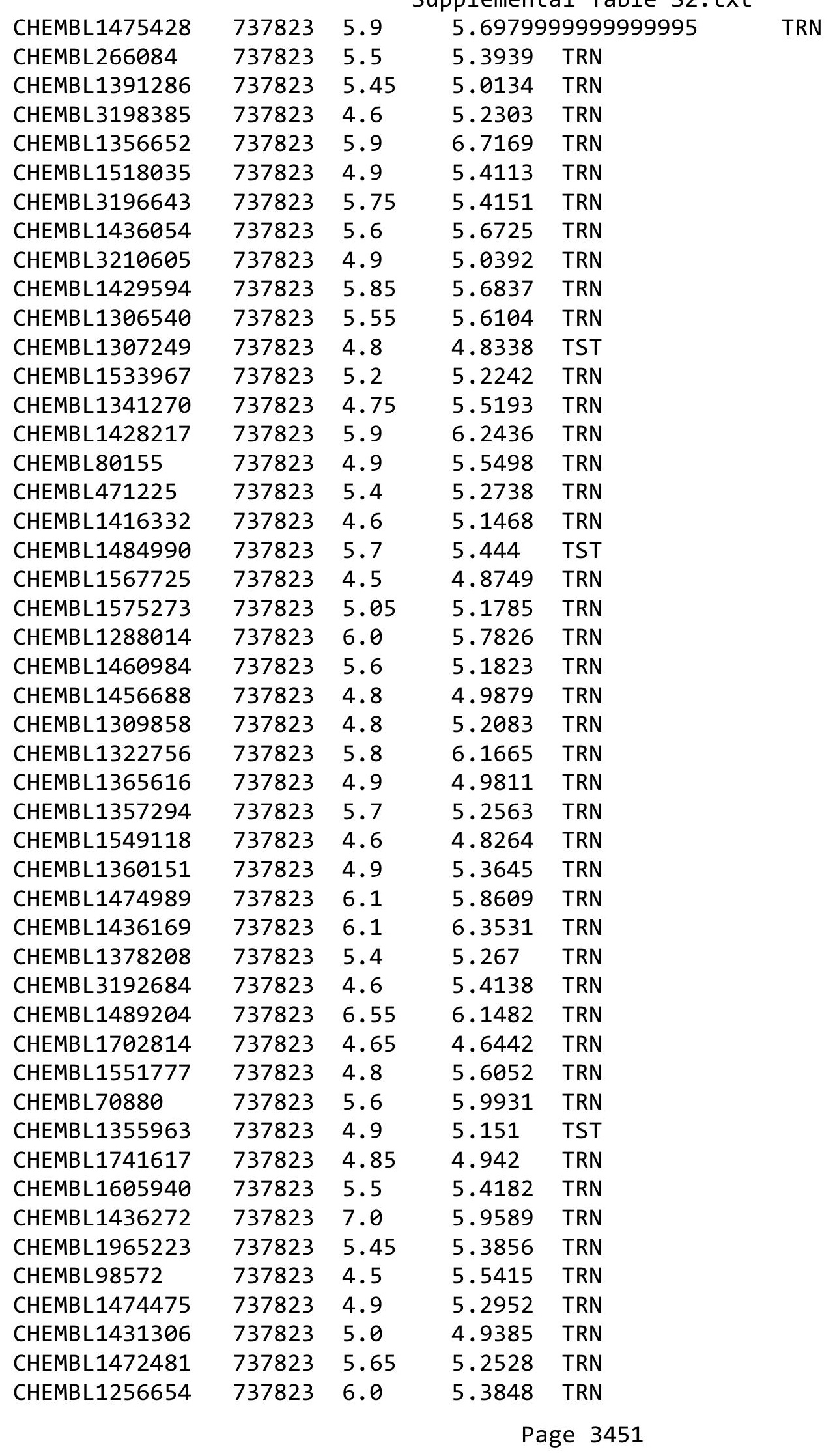




\begin{tabular}{|c|c|c|c|c|c|}
\hline \\
\hline CHEMBL1585011 & 737823 & 7.0 & 5.6425 & TST & \\
\hline CHEMBL1441148 & 737823 & 5.45 & 5.171 & TRN & \\
\hline CHEMBL369379 & 737823 & 5.3 & 5.3265 & TRN & \\
\hline CHEMBL1424256 & 737823 & 4.9 & 5.4102 & TRN & \\
\hline CHEMBL1559650 & 737823 & 5.25 & 5.4597 & TRN & \\
\hline CHEMBL1603192 & 737823 & 4.95 & 5.6077 & TRN & \\
\hline CHEMBL1366979 & 737823 & 4.85 & 5.3783 & TRN & \\
\hline CHEMBL1741607 & 737823 & 5.3 & 5.3949 & TST & \\
\hline CHEMBL1487205 & 737823 & 6.4 & 5.902 & TST & \\
\hline CHEMBL1580610 & 737823 & 6.1 & 5.0647 & TRN & \\
\hline CHEMBL1555156 & 737823 & 5.5 & 5.32700 & 0000000001 & TRN \\
\hline CHEMBL1568982 & 737823 & 6.8 & 5.6051 & TRN & \\
\hline CHEMBL1444545 & 737823 & 4.85 & 5.2538 & TRN & \\
\hline CHEMBL1499721 & 737823 & 4.4 & 5.4793 & TST & \\
\hline CHEMBL1301014 & 737823 & 6.3 & 5.7379 & TRN & \\
\hline CHEMBL1561068 & 737823 & 6.4 & 5.8872 & TRN & \\
\hline CHEMBL1367149 & 737823 & 4.8 & 5.0144 & TRN & \\
\hline CHEMBL1352554 & 737823 & 4.6 & 4.7776 & TRN & \\
\hline CHEMBL1534214 & 737823 & 5.45 & 5.6502 & TST & \\
\hline CHEMBL1741756 & 737823 & 4.9 & 4.8099 & TRN & \\
\hline CHEMBL1523900 & 737823 & 5.7 & 5.7901 & TRN & \\
\hline CHEMBL1555132 & 737823 & 4.7 & 4.9674 & TRN & \\
\hline CHEMBL1345757 & 737823 & 5.15 & 5.0886 & TRN & \\
\hline CHEMBL1347942 & 737823 & 5.0 & 5.4068 & TRN & \\
\hline CHEMBL1079460 & 737823 & 5.4 & 5.3466 & TST & \\
\hline CHEMBL1431290 & 737823 & 5.5 & 4.7999 & TRN & \\
\hline CHEMBL1366383 & 737823 & 5.65 & 5.8126 & TRN & \\
\hline CHEMBL1371821 & 737823 & 5.75 & 5.4122 & TRN & \\
\hline CHEMBL1551036 & 737823 & 4.7 & 5.0191 & TRN & \\
\hline CHEMBL1611893 & 737823 & 4.9 & 4.9948 & TRN & \\
\hline CHEMBL1523995 & 737823 & 4.8 & 5.3049 & TST & \\
\hline CHEMBL1402138 & 737823 & 4.9 & 4.8915 & TRN & \\
\hline CHEMBL222519 & 737823 & -0.0 & 5.3253 & TRN & \\
\hline CHEMBL1329408 & 737823 & 6.2 & 5.5226 & TRN & \\
\hline CHEMBL1484944 & 737823 & 6.5 & 5.2489 & TRN & \\
\hline CHEMBL1355408 & 737823 & 7.6 & 6.7429 & TRN & \\
\hline CHEMBL1312373 & 737823 & 4.6 & 4.6468 & TRN & \\
\hline CHEMBL1363467 & 737823 & 4.6 & 4.6539 & TRN & \\
\hline CHEMBL1373464 & 737823 & 4.6 & 4.8671 & TRN & \\
\hline CHEMBL1478430 & 737823 & 4.9 & 5.4949 & TRN & \\
\hline CHEMBL1324157 & 737823 & 5.9 & 5.34200 & 20000000005 & TRN \\
\hline CHEMBL1337895 & 737823 & 4.5 & 5.3682 & TRN & \\
\hline CHEMBL447347 & 737823 & 5.4 & 6.2507 & TRN & \\
\hline CHEMBL1595644 & 737823 & 5.4 & 5.41 & TST & \\
\hline CHEMBL1414719 & 737823 & 6.25 & 5.5952 & TRN & \\
\hline CHEMBL1327912 & 737823 & 5.25 & 5.419 & TRN & \\
\hline CHEMBL1437713 & 737823 & 4.8 & 5.3216 & TRN & \\
\hline CHEMBL1741923 & 737823 & 5.4 & 5.4568 & TRN & \\
\hline
\end{tabular}




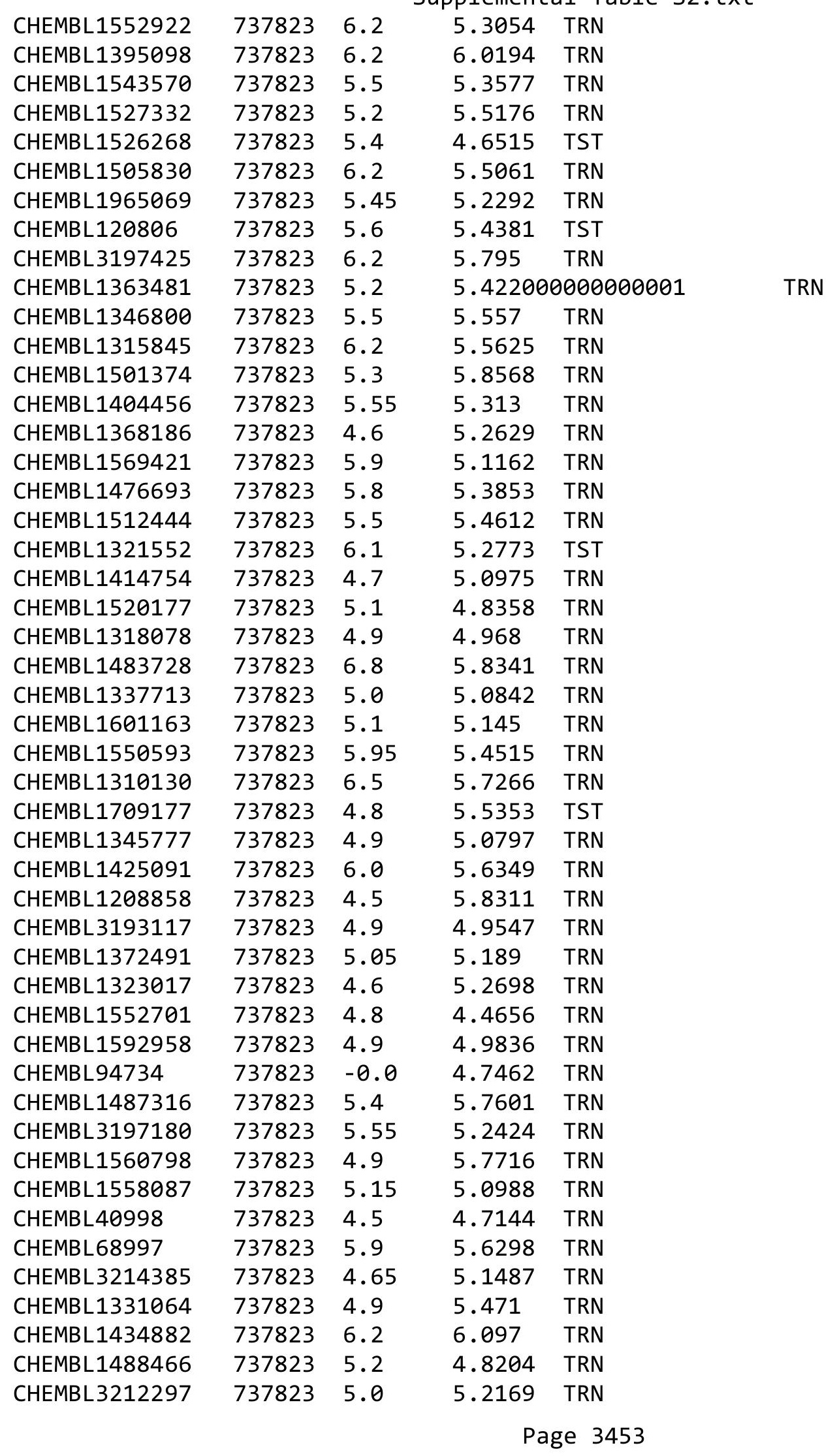




\begin{tabular}{|c|c|c|c|c|c|}
\hline \multicolumn{6}{|c|}{ Supplemental Table S2.txt } \\
\hline CHEMBL1386361 & 737823 & 4.85 & 5.4793 & TRN & \\
\hline CHEMBL1424808 & 737823 & 5.2 & 4.852 & TRN & \\
\hline CHEMBL1435889 & 737823 & 4.8 & 4.6992 & TRN & \\
\hline CHEMBL1482789 & 737823 & 5.35 & 4.7257 & TST & \\
\hline CHEMBL1395974 & 737823 & 5.5 & 5.5552 & TRN & \\
\hline CHEMBL1437825 & 737823 & 5.7 & 5.091 & TRN & \\
\hline CHEMBL1566780 & 737823 & 5.9 & 5.2498 & TRN & \\
\hline CHEMBL1452894 & 737823 & 4.5 & 4.5197 & TRN & \\
\hline CHEMBL1306727 & 737823 & 4.95 & 4.9927 & TRN & \\
\hline CHEMBL1968162 & 737823 & 4.85 & 5.4695 & TRN & \\
\hline CHEMBL1606201 & 737823 & 4.7 & 5.4251 & TRN & \\
\hline CHEMBL1496776 & 737823 & 5.8 & 5.358 & TRN & \\
\hline CHEMBL1333783 & 737823 & 4.8 & 5.1891 & TRN & \\
\hline CHEMBL1408922 & 737823 & -0.0 & 4.8282 & TST & \\
\hline CHEMBL1582198 & 737823 & 5.4 & 5.13 & TRN & \\
\hline CHEMBL1435604 & 737823 & 4.8 & 4.4248 & TRN & \\
\hline CHEMBL1509561 & 737823 & -0.0 & 4.6032 & TRN & \\
\hline CHEMBL1316516 & 737823 & 5.0 & 5.0859 & TRN & \\
\hline CHEMBL1505574 & 737823 & 4.9 & 4.9347 & TRN & \\
\hline CHEMBL1316714 & 737823 & 4.4 & 4.8529 & TRN & \\
\hline CHEMBL 3190580 & 737823 & 6.1 & 5.4144 & TRN & \\
\hline CHEMBL1742348 & 737823 & 4.8 & 4.6888 & TRN & \\
\hline CHEMBL1395421 & 737823 & 4.5 & 5.0184 & TST & \\
\hline CHEMBL1575726 & 737823 & 5.2 & 5.1262 & TRN & \\
\hline CHEMBL1567176 & 737823 & 4.6 & 4.5983 & TRN & \\
\hline CHEMBL1395009 & 737823 & 6.8 & 5.3174 & TRN & \\
\hline CHEMBL1436222 & 737823 & 4.8 & 5.2551 & TRN & \\
\hline CHEMBL1389499 & 737823 & 5.3 & 5.6585 & TST & \\
\hline CHEMBL1523204 & 737823 & 4.6 & 5.0548 & TST & \\
\hline CHEMBL1553114 & 737823 & 4.9 & 5.1767 & TRN & \\
\hline CHEMBL1469212 & 737823 & 5.6 & 5.1521 & TRN & \\
\hline CHEMBL1581594 & 737823 & 5.7 & 5.0581 & TRN & \\
\hline CHEMBL1442106 & 737823 & 6.0 & 5.5784 & TRN & \\
\hline CHEMBL 7257 & 737823 & 4.8 & 5.2244 & TRN & \\
\hline CHEMBL1514640 & 737823 & 4.9 & 4.68199 & 99999999995 & TRN \\
\hline CHEMBL1443163 & 737823 & 4.5 & 5.3089 & TRN & \\
\hline CHEMBL1412429 & 737823 & 5.6 & 5.4604 & TRN & \\
\hline CHEMBL1599602 & 737823 & 5.5 & 5.6422 & TRN & \\
\hline CHEMBL1734210 & 737823 & 4.85 & 5.2745 & TRN & \\
\hline CHEMBL1741427 & 737823 & 6.7 & 5.391 & TST & \\
\hline CHEMBL1428264 & 737823 & 5.4 & 5.5064 & TRN & \\
\hline CHEMBL1317986 & 737823 & 6.4 & 5.8869 & TRN & \\
\hline CHEMBL1610118 & 737823 & 5.9 & 5.4096 & TRN & \\
\hline CHEMBL1741640 & 737823 & 5.1 & 4.9843 & TRN & \\
\hline CHEMBL1570658 & 737823 & 6.3 & 5.6341 & TRN & \\
\hline CHEMBL1256851 & 737823 & 6.3 & 6.4458 & TST & \\
\hline CHEMBL1741379 & 737823 & 5.6 & 5.4849 & TRN & \\
\hline CHEMBL1374729 & 737823 & 4.75 & 5.5546 & TRN & \\
\hline
\end{tabular}




\begin{tabular}{|c|c|c|c|c|}
\hline \multicolumn{5}{|c|}{ Supplemental Table S2.txt } \\
\hline CHEMBL1522517 & 737823 & 4.85 & 4.9208 & TRN \\
\hline CHEMBL1433173 & 737823 & 5.15 & 4.9709 & TRN \\
\hline CHEMBL1342006 & 737823 & 5.05 & 5.6454 & TRN \\
\hline CHEMBL1514416 & 737823 & 6.7 & 5.8024 & TRN \\
\hline CHEMBL1479792 & 737823 & 6.0 & 5.5275 & TRN \\
\hline CHEMBL1362108 & 737823 & 6.2 & 5.9585 & TRN \\
\hline CHEMBL490756 & 737823 & 5.9 & 5.9803 & TRN \\
\hline CHEMBL1511690 & 737823 & 6.4 & 5.50700 & 0000000001 \\
\hline CHEMBL1554564 & 737823 & 4.7 & 4.7899 & TRN \\
\hline CHEMBL1331952 & 737823 & 4.5 & 5.0972 & TRN \\
\hline CHEMBL1321660 & 737823 & 6.0 & 5.6415 & TRN \\
\hline CHEMBL1588011 & 737823 & 5.4 & 5.2558 & TRN \\
\hline CHEMBL1546037 & 737823 & 6.0 & 5.8733 & TRN \\
\hline CHEMBL1608326 & 737823 & 5.1 & 4.7554 & TST \\
\hline CHEMBL1383867 & 737823 & 4.8 & 5.0861 & TRN \\
\hline CHEMBL1410627 & 737823 & 5.9 & 5.4275 & TST \\
\hline CHEMBL1316897 & 737823 & 4.9 & 4.5135 & TRN \\
\hline CHEMBL1530523 & 737823 & 5.05 & 5.359 & TRN \\
\hline CHEMBL1319286 & 737823 & 4.8 & 4.9266 & TRN \\
\hline CHEMBL1493566 & 737823 & 4.55 & 5.2502 & TRN \\
\hline CHEMBL1606369 & 737823 & 4.8 & 5.2588 & TRN \\
\hline CHEMBL1488477 & 737823 & 4.9 & 5.7655 & TRN \\
\hline CHEMBL1590663 & 737823 & 5.0 & 4.9057 & TRN \\
\hline CHEMBL1425631 & 737823 & 4.85 & 5.5285 & TRN \\
\hline CHEMBL1551284 & 737823 & 5.4 & 5.7594 & TRN \\
\hline CHEMBL1569213 & 737823 & 5.9 & 5.1956 & TST \\
\hline CHEMBL1380424 & 737823 & 4.6 & 5.0847 & TRN \\
\hline CHEMBL356688 & 737823 & 4.5 & 4.908 & TRN \\
\hline CHEMBL 367553 & 737823 & 5.4 & 5.4014 & TRN \\
\hline CHEMBL1365269 & 737823 & 5.65 & 5.2576 & TRN \\
\hline CHEMBL1491551 & 737823 & 4.8 & 4.8633 & TRN \\
\hline CHEMBL1351838 & 737823 & 5.2 & 5.5713 & TST \\
\hline CHEMBL1602966 & 737823 & 5.6 & 5.4897 & TST \\
\hline CHEMBL34241 & 737823 & 4.5 & 5.104 & TST \\
\hline CHEMBL1523055 & 737823 & 5.1 & 4.8311 & TRN \\
\hline CHEMBL1472248 & 737823 & 5.65 & 5.4018 & TRN \\
\hline CHEMBL1457544 & 737823 & 4.8 & 5.1512 & TRN \\
\hline CHEMBL1557810 & 737823 & 5.6 & 4.9077 & TRN \\
\hline CHEMBL1375474 & 737823 & 4.5 & 4.8586 & TRN \\
\hline CHEMBL1564461 & 737823 & 6.0 & 5.4868 & TRN \\
\hline CHEMBL1574531 & 737823 & 4.85 & 5.121 & TRN \\
\hline CHEMBL93655 & 737823 & 6.6 & 5.3693 & TRN \\
\hline CHEMBL1371217 & 737823 & 5.4 & 5.4523 & TRN \\
\hline CHEMBL1359774 & 737823 & 4.4 & 5.3499 & TRN \\
\hline CHEMBL1736254 & 737823 & 5.5 & 5.7671 & TST \\
\hline CHEMBL1409852 & 737823 & 5.8 & 5.56 & TRN \\
\hline CHEMBL1465191 & 737823 & 5.55 & 5.6276 & TRN \\
\hline CHEMBL1596063 & 737823 & 7.2 & 5.4734 & TST \\
\hline
\end{tabular}




\begin{tabular}{|c|c|c|c|c|c|}
\hline \multicolumn{6}{|c|}{ Supplemental Table S2.txt } \\
\hline CHEMBL1725938 & 737823 & 6.5 & 5.4739 & TST & \\
\hline CHEMBL1610961 & 737823 & 5.15 & 4.9535 & TRN & \\
\hline CHEMBL1519453 & 737823 & 5.35 & 5.7459 & TST & \\
\hline CHEMBL1317506 & 737823 & 5.2 & 5.0631 & TRN & \\
\hline CHEMBL1727976 & 737823 & 6.45 & 5.3807 & TRN & \\
\hline CHEMBL1521490 & 737823 & 6.6 & 6.3375 & TRN & \\
\hline CHEMBL1415569 & 737823 & 5.6 & 5.3344 & TRN & \\
\hline CHEMBL1368604 & 737823 & 6.1 & 5.4052 & TRN & \\
\hline CHEMBL1355896 & 737823 & 6.4 & 6.1088 & TRN & \\
\hline CHEMBL1476952 & 737823 & 5.1 & 5.7743 & TRN & \\
\hline CHEMBL1402011 & 737823 & 4.75 & 4.8623 & TRN & \\
\hline CHEMBL1421764 & 737823 & 5.3 & 5.3816 & TRN & \\
\hline CHEMBL1543433 & 737823 & 5.6 & 5.5013 & TRN & \\
\hline CHEMBL1446905 & 737823 & 4.4 & 5.1444 & TRN & \\
\hline CHEMBL1437783 & 737823 & 5.5 & 5.3313 & TRN & \\
\hline CHEMBL1368843 & 737823 & 5.0 & 4.7944 & TRN & \\
\hline CHEMBL1312422 & 737823 & 5.45 & 5.3128 & TRN & \\
\hline CHEMBL1490024 & 737823 & 5.3 & 5.6486 & TRN & \\
\hline CHEMBL1593774 & 737823 & 6.2 & 5.6181 & TRN & \\
\hline CHEMBL1417636 & 737823 & 6.8 & 6.5858 & TRN & \\
\hline CHEMBL1570921 & 737823 & 4.9 & 4.8673 & TST & \\
\hline CHEMBL1422629 & 737823 & 5.5 & 5.6979 & TRN & \\
\hline CHEMBL1370632 & 737823 & 6.05 & 5.3535 & TRN & \\
\hline CHEMBL1496315 & 737823 & 5.8 & 5.7147 & TRN & \\
\hline CHEMBL1319275 & 737823 & 5.0 & 5.32100 & 0000000001 & TRN \\
\hline CHEMBL1613347 & 737823 & 5.1 & 5.1135 & TRN & \\
\hline CHEMBL3212510 & 737823 & 5.35 & 5.1951 & TRN & \\
\hline CHEMBL1513578 & 737823 & 6.5 & 6.2931 & TRN & \\
\hline CHEMBL1443798 & 737823 & 4.95 & 5.4135 & TST & \\
\hline CHEMBL1485287 & 737823 & 6.7 & 5.3522 & TST & \\
\hline CHEMBL3194935 & 737823 & 5.7 & 5.5363 & TRN & \\
\hline CHEMBL1319783 & 737823 & 4.9 & 4.8686 & TRN & \\
\hline CHEMBL1321695 & 737823 & 5.1 & 5.3861 & TRN & \\
\hline CHEMBL3197934 & 737823 & 5.35 & 5.043 & TRN & \\
\hline CHEMBL1988310 & 737823 & 4.8 & 5.1279 & TRN & \\
\hline CHEMBL1350120 & 737823 & 5.35 & 5.7494 & TRN & \\
\hline CHEMBL1481127 & 737823 & 5.5 & 5.4568 & TRN & \\
\hline CHEMBL490706 & 737823 & 5.5 & 5.4525 & TRN & \\
\hline CHEMBL1479372 & 737823 & 4.8 & 5.0251 & TRN & \\
\hline CHEMBL1742052 & 737823 & 5.5 & 4.7265 & TRN & \\
\hline CHEMBL1436957 & 737823 & 4.9 & 4.8986 & TRN & \\
\hline CHEMBL1330483 & 737823 & 5.3 & 4.6045 & TRN & \\
\hline CHEMBL303579 & 737823 & 5.5 & 5.4293 & TRN & \\
\hline CHEMBL182310 & 737823 & 5.2 & 5.0034 & TRN & \\
\hline CHEMBL1581598 & 737823 & 6.0 & 5.7069 & TRN & \\
\hline CHEMBL1577205 & 737823 & 4.8 & 5.0383 & TRN & \\
\hline CHEMBL489738 & 737823 & 6.2 & 5.7332 & TRN & \\
\hline CHEMBL1611218 & 737823 & 4.8 & 5.2577 & TST & \\
\hline
\end{tabular}




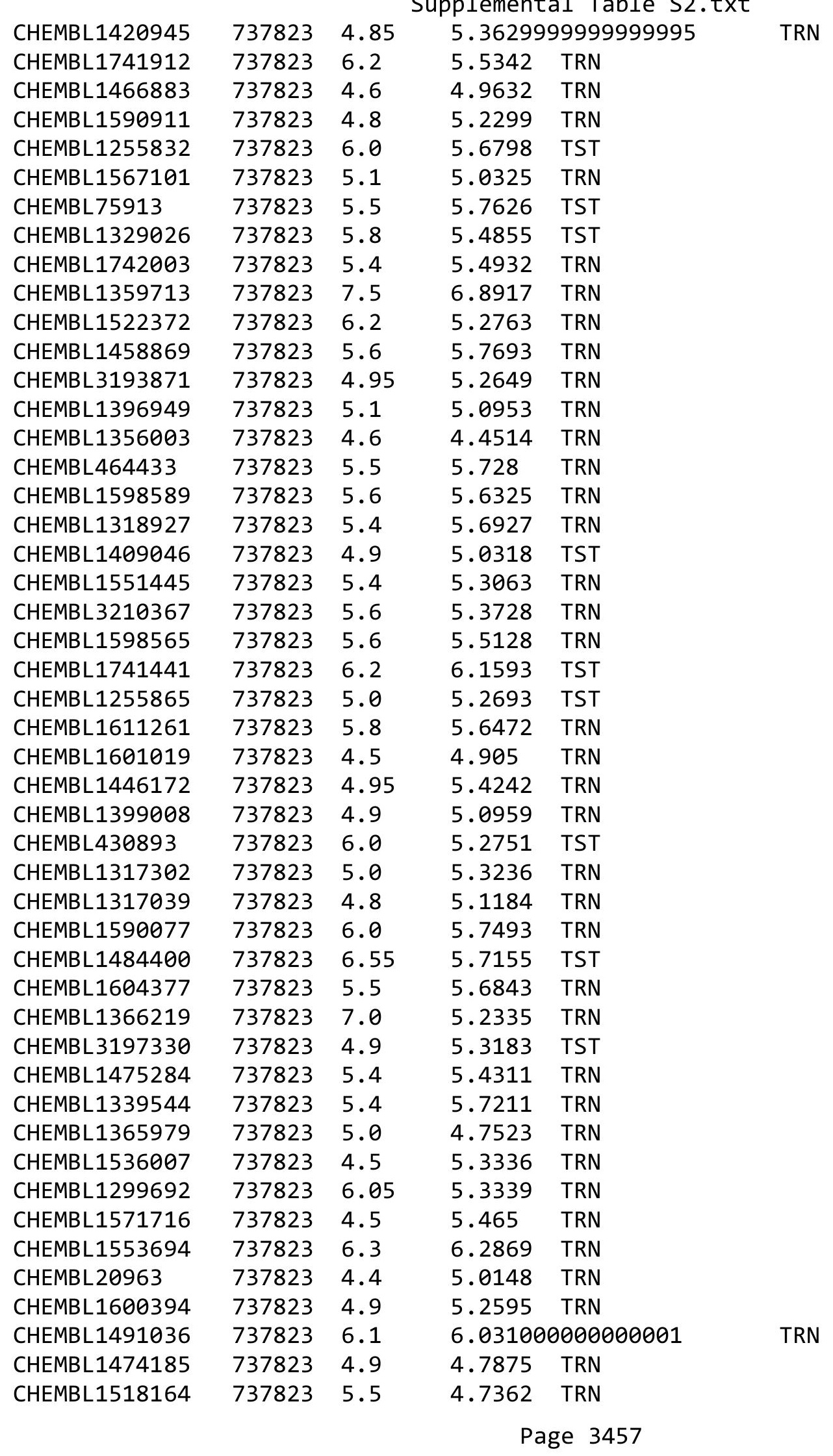




\begin{tabular}{|c|c|c|c|c|}
\hline \multicolumn{5}{|c|}{ Supplemental Table S2.txt } \\
\hline CHEMBL1548101 & 737823 & 6.25 & 5.5229 & TRN \\
\hline CHEMBL1600813 & 737823 & 4.9 & 4.766 & TRN \\
\hline CHEMBL1489359 & 737823 & 5.5 & 4.8123 & TRN \\
\hline CHEMBL106780 & 737823 & 5.95 & 5.4885 & TRN \\
\hline CHEMBL1085765 & 737823 & 5.0 & 5.249 & TRN \\
\hline CHEMBL1385137 & 737823 & 4.85 & 5.175 & TST \\
\hline CHEMBL1270169 & 737823 & 5.5 & 5.7305 & TRN \\
\hline CHEMBL1573783 & 737823 & 5.1 & 5.7 & TRN \\
\hline CHEMBL294747 & 737823 & 4.6 & 4.8424 & TRN \\
\hline CHEMBL1329197 & 737823 & 5.65 & 5.5963 & TRN \\
\hline CHEMBL1356262 & 737823 & 5.4 & 5.5124 & TRN \\
\hline CHEMBL1362669 & 737823 & 4.9 & 5.2336 & TRN \\
\hline CHEMBL1530695 & 737823 & 4.55 & 4.6941 & TRN \\
\hline CHEMBL1369990 & 737823 & 6.0 & 4.8448 & TST \\
\hline CHEMBL1353322 & 737823 & 6.45 & 5.3238 & TRN \\
\hline CHEMBL1411662 & 737823 & 5.5 & 5.8672 & TRN \\
\hline CHEMBL1317533 & 737823 & 4.3 & 5.1383 & TRN \\
\hline CHEMBL1365848 & 737823 & 4.85 & 4.9443 & TRN \\
\hline CHEMBL1417583 & 737823 & 4.65 & 4.7726 & TRN \\
\hline CHEMBL1418130 & 737823 & 5.3 & 5.6761 & TRN \\
\hline CHEMBL1372102 & 737823 & 5.75 & 5.6704 & TST \\
\hline CHEMBL1412209 & 737823 & 4.8 & 4.8008 & TRN \\
\hline CHEMBL1524629 & 737823 & 7.05 & 6.124 & TRN \\
\hline CHEMBL1372952 & 737823 & 4.6 & 5.0467 & TRN \\
\hline CHEMBL146855 & 737823 & 6.0 & 5.4326 & TST \\
\hline CHEMBL1501836 & 737823 & 5.8 & 5.7452 & TST \\
\hline CHEMBL1742247 & 737823 & 5.5 & 5.4508 & TRN \\
\hline CHEMBL1498886 & 737823 & 6.25 & 5.5245 & TRN \\
\hline CHEMBL1724565 & 737823 & 5.0 & 5.2241 & TRN \\
\hline CHEMBL1483341 & 737823 & 5.8 & 5.1818 & TST \\
\hline CHEMBL37312 & 737823 & 5.1 & 5.3019 & TRN \\
\hline CHEMBL1568111 & 737823 & 5.6 & 5.5188 & TRN \\
\hline CHEMBL1567020 & 737823 & -0.0 & 5.3957 & TST \\
\hline CHEMBL1510646 & 737823 & 5.55 & 5.9443 & TRN \\
\hline CHEMBL1516331 & 737823 & 5.4 & 5.3175 & TRN \\
\hline CHEMBL 216973 & 737823 & 4.9 & 5.4819 & TRN \\
\hline CHEMBL1430661 & 737823 & 6.2 & 5.3287 & TRN \\
\hline CHEMBL1453620 & 737823 & 4.9 & 5.5844 & TRN \\
\hline CHEMBL1316055 & 737823 & 5.9 & 5.9646 & TRN \\
\hline CHEMBL3189451 & 737823 & 5.2 & 5.5161 & TRN \\
\hline CHEMBL 281622 & 737823 & 4.6 & 5.7173 & TST \\
\hline CHEMBL 1741848 & 737823 & 5.4 & 5.4523 & TRN \\
\hline CHEMBL1523390 & 737823 & 5.5 & 5.1592 & TST \\
\hline CHEMBL1524331 & 737823 & 4.8 & 4.9578 & TRN \\
\hline CHEMBL1524211 & 737823 & 5.9 & 5.6186 & TRN \\
\hline CHEMBL1336060 & 737823 & 4.6 & 4.8505 & TRN \\
\hline CHEMBL1315318 & 737823 & 5.7 & 5.7982 & TRN \\
\hline CHEMBL1517643 & 737823 & 5.5 & 5.6259 & TRN \\
\hline
\end{tabular}




\begin{tabular}{|c|c|c|c|c|}
\hline \multicolumn{5}{|c|}{ Supplemental Table S2.txt } \\
\hline CHEMBL1569035 & 737823 & 5.05 & 5.2663 & TRN \\
\hline CHEMBL1560603 & 737823 & 5.0 & 5.1863 & TRN \\
\hline CHEMBL406845 & 737823 & 6.0 & 5.5637 & TRN \\
\hline CHEMBL1590197 & 737823 & 5.1 & 5.34 & TRN \\
\hline CHEMBL1420531 & 737823 & 5.0 & 5.477 & TRN \\
\hline CHEMBL81977 & 737823 & 4.4 & 4.9044 & TST \\
\hline CHEMBL1742136 & 737823 & 5.9 & 5.6844 & TRN \\
\hline CHEMBL1256816 & 737823 & 4.9 & 4.9426 & TRN \\
\hline CHEMBL1472922 & 737823 & 4.8 & 5.3064 & TRN \\
\hline CHEMBL1515366 & 737823 & 5.2 & 5.6068 & TRN \\
\hline CHEMBL1569337 & 737823 & 5.15 & 5.1202 & TRN \\
\hline CHEMBL1325335 & 737823 & 4.8 & 4.817 & TRN \\
\hline CHEMBL186526 & 737823 & 5.9 & 5.1015 & TRN \\
\hline CHEMBL1600612 & 737823 & 4.9 & 4.8327 & TRN \\
\hline CHEMBL1602329 & 737823 & 4.8 & 5.2466 & TRN \\
\hline CHEMBL1554567 & 737823 & 4.8 & 5.3955 & TRN \\
\hline CHEMBL1453591 & 737823 & 5.55 & 5.6374 & TRN \\
\hline CHEMBL1369438 & 737823 & 4.6 & 4.6215 & TRN \\
\hline CHEMBL1356280 & 737823 & 4.7 & 5.0183 & TST \\
\hline CHEMBL1339267 & 737823 & 4.4 & 5.1343 & TRN \\
\hline CHEMBL1255737 & 737823 & 6.0 & 5.4072 & TRN \\
\hline CHEMBL1328286 & 737823 & 6.7 & 5.2389 & TRN \\
\hline CHEMBL1316348 & 737823 & 4.8 & 4.7302 & TRN \\
\hline CHEMBL3211021 & 737823 & 6.05 & 5.5753 & TRN \\
\hline CHEMBL1369078 & 737823 & 4.75 & 5.1864 & TRN \\
\hline CHEMBL1534237 & 737823 & 4.7 & 5.2209 & TRN \\
\hline CHEMBL1551884 & 737823 & 4.7 & 4.8326 & TRN \\
\hline CHEMBL1601662 & 737823 & 5.5 & 5.349 & TRN \\
\hline CHEMBL1414668 & 737823 & 4.85 & 4.9211 & TRN \\
\hline CHEMBL1396809 & 737823 & 4.9 & 5.0614 & TRN \\
\hline CHEMBL1551503 & 737823 & 6.3 & 6.5584 & TRN \\
\hline CHEMBL 1454178 & 737823 & 4.9 & 5.0221 & TRN \\
\hline CHEMBL1322686 & 737823 & 4.7 & 5.1187 & TRN \\
\hline CHEMBL1398185 & 737823 & 5.7 & 5.4608 & TRN \\
\hline CHEMBL323356 & 737823 & 5.3 & 5.4705 & TRN \\
\hline CHEMBL1472322 & 737823 & 4.9 & 4.9216 & TRN \\
\hline CHEMBL 1717653 & 737823 & 5.0 & 5.5575 & TRN \\
\hline CHEMBL1407398 & 737823 & 5.0 & 5.3557 & TRN \\
\hline CHEMBL1470051 & 737823 & 4.85 & 5.269 & TRN \\
\hline CHEMBL1491966 & 737823 & 5.3 & 5.5293 & TRN \\
\hline CHEMBL1400043 & 737823 & 5.7 & 5.291 & TRN \\
\hline CHEMBL1489980 & 737823 & 5.1 & 5.2432 & TRN \\
\hline CHEMBL1741448 & 737823 & 5.7 & 5.5215 & TRN \\
\hline CHEMBL1429416 & 737823 & 4.8 & 5.2397 & TRN \\
\hline CHEMBL1426599 & 737823 & 4.95 & 5.0557 & TRN \\
\hline CHEMBL1453715 & 737823 & 5.4 & 5.2275 & TST \\
\hline CHEMBL 1567410 & 737823 & 6.25 & 5.9701 & TRN \\
\hline CHEMBL1612968 & 737823 & 5.6 & 4.7248 & TRN \\
\hline
\end{tabular}




\begin{tabular}{|c|c|c|c|c|c|}
\hline \\
\hline CHEMBL1515004 & 737823 & 5.2 & 5.0384 & TRN & \\
\hline CHEMBL1447721 & 737823 & 5.3 & 5.4294 & TST & \\
\hline CHEMBL1612893 & 737823 & 4.7 & 4.8794 & TRN & \\
\hline CHEMBL1610995 & 737823 & 5.5 & 5.335 & TRN & \\
\hline CHEMBL1741430 & 737823 & 5.6 & 5.3641 & TRN & \\
\hline CHEMBL1500398 & 737823 & 4.75 & 5.7343 & TRN & \\
\hline CHEMBL1575849 & 737823 & 4.5 & 4.9221 & TRN & \\
\hline CHEMBL1964690 & 737823 & 5.45 & 5.4317 & TRN & \\
\hline CHEMBL1475941 & 737823 & 4.9 & 5.4239 & TRN & \\
\hline CHEMBL1455926 & 737823 & 4.6 & 5.6296 & TRN & \\
\hline CHEMBL1489528 & 737823 & 4.8 & 5.2704 & TRN & \\
\hline CHEMBL1351101 & 737823 & 4.8 & 5.013 & TRN & \\
\hline CHEMBL1491455 & 737823 & 5.3 & 5.2272 & TST & \\
\hline CHEMBL399705 & 737823 & 5.4 & 5.57100 & 0000000001 & TST \\
\hline CHEMBL1334821 & 737823 & 5.3 & 4.6605 & TRN & \\
\hline CHEMBL 255027 & 737823 & 5.8 & 4.7939 & TRN & \\
\hline CHEMBL1742079 & 737823 & 5.1 & 5.2081 & TRN & \\
\hline CHEMBL605003 & 737823 & 6.5 & 5.2461 & TST & \\
\hline CHEMBL3195611 & 737823 & 5.55 & 5.5648 & TRN & \\
\hline CHEMBL1384797 & 737823 & 4.5 & 5.8469 & TRN & \\
\hline CHEMBL1424761 & 737823 & 5.45 & 5.5153 & TRN & \\
\hline CHEMBL1442091 & 737823 & 4.75 & 5.0667 & TRN & \\
\hline CHEMBL1414633 & 737823 & 5.35 & 5.2949 & TRN & \\
\hline CHEMBL1742192 & 737823 & 5.4 & 5.2473 & TRN & \\
\hline CHEMBL1517085 & 737823 & 5.0 & 5.5143 & TRN & \\
\hline CHEMBL1584775 & 737823 & 4.8 & 5.0857 & TST & \\
\hline CHEMBL1305215 & 737823 & 4.7 & 4.914 & TRN & \\
\hline CHEMBL1580216 & 737823 & 4.9 & 5.012 & TRN & \\
\hline CHEMBL1435227 & 737823 & 5.6 & 5.4757 & TRN & \\
\hline CHEMBL1529853 & 737823 & 4.55 & 5.6094 & TRN & \\
\hline CHEMBL1569277 & 737823 & 6.5 & 6.2177 & TST & \\
\hline CHEMBL1304727 & 737823 & 4.6 & 5.1125 & TST & \\
\hline CHEMBL1413685 & 737823 & 5.65 & 5.3756 & TRN & \\
\hline CHEMBL1576560 & 737823 & 5.4 & 4.9985 & TRN & \\
\hline CHEMBL1419233 & 737823 & 5.05 & 5.5988 & TRN & \\
\hline CHEMBL1450115 & 737823 & 5.05 & 5.1664 & TRN & \\
\hline CHEMBL1403488 & 737823 & 5.4 & 5.1599 & TRN & \\
\hline CHEMBL1524001 & 737823 & 5.3 & 5.3118 & TRN & \\
\hline CHEMBL1355881 & 737823 & 5.5 & 5.263 & TRN & \\
\hline CHEMBL1309064 & 737823 & 5.0 & 4.6834 & TRN & \\
\hline CHEMBL1520292 & 737823 & 4.7 & 4.8692 & TRN & \\
\hline CHEMBL1591908 & 737823 & 6.7 & 4.8262 & TRN & \\
\hline CHEMBL1314255 & 737823 & 6.5 & 5.5789 & TRN & \\
\hline CHEMBL1438434 & 737823 & 4.85 & 5.2796 & TST & \\
\hline CHEMBL1433668 & 737823 & 6.0 & 5.2806 & TRN & \\
\hline CHEMBL1529700 & 737823 & 4.9 & 4.99 & TRN & \\
\hline CHEMBL1489353 & 737823 & 6.3 & 6.1088 & TRN & \\
\hline CHEMBL1371140 & 737823 & 5.3 & 5.2749 & TRN & \\
\hline
\end{tabular}




\begin{tabular}{|c|c|c|c|c|c|}
\hline CHEMBL1555314 & 737823 & 4.9 & 4.9235 & TRN & \\
\hline CHEMBL1365175 & 737823 & 4.9 & \multicolumn{2}{|c|}{4.8919999999999995} & TRN \\
\hline CHEMBL1552519 & 737823 & 4.6 & \multicolumn{2}{|c|}{5.992999999999999} & TRN \\
\hline CHEMBL544713 & 737823 & 4.9 & 5.4428 & TRN & \\
\hline CHEMBL1552161 & 737823 & 6.9 & 5.7449 & TRN & \\
\hline CHEMBL3194219 & 737823 & 5.15 & 5.1614 & TRN & \\
\hline CHEMBL1311026 & 737823 & 5.45 & 6.1193 & TST & \\
\hline CHEMBL1333556 & 737823 & 6.5 & 5.6214 & TRN & \\
\hline CHEMBL1495971 & 737823 & 5.65 & 5.8058 & TST & \\
\hline CHEMBL1389097 & 737823 & 5.3 & 5.0153 & TRN & \\
\hline CHEMBL323542 & 737823 & 5.6 & 5.1624 & TST & \\
\hline CHEMBL1484447 & 737823 & 6.4 & 5.3433 & TRN & \\
\hline CHEMBL1556610 & 737823 & 5.3 & \multicolumn{2}{|c|}{5.327000000000001} & TRN \\
\hline CHEMBL409024 & 737823 & 4.7 & 4.8812 & TRN & \\
\hline CHEMBL1567933 & 737823 & 5.3 & 4.8302 & TRN & \\
\hline CHEMBL1513801 & 737823 & 5.3 & 5.4591 & TRN & \\
\hline CHEMBL1305916 & 737823 & 5.9 & 5.0896 & TST & \\
\hline CHEMBL1552677 & 737823 & 4.9 & 5.608 & TRN & \\
\hline CHEMBL1571807 & 737823 & 6.0 & 5.9616 & TRN & \\
\hline CHEMBL362223 & 737823 & 4.8 & \multicolumn{2}{|c|}{5.196000000000001} & TRN \\
\hline CHEMBL1496891 & 737823 & 5.2 & 5.284 & TRN & \\
\hline CHEMBL1518558 & 737823 & 5.55 & 5.3618 & TRN & \\
\hline CHEMBL1340517 & 737823 & 6.15 & 5.4533 & TRN & \\
\hline CHEMBL1452961 & 737823 & 5.55 & 5.0235 & TRN & \\
\hline CHEMBL3210612 & 737823 & 5.0 & 5.4786 & TRN & \\
\hline CHEMBL1741918 & 737823 & 4.6 & 5.1819 & TRN & \\
\hline CHEMBL1393435 & 737823 & 5.3 & 5.1119 & TST & \\
\hline CHEMBL1405892 & 737823 & 5.0 & 5.4522 & TST & \\
\hline CHEMBL1441088 & 737823 & 5.4 & 5.5126 & TRN & \\
\hline CHEMBL1558076 & 737823 & 4.8 & 5.7889 & TRN & \\
\hline CHEMBL1398683 & 737823 & 4.5 & 4.9008 & TST & \\
\hline CHEMBL1398600 & 737823 & 5.4 & 5.4561 & TRN & \\
\hline CHEMBL293749 & 737823 & 5.0 & 5.1852 & TRN & \\
\hline CHEMBL1378691 & 737823 & 5.2 & 5.4792 & TRN & \\
\hline CHEMBL1331148 & 737823 & 4.8 & 5.3757 & TRN & \\
\hline CHEMBL1488918 & 737823 & 5.1 & 5.526 & TRN & \\
\hline CHEMBL1347262 & 737823 & 5.6 & 5.1883 & TRN & \\
\hline CHEMBL40004 & 737823 & 6.1 & 5.5053 & TRN & \\
\hline CHEMBL1459860 & 737823 & 4.9 & 5.0176 & TRN & \\
\hline CHEMBL1182777 & 737823 & 4.8 & \multicolumn{2}{|c|}{5.702999999999999} & TST \\
\hline CHEMBL1544254 & 737823 & 5.45 & 5.3095 & TRN & \\
\hline CHEMBL1482542 & 737823 & 4.5 & 5.0494 & TRN & \\
\hline CHEMBL1698288 & 737823 & 6.1 & 5.7306 & TRN & \\
\hline CHEMBL1713947 & 737823 & 4.4 & 4.9806 & TRN & \\
\hline CHEMBL1515372 & 737823 & 4.6 & 5.0438 & TRN & \\
\hline CHEMBL1741376 & 737823 & 4.6 & 5.6838 & TST & \\
\hline CHEMBL1462380 & 737823 & 5.3 & 5.715 & TRN & \\
\hline CHEMBL1551979 & 737823 & 6.0 & 5.9032 & TRN & \\
\hline
\end{tabular}




\begin{tabular}{|c|c|c|c|c|}
\hline \multicolumn{5}{|c|}{ Supplemental Table S2.txt } \\
\hline CHEMBL148296 & 737823 & 6.8 & 5.7424 & TRN \\
\hline CHEMBL1331122 & 737823 & 6.0 & 5.6587 & TST \\
\hline CHEMBL1507792 & 737823 & 4.55 & 5.0122 & TRN \\
\hline CHEMBL1342336 & 737823 & 4.85 & 5.2855 & TRN \\
\hline CHEMBL1592371 & 737823 & 5.0 & 4.917 & TRN \\
\hline CHEMBL1387472 & 737823 & 5.4 & 5.6846 & TRN \\
\hline CHEMBL 236789 & 737823 & 4.4 & 4.7045 & TRN \\
\hline CHEMBL1361596 & 737823 & 4.9 & 5.0424 & TST \\
\hline CHEMBL1553001 & 737823 & 5.3 & 5.675 & TRN \\
\hline CHEMBL1523188 & 737823 & 4.8 & 5.19 & TST \\
\hline CHEMBL1612582 & 737823 & 6.3 & 5.6089 & TRN \\
\hline CHEMBL1389838 & 737823 & 4.9 & 4.9973 & TRN \\
\hline CHEMBL1550134 & 737823 & 4.6 & 4.9171 & TRN \\
\hline CHEMBL1431953 & 737823 & 6.05 & 5.7799 & TST \\
\hline CHEMBL1357498 & 737823 & 4.9 & 5.0787 & TRN \\
\hline CHEMBL75035 & 737823 & 4.5 & 4.9492 & TRN \\
\hline CHEMBL1435702 & 737823 & 4.7 & 4.8017 & TRN \\
\hline CHEMBL1328887 & 737823 & 5.0 & 5.3399 & TRN \\
\hline CHEMBL1417552 & 737823 & 6.1 & 5.9301 & TRN \\
\hline CHEMBL1358065 & 737823 & 5.3 & 5.3258 & TRN \\
\hline CHEMBL1405132 & 737823 & 4.6 & 5.5027 & TST \\
\hline CHEMBL1550240 & 737823 & 5.7 & 4.9996 & TST \\
\hline CHEMBL1356497 & 737823 & 5.5 & 5.473 & TRN \\
\hline CHEMBL1529009 & 737823 & 6.0 & 5.2573 & TRN \\
\hline CHEMBL1491545 & 737823 & 6.7 & 6.4663 & TRN \\
\hline CHEMBL1519373 & 737823 & 5.15 & 5.5459 & TRN \\
\hline CHEMBL3193784 & 737823 & 5.85 & 5.69 & TRN \\
\hline CHEMBL1519980 & 737823 & 4.8 & 5.1167 & TRN \\
\hline CHEMBL1528262 & 737823 & 4.6 & 5.4987 & TRN \\
\hline CHEMBL1255649 & 737823 & 6.0 & 4.6841 & TST \\
\hline CHEMBL3209584 & 737823 & 5.75 & 5.336 & TRN \\
\hline CHEMBL52387 & 737823 & 4.9 & 5.6271 & TRN \\
\hline CHEMBL1482566 & 737823 & 6.8 & 6.0566 & TRN \\
\hline CHEMBL1547711 & 737823 & 5.15 & 5.4432 & TRN \\
\hline CHEMBL1355111 & 737823 & 5.5 & 5.3656 & TRN \\
\hline CHEMBL1516851 & 737823 & 5.65 & 5.5307 & TRN \\
\hline CHEMBL3145283 & 737823 & 4.9 & 5.3414 & TST \\
\hline CHEMBL1441218 & 737823 & 5.05 & 5.5157 & TRN \\
\hline CHEMBL1433805 & 737823 & 6.0 & 5.5936 & TRN \\
\hline CHEMBL1442440 & 737823 & 6.5 & 5.8025 & TRN \\
\hline CHEMBL86931 & 737823 & 4.8 & 5.0776 & TST \\
\hline CHEMBL1325392 & 737823 & 6.2 & 5.5412 & TRN \\
\hline CHEMBL1546816 & 737823 & 6.25 & 5.2143 & TRN \\
\hline CHEMBL1742029 & 737823 & 4.8 & 5.1351 & TRN \\
\hline CHEMBL1595551 & 737823 & 4.85 & 5.1234 & TRN \\
\hline CHEMBL1576446 & 737823 & 5.55 & 5.7798 & TRN \\
\hline CHEMBL 3194920 & 737823 & 5.4 & 5.4372 & TRN \\
\hline CHEMBL1404501 & 737823 & 5.7 & 5.0047 & TRN \\
\hline
\end{tabular}




\begin{tabular}{|c|c|c|c|c|c|}
\hline & & & & & \\
\hline CHEMBL1505006 & 737823 & 5.6 & 5.3691 & TRN & \\
\hline CHEMBL1358215 & 737823 & 5.7 & 5.83299 & 9999999999 & TRN \\
\hline CHEMBL1552478 & 737823 & 4.8 & 4.8401 & TRN & \\
\hline CHEMBL1535022 & 737823 & 5.5 & 5.2588 & TRN & \\
\hline CHEMBL1330587 & 737823 & 5.6 & 5.3795 & TRN & \\
\hline CHEMBL1409313 & 737823 & 5.25 & 5.2824 & TRN & \\
\hline CHEMBL1327793 & 737823 & 6.0 & 5.9809 & TST & \\
\hline CHEMBL1358033 & 737823 & 5.0 & 5.3383 & TRN & \\
\hline CHEMBL155265 & 737823 & 4.5 & 5.2889 & TRN & \\
\hline CHEMBL1436179 & 737823 & 5.7 & 5.4139 & TRN & \\
\hline CHEMBL1448974 & 737823 & 5.9 & 5.9098 & TRN & \\
\hline CHEMBL1552272 & 737823 & 5.0 & 5.0727 & TRN & \\
\hline CHEMBL3192306 & 737823 & 5.65 & 5.6009 & TRN & \\
\hline CHEMBL1741650 & 737823 & 4.9 & 5.2603 & TRN & \\
\hline CHEMBL1522232 & 737823 & 4.95 & 5.1614 & TRN & \\
\hline CHEMBL1368632 & 737823 & 4.4 & 5.4081 & TST & \\
\hline CHEMBL1525291 & 737823 & 5.8 & 5.9539 & TST & \\
\hline CHEMBL1326341 & 737823 & 6.5 & 4.9639 & TRN & \\
\hline CHEMBL1436228 & 737823 & 5.0 & 4.7835 & TRN & \\
\hline CHEMBL1369376 & 737823 & 6.2 & 5.0996 & TRN & \\
\hline CHEMBL1502235 & 737823 & 4.55 & 5.2533 & TRN & \\
\hline CHEMBL1396384 & 737823 & 5.9 & 6.3827 & TRN & \\
\hline CHEMBL1338884 & 737823 & 4.85 & 4.8801 & TRN & \\
\hline CHEMBL1485818 & 737823 & 4.75 & 5.404 & TRN & \\
\hline CHEMBL1408176 & 737823 & 5.5 & 5.4886 & TRN & \\
\hline CHEMBL584854 & 737823 & 4.8 & 5.5146 & TRN & \\
\hline CHEMBL1352133 & 737823 & 4.9 & 5.3145 & TRN & \\
\hline CHEMBL1552720 & 737823 & 6.6 & 5.5188 & TRN & \\
\hline CHEMBL1987087 & 737823 & 5.65 & 5.3135 & TST & \\
\hline CHEMBL1564828 & 737823 & 4.85 & 5.4466 & TRN & \\
\hline CHEMBL1317620 & 737823 & 4.4 & 4.5714 & TRN & \\
\hline CHEMBL1410848 & 737823 & 5.4 & 5.49299 & 9999999999 & TRN \\
\hline CHEMBL1448473 & 737823 & 5.4 & 5.2169 & TRN & \\
\hline CHEMBL 845 & 737823 & 4.5 & 5.0602 & TRN & \\
\hline CHEMBL1610375 & 737823 & 6.5 & 6.0157 & TRN & \\
\hline CHEMBL10284 & 737823 & 5.1 & 5.6943 & TRN & \\
\hline CHEMBL1457014 & 737823 & 4.85 & 5.3122 & TST & \\
\hline CHEMBL1567634 & 737823 & 5.4 & 5.9537 & TRN & \\
\hline CHEMBL 299155 & 737823 & 4.4 & 5.78299 & 99999999995 & TRN \\
\hline CHEMBL1346283 & 737823 & 4.55 & 5.2034 & TRN & \\
\hline CHEMBL1359108 & 737823 & 5.2 & 4.731 & TRN & \\
\hline CHEMBL1590789 & 737823 & 5.2 & 4.7413 & TRN & \\
\hline CHEMBL1512023 & 737823 & 6.0 & 5.0582 & TRN & \\
\hline CHEMBL1597569 & 737823 & 6.2 & 5.1213 & TRN & \\
\hline CHEMBL1397238 & 737823 & 5.2 & 5.0678 & TRN & \\
\hline CHEMBL1501953 & 737823 & 4.65 & 5.1504 & TST & \\
\hline CHEMBL1466128 & 737823 & 5.6 & 4.8585 & TRN & \\
\hline CHEMBL1366778 & 737823 & 5.05 & 4.9167 & TRN & \\
\hline
\end{tabular}




\begin{tabular}{|c|c|c|c|c|c|}
\hline \\
\hline CHEMBL601110 & 737823 & 7.0 & 5.9139 & TRN & \\
\hline CHEMBL1332990 & 737823 & 5.35 & 5.1933 & TRN & \\
\hline CHEMBL1315292 & 737823 & 6.5 & 6.2489 & TRN & \\
\hline CHEMBL1435638 & 737823 & 5.8 & 6.0973 & TRN & \\
\hline CHEMBL1499071 & 737823 & 4.7 & 5.2692 & TRN & \\
\hline CHEMBL1700160 & 737823 & 4.8 & 4.8169 & TRN & \\
\hline CHEMBL1320206 & 737823 & 6.2 & 5.4458 & TRN & \\
\hline CHEMBL1409646 & 737823 & 7.9 & 5.3032 & TRN & \\
\hline CHEMBL1565842 & 737823 & 6.3 & 5.3053 & TRN & \\
\hline CHEMBL1428357 & 737823 & 5.2 & 4.9289 & TRN & \\
\hline CHEMBL1725383 & 737823 & 4.85 & 5.6177 & TST & \\
\hline CHEMBL3195732 & 737823 & 5.7 & 5.7954 & TRN & \\
\hline CHEMBL1484231 & 737823 & 4.6 & 5.5902 & TST & \\
\hline CHEMBL1490904 & 737823 & 5.5 & 5.0047 & TRN & \\
\hline CHEMBL1474410 & 737823 & 5.8 & 5.1745 & TRN & \\
\hline CHEMBL567332 & 737823 & 5.3 & 5.9946 & TRN & \\
\hline CHEMBL1435947 & 737823 & 4.8 & 4.9438 & TRN & \\
\hline CHEMBL1361797 & 737823 & 5.85 & 5.5937 & TRN & \\
\hline CHEMBL1335319 & 737823 & 4.5 & 5.0043 & TRN & \\
\hline CHEMBL3196573 & 737823 & 5.7 & 5.5339 & TRN & \\
\hline CHEMBL1510298 & 737823 & 4.85 & 5.6104 & TRN & \\
\hline CHEMBL410063 & 737823 & 4.5 & 5.3201 & TST & \\
\hline CHEMBL1522752 & 737823 & 5.1 & 5.7335 & TST & \\
\hline CHEMBL1573244 & 737823 & 4.85 & 5.0989 & TRN & \\
\hline CHEMBL1328565 & 737823 & 4.8 & 4.8362 & TRN & \\
\hline CHEMBL1605619 & 737823 & 5.6 & 5.15600 & $\partial 000000001$ & TRN \\
\hline CHEMBL1415852 & 737823 & 5.5 & 6.004 & TST & \\
\hline CHEMBL1559756 & 737823 & 5.4 & 5.63 & TRN & \\
\hline CHEMBL1436976 & 737823 & 5.7 & 5.5825 & TRN & \\
\hline CHEMBL1566936 & 737823 & 5.3 & 5.1482 & TRN & \\
\hline CHEMBL32142 & 737823 & 6.0 & 4.8319 & TST & \\
\hline CHEMBL1379086 & 737823 & 6.3 & 5.3213 & TRN & \\
\hline CHEMBL1354272 & 737823 & 4.8 & 4.7915 & TRN & \\
\hline CHEMBL1324667 & 737823 & 4.8 & 4.5052 & TRN & \\
\hline CHEMBL1369515 & 737823 & 6.0 & 5.5957 & TRN & \\
\hline CHEMBL1506693 & 737823 & 5.0 & 5.3847 & TRN & \\
\hline CHEMBL504911 & 737823 & 4.9 & 5.3383 & TRN & \\
\hline CHEMBL1270410 & 737823 & 6.4 & 5.727 & TRN & \\
\hline CHEMBL1443681 & 737823 & 5.3 & 5.6099 & TRN & \\
\hline CHEMBL1603871 & 737823 & 5.5 & 5.4299 & TRN & \\
\hline CHEMBL1354678 & 737823 & 5.3 & 5.2493 & TRN & \\
\hline CHEMBL1593545 & 737823 & 5.5 & 5.4553 & TRN & \\
\hline CHEMBL1563497 & 737823 & 7.4 & 5.8311 & TRN & \\
\hline CHEMBL556001 & 737823 & 6.0 & 5.5344 & TRN & \\
\hline CHEMBL1501275 & 737823 & 5.5 & 5.8343 & TRN & \\
\hline CHEMBL65063 & 737823 & 5.2 & 5.3814 & TRN & \\
\hline CHEMBL 3198146 & 737823 & 5.3 & 5.3465 & TRN & \\
\hline CHEMBL3214169 & 737823 & 5.9 & 5.6057 & TRN & \\
\hline
\end{tabular}




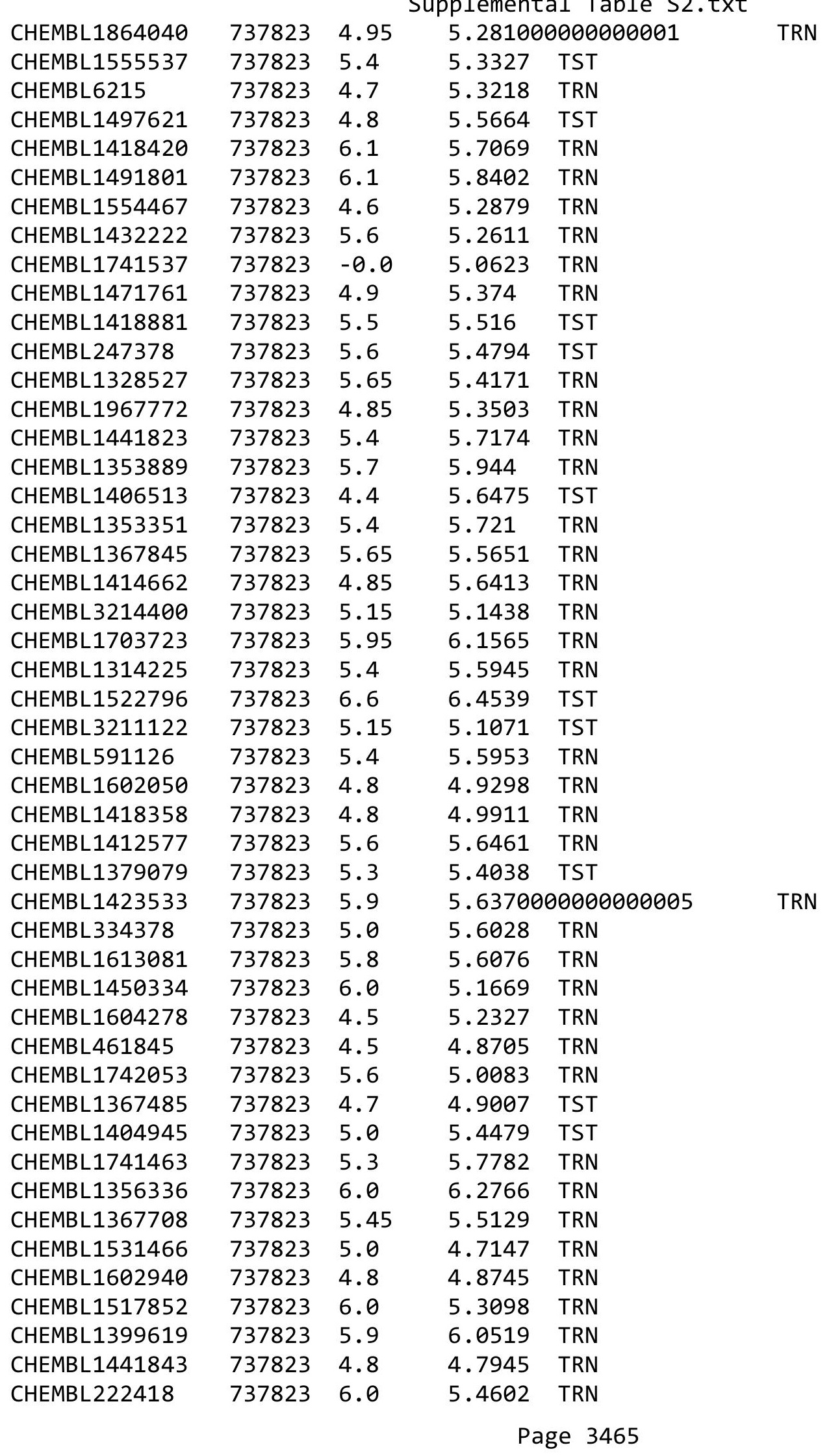




\begin{tabular}{|c|c|c|c|c|c|}
\hline & & & & & \\
\hline CHEMBL1343620 & 737823 & 5.4 & 4.9842 & TRN & \\
\hline CHEMBL3212240 & 737823 & 5.2 & 5.5791 & TRN & \\
\hline CHEMBL1316759 & 737823 & 4.8 & 5.2253 & TRN & \\
\hline CHEMBL1438674 & 737823 & 5.6 & 5.8448 & TRN & \\
\hline CHEMBL1588072 & 737823 & 4.9 & 5.2895 & TRN & \\
\hline CHEMBL1332759 & 737823 & 4.5 & 4.5541 & TRN & \\
\hline CHEMBL1462428 & 737823 & 5.85 & 5.2094 & TST & \\
\hline CHEMBL1361000 & 737823 & 5.1 & 5.36700 & 0000000001 & TST \\
\hline CHEMBL1497504 & 737823 & 5.25 & 5.8459 & TRN & \\
\hline CHEMBL1383532 & 737823 & 5.7 & 5.598 & TST & \\
\hline CHEMBL1437138 & 737823 & 6.0 & 5.3975 & TRN & \\
\hline CHEMBL538430 & 737823 & 4.85 & 5.0386 & TRN & \\
\hline CHEMBL1360434 & 737823 & 5.7 & 5.699 & TRN & \\
\hline CHEMBL1452413 & 737823 & 5.9 & 5.4466 & TRN & \\
\hline CHEMBL1538297 & 737823 & 5.25 & 5.3191 & TRN & \\
\hline CHEMBL1322959 & 737823 & 6.0 & 5.3513 & TST & \\
\hline CHEMBL1353758 & 737823 & 4.9 & 5.4684 & TRN & \\
\hline CHEMBL1472898 & 737823 & 5.5 & 5.6825 & TRN & \\
\hline CHEMBL1382242 & 737823 & 4.95 & 5.1655 & TRN & \\
\hline CHEMBL1414438 & 737823 & 4.85 & 5.25299 & 9999999999 & TRN \\
\hline CHEMBL3196069 & 737823 & 4.4 & 5.6492 & TRN & \\
\hline CHEMBL1401960 & 737823 & 7.15 & 5.5886 & TRN & \\
\hline CHEMBL1440067 & 737823 & 4.8 & 5.1807 & TRN & \\
\hline CHEMBL1357183 & 737823 & 5.0 & 5.614 & TRN & \\
\hline CHEMBL1789988 & 737823 & 5.6 & 5.5479 & TRN & \\
\hline CHEMBL1406082 & 737823 & 6.6 & 5.7329 & TRN & \\
\hline CHEMBL3210042 & 737823 & 5.35 & 5.4645 & TRN & \\
\hline CHEMBL1484949 & 737823 & 4.8 & 4.8449 & TRN & \\
\hline CHEMBL1414910 & 737823 & 5.4 & 5.1263 & TRN & \\
\hline CHEMBL1454841 & 737823 & 5.2 & 5.4882 & TRN & \\
\hline CHEMBL1338095 & 737823 & 4.8 & 5.08 & TRN & \\
\hline CHEMBL1389308 & 737823 & 4.5 & 4.8309 & TRN & \\
\hline CHEMBL1392868 & 737823 & 4.8 & 5.3875 & TRN & \\
\hline CHEMBL1576517 & 737823 & 4.85 & 5.1185 & TST & \\
\hline CHEMBL 22304 & 737823 & 6.0 & 4.842 & TST & \\
\hline CHEMBL1315336 & 737823 & 4.7 & 5.3334 & TRN & \\
\hline CHEMBL1487561 & 737823 & 4.9 & 4.9394 & TRN & \\
\hline CHEMBL1742168 & 737823 & 4.8 & 5.5197 & TRN & \\
\hline CHEMBL1234985 & 737823 & 5.1 & 4.9726 & TRN & \\
\hline CHEMBL1602849 & 737823 & 4.8 & 5.5501 & TRN & \\
\hline CHEMBL1589098 & 737823 & 4.7 & 5.5892 & TRN & \\
\hline CHEMBL1598771 & 737823 & 4.4 & 5.1514 & TST & \\
\hline CHEMBL345083 & 737823 & 7.2 & 5.013 & TST & \\
\hline CHEMBL3192246 & 737823 & 5.65 & 5.7369 & TRN & \\
\hline CHEMBL1330781 & 737823 & 5.75 & 5.8143 & TRN & \\
\hline CHEMBL1336082 & 737823 & 5.45 & 5.3235 & TRN & \\
\hline CHEMBL1549392 & 737823 & 4.7 & 4.8081 & TST & \\
\hline CHEMBL1367368 & 737823 & 5.4 & 5.0883 & TRN & \\
\hline & & & & e 3466 & \\
\hline
\end{tabular}




\begin{tabular}{|c|c|c|c|c|}
\hline \multicolumn{5}{|c|}{ Supplemental Table S2.txt } \\
\hline CHEMBL1373258 & 737823 & 4.75 & 5.5386 & TRN \\
\hline CHEMBL1515253 & 737823 & 5.9 & 5.4687 & TRN \\
\hline CHEMBL1332182 & 737823 & 5.1 & 5.2976 & TST \\
\hline CHEMBL521971 & 737823 & 4.8 & 4.8051 & TRN \\
\hline CHEMBL3210631 & 737823 & 5.4 & 5.2816 & TRN \\
\hline CHEMBL1340458 & 737823 & 5.4 & 5.4545 & TRN \\
\hline CHEMBL1566188 & 737823 & 5.3 & 5.3309 & TST \\
\hline CHEMBL1600269 & 737823 & 5.9 & 5.0228 & TRN \\
\hline CHEMBL1610003 & 737823 & 4.8 & 4.9899 & TRN \\
\hline CHEMBL1356234 & 737823 & 4.9 & 4.9028 & TRN \\
\hline CHEMBL1407953 & 737823 & 5.0 & 5.2461 & TRN \\
\hline CHEMBL1456076 & 737823 & 5.2 & 5.4629 & TRN \\
\hline CHEMBL1344769 & 737823 & 4.4 & 5.1302 & TST \\
\hline CHEMBL1513078 & 737823 & 4.8 & 5.3682 & TRN \\
\hline CHEMBL1371756 & 737823 & 5.3 & 5.9465 & TRN \\
\hline CHEMBL1425899 & 737823 & 5.6 & 5.4716 & TRN \\
\hline CHEMBL1368887 & 737823 & 6.0 & 5.4534 & TRN \\
\hline CHEMBL1599054 & 737823 & 4.4 & 5.2077 & TRN \\
\hline CHEMBL1573957 & 737823 & 4.9 & 5.4244 & TST \\
\hline CHEMBL1454920 & 737823 & 5.5 & 4.7775 & TRN \\
\hline CHEMBL1582320 & 737823 & 4.85 & 5.1575 & TRN \\
\hline CHEMBL1536169 & 737823 & 5.5 & 4.8985 & TST \\
\hline CHEMBL1428890 & 737823 & 5.2 & 5.1506 & TRN \\
\hline CHEMBL559612 & 737823 & 4.6 & 4.9506 & TST \\
\hline CHEMBL1459487 & 737823 & 4.85 & 5.4359 & TRN \\
\hline CHEMBL1577854 & 737823 & 4.85 & 4.923 & TRN \\
\hline CHEMBL1528441 & 737823 & 4.4 & 5.2052 & TST \\
\hline CHEMBL1398321 & 737823 & 4.8 & 5.3588 & TST \\
\hline CHEMBL1741496 & 737823 & 4.75 & 5.4499 & TRN \\
\hline CHEMBL1395564 & 737823 & 5.1 & 5.2413 & TRN \\
\hline CHEMBL1703148 & 737823 & 5.05 & 5.2728 & TRN \\
\hline CHEMBL1541004 & 737823 & 6.0 & 5.9264 & TRN \\
\hline CHEMBL1708264 & 737823 & 5.05 & 5.0539 & TRN \\
\hline CHEMBL1314371 & 737823 & 5.4 & 5.5119 & TRN \\
\hline CHEMBL3196958 & 737823 & 5.3 & 5.4573 & TRN \\
\hline CHEMBL3350578 & 737823 & 6.3 & 5.7331 & TST \\
\hline CHEMBL 1578474 & 737823 & 4.5 & 5.0513 & TRN \\
\hline CHEMBL1256751 & 737823 & 4.9 & 4.8929 & TRN \\
\hline CHEMBL1504668 & 737823 & 4.85 & 5.2131 & TRN \\
\hline CHEMBL1592547 & 737823 & 4.8 & 4.9445 & TRN \\
\hline CHEMBL1593853 & 737823 & 5.6 & 5.5552 & TRN \\
\hline CHEMBL1563304 & 737823 & 5.4 & 5.6495 & TRN \\
\hline CHEMBL1436160 & 737823 & 4.6 & 4.6509 & TRN \\
\hline CHEMBL3191520 & 737823 & 5.7 & 5.3146 & TRN \\
\hline CHEMBL1362390 & 737823 & 4.8 & 4.9778 & TST \\
\hline CHEMBL1450805 & 737823 & 5.5 & 5.6948 & TRN \\
\hline CHEMBL1421334 & 737823 & 5.95 & 5.4292 & TST \\
\hline CHEMBL1430258 & 737823 & 5.1 & 4.7531 & TRN \\
\hline
\end{tabular}




\begin{tabular}{|c|c|c|c|c|c|}
\hline \multicolumn{6}{|c|}{ Supplemental Table S2.txt } \\
\hline CHEMBL1330449 & 737823 & 5.6 & 5.7461 & TRN & \\
\hline CHEMBL1471648 & 737823 & 4.65 & 5.5022 & TRN & \\
\hline CHEMBL1354941 & 737823 & 5.7 & 5.5502 & TRN & \\
\hline CHEMBL1734883 & 737823 & 4.9 & 5.0236 & TRN & \\
\hline CHEMBL1432632 & 737823 & 4.7 & 5.4321 & TRN & \\
\hline CHEMBL1565190 & 737823 & 5.8 & 5.5244 & TRN & \\
\hline CHEMBL1543205 & 737823 & 4.8 & 5.148 & TRN & \\
\hline CHEMBL3197465 & 737823 & 4.8 & 5.0714 & TRN & \\
\hline CHEMBL1357956 & 737823 & 4.9 & 4.9846 & TRN & \\
\hline CHEMBL1585900 & 737823 & 4.7 & 5.1985 & TRN & \\
\hline CHEMBL1430379 & 737823 & 4.8 & 5.2605 & TRN & \\
\hline CHEMBL1449420 & 737823 & 4.7 & 4.9065 & TRN & \\
\hline CHEMBL1433455 & 737823 & 4.5 & 5.0153 & TRN & \\
\hline CHEMBL1488504 & 737823 & 4.9 & 5.3273 & TRN & \\
\hline CHEMBL1567435 & 737823 & 5.4 & 5.6192 & TRN & \\
\hline CHEMBL1532386 & 737823 & 5.5 & 5.1004 & TRN & \\
\hline CHEMBL145346 & 737823 & 6.85 & 5.3634 & TRN & \\
\hline CHEMBL565359 & 737823 & 4.65 & 5.5985 & TRN & \\
\hline CHEMBL1529652 & 737823 & 4.65 & 5.3501 & TRN & \\
\hline CHEMBL1317451 & 737823 & 4.5 & 4.5988 & TRN & \\
\hline CHEMBL1626013 & 737823 & 5.3 & 5.1891 & TST & \\
\hline CHEMBL1516028 & 737823 & 6.0 & 5.8211 & TRN & \\
\hline CHEMBL1380684 & 737823 & 6.0 & 5.3289 & TRN & \\
\hline CHEMBL1382955 & 737823 & 6.25 & 5.643 & TRN & \\
\hline CHEMBL1382355 & 737823 & 4.8 & 5.0305 & TRN & \\
\hline CHEMBL1427581 & 737823 & 4.6 & 5.5439 & TRN & \\
\hline CHEMBL1490223 & 737823 & 4.7 & 5.0938 & TRN & \\
\hline CHEMBL1388668 & 737823 & 5.55 & 5.624 & TRN & \\
\hline CHEMBL1560487 & 737823 & 5.6 & 5.6073 & TRN & \\
\hline CHEMBL1597410 & 737823 & 4.6 & 4.5072 & TRN & \\
\hline CHEMBL123433 & 737823 & 6.4 & 5.0222 & TST & \\
\hline CHEMBL1452389 & 737823 & 5.6 & 5.9689 & TRN & \\
\hline CHEMBL1528415 & 737823 & 5.4 & 5.271 & TRN & \\
\hline CHEMBL1552864 & 737823 & 5.4 & 5.33299 & 9999999999 & TRN \\
\hline CHEMBL1558934 & 737823 & 5.7 & 5.8172 & TRN & \\
\hline CHEMBL1607443 & 737823 & 5.2 & 5.4114 & TRN & \\
\hline CHEMBL513116 & 737823 & 6.0 & 5.3757 & TRN & \\
\hline CHEMBL1356041 & 737823 & 4.9 & 5.2801 & TRN & \\
\hline CHEMBL1701728 & 737823 & 5.4 & 4.8969 & TRN & \\
\hline CHEMBL1464821 & 737823 & 5.3 & 5.5102 & TRN & \\
\hline CHEMBL1354273 & 737823 & 4.9 & 4.695 & TRN & \\
\hline CHEMBL1449111 & 737823 & 4.6 & 5.1583 & TST & \\
\hline CHEMBL1310646 & 737823 & 4.8 & 4.9395 & TRN & \\
\hline CHEMBL3208441 & 737823 & 5.45 & 5.1732 & TRN & \\
\hline CHEMBL1451747 & 737823 & 4.85 & 5.0405 & TRN & \\
\hline CHEMBL502257 & 737823 & 6.0 & 5.5684 & TRN & \\
\hline CHEMBL1512693 & 737823 & 5.9 & 5.8554 & TRN & \\
\hline CHEMBL1552572 & 737823 & 4.7 & 5.5682 & TRN & \\
\hline
\end{tabular}




\begin{tabular}{|c|c|c|c|c|c|}
\hline & & \multicolumn{4}{|c|}{ Supplemental Table S2.txt } \\
\hline CHEMBL1431523 & 737823 & 5.15 & \multicolumn{2}{|c|}{5.6370000000000005} & TRN \\
\hline CHEMBL1502327 & 737823 & 5.55 & 5.8214 & TST & \\
\hline CHEMBL1305585 & 737823 & 4.55 & 5.4022 & TST & \\
\hline CHEMBL1411146 & 737823 & 5.5 & 5.9718 & TRN & \\
\hline CHEMBL1710426 & 737823 & 4.8 & 5.4291 & TRN & \\
\hline CHEMBL273291 & 737823 & 6.0 & 4.699 & TST & \\
\hline CHEMBL1600340 & 737823 & 5.5 & 5.3795 & TRN & \\
\hline CHEMBL1359472 & 737823 & 4.9 & 4.8407 & TRN & \\
\hline CHEMBL1490820 & 737823 & 5.6 & 5.8172 & TRN & \\
\hline CHEMBL18132 & 737823 & 6.0 & 5.6598 & TRN & \\
\hline CHEMBL1456330 & 737823 & 5.7 & 5.8744 & TST & \\
\hline CHEMBL1404317 & 737823 & 5.0 & 5.3426 & TRN & \\
\hline CHEMBL1318045 & 737823 & 4.8 & 5.1136 & TRN & \\
\hline CHEMBL1374204 & 737823 & 4.4 & 4.86 & TRN & \\
\hline CHEMBL1452272 & 737823 & 4.9 & 5.2225 & TRN & \\
\hline CHEMBL3195855 & 737823 & 6.3 & 5.3626 & TRN & \\
\hline CHEMBL3212049 & 737823 & 5.65 & 5.6356 & TRN & \\
\hline CHEMBL1318622 & 737823 & 5.5 & 5.5143 & TRN & \\
\hline CHEMBL1502952 & 737823 & 6.0 & 5.7462 & TRN & \\
\hline CHEMBL1383897 & 737823 & 5.4 & 5.2196 & TRN & \\
\hline CHEMBL1965376 & 737823 & 5.2 & 5.0235 & TRN & \\
\hline CHEMBL1517765 & 737823 & 4.8 & 4.981 & TRN & \\
\hline CHEMBL270299 & 737823 & 5.8 & 5.3374 & TRN & \\
\hline CHEMBL1582760 & 737823 & 5.1 & 5.5613 & TST & \\
\hline CHEMBL428768 & 737823 & 6.0 & 5.2719 & TRN & \\
\hline CHEMBL1397604 & 737823 & 5.0 & 5.1929 & TRN & \\
\hline CHEMBL1397671 & 737823 & 5.5 & 5.586 & TRN & \\
\hline CHEMBL1580127 & 737823 & 5.0 & 4.8606 & TRN & \\
\hline CHEMBL1741473 & 737823 & 5.9 & 4.8551 & TRN & \\
\hline CHEMBL1368357 & 737823 & 4.9 & 5.3944 & TRN & \\
\hline CHEMBL1436049 & 737823 & 6.2 & 5.829 & TRN & \\
\hline CHEMBL1741782 & 737823 & 4.85 & 5.1426 & TRN & \\
\hline CHEMBL28 & 737823 & 6.0 & 5.8372 & TRN & \\
\hline CHEMBL3193125 & 737823 & 5.5 & 5.3827 & TRN & \\
\hline CHEMBL490577 & 737823 & 5.4 & \multicolumn{2}{|c|}{5.252999999999999} & TRN \\
\hline CHEMBL1549020 & 737823 & 5.0 & 5.316 & TRN & \\
\hline CHEMBL1558526 & 737823 & 5.5 & 5.3714 & TRN & \\
\hline CHEMBL1584911 & 737823 & 4.6 & 4.971 & TRN & \\
\hline CHEMBL1318495 & 737823 & 5.9 & 6.0928 & TRN & \\
\hline CHEMBL1608125 & 737823 & 6.1 & 5.8451 & TRN & \\
\hline CHEMBL447001 & 737823 & 4.5 & 4.7934 & TST & \\
\hline CHEMBL1741789 & 737823 & 5.7 & 5.5871 & TRN & \\
\hline CHEMBL1440157 & 737823 & 6.8 & 5.9513 & TRN & \\
\hline CHEMBL994 & 737823 & 6.7 & 5.6459 & TRN & \\
\hline CHEMBL1608097 & 737823 & 6.1 & 5.6868 & TRN & \\
\hline CHEMBL1430016 & 737823 & 6.15 & 5.7558 & TRN & \\
\hline CHEMBL1718206 & 737823 & 5.35 & 4.9045 & TRN & \\
\hline CHEMBL1340374 & 737823 & 6.25 & 5.6227 & TST & \\
\hline
\end{tabular}




\begin{tabular}{|c|c|c|c|c|c|}
\hline \\
\hline CHEMBL1388158 & 737823 & 5.4 & 6.106 & TST & \\
\hline CHEMBL1331751 & 737823 & 4.85 & 5.0823 & TRN & \\
\hline CHEMBL1473430 & 737823 & 6.4 & 6.1795 & TRN & \\
\hline CHEMBL1554664 & 737823 & 6.0 & 5.8925 & TRN & \\
\hline CHEMBL1347631 & 737823 & 4.8 & 5.4723 & TRN & \\
\hline CHEMBL1742229 & 737823 & 5.4 & 4.8236 & TRN & \\
\hline CHEMBL1496576 & 737823 & 4.9 & 4.7176 & TRN & \\
\hline CHEMBL293341 & 737823 & 4.7 & 5.3987 & TRN & \\
\hline CHEMBL1612230 & 737823 & 5.0 & 5.6779 & TST & \\
\hline CHEMBL1593068 & 737823 & 5.5 & 5.5938 & TRN & \\
\hline CHEMBL1555118 & 737823 & 5.0 & 5.38 & TRN & \\
\hline CHEMBL1347205 & 737823 & 4.95 & 5.3121 & TRN & \\
\hline CHEMBL1317748 & 737823 & 5.4 & 5.7558 & TRN & \\
\hline CHEMBL1303450 & 737823 & 4.8 & 5.36100 & 0000000001 & TRN \\
\hline CHEMBL1256814 & 737823 & 4.5 & 4.9926 & TRN & \\
\hline CHEMBL1362630 & 737823 & 6.6 & 5.1979 & TRN & \\
\hline CHEMBL1588990 & 737823 & 6.05 & 5.5708 & TRN & \\
\hline CHEMBL1497610 & 737823 & 5.0 & 4.9153 & TRN & \\
\hline CHEMBL1473996 & 737823 & 6.7 & 6.4609 & TRN & \\
\hline CHEMBL1446335 & 737823 & 5.1 & 5.2271 & TRN & \\
\hline CHEMBL1516653 & 737823 & 5.4 & 5.1894 & TRN & \\
\hline CHEMBL1477830 & 737823 & 5.7 & 5.2064 & TST & \\
\hline CHEMBL1376952 & 737823 & 5.5 & 5.25700 & 0000000001 & TRN \\
\hline CHEMBL1544332 & 737823 & 6.1 & 5.5886 & TRN & \\
\hline CHEMBL1723585 & 737823 & 4.85 & 4.8126 & TRN & \\
\hline CHEMBL1447313 & 737823 & 5.0 & 5.5205 & TRN & \\
\hline CHEMBL1545534 & 737823 & 6.4 & 5.7023 & TRN & \\
\hline CHEMBL1358416 & 737823 & 4.4 & 4.6651 & TRN & \\
\hline CHEMBL1515221 & 737823 & 6.5 & 6.1058 & TRN & \\
\hline CHEMBL1391737 & 737823 & 5.05 & 5.5587 & TRN & \\
\hline CHEMBL1363594 & 737823 & 5.5 & 5.3554 & TRN & \\
\hline CHEMBL1458985 & 737823 & 4.65 & 5.1319 & TRN & \\
\hline CHEMBL62 & 737823 & 6.0 & 4.9217 & TST & \\
\hline CHEMBL137648 & 737823 & 4.4 & 4.8461 & TRN & \\
\hline CHEMBL3197678 & 737823 & 5.45 & 5.4879 & TRN & \\
\hline CHEMBL1355227 & 737823 & 4.9 & 4.678 & TRN & \\
\hline CHEMBL1554725 & 737823 & 5.4 & 5.4371 & TRN & \\
\hline CHEMBL1492616 & 737823 & 5.0 & 4.7965 & TRN & \\
\hline CHEMBL269366 & 737823 & 4.8 & 5.2266 & TST & \\
\hline CHEMBL1328726 & 737823 & 4.9 & 4.9011 & TRN & \\
\hline CHEMBL3208772 & 737823 & 4.6 & 4.7652 & TRN & \\
\hline CHEMBL1475079 & 737823 & 6.2 & 5.32299 & 99999999995 & TRN \\
\hline CHEMBL1401539 & 737823 & 5.3 & 5.3134 & TRN & \\
\hline CHEMBL1394302 & 737823 & 7.8 & 6.0825 & TRN & \\
\hline CHEMBL1475686 & 737823 & 5.0 & 5.5826 & TRN & \\
\hline CHEMBL1595910 & 737823 & 5.4 & 5.8449 & TRN & \\
\hline CHEMBL1532230 & 737823 & 4.6 & 5.1953 & TRN & \\
\hline CHEMBL1607997 & 737823 & 5.35 & 5.8583 & TST & \\
\hline
\end{tabular}




\begin{tabular}{|c|c|c|c|c|c|}
\hline \multirow[b]{2}{*}{ CHEMBL1370244 } & \multirow[b]{2}{*}{737823} & \\
\hline & & 4.8 & 5.2697 & TRN & \\
\hline CHEMBL 2062345 & 737823 & 5.0 & 5.5632 & TST & \\
\hline CHEMBL1433705 & 737823 & 6.3 & 5.5421 & TRN & \\
\hline CHEMBL1402552 & 737823 & 4.6 & 5.7485 & TST & \\
\hline CHEMBL1572118 & 737823 & 5.75 & 5.3146 & TRN & \\
\hline CHEMBL1369824 & 737823 & 4.9 & 5.1543 & TRN & \\
\hline CHEMBL1611022 & 737823 & 5.3 & 5.0693 & TST & \\
\hline CHEMBL1554194 & 737823 & 5.8 & 5.7467 & TRN & \\
\hline CHEMBL1568786 & 737823 & 5.8 & 5.6112 & TRN & \\
\hline CHEMBL1437650 & 737823 & 6.1 & 5.4673 & TRN & \\
\hline CHEMBL1394944 & 737823 & 5.5 & 5.6924 & TRN & \\
\hline CHEMBL1375285 & 737823 & 4.5 & 5.0939 & TRN & \\
\hline CHEMBL1587412 & 737823 & 4.8 & 5.2718 & TST & \\
\hline CHEMBL1348181 & 737823 & 5.1 & 5.6029 & TRN & \\
\hline CHEMBL1505375 & 737823 & 4.9 & 5.19600 & 0000000001 & TRN \\
\hline CHEMBL1424097 & 737823 & 5.1 & 5.4248 & TST & \\
\hline CHEMBL1544155 & 737823 & 4.85 & 5.4652 & TRN & \\
\hline CHEMBL1338917 & 737823 & 4.9 & 5.4143 & TRN & \\
\hline CHEMBL1337873 & 737823 & 4.85 & 5.088 & TRN & \\
\hline CHEMBL1320904 & 737823 & 4.7 & 5.0918 & TRN & \\
\hline CHEMBL1564907 & 737823 & 5.3 & 5.0096 & TRN & \\
\hline CHEMBL1499501 & 737823 & 7.4 & 5.1711 & TRN & \\
\hline CHEMBL1496125 & 737823 & 5.6 & 5.6961 & TRN & \\
\hline CHEMBL1310057 & 737823 & 4.9 & 5.5214 & TRN & \\
\hline CHEMBL1416426 & 737823 & 6.4 & 5.67399 & 99999999995 & TRN \\
\hline CHEMBL1500641 & 737823 & 4.65 & 5.0987 & TRN & \\
\hline CHEMBL1368860 & 737823 & 6.0 & 5.2673 & TRN & \\
\hline CHEMBL1474875 & 737823 & 5.0 & 4.7792 & TRN & \\
\hline CHEMBL1232474 & 737823 & 7.0 & 6.6899 & TRN & \\
\hline CHEMBL3194665 & 737823 & 6.15 & 5.3681 & TST & \\
\hline CHEMBL1525456 & 737823 & 5.5 & 5.5594 & TRN & \\
\hline CHEMBL1318580 & 737823 & 4.6 & 4.8317 & TRN & \\
\hline CHEMBL1438690 & 737823 & 5.0 & 5.7728 & TRN & \\
\hline CHEMBL1367767 & 737823 & 4.85 & 4.9464 & TST & \\
\hline CHEMBL1257078 & 737823 & 4.9 & 5.4925 & TST & \\
\hline CHEMBL1534248 & 737823 & 7.2 & 5.6751 & TRN & \\
\hline CHEMBL1522198 & 737823 & 5.05 & 5.0256 & TST & \\
\hline CHEMBL1389176 & 737823 & 5.6 & 5.6709 & TRN & \\
\hline CHEMBL1608678 & 737823 & 5.1 & 4.7713 & TRN & \\
\hline CHEMBL1708647 & 737823 & 4.85 & 5.3729 & TRN & \\
\hline CHEMBL1468521 & 737823 & 5.3 & 5.579 & TRN & \\
\hline CHEMBL1472456 & 737823 & 4.9 & 4.9626 & TRN & \\
\hline CHEMBL1478570 & 737823 & 4.8 & 5.2034 & TRN & \\
\hline CHEMBL1409436 & 737823 & 5.3 & 5.343 & TST & \\
\hline CHEMBL1332033 & 737823 & 5.6 & 6.1343 & TRN & \\
\hline CHEMBL1530352 & 737823 & 5.3 & 5.3566 & TST & \\
\hline CHEMBL1474111 & 737823 & 4.8 & 4.9309 & TRN & \\
\hline CHEMBL1505191 & 737823 & 5.7 & 5.7696 & TRN & \\
\hline & & & & 3471 & \\
\hline
\end{tabular}




\begin{tabular}{|c|c|c|c|c|c|}
\hline \multicolumn{6}{|c|}{ Supplemental Table S2.txt } \\
\hline CHEMBL1306717 & 737823 & 5.4 & 5.5966 & TRN & \\
\hline CHEMBL1376723 & 737823 & 4.8 & 5.2371 & TST & \\
\hline CHEMBL1500383 & 737823 & 4.95 & 5.2713 & TRN & \\
\hline CHEMBL1317148 & 737823 & 4.8 & 4.9057 & TST & \\
\hline CHEMBL1474195 & 737823 & 6.4 & 5.7926 & TRN & \\
\hline CHEMBL1494697 & 737823 & 5.8 & 5.32799 & 9999999999 & TRN \\
\hline CHEMBL1529730 & 737823 & 4.8 & 5.2716 & TRN & \\
\hline CHEMBL294989 & 737823 & 4.5 & 5.0314 & TRN & \\
\hline CHEMBL189724 & 737823 & 6.3 & 5.0795 & TST & \\
\hline CHEMBL1428944 & 737823 & 5.4 & 4.8508 & TRN & \\
\hline CHEMBL1516500 & 737823 & 5.15 & 5.2919 & TRN & \\
\hline CHEMBL1604421 & 737823 & 4.6 & 5.002 & TRN & \\
\hline CHEMBL1527168 & 737823 & 7.0 & 6.2311 & TRN & \\
\hline CHEMBL1566751 & 737823 & 6.05 & 5.3711 & TST & \\
\hline CHEMBL1983345 & 737823 & 5.9 & 5.5074 & TRN & \\
\hline CHEMBL1363272 & 737823 & 4.55 & 5.0021 & TRN & \\
\hline CHEMBL1468324 & 737823 & 5.25 & 4.869 & TRN & \\
\hline CHEMBL1568178 & 737823 & 6.7 & 6.54799 & 9999999999 & TRN \\
\hline CHEMBL1308726 & 737823 & 4.7 & 4.9385 & TRN & \\
\hline CHEMBL1358122 & 737823 & 5.7 & 5.4518 & TRN & \\
\hline CHEMBL1417341 & 737823 & 5.55 & 5.7996 & TRN & \\
\hline CHEMBL1502348 & 737823 & 4.7 & 5.0121 & TRN & \\
\hline CHEMBL1417135 & 737823 & 5.5 & 5.7989 & TRN & \\
\hline CHEMBL1401348 & 737823 & 5.1 & 4.8807 & TRN & \\
\hline CHEMBL1525437 & 737823 & 5.55 & 5.8426 & TRN & \\
\hline CHEMBL1741783 & 737823 & 5.6 & 5.1401 & TRN & \\
\hline CHEMBL1409148 & 737823 & 6.0 & 5.2872 & TRN & \\
\hline CHEMBL1455604 & 737823 & 6.35 & 5.7303 & TRN & \\
\hline CHEMBL1597434 & 737823 & 4.8 & 4.746 & TRN & \\
\hline CHEMBL1597015 & 737823 & 5.1 & 5.2976 & TRN & \\
\hline CHEMBL3209826 & 737823 & 4.9 & 5.4375 & TRN & \\
\hline CHEMBL1587109 & 737823 & 5.35 & 5.5745 & TRN & \\
\hline CHEMBL1330057 & 737823 & 5.5 & 5.2604 & TRN & \\
\hline CHEMBL1510054 & 737823 & 5.05 & 5.5491 & TRN & \\
\hline CHEMBL1434460 & 737823 & 4.6 & 5.0623 & TRN & \\
\hline CHEMBL1578958 & 737823 & 4.95 & 5.4836 & TRN & \\
\hline CHEMBL1519576 & 737823 & 7.3 & 5.5357 & TRN & \\
\hline CHEMBL1574693 & 737823 & 5.8 & 5.9734 & TRN & \\
\hline CHEMBL1607868 & 737823 & 4.6 & 5.2467 & TRN & \\
\hline CHEMBL1418074 & 737823 & 5.55 & 5.655 & TRN & \\
\hline CHEMBL1521167 & 737823 & 5.3 & 5.234 & TST & \\
\hline CHEMBL 250892 & 737823 & 4.8 & 4.7555 & TRN & \\
\hline CHEMBL1410933 & 737823 & 5.05 & 5.0911 & TRN & \\
\hline CHEMBL1412225 & 737823 & 5.3 & 5.0755 & TRN & \\
\hline CHEMBL1400546 & 737823 & 4.8 & 5.3399 & TST & \\
\hline CHEMBL1715733 & 737823 & 5.6 & 5.6142 & TRN & \\
\hline CHEMBL1398137 & 737823 & 4.8 & 4.8577 & TRN & \\
\hline CHEMBL1458916 & 737823 & 5.45 & 5.5157 & TRN & \\
\hline
\end{tabular}




\begin{tabular}{|c|c|c|c|c|c|}
\hline & & & & & \\
\hline CHEMBL1322639 & 737823 & 6.5 & 5.4991 & TST & \\
\hline CHEMBL1593269 & 737823 & 4.6 & 5.1499 & TRN & \\
\hline CHEMBL1493054 & 737823 & 5.7 & 5.8294 & TRN & \\
\hline CHEMBL1545514 & 737823 & 4.9 & 4.8826 & TRN & \\
\hline CHEMBL1455570 & 737823 & 5.4 & 5.1751 & TRN & \\
\hline CHEMBL1561927 & 737823 & 5.15 & 5.7219 & TRN & \\
\hline CHEMBL1494196 & 737823 & 4.7 & 5.5514 & TRN & \\
\hline CHEMBL 305195 & 737823 & 6.0 & 5.0095 & TRN & \\
\hline CHEMBL1514129 & 737823 & 6.0 & 6.0192 & TRN & \\
\hline CHEMBL1570352 & 737823 & 4.9 & 4.8992 & TRN & \\
\hline CHEMBL1496004 & 737823 & 5.05 & 5.3772 & TRN & \\
\hline CHEMBL1307848 & 737823 & 5.65 & 5.2086 & TRN & \\
\hline CHEMBL1742054 & 737823 & 5.6 & 5.171 & TRN & \\
\hline CHEMBL180162 & 737823 & 4.8 & 5.0102 & TRN & \\
\hline CHEMBL1592803 & 737823 & 5.9 & 5.8713 & TRN & \\
\hline CHEMBL1607646 & 737823 & 5.2 & 5.2625 & TRN & \\
\hline CHEMBL1388711 & 737823 & 5.4 & 5.3289 & TRN & \\
\hline CHEMBL492127 & 737823 & 5.3 & 5.205 & TRN & \\
\hline CHEMBL1542159 & 737823 & 5.5 & 5.3804 & TRN & \\
\hline CHEMBL1603777 & 737823 & 6.6 & 5.41100 & 00000000005 & TRN \\
\hline CHEMBL1408138 & 737823 & 6.4 & 5.7273 & TRN & \\
\hline CHEMBL1593365 & 737823 & 5.4 & 5.37299 & 9999999999 & TRN \\
\hline CHEMBL1566442 & 737823 & 5.1 & 5.0393 & TRN & \\
\hline CHEMBL1384678 & 737823 & 4.8 & 5.0594 & TRN & \\
\hline CHEMBL1379991 & 737823 & 5.0 & 5.1764 & TST & \\
\hline CHEMBL1600780 & 737823 & 6.0 & 5.5359 & TRN & \\
\hline CHEMBL1342791 & 737823 & 6.3 & 5.3501 & TRN & \\
\hline CHEMBL1549980 & 737823 & 5.45 & 5.2098 & TRN & \\
\hline CHEMBL1317884 & 737823 & 5.3 & 5.2632 & TRN & \\
\hline CHEMBL1547626 & 737823 & 4.85 & 5.1781 & TST & \\
\hline CHEMBL1451957 & 737823 & 5.0 & 5.0459 & TRN & \\
\hline CHEMBL1440509 & 737823 & 5.2 & 5.6402 & TRN & \\
\hline CHEMBL3199785 & 737823 & 4.75 & 4.9905 & TRN & \\
\hline CHEMBL1433596 & 737823 & 4.7 & 5.0167 & TRN & \\
\hline CHEMBL1510347 & 737823 & 4.8 & 5.5347 & TST & \\
\hline CHEMBL1727071 & 737823 & 6.0 & 5.4493 & TRN & \\
\hline CHEMBL1438786 & 737823 & 7.2 & 4.9596 & TST & \\
\hline CHEMBL1415331 & 737823 & 4.75 & 5.0631 & TRN & \\
\hline CHEMBL1517404 & 737823 & 4.4 & 4.7079 & TRN & \\
\hline CHEMBL1588074 & 737823 & 5.3 & 5.6385 & TRN & \\
\hline CHEMBL1348638 & 737823 & 5.35 & 5.1297 & TST & \\
\hline CHEMBL1495580 & 737823 & 5.9 & 5.3601 & TST & \\
\hline CHEMBL1371238 & 737823 & 5.4 & 5.4723 & TRN & \\
\hline CHEMBL1611630 & 737823 & 6.9 & 5.3207 & TRN & \\
\hline CHEMBL1328428 & 737823 & 4.65 & 5.3552 & TST & \\
\hline CHEMBL1581905 & 737823 & 4.85 & 4.8252 & TRN & \\
\hline CHEMBL1529330 & 737823 & 5.2 & 5.1496 & TRN & \\
\hline CHEMBL1741992 & 737823 & 4.6 & 5.4248 & TST & \\
\hline
\end{tabular}




\begin{tabular}{|c|c|c|c|c|}
\hline \multicolumn{5}{|c|}{ pplemental T } \\
\hline CHEMBL1385440 & 737823 & 5.8 & 5.3944 & TRN \\
\hline CHEMBL1412847 & 737823 & 5.2 & 5.5762 & TRN \\
\hline CHEMBL1390934 & 737823 & 5.3 & 5.5115 & TRN \\
\hline CHEMBL1366297 & 737823 & 4.8 & 5.3285 & TRN \\
\hline CHEMBL1572275 & 737823 & 4.8 & 4.993 & TRN \\
\hline CHEMBL1418097 & 737823 & 6.0 & 5.4517 & TRN \\
\hline CHEMBL1587094 & 737823 & 5.15 & 5.8689 & TST \\
\hline CHEMBL1355710 & 737823 & 5.7 & 4.9035 & TRN \\
\hline CHEMBL399491 & 737823 & 6.0 & 5.2251 & TRN \\
\hline CHEMBL1488294 & 737823 & 5.4 & 4.9753 & TRN \\
\hline CHEMBL1573739 & 737823 & 4.5 & 4.9767 & TRN \\
\hline CHEMBL1436882 & 737823 & 6.0 & 5.6017 & TST \\
\hline CHEMBL1541564 & 737823 & 4.55 & 4.7884 & TRN \\
\hline CHEMBL1317172 & 737823 & 6.0 & 4.6257 & TRN \\
\hline CHEMBL1579683 & 737823 & 4.85 & 5.2645 & TRN \\
\hline CHEMBL1551841 & 737823 & 5.3 & 5.2937 & TRN \\
\hline CHEMBL1717521 & 737823 & 4.95 & 4.3848 & TRN \\
\hline CHEMBL1591673 & 737823 & 5.3 & 5.2001 & TRN \\
\hline CHEMBL1356107 & 737823 & 5.7 & 5.86 & TRN \\
\hline CHEMBL1553804 & 737823 & 5.5 & 5.4436 & TRN \\
\hline CHEMBL1304072 & 737823 & 4.6 & 5.0014 & TRN \\
\hline CHEMBL1453244 & 737823 & 4.5 & 4.8169 & TRN \\
\hline CHEMBL1490268 & 737823 & 5.6 & 5.2246 & TRN \\
\hline CHEMBL1415482 & 737823 & 5.4 & 5.6066 & TRN \\
\hline CHEMBL1742273 & 737823 & 6.15 & 5.4222 & TRN \\
\hline CHEMBL1607234 & 737823 & 5.4 & 4.4644 & TRN \\
\hline CHEMBL1556928 & 737823 & 4.85 & 5.1492 & TRN \\
\hline CHEMBL1526170 & 737823 & 4.8 & 4.854 & TRN \\
\hline CHEMBL1741579 & 737823 & 5.1 & 5.1565 & TRN \\
\hline CHEMBL1358758 & 737823 & 4.9 & 4.8312 & TRN \\
\hline CHEMBL3197177 & 737823 & 5.0 & 5.4106 & TRN \\
\hline CHEMBL196677 & 737823 & 4.5 & 4.8004 & TRN \\
\hline CHEMBL1554246 & 737823 & 4.9 & 4.8172 & TRN \\
\hline CHEMBL1551090 & 737823 & 4.8 & 4.7418 & TRN \\
\hline CHEMBL1397079 & 737823 & 5.7 & 5.564 & TRN \\
\hline CHEMBL1394223 & 737823 & 4.9 & 4.7966 & TRN \\
\hline CHEMBL1497925 & 737823 & 4.95 & 4.99 & TRN \\
\hline CHEMBL1327351 & 737823 & 4.9 & 5.0228 & TRN \\
\hline CHEMBL1561346 & 737823 & 4.6 & 4.989 & TRN \\
\hline CHEMBL1514272 & 737823 & 4.8 & 5.0956 & TRN \\
\hline CHEMBL1591460 & 737823 & 5.1 & 5.2916 & TRN \\
\hline CHEMBL1388488 & 737823 & 5.1 & 4.8636 & TRN \\
\hline CHEMBL1416491 & 737823 & 4.7 & 5.3661 & TRN \\
\hline CHEMBL1559618 & 737823 & 5.15 & 5.3531 & TST \\
\hline CHEMBL1333519 & 737823 & 6.25 & 5.7723 & TRN \\
\hline CHEMBL299052 & 737823 & 4.8 & 5.106 & TRN \\
\hline CHEMBL1448819 & 737823 & 5.5 & 5.3634 & TRN \\
\hline CHEMBL1572935 & 737823 & 5.2 & 5.561 & TRN \\
\hline
\end{tabular}




\begin{tabular}{|c|c|c|c|c|c|}
\hline \multicolumn{6}{|c|}{ Supplemental Table S2.txt } \\
\hline CHEMBL1603700 & 737823 & 4.95 & 5.4395 & TRN & \\
\hline CHEMBL1337092 & 737823 & 6.1 & 5.5732 & TRN & \\
\hline CHEMBL1328166 & 737823 & 5.35 & 5.1621 & TRN & \\
\hline CHEMBL1507167 & 737823 & 5.8 & 5.6388 & TRN & \\
\hline CHEMBL3193586 & 737823 & 5.5 & 5.4807 & TRN & \\
\hline CHEMBL1544757 & 737823 & 4.5 & 5.114 & TST & \\
\hline CHEMBL169233 & 737823 & 4.8 & 5.6026 & TST & \\
\hline CHEMBL1433724 & 737823 & 6.6 & 6.3802 & TRN & \\
\hline CHEMBL1471064 & 737823 & 5.7 & 5.4704 & TRN & \\
\hline CHEMBL1732963 & 737823 & 5.1 & 5.2191 & TRN & \\
\hline CHEMBL1377151 & 737823 & 5.8 & 5.59399 & 9999999999 & TRN \\
\hline CHEMBL1450395 & 737823 & 5.9 & 5.5182 & TST & \\
\hline CHEMBL1330468 & 737823 & 5.5 & 5.1791 & TRN & \\
\hline CHEMBL1567447 & 737823 & 4.8 & 5.5375 & TRN & \\
\hline CHEMBL1463140 & 737823 & 4.85 & 5.0154 & TRN & \\
\hline CHEMBL3192460 & 737823 & 4.8 & 5.5034 & TST & \\
\hline CHEMBL1438358 & 737823 & 6.6 & 5.4165 & TRN & \\
\hline CHEMBL329872 & 737823 & 4.9 & 5.5379 & TRN & \\
\hline CHEMBL1516817 & 737823 & 4.75 & 4.6351 & TRN & \\
\hline CHEMBL1741882 & 737823 & 5.6 & 5.2038 & TST & \\
\hline CHEMBL40157 & 737823 & 4.6 & 5.0381 & TST & \\
\hline CHEMBL1741955 & 737823 & 5.9 & 5.0171 & TRN & \\
\hline CHEMBL1706387 & 737823 & 4.75 & 5.1104 & TST & \\
\hline CHEMBL1488167 & 737823 & 6.2 & 5.84200 & 00000000005 & TRN \\
\hline CHEMBL1311305 & 737823 & 6.9 & 5.8878 & TRN & \\
\hline CHEMBL267014 & 737823 & 4.8 & 5.4796 & TRN & \\
\hline CHEMBL1494778 & 737823 & 5.1 & 4.9875 & TRN & \\
\hline CHEMBL1335332 & 737823 & 5.7 & 5.5594 & TRN & \\
\hline CHEMBL1340051 & 737823 & 5.35 & 5.1182 & TST & \\
\hline CHEMBL1572789 & 737823 & 4.95 & 4.817 & TRN & \\
\hline CHEMBL1256911 & 737823 & 4.8 & 5.4813 & TRN & \\
\hline CHEMBL1578596 & 737823 & 4.95 & 5.0532 & TRN & \\
\hline CHEMBL1405386 & 737823 & 4.85 & 5.1011 & TST & \\
\hline CHEMBL1328480 & 737823 & 5.6 & 6.1948 & TRN & \\
\hline CHEMBL465843 & 737823 & 6.7 & 5.5292 & TRN & \\
\hline CHEMBL1357551 & 737823 & 4.8 & 4.775 & TRN & \\
\hline CHEMBL1545790 & 737823 & 5.8 & 5.2368 & TRN & \\
\hline CHEMBL1579705 & 737823 & 5.7 & 4.9893 & TRN & \\
\hline CHEMBL67378 & 737823 & 4.6 & 5.1442 & TST & \\
\hline CHEMBL1338229 & 737823 & 4.8 & 5.1539 & TRN & \\
\hline CHEMBL1416812 & 737823 & 4.9 & 5.3571 & TRN & \\
\hline CHEMBL1432807 & 737823 & 5.7 & 4.9711 & TST & \\
\hline CHEMBL1320019 & 737823 & 6.4 & 5.3861 & TRN & \\
\hline CHEMBL1315968 & 737823 & 5.0 & 5.3207 & TRN & \\
\hline CHEMBL1433730 & 737823 & 6.0 & 5.642 & TRN & \\
\hline CHEMBL1391390 & 737823 & 5.05 & 5.1648 & TST & \\
\hline CHEMBL1593926 & 737823 & 5.2 & 5.4695 & TRN & \\
\hline CHEMBL1376987 & 737823 & 5.7 & 5.3928 & TRN & \\
\hline
\end{tabular}




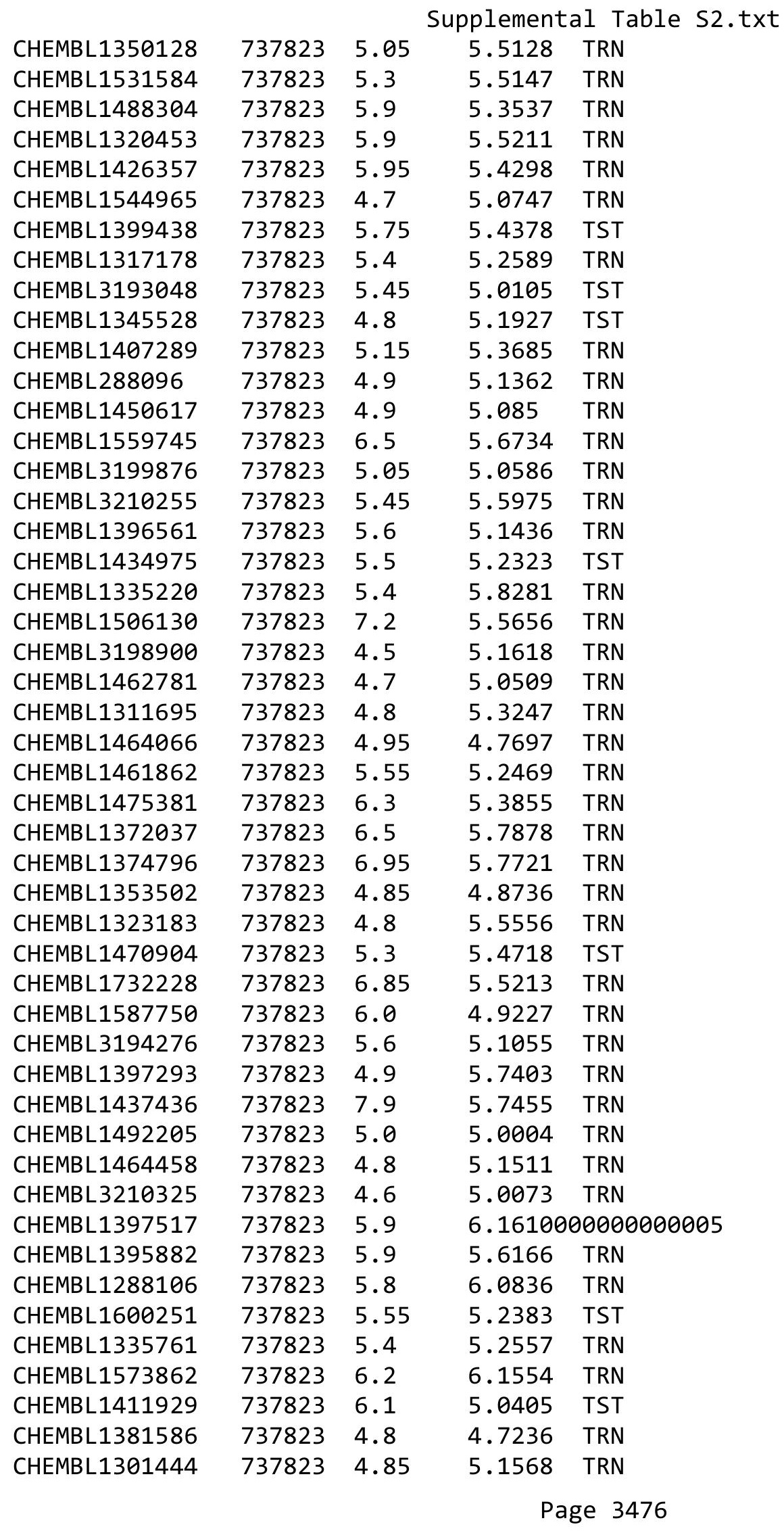




\begin{tabular}{|c|c|c|c|c|}
\hline \multicolumn{5}{|c|}{ Supplemental Table S2.txt } \\
\hline CHEMBL447507 & 737823 & 5.7 & 5.6619 & TRN \\
\hline CHEMBL1570922 & 737823 & 5.3 & 5.3514 & TRN \\
\hline CHEMBL1463329 & 737823 & 5.45 & 5.1471 & TST \\
\hline CHEMBL1544662 & 737823 & 4.65 & 5.1789 & TRN \\
\hline CHEMBL1336175 & 737823 & 6.1 & 5.407 & TRN \\
\hline CHEMBL1552028 & 737823 & 4.8 & 5.1149 & TRN \\
\hline CHEMBL1253351 & 737823 & 6.0 & 5.21200 & 0000000001 \\
\hline CHEMBL1438199 & 737823 & 4.95 & 5.2908 & TRN \\
\hline CHEMBL1473990 & 737823 & 4.7 & 4.9437 & TRN \\
\hline CHEMBL1422001 & 737823 & 5.35 & 5.4119 & TRN \\
\hline CHEMBL1546326 & 737823 & 4.95 & 4.9105 & TRN \\
\hline CHEMBL1453367 & 737823 & 4.9 & 5.2162 & TRN \\
\hline CHEMBL319244 & 737823 & 6.0 & 5.2561 & TRN \\
\hline CHEMBL1255758 & 737823 & 4.8 & 5.4004 & TST \\
\hline CHEMBL1544494 & 737823 & 5.35 & 5.4287 & TRN \\
\hline CHEMBL1741821 & 737823 & 4.8 & 5.0746 & TRN \\
\hline CHEMBL1489213 & 737823 & -0.0 & 4.7088 & TRN \\
\hline CHEMBL1599118 & 737823 & 6.1 & 5.8639 & TRN \\
\hline CHEMBL3191740 & 737823 & 6.05 & 5.4638 & TST \\
\hline CHEMBL1484371 & 737823 & 4.9 & 5.1694 & TST \\
\hline CHEMBL1389564 & 737823 & 7.5 & 5.0225 & TRN \\
\hline CHEMBL1512359 & 737823 & 6.4 & 5.9983 & TRN \\
\hline CHEMBL1412864 & 737823 & 5.6 & 5.0497 & TRN \\
\hline CHEMBL1443021 & 737823 & 4.55 & 5.5398 & TST \\
\hline CHEMBL1413858 & 737823 & 5.3 & 5.3439 & TRN \\
\hline CHEMBL1490292 & 737823 & 4.4 & 4.9876 & TRN \\
\hline CHEMBL1530654 & 737823 & 4.8 & 4.8691 & TRN \\
\hline CHEMBL1320947 & 737823 & 5.4 & 5.2498 & TRN \\
\hline CHEMBL1384414 & 737823 & 5.55 & 5.3697 & TRN \\
\hline CHEMBL1439126 & 737823 & 5.4 & 5.7946 & TRN \\
\hline CHEMBL145725 & 737823 & 4.4 & 5.1575 & TST \\
\hline CHEMBL393417 & 737823 & 4.8 & 5.4806 & TST \\
\hline CHEMBL1256148 & 737823 & 6.0 & 5.2339 & TST \\
\hline CHEMBL1451979 & 737823 & 4.75 & 5.2982 & TRN \\
\hline CHEMBL1582125 & 737823 & 5.45 & 5.456 & TRN \\
\hline CHEMBL1595576 & 737823 & 5.6 & 6.0151 & TRN \\
\hline CHEMBL1592289 & 737823 & 5.1 & 4.4861 & TRN \\
\hline CHEMBL475198 & 737823 & 5.9 & 5.7553 & TRN \\
\hline CHEMBL1554453 & 737823 & 4.8 & 5.0216 & TRN \\
\hline CHEMBL39947 & 737823 & 5.4 & 5.3107 & TST \\
\hline CHEMBL1502425 & 737823 & 6.3 & 5.6963 & TRN \\
\hline CHEMBL1575432 & 737823 & 5.9 & 5.5384 & TRN \\
\hline CHEMBL3213468 & 737823 & 4.6 & 4.9746 & TRN \\
\hline CHEMBL1538954 & 737823 & 6.8 & 5.6983 & TRN \\
\hline CHEMBL572203 & 737823 & 4.9 & 5.1354 & TRN \\
\hline CHEMBL1187946 & 737823 & 5.7 & 4.9488 & TST \\
\hline CHEMBL1441404 & 737823 & 5.9 & 4.7823 & TRN \\
\hline CHEMBL1459485 & 737823 & 4.55 & 4.8706 & TRN \\
\hline
\end{tabular}




\begin{tabular}{|c|c|c|c|c|c|}
\hline \\
\hline CHEMBL3189779 & 737823 & 4.8 & 5.3492 & TRN & \\
\hline CHEMBL1412697 & 737823 & 4.7 & 5.0331 & TRN & \\
\hline CHEMBL1462541 & 737823 & 4.85 & 5.184 & TST & \\
\hline CHEMBL1742278 & 737823 & 4.85 & 5.2084 & TRN & \\
\hline CHEMBL1389433 & 737823 & 5.5 & 5.3135 & TRN & \\
\hline CHEMBL1522897 & 737823 & 4.8 & 5.8214 & TRN & \\
\hline CHEMBL1606258 & 737823 & 4.65 & 5.428 & TRN & \\
\hline CHEMBL1579698 & 737823 & 4.85 & 5.2276 & TRN & \\
\hline CHEMBL1380212 & 737823 & 5.3 & 5.0672 & TRN & \\
\hline CHEMBL1426283 & 737823 & 5.9 & 5.66100 & 00000000005 & TRN \\
\hline CHEMBL1596831 & 737823 & 6.8 & 5.8309 & TST & \\
\hline CHEMBL1463847 & 737823 & 4.55 & 5.5957 & TST & \\
\hline CHEMBL1359469 & 737823 & 5.45 & 5.7187 & TRN & \\
\hline CHEMBL1554659 & 737823 & 5.7 & 5.4672 & TRN & \\
\hline CHEMBL1525792 & 737823 & 5.4 & 5.5722 & TRN & \\
\hline CHEMBL1388665 & 737823 & 5.15 & 5.153 & TRN & \\
\hline CHEMBL1741985 & 737823 & 4.9 & 5.0818 & TST & \\
\hline CHEMBL1443898 & 737823 & 5.2 & 4.6514 & TST & \\
\hline CHEMBL1256290 & 737823 & 5.0 & 5.235 & TST & \\
\hline CHEMBL1346226 & 737823 & 5.6 & 5.6868 & TRN & \\
\hline CHEMBL1366085 & 737823 & 7.1 & 5.7124 & TRN & \\
\hline CHEMBL1612486 & 737823 & 4.85 & 5.2965 & TRN & \\
\hline CHEMBL19612 & 737823 & 4.5 & 5.2483 & TST & \\
\hline CHEMBL1741947 & 737823 & 5.4 & 4.8031 & TRN & \\
\hline CHEMBL3208761 & 737823 & 5.55 & 5.5394 & TRN & \\
\hline CHEMBL1711461 & 737823 & 4.9 & 5.1818 & TRN & \\
\hline CHEMBL1355720 & 737823 & 4.7 & 5.4886 & TRN & \\
\hline CHEMBL1364135 & 737823 & 5.5 & 5.1841 & TRN & \\
\hline CHEMBL1517241 & 737823 & 6.3 & 6.1532 & TRN & \\
\hline CHEMBL1321094 & 737823 & 4.6 & 5.6266 & TRN & \\
\hline CHEMBL1527955 & 737823 & 5.5 & 5.7438 & TST & \\
\hline CHEMBL1397218 & 737823 & 5.5 & 5.2938 & TST & \\
\hline CHEMBL1600292 & 737823 & 6.4 & 5.8101 & TRN & \\
\hline CHEMBL3145155 & 737823 & 5.15 & 5.0332 & TST & \\
\hline CHEMBL1374696 & 737823 & 5.6 & 5.1157 & TRN & \\
\hline CHEMBL3192681 & 737823 & 6.0 & 5.3258 & TRN & \\
\hline CHEMBL1522673 & 737823 & 6.1 & 6.1422 & TRN & \\
\hline CHEMBL1400575 & 737823 & 5.2 & 5.2863 & TRN & \\
\hline CHEMBL1424276 & 737823 & 5.75 & 5.3756 & TST & \\
\hline CHEMBL 72135 & 737823 & 5.65 & 5.4645 & TST & \\
\hline CHEMBL 250053 & 737823 & 4.4 & 4.7615 & TST & \\
\hline CHEMBL1592464 & 737823 & 6.2 & 5.9717 & TRN & \\
\hline CHEMBL3213461 & 737823 & 5.4 & 5.3086 & TST & \\
\hline CHEMBL1410367 & 737823 & 5.6 & 5.0569 & TRN & \\
\hline CHEMBL3190572 & 737823 & 6.95 & 5.6109 & TRN & \\
\hline CHEMBL1375127 & 737823 & -0.0 & 5.4871 & TRN & \\
\hline CHEMBL1374426 & 737823 & 5.5 & 5.556 & TST & \\
\hline CHEMBL1562730 & 737823 & 4.85 & 4.5919 & TRN & \\
\hline
\end{tabular}




\begin{tabular}{|c|c|c|c|c|}
\hline \multicolumn{5}{|c|}{ Supplemental Table S2.txt } \\
\hline CHEMBL63154 & 737823 & 4.8 & 5.5178 & TRN \\
\hline CHEMBL1369886 & 737823 & 6.0 & 5.2898 & TRN \\
\hline CHEMBL1315609 & 737823 & 6.5 & 6.1573 & TRN \\
\hline CHEMBL 3213467 & 737823 & 6.05 & 5.4227 & TRN \\
\hline CHEMBL1415547 & 737823 & 5.35 & 5.2513 & TRN \\
\hline CHEMBL1393064 & 737823 & 5.0 & 5.3112 & TRN \\
\hline CHEMBL1478545 & 737823 & 5.3 & 5.6374 & TRN \\
\hline CHEMBL1519137 & 737823 & 4.8 & 5.4776 & TST \\
\hline CHEMBL1460996 & 737823 & 4.7 & 4.9527 & TRN \\
\hline CHEMBL1724898 & 737823 & 5.5 & 4.7382 & TRN \\
\hline CHEMBL1255837 & 737823 & 4.5 & 5.2016 & TST \\
\hline CHEMBL1400921 & 737823 & 4.8 & 5.6018 & TRN \\
\hline CHEMBL1514276 & 737823 & 6.4 & 5.2818 & TST \\
\hline CHEMBL1299867 & 737823 & 4.8 & 5.2003 & TRN \\
\hline CHEMBL1489668 & 737823 & -0.0 & 4.8501 & TRN \\
\hline CHEMBL1593601 & 737823 & 4.8 & 4.8147 & TRN \\
\hline CHEMBL3210478 & 737823 & 5.8 & 5.476 & TRN \\
\hline CHEMBL1435444 & 737823 & 4.5 & 5.1589 & TRN \\
\hline CHEMBL1437064 & 737823 & 6.2 & 5.7395 & TRN \\
\hline CHEMBL1534591 & 737823 & 4.8 & 4.8722 & TRN \\
\hline CHEMBL1320051 & 737823 & 4.7 & 5.2798 & TRN \\
\hline CHEMBL1303935 & 737823 & 4.7 & 4.9045 & TRN \\
\hline CHEMBL1312265 & 737823 & 4.75 & 5.1837 & TRN \\
\hline CHEMBL1446467 & 737823 & 5.4 & 5.5717 & TST \\
\hline CHEMBL1599585 & 737823 & 5.5 & 5.5752 & TRN \\
\hline CHEMBL1408286 & 737823 & 5.6 & 5.7236 & TRN \\
\hline CHEMBL1449293 & 737823 & 5.2 & 4.9865 & TRN \\
\hline CHEMBL1255867 & 737823 & 4.8 & 4.9846 & TRN \\
\hline CHEMBL1590821 & 737823 & 6.0 & 5.506 & TRN \\
\hline CHEMBL1511986 & 737823 & 5.9 & 5.8837 & TRN \\
\hline CHEMBL1369212 & 737823 & 6.0 & 4.9482 & TRN \\
\hline CHEMBL1358659 & 737823 & 4.5 & 4.9995 & TST \\
\hline CHEMBL1302790 & 737823 & 6.7 & 5.825 & TRN \\
\hline CHEMBL3195098 & 737823 & 5.45 & 5.3849 & TRN \\
\hline CHEMBL1557279 & 737823 & 5.3 & 5.2985 & TST \\
\hline CHEMBL277127 & 737823 & 5.4 & 5.153 & TRN \\
\hline CHEMBL189438 & 737823 & 4.9 & 5.0023 & TST \\
\hline CHEMBL1349875 & 737823 & 5.0 & 5.1959 & TRN \\
\hline CHEMBL1560764 & 737823 & 5.1 & 5.5549 & TRN \\
\hline CHEMBL1299891 & 737823 & 4.9 & 5.7154 & TRN \\
\hline CHEMBL1434817 & 737823 & 5.8 & 5.9532 & TRN \\
\hline CHEMBL1591815 & 737823 & 5.5 & 5.7927 & TRN \\
\hline CHEMBL1435033 & 737823 & 4.4 & 4.8833 & TST \\
\hline CHEMBL1465834 & 737823 & 4.75 & 4.8905 & TRN \\
\hline CHEMBL1472687 & 737823 & 5.3 & 5.3771 & TRN \\
\hline CHEMBL1473844 & 737823 & 5.1 & 5.2119 & TRN \\
\hline CHEMBL1385495 & 737823 & 6.1 & 5.1013 & TRN \\
\hline CHEMBL1742301 & 737823 & 5.1 & 5.506 & TST \\
\hline
\end{tabular}




\begin{tabular}{|c|c|c|c|c|c|}
\hline \multicolumn{6}{|c|}{ Supplemental Table S2.txt } \\
\hline CHEMBL1551515 & 737823 & 4.7 & 5.2525 & TRN & \\
\hline CHEMBL1568080 & 737823 & 4.6 & 4.8374 & TRN & \\
\hline CHEMBL3193223 & 737823 & 5.65 & 5.3043 & TRN & \\
\hline CHEMBL581929 & 737823 & 4.8 & 5.1909 & TRN & \\
\hline CHEMBL1428001 & 737823 & 5.7 & 5.1518 & TRN & \\
\hline CHEMBL1393933 & 737823 & 4.95 & 5.0258 & TRN & \\
\hline CHEMBL474415 & 737823 & 4.5 & 4.9733 & TRN & \\
\hline CHEMBL1556377 & 737823 & 6.0 & 5.8785 & TRN & \\
\hline CHEMBL 29197 & 737823 & 6.3 & 5.5694 & TRN & \\
\hline CHEMBL1596698 & 737823 & 5.7 & 5.3618 & TRN & \\
\hline CHEMBL1570465 & 737823 & 5.3 & 5.7435 & TRN & \\
\hline CHEMBL1333384 & 737823 & 5.1 & 5.5616 & TRN & \\
\hline CHEMBL1716644 & 737823 & 6.4 & 5.1961 & TRN & \\
\hline CHEMBL375270 & 737823 & 6.2 & 5.5154 & TRN & \\
\hline CHEMBL1406410 & 737823 & 5.1 & 5.5821 & TRN & \\
\hline CHEMBL238624 & 737823 & 6.1 & 5.5155 & TST & \\
\hline CHEMBL1717360 & 737823 & 4.7 & 5.2903 & TRN & \\
\hline CHEMBL1599059 & 737823 & 5.7 & 5.7519 & TRN & \\
\hline CHEMBL1340893 & 737823 & 4.85 & 5.2003 & TRN & \\
\hline CHEMBL1449036 & 737823 & 6.1 & 5.438 & TRN & \\
\hline CHEMBL1356083 & 737823 & 4.7 & 5.4299 & TRN & \\
\hline CHEMBL1479203 & 737823 & 5.3 & 5.397 & TRN & \\
\hline CHEMBL1368670 & 737823 & 5.95 & 5.7716 & TRN & \\
\hline CHEMBL1590601 & 737823 & 5.1 & 5.1554 & TRN & \\
\hline CHEMBL1309259 & 737823 & 5.15 & 4.9522 & TRN & \\
\hline CHEMBL1533572 & 737823 & 7.0 & 6.2062 & TRN & \\
\hline CHEMBL1376736 & 737823 & 4.9 & 4.981 & TRN & \\
\hline CHEMBL1984764 & 737823 & 7.2 & 6.0497 & TRN & \\
\hline CHEMBL1514607 & 737823 & 4.5 & 5.0649 & TRN & \\
\hline CHEMBL1603884 & 737823 & 5.5 & 5.12299 & 9999999999 & TRN \\
\hline CHEMBL1742062 & 737823 & 4.85 & 4.848 & TRN & \\
\hline CHEMBL1601398 & 737823 & 4.85 & 5.3802 & TRN & \\
\hline CHEMBL1327355 & 737823 & 6.0 & 6.1566 & TRN & \\
\hline CHEMBL576349 & 737823 & 6.3 & 5.3868 & TRN & \\
\hline CHEMBL1412756 & 737823 & 4.65 & 5.0251 & TRN & \\
\hline CHEMBL1354864 & 737823 & 5.1 & 5.2056 & TRN & \\
\hline CHEMBL1396595 & 737823 & 6.5 & 6.7051 & TRN & \\
\hline CHEMBL1433950 & 737823 & 5.9 & 4.886 & TRN & \\
\hline CHEMBL1467171 & 737823 & 4.9 & 5.2693 & TST & \\
\hline CHEMBL1429762 & 737823 & 5.45 & 5.8367 & TRN & \\
\hline CHEMBL1455462 & 737823 & 5.3 & 5.3118 & TRN & \\
\hline CHEMBL1314211 & 737823 & 5.5 & 5.6402 & TRN & \\
\hline CHEMBL1336412 & 737823 & 5.7 & 5.7 & TST & \\
\hline CHEMBL1598062 & 737823 & 4.9 & 5.1625 & TRN & \\
\hline CHEMBL1331288 & 737823 & 4.9 & 4.8693 & TRN & \\
\hline CHEMBL1494177 & 737823 & 6.0 & 5.4297 & TRN & \\
\hline CHEMBL356911 & 737823 & -0.0 & 4.7931 & TRN & \\
\hline CHEMBL1482342 & 737823 & 5.6 & 5.7003 & TRN & \\
\hline
\end{tabular}




\begin{tabular}{|c|c|c|c|c|c|}
\hline \multirow{3}{*}{$\begin{array}{l}\text { CHEMBL1553322 } \\
\text { CHEMBL1514359 }\end{array}$} & \multirow{3}{*}{$\begin{array}{l}737823 \\
737823\end{array}$} & & \\
\hline & & 5.7 & \multicolumn{2}{|c|}{5.462000000000001} & TRN \\
\hline & & 5.7 & 5.5408 & TRN & \\
\hline CHEMBL1568009 & 737823 & 5.1 & \multicolumn{2}{|c|}{5.257999999999999} & TST \\
\hline CHEMBL1402106 & 737823 & 5.5 & 5.3982 & TRN & \\
\hline CHEMBL1335352 & 737823 & 5.9 & 5.3412 & TRN & \\
\hline CHEMBL65 & 737823 & 6.0 & 5.8252 & TRN & \\
\hline CHEMBL1515614 & 737823 & 4.9 & 4.3815 & TRN & \\
\hline CHEMBL1560296 & 737823 & 5.05 & 5.4328 & TRN & \\
\hline CHEMBL1480371 & 737823 & 4.5 & 5.249 & TRN & \\
\hline CHEMBL39 & 737823 & 6.0 & 5.1869 & TRN & \\
\hline CHEMBL1556569 & 737823 & 5.05 & 5.1907 & TST & \\
\hline CHEMBL1464331 & 737823 & 4.75 & 5.0897 & TRN & \\
\hline CHEMBL1446078 & 737823 & 5.65 & 5.2837 & TRN & \\
\hline CHEMBL1576662 & 737823 & 4.8 & 5.3746 & TST & \\
\hline CHEMBL1742359 & 737823 & 7.6 & 5.7353 & TST & \\
\hline CHEMBL1580159 & 737823 & 5.0 & \multicolumn{2}{|c|}{5.417999999999999} & TRN \\
\hline CHEMBL1971532 & 737823 & 5.5 & 5.8362 & TRN & \\
\hline CHEMBL1558413 & 737823 & 4.95 & 5.2891 & TST & \\
\hline CHEMBL1552172 & 737823 & 4.8 & 5.5707 & TRN & \\
\hline CHEMBL1514280 & 737823 & 5.6 & 5.7083 & TRN & \\
\hline CHEMBL3212471 & 737823 & 4.9 & 5.1444 & TST & \\
\hline CHEMBL1307486 & 737823 & 6.0 & 5.2833 & TRN & \\
\hline CHEMBL1404529 & 737823 & 4.85 & 5.3494 & TRN & \\
\hline CHEMBL1403982 & 737823 & 6.1 & 5.669 & TRN & \\
\hline CHEMBL1301385 & 737823 & 6.5 & 6.0572 & TRN & \\
\hline CHEMBL1254361 & 737823 & 6.3 & 5.9832 & TRN & \\
\hline CHEMBL3196220 & 737823 & 5.85 & 5.2891 & TRN & \\
\hline CHEMBL1316402 & 737823 & 6.4 & 5.9667 & TRN & \\
\hline CHEMBL 3214622 & 737823 & 5.35 & 5.2315 & TRN & \\
\hline CHEMBL1385802 & 737823 & 4.4 & 4.8493 & TRN & \\
\hline CHEMBL1319303 & 737823 & 5.5 & 5.2671 & TRN & \\
\hline CHEMBL1741744 & 737823 & 4.8 & 5.5777 & TRN & \\
\hline CHEMBL1571984 & 737823 & 5.75 & 5.2842 & TRN & \\
\hline CHEMBL1407910 & 737823 & 6.6 & 6.2577 & TRN & \\
\hline CHEMBL1516701 & 737823 & 6.6 & 5.725 & TRN & \\
\hline CHEMBL1525487 & 737823 & 4.9 & 5.2201 & TRN & \\
\hline CHEMBL1331154 & 737823 & 5.0 & 5.0045 & TRN & \\
\hline CHEMBL1484861 & 737823 & 5.9 & 5.4377 & TRN & \\
\hline CHEMBL1468477 & 737823 & 5.6 & 5.4103 & TRN & \\
\hline CHEMBL1602886 & 737823 & 5.5 & 5.4299 & TRN & \\
\hline CHEMBL1508837 & 737823 & 5.75 & 5.4518 & TRN & \\
\hline CHEMBL1478761 & 737823 & 6.3 & \multicolumn{2}{|c|}{6.332000000000001} & TRN \\
\hline CHEMBL1606729 & 737823 & 4.55 & 5.638 & TRN & \\
\hline CHEMBL1329855 & 737823 & 4.65 & 4.8214 & TRN & \\
\hline CHEMBL1308209 & 737823 & 4.55 & 5.4747 & TRN & \\
\hline CHEMBL1319506 & 737823 & 5.3 & 5.2851 & TRN & \\
\hline CHEMBL1432466 & 737823 & 6.0 & \multicolumn{2}{|c|}{5.446000000000001} & TRN \\
\hline \multirow[t]{2}{*}{ CHEMBL1591874 } & 737823 & 6.0 & 5.1699 & TRN & \\
\hline & & & \multicolumn{2}{|c|}{ Page 3481} & \\
\hline
\end{tabular}




\begin{tabular}{|c|c|c|c|c|c|}
\hline & & \multicolumn{4}{|c|}{ Supplemental Table S2.txt } \\
\hline CHEMBL3192117 & 737823 & 5.35 & 5.1506 & TRN & \\
\hline CHEMBL3195378 & 737823 & 5.3 & 5.0253 & TRN & \\
\hline CHEMBL1367399 & 737823 & 4.9 & 5.3867 & TRN & \\
\hline CHEMBL1329597 & 737823 & 5.4 & 5.403 & TRN & \\
\hline CHEMBL1317761 & 737823 & 6.0 & 5.4867 & TRN & \\
\hline CHEMBL1301598 & 737823 & 5.95 & 5.4416 & TRN & \\
\hline CHEMBL1484614 & 737823 & 4.9 & \multicolumn{2}{|c|}{5.218999999999999} & TRN \\
\hline CHEMBL1587783 & 737823 & 4.8 & 5.2275 & TRN & \\
\hline CHEMBL1320765 & 737823 & 4.9 & 5.3232 & TRN & \\
\hline CHEMBL1435912 & 737823 & 5.0 & 5.4011 & TRN & \\
\hline CHEMBL1446731 & 737823 & 5.1 & 5.8184 & TRN & \\
\hline CHEMBL1598909 & 737823 & 5.45 & 5.5796 & TRN & \\
\hline CHEMBL1374373 & 737823 & 6.45 & 5.936 & TST & \\
\hline CHEMBL1368722 & 737823 & 4.8 & 5.1974 & TRN & \\
\hline CHEMBL1373621 & 737823 & 5.5 & 5.4036 & TRN & \\
\hline CHEMBL1354154 & 737823 & 5.5 & \multicolumn{2}{|c|}{5.792000000000001} & TRN \\
\hline CHEMBL1471920 & 737823 & 5.95 & \multicolumn{2}{|c|}{5.582000000000001} & TRN \\
\hline CHEMBL1526515 & 737823 & 5.6 & 5.4812 & TRN & \\
\hline CHEMBL1399862 & 737823 & 5.7 & 5.4635 & TRN & \\
\hline CHEMBL1604879 & 737823 & 4.9 & 5.2822 & TRN & \\
\hline CHEMBL1393189 & 737823 & 5.4 & 5.8034 & TST & \\
\hline CHEMBL1501724 & 737823 & 5.8 & 5.5377 & TST & \\
\hline CHEMBL1596477 & 737823 & 4.8 & 5.098 & TRN & \\
\hline CHEMBL1482243 & 737823 & 5.7 & 5.296 & TRN & \\
\hline CHEMBL1430702 & 737823 & 5.45 & 5.4007 & TRN & \\
\hline CHEMBL1552294 & 737823 & 5.1 & 5.1179 & TRN & \\
\hline CHEMBL1526213 & 737823 & 5.3 & 5.4714 & TRN & \\
\hline CHEMBL1454212 & 737823 & 4.75 & 5.073 & TRN & \\
\hline CHEMBL1604036 & 737823 & 5.4 & 4.8409 & TST & \\
\hline CHEMBL1314956 & 737823 & 6.0 & 5.9151 & TRN & \\
\hline CHEMBL1560912 & 737823 & 5.2 & 5.1442 & TST & \\
\hline CHEMBL1408856 & 737823 & 5.9 & 5.9677 & TRN & \\
\hline CHEMBL1561366 & 737823 & 6.9 & 5.8133 & TRN & \\
\hline CHEMBL1325833 & 737823 & 4.6 & 5.0204 & TRN & \\
\hline CHEMBL1404093 & 737823 & 6.4 & 6.0695 & TRN & \\
\hline CHEMBL1461873 & 737823 & 5.65 & 5.2659 & TRN & \\
\hline CHEMBL1348303 & 737823 & 6.7 & 5.7526 & TRN & \\
\hline CHEMBL1419356 & 737823 & 5.35 & 5.6048 & TRN & \\
\hline CHEMBL1419618 & 737823 & 4.9 & 5.0091 & TST & \\
\hline CHEMBL1600561 & 737823 & 5.4 & 5.522 & TRN & \\
\hline CHEMBL1552353 & 737823 & 4.8 & 5.2659 & TRN & \\
\hline CHEMBL1537215 & 737823 & 6.5 & 5.0036 & TRN & \\
\hline CHEMBL1353749 & 737823 & 4.75 & 5.1456 & TRN & \\
\hline CHEMBL1406121 & 737823 & 5.1 & 5.1798 & TST & \\
\hline CHEMBL151 & 737823 & 6.6 & 5.8177 & TRN & \\
\hline CHEMBL1519978 & 737823 & 4.8 & 4.6898 & TRN & \\
\hline CHEMBL1563066 & 737823 & 5.5 & 5.2007 & TRN & \\
\hline CHEMBL1607605 & 737823 & 5.45 & 5.1189 & TRN & \\
\hline
\end{tabular}




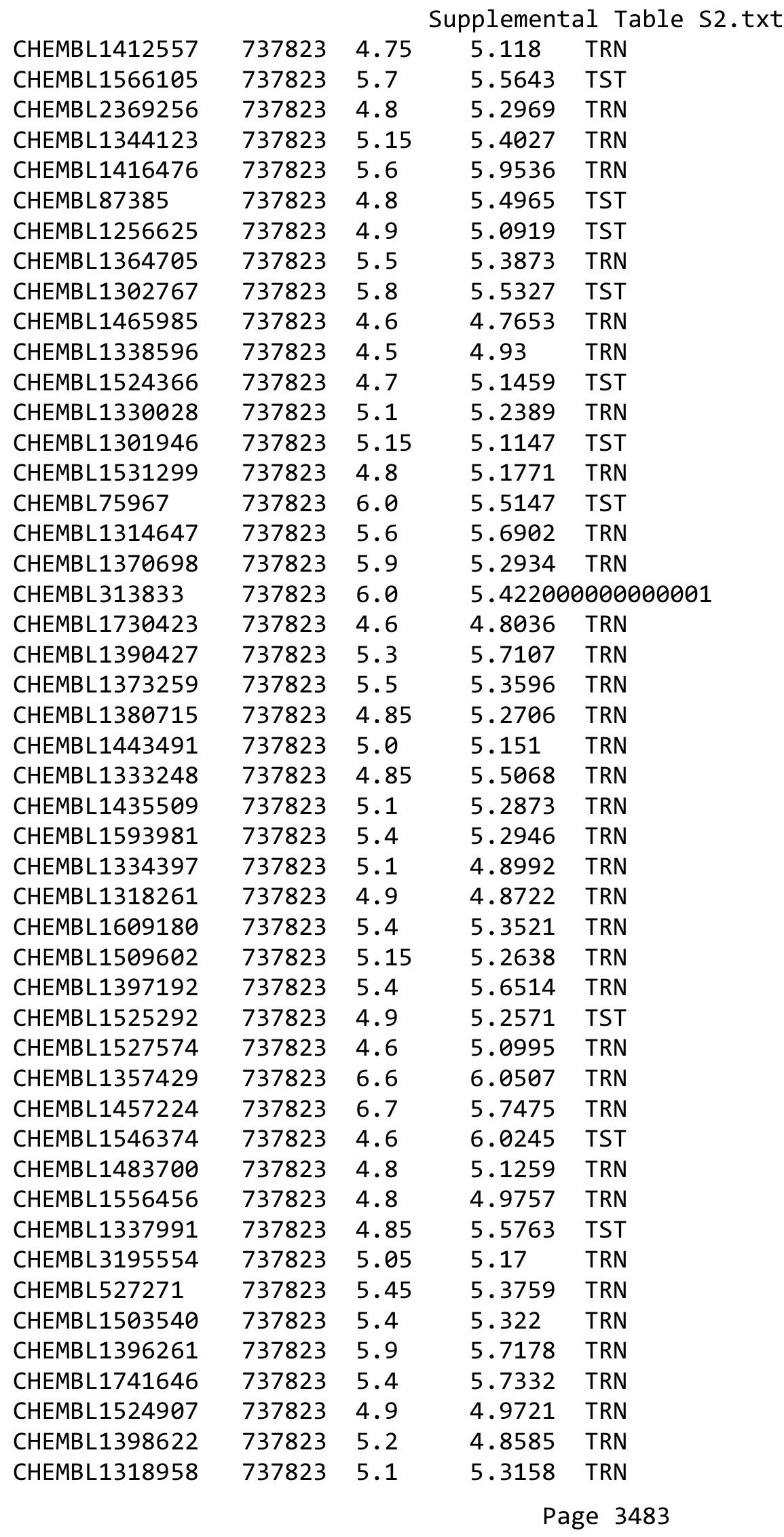




\begin{tabular}{|c|c|c|c|c|c|}
\hline & & & & & \\
\hline CHEMBL1340538 & 737823 & 4.85 & 5.0327 & TRN & \\
\hline CHEMBL1402799 & 737823 & 6.4 & 5.4613 & TRN & \\
\hline CHEMBL1497898 & 737823 & 6.2 & 5.5092 & TRN & \\
\hline CHEMBL1454035 & 737823 & 5.8 & 5.4331 & TRN & \\
\hline CHEMBL1450157 & 737823 & 4.9 & 5.5296 & TST & \\
\hline CHEMBL1605811 & 737823 & 4.8 & 5.5482 & TST & \\
\hline CHEMBL1492898 & 737823 & 5.3 & 5.5127 & TST & \\
\hline CHEMBL429773 & 737823 & 5.4 & 5.1668 & TRN & \\
\hline CHEMBL1331105 & 737823 & 4.9 & 5.0423 & TRN & \\
\hline CHEMBL1496761 & 737823 & 6.05 & 5.7558 & TRN & \\
\hline CHEMBL1201074 & 737823 & 6.5 & 5.23799 & 99999999995 & TRN \\
\hline CHEMBL1553768 & 737823 & 6.0 & 5.2605 & TST & \\
\hline CHEMBL1742165 & 737823 & 4.6 & 4.8133 & TRN & \\
\hline CHEMBL1453749 & 737823 & 4.8 & 5.2168 & TRN & \\
\hline CHEMBL1307201 & 737823 & 6.05 & 5.5224 & TRN & \\
\hline CHEMBL1362918 & 737823 & 4.6 & 5.5323 & TRN & \\
\hline CHEMBL126077 & 737823 & 7.5 & 5.7043 & TST & \\
\hline CHEMBL1412450 & 737823 & 5.1 & 5.0184 & TRN & \\
\hline CHEMBL1370805 & 737823 & 6.5 & 5.5125 & TRN & \\
\hline CHEMBL1583067 & 737823 & 5.45 & 5.5293 & TRN & \\
\hline CHEMBL3211511 & 737823 & 4.85 & 5.17200 & 0000000001 & TRN \\
\hline CHEMBL1561023 & 737823 & 6.8 & 6.2467 & TRN & \\
\hline CHEMBL1742129 & 737823 & 5.4 & 5.124 & TST & \\
\hline CHEMBL1400309 & 737823 & 5.2 & 4.5796 & TRN & \\
\hline CHEMBL1562527 & 737823 & 5.1 & 5.2897 & TRN & \\
\hline CHEMBL1311531 & 737823 & 6.7 & 5.2732 & TRN & \\
\hline CHEMBL1363697 & 737823 & 6.5 & 5.3596 & TRN & \\
\hline CHEMBL1312169 & 737823 & 4.8 & 5.3483 & TRN & \\
\hline CHEMBL1330296 & 737823 & 4.7 & 5.3384 & TRN & \\
\hline CHEMBL1369812 & 737823 & 5.5 & 5.5898 & TRN & \\
\hline CHEMBL1494717 & 737823 & 4.85 & 5.1567 & TRN & \\
\hline CHEMBL1742094 & 737823 & 5.2 & 5.3638 & TRN & \\
\hline CHEMBL19980 & 737823 & 4.8 & 5.2408 & TST & \\
\hline CHEMBL1742171 & 737823 & 4.9 & 5.2288 & TRN & \\
\hline CHEMBL1474479 & 737823 & 4.4 & 5.0821 & TRN & \\
\hline CHEMBL1372371 & 737823 & 6.2 & 6.0242 & TRN & \\
\hline CHEMBL1452250 & 737823 & 6.7 & 6.0827 & TRN & \\
\hline CHEMBL1527029 & 737823 & 4.8 & 5.1023 & TRN & \\
\hline CHEMBL1327204 & 737823 & 4.5 & 4.7 & TRN & \\
\hline CHEMBL1358756 & 737823 & 5.6 & 5.1961 & TRN & \\
\hline CHEMBL1507654 & 737823 & 5.0 & 5.2072 & TST & \\
\hline CHEMBL1610577 & 737823 & 5.4 & 5.3523 & TST & \\
\hline CHEMBL1312033 & 737823 & 7.5 & 5.5307 & TRN & \\
\hline CHEMBL1363398 & 737823 & 4.9 & 5.6491 & TRN & \\
\hline CHEMBL1450677 & 737823 & 5.4 & 5.2206 & TRN & \\
\hline CHEMBL1435009 & 737823 & 5.6 & 5.8517 & TRN & \\
\hline CHEMBL1579814 & 737823 & 4.95 & 5.4457 & TRN & \\
\hline CHEMBL 2002680 & 737823 & 5.75 & 5.0786 & TRN & \\
\hline
\end{tabular}




\begin{tabular}{|c|c|c|c|c|c|}
\hline \multicolumn{6}{|c|}{ splemental labıe sz } \\
\hline CHEMBL1490884 & 737823 & 5.45 & 5.1267 & TRN & \\
\hline CHEMBL1397623 & 737823 & 5.6 & 5.6961 & TRN & \\
\hline CHEMBL568379 & 737823 & 6.4 & 6.2385 & TRN & \\
\hline CHEMBL3212319 & 737823 & 5.3 & 5.0376 & TRN & \\
\hline CHEMBL1532555 & 737823 & 4.8 & 4.8303 & TRN & \\
\hline CHEMBL1597692 & 737823 & 4.4 & 5.1243 & TST & \\
\hline CHEMBL1526613 & 737823 & 5.7 & 5.5812 & TRN & \\
\hline CHEMBL1357167 & 737823 & 6.0 & 6.1247 & TRN & \\
\hline CHEMBL1389291 & 737823 & 5.4 & 5.0727 & TRN & \\
\hline CHEMBL1458424 & 737823 & 4.6 & 4.9182 & TRN & \\
\hline CHEMBL1352225 & 737823 & 6.2 & 5.3292 & TRN & \\
\hline CHEMBL1399621 & 737823 & 4.95 & 5.0829 & TRN & \\
\hline CHEMBL1416913 & 737823 & 5.7 & 5.4395 & TRN & \\
\hline CHEMBL1468225 & 737823 & 4.95 & 5.2805 & TRN & \\
\hline CHEMBL1742219 & 737823 & 4.65 & 5.4219 & TRN & \\
\hline CHEMBL1424815 & 737823 & 6.2 & 5.8004 & TST & \\
\hline CHEMBL1985350 & 737823 & 4.6 & 5.2652 & TST & \\
\hline CHEMBL1505211 & 737823 & 5.1 & 5.1874 & TST & \\
\hline CHEMBL1741359 & 737823 & 5.1 & 5.7501 & TRN & \\
\hline CHEMBL1611508 & 737823 & 5.4 & 5.1655 & TRN & \\
\hline CHEMBL1578122 & 737823 & 5.5 & 5.3684 & TRN & \\
\hline CHEMBL1482968 & 737823 & 5.7 & 5.2393 & TRN & \\
\hline CHEMBL3194547 & 737823 & 5.1 & 5.1113 & TRN & \\
\hline CHEMBL1354145 & 737823 & 4.4 & 4.6928 & TRN & \\
\hline CHEMBL1364243 & 737823 & 6.0 & 5.0727 & TRN & \\
\hline CHEMBL1457419 & 737823 & 6.1 & 6.1182 & TST & \\
\hline CHEMBL1512701 & 737823 & 4.8 & 5.4579 & TRN & \\
\hline CHEMBL1724190 & 737823 & 4.85 & 5.4098 & TRN & \\
\hline CHEMBL3207687 & 737823 & 4.6 & 5.2634 & TRN & \\
\hline CHEMBL1721518 & 737823 & 4.95 & 5.1952 & TRN & \\
\hline CHEMBL258893 & 737823 & 5.0 & 5.5312 & TST & \\
\hline CHEMBL1473715 & 737823 & 4.8 & 4.952 & TRN & \\
\hline CHEMBL3207696 & 737823 & 5.2 & 5.5577 & TRN & \\
\hline CHEMBL1587178 & 737823 & 4.8 & 5.2343 & TRN & \\
\hline CHEMBL1577148 & 737823 & 4.65 & 5.2918 & TRN & \\
\hline CHEMBL1531108 & 737823 & 6.5 & 5.1745 & TRN & \\
\hline CHEMBL1506203 & 737823 & 4.85 & 5.3265 & TRN & \\
\hline CHEMBL1515508 & 737823 & 4.9 & 5.3272 & TRN & \\
\hline CHEMBL1438748 & 737823 & 4.9 & 5.6538 & TRN & \\
\hline CHEMBL1585273 & 737823 & 6.95 & 5.4302 & TST & \\
\hline CHEMBL539947 & 737823 & 4.9 & 5.4634 & TRN & \\
\hline CHEMBL1234696 & 737823 & 4.6 & 5.3526 & TRN & \\
\hline CHEMBL1573743 & 737823 & 5.8 & 5.1271 & TRN & \\
\hline CHEMBL1558420 & 737823 & 4.6 & 4.7896 & TRN & \\
\hline CHEMBL567175 & 737823 & 4.4 & 5.477 & TST & \\
\hline CHEMBL1395054 & 737823 & 5.1 & 5.16299 & 9999999999 & TRN \\
\hline CHEMBL1324775 & 737823 & 5.4 & 6.0849 & TRN & \\
\hline CHEMBL1450716 & 737823 & 5.5 & 5.94799 & 99999999995 & TRN \\
\hline & & & & e 3485 & \\
\hline
\end{tabular}




\begin{tabular}{|c|c|c|c|c|c|}
\hline \\
\hline CHEMBL1485323 & 737823 & 5.6 & 5.5523 & TRN & \\
\hline CHEMBL1533197 & 737823 & 5.5 & 5.2714 & TRN & \\
\hline CHEMBL250428 & 737823 & 6.7 & 5.4807 & TRN & \\
\hline CHEMBL1533246 & 737823 & 7.0 & 5.1567 & TRN & \\
\hline CHEMBL1467332 & 737823 & 6.1 & 5.5142 & TST & \\
\hline CHEMBL1508826 & 737823 & 5.1 & 4.8886 & TRN & \\
\hline CHEMBL1513030 & 737823 & 5.9 & 5.6489 & TRN & \\
\hline CHEMBL275084 & 737823 & 4.7 & 5.4288 & TST & \\
\hline CHEMBL42485 & 737823 & 6.4 & 6.0006 & TST & \\
\hline CHEMBL1561718 & 737823 & 5.6 & 5.7958 & TRN & \\
\hline CHEMBL3191244 & 737823 & 5.7 & 5.3267 & TRN & \\
\hline CHEMBL3145025 & 737823 & 4.65 & 5.3858 & TRN & \\
\hline CHEMBL1255936 & 737823 & 5.1 & 5.7037 & TRN & \\
\hline CHEMBL1312970 & 737823 & 4.65 & 5.4034 & TRN & \\
\hline CHEMBL1352783 & 737823 & 4.9 & 5.1248 & TRN & \\
\hline CHEMBL1358939 & 737823 & 5.5 & 5.5366 & TRN & \\
\hline CHEMBL1377526 & 737823 & 4.9 & 5.0033 & TRN & \\
\hline CHEMBL1353611 & 737823 & 4.5 & 4.8342 & TRN & \\
\hline CHEMBL1445094 & 737823 & 6.2 & 5.751 & TRN & \\
\hline CHEMBL1492293 & 737823 & 5.0 & 5.1266 & TRN & \\
\hline CHEMBL1477506 & 737823 & 5.4 & 5.7126 & TRN & \\
\hline CHEMBL1532720 & 737823 & 6.9 & 6.3406 & TRN & \\
\hline CHEMBL1487692 & 737823 & 4.9 & 5.279 & TRN & \\
\hline CHEMBL1741516 & 737823 & 5.2 & 5.3089 & TST & \\
\hline CHEMBL87418 & 737823 & 5.0 & 5.0741 & TRN & \\
\hline CHEMBL3211887 & 737823 & 4.7 & 5.4965 & TST & \\
\hline CHEMBL1545002 & 737823 & 4.6 & 5.2745 & TRN & \\
\hline CHEMBL1405001 & 737823 & 5.2 & 4.9707 & TRN & \\
\hline CHEMBL1741816 & 737823 & 4.6 & 5.1368 & TST & \\
\hline CHEMBL1574476 & 737823 & 5.7 & 5.1448 & TRN & \\
\hline CHEMBL1467940 & 737823 & 5.4 & 5.9804 & TST & \\
\hline CHEMBL1705167 & 737823 & 4.8 & 5.23600 & 2000000001 & TST \\
\hline CHEMBL1511393 & 737823 & 5.6 & 5.5365 & TST & \\
\hline CHEMBL1437244 & 737823 & 4.9 & 4.9397 & TST & \\
\hline CHEMBL1473099 & 737823 & 4.8 & 5.5748 & TRN & \\
\hline CHEMBL1453208 & 737823 & 4.8 & 4.9508 & TRN & \\
\hline CHEMBL1357186 & 737823 & 5.4 & 5.2965 & TRN & \\
\hline CHEMBL1590048 & 737823 & 6.1 & 5.5242 & TRN & \\
\hline CHEMBL1400398 & 737823 & 5.4 & 5.33700 & 0000000001 & TRN \\
\hline CHEMBL1742210 & 737823 & 6.8 & 5.8486 & TST & \\
\hline CHEMBL63349 & 737823 & 6.7 & 5.7576 & TRN & \\
\hline CHEMBL1457262 & 737823 & 4.7 & 4.9816 & TRN & \\
\hline CHEMBL1427186 & 737823 & 4.8 & 5.0952 & TRN & \\
\hline CHEMBL1725270 & 737823 & 4.5 & 5.4 & TRN & \\
\hline CHEMBL1512190 & 737823 & 5.5 & 5.8993 & TRN & \\
\hline CHEMBL1375046 & 737823 & 6.9 & 5.5411 & TRN & \\
\hline CHEMBL1477299 & 737823 & 5.5 & 5.5199 & TRN & \\
\hline CHEMBL198159 & 737823 & 4.9 & 5.0577 & TRN & \\
\hline
\end{tabular}




\begin{tabular}{|c|c|c|c|c|c|}
\hline \multicolumn{6}{|c|}{ Supplemental Table s2.txt } \\
\hline CHEMBL1419738 & 737823 & 5.0 & 5.0058 & TRN & \\
\hline CHEMBL1316075 & 737823 & 7.0 & 6.0552 & TRN & \\
\hline CHEMBL1483302 & 737823 & 6.5 & 4.8109 & TRN & \\
\hline CHEMBL489534 & 737823 & 5.4 & 5.3614 & TRN & \\
\hline CHEMBL1333454 & 737823 & 6.6 & 5.7245 & TRN & \\
\hline CHEMBL1463376 & 737823 & 4.9 & 5.1409 & TRN & \\
\hline CHEMBL1489016 & 737823 & 5.9 & 5.7957 & TRN & \\
\hline CHEMBL1372696 & 737823 & 6.15 & 5.1408 & TRN & \\
\hline CHEMBL1371698 & 737823 & 6.0 & 5.6775 & TRN & \\
\hline CHEMBL1393481 & 737823 & 5.05 & 5.1252 & TRN & \\
\hline CHEMBL1403769 & 737823 & 4.9 & 4.995 & TRN & \\
\hline CHEMBL1590213 & 737823 & 4.9 & 5.4587 & TRN & \\
\hline CHEMBL1335471 & 737823 & 4.8 & 4.8929 & TST & \\
\hline CHEMBL 265699 & 737823 & 5.5 & 5.7681 & TRN & \\
\hline CHEMBL1309557 & 737823 & 5.1 & 5.6819 & TRN & \\
\hline CHEMBL1510521 & 737823 & 5.65 & 5.6027 & TST & \\
\hline CHEMBL1342908 & 737823 & 4.9 & 5.0426 & TRN & \\
\hline CHEMBL1406307 & 737823 & 7.7001 & 6.1254 & TRN & \\
\hline CHEMBL1544991 & 737823 & 4.8 & 5.2198 & TRN & \\
\hline CHEMBL1598896 & 737823 & 5.1 & 5.4524 & TRN & \\
\hline CHEMBL1444856 & 737823 & 5.0 & 5.2472 & TRN & \\
\hline CHEMBL1477071 & 737823 & 5.2 & 5.8165 & TRN & \\
\hline CHEMBL1543760 & 737823 & 5.05 & 5.8246 & TRN & \\
\hline CHEMBL1422181 & 737823 & 5.05 & 5.1186 & TRN & \\
\hline CHEMBL1526262 & 737823 & 6.05 & 5.5902 & TRN & \\
\hline CHEMBL1512878 & 737823 & 4.9 & 4.9649 & TRN & \\
\hline CHEMBL1449490 & 737823 & 5.5 & 5.3751 & TST & \\
\hline CHEMBL 349384 & 737823 & 4.5 & 5.0656 & TST & \\
\hline CHEMBL1409938 & 737823 & 4.85 & 4.9533 & TRN & \\
\hline CHEMBL282489 & 737823 & 4.5 & 5.2443 & TST & \\
\hline CHEMBL3214072 & 737823 & 4.8 & 4.8169 & TRN & \\
\hline CHEMBL1417980 & 737823 & 4.95 & 5.4441 & TRN & \\
\hline CHEMBL1495773 & 737823 & 4.9 & 5.2289 & TRN & \\
\hline CHEMBL1558609 & 737823 & 5.2 & 4.9866 & TRN & \\
\hline CHEMBL1407064 & 737823 & 4.95 & 5.3349 & TRN & \\
\hline CHEMBL1414683 & 737823 & 4.65 & 4.9831 & TRN & \\
\hline CHEMBL1450934 & 737823 & 4.65 & 5.1426 & TRN & \\
\hline CHEMBL1741975 & 737823 & 5.65 & 5.1014 & TRN & \\
\hline CHEMBL1583562 & 737823 & 4.8 & 4.699 & TRN & \\
\hline CHEMBL3214239 & 737823 & 4.85 & 5.33700 & 0000000001 & TRN \\
\hline CHEMBL1533680 & 737823 & 5.0 & 5.3407 & TRN & \\
\hline CHEMBL1527911 & 737823 & 5.85 & 5.0312 & TRN & \\
\hline CHEMBL1348374 & 737823 & 4.85 & 4.9197 & TRN & \\
\hline CHEMBL1316317 & 737823 & 5.9 & 5.4385 & TRN & \\
\hline CHEMBL1382711 & 737823 & 5.75 & 5.7167 & TRN & \\
\hline CHEMBL1503679 & 737823 & 4.65 & 4.9057 & TRN & \\
\hline CHEMBL1492727 & 737823 & 4.7 & 5.1572 & TRN & \\
\hline CHEMBL1607752 & 737823 & 5.75 & 5.3997 & TST & \\
\hline
\end{tabular}




\begin{tabular}{|c|c|c|c|c|c|}
\hline \\
\hline CHEMBL1464371 & 737823 & 4.9 & 5.8109 & TST & \\
\hline CHEMBL1603393 & 737823 & 5.1 & 5.334 & TRN & \\
\hline CHEMBL1532949 & 737823 & 4.85 & 4.869 & TRN & \\
\hline CHEMBL3145119 & 737823 & 4.8 & 5.3968 & TST & \\
\hline CHEMBL1395162 & 737823 & 5.9 & 5.1776 & TRN & \\
\hline CHEMBL1491098 & 737823 & 5.45 & 5.3673 & TRN & \\
\hline CHEMBL3197594 & 737823 & 5.7 & 5.4328 & TRN & \\
\hline CHEMBL1540172 & 737823 & 5.65 & 5.1332 & TST & \\
\hline CHEMBL1537183 & 737823 & 4.8 & 5.371 & TRN & \\
\hline CHEMBL1318411 & 737823 & 4.9 & 4.8817 & TRN & \\
\hline CHEMBL1489765 & 737823 & 4.55 & 4.9218 & TRN & \\
\hline CHEMBL268609 & 737823 & 6.0 & 5.5241 & TRN & \\
\hline CHEMBL1407840 & 737823 & 5.2 & 5.4929 & TRN & \\
\hline CHEMBL1483088 & 737823 & 5.35 & 5.6554 & TRN & \\
\hline CHEMBL1474056 & 737823 & 5.1 & 5.2731 & TRN & \\
\hline CHEMBL1413097 & 737823 & 4.5 & 4.971 & TST & \\
\hline CHEMBL1610409 & 737823 & 5.9 & 5.3306 & TRN & \\
\hline CHEMBL3192650 & 737823 & 4.85 & 5.0943 & TRN & \\
\hline CHEMBL1439631 & 737823 & 5.7 & 5.379 & TRN & \\
\hline CHEMBL1527209 & 737823 & 4.5 & 4.5037 & TRN & \\
\hline CHEMBL1549336 & 737823 & 5.7 & 5.4835 & TRN & \\
\hline CHEMBL1516787 & 737823 & 4.7 & 4.8987 & TRN & \\
\hline CHEMBL1418437 & 737823 & 4.95 & 5.5615 & TRN & \\
\hline CHEMBL492611 & 737823 & 4.4 & 4.877 & TRN & \\
\hline CHEMBL1299933 & 737823 & 5.0 & 5.6643 & TRN & \\
\hline CHEMBL1324494 & 737823 & 6.4 & 5.6247 & TRN & \\
\hline CHEMBL1335862 & 737823 & 6.4 & 5.3458 & TST & \\
\hline CHEMBL1591121 & 737823 & 4.6 & 4.8836 & TRN & \\
\hline CHEMBL1553766 & 737823 & 5.3 & 5.7725 & TRN & \\
\hline CHEMBL1556106 & 737823 & 4.85 & 5.1731 & TRN & \\
\hline CHEMBL1569718 & 737823 & 5.2 & 5.4833 & TRN & \\
\hline CHEMBL1329927 & 737823 & 6.0 & 5.19600 & 0000000001 & TRN \\
\hline CHEMBL1483077 & 737823 & 4.95 & 5.5968 & TRN & \\
\hline CHEMBL1317982 & 737823 & 4.9 & 5.3567 & TRN & \\
\hline CHEMBL398673 & 737823 & 6.0 & 4.7778 & TST & \\
\hline CHEMBL1337146 & 737823 & 5.7 & 5.6163 & TRN & \\
\hline CHEMBL1518362 & 737823 & 6.15 & 5.5591 & TRN & \\
\hline CHEMBL1315461 & 737823 & 4.8 & 5.021 & TRN & \\
\hline CHEMBL 31741 & 737823 & 5.6 & 5.6945 & TRN & \\
\hline CHEMBL3210860 & 737823 & 6.2 & 5.6436 & TRN & \\
\hline CHEMBL1742072 & 737823 & 5.4 & 5.5418 & TRN & \\
\hline CHEMBL1401786 & 737823 & 5.1 & 4.9327 & TRN & \\
\hline CHEMBL1333156 & 737823 & 4.9 & 5.3985 & TRN & \\
\hline CHEMBL1324352 & 737823 & 5.15 & 5.314 & TRN & \\
\hline CHEMBL522600 & 737823 & 5.0 & 5.3638 & TRN & \\
\hline CHEMBL1509531 & 737823 & 4.8 & 5.54200 & 2000000001 & TRN \\
\hline CHEMBL1562643 & 737823 & 5.4 & 5.5167 & TRN & \\
\hline CHEMBL1592227 & 737823 & 6.5 & 5.7423 & TRN & \\
\hline
\end{tabular}




\begin{tabular}{|c|c|c|c|c|c|}
\hline \\
\hline CHEMBL1570788 & 737823 & 4.7 & 5.4362 & TST & \\
\hline CHEMBL1482510 & 737823 & 6.1 & 5.4583 & TRN & \\
\hline CHEMBL1412815 & 737823 & 4.4 & 5.2487 & TRN & \\
\hline CHEMBL1516232 & 737823 & 6.0 & 5.9364 & TRN & \\
\hline CHEMBL1473188 & 737823 & 4.9 & 4.9305 & TRN & \\
\hline CHEMBL1514512 & 737823 & 4.5 & 5.1216 & TST & \\
\hline CHEMBL1328274 & 737823 & 4.9 & 4.5589 & TRN & \\
\hline CHEMBL1590242 & 737823 & 5.6 & 5.3539 & TRN & \\
\hline CHEMBL1486498 & 737823 & 5.4 & 5.3194 & TRN & \\
\hline CHEMBL1583279 & 737823 & 4.9 & 5.0519 & TRN & \\
\hline CHEMBL1533465 & 737823 & 6.7 & 5.8574 & TRN & \\
\hline CHEMBL1433226 & 737823 & 6.7 & 5.428 & TRN & \\
\hline CHEMBL1416766 & 737823 & 4.95 & 5.3193 & TST & \\
\hline CHEMBL1465287 & 737823 & 4.85 & 5.4613 & TRN & \\
\hline CHEMBL3210081 & 737823 & 6.1 & 5.6401 & TRN & \\
\hline CHEMBL1521784 & 737823 & 4.8 & 5.1099 & TRN & \\
\hline CHEMBL1741531 & 737823 & 4.4 & 5.0091 & TST & \\
\hline CHEMBL1493369 & 737823 & 4.7 & 5.0615 & TRN & \\
\hline CHEMBL1606892 & 737823 & 5.6 & 5.2816 & TRN & \\
\hline CHEMBL1415406 & 737823 & 5.7 & 5.7258 & TRN & \\
\hline CHEMBL1325530 & 737823 & 6.1 & 5.6428 & TRN & \\
\hline CHEMBL1403078 & 737823 & 5.95 & 5.4236 & TST & \\
\hline CHEMBL1588100 & 737823 & 7.6 & 5.2294 & TRN & \\
\hline CHEMBL1303739 & 737823 & 6.0 & 5.0592 & TRN & \\
\hline CHEMBL1536254 & 737823 & 5.0 & 5.1728 & TRN & \\
\hline CHEMBL1462936 & 737823 & 4.8 & 5.7415 & TRN & \\
\hline CHEMBL 2369341 & 737823 & 5.0 & 4.8946 & TRN & \\
\hline CHEMBL3190647 & 737823 & 4.6 & 5.3241 & TRN & \\
\hline CHEMBL1590458 & 737823 & 6.0 & 5.3815 & TRN & \\
\hline CHEMBL1450942 & 737823 & 4.6 & 5.41100 & 00000000005 & TRN \\
\hline CHEMBL1542112 & 737823 & 4.8 & 4.887 & TRN & \\
\hline CHEMBL1605586 & 737823 & 5.25 & 5.4679 & TRN & \\
\hline CHEMBL1358586 & 737823 & 4.8 & 5.2034 & TRN & \\
\hline CHEMBL1256147 & 737823 & 4.5 & 5.2222 & TST & \\
\hline CHEMBL1491674 & 737823 & 4.85 & 5.4393 & TRN & \\
\hline CHEMBL1741851 & 737823 & 5.5 & 5.3656 & TRN & \\
\hline CHEMBL1561209 & 737823 & 4.55 & 5.2241 & TRN & \\
\hline CHEMBL1408427 & 737823 & 6.5 & 6.5727 & TRN & \\
\hline CHEMBL1488420 & 737823 & 6.5 & 5.7449 & TST & \\
\hline CHEMBL1530613 & 737823 & 7.0 & 5.7573 & TST & \\
\hline CHEMBL3197893 & 737823 & 4.7 & 5.2961 & TRN & \\
\hline CHEMBL1574106 & 737823 & 5.4 & 5.4055 & TRN & \\
\hline CHEMBL1451119 & 737823 & 5.6 & 5.2961 & TRN & \\
\hline CHEMBL1521453 & 737823 & 6.0 & 5.7462 & TST & \\
\hline CHEMBL582444 & 737823 & 4.9 & 5.2704 & TST & \\
\hline CHEMBL1400835 & 737823 & 5.2 & 5.3909 & TRN & \\
\hline CHEMBL1433704 & 737823 & 5.8 & 5.4296 & TRN & \\
\hline CHEMBL1331969 & 737823 & 4.95 & 5.4387 & TRN & \\
\hline
\end{tabular}




\begin{tabular}{|c|c|c|c|c|c|}
\hline \multicolumn{6}{|c|}{ Supplemental Table S2.txt } \\
\hline CHEMBL1564261 & 737823 & 5.75 & 5.8931 & TRN & \\
\hline CHEMBL1331780 & 737823 & 5.35 & 5.3864 & TRN & \\
\hline CHEMBL344127 & 737823 & 4.4 & 4.7289 & TRN & \\
\hline CHEMBL3199351 & 737823 & 6.0 & 5.4067 & TRN & \\
\hline CHEMBL1586684 & 737823 & 4.9 & 5.4177 & TRN & \\
\hline CHEMBL1372548 & 737823 & 7.5 & 5.5833 & TRN & \\
\hline CHEMBL1474776 & 737823 & 4.5 & 5.8387 & TRN & \\
\hline CHEMBL1455767 & 737823 & 4.8 & 5.3155 & TRN & \\
\hline CHEMBL1442761 & 737823 & 4.65 & 4.9599 & TRN & \\
\hline CHEMBL1452436 & 737823 & 5.4 & 5.6653 & TST & \\
\hline CHEMBL 3208454 & 737823 & 5.35 & 5.1838 & TRN & \\
\hline CHEMBL1378353 & 737823 & 5.05 & 5.5237 & TRN & \\
\hline CHEMBL50267 & 737823 & 4.4 & 5.5412 & TST & \\
\hline CHEMBL1435809 & 737823 & 5.0 & 5.3209 & TRN & \\
\hline CHEMBL1376097 & 737823 & 4.5 & 4.9744 & TRN & \\
\hline CHEMBL3193097 & 737823 & 4.8 & 5.1984 & TRN & \\
\hline CHEMBL1540150 & 737823 & 5.0 & 4.5419 & TRN & \\
\hline CHEMBL1502591 & 737823 & 5.1 & 5.3857 & TRN & \\
\hline CHEMBL1350756 & 737823 & 4.9 & 5.3379 & TRN & \\
\hline CHEMBL 251647 & 737823 & 4.8 & 5.3749 & TST & \\
\hline CHEMBL1539972 & 737823 & 6.0 & 5.5428 & TRN & \\
\hline CHEMBL143360 & 737823 & 4.4 & 4.9909 & TRN & \\
\hline CHEMBL137246 & 737823 & 5.3 & 5.1921 & TRN & \\
\hline CHEMBL1356630 & 737823 & 4.9 & 5.7996 & TRN & \\
\hline CHEMBL1602892 & 737823 & 5.65 & 5.099 & TRN & \\
\hline CHEMBL469309 & 737823 & 5.9 & 5.4131 & TRN & \\
\hline CHEMBL1322414 & 737823 & 5.1 & 5.53600 & 00000000005 & TST \\
\hline CHEMBL3194051 & 737823 & 4.4 & 5.454 & TST & \\
\hline CHEMBL1544287 & 737823 & 5.1 & 5.4673 & TST & \\
\hline CHEMBL1352096 & 737823 & 4.4 & 5.0931 & TRN & \\
\hline CHEMBL1305631 & 737823 & 4.8 & 5.0951 & TRN & \\
\hline CHEMBL1532438 & 737823 & 5.1 & 4.7781 & TRN & \\
\hline CHEMBL1516262 & 737823 & 5.9 & 5.4278 & TRN & \\
\hline CHEMBL1594086 & 737823 & 5.3 & 5.0487 & TRN & \\
\hline CHEMBL1537609 & 737823 & 4.85 & 5.1311 & TRN & \\
\hline CHEMBL1742105 & 737823 & 6.55 & 5.4734 & TRN & \\
\hline CHEMBL1391974 & 737823 & 4.95 & 5.7543 & TST & \\
\hline CHEMBL1338861 & 737823 & 5.1 & 5.20200 & 0000000001 & TRN \\
\hline CHEMBL1563008 & 737823 & 5.65 & 5.6094 & TRN & \\
\hline CHEMBL1489140 & 737823 & 5.2 & 4.8157 & TST & \\
\hline CHEMBL1564816 & 737823 & 4.4 & 5.1185 & TRN & \\
\hline CHEMBL1527923 & 737823 & 5.3 & 5.7616 & TRN & \\
\hline CHEMBL1446112 & 737823 & 4.7 & 5.1382 & TRN & \\
\hline CHEMBL200309 & 737823 & 4.5 & 4.405 & TST & \\
\hline CHEMBL1573944 & 737823 & 6.3 & 5.7284 & TST & \\
\hline CHEMBL1487219 & 737823 & 4.8 & 5.4436 & TST & \\
\hline CHEMBL1444331 & 737823 & 5.35 & 5.2565 & TRN & \\
\hline CHEMBL1505265 & 737823 & 5.4 & 5.0067 & TRN & \\
\hline
\end{tabular}




\begin{tabular}{|c|c|c|c|c|c|}
\hline & & \\
\hline CHEMBL1552708 & 737823 & 5.4 & 5.4502 & TST & \\
\hline CHEMBL 7644 & 737823 & 6.9 & 5.9376 & TST & \\
\hline CHEMBL1372106 & 737823 & 5.4 & 5.5329 & TRN & \\
\hline CHEMBL1314625 & 737823 & 5.0 & 5.5653 & TRN & \\
\hline CHEMBL1389463 & 737823 & 4.8 & 5.3475 & TST & \\
\hline CHEMBL1605309 & 737823 & 6.2 & 5.0676 & TRN & \\
\hline CHEMBL1457723 & 737823 & 5.75 & 5.2673 & TRN & \\
\hline CHEMBL1448839 & 737823 & 4.8 & 5.2382 & TRN & \\
\hline CHEMBL1563032 & 737823 & 5.4 & 5.6081 & TRN & \\
\hline CHEMBL1435216 & 737823 & 5.7 & 5.7088 & TRN & \\
\hline CHEMBL1376224 & 737823 & 4.85 & 4.8656 & TRN & \\
\hline CHEMBL1485231 & 737823 & 4.55 & 4.8595 & TST & \\
\hline CHEMBL1394258 & 737823 & 4.9 & 4.9411 & TRN & \\
\hline CHEMBL1410676 & 737823 & 6.3 & 5.7545 & TRN & \\
\hline CHEMBL 3213457 & 737823 & 7.5 & 5.9012 & TST & \\
\hline CHEMBL1093717 & 737823 & 4.5 & 5.2754 & TRN & \\
\hline CHEMBL1548428 & 737823 & 5.1 & 4.9894 & TRN & \\
\hline CHEMBL1435296 & 737823 & 5.1 & 5.0887 & TRN & \\
\hline CHEMBL3199680 & 737823 & 5.4 & 4.8766 & TRN & \\
\hline CHEMBL1466490 & 737823 & 5.65 & 5.593 & TRN & \\
\hline CHEMBL1310965 & 737823 & 5.15 & 5.6545 & TRN & \\
\hline CHEMBL1443967 & 737823 & 5.05 & 5.3809 & TRN & \\
\hline CHEMBL1566428 & 737823 & 5.9 & 5.6899 & TRN & \\
\hline CHEMBL1466162 & 737823 & 4.55 & 5.0688 & TRN & \\
\hline CHEMBL1316056 & 737823 & 6.5 & 6.3176 & TRN & \\
\hline CHEMBL1473448 & 737823 & 4.9 & 4.6766 & TRN & \\
\hline CHEMBL1410075 & 737823 & 5.9 & 5.4039 & TRN & \\
\hline CHEMBL1463053 & 737823 & 4.7 & 5.1556 & TRN & \\
\hline CHEMBL221721 & 737823 & 5.4 & 5.1822 & TRN & \\
\hline CHEMBL1455783 & 737823 & 5.4 & 5.0332 & TRN & \\
\hline CHEMBL3208184 & 737823 & 5.3 & 5.4534 & TRN & \\
\hline CHEMBL1341328 & 737823 & 5.3 & 5.2705 & TRN & \\
\hline CHEMBL1354353 & 737823 & 6.2 & 5.4016 & TRN & \\
\hline CHEMBL1444141 & 737823 & 4.9 & 4.8221 & TRN & \\
\hline CHEMBL1389005 & 737823 & 6.9 & 4.8075 & TRN & \\
\hline CHEMBL1314486 & 737823 & 6.4 & 6.0071 & TRN & \\
\hline CHEMBL1742215 & 737823 & 4.8 & 5.0006 & TRN & \\
\hline CHEMBL1529365 & 737823 & 5.8 & 5.9409 & TRN & \\
\hline CHEMBL 297784 & 737823 & 6.0 & 5.6953 & TRN & \\
\hline CHEMBL1352616 & 737823 & 5.25 & 5.5852 & TRN & \\
\hline CHEMBL1544856 & 737823 & 4.8 & 5.2311 & TRN & \\
\hline CHEMBL1449918 & 737823 & 6.6 & 5.8262 & TRN & \\
\hline CHEMBL1502745 & 737823 & 5.55 & 5.6822 & TRN & \\
\hline CHEMBL1374527 & 737823 & 5.5 & 5.9992 & TRN & \\
\hline CHEMBL1314022 & 737823 & 4.5 & 5.4039 & TST & \\
\hline CHEMBL1382075 & 737823 & 4.75 & 4.863 & TRN & \\
\hline CHEMBL1545995 & 737823 & 5.95 & 5.6065 & TRN & \\
\hline CHEMBL1968402 & 737823 & 6.05 & 5.53799 & 9999999999 & TRN \\
\hline & & & & e 3491 & \\
\hline
\end{tabular}




\begin{tabular}{|c|c|c|c|c|}
\hline \multicolumn{5}{|c|}{ Supplemental Table S2.txt } \\
\hline CHEMBL1338077 & 737823 & 4.6 & 5.4422 & TRN \\
\hline CHEMBL1457390 & 737823 & 5.6 & 5.4855 & TRN \\
\hline CHEMBL90472 & 737823 & 6.0 & 5.2862 & TST \\
\hline CHEMBL1369388 & 737823 & 5.2 & 5.3747 & TST \\
\hline CHEMBL1451986 & 737823 & 5.4 & 5.5842 & TST \\
\hline CHEMBL1605000 & 737823 & 4.85 & 5.4359 & TRN \\
\hline CHEMBL1542591 & 737823 & 4.6 & 4.8641 & TRN \\
\hline CHEMBL1606968 & 737823 & 5.45 & 5.4742 & TRN \\
\hline CHEMBL1512413 & 737823 & 5.9 & 5.6977 & TRN \\
\hline CHEMBL1357247 & 737823 & 5.6 & 5.9359 & TST \\
\hline CHEMBL1486380 & 737823 & 4.7 & 5.1149 & TRN \\
\hline CHEMBL1351829 & 737823 & 5.9 & 5.3538 & TRN \\
\hline CHEMBL1586365 & 737823 & 4.8 & 4.6899 & TRN \\
\hline CHEMBL1596246 & 737823 & 5.7 & 5.5078 & TRN \\
\hline CHEMBL1515449 & 737823 & 6.4 & 6.0576 & TRN \\
\hline CHEMBL1392154 & 737823 & 4.4 & 4.8655 & TRN \\
\hline CHEMBL1308948 & 737823 & 4.6 & 5.7476 & TST \\
\hline CHEMBL1369062 & 737823 & 4.7 & 4.769 & TRN \\
\hline CHEMBL1449916 & 737823 & 6.25 & 5.7771 & TRN \\
\hline CHEMBL1584783 & 737823 & 5.4 & 5.3505 & TST \\
\hline CHEMBL1478762 & 737823 & 5.2 & 6.1146 & TRN \\
\hline CHEMBL1338163 & 737823 & 4.8 & 4.9883 & TRN \\
\hline CHEMBL1441192 & 737823 & 5.3 & 5.2184 & TRN \\
\hline CHEMBL1318454 & 737823 & 4.9 & 5.2743 & TRN \\
\hline CHEMBL1364871 & 737823 & 4.8 & 5.4718 & TRN \\
\hline CHEMBL1475257 & 737823 & 6.1 & 5.4902 & TRN \\
\hline CHEMBL1587843 & 737823 & 5.05 & 5.1609 & TRN \\
\hline CHEMBL1466677 & 737823 & 4.9 & 5.3364 & TRN \\
\hline CHEMBL 3661417 & 737823 & 5.2 & 5.5537 & TST \\
\hline CHEMBL1742361 & 737823 & 4.45 & 5.3525 & TST \\
\hline CHEMBL1966867 & 737823 & 4.95 & 5.6575 & TRN \\
\hline CHEMBL1329418 & 737823 & 5.9 & 5.8938 & TRN \\
\hline CHEMBL1374544 & 737823 & 6.3 & 6.4435 & TRN \\
\hline CHEMBL1452316 & 737823 & 5.7 & 5.1969 & TST \\
\hline CHEMBL1529490 & 737823 & 5.6 & 5.3024 & TRN \\
\hline CHEMBL1569345 & 737823 & 5.5 & 5.2519 & TRN \\
\hline CHEMBL94990 & 737823 & 4.4 & 4.8842 & TRN \\
\hline CHEMBL1741384 & 737823 & 5.5 & 5.3778 & TST \\
\hline CHEMBL1314011 & 737823 & 4.95 & 5.7038 & TRN \\
\hline CHEMBL1400427 & 737823 & 4.9 & 5.0775 & TRN \\
\hline CHEMBL1500174 & 737823 & 4.55 & 5.2677 & TRN \\
\hline CHEMBL 1558834 & 737823 & 5.5 & 5.5506 & TRN \\
\hline CHEMBL3210945 & 737823 & 5.7 & 6.0053 & TRN \\
\hline CHEMBL1742356 & 737823 & 5.4 & 4.5708 & TST \\
\hline CHEMBL3192006 & 737823 & 5.2 & 5.2448 & TST \\
\hline CHEMBL1473874 & 737823 & 5.5 & 5.4825 & TST \\
\hline CHEMBL1397877 & 737823 & 4.5 & 5.1726 & TRN \\
\hline CHEMBL1416272 & 737823 & 6.3 & 5.8896 & TRN \\
\hline
\end{tabular}




\begin{tabular}{|c|c|c|c|c|c|}
\hline \\
\hline CHEMBL1426487 & 737823 & 4.85 & 5.4643 & TRN & \\
\hline CHEMBL1366393 & 737823 & 5.5 & 6.0649 & TRN & \\
\hline CHEMBL1611423 & 737823 & 5.4 & 5.4193 & TRN & \\
\hline CHEMBL1475810 & 737823 & 5.0 & 4.8508 & TRN & \\
\hline CHEMBL1550463 & 737823 & 4.85 & 5.2182 & TRN & \\
\hline CHEMBL1478221 & 737823 & 4.7 & 4.9164 & TRN & \\
\hline CHEMBL1366260 & 737823 & 4.7 & 5.401 & TRN & \\
\hline CHEMBL1422113 & 737823 & 4.6 & 5.3426 & TRN & \\
\hline CHEMBL1741350 & 737823 & 5.9 & 5.2418 & TST & \\
\hline CHEMBL1741677 & 737823 & 5.4 & 5.61299 & 99999999995 & TRN \\
\hline CHEMBL1594058 & 737823 & 4.9 & 5.4307 & TRN & \\
\hline CHEMBL1591757 & 737823 & 5.5 & 5.6349 & TRN & \\
\hline CHEMBL1394714 & 737823 & 4.9 & 5.7331 & TRN & \\
\hline CHEMBL1741619 & 737823 & 5.2 & 5.6546 & TRN & \\
\hline CHEMBL1485629 & 737823 & 4.5 & 4.9897 & TST & \\
\hline CHEMBL1724716 & 737823 & 4.6 & 4.9154 & TRN & \\
\hline CHEMBL1439172 & 737823 & 4.8 & 5.4091 & TST & \\
\hline CHEMBL1324891 & 737823 & 4.8 & 4.8911 & TRN & \\
\hline CHEMBL1489551 & 737823 & 6.1 & 5.6979 & TRN & \\
\hline CHEMBL1451824 & 737823 & 5.3 & 5.3957 & TRN & \\
\hline CHEMBL1454735 & 737823 & 5.1 & 5.0435 & TRN & \\
\hline CHEMBL404505 & 737823 & 5.3 & 5.8399 & TST & \\
\hline CHEMBL1348021 & 737823 & 4.85 & 4.7904 & TRN & \\
\hline CHEMBL1513659 & 737823 & 5.9 & 5.5539 & TRN & \\
\hline CHEMBL1421568 & 737823 & 4.85 & 5.2595 & TRN & \\
\hline CHEMBL3213969 & 737823 & 5.25 & 5.1663 & TRN & \\
\hline CHEMBL3207753 & 737823 & 6.05 & 5.8457 & TRN & \\
\hline CHEMBL11348 & 737823 & 6.0 & 5.7471 & TRN & \\
\hline CHEMBL1588312 & 737823 & 5.6 & 5.8786 & TRN & \\
\hline CHEMBL1313647 & 737823 & 5.4 & 5.4553 & TST & \\
\hline CHEMBL1496744 & 737823 & 5.9 & 5.5303 & TRN & \\
\hline CHEMBL1972824 & 737823 & 5.05 & 5.8498 & TRN & \\
\hline CHEMBL 225230 & 737823 & 5.4 & 4.9937 & TRN & \\
\hline CHEMBL1337622 & 737823 & 4.5 & 5.1904 & TRN & \\
\hline CHEMBL3210412 & 737823 & 5.0 & 5.6437 & TRN & \\
\hline CHEMBL1436125 & 737823 & 6.4 & 6.4877 & TRN & \\
\hline CHEMBL1456743 & 737823 & 5.75 & 5.4052 & TRN & \\
\hline CHEMBL1344331 & 737823 & 4.8 & 5.3969 & TRN & \\
\hline CHEMBL1730298 & 737823 & 5.1 & 4.6572 & TRN & \\
\hline CHEMBL1471858 & 737823 & 5.65 & 5.5858 & TRN & \\
\hline CHEMBL1421108 & 737823 & 5.45 & 5.67299 & 9999999999 & TRN \\
\hline CHEMBL1520507 & 737823 & 4.85 & 5.6277 & TRN & \\
\hline CHEMBL1531676 & 737823 & 4.9 & 5.3871 & TST & \\
\hline CHEMBL35482 & 737823 & 6.7 & 5.8896 & TRN & \\
\hline CHEMBL3195205 & 737823 & 5.1 & 4.8088 & TRN & \\
\hline CHEMBL1569585 & 737823 & 4.8 & 5.0979 & TRN & \\
\hline CHEMBL1575508 & 737823 & 5.4 & 4.8319 & TRN & \\
\hline CHEMBL1709586 & 737823 & 4.8 & 5.5839 & TRN & \\
\hline
\end{tabular}




\begin{tabular}{|c|c|c|c|c|}
\hline & & & pplement & $\mathrm{a} \perp \mathrm{Ta}$ \\
\hline CHEMBL1416055 & 737823 & 4.8 & 5.1431 & TST \\
\hline CHEMBL1531779 & 737823 & 4.95 & 5.2584 & TST \\
\hline CHEMBL1591275 & 737823 & 5.3 & 5.2598 & TRN \\
\hline CHEMBL1371726 & 737823 & 4.6 & 5.1785 & TRN \\
\hline CHEMBL1395241 & 737823 & 4.6 & 4.9224 & TRN \\
\hline CHEMBL1313043 & 737823 & 5.35 & 5.644 & TRN \\
\hline CHEMBL1387587 & 737823 & 5.85 & 5.2925 & TST \\
\hline CHEMBL1499633 & 737823 & 6.4 & 5.1382 & TRN \\
\hline CHEMBL1597209 & 737823 & 4.9 & 5.0465 & TRN \\
\hline CHEMBL1553352 & 737823 & 6.4 & 5.765 & TRN \\
\hline CHEMBL1300079 & 737823 & 4.9 & 4.5709 & TRN \\
\hline CHEMBL1318105 & 737823 & 5.1 & 5.0931 & TST \\
\hline CHEMBL1331657 & 737823 & 4.7 & 4.8971 & TRN \\
\hline CHEMBL1491332 & 737823 & 5.5 & 5.2166 & TRN \\
\hline CHEMBL1329094 & 737823 & 4.8 & 4.8206 & TRN \\
\hline CHEMBL1431037 & 737823 & 5.0 & 5.2963 & TRN \\
\hline CHEMBL1395431 & 737823 & 5.0 & 5.6331 & TRN \\
\hline CHEMBL1438456 & 737823 & 5.55 & 5.523 & TRN \\
\hline CHEMBL1587995 & 737823 & 4.85 & 5.2621 & TST \\
\hline CHEMBL1317494 & 737823 & 5.7 & 5.8588 & TRN \\
\hline CHEMBL1420088 & 737823 & 5.0 & 5.3365 & TRN \\
\hline CHEMBL1406703 & 737823 & 5.1 & 5.4577 & TST \\
\hline CHEMBL1699046 & 737823 & 5.0 & 5.405 & TST \\
\hline CHEMBL1533232 & 737823 & 4.4 & 5.0133 & TRN \\
\hline CHEMBL1496056 & 737823 & 5.15 & 5.1847 & TRN \\
\hline CHEMBL1448073 & 737823 & 5.2 & 5.3953 & TRN \\
\hline CHEMBL1552752 & 737823 & 5.7 & 6.3359 & TRN \\
\hline CHEMBL1580116 & 737823 & 4.9 & 5.477 & TRN \\
\hline CHEMBL1348869 & 737823 & 8.0 & 5.312 & TST \\
\hline CHEMBL3194368 & 737823 & 6.0 & 5.4918 & TRN \\
\hline CHEMBL1347770 & 737823 & 5.95 & 5.4428 & TRN \\
\hline CHEMBL1525473 & 737823 & 4.9 & 5.7098 & TST \\
\hline CHEMBL1358588 & 737823 & 5.6 & 5.7689 & TRN \\
\hline CHEMBL1348133 & 737823 & 6.8 & 4.9169 & TRN \\
\hline CHEMBL1444745 & 737823 & 4.65 & 4.9281 & TRN \\
\hline CHEMBL1528670 & 737823 & 5.6 & 5.2793 & TRN \\
\hline CHEMBL1583992 & 737823 & 4.9 & 5.2967 & TRN \\
\hline CHEMBL1356138 & 737823 & 5.0 & 5.2317 & TRN \\
\hline CHEMBL71492 & 737823 & 4.7 & 5.1187 & TRN \\
\hline CHEMBL1598680 & 737823 & 6.0 & 5.3304 & TRN \\
\hline CHEMBL1440293 & 737823 & 6.15 & 5.5673 & TST \\
\hline CHEMBL1315725 & 737823 & 5.8 & 4.9184 & TST \\
\hline CHEMBL342375 & 737823 & 4.4 & 5.2257 & TST \\
\hline CHEMBL1327247 & 737823 & 5.5 & 5.3238 & TRN \\
\hline CHEMBL1310284 & 737823 & 5.85 & 5.3078 & TRN \\
\hline CHEMBL1450553 & 737823 & 5.4 & 5.6011 & TST \\
\hline CHEMBL1496691 & 737823 & 6.1 & 5.3624 & TRN \\
\hline CHEMBL1419811 & 737823 & 4.9 & 5.4139 & TST \\
\hline
\end{tabular}




\begin{tabular}{|c|c|c|c|c|}
\hline \multicolumn{5}{|c|}{ pplemental T } \\
\hline CHEMBL1449268 & 737823 & 4.8 & 5.4412 & TRN \\
\hline CHEMBL1388353 & 737823 & 6.4 & 5.7026 & TRN \\
\hline CHEMBL1512540 & 737823 & 6.2 & 5.7739 & TRN \\
\hline CHEMBL1535372 & 737823 & 6.0 & 5.4687 & TRN \\
\hline CHEMBL1374710 & 737823 & 5.7 & 5.7438 & TRN \\
\hline CHEMBL3197136 & 737823 & 7.35 & 6.1061 & TRN \\
\hline CHEMBL1611062 & 737823 & 5.0 & 4.7259 & TRN \\
\hline CHEMBL1379160 & 737823 & 4.6 & 4.8639 & TRN \\
\hline CHEMBL1358614 & 737823 & 5.6 & 5.7218 & TRN \\
\hline CHEMBL1340514 & 737823 & 4.65 & 5.374 & TRN \\
\hline CHEMBL313737 & 737823 & 6.5 & 5.3091 & TST \\
\hline CHEMBL1356118 & 737823 & 4.9 & 4.7951 & TRN \\
\hline CHEMBL1513511 & 737823 & 5.9 & 6.4255 & TRN \\
\hline CHEMBL1476526 & 737823 & 5.6 & 5.8208 & TRN \\
\hline CHEMBL1601477 & 737823 & 4.8 & 5.0865 & TRN \\
\hline CHEMBL1558574 & 737823 & 4.9 & 4.9738 & TRN \\
\hline CHEMBL1397353 & 737823 & 4.9 & 4.9266 & TRN \\
\hline CHEMBL1403483 & 737823 & 5.7 & 5.2833 & TRN \\
\hline CHEMBL1554579 & 737823 & 6.7 & 6.4951 & TRN \\
\hline CHEMBL1487441 & 737823 & 5.0 & 5.1586 & TRN \\
\hline CHEMBL1547700 & 737823 & 4.7 & 4.7903 & TRN \\
\hline CHEMBL1562420 & 737823 & 5.4 & 5.4415 & TRN \\
\hline CHEMBL1355203 & 737823 & 5.7 & 4.9618 & TRN \\
\hline CHEMBL1571457 & 737823 & 4.9 & 5.1405 & TRN \\
\hline CHEMBL1433093 & 737823 & 4.75 & 5.3289 & TST \\
\hline CHEMBL1319381 & 737823 & 5.2 & 5.346 & TRN \\
\hline CHEMBL244948 & 737823 & 4.8 & 5.9601 & TST \\
\hline CHEMBL1311739 & 737823 & 5.65 & 5.0027 & TRN \\
\hline CHEMBL1473755 & 737823 & 6.2 & 6.3496 & TRN \\
\hline CHEMBL3193547 & 737823 & 5.65 & 5.9004 & TRN \\
\hline CHEMBL12014 & 737823 & 6.0 & 5.9735 & TRN \\
\hline CHEMBL1478703 & 737823 & 4.85 & 4.7507 & TRN \\
\hline CHEMBL1387342 & 737823 & 5.6 & 5.1787 & TRN \\
\hline CHEMBL3211476 & 737823 & 6.6 & 5.2145 & TST \\
\hline CHEMBL1313179 & 737823 & 4.6 & 4.6123 & TRN \\
\hline CHEMBL1301725 & 737823 & 5.65 & 5.4531 & TRN \\
\hline CHEMBL1441290 & 737823 & 5.0 & 4.9053 & TRN \\
\hline CHEMBL1514505 & 737823 & 6.1 & 5.9011 & TRN \\
\hline CHEMBL1394956 & 737823 & 4.6 & 4.9324 & TRN \\
\hline CHEMBL1600131 & 737823 & 4.6 & 5.0485 & TRN \\
\hline CHEMBL1483855 & 737823 & 5.1 & 6.0484 & TRN \\
\hline CHEMBL1408419 & 737823 & 5.5 & 5.2119 & TST \\
\hline CHEMBL1513188 & 737823 & 5.8 & 5.6179 & TRN \\
\hline CHEMBL1741771 & 737823 & 5.2 & 4.8474 & TRN \\
\hline CHEMBL1519261 & 737823 & 4.8 & 5.3591 & TRN \\
\hline CHEMBL1518686 & 737823 & 6.0 & 5.6245 & TRN \\
\hline CHEMBL1403311 & 737823 & 5.1 & 5.6109 & TST \\
\hline CHEMBL420539 & 737823 & 5.95 & 6.2011 & TRN \\
\hline
\end{tabular}




\begin{tabular}{|c|c|c|c|c|c|}
\hline \\
\hline CHEMBL1546249 & 737823 & 4.7 & 5.7863 & TST & \\
\hline CHEMBL1408486 & 737823 & 4.9 & 5.6124 & TRN & \\
\hline CHEMBL262083 & 737823 & 4.9 & 5.4507 & TST & \\
\hline CHEMBL292477 & 737823 & 4.5 & 5.0793 & TRN & \\
\hline CHEMBL1588553 & 737823 & 6.4 & 5.9281 & TRN & \\
\hline CHEMBL1317932 & 737823 & 5.9 & 5.7138 & TRN & \\
\hline CHEMBL1521286 & 737823 & 5.6 & 6.1086 & TST & \\
\hline CHEMBL1363499 & 737823 & 4.75 & 4.7397 & TRN & \\
\hline CHEMBL1450466 & 737823 & 4.7 & 4.8847 & TST & \\
\hline CHEMBL1497805 & 737823 & 5.0 & 5.3374 & TRN & \\
\hline CHEMBL1392935 & 737823 & 4.8 & 5.1771 & TRN & \\
\hline CHEMBL1372850 & 737823 & 5.8 & 5.6795 & TRN & \\
\hline CHEMBL1555480 & 737823 & 5.0 & 4.7688 & TRN & \\
\hline CHEMBL1432126 & 737823 & 4.7 & 5.3556 & TST & \\
\hline CHEMBL1319717 & 737823 & 4.7 & 5.6242 & TRN & \\
\hline CHEMBL1336793 & 737823 & 7.0 & 5.3658 & TRN & \\
\hline CHEMBL1318285 & 737823 & 6.2 & 5.67200 & 0000000001 & TRN \\
\hline CHEMBL1403931 & 737823 & 5.0 & 4.6882 & TST & \\
\hline CHEMBL3207538 & 737823 & 5.2 & 5.2486 & TRN & \\
\hline CHEMBL1612620 & 737823 & 5.5 & 5.53100 & 3000000001 & TRN \\
\hline CHEMBL1322349 & 737823 & 6.8 & 5.7959 & TRN & \\
\hline CHEMBL467085 & 737823 & 4.8 & 5.3722 & TRN & \\
\hline CHEMBL1443480 & 737823 & 5.0 & 5.3378 & TRN & \\
\hline CHEMBL1355185 & 737823 & 7.1 & 5.6046 & TRN & \\
\hline CHEMBL7634 & 737823 & 4.5 & 5.0433 & TST & \\
\hline CHEMBL1339054 & 737823 & 4.8 & 5.0489 & TRN & \\
\hline CHEMBL1374947 & 737823 & 5.45 & 5.5318 & TRN & \\
\hline CHEMBL18785 & 737823 & 6.6 & 5.6314 & TRN & \\
\hline CHEMBL3212805 & 737823 & 6.05 & 5.2739 & TRN & \\
\hline CHEMBL1595868 & 737823 & 5.4 & 5.5861 & TRN & \\
\hline CHEMBL1328880 & 737823 & 5.45 & 5.6162 & TRN & \\
\hline CHEMBL1396230 & 737823 & 5.0 & 5.2984 & TRN & \\
\hline CHEMBL1741902 & 737823 & 4.9 & 4.7756 & TRN & \\
\hline CHEMBL1522155 & 737823 & 5.1 & 5.0663 & TRN & \\
\hline CHEMBL 1476580 & 737823 & 5.0 & 4.9797 & TRN & \\
\hline CHEMBL1354426 & 737823 & 5.7 & 5.8299 & TRN & \\
\hline CHEMBL106265 & 737823 & 4.9 & 5.29899 & 99999999995 & TRN \\
\hline CHEMBL1492641 & 737823 & 5.65 & 5.3826 & TRN & \\
\hline CHEMBL1361839 & 737823 & 4.6 & 4.5546 & TRN & \\
\hline CHEMBL1372406 & 737823 & 5.7 & 5.4798 & TRN & \\
\hline CHEMBL1465393 & 737823 & 5.55 & 5.2243 & TRN & \\
\hline CHEMBL1979849 & 737823 & 5.1 & 5.1555 & TRN & \\
\hline CHEMBL1551557 & 737823 & 5.6 & 5.3102 & TRN & \\
\hline CHEMBL1462374 & 737823 & 4.9 & 4.84399 & 9999999999 & TRN \\
\hline CHEMBL1430137 & 737823 & 5.35 & 5.4876 & TRN & \\
\hline CHEMBL1343426 & 737823 & 4.8 & 5.3416 & TST & \\
\hline CHEMBL1369223 & 737823 & 5.15 & 5.534 & TRN & \\
\hline CHEMBL1538879 & 737823 & 6.0 & 5.724 & TST & \\
\hline
\end{tabular}




\begin{tabular}{|c|c|c|c|c|}
\hline \\
\hline CHEMBL3198972 & 737823 & 5.0 & 5.4302 & TRN \\
\hline CHEMBL1495071 & 737823 & 4.4 & 5.3948 & TST \\
\hline CHEMBL1591758 & 737823 & 6.3 & 5.7974 & TRN \\
\hline CHEMBL1407035 & 737823 & 5.4 & 5.7402 & TRN \\
\hline CHEMBL 2062333 & 737823 & 4.9 & 4.9624 & TRN \\
\hline CHEMBL1307577 & 737823 & 5.0 & 4.8633 & TRN \\
\hline CHEMBL1464257 & 737823 & 4.8 & 5.0201 & TRN \\
\hline CHEMBL1504724 & 737823 & 4.85 & 5.2874 & TST \\
\hline CHEMBL1433898 & 737823 & 5.3 & 5.4914 & TRN \\
\hline CHEMBL1314222 & 737823 & 7.1 & 5.604 & TRN \\
\hline CHEMBL1482482 & 737823 & 4.75 & 5.1734 & TRN \\
\hline CHEMBL3209398 & 737823 & 4.8 & 5.224 & TRN \\
\hline CHEMBL1576078 & 737823 & 4.8 & 5.3937 & TST \\
\hline CHEMBL1346850 & 737823 & 4.85 & 5.2093 & TRN \\
\hline CHEMBL1574196 & 737823 & 5.9 & 5.3231 & TRN \\
\hline CHEMBL1388234 & 737823 & 4.6 & 5.2396 & TRN \\
\hline CHEMBL1576417 & 737823 & 4.9 & 5.3581 & TRN \\
\hline CHEMBL1531620 & 737823 & 4.85 & 4.9983 & TST \\
\hline CHEMBL3199540 & 737823 & 5.4 & 5.8333 & TRN \\
\hline CHEMBL3198037 & 737823 & 5.05 & 5.7695 & TST \\
\hline CHEMBL1569326 & 737823 & 4.95 & 4.9401 & TST \\
\hline CHEMBL1565848 & 737823 & 4.9 & 4.9677 & TST \\
\hline CHEMBL1336803 & 737823 & 4.9 & 5.0974 & TST \\
\hline CHEMBL1354363 & 737823 & 6.3 & 5.4604 & TST \\
\hline CHEMBL475375 & 737823 & 5.6 & 5.7601 & TST \\
\hline CHEMBL1401214 & 737823 & 4.8 & 4.9822 & TST \\
\hline CHEMBL1443713 & 737823 & 5.7 & 5.3975 & TST \\
\hline CHEMBL1568643 & 737823 & 5.0 & 5.5009 & TST \\
\hline CHEMBL1452391 & 737823 & 5.25 & 5.7614 & TST \\
\hline CHEMBL187216 & 737823 & 6.3 & 5.3135 & TST \\
\hline CHEMBL36148 & 737823 & 6.0 & 5.1012 & TST \\
\hline CHEMBL1459455 & 737823 & 5.55 & 5.4115 & TST \\
\hline CHEMBL1437288 & 737823 & 4.4 & 4.6976 & TST \\
\hline CHEMBL1484253 & 737823 & 6.1 & 5.7413 & TST \\
\hline CHEMBL1366926 & 737823 & 6.5 & 5.9931 & TST \\
\hline CHEMBL1304794 & 737823 & 5.5 & 4.9835 & TST \\
\hline CHEMBL1720191 & 737823 & 4.5 & 5.2174 & TST \\
\hline CHEMBL1560551 & 737823 & 6.1 & 5.5449 & TST \\
\hline CHEMBL1412519 & 737823 & 5.7 & 5.1812 & TST \\
\hline CHEMBL1447245 & 737823 & 4.9 & 5.8162 & TST \\
\hline CHEMBL1256360 & 737823 & 4.9 & 5.0388 & TST \\
\hline CHEMBL1401324 & 737823 & 4.9 & 5.3692 & TST \\
\hline CHEMBL1337409 & 737823 & 4.65 & 5.1555 & TST \\
\hline CHEMBL1404788 & 737823 & 5.1 & 5.0562 & TST \\
\hline CHEMBL1562047 & 737823 & 5.3 & 5.3249 & TST \\
\hline CHEMBL1433725 & 737823 & 5.2 & 4.95100 & 00000000005 \\
\hline CHEMBL1396236 & 737823 & 5.8 & 5.529 & TST \\
\hline CHEMBL1591487 & 737823 & 4.8 & 5.1433 & TST \\
\hline
\end{tabular}




\begin{tabular}{|c|c|c|c|c|c|}
\hline & & \multicolumn{4}{|c|}{ Supplemental Table S2.txt } \\
\hline CHEMBL1988535 & 737823 & 4.85 & 5.351 & TST & \\
\hline CHEMBL1471561 & 737823 & 5.2 & 5.1988 & TST & \\
\hline CHEMBL1352502 & 737823 & 4.5 & 4.9861 & TST & \\
\hline CHEMBL1347451 & 737823 & 6.45 & 5.2788 & TST & \\
\hline CHEMBL1563724 & 737823 & 4.6 & 5.4334 & TST & \\
\hline CHEMBL1328339 & 737823 & 5.8 & 5.6293 & TST & \\
\hline CHEMBL1374913 & 737823 & 4.5 & 4.5077 & TST & \\
\hline CHEMBL3192331 & 737823 & 6.7 & 5.9492 & TST & \\
\hline CHEMBL 3208106 & 737823 & 4.95 & 5.1872 & TST & \\
\hline CHEMBL1589070 & 737823 & 4.7 & 4.8352 & TST & \\
\hline CHEMBL1371869 & 737823 & 4.75 & 5.3877 & TST & \\
\hline CHEMBL1496074 & 737823 & 4.85 & 4.8601 & TST & \\
\hline CHEMBL1417025 & 737823 & 5.3 & 5.3239 & TST & \\
\hline CHEMBL1560630 & 737823 & 5.0 & 4.9744 & TST & \\
\hline CHEMBL1597869 & 737823 & 4.85 & 5.2737 & TST & \\
\hline CHEMBL1382227 & 737823 & 4.9 & 4.8635 & TST & \\
\hline CHEMBL1322207 & 737823 & 5.5 & 5.5405 & TST & \\
\hline CHEMBL1597288 & 737823 & 4.8 & 5.1341 & TST & \\
\hline CHEMBL1367733 & 737823 & 6.1 & 5.5175 & TST & \\
\hline CHEMBL1318375 & 737823 & 5.8 & 5.5946 & TST & \\
\hline CHEMBL1593827 & 737823 & 6.0 & 6.0902 & TST & \\
\hline CHEMBL1474281 & 737823 & 4.7 & 5.2435 & TST & \\
\hline CHEMBL1597474 & 737823 & 6.3 & 5.7405 & TST & \\
\hline CHEMBL491548 & 737823 & 4.8 & 4.9364 & TST & \\
\hline CHEMBL1375382 & 737823 & 5.2 & 4.8666 & TST & \\
\hline CHEMBL1409369 & 737823 & 4.8 & 5.7387 & TST & \\
\hline CHEMBL1415777 & 737823 & 5.0 & 4.7439 & TST & \\
\hline CHEMBL1422980 & 737823 & 4.6 & 5.2272 & TST & \\
\hline CHEMBL1517051 & 737823 & 5.5 & 5.2298 & TST & \\
\hline CHEMBL1451667 & 737823 & 5.4 & 4.7416 & TST & \\
\hline CHEMBL1514153 & 737823 & 4.8 & 5.2242 & TST & \\
\hline CHEMBL1487159 & 737823 & 5.45 & 5.2304 & TST & \\
\hline CHEMBL1741609 & 737823 & 4.9 & 5.2986 & TST & \\
\hline CHEMBL1469990 & 737823 & 4.8 & 5.54299 & & TST \\
\hline CHEMBL1470721 & 737823 & 6.2 & 5.6979 & TST & \\
\hline CHEMBL1381896 & 737823 & 4.6 & 4.9613 & TST & \\
\hline CHEMBL1301716 & 737823 & 5.85 & 5.1816 & TST & \\
\hline CHEMBL1312725 & 737823 & 5.05 & 5.1325 & TST & \\
\hline CHEMBL 388342 & 737823 & 6.0 & 5.3981 & TST & \\
\hline CHEMBL1533768 & 737823 & 6.3 & 5.2344 & TST & \\
\hline CHEMBL1425511 & 737823 & 5.65 & 5.4174 & TST & \\
\hline CHEMBL1496560 & 737823 & 5.9 & 5.7293 & TST & \\
\hline CHEMBL1997370 & 737823 & 5.6 & 5.3905 & TST & \\
\hline CHEMBL1318228 & 737823 & 4.9 & 5.7638 & TST & \\
\hline CHEMBL1409547 & 737823 & 6.8 & 5.6843 & TST & \\
\hline CHEMBL131244 & 737823 & 4.4 & 4.5743 & TST & \\
\hline CHEMBL1445840 & 737823 & 5.7 & 5.3401 & TST & \\
\hline CHEMBL1327403 & 737823 & 5.0 & 5.0207 & TST & \\
\hline
\end{tabular}




\begin{tabular}{|c|c|c|c|c|}
\hline & & & pplement & al $\mathrm{Ta}$ \\
\hline CHEMBL1394118 & 737823 & 4.8 & 5.4377 & TST \\
\hline CHEMBL1495261 & 737823 & 4.4 & 4.8664 & TST \\
\hline CHEMBL1568233 & 737823 & 5.1 & 5.3571 & TST \\
\hline CHEMBL1355762 & 737823 & 4.9 & 5.3781 & TST \\
\hline CHEMBL1544180 & 737823 & 4.85 & 5.5142 & TST \\
\hline CHEMBL1590270 & 737823 & 5.4 & 5.516 & TST \\
\hline CHEMBL 3190254 & 737823 & 6.3 & 5.5314 & TST \\
\hline CHEMBL1313549 & 737823 & 5.55 & 5.1597 & TST \\
\hline CHEMBL1733817 & 737823 & 4.85 & 5.2781 & TST \\
\hline CHEMBL1332286 & 737823 & 4.95 & 5.2081 & TST \\
\hline CHEMBL1557811 & 737823 & 4.4 & 4.9966 & TST \\
\hline CHEMBL1256735 & 737823 & 5.4 & 5.1254 & TST \\
\hline CHEMBL 3194024 & 737823 & 4.85 & 5.0187 & TST \\
\hline CHEMBL1378339 & 737823 & 5.0 & 5.8361 & TST \\
\hline CHEMBL1354093 & 737823 & 6.1 & 5.8667 & TST \\
\hline CHEMBL899 & 737823 & 5.45 & 5.6424 & TST \\
\hline CHEMBL1501400 & 737823 & 5.6 & 5.6358 & TST \\
\hline CHEMBL1474633 & 737823 & 4.9 & 5.1367 & TST \\
\hline CHEMBL1603471 & 737823 & 4.8 & 4.7627 & TST \\
\hline CHEMBL1350043 & 737823 & 5.3 & 5.8054 & TST \\
\hline CHEMBL1598230 & 737823 & 5.6 & 5.5041 & TST \\
\hline CHEMBL1397825 & 737823 & 4.8 & 4.9738 & TST \\
\hline CHEMBL1386397 & 737823 & 4.85 & 5.0504 & TST \\
\hline CHEMBL1608175 & 737823 & 6.3 & 5.6828 & TST \\
\hline CHEMBL1592963 & 737823 & 5.6 & 5.8627 & TST \\
\hline CHEMBL1527006 & 737823 & 5.7 & 5.3688 & TST \\
\hline CHEMBL1568854 & 737823 & 5.1 & 5.2776 & TST \\
\hline CHEMBL1337781 & 737823 & 5.8 & 5.4622 & TST \\
\hline CHEMBL1322942 & 737823 & 5.3 & 5.2638 & TST \\
\hline CHEMBL1391091 & 737823 & 5.2 & 4.9613 & TST \\
\hline CHEMBL1314100 & 737823 & 4.85 & 5.4698 & TST \\
\hline CHEMBL1302442 & 737823 & 5.65 & 5.4788 & TST \\
\hline CHEMBL1364611 & 737823 & 6.8 & 6.3224 & TST \\
\hline CHEMBL1300567 & 737823 & 6.4 & 5.6659 & TST \\
\hline CHEMBL1515736 & 737823 & 6.1 & 5.8152 & TST \\
\hline CHEMBL1741856 & 737823 & 5.2 & 5.1379 & TST \\
\hline CHEMBL1473055 & 737823 & 4.8 & 5.1107 & TST \\
\hline CHEMBL1454402 & 737823 & 5.4 & 5.5205 & TST \\
\hline CHEMBL1380350 & 737823 & 5.85 & 5.7878 & TST \\
\hline CHEMBL1314971 & 737823 & 5.1 & 5.0404 & TST \\
\hline CHEMBL1406644 & 737823 & 5.3 & 5.2393 & TST \\
\hline CHEMBL1368895 & 737823 & 4.6 & 4.9927 & TST \\
\hline CHEMBL553503 & 737823 & 5.0 & 5.149 & TST \\
\hline CHEMBL1441066 & 737823 & 5.0 & 5.0664 & TST \\
\hline CHEMBL 3212802 & 737823 & 5.35 & 5.6248 & TST \\
\hline CHEMBL1400535 & 737823 & 5.6 & 5.6659 & TST \\
\hline CHEMBL1443952 & 737823 & 5.1 & 5.5179 & TST \\
\hline CHEMBL3194362 & 737823 & 6.15 & 5.4121 & TST \\
\hline
\end{tabular}




\begin{tabular}{|c|c|c|c|c|c|}
\hline \multirow[b]{2}{*}{ CHEMBL1405043 } & \multicolumn{5}{|c|}{ Supplemental Table s2.txt } \\
\hline & 737823 & 5.5 & 5.65 & TST & \\
\hline CHEMBL1557721 & 737823 & 5.65 & 5.5143 & TST & \\
\hline CHEMBL1570716 & 737823 & 6.0 & 5.32299 & 99999999995 & TST \\
\hline CHEMBL1595404 & 737823 & 4.6 & 4.8593 & TST & \\
\hline CHEMBL1331786 & 737823 & 6.0 & 5.2703 & TST & \\
\hline CHEMBL3213029 & 737823 & 4.7 & 5.1559 & TST & \\
\hline CHEMBL1505600 & 737823 & 4.7 & 5.3856 & TST & \\
\hline CHEMBL1397871 & 737823 & 5.4 & 5.4883 & TST & \\
\hline CHEMBL1376048 & 737823 & 6.9 & 5.8505 & TST & \\
\hline CHEMBL1479771 & 737823 & 5.4 & 5.0393 & TST & \\
\hline CHEMBL1521564 & 737823 & 4.9 & 5.1692 & TST & \\
\hline CHEMBL1468692 & 737823 & 6.7 & 5.7589 & TST & \\
\hline CHEMBL1605922 & 737823 & 6.5 & 4.9199 & TST & \\
\hline CHEMBL1559663 & 737823 & 4.5 & 5.2471 & TST & \\
\hline CHEMBL117 & 737823 & 7.7001 & 5.9864 & TST & \\
\hline CHEMBL1532604 & 737823 & 5.0 & 4.69600 & 0000000001 & TST \\
\hline CHEMBL3195449 & 737823 & 4.45 & 4.7353 & TST & \\
\hline CHEMBL1392275 & 737823 & 4.7 & 4.8872 & TST & \\
\hline CHEMBL1367377 & 737823 & 4.8 & 5.2955 & TST & \\
\hline CHEMBL452153 & 737823 & 6.0 & 5.8902 & TST & \\
\hline CHEMBL1411609 & 737823 & 6.3 & 5.6261 & TST & \\
\hline CHEMBL1499893 & 737823 & 5.7 & 5.1042 & TST & \\
\hline CHEMBL1598394 & 737823 & 5.0 & 5.25700 & 0000000001 & TST \\
\hline CHEMBL1480273 & 737823 & 5.2 & 5.325 & TST & \\
\hline CHEMBL1303933 & 737823 & 5.0 & 5.0062 & TST & \\
\hline CHEMBL1437991 & 737823 & 5.6 & 5.5324 & TST & \\
\hline CHEMBL1706489 & 737823 & 4.8 & 5.1579 & TST & \\
\hline CHEMBL1410869 & 737823 & 6.7 & 5.9261 & TST & \\
\hline CHEMBL1324032 & 737823 & 6.4 & 5.8476 & TST & \\
\hline CHEMBL1609813 & 737823 & 4.4 & 4.9621 & TST & \\
\hline CHEMBL1710661 & 737823 & 4.85 & 4.955 & TST & \\
\hline CHEMBL1516187 & 737823 & 5.8 & 5.50700 & 0000000001 & TST \\
\hline CHEMBL129795 & 737823 & 5.3 & 5.1982 & TST & \\
\hline CHEMBL1480796 & 737823 & 4.95 & 5.2541 & TST & \\
\hline CHEMBL1407572 & 737823 & 4.8 & 5.2254 & TST & \\
\hline CHEMBL1420898 & 737823 & 4.8 & 5.1663 & TST & \\
\hline CHEMBL1484214 & 737823 & 5.15 & 4.6635 & TST & \\
\hline CHEMBL1256177 & 737823 & 6.0 & 5.2542 & TST & \\
\hline CHEMBL1448979 & 737823 & 4.6 & 5.5037 & TST & \\
\hline CHEMBL1381829 & 737823 & 6.15 & 5.4577 & TST & \\
\hline CHEMBL1741719 & 737823 & 7.0 & 4.9582 & TST & \\
\hline CHEMBL8165 & 737823 & 5.8 & 5.4896 & TST & \\
\hline CHEMBL1301471 & 737823 & 4.8 & 5.2503 & TST & \\
\hline CHEMBL1476055 & 737823 & 6.2 & 5.2405 & TST & \\
\hline CHEMBL1490143 & 737823 & 5.75 & 5.3871 & TST & \\
\hline CHEMBL1498258 & 737823 & 5.1 & 5.3109 & TST & \\
\hline CHEMBL1419672 & 737823 & 4.95 & 5.1366 & TST & \\
\hline CHEMBL1462808 & 737823 & 4.85 & 5.7382 & TST & \\
\hline & & & & 3500 & \\
\hline
\end{tabular}




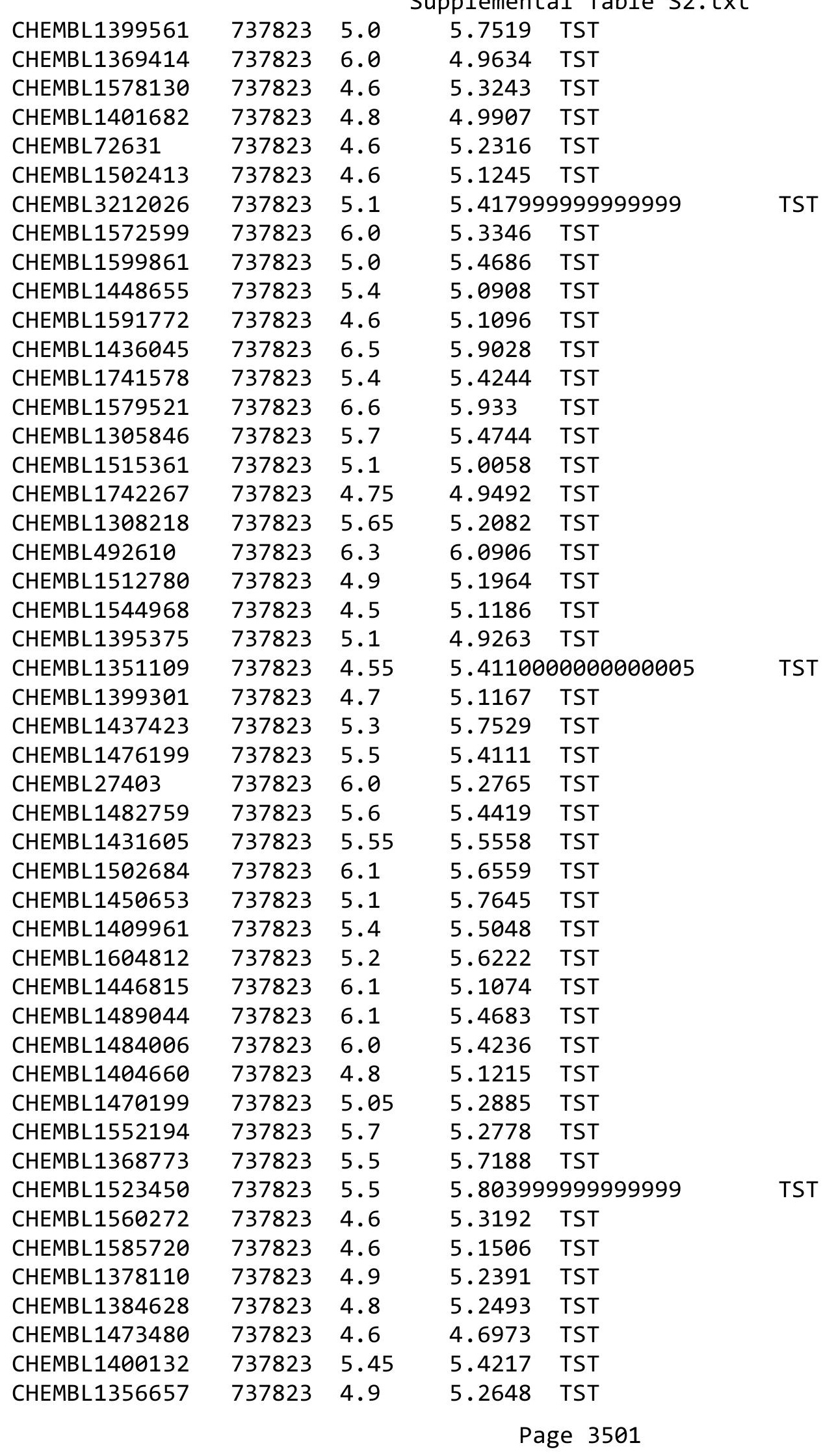




\begin{tabular}{|c|c|c|c|c|c|}
\hline \multicolumn{6}{|c|}{ Supplemental Table S2.txt } \\
\hline CHEMBL1313409 & 737823 & 5.0 & 5.6079 & TST & \\
\hline CHEMBL1301140 & 737823 & 4.75 & 4.7317 & TST & \\
\hline CHEMBL1458143 & 737823 & 4.95 & 5.1713 & TST & \\
\hline CHEMBL1362034 & 737823 & 5.5 & 5.5067 & TST & \\
\hline CHEMBL386466 & 737823 & 5.0 & 5.3795 & TST & \\
\hline CHEMBL1418947 & 737823 & 4.5 & 5.1108 & TST & \\
\hline CHEMBL1409782 & 737823 & 5.7 & 5.3321 & TST & \\
\hline CHEMBL1468272 & 737823 & 5.45 & 5.3872 & TST & \\
\hline CHEMBL1502697 & 737823 & 5.5 & 5.4268 & TST & \\
\hline CHEMBL1446244 & 737823 & 6.15 & 5.6136 & TST & \\
\hline CHEMBL1454049 & 737823 & 6.1 & 5.9073 & TST & \\
\hline CHEMBL3195510 & 737823 & 4.85 & 5.5286 & TST & \\
\hline CHEMBL1320485 & 737823 & 5.1 & 4.9573 & TST & \\
\hline CHEMBL1392564 & 737823 & 5.7 & 5.0188 & TST & \\
\hline CHEMBL1348845 & 737823 & 4.65 & 5.0062 & TST & \\
\hline CHEMBL1330323 & 737823 & 5.5 & 5.6959 & TST & \\
\hline CHEMBL1554960 & 737823 & 6.4 & 6.0073 & TST & \\
\hline CHEMBL1534082 & 737823 & 6.5 & 5.5871 & TST & \\
\hline CHEMBL1558184 & 737823 & 4.9 & 5.6088 & TST & \\
\hline CHEMBL1337584 & 737823 & 4.95 & 5.5835 & TST & \\
\hline CHEMBL1394137 & 737823 & 6.1 & 5.5408 & TST & \\
\hline CHEMBL56 & 737823 & 4.5 & 4.8037 & TST & \\
\hline CHEMBL1561156 & 737823 & 5.8 & 5.3261 & TST & \\
\hline CHEMBL1573683 & 737823 & 6.55 & 5.4708 & TST & \\
\hline CHEMBL1397782 & 737823 & 5.9 & 5.3444 & TST & \\
\hline CHEMBL29726 & 737823 & 4.4 & 4.5893 & TST & \\
\hline CHEMBL1571749 & 737823 & 8.2 & 4.9741 & TST & \\
\hline CHEMBL3212631 & 737823 & 4.85 & 5.2745 & TST & \\
\hline CHEMBL1461359 & 737823 & 4.85 & 5.2217 & TST & \\
\hline CHEMBL1311840 & 737823 & 5.9 & 5.3375 & TST & \\
\hline CHEMBL1546480 & 737823 & 4.9 & 5.0473 & TST & \\
\hline CHEMBL1468024 & 737823 & 5.5 & 5.3195 & TST & \\
\hline CHEMBL1330407 & 737823 & 5.8 & 5.5217 & TST & \\
\hline CHEMBL1477644 & 737823 & 6.95 & 6.13 & TST & \\
\hline CHEMBL1515899 & 737823 & 5.1 & 5.4076 & TST & \\
\hline CHEMBL1361750 & 737823 & 5.3 & 5.2929 & TST & \\
\hline CHEMBL1539764 & 737823 & 4.6 & 5.12799 & 9999999999 & TST \\
\hline CHEMBL1741802 & 737823 & 6.8 & 5.0215 & TST & \\
\hline CHEMBL1445233 & 737823 & 4.85 & 5.517 & TST & \\
\hline CHEMBL86676 & 737823 & 6.8 & 5.1729 & TST & \\
\hline CHEMBL1564379 & 737823 & 4.4 & 4.8808 & TST & \\
\hline CHEMBL1988621 & 737823 & 5.1 & 5.2337 & TST & \\
\hline CHEMBL1356106 & 737823 & 4.9 & 4.8955 & TST & \\
\hline CHEMBL1413132 & 737823 & 5.4 & 5.4303 & TST & \\
\hline CHEMBL1400976 & 737823 & 5.1 & 5.03600 & 00000000005 & TST \\
\hline CHEMBL1512312 & 737823 & 6.0 & 5.7766 & TST & \\
\hline CHEMBL1600421 & 737823 & 5.45 & 5.5812 & TST & \\
\hline CHEMBL287045 & 737823 & 4.9 & 5.0776 & TST & \\
\hline
\end{tabular}




\begin{tabular}{|c|c|c|c|c|c|}
\hline \multirow{3}{*}{$\begin{array}{l}\text { CHEMBL1327171 } \\
\text { CHEMBL } 1349620\end{array}$} & & \multicolumn{4}{|c|}{ Supplemental Table S2.txt } \\
\hline & & 6.05 & 5.46399 & 99999999995 & TST \\
\hline & 737823 & 4.85 & 5.7308 & TST & \\
\hline CHEMBL1479106 & 737823 & 4.9 & 4.9318 & TST & \\
\hline CHEMBL1358208 & 737823 & 6.8 & 5.1062 & TST & \\
\hline CHEMBL1446523 & 737823 & 6.6 & 6.4187 & TST & \\
\hline CHEMBL1496344 & 737823 & 5.95 & 5.3681 & TST & \\
\hline CHEMBL1352745 & 737823 & 5.05 & 5.5008 & TST & \\
\hline CHEMBL1441415 & 737823 & 6.3 & 6.3069 & TST & \\
\hline CHEMBL1357909 & 737823 & 5.3 & 5.4022 & TST & \\
\hline CHEMBL3214362 & 737823 & 4.6 & 5.3386 & TST & \\
\hline CHEMBL1592481 & 737823 & 5.2 & 5.0822 & TST & \\
\hline CHEMBL1591381 & 737823 & 4.6 & 4.7075 & TST & \\
\hline CHEMBL1302695 & 737823 & 5.8 & 5.4967 & TST & \\
\hline CHEMBL566899 & 737823 & 6.6 & 6.4839 & TST & \\
\hline CHEMBL1395297 & 737823 & 4.7 & 5.0473 & TST & \\
\hline CHEMBL 25230 & 737823 & 4.4 & 4.8772 & TST & \\
\hline CHEMBL1439808 & 737823 & 4.5 & 5.5354 & TST & \\
\hline CHEMBL1406530 & 737823 & 4.65 & 4.8863 & TST & \\
\hline CHEMBL1180496 & 737823 & 4.5 & 4.7428 & TST & \\
\hline CHEMBL1596765 & 737823 & 5.55 & 5.3596 & TST & \\
\hline CHEMBL1450153 & 737823 & 4.95 & 5.3661 & TST & \\
\hline CHEMBL1573555 & 737823 & 5.9 & 5.3371 & TST & \\
\hline CHEMBL1368942 & 737823 & 4.9 & 5.0881 & TST & \\
\hline CHEMBL1741880 & 737823 & 6.4 & 5.3195 & TST & \\
\hline CHEMBL1307282 & 737823 & 5.85 & 5.4627 & TST & \\
\hline CHEMBL1597169 & 737823 & 5.2 & 5.4752 & TST & \\
\hline CHEMBL10009 & 737823 & 5.6 & 5.3975 & TST & \\
\hline CHEMBL1496596 & 737823 & 7.4 & 6.0874 & TST & \\
\hline CHEMBL1425063 & 737823 & 4.5 & 5.6026 & TST & \\
\hline CHEMBL1742013 & 737823 & -0.0 & 5.3455 & TST & \\
\hline CHEMBL1588068 & 737823 & 4.9 & 5.0018 & TST & \\
\hline CHEMBL1366061 & 737823 & 5.6 & 5.316 & TST & \\
\hline CHEMBL1465094 & 737823 & 5.05 & 5.3344 & TST & \\
\hline CHEMBL1357381 & 737823 & 5.6 & 5.7713 & TST & \\
\hline CHEMBL1256020 & 737823 & 6.0 & 4.9472 & TST & \\
\hline CHEMBL1499116 & 737823 & 5.55 & 5.0796 & TST & \\
\hline CHEMBL1433464 & 737823 & 5.9 & 6.1047 & TST & \\
\hline CHEMBL1340837 & 737823 & 4.75 & 5.5113 & TST & \\
\hline CHEMBL 294649 & 737823 & 4.8 & 4.8309 & TST & \\
\hline CHEMBL1437176 & 737823 & 5.9 & 5.4789 & TST & \\
\hline CHEMBL1323342 & 737823 & 5.85 & 5.2198 & TST & \\
\hline CHEMBL1413340 & 737823 & 4.7 & 5.1052 & TST & \\
\hline CHEMBL1337725 & 737823 & 4.85 & 5.3947 & TST & \\
\hline CHEMBL 1370377 & 737823 & 5.5 & 4.7891 & TST & \\
\hline CHEMBL1448161 & 737823 & 5.9 & 5.4653 & TST & \\
\hline CHEMBL597047 & 737823 & 5.55 & 5.608 & TST & \\
\hline CHEMBL1367944 & 737823 & 4.8 & 5.4824 & TST & \\
\hline CHEMBL1362111 & 737823 & 6.0 & 5.4811 & TST & \\
\hline
\end{tabular}




\begin{tabular}{|c|c|c|c|c|c|}
\hline \\
\hline CHEMBL34704 & 737823 & 6.0 & 5.3261 & TST & \\
\hline CHEMBL1742205 & 737823 & 5.2 & 5.6321 & TST & \\
\hline CHEMBL3212934 & 737823 & 5.1 & 5.5946 & TST & \\
\hline CHEMBL1595862 & 737823 & 4.6 & 5.2606 & TST & \\
\hline CHEMBL1489402 & 737823 & 5.3 & 5.5471 & TST & \\
\hline CHEMBL1490079 & 737823 & 5.7 & 5.2348 & TST & \\
\hline CHEMBL1329478 & 737823 & 5.4 & 5.4226 & TST & \\
\hline CHEMBL1200938 & 737823 & 4.8 & 5.0216 & TST & \\
\hline CHEMBL1465552 & 737823 & 5.7 & 5.4847 & TST & \\
\hline CHEMBL1371431 & 737823 & 4.7 & 5.2703 & TST & \\
\hline CHEMBL1505628 & 737823 & 4.9 & 5.6604 & TST & \\
\hline CHEMBL1411148 & 737823 & 5.9 & 5.4314 & TST & \\
\hline CHEMBL12344 & 737823 & 5.3 & 4.74100 & 00000000005 & TST \\
\hline CHEMBL1485384 & 737823 & 5.1 & 5.5104 & TST & \\
\hline CHEMBL1447481 & 737823 & 6.1 & 5.5062 & TST & \\
\hline CHEMBL1390229 & 737823 & 5.2 & 5.2795 & TST & \\
\hline CHEMBL1322376 & 737823 & 5.8 & 5.5483 & TST & \\
\hline CHEMBL1587554 & 737823 & 5.65 & 5.2789 & TST & \\
\hline CHEMBL1536188 & 737823 & 5.25 & 5.1189 & TST & \\
\hline CHEMBL1492801 & 737823 & 5.9 & 5.6262 & TST & \\
\hline CHEMBL1553070 & 737823 & 6.8 & 6.1648 & TST & \\
\hline CHEMBL1550000 & 737823 & 5.35 & 5.7549 & TST & \\
\hline CHEMBL3197786 & 737823 & 5.7 & 5.5501 & TST & \\
\hline CHEMBL1588802 & 737823 & 6.1 & 5.6804 & TST & \\
\hline CHEMBL1452932 & 737823 & 5.7 & 4.8782 & TST & \\
\hline CHEMBL1442542 & 737823 & 4.5 & 5.1697 & TST & \\
\hline CHEMBL1390122 & 737823 & 5.65 & 5.607 & TST & \\
\hline CHEMBL574985 & 737823 & 7.3 & 5.6072 & TST & \\
\hline CHEMBL1993145 & 737823 & 4.9 & 5.3948 & TST & \\
\hline CHEMBL34730 & 737823 & 6.9 & 4.989 & TST & \\
\hline CHEMBL1373147 & 737823 & 4.5 & 4.827 & TST & \\
\hline CHEMBL1570196 & 737823 & 6.9 & 5.5609 & TST & \\
\hline CHEMBL1480087 & 737823 & 5.5 & 5.1999 & TST & \\
\hline CHEMBL1472052 & 737823 & 4.9 & 5.2667 & TST & \\
\hline CHEMBL1572173 & 737823 & 6.0 & 5.5102 & TST & \\
\hline CHEMBL1314182 & 737823 & 5.5 & 5.6709 & TST & \\
\hline CHEMBL1567589 & 737823 & 5.65 & 5.4598 & TST & \\
\hline CHEMBL53898 & 737823 & 4.9 & 5.27 & TST & \\
\hline CHEMBL1522134 & 737823 & 4.8 & 5.2528 & TST & \\
\hline CHEMBL1302141 & 737823 & 5.45 & 5.0458 & TST & \\
\hline CHEMBL1352269 & 737823 & 5.3 & 5.6797 & TST & \\
\hline CHEMBL1516265 & 737823 & 5.3 & 4.9009 & TST & \\
\hline CHEMBL1741337 & 737823 & 4.8 & 4.5967 & TST & \\
\hline CHEMBL1514484 & 737823 & 4.4 & 4.8154 & TST & \\
\hline CHEMBL1472705 & 737823 & 6.4 & 5.5999 & TST & \\
\hline CHEMBL1483214 & 737823 & 5.0 & 5.3639 & TST & \\
\hline CHEMBL3198953 & 737823 & 5.8 & 5.4653 & TST & \\
\hline CHEMBL1311806 & 737823 & 4.85 & 5.0003 & TST & \\
\hline
\end{tabular}




\begin{tabular}{|c|c|c|c|c|c|}
\hline \multicolumn{6}{|c|}{ splement } \\
\hline CHEMBL1418864 & 737823 & 6.45 & 5.4879 & TST & \\
\hline CHEMBL1474114 & 737823 & 6.1 & 5.2531 & TST & \\
\hline CHEMBL1434286 & 737823 & 4.4 & 4.8781 & TST & \\
\hline CHEMBL1613338 & 737823 & 5.2 & 5.2866 & TST & \\
\hline CHEMBL1349372 & 737823 & 4.6 & 5.2298 & TST & \\
\hline CHEMBL1352525 & 737823 & 4.8 & 5.24799 & 9999999999 & TST \\
\hline CHEMBL75773 & 737823 & 4.4 & 4.9396 & TST & \\
\hline CHEMBL1967062 & 737823 & 5.65 & 5.0767 & TST & \\
\hline CHEMBL1377106 & 737823 & 4.6 & 4.5398 & TST & \\
\hline CHEMBL1543038 & 737823 & 4.8 & 5.5748 & TST & \\
\hline CHEMBL1368643 & 737823 & 6.9 & 5.7538 & TST & \\
\hline CHEMBL1354281 & 737823 & 5.2 & 5.1173 & TST & \\
\hline CHEMBL1327004 & 737823 & 4.6 & 5.2572 & TST & \\
\hline CHEMBL1335686 & 737823 & 4.85 & 5.2702 & TST & \\
\hline CHEMBL1356721 & 737823 & 5.6 & 5.5447 & TST & \\
\hline CHEMBL1581533 & 737823 & 4.85 & 5.499 & TST & \\
\hline CHEMBL1321511 & 737823 & 5.3 & 5.5092 & TST & \\
\hline CHEMBL1518182 & 737823 & 4.6 & 5.3699 & TST & \\
\hline CHEMBL1511408 & 737823 & 5.15 & 5.3711 & TST & \\
\hline CHEMBL1380844 & 737823 & 5.45 & 5.3148 & TST & \\
\hline CHEMBL1419743 & 737823 & 5.4 & 5.3307 & TST & \\
\hline CHEMBL1335617 & 737823 & 5.0 & 4.9682 & TST & \\
\hline CHEMBL1595944 & 737823 & 4.6 & 4.8734 & TST & \\
\hline CHEMBL1571679 & 737823 & 6.2 & 5.9385 & TST & \\
\hline CHEMBL1589809 & 737823 & 5.0 & 5.4322 & TST & \\
\hline CHEMBL1544721 & 737823 & 5.05 & 5.0998 & TST & \\
\hline CHEMBL1371947 & 737823 & 5.8 & 5.6646 & TST & \\
\hline CHEMBL1434022 & 737823 & 4.7 & 4.7381 & TST & \\
\hline CHEMBL1415790 & 737823 & 5.1 & 5.5957 & TST & \\
\hline CHEMBL3214150 & 737823 & 5.1 & 4.9239 & TST & \\
\hline CHEMBL1551990 & 737823 & 6.1 & 5.8059 & TST & \\
\hline CHEMBL1568575 & 737823 & 6.7 & 6.2566 & TST & \\
\hline CHEMBL1404408 & 737823 & 7.2 & 6.0591 & TST & \\
\hline CHEMBL1594232 & 737823 & 4.5 & 4.9516 & TST & \\
\hline CHEMBL3189715 & 737823 & 4.8 & 5.1015 & TST & \\
\hline CHEMBL565654 & 737823 & 6.3 & 6.0602 & TST & \\
\hline CHEMBL1457317 & 737823 & 4.8 & 5.4246 & TST & \\
\hline CHEMBL3209203 & 737823 & 5.3 & 5.5498 & TST & \\
\hline CHEMBL1572167 & 737823 & 4.9 & 4.831 & TST & \\
\hline CHEMBL1311526 & 737823 & 5.35 & 5.1094 & TST & \\
\hline CHEMBL1566202 & 737823 & 4.8 & 5.50200 & 0000000001 & TST \\
\hline CHEMBL1741752 & 737823 & 5.5 & 5.3516 & TST & \\
\hline CHEMBL1464437 & 737823 & 5.7 & 5.3876 & TST & \\
\hline CHEMBL1501406 & 737823 & 4.4 & 5.2418 & TST & \\
\hline CHEMBL1475137 & 737823 & 4.5 & 5.1287 & TST & \\
\hline CHEMBL1487164 & 737823 & 5.1 & 5.1103 & TST & \\
\hline CHEMBL1535604 & 737823 & 4.95 & 5.0135 & TST & \\
\hline CHEMBL1459899 & 737823 & 4.8 & 5.5901 & TST & \\
\hline
\end{tabular}




\begin{tabular}{|c|c|c|c|c|}
\hline \multicolumn{5}{|c|}{ pplemental } \\
\hline CHEMBL1479767 & 737823 & 5.7 & 5.1211 & TST \\
\hline CHEMBL1469737 & 737823 & 5.2 & 4.8576 & TST \\
\hline CHEMBL1568946 & 737823 & 5.25 & 5.3727 & TST \\
\hline CHEMBL1256661 & 737823 & 6.2 & 5.1808 & TST \\
\hline CHEMBL1578653 & 737823 & 4.9 & 5.6793 & TST \\
\hline CHEMBL1317588 & 737823 & 5.8 & 6.0003 & TST \\
\hline CHEMBL1308361 & 737823 & 5.75 & 5.3276 & TST \\
\hline CHEMBL1431337 & 737823 & 4.45 & 5.3065 & TST \\
\hline CHEMBL1723467 & 737823 & 4.85 & 5.1092 & TST \\
\hline CHEMBL1395344 & 737823 & 6.3 & 6.7789 & TST \\
\hline CHEMBL1325735 & 737823 & 6.7 & 5.9289 & TST \\
\hline CHEMBL1568588 & 737823 & 4.9 & 4.9419 & TST \\
\hline CHEMBL1517099 & 737823 & 5.7 & 5.2898 & TST \\
\hline CHEMBL 2374026 & 737823 & 5.6 & 5.0279 & TST \\
\hline CHEMBL1355242 & 737823 & 4.6 & 5.1747 & TST \\
\hline CHEMBL1445685 & 737823 & 5.1 & 5.8391 & TST \\
\hline CHEMBL1304296 & 737823 & 4.85 & 5.1962 & TST \\
\hline CHEMBL1553902 & 737823 & 5.4 & 5.3962 & TST \\
\hline CHEMBL1495763 & 737823 & 5.45 & 5.7925 & TST \\
\hline CHEMBL11684 & 737823 & 6.0 & 5.3079 & TST \\
\hline CHEMBL1491104 & 737823 & 6.1 & 5.4869 & TST \\
\hline CHEMBL1582470 & 737823 & 4.9 & 5.4012 & TST \\
\hline CHEMBL 1310248 & 737823 & 5.65 & 5.5068 & TST \\
\hline CHEMBL1577571 & 737823 & 5.3 & 5.3917 & TST \\
\hline CHEMBL1310995 & 737823 & 4.6 & 5.0724 & TST \\
\hline CHEMBL1321719 & 737823 & 4.85 & 5.2825 & TST \\
\hline CHEMBL1612602 & 737823 & 5.1 & 5.1422 & TST \\
\hline CHEMBL 1742156 & 737823 & 4.85 & 4.993 & TST \\
\hline CHEMBL1377321 & 737823 & 5.05 & 5.3226 & TST \\
\hline CHEMBL1505717 & 737823 & 5.0 & 5.3895 & TST \\
\hline CHEMBL1590266 & 737823 & 4.6 & 5.4232 & TST \\
\hline CHEMBL3197073 & 737823 & 4.85 & 5.5318 & TST \\
\hline CHEMBL1510918 & 737823 & 5.6 & 5.4487 & TST \\
\hline CHEMBL1572184 & 737823 & 5.9 & 5.3635 & TST \\
\hline CHEMBL1376622 & 737823 & 4.6 & 5.2677 & TST \\
\hline CHEMBL1598492 & 737823 & 4.85 & 4.6951 & TST \\
\hline CHEMBL1566490 & 737823 & 5.6 & 5.6079 & TST \\
\hline CHEMBL1416389 & 737823 & 6.0 & 5.5059 & TST \\
\hline CHEMBL1741725 & 737823 & 5.1 & 4.8165 & TST \\
\hline CHEMBL1406495 & 737823 & 4.8 & 5.2945 & TST \\
\hline CHEMBL3195528 & 737823 & 5.45 & 5.4517 & TST \\
\hline CHEMBL1609333 & 737823 & 5.2 & 5.3164 & TST \\
\hline CHEMBL1316745 & 737823 & 5.3 & 4.6492 & TST \\
\hline CHEMBL1341313 & 737823 & 4.95 & 5.2442 & TST \\
\hline CHEMBL1435885 & 737823 & 6.3 & 5.067 & TST \\
\hline CHEMBL1565610 & 737823 & 4.75 & 5.0746 & TST \\
\hline CHEMBL1472880 & 737823 & 5.4 & 5.3825 & TST \\
\hline CHEMBL1372330 & 737823 & 6.0 & 5.2157 & TST \\
\hline
\end{tabular}




\begin{tabular}{|c|c|c|c|c|}
\hline & & & pplement & al $\mathrm{Ta}$ \\
\hline CHEMBL1484742 & 737823 & 4.4 & 4.8862 & TST \\
\hline CHEMBL1549431 & 737823 & 5.85 & 5.8338 & TST \\
\hline CHEMBL16857 & 737823 & 6.0 & 5.205 & TST \\
\hline CHEMBL1475620 & 737823 & 4.7 & 4.8238 & TST \\
\hline CHEMBL471226 & 737823 & 6.7 & 5.8027 & TST \\
\hline CHEMBL1436540 & 737823 & 5.4 & 5.4938 & TST \\
\hline CHEMBL1330299 & 737823 & 6.9 & 5.7282 & TST \\
\hline CHEMBL1542262 & 737823 & 4.8 & 4.9459 & TST \\
\hline CHEMBL1425971 & 737823 & 4.8 & 5.2615 & TST \\
\hline CHEMBL1598878 & 737823 & 5.1 & 4.8844 & TST \\
\hline CHEMBL1488236 & 737823 & 5.15 & 5.2607 & TST \\
\hline CHEMBL1596186 & 737823 & 5.5 & 5.4498 & TST \\
\hline CHEMBL1369863 & 737823 & 5.1 & 4.8223 & TST \\
\hline CHEMBL1507676 & 737823 & 4.9 & 5.6597 & TST \\
\hline CHEMBL1727670 & 737823 & 4.95 & 5.1317 & TST \\
\hline CHEMBL1493037 & 737823 & 4.8 & 5.4378 & TST \\
\hline CHEMBL1404595 & 737823 & 5.05 & 5.143 & TST \\
\hline CHEMBL1371243 & 737823 & 5.0 & 5.4502 & TST \\
\hline CHEMBL1480806 & 737823 & 6.8 & 6.527 & TST \\
\hline CHEMBL1358009 & 737823 & 5.4 & 5.0008 & TST \\
\hline CHEMBL1308408 & 737823 & 5.85 & 5.6697 & TST \\
\hline CHEMBL1200766 & 737823 & 5.5 & 5.1092 & TST \\
\hline CHEMBL1575087 & 737823 & 4.75 & 5.2431 & TST \\
\hline CHEMBL1436521 & 737823 & 5.1 & 5.2242 & TST \\
\hline CHEMBL1481510 & 737823 & 5.4 & 5.4067 & TST \\
\hline CHEMBL1413404 & 737823 & 5.0 & 4.8272 & TST \\
\hline CHEMBL113142 & 737823 & 4.5 & 5.0161 & TST \\
\hline CHEMBL1710820 & 737823 & 5.0 & 5.4066 & TST \\
\hline CHEMBL1357182 & 737823 & 5.0 & 4.8607 & TST \\
\hline CHEMBL1357930 & 737823 & 5.0 & 4.7049 & TST \\
\hline CHEMBL1580099 & 737823 & 5.0 & 5.1443 & TST \\
\hline CHEMBL1525822 & 737823 & 5.5 & 5.6222 & TST \\
\hline CHEMBL1579360 & 737823 & 4.9 & 5.334 & TST \\
\hline CHEMBL1322740 & 737823 & 5.4 & 5.7322 & TST \\
\hline CHEMBL1539911 & 737823 & 4.4 & 5.0406 & TST \\
\hline CHEMBL1532380 & 737823 & 5.15 & 5.255 & TST \\
\hline CHEMBL1477492 & 737823 & 4.7 & 4.9064 & TST \\
\hline CHEMBL1348445 & 737823 & 5.0 & 5.3851 & TST \\
\hline CHEMBL1742208 & 737823 & 4.6 & 5.4507 & TST \\
\hline CHEMBL 3208230 & 737823 & 4.6 & 4.9122 & TST \\
\hline CHEMBL3190451 & 737823 & 4.95 & 5.3191 & TST \\
\hline CHEMBL1383155 & 737823 & 5.1 & 5.1893 & TST \\
\hline CHEMBL1524323 & 737823 & 5.85 & 5.6422 & TST \\
\hline CHEMBL1350038 & 737823 & 5.2 & 5.0318 & TST \\
\hline CHEMBL1323499 & 737823 & 5.4 & 5.2302 & TST \\
\hline CHEMBL1449669 & 737823 & 4.9 & 5.347 & TST \\
\hline CHEMBL1549491 & 737823 & 4.85 & 5.3377 & TST \\
\hline CHEMBL1599492 & 737823 & 4.6 & 4.9891 & TST \\
\hline
\end{tabular}




\begin{tabular}{|c|c|c|c|c|}
\hline \multicolumn{5}{|c|}{ Supplemental Table S2.txt } \\
\hline CHEMBL1595371 & 737823 & 6.2 & 5.6745 & TST \\
\hline CHEMBL3195990 & 737823 & 5.5 & 5.5013 & TST \\
\hline CHEMBL1557715 & 737823 & 4.75 & 4.8537 & TST \\
\hline CHEMBL1441787 & 737823 & 4.8 & 4.774 & TST \\
\hline CHEMBL1560141 & 737823 & 4.65 & 4.9971 & TST \\
\hline CHEMBL1360739 & 737823 & 5.95 & 5.2814 & TST \\
\hline CHEMBL1504687 & 737823 & 5.1 & 5.5996 & TST \\
\hline CHEMBL1361133 & 737823 & 5.6 & 5.3373 & TST \\
\hline CHEMBL1334687 & 737823 & 6.7 & 5.4601 & TST \\
\hline CHEMBL1474318 & 737823 & 5.9 & 5.6925 & TST \\
\hline CHEMBL1403709 & 737823 & 4.9 & 5.4586 & TST \\
\hline CHEMBL1414780 & 737823 & 5.6 & 5.6589 & TST \\
\hline CHEMBL1396693 & 737823 & 4.8 & 4.9426 & TST \\
\hline CHEMBL1548799 & 737823 & 5.0 & 4.7418 & TST \\
\hline CHEMBL1741458 & 737823 & 5.5 & 5.1439 & TST \\
\hline CHEMBL1442997 & 737823 & 4.7 & 4.8199 & TST \\
\hline CHEMBL1373998 & 737823 & 5.9 & 5.5799 & TST \\
\hline CHEMBL1317324 & 737823 & 4.4 & 5.0657 & TST \\
\hline CHEMBL1501511 & 737823 & 5.05 & 5.2856 & TST \\
\hline CHEMBL1525931 & 737823 & 4.85 & 5.0695 & TST \\
\hline CHEMBL1372363 & 737823 & 5.1 & 5.268 & TST \\
\hline CHEMBL3196654 & 737823 & 6.55 & 5.6998 & TST \\
\hline CHEMBL1460094 & 737823 & 4.6 & 5.7236 & TST \\
\hline CHEMBL1512763 & 737823 & 5.2 & 4.8047 & TST \\
\hline CHEMBL1435788 & 737823 & 4.8 & 5.117 & TST \\
\hline CHEMBL1515918 & 737823 & 6.4 & 6.0104 & TST \\
\hline CHEMBL1387125 & 737823 & 4.95 & 5.5977 & TST \\
\hline CHEMBL1592388 & 737823 & 5.5 & 5.3601 & TST \\
\hline CHEMBL1447333 & 737823 & 5.5 & 5.4642 & TST \\
\hline CHEMBL1400192 & 737823 & 6.1 & 6.0689 & TST \\
\hline CHEMBL311489 & 737823 & -0.0 & 5.4729 & TST \\
\hline CHEMBL1483213 & 737823 & 5.2 & 5.4814 & TST \\
\hline CHEMBL1542016 & 737823 & 4.8 & 5.1735 & TST \\
\hline CHEMBL1444654 & 737823 & 5.1 & 5.4312 & TST \\
\hline CHEMBL1474816 & 737823 & 6.1 & 4.8399 & TST \\
\hline CHEMBL1529076 & 737823 & 5.35 & 5.1598 & TST \\
\hline CHEMBL 1405860 & 737823 & 6.1 & 5.092 & TST \\
\hline CHEMBL113830 & 737823 & 6.0 & 4.9995 & TST \\
\hline CHEMBL1325766 & 737823 & 5.7 & 5.6262 & TST \\
\hline CHEMBL1606259 & 737823 & 4.85 & 4.6425 & TST \\
\hline CHEMBL1355256 & 737823 & 5.8 & 5.3731 & TST \\
\hline CHEMBL1506056 & 737823 & 5.3 & 5.375 & TST \\
\hline CHEMBL1558418 & 737823 & 5.4 & 4.8899 & TST \\
\hline CHEMBL1326228 & 737823 & 5.7 & 5.3995 & TST \\
\hline CHEMBL1473149 & 737823 & 5.1 & 4.9922 & TST \\
\hline CHEMBL1317795 & 737823 & 4.8 & 5.1105 & TST \\
\hline CHEMBL1316709 & 737823 & 5.5 & 5.7652 & TST \\
\hline CHEMBL1441667 & 737823 & 4.75 & 5.2141 & TST \\
\hline
\end{tabular}




\begin{tabular}{|c|c|c|c|c|}
\hline & & & pplement & al Table S \\
\hline CHEMBL140220 & 737823 & 7.0 & 5.4962 & TST \\
\hline CHEMBL1339210 & 737823 & 4.8 & 5.6296 & TST \\
\hline CHEMBL1473934 & 737823 & 6.1 & 5.2591 & TST \\
\hline CHEMBL1361808 & 737823 & 5.85 & 5.3133 & TST \\
\hline CHEMBL1423810 & 737823 & 6.05 & 5.8688 & TST \\
\hline CHEMBL492132 & 737823 & 4.8 & 4.6535 & TST \\
\hline CHEMBL1728908 & 737823 & 4.95 & 5.4564 & TST \\
\hline CHEMBL77030 & 737823 & 6.0 & 5.3773 & TST \\
\hline CHEMBL1592035 & 737823 & 4.7 & 4.857 & TST \\
\hline CHEMBL1561500 & 737823 & 4.8 & 5.24299 & 9999999999 \\
\hline CHEMBL1973500 & 737823 & 5.25 & 5.2358 & TST \\
\hline CHEMBL1501882 & 737823 & 5.2 & 4.9294 & TST \\
\hline CHEMBL1435666 & 737823 & 4.9 & 5.2503 & TST \\
\hline CHEMBL3189564 & 737823 & 4.85 & 5.2432 & TST \\
\hline CHEMBL 3211347 & 737823 & 4.9 & 5.3693 & TST \\
\hline CHEMBL608555 & 737823 & 6.0 & 4.5888 & TST \\
\hline CHEMBL1436324 & 737823 & 6.1 & 5.6423 & TST \\
\hline CHEMBL1381224 & 737823 & 4.6 & 5.1145 & TST \\
\hline CHEMBL1429121 & 737823 & 5.7 & 5.774 & TST \\
\hline CHEMBL1335826 & 737823 & 4.5 & 4.9836 & TST \\
\hline CHEMBL1424384 & 737823 & 5.85 & 5.3293 & TST \\
\hline CHEMBL1395620 & 737823 & 5.3 & 5.6444 & TST \\
\hline CHEMBL1574233 & 737823 & 4.55 & 4.8925 & TST \\
\hline CHEMBL1741666 & 737823 & 4.95 & 4.9619 & TST \\
\hline CHEMBL1427548 & 737823 & 4.5 & 5.2503 & TST \\
\hline CHEMBL1316979 & 737823 & 6.2 & 6.1611 & TST \\
\hline CHEMBL1344602 & 737823 & 5.55 & 5.2936 & TST \\
\hline CHEMBL497939 & 737823 & 4.5 & 5.0785 & TST \\
\hline CHEMBL1339029 & 737823 & 4.4 & 5.4475 & TST \\
\hline CHEMBL1506245 & 737823 & 4.8 & 5.5316 & TST \\
\hline CHEMBL 3197871 & 737823 & 5.8 & 5.7809 & TST \\
\hline CHEMBL1356060 & 737823 & 6.4 & 6.1423 & TST \\
\hline CHEMBL1403034 & 737823 & 5.4 & 5.013 & TST \\
\hline CHEMBL3189813 & 737823 & 4.75 & 5.0685 & TST \\
\hline CHEMBL542493 & 737823 & 5.5 & 5.2059 & TST \\
\hline CHEMBL1555067 & 737823 & 4.5 & 4.724 & TST \\
\hline CHEMBL1710090 & 737823 & 5.4 & 5.0227 & TST \\
\hline CHEMBL1354408 & 737823 & 5.0 & 5.0713 & TST \\
\hline CHEMBL1566209 & 737823 & 5.1 & 5.2112 & TST \\
\hline CHEMBL1590992 & 737823 & 5.0 & 4.5672 & TST \\
\hline CHEMBL1581350 & 737823 & 6.2 & 5.8868 & TST \\
\hline CHEMBL1742352 & 737823 & 5.1 & 5.6505 & TST \\
\hline CHEMBL1415488 & 737823 & 5.4 & 5.2242 & TST \\
\hline CHEMBL3195142 & 737823 & 5.8 & 5.0 & TST \\
\hline CHEMBL1394887 & 737823 & 6.2 & 5.6152 & TST \\
\hline CHEMBL1359620 & 737823 & 6.0 & 5.1743 & TST \\
\hline CHEMBL1363474 & 737823 & 5.9 & 5.2069 & TST \\
\hline CHEMBL1554577 & 737823 & 6.2 & 5.8759 & TST \\
\hline
\end{tabular}




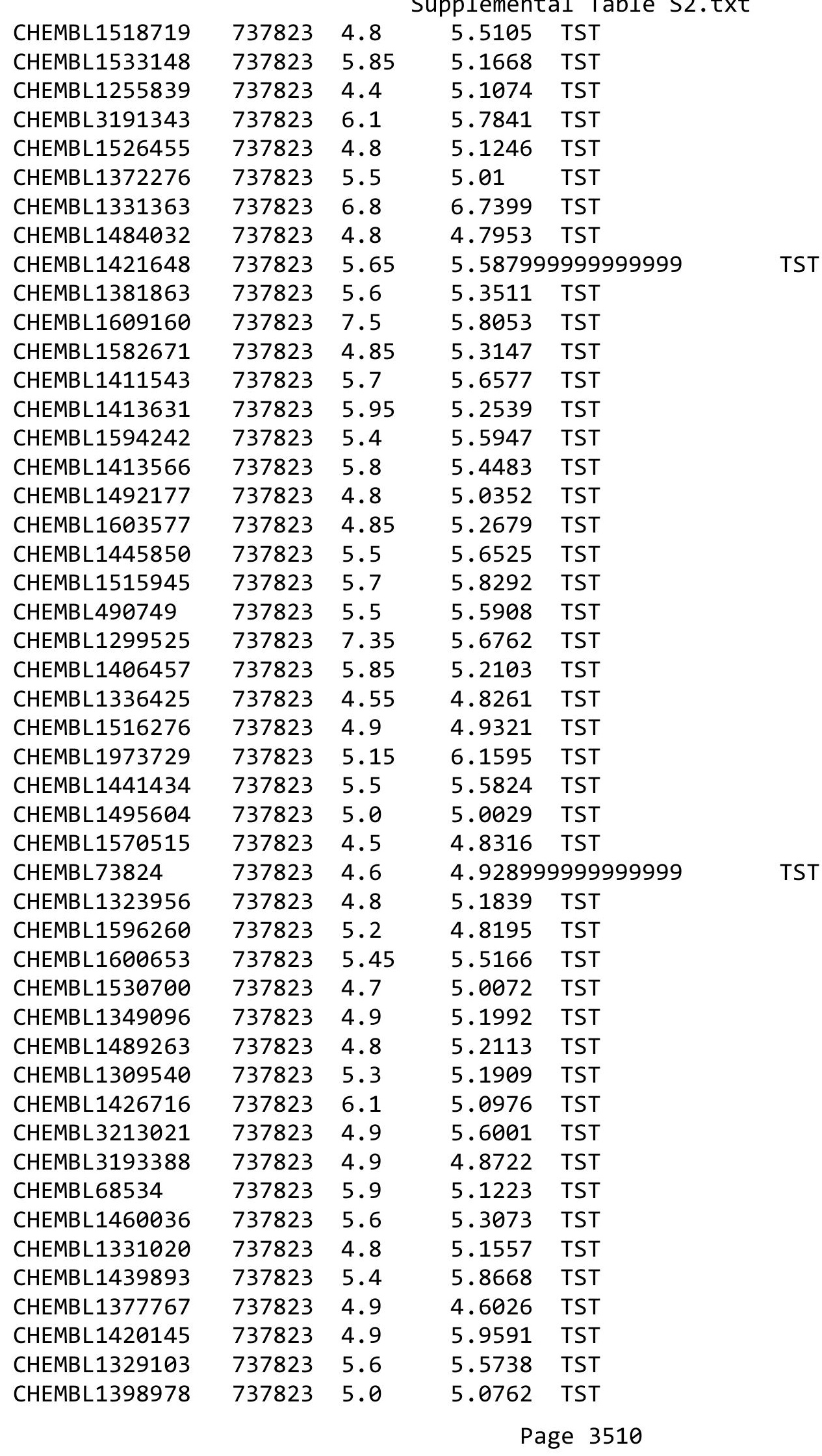




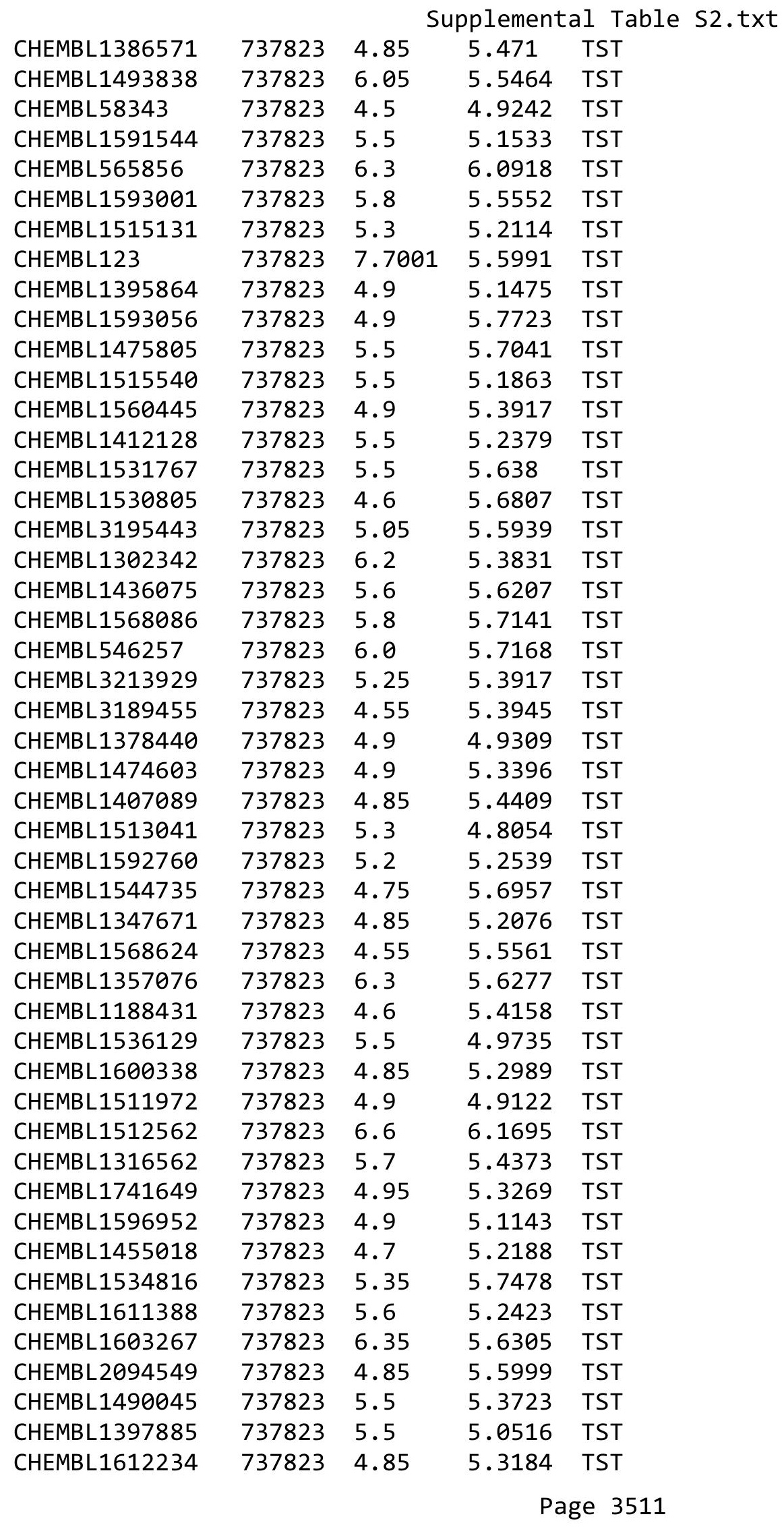




\begin{tabular}{|c|c|c|c|c|}
\hline \multicolumn{5}{|c|}{ Supplemental Table s2.txt } \\
\hline CHEMBL1448228 & 737823 & 6.1 & 5.245 & TST \\
\hline CHEMBL1373797 & 737823 & 4.85 & 5.1833 & TST \\
\hline CHEMBL1407677 & 737823 & 4.9 & 5.0729 & TST \\
\hline CHEMBL1610605 & 737823 & 5.65 & 5.4054 & TST \\
\hline CHEMBL1315716 & 737823 & 4.8 & 4.9368 & TST \\
\hline CHEMBL1352396 & 737823 & 5.65 & 5.7096 & TST \\
\hline CHEMBL1369631 & 737823 & 4.7 & 5.4293 & TST \\
\hline CHEMBL1414219 & 737823 & 5.5 & 5.7068 & TST \\
\hline CHEMBL1405538 & 737823 & 4.5 & 5.3417 & TST \\
\hline CHEMBL1233960 & 737823 & 5.4 & 5.4978 & TST \\
\hline CHEMBL1314247 & 737823 & 6.7 & 6.2224 & TST \\
\hline CHEMBL1354561 & 737823 & 5.9 & 6.2966 & TST \\
\hline CHEMBL1494529 & 737823 & 4.8 & 5.2728 & TST \\
\hline CHEMBL1331131 & 737823 & 4.4 & 5.1729 & TST \\
\hline CHEMBL 222993 & 737823 & 5.9 & 5.8172 & TST \\
\hline CHEMBL520107 & 737823 & 4.9 & 5.0687 & TST \\
\hline CHEMBL1370053 & 737823 & 5.0 & 5.3433 & TST \\
\hline CHEMBL 1357674 & 737823 & 5.9 & 5.2761 & TST \\
\hline CHEMBL1322219 & 737823 & 5.2 & 5.4579 & TST \\
\hline CHEMBL1500967 & 737823 & 4.9 & 4.7268 & TST \\
\hline CHEMBL1374849 & 737823 & 4.5 & 4.5917 & TST \\
\hline CHEMBL1395226 & 737823 & 4.8 & 4.9108 & TST \\
\hline CHEMBL1328389 & 737823 & 5.1 & 5.1175 & TST \\
\hline CHEMBL1419308 & 737823 & 4.85 & 5.4434 & TST \\
\hline CHEMBL3210053 & 737823 & 6.15 & 5.5591 & TST \\
\hline CHEMBL1590354 & 737823 & 6.5 & 5.5956 & TST \\
\hline CHEMBL127421 & 737823 & 4.5 & 4.8275 & TST \\
\hline CHEMBL 180427 & 737823 & 4.9 & 5.5494 & TST \\
\hline CHEMBL1366112 & 737823 & 5.45 & 5.3991 & TST \\
\hline CHEMBL1500226 & 737823 & 5.4 & 5.4478 & TST \\
\hline CHEMBL1566987 & 737823 & 6.0 & 6.0878 & TST \\
\hline CHEMBL1447487 & 737823 & 4.9 & 5.5866 & TST \\
\hline CHEMBL1438722 & 737823 & 5.35 & 5.5189 & TST \\
\hline CHEMBL1475083 & 737823 & 4.5 & 4.9205 & TST \\
\hline CHEMBL1475375 & 737823 & 5.3 & 5.1577 & TST \\
\hline CHEMBL1490799 & 737823 & 4.55 & 5.7137 & TST \\
\hline CHEMBL1372028 & 737823 & 5.6 & 6.3671 & TST \\
\hline CHEMBL1407307 & 737823 & 4.6 & 4.9377 & TST \\
\hline CHEMBL1500518 & 737823 & 5.75 & 5.6726 & TST \\
\hline CHEMBL 1447528 & 737823 & 5.6 & 5.4722 & TST \\
\hline CHEMBL1396783 & 737823 & 4.7 & 4.6573 & TST \\
\hline CHEMBL1490646 & 737823 & 5.15 & 4.8982 & TST \\
\hline CHEMBL490718 & 737823 & 4.6 & 5.1144 & TST \\
\hline CHEMBL1491259 & 737823 & 4.6 & 5.1088 & TST \\
\hline CHEMBL1706244 & 737823 & 5.5 & 5.2002 & TST \\
\hline CHEMBL1362264 & 737823 & 5.0 & 4.94600 & 0000000001 \\
\hline CHEMBL1562715 & 737823 & 4.9 & 5.3655 & TST \\
\hline CHEMBL1364808 & 737823 & 6.8 & 5.2981 & TST \\
\hline
\end{tabular}




\begin{tabular}{|c|c|c|c|c|}
\hline & & & & \\
\hline CHEMBL1305576 & 737823 & 4.6 & 4.913 & TST \\
\hline CHEMBL1512838 & 737823 & 5.9 & 5.1931 & TST \\
\hline CHEMBL1449417 & 737823 & 5.9 & 5.4309 & TST \\
\hline CHEMBL1379690 & 737823 & 5.85 & 5.6752 & TST \\
\hline CHEMBL1580945 & 737823 & 4.9 & 5.334 & TST \\
\hline CHEMBL1324405 & 737823 & 6.0 & 5.3768 & TST \\
\hline CHEMBL1569891 & 737823 & 5.5 & 5.1039 & TST \\
\hline CHEMBL1524183 & 737823 & 5.1 & 5.5705 & TST \\
\hline CHEMBL1314473 & 737823 & 5.4 & 5.2038 & TST \\
\hline CHEMBL1328118 & 737823 & 6.15 & 5.3859 & TST \\
\hline CHEMBL1510728 & 737823 & 5.35 & 5.9564 & TST \\
\hline CHEMBL1514458 & 737823 & 4.9 & 4.9757 & TST \\
\hline CHEMBL 3195730 & 737823 & 6.05 & 5.2084 & TST \\
\hline CHEMBL1560435 & 737823 & 5.15 & 5.319 & TST \\
\hline CHEMBL1458047 & 737823 & 5.7 & 5.4873 & TST \\
\hline CHEMBL165 & 737823 & 6.0 & 5.8391 & TST \\
\hline CHEMBL 2374368 & 737823 & 6.2 & 5.6539 & TST \\
\hline CHEMBL1581282 & 737823 & 4.9 & 5.4619 & TST \\
\hline CHEMBL1721191 & 737823 & 4.8 & 4.9105 & TST \\
\hline CHEMBL1579328 & 737823 & 4.8 & 5.3315 & TST \\
\hline CHEMBL1465707 & 737823 & 4.6 & 5.0891 & TST \\
\hline CHEMBL1395337 & 737823 & 5.6 & 6.2799 & TST \\
\hline CHEMBL1412328 & 737823 & 5.8 & 5.3265 & TST \\
\hline CHEMBL1507494 & 737823 & 4.4 & 5.1822 & TST \\
\hline CHEMBL1444270 & 737823 & 4.7 & 4.9686 & TST \\
\hline CHEMBL1475860 & 737823 & 5.1 & 5.0149 & TST \\
\hline CHEMBL577635 & 737823 & 4.8 & 5.4755 & TST \\
\hline CHEMBL1601015 & 737823 & 4.85 & 5.0596 & TST \\
\hline CHEMBL1383190 & 737823 & 5.7 & 5.2842 & TST \\
\hline CHEMBL520992 & 737823 & 4.4 & 4.8078 & TST \\
\hline CHEMBL1556993 & 737823 & 5.5 & 5.5257 & TST \\
\hline CHEMBL1582548 & 737823 & 5.45 & 5.3789 & TST \\
\hline CHEMBL1318310 & 737823 & 6.5 & 6.0143 & TST \\
\hline CHEMBL1435032 & 737823 & 5.9 & 5.7569 & TST \\
\hline CHEMBL1355672 & 737823 & 4.9 & 5.3536 & TST \\
\hline CHEMBL1319312 & 737823 & 5.3 & 5.7971 & TST \\
\hline CHEMBL1586050 & 737823 & 4.8 & 5.4036 & TST \\
\hline CHEMBL1500686 & 737823 & 4.8 & 4.7573 & TST \\
\hline CHEMBL1328562 & 737823 & 5.4 & 5.8506 & TST \\
\hline CHEMBL1481984 & 737823 & 5.0 & 4.7442 & TST \\
\hline CHEMBL1306197 & 737823 & 5.7 & 5.646 & TST \\
\hline CHEMBL1566571 & 737823 & 5.6 & 5.24200 & 0000000001 \\
\hline CHEMBL1484108 & 737823 & 6.2 & 5.7966 & TST \\
\hline CHEMBL1542296 & 737823 & 6.2 & 5.4198 & TST \\
\hline CHEMBL1583568 & 737823 & 6.05 & 5.2579 & TST \\
\hline CHEMBL1408908 & 737823 & 5.65 & 5.7492 & TST \\
\hline CHEMBL1302696 & 737823 & 5.15 & 5.3625 & TST \\
\hline \multirow[t]{2}{*}{ CHEMBL1453655 } & 737823 & 5.7 & 5.5752 & TST \\
\hline & & & \multicolumn{2}{|c|}{ Page 3513} \\
\hline
\end{tabular}




\begin{tabular}{|c|c|c|c|c|}
\hline \multicolumn{5}{|c|}{ lemen } \\
\hline CHEMBL1447428 & 737823 & 6.1 & 5.4962 & TST \\
\hline CHEMBL1591459 & 737823 & 6.2 & 5.7622 & TST \\
\hline CHEMBL1361513 & 737823 & 6.5 & 5.8858 & TST \\
\hline CHEMBL1423348 & 737823 & 4.9 & 5.0619 & TST \\
\hline CHEMBL1336166 & 737823 & 7.1 & 5.2162 & TST \\
\hline CHEMBL3211571 & 737823 & 4.85 & 5.1754 & TST \\
\hline CHEMBL1595500 & 737823 & 5.8 & 5.5874 & TST \\
\hline CHEMBL1560839 & 737823 & 4.7 & 4.8024 & TST \\
\hline CHEMBL490742 & 737823 & 5.3 & 5.5866 & TST \\
\hline CHEMBL1438928 & 737823 & 4.8 & 5.2083 & TST \\
\hline CHEMBL1541058 & 737823 & 5.6 & 5.4906 & TST \\
\hline CHEMBL1323385 & 737823 & 5.3 & 5.5936 & TST \\
\hline CHEMBL1436507 & 737823 & 4.8 & 5.1563 & TST \\
\hline CHEMBL1390028 & 737823 & 5.35 & 5.271 & TST \\
\hline CHEMBL1392865 & 737823 & 5.6 & 5.5904 & TST \\
\hline CHEMBL3193508 & 737823 & 5.4 & 5.6297 & TST \\
\hline CHEMBL1349047 & 737823 & 6.2 & 5.419 & TST \\
\hline CHEMBL1554910 & 737823 & 5.9 & 5.9401 & TST \\
\hline CHEMBL1311520 & 737823 & 5.75 & 5.4101 & TST \\
\hline CHEMBL1473849 & 737823 & 4.4 & 5.0485 & TST \\
\hline CHEMBL15192 & 737823 & 5.4 & 5.1523 & TST \\
\hline CHEMBL1590378 & 737823 & 6.0 & 4.9773 & TST \\
\hline CHEMBL1430600 & 737823 & 5.15 & 4.9931 & TST \\
\hline CHEMBL1451302 & 737823 & 5.3 & 5.0273 & TST \\
\hline CHEMBL1531871 & 737823 & 4.6 & 4.8777 & TST \\
\hline CHEMBL1314451 & 737823 & 5.5 & 5.8003 & TST \\
\hline CHEMBL1520153 & 737823 & 5.3 & 5.3175 & TST \\
\hline CHEMBL3191804 & 737823 & 6.0 & 5.2165 & TST \\
\hline CHEMBL1569962 & 737823 & 6.1 & 5.5963 & TST \\
\hline CHEMBL1301521 & 737823 & 4.9 & 5.3448 & TST \\
\hline CHEMBL1601111 & 737823 & 4.95 & 5.1201 & TST \\
\hline CHEMBL3209158 & 737823 & 5.7 & 5.8972 & TST \\
\hline CHEMBL1570881 & 737823 & 5.0 & 5.2385 & TST \\
\hline CHEMBL1594372 & 737823 & 5.1 & 5.2905 & TST \\
\hline CHEMBL 2007077 & 737823 & 5.9 & 5.6312 & TST \\
\hline CHEMBL1360650 & 737823 & 4.6 & 4.7219 & TST \\
\hline CHEMBL1435301 & 737823 & 4.5 & 4.6514 & TST \\
\hline CHEMBL1433259 & 737823 & 4.95 & 5.3065 & TST \\
\hline CHEMBL1511555 & 737823 & 4.65 & 4.8697 & TST \\
\hline CHEMBL1494979 & 737823 & 4.75 & 5.6319 & TST \\
\hline CHEMBL1494865 & 737823 & 4.85 & 4.7382 & TST \\
\hline CHEMBL1490195 & 737823 & 5.4 & 5.465 & TST \\
\hline CHEMBL1731600 & 737823 & 6.15 & 5.3032 & TST \\
\hline CHEMBL1529093 & 737823 & 5.4 & 4.9438 & TST \\
\hline CHEMBL1451149 & 737823 & 5.2 & 5.5118 & TST \\
\hline CHEMBL1376178 & 737823 & 5.3 & 5.2241 & TST \\
\hline CHEMBL1499214 & 737823 & 5.6 & 5.5471 & TST \\
\hline CHEMBL1448726 & 737823 & 4.7 & 4.6634 & TST \\
\hline
\end{tabular}




\begin{tabular}{|c|c|c|c|c|}
\hline \multicolumn{5}{|c|}{ Supplemental Tab } \\
\hline CHEMBL1316647 & 737823 & 4.9 & 5.138 & TST \\
\hline CHEMBL1409815 & 737823 & 4.4 & 4.407 & TST \\
\hline CHEMBL1436832 & 737823 & 6.6 & 5.684 & TST \\
\hline CHEMBL52030 & 737823 & 4.4 & 5.1112 & TST \\
\hline CHEMBL1353128 & 737823 & 4.95 & 5.2295 & TST \\
\hline CHEMBL1371661 & 737823 & 4.7 & 5.0653 & TST \\
\hline CHEMBL1567923 & 737823 & 6.6 & 5.5837 & TST \\
\hline CHEMBL1256178 & 737823 & 4.8 & 5.1341 & TST \\
\hline CHEMBL1572371 & 737823 & 5.95 & 5.2798 & TST \\
\hline CHEMBL1422254 & 737823 & 4.8 & 4.8884 & TST \\
\hline CHEMBL1358092 & 737823 & 6.4 & 6.2135 & TST \\
\hline CHEMBL1531663 & 737823 & 4.95 & 5.4539 & TST \\
\hline CHEMBL1567121 & 737823 & 5.4 & 5.2616 & TST \\
\hline CHEMBL1417837 & 737823 & 5.6 & 5.371 & TST \\
\hline CHEMBL3211454 & 737823 & 5.25 & 5.5833 & TST \\
\hline CHEMBL 1461253 & 737823 & 5.95 & 5.6974 & TST \\
\hline CHEMBL3212628 & 737823 & 5.1 & 5.7238 & TST \\
\hline CHEMBL1557355 & 737823 & 5.25 & 5.7339 & TST \\
\hline CHEMBL1365033 & 737823 & 5.65 & 5.7693 & TST \\
\hline CHEMBL1603371 & 737823 & 5.6 & 5.6244 & TST \\
\hline CHEMBL1368664 & 737823 & 6.0 & 5.4711 & TST \\
\hline CHEMBL1592754 & 737823 & 5.6 & 5.7867 & TST \\
\hline CHEMBL1310196 & 737823 & 5.3 & 4.8301 & TST \\
\hline CHEMBL1366296 & 737823 & 5.4 & 5.0687 & TST \\
\hline CHEMBL1741329 & 737823 & 4.65 & 5.6305 & TST \\
\hline CHEMBL1543285 & 737823 & 4.8 & 5.5018 & TST \\
\hline CHEMBL1311780 & 737823 & 6.6 & 4.6822 & TST \\
\hline CHEMBL1518970 & 737823 & 4.9 & 5.1401 & TST \\
\hline CHEMBL1327915 & 737823 & 5.7 & 4.7411 & TST \\
\hline CHEMBL1399481 & 737823 & 5.0 & 4.8437 & TST \\
\hline CHEMBL1554826 & 737823 & 5.4 & 5.2503 & TST \\
\hline CHEMBL1725130 & 737823 & 4.8 & 4.9197 & TST \\
\hline CHEMBL1611413 & 737823 & 5.9 & 5.7751 & TST \\
\hline CHEMBL1742265 & 737823 & 5.5 & 4.9116 & TST \\
\hline CHEMBL1610132 & 737823 & 6.1 & 5.4108 & TST \\
\hline CHEMBL1522864 & 737823 & 4.75 & 4.7071 & TST \\
\hline CHEMBL391997 & 737823 & 4.7 & 5.3749 & TST \\
\hline CHEMBL1315083 & 737823 & 5.6 & 5.8568 & TST \\
\hline CHEMBL1358722 & 737823 & 4.4 & 5.2389 & TST \\
\hline CHEMBL1447746 & 737823 & 6.2 & 5.2893 & TST \\
\hline CHEMBL1383496 & 737823 & 6.4 & 5.5659 & TST \\
\hline CHEMBL66966 & 737823 & 4.6 & 4.8664 & TST \\
\hline CHEMBL1419479 & 737823 & 5.3 & 4.8379 & TST \\
\hline CHEMBL1533643 & 737823 & 6.3 & 5.9568 & TST \\
\hline CHEMBL1303347 & 737823 & 4.4 & 4.9164 & TST \\
\hline CHEMBL1310885 & 737823 & 8.0 & 4.9237 & TST \\
\hline CHEMBL1356372 & 737823 & 5.0 & 5.6123 & TST \\
\hline CHEMBL1605632 & 737823 & 4.7 & 4.9644 & TST \\
\hline
\end{tabular}




\begin{tabular}{|c|c|c|c|c|}
\hline \multicolumn{5}{|c|}{ Supplemental Table S2.txt } \\
\hline CHEMBL1551331 & 737823 & 4.6 & 4.981 & TST \\
\hline CHEMBL1313588 & 737823 & 5.25 & 5.6444 & TST \\
\hline CHEMBL1511940 & 737823 & 4.8 & 5.2573 & TST \\
\hline CHEMBL440084 & 737823 & 4.8 & 5.5182 & TST \\
\hline CHEMBL1463367 & 737823 & 4.6 & 4.9229 & TST \\
\hline CHEMBL1371898 & 737823 & 4.9 & 5.5287 & TST \\
\hline CHEMBL1486659 & 737823 & 5.4 & 5.5122 & TST \\
\hline CHEMBL1571692 & 737823 & 6.0 & 5.1525 & TST \\
\hline CHEMBL1514010 & 737823 & 5.5 & 5.7788 & TST \\
\hline CHEMBL1527195 & 737823 & 5.1 & 4.8202 & TST \\
\hline CHEMBL 2179544 & 872705 & 4.0 & 3.6527 & TRN \\
\hline CHEMBL 2179525 & 872705 & 5.8861 & 6.0058 & TRN \\
\hline CHEMBL 2179540 & 872705 & 5.3279 & 5.3828 & TRN \\
\hline CHEMBL 2179535 & 872705 & 4.0 & 4.3069 & TRN \\
\hline CHEMBL2179966 & 872705 & 5.2291 & 5.5021 & TRN \\
\hline CHEMBL 2179560 & 872705 & 4.8539 & 4.2059 & TST \\
\hline CHEMBL 2179518 & 872705 & 4.0 & 3.9076 & TRN \\
\hline CHEMBL1876219 & 872705 & 4.1487 & 4.0684 & TST \\
\hline CHEMBL 3094074 & 872705 & 4.4685 & 4.5269 & TRN \\
\hline CHEMBL 2179527 & 872705 & 4.0 & 4.4746 & TRN \\
\hline CHEMBL 2179545 & 872705 & 4.0 & 4.3397 & TRN \\
\hline CHEMBL 2179533 & 872705 & 5.3372 & 4.8542 & TRN \\
\hline CHEMBL 2179532 & 872705 & 4.0 & 4.4629 & TRN \\
\hline CHEMBL 2179538 & 872705 & 5.0862 & 4.9471 & TRN \\
\hline CHEMBL 3094096 & 872705 & 5.0862 & 4.9231 & TRN \\
\hline CHEMBL 2179531 & 872705 & 5.585 & 5.1913 & TRN \\
\hline CHEMBL 2179528 & 872705 & 4.0 & 4.3263 & TRN \\
\hline CHEMBL 2179551 & 872705 & 4.0 & 3.9411 & TRN \\
\hline CHEMBL 2179961 & 872705 & 6.0757 & 5.1636 & TST \\
\hline CHEMBL 2179559 & 872705 & 4.0 & 3.8386 & TRN \\
\hline CHEMBL 2179536 & 872705 & 5.0655 & 4.8368 & TRN \\
\hline CHEMBL 2179962 & 872705 & 7.699 & 4.5632 & TST \\
\hline CHEMBL 2179537 & 872705 & 5.0555 & 4.6891 & TRN \\
\hline CHEMBL 2179957 & 872705 & 5.1192 & 5.1908 & TST \\
\hline CHEMBL 2179519 & 872705 & 4.699 & 5.2731 & TST \\
\hline CHEMBL 2179553 & 872705 & 4.0 & 4.2994 & TRN \\
\hline CHEMBL 2179539 & 872705 & 5.4318 & 5.0956 & TRN \\
\hline CHEMBL 2179543 & 872705 & 4.0 & 3.8929 & TRN \\
\hline CHEMBL 2179956 & 872705 & 4.7212 & 4.6319 & TRN \\
\hline CHEMBL 2179548 & 872705 & 4.0 & 4.1722 & TRN \\
\hline CHEMBL 2179547 & 872705 & 4.0 & 4.3198 & TRN \\
\hline CHEMBL 2179552 & 872705 & 4.0 & 4.3006 & TRN \\
\hline CHEMBL 2179524 & 872705 & 4.0 & 4.5227 & TST \\
\hline CHEMBL 2179530 & 872705 & 4.0 & 4.2108 & TRN \\
\hline CHEMBL 2179526 & 872705 & 5.9208 & 5.9173 & TRN \\
\hline CHEMBL 2179542 & 872705 & 4.0 & 3.6145 & TRN \\
\hline CHEMBL 2179546 & 872705 & 4.0 & 3.9278 & TRN \\
\hline CHEMBL 2179555 & 872705 & 4.8539 & 5.2361 & TRN \\
\hline
\end{tabular}




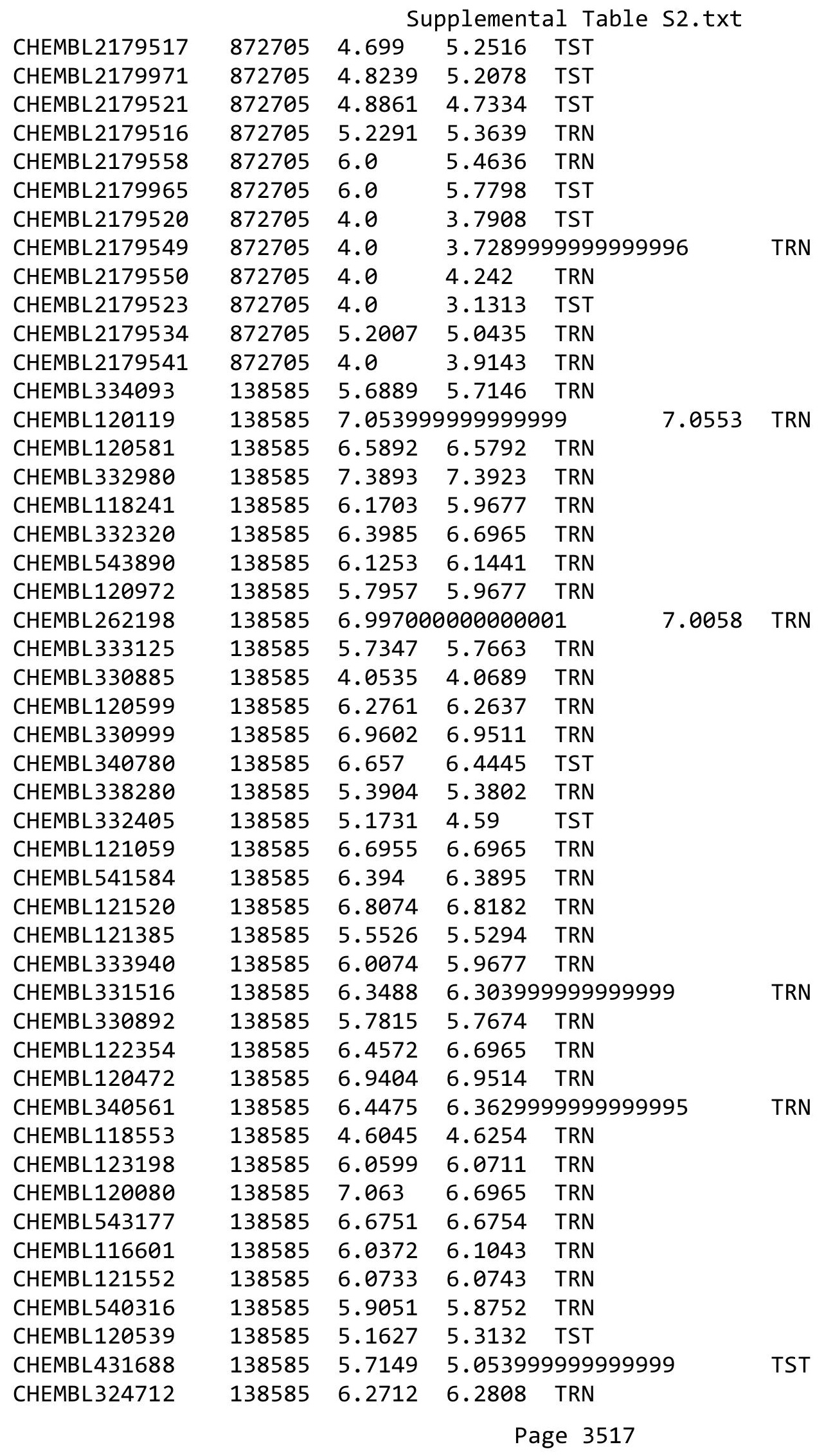




\begin{tabular}{|c|c|c|c|c|c|}
\hline \multicolumn{6}{|c|}{ Supplemental Table S2.txt } \\
\hline CHEMBL122353 & 138585 & 5.636 & 5.6619 & TST & \\
\hline CHEMBL324936 & 138585 & 6.5239 & 6.9049 & TST & \\
\hline CHEMBL332645 & 138585 & 4.7759 & 4.4372 & TST & \\
\hline CHEMBL 334245 & 138585 & 6.7891 & 6.6965 & TRN & \\
\hline CHEMBL121298 & 138585 & 4.8444 & 5.1845 & TST & \\
\hline CHEMBL120135 & 138585 & 6.0 & 6.807 & TST & \\
\hline CHEMBL123099 & 138585 & 4.2799 & 4.2801 & TRN & \\
\hline CHEMBL332335 & 138585 & 5.7723 & 5.7714 & TRN & \\
\hline CHEMBL121476 & 138585 & 5.9604 & 5.9677 & TST & \\
\hline CHEMBL120109 & 138585 & 5.2578 & 5.2506 & TRN & \\
\hline CHEMBL120329 & 138585 & 6.1649 & 6.1732 & TRN & \\
\hline CHEMBL120963 & 138585 & 5.2966 & 5.2943 & TRN & \\
\hline CHEMBL124173 & 138585 & 5.8265 & 6.0186 & TST & \\
\hline CHEMBL332181 & 138585 & 6.5376 & 6.3547 & TST & \\
\hline CHEMBL121299 & 138585 & 5.9141 & 4.7002 & TST & \\
\hline CHEMBL1353474 & 1301681 & 3.0685 & 2.5149 & TRN & \\
\hline CHEMBL1547232 & 1301681 & 3.0688 & 3.5598 & TRN & \\
\hline CHEMBL3184181 & 1301681 & 3.5463 & 3.3877 & TRN & \\
\hline CHEMBL1418720 & 1301681 & 4.5073 & 3.8503 & TRN & \\
\hline CHEMBL1388241 & 1301681 & 3.0683 & 3.0142 & TRN & \\
\hline CHEMBL3192707 & 1301681 & 3.0685 & 3.7326 & TST & \\
\hline CHEMBL1569724 & 1301681 & 3.0686 & 2.8813 & TRN & \\
\hline CHEMBL1364108 & 1301681 & 3.0685 & 3.5176 & TRN & \\
\hline CHEMBL1348332 & 1301681 & 3.0684 & 3.2748 & TRN & \\
\hline CHEMBL1905325 & 1301681 & $4.1930 e$ & 00000000 & 4.0548 & TRN \\
\hline CHEMBL1377607 & 1301681 & 3.0686 & 3.1223 & TRN & \\
\hline CHEMBL1487136 & 1301681 & 3.0685 & 3.5262 & TST & \\
\hline CHEMBL3187672 & 1301681 & 3.0687 & 3.1581 & TRN & \\
\hline CHEMBL 2355112 & 1301681 & 3.0685 & 3.6363 & TRN & \\
\hline CHEMBL1469224 & 1301681 & 3.0685 & 3.1724 & TRN & \\
\hline CHEMBL 262627 & 1301681 & 3.0686 & 3.4361 & TRN & \\
\hline CHEMBL1547430 & 1301681 & 3.0686 & 3.4235 & TRN & \\
\hline CHEMBL1610504 & 1301681 & 4.0662 & 3.3102 & TST & \\
\hline CHEMBL 2141681 & 1301681 & 3.5457 & 3.3772 & TRN & \\
\hline CHEMBL1310753 & 1301681 & 3.0682 & 2.49300 & 00000000003 & TRN \\
\hline CHEMBL1468672 & 1301681 & 4.2987 & 3.8237 & TRN & \\
\hline CHEMBL1708045 & 1301681 & 4.4374 & 3.7902 & TST & \\
\hline CHEMBL1699691 & 1301681 & 3.0682 & 3.9913 & TST & \\
\hline CHEMBL1540891 & 1301681 & 3.0686 & 3.4377 & TRN & \\
\hline CHEMBL1538692 & 1301681 & 4.1107 & 3.6595 & TRN & \\
\hline CHEMBL 225963 & 1301681 & 3.0686 & 3.0643 & TRN & \\
\hline CHEMBL1721226 & 1301681 & 3.5458 & 3.8892 & TRN & \\
\hline CHEMBL1576078 & 1301681 & 3.0685 & 3.2389 & TST & \\
\hline CHEMBL1582710 & 1301681 & 3.0686 & 3.4943 & TRN & \\
\hline CHEMBL1442515 & 1301681 & 4.2031 & 3.6475 & TRN & \\
\hline CHEMBL1420175 & 1301681 & 4.4761 & 3.5092 & TST & \\
\hline CHEMBL1423731 & 1301681 & 4.3938 & 3.6758 & TRN & \\
\hline CHEMBL1401965 & 1301681 & 3.5457 & 3.7138 & TRN & \\
\hline
\end{tabular}


Supplemental Table S2.txt

\begin{tabular}{|c|c|c|c|c|c|}
\hline CHEMBL493153 & 1301681 & 3.0686 & 3.063 & TRN & \\
\hline CHEMBL3192108 & 1301681 & 3.0685 & 3.4883 & TRN & \\
\hline CHEMBL1339121 & 1301681 & 4.437 & 3.7413 & TRN & \\
\hline CHEMBL1567944 & 1301681 & 3.0684 & 3.721 & TST & \\
\hline CHEMBL3187992 & 1301681 & 3.0689 & 4.1411 & TST & \\
\hline CHEMBL1423660 & 1301681 & 3.0685 & 3.2628 & TRN & \\
\hline CHEMBL1600776 & 1301681 & 3.0686 & 3.6162 & TRN & \\
\hline CHEMBL1902767 & 1301681 & 4.2083 & 4.128 & TRN & \\
\hline CHEMBL1491079 & 1301681 & 4.4212 & 3.8709 & TRN & \\
\hline CHEMBL1348555 & 1301681 & 4.0505 & 2.6633 & TRN & \\
\hline CHEMBL1472925 & 1301681 & 4.2242 & 3.7217 & TRN & \\
\hline CHEMBL1457961 & 1301681 & 3.0689 & 3.2166 & TRN & \\
\hline CHEMBL1320669 & 1301681 & 3.0683 & 3.50600 & 00000000002 & TRN \\
\hline CHEMBL1441604 & 1301681 & 4.1338 & 3.1595 & TRN & \\
\hline CHEMBL1406208 & 1301681 & 3.0686 & 3.4743 & TRN & \\
\hline CHEMBL 2140922 & 1301681 & 4.9026 & 3.7817 & TRN & \\
\hline CHEMBL116919 & 1301681 & 3.0685 & 3.31699 & 99999999997 & TRN \\
\hline CHEMBL1478310 & 1301681 & 3.0685 & 3.1836 & TRN & \\
\hline CHEMBL1732861 & 1301681 & 4.6709 & 3.9869 & TRN & \\
\hline CHEMBL1567331 & 1301681 & 3.0685 & 3.1664 & TRN & \\
\hline CHEMBL1361461 & 1301681 & 3.0685 & 3.6793 & TRN & \\
\hline CHEMBL1605536 & 1301681 & 3.0686 & 3.6333 & TRN & \\
\hline CHEMBL1427065 & 1301681 & 3.0686 & 3.1256 & TRN & \\
\hline CHEMBL1341031 & 1301681 & 3.0685 & 3.2729 & TRN & \\
\hline CHEMBL1358722 & 1301681 & 3.0685 & 3.5847 & TST & \\
\hline CHEMBL1349075 & 1301681 & 3.0686 & 3.2598 & TRN & \\
\hline CHEMBL1428488 & 1301681 & 3.5456 & 3.7746 & TRN & \\
\hline CHEMBL1367597 & 1301681 & 3.0684 & 2.6448 & TRN & \\
\hline CHEMBL1550278 & 1301681 & 3.0683 & 3.1876 & TRN & \\
\hline CHEMBL1711093 & 1301681 & 3.0686 & 3.4851 & TRN & \\
\hline CHEMBL1306281 & 1301681 & 4.0966 & 3.6831 & TRN & \\
\hline CHEMBL1867903 & 1301681 & 4.0786 & 3.9463 & TRN & \\
\hline CHEMBL1323872 & 1301681 & 4.5553 & 3.9073 & TRN & \\
\hline CHEMBL1973921 & 1301681 & 3.5457 & 4.3792 & TRN & \\
\hline CHEMBL1308328 & 1301681 & 3.0685 & 3.1059 & TRN & \\
\hline CHEMBL1603001 & 1301681 & 3.5456 & 3.387 & TRN & \\
\hline CHEMBL1543258 & 1301681 & 3.0686 & 3.8816 & TST & \\
\hline CHEMBL1528781 & 1301681 & 3.0684 & 3.7682 & TRN & \\
\hline CHEMBL1589677 & 1301681 & 3.0685 & 3.1115 & TRN & \\
\hline CHEMBL1609476 & 1301681 & 3.0684 & 3.4979 & TRN & \\
\hline CHEMBL1508914 & 1301681 & 3.0684 & 3.14300 & 00000000002 & TRN \\
\hline CHEMBL1308223 & 1301681 & 3.0686 & 3.2864 & TRN & \\
\hline CHEMBL1903414 & 1301681 & 4.2723 & 4.0594 & TRN & \\
\hline CHEMBL1339737 & 1301681 & 3.0683 & 3.076 & TRN & \\
\hline CHEMBL1445198 & 1301681 & 3.0684 & 3.3065 & TST & \\
\hline CHEMBL1523841 & 1301681 & 3.0686 & 3.7893 & TST & \\
\hline CHEMBL1333600 & 1301681 & 3.0685 & 3.4515 & TST & \\
\hline CHEMBL1407955 & 1301681 & 4.9204 & 3.6869 & TRN & \\
\hline
\end{tabular}

Page 3519 
Supplemental Table S2.txt

\begin{tabular}{|c|c|c|c|c|c|}
\hline CHEMBL1586284 & 1301681 & 3.0685 & 3.8249 & TRN & \\
\hline CHEMBL95431 & 1301681 & 3.0685 & 2.9631 & TRN & \\
\hline CHEMBL1561171 & 1301681 & 3.0686 & 3.4874 & TRN & \\
\hline CHEMBL1422386 & 1301681 & 4.3434 & 3.9438 & TRN & \\
\hline CHEMBL1734361 & 1301681 & 4.8794 & 4.3329 & TRN & \\
\hline CHEMBL1486664 & 1301681 & 3.5457 & 3.4563 & TRN & \\
\hline CHEMBL1366727 & 1301681 & 3.0686 & 2.9512 & TRN & \\
\hline CHEMBL1334003 & 1301681 & 3.0686 & 3.2323 & TRN & \\
\hline CHEMBL1542594 & 1301681 & 3.5456 & 3.50699 & 99999999997 & TRN \\
\hline CHEMBL1893675 & 1301681 & 4.9858 & 4.2419 & TRN & \\
\hline CHEMBL1374425 & 1301681 & 3.5457 & 3.4955 & TRN & \\
\hline CHEMBL1710219 & 1301681 & 3.0689 & 3.451 & TRN & \\
\hline CHEMBL1312690 & 1301681 & 3.0685 & 3.5039 & TRN & \\
\hline CHEMBL1601456 & 1301681 & 4.2017 & 3.6468 & TRN & \\
\hline CHEMBL1538246 & 1301681 & 4.2693 & 3.7078 & TRN & \\
\hline CHEMBL1717082 & 1301681 & 3.0688 & 3.6513 & TRN & \\
\hline CHEMBL1306343 & 1301681 & 3.0686 & 3.3868 & TRN & \\
\hline CHEMBL1331541 & 1301681 & 3.0685 & 3.6506 & TRN & \\
\hline CHEMBL1461631 & 1301681 & 3.0685 & 3.3434 & TST & \\
\hline CHEMBL1544743 & 1301681 & 3.0685 & 3.0961 & TRN & \\
\hline CHEMBL1533321 & 1301681 & 3.0686 & 3.2496 & TRN & \\
\hline CHEMBL1497024 & 1301681 & 3.0685 & 3.3147 & TRN & \\
\hline CHEMBL1511029 & 1301681 & 3.0686 & 3.3592 & TRN & \\
\hline CHEMBL1604200 & 1301681 & 3.0687 & 3.1765 & TRN & \\
\hline CHEMBL1437030 & 1301681 & 3.0686 & 3.0984 & TRN & \\
\hline CHEMBL584442 & 1301681 & 3.0685 & 3.7967 & TRN & \\
\hline CHEMBL1725453 & 1301681 & 3.0689 & 3.12100 & 00000000004 & TRN \\
\hline CHEMBL 2362703 & 1301681 & 3.0688 & 3.1181 & TRN & \\
\hline CHEMBL1446412 & 1301681 & 3.0685 & 3.0781 & TRN & \\
\hline CHEMBL1877172 & 1301681 & 3.0684 & 3.8585 & TRN & \\
\hline CHEMBL1387401 & 1301681 & 3.0686 & 3.6183 & TRN & \\
\hline CHEMBL1997543 & 1301681 & 3.0686 & 3.3418 & TST & \\
\hline CHEMBL1595779 & 1301681 & 3.0685 & 3.345 & TRN & \\
\hline CHEMBL1581759 & 1301681 & 3.0686 & 4.2349 & TST & \\
\hline CHEMBL1382917 & 1301681 & 4.2682 & 4.0554 & TRN & \\
\hline CHEMBL1524014 & 1301681 & 3.0686 & 3.3509 & TST & \\
\hline CHEMBL1321271 & 1301681 & 3.0687 & 3.1415 & TRN & \\
\hline CHEMBL1575397 & 1301681 & 3.0685 & 3.3389 & TST & \\
\hline CHEMBL 272945 & 1301681 & 4.141 & 3.1758 & TRN & \\
\hline CHEMBL1704996 & 1301681 & 3.0686 & 3.0493 & TRN & \\
\hline CHEMBL1468075 & 1301681 & 3.0685 & 2.6084 & TRN & \\
\hline CHEMBL1360480 & 1301681 & 3.0685 & 3.3061 & TRN & \\
\hline CHEMBL1308547 & 1301681 & 3.0685 & 3.5684 & TRN & \\
\hline CHEMBL1713335 & 1301681 & 4.43199 & 99999999 & 4.4174 & נכו \\
\hline CHEMBL1596496 & 1301681 & 3.0685 & 3.1946 & TST & \\
\hline CHEMBL584883 & 1301681 & 3.0683 & 3.4562 & TRN & \\
\hline CHEMBL1434450 & 1301681 & 4.8752 & 3.6889 & TRN & \\
\hline CHEMBL1584471 & 1301681 & 3.0685 & 3.0806 & TRN & \\
\hline
\end{tabular}


Supplemental Table S2.txt

\begin{tabular}{|c|c|c|c|c|}
\hline 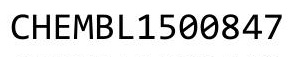 & & & & \\
\hline HEMBL1323442 & 301681 & 526 & 4029 & \\
\hline HEMBL1575768 & 301681 & 685 & 0666 & \\
\hline & & & & \\
\hline EMBL14 & 81 & & 4301 & \\
\hline HEMBL1470979 & 301681 & 463 & 6165 & \\
\hline HEMBL1902024 & 301681 & 4.8948 & .2823 & \\
\hline HEMBL1513705 & 681 & 57 & 9077 & \\
\hline 112 & 81 & 684 & 762 & \\
\hline IEMBL13 & 81 & 685 & .8378 & \\
\hline HEMBL1386344 & 301681 & 685 & 3726 & \\
\hline HEMBL 2136643 & 301681 & 686 & 9848 & \\
\hline HEMBL3197447 & 681 & 685 & 6504 & \\
\hline 262 & 81 & 685 & 1652 & \\
\hline HEMBL14 & 81 & 686 & 1489 & \\
\hline HEMBL15 & 681 & 681 & 0274 & \\
\hline HEMBL15 & 681 & 686 & & \\
\hline HEMBL143 & $\delta 1$ & 898 & 577 & \\
\hline HEMBL17 & 31 & 29 & 01 & \\
\hline HEMBL1: & 81 & 86 & 5399 & \\
\hline HEMBL31 & 81 & 895 & & RN \\
\hline HEMBL137 & 81 & 583 & 555 & ГRN \\
\hline HEMBL 21 & 81 & & 89 & \\
\hline HEMBL13 & & 584 & & \\
\hline 54 & 31 & 86 & 34 & RN \\
\hline AEMBL15 & 31 & 684 & & RN \\
\hline JEMBL14 & 81 & 125 & 558 & TRN \\
\hline HEMBL13 & 36 & & 352 & $\mathrm{RN}$ \\
\hline HEM & 31 & 36 & & KIV \\
\hline HEME & 31 & 83 & 57 & ST \\
\hline HEMBL 144 & 31 & 86 & & \\
\hline HEMBL1399478 & 301681 & 3.0686 & 867 & ГRN \\
\hline HEMBL18 & 30 & 499 & & \\
\hline 8 & 1 & 35 & & ST \\
\hline HEMBL148 & & & 5883 & RN \\
\hline HEMBL1610756 & 301 & & 725 & TST \\
\hline HEMBL1338085 & 301 & 349 & 533 & $\Gamma \mathrm{RN}$ \\
\hline JEMBL319 & 30 & 85 & 12 & \\
\hline IIM & & & & ST \\
\hline HEMBL17 & & 4.2874 & & IST \\
\hline HEMBL1300302 & 81 & 457 & 501 & ГRN \\
\hline HEMBL 14 & 30 & 585 & 536 & RN \\
\hline HEMBL149 & 301 & & & \\
\hline HEMBL1503651 & 81 & & 466 & ST \\
\hline HEMBL1579602 & 1301681 & 3.0684 & 5385 & RN \\
\hline HEMBL173 & 1301 & .5454 & 992 & ST \\
\hline$L 2$ & 30 & & & \\
\hline תז יחנזי & & & & \\
\hline
\end{tabular}

Page 3521 
Supplemental Table S2.txt

\begin{tabular}{|c|c|c|c|c|c|}
\hline CHEMBL580340 & 1301681 & 4.276 & 3.8077 & TRN & \\
\hline CHEMBL1357535 & 1301681 & 3.0686 & 3.18 & TRN & \\
\hline CHEMBL1446827 & 1301681 & 3.0687 & 3.306 & TRN & \\
\hline CHEMBL1343728 & 1301681 & 4.3459 & 3.7701 & TRN & \\
\hline CHEMBL1314867 & 1301681 & 3.5457 & 3.3578 & TRN & \\
\hline CHEMBL1402539 & 1301681 & 3.0683 & 3.3728 & TRN & \\
\hline CHEMBL1466305 & 1301681 & 3.0686 & 3.5174 & TRN & \\
\hline CHEMBL1315391 & 1301681 & 4.244 & 3.9249 & TRN & \\
\hline CHEMBL1310479 & 1301681 & 3.0685 & 3.6575 & TRN & \\
\hline CHEMBL1877083 & 1301681 & 4.2272 & 3.866 & TRN & \\
\hline CHEMBL1525599 & 1301681 & 3.0685 & 3.6525 & TRN & \\
\hline CHEMBL1449336 & 1301681 & 3.5457 & 3.4117 & TRN & \\
\hline CHEMBL1734142 & 1301681 & 3.0685 & 3.718 & TST & \\
\hline CHEMBL 2137984 & 1301681 & 4.6755 & 3.7304 & TRN & \\
\hline CHEMBL1404493 & 1301681 & 4.5103 & 4.0274 & TRN & \\
\hline CHEMBL1371706 & 1301681 & 3.0686 & 3.5002 & TRN & \\
\hline CHEMBL1583585 & 1301681 & 4.075 & 3.74300 & 00000000003 & TRN \\
\hline CHEMBL530291 & 1301681 & 3.0686 & 3.2996 & TRN & \\
\hline CHEMBL1484487 & 1301681 & 3.0686 & 3.2248 & TST & \\
\hline CHEMBL1573112 & 1301681 & 4.1957 & 3.6109 & TRN & \\
\hline CHEMBL1711360 & 1301681 & 3.0687 & 3.508 & TRN & \\
\hline CHEMBL1559053 & 1301681 & 3.0685 & 3.4668 & TRN & \\
\hline CHEMBL1720343 & 1301681 & 3.068 & 3.2554 & TRN & \\
\hline CHEMBL1342790 & 1301681 & 3.0686 & 3.3389 & TST & \\
\hline CHEMBL1878609 & 1301681 & 4.3628 & 3.7818 & TRN & \\
\hline CHEMBL1496004 & 1301681 & 4.4022 & 3.7865 & TRN & \\
\hline CHEMBL1367466 & 1301681 & 3.0685 & 3.5292 & TRN & \\
\hline CHEMBL509617 & 1301681 & 3.0689 & 3.6866 & TST & \\
\hline CHEMBL1482468 & 1301681 & 3.0686 & 3.3994 & TRN & \\
\hline CHEMBL1727678 & 1301681 & 4.5804 & 4.051 & TST & \\
\hline CHEMBL1566205 & 1301681 & 3.0685 & 3.1133 & TRN & \\
\hline CHEMBL1420007 & 1301681 & 3.0686 & 3.2468 & TST & \\
\hline CHEMBL1528668 & 1301681 & 3.0687 & 3.4934 & TST & \\
\hline CHEMBL1519558 & 1301681 & 3.0685 & 3.3663 & TRN & \\
\hline CHEMBL1444822 & 1301681 & 3.0686 & 3.3697 & TST & \\
\hline CHEMBL1575502 & 1301681 & 4.6581 & 3.9579 & TST & \\
\hline CHEMBL1428181 & 1301681 & 4.1786 & 3.5425 & TST & \\
\hline CHEMBL 3182910 & 1301681 & 3.0686 & 3.2381 & TST & \\
\hline CHEMBL1448690 & 1301681 & 3.0685 & 3.6652 & TST & \\
\hline CHEMBL 3186963 & 1301681 & 3.0685 & 3.4379 & TST & \\
\hline CHEMBL1415184 & 1301681 & 3.0685 & 3.4396 & TST & \\
\hline CHEMBL1380507 & 1301681 & 3.0682 & 3.5949 & TST & \\
\hline CHEMBL1552591 & 1301681 & 4.899 & 3.5327 & TST & \\
\hline CHEMBL1429289 & 1301681 & 3.0686 & 3.6975 & TST & \\
\hline CHEMBL1482671 & 1301681 & 3.0684 & 3.4505 & TST & \\
\hline CHEMBL1611369 & 1301681 & 3.0686 & 3.4408 & TST & \\
\hline CHEMBL1314757 & 1301681 & 4.2174 & 2.9131 & TST & \\
\hline CHEMBL1448828 & 1301681 & 3.0686 & 2.9347 & TST & \\
\hline
\end{tabular}


Supplemental Table S2.txt

\begin{tabular}{|c|c|c|c|c|c|}
\hline CHEMBL1485417 & 1301681 & 3.0685 & 3.4377 & TST & \\
\hline CHEMBL1530686 & 1301681 & 4.2454 & 3.5717 & TST & \\
\hline CHEMBL1344838 & 1301681 & 4.5161 & 3.5456 & TST & \\
\hline CHEMBL1081764 & 620646 & 4.0 & 3.9974 & TRN & \\
\hline CHEMBL1080188 & 620646 & 4.0 & 3.9143 & TRN & \\
\hline CHEMBL1079982 & 620646 & 4.0 & 4.0908 & TRN & \\
\hline CHEMBL1082118 & 620646 & 4.0 & 4.3069 & TRN & \\
\hline CHEMBL1079618 & 620646 & 4.0 & 3.8782 & TRN & \\
\hline CHEMBL1079449 & 620646 & 4.0 & 3.9512 & TRN & \\
\hline CHEMBL1081046 & 620646 & 4.0 & 4.4054 & TST & \\
\hline CHEMBL1079983 & 620646 & 4.0 & 3.8877 & TRN & \\
\hline CHEMBL1075895 & 620646 & 6.3872 & \multicolumn{2}{|c|}{6.707000000000001} & TRN \\
\hline CHEMBL1081601 & 620646 & 4.0 & 4.1091 & TRN & \\
\hline CHEMBL1081963 & 620646 & 4.0 & 4.9149 & TST & \\
\hline CHEMBL1079984 & 620646 & 4.0 & 3.9693 & TRN & \\
\hline CHEMBL1082089 & 620646 & 4.0 & 3.89 & TRN & \\
\hline CHEMBL1081771 & 620646 & 4.0 & 4.0172 & TRN & \\
\hline CHEMBL279053 & 620646 & 5.8861 & 6.9824 & TST & \\
\hline CHEMBL1081786 & 620646 & 5.2798 & 5.4768 & TRN & \\
\hline CHEMBL1081926 & 620646 & 4.0 & 3.9048 & TRN & \\
\hline CHEMBL1076151 & 620646 & 4.0 & 3.9946 & TRN & \\
\hline CHEMBL1080013 & 620646 & 4.0 & 4.1318 & TRN & \\
\hline CHEMBL1081410 & 620646 & 4.0 & 4.0503 & TRN & \\
\hline CHEMBL1075683 & 620646 & 6.041 & 5.3656 & TRN & \\
\hline CHEMBL1079821 & 620646 & 4.0 & 3.7797 & TRN & \\
\hline CHEMBL1080349 & 620646 & 4.0 & 4.5375 & TRN & \\
\hline CHEMBL1075706 & 620646 & 4.0 & 4.0089 & TRN & \\
\hline CHEMBL1080356 & 620646 & 4.0 & 3.9904 & TRN & \\
\hline CHEMBL1075723 & 620646 & 6.1612 & 5.8049 & TRN & \\
\hline CHEMBL1079911 & 620646 & 4.0 & 4.0482 & TRN & \\
\hline CHEMBL1080708 & 620646 & 4.0 & 3.9695 & TRN & \\
\hline CHEMBL1079646 & 620646 & 4.0 & 3.9912 & TRN & \\
\hline CHEMBL1080312 & 620646 & 4.0 & 3.9954 & TRN & \\
\hline CHEMBL1081044 & 620646 & 4.0 & 4.4848 & TST & \\
\hline CHEMBL1080033 & 620646 & 4.0 & 4.0799 & TRN & \\
\hline CHEMBL1080535 & 620646 & 4.0 & 4.05699 & 99999999995 & TRN \\
\hline CHEMBL1079488 & 620646 & 5.3893 & 3.707 & TST & \\
\hline CHEMBL1080365 & 620646 & 6.7959 & 6.6935 & TRN & \\
\hline CHEMBL1082090 & 620646 & 4.0 & 4.228 & TRN & \\
\hline CHEMBL1079489 & 620646 & 6.3188 & 4.0662 & TST & \\
\hline CHEMBL1075703 & 620646 & 4.0 & 4.1912 & TRN & \\
\hline CHEMBL1081763 & 620646 & 4.0 & 3.7703 & TRN & \\
\hline CHEMBL1080108 & 620646 & 4.0 & 3.8247 & TRN & \\
\hline CHEMBL1075772 & 620646 & 4.0 & 4.0394 & TST & \\
\hline CHEMBL1080361 & 620646 & 6.5229 & 5.262006 & 00000000005 & TST \\
\hline CHEMBL1075682 & 620646 & 4.0 & 4.6276 & TRN & \\
\hline CHEMBL1080355 & 620646 & 4.0 & 4.0514 & TRN & \\
\hline CHEMBL1079503 & 620646 & 4.0 & 4.0269 & TRN & \\
\hline
\end{tabular}




\begin{tabular}{|c|c|c|c|c|}
\hline & & & spraters & \\
\hline CHEMBL1080821 & 620646 & 4.0 & 4.0216 & TRN \\
\hline CHEMBL1081241 & 620646 & 4.0 & 4.5806 & TST \\
\hline CHEMBL1079504 & 620646 & 4.0 & 4.0192 & TRN \\
\hline CHEMBL1081730 & 620646 & 4.0 & 3.8769 & TRN \\
\hline CHEMBL1076175 & 620646 & 4.0 & 3.9152 & TRN \\
\hline CHEMBL1082117 & 620646 & 4.0 & 4.1895 & TRN \\
\hline CHEMBL1075704 & 620646 & 4.0 & 3.7871 & TRN \\
\hline CHEMBL1081749 & 620646 & 4.0 & 4.0308 & TRN \\
\hline CHEMBL210469 & 620646 & 4.0 & 4.3345 & TST \\
\hline CHEMBL1081962 & 620646 & 4.0 & 4.1467 & TRN \\
\hline CHEMBL1081751 & 620646 & 4.0 & 3.9931 & TRN \\
\hline CHEMBL1080173 & 620646 & 4.0 & 4.1537 & TRN \\
\hline CHEMBL1075893 & 620646 & 4.0 & 4.0018 & TRN \\
\hline CHEMBL1079382 & 620646 & 4.0 & 4.4459 & TST \\
\hline CHEMBL1081004 & 620646 & 4.0 & 4.0805 & TRN \\
\hline CHEMBL1079617 & 620646 & 4.0 & 3.8235 & TRN \\
\hline CHEMBL1081224 & 620646 & 4.0 & 4.0096 & TRN \\
\hline CHEMBL1081600 & 620646 & 4.0 & 4.042 & TRN \\
\hline CHEMBL1081964 & 620646 & 4.0 & 3.8726 & TRN \\
\hline CHEMBL1081602 & 620646 & 4.0 & 4.1062 & TRN \\
\hline CHEMBL1081223 & 620646 & 4.0 & 3.9942 & TRN \\
\hline CHEMBL1079668 & 620646 & 4.0 & 3.9246 & TRN \\
\hline CHEMBL1080184 & 620646 & 4.0 & 4.4375 & TRN \\
\hline CHEMBL1080168 & 620646 & 4.0 & 4.0509 & TRN \\
\hline CHEMBL1080534 & 620646 & 4.0 & 3.983 & TRN \\
\hline CHEMBL1080025 & 620646 & 4.0 & 4.0028 & TRN \\
\hline CHEMBL1079965 & 620646 & 4.0 & 4.1095 & TRN \\
\hline CHEMBL1079739 & 620646 & 4.0 & 3.8572 & TRN \\
\hline CHEMBL1079962 & 620646 & 6.0757 & 5.9995 & TRN \\
\hline CHEMBL1080699 & 620646 & 6.1024 & 5.767 & TRN \\
\hline CHEMBL1080026 & 620646 & 4.0 & 3.9986 & TRN \\
\hline CHEMBL1079910 & 620646 & 4.0 & 4.0867 & TRN \\
\hline CHEMBL1075836 & 620646 & 5.7011 & 5.249 & TRN \\
\hline CHEMBL1080140 & 620646 & 5.9747 & 5.732 & TRN \\
\hline CHEMBL1082131 & 620646 & 4.0 & 3.9303 & TRN \\
\hline CHEMBL1081387 & 620646 & 4.0 & 4.0241 & TRN \\
\hline CHEMBL1075835 & 620646 & 4.0 & 4.2282 & TRN \\
\hline CHEMBL1081206 & 620646 & 4.0 & 4.5269 & TST \\
\hline CHEMBL1079925 & 620646 & 4.0 & 3.832 & TRN \\
\hline CHEMBL1081045 & 620646 & 4.0 & 4.1076 & TRN \\
\hline CHEMBL1081603 & 620646 & 4.0 & 3.8771 & TRN \\
\hline CHEMBL1080368 & 620646 & 5.585 & 5.2997 & TRN \\
\hline CHEMBL1082114 & 620646 & 4.0 & 3.9603 & TRN \\
\hline CHEMBL1082116 & 620646 & 4.0 & 3.9199 & TRN \\
\hline CHEMBL1079669 & 620646 & 5.9626 & 5.2589 & TST \\
\hline CHEMBL1080532 & 620646 & 4.0 & 4.0192 & TRN \\
\hline CHEMBL1081950 & 620646 & 5.2716 & 5.3021 & TRN \\
\hline CHEMBL1075724 & 620646 & 5.7986 & 5.9806 & TRN \\
\hline
\end{tabular}




\begin{tabular}{|c|c|c|c|c|c|}
\hline \multicolumn{6}{|c|}{ Supplemental Table S2.txt } \\
\hline CHEMBL1080533 & 620646 & 4.0 & 4.1062 & TRN & \\
\hline CHEMBL1081391 & 620646 & 4.0 & 3.7539 & TRN & \\
\hline CHEMBL1082137 & 620646 & 4.0 & 4.0139 & TRN & \\
\hline CHEMBL1082115 & 620646 & 4.0 & 4.0495 & TRN & \\
\hline CHEMBL1081756 & 620646 & 4.0 & 4.0162 & TST & \\
\hline CHEMBL1081424 & 620646 & 4.0 & 4.0963 & TST & \\
\hline CHEMBL1075732 & 620646 & 6.1549 & 6.434 & TRN & \\
\hline CHEMBL1081750 & 620646 & 4.0 & 4.013 & TRN & \\
\hline CHEMBL1080369 & 620646 & 4.0 & 4.0322 & TRN & \\
\hline CHEMBL1081949 & 620646 & 4.0 & 4.1737 & TRN & \\
\hline CHEMBL1075894 & 620646 & 5.9208 & 5.7029 & TRN & \\
\hline CHEMBL1079961 & 620646 & 6.0969 & 6.1753 & TRN & \\
\hline CHEMBL1080873 & 620646 & 4.0 & 3.8489 & TRN & \\
\hline CHEMBL1081591 & 620646 & 4.0 & 4.0375 & TRN & \\
\hline CHEMBL1080143 & 620646 & 4.0 & 3.9505 & TRN & \\
\hline CHEMBL1080363 & 620646 & 4.0 & 3.9522 & TRN & \\
\hline CHEMBL1080540 & 620646 & 4.0 & 4.3153 & TST & \\
\hline CHEMBL1075725 & 620646 & 5.9393 & 5.9795 & TRN & \\
\hline CHEMBL1080172 & 620646 & 4.0 & 5.3527 & TST & \\
\hline CHEMBL1080032 & 620646 & 4.0 & 4.1494 & TST & \\
\hline CHEMBL1081951 & 620646 & 4.0 & 4.1273 & TST & \\
\hline CHEMBL1080187 & 620646 & 4.0 & 4.0123 & TST & \\
\hline CHEMBL1079826 & 620646 & 4.0 & 4.3422 & TST & \\
\hline CHEMBL1075665 & 620646 & 4.0 & 5.1024 & TST & \\
\hline CHEMBL1075705 & 620646 & 5.284 & 3.9342 & TST & \\
\hline CHEMBL1080366 & 620646 & 4.0 & 4.0753 & TST & \\
\hline CHEMBL1079505 & 620646 & 4.0 & 4.9592 & TST & \\
\hline CHEMBL1081380 & 620646 & 4.0 & 4.0549 & TST & \\
\hline CHEMBL1081003 & 620646 & 5.6253 & 5.5634 & TST & \\
\hline CHEMBL1075856 & 620646 & 4.0 & 4.137 & TST & \\
\hline CHEMBL1081729 & 620646 & 4.0 & 3.83399 & 99999999996 & TST \\
\hline CHEMBL1081207 & 620646 & 4.0 & 4.882 & TST & \\
\hline CHEMBL1079677 & 620646 & 4.0 & 4.0544 & TST & \\
\hline CHEMBL1079981 & 620646 & 4.0 & 4.3047 & TST & \\
\hline CHEMBL3134519 & 1298620 & 8.9586 & 9.0741 & TRN & \\
\hline CHEMBL3134559 & 1298620 & 7.5317 & 7.3503 & TRN & \\
\hline CHEMBL 3134540 & 1298620 & 7.2976 & 7.12200 & 0000000001 & TRN \\
\hline CHEMBL3134526 & 1298620 & 8.1871 & 8.5789 & TST & \\
\hline CHEMBL3134542 & 1298620 & 7.3726 & 7.57799 & 9999999999 & TRN \\
\hline CHEMBL 3134522 & 1298620 & 7.4672 & 7.269 & TRN & \\
\hline CHEMBL3134541 & 1298620 & 7.3536 & 7.3577 & TRN & \\
\hline CHEMBL3134532 & 1298620 & 8.0555 & 8.0951 & TRN & \\
\hline CHEMBL3134556 & 1298620 & 8.1612 & 8.3074 & TRN & \\
\hline CHEMBL 3134543 & 1298620 & 8.0458 & 7.9412 & TRN & \\
\hline CHEMBL3134529 & 1298620 & 8.8861 & 8.8234 & TRN & \\
\hline CHEMBL3134520 & 1298620 & 7.2097 & 7.2907 & TRN & \\
\hline CHEMBL3134517 & 1298620 & 7.6021 & 7.5876 & TRN & \\
\hline CHEMBL3134548 & 1298620 & 6.767 & 7.0278 & TRN & \\
\hline
\end{tabular}


Supplemental Table S2.txt

\begin{tabular}{|c|c|c|c|c|c|c|}
\hline CHEMBL 3134538 & 1298620 & 6.7235 & 6.79 & TRN & & \\
\hline CHEMBL 3134518 & 1298620 & 7.6162 & 8.1958 & TRN & & \\
\hline CHEMBL 3134554 & 1298620 & 8.0757 & 8.0676 & TRN & & \\
\hline CHEMBL 3134555 & 1298620 & 8.1427 & 8.2134 & TRN & & \\
\hline CHEMBL 3134535 & 1298620 & 8.1367 & 8.0529 & TRN & & \\
\hline CHEMBL 3134539 & 1298620 & 7.4437 & 7.5275 & TRN & & \\
\hline CHEMBL 3134525 & 1298620 & 7.4815 & 7.4972 & TRN & & \\
\hline CHEMBL 3134523 & 1298620 & 7.8794 & 7.8557 & TRN & & \\
\hline CHEMBL 3134557 & 1298620 & 8.041 & 7.9512 & TRN & & \\
\hline CHEMBL 3134563 & 1298620 & 7.5969 & 7.4293 & TRN & & \\
\hline CHEMBL 3134530 & 1298620 & 9.5229 & 9.2773 & TRN & & \\
\hline CHEMBL 3134564 & 1298620 & \multicolumn{3}{|c|}{5.3229999999999995} & 5.4926 & TST \\
\hline CHEMBL 3134531 & 1298620 & 9.5229 & 9.6336 & TRN & & \\
\hline CHEMBL 3134547 & 1298620 & 8.7447 & 8.367 & TRN & & \\
\hline CHEMBL 3134534 & 1298620 & 9.301 & 9.3652 & TRN & & \\
\hline CHEMBL 3134545 & 1298620 & 8.1024 & 7.9443 & TRN & & \\
\hline CHEMBL 3134536 & 1298620 & 7.5884 & 7.6327 & TST & & \\
\hline CHEMBL 3134569 & 1298620 & 7.3904 & \multicolumn{3}{|c|}{7.332000000000001} & זענו \\
\hline CHEMBL 3134546 & 1298620 & 8.3665 & 8.4346 & TRN & & \\
\hline CHEMBL 3134533 & 1298620 & 7.4698 & 7.5647 & TST & & \\
\hline CHEMBL 3134544 & 1298620 & 8.2007 & 8.3339 & TRN & & \\
\hline CHEMBL 3134558 & 1298620 & 8.9208 & 8.6657 & TRN & & \\
\hline CHEMBL 3134527 & 1298620 & 8.6198 & 8.9007 & TST & & \\
\hline CHEMBL 3134550 & 1298620 & 8.0757 & 8.0285 & TRN & & \\
\hline CHEMBL 3134561 & 1298620 & 8.8539 & 9.0802 & TRN & & \\
\hline CHEMBL 3134524 & 1298620 & \multicolumn{3}{|c|}{6.752000000000001} & 6.4095 & $\mathrm{~N}$ \\
\hline CHEMBL 3134560 & 1298620 & 8.8539 & 8.7463 & TRN & & \\
\hline CHEMBL 3134566 & 1298620 & 7.4214 & \multicolumn{3}{|c|}{7.127000000000001} & ונדו \\
\hline CHEMBL1951577 & 1298620 & 8.0915 & 7.8923 & TRN & & \\
\hline CHEMBL 3134562 & 1298620 & 5.6568 & 5.9039 & TRN & & \\
\hline CHEMBL 3134553 & 1298620 & 7.4868 & 7.5745 & TRN & & \\
\hline CHEMBL 3134537 & 1298620 & 6.8729 & 6.9232 & TRN & & \\
\hline CHEMBL 3134528 & 1298620 & 9.0458 & 9.0726 & TRN & & \\
\hline CHEMBL3134549 & 1298620 & 7.0472 & 7.2066 & TRN & & \\
\hline CHEMBL 3134521 & 1298620 & 7.3799 & 7.0144 & TST & & \\
\hline CHEMBL3134565 & 1298620 & 7.3391 & 7.1543 & TST & & \\
\hline CHEMBL 3134567 & 1298620 & 7.433 & 7.3864 & TST & & \\
\hline CHEMBL 3134568 & 1298620 & 7.399 & 7.2947 & TST & & \\
\hline CHEMBL 3134552 & 1298620 & 7.4634 & 7.7281 & TST & & \\
\hline CHEMBL 3134570 & 1298620 & 7.4789 & 7.3872 & TST & & \\
\hline CHEMBL 3134551 & 1298620 & 8.1612 & 8.1643 & TST & & \\
\hline CHEMBL 3933860 & 1641544 & 8.3979 & 8.2619 & TRN & & \\
\hline CHEMBL 3928825 & 1641544 & 7.2749 & 7.2314 & TRN & & \\
\hline CHEMBL 3914841 & 1641544 & 7.767 & 7.6025 & TST & & \\
\hline CHEMBL 3907177 & 1641544 & 7.9914 & 7.64 & TRN & & \\
\hline CHEMBL 3920492 & 1641544 & 7.4647 & 7.4274 & TST & & \\
\hline CHEMBL 3906773 & 1641544 & 8.6576 & 8.4575 & TRN & & \\
\hline CHEMBL 3924952 & 1641544 & 8.6021 & 7.8258 & TRN & & \\
\hline
\end{tabular}


Supplemental Table S2.txt

\begin{tabular}{|c|c|c|c|c|}
\hline 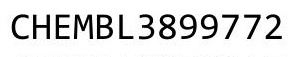 & & ( & & \\
\hline HEMBL3978817 & 541544 & 8.0506 & 8.1021 & \\
\hline HEMBL3948433 & 41544 & 0555 & ל & \\
\hline & & 73 & 8772 & \\
\hline AEMBL3 & 544 & 447 & 4639 & \\
\hline AEMBL3927729 & 641544 & .9208 & . 3784 & \\
\hline HEMBL 3978444 & 641544 & 7.9666 & .2213 & \\
\hline HEMBL3892493 & 544 & 8.585 & 6034 & \\
\hline HEMBL3 & 44 & 1559 & 4071 & \\
\hline HEMBL3 & 44 & 8.8861 & 5341 & \\
\hline HEMBL3905543 & 544 & 3.8861 & .4192 & \\
\hline HEMBL3963683 & 544 & 8.6383 & 6315 & \\
\hline HEMBL3950014 & 44 & 2366 & 3039 & \\
\hline HEMBL; & 44 & 7.7447 & .9701 & \\
\hline HEMBL3 & & 6.5622 & 7.2995 & \\
\hline HEMBL3916580 & 544 & 7.1733 & 6653 & \\
\hline HEMBL3958767 & 544 & 8.2076 & & \\
\hline HEMBL3 & 44 & 386 & 11 & \\
\hline HEN & 44 & 208 & 41 & \\
\hline 42 & & 706 & 49 & \\
\hline HEMBL3S & 44 & 8.4815 & 8.1942 & \\
\hline AEMBL3916955 & & 75 & & \\
\hline HEMBL3 & 64 & 041 & 14 & \\
\hline HEN & 6 & 665 & & \\
\hline 08 & 44 & 01 & & RN \\
\hline 510 & & 905 & & RN \\
\hline AEMBL 3958824 & 4 & 26 & & RN \\
\hline HEMBL3 & 6 & 471 & 68 & Iv \\
\hline HEN & 4 & 768 & & RN \\
\hline 338 & 14 & 05 & 478 & RN \\
\hline AEMBL3 & & & & ST \\
\hline HEMBL3960737 & 6 & 871 & & IST \\
\hline AEMBL3 & & 38 & & RN \\
\hline 9 & 4 & 18 & & RN \\
\hline 29 & & 28 & 92 & RN \\
\hline AEMBL3965721 & & 212 & 59 & RN \\
\hline AEMBL3915649 & 6 & 6.8894 & & ST \\
\hline 4 & & 32 & & RN \\
\hline - & & 88 & & RN \\
\hline HEMBL & & & 7649 & RN \\
\hline AEMBL3947766 & 44 & 7.4763 & & RN \\
\hline AEMBL & +4 & 239 & & RN \\
\hline 236 & & 382 & & \\
\hline HEMBL3 & & & & RN \\
\hline HEMBL3917690 & 544 & 8.301 & 1926 & RN \\
\hline AEMBL3E & 16 & 8.8861 & 232 & RN \\
\hline & & & & \\
\hline & זדם & & & \\
\hline
\end{tabular}


Supplemental Table S2.txt

\begin{tabular}{|c|c|c|c|c|c|c|}
\hline CHEMBL3909584 & 1641544 & 7.0991 & 8.1559 & TRN & & \\
\hline CHEMBL3935404 & 1641544 & 7.8508 & 7.6825 & TRN & & \\
\hline CHEMBL3890419 & 1641544 & 7.6517 & 7.3391 & TST & & \\
\hline CHEMBL 3980983 & 1641544 & 6.8665 & 7.0302 & TRN & & \\
\hline CHEMBL 3950445 & 1641544 & 7.7496 & 7.9145 & TRN & & \\
\hline CHEMBL3917370 & 1641544 & 7.5171 & 7.6686 & TST & & \\
\hline CHEMBL3933936 & 1641544 & 7.7447 & 7.8575 & TRN & & \\
\hline CHEMBL3911104 & 1641544 & 9.0757 & 8.8895 & TRN & & \\
\hline CHEMBL3953097 & 1641544 & 7.6364 & 7.8006 & TST & & \\
\hline CHEMBL 3914223 & 1641544 & 7.9957 & 8.1108 & TRN & & \\
\hline CHEMBL 3982526 & 1641544 & 8.5229 & 8.7028 & TRN & & \\
\hline CHEMBL3921115 & 1641544 & 8.5528 & 8.6205 & TST & & \\
\hline CHEMBL 3982460 & 1641544 & 7.8761 & 7.7838 & TRN & & \\
\hline CHEMBL3947850 & 1641544 & 9.1308 & 8.4806 & TRN & & \\
\hline CHEMBL 3891527 & 1641544 & 8.2596 & 8.0279 & TRN & & \\
\hline CHEMBL 3920048 & 1641544 & 7.9355 & 8.2904 & TRN & & \\
\hline CHEMBL3979505 & 1641544 & 9.0809 & 8.8592 & TRN & & \\
\hline CHEMBL3895136 & 1641544 & 8.0605 & 7.8914 & TST & & \\
\hline CHEMBL 3957998 & 1641544 & 7.2741 & 7.5527 & TRN & & \\
\hline CHEMBL 3906254 & 1641544 & 9.1192 & 8.7076 & TRN & & \\
\hline CHEMBL3931527 & 1641544 & 6.4855 & 7.7573 & TRN & & \\
\hline CHEMBL3891653 & 1641544 & 7.4214 & 7.1782 & TRN & & \\
\hline CHEMBL3925425 & 1641544 & 8.4949 & 8.494 & TRN & & \\
\hline CHEMBL3901199 & 1641544 & 8.3665 & 8.3903 & TST & & \\
\hline CHEMBL3976953 & 1641544 & 8.3565 & 8.2471 & TRN & & \\
\hline CHEMBL 3982940 & 1641544 & 6.2848 & 6.6667 & TST & & \\
\hline CHEMBL3917088 & 1641544 & 7.9431 & 7.4806 & TRN & & \\
\hline CHEMBL3985085 & 1641544 & 8.1612 & 8.6251 & TRN & & \\
\hline CHEMBL 3891840 & 1641544 & 7.76200 & 00000000 & 305 & 7.3782 & TRN \\
\hline CHEMBL3906879 & 1641544 & 7.5031 & 7.0565 & TRN & & \\
\hline CHEMBL3976575 & 1641544 & 7.3615 & 7.858 & TRN & & \\
\hline CHEMBL 3952841 & 1641544 & 7.8041 & 8.0143 & TRN & & \\
\hline CHEMBL3982212 & 1641544 & 7.9469 & 7.9391 & TRN & & \\
\hline CHEMBL3926269 & 1641544 & 8.585 & 8.6724 & TRN & & \\
\hline CHEMBL 3950078 & 1641544 & 6.5436 & 7.0688 & TST & & \\
\hline CHEMBL3944456 & 1641544 & 6.6289 & 6.8086 & TST & & \\
\hline CHEMBL 3941801 & 1641544 & 7.1593 & 6.9914 & TRN & & \\
\hline CHEMBL3905932 & 1641544 & 7.8125 & 7.956 & TRN & & \\
\hline CHEMBL 3932180 & 1641544 & 8.4089 & 7.8494 & TRN & & \\
\hline CHEMBL 3942527 & 1641544 & 9.1249 & 8.6329 & TRN & & \\
\hline CHEMBL3912926 & 1641544 & 7.5143 & 7.7771 & TRN & & \\
\hline CHEMBL 3921544 & 1641544 & 7.9066 & 7.2066 & TRN & & \\
\hline CHEMBL 3920634 & 1641544 & 8.6778 & 8.755 & TRN & & \\
\hline CHEMBL 3972632 & 1641544 & 8.6383 & 8.4629 & TRN & & \\
\hline CHEMBL 3939106 & 1641544 & 8.5229 & 8.254 & TRN & & \\
\hline CHEMBL 3910575 & 1641544 & 9.2007 & 8.6901 & TRN & & \\
\hline CHEMBL 3940880 & 1641544 & 8.7696 & 8.9213 & TRN & & \\
\hline CHEMBL 3891129 & 1641544 & 8.5086 & 8.4153 & TRN & & \\
\hline
\end{tabular}

Page 3528 
Supplemental Table S2.txt

\begin{tabular}{|c|c|c|c|c|}
\hline CHEMBL3901959 & 1641544 & 7.7235 & 7.6623 & TRN \\
\hline CHEMBL3915707 & 1641544 & 7.6904 & 8.4829 & TRN \\
\hline CHEMBL3922345 & 1641544 & 8.7696 & 8.377 & TST \\
\hline CHEMBL 3927275 & 1641544 & 8.1249 & 8.311 & TRN \\
\hline CHEMBL 3914893 & 1641544 & 8.1308 & 8.0902 & TRN \\
\hline CHEMBL 3960784 & 1641544 & 8.6198 & 8.3101 & TRN \\
\hline CHEMBL3914365 & 1641544 & 6.2765 & 7.3538 & TST \\
\hline CHEMBL 3918319 & 1641544 & 7.61799 & 999999999 & 7.5625 \\
\hline CHEMBL3918287 & 1641544 & 7.9172 & 7.7366 & TRN \\
\hline CHEMBL 3896902 & 1641544 & 7.9136 & 7.3508 & TRN \\
\hline CHEMBL 3957506 & 1641544 & 7.1314 & 6.9105 & TRN \\
\hline CHEMBL 3906205 & 1641544 & 7.8013 & 8.4371 & TRN \\
\hline CHEMBL 3953746 & 1641544 & 7.8601 & 7.7541 & TST \\
\hline CHEMBL3911074 & 1641544 & 7.4377 & 7.8664 & TRN \\
\hline CHEMBL 3903195 & 1641544 & 7.6108 & 7.4314 & TRN \\
\hline CHEMBL3939676 & 1641544 & 7.5884 & 7.8137 & TRN \\
\hline CHEMBL3899118 & 1641544 & 7.1524 & 7.7501 & TRN \\
\hline CHEMBL 3979562 & 1641544 & 7.6091 & 7.9062 & TRN \\
\hline CHEMBL3895651 & 1641544 & 6.9031 & 7.1772 & TST \\
\hline CHEMBL 3897979 & 1641544 & 8.1871 & 8.4758 & TRN \\
\hline CHEMBL3957020 & 1641544 & 7.9788 & 7.952999 & э999999999 \\
\hline CHEMBL 3889697 & 1641544 & 7.5317 & 7.6552 & TRN \\
\hline CHEMBL 3898174 & 1641544 & 7.9914 & 7.9612 & TRN \\
\hline CHEMBL3931499 & 1641544 & 7.5114 & 7.6789 & TRN \\
\hline CHEMBL 3963357 & 1641544 & 7.8665 & 8.1442 & TRN \\
\hline CHEMBL3898595 & 1641544 & 8.8539 & 8.5462 & TRN \\
\hline CHEMBL 3972074 & 1641544 & 8.2676 & 8.1463 & TRN \\
\hline CHEMBL 3943998 & 1641544 & 7.9626 & 8.2928 & TRN \\
\hline CHEMBL3907725 & 1641544 & 8.0458 & 7.7287 & TRN \\
\hline CHEMBL3931332 & 1641544 & 7.7167 & 6.9829 & TRN \\
\hline CHEMBL3945583 & 1641544 & 8.2076 & 8.724 & TRN \\
\hline CHEMBL 3939053 & 1641544 & 9.0969 & 7.7791 & TRN \\
\hline CHEMBL3915758 & 1641544 & 7.7595 & 8.2295 & TRN \\
\hline CHEMBL3931182 & 1641544 & 8.0706 & 8.2715 & TST \\
\hline CHEMBL3949648 & 1641544 & 8.0132 & 7.6482 & TRN \\
\hline CHEMBL3921771 & 1641544 & 4.6198 & 6.1534 & TRN \\
\hline CHEMBL 3893686 & 1641544 & 7.1433 & 7.3488 & TRN \\
\hline CHEMBL 3920004 & 1641544 & 8.7212 & 8.6036 & TRN \\
\hline CHEMBL 3978601 & 1641544 & 8.3468 & 8.2017 & TRN \\
\hline CHEMBL3919590 & 1641544 & 8.4318 & 8.0746 & TRN \\
\hline CHEMBL3893858 & 1641544 & 8.4949 & 8.4023 & TRN \\
\hline CHEMBL3980661 & 1641544 & 8.0605 & 8.554 & TRN \\
\hline CHEMBL 3975757 & 1641544 & 8.1739 & 8.0546 & TST \\
\hline CHEMBL 3918840 & 1641544 & 7.251 & 7.1267 & TST \\
\hline CHEMBL3899717 & 1641544 & 8.0555 & 8.1487 & TST \\
\hline CHEMBL3956079 & 1641544 & 5.1487 & 5.5602 & TST \\
\hline CHEMBL 3916729 & 1641544 & 7.8097 & 7.1228 & TRN \\
\hline CHEMBL 3895031 & 1641544 & 7.9469 & 7.7628 & TRN \\
\hline
\end{tabular}


Supplemental Table S2.txt

\begin{tabular}{|c|c|c|c|c|c|c|}
\hline CHEMBL3968656 & 1641544 & 6.4295 & 7.5588 & TRN & & \\
\hline CHEMBL3928904 & 1641544 & 9.28399 & 99999999 & 99 & 8.7999 & TRN \\
\hline CHEMBL 3966441 & 1641544 & 7.0851 & 7.2945 & TRN & & \\
\hline CHEMBL3927745 & 1641544 & 8.2518 & 8.1131 & TRN & & \\
\hline CHEMBL 3904546 & 1641544 & 6.3936 & 6.4598 & TST & & \\
\hline CHEMBL 3941493 & 1641544 & 6.6478 & 6.6358 & TRN & & \\
\hline CHEMBL3946150 & 1641544 & 7.9066 & 7.99200 & 0000000001 & & TRN \\
\hline CHEMBL3946189 & 1641544 & 8.2007 & 7.7973 & TRN & & \\
\hline CHEMBL3950512 & 1641544 & 8.7447 & 8.8592 & TRN & & \\
\hline CHEMBL 3947757 & 1641544 & 8.1805 & 8.0785 & TRN & & \\
\hline CHEMBL 3890504 & 1641544 & 8.7773 & 8.8905 & TRN & & \\
\hline CHEMBL 3927753 & 1641544 & 7.8928 & 7.3612 & TST & & \\
\hline CHEMBL 3926083 & 1641544 & 7.3125 & 7.6467 & TRN & & \\
\hline CHEMBL3982262 & 1641544 & 8.5229 & 8.755 & TRN & & \\
\hline CHEMBL 3924634 & 1641544 & 7.3696 & 7.6803 & TST & & \\
\hline CHEMBL3913918 & 1641544 & 8.3665 & 8.1951 & TRN & & \\
\hline CHEMBL3918915 & 1641544 & 8.4685 & 7.9156 & TRN & & \\
\hline CHEMBL 3907558 & 1641544 & 9.0655 & 8.5589 & TRN & & \\
\hline CHEMBL3983438 & 1641544 & 7.4609 & 7.6736 & TRN & & \\
\hline CHEMBL 3953714 & 1641544 & 7.9066 & 7.4134 & TRN & & \\
\hline CHEMBL 3914514 & 1641544 & 6.0259 & 6.3082 & TST & & \\
\hline CHEMBL 3936793 & 1641544 & 7.3851 & 7.7764 & TRN & & \\
\hline CHEMBL 3953827 & 1641544 & 8.9586 & 8.8881 & TRN & & \\
\hline CHEMBL3924540 & 1641544 & 7.7167 & 7.5846 & TRN & & \\
\hline CHEMBL 3955367 & 1641544 & 8.7212 & 8.0913 & TRN & & \\
\hline CHEMBL3908231 & 1641544 & 8.3872 & 8.2282 & TRN & & \\
\hline CHEMBL3943316 & 1641544 & 8.9208 & 8.4265 & TRN & & \\
\hline CHEMBL3967185 & 1641544 & 8.2676 & 8.0005 & TRN & & \\
\hline CHEMBL3941894 & 1641544 & 9.0655 & 8.0821 & TRN & & \\
\hline CHEMBL 3984959 & 1641544 & 7.6421 & 7.3437 & TRN & & \\
\hline CHEMBL3922190 & 1641544 & 7.3019 & 8.158 & TRN & & \\
\hline CHEMBL 3951463 & 1641544 & 7.9393 & 8.0709 & TRN & & \\
\hline CHEMBL 3944006 & 1641544 & 6.1518 & 6.9108 & TST & & \\
\hline CHEMBL3906617 & 1641544 & 7.6676 & 7.6529 & TRN & & \\
\hline CHEMBL 3889757 & 1641544 & 8.9208 & 8.9499 & TRN & & \\
\hline CHEMBL3942897 & 1641544 & 8.7447 & 8.7292 & TRN & & \\
\hline CHEMBL 3907303 & 1641544 & 7.9547 & 7.3199 & TST & & \\
\hline CHEMBL 3927267 & 1641544 & 7.0218 & 7.5397 & TRN & & \\
\hline CHEMBL 3904317 & 1641544 & 7.8239 & 8.4045 & TRN & & \\
\hline CHEMBL3969220 & 1641544 & 7.6716 & 7.9219 & TRN & & \\
\hline CHEMBL3912703 & 1641544 & 5.699 & 6.6321 & TRN & & \\
\hline CHEMBL3913327 & 1641544 & 6.9245 & 7.8802 & TST & & \\
\hline CHEMBL 3894835 & 1641544 & 7.433 & 7.8278 & TRN & & \\
\hline CHEMBL 3893773 & 1641544 & 7.4248 & 6.6582 & TRN & & \\
\hline CHEMBL3960489 & 1641544 & 7.7144 & 7.7651 & TRN & & \\
\hline CHEMBL 3898684 & 1641544 & 9.4089 & 9.0504 & TRN & & \\
\hline CHEMBL 3959580 & 1641544 & 7.6799 & 7.9269 & TRN & & \\
\hline CHEMBL3937631 & 1641544 & 7.8477 & 7.7547 & TRN & & \\
\hline
\end{tabular}


Supplemental Table S2.txt

\begin{tabular}{|c|c|c|c|c|c|c|}
\hline CHEMBL3918136 & 1641544 & 6.4949 & 6.8528 & TST & & \\
\hline CHEMBL3917193 & 1641544 & 8.1805 & 8.1118 & TST & & \\
\hline CHEMBL3961369 & 1641544 & 5.7696 & 6.2305 & TST & & \\
\hline CHEMBL3973801 & 1641544 & 7.7959 & 7.7448 & TST & & \\
\hline CHEMBL3980612 & 1641544 & 7.2 & 7.1557 & TST & & \\
\hline CHEMBL3966509 & 1641544 & 7.8386 & 7.7369 & TST & & \\
\hline CHEMBL3955835 & 1641544 & 8.6198 & 8.6251 & TRN & & \\
\hline CHEMBL3931770 & 1641544 & 7.11799 & 99999999 & 99 & 6.8994 & TRN \\
\hline CHEMBL3979067 & 1641544 & 7.7471 & 7.6488 & TRN & & \\
\hline CHEMBL3930704 & 1641544 & 5.7959 & 6.3625 & TRN & & \\
\hline CHEMBL3923948 & 1641544 & 8.2291 & 7.78799 & 999999999 & & TRN \\
\hline CHEMBL 3908833 & 1641544 & 7.7799 & 8.0703 & TRN & & \\
\hline CHEMBL3945636 & 1641544 & 9.0555 & 8.5917 & TRN & & \\
\hline CHEMBL3940693 & 1641544 & 7.5544 & 7.5748 & TRN & & \\
\hline CHEMBL 3985382 & 1641544 & 7.0168 & 7.4198 & TST & & \\
\hline CHEMBL 3974976 & 1641544 & 8.041 & 8.4464 & TRN & & \\
\hline CHEMBL3921276 & 1641544 & 8.6021 & 8.6987 & TRN & & \\
\hline CHEMBL 3986256 & 1641544 & 8.5528 & 8.4116 & TRN & & \\
\hline CHEMBL 3974497 & 1641544 & 9.0915 & 8.8411 & TRN & & \\
\hline CHEMBL3953353 & 1641544 & 8.6198 & 8.2104 & TRN & & \\
\hline CHEMBL 3944508 & 1641544 & 6.7423 & 7.3449 & TRN & & \\
\hline CHEMBL3964225 & 1641544 & 7.9957 & 8.1607 & TRN & & \\
\hline CHEMBL 3970319 & 1641544 & 7.5391 & 7.6975 & TRN & & \\
\hline CHEMBL 3964534 & 1641544 & 6.0 & 6.6476 & TRN & & \\
\hline CHEMBL3935168 & 1641544 & 6.7447 & 7.4932 & TRN & & \\
\hline CHEMBL3909724 & 1641544 & 6.1972 & 6.6247 & TST & & \\
\hline CHEMBL3891591 & 1641544 & 6.7375 & 6.7831 & TRN & & \\
\hline CHEMBL3951504 & 1641544 & 8.5686 & 8.3568 & TRN & & \\
\hline CHEMBL3903136 & 1641544 & 7.8069 & 8.6028 & TRN & & \\
\hline CHEMBL3936098 & 1641544 & 7.2557 & 7.4319 & TRN & & \\
\hline CHEMBL3981102 & 1641544 & 6.4789 & 6.3173 & TST & & \\
\hline CHEMBL 3911704 & 1641544 & 7.9136 & 7.8338 & TRN & & \\
\hline CHEMBL 3889659 & 1641544 & 7.0964 & 7.8694 & TRN & & \\
\hline CHEMBL 3891841 & 1641544 & 7.1898 & 7.0429 & TRN & & \\
\hline CHEMBL 3933555 & 1641544 & 8.5229 & 8.4983 & TRN & & \\
\hline CHEMBL3904365 & 1641544 & 9.1427 & 8.3705 & TRN & & \\
\hline CHEMBL 3897186 & 1641544 & 7.067 & 7.6763 & TRN & & \\
\hline CHEMBL 3971671 & 1641544 & 6.8297 & 6.6758 & TRN & & \\
\hline CHEMBL3902077 & 1641544 & 7.1433 & 7.3867 & TST & & \\
\hline CHEMBL3957775 & 1641544 & 7.567 & 7.2891 & TRN & & \\
\hline CHEMBL3908562 & 1641544 & 6.4609 & 6.4357 & TRN & & \\
\hline CHEMBL3941303 & 1641544 & 8.585 & 7.9811 & TRN & & \\
\hline CHEMBL3978741 & 1641544 & 7.75200 & 300000006 & & 7.3885 & TRN \\
\hline CHEMBL 3954903 & 1641544 & 7.2062 & 7.9946 & TRN & & \\
\hline CHEMBL 3948752 & 1641544 & 7.7773 & 7.8611 & TRN & & \\
\hline CHEMBL 3904028 & 1641544 & 7.9469 & 7.4204 & TRN & & \\
\hline CHEMBL3933967 & 1641544 & 7.9788 & 6.8723 & TRN & & \\
\hline CHEMBL3974260 & 1641544 & 8.6021 & 8.7586 & TRN & & \\
\hline
\end{tabular}


Supplemental Table S2.txt

\begin{tabular}{|c|c|c|c|c|c|c|}
\hline CHEMBL3914979 & 1641544 & 8.8239 & 8.8725 & TRN & & \\
\hline CHEMBL 3904424 & 1641544 & 8.1871 & 7.8856 & TRN & & \\
\hline CHEMBL3970135 & 1641544 & 8.0506 & 7.6639 & TRN & & \\
\hline CHEMBL 3955072 & 1641544 & 7.2306 & 8.4342 & TRN & & \\
\hline CHEMBL3930727 & 1641544 & 7.1818 & 7.2643 & TRN & & \\
\hline CHEMBL3898658 & 1641544 & 7.6882 & 7.9693 & TST & & \\
\hline CHEMBL3912882 & 1641544 & 7.6676 & 7.6702 & TRN & & \\
\hline CHEMBL3965455 & 1641544 & 8.2147 & 7.2568 & TRN & & \\
\hline CHEMBL3949335 & 1641544 & 8.301 & 8.3186 & TRN & & \\
\hline CHEMBL3940538 & 1641544 & 8.5376 & 8.1711 & TRN & & \\
\hline CHEMBL3928793 & 1641544 & 8.2757 & 7.8176 & TRN & & \\
\hline CHEMBL3947421 & 1641544 & 6.8097 & 6.6613 & TST & & \\
\hline CHEMBL3979492 & 1641544 & 6.5784 & 6.671 & TRN & & \\
\hline CHEMBL3895660 & 1641544 & 6.0 & 6.809 & TRN & & \\
\hline CHEMBL3960347 & 1641544 & 5.9586 & 6.2533 & TST & & \\
\hline CHEMBL3955571 & 1641544 & 7.1397 & 6.9419 & TRN & & \\
\hline CHEMBL3924817 & 1641544 & 7.0301 & 6.7091 & TRN & & \\
\hline CHEMBL3933951 & 1641544 & 7.4828 & 7.6094 & TRN & & \\
\hline CHEMBL3917277 & 1641544 & 6.1798 & 6.5409 & TST & & \\
\hline CHEMBL3983858 & 1641544 & 7.6162 & 7.776 & TRN & & \\
\hline CHEMBL 3936731 & 1641544 & 6.9508 & 7.0215 & TRN & & \\
\hline CHEMBL 3908164 & 1641544 & 5.2596 & 5.9545 & TST & & \\
\hline CHEMBL3907322 & 1641544 & 8.8239 & 8.6693 & TRN & & \\
\hline CHEMBL3926264 & 1641544 & 7.2899 & 7.7053 & TRN & & \\
\hline CHEMBL3953396 & 1641544 & 7.16299 & 79999999 & 99 & 7.7139999999999995 & TRN \\
\hline CHEMBL 3970220 & 1641544 & 8.8539 & 8.8785 & TRN & & \\
\hline CHEMBL3964603 & 1641544 & 7.7447 & 8.3348 & TRN & & \\
\hline CHEMBL3907052 & 1641544 & 8.6778 & 8.9197 & TRN & & \\
\hline CHEMBL 3903237 & 1641544 & 7.6904 & 7.9116 & TRN & & \\
\hline CHEMBL3891149 & 1641544 & 7.9914 & 7.8016 & TRN & & \\
\hline CHEMBL 3889688 & 1641544 & 7.9626 & 8.0515 & TRN & & \\
\hline CHEMBL3906371 & 1641544 & 8.8539 & 8.5875 & TRN & & \\
\hline CHEMBL 3907464 & 1641544 & 7.8297 & 7.7097 & TRN & & \\
\hline CHEMBL3945495 & 1641544 & 7.2628 & 7.2313 & TRN & & \\
\hline CHEMBL3894401 & 1641544 & 8.7447 & 7.1922 & TRN & & \\
\hline CHEMBL 3897898 & 1641544 & 6.6716 & 6.9028 & TRN & & \\
\hline CHEMBL3928532 & 1641544 & 5.4437 & 5.8399 & TST & & \\
\hline CHEMBL3907963 & 1641544 & 7.9172 & 8.0938 & TRN & & \\
\hline CHEMBL3923757 & 1641544 & 8.4437 & 8.2929 & TRN & & \\
\hline CHEMBL3917280 & 1641544 & 7.7721 & 7.6282 & TST & & \\
\hline CHEMBL3950957 & 1641544 & 7.6478 & 7.8224 & TRN & & \\
\hline CHEMBL3896993 & 1641544 & 8.3665 & 7.9581 & TRN & & \\
\hline CHEMBL3985704 & 1641544 & 8.1192 & 7.7758 & TRN & & \\
\hline CHEMBL3964678 & 1641544 & 8.3372 & 8.4712 & TRN & & \\
\hline CHEMBL3910860 & 1641544 & 5.6383 & 6.5227 & TST & & \\
\hline CHEMBL3962653 & 1641544 & 7.3197 & 7.5048 & TRN & & \\
\hline CHEMBL3957167 & 1641544 & 7.9281 & 8.0397 & TRN & & \\
\hline CHEMBL3922813 & 1641544 & 6.1798 & 6.2875 & TRN & & \\
\hline
\end{tabular}

Page 3532 
Supplemental Table S2.txt

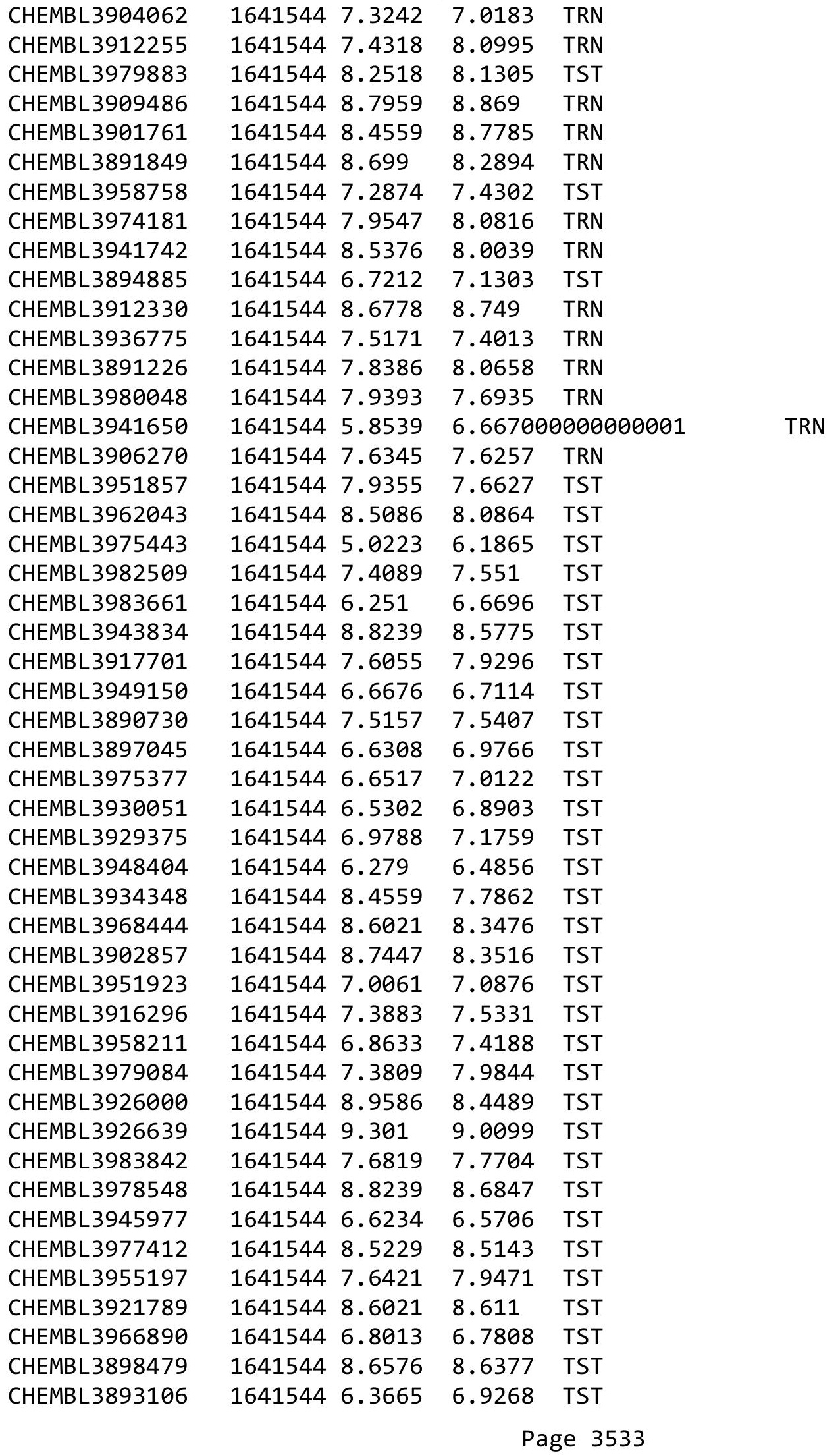




\begin{tabular}{|c|c|c|c|c|c|}
\hline & & \multicolumn{4}{|c|}{ Supplemental Table S2.txt } \\
\hline CHEMBL1406340 & 688849 & 2.5229 & 4.27 & TRN & \\
\hline CHEMBL1379433 & 688849 & 2.5229 & 2.5059 & TRN & \\
\hline CHEMBL1308318 & 688849 & 2.5229 & 2.8891 & TRN & \\
\hline CHEMBL1428824 & 688849 & 3.9842 & 2.8278 & TRN & \\
\hline CHEMBL3191761 & 688849 & 2.5229 & 3.8659 & TRN & \\
\hline CHEMBL1390797 & 688849 & 4.7712 & 4.3033 & TRN & \\
\hline CHEMBL1409312 & 688849 & 2.5229 & 2.7229 & TRN & \\
\hline CHEMBL1342776 & 688849 & 5.3413 & 3.8139 & TRN & \\
\hline CHEMBL1533201 & 688849 & 2.5229 & 2.9755 & TRN & \\
\hline CHEMBL1353004 & 688849 & 2.5229 & 5.2413 & TRN & \\
\hline CHEMBL470881 & 688849 & 4.164 & 4.9678 & TST & \\
\hline CHEMBL1568474 & 688849 & 4.6489 & 4.7507 & TRN & \\
\hline CHEMBL1304024 & 688849 & 4.5593 & 3.8753 & TST & \\
\hline CHEMBL1464243 & 688849 & 4.1684 & 2.7239 & TRN & \\
\hline CHEMBL1491588 & 688849 & 4.9824 & 4.4813 & TRN & \\
\hline CHEMBL1405606 & 688849 & 4.2644 & 4.0247 & TRN & \\
\hline CHEMBL1497773 & 688849 & 5.0629 & 4.3346 & TRN & \\
\hline CHEMBL1348625 & 688849 & 2.5229 & 2.7569 & TRN & \\
\hline CHEMBL1968992 & 688849 & 4.705 & 4.2542 & TRN & \\
\hline CHEMBL1324317 & 688849 & 2.5229 & 2.6799 & TRN & \\
\hline CHEMBL102714 & 688849 & 4.5854 & 4.04899 & 99999999995 & TRN \\
\hline CHEMBL1307886 & 688849 & 6.2612 & 5.4218 & TRN & \\
\hline CHEMBL1408193 & 688849 & 2.5229 & 2.7551 & TRN & \\
\hline CHEMBL1413142 & 688849 & 3.79600 & 00000000 & 5.2029 & TRN \\
\hline CHEMBL1611573 & 688849 & 2.5229 & 2.6638 & TST & \\
\hline CHEMBL1427522 & 688849 & 4.1005 & 4.3256 & TRN & \\
\hline CHEMBL1995948 & 688849 & 2.5229 & 2.6966 & TRN & \\
\hline CHEMBL1344572 & 688849 & 3.9835 & 3.404 & TRN & \\
\hline CHEMBL1450930 & 688849 & 2.5229 & 4.2295 & TRN & \\
\hline CHEMBL1503175 & 688849 & 5.0669 & 4.4424 & TRN & \\
\hline CHEMBL1995904 & 688849 & 2.5229 & 3.2952 & TRN & \\
\hline CHEMBL1444054 & 688849 & 2.5229 & 2.4854 & TRN & \\
\hline CHEMBL1349172 & 688849 & 2.5229 & 2.7917 & TRN & \\
\hline CHEMBL1339669 & 688849 & 4.5029 & 4.0455 & TRN & \\
\hline CHEMBL1606453 & 688849 & 2.5229 & 2.4545 & TRN & \\
\hline CHEMBL1504586 & 688849 & 4.1315 & 4.1957 & TST & \\
\hline CHEMBL1612493 & 688849 & 2.5229 & 3.682 & TST & \\
\hline CHEMBL1528985 & 688849 & 2.5229 & 2.9592 & TST & \\
\hline CHEMBL1565662 & 688849 & 2.5229 & 3.6692 & TRN & \\
\hline CHEMBL1423828 & 688849 & 2.5229 & 4.4959 & TRN & \\
\hline CHEMBL1301239 & 688849 & 2.5229 & 3.7607 & TRN & \\
\hline CHEMBL 1475386 & 688849 & 2.5229 & 2.7658 & TRN & \\
\hline CHEMBL1503564 & 688849 & 2.5229 & 2.736 & TRN & \\
\hline CHEMBL1995336 & 688849 & 3.5518 & 3.5448 & TRN & \\
\hline CHEMBL1573071 & 688849 & 2.5229 & 2.9032 & TST & \\
\hline CHEMBL3196206 & 688849 & 2.5229 & 2.832 & TRN & \\
\hline CHEMBL1471997 & 688849 & 2.5229 & 2.6559 & TRN & \\
\hline CHEMBL3145379 & 688849 & 2.5229 & 4.0355 & TRN & \\
\hline
\end{tabular}




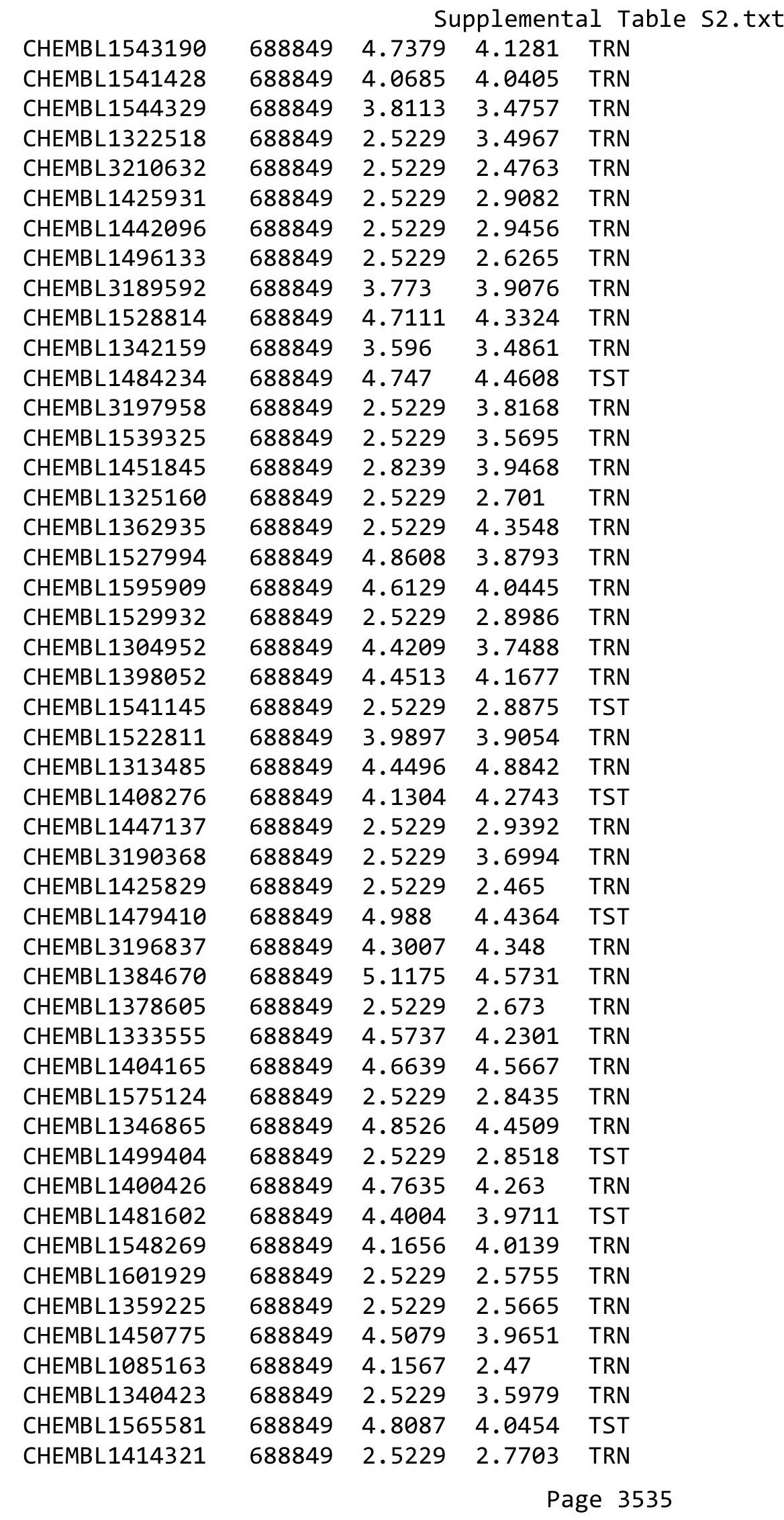


Supplemental Table S2.txt

\begin{tabular}{|c|c|c|c|c|}
\hline CHEMBL1497920 & 688849 & 2.5229 & 3.6298 & TRN \\
\hline CHEMBL1970867 & 688849 & 3.5504 & 4.655 & TRN \\
\hline CHEMBL1451538 & 688849 & 4.2989 & 3.9464 & TRN \\
\hline CHEMBL1588976 & 688849 & 2.5229 & 2.8071 & TRN \\
\hline CHEMBL1557268 & 688849 & 5.0621 & 4.1975 & TRN \\
\hline CHEMBL1360263 & 688849 & 4.5185 & 2.64 & TRN \\
\hline CHEMBL1380513 & 688849 & 2.5229 & 4.1308 & TRN \\
\hline CHEMBL1364329 & 688849 & 2.5229 & 2.7976 & TRN \\
\hline CHEMBL 1438660 & 688849 & 2.5229 & 2.4867 & TRN \\
\hline CHEMBL1569474 & 688849 & 2.5229 & 2.4837 & TRN \\
\hline CHEMBL3192762 & 688849 & 2.5229 & 2.9254 & TRN \\
\hline CHEMBL1986342 & 688849 & 5.9722 & 4.9967 & TST \\
\hline CHEMBL1325819 & 688849 & 2.5229 & 4.9354 & TRN \\
\hline CHEMBL1613515 & 688849 & 4.0504 & 3.7445 & TRN \\
\hline CHEMBL1323213 & 688849 & 2.5229 & 4.2644 & TST \\
\hline CHEMBL1611294 & 688849 & 2.5229 & 2.9095 & TRN \\
\hline CHEMBL1464200 & 688849 & 2.5229 & 3.0805 & TST \\
\hline CHEMBL252417 & 688849 & 4.4152 & 4.0805 & TRN \\
\hline CHEMBL3198710 & 688849 & 2.5229 & 3.6243 & TRN \\
\hline CHEMBL1421529 & 688849 & 2.5229 & 2.6617 & TRN \\
\hline CHEMBL1370073 & 688849 & 2.5229 & 3.9514 & TRN \\
\hline CHEMBL1326103 & 688849 & 2.5229 & 2.6483 & TST \\
\hline CHEMBL1392395 & 688849 & 2.5229 & 3.8356 & TRN \\
\hline CHEMBL1524306 & 688849 & 2.5229 & 2.7633 & TRN \\
\hline CHEMBL1445820 & 688849 & 2.5229 & 2.5806 & TRN \\
\hline CHEMBL1564532 & 688849 & 4.0357 & 3.6489 & TRN \\
\hline CHEMBL1356088 & 688849 & 2.5229 & 2.8822 & TRN \\
\hline CHEMBL1323676 & 688849 & 2.5229 & 2.5551 & TRN \\
\hline CHEMBL1513075 & 688849 & 2.5229 & 3.8352 & TRN \\
\hline CHEMBL1406795 & 688849 & 4.7058 & 4.3852 & TRN \\
\hline CHEMBL1529238 & 688849 & 4.6348 & 4.0524 & TRN \\
\hline CHEMBL3198297 & 688849 & 2.5229 & 2.9185 & TRN \\
\hline CHEMBL1434839 & 688849 & 2.5229 & 2.7403 & TRN \\
\hline CHEMBL1461518 & 688849 & 5.0172 & 4.2709 & TRN \\
\hline CHEMBL3193269 & 688849 & 4.3508 & 3.5746 & TRN \\
\hline CHEMBL1369154 & 688849 & 5.146 & 4.4453 & TRN \\
\hline CHEMBL1458441 & 688849 & 2.5229 & 2.8566 & TRN \\
\hline CHEMBL1343563 & 688849 & 2.5229 & 3.5256 & TRN \\
\hline CHEMBL1421819 & 688849 & 4.1165 & 5.1362 & TRN \\
\hline CHEMBL1536155 & 688849 & 2.5229 & 2.8599 & TST \\
\hline CHEMBL1543180 & 688849 & 5.1502 & 4.2927 & TRN \\
\hline CHEMBL1443882 & 688849 & 4.4975 & 4.0959 & TRN \\
\hline CHEMBL1200567 & 688849 & 2.5229 & 4.07 & TST \\
\hline CHEMBL1348958 & 688849 & 2.5229 & 4.1371 & TRN \\
\hline CHEMBL1597190 & 688849 & 2.5229 & 2.7658 & TST \\
\hline CHEMBL1608866 & 688849 & 2.5229 & 2.87399 & 99999999997 \\
\hline CHEMBL1372920 & 688849 & 5.1484 & 5.3262 & TRN \\
\hline CHEMBL1569253 & 688849 & 2.5229 & 2.549 & TRN \\
\hline
\end{tabular}




\begin{tabular}{|c|c|c|c|c|c|c|}
\hline & & \multicolumn{5}{|c|}{ Supplemental Table S2.txt } \\
\hline CHEMBL256098 & 688849 & 2.5229 & 2.6465 & TRN & & \\
\hline CHEMBL1352848 & 688849 & 2.5229 & 2.5859 & TRN & & \\
\hline CHEMBL1468179 & 688849 & 2.5229 & 3.7617 & TRN & & \\
\hline CHEMBL 2000039 & 688849 & 4.6572 & 3.7669 & TRN & & \\
\hline CHEMBL1607959 & 688849 & 2.5229 & 3.6445 & TST & & \\
\hline CHEMBL1462639 & 688849 & 2.5229 & 2.6686 & TRN & & \\
\hline CHEMBL1553272 & 688849 & 2.5229 & 3.7382 & TRN & & \\
\hline CHEMBL1508945 & 688849 & 2.5229 & 2.5934 & TRN & & \\
\hline CHEMBL1311625 & 688849 & 2.5229 & 2.8448 & TST & & \\
\hline CHEMBL1577588 & 688849 & 2.5229 & 2.7561 & TRN & & \\
\hline CHEMBL1391884 & 688849 & 2.5229 & 2.5891 & TRN & & \\
\hline CHEMBL1604408 & 688849 & 4.7547 & 3.7129 & TRN & & \\
\hline CHEMBL1555752 & 688849 & 2.5229 & 4.1823 & TRN & & \\
\hline CHEMBL1311214 & 688849 & 4.0288 & 3.6711 & TRN & & \\
\hline CHEMBL1486177 & 688849 & 2.5229 & 2.8054 & TST & & \\
\hline CHEMBL1309512 & 688849 & 2.5229 & 2.8172 & TRN & & \\
\hline CHEMBL1583777 & 688849 & 2.5229 & 2.7626 & TRN & & \\
\hline CHEMBL1532783 & 688849 & 2.5229 & 2.7616 & TRN & & \\
\hline CHEMBL1382193 & 688849 & 2.5229 & 2.8198 & TRN & & \\
\hline CHEMBL1580472 & 688849 & 5.2629 & 2.9794 & TRN & & \\
\hline CHEMBL1334711 & 688849 & 2.5229 & 4.0268 & TRN & & \\
\hline CHEMBL1528875 & 688849 & 2.5229 & 2.5985 & TRN & & \\
\hline CHEMBL3194876 & 688849 & 4.1465 & 5.4287 & TRN & & \\
\hline CHEMBL1434851 & 688849 & 2.5229 & 2.6155 & TRN & & \\
\hline CHEMBL1368520 & 688849 & 2.5229 & 2.821 & TST & & \\
\hline CHEMBL1499978 & 688849 & 2.5229 & 3.9613 & TRN & & \\
\hline CHEMBL1526323 & 688849 & 2.5229 & 2.608 & TRN & & \\
\hline CHEMBL1572536 & 688849 & 2.5229 & 2.718 & TRN & & \\
\hline CHEMBL 225230 & 688849 & 5.2549 & 4.6095 & TST & & \\
\hline CHEMBL1398799 & 688849 & 4.243 & 2.5763 & TRN & & \\
\hline CHEMBL1369329 & 688849 & 2.5229 & 3.6634 & TRN & & \\
\hline CHEMBL1444958 & 688849 & 4.8083 & 4.1656 & TRN & & \\
\hline CHEMBL1535786 & 688849 & 2.5229 & 2.9116 & TRN & & \\
\hline CHEMBL1414746 & 688849 & 5.2353 & 4.4951 & TST & & \\
\hline CHEMBL1390316 & 688849 & $4.4510 e$ & j0000000 & 005 & 2.5534 & TRN \\
\hline CHEMBL1417293 & 688849 & 2.5229 & 3.6919 & TST & & \\
\hline CHEMBL1884996 & 688849 & 2.5229 & 2.7305 & TRN & & \\
\hline CHEMBL1488688 & 688849 & 2.5229 & 2.8985 & TRN & & \\
\hline CHEMBL1974501 & 688849 & 2.5229 & 2.7428 & TRN & & \\
\hline CHEMBL1597246 & 688849 & 2.5229 & 2.7906 & TRN & & \\
\hline CHEMBL1510183 & 688849 & 2.5229 & 2.5197 & TRN & & \\
\hline CHEMBL3193719 & 688849 & 2.5229 & 2.867 & TRN & & \\
\hline CHEMBL1304721 & 688849 & 4.9639 & 3.1025 & TRN & & \\
\hline CHEMBL1978388 & 688849 & 2.5229 & 2.6146 & TRN & & \\
\hline CHEMBL1488551 & 688849 & 4.8056 & 4.125 & TRN & & \\
\hline CHEMBL1571941 & 688849 & 2.5229 & 2.8102 & TRN & & \\
\hline CHEMBL1322092 & 688849 & 4.6194 & 3.907 & TRN & & \\
\hline CHEMBL1351549 & 688849 & 4.1875 & 4.2098 & TRN & & \\
\hline
\end{tabular}




\begin{tabular}{|c|c|c|c|c|}
\hline & & & pplement & al Table S2. \\
\hline CHEMBL1459555 & 688849 & 4.6144 & 3.8827 & TRN \\
\hline CHEMBL1354008 & 688849 & 2.5229 & 2.7093 & TRN \\
\hline CHEMBL1385898 & 688849 & 2.5229 & 2.556 & TRN \\
\hline CHEMBL1383060 & 688849 & 2.5229 & 3.0795 & TRN \\
\hline CHEMBL1588786 & 688849 & 3.9628 & 3.3104 & TRN \\
\hline CHEMBL1471266 & 688849 & 3.5839 & 4.4061 & TRN \\
\hline CHEMBL1348415 & 688849 & 2.8239 & 4.2816 & TRN \\
\hline CHEMBL1403327 & 688849 & 2.5229 & 2.70300 & 20000000003 \\
\hline CHEMBL 212414 & 688849 & 2.5229 & 3.4816 & TRN \\
\hline CHEMBL1334452 & 688849 & 2.5229 & 4.1566 & TRN \\
\hline CHEMBL1610739 & 688849 & 2.5229 & 3.7399 & TRN \\
\hline CHEMBL1494087 & 688849 & 2.5229 & 2.9397 & TRN \\
\hline CHEMBL1497731 & 688849 & 2.5229 & 2.6997 & TRN \\
\hline CHEMBL1605668 & 688849 & 2.5229 & 2.6638 & TRN \\
\hline CHEMBL1990825 & 688849 & 2.5229 & 2.6304 & TRN \\
\hline CHEMBL3191123 & 688849 & 2.5229 & 2.6317 & TST \\
\hline CHEMBL1608853 & 688849 & 2.5229 & 4.0673 & TRN \\
\hline CHEMBL201289 & 688849 & 5.0085 & 4.3716 & TRN \\
\hline CHEMBL1491562 & 688849 & 4.9505 & 4.2179 & TRN \\
\hline CHEMBL1393757 & 688849 & 2.5229 & 2.7662 & TRN \\
\hline CHEMBL1464656 & 688849 & 5.36 & 4.2354 & TRN \\
\hline CHEMBL1392590 & 688849 & 2.5229 & 2.6547 & TRN \\
\hline CHEMBL1091723 & 688849 & 2.5229 & 2.8445 & TRN \\
\hline CHEMBL1573238 & 688849 & 2.5229 & 2.6801 & TRN \\
\hline CHEMBL3189520 & 688849 & 2.5229 & 2.7282 & TST \\
\hline CHEMBL3191841 & 688849 & 4.3839 & 2.8099 & TST \\
\hline CHEMBL1577264 & 688849 & 2.5229 & 3.072 & TRN \\
\hline CHEMBL1432850 & 688849 & 2.5229 & 3.6732 & TRN \\
\hline CHEMBL1422203 & 688849 & 4.7358 & 4.3944 & TST \\
\hline CHEMBL1494599 & 688849 & 4.1977 & 3.7381 & TRN \\
\hline CHEMBL1543950 & 688849 & 2.5229 & 2.5216 & TRN \\
\hline CHEMBL3213389 & 688849 & 4.3052 & 3.9436 & TRN \\
\hline CHEMBL1423851 & 688849 & 2.5229 & 2.6675 & TRN \\
\hline CHEMBL1449738 & 688849 & 2.5229 & 2.6368 & TRN \\
\hline CHEMBL1431160 & 688849 & 2.5229 & 2.8389 & TRN \\
\hline CHEMBL1410130 & 688849 & 2.5229 & 2.7915 & TRN \\
\hline CHEMBL1446838 & 688849 & 2.5229 & 2.4726 & TRN \\
\hline CHEMBL1403049 & 688849 & 2.5229 & 2.7719 & TST \\
\hline CHEMBL1536438 & 688849 & 4.1049 & 3.7595 & TRN \\
\hline CHEMBL1325563 & 688849 & 4.258 & 3.6432 & TRN \\
\hline CHEMBL1382572 & 688849 & 4.2573 & 4.1627 & TRN \\
\hline CHEMBL 2007274 & 688849 & 2.5229 & 2.8967 & TRN \\
\hline CHEMBL1416049 & 688849 & 4.4943 & 4.5479 & TST \\
\hline CHEMBL1523528 & 688849 & 2.5229 & 3.1649 & TRN \\
\hline CHEMBL1309068 & 688849 & 5.2626 & 4.2923 & TRN \\
\hline CHEMBL1303246 & 688849 & 4.3814 & 3.8466 & TST \\
\hline CHEMBL1306578 & 688849 & 2.5229 & 2.8046 & TRN \\
\hline CHEMBL1348800 & 688849 & 4.1345 & 2.9706 & TRN \\
\hline
\end{tabular}


Supplemental Table S2.txt

\begin{tabular}{|c|c|c|c|c|c|}
\hline CHEMBL1303193 & 688849 & 2.5229 & 2.6281 & TRN & \\
\hline CHEMBL1533217 & 688849 & 4.1667 & 4.4269 & TRN & \\
\hline CHEMBL 27871 & 688849 & 4.9168 & 4.126 & TST & \\
\hline CHEMBL1307592 & 688849 & 2.5229 & 2.8187 & TRN & \\
\hline CHEMBL1501269 & 688849 & 2.5229 & 2.8566 & TST & \\
\hline CHEMBL1502153 & 688849 & 2.5229 & 3.3568 & TRN & \\
\hline CHEMBL1612744 & 688849 & 2.5229 & 2.8221 & TST & \\
\hline CHEMBL1440463 & 688849 & 2.5229 & 2.7221 & TRN & \\
\hline CHEMBL1583157 & 688849 & 2.5229 & 2.5701 & TRN & \\
\hline CHEMBL1488693 & 688849 & 4.8867 & 4.1134 & TRN & \\
\hline CHEMBL1568292 & 688849 & 3.7299 & 4.1979 & TRN & \\
\hline CHEMBL1561932 & 688849 & 2.5229 & 2.5163 & TRN & \\
\hline CHEMBL1966869 & 688849 & 4.0437 & 2.6108 & TRN & \\
\hline CHEMBL1358863 & 688849 & 2.5229 & 3.5284 & TRN & \\
\hline CHEMBL1421081 & 688849 & 2.5229 & 4.2266 & TST & \\
\hline CHEMBL1462806 & 688849 & 2.5229 & 2.8743 & TST & \\
\hline CHEMBL 2004322 & 688849 & 4.0881 & 4.2586 & TST & \\
\hline CHEMBL1562537 & 688849 & 2.5229 & 2.9342 & TRN & \\
\hline CHEMBL1497838 & 688849 & 4.6882 & 4.3036 & TST & \\
\hline CHEMBL257359 & 688849 & 4.9578 & 4.0871 & TRN & \\
\hline CHEMBL1359469 & 688849 & 4.9529 & 4.6105 & TRN & \\
\hline CHEMBL1604191 & 688849 & 2.5229 & 2.8915 & TRN & \\
\hline CHEMBL 3192866 & 688849 & 2.5229 & 3.8085 & TRN & \\
\hline CHEMBL1451836 & 688849 & 4.2376 & 3.887 & TRN & \\
\hline CHEMBL1433911 & 688849 & 4.5117 & 4.1165 & TRN & \\
\hline CHEMBL1410740 & 688849 & 2.5229 & 2.83 & TRN & \\
\hline CHEMBL1586152 & 688849 & 4.2224 & 3.7268 & TRN & \\
\hline CHEMBL1392399 & 688849 & 2.5229 & 2.6019 & TRN & \\
\hline CHEMBL1401639 & 688849 & 4.711 & 3.8802 & TRN & \\
\hline CHEMBL2003195 & 688849 & 2.5229 & 3.7872 & TRN & \\
\hline CHEMBL1582163 & 688849 & 2.5229 & 2.6346 & TRN & \\
\hline CHEMBL1373655 & 688849 & 4.7018 & 4.0161 & TRN & \\
\hline CHEMBL1524225 & 688849 & 5.9805 & 4.855 & TRN & \\
\hline CHEMBL1308104 & 688849 & 4.6035 & 4.0869 & TRN & \\
\hline CHEMBL1451040 & 688849 & 2.5229 & 4.1576 & TRN & \\
\hline CHEMBL1529248 & 688849 & 2.5229 & 2.7661 & TRN & \\
\hline CHEMBL3193122 & 688849 & 2.5229 & 2.83600 & 20000000003 & TRN \\
\hline CHEMBL1558352 & 688849 & 2.5229 & 3.7602 & TRN & \\
\hline CHEMBL1365234 & 688849 & 4.7889 & 4.8282 & TRN & \\
\hline CHEMBL 3189865 & 688849 & 4.2262 & 3.863 & TRN & \\
\hline CHEMBL1415476 & 688849 & 2.5229 & 2.8874 & TRN & \\
\hline CHEMBL3198213 & 688849 & 4.1164 & 4.2447 & TST & \\
\hline CHEMBL1535605 & 688849 & 2.5229 & 2.758 & TRN & \\
\hline CHEMBL1508461 & 688849 & 2.5229 & 2.7069 & TRN & \\
\hline CHEMBL1365461 & 688849 & 4.5866 & 4.1226 & TRN & \\
\hline CHEMBL1346124 & 688849 & 2.5229 & 2.5623 & TRN & \\
\hline CHEMBL1379179 & 688849 & 2.5229 & 2.9572 & TRN & \\
\hline CHEMBL1313262 & 688849 & 2.5229 & 2.9898 & TST & \\
\hline
\end{tabular}

Page 3539 


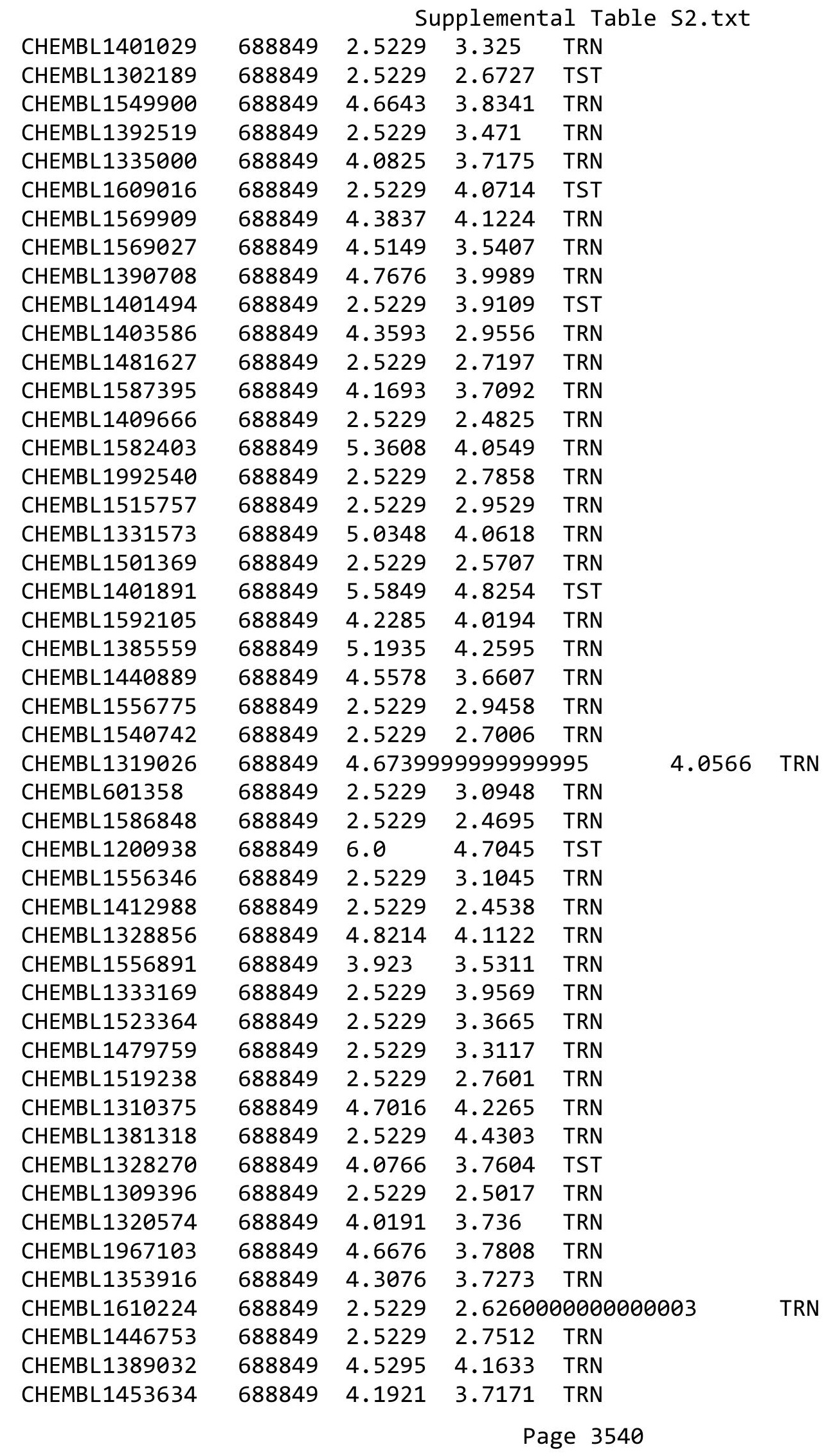


Supplemental Table S2.txt

\begin{tabular}{|c|c|c|c|c|c|}
\hline CHEMBL1526069 & 688849 & 2.5229 & 4.2337 & TRN & \\
\hline CHEMBL1374016 & 688849 & 5.3774 & 4.4561 & TRN & \\
\hline CHEMBL444478 & 688849 & 4.6866 & 4.28600 & 30000000005 & TRN \\
\hline CHEMBL1996567 & 688849 & 2.5229 & 2.4783 & TRN & \\
\hline CHEMBL1373556 & 688849 & 4.2825 & 3.0154 & TRN & \\
\hline CHEMBL3198930 & 688849 & 3.9039 & 2.7845 & TRN & \\
\hline CHEMBL1555657 & 688849 & 2.5229 & 3.845 & TRN & \\
\hline CHEMBL1342622 & 688849 & 4.9245 & 4.3465 & TRN & \\
\hline CHEMBL1382089 & 688849 & 2.5229 & 2.6684 & TRN & \\
\hline CHEMBL1493371 & 688849 & 2.5229 & 2.662 & TRN & \\
\hline CHEMBL1387790 & 688849 & 4.5668 & 3.8383 & TRN & \\
\hline CHEMBL1507424 & 688849 & 2.5229 & 2.5598 & TRN & \\
\hline CHEMBL1569232 & 688849 & 6.76200 & $\partial 0000000$ & 5.9477 & TRN \\
\hline CHEMBL1303235 & 688849 & 4.651 & 3.8558 & TRN & \\
\hline CHEMBL1520254 & 688849 & 4.4845 & 4.0487 & TRN & \\
\hline CHEMBL1325440 & 688849 & 4.0569 & 3.8667 & TRN & \\
\hline CHEMBL1418568 & 688849 & 5.2915 & 4.374 & TST & \\
\hline CHEMBL1572101 & 688849 & 2.5229 & 2.6757 & TRN & \\
\hline CHEMBL1312212 & 688849 & 4.745 & 4.3642 & TRN & \\
\hline CHEMBL1589595 & 688849 & 2.5229 & 3.861 & TRN & \\
\hline CHEMBL1564690 & 688849 & 2.5229 & 2.8116 & TST & \\
\hline CHEMBL3194688 & 688849 & 2.5229 & 2.8801 & TRN & \\
\hline CHEMBL1573579 & 688849 & 4.4438 & 3.7701 & TRN & \\
\hline CHEMBL 3189263 & 688849 & 2.5229 & 2.6318 & TRN & \\
\hline CHEMBL1369102 & 688849 & 4.7948 & 3.9139 & TRN & \\
\hline CHEMBL1336930 & 688849 & 4.5474 & 3.7128 & TRN & \\
\hline CHEMBL1325348 & 688849 & 4.1972 & 3.8854 & TRN & \\
\hline CHEMBL1537327 & 688849 & 2.5229 & 2.9062 & TRN & \\
\hline CHEMBL1369175 & 688849 & 2.5229 & 2.5512 & TRN & \\
\hline CHEMBL 2006431 & 688849 & 2.5229 & 3.5084 & TST & \\
\hline CHEMBL1564699 & 688849 & 4.4343 & 4.5942 & TRN & \\
\hline CHEMBL1409616 & 688849 & 2.5229 & 3.4694 & TRN & \\
\hline CHEMBL 288096 & 688849 & 2.5229 & 3.1787 & TST & \\
\hline CHEMBL1361188 & 688849 & 5.0331 & 4.0161 & TRN & \\
\hline CHEMBL1587521 & 688849 & 4.2958 & 3.8695 & TRN & \\
\hline CHEMBL1549526 & 688849 & 2.5229 & 2.6596 & TRN & \\
\hline CHEMBL1567800 & 688849 & 2.5229 & 3.8476 & TRN & \\
\hline CHEMBL1989592 & 688849 & 2.5229 & 3.0333 & TRN & \\
\hline CHEMBL1365599 & 688849 & 2.5229 & 3.9948 & TRN & \\
\hline CHEMBL1984130 & 688849 & 2.5229 & 2.7906 & TRN & \\
\hline CHEMBL1512268 & 688849 & 2.5229 & 2.6451 & TRN & \\
\hline CHEMBL1558007 & 688849 & 4.1481 & 3.9353 & TRN & \\
\hline CHEMBL1460765 & 688849 & 2.5229 & 2.8298 & TRN & \\
\hline CHEMBL3191304 & 688849 & 4.6202 & 4.4478 & TRN & \\
\hline CHEMBL 3212133 & 688849 & 2.5229 & 2.7712 & TRN & \\
\hline CHEMBL1597452 & 688849 & 2.5229 & 3.0387 & TRN & \\
\hline CHEMBL1597974 & 688849 & 4.7441 & 4.1239 & TRN & \\
\hline CHEMBL1490148 & 688849 & 2.5229 & 2.7941 & TRN & \\
\hline
\end{tabular}




\begin{tabular}{|c|c|c|c|c|c|}
\hline & & \multicolumn{4}{|c|}{ Supplemental Table S2.txt } \\
\hline CHEMBL1583064 & 688849 & 2.5229 & 2.6532 & TST & \\
\hline CHEMBL 269410 & 688849 & 4.769 & 4.1891 & TRN & \\
\hline CHEMBL1565114 & 688849 & 2.5229 & 2.5443 & TRN & \\
\hline CHEMBL1306005 & 688849 & 4.5943 & 3.8818 & TST & \\
\hline CHEMBL1468099 & 688849 & 4.3417 & 4.488 & TST & \\
\hline CHEMBL1338176 & 688849 & 3.8622 & 3.4651 & TST & \\
\hline CHEMBL1460470 & 688849 & 4.8717 & 4.0753 & TST & \\
\hline CHEMBL3199799 & 688849 & 2.5229 & 2.8096 & TRN & \\
\hline CHEMBL1410314 & 688849 & 2.5229 & 4.3038 & TRN & \\
\hline CHEMBL1430739 & 688849 & 4.6118 & 3.9094 & TST & \\
\hline CHEMBL36654 & 688849 & 4.7737 & 4.2009 & TST & \\
\hline CHEMBL1519146 & 688849 & 2.5229 & 3.9767 & TRN & \\
\hline CHEMBL1341918 & 688849 & 2.5229 & 2.4754 & TRN & \\
\hline CHEMBL1463475 & 688849 & 2.5229 & 2.4716 & TRN & \\
\hline CHEMBL1466912 & 688849 & 2.5229 & 3.7967 & TRN & \\
\hline CHEMBL1580545 & 688849 & 2.5229 & 2.82899 & 99999999997 & TST \\
\hline CHEMBL1371292 & 688849 & 4.3054 & 3.4687 & TRN & \\
\hline CHEMBL1445412 & 688849 & 5.147 & 4.2235 & TRN & \\
\hline CHEMBL1310269 & 688849 & 4.4437 & 3.7816 & TRN & \\
\hline CHEMBL3199005 & 688849 & 2.5229 & 2.8515 & TRN & \\
\hline CHEMBL1573707 & 688849 & 5.1565 & 3.5342 & TRN & \\
\hline CHEMBL3199468 & 688849 & 4.1551 & 4.9259 & TRN & \\
\hline CHEMBL1337737 & 688849 & 2.5229 & 2.7731 & TST & \\
\hline CHEMBL1369478 & 688849 & 2.5229 & 2.6412 & TST & \\
\hline CHEMBL449081 & 688849 & 4.9518 & 4.2794 & TST & \\
\hline CHEMBL 1257041 & 688849 & 5.2668 & 4.6461 & TST & \\
\hline CHEMBL1310353 & 688849 & 4.4772 & 4.06800 & 00000000005 & TRN \\
\hline CHEMBL1453783 & 688849 & 2.5229 & 3.0041 & TRN & \\
\hline CHEMBL 3214605 & 688849 & 2.5229 & 2.4893 & TRN & \\
\hline CHEMBL1574785 & 688849 & 4.5549 & 3.8718 & TRN & \\
\hline CHEMBL1311174 & 688849 & 5.5488 & 3.95399 & 99999999997 & TRN \\
\hline CHEMBL1509548 & 688849 & 2.5229 & 2.7512 & TRN & \\
\hline CHEMBL1577208 & 688849 & 2.5229 & 2.8385 & TRN & \\
\hline CHEMBL3198237 & 688849 & 2.5229 & 3.75 & TRN & \\
\hline CHEMBL1539384 & 688849 & 4.9293 & 4.1885 & TST & \\
\hline CHEMBL1505230 & 688849 & 2.5229 & 3.4699 & TRN & \\
\hline CHEMBL1334062 & 688849 & 4.7534 & 4.1434 & TST & \\
\hline CHEMBL1350912 & 688849 & 4.6974 & 2.9039 & TRN & \\
\hline CHEMBL1310100 & 688849 & 2.5229 & 3.06 & TRN & \\
\hline CHEMBL1340752 & 688849 & 2.5229 & 2.7377 & TRN & \\
\hline CHEMBL1308521 & 688849 & 4.1779 & 3.3406 & TRN & \\
\hline CHEMBL1553837 & 688849 & 4.7067 & 4.1744 & TRN & \\
\hline CHEMBL1602489 & 688849 & 4.2418 & 4.3897 & TRN & \\
\hline CHEMBL1331639 & 688849 & 2.5229 & 3.9625 & TRN & \\
\hline CHEMBL1580198 & 688849 & 3.9917 & 3.8282 & TRN & \\
\hline CHEMBL3190891 & 688849 & 4.7354 & 3.0728 & TRN & \\
\hline CHEMBL3195360 & 688849 & 3.67100 & j0000000 & 4.7997 & TRN \\
\hline CHEMBL1460922 & 688849 & 2.5229 & 2.7554 & TST & \\
\hline
\end{tabular}


Supplemental Table S2.txt

\begin{tabular}{|c|c|c|c|c|c|}
\hline CHEMBL1098875 & 688849 & 2.5229 & 2.9269 & TRN & \\
\hline CHEMBL1536243 & 688849 & 3.5642 & 4.1428 & TRN & \\
\hline CHEMBL1580235 & 688849 & 2.5229 & 2.6562 & TST & \\
\hline CHEMBL1584450 & 688849 & 2.5229 & 3.0334 & TRN & \\
\hline CHEMBL1545278 & 688849 & 4.9339 & 4.3676 & TRN & \\
\hline CHEMBL1447301 & 688849 & 4.5647 & 4.1478 & TRN & \\
\hline CHEMBL1391547 & 688849 & 5.3368 & 4.079 & TRN & \\
\hline CHEMBL1565767 & 688849 & 4.6517 & 4.64 & TRN & \\
\hline CHEMBL1523225 & 688849 & 2.5229 & 2.8204 & TST & \\
\hline CHEMBL1605463 & 688849 & 4.7387 & 3.8873 & TRN & \\
\hline CHEMBL1342581 & 688849 & 2.5229 & 2.7255 & TRN & \\
\hline CHEMBL 3197005 & 688849 & 5.0979 & 4.0947 & TRN & \\
\hline CHEMBL1596184 & 688849 & 2.5229 & 3.5376 & TST & \\
\hline CHEMBL 3189447 & 688849 & 2.5229 & 3.7068 & TRN & \\
\hline CHEMBL1466639 & 688849 & 2.5229 & 3.0444 & TRN & \\
\hline CHEMBL1567874 & 688849 & 4.3313 & 3.64600 & 30000000004 & TRN \\
\hline CHEMBL1393005 & 688849 & 2.5229 & 2.7749 & TRN & \\
\hline CHEMBL1361794 & 688849 & 2.5229 & 2.6449 & TRN & \\
\hline CHEMBL1519231 & 688849 & 2.5229 & 3.7169 & TRN & \\
\hline CHEMBL1517097 & 688849 & 4.6553 & 4.1915 & TRN & \\
\hline CHEMBL305978 & 688849 & 4.6664 & 4.3406 & TRN & \\
\hline CHEMBL1445654 & 688849 & 4.6081 & 4.6853 & TRN & \\
\hline CHEMBL66966 & 688849 & 4.8663 & 4.3914 & TRN & \\
\hline CHEMBL1968789 & 688849 & 4.3917 & 4.6903 & TRN & \\
\hline CHEMBL1503188 & 688849 & 2.5229 & 2.6198 & TRN & \\
\hline CHEMBL1582178 & 688849 & 3.9817 & 3.8351 & TST & \\
\hline CHEMBL1360038 & 688849 & 2.5229 & 2.6887 & TRN & \\
\hline CHEMBL1511605 & 688849 & 4.2541 & 4.1074 & TRN & \\
\hline CHEMBL1565785 & 688849 & 2.5229 & 4.0241 & TRN & \\
\hline CHEMBL1322202 & 688849 & 2.5229 & 2.7972 & TST & \\
\hline CHEMBL1343123 & 688849 & 2.5229 & 2.8211 & TRN & \\
\hline CHEMBL1458456 & 688849 & 5.5267 & 4.4348 & TRN & \\
\hline CHEMBL1543588 & 688849 & 2.5229 & 2.6851 & TRN & \\
\hline CHEMBL1517523 & 688849 & 2.5229 & 3.5829 & TRN & \\
\hline CHEMBL 3189560 & 688849 & 2.5229 & 3.8915 & TST & \\
\hline CHEMBL1534274 & 688849 & 2.5229 & 2.4903 & TRN & \\
\hline CHEMBL1439525 & 688849 & 4.1371 & 3.7313 & TST & \\
\hline CHEMBL1436898 & 688849 & 4.6631 & 4.3949 & TRN & \\
\hline CHEMBL 3212916 & 688849 & 4.4588 & 3.8722 & TST & \\
\hline CHEMBL1479366 & 688849 & 4.6337 & 4.2506 & TRN & \\
\hline CHEMBL1495485 & 688849 & 4.7488 & 3.9933 & TRN & \\
\hline CHEMBL1351902 & 688849 & 2.5229 & 4.0081 & TRN & \\
\hline CHEMBL1608481 & 688849 & 4.6001 & 2.8832 & TRN & \\
\hline CHEMBL1368153 & 688849 & 2.5229 & 2.9482 & TRN & \\
\hline CHEMBL1564075 & 688849 & 4.5696 & 3.4674 & TRN & \\
\hline CHEMBL1997564 & 688849 & 2.5229 & 2.65100 & 30000000002 & TRN \\
\hline CHEMBL1541438 & 688849 & 2.5229 & 2.5818 & TRN & \\
\hline CHEMBL1347724 & 688849 & 2.5229 & 2.8367 & TRN & \\
\hline
\end{tabular}

Page 3543 
Supplemental Table S2.txt

\begin{tabular}{|c|c|c|c|c|}
\hline AEMBL & & 29 & 37 & \\
\hline HEMRI 1429189 & & 7431 & 4.4587 & \\
\hline AEMBL & & 3213 & & \\
\hline AEMBL1530689 & 8849 & 5229 & 8384 & \\
\hline HEMBL1405177 & 88849 & .8529 & .2981 & \\
\hline JEMBL14 & 8849 & 229 & 8878 & \\
\hline FMBI & 8849 & & & 20. \\
\hline AEMBL1976044 & 38849 & 2.5229 & 8316 & PN \\
\hline AEMBL1454775 & 88849 & 5229 & 5132 & \\
\hline HEMBL3196856 & 88849 & .5229 & 9525 & \\
\hline HEMBL $319 e$ & 8849 & 229 & 3796 & \\
\hline IEMBL148 & 849 & & & \\
\hline HEMBL14C & 38849 & 229 & 482 & \\
\hline AEMBL3189823 & 8849 & 049 & 5397 & \\
\hline HEMBL14891 & 849 & 65 & 35 & \\
\hline IEMBL13 & 849 & 29 & 33 & \\
\hline AEMBL15 & & & & \\
\hline HEMBL151 & 849 & 229 & 73 & \\
\hline HEMBL129 & 849 & 112 & 1558 & \\
\hline AEMBL1445300 & 19 & 29 & 39 & KIV \\
\hline IEMBL13 & 19 & & 87 & RN \\
\hline IEMBL14 & & & & וב \\
\hline AFMBI 31 & 49 & 92 & 05 & RN \\
\hline IEMBL16e & 49 & & & \\
\hline EMBL146C & 49 & 29 & 555 & RIV \\
\hline EMBL13S & 9 & & 848 & RN \\
\hline FMBI: & & & 61 & $\mathrm{RN}$ \\
\hline & & & & RN \\
\hline IEMBL15 & & & & 「RN \\
\hline IEMBL15000 & 8849 & 6 & 554 & $\mathrm{RN}$ \\
\hline EMBL12 & 49 & & 57 & $\mathrm{RN}$ \\
\hline 2 & 19 & & & RN \\
\hline & & & & RN \\
\hline IEMBL1596 & & & & 「RN \\
\hline IEMBL1539 & 8849 & & 196 & ST \\
\hline IFMRI 14 & 49 & & 88 & 「RN \\
\hline & & & & 「RN \\
\hline & & & & RN \\
\hline IEMBL1471750 & 38849 & 29 & 517 & $\Gamma$ \\
\hline MBL14 & 3849 & & 284 & IST \\
\hline HEMBL 21353 & 38849 & & 577 & \\
\hline & & & & RN \\
\hline HEMBL1383 & & & 7723 & RN \\
\hline EMBL14 & 8849 & 21 & 79 & TR \\
\hline 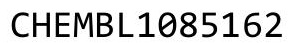 & & & & \\
\hline HEMBL 3191088 & 88849 & & & \\
\hline HEMBL153760 & & & & \\
\hline CHEMBL1383461 & 688849 & 4.4693 & 4.6695 & \\
\hline
\end{tabular}


Supplemental Table S2.txt

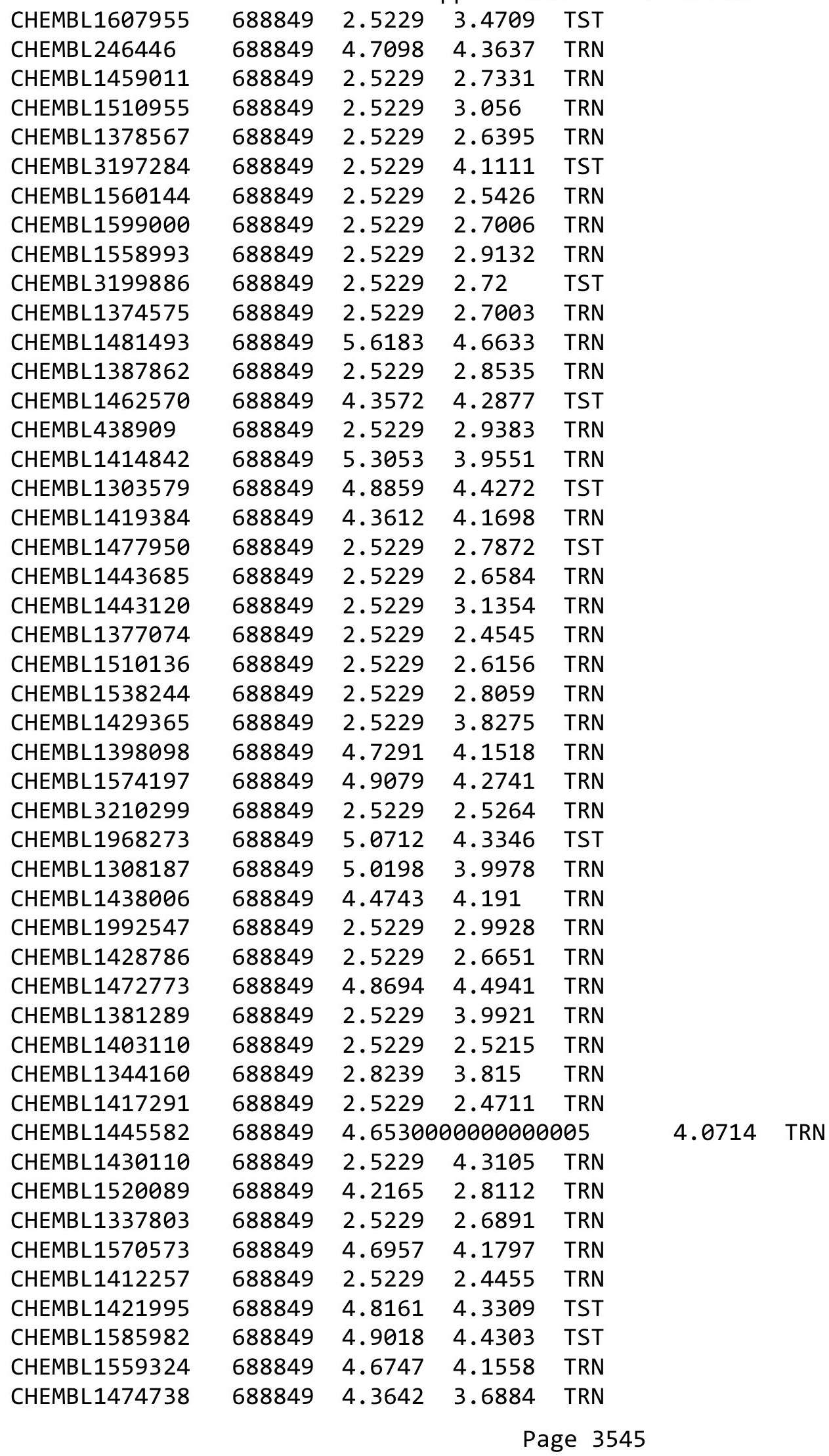




\begin{tabular}{|c|c|c|c|c|}
\hline \multicolumn{5}{|c|}{ Supplementa] } \\
\hline 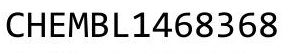 & (s) & 4.7765 & & \\
\hline HEMBL1528899 & 88849 & .9534 & 6715 & \\
\hline HEMBL196 & 19 & & & \\
\hline HEMBL132 & & & & \\
\hline HEMBL152 & & & & \\
\hline HEMBL1485368 & 88849 & 3954 & 7565 & \\
\hline HEMBL1505429 & 49 & 2.5229 & 3.6651 & \\
\hline HEMBL1 & 19 & & & \\
\hline JEMBL52 & 49 & 32 & 81 & \\
\hline HEMBL & & & & \\
\hline HEMBL1 & 49 & 4.4385 & & \\
\hline HEMBL1 & 49 & 2.5229 & & \\
\hline HEMBL & 9 & 2.5 & 2.6 & \\
\hline AEMBL & 9 & & 3.7 & \\
\hline HEMBL: & 19 & & & \\
\hline HEMBL] & 49 & & 4.3353 & \\
\hline HEMBL: & 19 & & & \\
\hline HEMBL: & 68 & & & \\
\hline HEMBL & 9 & & & \\
\hline HEMBL: & 9 & & & \\
\hline 14 & & & & \\
\hline HEMBL: & 9 & & & \\
\hline HEMBL & 68 & & 3.7 & \\
\hline ABL & & & & \\
\hline 32 & & & & \\
\hline 99 & & & & \\
\hline HEMBL: & & & & \\
\hline HEMBL1 & $600+2+2$ & & & \\
\hline MBL & & & & \\
\hline 65 & & 29 & 49 & \\
\hline 231 & & & & \\
\hline HEMBL & 9 & & & \\
\hline 75 & & & & \\
\hline 78 & & & 4.6 & \\
\hline 35 & & & 2. & \\
\hline HEMBL: & & & 2.7 & \\
\hline HEMBL1 & $68 \varepsilon$ & 4.3 & 2.5343 & \\
\hline & & & & \\
\hline 64 & & 9 & 2 . & TR \\
\hline 39 & & 7939 & & TR \\
\hline CHEMBL 1 & & 6.0 & 4.8 & 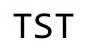 \\
\hline CHEMBL 1 & 9 & 3.81 & 3. & \\
\hline & & & & R \\
\hline CHEMBL1 & & 2.5229 & 2.9091 & Oan \\
\hline CHEMBL1 & & 3.8462 & 4.1369 & TR \\
\hline CHEMBL 1 & & 2.5229 & 2. & -1 \\
\hline CHEMBL 1 & $68 \varepsilon$ & 4.9813 & 4.0234 & \\
\hline CHEMBL1310926 & 688849 & 3.8098 & 3.7803 & $\mathbf{n}$ \\
\hline
\end{tabular}

Page 3546 
Supplemental Table S2.txt

\begin{tabular}{|c|c|c|c|c|}
\hline CHEMBL1334290 & 688849 & 3.6923 & 2.8145 & TRN \\
\hline CHEMBL1442704 & 688849 & 2.5229 & 2.6219 & TRN \\
\hline CHEMBL1375215 & 688849 & 2.5229 & 2.5555 & TRN \\
\hline CHEMBL1300484 & 688849 & 2.5229 & 2.6446 & TRN \\
\hline CHEMBL1398190 & 688849 & 4.6805 & 3.6933 & TRN \\
\hline CHEMBL1322709 & 688849 & 3.9578 & 3.8498 & TRN \\
\hline CHEMBL1346461 & 688849 & 2.5229 & 2.715 & TRN \\
\hline CHEMBL 3190705 & 688849 & 2.5229 & 2.7643 & TRN \\
\hline CHEMBL1589659 & 688849 & 4.2097 & 3.6653 & TST \\
\hline CHEMBL1495771 & 688849 & 2.5229 & 2.7209 & TRN \\
\hline CHEMBL1324856 & 688849 & 5.1708 & 3.9281 & TRN \\
\hline CHEMBL232148 & 688849 & 2.5229 & 4.0801 & TRN \\
\hline CHEMBL1541803 & 688849 & 4.4667 & 3.9063 & TRN \\
\hline CHEMBL 3190482 & 688849 & 2.5229 & 2.9155 & TST \\
\hline CHEMBL1352343 & 688849 & 2.5229 & 2.6862 & TRN \\
\hline CHEMBL1584895 & 688849 & 2.5229 & 4.3981 & TRN \\
\hline CHEMBL1332421 & 688849 & 3.9305 & 4.1625 & TRN \\
\hline CHEMBL256097 & 688849 & 2.5229 & 2.6654 & TRN \\
\hline CHEMBL1967220 & 688849 & 2.5229 & 4.3286 & TRN \\
\hline CHEMBL1300605 & 688849 & 4.3608 & 2.7462 & TRN \\
\hline CHEMBL1349197 & 688849 & 4.2769 & 4.4335 & TRN \\
\hline CHEMBL1448592 & 688849 & 2.5229 & 2.8396 & TST \\
\hline CHEMBL 3196884 & 688849 & 4.5083 & 4.3562 & TRN \\
\hline CHEMBL1308784 & 688849 & 3.7246 & 3.3653 & TRN \\
\hline CHEMBL1448173 & 688849 & 4.2825 & 4.1488 & TRN \\
\hline CHEMBL1518696 & 688849 & 5.154 & 4.2159 & TRN \\
\hline CHEMBL1544326 & 688849 & 2.5229 & 2.8583 & TRN \\
\hline CHEMBL1363989 & 688849 & 4.3986 & 3.9354 & TRN \\
\hline CHEMBL1301852 & 688849 & 2.5229 & 2.9471 & TST \\
\hline CHEMBL1354279 & 688849 & 2.5229 & 2.5549 & TRN \\
\hline CHEMBL223453 & 688849 & 2.5229 & 4.6401 & TST \\
\hline CHEMBL1311500 & 688849 & 4.0468 & 3.93600 & 00000000004 \\
\hline CHEMBL1510513 & 688849 & 2.5229 & 3.8612 & TST \\
\hline CHEMBL1605960 & 688849 & 2.5229 & 4.8535 & TRN \\
\hline CHEMBL1598948 & 688849 & 2.5229 & 2.6346 & TRN \\
\hline CHEMBL2001481 & 688849 & 5.2444 & 4.294 & TRN \\
\hline CHEMBL1986418 & 688849 & 4.3124 & 4.5132 & TRN \\
\hline CHEMBL 2006012 & 688849 & 2.5229 & 2.9873 & TRN \\
\hline CHEMBL1481417 & 688849 & 5.1196 & 4.7207 & TST \\
\hline CHEMBL1589492 & 688849 & 2.5229 & 2.7521 & TST \\
\hline CHEMBL1514691 & 688849 & 4.1604 & 4.0949 & TRN \\
\hline CHEMBL1388300 & 688849 & 3.83 & 4.0362 & TRN \\
\hline CHEMBL1583552 & 688849 & 3.9018 & 2.8283 & TST \\
\hline CHEMBL1481257 & 688849 & 2.5229 & 2.642 & TRN \\
\hline CHEMBL1426306 & 688849 & 4.6425 & 3.9906 & TST \\
\hline CHEMBL1456926 & 688849 & 2.5229 & 2.6672 & TST \\
\hline CHEMBL1430625 & 688849 & 4.1041 & 2.4848 & TRN \\
\hline CHEMBL1330366 & 688849 & 4.1973 & 3.7803 & TRN \\
\hline
\end{tabular}


Supplemental Table S2.txt

\begin{tabular}{|c|c|c|c|c|}
\hline CHEMBL1376711 & 688849 & 4.9823 & 4.2659 & TRN \\
\hline CHEMBL1309157 & 688849 & 2.5229 & 2.917 & TRN \\
\hline CHEMBL1492305 & 688849 & 5.4694 & 4.1471 & TRN \\
\hline CHEMBL1428153 & 688849 & 4.3332 & 4.1385 & TST \\
\hline CHEMBL1609926 & 688849 & 2.5229 & 3.6437 & TRN \\
\hline CHEMBL1424261 & 688849 & 4.9669 & 4.5195 & TRN \\
\hline CHEMBL1364410 & 688849 & 4.7341 & 3.9517 & TRN \\
\hline CHEMBL1966852 & 688849 & 3.8521 & 2.6576 & TRN \\
\hline CHEMBL1429733 & 688849 & 2.5229 & 2.8561 & TST \\
\hline CHEMBL1501444 & 688849 & 2.5229 & 2.8555 & TRN \\
\hline CHEMBL1471665 & 688849 & 2.5229 & 2.9125 & TRN \\
\hline CHEMBL1563808 & 688849 & 4.6004 & 3.6054 & TRN \\
\hline CHEMBL1568537 & 688849 & 2.5229 & 2.5454 & TRN \\
\hline CHEMBL1318199 & 688849 & 2.5229 & 2.4683 & TRN \\
\hline CHEMBL1519638 & 688849 & 2.5229 & 2.5172 & TRN \\
\hline CHEMBL1545689 & 688849 & 2.5229 & 4.1007 & TRN \\
\hline CHEMBL1300836 & 688849 & 3.1249 & 4.4684 & TST \\
\hline CHEMBL1987928 & 688849 & 5.2869 & 4.9072 & TRN \\
\hline CHEMBL3198393 & 688849 & 2.5229 & 2.8415 & TRN \\
\hline CHEMBL1522044 & 688849 & 4.8412 & 4.2731 & TRN \\
\hline CHEMBL1366453 & 688849 & 4.5543 & 4.0596 & TRN \\
\hline CHEMBL1415136 & 688849 & 3.7859 & 3.8014 & TRN \\
\hline CHEMBL1413137 & 688849 & 2.5229 & 2.7155 & TRN \\
\hline CHEMBL1346486 & 688849 & 3.9832 & 4.3718 & TST \\
\hline CHEMBL1550366 & 688849 & 5.1271 & 4.7446 & TRN \\
\hline CHEMBL515248 & 688849 & 4.9643 & 3.9892 & TRN \\
\hline CHEMBL1374771 & 688849 & 2.5229 & 2.4869 & TRN \\
\hline CHEMBL1428718 & 688849 & 2.5229 & 2.5132 & TRN \\
\hline CHEMBL1583293 & 688849 & 4.1441 & 3.5037 & TRN \\
\hline CHEMBL1359261 & 688849 & 2.5229 & 4.2896 & TRN \\
\hline CHEMBL1320111 & 688849 & 2.5229 & 3.9761 & TRN \\
\hline CHEMBL1330710 & 688849 & 4.3999 & 3.9381 & TRN \\
\hline CHEMBL1314913 & 688849 & 4.9146 & 4.113 & TST \\
\hline CHEMBL1485275 & 688849 & 2.5229 & 4.1742 & TST \\
\hline CHEMBL3209532 & 688849 & 2.5229 & 2.9356 & TRN \\
\hline CHEMBL1362862 & 688849 & 4.5352 & 4.1314 & TRN \\
\hline CHEMBL1586651 & 688849 & 4.8844 & 4.4443 & TRN \\
\hline CHEMBL1600808 & 688849 & 2.5229 & 2.76 & TRN \\
\hline CHEMBL1570306 & 688849 & 2.5229 & 2.8136 & TST \\
\hline CHEMBL1528856 & 688849 & 4.5314 & 4.2038 & TRN \\
\hline CHEMBL1312488 & 688849 & 2.5229 & 2.8526 & TST \\
\hline CHEMBL1326683 & 688849 & 5.0945 & 4.2193 & TST \\
\hline CHEMBL1998057 & 688849 & 4.2629 & 2.8666 & TRN \\
\hline CHEMBL1563370 & 688849 & 2.5229 & 3.89899 & 99999999996 \\
\hline CHEMBL1983389 & 688849 & 4.3826 & 3.8261 & TST \\
\hline CHEMBL1529274 & 688849 & 2.5229 & 2.8503 & TRN \\
\hline CHEMBL1428927 & 688849 & 2.5229 & 3.5378 & TRN \\
\hline CHEMBL3196505 & 688849 & 2.5229 & 2.87 & TRN \\
\hline
\end{tabular}


Supplemental Table S2.txt

\begin{tabular}{|c|c|c|c|c|}
\hline CHEMBL1568754 & 688849 & 2.5229 & 2.7654 & TRN \\
\hline CHEMBL1313997 & 688849 & 4.5082 & 3.9058 & TRN \\
\hline CHEMBL1408741 & 688849 & 4.1637 & 3.5485 & TRN \\
\hline CHEMBL1530303 & 688849 & 2.5229 & 2.7926 & TRN \\
\hline CHEMBL 2007077 & 688849 & 4.7306 & 4.1499 & TRN \\
\hline CHEMBL1521250 & 688849 & 5.501 & 4.2854 & TRN \\
\hline CHEMBL1492475 & 688849 & 2.5229 & 2.5451 & TRN \\
\hline CHEMBL1536407 & 688849 & 2.5229 & 2.6875 & TRN \\
\hline CHEMBL1597556 & 688849 & 2.5229 & 2.476 & TRN \\
\hline CHEMBL1326075 & 688849 & 2.5229 & 2.7108 & TRN \\
\hline CHEMBL1527687 & 688849 & 2.5229 & 2.8334 & TST \\
\hline CHEMBL1321017 & 688849 & 4.9102 & 4.2588 & TRN \\
\hline CHEMBL1335905 & 688849 & 3.9282 & 5.1654 & TRN \\
\hline CHEMBL3191703 & 688849 & 2.5229 & 2.6844 & TRN \\
\hline CHEMBL1409827 & 688849 & 2.5229 & 2.5004 & TRN \\
\hline CHEMBL1410936 & 688849 & 2.5229 & 2.5689 & TRN \\
\hline CHEMBL1540881 & 688849 & 2.5229 & 2.8561 & TRN \\
\hline CHEMBL1326666 & 688849 & 2.5229 & 3.5166 & TRN \\
\hline CHEMBL1607263 & 688849 & 4.4495 & 4.4259 & TRN \\
\hline CHEMBL1541295 & 688849 & 4.1742 & 3.9595 & TRN \\
\hline CHEMBL1481714 & 688849 & 2.5229 & 3.6678 & TRN \\
\hline CHEMBL1451725 & 688849 & 4.1186 & 4.1081 & TRN \\
\hline CHEMBL1607380 & 688849 & 5.0324 & 4.2177 & TRN \\
\hline CHEMBL1444791 & 688849 & 4.3781 & 2.8372 & TRN \\
\hline CHEMBL1415103 & 688849 & 3.7798 & 2.82800 & 30000000003 \\
\hline CHEMBL1446410 & 688849 & 2.5229 & 3.0443 & TRN \\
\hline CHEMBL1505358 & 688849 & 4.1906 & 4.3047 & TRN \\
\hline CHEMBL1455287 & 688849 & 2.5229 & 2.8667 & TRN \\
\hline CHEMBL1588034 & 688849 & 2.5229 & 2.8819 & TRN \\
\hline CHEMBL1364595 & 688849 & 4.8194 & 4.5156 & TRN \\
\hline CHEMBL1352344 & 688849 & 2.5229 & 2.6987 & TRN \\
\hline CHEMBL3198578 & 688849 & 2.5229 & 3.7311 & TRN \\
\hline CHEMBL1455121 & 688849 & 4.9913 & 4.1399 & TRN \\
\hline CHEMBL1328733 & 688849 & 4.4855 & 3.6341 & TRN \\
\hline CHEMBL1544064 & 688849 & 2.5229 & 2.8386 & TRN \\
\hline CHEMBL1575649 & 688849 & 4.4071 & 4.1426 & TRN \\
\hline CHEMBL1526855 & 688849 & 3.8559 & 4.1091 & TRN \\
\hline CHEMBL1543214 & 688849 & 2.5229 & 2.5144 & TRN \\
\hline CHEMBL1391432 & 688849 & 2.5229 & 2.9378 & TST \\
\hline CHEMBL1972190 & 688849 & 2.5229 & 2.6896 & TRN \\
\hline CHEMBL1603748 & 688849 & 2.5229 & 2.7863 & TRN \\
\hline CHEMBL1428663 & 688849 & 3.6059 & 2.7695 & TRN \\
\hline CHEMBL1595818 & 688849 & 2.5229 & 2.4893 & TRN \\
\hline CHEMBL1331156 & 688849 & 4.664 & 4.1191 & TRN \\
\hline CHEMBL1387618 & 688849 & 4.1674 & 3.8413 & TRN \\
\hline CHEMBL1541213 & 688849 & 2.5229 & 2.7671 & TST \\
\hline CHEMBL278037 & 688849 & 4.8859 & 4.0375 & TRN \\
\hline CHEMBL1340288 & 688849 & 2.5229 & 2.7505 & TRN \\
\hline
\end{tabular}


Supplemental Table S2.txt

\begin{tabular}{|c|c|c|c|c|}
\hline AEMBL1423165 & 38849 & & & \\
\hline & & 5.5014 & 11550 & \\
\hline & & & & \\
\hline IEMBL1 & & & & \\
\hline AEMBL1 & 8849 & 229 & & \\
\hline AEMBL1429575 & 88849 & 5229 & 124 & \\
\hline AEMBL] & 3849 & 229 & & \\
\hline EMBL & & & & \\
\hline AEMBL1 & 8849 & 2.5229 & & \\
\hline AEMBL39 & 38849 & 2604 & 258 & \\
\hline AEMBL1 & 38849 & 1817 & & \\
\hline IEMBL: & 849 & 805 & & \\
\hline IEMBL & & & & \\
\hline AEMBL. & 8849 & 405 & 69 & \\
\hline AEMBLI & 849 & 425 & & \\
\hline AEMBL: & 8849 & 2.5229 & 41 & \\
\hline AEMBL & 849 & & & \\
\hline AEMBL & 849 & & & \\
\hline AEMBL & 849 & 229 & & \\
\hline IEMBL & 49 & 94 & & \\
\hline AEMBL & 19 & 229 & & \\
\hline EMBL & 9 & 72 & & \\
\hline EMB & 49 & 21 & & \\
\hline 14 & & 926 & & \\
\hline IEMBL: & & & & KI \\
\hline IEMBL & -9 & 229 & & \\
\hline EMBL & & 29 & & $x_{1}+2$ \\
\hline 7 & 49 & 29 & & RN \\
\hline IEMBL & & 229 & & \\
\hline AEMBL $\angle$ & 19 & & & RN \\
\hline AEMBL & 9 & 89 & & $\mathrm{RI}$ \\
\hline 1 & & & & r \\
\hline 2 & 9 & 29 & & RN \\
\hline AEMBL & & & & \\
\hline HEMBL1559983 & 3849 & 229 & & RI \\
\hline AEMBL & 9 & 29 & 01 & $\mathrm{R}$ \\
\hline 6 & & 72 & & $\mathrm{R} N$ \\
\hline & & & & RI \\
\hline AEMBL1 & 8849 & 094 & & $R D$ \\
\hline IEMBL: & 8849 & 168 & & \\
\hline AEMBL & 3849 & 229 & & \\
\hline & & & & \\
\hline HEMBL & & 229 & & RI \\
\hline EMBL: & 8849 & 001 & 63 & $\mathrm{R}$ \\
\hline 政 & & 229 & & $\mathrm{R}$ \\
\hline HEMBL & & & & \\
\hline CHEMBLI & & 2.5229 & & \\
\hline CHEMBL1342337 & 688849 & 2.5229 & 4.0283 & $\mathrm{~K}$ \\
\hline
\end{tabular}

Page 3550 


\begin{tabular}{|c|c|c|c|c|c|}
\hline \multirow[b]{2}{*}{ CHEMBL1402546 } & & \multicolumn{4}{|c|}{ Supplemental Table S2.txt } \\
\hline & 688849 & 3.5845 & 2.8868 & TST & \\
\hline CHEMBL1485442 & 688849 & $5.2520 e$ & 00000000 & 4.4344 & TST \\
\hline CHEMBL1611689 & 688849 & 2.5229 & 3.3583 & TRN & \\
\hline CHEMBL1565141 & 688849 & 2.5229 & 2.4831 & TRN & \\
\hline CHEMBL3193419 & 688849 & 2.5229 & 3.5134 & TRN & \\
\hline CHEMBL3145161 & 688849 & 4.8121 & 4.5843 & TRN & \\
\hline CHEMBL1394204 & 688849 & 2.5229 & 2.7397 & TRN & \\
\hline CHEMBL1423496 & 688849 & 4.8017 & 2.9943 & TRN & \\
\hline CHEMBL1972621 & 688849 & 3.7539 & 3.4197 & TRN & \\
\hline CHEMBL1560833 & 688849 & 5.7547 & 4.9942 & TRN & \\
\hline CHEMBL1732424 & 688849 & 5.1898 & 4.2695 & TRN & \\
\hline CHEMBL1582771 & 688849 & 5.1012 & 4.3664 & TRN & \\
\hline CHEMBL1325617 & 688849 & 2.5229 & 2.786 & TRN & \\
\hline CHEMBL1360509 & 688849 & 4.0711 & 4.9364 & TRN & \\
\hline CHEMBL3192138 & 688849 & 2.5229 & 2.75600 & 00000000002 & TRN \\
\hline CHEMBL1469528 & 688849 & 4.4658 & 3.8846 & TRN & \\
\hline CHEMBL1423093 & 688849 & 2.5229 & 2.7126 & TRN & \\
\hline CHEMBL1543229 & 688849 & 3.9398 & 3.0015 & TRN & \\
\hline CHEMBL1369950 & 688849 & 4.6229 & 2.6105 & TRN & \\
\hline CHEMBL1487918 & 688849 & 4.8415 & 4.35800 & 00000000005 & TRN \\
\hline CHEMBL1339485 & 688849 & 2.5229 & 2.9115 & TRN & \\
\hline CHEMBL1516769 & 688849 & 5.026 & 4.2933 & TRN & \\
\hline CHEMBL1532663 & 688849 & 4.3896 & 3.5833 & TRN & \\
\hline CHEMBL1392231 & 688849 & 5.3306 & 3.93899 & 99999999996 & TRN \\
\hline CHEMBL1308455 & 688849 & 2.5229 & 2.6992 & TRN & \\
\hline CHEMBL1380856 & 688849 & 5.1429 & 4.5261 & TRN & \\
\hline CHEMBL1989662 & 688849 & 4.0725 & 4.1858 & TST & \\
\hline CHEMBL1600733 & 688849 & 2.5229 & 2.5669 & TRN & \\
\hline CHEMBL1502018 & 688849 & 4.8892 & 4.2792 & TRN & \\
\hline CHEMBL1334926 & 688849 & 4.4126 & 3.8011 & TST & \\
\hline CHEMBL1374397 & 688849 & 2.5229 & 2.752 & TRN & \\
\hline CHEMBL1392426 & 688849 & 4.4436 & 3.6158 & TRN & \\
\hline CHEMBL1607746 & 688849 & 2.5229 & 2.9796 & TRN & \\
\hline CHEMBL1368206 & 688849 & 2.5229 & 2.6924 & TRN & \\
\hline CHEMBL1457473 & 688849 & 2.5229 & 2.6323 & TRN & \\
\hline CHEMBL1556332 & 688849 & 4.9294 & 4.3259 & TST & \\
\hline CHEMBL1358059 & 688849 & 4.6548 & 4.0461 & TRN & \\
\hline CHEMBL1380440 & 688849 & 2.5229 & 2.6034 & TRN & \\
\hline CHEMBL1566684 & 688849 & 2.5229 & 4.317 & TRN & \\
\hline CHEMBL1440038 & 688849 & 4.561 & 3.2738 & TRN & \\
\hline CHEMBL1609128 & 688849 & 4.9409 & 4.2951 & TRN & \\
\hline CHEMBL1378413 & 688849 & 5.3371 & 4.2691 & TRN & \\
\hline CHEMBL1303188 & 688849 & 5.1265 & 4.3854 & TRN & \\
\hline CHEMBL1570453 & 688849 & 2.5229 & 2.8167 & TRN & \\
\hline CHEMBL1470310 & 688849 & 2.5229 & 2.6931 & TRN & \\
\hline CHEMBL1377284 & 688849 & 2.5229 & 2.8452 & TRN & \\
\hline CHEMBL1398855 & 688849 & 3.9676 & 3.9444 & TST & \\
\hline CHEMBL1600440 & 688849 & 5.058 & 4.2845 & TRN & \\
\hline
\end{tabular}




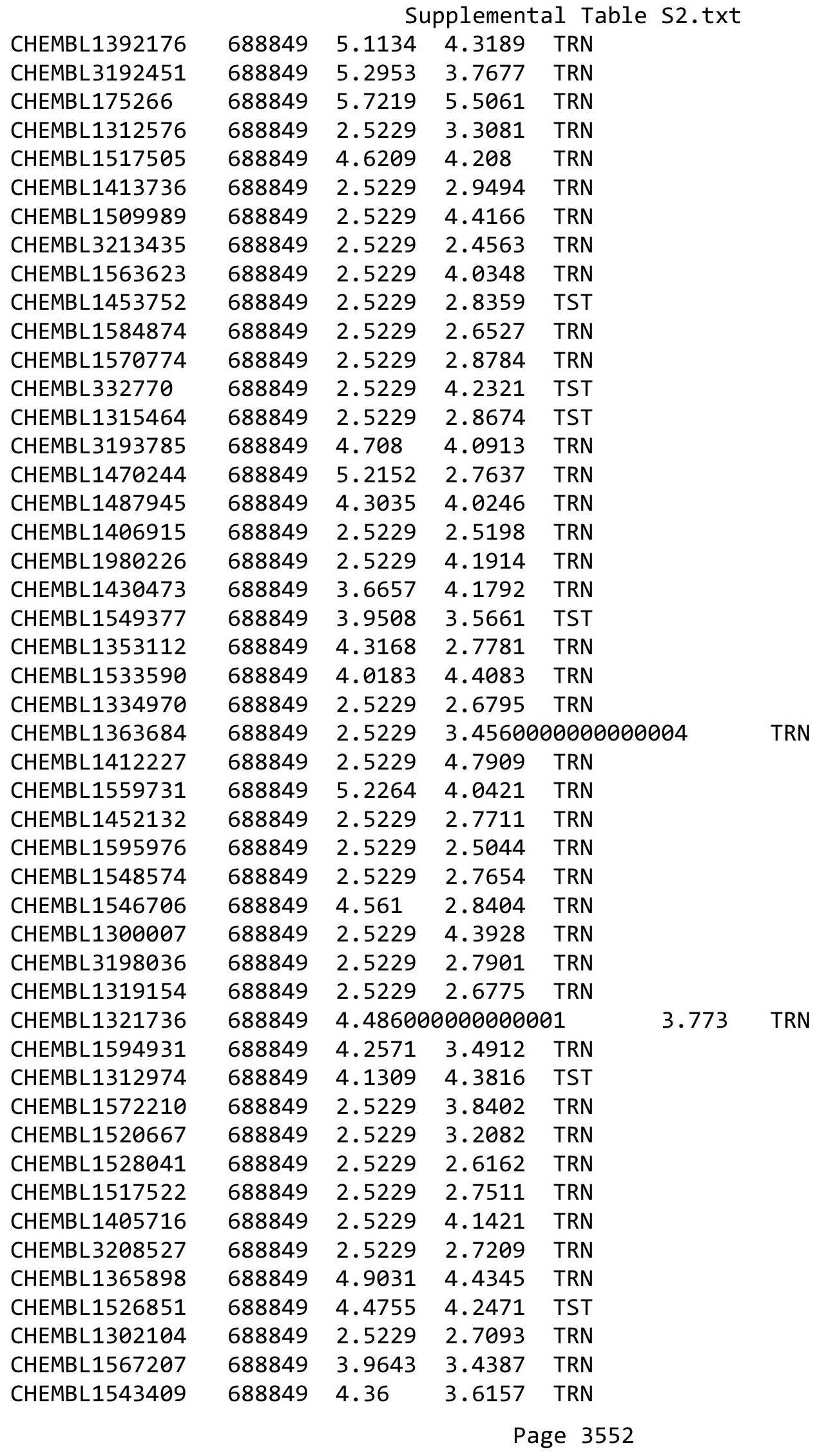


Supplemental Table S2.txt

\begin{tabular}{|c|c|c|c|c|c|}
\hline CHEMBL1424710 & 688849 & 2.5229 & 2.4564 & TRN & \\
\hline CHEMBL1555625 & 688849 & 2.5229 & 2.9114 & TRN & \\
\hline CHEMBL1323320 & 688849 & 2.5229 & 2.6996 & TRN & \\
\hline CHEMBL1508001 & 688849 & 4.3729 & 4.0019 & TRN & \\
\hline CHEMBL1325374 & 688849 & 2.5229 & 2.4536 & TRN & \\
\hline CHEMBL1315054 & 688849 & 2.5229 & 3.9971 & TRN & \\
\hline CHEMBL 3193220 & 688849 & 2.5229 & 2.8804 & TRN & \\
\hline CHEMBL1456636 & 688849 & 2.5229 & 2.6229 & TRN & \\
\hline CHEMBL1532897 & 688849 & 2.5229 & 2.77399 & 99999999996 & TRN \\
\hline CHEMBL1524932 & 688849 & 4.3933 & 3.8841 & TRN & \\
\hline CHEMBL463563 & 688849 & 4.3185 & 4.4389 & TRN & \\
\hline CHEMBL1339859 & 688849 & 2.5229 & 2.4544 & TRN & \\
\hline CHEMBL 3198022 & 688849 & 2.5229 & 2.7083 & TRN & \\
\hline CHEMBL1356209 & 688849 & 2.5229 & 2.5092 & TRN & \\
\hline CHEMBL1579691 & 688849 & 2.5229 & 2.9842 & TRN & \\
\hline CHEMBL410063 & 688849 & 4.7768 & 4.2315 & TST & \\
\hline CHEMBL565657 & 688849 & 2.5229 & 2.7771 & TRN & \\
\hline CHEMBL1449875 & 688849 & 4.5949 & 4.2367 & TRN & \\
\hline CHEMBL165 & 688849 & 2.5229 & 3.52699 & 99999999997 & TRN \\
\hline CHEMBL1561077 & 688849 & 4.3684 & 4.2056 & TRN & \\
\hline CHEMBL1472200 & 688849 & 4.5661 & 4.4473 & TRN & \\
\hline CHEMBL1353270 & 688849 & 2.5229 & 2.8068 & TST & \\
\hline CHEMBL1409714 & 688849 & 5.1442 & 3.7998 & TRN & \\
\hline CHEMBL1329597 & 688849 & 5.1791 & 4.4887 & TRN & \\
\hline CHEMBL1331797 & 688849 & 2.5229 & 2.4724 & TRN & \\
\hline CHEMBL1385400 & 688849 & 2.5229 & 2.7186 & TRN & \\
\hline CHEMBL1578944 & 688849 & 4.7632 & 4.308 & TRN & \\
\hline CHEMBL1366593 & 688849 & 4.6041 & 4.2252 & TRN & \\
\hline CHEMBL1578403 & 688849 & 2.5229 & 2.9515 & TRN & \\
\hline CHEMBL1346195 & 688849 & 4.3572 & 3.3897 & TRN & \\
\hline CHEMBL1370349 & 688849 & 2.5229 & 2.888 & TRN & \\
\hline CHEMBL1401406 & 688849 & 4.4342 & 4.1583 & TRN & \\
\hline CHEMBL1430184 & 688849 & 4.5251 & 3.972 & TRN & \\
\hline CHEMBL1532412 & 688849 & 5.4027 & 4.1922 & TRN & \\
\hline CHEMBL1999960 & 688849 & 2.5229 & 2.8609 & TRN & \\
\hline CHEMBL1332240 & 688849 & 4.2567 & 3.8354 & TRN & \\
\hline CHEMBL1544034 & 688849 & 2.5229 & 2.6277 & TRN & \\
\hline CHEMBL1441921 & 688849 & 4.1924 & 3.977 & TRN & \\
\hline CHEMBL1385808 & 688849 & 2.5229 & 4.0201 & TST & \\
\hline CHEMBL1374603 & 688849 & 4.8448 & 4.4526 & TRN & \\
\hline CHEMBL1569384 & 688849 & 2.5229 & 3.7223 & TRN & \\
\hline CHEMBL1520689 & 688849 & 2.5229 & 2.8714 & TRN & \\
\hline CHEMBL1455143 & 688849 & 2.5229 & 2.6863 & TRN & \\
\hline CHEMBL1470314 & 688849 & 2.5229 & 2.8147 & TRN & \\
\hline CHEMBL1401955 & 688849 & 4.0043 & 4.2701 & TRN & \\
\hline CHEMBL1485960 & 688849 & 2.5229 & 2.9364 & TRN & \\
\hline CHEMBL1559190 & 688849 & 2.5229 & 2.6962 & TRN & \\
\hline CHEMBL213017 & 688849 & 2.5229 & 3.8226 & TRN & \\
\hline
\end{tabular}


Supplemental Table S2.txt

\begin{tabular}{|c|c|c|c|c|}
\hline AEMBL: & & 29 & & \\
\hline HEMRI 1499314 & & 6386 & & \\
\hline AEMBL3 & & 5229 & & \\
\hline IEMBL1392373 & 8849 & 067 & 5683 & \\
\hline HEMBL1490600 & 88849 & 2807 & 9557 & \\
\hline HEMBL15 & 8849 & 229 & 5995 & \\
\hline IFMRI 3 & 8849 & 229 & & \\
\hline AEMBL15 & 38849 & 3233 & 9327 & \\
\hline HEMBL13 & 88849 & 9049 & 4064 & \\
\hline HEMBL14 & 88849 & .7887 & 5268 & \\
\hline AEMBL14 & 8849 & 324 & 8332 & \\
\hline AEMBL1: & 849 & 229 & 8876 & \\
\hline AEMBL14 & 38849 & 2.5229 & 8798 & \\
\hline IEMBL15 & 38849 & 229 & 5221 & \\
\hline AEMBL14 & 38849 & 229 & 8108 & \\
\hline IEMBL1 & 849 & 229 & 3094 & \\
\hline IEMBL1 & & 29 & & \\
\hline AEMBL1: & 849 & 229 & 191 & \\
\hline IEMBL14 & 849 & 508 & & \\
\hline AEMBL13 & 19 & 229 & 9601 & KIV \\
\hline EMBL1 & 19 & 229 & 644 & RN \\
\hline EMBL1 & & 29 & & RN \\
\hline AEMBL3. & 49 & 229 & 576 & RN \\
\hline AEMBL13 & 49 & & 149 & \\
\hline IEMBL1 & 49 & 29 & 331 & RIN \\
\hline EMBL1 & 9 & 29 & 544 & RN \\
\hline EMBL 1 & 9 & & & $\mathrm{RN}$ \\
\hline 00 & & & 272 & RN \\
\hline IEMBL1 & & & & Ih \\
\hline IEMBL31 & 8849 & 29 & 3797 & $\mathrm{RN}$ \\
\hline EMBL1 & 49 & & 48 & RN \\
\hline 49 & & & & ST \\
\hline & & & & $\mathrm{RN}$ \\
\hline IEMBL15 & & & & 「RN \\
\hline AEMBL15 & 8849 & 386 & 739 & RN \\
\hline IFMRI 15 & 49 & 29 & 39 & RN \\
\hline & & & & RN \\
\hline HEMBL1: & & & & RN \\
\hline AEMBL15 & 38849 & 33 & 838 & $\Gamma R$ \\
\hline EMBL1: & 8849 & & 036 & 「RN \\
\hline HEMBL1C & 38849 & 29 & 983 & TRN \\
\hline & & & 1.0459 & $\mathrm{RN}$ \\
\hline HEMBL19 & & & 3.7327 & 「RN \\
\hline IEMBL1: & 8849 & 29 & 038 & TR \\
\hline 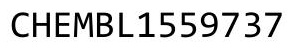 & & & 234 & \\
\hline HEMBL14 & 88849 & 2.5229 & 2.9446 & \\
\hline HEMBL15 & 88849 & 2.5229 & 2.4615 & \\
\hline CHEMBL1312377 & 688849 & 4.3542 & 2.8871 & \\
\hline
\end{tabular}

Page 3554 


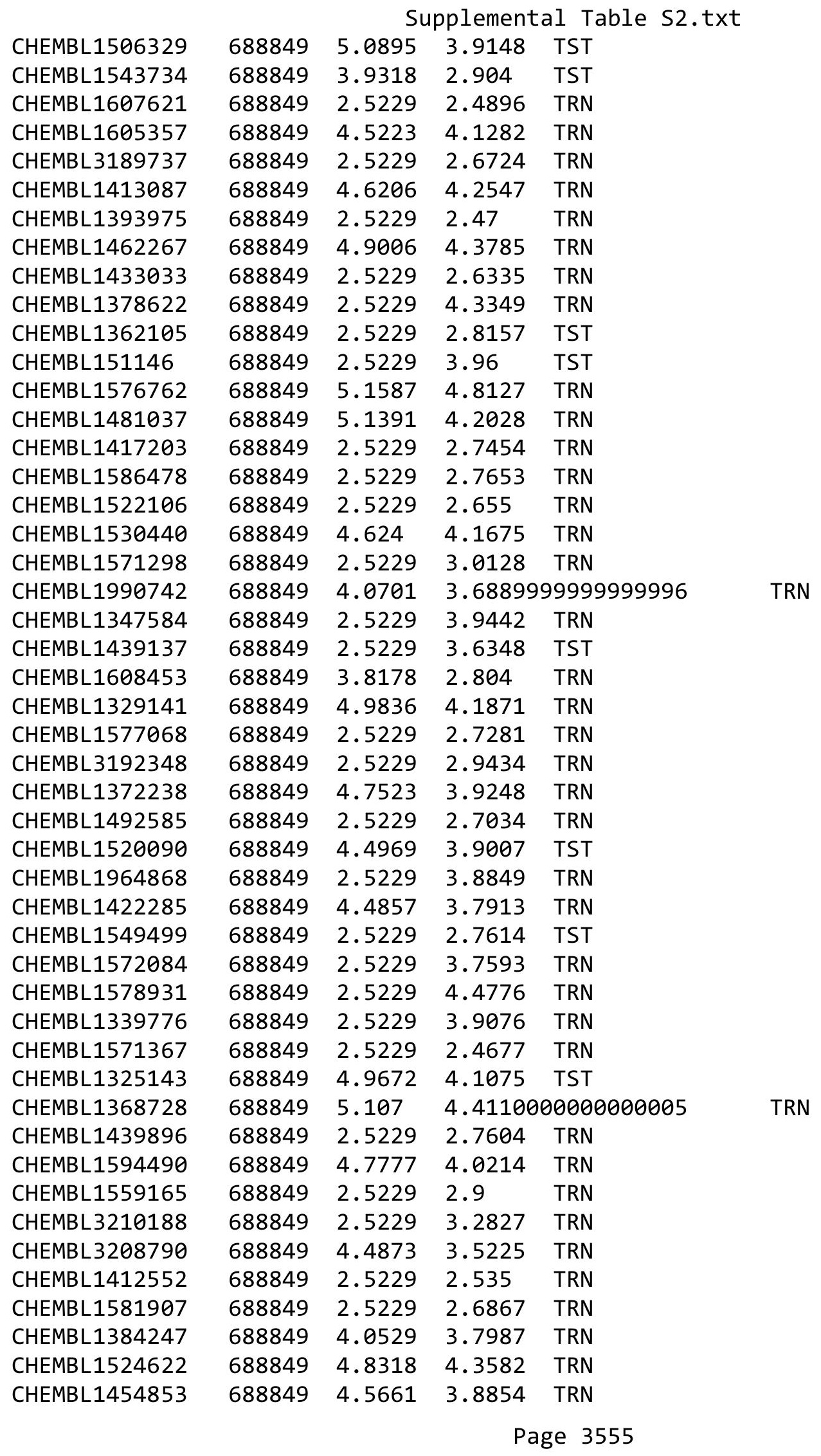




\begin{tabular}{|c|c|c|c|c|c|c|}
\hline & & \multicolumn{5}{|c|}{ Supplemental Table s2.txt } \\
\hline CHEMBL1337325 & 688849 & 4.8628 & 3.9267 & TST & & \\
\hline CHEMBL1486880 & 688849 & 2.5229 & 2.5257 & TRN & & \\
\hline CHEMBL1527986 & 688849 & 2.5229 & 4.0316 & TRN & & \\
\hline CHEMBL1540401 & 688849 & 5.6392 & 4.4825 & TRN & & \\
\hline CHEMBL1448410 & 688849 & 4.4014 & 3.93899 & 99999999996 & & TRN \\
\hline CHEMBL1317867 & 688849 & 2.5229 & 2.5275 & TRN & & \\
\hline CHEMBL1416061 & 688849 & 2.5229 & 2.5282 & TRN & & \\
\hline CHEMBL1466200 & 688849 & 4.5477 & 4.4202 & TRN & & \\
\hline CHEMBL1492232 & 688849 & 4.1856 & 3.7639 & TRN & & \\
\hline CHEMBL156383 & 688849 & 5.1966 & 4.5555 & TRN & & \\
\hline CHEMBL1332375 & 688849 & 2.5229 & 2.4745 & TRN & & \\
\hline CHEMBL 3190340 & 688849 & 6.4271 & 4.5961 & TRN & & \\
\hline CHEMBL1516858 & 688849 & 4.1069 & 4.2378 & TRN & & \\
\hline CHEMBL1456923 & 688849 & 2.5229 & 2.7653 & TST & & \\
\hline CHEMBL1584866 & 688849 & 2.5229 & 2.6924 & TRN & & \\
\hline CHEMBL136344 & 688849 & 3.8737 & 3.066006 & 0000000000 & & TRN \\
\hline CHEMBL1525895 & 688849 & 2.5229 & 2.6444 & TRN & & \\
\hline CHEMBL1366561 & 688849 & $5.1110 e$ & 300000006 & $\partial 1$ & .5324 & TRN \\
\hline CHEMBL1606686 & 688849 & 2.5229 & 4.3708 & TRN & & \\
\hline CHEMBL1311486 & 688849 & 2.5229 & 3.4253 & TRN & & \\
\hline CHEMBL1558159 & 688849 & 5.0462 & 3.8616 & TRN & & \\
\hline CHEMBL3196179 & 688849 & 2.5229 & 2.8549 & TRN & & \\
\hline CHEMBL1420395 & 688849 & 4.5839 & 3.5489 & TRN & & \\
\hline CHEMBL239103 & 688849 & 4.7659 & 4.4553 & TST & & \\
\hline CHEMBL1400010 & 688849 & 2.5229 & 2.7257 & TRN & & \\
\hline CHEMBL1490217 & 688849 & 2.5229 & 2.6904 & TRN & & \\
\hline CHEMBL1493791 & 688849 & 2.5229 & 3.924 & TRN & & \\
\hline CHEMBL1536221 & 688849 & 2.5229 & 2.7239 & TRN & & \\
\hline CHEMBL1373732 & 688849 & 2.5229 & 3.9314 & TRN & & \\
\hline CHEMBL1539255 & 688849 & 2.5229 & 3.8875 & TRN & & \\
\hline CHEMBL1351799 & 688849 & $4.7010 €$ & 00000000 & 205 & .9575 & TRN \\
\hline CHEMBL495123 & 688849 & 4.436 & 4.3026 & TST & & \\
\hline CHEMBL1469444 & 688849 & 5.0556 & 4.3645 & TRN & & \\
\hline CHEMBL1344463 & 688849 & 2.5229 & 2.491 & TRN & & \\
\hline CHEMBL1306697 & 688849 & 2.5229 & 3.8588 & TRN & & \\
\hline CHEMBL1438738 & 688849 & 2.5229 & 2.5373 & TRN & & \\
\hline CHEMBL1301464 & 688849 & 2.5229 & 2.625 & TRN & & \\
\hline CHEMBL1475027 & 688849 & 2.5229 & 2.8719 & TRN & & \\
\hline CHEMBL1483095 & 688849 & 6.0645 & 4.2566 & TRN & & \\
\hline CHEMBL1588325 & 688849 & 2.5229 & 2.6284 & TRN & & \\
\hline CHEMBL1311929 & 688849 & 4.4029 & 4.5554 & TRN & & \\
\hline CHEMBL1562320 & 688849 & 5.1171 & 4.5787 & TRN & & \\
\hline CHEMBL1369743 & 688849 & 2.5229 & 2.6584 & TRN & & \\
\hline CHEMBL1322615 & 688849 & 4.4311 & 3.7763 & TRN & & \\
\hline CHEMBL1460525 & 688849 & 2.5229 & 2.7607 & TRN & & \\
\hline CHEMBL1348294 & 688849 & 2.5229 & 2.6978 & TRN & & \\
\hline CHEMBL1597773 & 688849 & 2.5229 & 2.87899 & 99999999996 & & TST \\
\hline CHEMBL1508788 & 688849 & 5.7967 & 4.621 & TRN & & \\
\hline
\end{tabular}


Supplemental Table S2.txt

\begin{tabular}{|c|c|c|c|c|}
\hline & & & & \\
\hline AEMBL14 & 38849 & 5229 & 3.08 & \\
\hline IEMBL1373237 & 849 & 229 & 5792 & \\
\hline HEMBL3208977 & 849 & 229 & 9646 & \\
\hline & 349 & & 261 & \\
\hline AEMBL319 & 349 & & 295 & \\
\hline AEMBL1558731 & 3849 & 229 & 9378 & \\
\hline AEMBL1589514 & 88849 & 754 & 3861 & \\
\hline AEMBL1477352 & 849 & & 568 & \\
\hline IEMBL154 & 349 & & 892 & \\
\hline AEMBL 319 & 49 & & 114 & \\
\hline AEMBL1397898 & 688849 & 229 & 7528 & \\
\hline AEMBL 297453 & 849 & & 9631 & 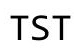 \\
\hline AEMBL144 & 49 & & 192 & \\
\hline IEMBL15\& & 49 & & 709 & \\
\hline HEMBL154 & & & 472 & \\
\hline AEMBL1332539 & 849 & & 871 & RN \\
\hline AEMBL1493686 & 49 & & 906 & \\
\hline IEMBL14 & 19 & & & \\
\hline IEMBL136 & & & 092 & \\
\hline HEMBL199 & & & 169 & \\
\hline AEMBL1465545 & & & 587 & \\
\hline HEMBL131 & & & & \\
\hline IEMBL16 & & & 668 & SI \\
\hline EMBL16 & & & 172 & $x^{2}+2+$ \\
\hline IFMDI 15 & & & & \\
\hline AEMBL143 & & & 244 & RN \\
\hline AEMBL1509 & & & & \\
\hline EMBL154 & & & 534 & ST \\
\hline 15 & & & 124 & . \\
\hline 2 & & & 455 & . \\
\hline AEMBL1447403 & & & & $\mathrm{RN}$ \\
\hline AEMBL3195238 & & & 57 & ST \\
\hline EMBL15: & & & 586 & RI \\
\hline$\llcorner 15$ & & & 732 & . \\
\hline 3 & & & 96 & . \\
\hline AEMBL151 & & & 022 & RN \\
\hline AEMBL1508 & & & 035 & ST \\
\hline EMBL14C & & & 602 & RI \\
\hline הר וסנוזו & & & 741 & \\
\hline & & & 947 & RN \\
\hline AEMBL1307487 & 3849 & & 3.3974 & $\mathrm{R}$ \\
\hline AEMBL156 & & & 862 & TS \\
\hline 24 & & & & TS \\
\hline HEMBL 14 & & & 4.8292 & \\
\hline CHEMBL 14 & & & 2.4819 & $\mathrm{~N}$ \\
\hline HEMBL139306 & 8849 & 2.5229 & 2.7541 & $\mathrm{TR}$ \\
\hline HEMBL1304473 & 688849 & 2.5229 & 2.6327 & \\
\hline
\end{tabular}

Page 3557 
Supplemental Table S2.txt

\begin{tabular}{|c|c|c|c|c|c|}
\hline CHEMBL1585863 & 688849 & 2.5229 & 2.6005 & TRN & \\
\hline CHEMBL1380676 & 688849 & 4.7315 & 2.9837 & TRN & \\
\hline CHEMBL1319488 & 688849 & 2.5229 & 3.9408 & TRN & \\
\hline CHEMBL1537916 & 688849 & 2.5229 & 2.8423 & TRN & \\
\hline CHEMBL1443822 & 688849 & 4.227 & 3.6016 & TRN & \\
\hline CHEMBL1378352 & 688849 & 2.5229 & 2.609 & TRN & \\
\hline CHEMBL1443797 & 688849 & 2.5229 & 3.549 & TRN & \\
\hline CHEMBL1348355 & 688849 & 3.8738 & 4.2891 & TRN & \\
\hline CHEMBL 3195188 & 688849 & 2.5229 & 4.136 & TST & \\
\hline CHEMBL1468476 & 688849 & 2.5229 & 3.6452 & TRN & \\
\hline CHEMBL1509330 & 688849 & 2.5229 & 2.5021 & TRN & \\
\hline CHEMBL1417309 & 688849 & 4.4889 & 4.3212 & TRN & \\
\hline CHEMBL1612322 & 688849 & 2.5229 & 2.5356 & TRN & \\
\hline CHEMBL1595587 & 688849 & 5.0215 & 4.3239 & TRN & \\
\hline CHEMBL 3210436 & 688849 & 2.5229 & 2.4568 & TRN & \\
\hline CHEMBL399293 & 688849 & 2.5229 & 2.9308 & TST & \\
\hline CHEMBL1379164 & 688849 & 4.0485 & 3.7806 & TST & \\
\hline CHEMBL1337402 & 688849 & 2.5229 & 4.04 & TRN & \\
\hline CHEMBL1430927 & 688849 & 4.3615 & 2.742 & TRN & \\
\hline CHEMBL1556162 & 688849 & 2.5229 & 2.718 & TRN & \\
\hline CHEMBL3216654 & 688849 & 4.3713 & 3.8842 & TST & \\
\hline CHEMBL1494729 & 688849 & 5.169 & 3.91300 & 00000000003 & TRN \\
\hline CHEMBL1584730 & 688849 & 5.2799 & 4.539 & TRN & \\
\hline CHEMBL1583536 & 688849 & 2.5229 & 2.7791 & TRN & \\
\hline CHEMBL1270192 & 688849 & 2.5229 & 2.6969 & TRN & \\
\hline CHEMBL1464392 & 688849 & 2.5229 & 2.7273 & TRN & \\
\hline CHEMBL1389549 & 688849 & 4.8973 & 4.3768 & TRN & \\
\hline CHEMBL1536196 & 688849 & 4.458 & 4.2064 & TRN & \\
\hline CHEMBL1401755 & 688849 & 2.5229 & 3.6694 & TRN & \\
\hline CHEMBL1375636 & 688849 & 4.7739 & 4.1407 & TST & \\
\hline CHEMBL1372505 & 688849 & 4.8727 & 3.6218 & TRN & \\
\hline CHEMBL1304684 & 688849 & 2.5229 & 2.8479 & TRN & \\
\hline CHEMBL1378007 & 688849 & 2.5229 & 2.7129 & TRN & \\
\hline CHEMBL1560309 & 688849 & 2.5229 & 2.7902 & TRN & \\
\hline CHEMBL1538427 & 688849 & 2.5229 & 2.7742 & TRN & \\
\hline CHEMBL1613430 & 688849 & 2.5229 & 2.8691 & TRN & \\
\hline CHEMBL 3199002 & 688849 & 4.2455 & 3.8813 & TRN & \\
\hline CHEMBL 3195281 & 688849 & 4.4513 & 3.95399 & 99999999997 & TST \\
\hline CHEMBL1612714 & 688849 & 2.5229 & 2.8011 & TRN & \\
\hline CHEMBL1569836 & 688849 & 2.5229 & 2.6555 & TRN & \\
\hline CHEMBL3211410 & 688849 & 2.5229 & 2.6689 & TST & \\
\hline CHEMBL1425725 & 688849 & 4.3559 & 4.022 & TRN & \\
\hline CHEMBL511385 & 688849 & 4.2769 & 3.3685 & TRN & \\
\hline CHEMBL1403546 & 688849 & 4.5192 & 3.8156 & TRN & \\
\hline CHEMBL1406528 & 688849 & 4.4551 & 3.9928 & TRN & \\
\hline CHEMBL1490312 & 688849 & 2.5229 & 2.8329 & TRN & \\
\hline CHEMBL1427125 & 688849 & 2.5229 & 2.6438 & TRN & \\
\hline CHEMBL1507529 & 688849 & 4.2844 & 3.6604 & TRN & \\
\hline
\end{tabular}




\begin{tabular}{|c|c|c|c|c|c|}
\hline & & \multicolumn{4}{|c|}{ Supplemental Table s2.txt } \\
\hline CHEMBL1331211 & 688849 & 4.6835 & 4.5339 & TRN & \\
\hline CHEMBL1530459 & 688849 & 2.5229 & 2.972 & TRN & \\
\hline CHEMBL1497153 & 688849 & 4.8268 & 4.4259 & TRN & \\
\hline CHEMBL1417099 & 688849 & 4.1823 & 3.8746 & TST & \\
\hline CHEMBL1457752 & 688849 & 4.4164 & 2.77600 & 00000000002 & TRN \\
\hline CHEMBL3199707 & 688849 & 2.5229 & 2.9109 & TRN & \\
\hline CHEMBL1390702 & 688849 & 2.5229 & 3.773 & TRN & \\
\hline CHEMBL1373688 & 688849 & 2.5229 & 2.9418 & TRN & \\
\hline CHEMBL1416658 & 688849 & 2.5229 & 2.7662 & TRN & \\
\hline CHEMBL1533557 & 688849 & 2.8239 & 3.4426 & TRN & \\
\hline CHEMBL250499 & 688849 & 2.5229 & 2.9283 & TST & \\
\hline CHEMBL1580081 & 688849 & 2.5229 & 2.8647 & TRN & \\
\hline CHEMBL1346615 & 688849 & 2.5229 & 2.8434 & TRN & \\
\hline CHEMBL1598843 & 688849 & 4.2718 & 3.63199 & 99999999997 & TRN \\
\hline CHEMBL1462002 & 688849 & 4.6561 & 5.0395 & TRN & \\
\hline CHEMBL3190785 & 688849 & 2.5229 & 3.8172 & TRN & \\
\hline CHEMBL1587179 & 688849 & 2.5229 & 2.7079 & TST & \\
\hline CHEMBL1482438 & 688849 & 2.5229 & 3.6587 & TRN & \\
\hline CHEMBL1403999 & 688849 & 4.5057 & 3.9658 & TRN & \\
\hline CHEMBL1363642 & 688849 & 2.5229 & 2.7767 & TRN & \\
\hline CHEMBL1341586 & 688849 & 4.0733 & 3.4676 & TRN & \\
\hline CHEMBL3193300 & 688849 & $4.4060 e$ & 00000000 & 2.7411 & TRN \\
\hline CHEMBL1522155 & 688849 & 5.2664 & 5.2562 & TRN & \\
\hline CHEMBL1574316 & 688849 & 2.5229 & 2.6653 & TRN & \\
\hline CHEMBL1438779 & 688849 & 3.72 & 4.0287 & TRN & \\
\hline CHEMBL1476797 & 688849 & 5.277 & 4.5937 & TRN & \\
\hline CHEMBL1319448 & 688849 & 2.5229 & 2.7792 & TRN & \\
\hline CHEMBL1469895 & 688849 & 5.1011 & 4.2374 & TRN & \\
\hline CHEMBL1382870 & 688849 & 2.5229 & 2.5705 & TRN & \\
\hline CHEMBL1511743 & 688849 & 2.5229 & 2.6972 & TRN & \\
\hline CHEMBL3210868 & 688849 & 2.5229 & 2.8502 & TRN & \\
\hline CHEMBL1343099 & 688849 & 4.2533 & 4.3517 & TRN & \\
\hline CHEMBL1414875 & 688849 & 4.1153 & 3.5149 & TRN & \\
\hline CHEMBL1568441 & 688849 & 2.5229 & 3.3434 & TRN & \\
\hline CHEMBL1369958 & 688849 & 2.5229 & 2.8241 & TRN & \\
\hline CHEMBL1376453 & 688849 & 3.7044 & 4.3937 & TRN & \\
\hline CHEMBL1340338 & 688849 & 4.8435 & 5.0959 & TRN & \\
\hline CHEMBL1452636 & 688849 & 2.5229 & 2.5073 & TRN & \\
\hline CHEMBL 2000240 & 688849 & 2.5229 & 2.8465 & TRN & \\
\hline CHEMBL1255778 & 688849 & 4.4265 & 5.4755 & TST & \\
\hline CHEMBL1488981 & 688849 & 4.5107 & 4.0199 & TRN & \\
\hline CHEMBL1589299 & 688849 & 4.3236 & 3.8796 & TRN & \\
\hline CHEMBL1388398 & 688849 & 4.4101 & 3.7086 & TRN & \\
\hline CHEMBL1390667 & 688849 & 2.5229 & 2.4661 & TRN & \\
\hline CHEMBL3189964 & 688849 & 2.5229 & 2.8617 & TRN & \\
\hline CHEMBL1501715 & 688849 & 2.5229 & 2.6363 & TRN & \\
\hline CHEMBL66953 & 688849 & 5.1825 & 5.467006 & 00000000005 & TST \\
\hline CHEMBL1576943 & 688849 & 2.5229 & 3.4793 & TRN & \\
\hline
\end{tabular}


Supplemental Table S2.txt

\begin{tabular}{|c|c|c|c|c|}
\hline CHEMBL1450347 & 688849 & 2.5229 & 2.4952 & TRN \\
\hline CHEMBL1439218 & 688849 & 4.5005 & 4.0971 & TRN \\
\hline CHEMBL1323719 & 688849 & 4.0305 & 4.1109 & TRN \\
\hline CHEMBL1510455 & 688849 & 2.5229 & 4.0555 & TRN \\
\hline CHEMBL1464859 & 688849 & 2.5229 & 2.6998 & TRN \\
\hline CHEMBL1462735 & 688849 & 2.5229 & 2.5394 & TRN \\
\hline CHEMBL1531566 & 688849 & 5.5494 & 4.4986 & TRN \\
\hline CHEMBL1462008 & 688849 & 2.5229 & 2.5129 & TRN \\
\hline CHEMBL1327594 & 688849 & 4.7257 & 3.9465 & TRN \\
\hline CHEMBL1588765 & 688849 & 4.1033 & 3.8935 & TRN \\
\hline CHEMBL1353023 & 688849 & 4.9378 & 3.8469 & TRN \\
\hline CHEMBL1549255 & 688849 & 2.5229 & 2.7275 & TRN \\
\hline CHEMBL1389770 & 688849 & 5.2472 & 3.9215 & TRN \\
\hline CHEMBL1363496 & 688849 & 4.0672 & 4.105 & TRN \\
\hline CHEMBL1532451 & 688849 & 2.5229 & 4.2246 & TRN \\
\hline CHEMBL1388156 & 688849 & 2.5229 & 2.752 & TRN \\
\hline CHEMBL1523709 & 688849 & 2.5229 & 2.8204 & TRN \\
\hline CHEMBL212827 & 688849 & 4.8556 & 3.8449 & TRN \\
\hline CHEMBL1431657 & 688849 & 2.5229 & 2.8151 & TST \\
\hline CHEMBL1459515 & 688849 & 4.5682 & 4.1178 & TST \\
\hline CHEMBL3198724 & 688849 & 2.5229 & 3.1919 & TRN \\
\hline CHEMBL1548111 & 688849 & 4.8025 & 3.9539 & TRN \\
\hline CHEMBL1492654 & 688849 & 4.4096 & 3.88100 & 00000000002 \\
\hline CHEMBL1454835 & 688849 & 2.5229 & 3.9252 & TRN \\
\hline CHEMBL1310909 & 688849 & 4.3288 & 3.883 & TRN \\
\hline CHEMBL1559962 & 688849 & 2.5229 & 2.7754 & TRN \\
\hline CHEMBL1376421 & 688849 & 4.4656 & 3.7795 & TRN \\
\hline CHEMBL1598439 & 688849 & 2.5229 & 4.0775 & TRN \\
\hline CHEMBL1349942 & 688849 & 4.0826 & 2.5741 & TRN \\
\hline CHEMBL1334207 & 688849 & 2.5229 & 2.5196 & TRN \\
\hline CHEMBL1521764 & 688849 & 2.5229 & 2.7187 & TST \\
\hline CHEMBL3191954 & 688849 & 2.5229 & 2.6547 & TRN \\
\hline CHEMBL1418857 & 688849 & 2.5229 & 3.7183 & TST \\
\hline CHEMBL1612672 & 688849 & 2.5229 & 2.7099 & TRN \\
\hline CHEMBL 1386348 & 688849 & 4.64 & 3.8906 & TRN \\
\hline CHEMBL1600686 & 688849 & 2.5229 & 4.5983 & TRN \\
\hline CHEMBL3192454 & 688849 & 4.5219 & 4.0437 & TRN \\
\hline CHEMBL3191029 & 688849 & 4.0649 & 3.8728 & TRN \\
\hline CHEMBL1487928 & 688849 & 5.2444 & 2.9824 & TRN \\
\hline CHEMBL1965698 & 688849 & 2.5229 & 2.747 & TRN \\
\hline CHEMBL1598223 & 688849 & 5.5025 & 4.4919 & TST \\
\hline CHEMBL1609014 & 688849 & 2.5229 & 3.6112 & TRN \\
\hline CHEMBL420385 & 688849 & 2.5229 & 2.5973 & TRN \\
\hline CHEMBL1463477 & 688849 & 4.268 & 4.927 & TRN \\
\hline CHEMBL1304449 & 688849 & 2.5229 & 2.951 & TRN \\
\hline CHEMBL1577302 & 688849 & 4.2076 & 4.0243 & TST \\
\hline CHEMBL1981657 & 688849 & 4.5239 & 4.13399 & 99999999995 \\
\hline CHEMBL1506185 & 688849 & 6.1805 & 6.2942 & TST \\
\hline
\end{tabular}


Supplemental Table S2.txt

\begin{tabular}{|c|c|c|c|c|c|}
\hline CHEMBL1269379 & 688849 & 2.5229 & 2.7884 & TST & \\
\hline CHEMBL1308231 & 688849 & 2.5229 & 2.7143 & TRN & \\
\hline CHEMBL1418504 & 688849 & 2.5229 & \multicolumn{2}{|c|}{2.8160000000000003} & TST \\
\hline CHEMBL 3194441 & 688849 & 3.8961 & 3.5581 & TRN & \\
\hline CHEMBL3198280 & 688849 & 2.5229 & 2.8683 & TRN & \\
\hline CHEMBL1340041 & 688849 & 5.1934 & 4.2517 & TRN & \\
\hline CHEMBL1545858 & 688849 & 2.5229 & 4.7054 & TRN & \\
\hline CHEMBL1443760 & 688849 & 2.5229 & 2.7465 & TRN & \\
\hline CHEMBL1343532 & 688849 & 3.9655 & 3.4926 & TRN & \\
\hline CHEMBL1565096 & 688849 & 2.5229 & 2.6001 & TRN & \\
\hline CHEMBL1333824 & 688849 & 4.6327 & 3.8834 & TRN & \\
\hline CHEMBL1428135 & 688849 & 4.3291 & 4.0683 & TRN & \\
\hline CHEMBL1522846 & 688849 & 4.3386 & 4.1268 & TST & \\
\hline CHEMBL1605770 & 688849 & 4.0759 & 2.5227 & TRN & \\
\hline CHEMBL1570525 & 688849 & 2.5229 & 2.9293 & TST & \\
\hline CHEMBL1378424 & 688849 & 2.5229 & 2.8163 & TRN & \\
\hline CHEMBL1301252 & 688849 & 2.5229 & 2.7326 & TRN & \\
\hline CHEMBL3190610 & 688849 & 4.114 & 3.9486 & TRN & \\
\hline CHEMBL 1387110 & 688849 & 4.7162 & 3.0428 & TRN & \\
\hline CHEMBL 1468490 & 688849 & 4.6387 & 4.1131 & TRN & \\
\hline CHEMBL1414498 & 688849 & 4.7305 & 2.9022 & TRN & \\
\hline CHEMBL3209168 & 688849 & 2.5229 & 2.8758 & TRN & \\
\hline CHEMBL1411766 & 688849 & 4.7293 & 3.9895 & TRN & \\
\hline CHEMBL1564932 & 688849 & 4.8319 & 4.4064 & TST & \\
\hline CHEMBL1536229 & 688849 & 2.5229 & 2.9277 & TRN & \\
\hline CHEMBL1401266 & 688849 & 2.5229 & 2.8051 & TRN & \\
\hline CHEMBL1612106 & 688849 & 4.8452 & 4.2985 & TRN & \\
\hline CHEMBL1588042 & 688849 & 4.0247 & 3.6759 & TST & \\
\hline CHEMBL1424930 & 688849 & 2.5229 & 2.8613 & TRN & \\
\hline CHEMBL1408827 & 688849 & 4.4229 & 4.0989 & TRN & \\
\hline CHEMBL1342667 & 688849 & 4.9391 & 3.7435 & TRN & \\
\hline CHEMBL 2005721 & 688849 & 2.5229 & 2.6966 & TRN & \\
\hline CHEMBL1380580 & 688849 & 2.5229 & 2.8737 & TRN & \\
\hline CHEMBL1448972 & 688849 & 4.2201 & 2.911 & TRN & \\
\hline CHEMBL1412067 & 688849 & 6.4401 & 5.4571 & TRN & \\
\hline CHEMBL1977974 & 688849 & 2.5229 & 2.6101 & TRN & \\
\hline CHEMBL1333659 & 688849 & 3.6016 & 3.7194 & TRN & \\
\hline CHEMBL3190069 & 688849 & 2.5229 & 5.5745 & TRN & \\
\hline CHEMBL1545104 & 688849 & 2.5229 & 2.9071 & TRN & \\
\hline CHEMBL3194726 & 688849 & 2.5229 & \multicolumn{2}{|c|}{2.7460000000000004} & TRN \\
\hline CHEMBL1370952 & 688849 & 4.3413 & 4.0913 & TRN & \\
\hline CHEMBL 1350455 & 688849 & 2.5229 & 2.7548 & TST & \\
\hline CHEMBL1299990 & 688849 & 4.7208 & 4.1358 & TST & \\
\hline CHEMBL1396089 & 688849 & 4.9297 & 4.324 & TRN & \\
\hline CHEMBL1547446 & 688849 & 4.4745 & \multicolumn{2}{|c|}{3.9530000000000003} & TRN \\
\hline CHEMBL1440861 & 688849 & 2.5229 & 2.7182 & TRN & \\
\hline CHEMBL1353221 & 688849 & 2.5229 & 3.8632 & TST & \\
\hline CHEMBL1450422 & 688849 & 2.5229 & 3.4501 & TRN & \\
\hline
\end{tabular}


Supplemental Table S2.txt

\begin{tabular}{|c|c|c|c|c|c|}
\hline CHEMBL1562170 & 688849 & 4.7971 & 4.0114 & TRN & \\
\hline CHEMBL1462800 & 688849 & 2.5229 & 2.6928 & TRN & \\
\hline CHEMBL1329106 & 688849 & 4.4399 & 3.4529 & TRN & \\
\hline CHEMBL1305441 & 688849 & 2.5229 & 3.6846 & TRN & \\
\hline CHEMBL1504595 & 688849 & 4.6096 & 4.1884 & TRN & \\
\hline CHEMBL1452684 & 688849 & 4.749 & 4.5418 & TRN & \\
\hline CHEMBL1322274 & 688849 & 2.5229 & 3.6727 & TRN & \\
\hline CHEMBL1609156 & 688849 & 2.5229 & 3.0749 & TRN & \\
\hline CHEMBL1301052 & 688849 & 5.0185 & 4.1979 & TRN & \\
\hline CHEMBL1989090 & 688849 & 4.1372 & 3.8106 & TRN & \\
\hline CHEMBL1452945 & 688849 & 5.8505 & 4.9025 & TRN & \\
\hline CHEMBL1442893 & 688849 & 4.4633 & 4.0048 & TRN & \\
\hline CHEMBL1507021 & 688849 & 4.8084 & 4.2647 & TRN & \\
\hline CHEMBL1447034 & 688849 & 4.4275 & 4.1108 & TRN & \\
\hline CHEMBL1526699 & 688849 & 4.7802 & 3.7816 & TRN & \\
\hline CHEMBL 3235884 & 688849 & 2.5229 & 2.6056 & TRN & \\
\hline CHEMBL1439143 & 688849 & 2.5229 & 2.8171 & TRN & \\
\hline CHEMBL1317660 & 688849 & 2.5229 & 4.5219 & TRN & \\
\hline CHEMBL1349475 & 688849 & 4.077 & 3.68399 & & TRN \\
\hline CHEMBL1998521 & 688849 & 4.6325 & 3.8414 & TST & \\
\hline CHEMBL1339509 & 688849 & 2.5229 & 2.8327 & TRN & \\
\hline CHEMBL516954 & 688849 & 2.5229 & 2.4824 & TRN & \\
\hline CHEMBL1538997 & 688849 & 4.398 & 2.7671 & TRN & \\
\hline CHEMBL1587291 & 688849 & 2.5229 & 3.5826 & TRN & \\
\hline CHEMBL1522324 & 688849 & 5.1382 & 4.4484 & TRN & \\
\hline CHEMBL1492148 & 688849 & 2.5229 & 3.9057 & TRN & \\
\hline CHEMBL1447098 & 688849 & 4.5415 & 2.6763 & TRN & \\
\hline CHEMBL1392292 & 688849 & 3.6391 & 3.53 & TRN & \\
\hline CHEMBL1310865 & 688849 & 4.1034 & 4.4067 & TRN & \\
\hline CHEMBL1409413 & 688849 & 4.1643 & 4.3397 & TRN & \\
\hline CHEMBL1544349 & 688849 & 4.3576 & 3.9461 & TST & \\
\hline CHEMBL1348235 & 688849 & 2.5229 & 2.89399 & 99999999997 & w \\
\hline CHEMBL 2006740 & 688849 & 4.9119 & 3.9303 & TRN & \\
\hline CHEMBL339587 & 688849 & 2.5229 & 3.9815 & TRN & \\
\hline CHEMBL1545032 & 688849 & 2.5229 & 2.8312 & TRN & \\
\hline CHEMBL1566575 & 688849 & 2.5229 & 2.6676 & TRN & \\
\hline CHEMBL1438434 & 688849 & 2.5229 & 2.6307 & TRN & \\
\hline CHEMBL1313065 & 688849 & 2.5229 & 2.6933 & TRN & \\
\hline CHEMBL1599761 & 688849 & 3.90199 & 79999999 & 4.0002 & \\
\hline CHEMBL1381495 & 688849 & 4.6958 & 4.0741 & TST & \\
\hline CHEMBL1501465 & 688849 & 4.5475 & 3.6878 & TRN & \\
\hline CHEMBL1541499 & 688849 & 2.5229 & 2.5521 & TRN & \\
\hline CHEMBL1537711 & 688849 & 2.5229 & 2.7347 & TRN & \\
\hline CHEMBL1489590 & 688849 & 4.3209 & 3.8644 & TRN & \\
\hline CHEMBL1401536 & 688849 & 4.5275 & 4.0409 & TST & \\
\hline CHEMBL1541354 & 688849 & 2.5229 & 2.7644 & TRN & \\
\hline CHEMBL1349676 & 688849 & 4.3287 & 3.9627 & TRN & \\
\hline CHEMBL1418763 & 688849 & 2.5229 & 2.7713 & TRN & \\
\hline
\end{tabular}




\begin{tabular}{|c|c|c|c|c|c|}
\hline & & \multicolumn{4}{|c|}{ Supplemental Table S2.txt } \\
\hline CHEMBL1558169 & 688849 & 2.5229 & 2.6682 & TRN & \\
\hline CHEMBL1402117 & 688849 & 5.3137 & 4.5847 & TST & \\
\hline CHEMBL39947 & 688849 & 4.686 & 3.9556 & TST & \\
\hline CHEMBL1561889 & 688849 & 4.4098 & 3.8818 & TST & \\
\hline CHEMBL1383134 & 688849 & 2.5229 & 2.8458 & TRN & \\
\hline CHEMBL1365400 & 688849 & 4.4071 & 3.8177 & TRN & \\
\hline CHEMBL1344339 & 688849 & 2.5229 & 4.6472 & TST & \\
\hline CHEMBL1307262 & 688849 & 4.5964 & 4.1828 & TRN & \\
\hline CHEMBL3197557 & 688849 & 4.8899 & 5.3069 & TRN & \\
\hline CHEMBL 1366788 & 688849 & 4.5554 & 4.2425 & TRN & \\
\hline CHEMBL1977082 & 688849 & 4.5477 & 4.1678 & TRN & \\
\hline CHEMBL1391513 & 688849 & 3.7866 & 2.7803 & TRN & \\
\hline CHEMBL1488502 & 688849 & 2.5229 & 2.591 & TRN & \\
\hline CHEMBL1610857 & 688849 & 4.1839 & 2.8121 & TRN & \\
\hline CHEMBL1595087 & 688849 & 2.5229 & 2.9272 & TST & \\
\hline CHEMBL1419164 & 688849 & 5.5819 & 5.4075 & TRN & \\
\hline CHEMBL1399551 & 688849 & 2.5229 & 2.6726 & TRN & \\
\hline CHEMBL1479965 & 688849 & 4.6042 & 3.9151 & TST & \\
\hline CHEMBL1541028 & 688849 & 2.5229 & 2.5468 & TRN & \\
\hline CHEMBL1511669 & 688849 & 2.5229 & 2.6869 & TRN & \\
\hline CHEMBL1529460 & 688849 & 4.4757 & 3.9149 & TST & \\
\hline CHEMBL1408817 & 688849 & 2.5229 & 2.747 & TRN & \\
\hline CHEMBL1421193 & 688849 & 4.2097 & 3.87100 & 00000000004 & TRN \\
\hline CHEMBL1455361 & 688849 & 4.6655 & 4.2509 & TRN & \\
\hline CHEMBL1502526 & 688849 & 2.5229 & 2.6797 & TRN & \\
\hline CHEMBL371107 & 688849 & 2.5229 & 2.6401 & TRN & \\
\hline CHEMBL1490535 & 688849 & 2.5229 & 4.1182 & TRN & \\
\hline CHEMBL1609922 & 688849 & 2.5229 & 2.4651 & TRN & \\
\hline CHEMBL1503219 & 688849 & 2.5229 & 2.6577 & TRN & \\
\hline CHEMBL1327880 & 688849 & 2.5229 & 4.5753 & TST & \\
\hline CHEMBL1541029 & 688849 & 2.5229 & 3.6031 & TRN & \\
\hline CHEMBL1489587 & 688849 & $5.1080 e$ & 0000000 & 4.5066 & TRN \\
\hline CHEMBL1386945 & 688849 & 4.3923 & 3.7808 & TRN & \\
\hline CHEMBL1545894 & 688849 & 4.3195 & 3.5015 & TRN & \\
\hline CHEMBL1450204 & 688849 & 3.8815 & 2.7448 & TRN & \\
\hline CHEMBL1421318 & 688849 & 2.5229 & 2.6848 & TST & \\
\hline CHEMBL3195145 & 688849 & 2.5229 & 3.2183 & TRN & \\
\hline CHEMBL1387236 & 688849 & 2.5229 & 2.7279 & TRN & \\
\hline CHEMBL1338320 & 688849 & 2.5229 & 2.9143 & TRN & \\
\hline CHEMBL1333404 & 688849 & 2.5229 & 2.9178 & TST & \\
\hline CHEMBL1301619 & 688849 & 2.5229 & 2.7343 & TRN & \\
\hline CHEMBL1456973 & 688849 & 2.5229 & 3.7918 & TST & \\
\hline CHEMBL1402328 & 688849 & 2.5229 & 2.5903 & TRN & \\
\hline CHEMBL1327510 & 688849 & 2.5229 & 2.9346 & TST & \\
\hline CHEMBL1385851 & 688849 & 2.5229 & 2.8145 & TST & \\
\hline CHEMBL3198220 & 688849 & 2.5229 & 2.8308 & TRN & \\
\hline CHEMBL1310901 & 688849 & 3.7568 & 2.6979 & TST & \\
\hline CHEMBL1328497 & 688849 & 2.5229 & 3.8425 & TRN & \\
\hline
\end{tabular}


Supplemental Table S2.txt

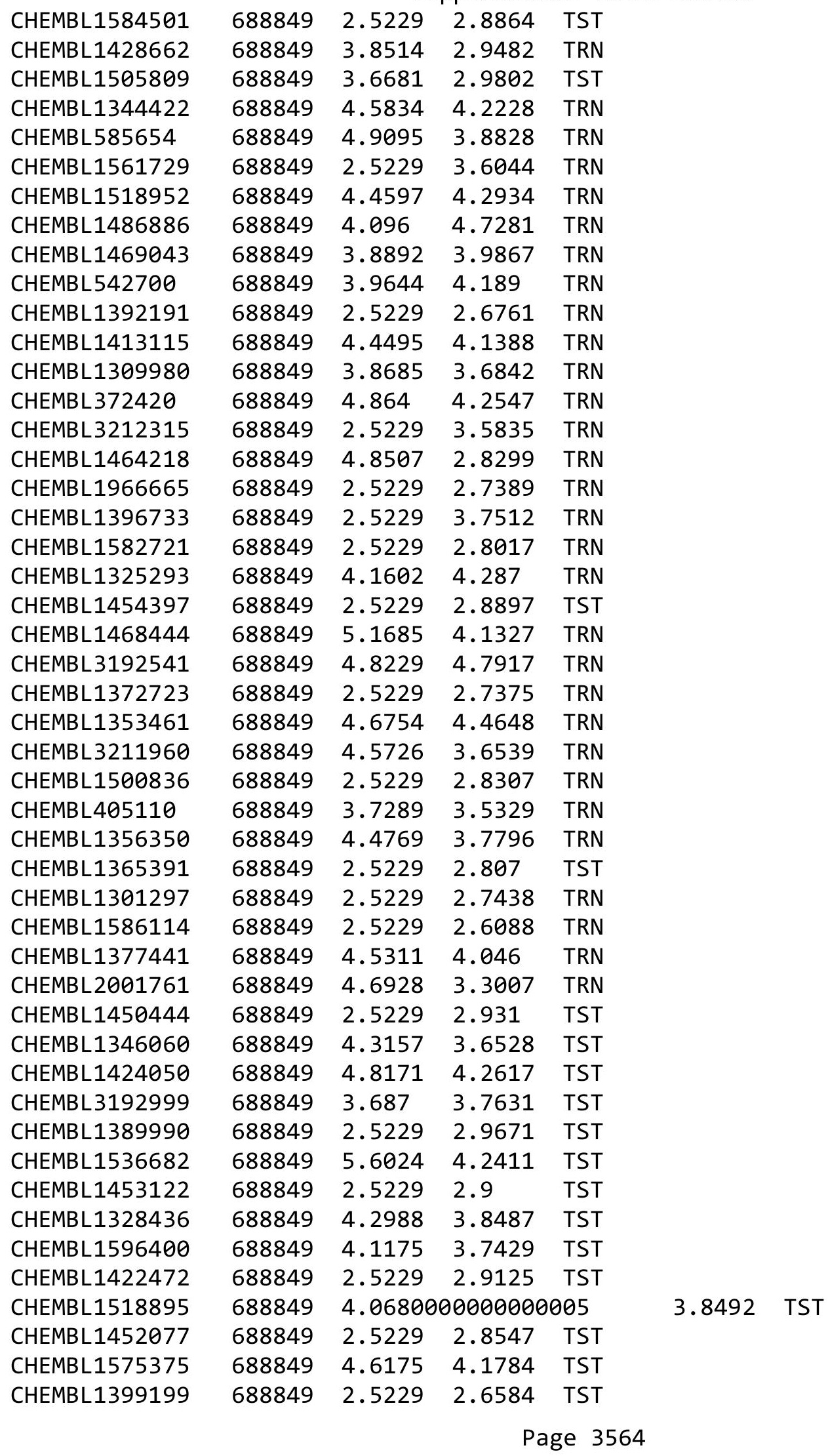


Supplemental Table S2.txt

\begin{tabular}{|c|c|c|c|c|}
\hline CHEMBL1570806 & 688849 & 2.5229 & 2.7808 & TST \\
\hline CHEMBL1565291 & 688849 & 2.5229 & 3.7734 & TST \\
\hline CHEMBL2005497 & 688849 & 2.5229 & 2.6989 & TST \\
\hline CHEMBL1409269 & 688849 & 4.5941 & 4.083 & TST \\
\hline CHEMBL1318390 & 688849 & 4.689 & 4.2503 & TST \\
\hline CHEMBL1567923 & 688849 & 5.0091 & 4.2707 & TST \\
\hline CHEMBL1466366 & 688849 & 5.0144 & 4.3102 & TST \\
\hline CHEMBL1508452 & 688849 & 2.5229 & 4.516 & TST \\
\hline CHEMBL1598957 & 688849 & 2.5229 & 2.6189 & TST \\
\hline CHEMBL1498133 & 688849 & 3.8425 & 3.7735 & TST \\
\hline CHEMBL1578045 & 688849 & 2.5229 & 4.33 & TST \\
\hline CHEMBL483531 & 688849 & 4.5091 & 2.9979 & TST \\
\hline CHEMBL1466582 & 688849 & 5.6615 & 4.3828 & TST \\
\hline CHEMBL1432696 & 688849 & 2.5229 & 2.9388 & TST \\
\hline CHEMBL1306359 & 688849 & 2.5229 & 2.8282 & TST \\
\hline CHEMBL1455582 & 688849 & 2.5229 & 2.7554 & TST \\
\hline CHEMBL1494725 & 688849 & 2.5229 & 4.1143 & TST \\
\hline CHEMBL3213030 & 688849 & 2.5229 & 2.8005 & TST \\
\hline CHEMBL1576876 & 688849 & 2.5229 & 2.603 & TST \\
\hline CHEMBL1477236 & 688849 & 4.3846 & 3.7909 & TST \\
\hline CHEMBL365342 & 688849 & 2.5229 & 4.0131 & TST \\
\hline CHEMBL1459241 & 688849 & 2.5229 & 3.9196 & TST \\
\hline CHEMBL1533621 & 688849 & 4.3225 & 4.0849 & TST \\
\hline CHEMBL1430395 & 688849 & 4.4425 & 2.8613 & TST \\
\hline CHEMBL1381601 & 688849 & 2.5229 & 2.7926 & TST \\
\hline CHEMBL1484906 & 688849 & 2.5229 & 2.8411 & TST \\
\hline CHEMBL1530465 & 688849 & 2.5229 & 3.9437 & TST \\
\hline CHEMBL1436378 & 688849 & 2.5229 & 2.7385 & TST \\
\hline CHEMBL1581512 & 688849 & 5.117 & 3.9673 & TST \\
\hline CHEMBL1502246 & 688849 & 3.8237 & 3.5819 & TST \\
\hline CHEMBL122330 & 688849 & 5.0468 & 4.2835 & TST \\
\hline CHEMBL1400829 & 688849 & 2.5229 & 2.6645 & TST \\
\hline CHEMBL1304349 & 688849 & 4.2539 & 3.9483 & TST \\
\hline CHEMBL1380331 & 688849 & 2.5229 & 2.8104 & TST \\
\hline CHEMBL1530675 & 688849 & 2.5229 & 2.8124 & TST \\
\hline CHEMBL1576646 & 688849 & 2.5229 & 2.7209 & TST \\
\hline CHEMBL3191714 & 688849 & 4.1473 & 4.09699 & 99999999995 \\
\hline CHEMBL3207893 & 688849 & 3.6576 & 2.8776 & TST \\
\hline CHEMBL1592529 & 688849 & 4.4931 & 3.8899 & TST \\
\hline CHEMBL1335965 & 688849 & 4.9622 & 4.3048 & TST \\
\hline CHEMBL1519456 & 688849 & 2.5229 & 2.6936 & TST \\
\hline CHEMBL1464230 & 688849 & 2.5229 & 2.9254 & TST \\
\hline CHEMBL1511185 & 688849 & 4.5911 & 3.4041 & TST \\
\hline CHEMBL1516755 & 688849 & 2.5229 & 2.516 & TST \\
\hline CHEMBL1459194 & 688849 & 2.5229 & 2.6305 & TST \\
\hline CHEMBL2003886 & 688849 & 2.5229 & 2.9116 & TST \\
\hline CHEMBL1368559 & 688849 & 5.1132 & 4.3226 & TST \\
\hline CHEMBL1571307 & 688849 & 2.5229 & 3.892 & TST \\
\hline
\end{tabular}




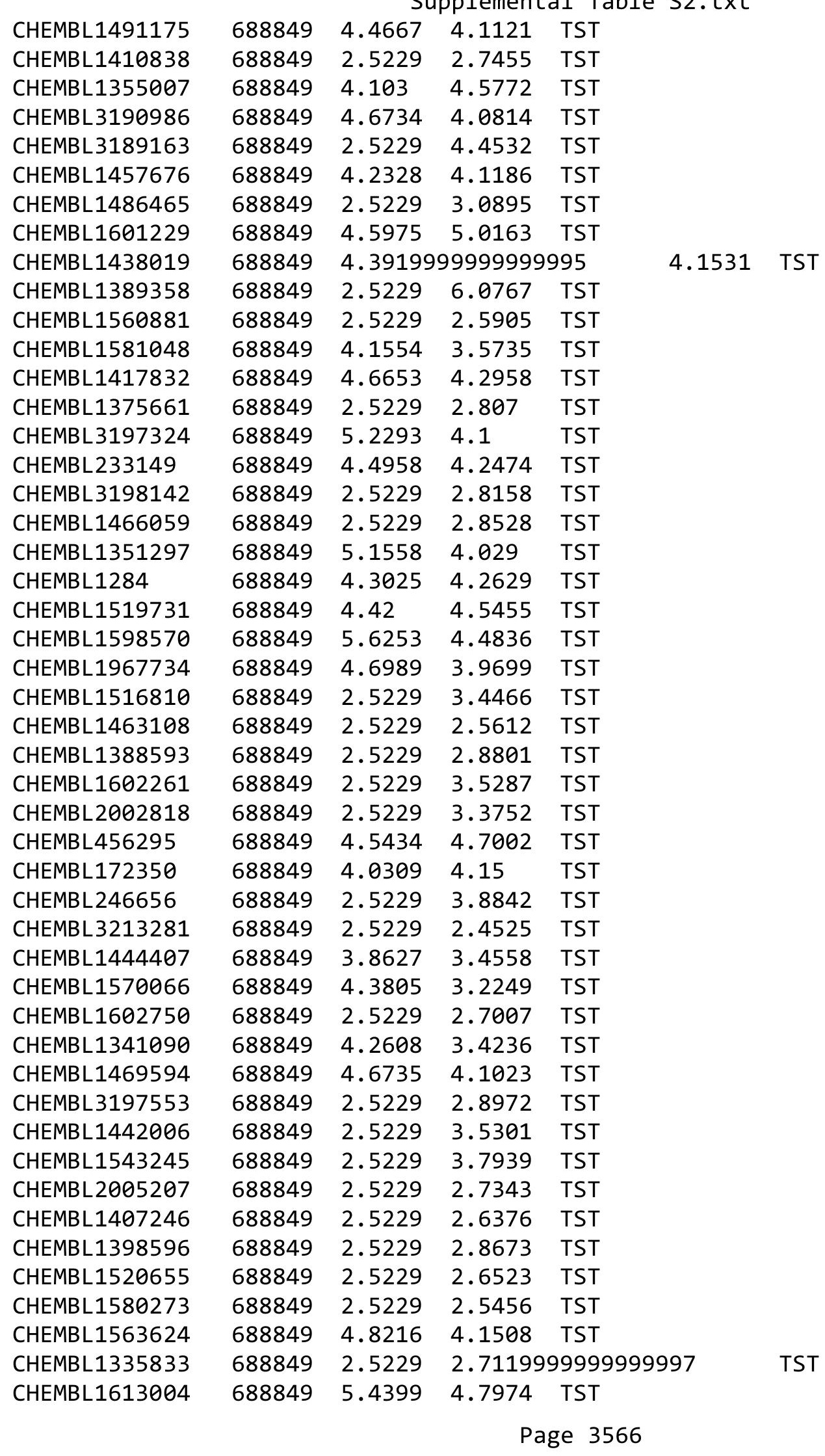




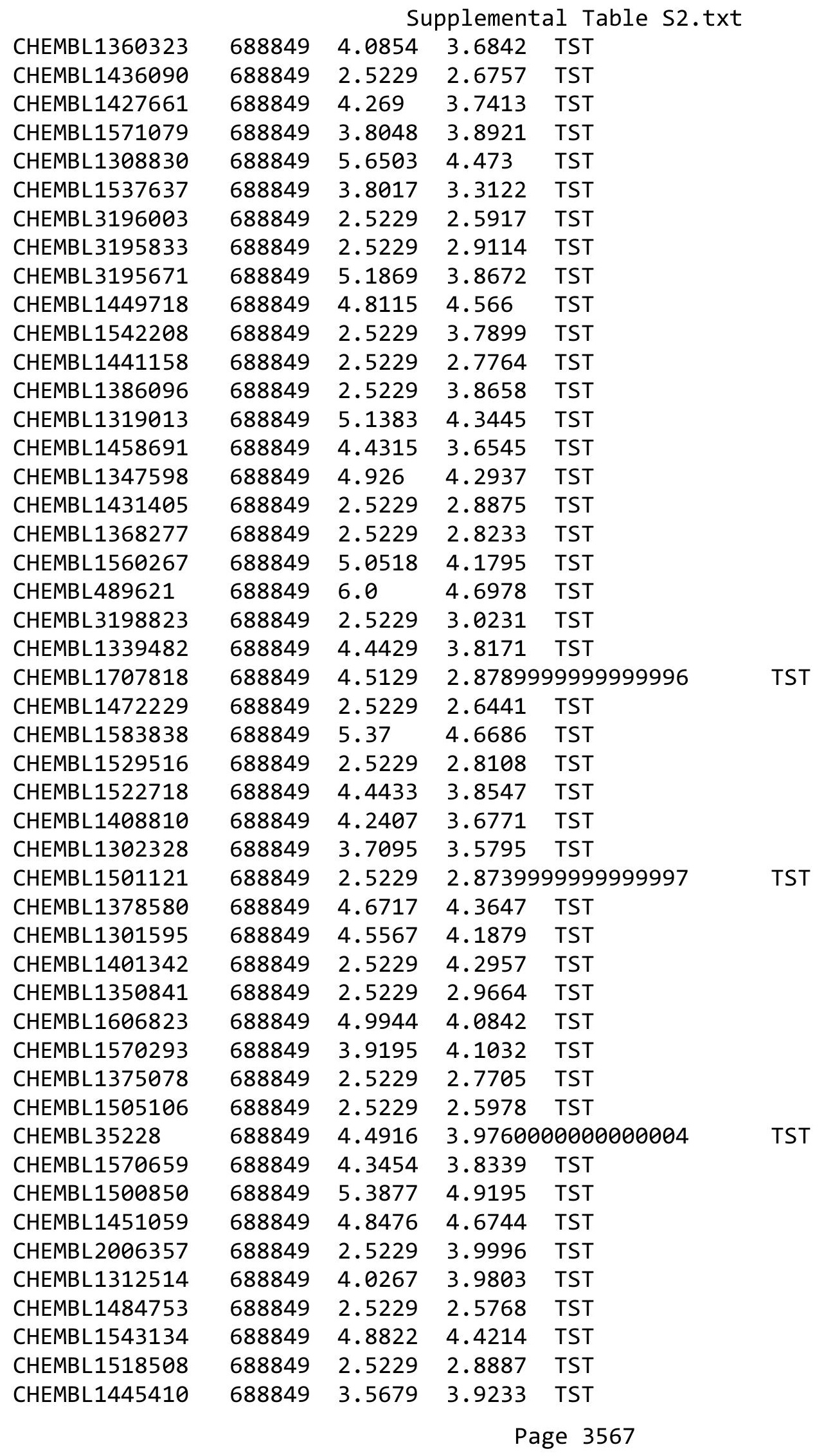




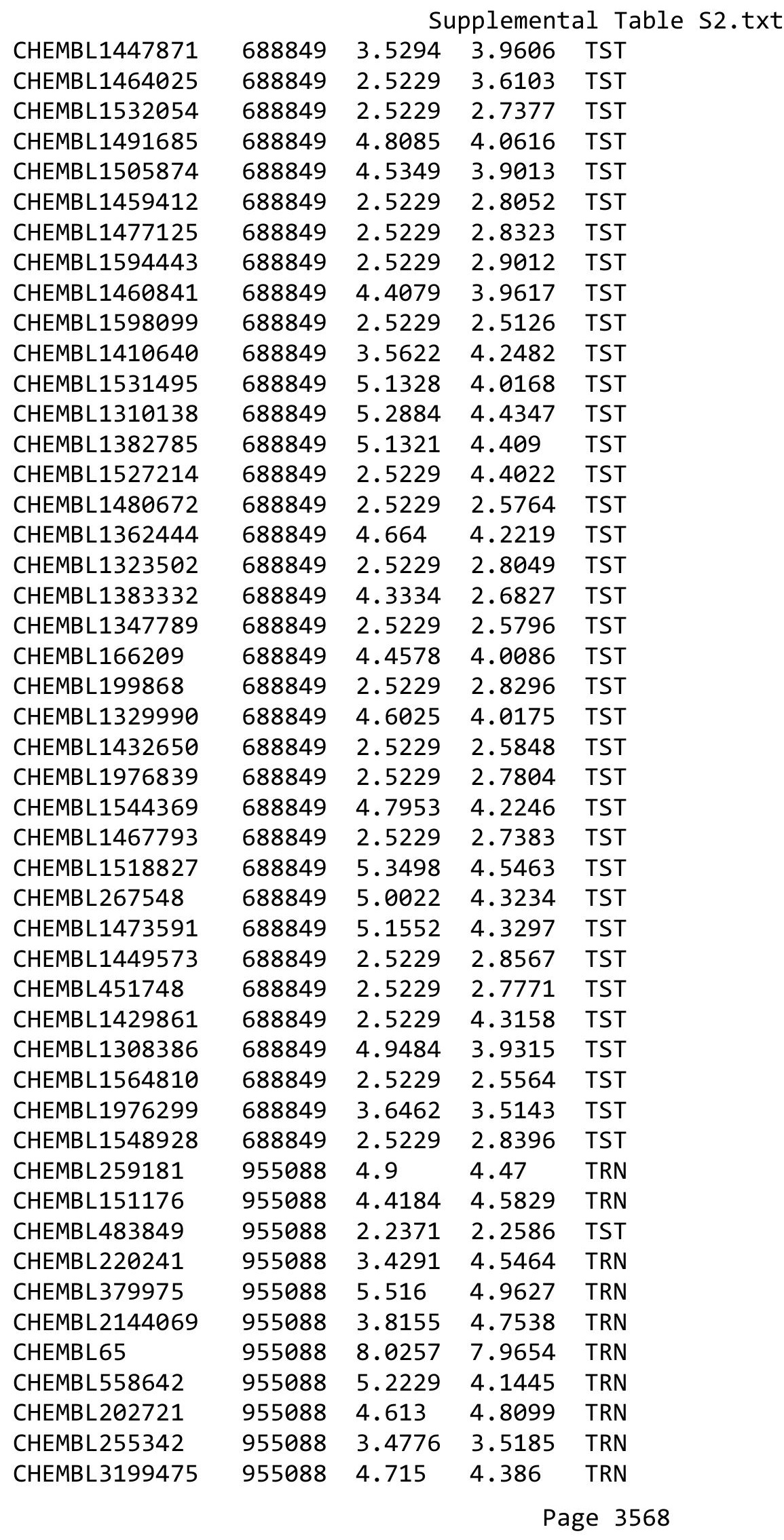




\begin{tabular}{|c|c|c|c|c|c|c|}
\hline & & \multicolumn{5}{|c|}{ Supplemental Table S2.txt } \\
\hline CHEMBL 3186408 & 955088 & 3.4439 & 3.7975 & TST & & \\
\hline CHEMBL221137 & 955088 & 4.1775 & 4.6185 & TRN & & \\
\hline CHEMBL9470 & 955088 & 5.9698 & 5.7708 & TRN & & \\
\hline CHEMBL 2137530 & 955088 & \multicolumn{3}{|c|}{4.843999999999999} & 4.6353 & TRN \\
\hline CHEMBL512504 & 955088 & 3.9582 & 4.7511 & TRN & & \\
\hline CHEMBL585951 & 955088 & 6.4362 & 6.0347 & TRN & & \\
\hline CHEMBL449158 & 955088 & 7.3306 & 6.6613 & TST & & \\
\hline CHEMBL 222102 & 955088 & 3.3971 & 3.6975 & TRN & & \\
\hline CHEMBL472940 & 955088 & 3.3163 & 3.6327 & TRN & & \\
\hline CHEMBL1516890 & 955088 & 4.0047 & 3.9197 & TRN & & \\
\hline CHEMBL393929 & 955088 & 4.0088 & 3.7813 & TRN & & \\
\hline CHEMBL1909414 & 955088 & 3.6811 & 3.7755 & TRN & & \\
\hline CHEMBL373751 & 955088 & 2.9206 & 3.5797 & TRN & & \\
\hline CHEMBL192566 & 955088 & \multicolumn{3}{|c|}{9.056000000000001} & 7.8508 & TST \\
\hline CHEMBL191334 & 955088 & 3.7263 & 4.1389 & TRN & & \\
\hline CHEMBL 2363137 & 955088 & 5.496 & 4.717 & TRN & & \\
\hline CHEMBL92309 & 955088 & 2.6677 & 2.9387 & TST & & \\
\hline CHEMBL 258844 & 955088 & 4.8707 & 4.3373 & TRN & & \\
\hline CHEMBL188678 & 955088 & 4.3122 & 4.3039 & TRN & & \\
\hline CHEMBL1230020 & 955088 & 3.4268 & 3.9364 & TRN & & \\
\hline CHEMBL1190711 & 955088 & 4.6722 & 4.9108 & TRN & & \\
\hline CHEMBL1788116 & 955088 & 5.3207 & 4.3093 & TRN & & \\
\hline CHEMBL135561 & 955088 & 4.6492 & 4.4146 & TRN & & \\
\hline CHEMBL 2134202 & 955088 & 3.3516 & 4.1157 & TRN & & \\
\hline CHEMBL509032 & 955088 & 4.2801 & 5.4376 & TRN & & \\
\hline CHEMBL 210618 & 955088 & 4.8794 & 3.3357 & TRN & & \\
\hline CHEMBL3349342 & 955088 & 4.8392 & 4.9781 & TRN & & \\
\hline CHEMBL573107 & 955088 & 5.532 & 5.0378 & TRN & & \\
\hline CHEMBL217354 & 955088 & 6.5525 & 5.9552 & TRN & & \\
\hline CHEMBL189584 & 955088 & 3.9172 & 4.4372 & TRN & & \\
\hline CHEMBL1404918 & 955088 & 2.844 & 2.8151 & TRN & & \\
\hline CHEMBL102714 & 955088 & 3.287 & 3.5189 & TST & & \\
\hline CHEMBL1357247 & 955088 & 3.7498 & 3.1492 & TST & & \\
\hline CHEMBL 240954 & 955088 & 4.2569 & 3.6788 & TST & & \\
\hline CHEMBL577784 & 955088 & 5.1444 & 5.0916 & TST & & \\
\hline CHEMBL3392440 & 955088 & 3.2152 & 3.8752 & TST & & \\
\hline CHEMBL399530 & 955088 & 4.9555 & 4.5096 & TST & & \\
\hline CHEMBL1186585 & 955088 & 3.8901 & 4.1878 & TST & & \\
\hline CHEMBL412142 & 955088 & 3.7242 & 3.9771 & TST & & \\
\hline CHEMBL335432 & 154975 & 7.8239 & 6.6165 & TST & & \\
\hline CHEMBL 133120 & 154975 & 5.7212 & 5.4683 & TST & & \\
\hline CHEMBL541329 & 154975 & 4.6383 & 6.356 & TST & & \\
\hline CHEMBL544607 & 154975 & 7.4949 & 6.7998 & TRN & & \\
\hline CHEMBL553152 & 154975 & 5.7212 & 6.0553 & TST & & \\
\hline CHEMBL336612 & 154975 & 7.6778 & 6.25899 & 99999 & 995 & TRN \\
\hline CHEMBL 3217088 & 154975 & 7.585 & 6.6694 & TRN & & \\
\hline CHEMBL3216197 & 154975 & 8.7212 & 6.7149 & TRN & & \\
\hline CHEMBL3215984 & 154975 & 5.3188 & 6.6524 & TRN & & \\
\hline
\end{tabular}




\begin{tabular}{|c|c|c|c|c|c|}
\hline \multirow[b]{2}{*}{ CHEMBL335113 } & \multicolumn{5}{|c|}{ Supplemental Table S2.txt } \\
\hline & 154975 & 8.0 & 6.8025 & TRN & \\
\hline CHEMBL132246 & 154975 & 4.9586 & 5.5904 & TRN & \\
\hline CHEMBL132821 & 154975 & 4.6021 & 5.6057 & TRN & \\
\hline CHEMBL540829 & 154975 & 5.585 & 6.4467 & TRN & \\
\hline CHEMBL554463 & 154975 & 7.4437 & 6.7015 & TRN & \\
\hline CHEMBL3216628 & 154975 & 7.0605 & 6.4979 & TST & \\
\hline CHEMBL133964 & 154975 & 5.585 & 6.7795 & TRN & \\
\hline CHEMBL317193 & 154975 & 8.0 & 6.8068 & TRN & \\
\hline CHEMBL429877 & 154975 & 5.585 & \multicolumn{2}{|c|}{6.0760000000000005} & TRN \\
\hline CHEMBL133555 & 154975 & 5.0458 & 5.6235 & TRN & \\
\hline CHEMBL3215980 & 154975 & 6.284 & 6.7339 & TRN & \\
\hline CHEMBL132824 & 154975 & 5.6383 & 6.6679 & TRN & \\
\hline CHEMBL335044 & 154975 & 6.6383 & 6.8106 & TRN & \\
\hline CHEMBL132665 & 154975 & 4.3565 & 6.4503 & TST & \\
\hline CHEMBL132636 & 154975 & 6.1427 & 6.3286 & TRN & \\
\hline CHEMBL6244 & 154975 & 5.0269 & 3.8319 & TRN & \\
\hline CHEMBL134025 & 154975 & 5.284 & 6.3272 & TRN & \\
\hline CHEMBL132028 & 154975 & 4.1367 & 3.8726 & TRN & \\
\hline CHEMBL132655 & 154975 & 4.6778 & 5.4365 & TRN & \\
\hline CHEMBL3215547 & 154975 & 4.7696 & 4.9101 & TRN & \\
\hline CHEMBL133425 & 154975 & 6.3372 & 5.4633 & TRN & \\
\hline CHEMBL3216385 & 154975 & 5.6576 & 6.4947 & TRN & \\
\hline CHEMBL443811 & 154975 & 2.699 & \multicolumn{2}{|c|}{5.962999999999999} & TRN \\
\hline CHEMBL134143 & 154975 & 7.585 & 6.5547 & TST & \\
\hline CHEMBL3215728 & 154975 & 5.7212 & 5.3055 & TRN & \\
\hline CHEMBL553093 & 154975 & 5.2596 & 6.728 & TRN & \\
\hline CHEMBL134094 & 154975 & 6.8861 & 6.871 & TRN & \\
\hline CHEMBL335176 & 154975 & 6.699 & 6.6233 & TST & \\
\hline CHEMBL545773 & 154975 & 7.301 & 6.8302 & TRN & \\
\hline CHEMBL542731 & 154975 & 6.2007 & 6.7706 & TRN & \\
\hline CHEMBL133921 & 154975 & 6.6198 & 6.5579 & TST & \\
\hline CHEMBL554398 & 154975 & 5.5528 & 6.5352 & TRN & \\
\hline CHEMBL134965 & 154975 & 5.2441 & 5.7046 & TRN & \\
\hline CHEMBL545072 & 154975 & 7.2218 & 6.5723 & TRN & \\
\hline CHEMBL543662 & 154975 & 5.8861 & 4.8528 & TRN & \\
\hline CHEMBL423717 & 154975 & 3.699 & 6.499 & TRN & \\
\hline CHEMBL134123 & 154975 & 7.6198 & \multicolumn{2}{|c|}{6.632999999999999} & TRN \\
\hline CHEMBL423711 & 154975 & 5.1308 & 5.6564 & TRN & \\
\hline CHEMBL 340989 & 154975 & 6.1675 & 6.4807 & TRN & \\
\hline CHEMBL3215746 & 154975 & 6.3979 & 5.4151 & TRN & \\
\hline CHEMBL334852 & 154975 & 4.9586 & 6.1455 & TST & \\
\hline CHEMBL131597 & 154975 & 6.4437 & 6.7985 & TRN & \\
\hline CHEMBL131690 & 154975 & 6.284 & 6.4394 & TST & \\
\hline CHEMBL552771 & 154975 & 6.0362 & \multicolumn{2}{|c|}{5.962999999999999} & TRN \\
\hline CHEMBL134877 & 154975 & 5.585 & 5.6942 & TRN & \\
\hline CHEMBL 338940 & 154975 & 8.5686 & 6.3695 & TRN & \\
\hline CHEMBL545306 & 154975 & 6.6198 & 6.5671 & TRN & \\
\hline CHEMBL543420 & 154975 & 6.6576 & 6.8486 & TRN & \\
\hline
\end{tabular}




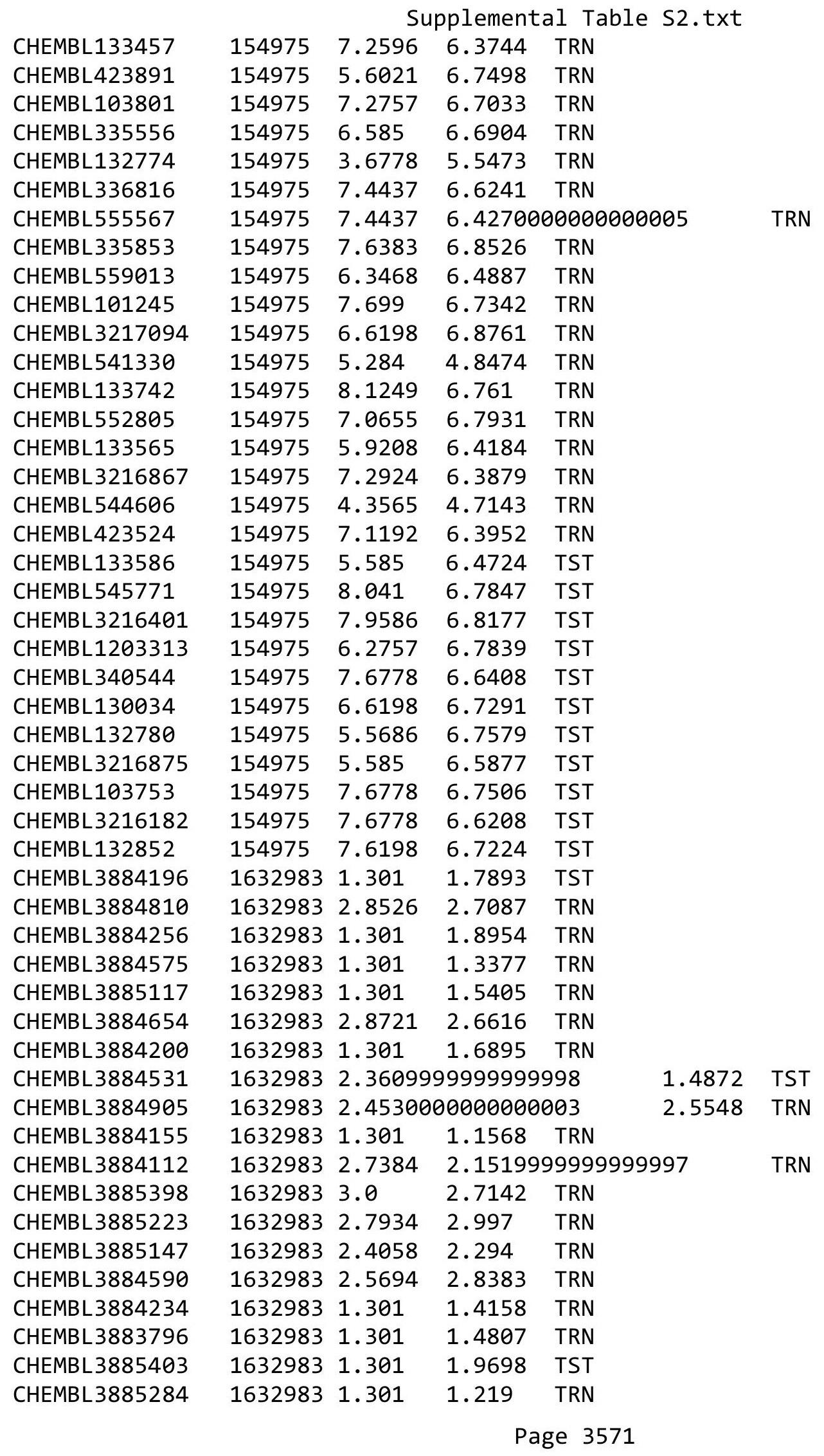


Supplemental Table S2.txt

\begin{tabular}{|c|c|c|c|c|}
\hline CHEMBL3884718 & 1632983 & 2.4409 & 2.2007 & TRN \\
\hline CHEMBL3885330 & 1632983 & 1.301 & 1.6074 & TST \\
\hline CHEMBL 3884868 & 1632983 & 3.14 & 2.5781 & TRN \\
\hline CHEMBL 3885044 & 1632983 & 2.489 & 2.07 & TRN \\
\hline CHEMBL 3884623 & 1632983 & 2.3576 & 1.5403 & TRN \\
\hline CHEMBL 3884019 & 1632983 & 1.301 & 0.8734 & TRN \\
\hline CHEMBL3884770 & 1632983 & 1.301 & 1.4807 & TRN \\
\hline CHEMBL 3884550 & 1632983 & 2.7604 & 2.9725 & TRN \\
\hline CHEMBL 3884248 & 1632983 & 1.301 & 1.5033 & TRN \\
\hline CHEMBL3884958 & 1632983 & 2.3633 & 2.336 & TRN \\
\hline CHEMBL 3885324 & 1632983 & 2.6094 & 2.7204 & TRN \\
\hline CHEMBL3883954 & 1632983 & 2.8446 & 2.6735 & TRN \\
\hline CHEMBL3883426 & 1632983 & 3.1618 & 2.3974 & TRN \\
\hline CHEMBL 3884576 & 1632983 & 1.301 & 1.4395 & TRN \\
\hline CHEMBL3885311 & 1632983 & 1.301 & 1.1841 & TRN \\
\hline CHEMBL 3884189 & 1632983 & 1.301 & 1.7559 & TRN \\
\hline CHEMBL3883508 & 1632983 & 2.3819 & 2.1131 & TRN \\
\hline CHEMBL3884707 & 1632983 & 1.301 & 1.7537 & TST \\
\hline CHEMBL3884505 & 1632983 & 2.3731 & 1.9912 & TST \\
\hline CHEMBL3885086 & 1632983 & 1.301 & 1.8229 & TRN \\
\hline CHEMBL 3884891 & 1632983 & 3.2154 & 3.1715 & TRN \\
\hline CHEMBL3884339 & 1632983 & 2.6271 & 2.5773 & TRN \\
\hline CHEMBL3883601 & 1632983 & 2.7201 & 2.6466 & TRN \\
\hline CHEMBL 3885347 & 1632983 & 2.9678 & 3.2146 & TRN \\
\hline CHEMBL 3884063 & 1632983 & 1.301 & 1.325 & TRN \\
\hline CHEMBL3885105 & 1632983 & 1.301 & 2.2425 & TRN \\
\hline CHEMBL3883446 & 1632983 & 2.8809 & 3.1073 & TRN \\
\hline CHEMBL3884610 & 1632983 & 2.3446 & 2.2838 & TRN \\
\hline CHEMBL 3884895 & 1632983 & 1.301 & 1.5393 & TRN \\
\hline CHEMBL 3884805 & 1632983 & 2.5277 & 2.46 & TRN \\
\hline CHEMBL 3884750 & 1632983 & 1.301 & 1.3329 & TRN \\
\hline CHEMBL3884771 & 1632983 & 2.843 & 2.8613 & TRN \\
\hline CHEMBL3885464 & 1632983 & 2.3441 & 2.0764 & TST \\
\hline CHEMBL3885139 & 1632983 & 2.6893 & 2.6513 & TST \\
\hline CHEMBL 3883757 & 1632983 & 1.301 & 1.9382 & TST \\
\hline CHEMBL3885221 & 1632983 & 2.7403 & 1.9797 & TST \\
\hline CHEMBL 3884731 & 1632983 & 2.3038 & 1.9308 & TST \\
\hline CHEMBL 3883610 & 1632983 & 1.301 & 1.6683 & TST \\
\hline CHEMBL 3883767 & 1632983 & 2.306 & 1.1228 & TST \\
\hline CHEMBL3883666 & 1632983 & 2.4352 & 2.4435 & TST \\
\hline CHEMBL3883436 & 1632983 & 3.3866 & 2.7087 & TST \\
\hline CHEMBL 3883554 & 1633871 & 6.2218 & 5.3238 & TST \\
\hline CHEMBL3883489 & 1633871 & 4.4202 & 3.9629 & TRN \\
\hline CHEMBL3883376 & 1633871 & 4.3242 & 4.8021 & TRN \\
\hline CHEMBL 3884053 & 1633871 & 3.4089 & 3.2143 & TRN \\
\hline CHEMBL3884297 & 1633871 & 2.5376 & $3.15100 e$ & 00000000002 \\
\hline CHEMBL 3883567 & 1633871 & 4.0 & 3.4587 & TRN \\
\hline CHEMBL 3885134 & 1633871 & 3.1403 & 3.5568 & TRN \\
\hline
\end{tabular}


Supplemental Table S2.txt

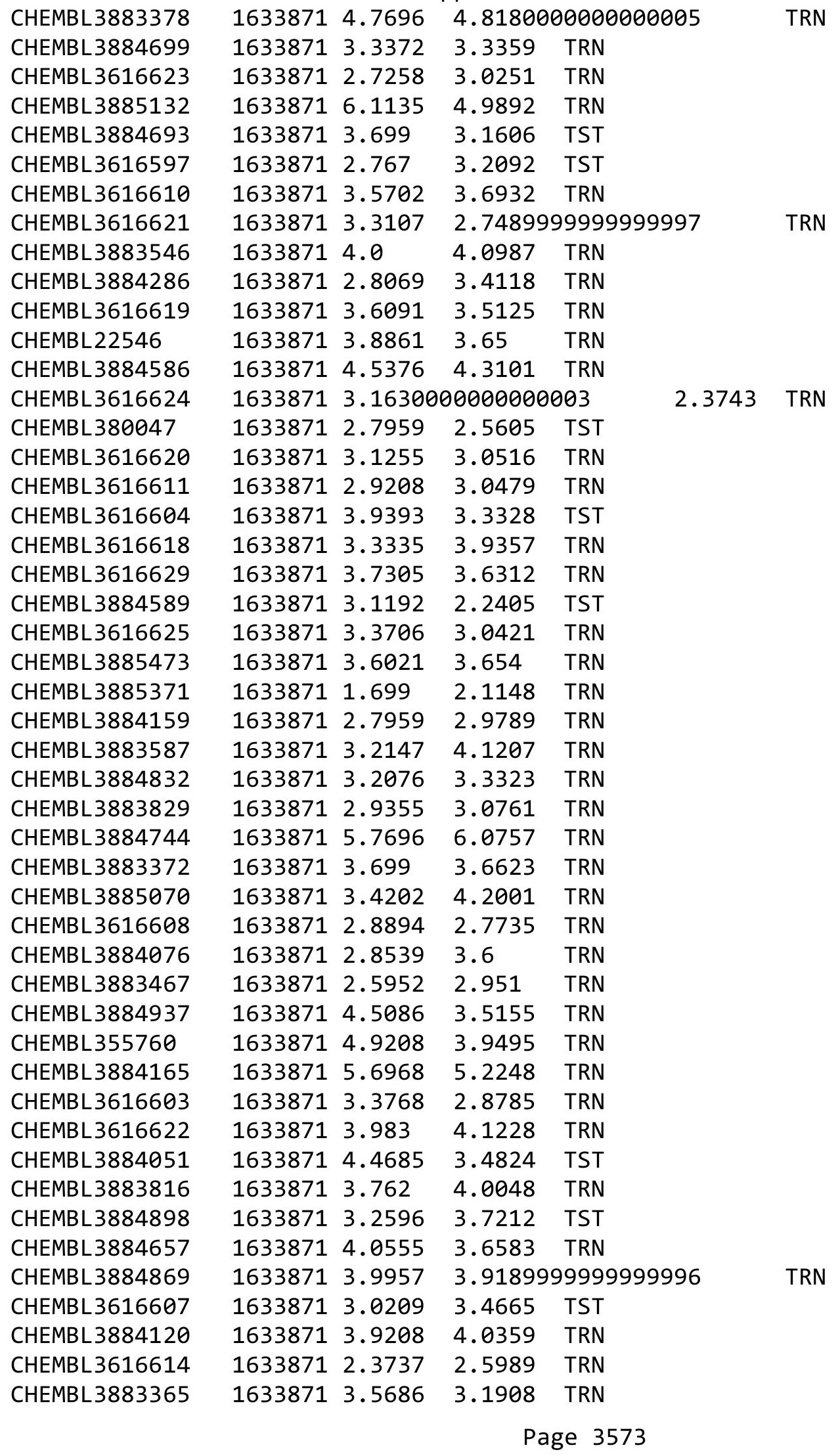


Supplemental Table S2.txt

\begin{tabular}{|c|c|c|c|c|}
\hline HEN & & & & \\
\hline HEMPI 2616612 & 871 & 2.8539 & 3.2609 & \\
\hline 100 & & & & \\
\hline AEMBL & & & & $2 \mathrm{~N}$ \\
\hline AEMBL1222275 & 33871 & & 5442 & \\
\hline HEMBL3884543 & 533871 & 3.7282 & .773 & \\
\hline HEMBL & 3871 & 89 & 3363 & \\
\hline 501 & 871 & & & $\mathrm{D}$ \\
\hline AEMBL3885444 & 633871 & & 3.1008 & \\
\hline HEMBL3885348 & 633871 & 1.699 & 4969 & \\
\hline HEMBL3885181 & 3871 & 4.4318 & .1835 & \\
\hline AEMBL3 & 871 & 28 & 9827 & \\
\hline AEMBL & & & & \\
\hline HEMBL36 & 871 & 696 & 2.639 & \\
\hline AEMBL3\& & 3871 & 07 & 085 & \\
\hline AEMBL36 & 533871 & כס & 789 & \\
\hline HEMBL3 & 71 & & 39 & \\
\hline HEMBL3 & & & & \\
\hline HEMBL3 & 3871 & 36 & 5662 & \\
\hline AEMBL3 & 71 & & & \\
\hline AEMBL3 & 71 & 599 & 86 & II \\
\hline AEMBL & & & & וד \\
\hline HEMBL & 71 & & & \\
\hline HEMBL & & & & TST \\
\hline AEMBL3 & & & & $\Gamma \mathrm{RN}$ \\
\hline HEMBL; & & & 451 & RN \\
\hline HEMBL & & & 86 & Niv \\
\hline HFMRI & 71 & & 29 & $\mathrm{RN}$ \\
\hline AEMBL3 & & & 828 & $\mathrm{in}$ \\
\hline HEMBL 38 & 71 & 39 & & 15 \\
\hline HEMBL3 & 371 & 14 & 932 & $\mathrm{RN}$ \\
\hline HEMBL & & & 17 & RN \\
\hline HEMBL: & 31 & & 88 & ל \\
\hline HEMBL19 & 31 & & 833 & IRN \\
\hline HEMBL1958447 & 06931 & 3. & 4322 & TST \\
\hline HEMBL1 & 31 & & 3212 & RN \\
\hline HFMRI - & & 778 & 88 & $\Gamma \mathrm{RN}$ \\
\hline HEMBL5 & & 5. & 815 & IRN \\
\hline HEMBL1958254 & 06931 & 5 & 376 & TRN \\
\hline AEMBL1 & 31 & & 1443 & TRN \\
\hline HEMBL1 & 306 & & 1084 & PNA \\
\hline CHEMBL1 & & 3. & .9602 & TRN \\
\hline HEMBL19 & 806931 & & 3531 & ГST \\
\hline HEMBL195 & 06931 & & 9101 & TRN \\
\hline MPI 1 & & & 1689 & IRN \\
\hline HEMBL1 & 806931 & & 1568 & \\
\hline CHEMBL195 & 806931 & 4.301 & 3.9273 & \\
\hline LHEMBL1958241 & 806931 & 3.0 & 3.4608 & - \\
\hline
\end{tabular}

Page 3574 


\begin{tabular}{|c|c|c|c|c|c|}
\hline \multicolumn{6}{|c|}{ Supplemental Table s2.txt } \\
\hline CHEMBL1361764 & 806931 & 3.0 & 3.2411 & TRN & \\
\hline CHEMBL1958252 & 806931 & 4.0 & 3.7094 & TRN & \\
\hline CHEMBL1958246 & 806931 & 3.0 & 3.3746 & TRN & \\
\hline CHEMBL1958245 & 806931 & 3.0 & 3.761 & TST & \\
\hline CHEMBL1958450 & 806931 & 3.0 & 2.7564 & TRN & \\
\hline CHEMBL1958448 & 806931 & 3.0 & 3.1051 & TRN & \\
\hline CHEMBL1814527 & 806931 & 3.0 & 3.49600 & 00000000004 & TRN \\
\hline CHEMBL1958251 & 806931 & 3.0 & 3.1191 & TRN & \\
\hline CHEMBL1958445 & 806931 & 4.0 & 3.8729 & TRN & \\
\hline CHEMBL392652 & 806931 & 3.0 & 4.0152 & TRN & \\
\hline CHEMBL1958453 & 806931 & 3.0 & 3.5623 & TRN & \\
\hline CHEMBL1958456 & 806931 & 4.7447 & 3.1056 & TST & \\
\hline CHEMBL1958257 & 806931 & 4.6576 & 3.6061 & TRN & \\
\hline CHEMBL1716365 & 806931 & 4.0088 & 3.3245 & TST & \\
\hline CHEMBL1958457 & 806931 & 4.0 & 3.265 & TST & \\
\hline CHEMBL1958444 & 806931 & 3.0 & 3.227 & TRN & \\
\hline CHEMBL1915698 & 806931 & 3.0 & 3.5877 & TST & \\
\hline CHEMBL1955892 & 806931 & 3.0 & 3.8234 & TRN & \\
\hline CHEMBL1958231 & 806931 & 4.7959 & 3.8555 & TRN & \\
\hline CHEMBL1958236 & 806931 & 4.2147 & 3.5291 & TRN & \\
\hline CHEMBL1958235 & 806931 & 4.2366 & 3.5501 & TRN & \\
\hline CHEMBL1958446 & 806931 & 4.0 & 3.7164 & TRN & \\
\hline CHEMBL1958452 & 806931 & 3.0 & 3.5366 & TRN & \\
\hline CHEMBL1958458 & 806931 & 3.0 & 3.0532 & TRN & \\
\hline CHEMBL71999 & 806931 & 3.0 & 3.6128 & TRN & \\
\hline CHEMBL1958263 & 806931 & 3.0 & 3.4672 & TRN & \\
\hline CHEMBL1958459 & 806931 & 3.0 & 3.0638 & TRN & \\
\hline CHEMBL1958255 & 806931 & 4.8239 & 3.2936 & TRN & \\
\hline CHEMBL1958244 & 806931 & 3.0 & 3.8058 & TRN & \\
\hline CHEMBL 1958248 & 806931 & 3.0 & 3.4898 & TRN & \\
\hline CHEMBL1958240 & 806931 & 3.0 & 3.3839 & TRN & \\
\hline CHEMBL1408276 & 806931 & 4.7447 & 3.3517 & TST & \\
\hline CHEMBL1958449 & 806931 & 3.0 & 2.7211 & TRN & \\
\hline CHEMBL390195 & 806931 & 3.0 & 3.9374 & TRN & \\
\hline CHEMBL1958253 & 806931 & 3.0 & 3.8139 & TRN & \\
\hline CHEMBL1958250 & 806931 & 3.0 & 3.35699 & 99999999998 & TRN \\
\hline CHEMBL 200346 & 806931 & 3.0 & 3.1199 & TRN & \\
\hline CHEMBL1958258 & 806931 & 4.2924 & 3.8058 & TRN & \\
\hline CHEMBL1958260 & 806931 & 4.2076 & 3.3757 & TRN & \\
\hline CHEMBL1958247 & 806931 & 3.0 & 3.0369 & TRN & \\
\hline CHEMBL1958264 & 806931 & 3.0 & 3.8272 & TRN & \\
\hline CHEMBL1958259 & 806931 & 4.2596 & 3.9139 & TRN & \\
\hline CHEMBL1958451 & 806931 & 4.1192 & 3.6361 & TRN & \\
\hline CHEMBL 383152 & 806931 & 3.0 & 3.5747 & TRN & \\
\hline CHEMBL1958442 & 806931 & 3.0 & 3.4165 & TST & \\
\hline CHEMBL345460 & 806931 & 3.0 & 3.6884 & TST & \\
\hline CHEMBL1958443 & 806931 & 4.0177 & 3.4834 & TST & \\
\hline CHEMBL1955890 & 806931 & 4.2007 & 3.4161 & TST & \\
\hline
\end{tabular}




\begin{tabular}{|c|c|c|c|c|}
\hline \multicolumn{5}{|c|}{ Supplemental Table s2.txt } \\
\hline CHEMBL1958239 & 806931 & 3.0 & 3.8371 & TST \\
\hline CHEMBL1958242 & 806931 & 3.0 & 3.9856 & TST \\
\hline CHEMBL104761 & 806931 & 3.0 & 3.8708 & TST \\
\hline CHEMBL1958249 & 806931 & 3.0 & 3.5876 & TST \\
\hline CHEMBL1958256 & 806931 & 4.6778 & 3.4158 & TST \\
\hline CHEMBL 3144561 & 49717 & 6.9208 & 7.3626 & TRN \\
\hline CHEMBL413548 & 49717 & 7.6778 & 7.4707 & TRN \\
\hline CHEMBL62345 & 49717 & 8.5376 & 8.2699 & TRN \\
\hline CHEMBL 3144565 & 49717 & 7.4089 & 7.644 & TRN \\
\hline CHEMBL3144539 & 49717 & 7.2596 & 7.1604 & TRN \\
\hline CHEMBL292071 & 49717 & 7.5528 & 7.9463 & TRN \\
\hline CHEMBL 3144536 & 49717 & 7.7959 & 7.4529 & TRN \\
\hline CHEMBL 292298 & 49717 & 8.1135 & 8.0525 & TRN \\
\hline CHEMBL292471 & 49717 & 7.4089 & 7.4233 & TST \\
\hline CHEMBL294304 & 49717 & 7.7212 & 7.18 & TRN \\
\hline CHEMBL418500 & 49717 & 6.9586 & 7.2252 & TST \\
\hline CHEMBL 3144534 & 49717 & 6.3979 & 6.8398 & TRN \\
\hline CHEMBL 3144550 & 49717 & 7.3098 & 7.2376 & TRN \\
\hline CHEMBL 3144546 & 49717 & 6.6021 & 6.4104 & TRN \\
\hline CHEMBL3144537 & 49717 & 7.6576 & 7.3114 & TRN \\
\hline CHEMBL 3144563 & 49717 & 7.1487 & 7.1323 & TRN \\
\hline CHEMBL 3144554 & 49717 & 7.5229 & 7.5406 & TRN \\
\hline CHEMBL433640 & 49717 & 8.3768 & 7.9602 & TRN \\
\hline CHEMBL 303994 & 49717 & 7.5229 & 7.3598 & TRN \\
\hline CHEMBL62887 & 49717 & 8.0969 & 7.9485 & TST \\
\hline CHEMBL418123 & 49717 & 7.4815 & 7.9213 & TST \\
\hline CHEMBL387073 & 49717 & 7.6576 & 8.1914 & TRN \\
\hline CHEMBL433636 & 49717 & 6.5086 & 6.3591 & TST \\
\hline CHEMBL 3144564 & 49717 & 7.8861 & 7.7093 & TRN \\
\hline CHEMBL59759 & 49717 & 6.041 & 6.1022 & TRN \\
\hline CHEMBL292490 & 49717 & 7.301 & 7.2302 & TRN \\
\hline CHEMBL 3144553 & 49717 & 7.1871 & 7.1537 & TRN \\
\hline CHEMBL 3144549 & 49717 & 6.8861 & 7.0273 & TRN \\
\hline CHEMBL293026 & 49717 & 7.8539 & 7.4734 & TST \\
\hline CHEMBL 3144542 & 49717 & 7.4202 & 7.5788 & TRN \\
\hline CHEMBL3144562 & 49717 & 6.8539 & 7.06 & TRN \\
\hline CHEMBL3144566 & 49717 & 7.1192 & 7.0669 & TRN \\
\hline CHEMBL 3144533 & 49717 & 6.3872 & 6.4448 & TRN \\
\hline CHEMBL59404 & 49717 & 7.2441 & 7.3369 & TST \\
\hline CHEMBL3144555 & 49717 & 7.1487 & 6.9607 & TRN \\
\hline CHEMBL3144531 & 49717 & 6.5086 & 6.4701 & TRN \\
\hline CHEMBL3144552 & 49717 & 6.6576 & 7.0025 & TRN \\
\hline CHEMBL64605 & 49717 & 5.7447 & 6.7295 & TST \\
\hline CHEMBL413768 & 49717 & 8.4202 & 8.4668 & TST \\
\hline CHEMBL278447 & 49717 & 8.3468 & 8.0395 & TST \\
\hline CHEMBL 3144543 & 49717 & 6.7959 & 6.7041 & TRN \\
\hline CHEMBL 3144545 & 49717 & 6.4089 & 6.0509 & TRN \\
\hline CHEMBL 3144560 & 49717 & 7.2441 & 7.2186 & TRN \\
\hline
\end{tabular}




\begin{tabular}{|c|c|c|c|c|}
\hline & & & pplement & al $\mathrm{T}$ \\
\hline CHEMBL 3144544 & 49717 & 6.5376 & 6.5192 & TRN \\
\hline CHEMBL60385 & 49717 & 7.8239 & 7.5993 & TRN \\
\hline CHEMBL 3144548 & 49717 & 7.3979 & 7.4079 & TRN \\
\hline CHEMBL302911 & 49717 & 7.284 & 7.705 & TST \\
\hline CHEMBL 3144538 & 49717 & 6.9586 & 7.1106 & TRN \\
\hline CHEMBL156559 & 49717 & 8.4318 & 7.6789 & TST \\
\hline CHEMBL 3144540 & 49717 & 6.8539 & 6.9177 & TRN \\
\hline CHEMBL3144551 & 49717 & 7.4815 & 7.2913 & TRN \\
\hline CHEMBL3144535 & 49717 & 6.7447 & 7.1582 & TRN \\
\hline CHEMBL292519 & 49717 & 7.8539 & 7.9239 & TST \\
\hline CHEMBL294542 & 49717 & 8.4685 & 8.2947 & TST \\
\hline CHEMBL 3144567 & 49717 & 6.9208 & 6.7223 & TRN \\
\hline CHEMBL3144541 & 49717 & 5.9586 & 6.678 & TRN \\
\hline CHEMBL1938917 & 797232 & 5.6576 & 5.6911 & TRN \\
\hline CHEMBL1939101 & 797232 & 4.7375 & 4.7957 & TRN \\
\hline CHEMBL1938903 & 797232 & 3.699 & 6.7025 & TST \\
\hline CHEMBL1397295 & 797232 & 5.0809 & 5.1029 & TRN \\
\hline CHEMBL1358228 & 797232 & 5.2218 & 5.2578 & TRN \\
\hline CHEMBL1939083 & 797232 & 3.699 & 3.7617 & TRN \\
\hline CHEMBL1939111 & 797232 & 6.6198 & 6.6791 & TRN \\
\hline CHEMBL1939104 & 797232 & 6.7447 & 6.8038 & TRN \\
\hline CHEMBL1939115 & 797232 & 7.1549 & 7.1802 & TRN \\
\hline CHEMBL1509101 & 797232 & 6.1024 & 6.3124 & TRN \\
\hline CHEMBL1938911 & 797232 & 5.1487 & 5.1022 & TRN \\
\hline CHEMBL1939112 & 797232 & 7.2218 & 7.0341 & TRN \\
\hline CHEMBL1939110 & 797232 & 7.0458 & 6.9436 & TRN \\
\hline CHEMBL1939076 & 797232 & 3.699 & 3.6656 & TRN \\
\hline CHEMBL1939074 & 797232 & 5.699 & 5.7059 & TRN \\
\hline CHEMBL1939097 & 797232 & 5.4202 & 5.3884 & TRN \\
\hline CHEMBL1939089 & 797232 & 6.5376 & 6.4754 & TRN \\
\hline CHEMBL1877309 & 797232 & 6.3872 & 6.3742 & TRN \\
\hline CHEMBL1939113 & 797232 & 6.8861 & 7.01 & TRN \\
\hline CHEMBL1939100 & 797232 & 3.699 & 3.6566 & TRN \\
\hline CHEMBL1939109 & 797232 & 6.2218 & 6.1721 & TRN \\
\hline CHEMBL1939120 & 797232 & 5.2147 & 5.1524 & TRN \\
\hline CHEMBL1938905 & 797232 & 4.7375 & 7.1852 & TST \\
\hline CHEMBL1939078 & 797232 & 5.9586 & 5.8683 & TRN \\
\hline CHEMBL1939085 & 797232 & 7.0 & 7.0242 & TRN \\
\hline CHEMBL1939094 & 797232 & 6.585 & 6.56 & TRN \\
\hline CHEMBL1939075 & 797232 & 3.699 & 3.6562 & TRN \\
\hline CHEMBL1939095 & 797232 & 6.6778 & 6.7812 & TRN \\
\hline CHEMBL1939086 & 797232 & 5.8861 & 5.8686 & TRN \\
\hline CHEMBL1085587 & 797232 & 7.1367 & 2.7689 & TST \\
\hline CHEMBL1938904 & 797232 & 4.7352 & 6.6919 & TST \\
\hline CHEMBL1938910 & 797232 & 5.0458 & 4.7691 & TST \\
\hline CHEMBL1939077 & 797232 & 4.7878 & 4.8271 & TRN \\
\hline CHEMBL1938912 & 797232 & 5.1612 & 6.4156 & TST \\
\hline CHEMBL1377752 & 797232 & 5.3665 & 5.3787 & TST \\
\hline
\end{tabular}




\begin{tabular}{|c|c|c|c|c|c|}
\hline & & \multicolumn{4}{|c|}{ Supplemental Table S2.txt } \\
\hline CHEMBL1939096 & 797232 & 6.6576 & 6.7678 & TRN & \\
\hline CHEMBL1939119 & 797232 & 5.129 & 5.1991 & TRN & \\
\hline CHEMBL1938907 & 797232 & 5.0 & 4.9665 & TST & \\
\hline CHEMBL1938901 & 797232 & 4.7011 & 5.6459 & TST & \\
\hline CHEMBL1376335 & 797232 & 4.8729 & 4.8603 & TRN & \\
\hline CHEMBL1089334 & 797232 & 7.4202 & 3.9821 & TST & \\
\hline CHEMBL1938913 & 797232 & 5.2218 & 4.5249 & TST & \\
\hline CHEMBL1939082 & 797232 & 5.8861 & 5.9177 & TRN & \\
\hline CHEMBL1938908 & 797232 & 3.699 & 6.0149 & TST & \\
\hline CHEMBL1413238 & 797232 & 5.8539 & 5.896 & TRN & \\
\hline CHEMBL1938902 & 797232 & 3.699 & 5.7508 & TST & \\
\hline CHEMBL1938914 & 797232 & 6.0269 & 5.1292 & TST & \\
\hline CHEMBL1938906 & 797232 & 4.762 & 5.9751 & TST & \\
\hline CHEMBL1939118 & 797232 & 5.1805 & 5.0806 & TRN & \\
\hline CHEMBL1311880 & 797232 & 6.6021 & 6.51399 & 9999999999 & TRN \\
\hline CHEMBL1939080 & 797232 & 4.9547 & 4.9886 & TRN & \\
\hline CHEMBL1939108 & 797232 & 6.8539 & 6.8836 & TRN & \\
\hline CHEMBL1939116 & 797232 & 7.0458 & 7.0255 & TRN & \\
\hline CHEMBL1939088 & 797232 & 6.2676 & 6.1825 & TRN & \\
\hline CHEMBL1939093 & 797232 & 6.3188 & 6.4235 & TRN & \\
\hline CHEMBL1939079 & 797232 & 3.699 & 3.7739 & TRN & \\
\hline CHEMBL1939091 & 797232 & 3.699 & 3.6437 & TRN & \\
\hline CHEMBL1939098 & 797232 & 6.3565 & 6.2733 & TRN & \\
\hline CHEMBL1939081 & 797232 & 5.1938 & 5.1571 & TRN & \\
\hline CHEMBL1939092 & 797232 & 3.699 & 3.7133 & TRN & \\
\hline CHEMBL1939103 & 797232 & 5.6778 & 5.6121 & TRN & \\
\hline CHEMBL1938909 & 797232 & 4.8827 & 6.2826 & TST & \\
\hline CHEMBL1938916 & 797232 & 5.8239 & 4.96399 & 99999999995 & TST \\
\hline CHEMBL1514868 & 797232 & 5.284 & 5.2621 & TRN & \\
\hline CHEMBL1939084 & 797232 & 5.3372 & 5.3966 & TRN & \\
\hline CHEMBL1939114 & 797232 & 6.5376 & 6.5634 & TRN & \\
\hline CHEMBL1939117 & 797232 & 6.6778 & 6.581 & TRN & \\
\hline CHEMBL1939090 & 797232 & 6.3565 & 6.2922 & TRN & \\
\hline CHEMBL1939121 & 797232 & 5.2147 & 5.4146 & TRN & \\
\hline CHEMBL1939087 & 797232 & 6.2518 & 6.2407 & TRN & \\
\hline CHEMBL1939099 & 797232 & 6.2924 & 6.12299 & 9999999999 & TRN \\
\hline CHEMBL1939102 & 797232 & 6.2441 & 6.3008 & TRN & \\
\hline CHEMBL1938918 & 797232 & 6.1024 & 5.7889 & TST & \\
\hline CHEMBL1938915 & 797232 & 5.6383 & 4.6193 & TST & \\
\hline CHEMBL1409617 & 688645 & 4.5601 & 3.6905 & TRN & \\
\hline CHEMBL3196709 & 688645 & 4.0513 & 3.4174 & TRN & \\
\hline CHEMBL1401462 & 688645 & 4.2909 & 3.4641 & TRN & \\
\hline CHEMBL1381655 & 688645 & 3.0 & 3.9908 & TRN & \\
\hline CHEMBL1440489 & 688645 & 3.0 & 3.7803 & TRN & \\
\hline CHEMBL1330800 & 688645 & 3.0 & 3.2791 & TRN & \\
\hline CHEMBL1537181 & 688645 & 4.3643 & 4.3438 & TRN & \\
\hline CHEMBL1383807 & 688645 & 4.1513 & 3.2281 & TRN & \\
\hline CHEMBL1375627 & 688645 & 3.0 & 3.4072 & TRN & \\
\hline
\end{tabular}




\begin{tabular}{|c|c|c|c|c|c|}
\hline & & \multicolumn{4}{|c|}{ Supplemental Table S2.txt } \\
\hline CHEMBL1518655 & 688645 & 4.4725 & 4.1637 & TRN & \\
\hline CHEMBL1582381 & 688645 & 4.7391 & 4.1103 & TRN & \\
\hline CHEMBL1490382 & 688645 & 4.4285 & 3.3279 & TRN & \\
\hline CHEMBL1494457 & 688645 & 4.1498 & 4.0141 & TRN & \\
\hline CHEMBL1539483 & 688645 & 4.2004 & 3.2926 & TST & \\
\hline CHEMBL1568151 & 688645 & 3.0 & 3.5707 & TRN & \\
\hline CHEMBL1562738 & 688645 & 4.4123 & 4.40300 & 00000000005 & TRN \\
\hline CHEMBL1722831 & 688645 & 4.9907 & 4.1652 & TST & \\
\hline CHEMBL1445032 & 688645 & 3.0 & 3.3336 & TRN & \\
\hline CHEMBL1594268 & 688645 & 4.1769 & 4.2763 & TRN & \\
\hline CHEMBL1305463 & 688645 & 4.302 & 4.3289 & TRN & \\
\hline CHEMBL3207955 & 688645 & 3.0 & 3.3036 & TRN & \\
\hline CHEMBL1501678 & 688645 & 3.0 & 3.6985 & TRN & \\
\hline CHEMBL1525515 & 688645 & 3.0 & 3.1055 & TRN & \\
\hline CHEMBL1382443 & 688645 & 7.71 & 3.88199 & 99999999997 & TST \\
\hline CHEMBL1359461 & 688645 & 3.0 & 4.1195 & TST & \\
\hline CHEMBL3194311 & 688645 & 3.0 & 3.8233 & TRN & \\
\hline CHEMBL1411223 & 688645 & 4.3717 & 4.3382 & TRN & \\
\hline CHEMBL1564446 & 688645 & 4.2966 & 4.2653 & TRN & \\
\hline CHEMBL1358862 & 688645 & 4.0956 & 3.5737 & TRN & \\
\hline CHEMBL1506895 & 688645 & 4.1991 & 3.7193 & TRN & \\
\hline CHEMBL1408451 & 688645 & 4.6621 & 4.3748 & TRN & \\
\hline CHEMBL1566209 & 688645 & 4.4882 & 4.4025 & TRN & \\
\hline CHEMBL1537356 & 688645 & 4.4487 & 4.3748 & TRN & \\
\hline CHEMBL1373725 & 688645 & 3.0 & 3.9074 & TRN & \\
\hline CHEMBL1427586 & 688645 & 3.0 & 3.7974 & TST & \\
\hline CHEMBL3196832 & 688645 & 3.0 & 3.5647 & TRN & \\
\hline CHEMBL1463369 & 688645 & 4.1868 & 3.2775 & TRN & \\
\hline CHEMBL1546307 & 688645 & 4.6865 & 4.1523 & TST & \\
\hline CHEMBL1611217 & 688645 & 3.0 & 3.4008 & TRN & \\
\hline CHEMBL1540232 & 688645 & 4.1934 & 3.7856 & TRN & \\
\hline CHEMBL1574669 & 688645 & 3.0 & 3.8381 & TRN & \\
\hline CHEMBL1343358 & 688645 & 3.0 & 3.2254 & TST & \\
\hline CHEMBL1424276 & 688645 & 3.0 & 2.582 & TST & \\
\hline CHEMBL3209134 & 688645 & 3.0 & 3.6756 & TRN & \\
\hline CHEMBL1457385 & 688645 & 4.3908 & 4.249 & TRN & \\
\hline CHEMBL1491028 & 688645 & 4.2143 & 4.3965 & TRN & \\
\hline CHEMBL1478726 & 688645 & 4.3798 & 4.439 & TRN & \\
\hline CHEMBL533293 & 688645 & 3.0 & 3.8514 & TST & \\
\hline CHEMBL1505844 & 688645 & 3.0 & 3.6384 & TRN & \\
\hline CHEMBL1449103 & 688645 & 4.0852 & 3.4138 & TRN & \\
\hline CHEMBL1385054 & 688645 & 4.3903 & 3.9971 & TRN & \\
\hline CHEMBL1571034 & 688645 & 3.0 & 2.6414 & TST & \\
\hline CHEMBL1364172 & 688645 & 3.0 & 3.4554 & TRN & \\
\hline CHEMBL1567829 & 688645 & 4.1605 & 3.7482 & TRN & \\
\hline CHEMBL1509974 & 688645 & 3.0 & 3.3606 & TRN & \\
\hline CHEMBL 1458810 & 688645 & 3.0 & 3.7134 & TRN & \\
\hline CHEMBL1413142 & 688645 & 4.4013 & 4.3616 & TRN & \\
\hline
\end{tabular}




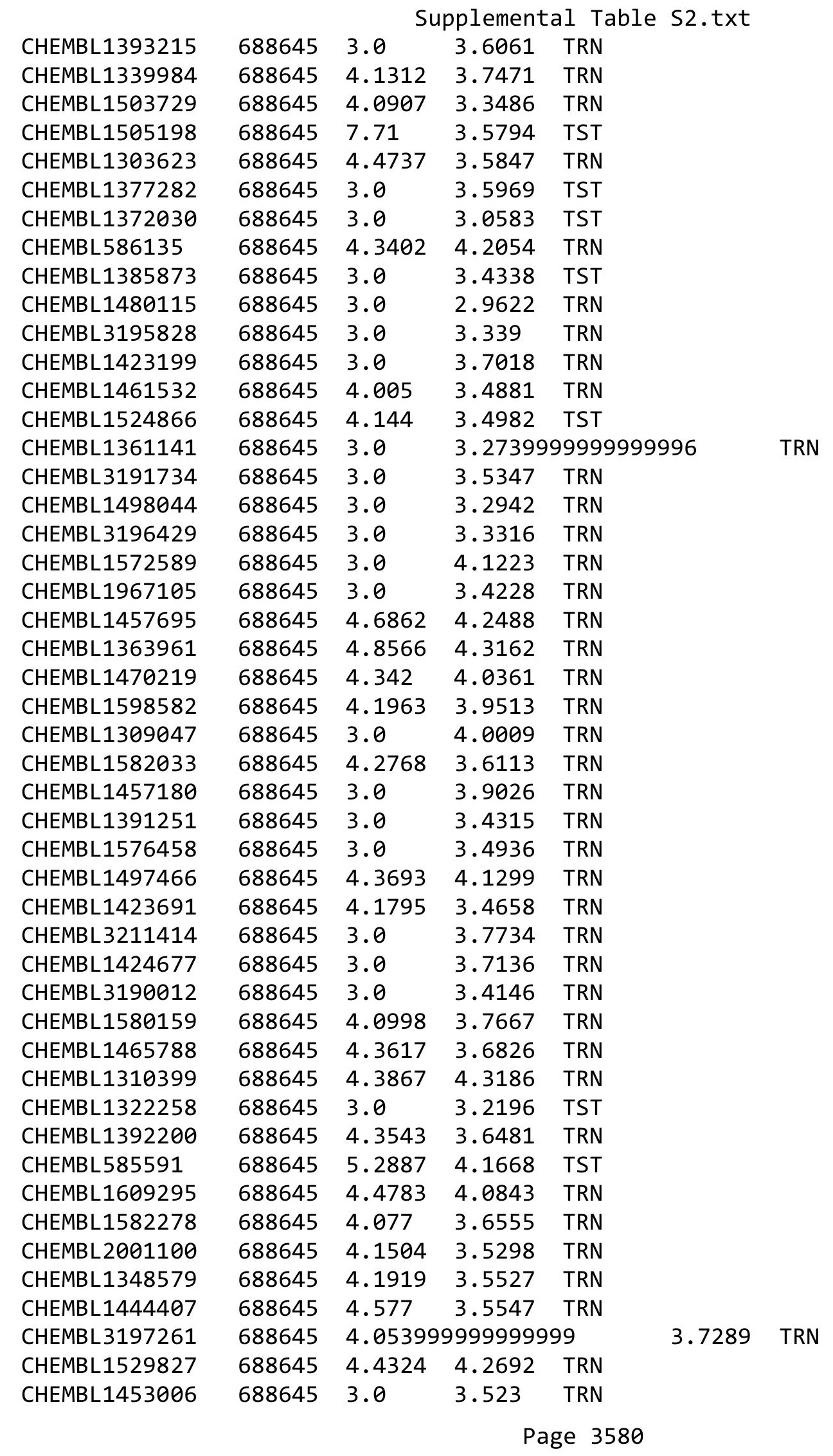




\begin{tabular}{|c|c|c|c|c|c|c|}
\hline \multicolumn{7}{|c|}{ Supplemental Table S2.txt } \\
\hline CHEMBL1457821 & 688645 & 3.0 & 3.3815 & TRN & & \\
\hline CHEMBL1408688 & 688645 & 3.0 & 3.1428 & TRN & & \\
\hline CHEMBL1544838 & 688645 & 4.3962 & 4.3577 & TRN & & \\
\hline CHEMBL1407064 & 688645 & 4.6196 & 4.1885 & TRN & & \\
\hline CHEMBL1350004 & 688645 & 3.0 & 4.0149 & TRN & & \\
\hline CHEMBL1609596 & 688645 & 4.372 & 4.0503 & TRN & & \\
\hline CHEMBL1499868 & 688645 & 4.2129 & 3.4581 & TRN & & \\
\hline CHEMBL1300370 & 688645 & 6.0497 & 4.3898 & TST & & \\
\hline CHEMBL1327409 & 688645 & 4.7183 & 4.4224 & TRN & & \\
\hline CHEMBL1339488 & 688645 & 4.1875 & 3.29600 & 0000000000 & 03 & TST \\
\hline CHEMBL1319190 & 688645 & 3.0 & 3.9932 & TRN & & \\
\hline CHEMBL1308240 & 688645 & 3.0 & 3.8123 & TRN & & \\
\hline CHEMBL1452776 & 688645 & 4.7216 & 4.1576 & TRN & & \\
\hline CHEMBL1539817 & 688645 & 4.2005 & 4.1125 & TRN & & \\
\hline CHEMBL1532795 & 688645 & 4.4668 & 4.1117 & TRN & & \\
\hline CHEMBL1464982 & 688645 & 4.2561 & 4.1827 & TRN & & \\
\hline CHEMBL1477384 & 688645 & 4.1011 & 3.5076 & TRN & & \\
\hline CHEMBL1313502 & 688645 & 4.1445 & 3.2726 & TST & & \\
\hline CHEMBL1569923 & 688645 & 4.44600 & 00000000 & & 4.3268 & TRN \\
\hline CHEMBL1368090 & 688645 & 3.0 & 3.3667 & TRN & & \\
\hline CHEMBL1527436 & 688645 & 4.3541 & 4.1239 & TST & & \\
\hline CHEMBL1335905 & 688645 & 4.4223 & 4.3672 & TST & & \\
\hline CHEMBL1450091 & 688645 & 4.4324 & 3.9991 & TST & & \\
\hline CHEMBL1327331 & 688645 & 4.8098 & 3.8373 & TST & & \\
\hline CHEMBL1497387 & 688645 & 4.188 & 4.0291 & TST & & \\
\hline CHEMBL3212503 & 688645 & 4.8292 & 4.1718 & TST & & \\
\hline CHEMBL1868277 & 688645 & 4.726 & 3.2374 & TST & & \\
\hline CHEMBL1328176 & 688645 & 4.0861 & 4.2467 & TST & & \\
\hline CHEMBL1380478 & 688645 & 4.2033 & 3.9026 & TST & & \\
\hline CHEMBL1518634 & 688645 & 3.0 & 2.9591 & TST & & \\
\hline CHEMBL1463790 & 688645 & 4.1168 & 3.909 & TST & & \\
\hline CHEMBL3192459 & 688645 & 3.0 & 3.5302 & TST & & \\
\hline CHEMBL1366670 & 688645 & 4.4079 & 4.2357 & TST & & \\
\hline CHEMBL1470921 & 688645 & 3.0 & 3.7359 & TST & & \\
\hline CHEMBL1703256 & 688645 & 4.3501 & 4.1745 & TST & & \\
\hline CHEMBL1402899 & 688645 & 4.1824 & 3.2108 & TST & & \\
\hline CHEMBL1682468 & 728129 & 6.7265 & 6.8279 & TRN & & \\
\hline CHEMBL1682579 & 728129 & 6.66700 & $\partial 0000000$ & & 6.5402 & TRN \\
\hline CHEMBL1682609 & 728129 & 6.443 & 6.1623 & TRN & & \\
\hline CHEMBL1682729 & 728129 & 4.8926 & 4.6005 & TST & & \\
\hline CHEMBL1682453 & 728129 & 7.1278 & 7.225 & TRN & & \\
\hline CHEMBL1682585 & 728129 & 6.5776 & 6.351 & TRN & & \\
\hline CHEMBL1682577 & 728129 & 6.1906 & 6.4791 & TST & & \\
\hline CHEMBL1682587 & 728129 & 6.5249 & 6.2918 & TRN & & \\
\hline CHEMBL1682462 & 728129 & 6.96899 & 99999999 & 99 & 6.7811 & TRN \\
\hline CHEMBL1682464 & 728129 & 6.7959 & 6.7725 & TRN & & \\
\hline CHEMBL1682603 & 728129 & 6.1972 & 5.8093 & TST & & \\
\hline CHEMBL1682703 & 728129 & 6.0307 & 5.4596 & TST & & \\
\hline
\end{tabular}




\begin{tabular}{|c|c|c|c|c|c|c|}
\hline \multirow[b]{2}{*}{ CHEMBL1682461 } & & \multicolumn{5}{|c|}{ Supplemental Table S2.txt } \\
\hline & 728129 & 6.5759 & 6.5109 & TRN & & \\
\hline CHEMBL1682586 & 728129 & 6.215 & 6.0591 & TRN & & \\
\hline CHEMBL1682599 & 728129 & 6.3184 & 6.4043 & TRN & & \\
\hline CHEMBL1682719 & 728129 & 5.2364 & 5.4348 & TRN & & \\
\hline CHEMBL1682447 & 728129 & 6.6609 & 6.7562 & TRN & & \\
\hline CHEMBL1682594 & 728129 & 6.4868 & 6.3236 & TRN & & \\
\hline CHEMBL1682601 & 728129 & 6.5468 & 6.3306 & TRN & & \\
\hline CHEMBL1682590 & 728129 & 6.2368 & 6.182 & TRN & & \\
\hline CHEMBL1682722 & 728129 & 4.8531 & 5.2669 & TRN & & \\
\hline CHEMBL1682720 & 728129 & 5.6879 & 5.8641 & TRN & & \\
\hline CHEMBL1682597 & 728129 & 6.2935 & 6.2867 & TRN & & \\
\hline CHEMBL1682593 & 728129 & 6.5837 & 6.4742 & TRN & & \\
\hline CHEMBL1682717 & 728129 & 5.2592 & 5.5559 & TRN & & \\
\hline CHEMBL1682466 & 728129 & 6.604 & 6.6199 & TRN & & \\
\hline CHEMBL1682727 & 728129 & 5.1544 & 4.9472 & TRN & & \\
\hline CHEMBL1682705 & 728129 & 6.1887 & 6.1653 & TRN & & \\
\hline CHEMBL1682714 & 728129 & 6.0159 & 5.5963 & TST & & \\
\hline CHEMBL1682582 & 728129 & 6.3514 & 6.3928 & TST & & \\
\hline CHEMBL1682604 & 728129 & 6.4823 & 5.9767 & TRN & & \\
\hline CHEMBL1682574 & 728129 & 6.3421 & 6.4246 & TRN & & \\
\hline CHEMBL1682600 & 728129 & 6.4962 & 6.3366 & TRN & & \\
\hline CHEMBL1682708 & 728129 & 6.1618 & 5.8736 & TRN & & \\
\hline CHEMBL1682583 & 728129 & 6.4951 & 6.711 & TRN & & \\
\hline CHEMBL1682460 & 728129 & 6.7256 & 6.5612 & TRN & & \\
\hline CHEMBL1682588 & 728129 & 6.2574 & 6.2306 & TRN & & \\
\hline CHEMBL1682450 & 728129 & 7.5513 & 6.8359 & TRN & & \\
\hline CHEMBL1682443 & 728129 & 6.9038 & 6.9198 & TST & & \\
\hline CHEMBL1682724 & 728129 & 4.8617 & 4.6594 & TRN & & \\
\hline CHEMBL1682456 & 728129 & 6.8788 & 6.7768 & TRN & & \\
\hline CHEMBL1682444 & 728129 & 7.2725 & 7.1481 & TRN & & \\
\hline CHEMBL1682723 & 728129 & 5.5464 & 5.6498 & TST & & \\
\hline CHEMBL1682446 & 728129 & 6.9215 & 7.1643 & TRN & & \\
\hline CHEMBL1682721 & 728129 & 5.4292 & 5.807 & TRN & & \\
\hline CHEMBL1682598 & 728129 & 6.4132 & 6.3756 & TRN & & \\
\hline CHEMBL1682725 & 728129 & 5.0322 & 5.0012 & TRN & & \\
\hline CHEMBL1682573 & 728129 & 6.4023 & 6.4864 & TRN & & \\
\hline CHEMBL1682607 & 728129 & 6.5265 & 6.1912 & TST & & \\
\hline CHEMBL1682576 & 728129 & 6.0058 & 6.2851 & TRN & & \\
\hline CHEMBL1682467 & 728129 & 6.9161 & 6.7318 & TRN & & \\
\hline CHEMBL1682730 & 728129 & 4.8915 & 4.7376 & TRN & & \\
\hline CHEMBL1682445 & 728129 & 6.98799 & 99999999 & 995 & 7.3072 & TRN \\
\hline CHEMBL1682602 & 728129 & 6.3281 & 6.2424 & TRN & & \\
\hline CHEMBL1682610 & 728129 & 6.3444 & 6.1386 & TST & & \\
\hline CHEMBL1682702 & 728129 & 5.76200 & 20000000 & 005 & 5.9747 & TRN \\
\hline CHEMBL1682716 & 728129 & 5.2202 & 5.6803 & TRN & & \\
\hline CHEMBL1682459 & 728129 & 6.5284 & 6.6414 & TRN & & \\
\hline CHEMBL1682458 & 728129 & 6.7962 & 6.7401 & TRN & & \\
\hline CHEMBL1682726 & 728129 & 4.9076 & 4.8663 & TRN & & \\
\hline
\end{tabular}


Supplemental Table S2.txt

\begin{tabular}{|c|c|c|c|c|}
\hline CHEMBL1682710 & 728129 & 5.7904 & 5.5086 & TRN \\
\hline CHEMBL1682452 & 728129 & 6.7582 & 6.8591 & TRN \\
\hline CHEMBL1682712 & 728129 & 5.2507 & 5.5334 & TRN \\
\hline CHEMBL1682575 & 728129 & 6.6647 & 6.8087 & TRN \\
\hline CHEMBL1682711 & 728129 & 6.0286 & 5.5264 & TST \\
\hline CHEMBL1682578 & 728129 & 6.5235 & 6.5281 & TRN \\
\hline CHEMBL1682572 & 728129 & 6.2914 & 6.3907 & TRN \\
\hline CHEMBL1682463 & 728129 & 6.6457 & 6.4824 & TRN \\
\hline CHEMBL1682700 & 728129 & 6.0468 & 6.0695 & TRN \\
\hline CHEMBL1682595 & 728129 & 6.5198 & 6.4948 & TRN \\
\hline CHEMBL1682704 & 728129 & 6.0837 & 6.2223 & TST \\
\hline CHEMBL1682591 & 728129 & 6.4815 & 6.6801 & TRN \\
\hline CHEMBL1682457 & 728129 & 6.6486 & 6.6966 & TRN \\
\hline CHEMBL1682706 & 728129 & 5.7075 & 5.8272 & TRN \\
\hline CHEMBL1682584 & 728129 & 6.4814 & 6.5076 & TRN \\
\hline CHEMBL1682718 & 728129 & 5.9169 & 5.7024 & TRN \\
\hline CHEMBL1682592 & 728129 & 6.4823 & 6.5659 & TRN \\
\hline CHEMBL1682581 & 728129 & 6.5959 & 6.212999 & 9999999999 \\
\hline CHEMBL1682701 & 728129 & 6.1836 & 5.9923 & TRN \\
\hline CHEMBL1682451 & 728129 & 6.5743 & 6.5291 & TRN \\
\hline CHEMBL1682608 & 728129 & 6.1162 & 6.2186 & TRN \\
\hline CHEMBL1682715 & 728129 & 5.7476 & 6.1405 & TRN \\
\hline CHEMBL1682709 & 728129 & 5.7065 & 5.9615 & TRN \\
\hline CHEMBL1682605 & 728129 & 6.3517 & 6.3274 & TRN \\
\hline CHEMBL1682707 & 728129 & 5.5842 & 5.7404 & TRN \\
\hline CHEMBL1682596 & 728129 & 6.5709 & 6.0148 & TST \\
\hline CHEMBL1682606 & 728129 & 6.0782 & 6.4373 & TST \\
\hline CHEMBL1681796 & 728129 & 6.9367 & 6.8406 & TST \\
\hline CHEMBL1682454 & 728129 & 6.5907 & 6.7961 & TST \\
\hline CHEMBL1682448 & 728129 & 7.2358 & 6.5516 & TST \\
\hline CHEMBL1682589 & 728129 & 6.6033 & 6.5707 & TST \\
\hline CHEMBL1682580 & 728129 & 6.4783 & 6.3627 & TST \\
\hline CHEMBL1682449 & 728129 & 7.2652 & 7.2244 & TST \\
\hline CHEMBL1682455 & 728129 & 6.3476 & 6.5822 & TST \\
\hline CHEMBL1682465 & 728129 & 6.755 & 6.6381 & TST \\
\hline CHEMBL1682728 & 728129 & 6.1001 & 5.0947 & TST \\
\hline CHEMBL1682713 & 728129 & 5.9427 & 5.9626 & TST \\
\hline CHEMBL1721015 & 737532 & 3.0969 & 3.6882 & TRN \\
\hline CHEMBL1479190 & 737532 & 3.0969 & 3.3573 & TST \\
\hline CHEMBL1729592 & 737532 & 3.0969 & 3.3452 & TST \\
\hline CHEMBL1537984 & 737532 & 4.2328 & 3.4185 & TRN \\
\hline CHEMBL1481150 & 737532 & 3.0969 & 3.2319 & TRN \\
\hline CHEMBL1442120 & 737532 & 3.0969 & 3.3466 & TST \\
\hline CHEMBL1532997 & 737532 & 3.0969 & 3.7079 & TRN \\
\hline CHEMBL1453017 & 737532 & 3.0969 & 3.0872 & TRN \\
\hline CHEMBL1456393 & 737532 & 3.0969 & 3.5623 & TRN \\
\hline CHEMBL1336825 & 737532 & 4.3947 & 3.3369 & TRN \\
\hline CHEMBL1424911 & 737532 & 3.0969 & 3.3674 & TRN \\
\hline
\end{tabular}


Supplemental Table S2.txt

\begin{tabular}{|c|c|c|c|c|}
\hline CHEMBL1412731 & 737532 & 4.6655 & 4.7548 & TRN \\
\hline CHEMBL1339149 & 737532 & 4.9066 & 5.0232 & TRN \\
\hline CHEMBL119878 & 737532 & 4.2668 & 3.7238 & TST \\
\hline CHEMBL1489664 & 737532 & 4.3851 & 3.5788 & TRN \\
\hline CHEMBL1397145 & 737532 & 3.0969 & 3.6101 & TRN \\
\hline CHEMBL1380069 & 737532 & 3.0969 & 3.1831 & TRN \\
\hline CHEMBL1501009 & 737532 & 4.2168 & 3.1843 & TRN \\
\hline CHEMBL1555928 & 737532 & 3.0969 & 3.6247 & TRN \\
\hline CHEMBL1484167 & 737532 & 3.0969 & 3.7528 & TST \\
\hline CHEMBL1392034 & 737532 & 4.3307 & 3.6911 & TRN \\
\hline CHEMBL1472879 & 737532 & 4.6216 & 3.9484 & TRN \\
\hline CHEMBL1566068 & 737532 & 3.0969 & 3.0717 & TRN \\
\hline CHEMBL1493248 & 737532 & 3.0969 & 3.7122 & TRN \\
\hline CHEMBL1523225 & 737532 & 3.0969 & 3.5874 & TST \\
\hline CHEMBL 3195177 & 737532 & 4.2411 & 3.8592 & TRN \\
\hline CHEMBL1729008 & 737532 & 3.0969 & 3.7339 & TST \\
\hline CHEMBL1501723 & 737532 & 3.0969 & 3.3395 & TRN \\
\hline CHEMBL1449018 & 737532 & 3.0969 & 3.385 & TRN \\
\hline CHEMBL 2000342 & 737532 & 3.0969 & 3.4541 & TRN \\
\hline CHEMBL1790039 & 737532 & 3.0969 & 3.2913 & TST \\
\hline CHEMBL1710816 & 737532 & 4.2411 & 3.9363 & TRN \\
\hline CHEMBL1712082 & 737532 & 3.0969 & 3.9023 & TST \\
\hline CHEMBL1380659 & 737532 & 4.466 & 3.3095 & TRN \\
\hline CHEMBL1388125 & 737532 & 3.0969 & 3.3316 & TRN \\
\hline CHEMBL3192506 & 737532 & 4.1752 & 3.5668 & TRN \\
\hline CHEMBL1334300 & 737532 & 4.3372 & 3.5992 & TRN \\
\hline CHEMBL1364723 & 737532 & 3.0969 & 3.3923 & TST \\
\hline CHEMBL1564699 & 737532 & 4.5243 & 3.9885 & TRN \\
\hline CHEMBL1418971 & 737532 & 3.0969 & 3.6889 & TRN \\
\hline CHEMBL3197706 & 737532 & 4.5003 & 3.2742 & TRN \\
\hline CHEMBL3191855 & 737532 & 3.0969 & 3.3684 & TRN \\
\hline CHEMBL3198590 & 737532 & 3.0969 & 3.3815 & TRN \\
\hline CHEMBL 3189722 & 737532 & 3.0969 & 3.739 & TRN \\
\hline CHEMBL1471361 & 737532 & 3.0969 & 3.26899 & 99999999997 \\
\hline CHEMBL1735740 & 737532 & 3.0969 & 3.4309 & TRN \\
\hline CHEMBL1717650 & 737532 & 3.0969 & 3.3857 & TRN \\
\hline CHEMBL1477589 & 737532 & 3.0969 & 3.4897 & TRN \\
\hline CHEMBL 3191304 & 737532 & 3.0969 & 3.5328 & TRN \\
\hline CHEMBL1504634 & 737532 & 4.327 & 4.0326 & TRN \\
\hline CHEMBL1722539 & 737532 & 3.0969 & 3.1876 & TRN \\
\hline CHEMBL1578299 & 737532 & 3.0969 & 3.6152 & TRN \\
\hline CHEMBL1966295 & 737532 & 3.0969 & 3.642 & TRN \\
\hline CHEMBL1318998 & 737532 & 3.0969 & 3.4913 & TRN \\
\hline CHEMBL1707960 & 737532 & 3.0969 & 3.3696 & TRN \\
\hline CHEMBL1971154 & 737532 & 3.0969 & 3.4493 & TRN \\
\hline CHEMBL1365064 & 737532 & 3.0969 & 3.1264 & TST \\
\hline CHEMBL1385949 & 737532 & 3.0969 & 3.2627 & TRN \\
\hline CHEMBL1736648 & 737532 & 4.209 & 3.85600 & 00000000003 \\
\hline
\end{tabular}


Supplemental Table S2.txt

\begin{tabular}{|c|c|c|c|c|}
\hline CHEMBL1587245 & 737532 & 4.3585 & 3.3863 & TRN \\
\hline CHEMBL1304584 & 737532 & 4.1925 & 3.8892 & TST \\
\hline CHEMBL1700880 & 737532 & 3.0969 & 3.3549 & TST \\
\hline CHEMBL3192682 & 737532 & 3.0969 & 3.8378 & TRN \\
\hline CHEMBL1569991 & 737532 & 3.0969 & 3.3648 & TST \\
\hline CHEMBL1549039 & 737532 & 3.0969 & 3.0025 & TRN \\
\hline CHEMBL82134 & 737532 & 3.0969 & 3.5594 & TST \\
\hline CHEMBL1529183 & 737532 & 3.0969 & 3.3941 & TRN \\
\hline CHEMBL1699039 & 737532 & 4.7986 & 4.574 & TRN \\
\hline CHEMBL1609871 & 737532 & 3.0969 & 3.6876 & TRN \\
\hline CHEMBL1607263 & 737532 & 4.301 & 4.0554 & TRN \\
\hline CHEMBL1318817 & 737532 & 4.1624 & 3.9032 & TRN \\
\hline CHEMBL1725665 & 737532 & 4.2581 & 3.5917 & TRN \\
\hline CHEMBL1553163 & 737532 & 4.7773 & 4.8581 & TRN \\
\hline CHEMBL1518503 & 737532 & 3.0969 & 3.5182 & TRN \\
\hline CHEMBL1609490 & 737532 & 3.0969 & 3.5044 & TRN \\
\hline CHEMBL1348445 & 737532 & 4.1681 & 3.8746 & TRN \\
\hline CHEMBL1565164 & 737532 & 3.0969 & 3.4786 & TRN \\
\hline CHEMBL1590701 & 737532 & 3.0969 & 3.0553 & TRN \\
\hline CHEMBL1463638 & 737532 & 3.0969 & 3.2099 & TRN \\
\hline CHEMBL1698153 & 737532 & 3.0969 & 3.4347 & TRN \\
\hline CHEMBL1323484 & 737532 & 3.0969 & 3.6558 & TRN \\
\hline CHEMBL1345026 & 737532 & 3.0969 & 3.4785 & TST \\
\hline CHEMBL1563951 & 737532 & 3.0969 & 3.4174 & TRN \\
\hline CHEMBL1703892 & 737532 & 3.0969 & 3.3926 & TRN \\
\hline CHEMBL1487368 & 737532 & 3.0969 & 3.821 & TRN \\
\hline CHEMBL1477845 & 737532 & 3.0969 & 3.4253 & TRN \\
\hline CHEMBL1542823 & 737532 & 3.0969 & 3.5478 & TRN \\
\hline CHEMBL1708074 & 737532 & 3.0969 & 3.6104 & TST \\
\hline CHEMBL1700720 & 737532 & 3.0969 & 3.2643 & TST \\
\hline CHEMBL1498754 & 737532 & 3.0969 & 3.1728 & TRN \\
\hline CHEMBL 288096 & 737532 & 3.0969 & 3.486 & TST \\
\hline CHEMBL1470492 & 737532 & 3.0969 & 3.3486 & TRN \\
\hline CHEMBL1564355 & 737532 & 3.0969 & 3.8006 & TRN \\
\hline CHEMBL1527565 & 737532 & 4.9547 & 3.8521 & TRN \\
\hline CHEMBL1714971 & 737532 & 4.1267 & 3.5551 & TRN \\
\hline CHEMBL1528757 & 737532 & 4.4855 & 3.1885 & TST \\
\hline CHEMBL1351333 & 737532 & 3.0969 & 3.4542 & TRN \\
\hline CHEMBL1601716 & 737532 & 4.9469 & 4.8214 & TRN \\
\hline CHEMBL1310862 & 737532 & 3.0969 & 3.46100 & 30000000003 \\
\hline CHEMBL1440703 & 737532 & 3.0969 & 3.5229 & TST \\
\hline CHEMBL1447124 & 737532 & 4.301 & 3.7927 & TRN \\
\hline CHEMBL1713376 & 737532 & 3.0969 & 3.8453 & TRN \\
\hline CHEMBL1327721 & 737532 & 3.0969 & 3.4516 & TRN \\
\hline CHEMBL445304 & 737532 & 4.6198 & 3.70399 & 99999999997 \\
\hline CHEMBL1548574 & 737532 & 3.0969 & 3.4663 & TRN \\
\hline CHEMBL1304359 & 737532 & 3.0969 & 3.4262 & TRN \\
\hline CHEMBL1277060 & 737532 & 3.0969 & 3.1305 & TRN \\
\hline
\end{tabular}


Supplemental Table S2.txt

\begin{tabular}{|c|c|c|c|c|c|}
\hline CHEMBL1410383 & 737532 & 4.5072 & 3.8667 & TRN & \\
\hline CHEMBL1705503 & 737532 & 3.0969 & \multicolumn{2}{|c|}{3.3560000000000003} & TRN \\
\hline CHEMBL363221 & 737532 & 3.0969 & 3.2842 & TRN & \\
\hline CHEMBL1702473 & 737532 & 4.2248 & 3.4715 & TST & \\
\hline CHEMBL1698608 & 737532 & 3.0969 & 3.2054 & TRN & \\
\hline CHEMBL1715446 & 737532 & 3.0969 & 3.6336 & TRN & \\
\hline CHEMBL1465938 & 737532 & 4.6757 & 4.0001 & TRN & \\
\hline CHEMBL1539384 & 737532 & 3.0969 & 3.2448 & TRN & \\
\hline CHEMBL1715126 & 737532 & 4.6216 & 3.492 & TRN & \\
\hline CHEMBL118678 & 737532 & 3.0969 & 3.6745 & TST & \\
\hline CHEMBL1710798 & 737532 & 4.9172 & 4.7092 & TRN & \\
\hline CHEMBL 2006418 & 737532 & 4.2549 & 3.5831 & TRN & \\
\hline CHEMBL1703976 & 737532 & 3.0969 & 3.5986 & TRN & \\
\hline CHEMBL1389498 & 737532 & 3.0969 & 3.2958 & TRN & \\
\hline CHEMBL1324790 & 737532 & 3.0969 & 3.2512 & TRN & \\
\hline CHEMBL1449479 & 737532 & 3.0969 & 3.3895 & TRN & \\
\hline CHEMBL1729300 & 737532 & 4.7282 & 3.88199 & 99999999997 & TRN \\
\hline CHEMBL1348432 & 737532 & 3.0969 & 3.1184 & TRN & \\
\hline CHEMBL1605172 & 737532 & 3.0969 & 3.4514 & TRN & \\
\hline CHEMBL1537872 & 737532 & 4.5768 & 3.8004 & TST & \\
\hline CHEMBL 1257041 & 737532 & 4.2007 & 3.423 & TST & \\
\hline CHEMBL1444730 & 737532 & 4.5157 & 4.1602 & TRN & \\
\hline CHEMBL1579122 & 737532 & 3.0969 & 3.4572 & TRN & \\
\hline CHEMBL1708363 & 737532 & 4.3526 & 3.4486 & TRN & \\
\hline CHEMBL1699355 & 737532 & 4.7696 & 4.7888 & TRN & \\
\hline CHEMBL1481042 & 737532 & 4.2993 & 3.5696 & TST & \\
\hline CHEMBL1727678 & 737532 & 3.0969 & 3.3725 & TRN & \\
\hline CHEMBL1608402 & 737532 & 3.0969 & 3.0117 & TRN & \\
\hline CHEMBL1463161 & 737532 & 3.0969 & 3.5695 & TRN & \\
\hline CHEMBL131037 & 737532 & 4.5686 & 3.9231 & TRN & \\
\hline CHEMBL1712649 & 737532 & 3.0969 & 3.6263 & TRN & \\
\hline CHEMBL98386 & 737532 & 4.9788 & 5.2015 & TRN & \\
\hline CHEMBL1461413 & 737532 & 3.0969 & 3.5138 & TST & \\
\hline CHEMBL1702253 & 737532 & 3.0969 & 3.0513 & TRN & \\
\hline CHEMBL1300266 & 737532 & 3.0969 & 3.7153 & TRN & \\
\hline CHEMBL1413554 & 737532 & 3.0969 & 3.5758 & TST & \\
\hline CHEMBL1989090 & 737532 & 3.0969 & 3.1707 & TRN & \\
\hline CHEMBL1377465 & 737532 & 4.6144 & 3.4681 & TRN & \\
\hline CHEMBL1553409 & 737532 & 3.0969 & 3.7282 & TRN & \\
\hline CHEMBL1310318 & 737532 & 4.857 & 4.7459 & TRN & \\
\hline CHEMBL483531 & 737532 & 4.5086 & 3.7389 & TRN & \\
\hline CHEMBL1489240 & 737532 & 3.0969 & 3.4567 & TRN & \\
\hline CHEMBL1448440 & 737532 & 3.0969 & 3.5192 & TRN & \\
\hline CHEMBL1378223 & 737532 & 4.4815 & 3.6144 & TST & \\
\hline CHEMBL3195749 & 737532 & 4.5654 & 3.8027 & TRN & \\
\hline CHEMBL1509920 & 737532 & 3.0969 & 3.5073 & TRN & \\
\hline CHEMBL1340352 & 737532 & 3.0969 & 3.1939 & TST & \\
\hline CHEMBL1462691 & 737532 & 3.0969 & 3.3618 & TRN & \\
\hline
\end{tabular}


Supplemental Table S2.txt

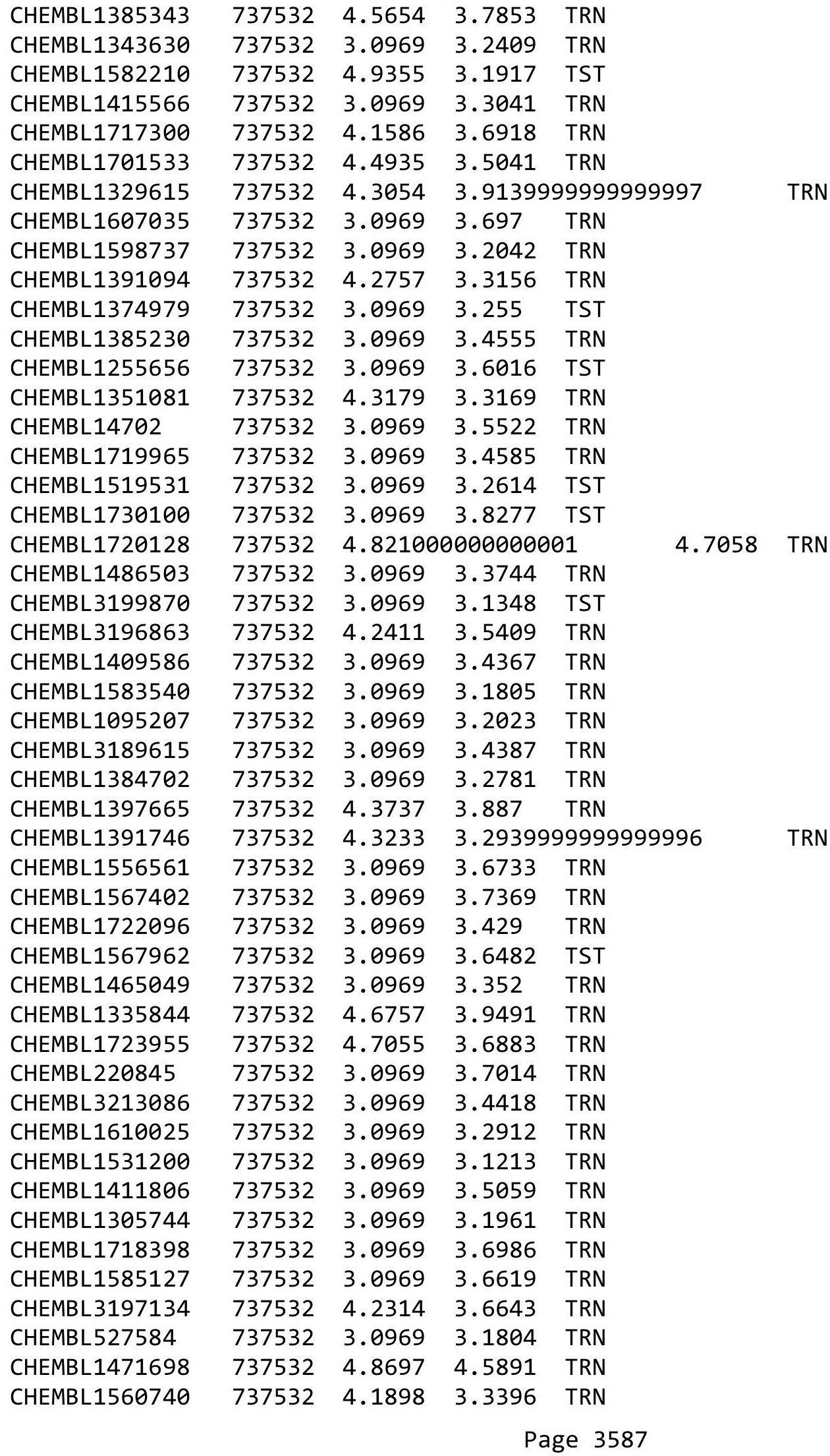


Supplemental Table S2.txt

\begin{tabular}{|c|c|c|c|c|}
\hline CHEMBL1387028 & 737532 & 3.0969 & 3.8042 & TRN \\
\hline CHEMBL1717890 & 737532 & 4.4473 & 3.6619 & TRN \\
\hline CHEMBL1714283 & 737532 & 3.0969 & 3.4339 & TRN \\
\hline CHEMBL1366328 & 737532 & 3.0969 & 3.3809 & TRN \\
\hline CHEMBL1487716 & 737532 & 3.0969 & 3.2456 & TRN \\
\hline CHEMBL45152 & 737532 & 5.0521 & 5.3155 & TRN \\
\hline CHEMBL1496195 & 737532 & 4.4101 & 3.3817 & TRN \\
\hline CHEMBL1719734 & 737532 & 3.0969 & 3.7684 & TRN \\
\hline CHEMBL1735864 & 737532 & 3.0969 & 3.8032 & TRN \\
\hline CHEMBL1432396 & 737532 & 3.0969 & 3.2381 & TRN \\
\hline CHEMBL1342337 & 737532 & 5.059 & 4.0944 & TRN \\
\hline CHEMBL1462764 & 737532 & 3.0969 & 3.5967 & TRN \\
\hline CHEMBL116548 & 737532 & 4.6799 & 3.7988 & TRN \\
\hline CHEMBL510515 & 737532 & 3.0969 & 3.4337 & TRN \\
\hline CHEMBL1718737 & 737532 & 3.0969 & 4.0604 & TRN \\
\hline CHEMBL1366942 & 737532 & 3.0969 & 3.7878 & TRN \\
\hline CHEMBL1477734 & 737532 & 4.5214 & 3.7518 & TRN \\
\hline CHEMBL1736537 & 737532 & 3.0969 & 3.763 & TRN \\
\hline CHEMBL1572324 & 737532 & 3.0969 & 3.6427 & TRN \\
\hline CHEMBL1394863 & 737532 & 3.0969 & 3.2317 & TRN \\
\hline CHEMBL1092816 & 737532 & 3.0969 & 3.259 & TRN \\
\hline CHEMBL1702711 & 737532 & 4.8508 & 4.9245 & TRN \\
\hline CHEMBL1320696 & 737532 & 3.0969 & 3.2199 & TRN \\
\hline CHEMBL1726592 & 737532 & 4.7375 & 4.5777 & TRN \\
\hline CHEMBL1453822 & 737532 & 3.0969 & 3.9538 & TRN \\
\hline CHEMBL1479427 & 737532 & 3.0969 & 3.062 & TRN \\
\hline CHEMBL1304193 & 737532 & 3.0969 & 3.5876 & TRN \\
\hline CHEMBL1419822 & 737532 & 4.3197 & 3.1943 & TST \\
\hline CHEMBL 75913 & 737532 & 4.1586 & 3.85100 & 00000000004 \\
\hline CHEMBL1427991 & 737532 & 3.0969 & 3.6259 & TRN \\
\hline CHEMBL1727570 & 737532 & 3.0969 & 3.2196 & TRN \\
\hline CHEMBL3191533 & 737532 & 3.0969 & 3.1051 & TRN \\
\hline CHEMBL1409735 & 737532 & 3.0969 & 2.8484 & TRN \\
\hline CHEMBL1419121 & 737532 & 3.0969 & 3.4633 & TRN \\
\hline CHEMBL3195533 & 737532 & 4.567 & 3.446 & TRN \\
\hline CHEMBL1556634 & 737532 & 4.3161 & 3.6998 & TRN \\
\hline CHEMBL1330954 & 737532 & 3.0969 & 3.7177 & TRN \\
\hline CHEMBL1308549 & 737532 & 3.0969 & 3.2027 & TRN \\
\hline CHEMBL1431126 & 737532 & 4.3809 & 3.5826 & TRN \\
\hline CHEMBL1353285 & 737532 & 4.1871 & 3.3012 & TRN \\
\hline CHEMBL1402473 & 737532 & 3.0969 & 3.5993 & TRN \\
\hline CHEMBL1597427 & 737532 & 3.0969 & 3.2505 & TRN \\
\hline CHEMBL3197607 & 737532 & 3.0969 & 3.1867 & TRN \\
\hline CHEMBL1375198 & 737532 & 4.2168 & 3.6695 & TST \\
\hline CHEMBL1716105 & 737532 & 3.0969 & 3.5061 & TST \\
\hline CHEMBL1524715 & 737532 & 3.0969 & 3.1179 & TRN \\
\hline CHEMBL1329974 & 737532 & 4.9136 & 3.8071 & TRN \\
\hline CHEMBL1320096 & 737532 & 4.5591 & 3.6437 & TRN \\
\hline
\end{tabular}

Page 3588 
Supplemental Table S2.txt

\begin{tabular}{|c|c|c|c|c|}
\hline CHEMBL1556351 & 737532 & 4.5498 & 3.6772 & TRN \\
\hline CHEMBL1411556 & 737532 & 3.0969 & 3.0644 & TRN \\
\hline CHEMBL1422613 & 737532 & 3.0969 & 3.2462 & TRN \\
\hline CHEMBL1425837 & 737532 & 4.308 & 4.3296 & TRN \\
\hline CHEMBL1546332 & 737532 & 3.0969 & 3.5672 & TRN \\
\hline CHEMBL1713097 & 737532 & 3.0969 & 3.4494 & TST \\
\hline CHEMBL1319596 & 737532 & 3.0969 & 3.384 & TRN \\
\hline CHEMBL1393611 & 737532 & 3.0969 & 3.2063 & TRN \\
\hline CHEMBL 3214079 & 737532 & 3.0969 & 3.4131 & TRN \\
\hline CHEMBL1333181 & 737532 & 4.2 & 3.4333 & TRN \\
\hline CHEMBL1471711 & 737532 & 4.2518 & 3.1667 & TRN \\
\hline CHEMBL1728153 & 737532 & 3.0969 & 3.5508 & TRN \\
\hline CHEMBL1736502 & 737532 & 4.3179 & 3.4589 & TRN \\
\hline CHEMBL 3208664 & 737532 & 3.0969 & 3.4139 & TRN \\
\hline CHEMBL52 & 737532 & 3.0969 & 3.6669 & TRN \\
\hline CHEMBL 3196881 & 737532 & 3.0969 & 3.5224 & TRN \\
\hline CHEMBL1710047 & 737532 & 4.4283 & 4.4505 & TRN \\
\hline CHEMBL1336386 & 737532 & 3.0969 & 3.4645 & TRN \\
\hline CHEMBL1361252 & 737532 & 3.0969 & 3.3303 & TRN \\
\hline CHEMBL1702945 & 737532 & 3.0969 & 3.5082 & TRN \\
\hline CHEMBL1702248 & 737532 & 4.3737 & 3.4447 & TST \\
\hline CHEMBL1304996 & 737532 & 3.0969 & 3.4027 & TRN \\
\hline CHEMBL1379740 & 737532 & 4.4306 & 3.4009 & TRN \\
\hline CHEMBL1401342 & 737532 & 3.0969 & 3.7837 & TRN \\
\hline CHEMBL1372495 & 737532 & 3.0969 & 2.8658 & TRN \\
\hline CHEMBL1305916 & 737532 & 3.0969 & 3.5146 & TRN \\
\hline CHEMBL1585485 & 737532 & 3.0969 & 3.2573 & TRN \\
\hline CHEMBL3192179 & 737532 & 4.3125 & 3.5723 & TRN \\
\hline CHEMBL1469008 & 737532 & 3.0969 & 3.141 & TRN \\
\hline CHEMBL1581385 & 737532 & 4.2749 & 3.502 & TRN \\
\hline CHEMBL 225903 & 737532 & 3.0969 & 3.3876 & TRN \\
\hline CHEMBL1523343 & 737532 & 3.0969 & 3.2897 & TRN \\
\hline CHEMBL1368818 & 737532 & 3.0969 & 3.3522 & TRN \\
\hline CHEMBL1982454 & 737532 & 3.0969 & 3.1623 & TRN \\
\hline CHEMBL1472466 & 737532 & 3.0969 & 3.0527 & TST \\
\hline CHEMBL458114 & 737532 & 4.3325 & 3.3839 & TRN \\
\hline CHEMBL1360765 & 737532 & 3.0969 & 3.3819 & TST \\
\hline CHEMBL1720314 & 737532 & 3.0969 & 3.7308 & TRN \\
\hline CHEMBL1312318 & 737532 & 4.6478 & 3.4093 & TRN \\
\hline CHEMBL 3189803 & 737532 & 4.2495 & 3.4807 & TRN \\
\hline CHEMBL 3190727 & 737532 & 4.3556 & 3.62100 & 00000000004 \\
\hline CHEMBL 3210640 & 737532 & 3.0969 & 3.3467 & TRN \\
\hline CHEMBL512216 & 737532 & 3.0969 & 3.708 & TST \\
\hline CHEMBL1385889 & 737532 & 3.0969 & 3.0898 & TRN \\
\hline CHEMBL1557622 & 737532 & 3.0969 & 3.6866 & TRN \\
\hline CHEMBL3198312 & 737532 & 3.0969 & 3.4805 & TRN \\
\hline CHEMBL1533008 & 737532 & 4.2226 & 3.4245 & TRN \\
\hline CHEMBL1342570 & 737532 & 3.0969 & 3.4556 & TRN \\
\hline
\end{tabular}


Supplemental Table S2.txt

\begin{tabular}{|c|c|c|c|c|}
\hline 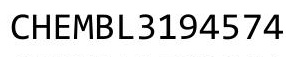 & & & & \\
\hline HEMBL1723964 & 37532 & .0969 & 5817 & $\pi$ \\
\hline HEMBL 257286 & 2 & 2848 & 64 & \\
\hline 399 & & & & \\
\hline AEMBL1723607 & & 162 & 341 & \\
\hline AEMBL1699398 & 37532 & 0969 & 5023 & \\
\hline HEMBL1529325 & 37532 & .301 & 8668 & \\
\hline HEMBL1530439 & & 3.0969 & 4384 & \\
\hline HEMBL47 & 32 & 2652 & 5584 & \\
\hline AEMBL15 & & 969 & 5851 & \\
\hline HEMBL3213331 & 37532 & $\partial 969$ & 74 & \\
\hline HEMBL1324935 & 32 & .0969 & 6519 & \\
\hline HEMBL12 & 32 & 482 & & \\
\hline HEMBL10 & 32 & 969 & 978 & \\
\hline HEMBL 14 & & 969 & 479 & \\
\hline HEMBL1527929 & 32 & 2676 & 8111 & \\
\hline HEMBL1428615 & & 969 & & \\
\hline HEMBL14 & 2 & 969 & 6673 & \\
\hline L15 & & 969 & 925 & \\
\hline HEMBL13 & & 716 & 05 & \\
\hline HEMBL1364896 & 32 & 3706 & 3909 & \\
\hline IEMBL13: & & 92 & & \\
\hline HEMBL15 & 32 & 969 & 951 & RIV \\
\hline HEM & & 59 & 343 & \\
\hline HEM & 32 & 37 & 541 & \\
\hline HEMBL 14 & & 9969 & 3934 & \\
\hline IEMBL14 & & 59 & & iv \\
\hline HEMBL14 & & 8 & 11 & \\
\hline HEM & & 59 & 11 & \\
\hline HEMRI $1 /$ & 2 & 69 & 381 & ST \\
\hline JEMBL15 & & 969 & & ST \\
\hline HEMBL1705412 & & 969 & 6662 & RN \\
\hline AEMBL17 & & 031 & 261 & RN \\
\hline 0 & 2 & & 46 & RN \\
\hline 93 & & 69 & 054 & $\mathrm{RN}$ \\
\hline AEMBL137 & & 969 & & ST \\
\hline HEMBL3214350 & & 969 & 7983 & RN \\
\hline 5 & & & & RIN \\
\hline ה19 וסמזו & & 59 & 89 & RIN \\
\hline HEMBL46 & & & & $\mathrm{RN}$ \\
\hline AEMBL3198697 & 32 & 969 & 5346 & RN \\
\hline HEMBL 14 & 2 & 969 & 3676 & RN \\
\hline & & 7 & & \\
\hline HEMBL 31 & & & 8089 & \\
\hline HEMBL1594545 & 737 & 445 & 3801 & $\mathrm{RN}$ \\
\hline AEMBL 7660 & 37 & 57 & 5409 & \\
\hline 100 & & & & \\
\hline גריברי & 737 & & & \\
\hline
\end{tabular}

Page 3590 
Supplemental Table S2.txt

\begin{tabular}{|c|c|c|c|c|c|}
\hline CHEMBL1309134 & 737532 & 3.0969 & 3.0412 & TRN & \\
\hline CHEMBL1533968 & 737532 & 3.0969 & 3.6474 & TRN & \\
\hline CHEMBL1391552 & 737532 & 4.9469 & 4.6538 & TRN & \\
\hline CHEMBL1426134 & 737532 & 3.0969 & 3.4526 & TRN & \\
\hline CHEMBL1449526 & 737532 & 4.3045 & 3.3817 & TRN & \\
\hline CHEMBL1514534 & 737532 & \multicolumn{2}{|c|}{ 4. 218999999999999} & 3.3489 & $\mathrm{~T}$ \\
\hline CHEMBL1347600 & 737532 & 3.0969 & 3.2359 & TST & \\
\hline CHEMBL1423667 & 737532 & 3.0969 & 3.3768 & TRN & \\
\hline CHEMBL1709564 & 737532 & 3.0969 & 3.3682 & TRN & \\
\hline CHEMBL1524916 & 737532 & 4.5129 & 3.5555 & TST & \\
\hline CHEMBL1968789 & 737532 & 3.0969 & 3.5974 & TRN & \\
\hline CHEMBL1451538 & 737532 & 4.5243 & 3.58399 & 99999999996 & mo \\
\hline CHEMBL1312502 & 737532 & 3.0969 & 3.2167 & TRN & \\
\hline CHEMBL1701411 & 737532 & 4.2441 & 3.4509 & TRN & \\
\hline CHEMBL1460878 & 737532 & 3.0969 & 3.1142 & TRN & \\
\hline CHEMBL1542413 & 737532 & 3.0969 & 3.4503 & TST & \\
\hline CHEMBL1706151 & 737532 & 3.0969 & 3.4258 & TRN & \\
\hline CHEMBL1565767 & 737532 & 4.4597 & 3.7469 & TRN & \\
\hline CHEMBL1699137 & 737532 & 3.0969 & 3.6392 & TRN & \\
\hline CHEMBL1712663 & 737532 & 4.5114 & 3.6409 & TST & \\
\hline CHEMBL1347633 & 737532 & 3.0969 & 3.4673 & TRN & \\
\hline CHEMBL1477787 & 737532 & 3.0969 & 3.6038 & TRN & \\
\hline CHEMBL1362714 & 737532 & 3.0969 & 3.3577 & TST & \\
\hline CHEMBL327502 & 737532 & 5.0177 & 5.0144 & TRN & \\
\hline CHEMBL1536873 & 737532 & 3.0969 & 3.2573 & TRN & \\
\hline CHEMBL1583616 & 737532 & 3.0969 & 3.1632 & TRN & \\
\hline CHEMBL1452103 & 737532 & 4.2644 & 3.4587 & TRN & \\
\hline CHEMBL1600326 & 737532 & 3.0969 & 3.4414 & TRN & \\
\hline CHEMBL1703503 & 737532 & 5.1481 & 4.729 & TRN & \\
\hline CHEMBL1444986 & 737532 & 3.0969 & 3.4477 & TRN & \\
\hline CHEMBL1390450 & 737532 & 3.0969 & 3.5322 & TRN & \\
\hline CHEMBL1427185 & 737532 & 3.0969 & 3.4861 & TRN & \\
\hline CHEMBL1408295 & 737532 & 3.0969 & 3.3724 & TRN & \\
\hline CHEMBL1733684 & 737532 & 4.5376 & 3.6332 & TST & \\
\hline CHEMBL1370221 & 737532 & 4.342 & 4.3674 & TRN & \\
\hline CHEMBL1312788 & 737532 & 3.0969 & 3.3077 & TRN & \\
\hline CHEMBL1606460 & 737532 & 3.0969 & 3.47600 & 20000000004 & \\
\hline CHEMBL1406389 & 737532 & 3.0969 & 3.2054 & TRN & \\
\hline CHEMBL1600114 & 737532 & 4.9788 & 4.1503 & TRN & \\
\hline CHEMBL1972037 & 737532 & 3.0969 & 3.6265 & TRN & \\
\hline CHEMBL1702981 & 737532 & 4.7496 & 4.8613 & TRN & \\
\hline CHEMBL3194593 & 737532 & 3.0969 & 3.6372 & TRN & \\
\hline CHEMBL572994 & 737532 & 4.1215 & 3.8607 & TRN & \\
\hline CHEMBL1715088 & 737532 & 3.0969 & 3.2452 & TRN & \\
\hline CHEMBL1381271 & 737532 & 3.0969 & 2.9774 & TRN & \\
\hline CHEMBL1504429 & 737532 & 3.0969 & 3.5813 & TRN & \\
\hline CHEMBL1982688 & 737532 & 3.0969 & 3.7807 & TRN & \\
\hline CHEMBL1724452 & 737532 & 3.0969 & 3.5909 & TRN & \\
\hline
\end{tabular}

Page 3591 


\begin{tabular}{|c|c|c|c|c|c|}
\hline & & \multicolumn{4}{|c|}{ Supplemental Table S2.txt } \\
\hline CHEMBL1302099 & 737532 & 3.0969 & 3.1372 & TRN & \\
\hline CHEMBL3208936 & 737532 & 3.0969 & 3.5512 & TRN & \\
\hline CHEMBL1698737 & 737532 & 3.0969 & 3.3469 & TRN & \\
\hline CHEMBL1427539 & 737532 & 4.202 & 3.676 & TRN & \\
\hline CHEMBL3189471 & 737532 & 3.0969 & 3.6699 & TRN & \\
\hline CHEMBL1426550 & 737532 & 3.0969 & 3.1374 & TRN & \\
\hline CHEMBL1510664 & 737532 & 3.0969 & 3.74899 & 99999999997 & TST \\
\hline CHEMBL3189691 & 737532 & 4.3788 & 3.6139 & TRN & \\
\hline CHEMBL 244649 & 737532 & 4.3979 & 3.3196 & TRN & \\
\hline CHEMBL1717420 & 737532 & 5.0376 & 4.667 & TRN & \\
\hline CHEMBL1557018 & 737532 & 3.0969 & 3.1526 & TRN & \\
\hline CHEMBL1558563 & 737532 & 4.2725 & 3.5488 & TRN & \\
\hline CHEMBL1567773 & 737532 & 4.2782 & 3.7932 & TRN & \\
\hline CHEMBL1471841 & 737532 & 4.4318 & 4.1419 & TRN & \\
\hline CHEMBL1319488 & 737532 & 3.0969 & 3.7943 & TRN & \\
\hline CHEMBL1322745 & 737532 & 3.0969 & 3.1489 & TRN & \\
\hline CHEMBL1423122 & 737532 & 4.2725 & 3.1388 & TRN & \\
\hline CHEMBL1728065 & 737532 & 4.2464 & 3.819 & TRN & \\
\hline CHEMBL 1478652 & 737532 & 3.0969 & 3.4764 & TST & \\
\hline CHEMBL1717071 & 737532 & 4.5735 & 3.8137 & TRN & \\
\hline CHEMBL3197910 & 737532 & 3.0969 & 3.2878 & TRN & \\
\hline CHEMBL1414595 & 737532 & 3.0969 & 3.1904 & TST & \\
\hline CHEMBL1704186 & 737532 & 3.0969 & 3.6745 & TRN & \\
\hline CHEMBL1432204 & 737532 & 3.0969 & 3.1961 & TRN & \\
\hline CHEMBL1312836 & 737532 & 3.0969 & 3.42199 & 99999999997 & TRN \\
\hline CHEMBL1589526 & 737532 & 3.0969 & 3.1799 & TST & \\
\hline CHEMBL1412451 & 737532 & 3.0969 & 3.5414 & TRN & \\
\hline CHEMBL3191188 & 737532 & 3.0969 & 3.5221 & TRN & \\
\hline CHEMBL1309972 & 737532 & 3.0969 & 3.7301 & TRN & \\
\hline CHEMBL3197242 & 737532 & 3.0969 & 3.5782 & TRN & \\
\hline CHEMBL1370704 & 737532 & 4.684 & 4.1057 & TRN & \\
\hline CHEMBL1560188 & 737532 & 3.0969 & 3.2603 & TRN & \\
\hline CHEMBL103583 & 737532 & 3.0969 & 3.7928 & TST & \\
\hline CHEMBL1332203 & 737532 & 3.0969 & 3.2554 & TRN & \\
\hline CHEMBL3192556 & 737532 & 3.0969 & 3.533 & TRN & \\
\hline CHEMBL467987 & 737532 & 4.1397 & 3.7048 & TST & \\
\hline CHEMBL1454269 & 737532 & 3.0969 & 3.5537 & TRN & \\
\hline CHEMBL1370822 & 737532 & 3.0969 & 3.33600 & 00000000003 & TRN \\
\hline CHEMBL1324104 & 737532 & 3.0969 & 3.5329 & TST & \\
\hline CHEMBL1380978 & 737532 & 3.0969 & 2.8353 & TRN & \\
\hline CHEMBL1337166 & 737532 & 3.0969 & 3.5364 & TRN & \\
\hline CHEMBL536950 & 737532 & 4.9957 & 4.1457 & TRN & \\
\hline CHEMBL452751 & 737532 & 3.0969 & 3.5966 & TST & \\
\hline CHEMBL1392315 & 737532 & 4.5129 & 4.659 & TRN & \\
\hline CHEMBL1566610 & 737532 & 3.0969 & 3.427 & TST & \\
\hline CHEMBL1514916 & 737532 & 3.0969 & 3.7225 & TST & \\
\hline CHEMBL1736559 & 737532 & 3.0969 & 3.5275 & TST & \\
\hline CHEMBL608699 & 737532 & 4.4425 & 4.8879 & TRN & \\
\hline
\end{tabular}


Supplemental Table S2.txt

\begin{tabular}{|c|c|c|c|c|}
\hline CHEMBL498373 & 737532 & 3.0969 & 3.4676 & TRN \\
\hline CHEMBL3199003 & 737532 & 3.0969 & 3.3488 & TRN \\
\hline CHEMBL1595227 & 737532 & 3.0969 & 3.3905 & TST \\
\hline CHEMBL1732317 & 737532 & 3.0969 & 3.248 & TST \\
\hline CHEMBL1706062 & 737532 & 4.2255 & 3.7451 & TRN \\
\hline CHEMBL1574351 & 737532 & 4.4672 & 4.0454 & TRN \\
\hline CHEMBL1504939 & 737532 & 3.0969 & 3.5792 & TRN \\
\hline CHEMBL1545058 & 737532 & 3.0969 & 2.9485 & TRN \\
\hline CHEMBL1993855 & 737532 & 4.9031 & 3.5697 & TRN \\
\hline CHEMBL1331149 & 737532 & 3.0969 & 3.1135 & TRN \\
\hline CHEMBL1352170 & 737532 & 4.2336 & 3.7596 & TST \\
\hline CHEMBL1530404 & 737532 & 3.0969 & 3.1546 & TRN \\
\hline CHEMBL51085 & 737532 & 4.8794 & 4.9935 & TRN \\
\hline CHEMBL1416184 & 737532 & 3.0969 & 3.3447 & TRN \\
\hline CHEMBL1368578 & 737532 & 3.0969 & 3.365 & TRN \\
\hline CHEMBL1736254 & 737532 & 4.5986 & 3.50399 & 99999999996 \\
\hline CHEMBL1969672 & 737532 & 4.52 & 3.5533 & TRN \\
\hline CHEMBL1731090 & 737532 & 4.4698 & 3.5595 & TRN \\
\hline CHEMBL1571835 & 737532 & 3.0969 & 3.6401 & TRN \\
\hline CHEMBL1359410 & 737532 & 4.618 & 4.3168 & TRN \\
\hline CHEMBL1503335 & 737532 & 3.0969 & 3.3823 & TRN \\
\hline CHEMBL3196864 & 737532 & 4.2716 & 3.5863 & TRN \\
\hline CHEMBL441433 & 737532 & 3.0969 & 3.7254 & TRN \\
\hline CHEMBL1402525 & 737532 & 3.0969 & 3.7215 & TRN \\
\hline CHEMBL1392885 & 737532 & 3.0969 & 3.7578 & TST \\
\hline CHEMBL1703714 & 737532 & 4.1952 & 3.6169 & TRN \\
\hline CHEMBL1613004 & 737532 & 4.3872 & 3.4087 & TST \\
\hline CHEMBL1449785 & 737532 & 4.3757 & 3.77100 & 30000000004 \\
\hline CHEMBL1465240 & 737532 & 3.0969 & 3.2896 & TRN \\
\hline CHEMBL1599257 & 737532 & 4.2314 & 3.2123 & TRN \\
\hline CHEMBL3197161 & 737532 & 3.0969 & 3.6004 & TRN \\
\hline CHEMBL1339349 & 737532 & 3.0969 & 3.2669 & TRN \\
\hline CHEMBL3197471 & 737532 & 3.0969 & 3.2333 & TRN \\
\hline CHEMBL1734152 & 737532 & 4.1373 & 3.7392 & TRN \\
\hline CHEMBL1465511 & 737532 & 4.4389 & 3.4013 & TRN \\
\hline CHEMBL1438567 & 737532 & 3.0969 & 3.5264 & TRN \\
\hline CHEMBL3192006 & 737532 & 3.0969 & 3.7003 & TST \\
\hline CHEMBL1531345 & 737532 & 4.2132 & 3.7706 & TRN \\
\hline CHEMBL1441974 & 737532 & 3.0969 & 3.3361 & TST \\
\hline CHEMBL1313139 & 737532 & 3.0969 & 3.1611 & TRN \\
\hline CHEMBL1333250 & 737532 & 4.7545 & 5.0144 & TRN \\
\hline CHEMBL1466201 & 737532 & 3.0969 & 3.7677 & TRN \\
\hline CHEMBL1706548 & 737532 & 4.8297 & 4.7381 & TRN \\
\hline CHEMBL1699069 & 737532 & 3.0969 & 3.3556 & TRN \\
\hline CHEMBL1497146 & 737532 & 3.0969 & 3.3887 & TRN \\
\hline CHEMBL1709906 & 737532 & 4.8962 & 4.7137 & TRN \\
\hline CHEMBL1475724 & 737532 & 3.0969 & 3.4341 & TRN \\
\hline CHEMBL1564773 & 737532 & 3.0969 & 3.2685 & TRN \\
\hline
\end{tabular}

Page 3593 


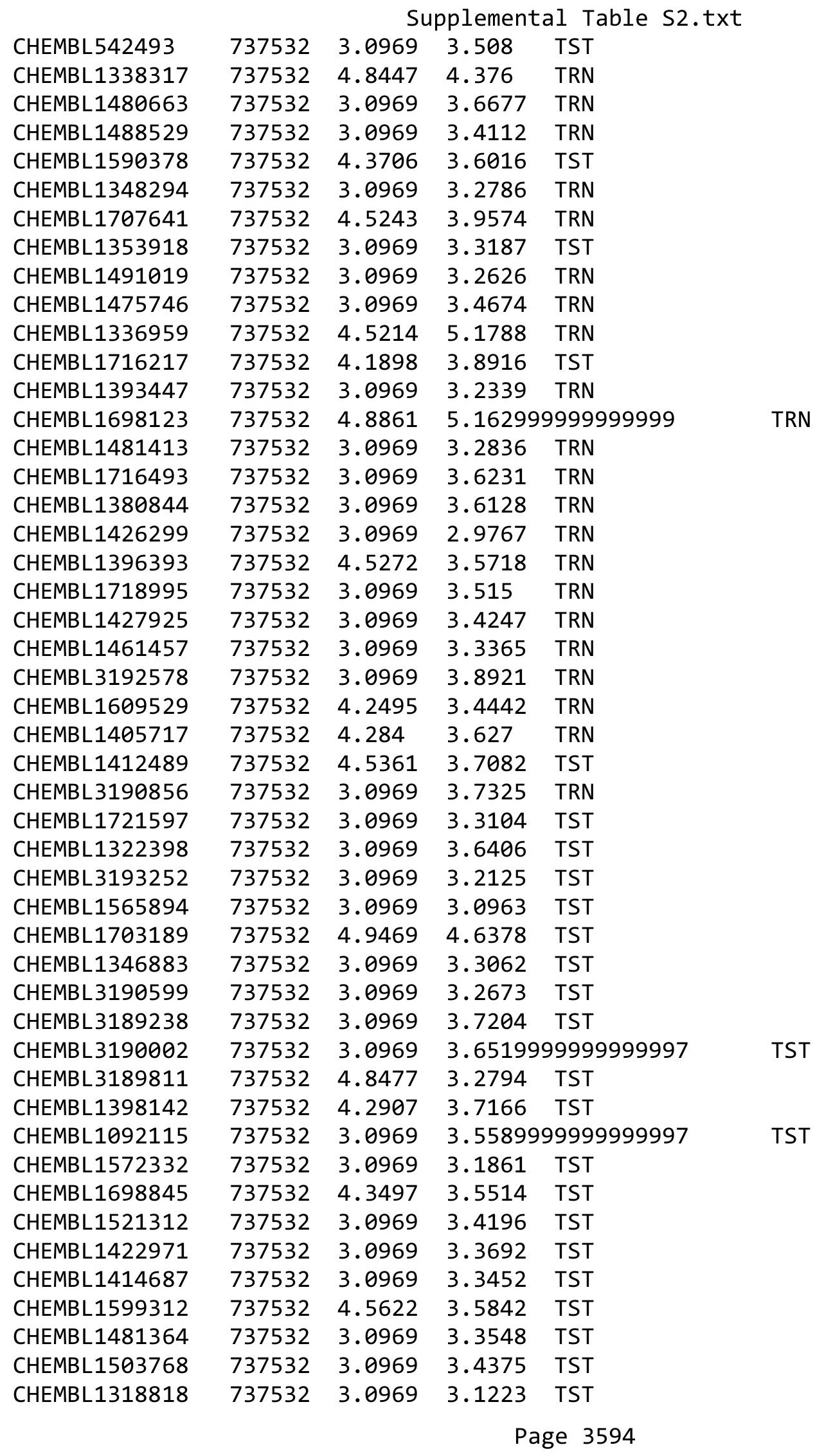


Supplemental Table S2.txt

\begin{tabular}{|c|c|c|c|c|}
\hline CHEMBL1442252 & 737532 & 3.0969 & 3.3375 & TST \\
\hline CHEMBL1586360 & 737532 & 3.0969 & 3.0842 & TST \\
\hline CHEMBL1566805 & 737532 & 3.0969 & 3.5132 & TST \\
\hline CHEMBL1546172 & 737532 & 3.0969 & 3.5961 & TST \\
\hline CHEMBL1342666 & 737532 & 3.0969 & 3.4042 & TST \\
\hline CHEMBL463783 & 737532 & 3.0969 & 3.1589 & TST \\
\hline CHEMBL1441874 & 737532 & 3.0969 & 3.5603 & TST \\
\hline CHEMBL1468193 & 737532 & 3.0969 & 3.2501 & TST \\
\hline CHEMBL1579380 & 737532 & 3.0969 & 3.54699 & 99999999997 \\
\hline CHEMBL1301842 & 737532 & 3.0969 & 3.4694 & TST \\
\hline CHEMBL1709419 & 737532 & 4.8268 & 4.6427 & TST \\
\hline CHEMBL1330951 & 737532 & 3.0969 & 3.2999 & TST \\
\hline CHEMBL1562104 & 737532 & 4.2269 & 3.7406 & TST \\
\hline CHEMBL1473548 & 737532 & 3.0969 & 3.7016 & TST \\
\hline CHEMBL1707222 & 737532 & 4.27 & 3.5709 & TST \\
\hline CHEMBL1968290 & 737532 & 3.0969 & 3.2972 & TST \\
\hline CHEMBL1613270 & 737532 & 4.109 & 3.2746 & TST \\
\hline CHEMBL 3196050 & 737532 & 3.0969 & 3.93399 & 99999999997 \\
\hline CHEMBL1548507 & 737532 & 3.0969 & 3.6075 & TST \\
\hline CHEMBL1542003 & 737532 & 4.6517 & 3.4935 & TST \\
\hline CHEMBL1447350 & 737532 & 4.3116 & 3.5208 & TST \\
\hline CHEMBL1432420 & 737532 & 3.0969 & 3.4355 & TST \\
\hline CHEMBL1698802 & 737532 & 4.4789 & 3.6122 & TST \\
\hline CHEMBL1568124 & 737532 & 3.0969 & 3.578006 & 00000000003 \\
\hline CHEMBL1480186 & 737532 & 4.8153 & 3.8219 & TST \\
\hline CHEMBL1966224 & 737532 & 4.1013 & 3.722 & TST \\
\hline CHEMBL1466117 & 737532 & 3.0969 & 3.4699 & TST \\
\hline CHEMBL1413005 & 737532 & 4.6556 & 3.5813 & TST \\
\hline CHEMBL1480480 & 737532 & 4.3635 & 3.2669 & TST \\
\hline CHEMBL1567159 & 737532 & 3.0969 & 3.2532 & TST \\
\hline CHEMBL1734268 & 737532 & 3.0969 & 3.6724 & TST \\
\hline CHEMBL1719648 & 737532 & 3.0969 & 3.6526 & TST \\
\hline CHEMBL1509082 & 737532 & 4.6556 & 4.4123 & TST \\
\hline CHEMBL1719817 & 737532 & 3.0969 & 3.4917 & TST \\
\hline CHEMBL1319020 & 737532 & 4.1029 & 3.7016 & TST \\
\hline CHEMBL1576254 & 737532 & 3.0969 & 3.2127 & TST \\
\hline CHEMBL1707429 & 737532 & 3.0969 & 3.7634 & TST \\
\hline CHEMBL1713817 & 737532 & 3.0969 & 3.6114 & TST \\
\hline CHEMBL1504286 & 737532 & 4.3325 & 4.2122 & TST \\
\hline CHEMBL3655778 & 1527922 & 8.8827 & 8.7843 & TRN \\
\hline CHEMBL3655837 & 1527922 & 8.9281 & 8.8435 & TRN \\
\hline CHEMBL 2381186 & 1527922 & 9.2381 & 9.0635 & TRN \\
\hline CHEMBL3655813 & 1527922 & 7.1726 & 7.1178 & TST \\
\hline CHEMBL 3655849 & 1527922 & 8.9666 & 8.781 & TRN \\
\hline CHEMBL3655790 & 1527922 & 8.6326 & 8.8003 & TRN \\
\hline CHEMBL 3655781 & 1527922 & 8.2125 & 8.1598 & TRN \\
\hline CHEMBL 3655843 & 1527922 & 7.6655 & 7.874 & TRN \\
\hline CHEMBL 3655848 & 1527922 & 8.5575 & 8.974 & TRN \\
\hline
\end{tabular}


Supplemental Table S2.txt

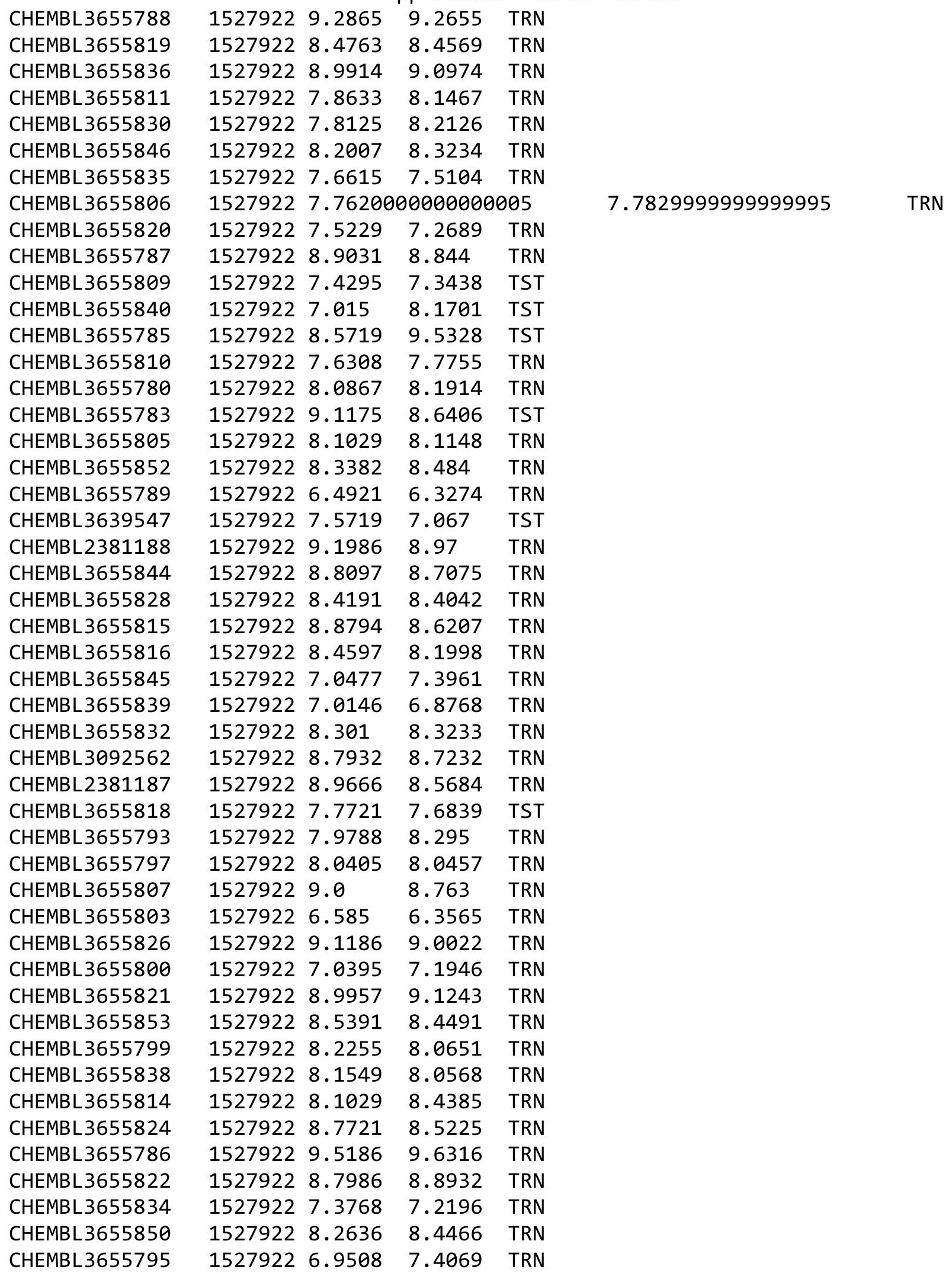

Page 3596 
Supplemental Table S2.txt

\begin{tabular}{|c|c|c|c|c|c|}
\hline CHEMBL3655791 & 1527922 & 7.9355 & 7.8717 & TRN & \\
\hline CHEMBL 3655808 & 1527922 & 7.6968 & 7.8826 & TRN & \\
\hline CHEMBL3655798 & 1527922 & 7.9747 & 8.0628 & TRN & \\
\hline CHEMBL 3655804 & 1527922 & 7.5258 & \multicolumn{2}{|c|}{7.547999999999999} & TRN \\
\hline CHEMBL 3655842 & 1527922 & 8.3089 & 8.1529 & TRN & \\
\hline CHEMBL2381185 & 1527922 & 9.0835 & 8.9239 & TRN & \\
\hline CHEMBL 3655829 & 1527922 & 8.3686 & 8.245 & TRN & \\
\hline CHEMBL3655794 & 1527922 & 7.4295 & 7.4688 & TRN & \\
\hline CHEMBL 3655817 & 1527922 & 7.7375 & 8.0371 & TRN & \\
\hline CHEMBL3655812 & 1527922 & 7.8665 & 7.8342 & TRN & \\
\hline CHEMBL 3655782 & 1527922 & 7.9706 & 7.7604 & TST & \\
\hline CHEMBL 3655841 & 1527922 & 6.9666 & 8.5761 & TST & \\
\hline CHEMBL 3655831 & 1527922 & 8.6498 & 8.3318 & TRN & \\
\hline CHEMBL 3655825 & 1527922 & 8.1221 & 8.3608 & TST & \\
\hline CHEMBL 3655847 & 1527922 & 8.6383 & 8.7715 & TST & \\
\hline CHEMBL3655827 & 1527922 & 8.8861 & 9.0357 & TST & \\
\hline CHEMBL2381189 & 1527922 & 8.6968 & 8.4523 & TST & \\
\hline CHEMBL 3655851 & 1527922 & \multicolumn{2}{|c|}{9.011000000000001} & 9.2965 & TST \\
\hline CHEMBL 3655801 & 1527922 & 7.1433 & 7.4297 & TST & \\
\hline CHEMBL 3655833 & 1527922 & 7.2168 & 8.4228 & TST & \\
\hline CHEMBL 3655802 & 1527922 & 6.6003 & 7.2043 & TST & \\
\hline CHEMBL3655784 & 1527922 & 8.0357 & 8.3162 & TST & \\
\hline CHEMBL3655796 & 1527922 & 6.5391 & 7.1797 & TST & \\
\hline CHEMBL3655792 & 1527922 & 8.8327 & 8.1362 & TST & \\
\hline CHEMBL 3655823 & 1527922 & 9.0182 & 9.1188 & TST & \\
\hline CHEMBL1546304 & 688337 & 5.4559 & 4.8987 & TRN & \\
\hline CHEMBL1533962 & 688337 & 4.9115 & 4.3052 & TRN & \\
\hline CHEMBL1609320 & 688337 & 5.4559 & 4.963999 & 99999999995 & TRN \\
\hline CHEMBL1531251 & 688337 & 3.4559 & 3.5881 & TRN & \\
\hline CHEMBL1468639 & 688337 & 3.4559 & 3.7118 & TRN & \\
\hline CHEMBL1336318 & 688337 & 5.1748 & 4.9026 & TRN & \\
\hline CHEMBL1471370 & 688337 & 5.4559 & 4.9881 & TRN & \\
\hline CHEMBL1608455 & 688337 & 4.6449 & 4.388 & TRN & \\
\hline CHEMBL1556933 & 688337 & 3.4559 & 3.2817 & TRN & \\
\hline CHEMBL1419672 & 688337 & 3.4559 & 3.5039 & TRN & \\
\hline CHEMBL1343692 & 688337 & 3.4559 & 2.9666 & TRN & \\
\hline CHEMBL1531118 & 688337 & 3.4559 & 4.0971 & TRN & \\
\hline CHEMBL1984816 & 688337 & 3.4559 & 2.8273 & TRN & \\
\hline CHEMBL1342624 & 688337 & 3.4559 & 3.3009 & TRN & \\
\hline CHEMBL1504083 & 688337 & 4.777 & 4.7823 & TRN & \\
\hline CHEMBL1381600 & 688337 & 5.4379 & 5.252006 & 3000000001 & TRN \\
\hline CHEMBL1326298 & 688337 & 3.4559 & 3.9777 & TRN & \\
\hline CHEMBL1426722 & 688337 & 4.9739 & 4.4473 & TST & \\
\hline CHEMBL2004475 & 688337 & 4.9751 & 4.8191 & TRN & \\
\hline CHEMBL1457690 & 688337 & 5.1332 & 4.3703 & TRN & \\
\hline CHEMBL1421312 & 688337 & 3.4559 & 3.9816 & TRN & \\
\hline CHEMBL1427664 & 688337 & 3.4559 & 3.9319 & TST & \\
\hline CHEMBL1360997 & 688337 & 3.4559 & 3.4268 & TRN & \\
\hline
\end{tabular}




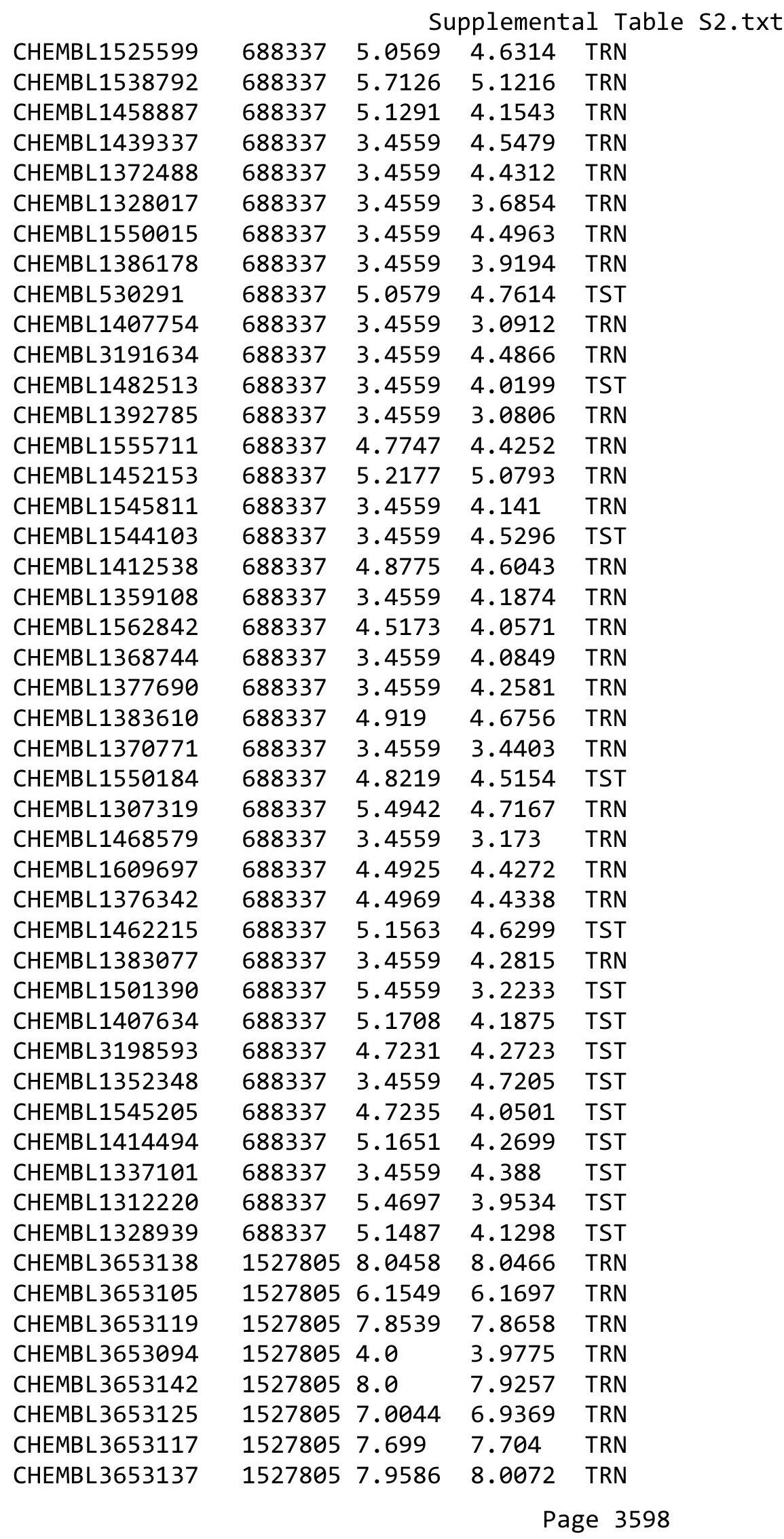


Supplemental Table S2.txt

\begin{tabular}{|c|c|c|c|c|c|}
\hline CHEMBL3653139 & 1527805 & 7.9208 & 7.8606 & TRN & \\
\hline CHEMBL3653104 & 1527805 & 5.9208 & 5.895 & TRN & \\
\hline CHEMBL3653109 & 1527805 & 6.2182 & 6.3511 & TST & \\
\hline CHEMBL3653140 & 1527805 & 7.1549 & 7.316 & TRN & \\
\hline CHEMBL3653113 & 1527805 & 7.3768 & 7.3555 & TRN & \\
\hline CHEMBL3653135 & 1527805 & 7.7959 & 7.8297 & TRN & \\
\hline CHEMBL3653133 & 1527805 & 8.1549 & 8.1915 & TRN & \\
\hline CHEMBL3653112 & 1527805 & 6.3143 & 6.1772 & TST & \\
\hline CHEMBL3653098 & 1527805 & 6.2757 & 6.2703 & TRN & \\
\hline CHEMBL3653111 & 1527805 & 5.5935 & 6.0871 & TST & \\
\hline CHEMBL 3674746 & 1527805 & 8.0 & 7.9648 & TRN & \\
\hline CHEMBL3653124 & 1527805 & 7.4949 & 7.5155 & TRN & \\
\hline CHEMBL3653129 & 1527805 & 4.0 & 4.0142 & TRN & \\
\hline CHEMBL3653102 & 1527805 & 6.5686 & 6.6587 & TST & \\
\hline CHEMBL3653128 & 1527805 & 7.2924 & 7.3375 & TRN & \\
\hline CHEMBL3653132 & 1527805 & 6.6778 & 6.6466 & TST & \\
\hline CHEMBL3653097 & 1527805 & 7.5086 & 7.5107 & TRN & \\
\hline CHEMBL3653101 & 1527805 & 7.2676 & 7.2643 & TRN & \\
\hline CHEMBL3653095 & 1527805 & 5.8861 & 5.8887 & TRN & \\
\hline CHEMBL3653121 & 1527805 & 6.5768 & 6.5259 & TST & \\
\hline CHEMBL3653106 & 1527805 & 5.0915 & 5.0915 & TRN & \\
\hline CHEMBL3653108 & 1527805 & 4.0 & 4.0056 & TRN & \\
\hline CHEMBL 3653100 & 1527805 & 7.6576 & 7.6966 & TRN & \\
\hline CHEMBL3653127 & 1527805 & 7.7959 & $7.80200 t$ & 00000000005 & TRN \\
\hline CHEMBL3653096 & 1527805 & 7.2366 & 7.2671 & TRN & \\
\hline CHEMBL3653141 & 1527805 & 8.0458 & 7.9841 & TRN & \\
\hline CHEMBL3653122 & 1527805 & 7.3565 & 7.3508 & TRN & \\
\hline CHEMBL3653126 & 1527805 & 6.6108 & 6.5929 & TRN & \\
\hline CHEMBL3653115 & 1527805 & 5.9788 & 5.9801 & TRN & \\
\hline CHEMBL3653103 & 1527805 & 7.0605 & 7.0486 & TRN & \\
\hline CHEMBL3653116 & 1527805 & 4.0 & 4.004 & TRN & \\
\hline CHEMBL3653130 & 1527805 & 7.7959 & 7.8001 & TRN & \\
\hline CHEMBL3653131 & 1527805 & 8.0 & 7.8959 & TRN & \\
\hline CHEMBL3653099 & 1527805 & 7.3872 & 7.3711 & TRN & \\
\hline CHEMBL3653120 & 1527805 & 7.9586 & 8.0031 & TRN & \\
\hline CHEMBL3653123 & 1527805 & 8.1549 & 7.9414 & TST & \\
\hline CHEMBL3653118 & 1527805 & 6.857 & 7.0807 & TST & \\
\hline CHEMBL3653136 & 1527805 & 7.9586 & 8.1321 & TST & \\
\hline CHEMBL3653114 & 1527805 & 6.058 & 5.9903 & TST & \\
\hline CHEMBL3653110 & 1527805 & 6.0246 & 6.2063 & TST & \\
\hline CHEMBL3653107 & 1527805 & 4.0 & 3.929 & TST & \\
\hline CHEMBL3653093 & 1527805 & 6.2757 & 6.1712 & TST & \\
\hline CHEMBL3653353 & 1528890 & 5.041 & 4.8188 & TRN & \\
\hline CHEMBL3261065 & 1528890 & 6.5229 & 6.1347 & TRN & \\
\hline CHEMBL3653473 & 1528890 & 6.1549 & 6.2449 & TRN & \\
\hline CHEMBL3653383 & 1528890 & 6.3768 & 6.2412 & TST & \\
\hline CHEMBL3653487 & 1528890 & 9.0 & 8.4401 & TRN & \\
\hline CHEMBL3653359 & 1528890 & 6.3768 & 5.8839 & TRN & \\
\hline
\end{tabular}


Supplemental Table S2.txt

\begin{tabular}{|c|c|c|c|c|c|}
\hline CHEMBL3653469 & 1528890 & 6.0862 & 6.1334 & TST & \\
\hline CHEMBL3653491 & 1528890 & 6.585 & 6.4755 & TRN & \\
\hline CHEMBL3653430 & 1528890 & 7.4685 & 6.7641 & TRN & \\
\hline CHEMBL3653501 & 1528890 & 6.7696 & 7.1877 & TRN & \\
\hline CHEMBL3653437 & 1528890 & 6.0862 & 5.7956 & TRN & \\
\hline CHEMBL3653385 & 1528890 & 6.7447 & 6.5435 & TRN & \\
\hline CHEMBL3653433 & 1528890 & 5.1079 & 5.343999 & 9999999999 & TRN \\
\hline CHEMBL3653490 & 1528890 & 8.5229 & 8.2872 & TRN & \\
\hline CHEMBL3653478 & 1528890 & 6.7447 & 6.6133 & TRN & \\
\hline CHEMBL 3653400 & 1528890 & 7.0 & 6.0913 & TST & \\
\hline CHEMBL3653498 & 1528890 & 7.7959 & 7.5796 & TRN & \\
\hline CHEMBL3653398 & 1528890 & 5.9208 & 6.2768 & TRN & \\
\hline CHEMBL3653504 & 1528890 & 6.4685 & 6.8417 & TRN & \\
\hline CHEMBL3653474 & 1528890 & 6.5376 & 5.9537 & TRN & \\
\hline CHEMBL 3653388 & 1528890 & 7.0757 & 6.5067 & TRN & \\
\hline CHEMBL3653495 & 1528890 & 8.0458 & 6.2461 & TST & \\
\hline CHEMBL3653408 & 1528890 & 7.3372 & 7.0833 & TST & \\
\hline CHEMBL3653428 & 1528890 & 6.6198 & 7.0634 & TRN & \\
\hline CHEMBL 3653452 & 1528890 & 7.1079 & 7.2295 & TRN & \\
\hline CHEMBL 3956867 & 1528890 & 7.0362 & 6.9821 & TST & \\
\hline CHEMBL3653477 & 1528890 & 6.9208 & 6.9468 & TRN & \\
\hline CHEMBL3653394 & 1528890 & 5.7055 & 5.8414 & TRN & \\
\hline CHEMBL3639522 & 1528890 & 6.4559 & 6.3754 & TRN & \\
\hline CHEMBL 3653405 & 1528890 & 7.585 & 7.0789 & TST & \\
\hline CHEMBL3653446 & 1528890 & 8.0 & 8.1264 & TRN & \\
\hline CHEMBL3653465 & 1528890 & 7.3768 & 7.327000 & 3000000001 & TRN \\
\hline CHEMBL3653357 & 1528890 & 5.699 & 5.7822 & TRN & \\
\hline CHEMBL3653367 & 1528890 & 6.4815 & 6.2983 & TRN & \\
\hline CHEMBL 3653377 & 1528890 & 6.0 & 7.3015 & TRN & \\
\hline CHEMBL 3653461 & 1528890 & 6.585 & 6.3928 & TRN & \\
\hline CHEMBL3653418 & 1528890 & 7.3565 & 6.9186 & TRN & \\
\hline CHEMBL 3653497 & 1528890 & 6.6778 & 7.0982 & TRN & \\
\hline CHEMBL3653361 & 1528890 & 6.0132 & 6.463999 & 99999999995 & TRN \\
\hline CHEMBL 3653403 & 1528890 & 7.4685 & 7.1307 & TST & \\
\hline CHEMBL 3653496 & 1528890 & 4.0 & 5.1466 & TRN & \\
\hline CHEMBL3653414 & 1528890 & 5.5229 & 5.3958 & TRN & \\
\hline CHEMBL 3653484 & 1528890 & 7.1805 & 7.0743 & TRN & \\
\hline CHEMBL3653387 & 1528890 & 6.3565 & 6.2843 & TRN & \\
\hline CHEMBL 3653371 & 1528890 & 6.2518 & 6.3617 & TRN & \\
\hline CHEMBL3653476 & 1528890 & 8.0969 & 7.2523 & TST & \\
\hline CHEMBL3653510 & 1528890 & 6.0 & 7.0316 & TRN & \\
\hline CHEMBL3653435 & 1528890 & 5.284 & 5.6705 & TRN & \\
\hline CHEMBL3653466 & 1528890 & 7.1249 & 7.3058 & TRN & \\
\hline CHEMBL 3653457 & 1528890 & 7.0315 & 6.6441 & TRN & \\
\hline CHEMBL 3653444 & 1528890 & 7.7447 & 7.6913 & TRN & \\
\hline CHEMBL3653363 & 1528890 & 2.8861 & 5.1908 & TST & \\
\hline CHEMBL3653449 & 1528890 & 6.699 & 6.794 & TRN & \\
\hline CHEMBL 3653460 & 1528890 & 6.0 & 5.6573 & TST & \\
\hline
\end{tabular}


Supplemental Table S2.txt

\begin{tabular}{|c|c|c|c|c|}
\hline S & 28890 & & & \\
\hline & 528890 & 5.9586 & & \\
\hline & 890 & & & \\
\hline IEMBL & 8890 & & & \\
\hline AEMBL & 528890 & & & \\
\hline HEMBL3653401 & 528890 & 7.9586 & 9624 & \\
\hline & 528890 & & & \\
\hline IFME & 8890 & & & \\
\hline AEMBL36 & 528890 & 5.284 & & \\
\hline HEMBL3653499 & 528890 & 7447 & 9307 & \\
\hline AEMBL3653360 & 528890 & 4.9586 & 5211 & \\
\hline IEMBL & 8890 & & 591 & \\
\hline AEMBL & 8890 & & & \\
\hline HEMBL3 & 528890 & 21 & 4343 & \\
\hline AEMBL3 & 528890 & 61 & & \\
\hline AEMBL36 & 28890 & 7. & 097 & \\
\hline AEMBL & 8890 & & 201 & \\
\hline HEMBL & 8890 & & & \\
\hline AEMBL3 & 528890 & & 5028 & \\
\hline IEMBL36 & 890 & & & \\
\hline HEMBL= & 896 & & 01 & RIV \\
\hline AEMBL & 3890 & & 28 & No \\
\hline AEMBL & 890 & & 307 & \\
\hline 339 & 3890 & 861 & 543 & \\
\hline AEMBL3 & & & & I RIV \\
\hline AEMBL & 3890 & 6 & 17 & RN \\
\hline AEMBL & 890 & & & Niv \\
\hline AFMRI : & 3890 & 7. & & \\
\hline HEMBL3E & 528890 & & & in \\
\hline HEMBL3653365 & & & & is \\
\hline HEMBL36 & 890 & & 109 & RN \\
\hline HEMBL & 90 & & & RN \\
\hline HEMPI & 90 & & 13 & \\
\hline HEMBL3653350 & 528890 & & 227 & IRN \\
\hline HEMBL3653386 & 528890 & 6. & 362 & TRN \\
\hline HEMBL36 & 3890 & & 736 & TRN \\
\hline HCMP - & & & 23 & $\Gamma \mathrm{RN}$ \\
\hline HEMBL & & & 436 & RN \\
\hline HEMBL3653507 & 528890 & & 1896 & TRN \\
\hline IEMBL3 & 528890 & & 5646 & TST \\
\hline HEMBL36 & 3890 & 8 & 2678 & . \\
\hline HEMBL 3 & 528890 & & & RIN \\
\hline HEMBL3653458 & 528890 & & 7275 & RN \\
\hline AEMBL3653396 & 528890 & 6.9586 & 7219 & RN \\
\hline 1. & 890 & & & \\
\hline HEMBL39 & 528890 & 861 & 8899 & \\
\hline HEMBL36534 & 528890 & & .0464 & \\
\hline CHEMBL3653379 & 152889 & 7.1487 & 7.2202 & ГRN \\
\hline
\end{tabular}

Page 3601 
Supplemental Table S2.txt

\begin{tabular}{|c|c|c|c|c|}
\hline CHEMBL3653382 & 1528890 & 7.301 & 6.8571 & TRN \\
\hline CHEMBL3653384 & 1528890 & 6.6383 & 6.5616 & TRN \\
\hline CHEMBL3653380 & 1528890 & 7.2518 & 6.859 & TRN \\
\hline CHEMBL3653426 & 1528890 & 7.5686 & 7.1969 & TRN \\
\hline CHEMBL 3653344 & 1528890 & 5.3279 & 5.3618 & TRN \\
\hline CHEMBL3653506 & 1528890 & 6.1549 & 6.836 & TRN \\
\hline CHEMBL3653432 & 1528890 & 6.0506 & 6.2293 & TST \\
\hline CHEMBL3653391 & 1528890 & 6.1079 & 6.4761 & TRN \\
\hline CHEMBL 3653443 & 1528890 & 8.2218 & 6.6613 & TST \\
\hline CHEMBL3653440 & 1528890 & 5.7212 & 5.6636 & TRN \\
\hline CHEMBL 3653436 & 1528890 & 5.3979 & 5.6018 & TRN \\
\hline CHEMBL3653475 & 1528890 & 5.9208 & 6.6015 & TST \\
\hline CHEMBL3653453 & 1528890 & 6.1308 & 6.0411 & TST \\
\hline CHEMBL3653421 & 1528890 & 7.0269 & 7.0889 & TRN \\
\hline CHEMBL3653373 & 1528890 & 4.0 & 4.9665 & TRN \\
\hline CHEMBL 3653415 & 1528890 & 5.5376 & 4.8013 & TRN \\
\hline CHEMBL3653372 & 1528890 & 6.9208 & 6.2059 & TRN \\
\hline CHEMBL3653448 & 1528890 & 7.4437 & 7.3878 & TRN \\
\hline CHEMBL3653492 & 1528890 & 7.9208 & 7.9541 & TRN \\
\hline CHEMBL3653358 & 1528890 & 6.4559 & 6.6343 & TRN \\
\hline CHEMBL3653488 & 1528890 & 8.0969 & 7.8021 & TRN \\
\hline CHEMBL3653471 & 1528890 & 7.0 & 6.9345 & TRN \\
\hline CHEMBL3653374 & 1528890 & 6.1079 & 5.7853 & TRN \\
\hline CHEMBL3653481 & 1528890 & 7.7447 & 7.6608 & TRN \\
\hline CHEMBL3653369 & 1528890 & 5.8539 & 6.4999 & TST \\
\hline CHEMBL3653395 & 1528890 & 7.0223 & 7.1422 & TRN \\
\hline CHEMBL3261067 & 1528890 & 8.0 & 7.1072 & TST \\
\hline CHEMBL 3653397 & 1528890 & 7.3979 & 7.0492 & TRN \\
\hline CHEMBL3653416 & 1528890 & 6.0315 & 6.2673 & TRN \\
\hline CHEMBL 3653508 & 1528890 & 7.301 & 7.2301 & TRN \\
\hline CHEMBL3653356 & 1528890 & 6.2518 & 6.2406 & TRN \\
\hline CHEMBL3653368 & 1528890 & 6.0 & 6.3084 & TST \\
\hline CHEMBL 3653494 & 1528890 & 7.3098 & 7.2181 & TRN \\
\hline CHEMBL3653455 & 1528890 & 6.7696 & 6.6268 & TRN \\
\hline CHEMBL3653346 & 1528890 & 4.0 & 5.7766 & TST \\
\hline CHEMBL3653348 & 1528890 & 6.2291 & 6.16299 & \\
\hline CHEMBL3653354 & 1528890 & 5.0362 & 5.0556 & TRN \\
\hline CHEMBL3653489 & 1528890 & 5.9208 & 6.0522 & TST \\
\hline CHEMBL3653393 & 1528890 & 7.2366 & 7.027 & TRN \\
\hline CHEMBL3653422 & 1528890 & 6.0 & 6.6837 & TRN \\
\hline CHEMBL3261063 & 1528890 & 6.6198 & 6.4716 & TRN \\
\hline CHEMBL3653402 & 1528890 & 8.0458 & 6.754 & TST \\
\hline CHEMBL3653410 & 1528890 & 7.4202 & 7.11100 & 0000000001 \\
\hline CHEMBL3653463 & 1528890 & 6.8861 & 7.4218 & TRN \\
\hline CHEMBL3653427 & 1528890 & 7.7447 & 7.2953 & TRN \\
\hline CHEMBL3653399 & 1528890 & 7.699 & 6.4389 & TST \\
\hline CHEMBL 3653345 & 1528890 & 6.2676 & 6.7099 & TRN \\
\hline CHEMBL3653451 & 1528890 & 7.6021 & 7.3798 & TRN \\
\hline
\end{tabular}


Supplemental Table S2.txt

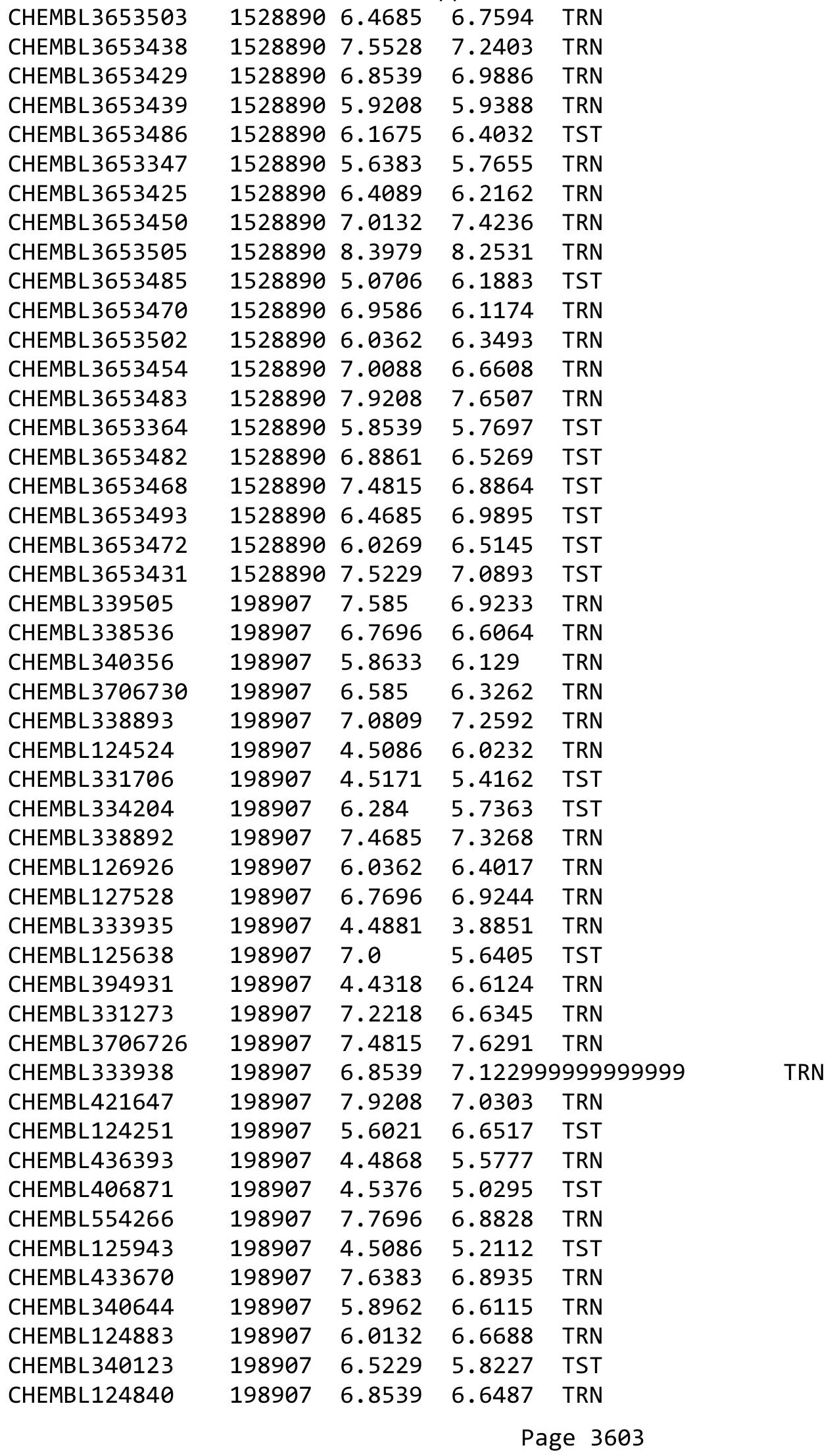




\begin{tabular}{|c|c|c|c|c|}
\hline & & & pplement & al Table S \\
\hline CHEMBL339975 & 198907 & 7.8539 & 7.2386 & TRN \\
\hline CHEMBL125699 & 198907 & 4.5376 & 5.0784 & TST \\
\hline CHEMBL333062 & 198907 & 6.1024 & 6.1661 & TRN \\
\hline CHEMBL124755 & 198907 & 6.1024 & 5.7167 & TRN \\
\hline CHEMBL446166 & 198907 & 6.9586 & 6.8382 & TRN \\
\hline CHEMBL333049 & 198907 & 6.699 & 7.0173 & TRN \\
\hline CHEMBL420913 & 198907 & 4.3872 & 5.0787 & TRN \\
\hline CHEMBL419417 & 198907 & 6.0088 & 6.9736 & TST \\
\hline CHEMBL338002 & 198907 & 7.5686 & 7.3934 & TRN \\
\hline CHEMBL435807 & 198907 & 7.3372 & 6.48 & TRN \\
\hline CHEMBL334128 & 198907 & 7.0506 & 6.794 & TRN \\
\hline CHEMBL3706729 & 198907 & 7.5229 & 7.1012 & TRN \\
\hline CHEMBL421631 & 198907 & 6.3768 & 5.3374 & TST \\
\hline CHEMBL 278315 & 198907 & 7.1549 & 6.0902 & TRN \\
\hline CHEMBL125370 & 198907 & 5.8861 & 6.6583 & TRN \\
\hline CHEMBL262808 & 198907 & 6.8239 & 6.4027 & TST \\
\hline CHEMBL332831 & 198907 & 7.3665 & 5.9141 & TRN \\
\hline CHEMBL123564 & 198907 & 7.2924 & 7.056 & TRN \\
\hline CHEMBL 333770 & 198907 & 6.6576 & 6.6495 & TRN \\
\hline CHEMBL337949 & 198907 & 5.8861 & 6.3082 & TRN \\
\hline CHEMBL339231 & 198907 & 7.4318 & 6.6838 & TRN \\
\hline CHEMBL63175 & 198907 & 7.0969 & 6.8631 & TRN \\
\hline CHEMBL126927 & 198907 & 5.7011 & 6.3541 & TRN \\
\hline CHEMBL434633 & 198907 & 4.4949 & 5.5593 & TST \\
\hline CHEMBL126116 & 198907 & 4.5686 & 6.4636 & TRN \\
\hline CHEMBL123835 & 198907 & 6.8861 & 6.944 & TRN \\
\hline CHEMBL339471 & 198907 & 7.301 & 6.5654 & TST \\
\hline CHEMBL 3706731 & 198907 & 6.1487 & 6.6392 & TRN \\
\hline CHEMBL 263699 & 198907 & 6.6778 & 6.4259 & TST \\
\hline CHEMBL127356 & 198907 & 6.7212 & 6.1039 & TRN \\
\hline CHEMBL125767 & 198907 & 7.1805 & 6.8652 & TRN \\
\hline CHEMBL3706725 & 198907 & 7.1805 & 7.2637 & TRN \\
\hline CHEMBL127520 & 198907 & 7.301 & 7.1346 & TRN \\
\hline CHEMBL339803 & 198907 & 6.3279 & 6.9861 & TRN \\
\hline CHEMBL338759 & 198907 & 4.4949 & 6.4589 & TRN \\
\hline CHEMBL125509 & 198907 & 7.9208 & 7.1404 & TRN \\
\hline CHEMBL444855 & 198907 & 7.0088 & 6.803 & TRN \\
\hline CHEMBL126986 & 198907 & 7.0 & 6.9543 & TRN \\
\hline CHEMBL421636 & 198907 & 6.4949 & 6.4273 & TRN \\
\hline CHEMBL332984 & 198907 & 4.5045 & 4.4075 & TRN \\
\hline CHEMBL127098 & 198907 & 6.0269 & 6.5354 & TST \\
\hline CHEMBL340038 & 198907 & 7.3979 & 7.0245 & TRN \\
\hline CHEMBL126225 & 198907 & 7.301 & 6.87700 & 0000000001 \\
\hline CHEMBL434049 & 198907 & 5.8239 & 4.8045 & TRN \\
\hline CHEMBL340169 & 198907 & 6.6383 & 6.4376 & TRN \\
\hline CHEMBL340799 & 198907 & 5.6925 & 6.6963 & TST \\
\hline CHEMBL124215 & 198907 & 7.301 & 6.7868 & TST \\
\hline CHEMBL340690 & 198907 & 5.9586 & 5.8164 & TST \\
\hline
\end{tabular}




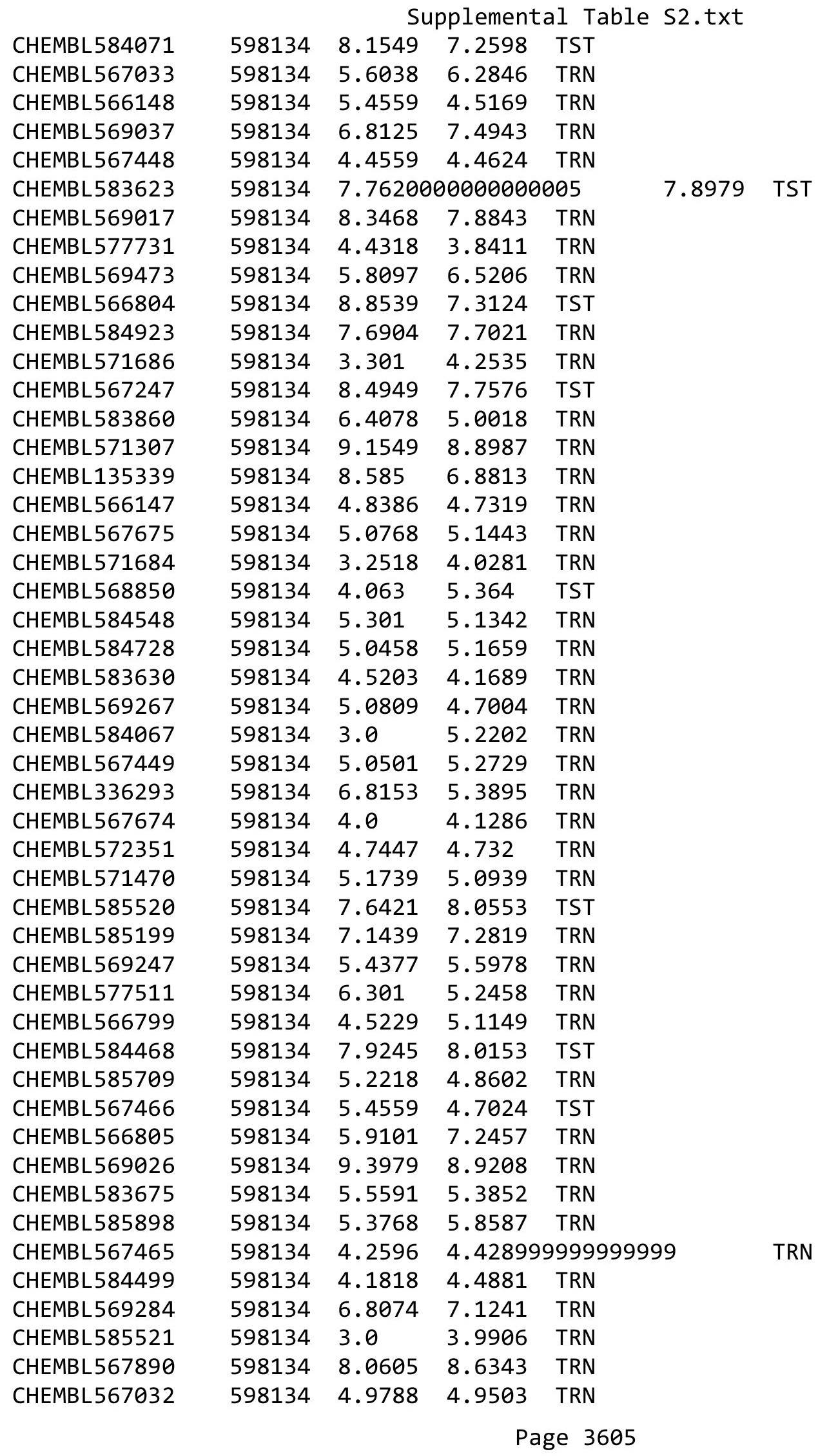




\begin{tabular}{|c|c|c|c|c|c|}
\hline \multicolumn{6}{|c|}{ Supplemental Table s2.txt } \\
\hline CHEMBL566587 & 598134 & 3.0 & 2.8538 & TRN & \\
\hline CHEMBL565522 & 598134 & 8.2676 & 7.2224 & TRN & \\
\hline CHEMBL585730 & 598134 & 4.0862 & 3.6304 & TRN & \\
\hline CHEMBL565310 & 598134 & 5.1739 & 5.1555 & TRN & \\
\hline CHEMBL584966 & 598134 & 8.5086 & 6.9327 & TST & \\
\hline CHEMBL584043 & 598134 & 7.6253 & 7.7068 & TST & \\
\hline CHEMBL567253 & 598134 & 4.4377 & 4.7545 & TST & \\
\hline CHEMBL583853 & 598134 & 4.757 & 4.6281 & TST & \\
\hline CHEMBL571685 & 598134 & 3.2676 & 4.7431 & TST & \\
\hline CHEMBL572359 & 598134 & 3.0 & 4.0184 & TST & \\
\hline CHEMBL583852 & 598134 & 3.0 & 4.40600 & 0000000001 & TST \\
\hline CHEMBL1338900 & 688343 & 4.4 & 4.397 & TRN & \\
\hline CHEMBL161343 & 688343 & 4.55 & 4.9516 & TRN & \\
\hline CHEMBL267548 & 688343 & 5.3 & 5.4267 & TRN & \\
\hline CHEMBL598952 & 688343 & 4.4 & 4.8215 & TST & \\
\hline CHEMBL1284 & 688343 & 5.1 & 5.2626 & TRN & \\
\hline CHEMBL1256996 & 688343 & 4.8 & 4.6299 & TRN & \\
\hline CHEMBL546257 & 688343 & 4.8 & 4.8507 & TRN & \\
\hline CHEMBL77030 & 688343 & 5.3 & 5.7167 & TRN & \\
\hline CHEMBL429711 & 688343 & 4.4 & 4.492 & TRN & \\
\hline CHEMBL274619 & 688343 & 4.5 & 5.3562 & TRN & \\
\hline CHEMBL56393 & 688343 & 6.5501 & 6.2286 & TRN & \\
\hline CHEMBL153036 & 688343 & 4.8 & 4.4914 & TRN & \\
\hline CHEMBL416657 & 688343 & 4.4 & 4.6939 & TRN & \\
\hline CHEMBL1253351 & 688343 & 5.6 & 5.5162 & TRN & \\
\hline CHEMBL17468 & 688343 & 5.2 & 4.48600 & 0000000001 & TRN \\
\hline CHEMBL1256911 & 688343 & 4.4 & 4.4998 & TRN & \\
\hline CHEMBL1414236 & 688343 & 5.65 & 5.1035 & TST & \\
\hline CHEMBL1255867 & 688343 & 4.8 & 4.7497 & TRN & \\
\hline CHEMBL216504 & 688343 & 5.0 & 5.0927 & TRN & \\
\hline CHEMBL1365553 & 688343 & 6.6 & 5.1127 & TRN & \\
\hline CHEMBL280563 & 688343 & 4.4 & 4.5683 & TRN & \\
\hline CHEMBL28 & 688343 & 4.4 & 5.0618 & TRN & \\
\hline CHEMBL1563352 & 688343 & 4.4 & 4.7243 & TRN & \\
\hline CHEMBL1255865 & 688343 & 4.4 & 4.4813 & TRN & \\
\hline CHEMBL77456 & 688343 & 4.65 & 4.402 & TRN & \\
\hline CHEMBL164 & 688343 & 6.45 & 6.0378 & TRN & \\
\hline CHEMBL1256623 & 688343 & 6.3 & 5.6355 & TRN & \\
\hline CHEMBL58033 & 688343 & 6.0 & 5.0937 & TRN & \\
\hline CHEMBL338790 & 688343 & 4.4 & 4.7738 & TRN & \\
\hline CHEMBL538595 & 688343 & 4.4 & 4.5399 & TRN & \\
\hline CHEMBL12014 & 688343 & 4.45 & 4.5027 & TRN & \\
\hline CHEMBL1605916 & 688343 & 4.4 & 4.8718 & TST & \\
\hline CHEMBL1378659 & 688343 & 4.45 & 4.9069 & TRN & \\
\hline CHEMBL1255647 & 688343 & 4.55 & 4.4035 & TRN & \\
\hline CHEMBL32307 & 688343 & 4.5 & 4.3652 & TRN & \\
\hline CHEMBL1376723 & 688343 & 4.4 & 4.8814 & TRN & \\
\hline CHEMBL1440857 & 688343 & 4.45 & 4.9914 & TST & \\
\hline
\end{tabular}




\begin{tabular}{|c|c|c|c|c|c|}
\hline \multicolumn{6}{|c|}{ Supplemental Table S2.txt } \\
\hline CHEMBL1433897 & 688343 & 4.8 & 4.4323 & TRN & \\
\hline CHEMBL454761 & 688343 & 4.35 & 4.9697 & TRN & \\
\hline CHEMBL1371781 & 688343 & 4.45 & 4.3539 & TRN & \\
\hline CHEMBL 269733 & 688343 & 5.85 & 5.4713 & TRN & \\
\hline CHEMBL2448607 & 688343 & 4.8 & 4.4138 & TRN & \\
\hline CHEMBL10009 & 688343 & 4.4 & 4.3018 & TRN & \\
\hline CHEMBL22870 & 688343 & 4.45 & 4.7033 & TRN & \\
\hline CHEMBL 8320 & 688343 & 4.85 & 4.3904 & TST & \\
\hline CHEMBL1526852 & 688343 & 4.8 & 4.6376 & TRN & \\
\hline CHEMBL559612 & 688343 & 4.45 & 4.566 & TRN & \\
\hline CHEMBL8197 & 688343 & 4.4 & 4.4854 & TRN & \\
\hline CHEMBL399043 & 688343 & 6.0 & 4.713 & TRN & \\
\hline CHEMBL 280998 & 688343 & 4.45 & 4.4235 & TRN & \\
\hline CHEMBL1725279 & 688343 & 4.8 & 4.6066 & TRN & \\
\hline CHEMBL 2374058 & 688343 & 4.4 & 4.5109 & TST & \\
\hline CHEMBL1320902 & 688343 & 5.75 & 5.643 & TRN & \\
\hline CHEMBL192566 & 688343 & 4.5 & 4.6545 & TST & \\
\hline CHEMBL123 & 688343 & 5.5 & 5.44600 & 0000000001 & TRN \\
\hline CHEMBL1323529 & 688343 & 4.45 & 4.4794 & TRN & \\
\hline CHEMBL1256813 & 688343 & 4.7 & 4.4618 & TRN & \\
\hline CHEMBL 280065 & 688343 & 4.45 & 4.3946 & TRN & \\
\hline CHEMBL1472989 & 688343 & 4.4 & 4.74 & TRN & \\
\hline CHEMBL109037 & 688343 & 6.95 & 6.0094 & TRN & \\
\hline CHEMBL 30432 & 688343 & 4.55 & 4.3828 & TRN & \\
\hline CHEMBL1528565 & 688343 & 4.4 & 4.7605 & TRN & \\
\hline CHEMBL 288174 & 688343 & 4.75 & 4.5638 & TRN & \\
\hline CHEMBL127421 & 688343 & 4.4 & 4.6401 & TRN & \\
\hline CHEMBL1224512 & 688343 & 6.1 & 5.7455 & TRN & \\
\hline CHEMBL1377507 & 688343 & 4.4 & 4.7959 & TST & \\
\hline CHEMBL538104 & 688343 & 4.4 & 4.5463 & TST & \\
\hline CHEMBL433461 & 688343 & 4.65 & 4.4525 & TRN & \\
\hline CHEMBL578741 & 688343 & 4.55 & 5.2324 & TRN & \\
\hline CHEMBL1256285 & 688343 & 4.35 & 4.3405 & TST & \\
\hline CHEMBL 289277 & 688343 & 4.45 & 5.107 & TRN & \\
\hline CHEMBL285819 & 688343 & 4.4 & 4.8604 & TRN & \\
\hline CHEMBL64239 & 688343 & 4.4 & 4.9704 & TRN & \\
\hline CHEMBL1367565 & 688343 & 4.4 & 4.4996 & TRN & \\
\hline CHEMBL1357894 & 688343 & 4.6 & 4.4874 & TRN & \\
\hline CHEMBL 263972 & 688343 & 5.45 & 4.8662 & TRN & \\
\hline CHEMBL10347 & 688343 & 7.4001 & 5.8793 & TRN & \\
\hline CHEMBL1257003 & 688343 & 5.65 & 5.7607 & TRN & \\
\hline CHEMBL1173475 & 688343 & 4.7 & 5.7752 & TRN & \\
\hline CHEMBL1456417 & 688343 & 4.4 & 4.4754 & TRN & \\
\hline CHEMBL 275938 & 688343 & 4.6 & 6.0353 & TRN & \\
\hline CHEMBL102714 & 688343 & 4.45 & 4.4925 & TRN & \\
\hline CHEMBL1472561 & 688343 & 4.4 & 4.4882 & TRN & \\
\hline CHEMBL1256655 & 688343 & 4.35 & 4.4884 & TRN & \\
\hline CHEMBL 23957 & 688343 & 4.4 & 5.2298 & TST & \\
\hline
\end{tabular}




\begin{tabular}{|c|c|c|c|c|c|}
\hline \multirow[b]{2}{*}{ CHEMBL542448 } & \multirow[b]{2}{*}{688343} & \multicolumn{4}{|c|}{ Supplemental Table s2.txt } \\
\hline & & 4.55 & 4.2621 & TST & \\
\hline CHEMBL1490919 & 688343 & 5.55 & $5.3770 e$ & 0000000001 & TRN \\
\hline CHEMBL1372588 & 688343 & 4.45 & 4.5383 & TRN & \\
\hline CHEMBL488803 & 688343 & 4.4 & 4.3208 & TRN & \\
\hline CHEMBL1597692 & 688343 & 4.35 & 4.8252 & TRN & \\
\hline CHEMBL1315457 & 688343 & 4.55 & 4.5901 & TRN & \\
\hline CHEMBL 28626 & 688343 & 5.3 & 5.7265 & TST & \\
\hline CHEMBL1255657 & 688343 & 4.7 & 4.5474 & TST & \\
\hline CHEMBL545184 & 688343 & 4.75 & 4.4997 & TST & \\
\hline CHEMBL88621 & 688343 & 4.8 & 4.73 & TST & \\
\hline CHEMBL 244948 & 688343 & 4.75 & 4.5754 & TST & \\
\hline CHEMBL105608 & 688343 & 4.4 & 4.7049 & TST & \\
\hline CHEMBL335231 & 688343 & 4.4 & 4.4905 & TST & \\
\hline CHEMBL72365 & 688343 & 4.4 & 4.86 & TST & \\
\hline CHEMBL351042 & 688343 & 5.0 & 5.5651 & TST & \\
\hline CHEMBL1200938 & 688343 & 4.4 & 4.5328 & TST & \\
\hline CHEMBL602375 & 688343 & 5.05 & 4.8784 & TST & \\
\hline CHEMBL20730 & 688343 & 4.85 & 4.5716 & TST & \\
\hline CHEMBL1329790 & 688343 & 4.8 & 4.4208 & TST & \\
\hline CHEMBL539947 & 688343 & 4.35 & 5.0009 & TST & \\
\hline CHEMBL484928 & 688343 & 4.4 & 4.4097 & TST & \\
\hline CHEMBL3981071 & 1637099 & 8.0 & 7.7177 & TRN & \\
\hline CHEMBL3918763 & 1637099 & 8.0 & 7.1496 & TRN & \\
\hline CHEMBL3940977 & 1637099 & 7.0 & 7.8792 & TRN & \\
\hline CHEMBL3941010 & 1637099 & 8.0 & 7.8863 & TRN & \\
\hline CHEMBL3944656 & 1637099 & 8.0 & 7.9971 & TRN & \\
\hline CHEMBL3977886 & 1637099 & 8.0 & 7.6375 & TRN & \\
\hline CHEMBL3949025 & 1637099 & 8.0 & 7.6053 & TRN & \\
\hline CHEMBL3903495 & 1637099 & 8.0 & 7.9962 & TRN & \\
\hline CHEMBL3954146 & 1637099 & 8.0 & 8.0443 & TRN & \\
\hline CHEMBL3892662 & 1637099 & 8.0 & 7.1227 & TST & \\
\hline CHEMBL3986207 & 1637099 & 7.0 & 7.1575 & TST & \\
\hline CHEMBL3980892 & 1637099 & 6.0 & 7.0484 & TST & \\
\hline CHEMBL3964912 & 1637099 & 6.0 & 6.2747 & TRN & \\
\hline CHEMBL2216876 & 1637099 & 8.0 & 8.0816 & TRN & \\
\hline CHEMBL 3957382 & 1637099 & 8.0 & 7.03799 & 9999999999 & TRN \\
\hline CHEMBL3934197 & 1637099 & 8.0 & 7.7844 & TST & \\
\hline CHEMBL3974179 & 1637099 & 8.0 & 7.848 & TRN & \\
\hline CHEMBL3959902 & 1637099 & 8.0 & 8.075 & TST & \\
\hline CHEMBL3946345 & 1637099 & 8.0 & 7.7803 & TST & \\
\hline CHEMBL3952054 & 1637099 & 8.0 & 7.8094 & TRN & \\
\hline CHEMBL3891083 & 1637099 & 7.0 & 7.21899 & 9999999999 & TRN \\
\hline CHEMBL3978357 & 1637099 & 8.0 & 7.6798 & TRN & \\
\hline CHEMBL3902945 & 1637099 & 8.0 & 7.7225 & TRN & \\
\hline CHEMBL3893129 & 1637099 & 7.0 & 7.016 & TRN & \\
\hline CHEMBL3929965 & 1637099 & 7.0 & 7.5647 & TRN & \\
\hline CHEMBL3969965 & 1637099 & 8.0 & 7.9763 & TST & \\
\hline CHEMBL3907233 & 1637099 & 8.0 & 7.1399 & TRN & \\
\hline
\end{tabular}




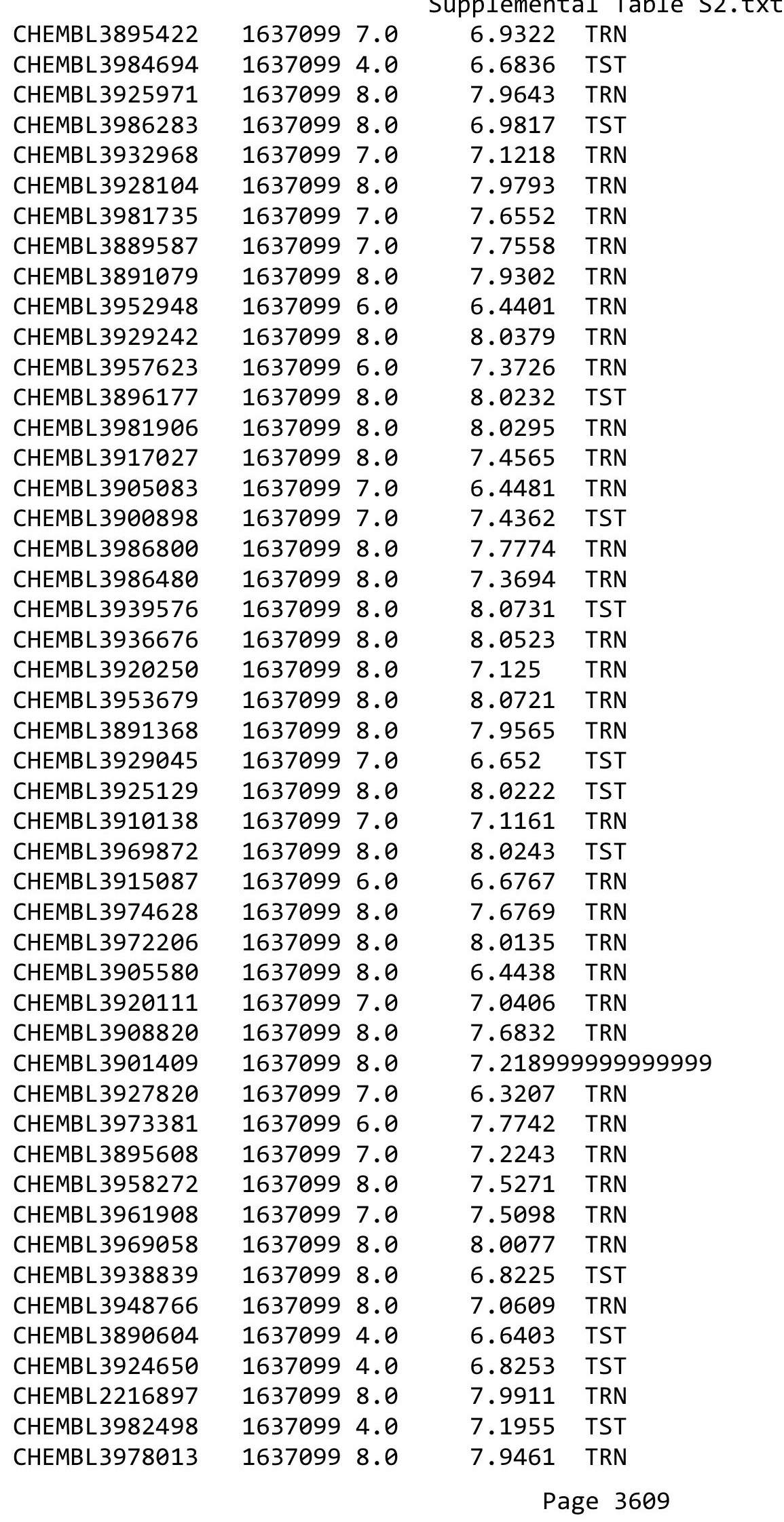




\begin{tabular}{|c|c|c|c|c|}
\hline & & & & \\
\hline CHEMBL3926573 & 1637099 & 8.0 & 7.6685 & TRN \\
\hline CHEMBL3898101 & 1637099 & 8.0 & 8.0677 & TRN \\
\hline CHEMBL3923189 & 1637099 & 8.0 & 7.7927 & TRN \\
\hline CHEMBL3903621 & 1637099 & 4.0 & 6.6799 & TST \\
\hline CHEMBL 3896670 & 1637099 & 7.0 & 6.9194 & TRN \\
\hline CHEMBL3958438 & 1637099 & 8.0 & 7.8324 & TRN \\
\hline CHEMBL3948488 & 1637099 & 7.0 & 7.2592 & TRN \\
\hline CHEMBL3954505 & 1637099 & 8.0 & 7.9328 & TRN \\
\hline CHEMBL3971985 & 1637099 & 8.0 & 7.928 & TST \\
\hline CHEMBL3966565 & 1637099 & 8.0 & 7.9927 & TRN \\
\hline CHEMBL3958566 & 1637099 & 7.0 & 7.5276 & TRN \\
\hline CHEMBL3892265 & 1637099 & 8.0 & 7.7 & TST \\
\hline CHEMBL3961040 & 1637099 & 8.0 & 7.595 & TRN \\
\hline CHEMBL3975881 & 1637099 & 7.0 & 7.1637 & TRN \\
\hline CHEMBL3983481 & 1637099 & 8.0 & 7.4364 & TRN \\
\hline CHEMBL3941546 & 1637099 & 7.0 & 6.5351 & TRN \\
\hline CHEMBL3957295 & 1637099 & 7.0 & 6.8922 & TST \\
\hline CHEMBL3957628 & 1637099 & 8.0 & 8.1045 & TST \\
\hline CHEMBL3962803 & 1637099 & 8.0 & 7.6649 & TRN \\
\hline CHEMBL 3942692 & 1637099 & 8.0 & 8.0587 & TRN \\
\hline CHEMBL 3954757 & 1637099 & 8.0 & 7.7665 & TRN \\
\hline CHEMBL3950472 & 1637099 & 8.0 & 7.5761 & TRN \\
\hline CHEMBL3967525 & 1637099 & 7.0 & 7.2452 & TRN \\
\hline CHEMBL3972202 & 1637099 & 8.0 & 7.739 & TRN \\
\hline CHEMBL3969116 & 1637099 & 8.0 & 7.6275 & TRN \\
\hline CHEMBL 3955440 & 1637099 & 8.0 & 8.0045 & TRN \\
\hline CHEMBL3937172 & 1637099 & 8.0 & 7.2362 & TRN \\
\hline CHEMBL3915138 & 1637099 & 8.0 & 7.9782 & TRN \\
\hline CHEMBL3965512 & 1637099 & 8.0 & 8.0408 & TRN \\
\hline CHEMBL3985393 & 1637099 & 7.0 & 7.5199 & TRN \\
\hline CHEMBL3946559 & 1637099 & 8.0 & 7.4553 & TST \\
\hline CHEMBL3969273 & 1637099 & 8.0 & 7.99 & TST \\
\hline CHEMBL3917917 & 1637099 & 8.0 & 7.985 & TRN \\
\hline CHEMBL3979467 & 1637099 & 8.0 & 8.0292 & TRN \\
\hline CHEMBL3919689 & 1637099 & 8.0 & 8.1105 & TRN \\
\hline CHEMBL3974173 & 1637099 & 6.0 & 6.7313 & TST \\
\hline CHEMBL3932981 & 1637099 & 7.0 & 7.2909 & TRN \\
\hline CHEMBL3941479 & 1637099 & 7.0 & 7.2497 & TRN \\
\hline CHEMBL3955031 & 1637099 & 8.0 & 8.113 & TST \\
\hline CHEMBL3960674 & 1637099 & 8.0 & 7.7763 & TRN \\
\hline CHEMBL 3921192 & 1637099 & 8.0 & 7.516 & TRN \\
\hline CHEMBL3892415 & 1637099 & 8.0 & 7.2757 & TRN \\
\hline CHEMBL3903458 & 1637099 & 6.0 & 6.5501 & TRN \\
\hline CHEMBL3954736 & 1637099 & 7.0 & 7.07700 & 0000000001 \\
\hline CHEMBL3915193 & 1637099 & 8.0 & 7.4484 & TRN \\
\hline CHEMBL 3971922 & 1637099 & 8.0 & 7.875 & TRN \\
\hline CHEMBL3907481 & 1637099 & 8.0 & 7.5531 & TRN \\
\hline CHEMBL 3922817 & 1637099 & 7.0 & 7.733 & TRN \\
\hline
\end{tabular}




\begin{tabular}{|c|c|c|c|c|}
\hline \\
\hline CHEMBL3935330 & 1637099 & 8.0 & 8.0028 & TRN \\
\hline CHEMBL 3917082 & 1637099 & 6.0 & 7.2205 & TST \\
\hline CHEMBL3917519 & 1637099 & 6.0 & 6.3234 & TST \\
\hline CHEMBL3969492 & 1637099 & 8.0 & 7.6977 & TRN \\
\hline CHEMBL3947356 & 1637099 & 8.0 & 6.5685 & TRN \\
\hline CHEMBL3896375 & 1637099 & 8.0 & 8.1041 & TRN \\
\hline CHEMBL3907964 & 1637099 & 8.0 & 7.6026 & TRN \\
\hline CHEMBL 3934621 & 1637099 & 7.0 & 7.2656 & TST \\
\hline CHEMBL 3934193 & 1637099 & 4.0 & 6.7067 & TST \\
\hline CHEMBL3915312 & 1637099 & 8.0 & 8.1294 & TST \\
\hline CHEMBL3939953 & 1637099 & 8.0 & 8.0343 & TRN \\
\hline CHEMBL3959833 & 1637099 & 8.0 & 8.0003 & TRN \\
\hline CHEMBL 3974554 & 1637099 & 6.0 & 6.3034 & TRN \\
\hline CHEMBL 3972055 & 1637099 & 8.0 & 7.7597 & TRN \\
\hline CHEMBL3957361 & 1637099 & 8.0 & 8.0116 & TRN \\
\hline CHEMBL3935435 & 1637099 & 6.0 & 7.2917 & TRN \\
\hline CHEMBL3979857 & 1637099 & 8.0 & 7.0997 & TRN \\
\hline CHEMBL3927115 & 1637099 & 6.0 & 7.2199 & TRN \\
\hline CHEMBL 3949241 & 1637099 & 8.0 & 7.9688 & TRN \\
\hline CHEMBL3941416 & 1637099 & 6.0 & 6.7961 & TST \\
\hline CHEMBL3949014 & 1637099 & 8.0 & 7.7769 & TRN \\
\hline CHEMBL3948376 & 1637099 & 8.0 & 7.9856 & TRN \\
\hline CHEMBL3933033 & 1637099 & 8.0 & 7.9967 & TST \\
\hline CHEMBL3953621 & 1637099 & 8.0 & 7.1458 & TRN \\
\hline CHEMBL3916649 & 1637099 & 8.0 & 7.8079 & TRN \\
\hline CHEMBL3898709 & 1637099 & 8.0 & 7.4662 & TRN \\
\hline CHEMBL3960932 & 1637099 & 8.0 & 7.6224 & TST \\
\hline CHEMBL3924404 & 1637099 & 7.0 & 7.7227 & TRN \\
\hline CHEMBL3978509 & 1637099 & 7.0 & 7.1953 & TST \\
\hline CHEMBL3955730 & 1637099 & 8.0 & 7.8932 & TRN \\
\hline CHEMBL3920543 & 1637099 & 8.0 & 7.4856 & TRN \\
\hline CHEMBL3908417 & 1637099 & 6.0 & 6.9063 & TRN \\
\hline CHEMBL3945843 & 1637099 & 6.0 & 6.9629 & TRN \\
\hline CHEMBL 3982444 & 1637099 & 6.0 & 6.9805 & TRN \\
\hline CHEMBL3982302 & 1637099 & 6.0 & 7.0643 & TRN \\
\hline CHEMBL3964189 & 1637099 & 8.0 & 8.0718 & TRN \\
\hline CHEMBL3950901 & 1637099 & 8.0 & 7.8717 & TRN \\
\hline CHEMBL3918718 & 1637099 & 8.0 & 7.8713 & TRN \\
\hline CHEMBL3923662 & 1637099 & 8.0 & 7.984 & TRN \\
\hline CHEMBL3932626 & 1637099 & 8.0 & 8.0166 & TRN \\
\hline CHEMBL3911175 & 1637099 & 8.0 & 6.9679 & TST \\
\hline CHEMBL3976216 & 1637099 & 6.0 & 7.6006 & TRN \\
\hline CHEMBL3919842 & 1637099 & 4.0 & 6.5781 & TRN \\
\hline CHEMBL 3932575 & 1637099 & 8.0 & 7.54299 & 9999999999 \\
\hline CHEMBL3937104 & 1637099 & 8.0 & 7.8186 & TRN \\
\hline CHEMBL 3946144 & 1637099 & 8.0 & 7.5984 & TRN \\
\hline CHEMBL3985764 & 1637099 & 7.0 & 7.5521 & TST \\
\hline CHEMBL3913415 & 1637099 & 8.0 & 7.3814 & TRN \\
\hline
\end{tabular}




\begin{tabular}{|c|c|c|c|c|}
\hline & & & ient & $a \perp 1 a$ \\
\hline CHEMBL 3897922 & 1637099 & 8.0 & 7.7905 & TRN \\
\hline CHEMBL3891191 & 1637099 & 8.0 & 7.8481 & TRN \\
\hline CHEMBL3974743 & 1637099 & 8.0 & 7.9665 & TRN \\
\hline CHEMBL 3977312 & 1637099 & 7.0 & 7.5661 & TRN \\
\hline CHEMBL3974367 & 1637099 & 8.0 & 8.079 & TRN \\
\hline CHEMBL3967531 & 1637099 & 4.0 & 6.7606 & TST \\
\hline CHEMBL3966914 & 1637099 & 7.0 & 7.1014 & TRN \\
\hline CHEMBL3971853 & 1637099 & 8.0 & 7.2856 & TRN \\
\hline CHEMBL 3944887 & 1637099 & 8.0 & 7.8416 & TRN \\
\hline CHEMBL3985898 & 1637099 & 8.0 & 7.6151 & TST \\
\hline CHEMBL3958796 & 1637099 & 7.0 & 7.5774 & TRN \\
\hline CHEMBL3932332 & 1637099 & 6.0 & 7.2811 & TST \\
\hline CHEMBL3981319 & 1637099 & 8.0 & 7.8723 & TRN \\
\hline CHEMBL3905612 & 1637099 & 8.0 & 7.6334 & TRN \\
\hline CHEMBL3983246 & 1637099 & 8.0 & 6.7651 & TST \\
\hline CHEMBL3980419 & 1637099 & 4.0 & 6.6816 & TST \\
\hline CHEMBL3962439 & 1637099 & 7.0 & 6.5972 & TRN \\
\hline CHEMBL3943361 & 1637099 & 8.0 & 7.5672 & TRN \\
\hline CHEMBL3936944 & 1637099 & 7.0 & 7.1849 & TRN \\
\hline CHEMBL3947509 & 1637099 & 8.0 & 6.9893 & TST \\
\hline CHEMBL 3949031 & 1637099 & 8.0 & 8.0361 & TRN \\
\hline CHEMBL3918477 & 1637099 & 8.0 & 7.9248 & TRN \\
\hline CHEMBL3928309 & 1637099 & 6.0 & 7.3401 & TRN \\
\hline CHEMBL3981328 & 1637099 & 8.0 & 8.0107 & TRN \\
\hline CHEMBL3939554 & 1637099 & 8.0 & 8.0635 & TRN \\
\hline CHEMBL3925535 & 1637099 & 7.0 & 7.2841 & TRN \\
\hline CHEMBL3913845 & 1637099 & 8.0 & 8.0011 & TRN \\
\hline CHEMBL3969911 & 1637099 & 8.0 & 7.8102 & TRN \\
\hline CHEMBL3919001 & 1637099 & 7.0 & 7.4076 & TST \\
\hline CHEMBL3895375 & 1637099 & 8.0 & 7.4174 & TRN \\
\hline CHEMBL3960966 & 1637099 & 8.0 & 7.5283 & TRN \\
\hline CHEMBL3901585 & 1637099 & 8.0 & 8.0309 & TST \\
\hline CHEMBL3962591 & 1637099 & 8.0 & 8.11 & TST \\
\hline CHEMBL3893036 & 1637099 & 7.0 & 7.3665 & TRN \\
\hline CHEMBL3950924 & 1637099 & 4.0 & 7.1086 & TST \\
\hline CHEMBL3905598 & 1637099 & 6.0 & 7.1292 & TRN \\
\hline CHEMBL3944018 & 1637099 & 8.0 & 7.893 & TRN \\
\hline CHEMBL3922769 & 1637099 & 8.0 & 7.5726 & TRN \\
\hline CHEMBL 3912530 & 1637099 & 8.0 & 7.6604 & TRN \\
\hline CHEMBL3912775 & 1637099 & 8.0 & 7.6681 & TRN \\
\hline CHEMBL3939713 & 1637099 & 8.0 & 7.9989 & TRN \\
\hline CHEMBL3900680 & 1637099 & 8.0 & 8.0024 & TRN \\
\hline CHEMBL3889687 & 1637099 & 8.0 & 7.6907 & TRN \\
\hline CHEMBL 3915590 & 1637099 & 8.0 & 7.4606 & TST \\
\hline CHEMBL 3951879 & 1637099 & 8.0 & 7.1545 & TRN \\
\hline CHEMBL 3979331 & 1637099 & 8.0 & 7.7723 & TRN \\
\hline CHEMBL3972637 & 1637099 & 8.0 & 7.45 & TST \\
\hline CHEMBL3918112 & 1637099 & 8.0 & 7.8238 & TST \\
\hline
\end{tabular}




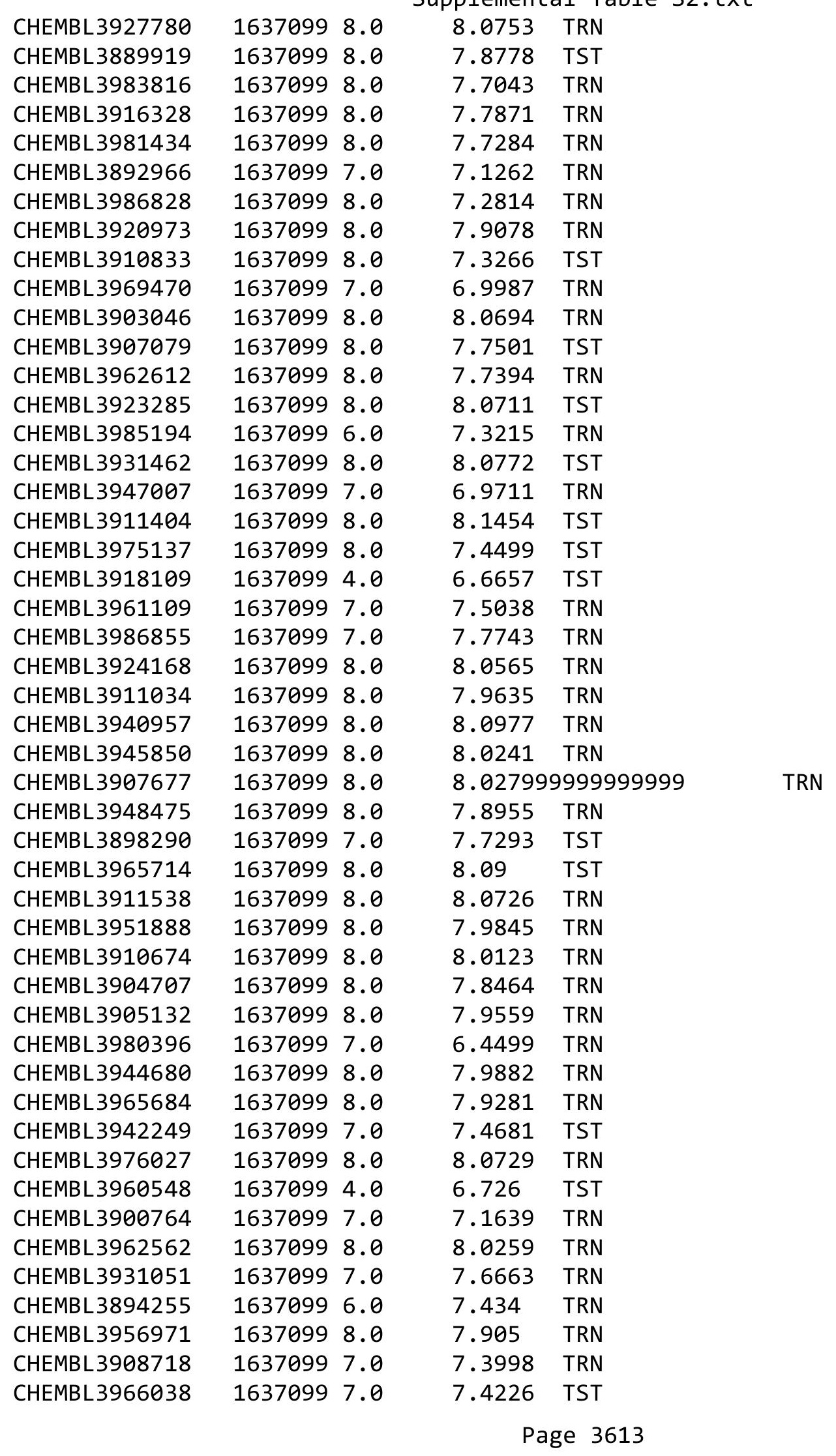




\begin{tabular}{|c|c|c|c|c|c|}
\hline & & & & & \\
\hline CHEMBL3966715 & 1637099 & 8.0 & 7.6849 & TST & \\
\hline CHEMBL3892726 & 1637099 & 7.0 & 7.4369 & TST & \\
\hline CHEMBL3912424 & 1637099 & 6.0 & 7.6025 & TRN & \\
\hline CHEMBL3985040 & 1637099 & 8.0 & 7.9792 & TRN & \\
\hline CHEMBL3973711 & 1637099 & 8.0 & 7.4972 & TRN & \\
\hline CHEMBL3922621 & 1637099 & 8.0 & 7.9851 & TST & \\
\hline CHEMBL3919824 & 1637099 & 7.0 & 7.4168 & TRN & \\
\hline CHEMBL3927712 & 1637099 & 8.0 & 7.7358 & TRN & \\
\hline CHEMBL3920754 & 1637099 & 8.0 & 7.3238 & TRN & \\
\hline CHEMBL3938644 & 1637099 & 6.0 & 6.7403 & TRN & \\
\hline CHEMBL3958075 & 1637099 & 8.0 & 8.1063 & TRN & \\
\hline CHEMBL3972682 & 1637099 & 8.0 & 7.9677 & TRN & \\
\hline CHEMBL3957119 & 1637099 & 8.0 & 8.0103 & TRN & \\
\hline CHEMBL3922415 & 1637099 & 8.0 & 8.1019 & TRN & \\
\hline CHEMBL3934207 & 1637099 & 6.0 & 6.5807 & TRN & \\
\hline CHEMBL3905246 & 1637099 & 8.0 & 7.3914 & TST & \\
\hline CHEMBL3919763 & 1637099 & 8.0 & 7.8927 & TST & \\
\hline CHEMBL3978491 & 1637099 & 8.0 & 8.0701 & TRN & \\
\hline CHEMBL3946653 & 1637099 & 6.0 & 7.2693 & TST & \\
\hline CHEMBL3985711 & 1637099 & 7.0 & 7.659 & TRN & \\
\hline CHEMBL 3980844 & 1637099 & 8.0 & 7.1067 & TRN & \\
\hline CHEMBL3975817 & 1637099 & 8.0 & 7.6621 & TRN & \\
\hline CHEMBL1715362 & 1301770 & 5.3925 & 5.4261 & TRN & \\
\hline CHEMBL1534753 & 1301770 & 4.9901 & 5.3372 & TRN & \\
\hline CHEMBL1436778 & 1301770 & 5.1046 & 5.4327 & TRN & \\
\hline CHEMBL1492110 & 1301770 & 4.8834 & 5.7614 & TRN & \\
\hline CHEMBL1369512 & 1301770 & 6.6289 & 6.8219 & TRN & \\
\hline CHEMBL1526174 & 1301770 & 4.823 & 5.33799 & 9999999999 & TRN \\
\hline CHEMBL1736479 & 1301770 & 8.0969 & 5.1048 & TRN & \\
\hline CHEMBL1556805 & 1301770 & 6.2823 & 5.6724 & TRN & \\
\hline CHEMBL1456904 & 1301770 & 5.0799 & 5.7038 & TRN & \\
\hline CHEMBL1552356 & 1301770 & 5.58 & 5.41299 & 9999999999 & TRN \\
\hline CHEMBL193872 & 1301770 & 5.2518 & 5.6635 & TRN & \\
\hline CHEMBL1370838 & 1301770 & 6.0083 & 5.6242 & TRN & \\
\hline CHEMBL1535361 & 1301770 & 6.2882 & 5.3997 & TRN & \\
\hline CHEMBL1422456 & 1301770 & 4.8897 & 5.1499 & TRN & \\
\hline CHEMBL1866054 & 1301770 & 5.1568 & 5.1275 & TST & \\
\hline CHEMBL1549290 & 1301770 & 4.7049 & 5.3402 & TRN & \\
\hline CHEMBL1503928 & 1301770 & 5.0074 & 5.2844 & TRN & \\
\hline CHEMBL1608529 & 1301770 & 8.0969 & 6.6637 & TRN & \\
\hline CHEMBL1302020 & 1301770 & 5.3675 & 5.401 & TRN & \\
\hline CHEMBL1698845 & 1301770 & 6.8153 & 6.1507 & TRN & \\
\hline CHEMBL3193947 & 1301770 & 4.8844 & 4.9597 & TRN & \\
\hline CHEMBL3184471 & 1301770 & 4.9751 & 5.3464 & TRN & \\
\hline CHEMBL1585527 & 1301770 & 6.0022 & 5.6427 & TRN & \\
\hline CHEMBL1334407 & 1301770 & 5.4498 & 5.4711 & TRN & \\
\hline CHEMBL1592706 & 1301770 & 6.1593 & 5.1876 & TRN & \\
\hline CHEMBL1391527 & 1301770 & 5.3595 & 5.7242 & TRN & \\
\hline
\end{tabular}


Supplemental Table S2.txt

\begin{tabular}{|c|c|c|c|c|c|c|}
\hline CHEMBL 2138440 & 1301770 & 6.1397 & 5.1704 & TRN & & \\
\hline CHEMBL1326083 & 1301770 & 5.8327 & 5.5637 & TRN & & \\
\hline CHEMBL1519424 & 1301770 & 5.3969 & 5.1397 & TRN & & \\
\hline CHEMBL1729203 & 1301770 & 6.1656 & 5.2478 & TRN & & \\
\hline CHEMBL 3184468 & 1301770 & 6.1152 & 5.6252 & TST & & \\
\hline CHEMBL 2007021 & 1301770 & 5.0516 & 5.5162 & TRN & & \\
\hline CHEMBL1361227 & 1301770 & 4.9408 & 5.1223 & TRN & & \\
\hline CHEMBL1548492 & 1301770 & 5.983 & 5.5944 & TRN & & \\
\hline CHEMBL1724408 & 1301770 & 6.6737 & 5.3075 & TRN & & \\
\hline CHEMBL3198957 & 1301770 & 4.8416 & 5.1067 & TRN & & \\
\hline CHEMBL1376142 & 1301770 & 5.05399 & 999999999 & 99 & 5.2844 & TRN \\
\hline CHEMBL1455794 & 1301770 & 4.9038 & 5.1132 & TRN & & \\
\hline CHEMBL1984240 & 1301770 & 6.2692 & 6.1096 & TRN & & \\
\hline CHEMBL 3189770 & 1301770 & 5.3536 & 5.3736 & TRN & & \\
\hline CHEMBL1472773 & 1301770 & 5.0223 & 5.1266 & TST & & \\
\hline CHEMBL1504569 & 1301770 & 6.067 & 5.4298 & TRN & & \\
\hline CHEMBL1481336 & 1301770 & 5.1096 & 5.3661 & TRN & & \\
\hline CHEMBL1734113 & 1301770 & 5.4437 & 5.2445 & TRN & & \\
\hline CHEMBL1453209 & 1301770 & 4.7224 & 5.0781 & TRN & & \\
\hline CHEMBL1377932 & 1301770 & 5.5575 & 5.4707 & TRN & & \\
\hline CHEMBL1735976 & 1301770 & 5.9101 & 5.3356 & TRN & & \\
\hline CHEMBL590927 & 1301770 & 6.063 & 5.6448 & TRN & & \\
\hline CHEMBL1904111 & 1301770 & 6.098 & 4.9227 & TRN & & \\
\hline CHEMBL 2143060 & 1301770 & 6.7055 & 5.1233 & TRN & & \\
\hline CHEMBL1503729 & 1301770 & 5.7352 & 5.7299 & TRN & & \\
\hline CHEMBL1790039 & 1301770 & 6.1643 & 6.0528 & TRN & & \\
\hline CHEMBL3194557 & 1301770 & 4.8022 & 5.0458 & TST & & \\
\hline CHEMBL1356021 & 1301770 & 6.6326 & 5.3003 & TRN & & \\
\hline CHEMBL1416696 & 1301770 & 4.8392 & 5.3283 & TST & & \\
\hline CHEMBL1468772 & 1301770 & 5.2154 & 5.0477 & TRN & & \\
\hline CHEMBL 3183147 & 1301770 & 4.9846 & 5.3316 & TRN & & \\
\hline CHEMBL1368463 & 1301770 & 4.9523 & 5.4337 & TRN & & \\
\hline CHEMBL1405540 & 1301770 & 4.7215 & 5.3126 & TRN & & \\
\hline CHEMBL3199737 & 1301770 & 5.2336 & 5.4047 & TST & & \\
\hline CHEMBL1539359 & 1301770 & 5.1267 & 5.4628 & TRN & & \\
\hline CHEMBL1385128 & 1301770 & 4.7222 & 5.2853 & TRN & & \\
\hline CHEMBL1256656 & 1301770 & 4.8827 & 5.3751 & TRN & & \\
\hline CHEMBL1232381 & 1301770 & 8.0969 & 6.6374 & TRN & & \\
\hline CHEMBL3391979 & 1301770 & 6.0947 & 5.3745 & TRN & & \\
\hline CHEMBL1887855 & 1301770 & 4.7224 & 5.4129 & TRN & & \\
\hline CHEMBL1367933 & 1301770 & 5.1688 & 5.442 & TRN & & \\
\hline CHEMBL1710159 & 1301770 & 5.9666 & 5.5264 & TRN & & \\
\hline CHEMBL1351542 & 1301770 & 5.8125 & 5.4061 & TRN & & \\
\hline CHEMBL1409576 & 1301770 & 6.0255 & 5.4066 & TRN & & \\
\hline CHEMBL1340628 & 1301770 & 5.3556 & 5.3902 & TRN & & \\
\hline CHEMBL 3187269 & 1301770 & 4.8486 & 5.6243 & TRN & & \\
\hline CHEMBL1547739 & 1301770 & 5.1481 & 5.4293 & TRN & & \\
\hline CHEMBL1729624 & 1301770 & 5.16299 & 99999999 & 99 & 5.3185 & 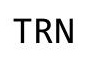 \\
\hline
\end{tabular}


Supplemental Table S2.txt

\begin{tabular}{|c|c|c|c|c|c|c|}
\hline CHEMBL1368594 & 1301770 & 5.4584 & 5.3539 & TRN & & \\
\hline CHEMBL1698877 & 1301770 & 4.7506 & 5.4515 & TRN & & \\
\hline CHEMBL1726049 & 1301770 & 5.2668 & 5.1616 & TRN & & \\
\hline CHEMBL405110 & 1301770 & 5.3893 & 5.3708 & TRN & & \\
\hline CHEMBL517186 & 1301770 & 5.6383 & 5.6389 & TST & & \\
\hline CHEMBL1300612 & 1301770 & 5.4365 & 5.4652 & TRN & & \\
\hline CHEMBL1887373 & 1301770 & 5.05399 & 999999999 & & 5.5116 & TST \\
\hline CHEMBL1467801 & 1301770 & 4.8294 & 5.2557 & TRN & & \\
\hline CHEMBL1709564 & 1301770 & 6.011 & 5.4663 & TRN & & \\
\hline CHEMBL1708596 & 1301770 & 5.5513 & 5.2215 & TRN & & \\
\hline CHEMBL1567139 & 1301770 & 4.8996 & 5.1227 & TRN & & \\
\hline CHEMBL1509764 & 1301770 & 5.1952 & 5.7347 & TRN & & \\
\hline CHEMBL1534514 & 1301770 & 4.8761 & 5.1627 & TRN & & \\
\hline CHEMBL1587558 & 1301770 & 6.6308 & 5.5327 & TRN & & \\
\hline CHEMBL1590190 & 1301770 & 5.2933 & 5.1768 & TST & & \\
\hline CHEMBL1378952 & 1301770 & 6.00700 & 000000000 & 01 & 5.5483 & TRN \\
\hline CHEMBL1704186 & 1301770 & 4.7324 & 5.1407 & TRN & & \\
\hline CHEMBL3195168 & 1301770 & 4.743 & 5.1205 & TRN & & \\
\hline CHEMBL1495240 & 1301770 & 4.7685 & 5.2082 & TRN & & \\
\hline CHEMBL1378659 & 1301770 & 5.2118 & 5.559 & TST & & \\
\hline CHEMBL1714574 & 1301770 & 4.8636 & 5.4664 & TST & & \\
\hline CHEMBL1427517 & 1301770 & 5.4634 & 5.4963 & TRN & & \\
\hline CHEMBL1878010 & 1301770 & 5.2581 & 5.317 & TRN & & \\
\hline CHEMBL1429434 & 1301770 & 4.9226 & 5.5334 & TRN & & \\
\hline CHEMBL1539155 & 1301770 & 5.4089 & 5.5841 & TRN & & \\
\hline CHEMBL1436792 & 1301770 & 6.3706 & 5.5572 & TRN & & \\
\hline CHEMBL1966798 & 1301770 & 5.2373 & 5.3573 & TRN & & \\
\hline CHEMBL1393129 & 1301770 & 4.8368 & 5.5953 & TRN & & \\
\hline CHEMBL3196561 & 1301770 & 5.1249 & 5.1467 & TRN & & \\
\hline CHEMBL1469642 & 1301770 & 4.8225 & 5.1288 & TST & & \\
\hline CHEMBL1569251 & 1301770 & 6.1186 & 5.8104 & TST & & \\
\hline CHEMBL3182167 & 1301770 & 4.9767 & 5.3354 & TRN & & \\
\hline CHEMBL1496982 & 1301770 & 5.3045 & 5.1632 & TRN & & \\
\hline CHEMBL 2145129 & 1301770 & 6.5058 & 5.3777 & TRN & & \\
\hline CHEMBL1900163 & 1301770 & 5.4377 & 5.5834 & TRN & & \\
\hline CHEMBL1982032 & 1301770 & 4.8668 & 5.3824 & TST & & \\
\hline CHEMBL585502 & 1301770 & 5.6271 & 5.4708 & TRN & & \\
\hline CHEMBL3199120 & 1301770 & 4.9404 & 5.4464 & TRN & & \\
\hline CHEMBL1200847 & 1301770 & 5.4776 & 5.5329 & TST & & \\
\hline CHEMBL1530087 & 1301770 & 5.1618 & 4.9763 & TRN & & \\
\hline CHEMBL1369945 & 1301770 & 4.9055 & 5.4722 & TRN & & \\
\hline CHEMBL 1478755 & 1301770 & 5.9788 & 5.5304 & TRN & & \\
\hline CHEMBL1713464 & 1301770 & 5.5513 & 5.6104 & TRN & & \\
\hline CHEMBL1608375 & 1301770 & 4.8047 & 4.8041 & TRN & & \\
\hline CHEMBL1506805 & 1301770 & 5.6364 & 5.4459 & TRN & & \\
\hline CHEMBL1607550 & 1301770 & 4.9965 & 5.0951 & TRN & & \\
\hline CHEMBL 1902072 & 1301770 & 4.8633 & 4.9435 & TRN & & \\
\hline \multirow[t]{2}{*}{ CHEMBL1603231 } & 1301770 & 4.9961 & $5.3210 e$ & 0000000001 & & TRN \\
\hline & & \multicolumn{5}{|c|}{ Page 3616} \\
\hline
\end{tabular}


Supplemental Table S2.txt

\begin{tabular}{|c|c|c|c|c|c|c|}
\hline CHEMBL1379122 & 1301770 & 4.9473 & 5.2362 & TRN & & \\
\hline CHEMBL1714220 & 1301770 & 4.9412 & 5.1242 & TRN & & \\
\hline CHEMBL 3193639 & 1301770 & 4.8864 & 5.999 & TST & & \\
\hline CHEMBL1470275 & 1301770 & 4.8398 & 5.3479 & TRN & & \\
\hline CHEMBL1446105 & 1301770 & 4.9722 & 5.3868 & TRN & & \\
\hline CHEMBL1365118 & 1301770 & 5.0088 & 5.7247 & TRN & & \\
\hline CHEMBL1513972 & 1301770 & 4.994 & 4.9873 & TST & & \\
\hline CHEMBL1322008 & 1301770 & 4.7783 & 5.0283 & TRN & & \\
\hline CHEMBL1863690 & 1301770 & 4.9562 & 5.4828 & TST & & \\
\hline CHEMBL1449490 & 1301770 & 4.8038 & 5.1483 & TST & & \\
\hline CHEMBL 3187290 & 1301770 & 4.8871 & 5.3645 & TST & & \\
\hline CHEMBL68096 & 1301770 & 5.5129 & 5.4074 & TRN & & \\
\hline CHEMBL1554805 & 1301770 & 5.2226 & 5.4579 & TRN & & \\
\hline CHEMBL1711432 & 1301770 & 5.5817 & 5.6976 & TRN & & \\
\hline CHEMBL1730190 & 1301770 & 4.702 & 5.1767 & TRN & & \\
\hline CHEMBL1880892 & 1301770 & 4.7678 & 5.3346 & TST & & \\
\hline CHEMBL1558183 & 1301770 & 5.5575 & 5.5169 & TRN & & \\
\hline CHEMBL1350270 & 1301770 & 5.9666 & 5.3733 & TRN & & \\
\hline CHEMBL1453914 & 1301770 & 4.7778 & 5.6064 & TST & & \\
\hline CHEMBL1347600 & 1301770 & 5.1343 & 5.2593 & TRN & & \\
\hline CHEMBL1345405 & 1301770 & 5.4012 & 5.0967 & TRN & & \\
\hline CHEMBL1492585 & 1301770 & 5.082 & 5.5359 & TRN & & \\
\hline CHEMBL1514592 & 1301770 & 4.9884 & 5.5341 & TRN & & \\
\hline CHEMBL 3193428 & 1301770 & 5.7905 & 5.9147 & TRN & & \\
\hline CHEMBL1885107 & 1301770 & 6.0 & 5.4257 & TRN & & \\
\hline CHEMBL457679 & 1301770 & 4.7657 & 5.4783 & TST & & \\
\hline CHEMBL1491258 & 1301770 & 5.2716 & 5.3668 & TRN & & \\
\hline CHEMBL 3184956 & 1301770 & 4.9722 & 5.2279 & TRN & & \\
\hline CHEMBL1722325 & 1301770 & 4.7635 & 5.6365 & TST & & \\
\hline CHEMBL 2369275 & 1301770 & 5.4067 & 5.2612 & TST & & \\
\hline CHEMBL 3191443 & 1301770 & 6.6038 & 5.5566 & TRN & & \\
\hline CHEMBL1331835 & 1301770 & 6.1675 & 5.3674 & TRN & & \\
\hline CHEMBL1367706 & 1301770 & 4.8245 & 5.0646 & TRN & & \\
\hline CHEMBL1992308 & 1301770 & 5.098 & 5.3773 & TST & & \\
\hline CHEMBL1409219 & 1301770 & 5.2321 & 5.1346 & TRN & & \\
\hline CHEMBL1580593 & 1301770 & 4.7421 & 5.2014 & TRN & & \\
\hline CHEMBL 1572785 & 1301770 & 5.0013 & 5.0713 & TRN & & \\
\hline CHEMBL1304402 & 1301770 & 5.6882 & 5.6422 & TRN & & \\
\hline CHEMBL 2006813 & 1301770 & 5.75200 & 00000000 & 01 & 5.4399 & TRN \\
\hline CHEMBL1713097 & 1301770 & 4.9465 & 5.3759 & TRN & & \\
\hline CHEMBL1731183 & 1301770 & 5.3675 & 5.6375 & TRN & & \\
\hline CHEMBL585622 & 1301770 & 5.2291 & 5.5342 & TRN & & \\
\hline CHEMBL1715785 & 1301770 & 5.1624 & 5.9184 & TRN & & \\
\hline CHEMBL1394831 & 1301770 & 4.8 & 5.263 & TST & & \\
\hline CHEMBL1531172 & 1301770 & 5.2343 & 5.3586 & TRN & & \\
\hline CHEMBL1426340 & 1301770 & 4.8438 & 5.507000 & 0000000001 & & TRN \\
\hline CHEMBL1484733 & 1301770 & 5.0438 & 4.9529 & TRN & & \\
\hline CHEMBL1608575 & 1301770 & 4.9274 & 4.9925 & TRN & & \\
\hline
\end{tabular}


Supplemental Table S2.txt

\begin{tabular}{|c|c|c|c|c|}
\hline CHEMBL1397463 & 1301770 & 5.2197 & 5.6717 & TRN \\
\hline CHEMBL1865717 & 1301770 & 4.9038 & 4.8959 & TRN \\
\hline CHEMBL1398686 & 1301770 & 5.5214 & 5.5597 & TRN \\
\hline CHEMBL1324303 & 1301770 & 4.8377 & 4.9215 & TRN \\
\hline CHEMBL1607785 & 1301770 & 4.7183 & 5.3519 & TST \\
\hline CHEMBL1500125 & 1301770 & 5.5986 & 5.3589 & TRN \\
\hline CHEMBL1334809 & 1301770 & 5.3307 & 5.3136 & TRN \\
\hline CHEMBL 2131514 & 1301770 & 4.9698 & 5.5143 & TRN \\
\hline CHEMBL3184121 & 1301770 & 4.9326 & 5.4367 & TRN \\
\hline CHEMBL1573586 & 1301770 & 5.5072 & 5.7371 & TRN \\
\hline CHEMBL1414834 & 1301770 & 5.6757 & 4.8353 & TRN \\
\hline CHEMBL1366268 & 1301770 & 4.7937 & 5.3181 & TRN \\
\hline CHEMBL1344330 & 1301770 & 5.983 & 5.5932 & TRN \\
\hline CHEMBL1903878 & 1301770 & 4.7865 & 4.8959 & TRN \\
\hline CHEMBL1485830 & 1301770 & 6.0164 & 5.2106 & TRN \\
\hline CHEMBL1540419 & 1301770 & 6.1537 & 5.2282 & TRN \\
\hline CHEMBL 2137367 & 1301770 & 4.9333 & 5.5458 & TRN \\
\hline CHEMBL1378637 & 1301770 & 4.8306 & 4.7786 & TRN \\
\hline CHEMBL1863579 & 1301770 & 6.2815 & 4.8931 & TRN \\
\hline CHEMBL1571318 & 1301770 & 4.9194 & 5.2367 & TRN \\
\hline CHEMBL1351964 & 1301770 & 5.5406 & 5.0503 & TRN \\
\hline CHEMBL1510543 & 1301770 & 5.2644 & 4.744 & TRN \\
\hline CHEMBL1334670 & 1301770 & 4.9731 & 5.3761 & TRN \\
\hline CHEMBL3188381 & 1301770 & 4.712 & 5.3782 & TRN \\
\hline CHEMBL1339810 & 1301770 & 4.9322 & 5.2774 & TRN \\
\hline CHEMBL1318284 & 1301770 & 5.1643 & 5.1628 & TRN \\
\hline CHEMBL1443194 & 1301770 & 5.0287 & 5.2753 & TST \\
\hline CHEMBL3184905 & 1301770 & 4.8687 & 5.069 & TRN \\
\hline CHEMBL1379163 & 1301770 & 4.8952 & 5.081 & TRN \\
\hline CHEMBL1727678 & 1301770 & 5.7258 & 5.7584 & TRN \\
\hline CHEMBL1443117 & 1301770 & 4.845 & 5.2791 & TRN \\
\hline CHEMBL1423086 & 1301770 & 4.7392 & 5.1641 & TRN \\
\hline CHEMBL1535752 & 1301770 & 5.2708 & 5.1392 & TRN \\
\hline CHEMBL1497149 & 1301770 & 4.8554 & 5.2196 & TRN \\
\hline CHEMBL1509229 & 1301770 & 4.927 & 5.0023 & TRN \\
\hline CHEMBL1370095 & 1301770 & 5.8125 & 4.6538 & TRN \\
\hline CHEMBL1335589 & 1301770 & 4.9914 & 5.5449 & TRN \\
\hline CHEMBL3183381 & 1301770 & 4.8914 & 5.4018 & TRN \\
\hline CHEMBL1449018 & 1301770 & 4.961 & 5.5023 & TRN \\
\hline CHEMBL1584391 & 1301770 & 4.7066 & 5.0682 & TRN \\
\hline CHEMBL1589223 & 1301770 & 5.3449 & 5.2529 & TRN \\
\hline CHEMBL1710358 & 1301770 & 5.7545 & 5.3226 & TRN \\
\hline CHEMBL1398645 & 1301770 & 5.0947 & \multicolumn{2}{|c|}{5.507999999999999} \\
\hline CHEMBL535307 & 1301770 & 5.1391 & 5.3108 & TST \\
\hline CHEMBL3181895 & 1301770 & 5.1068 & 5.5094 & TRN \\
\hline CHEMBL1287983 & 1301770 & 5.6144 & 5.4915 & TRN \\
\hline CHEMBL1337365 & 1301770 & 4.9523 & 5.1447 & TRN \\
\hline CHEMBL3189574 & 1301770 & 5.0595 & 5.2467 & TRN \\
\hline
\end{tabular}

Page 3618 
Supplemental Table S2.txt

\begin{tabular}{|c|c|c|c|c|}
\hline CHEMBL1413740 & 1301770 & 5.1898 & 4.6275 & TRN \\
\hline CHEMBL 1486266 & 1301770 & 5.0329 & 5.2041 & TRN \\
\hline CHEMBL1477039 & 1301770 & 4.8979 & 5.3213 & TRN \\
\hline CHEMBL1548574 & 1301770 & 4.8636 & 5.3761 & TRN \\
\hline CHEMBL1395615 & 1301770 & 6.6345 & 5.4551 & TRN \\
\hline CHEMBL1707960 & 1301770 & 4.8116 & 5.4455 & TRN \\
\hline CHEMBL1706082 & 1301770 & 6.16299 & 999999999 & 5.3809 \\
\hline CHEMBL1454819 & 1301770 & 5.4815 & 5.0477 & TRN \\
\hline CHEMBL 1873677 & 1301770 & 5.1085 & 5.1793 & TST \\
\hline CHEMBL1347799 & 1301770 & 4.9126 & 5.407 & TRN \\
\hline CHEMBL1719734 & 1301770 & 5.7825 & 5.5197 & TRN \\
\hline CHEMBL 1427520 & 1301770 & 5.7122 & 5.3083 & TRN \\
\hline CHEMBL 3192341 & 1301770 & 4.7452 & 5.0369 & TST \\
\hline CHEMBL 3184173 & 1301770 & 4.8179 & 5.2048 & TRN \\
\hline CHEMBL 1500051 & 1301770 & 5.0255 & 5.5512 & TRN \\
\hline CHEMBL 3186620 & 1301770 & 4.7934 & 5.4337 & TRN \\
\hline CHEMBL1613260 & 1301770 & 4.9187 & 5.1793 & TRN \\
\hline CHEMBL1480669 & 1301770 & 4.9094 & 5.4725 & TRN \\
\hline CHEMBL1495539 & 1301770 & 5.2604 & 5.3448 & TRN \\
\hline CHEMBL1476459 & 1301770 & 5.0195 & 5.3169 & TRN \\
\hline CHEMBL1732657 & 1301770 & 4.8254 & 5.3549 & TRN \\
\hline CHEMBL1576284 & 1301770 & 5.4498 & 5.7889 & TRN \\
\hline CHEMBL 3191713 & 1301770 & 5.8894 & 5.6444 & TRN \\
\hline CHEMBL1198307 & 1301770 & 4.8324 & 5.4109 & TRN \\
\hline CHEMBL 2362913 & 1301770 & 5.0301 & 5.1951 & TST \\
\hline CHEMBL1998516 & 1301770 & 5.0292 & 5.3291 & TRN \\
\hline CHEMBL1469120 & 1301770 & 4.8668 & 5.1716 & TRN \\
\hline CHEMBL1345320 & 1301770 & 4.8831 & 5.3544 & TRN \\
\hline CHEMBL 2001904 & 1301770 & 4.9263 & 5.577000 & 0000000001 \\
\hline CHEMBL 104663 & 1301770 & 5.5452 & 5.1944 & TRN \\
\hline CHEMBL1399113 & 1301770 & 8.0969 & 6.8783 & TRN \\
\hline CHEMBL602776 & 1301770 & 4.8204 & 5.2266 & TRN \\
\hline CHEMBL1435749 & 1301770 & 5.2832 & 5.3445 & TST \\
\hline CHEMBL1704366 & 1301770 & 5.9281 & 5.2036 & TST \\
\hline CHEMBL1345824 & 1301770 & 8.0969 & 5.8178 & TST \\
\hline CHEMBL1432479 & 1301770 & 4.9751 & 5.1101 & TST \\
\hline CHEMBL 1517325 & 1301770 & 5.6799 & 5.5609 & TST \\
\hline CHEMBL 1426072 & 1301770 & 6.5817 & 5.5063 & TST \\
\hline CHEMBL 3191387 & 1301770 & 6.0809 & 5.3886 & TST \\
\hline CHEMBL1323744 & 1301770 & 6.0926 & 5.4296 & TST \\
\hline CHEMBL1311154 & 1301770 & 8.0969 & 7.0684 & TST \\
\hline CHEMBL1427868 & 1301770 & 5.2262 & 5.2003 & TST \\
\hline CHEMBL1906093 & 1301770 & 4.7385 & 5.2979 & TST \\
\hline CHEMBL1342954 & 1301770 & 6.5901 & 5.6369 & TST \\
\hline CHEMBL493863 & 1301770 & 5.6108 & 5.5972 & TST \\
\hline CHEMBL 3191855 & 1301770 & 6.1403 & 6.3075 & TST \\
\hline CHEMBL 3182473 & 1301770 & 4.9473 & 5.3426 & TST \\
\hline CHEMBL 3185412 & 1301770 & 5.1175 & 5.1268 & TST \\
\hline
\end{tabular}


Supplemental Table S2.txt

\begin{tabular}{|c|c|c|c|c|}
\hline CHEMBL1560273 & 1301770 & 4.9702 & 5.1781 & TST \\
\hline CHEMBL1477065 & 1301770 & 4.8164 & 5.3718 & TST \\
\hline CHEMBL1699246 & 1301770 & 4.8841 & 5.2291 & TST \\
\hline CHEMBL1718137 & 1301770 & 5.7258 & 5.3413 & TST \\
\hline CHEMBL1865393 & 1301770 & 5.0991 & 5.8488 & TST \\
\hline CHEMBL1715809 & 1301770 & 5.3002 & 5.2445 & TST \\
\hline CHEMBL 3187430 & 1301770 & 5.0491 & 5.3448 & TST \\
\hline CHEMBL1601310 & 1301770 & 6.0752 & 5.2987 & TST \\
\hline CHEMBL1527955 & 1301770 & 4.9842 & 5.2926 & TST \\
\hline CHEMBL1476089 & 1301770 & 4.9423 & 5.7475 & TST \\
\hline CHEMBL1879963 & 1301770 & 5.0883 & 5.4782 & TST \\
\hline CHEMBL1497697 & 1301770 & 5.3002 & 5.0648 & TST \\
\hline CHEMBL1522216 & 1301770 & 5.8097 & 5.4389 & TST \\
\hline CHEMBL1477085 & 1301770 & 5.0467 & 5.2475 & TST \\
\hline CHEMBL1719965 & 1301770 & 4.8052 & 5.2513 & TST \\
\hline CHEMBL157754 & 1301770 & 5.0241 & 5.3245 & TST \\
\hline CHEMBL3194097 & 1301770 & 5.1568 & 5.2368 & TST \\
\hline CHEMBL1532649 & 1301770 & 4.8156 & 5.2505 & TST \\
\hline CHEMBL1461079 & 1301770 & 5.3298 & 5.2151 & TST \\
\hline CHEMBL1714971 & 1301770 & 5.6038 & 5.4874 & TST \\
\hline CHEMBL3185081 & 1301770 & 4.9274 & 5.4175 & TST \\
\hline CHEMBL1378768 & 1301770 & 5.0214 & 5.2533 & TST \\
\hline CHEMBL1502020 & 1301770 & 4.7582 & 5.5255 & TST \\
\hline CHEMBL153477 & 70611 & 3.301 & 3.341 & TRN \\
\hline CHEMBL345970 & 70611 & 3.301 & 3.6322 & TRN \\
\hline CHEMBL149635 & 70611 & 3.301 & 3.0025 & TRN \\
\hline CHEMBL436455 & 70611 & 4.2924 & 4.4025 & TRN \\
\hline CHEMBL358881 & 70611 & 3.301 & 3.6202 & TRN \\
\hline CHEMBL151537 & 70611 & 3.301 & 3.1921 & TST \\
\hline CHEMBL358429 & 70611 & 3.301 & 3.5468 & TRN \\
\hline CHEMBL347777 & 70611 & 3.301 & 3.4116 & TRN \\
\hline CHEMBL358240 & 70611 & 3.301 & 3.5269 & TRN \\
\hline CHEMBL346000 & 70611 & 3.301 & 3.6197 & TRN \\
\hline CHEMBL358469 & 70611 & 5.1871 & 5.2165 & TRN \\
\hline CHEMBL 75964 & 70611 & 3.301 & 3.608 & TRN \\
\hline CHEMBL450929 & 70611 & 4.3098 & 3.7892 & TRN \\
\hline CHEMBL153535 & 70611 & 3.301 & 3.3529 & TST \\
\hline CHEMBL150899 & 70611 & 3.301 & 3.2894 & TRN \\
\hline CHEMBL153084 & 70611 & 5.2757 & 4.9238 & TRN \\
\hline CHEMBL154750 & 70611 & 3.301 & 3.2487 & TRN \\
\hline CHEMBL153054 & 70611 & 5.1805 & 4.6039 & TRN \\
\hline CHEMBL152995 & 70611 & 3.301 & 3.6417 & TRN \\
\hline CHEMBL150912 & 70611 & 3.301 & 3.514 & TST \\
\hline CHEMBL153106 & 70611 & 3.301 & 4.246 & TRN \\
\hline CHEMBL358241 & 70611 & 3.301 & 3.4367 & TRN \\
\hline CHEMBL154978 & 70611 & 3.301 & 3.177 & TRN \\
\hline CHEMBL356237 & 70611 & 3.301 & 3.3561 & TRN \\
\hline CHEMBL153526 & 70611 & 4.301 & 3.4494 & TRN \\
\hline
\end{tabular}




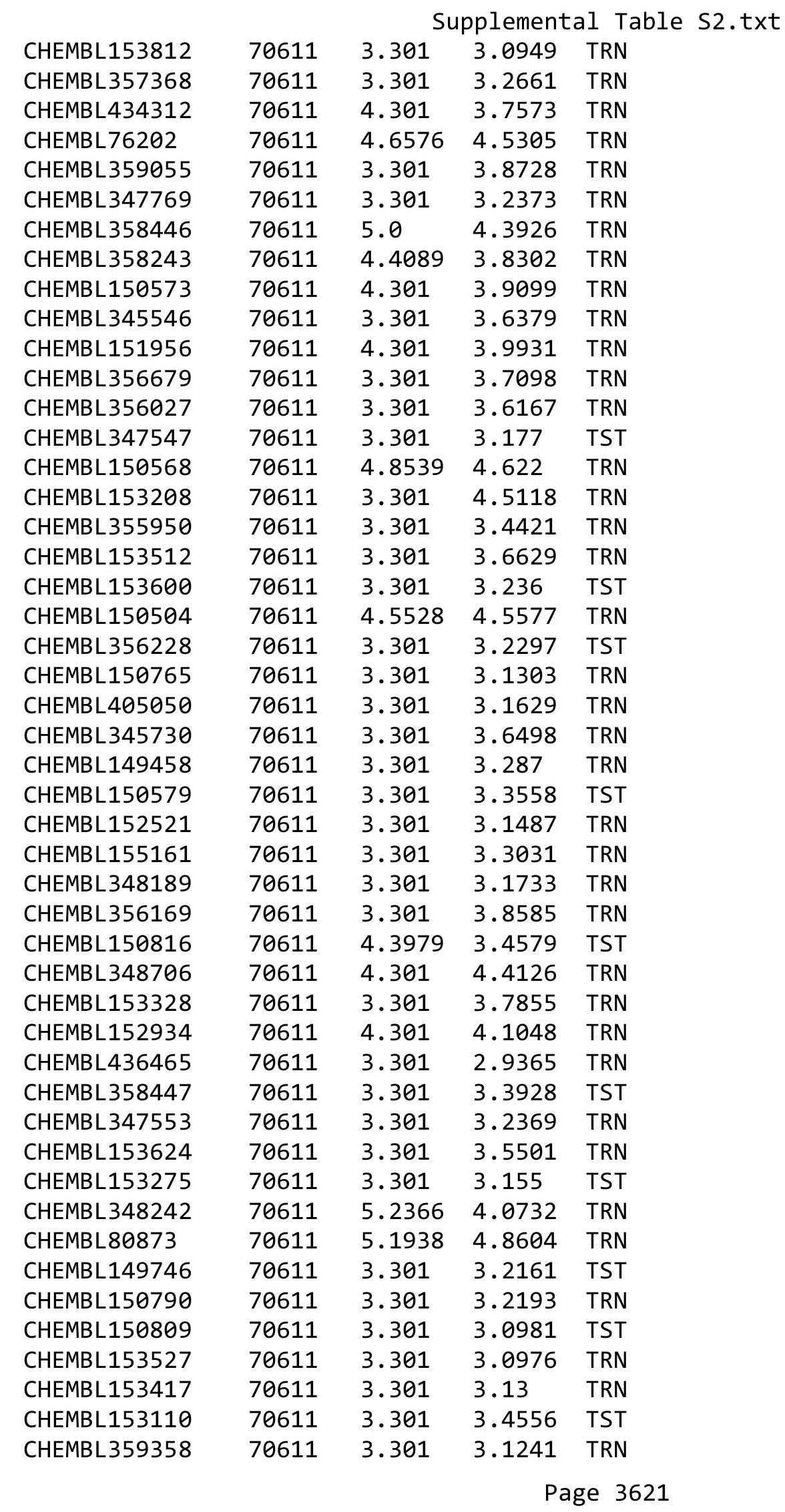




\begin{tabular}{|c|c|c|c|c|c|c|}
\hline & & \multicolumn{5}{|c|}{ Supplemental Table s2.txt } \\
\hline CHEMBL346870 & 70611 & 3.301 & 3.5338 & TRN & & \\
\hline CHEMBL150934 & 70611 & 3.301 & \multicolumn{3}{|c|}{3.1689999999999996} & TRN \\
\hline CHEMBL153101 & 70611 & 3.301 & 3.6881 & TRN & & \\
\hline CHEMBL153571 & 70611 & 3.301 & 3.4563 & TRN & & \\
\hline CHEMBL153682 & 70611 & 3.301 & \multicolumn{3}{|c|}{3.6910000000000003} & TRN \\
\hline CHEMBL 310080 & 70611 & 3.301 & 3.516 & TRN & & \\
\hline CHEMBL435677 & 70611 & 4.4559 & 4.0416 & TRN & & \\
\hline CHEMBL345775 & 70611 & 3.301 & 3.2307 & TRN & & \\
\hline CHEMBL150973 & 70611 & 4.4437 & 4.2988 & TRN & & \\
\hline CHEMBL155505 & 70611 & 3.301 & 3.8289 & TST & & \\
\hline CHEMBL358384 & 70611 & 3.301 & 4.3484 & TST & & \\
\hline CHEMBL357347 & 70611 & 4.301 & 3.603 & TST & & \\
\hline CHEMBL346611 & 70611 & 4.301 & 3.9216 & TST & & \\
\hline CHEMBL149573 & 70611 & 3.301 & 3.0577 & TST & & \\
\hline CHEMBL150575 & 70611 & 3.301 & 3.7 & TST & & \\
\hline CHEMBL153365 & 70611 & 3.301 & 3.1798 & TST & & \\
\hline CHEMBL153145 & 70611 & 3.301 & 3.0091 & TST & & \\
\hline CHEMBL149401 & 70611 & 4.301 & 3.8419 & TST & & \\
\hline CHEMBL155093 & 70611 & 3.301 & 3.7901 & TST & & \\
\hline CHEMBL56907 & 63997 & 8.9208 & 8.9003 & TRN & & \\
\hline CHEMBL 2372976 & 63997 & 8.5376 & 8.5736 & TRN & & \\
\hline CHEMBL2372992 & 63997 & 7.8539 & 7.82700 & 0000000001 & & TRN \\
\hline CHEMBL 2372977 & 63997 & 8.1079 & 8.1058 & TRN & & \\
\hline CHEMBL2372966 & 63997 & 8.4089 & 8.4034 & TRN & & \\
\hline CHEMBL291309 & 63997 & 8.2147 & 9.2984 & TST & & \\
\hline CHEMBL 301671 & 63997 & 6.7696 & 6.6919 & TRN & & \\
\hline CHEMBL 293497 & 63997 & 7.3665 & 7.3588 & TRN & & \\
\hline CHEMBL56852 & 63997 & 7.6021 & 7.6873 & TRN & & \\
\hline CHEMBL59258 & 63997 & \multicolumn{3}{|c|}{8.283999999999999} & 8.3137 & TRN \\
\hline CHEMBL417935 & 63997 & 8.8861 & 8.9132 & TRN & & \\
\hline CHEMBL55726 & 63997 & 8.5686 & 8.5526 & TRN & & \\
\hline CHEMBL2372980 & 63997 & 7.9586 & 7.9391 & TRN & & \\
\hline CHEMBL55210 & 63997 & 8.7212 & 8.7321 & TRN & & \\
\hline CHEMBL56342 & 63997 & 8.6021 & 8.6 & TRN & & \\
\hline CHEMBL56713 & 63997 & 8.7447 & 8.7169 & TRN & & \\
\hline CHEMBL293062 & 63997 & 8.0969 & 8.1015 & TRN & & \\
\hline CHEMBL2372982 & 63997 & 8.4202 & 8.4318 & TRN & & \\
\hline CHEMBL55912 & 63997 & 9.3665 & 9.4936 & TST & & \\
\hline CHEMBL56242 & 63997 & 8.9586 & 8.9637 & TRN & & \\
\hline CHEMBL2372978 & 63997 & 7.2007 & 7.7744 & TST & & \\
\hline CHEMBL299028 & 63997 & 7.2596 & 7.2643 & TRN & & \\
\hline CHEMBL56042 & 63997 & 7.2218 & 7.2112 & TRN & & \\
\hline CHEMBL59476 & 63997 & 7.9208 & 7.8162 & TRN & & \\
\hline CHEMBL54522 & 63997 & 8.4815 & 8.4784 & TRN & & \\
\hline CHEMBL3085439 & 63997 & 9.2076 & 9.2106 & TRN & & \\
\hline CHEMBL56496 & 63997 & 7.8239 & 7.8197 & TRN & & \\
\hline CHEMBL293809 & 63997 & 9.301 & 9.3239 & TRN & & \\
\hline CHEMBL2372981 & 63997 & 7.699 & 7.6978 & TRN & & \\
\hline
\end{tabular}




\begin{tabular}{|c|c|c|c|c|c|}
\hline \multicolumn{6}{|c|}{ Supplemental Table S2.txt } \\
\hline CHEMBL59091 & 63997 & 6.71 & 6.807 & TRN & \\
\hline CHEMBL56469 & 63997 & 9.0605 & 9.0784 & TRN & \\
\hline CHEMBL301691 & 63997 & 8.7959 & 8.796 & TRN & \\
\hline CHEMBL2372970 & 63997 & 8.699 & 8.2103 & TST & \\
\hline CHEMBL55161 & 63997 & 8.6383 & 8.6335 & TRN & \\
\hline CHEMBL2372965 & 63997 & 8.1675 & 8.184 & TRN & \\
\hline CHEMBL301825 & 63997 & 7.9586 & 7.9734 & TRN & \\
\hline CHEMBL55386 & 63997 & 8.4949 & 8.4754 & TRN & \\
\hline CHEMBL 293558 & 63997 & 8.9208 & 8.1631 & TST & \\
\hline CHEMBL542128 & 63997 & 8.7696 & 8.5994 & TST & \\
\hline CHEMBL2372967 & 63997 & 7.8239 & 7.8374 & TRN & \\
\hline CHEMBL2372974 & 63997 & 9.2007 & 9.1805 & TRN & \\
\hline CHEMBL2372971 & 63997 & 7.3468 & 7.3372 & TRN & \\
\hline CHEMBL55963 & 63997 & 8.7696 & 8.7671 & TRN & \\
\hline CHEMBL57368 & 63997 & 8.699 & 8.6964 & TRN & \\
\hline CHEMBL 2372968 & 63997 & 9.0 & 8.9829 & TRN & \\
\hline CHEMBL354883 & 63997 & 8.7959 & 8.8042 & TRN & \\
\hline CHEMBL2372972 & 63997 & 6.0915 & 6.098 & TRN & \\
\hline CHEMBL56136 & 63997 & 9.3872 & 9.3773 & TRN & \\
\hline CHEMBL 292141 & 63997 & 8.2676 & 8.6388 & TST & \\
\hline CHEMBL 2372975 & 63997 & 6.8239 & 7.5323 & TST & \\
\hline CHEMBL2372973 & 63997 & 7.7959 & 8.6366 & TST & \\
\hline CHEMBL418117 & 63997 & 8.7447 & 8.3452 & TST & \\
\hline CHEMBL2372969 & 63997 & 8.585 & 7.83899 & 99999999995 & TST \\
\hline CHEMBL2372979 & 63997 & 9.0177 & 8.4626 & TST & \\
\hline CHEMBL435774 & 63997 & 8.0 & 7.6642 & TST & \\
\hline CHEMBL 293707 & 63997 & 8.3768 & 8.4535 & TST & \\
\hline CHEMBL 3086320 & 1641041 & 6.0 & 6.0854 & TRN & \\
\hline CHEMBL 3660763 & 1641041 & 8.8539 & 8.7017 & TRN & \\
\hline CHEMBL 3085978 & 1641041 & 9.0969 & 9.4391 & TRN & \\
\hline CHEMBL 3085831 & 1641041 & 8.8239 & 8.8651 & TRN & \\
\hline CHEMBL 3660787 & 1641041 & 8.5376 & 8.0374 & TST & \\
\hline CHEMBL3660794 & 1641041 & 7.4815 & 7.4926 & TRN & \\
\hline CHEMBL3085827 & 1641041 & 7.7212 & 7.7031 & TRN & \\
\hline CHEMBL3660755 & 1641041 & 7.9066 & 8.1172 & TRN & \\
\hline CHEMBL 3085834 & 1641041 & 8.8861 & 8.7952 & TRN & \\
\hline CHEMBL3958194 & 1641041 & 9.1675 & 8.4596 & TST & \\
\hline CHEMBL3085975 & 1641041 & 8.699 & 8.7166 & TRN & \\
\hline CHEMBL 3086323 & 1641041 & 8.1427 & 8.1384 & TRN & \\
\hline CHEMBL3085974 & 1641041 & 8.7959 & 9.0299 & TRN & \\
\hline CHEMBL 3086322 & 1641041 & 8.7447 & 8.458 & TRN & \\
\hline CHEMBL3660802 & 1641041 & 9.0862 & 9.1228 & TST & \\
\hline CHEMBL3660784 & 1641041 & 7.585 & 7.0011 & TST & \\
\hline CHEMBL 3085828 & 1641041 & 9.0269 & 8.8674 & TRN & \\
\hline CHEMBL3660781 & 1641041 & 8.6021 & 8.0087 & TST & \\
\hline CHEMBL3660775 & 1641041 & 6.2218 & 6.1381 & TRN & \\
\hline CHEMBL3660804 & 1641041 & 7.1024 & 7.0003 & TST & \\
\hline CHEMBL 3660800 & 1641041 & 8.7696 & 8.3219 & TST & \\
\hline
\end{tabular}


Supplemental Table S2.txt

\begin{tabular}{|c|c|c|c|c|}
\hline . & 541041 & 8.8447 & & \\
\hline & & 8.0969 & 8.124 & \\
\hline & & & & \\
\hline AEMBL & & 2218 & 3746 & \\
\hline AEMBL3 & 041 & 7.7447 & 4379 & \\
\hline HEMBL3660772 & 641041 & 5.301 & .4182 & \\
\hline 316 & & & 305 & \\
\hline IFMPI & & & & RN \\
\hline AEMBL3 & 041 & 8.1113 & .846 & \\
\hline HEMBL3660803 & 041 & 7.4828 & .3754 & \\
\hline AEMBL3660795 & 041 & 8.0555 & 7.9 & \\
\hline IEMBL3 & 41 & 208 & 05 & \\
\hline IEMBL: & & & & \\
\hline HEMBL3660788 & 041 & 7.301 & 6.6415 & \\
\hline AEMBL3660773 & 041 & 6.5229 & 17 & \\
\hline AEMBL 30863 & 41 & 208 & 8.9477 & \\
\hline HEMBL36 & 41 & 36 & 66 & \\
\hline HEMBL36 & & & & \\
\hline HEMBL370 & & 9. & 9.0782 & \\
\hline AEMBL3 & 41 & & & \\
\hline HEMBL & 41 & 686 & 8 & KIV \\
\hline AEMBL: & & 51 & 32 & RN \\
\hline HEMBL; & & 59 & 27 & \\
\hline AFMRI & & 239 & 7.9055 & \\
\hline AEMBL 30863 & & & & $\Gamma \mathrm{RN}$ \\
\hline HEMBL; & 41 & 8. & 3604 & I RN \\
\hline HEMBL & & 51 & 585 & RN \\
\hline HFMBI : & & 91 & 112 & \\
\hline HEMBL3 & & 862 & 7.9682 & in \\
\hline HEMBL36607 & & 8 . & 3549 & 15 \\
\hline HEMBL3 & & & 168 & RN \\
\hline HEMBL & & & 02 & RN \\
\hline DOM & & 7. & 25 & 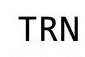 \\
\hline HEMBL30859 & & 8. & 564 & IR \\
\hline HEMBL36607 & & 8.4089 & 8.3002 & Th \\
\hline HEMBL3 & & 565 & $\partial 672$ & RIN \\
\hline HFMRI & & 8 & 1696 & $\Gamma \mathrm{RN}$ \\
\hline HEMBL; & & & 998 & IRN \\
\hline HEMBL3660757 & 41 & 8.0655 & .9153 & TST \\
\hline AEMBL3 & & 6.2218 & 2182 & TRN \\
\hline HEMBL36 & 41 & 283 & 2992 & \\
\hline HEMBL 3 & & & 5.4817 & ГST \\
\hline HEMBL3 & 341 & 8.0315 & 8.1369 & RN \\
\hline AEMBL3085832 & 341 & 8.7696 & .5764 & TRN \\
\hline 13 & & & 8.1366 & ב \\
\hline HEMBL3 & & & 3.3917 & \\
\hline CHEMBL 30859 & & 9.1938 & 8.8825 & \\
\hline CHEMBL3660793 & 1641041 & 6.8539 & 7.1168 & \\
\hline
\end{tabular}


Supplemental Table S2.txt

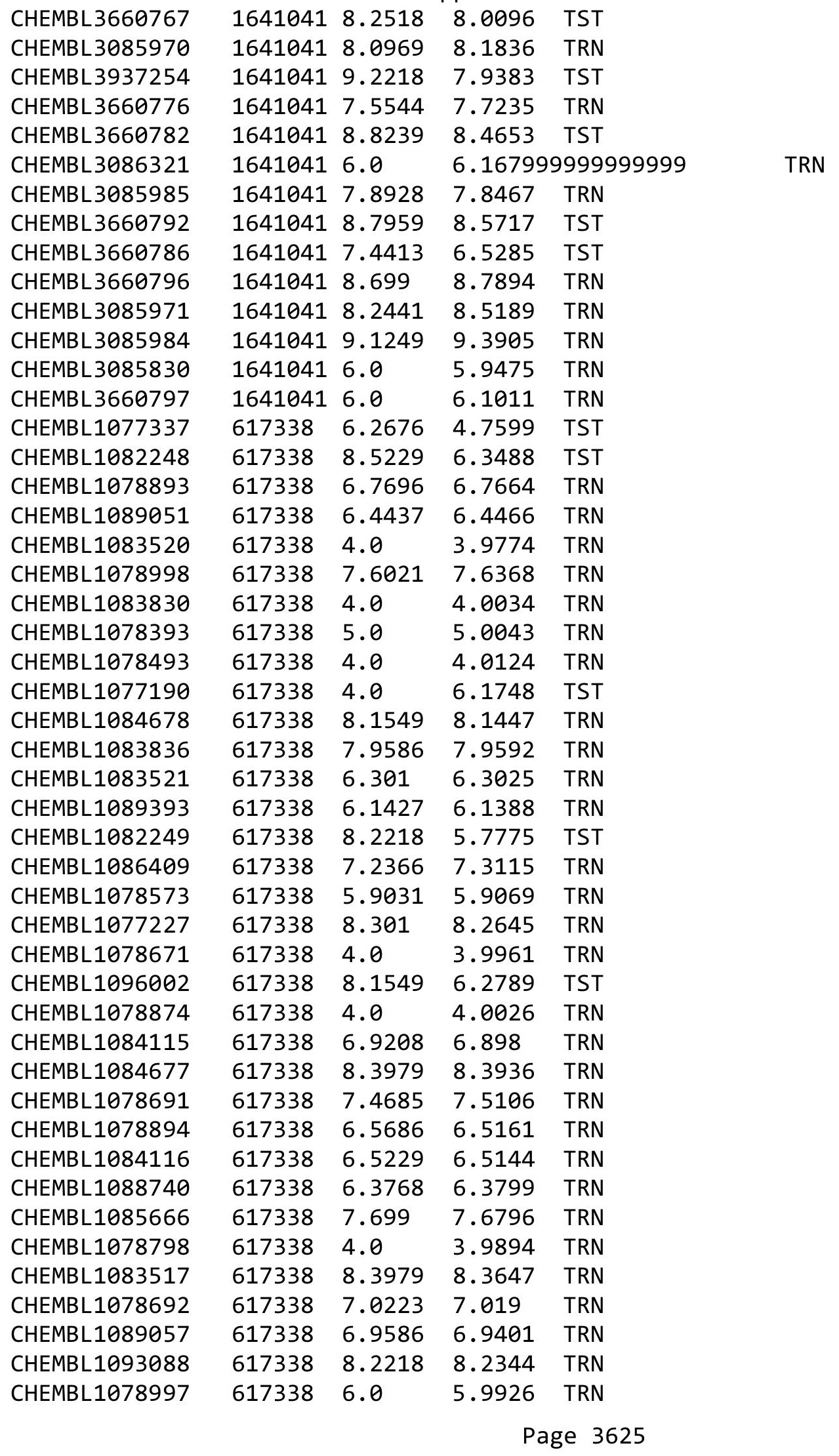




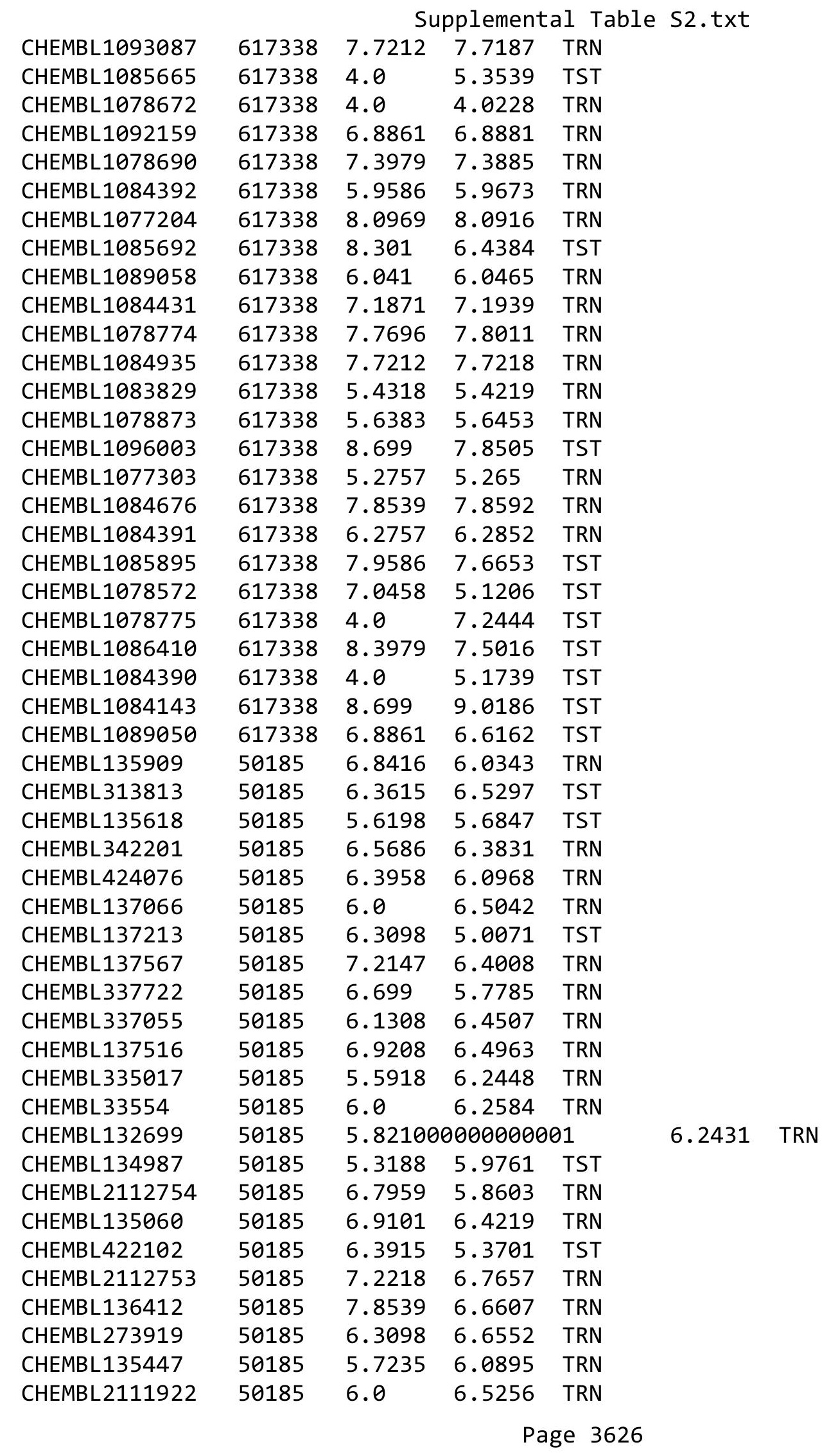




\begin{tabular}{|c|c|c|c|c|c|}
\hline \multirow[b]{2}{*}{ CHEMBL135364 } & \multicolumn{5}{|c|}{ Supplemental Table S2.txt } \\
\hline & 50185 & 7.1675 & 6.6394 & TRN & \\
\hline CHEMBL335239 & 50185 & 5.9586 & 5.96899 & 9999999999 & TRN \\
\hline CHEMBL434255 & 50185 & 8.5229 & 6.9702 & TRN & \\
\hline CHEMBL334592 & 50185 & 7.4685 & 7.4449 & TRN & \\
\hline CHEMBL 9449 & 50185 & 5.9208 & 6.6699 & TRN & \\
\hline CHEMBL340975 & 50185 & 4.7696 & 6.5056 & TRN & \\
\hline CHEMBL136436 & 50185 & 6.3872 & 6.7919 & TST & \\
\hline CHEMBL134750 & 50185 & 6.8861 & 6.3051 & TRN & \\
\hline CHEMBL135702 & 50185 & 7.585 & 6.2896 & TRN & \\
\hline CHEMBL133087 & 50185 & 6.1427 & 6.2803 & TRN & \\
\hline CHEMBL135901 & 50185 & 5.6778 & 6.1037 & TRN & \\
\hline CHEMBL137238 & 50185 & 6.5086 & 6.1218 & TST & \\
\hline CHEMBL132603 & 50185 & 8.0458 & 7.4893 & TRN & \\
\hline CHEMBL515268 & 50185 & 6.0969 & 6.2543 & TRN & \\
\hline CHEMBL137714 & 50185 & 5.51 & 6.3761 & TRN & \\
\hline CHEMBL137684 & 50185 & 6.7825 & 6.5399 & TRN & \\
\hline CHEMBL72546 & 50185 & 3.5229 & 6.3167 & TRN & \\
\hline CHEMBL445095 & 50185 & 6.0 & 6.221 & TRN & \\
\hline CHEMBL138592 & 50185 & 6.2218 & 6.4249 & TRN & \\
\hline CHEMBL 2112752 & 50185 & 5.7773 & 6.8566 & TRN & \\
\hline CHEMBL136990 & 50185 & 4.699 & 5.8619 & TST & \\
\hline CHEMBL134657 & 50185 & 6.4089 & 6.0961 & TRN & \\
\hline CHEMBL336221 & 50185 & 6.5884 & 6.4656 & TRN & \\
\hline CHEMBL417521 & 50185 & 6.6576 & 6.1502 & TRN & \\
\hline CHEMBL135638 & 50185 & 5.6198 & 5.8355 & TRN & \\
\hline CHEMBL134340 & 50185 & 6.0 & 6.2213 & TRN & \\
\hline CHEMBL343949 & 50185 & 5.2076 & 6.1877 & TRN & \\
\hline CHEMBL137779 & 50185 & 5.8539 & 6.1314 & TST & \\
\hline CHEMBL137748 & 50185 & 5.5229 & 6.1935 & TRN & \\
\hline CHEMBL336765 & 50185 & 5.8861 & 6.7013 & TRN & \\
\hline CHEMBL136966 & 50185 & 6.4685 & 6.7221 & TRN & \\
\hline CHEMBL342614 & 50185 & 7.2518 & 6.9486 & TRN & \\
\hline CHEMBL 2112751 & 50185 & 7.6778 & 5.6541 & TST & \\
\hline CHEMBL136608 & 50185 & 6.699 & 6.4126 & TRN & \\
\hline CHEMBL336749 & 50185 & 7.3372 & 6.2626 & TRN & \\
\hline CHEMBL 38404 & 50185 & 6.4318 & 5.5577 & TRN & \\
\hline CHEMBL336972 & 50185 & 7.2118 & 6.53799 & 9999999999 & TRN \\
\hline CHEMBL335865 & 50185 & 6.9208 & 6.45799 & 9999999999 & TRN \\
\hline CHEMBL 137240 & 50185 & 6.6778 & 7.49 & TRN & \\
\hline CHEMBL134618 & 50185 & 5.3979 & 5.6124 & TRN & \\
\hline CHEMBL135405 & 50185 & 4.2596 & 5.5613 & TRN & \\
\hline CHEMBL135538 & 50185 & 5.8861 & 6.3796 & TRN & \\
\hline CHEMBL2111921 & 50185 & 5.4202 & 6.561 & TST & \\
\hline CHEMBL337574 & 50185 & 6.3979 & 6.3331 & TRN & \\
\hline CHEMBL82685 & 50185 & 7.1871 & 6.5325 & TRN & \\
\hline CHEMBL342142 & 50185 & 5.5376 & 6.0928 & TRN & \\
\hline CHEMBL 335241 & 50185 & 5.6383 & 6.6264 & TRN & \\
\hline CHEMBL335951 & 50185 & 8.5229 & 6.5837 & TRN & \\
\hline
\end{tabular}




\begin{tabular}{|c|c|c|c|c|}
\hline & & & pplement & \\
\hline CHEMBL2112749 & 50185 & 5.3635 & 6.1004 & TRN \\
\hline CHEMBL136408 & 50185 & 8.0809 & 6.2839 & TRN \\
\hline CHEMBL542967 & 50185 & 6.1192 & 6.095 & TRN \\
\hline CHEMBL 342640 & 50185 & 5.9208 & 6.1948 & TRN \\
\hline CHEMBL135498 & 50185 & 6.983 & 6.6496 & TRN \\
\hline CHEMBL138122 & 50185 & 5.8861 & 5.3825 & TRN \\
\hline CHEMBL135289 & 50185 & 6.7447 & 6.8862 & TST \\
\hline CHEMBL137726 & 50185 & 6.7696 & 6.3913 & TRN \\
\hline CHEMBL135167 & 50185 & 6.5086 & 6.5569 & TRN \\
\hline CHEMBL135988 & 50185 & 5.1675 & 5.5931 & TRN \\
\hline CHEMBL135218 & 50185 & 6.7212 & 6.5276 & TRN \\
\hline CHEMBL355092 & 50185 & 6.0 & 6.3493 & TRN \\
\hline CHEMBL136975 & 50185 & 6.2472 & 5.704 & TRN \\
\hline CHEMBL137520 & 50185 & 5.5086 & 6.5703 & TRN \\
\hline CHEMBL135166 & 50185 & 5.6778 & 5.9194 & TRN \\
\hline CHEMBL132875 & 50185 & 7.4318 & 7.352 & TRN \\
\hline CHEMBL70380 & 50185 & 6.0 & 6.3567 & TST \\
\hline CHEMBL137043 & 50185 & 7.9586 & 7.4942 & TST \\
\hline CHEMBL135715 & 50185 & 6.9586 & 6.4266 & TST \\
\hline CHEMBL136038 & 50185 & 6.0458 & 6.393 & TST \\
\hline CHEMBL135371 & 50185 & 5.8539 & 6.4607 & TST \\
\hline CHEMBL 2112750 & 50185 & 5.1805 & 6.312 & TST \\
\hline CHEMBL335666 & 50185 & 8.0 & 6.329 & TST \\
\hline CHEMBL135433 & 50185 & 6.5086 & 6.2849 & TST \\
\hline CHEMBL136919 & 50185 & 8.1192 & 7.0434 & TST \\
\hline CHEMBL337065 & 50185 & 5.6778 & 5.6755 & TST \\
\hline CHEMBL337285 & 50185 & 6.3497 & 6.141 & TST \\
\hline CHEMBL40668 & 50185 & 6.9586 & 5.7133 & TST \\
\hline CHEMBL137810 & 50185 & 4.0 & 6.3237 & TST \\
\hline CHEMBL137208 & 50185 & 6.3665 & 6.5213 & TST \\
\hline CHEMBL360680 & 305784 & 5.0 & 4.9424 & TRN \\
\hline CHEMBL 360069 & 305784 & 6.8182 & 7.2786 & TRN \\
\hline CHEMBL360239 & 305784 & 6.1421 & 5.8273 & TST \\
\hline CHEMBL180784 & 305784 & 7.6383 & 7.7984 & TRN \\
\hline CHEMBL182638 & 305784 & 6.2147 & 5.8905 & TST \\
\hline CHEMBL179896 & 305784 & 5.0 & 4.8208 & TRN \\
\hline CHEMBL180384 & 305784 & 8.2218 & 7.8718 & TRN \\
\hline CHEMBL182487 & 305784 & 5.4572 & 5.3007 & TRN \\
\hline CHEMBL183774 & 305784 & 8.1549 & 8.0903 & TRN \\
\hline CHEMBL181152 & 305784 & 5.0 & 5.2088 & TRN \\
\hline CHEMBL182463 & 305784 & 7.1308 & 7.028 & TRN \\
\hline CHEMBL183585 & 305784 & 7.1249 & 7.2775 & TRN \\
\hline CHEMBL179060 & 305784 & 7.4089 & 7.0107 & TRN \\
\hline CHEMBL183043 & 305784 & 7.7959 & 7.7453 & TRN \\
\hline CHEMBL360087 & 305784 & 5.0 & 4.9092 & TRN \\
\hline CHEMBL180326 & 305784 & 6.2055 & 7.653 & TST \\
\hline CHEMBL183549 & 305784 & 6.2716 & 6.2066 & TRN \\
\hline CHEMBL183351 & 305784 & 8.301 & 8.2156 & TRN \\
\hline
\end{tabular}




\begin{tabular}{|c|c|c|c|c|c|c|}
\hline \\
\hline CHEMBL368219 & 305784 & 5.0 & 4.9638 & TRN & & \\
\hline CHEMBL183165 & 305784 & 5.0 & 5.1968 & TRN & & \\
\hline CHEMBL183292 & 305784 & 5.0 & 5.1303 & TRN & & \\
\hline CHEMBL361408 & 305784 & 6.3098 & 6.3873 & TRN & & \\
\hline CHEMBL183764 & 305784 & 7.9208 & 8.0011 & TRN & & \\
\hline CHEMBL180160 & 305784 & 5.0 & 4.9682 & TRN & & \\
\hline CHEMBL362644 & 305784 & 7.1612 & 7.4605 & TRN & & \\
\hline CHEMBL181519 & 305784 & 6.6459 & 6.5504 & TRN & & \\
\hline CHEMBL181010 & 305784 & 5.0 & 5.8938 & TST & & \\
\hline CHEMBL182327 & 305784 & 7.4685 & 7.5116 & TRN & & \\
\hline CHEMBL179524 & 305784 & 6.6799 & 7.6136 & TST & & \\
\hline CHEMBL180132 & 305784 & 6.3307 & 6.4253 & TRN & & \\
\hline CHEMBL182416 & 305784 & 6.8894 & 7.109 & TRN & & \\
\hline CHEMBL183326 & 305784 & 6.7212 & 6.2726 & TRN & & \\
\hline CHEMBL183724 & 305784 & 6.6216 & 7.025 & TST & & \\
\hline CHEMBL183137 & 305784 & 6.8153 & 6.8504 & TRN & & \\
\hline CHEMBL360119 & 305784 & 6.3851 & 6.4188 & TRN & & \\
\hline CHEMBL183558 & 305784 & 8.1549 & 7.8356 & TRN & & \\
\hline CHEMBL361627 & 305784 & 5.0 & 5.0927 & TRN & & \\
\hline CHEMBL182833 & 305784 & 6.8356 & 6.7453 & TRN & & \\
\hline CHEMBL179982 & 305784 & 6.644 & 7.8345 & TST & & \\
\hline CHEMBL183753 & 305784 & 5.0 & 4.987 & TRN & & \\
\hline CHEMBL361143 & 305784 & 5.2218 & 5.5503 & TRN & & \\
\hline CHEMBL180062 & 305784 & 7.6778 & 7.7609 & TRN & & \\
\hline CHEMBL180118 & 305784 & 6.475 & 7.6361 & TST & & \\
\hline CHEMBL182349 & 305784 & 7.3872 & 7.1803 & TRN & & \\
\hline CHEMBL179519 & 305784 & 7.8239 & 8.0744 & TRN & & \\
\hline CHEMBL181213 & 305784 & 6.4895 & 6.2014 & TRN & & \\
\hline CHEMBL427509 & 305784 & 6.5702 & 6.6686 & TRN & & \\
\hline CHEMBL359693 & 305784 & 7.1367 & 7.5988 & TST & & \\
\hline CHEMBL362216 & 305784 & 7.5376 & 7.718 & TRN & & \\
\hline CHEMBL360679 & 305784 & 6.1864 & 6.0917 & TRN & & \\
\hline CHEMBL369557 & 305784 & 8.301 & 7.8121 & TST & & \\
\hline CHEMBL362693 & 305784 & 5.0 & 6.4525 & TST & & \\
\hline CHEMBL181306 & 305784 & 6.75706 & 00000000 & 01 & 6.7261 & TST \\
\hline CHEMBL182345 & 305784 & 5.0 & 5.1182 & TRN & & \\
\hline CHEMBL361113 & 305784 & 5.0 & 5.7793 & TST & & \\
\hline CHEMBL183777 & 305784 & 7.2076 & 6.9624 & TST & & \\
\hline CHEMBL183654 & 305784 & 7.301 & 6.1666 & TST & & \\
\hline CHEMBL362196 & 305784 & 5.0 & 5.0402 & TRN & & \\
\hline CHEMBL183449 & 305784 & 7.1549 & 6.9963 & TRN & & \\
\hline CHEMBL3933372 & 1642522 & 8.699 & 8.5619 & TRN & & \\
\hline CHEMBL3907895 & 1642522 & 7.8239 & 8.3983 & TRN & & \\
\hline CHEMBL3896793 & 1642522 & 8.699 & 8.5442 & TRN & & \\
\hline CHEMBL3966671 & 1642522 & 7.5686 & 8.0716 & TRN & & \\
\hline CHEMBL 3922493 & 1642522 & 7.7696 & 8.5157 & TRN & & \\
\hline CHEMBL3913371 & 1642522 & 8.3979 & 8.4962 & TST & & \\
\hline CHEMBL3980029 & 1642522 & 7.5376 & 7.8621 & TRN & & \\
\hline
\end{tabular}




\begin{tabular}{|c|c|c|c|c|c|}
\hline \multicolumn{6}{|c|}{ Supplemental Table S2.txt } \\
\hline CHEMBL3973459 & 1642522 & 8.301 & 8.5782 & TRN & \\
\hline CHEMBL3895602 & 1642522 & 8.301 & 8.5494 & TRN & \\
\hline CHEMBL3917664 & 1642522 & 7.7696 & 7.8325 & TRN & \\
\hline CHEMBL3930709 & 1642522 & 7.5086 & 7.8671 & TRN & \\
\hline CHEMBL3971249 & 1642522 & 9.0 & 8.4701 & TRN & \\
\hline CHEMBL3947170 & 1642522 & 7.5686 & 7.6517 & TRN & \\
\hline CHEMBL3942748 & 1642522 & 8.699 & 8.4859 & TRN & \\
\hline CHEMBL3965526 & 1642522 & 9.0 & 8.6218 & TRN & \\
\hline CHEMBL 3972397 & 1642522 & 8.0969 & 8.2367 & TRN & \\
\hline CHEMBL3930313 & 1642522 & 8.699 & 8.4875 & TRN & \\
\hline CHEMBL3957505 & 1642522 & 8.5229 & 7.8331 & TRN & \\
\hline CHEMBL3899088 & 1642522 & 9.0 & 8.5989 & TST & \\
\hline CHEMBL3943393 & 1642522 & 8.1549 & 8.5834 & TRN & \\
\hline CHEMBL3984631 & 1642522 & 8.0 & 7.6544 & TRN & \\
\hline CHEMBL3963744 & 1642522 & 8.0 & 7.7643 & TRN & \\
\hline CHEMBL3920750 & 1642522 & 8.1549 & 8.5342 & TST & \\
\hline CHEMBL3929430 & 1642522 & 8.0 & 7.8212 & TRN & \\
\hline CHEMBL3892090 & 1642522 & 7.8239 & 7.6784 & TST & \\
\hline CHEMBL3975213 & 1642522 & 8.0 & 8.5021 & TRN & \\
\hline CHEMBL3936078 & 1642522 & 9.0 & 8.5119 & TRN & \\
\hline CHEMBL3900503 & 1642522 & 7.5376 & 8.34700 & 0000000001 & TRN \\
\hline CHEMBL3908864 & 1642522 & 8.5229 & 8.0963 & TRN & \\
\hline CHEMBL3962164 & 1642522 & 7.5376 & 8.4748 & TST & \\
\hline CHEMBL3922874 & 1642522 & 8.0 & 8.2206 & TRN & \\
\hline CHEMBL3971469 & 1642522 & 8.0 & 7.9222 & TRN & \\
\hline CHEMBL3915422 & 1642522 & 7.8861 & 8.5023 & TST & \\
\hline CHEMBL3935182 & 1642522 & 7.7959 & 8.0253 & TRN & \\
\hline CHEMBL3951961 & 1642522 & 8.301 & 8.5418 & TRN & \\
\hline CHEMBL3961755 & 1642522 & 8.0458 & 8.0441 & TST & \\
\hline CHEMBL3968836 & 1642522 & 8.699 & 7.9998 & TRN & \\
\hline CHEMBL3918347 & 1642522 & 7.5086 & 7.7782 & TRN & \\
\hline CHEMBL3956859 & 1642522 & 8.0969 & 8.2939 & TRN & \\
\hline CHEMBL3930119 & 1642522 & 7.9208 & 8.2772 & TRN & \\
\hline CHEMBL3945379 & 1642522 & 8.2218 & 8.456 & TRN & \\
\hline CHEMBL3931979 & 1642522 & 7.7447 & 7.8569 & TST & \\
\hline CHEMBL3935496 & 1642522 & 8.2218 & 8.5685 & TRN & \\
\hline CHEMBL3954257 & 1642522 & 8.0969 & 7.751 & TRN & \\
\hline CHEMBL3916641 & 1642522 & 7.5376 & 8.5111 & TST & \\
\hline CHEMBL3973387 & 1642522 & 8.699 & 8.571 & TRN & \\
\hline CHEMBL3922406 & 1642522 & 8.699 & 8.4845 & TRN & \\
\hline CHEMBL3969344 & 1642522 & 8.699 & 8.5392 & TRN & \\
\hline CHEMBL3981903 & 1642522 & 8.5229 & 8.5085 & TRN & \\
\hline CHEMBL3938389 & 1642522 & 7.6021 & 7.6517 & TRN & \\
\hline CHEMBL3949289 & 1642522 & 8.699 & 8.5482 & TRN & \\
\hline CHEMBL3967094 & 1642522 & 8.3979 & 8.1198 & TRN & \\
\hline CHEMBL3925270 & 1642522 & 8.5229 & 8.4617 & TRN & \\
\hline CHEMBL3913146 & 1642522 & 7.6383 & 8.398 & TST & \\
\hline CHEMBL3964498 & 1642522 & 9.0 & 8.4452 & TRN & \\
\hline
\end{tabular}


Supplemental Table S2.txt

\begin{tabular}{|c|c|c|c|c|c|}
\hline CHEMBL3914070 & 1642522 & 7.6021 & 7.7133 & TRN & \\
\hline CHEMBL 3957004 & 1642522 & 7.6198 & 7.6982 & TRN & \\
\hline CHEMBL3973620 & 1642522 & 8.699 & 8.5417 & TRN & \\
\hline CHEMBL3910450 & 1642522 & 7.5376 & 7.8083 & TRN & \\
\hline CHEMBL 3958421 & 1642522 & 9.0 & 8.6029 & TRN & \\
\hline CHEMBL3908120 & 1642522 & 7.5086 & 8.0521 & TRN & \\
\hline CHEMBL3963860 & 1642522 & 9.0 & 8.4588 & TRN & \\
\hline CHEMBL3946051 & 1642522 & 9.0 & 8.4958 & TRN & \\
\hline CHEMBL3906274 & 1642522 & 7.585 & 7.8024 & TRN & \\
\hline CHEMBL3891617 & 1642522 & 7.9586 & 7.9811 & TST & \\
\hline CHEMBL3984890 & 1642522 & 8.1549 & 7.75899 & & TRN \\
\hline CHEMBL 3970076 & 1642522 & 8.699 & 8.399 & TST & \\
\hline CHEMBL3932895 & 1642522 & 7.9208 & 8.1666 & TRN & \\
\hline CHEMBL3986818 & 1642522 & 8.2218 & 7.7967 & TST & \\
\hline CHEMBL 3946092 & 1642522 & 8.5229 & 8.4776 & TST & \\
\hline CHEMBL3940440 & 1642522 & 7.8539 & 8.4753 & TST & \\
\hline CHEMBL3923648 & 1642522 & 8.301 & 7.79299 & & TST \\
\hline CHEMBL3953150 & 1642522 & 7.6778 & 8.491 & TST & \\
\hline CHEMBL3940695 & 1642522 & 6.0 & 8.0781 & TST & \\
\hline CHEMBL 3895772 & 1642522 & 7.8239 & 8.1157 & TST & \\
\hline CHEMBL213912 & 475717 & 7.6 & 6.5131 & TST & \\
\hline CHEMBL129198 & 475717 & 7.8 & 8.2335 & TST & \\
\hline CHEMBL443764 & 475717 & 5.12 & 5.1528 & TRN & \\
\hline CHEMBL261320 & 475717 & 4.69 & 5.2944 & TST & \\
\hline CHEMBL1743969 & 475717 & 7.04 & 7.0979 & TRN & \\
\hline CHEMBL260565 & 475717 & 6.23 & 6.2222 & TRN & \\
\hline CHEMBL288591 & 475717 & 5.16 & 5.1528 & TRN & \\
\hline CHEMBL123137 & 475717 & 6.05 & 5.9654 & TRN & \\
\hline CHEMBL260850 & 475717 & 5.57 & 5.6109 & TRN & \\
\hline CHEMBL406345 & 475717 & 5.83 & 6.2205 & TST & \\
\hline CHEMBL406327 & 475717 & 6.01 & 5.9934 & TRN & \\
\hline CHEMBL261010 & 475717 & 6.64 & 6.654 & TRN & \\
\hline CHEMBL406558 & 475717 & 5.6 & 5.6224 & TRN & \\
\hline CHEMBL 261224 & 475717 & 7.24 & 7.2773 & TRN & \\
\hline CHEMBL 261517 & 475717 & 5.93 & 5.9519 & TRN & \\
\hline CHEMBL261519 & 475717 & 7.2 & 7.1554 & TRN & \\
\hline CHEMBL406379 & 475717 & 5.4 & 5.3795 & TRN & \\
\hline CHEMBL 260549 & 475717 & 8.25 & 8.2706 & TRN & \\
\hline CHEMBL262859 & 475717 & 7.93 & 7.9327 & TRN & \\
\hline CHEMBL 260444 & 475717 & 7.58 & 7.5227 & TRN & \\
\hline CHEMBL414183 & 475717 & 7.21 & 7.211 & TRN & \\
\hline CHEMBL405044 & 475717 & 6.47 & 6.4968 & TRN & \\
\hline CHEMBL428964 & 475717 & 5.4 & \multicolumn{2}{|c|}{5.3839999999999995} & TRN \\
\hline CHEMBL259839 & 475717 & 6.64 & 6.6179 & TRN & \\
\hline CHEMBL406123 & 475717 & 5.24 & 5.2609 & TRN & \\
\hline CHEMBL 260043 & 475717 & 4.88 & 4.9068 & TRN & \\
\hline CHEMBL429691 & 475717 & 5.81 & 5.7817 & TRN & \\
\hline CHEMBL 260851 & 475717 & 5.63 & 5.8492 & TRN & \\
\hline
\end{tabular}




\begin{tabular}{|c|c|c|c|c|c|}
\hline \multicolumn{6}{|c|}{ Supplemental Table S2.txt } \\
\hline CHEMBL405416 & 475717 & 5.66 & 5.595 & TRN & \\
\hline CHEMBL 261223 & 475717 & 6.24 & 6.2539 & TRN & \\
\hline CHEMBL 261222 & 475717 & 5.8 & 5.7566 & TRN & \\
\hline CHEMBL259536 & 475717 & 5.77 & 5.7825 & TRN & \\
\hline CHEMBL261225 & 475717 & 5.63 & 5.5518 & TRN & \\
\hline CHEMBL 260274 & 475717 & 5.89 & 5.8529 & TRN & \\
\hline CHEMBL410925 & 475717 & 6.57 & 6.54200 & 0000000001 & TRN \\
\hline CHEMBL 260456 & 475717 & 5.64 & 5.7517 & TRN & \\
\hline CHEMBL 260470 & 475717 & 5.86 & 5.9106 & TRN & \\
\hline CHEMBL428606 & 475717 & 6.15 & 6.0084 & TRN & \\
\hline CHEMBL259956 & 475717 & 5.36 & 5.3321 & TRN & \\
\hline CHEMBL 259955 & 475717 & 5.53 & 5.5325 & TRN & \\
\hline CHEMBL 259957 & 475717 & 6.33 & 6.34 & TRN & \\
\hline CHEMBL406380 & 475717 & 5.53 & 5.5098 & TRN & \\
\hline CHEMBL 260458 & 475717 & 6.32 & 5.556 & TST & \\
\hline CHEMBL402470 & 475717 & 6.53 & 5.6225 & TST & \\
\hline CHEMBL 261363 & 475717 & 6.49 & 5.6506 & TST & \\
\hline CHEMBL 260371 & 475717 & 5.13 & 5.7929 & TST & \\
\hline CHEMBL 260388 & 475717 & 6.44 & 6.3111 & TST & \\
\hline CHEMBL 261551 & 475717 & 7.4 & 5.6362 & TST & \\
\hline CHEMBL 260372 & 475717 & 4.99 & 6.4934 & TST & \\
\hline CHEMBL 259745 & 475717 & 6.7 & 6.5369 & TST & \\
\hline CHEMBL 260374 & 475717 & 7.2 & 5.319 & TST & \\
\hline CHEMBL 3979110 & 1642008 & 7.8239 & 7.6443 & TRN & \\
\hline CHEMBL 3943726 & 1642008 & 7.1192 & 7.0589 & TRN & \\
\hline CHEMBL 3929206 & 1642008 & 7.8861 & 7.9955 & TRN & \\
\hline CHEMBL 3985752 & 1642008 & 8.3665 & 8.2765 & TRN & \\
\hline CHEMBL 3946220 & 1642008 & 7.6576 & 7.5503 & TRN & \\
\hline CHEMBL3928262 & 1642008 & 7.4202 & 7.2166 & TRN & \\
\hline CHEMBL 3913735 & 1642008 & 6.3401 & 6.4997 & TST & \\
\hline CHEMBL 3933502 & 1642008 & 8.2007 & 8.26100 & 0000000001 & TRN \\
\hline CHEMBL 3902461 & 1642008 & 6.9872 & 7.2247 & TRN & \\
\hline CHEMBL 3968114 & 1642008 & 7.0706 & 7.1147 & TRN & \\
\hline CHEMBL 3975537 & 1642008 & 5.2143 & 6.2972 & TST & \\
\hline CHEMBL3901255 & 1642008 & 8.585 & 8.6808 & TRN & \\
\hline CHEMBL 3980150 & 1642008 & 8.4089 & 8.3509 & TRN & \\
\hline CHEMBL 3952878 & 1642008 & 7.9208 & 8.1844 & TRN & \\
\hline CHEMBL 3925176 & 1642008 & 8.3665 & 8.2399 & TRN & \\
\hline CHEMBL 3923937 & 1642008 & 7.5086 & 7.9032 & TRN & \\
\hline CHEMBL 3982553 & 1642008 & 6.3686 & 6.5073 & TRN & \\
\hline CHEMBL3979422 & 1642008 & 6.1349 & 6.2677 & TRN & \\
\hline CHEMBL 3962489 & 1642008 & 8.1367 & 8.0221 & TRN & \\
\hline CHEMBL 3960998 & 1642008 & 6.9136 & 7.0047 & TRN & \\
\hline CHEMBL3918095 & 1642008 & 8.1612 & 8.1547 & TRN & \\
\hline CHEMBL 3976618 & 1642008 & 6.7375 & 6.7391 & TRN & \\
\hline CHEMBL 3969832 & 1642008 & 7.3565 & 7.501 & TRN & \\
\hline CHEMBL 3938555 & 1642008 & 6.8013 & 6.6908 & TRN & \\
\hline CHEMBL3932882 & 1642008 & 8.1249 & 8.1737 & TRN & \\
\hline
\end{tabular}


Supplemental Table S2.txt

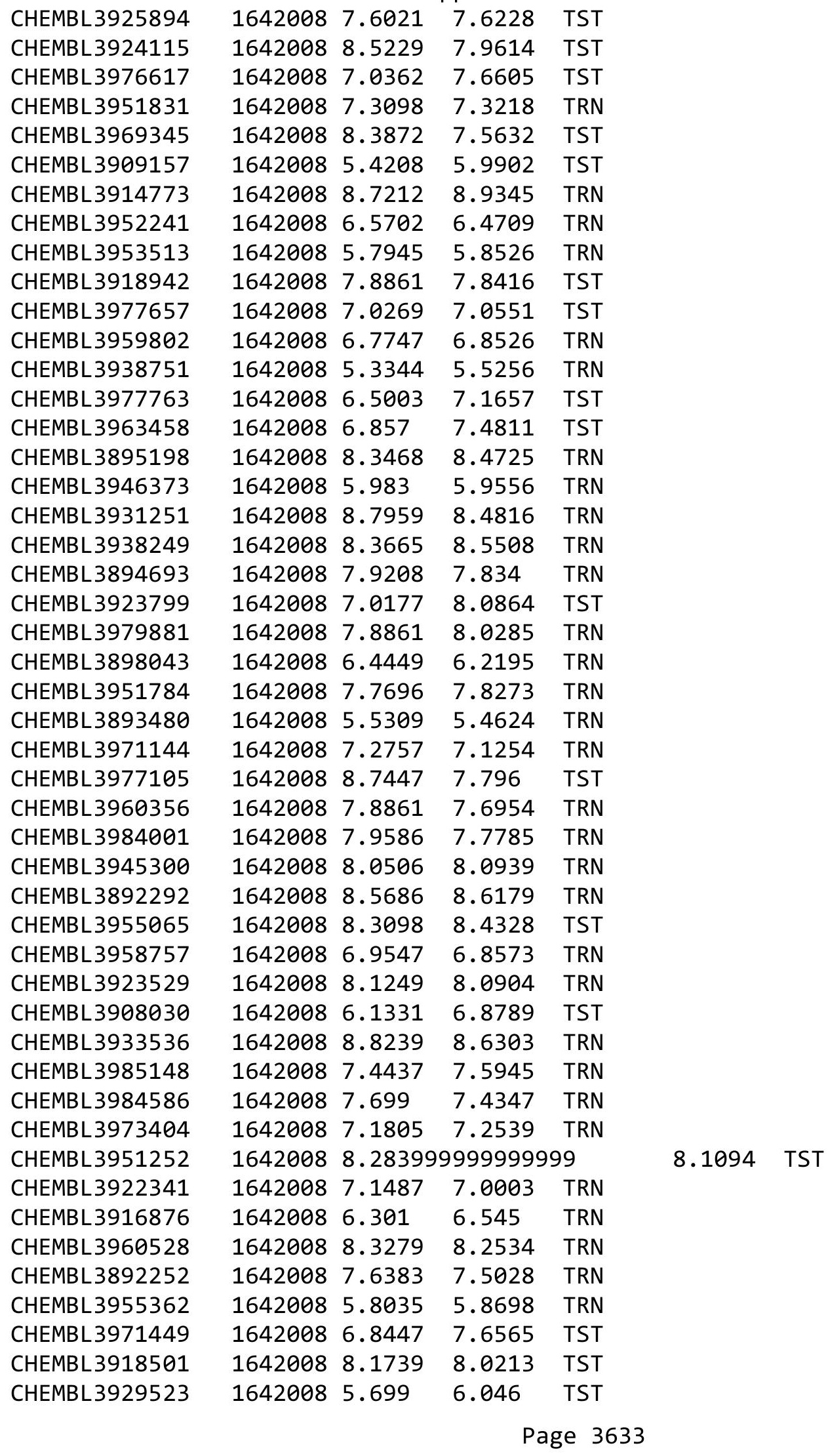


Supplemental Table S2.txt

\begin{tabular}{|c|c|c|c|c|}
\hline HEMBL3925886 & 1642008 & 7.699 & 7.5946 & TRN \\
\hline CHEMBL561769 & 72966 & 3.0 & 2.9987 & TRN \\
\hline $\mathrm{AFMBL}$ & 72966 & 6.0 & 0005 & TRN \\
\hline HEMBL 564049 & 72966 & 3.0 & 9998 & RN \\
\hline HEMBL559770 & 72966 & 4.2366 & .7733 & ST \\
\hline HEMBL 572120 & 72966 & 4.9586 & 4.958 & $\mathrm{RN}$ \\
\hline HEMBL5 & 72966 & 5.2218 & .2228 & RN \\
\hline AEMBL5 & 72966 & 5.3979 & 5.7328 & ГST \\
\hline HEMBL 560840 & 72966 & 4.6383 & 4.6328 & $\mathrm{RN}$ \\
\hline HEMBL562782 & 72966 & 3.0 & 3.0004 & RN \\
\hline HEMBL550965 & 72966 & 4.4202 & 4.4202 & $\mathrm{RN}$ \\
\hline AEMBL5 & 72966 & .7696 & .7726 & RN \\
\hline AEMBL & 2966 & .7696 & 4.7715 & 「RN \\
\hline HEMBL 549410 & 72966 & 3.0 & 3.0022 & 「RN \\
\hline AEMBL5 & 2966 & 4.8539 & 4.8548 & TRN \\
\hline HEMBL 562581 & 72966 & 5.5229 & 5.9852 & TST \\
\hline HEMBL5 & 72966 & 4.0757 & 4.3071 & IST \\
\hline HEMBL5 & 72966 & 3.0 & 3.0002 & 「RN \\
\hline AEMBL56 & 72966 & 5.5229 & 5.5227 & TRN \\
\hline AEMBL5 & 966 & 4.8539 & 4.8569 & TRN \\
\hline HEMBL 5 & 966 & 5.699 & 5.6978 & TRN \\
\hline AEMBL: & 966 & 5.699 & 5.699 & RN \\
\hline HEMBL: & 966 & 3.0 & 2.9966 & 「RN \\
\hline HEMBL 555241 & 72966 & 5.2218 & 5.222 & TRN \\
\hline HEMBL 564546 & 966 & 6.301 & 6.2987 & TRN \\
\hline HEMBL 5 & 2966 & 4.4949 & 4.4938 & TRN \\
\hline AEMBL: & 966 & 4.3768 & 4.378 & $\Gamma \mathrm{RN}$ \\
\hline AEMBL5 & 966 & 4.4437 & 4.4418 & TRN \\
\hline HEMBL549616 & 72966 & 5.699 & 5.6979 & TRN \\
\hline HEMBL 550751 & 966 & 6.0969 & 6.0968 & TRN \\
\hline HEMBL56 & 966 & 5.2218 & 5.2219 & TRN \\
\hline HEMBL: & 966 & 6.699 & 6.7005 & $\lceil\mathrm{RN}$ \\
\hline AEMBL & 66 & 3.0 & 3.0009 & TRN \\
\hline HEMBL 564453 & 72966 & 5.0969 & 5.0964 & TRN \\
\hline HEMBL 562224 & 72966 & 4.4437 & 4.4427 & TRN \\
\hline HEMBL5 & 2966 & 4.7447 & 4.4555 & TST \\
\hline HFMRI 5 & 66 & 4.2076 & 97 & TRN \\
\hline HEMBL5 & 966 & 4.284 & 4.2847 & TRN \\
\hline HEMBL 550694 & 72966 & 4.0605 & 4.4578 & TST \\
\hline IEMBL550773 & 72966 & 5.0969 & 5.0955 & TRN \\
\hline CHEMBL561239 & 2966 & 4.7696 & 4.7692 & TRN \\
\hline CHEMBL56 & 72966 & 4.4815 & 4.4761 & TRN \\
\hline CHEMBL559646 & 72966 & 5.1549 & 5.1563 & TRN \\
\hline HEMBL565191 & 72966 & 4.0809 & 4.087 & TRN \\
\hline MBL5 & 2966 & 3 . & 2.9989 & TRN \\
\hline CHEMBL54 & 72966 & 5.0 & 5.001 & IRIN \\
\hline CHEMBL560962 & 72966 & 5.1549 & 5.0692 & ГST \\
\hline CHEMBL554300 & 572966 & 4.3872 & 5.3707 & TST \\
\hline
\end{tabular}

Page 3634 


\begin{tabular}{|c|c|c|c|c|c|}
\hline \multicolumn{6}{|c|}{ ble S2. } \\
\hline CHEMBL541083 & 572966 & 4.9586 & 5.4166 & TST & \\
\hline CHEMBL550771 & 572966 & 5.2218 & 5.46700 & 20000000005 & TST \\
\hline CHEMBL541696 & 572966 & 4.1135 & 5.4438 & TST & \\
\hline CHEMBL552098 & 572966 & 3.0 & 3.6815 & TST & \\
\hline CHEMBL554556 & 572966 & 3.0 & 3.3796 & TST & \\
\hline CHEMBL564809 & 572966 & 4.6021 & 4.8569 & TST & \\
\hline CHEMBL1822070 & 766560 & 7.4202 & 7.4643 & TRN & \\
\hline CHEMBL1822104 & 766560 & 6.5686 & 6.5582 & TRN & \\
\hline CHEMBL1822255 & 766560 & 7.2076 & 7.2301 & TRN & \\
\hline CHEMBL1822262 & 766560 & 7.0809 & 7.0462 & TRN & \\
\hline CHEMBL1822258 & 766560 & 7.9208 & 7.9016 & TRN & \\
\hline CHEMBL1822108 & 766560 & 6.4685 & 6.4667 & TRN & \\
\hline CHEMBL1822102 & 766560 & 6.699 & 6.7448 & TRN & \\
\hline CHEMBL1822263 & 766560 & 4.0 & 6.5638 & TST & \\
\hline CHEMBL1822100 & 766560 & 6.9208 & 6.8964 & TRN & \\
\hline CHEMBL1822086 & 766560 & 5.8539 & 5.8442 & TRN & \\
\hline CHEMBL1822091 & 766560 & 7.5086 & 7.4851 & TRN & \\
\hline CHEMBL1822244 & 766560 & 7.0757 & 7.0573 & TRN & \\
\hline CHEMBL1822246 & 766560 & 7.4089 & 7.4061 & TRN & \\
\hline CHEMBL1822250 & 766560 & 6.6383 & 6.6324 & TRN & \\
\hline CHEMBL1822068 & 766560 & 7.699 & 7.7037 & TRN & \\
\hline CHEMBL1822101 & 766560 & 7.1249 & 6.8603 & TST & \\
\hline CHEMBL1822072 & 766560 & 6.4559 & 6.6763 & TST & \\
\hline CHEMBL1822088 & 766560 & 7.2076 & 7.2533 & TRN & \\
\hline CHEMBL1822265 & 766560 & 7.1805 & 7.1984 & TRN & \\
\hline CHEMBL1822094 & 766560 & 6.7447 & 6.6959 & TRN & \\
\hline CHEMBL1822243 & 766560 & 7.0655 & 7.067 & TRN & \\
\hline CHEMBL1822103 & 766560 & 6.6383 & 6.7979 & TST & \\
\hline CHEMBL1822106 & 766560 & 6.1487 & 5.9949 & TST & \\
\hline CHEMBL1822078 & 766560 & 7.0269 & 6.6201 & TST & \\
\hline CHEMBL1822098 & 766560 & 7.5528 & 7.5707 & TRN & \\
\hline CHEMBL1822093 & 766560 & 6.0809 & 6.0861 & TRN & \\
\hline CHEMBL1822242 & 766560 & 7.4437 & 7.4347 & TRN & \\
\hline CHEMBL1822090 & 766560 & 7.9586 & 7.9172 & TRN & \\
\hline CHEMBL 1822110 & 766560 & 7.2076 & 6.8611 & TST & \\
\hline CHEMBL1822099 & 766560 & 7.7447 & 7.6973 & TRN & \\
\hline CHEMBL1822073 & 766560 & 7.0969 & 7.0666 & TRN & \\
\hline CHEMBL1822074 & 766560 & 7.0 & 7.0462 & TRN & \\
\hline CHEMBL1822097 & 766560 & 7.2007 & 7.2178 & TRN & \\
\hline CHEMBL1822067 & 766560 & 7.7212 & 7.6444 & TRN & \\
\hline CHEMBL1822256 & 766560 & 7.7696 & 7.8084 & TRN & \\
\hline CHEMBL1822096 & 766560 & 6.301 & 6.3323 & TRN & \\
\hline CHEMBL1822253 & 766560 & 7.1192 & 7.1226 & TRN & \\
\hline CHEMBL1822095 & 766560 & 6.2007 & 6.1706 & TRN & \\
\hline CHEMBL1822092 & 766560 & 6.7696 & 6.7564 & TRN & \\
\hline CHEMBL1822252 & 766560 & 7.5528 & 7.5372 & TRN & \\
\hline CHEMBL1822260 & 766560 & 6.4685 & 6.4935 & TRN & \\
\hline CHEMBL1822085 & 766560 & 6.3872 & 6.0124 & TST & \\
\hline
\end{tabular}


Supplemental Table S2.txt

\begin{tabular}{|c|c|c|c|c|c|}
\hline CHEMBL1822071 & 766560 & 6.6021 & 6.8182 & TST & \\
\hline CHEMBL1822248 & 766560 & 7.2076 & 7.2112 & TRN & \\
\hline CHEMBL1822079 & 766560 & 6.7212 & 6.7503 & TST & \\
\hline CHEMBL1822264 & 766560 & 7.5229 & 7.4969 & TRN & \\
\hline CHEMBL1822109 & 766560 & 6.7696 & 6.6869 & TST & \\
\hline CHEMBL1822249 & 766560 & 6.5376 & 6.5352 & TRN & \\
\hline CHEMBL1822241 & 766560 & 7.3565 & 7.37200 & 0000000001 & тाт \\
\hline CHEMBL1822261 & 766560 & 6.5528 & 6.5511 & TRN & \\
\hline CHEMBL1822069 & 766560 & 7.3979 & 7.4226 & TRN & \\
\hline CHEMBL1822257 & 766560 & 8.041 & 8.08 & TRN & \\
\hline CHEMBL1822084 & 766560 & 6.3979 & 6.0074 & TST & \\
\hline CHEMBL1822080 & 766560 & 6.6861 & 6.6172 & TST & \\
\hline CHEMBL1822105 & 766560 & 5.585 & 6.2927 & TST & \\
\hline CHEMBL1822259 & 766560 & 7.699 & 7.687 & TRN & \\
\hline CHEMBL1822081 & 766560 & 6.5376 & 6.5297 & TST & \\
\hline CHEMBL1822075 & 766560 & 6.7447 & 6.7664 & TRN & \\
\hline CHEMBL1822247 & 766560 & 7.2218 & 7.23 & TRN & \\
\hline CHEMBL1822089 & 766560 & 7.8861 & 7.90799 & 99999999995 & \\
\hline CHEMBL1822082 & 766560 & 5.6778 & 6.2564 & TST & \\
\hline CHEMBL1822254 & 766560 & 7.3665 & 7.3537 & TRN & \\
\hline CHEMBL1822245 & 766560 & 6.5528 & 6.5581 & TRN & \\
\hline CHEMBL1822107 & 766560 & 6.585 & 6.1414 & TST & \\
\hline CHEMBL1822251 & 766560 & 7.9208 & 7.9326 & TRN & \\
\hline CHEMBL188632 & 311952 & 6.1759 & 6.1885 & TRN & \\
\hline CHEMBL185767 & 311952 & 5.8489 & 5.86299 & 99999999995 & \\
\hline CHEMBL426627 & 311952 & 5.8801 & 5.8631 & TRN & \\
\hline CHEMBL186567 & 311952 & 5.7462 & 5.7737 & TRN & \\
\hline CHEMBL188891 & 311952 & 6.2197 & 6.2916 & TRN & \\
\hline CHEMBL186143 & 311952 & 7.3188 & 7.2823 & TRN & \\
\hline CHEMBL185957 & 311952 & 6.9626 & 7.2121 & TST & \\
\hline CHEMBL188682 & 311952 & 8.2676 & 8.2362 & TRN & \\
\hline CHEMBL362764 & 311952 & 6.9431 & 6.8817 & TRN & \\
\hline CHEMBL186044 & 311952 & 7.5686 & 7.607 & TRN & \\
\hline CHEMBL189817 & 311952 & 8.5229 & 8.5334 & TRN & \\
\hline CHEMBL187638 & 311952 & 6.7375 & 6.7026 & TRN & \\
\hline CHEMBL425183 & 311952 & 6.251 & 6.2245 & TRN & \\
\hline CHEMBL 364121 & 311952 & 8.4089 & 8.3846 & TRN & \\
\hline CHEMBL363114 & 311952 & 6.8665 & 7.2564 & TST & \\
\hline CHEMBL189092 & 311952 & 8.7959 & 8.7889 & TRN & \\
\hline CHEMBL 362891 & 311952 & \multicolumn{2}{|c|}{6.821000000000001} & 6.8091 & TRN \\
\hline CHEMBL189131 & 311952 & 4.5229 & 4.5114 & TRN & \\
\hline CHEMBL364159 & 311952 & 8.7959 & 8.7273 & TRN & \\
\hline CHEMBL185704 & 311952 & 7.4685 & 7.4847 & TRN & \\
\hline CHEMBL189227 & 311952 & 4.5229 & 4.5239 & TRN & \\
\hline CHEMBL187298 & 311952 & 4.5229 & 4.5203 & TRN & \\
\hline CHEMBL189042 & 311952 & 8.0706 & 8.0728 & TRN & \\
\hline CHEMBL189406 & 311952 & 6.8239 & 6.845 & TRN & \\
\hline CHEMBL359983 & 311952 & 6.0 & 5.9613 & TRN & \\
\hline
\end{tabular}




\begin{tabular}{|c|c|c|c|c|c|}
\hline \multicolumn{6}{|c|}{ Supplemental Table S2.txt } \\
\hline CHEMBL188939 & 311952 & 6.0 & 5.9476 & TRN & \\
\hline CHEMBL188321 & 311952 & 4.5229 & 4.5453 & TRN & \\
\hline CHEMBL186997 & 311952 & 6.6904 & 6.8112 & TST & \\
\hline CHEMBL361294 & 311952 & 5.8545 & 5.7855 & TRN & \\
\hline CHEMBL186238 & 311952 & 8.4949 & 8.4906 & TRN & \\
\hline CHEMBL427525 & 311952 & 7.1249 & 7.148 & TRN & \\
\hline CHEMBL186983 & 311952 & 8.3768 & 8.3429 & TRN & \\
\hline CHEMBL188724 & 311952 & 7.1871 & 7.2496 & TRN & \\
\hline CHEMBL181650 & 311952 & 8.5686 & 8.5694 & TRN & \\
\hline CHEMBL186834 & 311952 & 6.0 & 6.0536 & TRN & \\
\hline CHEMBL189705 & 311952 & 6.4191 & 6.4273 & TRN & \\
\hline CHEMBL189702 & 311952 & 7.8239 & 7.8324 & TRN & \\
\hline CHEMBL188372 & 311952 & 8.8539 & 8.8424 & TRN & \\
\hline CHEMBL185956 & 311952 & 6.0 & 5.9718 & TRN & \\
\hline CHEMBL186323 & 311952 & 7.3768 & 7.3303 & TRN & \\
\hline CHEMBL186081 & 311952 & 9.4949 & 8.9528 & TST & \\
\hline CHEMBL364788 & 311952 & 7.2291 & 7.3715 & TST & \\
\hline CHEMBL365487 & 311952 & 7.3468 & 7.4738 & TRN & \\
\hline CHEMBL186187 & 311952 & 6.3197 & 6.2701 & TST & \\
\hline CHEMBL189034 & 311952 & 7.3665 & 7.0537 & TST & \\
\hline CHEMBL362289 & 311952 & 7.4815 & 7.4745 & TRN & \\
\hline CHEMBL188356 & 311952 & 7.5686 & 7.4609 & TST & \\
\hline CHEMBL186875 & 311952 & 7.1675 & 7.1963 & TRN & \\
\hline CHEMBL189648 & 311952 & 7.8239 & 7.8147 & TRN & \\
\hline CHEMBL364107 & 311952 & 8.0458 & 8.1291 & TRN & \\
\hline CHEMBL362883 & 311952 & 6.7878 & 6.9897 & TST & \\
\hline CHEMBL362118 & 311952 & 7.4437 & 7.2811 & TST & \\
\hline CHEMBL188573 & 311952 & 6.0 & 6.19600 & 0000000001 & TST \\
\hline CHEMBL187316 & 311952 & 4.5229 & 4.8601 & TST & \\
\hline CHEMBL184739 & 311952 & 7.4089 & 6.9582 & TST & \\
\hline CHEMBL361685 & 311952 & 8.28399 & 79999999 & 7.8022 & TST \\
\hline CHEMBL1323900 & 737205 & 3.0 & 3.1294 & TRN & \\
\hline CHEMBL522990 & 737205 & 3.0 & 2.9621 & TRN & \\
\hline CHEMBL1314122 & 737205 & 4.6882 & 4.2431 & TRN & \\
\hline CHEMBL1390605 & 737205 & 3.0 & 3.045 & TST & \\
\hline CHEMBL1481632 & 737205 & 3.0 & 3.048 & TRN & \\
\hline CHEMBL1574857 & 737205 & 3.0 & 3.0089 & TRN & \\
\hline CHEMBL1371869 & 737205 & 3.0 & 3.1418 & TRN & \\
\hline CHEMBL1712676 & 737205 & 3.0 & 2.9388 & TRN & \\
\hline CHEMBL1505816 & 737205 & 3.0 & 3.9295 & TRN & \\
\hline CHEMBL3193527 & 737205 & 3.0 & 3.9714 & TRN & \\
\hline CHEMBL1342091 & 737205 & 5.2255 & 4.333 & TRN & \\
\hline CHEMBL1311580 & 737205 & 3.0 & 3.1246 & TST & \\
\hline CHEMBL1472524 & 737205 & 3.0 & 3.1626 & TST & \\
\hline CHEMBL1417168 & 737205 & 3.0 & 2.9713 & TRN & \\
\hline CHEMBL1438081 & 737205 & 3.0 & 3.2463 & TRN & \\
\hline CHEMBL1518080 & 737205 & 3.0 & 3.0249 & TST & \\
\hline CHEMBL490355 & 737205 & 4.1726 & 3.6771 & TRN & \\
\hline
\end{tabular}




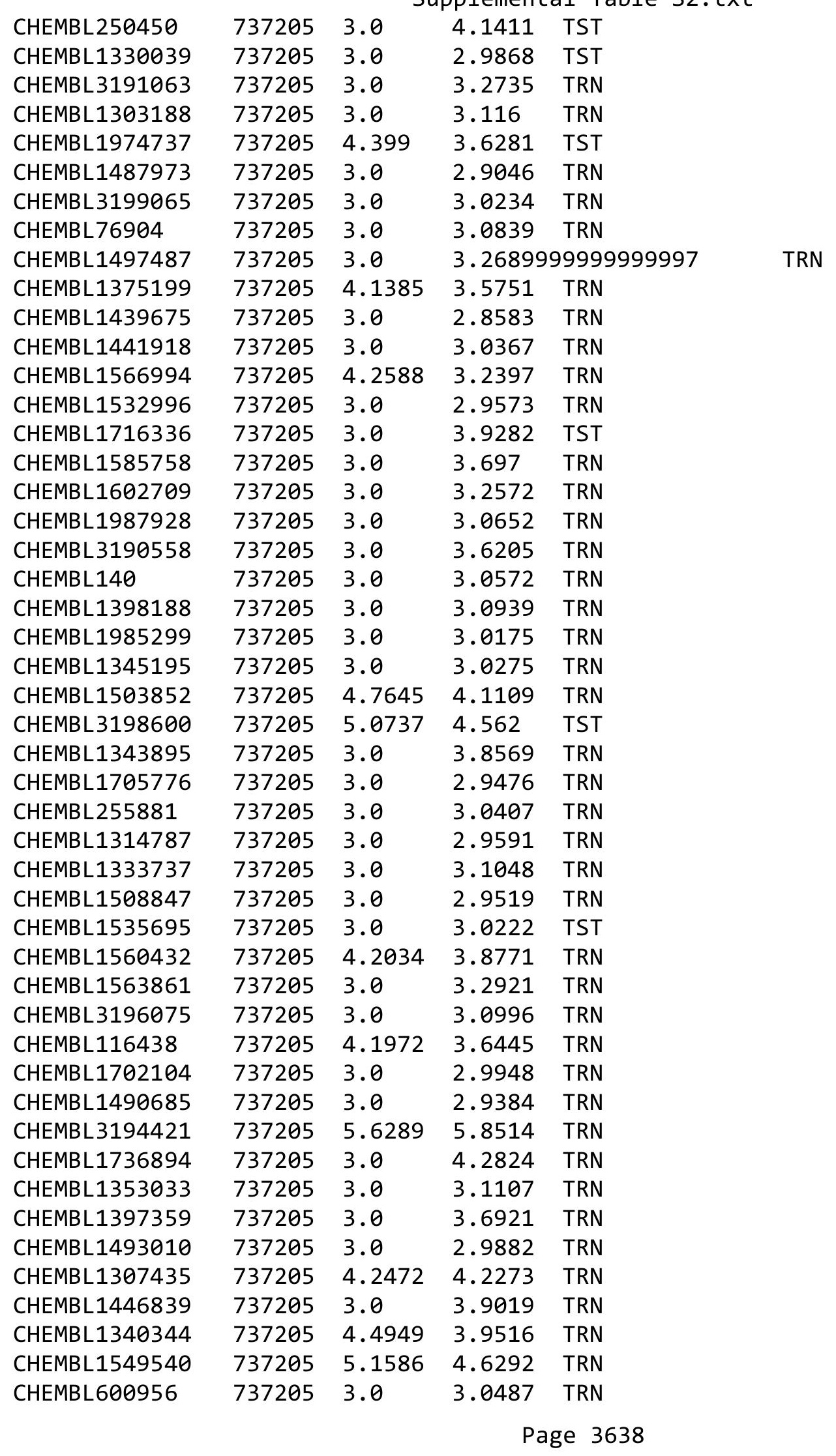




\begin{tabular}{|c|c|c|c|c|c|}
\hline \multicolumn{6}{|c|}{ Supplemental Table S2.txt } \\
\hline CHEMBL1342821 & 737205 & 3.0 & 4.3918 & TRN & \\
\hline CHEMBL1488474 & 737205 & 5.1355 & 3.9714 & TRN & \\
\hline CHEMBL1473059 & 737205 & 4.2204 & 3.5379 & TRN & \\
\hline CHEMBL1547446 & 737205 & 4.6126 & 4.1506 & TRN & \\
\hline CHEMBL3192085 & 737205 & 4.6615 & 3.9718 & TST & \\
\hline CHEMBL1310309 & 737205 & 3.0 & 3.0109 & TRN & \\
\hline CHEMBL1413866 & 737205 & 3.0 & 2.9602 & TRN & \\
\hline CHEMBL1500102 & 737205 & 4.3768 & 4.3364 & TRN & \\
\hline CHEMBL1534899 & 737205 & 3.0 & 3.075 & TRN & \\
\hline CHEMBL1402586 & 737205 & 3.0 & 2.8706 & TRN & \\
\hline CHEMBL1375627 & 737205 & 3.0 & 3.0154 & TRN & \\
\hline CHEMBL1532097 & 737205 & 4.6345 & 4.1133 & TRN & \\
\hline CHEMBL1370260 & 737205 & 3.0 & 4.1809 & TRN & \\
\hline CHEMBL179512 & 737205 & 3.0 & 3.2297 & TRN & \\
\hline CHEMBL3189823 & 737205 & 3.0 & 2.9938 & TRN & \\
\hline CHEMBL1980197 & 737205 & 4.1543 & 3.6951 & TRN & \\
\hline CHEMBL 2006611 & 737205 & 4.7447 & 4.0257 & TRN & \\
\hline CHEMBL1340656 & 737205 & 3.0 & 3.1607 & TRN & \\
\hline CHEMBL40275 & 737205 & 3.0 & 2.9316 & TRN & \\
\hline CHEMBL 210208 & 737205 & 3.0 & 3.0136 & TRN & \\
\hline CHEMBL1529306 & 737205 & 3.0 & 2.9882 & TRN & \\
\hline CHEMBL1594374 & 737205 & 3.0 & 3.1335 & TRN & \\
\hline CHEMBL1421399 & 737205 & 4.5157 & 3.8722 & TRN & \\
\hline CHEMBL1698793 & 737205 & 3.0 & 3.0885 & TRN & \\
\hline CHEMBL1499828 & 737205 & 3.0 & 2.9251 & TRN & \\
\hline CHEMBL1722786 & 737205 & 3.0 & 2.9765 & TRN & \\
\hline CHEMBL2003964 & 737205 & 3.0 & 4.1155 & TRN & \\
\hline CHEMBL1417524 & 737205 & 3.0 & 3.1626 & TRN & \\
\hline CHEMBL1508055 & 737205 & 3.0 & 2.93899 & 99999999996 & TRN \\
\hline CHEMBL1313502 & 737205 & 4.58 & 3.7073 & TST & \\
\hline CHEMBL1424867 & 737205 & 4.4045 & 3.9519 & TRN & \\
\hline CHEMBL1447139 & 737205 & 4.9914 & 4.2011 & TRN & \\
\hline CHEMBL1320230 & 737205 & 4.5654 & 3.781 & TRN & \\
\hline CHEMBL1989158 & 737205 & 3.0 & 3.0127 & TST & \\
\hline CHEMBL1980281 & 737205 & 3.0 & 3.1172 & TST & \\
\hline CHEMBL1980661 & 737205 & 3.0 & 3.0323 & TST & \\
\hline CHEMBL1305055 & 737205 & 3.0 & 2.9245 & TRN & \\
\hline CHEMBL1350188 & 737205 & 3.0 & 3.1289 & TRN & \\
\hline CHEMBL1567396 & 737205 & 3.0 & 3.39300 & 00000000002 & TST \\
\hline CHEMBL1984581 & 737205 & 3.0 & 2.9501 & TST & \\
\hline CHEMBL1350787 & 737205 & 3.0 & 4.4385 & TRN & \\
\hline CHEMBL1416189 & 737205 & 5.109 & 4.363 & TRN & \\
\hline CHEMBL1406077 & 737205 & 3.0 & 2.9522 & TRN & \\
\hline CHEMBL1340338 & 737205 & 3.0 & 3.0776 & TST & \\
\hline CHEMBL1309252 & 737205 & 3.0 & 3.27 & TRN & \\
\hline CHEMBL1525897 & 737205 & 5.2749 & 4.1924 & TRN & \\
\hline CHEMBL1451040 & 737205 & 3.0 & 3.0068 & TRN & \\
\hline CHEMBL1208858 & 737205 & 3.0 & 2.9928 & TST & \\
\hline
\end{tabular}




\begin{tabular}{|c|c|c|c|c|c|}
\hline \multicolumn{6}{|c|}{ Supplemental Table S2.txt } \\
\hline CHEMBL1098175 & 737205 & 3.0 & 2.9581 & TRN & \\
\hline CHEMBL1496952 & 737205 & 4.4647 & 4.0726 & TRN & \\
\hline CHEMBL1367272 & 737205 & 3.0 & 3.0014 & TST & \\
\hline CHEMBL1356184 & 737205 & 3.0 & 3.0579 & TST & \\
\hline CHEMBL1979849 & 737205 & 3.0 & 3.0677 & TST & \\
\hline CHEMBL1353324 & 737205 & 3.0 & 2.9589 & TST & \\
\hline CHEMBL1709713 & 737205 & 4.3716 & 3.6918 & TST & \\
\hline CHEMBL1733511 & 737205 & 5.1818 & 4.5252 & TST & \\
\hline CHEMBL81782 & 737205 & 3.0 & 2.9963 & TST & \\
\hline CHEMBL1609295 & 737205 & 4.8794 & 4.0772 & TST & \\
\hline CHEMBL1562260 & 737205 & 4.6383 & 4.152 & TST & \\
\hline CHEMBL1600440 & 737205 & 3.0 & 4.0124 & TST & \\
\hline CHEMBL1436898 & 737205 & 3.0 & 3.1783 & TST & \\
\hline CHEMBL1496986 & 737205 & 3.0 & 3.0706 & TST & \\
\hline CHEMBL1589514 & 737205 & 4.1878 & 3.9059 & TST & \\
\hline CHEMBL186564 & 409105 & 7.301 & 7.4009 & TRN & \\
\hline CHEMBL 214028 & 409105 & 6.3188 & 6.2417 & TRN & \\
\hline CHEMBL 334333 & 409105 & 4.5528 & 5.0187 & TRN & \\
\hline CHEMBL217039 & 409105 & 8.8861 & 8.9306 & TRN & \\
\hline CHEMBL131346 & 409105 & 7.5229 & 7.316 & TST & \\
\hline CHEMBL217507 & 409105 & 5.6517 & 8.3639 & TST & \\
\hline CHEMBL214617 & 409105 & 9.1549 & 8.832 & TRN & \\
\hline CHEMBL337985 & 409105 & 5.3497 & 5.6724 & TRN & \\
\hline CHEMBL 364623 & 409105 & 9.0 & 8.5602 & TRN & \\
\hline CHEMBL386118 & 409105 & 9.699 & 9.8855 & TRN & \\
\hline CHEMBL189675 & 409105 & 8.1739 & 8.0247 & TRN & \\
\hline CHEMBL131661 & 409105 & 6.4437 & 6.4093 & TRN & \\
\hline CHEMBL365505 & 409105 & 9.2218 & 9.0814 & TRN & \\
\hline CHEMBL 216448 & 409105 & 5.8861 & 5.7512 & TRN & \\
\hline CHEMBL132448 & 409105 & 4.9031 & 4.7372 & TRN & \\
\hline CHEMBL 273250 & 409105 & 9.301 & 9.3562 & TRN & \\
\hline CHEMBL 384822 & 409105 & 6.8861 & 6.8833 & TRN & \\
\hline CHEMBL307976 & 409105 & 5.301 & 6.0903 & TST & \\
\hline CHEMBL215630 & 409105 & 6.8861 & 6.9669 & TRN & \\
\hline CHEMBL128377 & 409105 & 5.8539 & 5.7314 & TRN & \\
\hline CHEMBL408027 & 409105 & 5.8729 & 7.5297 & TST & \\
\hline CHEMBL129454 & 409105 & 5.3565 & 5.4301 & TRN & \\
\hline CHEMBL189776 & 409105 & 8.9208 & 8.56899 & 9999999999 & TRN \\
\hline CHEMBL186568 & 409105 & 9.301 & 9.0243 & TRN & \\
\hline CHEMBL384545 & 409105 & 8.2007 & 8.1474 & TRN & \\
\hline CHEMBL 385172 & 409105 & 8.3098 & 8.4745 & TRN & \\
\hline CHEMBL405630 & 409105 & 9.5229 & 9.4258 & TRN & \\
\hline CHEMBL385698 & 409105 & 10.6990 & 30000000 & 10.4872 & TRN \\
\hline CHEMBL217506 & 409105 & 5.9208 & 6.1095 & TRN & \\
\hline CHEMBL 385191 & 409105 & 4.9179 & 5.1941 & TRN & \\
\hline CHEMBL189649 & 409105 & 9.301 & 9.5878 & TRN & \\
\hline CHEMBL 127500 & 409105 & 6.1487 & 6.2742 & TRN & \\
\hline CHEMBL386167 & 409105 & 7.7696 & 8.2581 & TST & \\
\hline
\end{tabular}




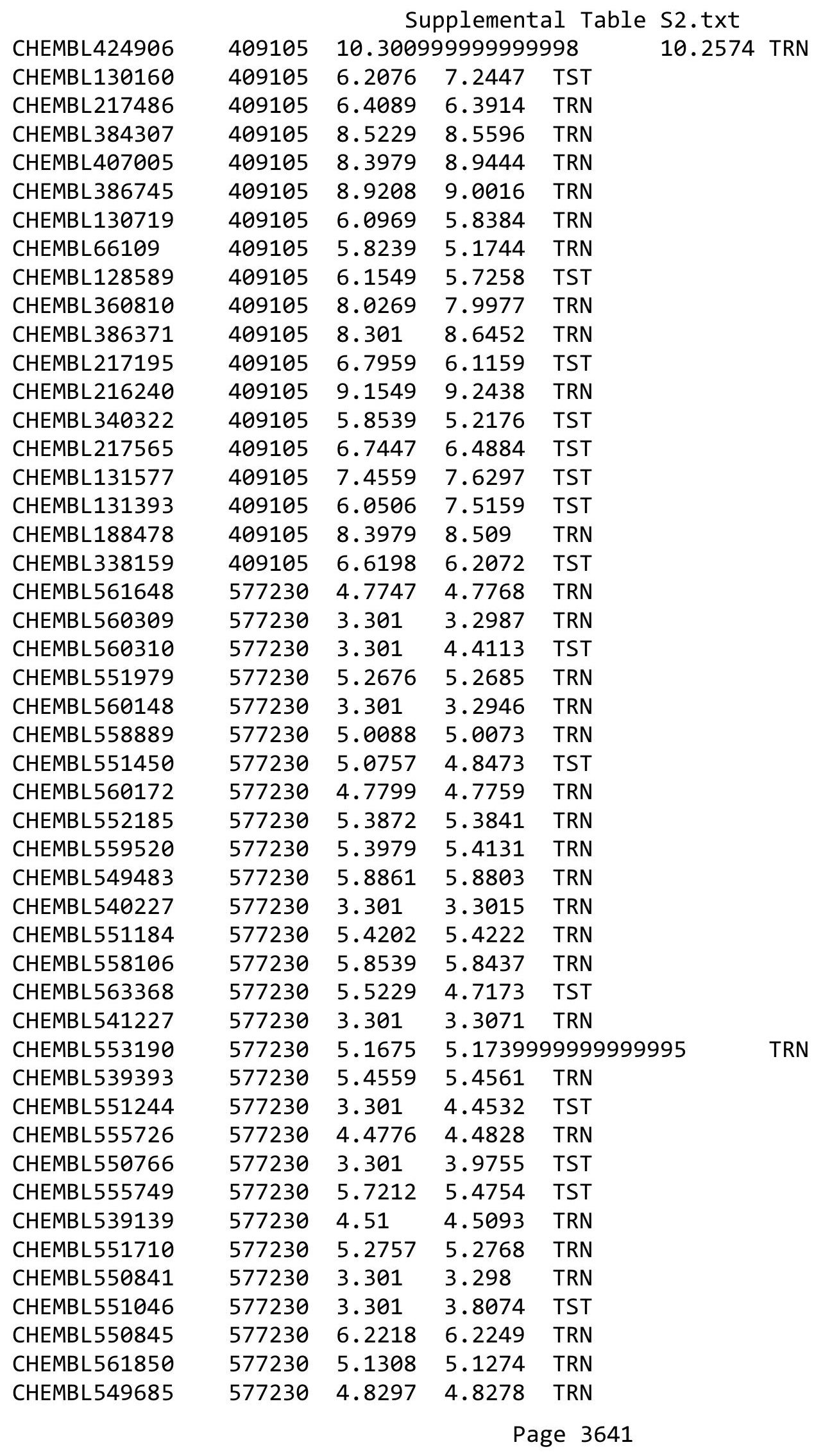




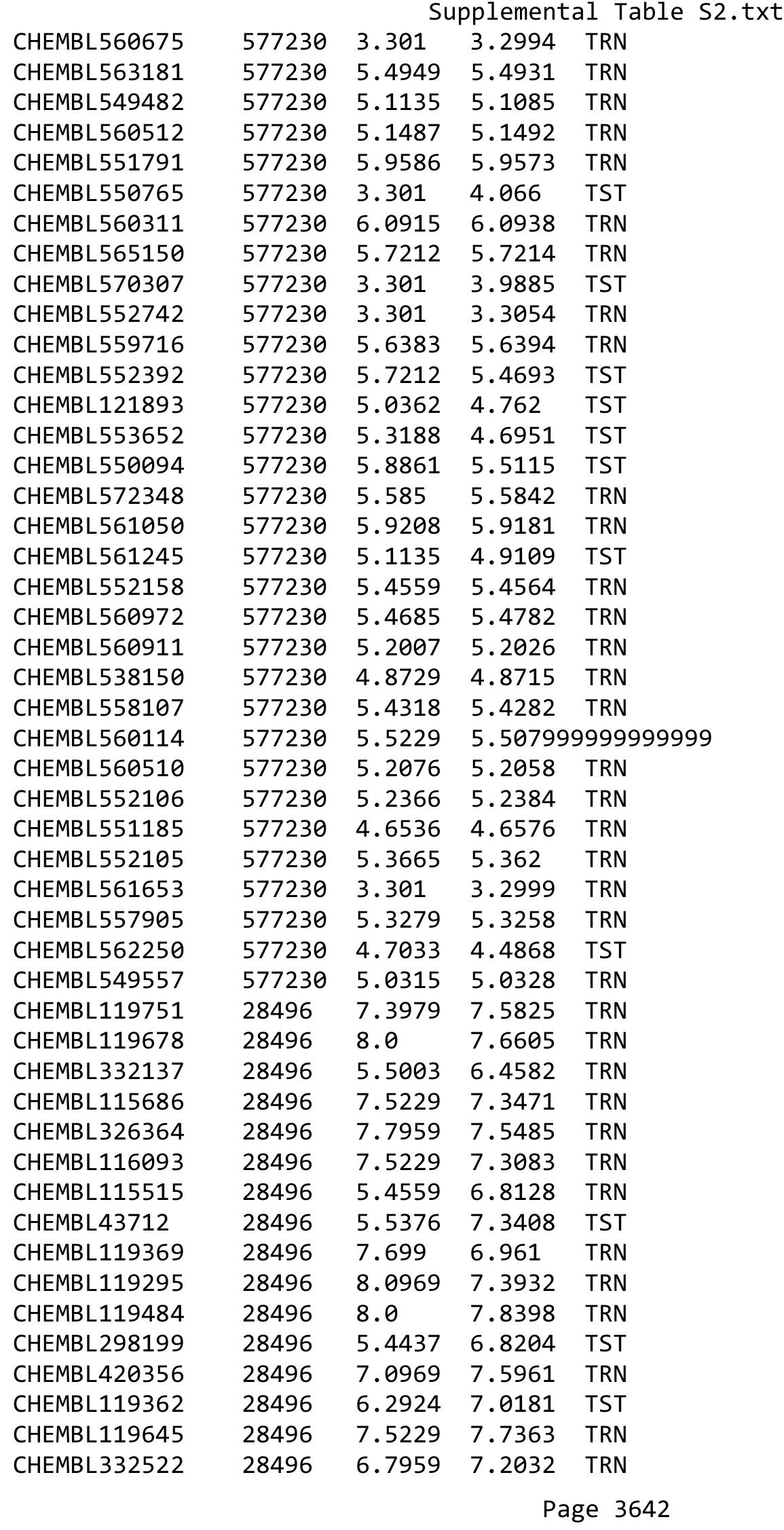




\begin{tabular}{|c|c|c|c|c|c|}
\hline & & \multicolumn{4}{|c|}{ Supplemental Table S2.txt } \\
\hline CHEMBL119729 & 28496 & 7.6383 & 7.0578 & TRN & \\
\hline CHEMBL119606 & 28496 & 7.5229 & 7.3122 & TST & \\
\hline CHEMBL331023 & 28496 & 7.7959 & 7.5438 & TRN & \\
\hline CHEMBL118701 & 28496 & 7.2218 & 7.364 & TRN & \\
\hline CHEMBL119586 & 28496 & 7.1549 & 6.566 & TRN & \\
\hline CHEMBL 295608 & 28496 & 3.301 & 6.5561 & TST & \\
\hline CHEMBL48034 & 28496 & 6.3098 & 6.8773 & TRN & \\
\hline CHEMBL332967 & 28496 & 7.3979 & 7.569 & TRN & \\
\hline CHEMBL325204 & 28496 & 5.1427 & 6.1886 & TST & \\
\hline CHEMBL332966 & 28496 & 6.041 & 7.3698 & TRN & \\
\hline CHEMBL119272 & 28496 & 7.0 & 6.7484 & TRN & \\
\hline CHEMBL119644 & 28496 & 6.699 & 6.4439 & TRN & \\
\hline CHEMBL49367 & 28496 & 4.3768 & 6.8268 & TST & \\
\hline CHEMBL 326045 & 28496 & 7.301 & 7.2061 & TRN & \\
\hline CHEMBL331131 & 28496 & 7.0969 & 6.9112 & TRN & \\
\hline CHEMBL117919 & 28496 & 7.3979 & 7.4595 & TRN & \\
\hline CHEMBL115514 & 28496 & 8.0969 & 7.0617 & TRN & \\
\hline CHEMBL119169 & 28496 & 7.699 & 7.5426 & TRN & \\
\hline CHEMBL119081 & 28496 & 7.5229 & 7.2061 & TRN & \\
\hline CHEMBL333504 & 28496 & 7.1549 & 7.0783 & TRN & \\
\hline CHEMBL332705 & 28496 & 6.8239 & 6.8973 & TRN & \\
\hline CHEMBL115682 & 28496 & 7.5229 & 6.4463 & TRN & \\
\hline CHEMBL331185 & 28496 & 5.4437 & 6.2155 & TRN & \\
\hline CHEMBL118231 & 28496 & 6.3979 & 7.7073 & TST & \\
\hline CHEMBL334218 & 28496 & 7.6021 & 7.5651 & TRN & \\
\hline CHEMBL119759 & 28496 & 7.699 & 7.6017 & TRN & \\
\hline CHEMBL120285 & 28496 & 7.1549 & 7.0792 & TRN & \\
\hline CHEMBL 325663 & 28496 & 6.699 & 7.0101 & TRN & \\
\hline CHEMBL332487 & 28496 & 6.6383 & 6.4483 & TRN & \\
\hline CHEMBL333653 & 28496 & 7.301 & 7.6424 & TRN & \\
\hline CHEMBL323894 & 28496 & 7.2366 & 7.4141 & TST & \\
\hline CHEMBL325036 & 28496 & 6.7696 & 7.2309 & TRN & \\
\hline CHEMBL332389 & 28496 & 7.301 & 7.2905 & TST & \\
\hline CHEMBL 333013 & 28496 & 8.0 & 7.4252 & TST & \\
\hline CHEMBL119271 & 28496 & 7.4685 & 7.5228 & TST & \\
\hline CHEMBL115698 & 28496 & 6.5528 & 7.2462 & TST & \\
\hline CHEMBL3935407 & 1642077 & 8.7959 & 8.6592 & TST & \\
\hline CHEMBL3910979 & 1642077 & 8.5376 & 8.4332 & TRN & \\
\hline CHEMBL 3949234 & 1642077 & 6.0 & 6.1486 & TRN & \\
\hline CHEMBL3916196 & 1642077 & 8.5528 & 8.2646 & TRN & \\
\hline CHEMBL3957722 & 1642077 & 9.8665 & 9.8033 & TST & \\
\hline CHEMBL3909351 & 1642077 & 10.6990 & 30000000 & 002 & 10.3172 \\
\hline CHEMBL3962885 & 1642077 & 8.3925 & 8.2183 & TST & \\
\hline CHEMBL 3926451 & 1642077 & 8.4248 & 8.0872 & TST & \\
\hline CHEMBL3974543 & 1642077 & 6.0 & 5.9708 & TRN & \\
\hline CHEMBL3933719 & 1642077 & 9.2226 & 9.3764 & TST & \\
\hline CHEMBL3971171 & 1642077 & 7.8327 & 8.4236 & TRN & \\
\hline CHEMBL3924828 & 1642077 & 9.7212 & 9.8732 & TRN & \\
\hline
\end{tabular}


Supplemental Table S2.txt

\begin{tabular}{|c|c|c|c|c|}
\hline CHEMBL3926975 & 1642077 & 8.699 & 8.6546 & TRN \\
\hline CHEMBL3960320 & 1642077 & 9.0969 & 8.9346 & TRN \\
\hline CHEMBL3927716 & 1642077 & 9.5654 & 9.4261 & TST \\
\hline CHEMBL3952715 & 1642077 & 7.3788 & 7.4164 & TRN \\
\hline CHEMBL 3982591 & 1642077 & 8.4789 & 8.7731 & TRN \\
\hline CHEMBL3913376 & 1642077 & 8.699 & 8.962 & TRN \\
\hline CHEMBL3961328 & 1642077 & 9.4711 & 8.9728 & TRN \\
\hline CHEMBL3934584 & 1642077 & 8.7447 & 8.245 & TRN \\
\hline CHEMBL3967337 & 1642077 & 6.0 & 6.2569 & TRN \\
\hline CHEMBL 3924143 & 1642077 & 9.6162 & 9.4582 & TRN \\
\hline CHEMBL 3965003 & 1642077 & 8.2676 & 8.5302 & TRN \\
\hline CHEMBL3919362 & 1642077 & 9.6615 & 9.9436 & TRN \\
\hline CHEMBL 3961358 & 1642077 & 7.1831 & 6.7567 & TRN \\
\hline CHEMBL3941161 & 1642077 & 6.2269 & 6.8891 & TST \\
\hline CHEMBL 3964367 & 1642077 & 9.0585 & 8.8052 & TST \\
\hline CHEMBL 3909217 & 1642077 & 10.1135 & 10.2131 & TRN \\
\hline CHEMBL3978132 & 1642077 & 8.585 & 8.8373 & TRN \\
\hline CHEMBL 3891942 & 1642077 & 7.9281 & 8.142999 & (999999999 \\
\hline CHEMBL 3910145 & 1642077 & 6.0 & 6.3518 & TRN \\
\hline CHEMBL3943561 & 1642077 & 7.4572 & 7.5249 & TRN \\
\hline CHEMBL 3897988 & 1642077 & 9.7144 & 9.7385 & TRN \\
\hline CHEMBL3940085 & 1642077 & 6.7235 & 6.9983 & TST \\
\hline CHEMBL3906911 & 1642077 & 7.8013 & 7.9432 & TRN \\
\hline CHEMBL 3964978 & 1642077 & 8.3468 & 8.255 & TRN \\
\hline CHEMBL 3977800 & 1642077 & 8.2757 & 8.0667 & TRN \\
\hline CHEMBL 3894757 & 1642077 & 7.9788 & 8.0522 & TRN \\
\hline CHEMBL3919616 & 1642077 & 9.9586 & 10.0239 & TRN \\
\hline CHEMBL 3954143 & 1642077 & 6.2832 & 6.2734 & TRN \\
\hline CHEMBL3939819 & 1642077 & 8.8386 & 8.0158 & TRN \\
\hline CHEMBL3896195 & 1642077 & 10.1759 & 9.1847 & TST \\
\hline CHEMBL3984361 & 1642077 & 8.0665 & 7.8648 & TST \\
\hline CHEMBL 3966323 & 1642077 & 6.8827 & 6.798999 & 9999999995 \\
\hline CHEMBL 3986680 & 1642077 & 8.4711 & 8.5888 & TST \\
\hline CHEMBL3934276 & 1642077 & 7.9208 & 8.1888 & TRN \\
\hline CHEMBL3970207 & 1642077 & 9.1549 & 8.7316 & TRN \\
\hline CHEMBL 3956884 & 1642077 & 9.2218 & 9.4536 & TRN \\
\hline CHEMBL3904282 & 1642077 & 9.2218 & 9.2917 & TRN \\
\hline CHEMBL 3933867 & 1642077 & 6.6216 & 6.6982 & TRN \\
\hline CHEMBL3916951 & 1642077 & 8.0506 & 8.2087 & TRN \\
\hline CHEMBL3974890 & 1642077 & 6.7773 & 6.6321 & TRN \\
\hline CHEMBL 3967917 & 1642077 & 8.7447 & 8.4703 & TRN \\
\hline CHEMBL3979954 & 1642077 & 6.0 & 5.9881 & TRN \\
\hline CHEMBL3949174 & 1642077 & 8.3979 & 8.6054 & TRN \\
\hline CHEMBL3975613 & 1642077 & 8.1079 & 8.1874 & TRN \\
\hline CHEMBL3947143 & 1642077 & 9.7144 & 9.7582 & TRN \\
\hline CHEMBL 3975814 & 1642077 & 6.6126 & 6.4032 & TRN \\
\hline CHEMBL3901085 & 1642077 & 8.6198 & 8.8481 & TRN \\
\hline CHEMBL3978539 & 1642077 & 6.0 & 6.0515 & TRN \\
\hline
\end{tabular}


Supplemental Table S2.txt

\begin{tabular}{|c|c|c|c|c|c|c|}
\hline CHEMBL3978475 & 1642077 & 9.0173 & 8.9173 & TST & & \\
\hline CHEMBL3956736 & 1642077 & 9.0969 & 8.8131 & TRN & & \\
\hline CHEMBL3966109 & 1642077 & 7.9666 & 7.9102 & TRN & & \\
\hline CHEMBL3916993 & 1642077 & 8.8794 & 8.6182 & TRN & & \\
\hline CHEMBL3945507 & 1642077 & 6.5901 & 6.5038 & TRN & & \\
\hline CHEMBL3897826 & 1642077 & 8.9547 & 9.1874 & TRN & & \\
\hline CHEMBL3913792 & 1642077 & 7.1851 & 7.5227 & TRN & & \\
\hline CHEMBL3915882 & 1642077 & 8.1085 & 8.5357 & TST & & \\
\hline CHEMBL3893675 & 1642077 & 8.251 & 8.6599 & TRN & & \\
\hline CHEMBL3940091 & 1642077 & 10.9208 & 9.8243 & TRN & & \\
\hline CHEMBL3890727 & 1642077 & 9.7905 & 9.7458 & TST & & \\
\hline CHEMBL3934565 & 1642077 & 9.6198 & 9.3606 & TRN & & \\
\hline CHEMBL3946889 & 1642077 & 7.1249 & 7.4505 & TRN & & \\
\hline CHEMBL3944421 & 1642077 & 10.0 & 10.1103 & TST & & \\
\hline CHEMBL3912000 & 1642077 & 8.1079 & 7.8509 & TRN & & \\
\hline CHEMBL3966072 & 1642077 & 6.0 & 6.063 & TRN & & \\
\hline CHEMBL3891210 & 1642077 & 9.3979 & 8.9635 & TRN & & \\
\hline CHEMBL 3980680 & 1642077 & 7.9208 & 8.1783 & TRN & & \\
\hline CHEMBL3933088 & 1642077 & 7.2027 & 6.6707 & TRN & & \\
\hline CHEMBL3899758 & 1642077 & 6.0 & 5.8103 & TST & & \\
\hline CHEMBL3895124 & 1642077 & 10.4225 & 10.9878 & TST & & \\
\hline CHEMBL3926620 & 1642077 & 9.1733 & 9.3259 & TRN & & \\
\hline CHEMBL3973409 & 1642077 & 5.7721 & 5.9269 & TST & & \\
\hline CHEMBL3934590 & 1642077 & 8.5952 & 8.8103 & TRN & & \\
\hline CHEMBL3923557 & 1642077 & 6.0 & 7.9843 & TRN & & \\
\hline CHEMBL3934338 & 1642077 & 8.7852 & 7.9526 & TRN & & \\
\hline CHEMBL3904050 & 1642077 & 9.2218 & 9.7611 & TRN & & \\
\hline CHEMBL3902617 & 1642077 & 8.0177 & 7.4802 & TRN & & \\
\hline CHEMBL3918795 & 1642077 & 7.4724 & 7.3776 & TST & & \\
\hline CHEMBL3931746 & 1642077 & 7.9788 & 8.1321 & TRN & & \\
\hline CHEMBL3957073 & 1642077 & 9.2441 & 9.2279 & TRN & & \\
\hline CHEMBL3957954 & 1642077 & 9.5229 & 9.4924 & TRN & & \\
\hline CHEMBL3918273 & 1642077 & 10.0 & 9.6266 & TRN & & \\
\hline CHEMBL3919725 & 1642077 & 10.1192 & 10.0522 & TRN & & \\
\hline CHEMBL3897690 & 1642077 & 8.7144 & 8.3097 & TRN & & \\
\hline CHEMBL3963838 & 1642077 & 8.7696 & 8.8666 & TRN & & \\
\hline CHEMBL3947213 & 1642077 & 6.0 & 5.5914 & TRN & & \\
\hline CHEMBL3937682 & 1642077 & 7.3883 & 6.9637 & TRN & & \\
\hline CHEMBL3892131 & 1642077 & 6.71899 & 999999999 & 99 & 6.7999 & TRN \\
\hline CHEMBL3955880 & 1642077 & 9.3279 & 9.0531 & TRN & & \\
\hline CHEMBL 3894748 & 1642077 & 6.0 & 6.4729 & TRN & & \\
\hline CHEMBL3905644 & 1642077 & 7.9101 & 7.7706 & TRN & & \\
\hline CHEMBL3905697 & 1642077 & 6.0 & 6.5457 & TRN & & \\
\hline CHEMBL3956734 & 1642077 & 7.2652 & 7.5197 & TRN & & \\
\hline CHEMBL3925309 & 1642077 & 8.0605 & 8.3166 & TRN & & \\
\hline CHEMBL3925198 & 1642077 & 8.6778 & 8.4218 & TRN & & \\
\hline CHEMBL3894496 & 1642077 & 8.5528 & 7.6159 & TRN & & \\
\hline CHEMBL 3966363 & 1642077 & 6.0 & 6.2168 & TRN & & \\
\hline
\end{tabular}


Supplemental Table S2.txt

\begin{tabular}{|c|c|c|c|c|}
\hline CHEMBL3917176 & 1642077 & 5.9788 & 6.4779 & TRN \\
\hline CHEMBL3925684 & 1642077 & 6.7282 & 6.6024 & TRN \\
\hline CHEMBL3926513 & 1642077 & 6.8962 & 7.1254 & TRN \\
\hline CHEMBL3903837 & 1642077 & 9.5272 & 9.5237 & TRN \\
\hline CHEMBL3984961 & 1642077 & 9.699 & 9.9232 & TST \\
\hline CHEMBL3901445 & 1642077 & 7.6459 & 7.7602 & TRN \\
\hline CHEMBL3979678 & 1642077 & 6.0 & 6.8743 & TRN \\
\hline CHEMBL3940411 & 1642077 & 9.0545 & 9.0349 & TRN \\
\hline CHEMBL3980526 & 1642077 & 6.0 & 6.1125 & TRN \\
\hline CHEMBL3943059 & 1642077 & 7.2083 & 6.7296 & TRN \\
\hline CHEMBL3913500 & 1642077 & 8.4559 & 7.978 & TST \\
\hline CHEMBL3926782 & 1642077 & 9.5229 & 9.399 & TRN \\
\hline CHEMBL3934918 & 1642077 & 8.8894 & 8.7535 & TST \\
\hline CHEMBL3909184 & 1642077 & 7.3429 & 7.5422 & TRN \\
\hline CHEMBL3911461 & 1642077 & 9.699 & 9.8091 & TRN \\
\hline CHEMBL3903730 & 1642077 & 7.4034 & 7.5158 & TRN \\
\hline CHEMBL3976306 & 1642077 & 8.4559 & 8.442 & TRN \\
\hline CHEMBL3907606 & 1642077 & 7.7852 & 7.9876 & TRN \\
\hline CHEMBL3940464 & 1642077 & 8.2366 & 8.5844 & TST \\
\hline CHEMBL3958862 & 1642077 & 10.0 & 9.9187 & TRN \\
\hline CHEMBL3912577 & 1642077 & 8.5575 & 8.8063 & TRN \\
\hline CHEMBL3906819 & 1642077 & 7.5817 & 7.8398 & TRN \\
\hline CHEMBL3890346 & 1642077 & 9.7721 & 9.7997 & TRN \\
\hline CHEMBL3985049 & 1642077 & 7.4461 & 7.1842 & TST \\
\hline CHEMBL3972842 & 1642077 & 8.3872 & 8.125 & TRN \\
\hline CHEMBL3925989 & 1642077 & 7.0061 & 7.0999 & TRN \\
\hline CHEMBL3916586 & 1642077 & 7.4572 & 7.6153 & TRN \\
\hline CHEMBL3918907 & 1642077 & 10.4225 & 7.17299 & э999999999 \\
\hline CHEMBL3909785 & 1642077 & 9.4089 & 9.2125 & TRN \\
\hline CHEMBL3973280 & 1642077 & 8.8665 & 8.8979 & TRN \\
\hline CHEMBL3976384 & 1642077 & 7.4622 & 7.6519 & TST \\
\hline CHEMBL3919294 & 1642077 & 8.301 & 8.4692 & TRN \\
\hline CHEMBL3963777 & 1642077 & 8.4949 & 8.2251 & TRN \\
\hline CHEMBL3948078 & 1642077 & 7.6126 & 7.8713 & TRN \\
\hline CHEMBL3899535 & 1642077 & 8.9508 & 8.7774 & TRN \\
\hline CHEMBL3985959 & 1642077 & 9.0969 & 8.7329 & TRN \\
\hline CHEMBL3898395 & 1642077 & 8.8962 & 8.8197 & TRN \\
\hline CHEMBL3983220 & 1642077 & 7.9245 & 7.78600 & 30000000005 \\
\hline CHEMBL 3948083 & 1642077 & 7.2366 & 7.6648 & TRN \\
\hline CHEMBL3889998 & 1642077 & 8.3979 & 8.5074 & TRN \\
\hline CHEMBL3914535 & 1642077 & 9.71 & 9.5397 & TRN \\
\hline CHEMBL3934853 & 1642077 & 8.0 & 8.1701 & TRN \\
\hline CHEMBL3969013 & 1642077 & 7.9706 & 8.401 & TRN \\
\hline CHEMBL 3910446 & 1642077 & 9.7959 & 9.8817 & TRN \\
\hline CHEMBL3891675 & 1642077 & 7.9208 & 8.6456 & TRN \\
\hline CHEMBL3941570 & 1642077 & 6.0 & 6.2427 & TRN \\
\hline CHEMBL3809623 & 1642077 & 8.7696 & 8.7327 & TST \\
\hline CHEMBL3935709 & 1642077 & 8.6383 & 8.4167 & TRN \\
\hline
\end{tabular}


Supplemental Table S2.txt

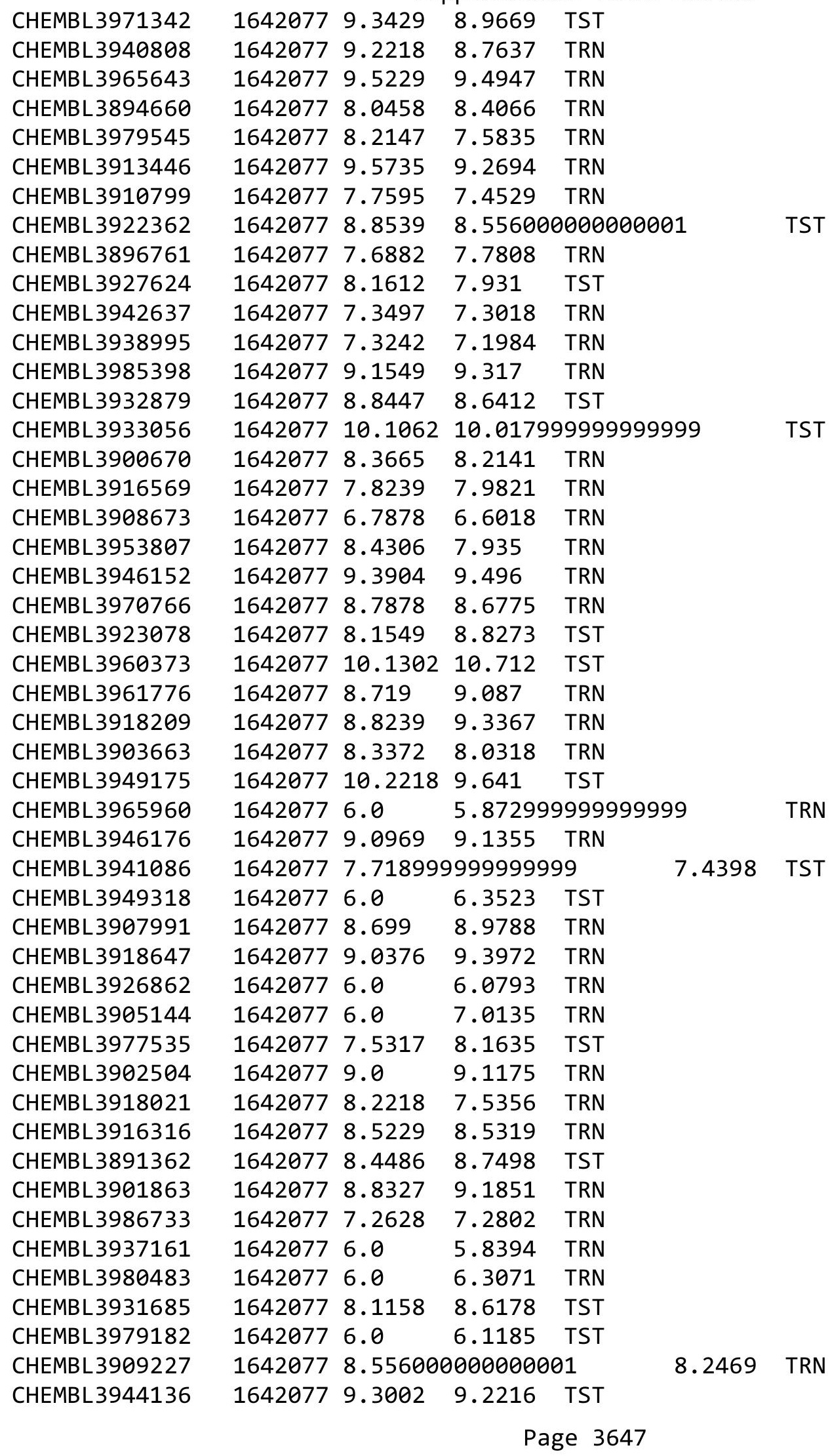


Supplemental Table S2.txt

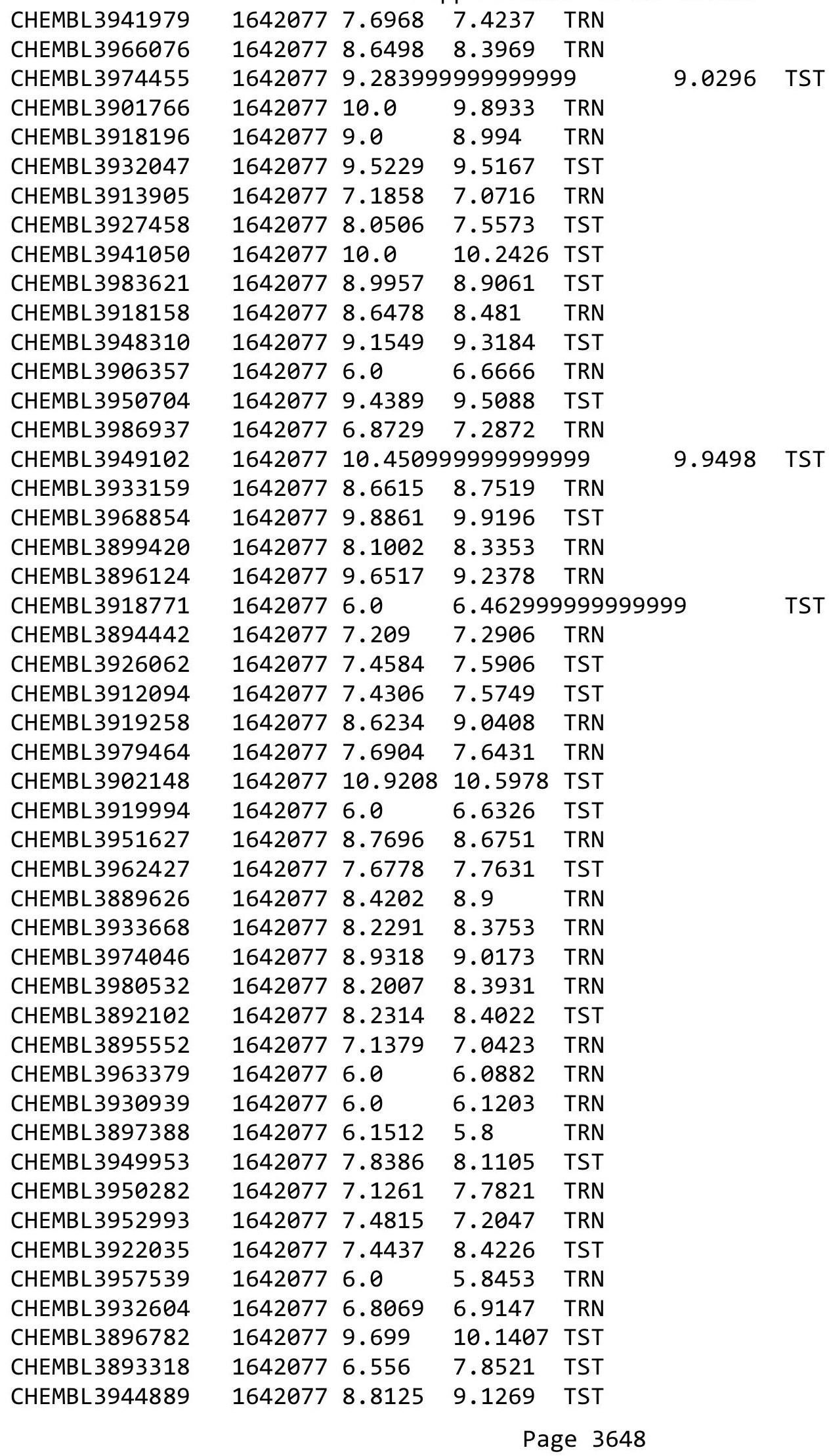


Supplemental Table S2.txt

\begin{tabular}{|c|c|c|c|c|c|}
\hline CHEMBL 3962883 & 1642077 & 7.0862 & 7.2115 & TRN & \\
\hline CHEMBL 3972296 & 1642077 & 8.4413 & 8.77799 & 7999999999 & TRN \\
\hline CHEMBL3891287 & 1642077 & 8.2147 & 8.1808 & TRN & \\
\hline CHEMBL 3907325 & 1642077 & 8.0894 & 8.5279 & TRN & \\
\hline CHEMBL 3949896 & 1642077 & 7.2034 & 7.3157 & TRN & \\
\hline CHEMBL3936529 & 1642077 & 6.857 & 7.15600 & 0000000001 & TRN \\
\hline CHEMBL3929651 & 1642077 & 8.8386 & 8.5664 & TRN & \\
\hline CHEMBL 3937248 & 1642077 & 7.7055 & 7.3339 & TRN & \\
\hline CHEMBL3918797 & 1642077 & 8.8861 & 9.2765 & TRN & \\
\hline CHEMBL3986567 & 1642077 & 8.9101 & 9.1507 & TST & \\
\hline CHEMBL3897606 & 1642077 & 9.5607 & 9.6755 & TST & \\
\hline CHEMBL3936412 & 1642077 & 8.6655 & 8.2211 & TRN & \\
\hline CHEMBL 3933742 & 1642077 & 9.301 & 9.582 & TST & \\
\hline CHEMBL3931370 & 1642077 & 8.5591 & 7.9896 & TRN & \\
\hline CHEMBL 3934242 & 1642077 & 8.7305 & 8.1813 & TRN & \\
\hline CHEMBL3917533 & 1642077 & 7.0857 & 6.9481 & TRN & \\
\hline CHEMBL3943301 & 1642077 & 6.0 & 6.4342 & TRN & \\
\hline CHEMBL3981216 & 1642077 & 7.644 & 8.2531 & TRN & \\
\hline CHEMBL 3892409 & 1642077 & 8.2518 & 8.705 & TRN & \\
\hline CHEMBL3962064 & 1642077 & 9.3979 & 9.4586 & TST & \\
\hline CHEMBL3891786 & 1642077 & 8.6459 & 8.7817 & TRN & \\
\hline CHEMBL3903686 & 1642077 & 10.4461 & 9.5769 & TRN & \\
\hline CHEMBL3939400 & 1642077 & 7.4763 & 7.4725 & TRN & \\
\hline CHEMBL 2113323 & 450707 & 6.0 & 6.5728 & TRN & \\
\hline CHEMBL240746 & 450707 & 6.5935 & 6.4222 & TRN & \\
\hline CHEMBL391922 & 450707 & 6.3298 & 6.5724 & TRN & \\
\hline CHEMBL253126 & 450707 & 8.2518 & 7.7082 & TRN & \\
\hline CHEMBL240179 & 450707 & 6.1198 & \multicolumn{2}{|c|}{6.297000000000001} & TRN \\
\hline CHEMBL 2113322 & 450707 & 7.8861 & 7.3186 & TRN & \\
\hline CHEMBL 393692 & 450707 & 6.8601 & 6.8557 & TST & \\
\hline CHEMBL398797 & 450707 & 5.0 & 5.3934 & TST & \\
\hline CHEMBL396681 & 450707 & 7.3565 & 7.3961 & TRN & \\
\hline CHEMBL241775 & 450707 & 8.0 & 7.5488 & TRN & \\
\hline CHEMBL415674 & 450707 & 7.4559 & 7.5748 & TRN & \\
\hline CHEMBL 2113319 & 450707 & 6.0 & 6.7909 & TRN & \\
\hline CHEMBL2113317 & 450707 & 6.7212 & 6.7267 & TRN & \\
\hline CHEMBL241242 & 450707 & 7.2291 & 7.2834 & TRN & \\
\hline CHEMBL266063 & 450707 & 9.5229 & 8.8388 & TRN & \\
\hline CHEMBL392663 & 450707 & 7.2007 & 7.0521 & TRN & \\
\hline CHEMBL239464 & 450707 & 6.7496 & 6.7115 & TRN & \\
\hline CHEMBL397593 & 450707 & 8.2218 & 8.3353 & TRN & \\
\hline CHEMBL239007 & 450707 & 6.426 & 6.2614 & TRN & \\
\hline CHEMBL392902 & 450707 & 6.5607 & 6.6536 & TRN & \\
\hline CHEMBL394179 & 450707 & 5.0 & 4.9526 & TRN & \\
\hline CHEMBL393693 & 450707 & 7.4202 & 7.7942 & TRN & \\
\hline CHEMBL 2113320 & 450707 & 6.4559 & 5.6245 & TRN & \\
\hline CHEMBL400814 & 450707 & 7.4949 & 6.6145 & TRN & \\
\hline CHEMBL396682 & 450707 & 6.3098 & 6.534 & TRN & \\
\hline
\end{tabular}




\begin{tabular}{|c|c|c|c|c|c|c|}
\hline & & \multicolumn{5}{|c|}{ Supplemental Table S2.txt } \\
\hline CHEMBL240509 & 450707 & 9.2218 & 8.7053 & TRN & & \\
\hline CHEMBL391859 & 450707 & 6.2518 & 6.1351 & TRN & & \\
\hline CHEMBL394054 & 450707 & 6.8729 & 6.7249 & TRN & & \\
\hline CHEMBL374073 & 450707 & 7.8239 & 7.9301 & TRN & & \\
\hline CHEMBL391588 & 450707 & 9.0458 & 8.8031 & TST & & \\
\hline CHEMBL240392 & 450707 & 5.0 & 5.0698 & TRN & & \\
\hline CHEMBL414132 & 450707 & 6.8861 & 6.8121 & TRN & & \\
\hline CHEMBL398607 & 450707 & 5.0 & 4.8917 & TST & & \\
\hline CHEMBL395441 & 450707 & \multicolumn{3}{|c|}{6.7620000000000005} & 6.6139 & TST \\
\hline CHEMBL391980 & 450707 & 7.7447 & 7.273 & TST & & \\
\hline CHEMBL 2113327 & 450707 & 7.0177 & 7.244 & TRN & & \\
\hline CHEMBL 240522 & 450707 & 7.2676 & 7.0836 & TST & & \\
\hline CHEMBL397594 & 450707 & 7.7447 & 7.53299 & 999999999s & 95 & TST \\
\hline CHEMBL 2113326 & 450707 & 7.1549 & 7.2491 & TRN & & \\
\hline CHEMBL 240599 & 450707 & 5.0 & 5.7501 & TST & & \\
\hline CHEMBL 2113328 & 450707 & 7.7212 & 7.8476 & TRN & & \\
\hline CHEMBL393565 & 450707 & 6.8125 & 7.004 & TRN & & \\
\hline CHEMBL277376 & 450707 & 6.0 & 7.0169 & TRN & & \\
\hline CHEMBL428383 & 450707 & \multicolumn{3}{|c|}{6.757000000000001} & 6.9226 & TST \\
\hline CHEMBL 374643 & 450707 & 8.2218 & 8.0631 & TRN & & \\
\hline CHEMBL427680 & 450707 & 5.0 & 6.2723 & TST & & \\
\hline CHEMBL392191 & 450707 & 7.4949 & 8.0107 & TST & & \\
\hline CHEMBL 2113324 & 450707 & 9.301 & 9.2936 & TRN & & \\
\hline CHEMBL 2113325 & 450707 & 7.6198 & 8.3599 & TRN & & \\
\hline CHEMBL241033 & 450707 & 6.9469 & 7.0738 & TST & & \\
\hline CHEMBL 2113321 & 450707 & 8.1871 & 8.3587 & TRN & & \\
\hline CHEMBL391423 & 456071 & 4.1549 & 3.9691 & TRN & & \\
\hline CHEMBL244458 & 456071 & 3.0 & 3.2009 & TRN & & \\
\hline CHEMBL240334 & 456071 & 4.4437 & 3.7748 & TRN & & \\
\hline CHEMBL240329 & 456071 & 4.4815 & 4.8678 & TRN & & \\
\hline CHEMBL240543 & 456071 & 4.6021 & 4.3714 & TRN & & \\
\hline CHEMBL 241358 & 456071 & 3.6498 & 3.886 & TRN & & \\
\hline CHEMBL 240974 & 456071 & 4.0 & 4.4277 & TRN & & \\
\hline CHEMBL 240548 & 456071 & 4.0706 & 3.8567 & TRN & & \\
\hline CHEMBL240506 & 456071 & 6.2218 & 5.7188 & TRN & & \\
\hline CHEMBL240712 & 456071 & 3.6003 & 4.1822 & TST & & \\
\hline CHEMBL401049 & 456071 & 4.9586 & 5.1845 & TRN & & \\
\hline CHEMBL239056 & 456071 & 4.1805 & 4.1554 & TRN & & \\
\hline CHEMBL 240546 & 456071 & 4.2366 & 4.3842 & TRN & & \\
\hline CHEMBL388276 & 456071 & 5.699 & 5.2546 & TRN & & \\
\hline CHEMBL399006 & 456071 & 4.2218 & 4.2253 & TRN & & \\
\hline CHEMBL401050 & 456071 & 4.9208 & 4.4787 & TRN & & \\
\hline CHEMBL238849 & 456071 & 3.0 & 3.5061 & TRN & & \\
\hline CHEMBL401051 & 456071 & 3.0 & 3.5837 & TRN & & \\
\hline CHEMBL391444 & 456071 & 3.1675 & 3.1299 & TRN & & \\
\hline CHEMBL240754 & 456071 & 3.0 & 3.6802 & TST & & \\
\hline CHEMBL240973 & 456071 & 3.0 & 3.3722 & TRN & & \\
\hline CHEMBL240513 & 456071 & 4.4318 & 4.2158 & TRN & & \\
\hline
\end{tabular}




\begin{tabular}{|c|c|c|c|c|c|}
\hline & & \multicolumn{4}{|c|}{ Supplemental Table S2.txt } \\
\hline CHEMBL391519 & 456071 & 4.5376 & 4.9167 & TRN & \\
\hline CHEMBL394458 & 456071 & 2.0 & 2.6002 & TST & \\
\hline CHEMBL399211 & 456071 & 3.0 & 3.1484 & TRN & \\
\hline CHEMBL209453 & 456071 & 3.8861 & 3.8513 & TRN & \\
\hline CHEMBL241183 & 456071 & 4.0969 & 3.6825 & TRN & \\
\hline CHEMBL240512 & 456071 & 3.6778 & 4.2227 & TST & \\
\hline CHEMBL240752 & 456071 & 4.699 & 4.2845 & TRN & \\
\hline CHEMBL 276600 & 456071 & 3.0 & 3.1396 & TRN & \\
\hline CHEMBL 240544 & 456071 & 4.0506 & 3.984 & TRN & \\
\hline CHEMBL241606 & 456071 & 4.4949 & 4.2862 & TRN & \\
\hline CHEMBL240547 & 456071 & 4.7959 & 4.4772 & TRN & \\
\hline CHEMBL238633 & 456071 & 4.0362 & 3.9823 & TRN & \\
\hline CHEMBL392160 & 456071 & 4.7696 & 4.8555 & TRN & \\
\hline CHEMBL182653 & 456071 & 4.4089 & 3.8926 & TRN & \\
\hline CHEMBL394650 & 456071 & 4.7447 & 4.8754 & TRN & \\
\hline CHEMBL 241185 & 456071 & 4.0 & 3.8159 & TRN & \\
\hline CHEMBL239696 & 456071 & 4.699 & 4.6343 & TRN & \\
\hline CHEMBL239029 & 456071 & 3.1361 & 2.7655 & TRN & \\
\hline CHEMBL 240330 & 456071 & 4.3188 & 3.7138 & TRN & \\
\hline CHEMBL240753 & 456071 & 3.0 & 3.508 & TRN & \\
\hline CHEMBL241397 & 456071 & 5.3979 & 5.0767 & TRN & \\
\hline CHEMBL394397 & 456071 & 3.0 & 3.0455 & TRN & \\
\hline CHEMBL391729 & 456071 & 3.8861 & 3.9272 & TRN & \\
\hline CHEMBL 239484 & 456071 & 4.1549 & 4.121 & TRN & \\
\hline CHEMBL391411 & 456071 & 4.585 & 4.4268 & TRN & \\
\hline CHEMBL240299 & 456071 & 4.3665 & 4.3924 & TST & \\
\hline CHEMBL238632 & 456071 & 4.0506 & 3.9526 & TRN & \\
\hline CHEMBL 239274 & 456071 & 4.3098 & 4.0976 & TST & \\
\hline CHEMBL 240542 & 456071 & 4.0915 & 4.4061 & TRN & \\
\hline CHEMBL 238634 & 456071 & 3.0 & 2.97600 & 00000000004 & TRN \\
\hline CHEMBL241184 & 456071 & 4.0 & 3.4259 & TRN & \\
\hline CHEMBL239485 & 456071 & 4.9208 & 5.0295 & TRN & \\
\hline CHEMBL240331 & 456071 & 4.1135 & 4.4317 & TRN & \\
\hline CHEMBL 239482 & 456071 & 4.5229 & 4.7662 & TRN & \\
\hline CHEMBL 240300 & 456071 & 3.0969 & 3.5417 & TRN & \\
\hline CHEMBL241398 & 456071 & 3.699 & 3.9534 & TRN & \\
\hline CHEMBL 241804 & 456071 & 4.7447 & 4.7704 & TRN & \\
\hline CHEMBL 394457 & 456071 & 3.266 & 3.3831 & TRN & \\
\hline CHEMBL 241596 & 456071 & 4.3372 & 4.8156 & TRN & \\
\hline CHEMBL395590 & 456071 & 3.3372 & 3.1871 & TRN & \\
\hline CHEMBL239483 & 456071 & 4.1427 & 4.4201 & TRN & \\
\hline CHEMBL395448 & 456071 & 4.5229 & 4.6691 & TRN & \\
\hline CHEMBL 240333 & 456071 & 4.0809 & 4.1389 & TST & \\
\hline CHEMBL148472 & 456071 & 4.3279 & 4.6245 & TRN & \\
\hline CHEMBL241598 & 456071 & 4.5528 & 4.5386 & TRN & \\
\hline CHEMBL 240511 & 456071 & 4.0757 & 3.9173 & TST & \\
\hline CHEMBL240975 & 456071 & 3.0 & 3.7555 & TST & \\
\hline CHEMBL 394683 & 456071 & 4.2441 & 3.6633 & TST & \\
\hline
\end{tabular}




\begin{tabular}{|c|c|c|c|c|}
\hline & \multicolumn{4}{|c|}{ Supplemental Table S2.txt } \\
\hline CHEMBL 239244 & 456071 & 4.2218 & 4.2 & TST \\
\hline CHEMBL399412 & 456071 & 4.0 & 4.4083 & TST \\
\hline CHEMBL239684 & 456071 & 3.0 & 3.2919 & TST \\
\hline CHEMBL241396 & 456071 & 4.2757 & 4.3617 & TST \\
\hline CHEMBL 227400 & 456071 & 3.0 & 3.0891 & TST \\
\hline CHEMBL241597 & 456071 & 6.0 & 5.3719 & TST \\
\hline CHEMBL 239057 & 456071 & 5.3979 & 4.9366 & TST \\
\hline CHEMBL240332 & 456071 & 3.6576 & 4.4118 & TST \\
\hline CHEMBL241359 & 456071 & 4.8861 & 4.5605 & TST \\
\hline CHEMBL239275 & 456071 & 4.0458 & 3.464 & TST \\
\hline CHEMBL2180819 & 1528180 & 7.585 & 7.691 & TRN \\
\hline CHEMBL 3683963 & 1528180 & 6.3279 & 6.6233 & TRN \\
\hline CHEMBL3683980 & 1528180 & 5.9101 & 6.3201 & TRN \\
\hline CHEMBL3683951 & 1528180 & 8.1549 & 7.9701 & TRN \\
\hline CHEMBL3683935 & 1528180 & 8.0969 & 6.8232 & TST \\
\hline CHEMBL3683955 & 1528180 & 7.1871 & 7.0335 & TRN \\
\hline CHEMBL3639828 & 1528180 & 6.1135 & 6.2969 & TRN \\
\hline CHEMBL3683975 & 1528180 & 5.684 & 5.8902 & TRN \\
\hline CHEMBL2180818 & 1528180 & 7.6383 & 7.626 & TRN \\
\hline CHEMBL3683956 & 1528180 & 6.2757 & 6.2438 & TRN \\
\hline CHEMBL3683945 & 1528180 & 7.0969 & 6.9702 & TRN \\
\hline CHEMBL3683961 & 1528180 & 5.9208 & 6.3805 & TRN \\
\hline CHEMBL3683964 & 1528180 & 7.284 & 6.9204 & TRN \\
\hline CHEMBL3683946 & 1528180 & 7.1549 & 6.9958 & TRN \\
\hline CHEMBL 3683965 & 1528180 & 5.6421 & 6.0994 & TRN \\
\hline CHEMBL 3683968 & 1528180 & 6.0 & 5.699 & TRN \\
\hline CHEMBL 2180821 & 1528180 & 7.5086 & 7.626 & TRN \\
\hline CHEMBL3683974 & 1528180 & 5.6021 & 5.5872 & TRN \\
\hline CHEMBL3683940 & 1528180 & 8.5229 & 7.6643 & TST \\
\hline CHEMBL3683932 & 1528180 & 5.5376 & 5.4066 & TRN \\
\hline CHEMBL3683981 & 1528180 & 4.8962 & 4.9933 & TRN \\
\hline CHEMBL2180817 & 1528180 & 7.8239 & 7.7402 & TRN \\
\hline CHEMBL3683966 & 1528180 & 7.3372 & 6.4643 & TRN \\
\hline CHEMBL3683939 & 1528180 & 9.0 & 7.8235 & TST \\
\hline CHEMBL3683947 & 1528180 & 8.0458 & 7.6897 & TRN \\
\hline CHEMBL 2420366 & 1528180 & 6.2218 & 6.2289 & TRN \\
\hline CHEMBL3683979 & 1528180 & 5.7447 & 5.8139 & TRN \\
\hline CHEMBL 2180820 & 1528180 & 7.8861 & 7.8799 & TRN \\
\hline CHEMBL3683938 & 1528180 & 8.699 & 7.5968 & TST \\
\hline CHEMBL 3683960 & 1528180 & 6.8239 & 6.0561 & TRN \\
\hline CHEMBL3683933 & 1528180 & 6.3872 & 5.1542 & TST \\
\hline CHEMBL3683971 & 1528180 & 5.585 & 6.0906 & TRN \\
\hline CHEMBL3683936 & 1528180 & 8.2218 & 6.5034 & TST \\
\hline CHEMBL3683967 & 1528180 & 6.2573 & 6.7671 & TRN \\
\hline CHEMBL 3683949 & 1528180 & 7.9208 & 8.0342 & TRN \\
\hline CHEMBL3683954 & 1528180 & 5.3372 & 6.3195 & TST \\
\hline CHEMBL3683943 & 1528180 & 6.0458 & 5.8721 & TST \\
\hline CHEMBL3683973 & 1528180 & 7.2676 & 6.359 & TRN \\
\hline
\end{tabular}


Supplemental Table S2.txt

\begin{tabular}{|c|c|c|c|c|}
\hline 然 & & & & \\
\hline HEMBL3683950 & 528180 & 7.284 & 6208 & \\
\hline & 80 & 49 & & \\
\hline 33944 & 28180 & 458 & 1469 & \\
\hline IEMBL 3683934 & 528180 & 5.9208 & 8124 & \\
\hline AEMBL3683978 & 528180 & 5.7959 & .5016 & \\
\hline HEMBL3683976 & 528180 & 6.3565 & .1705 & \\
\hline IEMBL 3683948 & 528180 & 198 & 4156 & \\
\hline 83972 & 528180 & 969 & 6.359 & \\
\hline AEMBL2180830 & 528180 & 7.4089 & 7.7402 & \\
\hline AEMBL3683952 & 528180 & 7.0 & 7.4251 & \\
\hline AEMBL3683957 & 528180 & 4.8962 & .5585 & \\
\hline 3970 & & & & \\
\hline 83958 & 528180 & 757 & 7.2872 & \\
\hline AEMBL3683977 & 528180 & 153 & . 1481 & \\
\hline AEMBL3683959 & 528180 & 079 & 1416 & \\
\hline HEMBL12 & 4707 & 952 & 3.6157 & \\
\hline HEMBL16 & & 725 & 43 & \\
\hline HEMBL22 & 97 & 316 & 4.711 & \\
\hline AEMBL21 & 97 & 222 & 3618 & \\
\hline AEMBL392695 & 77 & 282 & $4.3 / 36$ & KIV \\
\hline HEMBL1590308 & 17 & 579 & 3.1228 & \\
\hline HEMBL1909414 & & 73 & 4.5881 & \\
\hline AEMBL577784 & & 388 & 5.4815 & \\
\hline AEMBL192566 & 7 & 25 & 964 & SI \\
\hline AEMBL16 & & 74 & 3.2574 & RN \\
\hline AEMBL2 2 & 7 & 653 & 4.0894 & RN \\
\hline AEM & & 86 & .8248 & RN \\
\hline AEMBL9. & & & 11 & ST \\
\hline HEMBL 393929 & 97 & 78 & 28 & RN \\
\hline IEMBL472940 & & 984 & 5006 & RN \\
\hline AFMBI 13 & & 9 & 2.5126 & RN \\
\hline 10 & & & 764 & ST \\
\hline HEMBL1970879 & & & 971 & RN \\
\hline JEMBL1190711 & 7 & 854 & 9786 & RN \\
\hline AEMBL300389 & & & 11 & \\
\hline 1221127 & & & 87 & ST \\
\hline HEMBL 318640 & & & 3.6994 & ST \\
\hline HEMBL449158 & 54707 & 579 & 6.5738 & IST \\
\hline IEMBL19133 & 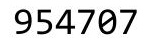 & 859 & 3.7567 & RN \\
\hline AEMBL512504 & 7 & 073 & 5.5243 & RN \\
\hline HEMBL135561 & & & 3.9559 & RN \\
\hline HEMBL 259181 & 07 & 4.2804 & 4.3577 & $\mathrm{RN}$ \\
\hline HEMBL483847 & 54707 & 3.708 & 3.7828 & RN \\
\hline EMBL17881 & & 376 & 3.2303 & RN \\
\hline HEMBL189584 & & 4.2341 & 4.2589 & \\
\hline HEMBL 12300 & 954707 & 2.9573 & 2.9947 & \\
\hline CHEMBL 558642 & 954707 & 4.038 & 3.8697 & RN \\
\hline
\end{tabular}

Page 3653 
Supplemental Table S2.txt

\begin{tabular}{|c|c|c|c|c|}
\hline 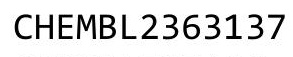 & & 784 & & \\
\hline HEMBL515416 & 54707 & 4.3589 & 688 & \\
\hline HEMBL2005886 & 54707 & 1656 & 1919 & \\
\hline HEMBL92309 & 07 & & & \\
\hline AEMBL3349342 & 107 & 979 & & \\
\hline AEMBL573107 & 54707 & 9783 & 8029 & \\
\hline AEMBL412142 & 54707 & 3.5481 & .4751 & \\
\hline AEMBL509032 & & & & \\
\hline IEMBL 213100 & 107 & 15 & & \\
\hline AEMBL379300 & & & & \\
\hline AEMBL210618 & 54707 & 3.9603 & 9951 & \\
\hline AEMBL585951 & 707 & & & \\
\hline AEMBL258844 & & 18 & 29 & \\
\hline AEMBL1256459 & & & & \\
\hline AEMBL3199475 & & & & \\
\hline AEMBL 202721 & 97 & & 692 & \\
\hline AEMBL373751 & & & & \\
\hline HEMBL188678 & 7 & & & \\
\hline HEMBL 222102 & & & & \\
\hline HEMBL180127 & & & & \\
\hline AEMBL514499 & & & 62 & \\
\hline AEMBL1404918 & & & & \\
\hline AEMBL1315701 & & & & \\
\hline HEMBL1304293 & & & & \\
\hline AEMBL1456530 & & & & \\
\hline AEMBL1378260 & & & & \\
\hline AEMBL1435343 & & & & \\
\hline AEMBL3191432 & & & & \\
\hline AEMBL1606583 & & & & \\
\hline 458 & & & 22 & \\
\hline HEMBL1425188 & & & & \\
\hline HEMBL1528425 & & & 663 & \\
\hline 76 & & & 77 & \\
\hline 9359 & & & & \\
\hline HEMBL 81324 & & & & RN \\
\hline HEMBL1489929 & & & & \\
\hline AEMBL1601781 & & & 528 & \\
\hline 1304292 & & & & \\
\hline 1481342 & & & 576 & Trv \\
\hline HEMBL1461446 & & & & RI \\
\hline AEMBL1408094 & 68 & & & R \\
\hline AEMBL1484783 & & & & \\
\hline HEMBL1565592 & & & 4.4992 & \\
\hline CHEMBL1460656 & & & & \\
\hline HEMBL 217920 & & & & RN \\
\hline AEMBL1242180 & 68 & 4. & 119 & TS \\
\hline 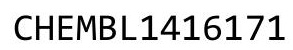 & & & & \\
\hline HEMBL 319173 & & 3.9948 & 4.2142 & \\
\hline
\end{tabular}

Page 3654 


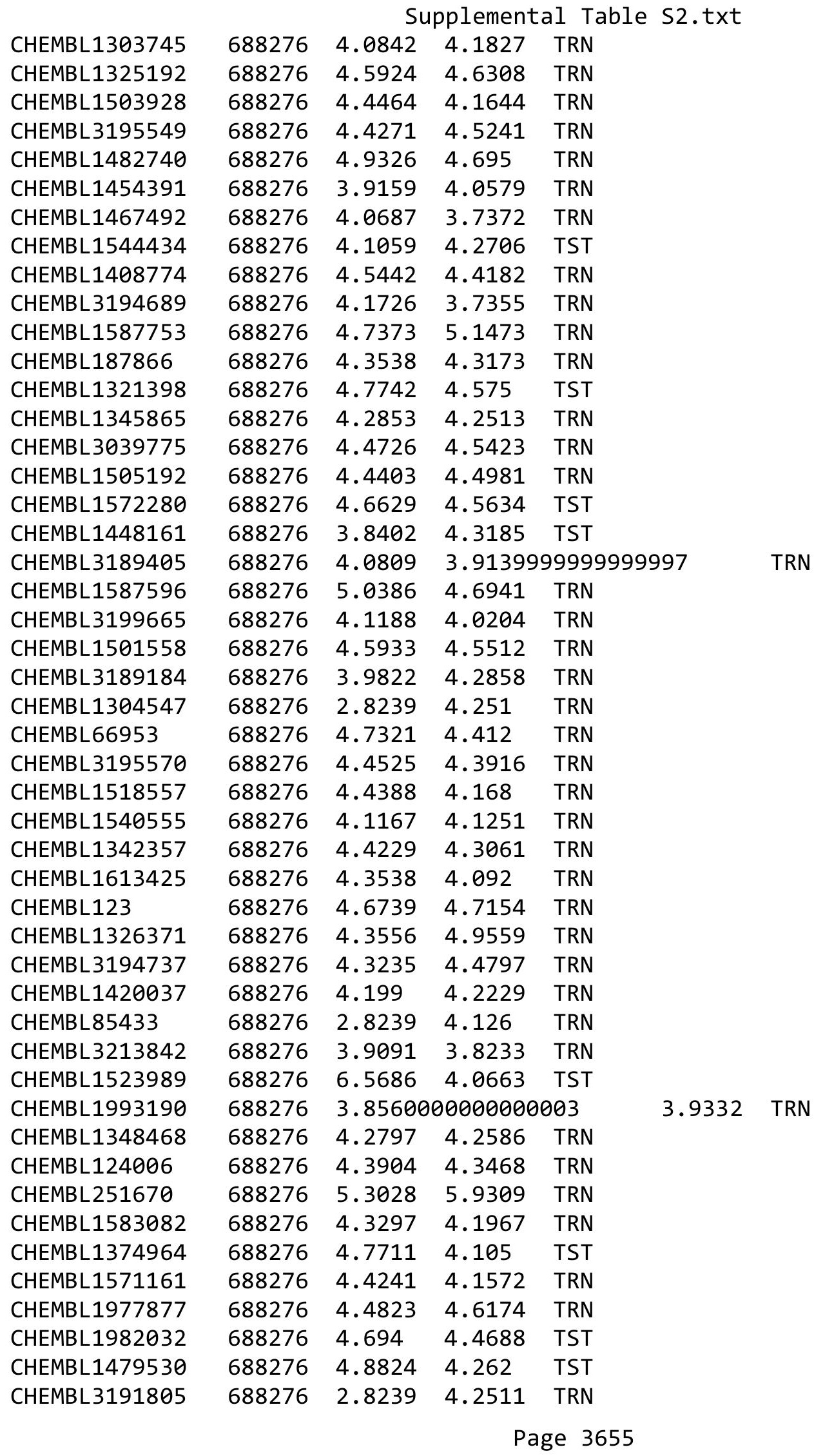




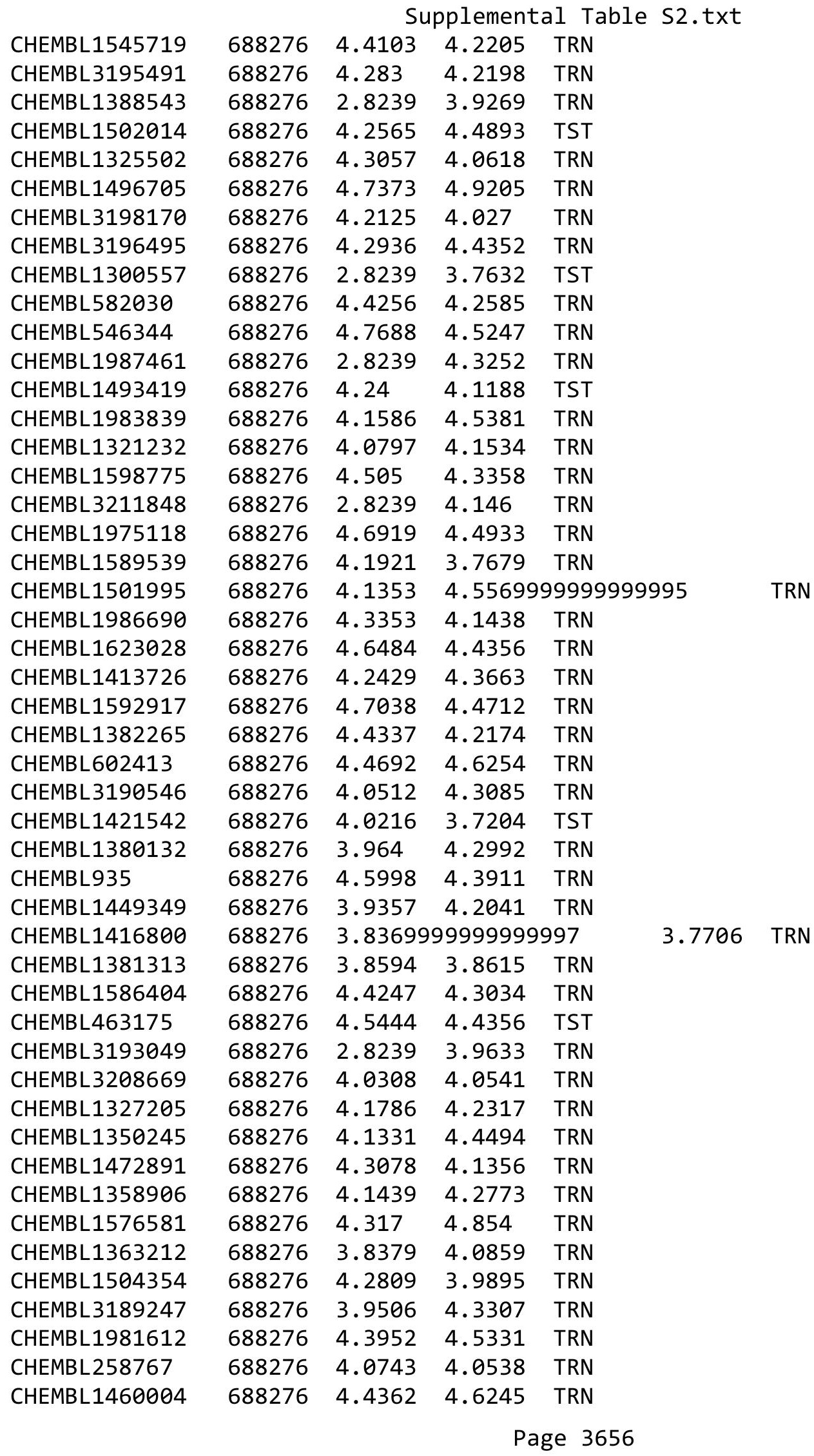


Supplemental Table S2.txt

\begin{tabular}{|c|c|c|c|c|}
\hline HEN & & & & \\
\hline & 88276 & 4.7058 & 4.680 & \\
\hline & 276 & & & \\
\hline IEMBL132 & & & & Ne \\
\hline AEMBL1559687 & 8276 & 35 & 2043 & \\
\hline HEMBL1424607 & 88276 & 2339 & 1771 & \\
\hline HEMBL131 & & & 477 & \\
\hline IFMBI 130 & & & 1024 & Du \\
\hline AEMBL1360341 & & & 1195 & \\
\hline HEMBL1587760 & 88276 & & 8467 & \\
\hline HEMBL1208858 & 76 & & 6505 & \\
\hline IEMBL151 & & & 864 & \\
\hline IEMBL14 & & & 773 & \\
\hline HEMBL13. & & & 9336 & \\
\hline HEMBL125 & & & 3833 & \\
\hline AEMBL188 & 0 & 71 & 9305 & \\
\hline AEMBL16 & & & 698 & \\
\hline HEMBL 14 & & & & \\
\hline JEMBL14 & & & 5024 & \\
\hline AEMBL15 & & & 039 & \\
\hline HEMLI & & & 777 & RIN \\
\hline AEMBL13 & & & 296 & 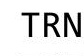 \\
\hline AEMBL13 & & & 39 & \\
\hline 886 & & & 919 & \\
\hline IEMBL 14 & & & & ras \\
\hline HEMBL1C & & & 553 & KIV \\
\hline HEMBL13 & & & 261 & RN \\
\hline HFMBI 14 & & & & \\
\hline JEMBL 20 & & & 7177 & I KIV \\
\hline HEMBL1987472 & & & 337 & 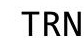 \\
\hline HEMBL15 & & & 143 & RN \\
\hline HEMBL1 & & & 405 & RN \\
\hline $15 M P \mid 1$ & & & 845 & RN \\
\hline HEMBL1583127 & & & 201 & IRN \\
\hline HEMBL1581725 & & & 711 & $T$ \\
\hline HEMBL13 & & & 709 & | \\
\hline HEMPI 1 & & & 349 & $\Gamma \mathrm{RN}$ \\
\hline & & & 064 & IST \\
\hline HEMBL1401052 & & & 1432 & TRN \\
\hline HEMBL136 & & & 7849 & RN \\
\hline HEMBL152 & & & 5718 & \\
\hline HEMBL159 & & & 3539 & TRN \\
\hline HEMBL1578054 & & & 1978 & $\Gamma \mathrm{RN}$ \\
\hline AEMBL1964909 & 6 & 35 & 6996 & TRN \\
\hline HEMBL143 & & & 2903 & $T$ \\
\hline CHEMBL161 & & & 276 & \\
\hline CHEMBL1398607 & & 3.85 & .5504 & \\
\hline HEMBL 255068 & 688276 & 4.1838 & 4.2652 & \\
\hline
\end{tabular}

Page 3657 


\begin{tabular}{|c|c|c|c|c|c|c|}
\hline & & \multicolumn{5}{|c|}{ Supplemental Table S2.txt } \\
\hline CHEMBL1572031 & 688276 & 4.0268 & 4.052 & TRN & & \\
\hline CHEMBL1561153 & 688276 & 4.1914 & 4.4534 & TRN & & \\
\hline CHEMBL1419585 & 688276 & 4.0598 & 4.2768 & TRN & & \\
\hline CHEMBL584269 & 688276 & 4.6844 & 4.9826 & TRN & & \\
\hline CHEMBL1487644 & 688276 & 3.8597 & 4.0205 & TST & & \\
\hline CHEMBL3196837 & 688276 & 4.4181 & 4.2466 & TRN & & \\
\hline CHEMBL1548629 & 688276 & 2.8239 & 3.9601 & TRN & & \\
\hline CHEMBL1415720 & 688276 & 4.4001 & 4.4124 & TST & & \\
\hline CHEMBL1969543 & 688276 & 4.4403 & 4.4623 & TRN & & \\
\hline CHEMBL1361227 & 688276 & 4.05 & 3.7679 & TRN & & \\
\hline CHEMBL142630 & 688276 & 2.8239 & 4.2118 & TRN & & \\
\hline CHEMBL1418885 & 688276 & 4.6619 & 4.4192 & TRN & & \\
\hline CHEMBL1309806 & 688276 & 4.2776 & 4.4262 & TRN & & \\
\hline CHEMBL1468260 & 688276 & 4.29899 & 99999999 & 995 & 4.2134 & TRN \\
\hline CHEMBL1422282 & 688276 & 3.8674 & 4.1163 & TRN & & \\
\hline CHEMBL1451747 & 688276 & 4.4225 & 4.3228 & TST & & \\
\hline CHEMBL1548026 & 688276 & 4.4219 & 4.2148 & TRN & & \\
\hline CHEMBL1328072 & 688276 & 4.3024 & 3.7757 & TRN & & \\
\hline CHEMBL1403921 & 688276 & 4.2527 & 3.7466 & TRN & & \\
\hline CHEMBL1556561 & 688276 & 3.9544 & 4.0908 & TRN & & \\
\hline CHEMBL1304979 & 688276 & 4.2301 & 4.2907 & TRN & & \\
\hline CHEMBL1331019 & 688276 & 4.4612 & 4.3153 & TRN & & \\
\hline CHEMBL1569910 & 688276 & 4.018 & 4.4404 & TRN & & \\
\hline CHEMBL1504766 & 688276 & 4.4563 & 4.3439 & TRN & & \\
\hline CHEMBL1600045 & 688276 & 4.0633 & 4.2559 & TRN & & \\
\hline CHEMBL1605784 & 688276 & 4.1506 & 4.3443 & TRN & & \\
\hline CHEMBL1326318 & 688276 & 3.8662 & 4.1705 & TRN & & \\
\hline CHEMBL1593697 & 688276 & 6.0 & 5.3441 & TST & & \\
\hline CHEMBL1396209 & 688276 & 4.8058 & 4.5958 & TST & & \\
\hline CHEMBL1532831 & 688276 & 2.8239 & 4.2675 & TRN & & \\
\hline CHEMBL1349146 & 688276 & 4.3699 & 4.4171 & TRN & & \\
\hline CHEMBL1587804 & 688276 & 3.972 & 3.8398 & TRN & & \\
\hline CHEMBL3195608 & 688276 & 4.5632 & 4.3473 & TRN & & \\
\hline CHEMBL1535991 & 688276 & 4.4012 & 4.1344 & TRN & & \\
\hline CHEMBL1507242 & 688276 & 3.9951 & 4.0354 & TRN & & \\
\hline CHEMBL1440235 & 688276 & 4.7077 & 4.2298 & TRN & & \\
\hline CHEMBL1572896 & 688276 & 4.3263 & 4.0937 & TRN & & \\
\hline CHEMBL1321283 & 688276 & 2.8239 & 3.5554 & TRN & & \\
\hline CHEMBL1515503 & 688276 & 3.8378 & 3.5673 & TST & & \\
\hline CHEMBL1340487 & 688276 & 3.8384 & 3.9361 & TRN & & \\
\hline CHEMBL1548109 & 688276 & 4.4679 & 4.6519 & TRN & & \\
\hline CHEMBL1397507 & 688276 & 5.1273 & 4.6555 & TST & & \\
\hline CHEMBL1426788 & 688276 & 4.43199 & 99999999 & 995 & 4.2812 & 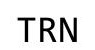 \\
\hline CHEMBL1494444 & 688276 & 4.357 & 4.1897 & TST & & \\
\hline CHEMBL1430611 & 688276 & 6.2757 & 4.7111 & TST & & \\
\hline CHEMBL1605010 & 688276 & 4.0106 & 4.0923 & TRN & & \\
\hline CHEMBL1338743 & 688276 & 4.5262 & 4.2415 & TRN & & \\
\hline CHEMBL3196813 & 688276 & 4.3961 & 4.3633 & TRN & & \\
\hline
\end{tabular}


Supplemental Table S2.txt

\begin{tabular}{|c|c|c|c|c|}
\hline 9613 & 38276 & 4.6078 & & \\
\hline & 88276 & 4.5075 & & \\
\hline & & & & \\
\hline EMBL1 & & 8239 & & \\
\hline IEMBL1 & 8276 & 836 & & \\
\hline HEMBL3213606 & 38276 & .519 & 4229 & \\
\hline AEMBL & 276 & & & \\
\hline EMBL & & & & \\
\hline HEMBL1 & & 2009 & & \\
\hline AEMBL1 & 38276 & .91 & 2836 & \\
\hline AEMBL: & 38276 & 4.4556 & 91 & \\
\hline IEMBL: & 76 & & 526 & \\
\hline IEMBL & & & & \\
\hline AEMBL & & 4.5727 & 2611 & \\
\hline AEMBL & 76 & 239 & 1224 & ST \\
\hline AEMBL & 6 & 5 & 567 & \\
\hline AEMBL & & & & \\
\hline AEMBL & & & & \\
\hline AEMBL & & & & \\
\hline IEMBL & & & & ST \\
\hline |EMB & & 4 & 72 & \\
\hline EMB & & & 43 & \\
\hline EMB & & & & Iiv \\
\hline 11 & & & & \\
\hline IEMBL & & & & $2 \mathrm{~N}$ \\
\hline IEMBL & & & 98 & RI \\
\hline EMB & & & 92 & - \\
\hline 93 & & & 14 & RN \\
\hline IEMBL & & & & \\
\hline AEMBL & & & & 「RN \\
\hline IEMBL & & & 55 & $\mathrm{RI}$ \\
\hline 42 & & 3 & 77 & 年 \\
\hline 5044 & & & 06 & RN \\
\hline AEMBL & & 992 & & RI \\
\hline HEMBL: & & & & ST \\
\hline IEMBL & & & & ST \\
\hline$M$ & & & 31 & RN \\
\hline & & & & R1 \\
\hline HEMBL: & 8276 & 5146 & 16 & RI \\
\hline IEMBL: & & 239 & 44 & $S$ \\
\hline AEMBL & & 14 & 87 & TRN \\
\hline СџгмоР & & & & RN \\
\hline HEMBL & & 3051 & 4611 & RI \\
\hline IEMBL & 76 & 5794 & 5693 & RI \\
\hline 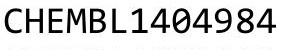 & & 089 & & RI \\
\hline CHEMBLI & & & 4.9949 & \\
\hline CHEMBLI & & & 3.8102 & \\
\hline CHEMBL1546826 & 688276 & 4.2837 & 4.1983 & TR \\
\hline
\end{tabular}

Page 3659 


\begin{tabular}{|c|c|c|c|c|c|}
\hline & & & & & \\
\hline CHEMBL11908 & 688276 & 4.0333 & 4.2339 & TRN & \\
\hline CHEMBL1460809 & 688276 & 4.3334 & 4.0126 & TST & \\
\hline CHEMBL1359397 & 688276 & 4.2507 & 3.977 & TRN & \\
\hline CHEMBL1437542 & 688276 & 4.7991 & 4.2398 & TRN & \\
\hline CHEMBL1543738 & 688276 & 2.8239 & 4.0246 & TRN & \\
\hline CHEMBL1497697 & 688276 & 4.4218 & 4.2164 & TRN & \\
\hline CHEMBL1450086 & 688276 & 5.0066 & 4.8287 & TRN & \\
\hline CHEMBL1373650 & 688276 & 4.1157 & 4.3509 & TRN & \\
\hline CHEMBL1328510 & 688276 & 6.0 & 5.4313 & TRN & \\
\hline CHEMBL3195264 & 688276 & 4.0297 & 4.1797 & TST & \\
\hline CHEMBL1986151 & 688276 & 4.123 & 4.492 & TRN & \\
\hline CHEMBL578294 & 688276 & 4.4149 & 4.2602 & TRN & \\
\hline CHEMBL 3145245 & 688276 & 4.3702 & 4.1428 & TRN & \\
\hline CHEMBL3197662 & 688276 & 4.3707 & 4.4041 & TRN & \\
\hline CHEMBL1527341 & 688276 & 4.6988 & 4.8951 & TRN & \\
\hline CHEMBL1513816 & 688276 & 4.5167 & 4.0094 & TRN & \\
\hline CHEMBL1390072 & 688276 & 4.1245 & 4.1107 & TRN & \\
\hline CHEMBL581868 & 688276 & 4.1875 & 4.3933 & TRN & \\
\hline CHEMBL1431093 & 688276 & 4.2933 & 4.2585 & TRN & \\
\hline CHEMBL1360870 & 688276 & 4.6254 & 4.17399 & 99999999995 & TST \\
\hline CHEMBL1416618 & 688276 & 4.3348 & 4.3093 & TST & \\
\hline CHEMBL3194579 & 688276 & 4.8016 & 4.3507 & TRN & \\
\hline CHEMBL580609 & 688276 & 4.3206 & 4.0298 & TRN & \\
\hline CHEMBL1380943 & 688276 & 4.6684 & 4.388 & TRN & \\
\hline CHEMBL3197991 & 688276 & 4.2161 & 4.2623 & TRN & \\
\hline CHEMBL1981840 & 688276 & 4.433 & 4.1774 & TRN & \\
\hline CHEMBL2369168 & 688276 & 4.4035 & 4.4405 & TRN & \\
\hline CHEMBL 2000750 & 688276 & 4.5885 & 4.4404 & TRN & \\
\hline CHEMBL3199025 & 688276 & 3.8842 & 4.1692 & TRN & \\
\hline CHEMBL1430824 & 688276 & 2.8239 & 4.1358 & TRN & \\
\hline CHEMBL1353553 & 688276 & 4.7144 & 4.4701 & TRN & \\
\hline CHEMBL1328118 & 688276 & 4.4204 & 4.2837 & TRN & \\
\hline CHEMBL1487428 & 688276 & 4.0176 & 3.6729 & TRN & \\
\hline CHEMBL566933 & 688276 & 4.0856 & 4.3193 & TRN & \\
\hline CHEMBL172 & 688276 & 4.4223 & 4.3764 & TST & \\
\hline CHEMBL1349892 & 688276 & 4.5317 & 4.2777 & TRN & \\
\hline CHEMBL1403380 & 688276 & 4.1047 & 4.165 & TRN & \\
\hline CHEMBL442906 & 688276 & 4.1677 & 4.0699 & TRN & \\
\hline CHEMBL1330520 & 688276 & 4.3349 & 4.3622 & TRN & \\
\hline CHEMBL1322645 & 688276 & 4.4522 & 4.2463 & TST & \\
\hline CHEMBL1551525 & 688276 & 3.8985 & 4.1158 & TRN & \\
\hline CHEMBL1538399 & 688276 & 4.7055 & 4.2834 & TRN & \\
\hline CHEMBL1964405 & 688276 & 4.2603 & 4.1605 & TRN & \\
\hline CHEMBL1398224 & 688276 & 4.6234 & 4.4754 & TST & \\
\hline CHEMBL1573754 & 688276 & 4.4947 & 4.4378 & TST & \\
\hline CHEMBL1387500 & 688276 & 4.1952 & 4.2136 & TRN & \\
\hline CHEMBL1579686 & 688276 & 4.7744 & 4.6381 & TRN & \\
\hline CHEMBL1382888 & 688276 & 3.9208 & 3.591 & TRN & \\
\hline
\end{tabular}




\begin{tabular}{|c|c|c|c|c|c|}
\hline & & \multicolumn{4}{|c|}{ Supplemental Table S2.txt } \\
\hline CHEMBL1339092 & 688276 & 4.3964 & 4.163 & TST & \\
\hline CHEMBL1478496 & 688276 & 4.7395 & 4.5652 & TRN & \\
\hline CHEMBL2373661 & 688276 & 5.4034 & 4.7488 & TST & \\
\hline CHEMBL1613582 & 688276 & 4.1699 & 4.2128 & TRN & \\
\hline CHEMBL1329197 & 688276 & 4.4365 & 4.2325 & TRN & \\
\hline CHEMBL1330992 & 688276 & 4.0132 & 4.2313 & TRN & \\
\hline CHEMBL1430795 & 688276 & 4.0827 & 4.1738 & TRN & \\
\hline CHEMBL1964793 & 688276 & 4.9602 & 4.4481 & TRN & \\
\hline CHEMBL1348582 & 688276 & 4.5943 & 4.5286 & TRN & \\
\hline CHEMBL 1463600 & 688276 & 4.2498 & 4.6189 & TRN & \\
\hline CHEMBL1432314 & 688276 & 4.1443 & 4.1154 & TRN & \\
\hline CHEMBL1415035 & 688276 & 4.2351 & 4.1968 & TRN & \\
\hline CHEMBL 3196547 & 688276 & 4.4312 & 4.5038 & TRN & \\
\hline CHEMBL1993199 & 688276 & 4.3939 & 4.0849 & TRN & \\
\hline CHEMBL1315948 & 688276 & 4.3842 & 4.3177 & TRN & \\
\hline CHEMBL1440518 & 688276 & 4.6212 & 4.3839 & TRN & \\
\hline CHEMBL1370471 & 688276 & 4.9821 & 4.8802 & TRN & \\
\hline CHEMBL1378019 & 688276 & 4.7104 & 4.2357 & TRN & \\
\hline CHEMBL1402405 & 688276 & 4.7698 & 4.3473 & TRN & \\
\hline CHEMBL1555833 & 688276 & 4.4249 & 4.1499 & TRN & \\
\hline CHEMBL1443984 & 688276 & 4.1122 & 4.251 & TRN & \\
\hline CHEMBL1586727 & 688276 & 4.1209 & 4.3651 & TRN & \\
\hline CHEMBL1470669 & 688276 & 4.1644 & 3.7668 & TRN & \\
\hline CHEMBL1710 & 688276 & 4.4369 & 4.2225 & TRN & \\
\hline CHEMBL1498307 & 688276 & 4.7277 & 4.5766 & TRN & \\
\hline CHEMBL1582968 & 688276 & 4.2135 & 4.1903 & TRN & \\
\hline CHEMBL3195484 & 688276 & 4.6216 & 4.6191 & TST & \\
\hline CHEMBL603020 & 688276 & 4.5852 & 4.8991 & TRN & \\
\hline CHEMBL1570835 & 688276 & 4.5882 & 4.5223 & TRN & \\
\hline CHEMBL 1556072 & 688276 & 4.2988 & 4.0319 & TRN & \\
\hline CHEMBL1928491 & 688276 & 4.5158 & 4.4548 & TRN & \\
\hline CHEMBL1304363 & 688276 & 4.6708 & 4.7396 & TRN & \\
\hline CHEMBL609606 & 688276 & 4.4042 & 4.434 & TST & \\
\hline CHEMBL1996376 & 688276 & 3.9966 & 4.3387 & TRN & \\
\hline CHEMBL3194449 & 688276 & 4.4295 & 4.266 & TRN & \\
\hline CHEMBL1425438 & 688276 & 4.11100 & 00000000 & 01 & 4.171 \\
\hline CHEMBL1437560 & 688276 & 4.6887 & 4.3756 & TRN & \\
\hline CHEMBL1432654 & 688276 & 4.0068 & 4.1063 & TRN & \\
\hline CHEMBL532641 & 688276 & 4.419 & 4.7145 & TRN & \\
\hline CHEMBL1539127 & 688276 & 4.2815 & 4.2948 & TRN & \\
\hline CHEMBL1451888 & 688276 & 4.4346 & 4.1524 & TRN & \\
\hline CHEMBL1470633 & 688276 & 4.4664 & 4.2249 & TRN & \\
\hline CHEMBL1568414 & 688276 & 4.6724 & 4.5902 & TRN & \\
\hline CHEMBL1475023 & 688276 & 4.1272 & 4.1867 & TRN & \\
\hline CHEMBL1539867 & 688276 & 3.8259 & 3.966 & TST & \\
\hline CHEMBL1348503 & 688276 & 2.8239 & 3.7657 & TRN & \\
\hline CHEMBL1495072 & 688276 & 4.4342 & 4.5271 & TRN & \\
\hline CHEMBL1321310 & 688276 & 4.0269 & 4.1079 & TRN & \\
\hline
\end{tabular}




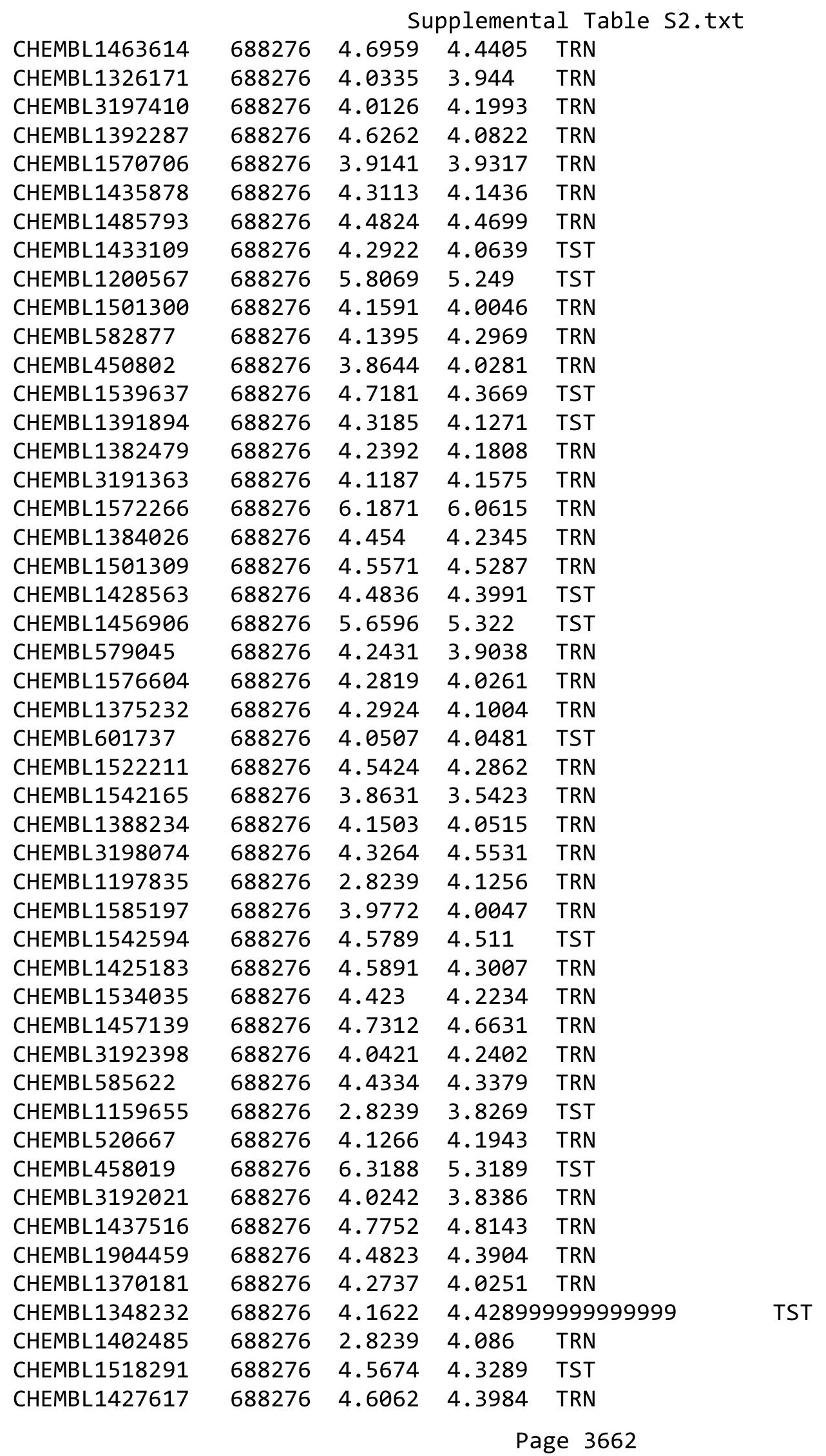




\begin{tabular}{|c|c|c|c|c|c|c|}
\hline & & \multicolumn{5}{|c|}{ Supplemental Table S2.txt } \\
\hline CHEMBL1596681 & 688276 & 4.9735 & 4.8494 & TRN & & \\
\hline CHEMBL1401989 & 688276 & 4.5144 & 4.16100 & 00000000 & 005 & TRN \\
\hline CHEMBL3191309 & 688276 & 4.6607 & 4.3064 & TRN & & \\
\hline CHEMBL1448800 & 688276 & 4.1069 & 4.5045 & TRN & & \\
\hline CHEMBL1307096 & 688276 & 2.8239 & 4.1088 & TRN & & \\
\hline CHEMBL1300831 & 688276 & 4.5391 & 4.4833 & TRN & & \\
\hline CHEMBL1600851 & 688276 & 3.8807 & 4.0335 & TST & & \\
\hline CHEMBL591404 & 688276 & 4.9867 & 4.545 & TRN & & \\
\hline CHEMBL1383932 & 688276 & 2.8239 & 3.8355 & TRN & & \\
\hline CHEMBL1521960 & 688276 & 5.0531 & 5.0002 & TST & & \\
\hline CHEMBL590666 & 688276 & 4.413 & 4.2819 & TRN & & \\
\hline CHEMBL1561133 & 688276 & 4.4274 & 4.3127 & TRN & & \\
\hline CHEMBL1344070 & 688276 & 4.4235 & 4.1327 & TRN & & \\
\hline CHEMBL1509380 & 688276 & 4.9978 & 5.0561 & TRN & & \\
\hline CHEMBL1549420 & 688276 & 3.9205 & 4.2868 & TRN & & \\
\hline CHEMBL1383228 & 688276 & 4.417 & 4.2577 & TRN & & \\
\hline CHEMBL3196295 & 688276 & 3.8654 & 4.0526 & TRN & & \\
\hline CHEMBL1609756 & 688276 & 4.7022 & 4.3213 & TRN & & \\
\hline CHEMBL 3190825 & 688276 & 4.5418 & 4.5216 & TRN & & \\
\hline CHEMBL1568848 & 688276 & 4.5694 & 4.5032 & TRN & & \\
\hline CHEMBL1580272 & 688276 & 5.0334 & 4.8085 & TRN & & \\
\hline CHEMBL1492696 & 688276 & 4.2197 & 4.421 & TRN & & \\
\hline CHEMBL1544460 & 688276 & 4.5722 & 4.3808 & TRN & & \\
\hline CHEMBL1411632 & 688276 & 3.8372 & 3.8434 & TST & & \\
\hline CHEMBL1478852 & 688276 & 4.5759 & 4.2308 & TST & & \\
\hline CHEMBL1497201 & 688276 & 2.8239 & 4.0091 & TRN & & \\
\hline CHEMBL1500500 & 688276 & 4.7124 & 4.4068 & TRN & & \\
\hline CHEMBL1580510 & 688276 & 4.1035 & 3.7992 & TRN & & \\
\hline CHEMBL1984876 & 688276 & 4.501 & 4.4744 & TRN & & \\
\hline CHEMBL1357255 & 688276 & 4.4281 & 4.3293 & TRN & & \\
\hline CHEMBL3194811 & 688276 & 4.4037 & 4.2012 & TRN & & \\
\hline CHEMBL1500188 & 688276 & 4.452 & 4.5563 & TST & & \\
\hline CHEMBL345124 & 688276 & 3.8936 & 3.8771 & TST & & \\
\hline CHEMBL1499792 & 688276 & 4.4326 & 4.7252 & TRN & & \\
\hline CHEMBL1376732 & 688276 & 3.9635 & 4.1783 & TRN & & \\
\hline CHEMBL1326083 & 688276 & $4.4510 e$ & 00000000 & 205 & 4.5411 & TRN \\
\hline CHEMBL591137 & 688276 & 4.6358 & 4.5121 & TRN & & \\
\hline CHEMBL1524052 & 688276 & 4.5075 & 4.2828 & TRN & & \\
\hline CHEMBL1439747 & 688276 & 4.2096 & 4.0454 & TST & & \\
\hline CHEMBL1581182 & 688276 & 4.7997 & 4.6659 & TRN & & \\
\hline CHEMBL1472455 & 688276 & 4.556 & 4.2301 & TRN & & \\
\hline CHEMBL1555739 & 688276 & 4.3906 & 4.231 & TRN & & \\
\hline CHEMBL1308845 & 688276 & 4.4254 & 4.2548 & TRN & & \\
\hline CHEMBL1378190 & 688276 & 3.8775 & 4.0661 & TRN & & \\
\hline CHEMBL1410230 & 688276 & 4.1513 & 4.405 & TRN & & \\
\hline CHEMBL1336446 & 688276 & 2.8239 & 4.1915 & TRN & & \\
\hline CHEMBL1502346 & 688276 & 4.2465 & 4.1715 & TRN & & \\
\hline CHEMBL1600807 & 688276 & 4.0715 & 3.9538 & TRN & & \\
\hline
\end{tabular}




\begin{tabular}{|c|c|c|c|c|c|}
\hline \multicolumn{6}{|c|}{ Supplemental Table S2.txt } \\
\hline CHEMBL577546 & 688276 & 4.2151 & 4.4613 & TRN & \\
\hline CHEMBL1385206 & 688276 & 5.0516 & 4.8799 & TRN & \\
\hline CHEMBL1556844 & 688276 & 4.2328 & 4.1363 & TRN & \\
\hline CHEMBL 3199413 & 688276 & 4.1881 & 4.2085 & TRN & \\
\hline CHEMBL1478435 & 688276 & 2.8239 & 4.1978 & TRN & \\
\hline CHEMBL 3192557 & 688276 & 4.9318 & 4.3716 & TRN & \\
\hline CHEMBL1560982 & 688276 & 4.2939 & 4.3306 & TRN & \\
\hline CHEMBL249032 & 688276 & 4.1321 & 4.1277 & TRN & \\
\hline CHEMBL1582923 & 688276 & 4.46 & 4.0889 & TRN & \\
\hline CHEMBL1353170 & 688276 & 4.3068 & 4.4977 & TRN & \\
\hline CHEMBL1327202 & 688276 & 5.4179 & 4.7902 & TRN & \\
\hline CHEMBL1999984 & 688276 & 3.9668 & 4.0763 & TRN & \\
\hline CHEMBL 3197506 & 688276 & 4.1106 & 4.4123 & TRN & \\
\hline CHEMBL1332952 & 688276 & 4.4597 & 4.6478 & TRN & \\
\hline CHEMBL1330954 & 688276 & 4.0482 & 4.093 & TRN & \\
\hline CHEMBL428064 & 688276 & 5.4789 & 5.3723 & TRN & \\
\hline CHEMBL1549574 & 688276 & 4.4547 & 4.2753 & TRN & \\
\hline CHEMBL3211290 & 688276 & 4.7036 & 4.6283 & TRN & \\
\hline CHEMBL1443946 & 688276 & 4.2428 & 4.4493 & TRN & \\
\hline CHEMBL1578958 & 688276 & 4.0073 & 3.7835 & TRN & \\
\hline CHEMBL1409219 & 688276 & 4.0826 & 3.7376 & TRN & \\
\hline CHEMBL1616787 & 688276 & 4.7865 & 4.1502 & TRN & \\
\hline CHEMBL584626 & 688276 & 4.1379 & 4.3922 & TRN & \\
\hline CHEMBL 3192690 & 688276 & 4.1327 & 4.1273 & TRN & \\
\hline CHEMBL1169627 & 688276 & 4.0297 & 4.0321 & TST & \\
\hline CHEMBL1598087 & 688276 & 4.2692 & 3.696 & TRN & \\
\hline CHEMBL1413504 & 688276 & 4.4225 & 4.2628 & TRN & \\
\hline CHEMBL1604894 & 688276 & 3.96 & 3.9291 & TRN & \\
\hline CHEMBL1511913 & 688276 & 4.4073 & 4.2544 & TST & \\
\hline CHEMBL1608917 & 688276 & 4.2997 & 4.0039 & TRN & \\
\hline CHEMBL1418750 & 688276 & 4.4279 & 4.2902 & TRN & \\
\hline CHEMBL1342066 & 688276 & 4.3661 & 3.8112 & TRN & \\
\hline CHEMBL1454171 & 688276 & 4.721 & 4.3959 & TST & \\
\hline CHEMBL1491847 & 688276 & 4.9846 & 4.6807 & TRN & \\
\hline CHEMBL1511774 & 688276 & 4.9055 & 4.3368 & TRN & \\
\hline CHEMBL1469093 & 688276 & 2.8239 & 4.0978 & TST & \\
\hline CHEMBL3209306 & 688276 & 4.5033 & 4.59399 & 9999999999 & TRN \\
\hline CHEMBL1359729 & 688276 & 3.9298 & 4.1099 & TST & \\
\hline CHEMBL1549308 & 688276 & 4.5941 & 4.3335 & TST & \\
\hline CHEMBL1484328 & 688276 & 4.0872 & 4.2822 & TRN & \\
\hline CHEMBL1532953 & 688276 & 5.0128 & 4.5299 & TRN & \\
\hline CHEMBL1567072 & 688276 & 4.2349 & 4.1869 & TST & \\
\hline CHEMBL 2002465 & 688276 & 4.3436 & 4.4809 & TRN & \\
\hline CHEMBL1418814 & 688276 & 2.8239 & 3.8295 & TRN & \\
\hline CHEMBL1463390 & 688276 & 3.9468 & 4.1976 & TRN & \\
\hline CHEMBL1309128 & 688276 & 3.8845 & 3.8109 & TRN & \\
\hline CHEMBL3195685 & 688276 & 4.327 & 4.2989 & TRN & \\
\hline CHEMBL1308051 & 688276 & 4.1174 & 4.1103 & TRN & \\
\hline
\end{tabular}




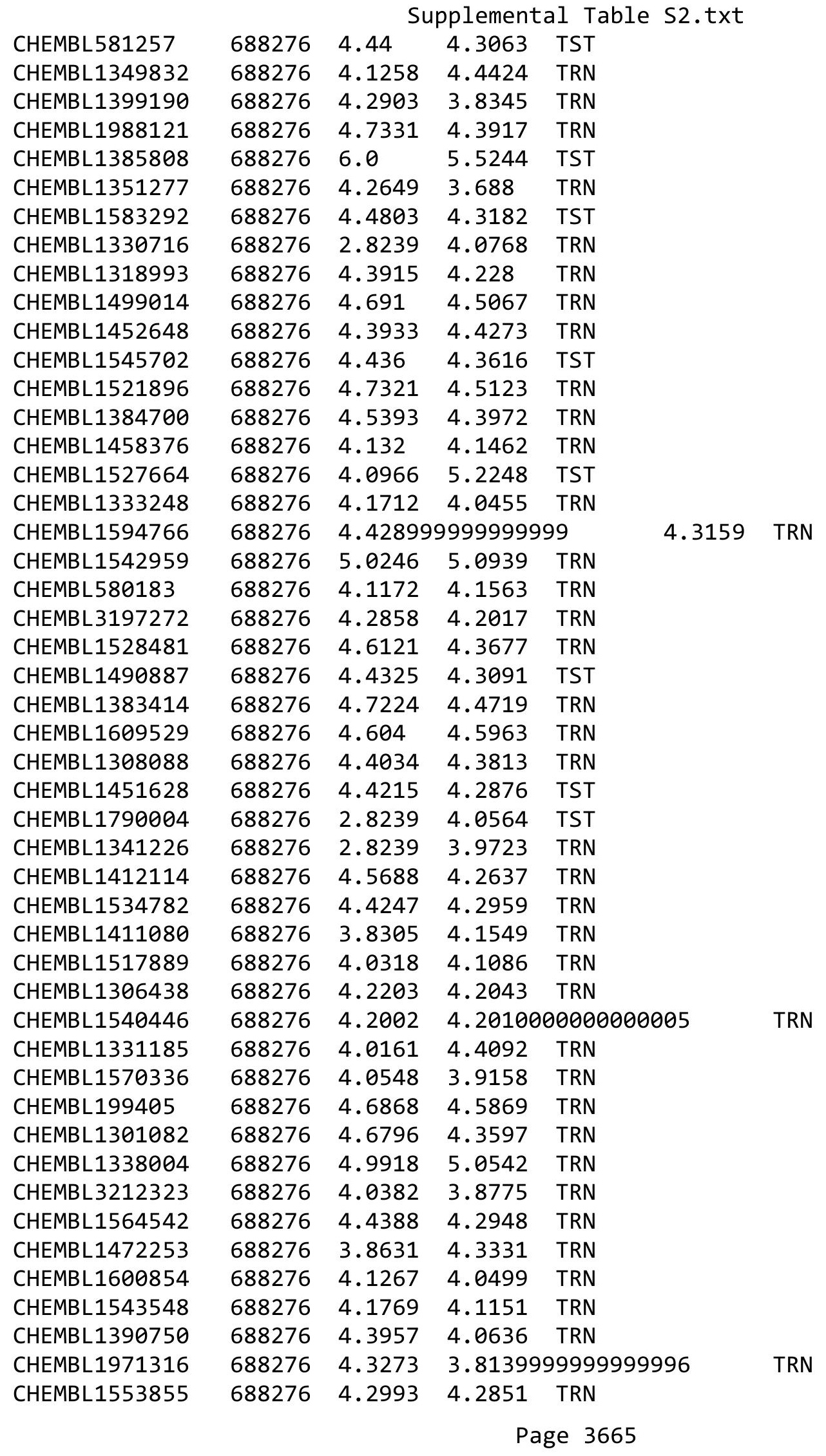




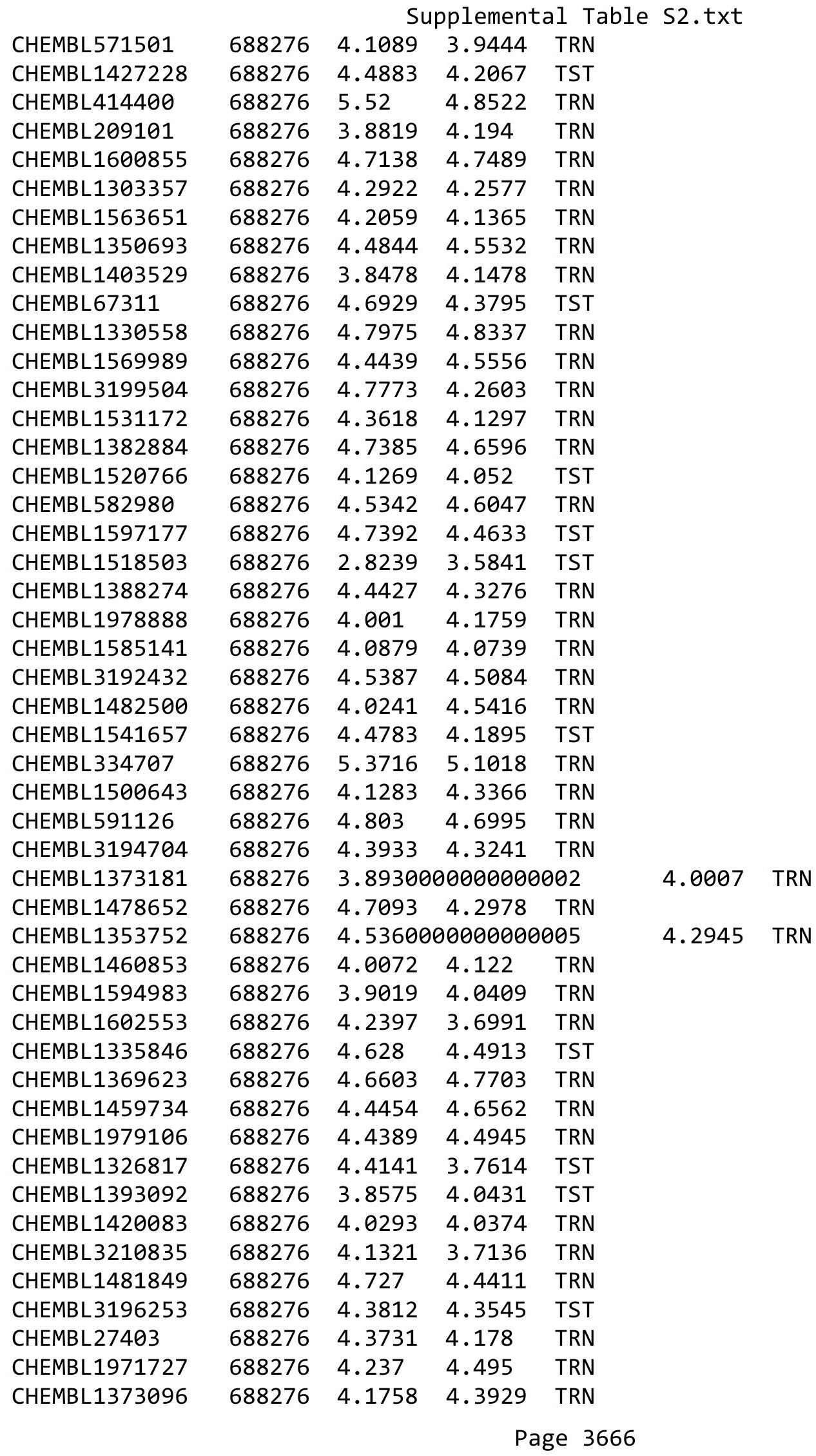




\begin{tabular}{|c|c|c|c|c|c|c|c|}
\hline \multirow[b]{2}{*}{ CHEMBL309016 } & & \\
\hline & 688276 & 4.3471 & 4.2104 & TRN & & & \\
\hline CHEMBL1457644 & 688276 & 4.0019 & 4.3549 & TRN & & & \\
\hline CHEMBL530049 & 688276 & 5.1319 & 4.8667 & TRN & & & \\
\hline CHEMBL1447259 & 688276 & 3.9717 & 4.0324 & TRN & & & \\
\hline CHEMBL1408115 & 688276 & 2.8239 & 4.104 & TRN & & & \\
\hline CHEMBL1472369 & 688276 & 2.8239 & 4.08899 & 999999999 & 95 & TRN & \\
\hline CHEMBL1588889 & 688276 & 4.0447 & 4.2674 & TRN & & & \\
\hline CHEMBL445102 & 688276 & 4.5264 & 4.173 & TRN & & & \\
\hline CHEMBL1406235 & 688276 & 4.0884 & 3.99899 & 999999999 & 97 & TRN & \\
\hline CHEMBL1607938 & 688276 & 4.11600 & 000000006 & 205 & 4.1065 & TRN & \\
\hline CHEMBL1301975 & 688276 & 4.5131 & 3.7792 & TRN & & & \\
\hline CHEMBL1448592 & 688276 & 4.459 & 4.7576 & TST & & & \\
\hline CHEMBL1332013 & 688276 & 4.2268 & $3.68600 t$ & 000000000 & 04 & TRN & \\
\hline CHEMBL1318861 & 688276 & 5.2749 & 5.1678 & TST & & & \\
\hline CHEMBL1389832 & 688276 & 4.6087 & 4.3515 & TST & & & \\
\hline CHEMBL1392466 & 688276 & 3.8247 & 4.0345 & TRN & & & \\
\hline CHEMBL1449490 & 688276 & 4.7174 & 4.1564 & TST & & & \\
\hline CHEMBL19954 & 688276 & 4.6682 & 4.6324 & TRN & & & \\
\hline CHEMBL1446900 & 688276 & 3.8596 & 4.2254 & TRN & & & \\
\hline CHEMBL1485234 & 688276 & 4.02800 & 00000000 & 205 & 3.9006 & TRN & \\
\hline CHEMBL1366004 & 688276 & 4.4646 & 4.3843 & TRN & & & \\
\hline CHEMBL1326203 & 688276 & 4.4249 & 4.4092 & TRN & & & \\
\hline CHEMBL1485332 & 688276 & 4.1638 & 3.9008 & TRN & & & \\
\hline CHEMBL1498173 & 688276 & 4.1194 & 4.2093 & TRN & & & \\
\hline CHEMBL3191484 & 688276 & 3.8251 & 4.1628 & TRN & & & \\
\hline CHEMBL1341256 & 688276 & 2.8239 & 3.7066 & TRN & & & \\
\hline CHEMBL3190369 & 688276 & 4.8187 & 4.6485 & TST & & & \\
\hline CHEMBL1541209 & 688276 & 2.8239 & 4.0464 & TRN & & & \\
\hline CHEMBL581346 & 688276 & 4.3376 & 3.883 & TRN & & & \\
\hline CHEMBL1966224 & 688276 & 4.4733 & 3.6102 & TRN & & & \\
\hline CHEMBL1980844 & 688276 & 4.783 & 4.4332 & TST & & & \\
\hline CHEMBL1379600 & 688276 & 4.1344 & 4.1211 & TRN & & & \\
\hline CHEMBL1469216 & 688276 & 4.3425 & 4.1095 & TRN & & & \\
\hline CHEMBL1556805 & 688276 & 3.8935 & 4.6235 & TST & & & \\
\hline CHEMBL1512990 & 688276 & 4.0847 & 4.0753 & TRN & & & \\
\hline CHEMBL71936 & 688276 & 4.1329 & 3.7419 & TRN & & & \\
\hline CHEMBL1411646 & 688276 & 4.4165 & 4.4563 & TRN & & & \\
\hline CHEMBL1365234 & 688276 & 2.8239 & 4.1143 & TST & & & \\
\hline CHEMBL 2369277 & 688276 & 4.574 & 4.4755 & TRN & & & \\
\hline CHEMBL1432642 & 688276 & 4.0834 & 3.9627 & TRN & & & \\
\hline CHEMBL1429241 & 688276 & 3.9998 & 3.7665 & TRN & & & \\
\hline CHEMBL1375576 & 688276 & 4.1935 & 4.1243 & TST & & & \\
\hline CHEMBL1989158 & 688276 & 4.0801 & 4.0456 & TST & & & \\
\hline CHEMBL1198307 & 688276 & 4.7073 & 4.6119 & TRN & & & \\
\hline CHEMBL1452644 & 688276 & 4.23600 & 0000000 & & 4.1610 & 00000000005 & TRN \\
\hline CHEMBL567422 & 688276 & 4.0981 & 4.2137 & TST & & & \\
\hline CHEMBL1310009 & 688276 & 4.4233 & 4.3776 & TRN & & & \\
\hline CHEMBL1369287 & 688276 & 4.4537 & 4.4293 & TRN & & & \\
\hline
\end{tabular}




\begin{tabular}{|c|c|c|c|c|c|}
\hline \multicolumn{6}{|c|}{ Supplemental Table S2.txt } \\
\hline CHEMBL1091556 & 688276 & 3.9507 & 3.9904 & TRN & \\
\hline CHEMBL1307428 & 688276 & 4.0261 & 3.9229 & TRN & \\
\hline CHEMBL1345320 & 688276 & 4.4381 & 4.3322 & TRN & \\
\hline CHEMBL1565674 & 688276 & 4.4238 & 4.5432 & TRN & \\
\hline CHEMBL1559430 & 688276 & 2.8239 & 4.0521 & TST & \\
\hline CHEMBL1355961 & 688276 & 4.7003 & 4.348 & TRN & \\
\hline CHEMBL1410641 & 688276 & 4.7397 & 4.2052 & TST & \\
\hline CHEMBL1256876 & 688276 & 4.5685 & 4.3174 & TST & \\
\hline CHEMBL587892 & 688276 & 4.4399 & 4.4196 & TRN & \\
\hline CHEMBL1433069 & 688276 & 4.0956 & 4.1317 & TRN & \\
\hline CHEMBL601547 & 688276 & 4.507 & 4.7432 & TRN & \\
\hline CHEMBL 2004056 & 688276 & 4.3349 & 4.3847 & TRN & \\
\hline CHEMBL1441677 & 688276 & 4.4291 & 4.4079 & TRN & \\
\hline CHEMBL1550934 & 688276 & 4.5779 & 4.2817 & TST & \\
\hline CHEMBL1958251 & 688276 & 4.7625 & 4.6581 & TRN & \\
\hline CHEMBL3196257 & 688276 & 4.2606 & 4.292 & TRN & \\
\hline CHEMBL1485275 & 688276 & 6.0 & 5.5871 & TST & \\
\hline CHEMBL1578251 & 688276 & 3.8986 & 3.9314 & TRN & \\
\hline CHEMBL1466250 & 688276 & 4.1428 & 3.9996 & TRN & \\
\hline CHEMBL586135 & 688276 & 4.9492 & 4.9068 & TST & \\
\hline CHEMBL1573501 & 688276 & 3.844 & 4.0159 & TRN & \\
\hline CHEMBL601757 & 688276 & 5.6345 & 5.2436 & TST & \\
\hline CHEMBL3196546 & 688276 & 3.9892 & 4.0721 & TRN & \\
\hline CHEMBL3193098 & 688276 & 4.7897 & 4.5337 & TRN & \\
\hline CHEMBL1455197 & 688276 & 4.1182 & 4.1265 & TRN & \\
\hline CHEMBL570345 & 688276 & 4.4 & 4.48300 & 00000000005 & TRN \\
\hline CHEMBL1401657 & 688276 & 4.1532 & 4.3095 & TRN & \\
\hline CHEMBL1458403 & 688276 & 4.6368 & 4.3541 & TRN & \\
\hline CHEMBL1385558 & 688276 & 4.4731 & 4.3491 & TRN & \\
\hline CHEMBL3190747 & 688276 & 4.1309 & 4.295 & TRN & \\
\hline CHEMBL1486163 & 688276 & 4.0912 & 4.015 & TRN & \\
\hline CHEMBL1581682 & 688276 & 4.2127 & 3.9407 & TST & \\
\hline CHEMBL1487183 & 688276 & 5.3325 & 4.9584 & TST & \\
\hline CHEMBL1468104 & 688276 & 4.1012 & 4.27800 & 00000000005 & TST \\
\hline CHEMBL3197818 & 688276 & 4.1331 & 4.3142 & TRN & \\
\hline CHEMBL1536493 & 688276 & 4.3273 & 4.1591 & TRN & \\
\hline CHEMBL1996730 & 688276 & 5.0311 & 4.7774 & TRN & \\
\hline CHEMBL1589425 & 688276 & 4.8539 & 4.6919 & TRN & \\
\hline CHEMBL1511404 & 688276 & 4.1294 & 3.9204 & TRN & \\
\hline CHEMBL1142 & 688276 & 4.1514 & 4.2003 & TST & \\
\hline CHEMBL1514381 & 688276 & 4.2602 & 4.2628 & TRN & \\
\hline CHEMBL1382760 & 688276 & 3.9698 & 4.2506 & TRN & \\
\hline CHEMBL1524515 & 688276 & 4.7272 & 4.6015 & TRN & \\
\hline CHEMBL1332978 & 688276 & 4.3801 & 4.3159 & TRN & \\
\hline CHEMBL1411779 & 688276 & 4.098 & 4.2067 & TRN & \\
\hline CHEMBL 2006730 & 688276 & 4.0971 & 4.1204 & TRN & \\
\hline CHEMBL1477547 & 688276 & 4.4699 & 4.2148 & TRN & \\
\hline CHEMBL1974537 & 688276 & 3.8516 & 3.9195 & TST & \\
\hline
\end{tabular}




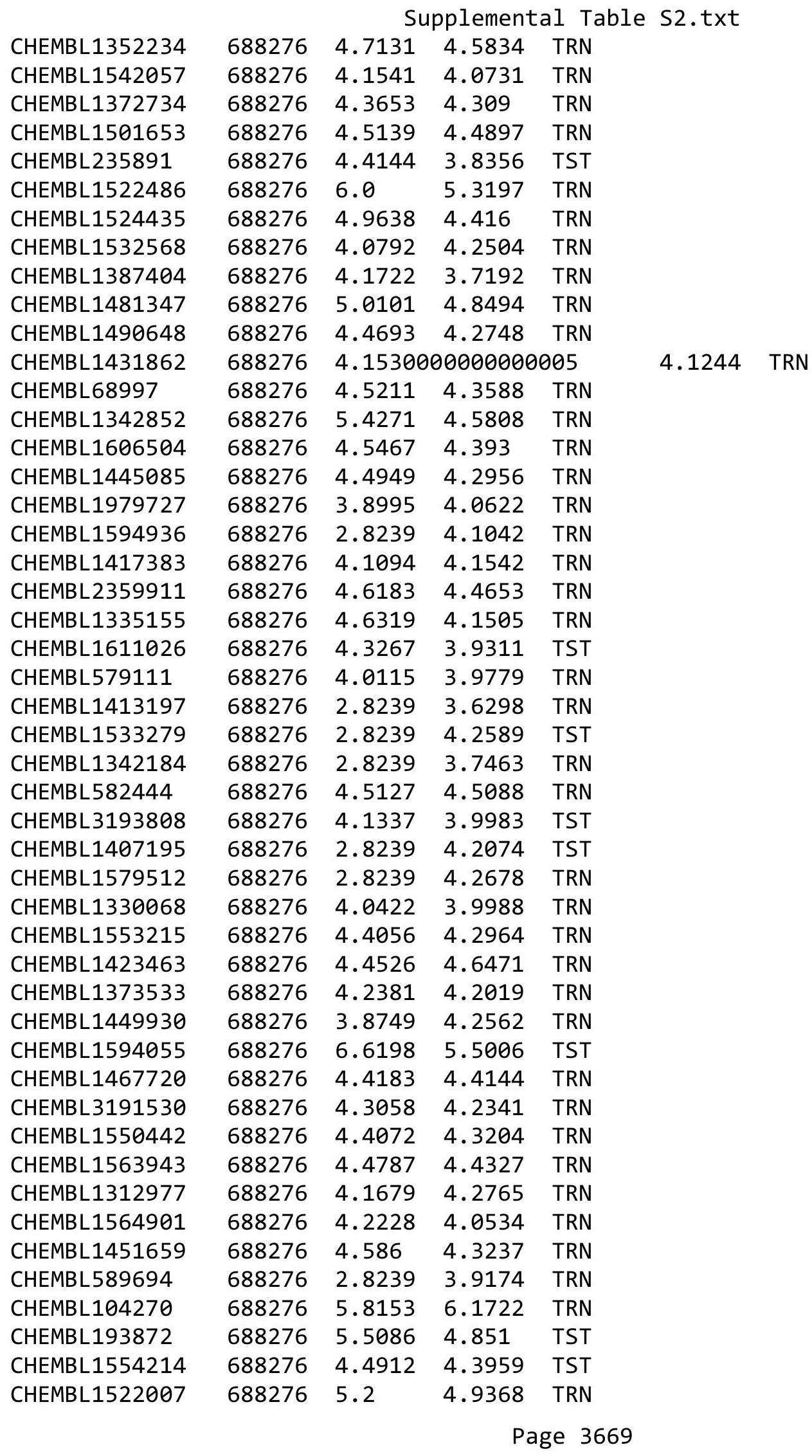


Supplemental Table S2.txt

\begin{tabular}{|c|c|c|c|c|c|c|}
\hline CHEMBL1492609 & 688276 & 3.9571 & 3.8642 & TST & & \\
\hline CHEMBL1563862 & 688276 & 4.26699 & 99999999 & 995 & 3.9973 & TRN \\
\hline CHEMBL1314743 & 688276 & 4.5807 & 4.2657 & TRN & & \\
\hline CHEMBL1986183 & 688276 & 3.9853 & 4.3082 & TST & & \\
\hline CHEMBL 3195334 & 688276 & 4.1909 & 4.3275 & TST & & \\
\hline CHEMBL1452301 & 688276 & 4.3801 & 4.3551 & TRN & & \\
\hline CHEMBL1329129 & 688276 & 4.8671 & 4.5167 & TRN & & \\
\hline CHEMBL1503034 & 688276 & 4.5524 & 4.461 & TRN & & \\
\hline CHEMBL1390000 & 688276 & 4.1854 & 4.1604 & TRN & & \\
\hline CHEMBL1342570 & 688276 & 4.56 & 4.1265 & TRN & & \\
\hline CHEMBL1406274 & 688276 & 6.0 & 5.0492 & TRN & & \\
\hline CHEMBL1388845 & 688276 & 4.4223 & 4.6465 & TRN & & \\
\hline CHEMBL578928 & 688276 & 4.4424 & 4.362 & TRN & & \\
\hline CHEMBL1562066 & 688276 & 4.7129 & 4.4387 & TRN & & \\
\hline CHEMBL1424404 & 688276 & 4.0096 & 4.0725 & TRN & & \\
\hline CHEMBL1527503 & 688276 & 3.9779 & 3.9785 & TST & & \\
\hline CHEMBL1975961 & 688276 & 4.1076 & 4.3348 & TRN & & \\
\hline CHEMBL1605613 & 688276 & 4.0981 & 4.0313 & TRN & & \\
\hline CHEMBL1305911 & 688276 & 4.4295 & 4.1905 & TRN & & \\
\hline CHEMBL1403875 & 688276 & 4.1838 & 4.0258 & TRN & & \\
\hline CHEMBL1478009 & 688276 & 3.8818 & 4.1076 & TRN & & \\
\hline CHEMBL1200847 & 688276 & 4.9767 & 4.2945 & TRN & & \\
\hline CHEMBL1495292 & 688276 & 3.8254 & 4.1286 & TRN & & \\
\hline CHEMBL1530234 & 688276 & 3.9483 & 4.1924 & TRN & & \\
\hline CHEMBL1545044 & 688276 & 3.8359 & 4.4148 & TRN & & \\
\hline CHEMBL1466182 & 688276 & 4.4913 & 4.2268 & TRN & & \\
\hline CHEMBL1994463 & 688276 & 4.5682 & 4.3465 & TST & & \\
\hline CHEMBL1310458 & 688276 & 3.9813 & 4.1338 & TRN & & \\
\hline CHEMBL1308879 & 688276 & 4.667 & 4.9216 & TRN & & \\
\hline CHEMBL1395220 & 688276 & 4.2618 & 4.2286 & TST & & \\
\hline CHEMBL3195766 & 688276 & 3.9653 & 3.8698 & TRN & & \\
\hline CHEMBL1340754 & 688276 & 4.7375 & 4.4266 & TRN & & \\
\hline CHEMBL1421414 & 688276 & 3.8387 & 3.9063 & TST & & \\
\hline CHEMBL1350506 & 688276 & 4.37 & 4.1551 & TRN & & \\
\hline CHEMBL532239 & 688276 & 4.7991 & 4.8416 & TRN & & \\
\hline CHEMBL1373092 & 688276 & 4.4085 & 4.1737 & TRN & & \\
\hline CHEMBL1304297 & 688276 & 4.0421 & 3.9003 & TRN & & \\
\hline CHEMBL3199489 & 688276 & \multicolumn{3}{|c|}{4.0089999999999995} & 4.0431 & TRN \\
\hline CHEMBL 2006545 & 688276 & 4.5781 & 4.4069 & TRN & & \\
\hline CHEMBL530609 & 688276 & 4.3525 & 4.5455 & TRN & & \\
\hline CHEMBL1440420 & 688276 & 4.4292 & 4.1505 & TRN & & \\
\hline CHEMBL1414065 & 688276 & 3.8316 & 4.2967 & TRN & & \\
\hline CHEMBL1362047 & 688276 & 4.5825 & 4.2006 & TRN & & \\
\hline CHEMBL1398181 & 688276 & 4.4414 & 4.2987 & TRN & & \\
\hline CHEMBL 3213876 & 688276 & 4.4938 & 4.4814 & TRN & & \\
\hline CHEMBL1525481 & 688276 & 4.8233 & 4.0099 & TRN & & \\
\hline CHEMBL1462016 & 688276 & 4.1624 & 4.1268 & TRN & & \\
\hline CHEMBL1380091 & 688276 & 4.8716 & 4.2081 & TRN & & \\
\hline
\end{tabular}


Supplemental Table S2.txt

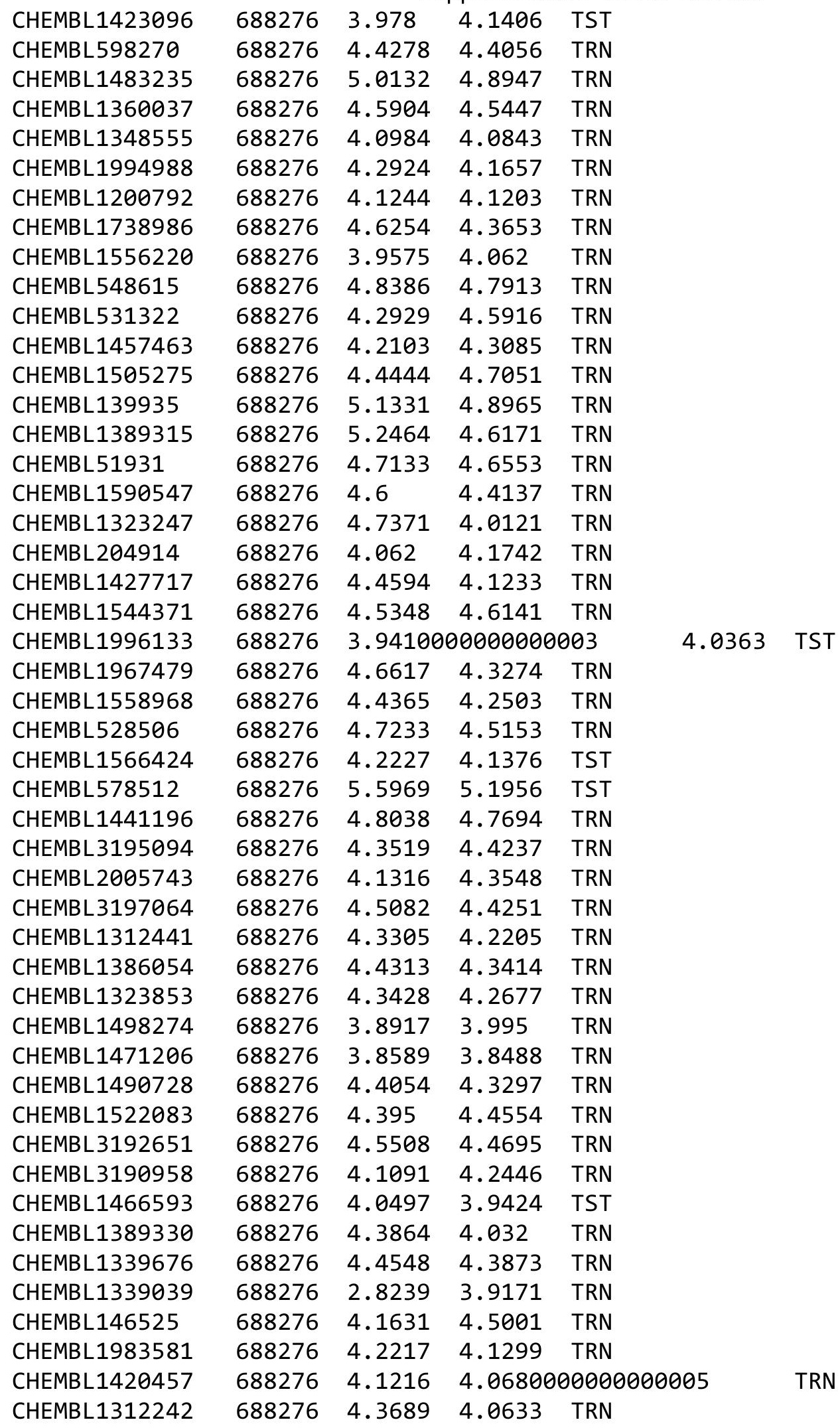

Page 3671 


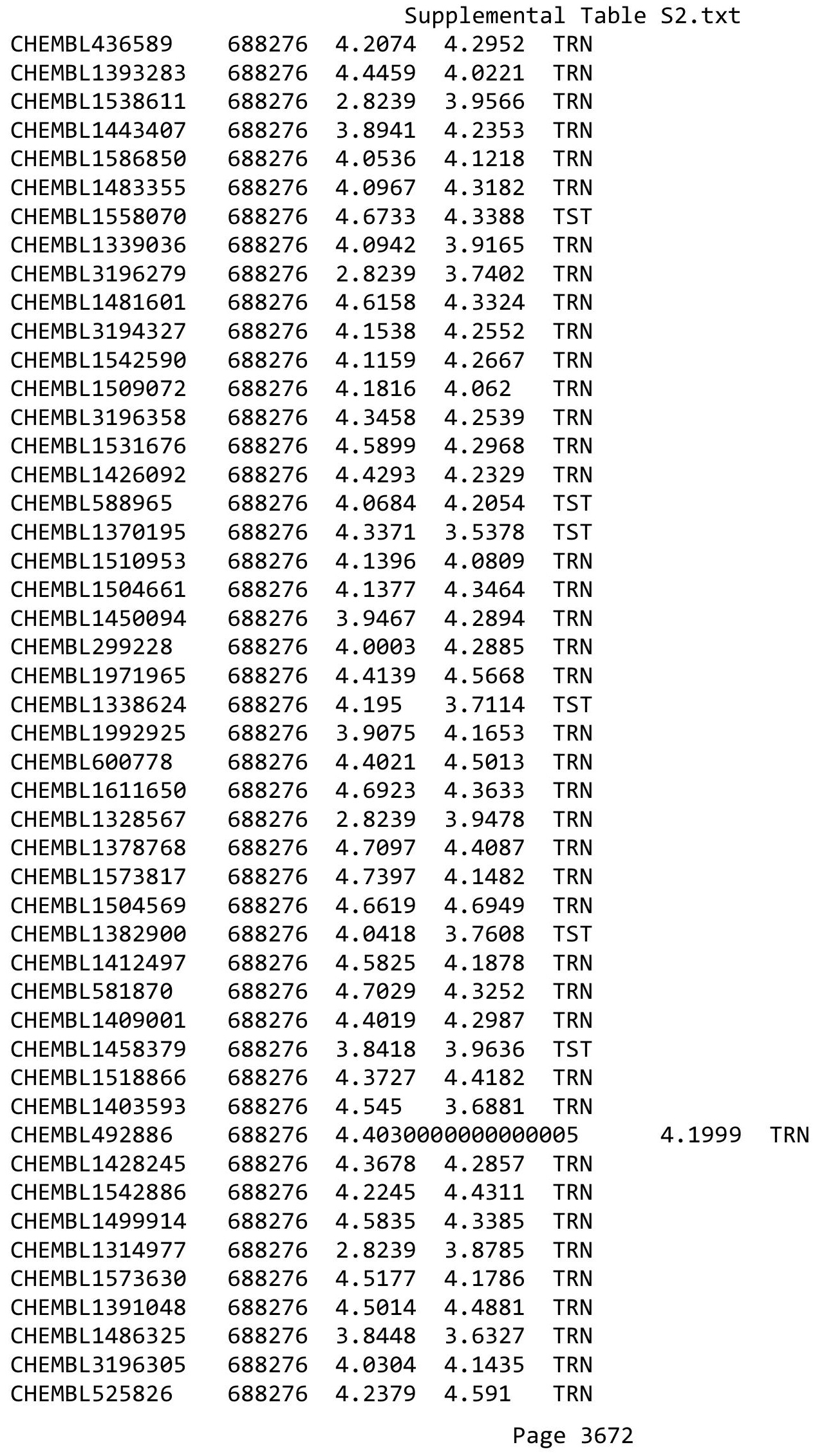


Supplemental Table S2.txt

\begin{tabular}{|c|c|c|c|c|}
\hline CHEMBL1342436 & 688276 & 4.6724 & 4.4069 & TST \\
\hline CHEMBL1520233 & 688276 & 4.8213 & 3.9952 & TRN \\
\hline CHEMBL1568905 & 688276 & 3.9332 & 4.136 & TST \\
\hline CHEMBL1588476 & 688276 & 4.2005 & 4.2983 & TST \\
\hline CHEMBL142816 & 688276 & 4.4938 & 4.5071 & TST \\
\hline CHEMBL 226876 & 688276 & 4.3208 & 4.2071 & TRN \\
\hline CHEMBL1424729 & 688276 & 4.4217 & 4.3649 & TST \\
\hline CHEMBL1495602 & 688276 & 4.4981 & 4.2521 & TRN \\
\hline CHEMBL1321297 & 688276 & 4.9846 & 4.2418 & TRN \\
\hline CHEMBL1444767 & 688276 & 4.4207 & 4.3711 & TRN \\
\hline CHEMBL1597839 & 688276 & 4.477 & 4.0007 & TRN \\
\hline CHEMBL1600940 & 688276 & 4.2431 & 4.0192 & TRN \\
\hline CHEMBL1384387 & 688276 & 4.5809 & 4.6919 & TRN \\
\hline CHEMBL1392912 & 688276 & 4.7181 & 4.2632 & TRN \\
\hline CHEMBL1520808 & 688276 & 3.8647 & 4.3137 & TRN \\
\hline CHEMBL1304172 & 688276 & 4.3965 & 4.623 & TRN \\
\hline CHEMBL1306267 & 688276 & 4.488 & 4.4368 & TRN \\
\hline CHEMBL1582934 & 688276 & 4.0938 & 4.3423 & TRN \\
\hline CHEMBL1587205 & 688276 & 4.5635 & 4.43199 & 99999999995 \\
\hline CHEMBL 3189889 & 688276 & 2.8239 & 3.5922 & TST \\
\hline CHEMBL1421862 & 688276 & 4.3256 & 4.0814 & TST \\
\hline CHEMBL1459764 & 688276 & 4.7138 & 4.352 & TST \\
\hline CHEMBL1564526 & 688276 & 4.1945 & 4.0791 & TST \\
\hline CHEMBL1385701 & 688276 & 4.1898 & 4.4763 & TST \\
\hline CHEMBL1313622 & 688276 & 4.4285 & 4.2351 & TST \\
\hline CHEMBL1201074 & 688276 & 4.1475 & 4.2154 & TST \\
\hline CHEMBL1312571 & 688276 & 4.0902 & 4.2146 & TST \\
\hline CHEMBL1299724 & 688276 & 2.8239 & 4.1143 & TST \\
\hline CHEMBL1564731 & 688276 & 4.0368 & 4.1111 & TST \\
\hline CHEMBL1378707 & 688276 & 4.527 & 4.2369 & TST \\
\hline CHEMBL56543 & 688276 & 3.8804 & 4.1078 & TST \\
\hline CHEMBL153535 & 688276 & 4.0291 & 4.1374 & TST \\
\hline CHEMBL1365988 & 688276 & 4.596 & 4.5786 & TST \\
\hline CHEMBL1980226 & 688276 & 4.48 & 4.4415 & TST \\
\hline CHEMBL3190330 & 688276 & 4.4326 & 4.5103 & TST \\
\hline CHEMBL599890 & 688276 & 4.2845 & 4.5215 & TST \\
\hline CHEMBL1491778 & 688276 & 4.0655 & 4.1903 & TST \\
\hline CHEMBL 283849 & 688276 & 5.9747 & 5.2768 & TST \\
\hline CHEMBL3193315 & 688276 & 3.8669 & 4.2586 & TST \\
\hline CHEMBL1347071 & 688276 & 4.8199 & 4.7807 & TST \\
\hline CHEMBL405110 & 688276 & 4.3438 & 4.4823 & TST \\
\hline CHEMBL1330220 & 688276 & 4.9062 & 4.6078 & TST \\
\hline CHEMBL1546374 & 688276 & 4.3915 & 4.4806 & TST \\
\hline CHEMBL1574121 & 688276 & 4.5779 & 4.4582 & TST \\
\hline CHEMBL578872 & 688276 & 4.0951 & 4.2082 & TST \\
\hline CHEMBL 3193701 & 688276 & 4.4297 & 4.5483 & TST \\
\hline CHEMBL1401435 & 688276 & 4.3034 & 4.2215 & TST \\
\hline CHEMBL1474571 & 688276 & 4.4582 & 4.5238 & TST \\
\hline
\end{tabular}




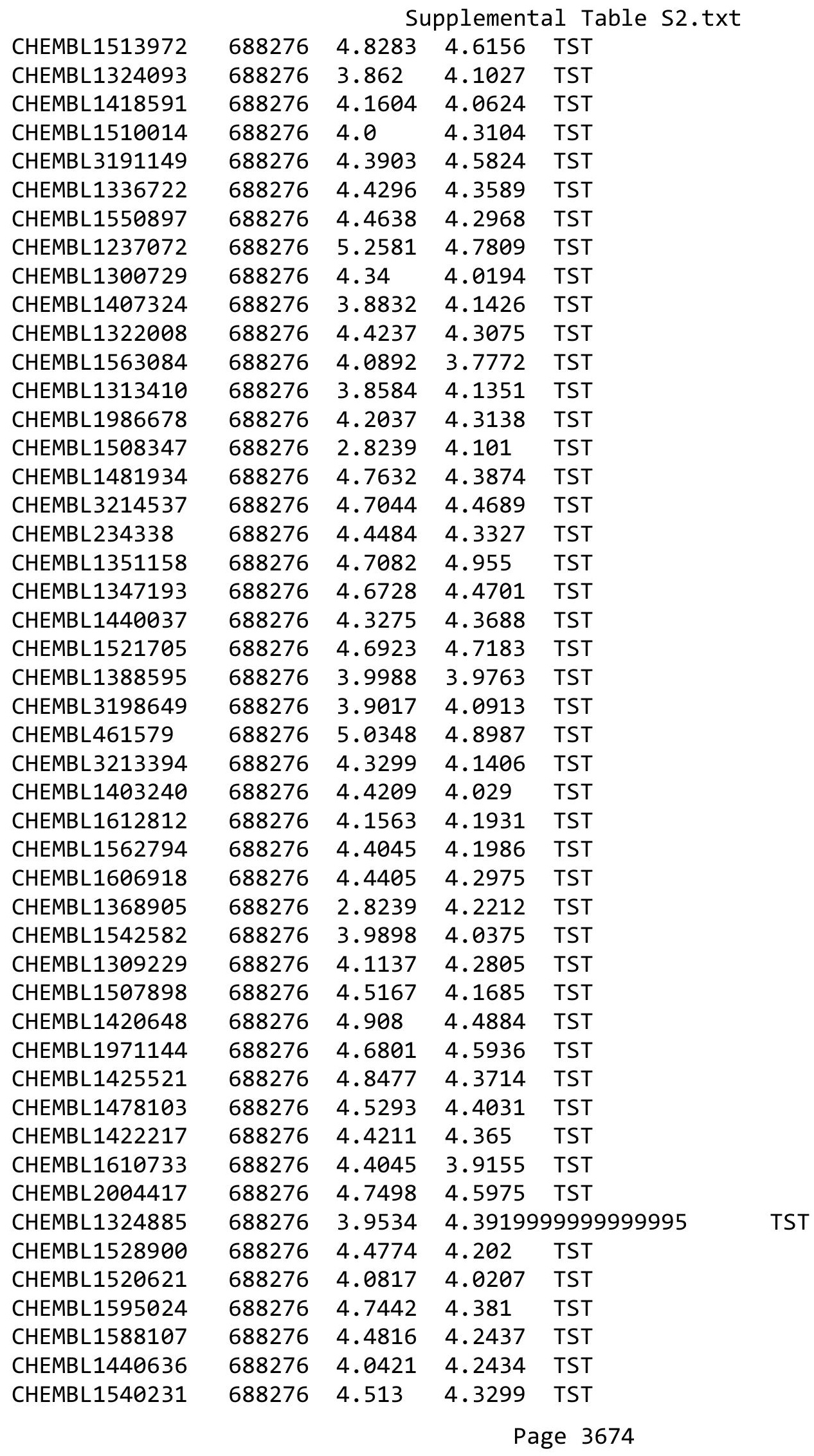




\begin{tabular}{|c|c|c|c|c|}
\hline \multicolumn{5}{|c|}{ Supplemental Tab. } \\
\hline CHEMBL1340176 & 688276 & 3.8397 & 3.6036 & TST \\
\hline CHEMBL3197977 & 688276 & 4.137 & 4.2444 & TST \\
\hline CHEMBL3210907 & 688276 & 3.9885 & 4.3208 & TST \\
\hline CHEMBL1995193 & 688276 & 2.8239 & 4.2681 & TST \\
\hline CHEMBL1507990 & 688276 & 4.4369 & 4.3902 & TST \\
\hline CHEMBL1412043 & 688276 & 4.2763 & 3.6516 & TST \\
\hline CHEMBL1419803 & 688276 & 4.5488 & 4.0972 & TST \\
\hline CHEMBL3192078 & 688276 & 4.0878 & 4.3013 & TST \\
\hline CHEMBL1992490 & 688276 & 3.8853 & 3.9764 & TST \\
\hline CHEMBL1560273 & 688276 & 4.5789 & 4.2768 & TST \\
\hline CHEMBL1498511 & 688276 & 4.4359 & 4.0499 & TST \\
\hline CHEMBL1389994 & 688276 & 4.5586 & 4.3335 & TST \\
\hline CHEMBL1484943 & 688276 & 4.3806 & 3.8316 & TST \\
\hline CHEMBL1716494 & 688276 & 4.5378 & 4.4564 & TST \\
\hline CHEMBL186248 & 688276 & 3.9228 & 3.9082 & TST \\
\hline CHEMBL1608686 & 688276 & 4.5735 & 4.1985 & TST \\
\hline CHEMBL1484627 & 688276 & 4.4579 & 4.3295 & TST \\
\hline CHEMBL1478460 & 688276 & 4.2518 & 4.4935 & TST \\
\hline CHEMBL1375045 & 688276 & 4.7144 & 4.7646 & TST \\
\hline CHEMBL601578 & 688276 & 4.0232 & 4.4954 & TST \\
\hline CHEMBL1405964 & 688276 & 5.0273 & 4.5299 & TST \\
\hline CHEMBL 290077 & 688276 & 4.6183 & 4.7661 & TST \\
\hline CHEMBL1230020 & 954767 & 3.4416 & 4.1108 & TRN \\
\hline CHEMBL515416 & 954767 & 5.1379 & 4.2629 & TRN \\
\hline CHEMBL 2005886 & 954767 & 3.7735 & 3.9663 & TRN \\
\hline CHEMBL 220241 & 954767 & 4.2456 & 4.1779 & TRN \\
\hline CHEMBL65 & 954767 & 7.388 & 7.6253 & TRN \\
\hline CHEMBL1673039 & 954767 & 2.8109 & 4.0301 & TRN \\
\hline CHEMBL379300 & 954767 & 6.1322 & 5.6112 & TRN \\
\hline CHEMBL 373751 & 954767 & 3.4277 & 3.5594 & TRN \\
\hline CHEMBL558642 & 954767 & 3.8379 & 3.5991 & TRN \\
\hline CHEMBL 9470 & 954767 & 3.96 & 5.3521 & TST \\
\hline CHEMBL191334 & 954767 & 3.6024 & 4.0746 & TRN \\
\hline CHEMBL 259181 & 954767 & 4.3211 & 4.1169 & TRN \\
\hline CHEMBL1190711 & 954767 & 4.1377 & 4.7843 & TRN \\
\hline CHEMBL210618 & 954767 & 3.7458 & 3.7597 & TRN \\
\hline CHEMBL135561 & 954767 & 3.7902 & 3.9931 & TRN \\
\hline CHEMBL 258844 & 954767 & 3.8046 & 3.9263 & TRN \\
\hline CHEMBL300389 & 954767 & 5.7516 & 6.03 & TRN \\
\hline CHEMBL483847 & 954767 & 3.6781 & 3.8855 & TRN \\
\hline CHEMBL180127 & 954767 & 4.5232 & 3.9797 & TRN \\
\hline CHEMBL192566 & 954767 & 6.5745 & 7.0787 & TST \\
\hline CHEMBL573107 & 954767 & 5.1676 & 5.0141 & TRN \\
\hline CHEMBL1516890 & 954767 & 4.3101 & 4.1036 & TRN \\
\hline CHEMBL92309 & 954767 & 3.5634 & 2.9542 & TST \\
\hline CHEMBL 213100 & 954767 & 3.8408 & 3.4194 & TRN \\
\hline CHEMBL2363137 & 954767 & 4.0218 & 4.3356 & TRN \\
\hline CHEMBL 209148 & 954767 & 3.4475 & 3.6448 & TRN \\
\hline
\end{tabular}




\begin{tabular}{|c|c|c|c|c|c|c|}
\hline \multicolumn{7}{|c|}{ Supplemental Table S2.txt } \\
\hline CHEMBL512504 & 954767 & 6.1399 & 6.1312 & TRN & & \\
\hline CHEMBL1643959 & 954767 & 2.718 & 3.1163 & TRN & & \\
\hline CHEMBL3199475 & 954767 & 5.5389 & 4.6104 & TRN & & \\
\hline CHEMBL393929 & 954767 & 5.4589 & 4.2856 & TRN & & \\
\hline CHEMBL1242367 & 954767 & 4.5411 & 3.81600 & 00000000003 & TRN & \\
\hline CHEMBL1256459 & 954767 & 5.9533 & 5.9429 & TRN & & \\
\hline CHEMBL1357247 & 954767 & 3.9455 & 3.1695 & TRN & & \\
\hline CHEMBL412142 & 954767 & $3.4160 e$ & 00000000 & 3.85699 & 99999999998 & TRN \\
\hline CHEMBL379975 & 954767 & 5.8058 & 5.3728 & TRN & & \\
\hline CHEMBL202721 & 954767 & 4.1183 & 4.6868 & TRN & & \\
\hline CHEMBL1909414 & 954767 & 3.398 & 4.1593 & TRN & & \\
\hline CHEMBL472940 & 954767 & 2.5598 & 3.8085 & TRN & & \\
\hline CHEMBL221137 & 954767 & 4.4027 & 4.4406 & TST & & \\
\hline CHEMBL240954 & 954767 & 3.855 & 4.0966 & TRN & & \\
\hline CHEMBL 2144069 & 954767 & 3.6373 & 3.82800 & 00000000003 & TRN & \\
\hline CHEMBL1404918 & 954767 & 2.8906 & 3.0723 & TRN & & \\
\hline CHEMBL392695 & 954767 & 5.2783 & 4.6695 & TRN & & \\
\hline CHEMBL1970879 & 954767 & 4.6521 & 3.6114 & TRN & & \\
\hline CHEMBL514499 & 954767 & 7.1059 & 6.0949 & TST & & \\
\hline CHEMBL3349342 & 954767 & 3.5602 & 4.1788 & TST & & \\
\hline CHEMBL585951 & 954767 & 5.5898 & 5.7516 & TST & & \\
\hline CHEMBL449158 & 954767 & 6.34399 & 99999999 & 6.1351 & TST & \\
\hline CHEMBL509032 & 954767 & 3.61 & 4.5805 & TST & & \\
\hline CHEMBL3186408 & 954767 & 3.2031 & 3.7748 & TST & & \\
\hline CHEMBL3392440 & 954767 & 3.7394 & 3.7554 & TST & & \\
\hline CHEMBL189584 & 954767 & 5.0701 & 4.6471 & TST & & \\
\hline CHEMBL1590308 & 954767 & 3.248 & 3.3158 & TST & & \\
\hline CHEMBL1788116 & 954767 & 3.388 & 3.9421 & TST & & \\
\hline CHEMBL 3210930 & 688230 & 3.0379 & 4.6194 & TRN & & \\
\hline CHEMBL1561576 & 688230 & 5.5728 & 5.0929 & TRN & & \\
\hline CHEMBL1373822 & 688230 & 5.8019 & 5.84399 & 9999999999 & TRN & \\
\hline CHEMBL1303116 & 688230 & 5.1288 & 5.268 & TRN & & \\
\hline CHEMBL1351173 & 688230 & 4.9462 & 5.038 & TRN & & \\
\hline CHEMBL1527352 & 688230 & 5.9983 & 5.3127 & TRN & & \\
\hline CHEMBL3192859 & 688230 & 5.2102 & 4.8245 & TRN & & \\
\hline CHEMBL1331513 & 688230 & 5.5524 & 5.4403 & TRN & & \\
\hline CHEMBL1369293 & 688230 & 5.7326 & 5.6412 & TRN & & \\
\hline CHEMBL1485041 & 688230 & 4.9016 & 5.3395 & TRN & & \\
\hline CHEMBL1596262 & 688230 & 5.4711 & 6.0983 & TRN & & \\
\hline CHEMBL1489187 & 688230 & 5.58 & 5.6175 & TRN & & \\
\hline CHEMBL1432238 & 688230 & 5.4595 & 5.2741 & TRN & & \\
\hline CHEMBL1375468 & 688230 & 5.4374 & 5.193 & TRN & & \\
\hline CHEMBL1425667 & 688230 & 5.8289 & 5.075 & TST & & \\
\hline CHEMBL1509099 & 688230 & 5.2128 & 5.6135 & TRN & & \\
\hline CHEMBL1398824 & 688230 & 5.4675 & 5.1024 & TST & & \\
\hline CHEMBL1386446 & 688230 & 6.0732 & 5.1152 & TRN & & \\
\hline CHEMBL 1554350 & 688230 & 5.375 & 5.4537 & TRN & & \\
\hline CHEMBL1979558 & 688230 & 4.9469 & 5.5007 & TST & & \\
\hline
\end{tabular}




\begin{tabular}{|c|c|c|c|c|c|}
\hline & & & & & \\
\hline CHEMBL1551329 & 688230 & 6.2342 & 5.8408 & TRN & \\
\hline CHEMBL3197908 & 688230 & 5.4232 & 5.1448 & TRN & \\
\hline CHEMBL1577703 & 688230 & 5.9307 & 6.2902 & TRN & \\
\hline CHEMBL1372374 & 688230 & 6.7095 & 5.6232 & TRN & \\
\hline CHEMBL1579318 & 688230 & 5.6639 & 5.751 & TRN & \\
\hline CHEMBL 244683 & 688230 & 4.4697 & 5.4602 & TRN & \\
\hline CHEMBL1383935 & 688230 & 6.041 & 6.1347 & TST & \\
\hline CHEMBL1613234 & 688230 & 5.4817 & 5.3341 & TRN & \\
\hline CHEMBL582980 & 688230 & 4.9462 & 4.9663 & TRN & \\
\hline CHEMBL1369106 & 688230 & 5.9208 & 5.2997 & TRN & \\
\hline CHEMBL1402878 & 688230 & 5.3107 & 6.3443 & TRN & \\
\hline CHEMBL1576542 & 688230 & 5.184 & 5.0685 & TST & \\
\hline CHEMBL3190491 & 688230 & 4.9104 & 4.968 & TST & \\
\hline CHEMBL1533640 & 688230 & 6.1346 & 5.2027 & TRN & \\
\hline CHEMBL3194048 & 688230 & 5.3224 & 5.1526 & TRN & \\
\hline CHEMBL1462325 & 688230 & 7.1635 & 5.862 & TRN & \\
\hline CHEMBL1481388 & 688230 & 5.4459 & 5.17299 & 9999999999 & TRN \\
\hline CHEMBL1510252 & 688230 & 5.5203 & 5.3311 & TRN & \\
\hline CHEMBL1578889 & 688230 & 5.3743 & 5.2805 & TRN & \\
\hline CHEMBL1344938 & 688230 & 5.9634 & 5.7853 & TRN & \\
\hline CHEMBL1337776 & 688230 & 5.4468 & 5.1386 & TRN & \\
\hline CHEMBL1518278 & 688230 & 5.5366 & 5.7043 & TRN & \\
\hline CHEMBL1459296 & 688230 & 5.9423 & 5.4545 & TRN & \\
\hline CHEMBL1413196 & 688230 & 6.0155 & 5.59200 & 00000000005 & TRN \\
\hline CHEMBL1506607 & 688230 & 5.5887 & 5.9948 & TRN & \\
\hline CHEMBL 2004756 & 688230 & 5.2507 & 5.0408 & TRN & \\
\hline CHEMBL3213524 & 688230 & 5.2628 & 4.8962 & TRN & \\
\hline CHEMBL1307677 & 688230 & 5.1894 & 5.3472 & TST & \\
\hline CHEMBL1445852 & 688230 & 5.7319 & 5.5574 & TRN & \\
\hline CHEMBL1476893 & 688230 & 5.4712 & 5.9196 & TST & \\
\hline CHEMBL1421125 & 688230 & 5.9179 & 5.3378 & TRN & \\
\hline CHEMBL585222 & 688230 & 5.4607 & 4.9874 & TRN & \\
\hline CHEMBL1491587 & 688230 & 5.7597 & 5.0294 & TRN & \\
\hline CHEMBL1544647 & 688230 & 6.3161 & 6.1562 & TRN & \\
\hline CHEMBL490592 & 688230 & 3.9918 & 4.8131 & TRN & \\
\hline CHEMBL1483899 & 688230 & 5.2427 & 5.3542 & TRN & \\
\hline CHEMBL1382475 & 688230 & 5.7796 & 5.7363 & TRN & \\
\hline CHEMBL1404230 & 688230 & 5.4034 & 5.4912 & TRN & \\
\hline CHEMBL1486581 & 688230 & 5.3501 & 5.94 & TRN & \\
\hline CHEMBL1393674 & 688230 & 6.0026 & 6.2261 & TRN & \\
\hline CHEMBL1319897 & 688230 & 4.59699 & 99999999 & 5.3252 & TRN \\
\hline CHEMBL1487460 & 688230 & 6.5435 & 5.4108 & TST & \\
\hline CHEMBL1427854 & 688230 & 5.2312 & 5.8219 & TRN & \\
\hline CHEMBL3195346 & 688230 & 3.0378 & 4.6703 & TRN & \\
\hline CHEMBL1340000 & 688230 & 5.2646 & 5.2491 & TRN & \\
\hline CHEMBL1407509 & 688230 & 4.4692 & 5.1442 & TRN & \\
\hline CHEMBL1537068 & 688230 & 5.1693 & 5.5577 & TRN & \\
\hline CHEMBL26138 & 688230 & 5.4759 & 5.6958 & TST & \\
\hline
\end{tabular}


Supplemental Table S2.txt

\begin{tabular}{|c|c|c|c|c|c|}
\hline CHEMBL1567449 & 688230 & 5.6474 & 5.2692 & TRN & \\
\hline CHEMBL1545746 & 688230 & 5.3852 & 5.4087 & TRN & \\
\hline CHEMBL1414242 & 688230 & 5.5507 & 6.3566 & TRN & \\
\hline CHEMBL3189738 & 688230 & 5.8407 & 5.0641 & TRN & \\
\hline CHEMBL1516375 & 688230 & 6.4283 & 5.1199 & TST & \\
\hline CHEMBL1400961 & 688230 & 4.9465 & 5.4979 & TRN & \\
\hline CHEMBL1327628 & 688230 & 4.9465 & 5.692 & TRN & \\
\hline CHEMBL 3192787 & 688230 & 5.2614 & 5.2964 & TRN & \\
\hline CHEMBL400585 & 688230 & 5.317 & 5.1512 & TRN & \\
\hline CHEMBL1392445 & 688230 & 5.9144 & 5.3049 & TST & \\
\hline CHEMBL1430347 & 688230 & 5.5485 & 5.1928 & TST & \\
\hline CHEMBL1318995 & 688230 & 5.7555 & 5.6473 & TRN & \\
\hline CHEMBL1488455 & 688230 & 6.0652 & 6.3846 & TRN & \\
\hline CHEMBL1484640 & 688230 & 5.6619 & 5.308 & TRN & \\
\hline CHEMBL1520832 & 688230 & 7.6536 & 6.4956 & TRN & \\
\hline CHEMBL 232148 & 688230 & 6.625 & 5.2629 & TST & \\
\hline CHEMBL3198275 & 688230 & 5.1731 & 5.0865 & TRN & \\
\hline CHEMBL1605416 & 688230 & 4.9196 & 5.2118 & TRN & \\
\hline CHEMBL1303938 & 688230 & 5.1106 & 5.5503 & TRN & \\
\hline CHEMBL1311023 & 688230 & 4.9462 & 5.2411 & TRN & \\
\hline CHEMBL1545718 & 688230 & 5.83299 & 999999999 & 5.6851 & TRN \\
\hline CHEMBL1324157 & 688230 & 4.9606 & 5.3034 & TRN & \\
\hline CHEMBL1557667 & 688230 & 6.0673 & 5.6673 & TRN & \\
\hline CHEMBL1569192 & 688230 & 5.8339 & 5.0851 & TRN & \\
\hline CHEMBL1506957 & 688230 & 6.3221 & 5.6231 & TRN & \\
\hline CHEMBL1501549 & 688230 & 5.8901 & 6.0789 & TRN & \\
\hline CHEMBL1600434 & 688230 & 5.2034 & 5.308 & TRN & \\
\hline CHEMBL1427162 & 688230 & 5.2822 & 5.6725 & TRN & \\
\hline CHEMBL3213880 & 688230 & 5.0708 & 5.266 & TRN & \\
\hline CHEMBL1975888 & 688230 & 3.0378 & 4.6888 & TRN & \\
\hline CHEMBL1964748 & 688230 & 5.2468 & 4.8704 & TRN & \\
\hline CHEMBL1346834 & 688230 & 5.8027 & 5.8194 & TRN & \\
\hline CHEMBL532504 & 688230 & 4.9173 & 4.971 & TRN & \\
\hline CHEMBL1577852 & 688230 & 5.5825 & 5.2526 & TRN & \\
\hline CHEMBL 3193884 & 688230 & 6.2644 & 4.9886 & TRN & \\
\hline CHEMBL1430231 & 688230 & 6.4548 & 6.1999 & TRN & \\
\hline CHEMBL1448943 & 688230 & 5.4235 & 5.7173 & TRN & \\
\hline CHEMBL1542516 & 688230 & 5.8652 & 5.4908 & TRN & \\
\hline CHEMBL1991679 & 688230 & 5.4235 & 4.8176 & TRN & \\
\hline CHEMBL1584969 & 688230 & 3.0373 & 4.9627 & TRN & \\
\hline CHEMBL 3190804 & 688230 & 3.0377 & 4.9231 & TST & \\
\hline CHEMBL1300615 & 688230 & \multicolumn{3}{|c|}{5.656000000000001} & TST \\
\hline CHEMBL448245 & 688230 & 5.7438 & 6.2649 & TST & \\
\hline CHEMBL3195512 & 688230 & 5.2828 & 5.2424 & TST & \\
\hline CHEMBL1535518 & 688230 & 4.9756 & 5.6439 & TST & \\
\hline CHEMBL 295786 & 688230 & 6.0889 & 5.3485 & TST & \\
\hline CHEMBL1600251 & 688230 & 5.029 & 5.252000 & 0000000001 & וSI \\
\hline CHEMBL 2006030 & 688230 & 5.9516 & 5.9616 & TST & \\
\hline
\end{tabular}




\begin{tabular}{|c|c|c|c|c|c|}
\hline & & & & & \\
\hline CHEMBL1481360 & 688230 & 5.4887 & 5.2647 & TST & \\
\hline CHEMBL1336615 & 688230 & 5.2915 & 5.3368 & TST & \\
\hline CHEMBL1213905 & 688230 & 5.4229 & 5.9558 & TST & \\
\hline CHEMBL1601528 & 688230 & 5.4679 & 5.9312 & TST & \\
\hline CHEMBL597452 & 688230 & 6.9331 & 5.5987 & TST & \\
\hline CHEMBL1529540 & 688230 & 6.3391 & 5.6224 & TST & \\
\hline CHEMBL1383970 & 688230 & 5.8133 & 6.13700 & 00000000005 & TST \\
\hline CHEMBL 3214386 & 688230 & 5.3273 & 5.7003 & TST & \\
\hline CHEMBL1509929 & 688230 & 6.4049 & 5.7992 & TST & \\
\hline CHEMBL3190223 & 688230 & 4.4692 & 5.2183 & TST & \\
\hline CHEMBL 3084822 & 53208 & 7.1549 & 7.0626 & TRN & \\
\hline CHEMBL318511 & 53208 & 4.279 & 4.3762 & TST & \\
\hline CHEMBL96814 & 53208 & 5.1308 & 4.4927 & TRN & \\
\hline CHEMBL96299 & 53208 & 6.4609 & 6.99799 & 9999999999 & TRN \\
\hline CHEMBL96453 & 53208 & 6.0052 & 6.6487 & TRN & \\
\hline CHEMBL 96160 & 53208 & 6.5751 & 6.9502 & TRN & \\
\hline CHEMBL318612 & 53208 & 3.9872 & 6.6722 & TST & \\
\hline CHEMBL 3084824 & 53208 & 6.8268 & 7.3616 & TRN & \\
\hline CHEMBL 3084818 & 53208 & 6.7375 & 7.1094 & TRN & \\
\hline CHEMBL 3084819 & 53208 & 7.7447 & 7.2922 & TRN & \\
\hline CHEMBL328994 & 53208 & 6.8761 & 6.7749 & TRN & \\
\hline CHEMBL96607 & 53208 & 6.4295 & 6.6067 & TRN & \\
\hline CHEMBL317787 & 53208 & 6.5834 & 6.7965 & TRN & \\
\hline CHEMBL 3084823 & 53208 & 7.2076 & 7.1723 & TRN & \\
\hline CHEMBL94147 & 53208 & 6.5361 & 7.08299 & 9999999999 & TRN \\
\hline CHEMBL 327166 & 53208 & 7.5376 & 7.0322 & TRN & \\
\hline CHEMBL317331 & 53208 & 2.0 & 4.198 & TST & \\
\hline CHEMBL96666 & 53208 & 8.699 & 6.5075 & TST & \\
\hline CHEMBL93847 & 53208 & 6.4711 & 6.9214 & TRN & \\
\hline CHEMBL 3084825 & 53208 & 7.6576 & 6.9031 & TRN & \\
\hline CHEMBL 92710 & 53208 & 6.5918 & 6.9403 & TRN & \\
\hline CHEMBL307636 & 53208 & 8.699 & 6.7065 & TST & \\
\hline CHEMBL 330326 & 53208 & 6.4001 & 6.9101 & TRN & \\
\hline CHEMBL96942 & 53208 & 6.5157 & 6.4162 & TRN & \\
\hline CHEMBL96891 & 53208 & 3.9626 & 6.6278 & TRN & \\
\hline CHEMBL318775 & 53208 & 6.9914 & 6.8665 & TRN & \\
\hline CHEMBL 3084812 & 53208 & 8.1549 & 6.8711 & TRN & \\
\hline CHEMBL 3084820 & 53208 & 8.0 & 7.1126 & TST & \\
\hline CHEMBL92711 & 53208 & 7.4815 & 6.7558 & TRN & \\
\hline CHEMBL 3084813 & 53208 & 3.0311 & 3.0086 & TRN & \\
\hline CHEMBL 3084815 & 53208 & 8.301 & 7.4453 & TRN & \\
\hline CHEMBL93354 & 53208 & 7.4437 & 6.9652 & TRN & \\
\hline CHEMBL328613 & 53208 & 4.5834 & 4.2348 & TST & \\
\hline CHEMBL96577 & 53208 & 6.3605 & 6.6562 & TRN & \\
\hline CHEMBL96080 & 53208 & 6.2132 & 7.1079 & TRN & \\
\hline CHEMBL94046 & 53208 & 4.7282 & 6.4839 & TRN & \\
\hline CHEMBL322904 & 53208 & 2.301 & 6.7848 & TST & \\
\hline CHEMBL77539 & 53208 & 8.0969 & 6.5277 & TRN & \\
\hline
\end{tabular}




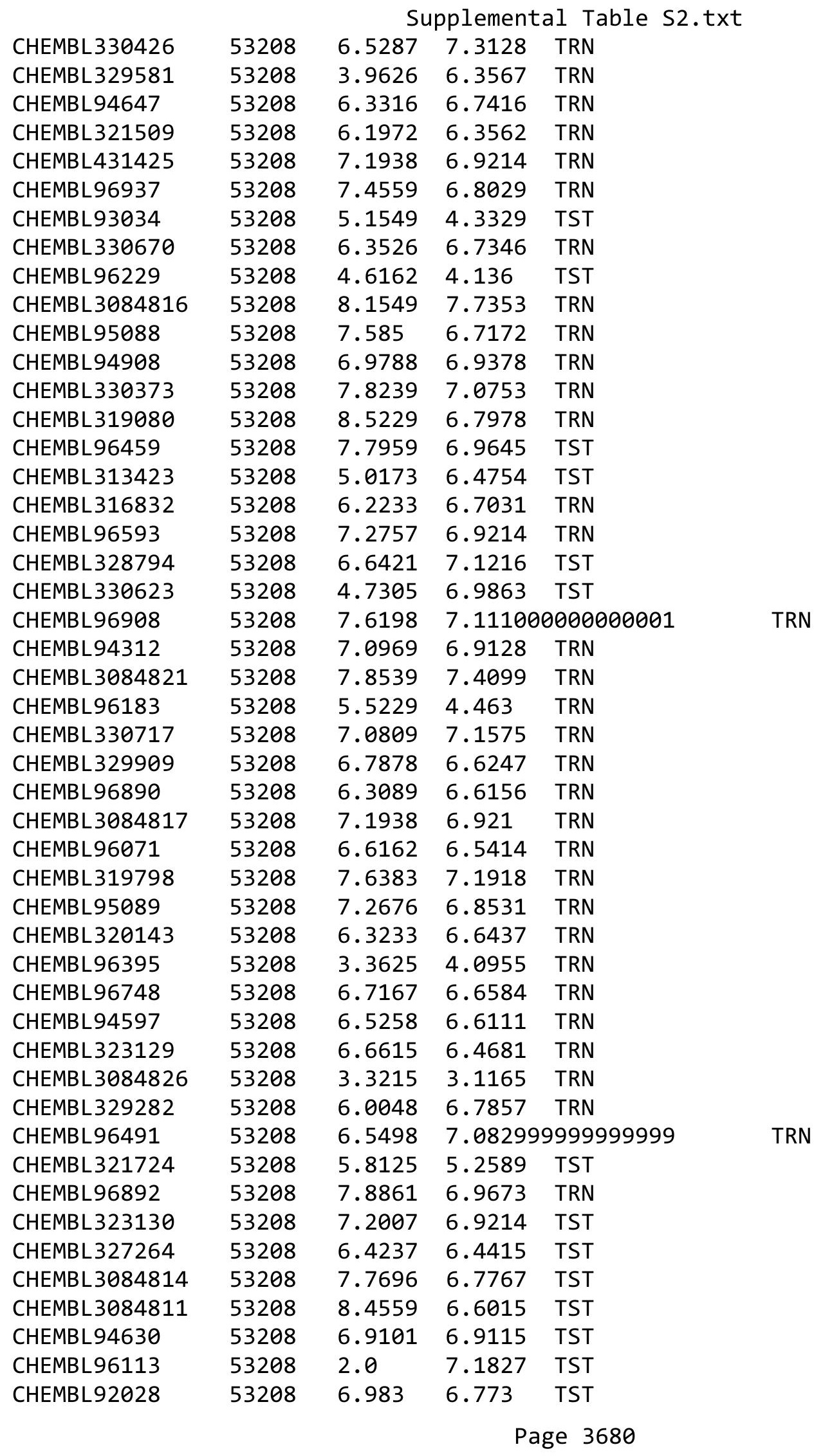




\begin{tabular}{|c|}
\hline CHEMBL213670 \\
\hline CHEMBL 214800 \\
\hline CHEMBL212003 \\
\hline CHEMBL384799 \\
\hline CHEMBL384723 \\
\hline CHEMBL384565 \\
\hline CHEMBL427743 \\
\hline CHEMBL214845 \\
\hline CHEMBL 214873 \\
\hline CHEMBL379548 \\
\hline CHEMBL424864 \\
\hline CHEMBL 212942 \\
\hline CHEMBL384409 \\
\hline CHEMBL405544 \\
\hline CHEMBL385454 \\
\hline CHEMBL 214829 \\
\hline CHEMBL 214904 \\
\hline CHEMBL375872 \\
\hline CHEMBL384080 \\
\hline CHEMBL 215424 \\
\hline CHEMBL386113 \\
\hline CHEMBL377252 \\
\hline CHEMBL426142 \\
\hline CHEMBL386714 \\
\hline CHEMBL443577 \\
\hline CHEMBL211931 \\
\hline CHEMBL 215274 \\
\hline CHEMBL408093 \\
\hline CHEMBL 213976 \\
\hline CHEMBL425807 \\
\hline CHEMBL384408 \\
\hline CHEMBL437718 \\
\hline CHEMBL386757 \\
\hline CHEMBL386204 \\
\hline CHEMBL 214950 \\
\hline CHEMBL 213717 \\
\hline CHEMBL 215325 \\
\hline CHEMBL386701 \\
\hline CHEMBL 215499 \\
\hline CHEMBL381798 \\
\hline CHEMBL405543 \\
\hline CHEMBL384091 \\
\hline CHEMBL214751 \\
\hline CHEMBL385399 \\
\hline CHEMBL384539 \\
\hline CHEMBL386706 \\
\hline CHEMBL415453 \\
\hline CHEMBL383872 \\
\hline
\end{tabular}

Supplemental Table S2.txt

$\begin{array}{llll}402775 & 6.2343 & 6.3003 & \text { TRN } \\ 402775 & 6.6882 & 8.2166 & \text { TRN } \\ 402775 & 4.0 & 5.1284 & \text { TRN } \\ 402775 & 7.585 & 6.3382 & \text { TST } \\ 402775 & 6.0691 & 5.9536 & \text { TRN } \\ 402775 & 5.1938 & 5.2268 & \text { TRN } \\ 402775 & 6.4559 & 6.8885 & \text { TRN } \\ 402775 & 6.2403 & 6.4941 & \text { TRN } \\ 402775 & 6.426 & 5.9826 & \text { TRN } \\ 402775 & 7.2924 & 6.3393 & \text { TRN } \\ 402775 & 7.3188 & 6.6935 & \text { TRN } \\ 402775 & 6.5302 & 6.9739 & \text { TST } \\ 402775 & 5.699 & 6.7976 & \text { TST } \\ 402775 & 6.585 & 5.8247 & \text { TRN } \\ 402775 & 8.9586 & 8.3091 & \text { TRN } \\ 402775 & 6.1427 & 6.6669 & \text { TST } \\ 402775 & 6.4698 & 6.4012 & \text { TST } \\ 402775 & 5.4202 & 5.5138 & \text { TRN } \\ 402775 & 5.1612 & 5.8234 & \text { TRN } \\ 402775 & 6.0155 & 6.8726 & \text { TST } \\ 402775 & 6.3696 & 6.0241 & \text { TRN } \\ 402775 & 6.4949 & 6.807 & \text { TST } \\ 402775 & 6.0074 & 6.0494 & \text { TRN } \\ 402775 & 5.9767 & 5.6866 & \text { TRN } \\ 402775 & 5.9788 & 6.6747 & \text { TST } \\ 402775 & 6.8069 & 6.3101 & \text { TRN } \\ 402775 & 7.9586 & 7.7438 & \text { TRN } \\ 402775 & 7.6383 & 6.5091 & \text { TST } \\ 402775 & 7.5376 & 6.5948 & \text { TST } \\ 402775 & 6.068 & 6.4807 & \text { TST } \\ 402775 & 6.9586 & 6.7677 & \text { TRN } \\ 402775 & 6.983 & 7.7697 & \text { TRN } \\ 402775 & 7.7212 & 7.8119 & \text { TRN } \\ 402775 & 6.8447 & 5.7086 & \text { TRN } \\ 402775 & 6.0 & 6.233 & \text { TST } \\ 402775 & 4.699 & 6.3289 & \text { TRN } \\ 402775 & 8.2007 & 7.4358 & \text { TRN } \\ 402775 & 5.9488 & 6.2978 & \text { TRN } \\ 402775 & 7.9586 & 7.3978 & \text { TRN } \\ 402775 & 5.6478 & 6.3226 & \text { TST } \\ 402775 & 6.0915 & 5.6484 & \text { TRN } \\ 402775 & 5.5376 & 6.4246 & \text { TRN } \\ 402775 & 5.2147 & 5.5113 & \text { TRN } \\ 402775 & 5.2727 & 6.3474 & \text { TRN } \\ 402775 & 7.5686 & 6.0703 & \text { TRN } \\ 402775 & 5.5528 & 5.9523 & \text { TRN } \\ 402775 & 6.1643 & 5.8867 & \text { TRN } \\ 402775 & 7.5686 & 7.3138 & \text { TRN }\end{array}$


Supplemental Table S2.txt

\begin{tabular}{|c|c|c|c|c|c|}
\hline CHEMBL 215549 & 402775 & 4.699 & 5.3464 & TRN & \\
\hline CHEMBL 214507 & 402775 & 7.9586 & 7.5785 & TRN & \\
\hline CHEMBL1215803 & 650213 & 3.6234 & 3.3736 & TRN & \\
\hline CHEMBL1215003 & 650213 & 4.2596 & 3.9674 & TRN & \\
\hline CHEMBL1215513 & 650213 & 4.3372 & 3.9446 & TRN & \\
\hline CHEMBL1215439 & 650213 & 3.7905 & 3.2275 & TRN & \\
\hline CHEMBL1215007 & 650213 & 5.1549 & 4.5354 & TST & \\
\hline CHEMBL1214861 & 650213 & 3.5817 & 3.1189 & TRN & \\
\hline CHEMBL1214716 & 650213 & 4.699 & 4.6025 & TRN & \\
\hline CHEMBL1215364 & 650213 & 2.5229 & 3.0324 & TRN & \\
\hline CHEMBL1214939 & 650213 & 3.9788 & 4.1978 & TST & \\
\hline CHEMBL1215717 & 650213 & 2.5229 & 2.3926 & TRN & \\
\hline CHEMBL1214718 & 650213 & 4.4437 & 4.6646 & TRN & \\
\hline CHEMBL1214795 & 650213 & 4.2924 & 3.8689 & TST & \\
\hline CHEMBL1215080 & 650213 & 3.8601 & 4.1235 & TRN & \\
\hline CHEMBL1215004 & 650213 & 4.585 & 4.6197 & TRN & \\
\hline CHEMBL1215366 & 650213 & 5.301 & 5.6044 & TRN & \\
\hline CHEMBL1215512 & 650213 & 4.0862 & 3.6189 & TRN & \\
\hline CHEMBL400566 & 650213 & 4.7447 & 4.2457 & TRN & \\
\hline CHEMBL1215798 & 650213 & 3.7055 & 2.988 & TST & \\
\hline CHEMBL1215796 & 650213 & 4.0315 & 4.1765 & TRN & \\
\hline CHEMBL1214865 & 650213 & 4.5229 & 4.4154 & TST & \\
\hline CHEMBL1214790 & 650213 & 4.0088 & 3.301 & TRN & \\
\hline CHEMBL1214866 & 650213 & 2.5229 & 2.5853 & TRN & \\
\hline CHEMBL1214719 & 650213 & 4.1675 & 4.1555 & TRN & \\
\hline CHEMBL1214867 & 650213 & 2.5229 & 2.5743 & TRN & \\
\hline CHEMBL1215648 & 650213 & 4.1024 & 3.9446 & TRN & \\
\hline CHEMBL1214715 & 650213 & 4.7696 & 5.034 & TRN & \\
\hline CHEMBL1214863 & 650213 & 3.5229 & 3.5185 & TST & \\
\hline CHEMBL1215511 & 650213 & 2.5229 & 2.5122 & TRN & \\
\hline CHEMBL1214646 & 650213 & 2.5229 & 2.3065 & TST & \\
\hline CHEMBL1215797 & 650213 & 3.752 & 3.6545 & TRN & \\
\hline CHEMBL1214714 & 650213 & 3.6289 & 2.9438 & TST & \\
\hline CHEMBL1215365 & 650213 & 5.5229 & \multicolumn{2}{|c|}{5.452999999999999} & TRN \\
\hline CHEMBL1214793 & 650213 & 2.5229 & 3.1249 & TRN & \\
\hline CHEMBL1215650 & 650213 & 2.5229 & 2.2844 & TRN & \\
\hline CHEMBL1215800 & 650213 & 3.5544 & 3.3244 & TRN & \\
\hline CHEMBL1215510 & 650213 & 4.5229 & 4.5858 & TRN & \\
\hline CHEMBL1215581 & 650213 & 2.5229 & 2.487 & TRN & \\
\hline CHEMBL1215442 & 650213 & 3.8894 & 3.8901 & TRN & \\
\hline CHEMBL1214649 & 650213 & 4.1079 & 3.6466 & TST & \\
\hline CHEMBL1215156 & 650213 & 4.284 & 4.6437 & TRN & \\
\hline CHEMBL1215651 & 650213 & 4.0506 & 4.0611 & TRN & \\
\hline CHEMBL1214797 & 650213 & 2.5229 & 2.5015 & TRN & \\
\hline CHEMBL1214645 & 650213 & 2.5229 & 3.2354 & TRN & \\
\hline CHEMBL1215081 & 650213 & 4.4685 & 4.4854 & TRN & \\
\hline CHEMBL1214713 & 650213 & 4.1612 & 3.8671 & TRN & \\
\hline CHEMBL1215649 & 650213 & 3.9747 & 4.0365 & TRN & \\
\hline
\end{tabular}

Page 3682 
Supplemental Table S2.txt

\begin{tabular}{|c|c|c|c|c|c|}
\hline CHEMBL1214791 & 650213 & 3.5229 & 3.2702 & TRN & \\
\hline CHEMBL1215079 & 650213 & 4.5229 & 4.2858 & TRN & \\
\hline CHEMBL1215719 & 650213 & 2.5229 & 3.2186 & TRN & \\
\hline CHEMBL1214798 & 650213 & 2.5229 & 2.6314 & TRN & \\
\hline CHEMBL1215291 & 650213 & 4.8239 & 4.5546 & TRN & \\
\hline CHEMBL1215006 & 650213 & 4.4559 & 3.7972 & TRN & \\
\hline CHEMBL1214868 & 650213 & 3.8069 & 3.5416 & TST & \\
\hline CHEMBL1215154 & 650213 & 3.9586 & 3.5921 & TRN & \\
\hline CHEMBL1215225 & 650213 & 2.5229 & 3.0145 & TRN & \\
\hline CHEMBL1214794 & 650213 & 3.5817 & 3.0586 & TST & \\
\hline CHEMBL1215157 & 650213 & 3.6144 & 3.9377 & TRN & \\
\hline CHEMBL1215579 & 650213 & 2.5229 & 2.8104 & TRN & \\
\hline CHEMBL1215440 & 650213 & 4.0088 & 3.7589 & TRN & \\
\hline CHEMBL1214935 & 650213 & 4.0088 & 4.2615 & TRN & \\
\hline CHEMBL1214862 & 650213 & 3.5229 & 2.812 & TST & \\
\hline CHEMBL1214717 & 650213 & 4.5086 & 4.4937 & TRN & \\
\hline CHEMBL1215082 & 650213 & 4.0315 & 3.8381 & TRN & \\
\hline CHEMBL1215226 & 650213 & 4.4815 & 4.459 & TRN & \\
\hline CHEMBL1215802 & 650213 & 3.6861 & 3.313999 & 9999999996 & TRN \\
\hline CHEMBL1214869 & 650213 & 2.5229 & 2.8073 & TRN & \\
\hline CHEMBL1215799 & 650213 & 4.5229 & 4.6699 & TRN & \\
\hline CHEMBL1212961 & 650213 & 2.5229 & 2.5238 & TRN & \\
\hline CHEMBL1215227 & 650213 & 4.8861 & 4.849 & TRN & \\
\hline CHEMBL1215005 & 650213 & 2.5229 & 2.4898 & TRN & \\
\hline CHEMBL1215224 & 650213 & 3.9626 & 3.6367 & TRN & \\
\hline CHEMBL1214934 & 650213 & 4.0706 & 4.2347 & TRN & \\
\hline CHEMBL1214647 & 650213 & 4.1805 & 4.6065 & TRN & \\
\hline CHEMBL1214937 & 650213 & 4.2924 & 4.3637 & TRN & \\
\hline CHEMBL1215578 & 650213 & 3.9626 & 3.9273 & TRN & \\
\hline CHEMBL1215718 & 650213 & 2.5229 & 3.1712 & TRN & \\
\hline CHEMBL1214940 & 650213 & 4.5086 & 4.6199 & TRN & \\
\hline CHEMBL1215292 & 650213 & 2.5229 & 3.5773 & TRN & \\
\hline CHEMBL1214792 & 650213 & 2.5229 & 3.115 & TST & \\
\hline CHEMBL1215290 & 650213 & 5.2218 & 4.5389 & TRN & \\
\hline CHEMBL1214941 & 650213 & 4.3098 & 4.2664 & TRN & \\
\hline CHEMBL1214648 & 650213 & 4.6021 & 4.6766 & TRN & \\
\hline CHEMBL1214796 & 650213 & 2.5229 & 3.2286 & TST & \\
\hline CHEMBL1214864 & 650213 & 3.5229 & 3.2316 & TST & \\
\hline CHEMBL1214936 & 650213 & 4.4437 & 5.2042 & TST & \\
\hline CHEMBL1215580 & 650213 & 4.4089 & 3.9065 & TST & \\
\hline CHEMBL1214720 & 650213 & 3.9136 & 2.6178 & TST & \\
\hline CHEMBL1215801 & 650213 & 4.9586 & 4.0883 & TST & \\
\hline CHEMBL1215716 & 650213 & 3.8416 & 3.1428 & TST & \\
\hline CHEMBL1214938 & 650213 & 2.5229 & 2.3759 & TST & \\
\hline CHEMBL1215155 & 650213 & 4.8861 & 4.6522 & TST & \\
\hline CHEMBL1215441 & 650213 & 4.7447 & 3.9472 & TST & \\
\hline CHEMBL1215367 & 650213 & 2.5229 & 2.9188 & TST & \\
\hline CHEMBL474814 & 519272 & 5.9706 & 5.9075 & TRN & \\
\hline
\end{tabular}




\begin{tabular}{|c|c|c|c|c|c|}
\hline & & & & & \\
\hline CHEMBL474789 & 519272 & 5.9957 & 6.5792 & TST & \\
\hline CHEMBL475867 & 519272 & 5.7696 & 5.7695 & TST & \\
\hline CHEMBL482074 & 519272 & 5.8297 & 5.6738 & TST & \\
\hline CHEMBL475265 & 519272 & 6.0269 & 6.0343 & TRN & \\
\hline CHEMBL521411 & 519272 & 4.0 & 4.0257 & TRN & \\
\hline CHEMBL482170 & 519272 & 6.2076 & 5.9709 & TRN & \\
\hline CHEMBL475668 & 519272 & 5.5575 & 5.6445 & TRN & \\
\hline CHEMBL514963 & 519272 & 6.0969 & 6.0185 & TRN & \\
\hline CHEMBL469894 & 519272 & 5.7773 & 5.724 & TRN & \\
\hline CHEMBL474201 & 519272 & 5.9031 & 5.9186 & TRN & \\
\hline CHEMBL480379 & 519272 & 5.4698 & 5.4312 & TRN & \\
\hline CHEMBL481574 & 519272 & 5.6421 & 5.8315 & TST & \\
\hline CHEMBL519950 & 519272 & 5.9172 & 5.8734 & TRN & \\
\hline CHEMBL481896 & 519272 & 6.2076 & 6.2183 & TRN & \\
\hline CHEMBL481895 & 519272 & 5.6345 & 5.6489 & TRN & \\
\hline CHEMBL474795 & 519272 & 5.8013 & 5.5929 & TST & \\
\hline CHEMBL475770 & 519272 & 5.8794 & 5.8894 & TRN & \\
\hline CHEMBL473638 & 519272 & 5.8928 & 5.8738 & TRN & \\
\hline CHEMBL482362 & 519272 & 6.0809 & 6.1715 & TRN & \\
\hline CHEMBL472143 & 519272 & 6.1135 & 6.0974 & TRN & \\
\hline CHEMBL475029 & 519272 & 5.8447 & 5.2667 & TST & \\
\hline CHEMBL480929 & 519272 & 4.0 & 4.2234 & TRN & \\
\hline CHEMBL481505 & 519272 & 6.0 & 6.1478 & TRN & \\
\hline CHEMBL473842 & 519272 & 6.0862 & 6.4874 & TST & \\
\hline CHEMBL482364 & 519272 & 5.6326 & 5.66 & TRN & \\
\hline CHEMBL475460 & 519272 & 5.7144 & 6.3623 & TST & \\
\hline CHEMBL481894 & 519272 & 6.4559 & 6.4643 & TRN & \\
\hline CHEMBL519468 & 519272 & 5.7799 & 5.5262 & TRN & \\
\hline CHEMBL514954 & 519272 & 5.8416 & 6.0412 & TST & \\
\hline CHEMBL475771 & 519272 & 5.6162 & 5.6037 & TRN & \\
\hline CHEMBL473434 & 519272 & 4.0 & 3.9376 & TRN & \\
\hline CHEMBL480567 & 519272 & 6.3098 & 6.4875 & TRN & \\
\hline CHEMBL473433 & 519272 & 5.7645 & 5.8203 & TRN & \\
\hline CHEMBL481899 & 519272 & 5.9914 & 5.9279 & TRN & \\
\hline CHEMBL474788 & 519272 & 5.9508 & 5.2388 & TST & \\
\hline CHEMBL472144 & 519272 & 6.0269 & 6.1311 & TRN & \\
\hline CHEMBL473841 & 519272 & 6.2518 & 6.3829 & TST & \\
\hline CHEMBL480766 & 519272 & 5.8761 & 5.8829 & TRN & \\
\hline CHEMBL482361 & 519272 & 5.7328 & 5.7857 & TRN & \\
\hline CHEMBL482073 & 519272 & 6.1079 & 6.0698 & TRN & \\
\hline CHEMBL475435 & 519272 & 5.7235 & 6.2118 & TST & \\
\hline CHEMBL475667 & 519272 & 5.9245 & 5.9151 & TRN & \\
\hline CHEMBL482360 & 519272 & 5.9136 & 5.88299 & 9999999999 & TRN \\
\hline CHEMBL521273 & 519272 & 5.8697 & 5.8465 & TRN & \\
\hline CHEMBL482171 & 519272 & 6.0809 & 6.1308 & TRN & \\
\hline CHEMBL481364 & 519272 & 4.0 & 3.8996 & TRN & \\
\hline CHEMBL482365 & 519272 & 4.0 & 4.0971 & TRN & \\
\hline CHEMBL473637 & 519272 & 6.1079 & 5.7383 & TST & \\
\hline
\end{tabular}




\begin{tabular}{|c|c|c|c|c|c|c|}
\hline & & \multicolumn{5}{|c|}{ Supplemental Table S2.txt } \\
\hline CHEMBL482072 & 519272 & 5.3152 & 5.324 & TRN & & \\
\hline CHEMBL481715 & 519272 & 5.7212 & 5.814 & TRN & & \\
\hline CHEMBL473636 & 519272 & 5.7375 & 5.7741 & TST & & \\
\hline CHEMBL475598 & 519272 & 5.8827 & 6.3415 & TST & & \\
\hline CHEMBL481365 & 519272 & 4.0 & 4.0163 & TRN & & \\
\hline CHEMBL480188 & 519272 & 6.1549 & 6.1274 & TRN & & \\
\hline CHEMBL475436 & 519272 & 6.0044 & 6.2722 & TST & & \\
\hline CHEMBL482160 & 519272 & 6.3372 & 6.2701 & TRN & & \\
\hline CHEMBL514780 & 519272 & 5.6308 & 5.6477 & TRN & & \\
\hline CHEMBL481506 & 519272 & 6.0809 & 6.1587 & TRN & & \\
\hline CHEMBL480767 & 519272 & 5.4724 & 5.4175 & TRN & & \\
\hline CHEMBL474607 & 519272 & 6.1192 & 6.0407 & TRN & & \\
\hline CHEMBL512902 & 519272 & 5.5258 & 5.4959 & TRN & & \\
\hline CHEMBL481320 & 519272 & 4.0 & 3.9754 & TRN & & \\
\hline CHEMBL3352885 & 1437207 & 6.9516 & 7.2662 & TST & & \\
\hline CHEMBL3359213 & 1437207 & 6.7258 & 6.6762 & TRN & & \\
\hline CHEMBL3359217 & 1437207 & 6.015 & 6.0706 & TRN & & \\
\hline CHEMBL3359220 & 1437207 & 8.6326 & 8.6543 & TRN & & \\
\hline CHEMBL3359231 & 1437207 & 7.3546 & 7.3135 & TST & & \\
\hline CHEMBL3358640 & 1437207 & 7.9281 & 7.9043 & TRN & & \\
\hline CHEMBL3359212 & 1437207 & 7.4572 & 7.4356 & TRN & & \\
\hline CHEMBL3359214 & 1437207 & 7.7144 & 7.7238 & TRN & & \\
\hline CHEMBL3358646 & 1437207 & $6.8210 e$ & 300000006 & 01 & 6.8067 & TRN \\
\hline CHEMBL3359239 & 1437207 & 8.9747 & 8.9431 & TRN & & \\
\hline CHEMBL3358647 & 1437207 & 7.644 & 7.6199 & TRN & & \\
\hline CHEMBL3359223 & 1437207 & 6.6615 & 6.7165 & TRN & & \\
\hline CHEMBL3359227 & 1437207 & 6.1337 & 6.0876 & TRN & & \\
\hline CHEMBL3359243 & 1437207 & 7.2306 & 7.2171 & TRN & & \\
\hline CHEMBL3359211 & 1437207 & 7.6882 & 7.6727 & TRN & & \\
\hline CHEMBL3358638 & 1437207 & 6.9355 & 6.8793 & TRN & & \\
\hline CHEMBL3359210 & 1437207 & 7.4112 & 7.1142 & TST & & \\
\hline CHEMBL3359224 & 1437207 & 7.7144 & 7.7309 & TRN & & \\
\hline CHEMBL3358653 & 1437207 & 7.0846 & 6.5592 & TST & & \\
\hline CHEMBL3358651 & 1437207 & 4.699 & 4.7079 & TRN & & \\
\hline CHEMBL3359218 & 1437207 & 8.0218 & 7.9533 & TRN & & \\
\hline CHEMBL3358639 & 1437207 & 6.3747 & 6.3942 & TRN & & \\
\hline CHEMBL3359221 & 1437207 & 7.6498 & 7.66 & TRN & & \\
\hline CHEMBL3359216 & 1437207 & 6.5969 & 6.5575 & TRN & & \\
\hline CHEMBL3359219 & 1437207 & 8.426 & 8.3984 & TRN & & \\
\hline CHEMBL3359226 & 1437207 & 6.556 & 6.5606 & TRN & & \\
\hline CHEMBL3359238 & 1437207 & 9.0132 & 9.0425 & TRN & & \\
\hline CHEMBL3359232 & 1437207 & 7.2299 & 7.4123 & TST & & \\
\hline CHEMBL3359228 & 1437207 & 7.9431 & 7.9658 & TRN & & \\
\hline CHEMBL3358635 & 1437207 & 7.0214 & 6.8425 & TRN & & \\
\hline CHEMBL3358643 & 1437207 & 6.4237 & 6.6599 & TST & & \\
\hline CHEMBL3359235 & 1437207 & 8.4112 & 8.4365 & TRN & & \\
\hline CHEMBL3359244 & 1437207 & 7.4034 & 7.4118 & TRN & & \\
\hline CHEMBL3358645 & 1437207 & 6.4962 & 6.4932 & TRN & & \\
\hline
\end{tabular}




\begin{tabular}{|c|c|c|c|c|c|}
\hline \multicolumn{6}{|c|}{ Supplemental Table S2.txt } \\
\hline CHEMBL3358642 & 1437207 & 7.52 & 7.4902 & TRN & \\
\hline CHEMBL3358633 & 1437207 & 4.699 & 4.6885 & TRN & \\
\hline CHEMBL3359241 & 1437207 & 6.9914 & 7.0113 & TRN & \\
\hline CHEMBL3358654 & 1437207 & 7.32700 & 0000000 & 6.8786 & TST \\
\hline CHEMBL3359237 & 1437207 & 8.9431 & 8.9192 & TRN & \\
\hline CHEMBL 3358634 & 1437207 & 7.4401 & 7.5422 & TRN & \\
\hline CHEMBL3359233 & 1437207 & 6.8586 & 6.9812 & TST & \\
\hline CHEMBL3358652 & 1437207 & 7.8665 & 7.9043 & TRN & \\
\hline CHEMBL3359234 & 1437207 & 8.7077 & 8.6836 & TST & \\
\hline CHEMBL3359222 & 1437207 & 7.4101 & 7.4463 & TRN & \\
\hline CHEMBL 3358637 & 1437207 & 4.699 & 5.6172 & TRN & \\
\hline CHEMBL3358644 & 1437207 & 6.3354 & 6.3358 & TRN & \\
\hline CHEMBL3358649 & 1437207 & 7.7282 & 7.7349 & TRN & \\
\hline CHEMBL3352879 & 1437207 & 6.3134 & 5.6632 & TST & \\
\hline CHEMBL3359240 & 1437207 & 7.0467 & 7.8178 & TST & \\
\hline CHEMBL3359215 & 1437207 & 7.5591 & 7.5556 & TRN & \\
\hline CHEMBL3359225 & 1437207 & 7.5591 & 7.5593 & TRN & \\
\hline CHEMBL3358636 & 1437207 & 6.4101 & 5.6172 & TRN & \\
\hline CHEMBL3358641 & 1437207 & 7.7773 & 7.8431 & TRN & \\
\hline CHEMBL3358648 & 1437207 & 7.5143 & 7.54 & TRN & \\
\hline CHEMBL3359229 & 1437207 & 8.4547 & 8.4332 & TST & \\
\hline CHEMBL3359230 & 1437207 & 8.3958 & 8.6805 & TST & \\
\hline CHEMBL3358650 & 1437207 & 4.699 & 4.6733 & TRN & \\
\hline CHEMBL3359236 & 1437207 & 8.3546 & 8.8462 & TST & \\
\hline CHEMBL3359242 & 1437207 & 6.7282 & 7.3139 & TST & \\
\hline CHEMBL 78198 & 51590 & 5.0969 & 4.9951 & TRN & \\
\hline CHEMBL 79047 & 51590 & 5.0862 & 3.9666 & TST & \\
\hline CHEMBL 80874 & 51590 & 5.4202 & 4.9951 & TRN & \\
\hline CHEMBL 78670 & 51590 & 5.284 & 5.1012 & TST & \\
\hline CHEMBL79044 & 51590 & 5.1249 & 5.351 & TRN & \\
\hline CHEMBL81614 & 51590 & 5.0 & 4.5295 & TRN & \\
\hline CHEMBL27909 & 51590 & 4.8239 & 4.8026 & TRN & \\
\hline CHEMBL 81145 & 51590 & 3.0969 & 3.76899 & 99999999997 & TRN \\
\hline CHEMBL80313 & 51590 & 5.0 & 4.3893 & TRN & \\
\hline CHEMBL81149 & 51590 & 4.9586 & 4.8026 & TRN & \\
\hline CHEMBL29142 & 51590 & 4.8861 & 4.775 & TRN & \\
\hline CHEMBL 80188 & 51590 & 5.3098 & 5.1012 & TST & \\
\hline CHEMBL420586 & 51590 & 4.4815 & 4.775 & TRN & \\
\hline CHEMBL 28743 & 51590 & 3.6576 & 4.1766 & TRN & \\
\hline CHEMBL79069 & 51590 & 3.2218 & 3.76899 & 99999999997 & TRN \\
\hline CHEMBL27912 & 51590 & 4.699 & 4.92 & TRN & \\
\hline CHEMBL 82255 & 51590 & 3.2218 & 3.76899 & 99999999997 & TRN \\
\hline CHEMBL40258 & 51590 & 5.2218 & 4.775 & TRN & \\
\hline CHEMBL46257 & 51590 & 2.3468 & 1.82599 & 99999999998 & TRN \\
\hline CHEMBL 82549 & 51590 & 4.9208 & 4.6034 & TST & \\
\hline CHEMBL82254 & 51590 & 3.8861 & 3.76899 & 99999999997 & TRN \\
\hline CHEMBL23194 & 51590 & 5.3665 & 4.6896 & TRN & \\
\hline CHEMBL 28489 & 51590 & 5.3098 & 4.9951 & TRN & \\
\hline
\end{tabular}




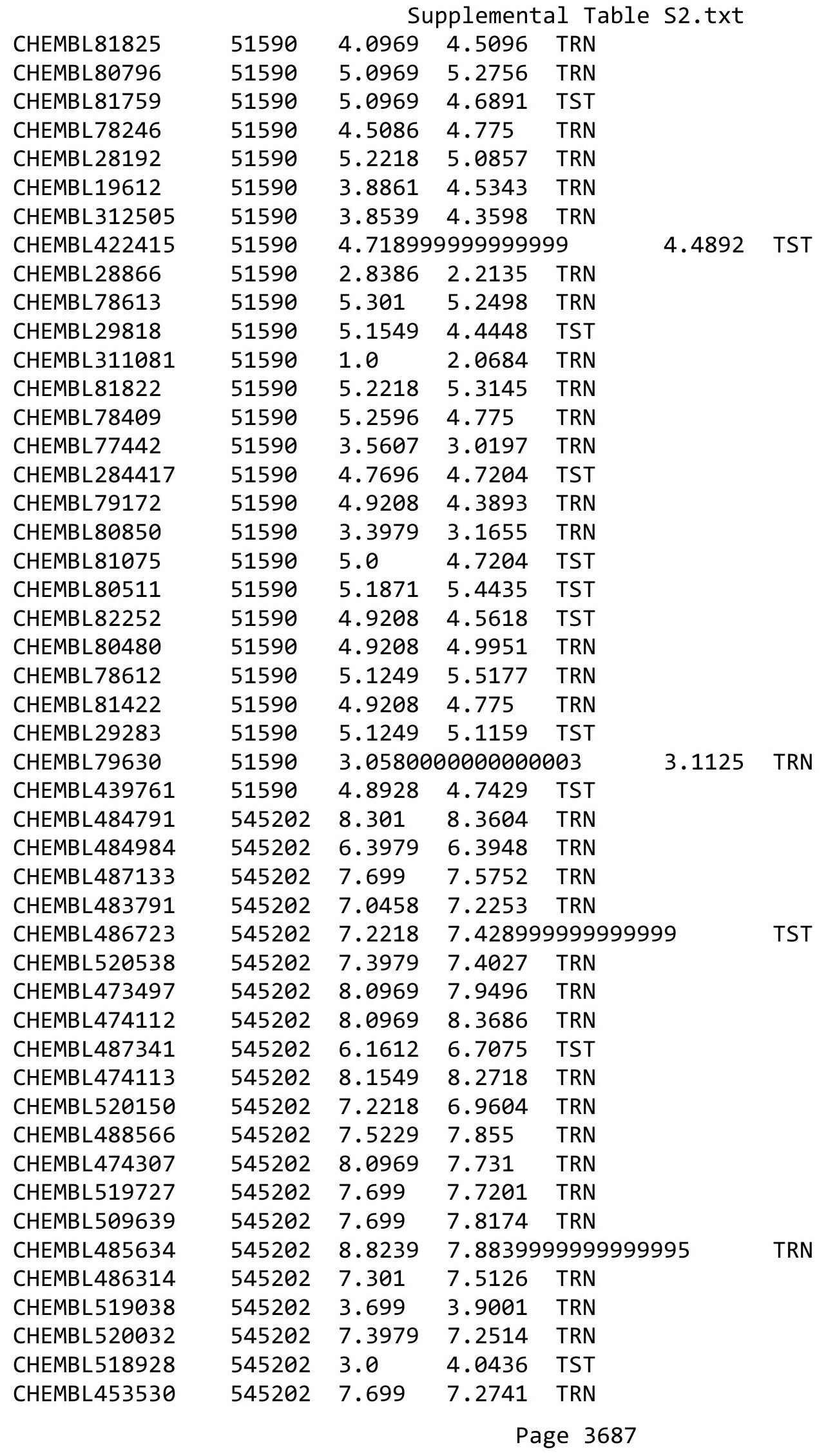




\begin{tabular}{|c|c|c|c|c|}
\hline & & & pplement & al $\mathrm{T}$ \\
\hline CHEMBL355113 & 545202 & 8.1549 & 7.7947 & TST \\
\hline CHEMBL483967 & 545202 & 7.5229 & 7.3712 & TRN \\
\hline CHEMBL484819 & 545202 & 8.301 & 7.7798 & TST \\
\hline CHEMBL472890 & 545202 & 8.0969 & 8.0678 & TRN \\
\hline CHEMBL519832 & 545202 & 7.301 & 4.4582 & TST \\
\hline CHEMBL352047 & 545202 & 7.6021 & 7.8965 & TRN \\
\hline CHEMBL484792 & 545202 & 7.2218 & 7.5796 & TRN \\
\hline CHEMBL488377 & 545202 & 7.1549 & 6.8938 & TRN \\
\hline CHEMBL487329 & 545202 & 7.301 & 7.7728 & TRN \\
\hline CHEMBL521236 & 545202 & 8.1549 & 8.0365 & TRN \\
\hline CHEMBL519825 & 545202 & 7.301 & 7.0658 & TRN \\
\hline CHEMBL487340 & 545202 & 4.7696 & 4.6466 & TRN \\
\hline CHEMBL483776 & 545202 & 4.6576 & 5.2491 & TRN \\
\hline CHEMBL520320 & 545202 & 7.4559 & 7.5506 & TRN \\
\hline CHEMBL475318 & 545202 & 5.2518 & 5.6338 & TRN \\
\hline CHEMBL486108 & 545202 & 6.0 & 6.5005 & TRN \\
\hline CHEMBL483966 & 545202 & 7.301 & 7.3841 & TRN \\
\hline CHEMBL520665 & 545202 & 8.2218 & 8.2004 & TRN \\
\hline CHEMBL484822 & 545202 & 7.699 & 7.7269 & TRN \\
\hline CHEMBL474306 & 545202 & 6.3979 & 6.0494 & TRN \\
\hline CHEMBL485900 & 545202 & 4.0809 & 6.1088 & TST \\
\hline CHEMBL488580 & 545202 & 3.0 & 5.9483 & TST \\
\hline CHEMBL486523 & 545202 & 5.0706 & 7.1724 & TST \\
\hline CHEMBL486527 & 545202 & 6.5229 & 6.5474 & TRN \\
\hline CHEMBL488565 & 545202 & 4.5376 & 4.9465 & TRN \\
\hline CHEMBL453271 & 545202 & 7.3979 & 7.3481 & TRN \\
\hline CHEMBL488153 & 545202 & 5.585 & 5.2887 & TST \\
\hline CHEMBL453531 & 545202 & 7.5229 & 7.4565 & TRN \\
\hline CHEMBL514482 & 545202 & 7.1549 & 7.477 & TRN \\
\hline CHEMBL475722 & 545202 & 8.0458 & 7.9314 & TRN \\
\hline CHEMBL483775 & 545202 & 5.0458 & 4.7493 & TRN \\
\hline CHEMBL487134 & 545202 & 7.5229 & 7.4401 & TRN \\
\hline CHEMBL473913 & 545202 & 7.699 & 7.1591 & TRN \\
\hline CHEMBL484823 & 545202 & 3.0 & 2.7179 & TRN \\
\hline CHEMBL488150 & 545202 & 7.699 & 7.5781 & TRN \\
\hline CHEMBL484982 & 545202 & 6.699 & 7.0455 & TST \\
\hline CHEMBL528320 & 545202 & 6.1549 & 5.4615 & TST \\
\hline CHEMBL472891 & 545202 & 8.0 & 8.1169 & TRN \\
\hline CHEMBL475726 & 545202 & 6.301 & 6.5213 & TRN \\
\hline CHEMBL520666 & 545202 & 6.699 & 7.579 & TST \\
\hline CHEMBL350396 & 545202 & 8.0969 & 8.3226 & TRN \\
\hline CHEMBL472889 & 545202 & 6.4559 & 6.3211 & TRN \\
\hline CHEMBL486107 & 545202 & 7.3979 & 7.1921 & TRN \\
\hline CHEMBL484983 & 545202 & 6.699 & 6.5776 & TRN \\
\hline CHEMBL166179 & 545202 & 7.0 & 7.2068 & TRN \\
\hline CHEMBL166332 & 545202 & 6.3979 & 6.2685 & TRN \\
\hline CHEMBL484790 & 545202 & 7.301 & 7.6305 & TST \\
\hline CHEMBL488374 & 545202 & 6.699 & 5.1046 & TST \\
\hline
\end{tabular}




\begin{tabular}{|c|c|c|c|c|c|}
\hline \multirow[b]{2}{*}{ CHEMBL527202 } & \multicolumn{5}{|c|}{ Supplemental Table S2.txt } \\
\hline & 545202 & 8.0 & 7.7517 & TST & \\
\hline CHEMBL514814 & 545202 & 7.5229 & 7.1091 & TST & \\
\hline CHEMBL515566 & 545202 & 7.699 & 7.7778 & TST & \\
\hline CHEMBL475317 & 545202 & 7.0 & 6.00899 & 99999999995 & TST \\
\hline CHEMBL 1170465 & 642499 & 6.0362 & 5.6512 & TRN & \\
\hline CHEMBL1170474 & 642499 & 6.1308 & 5.9573 & TRN & \\
\hline CHEMBL1171632 & 642499 & 5.9245 & 5.9589 & TRN & \\
\hline CHEMBL1170664 & 642499 & 5.7011 & 5.4414 & TST & \\
\hline CHEMBL1169898 & 642499 & 5.9031 & 5.54 & TST & \\
\hline CHEMBL1170673 & 642499 & 6.699 & 6.919 & TRN & \\
\hline CHEMBL1170271 & 642499 & 6.0862 & 6.0796 & TRN & \\
\hline CHEMBL1170279 & 642499 & 6.2291 & 5.7411 & TST & \\
\hline CHEMBL1170100 & 642499 & 6.2441 & 6.0524 & TRN & \\
\hline CHEMBL1173284 & 642499 & 5.8761 & 6.0207 & TRN & \\
\hline CHEMBL1170687 & 642499 & 6.0969 & 5.7328 & TST & \\
\hline CHEMBL1172795 & 642499 & 5.9031 & 6.184 & TRN & \\
\hline CHEMBL1170679 & 642499 & 6.8239 & 6.8721 & TRN & \\
\hline CHEMBL1169894 & 642499 & 6.0862 & 6.1392 & TRN & \\
\hline CHEMBL1173505 & 642499 & 4.301 & 4.9461 & TRN & \\
\hline CHEMBL1173359 & 642499 & 7.2007 & 7.4436 & TST & \\
\hline CHEMBL1169707 & 642499 & 6.7696 & 6.3606 & TRN & \\
\hline CHEMBL1172791 & 642499 & 5.9586 & 6.1769 & TRN & \\
\hline CHEMBL1172790 & 642499 & 5.8297 & 6.0785 & TRN & \\
\hline CHEMBL1172868 & 642499 & 5.8894 & 5.5095 & TRN & \\
\hline CHEMBL1173431 & 642499 & 6.0177 & 5.9998 & TRN & \\
\hline CHEMBL1170682 & 642499 & 5.9393 & 5.8954 & TRN & \\
\hline CHEMBL1172792 & 642499 & 6.7212 & 6.76 & TRN & \\
\hline CHEMBL1173136 & 642499 & 6.301 & 6.0835 & TRN & \\
\hline CHEMBL1170091 & 642499 & 6.4318 & 6.9776 & TRN & \\
\hline CHEMBL1170688 & 642499 & 5.6968 & 5.1955 & TST & \\
\hline CHEMBL1172403 & 642499 & 6.5376 & 6.5754 & TRN & \\
\hline CHEMBL1172938 & 642499 & 5.7905 & 6.3065 & TST & \\
\hline CHEMBL1173709 & 642499 & 5.7144 & 5.3643 & TST & \\
\hline CHEMBL1173502 & 642499 & 6.2676 & 6.651 & TRN & \\
\hline CHEMBL1170466 & 642499 & 6.3188 & 6.3644 & TRN & \\
\hline CHEMBL1170672 & 642499 & 6.8539 & 6.8071 & TRN & \\
\hline CHEMBL1172404 & 642499 & 6.8539 & 6.8922 & TRN & \\
\hline CHEMBL1169708 & 642499 & 6.585 & 6.6725 & TRN & \\
\hline CHEMBL1172933 & 642499 & 6.1612 & 5.9238 & TST & \\
\hline CHEMBL1172865 & 642499 & 4.301 & 3.9497 & TRN & \\
\hline CHEMBL1170890 & 642499 & 6.1675 & 6.0381 & TRN & \\
\hline CHEMBL1172727 & 642499 & 6.6576 & 6.5805 & TRN & \\
\hline CHEMBL1173507 & 642499 & 4.301 & 4.9334 & TRN & \\
\hline CHEMBL1170086 & 642499 & 7.4318 & 6.8798 & TRN & \\
\hline CHEMBL1172723 & 642499 & 5.8447 & 4.8737 & TST & \\
\hline CHEMBL1170886 & 642499 & 6.7696 & 6.919 & TRN & \\
\hline CHEMBL 1173286 & 642499 & 6.1871 & 6.2151 & TRN & \\
\hline CHEMBL1170680 & 642499 & 6.2676 & 6.3566 & TRN & \\
\hline
\end{tabular}




\begin{tabular}{|c|c|c|c|c|c|}
\hline \multirow[b]{2}{*}{ CHEMBL1173283 } & \multicolumn{5}{|c|}{ suppsemerticas } \\
\hline & 642499 & 6.284 & 5.9495 & TRN & \\
\hline CHEMBL1172934 & 642499 & 6.3279 & 6.7531 & TRN & \\
\hline CHEMBL1172864 & 642499 & 4.301 & 4.513 & TRN & \\
\hline CHEMBL1171436 & 642499 & 6.1308 & 5.9202 & TRN & \\
\hline CHEMBL1170274 & 642499 & 5.8601 & 6.0882 & TRN & \\
\hline CHEMBL1173508 & 642499 & 5.9136 & 5.4101 & TST & \\
\hline CHEMBL1173706 & 642499 & 5.8182 & 5.7863 & TST & \\
\hline CHEMBL1173435 & 642499 & 6.301 & 6.4812 & TRN & \\
\hline CHEMBL1170473 & 642499 & 5.6021 & 5.9695 & TRN & \\
\hline CHEMBL1170276 & 642499 & 5.9355 & 6.1563 & TRN & \\
\hline CHEMBL1173503 & 642499 & 5.71 & 6.0645 & TRN & \\
\hline CHEMBL1170463 & 642499 & 6.0 & 4.2117 & TST & \\
\hline CHEMBL1172595 & 642499 & 5.8633 & 6.0272 & TRN & \\
\hline CHEMBL1173206 & 642499 & 5.9508 & 6.0311 & TST & \\
\hline CHEMBL1173576 & 642499 & 6.0655 & 6.0863 & TRN & \\
\hline CHEMBL1170282 & 642499 & 6.1079 & 6.379 & TRN & \\
\hline CHEMBL1173005 & 642499 & 5.9136 & 6.13899 & 9999999999 & TRN \\
\hline CHEMBL1173281 & 642499 & 5.983 & 5.8655 & TST & \\
\hline CHEMBL1170689 & 642499 & 5.8697 & 5.17299 & 9999999999 & TST \\
\hline CHEMBL1173282 & 642499 & 6.3279 & 6.21200 & 0000000001 & TRN \\
\hline CHEMBL1170472 & 642499 & 5.9172 & 5.86600 & 00000000005 & TRN \\
\hline CHEMBL1173501 & 642499 & 6.0315 & 5.9461 & TRN & \\
\hline CHEMBL1173207 & 642499 & 5.8125 & 6.2742 & TST & \\
\hline CHEMBL1173504 & 642499 & 4.301 & 5.4029 & TRN & \\
\hline CHEMBL1173774 & 642499 & 5.8729 & 5.6649 & TST & \\
\hline CHEMBL1170671 & 642499 & 7.0458 & 6.5897 & TRN & \\
\hline CHEMBL1173506 & 642499 & 6.2147 & 4.9289 & TST & \\
\hline CHEMBL1171041 & 642499 & 7.1612 & 6.8922 & TRN & \\
\hline CHEMBL1170892 & 642499 & 7.4949 & 7.2523 & TRN & \\
\hline CHEMBL1170275 & 642499 & 6.585 & 6.3098 & TRN & \\
\hline CHEMBL1170099 & 642499 & 6.5528 & 6.5989 & TRN & \\
\hline CHEMBL1169899 & 642499 & 6.5229 & 6.2641 & TRN & \\
\hline CHEMBL1170696 & 642499 & 6.7696 & 6.7976 & TRN & \\
\hline CHEMBL1170273 & 642499 & 5.2823 & 5.8508 & TST & \\
\hline CHEMBL1170442 & 642499 & 5.7212 & 4.3873 & TST & \\
\hline CHEMBL1173061 & 642499 & 5.9666 & 6.1302 & TRN & \\
\hline CHEMBL1173127 & 642499 & 5.7959 & 5.4872 & TRN & \\
\hline CHEMBL1173777 & 642499 & 6.8239 & 6.2613 & TRN & \\
\hline CHEMBL1170897 & 642499 & 6.0655 & 4.65 & TST & \\
\hline CHEMBL1173135 & 642499 & 6.585 & 6.5728 & TRN & \\
\hline CHEMBL1173062 & 642499 & 6.0605 & 6.0587 & TRN & \\
\hline CHEMBL1172405 & 642499 & 6.0177 & 5.8678 & TRN & \\
\hline CHEMBL1173434 & 642499 & 5.6635 & 5.5296 & TRN & \\
\hline CHEMBL1170291 & 642499 & 5.9706 & 5.8057 & TRN & \\
\hline CHEMBL1169724 & 642499 & 6.9208 & 6.6892 & TRN & \\
\hline CHEMBL1172793 & 642499 & 6.8239 & 6.7342 & TRN & \\
\hline CHEMBL1172794 & 642499 & 6.4559 & 6.1766 & TRN & \\
\hline CHEMBL1170280 & 642499 & 5.75700 & 30000000 & 5.474 & TST \\
\hline & & & & 3690 & \\
\hline
\end{tabular}


Supplemental Table S2.txt

\begin{tabular}{|c|c|c|c|c|c|}
\hline CHEMBL1172867 & 642499 & 6.3872 & 6.1505 & TRN & \\
\hline CHEMBL1172724 & 642499 & 5.6459 & 5.2114 & TST & \\
\hline CHEMBL1173570 & 642499 & 5.9788 & 5.4856 & TRN & \\
\hline CHEMBL1169709 & 642499 & 6.2366 & 6.167999 & 9999999999 & TRN \\
\hline CHEMBL1169900 & 642499 & 5.7375 & 5.4071 & TRN & \\
\hline CHEMBL1172722 & 642499 & 6.2366 & 6.1433 & TRN & \\
\hline CHEMBL1171092 & 642499 & 5.8041 & 6.0536 & TRN & \\
\hline CHEMBL1170088 & 642499 & 5.301 & 5.5787 & TRN & \\
\hline CHEMBL1172398 & 642499 & 6.1024 & 6.0702 & TRN & \\
\hline CHEMBL1170272 & 642499 & 4.301 & 6.1837 & TST & \\
\hline CHEMBL1170681 & 642499 & 6.5686 & 6.2818 & TRN & \\
\hline CHEMBL1173575 & 642499 & 6.0655 & 6.6958 & TRN & \\
\hline CHEMBL1170464 & 642499 & 5.9547 & 3.6635 & TST & \\
\hline CHEMBL1171992 & 642499 & 5.6234 & 5.4717 & TRN & \\
\hline CHEMBL1172863 & 642499 & 4.301 & 4.3104 & TRN & \\
\hline CHEMBL1173063 & 642499 & 6.2366 & 6.4819 & TRN & \\
\hline CHEMBL1173365 & 642499 & 6.1135 & 6.4318 & TRN & \\
\hline CHEMBL1172596 & 642499 & 6.1612 & 6.6043 & TRN & \\
\hline CHEMBL1171486 & 642499 & 5.9136 & 5.8967 & TRN & \\
\hline CHEMBL1173360 & 642499 & 7.2218 & 7.1773 & TRN & \\
\hline CHEMBL1173205 & 642499 & 5.699 & \multicolumn{2}{|c|}{6.287999999999999} & TST \\
\hline CHEMBL1173208 & 642499 & 6.6021 & 6.6372 & TST & \\
\hline CHEMBL1170288 & 642499 & 6.0458 & 3.1656 & TST & \\
\hline CHEMBL1172789 & 642499 & 6.7696 & 6.7051 & TRN & \\
\hline CHEMBL1173364 & 642499 & 6.1487 & 6.5118 & TRN & \\
\hline CHEMBL1170686 & 642499 & 5.9393 & 4.9313 & TST & \\
\hline CHEMBL1170093 & 642499 & 6.7212 & 6.9098 & TRN & \\
\hline CHEMBL1172869 & 642499 & 6.1739 & 6.0474 & TRN & \\
\hline CHEMBL1170281 & 642499 & 6.2291 & 4.3194 & TST & \\
\hline CHEMBL1172726 & 642499 & 6.9586 & 6.9654 & TRN & \\
\hline CHEMBL1170098 & 642499 & 6.7447 & 6.8053 & TRN & \\
\hline CHEMBL1173433 & 642499 & 5.9208 & 5.9652 & TRN & \\
\hline CHEMBL1173071 & 642499 & 5.5229 & 5.5803 & TRN & \\
\hline CHEMBL1170891 & 642499 & 7.2291 & 6.8167 & TRN & \\
\hline CHEMBL1170439 & 642499 & 5.8268 & 5.8337 & TRN & \\
\hline CHEMBL1170092 & 642499 & 7.1612 & 7.3181 & TRN & \\
\hline CHEMBL1173362 & 642499 & 6.9586 & 6.8106 & TRN & \\
\hline CHEMBL1172597 & 642499 & 5.9318 & 6.0295 & TRN & \\
\hline CHEMBL1170069 & 642499 & 6.1367 & 6.0702 & TRN & \\
\hline CHEMBL1172862 & 642499 & 6.2218 & 6.8124 & TRN & \\
\hline CHEMBL1169706 & 642499 & 6.5376 & 6.3191 & TST & \\
\hline CHEMBL1169722 & 642499 & 5.4191 & 6.1211 & TST & \\
\hline CHEMBL1172725 & 642499 & 7.3979 & 7.0147 & TRN & \\
\hline CHEMBL1173361 & 642499 & 7.1675 & 7.3668 & TRN & \\
\hline CHEMBL1169903 & 642499 & 6.2218 & 6.1385 & TRN & \\
\hline CHEMBL1172406 & 642499 & 6.2291 & 6.1897 & TRN & \\
\hline CHEMBL1173569 & 642499 & 4.301 & 4.2267 & TRN & \\
\hline CHEMBL1170087 & 642499 & 6.4559 & 6.1392 & TRN & \\
\hline
\end{tabular}


Supplemental Table S2.txt

\begin{tabular}{|c|c|c|c|c|}
\hline CHEMBL1172939 & 642499 & 6.0506 & 6.6626 & TST \\
\hline CHEMBL1172866 & 642499 & 6.3188 & 6.3098 & TST \\
\hline CHEMBL1172788 & 642499 & 5.6925 & 6.4053 & TST \\
\hline CHEMBL1169725 & 642499 & 5.6556 & 5.5848 & TRN \\
\hline CHEMBL1173004 & 642499 & 6.0862 & 6.0972 & TRN \\
\hline CHEMBL1170871 & 642499 & 7.4647 & 6.331 & TRN \\
\hline CHEMBL1173578 & 642499 & 6.0362 & 6.1882 & TRN \\
\hline CHEMBL1173132 & 642499 & 5.7011 & 6.2456 & TST \\
\hline CHEMBL1170887 & 642499 & 7.3372 & 6.74700 & 0000000001 \\
\hline CHEMBL1172728 & 642499 & 7.5376 & 7.3597 & TST \\
\hline CHEMBL1172207 & 642499 & 5.6925 & 5.9487 & TRN \\
\hline CHEMBL1171500 & 642499 & 6.1249 & 6.2612 & TRN \\
\hline CHEMBL 3642185 & 1527711 & 6.5918 & 6.8095 & TRN \\
\hline CHEMBL 3642176 & 1527711 & 7.0458 & 6.3656 & TST \\
\hline CHEMBL 3642189 & 1527711 & 8.301 & 8.5387 & TRN \\
\hline CHEMBL 3642208 & 1527711 & 8.699 & 8.6985 & TRN \\
\hline CHEMBL3642177 & 1527711 & 6.4342 & 6.5697 & TST \\
\hline CHEMBL 3957823 & 1527711 & 8.3979 & 7.5487 & TST \\
\hline CHEMBL 3642225 & 1527711 & 5.8383 & 5.8857 & TRN \\
\hline CHEMBL3642191 & 1527711 & 8.699 & 8.6635 & TRN \\
\hline CHEMBL3642216 & 1527711 & 5.8398 & 5.9752 & TRN \\
\hline CHEMBL 3642227 & 1527711 & 5.6107 & 5.3688 & TRN \\
\hline CHEMBL 3642197 & 1527711 & 10.0 & 10.0352 & TRN \\
\hline CHEMBL 3639410 & 1527711 & 9.0 & 9.2419 & TRN \\
\hline CHEMBL 3642195 & 1527711 & 8.699 & 8.7942 & TRN \\
\hline CHEMBL 3642190 & 1527711 & 7.8861 & 8.0599 & TRN \\
\hline CHEMBL 3642181 & 1527711 & 8.301 & 8.3752 & TRN \\
\hline CHEMBL 3642196 & 1527711 & 9.0 & 8.9051 & TRN \\
\hline CHEMBL 3642192 & 1527711 & 9.0 & 8.9189 & TRN \\
\hline CHEMBL 2180798 & 1527711 & 10.0 & 9.3993 & TRN \\
\hline CHEMBL 3642215 & 1527711 & 6.2132 & 6.4211 & TRN \\
\hline CHEMBL 3642223 & 1527711 & 7.0605 & 7.3303 & TRN \\
\hline CHEMBL 3642226 & 1527711 & 6.1073 & 5.9913 & TRN \\
\hline CHEMBL 3642207 & 1527711 & 7.6778 & 7.857 & TRN \\
\hline CHEMBL 3642211 & 1527711 & 7.6198 & 7.5463 & TRN \\
\hline CHEMBL 3644766 & 1527711 & 6.7282 & 6.9714 & TST \\
\hline CHEMBL 3642220 & 1527711 & 8.3979 & 8.3199 & TRN \\
\hline CHEMBL 3642219 & 1527711 & 9.0 & 7.657 & TST \\
\hline CHEMBL 3642209 & 1527711 & 8.5229 & 8.5793 & TRN \\
\hline CHEMBL 3644764 & 1527711 & 5.6899 & 7.07 & TST \\
\hline CHEMBL 3642184 & 1527711 & 8.301 & 8.3782 & TRN \\
\hline CHEMBL 3642210 & 1527711 & 8.5229 & 8.7848 & TRN \\
\hline CHEMBL3642182 & 1527711 & 6.9136 & 6.7088 & TRN \\
\hline CHEMBL 3642221 & 1527711 & 7.4815 & 6.8322 & TST \\
\hline CHEMBL 3642199 & 1527711 & 8.5229 & 8.5451 & TRN \\
\hline CHEMBL 3642201 & 1527711 & 8.699 & 8.7474 & TRN \\
\hline CHEMBL3642186 & 1527711 & 9.0 & 9.1806 & TRN \\
\hline CHEMBL 2180800 & 1527711 & 8.699 & 7.4423 & TST \\
\hline
\end{tabular}




$$
\text { Supplemental Table S2.txt }
$$

\begin{tabular}{|c|c|c|c|c|c|}
\hline CHEMBL 3642198 & 1527711 & 8.699 & 8.7 & TRN & \\
\hline CHEMBL 3642212 & 1527711 & 8.3979 & 8.411 & TRN & \\
\hline CHEMBL 3642180 & 1527711 & 8.0 & 6.9141 & TST & \\
\hline CHEMBL 3642204 & 1527711 & 9.0 & 9.1635 & TRN & \\
\hline CHEMBL3642217 & 1527711 & 6.3615 & 6.0905 & TST & \\
\hline CHEMBL 3642206 & 1527711 & 9.0 & 8.9588 & TRN & \\
\hline CHEMBL 3642224 & 1527711 & 8.3979 & 8.2249 & TRN & \\
\hline CHEMBL 3642200 & 1527711 & 9.0 & 8.9826 & TRN & \\
\hline CHEMBL 3642193 & 1527711 & 8.3979 & 8.4265 & TRN & \\
\hline CHEMBL3642194 & 1527711 & 8.699 & 8.5921 & TRN & \\
\hline CHEMBL 3642179 & 1527711 & 7.6383 & 6.1083 & TST & \\
\hline CHEMBL 3642205 & 1527711 & 6.7696 & 6.7669 & TRN & \\
\hline CHEMBL 3642203 & 1527711 & 9.0 & 8.9018 & TRN & \\
\hline CHEMBL 2180799 & 1527711 & 10.0 & 9.9658 & TRN & \\
\hline CHEMBL 3642222 & 1527711 & 7.699 & 7.7018 & TRN & \\
\hline CHEMBL 3642202 & 1527711 & 8.301 & 8.42799 & 9999999999 & TRN \\
\hline CHEMBL 3642214 & 1527711 & 5.1953 & 4.9592 & TST & \\
\hline CHEMBL 3644765 & 1527711 & 7.2596 & 7.645 & TST & \\
\hline CHEMBL 3642230 & 1527711 & 7.5528 & 7.194 & TRN & \\
\hline CHEMBL 3642229 & 1527711 & 8.2218 & 8.0263 & TRN & \\
\hline CHEMBL 3642178 & 1527711 & 7.3188 & 6.4139 & TST & \\
\hline CHEMBL 3642188 & 1527711 & 8.699 & 8.7069 & TRN & \\
\hline CHEMBL 3642218 & 1527711 & 6.1284 & 7.2898 & TST & \\
\hline CHEMBL 3642187 & 1527711 & 8.3979 & 8.1855 & TRN & \\
\hline CHEMBL 3642183 & 1527711 & 8.699 & 8.5391 & TRN & \\
\hline CHEMBL 3642228 & 1527711 & 8.1549 & 8.0266 & TRN & \\
\hline CHEMBL 3642213 & 1527711 & 5.7261 & 6.3546 & TST & \\
\hline CHEMBL 3644763 & 1527711 & 6.4855 & 6.6346 & TRN & \\
\hline CHEMBL1978271 & 809131 & 6.5 & 6.7036 & TRN & \\
\hline CHEMBL 2007266 & 809131 & 4.4 & 4.7146 & TRN & \\
\hline CHEMBL 202721 & 809131 & 4.4 & 4.0063 & TRN & \\
\hline CHEMBL 2000568 & 809131 & 4.4 & 4.3198 & TRN & \\
\hline CHEMBL1994308 & 809131 & 4.4 & 4.7937 & TRN & \\
\hline CHEMBL 2007097 & 809131 & 4.3 & 4.0833 & TRN & \\
\hline CHEMBL1825138 & 809131 & 4.4 & 4.7475 & TST & \\
\hline CHEMBL1973516 & 809131 & 4.4 & 4.1387 & TRN & \\
\hline CHEMBL1974328 & 809131 & 4.4 & 4.0797 & TRN & \\
\hline CHEMBL509032 & 809131 & 4.4 & 4.4831 & TRN & \\
\hline CHEMBL 388311 & 809131 & 6.2 & 5.6553 & TRN & \\
\hline CHEMBL1998765 & 809131 & 6.2 & 6.4735 & TRN & \\
\hline CHEMBL1964948 & 809131 & 6.9 & 6.2391 & TRN & \\
\hline CHEMBL1973013 & 809131 & 4.4 & 4.5809 & TRN & \\
\hline CHEMBL1987430 & 809131 & 4.4 & 4.0851 & TRN & \\
\hline CHEMBL1993413 & 809131 & 5.5 & 4.8207 & TRN & \\
\hline CHEMBL205415 & 809131 & 4.4 & 4.2999 & TRN & \\
\hline CHEMBL1975927 & 809131 & 4.4 & 4.846 & TRN & \\
\hline CHEMBL1986943 & 809131 & 4.4 & 5.5117 & TRN & \\
\hline CHEMBL289959 & 809131 & 4.1 & 3.7384 & TRN & \\
\hline
\end{tabular}




\begin{tabular}{|c|c|c|c|c|}
\hline & & & ement & al $\mathrm{T}$ \\
\hline CHEMBL1997119 & 809131 & 4.3 & 4.0267 & TRN \\
\hline CHEMBL1977138 & 809131 & 5.5 & 5.6384 & TRN \\
\hline CHEMBL1978448 & 809131 & 4.4 & 4.4972 & TST \\
\hline CHEMBL1980329 & 809131 & 5.6 & 5.0072 & TRN \\
\hline CHEMBL1992042 & 809131 & 4.4 & 4.798 & TRN \\
\hline CHEMBL1986265 & 809131 & 4.4 & 4.8345 & TRN \\
\hline CHEMBL1967211 & 809131 & 4.1 & 5.2423 & TST \\
\hline CHEMBL1968727 & 809131 & 6.1 & 6.2564 & TRN \\
\hline CHEMBL1991734 & 809131 & 6.2 & 5.7493 & TRN \\
\hline CHEMBL 21156 & 809131 & 4.4 & 5.636 & TRN \\
\hline CHEMBL 1380050 & 809131 & 4.3 & 4.4881 & TRN \\
\hline CHEMBL1994724 & 809131 & 4.4 & 4.5405 & TRN \\
\hline CHEMBL1989267 & 809131 & 5.4 & 5.9268 & TRN \\
\hline CHEMBL1991782 & 809131 & 3.1 & 3.1645 & TRN \\
\hline CHEMBL1983348 & 809131 & 4.4 & 4.4279 & TRN \\
\hline CHEMBL 1974574 & 809131 & 4.4 & 5.0183 & TRN \\
\hline CHEMBL1970290 & 809131 & 7.1 & 6.6521 & TRN \\
\hline CHEMBL1993877 & 809131 & 4.4 & 4.4287 & TRN \\
\hline CHEMBL1996500 & 809131 & 8.5 & 8.7382 & TRN \\
\hline CHEMBL1973363 & 809131 & 5.6 & 5.1282 & TRN \\
\hline CHEMBL1965469 & 809131 & 6.1 & 6.2673 & TRN \\
\hline CHEMBL1986177 & 809131 & 4.4 & 4.1998 & TRN \\
\hline CHEMBL1989708 & 809131 & 4.4 & 5.1218 & TRN \\
\hline CHEMBL1976420 & 809131 & 4.4 & 4.6495 & TRN \\
\hline CHEMBL1998253 & 809131 & 4.4 & 4.1799 & TST \\
\hline CHEMBL1981744 & 809131 & 4.4 & 4.1875 & TRN \\
\hline CHEMBL1985367 & 809131 & 4.4 & 4.3995 & TRN \\
\hline CHEMBL1996510 & 809131 & 4.4 & 4.8966 & TRN \\
\hline CHEMBL 2000029 & 809131 & 4.4 & 4.163 & TRN \\
\hline CHEMBL1995172 & 809131 & 4.4 & 4.0088 & TST \\
\hline CHEMBL 2001584 & 809131 & 4.4 & 5.1426 & TRN \\
\hline CHEMBL1973961 & 809131 & 4.4 & 4.4803 & TRN \\
\hline CHEMBL1967998 & 809131 & 4.4 & 4.5074 & TRN \\
\hline CHEMBL1978562 & 809131 & 5.7 & 5.104 & TRN \\
\hline CHEMBL1994977 & 809131 & 6.6 & 6.3032 & TRN \\
\hline CHEMBL 2001149 & 809131 & 4.4 & 4.5419 & TRN \\
\hline CHEMBL 2005478 & 809131 & 5.5 & 5.2808 & TRN \\
\hline CHEMBL1996646 & 809131 & 4.4 & 5.1058 & TRN \\
\hline CHEMBL1979773 & 809131 & 6.1 & 6.1472 & TRN \\
\hline CHEMBL1989471 & 809131 & 4.4 & 4.8708 & TST \\
\hline CHEMBL 2002099 & 809131 & 4.4 & 4.0927 & TRN \\
\hline CHEMBL1996702 & 809131 & 4.4 & 4.1661 & TRN \\
\hline CHEMBL 2007124 & 809131 & 4.4 & 4.9545 & TRN \\
\hline CHEMBL1978195 & 809131 & 4.4 & 4.806 & TRN \\
\hline CHEMBL 2006439 & 809131 & 4.4 & 4.8206 & TRN \\
\hline CHEMBL1985681 & 809131 & 4.4 & 4.5263 & TRN \\
\hline CHEMBL 2002660 & 809131 & 6.4 & 6.4218 & TRN \\
\hline CHEMBL1982711 & 809131 & 4.4 & 4.1616 & TRN \\
\hline
\end{tabular}




\begin{tabular}{|c|c|c|c|c|c|}
\hline \multicolumn{6}{|c|}{ Supplemental Table S2.txt } \\
\hline CHEMBL1984842 & 809131 & 8.8 & 8.8173 & TRN & \\
\hline CHEMBL 2004118 & 809131 & 4.4 & 4.5027 & TRN & \\
\hline CHEMBL1996345 & 809131 & 4.4 & 4.3519 & TRN & \\
\hline CHEMBL 2004025 & 809131 & 4.4 & 5.1343 & TRN & \\
\hline CHEMBL1996048 & 809131 & 4.4 & 4.6983 & TRN & \\
\hline CHEMBL50894 & 809131 & 4.4 & 4.06800 & 00000000005 & TRN \\
\hline CHEMBL1976158 & 809131 & 6.0 & 5.7683 & TRN & \\
\hline CHEMBL1995211 & 809131 & 4.4 & 4.1418 & TRN & \\
\hline CHEMBL1965033 & 809131 & 5.7 & 5.7834 & TRN & \\
\hline CHEMBL461876 & 809131 & 4.4 & 4.8839 & TRN & \\
\hline CHEMBL 2006299 & 809131 & 4.4 & 4.6285 & TRN & \\
\hline CHEMBL1971519 & 809131 & 4.3 & 3.8022 & TRN & \\
\hline CHEMBL1997335 & 809131 & 6.3 & 5.1883 & TRN & \\
\hline CHEMBL1965169 & 809131 & 4.4 & 4.4157 & TRN & \\
\hline CHEMBL1991818 & 809131 & 4.4 & 4.5719 & TRN & \\
\hline CHEMBL1081312 & 809131 & 5.6 & 5.1182 & TRN & \\
\hline CHEMBL1971132 & 809131 & 4.4 & 4.6272 & TRN & \\
\hline CHEMBL1965170 & 809131 & 4.4 & 4.9269 & TRN & \\
\hline CHEMBL1994808 & 809131 & 4.1 & 4.6148 & TRN & \\
\hline CHEMBL 2005792 & 809131 & 9.3 & 9.0055 & TRN & \\
\hline CHEMBL1986503 & 809131 & 5.5 & 4.6832 & TST & \\
\hline CHEMBL1972355 & 809131 & 5.4 & 5.5366 & TRN & \\
\hline CHEMBL1997892 & 809131 & 7.0 & 6.0822 & TRN & \\
\hline CHEMBL1991377 & 809131 & 6.4 & 5.1383 & TRN & \\
\hline CHEMBL1997193 & 809131 & 5.6 & 4.5796 & TST & \\
\hline CHEMBL1964902 & 809131 & 7.0 & 6.9445 & TRN & \\
\hline CHEMBL1973868 & 809131 & 4.4 & 4.9002 & TRN & \\
\hline CHEMBL1972462 & 809131 & 4.4 & 3.9305 & TRN & \\
\hline CHEMBL1983715 & 809131 & 6.2 & 6.5118 & TRN & \\
\hline CHEMBL1984500 & 809131 & 3.1 & 3.4088 & TRN & \\
\hline CHEMBL 2002992 & 809131 & 4.4 & 4.1648 & TRN & \\
\hline CHEMBL1982700 & 809131 & 4.4 & 4.5221 & TRN & \\
\hline CHEMBL10 & 809131 & 7.7 & 7.405 & TRN & \\
\hline CHEMBL1980763 & 809131 & 4.4 & 4.4958 & TRN & \\
\hline CHEMBL1977634 & 809131 & 6.6 & 6.5448 & TRN & \\
\hline CHEMBL1977931 & 809131 & 4.1 & 4.1891 & TRN & \\
\hline CHEMBL1969156 & 809131 & 5.0 & 4.3677 & TRN & \\
\hline CHEMBL 2007479 & 809131 & 4.4 & 4.0883 & TRN & \\
\hline CHEMBL1971606 & 809131 & 4.4 & 4.1987 & TRN & \\
\hline CHEMBL1972220 & 809131 & 6.7 & 5.5403 & TRN & \\
\hline CHEMBL1981215 & 809131 & 4.4 & 4.2598 & TRN & \\
\hline CHEMBL 2003785 & 809131 & 4.8 & 4.4072 & TRN & \\
\hline CHEMBL1973720 & 809131 & 5.7 & 5.3428 & TRN & \\
\hline CHEMBL1999414 & 809131 & 5.6 & 4.9071 & TRN & \\
\hline CHEMBL1967336 & 809131 & 4.4 & 4.552 & TRN & \\
\hline CHEMBL 2001923 & 809131 & 4.4 & 5.2453 & TRN & \\
\hline CHEMBL1983070 & 809131 & 4.4 & 4.4318 & TRN & \\
\hline CHEMBL 2003514 & 809131 & 4.4 & 4.4817 & TRN & \\
\hline
\end{tabular}




\begin{tabular}{|c|c|c|c|c|c|}
\hline & & \multicolumn{4}{|c|}{ Supplemental Table S2.txt } \\
\hline CHEMBL1967992 & 809131 & 4.4 & \multicolumn{2}{|c|}{5.093999999999999} & TRN \\
\hline CHEMBL1989043 & 809131 & 4.4 & 4.346 & TRN & \\
\hline CHEMBL1981671 & 809131 & 4.4 & \multicolumn{2}{|c|}{3.9760000000000004} & TRN \\
\hline CHEMBL 2006450 & 809131 & 4.4 & 4.4129 & TRN & \\
\hline CHEMBL 2001987 & 809131 & 4.4 & 4.3301 & TRN & \\
\hline CHEMBL1994555 & 809131 & 4.4 & 4.1061 & TRN & \\
\hline CHEMBL1164180 & 809131 & 4.4 & 4.9961 & TST & \\
\hline CHEMBL1975121 & 809131 & 4.4 & 4.4533 & TRN & \\
\hline CHEMBL1983640 & 809131 & 6.3 & 5.5127 & TRN & \\
\hline CHEMBL1997611 & 809131 & 4.4 & 5.459 & TST & \\
\hline CHEMBL1971943 & 809131 & 4.4 & 4.3505 & TRN & \\
\hline CHEMBL 2002723 & 809131 & 5.5 & 5.2403 & TRN & \\
\hline CHEMBL1984686 & 809131 & 4.4 & 4.5528 & TST & \\
\hline CHEMBL1973793 & 809131 & 5.8 & 5.0232 & TRN & \\
\hline CHEMBL1992073 & 809131 & 4.4 & 4.3383 & TRN & \\
\hline CHEMBL1992334 & 809131 & 6.2 & 6.3932 & TRN & \\
\hline CHEMBL1990254 & 809131 & 4.4 & 4.4728 & TRN & \\
\hline CHEMBL1986143 & 809131 & 4.4 & 4.5014 & TRN & \\
\hline CHEMBL1972934 & 809131 & 4.4 & 3.7683 & TRN & \\
\hline CHEMBL 2007559 & 809131 & 4.4 & 4.3843 & TRN & \\
\hline CHEMBL1992581 & 809131 & 4.4 & \multicolumn{2}{|c|}{4.5089999999999995} & TRN \\
\hline CHEMBL 2004290 & 809131 & 4.4 & 5.3284 & TRN & \\
\hline CHEMBL1983573 & 809131 & 4.9 & 4.3296 & TRN & \\
\hline CHEMBL1975923 & 809131 & 6.2 & 5.1153 & TST & \\
\hline CHEMBL1984847 & 809131 & 4.4 & 5.1763 & TRN & \\
\hline CHEMBL 2005449 & 809131 & 4.4 & \multicolumn{2}{|c|}{4.5360000000000005} & TRN \\
\hline CHEMBL1996576 & 809131 & 4.4 & 4.666 & TST & \\
\hline CHEMBL1991678 & 809131 & 9.9 & 9.1223 & TRN & \\
\hline CHEMBL1987998 & 809131 & 4.4 & 4.2973 & TRN & \\
\hline CHEMBL1990496 & 809131 & 9.6 & 8.4755 & TRN & \\
\hline CHEMBL242865 & 809131 & 5.9 & 6.1154 & TRN & \\
\hline CHEMBL235157 & 809131 & 4.4 & 4.3144 & TST & \\
\hline CHEMBL1983884 & 809131 & 3.1 & 4.0406 & TRN & \\
\hline CHEMBL 2004159 & 809131 & 4.4 & 4.7679 & TRN & \\
\hline CHEMBL1978371 & 809131 & 4.4 & 5.1028 & TST & \\
\hline CHEMBL440084 & 809131 & 4.4 & 4.7812 & TRN & \\
\hline CHEMBL550275 & 809131 & 5.6 & 5.438 & TRN & \\
\hline CHEMBL1998110 & 809131 & 4.4 & 4.6196 & TRN & \\
\hline CHEMBL1978166 & 809131 & 6.0 & 5.6022 & TRN & \\
\hline CHEMBL1972454 & 809131 & 5.1 & 4.7666 & TRN & \\
\hline CHEMBL 2001451 & 809131 & 6.1 & 6.2363 & TRN & \\
\hline CHEMBL1990590 & 809131 & 4.4 & 4.5277 & TRN & \\
\hline CHEMBL1977814 & 809131 & 4.4 & 5.2811 & TST & \\
\hline CHEMBL86755 & 809131 & 4.4 & 4.7206 & TRN & \\
\hline CHEMBL1965660 & 809131 & 4.4 & 5.0816 & TRN & \\
\hline CHEMBL1966175 & 809131 & 4.4 & 4.2716 & TRN & \\
\hline CHEMBL 2007375 & 809131 & 4.4 & 4.3475 & TRN & \\
\hline CHEMBL379975 & 809131 & 4.4 & 4.3394 & TRN & \\
\hline
\end{tabular}




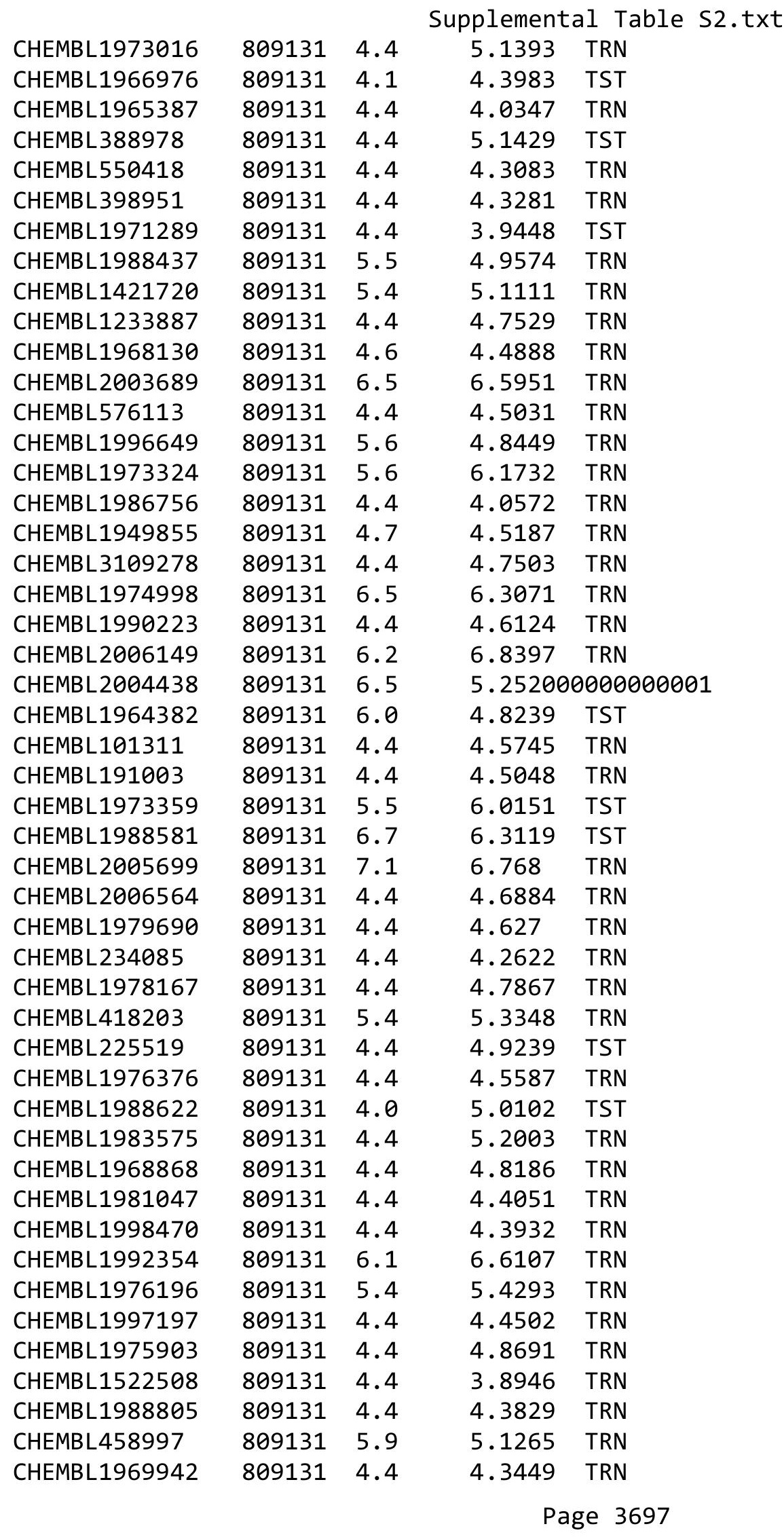




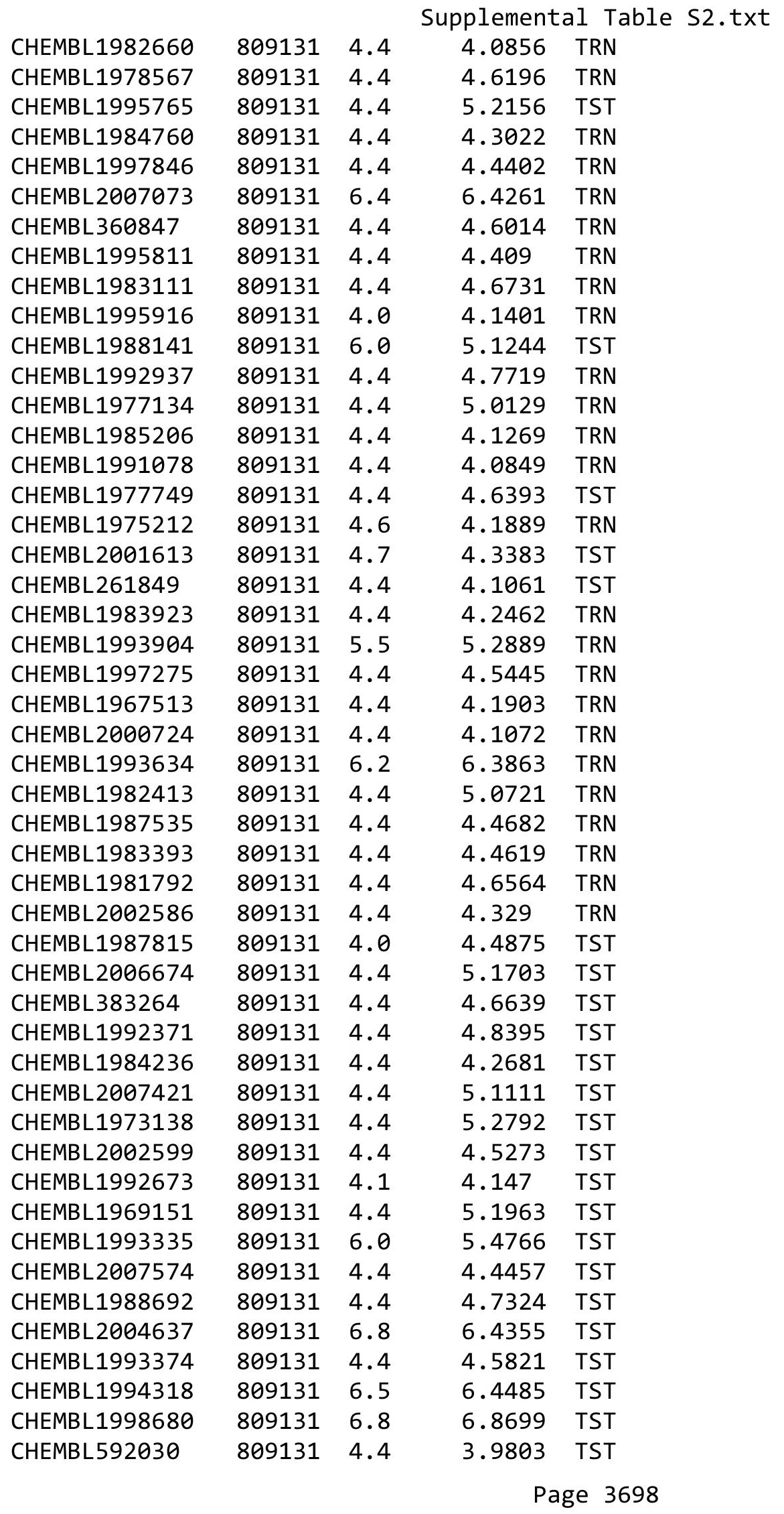




\begin{tabular}{|c|c|c|c|c|}
\hline \multicolumn{5}{|c|}{ Supplemental Table S2.txt } \\
\hline CHEMBL1999506 & 809131 & 6.6 & 6.1921 & TST \\
\hline CHEMBL1605605 & 809131 & 4.4 & 4.632 & TST \\
\hline CHEMBL2002736 & 809131 & 4.4 & 3.6893 & TST \\
\hline CHEMBL1997007 & 809131 & 4.4 & 4.0142 & TST \\
\hline CHEMBL1970352 & 809131 & 5.5 & 5.2592 & TST \\
\hline CHEMBL 2002690 & 809131 & 5.6 & 4.6764 & TST \\
\hline CHEMBL1980167 & 809131 & 5.9 & 6.2827 & TST \\
\hline CHEMBL278041 & 809131 & 8.3 & 6.9273 & TST \\
\hline CHEMBL 215152 & 809131 & 4.4 & 4.4175 & TST \\
\hline CHEMBL2006765 & 809131 & 4.4 & 4.8817 & TST \\
\hline CHEMBL1986590 & 809131 & 4.4 & 4.4172 & TST \\
\hline CHEMBL1870106 & 809131 & 4.4 & 4.8799 & TST \\
\hline CHEMBL406845 & 809131 & 6.3 & 5.8094 & TST \\
\hline CHEMBL1980246 & 809131 & 4.4 & 3.3754 & TST \\
\hline CHEMBL1983980 & 809131 & 6.0 & 6.0062 & TST \\
\hline CHEMBL1999484 & 809131 & 4.5 & 5.8586 & TST \\
\hline CHEMBL1984296 & 809131 & 4.4 & 5.5648 & TST \\
\hline CHEMBL1986899 & 809131 & 6.4 & 4.8939 & TST \\
\hline CHEMBL1984038 & 809131 & 4.4 & 5.2365 & TST \\
\hline CHEMBL1993661 & 809131 & 4.4 & 4.9465 & TST \\
\hline CHEMBL1968705 & 809131 & 4.4 & 3.77 & TST \\
\hline CHEMBL1991410 & 809131 & 4.4 & 4.6599 & TST \\
\hline CHEMBL1964441 & 809131 & 4.4 & 5.0989 & TST \\
\hline CHEMBL546797 & 809131 & 4.4 & 3.9885 & TST \\
\hline CHEMBL3922110 & 1642123 & 4.0 & 4.1309 & TRN \\
\hline CHEMBL3982308 & 1642123 & 4.0 & 3.668 & TRN \\
\hline CHEMBL3972174 & 1642123 & 4.0 & 4.54 & TRN \\
\hline CHEMBL3955149 & 1642123 & 4.0 & 4.351 & TST \\
\hline CHEMBL 3941805 & 1642123 & 4.0 & 3.7777 & TRN \\
\hline CHEMBL3940136 & 1642123 & 4.0 & 3.8049 & TRN \\
\hline CHEMBL3958638 & 1642123 & 4.0 & 4.3334 & TRN \\
\hline CHEMBL 3897142 & 1642123 & 4.0 & 4.2692 & TRN \\
\hline CHEMBL 3924010 & 1642123 & 4.0 & 3.9184 & TRN \\
\hline CHEMBL 3982644 & 1642123 & 4.0 & 3.9104 & TRN \\
\hline CHEMBL3932963 & 1642123 & 4.0 & 3.8877 & TRN \\
\hline CHEMBL3890097 & 1642123 & 4.0 & 3.7342 & TRN \\
\hline CHEMBL3980218 & 1642123 & 4.0 & 3.7665 & TRN \\
\hline CHEMBL3890622 & 1642123 & 4.0 & 4.0581 & TRN \\
\hline CHEMBL 3933997 & 1642123 & 4.0 & 4.3725 & TRN \\
\hline CHEMBL 3898241 & 1642123 & 4.0 & 3.9411 & TRN \\
\hline CHEMBL3921745 & 1642123 & 4.0 & 3.9649 & TRN \\
\hline CHEMBL3916573 & 1642123 & 4.0 & 3.8004 & TRN \\
\hline CHEMBL3980858 & 1642123 & 4.0 & 4.1856 & TST \\
\hline CHEMBL 3894051 & 1642123 & 4.0 & 4.0942 & TRN \\
\hline CHEMBL3904541 & 1642123 & 4.0 & 3.9843 & TRN \\
\hline CHEMBL 3923434 & 1642123 & 4.0 & 3.9993 & TRN \\
\hline CHEMBL3894170 & 1642123 & 4.0 & 4.1661 & TRN \\
\hline CHEMBL3941673 & 1642123 & 4.0 & 3.8243 & TRN \\
\hline
\end{tabular}




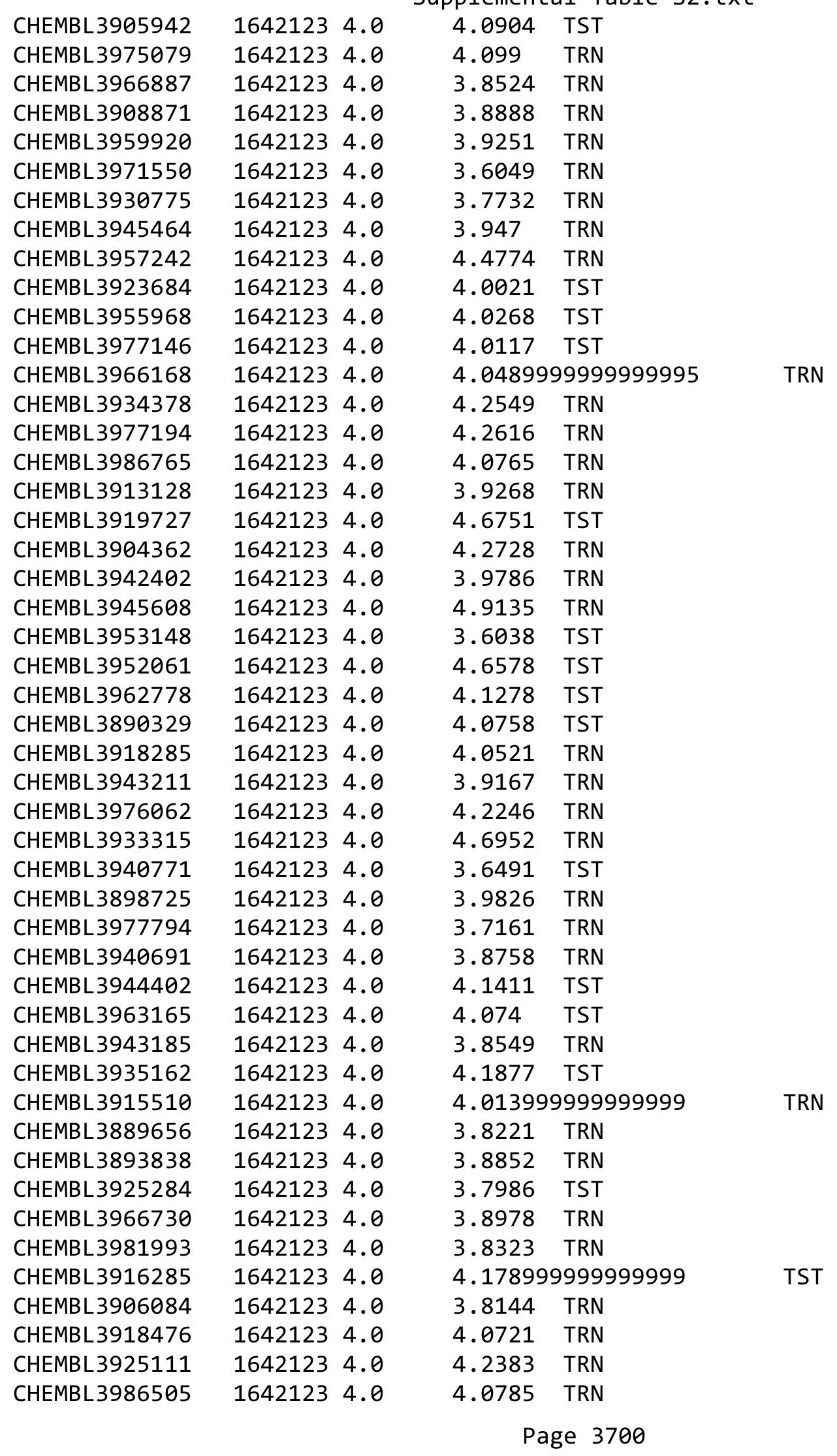




\begin{tabular}{|c|c|c|c|c|c|}
\hline & & & & & \\
\hline CHEMBL3943441 & 1642123 & 4.0 & 4.1495 & TRN & \\
\hline CHEMBL3978856 & 1642123 & 4.0 & 3.81699 & 99999999997 & TRN \\
\hline CHEMBL3945954 & 1642123 & 4.0 & 3.8232 & TRN & \\
\hline CHEMBL3939531 & 1642123 & 4.0 & 3.6866 & TRN & \\
\hline CHEMBL3906536 & 1642123 & 4.0 & 3.9535 & TRN & \\
\hline CHEMBL3971251 & 1642123 & 4.0 & 4.0965 & TRN & \\
\hline CHEMBL3966810 & 1642123 & 4.0 & 3.7704 & TRN & \\
\hline CHEMBL3920679 & 1642123 & 4.0 & 3.928 & TST & \\
\hline CHEMBL3918794 & 1642123 & 4.0 & 4.1861 & TST & \\
\hline CHEMBL3969693 & 1642123 & 4.0 & 4.0999 & TRN & \\
\hline CHEMBL3984692 & 1642123 & 4.0 & 4.0579 & TRN & \\
\hline CHEMBL 3960124 & 1642123 & 4.0 & 4.1511 & TST & \\
\hline CHEMBL3942709 & 1642123 & 4.0 & 4.2549 & TST & \\
\hline CHEMBL3974913 & 1642123 & 4.0 & 4.0101 & TRN & \\
\hline CHEMBL 3942094 & 1642123 & 6.7212 & 5.53700 & 0000000001 & TRN \\
\hline CHEMBL 3979781 & 1642123 & 4.0 & 4.0708 & TRN & \\
\hline CHEMBL3903034 & 1642123 & 4.0 & 4.09 & TST & \\
\hline CHEMBL3956205 & 1642123 & 4.0 & 3.9536 & TRN & \\
\hline CHEMBL3890458 & 1642123 & 4.0 & 4.3903 & TST & \\
\hline CHEMBL 3970243 & 1642123 & 4.0 & 3.8665 & TRN & \\
\hline CHEMBL 3903776 & 1642123 & 4.0 & 4.17 & TRN & \\
\hline CHEMBL3932973 & 1642123 & 4.0 & 4.0032 & TRN & \\
\hline CHEMBL 3907210 & 1642123 & 4.0 & 4.2612 & TST & \\
\hline CHEMBL3900539 & 1642123 & 4.0 & 4.0902 & TST & \\
\hline CHEMBL 3937055 & 1642123 & 4.0 & 4.2438 & TRN & \\
\hline CHEMBL3912664 & 1642123 & 4.0 & 4.1341 & TRN & \\
\hline CHEMBL3965091 & 1642123 & 4.0 & 3.8774 & TRN & \\
\hline CHEMBL3893161 & 1642123 & 4.0 & 3.9956 & TRN & \\
\hline CHEMBL3893742 & 1642123 & 4.0 & 4.0521 & TRN & \\
\hline CHEMBL 3962970 & 1642123 & 4.0 & 4.0252 & TRN & \\
\hline CHEMBL3950922 & 1642123 & 6.9586 & 6.1184 & TRN & \\
\hline CHEMBL3961882 & 1642123 & 4.0 & 3.9181 & TRN & \\
\hline CHEMBL 3947665 & 1642123 & 4.0 & 3.9447 & TRN & \\
\hline CHEMBL3943882 & 1642123 & 4.0 & 3.9487 & TRN & \\
\hline CHEMBL3918005 & 1642123 & 4.0 & 4.1428 & TST & \\
\hline CHEMBL3919449 & 1642123 & 4.0 & 4.2715 & TRN & \\
\hline CHEMBL 3940907 & 1642123 & 4.0 & 4.0015 & TRN & \\
\hline CHEMBL 3982907 & 1642123 & 4.0 & 4.2059 & TST & \\
\hline CHEMBL3903761 & 1642123 & 4.0 & 4.2473 & TRN & \\
\hline CHEMBL 3921971 & 1642123 & 4.0 & 3.8286 & TRN & \\
\hline CHEMBL3894408 & 1642123 & 4.0 & 3.7352 & TST & \\
\hline CHEMBL 3914922 & 1642123 & 6.0891 & 4.8396 & TST & \\
\hline CHEMBL 3952968 & 1642123 & 4.0 & 4.0216 & TST & \\
\hline CHEMBL3908763 & 1642123 & 6.8398 & 4.4619 & TST & \\
\hline CHEMBL3901550 & 1642123 & 4.0 & 4.0271 & TRN & \\
\hline CHEMBL 3933185 & 1642123 & 4.0 & 4.125 & TRN & \\
\hline CHEMBL 3945888 & 1642123 & 4.0 & 4.1193 & TST & \\
\hline CHEMBL3954854 & 1642123 & 4.0 & 4.1228 & TRN & \\
\hline
\end{tabular}




\begin{tabular}{|c|c|c|c|c|c|}
\hline & & & & & \\
\hline CHEMBL3957631 & 1642123 & 4.0 & 3.9417 & TRN & \\
\hline CHEMBL3943239 & 1642123 & 4.0 & 4.1965 & TRN & \\
\hline CHEMBL3966218 & 1642123 & 4.0 & 3.6248 & TST & \\
\hline CHEMBL3916408 & 1642123 & 4.0 & 4.0413 & TRN & \\
\hline CHEMBL3917714 & 1642123 & 4.0 & 3.6951 & TRN & \\
\hline CHEMBL3958413 & 1642123 & 4.0 & 4.2611 & TRN & \\
\hline CHEMBL3979919 & 1642123 & 4.0 & 4.4583 & TST & \\
\hline CHEMBL3973847 & 1642123 & 4.0 & 4.0517 & TRN & \\
\hline CHEMBL3982567 & 1642123 & 4.0 & 4.0526 & TRN & \\
\hline CHEMBL3891677 & 1642123 & 4.0 & 4.3666 & TST & \\
\hline CHEMBL3983255 & 1642123 & 4.0 & 3.8093 & TRN & \\
\hline CHEMBL3936627 & 1642123 & 6.7212 & 6.0086 & TRN & \\
\hline CHEMBL3968694 & 1642123 & 4.0 & 3.8549 & TST & \\
\hline CHEMBL3903056 & 1642123 & 4.0 & 3.8801 & TRN & \\
\hline CHEMBL3918150 & 1642123 & 4.0 & 3.8348 & TRN & \\
\hline CHEMBL3962514 & 1642123 & 4.0 & 3.9023 & TST & \\
\hline CHEMBL3940981 & 1642123 & 4.0 & 3.9823 & TRN & \\
\hline CHEMBL3950162 & 1642123 & 4.0 & 3.9883 & TRN & \\
\hline CHEMBL3978125 & 1642123 & 4.0 & 4.1253 & TRN & \\
\hline CHEMBL3914653 & 1642123 & 4.0 & 3.8377 & TRN & \\
\hline CHEMBL3926699 & 1642123 & 4.0 & 4.3767 & TRN & \\
\hline CHEMBL3893170 & 1642123 & 6.3188 & 4.9465 & TRN & \\
\hline CHEMBL3927530 & 1642123 & 4.0 & 3.9042 & TRN & \\
\hline CHEMBL3925710 & 1642123 & 4.0 & 3.7228 & TRN & \\
\hline CHEMBL3895595 & 1642123 & 4.0 & 4.0808 & TRN & \\
\hline CHEMBL3897056 & 1642123 & 4.0 & 4.253 & TRN & \\
\hline CHEMBL3911558 & 1642123 & 4.0 & 3.9387 & TRN & \\
\hline CHEMBL3958269 & 1642123 & 4.0 & 3.8795 & TST & \\
\hline CHEMBL3968008 & 1642123 & 4.0 & 3.8813 & TST & \\
\hline CHEMBL3966311 & 1642123 & 4.0 & 3.9129 & TRN & \\
\hline CHEMBL3950692 & 1642123 & 4.0 & 3.8669 & TRN & \\
\hline CHEMBL3907596 & 1642123 & 4.0 & 4.035 & TRN & \\
\hline CHEMBL3920942 & 1642123 & 4.0 & 4.2061 & TRN & \\
\hline CHEMBL3945306 & 1642123 & 4.0 & 3.8848 & TRN & \\
\hline CHEMBL3940187 & 1642123 & 7.0453 & 4.63899 & 9999999999 & TST \\
\hline CHEMBL3958336 & 1642123 & 4.0 & 4.4943 & TRN & \\
\hline CHEMBL3897115 & 1642123 & 4.0 & 4.0203 & TRN & \\
\hline CHEMBL3927770 & 1642123 & 4.0 & 4.8569 & TRN & \\
\hline CHEMBL3967345 & 1642123 & 4.0 & 4.0805 & TRN & \\
\hline CHEMBL3933180 & 1642123 & 4.0 & 3.4629 & TST & \\
\hline CHEMBL3966413 & 1642123 & 4.0 & 4.4932 & TRN & \\
\hline CHEMBL3939925 & 1642123 & 4.0 & 4.0645 & TRN & \\
\hline CHEMBL3949331 & 1642123 & 4.0 & 3.9933 & TRN & \\
\hline CHEMBL3976801 & 1642123 & 4.0 & 4.1143 & TRN & \\
\hline CHEMBL3932300 & 1642123 & 4.0 & 4.2845 & TRN & \\
\hline CHEMBL3918459 & 1642123 & 4.0 & 4.0802 & TRN & \\
\hline CHEMBL3892349 & 1642123 & 4.0 & 3.7004 & TST & \\
\hline CHEMBL3948314 & 1642123 & 4.0 & 4.1601 & TRN & \\
\hline & & & & 3702 & \\
\hline
\end{tabular}




\begin{tabular}{|c|c|c|c|c|c|c|}
\hline \multicolumn{7}{|c|}{ r } \\
\hline CHEMBL3896366 & 1642123 & 4.0 & 4.2206 & TRN & & \\
\hline CHEMBL3909578 & 1642123 & 4.0 & 3.8157 & TST & & \\
\hline CHEMBL3937227 & 1642123 & 4.0 & 4.1362 & TRN & & \\
\hline CHEMBL3922649 & 1642123 & 4.0 & 3.7173 & TRN & & \\
\hline CHEMBL1493353 & 688670 & 4.7693 & 4.8069 & TRN & & \\
\hline CHEMBL1606520 & 688670 & 5.522 & 5.2053 & TRN & & \\
\hline CHEMBL1584189 & 688670 & 4.6476 & 4.6474 & TRN & & \\
\hline CHEMBL1346167 & 688670 & 3.2245 & 4.519 & TRN & & \\
\hline CHEMBL1358969 & 688670 & 4.7767 & 4.65 & TRN & & \\
\hline CHEMBL1498006 & 688670 & 5.3018 & 5.1294 & TRN & & \\
\hline CHEMBL3213100 & 688670 & 5.3748 & 5.2593 & TRN & & \\
\hline CHEMBL1605748 & 688670 & 4.8827 & 4.7088 & TRN & & \\
\hline CHEMBL1326008 & 688670 & 5.3526 & 5.0629 & TRN & & \\
\hline CHEMBL1578600 & 688670 & 7.2648 & 6.0877 & TST & & \\
\hline CHEMBL1458632 & 688670 & 4.9084 & 4.6754 & TRN & & \\
\hline CHEMBL1576713 & 688670 & 4.1787 & 5.5943 & TRN & & \\
\hline CHEMBL1516970 & 688670 & 5.1745 & 5.2576 & TRN & & \\
\hline CHEMBL3191768 & 688670 & 5.2144 & 5.1547 & TRN & & \\
\hline CHEMBL1577867 & 688670 & 4.7106 & 4.3547 & TRN & & \\
\hline CHEMBL1538097 & 688670 & 4.9691 & 4.5934 & TRN & & \\
\hline CHEMBL1464372 & 688670 & 4.7439 & 4.7065 & TRN & & \\
\hline CHEMBL1527705 & 688670 & 3.2245 & 4.4775 & TRN & & \\
\hline CHEMBL1551022 & 688670 & 4.6051 & 4.2335 & TRN & & \\
\hline CHEMBL1481755 & 688670 & 5.0147 & 4.707 & TRN & & \\
\hline CHEMBL1606872 & 688670 & 5.325 & 5.4019 & TRN & & \\
\hline CHEMBL1447888 & 688670 & 5.845 & 5.9726 & TRN & & \\
\hline CHEMBL1522756 & 688670 & 4.6989 & 4.5932 & TRN & & \\
\hline CHEMBL1315870 & 688670 & 4.5865 & 4.4383 & TST & & \\
\hline CHEMBL1379746 & 688670 & 5.1363 & 5.053 & TST & & \\
\hline CHEMBL3193161 & 688670 & 5.0011 & 5.0098 & TRN & & \\
\hline CHEMBL3196601 & 688670 & 4.6357 & 4.426 & TRN & & \\
\hline CHEMBL1435494 & 688670 & 4.6354 & 4.5285 & TST & & \\
\hline CHEMBL1452412 & 688670 & 4.3045 & 4.383 & TRN & & \\
\hline CHEMBL1559733 & 688670 & 4.8785 & 4.8743 & TRN & & \\
\hline CHEMBL1532258 & 688670 & 4.8035 & 4.4019 & TRN & & \\
\hline CHEMBL1534296 & 688670 & 4.9801 & 4.6229 & TRN & & \\
\hline CHEMBL1469441 & 688670 & 5.704 & 5.7545 & TRN & & \\
\hline CHEMBL1448093 & 688670 & 4.85800 & 00000000 & 205 & 4.6588 & TST \\
\hline CHEMBL1345758 & 688670 & 4.6893 & 4.5209 & TRN & & \\
\hline CHEMBL1603777 & 688670 & 4.746 & 4.6664 & TST & & \\
\hline CHEMBL1388851 & 688670 & 5.2954 & 5.3064 & TRN & & \\
\hline CHEMBL1574794 & 688670 & 5.2166 & 4.8366 & TST & & \\
\hline CHEMBL1537904 & 688670 & 4.8768 & 4.7716 & TST & & \\
\hline CHEMBL1389969 & 688670 & 5.1886 & 4.6824 & TRN & & \\
\hline CHEMBL335619 & 688670 & 4.8887 & 4.7048 & TRN & & \\
\hline CHEMBL1548211 & 688670 & 5.1886 & 4.9898 & TRN & & \\
\hline CHEMBL1579462 & 688670 & 4.859 & 4.596 & TRN & & \\
\hline CHEMBL1445684 & 688670 & 4.2558 & 4.3436 & TRN & & \\
\hline
\end{tabular}


Supplemental Table S2.txt

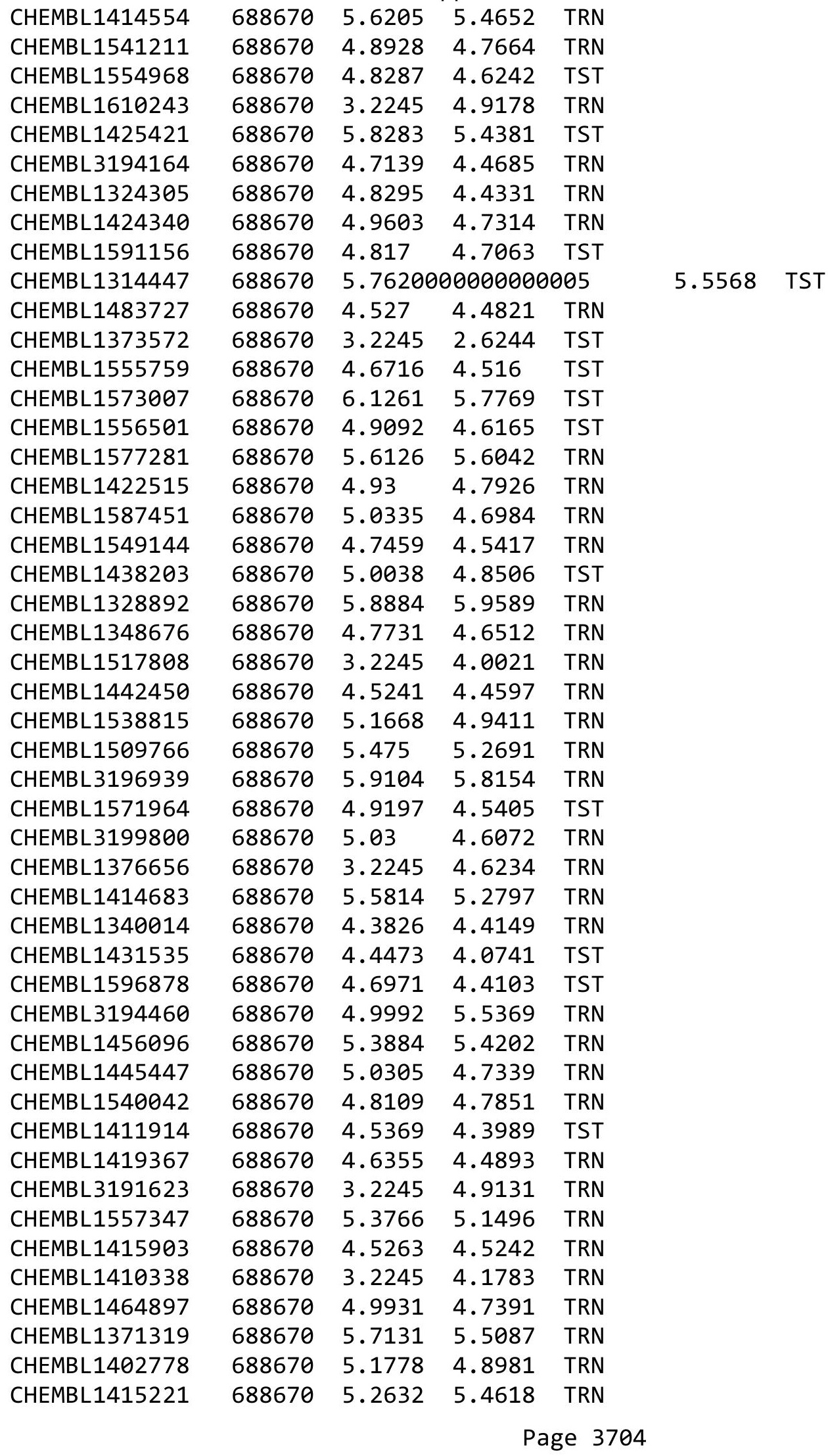


Supplemental Table S2.txt

\begin{tabular}{|c|c|c|c|c|}
\hline CHEMBL1400031 & 688670 & 4.8121 & 4.5708 & TRN \\
\hline CHEMBL1397449 & 688670 & 4.6797 & 4.3613 & TST \\
\hline CHEMBL3190779 & 688670 & 5.9983 & 5.8714 & TRN \\
\hline CHEMBL1299716 & 688670 & 4.7995 & 4.65 & TST \\
\hline CHEMBL1371432 & 688670 & 4.8516 & 4.4393 & TRN \\
\hline CHEMBL1378904 & 688670 & 5.1594 & 4.8916 & TRN \\
\hline CHEMBL1423602 & 688670 & 4.8133 & 4.7903 & TST \\
\hline CHEMBL1573854 & 688670 & 5.6164 & 5.3496 & TRN \\
\hline CHEMBL1550381 & 688670 & 3.2245 & 4.4347 & TST \\
\hline CHEMBL1455265 & 688670 & 5.3208 & 5.0893 & TST \\
\hline CHEMBL3194647 & 688670 & 3.2245 & 3.4156 & TRN \\
\hline CHEMBL1558250 & 688670 & 5.2702 & 5.0266 & TRN \\
\hline CHEMBL1511843 & 688670 & 4.7413 & 4.7731 & TRN \\
\hline CHEMBL1401466 & 688670 & 5.3012 & 5.0902 & TRN \\
\hline CHEMBL1431288 & 688670 & 5.1008 & 4.9609 & TST \\
\hline CHEMBL1556931 & 688670 & 4.7969 & 4.5472 & TRN \\
\hline CHEMBL1594123 & 688670 & 5.1791 & 4.9517 & TST \\
\hline CHEMBL1390220 & 688670 & 4.8423 & 4.6232 & TRN \\
\hline CHEMBL3197536 & 688670 & 5.1992 & 5.1251 & TRN \\
\hline CHEMBL1381292 & 688670 & 4.8266 & 4.5724 & TRN \\
\hline CHEMBL1565378 & 688670 & 4.7869 & 4.651 & TRN \\
\hline CHEMBL1537972 & 688670 & 4.8693 & 4.6064 & TRN \\
\hline CHEMBL3194162 & 688670 & 5.0387 & 5.4617 & TRN \\
\hline CHEMBL1463059 & 688670 & 3.2245 & 4.33 & TRN \\
\hline CHEMBL1597507 & 688670 & 5.1902 & 4.7376 & TST \\
\hline CHEMBL1345175 & 688670 & 4.8597 & 4.6907 & TRN \\
\hline CHEMBL1368761 & 688670 & 4.8359 & 4.5074 & TST \\
\hline CHEMBL1455686 & 688670 & 4.5266 & 4.3555 & TRN \\
\hline CHEMBL1391244 & 688670 & 4.4672 & 4.3698 & TRN \\
\hline CHEMBL1328086 & 688670 & 3.2245 & 2.9983 & TST \\
\hline CHEMBL1492629 & 688670 & 6.3439 & 6.1772 & TRN \\
\hline CHEMBL590888 & 817943 & 4.7897 & 4.7518 & TST \\
\hline CHEMBL588155 & 817943 & 3.4948 & 4.4953 & TRN \\
\hline CHEMBL529984 & 817943 & 4.7959 & 4.5789 & TRN \\
\hline CHEMBL124006 & 817943 & 5.9939 & 6.1715 & TRN \\
\hline CHEMBL587371 & 817943 & 3.4948 & 3.9939 & TRN \\
\hline CHEMBL580249 & 817943 & 3.4948 & 3.6065 & TRN \\
\hline CHEMBL591128 & 817943 & 3.4948 & 3.9296 & TRN \\
\hline CHEMBL591393 & 817943 & 4.7897 & 5.037 & TRN \\
\hline CHEMBL578508 & 817943 & 3.4948 & 3.6921 & TRN \\
\hline CHEMBL532015 & 817943 & 3.4948 & 3.5354 & TRN \\
\hline CHEMBL584240 & 817943 & 3.4948 & 4.1584 & TRN \\
\hline CHEMBL600132 & 817943 & 5.3949 & 4.5512 & TST \\
\hline CHEMBL1744512 & 817943 & 3.4948 & \multicolumn{2}{|c|}{3.9589999999999996} \\
\hline CHEMBL585622 & 817943 & 5.9247 & 5.442 & TRN \\
\hline CHEMBL524784 & 817943 & 3.4948 & 3.9182 & TRN \\
\hline CHEMBL549216 & 817943 & 4.5952 & 4.7286 & TRN \\
\hline CHEMBL106525 & 817943 & 5.3918 & 5.4763 & TRN \\
\hline
\end{tabular}




\begin{tabular}{|c|c|c|c|c|c|}
\hline \multirow[b]{2}{*}{ CHEMBL531290 } & & \multicolumn{4}{|c|}{ Supplemental Table S2.txt } \\
\hline & 817943 & 4.9198 & 4.35800 & 00000000005 & TST \\
\hline CHEMBL580159 & 817943 & 4.7959 & 4.4156 & TRN & \\
\hline CHEMBL601612 & 817943 & 3.4948 & 4.336 & TST & \\
\hline CHEMBL 2028062 & 817943 & 4.5952 & 4.0067 & TRN & \\
\hline CHEMBL600439 & 817943 & 3.4948 & 4.6298 & TST & \\
\hline CHEMBL1623897 & 817943 & 3.4948 & 4.0192 & TRN & \\
\hline CHEMBL588501 & 817943 & 5.3918 & 5.6792 & TRN & \\
\hline CHEMBL592123 & 817943 & 5.7993 & 5.7013 & TRN & \\
\hline CHEMBL525486 & 817943 & 5.1973 & 5.1429 & TRN & \\
\hline CHEMBL601534 & 817943 & 4.9198 & 4.7722 & TST & \\
\hline CHEMBL602409 & 817943 & 3.4948 & 3.588 & TRN & \\
\hline CHEMBL 2028058 & 817943 & 4.9198 & 4.5266 & TRN & \\
\hline CHEMBL580580 & 817943 & 5.3645 & 4.593 & TRN & \\
\hline CHEMBL529919 & 817943 & 3.4948 & 3.9724 & TRN & \\
\hline CHEMBL530978 & 817943 & 5.3918 & 4.5412 & TRN & \\
\hline CHEMBL546799 & 817943 & 5.3918 & 4.3265 & TRN & \\
\hline CHEMBL591887 & 817943 & 3.4948 & 4.2647 & TRN & \\
\hline CHEMBL585243 & 817943 & 4.7897 & 3.9835 & TRN & \\
\hline CHEMBL604389 & 817943 & 4.7897 & 3.6351 & TRN & \\
\hline CHEMBL586078 & 817943 & 3.4948 & 3.6691 & TRN & \\
\hline CHEMBL 2028041 & 817943 & 5.3645 & 4.5323 & TRN & \\
\hline CHEMBL 2028068 & 817943 & 3.4948 & 4.322 & TST & \\
\hline CHEMBL582119 & 817943 & 3.4948 & 3.7334 & TST & \\
\hline CHEMBL591395 & 817943 & 4.5952 & 4.0727 & TRN & \\
\hline CHEMBL535730 & 817943 & 5.3645 & 4.7169 & TST & \\
\hline CHEMBL582286 & 817943 & 4.7624 & 4.3824 & TRN & \\
\hline CHEMBL525519 & 817943 & 4.9949 & 4.4918 & TRN & \\
\hline CHEMBL589224 & 817943 & 3.4948 & 4.147 & TST & \\
\hline CHEMBL591147 & 817943 & 3.4948 & 4.0278 & TRN & \\
\hline CHEMBL470514 & 817943 & 5.2689 & 4.8131 & TRN & \\
\hline CHEMBL527620 & 817943 & 4.7897 & 4.5623 & TRN & \\
\hline CHEMBL 2028052 & 817943 & 4.7897 & 3.4975 & TRN & \\
\hline CHEMBL602234 & 817943 & 5.4674 & 5.2887 & TRN & \\
\hline CHEMBL529603 & 817943 & 3.4948 & 3.6711 & TRN & \\
\hline CHEMBL600235 & 817943 & 3.4948 & 5.4303 & TRN & \\
\hline CHEMBL590914 & 817943 & 5.3227 & 4.8413 & TRN & \\
\hline CHEMBL532141 & 817943 & 5.3979 & 4.7464 & TRN & \\
\hline CHEMBL589951 & 817943 & 3.4948 & 3.8195 & TRN & \\
\hline CHEMBL532510 & 817943 & 3.4948 & 3.694 & TRN & \\
\hline CHEMBL531611 & 817943 & 4.9931 & 4.5132 & TRN & \\
\hline CHEMBL596852 & 817943 & 5.3918 & 6.0833 & TRN & \\
\hline CHEMBL 2028048 & 817943 & 3.4948 & 4.4383 & TRN & \\
\hline CHEMBL581194 & 817943 & 4.7357 & 4.8877 & TRN & \\
\hline CHEMBL533855 & 817943 & 5.5986 & 4.8888 & TRN & \\
\hline CHEMBL600305 & 817943 & 3.4948 & 3.5519 & TRN & \\
\hline CHEMBL603943 & 817943 & 3.4948 & 3.5706 & TRN & \\
\hline CHEMBL592786 & 817943 & 3.4948 & 4.0769 & TRN & \\
\hline CHEMBL578030 & 817943 & 5.3979 & 4.8944 & TRN & \\
\hline
\end{tabular}




\begin{tabular}{|c|c|c|c|c|c|}
\hline \multirow{3}{*}{$\begin{array}{l}\text { CHEMBL } 580757 \\
\text { CHEMBL } 578294\end{array}$} & & \multicolumn{4}{|c|}{ Supplemental Table S2.txt } \\
\hline & 817943 & 3.4948 & \multicolumn{2}{|c|}{3.6289999999999996} & TRN \\
\hline & 817943 & 5.3645 & 5.3292 & TRN & \\
\hline CHEMBL589733 & 817943 & 4.7897 & 5.5075 & TRN & \\
\hline CHEMBL578952 & 817943 & 3.4948 & 3.5721 & TRN & \\
\hline CHEMBL548399 & 817943 & 3.4948 & 3.3584 & TRN & \\
\hline CHEMBL602179 & 817943 & 3.4948 & 3.5837 & TRN & \\
\hline CHEMBL580654 & 817943 & 4.7897 & \multicolumn{2}{|c|}{3.4019999999999997} & TRN \\
\hline CHEMBL587485 & 817943 & 3.4948 & 3.5292 & TRN & \\
\hline CHEMBL581489 & 817943 & 3.4948 & 3.5336 & TRN & \\
\hline CHEMBL602127 & 817943 & 4.7959 & 3.9691 & TRN & \\
\hline CHEMBL 2028049 & 817943 & 4.7897 & 3.6462 & TRN & \\
\hline CHEMBL527131 & 817943 & 3.4948 & 3.5528 & TRN & \\
\hline CHEMBL597262 & 817943 & 3.4948 & 3.5978 & TRN & \\
\hline CHEMBL586310 & 817943 & 3.4948 & 3.5258 & TRN & \\
\hline CHEMBL580876 & 817943 & 3.4948 & \multicolumn{2}{|c|}{3.4989999999999997} & TRN \\
\hline CHEMBL528734 & 817943 & 3.4948 & 3.8248 & TRN & \\
\hline CHEMBL601492 & 817943 & 3.4948 & 4.4737 & TRN & \\
\hline CHEMBL600488 & 817943 & 3.4948 & \multicolumn{2}{|c|}{3.5580000000000003} & TRN \\
\hline CHEMBL1545915 & 817943 & 3.4948 & 3.7353 & TRN & \\
\hline CHEMBL601786 & 817943 & 3.4948 & 4.0834 & TRN & \\
\hline CHEMBL582079 & 817943 & 4.7959 & 4.3545 & TRN & \\
\hline CHEMBL531222 & 817943 & 3.4948 & 3.7349 & TRN & \\
\hline CHEMBL582478 & 817943 & 3.4948 & 4.7928 & TRN & \\
\hline CHEMBL596652 & 817943 & 3.4948 & 3.5534 & TRN & \\
\hline CHEMBL579760 & 817943 & 4.7928 & 4.5411 & TST & \\
\hline CHEMBL579315 & 817943 & 3.4948 & 3.6374 & TRN & \\
\hline CHEMBL601528 & 817943 & 3.4948 & 3.9787 & TRN & \\
\hline CHEMBL529348 & 817943 & 4.7897 & 4.5031 & TRN & \\
\hline CHEMBL602312 & 817943 & 5.3979 & 5.3023 & TRN & \\
\hline CHEMBL584655 & 817943 & 5.1973 & 4.4316 & TRN & \\
\hline CHEMBL 2028063 & 817943 & 5.1973 & 4.8746 & TRN & \\
\hline CHEMBL533917 & 817943 & 4.78 & 6.2952 & TRN & \\
\hline CHEMBL525826 & 817943 & 5.3645 & 4.7907 & TRN & \\
\hline CHEMBL582180 & 817943 & 4.7624 & 4.3474 & TRN & \\
\hline CHEMBL581874 & 817943 & 3.4948 & 3.8197 & TRN & \\
\hline CHEMBL586704 & 817943 & 3.4948 & 4.072 & TRN & \\
\hline CHEMBL529732 & 817943 & 3.4948 & 3.3739 & TRN & \\
\hline CHEMBL603945 & 817943 & 4.9966 & 4.3873 & TRN & \\
\hline CHEMBL580381 & 817943 & 3.4948 & 3.97 & TRN & \\
\hline CHEMBL545880 & 817943 & 4.7206 & 4.4373 & TRN & \\
\hline CHEMBL592338 & 817943 & 3.4948 & 3.8655 & TRN & \\
\hline CHEMBL533598 & 817943 & 5.3227 & 4.8306 & TRN & \\
\hline CHEMBL586888 & 817943 & 3.4948 & 4.385 & TRN & \\
\hline CHEMBL597855 & 817943 & 4.7897 & 4.2974 & TRN & \\
\hline CHEMBL577012 & 817943 & 3.4948 & 3.8223 & TRN & \\
\hline CHEMBL526587 & 817943 & 3.4948 & 3.64600 & 00000000004 & TRN \\
\hline CHEMBL596643 & 817943 & 3.4948 & 3.6937 & TRN & \\
\hline CHEMBL581175 & 817943 & 4.6454 & 4.0281 & TRN & \\
\hline
\end{tabular}


Supplemental Table S2.txt

\begin{tabular}{|c|c|c|c|c|}
\hline CHEMBL534283 & 817943 & 5.527 & 4.735 & TST \\
\hline CHEMBL 2028060 & 817943 & 4.5952 & 3.8144 & TRN \\
\hline CHEMBL1594640 & 817943 & 3.4948 & 3.6427 & TRN \\
\hline CHEMBL592550 & 817943 & 3.4948 & 4.3034 & TRN \\
\hline CHEMBL527541 & 817943 & 3.4948 & 4.018 & TRN \\
\hline CHEMBL580353 & 817943 & 3.4948 & 3.8488 & TRN \\
\hline CHEMBL 2021322 & 817943 & 4.78 & 4.302 & TRN \\
\hline CHEMBL582486 & 817943 & 3.4948 & 3.6471 & TST \\
\hline CHEMBL600356 & 817943 & 3.4948 & 4.1153 & TST \\
\hline CHEMBL602580 & 817943 & 5.5219 & 5.9065 & TST \\
\hline CHEMBL598369 & 817943 & 3.4948 & 3.5153 & TRN \\
\hline CHEMBL590159 & 817943 & 4.7624 & 3.7507 & TRN \\
\hline CHEMBL 2028044 & 817943 & 3.4948 & 3.9724 & TRN \\
\hline CHEMBL585264 & 817943 & 4.6669 & 4.297 & TST \\
\hline CHEMBL534190 & 817943 & 3.4948 & 3.7711 & TRN \\
\hline CHEMBL585686 & 817943 & 3.4948 & 3.5803 & TRN \\
\hline CHEMBL601566 & 817943 & 3.4948 & 4.0611 & TST \\
\hline CHEMBL 2028054 & 817943 & 4.7897 & 3.6801 & TST \\
\hline CHEMBL529773 & 817943 & 3.4948 & 4.4487 & TRN \\
\hline CHEMBL579294 & 817943 & 4.5952 & 4.1682 & TRN \\
\hline CHEMBL125044 & 817943 & 3.4948 & 3.4716 & TRN \\
\hline CHEMBL 206540 & 817943 & 3.4948 & 3.5952 & TRN \\
\hline CHEMBL49055 & 817943 & 5.1973 & 5.106 & TRN \\
\hline CHEMBL600906 & 817943 & 3.4948 & 3.5102 & TRN \\
\hline CHEMBL581349 & 817943 & 3.4948 & 3.6602 & TRN \\
\hline CHEMBL602366 & 817943 & 3.4948 & 3.5727 & TRN \\
\hline CHEMBL 2028051 & 817943 & 4.7928 & 4.277 & TRN \\
\hline CHEMBL547266 & 817943 & 5.3918 & 5.7244 & TRN \\
\hline CHEMBL579300 & 817943 & 4.9966 & 4.4241 & TRN \\
\hline CHEMBL546168 & 817943 & 3.4948 & 3.8597 & TRN \\
\hline CHEMBL1459149 & 817943 & 4.7897 & 3.7492 & TST \\
\hline CHEMBL607308 & 817943 & 3.4948 & 4.5055 & TRN \\
\hline CHEMBL536421 & 817943 & 3.4948 & 3.5969 & TRN \\
\hline CHEMBL 2028050 & 817943 & 5.9247 & 5.2186 & TRN \\
\hline CHEMBL607688 & 817943 & 4.7624 & 4.2149 & TRN \\
\hline CHEMBL529874 & 817943 & 3.4948 & 3.7591 & TST \\
\hline CHEMBL524973 & 817943 & 4.7897 & 4.8639 & TRN \\
\hline CHEMBL604323 & 817943 & 3.4948 & 3.6397 & TRN \\
\hline CHEMBL587104 & 817943 & 4.5952 & 4.3784 & TRN \\
\hline CHEMBL601567 & 817943 & 4.78 & 4.0424 & TRN \\
\hline CHEMBL537505 & 817943 & 3.4948 & 4.0763 & TRN \\
\hline CHEMBL584829 & 817943 & 4.7928 & 4.5987 & TRN \\
\hline CHEMBL601806 & 817943 & 4.7897 & 4.3736 & TST \\
\hline CHEMBL1619026 & 817943 & 4.78 & 4.2029 & TRN \\
\hline CHEMBL548338 & 817943 & 4.7959 & \multicolumn{2}{|c|}{ 4. 321000000000001} \\
\hline CHEMBL590212 & 817943 & 5.2689 & 4.8831 & TRN \\
\hline CHEMBL528533 & 817943 & 5.3918 & 4.7442 & TRN \\
\hline CHEMBL582070 & 817943 & 3.4948 & 4.4328 & TRN \\
\hline
\end{tabular}




\begin{tabular}{|c|c|c|c|c|}
\hline & & & pplement & al $\mathrm{Tc}$ \\
\hline CHEMBL579331 & 817943 & 3.4948 & 4.1535 & TRN \\
\hline CHEMBL530531 & 817943 & 5.3821 & 5.5255 & TST \\
\hline CHEMBL537778 & 817943 & 5.3918 & 4.9687 & TRN \\
\hline CHEMBL585839 & 817943 & 3.4948 & 3.5409 & TRN \\
\hline CHEMBL582767 & 817943 & 6.0 & 5.8121 & TST \\
\hline CHEMBL586344 & 817943 & 3.4948 & 3.6729 & TST \\
\hline CHEMBL525692 & 817943 & 4.7897 & 3.9703 & TRN \\
\hline CHEMBL546162 & 817943 & 4.78 & 4.5481 & TRN \\
\hline CHEMBL592044 & 817943 & 3.4948 & 4.2373 & TST \\
\hline CHEMBL597444 & 817943 & 3.4948 & 3.8022 & TRN \\
\hline CHEMBL582547 & 817943 & 5.3645 & 5.1341 & TRN \\
\hline CHEMBL586468 & 817943 & 3.4948 & 3.452 & TRN \\
\hline CHEMBL586442 & 817943 & 3.4948 & 3.4175 & TRN \\
\hline CHEMBL606252 & 817943 & 3.4948 & 3.8524 & TRN \\
\hline CHEMBL591890 & 817943 & 4.7206 & 4.3779 & TST \\
\hline CHEMBL588516 & 817943 & 3.4948 & 3.5213 & TRN \\
\hline CHEMBL 2028045 & 817943 & 4.7959 & 3.7654 & TRN \\
\hline CHEMBL586026 & 817943 & 4.7897 & 4.8821 & TST \\
\hline CHEMBL589916 & 817943 & 3.4948 & 3.5682 & TRN \\
\hline CHEMBL582495 & 817943 & 4.7206 & 4.7145 & TRN \\
\hline CHEMBL527730 & 817943 & 5.527 & 5.2468 & TRN \\
\hline CHEMBL548901 & 817943 & 5.1973 & 4.3605 & TRN \\
\hline CHEMBL601348 & 817943 & 4.7357 & 3.6554 & TST \\
\hline CHEMBL587083 & 817943 & 4.7897 & 4.5148 & TRN \\
\hline CHEMBL586178 & 817943 & 3.4948 & 3.6654 & TRN \\
\hline CHEMBL590674 & 817943 & 5.3645 & 4.7822 & TRN \\
\hline CHEMBL494669 & 817943 & 6.0753 & 5.1443 & TRN \\
\hline CHEMBL547614 & 817943 & 3.4948 & 3.5025 & TST \\
\hline CHEMBL 2028042 & 817943 & 3.4948 & 3.49 & TRN \\
\hline CHEMBL 2028055 & 817943 & 4.7897 & 4.4822 & TRN \\
\hline CHEMBL532079 & 817943 & 4.7959 & 4.4602 & TRN \\
\hline CHEMBL590201 & 817943 & 4.7624 & 4.0683 & TRN \\
\hline CHEMBL547476 & 817943 & 3.4948 & 3.6371 & TRN \\
\hline CHEMBL601825 & 817943 & 3.4948 & 3.5936 & TRN \\
\hline CHEMBL590919 & 817943 & 5.3227 & 4.9391 & TRN \\
\hline CHEMBL1615697 & 817943 & 4.7897 & 4.2385 & TST \\
\hline CHEMBL608855 & 817943 & 4.7624 & 4.189 & TST \\
\hline CHEMBL587989 & 817943 & 4.5952 & 3.6293 & TRN \\
\hline CHEMBL591641 & 817943 & 3.4948 & 4.0734 & TRN \\
\hline CHEMBL526800 & 817943 & 4.7897 & 4.4614 & TRN \\
\hline CHEMBL577445 & 817943 & 4.7959 & 3.7288 & TRN \\
\hline CHEMBL532525 & 817943 & 3.4948 & 4.0824 & TRN \\
\hline CHEMBL599886 & 817943 & 3.4948 & 3.9334 & TST \\
\hline CHEMBL606159 & 817943 & 3.4948 & 4.1502 & TRN \\
\hline CHEMBL317364 & 817943 & 4.7624 & 4.4949 & TRN \\
\hline CHEMBL602413 & 817943 & 5.5986 & 5.175 & TRN \\
\hline CHEMBL589922 & 817943 & 4.5952 & 4.2094 & TRN \\
\hline CHEMBL601957 & 817943 & 3.4948 & 4.9284 & TRN \\
\hline
\end{tabular}




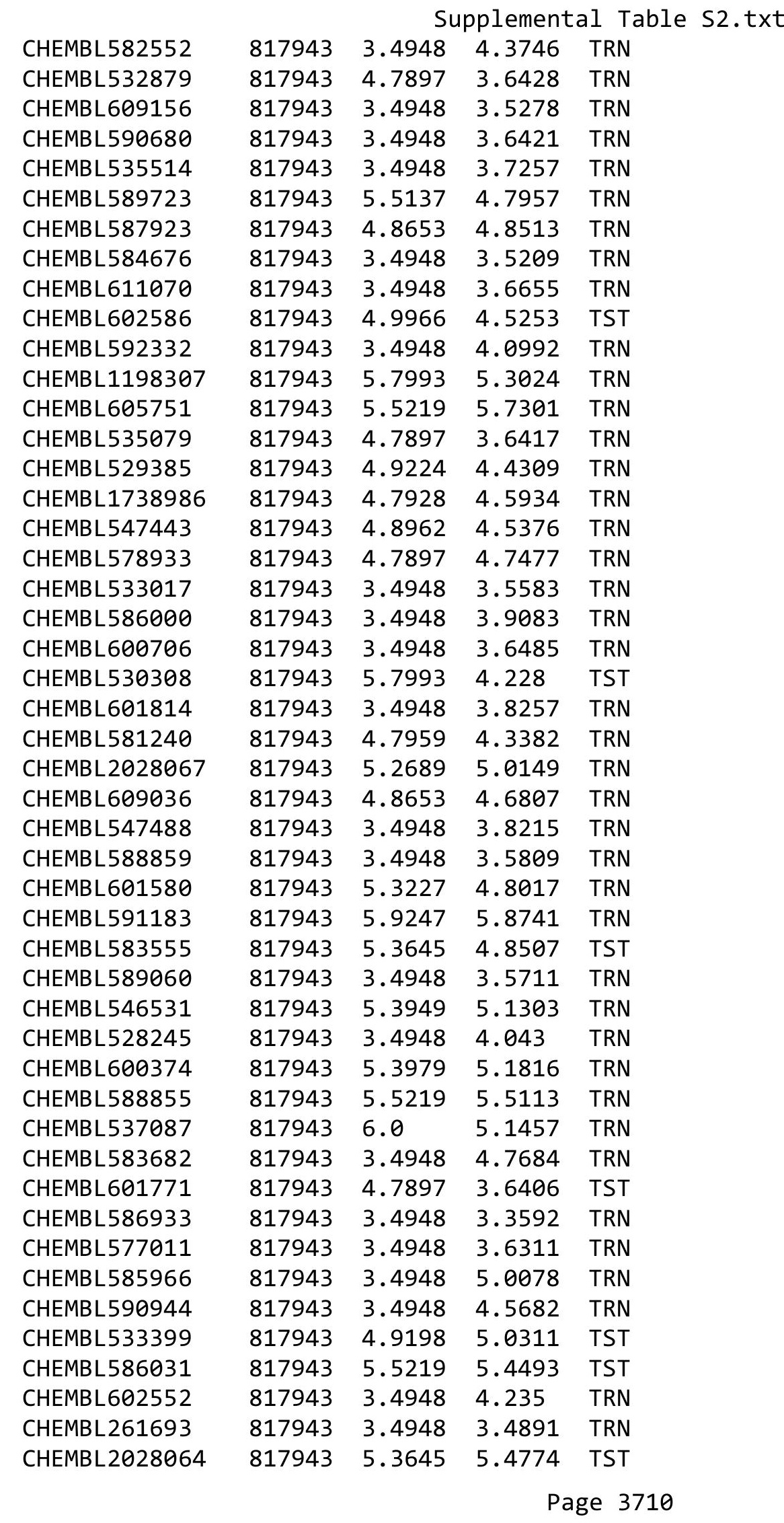


Supplemental Table S2.txt

\begin{tabular}{|c|c|c|c|c|c|}
\hline CHEMBL587892 & 817943 & 5.3979 & 4.935 & TRN & \\
\hline CHEMBL590675 & 817943 & 3.4948 & 4.0548 & TRN & \\
\hline CHEMBL584237 & 817943 & 3.4948 & 3.9441 & TRN & \\
\hline CHEMBL588481 & 817943 & 5.7993 & 5.2256 & TRN & \\
\hline CHEMBL606531 & 817943 & 3.4948 & 4.3765 & TRN & \\
\hline CHEMBL601743 & 817943 & 5.3645 & 4.5302 & TRN & \\
\hline CHEMBL589205 & 817943 & 4.7624 & 4.0194 & TRN & \\
\hline CHEMBL 2028061 & 817943 & 3.4948 & 3.7739 & TRN & \\
\hline CHEMBL590182 & 817943 & 3.4948 & 3.7266 & TRN & \\
\hline CHEMBL549208 & 817943 & 3.4948 & 4.4117 & TRN & \\
\hline CHEMBL547269 & 817943 & 5.1973 & 4.8316 & TRN & \\
\hline CHEMBL582420 & 817943 & 4.7897 & 3.4601 & TRN & \\
\hline CHEMBL592344 & 817943 & 3.4948 & 4.1001 & TRN & \\
\hline CHEMBL95606 & 817943 & 3.4948 & 3.7517 & TST & \\
\hline CHEMBL 2028056 & 817943 & 4.6669 & 4.3288 & TRN & \\
\hline CHEMBL548209 & 817943 & 3.4948 & 5.3196 & TRN & \\
\hline CHEMBL601158 & 817943 & 3.4948 & 3.5937 & TRN & \\
\hline CHEMBL589422 & 817943 & 4.7897 & 4.2953 & TST & \\
\hline CHEMBL590686 & 817943 & 4.7897 & 4.5584 & TRN & \\
\hline CHEMBL596856 & 817943 & 3.4948 & 4.1384 & TRN & \\
\hline CHEMBL580819 & 817943 & 3.4948 & 3.5799 & TRN & \\
\hline CHEMBL533999 & 817943 & 3.4948 & 3.5567 & TRN & \\
\hline CHEMBL604982 & 817943 & 3.4948 & 4.0433 & TRN & \\
\hline CHEMBL581475 & 817943 & 3.4948 & 3.5462 & TRN & \\
\hline CHEMBL591362 & 817943 & 5.7993 & 5.5894 & TRN & \\
\hline CHEMBL597248 & 817943 & 6.1505 & 5.2966 & TRN & \\
\hline CHEMBL592305 & 817943 & 3.4948 & 3.6686 & TST & \\
\hline CHEMBL588732 & 817943 & 4.5952 & 3.6871 & TRN & \\
\hline CHEMBL586033 & 817943 & 6.0 & 5.7141 & TRN & \\
\hline CHEMBL526981 & 817943 & 3.4948 & 4.1189 & TRN & \\
\hline CHEMBL533563 & 817943 & 4.5952 & 4.4688 & TST & \\
\hline CHEMBL459199 & 817943 & 4.9931 & 4.6121 & TRN & \\
\hline CHEMBL532155 & 817943 & 3.4948 & 3.9321 & TRN & \\
\hline CHEMBL587288 & 817943 & 3.4948 & 3.5092 & TRN & \\
\hline CHEMBL577014 & 817943 & 4.7897 & 4.891999 & 99999999995 & TRN \\
\hline CHEMBL530973 & 817943 & 3.4948 & 3.5388 & TRN & \\
\hline CHEMBL598279 & 817943 & 5.99700 & 000000000 & 5.2519 & TRN \\
\hline CHEMBL 2028053 & 817943 & 3.4948 & 3.5609 & TRN & \\
\hline CHEMBL536393 & 817943 & 3.4948 & 3.4216 & TRN & \\
\hline CHEMBL338094 & 817943 & 3.4948 & 3.4969 & TRN & \\
\hline CHEMBL600174 & 817943 & 3.4948 & 4.0853 & TRN & \\
\hline CHEMBL 2028047 & 817943 & 4.7897 & 4.6604 & TRN & \\
\hline CHEMBL1460047 & 817943 & 3.4948 & 3.7874 & TST & \\
\hline CHEMBL582666 & 817943 & 3.4948 & 5.2034 & TRN & \\
\hline CHEMBL602211 & 817943 & 3.4948 & 3.7451 & TRN & \\
\hline CHEMBL580188 & 817943 & 3.4948 & 3.4864 & TRN & \\
\hline CHEMBL603686 & 817943 & 4.5952 & 4.4285 & TRN & \\
\hline CHEMBL577874 & 817943 & 5.3645 & 4.6639 & TRN & \\
\hline
\end{tabular}




\begin{tabular}{|c|c|c|c|c|c|}
\hline \multicolumn{6}{|c|}{ Supplemental Table S2.txt } \\
\hline CHEMBL528492 & 817943 & 3.4948 & 3.8033 & TRN & \\
\hline CHEMBL591637 & 817943 & 6.473 & 5.6235 & TRN & \\
\hline CHEMBL589236 & 817943 & 3.4948 & 3.5941 & TRN & \\
\hline CHEMBL529640 & 817943 & 4.7959 & 4.4509 & TRN & \\
\hline CHEMBL 2028066 & 817943 & 4.7624 & 4.3654 & TST & \\
\hline CHEMBL531060 & 817943 & 3.4948 & 4.0326 & TRN & \\
\hline CHEMBL1616787 & 817943 & 5.3918 & 4.938 & TRN & \\
\hline CHEMBL548374 & 817943 & 5.3227 & 5.0171 & TRN & \\
\hline CHEMBL 600030 & 817943 & 3.4948 & 3.6943 & TRN & \\
\hline CHEMBL585983 & 817943 & 3.4948 & 4.2854 & TRN & \\
\hline CHEMBL1740701 & 817943 & 3.4948 & 3.8215 & TRN & \\
\hline CHEMBL602940 & 817943 & 3.4948 & 4.5711 & TST & \\
\hline CHEMBL1485159 & 817943 & 3.4948 & 4.4424 & TRN & \\
\hline CHEMBL581860 & 817943 & 5.5219 & 5.3054 & TRN & \\
\hline CHEMBL600444 & 817943 & 3.4948 & 4.1346 & TRN & \\
\hline CHEMBL534589 & 817943 & 3.4948 & 3.4169 & TRN & \\
\hline CHEMBL528437 & 817943 & 5.3918 & 4.8759 & TRN & \\
\hline CHEMBL524930 & 817943 & 4.7959 & 4.3102 & TRN & \\
\hline CHEMBL602764 & 817943 & 3.4948 & 3.5511 & TRN & \\
\hline CHEMBL577440 & 817943 & 3.4948 & 3.6503 & TRN & \\
\hline CHEMBL590933 & 817943 & 5.5952 & 5.43 & TRN & \\
\hline CHEMBL580516 & 817943 & 5.9247 & 5.19 & TRN & \\
\hline CHEMBL584841 & 817943 & 4.8653 & 4.4948 & TRN & \\
\hline CHEMBL530149 & 817943 & 3.4948 & 3.61899 & 99999999998 & TRN \\
\hline CHEMBL581187 & 817943 & 3.4948 & 4.2064 & TRN & \\
\hline CHEMBL579443 & 817943 & 3.4948 & 4.5813 & TRN & \\
\hline CHEMBL535556 & 817943 & 4.78 & 4.0769 & TRN & \\
\hline CHEMBL580388 & 817943 & 3.4948 & 3.7597 & TST & \\
\hline CHEMBL590435 & 817943 & 3.4948 & 3.3996 & TRN & \\
\hline CHEMBL537071 & 817943 & 3.4948 & 4.3884 & TRN & \\
\hline CHEMBL589946 & 817943 & 4.9931 & 4.8147 & TRN & \\
\hline CHEMBL605281 & 817943 & 3.4948 & 3.9158 & TRN & \\
\hline CHEMBL530223 & 817943 & 5.2474 & 4.4232 & TRN & \\
\hline CHEMBL581225 & 817943 & 5.9939 & 4.8626 & TST & \\
\hline CHEMBL549210 & 817943 & 4.7928 & 4.5894 & TRN & \\
\hline CHEMBL529968 & 817943 & 3.4948 & 3.6154 & TRN & \\
\hline CHEMBL 2028043 & 817943 & 5.3918 & 5.1623 & TRN & \\
\hline CHEMBL475813 & 817943 & 3.4948 & 3.7198 & TRN & \\
\hline CHEMBL 2028059 & 817943 & 3.4948 & 4.4351 & TRN & \\
\hline CHEMBL599100 & 817943 & 3.4948 & 3.9751 & TRN & \\
\hline CHEMBL601325 & 817943 & 5.3645 & 4.3365 & TST & \\
\hline CHEMBL590683 & 817943 & 3.4948 & 4.7242 & TRN & \\
\hline CHEMBL587825 & 817943 & 4.7897 & 3.8694 & TST & \\
\hline CHEMBL587022 & 817943 & 4.7624 & 4.0184 & TST & \\
\hline CHEMBL530438 & 817943 & 3.4948 & 4.2422 & TST & \\
\hline CHEMBL532987 & 817943 & 3.4948 & 4.2209 & TST & \\
\hline CHEMBL592808 & 817943 & 4.9931 & 4.5881 & TST & \\
\hline CHEMBL579105 & 817943 & 5.5895 & 5.0117 & TST & \\
\hline
\end{tabular}




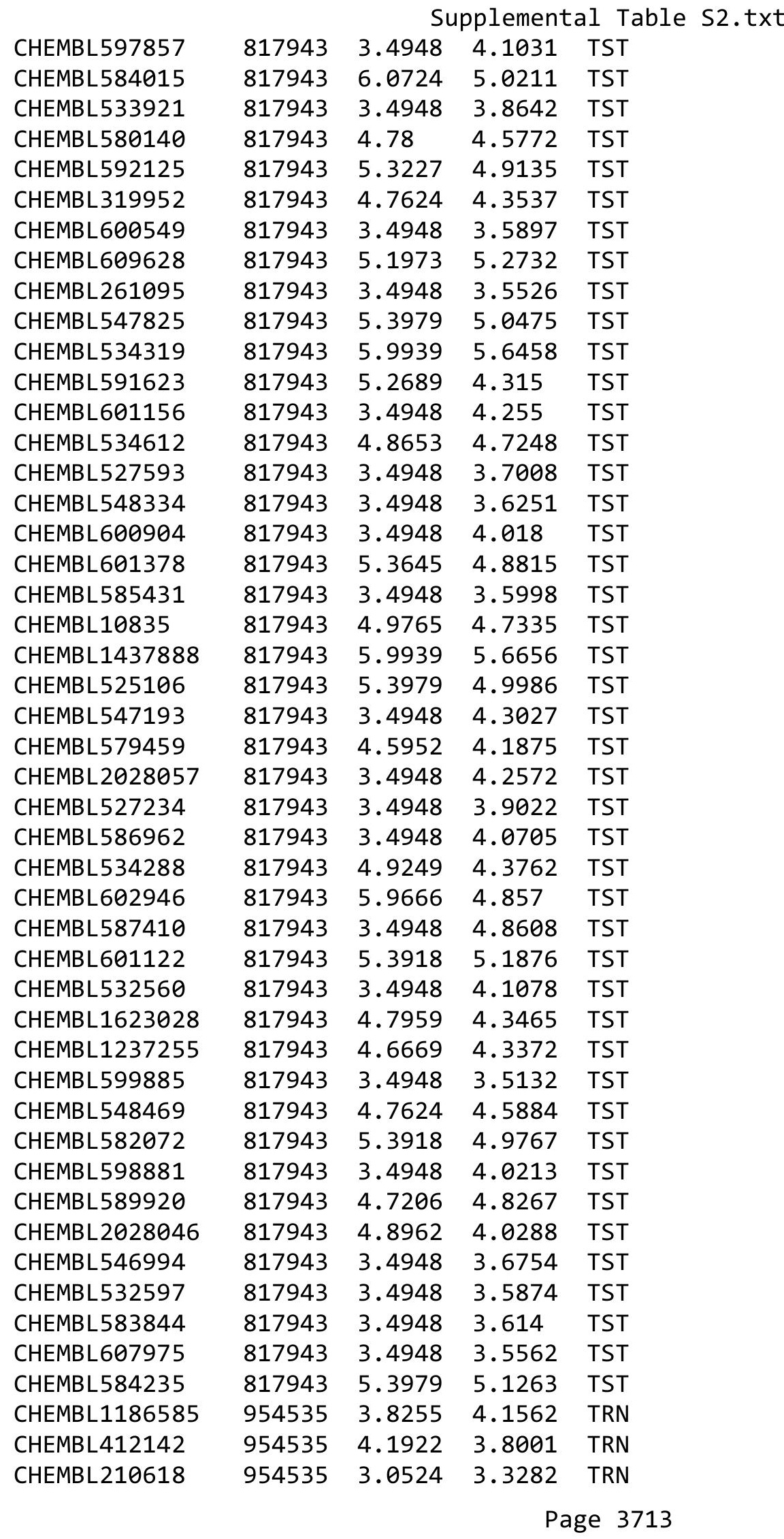




\begin{tabular}{|c|c|c|c|c|c|}
\hline \multicolumn{6}{|c|}{ Supplemental Table S2.txt } \\
\hline CHEMBL573107 & 954535 & 5.2405 & 5.0217 & TRN & \\
\hline CHEMBL514499 & 954535 & 5.9417 & 6.2491 & TRN & \\
\hline CHEMBL1242367 & 954535 & 3.3871 & 3.2656 & TRN & \\
\hline CHEMBL3199475 & 954535 & 3.3894 & 3.2235 & TRN & \\
\hline CHEMBL92309 & 954535 & 1.8475 & 2.1943 & TST & \\
\hline CHEMBL1643959 & 954535 & 2.5627 & 2.8942 & TRN & \\
\hline CHEMBL 300389 & 954535 & 5.5437 & 5.7886 & TRN & \\
\hline CHEMBL577784 & 954535 & 5.223 & 4.9772 & TRN & \\
\hline CHEMBL191334 & 954535 & 3.1537 & 3.4337 & TRN & \\
\hline CHEMBL1970879 & 954535 & 3.427 & 3.174 & TRN & \\
\hline CHEMBL3349342 & 954535 & 3.9217 & 4.3303 & TRN & \\
\hline CHEMBL483847 & 954535 & 3.8824 & 3.8449 & TRN & \\
\hline CHEMBL202721 & 954535 & 3.5434 & 4.1792 & TRN & \\
\hline CHEMBL258844 & 954535 & 3.261 & $3.2880 e$ & 00000000003 & $T$ \\
\hline CHEMBL3186408 & 954535 & 3.2543 & 3.1815 & TST & \\
\hline CHEMBL379975 & 954535 & 5.0694 & 4.9743 & TRN & \\
\hline CHEMBL222102 & 954535 & 3.53800 & g000000e & 3.7112 & TRN \\
\hline CHEMBL483849 & 954535 & 2.57 & 2.2651 & TRN & \\
\hline CHEMBL240954 & 954535 & 2.9732 & 3.4934 & TST & \\
\hline CHEMBL192566 & 954535 & 4.1283 & 6.7886 & TST & \\
\hline CHEMBL472940 & 954535 & 2.4911 & 2.1275 & TRN & \\
\hline CHEMBL399530 & 954535 & 4.4529 & 4.4145 & TRN & \\
\hline CHEMBL188678 & 954535 & 4.0932 & 4.1499 & TRN & \\
\hline CHEMBL135561 & 954535 & 3.6978 & 3.8006 & TRN & \\
\hline CHEMBL449158 & 954535 & 6.6951 & 6.4656 & TST & \\
\hline CHEMBL1357247 & 954535 & 3.1147 & 2.7861 & TRN & \\
\hline CHEMBL 213100 & 954535 & 3.0273 & 3.6381 & TRN & \\
\hline CHEMBL 2137530 & 954535 & 4.1843 & 4.405 & TRN & \\
\hline CHEMBL1788116 & 954535 & 2.6905 & 3.3368 & TRN & \\
\hline CHEMBL1230020 & 954535 & 4.8018 & 4.2486 & TRN & \\
\hline CHEMBL1909414 & 954535 & 3.5209 & 3.6556 & TRN & \\
\hline CHEMBL102714 & 954535 & 3.1369 & 3.6171 & TRN & \\
\hline CHEMBL9470 & 954535 & 3.7099 & 4.9003 & TST & \\
\hline CHEMBL259181 & 954535 & 2.6293 & 2.8364 & TRN & \\
\hline CHEMBL392695 & 954535 & 5.6023 & 4.7403 & TRN & \\
\hline CHEMBL515416 & 954535 & 4.2063 & 4.2402 & TRN & \\
\hline CHEMBL217354 & 954535 & 6.4348 & 6.4595 & TRN & \\
\hline CHEMBL558642 & 954535 & 2.5583 & 2.1831 & TRN & \\
\hline CHEMBL1516890 & 954535 & 3.6174 & 4.0036 & TRN & \\
\hline CHEMBL 255342 & 954535 & 4.2723 & 3.4874 & TRN & \\
\hline CHEMBL1256459 & 954535 & 6.8547 & 6.2677 & TRN & \\
\hline CHEMBL 221137 & 954535 & 4.3156 & 3.8686 & TST & \\
\hline CHEMBL1190711 & 954535 & 2.772 & 2.8562 & TRN & \\
\hline CHEMBL512504 & 954535 & 3.5795 & 3.5684 & TRN & \\
\hline CHEMBL2134202 & 954535 & 3.7359 & 3.8513 & TRN & \\
\hline CHEMBL585951 & 954535 & 5.4877 & 5.1687 & TRN & \\
\hline CHEMBL 220241 & 954535 & 3.7529 & 4.0008 & TRN & \\
\hline CHEMBL 2144069 & 954535 & 3.2256 & 3.3797 & TRN & \\
\hline
\end{tabular}




\begin{tabular}{|c|c|c|c|c|c|c|}
\hline \multirow[b]{2}{*}{ CHEMBL1404918 } & \multirow[b]{2}{*}{954535} & \multicolumn{5}{|c|}{ Supplemental Table S2.txt } \\
\hline & & 2.7263 & 2.8218 & TRN & & \\
\hline CHEMBL 2005886 & 954535 & 3.3751 & 3.1392 & TRN & & \\
\hline CHEMBL209148 & 954535 & \multicolumn{3}{|c|}{3.4389999999999996} & 3.1168 & TRN \\
\hline CHEMBL1590308 & 954535 & 2.4486 & 3.1721 & TST & & \\
\hline CHEMBL189584 & 954535 & 3.802 & 4.2912 & TST & & \\
\hline CHEMBL65 & 954535 & \multicolumn{3}{|c|}{6.202000000000001} & 7.3964 & TST \\
\hline CHEMBL 379300 & 954535 & 5.6711 & 5.7271 & TST & & \\
\hline CHEMBL2363137 & 954535 & 4.6888 & 4.1189 & TST & & \\
\hline CHEMBL180127 & 954535 & 3.1639 & 3.5862 & TST & & \\
\hline CHEMBL1673039 & 954535 & 3.6389 & 3.4766 & TST & & \\
\hline CHEMBL 373751 & 954535 & 3.1956 & 3.5609 & TST & & \\
\hline CHEMBL393929 & 954535 & 3.5003 & 3.8842 & TST & & \\
\hline CHEMBL539400 & 579309 & 7.1024 & 7.2847 & TST & & \\
\hline CHEMBL561982 & 579309 & 6.1864 & 6.2223 & TRN & & \\
\hline CHEMBL551257 & 579309 & 6.9208 & 7.2013 & TRN & & \\
\hline CHEMBL562570 & 579309 & 6.9431 & 7.0093 & TST & & \\
\hline CHEMBL556699 & 579309 & 6.8447 & 7.1974 & TRN & & \\
\hline CHEMBL562787 & 579309 & 6.6091 & 6.7182 & TRN & & \\
\hline CHEMBL563355 & 579309 & 4.8069 & 7.4297 & TST & & \\
\hline CHEMBL540490 & 579309 & 6.4365 & 6.7635 & TRN & & \\
\hline CHEMBL551922 & 579309 & 6.8794 & 7.0216 & TRN & & \\
\hline CHEMBL559788 & 579309 & 7.5686 & 6.9394 & TRN & & \\
\hline CHEMBL549360 & 579309 & 6.6778 & 7.0719 & TRN & & \\
\hline CHEMBL556417 & 579309 & 5.7062 & 7.1066 & TRN & & \\
\hline CHEMBL551459 & 579309 & 6.8633 & 6.8683 & TRN & & \\
\hline CHEMBL559468 & 579309 & 6.7471 & 6.2313 & TRN & & \\
\hline CHEMBL559924 & 579309 & 7.699 & 7.5132 & TST & & \\
\hline CHEMBL539429 & 579309 & 7.699 & 6.8216 & TRN & & \\
\hline CHEMBL550507 & 579309 & 6.8601 & 7.0245 & TST & & \\
\hline CHEMBL560856 & 579309 & 6.7545 & 6.8323 & TRN & & \\
\hline CHEMBL560576 & 579309 & 8.0969 & 7.1448 & TRN & & \\
\hline CHEMBL554520 & 579309 & 6.7721 & 6.695 & TRN & & \\
\hline CHEMBL555876 & 579309 & 6.8928 & 6.5936 & TRN & & \\
\hline CHEMBL550163 & 579309 & 7.9586 & 7.1837 & TST & & \\
\hline CHEMBL551516 & 579309 & 6.2604 & 6.1262 & TRN & & \\
\hline CHEMBL559864 & 579309 & 5.6655 & 6.6066 & TST & & \\
\hline CHEMBL560783 & 579309 & 7.7447 & 7.9458 & TRN & & \\
\hline CHEMBL563829 & 579309 & 6.6289 & 6.776 & TRN & & \\
\hline CHEMBL564061 & 579309 & 6.7471 & 6.7871 & TRN & & \\
\hline CHEMBL559205 & 579309 & 7.0555 & 7.0681 & TST & & \\
\hline CHEMBL552192 & 579309 & 7.6021 & 7.0403 & TST & & \\
\hline CHEMBL564867 & 579309 & 7.9208 & 7.5932 & TRN & & \\
\hline CHEMBL556182 & 579309 & 6.8996 & 6.9871 & TRN & & \\
\hline CHEMBL550916 & 579309 & 8.5229 & 8.0847 & TRN & & \\
\hline CHEMBL563418 & 579309 & 5.5817 & 5.376 & TRN & & \\
\hline CHEMBL561783 & 579309 & 6.4202 & 6.4056 & TRN & & \\
\hline CHEMBL551798 & 579309 & 6.76200 & 30000000 & 205 & 6.6116 & TRN \\
\hline CHEMBL565097 & 579309 & 6.9136 & 6.9509 & TST & & \\
\hline
\end{tabular}




\begin{tabular}{|c|c|c|c|c|c|c|}
\hline \multicolumn{7}{|c|}{ s.t. } \\
\hline CHEMBL557439 & 579309 & 6.8327 & 6.9337 & TRN & & \\
\hline CHEMBL563010 & 579309 & 6.5952 & 6.9995 & TRN & & \\
\hline CHEMBL540494 & 579309 & 6.6308 & 6.5025 & TRN & & \\
\hline CHEMBL558116 & 579309 & 6.6778 & 6.782 & TRN & & \\
\hline CHEMBL557435 & 579309 & 6.5918 & 6.5142 & TRN & & \\
\hline CHEMBL559529 & 579309 & 7.0223 & 6.9881 & TST & & \\
\hline CHEMBL550918 & 579309 & 5.6194 & 6.5696 & TRN & & \\
\hline CHEMBL551518 & 579309 & 6.8041 & 6.9797 & TRN & & \\
\hline CHEMBL562588 & 579309 & 7.699 & 7.4122 & TRN & & \\
\hline CHEMBL562602 & 579309 & 6.9245 & 6.7161 & TRN & & \\
\hline CHEMBL556483 & 579309 & 6.61799 & 99999999 & 99 & 6.5988 & TRN \\
\hline CHEMBL557710 & 579309 & 5.699 & 6.785 & TST & & \\
\hline CHEMBL558404 & 579309 & 7.4949 & 7.2487 & TST & & \\
\hline CHEMBL549977 & 579309 & 6.6326 & 6.5725 & TRN & & \\
\hline CHEMBL562879 & 579309 & 7.1675 & 6.8647 & TRN & & \\
\hline CHEMBL550992 & 579309 & 4.9863 & 6.2074 & TST & & \\
\hline CHEMBL549428 & 579309 & 7.1249 & 7.1827 & TRN & & \\
\hline CHEMBL561923 & 579309 & 7.7447 & 7.4006 & TRN & & \\
\hline CHEMBL549900 & 579309 & 7.9586 & 7.5416 & TRN & & \\
\hline CHEMBL553470 & 579309 & 7.7959 & 7.3387 & TRN & & \\
\hline CHEMBL561785 & 579309 & 3.9237 & 5.2393 & TST & & \\
\hline CHEMBL558947 & 579309 & 5.3089 & 5.4628 & TRN & & \\
\hline CHEMBL563562 & 579309 & 5.8125 & 6.522 & TST & & \\
\hline CHEMBL564797 & 579309 & 5.6271 & 6.6296 & TST & & \\
\hline CHEMBL564188 & 579309 & 6.7852 & 7.3241 & TRN & & \\
\hline CHEMBL564915 & 579309 & 6.8633 & 7.6236 & TST & & \\
\hline CHEMBL563459 & 579309 & 6.7496 & 6.7854 & TRN & & \\
\hline CHEMBL563690 & 579309 & 4.8969 & 4.5623 & TRN & & \\
\hline CHEMBL560180 & 579309 & 7.6383 & 7.4312 & TRN & & \\
\hline CHEMBL549981 & 579309 & 6.8182 & 6.9187 & TRN & & \\
\hline CHEMBL562061 & 579309 & 6.8894 & 7.1347 & TRN & & \\
\hline CHEMBL561784 & 579309 & 6.5918 & 6.4845 & TRN & & \\
\hline CHEMBL560259 & 579309 & 6.6517 & 7.1391 & TST & & \\
\hline CHEMBL551661 & 579309 & 5.6596 & 6.3098 & TRN & & \\
\hline CHEMBL557643 & 579309 & 6.7447 & 6.5359 & TRN & & \\
\hline CHEMBL550386 & 579309 & 7.1871 & 7.2042 & TRN & & \\
\hline CHEMBL561859 & 579309 & 6.6126 & 6.7099 & TRN & & \\
\hline CHEMBL549839 & 579309 & 5.9431 & 6.4909 & TRN & & \\
\hline CHEMBL 249279 & 456312 & 6.4202 & 6.4198 & TRN & & \\
\hline CHEMBL 249721 & 456312 & 7.0223 & 7.0223 & TRN & & \\
\hline CHEMBL 398253 & 456312 & 7.8861 & 7.8859 & TRN & & \\
\hline CHEMBL249720 & 456312 & 6.585 & 6.5855 & TRN & & \\
\hline CHEMBL398511 & 456312 & 6.6383 & 6.6385 & TRN & & \\
\hline CHEMBL 249886 & 456312 & 7.8861 & 7.8858 & TRN & & \\
\hline CHEMBL398514 & 456312 & 6.5686 & 6.5689 & TRN & & \\
\hline CHEMBL 250335 & 456312 & 6.5376 & 6.5378 & TRN & & \\
\hline CHEMBL 249508 & 456312 & 7.6383 & 7.6384 & TRN & & \\
\hline CHEMBL 249482 & 456312 & 8.1549 & 8.1549 & TRN & & \\
\hline
\end{tabular}




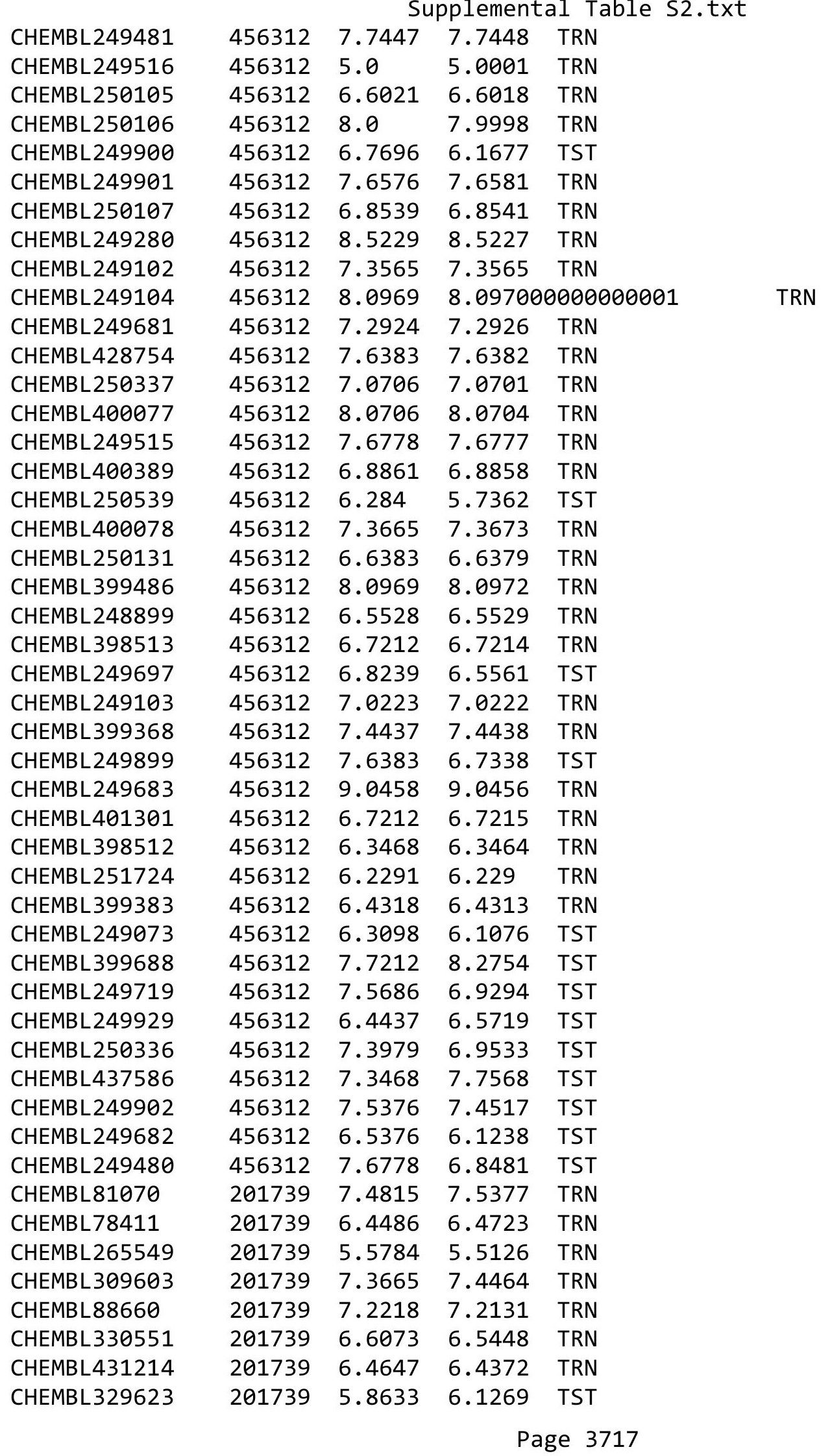




\begin{tabular}{|c|c|c|c|c|c|c|}
\hline & & \multicolumn{5}{|c|}{ Supplemental Table S2.txt } \\
\hline CHEMBL 90975 & 201739 & 6.8539 & 6.8363 & TRN & & \\
\hline CHEMBL88932 & 201739 & 7.1249 & 7.0248 & TRN & & \\
\hline CHEMBL314379 & 201739 & 5.0716 & 5.0187 & TRN & & \\
\hline CHEMBL314423 & 201739 & 6.4672 & 7.261 & TST & & \\
\hline CHEMBL421364 & 201739 & 5.2034 & 5.2647 & TRN & & \\
\hline CHEMBL91628 & 201739 & 7.0862 & 7.1527 & TRN & & \\
\hline CHEMBL430455 & 201739 & 6.6198 & 6.6684 & TRN & & \\
\hline CHEMBL 78777 & 201739 & 8.0969 & 7.9925 & TRN & & \\
\hline CHEMBL81626 & 201739 & 6.6162 & 6.6453 & TRN & & \\
\hline CHEMBL91828 & 201739 & 5.1397 & 4.6002 & TST & & \\
\hline CHEMBL310170 & 201739 & 7.8539 & 7.8563 & TRN & & \\
\hline CHEMBL91791 & 201739 & 7.0362 & 6.5235 & TST & & \\
\hline CHEMBL282433 & 201739 & 7.5086 & 7.4879 & TRN & & \\
\hline CHEMBL89344 & 201739 & 7.041 & 6.2886 & TST & & \\
\hline CHEMBL 90643 & 201739 & 5.5376 & 5.5025 & TRN & & \\
\hline CHEMBL91946 & 201739 & 5.5686 & 5.5352 & TRN & & \\
\hline CHEMBL312600 & 201739 & 7.8861 & 7.8632 & TRN & & \\
\hline CHEMBL441453 & 201739 & 5.1439 & 6.3362 & TST & & \\
\hline CHEMBL92095 & 201739 & 5.6778 & 5.7228 & TRN & & \\
\hline CHEMBL89811 & 201739 & 5.9172 & 5.8779 & TRN & & \\
\hline CHEMBL81594 & 201739 & 5.091 & 6.3331 & TST & & \\
\hline CHEMBL280243 & 201739 & 7.0555 & 6.9839 & TRN & & \\
\hline CHEMBL78306 & 201739 & 7.2291 & 7.1931 & TST & & \\
\hline CHEMBL420245 & 201739 & 5.6596 & 5.6917 & TRN & & \\
\hline CHEMBL313649 & 201739 & 5.1007 & 5.1698 & TRN & & \\
\hline CHEMBL412674 & 201739 & $5.2020 e$ & 0000000 & $\partial 1$ & 5.2302 & TRN \\
\hline CHEMBL90508 & 201739 & 7.3979 & 7.4099 & TRN & & \\
\hline CHEMBL 88465 & 201739 & 5.3188 & 5.1574 & TRN & & \\
\hline CHEMBL310729 & 201739 & 5.7011 & 5.6982 & TRN & & \\
\hline CHEMBL78083 & 201739 & 6.6108 & 6.5988 & TRN & & \\
\hline CHEMBL 81602 & 201739 & 6.2716 & 6.3135 & TRN & & \\
\hline CHEMBL 88161 & 201739 & 4.9706 & 5.0408 & TRN & & \\
\hline CHEMBL90326 & 201739 & 5.52 & 5.5461 & TRN & & \\
\hline CHEMBL 79509 & 201739 & 6.7825 & 6.8853 & TRN & & \\
\hline CHEMBL 314710 & 201739 & 5.8508 & 5.8929 & TRN & & \\
\hline CHEMBL 82078 & 201739 & 7.0177 & 7.0586 & TRN & & \\
\hline CHEMBL328986 & 201739 & 6.0 & 5.9882 & TRN & & \\
\hline CHEMBL91713 & 201739 & 7.2676 & 7.3703 & TRN & & \\
\hline CHEMBL91145 & 201739 & 5.9706 & 5.8929 & TRN & & \\
\hline CHEMBL 81678 & 201739 & 6.9031 & 6.8332 & TRN & & \\
\hline CHEMBL420979 & 201739 & 5.7305 & 5.7161 & TRN & & \\
\hline CHEMBL88639 & 201739 & 4.8861 & 4.9664 & TRN & & \\
\hline CHEMBL315051 & 201739 & 7.5376 & 7.4272 & TST & & \\
\hline CHEMBL77675 & 201739 & 6.4012 & 6.3529 & TRN & & \\
\hline CHEMBL 88146 & 201739 & 5.6402 & 5.7021 & TST & & \\
\hline CHEMBL 79437 & 201739 & 7.3768 & 7.455 & TST & & \\
\hline CHEMBL431462 & 201739 & 5.5622 & 5.1341 & TST & & \\
\hline CHEMBL90288 & 201739 & 4.9586 & 4.8461 & TST & & \\
\hline
\end{tabular}




\begin{tabular}{|c|c|c|c|c|c|}
\hline \\
\hline CHEMBL90809 & 201739 & 5.2125 & 4.9829 & TST & \\
\hline CHEMBL91222 & 201739 & 6.4547 & 6.5743 & TST & \\
\hline CHEMBL1978271 & 809279 & 4.8 & 4.8182 & TRN & \\
\hline CHEMBL2007266 & 809279 & 4.8 & 4.8336 & TRN & \\
\hline CHEMBL202721 & 809279 & 4.8 & 4.7968 & TRN & \\
\hline CHEMBL2000568 & 809279 & 4.8 & 4.831 & TRN & \\
\hline CHEMBL2007097 & 809279 & 5.3 & 4.6262 & TRN & \\
\hline CHEMBL1825138 & 809279 & 4.8 & 5.456 & TST & \\
\hline CHEMBL1973516 & 809279 & 4.8 & 5.2408 & TRN & \\
\hline CHEMBL1974328 & 809279 & 4.8 & 5.1148 & TRN & \\
\hline CHEMBL243298 & 809279 & 7.5 & 6.9778 & TRN & \\
\hline CHEMBL509032 & 809279 & 4.8 & 5.0164 & TRN & \\
\hline CHEMBL1980435 & 809279 & 5.8 & 6.2863 & TRN & \\
\hline CHEMBL143703 & 809279 & 3.2 & 3.4524 & TRN & \\
\hline CHEMBL388311 & 809279 & 6.8 & 7.9918 & TRN & \\
\hline CHEMBL1964948 & 809279 & 4.8 & 4.3389 & TRN & \\
\hline CHEMBL1973013 & 809279 & 6.4 & 6.4501 & TRN & \\
\hline CHEMBL1995813 & 809279 & 7.5 & 7.1369 & TRN & \\
\hline CHEMBL1966204 & 809279 & 6.9 & 7.3683 & TRN & \\
\hline CHEMBL1987430 & 809279 & 4.9 & 4.8718 & TRN & \\
\hline CHEMBL244378 & 809279 & 7.8 & 7.4932 & TRN & \\
\hline CHEMBL1993413 & 809279 & 4.8 & 4.5596 & TRN & \\
\hline CHEMBL 205415 & 809279 & 6.0 & 5.47 & TRN & \\
\hline CHEMBL1975927 & 809279 & 4.8 & 3.9804 & TRN & \\
\hline CHEMBL1986943 & 809279 & 8.9 & 7.8942 & TRN & \\
\hline CHEMBL289959 & 809279 & 3.2 & 3.6941 & TRN & \\
\hline CHEMBL1997119 & 809279 & 4.8 & 4.29899 & 99999999995 & TRN \\
\hline CHEMBL1977138 & 809279 & 6.7 & 6.4982 & TRN & \\
\hline CHEMBL 2000879 & 809279 & 4.3 & 4.4435 & TST & \\
\hline CHEMBL1978448 & 809279 & 4.8 & 4.3103 & TST & \\
\hline CHEMBL1980329 & 809279 & 7.1 & 5.9167 & TRN & \\
\hline CHEMBL 2004515 & 809279 & 3.2 & 4.7774 & TRN & \\
\hline CHEMBL1992042 & 809279 & 6.6 & 6.2022 & TRN & \\
\hline CHEMBL1986265 & 809279 & 4.8 & 4.9575 & TRN & \\
\hline CHEMBL1971172 & 809279 & 7.5 & 6.6763 & TRN & \\
\hline CHEMBL1967211 & 809279 & 3.2 & 3.4918 & TRN & \\
\hline CHEMBL1991734 & 809279 & 7.0 & 6.3461 & TST & \\
\hline CHEMBL21156 & 809279 & 4.8 & 4.5473 & TST & \\
\hline CHEMBL1994724 & 809279 & 4.8 & 4.4532 & TRN & \\
\hline CHEMBL1989267 & 809279 & 4.8 & 5.6553 & TRN & \\
\hline CHEMBL1991782 & 809279 & 3.5 & 4.4559 & TRN & \\
\hline CHEMBL 2002105 & 809279 & 4.8 & 5.2614 & TRN & \\
\hline CHEMBL1983348 & 809279 & 6.1 & 6.1405 & TST & \\
\hline CHEMBL1970290 & 809279 & 4.8 & 5.0105 & TRN & \\
\hline CHEMBL1968394 & 809279 & 3.2 & 3.3029 & TRN & \\
\hline CHEMBL1993877 & 809279 & 4.8 & 5.1417 & TRN & \\
\hline CHEMBL1974480 & 809279 & 6.1 & 5.334 & TST & \\
\hline CHEMBL1996500 & 809279 & 4.8 & 5.2962 & TST & \\
\hline
\end{tabular}




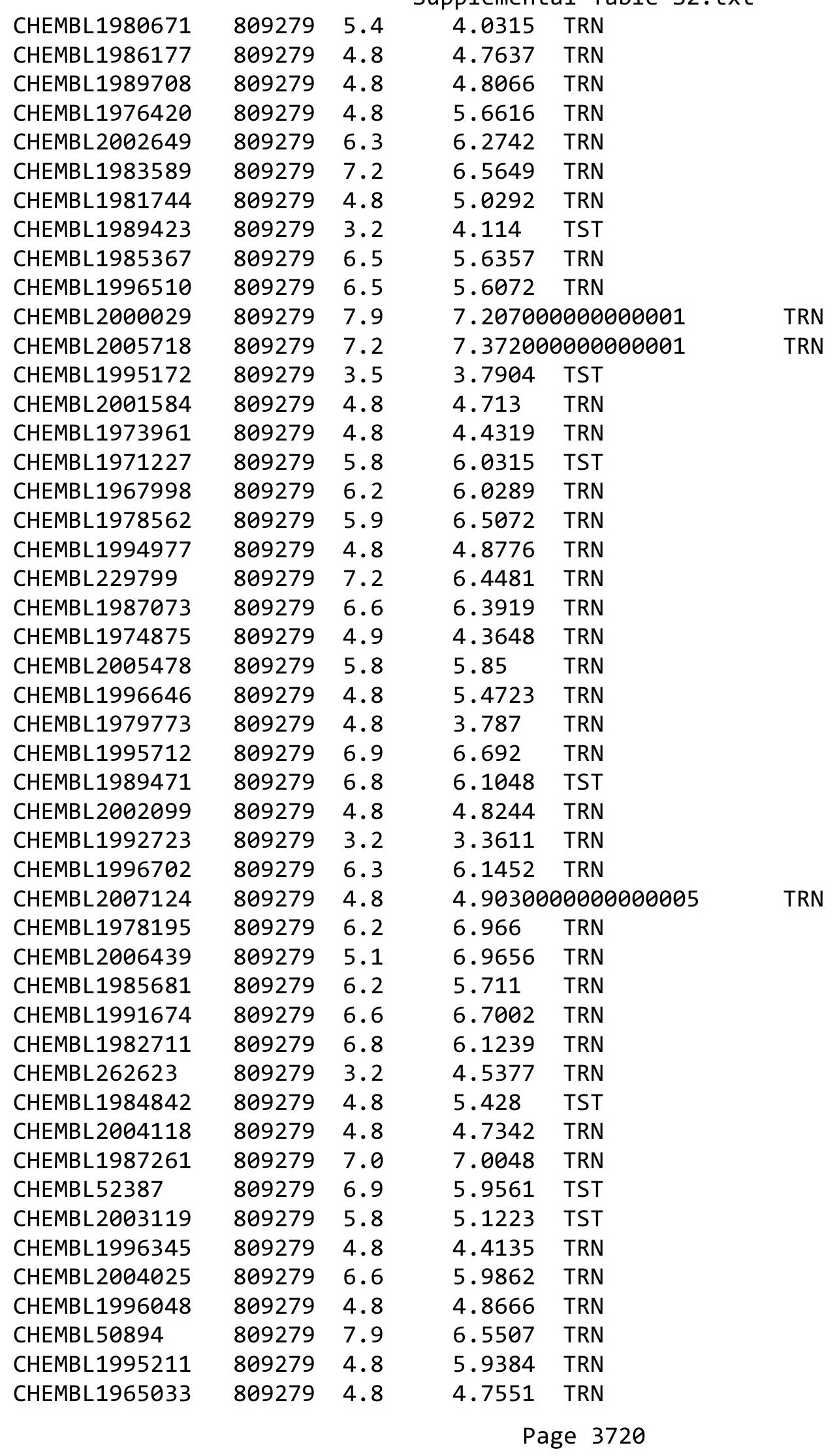




\begin{tabular}{|c|c|c|c|c|c|}
\hline & & & & & \\
\hline CHEMBL461876 & 809279 & 4.8 & 4.3675 & TRN & \\
\hline CHEMBL 2006299 & 809279 & 4.8 & 4.8221 & TRN & \\
\hline CHEMBL1971519 & 809279 & 3.2 & 4.0045 & TRN & \\
\hline CHEMBL1980562 & 809279 & 8.6 & 7.5546 & TRN & \\
\hline CHEMBL1997335 & 809279 & 6.7 & 5.4804 & TRN & \\
\hline CHEMBL1965169 & 809279 & 4.8 & 5.58899 & 99999999995 & TRN \\
\hline CHEMBL1081312 & 809279 & 4.8 & 5.4571 & TRN & \\
\hline CHEMBL1965170 & 809279 & 4.8 & 5.083 & TRN & \\
\hline CHEMBL1985723 & 809279 & 7.0 & 6.4637 & TRN & \\
\hline CHEMBL 2005792 & 809279 & 4.8 & 5.5482 & TST & \\
\hline CHEMBL1991867 & 809279 & 4.9 & 4.7235 & TRN & \\
\hline CHEMBL1979933 & 809279 & 6.8 & 6.8286 & TRN & \\
\hline CHEMBL1972355 & 809279 & 6.8 & 6.8695 & TST & \\
\hline CHEMBL1997892 & 809279 & 4.8 & 4.7407 & TRN & \\
\hline CHEMBL2001641 & 809279 & 5.0 & 4.8479 & TRN & \\
\hline CHEMBL1976936 & 809279 & 6.2 & 6.501 & TRN & \\
\hline CHEMBL1964902 & 809279 & 4.8 & 4.7147 & TRN & \\
\hline CHEMBL1973868 & 809279 & 6.0 & 5.53100 & 3000000001 & TRN \\
\hline CHEMBL1977128 & 809279 & 7.1 & 6.5975 & TRN & \\
\hline CHEMBL1972988 & 809279 & 6.0 & 6.1055 & TRN & \\
\hline CHEMBL1965702 & 809279 & 6.7 & 6.5667 & TRN & \\
\hline CHEMBL1983715 & 809279 & 6.8 & 6.1514 & TRN & \\
\hline CHEMBL1958401 & 809279 & 7.3 & 6.8075 & TRN & \\
\hline CHEMBL1987448 & 809279 & 8.4 & 8.0686 & TRN & \\
\hline CHEMBL 2002992 & 809279 & 4.8 & 5.2978 & TRN & \\
\hline CHEMBL1982700 & 809279 & 4.8 & 4.6925 & TRN & \\
\hline CHEMBL10 & 809279 & 4.8 & 5.5113 & TRN & \\
\hline CHEMBL 2005216 & 809279 & 6.4 & 6.5979 & TRN & \\
\hline CHEMBL1980763 & 809279 & 4.8 & 4.5851 & TRN & \\
\hline CHEMBL1977931 & 809279 & 4.3 & 4.337 & TRN & \\
\hline CHEMBL1976872 & 809279 & 3.2 & 3.6336 & TRN & \\
\hline CHEMBL 2006456 & 809279 & 7.8 & 7.6368 & TRN & \\
\hline CHEMBL1969156 & 809279 & 3.2 & 3.6598 & TRN & \\
\hline CHEMBL 375530 & 809279 & 6.9 & 4.9514 & TST & \\
\hline CHEMBL2007479 & 809279 & 6.7 & 5.9164 & TRN & \\
\hline CHEMBL1964340 & 809279 & 6.7 & 7.3081 & TRN & \\
\hline CHEMBL1971606 & 809279 & 4.8 & 4.77 & TRN & \\
\hline CHEMBL1999120 & 809279 & 4.4 & 4.3987 & TST & \\
\hline CHEMBL1972220 & 809279 & 4.8 & 5.5724 & TRN & \\
\hline CHEMBL1972583 & 809279 & 3.2 & 3.8074 & TRN & \\
\hline CHEMBL1981215 & 809279 & 4.8 & 4.9631 & TRN & \\
\hline CHEMBL 2003785 & 809279 & 3.2 & 4.3736 & TRN & \\
\hline CHEMBL1967662 & 809279 & 6.8 & 7.4825 & TRN & \\
\hline CHEMBL354676 & 809279 & 5.4 & 3.4827 & TRN & \\
\hline CHEMBL1999414 & 809279 & 4.8 & 4.487 & TRN & \\
\hline CHEMBL1967336 & 809279 & 6.0 & 6.3965 & TRN & \\
\hline CHEMBL2001923 & 809279 & 4.8 & 5.0464 & TRN & \\
\hline CHEMBL1983070 & 809279 & 4.8 & 4.2026 & TRN & \\
\hline & & & & e 3721 & \\
\hline
\end{tabular}




\begin{tabular}{|c|c|c|c|c|c|}
\hline \multicolumn{6}{|c|}{ Supplemental Table S2.txt } \\
\hline CHEMBL 2003514 & 809279 & 4.8 & 4.9826 & TRN & \\
\hline CHEMBL1970340 & 809279 & 4.8 & 4.6356 & TRN & \\
\hline CHEMBL1967992 & 809279 & 7.0 & 5.9034 & TRN & \\
\hline CHEMBL1989043 & 809279 & 7.2 & 6.2772 & TRN & \\
\hline CHEMBL 2006450 & 809279 & 4.8 & 5.1114 & TRN & \\
\hline CHEMBL1967538 & 809279 & 3.2 & 3.9058 & TRN & \\
\hline CHEMBL 2001987 & 809279 & 4.8 & 4.9426 & TRN & \\
\hline CHEMBL1994555 & 809279 & 6.1 & 5.7076 & TRN & \\
\hline CHEMBL1968515 & 809279 & 3.2 & 4.2994 & TST & \\
\hline CHEMBL1164180 & 809279 & 4.8 & 5.2467 & TST & \\
\hline CHEMBL1975121 & 809279 & 4.8 & 5.0234 & TRN & \\
\hline CHEMBL1983640 & 809279 & 4.8 & 5.1431 & TRN & \\
\hline CHEMBL1997554 & 809279 & 7.4 & 7.0256 & TRN & \\
\hline CHEMBL1980003 & 809279 & 4.4 & 3.8956 & TRN & \\
\hline CHEMBL1971943 & 809279 & 4.8 & 4.9355 & TRN & \\
\hline CHEMBL 2002723 & 809279 & 6.0 & 5.13200 & 0000000001 & TRN \\
\hline CHEMBL1984686 & 809279 & 6.1 & 5.3698 & TST & \\
\hline CHEMBL1973793 & 809279 & 4.8 & 4.638 & TST & \\
\hline CHEMBL1980178 & 809279 & 6.9 & 7.0067 & TRN & \\
\hline CHEMBL1969588 & 809279 & 7.0 & 7.7336 & TRN & \\
\hline CHEMBL1992073 & 809279 & 4.8 & 5.1499 & TRN & \\
\hline CHEMBL1990254 & 809279 & 6.8 & 5.6384 & TRN & \\
\hline CHEMBL1986143 & 809279 & 4.8 & 5.3081 & TRN & \\
\hline CHEMBL1972934 & 809279 & 5.1 & 4.8904 & TRN & \\
\hline CHEMBL 2007559 & 809279 & 4.8 & 4.4939 & TRN & \\
\hline CHEMBL1992581 & 809279 & 4.8 & 5.404 & TRN & \\
\hline CHEMBL 2004290 & 809279 & 5.9 & 5.0424 & TRN & \\
\hline CHEMBL1986499 & 809279 & 6.3 & 7.2061 & TRN & \\
\hline CHEMBL1975921 & 809279 & 4.9 & 5.4878 & TRN & \\
\hline CHEMBL1983573 & 809279 & 5.4 & 3.8739 & TRN & \\
\hline CHEMBL1975923 & 809279 & 5.1 & 5.4387 & TST & \\
\hline CHEMBL1984847 & 809279 & 4.8 & 5.0679 & TRN & \\
\hline CHEMBL1984402 & 809279 & 3.2 & 4.1628 & TRN & \\
\hline CHEMBL 2005449 & 809279 & 5.9 & 6.2723 & TRN & \\
\hline CHEMBL1996576 & 809279 & 4.8 & 4.8084 & TST & \\
\hline CHEMBL1991678 & 809279 & 4.8 & 5.5766 & TST & \\
\hline CHEMBL1987998 & 809279 & 4.8 & 4.7158 & TRN & \\
\hline CHEMBL1971534 & 809279 & 6.3 & 5.7284 & TRN & \\
\hline CHEMBL1990496 & 809279 & 4.8 & 5.0564 & TRN & \\
\hline CHEMBL1992363 & 809279 & 6.7 & 7.0701 & TRN & \\
\hline CHEMBL242865 & 809279 & 7.1 & 7.2027 & TRN & \\
\hline CHEMBL235157 & 809279 & 4.8 & 4.6686 & TRN & \\
\hline CHEMBL1982271 & 809279 & 8.3 & 7.9777 & TRN & \\
\hline CHEMBL 2004159 & 809279 & 4.8 & 4.8438 & TRN & \\
\hline CHEMBL396523 & 809279 & 7.4 & 7.7226 & TRN & \\
\hline CHEMBL1978371 & 809279 & 6.4 & 5.8828 & TST & \\
\hline CHEMBL440084 & 809279 & 4.8 & 5.1759 & TRN & \\
\hline CHEMBL1998110 & 809279 & 4.8 & 4.5981 & TRN & \\
\hline
\end{tabular}




\begin{tabular}{|c|c|c|c|c|}
\hline & & & pplement & al $\mathrm{Ta}$ \\
\hline CHEMBL1978166 & 809279 & 6.0 & 6.0504 & TRN \\
\hline CHEMBL1981079 & 809279 & 8.2 & 8.0544 & TRN \\
\hline CHEMBL1972454 & 809279 & 3.2 & 3.4797 & TRN \\
\hline CHEMBL1990590 & 809279 & 4.8 & 4.4577 & TRN \\
\hline CHEMBL1977814 & 809279 & 5.8 & 4.9185 & TRN \\
\hline CHEMBL1974617 & 809279 & 5.3 & 5.9478 & TRN \\
\hline CHEMBL86755 & 809279 & 4.8 & 5.0595 & TRN \\
\hline CHEMBL1965660 & 809279 & 8.4 & 8.4962 & TRN \\
\hline CHEMBL1972290 & 809279 & 7.1 & 7.0713 & TRN \\
\hline CHEMBL1966175 & 809279 & 4.8 & 5.3243 & TRN \\
\hline CHEMBL2007375 & 809279 & 4.8 & 4.5593 & TRN \\
\hline CHEMBL379975 & 809279 & 4.8 & 7.2942 & TST \\
\hline CHEMBL1973016 & 809279 & 6.1 & 5.4063 & TRN \\
\hline CHEMBL1965387 & 809279 & 4.8 & 4.8372 & TRN \\
\hline CHEMBL 2001539 & 809279 & 4.7 & 4.5788 & TST \\
\hline CHEMBL388978 & 809279 & 7.9 & 7.2218 & TST \\
\hline CHEMBL1997041 & 809279 & 3.2 & 4.5319 & TRN \\
\hline CHEMBL1984548 & 809279 & 8.6 & 8.7447 & TRN \\
\hline CHEMBL550418 & 809279 & 6.8 & 6.2053 & TRN \\
\hline CHEMBL1986666 & 809279 & 6.7 & 6.495 & TRN \\
\hline CHEMBL398951 & 809279 & 4.8 & 3.6797 & TST \\
\hline CHEMBL1971289 & 809279 & 6.2 & 5.6618 & TST \\
\hline CHEMBL1988437 & 809279 & 4.8 & 4.7311 & TRN \\
\hline CHEMBL1421720 & 809279 & 6.6 & 6.6032 & TRN \\
\hline CHEMBL1233887 & 809279 & 4.8 & 5.2208 & TRN \\
\hline CHEMBL1968130 & 809279 & 3.2 & 4.9896 & TRN \\
\hline CHEMBL1996649 & 809279 & 4.8 & 4.6303 & TRN \\
\hline CHEMBL1986756 & 809279 & 4.8 & 4.8573 & TRN \\
\hline CHEMBL1949855 & 809279 & 5.6 & 4.8038 & TRN \\
\hline CHEMBL1972339 & 809279 & 6.9 & 7.6354 & TRN \\
\hline CHEMBL3109278 & 809279 & 4.8 & 4.6407 & TRN \\
\hline CHEMBL1727312 & 809279 & 3.2 & 3.571 & TRN \\
\hline CHEMBL 2004438 & 809279 & 4.8 & 4.7789 & TRN \\
\hline CHEMBL1964382 & 809279 & 4.8 & 4.621 & TST \\
\hline CHEMBL101311 & 809279 & 6.2 & 5.2931 & TRN \\
\hline CHEMBL191003 & 809279 & 7.8 & 6.0221 & TRN \\
\hline CHEMBL1973359 & 809279 & 7.4 & 6.5633 & TST \\
\hline CHEMBL1983595 & 809279 & 6.2 & 6.129 & TRN \\
\hline CHEMBL1995740 & 809279 & 6.2 & 6.3062 & TRN \\
\hline CHEMBL1988581 & 809279 & 7.7 & 6.8575 & TST \\
\hline CHEMBL1990162 & 809279 & 6.7 & 6.9153 & TRN \\
\hline CHEMBL2005699 & 809279 & 4.8 & 4.7003 & TRN \\
\hline CHEMBL1992220 & 809279 & 8.4 & 8.5877 & TRN \\
\hline CHEMBL 2006564 & 809279 & 4.8 & 5.1983 & TRN \\
\hline CHEMBL1980253 & 809279 & 7.6 & 7.6937 & TRN \\
\hline CHEMBL1979690 & 809279 & 6.3 & 6.1644 & TRN \\
\hline CHEMBL 234085 & 809279 & 4.8 & 4.9902 & TRN \\
\hline CHEMBL1978167 & 809279 & 4.8 & 5.5789 & TRN \\
\hline
\end{tabular}




\begin{tabular}{|c|c|c|c|c|c|}
\hline \\
\hline CHEMBL418203 & 809279 & 9.2 & 6.5994 & TST & \\
\hline CHEMBL243664 & 809279 & 5.9 & 5.3877 & TST & \\
\hline CHEMBL225519 & 809279 & 8.0 & 7.6284 & TRN & \\
\hline CHEMBL1994159 & 809279 & 3.2 & 3.8367 & TRN & \\
\hline CHEMBL1976376 & 809279 & 4.8 & 4.6615 & TRN & \\
\hline CHEMBL1988622 & 809279 & 3.2 & 3.5988 & TRN & \\
\hline CHEMBL1983575 & 809279 & 6.0 & 5.7791 & TRN & \\
\hline CHEMBL1986722 & 809279 & 6.0 & 4.8729 & TRN & \\
\hline CHEMBL1968868 & 809279 & 4.8 & 5.0961 & TRN & \\
\hline CHEMBL1981047 & 809279 & 4.8 & 4.3929 & TRN & \\
\hline CHEMBL229968 & 809279 & 6.7 & 6.5687 & TRN & \\
\hline CHEMBL1998470 & 809279 & 6.7 & 5.8873 & TRN & \\
\hline CHEMBL1996980 & 809279 & 8.5 & 8.4253 & TRN & \\
\hline CHEMBL1976196 & 809279 & 5.8 & 5.5037 & TST & \\
\hline CHEMBL1987948 & 809279 & 7.3 & 7.0555 & TRN & \\
\hline CHEMBL1997197 & 809279 & 7.0 & 5.7166 & TRN & \\
\hline CHEMBL1983630 & 809279 & 4.8 & 4.4618 & TRN & \\
\hline CHEMBL1994669 & 809279 & 8.7 & 9.0107 & TRN & \\
\hline CHEMBL1975903 & 809279 & 7.5 & 6.0077 & TRN & \\
\hline CHEMBL1522508 & 809279 & 3.2 & 4.1546 & TRN & \\
\hline CHEMBL1973795 & 809279 & 3.2 & 3.3972 & TRN & \\
\hline CHEMBL458997 & 809279 & 4.8 & 4.7351 & TRN & \\
\hline CHEMBL1988805 & 809279 & 6.3 & 4.6553 & TRN & \\
\hline CHEMBL1969942 & 809279 & 4.8 & 4.8061 & TRN & \\
\hline CHEMBL1982660 & 809279 & 4.8 & 5.5134 & TRN & \\
\hline CHEMBL1978567 & 809279 & 4.8 & 4.5981 & TRN & \\
\hline CHEMBL1965838 & 809279 & 4.3 & 4.644 & TST & \\
\hline CHEMBL1977223 & 809279 & 7.4 & 7.1524 & TRN & \\
\hline CHEMBL1995765 & 809279 & 5.4 & 5.306 & TRN & \\
\hline CHEMBL1976290 & 809279 & 3.2 & 3.302 & TRN & \\
\hline CHEMBL1984760 & 809279 & 4.8 & 4.756 & TRN & \\
\hline CHEMBL2003856 & 809279 & 4.6 & 6.6529 & TRN & \\
\hline CHEMBL1997846 & 809279 & 4.4 & 5.4644 & TRN & \\
\hline CHEMBL360847 & 809279 & 4.8 & 5.3067 & TRN & \\
\hline CHEMBL1995811 & 809279 & 6.4 & 7.0904 & TRN & \\
\hline CHEMBL1992231 & 809279 & 6.1 & 6.0538 & TRN & \\
\hline CHEMBL1995916 & 809279 & 3.2 & 3.5624 & TRN & \\
\hline CHEMBL1983111 & 809279 & 6.5 & 6.6277 & TRN & \\
\hline CHEMBL1988141 & 809279 & 7.3 & 6.5932 & TST & \\
\hline CHEMBL1992937 & 809279 & 7.2 & $6.3270 e$ & 2000000001 & TRN \\
\hline CHEMBL451401 & 809279 & 3.2 & 4.2211 & TRN & \\
\hline CHEMBL1977134 & 809279 & 4.8 & 4.7231 & TRN & \\
\hline CHEMBL1968930 & 809279 & 8.3 & 7.9848 & TRN & \\
\hline CHEMBL1970873 & 809279 & 3.2 & 4.1438 & TRN & \\
\hline CHEMBL1985206 & 809279 & 4.8 & 5.0042 & TRN & \\
\hline CHEMBL1991078 & 809279 & 6.3 & 6.5253 & TRN & \\
\hline CHEMBL1977749 & 809279 & 6.2 & 5.2042 & TST & \\
\hline CHEMBL 2002450 & 809279 & 3.2 & 3.5562 & TRN & \\
\hline
\end{tabular}




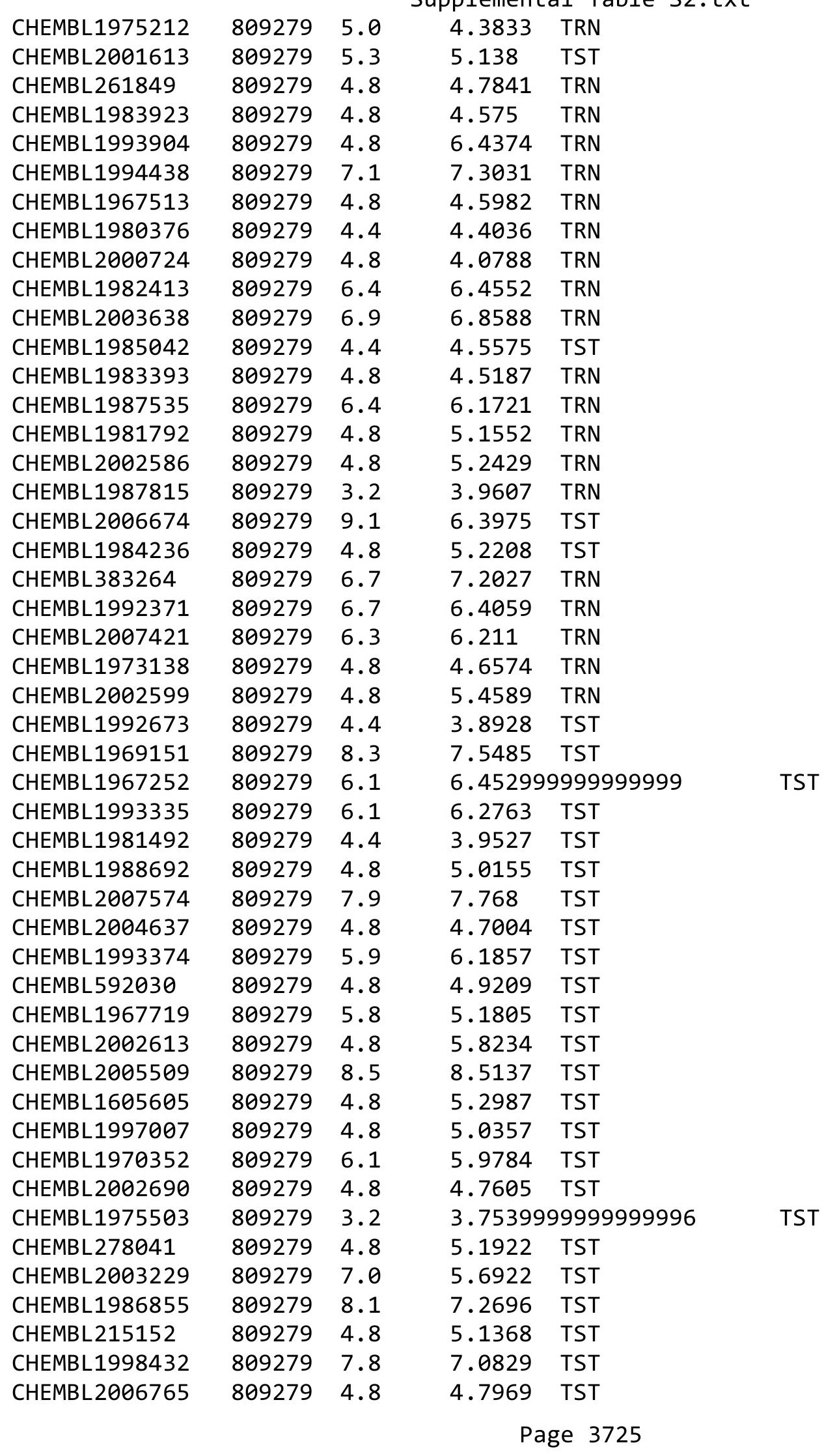




\begin{tabular}{|c|c|c|c|c|c|}
\hline \multicolumn{6}{|c|}{ teme } \\
\hline CHEMBL1986590 & 809279 & 4.8 & 5.285 & TST & \\
\hline CHEMBL1870106 & 809279 & 4.8 & 5.7612 & TST & \\
\hline CHEMBL406845 & 809279 & 4.8 & 4.7696 & TST & \\
\hline CHEMBL1980246 & 809279 & 6.9 & 5.5184 & TST & \\
\hline CHEMBL1983980 & 809279 & 6.4 & 6.314 & TST & \\
\hline CHEMBL482538 & 809279 & 6.4 & 4.9304 & TST & \\
\hline CHEMBL1999484 & 809279 & 7.2 & 6.0549 & TST & \\
\hline CHEMBL1973399 & 809279 & 3.2 & 4.5689 & TST & \\
\hline CHEMBL1984296 & 809279 & 6.4 & 5.5855 & TST & \\
\hline CHEMBL1986899 & 809279 & 4.8 & 5.1115 & TST & \\
\hline CHEMBL1996837 & 809279 & 4.5 & 4.4508 & TST & \\
\hline CHEMBL1984038 & 809279 & 6.0 & 5.1321 & TST & \\
\hline CHEMBL1965683 & 809279 & 4.5 & 4.9114 & TST & \\
\hline CHEMBL1964718 & 809279 & 4.4 & 3.8376 & TST & \\
\hline CHEMBL1993661 & 809279 & 7.0 & 5.4116 & TST & \\
\hline CHEMBL1968705 & 809279 & 4.8 & 4.6346 & TST & \\
\hline CHEMBL1991410 & 809279 & 4.8 & 4.4984 & TST & \\
\hline CHEMBL1964441 & 809279 & 4.8 & 4.7213 & TST & \\
\hline CHEMBL1986684 & 809279 & 3.2 & 4.1023 & TST & \\
\hline CHEMBL546797 & 809279 & 6.4 & 5.4997 & TST & \\
\hline CHEMBL 289210 & 103102 & 5.45100 & 30000000 & 5.7806 & TRN \\
\hline CHEMBL291072 & 103102 & 2.7428 & 2.6533 & TRN & \\
\hline CHEMBL 289208 & 103102 & 2.6573 & 2.6637 & TST & \\
\hline CHEMBL 290703 & 103102 & 5.0092 & 4.4177 & TRN & \\
\hline CHEMBL39904 & 103102 & 4.959 & 5.2751 & TRN & \\
\hline CHEMBL 289379 & 103102 & 2.9718 & 2.7857 & TST & \\
\hline CHEMBL39105 & 103102 & 3.3116 & 3.2499 & TRN & \\
\hline CHEMBL39414 & 103102 & 5.0462 & 4.8921 & TST & \\
\hline CHEMBL 289913 & 103102 & 3.3407 & 3.80899 & 99999999997 & TRN \\
\hline CHEMBL 288339 & 103102 & 2.4439 & 2.6776 & TRN & \\
\hline CHEMBL38391 & 103102 & 3.1716 & 3.2727 & TRN & \\
\hline CHEMBL39815 & 103102 & 3.4795 & 3.2465 & TRN & \\
\hline CHEMBL 288964 & 103102 & 4.6782 & 4.0601 & TRN & \\
\hline CHEMBL 289423 & 103102 & 5.8861 & 6.0062 & TRN & \\
\hline CHEMBL 279411 & 103102 & 2.9207 & 2.8739 & TRN & \\
\hline CHEMBL 290021 & 103102 & 3.3893 & 3.5949 & TST & \\
\hline CHEMBL 287755 & 103102 & 3.8716 & 2.571 & TST & \\
\hline CHEMBL 289608 & 103102 & 2.7897 & 2.7091 & TRN & \\
\hline CHEMBL 288161 & 103102 & 2.8982 & 2.432 & TST & \\
\hline CHEMBL 290020 & 103102 & 3.4124 & 3.5244 & TST & \\
\hline CHEMBL 289090 & 103102 & 2.7279 & 2.9603 & TRN & \\
\hline CHEMBL 290159 & 103102 & 5.284 & 5.1985 & TRN & \\
\hline CHEMBL 289785 & 103102 & 5.6635 & 5.7057 & TRN & \\
\hline CHEMBL 289591 & 103102 & 3.5549 & 3.7806 & TRN & \\
\hline CHEMBL291259 & 103102 & 3.3014 & 3.5841 & TST & \\
\hline CHEMBL39115 & 103102 & 4.6332 & 4.1051 & TRN & \\
\hline CHEMBL 288587 & 103102 & 5.0501 & 4.9437 & TRN & \\
\hline CHEMBL 287131 & 103102 & 5.1818 & 4.5977 & TST & \\
\hline
\end{tabular}




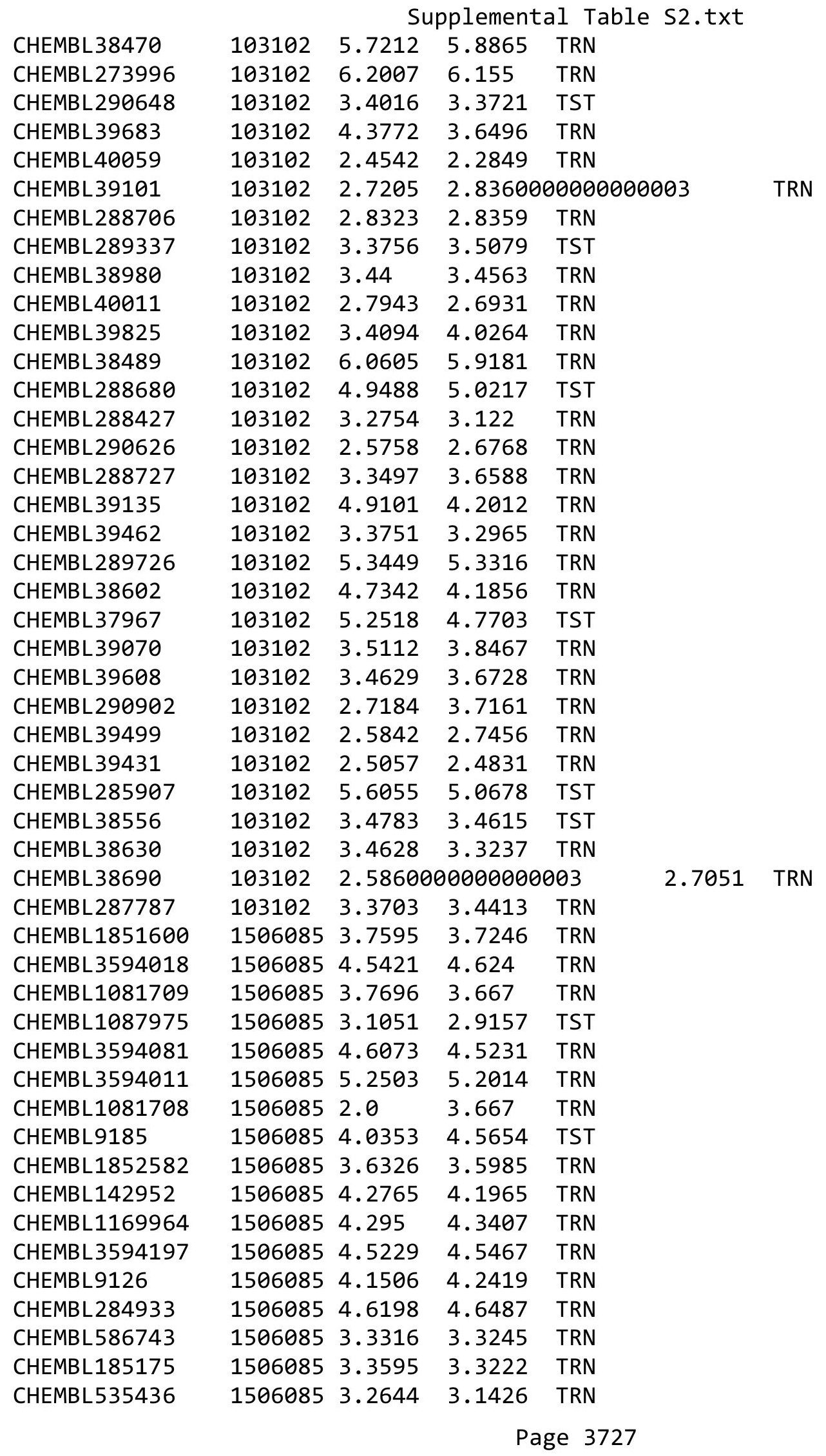


Supplemental Table S2.txt

\begin{tabular}{|c|c|c|c|c|c|c|}
\hline CHEMBL181480 & 1506085 & 5.2565 & 4.6689 & TST & & \\
\hline CHEMBL1170548 & 1506085 & 4.0691 & 4.0738 & TRN & & \\
\hline CHEMBL69590 & 1506085 & 3.6108 & 4.7154 & TST & & \\
\hline CHEMBL3594083 & 1506085 & 4.5072 & 4.3748 & TRN & & \\
\hline CHEMBL537055 & 1506085 & 3.5784 & 4.1559 & TST & & \\
\hline CHEMBL1963648 & 1506085 & 2.0 & 1.8602 & TRN & & \\
\hline CHEMBL1851728 & 1506085 & 3.8153 & 3.8573 & TRN & & \\
\hline CHEMBL22629 & 1506085 & 3.8297 & 4.08899 & 99999999 & 995 & TRN \\
\hline CHEMBL3594010 & 1506085 & 4.3737 & 4.5306 & TRN & & \\
\hline CHEMBL3594016 & 1506085 & 5.6716 & 5.6671 & TRN & & \\
\hline CHEMBL537516 & 1506085 & 3.4306 & 3.4091 & TRN & & \\
\hline CHEMBL535664 & 1506085 & 3.7986 & 3.8859 & TRN & & \\
\hline CHEMBL 9053 & 1506085 & 3.9872 & 4.072 & TRN & & \\
\hline CHEMBL1170985 & 1506085 & 4.2636 & 4.4549 & TRN & & \\
\hline CHEMBL279660 & 1506085 & 4.5129 & 4.5002 & TRN & & \\
\hline CHEMBL3594013 & 1506085 & 4.4145 & 4.4025 & TRN & & \\
\hline CHEMBL1080776 & 1506085 & 4.5575 & 3.667 & TRN & & \\
\hline CHEMBL535205 & 1506085 & 3.85699 & 99999999 & 998 & 3.9081 & TRN \\
\hline CHEMBL102740 & 1506085 & 3.7077 & 4.368 & TST & & \\
\hline CHEMBL165542 & 1506085 & 4.752 & 4.8277 & TRN & & \\
\hline CHEMBL3594007 & 1506085 & 3.4647 & 3.3202 & TRN & & \\
\hline CHEMBL269032 & 1506085 & 5.26200 & 00000000 & 205 & 5.0915 & TRN \\
\hline CHEMBL3594080 & 1506085 & 4.8601 & 4.8806 & TRN & & \\
\hline CHEMBL 283745 & 1506085 & 4.0747 & 4.2383 & TRN & & \\
\hline CHEMBL9391 & 1506085 & 4.4353 & 4.4709 & TRN & & \\
\hline CHEMBL3594012 & 1506085 & 4.684 & 4.6168 & TRN & & \\
\hline CHEMBL 88670 & 1506085 & 3.8447 & 4.3772 & TST & & \\
\hline CHEMBL183814 & 1506085 & 4.3316 & 4.0098 & TST & & \\
\hline CHEMBL1170755 & 1506085 & 4.3179 & 4.3858 & TRN & & \\
\hline CHEMBL9121 & 1506085 & 3.4895 & 4.0378 & TST & & \\
\hline CHEMBL3594195 & 1506085 & 5.1701 & 5.2184 & TRN & & \\
\hline CHEMBL185172 & 1506085 & 4.7352 & 4.336 & TST & & \\
\hline CHEMBL3594014 & 1506085 & 4.9031 & 4.7646 & TRN & & \\
\hline CHEMBL3594017 & 1506085 & 5.8794 & 5.76 & TRN & & \\
\hline CHEMBL89159 & 1506085 & 3.3696 & 3.9312 & TST & & \\
\hline CHEMBL3593841 & 1506085 & 3.8297 & 3.9817 & TRN & & \\
\hline CHEMBL1963636 & 1506085 & 2.0 & 1.8066 & TRN & & \\
\hline CHEMBL3593840 & 1506085 & 4.6038 & 4.5345 & TRN & & \\
\hline CHEMBL185063 & 1506085 & 3.1707 & 3.2252 & TRN & & \\
\hline CHEMBL3594009 & 1506085 & 4.6234 & 4.6301 & TRN & & \\
\hline CHEMBL137195 & 1506085 & 4.6216 & 4.3748 & TRN & & \\
\hline CHEMBL24057 & 1506085 & 5.1261 & 5.0975 & TRN & & \\
\hline CHEMBL1081886 & 1506085 & 3.9547 & 3.667 & TRN & & \\
\hline CHEMBL9341 & 1506085 & 3.4101 & 3.597 & TST & & \\
\hline CHEMBL 9025 & 1506085 & 3.6737 & 3.7933 & TST & & \\
\hline CHEMBL3594015 & 1506085 & 3.8447 & 3.9861 & TRN & & \\
\hline CHEMBL365916 & 1506085 & 4.5901 & 3.8458 & TST & & \\
\hline CHEMBL 8892 & 1506085 & 3.9747 & 4.1242 & TST & & \\
\hline
\end{tabular}




\begin{tabular}{|c|c|c|c|c|c|}
\hline \multicolumn{6}{|c|}{ Supplemental Table S2.txt } \\
\hline CHEMBL88596 & 1506085 & 4.067 & 4.0522 & TST & \\
\hline CHEMBL3594082 & 1506085 & 4.5952 & 4.3748 & TRN & \\
\hline CHEMBL424711 & 1506085 & 4.466 & 4.6179 & TST & \\
\hline CHEMBL1963649 & 1506085 & 2.0 & 2.6622 & TRN & \\
\hline CHEMBL1081887 & 1506085 & 4.2034 & 3.667 & TRN & \\
\hline CHEMBL9490 & 1506085 & 3.2503 & 3.782 & TST & \\
\hline CHEMBL3594008 & 1506085 & 4.5361 & 4.4821 & TRN & \\
\hline CHEMBL1962539 & 1506085 & 2.9179 & 2.6622 & TRN & \\
\hline CHEMBL1852874 & 1506085 & 4.1255 & 4.093 & TRN & \\
\hline CHEMBL249456 & 1506085 & 5.1739 & 4.4806 & TST & \\
\hline CHEMBL3594196 & 1506085 & 4.9318 & 4.9371 & TRN & \\
\hline CHEMBL1232046 & 1506085 & 4.8729 & 4.8785 & TRN & \\
\hline CHEMBL9531 & 1506085 & 4.1494 & 4.2232 & TRN & \\
\hline CHEMBL 229102 & 1506085 & 5.2147 & 5.0547 & TST & \\
\hline CHEMBL3645279 & 1528694 & 10.0 & 9.7423 & TST & \\
\hline CHEMBL3645335 & 1528694 & 10.0 & 9.38 & TRN & \\
\hline CHEMBL3645309 & 1528694 & 10.0 & 8.5429 & TRN & \\
\hline CHEMBL 3645344 & 1528694 & 9.699 & 9.193 & TRN & \\
\hline CHEMBL 3645308 & 1528694 & 6.0 & 8.0214 & TRN & \\
\hline CHEMBL3645289 & 1528694 & 6.0 & 5.5722 & TST & \\
\hline CHEMBL3645349 & 1528694 & 6.0 & 5.176 & TRN & \\
\hline CHEMBL 3645326 & 1528694 & 10.0 & 10.1346 & TST & \\
\hline CHEMBL3645339 & 1528694 & 9.699 & 9.7056 & TRN & \\
\hline CHEMBL 3645351 & 1528694 & 6.0 & $5.99100 t$ & 00000000005 & TRN \\
\hline CHEMBL3645319 & 1528694 & 9.699 & 9.1706 & TST & \\
\hline CHEMBL3645359 & 1528694 & 10.0 & 9.9491 & TRN & \\
\hline CHEMBL 3645324 & 1528694 & 10.0 & 9.8686 & TRN & \\
\hline CHEMBL3645363 & 1528694 & 10.0 & 10.0465 & TRN & \\
\hline CHEMBL 3645298 & 1528694 & 10.0 & 9.8936 & TRN & \\
\hline CHEMBL3645364 & 1528694 & 10.0 & 9.7742 & TRN & \\
\hline CHEMBL3645322 & 1528694 & 6.0 & 8.1894 & TRN & \\
\hline CHEMBL 3645312 & 1528694 & 9.699 & 9.086 & TRN & \\
\hline CHEMBL 3645276 & 1528694 & 10.0 & 10.0398 & TST & \\
\hline CHEMBL 3645345 & 1528694 & 6.0 & 6.5866 & TRN & \\
\hline CHEMBL 3645340 & 1528694 & 9.5229 & 9.6012 & TRN & \\
\hline CHEMBL3645318 & 1528694 & 10.0 & 8.9628 & TST & \\
\hline CHEMBL 3645310 & 1528694 & 9.699 & 9.2948 & TRN & \\
\hline CHEMBL 3645327 & 1528694 & 10.0 & 10.0274 & TRN & \\
\hline CHEMBL 3645274 & 1528694 & 10.0 & 10.191 & TRN & \\
\hline CHEMBL 3645278 & 1528694 & 10.0 & 10.183 & TST & \\
\hline CHEMBL3645311 & 1528694 & 6.0 & 6.6167 & TRN & \\
\hline CHEMBL 3645336 & 1528694 & 9.3979 & 8.6744 & TRN & \\
\hline CHEMBL3645281 & 1528694 & 6.0 & 5.5481 & TST & \\
\hline CHEMBL 3645332 & 1528694 & 6.0 & 5.7774 & TRN & \\
\hline CHEMBL3645329 & 1528694 & 9.5229 & 9.5471 & TRN & \\
\hline CHEMBL3645296 & 1528694 & 9.699 & 9.9117 & TRN & \\
\hline CHEMBL3666066 & 1528694 & 10.0 & 10.0103 & TRN & \\
\hline CHEMBL3645325 & 1528694 & 10.0 & 9.9681 & TRN & \\
\hline
\end{tabular}


Supplemental Table S2.txt

\begin{tabular}{|c|c|c|c|c|}
\hline (2) & 8694 & & 9.4779 & TR \\
\hline HEMBL3645356 & 528694 & 10.0 & 8.965 & \\
\hline & 28694 & & & \\
\hline EMBL & 28694 & 10.0 & 933 & PN \\
\hline AEMBL3645341 & 528694 & 6.0 & 8001 & \\
\hline AEMBL3645353 & 528694 & 6.0 & 5662 & \\
\hline HEMBL & 528694 & 10.0 & 157 & \\
\hline 95 & 28694 & 10.0 & 502 & \\
\hline IEMBL36 & 528694 & 10.0 & .4619 & \\
\hline HEMBL 364 & 528694 & 9.522 & .503 & \\
\hline HEMBL3645315 & 528694 & 6.0 & .6983 & \\
\hline IEMBL36 & 528694 & 9.699 & 9864 & \\
\hline HEMBL & 28694 & & 274 & ST \\
\hline HEMBL3 & 528694 & 10.0 & 9.2294 & \\
\hline AEMBL36 & 528694 & 10.0 & .0619 & \\
\hline AEMBL3666068 & 528694 & 10.0 & 10.1801 & \\
\hline HEMBL36 & 28694 & 9.522 & 24 & RIN \\
\hline HEMBL36 & 28694 & 10.0 & 472 & RN \\
\hline HEMBL36 & 528694 & 10.0 & 9.7755 & \\
\hline AEMBL36 & 528694 & 9.52 & 876 & RN \\
\hline IEMBL 364 & 528694 & 9.699 & 9.6011 & RIN \\
\hline HEMBL3 & 528694 & 10 & 32 & $2 \mathrm{~N}$ \\
\hline HEMBL3 & 528694 & 9. & 305 & \\
\hline 277 & 528694 & 10.0 & 705 & TRN \\
\hline AEMBL36 & 528694 & 6. & 88 & RIV \\
\hline AEMBL3 & 28694 & 10 & 17 & RN \\
\hline HEMBL36 & 528694 & 9.69 & 308 & TRN \\
\hline 287 & 528694 & 10.0 & 114 & \\
\hline HEMBL36 & 528694 & & 818 & TST \\
\hline HEMBL36 & 528694 & 16 & 93 & ISI \\
\hline AEMBL36 & 28694 & 10 & 877 & TST \\
\hline HEMBL 36 & 94 & 9. & & \\
\hline 99 & 94 & 99 & & TRN \\
\hline HEMBL 364 & & & 416 & TST \\
\hline HEMBL 368 & 527946 & 10.0 & 794 & TRN \\
\hline HEMBL36 & 79 & 10.2 & 268 & RN \\
\hline 886 & 16 & 9. & & RN \\
\hline & 527946 & 9.301 & 513 & TST \\
\hline HEMBL3680089 & 527946 & 7.1938 & 7.7843 & TRN \\
\hline AEMBL36 & 5279 & 9. & 9 . & TRN \\
\hline HEMBL36 & 527946 & 10.52 & 10.4384 & TRN \\
\hline HEMBL 36 & 1527946 & 10.0 & 10.4332 & TRN \\
\hline HEMBL 36 & 527946 & 8.1367 & 9.2838 & TRN \\
\hline HEMBL3680080 & 527946 & 9.699 & 9.1802 & זRN \\
\hline EMBL3 & 5279 & & 7.5977 & \\
\hline HEMBL368 & 1527946 & (l) & 9.4917 & \\
\hline CHEMBL 36 & 1527946 & 8.6778 & 8.6727 & RN \\
\hline CHEMBL 368008 & 1527946 & 9.699 & 10.0516 & RN \\
\hline
\end{tabular}

Page 3730 
Supplemental Table S2.txt

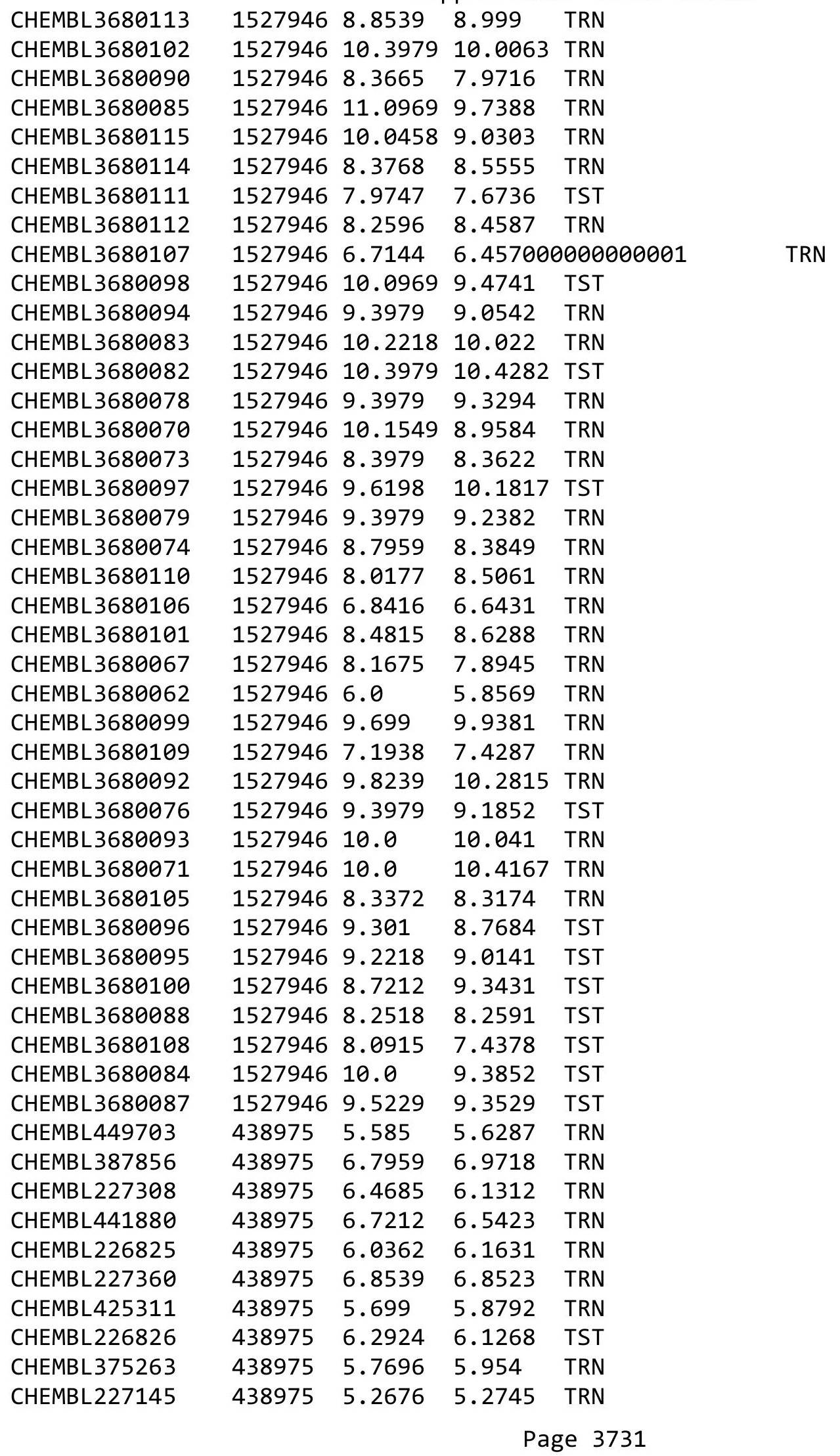




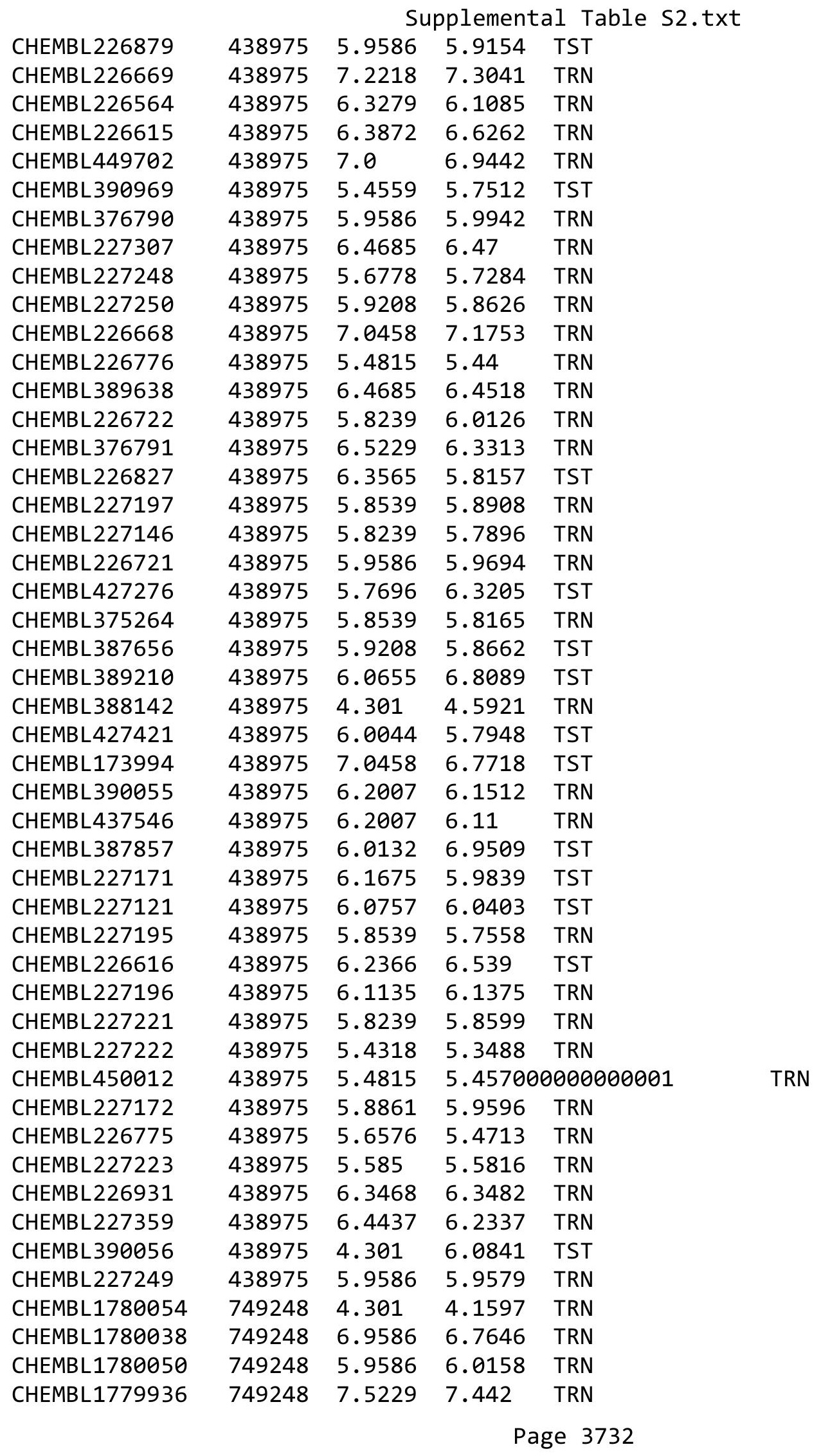




\begin{tabular}{|c|c|c|c|c|}
\hline & & & pplement & al $\mathrm{Tc}$ \\
\hline CHEMBL1779930 & 749248 & 5.2161 & 5.1774 & TRN \\
\hline CHEMBL1779931 & 749248 & 5.2118 & 5.0771 & TRN \\
\hline CHEMBL1780055 & 749248 & 4.301 & 4.3138 & TRN \\
\hline CHEMBL1779938 & 749248 & 7.3979 & 7.0528 & TRN \\
\hline CHEMBL1779933 & 749248 & 4.301 & 4.1837 & TRN \\
\hline CHEMBL1779942 & 749248 & 7.1549 & 7.1945 & TRN \\
\hline CHEMBL1780057 & 749248 & 4.301 & 4.0039 & TRN \\
\hline CHEMBL1780041 & 749248 & 6.6576 & 6.6662 & TRN \\
\hline CHEMBL1780049 & 749248 & 4.301 & 4.4938 & TRN \\
\hline CHEMBL1780039 & 749248 & 6.8861 & 6.9376 & TRN \\
\hline CHEMBL1780042 & 749248 & 5.6696 & 5.6308 & TRN \\
\hline CHEMBL1780043 & 749248 & 4.301 & 5.3513 & TST \\
\hline CHEMBL1780037 & 749248 & 7.0458 & 6.9179 & TRN \\
\hline CHEMBL1780064 & 749248 & 5.9281 & 5.1068 & TST \\
\hline CHEMBL1780044 & 749248 & 5.7595 & 6.2504 & TST \\
\hline CHEMBL1780059 & 749248 & 5.4763 & 6.181 & TST \\
\hline CHEMBL1780045 & 749248 & 6.2007 & 6.1053 & TRN \\
\hline CHEMBL1780046 & 749248 & 4.301 & 4.3331 & TRN \\
\hline CHEMBL1780060 & 749248 & 5.7423 & 6.4177 & TST \\
\hline CHEMBL1780053 & 749248 & 4.301 & 4.3098 & TRN \\
\hline CHEMBL1780063 & 749248 & 5.8297 & 6.5609 & TST \\
\hline CHEMBL1779937 & 749248 & 7.3979 & 7.4107 & TRN \\
\hline CHEMBL1780052 & 749248 & 4.301 & 4.5209 & TRN \\
\hline CHEMBL1780040 & 749248 & 6.8539 & 6.9573 & TRN \\
\hline CHEMBL1780047 & 749248 & 5.7878 & 5.8964 & TRN \\
\hline CHEMBL1779943 & 749248 & 7.1549 & 7.2934 & TRN \\
\hline CHEMBL1780035 & 749248 & 7.0969 & 7.1908 & TRN \\
\hline CHEMBL507974 & 749248 & 8.2218 & 5.4147 & TST \\
\hline CHEMBL1780036 & 749248 & 7.0458 & 7.1085 & TRN \\
\hline CHEMBL1779935 & 749248 & 7.699 & 7.73 & TRN \\
\hline CHEMBL1779922 & 749248 & 5.2161 & 3.3423 & TST \\
\hline CHEMBL1779929 & 749248 & 5.3799 & 5.3248 & TRN \\
\hline CHEMBL1780056 & 749248 & 4.301 & 4.5134 & TRN \\
\hline CHEMBL1779920 & 749248 & 6.5229 & 3.485 & TST \\
\hline CHEMBL1779934 & 749248 & 4.301 & 4.3964 & TRN \\
\hline CHEMBL1780061 & 749248 & 8.5229 & 6.0727 & TST \\
\hline CHEMBL1779940 & 749248 & 7.2218 & 7.3376 & TRN \\
\hline CHEMBL1779941 & 749248 & 7.2218 & 7.1961 & TRN \\
\hline CHEMBL1779925 & 749248 & 6.3188 & 6.2675 & TRN \\
\hline CHEMBL1779932 & 749248 & 5.1325 & 5.3738 & TRN \\
\hline CHEMBL1780051 & 749248 & 7.5229 & 7.3877 & TRN \\
\hline CHEMBL1779927 & 749248 & 5.8013 & 5.6581 & TRN \\
\hline CHEMBL1779939 & 749248 & 7.2218 & 7.3134 & TRN \\
\hline CHEMBL1779924 & 749248 & 6.5686 & 6.7308 & TRN \\
\hline CHEMBL1780062 & 749248 & 6.3565 & 6.779 & TST \\
\hline CHEMBL1780058 & 749248 & 4.301 & 4.2869 & TRN \\
\hline CHEMBL1777835 & 749248 & 4.0 & 3.5598 & TST \\
\hline CHEMBL1779923 & 749248 & 6.699 & 6.6127 & TRN \\
\hline
\end{tabular}




\begin{tabular}{|c|c|c|c|c|}
\hline & & & & \\
\hline CHEMBL1780048 & 749248 & 5.7212 & 5.5775 & TRA \\
\hline CHEMBL1779921 & 749248 & 6.699 & 2.305 & \\
\hline CHEMBL1779928 & 749248 & 5.4935 & 5.6665 & \\
\hline CHEMBL1779926 & 49248 & 5.9245 & 5.5105 & \\
\hline CHEMBL26515 & 30747 & 5.699 & 5.6967 & \\
\hline CHEMBL 224900 & 430747 & 4.0 & 3.9919 & \\
\hline CHEMBL25829 & 30747 & 4.6021 & 4.5997 & \\
\hline CHEMBL223341 & 30747 & 5.6021 & 5.5995 & \\
\hline CHEMBL224674 & 430747 & 5.2218 & 5.2268 & \\
\hline CHEMBL224233 & 30747 & 3.0 & 3.214 & \\
\hline CHEMBL85398 & 430747 & 4.0 & 3.8121 & \\
\hline CHEMBL224287 & 30747 & 4.0 & 3.9989 & \\
\hline CHEMBL224043 & 30747 & 4.0 & 3.9949 & \\
\hline CHEMBL224231 & 47 & 4.9208 & 4.1941 & \\
\hline CHEMBL 2 & & 3.0 & 2.9979 & \\
\hline CHEMBL374159 & & 3.0 & 4.6649 & \\
\hline CHEMBL287864 & 30747 & 5.699 & 5.6928 & \\
\hline CHEMBL225554 & 47 & 4.4559 & 4.4562 & \\
\hline CHEMBL & & 4.9208 & 4.9187 & \\
\hline CHEMBL 2 & & 4.4559 & 4.4612 & \\
\hline CHEMBL388086 & 747 & 3.0 & 3.003 & \\
\hline CHEMBL387881 & 47 & 4.301 & 4.3065 & 10 \\
\hline CHEMBL224301 & 43 & 5.5229 & 5.5141 & $|\mathrm{R}|$ \\
\hline CHEMBL2 & & 5.699 & 5.7003 & TRA \\
\hline CHEMBL 1 & 47 & 4.0 & 3.9969 & \\
\hline CHEMBL 26274 & 43 & 5.699 & 5.6958 & TRA \\
\hline CHEMBL24494 & 47 & 5.3979 & 5.4012 & TR \\
\hline CHEMBL 388088 & & 5.699 & 5.697 & TRN \\
\hline CHEMBL 1 & & 4.0 & 3.5194 & TST \\
\hline CHEMBL 2 & 47 & 5.301 & 5.2995 & TRN \\
\hline CHEMBL284365 & & 5.0 & 5.0034 & TRA \\
\hline CHEMBL224441 & 430747 & 4.0 & 3.9984 & $\mathrm{TR}$ \\
\hline CHEMBL387762 & & 5.2218 & 4.3804 & TST \\
\hline CHEMBL24537 & & 5.3979 & 5.4004 & TRA \\
\hline CHEMBL25820 & 47 & 5.3979 & 5.3959 & TRN \\
\hline CHEMBL24753 & 430747 & 5.301 & 5.3055 & TRA \\
\hline CHEMBL375657 & 430747 & 4.9208 & 4.9209 & $\mathrm{TR}$ \\
\hline CHEMBL 2 & & 4. & 3.9931 & TRI \\
\hline CHEMBL3 & 43 & 5.5229 & 5.521 & TRA \\
\hline CHEMBL224232 & 430747 & 5.5229 & 5.5303 & TRA \\
\hline CHEMBL376592 & 430747 & 3.301 & 3.3027 & TRA \\
\hline CHEMBL223342 & 430747 & 5.699 & 5.7098 & $\mathrm{TR}$ \\
\hline CHEMBL23840 & & 5.2218 & 5.2221 & TRI \\
\hline CHEMBL417835 & 430747 & 5.2218 & 5.222 & $\mathrm{TR}$ \\
\hline CHEMBL390546 & 430747 & 4.0 & 3.9987 & TRN \\
\hline CHEMBL224979 & 430747 & 5.5229 & 5.5199 & TRI \\
\hline CHEMBL389053 & 430747 & 4.0 & 4.0052 & $\mathrm{TR}$ \\
\hline CHEMBL225037 & 430747 & 5.301 & 5.3018 & $\mathrm{TR}$ \\
\hline
\end{tabular}




\begin{tabular}{|c|c|c|c|c|}
\hline \multicolumn{5}{|c|}{ Supplemental Table S2.txt } \\
\hline CHEMBL390330 & 430747 & 4.0 & 4.001 & TRN \\
\hline CHEMBL 225440 & 430747 & 4.1871 & 4.2007 & TRN \\
\hline CHEMBL224236 & 430747 & 5.0706 & 5.0677 & TRN \\
\hline CHEMBL224367 & 430747 & 4.6021 & 4.5974 & TRN \\
\hline CHEMBL24693 & 430747 & 5.0 & 3.6995 & TST \\
\hline CHEMBL388979 & 430747 & 6.0 & 5.6696 & TST \\
\hline CHEMBL224633 & 430747 & 4.0 & 3.7416 & TST \\
\hline CHEMBL286009 & 430747 & 5.0 & 4.6712 & TST \\
\hline CHEMBL 224288 & 430747 & 4.0 & 4.4431 & TST \\
\hline CHEMBL24721 & 430747 & 5.9586 & 5.1843 & TST \\
\hline CHEMBL26241 & 430747 & 5.1549 & 5.1707 & TST \\
\hline CHEMBL24167 & 430747 & 4.0 & 3.708 & TST \\
\hline CHEMBL224235 & 430747 & 4.0 & 4.059 & TST \\
\hline CHEMBL1872300 & 752430 & 3.0044 & 2.9828 & TRN \\
\hline CHEMBL1893861 & 752430 & 3.0044 & 2.5909 & TRN \\
\hline CHEMBL1904381 & 752430 & 3.0044 & 3.2853 & TRN \\
\hline CHEMBL1577231 & 752430 & 5.9318 & 5.8956 & TRN \\
\hline CHEMBL1887272 & 752430 & 5.2262 & 4.8708 & TRN \\
\hline CHEMBL1896001 & 752430 & 5.3556 & 4.8972 & TRN \\
\hline CHEMBL1553773 & 752430 & 5.5935 & 5.4854 & TRN \\
\hline CHEMBL1699684 & 752430 & 3.0044 & 3.1173 & TRN \\
\hline CHEMBL1316867 & 752430 & 6.2882 & 6.3305 & TRN \\
\hline CHEMBL1878555 & 752430 & 3.0044 & 2.9024 & TRN \\
\hline CHEMBL1877777 & 752430 & 5.684 & 6.0666 & TRN \\
\hline CHEMBL1868902 & 752430 & 5.2774 & 5.1928 & TRN \\
\hline CHEMBL1901952 & 752430 & 5.8041 & 5.3886 & TRN \\
\hline CHEMBL1871228 & 752430 & 6.1255 & 6.0023 & TRN \\
\hline CHEMBL1902007 & 752430 & 4.7447 & 4.6141 & TRN \\
\hline CHEMBL1883713 & 752430 & 3.0044 & 3.0575 & TRN \\
\hline CHEMBL1899595 & 752430 & 5.4342 & 5.0268 & TRN \\
\hline CHEMBL1890960 & 752430 & 3.0044 & 3.4688 & TRN \\
\hline CHEMBL1876444 & 752430 & 3.0044 & 2.7574 & TRN \\
\hline CHEMBL1900875 & 752430 & 3.0044 & 3.2688 & TRN \\
\hline CHEMBL1886317 & 752430 & 4.9747 & 4.7239 & TRN \\
\hline CHEMBL1904010 & 752430 & 3.0044 & 2.9935 & TRN \\
\hline CHEMBL1896263 & 752430 & 5.4737 & 5.3529 & TRN \\
\hline CHEMBL1705186 & 752430 & 5.5969 & 5.66 & TRN \\
\hline CHEMBL1881032 & 752430 & 3.0044 & 3.1103 & TST \\
\hline CHEMBL1865625 & 752430 & 4.5114 & 4.5882 & TRN \\
\hline CHEMBL1885333 & 752430 & 3.0044 & 2.7776 & TRN \\
\hline CHEMBL1878966 & 752430 & 3.0044 & 3.0976 & TST \\
\hline CHEMBL1866613 & 752430 & 5.9957 & 5.995 & TRN \\
\hline CHEMBL145850 & 752430 & 3.0044 & 3.052 & TRN \\
\hline CHEMBL1409038 & 752430 & 3.0044 & 3.0698 & TRN \\
\hline CHEMBL1889468 & 752430 & 3.0044 & 2.8746 & TRN \\
\hline CHEMBL1864747 & 752430 & 5.4437 & 5.2342 & TRN \\
\hline CHEMBL1882443 & 752430 & 5.3161 & 5.2031 & TRN \\
\hline CHEMBL1437840 & 752430 & 3.0044 & 2.8866 & TRN \\
\hline
\end{tabular}




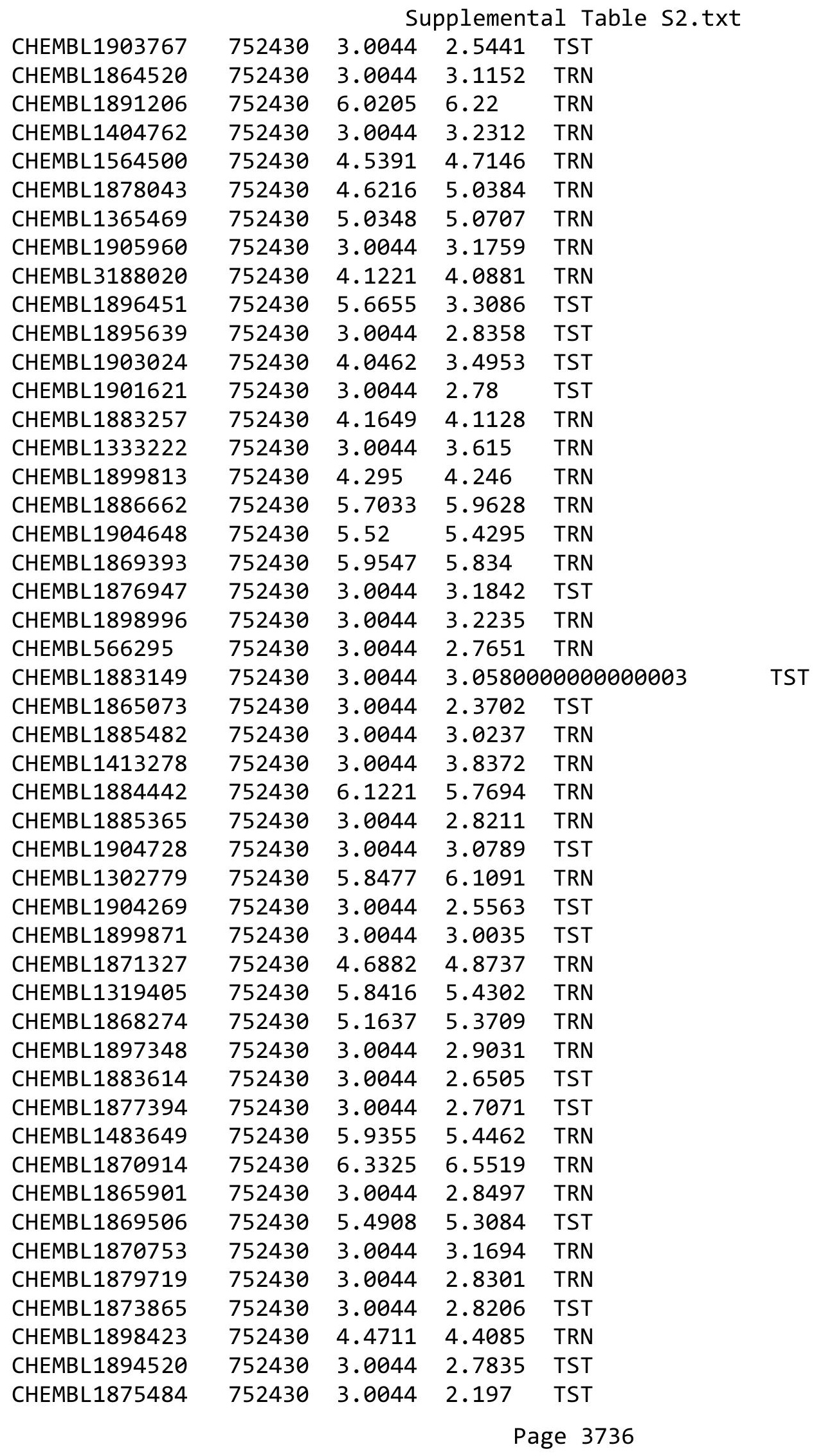




\begin{tabular}{|c|c|c|c|c|c|c|}
\hline \multirow[b]{2}{*}{ CHEMBL1890481 } & \multicolumn{6}{|c|}{ Supplemental Table S2.txt } \\
\hline & 752430 & 3.0044 & 2.6519 & TST & & \\
\hline CHEMBL1877480 & 752430 & 3.0044 & 3.1933 & TRN & & \\
\hline CHEMBL1872841 & 752430 & 4.475 & 4.6699 & TRN & & \\
\hline CHEMBL1874506 & 752430 & 4.4685 & 4.6937 & TRN & & \\
\hline CHEMBL1874988 & 752430 & 4.5498 & 4.2415 & TRN & & \\
\hline CHEMBL1899989 & 752430 & 5.3969 & 5.4049 & TRN & & \\
\hline CHEMBL1897885 & 752430 & 4.3134 & 4.1882 & TRN & & \\
\hline CHEMBL1864230 & 752430 & 3.0044 & 2.9659 & TST & & \\
\hline CHEMBL1903348 & 752430 & 5.4473 & 5.5694 & TRN & & \\
\hline CHEMBL1894778 & 752430 & 3.0044 & 2.8362 & TRN & & \\
\hline CHEMBL1888240 & 752430 & 3.0044 & 3.0191 & TST & & \\
\hline CHEMBL1904649 & 752430 & 3.0044 & 2.4188 & TST & & \\
\hline CHEMBL1882689 & 752430 & 3.0044 & 2.8407 & TST & & \\
\hline CHEMBL1873341 & 752430 & 3.0044 & 3.2373 & TRN & & \\
\hline CHEMBL1878061 & 752430 & 4.98300 & 00000000 & 005 & 5.1991 & TRN \\
\hline CHEMBL1905421 & 752430 & 3.0044 & 2.727 & TST & & \\
\hline CHEMBL1870529 & 752430 & 3.0044 & 3.0239 & TST & & \\
\hline CHEMBL1886655 & 752430 & 3.0044 & 2.8455 & TRN & & \\
\hline CHEMBL 270900 & 464619 & 2.3737 & 3.1028 & TRN & & \\
\hline CHEMBL 308767 & 464619 & 5.5686 & 4.4822 & TRN & & \\
\hline CHEMBL267337 & 464619 & 2.75699 & 79999999 & 997 & 4.499 & TST \\
\hline CHEMBL 271809 & 464619 & 4.0788 & 4.4677 & TRN & & \\
\hline CHEMBL553649 & 464619 & 2.51 & 3.1954 & TRN & & \\
\hline CHEMBL 270752 & 464619 & 2.4225 & 2.965 & TRN & & \\
\hline CHEMBL 243288 & 464619 & 5.7852 & 5.2553 & TRN & & \\
\hline CHEMBL75414 & 464619 & 5.0088 & 4.2238 & TST & & \\
\hline CHEMBL73758 & 464619 & 2.6696 & 3.6425 & TRN & & \\
\hline CHEMBL3216997 & 464619 & 4.9393 & 4.5303 & TRN & & \\
\hline CHEMBL423676 & 464619 & 2.6536 & 3.2671 & TRN & & \\
\hline CHEMBL548436 & 464619 & 2.6289 & 4.1867 & TRN & & \\
\hline CHEMBL 271808 & 464619 & 2.4001 & 2.3104 & TRN & & \\
\hline CHEMBL 271534 & 464619 & 4.3054 & 4.2005 & TRN & & \\
\hline CHEMBL 271749 & 464619 & 4.4295 & 4.3167 & TRN & & \\
\hline CHEMBL186961 & 464619 & 2.342 & 2.7205 & TRN & & \\
\hline CHEMBL407777 & 464619 & 4.3335 & 4.2096 & TST & & \\
\hline CHEMBL 270122 & 464619 & 3.7781 & 4.0474 & TRN & & \\
\hline CHEMBL443320 & 464619 & 3.7217 & 2.8597 & TRN & & \\
\hline CHEMBL243061 & 464619 & 2.4295 & 2.0244 & TRN & & \\
\hline CHEMBL404605 & 464619 & 3.5092 & 3.8642 & TRN & & \\
\hline CHEMBL42751 & 464619 & 2.4112 & 2.4657 & TRN & & \\
\hline CHEMBL536556 & 464619 & 2.5467 & 2.5988 & TRN & & \\
\hline CHEMBL1162155 & 464619 & 2.6308 & 3.1955 & TRN & & \\
\hline CHEMBL539632 & 464619 & 4.9281 & 4.1885 & TST & & \\
\hline CHEMBL 9441 & 464619 & 3.7597 & 3.3317 & TRN & & \\
\hline CHEMBL390246 & 464619 & 2.4895 & 2.1017 & TRN & & \\
\hline CHEMBL539868 & 464619 & 2.3757 & 2.6019 & TRN & & \\
\hline CHEMBL 271578 & 464619 & 2.3716 & 2.1367 & TRN & & \\
\hline CHEMBL271996 & 464619 & 3.983 & 3.8453 & TRN & & \\
\hline
\end{tabular}




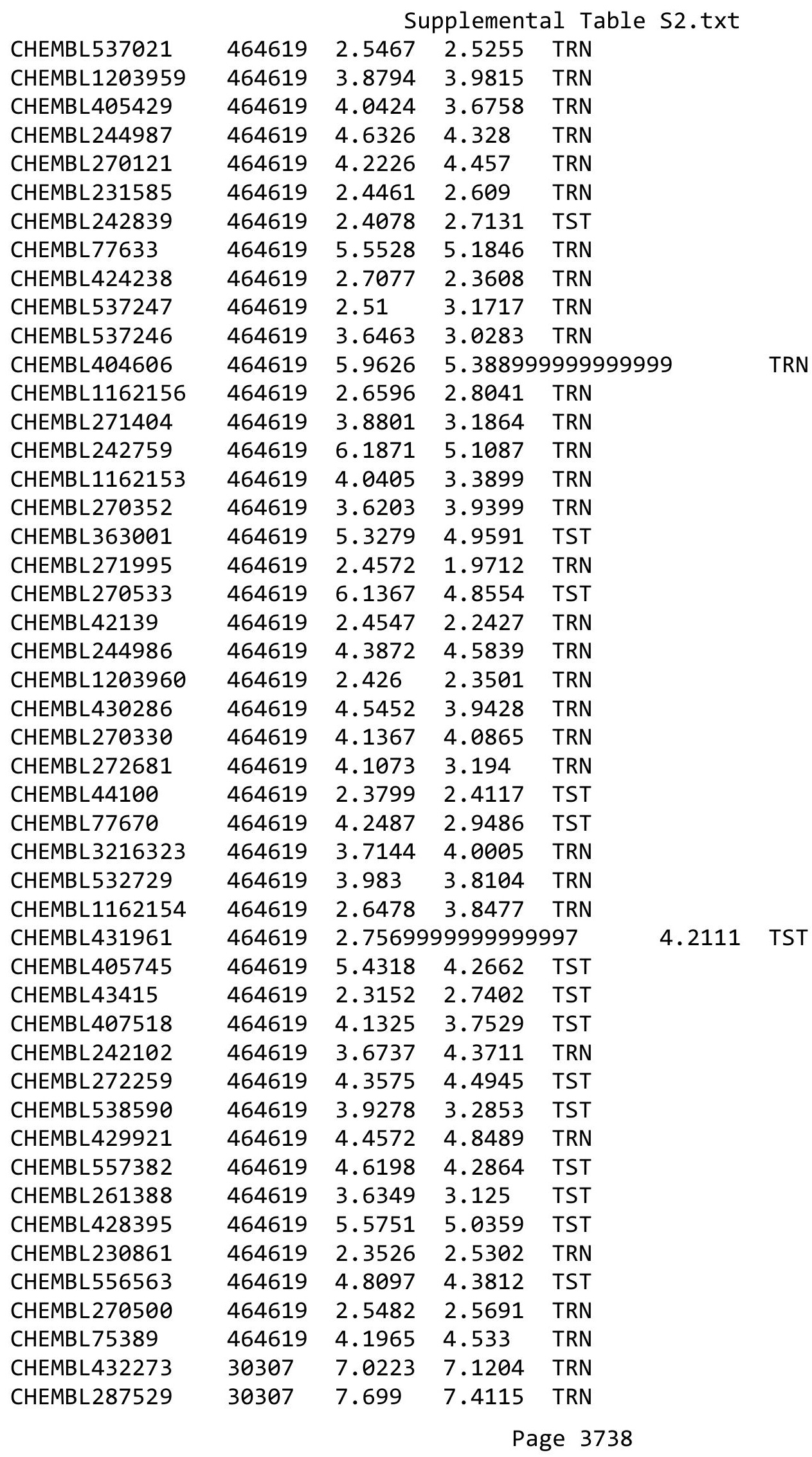




\begin{tabular}{|c|c|c|c|c|c|}
\hline \multicolumn{6}{|c|}{ Supplemental Table S2.txt } \\
\hline CHEMBL32478 & 30307 & 6.8861 & 6.8973 & TRN & \\
\hline CHEMBL33591 & 30307 & 6.684 & 6.9892 & TRN & \\
\hline CHEMBL32757 & 30307 & 6.9872 & 6.5533 & TRN & \\
\hline CHEMBL 32534 & 30307 & 6.8794 & 7.1688 & TRN & \\
\hline CHEMBL431703 & 30307 & 7.4437 & 7.4901 & TRN & \\
\hline CHEMBL34097 & 30307 & 6.9547 & 6.75700 & 0000000001 & TRN \\
\hline CHEMBL 285900 & 30307 & 7.2518 & 6.794 & TRN & \\
\hline CHEMBL2112066 & 30307 & 6.7328 & 7.2016 & TRN & \\
\hline CHEMBL 32581 & 30307 & 7.2366 & 7.3545 & TRN & \\
\hline CHEMBL32751 & 30307 & 6.9586 & 7.3994 & TRN & \\
\hline CHEMBL408186 & 30307 & 7.4202 & 6.6965 & TRN & \\
\hline CHEMBL286212 & 30307 & 7.0458 & 6.9293 & TRN & \\
\hline CHEMBL 32950 & 30307 & 7.1079 & 6.7612 & TRN & \\
\hline CHEMBL33653 & 30307 & 7.1805 & 6.8988 & TRN & \\
\hline CHEMBL555577 & 30307 & 5.6851 & 6.3532 & TRN & \\
\hline CHEMBL32388 & 30307 & 7.0706 & 7.1666 & TRN & \\
\hline CHEMBL32481 & 30307 & 7.4559 & 6.6404 & TRN & \\
\hline CHEMBL 32507 & 30307 & 5.0 & 7.2459 & TST & \\
\hline CHEMBL32288 & 30307 & 7.0655 & 7.4379 & TRN & \\
\hline CHEMBL 289903 & 30307 & 7.9208 & 7.4984 & TRN & \\
\hline CHEMBL33491 & 30307 & 8.0 & 7.5235 & TRN & \\
\hline CHEMBL 32225 & 30307 & 7.5528 & 6.7322 & TRN & \\
\hline CHEMBL34281 & 30307 & 7.0655 & 7.3485 & TRN & \\
\hline CHEMBL32150 & 30307 & 7.0 & 6.5677 & TRN & \\
\hline CHEMBL33602 & 30307 & 6.6289 & 6.4262 & TST & \\
\hline CHEMBL36352 & 30307 & 5.0 & 6.1231 & TRN & \\
\hline CHEMBL433235 & 30307 & 5.9948 & 7.0576 & TRN & \\
\hline CHEMBL32697 & 30307 & 6.5186 & 7.2694 & TRN & \\
\hline CHEMBL 32447 & 30307 & 6.1878 & 7.1657 & TRN & \\
\hline CHEMBL33305 & 30307 & 7.9208 & 7.494 & TRN & \\
\hline CHEMBL32281 & 30307 & 7.4685 & 6.7935 & TRN & \\
\hline CHEMBL 32582 & 30307 & 7.3279 & 7.3472 & TRN & \\
\hline CHEMBL417312 & 30307 & 6.466 & 6.5212 & TRN & \\
\hline CHEMBL 32289 & 30307 & 7.0555 & 6.6775 & TRN & \\
\hline CHEMBL2112067 & 30307 & 7.0315 & 7.1825 & TRN & \\
\hline CHEMBL 286420 & 30307 & 7.3872 & 7.7836 & TRN & \\
\hline CHEMBL32755 & 30307 & 5.0 & 6.0206 & TRN & \\
\hline CHEMBL 287493 & 30307 & 7.1079 & 6.6189 & TRN & \\
\hline CHEMBL32802 & 30307 & 7.7959 & 7.6227 & TRN & \\
\hline CHEMBL284615 & 30307 & 7.4949 & 7.5189 & TRN & \\
\hline CHEMBL32425 & 30307 & 6.7959 & 6.6694 & TRN & \\
\hline CHEMBL32770 & 30307 & 7.301 & 6.8674 & TRN & \\
\hline CHEMBL32591 & 30307 & 7.7447 & 6.7176 & TRN & \\
\hline CHEMBL 286102 & 30307 & 7.0915 & 6.8551 & TRN & \\
\hline CHEMBL32311 & 30307 & 7.2291 & 6.9819 & TRN & \\
\hline CHEMBL33930 & 30307 & 7.2596 & 7.2239 & TRN & \\
\hline CHEMBL32205 & 30307 & 5.0 & 6.5247 & TST & \\
\hline CHEMBL32598 & 30307 & 8.0458 & 6.7776 & TST & \\
\hline
\end{tabular}




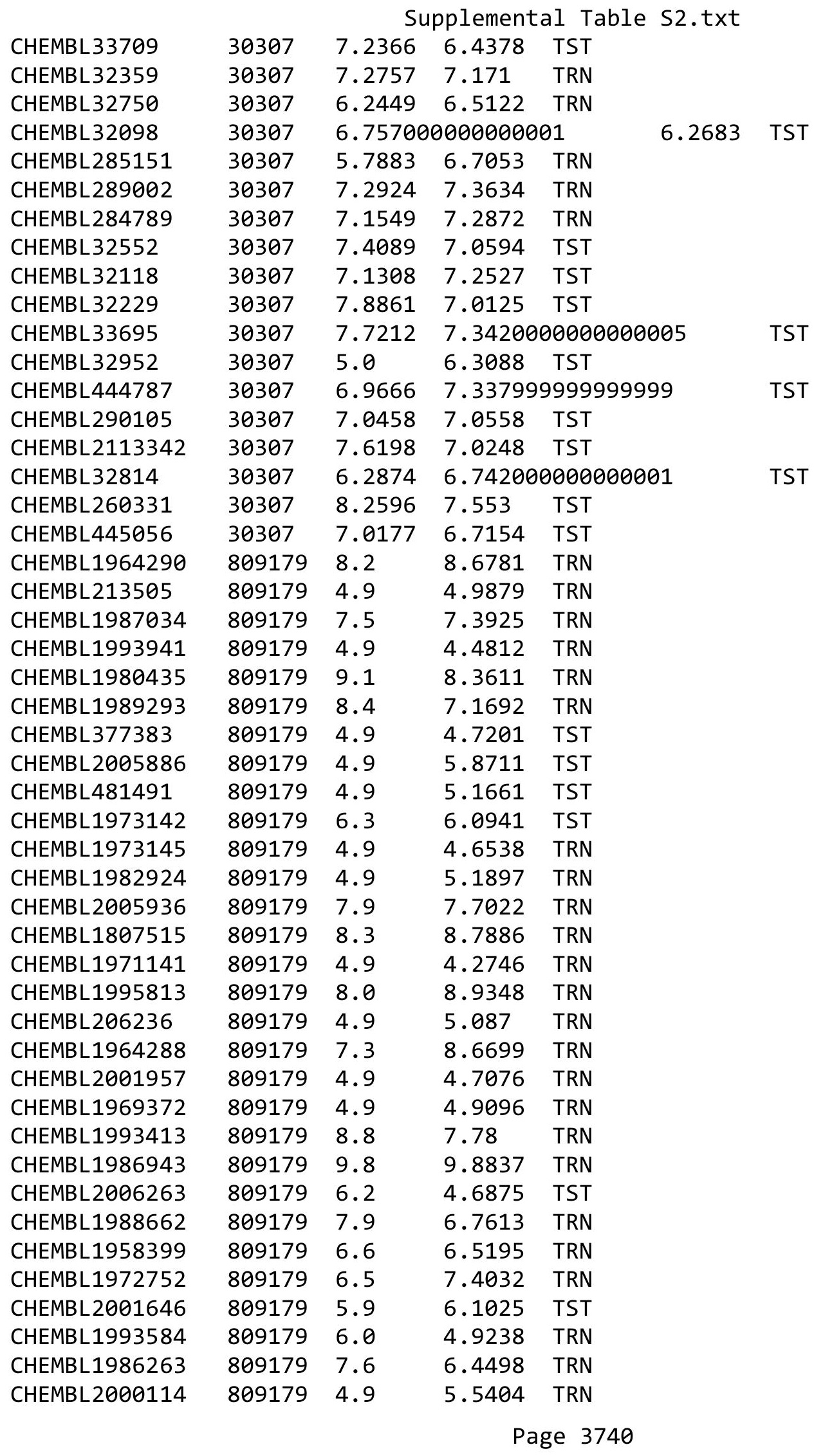




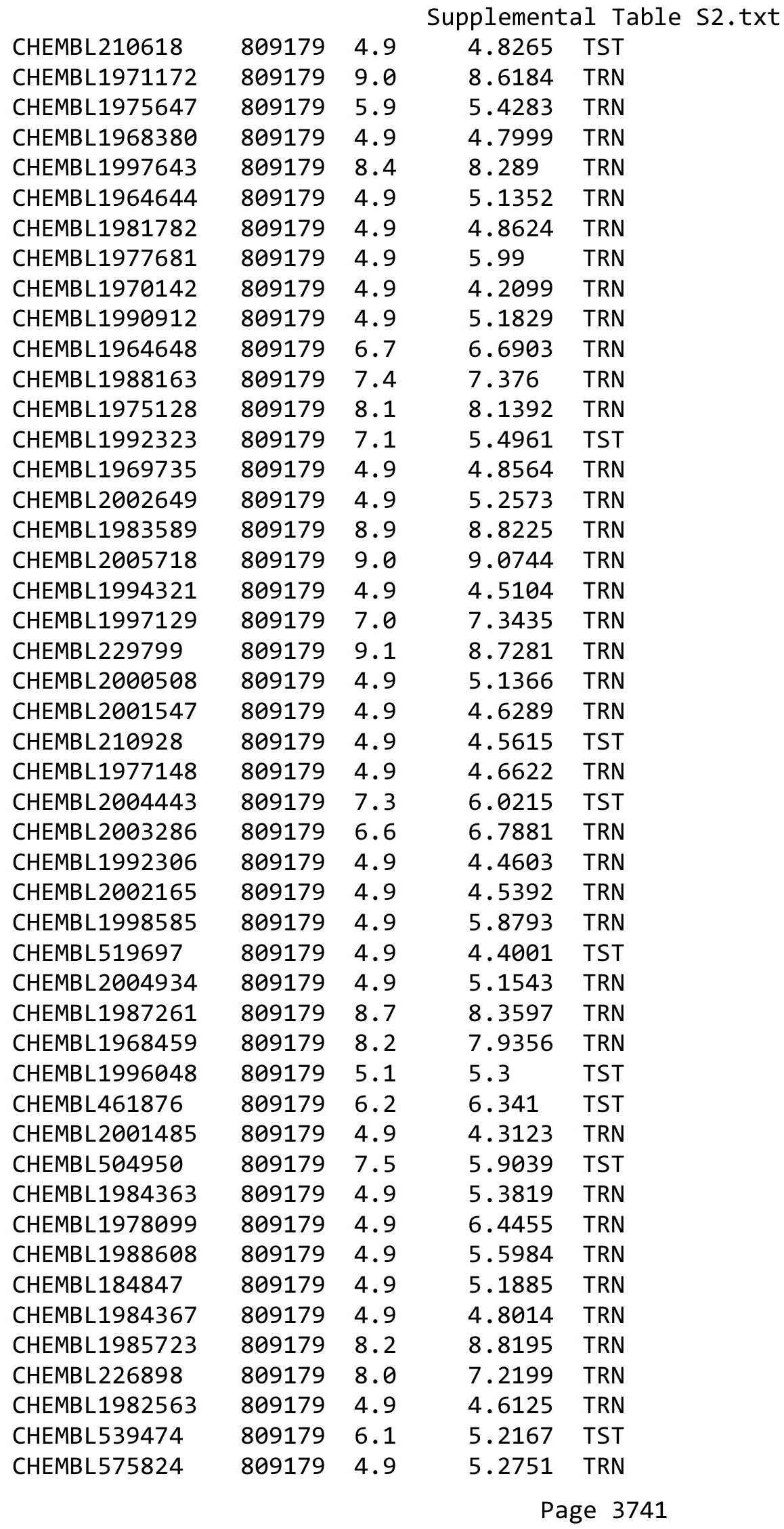




\begin{tabular}{|c|c|c|c|c|}
\hline & & & & $a+1 a$ \\
\hline CHEMBL1988387 & 809179 & 4.9 & 5.3489 & TRN \\
\hline CHEMBL1977128 & 809179 & 8.9 & 8.8851 & TRN \\
\hline CHEMBL1990288 & 809179 & 4.9 & 5.0778 & TRN \\
\hline CHEMBL1989708 & 809179 & 4.9 & 4.6777 & TRN \\
\hline CHEMBL1970074 & 809179 & 4.9 & 4.8034 & TRN \\
\hline CHEMBL 244627 & 809179 & 7.3 & 6.7254 & TRN \\
\hline CHEMBL1965702 & 809179 & 8.5 & 8.5183 & TRN \\
\hline CHEMBL1986970 & 809179 & 4.9 & 5.5622 & TRN \\
\hline CHEMBL 2002456 & 809179 & 8.6 & 7.5558 & TRN \\
\hline CHEMBL1958401 & 809179 & 8.6 & 7.4839 & TRN \\
\hline CHEMBL 2003456 & 809179 & 4.9 & 5.3304 & TRN \\
\hline CHEMBL1966816 & 809179 & 4.9 & 5.7958 & TRN \\
\hline CHEMBL1972584 & 809179 & 4.9 & 5.0885 & TRN \\
\hline CHEMBL 2002992 & 809179 & 4.9 & 4.7149 & TST \\
\hline CHEMBL560813 & 809179 & 4.9 & 4.8628 & TRN \\
\hline CHEMBL1968791 & 809179 & 4.9 & 5.8552 & TRN \\
\hline CHEMBL1971186 & 809179 & 4.9 & 5.1848 & TRN \\
\hline CHEMBL 2003482 & 809179 & 4.9 & 5.2102 & TRN \\
\hline CHEMBL 2006456 & 809179 & 9.0 & 8.9445 & TRN \\
\hline CHEMBL1973211 & 809179 & 4.9 & 4.9815 & TRN \\
\hline CHEMBL1984700 & 809179 & 4.9 & 4.86100 & 0000000001 \\
\hline CHEMBL1998953 & 809179 & 7.5 & 6.9226 & TRN \\
\hline CHEMBL1964340 & 809179 & 8.7 & 8.8555 & TRN \\
\hline CHEMBL1972125 & 809179 & 4.9 & 4.547 & TRN \\
\hline CHEMBL1976134 & 809179 & 4.9 & 6.0505 & TRN \\
\hline CHEMBL1965131 & 809179 & 6.2 & 6.1177 & TST \\
\hline CHEMBL1999279 & 809179 & 7.7 & 8.8877 & TRN \\
\hline CHEMBL1995201 & 809179 & 7.3 & 6.2974 & TRN \\
\hline CHEMBL1972158 & 809179 & 8.8 & 8.4131 & TRN \\
\hline CHEMBL1967662 & 809179 & 9.2 & 9.0552 & TRN \\
\hline CHEMBL1999414 & 809179 & 5.1 & 5.3982 & TRN \\
\hline CHEMBL1970340 & 809179 & 4.9 & 5.4738 & TRN \\
\hline CHEMBL 2005186 & 809179 & 4.9 & 5.3681 & TRN \\
\hline CHEMBL 2006450 & 809179 & 9.3 & 7.8988 & TRN \\
\hline CHEMBL1975534 & 809179 & 4.9 & 5.4394 & TST \\
\hline CHEMBL1993424 & 809179 & 4.9 & 6.0553 & TRN \\
\hline CHEMBL1966703 & 809179 & 4.9 & 5.2667 & TST \\
\hline CHEMBL1969561 & 809179 & 6.3 & 6.0007 & TRN \\
\hline CHEMBL1975121 & 809179 & 4.9 & 4.8296 & TRN \\
\hline CHEMBL1997554 & 809179 & 8.3 & 7.6893 & TRN \\
\hline CHEMBL1997023 & 809179 & 7.4 & 6.0089 & TST \\
\hline CHEMBL1968015 & 809179 & 5.7 & 6.9022 & TRN \\
\hline CHEMBL1964687 & 809179 & 4.9 & 4.9718 & TRN \\
\hline CHEMBL1971943 & 809179 & 6.7 & 6.6877 & TRN \\
\hline CHEMBL1974254 & 809179 & 4.9 & 4.7436 & TRN \\
\hline CHEMBL1988537 & 809179 & 4.9 & 5.5861 & TST \\
\hline CHEMBL1969049 & 809179 & 4.9 & 5.0665 & TRN \\
\hline CHEMBL 2005828 & 809179 & 4.9 & 5.3047 & TRN \\
\hline
\end{tabular}




\begin{tabular}{|c|c|c|c|c|c|}
\hline \\
\hline CHEMBL1980178 & 809179 & 9.1 & 8.5698 & TRN & \\
\hline CHEMBL1998611 & 809179 & 6.5 & 5.6592 & TST & \\
\hline CHEMBL1987881 & 809179 & 6.6 & 6.0736 & TRN & \\
\hline CHEMBL1975900 & 809179 & 4.9 & 5.322 & TRN & \\
\hline CHEMBL255822 & 809179 & 7.0 & 7.04200 & 0000000001 & TRN \\
\hline CHEMBL1972221 & 809179 & 4.9 & 5.3543 & TRN & \\
\hline CHEMBL 2006778 & 809179 & 4.9 & 5.0397 & TRN & \\
\hline CHEMBL1981511 & 809179 & 6.9 & 6.2947 & TRN & \\
\hline CHEMBL378627 & 809179 & 4.9 & 4.3076 & TST & \\
\hline CHEMBL1996979 & 809179 & 4.9 & 5.9233 & TRN & \\
\hline CHEMBL1968406 & 809179 & 4.9 & 4.862 & TRN & \\
\hline CHEMBL1975175 & 809179 & 6.4 & 6.0647 & TST & \\
\hline CHEMBL1998545 & 809179 & 4.9 & 5.2279 & TRN & \\
\hline CHEMBL1986869 & 809179 & 4.9 & 4.9121 & TST & \\
\hline CHEMBL1682558 & 809179 & 4.9 & 5.0527 & TRN & \\
\hline CHEMBL1990496 & 809179 & 4.9 & 5.0141 & TST & \\
\hline CHEMBL1998068 & 809179 & 8.7 & 8.9524 & TRN & \\
\hline CHEMBL2002479 & 809179 & 4.9 & 5.7341 & TRN & \\
\hline CHEMBL1974582 & 809179 & 7.0 & 6.0322 & TRN & \\
\hline CHEMBL1967094 & 809179 & 4.9 & 4.5388 & TRN & \\
\hline CHEMBL 2003341 & 809179 & 4.9 & 5.3378 & TRN & \\
\hline CHEMBL1990708 & 809179 & 8.3 & 6.6744 & TRN & \\
\hline CHEMBL1999590 & 809179 & 4.9 & 4.5492 & TST & \\
\hline CHEMBL1981079 & 809179 & 9.4 & 9.0688 & TRN & \\
\hline CHEMBL1980489 & 809179 & 4.9 & 5.3371 & TRN & \\
\hline CHEMBL 2000832 & 809179 & 4.9 & 5.2218 & TRN & \\
\hline CHEMBL1967116 & 809179 & 4.9 & 4.8376 & TRN & \\
\hline CHEMBL1970709 & 809179 & 4.9 & 4.712 & TRN & \\
\hline CHEMBL1965660 & 809179 & 9.7 & 9.6236 & TRN & \\
\hline CHEMBL1998112 & 809179 & 4.9 & 4.8678 & TRN & \\
\hline CHEMBL1972290 & 809179 & 8.6 & 9.0033 & TRN & \\
\hline CHEMBL1969126 & 809179 & 4.9 & 4.3846 & TRN & \\
\hline CHEMBL1980896 & 809179 & 4.9 & 4.84699 & 99999999995 & TRN \\
\hline CHEMBL1970104 & 809179 & 4.9 & 5.847 & TST & \\
\hline CHEMBL1991429 & 809179 & 4.9 & 4.488 & TRN & \\
\hline CHEMBL1964777 & 809179 & 5.9 & 6.0956 & TST & \\
\hline CHEMBL1971149 & 809179 & 4.9 & 4.7542 & TRN & \\
\hline CHEMBL1999714 & 809179 & 4.9 & 4.4113 & TRN & \\
\hline CHEMBL1994040 & 809179 & 4.9 & 4.7339 & TRN & \\
\hline CHEMBL1984548 & 809179 & 8.3 & 7.8904 & TRN & \\
\hline CHEMBL1998773 & 809179 & 7.1 & 6.3372 & TRN & \\
\hline CHEMBL579246 & 809179 & 4.9 & 4.9668 & TRN & \\
\hline CHEMBL398951 & 809179 & 4.9 & 4.7912 & TST & \\
\hline CHEMBL1982506 & 809179 & 4.9 & 5.1494 & TST & \\
\hline CHEMBL2004716 & 809179 & 4.9 & 5.3477 & TRN & \\
\hline CHEMBL1968127 & 809179 & 4.9 & 4.8817 & TRN & \\
\hline CHEMBL1975233 & 809179 & 4.9 & 3.9145 & TRN & \\
\hline CHEMBL1985406 & 809179 & 4.9 & 5.7547 & TRN & \\
\hline
\end{tabular}




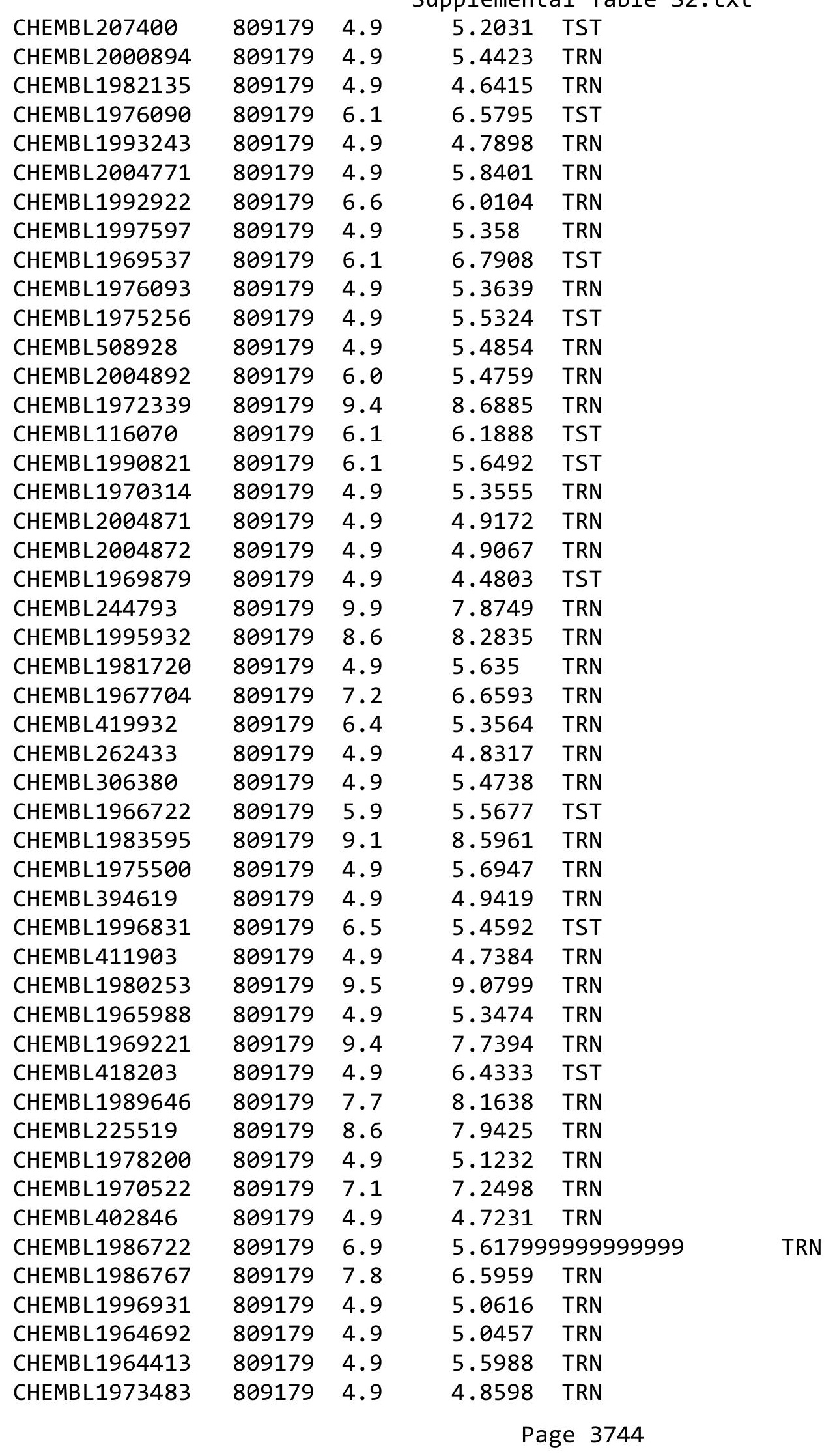




\begin{tabular}{|c|c|c|c|c|c|}
\hline \\
\hline CHEMBL1998470 & 809179 & 9.1 & 8.381 & TRN & \\
\hline CHEMBL1996980 & 809179 & 9.5 & 9.7567 & TRN & \\
\hline CHEMBL1969920 & 809179 & 8.1 & 8.9742 & TRN & \\
\hline CHEMBL1994669 & 809179 & 8.6 & 7.8928 & TRN & \\
\hline CHEMBL1997340 & 809179 & 4.9 & 5.0136 & TRN & \\
\hline CHEMBL2004365 & 809179 & 6.1 & 5.5636 & TST & \\
\hline CHEMBL1522508 & 809179 & 4.9 & 4.7201 & TRN & \\
\hline CHEMBL1090360 & 809179 & 4.9 & 4.4129 & TRN & \\
\hline CHEMBL 226232 & 809179 & 6.9 & 7.5309 & TRN & \\
\hline CHEMBL210887 & 809179 & 4.9 & 5.2731 & TST & \\
\hline CHEMBL458997 & 809179 & 6.5 & 6.9411 & TRN & \\
\hline CHEMBL1971021 & 809179 & 4.9 & 4.3098 & TRN & \\
\hline CHEMBL227271 & 809179 & 7.7 & 8.1249 & TRN & \\
\hline CHEMBL583144 & 809179 & 6.9 & 6.70799 & 9999999999 & TST \\
\hline CHEMBL1974310 & 809179 & 6.1 & 6.5721 & TST & \\
\hline CHEMBL1982660 & 809179 & 4.9 & 5.7072 & TRN & \\
\hline CHEMBL1994693 & 809179 & 4.9 & 4.5145 & TRN & \\
\hline CHEMBL1982957 & 809179 & 6.2 & 5.4012 & TRN & \\
\hline CHEMBL1725279 & 809179 & 6.0 & 7.1014 & TST & \\
\hline CHEMBL 2002346 & 809179 & 8.5 & 8.4993 & TRN & \\
\hline CHEMBL1975138 & 809179 & 4.9 & 5.3817 & TST & \\
\hline CHEMBL424872 & 809179 & 4.9 & 4.6054 & TST & \\
\hline CHEMBL412142 & 809179 & 4.9 & 5.6738 & TST & \\
\hline CHEMBL1985153 & 809179 & 7.5 & 6.0742 & TRN & \\
\hline CHEMBL1980704 & 809179 & 4.9 & 5.45 & TST & \\
\hline CHEMBL 2003271 & 809179 & 6.5 & 6.3353 & TST & \\
\hline CHEMBL1966808 & 809179 & 7.9 & 6.9951 & TST & \\
\hline CHEMBL2004447 & 809179 & 4.9 & 5.093 & TST & \\
\hline CHEMBL1992231 & 809179 & 8.6 & 7.6681 & TRN & \\
\hline CHEMBL1983111 & 809179 & 6.5 & 6.5241 & TRN & \\
\hline CHEMBL1973860 & 809179 & 4.9 & 4.6882 & TRN & \\
\hline CHEMBL260135 & 809179 & 4.9 & 4.86 & TST & \\
\hline CHEMBL220241 & 809179 & 7.1 & 6.2693 & TST & \\
\hline CHEMBL 2004544 & 809179 & 6.5 & 5.2579 & TST & \\
\hline CHEMBL1983157 & 809179 & 7.9 & 7.4994 & TRN & \\
\hline CHEMBL1982610 & 809179 & 4.9 & 5.3458 & TST & \\
\hline CHEMBL1966040 & 809179 & 7.9 & 7.3168 & TRN & \\
\hline CHEMBL1988300 & 809179 & 4.9 & 5.3247 & TRN & \\
\hline CHEMBL1991078 & 809179 & 8.9 & 8.4768 & TRN & \\
\hline CHEMBL1987359 & 809179 & 4.9 & 4.8498 & TST & \\
\hline CHEMBL1994438 & 809179 & 8.3 & 8.7365 & TRN & \\
\hline CHEMBL1969502 & 809179 & 4.9 & 5.0726 & TST & \\
\hline CHEMBL1996447 & 809179 & 7.8 & 7.2193 & TRN & \\
\hline CHEMBL1682553 & 809179 & 6.9 & 7.1768 & TRN & \\
\hline CHEMBL1983963 & 809179 & 4.9 & 4.6933 & TRN & \\
\hline CHEMBL1997764 & 809179 & 4.9 & 5.3534 & TRN & \\
\hline CHEMBL1985092 & 809179 & 4.9 & 6.3092 & TST & \\
\hline CHEMBL1981410 & 809179 & 4.9 & 4.6129 & TRN & \\
\hline
\end{tabular}




\begin{tabular}{|c|c|c|c|c|c|}
\hline \\
\hline CHEMBL1996234 & 809179 & 4.9 & 5.0607 & TRN & \\
\hline CHEMBL1967544 & 809179 & 4.9 & 5.9053 & TRN & \\
\hline CHEMBL223367 & 809179 & 4.9 & 4.6152 & TST & \\
\hline CHEMBL340384 & 809179 & 6.2 & 6.5869 & TRN & \\
\hline CHEMBL1969151 & 809179 & 9.5 & 9.2548 & TRN & \\
\hline CHEMBL1996587 & 809179 & 4.9 & 3.7609 & TRN & \\
\hline CHEMBL 2007574 & 809179 & 8.0 & 9.0217 & TRN & \\
\hline CHEMBL1964804 & 809179 & 4.9 & 5.3884 & TRN & \\
\hline CHEMBL 2000354 & 809179 & 7.3 & 7.2004 & TRN & \\
\hline CHEMBL1965507 & 809179 & 4.9 & 4.5671 & TRN & \\
\hline CHEMBL 274064 & 809179 & 4.9 & 5.6611 & TRN & \\
\hline CHEMBL1967564 & 809179 & 4.9 & 5.2591 & TRN & \\
\hline CHEMBL592030 & 809179 & 7.9 & 7.7873 & TST & \\
\hline CHEMBL 2000071 & 809179 & 6.4 & 6.1872 & TRN & \\
\hline CHEMBL1979176 & 809179 & 4.9 & 4.9586 & TRN & \\
\hline CHEMBL 2002613 & 809179 & 9.4 & 8.2192 & TRN & \\
\hline CHEMBL1971556 & 809179 & 6.9 & 6.0902 & TRN & \\
\hline CHEMBL2000408 & 809179 & 4.9 & 4.7037 & TRN & \\
\hline CHEMBL 248757 & 809179 & 4.9 & 4.1251 & TST & \\
\hline CHEMBL1978014 & 809179 & 4.9 & 5.45299 & 9999999999 & TRN \\
\hline CHEMBL1974250 & 809179 & 8.3 & 7.5135 & TRN & \\
\hline CHEMBL1994538 & 809179 & 4.9 & 5.1613 & TRN & \\
\hline CHEMBL1983195 & 809179 & 6.3 & 4.6328 & TST & \\
\hline CHEMBL1975490 & 809179 & 4.9 & 6.5635 & TRN & \\
\hline CHEMBL1964444 & 809179 & 4.9 & 6.1224 & TRN & \\
\hline CHEMBL1986139 & 809179 & 4.9 & 5.3637 & TRN & \\
\hline CHEMBL1980540 & 809179 & 4.9 & 5.6058 & TRN & \\
\hline CHEMBL2003229 & 809179 & 7.9 & 7.3239 & TRN & \\
\hline CHEMBL1979883 & 809179 & 4.9 & 5.1338 & TRN & \\
\hline CHEMBL1984162 & 809179 & 4.9 & 6.901 & TRN & \\
\hline CHEMBL1988331 & 809179 & 8.9 & 8.7107 & TRN & \\
\hline CHEMBL1998432 & 809179 & 9.0 & 8.8604 & TRN & \\
\hline CHEMBL491758 & 809179 & 4.9 & 5.9652 & TRN & \\
\hline CHEMBL549730 & 809179 & 6.2 & 6.0703 & TRN & \\
\hline CHEMBL1998826 & 809179 & 7.9 & 6.6405 & TRN & \\
\hline CHEMBL1970189 & 809179 & 4.9 & 4.9647 & TST & \\
\hline CHEMBL1996791 & 809179 & 5.9 & 5.6659 & TRN & \\
\hline CHEMBL371206 & 809179 & 4.9 & 5.6219 & TRN & \\
\hline CHEMBL1974664 & 809179 & 4.9 & 5.1791 & TST & \\
\hline CHEMBL1974288 & 809179 & 4.9 & 5.0111 & TRN & \\
\hline CHEMBL213207 & 809179 & 8.1 & 8.7546 & TRN & \\
\hline CHEMBL196363 & 809179 & 4.9 & 5.0273 & TRN & \\
\hline CHEMBL1190711 & 809179 & 7.7 & 5.1594 & TRN & \\
\hline CHEMBL1968705 & 809179 & 4.9 & 5.4574 & TRN & \\
\hline CHEMBL1991410 & 809179 & 8.6 & 7.7302 & TRN & \\
\hline CHEMBL404367 & 809179 & 4.9 & 4.7269 & TRN & \\
\hline CHEMBL1966343 & 809179 & 7.3 & 7.3651 & TRN & \\
\hline CHEMBL1967887 & 809179 & 7.0 & 6.8682 & TRN & \\
\hline
\end{tabular}




\begin{tabular}{|c|c|c|c|c|c|}
\hline & & & & & \\
\hline CHEMBL 2000568 & 809179 & 4.9 & 5.1256 & TRN & \\
\hline CHEMBL 2000335 & 809179 & 4.9 & 5.2608 & TRN & \\
\hline CHEMBL1993648 & 809179 & 7.2 & 7.2526 & TRN & \\
\hline CHEMBL1988717 & 809179 & 4.9 & 4.6383 & TRN & \\
\hline CHEMBL1974328 & 809179 & 7.2 & 6.9141 & TRN & \\
\hline CHEMBL509032 & 809179 & 5.0 & 5.4411 & TRN & \\
\hline CHEMBL1971951 & 809179 & 8.1 & 6.4714 & TRN & \\
\hline CHEMBL1973808 & 809179 & 4.9 & 4.5164 & TRN & \\
\hline CHEMBL 2000429 & 809179 & 4.9 & 4.76699 & 99999999995 & TRN \\
\hline CHEMBL1972576 & 809179 & 4.9 & 4.30399 & 9999999999 & TRN \\
\hline CHEMBL1990254 & 809179 & 4.9 & 5.3817 & TRN & \\
\hline CHEMBL1976673 & 809179 & 6.3 & 5.8274 & TST & \\
\hline CHEMBL1992342 & 809179 & 4.9 & 5.4477 & TRN & \\
\hline CHEMBL 2003682 & 809179 & 8.2 & 6.9697 & TRN & \\
\hline CHEMBL1988173 & 809179 & 6.6 & 5.6501 & TST & \\
\hline CHEMBL1164265 & 809179 & 5.1 & 5.1831 & TST & \\
\hline CHEMBL1989805 & 809179 & 6.7 & 4.9388 & TST & \\
\hline CHEMBL1966204 & 809179 & 9.1 & 8.9204 & TRN & \\
\hline CHEMBL1965423 & 809179 & 4.9 & 4.8298 & TRN & \\
\hline CHEMBL1983025 & 809179 & 4.9 & 5.255 & TRN & \\
\hline CHEMBL 205415 & 809179 & 6.0 & 6.2975 & TRN & \\
\hline CHEMBL1999153 & 809179 & 8.9 & 8.8594 & TRN & \\
\hline CHEMBL1969473 & 809179 & 9.2 & 7.7797 & TRN & \\
\hline CHEMBL1977135 & 809179 & 4.6 & 5.1541 & TRN & \\
\hline CHEMBL 2001920 & 809179 & 4.9 & 6.3414 & TST & \\
\hline CHEMBL1985654 & 809179 & 8.0 & 8.3787 & TRN & \\
\hline CHEMBL1241473 & 809179 & 8.2 & 7.9599 & TRN & \\
\hline CHEMBL1978448 & 809179 & 7.0 & 6.3197 & TST & \\
\hline CHEMBL1983855 & 809179 & 7.5 & $6.7570 e$ & 0000000001 & TRN \\
\hline CHEMBL 2001257 & 809179 & 4.9 & 4.7847 & TRN & \\
\hline CHEMBL1992536 & 809179 & 4.9 & 5.2144 & TRN & \\
\hline CHEMBL1987793 & 809179 & 6.3 & $6.2120 e$ & 3000000001 & TST \\
\hline CHEMBL1992740 & 809179 & 4.9 & 5.1442 & TRN & \\
\hline CHEMBL1964519 & 809179 & 9.9 & 8.6421 & TRN & \\
\hline CHEMBL439340 & 809179 & 4.9 & 4.8639 & TRN & \\
\hline CHEMBL 2006188 & 809179 & 4.9 & 5.4356 & TRN & \\
\hline CHEMBL1967531 & 809179 & 4.9 & 6.0521 & TRN & \\
\hline CHEMBL1970913 & 809179 & 4.9 & 4.94 & TRN & \\
\hline CHEMBL1973893 & 809179 & 4.9 & 5.3664 & TRN & \\
\hline CHEMBL 2004631 & 809179 & 7.5 & 8.1031 & TRN & \\
\hline CHEMBL1997534 & 809179 & 4.9 & 6.1188 & TRN & \\
\hline CHEMBL1996500 & 809179 & 4.9 & 4.7244 & TRN & \\
\hline CHEMBL1985095 & 809179 & 6.9 & 6.2555 & TST & \\
\hline CHEMBL1682540 & 809179 & 6.4 & 6.3643 & TRN & \\
\hline CHEMBL1983315 & 809179 & 8.6 & 8.7487 & TRN & \\
\hline CHEMBL1976420 & 809179 & 6.7 & 5.4357 & TST & \\
\hline CHEMBL 2002446 & 809179 & 4.9 & 4.9821 & TST & \\
\hline CHEMBL497151 & 809179 & 7.4 & 6.9466 & TST & \\
\hline & & & & 3747 & \\
\hline
\end{tabular}




\begin{tabular}{|c|c|c|c|c|}
\hline & & & pplement & $\mathrm{a} \perp \mathrm{Ta}$ \\
\hline CHEMBL2000029 & 809179 & 8.5 & 8.2924 & TRN \\
\hline CHEMBL1973961 & 809179 & 5.1 & 5.4281 & TRN \\
\hline CHEMBL 246970 & 809179 & 4.9 & 4.1882 & TRN \\
\hline CHEMBL3145311 & 809179 & 6.3 & 5.9389 & TST \\
\hline CHEMBL340921 & 809179 & 4.9 & 5.6617 & TRN \\
\hline CHEMBL1999718 & 809179 & 4.9 & 5.085 & TRN \\
\hline CHEMBL1987073 & 809179 & 8.9 & 8.5326 & TRN \\
\hline CHEMBL1276446 & 809179 & 6.9 & 6.1419 & TST \\
\hline CHEMBL1995712 & 809179 & 8.7 & 8.565 & TRN \\
\hline CHEMBL1977346 & 809179 & 4.9 & 5.1921 & TRN \\
\hline CHEMBL1971649 & 809179 & 4.9 & 4.9183 & TRN \\
\hline CHEMBL1975440 & 809179 & 7.9 & 6.6684 & TRN \\
\hline CHEMBL 2006439 & 809179 & 9.3 & 9.4183 & TRN \\
\hline CHEMBL 2006156 & 809179 & 6.3 & 5.0364 & TST \\
\hline CHEMBL1969190 & 809179 & 4.9 & 4.7275 & TRN \\
\hline CHEMBL1973937 & 809179 & 4.9 & 4.3982 & TRN \\
\hline CHEMBL1991674 & 809179 & 9.0 & 9.008 & TRN \\
\hline CHEMBL1982711 & 809179 & 6.5 & 6.5806 & TRN \\
\hline CHEMBL1682346 & 809179 & 7.9 & 8.2914 & TRN \\
\hline CHEMBL 2007044 & 809179 & 4.9 & 4.3511 & TST \\
\hline CHEMBL1994241 & 809179 & 6.6 & 5.8918 & TST \\
\hline CHEMBL223460 & 809179 & 4.9 & 4.3483 & TST \\
\hline CHEMBL50894 & 809179 & 6.4 & 7.0742 & TST \\
\hline CHEMBL1988838 & 809179 & 6.2 & 6.6425 & TRN \\
\hline CHEMBL1981725 & 809179 & 4.9 & 6.045 & TRN \\
\hline CHEMBL1980562 & 809179 & 9.6 & 9.3675 & TRN \\
\hline CHEMBL1982866 & 809179 & 4.9 & 4.706 & TRN \\
\hline CHEMBL 2004156 & 809179 & 7.2 & 5.9963 & TST \\
\hline CHEMBL1979933 & 809179 & 9.4 & 8.2035 & TRN \\
\hline CHEMBL1965570 & 809179 & 4.9 & 5.4938 & TRN \\
\hline CHEMBL 2007592 & 809179 & 4.9 & 6.2429 & TST \\
\hline CHEMBL1976936 & 809179 & 9.0 & 8.8979 & TRN \\
\hline CHEMBL 210963 & 809179 & 4.9 & 4.2701 & TST \\
\hline CHEMBL 2005387 & 809179 & 8.7 & 8.8064 & TRN \\
\hline CHEMBL1082440 & 809179 & 4.9 & 4.6476 & TST \\
\hline CHEMBL1614705 & 809179 & 4.9 & 5.5104 & TST \\
\hline CHEMBL1982400 & 809179 & 8.1 & 8.6833 & TRN \\
\hline CHEMBL1984633 & 809179 & 4.9 & 4.5981 & TRN \\
\hline CHEMBL1972988 & 809179 & 6.7 & 8.0002 & TRN \\
\hline CHEMBL1965845 & 809179 & 4.9 & 6.1311 & TRN \\
\hline CHEMBL 2006715 & 809179 & 4.9 & 4.8724 & TRN \\
\hline CHEMBL1986597 & 809179 & 4.9 & 5.2692 & TRN \\
\hline CHEMBL1990482 & 809179 & 5.2 & 5.0736 & TRN \\
\hline CHEMBL1990904 & 809179 & 4.9 & 5.2974 & TRN \\
\hline CHEMBL1987448 & 809179 & 8.8 & 9.2642 & TRN \\
\hline CHEMBL2005475 & 809179 & 4.9 & 5.7896 & TRN \\
\hline CHEMBL183844 & 809179 & 4.9 & 4.5582 & TRN \\
\hline CHEMBL220057 & 809179 & 4.9 & 5.3617 & TRN \\
\hline
\end{tabular}




\begin{tabular}{|c|c|c|c|c|c|}
\hline \\
\hline CHEMBL1682545 & 809179 & 4.9 & 5.256 & TRN & \\
\hline CHEMBL383541 & 809179 & 6.4 & 5.3425 & TRN & \\
\hline CHEMBL 2001224 & 809179 & 4.9 & 3.9755 & TRN & \\
\hline CHEMBL10 & 809179 & 4.9 & 5.2308 & TRN & \\
\hline CHEMBL1982982 & 809179 & 6.8 & 5.3859 & TRN & \\
\hline CHEMBL1976732 & 809179 & 4.9 & 4.4558 & TRN & \\
\hline CHEMBL 2005216 & 809179 & 9.4 & 9.1796 & TRN & \\
\hline CHEMBL1969506 & 809179 & 4.9 & 4.7712 & TRN & \\
\hline CHEMBL1964937 & 809179 & 4.9 & 6.2159 & TRN & \\
\hline CHEMBL1980163 & 809179 & 4.9 & 5.1322 & TRN & \\
\hline CHEMBL 2005899 & 809179 & 6.2 & 5.96399 & 99999999995 & TRN \\
\hline CHEMBL1682552 & 809179 & 6.3 & 7.0746 & TRN & \\
\hline CHEMBL1987745 & 809179 & 7.7 & 7.1522 & TRN & \\
\hline CHEMBL105739 & 809179 & 4.9 & 4.96899 & 9999999999 & TRN \\
\hline CHEMBL379300 & 809179 & 7.9 & 7.3641 & TRN & \\
\hline CHEMBL1973720 & 809179 & 9.5 & 9.2264 & TRN & \\
\hline CHEMBL1969523 & 809179 & 6.9 & 6.5593 & TRN & \\
\hline CHEMBL1986781 & 809179 & 4.9 & 5.3181 & TRN & \\
\hline CHEMBL526133 & 809179 & 8.3 & 7.001 & TRN & \\
\hline CHEMBL1979057 & 809179 & 4.9 & 5.3373 & TRN & \\
\hline CHEMBL387971 & 809179 & 4.9 & 4.9681 & TST & \\
\hline CHEMBL1999428 & 809179 & 4.9 & 5.1165 & TRN & \\
\hline CHEMBL1967560 & 809179 & 4.9 & 4.6037 & TRN & \\
\hline CHEMBL1516890 & 809179 & 4.9 & 6.1292 & TST & \\
\hline CHEMBL211378 & 809179 & 4.9 & 4.721 & TRN & \\
\hline CHEMBL1682358 & 809179 & 7.5 & 7.8448 & TRN & \\
\hline CHEMBL1982465 & 809179 & 4.9 & 4.754 & TRN & \\
\hline CHEMBL 2001751 & 809179 & 6.6 & 6.5529 & TRN & \\
\hline CHEMBL 2003420 & 809179 & 4.9 & 4.9406 & TRN & \\
\hline CHEMBL1984586 & 809179 & 4.9 & 5.4147 & TRN & \\
\hline CHEMBL1972659 & 809179 & 4.9 & 4.7133 & TST & \\
\hline CHEMBL1973395 & 809179 & 7.9 & 6.5684 & TRN & \\
\hline CHEMBL 272453 & 809179 & 4.9 & 5.0439 & TRN & \\
\hline CHEMBL1970217 & 809179 & 4.9 & 4.555 & TRN & \\
\hline CHEMBL 2005528 & 809179 & 4.9 & 5.53299 & 99999999995 & TST \\
\hline CHEMBL185569 & 809179 & 4.9 & 5.2441 & TRN & \\
\hline CHEMBL1969843 & 809179 & 6.9 & 6.0392 & TRN & \\
\hline CHEMBL 2007002 & 809179 & 4.9 & 5.8896 & TRN & \\
\hline CHEMBL1987007 & 809179 & 4.9 & 4.8032 & TRN & \\
\hline CHEMBL1984711 & 809179 & 4.9 & 5.6906 & TRN & \\
\hline CHEMBL484390 & 809179 & 4.9 & 4.3046 & TST & \\
\hline CHEMBL1979252 & 809179 & 4.9 & 5.5497 & TRN & \\
\hline CHEMBL1682341 & 809179 & 7.2 & 6.5309 & TRN & \\
\hline CHEMBL 2004290 & 809179 & 4.9 & 4.7175 & TRN & \\
\hline CHEMBL1986499 & 809179 & 8.8 & 8.3965 & TRN & \\
\hline CHEMBL1972937 & 809179 & 4.9 & 6.6263 & TRN & \\
\hline CHEMBL 2000393 & 809179 & 4.9 & 5.5028 & TST & \\
\hline CHEMBL 2001477 & 809179 & 7.0 & 5.3045 & TRN & \\
\hline
\end{tabular}




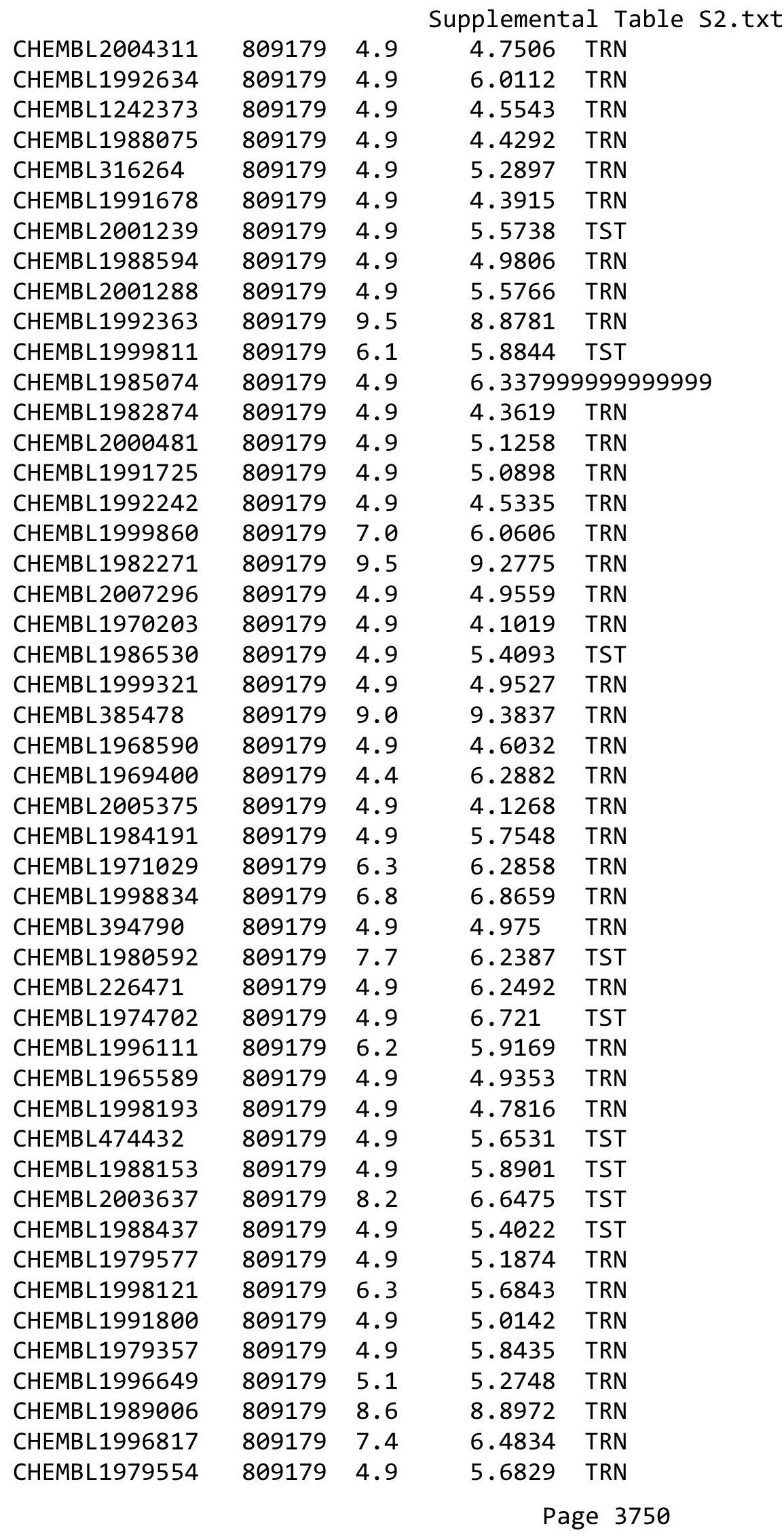




\begin{tabular}{|c|c|c|c|c|}
\hline & & & Supplement & \\
\hline CHEMBL468280 & 809179 & 4.9 & 5.1806 & TST \\
\hline CHEMBL1990884 & 809179 & 4.9 & 4.9306 & TRN \\
\hline CHEMBL1996339 & 809179 & 9.1 & 9.0053 & TRN \\
\hline CHEMBL3109278 & 809179 & 4.9 & 5.0573 & TRN \\
\hline CHEMBL256835 & 809179 & 4.9 & 4.8296 & TRN \\
\hline CHEMBL1980142 & 809179 & 4.9 & 4.6068 & TRN \\
\hline CHEMBL41783 & 809179 & 4.9 & 4.7732 & TRN \\
\hline CHEMBL271381 & 809179 & 4.9 & 4.4365 & TRN \\
\hline CHEMBL2006785 & 809179 & 4.9 & 5.7403 & TST \\
\hline CHEMBL1982466 & 809179 & 4.9 & 4.6297 & TRN \\
\hline CHEMBL1995740 & 809179 & 4.9 & 5.3188 & TRN \\
\hline CHEMBL1990162 & 809179 & 8.5 & 8.7927 & TRN \\
\hline CHEMBL1992220 & 809179 & 9.7 & 9.4772 & TRN \\
\hline CHEMBL234085 & 809179 & 4.9 & 4.5346 & TST \\
\hline CHEMBL1995832 & 809179 & 4.9 & 4.5685 & TRN \\
\hline CHEMBL1969042 & 809179 & 4.9 & 5.8396 & TST \\
\hline CHEMBL 2000345 & 809179 & 6.5 & 5.7069 & TST \\
\hline CHEMBL1999931 & 809179 & 9.3 & 9.1887 & TRN \\
\hline CHEMBL1375418 & 809179 & 4.6 & 4.6728 & TRN \\
\hline CHEMBL 2007064 & 809179 & 4.9 & 4.9672 & TRN \\
\hline CHEMBL1981047 & 809179 & 4.9 & 5.0592 & TRN \\
\hline CHEMBL229968 & 809179 & 7.9 & 8.4256 & TRN \\
\hline CHEMBL1976240 & 809179 & 4.9 & 5.1913 & TRN \\
\hline CHEMBL1987948 & 809179 & 9.2 & 8.7558 & TRN \\
\hline CHEMBL1979093 & 809179 & 4.9 & 4.8404 & TRN \\
\hline CHEMBL1968151 & 809179 & 7.2 & 6.4619 & TST \\
\hline CHEMBL1987009 & 809179 & 4.9 & 5.0454 & TRN \\
\hline CHEMBL 379218 & 809179 & 7.9 & 8.4594 & TRN \\
\hline CHEMBL2003817 & 809179 & 4.9 & 4.9266 & TRN \\
\hline CHEMBL1994830 & 809179 & 4.9 & 6.0886 & TST \\
\hline CHEMBL226403 & 809179 & 4.9 & 7.0092 & TRN \\
\hline CHEMBL2005631 & 809179 & 4.9 & 5.0493 & TRN \\
\hline CHEMBL1994938 & 809179 & 4.9 & 5.0776 & TRN \\
\hline CHEMBL1977223 & 809179 & 7.2 & 8.3892 & TRN \\
\hline CHEMBL1236126 & 809179 & 4.9 & 4.7926 & TST \\
\hline CHEMBL1966279 & 809179 & 4.9 & 4.8867 & TRN \\
\hline CHEMBL1997846 & 809179 & 8.7 & 8.3193 & TRN \\
\hline CHEMBL2003856 & 809179 & 7.0 & 7.5466 & TRN \\
\hline CHEMBL2004419 & 809179 & 4.9 & 4.6339 & TRN \\
\hline CHEMBL1995811 & 809179 & 8.5 & 8.6055 & TRN \\
\hline CHEMBL1994074 & 809179 & 4.9 & 5.9718 & TRN \\
\hline CHEMBL1992937 & 809179 & 4.9 & 6.4294 & TST \\
\hline CHEMBL1968930 & 809179 & 9.0 & 9.3054 & TRN \\
\hline CHEMBL1972119 & 809179 & 4.9 & 5.061 & TRN \\
\hline CHEMBL1986328 & 809179 & 6.4 & 4.7345 & TST \\
\hline CHEMBL95692 & 809179 & 4.9 & 5.0951 & TRN \\
\hline CHEMBL1090356 & 809179 & 4.9 & 4.4413 & TRN \\
\hline CHEMBL1976455 & 809179 & 4.9 & 5.8944 & TRN \\
\hline
\end{tabular}




\begin{tabular}{|c|c|c|c|c|}
\hline & & & & \\
\hline CHEMBL1983923 & 809179 & 4.9 & 6.2334 & TST \\
\hline CHEMBL1983534 & 809179 & 4.9 & 4.825 & TRN \\
\hline CHEMBL1970950 & 809179 & 7.5 & 6.3783 & TRN \\
\hline CHEMBL1982361 & 809179 & 6.3 & 5.4771 & TRN \\
\hline CHEMBL1999112 & 809179 & 4.9 & 4.6002 & TST \\
\hline CHEMBL1982122 & 809179 & 4.9 & 5.1333 & TRN \\
\hline CHEMBL 2000801 & 809179 & 4.9 & 4.2959 & TRN \\
\hline CHEMBL1682546 & 809179 & 4.9 & 5.4757 & TRN \\
\hline CHEMBL1991395 & 809179 & 4.9 & 5.1751 & TRN \\
\hline CHEMBL1971245 & 809179 & 4.9 & 5.4869 & TRN \\
\hline CHEMBL1972142 & 809179 & 4.9 & 4.4588 & TRN \\
\hline CHEMBL1966514 & 809179 & 4.9 & 4.8667 & TRN \\
\hline CHEMBL 2003638 & 809179 & 9.2 & 8.7054 & TRN \\
\hline CHEMBL296586 & 809179 & 7.0 & 6.4205 & TST \\
\hline CHEMBL1996066 & 809179 & 4.9 & 6.2468 & TST \\
\hline CHEMBL1993722 & 809179 & 6.6 & 5.8361 & TRN \\
\hline CHEMBL1375640 & 809179 & 5.9 & 5.9249 & TST \\
\hline CHEMBL1979970 & 809179 & 4.9 & 5.0806 & TRN \\
\hline CHEMBL249282 & 809179 & 4.9 & 4.4286 & TST \\
\hline CHEMBL1970821 & 809179 & 9.1 & 8.9094 & TRN \\
\hline CHEMBL 2006237 & 809179 & 4.9 & 4.8664 & TRN \\
\hline CHEMBL1967720 & 809179 & 4.9 & 4.8366 & TST \\
\hline CHEMBL 2005509 & 809179 & 9.8 & 9.5107 & TST \\
\hline CHEMBL1572266 & 809179 & 4.9 & 5.2935 & TST \\
\hline CHEMBL1991138 & 809179 & 4.9 & 4.8799 & TST \\
\hline CHEMBL1979516 & 809179 & 4.9 & 4.5215 & TST \\
\hline CHEMBL1605605 & 809179 & 4.9 & 4.0841 & TST \\
\hline CHEMBL1989029 & 809179 & 4.9 & 6.1026 & TST \\
\hline CHEMBL392642 & 809179 & 4.9 & 4.3875 & TST \\
\hline CHEMBL514499 & 809179 & 4.9 & 5.2918 & TST \\
\hline CHEMBL1965631 & 809179 & 6.6 & 8.0259 & TST \\
\hline CHEMBL1980144 & 809179 & 4.9 & 4.8971 & TST \\
\hline CHEMBL1682554 & 809179 & 8.0 & 7.107 & TST \\
\hline CHEMBL1991188 & 809179 & 4.9 & 5.4272 & TST \\
\hline CHEMBL1972849 & 809179 & 4.9 & 3.9733 & TST \\
\hline CHEMBL 377408 & 809179 & 4.9 & 4.5381 & TST \\
\hline CHEMBL1986855 & 809179 & 9.0 & 8.6202 & TST \\
\hline CHEMBL231209 & 809179 & 4.9 & 4.6252 & TST \\
\hline CHEMBL1976220 & 809179 & 4.9 & 4.6823 & TST \\
\hline CHEMBL1989136 & 809179 & 8.1 & 6.6139 & TST \\
\hline CHEMBL 259922 & 809179 & 4.9 & 4.8698 & TST \\
\hline CHEMBL1997617 & 809179 & 4.9 & 6.041 & TST \\
\hline CHEMBL1982383 & 809179 & 4.9 & 4.7802 & TST \\
\hline CHEMBL1969301 & 809179 & 4.9 & 4.7818 & TST \\
\hline CHEMBL17370 & 809179 & 4.9 & 5.48 & TST \\
\hline CHEMBL1987910 & 809179 & 4.9 & 4.835 & TST \\
\hline CHEMBL1983932 & 809179 & 4.9 & 5.7444 & TST \\
\hline CHEMBL1997822 & 809179 & 4.9 & 4.8539 & TST \\
\hline
\end{tabular}




\begin{tabular}{|c|c|c|c|c|c|c|}
\hline \\
\hline CHEMBL1966578 & 809179 & 5.4 & 6.8104 & TST & & \\
\hline CHEMBL1991285 & 809179 & 4.9 & 3.8616 & TST & & \\
\hline CHEMBL1984038 & 809179 & 4.9 & 5.0571 & TST & & \\
\hline CHEMBL1974416 & 809179 & 4.9 & 5.4335 & TST & & \\
\hline CHEMBL1993661 & 809179 & 8.3 & 6.7347 & TST & & \\
\hline CHEMBL1705535 & 737417 & 3.0969 & 3.1809 & TRN & & \\
\hline CHEMBL2000686 & 737417 & 3.0969 & 3.3029 & TRN & & \\
\hline CHEMBL3145282 & 737417 & 3.0969 & 3.0343 & TRN & & \\
\hline CHEMBL263972 & 737417 & 4.7471 & 4.4755 & TST & & \\
\hline CHEMBL1516663 & 737417 & 3.0969 & 3.2987 & TRN & & \\
\hline CHEMBL169811 & 737417 & 3.0969 & 3.3153 & TRN & & \\
\hline CHEMBL1557023 & 737417 & 3.0969 & 3.1161 & TRN & & \\
\hline CHEMBL1559226 & 737417 & 4.5272 & 4.4089 & TRN & & \\
\hline CHEMBL51085 & 737417 & 4.3778 & 4.4255 & TST & & \\
\hline CHEMBL1582527 & 737417 & 4.4045 & 4.2352 & TRN & & \\
\hline CHEMBL1464186 & 737417 & 4.4949 & 4.4395 & TRN & & \\
\hline CHEMBL1308783 & 737417 & 4.5114 & 4.4395 & TRN & & \\
\hline CHEMBL1545605 & 737417 & 4.6635 & 4.4128 & TRN & & \\
\hline CHEMBL1318817 & 737417 & 4.3778 & 4.4123 & TRN & & \\
\hline CHEMBL1790033 & 737417 & 5.284 & 4.9988 & TRN & & \\
\hline CHEMBL1968355 & 737417 & 4.399 & 4.3283 & TRN & & \\
\hline CHEMBL1417967 & 737417 & 4.38399 & 99999999 & 995 & 4.5198 & TRN \\
\hline CHEMBL3195322 & 737417 & 3.0969 & 3.1606 & TRN & & \\
\hline CHEMBL1578997 & 737417 & 4.9747 & 4.8342 & TRN & & \\
\hline CHEMBL1322745 & 737417 & 3.0969 & 3.0941 & TRN & & \\
\hline CHEMBL1728993 & 737417 & 4.2741 & 4.4604 & TRN & & \\
\hline CHEMBL1419292 & 737417 & 4.6216 & 4.6148 & TRN & & \\
\hline CHEMBL1717079 & 737417 & 3.0969 & 3.0262 & TRN & & \\
\hline CHEMBL75913 & 737417 & 4.2573 & 4.4457 & TRN & & \\
\hline CHEMBL600862 & 737417 & 3.0969 & 2.9958 & TRN & & \\
\hline CHEMBL3192625 & 737417 & 3.0969 & 3.0272 & TRN & & \\
\hline CHEMBL1550584 & 737417 & 3.0969 & 2.7884 & TRN & & \\
\hline CHEMBL1470212 & 737417 & 3.0969 & 3.4209 & TRN & & \\
\hline CHEMBL2000342 & 737417 & 4.1844 & 4.1805 & TRN & & \\
\hline CHEMBL1705697 & 737417 & 4.4672 & 4.4698 & TST & & \\
\hline CHEMBL2369189 & 737417 & 3.0969 & 3.0705 & TRN & & \\
\hline CHEMBL3192841 & 737417 & 3.0969 & 3.0874 & TRN & & \\
\hline CHEMBL1461181 & 737417 & 4.2741 & 4.3942 & TRN & & \\
\hline CHEMBL1312377 & 737417 & 5.1844 & 5.0453 & TRN & & \\
\hline CHEMBL1721577 & 737417 & 3.0969 & 3.1019 & TRN & & \\
\hline CHEMBL1330332 & 737417 & 4.3072 & 4.779 & TST & & \\
\hline CHEMBL1341159 & 737417 & 3.0969 & 3.6205 & TRN & & \\
\hline CHEMBL1701797 & 737417 & 3.0969 & 3.2129 & TRN & & \\
\hline CHEMBL1523347 & 737417 & 4.6073 & 4.8201 & TRN & & \\
\hline CHEMBL1708343 & 737417 & 3.0969 & 3.1356 & TRN & & \\
\hline CHEMBL1725990 & 737417 & 3.0969 & 3.0642 & TRN & & \\
\hline CHEMBL1546933 & 737417 & 4.4921 & 4.3726 & TRN & & \\
\hline CHEMBL1589350 & 737417 & 4.7496 & 4.7593 & TRN & & \\
\hline
\end{tabular}


Supplemental Table S2.txt

\begin{tabular}{|c|c|c|c|c|}
\hline & & & & s \\
\hline HEMBL1426637 & 37417 & 4.2403 & 3.9711 & \\
\hline AEMBL1604990 & 7417 & 3242 & 51 & \\
\hline 303 & & & & \\
\hline EMBL150 & 37417 & & & \\
\hline IEMBL1708020 & 37417 & 0969 & 8659 & \\
\hline HEMBL3195968 & 37417 & .3737 & .0691 & \\
\hline HEMBL1702026 & 37417 & & & \\
\hline EMBL14 & 37417 & 15 & & \\
\hline EMBL1325587 & 17 & & & \\
\hline HEMBL1344977 & 37417 & 6198 & 35 & \\
\hline AEMBL1704311 & 17 & 81 & & \\
\hline HEMBL1345979 & 37 & 7144 & 57 & \\
\hline 392 & 17 & 77 & & \\
\hline IEMBL147 & 17 & 02 & & \\
\hline AEMBL1329129 & 37417 & 9969 & & \\
\hline AEMBL1733942 & 7 & & & \\
\hline HEMBL12S & 7 & 88 & 52 & RIN \\
\hline EM & 7 & & & $\mathrm{RN}$ \\
\hline EM & 7 & & & \\
\hline AEMBL1451037 & 17 & & & \\
\hline IEMBL1528481 & & & & TRN \\
\hline AEMBL17 & 37 & & & RIN \\
\hline EM & 7 & & & RN \\
\hline 94 & 7 & & & \\
\hline 1527942 & .7 & & & 1 \\
\hline EMBL1501771 & & & & TRN \\
\hline IEMBL17080 & 7 & & & ST \\
\hline EM & 7 & & & ST \\
\hline 38 & 7 & & & RN \\
\hline & & & & RN \\
\hline EMBL1444349 & 7 & & & TST \\
\hline-20 & 7 & & & ST \\
\hline 2 & 7 & & & RN \\
\hline 78 & & & & RN \\
\hline IEMBL1976317 & & & & $\mathrm{RN}$ \\
\hline EMBL1339349 & 7 & & & RN \\
\hline & 7 & & 12 & RN \\
\hline 0 & 7 & & 22 & ST \\
\hline & & & 4.5 & RN \\
\hline IEMBL3196606 & 7 & & 43 & RN \\
\hline מחסקים & 37 & & & RN \\
\hline & 7 & & & ST \\
\hline HEMBL1553908 & .7 & & & ST \\
\hline HEMBL1438779 & .7 & & 4.57 & ST \\
\hline EMBL1430796 & 7 & & 4.4483 & TST \\
\hline-2 & & & & TST \\
\hline & לרי & & 4.0294 & \\
\hline
\end{tabular}

Page 3754 
Supplemental Table S2.txt

\begin{tabular}{|c|c|c|c|c|}
\hline 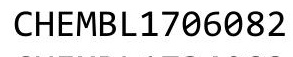 & $+1 /$ & & & \\
\hline HEMBL1734083 & 37417 & 5.9747 & $\partial 942$ & \\
\hline AEMBL1498652 & 37417 & 4306 & 5334 & \\
\hline L1709153 & 37417 & 969 & 498 & \\
\hline AEMBL1470492 & 3417 & & & \\
\hline AEMBL1382826 & 37417 & & 3703 & \\
\hline AEMBL1432648 & 37417 & 4.3372 & 7843 & \\
\hline HEMBL1414923 & 37417 & 69 & 0338 & \\
\hline AEMBL1576392 & 17 & & & \\
\hline IEMBL1371983 & & & & \\
\hline AEMBL2382342 & 58305 & 069 & 411 & \\
\hline AEMBL2382369 & 58305 & & 555 & \\
\hline AEMBL 2382374 & 58305 & & & \\
\hline IEMBL2382365 & $\partial 5$ & & & \\
\hline AEMBL2382377 & & & & \\
\hline AEMBL 2382285 & & & & \\
\hline IEMBL 238 & & & & \\
\hline IEMBL 2158050 & 35 & 59 & 27 & \\
\hline 2382 & & & & \\
\hline 56 & & & & \\
\hline AEMBL2382353 & & & & \\
\hline AEN & & & & \\
\hline IEMBL 2382347 & 35 & & & \\
\hline 238033 & & & & \\
\hline 3 & & & & \\
\hline 2382363 & & & & \\
\hline L238 & & & & \\
\hline L2382383 & & & & \\
\hline 238033 & & & & \\
\hline 382 & & & & \\
\hline & & & & \\
\hline L2382 & & & & \\
\hline L2382376 & & & & \\
\hline 2382362 & & & & \\
\hline 36 & & & & \\
\hline AEMBL2382385 & & & & \\
\hline AEMBL2382351 & & & & \\
\hline EMBL2382378 & & & & \\
\hline IEMBL2382352 & & & & \\
\hline 2382 & & & & ST \\
\hline AEMBL2382350 & & & 9024 & $\mathrm{RI}$ \\
\hline HEMBL2382364 & 25 & & & \\
\hline :MABL $23823 / 3$ & & & & \\
\hline HEMBL2382366 & & & 332 & \\
\hline CHEMBL2159976 & & & 3681 & ST \\
\hline AEMBL2382354 & 58305 & 5.8069 & .6825 & TRN \\
\hline HEMBL2382370 & & 69 & . 5994 & $\mathrm{TR}$ \\
\hline HEMPI 23023 & 58305 & .7212 & .6163 & \\
\hline
\end{tabular}




\begin{tabular}{|c|c|c|c|c|c|}
\hline \multicolumn{6}{|c|}{ Supplemental Table S2.txt } \\
\hline CHEMBL 2382360 & 958305 & 5.2041 & 5.1675 & TRN & \\
\hline CHEMBL 2382284 & 958305 & 3.6021 & 4.6455 & TST & \\
\hline CHEMBL 2382371 & 958305 & 5.2041 & 5.0983 & TRN & \\
\hline CHEMBL 2382380 & 958305 & 5.8069 & 5.9441 & TRN & \\
\hline CHEMBL 2382382 & 958305 & 5.2041 & 5.1822 & TRN & \\
\hline CHEMBL 2382384 & 958305 & 5.5045 & 5.4423 & TRN & \\
\hline CHEMBL 2382341 & 958305 & 4.9031 & 5.2848 & TRN & \\
\hline CHEMBL 2382372 & 958305 & 5.8069 & 5.8156 & TRN & \\
\hline CHEMBL 2382283 & 958305 & 4.7212 & 4.8403 & TST & \\
\hline CHEMBL 2382368 & 958305 & 5.3279 & 5.2469 & TRN & \\
\hline CHEMBL 2380332 & 958305 & 4.7212 & 5.2256 & TST & \\
\hline CHEMBL 2382349 & 958305 & 5.3279 & 5.2747 & TRN & \\
\hline CHEMBL 2382357 & 958305 & 5.2041 & 5.169 & TRN & \\
\hline CHEMBL 2382346 & 958305 & 5.0269 & 4.959 & TRN & \\
\hline CHEMBL 2382344 & 958305 & 3.301 & 5.2106 & TST & \\
\hline CHEMBL 2382355 & 958305 & 5.6198 & 5.4758 & TST & \\
\hline CHEMBL 2382345 & 958305 & 5.5229 & 5.3893 & TST & \\
\hline CHEMBL 2382287 & 958305 & 5.9245 & 5.4612 & TST & \\
\hline CHEMBL 2382361 & 958305 & 5.5045 & 5.8222 & TST & \\
\hline CHEMBL 2382379 & 958305 & 5.6383 & 5.0983 & TST & \\
\hline CHEMBL3910963 & 1640508 & 5.8861 & 5.6395 & TST & \\
\hline CHEMBL 3917928 & 1640508 & 6.3188 & 5.91799 & 9999999999 & TRN \\
\hline CHEMBL 3985183 & 1640508 & 4.8239 & 5.523 & TST & \\
\hline CHEMBL 3910500 & 1640508 & 6.8239 & 6.7815 & TRN & \\
\hline CHEMBL 3951934 & 1640508 & 5.3979 & 5.4886 & TRN & \\
\hline CHEMBL3899599 & 1640508 & 5.9586 & 5.4667 & TRN & \\
\hline CHEMBL 3897764 & 1640508 & 6.5229 & 5.6578 & TST & \\
\hline CHEMBL3962277 & 1640508 & 3.699 & 5.4334 & TST & \\
\hline CHEMBL 3898260 & 1640508 & 5.9031 & 5.8057 & TRN & \\
\hline CHEMBL3908137 & 1640508 & 5.6198 & 5.6818 & TRN & \\
\hline CHEMBL 3907283 & 1640508 & 6.2041 & 5.6481 & TRN & \\
\hline CHEMBL 3949871 & 1640508 & 6.8069 & 6.8666 & TRN & \\
\hline CHEMBL3977115 & 1640508 & 5.8239 & 5.6817 & TRN & \\
\hline CHEMBL 3938906 & 1640508 & 5.8861 & 6.4894 & TRN & \\
\hline CHEMBL3939974 & 1640508 & 6.9031 & 6.6451 & TRN & \\
\hline CHEMBL 3979391 & 1640508 & 6.2041 & 6.2218 & TRN & \\
\hline CHEMBL 3960678 & 1640508 & 6.2218 & 6.0263 & TRN & \\
\hline CHEMBL3952659 & 1640508 & 5.699 & 5.8118 & TRN & \\
\hline CHEMBL 3985930 & 1640508 & 5.0 & 5.7875 & TRN & \\
\hline CHEMBL 3894189 & 1640508 & 5.6021 & 5.3671 & TRN & \\
\hline CHEMBL3936099 & 1640508 & 6.1871 & 5.8389 & TST & \\
\hline CHEMBL 3925531 & 1640508 & 5.5528 & 6.1523 & TRN & \\
\hline CHEMBL3891749 & 1640508 & 6.9031 & 6.169 & TST & \\
\hline CHEMBL 3922215 & 1640508 & 5.4685 & 5.0592 & TRN & \\
\hline CHEMBL3916555 & 1640508 & 6.5528 & 6.1101 & TRN & \\
\hline CHEMBL 3894036 & 1640508 & 5.4559 & 5.6903 & TRN & \\
\hline CHEMBL 3916253 & 1640508 & 5.8861 & 6.8291 & TRN & \\
\hline CHEMBL3919819 & 1640508 & 5.301 & 5.7364 & TST & \\
\hline
\end{tabular}


Supplemental Table S2.txt

\begin{tabular}{|c|c|c|c|c|c|}
\hline CHEMBL 3961256 & 1640508 & 5.699 & 5.724 & TST & \\
\hline CHEMBL3925567 & 1640508 & 6.7258 & 6.1522 & TRN & \\
\hline CHEMBL3955241 & 1640508 & 3.699 & 4.3335 & TRN & \\
\hline CHEMBL3949654 & 1640508 & 6.0 & 5.8714 & TRN & \\
\hline CHEMBL3978802 & 1640508 & 6.8239 & 6.7823 & TRN & \\
\hline CHEMBL3892179 & 1640508 & 5.6021 & 5.7495 & TRN & \\
\hline CHEMBL3953132 & 1640508 & 6.5229 & 6.4173 & TRN & \\
\hline CHEMBL3918743 & 1640508 & 3.699 & 4.1994 & TRN & \\
\hline CHEMBL 3952523 & 1640508 & 6.0 & 5.2984 & TRN & \\
\hline CHEMBL3944376 & 1640508 & 5.2291 & 5.4627 & TRN & \\
\hline CHEMBL 3986045 & 1640508 & 5.699 & 5.5805 & TST & \\
\hline CHEMBL3969450 & 1640508 & 6.699 & 6.6561 & TRN & \\
\hline CHEMBL3946581 & 1640508 & 5.301 & 4.8459 & TRN & \\
\hline CHEMBL3931258 & 1640508 & 3.9031 & 5.4164 & TST & \\
\hline CHEMBL3898706 & 1640508 & 6.3468 & 7.3222 & TRN & \\
\hline CHEMBL3978032 & 1640508 & 6.6021 & 6.1061 & TRN & \\
\hline CHEMBL3909809 & 1640508 & 3.699 & 4.4138 & TRN & \\
\hline CHEMBL3893437 & 1640508 & 6.2041 & 5.6697 & TST & \\
\hline CHEMBL3951958 & 1640508 & 6.0 & 5.7085 & TRN & \\
\hline CHEMBL3922118 & 1640508 & 7.1024 & 6.9068 & TRN & \\
\hline CHEMBL3982640 & 1640508 & 7.0969 & 6.2007 & TRN & \\
\hline CHEMBL3932741 & 1640508 & 5.1079 & 5.776 & TST & \\
\hline CHEMBL3908996 & 1640508 & 6.3468 & 5.8739 & TST & \\
\hline CHEMBL3934855 & 1640508 & 7.0458 & 6.5637 & TRN & \\
\hline CHEMBL3925383 & 1640508 & 6.8239 & 6.8692 & TRN & \\
\hline CHEMBL3936174 & 1640508 & 5.0 & 5.1362 & TRN & \\
\hline CHEMBL3929640 & 1640508 & 5.3979 & 5.2589 & TST & \\
\hline CHEMBL3957893 & 1640508 & 5.1192 & 6.0894 & TST & \\
\hline CHEMBL3981936 & 1640508 & 5.301 & 6.084 & TRN & \\
\hline CHEMBL500329 & 558174 & 6.9788 & 6.7895 & TRN & \\
\hline CHEMBL451076 & 558174 & 5.4976 & 5.5572 & TRN & \\
\hline CHEMBL487223 & 558174 & 6.1864 & 6.4851 & TRN & \\
\hline CHEMBL529660 & 558174 & 5.8386 & 5.9413 & TRN & \\
\hline CHEMBL443922 & 558174 & 6.8416 & 6.9892 & TST & \\
\hline CHEMBL488261 & 558174 & 7.0482 & 7.3836 & TRN & \\
\hline CHEMBL488434 & 558174 & 6.3054 & 6.4853 & TRN & \\
\hline CHEMBL472388 & 558174 & 7.4597 & 7.6381 & TRN & \\
\hline CHEMBL448461 & 558174 & 5.6968 & 5.8621 & TRN & \\
\hline CHEMBL449542 & 558174 & 7.32700 & 300000006 & 7.4498 & TRN \\
\hline CHEMBL462387 & 558174 & 8.1811 & 8.0556 & TRN & \\
\hline CHEMBL488241 & 558174 & 7.1778 & 7.2464 & TRN & \\
\hline CHEMBL507884 & 558174 & 5.7447 & 5.8318 & TRN & \\
\hline CHEMBL488437 & 558174 & 6.5214 & 6.4401 & TRN & \\
\hline CHEMBL455426 & 558174 & 5.8097 & 6.17299 & 9999999999 & TST \\
\hline CHEMBL454656 & 558174 & 6.4225 & 6.391 & TRN & \\
\hline CHEMBL454288 & 558174 & 7.1296 & 8.4364 & TST & \\
\hline CHEMBL510435 & 558174 & 6.5017 & 6.3922 & TRN & \\
\hline CHEMBL527094 & 558174 & 7.0555 & 7.1464 & TRN & \\
\hline
\end{tabular}




\begin{tabular}{|c|c|c|c|c|c|}
\hline \\
\hline CHEMBL507075 & 558174 & 6.4895 & 6.4548 & TRN & \\
\hline CHEMBL488242 & 558174 & 5.9788 & 5.9569 & TRN & \\
\hline CHEMBL488021 & 558174 & 7.2807 & 7.2729 & TRN & \\
\hline CHEMBL453631 & 558174 & 6.7645 & 6.6614 & TRN & \\
\hline CHEMBL487188 & 558174 & 6.6038 & 6.7026 & TRN & \\
\hline CHEMBL451330 & 558174 & 8.0405 & 8.0 & TRN & \\
\hline CHEMBL454657 & 558174 & 7.1273 & 7.1112 & TRN & \\
\hline CHEMBL453879 & 558174 & 7.2154 & 7.3822 & TRN & \\
\hline CHEMBL453630 & 558174 & 6.5361 & 6.4997 & TRN & \\
\hline CHEMBL449048 & 558174 & 7.3134 & 7.2905 & TRN & \\
\hline CHEMBL455423 & 558174 & 7.4342 & 7.68 & TST & \\
\hline CHEMBL472389 & 558174 & 6.1739 & 6.1094 & TRN & \\
\hline CHEMBL455511 & 558174 & 6.4248 & $7.40600 t$ & 0000000001 & TST \\
\hline CHEMBL442923 & 558174 & 6.2403 & 6.1265 & TRN & \\
\hline CHEMBL488069 & 558174 & 7.38200 & 0000000 & 7.2839 & TRN \\
\hline CHEMBL453880 & 558174 & 7.3107 & 7.2633 & TRN & \\
\hline CHEMBL455424 & 558174 & 5.2541 & 5.2959 & TRN & \\
\hline CHEMBL487053 & 558174 & 7.0565 & 6.5757 & TST & \\
\hline CHEMBL475121 & 558174 & 8.46600 & 0000000 & 8.4022 & TRN \\
\hline CHEMBL487221 & 558174 & 6.4214 & 6.4145 & TRN & \\
\hline CHEMBL508192 & 558174 & 7.2588 & 7.7368 & TST & \\
\hline CHEMBL488911 & 558174 & 6.1403 & 6.9931 & TST & \\
\hline CHEMBL487222 & 558174 & 6.7471 & 6.3028 & TST & \\
\hline CHEMBL513629 & 558174 & 8.1662 & 8.5315 & TST & \\
\hline CHEMBL455184 & 558174 & 7.4828 & 7.4603 & TRN & \\
\hline CHEMBL488435 & 558174 & 6.104 & 6.2627 & TRN & \\
\hline CHEMBL488912 & 558174 & 6.1421 & 6.0552 & TRN & \\
\hline CHEMBL462226 & 558174 & 7.0448 & 6.9559 & TRN & \\
\hline CHEMBL447733 & 558174 & 6.0 & 6.975 & TST & \\
\hline CHEMBL488260 & 558174 & 6.4413 & 6.3908 & TRN & \\
\hline CHEMBL451178 & 558174 & 5.6498 & 7.2644 & TST & \\
\hline CHEMBL455425 & 558174 & 7.1002 & 7.15799 & 99999999995 & TRN \\
\hline CHEMBL452091 & 558174 & 8.0438 & 7.9724 & TRN & \\
\hline CHEMBL461631 & 558174 & 8.451 & 9.0895 & TST & \\
\hline CHEMBL455675 & 558174 & 6.6383 & 6.6094 & TRN & \\
\hline CHEMBL505091 & 558174 & 6.3675 & 6.3253 & TRN & \\
\hline CHEMBL444203 & 558174 & 6.6861 & 6.5266 & TST & \\
\hline CHEMBL447864 & 558174 & 8.9281 & 8.9853 & TRN & \\
\hline CHEMBL 257423 & 558174 & 5.7033 & 6.9272 & TST & \\
\hline CHEMBL451137 & 558174 & 7.1752 & 7.0585 & TRN & \\
\hline CHEMBL507721 & 558174 & 6.5622 & 6.4914 & TRN & \\
\hline CHEMBL445754 & 558174 & 7.2358 & 7.0241 & TRN & \\
\hline CHEMBL488060 & 558174 & 6.6861 & 6.3679 & TRN & \\
\hline CHEMBL450714 & 558174 & 6.3391 & 7.6091 & TST & \\
\hline CHEMBL462225 & 558174 & 7.2924 & 7.3456 & TRN & \\
\hline CHEMBL 2180200 & 878241 & 4.6599 & 4.7033 & TRN & \\
\hline CHEMBL 2179795 & 878241 & 6.7212 & 7.261 & TRN & \\
\hline CHEMBL2179824 & 878241 & 4.6692 & 4.7707 & TRN & \\
\hline
\end{tabular}




\begin{tabular}{|c|c|c|c|c|c|c|}
\hline & & \multicolumn{5}{|c|}{ Supplemental Table S2.txt } \\
\hline CHEMBL 2179829 & 878241 & 4.6396 & 5.2623 & TRN & & \\
\hline CHEMBL 2179814 & 878241 & 3.0 & 6.3185 & TST & & \\
\hline CHEMBL2179822 & 878241 & 5.1209 & 4.5756 & TRN & & \\
\hline CHEMBL 2179784 & 878241 & 5.0555 & 5.1072 & TRN & & \\
\hline CHEMBL 2179794 & 878241 & 6.8861 & 6.7515 & TRN & & \\
\hline CHEMBL2180202 & 878241 & 5.6029 & 5.5853 & TRN & & \\
\hline CHEMBL 2179813 & 878241 & 4.9634 & 5.0455 & TST & & \\
\hline CHEMBL 2179812 & 878241 & \multicolumn{3}{|c|}{5.757000000000001} & 5.3611 & TRN \\
\hline CHEMBL 2179811 & 878241 & 5.1891 & 5.9349 & TRN & & \\
\hline CHEMBL2179805 & 878241 & 8.699 & 8.0431 & TRN & & \\
\hline CHEMBL2179803 & 878241 & 6.1427 & 6.5808 & TRN & & \\
\hline CHEMBL 2179808 & 878241 & 5.3893 & 4.7494 & TRN & & \\
\hline CHEMBL2179797 & 878241 & 6.699 & 7.5562 & TRN & & \\
\hline CHEMBL 2179801 & 878241 & 6.284 & 6.1277 & TRN & & \\
\hline CHEMBL2179782 & 878241 & 3.0 & 3.9872 & TRN & & \\
\hline CHEMBL 2179783 & 878241 & 3.0 & 2.9791 & TRN & & \\
\hline CHEMBL 2179798 & 878241 & 6.1427 & 6.2811 & TRN & & \\
\hline CHEMBL 2179786 & 878241 & 5.7747 & 5.5146 & TRN & & \\
\hline CHEMBL2179809 & 878241 & 5.8182 & 5.7656 & TRN & & \\
\hline CHEMBL 2179828 & 878241 & 5.9809 & 4.8331 & TRN & & \\
\hline CHEMBL 2180199 & 878241 & 4.6895 & 5.7348 & TST & & \\
\hline CHEMBL 2179802 & 878241 & 5.9914 & 6.2577 & TRN & & \\
\hline CHEMBL 2179821 & 878241 & 4.1871 & 4.3262 & TRN & & \\
\hline CHEMBL 2179831 & 878241 & 4.9971 & 5.2583 & TRN & & \\
\hline CHEMBL 2179793 & 878241 & 3.0 & 2.7896 & TRN & & \\
\hline CHEMBL 2179825 & 878241 & 5.1775 & 5.2346 & TRN & & \\
\hline CHEMBL 2179781 & 878241 & 8.0 & 5.1349 & TRN & & \\
\hline CHEMBL 2179807 & 878241 & 6.699 & 6.0509 & TRN & & \\
\hline CHEMBL2179796 & 878241 & 6.7447 & 6.9093 & TRN & & \\
\hline CHEMBL 2179780 & 878241 & 7.0 & 6.2266 & TRN & & \\
\hline CHEMBL 2179819 & 878241 & 3.0 & 3.5838 & TRN & & \\
\hline CHEMBL2179799 & 878241 & 5.8508 & 6.5386 & TRN & & \\
\hline CHEMBL 2179820 & 878241 & 3.0 & 3.7731 & TRN & & \\
\hline CHEMBL 2179800 & 878241 & 6.6778 & 6.6995 & TRN & & \\
\hline CHEMBL 2179818 & 878241 & 3.0 & 4.0112 & TRN & & \\
\hline CHEMBL2179792 & 878241 & 3.0 & 2.7457 & TRN & & \\
\hline CHEMBL 2179806 & 878241 & 8.0 & 5.9532 & TRN & & \\
\hline CHEMBL 2179827 & 878241 & 5.0788 & 5.1527 & TST & & \\
\hline CHEMBL 2179787 & 878241 & 3.0 & 2.3826 & TRN & & \\
\hline CHEMBL 2177131 & 878241 & 3.0 & 2.8684 & TRN & & \\
\hline CHEMBL 2180203 & 878241 & 4.2802 & 5.0923 & TRN & & \\
\hline CHEMBL2179830 & 878241 & 4.9862 & 5.6862 & TRN & & \\
\hline CHEMBL 2179823 & 878241 & 3.0 & 4.7755 & TRN & & \\
\hline CHEMBL 2179810 & 878241 & 5.6091 & 5.4034 & TRN & & \\
\hline CHEMBL 2179817 & 878241 & 3.0 & 5.073 & TST & & \\
\hline CHEMBL 2180201 & 878241 & 5.3541 & 5.0076 & TST & & \\
\hline CHEMBL2179826 & 878241 & 4.6712 & 5.2393 & TST & & \\
\hline CHEMBL2180198 & 878241 & 5.1274 & 5.3691 & TST & & \\
\hline
\end{tabular}




\begin{tabular}{|c|c|c|c|c|c|c|}
\hline & & \multicolumn{5}{|c|}{ Supplemental Table S2.txt } \\
\hline CHEMBL 2180204 & 878241 & 4.7509 & 5.2642 & TST & & \\
\hline CHEMBL 2179790 & 878241 & 7.1367 & 7.5239 & TST & & \\
\hline CHEMBL2179791 & 878241 & 3.0 & 4.4447 & TST & & \\
\hline CHEMBL 2179789 & 878241 & 3.0 & 2.8297 & TST & & \\
\hline CHEMBL 2179815 & 878241 & 4.4411 & 5.6726 & TST & & \\
\hline CHEMBL 2179785 & 878241 & 3.0 & 1.9603 & TST & & \\
\hline CHEMBL 2180197 & 878241 & 5.0076 & 5.6324 & TST & & \\
\hline CHEMBL1271970 & 674829 & 6.857 & 6.5518 & TRN & & \\
\hline CHEMBL1271739 & 674829 & 4.0 & 3.8846 & TRN & & \\
\hline CHEMBL1271474 & 674829 & 5.2596 & 5.2321 & TRN & & \\
\hline CHEMBL1271738 & 674829 & 4.0 & 4.1303 & TRN & & \\
\hline CHEMBL1272184 & 674829 & 7.2076 & 6.9708 & TRN & & \\
\hline CHEMBL1271737 & 674829 & 7.0 & 6.8085 & TRN & & \\
\hline CHEMBL1271525 & 674829 & 7.0458 & 7.0037 & TRN & & \\
\hline CHEMBL1272023 & 674829 & 8.0969 & 8.0117 & TRN & & \\
\hline CHEMBL1272129 & 674829 & 7.585 & 7.7537 & TRN & & \\
\hline CHEMBL1271526 & 674829 & 5.7447 & 5.7276 & TRN & & \\
\hline CHEMBL1272079 & 674829 & 4.0 & 4.1784 & TRN & & \\
\hline CHEMBL1271912 & 674829 & 7.1367 & 6.9324 & TRN & & \\
\hline CHEMBL1271581 & 674829 & 4.0 & 4.1495 & TRN & & \\
\hline CHEMBL1271799 & 674829 & 4.0 & 3.0871 & TST & & \\
\hline CHEMBL1269065 & 674829 & 4.0 & 4.1432 & TST & & \\
\hline CHEMBL1272130 & 674829 & 7.1308 & 7.2628 & TRN & & \\
\hline CHEMBL1271740 & 674829 & 6.2248 & 6.1826 & TRN & & \\
\hline CHEMBL1272081 & 674829 & 4.0 & 4.1053 & TRN & & \\
\hline CHEMBL1272080 & 674829 & 4.0 & 3.9873 & TRN & & \\
\hline CHEMBL1271798 & 674829 & 4.0 & 4.2252 & TRN & & \\
\hline CHEMBL1269064 & 674829 & 4.0 & 3.8711 & TRN & & \\
\hline CHEMBL1271801 & 674829 & 6.9706 & 7.2029 & TRN & & \\
\hline CHEMBL1271579 & 674829 & 4.0 & 3.9475 & TRN & & \\
\hline CHEMBL1271967 & 674829 & 7.5086 & 7.3962 & TRN & & \\
\hline CHEMBL1271685 & 674829 & 4.0 & 3.6388 & TRN & & \\
\hline CHEMBL1271968 & 674829 & 7.5528 & 7.7551 & TRN & & \\
\hline CHEMBL1272183 & 674829 & 7.0969 & 7.0635 & TRN & & \\
\hline CHEMBL1271741 & 674829 & 4.0 & 3.8674 & TRN & & \\
\hline CHEMBL1271911 & 674829 & 4.0 & 3.6215 & TST & & \\
\hline CHEMBL1271857 & 674829 & 4.0 & 4.1599 & TRN & & \\
\hline CHEMBL1269808 & 674829 & 4.0 & 4.1969 & TRN & & \\
\hline CHEMBL1271914 & 674829 & 6.5114 & 6.8677 & TRN & & \\
\hline CHEMBL1272026 & 674829 & 5.8539 & 5.9087 & TRN & & \\
\hline CHEMBL1271580 & 674829 & 6.75700 & 00000000 & $\partial 1$ & 6.8028 & TRN \\
\hline CHEMBL1271854 & 674829 & 4.0 & 3.7472 & TST & & \\
\hline CHEMBL1272239 & 674829 & 6.71899 & 999999995 & 99 & 6.8214 & TRN \\
\hline CHEMBL1272293 & 674829 & 4.0 & 4.1437 & TRN & & \\
\hline CHEMBL1269807 & 674829 & 6.2007 & 6.1749 & TRN & & \\
\hline CHEMBL1271856 & 674829 & 4.0 & 3.9149 & TST & & \\
\hline CHEMBL1271797 & 674829 & 5.6778 & 5.6663 & TRN & & \\
\hline CHEMBL1269043 & 674829 & 5.8539 & 5.7199 & TRN & & \\
\hline
\end{tabular}


Supplemental Table S2.txt

\begin{tabular}{|c|c|c|c|c|c|}
\hline CHEMBL1272131 & 674829 & 5.6778 & 5.3108 & TRN & \\
\hline CHEMBL1271633 & 674829 & 4.0 & 3.413006 & 00000000003 & TST \\
\hline CHEMBL1271473 & 674829 & 4.0 & 4.0619 & TRN & \\
\hline CHEMBL1271855 & 674829 & 4.0 & 3.8201 & TST & \\
\hline CHEMBL1271800 & 674829 & 7.3665 & 7.5028 & TST & \\
\hline CHEMBL1271913 & 674829 & 7.1549 & 7.5421 & TST & \\
\hline CHEMBL1269063 & 674829 & 4.0 & 3.9936 & TRN & \\
\hline CHEMBL1271969 & 674829 & 7.2518 & 7.4653 & TST & \\
\hline CHEMBL1271684 & 674829 & 4.0 & 3.3223 & TST & \\
\hline CHEMBL1272292 & 674829 & 4.0 & 4.192 & TST & \\
\hline CHEMBL1272082 & 674829 & 7.3188 & 7.2314 & TST & \\
\hline CHEMBL1272027 & 674829 & 4.0 & 3.5795 & TST & \\
\hline CHEMBL3113740 & 1290419 & 6.8125 & 6.8144 & TRN & \\
\hline CHEMBL 3113550 & 1290419 & 7.1871 & 7.1976 & TRN & \\
\hline CHEMBL3113758 & 1290419 & 5.8962 & 5.896 & TRN & \\
\hline CHEMBL3113542 & 1290419 & 4.0 & 5.1537 & TST & \\
\hline CHEMBL3113749 & 1290419 & 7.7212 & 7.7241 & TRN & \\
\hline CHEMBL 3113541 & 1290419 & 5.6156 & 5.6169 & TRN & \\
\hline CHEMBL 3113773 & 1290419 & 6.1403 & 6.1323 & TRN & \\
\hline CHEMBL3113769 & 1290419 & 5.9393 & 6.3138 & TST & \\
\hline CHEMBL3113767 & 1290419 & 5.5769 & 5.5794 & TRN & \\
\hline CHEMBL3113739 & 1290419 & 6.1707 & 6.1704 & TRN & \\
\hline CHEMBL3113746 & 1290419 & 8.5229 & 8.5013 & TRN & \\
\hline CHEMBL3113551 & 1290419 & 5.71 & 5.7097 & TRN & \\
\hline CHEMBL3113762 & 1290419 & 5.7447 & 5.7427 & TRN & \\
\hline CHEMBL3113549 & 1290419 & 5.9642 & 5.9661 & TRN & \\
\hline CHEMBL3113772 & 1290419 & 6.8097 & 6.8125 & TRN & \\
\hline CHEMBL 3113544 & 1290419 & 6.8477 & \multicolumn{2}{|c|}{6.797000000000001} & TST \\
\hline CHEMBL 3113745 & 1290419 & 8.0458 & 8.045 & TRN & \\
\hline CHEMBL3113771 & 1290419 & 7.4949 & 7.4998 & TRN & \\
\hline CHEMBL3113759 & 1290419 & 7.3979 & 7.3964 & TRN & \\
\hline CHEMBL 3113751 & 1290419 & 7.3468 & 7.3569 & TRN & \\
\hline CHEMBL3113753 & 1290419 & 6.8508 & 6.8454 & TRN & \\
\hline CHEMBL3113539 & 1290419 & 6.2596 & 6.2636 & TRN & \\
\hline CHEMBL3113775 & 1290419 & 6.5784 & 6.5778 & TRN & \\
\hline CHEMBL3113760 & 1290419 & 6.27 & 6.273 & TRN & \\
\hline CHEMBL3113747 & 1290419 & 7.8539 & 7.8545 & TRN & \\
\hline CHEMBL 3113548 & 1290419 & 6.6478 & 6.6538 & TRN & \\
\hline CHEMBL3113770 & 1290419 & 8.3979 & 8.395 & TRN & \\
\hline CHEMBL3113750 & 1290419 & 7.8539 & 7.8488 & TRN & \\
\hline CHEMBL3113774 & 1290419 & 6.5467 & 6.5427 & TRN & \\
\hline CHEMBL3113536 & 1290419 & 5.3113 & 5.3155 & TRN & \\
\hline CHEMBL 3113540 & 1290419 & 6.4815 & 6.4838 & TRN & \\
\hline CHEMBL3113766 & 1290419 & 7.6576 & 7.6592 & TRN & \\
\hline CHEMBL3113534 & 1290419 & 5.4577 & 5.4481 & TRN & \\
\hline CHEMBL3113755 & 1290419 & 7.7696 & \multicolumn{2}{|c|}{7.787000000000001} & TRN \\
\hline CHEMBL3113754 & 1290419 & 7.2676 & 7.2522 & TRN & \\
\hline CHEMBL3113546 & 1290419 & 6.7721 & 6.7684 & TRN & \\
\hline
\end{tabular}


Supplemental Table S2.txt

\begin{tabular}{|c|c|c|c|c|}
\hline CHEMBL 3113543 & 1290419 & 5.013 & 5.0079 & TRN \\
\hline CHEMBL 3113752 & 1290419 & 8.301 & 8.3035 & TRN \\
\hline CHEMBL3113761 & 1290419 & 5.8517 & 5.8466 & TRN \\
\hline CHEMBL 3113538 & 1290419 & 6.6655 & 6.6744 & TRN \\
\hline CHEMBL3113535 & 1290419 & 5.358 & 5.3595 & TRN \\
\hline CHEMBL 3113743 & 1290419 & 7.4685 & 7.4697 & TRN \\
\hline CHEMBL 3112599 & 1290419 & 5.7986 & \multicolumn{2}{|c|}{5.672999999999999} \\
\hline CHEMBL 3113537 & 1290419 & 5.9034 & 5.903 & TRN \\
\hline CHEMBL 3113741 & 1290419 & 7.4949 & 7.3425 & TST \\
\hline CHEMBL3113757 & 1290419 & 5.5719 & 5.8461 & TST \\
\hline CHEMBL3113742 & 1290419 & 8.699 & 8.355 & TST \\
\hline CHEMBL 3113748 & 1290419 & 7.8539 & 7.9469 & TST \\
\hline CHEMBL 3113552 & 1290419 & 7.1135 & 6.9696 & TST \\
\hline CHEMBL 3113756 & 1290419 & 6.3851 & 6.2427 & TST \\
\hline CHEMBL3113547 & 1290419 & 6.2749 & 6.6374 & TST \\
\hline CHEMBL 3113545 & 1290419 & 6.8665 & \multicolumn{2}{|c|}{6.7139999999999995} \\
\hline CHEMBL 3113744 & 1290419 & 7.6021 & 7.7688 & TST \\
\hline CHEMBL 3113768 & 1290419 & 4.0 & 5.69 & TST \\
\hline CHEMBL3426778 & 1478163 & 3.6021 & 3.6793 & TRN \\
\hline CHEMBL190438 & 1478163 & 4.5317 & 5.3108 & TRN \\
\hline CHEMBL364456 & 1478163 & 6.301 & 6.5045 & TRN \\
\hline CHEMBL370286 & 1478163 & 5.9469 & 5.5519 & TRN \\
\hline CHEMBL 3426760 & 1478163 & 5.3279 & 6.2477 & TST \\
\hline CHEMBL 3426734 & 1478163 & 6.6198 & 6.5031 & TRN \\
\hline CHEMBL192013 & 1478163 & 6.585 & 6.3081 & TRN \\
\hline CHEMBL 3426743 & 1478163 & 5.2924 & 5.4565 & TRN \\
\hline CHEMBL193892 & 1478163 & 5.2076 & 4.9396 & TRN \\
\hline CHEMBL 3426746 & 1478163 & 5.5622 & 5.7683 & TRN \\
\hline CHEMBL 3426751 & 1478163 & 4.8447 & 4.9999 & TRN \\
\hline CHEMBL426086 & 1478163 & 5.8239 & 6.3825 & TRN \\
\hline CHEMBL 3426759 & 1478163 & 5.2676 & 6.3377 & TST \\
\hline CHEMBL 3426772 & 1478163 & 3.0 & 3.3092 & TRN \\
\hline CHEMBL192480 & 1478163 & 6.7696 & 6.5887 & TRN \\
\hline CHEMBL 3426771 & 1478163 & 4.4522 & 4.0961 & TRN \\
\hline CHEMBL 3426781 & 1478163 & 6.6576 & 5.8606 & TRN \\
\hline CHEMBL 3426741 & 1478163 & 6.5421 & 6.0961 & TRN \\
\hline CHEMBL 3426762 & 1478163 & 6.1549 & 6.1464 & TRN \\
\hline CHEMBL 3426750 & 1478163 & 4.6021 & 4.8892 & TRN \\
\hline CHEMBL3426785 & 1478163 & 6.5768 & 5.5226 & TST \\
\hline CHEMBL200102 & 1478163 & 7.585 & 5.5432 & TST \\
\hline CHEMBL 3426733 & 1478163 & 6.4089 & \multicolumn{2}{|c|}{6.742000000000001} \\
\hline CHEMBL 3426782 & 1478163 & 5.4634 & 5.563 & TRN \\
\hline CHEMBL 3426765 & 1478163 & 3.0 & 2.6387 & TRN \\
\hline CHEMBL 3426770 & 1478163 & 3.0 & 2.9292 & TRN \\
\hline CHEMBL 3426748 & 1478163 & 6.3675 & 5.6344 & TRN \\
\hline CHEMBL190439 & 1478163 & 6.4559 & 6.0926 & TRN \\
\hline CHEMBL 3426767 & 1478163 & 3.0 & 3.2529 & TRN \\
\hline CHEMBL 3426784 & 1478163 & 6.9957 & 4.9795 & TST \\
\hline
\end{tabular}

Page 3762 
Supplemental Table S2.txt

\begin{tabular}{|c|c|c|c|c|c|c|}
\hline CHEMBL364239 & 1478163 & 5.9431 & 5.5913 & TRN & & \\
\hline CHEMBL3426740 & 1478163 & 5.6778 & 5.7468 & TRN & & \\
\hline CHEMBL3426747 & 1478163 & 5.78299 & 79999999ऽ & 995 & 5.7786 & TRN \\
\hline CHEMBL3426758 & 1478163 & 6.0362 & 5.6425 & TRN & & \\
\hline CHEMBL3426742 & 1478163 & 6.1772 & 6.2274 & TRN & & \\
\hline CHEMBL3426753 & 1478163 & 4.301 & 5.4098 & TRN & & \\
\hline CHEMBL 3426754 & 1478163 & 6.0969 & 5.721 & TRN & & \\
\hline CHEMBL3426773 & 1478163 & 3.0 & 4.1931 & TST & & \\
\hline CHEMBL 3426780 & 1478163 & 6.3872 & 6.1113 & TRN & & \\
\hline CHEMBL371570 & 1478163 & 4.4622 & 5.2244 & TRN & & \\
\hline CHEMBL3426779 & 1478163 & 5.6144 & 4.2417 & TST & & \\
\hline CHEMBL3426735 & 1478163 & 6.5376 & 6.2376 & TRN & & \\
\hline CHEMBL371372 & 1478163 & 5.8539 & 5.4101 & TRN & & \\
\hline CHEMBL3426744 & 1478163 & 6.2518 & 5.8118 & TRN & & \\
\hline CHEMBL3426738 & 1478163 & 6.15799 & 79999999 & 995 & 6.5924 & TRN \\
\hline CHEMBL3426736 & 1478163 & 5.7212 & 6.4132 & TRN & & \\
\hline CHEMBL3426761 & 1478163 & 6.301 & 5.9342 & TST & & \\
\hline CHEMBL195096 & 1478163 & 4.9412 & 5.6486 & TRN & & \\
\hline CHEMBL 3426764 & 1478163 & 4.0 & 3.7963 & TST & & \\
\hline CHEMBL3426787 & 1478163 & 5.9208 & 3.4992 & TST & & \\
\hline CHEMBL3426757 & 1478163 & 5.301 & 5.5399 & TRN & & \\
\hline CHEMBL3426755 & 1478163 & 5.6055 & 5.2426 & TRN & & \\
\hline CHEMBL3426752 & 1478163 & 5.2366 & 5.2872 & TRN & & \\
\hline CHEMBL3426776 & 1478163 & 5.6819 & 4.1719 & TST & & \\
\hline CHEMBL424824 & 1478163 & 5.7878 & 5.6379 & TRN & & \\
\hline CHEMBL3426774 & 1478163 & 4.0 & 4.0377 & TST & & \\
\hline CHEMBL3426756 & 1478163 & 6.4089 & 6.3221 & TRN & & \\
\hline CHEMBL3426768 & 1478163 & 5.6253 & 4.1184 & TST & & \\
\hline CHEMBL3426737 & 1478163 & 5.1118 & 5.7384 & TRN & & \\
\hline CHEMBL3426763 & 1478163 & 6.4685 & 5.747006 & 0000000001 & & TST \\
\hline CHEMBL3426745 & 1478163 & 6.2993 & 5.8464 & TRN & & \\
\hline CHEMBL3426739 & 1478163 & 6.3665 & 6.5993 & TRN & & \\
\hline CHEMBL3426775 & 1478163 & 3.0 & 3.5087 & TST & & \\
\hline CHEMBL3426749 & 1478163 & 4.301 & 4.7747 & TRN & & \\
\hline CHEMBL3426777 & 1478163 & 4.699 & 3.5921 & TST & & \\
\hline CHEMBL3426769 & 1478163 & 4.9292 & 3.3452 & TST & & \\
\hline CHEMBL3426783 & 1478163 & 5.9666 & 5.2695 & TRN & & \\
\hline CHEMBL3426766 & 1478163 & 3.0 & 3.0703 & TST & & \\
\hline CHEMBL365118 & 1478163 & 6.9208 & 6.5312 & TRN & & \\
\hline CHEMBL364450 & 1478163 & 6.2757 & 6.5022 & TRN & & \\
\hline CHEMBL3658305 & 1528507 & 4.0 & 4.0646 & TRN & & \\
\hline CHEMBL3342304 & 1528507 & 6.5575 & 6.5534 & TRN & & \\
\hline CHEMBL3342277 & 1528507 & 4.301 & 4.6884 & TRN & & \\
\hline CHEMBL3658324 & 1528507 & 4.301 & 4.7969 & TRN & & \\
\hline CHEMBL3658330 & 1528507 & 4.301 & 4.3572 & TRN & & \\
\hline CHEMBL3658253 & 1528507 & 4.301 & 4.4826 & TST & & \\
\hline CHEMBL3658269 & 1528507 & 4.0 & 3.5429 & TRN & & \\
\hline CHEMBL3658270 & 1528507 & 4.0 & 3.8753 & TRN & & \\
\hline
\end{tabular}


Supplemental Table S2.txt

\begin{tabular}{|c|c|c|c|c|c|}
\hline CHEMBL3342310 & 1528507 & 6.1198 & 6.1968 & TRN & \\
\hline CHEMBL3658346 & 1528507 & 5.1421 & 5.773 & TST & \\
\hline CHEMBL3658336 & 1528507 & 5.9101 & 5.7942 & TRN & \\
\hline CHEMBL3342298 & 1528507 & 4.0 & 3.9674 & TRN & \\
\hline CHEMBL3658306 & 1528507 & 4.301 & 4.3788 & TRN & \\
\hline CHEMBL 3342287 & 1528507 & 4.0 & 4.2201 & TST & \\
\hline CHEMBL3342279 & 1528507 & 4.0 & 5.0247 & TST & \\
\hline CHEMBL3342301 & 1528507 & 4.0 & 3.6496 & TRN & \\
\hline CHEMBL 3658293 & 1528507 & 4.0 & 4.1751 & TRN & \\
\hline CHEMBL3658308 & 1528507 & 4.0 & 3.9844 & TRN & \\
\hline CHEMBL 3342321 & 1528507 & 6.0506 & 6.0362 & TRN & \\
\hline CHEMBL 3658312 & 1528507 & 5.7423 & 5.9561 & TRN & \\
\hline CHEMBL 3658247 & 1528507 & 5.8 & 5.5341 & TRN & \\
\hline CHEMBL 3658316 & 1528507 & 6.1079 & \multicolumn{2}{|c|}{5.821000000000001} & TRN \\
\hline CHEMBL 3658320 & 1528507 & 4.301 & 4.5609 & TRN & \\
\hline CHEMBL 3639571 & 1528507 & 7.0915 & 7.3282 & TRN & \\
\hline CHEMBL3658340 & 1528507 & 6.9355 & 6.8495 & TRN & \\
\hline CHEMBL3342302 & 1528507 & 4.0 & 3.6136 & TRN & \\
\hline CHEMBL 3342309 & 1528507 & 5.6737 & 5.5121 & TRN & \\
\hline CHEMBL3658244 & 1528507 & 4.301 & 4.816 & TST & \\
\hline CHEMBL3658331 & 1528507 & 4.301 & 3.8708 & TRN & \\
\hline CHEMBL3658311 & 1528507 & 5.9031 & 5.4325 & TRN & \\
\hline CHEMBL3342288 & 1528507 & 4.301 & 4.6414 & TST & \\
\hline CHEMBL3658267 & 1528507 & 4.301 & 4.9879 & TST & \\
\hline CHEMBL3658251 & 1528507 & 4.301 & 4.2489 & TRN & \\
\hline CHEMBL 3658256 & 1528507 & 4.0 & 4.433 & TST & \\
\hline CHEMBL3658295 & 1528507 & 4.301 & 4.4278 & TRN & \\
\hline CHEMBL 3658274 & 1528507 & 6.6778 & 6.6026 & TRN & \\
\hline CHEMBL 3342275 & 1528507 & 4.301 & 5.8825 & TST & \\
\hline CHEMBL 3658262 & 1528507 & 4.0 & 4.3235 & TST & \\
\hline CHEMBL 3658302 & 1528507 & 4.0 & 3.9718 & TRN & \\
\hline CHEMBL3342316 & 1528507 & 4.0 & 4.5693 & TRN & \\
\hline CHEMBL 3658283 & 1528507 & 4.301 & 4.4209 & TRN & \\
\hline CHEMBL3658264 & 1528507 & 4.0 & 5.2913 & TST & \\
\hline CHEMBL3658348 & 1528507 & 5.9101 & 6.8046 & TST & \\
\hline CHEMBL3342313 & 1528507 & 6.5607 & 6.5236 & TRN & \\
\hline CHEMBL3658288 & 1528507 & 5.9393 & 5.1722 & TRN & \\
\hline CHEMBL3658249 & 1528507 & 4.301 & 4.1638 & TRN & \\
\hline CHEMBL3342293 & 1528507 & 4.0 & 4.8 & TRN & \\
\hline CHEMBL3342292 & 1528507 & 4.0 & 4.1545 & TRN & \\
\hline CHEMBL3658273 & 1528507 & 6.0696 & 6.0984 & TRN & \\
\hline CHEMBL3342303 & 1528507 & 5.7932 & 5.9393 & TRN & \\
\hline CHEMBL3426950 & 1528507 & 4.0 & 4.0101 & TRN & \\
\hline CHEMBL3658338 & 1528507 & 7.4318 & 7.608 & TRN & \\
\hline CHEMBL3658254 & 1528507 & 4.0 & 4.6226 & TST & \\
\hline CHEMBL 3658344 & 1528507 & 4.0 & 4.8849 & TST & \\
\hline CHEMBL3658325 & 1528507 & 4.301 & 5.3556 & TRN & \\
\hline CHEMBL3342300 & 1528507 & 4.0 & 3.9847 & TRN & \\
\hline
\end{tabular}




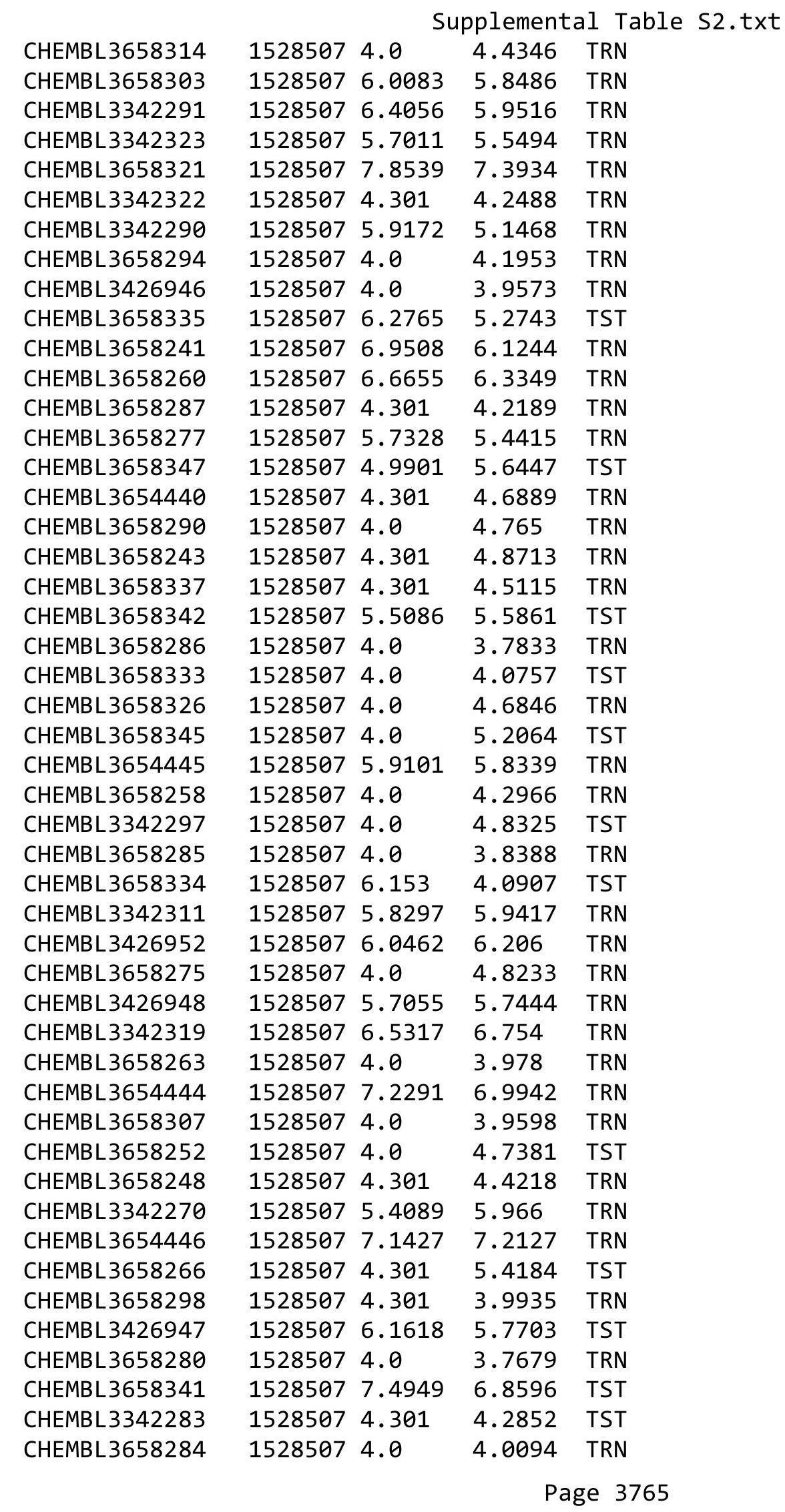




\begin{tabular}{|c|c|c|c|c|c|c|}
\hline CHEMBL 3658289 & 1528507 & 4.0 & 3.9241 & TRN & & \\
\hline CHEMBL 3342315 & 1528507 & 4.0 & 4.2009 & TRN & & \\
\hline CHEMBL3658272 & 1528507 & 4.0 & 4.6001 & TRN & & \\
\hline CHEMBL 3658257 & 1528507 & 4.0 & 4.1816 & TRN & & \\
\hline CHEMBL 3342280 & 1528507 & 4.0 & 3.9841 & TST & & \\
\hline CHEMBL3658261 & 1528507 & 4.301 & 4.791 & TRN & & \\
\hline CHEMBL3658317 & 1528507 & 4.301 & 3.8113 & TRN & & \\
\hline CHEMBL3658313 & 1528507 & 4.0 & 4.2774 & TRN & & \\
\hline CHEMBL 3654441 & 1528507 & 7.5528 & 7.2271 & TRN & & \\
\hline CHEMBL3658299 & 1528507 & 4.0 & 4.2847 & TRN & & \\
\hline CHEMBL3658304 & 1528507 & 4.0 & 4.3634 & TRN & & \\
\hline CHEMBL 3426944 & 1528507 & 7.6576 & 8.023 & TRN & & \\
\hline CHEMBL 3658250 & 1528507 & 4.0 & 3.7881 & TRN & & \\
\hline CHEMBL3426945 & 1528507 & 7.1024 & 7.1716 & TRN & & \\
\hline CHEMBL 3658245 & 1528507 & 6.4559 & 5.9966 & TRN & & \\
\hline CHEMBL3658339 & 1528507 & 4.0 & 3.9204 & TRN & & \\
\hline CHEMBL3426951 & 1528507 & 6.4123 & 6.7095 & TRN & & \\
\hline CHEMBL3658309 & 1528507 & 4.0 & 4.7012 & TRN & & \\
\hline CHEMBL 3342284 & 1528507 & 4.301 & 4.5473 & TRN & & \\
\hline CHEMBL 3342294 & 1528507 & 4.0 & 3.8693 & TRN & & \\
\hline CHEMBL 3658318 & 1528507 & 4.0 & 3.6944 & TRN & & \\
\hline CHEMBL 3658279 & 1528507 & 4.301 & 4.1834 & TRN & & \\
\hline CHEMBL3342269 & 1528507 & 7.4202 & 7.2566 & TRN & & \\
\hline CHEMBL 3658271 & 1528507 & 4.301 & 3.7439 & TRN & & \\
\hline CHEMBL 3658255 & 1528507 & 4.0 & 4.607 & TST & & \\
\hline CHEMBL 3658276 & 1528507 & 4.301 & 4.4477 & TRN & & \\
\hline CHEMBL3658322 & 1528507 & 4.301 & 3.9251 & TRN & & \\
\hline CHEMBL3342278 & 1528507 & 4.0 & 4.8825 & TST & & \\
\hline CHEMBL 3658281 & 1528507 & 4.0 & 4.3248 & TRN & & \\
\hline CHEMBL 3342281 & 1528507 & 4.301 & 4.0896 & TRN & & \\
\hline CHEMBL 3658265 & 1528507 & 4.0 & 3.8593 & TRN & & \\
\hline CHEMBL3658282 & 1528507 & 4.0 & 3.3354 & TRN & & \\
\hline CHEMBL3342306 & 1528507 & 4.0 & 4.3615 & TRN & & \\
\hline CHEMBL3342295 & 1528507 & 4.301 & 4.5324 & TRN & & \\
\hline CHEMBL3342289 & 1528507 & 4.0 & 4.2792 & TRN & & \\
\hline CHEMBL3658327 & 1528507 & 5.6498 & 5.7533 & TRN & & \\
\hline CHEMBL3426949 & 1528507 & 7.284 & 6.7132 & TRN & & \\
\hline CHEMBL3658319 & 1528507 & 4.0 & 4.0715 & TRN & & \\
\hline CHEMBL3342320 & 1528507 & 7.1079 & 7.1443 & TRN & & \\
\hline CHEMBL3342296 & 1528507 & 4.0 & 4.1279 & TRN & & \\
\hline CHEMBL 3342317 & 1528507 & 6.284 & 5.9858 & TRN & & \\
\hline CHEMBL 3654442 & 1528507 & 5.9747 & 5.7649 & TRN & & \\
\hline CHEMBL3658292 & 1528507 & 4.0 & 3.5221 & TRN & & \\
\hline CHEMBL3342276 & 1528507 & 4.0 & 3.1545 & TST & & \\
\hline CHEMBL 3658300 & 1528507 & 4.0 & 4.2322 & TRN & & \\
\hline CHEMBL 3658296 & 1528507 & 5.433 & 4.7988 & TRN & & \\
\hline CHEMBL3342312 & 1528507 & 6.76200 & 0000000 & 005 & 6.8173 & TRN \\
\hline CHEMBL 3654443 & 1528507 & 6.21399 & 9999999 & 995 & 6.2173 & TRN \\
\hline
\end{tabular}


Supplemental Table S2.txt

\begin{tabular}{|c|c|c|c|c|c|}
\hline CHEMBL3658323 & 1528507 & 6.7122 & 5.4611 & TRN & \\
\hline CHEMBL 3658259 & 1528507 & 4.301 & \multicolumn{2}{|c|}{3.7969999999999997} & TRN \\
\hline CHEMBL3658246 & 1528507 & 6.1192 & 4.3833 & TST & \\
\hline CHEMBL3658301 & 1528507 & 4.301 & 4.0857 & TRN & \\
\hline CHEMBL 3658328 & 1528507 & 4.301 & 4.3869 & TRN & \\
\hline CHEMBL3342308 & 1528507 & 4.301 & 4.6597 & TRN & \\
\hline CHEMBL 3658297 & 1528507 & 4.0 & 4.6017 & TRN & \\
\hline CHEMBL3658329 & 1528507 & 4.0 & 4.3275 & TRN & \\
\hline CHEMBL 3658310 & 1528507 & 4.301 & 4.2082 & TRN & \\
\hline CHEMBL 3342282 & 1528507 & 6.266 & 6.1242 & TST & \\
\hline CHEMBL3342314 & 1528507 & 6.556 & 6.2861 & TRN & \\
\hline CHEMBL3658332 & 1528507 & 4.0 & 3.7474 & TRN & \\
\hline CHEMBL3658343 & 1528507 & 6.7799 & 7.3007 & TST & \\
\hline CHEMBL 3658278 & 1528507 & 7.7959 & 5.0079 & TST & \\
\hline CHEMBL 3342273 & 1528507 & 4.0 & 4.2476 & TST & \\
\hline CHEMBL3658291 & 1528507 & 4.0 & 5.0057 & TST & \\
\hline CHEMBL3342274 & 1528507 & 4.0 & 5.2735 & TST & \\
\hline CHEMBL3658315 & 1528507 & 4.301 & 4.5568 & TST & \\
\hline CHEMBL3342272 & 1528507 & 4.301 & 4.562 & TST & \\
\hline CHEMBL 3658242 & 1528507 & 4.0 & 4.0246 & TST & \\
\hline CHEMBL3342318 & 1528507 & 6.9788 & \multicolumn{2}{|c|}{6.132000000000001} & TST \\
\hline CHEMBL3342285 & 1528507 & 4.301 & 5.2297 & TST & \\
\hline CHEMBL3342299 & 1528507 & 4.301 & 2.9496 & TST & \\
\hline CHEMBL 3658268 & 1528507 & 4.301 & 4.7882 & TST & \\
\hline CHEMBL 3658349 & 1528507 & 5.9245 & 6.6136 & TST & \\
\hline CHEMBL118518 & 199699 & 8.2218 & 7.9925 & TRN & \\
\hline CHEMBL268567 & 199699 & 7.9208 & 7.2018 & TST & \\
\hline CHEMBL115960 & 199699 & 6.9208 & \multicolumn{2}{|c|}{7.122000000000001} & TRN \\
\hline CHEMBL117093 & 199699 & 7.4559 & \multicolumn{2}{|c|}{6.946000000000001} & TRN \\
\hline CHEMBL119711 & 199699 & 6.2218 & 6.2228 & TRN & \\
\hline CHEMBL326771 & 199699 & 7.8861 & 8.0463 & TRN & \\
\hline CHEMBL331584 & 199699 & 8.1549 & 8.4624 & TRN & \\
\hline CHEMBL115981 & 199699 & 6.7696 & 6.7709 & TRN & \\
\hline CHEMBL118074 & 199699 & 8.0969 & \multicolumn{2}{|c|}{7.821000000000001} & TRN \\
\hline CHEMBL119523 & 199699 & 6.6778 & 6.6201 & TRN & \\
\hline CHEMBL119815 & 199699 & 7.0969 & 6.7524 & TRN & \\
\hline CHEMBL119901 & 199699 & 5.0 & 4.8871 & TST & \\
\hline CHEMBL119599 & 199699 & 6.9586 & 6.455 & TRN & \\
\hline CHEMBL116070 & 199699 & 8.3979 & 8.2719 & TRN & \\
\hline CHEMBL116307 & 199699 & 7.699 & 7.4786 & TRN & \\
\hline CHEMBL117894 & 199699 & 8.301 & 8.2126 & TRN & \\
\hline CHEMBL117936 & 199699 & 7.4559 & 7.4844 & TRN & \\
\hline CHEMBL119039 & 199699 & 8.3979 & 8.2316 & TRN & \\
\hline CHEMBL118022 & 199699 & 7.5528 & 7.6125 & TRN & \\
\hline CHEMBL115971 & 199699 & 7.7447 & 8.0442 & TRN & \\
\hline CHEMBL326712 & 199699 & 6.9586 & 7.0085 & TRN & \\
\hline CHEMBL115966 & 199699 & 7.6021 & 7.6742 & TRN & \\
\hline CHEMBL117571 & 199699 & 7.1024 & 7.2435 & TRN & \\
\hline
\end{tabular}




\begin{tabular}{|c|c|c|c|c|c|}
\hline \multirow[b]{2}{*}{ CHEMBL325893 } & \multicolumn{5}{|c|}{ Supplemental Table S2.txt } \\
\hline & 199699 & 6.0969 & 6.1639 & TRN & \\
\hline CHEMBL119733 & 199699 & 9.0 & 8.4969 & TRN & \\
\hline CHEMBL119532 & 199699 & 6.8239 & 6.6993 & TRN & \\
\hline CHEMBL118113 & 199699 & 8.699 & 8.6156 & TST & \\
\hline CHEMBL325651 & 199699 & 7.4685 & 7.1597 & TRN & \\
\hline CHEMBL325618 & 199699 & 5.0 & 5.5571 & TRN & \\
\hline CHEMBL118089 & 199699 & 7.5086 & 7.3639 & TRN & \\
\hline CHEMBL325286 & 199699 & 6.0269 & 6.1883 & TST & \\
\hline CHEMBL326360 & 199699 & 5.0 & 5.1624 & TST & \\
\hline CHEMBL117565 & 199699 & 6.3279 & 5.6417 & TST & \\
\hline CHEMBL118034 & 199699 & 8.301 & 8.3139 & TRN & \\
\hline CHEMBL326120 & 199699 & 8.2218 & 8.3535 & TRN & \\
\hline CHEMBL119501 & 199699 & 9.1549 & 8.9522 & TRN & \\
\hline CHEMBL115462 & 199699 & 6.1739 & 6.2654 & TRN & \\
\hline CHEMBL323832 & 199699 & 6.2007 & 6.1141 & TRN & \\
\hline CHEMBL119732 & 199699 & 7.5229 & 7.6979 & TRN & \\
\hline CHEMBL117452 & 199699 & 6.0635 & 5.2093 & TST & \\
\hline CHEMBL119091 & 199699 & 7.5086 & 7.3582 & TRN & \\
\hline CHEMBL118299 & 199699 & 7.6778 & 7.5461 & TRN & \\
\hline CHEMBL115431 & 199699 & 6.9586 & 7.5758 & TRN & \\
\hline CHEMBL119861 & 199699 & 6.284 & 6.6121 & TRN & \\
\hline CHEMBL326271 & 199699 & 8.1549 & 8.3286 & TRN & \\
\hline CHEMBL115815 & 199699 & 7.1549 & 7.0332 & TRN & \\
\hline CHEMBL324824 & 199699 & 6.5229 & 6.9421 & TRN & \\
\hline CHEMBL116152 & 199699 & 8.2218 & 8.271 & TRN & \\
\hline CHEMBL116454 & 199699 & 7.5528 & 7.7888 & TST & \\
\hline CHEMBL117292 & 199699 & 6.9208 & 6.9271 & TST & \\
\hline CHEMBL117746 & 199699 & 8.301 & 8.6265 & TRN & \\
\hline CHEMBL324158 & 199699 & 7.1192 & 7.24700 & 0000000001 & TRN \\
\hline CHEMBL325184 & 199699 & 8.699 & 8.3348 & TRN & \\
\hline CHEMBL115637 & 199699 & 8.0458 & 7.7758 & TRN & \\
\hline CHEMBL331248 & 199699 & 5.0 & 5.1365 & TRN & \\
\hline CHEMBL115534 & 199699 & 6.0605 & 6.2259 & TRN & \\
\hline CHEMBL119705 & 199699 & 6.7447 & 7.03799 & 9999999999 & TRN \\
\hline CHEMBL116089 & 199699 & 7.7212 & 8.0557 & TRN & \\
\hline CHEMBL119886 & 199699 & 6.9208 & 7.0688 & TRN & \\
\hline CHEMBL419046 & 199699 & 7.6021 & 7.5332 & TST & \\
\hline CHEMBL325033 & 199699 & 7.3665 & 7.00700 & $\partial 000000001$ & TST \\
\hline CHEMBL421231 & 199699 & 5.1457 & 5.8282 & TST & \\
\hline CHEMBL116958 & 199699 & 6.1675 & 6.046 & TST & \\
\hline CHEMBL117671 & 199699 & 6.9393 & 6.8652 & TST & \\
\hline CHEMBL116363 & 199699 & 7.8861 & 7.3855 & TRN & \\
\hline CHEMBL324133 & 199699 & 7.0 & 6.8569 & TRN & \\
\hline CHEMBL117367 & 199699 & 6.0605 & 5.8906 & TST & \\
\hline CHEMBL6370 & 199699 & 4.3979 & 4.8961 & TST & \\
\hline CHEMBL119183 & 199699 & 7.7959 & 7.9816 & TRN & \\
\hline CHEMBL267678 & 199699 & 7.699 & 6.8771 & TST & \\
\hline CHEMBL119348 & 199699 & 6.1135 & 5.8086 & TST & \\
\hline
\end{tabular}




\begin{tabular}{|c|c|c|c|c|c|}
\hline \multicolumn{6}{|c|}{ Supplemental Table S2.txt } \\
\hline CHEMBL117279 & 199699 & 8.2218 & 8.5837 & TRN & \\
\hline CHEMBL119522 & 199699 & 6.1871 & 5.976 & TST & \\
\hline CHEMBL118114 & 199699 & 5.0 & 5.1005 & TST & \\
\hline CHEMBL117453 & 199699 & 7.699 & 7.4805 & TRN & \\
\hline CHEMBL118358 & 199699 & 6.0809 & 6.0123 & TST & \\
\hline CHEMBL118886 & 199699 & 8.0969 & 7.8284 & TRN & \\
\hline CHEMBL331055 & 199699 & 6.8239 & 6.6776 & TRN & \\
\hline CHEMBL119335 & 199699 & 8.5528 & 8.3456 & TRN & \\
\hline CHEMBL115432 & 199699 & 6.4318 & 6.0849 & TRN & \\
\hline CHEMBL331662 & 199699 & 7.2218 & 6.8396 & TRN & \\
\hline CHEMBL117198 & 199699 & 8.5229 & 8.6477 & TRN & \\
\hline CHEMBL115742 & 199699 & 7.0 & 6.9898 & TRN & \\
\hline CHEMBL6320 & 199699 & 4.3979 & 4.8213 & TST & \\
\hline CHEMBL434222 & 199699 & 6.4202 & 6.8805 & TRN & \\
\hline CHEMBL117668 & 199699 & 8.301 & 8.5095 & TRN & \\
\hline CHEMBL118300 & 199699 & 7.2218 & 7.5596 & TRN & \\
\hline CHEMBL3589440 & 1503508 & 3.8239 & 4.5406 & TRN & \\
\hline CHEMBL3589448 & 1503508 & 3.8239 & 4.2094 & TRN & \\
\hline CHEMBL3590284 & 1503508 & 5.7959 & 5.922006 & $\partial 000000001$ & TRN \\
\hline CHEMBL3589455 & 1503508 & 3.8239 & 4.0491 & TRN & \\
\hline CHEMBL2347539 & 1503508 & 5.4437 & 6.4529 & TRN & \\
\hline CHEMBL3588866 & 1503508 & 5.3872 & 5.397 & TRN & \\
\hline CHEMBL3589446 & 1503508 & 5.0088 & 4.3204 & TRN & \\
\hline CHEMBL3589444 & 1503508 & 6.3565 & 5.7153 & TRN & \\
\hline CHEMBL3589443 & 1503508 & 5.8861 & 5.4432 & TRN & \\
\hline CHEMBL3590283 & 1503508 & 6.0362 & 5.8092 & TRN & \\
\hline CHEMBL3590285 & 1503508 & 3.8239 & 4.6643 & TST & \\
\hline CHEMBL3589435 & 1503508 & 6.3979 & 6.689 & TRN & \\
\hline CHEMBL3589433 & 1503508 & 6.2218 & 6.1251 & TRN & \\
\hline CHEMBL 2347404 & 1503508 & 5.5229 & 5.5731 & TRN & \\
\hline CHEMBL3589044 & 1503508 & 3.8239 & 5.1459 & TST & \\
\hline CHEMBL3589439 & 1503508 & 3.8239 & 4.1262 & TRN & \\
\hline CHEMBL3589441 & 1503508 & 3.8239 & 4.5615 & TRN & \\
\hline CHEMBL3589432 & 1503508 & 4.8239 & 5.48799 & 99999999995 & TRN \\
\hline CHEMBL3590286 & 1503508 & 3.8239 & 5.0664 & TST & \\
\hline CHEMBL3589430 & 1503508 & 5.8539 & 5.7906 & TRN & \\
\hline CHEMBL3589442 & 1503508 & 5.5686 & 5.0113 & TRN & \\
\hline CHEMBL3589451 & 1503508 & 5.1938 & 5.2475 & TRN & \\
\hline CHEMBL3589450 & 1503508 & 5.2441 & 4.9444 & TRN & \\
\hline CHEMBL3589452 & 1503508 & 3.8239 & 3.8292 & TRN & \\
\hline CHEMBL3590282 & 1503508 & 5.3872 & 4.9698 & TRN & \\
\hline CHEMBL3589449 & 1503508 & 3.8239 & 4.6145 & TRN & \\
\hline CHEMBL 2347538 & 1503508 & 5.5528 & 5.7891 & TRN & \\
\hline CHEMBL3589454 & 1503508 & 4.4685 & 3.5538 & TRN & \\
\hline CHEMBL3589431 & 1503508 & 6.699 & 5.5712 & TRN & \\
\hline CHEMBL3589437 & 1503508 & 3.8239 & 4.4015 & TST & \\
\hline CHEMBL3590280 & 1503508 & 3.8239 & 4.0961 & TRN & \\
\hline CHEMBL3589447 & 1503508 & 3.8239 & 4.0235 & TRN & \\
\hline
\end{tabular}


Supplemental Table S2.txt

\begin{tabular}{|c|c|c|c|c|c|}
\hline CHEMBL3590288 & 1503508 & 3.8239 & 4.4654 & TST & \\
\hline CHEMBL3590289 & 1503508 & 5.4685 & 5.1482 & TST & \\
\hline CHEMBL3589436 & 1503508 & 6.3979 & 6.516 & TRN & \\
\hline CHEMBL3590275 & 1503508 & 3.8239 & 4.7532 & TRN & \\
\hline CHEMBL3589457 & 1503508 & 5.8861 & 4.8267 & TRN & \\
\hline CHEMBL3590278 & 1503508 & 3.8239 & 4.465 & TRN & \\
\hline CHEMBL3589429 & 1503508 & 6.0458 & 5.9567 & TST & \\
\hline CHEMBL2347559 & 1503508 & 6.301 & 5.093 & TRN & \\
\hline CHEMBL3590287 & 1503508 & 4.5229 & 4.402 & TST & \\
\hline CHEMBL3589046 & 1503508 & 5.6198 & 5.5329 & TST & \\
\hline CHEMBL3590279 & 1503508 & 3.8239 & 3.7599 & TRN & \\
\hline CHEMBL3589438 & 1503508 & 3.8239 & 4.8443 & TST & \\
\hline CHEMBL3590276 & 1503508 & 6.3872 & 5.537006 & 2000000001 & TRN \\
\hline CHEMBL3589045 & 1503508 & 6.4949 & 5.3056 & TST & \\
\hline CHEMBL3589445 & 1503508 & 3.8239 & 4.1935 & TST & \\
\hline CHEMBL3589456 & 1503508 & 4.4949 & 3.9997 & TRN & \\
\hline CHEMBL3590281 & 1503508 & 3.8239 & 4.6578 & TRN & \\
\hline CHEMBL3590277 & 1503508 & 3.8239 & 4.2211 & TRN & \\
\hline CHEMBL3589453 & 1503508 & 3.8239 & 4.354 & TST & \\
\hline CHEMBL3589434 & 1503508 & 6.0 & 6.1587 & TRN & \\
\hline CHEMBL1863428 & 942987 & 3.0 & 3.1485 & TRN & \\
\hline CHEMBL1862938 & 942987 & 3.0 & 3.1525 & TRN & \\
\hline CHEMBL1863462 & 942987 & 3.0 & 3.1276 & TRN & \\
\hline CHEMBL1863139 & 942987 & 3.0 & 2.8609 & TRN & \\
\hline CHEMBL1862980 & 942987 & 4.2218 & 4.2226 & TRN & \\
\hline CHEMBL1862883 & 942987 & 4.2291 & 4.2038 & TRN & \\
\hline CHEMBL1863404 & 942987 & 3.0 & 3.1974 & TRN & \\
\hline CHEMBL1863131 & 942987 & 3.0 & 3.0365 & TRN & \\
\hline CHEMBL1862941 & 942987 & 4.1367 & 4.0674 & TRN & \\
\hline CHEMBL1863155 & 942987 & 4.1135 & 4.1777 & TRN & \\
\hline CHEMBL1863017 & 942987 & 4.2147 & 4.3391 & TRN & \\
\hline CHEMBL2334336 & 942987 & 4.3768 & 4.0956 & TRN & \\
\hline CHEMBL1862975 & 942987 & 3.0 & 3.0513 & TRN & \\
\hline CHEMBL1862818 & 942987 & 3.0 & 2.8674 & TRN & \\
\hline CHEMBL1863005 & 942987 & 4.2147 & 4.2436 & TRN & \\
\hline CHEMBL1863273 & 942987 & 3.0 & 2.8847 & TRN & \\
\hline CHEMBL1863506 & 942987 & 4.0969 & 4.1327 & TRN & \\
\hline CHEMBL1863166 & 942987 & 4.1612 & 4.1638 & TRN & \\
\hline CHEMBL1863090 & 942987 & 3.0 & 3.0213 & TRN & \\
\hline CHEMBL1863110 & 942987 & 4.3468 & $4.27800 t$ & 00000000005 & TRN \\
\hline CHEMBL1863211 & 942987 & 3.0 & 2.9958 & TRN & \\
\hline CHEMBL1863063 & 942987 & 3.0 & 2.8664 & TRN & \\
\hline CHEMBL1863409 & 942987 & 4.2366 & 4.2564 & TRN & \\
\hline CHEMBL1863002 & 942987 & 4.4685 & 4.3814 & TRN & \\
\hline CHEMBL1863115 & 942987 & 3.0 & 3.1172 & TST & \\
\hline CHEMBL1863212 & 942987 & 4.2291 & 4.3586 & TRN & \\
\hline CHEMBL1863455 & 942987 & 4.2291 & 4.1019 & TRN & \\
\hline CHEMBL1863433 & 942987 & 4.2518 & 4.2212 & TRN & \\
\hline
\end{tabular}




\begin{tabular}{|c|c|c|c|c|c|}
\hline \multirow[b]{2}{*}{ CHEMBL1862933 } & \multicolumn{5}{|c|}{ Supplemental Table S2.txt } \\
\hline & 942987 & 4.2291 & 4.2201 & TRN & \\
\hline CHEMBL1863055 & 942987 & 3.0 & 2.9339 & TRN & \\
\hline CHEMBL1863058 & 942987 & 3.0 & 2.8451 & TRN & \\
\hline CHEMBL1862866 & 942987 & 4.6383 & 4.569 & TRN & \\
\hline CHEMBL1863056 & 942987 & 3.0 & 2.951 & TRN & \\
\hline CHEMBL1862912 & 942987 & 3.0 & 3.3535 & TRN & \\
\hline CHEMBL1862798 & 942987 & 4.3665 & 4.4931 & TRN & \\
\hline CHEMBL1863046 & 942987 & 4.3665 & 4.2017 & TRN & \\
\hline CHEMBL1863040 & 942987 & 4.1739 & 4.2271 & TRN & \\
\hline CHEMBL1863116 & 942987 & 4.2076 & 4.0587 & TRN & \\
\hline CHEMBL1863145 & 942987 & 3.0 & 3.1142 & TRN & \\
\hline CHEMBL1863334 & 942987 & 4.2518 & 4.3643 & TRN & \\
\hline CHEMBL1863311 & 942987 & 3.0 & 2.9754 & TRN & \\
\hline CHEMBL1863487 & 942987 & 4.1739 & 4.1626 & TST & \\
\hline CHEMBL2334337 & 942987 & 4.0315 & 3.7304 & TST & \\
\hline CHEMBL2331581 & 942987 & 3.0 & 3.6852 & TST & \\
\hline CHEMBL1863128 & 942987 & 4.2924 & 4.1771 & TST & \\
\hline CHEMBL1863136 & 942987 & 4.2076 & 4.3114 & TST & \\
\hline CHEMBL1863288 & 942987 & 4.1135 & 3.5814 & TST & \\
\hline CHEMBL2334338 & 942987 & 3.0 & 3.0962 & TST & \\
\hline CHEMBL1863306 & 942987 & 4.1938 & 3.876006 & 00000000003 & TST \\
\hline CHEMBL1863474 & 942987 & 4.2518 & 3.8818 & TST & \\
\hline CHEMBL1862865 & 942987 & 4.2007 & 4.09 & TST & \\
\hline CHEMBL1862905 & 942987 & 4.2218 & 3.8823 & TST & \\
\hline CHEMBL1863393 & 942987 & 4.2076 & 3.6512 & TST & \\
\hline CHEMBL1863434 & 942987 & 3.0 & 3.4832 & TST & \\
\hline CHEMBL3934635 & 1640594 & 6.8239 & 6.6134 & TST & \\
\hline CHEMBL3941671 & 1640594 & 5.6882 & 5.7362 & TRN & \\
\hline CHEMBL3954879 & 1640594 & 7.0809 & 7.1732 & TRN & \\
\hline CHEMBL 3983305 & 1640594 & 6.8539 & 7.0413 & TRN & \\
\hline CHEMBL3909464 & 1640594 & 5.6753 & 5.6065 & TRN & \\
\hline CHEMBL 3943004 & 1640594 & 7.0 & 7.1151 & TST & \\
\hline CHEMBL3929605 & 1640594 & 7.1549 & 6.8992 & TST & \\
\hline CHEMBL3903289 & 1640594 & 6.9586 & 7.11100 & 0000000001 & TRN \\
\hline CHEMBL 3944110 & 1640594 & 4.301 & 5.7705 & TST & \\
\hline CHEMBL3897180 & 1640594 & 5.6345 & 5.5888 & TRN & \\
\hline CHEMBL3957319 & 1640594 & 7.1612 & 6.8937 & TRN & \\
\hline CHEMBL3970060 & 1640594 & 5.8861 & 5.9718 & TRN & \\
\hline CHEMBL3978164 & 1640594 & 5.8153 & 5.4758 & TST & \\
\hline CHEMBL 3892704 & 1640594 & 6.1739 & 5.2836 & TRN & \\
\hline CHEMBL3970140 & 1640594 & 6.8239 & 6.6679 & TST & \\
\hline CHEMBL3964375 & 1640594 & 5.4342 & 5.572 & TRN & \\
\hline CHEMBL3958940 & 1640594 & 5.5376 & 5.5267 & TST & \\
\hline CHEMBL3892100 & 1640594 & 6.2596 & 5.8404 & TRN & \\
\hline CHEMBL3936071 & 1640594 & 5.5918 & 5.7016 & TST & \\
\hline CHEMBL3958851 & 1640594 & 6.7447 & 6.7366 & TST & \\
\hline CHEMBL3967421 & 1640594 & 6.9586 & 6.9883 & TRN & \\
\hline CHEMBL3976927 & 1640594 & 4.699 & 5.0184 & TRN & \\
\hline
\end{tabular}


Supplemental Table S2.txt

\begin{tabular}{|c|c|c|c|c|}
\hline CHEMBL3913495 & 1640594 & 5.8239 & 6.041 & TRN \\
\hline CHEMBL 3899310 & 1640594 & 5.3665 & 5.5229 & TRN \\
\hline CHEMBL 3936148 & 1640594 & 5.6162 & 5.5407 & TRN \\
\hline CHEMBL3968814 & 1640594 & 6.7696 & 6.9751 & TST \\
\hline CHEMBL 3893941 & 1640594 & 5.6882 & 5.6763 & TRN \\
\hline CHEMBL 3965151 & 1640594 & 6.9208 & 6.6868 & TRN \\
\hline CHEMBL 3944249 & 1640594 & 6.5686 & 6.5557 & TRN \\
\hline CHEMBL3958498 & 1640594 & 6.7212 & 6.8933 & TRN \\
\hline CHEMBL3954407 & 1640594 & 6.7959 & 6.954 & TST \\
\hline CHEMBL 3902666 & 1640594 & 7.0 & 6.4157 & TRN \\
\hline CHEMBL3959693 & 1640594 & 6.7212 & 6.4217 & TST \\
\hline CHEMBL 3953446 & 1640594 & 6.9586 & 6.9906 & TRN \\
\hline CHEMBL 3935069 & 1640594 & 7.0655 & 6.963999 & 99999999995 \\
\hline CHEMBL 3911676 & 1640594 & 7.0969 & 6.7911 & TST \\
\hline CHEMBL 3956707 & 1640594 & 6.8861 & 7.0514 & TRN \\
\hline CHEMBL3965589 & 1640594 & 4.699 & 5.1752 & TRN \\
\hline CHEMBL3938852 & 1640594 & 6.5376 & 6.5944 & TRN \\
\hline CHEMBL 3954217 & 1640594 & 5.9626 & 5.7975 & TRN \\
\hline CHEMBL 3890582 & 1640594 & 6.7959 & 6.9835 & TRN \\
\hline CHEMBL 3900744 & 1640594 & 4.301 & 5.6703 & TST \\
\hline CHEMBL3974747 & 1640594 & 5.4789 & 5.4575 & TRN \\
\hline CHEMBL 3975197 & 1640594 & 5.7959 & 5.8955 & TRN \\
\hline CHEMBL 3942679 & 1640594 & 5.8861 & 5.7381 & TRN \\
\hline CHEMBL3957169 & 1640594 & 5.7235 & 5.5443 & TST \\
\hline CHEMBL 3975332 & 1640594 & 6.1079 & 6.0471 & TRN \\
\hline CHEMBL3983257 & 1640594 & 7.0 & 6.955 & TST \\
\hline CHEMBL 3966253 & 1640594 & 6.9586 & 6.6864 & TRN \\
\hline CHEMBL 3947561 & 1640594 & 6.4559 & 6.3052 & TRN \\
\hline CHEMBL3919655 & 1640594 & 4.301 & 5.636 & TST \\
\hline CHEMBL 3932132 & 1640594 & 6.9208 & 7.0304 & TRN \\
\hline CHEMBL 3894663 & 1640594 & 5.9586 & 5.5731 & TRN \\
\hline CHEMBL 3894215 & 1640594 & 6.8539 & 7.0642 & TRN \\
\hline CHEMBL3967772 & 1640594 & 6.8539 & 7.122999 & 9999999999 \\
\hline CHEMBL3948782 & 1640594 & 5.4449 & 5.4357 & TRN \\
\hline CHEMBL3912446 & 1640594 & 4.301 & 5.0915 & TRN \\
\hline CHEMBL3941147 & 1640594 & 6.7959 & 6.8938 & TST \\
\hline CHEMBL 3984413 & 1640594 & 5.5784 & 5.7229 & TRN \\
\hline CHEMBL3930120 & 1640594 & 7.0757 & 6.9974 & TRN \\
\hline CHEMBL3936447 & 1640594 & 5.5086 & 5.4531 & TRN \\
\hline CHEMBL3919774 & 1640594 & 4.699 & 5.1453 & TRN \\
\hline CHEMBL3973493 & 1640594 & 6.8239 & 6.3908 & TRN \\
\hline CHEMBL 3947338 & 1640594 & 6.7696 & 6.9327 & TRN \\
\hline CHEMBL3911675 & 1640594 & 6.6383 & 6.2501 & TRN \\
\hline CHEMBL3969651 & 1640594 & 5.6819 & 5.5364 & TRN \\
\hline CHEMBL 3962887 & 1640594 & 6.9208 & 6.943 & TRN \\
\hline CHEMBL3922490 & 1640594 & 5.6021 & 5.7962 & TRN \\
\hline CHEMBL 3917751 & 1640594 & 6.8861 & 7.0135 & TRN \\
\hline CHEMBL 3958963 & 1640594 & 5.8239 & 5.9111 & TRN \\
\hline
\end{tabular}


Supplemental Table S2.txt

\begin{tabular}{|c|c|c|c|c|}
\hline CHEMBL3897871 & 1640594 & 6.9208 & 7.0388 & TRN \\
\hline CHEMBL3948317 & 1640594 & 6.9208 & 6.9902 & TRN \\
\hline CHEMBL3973454 & 1640594 & 5.4202 & 5.4649 & TRN \\
\hline CHEMBL3933418 & 1640594 & 6.8861 & \multicolumn{2}{|c|}{6.7589999999999995} \\
\hline CHEMBL3958011 & 1640594 & 6.9208 & 7.0757 & TRN \\
\hline CHEMBL3984182 & 1640594 & 5.7959 & 5.5715 & TRN \\
\hline CHEMBL3932753 & 1640594 & 6.8239 & 6.3719 & TST \\
\hline CHEMBL3902346 & 1640594 & 6.1192 & 5.9806 & TRN \\
\hline CHEMBL3985466 & 1640594 & 7.0362 & 6.9181 & TRN \\
\hline CHEMBL3973643 & 1640594 & 4.699 & 4.8993 & TRN \\
\hline CHEMBL3914586 & 1640594 & 7.1192 & 7.1507 & TRN \\
\hline CHEMBL3929161 & 1640594 & 5.2518 & 5.4846 & TRN \\
\hline CHEMBL3919758 & 1640594 & 6.7959 & 6.7845 & TRN \\
\hline CHEMBL3965470 & 1640594 & 6.9586 & 6.86 & TST \\
\hline CHEMBL3940564 & 1640594 & 5.9586 & 6.0726 & TRN \\
\hline CHEMBL3898854 & 1640594 & 5.7959 & 5.9763 & TST \\
\hline CHEMBL3953000 & 1640594 & 6.2076 & 5.6141 & TRN \\
\hline CHEMBL3970200 & 1640594 & 7.1549 & 7.1202 & TRN \\
\hline CHEMBL346819 & 76063 & 5.4685 & 5.3991 & TRN \\
\hline CHEMBL 346293 & 76063 & 4.9208 & 4.8376 & TRN \\
\hline CHEMBL157751 & 76063 & 5.1675 & 5.2726 & TRN \\
\hline CHEMBL346917 & 76063 & 4.9208 & 5.2292 & TRN \\
\hline CHEMBL157099 & 76063 & 4.3565 & 4.7494 & TRN \\
\hline CHEMBL154784 & 76063 & 4.9586 & 4.934 & TRN \\
\hline CHEMBL347485 & 76063 & 4.8539 & 4.8227 & TRN \\
\hline CHEMBL157726 & 76063 & 4.3565 & 4.7057 & TST \\
\hline CHEMBL155575 & 76063 & 5.6021 & 4.9388 & TRN \\
\hline CHEMBL156817 & 76063 & 4.8861 & 5.1464 & TRN \\
\hline CHEMBL158181 & 76063 & 5.1308 & 4.954 & TRN \\
\hline CHEMBL347946 & 76063 & 4.4949 & 4.6115 & TST \\
\hline CHEMBL346998 & 76063 & 4.4815 & 4.9703 & TRN \\
\hline CHEMBL347649 & 76063 & 4.7959 & 4.7517 & TRN \\
\hline CHEMBL155019 & 76063 & 4.3665 & 4.6988 & TRN \\
\hline CHEMBL346567 & 76063 & 4.0 & 4.2821 & TRN \\
\hline CHEMBL347149 & 76063 & 3.0 & 3.6574 & TRN \\
\hline CHEMBL440543 & 76063 & 5.2441 & 4.6499 & TRN \\
\hline CHEMBL347483 & 76063 & 4.0088 & 3.9156 & TRN \\
\hline CHEMBL345427 & 76063 & 4.7959 & 4.7548 & TRN \\
\hline CHEMBL348090 & 76063 & 4.2218 & 4.6902 & TRN \\
\hline CHEMBL155660 & 76063 & 4.9586 & 4.3888 & TRN \\
\hline CHEMBL348541 & 76063 & 5.1249 & 4.3504 & TRN \\
\hline CHEMBL157861 & 76063 & 4.9208 & 5.3013 & TRN \\
\hline CHEMBL156341 & 76063 & 4.5086 & 4.6581 & TRN \\
\hline CHEMBL351764 & 76063 & 4.4949 & 4.6925 & TRN \\
\hline CHEMBL347442 & 76063 & 5.2596 & 4.8276 & TRN \\
\hline CHEMBL348886 & 76063 & 4.0 & 4.46899 & 9999999999 \\
\hline CHEMBL158003 & 76063 & 4.5528 & 4.4932 & TRN \\
\hline CHEMBL155435 & 76063 & 5.1249 & 4.8835 & TRN \\
\hline
\end{tabular}




\begin{tabular}{|c|c|c|c|c|c|}
\hline \multirow{3}{*}{ CHEMBL 350914} & & \multicolumn{4}{|c|}{ Supplemental Table S2.txt } \\
\hline & 76063 & 5.585 & 5.45700 & 0000000001 & TRN \\
\hline & 76063 & 4.301 & 4.6367 & TRN & \\
\hline CHEMBL154360 & 76063 & 4.3372 & 4.7016 & TST & \\
\hline CHEMBL155543 & 76063 & 4.1675 & 4.4177 & TST & \\
\hline CHEMBL345766 & 76063 & 4.0223 & 4.7143 & TST & \\
\hline CHEMBL346469 & 76063 & 3.0 & 4.1829 & TST & \\
\hline CHEMBL154737 & 76063 & 4.4559 & 4.8126 & TRN & \\
\hline CHEMBL158022 & 76063 & 4.8539 & 4.685 & TST & \\
\hline CHEMBL345354 & 76063 & 5.3188 & 4.6373 & TRN & \\
\hline CHEMBL158292 & 76063 & 4.8861 & 4.8555 & TRN & \\
\hline CHEMBL155083 & 76063 & 4.699 & 4.9497 & TST & \\
\hline CHEMBL157835 & 76063 & 4.2291 & 4.5578 & TST & \\
\hline CHEMBL154029 & 76063 & 4.4815 & 4.4426 & TRN & \\
\hline CHEMBL345658 & 76063 & 4.5686 & 4.269 & TST & \\
\hline CHEMBL158247 & 76063 & 4.1675 & 4.6849 & TRN & \\
\hline CHEMBL154423 & 76063 & 4.4437 & 4.6646 & TRN & \\
\hline CHEMBL351335 & 76063 & 5.1549 & 4.7326 & TRN & \\
\hline CHEMBL348081 & 76063 & 4.4949 & 4.5419 & TST & \\
\hline CHEMBL347598 & 76063 & 5.2218 & 4.8976 & TRN & \\
\hline CHEMBL156223 & 76063 & 4.7447 & 4.3457 & TRN & \\
\hline CHEMBL347265 & 76063 & 4.0915 & 4.0873 & TST & \\
\hline CHEMBL 350014 & 76063 & 4.2596 & 4.522 & TST & \\
\hline CHEMBL3890801 & 1642243 & 9.0 & 8.9385 & TRN & \\
\hline CHEMBL3932746 & 1642243 & 8.301 & 8.3939 & TRN & \\
\hline CHEMBL3939528 & 1642243 & 8.0 & 7.8225 & TRN & \\
\hline CHEMBL3957565 & 1642243 & 7.6778 & 7.831 & TST & \\
\hline CHEMBL3954883 & 1642243 & 6.3089 & 6.1614 & TRN & \\
\hline CHEMBL3938558 & 1642243 & 8.3979 & 8.3674 & TRN & \\
\hline CHEMBL3961486 & 1642243 & 6.4559 & 6.4734 & TRN & \\
\hline CHEMBL3939163 & 1642243 & 7.1487 & 7.1891 & TRN & \\
\hline CHEMBL3964734 & 1642243 & 7.4815 & 7.0811 & TRN & \\
\hline CHEMBL3898050 & 1642243 & 7.9208 & 7.7731 & TRN & \\
\hline CHEMBL3961372 & 1642243 & 7.8861 & 7.9529 & TRN & \\
\hline CHEMBL 3893814 & 1642243 & 7.7212 & 7.5153 & TRN & \\
\hline CHEMBL3954482 & 1642243 & 8.3979 & 8.3595 & TRN & \\
\hline CHEMBL3898517 & 1642243 & 6.8633 & 7.3047 & TRN & \\
\hline CHEMBL 3955467 & 1642243 & 7.1675 & 7.2847 & TRN & \\
\hline CHEMBL3957497 & 1642243 & 8.301 & 8.4806 & TRN & \\
\hline CHEMBL3945928 & 1642243 & 6.9626 & 6.9575 & TRN & \\
\hline CHEMBL3914821 & 1642243 & 7.8239 & 8.2975 & TST & \\
\hline CHEMBL3896437 & 1642243 & 7.9208 & 7.9416 & TRN & \\
\hline CHEMBL3930339 & 1642243 & 8.1549 & 8.3449 & TRN & \\
\hline CHEMBL3905756 & 1642243 & 7.0915 & 7.6342 & TRN & \\
\hline CHEMBL 3945784 & 1642243 & 8.5229 & 8.6239 & TRN & \\
\hline CHEMBL 3943434 & 1642243 & 8.0458 & 8.258 & TRN & \\
\hline CHEMBL3895309 & 1642243 & 6.5817 & 6.3292 & TRN & \\
\hline CHEMBL3931563 & 1642243 & 6.6498 & 6.7442 & TRN & \\
\hline CHEMBL3902684 & 1642243 & 7.5376 & 6.722 & TST & \\
\hline
\end{tabular}


Supplemental Table S2.txt

\begin{tabular}{|c|c|c|c|c|}
\hline CHEMBL3965454 & 1642243 & 8.3979 & 8.7567 & TRN \\
\hline CHEMBL3905718 & 1642243 & 8.5229 & 8.5203 & TRN \\
\hline CHEMBL3929291 & 1642243 & 7.4318 & 7.1037 & TST \\
\hline CHEMBL3937710 & 1642243 & 7.3372 & 7.28299 & 99999999995 \\
\hline CHEMBL3912149 & 1642243 & 8.3979 & 8.4469 & TRN \\
\hline CHEMBL3908868 & 1642243 & 8.3979 & 8.3847 & TRN \\
\hline CHEMBL3942930 & 1642243 & 7.4949 & 7.6369 & TRN \\
\hline CHEMBL3965186 & 1642243 & 8.699 & 8.5916 & TRN \\
\hline CHEMBL3978976 & 1642243 & 6.9666 & 7.8244 & TST \\
\hline CHEMBL3944891 & 1642243 & 7.1079 & 6.9083 & TRN \\
\hline CHEMBL3975195 & 1642243 & 7.3565 & 7.7011 & TRN \\
\hline CHEMBL3891245 & 1642243 & 9.0 & 9.1384 & TRN \\
\hline CHEMBL3946337 & 1642243 & 8.0 & 7.6514 & TRN \\
\hline CHEMBL3907156 & 1642243 & 6.8297 & 7.0883 & TRN \\
\hline CHEMBL3983752 & 1642243 & 8.5229 & 8.4981 & TRN \\
\hline CHEMBL3966602 & 1642243 & 7.4685 & 7.4728 & TRN \\
\hline CHEMBL3945376 & 1642243 & 9.0 & 8.4761 & TRN \\
\hline CHEMBL3975701 & 1642243 & 8.699 & 8.7008 & TRN \\
\hline CHEMBL3953098 & 1642243 & 6.8729 & 6.8834 & TRN \\
\hline CHEMBL 3982702 & 1642243 & 8.0969 & 7.7412 & TST \\
\hline CHEMBL3959549 & 1642243 & 8.1549 & 7.8338 & TRN \\
\hline CHEMBL3929535 & 1642243 & 8.301 & 8.3903 & TRN \\
\hline CHEMBL3953246 & 1642243 & 6.7055 & 6.9558 & TRN \\
\hline CHEMBL3951108 & 1642243 & 7.8239 & 7.5986 & TRN \\
\hline CHEMBL3924970 & 1642243 & 6.8729 & 7.0441 & TRN \\
\hline CHEMBL3980191 & 1642243 & 7.5528 & 7.3835 & TRN \\
\hline CHEMBL3889760 & 1642243 & 8.3979 & 8.3177 & TST \\
\hline CHEMBL3949324 & 1642243 & 9.0 & 7.8464 & TST \\
\hline CHEMBL3986576 & 1642243 & 7.3098 & 7.36 & TRN \\
\hline CHEMBL 3941822 & 1642243 & 7.1079 & 6.9497 & TRN \\
\hline CHEMBL3975156 & 1642243 & 6.3883 & 6.5695 & TRN \\
\hline CHEMBL3909219 & 1642243 & 7.7959 & 7.9991 & TRN \\
\hline CHEMBL3923474 & 1642243 & 6.6676 & 6.4565 & TST \\
\hline CHEMBL3943292 & 1642243 & 6.5768 & 6.0379 & TST \\
\hline CHEMBL3935410 & 1642243 & 6.7986 & 6.7242 & TRN \\
\hline CHEMBL3898019 & 1642243 & 9.0 & 8.7701 & TRN \\
\hline CHEMBL3931999 & 1642243 & 8.0 & 7.9416 & TRN \\
\hline CHEMBL3904983 & 1642243 & 8.1549 & 8.0984 & TRN \\
\hline CHEMBL3936166 & 1642243 & 8.0 & 7.9393 & TRN \\
\hline CHEMBL3983033 & 1642243 & 6.4134 & 6.7657 & TST \\
\hline CHEMBL3964821 & 1642243 & 7.699 & 7.5829 & TRN \\
\hline CHEMBL3931007 & 1642243 & 8.301 & 7.9852 & TRN \\
\hline CHEMBL3903121 & 1642243 & 6.6655 & 7.0963 & TST \\
\hline CHEMBL3895046 & 1642243 & 6.8729 & 6.5347 & TST \\
\hline CHEMBL3925614 & 1642243 & 8.699 & 8.1384 & TRN \\
\hline CHEMBL3900132 & 1642243 & 9.3979 & 8.3639 & TST \\
\hline CHEMBL3913386 & 1642243 & 7.9208 & 7.854 & TRN \\
\hline CHEMBL3921306 & 1642243 & 8.5229 & 8.1419 & TST \\
\hline
\end{tabular}


Supplemental Table S2.txt

\begin{tabular}{|c|c|c|c|c|}
\hline CHEMBL3895139 & 1642243 & 7.6576 & 7.9745 & TRN \\
\hline CHEMBL3951621 & 1642243 & 8.301 & 8.4696 & TRN \\
\hline CHEMBL3901603 & 1642243 & 7.8239 & 7.4713 & TST \\
\hline CHEMBL 3942984 & 1642243 & 7.585 & 6.4025 & TST \\
\hline CHEMBL 3955464 & 1642243 & 6.7258 & 7.1772 & TRN \\
\hline CHEMBL3968215 & 1642243 & 6.8097 & 6.5364 & TRN \\
\hline CHEMBL 3904650 & 1642243 & 9.0 & 8.9541 & TRN \\
\hline CHEMBL 3913632 & 1642243 & 7.7212 & 6.7863 & TST \\
\hline CHEMBL 3929063 & 1642243 & 7.7959 & \multicolumn{2}{|c|}{7.7989999999999995} \\
\hline CHEMBL3933763 & 1642243 & 9.0 & 9.0842 & TRN \\
\hline CHEMBL3900703 & 1642243 & 5.6038 & 5.7072 & TRN \\
\hline CHEMBL 3934149 & 1642243 & 8.5229 & 8.7203 & TRN \\
\hline CHEMBL3895781 & 1642243 & 8.699 & 8.419 & TRN \\
\hline CHEMBL 3949928 & 1642243 & 8.5229 & 8.7461 & TST \\
\hline CHEMBL3912367 & 1642243 & 7.4318 & 7.57 & TRN \\
\hline CHEMBL3930531 & 1642243 & 8.1549 & 7.8951 & TRN \\
\hline CHEMBL 3976741 & 1642243 & 8.1549 & 7.7461 & TRN \\
\hline CHEMBL3889790 & 1642243 & 7.5528 & 7.5096 & TRN \\
\hline CHEMBL 3931800 & 1642243 & 7.5528 & 6.2951 & TST \\
\hline CHEMBL3963024 & 1642243 & 7.4559 & 7.2863 & TRN \\
\hline CHEMBL3958351 & 1642243 & 6.7011 & 5.7814 & TST \\
\hline CHEMBL3970923 & 1642243 & 8.301 & 8.3293 & TRN \\
\hline CHEMBL3961980 & 1642243 & 8.5229 & 8.5263 & TRN \\
\hline CHEMBL 3891528 & 1642243 & 8.699 & 8.0448 & TST \\
\hline CHEMBL3974085 & 1642243 & 9.0 & 9.2579 & TST \\
\hline CHEMBL3931021 & 1642243 & 8.699 & 8.6875 & TRN \\
\hline CHEMBL3943072 & 1642243 & 8.0969 & 8.3361 & TRN \\
\hline CHEMBL3972572 & 1642243 & 7.5528 & 7.1885 & TRN \\
\hline CHEMBL 3944375 & 1642243 & 6.9469 & 7.0912 & TRN \\
\hline CHEMBL3901696 & 1642243 & 9.0 & 8.2873 & TST \\
\hline CHEMBL3946762 & 1642243 & 8.2218 & 7.9152 & TRN \\
\hline CHEMBL3929642 & 1642243 & 7.2218 & 7.2634 & TRN \\
\hline CHEMBL3949036 & 1642243 & 5.8996 & 7.4559 & TST \\
\hline CHEMBL 3945886 & 1642243 & 8.699 & 8.5446 & TRN \\
\hline CHEMBL3924510 & 1642243 & 6.6517 & 5.8263 & TST \\
\hline CHEMBL3909462 & 1642243 & 9.0 & 9.0465 & TRN \\
\hline CHEMBL3954299 & 1642243 & 9.1549 & 9.3452 & TST \\
\hline CHEMBL3985336 & 1642243 & 8.5229 & 8.6209 & TRN \\
\hline CHEMBL 3928410 & 1642243 & 8.3979 & 8.3303 & TRN \\
\hline CHEMBL3977372 & 1642243 & 8.0 & 7.8575 & TRN \\
\hline CHEMBL3959885 & 1642243 & 7.6021 & 7.558 & TRN \\
\hline CHEMBL3891347 & 1642243 & 6.3655 & 6.2547 & TRN \\
\hline CHEMBL3906731 & 1642243 & 8.3979 & 8.422 & TRN \\
\hline CHEMBL3923595 & 1642243 & 7.3279 & 7.535 & TRN \\
\hline CHEMBL3945446 & 1642243 & 7.0132 & 6.7969 & TRN \\
\hline CHEMBL3928881 & 1642243 & 6.4045 & 6.5966 & TRN \\
\hline CHEMBL3934906 & 1642243 & 6.3546 & 6.8736 & TRN \\
\hline CHEMBL3929250 & 1642243 & 8.0969 & 8.4577 & TRN \\
\hline
\end{tabular}


Supplemental Table S2.txt

\begin{tabular}{|c|c|c|c|c|}
\hline CHEMBL3953263 & 1642243 & 7.7959 & 7.9078 & TRN \\
\hline CHEMBL3979738 & 1642243 & 8.699 & 8.7989 & TRN \\
\hline CHEMBL3980568 & 1642243 & 7.2441 & 7.33899 & 99999999995 \\
\hline CHEMBL 3952675 & 1642243 & 7.3372 & 7.6826 & TRN \\
\hline CHEMBL3947287 & 1642243 & 8.699 & 8.4176 & TRN \\
\hline CHEMBL3920848 & 1642243 & 6.3958 & 7.4729 & TST \\
\hline CHEMBL3943417 & 1642243 & 7.7447 & 7.6603 & TRN \\
\hline CHEMBL3911168 & 1642243 & 8.1549 & 8.3376 & TRN \\
\hline CHEMBL3915113 & 1642243 & 8.1549 & 8.2987 & TRN \\
\hline CHEMBL3985505 & 1642243 & 7.7696 & 7.7292 & TRN \\
\hline CHEMBL 3936280 & 1642243 & 5.9788 & 6.0991 & TRN \\
\hline CHEMBL3890201 & 1642243 & 6.7144 & 6.8061 & TRN \\
\hline CHEMBL3905861 & 1642243 & 9.2218 & 9.0023 & TRN \\
\hline CHEMBL3895237 & 1642243 & 8.3979 & 8.4426 & TRN \\
\hline CHEMBL3963899 & 1642243 & 7.2291 & 7.3177 & TST \\
\hline CHEMBL3952306 & 1642243 & 8.0969 & 7.2826 & TST \\
\hline CHEMBL3984762 & 1642243 & 8.0969 & 7.846 & TRN \\
\hline CHEMBL3937058 & 1642243 & 8.301 & 6.8224 & TST \\
\hline CHEMBL3900269 & 1642243 & 7.6198 & 7.2747 & TST \\
\hline CHEMBL3936954 & 1642243 & 7.8239 & 5.7171 & TST \\
\hline CHEMBL3967888 & 1642243 & 7.1938 & 7.1994 & TST \\
\hline CHEMBL3940029 & 1642243 & 7.1549 & 7.3643 & TRN \\
\hline CHEMBL3970605 & 1642243 & 8.3979 & 8.3139 & TRN \\
\hline CHEMBL3982292 & 1642243 & 6.7144 & 7.2812 & TRN \\
\hline CHEMBL3894595 & 1642243 & 8.1549 & 7.6728 & TST \\
\hline CHEMBL3980047 & 1642243 & 6.7545 & 6.8406 & TRN \\
\hline CHEMBL3910181 & 1642243 & 7.2076 & 6.9376 & TRN \\
\hline CHEMBL3956806 & 1642243 & 8.5229 & 8.3639 & TRN \\
\hline CHEMBL3935914 & 1642243 & 7.3872 & 7.4492 & TRN \\
\hline CHEMBL3940156 & 1642243 & 8.301 & 8.3587 & TRN \\
\hline CHEMBL3952150 & 1642243 & 7.2441 & 7.2226 & TRN \\
\hline CHEMBL3982103 & 1642243 & 8.5229 & 8.1454 & TRN \\
\hline CHEMBL3961370 & 1642243 & 6.3915 & 6.6145 & TRN \\
\hline CHEMBL3921107 & 1642243 & 8.5229 & 8.536 & TRN \\
\hline CHEMBL3946666 & 1642243 & 8.301 & 8.2992 & TRN \\
\hline CHEMBL3947371 & 1642243 & 7.0605 & 6.8001 & TRN \\
\hline CHEMBL3986373 & 1642243 & 7.3665 & 7.1155 & TRN \\
\hline CHEMBL3982357 & 1642243 & 7.7212 & 6.8753 & TST \\
\hline CHEMBL3933098 & 1642243 & 8.5229 & 8.1623 & TST \\
\hline CHEMBL3981109 & 1642243 & 9.0969 & 9.1705 & TRN \\
\hline CHEMBL3964463 & 1642243 & 8.2218 & 8.4246 & TRN \\
\hline CHEMBL3974141 & 1642243 & 8.5229 & 8.4656 & TRN \\
\hline CHEMBL3892512 & 1642243 & 8.699 & 8.4945 & TRN \\
\hline CHEMBL3894771 & 1642243 & 7.7447 & 7.41 & TRN \\
\hline CHEMBL3942868 & 1642243 & 7.8861 & 7.6849 & TRN \\
\hline CHEMBL3971643 & 1642243 & 8.0969 & 8.6338 & TST \\
\hline CHEMBL3902809 & 1642243 & 7.6383 & 7.8293 & TST \\
\hline CHEMBL3942058 & 1642243 & 7.5528 & 7.7569 & TRN \\
\hline
\end{tabular}


Supplemental Table S2.txt

\begin{tabular}{|c|c|c|c|c|}
\hline CHEMBL3959051 & 1642243 & 8.0969 & 7.9946 & TRN \\
\hline CHEMBL3911318 & 1642243 & 7.9586 & 8.1509 & TRN \\
\hline CHEMBL3957586 & 1642243 & 8.0458 & 7.8084 & TRN \\
\hline CHEMBL3968182 & 1642243 & 8.3979 & 8.5503 & TRN \\
\hline CHEMBL 3907074 & 1642243 & 9.0 & 7.9705 & TST \\
\hline CHEMBL3911655 & 1642243 & 8.5229 & 8.2673 & TRN \\
\hline CHEMBL3889555 & 1642243 & 9.2218 & 9.1467 & TRN \\
\hline CHEMBL 3983278 & 1642243 & 8.5229 & 8.5951 & TRN \\
\hline CHEMBL3983126 & 1642243 & 8.2218 & 8.0539 & TRN \\
\hline CHEMBL 3931892 & 1642243 & 7.9586 & 7.3636 & TST \\
\hline CHEMBL 3971504 & 1642243 & 8.699 & 8.4261 & TRN \\
\hline CHEMBL3956362 & 1642243 & 6.9172 & 7.0693 & TRN \\
\hline CHEMBL 3891911 & 1642243 & 7.1549 & 7.2795 & TRN \\
\hline CHEMBL3953273 & 1642243 & 8.1549 & 8.0882 & TST \\
\hline CHEMBL 3919580 & 1642243 & 6.5901 & 7.141 & TRN \\
\hline CHEMBL3889959 & 1642243 & 7.3979 & 7.3425 & TST \\
\hline CHEMBL3964538 & 1642243 & 8.2218 & 8.2783 & TRN \\
\hline CHEMBL3950794 & 1642243 & 8.5229 & 8.4833 & TST \\
\hline CHEMBL 3912430 & 1642243 & 7.0088 & 6.4988 & TST \\
\hline CHEMBL 3979700 & 1642243 & 7.4559 & 7.5066 & TRN \\
\hline CHEMBL3895899 & 1642243 & 7.8239 & 7.5598 & TRN \\
\hline CHEMBL3969962 & 1642243 & 6.0799 & 6.0997 & TRN \\
\hline CHEMBL3944072 & 1642243 & 6.1079 & 6.0959 & TRN \\
\hline CHEMBL 3986963 & 1642243 & 9.0 & 8.8897 & TRN \\
\hline CHEMBL 3889608 & 1642243 & 8.699 & 8.6987 & TRN \\
\hline CHEMBL 3897927 & 1642243 & 6.5186 & 6.254 & TST \\
\hline CHEMBL 3972023 & 1642243 & 7.7447 & 7.5637 & TRN \\
\hline CHEMBL3915132 & 1642243 & 7.8239 & 7.7278 & TST \\
\hline CHEMBL3901589 & 1642243 & 7.8539 & 7.4711 & TST \\
\hline CHEMBL3934550 & 1642243 & 7.8861 & 7.9277 & TRN \\
\hline CHEMBL 3921014 & 1642243 & 8.699 & 8.6391 & TRN \\
\hline CHEMBL 3985828 & 1642243 & 8.2218 & 8.4943 & TRN \\
\hline CHEMBL3911787 & 1642243 & 9.0458 & 9.1166 & TRN \\
\hline CHEMBL3970899 & 1642243 & 6.4056 & 6.4754 & TRN \\
\hline CHEMBL3963330 & 1642243 & 6.9208 & 8.3201 & TST \\
\hline CHEMBL 3928082 & 1642243 & 7.0655 & 6.0912 & TST \\
\hline CHEMBL 3929887 & 1642243 & 7.1675 & 6.9044 & TRN \\
\hline CHEMBL3950776 & 1642243 & 8.699 & 8.6039 & TRN \\
\hline CHEMBL 3907656 & 1642243 & 8.2218 & 6.88 & TST \\
\hline CHEMBL 3941772 & 1642243 & 7.9208 & 8.0803 & TRN \\
\hline CHEMBL 3906672 & 1642243 & 7.8861 & 7.8671 & TRN \\
\hline CHEMBL3910481 & 1642243 & 6.7773 & 6.7122 & TST \\
\hline CHEMBL3910470 & 1642243 & 7.3979 & 7.5465 & TRN \\
\hline CHEMBL 3963500 & 1642243 & 8.301 & 8.2434 & TRN \\
\hline CHEMBL 3974670 & 1642243 & 8.699 & \multicolumn{2}{|c|}{ 8. 302999999999999} \\
\hline CHEMBL 3918991 & 1642243 & 7.4815 & 7.0715 & TST \\
\hline CHEMBL 3926761 & 1642243 & 8.3979 & 8.3827 & TRN \\
\hline CHEMBL 3900383 & 1642243 & 7.0605 & 7.1699 & TRN \\
\hline
\end{tabular}


Supplemental Table S2.txt

\begin{tabular}{|c|c|c|c|c|}
\hline 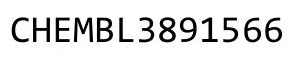 & & & & \\
\hline HEMBL3946013 & 642243 & 8.3979 & 8.5104 & \\
\hline & 243 & & & \\
\hline 214 & 243 & & 29 & \\
\hline IEMBL3922915 & 542243 & 1986 & 3297 & \\
\hline HEMBL3971888 & 642243 & 7.2924 & .7504 & \\
\hline HEMBL397 & 243 & 8.5229 & .5228 & \\
\hline 55 & 43 & & 676 & \\
\hline EMBL 396 & 243 & 58 & .1697 & \\
\hline HEMBL3937477 & 243 & 8.2218 & .9029 & \\
\hline HEMBL 3984938 & 243 & 7.585 & 4933 & \\
\hline HEMBL393 & 43 & 696 & 192 & \\
\hline 795 & & & & \\
\hline HEMBL3S & 43 & 208 & .0767 & \\
\hline AEMBL3923352 & 43 & 861 & 9947 & \\
\hline AEMBL3925289 & 43 & 9969 & 16 & \\
\hline AEMBL3S & 13 & 685 & 781 & \\
\hline HEMBL3S & & & & \\
\hline HEMBL3\& & & & 7.2243 & \\
\hline AEMBL39 & 43 & & & \\
\hline AEMBL3923212 & +3 & 7. & 7.6514 & \\
\hline HEMBL3S & 43 & 29 & 5392 & \\
\hline HEMBL3\& & & 79 & 66 & \\
\hline 127 & & 59 & 1848 & 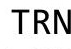 \\
\hline AEMBL3S & & & & RIV \\
\hline HEMBL & 43 & 6 & 98 & RN \\
\hline AEMBL3S & 43 & 83 & 17 & - \\
\hline 143 & & & 82 & RN \\
\hline HEMBL3 & 43 & & 7.3873 & RIN \\
\hline AEMBL3S & -3 & 7. & 35 & SI \\
\hline AEMBL3S & & & 051 & $\mathrm{RN}$ \\
\hline AEMBL 39 & & 12 & 113 & NIV \\
\hline 11 & & & 995 & RN \\
\hline HEMBL39 & & & & RN \\
\hline HEMBL 3944176 & 6 & 177 & 617 & RN \\
\hline HEMBL3 & 6 & & 284 & \\
\hline HEMRI & & 9 & 64 & RN \\
\hline 40 & & 9. & & RN \\
\hline HEMBL3890013 & 43 & 8.22 & 8.1915 & RN \\
\hline AEMBL39 & 6 & 626 & 6.8505 & RN \\
\hline HEMBL39 & 64 & 8 & 7.7777 & RN \\
\hline HEMBL39 & & & & RN \\
\hline HEMBL3958458 & 43 & 8.5229 & 7.4361 & ST \\
\hline HEMBL3892003 & 43 & 7.0809 & 7.8831 & ST \\
\hline EMBL3S & & & 8.4713 & R \\
\hline HEMBL39 & 164 & 8.0969 & 3.2996 & \\
\hline CHEMBL 39 & 164 & 8.301 & 8.1185 & \\
\hline CHEMBL3923052 & 1642243 & 8.699 & 8.9642 & \\
\hline
\end{tabular}


Supplemental Table S2.txt

\begin{tabular}{|c|c|c|c|c|c|}
\hline CHEMBL3975646 & 1642243 & 7.4437 & 7.3809 & TRN & \\
\hline CHEMBL3981571 & 1642243 & 8.3979 & 8.5691 & TRN & \\
\hline CHEMBL3901386 & 1642243 & 9.2218 & 8.9503 & TRN & \\
\hline CHEMBL3928462 & 1642243 & 8.301 & 8.0278 & TRN & \\
\hline CHEMBL3919039 & 1642243 & 8.2218 & 7.9417 & TRN & \\
\hline CHEMBL3962099 & 1642243 & 7.4437 & 7.6664 & TRN & \\
\hline CHEMBL3930062 & 1642243 & 5.9066 & 5.8491 & TRN & \\
\hline CHEMBL3959048 & 1642243 & 7.7447 & 7.9317 & TRN & \\
\hline CHEMBL3929790 & 1642243 & 8.301 & 8.1147 & TRN & \\
\hline CHEMBL3929817 & 1642243 & 7.3468 & 6.9023 & TRN & \\
\hline CHEMBL3963616 & 1642243 & 9.0458 & 9.0591 & TRN & \\
\hline CHEMBL3963631 & 1642243 & 8.699 & 7.521 & TST & \\
\hline CHEMBL3941353 & 1642243 & 9.0 & 8.2222 & TST & \\
\hline CHEMBL3894937 & 1642243 & 7.3979 & 7.1604 & TRN & \\
\hline CHEMBL3916030 & 1642243 & 9.0 & 9.0824 & TRN & \\
\hline CHEMBL3957872 & 1642243 & 6.3768 & 6.352 & TRN & \\
\hline CHEMBL3970913 & 1642243 & 6.7423 & 6.6399 & TRN & \\
\hline CHEMBL3983113 & 1642243 & 7.3768 & 7.1978 & TRN & \\
\hline CHEMBL3954282 & 1642243 & 7.1024 & 7.3443 & TRN & \\
\hline CHEMBL3908344 & 1642243 & 6.61799 & 99999999 & 7.2267 & TRN \\
\hline CHEMBL3950669 & 1642243 & 8.699 & 8.5927 & TRN & \\
\hline CHEMBL 3984097 & 1642243 & 6.5171 & 6.4039 & TRN & \\
\hline CHEMBL3940498 & 1642243 & 6.2782 & 6.406006 & 0000000001 & TRN \\
\hline CHEMBL3905071 & 1642243 & 8.3979 & 8.5479 & TRN & \\
\hline CHEMBL 3894448 & 1642243 & 8.0969 & 7.9081 & TRN & \\
\hline CHEMBL3960638 & 1642243 & 8.699 & 8.8238 & TRN & \\
\hline CHEMBL3936492 & 1642243 & 8.3979 & 7.6904 & TRN & \\
\hline CHEMBL3924230 & 1642243 & 8.5229 & 8.7151 & TRN & \\
\hline CHEMBL3984689 & 1642243 & 6.9172 & 6.954 & TRN & \\
\hline CHEMBL3941011 & 1642243 & 7.0915 & 7.2311 & TST & \\
\hline CHEMBL3900338 & 1642243 & 8.5229 & 8.5463 & TRN & \\
\hline CHEMBL 3890312 & 1642243 & 8.0 & 7.6514 & TRN & \\
\hline CHEMBL3969034 & 1642243 & 9.0969 & 9.3002 & TRN & \\
\hline CHEMBL3908701 & 1642243 & 6.7545 & 6.7822 & TST & \\
\hline CHEMBL3917109 & 1642243 & 7.6383 & 7.7661 & TRN & \\
\hline CHEMBL3978762 & 1642243 & 8.1549 & 8.3479 & TRN & \\
\hline CHEMBL3961653 & 1642243 & 8.2218 & 7.3177 & TST & \\
\hline CHEMBL3934774 & 1642243 & 7.8861 & 8.0077 & TRN & \\
\hline CHEMBL 3899432 & 1642243 & 8.0 & 8.1776 & TRN & \\
\hline CHEMBL3947322 & 1642243 & 6.6596 & 7.1116 & TRN & \\
\hline CHEMBL3953828 & 1642243 & 9.0 & 8.7375 & TRN & \\
\hline CHEMBL3937850 & 1642243 & 6.0 & 7.9657 & TRN & \\
\hline CHEMBL3944347 & 1642243 & 8.5229 & 8.6332 & TRN & \\
\hline CHEMBL3969117 & 1642243 & 6.3893 & 7.3405 & TST & \\
\hline CHEMBL3944977 & 1642243 & 8.3979 & \multicolumn{2}{|c|}{8.437000000000001} & TRN \\
\hline CHEMBL3936127 & 1642243 & 8.3979 & 8.1742 & TRN & \\
\hline CHEMBL3964181 & 1642243 & 8.2218 & 8.1639 & TRN & \\
\hline CHEMBL3956071 & 1642243 & 8.301 & 8.3443 & TRN & \\
\hline
\end{tabular}


Supplemental Table S2.txt

\begin{tabular}{|c|c|c|}
\hline & & \\
\hline HEMBL3985560 & 642243 & 8861 \\
\hline & & \\
\hline EMBL & 2243 & 362 \\
\hline UEMBL3941577 & 642243 & 8.154 \\
\hline HEMBL3931816 & 642243 & 8.221 \\
\hline HEMBL3914360 & 243 & .8539 \\
\hline 7708 & & \\
\hline EMBL 3898712 & 243 & 8.397 \\
\hline AEMBL3962062 & 243 & 7.60 \\
\hline HEMBL3961087 & 243 & 7.82 \\
\hline AEMBL3986916 & 43 & 6.838 \\
\hline IEMBL 3902012 & & 408 \\
\hline AEMBL3948330 & & 6.7423 \\
\hline AEMBL3956125 & 43 & 7.585 \\
\hline AEMBL3946422 & 43 & 148 \\
\hline HEMBL3982018 & +3 & 9 \\
\hline HEMBL3895018 & & 397 \\
\hline HEMBL3982167 & & 6.7399 \\
\hline HEMBL396 & 43 & 585 \\
\hline AEMBL3983662 & 43 & 229 \\
\hline HEMBL39 & +3 & 22 \\
\hline HEMBL39 & & 599 \\
\hline 3619 & & $\partial 969$ \\
\hline AEMBL39 & 43 & 8 \\
\hline AEMBL3983668 & 16 & 8 \\
\hline AEMBL39 & +3 & 5229 \\
\hline HEMBL3S & & 7 \\
\hline HEMBL39 & & \\
\hline HEMBL 397 & +3 & 7. \\
\hline HEMBL3904182 & 16 & 7.9208 \\
\hline AEMBL39 & 6 & 2441 \\
\hline 534 & 43 & 8.5229 \\
\hline HEMBL3909514 & 16 & 8.301 \\
\hline HEMBL3890373 & 16 & 7.823 \\
\hline HEMBL3924251 & 16 & 301 \\
\hline HEMBL39 & 16 & 2733 \\
\hline HEMBL3920616 & 16 & 9.301 \\
\hline HEMBL3980028 & 16 & 5.556 \\
\hline HEMBL3912608 & 16 & 8.301 \\
\hline CHEMBL3959846 & 164 & 9 \\
\hline CHEMBL3945528 & 164 & 8.699 \\
\hline HEMBL3932343 & 16 & 7.2441 \\
\hline HEMBL3914665 & 164 & 7.552 \\
\hline EMBL 391 & 64 & 7.8539 \\
\hline CHEMBL 3905974 & 164 & 7.769 \\
\hline CHEMBL3918536 & 1642243 & .790 \\
\hline CHEMBL3963833 & 1642243 & 9.0 \\
\hline
\end{tabular}

\begin{tabular}{ll}
9.133 & TRN \\
8.057 & TRN \\
7.6488 & TST \\
7.6894 & TST \\
8.2111 & TRN \\
7.5153 & TRN \\
8.0144 & TRN \\
6.6658 & TRN \\
7.7155 & TRN \\
7.4505 & TRN \\
7.5554 & TRN \\
7.0289 & TST \\
7.5664 & TRN \\
7.3847 & TST \\
8.0623 & TST \\
7.3589 & TRN \\
9.156 & TRN \\
8.4987 & TRN \\
6.7855 & TRN \\
7.7976 & TRN \\
8.6193 & TRN \\
7.1364 & TRN \\
7.9142 & TST \\
7.6152 & TST \\
8.1098 & TRN \\
8.2635 & TRN \\
7.572 & TST \\
7.9538 & TRN \\
7.8378 & TST \\
7.1773 & TRN \\
7.9472 & TRN \\
7.1784 & TRN \\
8.8958 & TRN \\
8.0596 & TST \\
7.7179 & TST \\
7.7854 & TRN \\
8.3865 & TRN \\
6.8242 & TST \\
9.0835 & TRN \\
6.7998 & TST \\
8.3969 & TRN \\
8.6771 & TRN \\
8.1757 & TST \\
7.9486 & TST \\
7.909 & TST \\
7.814 & TRN \\
\hline & TRN \\
\hline
\end{tabular}

Page 3781 


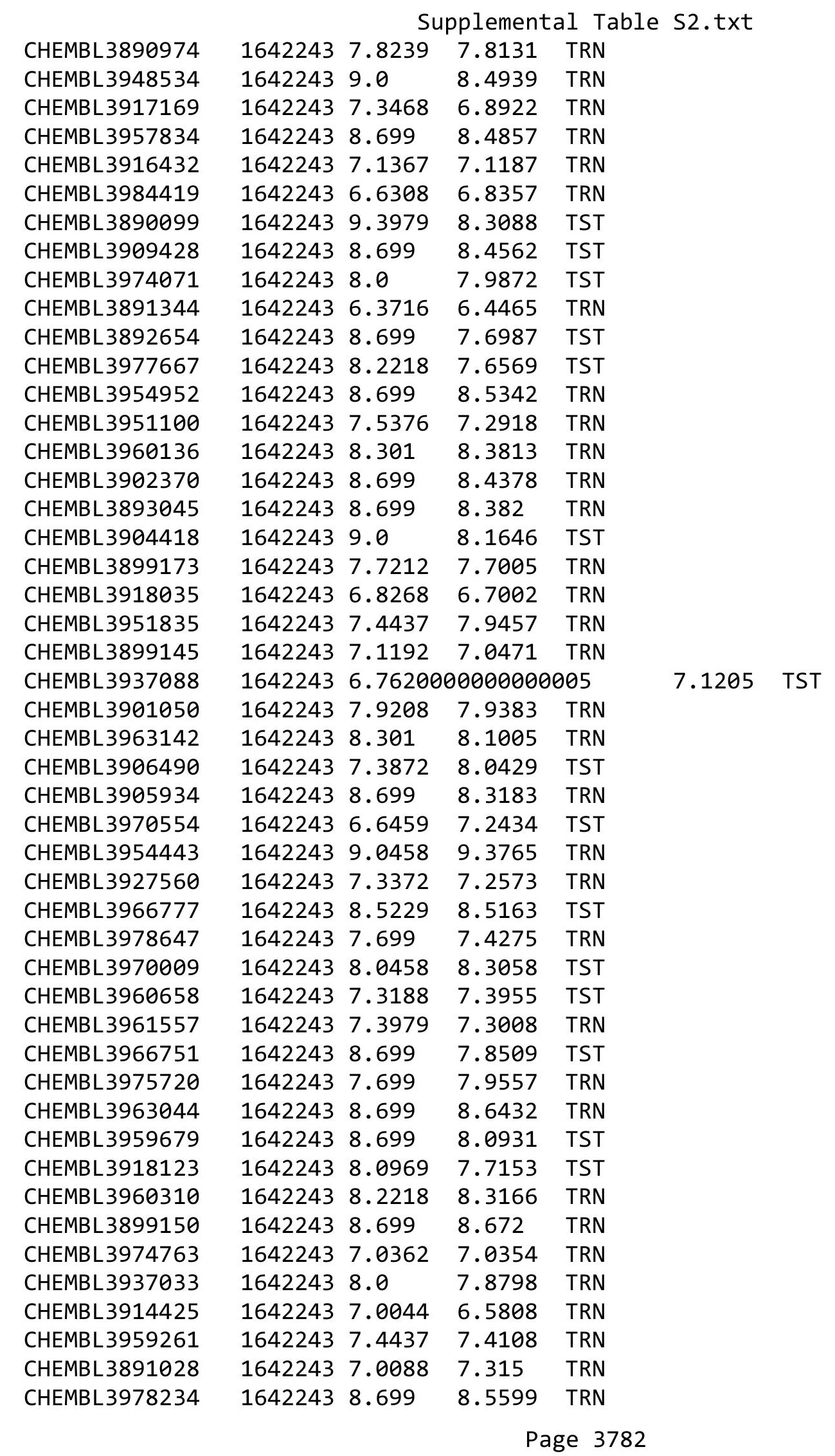


Supplemental Table S2.txt

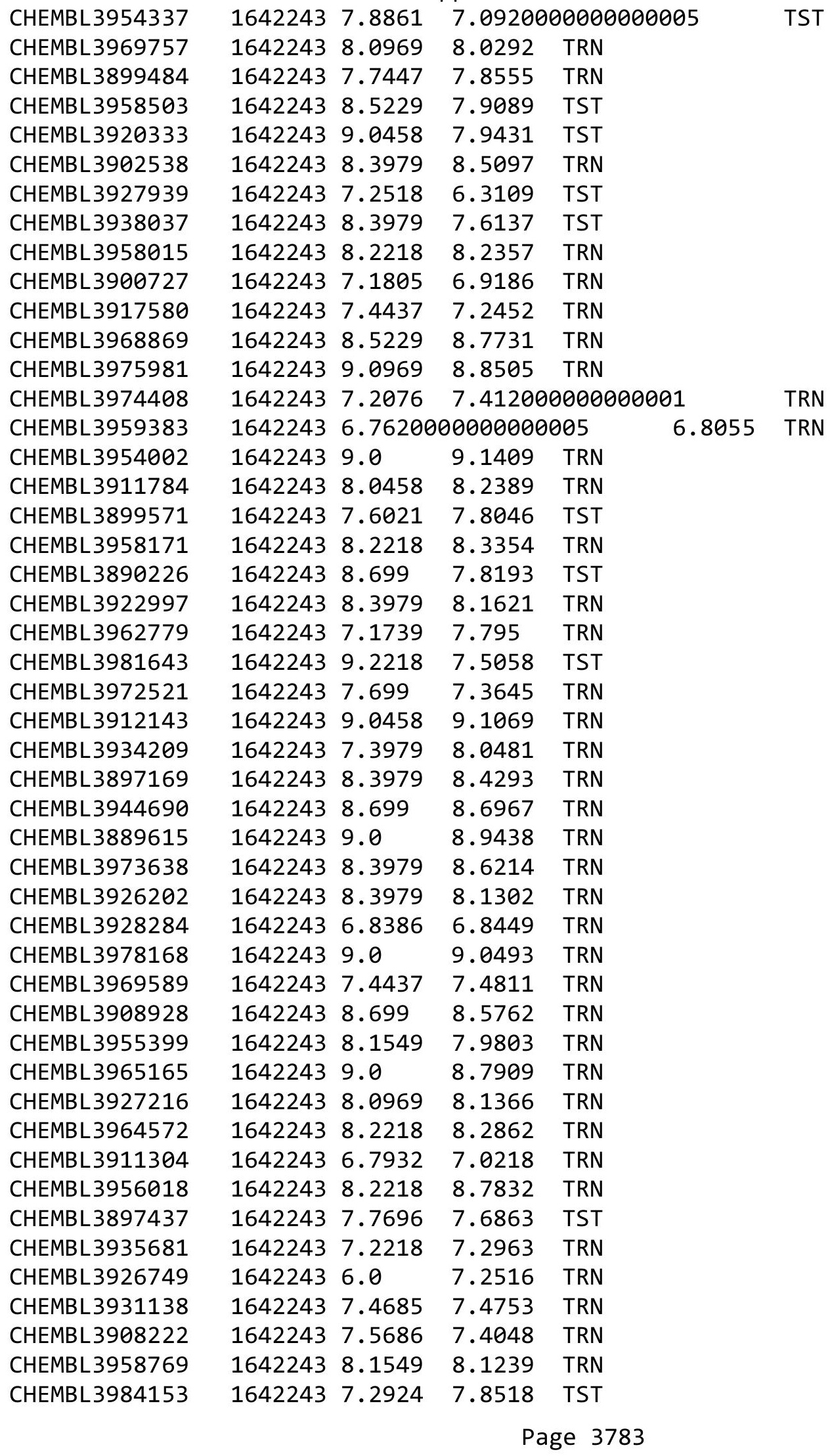


Supplemental Table S2.txt

\begin{tabular}{|c|c|c|c|c|c|c|}
\hline CHEMBL3941835 & 1642243 & 7.3565 & 7.3452 & TST & & \\
\hline CHEMBL3935694 & 1642243 & 7.4089 & 7.3635 & TRN & & \\
\hline CHEMBL3916838 & 1642243 & 6.6536 & 7.7376 & TST & & \\
\hline CHEMBL3910070 & 1642243 & 7.1938 & 7.1527 & TRN & & \\
\hline CHEMBL3946330 & 1642243 & 7.7212 & 7.9523 & TRN & & \\
\hline CHEMBL3942373 & 1642243 & 7.2291 & 6.9227 & TRN & & \\
\hline CHEMBL3960767 & 1642243 & 9.0458 & 9.088 & TRN & & \\
\hline CHEMBL3972507 & 1642243 & 8.5229 & 7.5144 & TST & & \\
\hline CHEMBL 3901900 & 1642243 & 6.8447 & 7.1411 & TRN & & \\
\hline CHEMBL3922992 & 1642243 & 8.5229 & 8.7343 & TRN & & \\
\hline CHEMBL3959405 & 1642243 & 6.5452 & 6.8131 & TRN & & \\
\hline CHEMBL 3945184 & 1642243 & 9.0458 & 7.8815 & TST & & \\
\hline CHEMBL3897863 & 1642243 & 6.6615 & 6.3274 & TRN & & \\
\hline CHEMBL3928319 & 1642243 & 8.301 & 8.1568 & TRN & & \\
\hline CHEMBL3979681 & 1642243 & 9.0 & 8.9821 & TST & & \\
\hline CHEMBL3902246 & 1642243 & 7.2218 & 7.2882 & TRN & & \\
\hline CHEMBL3957463 & 1642243 & 8.301 & 7.5877 & TST & & \\
\hline CHEMBL3932597 & 1642243 & 8.301 & 7.9675 & TST & & \\
\hline CHEMBL3914650 & 1642243 & 6.8239 & 6.8244 & TRN & & \\
\hline CHEMBL3934904 & 1642243 & 7.1938 & 7.7498 & TST & & \\
\hline CHEMBL3936948 & 1642243 & 8.699 & 8.4571 & TRN & & \\
\hline CHEMBL3983927 & 1642243 & 7.0605 & 6.9294 & TST & & \\
\hline CHEMBL3933343 & 1642243 & 7.3665 & 7.5561 & TRN & & \\
\hline CHEMBL 3980560 & 1642243 & 7.6778 & 7.4239 & TST & & \\
\hline CHEMBL3983592 & 1642243 & 7.7959 & 7.6982 & TST & & \\
\hline CHEMBL3902768 & 1642243 & 7.585 & 7.5257 & TRN & & \\
\hline CHEMBL3918951 & 1642243 & 7.4685 & 7.5739 & TRN & & \\
\hline CHEMBL3906940 & 1642243 & 6.9914 & 7.3277 & TRN & & \\
\hline CHEMBL3957679 & 1642243 & 8.699 & 8.3203 & TRN & & \\
\hline CHEMBL3937328 & 1642243 & 7.6778 & 7.9409 & TRN & & \\
\hline CHEMBL3925733 & 1642243 & 8.301 & 7.9724 & TST & & \\
\hline CHEMBL3984015 & 1642243 & 8.0 & 7.7521 & TST & & \\
\hline CHEMBL3951562 & 1642243 & 8.3979 & 8.2254 & TRN & & \\
\hline CHEMBL 3922447 & 1642243 & 7.7212 & 7.6948 & TRN & & \\
\hline CHEMBL3935099 & 1642243 & \multicolumn{3}{|c|}{6.327000000000001} & 6.2785 & TRN \\
\hline CHEMBL3917209 & 1642243 & 8.2218 & 8.391 & TST & & \\
\hline CHEMBL1964290 & 809155 & 6.0 & 6.3473 & TRN & & \\
\hline CHEMBL2003768 & 809155 & 4.0 & 3.7717 & TRN & & \\
\hline CHEMBL213505 & 809155 & 4.0 & 3.9032 & TRN & & \\
\hline CHEMBL1982880 & 809155 & 5.4 & 4.6909 & TRN & & \\
\hline CHEMBL1987034 & 809155 & 7.1 & 6.9928 & TRN & & \\
\hline CHEMBL1993941 & 809155 & 5.3 & 4.2747 & TRN & & \\
\hline CHEMBL377383 & 809155 & 5.3 & 5.1605 & TRN & & \\
\hline CHEMBL 2005886 & 809155 & 4.0 & 5.1105 & TRN & & \\
\hline CHEMBL481491 & 809155 & 4.0 & 3.8734 & TST & & \\
\hline CHEMBL1682345 & 809155 & 5.4 & 4.4556 & TRN & & \\
\hline CHEMBL1973142 & 809155 & 5.8 & 5.5138 & TRN & & \\
\hline CHEMBL1973145 & 809155 & 4.0 & 4.7115 & TRN & & \\
\hline
\end{tabular}




\begin{tabular}{|c|c|c|c|c|c|}
\hline \multicolumn{6}{|c|}{ Supplemental Table S2.txt } \\
\hline CHEMBL1982924 & 809155 & 5.7 & 5.5316 & TRN & \\
\hline CHEMBL 2005936 & 809155 & 5.2 & 5.2406 & TRN & \\
\hline CHEMBL1807515 & 809155 & 7.6 & 7.9243 & TRN & \\
\hline CHEMBL1971141 & 809155 & 4.0 & 4.1492 & TRN & \\
\hline CHEMBL1995813 & 809155 & 6.3 & 7.1786 & TRN & \\
\hline CHEMBL1979718 & 809155 & 4.0 & 4.7942 & TRN & \\
\hline CHEMBL206236 & 809155 & 5.3 & 4.3322 & TRN & \\
\hline CHEMBL523823 & 809155 & 4.0 & 4.2558 & TST & \\
\hline CHEMBL1562756 & 809155 & 4.0 & 4.5599 & TST & \\
\hline CHEMBL 244378 & 809155 & 7.4 & 7.8807 & TRN & \\
\hline CHEMBL2001957 & 809155 & 5.9 & 5.6551 & TRN & \\
\hline CHEMBL1969372 & 809155 & 5.7 & 6.0673 & TRN & \\
\hline CHEMBL1990583 & 809155 & 4.0 & 5.0336 & TRN & \\
\hline CHEMBL1986943 & 809155 & 7.7 & 7.7815 & TRN & \\
\hline CHEMBL 2006263 & 809155 & 6.0 & 5.0354 & TST & \\
\hline CHEMBL1993584 & 809155 & 4.0 & 4.8418 & TRN & \\
\hline CHEMBL1986263 & 809155 & 7.9 & 7.0312 & TRN & \\
\hline CHEMBL 2000114 & 809155 & 5.5 & 5.3799 & TRN & \\
\hline CHEMBL 210618 & 809155 & 5.3 & 4.6212 & TRN & \\
\hline CHEMBL1975647 & 809155 & 4.0 & 4.9566 & TRN & \\
\hline CHEMBL1968380 & 809155 & 6.5 & 5.9491 & TRN & \\
\hline CHEMBL1964644 & 809155 & 4.0 & 4.0155 & TRN & \\
\hline CHEMBL1981782 & 809155 & 5.7 & 5.0087 & TRN & \\
\hline CHEMBL1977681 & 809155 & 6.9 & 6.1115 & TRN & \\
\hline CHEMBL1970142 & 809155 & 4.0 & 4.6939 & TRN & \\
\hline CHEMBL1990912 & 809155 & 4.0 & 5.4387 & TRN & \\
\hline CHEMBL1988163 & 809155 & 6.7 & 6.8118 & TRN & \\
\hline CHEMBL1995592 & 809155 & 5.6 & 5.0224 & TST & \\
\hline CHEMBL 2006493 & 809155 & 4.0 & 4.0424 & TST & \\
\hline CHEMBL1996923 & 809155 & 4.0 & 3.9603 & TST & \\
\hline CHEMBL1983449 & 809155 & 4.0 & 3.7954 & TRN & \\
\hline CHEMBL1992323 & 809155 & 4.0 & 4.0006 & TRN & \\
\hline CHEMBL1969735 & 809155 & 6.1 & 5.8771 & TRN & \\
\hline CHEMBL 2003524 & 809155 & 5.3 & 4.4804 & TST & \\
\hline CHEMBL2002649 & 809155 & 6.0 & 5.0106 & TRN & \\
\hline CHEMBL437747 & 809155 & 8.1 & 5.7878 & TRN & \\
\hline CHEMBL1995172 & 809155 & 4.0 & 4.1106 & TST & \\
\hline CHEMBL507936 & 809155 & 4.0 & 4.3212 & TRN & \\
\hline CHEMBL104264 & 809155 & 6.0 & 4.9465 & TST & \\
\hline CHEMBL1994321 & 809155 & 4.0 & 5.0672 & TRN & \\
\hline CHEMBL1997129 & 809155 & 8.1 & 7.4376 & TRN & \\
\hline CHEMBL1984788 & 809155 & 4.0 & 4.3457 & TRN & \\
\hline CHEMBL451964 & 809155 & 4.0 & 4.67399 & 99999999995 & TRN \\
\hline CHEMBL1964307 & 809155 & 4.0 & 4.7148 & TRN & \\
\hline CHEMBL 2000508 & 809155 & 5.9 & 5.8674 & TRN & \\
\hline CHEMBL1971694 & 809155 & 4.0 & 3.97899 & 99999999996 & TST \\
\hline CHEMBL 2001547 & 809155 & 4.0 & 5.1445 & TRN & \\
\hline CHEMBL 210928 & 809155 & 4.0 & 4.5506 & TRN & \\
\hline
\end{tabular}




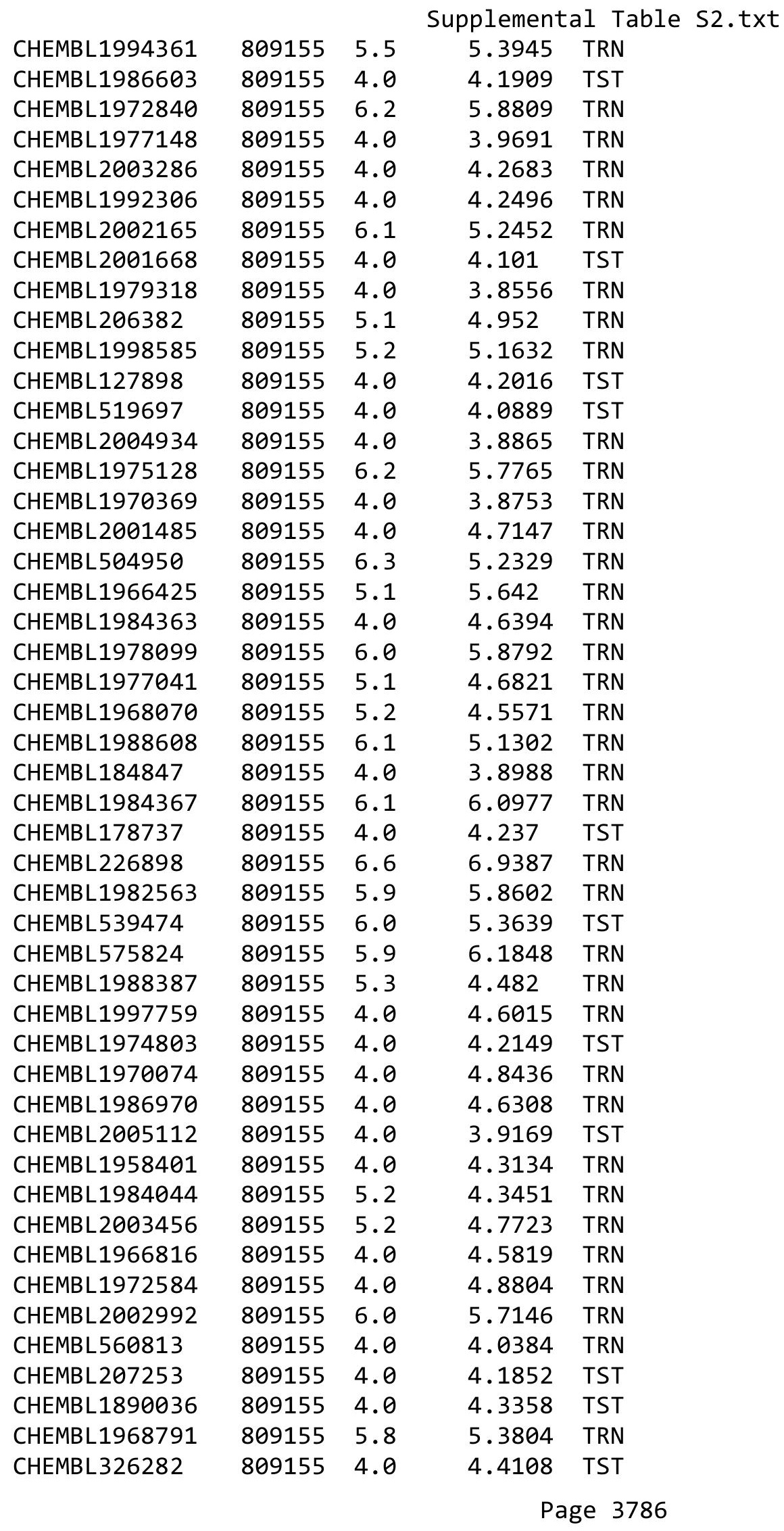




\begin{tabular}{|c|c|c|c|c|c|}
\hline \multicolumn{6}{|c|}{ Supplemental Table S2.txt } \\
\hline CHEMBL 2002682 & 809155 & 4.0 & 5.1851 & TST & \\
\hline CHEMBL1992732 & 809155 & 4.0 & 4.3734 & TST & \\
\hline CHEMBL1971186 & 809155 & 7.1 & 6.3577 & TRN & \\
\hline CHEMBL 2003482 & 809155 & 4.0 & 4.0576 & TRN & \\
\hline CHEMBL1973211 & 809155 & 5.5 & 5.2373 & TRN & \\
\hline CHEMBL1984700 & 809155 & 4.0 & 5.1855 & TRN & \\
\hline CHEMBL 2007151 & 809155 & 5.0 & 5.2541 & TRN & \\
\hline CHEMBL1972125 & 809155 & 5.5 & 5.1551 & TRN & \\
\hline CHEMBL1461728 & 809155 & 4.0 & 4.0727 & TRN & \\
\hline CHEMBL1976134 & 809155 & 5.9 & 5.5744 & TRN & \\
\hline CHEMBL1965131 & 809155 & 5.7 & 5.6301 & TRN & \\
\hline CHEMBL1995448 & 809155 & 4.0 & 5.2896 & TRN & \\
\hline CHEMBL1972158 & 809155 & 5.2 & 5.3599 & TRN & \\
\hline CHEMBL1974457 & 809155 & 4.0 & 5.0559 & TRN & \\
\hline CHEMBL 2006580 & 809155 & 4.0 & 4.6611 & TRN & \\
\hline CHEMBL 2006581 & 809155 & 5.9 & 5.53100 & 0000000001 & TRN \\
\hline CHEMBL 2006481 & 809155 & 4.0 & 3.8936 & TRN & \\
\hline CHEMBL1979855 & 809155 & 4.0 & 3.9483 & TRN & \\
\hline CHEMBL1970340 & 809155 & 5.1 & 4.2198 & TRN & \\
\hline CHEMBL 2005186 & 809155 & 4.0 & 5.0794 & TRN & \\
\hline CHEMBL1995927 & 809155 & 4.0 & 3.9655 & TST & \\
\hline CHEMBL1975534 & 809155 & 5.4 & 5.2751 & TRN & \\
\hline CHEMBL1993424 & 809155 & 5.7 & 5.9921 & TRN & \\
\hline CHEMBL1966703 & 809155 & 4.0 & 4.3134 & TST & \\
\hline CHEMBL1969561 & 809155 & 5.5 & 4.197 & TRN & \\
\hline CHEMBL1975121 & 809155 & 4.0 & 3.8868 & TRN & \\
\hline CHEMBL1997023 & 809155 & 4.0 & 4.0284 & TST & \\
\hline CHEMBL1964687 & 809155 & 4.0 & 4.9451 & TRN & \\
\hline CHEMBL1971943 & 809155 & 5.7 & 5.027 & TRN & \\
\hline CHEMBL1999918 & 809155 & 5.8 & 5.2705 & TRN & \\
\hline CHEMBL1974254 & 809155 & 4.0 & 4.2805 & TRN & \\
\hline CHEMBL1988537 & 809155 & 5.5 & 4.9936 & TST & \\
\hline CHEMBL1969049 & 809155 & 4.0 & 3.8827 & TRN & \\
\hline CHEMBL 2005828 & 809155 & 5.1 & 4.2744 & TRN & \\
\hline CHEMBL 2002240 & 809155 & 4.0 & 4.1792 & TRN & \\
\hline CHEMBL1991143 & 809155 & 4.0 & 4.0326 & TST & \\
\hline CHEMBL1998611 & 809155 & 5.9 & 5.3851 & TRN & \\
\hline CHEMBL485556 & 809155 & 4.0 & 4.3944 & TST & \\
\hline CHEMBL1975900 & 809155 & 5.1 & 3.8608 & TRN & \\
\hline CHEMBL 255822 & 809155 & 5.4 & 4.7232 & TRN & \\
\hline CHEMBL1972221 & 809155 & 4.0 & 4.0681 & TRN & \\
\hline CHEMBL 2006778 & 809155 & 6.1 & 5.5367 & TRN & \\
\hline CHEMBL378627 & 809155 & 5.8 & 5.6347 & TRN & \\
\hline CHEMBL1996979 & 809155 & 6.2 & 5.9101 & TRN & \\
\hline CHEMBL1997025 & 809155 & 5.6 & 5.1377 & TRN & \\
\hline CHEMBL1968406 & 809155 & 4.0 & 5.0103 & TRN & \\
\hline CHEMBL1982476 & 809155 & 5.9 & 4.6045 & TRN & \\
\hline CHEMBL1984274 & 809155 & 4.0 & 4.747 & TST & \\
\hline
\end{tabular}




\begin{tabular}{|c|c|c|c|c|}
\hline \multicolumn{5}{|c|}{ Supplemental Table S2.txt } \\
\hline CHEMBL1998545 & 809155 & 4.0 & 3.8054 & TRN \\
\hline CHEMBL1986869 & 809155 & 4.0 & 4.5742 & TRN \\
\hline CHEMBL 2006010 & 809155 & 4.0 & 3.7932 & TRN \\
\hline CHEMBL1682558 & 809155 & 5.1 & 4.3891 & TRN \\
\hline CHEMBL1990496 & 809155 & 8.2 & 6.1017 & TRN \\
\hline CHEMBL1997623 & 809155 & 4.0 & 4.3274 & TRN \\
\hline CHEMBL 2002479 & 809155 & 5.5 & 5.8488 & TRN \\
\hline CHEMBL1993166 & 809155 & 6.0 & 4.6605 & TRN \\
\hline CHEMBL1967094 & 809155 & 6.7 & 6.2455 & TRN \\
\hline CHEMBL1966035 & 809155 & 4.0 & 3.8376 & TRN \\
\hline CHEMBL 2003341 & 809155 & 4.0 & 3.9181 & TRN \\
\hline CHEMBL1992645 & 809155 & 4.0 & 4.7777 & TST \\
\hline CHEMBL1982992 & 809155 & 4.0 & 4.871 & TRN \\
\hline CHEMBL1974363 & 809155 & 4.0 & 4.8012 & TRN \\
\hline CHEMBL1999590 & 809155 & 4.0 & 4.3465 & TST \\
\hline CHEMBL1981079 & 809155 & 6.3 & 6.5987 & TRN \\
\hline CHEMBL1972276 & 809155 & 4.0 & 4.6744 & TRN \\
\hline CHEMBL1980489 & 809155 & 4.0 & 3.7428 & TRN \\
\hline CHEMBL 2000832 & 809155 & 4.0 & 5.4418 & TRN \\
\hline CHEMBL1967116 & 809155 & 5.5 & 5.0767 & TRN \\
\hline CHEMBL1977814 & 809155 & 4.0 & 4.2093 & TST \\
\hline CHEMBL513846 & 809155 & 5.2 & 4.8812 & TRN \\
\hline CHEMBL1970709 & 809155 & 4.0 & 4.0479 & TRN \\
\hline CHEMBL1965660 & 809155 & 6.5 & 6.7383 & TRN \\
\hline CHEMBL1998112 & 809155 & 4.0 & 4.404 & TRN \\
\hline CHEMBL1969126 & 809155 & 6.3 & 5.894 & TRN \\
\hline CHEMBL1980896 & 809155 & 5.4 & 4.8194 & TRN \\
\hline CHEMBL1975208 & 809155 & 4.0 & 3.9337 & TST \\
\hline CHEMBL1970104 & 809155 & 4.0 & 4.5655 & TRN \\
\hline CHEMBL1991429 & 809155 & 5.9 & 5.8503 & TRN \\
\hline CHEMBL1964777 & 809155 & 4.0 & 4.7742 & TRN \\
\hline CHEMBL1971149 & 809155 & 4.0 & 4.6042 & TRN \\
\hline CHEMBL1999714 & 809155 & 4.0 & 3.8737 & TRN \\
\hline CHEMBL1987533 & 809155 & 4.0 & 4.0303 & TRN \\
\hline CHEMBL1994040 & 809155 & 4.0 & 5.2147 & TRN \\
\hline CHEMBL388978 & 809155 & 8.6 & 6.5333 & TST \\
\hline CHEMBL579246 & 809155 & 6.5 & 6.3827 & TRN \\
\hline CHEMBL398951 & 809155 & 4.0 & 4.0796 & TST \\
\hline CHEMBL1982506 & 809155 & 5.1 & 4.7173 & TST \\
\hline CHEMBL 2004716 & 809155 & 6.2 & 5.4589 & TRN \\
\hline CHEMBL1968127 & 809155 & 5.6 & 5.6912 & TRN \\
\hline CHEMBL1975233 & 809155 & 4.1 & 4.6647 & TRN \\
\hline CHEMBL1985406 & 809155 & 4.0 & 4.9612 & TRN \\
\hline CHEMBL 207400 & 809155 & 4.0 & 4.1356 & TST \\
\hline CHEMBL 2000894 & 809155 & 5.5 & 5.4697 & TST \\
\hline CHEMBL 2002553 & 809155 & 4.0 & 3.9406 & TST \\
\hline CHEMBL1982135 & 809155 & 4.0 & 4.801 & TRN \\
\hline CHEMBL1976090 & 809155 & 6.0 & 5.4948 & TRN \\
\hline
\end{tabular}




\begin{tabular}{|c|c|c|c|c|c|}
\hline \multicolumn{6}{|c|}{ Supplemental Table S2.txt } \\
\hline CHEMBL1993243 & 809155 & 5.9 & 5.5967 & TRN & \\
\hline CHEMBL1992922 & 809155 & 5.5 & 5.7437 & TRN & \\
\hline CHEMBL 2004771 & 809155 & 4.0 & 4.1658 & TRN & \\
\hline CHEMBL399021 & 809155 & 5.8 & 5.0863 & TRN & \\
\hline CHEMBL1997597 & 809155 & 5.1 & 4.1599 & TRN & \\
\hline CHEMBL1969537 & 809155 & 6.3 & 4.2824 & TST & \\
\hline CHEMBL1976093 & 809155 & 5.5 & 5.5202 & TRN & \\
\hline CHEMBL210032 & 809155 & 4.0 & 4.7824 & TRN & \\
\hline CHEMBL1996543 & 809155 & 5.1 & 5.9693 & TRN & \\
\hline CHEMBL1975256 & 809155 & 4.0 & 3.9007 & TST & \\
\hline CHEMBL508928 & 809155 & 4.0 & 4.1494 & TRN & \\
\hline CHEMBL1991356 & 809155 & 4.0 & 4.1218 & TST & \\
\hline CHEMBL1983309 & 809155 & 4.0 & 3.9583 & TRN & \\
\hline CHEMBL 2004892 & 809155 & 5.3 & 4.7772 & TRN & \\
\hline CHEMBL1999126 & 809155 & 4.0 & 3.8829 & TST & \\
\hline CHEMBL1997503 & 809155 & 4.0 & 4.3328 & TST & \\
\hline CHEMBL116070 & 809155 & 4.0 & 4.2576 & TRN & \\
\hline CHEMBL1990821 & 809155 & 4.0 & 4.3761 & TST & \\
\hline CHEMBL1970314 & 809155 & 4.0 & 4.4224 & TRN & \\
\hline CHEMBL 2004871 & 809155 & 4.0 & 4.4324 & TRN & \\
\hline CHEMBL 2004872 & 809155 & 4.0 & 3.9569 & TRN & \\
\hline CHEMBL1727312 & 809155 & 4.0 & 3.9218 & TRN & \\
\hline CHEMBL1969879 & 809155 & 4.0 & 4.0574 & TRN & \\
\hline CHEMBL1981720 & 809155 & 6.0 & 5.4518 & TRN & \\
\hline CHEMBL419932 & 809155 & 5.7 & 5.2686 & TRN & \\
\hline CHEMBL262433 & 809155 & 4.0 & 4.0531 & TRN & \\
\hline CHEMBL 306380 & 809155 & 5.4 & 4.9525 & TRN & \\
\hline CHEMBL1966722 & 809155 & 5.7 & 4.8911 & TST & \\
\hline CHEMBL1975500 & 809155 & 5.4 & 5.1717 & TRN & \\
\hline CHEMBL1976328 & 809155 & 4.0 & 4.3818 & TRN & \\
\hline CHEMBL394619 & 809155 & 4.0 & 5.0967 & TRN & \\
\hline CHEMBL1964399 & 809155 & 6.2 & 5.4595 & TRN & \\
\hline CHEMBL1996831 & 809155 & 6.2 & 4.9252 & TST & \\
\hline CHEMBL411903 & 809155 & 5.9 & 5.28600 & 00000000005 & TRN \\
\hline CHEMBL1965988 & 809155 & 5.8 & 5.4906 & TRN & \\
\hline CHEMBL418203 & 809155 & 5.9 & 5.6511 & TST & \\
\hline CHEMBL1989646 & 809155 & 5.6 & 5.2612 & TRN & \\
\hline CHEMBL1682357 & 809155 & 4.0 & 4.4015 & TRN & \\
\hline CHEMBL225519 & 809155 & 6.2 & 5.6852 & TRN & \\
\hline CHEMBL209534 & 809155 & 5.8 & 5.4005 & TRN & \\
\hline CHEMBL1978200 & 809155 & 5.5 & 5.4332 & TRN & \\
\hline CHEMBL 2006631 & 809155 & 4.0 & 4.1838 & TRN & \\
\hline CHEMBL1970522 & 809155 & 5.6 & 4.8279 & TRN & \\
\hline CHEMBL1990415 & 809155 & 4.0 & 4.0233 & TRN & \\
\hline CHEMBL1966087 & 809155 & 4.0 & 4.0536 & TRN & \\
\hline CHEMBL1964692 & 809155 & 4.0 & 4.2852 & TRN & \\
\hline CHEMBL1996931 & 809155 & 4.0 & 3.8542 & TRN & \\
\hline CHEMBL1964413 & 809155 & 4.0 & 4.0733 & TRN & \\
\hline
\end{tabular}




\begin{tabular}{|c|c|c|c|c|c|}
\hline & & & & & \\
\hline CHEMBL1973483 & 809155 & 5.1 & 4.6861 & TRN & \\
\hline CHEMBL1984432 & 809155 & 4.0 & 4.3074 & TRN & \\
\hline CHEMBL1970735 & 809155 & 4.0 & 5.0307 & TRN & \\
\hline CHEMBL219722 & 809155 & 4.0 & 4.487 & TRN & \\
\hline CHEMBL1997340 & 809155 & 4.0 & 3.8179 & TRN & \\
\hline CHEMBL 2004365 & 809155 & 4.0 & 4.9484 & TST & \\
\hline CHEMBL1522508 & 809155 & 4.0 & 3.984 & TRN & \\
\hline CHEMBL1989474 & 809155 & 4.0 & 4.1916 & TRN & \\
\hline CHEMBL1090360 & 809155 & 5.1 & 5.5502 & TRN & \\
\hline CHEMBL210887 & 809155 & 4.0 & 4.9877 & TST & \\
\hline CHEMBL458997 & 809155 & 6.0 & 6.5596 & TRN & \\
\hline CHEMBL1971021 & 809155 & 4.0 & 4.0543 & TRN & \\
\hline CHEMBL227271 & 809155 & 6.8 & 7.3206 & TRN & \\
\hline CHEMBL583144 & 809155 & 5.5 & 4.9817 & TRN & \\
\hline CHEMBL1974310 & 809155 & 5.6 & 5.5563 & TRN & \\
\hline CHEMBL1982660 & 809155 & 4.0 & 4.2567 & TRN & \\
\hline CHEMBL1994693 & 809155 & 4.0 & 4.7892 & TRN & \\
\hline CHEMBL1982957 & 809155 & 7.1 & 6.4483 & TRN & \\
\hline CHEMBL1725279 & 809155 & 6.8 & 6.4296 & TST & \\
\hline CHEMBL1975138 & 809155 & 5.8 & 4.3324 & TST & \\
\hline CHEMBL424872 & 809155 & 5.6 & 5.5164 & TRN & \\
\hline CHEMBL 2006836 & 809155 & 4.0 & 3.8922 & TST & \\
\hline CHEMBL1971947 & 809155 & 4.0 & 4.8987 & TRN & \\
\hline CHEMBL412142 & 809155 & 4.0 & 4.2275 & TST & \\
\hline CHEMBL1980704 & 809155 & 4.0 & 4.0888 & TST & \\
\hline CHEMBL 2003271 & 809155 & 5.8 & 5.7249 & TRN & \\
\hline CHEMBL1966808 & 809155 & 4.0 & 3.8841 & TST & \\
\hline CHEMBL 2004447 & 809155 & 4.0 & 3.8927 & TRN & \\
\hline CHEMBL1983111 & 809155 & 7.2 & 6.6197 & TST & \\
\hline CHEMBL1973860 & 809155 & 5.5 & 4.7891 & TRN & \\
\hline CHEMBL1977713 & 809155 & 4.0 & 3.965 & TRN & \\
\hline CHEMBL260135 & 809155 & 4.0 & 4.1201 & TRN & \\
\hline CHEMBL220241 & 809155 & 5.7 & 5.0751 & TRN & \\
\hline CHEMBL 2004544 & 809155 & 5.6 & 4.9252 & TST & \\
\hline CHEMBL1982610 & 809155 & 4.0 & 4.0016 & TST & \\
\hline CHEMBL1999496 & 809155 & 4.0 & 4.072 & TRN & \\
\hline CHEMBL 2006933 & 809155 & 6.2 & 4.6279 & TST & \\
\hline CHEMBL1988300 & 809155 & 5.2 & 4.5625 & TRN & \\
\hline CHEMBL1991078 & 809155 & 5.7 & 5.7374 & TRN & \\
\hline CHEMBL1987359 & 809155 & 4.0 & 3.9921 & TST & \\
\hline CHEMBL 2000685 & 809155 & 6.5 & 4.7599 & TRN & \\
\hline CHEMBL1985311 & 809155 & 4.0 & 4.5819 & TRN & \\
\hline CHEMBL1989265 & 809155 & 4.0 & 4.7679 & TST & \\
\hline CHEMBL 2004647 & 809155 & 4.0 & 3.94 & TST & \\
\hline CHEMBL1969502 & 809155 & 6.2 & 5.3961 & TRN & \\
\hline CHEMBL1965910 & 809155 & 5.5 & 5.2353 & TRN & \\
\hline CHEMBL1682553 & 809155 & 5.9 & 5.21700 & 00000000005 & TRN \\
\hline CHEMBL1997764 & 809155 & 5.7 & 5.7429 & TRN & \\
\hline
\end{tabular}




\begin{tabular}{|c|c|c|c|c|c|}
\hline \multicolumn{6}{|c|}{ lable s } \\
\hline CHEMBL1983963 & 809155 & 4.0 & 4.8817 & TRN & \multirow{3}{*}{ TRN } \\
\hline CHEMBL 2000271 & 809155 & 6.4 & \multicolumn{2}{|c|}{6.542000000000001} & \\
\hline CHEMBL1985092 & 809155 & 5.3 & 5.2033 & TST & \\
\hline CHEMBL 2004692 & 809155 & 4.0 & 3.9139 & TST & \\
\hline CHEMBL1981410 & 809155 & 5.2 & 4.1518 & TRN & \\
\hline CHEMBL1996234 & 809155 & 4.0 & 4.4173 & TRN & \\
\hline CHEMBL1991434 & 809155 & 4.0 & 4.1155 & TST & \\
\hline CHEMBL1967544 & 809155 & 5.1 & 4.9708 & TRN & \\
\hline CHEMBL223367 & 809155 & 4.0 & 4.4134 & TST & \\
\hline CHEMBL340384 & 809155 & 7.1 & 6.6428 & TST & \\
\hline CHEMBL1996587 & 809155 & 5.7 & 5.7932 & TRN & \\
\hline CHEMBL1964804 & 809155 & 5.7 & 5.4847 & TRN & \\
\hline CHEMBL443962 & 809155 & 4.0 & 4.0996 & TST & \\
\hline CHEMBL 2000354 & 809155 & 5.4 & 4.9036 & TRN & \\
\hline CHEMBL1965507 & 809155 & 4.2 & 4.3964 & TRN & \\
\hline CHEMBL274064 & 809155 & 5.9 & 5.9216 & TRN & \\
\hline CHEMBL1967564 & 809155 & 4.0 & 3.864 & TRN & \\
\hline CHEMBL592030 & 809155 & 7.3 & 5.9462 & TST & \\
\hline CHEMBL 2000071 & 809155 & 4.2 & 5.9078 & TRN & \\
\hline CHEMBL1979176 & 809155 & 4.0 & 4.0015 & TRN & \\
\hline CHEMBL1970317 & 809155 & 6.0 & 4.5858 & TRN & \\
\hline CHEMBL 2000408 & 809155 & 6.1 & 5.9649 & TRN & \\
\hline CHEMBL248757 & 809155 & 4.0 & 3.8865 & TST & \\
\hline CHEMBL1978014 & 809155 & 4.0 & 4.1354 & TRN & \\
\hline CHEMBL1994538 & 809155 & 4.2 & 4.9275 & TRN & \\
\hline CHEMBL1983195 & 809155 & 4.0 & 4.8457 & TST & \\
\hline CHEMBL1975490 & 809155 & 5.2 & 5.301 & TRN & \\
\hline CHEMBL1964444 & 809155 & 4.0 & 5.0762 & TRN & \\
\hline CHEMBL1989957 & 809155 & 4.0 & 4.0659 & TRN & \\
\hline CHEMBL 2006567 & 809155 & 5.1 & 4.7668 & TRN & \\
\hline CHEMBL1986139 & 809155 & 4.0 & 4.0887 & TRN & \\
\hline CHEMBL383527 & 809155 & 4.0 & 4.4917 & TRN & \\
\hline CHEMBL1980540 & 809155 & 4.0 & 3.8387 & TRN & \\
\hline CHEMBL1979883 & 809155 & 5.3 & 5.2327 & TRN & \\
\hline CHEMBL1984162 & 809155 & 4.0 & 4.4685 & TRN & \\
\hline CHEMBL491758 & 809155 & 5.7 & 5.5539 & TRN & \\
\hline CHEMBL549730 & 809155 & 4.0 & 3.7838 & TRN & \\
\hline CHEMBL1682360 & 809155 & 4.0 & 4.2621 & TRN & \\
\hline CHEMBL1970189 & 809155 & 4.0 & 3.8457 & TRN & \\
\hline CHEMBL1996791 & 809155 & 4.0 & 4.8072 & TRN & \\
\hline CHEMBL371206 & 809155 & 4.0 & 4.3353 & TRN & \\
\hline CHEMBL1974664 & 809155 & 4.0 & 4.0483 & TST & \\
\hline CHEMBL1974288 & 809155 & 4.0 & 3.9226 & TRN & \\
\hline CHEMBL196363 & 809155 & 4.0 & 4.8502 & TRN & \\
\hline CHEMBL1190711 & 809155 & 6.9 & 5.79799 & 9999999999 & TRN \\
\hline CHEMBL1990346 & 809155 & 4.0 & 4.2875 & TRN & \\
\hline CHEMBL1981723 & 809155 & 5.5 & 5.1354 & TST & \\
\hline CHEMBL1968705 & 809155 & 5.1 & 5.1556 & TRN & \\
\hline & & & & 3791 & \\
\hline
\end{tabular}




\begin{tabular}{|c|c|c|c|c|c|}
\hline \multicolumn{6}{|c|}{ Supplemental Table S2.txt } \\
\hline CHEMBL404367 & 809155 & 4.0 & 5.0735 & TRN & \\
\hline CHEMBL1966343 & 809155 & 6.0 & 5.2488 & TRN & \\
\hline CHEMBL1967887 & 809155 & 6.2 & 6.2373 & TRN & \\
\hline CHEMBL 2000568 & 809155 & 5.3 & 5.0101 & TRN & \\
\hline CHEMBL 2000335 & 809155 & 4.0 & 4.8533 & TRN & \\
\hline CHEMBL1977604 & 809155 & 4.0 & 4.2062 & TST & \\
\hline CHEMBL1988717 & 809155 & 4.0 & 3.8995 & TRN & \\
\hline CHEMBL1974328 & 809155 & 6.9 & 6.3349 & TRN & \\
\hline CHEMBL509032 & 809155 & 7.3 & 7.0206 & TRN & \\
\hline CHEMBL573339 & 809155 & 4.0 & 4.6285 & TRN & \\
\hline CHEMBL1973808 & 809155 & 5.1 & \multicolumn{2}{|c|}{4.6530000000000005} & TRN \\
\hline CHEMBL 2000429 & 809155 & 5.6 & 5.6873 & TRN & \\
\hline CHEMBL1972576 & 809155 & 4.0 & 4.1438 & TRN & \\
\hline CHEMBL1992555 & 809155 & 4.0 & 4.2482 & TST & \\
\hline CHEMBL1992342 & 809155 & 5.5 & 4.7452 & TRN & \\
\hline CHEMBL1988173 & 809155 & 6.3 & 5.1786 & TST & \\
\hline CHEMBL535331 & 809155 & 4.0 & 4.1953 & TRN & \\
\hline CHEMBL1989805 & 809155 & 6.2 & 4.9651 & TST & \\
\hline CHEMBL1965423 & 809155 & 7.7 & 7.4722 & TRN & \\
\hline CHEMBL1982980 & 809155 & 5.2 & 4.1716 & TST & \\
\hline CHEMBL1983025 & 809155 & 5.1 & 5.2914 & TRN & \\
\hline CHEMBL205415 & 809155 & 5.3 & 4.5266 & TRN & \\
\hline CHEMBL1977135 & 809155 & 4.0 & 3.9008 & TRN & \\
\hline CHEMBL 2001920 & 809155 & 5.5 & 4.2424 & TRN & \\
\hline CHEMBL 2002322 & 809155 & 4.0 & 5.1123 & TRN & \\
\hline CHEMBL 2002323 & 809155 & 4.0 & 4.4726 & TST & \\
\hline CHEMBL1241473 & 809155 & 6.3 & 6.7155 & TRN & \\
\hline CHEMBL1978448 & 809155 & 6.7 & 4.559 & TST & \\
\hline CHEMBL 2004513 & 809155 & 4.0 & 4.1955 & TRN & \\
\hline CHEMBL1972258 & 809155 & 4.0 & 4.8427 & TRN & \\
\hline CHEMBL 2001257 & 809155 & 4.0 & 4.6654 & TRN & \\
\hline CHEMBL 2005548 & 809155 & 5.1 & 4.3308 & TRN & \\
\hline CHEMBL1992536 & 809155 & 4.0 & 4.0768 & TRN & \\
\hline CHEMBL1987793 & 809155 & 5.1 & \multicolumn{2}{|c|}{4.6530000000000005} & TST \\
\hline CHEMBL1992740 & 809155 & 4.0 & 3.8792 & TRN & \\
\hline CHEMBL 2002373 & 809155 & 5.3 & 4.8519 & TRN & \\
\hline CHEMBL439340 & 809155 & 4.1 & 4.4744 & TRN & \\
\hline CHEMBL 2006188 & 809155 & 4.0 & 3.9805 & TRN & \\
\hline CHEMBL1967531 & 809155 & 5.4 & 4.2945 & TRN & \\
\hline CHEMBL1970913 & 809155 & 4.0 & 3.9389 & TRN & \\
\hline CHEMBL1973893 & 809155 & 4.0 & 3.9925 & TRN & \\
\hline CHEMBL1995736 & 809155 & 5.6 & 5.1149 & TRN & \\
\hline CHEMBL1997534 & 809155 & 6.4 & 5.3255 & TRN & \\
\hline CHEMBL1996500 & 809155 & 5.5 & 4.7837 & TRN & \\
\hline CHEMBL1985095 & 809155 & 6.1 & 5.6744 & TST & \\
\hline CHEMBL1998551 & 809155 & 5.4 & 5.5302 & TRN & \\
\hline CHEMBL1977374 & 809155 & 5.9 & 5.6924 & TRN & \\
\hline CHEMBL1991180 & 809155 & 5.8 & 4.5224 & TST & \\
\hline
\end{tabular}




\begin{tabular}{|c|c|c|c|c|c|}
\hline \multirow[b]{2}{*}{ CHEMBL1682540 } & \multirow{2}{*}{809155} & \\
\hline & & 5.6 & 5.2868 & TRN & \\
\hline CHEMBL1978656 & 809155 & 4.0 & 4.648 & TRN & \\
\hline CHEMBL1976420 & 809155 & 4.0 & 4.3646 & TST & \\
\hline CHEMBL1994864 & 809155 & 4.0 & 3.74899 & 99999999997 & TRN \\
\hline CHEMBL413779 & 809155 & 4.0 & 4.239 & TST & \\
\hline CHEMBL2002446 & 809155 & 5.2 & 5.1651 & TST & \\
\hline CHEMBL497151 & 809155 & 4.0 & 4.038 & TRN & \\
\hline CHEMBL246970 & 809155 & 5.8 & 5.7268 & TRN & \\
\hline CHEMBL340921 & 809155 & 5.3 & 5.61799 & 9999999999 & TST \\
\hline CHEMBL373598 & 809155 & 4.0 & 4.2377 & TST & \\
\hline CHEMBL1999718 & 809155 & 4.0 & 3.95 & TRN & \\
\hline CHEMBL1276446 & 809155 & 7.3 & 5.0596 & TST & \\
\hline CHEMBL1977346 & 809155 & 4.0 & 4.046 & TRN & \\
\hline CHEMBL1971649 & 809155 & 4.0 & 3.9824 & TRN & \\
\hline CHEMBL2003657 & 809155 & 7.6 & 6.527 & TRN & \\
\hline CHEMBL1998435 & 809155 & 4.0 & 3.9826 & TRN & \\
\hline CHEMBL2006439 & 809155 & 6.7 & 5.8599 & TRN & \\
\hline CHEMBL2006156 & 809155 & 5.4 & 4.8239 & TST & \\
\hline CHEMBL1969190 & 809155 & 4.0 & 4.7252 & TRN & \\
\hline CHEMBL1973937 & 809155 & 4.0 & 5.07600 & 00000000005 & TRN \\
\hline CHEMBL1991674 & 809155 & 6.5 & 6.773 & TRN & \\
\hline CHEMBL1982711 & 809155 & 6.6 & 6.0967 & TRN & \\
\hline CHEMBL1987982 & 809155 & 4.0 & 4.713 & TST & \\
\hline CHEMBL1984842 & 809155 & 5.0 & 4.9805 & TRN & \\
\hline CHEMBL1969102 & 809155 & 5.8 & 5.1214 & TRN & \\
\hline CHEMBL1682346 & 809155 & 5.2 & 4.9312 & TRN & \\
\hline CHEMBL2007044 & 809155 & 4.0 & 4.1296 & TST & \\
\hline CHEMBL2001998 & 809155 & 4.0 & 4.4766 & TST & \\
\hline CHEMBL1994241 & 809155 & 5.7 & 5.5135 & TRN & \\
\hline CHEMBL223460 & 809155 & 4.0 & 3.9227 & TST & \\
\hline CHEMBL1998829 & 809155 & 5.3 & 5.2454 & TRN & \\
\hline CHEMBL50894 & 809155 & 4.0 & 4.5896 & TRN & \\
\hline CHEMBL1988838 & 809155 & 6.2 & 6.3634 & TRN & \\
\hline CHEMBL1981725 & 809155 & 6.9 & 6.2853 & TRN & \\
\hline CHEMBL375284 & 809155 & 4.0 & 4.504 & TRN & \\
\hline CHEMBL1982866 & 809155 & 4.0 & 4.1462 & TRN & \\
\hline CHEMBL2005792 & 809155 & 5.2 & 5.6318 & TRN & \\
\hline CHEMBL1968926 & 809155 & 4.0 & 3.9039 & TRN & \\
\hline CHEMBL365617 & 809155 & 5.8 & 5.2039 & TRN & \\
\hline CHEMBL1984206 & 809155 & 5.2 & 5.2843 & TRN & \\
\hline CHEMBL462120 & 809155 & 4.0 & 3.9467 & TST & \\
\hline CHEMBL1991577 & 809155 & 4.0 & 4.1098 & TRN & \\
\hline CHEMBL1965570 & 809155 & 4.0 & 4.9 & TRN & \\
\hline CHEMBL2007592 & 809155 & 4.0 & 4.07600 & 00000000005 & TST \\
\hline CHEMBL210963 & 809155 & 4.0 & 5.3361 & TRN & \\
\hline CHEMBL1082440 & 809155 & 5.4 & 5.1257 & TST & \\
\hline CHEMBL1614705 & 809155 & 4.0 & 4.3925 & TRN & \\
\hline CHEMBL1972362 & 809155 & 4.0 & 5.3601 & TRN & \\
\hline & & & & 3793 & \\
\hline
\end{tabular}




\begin{tabular}{|c|c|c|c|c|c|}
\hline \multicolumn{6}{|c|}{ Supplemental Table S2.txt } \\
\hline CHEMBL1984633 & 809155 & 4.0 & 3.9576 & TRN & \\
\hline CHEMBL 2007372 & 809155 & 4.0 & 4.6174 & TRN & \\
\hline CHEMBL1965845 & 809155 & 6.3 & 5.5671 & TRN & \\
\hline CHEMBL1982167 & 809155 & 4.0 & 4.5731 & TRN & \\
\hline CHEMBL 2006715 & 809155 & 6.0 & 5.5308 & TRN & \\
\hline CHEMBL1986597 & 809155 & 4.0 & 4.2662 & TRN & \\
\hline CHEMBL1971017 & 809155 & 5.7 & 5.4669 & TRN & \\
\hline CHEMBL1990482 & 809155 & 5.8 & 4.9166 & TRN & \\
\hline CHEMBL1990904 & 809155 & 6.2 & 6.4089 & TRN & \\
\hline CHEMBL 2005475 & 809155 & 6.9 & 6.2338 & TRN & \\
\hline CHEMBL 2000104 & 809155 & 5.6 & 5.4025 & TRN & \\
\hline CHEMBL402846 & 809155 & 4.0 & 4.9125 & TRN & \\
\hline CHEMBL1997349 & 809155 & 4.0 & 4.4136 & TST & \\
\hline CHEMBL183844 & 809155 & 4.0 & 3.9251 & TRN & \\
\hline CHEMBL220057 & 809155 & 4.0 & 5.0352 & TRN & \\
\hline CHEMBL1682545 & 809155 & 5.4 & 4.7446 & TRN & \\
\hline CHEMBL383541 & 809155 & 5.7 & 5.4057 & TRN & \\
\hline CHEMBL 2001224 & 809155 & 4.0 & 4.0173 & TRN & \\
\hline CHEMBL10 & 809155 & 5.2 & 4.9781 & TRN & \\
\hline CHEMBL1976732 & 809155 & 5.6 & 5.8996 & TRN & \\
\hline CHEMBL1969506 & 809155 & 4.0 & 4.2319 & TRN & \\
\hline CHEMBL1964937 & 809155 & 5.8 & 5.30200 & 00000000005 & TRN \\
\hline CHEMBL1980163 & 809155 & 4.0 & 3.8971 & TRN & \\
\hline CHEMBL590109 & 809155 & 6.1 & 5.846 & TST & \\
\hline CHEMBL1970879 & 809155 & 4.0 & 5.04899 & 99999999995 & TRN \\
\hline CHEMBL1989856 & 809155 & 4.0 & 4.3535 & TST & \\
\hline CHEMBL 2005899 & 809155 & 4.0 & 3.9333 & TRN & \\
\hline CHEMBL1682552 & 809155 & 5.3 & 4.9555 & TRN & \\
\hline CHEMBL 259850 & 809155 & 4.0 & 4.1375 & TRN & \\
\hline CHEMBL1972568 & 809155 & 4.0 & 3.9363 & TRN & \\
\hline CHEMBL1996155 & 809155 & 6.4 & 4.2823 & TRN & \\
\hline CHEMBL229799 & 809155 & 7.4 & 7.9549 & TRN & \\
\hline CHEMBL1682359 & 809155 & 5.1 & 4.3569 & TRN & \\
\hline CHEMBL105739 & 809155 & 5.3 & 5.1586 & TRN & \\
\hline CHEMBL 379300 & 809155 & 7.5 & 7.5874 & TRN & \\
\hline CHEMBL 203673 & 809155 & 4.0 & 4.908 & TRN & \\
\hline CHEMBL1969523 & 809155 & 6.9 & 5.8038 & TRN & \\
\hline CHEMBL207995 & 809155 & 5.1 & 4.7642 & TRN & \\
\hline CHEMBL1988995 & 809155 & 5.7 & 5.7783 & TRN & \\
\hline CHEMBL2001923 & 809155 & 4.0 & 4.4488 & TRN & \\
\hline CHEMBL1986781 & 809155 & 6.0 & 6.2273 & TRN & \\
\hline CHEMBL526133 & 809155 & 5.9 & 5.141 & TRN & \\
\hline CHEMBL1979057 & 809155 & 5.2 & 4.0802 & TRN & \\
\hline CHEMBL1981045 & 809155 & 4.0 & 4.67899 & 9999999999 & TRN \\
\hline CHEMBL 387971 & 809155 & 4.0 & 4.3513 & TST & \\
\hline CHEMBL1975418 & 809155 & 5.7 & 4.8712 & TRN & \\
\hline CHEMBL1992796 & 809155 & 4.0 & 4.3467 & TST & \\
\hline CHEMBL1999428 & 809155 & 4.0 & 3.802 & TRN & \\
\hline
\end{tabular}




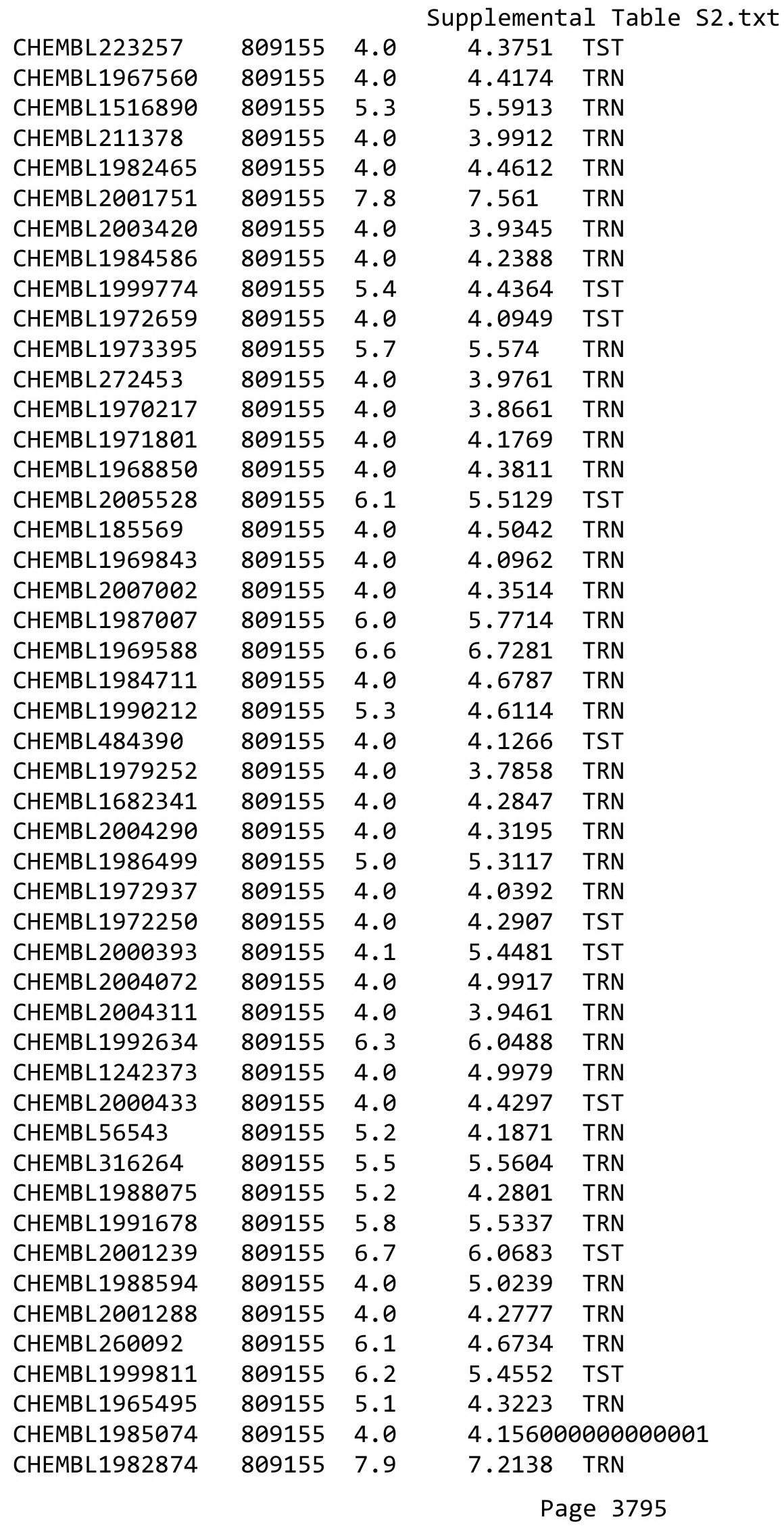




\begin{tabular}{|c|c|c|c|c|}
\hline \multicolumn{5}{|c|}{ Supplemental Table S2.txt } \\
\hline CHEMBL 2000481 & 809155 & 4.0 & 5.1757 & TRN \\
\hline CHEMBL1991725 & 809155 & 5.6 & 5.4746 & TRN \\
\hline CHEMBL1992242 & 809155 & 4.0 & 3.9149 & TRN \\
\hline CHEMBL 2007296 & 809155 & 4.0 & 4.0374 & TRN \\
\hline CHEMBL208637 & 809155 & 5.6 & 5.0569 & TRN \\
\hline CHEMBL396523 & 809155 & 7.3 & 7.8793 & TRN \\
\hline CHEMBL1970203 & 809155 & 4.0 & 4.1009 & TRN \\
\hline CHEMBL1986530 & 809155 & 4.0 & 4.4315 & TST \\
\hline CHEMBL1965351 & 809155 & 4.0 & 4.7998 & TST \\
\hline CHEMBL1999321 & 809155 & 4.0 & 3.8532 & TRN \\
\hline CHEMBL1968590 & 809155 & 6.7 & 5.9053 & TRN \\
\hline CHEMBL1999749 & 809155 & 6.3 & 4.5208 & TRN \\
\hline CHEMBL 2005375 & 809155 & 5.3 & 5.3257 & TRN \\
\hline CHEMBL1984191 & 809155 & 4.0 & 4.9518 & TRN \\
\hline CHEMBL1983006 & 809155 & 4.0 & 4.496 & TRN \\
\hline CHEMBL1972183 & 809155 & 4.0 & 4.0637 & TRN \\
\hline CHEMBL1971029 & 809155 & 6.8 & 7.4241 & TRN \\
\hline CHEMBL394790 & 809155 & 4.0 & 4.2567 & TRN \\
\hline CHEMBL226471 & 809155 & 6.6 & 6.1546 & TRN \\
\hline CHEMBL1974702 & 809155 & 4.0 & 4.0938 & TRN \\
\hline CHEMBL1996111 & 809155 & 5.2 & 4.6679 & TRN \\
\hline CHEMBL1965589 & 809155 & 5.5 & 5.551 & TRN \\
\hline CHEMBL1998193 & 809155 & 4.0 & 3.9655 & TRN \\
\hline CHEMBL474432 & 809155 & 5.4 & 4.3712 & TST \\
\hline CHEMBL1988153 & 809155 & 4.0 & 4.1302 & TRN \\
\hline CHEMBL1999556 & 809155 & 5.7 & 5.3868 & TRN \\
\hline CHEMBL1988437 & 809155 & 4.0 & 4.5288 & TST \\
\hline CHEMBL1968245 & 809155 & 5.7 & 5.0982 & TRN \\
\hline CHEMBL1998121 & 809155 & 6.5 & 5.8447 & TRN \\
\hline CHEMBL1979577 & 809155 & 5.5 & 5.2667 & TRN \\
\hline CHEMBL1991800 & 809155 & 4.0 & 5.5168 & TRN \\
\hline CHEMBL52387 & 809155 & 4.0 & 4.7832 & TST \\
\hline CHEMBL379835 & 809155 & 4.0 & 4.0578 & TST \\
\hline CHEMBL1979357 & 809155 & 4.0 & 4.0411 & TRN \\
\hline CHEMBL1980802 & 809155 & 4.0 & 4.3195 & TST \\
\hline CHEMBL1979554 & 809155 & 5.3 & 4.6561 & TRN \\
\hline CHEMBL1996817 & 809155 & 5.9 & 6.0584 & TRN \\
\hline CHEMBL3197315 & 809155 & 4.0 & 3.9277 & TST \\
\hline CHEMBL 2004355 & 809155 & 5.9 & 5.6092 & TRN \\
\hline CHEMBL468280 & 809155 & 4.0 & 4.0501 & TST \\
\hline CHEMBL1990884 & 809155 & 4.0 & 4.1312 & TRN \\
\hline CHEMBL3109278 & 809155 & 6.4 & 5.0464 & TRN \\
\hline CHEMBL 256835 & 809155 & 5.3 & 5.5451 & TRN \\
\hline CHEMBL1970006 & 809155 & 4.0 & 4.2914 & TST \\
\hline CHEMBL1980142 & 809155 & 4.0 & 3.8849 & TRN \\
\hline CHEMBL41783 & 809155 & 4.0 & 3.8926 & TRN \\
\hline CHEMBL 2004438 & 809155 & 4.0 & 4.1181 & TRN \\
\hline CHEMBL 2006276 & 809155 & 5.6 & 4.1976 & TRN \\
\hline
\end{tabular}




\begin{tabular}{|c|c|c|c|c|}
\hline \multicolumn{5}{|c|}{ Supplemental Table S2.txt } \\
\hline CHEMBL271381 & 809155 & 4.0 & 4.1857 & TRN \\
\hline CHEMBL 2006785 & 809155 & 4.0 & 4.1505 & TRN \\
\hline CHEMBL1982466 & 809155 & 4.0 & 4.4021 & TRN \\
\hline CHEMBL249697 & 809155 & 5.4 & 4.9674 & TST \\
\hline CHEMBL1995740 & 809155 & 4.0 & 4.2117 & TRN \\
\hline CHEMBL1996390 & 809155 & 4.0 & 4.9458 & TRN \\
\hline CHEMBL234085 & 809155 & 4.0 & 4.1445 & TRN \\
\hline CHEMBL1995832 & 809155 & 6.2 & 6.1572 & TRN \\
\hline CHEMBL1998414 & 809155 & 4.0 & 4.9905 & TRN \\
\hline CHEMBL1969042 & 809155 & 5.4 & 5.2882 & TST \\
\hline CHEMBL 2000345 & 809155 & 5.6 & 5.4979 & TRN \\
\hline CHEMBL1999931 & 809155 & 6.4 & 5.881 & TRN \\
\hline CHEMBL1991640 & 809155 & 5.4 & 4.5431 & TST \\
\hline CHEMBL1375418 & 809155 & 4.0 & 4.5735 & TRN \\
\hline CHEMBL 302449 & 809155 & 7.8 & 5.0769 & TST \\
\hline CHEMBL 2007064 & 809155 & 5.2 & 5.1319 & TRN \\
\hline CHEMBL1981047 & 809155 & 5.9 & 5.5253 & TST \\
\hline CHEMBL229968 & 809155 & 7.5 & 8.0821 & TRN \\
\hline CHEMBL1976240 & 809155 & 4.0 & 4.2024 & TRN \\
\hline CHEMBL1979093 & 809155 & 4.0 & 4.6788 & TRN \\
\hline CHEMBL1968151 & 809155 & 4.0 & 3.9132 & TST \\
\hline CHEMBL1381197 & 809155 & 4.0 & 4.4827 & TRN \\
\hline CHEMBL1987009 & 809155 & 6.6 & 6.3015 & TRN \\
\hline CHEMBL379218 & 809155 & 6.5 & 6.9957 & TRN \\
\hline CHEMBL 2003817 & 809155 & 5.1 & 4.7947 & TRN \\
\hline CHEMBL336961 & 809155 & 4.0 & 4.7539 & TRN \\
\hline CHEMBL1994830 & 809155 & 4.0 & 3.9999 & TRN \\
\hline CHEMBL1987054 & 809155 & 4.0 & 4.4595 & TRN \\
\hline CHEMBL1970083 & 809155 & 4.0 & 4.9447 & TRN \\
\hline CHEMBL 226403 & 809155 & 7.4 & 6.2612 & TRN \\
\hline CHEMBL 2005631 & 809155 & 4.0 & 4.9408 & TRN \\
\hline CHEMBL1994938 & 809155 & 6.2 & 5.7262 & TRN \\
\hline CHEMBL1825138 & 809155 & 5.8 & 5.032 & TST \\
\hline CHEMBL1977223 & 809155 & 5.5 & 5.2666 & TRN \\
\hline CHEMBL1236126 & 809155 & 4.0 & 4.5068 & TST \\
\hline CHEMBL1966279 & 809155 & 4.0 & 4.4277 & TRN \\
\hline CHEMBL1997846 & 809155 & 5.8 & 5.5598 & TRN \\
\hline CHEMBL 2004419 & 809155 & 7.3 & 6.9951 & TRN \\
\hline CHEMBL1991728 & 809155 & 6.2 & 4.5612 & TRN \\
\hline CHEMBL1975787 & 809155 & 5.9 & 5.4402 & TRN \\
\hline CHEMBL 2002407 & 809155 & 5.4 & 4.6777 & TRN \\
\hline CHEMBL1972489 & 809155 & 4.0 & 4.0013 & TRN \\
\hline CHEMBL1994074 & 809155 & 5.8 & 5.519 & TRN \\
\hline CHEMBL1992937 & 809155 & 5.3 & 4.7438 & TST \\
\hline CHEMBL1985566 & 809155 & 4.0 & 4.6142 & TRN \\
\hline CHEMBL536151 & 809155 & 4.0 & 4.4193 & TST \\
\hline CHEMBL1972119 & 809155 & 4.0 & 3.88 & TRN \\
\hline CHEMBL1986328 & 809155 & 4.0 & 4.7607 & TST \\
\hline
\end{tabular}




\begin{tabular}{|c|c|c|c|c|c|}
\hline & & \multicolumn{4}{|c|}{ Supplemental Table S2.txt } \\
\hline CHEMBL95692 & 809155 & 4.2 & $5.3320 t$ & 0000000001 & TRN \\
\hline CHEMBL1090356 & 809155 & 6.4 & 6.0396 & TRN & \\
\hline CHEMBL1976455 & 809155 & 4.3 & 5.3415 & TRN & \\
\hline CHEMBL1983923 & 809155 & 4.0 & 4.4722 & TST & \\
\hline CHEMBL1983534 & 809155 & 4.0 & 3.9348 & TRN & \\
\hline CHEMBL1982361 & 809155 & 4.0 & 3.804 & TRN & \\
\hline CHEMBL1999112 & 809155 & 4.0 & 4.2021 & TST & \\
\hline CHEMBL1982122 & 809155 & 4.0 & 4.4713 & TRN & \\
\hline CHEMBL 2000801 & 809155 & 4.0 & 3.9381 & TRN & \\
\hline CHEMBL1682546 & 809155 & 4.0 & 4.0998 & TRN & \\
\hline CHEMBL1991395 & 809155 & 5.8 & 5.9126 & TRN & \\
\hline CHEMBL1971245 & 809155 & 4.0 & 5.4086 & TRN & \\
\hline CHEMBL1987648 & 809155 & 5.1 & 5.4976 & TRN & \\
\hline CHEMBL1996780 & 809155 & 4.0 & 5.4920 & 0000000001 & TST \\
\hline CHEMBL1972142 & 809155 & 4.0 & 4.4198 & TRN & \\
\hline CHEMBL1966514 & 809155 & 5.5 & 5.0148 & TRN & \\
\hline CHEMBL 2003638 & 809155 & 5.8 & 5.9598 & TRN & \\
\hline CHEMBL 296586 & 809155 & 4.0 & 4.5924 & TRN & \\
\hline CHEMBL1996066 & 809155 & 6.5 & 5.2722 & TST & \\
\hline CHEMBL516429 & 809155 & 6.5 & 5.9611 & TRN & \\
\hline CHEMBL1972152 & 809155 & 5.4 & 4.1228 & TST & \\
\hline CHEMBL1993722 & 809155 & 4.0 & 4.3427 & TRN & \\
\hline CHEMBL1970806 & 809155 & 4.0 & 3.9558 & TST & \\
\hline CHEMBL 202635 & 809155 & 5.1 & 4.5177 & TRN & \\
\hline CHEMBL1375640 & 809155 & 4.0 & 4.5079 & TST & \\
\hline CHEMBL1979970 & 809155 & 4.0 & 3.8505 & TRN & \\
\hline CHEMBL 249282 & 809155 & 4.0 & 4.0202 & TST & \\
\hline CHEMBL1969264 & 809155 & 4.0 & 4.6575 & TRN & \\
\hline CHEMBL1973711 & 809155 & 4.0 & 4.5132 & TRN & \\
\hline CHEMBL 2006237 & 809155 & 5.6 & 4.8066 & TRN & \\
\hline CHEMBL1967720 & 809155 & 5.8 & 5.1477 & TRN & \\
\hline CHEMBL1572266 & 809155 & 4.0 & 4.2601 & TST & \\
\hline CHEMBL1991138 & 809155 & 5.5 & 5.0979 & TRN & \\
\hline CHEMBL1969755 & 809155 & 4.0 & 3.8826 & TRN & \\
\hline CHEMBL1979516 & 809155 & 4.0 & 4.0291 & TRN & \\
\hline CHEMBL1605605 & 809155 & 4.0 & 4.846 & TRN & \\
\hline CHEMBL1972820 & 809155 & 4.0 & 4.0467 & TST & \\
\hline CHEMBL1996208 & 809155 & 4.0 & 4.4065 & TST & \\
\hline CHEMBL1989029 & 809155 & 4.0 & 4.3975 & TRN & \\
\hline CHEMBL392642 & 809155 & 5.6 & 5.8106 & TST & \\
\hline CHEMBL514499 & 809155 & 4.0 & 3.9313 & TST & \\
\hline CHEMBL1965631 & 809155 & 4.0 & 5.0162 & TST & \\
\hline CHEMBL1980144 & 809155 & 4.0 & 4.8292 & TST & \\
\hline CHEMBL1991188 & 809155 & 4.0 & 3.9011 & TST & \\
\hline CHEMBL1972849 & 809155 & 5.4 & 5.6984 & TST & \\
\hline CHEMBL377408 & 809155 & 6.1 & 5.9384 & TST & \\
\hline CHEMBL 215152 & 809155 & 4.0 & 4.3998 & TST & \\
\hline CHEMBL231209 & 809155 & 4.0 & 4.7427 & TST & \\
\hline
\end{tabular}




\begin{tabular}{|c|c|c|c|c|c|}
\hline \multicolumn{6}{|c|}{ Supplemental Table s2.txt } \\
\hline CHEMBL1975357 & 809155 & 4.0 & 4.0777 & TST & \\
\hline CHEMBL1976220 & 809155 & 4.0 & 4.8454 & TST & \\
\hline CHEMBL259922 & 809155 & 4.0 & 3.975 & TST & \\
\hline CHEMBL1997617 & 809155 & 7.1 & 5.9897 & TST & \\
\hline CHEMBL1982383 & 809155 & 5.7 & 5.818 & TST & \\
\hline CHEMBL1969301 & 809155 & 4.0 & 4.3085 & TST & \\
\hline CHEMBL17370 & 809155 & 5.8 & 5.6853 & TST & \\
\hline CHEMBL1987910 & 809155 & 4.0 & 4.5275 & TST & \\
\hline CHEMBL1983932 & 809155 & 4.0 & 3.9592 & TST & \\
\hline CHEMBL1966069 & 809155 & 4.0 & 4.4373 & TST & \\
\hline CHEMBL1997822 & 809155 & 5.9 & 5.3372 & TST & \\
\hline CHEMBL1991285 & 809155 & 4.0 & 4.0393 & TST & \\
\hline CHEMBL 243088 & 809155 & 6.9 & 7.1637 & TST & \\
\hline CHEMBL1984038 & 809155 & 4.0 & 4.1533 & TST & \\
\hline CHEMBL1993661 & 809155 & 7.0 & 7.1517 & TST & \\
\hline CHEMBL1974416 & 809155 & 5.5 & 5.6876 & TST & \\
\hline CHEMBL 2004615 & 809155 & 4.0 & 4.0959 & TST & \\
\hline CHEMBL1984039 & 809155 & 4.0 & 4.5332 & TST & \\
\hline CHEMBL1997872 & 809155 & 5.4 & 4.2136 & TST & \\
\hline CHEMBL611585 & 30008 & 6.1612 & 6.282 & TRN & \\
\hline CHEMBL606230 & 30008 & 7.6737 & 7.2361 & TRN & \\
\hline CHEMBL604023 & 30008 & 6.9469 & 7.01 & TRN & \\
\hline CHEMBL611583 & 30008 & 9.3188 & 9.6125 & TST & \\
\hline CHEMBL611586 & 30008 & 8.1135 & 8.0677 & TRN & \\
\hline CHEMBL608177 & 30008 & 6.2757 & 6.1423 & TRN & \\
\hline CHEMBL609544 & 30008 & 6.1549 & 5.971 & TRN & \\
\hline CHEMBL605055 & 30008 & 6.7545 & 6.5591 & TRN & \\
\hline CHEMBL 2113450 & 30008 & 8.9208 & 8.9681 & TRN & \\
\hline CHEMBL606318 & 30008 & 7.0467 & 7.211 & TRN & \\
\hline CHEMBL610990 & 30008 & 7.3468 & 7.3242 & TRN & \\
\hline CHEMBL331372 & 30008 & 7.7212 & 7.5689 & TST & \\
\hline CHEMBL3350613 & 30008 & 8.6576 & 8.5469 & TST & \\
\hline CHEMBL374151 & 30008 & 5.9208 & 6.3908 & TRN & \\
\hline CHEMBL605056 & 30008 & 6.8861 & 7.2135 & TRN & \\
\hline CHEMBL610993 & 30008 & 7.1487 & 7.0728 & TRN & \\
\hline CHEMBL608462 & 30008 & 5.1308 & 5.2284 & TRN & \\
\hline CHEMBL610362 & 30008 & 8.4685 & 8.4848 & TST & \\
\hline CHEMBL608351 & 30008 & 7.2518 & 7.32100 & 2000000001 & TRN \\
\hline CHEMBL60860 & 30008 & 7.3768 & 7.2053 & TST & \\
\hline CHEMBL608949 & 30008 & 7.1192 & 7.1344 & TRN & \\
\hline CHEMBL603389 & 30008 & 7.0605 & 6.9342 & TRN & \\
\hline CHEMBL 2113504 & 30008 & 7.9208 & 7.6038 & TST & \\
\hline CHEMBL604647 & 30008 & 6.5017 & 6.7159 & TRN & \\
\hline CHEMBL609543 & 30008 & 7.9747 & 8.047 & TRN & \\
\hline CHEMBL610989 & 30008 & 5.3372 & 5.7037 & TRN & \\
\hline CHEMBL 387324 & 30008 & 6.7696 & 6.6385 & TRN & \\
\hline CHEMBL 285819 & 30008 & 7.1192 & 7.0833 & TRN & \\
\hline CHEMBL605057 & 30008 & 6.3116 & 6.2215 & TRN & \\
\hline
\end{tabular}




\begin{tabular}{|c|c|c|c|c|c|}
\hline & & & & & \\
\hline CHEMBL607772 & 30008 & 6.4437 & 6.2867 & TRN & \\
\hline CHEMBL608298 & 30008 & 7.585 & 8.4601 & TST & \\
\hline CHEMBL375190 & 30008 & 6.9626 & 6.2125 & TST & \\
\hline CHEMBL608463 & 30008 & 6.4949 & 6.5644 & TRN & \\
\hline CHEMBL608460 & 30008 & 7.055 & 7.4273 & TRN & \\
\hline CHEMBL608464 & 30008 & 7.7447 & 7.715 & TRN & \\
\hline CHEMBL607901 & 30008 & 5.9469 & 6.1964 & TRN & \\
\hline CHEMBL612214 & 30008 & 6.9208 & 7.1051 & TRN & \\
\hline CHEMBL607728 & 30008 & 7.4248 & 6.3434 & TST & \\
\hline CHEMBL612216 & 30008 & 7.6968 & 8.4226 & TST & \\
\hline CHEMBL605473 & 30008 & 5.9363 & 6.0322 & TRN & \\
\hline CHEMBL605265 & 30008 & 7.38399 & 99999999 & 7.7519 & TRN \\
\hline CHEMBL610651 & 30008 & 8.1871 & 8.008 & TST & \\
\hline CHEMBL604234 & 30008 & 7.6676 & 7.5428 & TRN & \\
\hline CHEMBL 223270 & 30008 & 6.9208 & 6.8345 & TRN & \\
\hline CHEMBL604851 & 30008 & 8.7959 & 8.28 & TRN & \\
\hline CHEMBL605685 & 30008 & 7.4401 & 7.4155 & TRN & \\
\hline CHEMBL607775 & 30008 & 8.1249 & 7.76399 & 9999999999 & TRN \\
\hline CHEMBL57706 & 30008 & 8.1249 & 8.2639 & TST & \\
\hline CHEMBL608753 & 30008 & 7.6882 & 7.5638 & TRN & \\
\hline CHEMBL606319 & 30008 & 7.7825 & 7.7909 & TST & \\
\hline CHEMBL607613 & 30008 & 7.4437 & 7.65799 & 99999999995 & TRN \\
\hline CHEMBL610138 & 30008 & 7.4949 & 7.4339 & TRN & \\
\hline CHEMBL607614 & 30008 & 5.4949 & 6.1477 & TRN & \\
\hline CHEMBL603602 & 30008 & 7.6861 & 7.4596 & TRN & \\
\hline CHEMBL606315 & 30008 & 5.8239 & 6.0975 & TRN & \\
\hline CHEMBL604649 & 30008 & 7.71 & 7.5314 & TRN & \\
\hline CHEMBL374685 & 30008 & 7.7696 & 7.1637 & TRN & \\
\hline CHEMBL426928 & 30008 & 7.0132 & 7.32299 & 99999999995 & TRN \\
\hline CHEMBL603812 & 30008 & 6.6308 & 6.8002 & TRN & \\
\hline CHEMBL611291 & 30008 & 8.0458 & 7.8053 & TRN & \\
\hline CHEMBL2113500 & 30008 & 7.4318 & 7.6112 & TST & \\
\hline CHEMBL611288 & 30008 & 8.3468 & 8.7726 & TST & \\
\hline CHEMBL605691 & 30008 & 7.0894 & 6.92 & TRN & \\
\hline CHEMBL 2113507 & 30008 & 8.2676 & 8.2114 & TST & \\
\hline CHEMBL611582 & 30008 & 8.5528 & 8.4181 & TRN & \\
\hline CHEMBL607773 & 30008 & 7.3979 & 7.4974 & TRN & \\
\hline CHEMBL612215 & 30008 & 6.3665 & 6.1793 & TRN & \\
\hline CHEMBL608918 & 30008 & 7.9172 & 8.2345 & TRN & \\
\hline CHEMBL611289 & 30008 & 7.2147 & 7.3912 & TRN & \\
\hline CHEMBL608948 & 30008 & 8.2076 & 8.7073 & TST & \\
\hline CHEMBL611290 & 30008 & 7.4089 & 7.6826 & TRN & \\
\hline CHEMBL604849 & 30008 & 7.2807 & 6.9765 & TST & \\
\hline CHEMBL605264 & 30008 & 7.2612 & 7.2169 & TST & \\
\hline CHEMBL611899 & 30008 & 6.8239 & 6.8526 & TRN & \\
\hline CHEMBL604440 & 30008 & 7.5622 & 8.3205 & TST & \\
\hline CHEMBL608947 & 30008 & 7.8928 & 8.0913 & TRN & \\
\hline CHEMBL610988 & 30008 & 7.2757 & 6.8047 & TRN & \\
\hline
\end{tabular}




\begin{tabular}{|c|c|c|c|c|c|}
\hline \multicolumn{6}{|c|}{ Supplemental Table S2.txt } \\
\hline CHEMBL611900 & 30008 & 5.2441 & 4.8361 & TRN & \\
\hline CHEMBL609493 & 30008 & 8.0 & 7.6364 & TST & \\
\hline CHEMBL345286 & 30008 & 5.7696 & 6.2507 & TRN & \\
\hline CHEMBL608063 & 30008 & 6.4815 & 6.5318 & TRN & \\
\hline CHEMBL608650 & 30008 & 5.6576 & 5.8979 & TRN & \\
\hline CHEMBL609244 & 30008 & 8.0132 & 7.6685 & TST & \\
\hline CHEMBL 2113499 & 30008 & 8.6383 & 7.9657 & TST & \\
\hline CHEMBL464859 & 30008 & 7.9066 & 7.6722 & TST & \\
\hline CHEMBL1807815 & 30008 & 6.0 & 5.5484 & TRN & \\
\hline CHEMBL608181 & 30008 & 7.3969 & 7.32600 & 00000000005 & TRN \\
\hline CHEMBL611293 & 30008 & 6.5686 & 6.4924 & TRN & \\
\hline CHEMBL609825 & 30008 & 7.9914 & 7.9784 & TRN & \\
\hline CHEMBL610992 & 30008 & 7.6576 & 7.5061 & TRN & \\
\hline CHEMBL609049 & 30008 & 6.8861 & 6.5625 & TRN & \\
\hline CHEMBL223846 & 30008 & 5.8239 & 5.7514 & TRN & \\
\hline CHEMBL608461 & 30008 & 7.9586 & 8.3119 & TRN & \\
\hline CHEMBL387354 & 30008 & 7.6576 & 7.2184 & TRN & \\
\hline CHEMBL608182 & 30008 & 6.7959 & 6.7723 & TRN & \\
\hline CHEMBL 3647020 & 1528850 & 8.3979 & 8.1886 & TRN & \\
\hline CHEMBL3897947 & 1528850 & 9.0 & 8.7388 & TRN & \\
\hline CHEMBL3646984 & 1528850 & 8.699 & 8.1125 & TRN & \\
\hline CHEMBL 3945767 & 1528850 & 7.7959 & 8.5064 & TRN & \\
\hline CHEMBL3647011 & 1528850 & 8.699 & 8.221 & TRN & \\
\hline CHEMBL3646904 & 1528850 & 8.3979 & 7.3644 & TST & \\
\hline CHEMBL3646918 & 1528850 & 7.9208 & 7.4509 & TRN & \\
\hline CHEMBL3647041 & 1528850 & 7.1079 & 7.3491 & TRN & \\
\hline CHEMBL3646932 & 1528850 & 8.699 & 7.7146 & TRN & \\
\hline CHEMBL3951815 & 1528850 & 8.0969 & 7.4397 & TRN & \\
\hline CHEMBL 3646966 & 1528850 & 7.1938 & 8.2184 & TRN & \\
\hline CHEMBL3646937 & 1528850 & 6.7852 & 7.9452 & TST & \\
\hline CHEMBL3929100 & 1528850 & 8.0458 & 8.5461 & TRN & \\
\hline CHEMBL3984527 & 1528850 & 9.0 & 8.7278 & TRN & \\
\hline CHEMBL3646985 & 1528850 & 7.1024 & 7.5445 & TRN & \\
\hline CHEMBL3970206 & 1528850 & 9.0 & 8.7232 & TRN & \\
\hline CHEMBL3647016 & 1528850 & 7.5086 & 8.1232 & TRN & \\
\hline CHEMBL3646992 & 1528850 & 7.6778 & 7.6017 & TRN & \\
\hline CHEMBL 3984783 & 1528850 & 7.5086 & 7.8454 & TRN & \\
\hline CHEMBL3647039 & 1528850 & 6.8827 & 7.5733 & TST & \\
\hline CHEMBL3646994 & 1528850 & 8.5229 & 7.9491 & TST & \\
\hline CHEMBL 3647028 & 1528850 & 9.0 & 8.2081 & TRN & \\
\hline CHEMBL3646933 & 1528850 & 8.3979 & 8.0845 & TST & \\
\hline CHEMBL3646991 & 1528850 & 6.0615 & 8.1692 & TST & \\
\hline CHEMBL3647026 & 1528850 & 8.3979 & 8.3402 & TRN & \\
\hline CHEMBL3646901 & 1528850 & 7.3188 & 7.6861 & TST & \\
\hline CHEMBL3922331 & 1528850 & 8.699 & 7.5341 & TRN & \\
\hline CHEMBL3901139 & 1528850 & 7.9208 & 8.5984 & TRN & \\
\hline CHEMBL3959480 & 1528850 & 8.699 & 8.0921 & TRN & \\
\hline CHEMBL3944773 & 1528850 & 8.301 & 7.74 & TRN & \\
\hline
\end{tabular}


Supplemental Table S2.txt

\begin{tabular}{|c|c|c|c|c|c|}
\hline CHEMBL3646995 & 1528850 & 7.6576 & 7.6056 & TST & \\
\hline CHEMBL3646982 & 1528850 & 8.0458 & 8.1023 & TRN & \\
\hline CHEMBL3646993 & 1528850 & 6.2596 & \multicolumn{2}{|c|}{7.702000000000001} & TST \\
\hline CHEMBL 3647021 & 1528850 & 9.0 & 8.3622 & TRN & \\
\hline CHEMBL3646988 & 1528850 & 6.7447 & 7.4763 & TST & \\
\hline CHEMBL3647015 & 1528850 & 7.6383 & 8.1533 & TRN & \\
\hline CHEMBL3646905 & 1528850 & 8.0 & 7.3371 & TST & \\
\hline CHEMBL3646989 & 1528850 & 7.9586 & \multicolumn{2}{|c|}{7.702000000000001} & TST \\
\hline CHEMBL 3647000 & 1528850 & 6.7055 & 7.68 & TST & \\
\hline CHEMBL 3940370 & 1528850 & 8.699 & 8.8625 & TRN & \\
\hline CHEMBL3647037 & 1528850 & 7.2366 & 7.8275 & TST & \\
\hline CHEMBL3899898 & 1528850 & 8.0969 & 8.4987 & TRN & \\
\hline CHEMBL3646926 & 1528850 & 6.1273 & 7.5286 & TST & \\
\hline CHEMBL3639459 & 1528850 & 7.4202 & 7.1902 & TRN & \\
\hline CHEMBL 3924190 & 1528850 & 9.0 & 7.6801 & TRN & \\
\hline CHEMBL3914200 & 1528850 & 8.0969 & 8.2779 & TRN & \\
\hline CHEMBL3646961 & 1528850 & 8.301 & 8.1406 & TST & \\
\hline CHEMBL3646999 & 1528850 & 6.1024 & 7.6204 & TST & \\
\hline CHEMBL3646909 & 1528850 & 7.2676 & 7.2875 & TST & \\
\hline CHEMBL3942129 & 1528850 & 7.6383 & 7.9822 & TRN & \\
\hline CHEMBL3911928 & 1528850 & 6.7878 & 7.3783 & TRN & \\
\hline CHEMBL3928558 & 1528850 & 7.5086 & 7.4171 & TRN & \\
\hline CHEMBL3646917 & 1528850 & 7.3372 & 7.483 & TRN & \\
\hline CHEMBL3646925 & 1528850 & 7.1871 & 7.4608 & TRN & \\
\hline CHEMBL 3890771 & 1528850 & 8.699 & 8.4672 & TRN & \\
\hline CHEMBL3646924 & 1528850 & 8.3979 & 8.1976 & TRN & \\
\hline CHEMBL3646915 & 1528850 & 8.0 & 7.4513 & TRN & \\
\hline CHEMBL3924109 & 1528850 & 8.3979 & 7.8803 & TRN & \\
\hline CHEMBL3949158 & 1528850 & 7.2518 & 7.8347 & TRN & \\
\hline CHEMBL 3889744 & 1528850 & 7.3979 & 8.1728 & TRN & \\
\hline CHEMBL3985025 & 1528850 & 8.699 & 8.4591 & TRN & \\
\hline CHEMBL3646927 & 1528850 & 7.5376 & 7.4573 & TRN & \\
\hline CHEMBL3646922 & 1528850 & 7.8239 & 7.3847 & TRN & \\
\hline CHEMBL 3932415 & 1528850 & 8.2218 & 8.4311 & TRN & \\
\hline CHEMBL3955168 & 1528850 & 7.5086 & 7.8279 & TRN & \\
\hline CHEMBL3646930 & 1528850 & 6.0 & 7.5777 & TRN & \\
\hline CHEMBL3646928 & 1528850 & 6.9508 & 7.5325 & TST & \\
\hline CHEMBL3968102 & 1528850 & 7.041 & 7.2827 & TRN & \\
\hline CHEMBL3899759 & 1528850 & 9.0 & 8.8144 & TRN & \\
\hline CHEMBL3977621 & 1528850 & 6.3335 & 7.2702 & TRN & \\
\hline CHEMBL3647002 & 1528850 & 7.7447 & 7.49700 & 0000000001 & TRN \\
\hline CHEMBL3936892 & 1528850 & 8.699 & 8.5311 & TRN & \\
\hline CHEMBL3647008 & 1528850 & 6.0 & 8.2101 & TRN & \\
\hline CHEMBL3646911 & 1528850 & 7.7212 & 7.4135 & TRN & \\
\hline CHEMBL3646950 & 1528850 & 8.3979 & 7.6356 & TRN & \\
\hline CHEMBL3891472 & 1528850 & 7.1249 & 7.2995 & TRN & \\
\hline CHEMBL 3899167 & 1528850 & 8.699 & 7.4448 & TRN & \\
\hline CHEMBL 3895276 & 1528850 & 9.301 & 8.5897 & TRN & \\
\hline
\end{tabular}


Supplemental Table S2.txt

\begin{tabular}{|c|c|c|c|c|}
\hline CHEMBL 3647012 & 1528850 & 9.0 & 8.1936 & TRN \\
\hline CHEMBL 3979813 & 1528850 & 9.301 & 8.0775 & TRN \\
\hline CHEMBL 3646998 & 1528850 & 6.7033 & 7.6244 & TST \\
\hline CHEMBL 3913951 & 1528850 & 8.0458 & 7.75 & TRN \\
\hline CHEMBL 3647032 & 1528850 & 7.699 & 8.1417 & TRN \\
\hline CHEMBL 3892386 & 1528850 & 8.301 & 8.8255 & TRN \\
\hline CHEMBL 3646919 & 1528850 & 6.0 & 7.5313 & TRN \\
\hline CHEMBL 3647036 & 1528850 & 7.2518 & 7.4325 & TRN \\
\hline CHEMBL 3646931 & 1528850 & 8.3979 & 7.9906 & TST \\
\hline CHEMBL 3646929 & 1528850 & 7.3279 & 7.96399 & 99999999995 \\
\hline CHEMBL 3646906 & 1528850 & 7.5229 & 7.3638 & TRN \\
\hline CHEMBL 3646990 & 1528850 & 7.4318 & 8.0264 & TST \\
\hline CHEMBL 3903681 & 1528850 & 8.699 & 8.878 & TRN \\
\hline CHEMBL 3646903 & 1528850 & 6.4711 & 7.7951 & TST \\
\hline CHEMBL 3646912 & 1528850 & 7.0269 & 7.2947 & TRN \\
\hline CHEMBL 3647027 & 1528850 & 7.1739 & 8.1774 & TRN \\
\hline CHEMBL 3944098 & 1528850 & 7.5229 & 8.2478 & TRN \\
\hline CHEMBL 3646987 & 1528850 & 6.8794 & 7.2947 & TRN \\
\hline CHEMBL 3647018 & 1528850 & 9.0 & 8.1035 & TRN \\
\hline CHEMBL 3967481 & 1528850 & 8.301 & 7.9654 & TRN \\
\hline CHEMBL 3944531 & 1528850 & 9.0 & 8.904 & TRN \\
\hline CHEMBL3899595 & 1528850 & 9.0 & 8.5708 & TRN \\
\hline CHEMBL 3646902 & 1528850 & 7.0458 & 7.6433 & TST \\
\hline CHEMBL 3905873 & 1528850 & 8.0969 & 8.8094 & TRN \\
\hline CHEMBL 3890781 & 1528850 & 8.2218 & 8.3888 & TRN \\
\hline CHEMBL 3914188 & 1528850 & 8.699 & 8.4963 & TRN \\
\hline CHEMBL 3647025 & 1528850 & 8.3979 & 8.2933 & TRN \\
\hline CHEMBL 3934836 & 1528850 & 8.3979 & 8.5149 & TRN \\
\hline CHEMBL 3646978 & 1528850 & 8.3979 & 7.7595 & TRN \\
\hline CHEMBL 3646986 & 1528850 & 7.1308 & 7.6578 & TST \\
\hline CHEMBL 3963795 & 1528850 & 7.7959 & 7.4701 & TRN \\
\hline CHEMBL 3646981 & 1528850 & 7.1135 & 7.9933 & TRN \\
\hline CHEMBL 3938323 & 1528850 & 8.2218 & 8.3969 & TRN \\
\hline CHEMBL 3647035 & 1528850 & 6.0 & 7.9419 & TST \\
\hline CHEMBL 3647040 & 1528850 & 6.0958 & 7.847 & TST \\
\hline CHEMBL 3931497 & 1528850 & 8.1549 & 7.9842 & TRN \\
\hline CHEMBL 3646983 & 1528850 & 8.2218 & 8.0679 & TRN \\
\hline CHEMBL 3949152 & 1528850 & 9.0 & 8.8598 & TRN \\
\hline CHEMBL 3646977 & 1528850 & 8.5229 & 7.9526 & TRN \\
\hline CHEMBL 3647038 & 1528850 & 7.8539 & 7.8 & TST \\
\hline CHEMBL 3913729 & 1528850 & 9.0 & 8.6655 & TRN \\
\hline CHEMBL 3960516 & 1528850 & 8.1549 & 7.3301 & TRN \\
\hline CHEMBL 3935964 & 1528850 & 7.6383 & 7.7061 & TST \\
\hline CHEMBL 3647023 & 1528850 & 8.699 & 8.209 & TRN \\
\hline CHEMBL 3971727 & 1528850 & 8.699 & 7.9816 & TRN \\
\hline CHEMBL 3905200 & 1528850 & 8.699 & 8.0733 & TRN \\
\hline CHEMBL 3903510 & 1528850 & 9.0 & 8.8444 & TRN \\
\hline CHEMBL 3646921 & 1528850 & 6.38200 & 30000000 & 7.2998 \\
\hline
\end{tabular}




\begin{tabular}{|c|c|c|c|c|c|}
\hline \multicolumn{6}{|c|}{ Supplemental Table S2.txt } \\
\hline CHEMBL3916867 & 1528850 & 9.0 & 8.5401 & TRN & \\
\hline CHEMBL3975983 & 1528850 & 9.0 & 8.5629 & TRN & \\
\hline CHEMBL3896906 & 1528850 & 6.0 & 7.7753 & TRN & \\
\hline CHEMBL 3647017 & 1528850 & 7.4949 & 8.1348 & TRN & \\
\hline CHEMBL3646947 & 1528850 & 6.5114 & 7.6768 & TRN & \\
\hline CHEMBL3646997 & 1528850 & 7.3768 & 8.0725 & TST & \\
\hline CHEMBL3646996 & 1528850 & 7.699 & 8.1467 & TST & \\
\hline CHEMBL 3905147 & 1528850 & 7.4089 & 7.5649 & TRN & \\
\hline CHEMBL3945609 & 1528850 & 7.699 & 7.6109 & TST & \\
\hline CHEMBL3646910 & 1528850 & 6.7959 & 7.2669 & TST & \\
\hline CHEMBL 307007 & 161891 & 4.699 & 4.655 & TRN & \\
\hline CHEMBL307152 & 161891 & 5.5331 & 5.3399 & TRN & \\
\hline CHEMBL73485 & 161891 & 3.699 & 3.4049 & TRN & \\
\hline CHEMBL306527 & 161891 & 3.699 & 3.9043 & TRN & \\
\hline CHEMBL311851 & 161891 & 4.7447 & 4.9781 & TRN & \\
\hline CHEMBL72069 & 161891 & 4.8794 & 3.8502 & TST & \\
\hline CHEMBL307630 & 161891 & 5.0391 & 5.0027 & TRN & \\
\hline CHEMBL 76332 & 161891 & 3.699 & 3.6265 & TRN & \\
\hline CHEMBL 73772 & 161891 & 3.699 & 3.5562 & TRN & \\
\hline CHEMBL 306748 & 161891 & 3.699 & 5.6687 & TST & \\
\hline CHEMBL308252 & 161891 & 4.9431 & 4.0418 & TST & \\
\hline CHEMBL441258 & 161891 & 3.699 & 3.5337 & TRN & \\
\hline CHEMBL 307219 & 161891 & 3.699 & 3.7078 & TST & \\
\hline CHEMBL76326 & 161891 & 5.2132 & 5.1518 & TRN & \\
\hline CHEMBL312292 & 161891 & 5.2299 & 5.2026 & TRN & \\
\hline CHEMBL75952 & 161891 & 3.699 & 4.0349 & TRN & \\
\hline CHEMBL 72808 & 161891 & 3.699 & 3.7491 & TRN & \\
\hline CHEMBL308994 & 161891 & 3.699 & 4.0371 & TRN & \\
\hline CHEMBL73742 & 161891 & 5.2749 & 5.3126 & TRN & \\
\hline CHEMBL 308541 & 161891 & 3.699 & 3.63 & TRN & \\
\hline CHEMBL73718 & 161891 & 5.4271 & 5.1426 & TRN & \\
\hline CHEMBL 72754 & 161891 & 4.699 & 4.9369 & TRN & \\
\hline CHEMBL306114 & 161891 & 3.699 & 4.1967 & TRN & \\
\hline CHEMBL 306082 & 161891 & 4.9318 & 4.5031 & TRN & \\
\hline CHEMBL308099 & 161891 & 5.6289 & 5.775 & TRN & \\
\hline CHEMBL72607 & 161891 & 3.699 & 3.6373 & TRN & \\
\hline CHEMBL310491 & 161891 & 3.699 & 4.0497 & TRN & \\
\hline CHEMBL76499 & 161891 & 3.699 & 3.7363 & TRN & \\
\hline CHEMBL 73781 & 161891 & 5.5017 & 4.9826 & TST & \\
\hline CHEMBL75368 & 161891 & 5.5243 & 5.2081 & TRN & \\
\hline CHEMBL73343 & 161891 & 5.983 & 4.1048 & TST & \\
\hline CHEMBL431181 & 161891 & 3.699 & 3.62899 & 99999999996 & TRN \\
\hline CHEMBL306367 & 161891 & 5.4089 & 4.4371 & TST & \\
\hline CHEMBL73499 & 161891 & 3.699 & 3.8299 & TRN & \\
\hline CHEMBL76337 & 161891 & 5.0804 & 5.3045 & TRN & \\
\hline CHEMBL 308479 & 161891 & 3.699 & 3.4713 & TRN & \\
\hline CHEMBL306034 & 161891 & 3.699 & 4.0378 & TST & \\
\hline CHEMBL75953 & 161891 & 5.4828 & 5.3679 & TRN & \\
\hline
\end{tabular}




\begin{tabular}{|c|c|c|c|c|c|}
\hline \multicolumn{6}{|c|}{ Supplemental Table S2.txt } \\
\hline CHEMBL306047 & 161891 & 3.699 & 3.6789 & TRN & \\
\hline CHEMBL 307150 & 161891 & 3.699 & 4.0314 & TRN & \\
\hline CHEMBL 308979 & 161891 & 5.3391 & 5.1268 & TRN & \\
\hline CHEMBL73080 & 161891 & 3.699 & 3.7533 & TRN & \\
\hline CHEMBL73413 & 161891 & 3.699 & 4.1504 & TRN & \\
\hline CHEMBL430606 & 161891 & 4.8894 & 5.0071 & TRN & \\
\hline CHEMBL306501 & 161891 & 5.4711 & 4.9019 & TST & \\
\hline CHEMBL74289 & 161891 & 3.699 & 3.6458 & TRN & \\
\hline CHEMBL 308594 & 161891 & 4.699 & 4.465 & TRN & \\
\hline CHEMBL 76390 & 161891 & 3.699 & 3.5518 & TRN & \\
\hline CHEMBL73832 & 161891 & 3.699 & 3.5641 & TRN & \\
\hline CHEMBL73764 & 161891 & 5.0083 & 5.2315 & TRN & \\
\hline CHEMBL73751 & 161891 & 4.699 & 5.1594 & TST & \\
\hline CHEMBL73794 & 161891 & 4.7799 & 4.7222 & TRN & \\
\hline CHEMBL 76464 & 161891 & 5.5331 & 4.7608 & TST & \\
\hline CHEMBL 74637 & 161891 & 6.0227 & 6.454 & TST & \\
\hline CHEMBL308116 & 161891 & 4.699 & 4.5636 & TRN & \\
\hline CHEMBL 306611 & 161891 & 3.699 & 3.6102 & TRN & \\
\hline CHEMBL 75984 & 161891 & 5.3915 & 5.1436 & TRN & \\
\hline CHEMBL 75610 & 161891 & 3.699 & 4.3219 & TST & \\
\hline CHEMBL72077 & 161891 & 3.699 & 3.6518 & TST & \\
\hline CHEMBL 310260 & 161891 & 5.7905 & 4.1544 & TST & \\
\hline CHEMBL 72076 & 161891 & 4.8508 & 4.7875 & TRN & \\
\hline CHEMBL 306856 & 161891 & 5.5513 & 4.8544 & TST & \\
\hline CHEMBL 3906088 & 1641688 & 8.699 & 8.6986 & TRN & \\
\hline CHEMBL3966382 & 1641688 & 8.1549 & 7.8521 & TST & \\
\hline CHEMBL 3917483 & 1641688 & 8.3979 & 8.3169 & TRN & \\
\hline CHEMBL3896274 & 1641688 & 7.7696 & 7.8051 & TRN & \\
\hline CHEMBL 3972800 & 1641688 & 7.7212 & 8.03 & TST & \\
\hline CHEMBL 3968013 & 1641688 & 7.9586 & 7.98799 & 99999999995 & TRN \\
\hline CHEMBL3916459 & 1641688 & 7.6198 & 7.5456 & TRN & \\
\hline CHEMBL3906005 & 1641688 & 8.0 & 8.1975 & TRN & \\
\hline CHEMBL3918564 & 1641688 & 8.3979 & 8.2912 & TRN & \\
\hline CHEMBL 3906367 & 1641688 & 7.9586 & 7.8769 & TRN & \\
\hline CHEMBL 3916843 & 1641688 & 7.9586 & 7.8826 & TRN & \\
\hline CHEMBL 3919480 & 1641688 & 7.8539 & 7.7694 & TRN & \\
\hline CHEMBL3949914 & 1641688 & 7.8539 & 7.881 & TRN & \\
\hline CHEMBL3986507 & 1641688 & 7.699 & 7.8872 & TRN & \\
\hline CHEMBL 3978824 & 1641688 & 8.2218 & 8.2317 & TRN & \\
\hline CHEMBL 3944929 & 1641688 & 7.7959 & 7.791 & TST & \\
\hline CHEMBL3911339 & 1641688 & 7.7447 & 7.7438 & TRN & \\
\hline CHEMBL 3972255 & 1641688 & 8.301 & 8.185 & TRN & \\
\hline CHEMBL3944753 & 1641688 & 8.5229 & 8.5138 & TRN & \\
\hline CHEMBL 3905688 & 1641688 & 7.9208 & 8.1206 & TRN & \\
\hline CHEMBL3967877 & 1641688 & 8.1549 & 8.2828 & TRN & \\
\hline CHEMBL 3932948 & 1641688 & 8.5229 & 8.4351 & TRN & \\
\hline CHEMBL3977907 & 1641688 & 8.0458 & 7.8154 & TST & \\
\hline CHEMBL3910302 & 1641688 & 7.9586 & 7.9522 & TRN & \\
\hline
\end{tabular}


Supplemental Table S2.txt

\begin{tabular}{|c|c|c|c|c|c|}
\hline CHEMBL3911858 & 1641688 & 4.0 & 3.9231 & TRN & \\
\hline CHEMBL3919076 & 1641688 & 7.7696 & 7.7198 & TST & \\
\hline CHEMBL3944578 & 1641688 & 8.5229 & 8.5935 & TRN & \\
\hline CHEMBL3911718 & 1641688 & 8.2218 & 8.3345 & TRN & \\
\hline CHEMBL 3948737 & 1641688 & 7.5686 & 7.8277 & TST & \\
\hline CHEMBL3965868 & 1641688 & 8.1549 & \multicolumn{2}{|c|}{7.952000000000001} & TST \\
\hline CHEMBL3970603 & 1641688 & 7.6778 & 7.1631 & TST & \\
\hline CHEMBL3951242 & 1641688 & 8.3979 & 8.2384 & TRN & \\
\hline CHEMBL3924912 & 1641688 & 8.699 & 8.6335 & TRN & \\
\hline CHEMBL3918251 & 1641688 & 7.9586 & 7.9177 & TRN & \\
\hline CHEMBL 3898150 & 1641688 & 8.1549 & 8.3375 & TRN & \\
\hline CHEMBL3961927 & 1641688 & 8.3979 & 8.304 & TRN & \\
\hline CHEMBL3910242 & 1641688 & 8.1549 & 8.1851 & TRN & \\
\hline CHEMBL 3937925 & 1641688 & 7.9586 & \multicolumn{2}{|c|}{7.707999999999999} & TST \\
\hline CHEMBL3926026 & 1641688 & 8.3979 & 8.359 & TRN & \\
\hline CHEMBL 3936588 & 1641688 & 7.7959 & \multicolumn{2}{|c|}{7.837000000000001} & TRN \\
\hline CHEMBL3895671 & 1641688 & 8.301 & 8.0434 & TST & \\
\hline CHEMBL 3897945 & 1641688 & 7.9208 & 7.8904 & TRN & \\
\hline CHEMBL 3942670 & 1641688 & 7.699 & \multicolumn{2}{|c|}{7.787999999999999} & TRN \\
\hline CHEMBL 3907284 & 1641688 & 8.0 & 7.6617 & TST & \\
\hline CHEMBL3890520 & 1641688 & 8.1549 & 8.0717 & TRN & \\
\hline CHEMBL3934764 & 1641688 & 8.5229 & 8.6101 & TRN & \\
\hline CHEMBL3979830 & 1641688 & 8.301 & 8.28 & TRN & \\
\hline CHEMBL3933714 & 1641688 & 7.4685 & 8.1028 & TST & \\
\hline CHEMBL3890891 & 1641688 & 8.0458 & 8.1062 & TRN & \\
\hline CHEMBL3958277 & 1641688 & 7.9586 & 7.8099 & TRN & \\
\hline CHEMBL3975323 & 1641688 & 7.7959 & 8.007 & TRN & \\
\hline CHEMBL3983962 & 1641688 & 7.7212 & 7.7566 & TST & \\
\hline CHEMBL3939959 & 1641688 & 8.2218 & 8.3532 & TRN & \\
\hline CHEMBL3897675 & 1641688 & 4.0 & 4.0879 & TRN & \\
\hline CHEMBL3891953 & 1641688 & 7.4089 & 7.6187 & TST & \\
\hline CHEMBL3981785 & 1641688 & 8.301 & 8.3632 & TRN & \\
\hline CHEMBL3934424 & 1641688 & 8.5229 & 8.504 & TRN & \\
\hline CHEMBL3943862 & 1641688 & 8.0458 & 7.8316 & TST & \\
\hline CHEMBL3986984 & 1641688 & 8.5229 & 8.2699 & TRN & \\
\hline CHEMBL3933264 & 1641688 & 8.0 & 7.8999 & TRN & \\
\hline CHEMBL3966952 & 1641688 & 8.301 & 7.8289 & TST & \\
\hline CHEMBL3980166 & 1641688 & 7.6198 & 7.7354 & TRN & \\
\hline CHEMBL3896004 & 1641688 & 8.5229 & 8.3652 & TRN & \\
\hline CHEMBL3927233 & 1641688 & 7.8861 & 7.8555 & TRN & \\
\hline CHEMBL3922427 & 1641688 & 8.3979 & 8.4283 & TRN & \\
\hline CHEMBL3920518 & 1641688 & 8.1549 & 7.7039 & TST & \\
\hline CHEMBL3964131 & 1641688 & 8.1549 & 8.0646 & TRN & \\
\hline CHEMBL3929416 & 1641688 & 7.699 & 7.5756 & TST & \\
\hline CHEMBL3904954 & 1641688 & 8.1549 & 8.1618 & TRN & \\
\hline CHEMBL 238856 & 450275 & 9.2218 & 8.2483 & TST & \\
\hline CHEMBL 239743 & 450275 & 8.0458 & 6.9848 & TST & \\
\hline CHEMBL394989 & 450275 & 4.7615 & 5.6571 & TRN & \\
\hline
\end{tabular}




\begin{tabular}{|c|c|c|c|c|c|}
\hline \multirow[b]{2}{*}{ CHEMBL399016 } & \multicolumn{5}{|c|}{ Supplemental Table S2.txt } \\
\hline & 450275 & 7.9208 & 7.5054 & TRN & \\
\hline CHEMBL239337 & 450275 & 9.5229 & 9.3131 & TRN & \\
\hline CHEMBL396816 & 450275 & 9.2218 & 8.89200 & 0000000001 & TRN \\
\hline CHEMBL239962 & 450275 & 5.7496 & 6.2811 & TST & \\
\hline CHEMBL 239940 & 450275 & 7.5229 & 7.3384 & TRN & \\
\hline CHEMBL239718 & 450275 & 7.7447 & 8.1657 & TRN & \\
\hline CHEMBL391164 & 450275 & 7.6383 & 6.9775 & TST & \\
\hline CHEMBL438132 & 450275 & 6.8761 & 6.6151 & TST & \\
\hline CHEMBL239342 & 450275 & 8.1549 & 8.661 & TRN & \\
\hline CHEMBL239919 & 450275 & 9.0 & 8.1302 & TST & \\
\hline CHEMBL391761 & 450275 & 5.6799 & 7.0001 & TRN & \\
\hline CHEMBL236161 & 450275 & 9.0 & 8.8766 & TST & \\
\hline CHEMBL427856 & 450275 & 7.0 & 7.7219 & TRN & \\
\hline CHEMBL238882 & 450275 & 8.0969 & 7.8548 & TST & \\
\hline CHEMBL 238922 & 450275 & 6.1871 & 6.2882 & TRN & \\
\hline CHEMBL240147 & 450275 & 5.2154 & 5.2536 & TRN & \\
\hline CHEMBL239126 & 450275 & 6.6615 & 5.8668 & TRN & \\
\hline CHEMBL240769 & 450275 & 6.6757 & 6.7434 & TRN & \\
\hline CHEMBL239281 & 450275 & 8.5229 & 7.8641 & TST & \\
\hline CHEMBL240386 & 450275 & 9.5229 & 8.7638 & TRN & \\
\hline CHEMBL238921 & 450275 & 7.4949 & 7.4484 & TRN & \\
\hline CHEMBL 240770 & 450275 & 7.4559 & 7.0878 & TRN & \\
\hline CHEMBL396683 & 450275 & 7.0315 & 6.9487 & TRN & \\
\hline CHEMBL239343 & 450275 & 8.5229 & 8.8541 & TRN & \\
\hline CHEMBL241666 & 450275 & 7.8861 & 7.2017 & TRN & \\
\hline CHEMBL239120 & 450275 & 8.3979 & 7.8349 & TRN & \\
\hline CHEMBL 239918 & 450275 & 7.6576 & 7.2017 & TRN & \\
\hline CHEMBL239719 & 450275 & 8.699 & 8.5951 & TRN & \\
\hline CHEMBL391165 & 450275 & 7.8861 & 7.4121 & TST & \\
\hline CHEMBL239122 & 450275 & 6.2233 & 5.8875 & TRN & \\
\hline CHEMBL238907 & 450275 & 8.699 & 8.7578 & TRN & \\
\hline CHEMBL 238464 & 450275 & 6.9706 & 7.601 & TRN & \\
\hline CHEMBL239063 & 450275 & 8.699 & 8.3443 & TRN & \\
\hline CHEMBL 395404 & 450275 & 8.5229 & 7.8949 & TRN & \\
\hline CHEMBL393110 & 450275 & 8.0458 & 8.661 & TRN & \\
\hline CHEMBL239717 & 450275 & 8.301 & 7.721 & TST & \\
\hline CHEMBL 240387 & 450275 & 7.5229 & 7.1528 & TRN & \\
\hline CHEMBL442246 & 450275 & 8.699 & 8.5752 & TRN & \\
\hline CHEMBL 238702 & 450275 & 8.1549 & 8.3993 & TRN & \\
\hline CHEMBL394482 & 450275 & 8.699 & 8.4418 & TRN & \\
\hline CHEMBL393696 & 450275 & 8.699 & 7.9054 & TST & \\
\hline CHEMBL 238701 & 450275 & 7.585 & 7.4817 & TRN & \\
\hline CHEMBL391762 & 450275 & 7.4949 & 7.6551 & TRN & \\
\hline CHEMBL 239064 & 450275 & 8.5229 & 8.5438 & TRN & \\
\hline CHEMBL238466 & 450275 & 8.0458 & 8.2538 & TRN & \\
\hline CHEMBL238700 & 450275 & 7.301 & 7.8949 & TRN & \\
\hline CHEMBL239338 & 450275 & 9.301 & 9.0644 & TRN & \\
\hline CHEMBL240148 & 450275 & 5.6536 & 5.5677 & TRN & \\
\hline
\end{tabular}




\begin{tabular}{|c|c|c|c|c|c|}
\hline \multicolumn{6}{|c|}{ Supplemental Table S2.txt } \\
\hline CHEMBL240388 & 450275 & 8.2218 & 8.4319 & TRN & \\
\hline CHEMBL239939 & 450275 & 7.0655 & 7.5519 & TST & \\
\hline CHEMBL239699 & 450275 & 7.4559 & 7.0675 & TRN & \\
\hline CHEMBL239934 & 450275 & 8.0458 & 9.1102 & TST & \\
\hline CHEMBL397172 & 450275 & 7.7447 & 8.054 & TRN & \\
\hline CHEMBL415331 & 450275 & 6.1487 & 6.0508 & TRN & \\
\hline CHEMBL240176 & 450275 & 6.2076 & 6.7325 & TRN & \\
\hline CHEMBL394990 & 450275 & 8.699 & 7.7057 & TST & \\
\hline CHEMBL3671134 & 1640347 & 8.8097 & 8.56299 & 9999999999 & TRN \\
\hline CHEMBL3676018 & 1640347 & 7.5114 & 7.28799 & 9999999999 & TRN \\
\hline CHEMBL3671145 & 1640347 & 8.6676 & 8.6366 & TRN & \\
\hline CHEMBL3675963 & 1640347 & 8.2125 & 7.3562 & TRN & \\
\hline CHEMBL3675933 & 1640347 & 8.4056 & 8.4011 & TRN & \\
\hline CHEMBL3676053 & 1640347 & 8.0655 & 8.3842 & TRN & \\
\hline CHEMBL3675965 & 1640347 & 9.0223 & 8.9003 & TST & \\
\hline CHEMBL3671132 & 1640347 & 9.0223 & 8.8873 & TRN & \\
\hline CHEMBL3676088 & 1640347 & 7.9788 & 7.6292 & TRN & \\
\hline CHEMBL3676091 & 1640347 & 7.7986 & 7.9105 & TRN & \\
\hline CHEMBL3639748 & 1640347 & 8.1805 & 8.7054 & TST & \\
\hline CHEMBL 3676089 & 1640347 & 7.9101 & 7.2005 & TRN & \\
\hline CHEMBL3675943 & 1640347 & 8.2924 & 8.2735 & TST & \\
\hline CHEMBL3675932 & 1640347 & 6.0 & 6.7234 & TRN & \\
\hline CHEMBL3671138 & 1640347 & 8.9788 & 8.6933 & TRN & \\
\hline CHEMBL 3676041 & 1640347 & 8.6021 & 8.9966 & TRN & \\
\hline CHEMBL3675972 & 1640347 & 8.2076 & 7.3279 & TRN & \\
\hline CHEMBL3676076 & 1640347 & 8.4815 & 6.9796 & TST & \\
\hline CHEMBL3675913 & 1640347 & 8.9208 & 8.4838 & TRN & \\
\hline CHEMBL3675942 & 1640347 & 9.2441 & 8.8906 & TRN & \\
\hline CHEMBL3675922 & 1640347 & 8.8239 & 8.611 & TRN & \\
\hline CHEMBL 3676022 & 1640347 & 8.8539 & 8.4552 & TRN & \\
\hline CHEMBL 3675941 & 1640347 & 9.2218 & 8.9766 & TRN & \\
\hline CHEMBL3676065 & 1640347 & 6.6148 & 7.6352 & TRN & \\
\hline CHEMBL3676010 & 1640347 & 7.58 & 7.6766 & TRN & \\
\hline CHEMBL3675908 & 1640347 & 8.71 & 8.9488 & TRN & \\
\hline CHEMBL3675956 & 1640347 & 8.9393 & 8.5806 & TRN & \\
\hline CHEMBL3675925 & 1640347 & 8.8239 & 9.0484 & TRN & \\
\hline CHEMBL3675966 & 1640347 & 8.4949 & 7.6152 & TRN & \\
\hline CHEMBL3902802 & 1640347 & 6.0 & 7.0401 & TST & \\
\hline CHEMBL3675951 & 1640347 & 7.0455 & 8.1693 & TST & \\
\hline CHEMBL3675936 & 1640347 & 8.6478 & 8.6361 & TRN & \\
\hline CHEMBL3676055 & 1640347 & 7.2104 & 7.7484 & TRN & \\
\hline CHEMBL3676003 & 1640347 & 6.0 & 7.2472 & TRN & \\
\hline CHEMBL3676095 & 1640347 & 7.1198 & 6.8523 & TRN & \\
\hline CHEMBL 3676042 & 1640347 & 8.8239 & 8.2233 & TRN & \\
\hline CHEMBL 3676064 & 1640347 & 8.3188 & 7.7335 & TRN & \\
\hline CHEMBL3675968 & 1640347 & 8.2924 & 7.1937 & TRN & \\
\hline CHEMBL3675934 & 1640347 & 8.0269 & 8.6408 & TRN & \\
\hline CHEMBL3675938 & 1640347 & 6.0 & 6.5752 & TRN & \\
\hline
\end{tabular}


Supplemental Table S2.txt

\begin{tabular}{|c|c|c|c|c|}
\hline CHEMBL3671153 & 1640347 & 9.3979 & 8.595 & TRN \\
\hline CHEMBL3676052 & 1640347 & 8.1308 & 7.3487 & TRN \\
\hline CHEMBL3675988 & 1640347 & 7.5243 & 7.5597 & TRN \\
\hline CHEMBL3671154 & 1640347 & 6.0 & 7.2802 & TRN \\
\hline CHEMBL3676040 & 1640347 & 8.3279 & 8.9462 & TRN \\
\hline CHEMBL3676002 & 1640347 & 5.5859 & 5.6213 & TRN \\
\hline CHEMBL3671135 & 1640347 & 9.3468 & 9.1445 & TRN \\
\hline CHEMBL3676019 & 1640347 & 8.9586 & 8.4297 & TRN \\
\hline CHEMBL3676008 & 1640347 & 8.1308 & 7.0474 & TRN \\
\hline CHEMBL3676092 & 1640347 & 8.5229 & 8.2147 & TRN \\
\hline CHEMBL3671156 & 1640347 & 8.5528 & 8.8527 & TRN \\
\hline CHEMBL3676057 & 1640347 & 7.1169 & 6.4413 & TRN \\
\hline CHEMBL3675953 & 1640347 & 7.4578 & 8.4551 & TST \\
\hline CHEMBL3675989 & 1640347 & 6.0 & 6.5009 & TRN \\
\hline CHEMBL3676005 & 1640347 & 8.301 & 7.7312 & TRN \\
\hline CHEMBL3675962 & 1640347 & 7.7932 & 8.7832 & TST \\
\hline CHEMBL3675926 & 1640347 & 9.2218 & 8.6731 & TRN \\
\hline CHEMBL 3675947 & 1640347 & 7.3531 & 8.1452 & TRN \\
\hline CHEMBL3671130 & 1640347 & 9.1549 & 8.7904 & TST \\
\hline CHEMBL3675918 & 1640347 & 9.0969 & 8.9991 & TRN \\
\hline CHEMBL3675914 & 1640347 & 8.6778 & 8.0372 & TRN \\
\hline CHEMBL3671152 & 1640347 & 8.4437 & 8.6062 & TST \\
\hline CHEMBL3676048 & 1640347 & 7.9101 & 7.9196 & TRN \\
\hline CHEMBL3675909 & 1640347 & 7.9747 & 7.0515 & TRN \\
\hline CHEMBL3675959 & 1640347 & 7.6767 & 8.6959 & TRN \\
\hline CHEMBL3676046 & 1640347 & 8.6021 & 7.8145 & TRN \\
\hline CHEMBL3675977 & 1640347 & 6.0 & 7.6057 & TRN \\
\hline CHEMBL3676045 & 1640347 & 8.7447 & 7.5373 & TRN \\
\hline CHEMBL3676050 & 1640347 & 7.9469 & 8.4432 & TRN \\
\hline CHEMBL3675980 & 1640347 & 8.1135 & 8.0254 & TRN \\
\hline CHEMBL3675986 & 1640347 & 7.51 & 8.0416 & TRN \\
\hline CHEMBL3675916 & 1640347 & 8.8861 & 8.9302 & TRN \\
\hline CHEMBL3675919 & 1640347 & 7.5391 & 8.1226 & TRN \\
\hline CHEMBL3676032 & 1640347 & 8.5229 & 7.747000 & 0000000001 \\
\hline CHEMBL3904952 & 1640347 & 9.0458 & 7.5392 & TST \\
\hline CHEMBL3676070 & 1640347 & 7.7799 & 8.5081 & TST \\
\hline CHEMBL3675975 & 1640347 & 7.9318 & 8.3852 & TRN \\
\hline CHEMBL3676061 & 1640347 & 7.8069 & 7.8169 & TRN \\
\hline CHEMBL3675981 & 1640347 & 7.7852 & 7.6977 & TRN \\
\hline CHEMBL3675961 & 1640347 & 7.5735 & 8.4129 & TST \\
\hline CHEMBL3971680 & 1640347 & 8.4437 & 7.2981 & TST \\
\hline CHEMBL3676063 & 1640347 & 8.1675 & 8.1201 & TRN \\
\hline CHEMBL3675923 & 1640347 & 8.8539 & 8.8688 & TRN \\
\hline CHEMBL3675976 & 1640347 & 8.28399 & 999999999 & 7.71 \\
\hline CHEMBL3676071 & 1640347 & 7.8447 & 8.026 & TST \\
\hline CHEMBL3675944 & 1640347 & 7.2197 & 7.9703 & TRN \\
\hline CHEMBL3676049 & 1640347 & 7.767 & 8.3653 & TRN \\
\hline CHEMBL 3676104 & 1640347 & 8.0506 & 7.9849 & TST \\
\hline
\end{tabular}




\begin{tabular}{|c|c|c|c|c|c|c|}
\hline \multicolumn{7}{|c|}{ Supplemental Table S2.txt } \\
\hline CHEMBL3675995 & 1640347 & 6.0 & 6.6129 & TRN & & \\
\hline CHEMBL3671151 & 1640347 & 8.9586 & 8.5786 & TST & & \\
\hline CHEMBL 3676073 & 1640347 & 7.4776 & 7.8021 & TST & & \\
\hline CHEMBL3676103 & 1640347 & 7.6615 & 8.0293 & TRN & & \\
\hline CHEMBL3676017 & 1640347 & 6.0 & 6.7435 & TRN & & \\
\hline CHEMBL3675969 & 1640347 & 6.2455 & 6.2079 & TRN & & \\
\hline CHEMBL 3671129 & 1640347 & 9.1549 & 8.6708 & TRN & & \\
\hline CHEMBL 3675945 & 1640347 & 7.6207 & 7.5877 & TRN & & \\
\hline CHEMBL 3676024 & 1640347 & 8.6778 & 8.2778 & TRN & & \\
\hline CHEMBL3675912 & 1640347 & 8.9586 & 8.4213 & TRN & & \\
\hline CHEMBL3676097 & 1640347 & 6.0 & 6.8935 & TRN & & \\
\hline CHEMBL 3675937 & 1640347 & 8.71 & 8.6834 & TST & & \\
\hline CHEMBL 3676080 & 1640347 & 7.8153 & 6.949 & TST & & \\
\hline CHEMBL 3675964 & 1640347 & 8.4437 & 8.5817 & TST & & \\
\hline CHEMBL3675911 & 1640347 & 8.8239 & 9.0559 & TRN & & \\
\hline CHEMBL3676075 & 1640347 & 7.767 & 6.2512 & TST & & \\
\hline CHEMBL3675952 & 1640347 & 8.27 & 8.6868 & TST & & \\
\hline CHEMBL3676006 & 1640347 & 7.3526 & 7.9557 & TRN & & \\
\hline CHEMBL3675992 & 1640347 & 7.6478 & 6.9388 & TRN & & \\
\hline CHEMBL 3675949 & 1640347 & 7.8996 & 8.2055 & TRN & & \\
\hline CHEMBL3675982 & 1640347 & 5.9239 & 6.0095 & TRN & & \\
\hline CHEMBL3675935 & 1640347 & 7.7708 & 7.4941 & TST & & \\
\hline CHEMBL 3671131 & 1640347 & 8.6383 & 8.5758 & TST & & \\
\hline CHEMBL 3675979 & 1640347 & 7.5952 & 8.0517 & TRN & & \\
\hline CHEMBL3676015 & 1640347 & 8.0269 & 8.2266 & TRN & & \\
\hline CHEMBL3916880 & 1640347 & 6.0 & 8.0425 & TST & & \\
\hline CHEMBL 3676087 & 1640347 & 7.2807 & 8.6457 & TST & & \\
\hline CHEMBL 3676058 & 1640347 & 8.6198 & 7.8541 & TRN & & \\
\hline CHEMBL 3676038 & 1640347 & 9.0458 & 9.0722 & TRN & & \\
\hline CHEMBL 3676067 & 1640347 & 7.8962 & 8.2163 & TRN & & \\
\hline CHEMBL 3676023 & 1640347 & 7.7423 & 8.0688 & TRN & & \\
\hline CHEMBL 3675957 & 1640347 & 8.5935 & 8.4286 & TRN & & \\
\hline CHEMBL 3671140 & 1640347 & 6.62299 & 99999999 & 99 & 7.2567 & TRN \\
\hline CHEMBL3676039 & 1640347 & 7.9355 & 8.7948 & TRN & & \\
\hline CHEMBL 3671141 & 1640347 & 9.301 & 9.3755 & TRN & & \\
\hline CHEMBL3675973 & 1640347 & 8.0458 & 7.74 & TRN & & \\
\hline CHEMBL 3675948 & 1640347 & 7.3138 & 7.8897 & TRN & & \\
\hline CHEMBL3675999 & 1640347 & 7.8928 & 7.8702 & TRN & & \\
\hline CHEMBL 3676077 & 1640347 & 8.3768 & 6.5197 & TST & & \\
\hline CHEMBL3676072 & 1640347 & 8.4089 & 8.1874 & TST & & \\
\hline CHEMBL3671143 & 1640347 & 9.2218 & 8.9125 & TST & & \\
\hline CHEMBL 3671148 & 1640347 & 9.2218 & 9.2344 & TRN & & \\
\hline CHEMBL3675991 & 1640347 & 7.3468 & 7.8191 & TRN & & \\
\hline CHEMBL 3676029 & 1640347 & 8.0044 & 8.2946 & TRN & & \\
\hline CHEMBL3675955 & 1640347 & 8.7447 & 8.2438 & TRN & & \\
\hline CHEMBL3675910 & 1640347 & 8.2757 & 7.3898 & TRN & & \\
\hline CHEMBL3675931 & 1640347 & 8.6478 & 8.2457 & TRN & & \\
\hline CHEMBL 3676090 & 1640347 & 7.8861 & 8.1825 & TRN & & \\
\hline
\end{tabular}

Page 3810 
Supplemental Table S2.txt

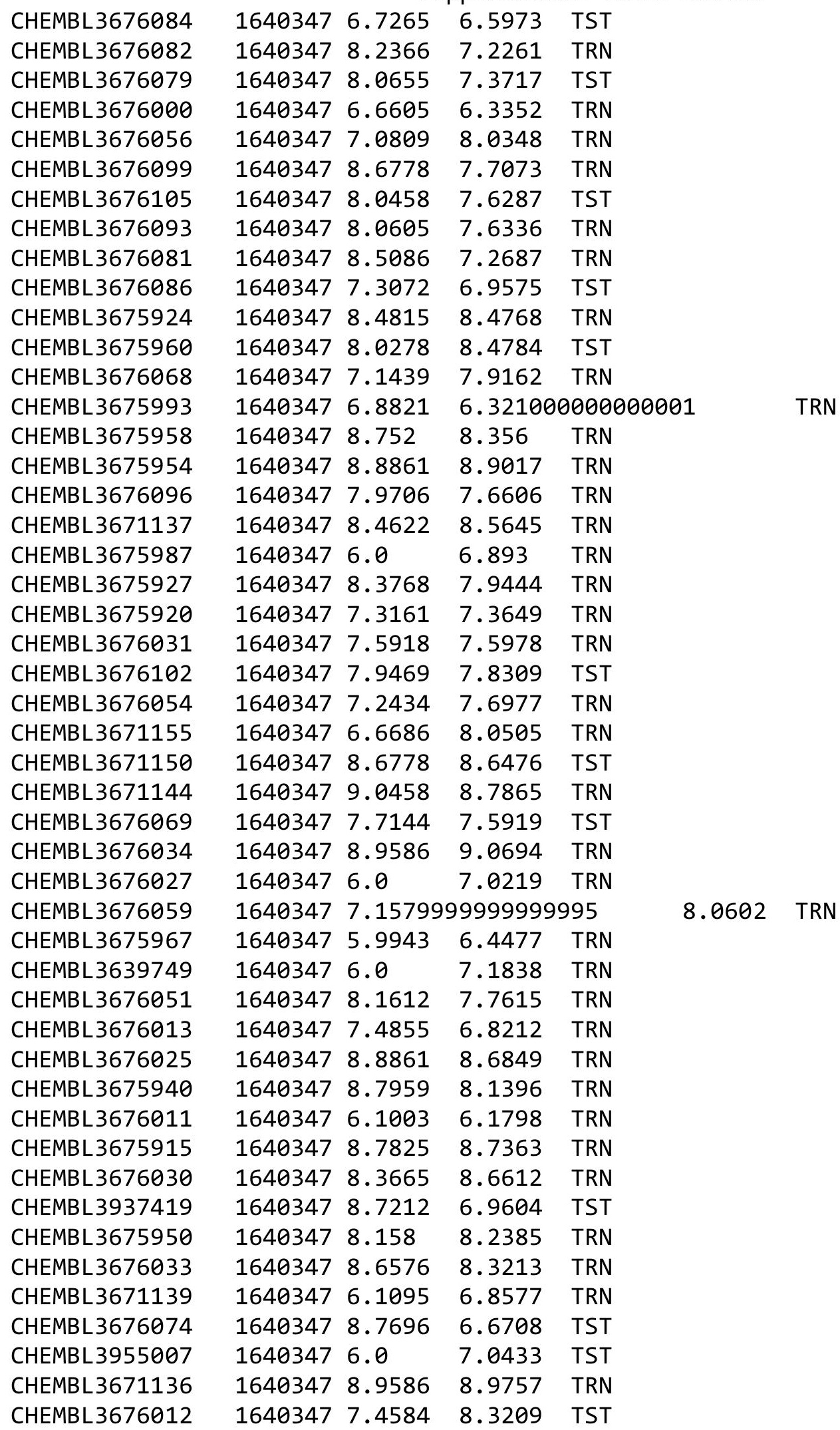

Page 3811 


\begin{tabular}{|c|c|c|c|c|c|c|}
\hline \multicolumn{7}{|c|}{ Supplemental Table S2.txt } \\
\hline CHEMBL3675983 & 1640347 & 6.0 & 6.2589 & TRN & & \\
\hline CHEMBL3676101 & 1640347 & 7.9957 & 7.8971 & TRN & & \\
\hline CHEMBL3675971 & 1640347 & 6.4653 & 6.4227 & TRN & & \\
\hline CHEMBL3675930 & 1640347 & 7.983 & 7.6224 & TRN & & \\
\hline CHEMBL3675917 & 1640347 & 9.1549 & 8.8767 & TRN & & \\
\hline CHEMBL3676047 & 1640347 & 8.0706 & 7.5479 & TRN & & \\
\hline CHEMBL3675985 & 1640347 & 7.4225 & 7.6942 & TRN & & \\
\hline CHEMBL3675921 & 1640347 & 6.0 & 7.334 & TRN & & \\
\hline CHEMBL3675929 & 1640347 & 8.1308 & 8.3096 & TRN & & \\
\hline CHEMBL3675970 & 1640347 & 8.2676 & 8.2156 & TRN & & \\
\hline CHEMBL3676026 & 1640347 & 9.699 & 8.536 & TRN & & \\
\hline CHEMBL3676060 & 1640347 & 6.3587 & 6.1341 & TRN & & \\
\hline CHEMBL3671149 & 1640347 & 8.5302 & 8.3263 & TST & & \\
\hline CHEMBL3671133 & 1640347 & 9.0223 & 8.8869 & TST & & \\
\hline CHEMBL3676094 & 1640347 & 8.3468 & 7.7883 & TRN & & \\
\hline CHEMBL3671142 & 1640347 & 9.2596 & 9.4417 & TRN & & \\
\hline CHEMBL3676085 & 1640347 & 6.959 & 6.7227 & TST & & \\
\hline CHEMBL3676016 & 1640347 & 7.8962 & 7.8113 & TST & & \\
\hline CHEMBL3676106 & 1640347 & 7.4179 & 7.6934 & TST & & \\
\hline CHEMBL3676001 & 1640347 & 6.3281 & 6.5468 & TST & & \\
\hline CHEMBL3671146 & 1640347 & 6.0 & 6.6872 & TST & & \\
\hline CHEMBL3676037 & 1640347 & 8.9208 & 8.7305 & TST & & \\
\hline CHEMBL3675946 & 1640347 & 8.06299 & 99999999 & 99 & 8.0093 & TST \\
\hline CHEMBL67035 & 177012 & 4.6778 & 4.8612 & TRN & & \\
\hline CHEMBL66291 & 177012 & 4.4437 & 4.4084 & TRN & & \\
\hline CHEMBL63206 & 177012 & 5.5528 & 5.5006 & TST & & \\
\hline CHEMBL303929 & 177012 & 4.6383 & 5.4814 & TST & & \\
\hline CHEMBL67726 & 177012 & 5.3098 & 5.2248 & TST & & \\
\hline CHEMBL67347 & 177012 & 5.5528 & 5.5939 & TST & & \\
\hline CHEMBL67849 & 177012 & 6.301 & 5.7528 & TRN & & \\
\hline CHEMBL302026 & 177012 & 6.2218 & 6.6676 & TRN & & \\
\hline CHEMBL421674 & 177012 & 5.5686 & 5.233 & TRN & & \\
\hline CHEMBL 303703 & 177012 & 5.0555 & 5.5167 & TST & & \\
\hline CHEMBL70039 & 177012 & 6.301 & 6.2286 & TRN & & \\
\hline CHEMBL67358 & 177012 & 6.0 & 6.4131 & TRN & & \\
\hline CHEMBL305788 & 177012 & 4.6021 & 5.8976 & TST & & \\
\hline CHEMBL304959 & 177012 & 5.5686 & 5.3154 & TRN & & \\
\hline CHEMBL66670 & 177012 & 5.8539 & 5.9236 & TRN & & \\
\hline CHEMBL65895 & 177012 & 4.9208 & 4.1132 & TST & & \\
\hline CHEMBL66147 & 177012 & 5.5086 & 5.5164 & TRN & & \\
\hline CHEMBL306901 & 177012 & 7.0 & 6.8597 & TRN & & \\
\hline CHEMBL66803 & 177012 & 4.4815 & 4.2171 & TRN & & \\
\hline CHEMBL66912 & 177012 & 5.1079 & 5.4705 & TRN & & \\
\hline CHEMBL68836 & 177012 & 5.4815 & 5.6741 & TRN & & \\
\hline CHEMBL68454 & 177012 & 6.0969 & 5.8071 & TRN & & \\
\hline CHEMBL 70135 & 177012 & 4.3768 & 4.4382 & TRN & & \\
\hline CHEMBL65859 & 177012 & 4.8539 & 5.0944 & TST & & \\
\hline CHEMBL305581 & 177012 & 4.5528 & 4.4426 & TRN & & \\
\hline
\end{tabular}




\begin{tabular}{|c|c|c|c|c|c|c|}
\hline & & \multicolumn{5}{|c|}{ Supplemental Table S2.txt } \\
\hline CHEMBL303682 & 177012 & 6.2218 & 6.0129 & TRN & & \\
\hline CHEMBL66186 & 177012 & 6.1549 & 6.2614 & TRN & & \\
\hline CHEMBL65899 & 177012 & 4.6021 & 4.496 & TRN & & \\
\hline CHEMBL66220 & 177012 & 5.8239 & 5.8947 & TRN & & \\
\hline CHEMBL67383 & 177012 & 6.0969 & 5.1667 & TST & & \\
\hline CHEMBL304337 & 177012 & 4.3468 & 5.3772 & TST & & \\
\hline CHEMBL66215 & 177012 & 5.4815 & 5.1553 & TRN & & \\
\hline CHEMBL417057 & 177012 & 5.3665 & 5.2363 & TRN & & \\
\hline CHEMBL67316 & 177012 & 6.301 & 5.9484 & TRN & & \\
\hline CHEMBL66974 & 177012 & 5.2596 & 5.6409 & TRN & & \\
\hline CHEMBL 303500 & 177012 & 6.5229 & 6.2548 & TRN & & \\
\hline CHEMBL302566 & 177012 & 5.0 & 5.0891 & TRN & & \\
\hline CHEMBL417205 & 177012 & 5.7212 & 5.8124 & TRN & & \\
\hline CHEMBL67112 & 177012 & 4.7212 & 5.0136 & TRN & & \\
\hline CHEMBL67202 & 177012 & 4.9586 & 5.0174 & TRN & & \\
\hline CHEMBL66341 & 177012 & 4.6383 & 4.8233 & TRN & & \\
\hline CHEMBL65965 & 177012 & 4.7696 & 5.1584 & TRN & & \\
\hline CHEMBL309124 & 177012 & 5.0969 & 4.254 & TST & & \\
\hline CHEMBL 308467 & 177012 & 5.8239 & 5.5801 & TRN & & \\
\hline CHEMBL305211 & 177012 & 5.0969 & 5.1493 & TRN & & \\
\hline CHEMBL70058 & 177012 & 4.8539 & 4.8433 & TRN & & \\
\hline CHEMBL 67553 & 177012 & 6.5229 & 6.4107 & TRN & & \\
\hline CHEMBL66509 & 177012 & 5.0458 & 6.1868 & TST & & \\
\hline CHEMBL 304299 & 177012 & 5.0 & 5.9457 & TST & & \\
\hline CHEMBL304057 & 177012 & 4.284 & 4.6399 & TRN & & \\
\hline CHEMBL1083169 & 635680 & 7.2725 & 7.335 & TRN & & \\
\hline CHEMBL1083744 & 635680 & 7.8153 & 7.7461 & TRN & & \\
\hline CHEMBL1086110 & 635680 & 8.1379 & 8.2005 & TRN & & \\
\hline CHEMBL1086265 & 635680 & 7.9626 & 7.8816 & TRN & & \\
\hline CHEMBL1083459 & 635680 & 7.0888 & 7.206 & TRN & & \\
\hline CHEMBL1086330 & 635680 & 6.2716 & 6.2777 & TRN & & \\
\hline CHEMBL1082608 & 635680 & 7.0477 & 6.9413 & TRN & & \\
\hline CHEMBL1086106 & 635680 & 7.4698 & 7.7233 & TST & & \\
\hline CHEMBL1086329 & 635680 & 7.2565 & 7.2892 & TRN & & \\
\hline CHEMBL1085312 & 635680 & $6.7570 e$ & 30000000 & $\partial 1$ & 6.3298 & TRN \\
\hline CHEMBL1085374 & 635680 & 8.1451 & 7.8847 & TRN & & \\
\hline CHEMBL1083776 & 635680 & 6.5686 & 6.5678 & TRN & & \\
\hline CHEMBL1084017 & 635680 & 5.9788 & 5.9003 & TRN & & \\
\hline CHEMBL1085646 & 635680 & 7.2899 & 7.2829 & TRN & & \\
\hline CHEMBL1084005 & 635680 & 6.2097 & 6.2771 & TRN & & \\
\hline CHEMBL1084018 & 635680 & 7.6402 & 7.4395 & TRN & & \\
\hline CHEMBL1083164 & 635680 & 7.6055 & 7.6035 & TRN & & \\
\hline CHEMBL1086107 & 635680 & 7.0904 & 7.1221 & TRN & & \\
\hline CHEMBL1083168 & 635680 & 6.1361 & 6.1556 & TRN & & \\
\hline CHEMBL1083167 & 635680 & 6.8268 & 6.9322 & TRN & & \\
\hline CHEMBL1084964 & 635680 & 7.9066 & 7.9833 & TRN & & \\
\hline CHEMBL1083775 & 635680 & 6.8794 & 6.9466 & TRN & & \\
\hline CHEMBL1085376 & 635680 & 6.2097 & 6.3157 & TRN & & \\
\hline
\end{tabular}




\begin{tabular}{|c|c|c|c|c|c|}
\hline \multicolumn{6}{|c|}{ Supplemental Table S2.txt } \\
\hline CHEMBL1085404 & 635680 & 7.8794 & 7.7878 & TRN & \\
\hline CHEMBL1083460 & 635680 & 6.3134 & 6.2702 & TRN & \\
\hline CHEMBL1083399 & 635680 & 7.6326 & 7.5955 & TRN & \\
\hline CHEMBL1084004 & 635680 & 5.6216 & 5.6408 & TRN & \\
\hline CHEMBL1083135 & 635680 & 6.4868 & 6.5136 & TRN & \\
\hline CHEMBL1083458 & 635680 & 6.6861 & 6.8644 & TRN & \\
\hline CHEMBL1082825 & 635680 & 6.5452 & \multicolumn{2}{|c|}{6.577000000000001} & TRN \\
\hline CHEMBL1083266 & 635680 & 7.1891 & 7.4699 & TRN & \\
\hline CHEMBL1084447 & 635680 & 7.8041 & 7.7765 & TRN & \\
\hline CHEMBL1085311 & 635680 & 8.0168 & 6.6326 & TST & \\
\hline CHEMBL1084007 & 635680 & 6.5467 & 6.5187 & TRN & \\
\hline CHEMBL1084169 & 635680 & 5.9226 & 6.0078 & TRN & \\
\hline CHEMBL1085055 & 635680 & 7.4389 & 7.4654 & TRN & \\
\hline CHEMBL1084334 & 635680 & 7.3391 & 7.2606 & TRN & \\
\hline CHEMBL1086262 & 635680 & 6.317 & 6.21 & TRN & \\
\hline CHEMBL1086352 & 635680 & 8.0799 & \multicolumn{2}{|c|}{7.997000000000001} & TST \\
\hline CHEMBL1083127 & 635680 & 6.4168 & 6.6301 & TST & \\
\hline CHEMBL1086263 & 635680 & 6.6091 & 6.6675 & TRN & \\
\hline CHEMBL1086264 & 635680 & 6.8356 & 6.6676 & TRN & \\
\hline CHEMBL1086111 & 635680 & 7.6003 & 7.4928 & TST & \\
\hline CHEMBL1083715 & 635680 & 6.3261 & 6.6898 & TRN & \\
\hline CHEMBL1085406 & 635680 & 8.8447 & 8.9145 & TRN & \\
\hline CHEMBL1085375 & 635680 & 7.4067 & 7.2777 & TRN & \\
\hline CHEMBL1085408 & 635680 & 6.9355 & 6.9901 & TRN & \\
\hline CHEMBL1085039 & 635680 & 6.0168 & \multicolumn{2}{|c|}{6.412000000000001} & TST \\
\hline CHEMBL1084713 & 635680 & 8.1349 & 8.1655 & TRN & \\
\hline CHEMBL1085407 & 635680 & 7.6696 & 7.6324 & TRN & \\
\hline CHEMBL1083777 & 635680 & 7.2007 & 7.1524 & TST & \\
\hline CHEMBL1083163 & 635680 & 7.0353 & 7.1083 & TST & \\
\hline CHEMBL1086112 & 635680 & 7.4881 & 8.1954 & TST & \\
\hline CHEMBL1085405 & 635680 & 8.5467 & 6.9092 & TST & \\
\hline CHEMBL1083576 & 635680 & 5.644 & 6.9706 & TST & \\
\hline CHEMBL1085373 & 635680 & 6.4191 & 6.504 & TST & \\
\hline CHEMBL1084006 & 635680 & 6.6799 & 6.709 & TST & \\
\hline CHEMBL1085151 & 635680 & 6.6517 & 7.1721 & TST & \\
\hline CHEMBL1083745 & 635680 & 6.4078 & 6.5859 & TST & \\
\hline CHEMBL66965 & 34583 & 8.2291 & 8.0012 & TRN & \\
\hline CHEMBL68052 & 34583 & 9.0969 & \multicolumn{2}{|c|}{8.732999999999999} & TRN \\
\hline CHEMBL 303347 & 34583 & 8.3768 & 8.2642 & TRN & \\
\hline CHEMBL67047 & 34583 & 5.6207 & 7.3731 & TST & \\
\hline CHEMBL441444 & 34583 & 8.1024 & 7.9348 & TST & \\
\hline CHEMBL303681 & 34583 & 5.6368 & 7.3689 & TST & \\
\hline CHEMBL417565 & 34583 & 7.8761 & 8.0012 & TRN & \\
\hline CHEMBL66172 & 34583 & 8.8239 & 8.7417 & TRN & \\
\hline CHEMBL67478 & 34583 & 7.4815 & 7.7214 & TRN & \\
\hline CHEMBL66211 & 34583 & 6.2874 & 7.3561 & TST & \\
\hline CHEMBL303219 & 34583 & 7.3696 & \multicolumn{2}{|c|}{7.5760000000000005} & TST \\
\hline CHEMBL65887 & 34583 & 7.4685 & 7.8222 & TRN & \\
\hline
\end{tabular}




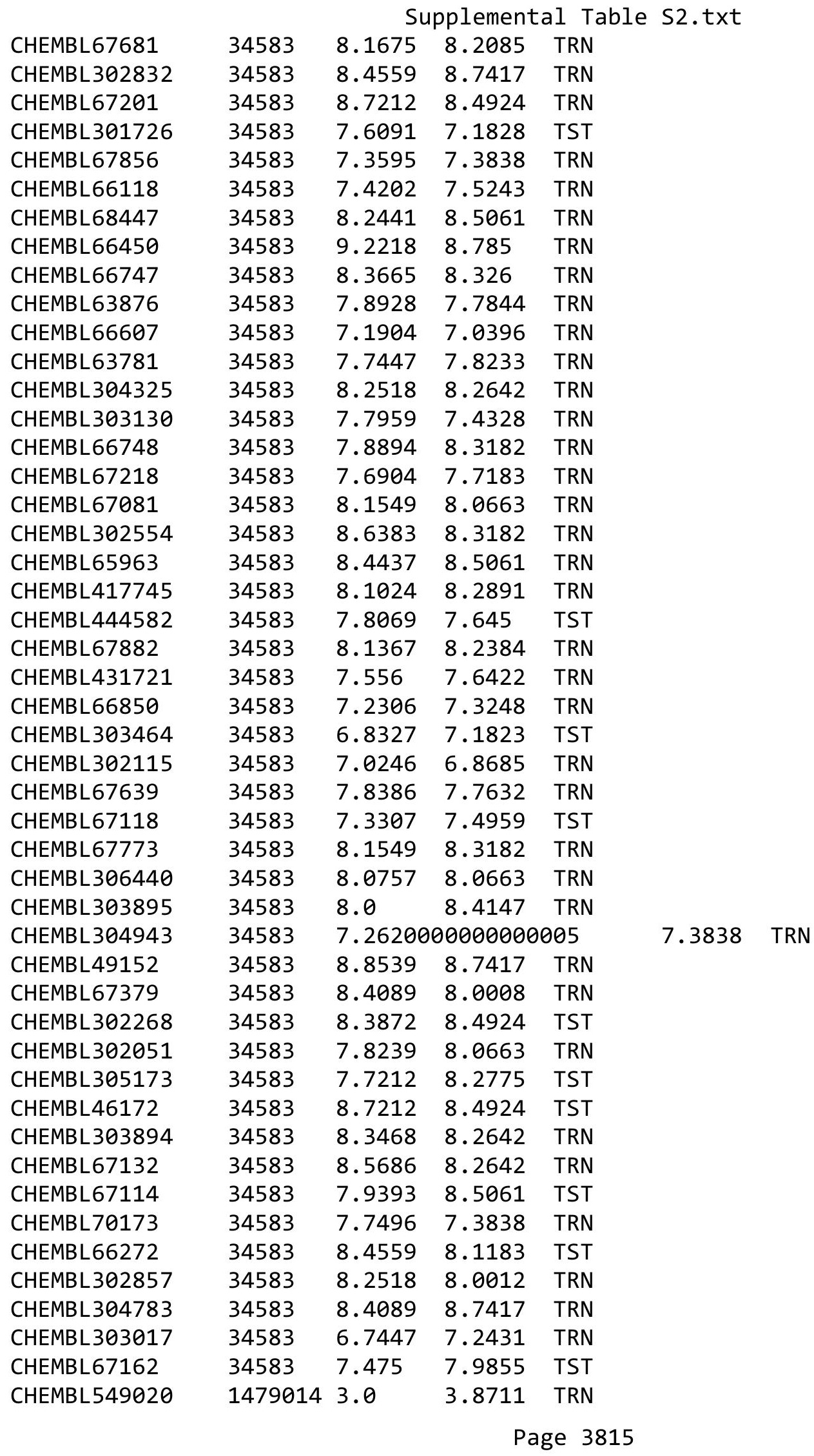




\begin{tabular}{|c|c|c|c|c|c|}
\hline \multirow{2}{*}{ CHEMBL526199 } & \multirow{2}{*}{1479014} & \\
\hline & & 4.8 & 3.9425 & \multicolumn{2}{|l|}{ TRN } \\
\hline CHEMBL3430919 & 1479014 & 3.0 & 4.3618 & \multicolumn{2}{|l|}{ TRN } \\
\hline CHEMBL528583 & 1479014 & 7.3 & 7.0555 & \multicolumn{2}{|l|}{ TRN } \\
\hline CHEMBL530358 & 1479014 & 5.2 & 3.9673 & \multicolumn{2}{|l|}{ TRN } \\
\hline CHEMBL530275 & 1479014 & 3.0 & 3.033 & \multicolumn{2}{|l|}{ TRN } \\
\hline CHEMBL534517 & 1479014 & 3.0 & 3.4996 & \multicolumn{2}{|l|}{ TRN } \\
\hline CHEMBL3430920 & 1479014 & 3.0 & 3.9072 & \multicolumn{2}{|l|}{ TRN } \\
\hline CHEMBL3430921 & 1479014 & 4.8 & 3.6049 & \multicolumn{2}{|l|}{ TST } \\
\hline CHEMBL3430922 & 1479014 & 4.7 & 3.85 & \multicolumn{2}{|l|}{ TST } \\
\hline CHEMBL 2098124 & 1479014 & 3.0 & 4.5475 & \multicolumn{2}{|l|}{ TRN } \\
\hline CHEMBL2098408 & 1479014 & 4.2 & 4.2484 & \multicolumn{2}{|l|}{ TRN } \\
\hline CHEMBL1578482 & 1479014 & 4.2 & 3.7859 & \multicolumn{2}{|l|}{ TRN } \\
\hline CHEMBL 2098276 & 1479014 & 4.4 & 4.5928 & \multicolumn{2}{|l|}{ TRN } \\
\hline CHEMBL3430923 & 1479014 & 6.5 & 4.7078 & \multicolumn{2}{|l|}{ TST } \\
\hline CHEMBL3430925 & 1479014 & 5.4 & 5.7418 & \multicolumn{2}{|l|}{ TST } \\
\hline CHEMBL3430926 & 1479014 & 3.0 & 3.8636 & \multicolumn{2}{|l|}{ TST } \\
\hline CHEMBL 2165401 & 1479014 & 4.1 & 3.6814 & \multicolumn{2}{|l|}{ TST } \\
\hline CHEMBL3430928 & 1479014 & 3.0 & 4.1399 & \multicolumn{2}{|l|}{ TRN } \\
\hline CHEMBL3430929 & 1479014 & 3.0 & 3.839 & TRN & \\
\hline CHEMBL3430930 & 1479014 & 3.0 & 3.7432 & TRN & \\
\hline CHEMBL305686 & 1479014 & 3.0 & 3.6021 & TST & \\
\hline CHEMBL3430931 & 1479014 & 7.0 & 5.0382 & TST & \\
\hline CHEMBL3430932 & 1479014 & 6.6 & 5.2159 & TST & \\
\hline CHEMBL1232777 & 1479014 & 3.0 & 3.2201 & TST & \\
\hline CHEMBL3430933 & 1479014 & 7.1 & 6.9203 & TRN & \\
\hline CHEMBL3430913 & 1479014 & 4.4 & 4.1018 & TRN & \\
\hline CHEMBL3430934 & 1479014 & 4.6 & 3.9521 & TRN & \\
\hline CHEMBL3430935 & 1479014 & 3.0 & 4.3359 & TST & \\
\hline CHEMBL3430936 & 1479014 & 3.0 & 3.4646 & TRN & \\
\hline CHEMBL3430937 & 1479014 & 6.3 & 6.8403 & TRN & \\
\hline CHEMBL3430938 & 1479014 & 4.0 & 4.3118 & TRN & \\
\hline CHEMBL3430939 & 1479014 & 4.1 & 4.2934 & TRN & \\
\hline CHEMBL3430940 & 1479014 & 4.2 & 4.8580 & 20000000005 & TRN \\
\hline CHEMBL 3430941 & 1479014 & 4.0 & 4.5685 & TRN & \\
\hline CHEMBL3430942 & 1479014 & 4.4 & 4.9833 & TRN & \\
\hline CHEMBL3430943 & 1479014 & 4.6 & 5.1581 & TRN & \\
\hline CHEMBL 3430944 & 1479014 & 4.4 & 4.4849 & TRN & \\
\hline CHEMBL3430945 & 1479014 & 3.0 & 4.53 & TRN & \\
\hline CHEMBL3430946 & 1479014 & 4.6 & 4.5135 & TRN & \\
\hline CHEMBL3430947 & 1479014 & 4.1 & 4.379 & TRN & \\
\hline CHEMBL 3430948 & 1479014 & 5.2 & 4.0793 & TRN & \\
\hline CHEMBL3430949 & 1479014 & 6.4 & 4.739 & TRN & \\
\hline CHEMBL1388922 & 1479014 & 3.0 & 4.3422 & TRN & \\
\hline CHEMBL3430950 & 1479014 & 3.0 & 4.613 & TRN & \\
\hline CHEMBL3430951 & 1479014 & 6.6 & 4.5136 & TST & \\
\hline CHEMBL1321334 & 1479014 & 3.0 & 4.205 & TRN & \\
\hline CHEMBL3430953 & 1479014 & 5.8 & 4.7368 & TRN & \\
\hline CHEMBL3430954 & 1479014 & 3.0 & 4.3055 & TRN & \\
\hline & & & & 3816 & \\
\hline
\end{tabular}




\begin{tabular}{|c|c|c|c|}
\hline & & & al \\
\hline CHEMBL3430955 & 14790143.0 & 3.4016 & TST \\
\hline CHEMBL3430956 & 14790143.0 & 3.7145 & TRN \\
\hline CHEMBL3430957 & 14790145.0 & 4.2987 & TRN \\
\hline CHEMBL 3430958 & $1479014 \quad 4.4$ & 4.0785 & TRN \\
\hline CHEMBL3430959 & 14790144.6 & 3.9396 & TRN \\
\hline CHEMBL3430960 & 14790146.8 & 6.5707 & TRN \\
\hline CHEMBL3430961 & 14790145.0 & 3.7784 & TRN \\
\hline CHEMBL3430962 & $1479014 \quad 4.7$ & 4.1254 & TRN \\
\hline CHEMBL 3430963 & 14790144.5 & 4.3993 & TRN \\
\hline CHEMBL3430964 & 14790142.9 & 4.415 & TRN \\
\hline CHEMBL3430965 & 14790143.0 & 3.3784 & TRN \\
\hline CHEMBL3430967 & 14790144.6 & 4.5262 & TRN \\
\hline CHEMBL3430968 & $1479014 \quad 4.4$ & 4.4468 & TRN \\
\hline CHEMBL3430969 & 14790144.5 & 4.4868 & TRN \\
\hline CHEMBL3430970 & 14790145.5 & 4.5836 & TRN \\
\hline CHEMBL1482137 & 14790144.6 & 4.3445 & TRN \\
\hline CHEMBL3430971 & 14790143.0 & 3.9801 & TRN \\
\hline CHEMBL3430972 & 14790143.0 & 3.9911 & TRN \\
\hline CHEMBL3430973 & 14790143.0 & 4.7167 & TRN \\
\hline CHEMBL3430974 & 14790143.0 & 3.5271 & TRN \\
\hline CHEMBL3430975 & 14790144.3 & 4.2506 & TRN \\
\hline CHEMBL3430976 & 14790144.2 & 4.1622 & TRN \\
\hline CHEMBL3430977 & 14790143.0 & 4.1642 & TST \\
\hline CHEMBL164422 & 14790144.5 & 3.6029 & TRN \\
\hline CHEMBL3430978 & 14790143.5 & 3.8613 & TRN \\
\hline CHEMBL3430979 & 14790143.0 & 3.3718 & TRN \\
\hline CHEMBL3430980 & 14790143.0 & 6.0801 & TRN \\
\hline CHEMBL1487481 & 14790143.0 & 4.6972 & TRN \\
\hline CHEMBL1487467 & 14790143.0 & 3.8425 & TRN \\
\hline CHEMBL3430981 & 14790144.9 & 4.6974 & TRN \\
\hline CHEMBL3430982 & 14790144.6 & 4.5188 & TRN \\
\hline CHEMBL3430983 & 14790144.6 & 4.7788 & TRN \\
\hline CHEMBL592827 & 14790147.1 & 7.0752 & TRN \\
\hline CHEMBL 3430984 & 14790143.0 & 2.5546 & TRN \\
\hline CHEMBL3430985 & 14790144.8 & 4.4715 & TRN \\
\hline CHEMBL1466712 & 14790143.0 & 3.6397 & TRN \\
\hline CHEMBL3430986 & 14790143.0 & 3.7717 & TRN \\
\hline CHEMBL3430987 & 14790145.0 & 4.2514 & TST \\
\hline CHEMBL 3430988 & 14790144.6 & 5.1272 & TRN \\
\hline CHEMBL3430989 & 14790143.0 & 3.6842 & TRN \\
\hline CHEMBL3430990 & 14790143.0 & 3.5128 & TRN \\
\hline CHEMBL3430991 & 14790144.7 & 4.2562 & TRN \\
\hline CHEMBL3430992 & 14790143.0 & 4.2076 & TRN \\
\hline CHEMBL3430993 & 14790143.0 & 4.8039 & TRN \\
\hline CHEMBL3430994 & 14790143.0 & 3.9708 & TRN \\
\hline CHEMBL3430995 & 14790143.0 & 3.9938 & TST \\
\hline CHEMBL3430996 & 14790143.0 & 4.3852 & TRN \\
\hline CHEMBL3430997 & 14790143.0 & 4.0137 & TRN \\
\hline
\end{tabular}




\begin{tabular}{|c|c|c|c|}
\hline & & & \\
\hline CHEMBL3430998 & 14790143.0 & 4.716 & TRN \\
\hline CHEMBL3430999 & 14790147.2 & 6.2678 & TRN \\
\hline CHEMBL3431000 & 14790143.0 & 3.7706 & TRN \\
\hline CHEMBL3431001 & 14790147.0 & 7.0699 & TRN \\
\hline CHEMBL3431002 & 14790145.0 & 5.2327 & TST \\
\hline CHEMBL3431003 & 14790146.0 & 4.4305 & TRN \\
\hline CHEMBL3431004 & 14790145.2 & 3.8825 & TRN \\
\hline CHEMBL3431005 & $1479014 \quad 4.8$ & 3.6528 & TRN \\
\hline CHEMBL3431006 & 14790145.0 & 3.7268 & TRN \\
\hline CHEMBL3431007 & $1479014 \quad 4.7$ & 3.9754 & TRN \\
\hline CHEMBL3431008 & $1479014 \quad 4.3$ & 3.9754 & TST \\
\hline CHEMBL3431009 & 14790143.0 & 3.7094 & TRN \\
\hline CHEMBL2355685 & 14790143.0 & 3.7959 & TST \\
\hline CHEMBL3431010 & $1479014 \quad 4.7$ & 4.3145 & TRN \\
\hline CHEMBL3431011 & 14790143.0 & 3.1714 & TRN \\
\hline CHEMBL3431012 & $1479014 \quad 4.9$ & 3.8637 & TST \\
\hline CHEMBL1731664 & $1479014 \quad 4.5$ & 3.9884 & TRN \\
\hline CHEMBL3431013 & 14790145.3 & 3.7457 & TRN \\
\hline CHEMBL3431014 & 14790146.0 & 6.2094 & TRN \\
\hline CHEMBL3431015 & 14790145.4 & 4.5475 & TRN \\
\hline CHEMBL3431016 & 14790147.3 & 6.892 & TRN \\
\hline CHEMBL3431017 & 14790143.0 & 3.9849 & TRN \\
\hline CHEMBL3431018 & $1479014 \quad 4.8$ & 4.6405 & TRN \\
\hline CHEMBL3431019 & $1479014 \quad 4.2$ & 3.443 & TRN \\
\hline CHEMBL3431020 & 14790147.4 & 6.1807 & TRN \\
\hline CHEMBL3431021 & 14790145.9 & 4.6188 & TRN \\
\hline CHEMBL3431022 & 14790145.3 & 4.2166 & TRN \\
\hline CHEMBL3431023 & 14790143.0 & 4.274 & TST \\
\hline CHEMBL3431024 & 14790144.3 & 4.5895 & TRN \\
\hline CHEMBL3431025 & 14790146.9 & 6.5276 & TRN \\
\hline CHEMBL3431026 & 14790143.0 & 3.5639 & TST \\
\hline CHEMBL3431027 & $1479014 \quad 4.5$ & 4.4102 & TRN \\
\hline CHEMBL3431028 & 14790147.2 & 6.5994 & TRN \\
\hline CHEMBL3431029 & 14790147.0 & 6.6397 & TRN \\
\hline CHEMBL3431030 & 14790144.6 & 3.9537 & TRN \\
\hline CHEMBL3431031 & 14790143.0 & 4.4028 & TRN \\
\hline CHEMBL3431032 & $1479014 \quad 4.4$ & 4.0181 & TRN \\
\hline CHEMBL1527364 & 14790145.2 & 4.388 & TRN \\
\hline CHEMBL 3430914 & 14790145.1 & 3.699 & TRN \\
\hline CHEMBL3431033 & 14790144.9 & 4.7772 & TRN \\
\hline CHEMBL 3431034 & $1479014 \quad 4.2$ & 4.0324 & TRN \\
\hline CHEMBL3431035 & 14790144.8 & 4.6734 & TRN \\
\hline CHEMBL3431036 & 14790143.0 & 4.1619 & TRN \\
\hline CHEMBL 3431037 & 14790145.1 & 4.9947 & TRN \\
\hline CHEMBL3431038 & 14790145.1 & 4.7197 & TRN \\
\hline CHEMBL3431039 & 14790147.2 & 6.8096 & TRN \\
\hline CHEMBL 3431040 & 14790145.0 & 4.4013 & TRN \\
\hline CHEMBL1354075 & $1479014 \quad 4.2$ & 4.6824 & TRN \\
\hline
\end{tabular}




\begin{tabular}{|c|c|c|c|c|c|}
\hline \multicolumn{6}{|c|}{ Supplemental Table S2.txt } \\
\hline CHEMBL3431041 & 1479014 & 5.2 & 4.2333 & TRN & \\
\hline CHEMBL3431042 & 1479014 & 3.0 & 3.4789 & TRN & \\
\hline CHEMBL3431043 & 1479014 & 3.0 & 4.1479 & TST & \\
\hline CHEMBL3431044 & 1479014 & 3.0 & 4.0632 & TST & \\
\hline CHEMBL3431045 & 1479014 & 4.2 & 4.3148 & TRN & \\
\hline CHEMBL3431046 & 1479014 & 3.0 & 3.0907 & TRN & \\
\hline CHEMBL3431047 & 1479014 & 3.0 & 3.7286 & TRN & \\
\hline CHEMBL3431048 & 1479014 & 4.4 & 4.1456 & TRN & \\
\hline CHEMBL3431049 & 1479014 & 4.1 & 3.8057 & TRN & \\
\hline CHEMBL3431050 & 1479014 & 4.6 & 3.8656 & TRN & \\
\hline CHEMBL3431051 & 1479014 & 4.3 & 4.0147 & TRN & \\
\hline CHEMBL3431052 & 1479014 & 3.0 & 3.3987 & TRN & \\
\hline CHEMBL3431053 & 1479014 & 3.0 & 3.4237 & TRN & \\
\hline CHEMBL2356808 & 1479014 & 3.0 & 3.8465 & TRN & \\
\hline CHEMBL 3431054 & 1479014 & 4.1 & 3.824 & TRN & \\
\hline CHEMBL3431055 & 1479014 & 7.2 & 5.3931 & TST & \\
\hline CHEMBL3431056 & 1479014 & 7.6 & 7.1048 & TRN & \\
\hline CHEMBL3431057 & 1479014 & 4.6 & 4.3152 & TST & \\
\hline CHEMBL2093320 & 1479014 & 3.0 & 4.5759 & TRN & \\
\hline CHEMBL3431058 & 1479014 & 4.0 & 3.3057 & TRN & \\
\hline CHEMBL3431059 & 1479014 & 3.0 & 3.3504 & TRN & \\
\hline CHEMBL3431060 & 1479014 & 3.0 & 3.1169 & TRN & \\
\hline CHEMBL3431061 & 1479014 & 3.0 & 3.1406 & TRN & \\
\hline CHEMBL3431062 & 1479014 & 3.0 & 3.4401 & TRN & \\
\hline CHEMBL3431063 & 1479014 & 3.0 & 3.0508 & TRN & \\
\hline CHEMBL3431064 & 1479014 & 3.0 & 3.5095 & TRN & \\
\hline CHEMBL3431065 & 1479014 & 3.0 & 4.2744 & TST & \\
\hline CHEMBL3431066 & 1479014 & 4.7 & 4.0186 & TRN & \\
\hline CHEMBL3431067 & 1479014 & 5.9 & 6.0808 & TRN & \\
\hline CHEMBL3431068 & 1479014 & 7.2 & 6.75200 & 0000000001 & TRN \\
\hline CHEMBL3431069 & 1479014 & 3.0 & 3.5075 & TRN & \\
\hline CHEMBL3431070 & 1479014 & 4.9 & 5.0349 & TRN & \\
\hline CHEMBL3431071 & 1479014 & 3.0 & 3.9778 & TST & \\
\hline CHEMBL3431072 & 1479014 & 3.0 & 4.3338 & TRN & \\
\hline CHEMBL3431073 & 1479014 & 4.9 & 5.2498 & TST & \\
\hline CHEMBL3431074 & 1479014 & 3.0 & 3.5499 & TRN & \\
\hline CHEMBL3431075 & 1479014 & 5.1 & 4.7959 & TST & \\
\hline CHEMBL3431076 & 1479014 & 5.8 & 5.9096 & TRN & \\
\hline CHEMBL3431077 & 1479014 & 3.0 & 4.9331 & TRN & \\
\hline CHEMBL3431078 & 1479014 & 5.1 & 5.0672 & TRN & \\
\hline CHEMBL3431079 & 1479014 & 3.0 & 3.6149 & TRN & \\
\hline CHEMBL3431080 & 1479014 & 6.8 & 6.9257 & TRN & \\
\hline CHEMBL3431081 & 1479014 & 3.0 & 4.0369 & TRN & \\
\hline CHEMBL3431082 & 1479014 & 5.1 & 4.4822 & TRN & \\
\hline CHEMBL3431083 & 1479014 & 4.9 & 3.5807 & TRN & \\
\hline CHEMBL3431084 & 1479014 & 3.0 & 3.7028 & TST & \\
\hline CHEMBL1585368 & 1479014 & 4.9 & 3.9102 & TRN & \\
\hline CHEMBL3431085 & 1479014 & 7.1 & 6.7672 & TRN & \\
\hline
\end{tabular}




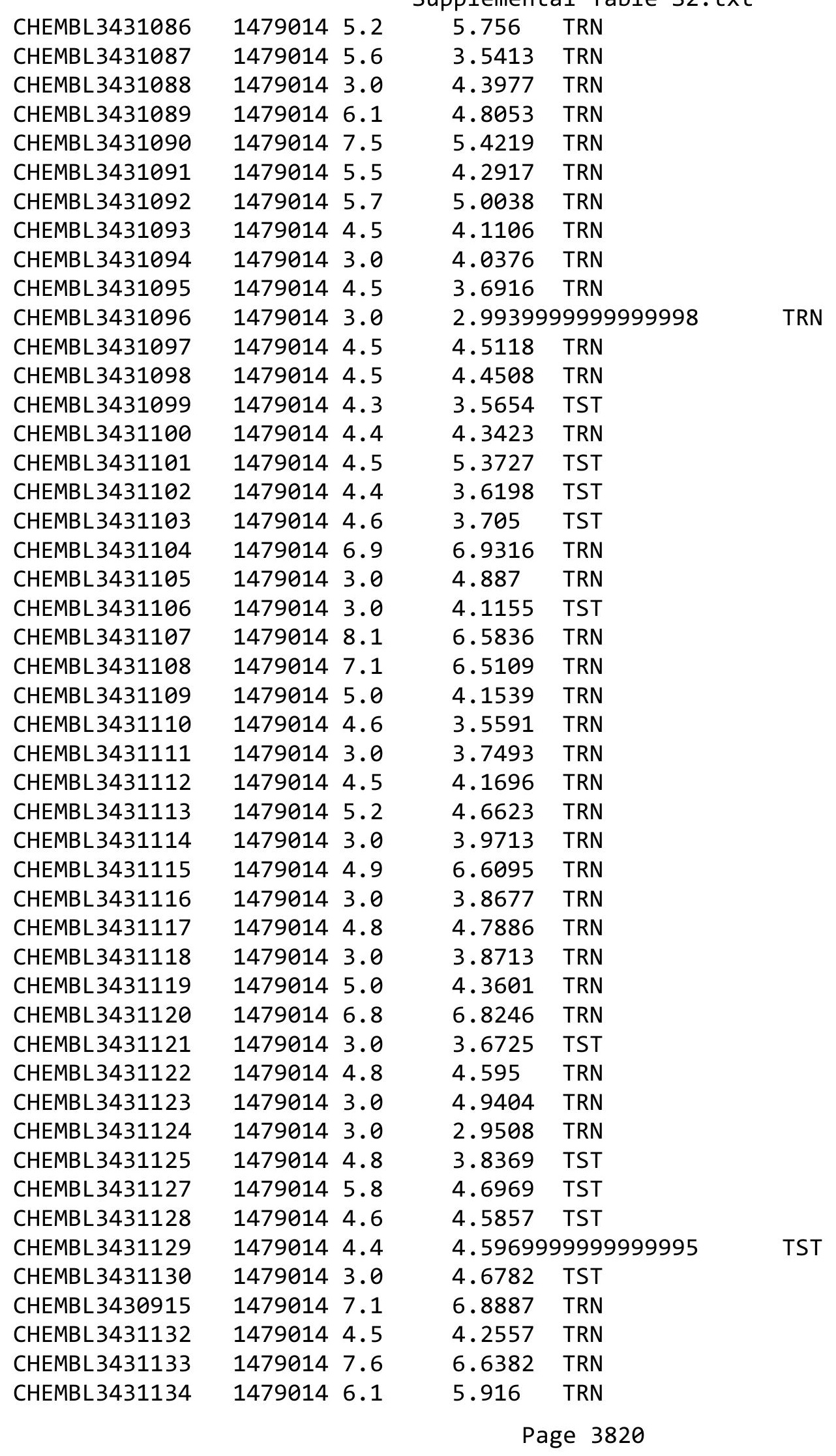




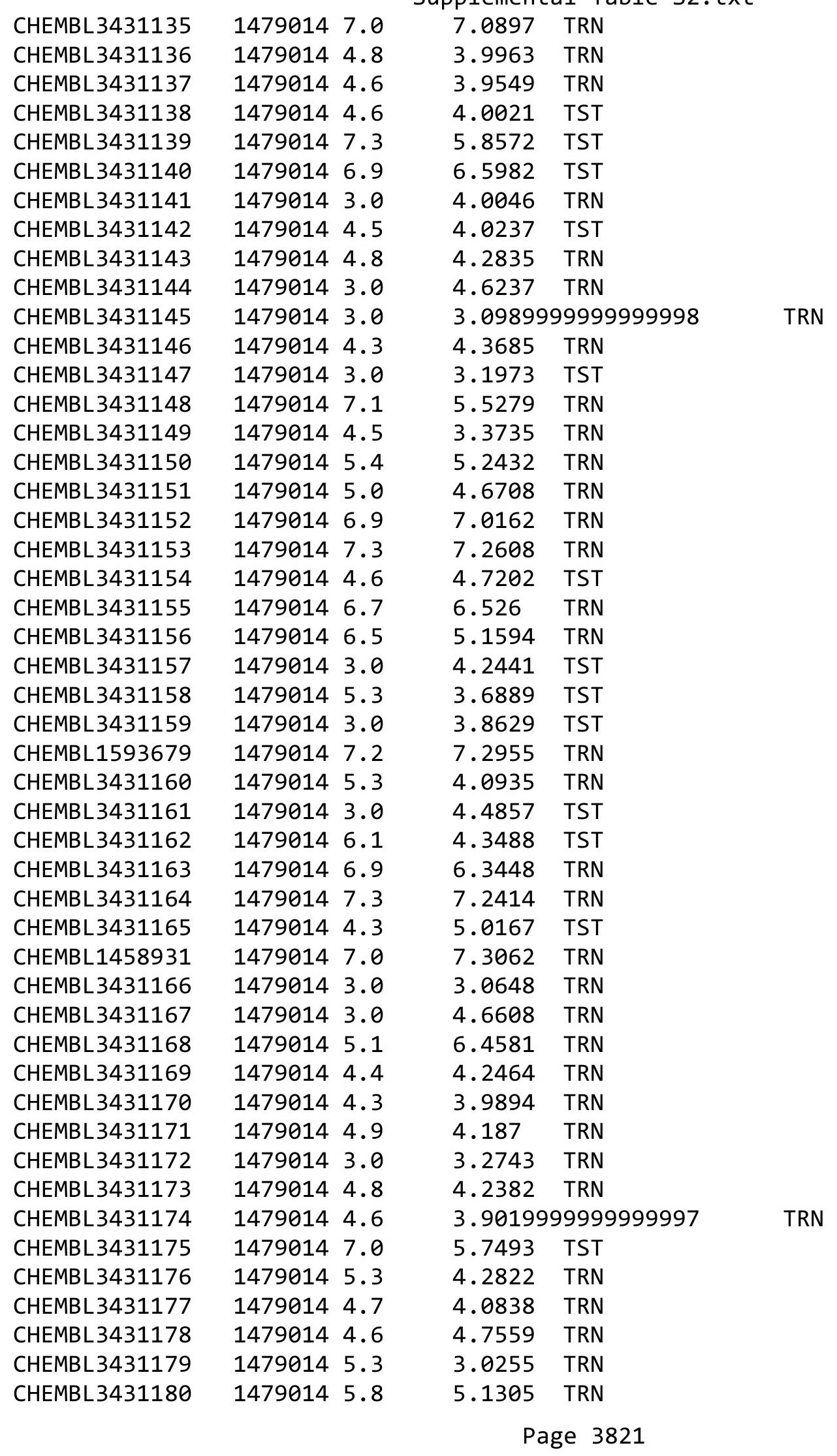




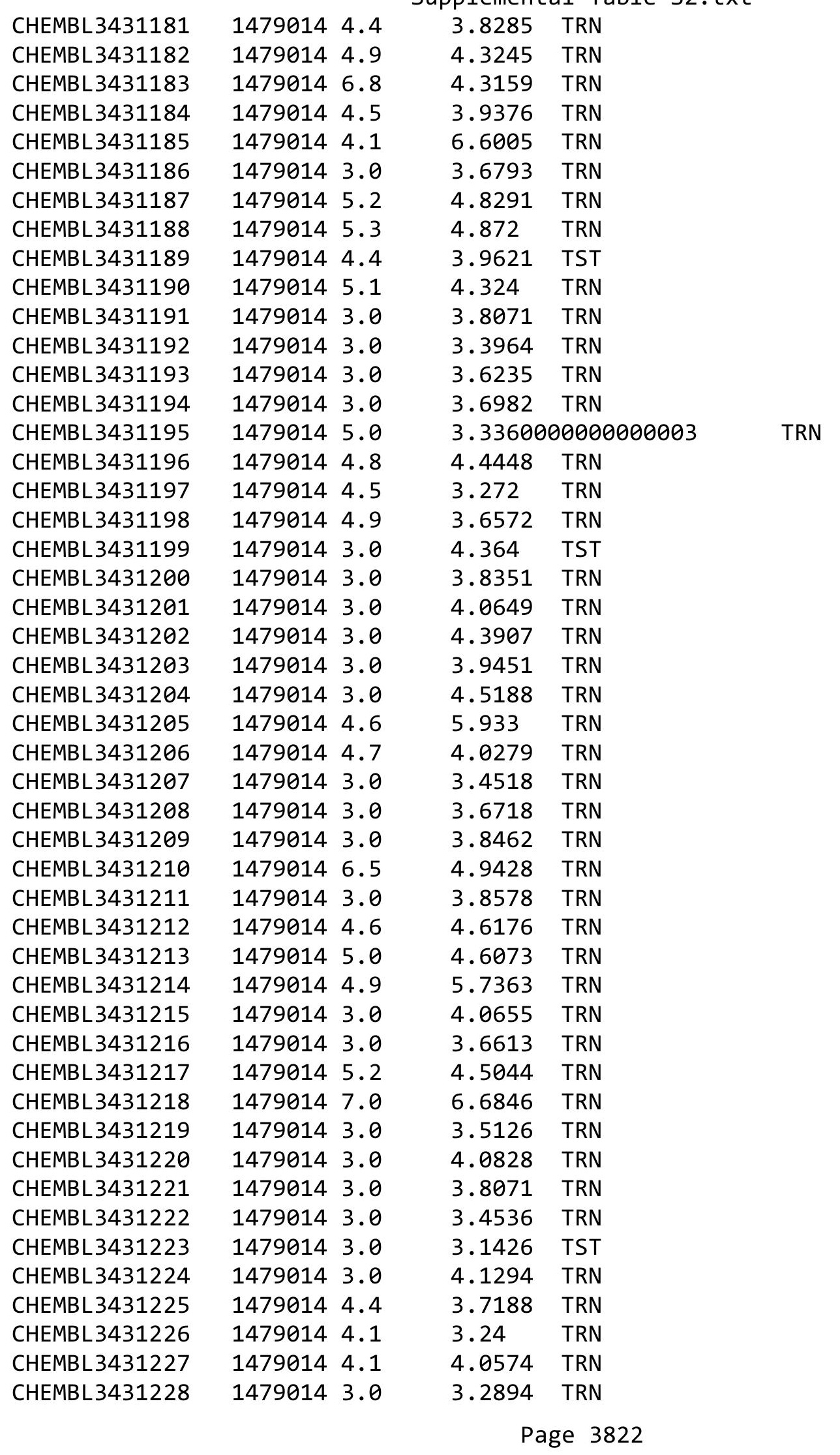




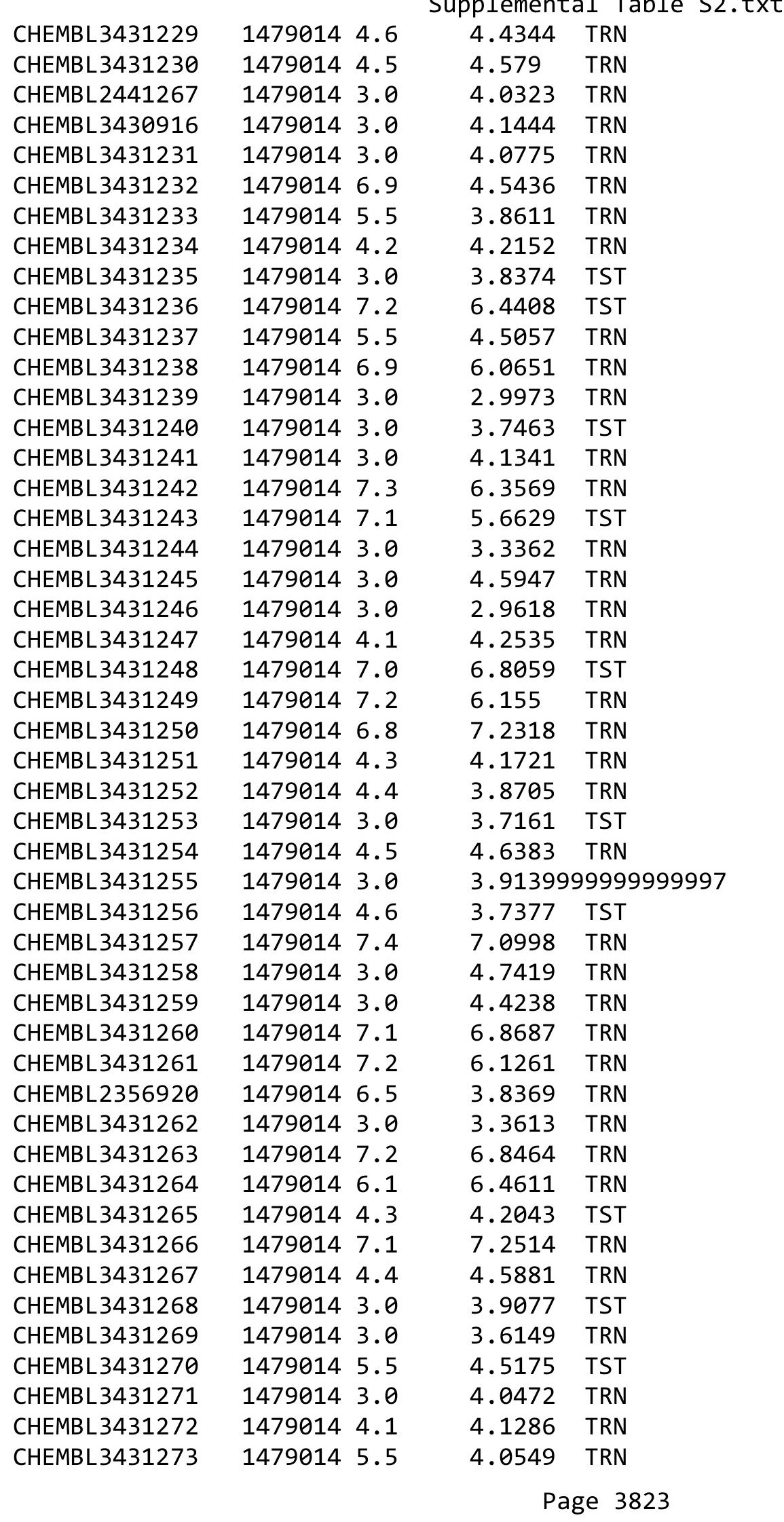




\begin{tabular}{|c|c|c|c|c|}
\hline & & & & \\
\hline CHEMBL3431274 & 14790143.0 & 3.6574 & TRN & \\
\hline CHEMBL3431275 & 14790144.6 & 3.9787 & TRN & \\
\hline CHEMBL3431276 & 14790143.0 & 3.8708 & TST & \\
\hline CHEMBL3431277 & $1479014 \quad 4.4$ & 4.2371 & TRN & \\
\hline CHEMBL3431278 & 14790144.2 & 4.0263 & TRN & \\
\hline CHEMBL3431279 & 14790144.4 & 3.1531 & TST & \\
\hline CHEMBL3431280 & 14790144.7 & 3.3021 & TST & \\
\hline CHEMBL3431281 & 14790146.9 & 4.2883 & TST & \\
\hline CHEMBL3431282 & 14790144.3 & 4.0883 & TST & \\
\hline CHEMBL3431283 & 14790144.0 & 3.6425 & TST & \\
\hline CHEMBL3431284 & 14790144.4 & 3.84899 & 99999999998 & TRN \\
\hline CHEMBL3431285 & 14790145.0 & 4.229 & TRN & \\
\hline CHEMBL3431286 & 14790144.1 & 3.8609 & TST & \\
\hline CHEMBL3431287 & 14790147.4 & 6.6117 & TST & \\
\hline CHEMBL3431288 & 14790145.1 & 4.1077 & TRN & \\
\hline CHEMBL3431289 & 14790143.0 & 4.3094 & TST & \\
\hline CHEMBL3431290 & 14790147.6 & 5.2797 & TRN & \\
\hline CHEMBL3431291 & 14790147.0 & 5.1312 & TRN & \\
\hline CHEMBL3431292 & 14790144.6 & 3.4312 & TRN & \\
\hline CHEMBL3431293 & 14790146.7 & 6.3194 & TRN & \\
\hline CHEMBL 3431294 & 14790144.0 & 4.2799 & TRN & \\
\hline CHEMBL3431295 & 14790143.0 & 3.5788 & TRN & \\
\hline CHEMBL3431296 & 14790143.0 & 3.7699 & TRN & \\
\hline CHEMBL3431297 & 14790143.0 & 3.574 & TRN & \\
\hline CHEMBL3431298 & 14790143.0 & 3.72399 & 99999999998 & TRN \\
\hline CHEMBL3431299 & 14790143.0 & 3.694 & TRN & \\
\hline CHEMBL3431300 & 14790147.2 & 6.5701 & TRN & \\
\hline CHEMBL3431301 & 14790145.2 & 6.0691 & TST & \\
\hline CHEMBL3431302 & 14790143.0 & 6.189 & TRN & \\
\hline CHEMBL3431303 & 14790147.2 & 7.428 & TRN & \\
\hline CHEMBL3431304 & 14790145.9 & 3.9505 & TRN & \\
\hline CHEMBL3431305 & 14790147.2 & 7.2761 & TRN & \\
\hline CHEMBL3431306 & 14790143.0 & 3.9211 & TRN & \\
\hline CHEMBL3431307 & 14790147.0 & 7.0125 & TRN & \\
\hline CHEMBL3431308 & 14790145.6 & 3.6542 & TRN & \\
\hline CHEMBL3431309 & 14790144.5 & 4.93 & TRN & \\
\hline CHEMBL3431310 & 14790145.3 & 4.5822 & TRN & \\
\hline CHEMBL3431311 & 14790144.7 & 4.6754 & TRN & \\
\hline CHEMBL3431312 & 14790145.3 & 4.7817 & TRN & \\
\hline CHEMBL3431313 & 14790144.8 & 4.5046 & TRN & \\
\hline CHEMBL3431314 & $1479014 \quad 4.4$ & 4.56800 & 00000000005 & TRN \\
\hline CHEMBL3431315 & 14790143.0 & 3.8283 & TRN & \\
\hline CHEMBL3431316 & 14790143.0 & 3.2597 & TST & \\
\hline CHEMBL3431317 & 14790143.0 & 3.5001 & TRN & \\
\hline CHEMBL3431318 & 14790147.1 & 6.3948 & TST & \\
\hline CHEMBL3431319 & 14790143.0 & 3.2485 & TRN & \\
\hline CHEMBL3431320 & 14790143.0 & 3.7772 & TST & \\
\hline CHEMBL3431321 & 14790147.1 & 4.9367 & TRN & \\
\hline
\end{tabular}




\begin{tabular}{|c|c|c|c|c|}
\hline \\
\hline CHEMBL3431322 & 14790143.0 & 4.434 & TRN & \\
\hline CHEMBL3431323 & 14790143.0 & 4.3482 & TRN & \\
\hline CHEMBL3431324 & 14790144.3 & 4.5047 & TST & \\
\hline CHEMBL3431325 & 14790144.1 & 4.2466 & TRN & \\
\hline CHEMBL3431326 & 14790147.0 & 5.7665 & TRN & \\
\hline CHEMBL3431327 & 14790145.2 & 3.9091 & TST & \\
\hline CHEMBL3431328 & 14790146.0 & 5.2749 & TST & \\
\hline CHEMBL3431329 & 14790144.5 & 4.2029 & TST & \\
\hline CHEMBL3430917 & 14790147.0 & 7.1987 & TRN & \\
\hline CHEMBL3431330 & 14790143.0 & 3.7517 & TRN & \\
\hline CHEMBL3431331 & 14790146.9 & 7.1199 & TRN & \\
\hline CHEMBL3431332 & 14790144.2 & 4.4706 & TRN & \\
\hline CHEMBL1582997 & 14790143.0 & 3.5596 & TRN & \\
\hline CHEMBL3431333 & 14790143.0 & 2.7776 & TRN & \\
\hline CHEMBL3431334 & 14790144.5 & 4.5969 & TRN & \\
\hline CHEMBL3431335 & 14790143.0 & 3.5204 & TRN & \\
\hline CHEMBL3431336 & $1479014 \quad 4.4$ & 4.7084 & TRN & \\
\hline CHEMBL3431339 & 14790145.9 & 4.4057 & TST & \\
\hline CHEMBL3431340 & 14790143.0 & 3.4763 & TRN & \\
\hline CHEMBL3431341 & 14790145.1 & 3.6896 & TRN & \\
\hline CHEMBL3431342 & 14790145.1 & 4.7107 & TRN & \\
\hline CHEMBL3431343 & 14790143.0 & 4.3935 & TRN & \\
\hline CHEMBL 3431344 & 14790144.8 & 4.2621 & TRN & \\
\hline CHEMBL3431345 & 14790144.3 & 3.6299 & TRN & \\
\hline CHEMBL3431346 & 14790143.0 & 3.94199 & 99999999997 & TRN \\
\hline CHEMBL1430615 & 14790144.2 & 4.9459 & TRN & \\
\hline CHEMBL3431347 & 14790144.4 & 4.881 & TRN & \\
\hline CHEMBL 3431348 & 14790143.0 & 3.6295 & TRN & \\
\hline CHEMBL3431349 & 14790143.0 & 4.0931 & TRN & \\
\hline CHEMBL3431350 & 14790145.2 & 4.6053 & TRN & \\
\hline CHEMBL465227 & 14790143.0 & 3.8341 & TRN & \\
\hline CHEMBL3431351 & $1479014 \quad 7.7$ & 6.7203 & TRN & \\
\hline CHEMBL1611993 & 14790143.0 & 4.4606 & TRN & \\
\hline CHEMBL3431352 & 14790143.0 & 4.2405 & TRN & \\
\hline CHEMBL3431353 & 14790143.0 & 3.9988 & TRN & \\
\hline CHEMBL1393829 & 14790144.3 & 4.7295 & TST & \\
\hline CHEMBL3431354 & 14790143.0 & 4.114 & TRN & \\
\hline CHEMBL3431355 & 14790147.3 & 7.4359 & TRN & \\
\hline CHEMBL3431356 & 14790145.6 & 4.1066 & TRN & \\
\hline CHEMBL3431357 & 14790144.8 & 4.8822 & TST & \\
\hline CHEMBL3431358 & 14790145.9 & 4.668 & TRN & \\
\hline CHEMBL3431359 & 14790146.7 & 7.0409 & TRN & \\
\hline CHEMBL3431360 & 14790144.3 & 3.9132 & TRN & \\
\hline CHEMBL3431361 & 14790145.1 & 2.9053 & TRN & \\
\hline CHEMBL1535535 & 14790147.4 & 7.2782 & TRN & \\
\hline CHEMBL 3431362 & 14790147.1 & 6.555 & TRN & \\
\hline CHEMBL 3431363 & 14790143.0 & 3.8406 & TRN & \\
\hline CHEMBL3431364 & 14790144.4 & 3.8554 & TRN & \\
\hline
\end{tabular}




\begin{tabular}{|c|c|c|c|c|}
\hline \multicolumn{5}{|l|}{ CHFMBI 3431365} \\
\hline CHEMBL3431365 & 14790143.0 & 3.9565 & TRN & \\
\hline CHEMBL3431366 & 14790144.1 & 4.3572 & TST & \\
\hline CHEMBL3431367 & 14790146.8 & 4.7125 & TST & \\
\hline CHEMBL 3431368 & 14790144.8 & 4.6513 & TRN & \\
\hline CHEMBL3431369 & 14790143.0 & 4.1218 & TRN & \\
\hline CHEMBL1447267 & 14790145.1 & 4.6328 & TRN & \\
\hline CHEMBL 3431370 & 14790143.0 & 4.5431 & TRN & \\
\hline CHEMBL1325144 & 14790147.2 & 7.1256 & TRN & \\
\hline CHEMBL1429841 & 14790143.0 & 2.7949 & TRN & \\
\hline CHEMBL3431371 & 14790146.8 & 6.718 & TRN & \\
\hline CHEMBL1308225 & 14790143.0 & 3.1285 & TST & \\
\hline CHEMBL 2441359 & 14790144.7 & 4.0305 & TRN & \\
\hline CHEMBL1517284 & $1479014 \quad 4.7$ & 3.5023 & TRN & \\
\hline CHEMBL3431372 & 14790145.5 & 5.1697 & TRN & \\
\hline CHEMBL3431373 & 14790145.9 & 4.5962 & TRN & \\
\hline CHEMBL3431374 & 14790146.9 & 6.4293 & TRN & \\
\hline CHEMBL3431375 & 14790147.2 & 6.4684 & TST & \\
\hline CHEMBL3431376 & 14790145.6 & 4.4114 & TRN & \\
\hline CHEMBL1365653 & 14790143.0 & 3.2404 & TRN & \\
\hline CHEMBL3431377 & 14790145.5 & 6.072 & TRN & \\
\hline CHEMBL3431378 & 14790145.0 & 3.9533 & TRN & \\
\hline CHEMBL3431379 & 14790144.9 & 3.8783 & TRN & \\
\hline CHEMBL1478826 & 14790143.0 & 3.2377 & TRN & \\
\hline CHEMBL1872842 & 14790143.0 & 3.7869 & TRN & \\
\hline CHEMBL3431380 & 14790145.6 & 4.4142 & TRN & \\
\hline CHEMBL3431381 & 14790143.0 & 3.5894 & TRN & \\
\hline CHEMBL3431382 & 14790145.0 & 3.7551 & TRN & \\
\hline CHEMBL3431383 & 14790145.3 & 4.497 & TRN & \\
\hline CHEMBL 3431384 & 14790145.1 & 4.1913 & TRN & \\
\hline CHEMBL3431385 & 14790143.0 & 4.0709 & TRN & \\
\hline CHEMBL3431386 & 14790147.0 & $5.6620 e$ & 0000000001 & TRN \\
\hline CHEMBL1730515 & 14790144.7 & 4.315 & TRN & \\
\hline CHEMBL3431387 & 14790144.5 & 4.4553 & TRN & \\
\hline CHEMBL3431388 & $1479014 \quad 4.4$ & 3.9966 & TRN & \\
\hline CHEMBL1566898 & 14790145.0 & 3.4819 & TRN & \\
\hline CHEMBL3431389 & 14790144.9 & $3.5180 e$ & 00000000002 & TRN \\
\hline CHEMBL3431390 & 14790144.6 & 5.0488 & TST & \\
\hline CHEMBL3431391 & 14790144.2 & 4.0074 & TRN & \\
\hline CHEMBL1489081 & 14790145.2 & 4.2196 & TRN & \\
\hline CHEMBL3431392 & 14790144.3 & 3.5443 & TRN & \\
\hline CHEMBL3431393 & 14790144.5 & 4.9025 & TRN & \\
\hline CHEMBL3431394 & 14790145.4 & 6.3889 & TRN & \\
\hline CHEMBL3431395 & 14790143.0 & 3.8654 & TRN & \\
\hline CHEMBL3431396 & 14790143.0 & 3.5527 & TRN & \\
\hline CHEMBL3431397 & 14790147.2 & 6.9728 & TRN & \\
\hline CHEMBL3431398 & $1479014 \quad 4.4$ & 3.1474 & TRN & \\
\hline CHEMBL3431399 & 14790143.0 & 4.4227 & TRN & \\
\hline CHEMBL3431400 & 14790147.2 & 6.9893 & TRN & \\
\hline
\end{tabular}




\begin{tabular}{|c|c|c|c|c|}
\hline \\
\hline CHEMBL1418463 & 14790145.0 & 4.7462 & TRN & \\
\hline CHEMBL3431401 & 14790146.0 & 6.3235 & TST & \\
\hline CHEMBL3431402 & 14790144.6 & 4.8484 & TST & \\
\hline CHEMBL3431403 & 14790144.7 & 3.7791 & TST & \\
\hline CHEMBL3431404 & $1479014 \quad 4.4$ & 3.8122 & TST & \\
\hline CHEMBL3431405 & 14790147.3 & 4.7739 & TST & \\
\hline CHEMBL3431406 & 14790143.0 & 3.4819 & TST & \\
\hline CHEMBL3431407 & 14790144.3 & 3.7318 & TST & \\
\hline CHEMBL3431408 & 14790147.5 & 6.3901 & TST & \\
\hline CHEMBL3431409 & 14790143.0 & 4.6718 & TST & \\
\hline CHEMBL3431410 & $1479014 \quad 4.7$ & 4.0782 & TST & \\
\hline CHEMBL3431411 & 14790143.0 & 4.802 & TST & \\
\hline CHEMBL3431412 & 14790143.0 & 3.6609 & TST & \\
\hline CHEMBL3431413 & 14790143.0 & 3.4181 & TST & \\
\hline CHEMBL3431414 & 14790143.0 & 3.6745 & TST & \\
\hline CHEMBL3431415 & 14790144.3 & 2.8408 & TST & \\
\hline CHEMBL3431416 & 14790143.0 & 3.9844 & TST & \\
\hline CHEMBL291721 & 14790143.0 & 4.0169 & TST & \\
\hline CHEMBL3431417 & 14790143.0 & 3.5703 & TST & \\
\hline CHEMBL3431418 & 14790147.7 & 6.3205 & TST & \\
\hline CHEMBL487186 & 14790146.9 & 5.7298 & TST & \\
\hline CHEMBL3431419 & 14790143.0 & 3.565 & TST & \\
\hline CHEMBL 3431420 & 14790145.0 & 3.9478 & TST & \\
\hline CHEMBL3431421 & 14790143.0 & 4.068006 & 20000000005 & TST \\
\hline CHEMBL3431422 & 14790143.0 & 3.1714 & TST & \\
\hline CHEMBL3431423 & 14790143.0 & 2.9596 & TST & \\
\hline CHEMBL3431424 & 14790147.1 & 6.6002 & TST & \\
\hline CHEMBL3431425 & 14790143.0 & 3.7981 & TST & \\
\hline CHEMBL3431426 & 14790144.6 & 4.6592 & TST & \\
\hline CHEMBL3431427 & 14790143.0 & 4.407 & TST & \\
\hline CHEMBL3431428 & 14790144.1 & 3.4619 & TST & \\
\hline CHEMBL1725748 & 14790143.0 & 4.105 & TST & \\
\hline CHEMBL3430918 & 14790147.8 & 5.1591 & TST & \\
\hline CHEMBL522630 & 14790143.0 & 4.3441 & TST & \\
\hline CHEMBL3431429 & 14790145.9 & 4.0745 & TST & \\
\hline CHEMBL523468 & 14790143.0 & 4.5031 & TST & \\
\hline CHEMBL523303 & 14790144.5 & 4.3923 & TST & \\
\hline CHEMBL3431430 & 14790147.8 & 5.94799 & 99999999995 & TST \\
\hline CHEMBL128672 & 14790147.3 & 4.4914 & TST & \\
\hline CHEMBL491149 & 14790143.0 & 4.4714 & TST & \\
\hline CHEMBL3431431 & 14790143.0 & 4.8427 & TST & \\
\hline CHEMBL3431432 & 14790144.8 & 4.7872 & TST & \\
\hline CHEMBL3431433 & 14790144.5 & 5.4327 & TST & \\
\hline CHEMBL3431434 & 14790147.5 & 5.351 & TST & \\
\hline CHEMBL3431435 & 14790143.0 & 5.1562 & TST & \\
\hline CHEMBL3431436 & 14790144.8 & 3.4303 & TST & \\
\hline CHEMBL3431438 & 14790144.5 & 4.008 & TST & \\
\hline CHEMBL3431439 & 14790143.0 & 3.7373 & TST & \\
\hline
\end{tabular}




\begin{tabular}{|c|c|c|c|c|}
\hline & & & oplemen & \\
\hline CHEMBL3431440 & 1479014 & 4.2 & 3.8779 & TST \\
\hline CHEMBL3431441 & 1479014 & 3.0 & 3.3945 & TST \\
\hline CHEMBL3431442 & 1479014 & 4.6 & 3.72 & TST \\
\hline CHEMBL3431443 & 1479014 & 6.0 & 5.0119 & TST \\
\hline CHEMBL3431444 & 1479014 & 4.4 & 3.3384 & TST \\
\hline CHEMBL1830908 & 768726 & 4.0 & 4.0289 & TRN \\
\hline CHEMBL1830693 & 768726 & 6.3872 & 6.3205 & TRN \\
\hline CHEMBL1209431 & 768726 & 6.0 & 5.0352 & TST \\
\hline CHEMBL1830910 & 768726 & 6.4089 & 6.4205 & TRN \\
\hline CHEMBL1830701 & 768726 & 5.6576 & 5.6508 & TRN \\
\hline CHEMBL1830702 & 768726 & 7.1871 & 7.1891 & TRN \\
\hline CHEMBL1830699 & 768726 & 4.0 & 3.8202 & TRN \\
\hline CHEMBL1830905 & 768726 & 6.1871 & 6.2109 & TRN \\
\hline CHEMBL1830697 & 768726 & 5.3372 & 2.8761 & TST \\
\hline CHEMBL1830906 & 768726 & 6.5376 & 6.5259 & TRN \\
\hline CHEMBL1830907 & 768726 & 5.3098 & 5.2865 & TRN \\
\hline CHEMBL1830714 & 768726 & 5.5229 & 5.5541 & TRN \\
\hline CHEMBL1830704 & 768726 & 4.0 & 3.7891 & TRN \\
\hline CHEMBL578988 & 768726 & 6.1249 & 3.9151 & TST \\
\hline CHEMBL1830897 & 768726 & 5.8861 & 5.8626 & TRN \\
\hline CHEMBL1830914 & 768726 & 7.2924 & 7.3107 & TRN \\
\hline CHEMBL1830915 & 768726 & 7.0 & 6.9659 & TRN \\
\hline CHEMBL1830709 & 768726 & 5.8861 & 5.9108 & TRN \\
\hline CHEMBL1830715 & 768726 & 4.0 & 3.9935 & TRN \\
\hline CHEMBL562551 & 768726 & 6.6198 & 6.5761 & TRN \\
\hline CHEMBL1830903 & 768726 & 6.9788 & 6.9702 & TRN \\
\hline CHEMBL1830705 & 768726 & 6.041 & 5.9733 & TRN \\
\hline CHEMBL1830710 & 768726 & 4.0 & 4.0051 & TRN \\
\hline CHEMBL1830901 & 768726 & 4.0 & 3.9861 & TRN \\
\hline CHEMBL1830696 & 768726 & 4.0 & 3.9727 & TRN \\
\hline CHEMBL1223381 & 768726 & 7.699 & 7.7331 & TRN \\
\hline CHEMBL1830898 & 768726 & 5.4685 & 5.4856 & TRN \\
\hline CHEMBL1830700 & 768726 & 4.0 & 3.9872 & TRN \\
\hline CHEMBL1830708 & 768726 & 4.0 & 4.1863 & TRN \\
\hline CHEMBL1830911 & 768726 & 6.4685 & 6.4916 & TRN \\
\hline CHEMBL1830899 & 768726 & 4.0 & 4.1813 & TRN \\
\hline CHEMBL1830909 & 768726 & 5.5686 & 5.6107 & TRN \\
\hline CHEMBL1830902 & 768726 & 6.1249 & 6.0857 & TRN \\
\hline CHEMBL1830707 & 768726 & 8.0458 & 7.6389 & TRN \\
\hline CHEMBL1830703 & 768726 & 4.0 & 4.0835 & TRN \\
\hline CHEMBL1830913 & 768726 & 4.0 & 4.0109 & TRN \\
\hline CHEMBL515763 & 768726 & 5.7696 & 5.2384 & TST \\
\hline CHEMBL1830694 & 768726 & 7.8861 & 7.9405 & TRN \\
\hline CHEMBL1830695 & 768726 & 7.2518 & 7.2804 & TRN \\
\hline CHEMBL1830698 & 768726 & 6.6576 & 7.0764 & TRN \\
\hline CHEMBL1830713 & 768726 & 5.6198 & 5.5772 & TRN \\
\hline CHEMBL473806 & 768726 & 5.5229 & 4.1058 & TST \\
\hline CHEMBL1830912 & 768726 & 6.2218 & 6.2977 & TST \\
\hline
\end{tabular}




\begin{tabular}{|c|c|c|c|c|c|}
\hline & & & & & \\
\hline CHEMBL1830900 & 768726 & 6.8539 & 6.3505 & TST & \\
\hline CHEMBL1830896 & 768726 & 4.0 & 4.8333 & TST & \\
\hline CHEMBL1830904 & 768726 & 5.9586 & 6.2851 & TST & \\
\hline CHEMBL1476108 & 768726 & 5.5086 & 3.826 & TST & \\
\hline CHEMBL1830712 & 768726 & 5.4949 & 5.7311 & TST & \\
\hline CHEMBL1830706 & 768726 & 4.0 & 3.6196 & TST & \\
\hline CHEMBL1830711 & 768726 & 8.1549 & 7.6041 & TST & \\
\hline CHEMBL1093239 & 626788 & 7.1891 & 7.2707 & TRN & \\
\hline CHEMBL1091165 & 626788 & 7.0841 & 7.1531 & TRN & \\
\hline CHEMBL1091621 & 626788 & 6.6002 & 6.7129 & TRN & \\
\hline CHEMBL1090888 & 626788 & 7.5654 & 7.3813 & TRN & \\
\hline CHEMBL1093897 & 626788 & 8.7212 & 8.7455 & TRN & \\
\hline CHEMBL1088780 & 626788 & 8.1871 & 8.1253 & TRN & \\
\hline CHEMBL1092871 & 626788 & 7.2565 & 7.375 & TRN & \\
\hline CHEMBL1090454 & 626788 & 7.8239 & 7.5231 & TST & \\
\hline CHEMBL1089455 & 626788 & 8.3872 & 8.3962 & TRN & \\
\hline CHEMBL1090222 & 626788 & 8.3468 & 8.4839 & TRN & \\
\hline CHEMBL1090507 & 626788 & 8.0088 & 8.1199 & TRN & \\
\hline CHEMBL1089491 & 626788 & 8.3665 & 8.5465 & TRN & \\
\hline CHEMBL1092230 & 626788 & 8.0269 & 8.091006 & 2000000001 & TRN \\
\hline CHEMBL1088823 & 626788 & 8.28399 & 99999999 & 8.1345 & TRN \\
\hline CHEMBL1089446 & 626788 & 6.1681 & 6.0875 & TRN & \\
\hline CHEMBL1093133 & 626788 & 7.8962 & 7.9566 & TST & \\
\hline CHEMBL1088822 & 626788 & 8.1612 & 8.2404 & TRN & \\
\hline CHEMBL479868 & 626788 & 7.9706 & 7.8593 & TRN & \\
\hline CHEMBL1090102 & 626788 & 6.585 & 6.4802 & TST & \\
\hline CHEMBL1091606 & 626788 & 6.6003 & 6.6819 & TRN & \\
\hline CHEMBL1090501 & 626788 & 8.2518 & 7.8665 & TRN & \\
\hline CHEMBL1090342 & 626788 & 7.0155 & 7.3583 & TST & \\
\hline CHEMBL1089807 & 626788 & 7.6216 & 7.5192 & TRN & \\
\hline CHEMBL1089481 & 626788 & 6.8649 & 6.8957 & TRN & \\
\hline CHEMBL1088846 & 626788 & 8.0915 & 8.1699 & TRN & \\
\hline CHEMBL1089161 & 626788 & 8.1675 & 8.1263 & TRN & \\
\hline CHEMBL1093791 & 626788 & 7.7122 & 7.7279 & TRN & \\
\hline CHEMBL1088815 & 626788 & 7.9914 & 8.1096 & TRN & \\
\hline CHEMBL1090499 & 626788 & 7.1938 & 7.04899 & 99999999995 & TRN \\
\hline CHEMBL1093790 & 626788 & 7.7595 & 8.1268 & TST & \\
\hline CHEMBL585507 & 626788 & 6.0555 & 6.0751 & TRN & \\
\hline CHEMBL1091893 & 626788 & 7.0325 & 7.4914 & TRN & \\
\hline CHEMBL1093559 & 626788 & 8.0315 & 8.0698 & TRN & \\
\hline CHEMBL1090112 & 626788 & 8.3565 & 8.4715 & TRN & \\
\hline CHEMBL1090455 & 626788 & 7.4698 & 7.3369 & TST & \\
\hline CHEMBL1089313 & 626788 & 6.7284 & 6.6595 & TRN & \\
\hline CHEMBL1092991 & 626788 & 6.1421 & 6.2513 & TRN & \\
\hline CHEMBL1093124 & 626788 & 7.0186 & 7.3814 & TST & \\
\hline CHEMBL1089806 & 626788 & 6.1805 & 6.6752 & TST & \\
\hline CHEMBL1093797 & 626788 & 8.4815 & 8.1955 & TRN & \\
\hline CHEMBL1093792 & 626788 & 8.1192 & 8.4044 & TST & \\
\hline
\end{tabular}




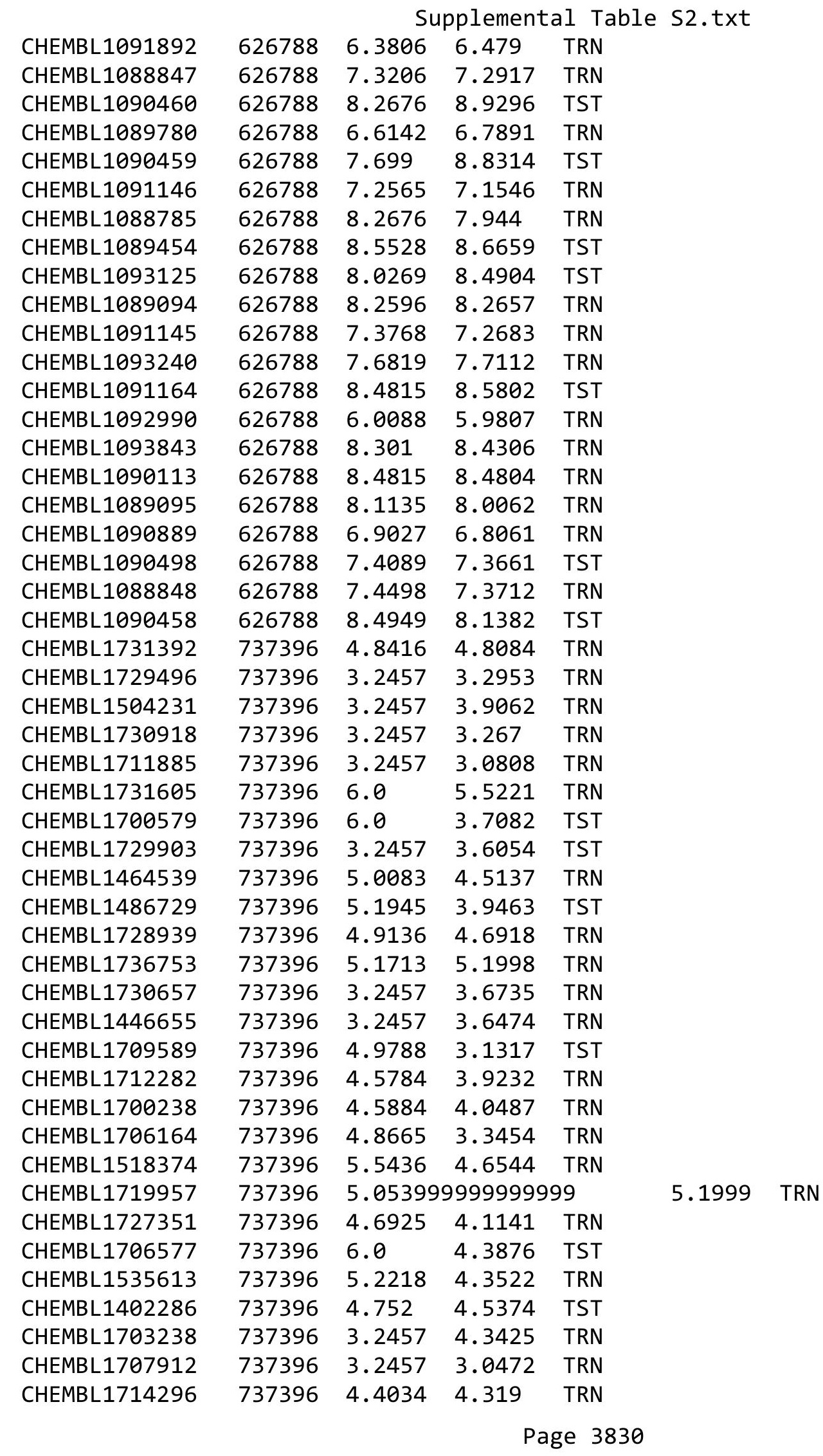




\begin{tabular}{|c|c|c|c|c|}
\hline & & & oplement & al $\mathrm{Ta}$ \\
\hline CHEMBL1722589 & 737396 & 3.2457 & 3.7079 & TRN \\
\hline CHEMBL1709429 & 737396 & 3.2457 & 3.8221 & TRN \\
\hline CHEMBL1698049 & 737396 & 3.2457 & 4.0183 & TRN \\
\hline CHEMBL1399979 & 737396 & 5.4868 & 5.5439 & TRN \\
\hline CHEMBL1308068 & 737396 & 4.9431 & 4.7686 & TRN \\
\hline CHEMBL1732080 & 737396 & 3.2457 & 3.2469 & TRN \\
\hline CHEMBL1731723 & 737396 & 4.3335 & 4.1995 & TRN \\
\hline CHEMBL1507308 & 737396 & 4.8761 & 4.9485 & TRN \\
\hline CHEMBL1721038 & 737396 & 4.9393 & 5.3218 & TRN \\
\hline CHEMBL1713271 & 737396 & 3.2457 & 3.5617 & TST \\
\hline CHEMBL1711025 & 737396 & 3.2457 & 3.1795 & TRN \\
\hline CHEMBL1729181 & 737396 & 5.0511 & 3.8036 & TST \\
\hline CHEMBL1706851 & 737396 & 5.0862 & 4.6613 & TRN \\
\hline CHEMBL1518888 & 737396 & 3.2457 & 4.4002 & TRN \\
\hline CHEMBL1729796 & 737396 & 3.2457 & 3.2412 & TRN \\
\hline CHEMBL1334484 & 737396 & 5.6162 & 3.8004 & TST \\
\hline CHEMBL1361703 & 737396 & 5.1062 & 5.0072 & TRN \\
\hline CHEMBL1701865 & 737396 & 3.2457 & 3.4793 & TRN \\
\hline CHEMBL1724143 & 737396 & 3.2457 & 3.3295 & TRN \\
\hline CHEMBL1725449 & 737396 & 5.1811 & 4.9504 & TRN \\
\hline CHEMBL1719047 & 737396 & 4.5935 & 4.3742 & TRN \\
\hline CHEMBL1733814 & 737396 & 3.2457 & 3.9923 & TST \\
\hline CHEMBL1600114 & 737396 & 6.556 & 3.9998 & TST \\
\hline CHEMBL1706750 & 737396 & 3.2457 & 4.0339 & TRN \\
\hline CHEMBL1714309 & 737396 & 5.04 & 5.1704 & TRN \\
\hline CHEMBL1732031 & 737396 & 5.2604 & 5.0251 & TRN \\
\hline CHEMBL3190104 & 737396 & 5.1555 & 3.4316 & TST \\
\hline CHEMBL1720079 & 737396 & 4.9547 & 5.2329 & TRN \\
\hline CHEMBL1700723 & 737396 & 3.2457 & 3.3474 & TRN \\
\hline CHEMBL1736986 & 737396 & 5.295 & 5.4346 & TRN \\
\hline CHEMBL1711163 & 737396 & 4.9914 & 4.8232 & TRN \\
\hline CHEMBL1708498 & 737396 & 4.7595 & 4.8843 & TRN \\
\hline CHEMBL1719138 & 737396 & 3.2457 & 3.1545 & TRN \\
\hline CHEMBL1729177 & 737396 & 4.6108 & 4.1014 & TRN \\
\hline CHEMBL1735822 & 737396 & 5.1118 & 5.0896 & TRN \\
\hline CHEMBL1728381 & 737396 & 3.2457 & 3.8425 & TRN \\
\hline CHEMBL1494713 & 737396 & 5.2441 & 4.5393 & TST \\
\hline CHEMBL1530437 & 737396 & 4.7167 & 5.1247 & TRN \\
\hline CHEMBL1705892 & 737396 & 3.2457 & 3.5263 & TRN \\
\hline CHEMBL1546396 & 737396 & 5.983 & 4.9358 & TST \\
\hline CHEMBL1713480 & 737396 & 5.4672 & 5.2713 & TRN \\
\hline CHEMBL1732001 & 737396 & 3.2457 & 3.5614 & TST \\
\hline CHEMBL1729929 & 737396 & 3.2457 & 3.4405 & TRN \\
\hline CHEMBL1703530 & 737396 & 4.6576 & 4.3583 & TRN \\
\hline CHEMBL1730170 & 737396 & 3.2457 & 4.0469 & TRN \\
\hline CHEMBL1713973 & 737396 & 3.2457 & 3.8865 & TST \\
\hline CHEMBL1722566 & 737396 & 5.5498 & 4.8821 & TST \\
\hline CHEMBL1526223 & 737396 & 3.2457 & 4.2631 & TST \\
\hline
\end{tabular}




\begin{tabular}{|c|c|c|c|c|c|c|}
\hline \multicolumn{7}{|c|}{ Supplemental Table S2.txt } \\
\hline CHEMBL1722076 & 737396 & 4.9626 & 4.8663 & TRN & & \\
\hline CHEMBL1704376 & 737396 & 3.2457 & 3.187 & TRN & & \\
\hline CHEMBL1720479 & 737396 & 3.2457 & 3.8003 & TRN & & \\
\hline CHEMBL1727691 & 737396 & 5.0491 & 3.2126 & TST & & \\
\hline CHEMBL1728154 & 737396 & 4.3497 & 3.5361 & TRN & & \\
\hline CHEMBL1722739 & 737396 & 4.5129 & 4.8886 & TRN & & \\
\hline CHEMBL1716638 & 737396 & 4.5072 & 4.4074 & TRN & & \\
\hline CHEMBL1736103 & 737396 & 3.2457 & 3.2461 & TRN & & \\
\hline CHEMBL1707378 & 737396 & 4.7447 & 4.5071 & TRN & & \\
\hline CHEMBL1699680 & 737396 & 4.7122 & 4.0776 & TRN & & \\
\hline CHEMBL1698101 & 737396 & 4.6383 & 4.7777 & TRN & & \\
\hline CHEMBL1360146 & 737396 & 4.7258 & 3.6514 & TST & & \\
\hline CHEMBL1728000 & 737396 & 4.9172 & 5.0046 & TST & & \\
\hline CHEMBL1481413 & 737396 & 5.3737 & 3.7896 & TST & & \\
\hline CHEMBL1715245 & 737396 & 4.9547 & 4.9167 & TST & & \\
\hline CHEMBL27261 & 30723 & 6.4609 & 6.4338 & TRN & & \\
\hline CHEMBL281468 & 30723 & 7.1871 & 7.1737 & TRN & & \\
\hline CHEMBL26897 & 30723 & 7.0269 & 7.0107 & TRN & & \\
\hline CHEMBL283847 & 30723 & 6.4855 & 6.4893 & TRN & & \\
\hline CHEMBL286959 & 30723 & 6.5768 & 6.5808 & TRN & & \\
\hline CHEMBL422399 & 30723 & 7.0915 & 7.1047 & TRN & & \\
\hline CHEMBL280982 & 30723 & 6.7055 & 6.7101 & TRN & & \\
\hline CHEMBL 282599 & 30723 & 5.6757 & 7.1498 & TST & & \\
\hline CHEMBL27032 & 30723 & 6.4225 & 6.4203 & TRN & & \\
\hline CHEMBL283908 & 30723 & 7.3565 & 7.3917 & TRN & & \\
\hline CHEMBL27883 & 30723 & 6.1057 & 6.09 & TRN & & \\
\hline CHEMBL28233 & 30723 & 6.76200 & 00000000 & 005 & 6.7521 & $\mathrm{TP}$ \\
\hline CHEMBL 283937 & 30723 & 7.1643 & 7.1853 & TRN & & \\
\hline CHEMBL281811 & 30723 & 4.76699 & 99999999 & 995 & 6.7131 & \\
\hline CHEMBL 25859 & 30723 & 7.4089 & 7.4058 & TRN & & \\
\hline CHEMBL27260 & 30723 & 7.2757 & 7.3216 & TRN & & \\
\hline CHEMBL285339 & 30723 & 6.3585 & 6.3677 & TRN & & \\
\hline CHEMBL26887 & 30723 & 6.6861 & 6.6474 & TRN & & \\
\hline CHEMBL280839 & 30723 & 6.5702 & 6.5432 & TST & & \\
\hline CHEMBL281657 & 30723 & 7.0716 & 7.0813 & TRN & & \\
\hline CHEMBL281305 & 30723 & 6.2218 & 6.2067 & TRN & & \\
\hline CHEMBL27714 & 30723 & 6.8827 & 6.8771 & TRN & & \\
\hline CHEMBL286285 & 30723 & 6.1451 & 6.1798 & TRN & & \\
\hline CHEMBL418196 & 30723 & 6.1308 & 6.0019 & TST & & \\
\hline CHEMBL447777 & 30723 & 6.6778 & 6.6947 & TRN & & \\
\hline CHEMBL431309 & 30723 & 4.7447 & 7.6702 & TST & & \\
\hline CHEMBL27140 & 30723 & 7.1938 & 7.1737 & TRN & & \\
\hline CHEMBL27215 & 30723 & 7.6198 & 7.5929 & TRN & & \\
\hline CHEMBL26070 & 30723 & 6.71 & 6.7073 & TRN & & \\
\hline CHEMBL 283406 & 30723 & 6.6421 & 6.6428 & TRN & & \\
\hline CHEMBL280796 & 30723 & 6.6655 & 6.6863 & TRN & & \\
\hline CHEMBL28395 & 30723 & 6.6655 & 6.6556 & TRN & & \\
\hline CHEMBL283896 & 30723 & 7.1675 & 7.1684 & TRN & & \\
\hline
\end{tabular}




\begin{tabular}{|c|c|c|c|c|c|}
\hline \multicolumn{6}{|c|}{ Supplemental Table S2.txt } \\
\hline CHEMBL26668 & 30723 & 7.2441 & 7.2561 & TRN & \\
\hline CHEMBL 27496 & 30723 & 7.3143 & 7.3086 & TRN & \\
\hline CHEMBL281885 & 30723 & 6.2874 & 6.2948 & TRN & \\
\hline CHEMBL281272 & 30723 & 6.3468 & 6.3582 & TRN & \\
\hline CHEMBL282864 & 30723 & 6.5735 & 6.5948 & TRN & \\
\hline CHEMBL28258 & 30723 & 7.4815 & 7.4444 & TRN & \\
\hline CHEMBL283184 & 30723 & 6.5186 & 6.5162 & TRN & \\
\hline CHEMBL26899 & 30723 & 4.8928 & 4.9041 & TRN & \\
\hline CHEMBL26979 & 30723 & 6.4437 & 6.4534 & TRN & \\
\hline CHEMBL26245 & 30723 & 5.0329 & 5.0216 & TRN & \\
\hline CHEMBL25799 & 30723 & 6.9208 & 6.3259 & TST & \\
\hline CHEMBL26069 & 30723 & 6.6946 & 6.7462 & TST & \\
\hline CHEMBL283906 & 30723 & 7.0809 & 7.0986 & TRN & \\
\hline CHEMBL26837 & 30723 & 6.4908 & 6.24700 & 0000000001 & TST \\
\hline CHEMBL 26792 & 30723 & 6.2798 & 6.2625 & TRN & \\
\hline CHEMBL 26698 & 30723 & 6.4365 & 6.2257 & TST & \\
\hline CHEMBL25976 & 30723 & 6.8447 & 6.8529 & TRN & \\
\hline CHEMBL285589 & 30723 & 5.9586 & 6.5634 & TST & \\
\hline CHEMBL27203 & 30723 & 6.8827 & 6.9007 & TRN & \\
\hline CHEMBL 25810 & 30723 & 5.3242 & 6.8762 & TST & \\
\hline CHEMBL280584 & 30723 & 5.7932 & 6.6918 & TST & \\
\hline CHEMBL283258 & 30723 & 6.4647 & 6.3014 & TST & \\
\hline CHEMBL 27508 & 30723 & 7.5072 & 7.4962 & TRN & \\
\hline CHEMBL 28046 & 30723 & 6.1904 & 6.6507 & TST & \\
\hline CHEMBL 25914 & 30723 & 6.0545 & 6.0478 & TRN & \\
\hline CHEMBL283939 & 30723 & 7.8539 & 7.8432 & TRN & \\
\hline CHEMBL25964 & 30723 & 7.2125 & 7.2493 & TRN & \\
\hline CHEMBL 27318 & 30723 & 7.1232 & 7.1409 & TRN & \\
\hline CHEMBL25906 & 30723 & 7.7235 & 7.7171 & TRN & \\
\hline CHEMBL 26963 & 30723 & 6.4855 & 6.46700 & 00000000005 & TRN \\
\hline CHEMBL 26138 & 30723 & 7.2676 & 7.24700 & 0000000001 & TRN \\
\hline CHEMBL282993 & 30723 & 6.5361 & 6.7753 & TST & \\
\hline CHEMBL 28052 & 30723 & 6.857 & 6.8428 & TRN & \\
\hline CHEMBL284571 & 30723 & 6.8153 & 6.7331 & TST & \\
\hline CHEMBL 281958 & 30723 & 6.3261 & 5.9968 & TST & \\
\hline CHEMBL28267 & 30723 & 6.8729 & 6.8617 & TRN & \\
\hline CHEMBL 26938 & 30723 & 7.2503 & 7.2398 & TRN & \\
\hline CHEMBL 28346 & 30723 & 5.4089 & 6.9412 & TST & \\
\hline CHEMBL282206 & 30723 & 6.4522 & 6.4503 & TRN & \\
\hline CHEMBL480005 & 491718 & 7.1024 & 7.144 & TRN & \\
\hline CHEMBL480884 & 491718 & 6.1433 & 6.0891 & TRN & \\
\hline CHEMBL451289 & 491718 & 7.3098 & 7.0402 & TRN & \\
\hline CHEMBL490067 & 491718 & 6.2314 & 6.3073 & TRN & \\
\hline CHEMBL481148 & 491718 & 7.8239 & 7.5973 & TRN & \\
\hline CHEMBL479970 & 491718 & 7.2007 & 7.1688 & TRN & \\
\hline CHEMBL482075 & 491718 & 7.1805 & 7.4571 & TRN & \\
\hline CHEMBL450723 & 491718 & 7.6021 & 7.7234 & TRN & \\
\hline CHEMBL520781 & 491718 & 7.3768 & 7.3788 & TRN & \\
\hline
\end{tabular}




\begin{tabular}{|c|c|c|c|c|}
\hline & & & & \\
\hline IEMBL482094 & 491718 & 6.4214 & 6.7428 & TS \\
\hline CHEMBL388710 & 491718 & 6.426 & 6.3142 & \\
\hline HEMBL510856 & 491718 & 7.3565 & 5657 & \\
\hline HEMBL481297 & 491718 & 7.0269 & .9281 & \\
\hline HEMBL481703 & 491718 & 8.0969 & 7.7754 & \\
\hline HEMBL4 & 491718 & 5.5513 & & \\
\hline HEMBL479971 & 491718 & 4202 & & \\
\hline HEMBL493249 & 491718 & 6.091 & 173 & \\
\hline HEMBL482765 & 491718 & 7.0605 & 6.9108 & \\
\hline HEMBL516915 & 491718 & 7.585 & & \\
\hline HEMBL & 491718 & 7.7447 & 55 & \\
\hline HEMBL & 491718 & 6.71 & 7.0522 & \\
\hline HEMBL & 491718 & 7.1308 & & \\
\hline HEMBL & 491718 & 962 & & \\
\hline HEMBL 2 & 491718 & 5.8996 & 44 & \\
\hline HEMBL & 718 & 7.8239 & & \\
\hline HEMBL & 491 & 308 & & \\
\hline HEMBL & 491 & 208 & & \\
\hline HEMBL & 491 & 979 & & \\
\hline HEMBL & 491 & 437 & & \\
\hline HEMBL & 491 & 393 & & \\
\hline HEMBL & 491 & 539 & & \\
\hline HEMBL & 491 & 811 & & \\
\hline HEMBL & 491 & 88 & & \\
\hline HEMBL & 491 & 307 & & \\
\hline HEMBL & 18 & 958 & & \\
\hline HEMBL & 491 & 586 & & \\
\hline AEMBL & 491 & 928 & & \\
\hline HEMBL: & 491 & 098 & & \\
\hline CHEMBL & 491 & 949 & & \\
\hline HFMR I & 18 & 157 & & \\
\hline HEMBL & 491 & 809 & & \\
\hline HEMBL & 491 & & & \\
\hline CHEMBL & 491 & 7.0458 & 43 & \\
\hline CHEMBL & 491 & 6.5331 & $L 23$ & I niv \\
\hline CHEMBL & 491 & 969 & 34 & \\
\hline CHEMBL & 491718 & 7.3372 & 46 & \\
\hline CHEMBL & 491718 & 6.9101 & & \\
\hline CHEMBL & 491718 & & & \\
\hline CHEMBL & 491 & 132 & & . \\
\hline CHEMBL 4 & 491718 & 595 & 12 & \\
\hline CHEMBL518961 & 491718 & 7.7959 & 7.7696 & \\
\hline CHEMBL482137 & 491718 & 7.7212 & 7.5936 & \\
\hline CHEMBL481311 & 491718 & 6.9586 & & TS \\
\hline CHEMBL481922 & 491718 & 6.9066 & 6.9214 & \\
\hline CHEMBL481136 & 491718 & 6.4134 & 6.8432 & \\
\hline CHEMBL244199 & 491718 & 6.4976 & 6.526 & \\
\hline 519134 & 91718 & 6.7352 & 7.2163 & \\
\hline
\end{tabular}

Page 3834 


\begin{tabular}{|c|c|c|c|c|}
\hline & & & oplement & al $\mathrm{T}$ \\
\hline CHEMBL446444 & 321538 & 4.5528 & 4.5326 & TRN \\
\hline CHEMBL194300 & 321538 & 4.7212 & 4.6478 & TRN \\
\hline CHEMBL194460 & 321538 & 4.1871 & 4.2727 & TRN \\
\hline CHEMBL371719 & 321538 & 4.7696 & 4.8942 & TRN \\
\hline CHEMBL372525 & 321538 & 4.7447 & 5.7036 & TST \\
\hline CHEMBL421353 & 321538 & 4.0315 & 4.2827 & TRN \\
\hline CHEMBL198366 & 321538 & 4.7959 & 4.8528 & TRN \\
\hline CHEMBL364520 & 321538 & 4.0757 & 4.0453 & TRN \\
\hline CHEMBL197626 & 321538 & 4.7447 & 4.6057 & TRN \\
\hline CHEMBL198718 & 321538 & 7.3098 & 7.3347 & TRN \\
\hline CHEMBL194572 & 321538 & 4.6778 & 4.5944 & TRN \\
\hline CHEMBL197882 & 321538 & 3.7773 & 3.7525 & TRN \\
\hline CHEMBL365185 & 321538 & 5.0044 & 4.9855 & TRN \\
\hline CHEMBL196821 & 321538 & 5.1308 & 5.0336 & TRN \\
\hline CHEMBL436119 & 321538 & 4.7447 & 4.7567 & TRN \\
\hline CHEMBL369909 & 321538 & 6.1739 & 6.1102 & TRN \\
\hline CHEMBL380801 & 321538 & 4.4949 & 4.5519 & TRN \\
\hline CHEMBL362185 & 321538 & 7.0 & 6.9769 & TRN \\
\hline CHEMBL193671 & 321538 & 5.2218 & 5.2289 & TRN \\
\hline CHEMBL196042 & 321538 & 4.1308 & 4.0372 & TRN \\
\hline CHEMBL371867 & 321538 & 4.5376 & 4.3889 & TRN \\
\hline CHEMBL199198 & 321538 & 4.3872 & 4.4394 & TRN \\
\hline CHEMBL196293 & 321538 & 5.3979 & 5.4486 & TRN \\
\hline CHEMBL372675 & 321538 & 4.0969 & 4.239 & TRN \\
\hline CHEMBL197721 & 321538 & 4.5528 & 4.5415 & TRN \\
\hline CHEMBL372984 & 321538 & 4.6198 & 4.6464 & TRN \\
\hline CHEMBL199153 & 321538 & 4.7447 & 4.5526 & TRN \\
\hline CHEMBL196012 & 321538 & 5.0809 & 5.0899 & TRN \\
\hline CHEMBL198098 & 321538 & 4.3188 & 4.2591 & TRN \\
\hline CHEMBL262732 & 321538 & 4.7447 & 4.7507 & TRN \\
\hline CHEMBL108253 & 321538 & 5.0969 & 5.1904 & TRN \\
\hline CHEMBL196447 & 321538 & 6.9586 & 6.9817 & TRN \\
\hline CHEMBL198423 & 321538 & 7.0 & 6.9915 & TRN \\
\hline CHEMBL198878 & 321538 & 4.5686 & 4.7051 & TST \\
\hline CHEMBL372359 & 321538 & 6.0223 & 5.9793 & TRN \\
\hline CHEMBL199195 & 321538 & 4.8861 & 4.8804 & TRN \\
\hline CHEMBL199200 & 321538 & 4.5229 & 4.5159 & TRN \\
\hline CHEMBL197557 & 321538 & 5.0862 & 5.0616 & TRN \\
\hline CHEMBL370821 & 321538 & 5.1249 & 5.1139 & TRN \\
\hline CHEMBL370124 & 321538 & 4.8861 & 4.9471 & TRN \\
\hline CHEMBL199039 & 321538 & 4.301 & 4.3351 & TRN \\
\hline CHEMBL194519 & 321538 & 4.7212 & 4.6143 & TRN \\
\hline CHEMBL426830 & 321538 & 5.8539 & 5.8498 & TRN \\
\hline CHEMBL197897 & 321538 & 4.8539 & 4.838 & TRN \\
\hline CHEMBL198879 & 321538 & 4.7959 & 5.5698 & TST \\
\hline CHEMBL197118 & 321538 & 4.585 & 6.2326 & TST \\
\hline CHEMBL194678 & 321538 & 4.301 & 4.3897 & TRN \\
\hline CHEMBL197953 & 321538 & 4.0894 & 5.5422 & TST \\
\hline
\end{tabular}




\begin{tabular}{|c|c|c|c|c|c|}
\hline \multicolumn{6}{|c|}{ Supplemental Table S2.txt } \\
\hline CHEMBL197296 & 321538 & 5.2007 & 5.2197 & TRN & \\
\hline CHEMBL382966 & 321538 & 4.301 & 4.2814 & TRN & \\
\hline CHEMBL16326 & 321538 & 5.2518 & 5.3482 & TRN & \\
\hline CHEMBL371987 & 321538 & 5.699 & 5.7629 & TRN & \\
\hline CHEMBL193447 & 321538 & 6.0 & 5.9573 & TRN & \\
\hline CHEMBL 372590 & 321538 & 7.2518 & 7.1947 & TRN & \\
\hline CHEMBL198813 & 321538 & 6.8539 & 6.8941 & TRN & \\
\hline CHEMBL199199 & 321538 & 4.3565 & 5.1322 & TST & \\
\hline CHEMBL196211 & 321538 & 4.3979 & 5.5324 & TST & \\
\hline CHEMBL198005 & 321538 & 4.0862 & 4.2195 & TST & \\
\hline CHEMBL196397 & 321538 & 5.3372 & 5.29799 & 9999999999 & TST \\
\hline CHEMBL194466 & 321538 & 4.8861 & 4.4624 & TST & \\
\hline CHEMBL196154 & 321538 & 6.4202 & 5.9346 & TST & \\
\hline CHEMBL197033 & 321538 & 5.0862 & 3.9221 & TST & \\
\hline CHEMBL194900 & 321538 & 4.2366 & 4.346 & TST & \\
\hline CHEMBL196621 & 321538 & 5.1739 & 5.0718 & TST & \\
\hline CHEMBL371538 & 321538 & 5.1192 & 4.6546 & TST & \\
\hline CHEMBL196421 & 321538 & 4.1675 & 4.0618 & TST & \\
\hline CHEMBL 370131 & 321538 & 4.9208 & 5.4221 & TST & \\
\hline CHEMBL 2144069 & 954595 & 3.4177 & 3.2674 & TRN & \\
\hline CHEMBL102714 & 954595 & 4.2437 & 3.9864 & TRN & \\
\hline CHEMBL1230020 & 954595 & 3.0236 & 3.1839 & TRN & \\
\hline CHEMBL483847 & 954595 & 4.463 & 4.3888 & TRN & \\
\hline CHEMBL1590308 & 954595 & 2.6136 & 3.4593 & TST & \\
\hline CHEMBL412142 & 954595 & 4.652 & 4.2271 & TRN & \\
\hline CHEMBL 210618 & 954595 & 3.025 & 3.2355 & TRN & \\
\hline CHEMBL189584 & 954595 & 3.7694 & 4.1008 & TRN & \\
\hline CHEMBL392695 & 954595 & 4.1791 & 3.7651 & TRN & \\
\hline CHEMBL509032 & 954595 & 4.3087 & 4.2097 & TRN & \\
\hline CHEMBL222102 & 954595 & 3.4518 & 3.9655 & TRN & \\
\hline CHEMBL1673039 & 954595 & 3.6536 & 3.9326 & TRN & \\
\hline CHEMBL 202721 & 954595 & 3.3935 & 3.9797 & TRN & \\
\hline CHEMBL3186408 & 954595 & 3.6977 & 3.5639 & TST & \\
\hline CHEMBL512504 & 954595 & 4.12 & 4.3771 & TRN & \\
\hline CHEMBL1788116 & 954595 & 3.39 & 3.5691 & TRN & \\
\hline CHEMBL 379300 & 954595 & 4.7984 & 4.4086 & TRN & \\
\hline CHEMBL 213100 & 954595 & 6.4869 & 6.7885 & TRN & \\
\hline CHEMBL 258844 & 954595 & 4.0786 & 4.2492 & TRN & \\
\hline CHEMBL221137 & 954595 & 3.7893 & 4.0497 & TST & \\
\hline CHEMBL483849 & 954595 & 3.0475 & 3.0339 & TST & \\
\hline CHEMBL 259181 & 954595 & 5.0698 & 4.548 & TRN & \\
\hline CHEMBL300389 & 954595 & 4.8336 & 4.9025 & TRN & \\
\hline CHEMBL3349342 & 954595 & 4.8674 & 4.5347 & TRN & \\
\hline CHEMBL1516890 & 954595 & 3.8159 & 3.8855 & TRN & \\
\hline CHEMBL1357247 & 954595 & 3.9097 & 3.5038 & TRN & \\
\hline CHEMBL 2363137 & 954595 & 3.9899 & 3.9247 & TRN & \\
\hline CHEMBL 217354 & 954595 & 5.0542 & 4.7435 & TRN & \\
\hline CHEMBL577784 & 954595 & 4.7635 & 4.6835 & TRN & \\
\hline
\end{tabular}




\begin{tabular}{|c|c|c|c|c|c|}
\hline & & \multicolumn{4}{|c|}{ Supplemental Table S2.txt } \\
\hline CHEMBL1256459 & 954595 & 4.8545 & 4.7687 & TRN & \\
\hline CHEMBL 209148 & 954595 & 3.8347 & 3.589 & TRN & \\
\hline CHEMBL1242367 & 954595 & 3.2768 & 3.6642 & TRN & \\
\hline CHEMBL92309 & 954595 & 2.6074 & 3.2752 & TST & \\
\hline CHEMBL1643959 & 954595 & 4.5458 & 4.0485 & TRN & \\
\hline CHEMBL 240954 & 954595 & 3.2398 & 3.8241 & TST & \\
\hline CHEMBL393929 & 954595 & 3.2531 & 3.4408 & TRN & \\
\hline CHEMBL379975 & 954595 & 3.8501 & 4.1337 & TRN & \\
\hline CHEMBL 2134202 & 954595 & 5.1236 & 4.4392 & TRN & \\
\hline CHEMBL65 & 954595 & 6.1478 & 6.3465 & TRN & \\
\hline CHEMBL573107 & 954595 & 4.8799 & 4.8318 & TRN & \\
\hline CHEMBL472940 & 954595 & 4.3161 & 4.2951 & TRN & \\
\hline CHEMBL 255342 & 954595 & 3.8004 & 3.8565 & TRN & \\
\hline CHEMBL558642 & 954595 & 2.8506 & 3.27600 & 00000000002 & TRN \\
\hline CHEMBL188678 & 954595 & 4.7692 & 4.4864 & TRN & \\
\hline CHEMBL1909414 & 954595 & 3.2432 & 3.3976 & TRN & \\
\hline CHEMBL 9470 & 954595 & 6.1094 & 5.1415 & TST & \\
\hline CHEMBL220241 & 954595 & 4.4088 & 4.4032 & TRN & \\
\hline CHEMBL1970879 & 954595 & 4.3638 & 4.5501 & TRN & \\
\hline CHEMBL3199475 & 954595 & 4.1487 & 4.2662 & TRN & \\
\hline CHEMBL192566 & 954595 & 5.729 & 5.6512 & TST & \\
\hline CHEMBL585951 & 954595 & 5.5171 & 5.5464 & TRN & \\
\hline CHEMBL135561 & 954595 & 4.2802 & 4.1052 & TRN & \\
\hline CHEMBL399530 & 954595 & 4.4624 & 4.6117 & TRN & \\
\hline CHEMBL373751 & 954595 & 3.4248 & 3.1516 & TRN & \\
\hline CHEMBL3392440 & 954595 & 3.8014 & 3.8246 & TRN & \\
\hline CHEMBL1186585 & 954595 & 3.7193 & 4.2372 & TRN & \\
\hline CHEMBL1190711 & 954595 & 3.5854 & 4.092 & TST & \\
\hline CHEMBL 2137530 & 954595 & 4.0983 & 4.1034 & TST & \\
\hline CHEMBL 2005886 & 954595 & 3.4232 & 4.2674 & TST & \\
\hline CHEMBL1404918 & 954595 & 2.9306 & 3.531 & TST & \\
\hline CHEMBL449158 & 954595 & 7.5859 & 5.3946 & TST & \\
\hline CHEMBL191334 & 954595 & 3.1837 & 4.2197 & TST & \\
\hline CHEMBL515416 & 954595 & 4.7155 & 3.9157 & TST & \\
\hline CHEMBL180127 & 954595 & 2.9544 & 3.6389 & TST & \\
\hline CHEMBL514499 & 954595 & 5.7811 & 4.2949 & TST & \\
\hline CHEMBL 2359863 & 1301902 & 6.0 & 5.4819 & TRN & \\
\hline CHEMBL2360842 & 1301902 & 6.0 & 5.4675 & TRN & \\
\hline CHEMBL1405749 & 1301902 & 4.9165 & 5.1974 & TST & \\
\hline CHEMBL 2356186 & 1301902 & 5.1518 & 5.276 & TRN & \\
\hline CHEMBL 2354712 & 1301902 & 4.5293 & 5.2326 & TRN & \\
\hline CHEMBL 3186447 & 1301902 & 4.26399 & 99999999 & 5.3798 & TRN \\
\hline CHEMBL1345220 & 1301902 & 4.8784 & 5.1382 & TST & \\
\hline CHEMBL591363 & 1301902 & 5.3401 & 5.1993 & TST & \\
\hline CHEMBL 2360811 & 1301902 & 6.0 & 5.2895 & TRN & \\
\hline CHEMBL2359040 & 1301902 & 4.4969 & 5.2644 & TRN & \\
\hline CHEMBL2361127 & 1301902 & 4.6192 & 4.7252 & TRN & \\
\hline CHEMBL1483562 & 1301902 & 5.0894 & 4.9446 & TST & \\
\hline
\end{tabular}


Supplemental Table S2.txt

\begin{tabular}{|c|c|c|c|}
\hline CHEMBL 2362547 & 1301902 & 4.9266 & 4.8354 \\
\hline CHEMBL2359003 & 1301902 & 4.3756 & 5.4014 \\
\hline HEMBL2355418 & 301902 & 896 & 893 \\
\hline AEMBL2355859 & 1301902 & 6.0 & 4313 \\
\hline HEMBL 2358244 & 1301902 & 4.4156 & 5.2853 \\
\hline CHEMBL1898843 & 1301902 & 4.5874 & 4.9756 \\
\hline CHEMBL 2359612 & 1301902 & 6.0 & 5.3945 \\
\hline AEMBL 2361299 & 1301902 & 4.2696 & 233 \\
\hline HEMBL2355186 & 1301902 & 4.4215 & 6624 \\
\hline CHEMBL1390112 & 1301902 & 4.5078 & 5.0859 \\
\hline CHEMBL 2360228 & 1301902 & 4.657 & 102 \\
\hline HEMBL2355480 & 1301902 & 352 & 988 \\
\hline CHEMBL 3184851 & 1301902 & 578 & 427 \\
\hline AEMBL2358923 & 1301902 & 4.3432 & 915 \\
\hline CHEMBL 2355550 & 1301902 & 4.7192 & 687 \\
\hline CHEMBL 2361002 & 1301902 & 6. & 627 \\
\hline 362783 & 1301902 & 14 & 528 \\
\hline AEMBL 2357535 & 1301902 & 6.0 & 039 \\
\hline AEMBL2356345 & 1301902 & 4.5479 & 5.3911 \\
\hline CHEMBL 2360506 & 1301902 & & 628 \\
\hline CHEMBL & 1301902 & 6 & 094 \\
\hline CHEMBL & 130 & & 276 \\
\hline CHEMBL & 130 & 34 & 877 \\
\hline CHEMBL2358200 & 1301902 & 4.5533 & 522 \\
\hline CHEMBL 2359785 & 1301902 & 6.0 & 223 \\
\hline CHEMBL1347023 & 1301902 & 03 & 128 \\
\hline CHEMBL & 130 & 4. & 116 \\
\hline 59989 & 1301 & 291 & 088 \\
\hline CHEMBL 2361273 & 1301902 & 4.2895 & 347 \\
\hline CHEMBL 2361222 & 1301902 & 6.0 & 265 \\
\hline CHEMBL 2356271 & 1301902 & & 988 \\
\hline $\mathrm{CHE}$ & 130 & 25 & 338 \\
\hline 95 & 130 & 4.8159 & 281 \\
\hline CHEMBL 2356947 & 1301902 & 6.0 & 762 \\
\hline CHEMBL 2355165 & 1301902 & 6. & 039 \\
\hline $\mathrm{CHE}$ & 130 & & \\
\hline 57163 & 1301 & 6 . & 819 \\
\hline CHEMBL2361605 & 1301902 & 4.6633 & 4.8746 \\
\hline CHEMBL 3182522 & 1301902 & 4.7924 & 5.2428 \\
\hline CHEMBL 2354903 & 1301902 & 4.4706 & 4.4421 \\
\hline CHEMBL1321427 & 1301902 & 06 & 609 \\
\hline CHEMBL1625031 & 1301902 & 4.3476 & 4.7285 \\
\hline CHEMBL 2358308 & 1301902 & 4.5957 & 5.3953 \\
\hline CHEMBL 2360276 & 1301902 & 4.3638 & 4.5844 \\
\hline CHEMBL 2356543 & 1301902 & 6.0 & 5.2259 \\
\hline CHEMBL 2132750 & 1301902 & 4.3753 & 4.7865 \\
\hline CHEMBL 2359728 & 1301902 & 4.9003 & 4.8525 \\
\hline CHEMBL 2356602 & 1301902 & 6.0 & 5.1601 \\
\hline
\end{tabular}

Page 3838 
Supplemental Table S2.txt

\begin{tabular}{|c|c|c|c|c|}
\hline & & 4.2916 & & \\
\hline & 301902 & 4.4674 & & \\
\hline & 01902 & 6.0 & & \\
\hline IEMBL & 301902 & & & \\
\hline IEMBL 2360787 & 301902 & 4. & 797 & \\
\hline 56174 & 02 & 6.0 & & \\
\hline 69 & 02 & 65 & & \\
\hline 166 & 02 & & & \\
\hline AEMBL2359952 & 301902 & 4.3058 & & \\
\hline AEMBL2358486 & 301902 & 319 & & \\
\hline 56746 & 02 & & & \\
\hline 37 & 02 & 66 & & \\
\hline IEME & 02 & & & \\
\hline 59541 & 902 & 6.0 & & \\
\hline 60167 & 902 & 4. & & \\
\hline 3 & 02 & 3 & & \\
\hline 9 & 02 & & & \\
\hline 97 & 02 & & & \\
\hline 74530 & 02 & & & \\
\hline 4 & 02 & & & \\
\hline 3 & 02 & 4. & & \\
\hline & 02 & & & \\
\hline 0 & 02 & 6 . & & \\
\hline 79170 & 02 & & & \\
\hline 65 & $\partial 2$ & & & \\
\hline 2 & 130 & 4. & & \\
\hline 0 & 02 & 6. & & \\
\hline 97 & 02 & 5 . & & \\
\hline 60055 & 02 & & & \\
\hline 57924 & 02 & & & \\
\hline & 02 & & & \\
\hline & 32 & & & \\
\hline & $\partial 2$ & & & \\
\hline & 02 & & & \\
\hline 359257 & 902 & & & \\
\hline & & & & \\
\hline & 32 & & & \\
\hline & & & & TR \\
\hline 159394 & 1301902 & 4.9197 & & 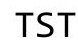 \\
\hline & 02 & & & \\
\hline & 130 & & & \\
\hline CHEMB & 130 & 6. & & \\
\hline CHEMBL & 130 & 4.3225 & & \\
\hline IEMBL & 1301902 & 6.6 & & $\mathrm{R}$ \\
\hline CHEMBL 2357518 & 1301902 & 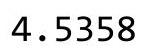 & & \\
\hline $\mathrm{CH}$ & 130 & & & \\
\hline & 1301902 & 4.5819 & & \\
\hline CHEMBL 2354348 & 1301902 & 4.2853 & 4.6616 & \\
\hline
\end{tabular}

Page 3839 


\begin{tabular}{|c|c|c|c|c|c|c|}
\hline \multicolumn{7}{|c|}{ Supplemental Table S2.txt } \\
\hline CHEMBL2362273 & 1301902 & 6.0 & 5.3848 & TRN & & \\
\hline CHEMBL2362650 & 1301902 & 5.34200 & 00000000 & 005 & 5.0731 & TST \\
\hline CHEMBL2360426 & 1301902 & 4.9059 & 5.194 & TRN & & \\
\hline CHEMBL1564801 & 1301902 & 4.8283 & 4.7547 & TST & & \\
\hline CHEMBL2358156 & 1301902 & 4.8216 & 4.8225 & TRN & & \\
\hline CHEMBL2362639 & 1301902 & 4.1939 & 5.3198 & TST & & \\
\hline CHEMBL2355506 & 1301902 & 4.3315 & 5.3029 & TRN & & \\
\hline CHEMBL 2357026 & 1301902 & 6.0 & 5.0837 & TRN & & \\
\hline CHEMBL2355635 & 1301902 & 6.0 & 5.0065 & TRN & & \\
\hline CHEMBL2355634 & 1301902 & 4.5993 & 4.6917 & TRN & & \\
\hline CHEMBL2358704 & 1301902 & 4.6334 & 4.8735 & TRN & & \\
\hline CHEMBL2359250 & 1301902 & 6.0 & 5.4612 & TRN & & \\
\hline CHEMBL2361979 & 1301902 & 4.7158 & 4.5538 & TRN & & \\
\hline CHEMBL 2362397 & 1301902 & 4.5782 & 4.6528 & TRN & & \\
\hline CHEMBL2360307 & 1301902 & 4.335 & 5.4582 & TRN & & \\
\hline CHEMBL2132699 & 1301902 & 6.0 & 5.5135 & TRN & & \\
\hline CHEMBL2359869 & 1301902 & 6.0 & 5.3966 & TRN & & \\
\hline CHEMBL 2355845 & 1301902 & 4.8514 & 4.8189 & TRN & & \\
\hline CHEMBL 2358870 & 1301902 & 4.643 & 4.842 & TRN & & \\
\hline CHEMBL1519285 & 1301902 & 4.7479 & 5.09399 & 9999999999 & & TST \\
\hline CHEMBL2359950 & 1301902 & 4.7084 & 5.4626 & TRN & & \\
\hline CHEMBL2355430 & 1301902 & 6.0 & 5.4887 & TRN & & \\
\hline CHEMBL1489779 & 1301902 & 5.7235 & 5.1735 & TST & & \\
\hline CHEMBL2362033 & 1301902 & 4.4275 & 4.2611 & TRN & & \\
\hline CHEMBL2360428 & 1301902 & 4.7481 & 5.5116 & TRN & & \\
\hline CHEMBL 2361274 & 1301902 & 5.0419 & 5.0936 & TRN & & \\
\hline CHEMBL1617452 & 1301902 & 5.1427 & 4.8444 & TST & & \\
\hline CHEMBL 2358998 & 1301902 & 4.4744 & 4.3406 & TRN & & \\
\hline CHEMBL 2360285 & 1301902 & 4.4344 & 4.4373 & TRN & & \\
\hline CHEMBL1559741 & 1301902 & 4.3876 & 4.7747 & TST & & \\
\hline CHEMBL 2357235 & 1301902 & 4.4196 & 5.3115 & TRN & & \\
\hline CHEMBL2355771 & 1301902 & 4.7802 & 4.7753 & TRN & & \\
\hline CHEMBL2357977 & 1301902 & 6.0 & 5.3113 & TRN & & \\
\hline CHEMBL2354505 & 1301902 & 4.5766 & 4.8899 & TRN & & \\
\hline CHEMBL2357087 & 1301902 & 5.2233 & 4.9332 & TRN & & \\
\hline CHEMBL2359502 & 1301902 & 6.0 & 5.4673 & TRN & & \\
\hline CHEMBL 2357794 & 1301902 & 4.6312 & 4.8443 & TRN & & \\
\hline CHEMBL2357916 & 1301902 & 4.5328 & 5.3411 & TRN & & \\
\hline CHEMBL 2354800 & 1301902 & 4.7493 & 4.7983 & TST & & \\
\hline CHEMBL 2361208 & 1301902 & 4.6284 & 5.4722 & TRN & & \\
\hline CHEMBL1452421 & 1301902 & 5.3125 & 5.1074 & TST & & \\
\hline CHEMBL2358509 & 1301902 & 4.2274 & 4.3323 & TRN & & \\
\hline CHEMBL2360971 & 1301902 & 4.5272 & 5.3351 & TRN & & \\
\hline CHEMBL 2357340 & 1301902 & 4.4869 & 5.2443 & TRN & & \\
\hline CHEMBL3182148 & 1301902 & 4.6664 & 4.7868 & TST & & \\
\hline CHEMBL2354698 & 1301902 & 4.6385 & 4.8248 & TRN & & \\
\hline CHEMBL2361179 & 1301902 & 4.3644 & 5.2406 & TRN & & \\
\hline CHEMBL2359983 & 1301902 & 4.4808 & 4.5682 & TST & & \\
\hline
\end{tabular}




$$
\text { Supplemental Table S2.txt }
$$

\begin{tabular}{|c|c|c|c|c|c|}
\hline CHEMBL2362415 & 1301902 & 4.7515 & 5.2308 & TRN & \\
\hline CHEMBL 2362144 & 1301902 & 4.9119 & 5.2941 & TRN & \\
\hline CHEMBL2359026 & 1301902 & 4.727 & 4.8647 & TRN & \\
\hline CHEMBL2355745 & 1301902 & 6.0 & 5.3223 & TRN & \\
\hline CHEMBL 2358490 & 1301902 & 6.0 & 5.5054 & TRN & \\
\hline CHEMBL 2356442 & 1301902 & 6.0 & 5.4673 & TRN & \\
\hline CHEMBL2362353 & 1301902 & 6.0 & 5.4703 & TRN & \\
\hline CHEMBL2362816 & 1301902 & 4.9739 & 4.6513 & TRN & \\
\hline CHEMBL1306900 & 1301902 & 4.9987 & 4.7507 & TST & \\
\hline CHEMBL1500469 & 1301902 & 5.2 & 5.0922 & TST & \\
\hline CHEMBL1487099 & 1301902 & 5.1457 & 5.4404 & TST & \\
\hline CHEMBL 2360282 & 1301902 & 4.6702 & 4.8157 & TRN & \\
\hline CHEMBL2357966 & 1301902 & 4.6229 & 4.7024 & TRN & \\
\hline CHEMBL2354539 & 1301902 & 4.9606 & 4.9353 & TST & \\
\hline CHEMBL2355758 & 1301902 & 6.0 & 5.4618 & TRN & \\
\hline CHEMBL 2355402 & 1301902 & 4.7319 & 5.3391 & TRN & \\
\hline CHEMBL2362538 & 1301902 & 6.0 & 5.1642 & TRN & \\
\hline CHEMBL1551808 & 1301902 & 4.9905 & 5.0857 & TST & \\
\hline CHEMBL2359667 & 1301902 & 4.4995 & 4.7528 & TRN & \\
\hline CHEMBL1711200 & 1301902 & 4.7226 & 4.747 & TST & \\
\hline CHEMBL2354757 & 1301902 & 6.0 & 5.3943 & TRN & \\
\hline CHEMBL2359037 & 1301902 & 5.3002 & 4.7599 & TRN & \\
\hline CHEMBL 2356480 & 1301902 & 6.0 & 5.4139 & TRN & \\
\hline CHEMBL2360927 & 1301902 & 6.0 & 5.3377 & TRN & \\
\hline CHEMBL2359591 & 1301902 & 6.0 & 5.1656 & TST & \\
\hline CHEMBL2361807 & 1301902 & 6.0 & 5.497006 & 0000000001 & TRN \\
\hline CHEMBL1350915 & 1301902 & 4.388 & 4.8577 & TST & \\
\hline CHEMBL 2355498 & 1301902 & 4.5435 & 4.8627 & TST & \\
\hline CHEMBL 2357286 & 1301902 & 6.0 & 5.28100 & 0000000001 & TRN \\
\hline CHEMBL 2357642 & 1301902 & 4.3615 & 5.1854 & TRN & \\
\hline CHEMBL1584985 & 1301902 & 5.27 & 5.1689 & TST & \\
\hline CHEMBL2355103 & 1301902 & 4.7144 & 4.8992 & TRN & \\
\hline CHEMBL2359372 & 1301902 & 4.3906 & 5.2797 & TRN & \\
\hline CHEMBL2359895 & 1301902 & 5.0458 & 5.3411 & TRN & \\
\hline CHEMBL2361832 & 1301902 & 5.0066 & 4.6351 & TRN & \\
\hline CHEMBL2358841 & 1301902 & 4.4229 & 4.3597 & TRN & \\
\hline CHEMBL2136465 & 1301902 & 4.5166 & 4.7696 & TRN & \\
\hline CHEMBL 2360439 & 1301902 & 4.6572 & 4.8605 & TRN & \\
\hline CHEMBL2355923 & 1301902 & 4.4173 & 5.4622 & TRN & \\
\hline CHEMBL2355724 & 1301902 & 6.0 & 5.3965 & TRN & \\
\hline CHEMBL2359046 & 1301902 & 4.3638 & 4.7461 & TRN & \\
\hline CHEMBL 2360368 & 1301902 & 4.1693 & 4.5894 & TRN & \\
\hline CHEMBL 2138714 & 1301902 & 5.2495 & 5.2948 & TST & \\
\hline CHEMBL 2356860 & 1301902 & 5.0575 & 4.7415 & TRN & \\
\hline CHEMBL2361591 & 1301902 & 6.0 & 5.1875 & TRN & \\
\hline CHEMBL2356019 & 1301902 & 4.743 & 4.7157 & TRN & \\
\hline CHEMBL2358020 & 1301902 & 4.7913 & 4.6417 & TRN & \\
\hline CHEMBL 2356872 & 1301902 & 6.0 & 5.3428 & TRN & \\
\hline
\end{tabular}


Supplemental Table S2.txt

\begin{tabular}{|c|c|c|c|c|c|c|}
\hline CHEMBL 2362712 & 1301902 & 5.1073 & 4.641 & TRN & & \\
\hline CHEMBL 2355085 & 1301902 & 4.7042 & 4.9776 & TRN & & \\
\hline CHEMBL2361968 & 1301902 & 4.51699 & 99999999 & 995 & 4.6958 & TRN \\
\hline CHEMBL2361842 & 1301902 & 4.2675 & 5.3695 & TRN & & \\
\hline CHEMBL1582221 & 1301902 & 4.3171 & 4.8495 & TST & & \\
\hline CHEMBL2361210 & 1301902 & 5.0155 & 4.6807 & TRN & & \\
\hline CHEMBL 2356215 & 1301902 & 4.363 & 4.7341 & TST & & \\
\hline CHEMBL 2357224 & 1301902 & 4.3563 & 4.7417 & TRN & & \\
\hline CHEMBL1536108 & 1301902 & 4.4678 & 4.7846 & TST & & \\
\hline CHEMBL3188924 & 1301902 & 6.0 & 4.3068 & TRN & & \\
\hline CHEMBL2354318 & 1301902 & 4.4742 & 4.3701 & TRN & & \\
\hline CHEMBL2361503 & 1301902 & 4.5991 & 4.2193 & TRN & & \\
\hline CHEMBL2356002 & 1301902 & 6.0 & 5.2738 & TRN & & \\
\hline CHEMBL 2359185 & 1301902 & 6.0 & 5.4233 & TRN & & \\
\hline CHEMBL 2357047 & 1301902 & 6.0 & 5.3868 & TRN & & \\
\hline CHEMBL2356688 & 1301902 & 6.0 & 5.3967 & TRN & & \\
\hline CHEMBL3187483 & 1301902 & 4.0223 & 4.8924 & TST & & \\
\hline CHEMBL3188783 & 1301902 & 4.3806 & 4.6897 & TRN & & \\
\hline CHEMBL 2359515 & 1301902 & 6.0 & 5.1461 & TRN & & \\
\hline CHEMBL 2136180 & 1301902 & 6.0 & 5.4948 & TRN & & \\
\hline CHEMBL 2358899 & 1301902 & 4.6289 & 5.2418 & TRN & & \\
\hline CHEMBL1392527 & 1301902 & 6.5229 & 5.3147 & TST & & \\
\hline CHEMBL1445297 & 1301902 & \multicolumn{3}{|c|}{5.752000000000001} & 5.4287 & TST \\
\hline CHEMBL 2356397 & 1301902 & 6.0 & 5.4826 & TRN & & \\
\hline CHEMBL2361659 & 1301902 & 4.8371 & 5.334 & TRN & & \\
\hline CHEMBL2355359 & 1301902 & 4.7066 & 4.6718 & TRN & & \\
\hline CHEMBL 2362628 & 1301902 & 4.3891 & 5.1784 & TST & & \\
\hline CHEMBL 2354815 & 1301902 & 6.0 & 5.2025 & TRN & & \\
\hline CHEMBL 3185444 & 1301902 & 4.4617 & 4.615 & TRN & & \\
\hline CHEMBL 2357390 & 1301902 & 4.6203 & 5.1556 & TRN & & \\
\hline CHEMBL2357075 & 1301902 & 4.6461 & 4.7356 & TRN & & \\
\hline CHEMBL 2359710 & 1301902 & 4.752 & 4.4174 & TRN & & \\
\hline CHEMBL 2360357 & 1301902 & 4.3865 & \multicolumn{3}{|c|}{5.2860000000000005} & TRN \\
\hline CHEMBL 2360483 & 1301902 & 4.7557 & 4.4361 & TRN & & \\
\hline CHEMBL 2360303 & 1301902 & 6.0 & 5.2929 & TRN & & \\
\hline CHEMBL1864597 & 1301902 & 6.0 & 5.3365 & TRN & & \\
\hline CHEMBL 2356655 & 1301902 & 4.3318 & 4.5787 & TRN & & \\
\hline CHEMBL 2356844 & 1301902 & 4.5941 & 4.5837 & TRN & & \\
\hline CHEMBL1488060 & 1301902 & 4.3683 & 4.7648 & TST & & \\
\hline CHEMBL3186226 & 1301902 & 4.3024 & 4.8819 & TRN & & \\
\hline CHEMBL 2356600 & 1301902 & 4.4837 & 4.8808 & TRN & & \\
\hline CHEMBL 2362170 & 1301902 & 4.87 & 4.63399 & 999999999s & 95 & TRN \\
\hline CHEMBL3182927 & 1301902 & 4.6133 & 4.485 & TRN & & \\
\hline CHEMBL1375884 & 1301902 & 5.1035 & 4.6039 & TST & & \\
\hline CHEMBL2355203 & 1301902 & 4.4954 & 4.5424 & TRN & & \\
\hline CHEMBL 2358051 & 1301902 & 4.7238 & 4.7314 & TRN & & \\
\hline CHEMBL 2355205 & 1301902 & 4.4887 & 5.3095 & TRN & & \\
\hline CHEMBL1622981 & 1301902 & 4.53600 & 30000000 & 005 & 4.7024 & TST \\
\hline
\end{tabular}


Supplemental Table S2.txt

\begin{tabular}{|c|c|c|c|c|c|}
\hline CHEMBL 3187662 & 1301902 & 4.498 & 5.2964 & TRN & \\
\hline CHEMBL 2354476 & 1301902 & 4.1925 & 4.4893 & TRN & \\
\hline CHEMBL 2355340 & 1301902 & 4.2425 & 4.498 & TRN & \\
\hline CHEMBL 2357149 & 1301902 & 4.5364 & 4.6127 & TRN & \\
\hline CHEMBL 2360631 & 1301902 & 6.0 & 5.2291 & TRN & \\
\hline CHEMBL 2359882 & 1301902 & 4.6985 & 5.4271 & TRN & \\
\hline CHEMBL1337726 & 1301902 & 5.056 & 4.7647 & TST & \\
\hline CHEMBL 2357640 & 1301902 & 6.0 & 5.2984 & TRN & \\
\hline CHEMBL1543417 & 1301902 & 4.6511 & 4.9729 & TST & \\
\hline CHEMBL 2356528 & 1301902 & 6.0 & 5.4931 & TRN & \\
\hline CHEMBL 2355313 & 1301902 & 4.5056 & 5.3781 & TRN & \\
\hline CHEMBL 2358823 & 1301902 & 6.0 & 5.4456 & TRN & \\
\hline CHEMBL 2358924 & 1301902 & 4.9974 & 5.0641 & TRN & \\
\hline CHEMBL 3182281 & 1301902 & 4.7231 & 4.8807 & TST & \\
\hline CHEMBL 2358424 & 1301902 & 6.0 & 5.4376 & TRN & \\
\hline CHEMBL585827 & 1301902 & 5.6108 & 5.0502 & TST & \\
\hline CHEMBL2361921 & 1301902 & 4.9031 & 5.1427 & TRN & \\
\hline CHEMBL 2359417 & 1301902 & 6.0 & 5.2459 & TRN & \\
\hline CHEMBL 3186044 & 1301902 & 4.5091 & 4.3882 & TRN & \\
\hline CHEMBL 2362454 & 1301902 & 4.8239 & 5.0983 & TRN & \\
\hline CHEMBL 2355520 & 1301902 & 4.6447 & 4.7365 & TRN & \\
\hline CHEMBL 2362772 & 1301902 & 4.684 & 5.2753 & TRN & \\
\hline CHEMBL 2143863 & 1301902 & 4.6702 & 5.4156 & TRN & \\
\hline CHEMBL1602637 & 1301902 & 4.3864 & 5.1233 & TST & \\
\hline CHEMBL 2359675 & 1301902 & 6.0 & 5.4843 & TRN & \\
\hline CHEMBL 2360358 & 1301902 & 4.7153 & 4.7981 & TRN & \\
\hline CHEMBL 2357399 & 1301902 & 4.7703 & 5.0028 & TRN & \\
\hline CHEMBL 2354341 & 1301902 & 4.4751 & 5.3503 & TST & \\
\hline CHEMBL 2359934 & 1301902 & 4.5414 & 4.2707 & TRN & \\
\hline CHEMBL 2355890 & 1301902 & 6.0 & 5.3564 & TRN & \\
\hline CHEMBL 2355076 & 1301902 & 4.6548 & 4.3332 & TRN & \\
\hline CHEMBL 2356106 & 1301902 & 4.5677 & 5.3064 & TRN & \\
\hline CHEMBL 2358940 & 1301902 & 6.0 & 5.4376 & TRN & \\
\hline CHEMBL257286 & 1301902 & 4.4106 & 4.7835 & TST & \\
\hline CHEMBL 2360720 & 1301902 & 4.7359 & 5.3755 & TRN & \\
\hline CHEMBL 3182041 & 1301902 & 4.1898 & 4.8386 & TST & \\
\hline CHEMBL 3183001 & 1301902 & 4.7233 & 5.3103 & TRN & \\
\hline CHEMBL 2355346 & 1301902 & 4.5214 & 4.6951 & TRN & \\
\hline CHEMBL 2357864 & 1301902 & 4.394 & 4.4102 & TST & \\
\hline CHEMBL 2361970 & 1301902 & 4.3609 & 5.0177 & TRN & \\
\hline CHEMBL 2362260 & 1301902 & 4.399 & 4.791 & TRN & \\
\hline CHEMBL 2142401 & 1301902 & 4.35800 & 00000006 & 005 & 4.5733 \\
\hline CHEMBL2359193 & 1301902 & 4.3651 & 4.8431 & TRN & \\
\hline CHEMBL 2357173 & 1301902 & 6.0 & 5.4797 & TRN & \\
\hline CHEMBL 2138317 & 1301902 & 4.5561 & 5.0853 & TRN & \\
\hline CHEMBL 2361946 & 1301902 & 4.4222 & 4.6443 & TRN & \\
\hline CHEMBL 2359406 & 1301902 & 5.1415 & 5.0065 & TST & \\
\hline CHEMBL1396619 & 1301902 & 4.7359 & 5.0 & TST & \\
\hline
\end{tabular}


Supplemental Table S2.txt

\begin{tabular}{|c|c|c|c|c|c|}
\hline CHEMBL1568022 & 1301902 & 4.8102 & 4.7534 & TST & \\
\hline CHEMBL 3187781 & 1301902 & 4.6876 & 4.9885 & TRN & \\
\hline CHEMBL1866791 & 1301902 & 4.5363 & 4.7164 & TST & \\
\hline CHEMBL2356820 & 1301902 & 6.0 & 5.2907 & TRN & \\
\hline CHEMBL 2362032 & 1301902 & 4.2493 & 4.0671 & TRN & \\
\hline CHEMBL1451348 & 1301902 & 4.5616 & 4.6949 & TST & \\
\hline CHEMBL2359846 & 1301902 & 4.3036 & 4.7883 & TRN & \\
\hline CHEMBL2354689 & 1301902 & 5.3747 & 4.8977 & TRN & \\
\hline CHEMBL 2357811 & 1301902 & 6.0 & 5.4119 & TRN & \\
\hline CHEMBL 2140530 & 1301902 & 4.1794 & 4.6712 & TST & \\
\hline CHEMBL1578386 & 1301902 & 4.6834 & 4.65 & TST & \\
\hline CHEMBL1305372 & 1301902 & 4.5795 & 4.8484 & TST & \\
\hline CHEMBL2356010 & 1301902 & 6.0 & 5.3725 & TST & \\
\hline CHEMBL3188311 & 1301902 & 4.3996 & 4.9372 & TST & \\
\hline CHEMBL 2354737 & 1301902 & 4.6343 & 4.7521 & TST & \\
\hline CHEMBL 2355817 & 1301902 & 4.9435 & 4.4016 & TST & \\
\hline CHEMBL1580784 & 1301902 & 4.3017 & 5.1743 & TST & \\
\hline CHEMBL2361755 & 1301902 & 6.0 & 5.1786 & TST & \\
\hline CHEMBL2360014 & 1301902 & 4.3686 & 4.537 & TST & \\
\hline CHEMBL1379675 & 1301902 & 5.0565 & 4.944 & TST & \\
\hline CHEMBL2360567 & 1301902 & 4.4178 & 4.8318 & TST & \\
\hline CHEMBL2362298 & 1301902 & 4.7943 & 4.9056 & TST & \\
\hline CHEMBL 2356340 & 1301902 & 4.4525 & 5.02 & TST & \\
\hline CHEMBL 2132942 & 1301902 & 4.6897 & 4.3857 & TST & \\
\hline CHEMBL2355407 & 1301902 & 5.2248 & 5.254 & TST & \\
\hline CHEMBL2359622 & 1301902 & 6.0 & 5.3513 & TST & \\
\hline CHEMBL1544186 & 1301902 & 4.8239 & 4.7751 & TST & \\
\hline CHEMBL2359131 & 1301902 & 6.0 & 5.3785 & TST & \\
\hline CHEMBL 2358824 & 1301902 & 6.0 & 5.4338 & TST & \\
\hline CHEMBL 27664 & 153318 & 5.87 & 5.5953 & TRN & \\
\hline CHEMBL143953 & 153318 & 2.72 & 4.6421 & TRN & \\
\hline CHEMBL118475 & 153318 & 3.64 & 4.1744 & TRN & \\
\hline CHEMBL 281864 & 153318 & 6.53 & 5.1671 & TRN & \\
\hline CHEMBL11862 & 153318 & 5.41 & 5.37200 & 0000000001 & TRN \\
\hline CHEMBL118310 & 153318 & 5.48 & 5.3365 & TRN & \\
\hline CHEMBL342957 & 153318 & 0.38 & 2.9624 & TST & \\
\hline CHEMBL323692 & 153318 & 4.55 & 4.6389 & TRN & \\
\hline CHEMBL310736 & 153318 & 5.24 & 5.1907 & TRN & \\
\hline CHEMBL26640 & 153318 & 4.7 & 4.9318 & TRN & \\
\hline CHEMBL28115 & 153318 & 3.48 & 4.5368 & TRN & \\
\hline CHEMBL144182 & 153318 & 5.98 & 5.1523 & TRN & \\
\hline CHEMBL27599 & 153318 & 5.9 & 5.0444 & TRN & \\
\hline CHEMBL144750 & 153318 & 4.44 & 4.4764 & TRN & \\
\hline CHEMBL14346 & 153318 & 5.01 & 5.0898 & TRN & \\
\hline CHEMBL 71354 & 153318 & 5.43 & 3.7598 & TRN & \\
\hline CHEMBL 284257 & 153318 & 3.0 & 3.8955 & TRN & \\
\hline CHEMBL38681 & 153318 & 6.58 & 4.7852 & TST & \\
\hline CHEMBL143615 & 153318 & 5.11 & 5.8197 & TRN & \\
\hline
\end{tabular}




\begin{tabular}{|c|c|c|c|c|c|}
\hline \multicolumn{6}{|c|}{ Supplemental Table S2.txt } \\
\hline CHEMBL28390 & 153318 & 5.24 & 4.1745 & TRN & \\
\hline CHEMBL128633 & 153318 & 5.33 & 2.9358 & TST & \\
\hline CHEMBL144427 & 153318 & 3.73 & 4.873 & TRN & \\
\hline CHEMBL280592 & 153318 & 5.01 & 4.9538 & TRN & \\
\hline CHEMBL68977 & 153318 & 3.96 & 4.8314 & TRN & \\
\hline CHEMBL26825 & 153318 & 5.17 & 4.9194 & TRN & \\
\hline CHEMBL 287837 & 153318 & 6.69 & 4.5603 & TST & \\
\hline CHEMBL26711 & 153318 & 5.57 & 5.3267 & TRN & \\
\hline CHEMBL28431 & 153318 & 4.85 & 4.9344 & TRN & \\
\hline CHEMBL27730 & 153318 & 5.58 & 5.2959 & TRN & \\
\hline CHEMBL131174 & 153318 & 5.08 & 3.1236 & TST & \\
\hline CHEMBL 27776 & 153318 & 4.32 & 5.1214 & TRN & \\
\hline CHEMBL25316 & 153318 & 4.21 & 4.30699 & 9999999995 & TRN \\
\hline CHEMBL 333343 & 153318 & 5.39 & 4.7355 & TRN & \\
\hline CHEMBL145491 & 153318 & 0.34 & 3.1872 & TST & \\
\hline CHEMBL 70546 & 153318 & 3.26 & 3.7426 & TRN & \\
\hline CHEMBL 308021 & 153318 & 4.04 & 4.2163 & TRN & \\
\hline CHEMBL522 & 153318 & 3.75 & 2.6036 & TST & \\
\hline CHEMBL112351 & 153318 & 2.0 & 0.9079 & TRN & \\
\hline CHEMBL141959 & 153318 & 4.62 & 5.3807 & TRN & \\
\hline CHEMBL26879 & 153318 & 5.31 & 5.0447 & TRN & \\
\hline CHEMBL144331 & 153318 & 6.54 & 5.4061 & TRN & \\
\hline CHEMBL 286495 & 153318 & 4.97 & 4.8709 & TRN & \\
\hline CHEMBL 27162 & 153318 & 5.87 & 5.6742 & TRN & \\
\hline CHEMBL441679 & 153318 & 5.54 & 4.7799 & TRN & \\
\hline CHEMBL358495 & 153318 & 2.94 & 3.4778 & TST & \\
\hline CHEMBL131412 & 153318 & 4.82 & 2.7868 & TST & \\
\hline CHEMBL 26828 & 153318 & 6.43 & 5.2431 & TRN & \\
\hline CHEMBL39125 & 153318 & 5.33 & 5.1458 & TRN & \\
\hline CHEMBL144444 & 153318 & 6.41 & 5.2679 & TRN & \\
\hline CHEMBL281289 & 153318 & 6.38 & 5.02800 & 00000000005 & TRN \\
\hline CHEMBL145519 & 153318 & 4.24 & 4.2844 & TRN & \\
\hline CHEMBL112964 & 153318 & 0.52 & 1.0711 & TRN & \\
\hline CHEMBL344291 & 153318 & 5.78 & 5.2489 & TRN & \\
\hline CHEMBL 286497 & 153318 & 5.58 & 5.2232 & TRN & \\
\hline CHEMBL 28340 & 153318 & 4.57 & 5.1511 & TRN & \\
\hline CHEMBL341882 & 153318 & 3.33 & 4.2382 & TRN & \\
\hline CHEMBL27639 & 153318 & 2.35 & 5.0969 & TRN & \\
\hline CHEMBL118420 & 153318 & 4.67 & 4.4586 & TST & \\
\hline CHEMBL69312 & 153318 & 3.22 & 4.5724 & TRN & \\
\hline CHEMBL22053 & 153318 & 4.3 & 3.5285 & TST & \\
\hline CHEMBL338311 & 153318 & 4.85 & 4.3326 & TRN & \\
\hline CHEMBL116945 & 153318 & 4.67 & 5.1065 & TRN & \\
\hline CHEMBL26717 & 153318 & 6.26 & 5.0429 & TST & \\
\hline CHEMBL 28228 & 153318 & 4.19 & 4.742 & TST & \\
\hline CHEMBL130744 & 153318 & 6.01 & 4.8066 & TST & \\
\hline CHEMBL 28329 & 153318 & 6.21 & 4.9299 & TST & \\
\hline CHEMBL145494 & 153318 & 5.34 & 5.0663 & TST & \\
\hline
\end{tabular}




\begin{tabular}{|c|c|c|c|c|c|}
\hline \multicolumn{6}{|c|}{ Supplemental Table S2.txt } \\
\hline CHEMBL27499 & 153318 & 6.74 & 3.9349 & TST & \\
\hline CHEMBL3343465 & 1436945 & 6.5686 & 6.5749 & TRN & \\
\hline CHEMBL3341775 & 1436945 & 6.1871 & 6.1796 & TRN & \\
\hline CHEMBL574581 & 1436945 & 3.301 & 4.2402 & TST & \\
\hline CHEMBL291507 & 1436945 & 4.5229 & 3.9311 & TST & \\
\hline CHEMBL3343468 & 1436945 & 5.4202 & 5.4357 & TRN & \\
\hline CHEMBL3343430 & 1436945 & 3.301 & 3.3285 & TRN & \\
\hline CHEMBL3343470 & 1436945 & 3.301 & 3.29399 & 99999999996 & TRN \\
\hline CHEMBL3343447 & 1436945 & 5.6576 & 5.6455 & TRN & \\
\hline CHEMBL 3343424 & 1436945 & 3.301 & 3.2941 & TRN & \\
\hline CHEMBL3343464 & 1436945 & 6.8539 & 6.8428 & TRN & \\
\hline CHEMBL 2386129 & 1436945 & 5.0223 & 5.0273 & TRN & \\
\hline CHEMBL3343451 & 1436945 & 3.301 & 3.31100 & 00000000004 & TRN \\
\hline CHEMBL3343457 & 1436945 & 6.1249 & 6.1436 & TRN & \\
\hline CHEMBL3343436 & 1436945 & 5.0223 & 5.0374 & TRN & \\
\hline CHEMBL3343452 & 1436945 & 5.0706 & 5.0721 & TRN & \\
\hline CHEMBL571264 & 1436945 & 4.5229 & 3.6107 & TST & \\
\hline CHEMBL3343428 & 1436945 & 3.301 & 3.2987 & TRN & \\
\hline CHEMBL 3343432 & 1436945 & 5.0 & 4.9802 & TRN & \\
\hline CHEMBL3343438 & 1436945 & 4.8665 & 4.8728 & TRN & \\
\hline CHEMBL3343444 & 1436945 & 6.8239 & 6.845 & TRN & \\
\hline CHEMBL574580 & 1436945 & 4.301 & 4.2843 & TRN & \\
\hline CHEMBL3343467 & 1436945 & 3.301 & 3.2942 & TST & \\
\hline CHEMBL 2386128 & 1436945 & 5.2291 & 5.2187 & TRN & \\
\hline CHEMBL3343443 & 1436945 & 6.2518 & 6.2807 & TRN & \\
\hline CHEMBL3343449 & 1436945 & 4.9031 & 4.9115 & TRN & \\
\hline CHEMBL3343466 & 1436945 & 6.5229 & 6.5058 & TRN & \\
\hline CHEMBL3343435 & 1436945 & 6.0605 & 6.0639 & TRN & \\
\hline CHEMBL3343455 & 1436945 & 6.0223 & 6.0204 & TRN & \\
\hline CHEMBL 3343445 & 1436945 & 6.8539 & 6.8603 & TRN & \\
\hline CHEMBL3343437 & 1436945 & 4.7905 & 4.7715 & TRN & \\
\hline CHEMBL 3343427 & 1436945 & 3.301 & 3.3062 & TRN & \\
\hline CHEMBL 2386127 & 1436945 & 6.5528 & 6.5077 & TRN & \\
\hline CHEMBL 2386126 & 1436945 & 6.7212 & 6.7248 & TRN & \\
\hline CHEMBL3343469 & 1436945 & 3.301 & 3.2988 & TRN & \\
\hline CHEMBL574582 & 1436945 & 3.301 & 4.1424 & TST & \\
\hline CHEMBL 3343463 & 1436945 & 6.6021 & 6.6557 & TRN & \\
\hline CHEMBL3343429 & 1436945 & 3.301 & 3.3034 & TRN & \\
\hline CHEMBL3343461 & 1436945 & 4.6478 & 4.6357 & TRN & \\
\hline CHEMBL 3343440 & 1436945 & 5.2596 & 5.2661 & TRN & \\
\hline CHEMBL3343453 & 1436945 & 5.4949 & 5.4947 & TRN & \\
\hline CHEMBL3343433 & 1436945 & 4.5686 & 4.5701 & TRN & \\
\hline CHEMBL3343450 & 1436945 & 5.7959 & 5.7708 & TRN & \\
\hline CHEMBL 2386125 & 1436945 & 5.0862 & 3.5187 & TST & \\
\hline CHEMBL3343448 & 1436945 & 5.6576 & 5.6635 & TRN & \\
\hline CHEMBL3343456 & 1436945 & 6.2218 & 6.2164 & TRN & \\
\hline CHEMBL3343458 & 1436945 & 6.0223 & 6.0282 & TRN & \\
\hline CHEMBL3343431 & 1436945 & 3.301 & 3.3061 & TRN & \\
\hline
\end{tabular}


Supplemental Table S2.txt

\begin{tabular}{|c|c|c|c|c|}
\hline CHEMBL3343460 & 1436945 & 4.5607 & 4.5512 & TRN \\
\hline CHEMBL 3343446 & 1436945 & 6.3098 & 6.3158 & TRN \\
\hline CHEMBL3343462 & 1436945 & 6.4685 & 6.4306 & TRN \\
\hline CHEMBL3343434 & 1436945 & 5.3468 & 4.3737 & TST \\
\hline CHEMBL 3343441 & 1436945 & 5.2518 & 5.2446 & TST \\
\hline CHEMBL3343426 & 1436945 & 4.3372 & 3.4641 & TST \\
\hline CHEMBL3343439 & 1436945 & 6.4202 & 5.33899 & 99999999995 \\
\hline CHEMBL3343425 & 1436945 & 3.301 & 3.1964 & TST \\
\hline CHEMBL570807 & 1436945 & 3.301 & 3.6253 & TST \\
\hline CHEMBL3343442 & 1436945 & 5.3468 & 5.0733 & TST \\
\hline CHEMBL3343459 & 1436945 & 4.3925 & 5.0054 & TST \\
\hline CHEMBL3343454 & 1436945 & 5.5086 & 6.4373 & TST \\
\hline CHEMBL 2442562 & 992720 & 5.0458 & 4.7805 & TRN \\
\hline CHEMBL 2442566 & 992720 & 6.0 & 4.9877 & TRN \\
\hline CHEMBL2442573 & 992720 & 5.4089 & 4.9299 & TRN \\
\hline CHEMBL 2442578 & 992720 & 5.4202 & 5.3499 & TRN \\
\hline CHEMBL 2442594 & 992720 & 6.0 & 5.7637 & TRN \\
\hline CHEMBL 2442589 & 992720 & 4.4318 & 3.6456 & TRN \\
\hline CHEMBL 2442580 & 992720 & 5.4202 & 5.4102 & TRN \\
\hline CHEMBL2442565 & 992720 & 4.5258 & 5.0209 & TRN \\
\hline CHEMBL 2442592 & 992720 & 6.0 & 6.005 & TRN \\
\hline CHEMBL 2442588 & 992720 & 5.1549 & 4.5882 & TRN \\
\hline CHEMBL 2442598 & 992720 & 6.0 & 5.9969 & TRN \\
\hline CHEMBL 2442544 & 992720 & 4.7645 & 5.1262 & TRN \\
\hline CHEMBL 2442557 & 992720 & 6.0 & 5.7424 & TRN \\
\hline CHEMBL 2442554 & 992720 & 6.0 & 5.902 & TRN \\
\hline CHEMBL 2442560 & 992720 & 6.0 & 5.7687 & TRN \\
\hline CHEMBL 2442568 & 992720 & 5.301 & 4.9924 & TST \\
\hline CHEMBL 2442555 & 992720 & 4.0 & 4.4134 & TRN \\
\hline CHEMBL 2442596 & 992720 & 6.0 & 6.0341 & TRN \\
\hline CHEMBL 2442567 & 992720 & 5.301 & 4.8698 & TST \\
\hline CHEMBL 2442582 & 992720 & 4.7959 & 4.9527 & TRN \\
\hline CHEMBL 2442561 & 992720 & 4.5817 & 4.5238 & TST \\
\hline CHEMBL 2442558 & 992720 & 4.4815 & 4.7376 & TRN \\
\hline CHEMBL 2442550 & 992720 & 6.0 & 6.1215 & TRN \\
\hline CHEMBL466267 & 992720 & 6.0 & 5.5323 & TRN \\
\hline CHEMBL 2442571 & 992720 & 4.5528 & 4.3538 & TST \\
\hline CHEMBL 2442569 & 992720 & 5.0 & 4.926 & TST \\
\hline CHEMBL 2440143 & 992720 & 5.2291 & 4.6122 & TST \\
\hline CHEMBL 2442575 & 992720 & 4.1972 & 3.7745 & TST \\
\hline CHEMBL 2442576 & 992720 & 4.7077 & 4.2758 & TRN \\
\hline CHEMBL373777 & 992720 & 4.0448 & 3.5306 & TST \\
\hline CHEMBL 2442548 & 992720 & 6.0 & 5.905 & TRN \\
\hline CHEMBL 2442590 & 992720 & 3.0 & 3.3272 & TRN \\
\hline CHEMBL 2442552 & 992720 & 6.0 & 6.1388 & TRN \\
\hline CHEMBL 2442564 & 992720 & 5.7696 & 4.9575 & TST \\
\hline CHEMBL 2442538 & 992720 & 4.6073 & 5.0515 & TRN \\
\hline CHEMBL2442586 & 992720 & 3.0 & 3.1794 & TRN \\
\hline
\end{tabular}


Supplemental Table S2.txt

\begin{tabular}{|c|c|c|c|c|}
\hline CHEMBL 2442572 & 992720 & 5.3279 & 4.7862 & TST \\
\hline CHEMBL 2442584 & 992720 & 5.4559 & 5.5956 & TRN \\
\hline CHEMBL 2442574 & 992720 & 5.1805 & 4.9535 & TST \\
\hline CHEMBL 2442577 & 992720 & 4.0424 & 5.4488 & TRN \\
\hline CHEMBL 2442585 & 992720 & 5.5376 & 5.4385 & TRN \\
\hline CHEMBL 2442570 & 992720 & 5.1249 & 4.9089 & TST \\
\hline CHEMBL 2442546 & 992720 & 6.0 & 6.0265 & TRN \\
\hline CHEMBL 2442579 & 992720 & 4.9208 & 5.0261 & TRN \\
\hline CHEMBL 2442541 & 992720 & 4.7352 & 4.9065 & TRN \\
\hline CHEMBL 2442583 & 992720 & 5.4202 & 5.2528 & TRN \\
\hline CHEMBL 2442587 & 992720 & 3.0 & 3.3713 & TRN \\
\hline CHEMBL 2442600 & 992720 & 6.0 & 6.0471 & TRN \\
\hline CHEMBL 2442581 & 992720 & 4.6576 & 4.7337 & TRN \\
\hline CHEMBL 2442563 & 992720 & 6.0 & 4.9816 & TST \\
\hline CHEMBL481628 & 515703 & 5.5229 & 5.1618 & TRN \\
\hline CHEMBL479455 & 515703 & 5.8239 & 5.7637 & TRN \\
\hline CHEMBL480421 & 515703 & 4.5229 & 5.5745 & TST \\
\hline CHEMBL481226 & 515703 & 5.2218 & 5.7822 & TRN \\
\hline CHEMBL480438 & 515703 & 6.0 & 5.5786 & TRN \\
\hline CHEMBL471963 & 515703 & 3.0 & 3.9514 & TRN \\
\hline CHEMBL455805 & 515703 & 6.0 & 5.2471 & TRN \\
\hline CHEMBL479855 & 515703 & 6.0 & 5.4589 & TRN \\
\hline CHEMBL480632 & 515703 & 5.5229 & 5.6624 & TRN \\
\hline CHEMBL479651 & 515703 & 6.301 & 6.0246 & TRN \\
\hline CHEMBL480257 & 515703 & 4.4559 & 5.4996 & TST \\
\hline CHEMBL518954 & 515703 & 6.5229 & 5.975 & TRN \\
\hline CHEMBL521083 & 515703 & 5.699 & 5.2957 & TRN \\
\hline CHEMBL482403 & 515703 & 6.0 & 5.3233 & TRN \\
\hline CHEMBL481428 & 515703 & 6.0 & 6.1641 & TRN \\
\hline CHEMBL481007 & 515703 & 5.3979 & 5.5096 & TST \\
\hline CHEMBL480833 & 515703 & 6.3979 & 5.8285 & TRN \\
\hline CHEMBL481217 & 515703 & 5.699 & 5.683 & TRN \\
\hline CHEMBL479857 & 515703 & 5.3979 & 5.7127 & TRN \\
\hline CHEMBL471965 & 515703 & 5.0 & 5.2145 & TRN \\
\hline CHEMBL471964 & 515703 & 6.0 & 5.2197 & TST \\
\hline CHEMBL481821 & 515703 & 5.0458 & 4.3723 & TRN \\
\hline CHEMBL480060 & 515703 & 5.5229 & 5.0166 & TST \\
\hline CHEMBL479456 & 515703 & 5.699 & 5.6745 & TRN \\
\hline CHEMBL481822 & 515703 & 5.0 & 4.2707 & TRN \\
\hline CHEMBL520101 & 515703 & 4.1549 & 5.1844 & TRN \\
\hline CHEMBL481426 & 515703 & 5.301 & 5.3716 & TRN \\
\hline CHEMBL481427 & 515703 & 5.5229 & 5.2768 & TRN \\
\hline CHEMBL516920 & 515703 & 6.0 & 5.8282 & TRN \\
\hline CHEMBL480061 & 515703 & 5.699 & 4.9013 & TRN \\
\hline CHEMBL481224 & 515703 & 3.0 & 5.0637 & TRN \\
\hline CHEMBL479448 & 515703 & 4.8239 & 5.2928 & TRN \\
\hline CHEMBL481229 & 515703 & 6.0969 & 6.17399 & 99999999995 \\
\hline CHEMBL479854 & 515703 & 5.5229 & 5.9489 & TRN \\
\hline
\end{tabular}




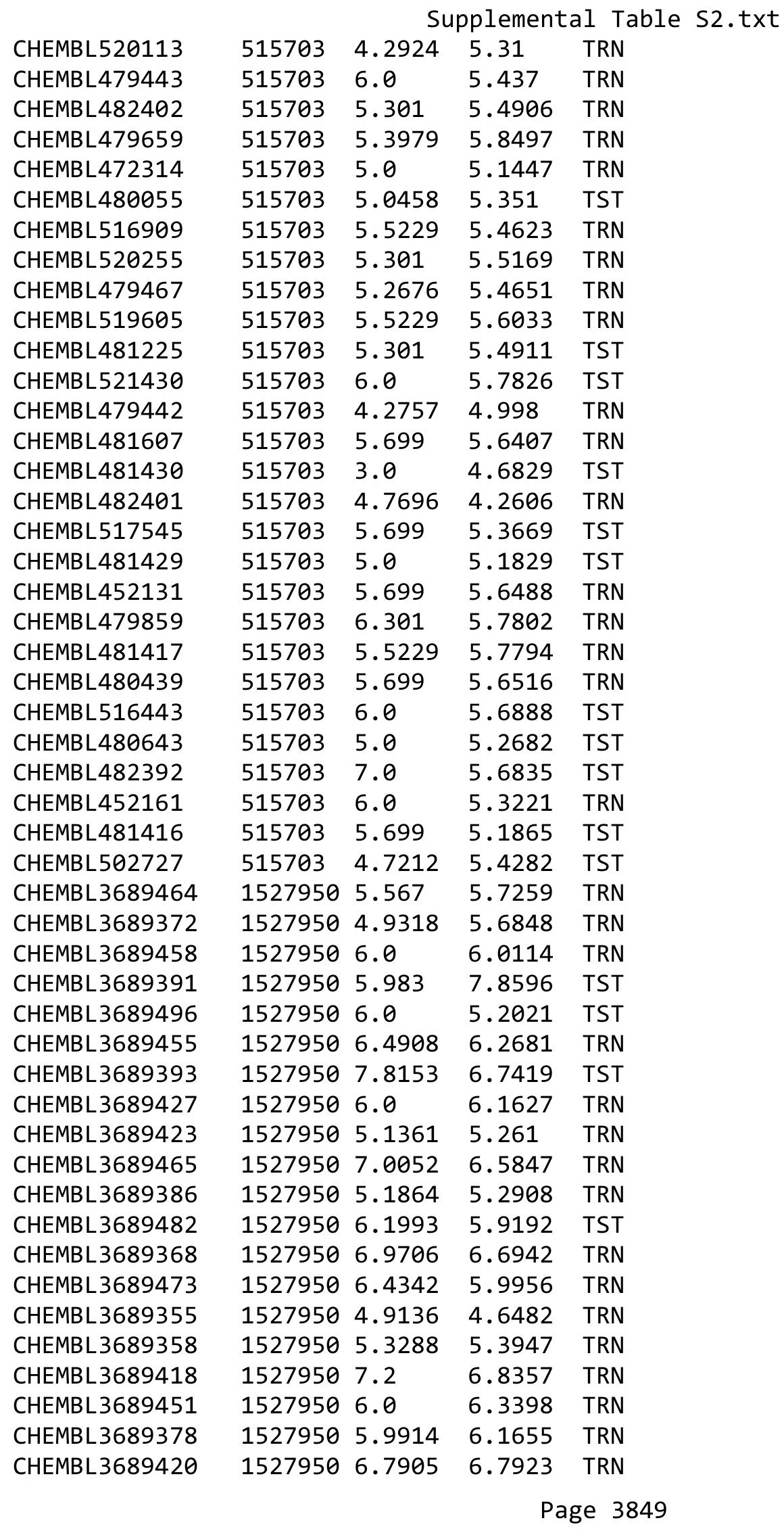


Supplemental Table S2.txt

\begin{tabular}{|c|c|c|c|c|c|c|}
\hline CHEMBL3689504 & 1527950 & 6.5638 & 5.9009 & TST & & \\
\hline CHEMBL3689449 & 1527950 & 6.2284 & 6.2907 & TRN & & \\
\hline CHEMBL3689354 & 1527950 & 5.5528 & 5.042 & TST & & \\
\hline CHEMBL3689476 & 1527950 & 4.8268 & 5.197 & TRN & & \\
\hline CHEMBL 3689387 & 1527950 & 6.2321 & 6.3493 & TRN & & \\
\hline CHEMBL3689383 & 1527950 & 6.8633 & 6.5408 & TRN & & \\
\hline CHEMBL3689375 & 1527950 & 7.061 & 6.8952 & TRN & & \\
\hline CHEMBL3689388 & 1527950 & 6.8069 & 6.3266 & TRN & & \\
\hline CHEMBL3689392 & 1527950 & 6.0 & 6.4239 & TRN & & \\
\hline CHEMBL3689362 & 1527950 & \multicolumn{3}{|c|}{5.617999999999999} & 5.5679 & TRN \\
\hline CHEMBL3689472 & 1527950 & 5.4377 & 5.2331 & TRN & & \\
\hline CHEMBL3689349 & 1527950 & 5.6402 & 5.6782 & TRN & & \\
\hline CHEMBL3639883 & 1527950 & 6.3635 & 5.7658 & TST & & \\
\hline CHEMBL3689380 & 1527950 & 5.5591 & 5.4893 & TRN & & \\
\hline CHEMBL 3689481 & 1527950 & 6.4921 & 6.7412 & TRN & & \\
\hline CHEMBL3689373 & 1527950 & \multicolumn{3}{|c|}{5.757000000000001} & 6.1395 & TRN \\
\hline CHEMBL3689439 & 1527950 & 6.0 & 5.7346 & TST & & \\
\hline CHEMBL 3689454 & 1527950 & 6.0 & 5.8846 & TRN & & \\
\hline CHEMBL 3689426 & 1527950 & 6.0 & \multicolumn{3}{|c|}{6.247999999999999} & TRN \\
\hline CHEMBL3689429 & 1527950 & 7.5317 & 7.1968 & TRN & & \\
\hline CHEMBL 3689471 & 1527950 & 5.4413 & 5.171 & TST & & \\
\hline CHEMBL3689419 & 1527950 & 6.9914 & 7.0529 & TRN & & \\
\hline CHEMBL3689369 & 1527950 & 6.2306 & 6.1379 & TRN & & \\
\hline CHEMBL3689491 & 1527950 & 6.0 & 6.7241 & TRN & & \\
\hline CHEMBL 3689345 & 1527950 & 6.4461 & 6.3941 & TRN & & \\
\hline CHEMBL 3689346 & 1527950 & 5.9101 & 5.8973 & TRN & & \\
\hline CHEMBL3689406 & 1527950 & 6.4868 & 6.0304 & TRN & & \\
\hline CHEMBL 3689444 & 1527950 & 6.7645 & 5.118 & TST & & \\
\hline CHEMBL3689389 & 1527950 & 7.2441 & 6.8718 & TRN & & \\
\hline CHEMBL3689402 & 1527950 & 6.5498 & 6.7846 & TRN & & \\
\hline CHEMBL 3639882 & 1527950 & 5.7328 & 8.5383 & TST & & \\
\hline CHEMBL373487 & 1527950 & \multicolumn{3}{|c|}{6.218999999999999} & 7.3819 & TST \\
\hline CHEMBL 3689400 & 1527950 & 7.4949 & 7.3713 & TRN & & \\
\hline CHEMBL 3689468 & 1527950 & 5.4306 & 5.2808 & TRN & & \\
\hline CHEMBL 3689443 & 1527950 & 6.9706 & 5.7144 & TST & & \\
\hline CHEMBL3689450 & 1527950 & 5.6925 & 4.3373 & TST & & \\
\hline CHEMBL3689398 & 1527950 & 6.7122 & 6.1269 & TRN & & \\
\hline CHEMBL 3689370 & 1527950 & 5.6716 & 5.5111 & TRN & & \\
\hline CHEMBL 3689442 & 1527950 & 7.4647 & 7.2964 & TRN & & \\
\hline CHEMBL 3689422 & 1527950 & 7.5171 & 7.5705 & TRN & & \\
\hline CHEMBL 3689474 & 1527950 & 5.9066 & 6.2842 & TRN & & \\
\hline CHEMBL 3689484 & 1527950 & 6.0 & 5.7201 & TRN & & \\
\hline CHEMBL 3689478 & 1527950 & 5.7773 & 6.1766 & TRN & & \\
\hline CHEMBL3689407 & 1527950 & 6.6345 & 7.235 & TRN & & \\
\hline CHEMBL3689379 & 1527950 & \multicolumn{3}{|c|}{7.1579999999999995} & 7.4374 & TRN \\
\hline CHEMBL 3689385 & 1527950 & 4.9318 & 5.0144 & TRN & & \\
\hline CHEMBL 3689357 & 1527950 & 5.4365 & 5.4304 & TRN & & \\
\hline \multirow[t]{2}{*}{ CHEMBL3689359 } & 1527950 & 5.0009 & 4.71899 & 9999999999 & & TRN \\
\hline & & \multicolumn{5}{|c|}{ Page 3850} \\
\hline
\end{tabular}


Supplemental Table S2.txt

\begin{tabular}{|c|c|c|c|c|}
\hline CHEMBL3689459 & 1527950 & 6.2381 & 6.1287 & TRN \\
\hline CHEMBL3689352 & 1527950 & 6.0 & 6.1311 & TRN \\
\hline CHEMBL 3689470 & 1527950 & 7.1314 & 6.7245 & TRN \\
\hline CHEMBL 3689348 & 1527950 & 6.5952 & 6.2671 & TRN \\
\hline CHEMBL3689425 & 1527950 & 5.7747 & 5.8945 & TRN \\
\hline CHEMBL 3689467 & 1527950 & 5.2426 & 5.1497 & TST \\
\hline CHEMBL 3689410 & 1527950 & 5.1752 & 5.2477 & TRN \\
\hline CHEMBL 3689479 & 1527950 & 5.3778 & 5.8769 & TST \\
\hline CHEMBL 3689365 & 1527950 & 6.2573 & 6.4793 & TRN \\
\hline CHEMBL3689347 & 1527950 & 5.2083 & 5.48799 & 99999999995 \\
\hline CHEMBL 3689363 & 1527950 & 4.8729 & 5.1963 & TRN \\
\hline CHEMBL 3689381 & 1527950 & 6.0 & 6.0865 & TRN \\
\hline CHEMBL3689367 & 1527950 & 6.4763 & 6.1819 & TRN \\
\hline CHEMBL 3689351 & 1527950 & 5.4634 & 5.1336 & TST \\
\hline CHEMBL3689490 & 1527950 & 6.0 & 5.8511 & TRN \\
\hline CHEMBL3689409 & 1527950 & 5.2182 & 5.2405 & TRN \\
\hline CHEMBL3689376 & 1527950 & 6.0 & 6.185 & TRN \\
\hline CHEMBL3689505 & 1527950 & 6.7747 & 5.1989 & TST \\
\hline CHEMBL3689390 & 1527950 & 6.1421 & 6.7301 & TRN \\
\hline CHEMBL3689489 & 1527950 & 6.0 & 6.3718 & TRN \\
\hline CHEMBL3689403 & 1527950 & 6.8097 & 6.9184 & TRN \\
\hline CHEMBL3689371 & 1527950 & 5.1805 & 5.6052 & TRN \\
\hline CHEMBL3689469 & 1527950 & 5.7496 & 5.9365 & TRN \\
\hline CHEMBL3689495 & 1527950 & 7.06 & 6.4981 & TRN \\
\hline CHEMBL 3689441 & 1527950 & 6.0 & 6.0811 & TST \\
\hline CHEMBL3689428 & 1527950 & 6.0 & 5.7843 & TRN \\
\hline CHEMBL 3689485 & 1527950 & 6.0 & 5.2466 & TST \\
\hline CHEMBL3689440 & 1527950 & 7.3675 & 7.2402 & TRN \\
\hline CHEMBL 3689460 & 1527950 & 6.5952 & 6.5538 & TRN \\
\hline CHEMBL 3689477 & 1527950 & 5.8268 & 5.9988 & TST \\
\hline CHEMBL3689421 & 1527950 & 7.5214 & 6.8419 & TRN \\
\hline CHEMBL 3689401 & 1527950 & 7.0595 & 7.1867 & TRN \\
\hline CHEMBL3689399 & 1527950 & 7.3233 & 7.381 & TRN \\
\hline CHEMBL 3689395 & 1527950 & 6.8794 & 6.324 & TST \\
\hline CHEMBL 3689452 & 1527950 & 5.8268 & 5.4829 & TST \\
\hline CHEMBL 3689374 & 1527950 & 5.7122 & 5.7843 & TRN \\
\hline CHEMBL 3689360 & 1527950 & 6.8697 & 7.7189 & TST \\
\hline CHEMBL 3689356 & 1527950 & 4.9136 & 5.0683 & TRN \\
\hline CHEMBL3689350 & 1527950 & 5.5607 & 5.4476 & TRN \\
\hline CHEMBL3689506 & 1527950 & 6.4168 & 5.8395 & TST \\
\hline CHEMBL3689377 & 1527950 & 6.6819 & 6.8728 & TRN \\
\hline CHEMBL3689424 & 1527950 & 6.5622 & 6.1743 & TRN \\
\hline CHEMBL3689457 & 1527950 & 5.4401 & 4.6172 & TST \\
\hline CHEMBL3689366 & 1527950 & 5.7932 & 5.4968 & TRN \\
\hline CHEMBL3689397 & 1527950 & 6.3615 & 6.4518 & TRN \\
\hline CHEMBL3689405 & 1527950 & 6.7825 & 6.5051 & TRN \\
\hline CHEMBL3689404 & 1527950 & 6.6517 & 6.5619 & TRN \\
\hline CHEMBL3689497 & 1527950 & 6.0 & 5.5887 & TST \\
\hline
\end{tabular}


Supplemental Table S2.txt

\begin{tabular}{|c|c|c|c|c|c|}
\hline CHEMBL 3689498 & 1527950 & 6.0 & 5.3444 & TST & \\
\hline CHEMBL 3689480 & 1527950 & 6.1451 & 6.4118 & TST & \\
\hline CHEMBL 3689353 & 1527950 & 5.7932 & 6.1058 & TRN & \\
\hline CHEMBL 3689411 & 1527950 & 5.2526 & 5.7935 & TST & \\
\hline CHEMBL 3689364 & 1527950 & 6.6003 & 6.5559 & TRN & \\
\hline CHEMBL 3689483 & 1527950 & 6.0 & 6.3672 & TST & \\
\hline CHEMBL3689412 & 1527950 & 6.0 & 5.7982 & TRN & \\
\hline CHEMBL 3689394 & 1527950 & 6.7235 & 6.6472 & TRN & \\
\hline CHEMBL3689475 & 1527950 & 5.3883 & 5.6714 & TST & \\
\hline CHEMBL 3689396 & 1527950 & 6.3261 & 6.3872 & TRN & \\
\hline CHEMBL3689466 & 1527950 & 5.5884 & 5.9858 & TST & \\
\hline CHEMBL 3689438 & 1527950 & 6.6021 & 6.4352 & TRN & \\
\hline CHEMBL 3689382 & 1527950 & 6.8416 & 7.1854 & TRN & \\
\hline CHEMBL 3689384 & 1527950 & 5.3565 & 5.4761 & TRN & \\
\hline CHEMBL 3689408 & 1527950 & 6.1805 & 5.9667 & TRN & \\
\hline CHEMBL3731319 & 1537646 & 8.0 & \multicolumn{2}{|c|}{6.372000000000001} & TRN \\
\hline CHEMBL3733058 & 1537646 & 8.0 & 6.4378 & TRN & \\
\hline CHEMBL 3732866 & 1537646 & 7.0 & 7.8159 & TRN & \\
\hline CHEMBL3732801 & 1537646 & 7.0 & 6.5152 & TST & \\
\hline CHEMBL 3729463 & 1537646 & 6.0 & 6.6465 & TRN & \\
\hline CHEMBL3729230 & 1537646 & 8.0 & 7.8506 & TRN & \\
\hline CHEMBL3731826 & 1537646 & 7.0 & 6.5979 & TRN & \\
\hline CHEMBL3729989 & 1537646 & 6.0 & 7.3181 & TRN & \\
\hline CHEMBL3730508 & 1537646 & 6.0 & 6.2 & TRN & \\
\hline CHEMBL 3729486 & 1537646 & 7.0 & 6.5228 & TRN & \\
\hline CHEMBL3731789 & 1537646 & 8.0 & 6.8566 & TRN & \\
\hline CHEMBL3728463 & 1537646 & 6.0 & 6.2403 & TRN & \\
\hline CHEMBL3730058 & 1537646 & 7.0 & 6.6102 & TRN & \\
\hline CHEMBL 3727843 & 1537646 & 8.0 & 6.9288 & TRN & \\
\hline CHEMBL 3731184 & 1537646 & 8.0 & 7.1523 & TRN & \\
\hline CHEMBL3732633 & 1537646 & 7.0 & 7.6839 & TRN & \\
\hline CHEMBL 3729548 & 1537646 & 7.0 & 6.7332 & TRN & \\
\hline CHEMBL3732002 & 1537646 & 7.0 & 6.6286 & TRN & \\
\hline CHEMBL3729467 & 1537646 & 7.0 & 6.9533 & TRN & \\
\hline CHEMBL3732303 & 1537646 & 6.0 & 6.733 & TRN & \\
\hline CHEMBL3731004 & 1537646 & 6.0 & 6.9295 & TRN & \\
\hline CHEMBL 3731283 & 1537646 & 6.0 & 6.7134 & TST & \\
\hline CHEMBL3732194 & 1537646 & 7.0 & 7.0911 & TRN & \\
\hline CHEMBL3731124 & 1537646 & 6.0 & 6.3968 & TST & \\
\hline CHEMBL3729725 & 1537646 & 7.0 & \multicolumn{2}{|c|}{6.547999999999999} & TRN \\
\hline CHEMBL3727940 & 1537646 & 8.0 & 7.7964 & TRN & \\
\hline CHEMBL3732819 & 1537646 & 8.0 & 6.9624 & TRN & \\
\hline CHEMBL3728935 & 1537646 & 7.0 & 6.4806 & TRN & \\
\hline CHEMBL3728570 & 1537646 & 8.0 & 7.7681 & TRN & \\
\hline CHEMBL3732286 & 1537646 & 6.0 & 6.553 & TRN & \\
\hline CHEMBL3730764 & 1537646 & 8.0 & 6.5153 & TRN & \\
\hline CHEMBL 3731567 & 1537646 & 6.0 & 6.5437 & TRN & \\
\hline \multirow[t]{2}{*}{ CHEMBL3730008 } & 1537646 & 6.0 & \multicolumn{2}{|c|}{6.622000000000001} & TST \\
\hline & & & & 3852 & \\
\hline
\end{tabular}




\begin{tabular}{|c|c|c|c|c|c|}
\hline \\
\hline CHEMBL3729326 & 1537646 & 7.0 & 6.6353 & TST & \\
\hline CHEMBL3730042 & 1537646 & 6.0 & 6.6264 & TRN & \\
\hline CHEMBL3730894 & 1537646 & 7.0 & 6.4389 & TRN & \\
\hline CHEMBL 3730087 & 1537646 & 7.0 & 6.1625 & TST & \\
\hline CHEMBL3732455 & 1537646 & 6.0 & 6.5585 & TRN & \\
\hline CHEMBL3728295 & 1537646 & 7.0 & 6.8615 & TRN & \\
\hline CHEMBL3733153 & 1537646 & 8.0 & 7.9152 & TRN & \\
\hline CHEMBL3727936 & 1537646 & 7.0 & 7.0748 & TST & \\
\hline CHEMBL 3732050 & 1537646 & 6.0 & 6.5235 & TRN & \\
\hline CHEMBL3732778 & 1537646 & 8.0 & 7.1434 & TRN & \\
\hline CHEMBL3732605 & 1537646 & 6.0 & 6.4811 & TST & \\
\hline CHEMBL3727383 & 1537646 & 7.0 & 6.6656 & TST & \\
\hline CHEMBL3733225 & 1537646 & 8.0 & 6.9492 & TRN & \\
\hline CHEMBL3730116 & 1537646 & 5.0 & 6.614 & TRN & \\
\hline CHEMBL3732063 & 1537646 & 7.0 & 6.6007 & TRN & \\
\hline CHEMBL3733349 & 1537646 & 5.0 & 6.3246 & TRN & \\
\hline CHEMBL3728080 & 1537646 & 6.0 & 6.7625 & TST & \\
\hline CHEMBL3729036 & 1537646 & 6.0 & 6.47 & TRN & \\
\hline CHEMBL3728923 & 1537646 & 8.0 & 7.9655 & TRN & \\
\hline CHEMBL3728914 & 1537646 & 6.0 & 6.694 & TRN & \\
\hline CHEMBL3730847 & 1537646 & 8.0 & 7.1217 & TRN & \\
\hline CHEMBL3729092 & 1537646 & 6.0 & 6.49100 & 00000000005 & TST \\
\hline CHEMBL3730816 & 1537646 & 7.0 & 6.6988 & TRN & \\
\hline CHEMBL3731663 & 1537646 & 7.0 & 7.03100 & $\partial 000000001$ & TRN \\
\hline CHEMBL3730567 & 1537646 & 7.0 & 6.8115 & TRN & \\
\hline CHEMBL3733131 & 1537646 & 7.0 & 6.9673 & TRN & \\
\hline CHEMBL3731784 & 1537646 & 8.0 & 7.2746 & TRN & \\
\hline CHEMBL3732806 & 1537646 & 6.0 & 6.8066 & TRN & \\
\hline CHEMBL 3732120 & 1537646 & 7.0 & 6.8732 & TST & \\
\hline CHEMBL3727386 & 1537646 & 7.0 & 6.8158 & TRN & \\
\hline CHEMBL3730383 & 1537646 & 8.0 & 7.9076 & TRN & \\
\hline CHEMBL3728555 & 1537646 & 7.0 & 6.7246 & TRN & \\
\hline CHEMBL3732568 & 1537646 & 6.0 & 6.6753 & TRN & \\
\hline CHEMBL3729058 & 1537646 & 6.0 & 6.0675 & TRN & \\
\hline CHEMBL3729038 & 1537646 & 6.0 & 6.1171 & TRN & \\
\hline CHEMBL3728334 & 1537646 & 7.0 & 6.943 & TRN & \\
\hline CHEMBL3732388 & 1537646 & 8.0 & 6.813 & TRN & \\
\hline CHEMBL3732869 & 1537646 & 6.0 & 6.8191 & TRN & \\
\hline CHEMBL3732349 & 1537646 & 7.0 & 6.7404 & TRN & \\
\hline CHEMBL 3732810 & 1537646 & 6.0 & 6.5745 & TRN & \\
\hline CHEMBL3731227 & 1537646 & 7.0 & 6.694 & TRN & \\
\hline CHEMBL3729167 & 1537646 & 7.0 & 6.4099 & TST & \\
\hline CHEMBL3729211 & 1537646 & 7.0 & 6.778 & TST & \\
\hline CHEMBL3733067 & 1537646 & 7.0 & 7.0192 & TRN & \\
\hline CHEMBL3729265 & 1537646 & 6.0 & 6.0575 & TRN & \\
\hline CHEMBL 3729483 & 1537646 & 6.0 & 6.53299 & 99999999995 & TRN \\
\hline CHEMBL3733033 & 1537646 & 8.0 & 7.1054 & TRN & \\
\hline CHEMBL 3730292 & 1537646 & 7.0 & 6.7487 & TRN & \\
\hline
\end{tabular}




\begin{tabular}{|c|c|c|c|c|}
\hline \multicolumn{5}{|c|}{ plemental Ta } \\
\hline CHEMBL3729302 & 1537646 & 6.0 & 6.2577 & TRN \\
\hline CHEMBL3728981 & 1537646 & 5.0 & 6.2257 & TST \\
\hline CHEMBL3729492 & 1537646 & 7.0 & 6.8921 & TRN \\
\hline CHEMBL3732013 & 1537646 & 6.0 & 6.715 & TRN \\
\hline CHEMBL3731036 & 1537646 & 7.0 & 6.5365 & TST \\
\hline CHEMBL3728950 & 1537646 & 7.0 & 7.6944 & TRN \\
\hline CHEMBL3728227 & 1537646 & 8.0 & 6.9826 & TRN \\
\hline CHEMBL3729959 & 1537646 & 6.0 & 6.4097 & TRN \\
\hline CHEMBL3732928 & 1537646 & 8.0 & 6.4512 & TRN \\
\hline CHEMBL3730259 & 1537646 & 6.0 & 6.5285 & TRN \\
\hline CHEMBL 3729572 & 1537646 & 7.0 & 6.2835 & TRN \\
\hline CHEMBL3732037 & 1537646 & 8.0 & 7.4557 & TRN \\
\hline CHEMBL3730864 & 1537646 & 8.0 & 6.4361 & TRN \\
\hline CHEMBL3732265 & 1537646 & 8.0 & 6.9516 & TRN \\
\hline CHEMBL3732575 & 1537646 & 7.0 & 6.9169 & TST \\
\hline CHEMBL3730011 & 1537646 & 7.0 & 6.965 & TRN \\
\hline CHEMBL3728248 & 1537646 & 7.0 & 6.8609 & TST \\
\hline CHEMBL 3728214 & 1537646 & 7.0 & 7.0414 & TST \\
\hline CHEMBL3731830 & 1537646 & 6.0 & 6.1168 & TRN \\
\hline CHEMBL 3728745 & 1537646 & 6.0 & 6.6443 & TRN \\
\hline CHEMBL 3728660 & 1537646 & 6.0 & 6.6308 & TRN \\
\hline CHEMBL3729526 & 1537646 & 8.0 & 7.7037 & TRN \\
\hline CHEMBL3730608 & 1537646 & 7.0 & 6.73 & TRN \\
\hline CHEMBL3730418 & 1537646 & 8.0 & 7.6367 & TRN \\
\hline CHEMBL3729630 & 1537646 & 7.0 & 6.836 & TST \\
\hline CHEMBL3731183 & 1537646 & 6.0 & 7.0983 & TRN \\
\hline CHEMBL3730155 & 1537646 & 8.0 & 6.8858 & TRN \\
\hline CHEMBL3729181 & 1537646 & 5.0 & 6.4558 & TST \\
\hline CHEMBL3730341 & 1537646 & 6.0 & 6.7191 & TST \\
\hline CHEMBL3728913 & 1537646 & 8.0 & 7.8582 & TRN \\
\hline CHEMBL3730984 & 1537646 & 7.0 & 6.6085 & TRN \\
\hline CHEMBL 3730484 & 1537646 & 7.0 & 7.6218 & TRN \\
\hline CHEMBL3730775 & 1537646 & 7.0 & 6.6877 & TRN \\
\hline CHEMBL3728447 & 1537646 & 8.0 & 7.3264 & TRN \\
\hline CHEMBL3732362 & 1537646 & 7.0 & 7.0526 & TRN \\
\hline CHEMBL3732124 & 1537646 & 6.0 & 6.7528 & TRN \\
\hline CHEMBL3728542 & 1537646 & 8.0 & 7.2718 & TRN \\
\hline CHEMBL 3729414 & 1537646 & 7.0 & 6.7363 & TRN \\
\hline CHEMBL3727857 & 1537646 & 7.0 & 6.8436 & TST \\
\hline CHEMBL3728428 & 1537646 & 8.0 & 6.6249 & TRN \\
\hline CHEMBL 3727747 & 1537646 & 6.0 & 6.4864 & TRN \\
\hline CHEMBL3730531 & 1537646 & 5.0 & 6.4122 & TST \\
\hline CHEMBL3731559 & 1537646 & 6.0 & 6.7686 & TRN \\
\hline CHEMBL3730784 & 1537646 & 7.0 & 6.3489 & TRN \\
\hline CHEMBL3727399 & 1537646 & 6.0 & 6.6591 & TST \\
\hline CHEMBL 3728423 & 1537646 & 6.0 & 6.3461 & TST \\
\hline CHEMBL3730167 & 1537646 & 5.0 & 6.7895 & TST \\
\hline CHEMBL 3732430 & 1537646 & 7.0 & 6.7668 & TRN \\
\hline
\end{tabular}




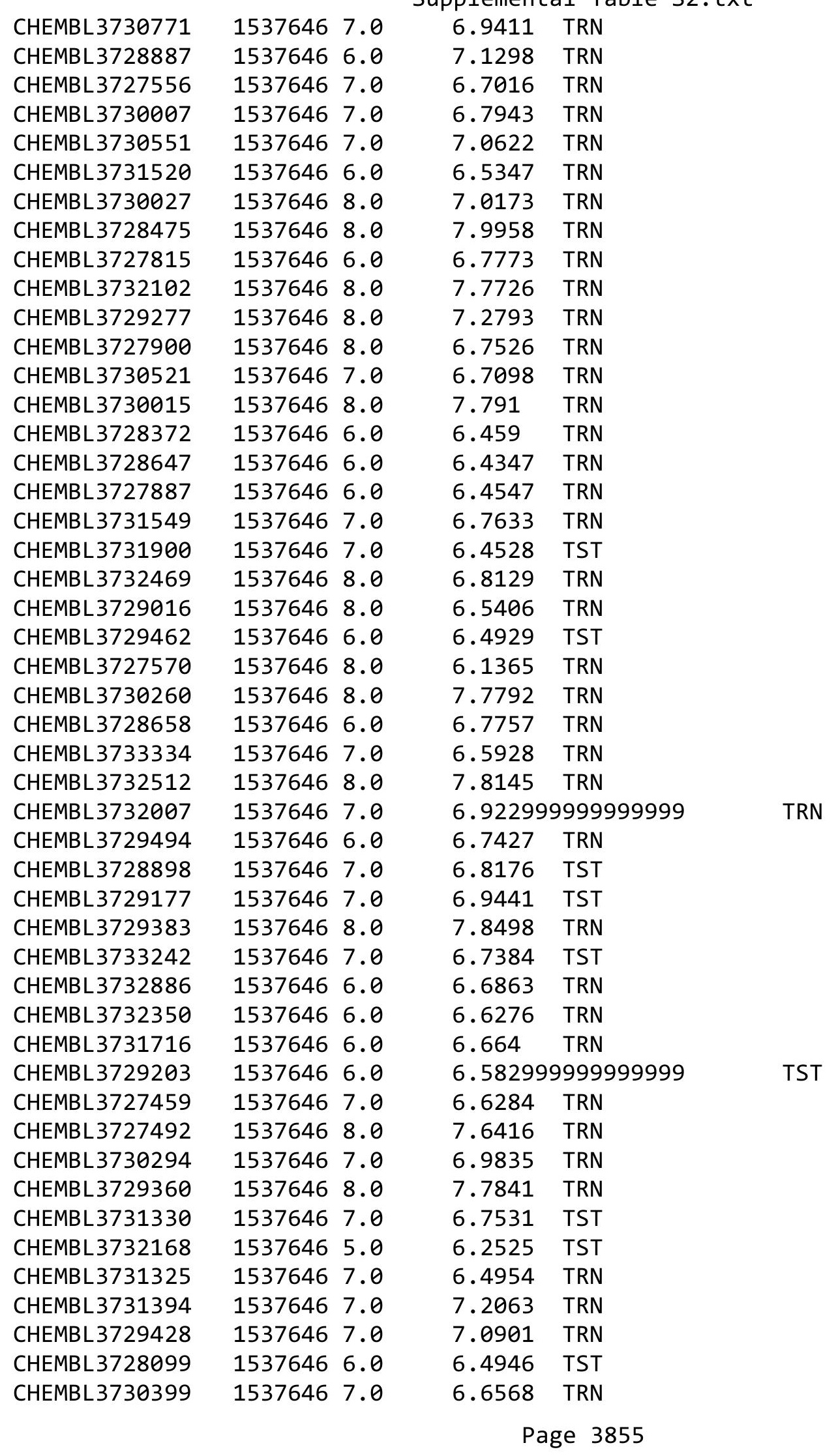




\begin{tabular}{|c|c|c|c|c|c|}
\hline & & & & & \\
\hline CHEMBL3731333 & 1537646 & 6.0 & 6.6062 & TRN & \\
\hline CHEMBL3730722 & 1537646 & 6.0 & 6.4844 & TRN & \\
\hline CHEMBL3729560 & 1537646 & 7.0 & 6.8754 & TRN & \\
\hline CHEMBL3727877 & 1537646 & 6.0 & 6.481 & TST & \\
\hline CHEMBL3729566 & 1537646 & 7.0 & 7.1131 & TRN & \\
\hline CHEMBL3728917 & 1537646 & 6.0 & 7.2674 & TRN & \\
\hline CHEMBL3732732 & 1537646 & 6.0 & 6.3822 & TST & \\
\hline CHEMBL3728846 & 1537646 & 5.0 & 6.6684 & TRN & \\
\hline CHEMBL3733258 & 1537646 & 6.0 & 6.689 & TRN & \\
\hline CHEMBL3732653 & 1537646 & 8.0 & 7.2884 & TRN & \\
\hline CHEMBL3732546 & 1537646 & 5.0 & 6.4896 & TRN & \\
\hline CHEMBL3733055 & 1537646 & 7.0 & 6.9221 & TRN & \\
\hline CHEMBL3732189 & 1537646 & 6.0 & 6.7545 & TRN & \\
\hline CHEMBL3732408 & 1537646 & 6.0 & 6.8427 & TST & \\
\hline CHEMBL 3732351 & 1537646 & 7.0 & 7.0458 & TRN & \\
\hline CHEMBL3727551 & 1537646 & 7.0 & 6.9589 & TRN & \\
\hline CHEMBL3729314 & 1537646 & 8.0 & 7.7357 & TRN & \\
\hline CHEMBL 3729042 & 1537646 & 5.0 & 6.2709 & TST & \\
\hline CHEMBL3731093 & 1537646 & 5.0 & 6.7963 & TRN & \\
\hline CHEMBL 3728267 & 1537646 & 6.0 & 6.5679 & TRN & \\
\hline CHEMBL 3727483 & 1537646 & 7.0 & 6.8506 & TRN & \\
\hline CHEMBL3731449 & 1537646 & 7.0 & 6.6211 & TRN & \\
\hline CHEMBL3727695 & 1537646 & 5.0 & 6.5142 & TST & \\
\hline CHEMBL 3727703 & 1537646 & 7.0 & 6.5711 & TRN & \\
\hline CHEMBL3728930 & 1537646 & 7.0 & 6.6302 & TRN & \\
\hline CHEMBL3731428 & 1537646 & 7.0 & 6.8273 & TRN & \\
\hline CHEMBL3732487 & 1537646 & 8.0 & 7.7729 & TRN & \\
\hline CHEMBL 3732401 & 1537646 & 6.0 & 6.6235 & TRN & \\
\hline CHEMBL3729441 & 1537646 & 5.0 & 6.5347 & TST & \\
\hline CHEMBL3730463 & 1537646 & 7.0 & 6.7574 & TST & \\
\hline CHEMBL 3730591 & 1537646 & 7.0 & 6.5342 & TRN & \\
\hline CHEMBL3729401 & 1537646 & 5.0 & 6.3891 & TST & \\
\hline CHEMBL3728307 & 1537646 & 7.0 & 6.277 & TRN & \\
\hline CHEMBL3728891 & 1537646 & 5.0 & 6.5946 & TRN & \\
\hline CHEMBL3728765 & 1537646 & 6.0 & 6.6685 & TST & \\
\hline CHEMBL 3730544 & 1537646 & 7.0 & 7.0774 & TRN & \\
\hline CHEMBL3732115 & 1537646 & 7.0 & 6.5388 & TRN & \\
\hline CHEMBL3733167 & 1537646 & 6.0 & 7.3271 & TST & \\
\hline CHEMBL3729065 & 1537646 & 5.0 & 6.13299 & 9999999999 & TST \\
\hline CHEMBL3728866 & 1537646 & 7.0 & 6.6564 & TRN & \\
\hline CHEMBL3729131 & 1537646 & 6.0 & 6.5849 & TST & \\
\hline CHEMBL3733197 & 1537646 & 6.0 & 6.2991 & TRN & \\
\hline CHEMBL3732374 & 1537646 & 7.0 & 6.8167 & TRN & \\
\hline CHEMBL3731100 & 1537646 & 7.0 & 7.7166 & TRN & \\
\hline CHEMBL3733299 & 1537646 & 8.0 & 7.7086 & TRN & \\
\hline CHEMBL3729635 & 1537646 & 6.0 & 6.6573 & TST & \\
\hline CHEMBL3730535 & 1537646 & 7.0 & 6.8803 & TST & \\
\hline CHEMBL3732022 & 1537646 & 7.0 & 6.96299 & 9999999999 & TRN \\
\hline & & & & 3856 & \\
\hline
\end{tabular}




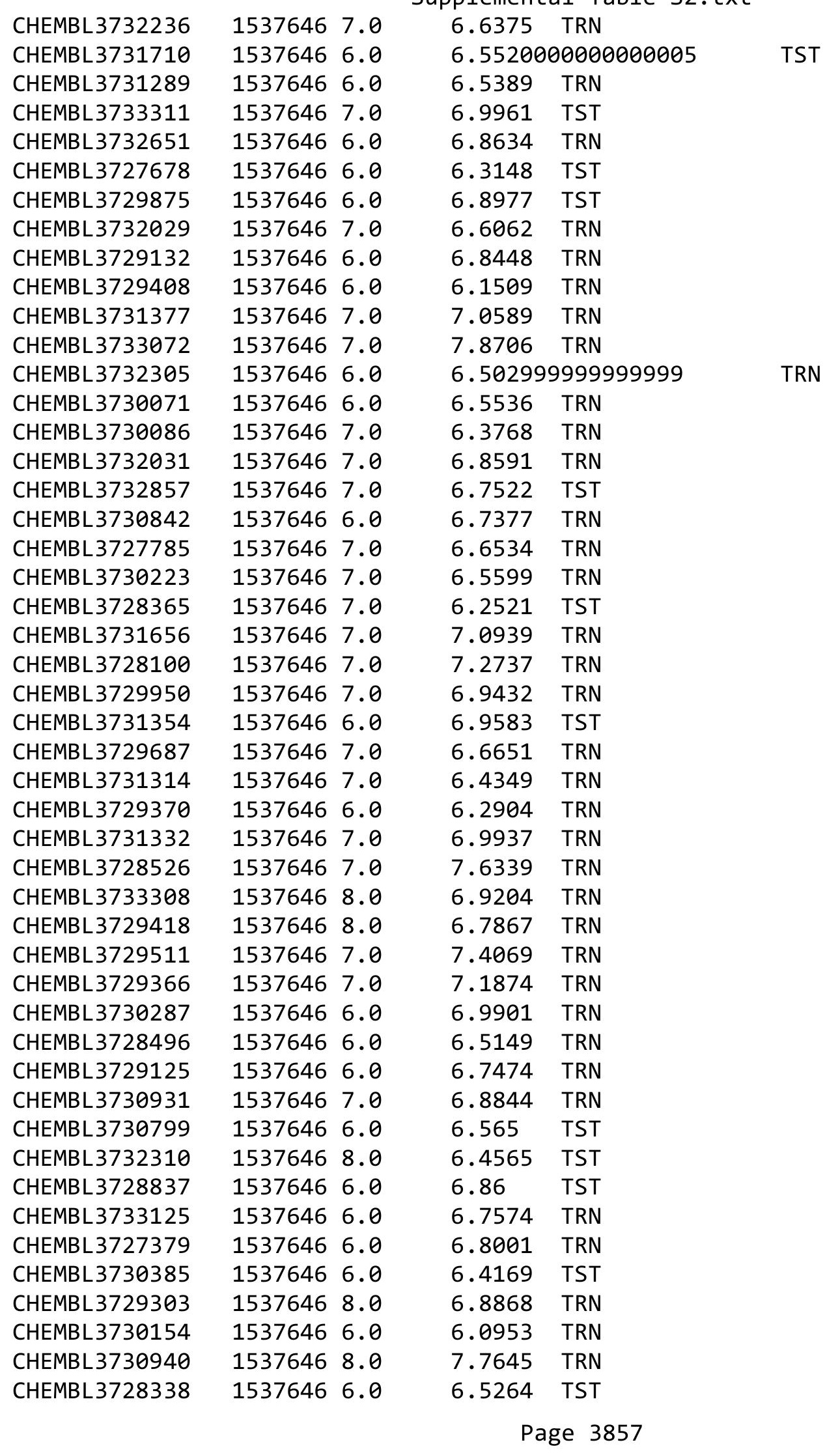




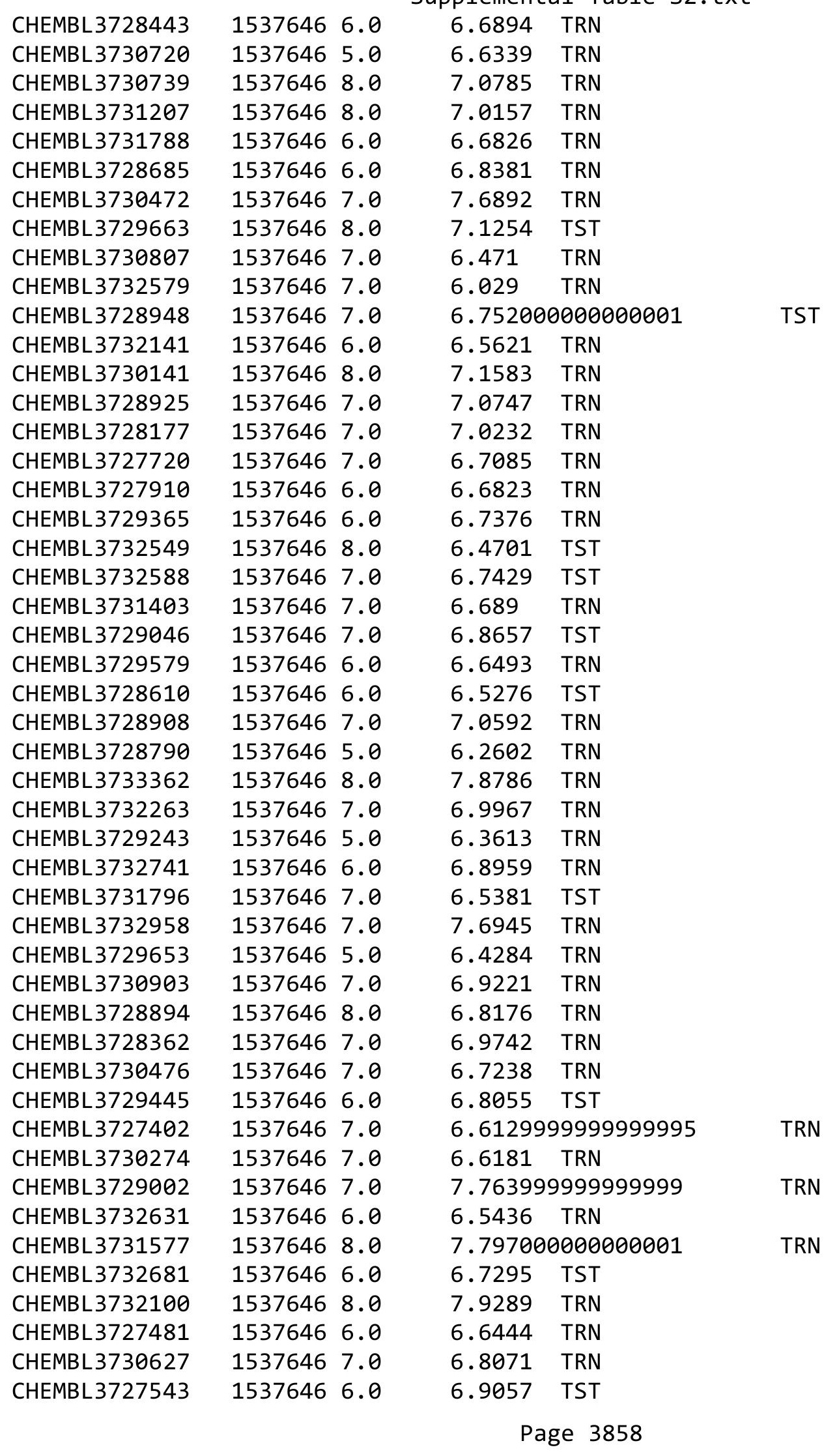




\begin{tabular}{|c|c|c|c|c|c|}
\hline & & & & & \\
\hline CHEMBL3727935 & 1537646 & 7.0 & 6.6232 & TRN & \\
\hline CHEMBL3731239 & 1537646 & 7.0 & 6.4053 & TRN & \\
\hline CHEMBL3729705 & 1537646 & 7.0 & 6.99100 & 00000000005 & TRN \\
\hline CHEMBL3729086 & 1537646 & 8.0 & 7.0729 & TRN & \\
\hline CHEMBL3731905 & 1537646 & 6.0 & 6.2355 & TST & \\
\hline CHEMBL3729437 & 1537646 & 5.0 & 6.4242 & TST & \\
\hline CHEMBL3732212 & 1537646 & 7.0 & 6.8765 & TST & \\
\hline CHEMBL3731143 & 1537646 & 6.0 & 6.4111 & TRN & \\
\hline CHEMBL 3732378 & 1537646 & 6.0 & 6.7362 & TST & \\
\hline CHEMBL3731295 & 1537646 & 7.0 & 6.9751 & TRN & \\
\hline CHEMBL3727420 & 1537646 & 5.0 & 6.416 & TST & \\
\hline CHEMBL3732019 & 1537646 & 7.0 & 6.6905 & TST & \\
\hline CHEMBL 3730430 & 1537646 & 7.0 & 6.5728 & TRN & \\
\hline CHEMBL 3730047 & 1537646 & 8.0 & 6.8575 & TRN & \\
\hline CHEMBL 3728641 & 1537646 & 7.0 & 6.3989 & TST & \\
\hline CHEMBL3730915 & 1537646 & 7.0 & 6.7498 & TRN & \\
\hline CHEMBL3727407 & 1537646 & 6.0 & 6.5648 & TRN & \\
\hline CHEMBL3727998 & 1537646 & 6.0 & 6.7887 & TST & \\
\hline CHEMBL3732961 & 1537646 & 7.0 & 6.2482 & TST & \\
\hline CHEMBL3731493 & 1537646 & 5.0 & 6.2121 & TST & \\
\hline CHEMBL3727970 & 1537646 & 6.0 & 6.3892 & TST & \\
\hline CHEMBL3730222 & 1537646 & 7.0 & 7.8933 & TRN & \\
\hline CHEMBL 3731247 & 1537646 & 6.0 & 6.2268 & TST & \\
\hline CHEMBL3729149 & 1537646 & 8.0 & 7.0695 & TRN & \\
\hline CHEMBL3731211 & 1537646 & 8.0 & 7.8355 & TRN & \\
\hline CHEMBL3731021 & 1537646 & 7.0 & 6.3773 & TRN & \\
\hline CHEMBL 3730010 & 1537646 & 7.0 & 6.8256 & TRN & \\
\hline CHEMBL3733063 & 1537646 & 6.0 & 6.4427 & TST & \\
\hline CHEMBL3733038 & 1537646 & 5.0 & 6.2049 & TST & \\
\hline CHEMBL 3727724 & 1537646 & 7.0 & 6.8281 & TST & \\
\hline CHEMBL3731912 & 1537646 & 7.0 & 7.0242 & TST & \\
\hline CHEMBL6316 & 82005 & 4.0757 & 4.2717 & TRN & \\
\hline CHEMBL6229 & 82005 & 4.0223 & 4.0614 & TST & \\
\hline CHEMBL266799 & 82005 & 3.0 & 3.9067 & TST & \\
\hline CHEMBL268070 & 82005 & 3.0 & 3.6162 & TRN & \\
\hline CHEMBL263080 & 82005 & 3.0 & 3.0549 & TRN & \\
\hline CHEMBL6371 & 82005 & 4.8239 & 3.9931 & TRN & \\
\hline CHEMBL269598 & 82005 & 4.0862 & 4.2043 & TRN & \\
\hline CHEMBL266708 & 82005 & 3.0 & 4.2642 & TRN & \\
\hline CHEMBL269056 & 82005 & 3.0 & 4.3494 & TST & \\
\hline CHEMBL6381 & 82005 & 4.8861 & 4.5008 & TRN & \\
\hline CHEMBL266198 & 82005 & 3.0 & 3.279 & TRN & \\
\hline CHEMBL267678 & 82005 & 3.8182 & 3.9863 & TRN & \\
\hline CHEMBL266197 & 82005 & 5.4949 & 4.6294 & TRN & \\
\hline CHEMBL6248 & 82005 & 4.7959 & 3.9282 & TST & \\
\hline CHEMBL 6430 & 82005 & 4.1427 & 3.9243 & TST & \\
\hline CHEMBL 266460 & 82005 & 4.3279 & 4.0977 & TRN & \\
\hline CHEMBL6257 & 82005 & 4.2076 & 3.4336 & TRN & \\
\hline & & & & 3859 & \\
\hline
\end{tabular}




\begin{tabular}{|c|c|c|c|c|c|}
\hline \multirow[b]{2}{*}{ CHEMBL267127 } & \multicolumn{5}{|c|}{ Supplemental Table S2.txt } \\
\hline & 82005 & 4.2924 & 4.2453 & TST & \\
\hline CHEMBL6258 & 82005 & 4.2007 & 4.4249 & TRN & \\
\hline CHEMBL6278 & 82005 & 4.1675 & 3.4468 & TRN & \\
\hline CHEMBL266798 & 82005 & 4.0223 & 4.2015 & TRN & \\
\hline CHEMBL 266572 & 82005 & 5.2366 & 4.4694 & TST & \\
\hline CHEMBL6542 & 82005 & 4.0223 & 3.3731 & TRN & \\
\hline CHEMBL 267125 & 82005 & 3.0 & 3.6151 & TRN & \\
\hline CHEMBL266429 & 82005 & 4.2924 & 4.3649 & TRN & \\
\hline CHEMBL269075 & 82005 & 4.284 & 4.2534 & TRN & \\
\hline CHEMBL262570 & 82005 & 5.0223 & 4.3248 & TRN & \\
\hline CHEMBL269497 & 82005 & 4.0177 & 3.7226 & TRN & \\
\hline CHEMBL 6830 & 82005 & 4.0 & 3.926 & TRN & \\
\hline CHEMBL6215 & 82005 & 3.0 & 4.243 & TST & \\
\hline CHEMBL6249 & 82005 & 3.0 & 4.1048 & TRN & \\
\hline CHEMBL 267456 & 82005 & 3.0 & 3.0387 & TRN & \\
\hline CHEMBL6442 & 82005 & 4.699 & 4.1452 & TRN & \\
\hline CHEMBL 6275 & 82005 & 4.6383 & 3.8156 & TRN & \\
\hline CHEMBL 268530 & 82005 & 4.1675 & 4.5215 & TRN & \\
\hline CHEMBL 267914 & 82005 & 4.3565 & 4.1903 & TRN & \\
\hline CHEMBL6324 & 82005 & 3.0 & 4.0291 & TRN & \\
\hline CHEMBL6264 & 82005 & 4.699 & 4.1885 & TRN & \\
\hline CHEMBL6523 & 82005 & 4.0706 & 4.7682 & TST & \\
\hline CHEMBL428508 & 82005 & 4.1308 & 4.2612 & TRN & \\
\hline CHEMBL 268667 & 82005 & 3.0 & 3.3047 & TRN & \\
\hline CHEMBL268567 & 82005 & 3.0 & 3.3377 & TRN & \\
\hline CHEMBL6534 & 82005 & 3.0 & 3.1715 & TRN & \\
\hline CHEMBL 6517 & 82005 & 4.3565 & 4.3387 & TRN & \\
\hline CHEMBL6369 & 82005 & 4.1739 & 4.374 & TRN & \\
\hline CHEMBL269495 & 82005 & 4.3188 & 4.3108 & TST & \\
\hline CHEMBL6762 & 82005 & 4.1675 & 4.3326 & TRN & \\
\hline CHEMBL6417 & 82005 & 3.0 & 4.2352 & TST & \\
\hline CHEMBL 6370 & 82005 & 4.1675 & 4.2131 & TST & \\
\hline CHEMBL 266064 & 82005 & 3.0 & 3.9164 & TST & \\
\hline CHEMBL1606476 & 1301804 & 3.1578 & 3.6373 & TRN & \\
\hline CHEMBL1545415 & 1301804 & 3.1579 & 3.7557 & TRN & \\
\hline CHEMBL1409138 & 1301804 & 4.1799 & 3.573 & TRN & \\
\hline CHEMBL1347809 & 1301804 & 4.0693 & 4.3612 & TRN & \\
\hline CHEMBL1336039 & 1301804 & 3.158 & 3.7058 & TST & \\
\hline CHEMBL1376406 & 1301804 & 4.6642 & 3.9417 & TST & \\
\hline CHEMBL3198786 & 1301804 & 4.3047 & 4.3537 & TRN & \\
\hline CHEMBL1736377 & 1301804 & 4.1834 & 4.5724 & TRN & \\
\hline CHEMBL1887359 & 1301804 & 4.1122 & 3.654 & TRN & \\
\hline CHEMBL3183085 & 1301804 & 3.158 & 3.66399 & 99999999997 & TRN \\
\hline CHEMBL1312211 & 1301804 & 5.0201 & 3.6644 & TRN & \\
\hline CHEMBL1347514 & 1301804 & 3.1579 & 3.7054 & TRN & \\
\hline CHEMBL1364037 & 1301804 & 3.6349 & 3.5394 & TRN & \\
\hline CHEMBL1378543 & 1301804 & 4.0108 & 3.6127 & TRN & \\
\hline CHEMBL1717752 & 1301804 & 5.0545 & 4.7835 & TRN & \\
\hline
\end{tabular}

Page 3860 
Supplemental Table S2.txt

\begin{tabular}{|c|c|c|c|c|c|}
\hline CHEMBL1394779 & 1301804 & 5.0121 & 3.577 & TRN & \\
\hline CHEMBL1516236 & 1301804 & 3.158 & \multicolumn{2}{|c|}{3.6010000000000004} & TRN \\
\hline CHEMBL1588106 & 1301804 & 4.1123 & 4.8116 & TST & \\
\hline CHEMBL1373781 & 1301804 & 5.0204 & 4.7999 & TST & \\
\hline CHEMBL1490757 & 1301804 & 5.4965 & 5.0086 & TRN & \\
\hline CHEMBL1490547 & 1301804 & 4.6248 & 3.6722 & TRN & \\
\hline CHEMBL1315592 & 1301804 & 3.1579 & 3.6408 & TRN & \\
\hline CHEMBL1592822 & 1301804 & 4.4703 & 4.657 & TRN & \\
\hline CHEMBL1372075 & 1301804 & 4.832 & 4.6673 & TRN & \\
\hline CHEMBL1602645 & 1301804 & 4.9161 & 4.8907 & TST & \\
\hline CHEMBL 2141662 & 1301804 & 5.0275 & 3.6175 & TRN & \\
\hline CHEMBL1502597 & 1301804 & 4.5269 & 3.6752 & TRN & \\
\hline CHEMBL1877249 & 1301804 & 4.5892 & 3.5411 & TRN & \\
\hline CHEMBL1457571 & 1301804 & 4.4584 & 3.61 & TRN & \\
\hline CHEMBL1386736 & 1301804 & 3.1583 & 3.6519 & TRN & \\
\hline CHEMBL1590875 & 1301804 & 4.6506 & 4.754 & TRN & \\
\hline CHEMBL1881965 & 1301804 & 3.1579 & 3.6107 & TRN & \\
\hline CHEMBL3196039 & 1301804 & 3.1583 & 3.8523 & TRN & \\
\hline CHEMBL1721390 & 1301804 & 3.6351 & 3.745 & TRN & \\
\hline CHEMBL3193564 & 1301804 & 3.1577 & 3.7719 & TRN & \\
\hline CHEMBL1573508 & 1301804 & 5.5439 & 3.6408 & TRN & \\
\hline CHEMBL1887044 & 1301804 & 3.1581 & 3.6636 & TRN & \\
\hline CHEMBL1422579 & 1301804 & 5.0243 & 3.6876 & TST & \\
\hline CHEMBL1711735 & 1301804 & 5.0537 & 4.8231 & TRN & \\
\hline CHEMBL1378955 & 1301804 & 4.9062 & 3.5868 & TRN & \\
\hline CHEMBL1871949 & 1301804 & 3.6351 & 4.3209 & TRN & \\
\hline CHEMBL1863771 & 1301804 & 5.1989 & 4.9189 & TST & \\
\hline CHEMBL1506625 & 1301804 & 4.1594 & 3.5565 & TRN & \\
\hline CHEMBL464404 & 1301804 & 5.0459 & 4.1503 & TRN & \\
\hline CHEMBL1438404 & 1301804 & 3.1579 & 3.5591 & TRN & \\
\hline CHEMBL1494819 & 1301804 & 4.5892 & 3.5846 & TRN & \\
\hline CHEMBL1361500 & 1301804 & 4.1751 & 3.9594 & TRN & \\
\hline CHEMBL1326667 & 1301804 & 5.7364 & 5.2091 & TRN & \\
\hline CHEMBL1508604 & 1301804 & 3.158 & 3.5611 & TRN & \\
\hline CHEMBL1606402 & 1301804 & 4.9881 & 4.2599 & TRN & \\
\hline CHEMBL1439765 & 1301804 & 4.1122 & 3.7161 & TST & \\
\hline CHEMBL1432094 & 1301804 & 3.1578 & 3.5789 & TRN & \\
\hline CHEMBL1601623 & 1301804 & 4.9742 & 3.6504 & TRN & \\
\hline CHEMBL1365294 & 1301804 & 3.1581 & 3.6294 & TRN & \\
\hline CHEMBL1703160 & 1301804 & 4.8021 & 4.8101 & TRN & \\
\hline CHEMBL2142902 & 1301804 & 4.4099 & 3.6753 & TRN & \\
\hline CHEMBL1585268 & 1301804 & 4.4355 & 4.3982 & TRN & \\
\hline CHEMBL1358781 & 1301804 & 3.1581 & 3.8409 & TRN & \\
\hline CHEMBL1537147 & 1301804 & 5.3872 & 5.1872 & TRN & \\
\hline CHEMBL1451464 & 1301804 & 5.1278 & 4.8345 & TRN & \\
\hline CHEMBL1473797 & 1301804 & 3.158 & 3.7196 & TRN & \\
\hline CHEMBL3192935 & 1301804 & 3.6353 & 3.7651 & TRN & \\
\hline CHEMBL1574559 & 1301804 & 5.0566 & 4.9383 & TRN & \\
\hline
\end{tabular}


Supplemental Table S2.txt

\begin{tabular}{|c|c|c|c|c|c|}
\hline CHEMBL1524206 & 1301804 & 3.158 & 3.8489 & TRN & \\
\hline CHEMBL1501442 & 1301804 & 5.4232 & 4.4203 & TRN & \\
\hline CHEMBL1347247 & 1301804 & 3.1581 & 3.6911 & TRN & \\
\hline CHEMBL1321896 & 1301804 & 3.1579 & 3.6158 & TRN & \\
\hline CHEMBL1529656 & 1301804 & 5.0125 & 4.8783 & TRN & \\
\hline CHEMBL1373003 & 1301804 & 5.4409 & 4.5141 & TRN & \\
\hline CHEMBL1558437 & 1301804 & 4.4581 & 4.3874 & TRN & \\
\hline CHEMBL1337320 & 1301804 & 3.158 & 3.7477 & TRN & \\
\hline CHEMBL1435494 & 1301804 & 4.3102 & 3.6276 & TRN & \\
\hline CHEMBL1432334 & 1301804 & 4.6281 & 4.8028 & TST & \\
\hline CHEMBL1386220 & 1301804 & 4.4969 & 4.4587 & TST & \\
\hline CHEMBL1602449 & 1301804 & 4.2012 & 4.4053 & TRN & \\
\hline CHEMBL1493719 & 1301804 & 3.1582 & 4.213 & TRN & \\
\hline CHEMBL1460295 & 1301804 & 3.158 & 3.7094 & TRN & \\
\hline CHEMBL 3187983 & 1301804 & 4.6213 & 4.7451 & TRN & \\
\hline CHEMBL1302721 & 1301804 & 5.157 & 4.9211 & TRN & \\
\hline CHEMBL 2132709 & 1301804 & 4.1123 & 3.6238 & TRN & \\
\hline CHEMBL1451792 & 1301804 & 4.479 & 3.6524 & TRN & \\
\hline CHEMBL1353415 & 1301804 & 3.1576 & 3.6763 & TST & \\
\hline CHEMBL 3196519 & 1301804 & 3.1578 & 3.7448 & TST & \\
\hline CHEMBL1524033 & 1301804 & 4.6813 & 4.6311 & TRN & \\
\hline CHEMBL1407044 & 1301804 & 3.158 & 3.6882 & TST & \\
\hline CHEMBL1306753 & 1301804 & 3.1579 & 3.7892 & TRN & \\
\hline CHEMBL1587269 & 1301804 & 4.8398 & 3.7727 & TRN & \\
\hline CHEMBL1865502 & 1301804 & 5.0797 & 3.8055 & TST & \\
\hline CHEMBL1504616 & 1301804 & 4.7828 & 4.5032 & TRN & \\
\hline CHEMBL1895868 & 1301804 & 3.6351 & 4.3508 & TST & \\
\hline CHEMBL1594956 & 1301804 & 5.0818 & 4.1423 & TST & \\
\hline CHEMBL1705631 & 1301804 & 5.0995 & 4.8775 & TRN & \\
\hline CHEMBL1437654 & 1301804 & 3.1578 & 3.6562 & TRN & \\
\hline CHEMBL1470749 & 1301804 & 4.88899 & 199999999 & 4.7627 & TST \\
\hline CHEMBL1360402 & 1301804 & 3.1576 & 3.5702 & TRN & \\
\hline CHEMBL1363933 & 1301804 & 4.8821 & 4.7954 & TRN & \\
\hline CHEMBL1371143 & 1301804 & 3.1579 & 3.6578 & TRN & \\
\hline CHEMBL1542674 & 1301804 & 3.158 & 3.696 & TST & \\
\hline CHEMBL 2142513 & 1301804 & 4.6181 & 4.5238 & TRN & \\
\hline CHEMBL1353321 & 1301804 & 4.6119 & 4.5369 & TRN & \\
\hline CHEMBL1329807 & 1301804 & 4.5711 & 3.5907 & TRN & \\
\hline CHEMBL1583091 & 1301804 & 4.8946 & 4.2782 & TRN & \\
\hline CHEMBL1430729 & 1301804 & 3.1581 & 3.663999 & و9999999997 & TRN \\
\hline CHEMBL1508966 & 1301804 & 4.7656 & 4.6105 & TRN & \\
\hline CHEMBL1880540 & 1301804 & 4.1123 & 3.6959 & TRN & \\
\hline CHEMBL1542959 & 1301804 & 3.158 & 3.7404 & TST & \\
\hline CHEMBL1364911 & 1301804 & 3.158 & 3.602 & TRN & \\
\hline CHEMBL1569787 & 1301804 & 5.0097 & 4.8784 & TRN & \\
\hline CHEMBL1576280 & 1301804 & 3.158 & 3.717 & TRN & \\
\hline CHEMBL1550191 & 1301804 & 3.158 & 3.5809 & TRN & \\
\hline CHEMBL 2362958 & 1301804 & 3.158 & 3.7562 & TRN & \\
\hline
\end{tabular}


Supplemental Table S2.txt

\begin{tabular}{|c|c|c|c|c|c|}
\hline CHEMBL1558209 & 1301804 & 4.4587 & 4.3341 & TRN & \\
\hline CHEMBL 2134346 & 1301804 & 5.0759 & 4.9945 & TST & \\
\hline CHEMBL1611892 & 1301804 & 4.1125 & 3.6472 & TRN & \\
\hline CHEMBL1557823 & 1301804 & 5.0791 & 4.6688 & TRN & \\
\hline CHEMBL1366193 & 1301804 & 3.1579 & 4.1391 & TRN & \\
\hline CHEMBL1967761 & 1301804 & 3.1582 & 3.6921 & TRN & \\
\hline CHEMBL1699044 & 1301804 & 4.9462 & 3.5767 & TRN & \\
\hline CHEMBL1454412 & 1301804 & 4.1122 & 3.5908 & TRN & \\
\hline CHEMBL1373593 & 1301804 & 5.2874 & 3.6191 & TRN & \\
\hline CHEMBL1716483 & 1301804 & 4.6056 & 3.591 & TRN & \\
\hline CHEMBL1607383 & 1301804 & 4.3371 & 4.4771 & TRN & \\
\hline CHEMBL1327318 & 1301804 & 3.1578 & 3.7633 & TRN & \\
\hline CHEMBL 2133347 & 1301804 & 4.5894 & 3.6503 & TRN & \\
\hline CHEMBL1601559 & 1301804 & 3.1579 & 3.7379 & TRN & \\
\hline CHEMBL1721084 & 1301804 & 4.0635 & 3.5476 & TRN & \\
\hline CHEMBL1582888 & 1301804 & 3.158 & 3.6786 & TST & \\
\hline CHEMBL1315929 & 1301804 & 3.1579 & 3.6279 & TRN & \\
\hline CHEMBL1398750 & 1301804 & 4.305 & 3.8075 & TRN & \\
\hline CHEMBL1346802 & 1301804 & 3.158 & 3.577 & TRN & \\
\hline CHEMBL1479448 & 1301804 & 4.6395 & 4.5713 & TRN & \\
\hline CHEMBL463783 & 1301804 & 3.1583 & 3.7177 & TRN & \\
\hline CHEMBL1506063 & 1301804 & $4.4110 e$ & 00000000 & 205 & 4.3566 \\
\hline CHEMBL1598114 & 1301804 & 3.1579 & 3.7133 & TRN & \\
\hline CHEMBL1447523 & 1301804 & 4.1123 & 4.3813 & TRN & \\
\hline CHEMBL1348562 & 1301804 & 3.1577 & 3.5809 & TRN & \\
\hline CHEMBL1424670 & 1301804 & 5.121 & 4.913 & TRN & \\
\hline CHEMBL1416843 & 1301804 & 3.1576 & 3.6294 & TRN & \\
\hline CHEMBL 2359574 & 1301804 & 4.4964 & 4.5564 & TRN & \\
\hline CHEMBL1605781 & 1301804 & 3.1578 & 4.867 & TRN & \\
\hline CHEMBL1431032 & 1301804 & 3.1578 & 3.7525 & TRN & \\
\hline CHEMBL1388099 & 1301804 & 3.158 & 3.7394 & TRN & \\
\hline CHEMBL1471010 & 1301804 & 4.8818 & 4.5487 & TST & \\
\hline CHEMBL1968290 & 1301804 & 4.5894 & 3.7116 & TRN & \\
\hline CHEMBL1365686 & 1301804 & 3.1578 & 4.3471 & TRN & \\
\hline CHEMBL1461443 & 1301804 & 3.158 & 3.6446 & TST & \\
\hline CHEMBL1605964 & 1301804 & 4.3191 & 3.6076 & TRN & \\
\hline CHEMBL1588572 & 1301804 & 3.1582 & 3.8013 & TRN & \\
\hline CHEMBL1324779 & 1301804 & 3.158 & 3.6074 & TRN & \\
\hline CHEMBL 2003621 & 1301804 & 3.1579 & 4.1183 & TRN & \\
\hline CHEMBL 2137070 & 1301804 & 3.158 & 3.5815 & TRN & \\
\hline CHEMBL1735346 & 1301804 & 3.1579 & 3.7778 & TRN & \\
\hline CHEMBL1424288 & 1301804 & 3.158 & 3.9825 & TRN & \\
\hline CHEMBL1995038 & 1301804 & 4.4126 & 4.3241 & TRN & \\
\hline CHEMBL1422332 & 1301804 & 4.1123 & 3.6485 & TST & \\
\hline CHEMBL1439267 & 1301804 & 5.1087 & 3.6056 & TRN & \\
\hline CHEMBL1487724 & 1301804 & 4.5892 & 4.4478 & TRN & \\
\hline CHEMBL 259421 & 1301804 & 3.1579 & 3.5599 & TRN & \\
\hline CHEMBL1601692 & 1301804 & 4.6823 & 3.707 & TRN & \\
\hline
\end{tabular}




$$
\text { Supplemental Table S2.txt }
$$

\begin{tabular}{|c|c|c|c|c|c|}
\hline CHEMBL1375645 & 1301804 & 5.0931 & 5.0 & TRN & \\
\hline CHEMBL1331073 & 1301804 & 3.158 & 3.5799 & TRN & \\
\hline CHEMBL1704039 & 1301804 & 3.158 & 3.5738 & TRN & \\
\hline CHEMBL1329900 & 1301804 & 3.1579 & 3.5984 & TRN & \\
\hline CHEMBL2130963 & 1301804 & 5.0892 & 4.9848 & TRN & \\
\hline CHEMBL1533796 & 1301804 & 3.1579 & 3.5424 & TRN & \\
\hline CHEMBL1344679 & 1301804 & 5.0862 & 4.8078 & TST & \\
\hline CHEMBL1546014 & 1301804 & 4.7069 & 4.5697 & TRN & \\
\hline CHEMBL1321112 & 1301804 & 3.1579 & 3.6859 & TST & \\
\hline CHEMBL39947 & 1301804 & 4.1122 & 3.7292 & TST & \\
\hline CHEMBL1530941 & 1301804 & 3.1579 & 3.6586 & TST & \\
\hline CHEMBL1586506 & 1301804 & 3.1579 & 4.4041 & TRN & \\
\hline CHEMBL1496781 & 1301804 & 3.1582 & 3.6132 & TRN & \\
\hline CHEMBL1588464 & 1301804 & 4.227 & 3.5969 & TRN & \\
\hline CHEMBL1530163 & 1301804 & 4.572 & 4.5779 & TRN & \\
\hline CHEMBL1584603 & 1301804 & 3.158 & 3.6157 & TRN & \\
\hline CHEMBL3193648 & 1301804 & 4.978 & 4.3854 & TRN & \\
\hline CHEMBL1488512 & 1301804 & 4.1656 & 4.9823 & TRN & \\
\hline CHEMBL1565062 & 1301804 & 3.1579 & 3.5976 & TRN & \\
\hline CHEMBL3192104 & 1301804 & 3.1579 & 3.6616 & TRN & \\
\hline CHEMBL3185348 & 1301804 & 4.5896 & 3.714 & TRN & \\
\hline CHEMBL1374247 & 1301804 & 3.158 & 3.697 & TRN & \\
\hline CHEMBL1712864 & 1301804 & 3.1577 & 3.6161 & TRN & \\
\hline CHEMBL1506178 & 1301804 & 3.1578 & 3.60699 & 99999999998 & TRN \\
\hline CHEMBL1487256 & 1301804 & 3.1581 & 3.6383 & TRN & \\
\hline CHEMBL1901560 & 1301804 & 5.0885 & 4.8764 & TST & \\
\hline CHEMBL1460115 & 1301804 & 3.158 & 3.5547 & TRN & \\
\hline CHEMBL1324435 & 1301804 & 4.6131 & 3.5728 & TRN & \\
\hline CHEMBL1874356 & 1301804 & 3.1576 & 3.5965 & TRN & \\
\hline CHEMBL1718195 & 1301804 & 3.1578 & 3.9014 & TST & \\
\hline CHEMBL1990646 & 1301804 & 3.1579 & 3.6617 & TRN & \\
\hline CHEMBL1502451 & 1301804 & 3.158 & 3.7214 & TRN & \\
\hline CHEMBL1357484 & 1301804 & 3.158 & 3.5955 & TRN & \\
\hline CHEMBL3182096 & 1301804 & 4.7643 & 4.6535 & TRN & \\
\hline CHEMBL1473647 & 1301804 & 3.158 & 3.9428 & TST & \\
\hline CHEMBL1511403 & 1301804 & 4.6007 & 3.6299 & TRN & \\
\hline CHEMBL1609089 & 1301804 & 3.158 & 3.6314 & TRN & \\
\hline CHEMBL1313283 & 1301804 & 3.158 & 3.7017 & TRN & \\
\hline CHEMBL1889559 & 1301804 & 4.6747 & 4.4512 & TST & \\
\hline CHEMBL1444202 & 1301804 & 5.5923 & 5.1966 & TRN & \\
\hline CHEMBL1525295 & 1301804 & 5.0664 & 3.6819 & TRN & \\
\hline CHEMBL1489145 & 1301804 & 3.158 & 3.5999 & TRN & \\
\hline CHEMBL1593867 & 1301804 & 4.6048 & 4.2791 & TST & \\
\hline CHEMBL1441379 & 1301804 & 3.158 & 4.1667 & TRN & \\
\hline CHEMBL1575060 & 1301804 & 3.1579 & 3.7913 & TRN & \\
\hline CHEMBL1472121 & 1301804 & 4.2764 & 3.7343 & TRN & \\
\hline CHEMBL1314107 & 1301804 & 3.158 & 3.5672 & TRN & \\
\hline CHEMBL1360923 & 1301804 & 4.9775 & 4.726 & TRN & \\
\hline
\end{tabular}


Supplemental Table S2.txt

\begin{tabular}{|c|c|c|c|c|c|c|}
\hline CHEMBL1463272 & 1301804 & 3.158 & 3.8138 & TRN & & \\
\hline CHEMBL1330051 & 1301804 & 4.7833 & 4.1721 & TRN & & \\
\hline CHEMBL 2137306 & 1301804 & 3.1581 & 3.5741 & TRN & & \\
\hline CHEMBL1384559 & 1301804 & 5.1637 & 4.9154 & TRN & & \\
\hline CHEMBL1869801 & 1301804 & 4.17899 & 99999999 & 99 & 3.8017 & TRN \\
\hline CHEMBL 3184838 & 1301804 & 3.1576 & 4.4315 & TRN & & \\
\hline CHEMBL1418079 & 1301804 & 3.158 & 3.6074 & TRN & & \\
\hline CHEMBL3183696 & 1301804 & 4.5487 & 4.3157 & TRN & & \\
\hline CHEMBL1699547 & 1301804 & 3.1581 & 3.739 & TRN & & \\
\hline CHEMBL1435925 & 1301804 & 4.3146 & 4.3247 & TRN & & \\
\hline CHEMBL1505436 & 1301804 & 5.0803 & 4.9198 & TRN & & \\
\hline CHEMBL1543409 & 1301804 & 4.9039 & 4.1734 & TRN & & \\
\hline CHEMBL1467282 & 1301804 & 4.2805 & 3.8958 & TST & & \\
\hline CHEMBL1317985 & 1301804 & 3.1579 & 3.6486 & TST & & \\
\hline CHEMBL1474437 & 1301804 & 3.1579 & 3.6766 & TST & & \\
\hline CHEMBL1540534 & 1301804 & 3.1581 & 3.5679 & TST & & \\
\hline CHEMBL1611295 & 1301804 & 3.1579 & 3.5392 & TST & & \\
\hline CHEMBL 2357190 & 1301804 & 3.1577 & 3.7292 & TST & & \\
\hline CHEMBL1456259 & 1301804 & 3.1579 & 4.3087 & TST & & \\
\hline CHEMBL1876094 & 1301804 & 5.1283 & 4.9637 & TST & & \\
\hline CHEMBL1905194 & 1301804 & 5.3413 & 5.0613 & TST & & \\
\hline CHEMBL1400479 & 1301804 & 4.7574 & 4.2008 & TST & & \\
\hline CHEMBL1367008 & 1301804 & 3.158 & 3.633 & TST & & \\
\hline CHEMBL 2357780 & 1301804 & 3.1587 & 3.6367 & TST & & \\
\hline CHEMBL1416214 & 1301804 & 4.9493 & 4.7529 & TST & & \\
\hline CHEMBL1530437 & 1301804 & 4.6384 & 4.7178 & TST & & \\
\hline CHEMBL1579546 & 1301804 & 3.1579 & 3.7715 & TST & & \\
\hline CHEMBL3194367 & 1301804 & 4.5369 & 4.5262 & TST & & \\
\hline CHEMBL1412337 & 1301804 & 3.158 & 3.699 & TST & & \\
\hline CHEMBL1489077 & 1301804 & \multicolumn{3}{|c|}{5.1979999999999995} & 3.6073 & TST \\
\hline CHEMBL1331133 & 1301804 & 4.3738 & 4.262 & TST & & \\
\hline CHEMBL1451599 & 1301804 & 4.8755 & 4.7913 & TST & & \\
\hline CHEMBL1350603 & 1301804 & 5.0683 & 4.9502 & TST & & \\
\hline CHEMBL1416838 & 1301804 & 3.1578 & 3.638 & TST & & \\
\hline CHEMBL1417560 & 1301804 & 4.5765 & 4.5194 & TST & & \\
\hline CHEMBL1388398 & 1301804 & 4.6221 & 3.7941 & TST & & \\
\hline CHEMBL1585947 & 1301804 & 3.158 & 3.5293 & TST & & \\
\hline CHEMBL1492496 & 1301804 & 4.8819 & 4.6965 & TST & & \\
\hline CHEMBL1727517 & 1301804 & 3.1578 & 3.7366 & TST & & \\
\hline CHEMBL1359133 & 1301804 & 4.3053 & 4.4132 & TST & & \\
\hline CHEMBL1456083 & 1301804 & 5.2615 & 3.6896 & TST & & \\
\hline CHEMBL1190711 & 954632 & 6.131 & 6.131 & TRN & & \\
\hline CHEMBL449158 & 954632 & 6.5694 & 7.1197 & TST & & \\
\hline CHEMBL 2005886 & 954632 & 5.7136 & 5.7136 & TRN & & \\
\hline CHEMBL1643959 & 954632 & 3.4138 & 3.4137 & TRN & & \\
\hline CHEMBL221137 & 954632 & 5.0455 & 5.6395 & TST & & \\
\hline CHEMBL189584 & 954632 & 4.4959 & 4.4959 & TRN & & \\
\hline CHEMBL 213100 & 954632 & 3.6192 & 3.6192 & TRN & & \\
\hline
\end{tabular}


Supplemental Table S2.txt

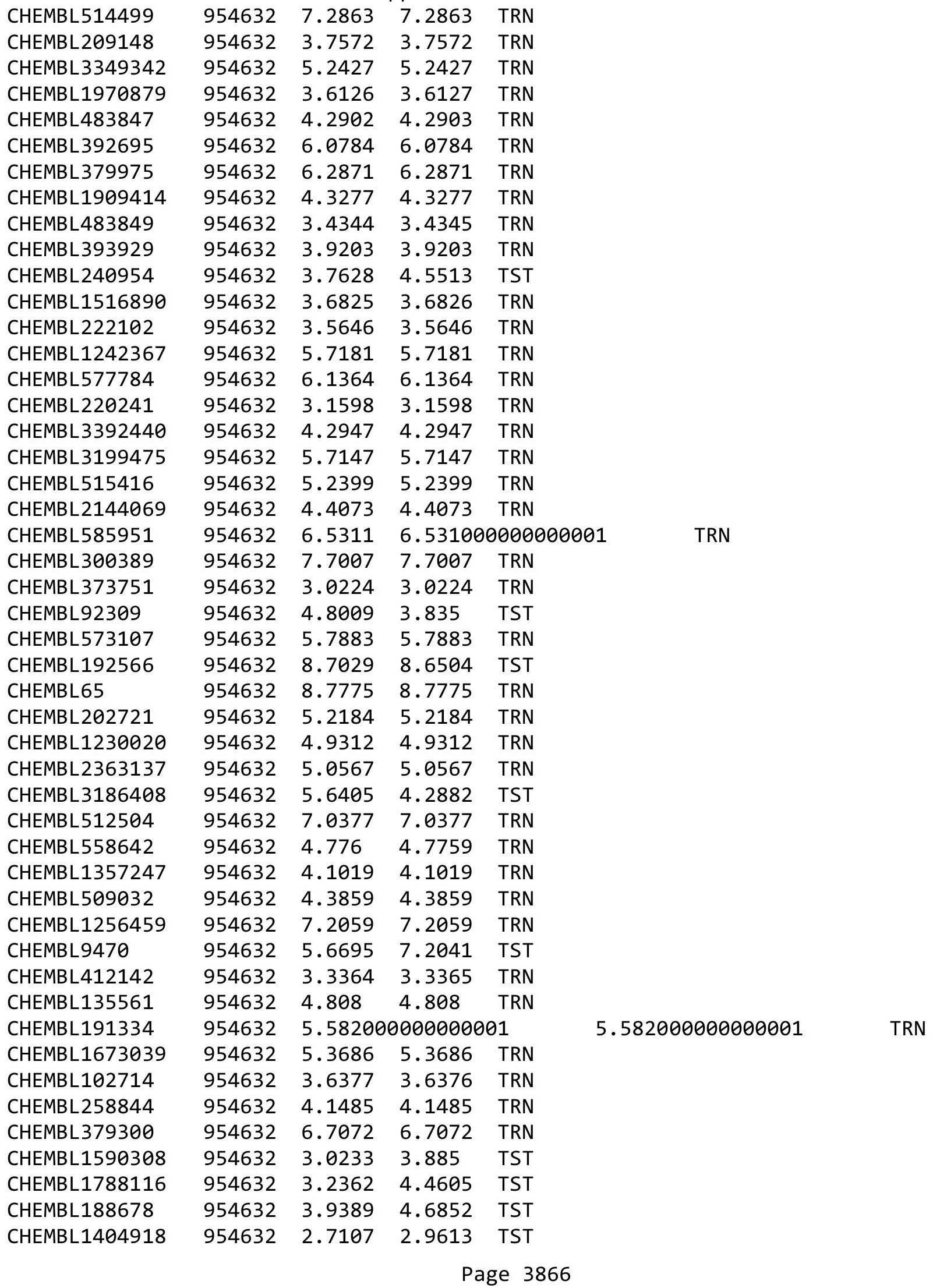




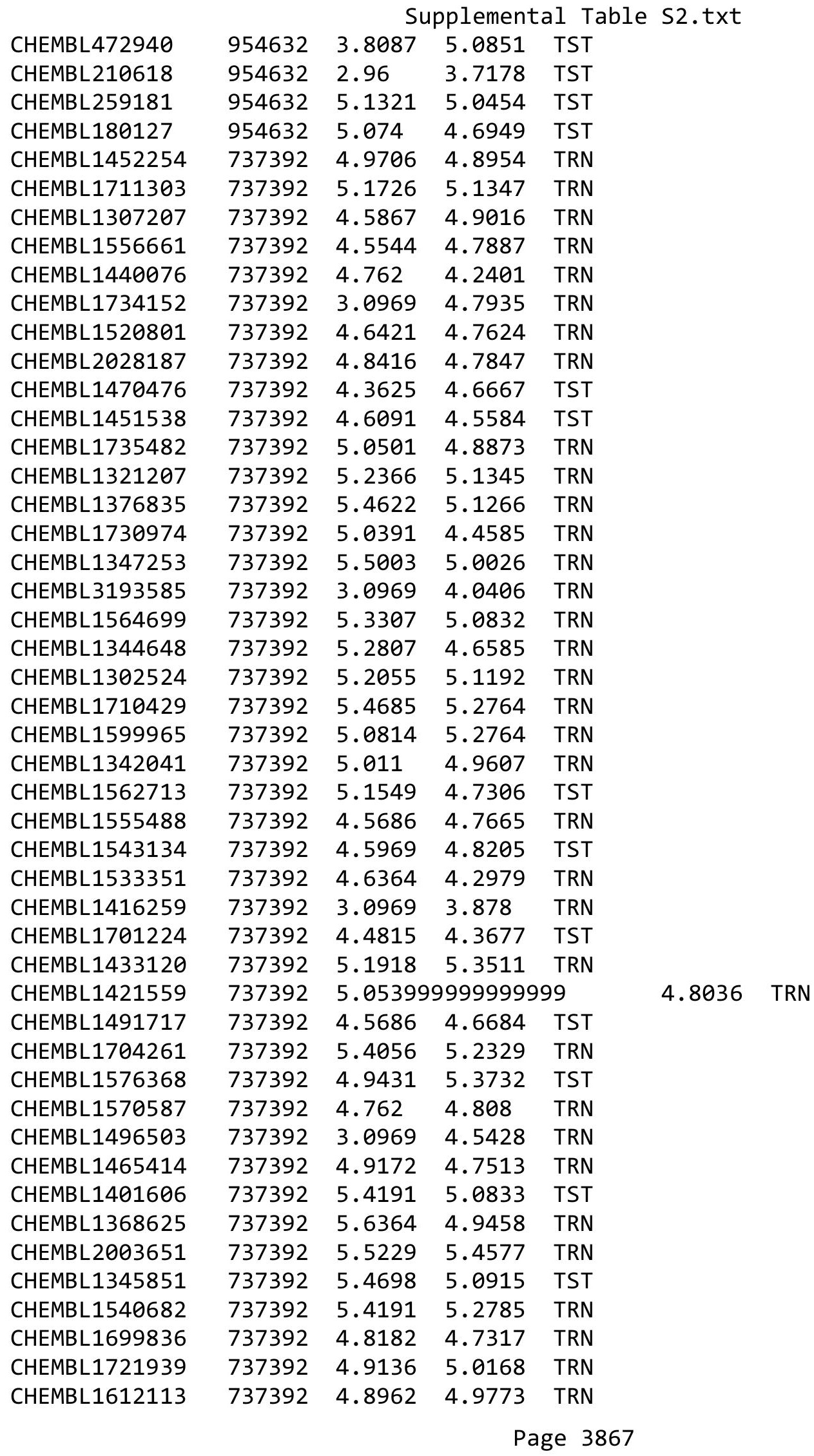




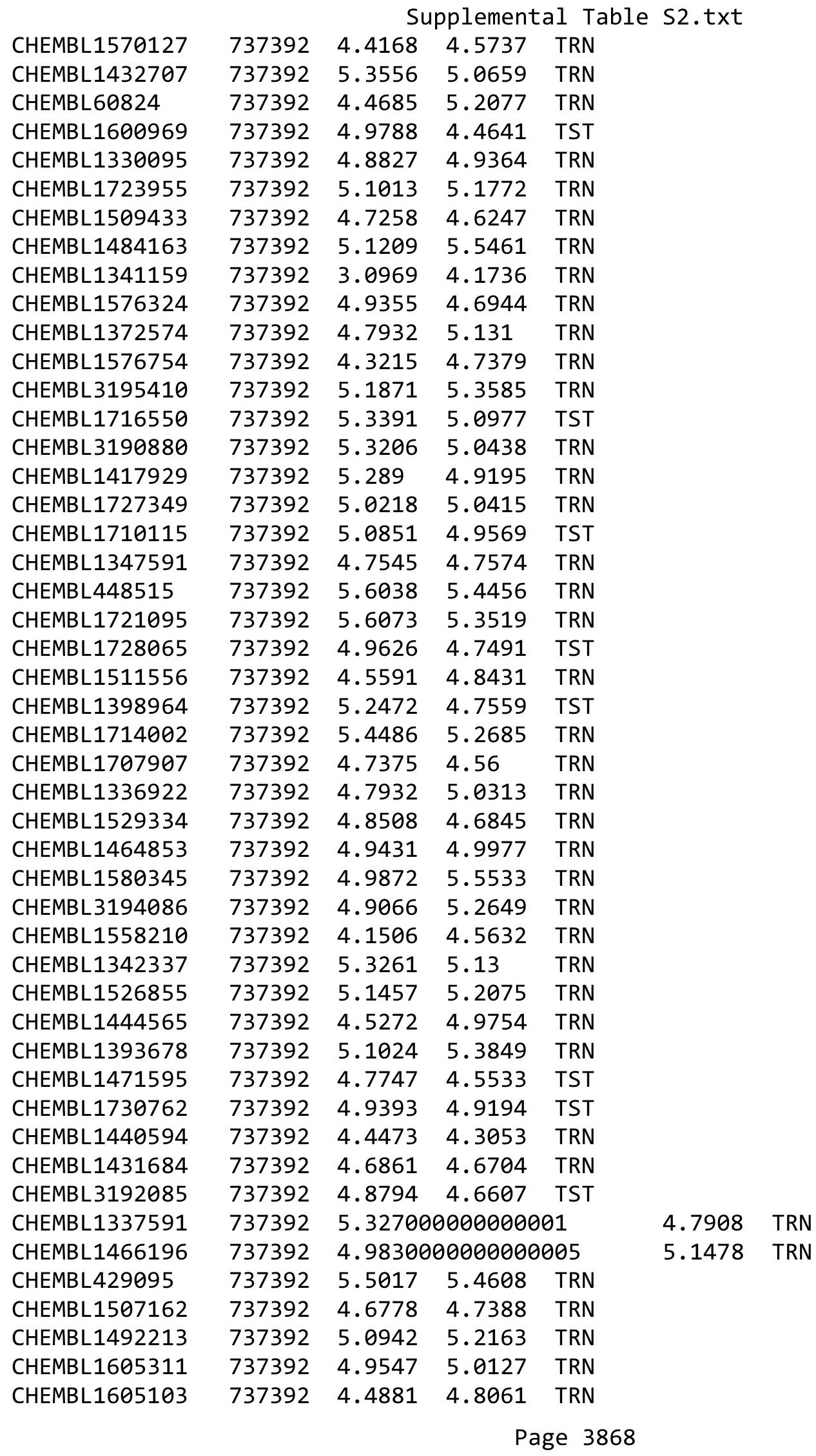




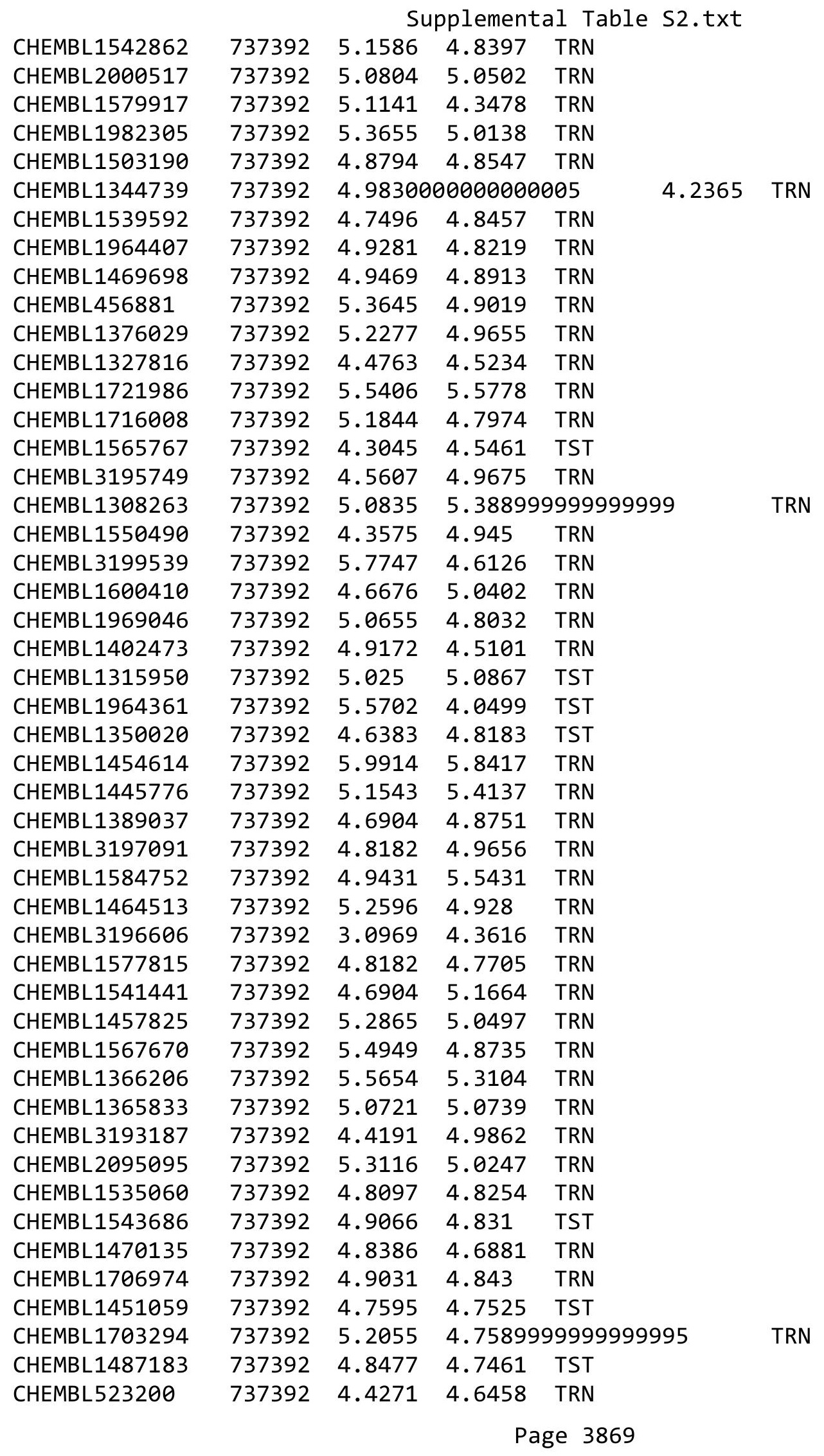


Supplemental Table S2.txt

\begin{tabular}{|c|c|c|c|c|c|c|}
\hline CHEMBL1727628 & 737392 & 5.1203 & 5.0454 & TRN & & \\
\hline CHEMBL1387028 & 737392 & 4.7986 & 5.2546 & TRN & & \\
\hline CHEMBL1305447 & 737392 & 4.9318 & 4.9455 & TST & & \\
\hline CHEMBL1999630 & 737392 & 5.5969 & 5.3375 & TRN & & \\
\hline CHEMBL1381676 & 737392 & 4.3862 & 4.2518 & TRN & & \\
\hline CHEMBL1702945 & 737392 & 4.7423 & 4.8876 & TRN & & \\
\hline CHEMBL1349727 & 737392 & 4.9957 & 5.0631 & TRN & & \\
\hline CHEMBL456295 & 737392 & 4.9172 & 5.2268 & TRN & & \\
\hline CHEMBL1310221 & 737392 & 5.6345 & 5.5902 & TRN & & \\
\hline CHEMBL1385561 & 737392 & 5.02 & 4.8132 & TRN & & \\
\hline CHEMBL1458873 & 737392 & 4.6498 & 4.7523 & TST & & \\
\hline CHEMBL1612983 & 737392 & 4.9666 & 4.75 & TRN & & \\
\hline CHEMBL1466225 & 737392 & 4.8665 & 4.8367 & TRN & & \\
\hline CHEMBL1706640 & 737392 & 5.5918 & 5.4349 & TRN & & \\
\hline CHEMBL1462889 & 737392 & 4.7595 & 5.0866 & TST & & \\
\hline CHEMBL 1445174 & 737392 & 3.0969 & 4.3295 & TRN & & \\
\hline CHEMBL1370183 & 737392 & 4.9136 & 5.5309 & TRN & & \\
\hline CHEMBL1453508 & 737392 & 4.76699 & 999999999 & 995 & 4.279 & TRN \\
\hline CHEMBL1359359 & 737392 & 5.475 & 5.2547 & TRN & & \\
\hline CHEMBL1366795 & 737392 & 4.757 & 4.6746 & TRN & & \\
\hline CHEMBL1587422 & 737392 & 4.8894 & 5.1936 & TRN & & \\
\hline CHEMBL1424259 & 737392 & 4.4789 & 4.8447 & TST & & \\
\hline CHEMBL1348946 & 737392 & 4.6055 & 4.3214 & TRN & & \\
\hline CHEMBL1966952 & 737392 & 4.5452 & 4.6809 & TRN & & \\
\hline CHEMBL1538225 & 737392 & 5.1891 & 5.4439 & TRN & & \\
\hline CHEMBL1724454 & 737392 & 5.6517 & 4.956 & TST & & \\
\hline CHEMBL1728280 & 737392 & 5.8069 & 5.2927 & TRN & & \\
\hline CHEMBL3197637 & 737392 & 5.4157 & 5.3694 & TRN & & \\
\hline CHEMBL1331791 & 737392 & 4.5884 & 4.3277 & TRN & & \\
\hline CHEMBL1729300 & 737392 & 5.4776 & 5.1215 & TRN & & \\
\hline CHEMBL1519030 & 737392 & 5.04 & 4.5761 & TST & & \\
\hline CHEMBL1500226 & 737392 & 4.6861 & 4.604 & TST & & \\
\hline CHEMBL1395907 & 737392 & 5.8729 & 5.6993 & TRN & & \\
\hline CHEMBL1326832 & 737392 & 5.0878 & 5.0098 & TRN & & \\
\hline CHEMBL1335844 & 737392 & 5.0031 & 4.8802 & TRN & & \\
\hline CHEMBL1303693 & 737392 & 4.7645 & 4.7192 & TRN & & \\
\hline CHEMBL1329141 & 737392 & 5.5901 & 4.9253 & TRN & & \\
\hline CHEMBL1996724 & 737392 & 5.4295 & 5.1723 & TRN & & \\
\hline CHEMBL1451931 & 737392 & 5.6021 & 5.5203 & TRN & & \\
\hline CHEMBL1968732 & 737392 & 5.7447 & 5.6581 & TRN & & \\
\hline CHEMBL1533248 & 737392 & \multicolumn{3}{|c|}{5.053999999999999} & 5.0179 & TRN \\
\hline CHEMBL1611371 & 737392 & 4.6459 & 4.6942 & TST & & \\
\hline CHEMBL1301125 & 737392 & 5.475 & 5.265 & TRN & & \\
\hline CHEMBL1545792 & 737392 & 5.2027 & 4.8703 & TRN & & \\
\hline CHEMBL1442136 & 737392 & 4.4473 & 4.4265 & TRN & & \\
\hline CHEMBL1329974 & 737392 & 5.2503 & 4.9621 & TRN & & \\
\hline CHEMBL1402848 & 737392 & 4.7258 & 4.9315 & TRN & & \\
\hline CHEMBL27953 & 737392 & 5.6615 & 5.0883 & TST & & \\
\hline
\end{tabular}


Supplemental Table S2.txt

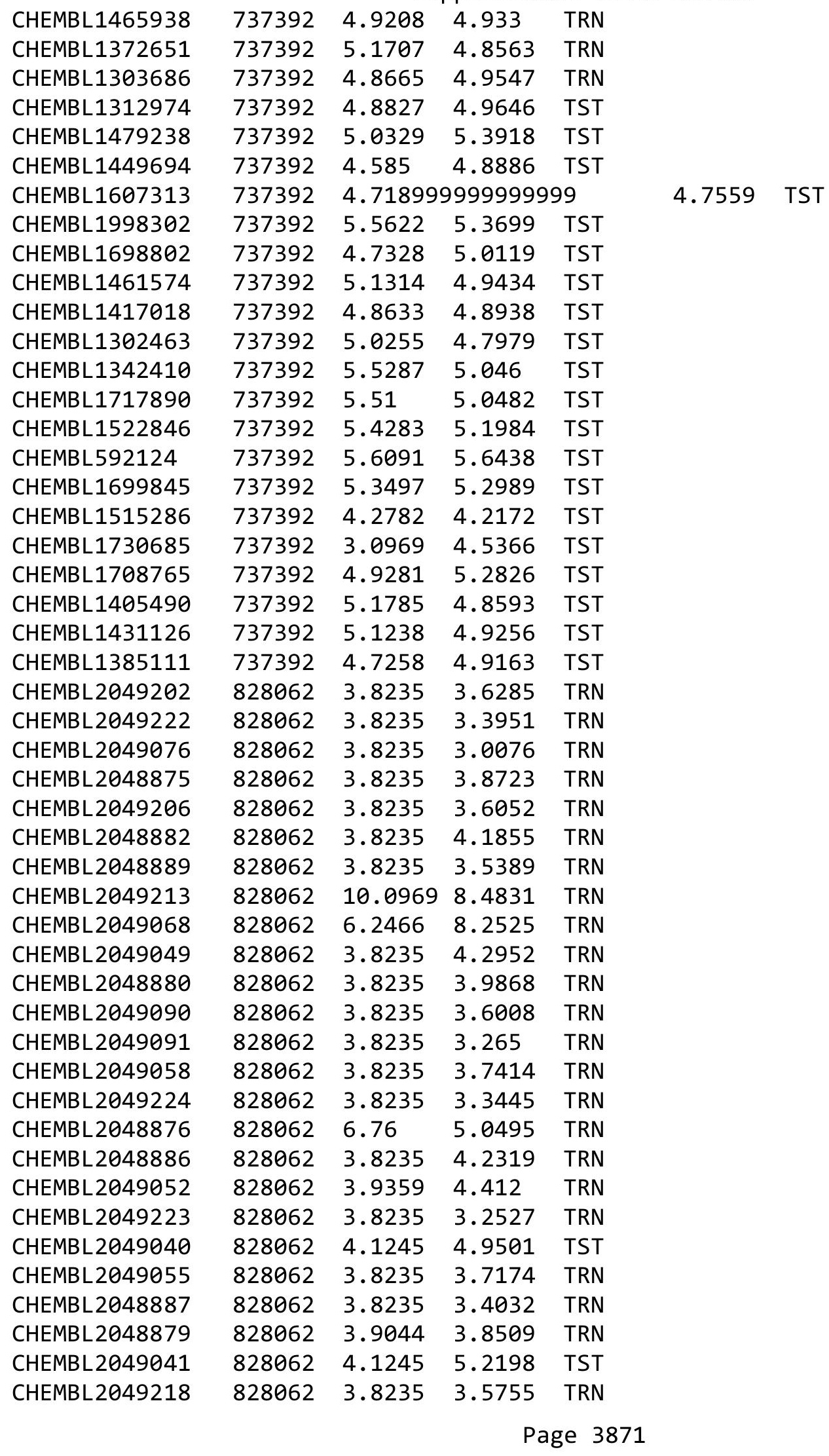




\begin{tabular}{|c|c|c|c|c|}
\hline & & Sup & oplement & al $\mathrm{Ta}$ \\
\hline CHEMBL2049221 & 828062 & 3.8235 & 3.8678 & TRN \\
\hline CHEMBL 2049220 & 828062 & 3.8235 & 3.7296 & TRN \\
\hline CHEMBL2049039 & 828062 & 4.1245 & 4.4095 & TST \\
\hline CHEMBL2049075 & 828062 & 3.8235 & 3.5243 & TRN \\
\hline CHEMBL 2049199 & 828062 & 3.8235 & 3.6788 & TRN \\
\hline CHEMBL 2049025 & 828062 & 4.1245 & 4.6024 & TST \\
\hline CHEMBL 2048892 & 828062 & 3.8235 & 3.9867 & TRN \\
\hline CHEMBL 2049088 & 828062 & 3.9075 & 4.1075 & TRN \\
\hline CHEMBL2049077 & 828062 & 3.8235 & 4.1161 & TRN \\
\hline CHEMBL 2049072 & 828062 & 3.8235 & 3.9488 & TRN \\
\hline CHEMBL 2049203 & 828062 & 3.8235 & 3.7186 & TRN \\
\hline CHEMBL 2049048 & 828062 & 3.8235 & 4.1822 & TRN \\
\hline CHEMBL 2049044 & 828062 & 3.8235 & 3.4558 & TRN \\
\hline CHEMBL 2049078 & 828062 & 3.8235 & 3.8561 & TRN \\
\hline CHEMBL 2049073 & 828062 & 3.8235 & 4.1268 & TRN \\
\hline CHEMBL 2049034 & 828062 & 5.5308 & 5.0021 & TST \\
\hline CHEMBL 2049082 & 828062 & 4.8235 & 6.1031 & TRN \\
\hline CHEMBL 2049062 & 828062 & 3.8235 & 4.5606 & TRN \\
\hline CHEMBL 2048881 & 828062 & 3.8235 & 3.5732 & TRN \\
\hline CHEMBL 2048898 & 828062 & 3.8235 & 4.5334 & TRN \\
\hline CHEMBL 2049056 & 828062 & 3.8235 & 3.4555 & TRN \\
\hline CHEMBL 2049200 & 828062 & 3.8235 & 3.6356 & TRN \\
\hline CHEMBL 2046470 & 828062 & 3.8235 & 4.0873 & TRN \\
\hline CHEMBL 2049065 & 828062 & 10.3979 & 6.8535 & TRN \\
\hline CHEMBL 2048884 & 828062 & 3.8235 & 3.9313 & TRN \\
\hline CHEMBL 2048901 & 828062 & 3.8235 & 4.4203 & TST \\
\hline CHEMBL 2049071 & 828062 & 3.8235 & 3.7816 & TRN \\
\hline CHEMBL 2048885 & 828062 & 3.8235 & 3.6952 & TRN \\
\hline CHEMBL 2048896 & 828062 & 7.2336 & 5.4416 & TRN \\
\hline CHEMBL 2049047 & 828062 & 10.3979 & 6.4455 & TRN \\
\hline CHEMBL 2049051 & 828062 & 3.8235 & 3.8645 & TRN \\
\hline CHEMBL 2049210 & 828062 & 3.8235 & 6.5607 & TRN \\
\hline CHEMBL 2049061 & 828062 & 3.8235 & 4.0363 & TRN \\
\hline CHEMBL 2049043 & 828062 & 3.8235 & 5.0331 & TRN \\
\hline CHEMBL 2049027 & 828062 & 4.1245 & 4.1472 & TST \\
\hline CHEMBL2049219 & 828062 & 3.8235 & 3.8969 & TRN \\
\hline CHEMBL 2049066 & 828062 & 3.8235 & 3.8448 & TRN \\
\hline CHEMBL 2049067 & 828062 & 3.8235 & 4.7783 & TRN \\
\hline CHEMBL 2049030 & 828062 & 4.1245 & 4.5313 & TST \\
\hline CHEMBL 2049029 & 828062 & 4.5891 & 4.5113 & TST \\
\hline CHEMBL 2049217 & 828062 & 3.8235 & 3.438 & TRN \\
\hline CHEMBL 2049063 & 828062 & 3.9171 & 3.9003 & TRN \\
\hline CHEMBL 2048874 & 828062 & 3.8235 & 4.8021 & TRN \\
\hline CHEMBL 2049204 & 828062 & 3.8235 & 3.8322 & TRN \\
\hline CHEMBL 2049070 & 828062 & 3.8235 & 3.7388 & TRN \\
\hline CHEMBL 2049021 & 828062 & 3.8235 & 4.6982 & TST \\
\hline CHEMBL 2049033 & 828062 & 4.1245 & 4.8427 & TST \\
\hline CHEMBL 2049032 & 828062 & 4.1245 & 4.6946 & TST \\
\hline
\end{tabular}




\begin{tabular}{|c|c|c|c|c|c|}
\hline & & \multicolumn{4}{|c|}{ Supplemental Table s2.txt } \\
\hline CHEMBL 2049215 & 828062 & 3.8235 & 3.3856 & TRN & \\
\hline CHEMBL 2049205 & 828062 & 3.8235 & 3.818 & TRN & \\
\hline CHEMBL 2049087 & 828062 & 3.9336 & 4.2214 & TRN & \\
\hline CHEMBL 2049057 & 828062 & 3.8235 & 3.8824 & TRN & \\
\hline CHEMBL 2049216 & 828062 & 3.8235 & 3.5061 & TRN & \\
\hline CHEMBL 2049064 & 828062 & 3.8235 & 4.3218 & TRN & \\
\hline CHEMBL 2048878 & 828062 & 3.8235 & 4.2326 & TRN & \\
\hline CHEMBL 2049080 & 828062 & 3.8235 & 3.5128 & TRN & \\
\hline CHEMBL 2049053 & 828062 & 3.9381 & 4.3606 & TRN & \\
\hline CHEMBL 2049207 & 828062 & 3.991 & 3.7578 & TRN & \\
\hline CHEMBL 2049074 & 828062 & 3.8235 & 3.7383 & TRN & \\
\hline CHEMBL 2049085 & 828062 & 3.9637 & 3.8319 & TRN & \\
\hline CHEMBL 2049201 & 828062 & 3.8235 & 3.7053 & TRN & \\
\hline CHEMBL 2048888 & 828062 & \multicolumn{3}{|c|}{7.218999999999999} & TRN \\
\hline CHEMBL 2049214 & 828062 & 3.8235 & 5.0697 & TRN & \\
\hline CHEMBL 2049054 & 828062 & 3.9171 & 4.162 & TRN & \\
\hline CHEMBL 2048890 & 828062 & 3.8235 & 3.9196 & TRN & \\
\hline CHEMBL 2049060 & 828062 & 3.8235 & 3.8651 & TRN & \\
\hline CHEMBL 2048900 & 828062 & 3.8235 & 5.0555 & TST & \\
\hline CHEMBL 2048893 & 828062 & 3.8235 & 4.3356 & TRN & \\
\hline CHEMBL 2048895 & 828062 & 3.8235 & 4.72199 & 99999999995 & TRN \\
\hline CHEMBL 2049083 & 828062 & 3.8235 & 3.9868 & TRN & \\
\hline CHEMBL 2048897 & 828062 & 3.8235 & 4.2739 & TRN & \\
\hline CHEMBL 2049023 & 828062 & 6.1777 & 6.1112 & TST & \\
\hline CHEMBL 2049035 & 828062 & 4.1245 & 4.2118 & TST & \\
\hline CHEMBL 2049028 & 828062 & 4.1245 & 4.1891 & TST & \\
\hline CHEMBL 2049050 & 828062 & 3.9846 & 4.0696 & TRN & \\
\hline CHEMBL 2048883 & 828062 & 3.8235 & 4.3132 & TRN & \\
\hline CHEMBL 2049212 & 828062 & 3.8235 & 4.5474 & TRN & \\
\hline CHEMBL 2049037 & 828062 & 4.1245 & 4.4063 & TST & \\
\hline CHEMBL 2048877 & 828062 & 3.8235 & 5.2239 & TRN & \\
\hline CHEMBL 2049084 & 828062 & 3.8235 & 4.1079 & TRN & \\
\hline CHEMBL150924 & 828062 & 3.8235 & 4.5198 & TST & \\
\hline CHEMBL 2049211 & 828062 & 3.8235 & 3.616 & TRN & \\
\hline CHEMBL 2048899 & 828062 & 4.1245 & 3.7851 & TST & \\
\hline CHEMBL 2048894 & 828062 & 3.8235 & 4.6924 & TRN & \\
\hline CHEMBL 2049031 & 828062 & 4.1245 & 3.6951 & TST & \\
\hline CHEMBL291083 & 828062 & 4.1245 & 4.9037 & TST & \\
\hline CHEMBL 2049022 & 828062 & 3.8235 & 5.5792 & TST & \\
\hline CHEMBL 2048891 & 828062 & 3.8235 & 3.8856 & TRN & \\
\hline CHEMBL 2049208 & 828062 & 3.8235 & 4.124 & TRN & \\
\hline CHEMBL 2049069 & 828062 & 3.8235 & 3.7492 & TRN & \\
\hline CHEMBL 2049209 & 828062 & 3.8235 & 3.7123 & TRN & \\
\hline CHEMBL 2049086 & 828062 & 3.8235 & 3.7228 & TRN & \\
\hline CHEMBL 2049225 & 828062 & 3.8235 & 3.9176 & TRN & \\
\hline CHEMBL 2049026 & 828062 & 4.1245 & 4.3508 & TST & \\
\hline CHEMBL 2049046 & 828062 & 3.8235 & 3.9338 & TRN & \\
\hline CHEMBL 2049089 & 828062 & 3.8692 & 3.7589 & TRN & \\
\hline
\end{tabular}




\begin{tabular}{|c|c|c|c|c|}
\hline \multicolumn{5}{|c|}{ Supplemental Table S2.txt } \\
\hline CHEMBL 2049024 & 828062 & 3.8235 & 4.4692 & TST \\
\hline CHEMBL 2048902 & 828062 & 4.1245 & 4.6469 & TST \\
\hline CHEMBL2049059 & 828062 & 3.8235 & 3.8742 & TST \\
\hline CHEMBL 2049079 & 828062 & 3.8235 & 3.1564 & TST \\
\hline CHEMBL 2049081 & 828062 & 3.8235 & 3.6741 & TST \\
\hline CHEMBL 2049042 & 828062 & 4.1245 & 4.2905 & TST \\
\hline CHEMBL 2049036 & 828062 & 4.1245 & 4.3999 & TST \\
\hline CHEMBL2049045 & 828062 & 10.3979 & 3.7094 & TST \\
\hline CHEMBL1369462 & 828062 & 3.8235 & 5.5797 & TST \\
\hline CHEMBL 2049038 & 828062 & 4.1245 & 5.6092 & TST \\
\hline CHEMBL1992242 & 809133 & 4.1 & 3.9162 & TRN \\
\hline CHEMBL1982271 & 809133 & 6.6 & 7.0324 & TRN \\
\hline CHEMBL 2007296 & 809133 & 4.1 & 3.9942 & TRN \\
\hline CHEMBL208637 & 809133 & 4.1 & 3.9461 & TRN \\
\hline CHEMBL396523 & 809133 & 6.4 & 6.9957 & TRN \\
\hline CHEMBL1970203 & 809133 & 7.2 & 6.2618 & TRN \\
\hline CHEMBL1986530 & 809133 & 4.1 & 4.9993 & TST \\
\hline CHEMBL1965351 & 809133 & 4.1 & 4.7808 & TST \\
\hline CHEMBL1999321 & 809133 & 4.1 & 3.6707 & TRN \\
\hline CHEMBL1968590 & 809133 & 5.5 & 5.6663 & TRN \\
\hline CHEMBL1999749 & 809133 & 4.1 & 4.184 & TRN \\
\hline CHEMBL 2005375 & 809133 & 4.1 & 3.9278 & TRN \\
\hline CHEMBL1984191 & 809133 & 4.1 & 4.3516 & TRN \\
\hline CHEMBL1983006 & 809133 & 5.5 & 4.2996 & TRN \\
\hline CHEMBL1972183 & 809133 & 4.1 & 4.0373 & TRN \\
\hline CHEMBL1971029 & 809133 & 8.0 & 7.0838 & TRN \\
\hline CHEMBL 383527 & 809133 & 4.1 & 4.7716 & TRN \\
\hline CHEMBL394790 & 809133 & 5.7 & 5.0309 & TRN \\
\hline CHEMBL226471 & 809133 & 4.1 & 4.7392 & TRN \\
\hline CHEMBL1974702 & 809133 & 4.1 & 4.4312 & TST \\
\hline CHEMBL1996111 & 809133 & 4.1 & 4.1769 & TRN \\
\hline CHEMBL1965589 & 809133 & 4.1 & 4.1399 & TRN \\
\hline CHEMBL1998193 & 809133 & 4.1 & 4.5083 & TRN \\
\hline CHEMBL379975 & 809133 & 7.6 & 6.4857 & TST \\
\hline CHEMBL474432 & 809133 & 6.7 & 6.3594 & TST \\
\hline CHEMBL1988153 & 809133 & 4.1 & 4.4526 & TRN \\
\hline CHEMBL1986666 & 809133 & 6.3 & 6.2744 & TRN \\
\hline CHEMBL1972584 & 809133 & 5.5 & 6.3328 & TRN \\
\hline CHEMBL1999556 & 809133 & 5.7 & 5.6508 & TRN \\
\hline CHEMBL1988437 & 809133 & 6.4 & 5.7243 & TST \\
\hline CHEMBL1968245 & 809133 & 4.1 & 4.4393 & TRN \\
\hline CHEMBL1979577 & 809133 & 5.4 & 6.1737 & TRN \\
\hline CHEMBL1998121 & 809133 & 5.7 & 5.6788 & TRN \\
\hline CHEMBL1991800 & 809133 & 4.1 & 4.4794 & TRN \\
\hline CHEMBL52387 & 809133 & 4.1 & 4.312 & TST \\
\hline CHEMBL379835 & 809133 & 4.1 & 3.6692 & TST \\
\hline CHEMBL1979357 & 809133 & 4.1 & 4.3094 & TRN \\
\hline CHEMBL1980802 & 809133 & 6.1 & 4.4275 & TST \\
\hline
\end{tabular}




\begin{tabular}{|c|c|c|c|c|}
\hline & & & Supplement & \\
\hline CHEMBL1996649 & 809133 & 6.9 & 7.3049 & TRN \\
\hline CHEMBL1996817 & 809133 & 7.1 & 7.2416 & TRN \\
\hline CHEMBL1979554 & 809133 & 4.1 & 4.5899 & TRN \\
\hline CHEMBL3197315 & 809133 & 4.1 & 3.5049 & TST \\
\hline CHEMBL 2004355 & 809133 & 4.1 & 4.5219 & TRN \\
\hline CHEMBL468280 & 809133 & 4.1 & 4.3602 & TST \\
\hline CHEMBL1990884 & 809133 & 4.1 & 3.9618 & TRN \\
\hline CHEMBL3109278 & 809133 & 7.0 & 7.1973 & TRN \\
\hline CHEMBL 256835 & 809133 & 4.1 & 4.7078 & TRN \\
\hline CHEMBL1970006 & 809133 & 4.1 & 4.6226 & TST \\
\hline CHEMBL1980142 & 809133 & 4.1 & 4.8085 & TRN \\
\hline CHEMBL41783 & 809133 & 4.1 & 4.0571 & TRN \\
\hline CHEMBL 2004438 & 809133 & 4.1 & 5.0845 & TRN \\
\hline CHEMBL 2006276 & 809133 & 4.1 & 3.9318 & TRN \\
\hline CHEMBL191003 & 809133 & 6.7 & 6.1951 & TRN \\
\hline CHEMBL 271381 & 809133 & 4.3 & 5.1866 & TRN \\
\hline CHEMBL 2006785 & 809133 & 4.1 & 3.9365 & TST \\
\hline CHEMBL1982466 & 809133 & 7.5 & 7.815 & TRN \\
\hline CHEMBL1995740 & 809133 & 4.1 & 4.6286 & TRN \\
\hline CHEMBL1990162 & 809133 & 4.5 & 4.8445 & TRN \\
\hline CHEMBL1996390 & 809133 & 4.1 & 4.3183 & TRN \\
\hline CHEMBL1992220 & 809133 & 7.3 & 7.317 & TRN \\
\hline CHEMBL1986943 & 809133 & 7.3 & 7.0824 & TRN \\
\hline CHEMBL 234085 & 809133 & 4.5 & 5.0658 & TRN \\
\hline CHEMBL1995832 & 809133 & 4.1 & 4.4619 & TRN \\
\hline CHEMBL1998414 & 809133 & 4.1 & 3.9537 & TRN \\
\hline CHEMBL1969042 & 809133 & 5.2 & 5.3679 & TST \\
\hline CHEMBL 2000345 & 809133 & 5.2 & 4.8382 & TRN \\
\hline CHEMBL1999931 & 809133 & 6.4 & 5.9919 & TRN \\
\hline CHEMBL1991640 & 809133 & 5.9 & 4.7053 & TST \\
\hline CHEMBL1375418 & 809133 & 4.1 & 4.593 & TRN \\
\hline CHEMBL 2007064 & 809133 & 6.2 & 6.8822 & TRN \\
\hline CHEMBL1981047 & 809133 & 6.4 & 5.9495 & TRN \\
\hline CHEMBL 229968 & 809133 & 7.2 & 7.1009 & TRN \\
\hline CHEMBL1976240 & 809133 & 4.1 & 4.1984 & TRN \\
\hline CHEMBL1987948 & 809133 & 6.5 & 6.3518 & TRN \\
\hline CHEMBL1979093 & 809133 & 6.0 & 5.9587 & TRN \\
\hline CHEMBL1968151 & 809133 & 4.1 & 4.03 & TST \\
\hline CHEMBL1381197 & 809133 & 4.1 & 4.5405 & TRN \\
\hline CHEMBL1987009 & 809133 & 5.6 & 5.4632 & TRN \\
\hline CHEMBL 379218 & 809133 & 6.2 & 6.4252 & TRN \\
\hline CHEMBL 2003817 & 809133 & 4.1 & 4.922 & TRN \\
\hline CHEMBL336961 & 809133 & 4.1 & 4.4216 & TRN \\
\hline CHEMBL1994830 & 809133 & 4.1 & 4.2995 & TRN \\
\hline CHEMBL1987054 & 809133 & 6.0 & 6.157 & TRN \\
\hline CHEMBL1970083 & 809133 & 6.7 & 6.7003 & TRN \\
\hline CHEMBL 226403 & 809133 & 4.1 & 4.5145 & TRN \\
\hline CHEMBL 2005631 & 809133 & 7.2 & 6.9572 & TRN \\
\hline
\end{tabular}




\begin{tabular}{|c|c|c|c|c|c|}
\hline \multicolumn{6}{|c|}{ Supplemental Table s2.txt } \\
\hline CHEMBL1994938 & 809133 & 5.1 & 5.53 & TRN & \\
\hline CHEMBL1977223 & 809133 & 4.1 & 4.676 & TRN & \\
\hline CHEMBL1966279 & 809133 & 6.3 & 5.1033 & TRN & \\
\hline CHEMBL1236126 & 809133 & 4.1 & 3.9254 & TST & \\
\hline CHEMBL1997846 & 809133 & 6.0 & 6.3159 & TRN & \\
\hline CHEMBL 2004419 & 809133 & 4.1 & 4.3787 & TRN & \\
\hline CHEMBL1991728 & 809133 & 6.3 & 6.4148 & TRN & \\
\hline CHEMBL1995811 & 809133 & 4.5 & 4.9352 & TRN & \\
\hline CHEMBL1975787 & 809133 & 5.6 & 5.3923 & TRN & \\
\hline CHEMBL 2002407 & 809133 & 4.1 & 4.8087 & TRN & \\
\hline CHEMBL1972489 & 809133 & 4.1 & 3.9815 & TRN & \\
\hline CHEMBL1994074 & 809133 & 5.1 & 4.7561 & TRN & \\
\hline CHEMBL1992937 & 809133 & 5.3 & 5.0041 & TST & \\
\hline CHEMBL1968930 & 809133 & 7.4 & 6.61100 & 0000000001 & TRN \\
\hline CHEMBL1985566 & 809133 & 4.1 & 3.9091 & TRN & \\
\hline CHEMBL536151 & 809133 & 4.1 & 4.195 & TST & \\
\hline CHEMBL1972119 & 809133 & 5.2 & 4.6033 & TRN & \\
\hline CHEMBL1986328 & 809133 & 4.1 & 3.6378 & TST & \\
\hline CHEMBL95692 & 809133 & 4.1 & 4.5935 & TRN & \\
\hline CHEMBL1090356 & 809133 & 6.3 & 5.961 & TRN & \\
\hline CHEMBL1976455 & 809133 & 5.8 & 5.1778 & TRN & \\
\hline CHEMBL1983923 & 809133 & 5.4 & 5.7542 & TST & \\
\hline CHEMBL1983534 & 809133 & 4.1 & 3.6645 & TRN & \\
\hline CHEMBL1982361 & 809133 & 4.1 & 4.0483 & TRN & \\
\hline CHEMBL1999112 & 809133 & 4.1 & 4.295 & TST & \\
\hline CHEMBL1982122 & 809133 & 4.1 & 4.0221 & TRN & \\
\hline CHEMBL 2000801 & 809133 & 4.1 & 4.1562 & TRN & \\
\hline CHEMBL1682546 & 809133 & 4.1 & 3.7913 & TRN & \\
\hline CHEMBL1991395 & 809133 & 4.1 & 4.2594 & TRN & \\
\hline CHEMBL1971245 & 809133 & 4.1 & 4.7564 & TRN & \\
\hline CHEMBL1987648 & 809133 & 4.1 & 4.3548 & TRN & \\
\hline CHEMBL1996780 & 809133 & 4.1 & 4.1068 & TST & \\
\hline CHEMBL1972142 & 809133 & 4.1 & 4.2045 & TRN & \\
\hline CHEMBL1966514 & 809133 & 6.6 & 7.1206 & TRN & \\
\hline CHEMBL 2003638 & 809133 & 4.6 & 4.9906 & TRN & \\
\hline CHEMBL296586 & 809133 & 6.2 & 5.5685 & TRN & \\
\hline CHEMBL1996066 & 809133 & 4.1 & 4.7311 & TST & \\
\hline CHEMBL516429 & 809133 & 6.1 & 5.9703 & TRN & \\
\hline CHEMBL1972152 & 809133 & 4.1 & 4.1404 & TST & \\
\hline CHEMBL1993722 & 809133 & 6.9 & 5.6755 & TRN & \\
\hline CHEMBL1970806 & 809133 & 4.1 & 4.1829 & TST & \\
\hline CHEMBL 202635 & 809133 & 4.1 & 4.6811 & TRN & \\
\hline CHEMBL1375640 & 809133 & 4.1 & 4.2057 & TST & \\
\hline CHEMBL1979970 & 809133 & 4.1 & 4.1293 & TRN & \\
\hline CHEMBL249282 & 809133 & 4.1 & 4.7127 & TST & \\
\hline CHEMBL1969264 & 809133 & 4.1 & 4.1776 & TRN & \\
\hline CHEMBL1973711 & 809133 & 4.1 & 4.0523 & TST & \\
\hline CHEMBL 2006237 & 809133 & 4.1 & 4.4508 & TRN & \\
\hline
\end{tabular}




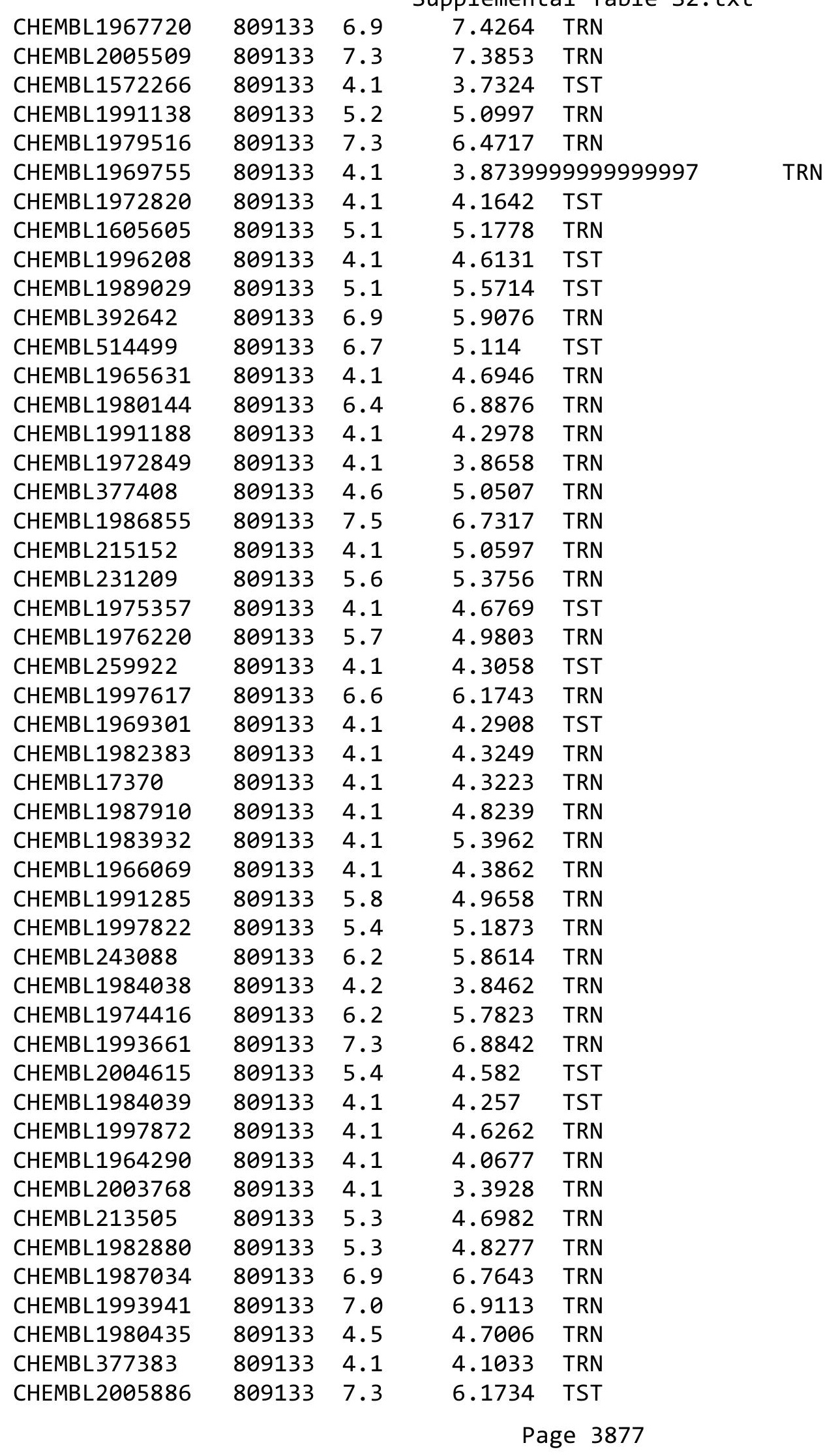




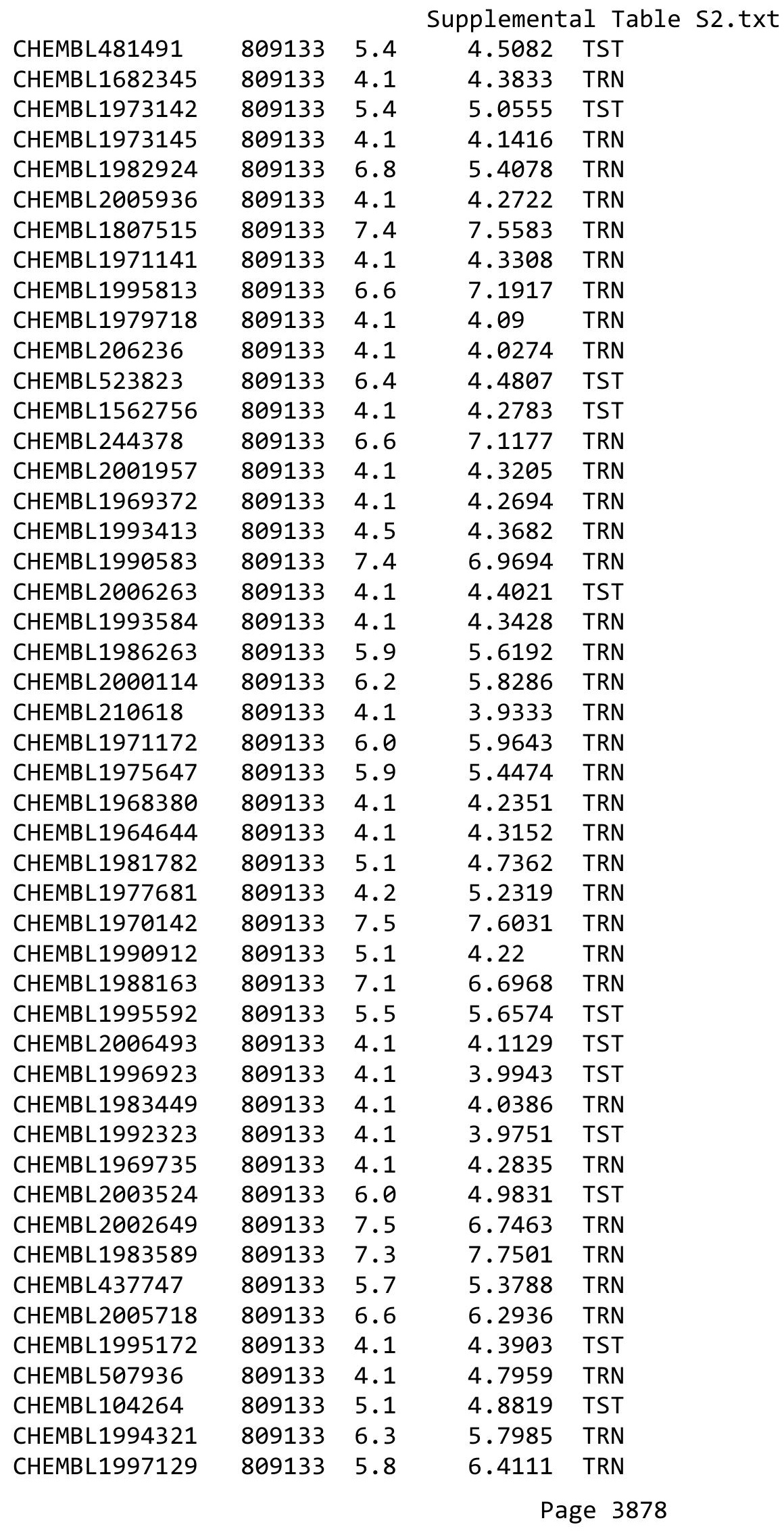




\begin{tabular}{|c|c|c|c|c|c|}
\hline \multicolumn{6}{|c|}{ Supplemental Table S2.txt } \\
\hline CHEMBL1984788 & 809133 & 4.1 & 4.2217 & TRN & \\
\hline CHEMBL451964 & 809133 & 4.1 & 4.3987 & TRN & \\
\hline CHEMBL1964307 & 809133 & 5.9 & 5.2437 & TRN & \\
\hline CHEMBL 2000508 & 809133 & 4.1 & 4.3079 & TRN & \\
\hline CHEMBL1971694 & 809133 & 4.1 & 4.5016 & TST & \\
\hline CHEMBL 2001547 & 809133 & 4.1 & 3.9368 & TRN & \\
\hline CHEMBL210928 & 809133 & 4.1 & 3.7138 & TRN & \\
\hline CHEMBL1994361 & 809133 & 5.7 & 4.83 & TRN & \\
\hline CHEMBL1986603 & 809133 & 4.1 & 4.27 & TST & \\
\hline CHEMBL1972840 & 809133 & 5.5 & 5.8286 & TRN & \\
\hline CHEMBL1977148 & 809133 & 7.9 & 7.0928 & TRN & \\
\hline CHEMBL1966842 & 809133 & 7.3 & 6.3205 & TRN & \\
\hline CHEMBL 2003286 & 809133 & 4.1 & $3.8360 e$ & 00000000003 & TRN \\
\hline CHEMBL1992306 & 809133 & 4.1 & 4.3776 & TRN & \\
\hline CHEMBL 2002165 & 809133 & 7.5 & 7.1982 & TRN & \\
\hline CHEMBL 2001668 & 809133 & 5.1 & 4.3904 & TST & \\
\hline CHEMBL1979318 & 809133 & 4.1 & 3.9972 & TRN & \\
\hline CHEMBL 206382 & 809133 & 4.1 & 4.053 & TRN & \\
\hline CHEMBL1998585 & 809133 & 6.1 & 5.5598 & TRN & \\
\hline CHEMBL127898 & 809133 & 5.1 & 3.6623 & TST & \\
\hline CHEMBL519697 & 809133 & 4.1 & 4.0862 & TST & \\
\hline CHEMBL 2004934 & 809133 & 4.1 & 4.1911 & TRN & \\
\hline CHEMBL1987261 & 809133 & 6.0 & 6.4567 & TRN & \\
\hline CHEMBL1975128 & 809133 & 4.1 & 5.0439 & TRN & \\
\hline CHEMBL1996048 & 809133 & 6.6 & 5.8072 & TST & \\
\hline CHEMBL1970369 & 809133 & 4.1 & 3.9518 & TRN & \\
\hline CHEMBL461876 & 809133 & 4.5 & 4.2859 & TST & \\
\hline CHEMBL 2001485 & 809133 & 6.7 & 6.62299 & 9999999999 & TRN \\
\hline CHEMBL504950 & 809133 & 5.3 & 5.0 & TRN & \\
\hline CHEMBL1966425 & 809133 & 5.5 & 5.711 & TRN & \\
\hline CHEMBL1984363 & 809133 & 6.1 & 5.0376 & TRN & \\
\hline CHEMBL1978099 & 809133 & 5.4 & 6.0785 & TRN & \\
\hline CHEMBL1977041 & 809133 & 6.1 & 7.2431 & TRN & \\
\hline CHEMBL1968070 & 809133 & 5.6 & 5.0686 & TRN & \\
\hline CHEMBL1988608 & 809133 & 4.1 & 4.9058 & TRN & \\
\hline CHEMBL184847 & 809133 & 5.4 & 5.1514 & TRN & \\
\hline CHEMBL1984367 & 809133 & 4.1 & 4.4594 & TRN & \\
\hline CHEMBL1985723 & 809133 & 6.5 & 6.5001 & TRN & \\
\hline CHEMBL178737 & 809133 & 4.1 & 4.7495 & TST & \\
\hline CHEMBL 226898 & 809133 & 7.1 & 6.7613 & TRN & \\
\hline CHEMBL1982563 & 809133 & 4.1 & 4.1588 & TRN & \\
\hline CHEMBL539474 & 809133 & 4.1 & 4.3879 & TST & \\
\hline CHEMBL575824 & 809133 & 6.0 & 5.7048 & TRN & \\
\hline CHEMBL1988387 & 809133 & 7.1 & 6.9915 & TRN & \\
\hline CHEMBL1977128 & 809133 & 4.5 & 4.5421 & TRN & \\
\hline CHEMBL1997759 & 809133 & 4.1 & 4.5094 & TRN & \\
\hline CHEMBL1990288 & 809133 & 4.1 & 4.1661 & TRN & \\
\hline CHEMBL1974803 & 809133 & 4.1 & 4.5103 & TST & \\
\hline
\end{tabular}




\begin{tabular}{|c|c|c|c|c|c|}
\hline & & \multicolumn{4}{|c|}{ Supplemental Table S2.txt } \\
\hline CHEMBL1970074 & 809133 & 5.1 & 4.7272 & TRN & \\
\hline CHEMBL1965702 & 809133 & 6.8 & 6.4624 & TRN & \\
\hline CHEMBL1986970 & 809133 & 4.1 & 3.9844 & TRN & \\
\hline CHEMBL2005112 & 809133 & 4.1 & 3.838 & TST & \\
\hline CHEMBL1958401 & 809133 & 4.1 & 4.3591 & TRN & \\
\hline CHEMBL1984044 & 809133 & 4.1 & 4.6035 & TRN & \\
\hline CHEMBL 2003456 & 809133 & 5.3 & 5.3189 & TRN & \\
\hline CHEMBL1966816 & 809133 & 6.8 & 5.9026 & TRN & \\
\hline CHEMBL2002992 & 809133 & 5.6 & 5.6668 & TRN & \\
\hline CHEMBL560813 & 809133 & 4.1 & 4.2761 & TRN & \\
\hline CHEMBL207253 & 809133 & 4.1 & 4.3426 & TST & \\
\hline CHEMBL1890036 & 809133 & 4.1 & 4.1431 & TST & \\
\hline CHEMBL1990635 & 809133 & 5.4 & 4.7336 & TST & \\
\hline CHEMBL1968791 & 809133 & 5.8 & 5.5418 & TRN & \\
\hline CHEMBL326282 & 809133 & 4.1 & 4.1766 & TST & \\
\hline CHEMBL 2002682 & 809133 & 5.4 & 4.3871 & TST & \\
\hline CHEMBL1992732 & 809133 & 4.1 & 4.3948 & TST & \\
\hline CHEMBL1971186 & 809133 & 4.1 & 4.2971 & TRN & \\
\hline CHEMBL2003482 & 809133 & 4.1 & 3.8672 & TRN & \\
\hline CHEMBL 2006456 & 809133 & 6.4 & 6.4964 & TRN & \\
\hline CHEMBL1973211 & 809133 & 6.4 & 5.8152 & TRN & \\
\hline CHEMBL1984700 & 809133 & 4.1 & 3.9854 & TRN & \\
\hline CHEMBL 2007151 & 809133 & 5.3 & 5.3622 & TRN & \\
\hline CHEMBL1998953 & 809133 & 6.9 & 6.4506 & TRN & \\
\hline CHEMBL1972125 & 809133 & 5.5 & 4.5049 & TRN & \\
\hline CHEMBL1461728 & 809133 & 4.1 & 4.1402 & TRN & \\
\hline CHEMBL1976134 & 809133 & 5.9 & 5.6076 & TRN & \\
\hline CHEMBL1965131 & 809133 & 5.3 & 5.3221 & TST & \\
\hline CHEMBL1995448 & 809133 & 4.1 & 4.1847 & TRN & \\
\hline CHEMBL1972158 & 809133 & 4.1 & 4.5776 & TRN & \\
\hline CHEMBL1974457 & 809133 & 4.1 & 4.2516 & TRN & \\
\hline CHEMBL 2006580 & 809133 & 4.1 & 4.0743 & TRN & \\
\hline CHEMBL1999414 & 809133 & 7.1 & 6.5854 & TRN & \\
\hline CHEMBL2001228 & 809133 & 4.5 & 5.9134 & TRN & \\
\hline CHEMBL 2006581 & 809133 & 4.1 & 4.5451 & TRN & \\
\hline CHEMBL 2006481 & 809133 & 4.1 & 3.99600 & 00000000004 & TRN \\
\hline CHEMBL1979855 & 809133 & 5.8 & 4.2055 & TST & \\
\hline CHEMBL1970340 & 809133 & 5.2 & 5.1366 & TRN & \\
\hline CHEMBL2005186 & 809133 & 5.6 & 4.4908 & TRN & \\
\hline CHEMBL1995927 & 809133 & 4.1 & 3.7211 & TST & \\
\hline CHEMBL2006450 & 809133 & 4.5 & 4.4985 & TRN & \\
\hline CHEMBL1975534 & 809133 & 4.1 & 4.7993 & TRN & \\
\hline CHEMBL1993424 & 809133 & 6.4 & 5.8498 & TRN & \\
\hline CHEMBL1966703 & 809133 & 4.1 & 4.3899 & TST & \\
\hline CHEMBL1969561 & 809133 & 4.1 & 4.2909 & TRN & \\
\hline CHEMBL1975121 & 809133 & 4.1 & 4.3017 & TRN & \\
\hline CHEMBL1997023 & 809133 & 4.1 & 4.2906 & TST & \\
\hline CHEMBL1964687 & 809133 & 4.1 & 4.6974 & TRN & \\
\hline
\end{tabular}




\begin{tabular}{|c|c|c|c|c|c|}
\hline \\
\hline CHEMBL1971943 & 809133 & 6.3 & 5.5633 & TRN & \\
\hline CHEMBL1999918 & 809133 & 5.8 & 5.684 & TRN & \\
\hline CHEMBL1974254 & 809133 & 7.5 & 7.2029 & TRN & \\
\hline CHEMBL1997924 & 809133 & 8.8 & 4.7963 & TST & \\
\hline CHEMBL1988537 & 809133 & 6.1 & 5.2797 & TST & \\
\hline CHEMBL1969049 & 809133 & 4.1 & 4.3588 & TRN & \\
\hline CHEMBL 2005828 & 809133 & 6.1 & 6.2997 & TRN & \\
\hline CHEMBL 2002240 & 809133 & 4.1 & 3.5677 & TRN & \\
\hline CHEMBL1978267 & 809133 & 6.6 & 6.0029 & TRN & \\
\hline CHEMBL1991143 & 809133 & 4.1 & 3.7031 & TST & \\
\hline CHEMBL1980178 & 809133 & 6.5 & 6.3987 & TRN & \\
\hline CHEMBL1998611 & 809133 & 5.6 & 5.3561 & TST & \\
\hline CHEMBL485556 & 809133 & 4.1 & 3.7526 & TST & \\
\hline CHEMBL1975900 & 809133 & 4.1 & 3.8961 & TRN & \\
\hline CHEMBL 255822 & 809133 & 4.1 & 3.8728 & TRN & \\
\hline CHEMBL1972221 & 809133 & 4.1 & 4.0995 & TRN & \\
\hline CHEMBL 2006778 & 809133 & 7.2 & 6.6581 & TRN & \\
\hline CHEMBL378627 & 809133 & 4.1 & 3.9418 & TRN & \\
\hline CHEMBL1996979 & 809133 & 4.2 & 5.49700 & 0000000001 & TRN \\
\hline CHEMBL1997025 & 809133 & 4.1 & 4.6817 & TRN & \\
\hline CHEMBL1968406 & 809133 & 4.1 & 4.7241 & TRN & \\
\hline CHEMBL1982476 & 809133 & 7.7 & 7.1626 & TRN & \\
\hline CHEMBL1984274 & 809133 & 4.1 & 4.5799 & TST & \\
\hline CHEMBL1998545 & 809133 & 4.1 & 3.7896 & TRN & \\
\hline CHEMBL1986869 & 809133 & 4.1 & 4.0867 & TRN & \\
\hline CHEMBL2006010 & 809133 & 5.4 & 4.7839 & TRN & \\
\hline CHEMBL1682558 & 809133 & 4.1 & 4.129 & TRN & \\
\hline CHEMBL1990496 & 809133 & 4.3 & 4.8758 & TRN & \\
\hline CHEMBL1997623 & 809133 & 4.1 & 5.3195 & TRN & \\
\hline CHEMBL2002479 & 809133 & 5.2 & 5.5053 & TRN & \\
\hline CHEMBL1993166 & 809133 & 6.5 & 6.1432 & TRN & \\
\hline CHEMBL1967094 & 809133 & 4.1 & 4.7167 & TRN & \\
\hline CHEMBL1966035 & 809133 & 4.1 & 3.6429 & TRN & \\
\hline CHEMBL2003341 & 809133 & 4.1 & 3.8418 & TRN & \\
\hline CHEMBL1992645 & 809133 & 4.1 & 3.8382 & TST & \\
\hline CHEMBL1982992 & 809133 & 4.1 & 4.7188 & TRN & \\
\hline CHEMBL1999590 & 809133 & 4.1 & 4.4157 & TST & \\
\hline CHEMBL1981079 & 809133 & 4.2 & 3.3161 & TRN & \\
\hline CHEMBL1978166 & 809133 & 4.6 & 6.4953 & TRN & \\
\hline CHEMBL1972276 & 809133 & 4.1 & 4.2033 & TRN & \\
\hline CHEMBL1980489 & 809133 & 4.1 & 3.7693 & TRN & \\
\hline CHEMBL 2000832 & 809133 & 5.5 & 4.9854 & TRN & \\
\hline CHEMBL1967116 & 809133 & 7.7 & 7.4266 & TRN & \\
\hline CHEMBL1977814 & 809133 & 4.1 & 4.2565 & TST & \\
\hline CHEMBL513846 & 809133 & 4.1 & 4.6453 & TRN & \\
\hline CHEMBL1970709 & 809133 & 4.1 & 4.2537 & TRN & \\
\hline CHEMBL1965660 & 809133 & 4.5 & 3.9339 & TRN & \\
\hline CHEMBL1998112 & 809133 & 4.1 & 4.648 & TRN & \\
\hline
\end{tabular}




\begin{tabular}{|c|c|c|c|c|}
\hline \multicolumn{5}{|c|}{ Supplemental Table S2.txt } \\
\hline CHEMBL1972290 & 809133 & 7.0 & 6.7149 & TRN \\
\hline CHEMBL1969126 & 809133 & 4.1 & 4.0447 & TRN \\
\hline CHEMBL1980896 & 809133 & 4.1 & 4.4161 & TRN \\
\hline CHEMBL1975208 & 809133 & 4.1 & 3.8535 & TST \\
\hline CHEMBL1970104 & 809133 & 6.2 & 6.0888 & TRN \\
\hline CHEMBL1991429 & 809133 & 5.2 & 6.0641 & TRN \\
\hline CHEMBL1964777 & 809133 & 4.1 & 4.6834 & TRN \\
\hline CHEMBL1971149 & 809133 & 4.1 & 3.8152 & TRN \\
\hline CHEMBL1999714 & 809133 & 4.1 & 3.8829 & TRN \\
\hline CHEMBL1994040 & 809133 & 4.1 & 4.1386 & TRN \\
\hline CHEMBL388978 & 809133 & 9.4 & 8.6622 & TST \\
\hline CHEMBL1984548 & 809133 & 8.4 & 7.7822 & TRN \\
\hline CHEMBL579246 & 809133 & 6.1 & 5.8486 & TRN \\
\hline CHEMBL398951 & 809133 & 4.1 & 5.0573 & TST \\
\hline CHEMBL1982506 & 809133 & 5.9 & 5.0616 & TST \\
\hline CHEMBL 2004716 & 809133 & 6.4 & 6.8039 & TRN \\
\hline CHEMBL1968127 & 809133 & 4.1 & 4.0397 & TRN \\
\hline CHEMBL1975233 & 809133 & 4.1 & 4.4492 & TRN \\
\hline CHEMBL1985406 & 809133 & 4.1 & 4.6593 & TRN \\
\hline CHEMBL 207400 & 809133 & 4.1 & 3.8464 & TST \\
\hline CHEMBL 2000894 & 809133 & 5.4 & 4.7712 & TST \\
\hline CHEMBL 2002553 & 809133 & 4.1 & 3.8768 & TST \\
\hline CHEMBL1982135 & 809133 & 5.1 & 5.3076 & TRN \\
\hline CHEMBL1976090 & 809133 & 5.5 & 5.4473 & TRN \\
\hline CHEMBL1993243 & 809133 & 5.4 & 5.2133 & TRN \\
\hline CHEMBL 2004771 & 809133 & 4.1 & 5.4776 & TRN \\
\hline CHEMBL1992922 & 809133 & 6.9 & 6.7683 & TRN \\
\hline CHEMBL399021 & 809133 & 5.7 & 5.6776 & TRN \\
\hline CHEMBL1997597 & 809133 & 4.1 & 3.8193 & TRN \\
\hline CHEMBL1969537 & 809133 & 4.1 & 4.5585 & TST \\
\hline CHEMBL1976093 & 809133 & 4.1 & 4.0367 & TRN \\
\hline CHEMBL210032 & 809133 & 4.1 & 4.1701 & TRN \\
\hline CHEMBL1996543 & 809133 & 4.1 & 4.8541 & TRN \\
\hline CHEMBL1975256 & 809133 & 4.1 & 3.8781 & TST \\
\hline CHEMBL508928 & 809133 & 6.8 & 6.1255 & TRN \\
\hline CHEMBL1991356 & 809133 & 4.1 & 4.1188 & TST \\
\hline CHEMBL1983309 & 809133 & 4.1 & 3.9418 & TRN \\
\hline CHEMBL 2004892 & 809133 & 4.1 & 4.1345 & TRN \\
\hline CHEMBL1999126 & 809133 & 5.1 & 4.056 & TST \\
\hline CHEMBL1997503 & 809133 & 4.1 & 4.4581 & TST \\
\hline CHEMBL1972339 & 809133 & 6.3 & 5.3362 & TRN \\
\hline CHEMBL116070 & 809133 & 4.1 & 4.4583 & TRN \\
\hline CHEMBL1990821 & 809133 & 4.1 & 4.1923 & TST \\
\hline CHEMBL1970314 & 809133 & 4.1 & 4.1551 & TRN \\
\hline CHEMBL 2004871 & 809133 & 4.1 & 4.1141 & TRN \\
\hline CHEMBL 2004872 & 809133 & 4.1 & 4.192 & TRN \\
\hline CHEMBL1727312 & 809133 & 4.1 & 3.908 & TRN \\
\hline CHEMBL1969879 & 809133 & 4.1 & 4.5214 & TRN \\
\hline
\end{tabular}




\begin{tabular}{|c|c|c|c|c|c|}
\hline \\
\hline CHEMBL1981720 & 809133 & 5.9 & 5.6371 & TRN & \\
\hline CHEMBL419932 & 809133 & 4.1 & 4.1572 & TRN & \\
\hline CHEMBL262433 & 809133 & 5.3 & 4.7074 & TRN & \\
\hline CHEMBL 306380 & 809133 & 5.4 & 4.9451 & TRN & \\
\hline CHEMBL1966722 & 809133 & 5.6 & 4.9967 & TST & \\
\hline CHEMBL1983595 & 809133 & 4.5 & 4.3848 & TRN & \\
\hline CHEMBL1975500 & 809133 & 4.1 & 4.6844 & TRN & \\
\hline CHEMBL1976328 & 809133 & 4.1 & 4.5269 & TRN & \\
\hline CHEMBL394619 & 809133 & 5.4 & 5.5246 & TRN & \\
\hline CHEMBL1964399 & 809133 & 4.1 & 4.8092 & TRN & \\
\hline CHEMBL1996831 & 809133 & 4.1 & 4.0041 & TST & \\
\hline CHEMBL411903 & 809133 & 6.5 & 6.1252 & TRN & \\
\hline CHEMBL1980253 & 809133 & 6.9 & 6.5526 & TRN & \\
\hline CHEMBL1965988 & 809133 & 5.9 & 6.3875 & TRN & \\
\hline CHEMBL418203 & 809133 & 4.5 & 4.9903 & TST & \\
\hline CHEMBL1989646 & 809133 & 4.1 & 4.087 & TRN & \\
\hline CHEMBL1682357 & 809133 & 4.1 & 4.36 & TRN & \\
\hline CHEMBL225519 & 809133 & 4.4 & 4.3408 & TRN & \\
\hline CHEMBL 209534 & 809133 & 4.1 & 4.4251 & TRN & \\
\hline CHEMBL1978200 & 809133 & 4.1 & 3.9426 & TRN & \\
\hline CHEMBL 2006631 & 809133 & 4.1 & 3.9908 & TRN & \\
\hline CHEMBL1970522 & 809133 & 4.1 & 4.1827 & TRN & \\
\hline CHEMBL1990415 & 809133 & 4.1 & 4.4255 & TRN & \\
\hline CHEMBL1966087 & 809133 & 4.1 & 4.0823 & TRN & \\
\hline CHEMBL1964692 & 809133 & 4.1 & 4.8861 & TRN & \\
\hline CHEMBL1996931 & 809133 & 4.1 & 3.7173 & TRN & \\
\hline CHEMBL1964413 & 809133 & 4.1 & 3.7378 & TRN & \\
\hline CHEMBL1973483 & 809133 & 5.2 & 4.8116 & TRN & \\
\hline CHEMBL1998470 & 809133 & 4.5 & 4.5455 & TRN & \\
\hline CHEMBL1996980 & 809133 & 6.8 & 7.3968 & TRN & \\
\hline CHEMBL1984432 & 809133 & 4.1 & 3.9827 & TRN & \\
\hline CHEMBL1970735 & 809133 & 4.1 & 3.8975 & TRN & \\
\hline CHEMBL 219722 & 809133 & 6.2 & 6.7538 & TRN & \\
\hline CHEMBL1994669 & 809133 & 8.5 & 8.23200 & 0000000001 & TRN \\
\hline CHEMBL1997340 & 809133 & 4.1 & 3.9019 & TRN & \\
\hline CHEMBL2004365 & 809133 & 4.1 & 4.1998 & TST & \\
\hline CHEMBL1522508 & 809133 & 4.1 & 3.4223 & TRN & \\
\hline CHEMBL1989474 & 809133 & 4.5 & 3.8203 & TRN & \\
\hline CHEMBL1090360 & 809133 & 6.2 & 5.9425 & TRN & \\
\hline CHEMBL210887 & 809133 & 4.1 & 4.1753 & TST & \\
\hline CHEMBL458997 & 809133 & 4.7 & 5.541 & TRN & \\
\hline CHEMBL1971021 & 809133 & 4.1 & 4.5161 & TRN & \\
\hline CHEMBL227271 & 809133 & 6.6 & 6.8735 & TRN & \\
\hline CHEMBL583144 & 809133 & 4.1 & 4.1138 & TST & \\
\hline CHEMBL1974310 & 809133 & 5.4 & 4.8809 & TRN & \\
\hline CHEMBL1982660 & 809133 & 6.3 & 5.3025 & TRN & \\
\hline CHEMBL1994693 & 809133 & 5.4 & 6.0009 & TRN & \\
\hline CHEMBL1982957 & 809133 & 7.1 & 7.1965 & TRN & \\
\hline
\end{tabular}




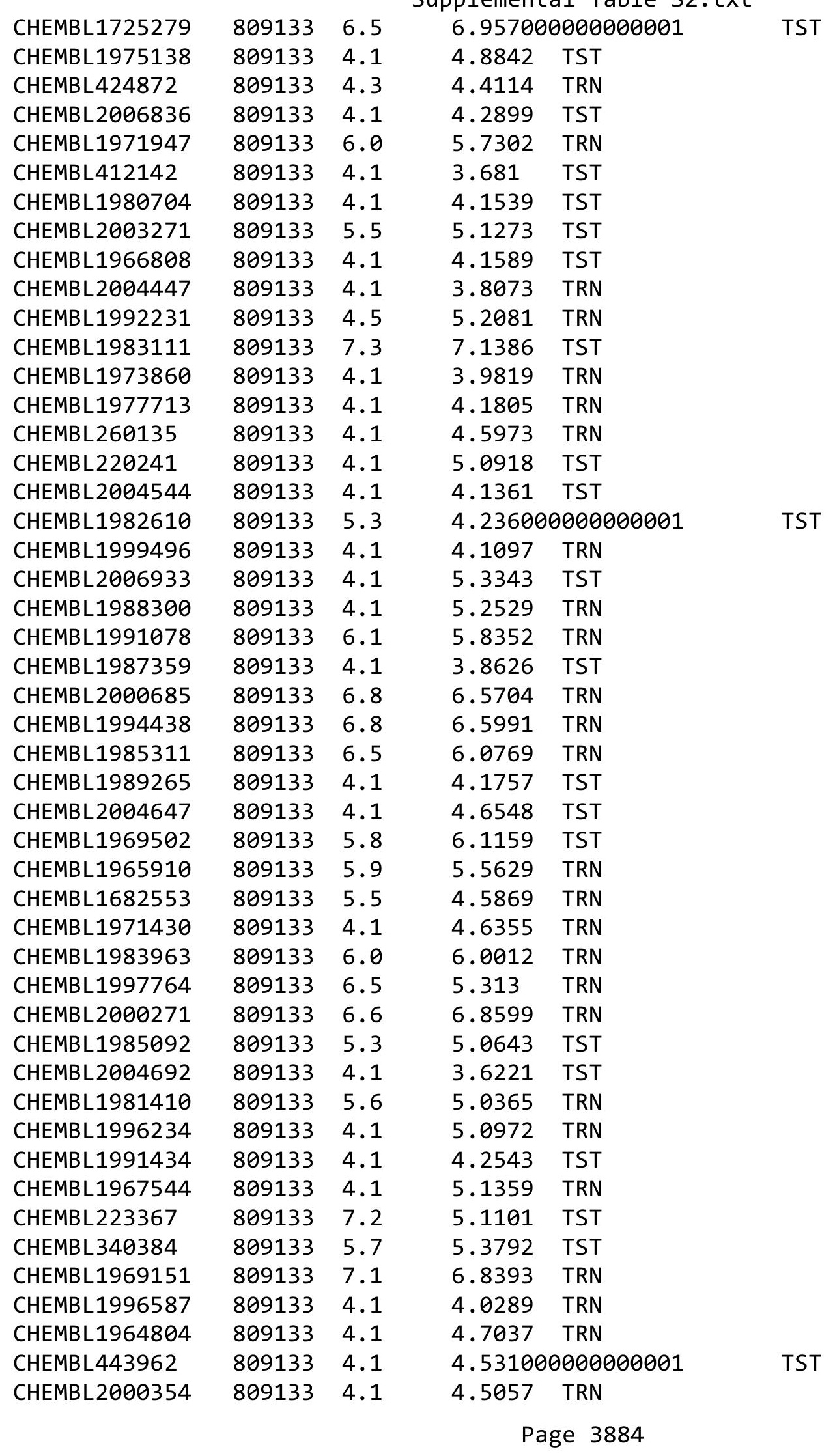




\begin{tabular}{|c|c|c|c|c|c|}
\hline & & & & & \\
\hline CHEMBL1965507 & 809133 & 6.6 & 6.4525 & TRN & \\
\hline CHEMBL 274064 & 809133 & 5.5 & 5.1856 & TRN & \\
\hline CHEMBL1967564 & 809133 & 4.1 & 3.94199 & 99999999997 & TRN \\
\hline CHEMBL592030 & 809133 & 6.3 & 6.08299 & 9999999999 & TST \\
\hline CHEMBL 2000071 & 809133 & 6.9 & 6.3853 & TRN & \\
\hline CHEMBL1979176 & 809133 & 4.1 & 4.1637 & TRN & \\
\hline CHEMBL1970317 & 809133 & 7.6 & 7.7185 & TRN & \\
\hline CHEMBL 2002613 & 809133 & 4.5 & 4.3886 & TRN & \\
\hline CHEMBL 2000408 & 809133 & 4.1 & 4.4254 & TRN & \\
\hline CHEMBL248757 & 809133 & 7.2 & 4.9666 & TST & \\
\hline CHEMBL1978014 & 809133 & 4.1 & 3.9032 & TRN & \\
\hline CHEMBL1994538 & 809133 & 5.4 & 5.0389 & TRN & \\
\hline CHEMBL1983195 & 809133 & 4.1 & 3.6629 & TST & \\
\hline CHEMBL1975490 & 809133 & 5.1 & 5.5483 & TRN & \\
\hline CHEMBL1964444 & 809133 & 6.8 & 5.4858 & TRN & \\
\hline CHEMBL1989957 & 809133 & 4.1 & 3.8638 & TRN & \\
\hline CHEMBL 2006567 & 809133 & 4.1 & 3.9708 & TRN & \\
\hline CHEMBL1986139 & 809133 & 4.1 & 3.8559 & TRN & \\
\hline CHEMBL1980540 & 809133 & 4.1 & 4.8084 & TRN & \\
\hline CHEMBL 278041 & 809133 & 4.6 & 4.6395 & TRN & \\
\hline CHEMBL1979883 & 809133 & 6.0 & 5.744 & TRN & \\
\hline CHEMBL1984162 & 809133 & 6.3 & 6.528 & TRN & \\
\hline CHEMBL1997051 & 809133 & 6.6 & 6.2686 & TRN & \\
\hline CHEMBL1998432 & 809133 & 7.5 & 7.0238 & TRN & \\
\hline CHEMBL491758 & 809133 & 5.7 & 5.5016 & TRN & \\
\hline CHEMBL549730 & 809133 & 4.1 & 3.5281 & TRN & \\
\hline CHEMBL1682360 & 809133 & 4.1 & 4.7587 & TRN & \\
\hline CHEMBL1970189 & 809133 & 4.1 & 4.2567 & TRN & \\
\hline CHEMBL1996791 & 809133 & 5.3 & 4.7751 & TRN & \\
\hline CHEMBL371206 & 809133 & 5.4 & 5.609 & TRN & \\
\hline CHEMBL1974664 & 809133 & 5.6 & 4.3616 & TST & \\
\hline CHEMBL406845 & 809133 & 4.6 & 4.5661 & TRN & \\
\hline CHEMBL1974288 & 809133 & 4.1 & 4.3818 & TRN & \\
\hline CHEMBL196363 & 809133 & 6.3 & 5.9009 & TRN & \\
\hline CHEMBL1190711 & 809133 & 5.8 & 4.9349 & TRN & \\
\hline CHEMBL1968705 & 809133 & 5.8 & 5.3101 & TRN & \\
\hline CHEMBL1991410 & 809133 & 4.5 & 4.3706 & TRN & \\
\hline CHEMBL404367 & 809133 & 5.2 & 5.2982 & TRN & \\
\hline CHEMBL1966343 & 809133 & 4.1 & 4.6709 & TRN & \\
\hline CHEMBL1967887 & 809133 & 5.6 & 5.6419 & TRN & \\
\hline CHEMBL 2000568 & 809133 & 5.3 & 5.1529 & TRN & \\
\hline CHEMBL 2000335 & 809133 & 6.7 & 6.358 & TRN & \\
\hline CHEMBL1977604 & 809133 & 4.1 & 3.9983 & TST & \\
\hline CHEMBL1988717 & 809133 & 6.3 & 6.0197 & TRN & \\
\hline CHEMBL1974328 & 809133 & 6.9 & 6.686 & TRN & \\
\hline CHEMBL509032 & 809133 & 6.9 & 7.2897 & TRN & \\
\hline CHEMBL 243298 & 809133 & 4.5 & 5.5912 & TRN & \\
\hline CHEMBL1973808 & 809133 & 4.1 & 4.13899 & 9999999999 & TRN \\
\hline & & & & e 3885 & \\
\hline
\end{tabular}




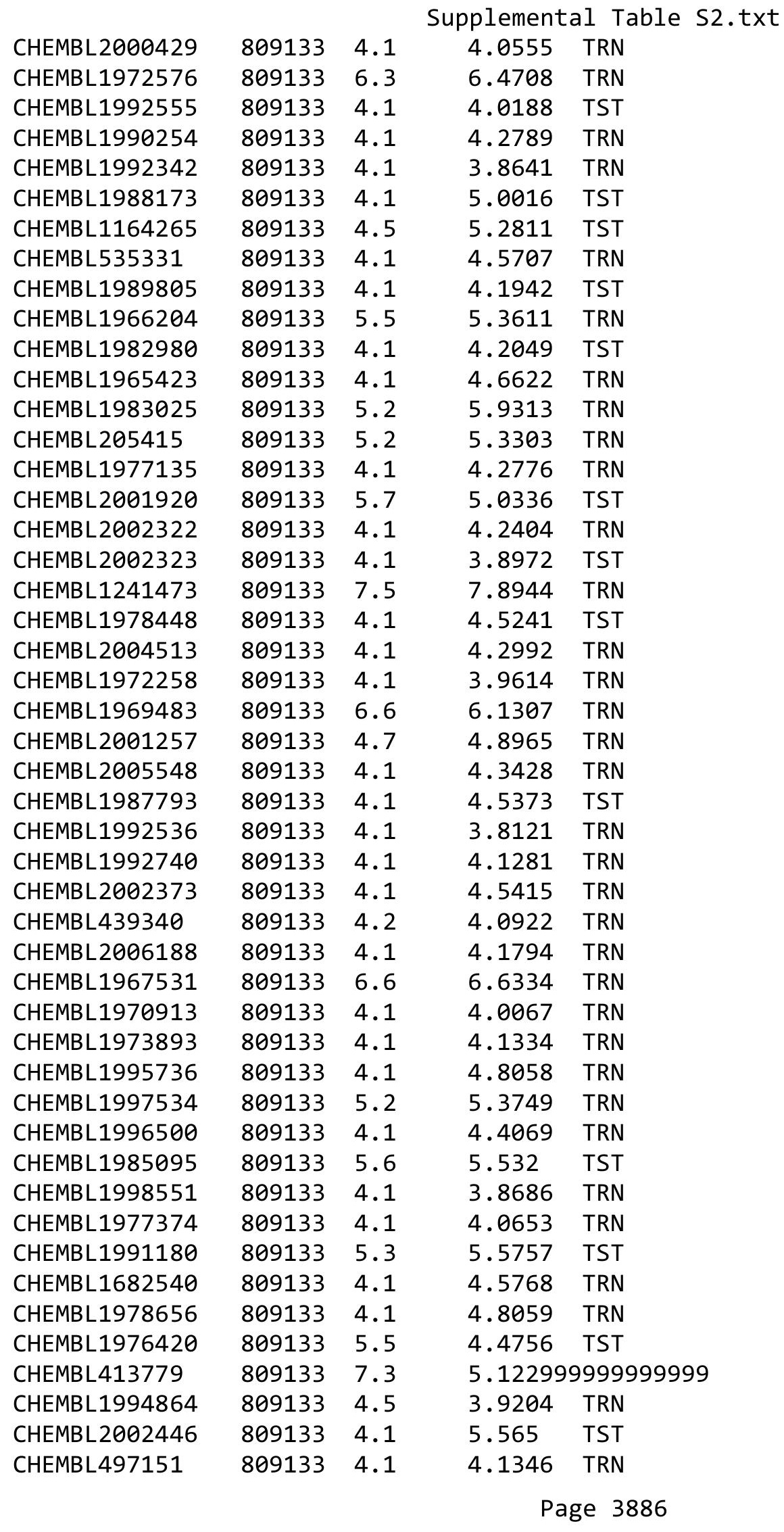




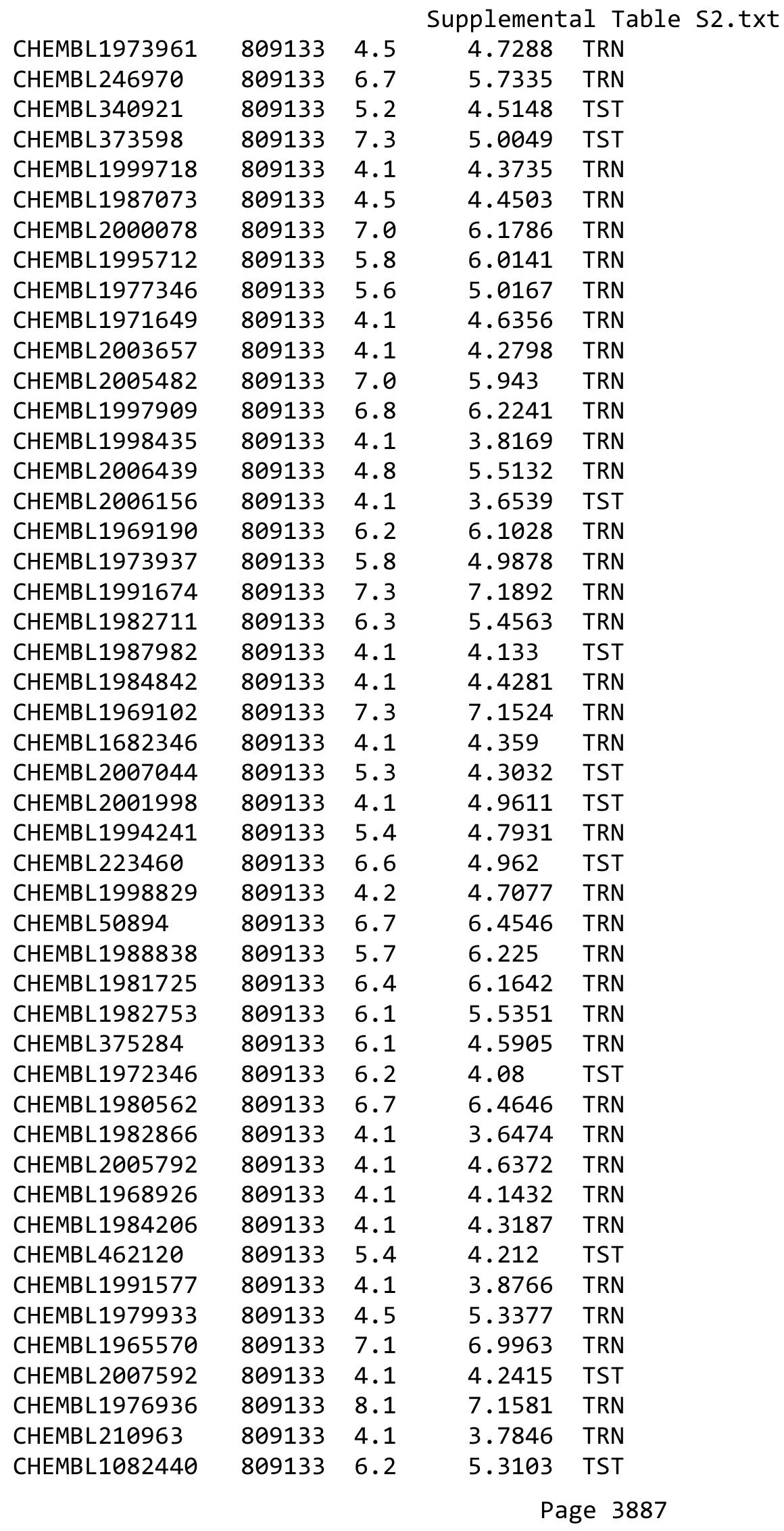




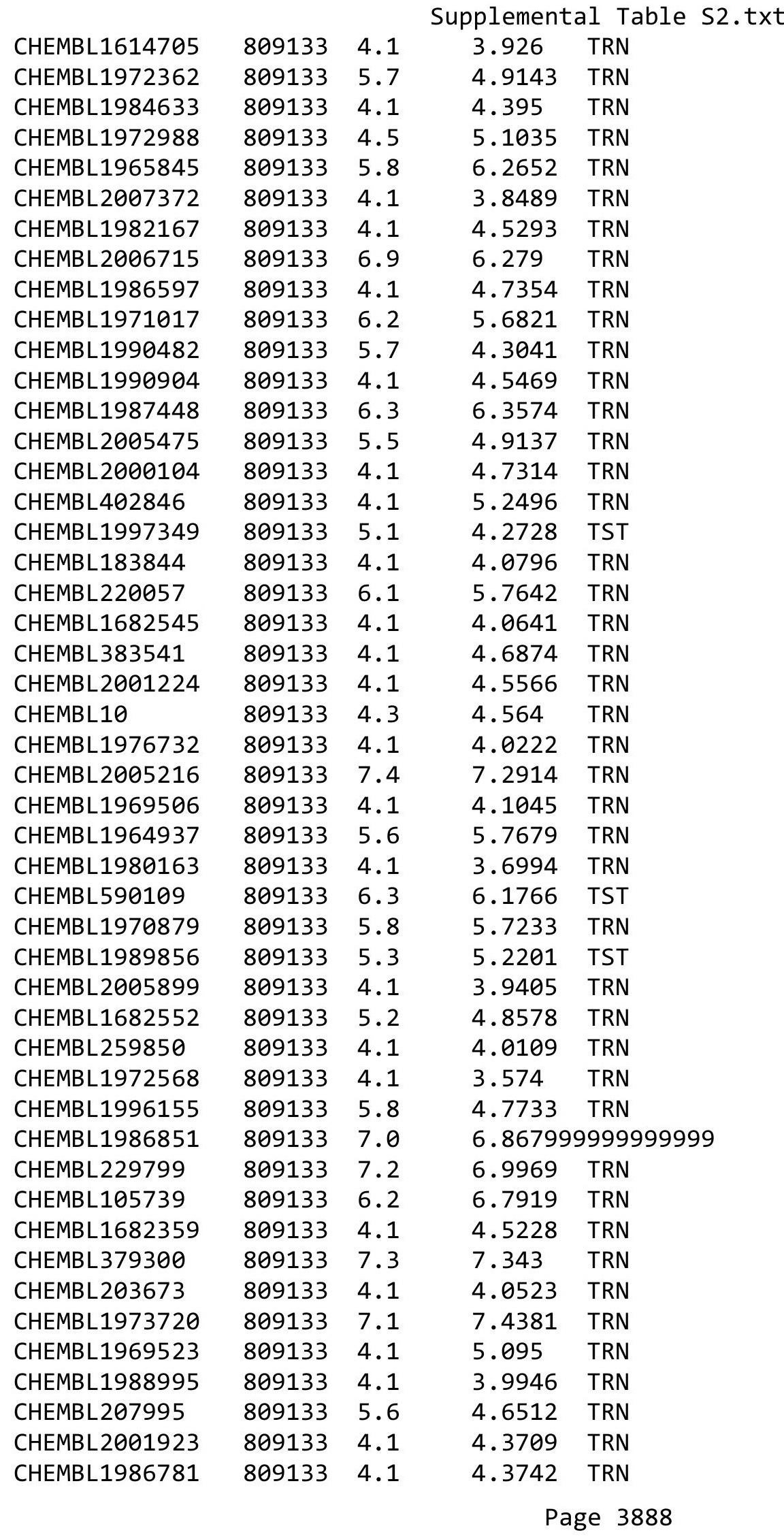




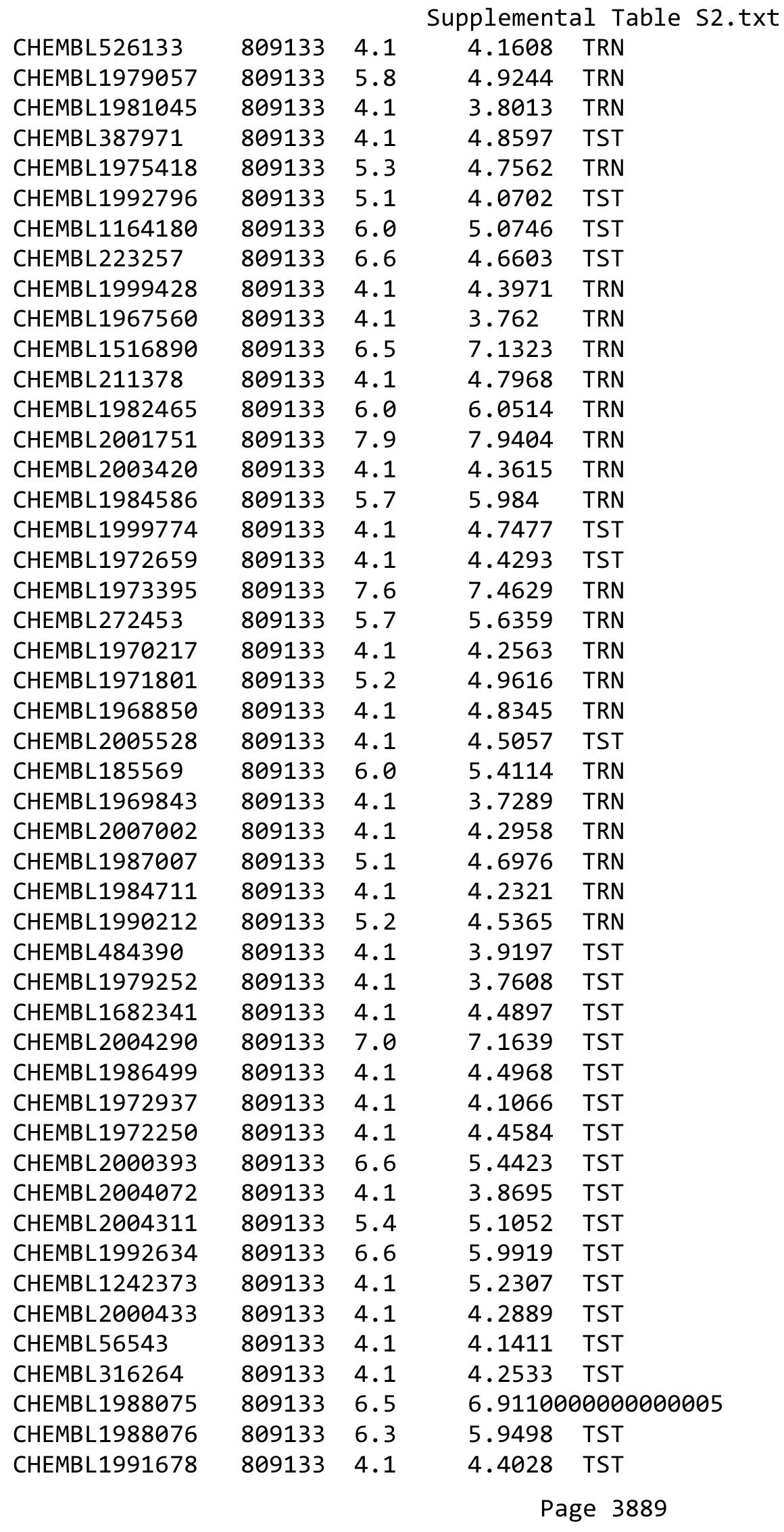




\begin{tabular}{|c|c|c|c|c|c|}
\hline & & & & & \\
\hline CHEMBL 2001239 & 809133 & 5.4 & 4.9119 & TST & \\
\hline CHEMBL1988594 & 809133 & 6.5 & 7.1238 & TST & \\
\hline CHEMBL 2001288 & 809133 & 4.1 & 4.4159 & TST & \\
\hline CHEMBL1992363 & 809133 & 6.0 & 5.6467 & TST & \\
\hline CHEMBL 260092 & 809133 & 6.4 & 6.1615 & TST & \\
\hline CHEMBL1999811 & 809133 & 4.1 & 4.5197 & TST & \\
\hline CHEMBL1965495 & 809133 & 5.6 & 5.50899 & 99999999995 & TST \\
\hline CHEMBL1985074 & 809133 & 4.1 & 3.9845 & TST & \\
\hline CHEMBL 2000481 & 809133 & 6.3 & 5.6075 & TST & \\
\hline CHEMBL1982874 & 809133 & 4.1 & 5.0574 & TST & \\
\hline CHEMBL1991725 & 809133 & 4.1 & 5.2117 & TST & \\
\hline CHEMBL194086 & 303563 & 5.2684 & 5.4928 & TRN & \\
\hline CHEMBL373158 & 303563 & 5.4377 & 5.7848 & TRN & \\
\hline CHEMBL365369 & 303563 & 5.3251 & 5.54200 & 0000000001 & TST \\
\hline CHEMBL192385 & 303563 & 5.0958 & 5.3316 & TST & \\
\hline CHEMBL195657 & 303563 & 6.3116 & 6.5621 & TRN & \\
\hline CHEMBL194435 & 303563 & 6.3615 & 6.0463 & TRN & \\
\hline CHEMBL192045 & 303563 & 5.4191 & 5.3189 & TRN & \\
\hline CHEMBL195488 & 303563 & 5.0472 & 5.2901 & TST & \\
\hline CHEMBL179752 & 303563 & 6.0799 & 6.2706 & TRN & \\
\hline CHEMBL194283 & 303563 & 7.301 & 6.8881 & TRN & \\
\hline CHEMBL366231 & 303563 & 5.8153 & 5.8817 & TRN & \\
\hline CHEMBL193810 & 303563 & 5.767 & 5.8817 & TRN & \\
\hline CHEMBL193656 & 303563 & 5.75200 & 00000000 & 5.8197 & TRN \\
\hline CHEMBL194885 & 303563 & 5.9208 & 6.0995 & TRN & \\
\hline CHEMBL192384 & 303563 & 4.2041 & 4.5116 & TRN & \\
\hline CHEMBL195473 & 303563 & 4.9508 & 4.462 & TST & \\
\hline CHEMBL193975 & 303563 & 5.9666 & 6.2269 & TRN & \\
\hline CHEMBL195671 & 303563 & 7.2076 & 6.9206 & TRN & \\
\hline CHEMBL195214 & 303563 & 6.4868 & 6.3644 & TRN & \\
\hline CHEMBL193633 & 303563 & 6.1146 & 6.1772 & TRN & \\
\hline CHEMBL194161 & 303563 & 6.4609 & 6.3247 & TRN & \\
\hline CHEMBL191824 & 303563 & 5.2857 & 5.3866 & TRN & \\
\hline CHEMBL434918 & 303563 & 5.6478 & 5.6854 & TRN & \\
\hline CHEMBL195291 & 303563 & 6.3197 & 6.0648 & TRN & \\
\hline CHEMBL194026 & 303563 & 5.1965 & 5.5048 & TRN & \\
\hline CHEMBL175547 & 303563 & 6.0809 & 6.1086 & TRN & \\
\hline CHEMBL193332 & 303563 & 5.9547 & 5.9359 & TRN & \\
\hline CHEMBL193828 & 303563 & 6.2636 & 6.1576 & TRN & \\
\hline CHEMBL193973 & 303563 & 6.4572 & 6.1761 & TRN & \\
\hline CHEMBL193827 & 303563 & 5.7033 & 5.8353 & TRN & \\
\hline CHEMBL193732 & 303563 & 4.9706 & 5.0829 & TRN & \\
\hline CHEMBL193818 & 303563 & 4.3958 & 4.2815 & TST & \\
\hline CHEMBL195353 & 303563 & 5.7645 & 5.9047 & TRN & \\
\hline CHEMBL195406 & 303563 & 6.224 & 6.0485 & TRN & \\
\hline CHEMBL191828 & 303563 & 5.1107 & 4.9882 & TRN & \\
\hline CHEMBL193369 & 303563 & 5.475 & 5.0325 & TRN & \\
\hline CHEMBL193931 & 303563 & 5.9031 & 5.8543 & TRN & \\
\hline
\end{tabular}




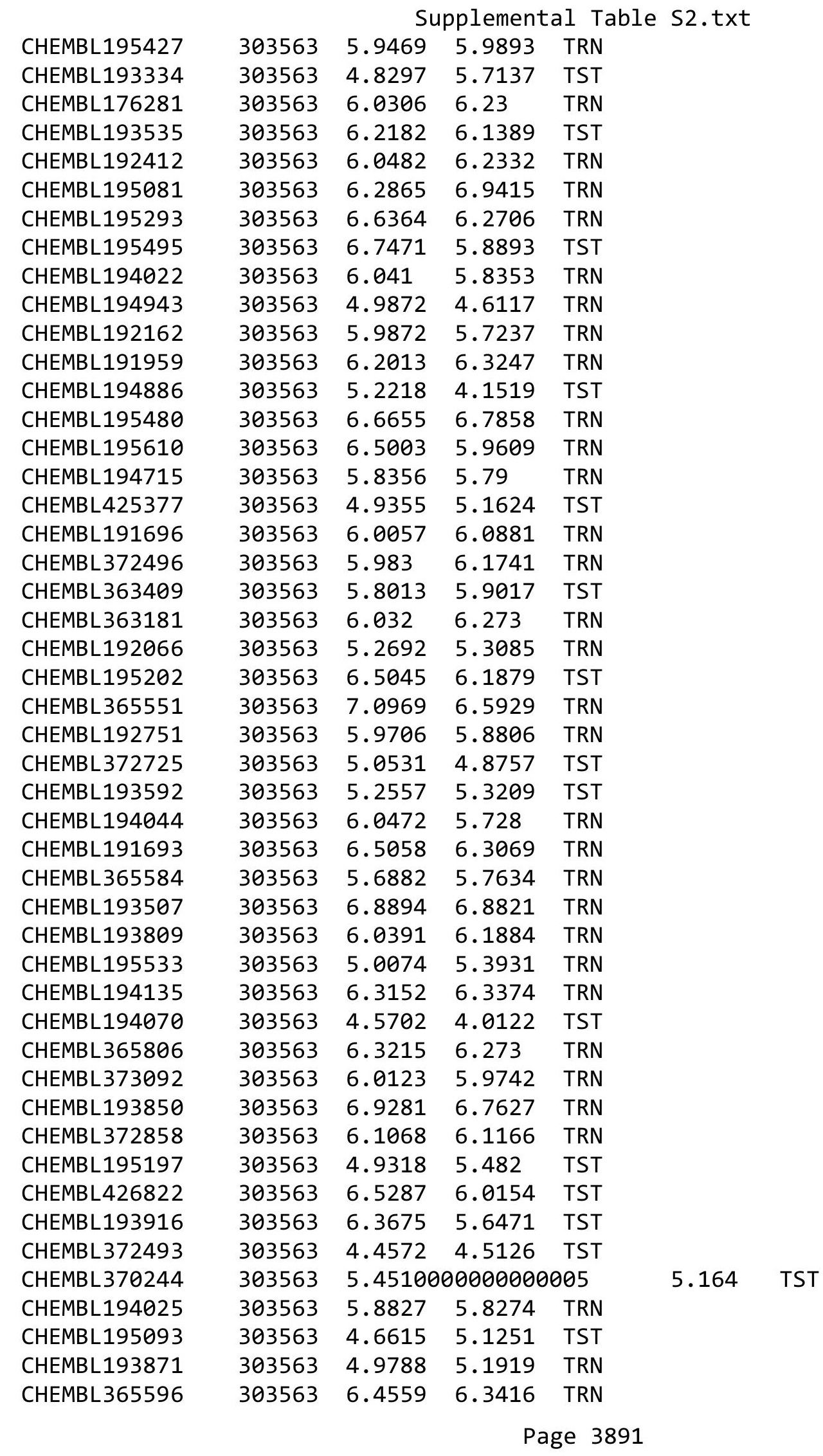




\begin{tabular}{|c|c|c|c|c|c|}
\hline & & & & & \\
\hline CHEMBL194040 & 303563 & 5.8827 & 6.0772 & TRN & \\
\hline CHEMBL193991 & 303563 & 5.7773 & 6.1389 & TST & \\
\hline CHEMBL193938 & 303563 & 6.6498 & 6.9311 & TRN & \\
\hline CHEMBL364047 & 303563 & 6.4634 & 6.5105 & TRN & \\
\hline CHEMBL191719 & 303563 & 5.9508 & 5.9242 & TRN & \\
\hline CHEMBL427357 & 303563 & 6.4056 & 6.1312 & TST & \\
\hline CHEMBL92309 & 954552 & 2.7081 & 2.5413 & TST & \\
\hline CHEMBL449158 & 954552 & 6.6732 & 7.5852 & TST & \\
\hline CHEMBL 373751 & 954552 & 3.2478 & 3.2656 & TRN & \\
\hline CHEMBL1404918 & 954552 & 2.6079 & 2.57899 & 99999999997 & TRN \\
\hline CHEMBL412142 & 954552 & 5.1949 & 5.2033 & TRN & \\
\hline CHEMBL483847 & 954552 & 3.6946 & 3.7155 & TRN & \\
\hline CHEMBL217354 & 954552 & 6.6379 & 6.6686 & TRN & \\
\hline CHEMBL3199475 & 954552 & 4.4248 & 4.4337 & TRN & \\
\hline CHEMBL 2144069 & 954552 & 5.4925 & 5.4995 & TRN & \\
\hline CHEMBL1909414 & 954552 & 6.1322 & 6.1809 & TRN & \\
\hline CHEMBL379975 & 954552 & 5.6526 & 5.6539 & TRN & \\
\hline CHEMBL1190711 & 954552 & 5.7227 & 5.7277 & TRN & \\
\hline CHEMBL3392440 & 954552 & 3.7071 & 3.7156 & TRN & \\
\hline CHEMBL1643959 & 954552 & 2.8415 & 2.8631 & TRN & \\
\hline CHEMBL 220241 & 954552 & 3.5767 & 3.5857 & TRN & \\
\hline CHEMBL558642 & 954552 & 3.2542 & 3.2319 & TRN & \\
\hline CHEMBL1230020 & 954552 & 4.757 & 4.7485 & TRN & \\
\hline CHEMBL 300389 & 954552 & 6.3028 & 6.3412 & TRN & \\
\hline CHEMBL1970879 & 954552 & 3.3011 & 3.2872 & TRN & \\
\hline CHEMBL191334 & 954552 & 3.2378 & 3.208 & TRN & \\
\hline CHEMBL1242367 & 954552 & 3.2465 & 3.2526 & TRN & \\
\hline CHEMBL392695 & 954552 & 3.266 & 3.2386 & TRN & \\
\hline CHEMBL573107 & 954552 & 4.9932 & 4.9775 & TRN & \\
\hline CHEMBL483849 & 954552 & 2.6723 & 1.2647 & TST & \\
\hline CHEMBL 255342 & 954552 & 3.0865 & 3.0589 & TRN & \\
\hline CHEMBL515416 & 954552 & 4.7527 & 4.7752 & TRN & \\
\hline CHEMBL9470 & 954552 & 5.1987 & 5.6724 & TST & \\
\hline CHEMBL577784 & 954552 & 5.3958 & 5.3769 & TRN & \\
\hline CHEMBL210618 & 954552 & 4.2236 & 4.2375 & TRN & \\
\hline CHEMBL509032 & 954552 & 4.9588 & 4.9588 & TRN & \\
\hline CHEMBL221137 & 954552 & 4.9304 & 4.1878 & TST & \\
\hline CHEMBL259181 & 954552 & 2.9529 & 2.9895 & TRN & \\
\hline CHEMBL180127 & 954552 & 2.7772 & 2.8071 & TRN & \\
\hline CHEMBL1673039 & 954552 & 2.9654 & 2.9761 & TRN & \\
\hline CHEMBL1256459 & 954552 & 6.3335 & 6.3372 & TRN & \\
\hline CHEMBL1590308 & 954552 & 2.6101 & 2.7878 & TST & \\
\hline CHEMBL209148 & 954552 & 2.4532 & 2.441 & TRN & \\
\hline CHEMBL393929 & 954552 & 5.2927 & 5.2709 & TRN & \\
\hline CHEMBL192566 & 954552 & 9.5306 & 9.4975 & TST & \\
\hline CHEMBL512504 & 954552 & 4.2294 & 4.2476 & TRN & \\
\hline CHEMBL189584 & 954552 & 3.7806 & 3.7626 & TRN & \\
\hline CHEMBL3349342 & 954552 & 6.9963 & 6.9715 & TRN & \\
\hline
\end{tabular}


Supplemental Table S2.txt

\begin{tabular}{|c|c|c|c|c|}
\hline CHEMBL102714 & 954552 & 4.3203 & 4.3201 & TRN \\
\hline CHEMBL258844 & 954552 & 4.0907 & 4.0833 & TRN \\
\hline CHEMBL202721 & 954552 & 4.8794 & 4.8902 & TRN \\
\hline CHEMBL585951 & 954552 & 6.2 & 6.1899 & TRN \\
\hline CHEMBL 2363137 & 954552 & 5.765 & 5.7476 & TRN \\
\hline CHEMBL1788116 & 954552 & 4.1798 & 4.206 & TRN \\
\hline CHEMBL399530 & 954552 & 4.7365 & 4.71399 & 99999999995 \\
\hline CHEMBL 2137530 & 954552 & 5.0309 & 4.9568 & TRN \\
\hline CHEMBL65 & 954552 & 7.2616 & 7.2655 & TRN \\
\hline CHEMBL1186585 & 954552 & 3.1344 & 3.1754 & TRN \\
\hline CHEMBL472940 & 954552 & 2.5092 & 2.5017 & TRN \\
\hline CHEMBL379300 & 954552 & 6.0796 & 6.0375 & TRN \\
\hline CHEMBL213100 & 954552 & 2.8751 & 2.8765 & TRN \\
\hline CHEMBL1516890 & 954552 & 3.7103 & 4.0142 & TST \\
\hline CHEMBL514499 & 954552 & 6.0466 & 5.5859 & TST \\
\hline CHEMBL222102 & 954552 & 3.733 & 3.009 & TST \\
\hline CHEMBL188678 & 954552 & 4.6956 & 4.3467 & TST \\
\hline CHEMBL240954 & 954552 & 3.0524 & 3.3027 & TST \\
\hline CHEMBL1357247 & 954552 & 3.1745 & 2.5976 & TST \\
\hline CHEMBL 2134202 & 954552 & 3.2966 & 3.3077 & TST \\
\hline CHEMBL 2005886 & 954552 & 3.1961 & 3.6077 & TST \\
\hline CHEMBL3186408 & 954552 & 3.0605 & 3.3761 & TST \\
\hline CHEMBL135561 & 954552 & 4.0688 & 4.0852 & TST \\
\hline CHEMBL3930712 & 1536410 & 9.1549 & 9.1545 & TRN \\
\hline CHEMBL3671821 & 1536410 & 7.7595 & 7.6885 & TST \\
\hline CHEMBL3671798 & 1536410 & 6.9784 & 7.0004 & TST \\
\hline CHEMBL3921778 & 1536410 & 7.4535 & 7.4536 & TRN \\
\hline CHEMBL3904719 & 1536410 & 7.3335 & 7.3335 & TRN \\
\hline CHEMBL3938492 & 1536410 & 8.5376 & 8.5377 & TRN \\
\hline CHEMBL3967051 & 1536410 & 7.9626 & 7.9621 & TRN \\
\hline CHEMBL3666891 & 1536410 & 7.8962 & 8.0718 & TST \\
\hline CHEMBL 3671790 & 1536410 & 9.0 & 8.8223 & TST \\
\hline CHEMBL3958599 & 1536410 & 7.1209 & 7.1206 & TRN \\
\hline CHEMBL3914475 & 1536410 & 9.2218 & 9.2215 & TRN \\
\hline CHEMBL3903392 & 1536410 & 6.5875 & 6.5878 & TRN \\
\hline CHEMBL3920984 & 1536410 & 8.8861 & 8.8865 & TRN \\
\hline CHEMBL3671799 & 1536410 & 7.1129 & 8.4206 & TST \\
\hline CHEMBL3904112 & 1536410 & 6.6442 & 6.6442 & TRN \\
\hline CHEMBL3984096 & 1536410 & 7.1586 & 7.159 & TRN \\
\hline CHEMBL3905516 & 1536410 & 8.0862 & 8.086 & TRN \\
\hline CHEMBL3671797 & 1536410 & 8.2147 & 8.1023 & TST \\
\hline CHEMBL3906521 & 1536410 & 7.5229 & 7.5229 & TRN \\
\hline CHEMBL3920681 & 1536410 & 10.0 & 10.0 & TRN \\
\hline CHEMBL3671817 & 1536410 & 8.6778 & 9.8793 & TST \\
\hline CHEMBL3915500 & 1536410 & 9.1549 & 9.1549 & TRN \\
\hline CHEMBL3944694 & 1536410 & 6.6216 & 6.6211 & TRN \\
\hline CHEMBL3978708 & 1536410 & 8.4202 & 8.4196 & TRN \\
\hline CHEMBL3931100 & 1536410 & 7.6946 & 7.6951 & TRN \\
\hline
\end{tabular}


Supplemental Table S2.txt

\begin{tabular}{|c|c|c|c|c|c|c|}
\hline CHEMBL3957553 & 1536410 & 7.8665 & 7.8666 & TRN & & \\
\hline CHEMBL3913113 & 1536410 & 6.5969 & 6.5967 & TRN & & \\
\hline CHEMBL3671795 & 1536410 & \multicolumn{3}{|c|}{6.9670000000000005} & 6.2339 & TST \\
\hline CHEMBL 3985562 & 1536410 & 9.1549 & 9.1549 & TRN & & \\
\hline CHEMBL3897444 & 1536410 & 8.8861 & 8.8857 & TRN & & \\
\hline CHEMBL 3671803 & 1536410 & 7.1979 & 8.0733 & TST & & \\
\hline CHEMBL3936572 & 1536410 & 8.3665 & 8.3668 & TRN & & \\
\hline CHEMBL3969688 & 1536410 & 8.8539 & 8.8543 & TRN & & \\
\hline CHEMBL3981118 & 1536410 & \multicolumn{3}{|c|}{7.7620000000000005} & 7.7618 & TRN \\
\hline CHEMBL3945064 & 1536410 & 8.3872 & 8.3871 & TRN & & \\
\hline CHEMBL 3967433 & 1536410 & 8.6576 & 8.6577 & TRN & & \\
\hline CHEMBL3893779 & 1536410 & 7.6003 & 7.5999 & TRN & & \\
\hline CHEMBL3671796 & 1536410 & 7.1403 & 7.33799 & 9999999999 & & \\
\hline CHEMBL 3943461 & 1536410 & 8.5686 & 8.5685 & TRN & & \\
\hline CHEMBL3671822 & 1536410 & 7.4283 & 7.334 & TST & & \\
\hline CHEMBL3972970 & 1536410 & 7.0762 & 7.0764 & TRN & & \\
\hline CHEMBL3963453 & 1536410 & 8.585 & 8.585 & TRN & & \\
\hline CHEMBL3937904 & 1536410 & 8.2366 & 8.2369 & TRN & & \\
\hline CHEMBL3982862 & 1536410 & 7.8729 & 7.8732 & TRN & & \\
\hline CHEMBL3921997 & 1536410 & 8.8539 & 8.8543 & TRN & & \\
\hline CHEMBL3941126 & 1536410 & 7.0083 & 7.0085 & TRN & & \\
\hline CHEMBL3899141 & 1536410 & 8.2676 & 8.2678 & TRN & & \\
\hline CHEMBL3937803 & 1536410 & 8.9208 & 8.9207 & TRN & & \\
\hline CHEMBL3952158 & 1536410 & 7.3391 & 7.2526 & TST & & \\
\hline CHEMBL 3671818 & 1536410 & 8.3665 & 8.3261 & TST & & \\
\hline CHEMBL1508267 & 809002 & 5.0958 & 5.0262 & TST & & \\
\hline CHEMBL1462756 & 809002 & 5.11 & 5.1088 & TRN & & \\
\hline CHEMBL492267 & 809002 & 5.5904 & 5.1584 & TRN & & \\
\hline CHEMBL1453780 & 809002 & 4.8726 & 5.1036 & TRN & & \\
\hline CHEMBL1387923 & 809002 & 5.4409 & 5.1069 & TRN & & \\
\hline CHEMBL1443177 & 809002 & 5.1344 & 4.9958 & TRN & & \\
\hline CHEMBL59530 & 809002 & 6.0223 & 5.75200 & 0000000001 & & \\
\hline CHEMBL1985459 & 809002 & 4.4 & 4.8405 & TRN & & \\
\hline CHEMBL1866510 & 809002 & 5.3514 & 5.5068 & TRN & & \\
\hline CHEMBL1504109 & 809002 & 4.9473 & 5.2052 & TRN & & \\
\hline CHEMBL1595937 & 809002 & 5.3214 & 4.8438 & TRN & & \\
\hline CHEMBL1728248 & 809002 & 4.7022 & 5.0684 & TRN & & \\
\hline CHEMBL1412433 & 809002 & 5.6704 & 5.5281 & TST & & \\
\hline CHEMBL1438505 & 809002 & 5.2224 & 5.3438 & TRN & & \\
\hline CHEMBL1885633 & 809002 & 5.4282 & 5.2324 & TRN & & \\
\hline CHEMBL1316462 & 809002 & 5.0035 & 4.9366 & TRN & & \\
\hline CHEMBL1355544 & 809002 & 4.9907 & 5.0036 & TRN & & \\
\hline CHEMBL1993555 & 809002 & 4.7696 & 5.0424 & TRN & & \\
\hline CHEMBL1994902 & 809002 & 4.914 & 4.8532 & TRN & & \\
\hline CHEMBL2001316 & 809002 & 4.8288 & 5.0265 & TRN & & \\
\hline CHEMBL1529280 & 809002 & 5.2026 & 4.8512 & TRN & & \\
\hline CHEMBL1412284 & 809002 & 5.1465 & 5.2674 & TRN & & \\
\hline CHEMBL1339694 & 809002 & 3.4454 & 4.5383 & TRN & & \\
\hline
\end{tabular}


Supplemental Table S2.txt

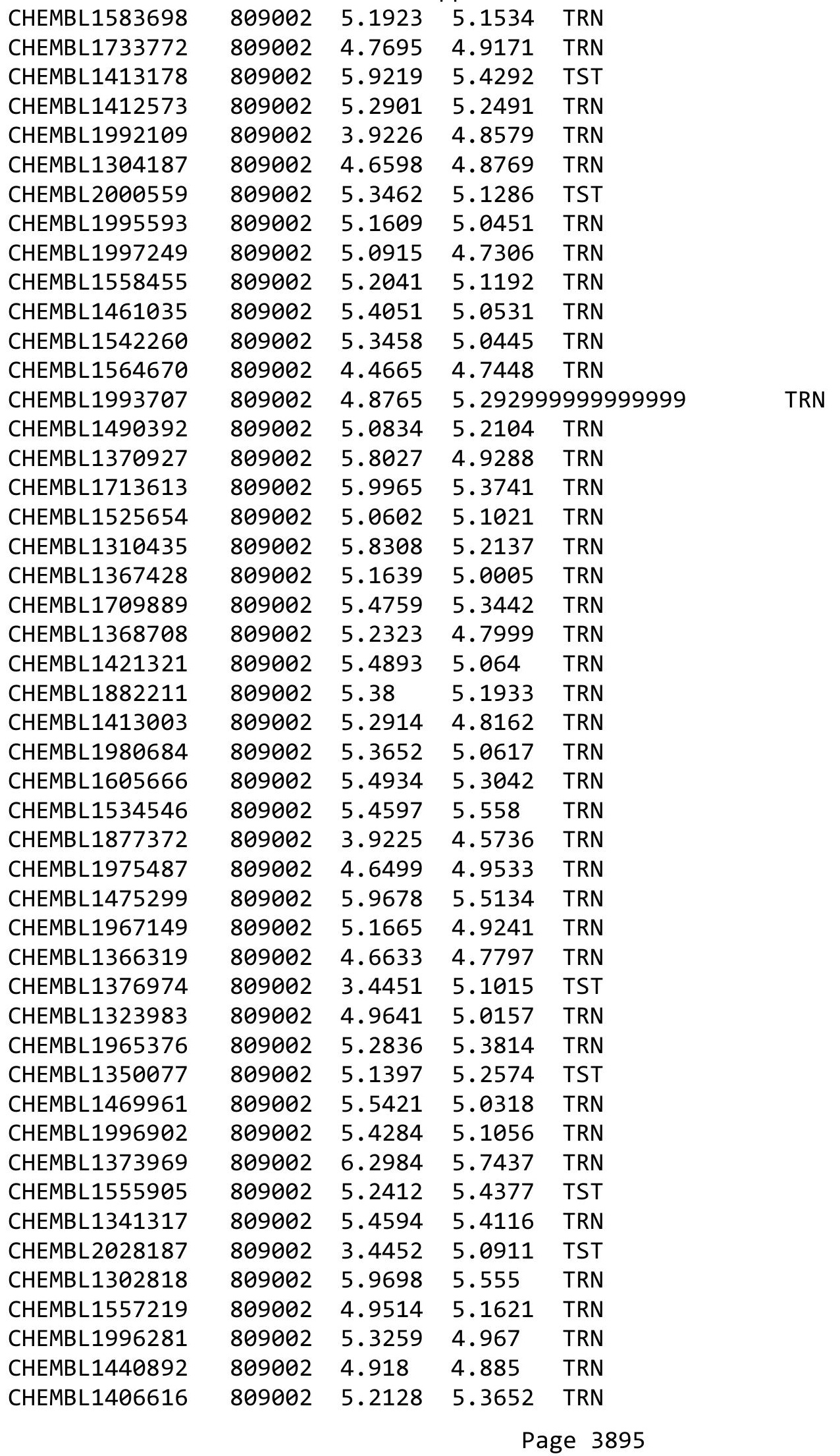




\begin{tabular}{|c|c|c|c|c|c|}
\hline \multicolumn{6}{|c|}{ Supplemental Table S2.txt } \\
\hline CHEMBL1372451 & 809002 & 5.2055 & 4.6394 & TRN & \\
\hline CHEMBL1337807 & 809002 & 3.4452 & 4.565 & TRN & \\
\hline CHEMBL1380143 & 809002 & 5.4734 & 5.28600 & 00000000005 & TRN \\
\hline CHEMBL1706512 & 809002 & 3.9224 & 4.5802 & TRN & \\
\hline CHEMBL1469670 & 809002 & 5.8005 & 5.99100 & 00000000005 & TRN \\
\hline CHEMBL1352064 & 809002 & 5.2575 & 5.2114 & TRN & \\
\hline CHEMBL1549657 & 809002 & 4.3992 & 4.9431 & TRN & \\
\hline CHEMBL1580065 & 809002 & 5.2812 & 5.204 & TRN & \\
\hline CHEMBL1452295 & 809002 & 5.1198 & 4.7392 & TRN & \\
\hline CHEMBL 2007313 & 809002 & 4.9897 & 4.9398 & TRN & \\
\hline CHEMBL1375217 & 809002 & 5.099 & 5.4401 & TRN & \\
\hline CHEMBL 2004809 & 809002 & 5.2579 & 5.459 & TRN & \\
\hline CHEMBL1699187 & 809002 & 6.3624 & 5.5833 & TRN & \\
\hline CHEMBL1985010 & 809002 & 3.4456 & 4.157 & TRN & \\
\hline CHEMBL1597286 & 809002 & 5.1669 & 5.3861 & TRN & \\
\hline CHEMBL1974053 & 809002 & 5.322 & 4.9881 & TRN & \\
\hline CHEMBL1899898 & 809002 & 5.4847 & 5.2871 & TRN & \\
\hline CHEMBL1479201 & 809002 & 5.0763 & 5.1532 & TST & \\
\hline CHEMBL1486651 & 809002 & 5.1917 & 4.7074 & TRN & \\
\hline CHEMBL1309164 & 809002 & 5.3818 & 4.829 & TST & \\
\hline CHEMBL1325021 & 809002 & 5.4248 & 5.3804 & TRN & \\
\hline CHEMBL1507740 & 809002 & 3.4452 & 4.59699 & 99999999995 & TRN \\
\hline CHEMBL1535999 & 809002 & 5.5794 & 5.2978 & TRN & \\
\hline CHEMBL1494091 & 809002 & 5.4148 & 5.1705 & TRN & \\
\hline CHEMBL1340423 & 809002 & 4.8956 & 4.7844 & TRN & \\
\hline CHEMBL1610875 & 809002 & 5.5605 & 5.7339 & TRN & \\
\hline CHEMBL1445386 & 809002 & 5.9792 & 6.6608 & TRN & \\
\hline CHEMBL1717026 & 809002 & 5.0863 & 5.4069 & TST & \\
\hline CHEMBL132431 & 809002 & 7.7303 & 5.1294 & TST & \\
\hline CHEMBL494325 & 809002 & 5.6385 & 5.4382 & TRN & \\
\hline CHEMBL1399772 & 809002 & 5.6799 & 5.4742 & TRN & \\
\hline CHEMBL1200512 & 809002 & 5.8811 & 6.5978 & TRN & \\
\hline CHEMBL1563358 & 809002 & 5.4049 & 5.1199 & TRN & \\
\hline CHEMBL1372947 & 809002 & 4.9189 & 5.4022 & TST & \\
\hline CHEMBL1368216 & 809002 & 5.5074 & 5.0017 & TRN & \\
\hline CHEMBL1418980 & 809002 & 5.7585 & 5.316 & TRN & \\
\hline CHEMBL1480880 & 809002 & 5.5002 & 4.8146 & TRN & \\
\hline CHEMBL1427335 & 809002 & 5.49 & 5.7712 & TRN & \\
\hline CHEMBL1585209 & 809002 & 5.4519 & 5.2777 & TST & \\
\hline CHEMBL1995641 & 809002 & 5.4427 & 5.2379 & TRN & \\
\hline CHEMBL1347672 & 809002 & 4.9493 & 4.8196 & TRN & \\
\hline CHEMBL479368 & 809002 & 5.1996 & 5.6042 & TRN & \\
\hline CHEMBL1903362 & 809002 & 4.7229 & 4.8869 & TST & \\
\hline CHEMBL1400379 & 809002 & 5.6745 & 5.3653 & TRN & \\
\hline CHEMBL1546346 & 809002 & 4.8664 & 5.0588 & TST & \\
\hline CHEMBL1438559 & 809002 & 5.0069 & 5.1238 & TRN & \\
\hline CHEMBL1528660 & 809002 & 5.4413 & 5.1206 & TRN & \\
\hline CHEMBL576412 & 809002 & 4.9398 & 4.9041 & TRN & \\
\hline
\end{tabular}




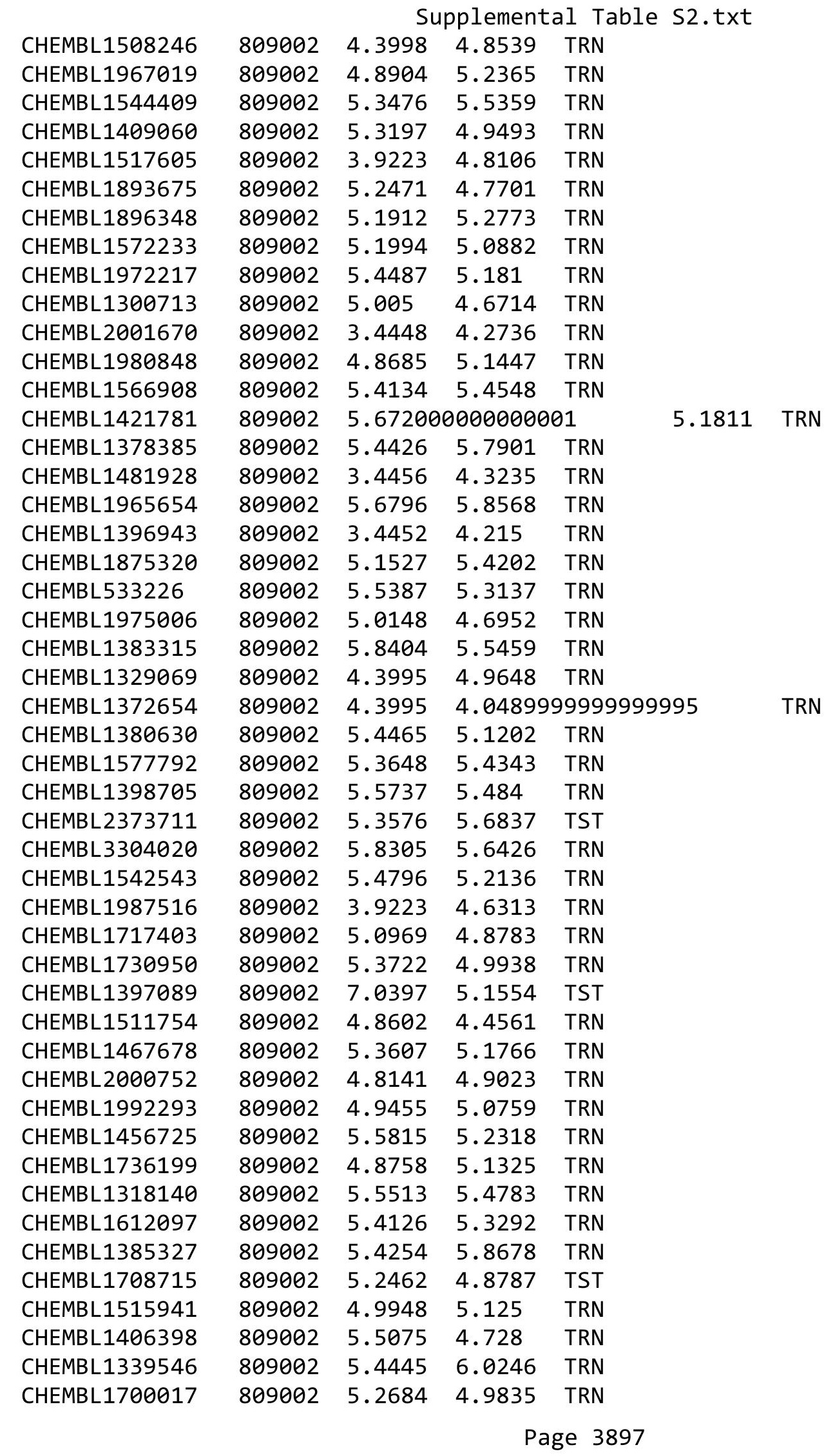




\begin{tabular}{|c|c|c|c|c|c|}
\hline \multicolumn{6}{|c|}{ Supplemental Table S2.txt } \\
\hline CHEMBL1494764 & 809002 & 5.0789 & 4.8254 & TRN & \\
\hline CHEMBL1965433 & 809002 & 4.9625 & 5.1833 & TRN & \\
\hline CHEMBL1464490 & 809002 & 5.0159 & 4.6645 & TRN & \\
\hline CHEMBL1487959 & 809002 & 4.958 & 5.8007 & TRN & \\
\hline CHEMBL1487723 & 809002 & 5.0947 & 5.0048 & TRN & \\
\hline CHEMBL1444434 & 809002 & 5.9931 & 5.2111 & TST & \\
\hline CHEMBL1488229 & 809002 & 4.8193 & 5.0727 & TRN & \\
\hline CHEMBL1339283 & 809002 & 5.0574 & 5.2642 & TRN & \\
\hline CHEMBL1597726 & 809002 & 4.9442 & 5.2815 & TRN & \\
\hline CHEMBL1318520 & 809002 & 4.9826 & 5.1859 & TRN & \\
\hline CHEMBL428909 & 809002 & 4.9576 & 5.352 & TRN & \\
\hline CHEMBL1440409 & 809002 & 5.3835 & 5.0348 & TRN & \\
\hline CHEMBL1327038 & 809002 & 5.1507 & 5.2913 & TRN & \\
\hline CHEMBL1584716 & 809002 & 4.7499 & 5.1702 & TRN & \\
\hline CHEMBL1491703 & 809002 & 3.4453 & 4.3838 & TRN & \\
\hline CHEMBL1411648 & 809002 & 4.9868 & 5.1048 & TRN & \\
\hline CHEMBL1502254 & 809002 & 5.6094 & 5.6072 & TRN & \\
\hline CHEMBL1466076 & 809002 & 4.7364 & 4.7114 & TRN & \\
\hline CHEMBL1974180 & 809002 & 5.2702 & 5.3604 & TRN & \\
\hline CHEMBL1976374 & 809002 & 4.567 & 4.8729 & TRN & \\
\hline CHEMBL1985479 & 809002 & 5.3638 & 5.1383 & TRN & \\
\hline CHEMBL1703566 & 809002 & 5.1127 & 4.7205 & TRN & \\
\hline CHEMBL1399858 & 809002 & 4.9532 & 5.2002 & TST & \\
\hline CHEMBL356169 & 809002 & 5.5242 & 5.1465 & TRN & \\
\hline CHEMBL1393156 & 809002 & 5.2281 & 5.2905 & TRN & \\
\hline CHEMBL565657 & 809002 & 5.8308 & 5.2926 & TST & \\
\hline CHEMBL1983418 & 809002 & 5.0185 & 5.01699 & 99999999995 & TRN \\
\hline CHEMBL1972216 & 809002 & 5.34 & 5.4984 & TRN & \\
\hline CHEMBL1307972 & 809002 & 5.8582 & 5.7939 & TRN & \\
\hline CHEMBL1600535 & 809002 & 5.2724 & 5.0034 & TRN & \\
\hline CHEMBL587564 & 809002 & 5.1264 & 5.1379 & TRN & \\
\hline CHEMBL485636 & 809002 & 5.225 & 5.0763 & TRN & \\
\hline CHEMBL1484503 & 809002 & 5.3352 & 4.7195 & TRN & \\
\hline CHEMBL1471916 & 809002 & 5.5694 & 4.6355 & TST & \\
\hline CHEMBL1713127 & 809002 & 6.1801 & 4.7755 & TST & \\
\hline CHEMBL1516127 & 809002 & 3.9224 & 4.1992 & TST & \\
\hline CHEMBL1568789 & 809002 & 3.4452 & 4.9488 & TST & \\
\hline CHEMBL1309254 & 809002 & 4.949 & 4.787 & TST & \\
\hline CHEMBL1585705 & 809002 & 5.2787 & 4.7649 & TST & \\
\hline CHEMBL1306377 & 809002 & 6.1179 & 5.1678 & TST & \\
\hline CHEMBL3195049 & 809002 & 5.2076 & 5.2048 & TST & \\
\hline CHEMBL1457927 & 809002 & 3.4453 & 4.6623 & TST & \\
\hline CHEMBL1312928 & 809002 & 5.4903 & 5.55200 & 00000000005 & TST \\
\hline CHEMBL1552808 & 809002 & 5.3539 & 5.8135 & TST & \\
\hline CHEMBL1540237 & 809002 & 5.1541 & 4.852 & TST & \\
\hline CHEMBL1480936 & 809002 & 5.184 & 4.8853 & TST & \\
\hline CHEMBL1721357 & 809002 & 4.3997 & 4.6127 & TST & \\
\hline CHEMBL1549424 & 809002 & 3.4453 & 4.9339 & TST & \\
\hline
\end{tabular}




\begin{tabular}{|c|c|c|c|c|c|c|}
\hline & & \multicolumn{5}{|c|}{ Supplemental Table S2.txt } \\
\hline CHEMBL1705854 & 809002 & 6.2825 & 5.5691 & TST & & \\
\hline CHEMBL95606 & 809002 & 5.1693 & 5.3181 & TST & & \\
\hline CHEMBL1323722 & 809002 & 5.1803 & 4.8234 & TST & & \\
\hline CHEMBL1611106 & 809002 & 6.1584 & 4.9039 & TST & & \\
\hline CHEMBL1724732 & 809002 & 5.1851 & 5.1604 & TST & & \\
\hline CHEMBL1393412 & 809002 & 5.3067 & 4.744 & TST & & \\
\hline CHEMBL1729353 & 809002 & 5.2721 & 5.0328 & TST & & \\
\hline CHEMBL1511273 & 809002 & 5.4453 & 5.5061 & TST & & \\
\hline CHEMBL1348955 & 809002 & 5.0999 & \multicolumn{3}{|c|}{5.162999999999999} & TST \\
\hline CHEMBL1331226 & 809002 & 5.1383 & 5.1291 & TST & & \\
\hline CHEMBL1612809 & 809002 & 5.8608 & 4.7684 & TST & & \\
\hline CHEMBL1528507 & 809002 & 5.5825 & 5.65 & TST & & \\
\hline CHEMBL1881832 & 809002 & 5.1511 & 5.5845 & TST & & \\
\hline CHEMBL1305435 & 809002 & 4.6356 & 5.2266 & TST & & \\
\hline CHEMBL1400374 & 809002 & 5.0825 & 4.9656 & TST & & \\
\hline CHEMBL1608402 & 809002 & 5.8931 & 4.9205 & TST & & \\
\hline CHEMBL1888871 & 809002 & 5.1144 & 5.0669 & TST & & \\
\hline CHEMBL1562983 & 809002 & 4.9353 & 5.3439 & TST & & \\
\hline CHEMBL1969300 & 809002 & \multicolumn{3}{|c|}{5.247999999999999} & 5.0985 & TST \\
\hline CHEMBL1345229 & 809002 & 4.9984 & 4.8099 & TST & & \\
\hline CHEMBL1465978 & 809002 & 5.3718 & 5.2258 & TST & & \\
\hline CHEMBL1719626 & 809002 & 5.0975 & 5.5724 & TST & & \\
\hline CHEMBL334255 & 688483 & 4.8 & 4.8454 & TRN & & \\
\hline CHEMBL440287 & 688483 & 4.3 & 4.4111 & TRN & & \\
\hline CHEMBL1447588 & 688483 & 4.9 & 4.8992 & TRN & & \\
\hline CHEMBL1535689 & 688483 & 4.4 & 4.2579 & TRN & & \\
\hline CHEMBL1331245 & 688483 & 4.3 & 4.1559 & TRN & & \\
\hline CHEMBL1522486 & 688483 & 4.6 & 4.5123 & TRN & & \\
\hline CHEMBL1414154 & 688483 & 4.1 & 4.1061 & TRN & & \\
\hline CHEMBL1308088 & 688483 & 4.8 & 4.7243 & TRN & & \\
\hline CHEMBL84685 & 688483 & 4.0 & 4.3641 & TRN & & \\
\hline CHEMBL194399 & 688483 & 4.1 & 4.2358 & TST & & \\
\hline CHEMBL1449018 & 688483 & 4.4 & 4.4829 & TRN & & \\
\hline CHEMBL162598 & 688483 & 4.3 & 4.2535 & TST & & \\
\hline CHEMBL1309179 & 688483 & 4.7 & 4.6644 & TRN & & \\
\hline CHEMBL1430204 & 688483 & 4.3 & 4.3268 & TRN & & \\
\hline CHEMBL1612246 & 688483 & 4.3 & 4.4131 & TRN & & \\
\hline CHEMBL1407826 & 688483 & 4.4 & 4.5966 & TST & & \\
\hline CHEMBL1366408 & 688483 & 4.4 & 4.5006 & TRN & & \\
\hline CHEMBL462576 & 688483 & 4.1 & 4.3849 & TST & & \\
\hline CHEMBL1519327 & 688483 & 6.1 & 6.1052 & TRN & & \\
\hline CHEMBL195953 & 688483 & 4.3 & 4.1487 & TST & & \\
\hline CHEMBL1451833 & 688483 & 4.4 & 4.3613 & TST & & \\
\hline CHEMBL1364985 & 688483 & 4.3 & 4.4466 & TRN & & \\
\hline CHEMBL1579130 & 688483 & 6.0 & 5.4706 & TRN & & \\
\hline CHEMBL1304981 & 688483 & 4.1 & 4.1626 & TRN & & \\
\hline CHEMBL1409985 & 688483 & 5.1 & 5.09399 & 9999999999 & & TRN \\
\hline CHEMBL1303139 & 688483 & 5.1 & 4.9889 & TRN & & \\
\hline
\end{tabular}




\begin{tabular}{|c|c|c|c|c|c|}
\hline \\
\hline CHEMBL1485360 & 688483 & 4.5 & 4.4925 & TST & \\
\hline CHEMBL1609459 & 688483 & 5.1 & 4.9796 & TRN & \\
\hline CHEMBL220845 & 688483 & 4.1 & 4.1865 & TRN & \\
\hline CHEMBL8739 & 688483 & 4.3 & $4.1610 e$ & 00000000005 & TRN \\
\hline CHEMBL36296 & 688483 & 4.1 & 4.1675 & TRN & \\
\hline CHEMBL1142 & 688483 & 4.3 & 4.2647 & TRN & \\
\hline CHEMBL1200471 & 688483 & 6.1 & 6.4039 & TRN & \\
\hline CHEMBL1236200 & 688483 & 4.1 & 4.3313 & TRN & \\
\hline CHEMBL1517425 & 688483 & 4.1 & 4.0905 & TRN & \\
\hline CHEMBL1562104 & 688483 & 5.4 & 5.2214 & TRN & \\
\hline CHEMBL402063 & 688483 & 4.3 & 5.2299 & TST & \\
\hline CHEMBL1496957 & 688483 & 4.7 & 4.5611 & TRN & \\
\hline CHEMBL1450607 & 688483 & 4.6 & 4.4864 & TST & \\
\hline CHEMBL44072 & 688483 & 4.4 & 4.2843 & TST & \\
\hline CHEMBL 28 & 688483 & 4.1 & 4.261 & TRN & \\
\hline CHEMBL1602699 & 688483 & 5.2 & 5.1358 & TRN & \\
\hline CHEMBL289277 & 688483 & 4.3 & 4.3093 & TRN & \\
\hline CHEMBL509531 & 688483 & 4.8 & 4.7538 & TST & \\
\hline CHEMBL1526319 & 688483 & 4.6 & 4.2804 & TRN & \\
\hline CHEMBL3391990 & 688483 & 4.3 & 4.3906 & TST & \\
\hline CHEMBL1529759 & 688483 & 4.1 & 4.3459 & TST & \\
\hline CHEMBL1558796 & 688483 & 4.3 & 4.4436 & TRN & \\
\hline CHEMBL1338613 & 688483 & 4.4 & 4.2662 & TRN & \\
\hline CHEMBL1530684 & 688483 & 4.4 & 4.2844 & TRN & \\
\hline CHEMBL935 & 688483 & 4.2 & 4.2723 & TRN & \\
\hline CHEMBL1549844 & 688483 & 4.4 & 4.5 & TST & \\
\hline CHEMBL1527567 & 688483 & 4.3 & 4.1938 & TRN & \\
\hline CHEMBL1485974 & 688483 & 4.4 & 4.284 & TRN & \\
\hline CHEMBL1600998 & 688483 & 5.2 & 5.2448 & TRN & \\
\hline CHEMBL1456906 & 688483 & 4.4 & 4.5248 & TST & \\
\hline CHEMBL196537 & 688483 & 4.3 & 4.1975 & TST & \\
\hline CHEMBL454173 & 688483 & 4.3 & 4.6677 & TRN & \\
\hline CHEMBL1489064 & 688483 & 4.1 & 4.1772 & TRN & \\
\hline CHEMBL 242080 & 688483 & 4.1 & 4.4374 & TRN & \\
\hline CHEMBL192627 & 688483 & 4.6 & 4.5055 & TST & \\
\hline CHEMBL1566504 & 688483 & 4.1 & 4.2695 & TST & \\
\hline CHEMBL443949 & 688483 & 4.3 & 4.356 & TRN & \\
\hline CHEMBL 280998 & 688483 & 4.3 & 4.3249 & TRN & \\
\hline CHEMBL1484480 & 688483 & 4.2 & 4.0607 & TRN & \\
\hline CHEMBL 140 & 688483 & 4.5 & 4.2979 & TRN & \\
\hline CHEMBL1408847 & 688483 & 5.1 & 5.1183 & TRN & \\
\hline CHEMBL1569226 & 688483 & 5.2 & 5.0595 & TRN & \\
\hline CHEMBL1524617 & 688483 & 5.1 & 4.9792 & TST & \\
\hline CHEMBL1499545 & 688483 & 5.1 & 5.147 & TRN & \\
\hline CHEMBL1492104 & 688483 & 4.6 & 4.6662 & TST & \\
\hline CHEMBL1526721 & 688483 & 5.0 & 4.9193 & TST & \\
\hline CHEMBL1495381 & 688483 & 4.8 & 4.9823 & TRN & \\
\hline CHEMBL486193 & 688483 & 4.1 & 4.657 & TRN & \\
\hline
\end{tabular}




\begin{tabular}{|c|c|c|c|c|c|c|}
\hline \multicolumn{7}{|c|}{ Supplemental Table S2.txt } \\
\hline CHEMBL230156 & 688483 & 4.3 & 4.1753 & TRN & & \\
\hline CHEMBL144530 & 688483 & 4.5 & 4.2249 & TRN & & \\
\hline CHEMBL1576086 & 688483 & 4.4 & 4.3183 & TRN & & \\
\hline CHEMBL1611235 & 688483 & 4.3 & 4.2699 & TRN & & \\
\hline CHEMBL1569493 & 688483 & 5.6 & 5.7018 & TRN & & \\
\hline CHEMBL1559341 & 688483 & 4.4 & 4.3488 & TRN & & \\
\hline CHEMBL1545634 & 688483 & 6.5 & 6.2832 & TRN & & \\
\hline CHEMBL105712 & 688483 & 4.9 & 4.8457 & TRN & & \\
\hline CHEMBL1492884 & 688483 & 4.4 & 4.2886 & TRN & & \\
\hline CHEMBL1448387 & 688483 & 4.4 & 4.4829 & TRN & & \\
\hline CHEMBL1428964 & 688483 & 4.1 & 4.3044 & TST & & \\
\hline CHEMBL1326083 & 688131 & 6.308 & 6.2279 & TRN & & \\
\hline CHEMBL1312275 & 688131 & 5.515 & 5.7292 & TRN & & \\
\hline CHEMBL1470139 & 688131 & 3.4202 & 4.3794 & TST & & \\
\hline CHEMBL1503688 & 688131 & 6.0742 & 5.2179 & TRN & & \\
\hline CHEMBL1349832 & 688131 & 6.0 & 5.6089 & TRN & & \\
\hline CHEMBL1887153 & 688131 & 6.0325 & 5.8214 & TRN & & \\
\hline CHEMBL1589335 & 688131 & 5.6655 & 5.5557 & TST & & \\
\hline CHEMBL1998184 & 688131 & 5.3485 & 4.9537 & TRN & & \\
\hline CHEMBL1562545 & 688131 & 3.4202 & 4.1816 & TRN & & \\
\hline CHEMBL528181 & 688131 & 5.6101 & 5.5345 & TRN & & \\
\hline CHEMBL1977301 & 688131 & 5.7296 & 5.5881 & TRN & & \\
\hline CHEMBL3196430 & 688131 & 3.4202 & 4.7956 & TRN & & \\
\hline CHEMBL1306983 & 688131 & 5.6444 & 5.334 & TRN & & \\
\hline CHEMBL1339135 & 688131 & 6.2757 & 4.7757 & TRN & & \\
\hline CHEMBL1393007 & 688131 & 5.4862 & 5.494 & TRN & & \\
\hline CHEMBL1481740 & 688131 & 3.4202 & 4.749 & TRN & & \\
\hline CHEMBL1460270 & 688131 & 3.4202 & 4.0905 & TRN & & \\
\hline CHEMBL1346226 & 688131 & 5.2765 & 5.3809 & TRN & & \\
\hline CHEMBL1577590 & 688131 & 5.8362 & 5.4868 & TRN & & \\
\hline CHEMBL1318350 & 688131 & 7.3372 & 7.8226 & TRN & & \\
\hline CHEMBL1479804 & 688131 & 5.5794 & 5.6558 & TRN & & \\
\hline CHEMBL3213934 & 688131 & 3.4202 & 4.874 & TST & & \\
\hline CHEMBL193872 & 688131 & 7.2924 & 7.355 & TRN & & \\
\hline CHEMBL1342141 & 688131 & 5.4602 & 4.1297 & TRN & & \\
\hline CHEMBL1462295 & 688131 & 4.8974 & 3.6367 & TRN & & \\
\hline CHEMBL537692 & 688131 & 3.4202 & 3.8053 & TRN & & \\
\hline CHEMBL3197232 & 688131 & 5.5909 & 5.0687 & TRN & & \\
\hline CHEMBL1433075 & 688131 & 6.1798 & 5.2626 & TST & & \\
\hline CHEMBL1505060 & 688131 & 3.4202 & 4.7634 & TRN & & \\
\hline CHEMBL1542802 & 688131 & 3.4202 & 4.8936 & TRN & & \\
\hline CHEMBL1328053 & 688131 & 5.7972 & 5.3326 & TRN & & \\
\hline CHEMBL1532068 & 688131 & $6.4510 e$ & 00000000 & 205 & 6.2971 & TRN \\
\hline CHEMBL1588660 & 688131 & 5.9543 & 5.3045 & TRN & & \\
\hline CHEMBL1522592 & 688131 & 3.4202 & 4.6571 & TRN & & \\
\hline CHEMBL1507026 & 688131 & 3.4202 & 4.6444 & TRN & & \\
\hline CHEMBL1505192 & 688131 & 8.5229 & 4.36 & TRN & & \\
\hline CHEMBL1509727 & 688131 & 5.8022 & 5.6015 & TRN & & \\
\hline
\end{tabular}


Supplemental Table S2.txt

\begin{tabular}{|c|c|c|c|c|c|}
\hline CHEMBL1470934 & 688131 & 6.3947 & 5.2528 & TRN & \\
\hline CHEMBL1349480 & 688131 & 5.9031 & 5.7664 & TRN & \\
\hline CHEMBL1447922 & 688131 & 5.4638 & 4.1766 & TRN & \\
\hline CHEMBL1331790 & 688131 & 5.9638 & 5.4329 & TRN & \\
\hline CHEMBL1424999 & 688131 & 3.4202 & 5.3399 & TRN & \\
\hline CHEMBL1430319 & 688131 & 5.5738 & 5.1537 & TST & \\
\hline CHEMBL1580472 & 688131 & 6.1662 & 6.8616 & TRN & \\
\hline CHEMBL1299903 & 688131 & 6.4001 & 5.4045 & TRN & \\
\hline CHEMBL1400007 & 688131 & 3.4202 & 3.7806 & TRN & \\
\hline CHEMBL1320059 & 688131 & 3.4202 & 3.9415 & TRN & \\
\hline CHEMBL1329395 & 688131 & 3.4202 & 4.9625 & TRN & \\
\hline CHEMBL1312619 & 688131 & 5.6617 & 4.9442 & TRN & \\
\hline CHEMBL1314190 & 688131 & 3.4202 & 4.074 & TST & \\
\hline CHEMBL3194528 & 688131 & 5.4794 & 5.3968 & TRN & \\
\hline CHEMBL1416456 & 688131 & 3.4202 & 5.1178 & TRN & \\
\hline CHEMBL1322516 & 688131 & 5.4224 & 5.063 & TST & \\
\hline CHEMBL3212594 & 688131 & 7.4437 & 4.9484 & TRN & \\
\hline CHEMBL3191022 & 688131 & 5.7962 & 5.2368 & TRN & \\
\hline CHEMBL1309059 & 688131 & 3.4202 & 5.3035 & TRN & \\
\hline CHEMBL590947 & 688131 & 5.7208 & 5.1516 & TRN & \\
\hline CHEMBL3190558 & 688131 & 4.5564 & 5.0793 & TRN & \\
\hline CHEMBL1543839 & 688131 & 3.4202 & 4.4657 & TRN & \\
\hline CHEMBL1993613 & 688131 & 5.4721 & 4.7938 & TRN & \\
\hline CHEMBL1474564 & 688131 & 5.7333 & 5.9715 & TRN & \\
\hline CHEMBL1398613 & 688131 & 3.4202 & 4.9116 & TST & \\
\hline CHEMBL3191763 & 688131 & 5.9784 & 3.9269 & TRN & \\
\hline CHEMBL1365375 & 688131 & 3.4202 & 4.3534 & TRN & \\
\hline CHEMBL1541536 & 688131 & 3.4202 & 5.1926 & TRN & \\
\hline CHEMBL1418430 & 688131 & 3.4202 & 4.6804 & TRN & \\
\hline CHEMBL1471200 & 688131 & 5.6931 & 4.9525 & TRN & \\
\hline CHEMBL1419104 & 688131 & 6.0487 & 5.3433 & TRN & \\
\hline CHEMBL1420655 & 688131 & 3.4202 & 4.2833 & TRN & \\
\hline CHEMBL1372492 & 688131 & 5.4 & 5.9356 & TRN & \\
\hline CHEMBL1463647 & 688131 & 5.3312 & 6.0425 & TST & \\
\hline CHEMBL1519902 & 688131 & 5.9539 & 6.2511 & TRN & \\
\hline CHEMBL1382884 & 688131 & 3.4202 & 5.1993 & TRN & \\
\hline CHEMBL1315921 & 688131 & 7.3372 & 4.4606 & TRN & \\
\hline CHEMBL3211998 & 688131 & 3.4202 & 5.4626 & TRN & \\
\hline CHEMBL1301480 & 688131 & 5.4889 & 6.1798 & TRN & \\
\hline CHEMBL1431710 & 688131 & 6.5287 & 5.70200 & 0000000001 & TRN \\
\hline CHEMBL3190230 & 688131 & 6.1296 & 5.1129 & TST & \\
\hline CHEMBL1352200 & 688131 & 5.553 & 5.1088 & TRN & \\
\hline CHEMBL1605026 & 688131 & 5.4302 & 5.1454 & TRN & \\
\hline CHEMBL1580637 & 688131 & 3.4202 & 4.6121 & TRN & \\
\hline CHEMBL3191808 & 688131 & 6.2062 & 5.9358 & TRN & \\
\hline CHEMBL1448722 & 688131 & 5.3485 & 4.9378 & TRN & \\
\hline CHEMBL3193305 & 688131 & 5.3493 & 5.8083 & TRN & \\
\hline CHEMBL1555271 & 688131 & 6.1831 & 6.3032 & TRN & \\
\hline
\end{tabular}

Page 3902 


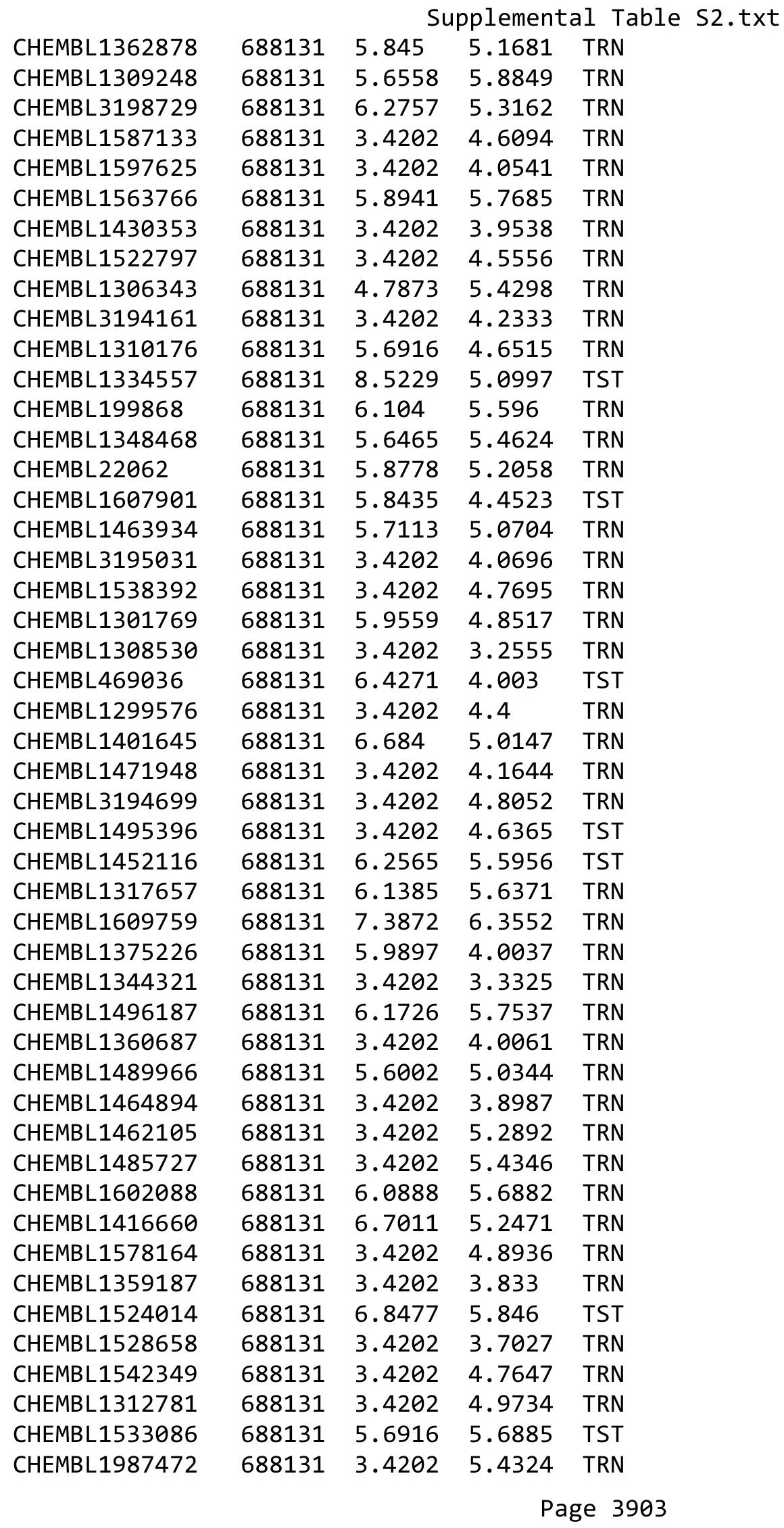


Supplemental Table S2.txt

\begin{tabular}{|c|c|c|c|c|c|c|}
\hline CHEMBL3190138 & 688131 & 3.4202 & 3.6794 & TRN & & \\
\hline CHEMBL3199737 & 688131 & 3.4202 & 5.1104 & TST & & \\
\hline CHEMBL1519558 & 688131 & 5.6983 & 5.0952 & TRN & & \\
\hline CHEMBL3199008 & 688131 & 3.4202 & 5.3535 & TRN & & \\
\hline CHEMBL1464385 & 688131 & 5.5519 & 5.269 & TRN & & \\
\hline CHEMBL3209413 & 688131 & 3.4202 & 4.7575 & TRN & & \\
\hline CHEMBL1458975 & 688131 & 5.6112 & 5.1217 & TRN & & \\
\hline CHEMBL586031 & 688131 & 5.9901 & 5.4426 & TRN & & \\
\hline CHEMBL1501041 & 688131 & 3.4202 & 3.8411 & TRN & & \\
\hline CHEMBL1581275 & 688131 & 3.4202 & 5.2414 & TRN & & \\
\hline CHEMBL240329 & 688131 & 3.4202 & 4.8714 & TRN & & \\
\hline CHEMBL1419305 & 688131 & 3.4202 & 4.794 & TRN & & \\
\hline CHEMBL1372914 & 688131 & 5.9212 & 5.3827 & TRN & & \\
\hline CHEMBL1572031 & 688131 & 5.6819 & 5.4407 & TRN & & \\
\hline CHEMBL1533007 & 688131 & 3.4202 & 4.5515 & TRN & & \\
\hline CHEMBL1333088 & 688131 & 5.9485 & 3.9906 & TST & & \\
\hline CHEMBL1864040 & 688131 & 3.4202 & 5.2763 & TRN & & \\
\hline CHEMBL1348448 & 688131 & 5.8438 & 5.36 & TRN & & \\
\hline CHEMBL1348093 & 688131 & 5.7215 & 5.2257 & TRN & & \\
\hline CHEMBL1582221 & 688131 & 5.9622 & 4.8216 & TRN & & \\
\hline CHEMBL1409333 & 688131 & 5.495 & 5.254 & TRN & & \\
\hline CHEMBL 2095095 & 688131 & 5.8684 & 5.1264 & TRN & & \\
\hline CHEMBL1493512 & 688131 & 3.4202 & 4.8847 & TRN & & \\
\hline CHEMBL1310139 & 688131 & $5.4460 e$ & 0000000 & & 5.2057 & TRN \\
\hline CHEMBL1491740 & 688131 & 5.13399 & 9999999 & 995 & 3.8789 & TRN \\
\hline CHEMBL1542594 & 688131 & 6.3449 & 5.8438 & TRN & & \\
\hline CHEMBL1310989 & 688131 & 3.4202 & 3.6409 & TRN & & \\
\hline CHEMBL1341726 & 688131 & 3.4202 & 3.9516 & TRN & & \\
\hline CHEMBL580727 & 688131 & 6.2518 & 5.8417 & TRN & & \\
\hline CHEMBL1582111 & 688131 & 3.4202 & 5.0479 & TRN & & \\
\hline CHEMBL599890 & 688131 & 5.7402 & 5.5288 & TRN & & \\
\hline CHEMBL1995550 & 688131 & 5.3934 & 5.1509 & TRN & & \\
\hline CHEMBL1538652 & 688131 & 3.4202 & 5.2803 & TRN & & \\
\hline CHEMBL1362788 & 688131 & 6.1302 & 5.0823 & TRN & & \\
\hline CHEMBL1515702 & 688131 & 5.4908 & 5.0181 & TRN & & \\
\hline CHEMBL1341697 & 688131 & 5.7452 & 5.3177 & TRN & & \\
\hline CHEMBL1369287 & 688131 & 5.1171 & 5.0528 & TST & & \\
\hline CHEMBL1525576 & 688131 & 6.0 & 4.8227 & TRN & & \\
\hline CHEMBL1598391 & 688131 & 5.3056 & 3.7172 & TRN & & \\
\hline CHEMBL3210642 & 688131 & 5.7675 & 5.2264 & TRN & & \\
\hline CHEMBL1342332 & 688131 & 3.4202 & 3.955 & TST & & \\
\hline CHEMBL1454778 & 688131 & 3.4202 & 3.8495 & TRN & & \\
\hline CHEMBL1324917 & 688131 & 5.6057 & 4.9342 & TRN & & \\
\hline CHEMBL1547925 & 688131 & 3.4202 & 4.585 & TRN & & \\
\hline CHEMBL1383916 & 688131 & 5.5157 & 5.1284 & TRN & & \\
\hline CHEMBL3198627 & 688131 & 3.4202 & 5.3933 & TRN & & \\
\hline CHEMBL1995715 & 688131 & 5.5482 & 5.1076 & TRN & & \\
\hline CHEMBL1503699 & 688131 & \multicolumn{3}{|c|}{5.702000000000001} & 5.3159 & TRN \\
\hline
\end{tabular}




\begin{tabular}{|c|c|c|c|c|c|c|}
\hline & & \multicolumn{5}{|c|}{ Supplemental Table S2.txt } \\
\hline CHEMBL3195142 & 688131 & 6.1226 & 5.5842 & TRN & & \\
\hline CHEMBL1994623 & 688131 & 8.5229 & 6.1709 & TRN & & \\
\hline CHEMBL1306256 & 688131 & 6.1561 & 4.1215 & TRN & & \\
\hline CHEMBL455284 & 688131 & 6.8356 & 6.3145 & TRN & & \\
\hline CHEMBL1538428 & 688131 & 5.5136 & 5.0703 & TST & & \\
\hline CHEMBL1575649 & 688131 & 3.4202 & 4.7893 & TRN & & \\
\hline CHEMBL1556838 & 688131 & 5.3529 & 5.3321 & TRN & & \\
\hline CHEMBL1534203 & 688131 & \multicolumn{3}{|c|}{6.218999999999999} & 5.9455 & TRN \\
\hline CHEMBL1422799 & 688131 & 5.4406 & 4.7726 & TRN & & \\
\hline CHEMBL1511029 & 688131 & 5.9322 & 5.5112 & TRN & & \\
\hline CHEMBL 3193134 & 688131 & 5.5177 & 5.1826 & TRN & & \\
\hline CHEMBL1501645 & 688131 & 3.4202 & 5.0533 & TRN & & \\
\hline CHEMBL1495072 & 688131 & 6.0969 & 5.939 & TRN & & \\
\hline CHEMBL1511757 & 688131 & 3.4202 & 3.8353 & TRN & & \\
\hline CHEMBL3195241 & 688131 & 6.4157 & 5.6352 & TRN & & \\
\hline CHEMBL1471627 & 688131 & 3.4202 & 3.6583 & TRN & & \\
\hline CHEMBL1469379 & 688131 & 5.4399 & 4.8218 & TRN & & \\
\hline CHEMBL1563370 & 688131 & 6.644 & 4.9238 & TST & & \\
\hline CHEMBL1574024 & 688131 & 6.3799 & 3.6218 & TRN & & \\
\hline CHEMBL1420516 & 688131 & 5.7144 & 4.7302 & TRN & & \\
\hline CHEMBL1500960 & 688131 & 5.2923 & 5.1473 & TST & & \\
\hline CHEMBL1408075 & 688131 & 6.2284 & 3.8884 & TRN & & \\
\hline CHEMBL1603456 & 688131 & 3.4202 & 4.8735 & TRN & & \\
\hline CHEMBL 2006545 & 688131 & 5.33 & 4.2858 & TRN & & \\
\hline CHEMBL1526249 & 688131 & 3.4202 & 5.21700 & 0000000000 & 05 & TRN \\
\hline CHEMBL1471521 & 688131 & 5.2639 & 3.6665 & TRN & & \\
\hline CHEMBL1365988 & 688131 & 6.08299 & 99999999 & 99 & 5.7926 & TRN \\
\hline CHEMBL3193869 & 688131 & 5.7433 & 4.9227 & TRN & & \\
\hline CHEMBL1587453 & 688131 & 5.3864 & 5.4498 & TRN & & \\
\hline CHEMBL1385118 & 688131 & 3.4202 & 4.4787 & TRN & & \\
\hline CHEMBL1577971 & 688131 & 3.4202 & 3.987 & TST & & \\
\hline CHEMBL1580434 & 688131 & 3.4202 & 5.3485 & TRN & & \\
\hline CHEMBL1351542 & 688131 & 6.1765 & 6.112 & TRN & & \\
\hline CHEMBL1789993 & 688131 & 7.301 & 5.5476 & TRN & & \\
\hline CHEMBL1541582 & 688131 & 5.6428 & 5.2638 & TRN & & \\
\hline CHEMBL1539124 & 688131 & 3.4202 & 4.5087 & TRN & & \\
\hline CHEMBL305686 & 688131 & 5.3872 & 4.4103 & TST & & \\
\hline CHEMBL1327172 & 688131 & 6.5317 & 5.6113 & TRN & & \\
\hline CHEMBL3212148 & 688131 & 3.4202 & 3.7719 & TRN & & \\
\hline CHEMBL1500188 & 688131 & 7.4089 & 7.0358 & TRN & & \\
\hline CHEMBL1527022 & 688131 & 5.63399 & 99999999 & 995 & 5.3279 & TRN \\
\hline CHEMBL1587027 & 688131 & 3.4202 & 5.2081 & TRN & & \\
\hline CHEMBL1538232 & 688131 & 6.8153 & 3.8057 & TRN & & \\
\hline CHEMBL1496313 & 688131 & 3.4202 & 4.92899 & 9999999999 & & TRN \\
\hline CHEMBL1386593 & 688131 & 5.0787 & 4.5637 & TST & & \\
\hline CHEMBL1416961 & 688131 & 5.4921 & 5.2684 & TRN & & \\
\hline CHEMBL1350258 & 688131 & 6.1273 & 5.3924 & TRN & & \\
\hline CHEMBL1391588 & 688131 & 5.7212 & 3.715 & TRN & & \\
\hline
\end{tabular}


Supplemental Table S2.txt

\begin{tabular}{|c|c|c|c|c|c|}
\hline CHEMBL3189966 & 688131 & 6.9431 & 5.3869 & TRN & \\
\hline CHEMBL1478797 & 688131 & 6.1605 & 5.2523 & TRN & \\
\hline CHEMBL1496854 & 688131 & 5.7844 & 5.2658 & TRN & \\
\hline CHEMBL1337224 & 688131 & 5.4755 & 5.1084 & TRN & \\
\hline CHEMBL1492378 & 688131 & 6.5622 & 5.0504 & TRN & \\
\hline CHEMBL1391457 & 688131 & 3.4202 & 5.068006 & 00000000005 & TRN \\
\hline CHEMBL1464569 & 688131 & 3.4202 & 4.0923 & TST & \\
\hline CHEMBL3191233 & 688131 & 3.4202 & 3.9814 & TRN & \\
\hline CHEMBL1995280 & 688131 & 5.2046 & 4.289 & TRN & \\
\hline CHEMBL 3194042 & 688131 & 3.4202 & 4.7396 & TRN & \\
\hline CHEMBL1528696 & 688131 & 5.8386 & 4.808 & TST & \\
\hline CHEMBL1505623 & 688131 & 3.4202 & 3.6764 & TRN & \\
\hline CHEMBL1328373 & 688131 & 3.4202 & 5.0392 & TRN & \\
\hline CHEMBL1536643 & 688131 & 3.4202 & 4.9656 & TRN & \\
\hline CHEMBL1504220 & 688131 & 5.7846 & 4.737 & TRN & \\
\hline CHEMBL1388595 & 688131 & 5.5461 & 5.9516 & TRN & \\
\hline CHEMBL1327470 & 688131 & 6.0013 & 5.7035 & TST & \\
\hline CHEMBL1372207 & 688131 & 3.4202 & 4.816 & TST & \\
\hline CHEMBL1487171 & 688131 & 3.4202 & 5.1163 & TRN & \\
\hline CHEMBL1470259 & 688131 & 4.7728 & 4.2629 & TRN & \\
\hline CHEMBL1300956 & 688131 & 5.5063 & 5.0708 & TST & \\
\hline CHEMBL600734 & 688131 & 6.15 & 5.8203 & TRN & \\
\hline CHEMBL1311226 & 688131 & 5.8908 & 5.312 & TRN & \\
\hline CHEMBL1383721 & 688131 & 6.6216 & 5.1595 & TRN & \\
\hline CHEMBL1997747 & 688131 & 6.1844 & 5.7625 & TRN & \\
\hline CHEMBL1497697 & 688131 & 3.4202 & 4.8169 & TST & \\
\hline CHEMBL1440300 & 688131 & 3.4202 & 5.1928 & TRN & \\
\hline CHEMBL1390766 & 688131 & 3.4202 & 4.4939 & TRN & \\
\hline CHEMBL1598581 & 688131 & 5.3938 & 5.4289 & TRN & \\
\hline CHEMBL1328504 & 688131 & 5.8965 & 5.0777 & TRN & \\
\hline CHEMBL3189193 & 688131 & \multicolumn{3}{|c|}{5.718999999999999} & \\
\hline CHEMBL1596325 & 688131 & 6.4078 & 5.3851 & TRN & \\
\hline CHEMBL1600678 & 688131 & 5.8854 & 5.5738 & TST & \\
\hline CHEMBL 3189613 & 688131 & 5.5139 & 5.1796 & TRN & \\
\hline CHEMBL1468661 & 688131 & 5.959 & 5.0615 & TRN & \\
\hline CHEMBL1352227 & 688131 & 5.2858 & 3.5894 & TRN & \\
\hline CHEMBL3145031 & 688131 & 6.1972 & 5.088999 & 99999999995 & וב \\
\hline CHEMBL1373688 & 688131 & 3.4202 & 3.9975 & TRN & \\
\hline CHEMBL1509327 & 688131 & 3.4202 & 5.1483 & TST & \\
\hline CHEMBL1595820 & 688131 & 6.4868 & 6.1936 & TRN & \\
\hline CHEMBL1337045 & 688131 & 5.7231 & 5.5811 & TRN & \\
\hline CHEMBL595700 & 688131 & 6.1062 & 5.6868 & TRN & \\
\hline CHEMBL1421997 & 688131 & 3.4202 & 3.7826 & TRN & \\
\hline CHEMBL512366 & 688131 & 5.5875 & 5.5141 & TRN & \\
\hline CHEMBL1369060 & 688131 & 3.4202 & 3.7884 & TRN & \\
\hline CHEMBL1981612 & 688131 & 5.54 & 5.4096 & TRN & \\
\hline CHEMBL1508931 & 688131 & 3.4202 & 4.0584 & TRN & \\
\hline CHEMBL1496767 & 688131 & 3.4202 & 4.2643 & TRN & \\
\hline
\end{tabular}


Supplemental Table S2.txt

\begin{tabular}{|c|c|c|c|c|}
\hline CHEMBL3192707 & 688131 & 5.6362 & 4.9195 & TST \\
\hline CHEMBL1608901 & 688131 & 3.4202 & 3.7278 & TRN \\
\hline CHEMBL3144960 & 688131 & 5.1123 & 4.8663 & TRN \\
\hline CHEMBL1414734 & 688131 & 5.0643 & 5.7474 & TST \\
\hline CHEMBL1304603 & 688131 & 6.0915 & 5.066 & TRN \\
\hline CHEMBL3211050 & 688131 & 6.1373 & 5.6279 & TRN \\
\hline CHEMBL1339571 & 688131 & 3.4202 & 4.8375 & TST \\
\hline CHEMBL1334044 & 688131 & 3.4202 & 4.5315 & TRN \\
\hline CHEMBL1351290 & 688131 & 5.5459 & 4.7101 & TST \\
\hline CHEMBL1378218 & 688131 & 3.4202 & 3.8593 & TRN \\
\hline CHEMBL1387710 & 688131 & 6.2757 & 5.2923 & TRN \\
\hline CHEMBL1343823 & 688131 & 6.8794 & 5.0061 & TRN \\
\hline CHEMBL3207597 & 688131 & 3.4202 & 4.6048 & TRN \\
\hline CHEMBL1424665 & 688131 & 6.6968 & 6.2741 & TRN \\
\hline CHEMBL1504569 & 688131 & 6.1701 & 5.6448 & TRN \\
\hline CHEMBL1545971 & 688131 & 5.7991 & 5.9473 & TRN \\
\hline CHEMBL1557243 & 688131 & 6.1979 & 5.3102 & TRN \\
\hline CHEMBL1497750 & 688131 & 5.8245 & 4.0608 & TRN \\
\hline CHEMBL3191817 & 688131 & 5.54899 & 79999999 & 5.3387 \\
\hline CHEMBL1469579 & 688131 & 6.0701 & 5.164 & TRN \\
\hline CHEMBL1559931 & 688131 & 3.4202 & 3.9363 & TRN \\
\hline CHEMBL1562664 & 688131 & 7.2596 & 6.0415 & TRN \\
\hline CHEMBL1338466 & 688131 & 3.4202 & 4.8383 & TRN \\
\hline CHEMBL1468776 & 688131 & 6.0168 & 5.7291 & TRN \\
\hline CHEMBL3190961 & 688131 & 5.2971 & 5.3696 & TRN \\
\hline CHEMBL1373038 & 688131 & 3.4202 & 3.86899 & 99999999998 \\
\hline CHEMBL461820 & 688131 & 3.4202 & 4.8727 & TST \\
\hline CHEMBL1301892 & 688131 & 3.4202 & 4.9687 & TRN \\
\hline CHEMBL1570176 & 688131 & 5.7788 & 5.0586 & TRN \\
\hline CHEMBL1448793 & 688131 & 6.8041 & 5.1239 & TRN \\
\hline CHEMBL1504461 & 688131 & 5.1448 & 5.2794 & TRN \\
\hline CHEMBL1606685 & 688131 & 6.9136 & 5.6627 & TRN \\
\hline CHEMBL3208133 & 688131 & 3.4202 & 3.7037 & TRN \\
\hline CHEMBL599924 & 688131 & 6.2007 & 5.7941 & TRN \\
\hline CHEMBL1364010 & 688131 & 5.2437 & 4.8993 & TRN \\
\hline CHEMBL1492078 & 688131 & 5.9767 & 5.073 & TST \\
\hline CHEMBL1566358 & 688131 & 5.8398 & 5.1845 & TRN \\
\hline CHEMBL1613178 & 688131 & 3.4202 & 3.9029 & TST \\
\hline CHEMBL1414580 & 688131 & 3.4202 & 5.0877 & TRN \\
\hline CHEMBL1483825 & 688131 & 5.8094 & 5.1799 & TRN \\
\hline CHEMBL1484139 & 688131 & 3.4202 & 4.5552 & TST \\
\hline CHEMBL1386508 & 688131 & 6.098 & 3.6988 & TRN \\
\hline CHEMBL1478041 & 688131 & 6.0458 & 5.9132 & TRN \\
\hline CHEMBL1307255 & 688131 & 6.6517 & 5.6589 & TRN \\
\hline CHEMBL1544114 & 688131 & 6.1024 & 6.3835 & TRN \\
\hline CHEMBL1425849 & 688131 & 3.4202 & 4.9486 & TRN \\
\hline CHEMBL1530097 & 688131 & 3.4202 & 5.2628 & TRN \\
\hline CHEMBL1564047 & 688131 & 3.4202 & 4.7574 & TST \\
\hline
\end{tabular}


Supplemental Table S2.txt

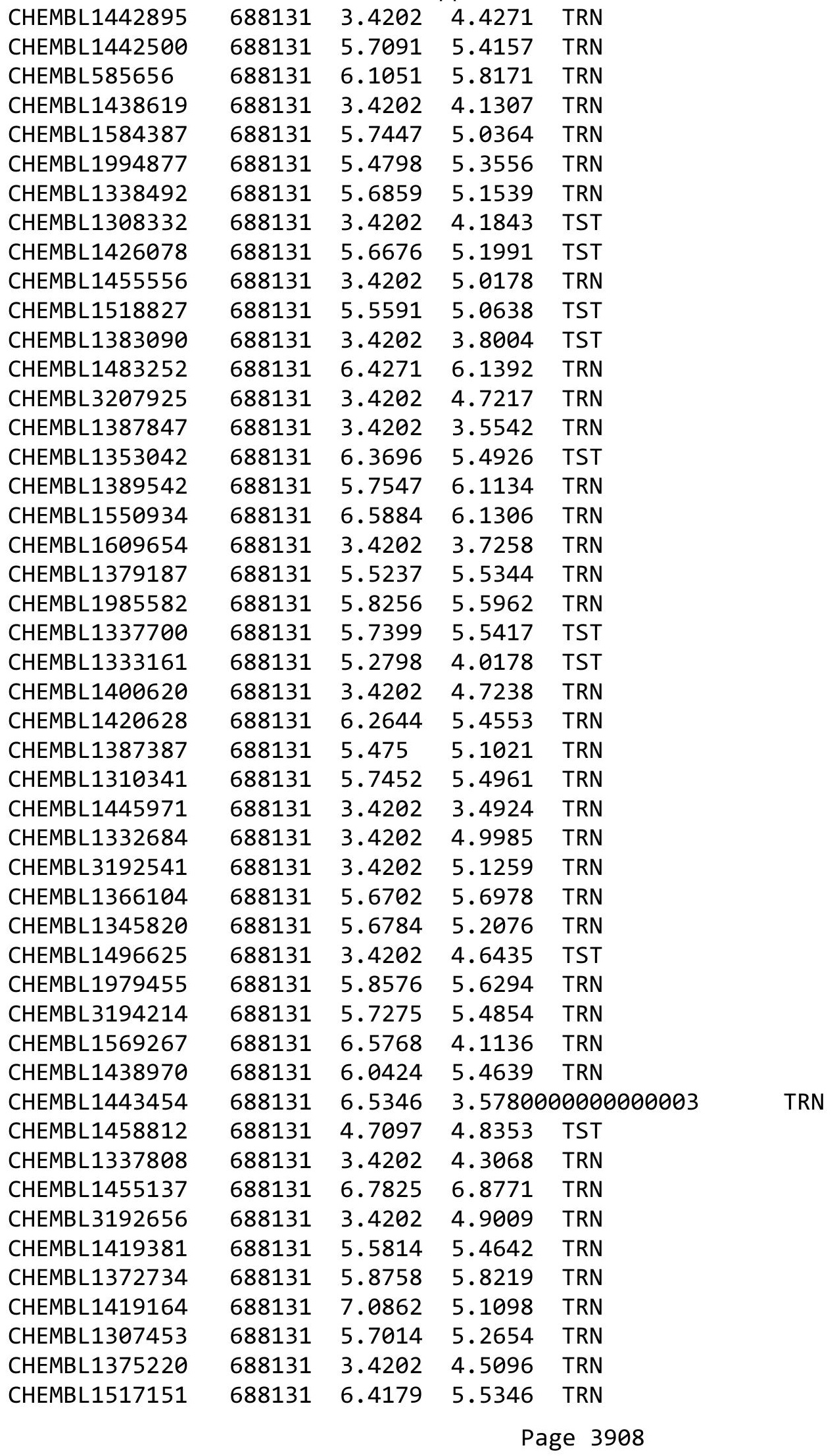



Supplemental Table S2.txt

\begin{tabular}{|c|c|c|c|c|}
\hline CHEMBL1333095 & 688131 & 5.9974 & 5.4249 & TST \\
\hline CHEMBL1428377 & 688131 & 3.4202 & 5.1335 & TRN \\
\hline CHEMBL1366055 & 688131 & 6.065 & 4.319 & TRN \\
\hline CHEMBL1469043 & 688131 & 3.4202 & 4.8043 & TRN \\
\hline CHEMBL1603092 & 688131 & 5.5286 & 4.9436 & TRN \\
\hline CHEMBL3213942 & 688131 & 3.4202 & 3.8754 & TRN \\
\hline CHEMBL3192779 & 688131 & 3.4202 & 5.0005 & TRN \\
\hline CHEMBL1364999 & 688131 & 7.0132 & 6.0218 & TRN \\
\hline CHEMBL1381679 & 688131 & 5.5891 & 5.1057 & TRN \\
\hline CHEMBL1388684 & 688131 & 5.568 & 5.1336 & TRN \\
\hline CHEMBL1423518 & 688131 & 5.4486 & 5.0812 & TST \\
\hline CHEMBL1605956 & 688131 & 6.2351 & 4.956 & TRN \\
\hline CHEMBL1505451 & 688131 & 3.4202 & 5.1488 & TRN \\
\hline CHEMBL1563323 & 688131 & 5.813 & 5.0528 & TRN \\
\hline CHEMBL1546228 & 688131 & 6.6253 & 5.324 & TRN \\
\hline CHEMBL1444424 & 688131 & 5.4828 & 4.0241 & TRN \\
\hline CHEMBL1790008 & 688131 & 6.9547 & 5.7147 & TRN \\
\hline CHEMBL1612613 & 688131 & 3.4202 & 3.9605 & TRN \\
\hline CHEMBL1338258 & 688131 & 3.4202 & 4.0969 & TRN \\
\hline CHEMBL1519338 & 688131 & 3.4202 & 4.7189 & TRN \\
\hline CHEMBL1491815 & 688131 & 6.7447 & 5.9433 & TRN \\
\hline CHEMBL3213908 & 688131 & 3.4202 & 3.7973 & TRN \\
\hline CHEMBL1321271 & 688131 & 5.4483 & 5.2635 & TRN \\
\hline CHEMBL1390658 & 688131 & 5.8013 & 5.1843 & TRN \\
\hline CHEMBL1351838 & 688131 & 3.4202 & 3.93 & TST \\
\hline CHEMBL1385466 & 688131 & 5.5913 & 4.9565 & TST \\
\hline CHEMBL1323553 & 688131 & 5.3679 & 4.9082 & TRN \\
\hline CHEMBL1374970 & 688131 & 5.3209 & 5.1773 & TST \\
\hline CHEMBL1341308 & 688131 & 5.6621 & 5.1271 & TRN \\
\hline CHEMBL1340519 & 688131 & 6.3635 & 5.7372 & TRN \\
\hline CHEMBL1402899 & 688131 & 6.1051 & 4.6598 & TST \\
\hline CHEMBL1463786 & 688131 & 5.902 & 5.8532 & TRN \\
\hline CHEMBL1609315 & 688131 & 5.9326 & 4.7079 & TST \\
\hline CHEMBL1413859 & 688131 & 3.4202 & 5.3968 & TRN \\
\hline CHEMBL1604425 & 688131 & 5.5314 & 5.1564 & TRN \\
\hline CHEMBL3392051 & 688131 & 6.4168 & 5.8124 & TST \\
\hline CHEMBL1558957 & 688131 & 3.4202 & 5.1433 & TRN \\
\hline CHEMBL1516797 & 688131 & 5.2394 & 3.736 & TRN \\
\hline CHEMBL3210143 & 688131 & 3.4202 & 4.029 & TRN \\
\hline CHEMBL1518873 & 688131 & 7.4559 & \multicolumn{2}{|c|}{6.257000000000001} \\
\hline CHEMBL1336054 & 688131 & 5.8345 & 5.1986 & TRN \\
\hline CHEMBL1366850 & 688131 & 3.4202 & 4.4036 & TRN \\
\hline CHEMBL1342093 & 688131 & 6.1302 & 5.2079 & TRN \\
\hline CHEMBL1336675 & 688131 & 5.7194 & 5.1284 & TRN \\
\hline CHEMBL1969712 & 688131 & 3.4202 & 4.8458 & TRN \\
\hline CHEMBL1417242 & 688131 & 5.7174 & 5.026 & TRN \\
\hline CHEMBL1326221 & 688131 & 3.4202 & 3.7161 & TRN \\
\hline CHEMBL1538246 & 688131 & 5.9957 & 5.5904 & TST \\
\hline
\end{tabular}


Supplemental Table S2.txt

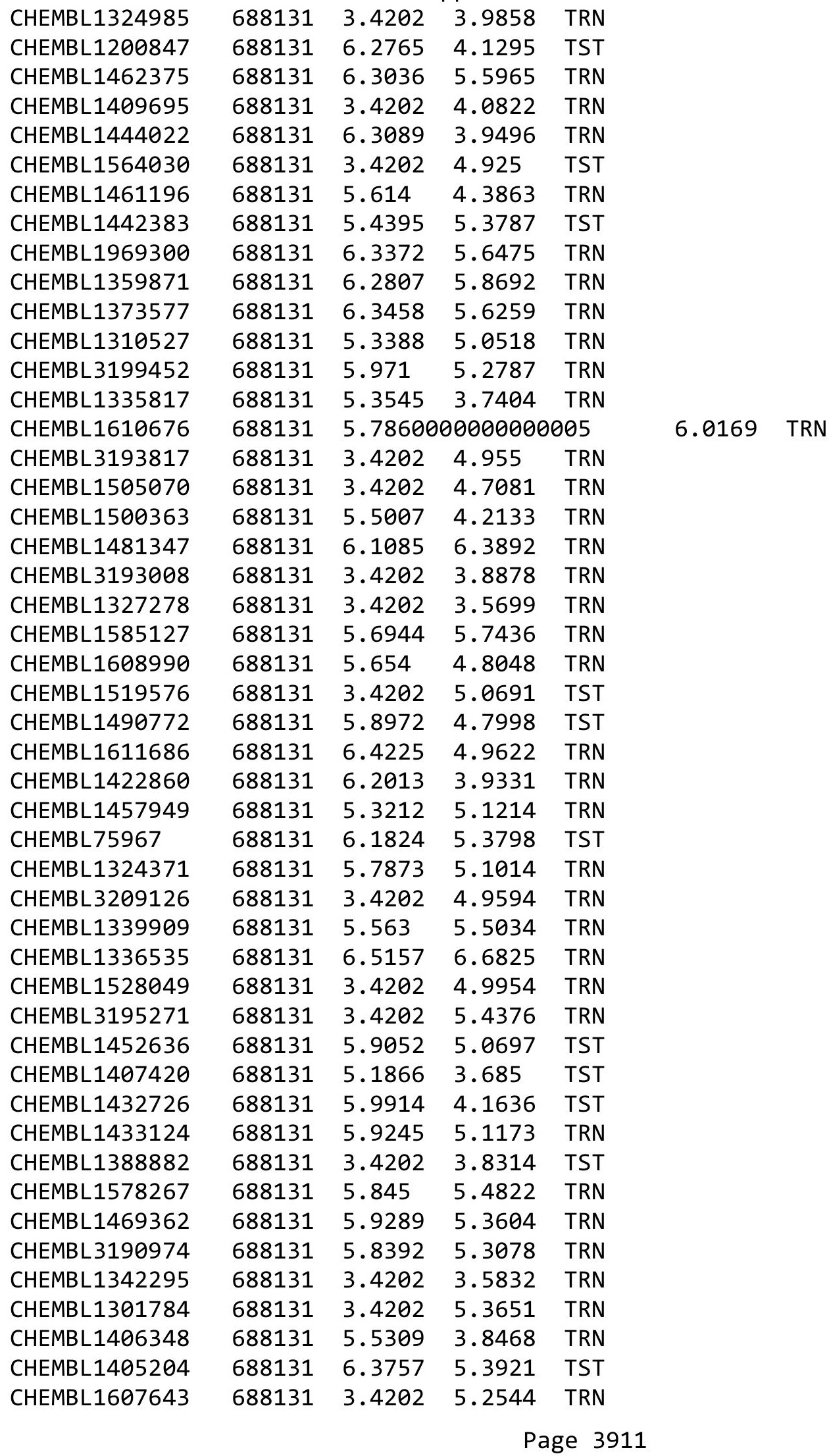




\begin{tabular}{|c|c|c|c|c|c|c|}
\hline & & \multicolumn{5}{|c|}{ Supplemental Table S2.txt } \\
\hline CHEMBL1347108 & 688131 & 3.4202 & 4.9429 & TRN & & \\
\hline CHEMBL1450615 & 688131 & 6.1593 & 5.8838 & TRN & & \\
\hline CHEMBL1521991 & 688131 & 6.066 & 4.9407 & TRN & & \\
\hline CHEMBL1309733 & 688131 & 3.4202 & 4.8002 & TST & & \\
\hline CHEMBL1567865 & 688131 & 3.4202 & 5.4379 & TRN & & \\
\hline CHEMBL1439576 & 688131 & 3.4202 & 4.7719 & TRN & & \\
\hline CHEMBL 3145245 & 688131 & 5.1695 & 5.4322 & TRN & & \\
\hline CHEMBL1483620 & 688131 & 5.6082 & 5.3598 & TRN & & \\
\hline CHEMBL1388116 & 688131 & 6.1175 & 4.9778 & TRN & & \\
\hline CHEMBL254576 & 688131 & 3.4202 & 5.1871 & TST & & \\
\hline CHEMBL1568337 & 688131 & 5.7142 & 5.3468 & TRN & & \\
\hline CHEMBL300389 & 688131 & 6.1765 & 5.5747 & TST & & \\
\hline CHEMBL1465946 & 688131 & 5.7799 & 5.7337 & TRN & & \\
\hline CHEMBL1365796 & 688131 & 5.8867 & 5.0261 & TRN & & \\
\hline CHEMBL1313101 & 688131 & 5.7275 & 5.7232 & TRN & & \\
\hline CHEMBL1528603 & 688131 & 3.4202 & 4.7649 & TRN & & \\
\hline CHEMBL3198581 & 688131 & $5.3820 e$ & 0000000 & $\partial 1$ & 5.222 & TRN \\
\hline CHEMBL3189582 & 688131 & 5.2942 & 5.4749 & TRN & & \\
\hline CHEMBL1994094 & 688131 & 3.4202 & 5.1375 & TRN & & \\
\hline CHEMBL1514790 & 688131 & 3.4202 & 4.6621 & TST & & \\
\hline CHEMBL1442114 & 688131 & 5.6615 & 5.3041 & TRN & & \\
\hline CHEMBL1408342 & 688131 & 5.5501 & 4.7469 & TRN & & \\
\hline CHEMBL1578007 & 688131 & 3.4202 & 3.8076 & TST & & \\
\hline CHEMBL1612118 & 688131 & 5.9714 & 4.8571 & TRN & & \\
\hline CHEMBL1583585 & 688131 & 6.3089 & 6.7688 & TRN & & \\
\hline CHEMBL1506750 & 688131 & 3.4202 & 5.1693 & TRN & & \\
\hline CHEMBL1492376 & 688131 & 3.4202 & 5.3414 & TRN & & \\
\hline CHEMBL1566955 & 688131 & 3.4202 & 3.6108 & TRN & & \\
\hline CHEMBL3198496 & 688131 & 3.4202 & 4.937 & TRN & & \\
\hline CHEMBL1563943 & 688131 & 5.4865 & 5.7621 & TRN & & \\
\hline CHEMBL1505028 & 688131 & 5.7095 & 5.5235 & TST & & \\
\hline CHEMBL1306749 & 688131 & 5.5081 & 4.9006 & TRN & & \\
\hline CHEMBL1468055 & 688131 & 3.4202 & 4.9909 & TST & & \\
\hline CHEMBL1426112 & 688131 & 6.2472 & 5.5481 & TST & & \\
\hline CHEMBL1388803 & 688131 & 5.7277 & 5.146 & TRN & & \\
\hline CHEMBL1546039 & 688131 & 5.1562 & 5.5269 & TRN & & \\
\hline CHEMBL1977678 & 688131 & 5.5267 & 4.8191 & TRN & & \\
\hline CHEMBL1988042 & 688131 & 6.3449 & 6.1238 & TRN & & \\
\hline CHEMBL1509676 & 688131 & 3.4202 & 4.8659 & TRN & & \\
\hline CHEMBL1594242 & 688131 & 5.7135 & 4.0798 & TRN & & \\
\hline CHEMBL1470712 & 688131 & 3.4202 & 4.6252 & TRN & & \\
\hline CHEMBL200965 & 688131 & 6.5735 & 5.4727 & TRN & & \\
\hline CHEMBL1393829 & 688131 & 6.2366 & 6.0906 & TRN & & \\
\hline CHEMBL530499 & 688131 & 6.1506 & 6.2536 & TRN & & \\
\hline CHEMBL1311826 & 688131 & 6.2233 & 6.1744 & TRN & & \\
\hline CHEMBL1600749 & 688131 & 4.9916 & 5.3073 & TRN & & \\
\hline CHEMBL1305499 & 688131 & 3.4202 & 3.2099 & TRN & & \\
\hline CHEMBL1324163 & 688131 & 3.4202 & 3.8868 & TRN & & \\
\hline
\end{tabular}




\begin{tabular}{|c|c|c|c|c|c|c|}
\hline & & \multicolumn{5}{|c|}{ Supplemental Table S2.txt } \\
\hline CHEMBL1513713 & 688131 & 5.6444 & 4.6818 & TRN & & \\
\hline CHEMBL1464485 & 688131 & 7.0362 & 5.3467 & TRN & & \\
\hline CHEMBL1432784 & 688131 & 5.5797 & 4.3644 & TRN & & \\
\hline CHEMBL 3397122 & 688131 & 3.4202 & 5.0725 & TRN & & \\
\hline CHEMBL1460301 & 688131 & 6.6556 & 4.9578 & TRN & & \\
\hline CHEMBL1305918 & 688131 & 3.4202 & 4.004 & TRN & & \\
\hline CHEMBL1989897 & 688131 & 5.8283 & 5.0073 & TRN & & \\
\hline CHEMBL1310438 & 688131 & 5.961 & 5.2513 & TRN & & \\
\hline CHEMBL1558065 & 688131 & 5.654 & 5.5413 & TRN & & \\
\hline CHEMBL1469888 & 688131 & 3.4202 & 4.7421 & TRN & & \\
\hline CHEMBL1392564 & 688131 & 6.2411 & 5.1782 & TRN & & \\
\hline CHEMBL1312049 & 688131 & 6.0716 & 5.7252 & TRN & & \\
\hline CHEMBL1390492 & 688131 & 6.0237 & 5.5094 & TRN & & \\
\hline CHEMBL1458210 & 688131 & 3.4202 & 4.1555 & TST & & \\
\hline CHEMBL1452779 & 688131 & 4.9136 & 5.7605 & TRN & & \\
\hline CHEMBL1376851 & 688131 & 3.4202 & 4.9569 & TST & & \\
\hline CHEMBL187263 & 688131 & 5.4501 & 5.6236 & TRN & & \\
\hline CHEMBL3197761 & 688131 & 6.3161 & 5.5588 & TRN & & \\
\hline CHEMBL1471206 & 688131 & 5.6657 & 5.4742 & TRN & & \\
\hline CHEMBL1416601 & 688131 & 6.0799 & 5.3761 & TRN & & \\
\hline CHEMBL1401668 & 688131 & 6.0942 & 3.7459 & TST & & \\
\hline CHEMBL1563898 & 688131 & 5.9694 & 5.3516 & TST & & \\
\hline CHEMBL1322948 & 688131 & 7.3372 & 4.5019 & TRN & & \\
\hline CHEMBL1596969 & 688131 & 3.4202 & 4.7323 & TRN & & \\
\hline CHEMBL3197902 & 688131 & 5.63299 & 99999999 & 99 & 4.8564 & TRN \\
\hline CHEMBL1343568 & 688131 & 3.4202 & 5.1901 & TRN & & \\
\hline CHEMBL1594846 & 688131 & 5.8216 & 5.8988 & TRN & & \\
\hline CHEMBL1453766 & 688131 & 3.4202 & 3.7604 & TRN & & \\
\hline CHEMBL1442878 & 688131 & 3.4202 & 4.5153 & TRN & & \\
\hline CHEMBL582073 & 688131 & 6.1494 & 5.4347 & TRN & & \\
\hline CHEMBL1609663 & 688131 & 6.4401 & 5.7499 & TRN & & \\
\hline CHEMBL1550278 & 688131 & 6.3936 & 5.8297 & TRN & & \\
\hline CHEMBL1307271 & 688131 & 3.4202 & 5.6798 & TRN & & \\
\hline CHEMBL1492918 & 688131 & 3.4202 & 3.884 & TRN & & \\
\hline CHEMBL1527180 & 688131 & 3.4202 & 4.8567 & TRN & & \\
\hline CHEMBL1370113 & 688131 & 3.4202 & 4.7571 & TRN & & \\
\hline CHEMBL3191534 & 688131 & 3.4202 & 4.0819 & TRN & & \\
\hline CHEMBL1484330 & 688131 & 5.8921 & 4.2892 & TRN & & \\
\hline CHEMBL1363249 & 688131 & 6.0381 & 5.5381 & TRN & & \\
\hline CHEMBL3197978 & 688131 & 5.9618 & 5.9051 & TRN & & \\
\hline CHEMBL1335117 & 688131 & 3.4202 & 3.8921 & TST & & \\
\hline CHEMBL1488279 & 688131 & 7.0223 & 5.5472 & TRN & & \\
\hline CHEMBL1448700 & 688131 & 6.52 & 3.9085 & TRN & & \\
\hline CHEMBL1466831 & 688131 & 5.6643 & 4.8316 & TRN & & \\
\hline CHEMBL1375115 & 688131 & 3.4202 & 5.0664 & TST & & \\
\hline CHEMBL1535759 & 688131 & 3.4202 & 4.7817 & TRN & & \\
\hline CHEMBL1528975 & 688131 & 5.4571 & 4.8063 & TRN & & \\
\hline CHEMBL1411342 & 688131 & 3.4202 & 3.987 & TRN & & \\
\hline
\end{tabular}




\begin{tabular}{|c|c|c|c|c|c|c|}
\hline & & \multicolumn{5}{|c|}{ Supplemental Table S2.txt } \\
\hline CHEMBL1530885 & 688131 & 5.4041 & 5.1473 & TRN & & \\
\hline CHEMBL1371877 & 688131 & 5.4901 & 5.2086 & TRN & & \\
\hline CHEMBL1379894 & 688131 & 6.2062 & 4.2401 & TRN & & \\
\hline CHEMBL1410441 & 688131 & 3.4202 & 4.1809 & TRN & & \\
\hline CHEMBL3145303 & 688131 & 5.5959 & 6.0637 & TRN & & \\
\hline CHEMBL1382821 & 688131 & 6.8861 & 3.908 & TRN & & \\
\hline CHEMBL1348263 & 688131 & 3.4202 & 5.007 & TRN & & \\
\hline CHEMBL1323428 & 688131 & 5.7802 & 5.274 & TRN & & \\
\hline CHEMBL1463257 & 688131 & 3.4202 & 4.8755 & TST & & \\
\hline CHEMBL1422472 & 688131 & 5.4173 & 5.3702 & TRN & & \\
\hline CHEMBL1371773 & 688131 & 8.5229 & 4.9234 & TRN & & \\
\hline CHEMBL1302283 & 688131 & 6.0531 & 5.3196 & TRN & & \\
\hline CHEMBL1437579 & 688131 & \multicolumn{3}{|c|}{6.617999999999999} & 5.3543 & TRN \\
\hline CHEMBL585221 & 688131 & 3.4202 & 6.0486 & TRN & & \\
\hline CHEMBL1444553 & 688131 & 3.4202 & 5.01 & TRN & & \\
\hline CHEMBL1499342 & 688131 & 5.7263 & 5.1827 & TRN & & \\
\hline CHEMBL1462215 & 688131 & 6.6737 & 7.2089 & TRN & & \\
\hline CHEMBL1431312 & 688131 & 3.4202 & 4.8161 & TRN & & \\
\hline CHEMBL 1332450 & 688131 & 6.1831 & 5.9479 & TRN & & \\
\hline CHEMBL1604864 & 688131 & 3.4202 & 4.3042 & TRN & & \\
\hline CHEMBL3193835 & 688131 & 6.6162 & 5.7557 & TST & & \\
\hline CHEMBL599255 & 688131 & 6.4584 & 5.7114 & TRN & & \\
\hline CHEMBL1337598 & 688131 & 3.4202 & 4.9236 & TRN & & \\
\hline CHEMBL1468668 & 688131 & 5.9187 & 5.3512 & TST & & \\
\hline CHEMBL1522807 & 688131 & 5.9041 & 5.8648 & TRN & & \\
\hline CHEMBL585591 & 688131 & 6.0106 & 6.4033 & TRN & & \\
\hline CHEMBL1529188 & 688131 & 3.4202 & 5.8627 & TRN & & \\
\hline CHEMBL1401188 & 688131 & 3.4202 & 4.4754 & TRN & & \\
\hline CHEMBL3197024 & 688131 & 6.1373 & 5.4242 & TRN & & \\
\hline CHEMBL1483387 & 688131 & 3.4202 & 3.5215 & TRN & & \\
\hline CHEMBL1500742 & 688131 & 6.0585 & 4.7516 & TRN & & \\
\hline CHEMBL1540525 & 688131 & 5.942 & 5.0817 & TRN & & \\
\hline CHEMBL1347962 & 688131 & 3.4202 & 4.7355 & TRN & & \\
\hline CHEMBL1376224 & 688131 & 3.4202 & 3.58 & TRN & & \\
\hline CHEMBL3192747 & 688131 & 5.4007 & 5.17299 & 9999999999 & & TRN \\
\hline CHEMBL1447219 & 688131 & 5.9961 & 6.0626 & TRN & & \\
\hline CHEMBL1504407 & 688131 & 5.8674 & 5.1838 & TST & & \\
\hline CHEMBL1483724 & 688131 & 4.8528 & 3.91 & TRN & & \\
\hline CHEMBL1477212 & 688131 & 6.0 & 5.7172 & TRN & & \\
\hline CHEMBL1348329 & 688131 & 6.1192 & 4.8042 & TST & & \\
\hline CHEMBL1307923 & 688131 & 3.4202 & 4.4108 & TRN & & \\
\hline CHEMBL1456728 & 688131 & 3.4202 & 3.928 & TRN & & \\
\hline CHEMBL1591171 & 688131 & 3.4202 & 4.9128 & TST & & \\
\hline CHEMBL1319004 & 688131 & 6.7305 & 5.0538 & TRN & & \\
\hline CHEMBL325841 & 688131 & 5.6743 & 5.2645 & TRN & & \\
\hline CHEMBL1380634 & 688131 & 3.4202 & 3.7144 & TRN & & \\
\hline CHEMBL3195036 & 688131 & 6.2941 & 6.0043 & TRN & & \\
\hline CHEMBL1587075 & 688131 & 5.347 & 5.0063 & TST & & \\
\hline
\end{tabular}


Supplemental Table S2.txt

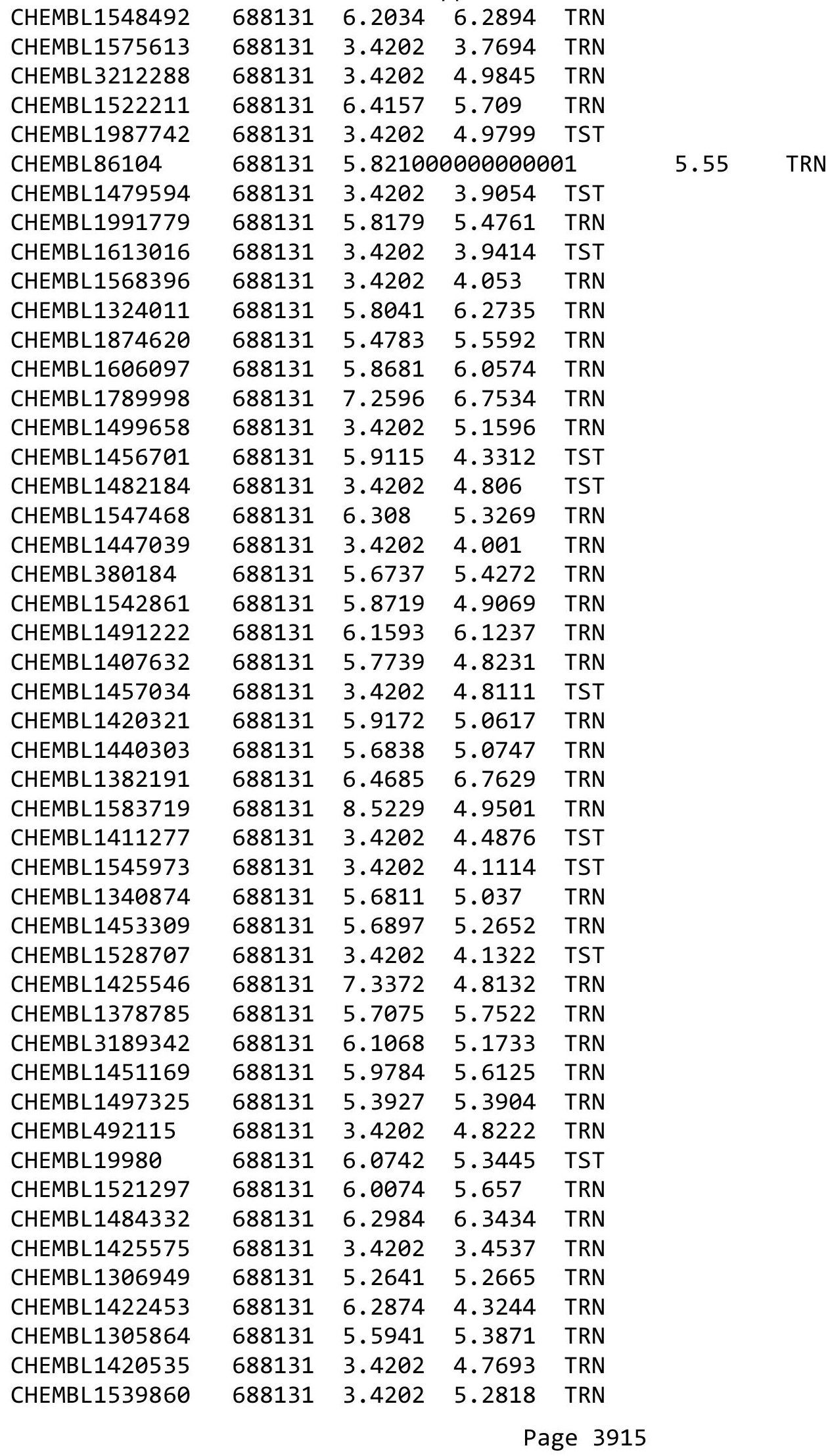




\begin{tabular}{|c|c|c|c|c|c|}
\hline \multicolumn{6}{|c|}{ Supplemental Table S2.txt } \\
\hline CHEMBL1541425 & 688131 & 4.9937 & 4.8545 & TRN & \\
\hline CHEMBL1378479 & 688131 & 6.1898 & 5.4784 & TST & \\
\hline CHEMBL1377316 & 688131 & 6.6162 & 5.7897 & TRN & \\
\hline CHEMBL1488035 & 688131 & 6.3546 & 5.8068 & TRN & \\
\hline CHEMBL405927 & 688131 & 5.8044 & 5.0522 & TRN & \\
\hline CHEMBL1367316 & 688131 & 5.7537 & 3.8972 & TRN & \\
\hline CHEMBL1550430 & 688131 & 5.9531 & 4.9577 & TRN & \\
\hline CHEMBL1420188 & 688131 & 6.0159 & 4.4268 & TRN & \\
\hline CHEMBL1390303 & 688131 & 6.3936 & 5.1534 & TRN & \\
\hline CHEMBL1517473 & 688131 & 6.1215 & 5.3767 & TRN & \\
\hline CHEMBL1705092 & 688131 & 3.4202 & 4.5755 & TRN & \\
\hline CHEMBL1326464 & 688131 & 5.6269 & 5.5432 & TRN & \\
\hline CHEMBL1330453 & 688131 & 6.1439 & 5.4223 & TRN & \\
\hline CHEMBL1468306 & 688131 & 5.4304 & 5.215 & TRN & \\
\hline CHEMBL1389318 & 688131 & 6.6861 & 6.0559 & TST & \\
\hline CHEMBL1560221 & 688131 & 5.4972 & 5.3737 & TRN & \\
\hline CHEMBL3192165 & 688131 & 5.9255 & 5.7996 & TRN & \\
\hline CHEMBL1576976 & 688131 & 5.4349 & 5.37200 & $\partial 000000001$ & TST \\
\hline CHEMBL1374234 & 688131 & 3.4202 & 5.3547 & TRN & \\
\hline CHEMBL1374462 & 688131 & 8.5229 & 6.2788 & TST & \\
\hline CHEMBL1502851 & 688131 & 3.4202 & 5.0134 & TRN & \\
\hline CHEMBL 2000368 & 688131 & 3.4202 & 5.0151 & TRN & \\
\hline CHEMBL1580315 & 688131 & 6.9914 & 5.231 & TRN & \\
\hline CHEMBL1375925 & 688131 & 5.5203 & 5.307 & TRN & \\
\hline CHEMBL1535533 & 688131 & 3.4202 & 4.5696 & TRN & \\
\hline CHEMBL1582488 & 688131 & 3.4202 & 5.3537 & TRN & \\
\hline CHEMBL1967081 & 688131 & 5.8033 & 5.7972 & TRN & \\
\hline CHEMBL 2005246 & 688131 & 5.6832 & 6.2048 & TRN & \\
\hline CHEMBL1383409 & 688131 & 3.4202 & 4.6991 & TRN & \\
\hline CHEMBL3209142 & 688131 & 3.4202 & 5.3419 & TRN & \\
\hline CHEMBL1576754 & 688131 & 3.4202 & 4.8222 & TRN & \\
\hline CHEMBL1349566 & 688131 & 5.8976 & 6.3556 & TRN & \\
\hline CHEMBL1533353 & 688131 & 6.3098 & 5.3263 & TRN & \\
\hline CHEMBL1455405 & 688131 & 3.4202 & 3.8049 & TRN & \\
\hline CHEMBL1352792 & 688131 & 5.9223 & 5.7031 & TRN & \\
\hline CHEMBL1348342 & 688131 & 3.4202 & 4.7854 & TRN & \\
\hline CHEMBL1457139 & 688131 & 5.8545 & 5.6105 & TRN & \\
\hline CHEMBL1465367 & 688131 & 3.4202 & 3.8099 & TRN & \\
\hline CHEMBL3198207 & 688131 & 5.7135 & 5.282 & TRN & \\
\hline CHEMBL1587434 & 688131 & 5.7645 & 5.1773 & TRN & \\
\hline CHEMBL1331639 & 688131 & 3.4202 & 4.8306 & TRN & \\
\hline CHEMBL1327455 & 688131 & 5.5265 & 6.2521 & TRN & \\
\hline CHEMBL1319294 & 688131 & 3.4202 & 3.85600 & 00000000003 & TRN \\
\hline CHEMBL1526624 & 688131 & 3.4202 & 4.5151 & TRN & \\
\hline CHEMBL1533308 & 688131 & 5.5839 & 5.0185 & TRN & \\
\hline CHEMBL1501268 & 688131 & 3.4202 & 3.9052 & TST & \\
\hline CHEMBL3196754 & 688131 & 6.1232 & 5.4596 & TRN & \\
\hline CHEMBL1327791 & 688131 & 3.4202 & 4.5555 & TRN & \\
\hline
\end{tabular}




\begin{tabular}{|c|c|c|c|c|c|c|}
\hline & & \multicolumn{5}{|c|}{ Supplemental Table S2.txt } \\
\hline CHEMBL1369893 & 688131 & 6.7328 & 5.9595 & TRN & & \\
\hline CHEMBL 3190585 & 688131 & 5.4147 & 6.6763 & TRN & & \\
\hline CHEMBL1457944 & 688131 & 3.4202 & 3.2286 & TRN & & \\
\hline CHEMBL1534520 & 688131 & 6.1029 & 5.1327 & TRN & & \\
\hline CHEMBL1429789 & 688131 & 3.4202 & 5.2155 & TRN & & \\
\hline CHEMBL1422696 & 688131 & 3.4202 & 4.7449 & TRN & & \\
\hline CHEMBL1339626 & 688131 & \multicolumn{3}{|c|}{6.718999999999999} & 3.9414 & TRN \\
\hline CHEMBL1447697 & 688131 & 5.697 & 5.4152 & TRN & & \\
\hline CHEMBL1496096 & 688131 & 3.4202 & 4.9607 & TRN & & \\
\hline CHEMBL1993662 & 688131 & 3.4202 & 4.0507 & TRN & & \\
\hline CHEMBL1467876 & 688131 & 5.4365 & 5.2036 & TRN & & \\
\hline CHEMBL1567688 & 688131 & 5.7312 & 5.3294 & TRN & & \\
\hline CHEMBL1998436 & 688131 & 3.4202 & 3.6453 & TRN & & \\
\hline CHEMBL459022 & 688131 & 3.4202 & 4.7991 & TST & & \\
\hline CHEMBL1391582 & 688131 & 3.4202 & 3.9136 & TST & & \\
\hline CHEMBL1430895 & 688131 & 3.4202 & 4.6343 & TRN & & \\
\hline CHEMBL1467326 & 688131 & 5.4917 & 5.4355 & TRN & & \\
\hline CHEMBL313163 & 688131 & 5.8108 & 5.3718 & TRN & & \\
\hline CHEMBL3193419 & 688131 & 6.466 & 5.8607 & TRN & & \\
\hline CHEMBL1588513 & 688131 & 6.0685 & 5.5871 & TRN & & \\
\hline CHEMBL3193010 & 688131 & 6.8386 & 5.7595 & TRN & & \\
\hline CHEMBL3190594 & 688131 & \multicolumn{3}{|c|}{5.922999999999999} & 5.8207 & TRN \\
\hline CHEMBL1311585 & 688131 & 3.4202 & 4.0476 & TRN & & \\
\hline CHEMBL1484456 & 688131 & 3.4202 & 3.9448 & TRN & & \\
\hline CHEMBL1362096 & 688131 & 5.7395 & 5.0925 & TRN & & \\
\hline CHEMBL1426383 & 688131 & 5.5904 & 5.2348 & TRN & & \\
\hline CHEMBL1440899 & 688131 & 3.4202 & 3.7473 & TRN & & \\
\hline CHEMBL1601709 & 688131 & 3.4202 & 3.7876 & TRN & & \\
\hline CHEMBL1408774 & 688131 & 5.9045 & 5.3606 & TRN & & \\
\hline CHEMBL1382011 & 688131 & 3.4202 & 4.9599 & TRN & & \\
\hline CHEMBL1505071 & 688131 & 5.6349 & 5.3114 & TRN & & \\
\hline CHEMBL1585777 & 688131 & 5.8187 & 5.5359 & TRN & & \\
\hline CHEMBL1598347 & 688131 & 5.4125 & 5.3151 & TRN & & \\
\hline CHEMBL1494743 & 688131 & 3.4202 & 3.9624 & TST & & \\
\hline CHEMBL1602841 & 688131 & 5.5251 & 5.2754 & TRN & & \\
\hline CHEMBL1543939 & 688131 & 5.3513 & 4.9262 & TST & & \\
\hline CHEMBL1500144 & 688131 & 3.4202 & 5.17899 & 9999999999 & & TRN \\
\hline CHEMBL1347211 & 688131 & 5.3835 & 3.6899 & TRN & & \\
\hline CHEMBL1600203 & 688131 & 3.4202 & 5.0086 & TRN & & \\
\hline CHEMBL1611574 & 688131 & 3.4202 & 4.5792 & TRN & & \\
\hline CHEMBL1401057 & 688131 & 6.5686 & 5.5475 & TRN & & \\
\hline CHEMBL1417389 & 688131 & 5.5154 & 4.6177 & TRN & & \\
\hline CHEMBL1379535 & 688131 & 3.4202 & 5.1116 & TRN & & \\
\hline CHEMBL3197625 & 688131 & 5.4223 & 4.9764 & TRN & & \\
\hline CHEMBL334707 & 688131 & 7.0757 & 6.0274 & TRN & & \\
\hline CHEMBL1524515 & 688131 & 3.4202 & 5.2319 & TRN & & \\
\hline CHEMBL 2000750 & 688131 & 6.1319 & 5.5509 & TRN & & \\
\hline CHEMBL1352732 & 688131 & 5.2037 & 3.4988 & TRN & & \\
\hline
\end{tabular}




\begin{tabular}{|c|c|c|c|c|c|c|}
\hline & & \multicolumn{5}{|c|}{ Supplemental Table S2.txt } \\
\hline CHEMBL1519688 & 688131 & 3.4202 & 4.1157 & TRN & & \\
\hline CHEMBL1564599 & 688131 & 6.7595 & 4.1555 & TRN & & \\
\hline CHEMBL1503006 & 688131 & 6.5918 & 6.0562 & TRN & & \\
\hline CHEMBL1351158 & 688131 & 5.6349 & 5.9507 & TRN & & \\
\hline CHEMBL1301513 & 688131 & 6.1925 & 5.2383 & TRN & & \\
\hline CHEMBL3213808 & 688131 & 3.4202 & 3.824 & TRN & & \\
\hline CHEMBL1346587 & 688131 & 5.4093 & 3.8962 & TRN & & \\
\hline CHEMBL1343392 & 688131 & 3.4202 & 4.4425 & TRN & & \\
\hline CHEMBL1436213 & 688131 & 5.7729 & 5.5143 & TRN & & \\
\hline CHEMBL1499914 & 688131 & 3.4202 & 5.0251 & TRN & & \\
\hline CHEMBL1091556 & 688131 & 3.4202 & 5.5258 & TRN & & \\
\hline CHEMBL1278181 & 688131 & 5.4531 & 5.2644 & TRN & & \\
\hline CHEMBL1390645 & 688131 & 3.4202 & 4.3646 & TRN & & \\
\hline CHEMBL1404792 & 688131 & 8.5229 & 8.202 & TRN & & \\
\hline CHEMBL1450261 & 688131 & 3.4202 & 5.2164 & TRN & & \\
\hline CHEMBL3199020 & 688131 & $5.8210 e$ & 00000000 & $\partial 1$ & 5.5215 & TRN \\
\hline CHEMBL1397742 & 688131 & 5.4974 & 5.1002 & TRN & & \\
\hline CHEMBL1547141 & 688131 & 3.4202 & 4.4109 & TST & & \\
\hline CHEMBL1563623 & 688131 & 5.9083 & 5.6454 & TRN & & \\
\hline CHEMBL1312953 & 688131 & 5.4825 & 6.4712 & TRN & & \\
\hline CHEMBL580955 & 688131 & 6.2069 & 6.391 & TRN & & \\
\hline CHEMBL1558160 & 688131 & 6.1035 & 4.8872 & TRN & & \\
\hline CHEMBL1536303 & 688131 & 3.4202 & 4.502 & TRN & & \\
\hline CHEMBL1442341 & 688131 & 6.6778 & 5.3786 & TRN & & \\
\hline CHEMBL518252 & 688131 & 6.5654 & 5.8783 & TST & & \\
\hline CHEMBL1550584 & 688131 & 3.4202 & 5.472 & TRN & & \\
\hline CHEMBL1389720 & 688131 & 3.4202 & 4.909 & TRN & & \\
\hline CHEMBL1349470 & 688131 & 3.4202 & 3.9587 & TRN & & \\
\hline CHEMBL585502 & 688131 & 8.5229 & 7.4166 & TRN & & \\
\hline CHEMBL1485006 & 688131 & 6.0706 & 5.2905 & TRN & & \\
\hline CHEMBL1334233 & 688131 & 5.8374 & 4.8204 & TRN & & \\
\hline CHEMBL1428240 & 688131 & 6.2418 & 5.3734 & TRN & & \\
\hline CHEMBL1529553 & 688131 & 5.6183 & 5.2572 & TRN & & \\
\hline CHEMBL1303953 & 688131 & 5.7523 & 4.5163 & TRN & & \\
\hline CHEMBL1393700 & 688131 & 5.9512 & 5.3152 & TRN & & \\
\hline CHEMBL3193326 & 688131 & 5.8353 & 5.5146 & TRN & & \\
\hline CHEMBL1547347 & 688131 & 6.2441 & 5.3449 & TRN & & \\
\hline CHEMBL1487401 & 688131 & 5.66 & 5.5653 & TRN & & \\
\hline CHEMBL1349452 & 688131 & 3.4202 & 4.621 & TRN & & \\
\hline CHEMBL 2004978 & 688131 & 6.1785 & 5.5622 & TRN & & \\
\hline CHEMBL1612493 & 688131 & 3.4202 & 5.7019 & TRN & & \\
\hline CHEMBL1390100 & 688131 & 3.4202 & 4.868 & TRN & & \\
\hline CHEMBL1319079 & 688131 & 6.15799 & 99999999 & 995 & 5.6863 & TRN \\
\hline CHEMBL3199286 & 688131 & 6.3969 & 6.0897 & TRN & & \\
\hline CHEMBL1502530 & 688131 & 5.7095 & 5.138 & TRN & & \\
\hline CHEMBL3192576 & 688131 & 3.4202 & 3.7871 & TRN & & \\
\hline CHEMBL1386774 & 688131 & 6.2328 & 5.4744 & TRN & & \\
\hline CHEMBL3145366 & 688131 & 5.5127 & 5.6782 & TRN & & \\
\hline
\end{tabular}


Supplemental Table S2.txt

\begin{tabular}{|c|c|c|c|c|c|c|}
\hline CHEMBL 3196257 & 688131 & 5.6398 & 5.4176 & TRN & & \\
\hline CHEMBL602363 & 688131 & 6.2248 & 5.6267 & TRN & & \\
\hline CHEMBL1409365 & 688131 & 3.4202 & 4.7799 & TST & & \\
\hline CHEMBL1420684 & 688131 & 5.5166 & 5.2259 & TST & & \\
\hline CHEMBL1407461 & 688131 & \multicolumn{3}{|c|}{5.678999999999999} & 5.4579 & TRN \\
\hline CHEMBL1550442 & 688131 & 6.4295 & 5.5286 & TRN & & \\
\hline CHEMBL1481746 & 688131 & 3.4202 & 5.0649 & TST & & \\
\hline CHEMBL1598785 & 688131 & 6.3344 & 6.245 & TRN & & \\
\hline CHEMBL1608104 & 688131 & 5.0788 & 4.998 & TST & & \\
\hline CHEMBL1534596 & 688131 & 6.1624 & 5.2954 & TRN & & \\
\hline CHEMBL523200 & 688131 & \multicolumn{3}{|c|}{5.8629999999999995} & 5.0121 & TRN \\
\hline CHEMBL1543977 & 688131 & 6.0867 & 5.2894 & TRN & & \\
\hline CHEMBL1340417 & 688131 & 5.5449 & 5.5147 & TRN & & \\
\hline CHEMBL1389836 & 688131 & 3.4202 & 5.2245 & TRN & & \\
\hline CHEMBL225963 & 688131 & 6.6757 & 5.5583 & TRN & & \\
\hline CHEMBL453974 & 688131 & 7.3098 & 6.0128 & TST & & \\
\hline CHEMBL 3189255 & 688131 & 5.4782 & 4.8932 & TRN & & \\
\hline CHEMBL1442155 & 688131 & \multicolumn{3}{|c|}{5.446000000000001} & 5.6679 & 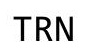 \\
\hline CHEMBL1516976 & 688131 & 3.4202 & 5.2225 & TST & & \\
\hline CHEMBL1451977 & 688131 & 5.6321 & 6.0111 & TRN & & \\
\hline CHEMBL1313263 & 688131 & 5.7815 & 4.8794 & TST & & \\
\hline CHEMBL548615 & 688131 & 5.7421 & 5.9837 & TRN & & \\
\hline CHEMBL1328184 & 688131 & 6.3665 & 5.4503 & TRN & & \\
\hline CHEMBL1390391 & 688131 & 3.4202 & 4.0144 & TRN & & \\
\hline CHEMBL1352909 & 688131 & 3.4202 & 4.9608 & TST & & \\
\hline CHEMBL1520187 & 688131 & 5.3871 & 4.9 & TST & & \\
\hline CHEMBL1310713 & 688131 & 6.0205 & 5.3654 & TRN & & \\
\hline CHEMBL 3189472 & 688131 & 3.4202 & 3.8189 & TRN & & \\
\hline CHEMBL1432888 & 688131 & 5.4752 & 5.1029 & TRN & & \\
\hline CHEMBL1567963 & 688131 & 5.2423 & 4.1679 & TST & & \\
\hline CHEMBL 3194562 & 688131 & 5.8732 & 5.4798 & TRN & & \\
\hline CHEMBL1508474 & 688131 & 5.7217 & 5.9686 & TRN & & \\
\hline CHEMBL1364071 & 688131 & 5.8582 & 5.2096 & TRN & & \\
\hline CHEMBL1576945 & 688131 & 5.8739 & 5.0923 & TST & & \\
\hline CHEMBL1331470 & 688131 & 3.4202 & 3.5651 & TRN & & \\
\hline CHEMBL3198754 & 688131 & 5.9755 & 5.4963 & TRN & & \\
\hline CHEMBL1539624 & 688131 & 6.0595 & 6.09200 & 000000000 & & rRN \\
\hline CHEMBL1562633 & 688131 & 3.4202 & 3.8058 & TRN & & \\
\hline CHEMBL1368410 & 688131 & 5.8125 & 5.3858 & TRN & & \\
\hline CHEMBL1366992 & 688131 & 5.5183 & 5.3897 & TST & & \\
\hline CHEMBL 3191182 & 688131 & 3.4202 & 5.4605 & TRN & & \\
\hline CHEMBL1602855 & 688131 & 5.9674 & 5.1737 & TRN & & \\
\hline CHEMBL1427508 & 688131 & 3.4202 & 4.8321 & TRN & & \\
\hline CHEMBL1502351 & 688131 & 5.8259 & 5.565 & TRN & & \\
\hline CHEMBL598263 & 688131 & 5.9851 & 5.5797 & TRN & & \\
\hline CHEMBL 3194752 & 688131 & 3.4202 & 5.4659 & TRN & & \\
\hline CHEMBL1425238 & 688131 & 5.3481 & 5.2372 & TRN & & \\
\hline CHEMBL1387894 & 688131 & 3.4202 & 4.5847 & TRN & & \\
\hline
\end{tabular}

Page 3919 
Supplemental Table s2.txt

\begin{tabular}{|c|c|c|c|c|}
\hline AEMBL1575805 & & 5.5677 & & \\
\hline HEMBL1488474 & & & 3.9629 & \\
\hline 929 & & & & \\
\hline EMBL1 & & & & \\
\hline IEMBL3 & 88131 & & & \\
\hline AEMBL1326523 & 88131 & 202 & 581 & \\
\hline 6264 & 88131 & & 821 & \\
\hline 5349 & & & & \\
\hline IEMBL & 88131 & & & \\
\hline AEMBL: & 88131 & & 4.8672 & \\
\hline AEMBL? & 88131 & & & \\
\hline 7043 & 88131 & & 834 & \\
\hline 081 & 131 & & & \\
\hline AEMBL & 88131 & & & \\
\hline IEMBL & 88131 & & & \\
\hline IEMBL & 88131 & & & \\
\hline 9610 & 88131 & & 17 & \\
\hline AEMBL & 88131 & & & \\
\hline 3257 & 88131 & & & \\
\hline 5030 & 31 & & & \\
\hline 3964 & 88131 & & 77 & \\
\hline 5177 & 1 & & 05 & \\
\hline 5988 & 1 & & & 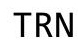 \\
\hline 868 & & & & \\
\hline 3943 & 1 & & & \\
\hline 3092 & 881 & & 39 & \\
\hline 9845 & 881 & & 78 & \\
\hline 4227 & 1 & & & ST \\
\hline 181 & & & & \\
\hline 361 & 1 & & & RI \\
\hline 7372 & 881 & & 68 & RI \\
\hline 7190 & 1 & & 55 & \\
\hline 758 & 1 & & & KIV \\
\hline & & & & RN \\
\hline & 1 & & & RI \\
\hline 506 & 381 & & 76 & $\mathrm{R}$ \\
\hline 715 & 1 & & & \\
\hline & & & & RN \\
\hline 7448 & & & & RI \\
\hline 5396 & 1 & & & \\
\hline 440 & 1 & & & \\
\hline 4231 & 881 & & & \\
\hline & & & & \\
\hline 0249 & 1 & & & $\mathrm{R}$ \\
\hline 9959 & 1 & & 4.2 & \\
\hline & & & & \\
\hline & & & 5.2356 & \\
\hline (arr & 88131 & 5.9 & 6.5803 & \\
\hline
\end{tabular}

Page 3920 
Supplemental Table S2.txt

\begin{tabular}{|c|c|c|c|c|}
\hline CHEMBL1472105 & 688131 & 6.4342 & 5.6072 & TRN \\
\hline CHEMBL1418460 & 688131 & 5.2962 & 4.8867 & TST \\
\hline CHEMBL1426340 & 688131 & 6.0991 & 5.8714 & TRN \\
\hline CHEMBL1996971 & 688131 & 3.4202 & 4.2734 & TRN \\
\hline CHEMBL1353757 & 688131 & 3.4202 & 5.3144 & TRN \\
\hline CHEMBL1322450 & 688131 & 3.4202 & 3.8758 & TST \\
\hline CHEMBL3213305 & 688131 & 3.4202 & \multicolumn{2}{|c|}{5.4510000000000005} \\
\hline CHEMBL1376904 & 688131 & 5.6273 & 5.1619 & TRN \\
\hline CHEMBL36654 & 688131 & 3.4202 & 4.16 & TST \\
\hline CHEMBL1545677 & 688131 & 6.2411 & 5.37 & TRN \\
\hline CHEMBL3193302 & 688131 & 3.4202 & 4.9305 & TST \\
\hline CHEMBL1381600 & 688131 & 5.9052 & 5.3208 & TRN \\
\hline CHEMBL1587806 & 688131 & 7.2676 & 5.7963 & TRN \\
\hline CHEMBL1499893 & 688131 & 6.1073 & 4.8588 & TRN \\
\hline CHEMBL1368792 & 688131 & 5.791 & 5.0634 & TRN \\
\hline CHEMBL1197556 & 688131 & 6.1945 & 7.3322 & TRN \\
\hline CHEMBL1365622 & 688131 & 5.5674 & 5.1858 & TRN \\
\hline CHEMBL1369698 & 688131 & 5.529 & 5.1909 & TRN \\
\hline CHEMBL1334791 & 688131 & 3.4202 & 4.9163 & TRN \\
\hline CHEMBL1603001 & 688131 & 6.1152 & 5.7847 & TRN \\
\hline CHEMBL1581503 & 688131 & 3.4202 & 3.7937 & TRN \\
\hline CHEMBL1990174 & 688131 & 5.9923 & 5.7188 & TRN \\
\hline CHEMBL1302990 & 688131 & 3.4202 & 4.3799 & TRN \\
\hline CHEMBL1569910 & 688131 & 6.4123 & 5.7077 & TRN \\
\hline CHEMBL3192681 & 688131 & 6.5638 & 4.8741 & TRN \\
\hline CHEMBL1389335 & 688131 & 5.9219 & 5.2697 & TRN \\
\hline CHEMBL1371081 & 688131 & 6.1844 & 5.3593 & TRN \\
\hline CHEMBL584442 & 688131 & 6.6216 & 6.806 & TRN \\
\hline CHEMBL3190095 & 688131 & 5.9952 & 5.0841 & TST \\
\hline CHEMBL1595934 & 688131 & 5.9614 & 5.0754 & TRN \\
\hline CHEMBL1511335 & 688131 & 3.4202 & 4.5299 & TRN \\
\hline CHEMBL1586169 & 688131 & 6.1331 & 5.3714 & TRN \\
\hline CHEMBL1556805 & 688131 & 8.5229 & 7.4225 & TRN \\
\hline CHEMBL1328566 & 688131 & 5.1808 & 4.289 & TRN \\
\hline CHEMBL1485259 & 688131 & 6.8182 & 5.3293 & TRN \\
\hline CHEMBL1595551 & 688131 & 3.4202 & 3.7442 & TRN \\
\hline CHEMBL1352766 & 688131 & 3.4202 & 3.9441 & TRN \\
\hline CHEMBL1576118 & 688131 & 5.8938 & 5.2146 & TRN \\
\hline CHEMBL1528505 & 688131 & 5.8775 & 5.4033 & TRN \\
\hline CHEMBL1350865 & 688131 & 3.4202 & 3.6683 & TRN \\
\hline CHEMBL1348803 & 688131 & 6.2676 & 5.0953 & TRN \\
\hline CHEMBL1303554 & 688131 & 3.4202 & 3.866 & TST \\
\hline CHEMBL3194039 & 688131 & 3.4202 & 4.4091 & TRN \\
\hline CHEMBL1319643 & 688131 & 3.4202 & 5.5557 & TRN \\
\hline CHEMBL1580948 & 688131 & 3.4202 & 5.4265 & TST \\
\hline CHEMBL1964389 & 688131 & 3.4202 & 4.3358 & TRN \\
\hline CHEMBL602718 & 688131 & 5.8294 & 5.9032 & TRN \\
\hline CHEMBL1573697 & 688131 & 5.5974 & 5.2309 & TRN \\
\hline
\end{tabular}

Page 3921 
Supplemental Table S2.txt

\begin{tabular}{|c|c|c|c|c|c|}
\hline CHEMBL1449718 & 688131 & 3.4202 & 5.0062 & TRN & \\
\hline CHEMBL1460056 & 688131 & 5.6821 & 5.5072 & TST & \\
\hline CHEMBL1453521 & 688131 & 5.0074 & 5.2552 & TRN & \\
\hline CHEMBL1346822 & 688131 & 6.8996 & 5.3797 & TRN & \\
\hline CHEMBL1424729 & 688131 & 4.9472 & 5.519 & TRN & \\
\hline CHEMBL1587732 & 688131 & 3.4202 & 4.7402 & TRN & \\
\hline CHEMBL1603982 & 688131 & 5.6015 & 5.2887 & TRN & \\
\hline CHEMBL1425019 & 688131 & 5.3391 & 5.2486 & TRN & \\
\hline CHEMBL1971033 & 688131 & 5.6828 & 5.4889 & TRN & \\
\hline CHEMBL1582831 & 688131 & 6.8697 & 5.8718 & TRN & \\
\hline CHEMBL1510020 & 688131 & 5.5592 & 5.3388 & TRN & \\
\hline CHEMBL1497897 & 688131 & 7.284 & 4.9294 & TRN & \\
\hline CHEMBL1426693 & 688131 & 5.2997 & 5.52 & TRN & \\
\hline CHEMBL1534309 & 688131 & 3.4202 & 3.9544 & TRN & \\
\hline CHEMBL1437130 & 688131 & 3.4202 & 3.9277 & TRN & \\
\hline CHEMBL1299335 & 688131 & 3.4202 & 4.8011 & TRN & \\
\hline CHEMBL1544679 & 688131 & 5.6647 & 5.648 & TRN & \\
\hline CHEMBL1985667 & 688131 & 5.9859 & 5.3077 & TRN & \\
\hline CHEMBL1363032 & 688131 & 5.6857 & 5.5689 & TRN & \\
\hline CHEMBL1578484 & 688131 & 5.9007 & 5.2223 & TRN & \\
\hline CHEMBL1503173 & 688131 & 5.4093 & 4.4525 & TRN & \\
\hline CHEMBL19954 & 688131 & 6.1561 & 5.7082 & TST & \\
\hline CHEMBL1603036 & 688131 & 3.4202 & 3.9172 & TRN & \\
\hline CHEMBL1472773 & 688131 & 6.9172 & 5.0655 & TST & \\
\hline CHEMBL591412 & 688131 & 6.3224 & 6.0275 & TRN & \\
\hline CHEMBL1443697 & 688131 & 3.4202 & 3.7167 & TRN & \\
\hline CHEMBL3193652 & 688131 & 5.63899 & 99999999 & 9 & 4.5972 \\
\hline CHEMBL585827 & 688131 & 6.2449 & 6.2449 & TRN & \\
\hline CHEMBL1469827 & 688131 & 5.7734 & 5.4867 & TRN & \\
\hline CHEMBL3192659 & 688131 & 5.6171 & 5.4226 & TRN & \\
\hline CHEMBL1503033 & 688131 & 5.8864 & 4.6536 & TST & \\
\hline CHEMBL1309091 & 688131 & 7.4318 & 4.5132 & TRN & \\
\hline CHEMBL1360505 & 688131 & 6.1296 & 5.2539 & TRN & \\
\hline CHEMBL1481849 & 688131 & 3.4202 & 4.8524 & TST & \\
\hline CHEMBL1547025 & 688131 & 3.4202 & 5.5289 & TRN & \\
\hline CHEMBL1331633 & 688131 & 3.4202 & 3.825 & TST & \\
\hline CHEMBL1445436 & 688131 & 3.4202 & 3.8373 & TRN & \\
\hline CHEMBL1601133 & 688131 & 5.7967 & 5.7613 & TRN & \\
\hline CHEMBL1489113 & 688131 & 5.6826 & 5.3266 & TRN & \\
\hline CHEMBL1371004 & 688131 & 5.7142 & 5.1886 & TRN & \\
\hline CHEMBL 3191432 & 688131 & 3.4202 & 5.3995 & TRN & \\
\hline CHEMBL1339488 & 688131 & 6.4921 & 4.4679 & TST & \\
\hline CHEMBL1541539 & 688131 & 3.4202 & 5.4891 & TRN & \\
\hline CHEMBL1345042 & 688131 & 3.4202 & 4.6269 & TST & \\
\hline CHEMBL577662 & 688131 & 5.3563 & 6.3891 & TRN & \\
\hline CHEMBL1450527 & 688131 & 6.3188 & 5.7408 & TRN & \\
\hline CHEMBL1520157 & 688131 & 6.279 & 5.3607 & TRN & \\
\hline CHEMBL1536073 & 688131 & 5.8193 & 5.1656 & TRN & \\
\hline
\end{tabular}




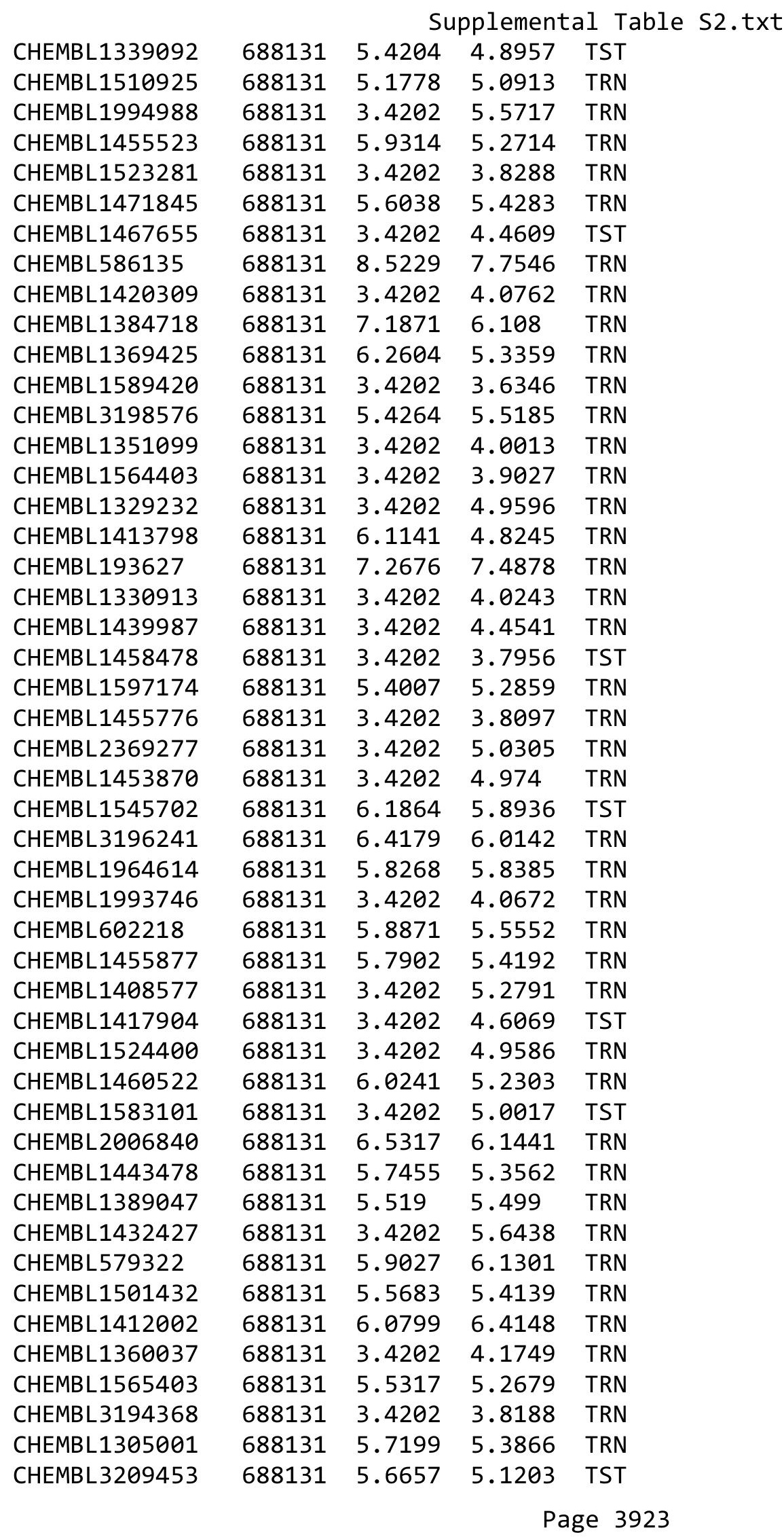


Supplemental Table S2.txt

\begin{tabular}{|c|c|c|c|c|c|}
\hline CHEMBL1583292 & 688131 & 5.4981 & 5.9881 & TST & \\
\hline CHEMBL1536493 & 688131 & 5.6944 & 5.4484 & TRN & \\
\hline CHEMBL1517490 & 688131 & 3.4202 & 3.8499 & TST & \\
\hline CHEMBL1993194 & 688131 & 6.7496 & 6.1489 & TRN & \\
\hline CHEMBL1339082 & 688131 & 3.4202 & 4.7925 & TRN & \\
\hline CHEMBL1352172 & 688131 & 3.4202 & 4.5713 & TRN & \\
\hline CHEMBL1419772 & 688131 & 6.4672 & 5.1013 & TST & \\
\hline CHEMBL1459060 & 688131 & 5.7978 & 4.9164 & TRN & \\
\hline CHEMBL1390521 & 688131 & 3.4202 & 4.8681 & TRN & \\
\hline CHEMBL1500266 & 688131 & 6.0269 & 5.3693 & TRN & \\
\hline CHEMBL1331900 & 688131 & 3.4202 & 4.5174 & TST & \\
\hline CHEMBL1377705 & 688131 & 5.9805 & 5.266 & TRN & \\
\hline CHEMBL1323512 & 688131 & 6.3675 & 5.7966 & TRN & \\
\hline CHEMBL1598643 & 688131 & 3.4202 & 4.521 & TRN & \\
\hline CHEMBL1447307 & 688131 & 3.4202 & 4.0956 & TRN & \\
\hline CHEMBL1609233 & 688131 & 3.4202 & 4.0684 & TRN & \\
\hline CHEMBL1612201 & 688131 & 5.6137 & 4.8768 & TST & \\
\hline CHEMBL1385356 & 688131 & 5.8765 & 4.0874 & TST & \\
\hline CHEMBL 87285 & 688131 & 6.0 & 5.4472 & TST & \\
\hline CHEMBL1409296 & 688131 & 5.5033 & 3.8937 & TRN & \\
\hline CHEMBL1995503 & 688131 & 5.4329 & 5.3031 & TRN & \\
\hline CHEMBL1308432 & 688131 & 6.9245 & 4.9311 & TRN & \\
\hline CHEMBL1451931 & 688131 & 5.7352 & 5.218 & TRN & \\
\hline CHEMBL1452795 & 688131 & 7.0809 & 4.1912 & TST & \\
\hline CHEMBL1408965 & 688131 & 6.0773 & 5.5844 & TRN & \\
\hline CHEMBL 375781 & 688131 & 6.8761 & 6.0442 & TST & \\
\hline CHEMBL1412223 & 688131 & 7.3979 & 3.8015 & TRN & \\
\hline CHEMBL1412068 & 688131 & 5.8911 & 5.1421 & TRN & \\
\hline CHEMBL1347212 & 688131 & 3.4202 & 4.8715 & TST & \\
\hline CHEMBL1560928 & 688131 & 5.3151 & 5.2471 & TRN & \\
\hline CHEMBL1329076 & 688131 & 3.4202 & 4.1849 & TST & \\
\hline CHEMBL1441467 & 688131 & 5.8162 & 5.1625 & TRN & \\
\hline CHEMBL1352025 & 688131 & 6.7878 & 5.171 & TST & \\
\hline CHEMBL251055 & 688131 & 5.5367 & 4.1799 & TST & \\
\hline CHEMBL1570820 & 688131 & 6.0246 & 5.0464 & TST & \\
\hline CHEMBL1309033 & 688131 & 3.4202 & 5.1777 & TRN & \\
\hline CHEMBL1348582 & 688131 & 6.1209 & 5.7392 & TRN & \\
\hline CHEMBL 2000445 & 688131 & 3.4202 & 4.68199 & 99999999995 & TRN \\
\hline CHEMBL1386851 & 688131 & 3.4202 & 4.8526 & TRN & \\
\hline CHEMBL1391547 & 688131 & 3.4202 & 4.7398 & TST & \\
\hline CHEMBL1582834 & 688131 & 3.4202 & 4.7152 & TRN & \\
\hline CHEMBL1417624 & 688131 & 3.4202 & 3.7151 & TST & \\
\hline CHEMBL1377849 & 688131 & 6.1586 & 6.2802 & TRN & \\
\hline CHEMBL1402166 & 688131 & 3.4202 & 5.9448 & TRN & \\
\hline CHEMBL1583801 & 688131 & 3.4202 & 5.3523 & TRN & \\
\hline CHEMBL1502143 & 688131 & 3.4202 & 4.872 & TST & \\
\hline CHEMBL1346637 & 688131 & 3.4202 & 5.481 & TRN & \\
\hline CHEMBL1584524 & 688131 & 5.8002 & 5.3632 & TRN & \\
\hline
\end{tabular}


Supplemental Table S2.txt

\begin{tabular}{|c|c|c|c|c|c|}
\hline CHEMBL3190697 & 688131 & 6.1169 & 5.224 & TRN & \\
\hline CHEMBL1353710 & 688131 & 5.5583 & \multicolumn{2}{|c|}{5.111000000000001} & TRN \\
\hline CHEMBL1574748 & 688131 & 3.4202 & 5.2516 & TRN & \\
\hline CHEMBL1377176 & 688131 & 5.6048 & 4.0614 & TST & \\
\hline CHEMBL1581668 & 688131 & 3.4202 & 3.7279 & TRN & \\
\hline CHEMBL1403085 & 688131 & 3.4202 & 5.405 & TRN & \\
\hline CHEMBL3184468 & 688131 & 5.3973 & 4.8566 & TST & \\
\hline CHEMBL1478465 & 688131 & 3.4202 & 4.9348 & TRN & \\
\hline CHEMBL1310309 & 688131 & 3.4202 & 3.8056 & TRN & \\
\hline CHEMBL1449523 & 688131 & 3.4202 & 5.4405 & TRN & \\
\hline CHEMBL1566224 & 688131 & 3.4202 & \multicolumn{2}{|c|}{4.7330000000000005} & TRN \\
\hline CHEMBL1312909 & 688131 & 5.7031 & 5.3571 & TRN & \\
\hline CHEMBL1337528 & 688131 & 5.3845 & 5.2027 & TRN & \\
\hline CHEMBL3199169 & 688131 & 3.4202 & 5.3695 & TRN & \\
\hline CHEMBL1502929 & 688131 & 5.7786 & 5.2764 & TRN & \\
\hline CHEMBL1569989 & 688131 & 5.8935 & 6.154 & TRN & \\
\hline CHEMBL1393266 & 688131 & 5.2828 & 4.9237 & TST & \\
\hline CHEMBL1324005 & 688131 & 5.7196 & 4.3646 & TRN & \\
\hline CHEMBL1610563 & 688131 & 5.8729 & 5.0745 & TRN & \\
\hline CHEMBL1577186 & 688131 & 3.4202 & 4.9614 & TST & \\
\hline CHEMBL1348119 & 688131 & 5.9408 & 5.7234 & TRN & \\
\hline CHEMBL1987579 & 688131 & 5.9735 & 5.4172 & TRN & \\
\hline CHEMBL1383334 & 688131 & 3.4202 & 5.0163 & TRN & \\
\hline CHEMBL1431928 & 688131 & 5.3817 & 5.1827 & TRN & \\
\hline CHEMBL1404493 & 688131 & 8.5229 & 8.228 & TRN & \\
\hline CHEMBL3199324 & 688131 & 3.4202 & 5.5549 & TRN & \\
\hline CHEMBL1598222 & 688131 & 5.5113 & 5.2477 & TRN & \\
\hline CHEMBL1976839 & 688131 & 3.4202 & 4.6516 & TRN & \\
\hline CHEMBL1381257 & 688131 & 3.4202 & 4.8645 & TRN & \\
\hline CHEMBL1566084 & 688131 & 3.4202 & 5.7344 & TRN & \\
\hline CHEMBL1403955 & 688131 & 3.4202 & 5.2364 & TRN & \\
\hline CHEMBL3210589 & 688131 & 3.4202 & 3.7334 & TRN & \\
\hline CHEMBL1400761 & 688131 & 3.4202 & 4.7621 & TST & \\
\hline CHEMBL1390963 & 688131 & 5.7637 & 5.6207 & TRN & \\
\hline CHEMBL1599674 & 688131 & 5.7104 & 5.3695 & TST & \\
\hline CHEMBL1390919 & 688131 & 3.4202 & 3.6117 & TRN & \\
\hline CHEMBL3210536 & 688131 & 3.4202 & 4.838 & TRN & \\
\hline CHEMBL1519450 & 688131 & 6.1599 & 6.1301 & TRN & \\
\hline CHEMBL1322883 & 688131 & 5.8074 & 4.7188 & TRN & \\
\hline CHEMBL1330029 & 688131 & 6.8508 & 4.995 & TRN & \\
\hline CHEMBL1373678 & 688131 & 5.9147 & 5.6306 & TRN & \\
\hline CHEMBL1989683 & 688131 & 3.4202 & 3.9433 & TRN & \\
\hline CHEMBL3197187 & 688131 & 3.4202 & 4.1001 & TRN & \\
\hline CHEMBL1439322 & 688131 & 3.4202 & 4.6516 & TRN & \\
\hline CHEMBL1352998 & 688131 & 3.4202 & 4.9795 & TRN & \\
\hline CHEMBL1308502 & 688131 & 3.4202 & 3.64899 & 99999999996 & TRN \\
\hline CHEMBL1490481 & 688131 & 6.6676 & 4.7875 & TRN & \\
\hline CHEMBL1388646 & 688131 & 3.4202 & 5.0385 & TRN & \\
\hline
\end{tabular}


Supplemental Table S2.txt

\begin{tabular}{|c|c|c|c|c|c|}
\hline CHEMBL1599520 & 688131 & 5.7373 & 5.2701 & TRN & \\
\hline CHEMBL569708 & 688131 & 5.2951 & 4.7399 & TRN & \\
\hline CHEMBL1392643 & 688131 & 3.4202 & 4.42399 & 99999999995 & TRN \\
\hline CHEMBL1340678 & 688131 & 5.8386 & 5.3358 & TRN & \\
\hline CHEMBL3192121 & 688131 & 3.4202 & 5.2276 & TRN & \\
\hline CHEMBL 2004417 & 688131 & 5.6321 & 5.4252 & TRN & \\
\hline CHEMBL1306283 & 688131 & 5.9066 & 6.0935 & TRN & \\
\hline CHEMBL1488696 & 688131 & 5.9318 & 5.2145 & TRN & \\
\hline CHEMBL601768 & 688131 & 6.4377 & 6.5852 & TRN & \\
\hline CHEMBL1347156 & 688131 & 5.8807 & 5.0641 & TRN & \\
\hline CHEMBL1534035 & 688131 & 6.0141 & 5.7692 & TRN & \\
\hline CHEMBL1371516 & 688131 & 3.4202 & 3.7869 & TRN & \\
\hline CHEMBL1452711 & 688131 & 5.5613 & 5.3364 & TRN & \\
\hline CHEMBL3210988 & 688131 & 6.1649 & 4.8876 & TRN & \\
\hline CHEMBL1520556 & 688131 & 5.8083 & 5.3115 & TRN & \\
\hline CHEMBL1609004 & 688131 & 3.4202 & 4.7473 & TST & \\
\hline CHEMBL389162 & 688131 & 5.1919 & 5.0909 & TRN & \\
\hline CHEMBL1459251 & 688131 & 5.9278 & 5.1402 & TST & \\
\hline CHEMBL1462283 & 688131 & 6.1972 & 5.7413 & TRN & \\
\hline CHEMBL1391837 & 688131 & 3.4202 & 3.8554 & TRN & \\
\hline CHEMBL1905194 & 688131 & 5.1992 & 4.7385 & TST & \\
\hline CHEMBL1442280 & 688131 & 6.1805 & 6.5047 & TRN & \\
\hline CHEMBL1970872 & 688131 & 4.8325 & 5.4181 & TRN & \\
\hline CHEMBL1406031 & 688131 & 5.6424 & 5.1598 & TST & \\
\hline CHEMBL1992631 & 688131 & 3.4202 & 4.0513 & TRN & \\
\hline CHEMBL1497549 & 688131 & 6.1203 & 5.893 & TRN & \\
\hline CHEMBL1333510 & 688131 & 3.4202 & 4.8243 & TRN & \\
\hline CHEMBL3194066 & 688131 & 5.5331 & 4.984 & TRN & \\
\hline CHEMBL1339533 & 688131 & 3.4202 & 4.1079 & TRN & \\
\hline CHEMBL1328925 & 688131 & 3.4202 & 4.8992 & TRN & \\
\hline CHEMBL597251 & 688131 & 3.4202 & 4.8923 & TST & \\
\hline CHEMBL1543255 & 688131 & 5.7212 & 5.1162 & TRN & \\
\hline CHEMBL1530274 & 688131 & 3.4202 & 4.6049 & TST & \\
\hline CHEMBL1491555 & 688131 & 6.1079 & 3.9981 & TRN & \\
\hline CHEMBL1497081 & 688131 & 3.4202 & 5.0888 & TST & \\
\hline CHEMBL1459813 & 688131 & 5.6517 & 5.3714 & TRN & \\
\hline CHEMBL1489956 & 688131 & 5.5312 & 5.13299 & 9999999999 & \\
\hline CHEMBL1465741 & 688131 & 3.4202 & 3.6051 & TRN & \\
\hline CHEMBL1538158 & 688131 & 5.4099 & 4.5668 & TRN & \\
\hline CHEMBL1373978 & 688131 & \multicolumn{2}{|c|}{6.752000000000001} & 4.6287 & \\
\hline CHEMBL1375254 & 688131 & 5.7565 & 4.9987 & TRN & \\
\hline CHEMBL1526730 & 688131 & 5.7865 & 4.6795 & TST & \\
\hline CHEMBL1503392 & 688131 & 5.7582 & 5.1323 & TRN & \\
\hline CHEMBL1610180 & 688131 & 3.4202 & 3.6883 & TRN & \\
\hline CHEMBL1604650 & 688131 & 5.6726 & 5.5651 & TRN & \\
\hline CHEMBL1497146 & 688131 & 3.4202 & 4.6429 & TRN & \\
\hline CHEMBL479107 & 688131 & 3.4202 & 4.8457 & TST & \\
\hline CHEMBL1362036 & 688131 & 5.5402 & 4.9247 & TRN & \\
\hline
\end{tabular}

Page 3926 


\begin{tabular}{|c|c|c|c|c|c|c|}
\hline & & \multicolumn{5}{|c|}{ Supplemental Table S2.txt } \\
\hline CHEMBL1548257 & 688131 & 5.2291 & 4.7169 & TRN & & \\
\hline CHEMBL1388738 & 688131 & 7.1612 & 4.9959 & TRN & & \\
\hline CHEMBL1520111 & 688131 & 5.4011 & 5.0213 & TRN & & \\
\hline CHEMBL1542804 & 688131 & 3.4202 & 5.195 & TRN & & \\
\hline CHEMBL1327656 & 688131 & 3.4202 & 4.9775 & TST & & \\
\hline CHEMBL1352904 & 688131 & 3.4202 & 4.4696 & TRN & & \\
\hline CHEMBL 3145085 & 688131 & 4.664 & 4.8075 & TRN & & \\
\hline CHEMBL1611301 & 688131 & \multicolumn{3}{|c|}{6.202000000000001} & .3807 & TRN \\
\hline CHEMBL1465297 & 688131 & 3.4202 & 4.0773 & TRN & & \\
\hline CHEMBL1430893 & 688131 & 6.1605 & 5.1168 & TRN & & \\
\hline CHEMBL1441218 & 688131 & 5.2109 & 5.3891 & TRN & & \\
\hline CHEMBL1508788 & 688131 & 5.6792 & 5.102 & TRN & & \\
\hline CHEMBL3195688 & 688131 & 6.0246 & 5.4287 & TRN & & \\
\hline CHEMBL3145287 & 688131 & 3.4202 & 5.3677 & TRN & & \\
\hline CHEMBL1498022 & 688131 & 6.129 & 5.4715 & TST & & \\
\hline CHEMBL1324531 & 688131 & 3.4202 & 5.2586 & TRN & & \\
\hline CHEMBL3190648 & 688131 & 6.6737 & 5.8133 & TRN & & \\
\hline CHEMBL1313283 & 688131 & 5.7208 & 5.2819 & TRN & & \\
\hline CHEMBL3189344 & 688131 & 5.8655 & 5.4801 & TRN & & \\
\hline CHEMBL1314125 & 688131 & 5.6273 & 5.1065 & TRN & & \\
\hline CHEMBL1986418 & 688131 & 6.1463 & 6.4211 & TRN & & \\
\hline CHEMBL1602534 & 688131 & 3.4202 & 3.8646 & TRN & & \\
\hline CHEMBL3196186 & 688131 & 5.3243 & 5.1921 & TRN & & \\
\hline CHEMBL1439020 & 688131 & 5.6223 & 5.191 & TRN & & \\
\hline CHEMBL3192856 & 688131 & 3.4202 & 5.2582 & TRN & & \\
\hline CHEMBL1585390 & 688131 & 6.1238 & 5.0657 & TRN & & \\
\hline CHEMBL3209627 & 688131 & 3.4202 & 4.7702 & TRN & & \\
\hline CHEMBL1548613 & 688131 & 5.9062 & 5.2962 & TST & & \\
\hline CHEMBL582652 & 688131 & 3.4202 & 4.3832 & TST & & \\
\hline CHEMBL3198692 & 688131 & 3.4202 & 4.008 & TRN & & \\
\hline CHEMBL 3196726 & 688131 & 6.3778 & 6.0154 & TRN & & \\
\hline CHEMBL1448592 & 688131 & 5.7597 & 5.6655 & TRN & & \\
\hline CHEMBL1445902 & 688131 & 3.4202 & 4.5049 & TRN & & \\
\hline CHEMBL1499496 & 688131 & 3.4202 & 4.4432 & TST & & \\
\hline CHEMBL1995800 & 688131 & 5.7773 & 3.9614 & TST & & \\
\hline CHEMBL1481390 & 688131 & 3.4202 & 4.6257 & TRN & & \\
\hline CHEMBL1322052 & 688131 & 6.1993 & 5.4927 & TRN & & \\
\hline CHEMBL 3194481 & 688131 & 3.4202 & 4.0053 & TRN & & \\
\hline CHEMBL1370513 & 688131 & 5.8564 & 6.08799 & 9999999999 & & TR \\
\hline CHEMBL1579999 & 688131 & 5.8854 & 5.3907 & TRN & & \\
\hline CHEMBL1451060 & 688131 & 6.7033 & 5.6848 & TRN & & \\
\hline CHEMBL1979784 & 688131 & 6.1141 & 5.6819 & TRN & & \\
\hline CHEMBL1332555 & 688131 & 3.4202 & 5.4496 & TRN & & \\
\hline CHEMBL1350780 & 688131 & 6.2083 & 6.2443 & TRN & & \\
\hline CHEMBL1478310 & 688131 & 3.4202 & 4.5042 & TRN & & \\
\hline CHEMBL1481045 & 688131 & 3.4202 & 4.8394 & TST & & \\
\hline CHEMBL1572967 & 688131 & 3.4202 & 4.0285 & TRN & & \\
\hline CHEMBL1966798 & 688131 & 3.4202 & 5.306 & TRN & & \\
\hline
\end{tabular}


Supplemental Table S2.txt

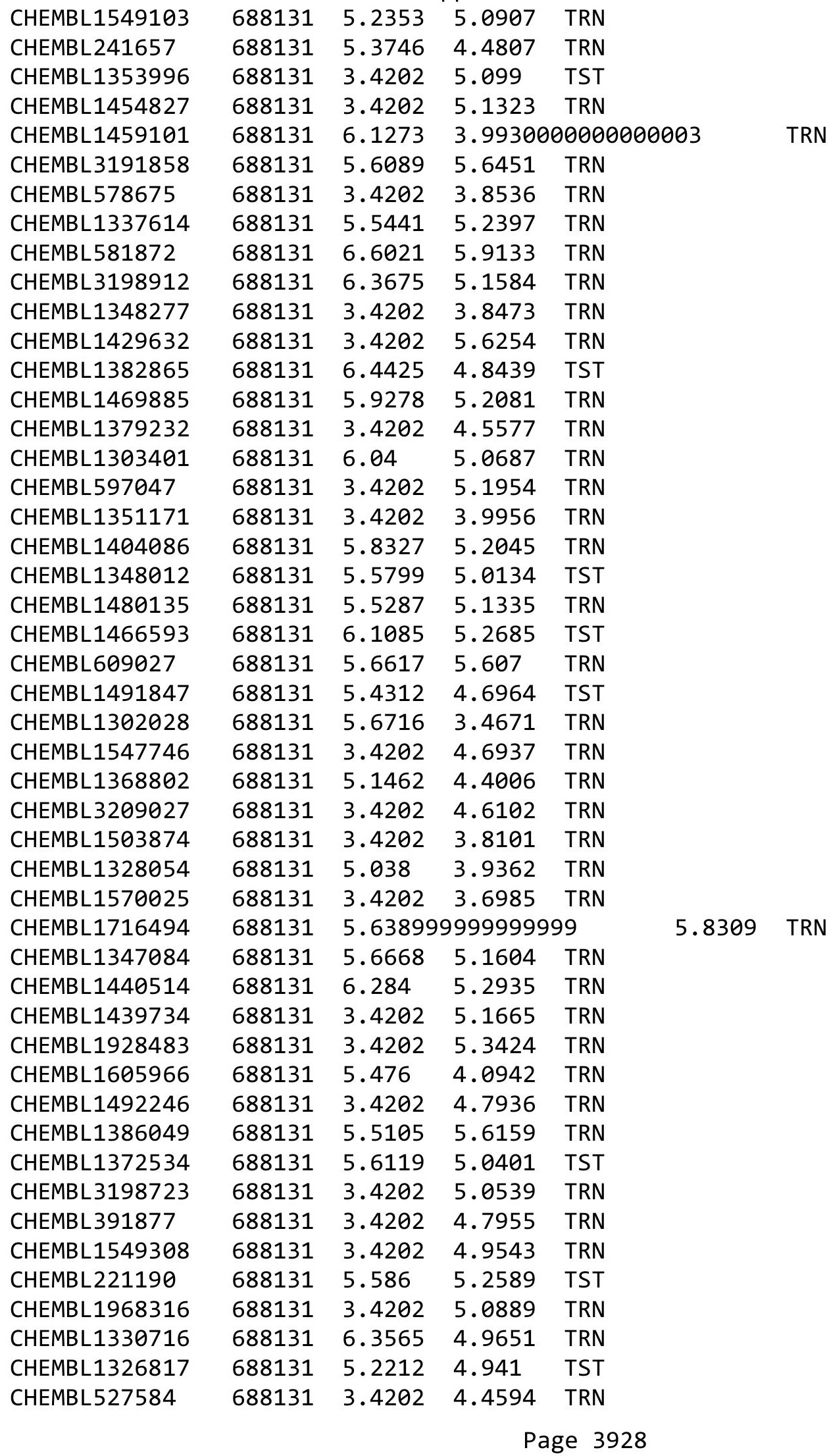


Supplemental Table S2.txt

\begin{tabular}{|c|c|c|c|c|}
\hline CHEMBL1990091 & 688131 & 3.4202 & 5.2689 & TRN \\
\hline CHEMBL1256876 & 688131 & 5.3527 & 5.0694 & TST \\
\hline CHEMBL1557784 & 688131 & 6.2233 & 5.1783 & TRN \\
\hline CHEMBL1464666 & 688131 & 6.2441 & 5.096999 & 99999999995 \\
\hline CHEMBL483768 & 688131 & 5.4895 & 5.2664 & TRN \\
\hline CHEMBL1490887 & 688131 & 3.4202 & 5.0038 & TST \\
\hline CHEMBL1426337 & 688131 & 5.6036 & 5.152 & TRN \\
\hline CHEMBL1322496 & 688131 & 6.1107 & 5.019 & TRN \\
\hline CHEMBL1503114 & 688131 & 3.4202 & 3.6368 & TRN \\
\hline CHEMBL1581042 & 688131 & 6.0311 & 5.4154 & TRN \\
\hline CHEMBL1587031 & 688131 & 3.4202 & 4.8515 & TST \\
\hline CHEMBL1582088 & 688131 & 3.4202 & 5.3024 & TRN \\
\hline CHEMBL1470483 & 688131 & 6.1624 & 4.9701 & TRN \\
\hline CHEMBL1585284 & 688131 & 3.4202 & 3.7265 & TRN \\
\hline CHEMBL1326457 & 688131 & 3.4202 & 4.3226 & TRN \\
\hline CHEMBL1325932 & 688131 & 3.4202 & 4.4977 & TRN \\
\hline CHEMBL1353536 & 688131 & 3.4202 & 5.2693 & TST \\
\hline CHEMBL1613503 & 688131 & 5.5003 & 4.7815 & TRN \\
\hline CHEMBL3197076 & 688131 & 5.5378 & 4.9046 & TST \\
\hline CHEMBL1340602 & 688131 & 5.5651 & 5.5299 & TRN \\
\hline CHEMBL1583911 & 688131 & 5.6891 & 4.9102 & TRN \\
\hline CHEMBL1552591 & 688131 & 6.056 & 4.9024 & TRN \\
\hline CHEMBL1340114 & 688131 & 6.8861 & 4.0237 & TRN \\
\hline CHEMBL1537973 & 688131 & 3.4202 & 4.8381 & TRN \\
\hline CHEMBL1549472 & 688131 & 5.4171 & 5.1828 & TRN \\
\hline CHEMBL1460705 & 688131 & 5.8465 & 5.8619 & TRN \\
\hline CHEMBL1387177 & 688131 & 3.4202 & 5.0727 & TRN \\
\hline CHEMBL1302439 & 688131 & 6.2967 & 5.6791 & TRN \\
\hline CHEMBL324389 & 688131 & 3.4202 & 4.8991 & TRN \\
\hline CHEMBL1485676 & 688131 & 3.4202 & 4.493 & TST \\
\hline CHEMBL1457320 & 688131 & 3.4202 & 3.6843 & TRN \\
\hline CHEMBL1359020 & 688131 & 3.4202 & 3.6946 & TRN \\
\hline CHEMBL1508647 & 688131 & 5.6866 & 5.4183 & TRN \\
\hline CHEMBL1489407 & 688131 & 3.4202 & 5.5506 & TRN \\
\hline CHEMBL1324454 & 688131 & 5.2874 & 4.8191 & TRN \\
\hline CHEMBL1502943 & 688131 & 3.4202 & 5.2808 & TST \\
\hline CHEMBL1328182 & 688131 & 5.6629 & 5.6948 & TRN \\
\hline CHEMBL1404163 & 688131 & 3.4202 & 3.6268 & TRN \\
\hline CHEMBL1529521 & 688131 & 5.4988 & 5.2025 & TRN \\
\hline CHEMBL 3198720 & 688131 & 5.901 & 5.6225 & TRN \\
\hline CHEMBL 3208223 & 688131 & 6.4157 & 5.1118 & TRN \\
\hline CHEMBL1545499 & 688131 & 3.4202 & 4.8058 & TRN \\
\hline CHEMBL1381962 & 688131 & 3.4202 & 3.9541 & TRN \\
\hline CHEMBL1985664 & 688131 & 5.4878 & 5.1316 & TRN \\
\hline CHEMBL1548429 & 688131 & 5.9401 & 5.1663 & TRN \\
\hline CHEMBL 3190322 & 688131 & 3.4202 & 4.7307 & TRN \\
\hline CHEMBL1392617 & 688131 & 3.4202 & 3.661 & TRN \\
\hline CHEMBL2006418 & 688131 & 3.4202 & 5.0286 & TRN \\
\hline
\end{tabular}


Supplemental Table S2.txt

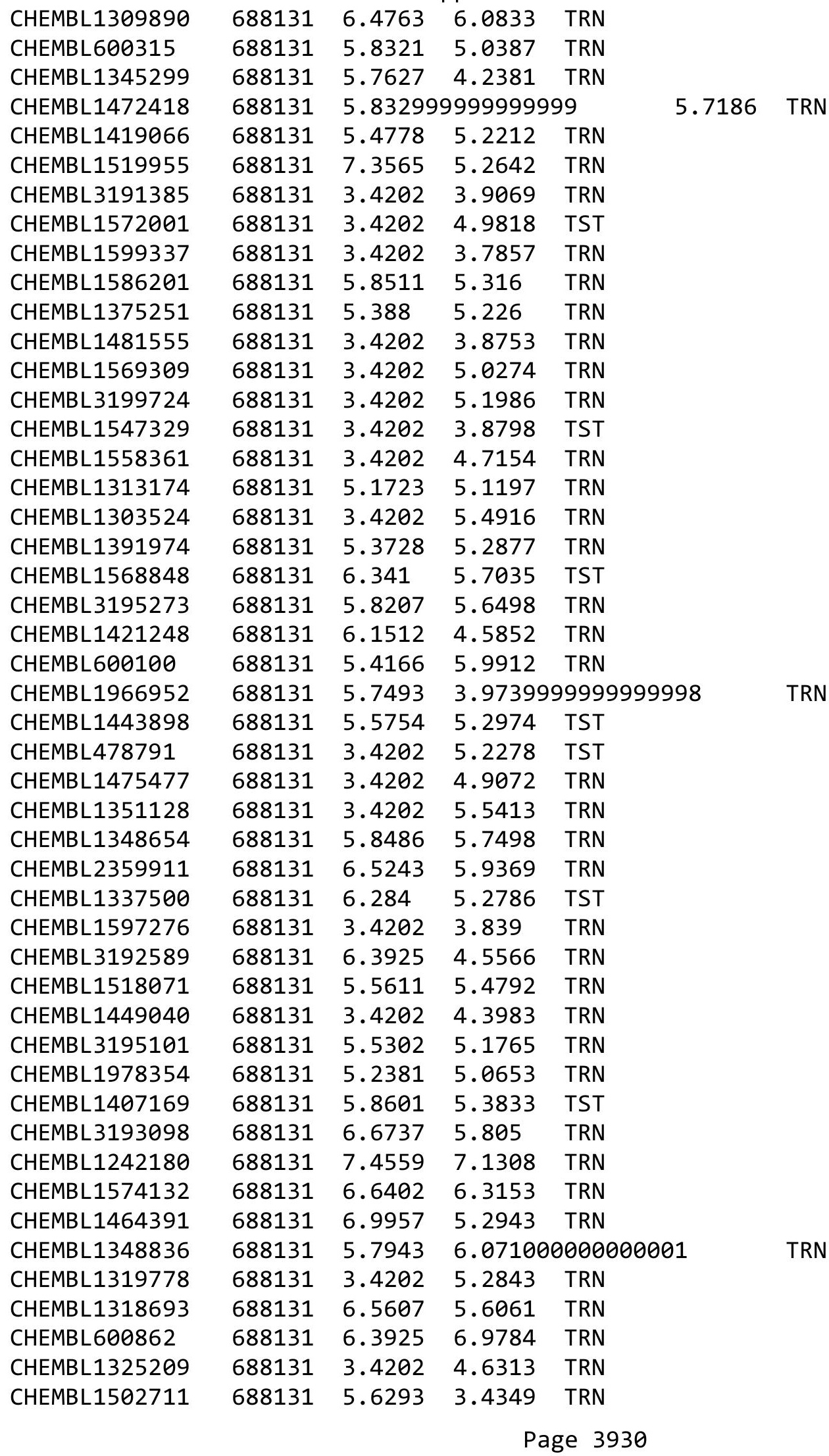


Supplemental Table S2.txt

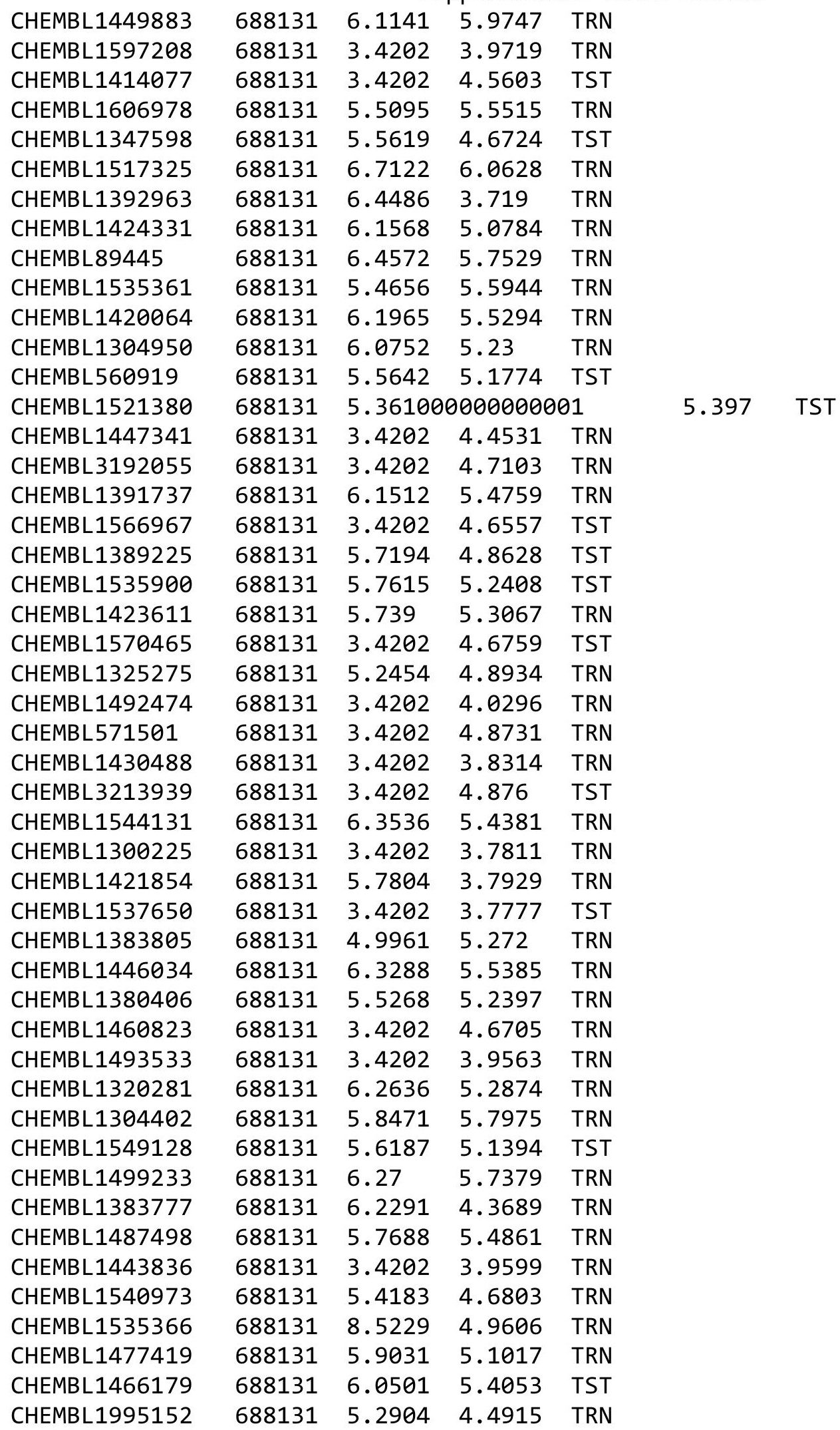

Page 3931 
Supplemental Table S2.txt

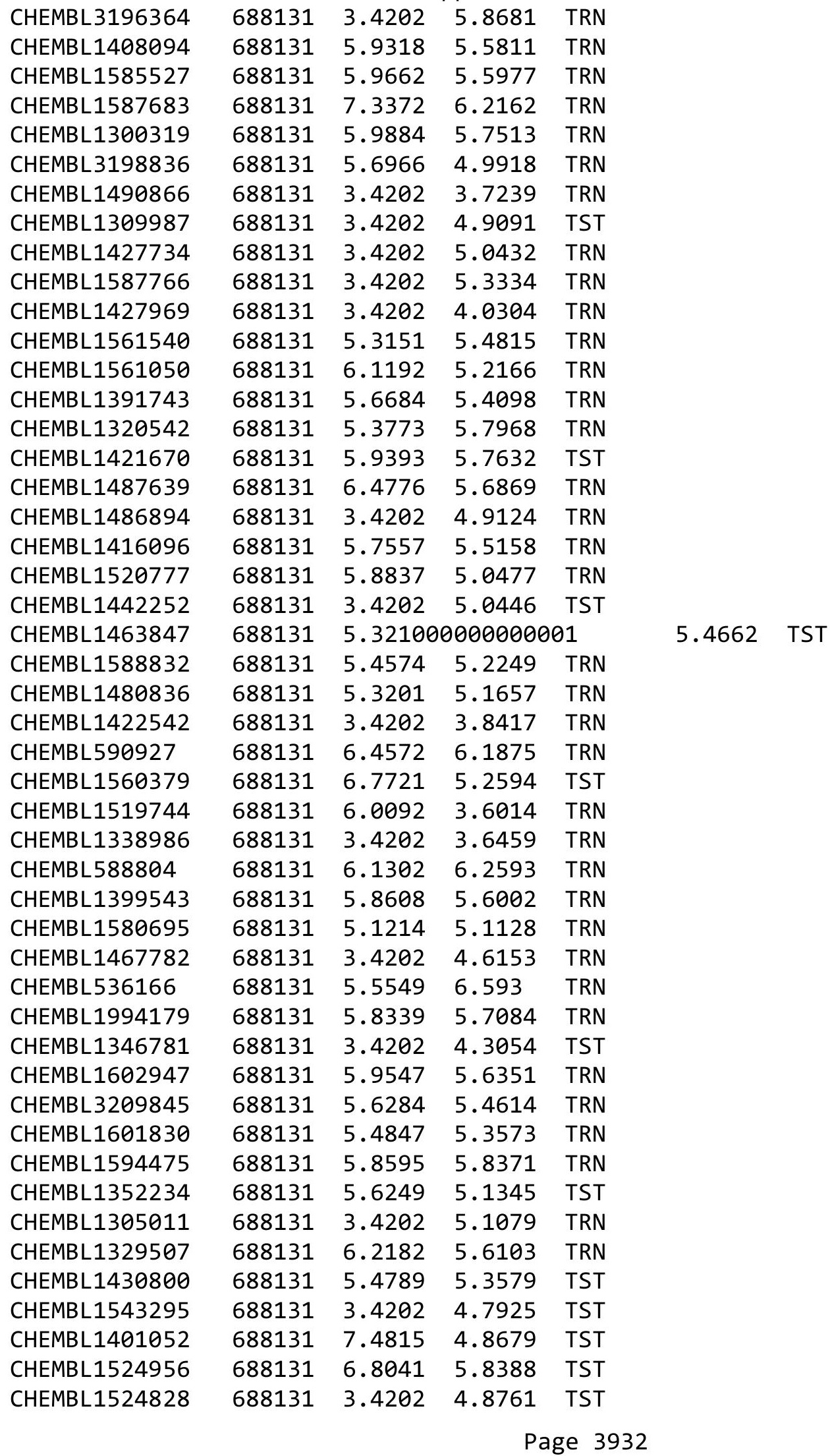


Supplemental Table S2.txt

\begin{tabular}{|c|c|c|c|c|c|}
\hline CHEMBL1434756 & 688131 & 3.4202 & 3.8915 & TST & \\
\hline CHEMBL3199328 & 688131 & 3.4202 & 5.0628 & TST & \\
\hline CHEMBL3209306 & 688131 & 5.5651 & 5.50899 & 99999999995 & TST \\
\hline CHEMBL3191371 & 688131 & 5.0192 & 4.8742 & TST & \\
\hline CHEMBL1405150 & 688131 & 6.3188 & 6.2868 & TST & \\
\hline CHEMBL1463750 & 688131 & 5.8002 & 5.7886 & TST & \\
\hline CHEMBL1563714 & 688131 & 6.2366 & 5.5759 & TST & \\
\hline CHEMBL530049 & 688131 & 5.8099 & 5.5106 & TST & \\
\hline CHEMBL1528330 & 688131 & 5.8804 & 5.2128 & TST & \\
\hline CHEMBL1347656 & 688131 & 5.4257 & 5.1075 & TST & \\
\hline CHEMBL1467211 & 688131 & 6.3089 & 5.6162 & TST & \\
\hline CHEMBL1392455 & 688131 & 6.9957 & 5.9901 & TST & \\
\hline CHEMBL1501102 & 688131 & 6.1308 & 5.3847 & TST & \\
\hline CHEMBL 3856090 & 688131 & 4.9338 & 5.0735 & TST & \\
\hline CHEMBL603522 & 688131 & 6.0173 & 6.2176 & TST & \\
\hline CHEMBL1545105 & 688131 & 6.2211 & 5.7897 & TST & \\
\hline CHEMBL3195040 & 688131 & 3.4202 & 4.8809 & TST & \\
\hline CHEMBL1479557 & 688131 & 6.3019 & 5.7263 & TST & \\
\hline CHEMBL1305208 & 688131 & 3.4202 & 4.0033 & TST & \\
\hline CHEMBL1299925 & 688131 & 3.4202 & 4.869 & TST & \\
\hline CHEMBL3198503 & 688131 & 6.4461 & 5.5415 & TST & \\
\hline CHEMBL3197825 & 688131 & 5.6085 & 5.3578 & TST & \\
\hline CHEMBL1455627 & 688131 & 5.9512 & 5.4429 & TST & \\
\hline CHEMBL1563462 & 688131 & 3.4202 & 4.8072 & TST & \\
\hline CHEMBL1406697 & 688131 & 6.4365 & 4.2124 & TST & \\
\hline CHEMBL3192257 & 688131 & 5.9842 & 4.8256 & TST & \\
\hline CHEMBL1418792 & 688131 & 3.4202 & 4.2204 & TST & \\
\hline CHEMBL1339696 & 688131 & 5.8236 & 4.7682 & TST & \\
\hline CHEMBL1430206 & 688131 & 3.4202 & 3.7349 & TST & \\
\hline CHEMBL1349338 & 688131 & 3.4202 & 5.2353 & TST & \\
\hline CHEMBL3191080 & 688131 & 5.3555 & 5.1939 & TST & \\
\hline CHEMBL1452090 & 688131 & 6.6737 & 6.0211 & TST & \\
\hline CHEMBL1997827 & 688131 & 3.4202 & 4.9363 & TST & \\
\hline CHEMBL1087588 & 688131 & 5.3044 & 4.7317 & TST & \\
\hline CHEMBL1360400 & 688131 & 5.1819 & 5.2594 & TST & \\
\hline CHEMBL1405070 & 688131 & 3.4202 & 4.0437 & TST & \\
\hline CHEMBL1481132 & 688131 & 6.041 & 5.31 & TST & \\
\hline CHEMBL1336834 & 688131 & 3.4202 & 4.0518 & TST & \\
\hline CHEMBL1428244 & 688131 & 5.5351 & 4.0877 & TST & \\
\hline CHEMBL1389295 & 688131 & 3.4202 & 3.7011 & TST & \\
\hline CHEMBL578944 & 688131 & 6.1739 & 4.41100 & 00000000005 & TST \\
\hline CHEMBL1545435 & 688131 & 3.4202 & 3.6738 & TST & \\
\hline CHEMBL1505875 & 688131 & 5.3328 & 5.0748 & TST & \\
\hline CHEMBL1434175 & 688131 & 5.5711 & 5.1636 & TST & \\
\hline CHEMBL1429980 & 688131 & 5.6317 & 5.4529 & TST & \\
\hline CHEMBL1506580 & 688131 & 6.1379 & 5.6069 & TST & \\
\hline CHEMBL1538399 & 688131 & 5.4777 & 5.1991 & TST & \\
\hline CHEMBL1323744 & 688131 & 3.4202 & 5.237 & TST & \\
\hline
\end{tabular}


Supplemental Table S2.txt

\begin{tabular}{|c|c|c|c|c|}
\hline $\mathrm{HEI}$ & & .7908 & & \\
\hline & 88131 & .4202 & 4.0014 & \\
\hline 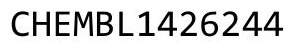 & & & & \\
\hline HEMBL133 & & 7799 & & \\
\hline AEMBL1572286 & 8131 & 202 & 7559 & \\
\hline HEMBL1431093 & 88131 & .4202 & 1779 & \\
\hline HEMBL31S & 131 & 202 & & \\
\hline IEMBI 152 & & & & \\
\hline AEMBL 321 & & 202 & 8934 & \\
\hline HEMBL1490555 & 88131 & 157 & 7836 & \\
\hline HEMBL1517847 & 88131 & 369 & 9 & \\
\hline IEMBL1 & 131 & 202 & 855 & \\
\hline IEMBL1 & & & & \\
\hline HEMBL1607272 & & 202 & 0142 & \\
\hline HEMBL142 & 31 & 35 & 2229 & \\
\hline AEMBL160 & 31 & 02 & & \\
\hline HEMBL1 & & 25 & & \\
\hline HEMBL3 & & & & \\
\hline HEMBL1 & & & 2202 & \\
\hline AEMBL1 & & & & \\
\hline HEMBLS & & & 33 & \\
\hline AEMBL & & & 61 & \\
\hline HEMBL: & & & & \\
\hline 423 & & & & \\
\hline HEMBL 321 & & & & \\
\hline HEMBL & & & 262 & \\
\hline HEMBL & & & 61 & \\
\hline HFMRI & & & & \\
\hline AEMBL1 & & & & \\
\hline HEMBL 314 & & & 626 & ГST \\
\hline HEMBL1 & & 202 & 5222 & ST \\
\hline AFMBI 1 & & & 386 & \\
\hline 7 & & & 978 & \\
\hline HEMBL133 & & & 595 & \\
\hline HEMBL1504321 & & 02 & 5878 & TST \\
\hline HEMBL1 & & 12 & 927 & \\
\hline HCMDI & & & 07 & \\
\hline JEMBL16e & & & & ST \\
\hline HEMBL1311007 & 88131 & 867 & 3079 & ГST \\
\hline IEMBL3 & & 03 & 428 & TST \\
\hline HEMBL1. & & 047 & 609 & \\
\hline CHEMBL1 & & & & 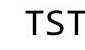 \\
\hline HEMBL137 & & 3959 & 2541 & IST \\
\hline AEMBL150 & 31 & 942 & 542 & TS \\
\hline EMBL1 & & & 26 & \\
\hline CHEMBL1510332 & & & & \\
\hline CHEMBL1581627 & & .0391 & 493 & \\
\hline HEMBL1578127 & 688131 & 6.5817 & 5.4021 & ГST \\
\hline
\end{tabular}

Page 3934 
Supplemental Table S2.txt

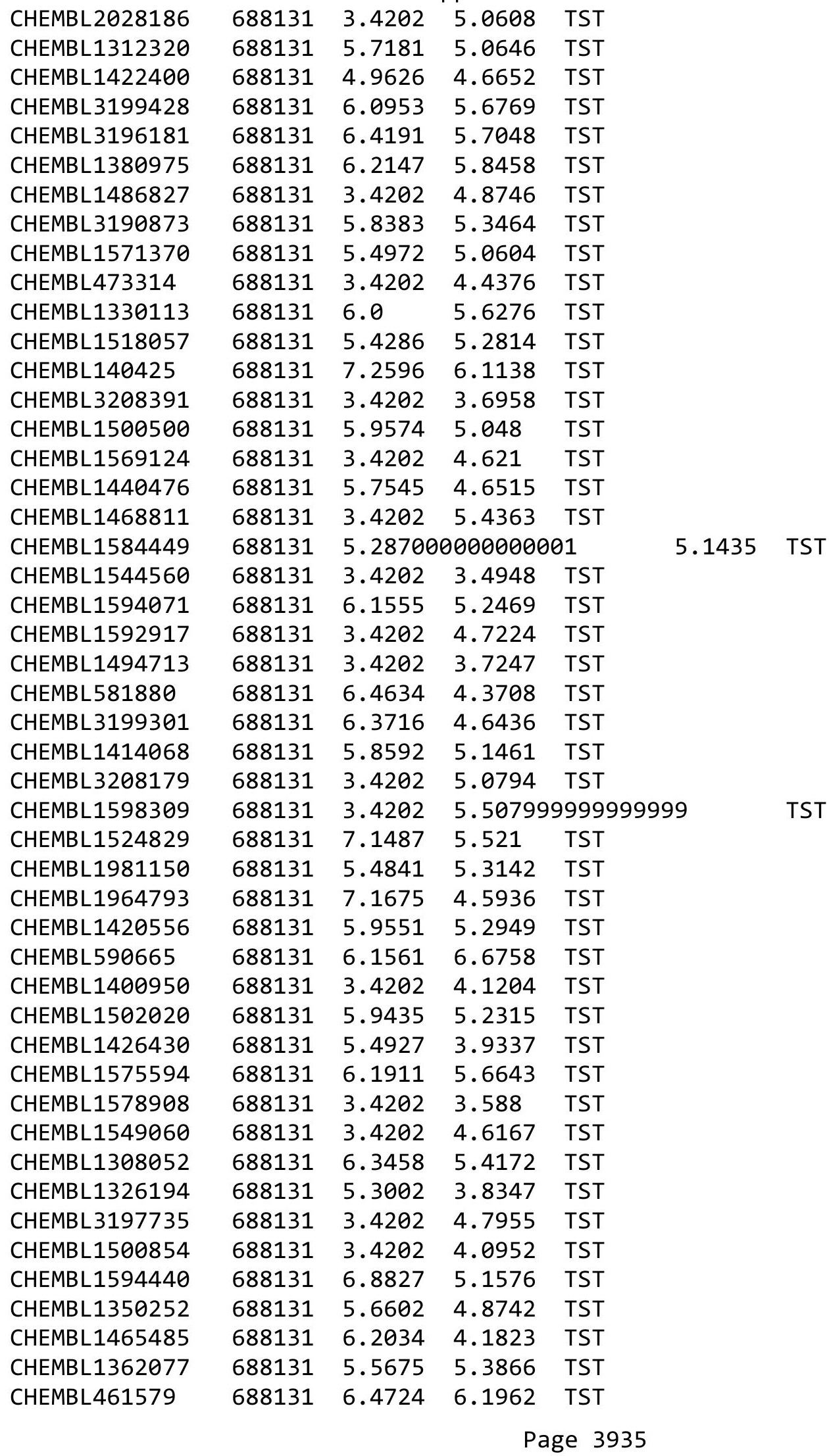




\begin{tabular}{|c|c|c|c|c|c|c|}
\hline & & \multicolumn{5}{|c|}{ Supplemental Table S2.txt } \\
\hline CHEMBL1553408 & 688131 & 5.8511 & 5.4319 & TST & & \\
\hline CHEMBL1541834 & 688131 & 6.1475 & 6.0015 & TST & & \\
\hline CHEMBL1302895 & 688131 & 5.6455 & 5.3973 & TST & & \\
\hline CHEMBL1350460 & 688131 & 3.4202 & 4.4157 & TST & & \\
\hline CHEMBL1355133 & 688131 & 5.5874 & 5.1935 & TST & & \\
\hline CHEMBL1349793 & 688131 & 5.3542 & 5.0254 & TST & & \\
\hline CHEMBL1450648 & 688131 & 3.4202 & 4.1449 & TST & & \\
\hline CHEMBL 2006909 & 688131 & \multicolumn{3}{|c|}{5.8629999999999995} & 5.1659 & TST \\
\hline CHEMBL 3208002 & 688131 & \multicolumn{3}{|c|}{5.303999999999999} & 5.0786 & TST \\
\hline CHEMBL1477033 & 688131 & 6.9586 & 5.4436 & TST & & \\
\hline CHEMBL1454030 & 688131 & 3.4202 & 4.4838 & TST & & \\
\hline CHEMBL1353882 & 688131 & 5.7102 & 4.4876 & TST & & \\
\hline CHEMBL1517609 & 688131 & 5.8392 & 5.1603 & TST & & \\
\hline CHEMBL1520276 & 688131 & 5.5805 & 5.4052 & TST & & \\
\hline CHEMBL1377364 & 688131 & 5.1856 & 3.6353 & TST & & \\
\hline CHEMBL 3197343 & 688131 & 6.2314 & 5.5404 & TST & & \\
\hline CHEMBL3195643 & 688131 & 3.4202 & 5.1636 & TST & & \\
\hline CHEMBL1446245 & 688131 & 5.8324 & 4.4324 & TST & & \\
\hline CHEMBL1582044 & 688131 & 3.4202 & 4.6678 & TST & & \\
\hline CHEMBL1537127 & 688131 & 3.4202 & 3.8279 & TST & & \\
\hline CHEMBL1609038 & 688131 & 5.3579 & 4.6256 & TST & & \\
\hline CHEMBL1306690 & 688131 & 5.6964 & 5.0239 & TST & & \\
\hline CHEMBL1390196 & 688131 & 3.4202 & 4.51 & TST & & \\
\hline CHEMBL1300080 & 688131 & 6.3298 & 6.5188 & TST & & \\
\hline CHEMBL1511594 & 688131 & 3.4202 & 3.8767 & TST & & \\
\hline CHEMBL1334608 & 688131 & 5.6728 & 5.1814 & TST & & \\
\hline CHEMBL1506216 & 688131 & 5.8348 & 5.4946 & TST & & \\
\hline CHEMBL1536869 & 688131 & 3.4202 & 4.9768 & TST & & \\
\hline CHEMBL1600855 & 688131 & 3.4202 & 4.1917 & TST & & \\
\hline CHEMBL1557142 & 688131 & 5.901 & 5.5296 & TST & & \\
\hline CHEMBL179315 & 981861 & 8.158 & 8.2774 & TRN & & \\
\hline CHEMBL179240 & 981861 & 8.4 & 8.8214 & TST & & \\
\hline CHEMBL175986 & 981861 & 8.174 & 8.9017 & TST & & \\
\hline CHEMBL179133 & 981861 & 8.001 & 8.0638 & TRN & & \\
\hline CHEMBL175871 & 981861 & 8.13 & 8.2213 & TRN & & \\
\hline CHEMBL366794 & 981861 & 7.925 & 7.6589 & TRN & & \\
\hline CHEMBL362038 & 981861 & 8.71 & 9.1312 & TST & & \\
\hline CHEMBL 362190 & 981861 & 8.996 & 9.4791 & TST & & \\
\hline CHEMBL 360448 & 981861 & 5.688 & 7.7964 & TST & & \\
\hline CHEMBL175494 & 981861 & 8.31 & 8.4051 & TST & & \\
\hline CHEMBL361412 & 981861 & 8.046 & 8.2733 & TST & & \\
\hline CHEMBL349464 & 981861 & 8.996 & 9.0672 & TRN & & \\
\hline CHEMBL165073 & 981861 & 8.987 & 9.0971 & TRN & & \\
\hline CHEMBL341376 & 981861 & 9.092 & 9.0322 & TRN & & \\
\hline CHEMBL424161 & 981861 & 9.367 & 9.376 & TRN & & \\
\hline CHEMBL349716 & 981861 & 9.066 & 9.0615 & TRN & & \\
\hline CHEMBL164325 & 981861 & 9.22200 & 00000000 & & 9.1755 & $\mid$ \\
\hline CHEMBL349611 & 981861 & 9.244 & 9.2137 & TRN & & \\
\hline
\end{tabular}




\begin{tabular}{|c|c|c|c|c|c|c|}
\hline & & & oplement & al & s2.txt & \\
\hline CHEMBL349954 & 981861 & 9.1429 & 99999999 & & 9.0598 & TRN \\
\hline CHEMBL165620 & 981861 & $9.097 €$ & 30000000 & & 9.1623 & TRN \\
\hline CHEMBL350830 & 981861 & 9.041 & 9.1811 & TRN & & \\
\hline CHEMBL167915 & 981861 & 9.26 & 9.2532 & TRN & & \\
\hline CHEMBL352192 & 981861 & 9.301 & 9.4342 & TRN & & \\
\hline CHEMBL164905 & 981861 & 9.469 & 9.4876 & TRN & & \\
\hline CHEMBL350042 & 981861 & 9.149 & 9.1632 & TRN & & \\
\hline CHEMBL350261 & 981861 & 9.398 & 9.2103 & TRN & & \\
\hline CHEMBL165560 & 981861 & 9.469 & 9.2677 & TRN & & \\
\hline CHEMBL164509 & 981861 & 9.292 & 9.1731 & TRN & & \\
\hline CHEMBL165778 & 981861 & 9.538 & 9.2952 & TRN & & \\
\hline CHEMBL350205 & 981861 & $9.347 €$ & 30000000 & & 9.3369 & TRN \\
\hline CHEMBL351075 & 981861 & 9.398 & 9.1944 & TRN & & \\
\hline CHEMBL355415 & 981861 & 9.092 & 9.3194 & TRN & & \\
\hline CHEMBL166301 & 981861 & 9.523 & 9.5833 & TRN & & \\
\hline CHEMBL352073 & 981861 & 9.699 & 9.4705 & TRN & & \\
\hline CHEMBL352345 & 981861 & 9.523 & 9.2314 & TRN & & \\
\hline CHEMBL164381 & 981861 & 9.066 & 9.177 & TRN & & \\
\hline CHEMBL164647 & 981861 & 9.252 & 9.2961 & TRN & & \\
\hline CHEMBL165044 & 981861 & 9.013 & 9.1521 & TRN & & \\
\hline CHEMBL164685 & 981861 & 9.066 & 9.2471 & TRN & & \\
\hline CHEMBL165600 & 981861 & 9.432 & 9.3344 & TRN & & \\
\hline CHEMBL165910 & 981861 & $9.187 €$ & 30000000 & & 9.3112 & TRN \\
\hline CHEMBL165083 & 981861 & $9.568 \mathrm{~s}$ & & & 9.595 & TRN \\
\hline CHEMBL164275 & 981861 & 8.523 & 8.4824 & TRN & & \\
\hline CHEMBL352796 & 981861 & 9.745 & 9.7083 & TRN & & \\
\hline CHEMBL167753 & 981861 & 9.538 & 9.5365 & TRN & & \\
\hline CHEMBL164281 & 981861 & 9.041 & 9.2423 & TRN & & \\
\hline CHEMBL164992 & 981861 & $9.097 €$ & 00000000 & & 9.2027 & TRN \\
\hline CHEMBL351211 & 981861 & 9.155 & 9.3539 & TRN & & \\
\hline CHEMBL164686 & 981861 & 9.131 & 9.1543 & TRN & & \\
\hline CHEMBL572765 & 981861 & 9.469 & 9.2637 & TRN & & \\
\hline CHEMBL348925 & 981861 & 9.337 & 9.2809 & TRN & & \\
\hline CHEMBL354161 & 981861 & 9.367 & 9.295 & TRN & & \\
\hline CHEMBL165224 & 981861 & 9.62 & 9.5388 & TRN & & \\
\hline CHEMBL349019 & 981861 & 8.469 & 8.53399 & 99999 & 99 & TRN \\
\hline CHEMBL145123 & 981861 & 7.2926 & 30000000 & & 7.3484 & TRN \\
\hline CHEMBL145734 & 981861 & 7.796 & 7.7932 & TRN & & \\
\hline CHEMBL341852 & 981861 & 7.149 & 7.1923 & TRN & & \\
\hline CHEMBL359379 & 981861 & 7.602 & 7.6298 & TRN & & \\
\hline CHEMBL423542 & 981861 & $6.367 €$ & 30000000 & & 7.6985 & TST \\
\hline CHEMBL137950 & 981861 & 8.0971 & 30000000 & & 8.0162 & TRN \\
\hline CHEMBL16867 & 981861 & 6.553 & 7.6254 & TST & & \\
\hline CHEMBL145623 & 981861 & 6.091 & 7.8619 & TST & & \\
\hline CHEMBL315150 & 981861 & 6.155 & 7.3518 & TST & & \\
\hline CHEMBL344724 & 981861 & $8.556 e$ & 30000000 & & 8.6104 & TRN \\
\hline CHEMBL357663 & 981861 & $9.097 €$ & 30000000 & & 9.0616 & TRN \\
\hline CHEMBL414620 & 981861 & 5.94 & 7.8386 & TST & & \\
\hline
\end{tabular}




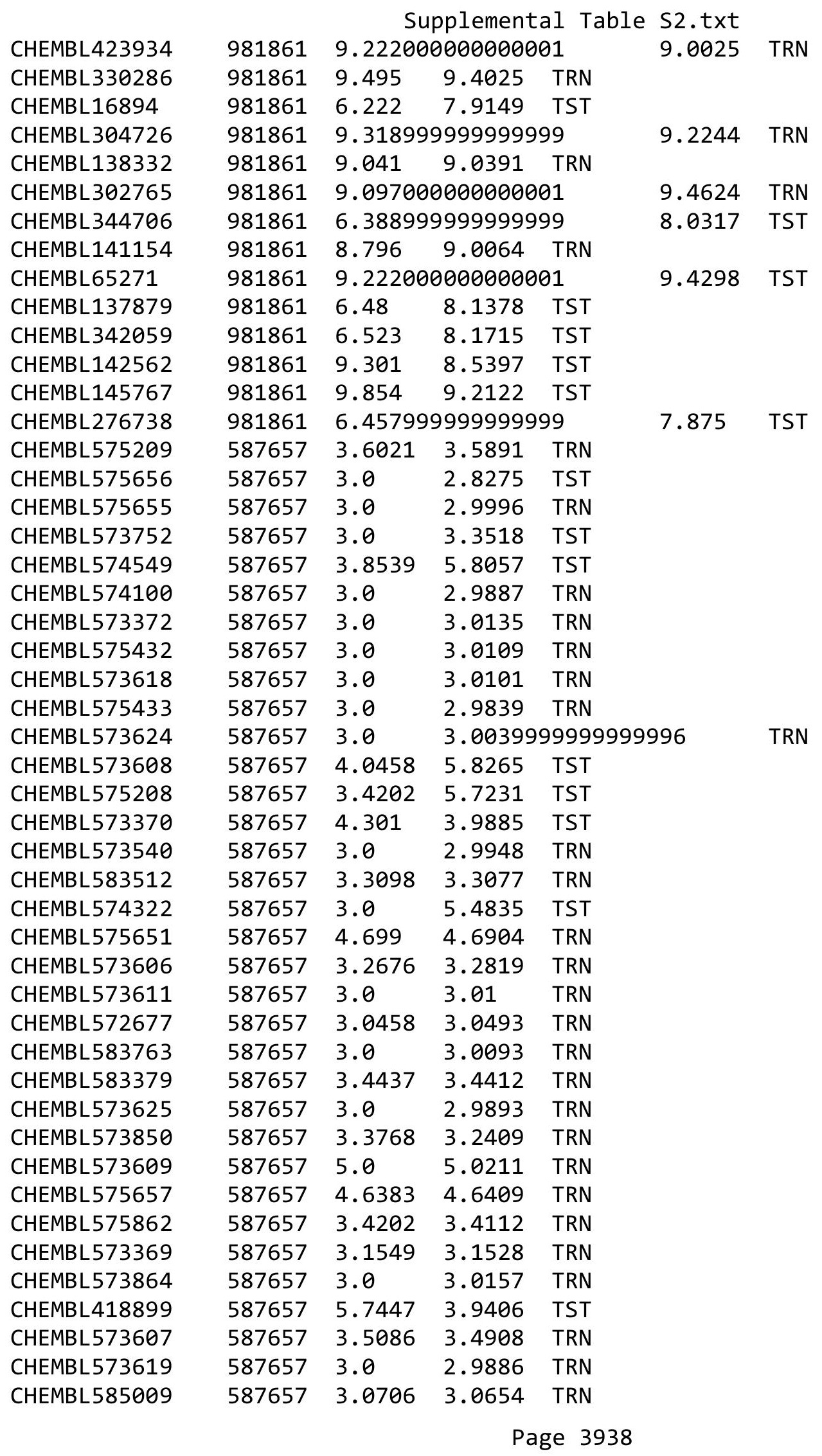




\begin{tabular}{|c|c|c|c|c|c|}
\hline \multicolumn{6}{|c|}{ Supplemental Table S2.txt } \\
\hline CHEMBL572646 & 587657 & 3.0 & 2.9991 & TRN & \\
\hline CHEMBL573132 & 587657 & 4.6198 & 4.6289 & TRN & \\
\hline CHEMBL574096 & 587657 & 3.301 & 3.3037 & TRN & \\
\hline CHEMBL575652 & 587657 & 3.0 & 2.9863 & TRN & \\
\hline CHEMBL573842 & 587657 & 5.1549 & 5.1557 & TRN & \\
\hline CHEMBL573626 & 587657 & 3.0 & 3.0025 & TRN & \\
\hline CHEMBL573352 & 587657 & 3.0 & 3.52399 & 99999999996 & TST \\
\hline CHEMBL583948 & 587657 & 3.0 & 3.0101 & TRN & \\
\hline CHEMBL573627 & 587657 & 3.0 & 2.9915 & TRN & \\
\hline CHEMBL575861 & 587657 & 5.0458 & 4.9063 & TST & \\
\hline CHEMBL573539 & 587657 & 3.0 & 3.0074 & TRN & \\
\hline CHEMBL584359 & 587657 & 3.0 & 3.0129 & TRN & \\
\hline CHEMBL573852 & 587657 & 3.0 & 5.1535 & TST & \\
\hline CHEMBL575650 & 587657 & 4.9208 & 4.9112 & TRN & \\
\hline CHEMBL564201 & 587657 & 4.585 & 4.7001 & TST & \\
\hline CHEMBL575426 & 587657 & 3.0 & 2.9991 & TRN & \\
\hline CHEMBL573628 & 587657 & 3.0 & 3.0665 & TRN & \\
\hline CHEMBL575210 & 587657 & 3.0 & 3.1291 & TRN & \\
\hline CHEMBL574095 & 587657 & 3.301 & 3.3285 & TRN & \\
\hline CHEMBL573542 & 587657 & 3.0 & 2.99899 & 99999999997 & TRN \\
\hline CHEMBL577182 & 587657 & 4.0969 & 4.0799 & TRN & \\
\hline CHEMBL583739 & 587657 & 3.0 & 2.9243 & TRN & \\
\hline CHEMBL573541 & 587657 & 3.0 & 2.9948 & TRN & \\
\hline CHEMBL572449 & 587657 & 3.0 & 3.0693 & TST & \\
\hline CHEMBL573371 & 587657 & 3.0 & 3.3377 & TST & \\
\hline CHEMBL584804 & 587657 & 3.0 & 3.0158 & TST & \\
\hline CHEMBL574101 & 587657 & 3.0 & 2.9302 & TST & \\
\hline CHEMBL306923 & 35129 & 8.5229 & 9.1098 & TST & \\
\hline CHEMBL419073 & 35129 & 9.2218 & 9.5074 & TRN & \\
\hline CHEMBL307359 & 35129 & 9.3979 & 9.4949 & TRN & \\
\hline CHEMBL 74514 & 35129 & 9.0969 & 9.582 & TRN & \\
\hline CHEMBL 70370 & 35129 & 10.0 & 9.6133 & TRN & \\
\hline CHEMBL 72595 & 35129 & 9.301 & 9.3088 & TRN & \\
\hline CHEMBL309455 & 35129 & 8.0 & 9.4607 & TST & \\
\hline CHEMBL70789 & 35129 & 10.0 & 9.3023 & TRN & \\
\hline CHEMBL 70793 & 35129 & 8.5229 & 9.3458 & TRN & \\
\hline CHEMBL311018 & 35129 & 9.5229 & 9.3106 & TRN & \\
\hline CHEMBL71286 & 35129 & 9.5229 & 9.1549 & TRN & \\
\hline CHEMBL306435 & 35129 & 9.0969 & 9.1849 & TRN & \\
\hline CHEMBL 309790 & 35129 & 9.5229 & 9.4082 & TRN & \\
\hline CHEMBL305238 & 35129 & 10.0 & 9.8293 & TRN & \\
\hline CHEMBL71172 & 35129 & 9.699 & 9.3379 & TRN & \\
\hline CHEMBL306924 & 35129 & 8.5229 & 9.033 & TST & \\
\hline CHEMBL 308323 & 35129 & 9.699 & 9.7214 & TRN & \\
\hline CHEMBL 71125 & 35129 & 9.2441 & 9.2319 & TRN & \\
\hline CHEMBL311625 & 35129 & 9.699 & 9.6608 & TRN & \\
\hline CHEMBL 302485 & 35129 & 8.0458 & 9.1358 & TST & \\
\hline CHEMBL 71220 & 35129 & 9.2218 & 9.4533 & TRN & \\
\hline
\end{tabular}




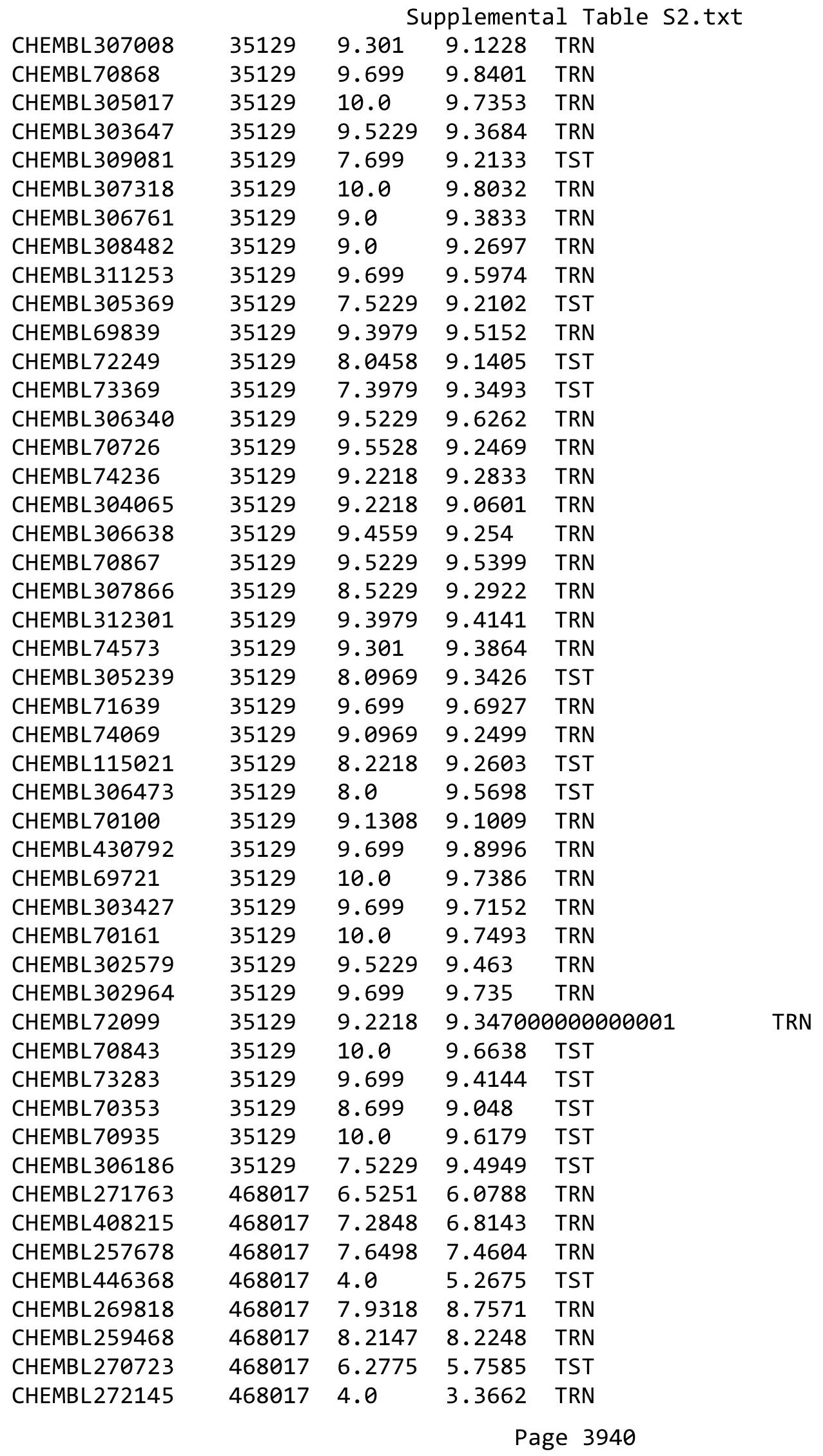




\begin{tabular}{|c|c|c|c|c|c|c|}
\hline \multirow[b]{2}{*}{ CHEMBL272863 } & \multicolumn{6}{|c|}{ Supplemental Table S2.txt } \\
\hline & 468017 & 4.0 & 4.2414 & TRN & & \\
\hline CHEMBL402784 & 468017 & 4.0 & 4.4962 & TRN & & \\
\hline CHEMBL403957 & 468017 & 8.2676 & 8.6397 & TRN & & \\
\hline CHEMBL406527 & 468017 & 7.4248 & 7.3818 & TRN & & \\
\hline CHEMBL270305 & 468017 & 7.9626 & 7.62299 & 9999999999 & & TRN \\
\hline CHEMBL407951 & 468017 & 4.0 & 6.2979 & TST & & \\
\hline CHEMBL408216 & 468017 & 6.8401 & 6.9744 & TRN & & \\
\hline CHEMBL272433 & 468017 & 8.9208 & 9.02700 & 0000000001 & & TRN \\
\hline CHEMBL257301 & 468017 & 4.0 & 6.352 & TST & & \\
\hline CHEMBL257300 & 468017 & 6.1972 & 6.3443 & TRN & & \\
\hline CHEMBL271104 & 468017 & 8.0088 & 7.8494 & TRN & & \\
\hline CHEMBL257103 & 468017 & 6.3225 & 5.6829 & TST & & \\
\hline CHEMBL257491 & 468017 & 6.1375 & 5.6679 & TST & & \\
\hline CHEMBL405743 & 468017 & 4.0 & 5.4007 & TRN & & \\
\hline CHEMBL271339 & 468017 & 7.1487 & 6.7162 & TRN & & \\
\hline CHEMBL408442 & 468017 & 5.9172 & 6.3688 & TRN & & \\
\hline CHEMBL407712 & 468017 & 4.0 & 3.4581 & TRN & & \\
\hline CHEMBL270294 & 468017 & 8.3872 & 7.8017 & TST & & \\
\hline CHEMBL403827 & 468017 & 6.6751 & 6.1925 & TRN & & \\
\hline CHEMBL272208 & 468017 & 6.5626 & 6.1659 & TRN & & \\
\hline CHEMBL270036 & 468017 & 4.0 & 3.5166 & TRN & & \\
\hline CHEMBL259680 & 468017 & 4.0 & 4.5471 & TRN & & \\
\hline CHEMBL271932 & 468017 & 8.2924 & 8.3924 & TRN & & \\
\hline CHEMBL408897 & 468017 & 6.095 & 5.3805 & TST & & \\
\hline CHEMBL270517 & 468017 & 6.9176 & 7.019 & TRN & & \\
\hline CHEMBL271173 & 468017 & 9.5229 & 9.5507 & TRN & & \\
\hline CHEMBL410524 & 468017 & 4.0 & 5.0106 & TRN & & \\
\hline CHEMBL405564 & 468017 & 8.0362 & 6.5735 & TRN & & \\
\hline CHEMBL257677 & 468017 & 7.4724 & 7.3083 & TRN & & \\
\hline CHEMBL271549 & 468017 & 8.6198 & 8.7363 & TRN & & \\
\hline CHEMBL403099 & 468017 & 6.2775 & 6.0969 & TRN & & \\
\hline CHEMBL403828 & 468017 & 4.0 & 5.5961 & TST & & \\
\hline CHEMBL403985 & 468017 & 4.0 & 4.3718 & TRN & & \\
\hline CHEMBL257493 & 468017 & 4.0 & 4.6781 & TRN & & \\
\hline CHEMBL270293 & 468017 & 9.3979 & 9.8049 & TRN & & \\
\hline CHEMBL272626 & 468017 & 4.0 & 4.5453 & TRN & & \\
\hline CHEMBL405123 & 468017 & 7.0778 & 6.8664 & TRN & & \\
\hline CHEMBL270510 & 468017 & 7.3152 & 7.0754 & TRN & & \\
\hline CHEMBL408788 & 468017 & 7.61799 & 99999999 & & 7.609 & TRN \\
\hline CHEMBL257295 & 468017 & 6.6225 & 5.8626 & TST & & \\
\hline CHEMBL259678 & 468017 & 6.5224 & 6.6408 & TRN & & \\
\hline CHEMBL271572 & 468017 & 5.4001 & 5.07600 & 0000000006 & 05 & TRN \\
\hline CHEMBL272239 & 468017 & 7.0424 & 6.62200 & 0000000001 & & TRN \\
\hline CHEMBL 270111 & 468017 & 5.8297 & 5.6689 & TST & & \\
\hline CHEMBL257299 & 468017 & 7.3526 & 7.513 & TRN & & \\
\hline CHEMBL272587 & 468017 & 5.7144 & 5.5263 & TRN & & \\
\hline CHEMBL404362 & 468017 & 6.98799 & 99999999 & 995 & 6.7013 & TRN \\
\hline CHEMBL257054 & 468017 & 7.4828 & 5.8086 & TST & & \\
\hline
\end{tabular}




\begin{tabular}{|c|c|c|c|c|c|}
\hline & & & & & \\
\hline CHEMBL271337 & 468017 & 6.8024 & 6.5759 & TRN & \\
\hline CHEMBL410232 & 468017 & 4.0 & 5.0044 & TRN & \\
\hline CHEMBL271348 & 468017 & 8.1249 & 8.4189 & TRN & \\
\hline CHEMBL271614 & 468017 & 7.9872 & 7.6651 & TRN & \\
\hline CHEMBL272862 & 468017 & 7.7447 & 7.5686 & TRN & \\
\hline CHEMBL271314 & 468017 & 4.0 & 5.6527 & TST & \\
\hline CHEMBL403720 & 468017 & 6.3425 & 5.5227 & TST & \\
\hline CHEMBL255378 & 468017 & 7.5969 & 7.0014 & TRN & \\
\hline CHEMBL270078 & 468017 & 8.9208 & 8.9255 & TRN & \\
\hline CHEMBL272678 & 468017 & 7.4179 & 7.57600 & 00000000005 & TRN \\
\hline CHEMBL 270351 & 468017 & 4.0 & 5.4898 & TST & \\
\hline CHEMBL273118 & 468017 & 6.5325 & 6.9737 & TRN & \\
\hline CHEMBL 271551 & 468017 & 6.8539 & 6.5896 & TRN & \\
\hline CHEMBL405071 & 468017 & 7.5072 & 7.5218 & TRN & \\
\hline CHEMBL271338 & 468017 & 8.6778 & 8.3898 & TRN & \\
\hline CHEMBL257108 & 468017 & 7.4353 & 7.47 & TRN & \\
\hline CHEMBL409467 & 468017 & 4.0 & 3.9249 & TRN & \\
\hline CHEMBL405841 & 468017 & 7.1124 & 6.7346 & TRN & \\
\hline CHEMBL410911 & 468017 & 4.0 & 5.6301 & TST & \\
\hline CHEMBL256847 & 468017 & 7.1624 & 7.0292 & TRN & \\
\hline CHEMBL272627 & 468017 & 7.3325 & 7.4263 & TRN & \\
\hline CHEMBL 272393 & 468017 & 7.1002 & 7.709 & TRN & \\
\hline CHEMBL442706 & 468017 & 6.8526 & 6.3658 & TRN & \\
\hline CHEMBL269832 & 468017 & 7.3072 & 7.296 & TRN & \\
\hline CHEMBL259469 & 468017 & 5.7167 & 5.9513 & TRN & \\
\hline CHEMBL406528 & 468017 & 5.4776 & 5.282 & TRN & \\
\hline CHEMBL271103 & 468017 & 7.0273 & 6.6303 & TST & \\
\hline CHEMBL 272605 & 468017 & 5.2426 & 4.573 & TST & \\
\hline CHEMBL409468 & 468017 & 5.5544 & 5.1598 & TST & \\
\hline CHEMBL414005 & 468017 & 6.565 & 5.0339 & TST & \\
\hline CHEMBL270730 & 468017 & 7.5406 & 6.5638 & TST & \\
\hline CHEMBL257483 & 468017 & 6.1025 & 5.2618 & TST & \\
\hline CHEMBL 271312 & 468017 & 6.2825 & 5.0177 & TST & \\
\hline CHEMBL3125465 & 1296583 & 4.1612 & 4.3986 & TRN & \\
\hline CHEMBL3125491 & 1296583 & 3.8508 & 3.7281 & TRN & \\
\hline CHEMBL3125476 & 1296583 & 4.8861 & 4.6977 & TRN & \\
\hline CHEMBL3125464 & 1296583 & 4.6778 & 4.6545 & TRN & \\
\hline CHEMBL 3125481 & 1296583 & 3.9031 & 4.0977 & TRN & \\
\hline CHEMBL3125475 & 1296583 & 4.6576 & 4.5418 & TRN & \\
\hline CHEMBL 3125462 & 1296583 & 4.6778 & 4.5849 & TRN & \\
\hline CHEMBL3125499 & 1296583 & 2.8239 & 3.4956 & TST & \\
\hline CHEMBL3125506 & 1296583 & 2.8239 & 2.7382 & TRN & \\
\hline CHEMBL3125495 & 1296583 & 4.3768 & 4.5735 & TST & \\
\hline CHEMBL3125468 & 1296583 & 4.2924 & 4.4547 & TRN & \\
\hline CHEMBL 3125469 & 1296583 & 4.301 & 4.3159 & TRN & \\
\hline CHEMBL3124946 & 1296583 & 4.8239 & 4.4721 & TRN & \\
\hline CHEMBL 3125466 & 1296583 & 5.0458 & 4.9155 & TRN & \\
\hline CHEMBL3125507 & 1296583 & 2.8239 & 2.6923 & TRN & \\
\hline
\end{tabular}

Page 3942 
Supplemental Table S2.txt

\begin{tabular}{|c|c|c|c|c|c|}
\hline CHEMBL 3125474 & 1296583 & 4.4089 & 4.3428 & TRN & \\
\hline CHEMBL3125500 & 1296583 & 2.8239 & 3.3926 & TST & \\
\hline CHEMBL3125479 & 1296583 & 2.8239 & 2.9045 & TRN & \\
\hline CHEMBL3125494 & 1296583 & 4.4815 & 4.6349 & TRN & \\
\hline CHEMBL3125489 & 1296583 & 2.8239 & 3.1026 & TRN & \\
\hline CHEMBL 3125470 & 1296583 & 2.8239 & 2.807 & TRN & \\
\hline CHEMBL 3125463 & 1296583 & 4.6021 & 4.7883 & TRN & \\
\hline CHEMBL3125486 & 1296583 & 4.1079 & 4.1842 & TRN & \\
\hline CHEMBL 3125490 & 1296583 & 4.4559 & 4.5903 & TRN & \\
\hline CHEMBL3125467 & 1296583 & 4.2441 & 4.3379 & TRN & \\
\hline CHEMBL 3125472 & 1296583 & 2.8239 & 2.8357 & TRN & \\
\hline CHEMBL 3125478 & 1296583 & 2.8239 & 3.0708 & TST & \\
\hline CHEMBL3125487 & 1296583 & 4.2076 & 4.1947 & TRN & \\
\hline CHEMBL3125496 & 1296583 & 3.8928 & 3.708 & TRN & \\
\hline CHEMBL3125502 & 1296583 & 2.8239 & 2.949 & TRN & \\
\hline CHEMBL 3125480 & 1296583 & 2.8239 & 2.8812 & TRN & \\
\hline CHEMBL3125483 & 1296583 & 3.9914 & 3.9615 & TRN & \\
\hline CHEMBL 3125488 & 1296583 & 4.2007 & 4.194 & TRN & \\
\hline CHEMBL 3125460 & 1296583 & 4.1367 & \multicolumn{2}{|c|}{4.1739999999999995} & TRN \\
\hline CHEMBL3125493 & 1296583 & 4.6778 & 4.7572 & TRN & \\
\hline CHEMBL3125485 & 1296583 & 4.0655 & 4.0875 & TRN & \\
\hline CHEMBL3125461 & 1296583 & 3.8356 & 3.8077 & TRN & \\
\hline CHEMBL3125504 & 1296583 & 2.8239 & 2.9524 & TRN & \\
\hline CHEMBL3125508 & 1296583 & 2.8239 & 2.8644 & TRN & \\
\hline CHEMBL3125492 & 1296583 & 4.2596 & 3.9177 & TRN & \\
\hline CHEMBL3125505 & 1296583 & 2.8239 & 2.639 & TRN & \\
\hline CHEMBL3125501 & 1296583 & 2.8239 & 3.0214 & TST & \\
\hline CHEMBL3125477 & 1296583 & 3.9666 & 3.4268 & TST & \\
\hline CHEMBL 3125503 & 1296583 & 2.8239 & 2.7243 & TST & \\
\hline CHEMBL3125473 & 1296583 & 2.8239 & 2.7095 & TST & \\
\hline CHEMBL3125484 & 1296583 & 2.8239 & 3.6589 & TST & \\
\hline CHEMBL3125482 & 1296583 & 4.1135 & 3.4445 & TST & \\
\hline CHEMBL 3125471 & 1296583 & 2.8239 & 4.1575 & TST & \\
\hline CHEMBL 3125498 & 1296583 & 3.8601 & 3.5374 & TST & \\
\hline CHEMBL3125497 & 1296583 & 3.9626 & 3.5729 & TST & \\
\hline CHEMBL 2024390 & 815276 & 5.0 & 4.4027 & TRN & \\
\hline CHEMBL2021991 & 815276 & 6.3979 & 6.7945 & TRN & \\
\hline CHEMBL 2024384 & 815276 & -0.0 & 2.8301 & TRN & \\
\hline CHEMBL2021975 & 815276 & 4.7328 & 4.2719 & TRN & \\
\hline CHEMBL2024399 & 815276 & 4.7825 & 5.3856 & TRN & \\
\hline CHEMBL 2021990 & 815276 & 6.4949 & 6.63399 & 99999999995 & TRN \\
\hline CHEMBL2024389 & 815276 & 4.7799 & 3.2191 & TRN & \\
\hline CHEMBL 2024386 & 815276 & 1.0 & 4.6068 & TST & \\
\hline CHEMBL 2024400 & 815276 & 5.8761 & 5.0632 & TRN & \\
\hline CHEMBL2021989 & 815276 & 4.5258 & 5.1158 & TRN & \\
\hline CHEMBL 2024401 & 815276 & 6.0809 & 6.1033 & TRN & \\
\hline CHEMBL2024308 & 815276 & 5.1512 & 4.9751 & TRN & \\
\hline CHEMBL2021980 & 815276 & -0.0 & 2.9086 & TRN & \\
\hline
\end{tabular}




\begin{tabular}{|c|c|c|c|c|c|c|}
\hline & & \multicolumn{5}{|c|}{ Supplemental Table S2.txt } \\
\hline CHEMBL 2021985 & 815276 & 6.301 & 6.1808 & TRN & & \\
\hline CHEMBL 2021969 & 815276 & 4.0405 & 3.7251 & TRN & & \\
\hline CHEMBL 2021986 & 815276 & 6.301 & 6.2697 & TRN & & \\
\hline CHEMBL 2024395 & 815276 & 4.8729 & 4.7034 & TRN & & \\
\hline CHEMBL 2024379 & 815276 & 1.0 & 4.6856 & TST & & \\
\hline CHEMBL 2024382 & 815276 & 6.4089 & 6.2135 & TRN & & \\
\hline CHEMBL 2021971 & 815276 & 4.7447 & 4.9107 & TRN & & \\
\hline CHEMBL 2024311 & 815276 & 6.6021 & 6.8302 & TRN & & \\
\hline CHEMBL 2024392 & 815276 & 4.0287 & 5.1912 & TST & & \\
\hline CHEMBL 2021984 & 815276 & 7.0969 & 6.8123 & TRN & & \\
\hline CHEMBL 2021970 & 815276 & 4.7077 & 3.8923 & TRN & & \\
\hline CHEMBL 2024391 & 815276 & 4.2692 & 4.6068 & TST & & \\
\hline CHEMBL 2021983 & 815276 & 6.4949 & 6.4871 & TRN & & \\
\hline CHEMBL 2021976 & 815276 & 5.3143 & 5.2754 & TRN & & \\
\hline CHEMBL 2021981 & 815276 & 4.9281 & 4.8089 & TRN & & \\
\hline CHEMBL 2021968 & 815276 & 5.7595 & 5.7099 & TRN & & \\
\hline CHEMBL 2024396 & 815276 & 6.7852 & 5.7682 & TRN & & \\
\hline CHEMBL 2024393 & 815276 & 4.0862 & 3.9776 & TRN & & \\
\hline CHEMBL 2024398 & 815276 & 5.0804 & 6.5881 & TST & & \\
\hline CHEMBL 2021992 & 815276 & 6.301 & 6.6007 & TRN & & \\
\hline CHEMBL 2021979 & 815276 & 5.0 & 4.8951 & TRN & & \\
\hline CHEMBL 2021973 & 815276 & 4.757 & 5.7821 & TST & & \\
\hline CHEMBL 2024309 & 815276 & 5.0 & 5.3552 & TRN & & \\
\hline CHEMBL 2024383 & 815276 & 1.0 & 3.8603 & TST & & \\
\hline CHEMBL 2024385 & 815276 & 4.0526 & 4.0409 & TRN & & \\
\hline CHEMBL 2021977 & 815276 & 1.0 & 5.5452 & TST & & \\
\hline CHEMBL 2024378 & 815276 & 6.8861 & 7.1716 & TRN & & \\
\hline CHEMBL 2024394 & 815276 & 4.1085 & 2.1459 & TRN & & \\
\hline CHEMBL 2024388 & 815276 & 3.9706 & 3.6257 & TRN & & \\
\hline CHEMBL 2021972 & 815276 & 4.5243 & 5.5452 & TST & & \\
\hline CHEMBL 2024380 & 815276 & 6.3979 & 6.5401 & TRN & & \\
\hline CHEMBL 2021974 & 815276 & 4.6459 & 4.542 & TRN & & \\
\hline CHEMBL 2021982 & 815276 & 6.3979 & 6.2893 & TRN & & \\
\hline CHEMBL 2021967 & 815276 & 5.5901 & 6.8955 & TST & & \\
\hline CHEMBL 2024387 & 815276 & 1.0 & 4.8559 & TST & & \\
\hline CHEMBL 2024381 & 815276 & 6.1549 & 5.8364 & TRN & & \\
\hline CHEMBL 2021988 & 815276 & 4.6799 & 5.1121 & TRN & & \\
\hline CHEMBL 2024397 & 815276 & 5.2175 & 6.3414 & TST & & \\
\hline CHEMBL 2021978 & 815276 & 4.8794 & 6.1117 & TST & & \\
\hline CHEMBL 2024310 & 815276 & 1.0 & 2.9574 & TST & & \\
\hline CHEMBL 2021987 & 815276 & $4.9830 e$ & 00000000 & 005 & 5.4201 & TRN \\
\hline CHEMBL1215719 & 650214 & 5.699 & 5.5812 & TRN & & \\
\hline CHEMBL1215005 & 650214 & 4.5528 & 4.613 & TRN & & \\
\hline CHEMBL1215227 & 650214 & 5.699 & 5.8327 & TRN & & \\
\hline CHEMBL1215367 & 650214 & 3.5513 & 3.5871 & TRN & & \\
\hline CHEMBL1214714 & 650214 & 3.5884 & 3.5929 & TST & & \\
\hline CHEMBL1212961 & 650214 & 2.5229 & 2.6118 & TRN & & \\
\hline CHEMBL1215799 & 650214 & 4.9208 & 5.0008 & TRN & & \\
\hline
\end{tabular}


Supplemental Table S2.txt

\begin{tabular}{|c|c|c|c|c|c|}
\hline CHEMBL1215798 & 650214 & 2.5229 & 3.6909 & TST & \\
\hline CHEMBL1214719 & 650214 & 4.6576 & 4.6613 & TRN & \\
\hline CHEMBL400566 & 650214 & 4.7447 & 4.4423 & TRN & \\
\hline CHEMBL1215512 & 650214 & 4.2366 & 3.5424 & TRN & \\
\hline CHEMBL1215800 & 650214 & 5.0458 & 5.2451 & TRN & \\
\hline CHEMBL1214648 & 650214 & 4.6576 & 4.7682 & TRN & \\
\hline CHEMBL1214717 & 650214 & 4.8539 & 4.7583 & TRN & \\
\hline CHEMBL1215442 & 650214 & 5.301 & 5.4023 & TRN & \\
\hline CHEMBL1214792 & 650214 & 2.5229 & 3.4384 & TST & \\
\hline CHEMBL1215292 & 650214 & 5.2218 & 4.9408 & TRN & \\
\hline CHEMBL1215290 & 650214 & 6.0 & 6.0123 & TRN & \\
\hline CHEMBL1215651 & 650214 & 4.4815 & 4.5605 & TRN & \\
\hline CHEMBL1214716 & 650214 & 5.0969 & 4.9177 & TRN & \\
\hline CHEMBL1214864 & 650214 & 2.5229 & 2.9107 & TST & \\
\hline CHEMBL1215440 & 650214 & 5.2218 & 5.2614 & TRN & \\
\hline CHEMBL1215155 & 650214 & 5.699 & 5.5872 & TRN & \\
\hline CHEMBL1214934 & 650214 & 4.4815 & 4.1192 & TRN & \\
\hline CHEMBL1214869 & 650214 & 3.6904 & 3.4958 & TRN & \\
\hline CHEMBL1215007 & 650214 & 5.3979 & 4.4789 & TST & \\
\hline CHEMBL1215717 & 650214 & 2.5229 & 2.7446 & TRN & \\
\hline CHEMBL1215293 & 650214 & 3.6904 & 4.4396 & TRN & \\
\hline CHEMBL1215224 & 650214 & 4.7959 & 4.8494 & TRN & \\
\hline CHEMBL1214645 & 650214 & 4.6198 & 4.6515 & TRN & \\
\hline CHEMBL1214793 & 650214 & 3.8182 & 3.3112 & TRN & \\
\hline CHEMBL1215511 & 650214 & 2.5229 & 2.546 & TRN & \\
\hline CHEMBL1214940 & 650214 & 5.2218 & 5.2116 & TRN & \\
\hline CHEMBL1215581 & 650214 & 3.9066 & 4.1726 & TRN & \\
\hline CHEMBL1215226 & 650214 & 5.699 & 5.3097 & TRN & \\
\hline CHEMBL1214794 & 650214 & 4.585 & 3.9488 & TST & \\
\hline CHEMBL1215510 & 650214 & 5.3979 & 5.2446 & TRN & \\
\hline CHEMBL1214646 & 650214 & 2.5229 & 3.2594 & TST & \\
\hline CHEMBL1214791 & 650214 & 2.5229 & 3.0216 & TRN & \\
\hline CHEMBL1215082 & 650214 & 4.0915 & 4.1609 & TRN & \\
\hline CHEMBL1215797 & 650214 & 4.4815 & 4.6049 & TRN & \\
\hline CHEMBL1214713 & 650214 & 4.7212 & 4.7329 & TRN & \\
\hline CHEMBL1214863 & 650214 & 3.8447 & 3.5375 & TST & \\
\hline CHEMBL1215079 & 650214 & 4.7696 & 4.5581 & TRN & \\
\hline CHEMBL1214720 & 650214 & 3.5467 & 3.4468 & TRN & \\
\hline CHEMBL1215716 & 650214 & 3.9547 & 3.9025 & TRN & \\
\hline CHEMBL1215648 & 650214 & 4.3768 & 4.3281 & TRN & \\
\hline CHEMBL1214935 & 650214 & 4.5086 & 4.5273 & TRN & \\
\hline CHEMBL1214798 & 650214 & 2.5229 & 2.56399 & 99999999996 & TRN \\
\hline CHEMBL1214796 & 650214 & 2.5229 & 3.2229 & TRN & \\
\hline CHEMBL1214647 & 650214 & 4.8861 & 5.2465 & TRN & \\
\hline CHEMBL1215580 & 650214 & 4.8239 & 4.8399 & TRN & \\
\hline CHEMBL1215796 & 650214 & 4.8239 & 4.8509 & TRN & \\
\hline CHEMBL1215365 & 650214 & 5.699 & 5.6508 & TRN & \\
\hline CHEMBL1214862 & 650214 & 2.5229 & 2.9079 & TST & \\
\hline
\end{tabular}


Supplemental Table S2.txt

\begin{tabular}{|c|c|c|c|c|c|}
\hline CHEMBL1214941 & 650214 & 5.1549 & 4.9381 & TRN & \\
\hline CHEMBL1214865 & 650214 & 5.5229 & 4.6043 & TST & \\
\hline CHEMBL1214715 & 650214 & 5.0969 & 5.098 & TRN & \\
\hline CHEMBL1215803 & 650214 & 4.6778 & 4.8166 & TRN & \\
\hline CHEMBL1214868 & 650214 & 4.1549 & 4.0446 & TST & \\
\hline CHEMBL1215003 & 650214 & 4.8239 & 4.7389 & TRN & \\
\hline CHEMBL1214939 & 650214 & 4.7212 & 4.5045 & TST & \\
\hline CHEMBL1215513 & 650214 & 4.4089 & 4.3215 & TRN & \\
\hline CHEMBL1215439 & 650214 & 4.3979 & 4.079 & TRN & \\
\hline CHEMBL1214936 & 650214 & 5.0458 & 5.0873 & TRN & \\
\hline CHEMBL1214867 & 650214 & \multicolumn{3}{|c|}{3.6180000000000003} & TRN \\
\hline CHEMBL1214649 & 650214 & 3.7352 & 3.7021 & TST & \\
\hline CHEMBL1214866 & 650214 & 2.5229 & 2.7977 & TRN & \\
\hline CHEMBL1214861 & 650214 & 3.6882 & \multicolumn{2}{|c|}{3.4010000000000002} & TRN \\
\hline CHEMBL1214937 & 650214 & 4.7959 & 4.7014 & TRN & \\
\hline CHEMBL1215802 & 650214 & 4.8861 & 5.1841 & TRN & \\
\hline CHEMBL1215650 & 650214 & 4.2007 & 3.8394 & TRN & \\
\hline CHEMBL1215291 & 650214 & 5.301 & 5.4312 & TRN & \\
\hline CHEMBL1215156 & 650214 & 4.7959 & 4.9178 & TRN & \\
\hline CHEMBL1214938 & 650214 & 2.5229 & 2.9251 & TRN & \\
\hline CHEMBL1215081 & 650214 & 4.7447 & 4.8155 & TRN & \\
\hline CHEMBL1214797 & 650214 & 2.5229 & 2.6488 & TRN & \\
\hline CHEMBL1214718 & 650214 & 4.699 & 4.9578 & TRN & \\
\hline CHEMBL1215364 & 650214 & 4.3665 & 4.5239 & TRN & \\
\hline CHEMBL1215718 & 650214 & 2.5229 & 3.0427 & TRN & \\
\hline CHEMBL1214795 & 650214 & 3.8539 & 3.5556 & TST & \\
\hline CHEMBL1215157 & 650214 & 4.9208 & 4.7142 & TRN & \\
\hline CHEMBL1215080 & 650214 & 4.7696 & 4.4397 & TRN & \\
\hline CHEMBL1215801 & 650214 & 5.699 & 5.7812 & TRN & \\
\hline CHEMBL1215441 & 650214 & 5.5229 & 5.3164 & TST & \\
\hline CHEMBL1214790 & 650214 & 3.7423 & 3.6512 & TST & \\
\hline CHEMBL1215006 & 650214 & 4.4437 & 3.8165 & TST & \\
\hline CHEMBL1215225 & 650214 & 5.0458 & 4.8885 & TST & \\
\hline CHEMBL1215579 & 650214 & 2.5229 & 4.0501 & TST & \\
\hline CHEMBL1215366 & 650214 & 5.699 & 5.5854 & TST & \\
\hline CHEMBL1215004 & 650214 & 4.9208 & 5.28799 & 9999999999 & TST \\
\hline CHEMBL1215649 & 650214 & 4.5528 & 3.7095 & TST & \\
\hline CHEMBL1215154 & 650214 & 4.6576 & 4.8223 & TST & \\
\hline CHEMBL1215578 & 650214 & 4.7447 & 4.8095 & TST & \\
\hline CHEMBL 2153149 & 852362 & 5.684 & 5.5721 & TRN & \\
\hline CHEMBL2152976 & 852362 & 4.0 & 4.5917 & TRN & \\
\hline CHEMBL 2153150 & 852362 & 4.0 & 4.1961 & TRN & \\
\hline CHEMBL 2152986 & 852362 & 4.0 & 5.3293 & TST & \\
\hline CHEMBL 2153127 & 852362 & 6.4815 & 5.7291 & TST & \\
\hline CHEMBL 2152980 & 852362 & 5.2299 & 5.24100 & 00000000005 & TRN \\
\hline CHEMBL 2153154 & 852362 & 6.0706 & 6.1443 & TRN & \\
\hline CHEMBL2153152 & 852362 & 5.3615 & 4.8478 & TRN & \\
\hline CHEMBL2152974 & 852362 & 5.2 & 5.0997 & TRN & \\
\hline
\end{tabular}




\begin{tabular}{|c|c|c|c|c|}
\hline \multicolumn{5}{|c|}{ Supplemental Table S2.txt } \\
\hline CHEMBL 2153145 & 852362 & 5.2343 & 4.853 & TRN \\
\hline CHEMBL 2153133 & 852362 & 6.699 & 7.0632 & TRN \\
\hline CHEMBL 2153130 & 852362 & 5.2457 & 5.2972 & TRN \\
\hline CHEMBL 2152988 & 852362 & 5.2503 & 5.0769 & TRN \\
\hline CHEMBL 2153129 & 852362 & 6.1192 & 6.2332 & TRN \\
\hline CHEMBL 2153144 & 852362 & 4.0 & 4.2668 & TRN \\
\hline CHEMBL 2152991 & 852362 & 5.4034 & 5.324 & TRN \\
\hline CHEMBL 2152989 & 852362 & 5.064 & 4.7227 & TRN \\
\hline CHEMBL 2153140 & 852362 & 4.0 & 4.0894 & TRN \\
\hline CHEMBL 2152994 & 852362 & 6.0269 & 6.4652 & TRN \\
\hline CHEMBL 2153132 & 852362 & 5.3458 & 5.7681 & TRN \\
\hline CHEMBL 2152987 & 852362 & 5.1101 & 4.8253 & TRN \\
\hline CHEMBL 2153134 & 852362 & 6.4089 & 6.9424 & TRN \\
\hline CHEMBL 2152990 & 852362 & 5.8125 & 5.8231 & TRN \\
\hline CHEMBL 2153137 & 852362 & 5.8386 & 5.6576 & TRN \\
\hline CHEMBL 2152993 & 852362 & 4.0 & 4.7857 & TST \\
\hline CHEMBL 2153147 & 852362 & 4.0 & 4.151 & TST \\
\hline CHEMBL 2153136 & 852362 & 6.0223 & 6.0338 & TST \\
\hline CHEMBL 2152979 & 852362 & 5.1146 & 4.9544 & TRN \\
\hline CHEMBL 2153139 & 852362 & 5.5817 & 5.193 & TRN \\
\hline CHEMBL 2152996 & 852362 & 5.8761 & 5.9063 & TRN \\
\hline CHEMBL 2153122 & 852362 & 6.2676 & 6.0372 & TRN \\
\hline CHEMBL 2153135 & 852362 & 9.0 & 7.9443 & TRN \\
\hline CHEMBL 2153143 & 852362 & 5.1904 & 4.9339 & TRN \\
\hline CHEMBL 2152982 & 852362 & 5.1637 & 5.3798 & TRN \\
\hline CHEMBL 2153141 & 852362 & 6.0655 & 5.7034 & TRN \\
\hline CHEMBL 2152983 & 852362 & 5.475 & 5.3284 & TST \\
\hline CHEMBL 2153131 & 852362 & 6.2007 & 6.6997 & TRN \\
\hline CHEMBL 2153148 & 852362 & 4.0 & 4.1649 & TRN \\
\hline CHEMBL 2152977 & 852362 & 4.0 & 4.4713 & TRN \\
\hline CHEMBL 2153138 & 852362 & 6.1367 & 5.515 & TRN \\
\hline CHEMBL 2152975 & 852362 & 5.8633 & 5.7566 & TST \\
\hline CHEMBL67 & 852362 & 9.0 & 8.3069 & TST \\
\hline CHEMBL 2152984 & 852362 & 5.0306 & 4.8757 & TST \\
\hline CHEMBL 2153126 & 852362 & 6.3372 & 6.1093 & TST \\
\hline CHEMBL 2153128 & 852362 & 5.9101 & 5.7139 & TRN \\
\hline CHEMBL 2153124 & 852362 & 5.9508 & 5.7758 & TRN \\
\hline CHEMBL 2152981 & 852362 & 5.1198 & 4.9344 & TST \\
\hline CHEMBL 2153151 & 852362 & 5.9788 & 5.7355 & TRN \\
\hline CHEMBL 2152998 & 852362 & 6.3468 & 6.3988 & TRN \\
\hline CHEMBL 2153155 & 852362 & 6.4685 & 7.2369 & TRN \\
\hline CHEMBL 2152978 & 852362 & 5.8125 & 5.8099 & TST \\
\hline CHEMBL 2152995 & 852362 & 6.6778 & 6.5771 & TRN \\
\hline CHEMBL 2152985 & 852362 & 4.0 & 4.4289 & TST \\
\hline CHEMBL 2153153 & 852362 & 6.0506 & 6.0437 & TRN \\
\hline CHEMBL 2153156 & 852362 & 5.8697 & 5.4488 & TST \\
\hline CHEMBL 2153142 & 852362 & 4.0 & 4.6679 & TRN \\
\hline CHEMBL 2153146 & 852362 & 5.7747 & 5.1494 & TST \\
\hline
\end{tabular}




\begin{tabular}{|c|c|c|c|c|c|c|}
\hline & & \multicolumn{5}{|c|}{ Supplemental Table S2.txt } \\
\hline CHEMBL2153125 & 852362 & 6.0506 & 6.1544 & TRN & & \\
\hline CHEMBL 2152997 & 852362 & 5.75200 & 00000000 & 01 & 5.5125 & TRN \\
\hline CHEMBL2152992 & 852362 & 6.2147 & 6.1272 & TST & & \\
\hline CHEMBL2153123 & 852362 & 6.1249 & 6.1919 & TRN & & \\
\hline CHEMBL 3924544 & 1637967 & 7.3565 & 6.1711 & TST & & \\
\hline CHEMBL3891392 & 1637967 & 8.3188 & 6.2844 & TST & & \\
\hline CHEMBL3914427 & 1637967 & 5.5086 & 5.5017 & TRN & & \\
\hline CHEMBL392765 & 1637967 & 6.5214 & 6.4761 & TRN & & \\
\hline CHEMBL3959021 & 1637967 & 6.466 & 6.4244 & TRN & & \\
\hline CHEMBL3922865 & 1637967 & 6.6345 & 6.5781 & TRN & & \\
\hline CHEMBL3896803 & 1637967 & 6.2604 & 5.4672 & TST & & \\
\hline CHEMBL3965798 & 1637967 & 6.0706 & 6.0177 & TRN & & \\
\hline CHEMBL3925126 & 1637967 & 6.3788 & 6.4227 & TRN & & \\
\hline CHEMBL3911147 & 1637967 & 5.0 & 5.9017 & TST & & \\
\hline CHEMBL3944650 & 1637967 & 5.0 & 5.0358 & TRN & & \\
\hline CHEMBL3901204 & 1637967 & 6.0 & 6.0634 & TRN & & \\
\hline CHEMBL3930293 & 1637967 & 7.1427 & 7.1581 & TRN & & \\
\hline CHEMBL 3905055 & 1637967 & 7.9586 & 7.9193 & TRN & & \\
\hline CHEMBL3927122 & 1637967 & 7.1308 & 7.1815 & TRN & & \\
\hline CHEMBL3926148 & 1637967 & 6.0526 & 6.0722 & TRN & & \\
\hline CHEMBL3919791 & 1637967 & 8.1805 & 7.2382 & TST & & \\
\hline CHEMBL3979164 & 1637967 & 6.4559 & 6.2024 & TRN & & \\
\hline CHEMBL3957090 & 1637967 & 6.3363 & 6.3816 & TRN & & \\
\hline CHEMBL3923386 & 1637967 & 4.3372 & 4.2442 & TRN & & \\
\hline CHEMBL 3923888 & 1637967 & 8.28399 & 99999999 & 99 & 7.6703 & TST \\
\hline CHEMBL 3943067 & 1637967 & 6.1675 & 6.2163 & TRN & & \\
\hline CHEMBL3914503 & 1637967 & 7.2518 & 6.1578 & TST & & \\
\hline CHEMBL3934652 & 1637967 & 6.9666 & 6.9124 & TRN & & \\
\hline CHEMBL3949614 & 1637967 & 6.0477 & 5.9931 & TRN & & \\
\hline CHEMBL3982679 & 1637967 & 7.1427 & 7.1446 & TRN & & \\
\hline CHEMBL3943400 & 1637967 & 6.7033 & 6.7641 & TRN & & \\
\hline CHEMBL3918882 & 1637967 & 6.1209 & 6.1521 & TRN & & \\
\hline CHEMBL3904391 & 1637967 & 4.6198 & 4.6352 & TRN & & \\
\hline CHEMBL3975092 & 1637967 & 6.2757 & 6.2534 & TRN & & \\
\hline CHEMBL3944193 & 1637967 & 5.7773 & 6.1807 & TST & & \\
\hline CHEMBL3908396 & 1637967 & 6.58 & 6.5676 & TRN & & \\
\hline CHEMBL3978209 & 1637967 & 5.8861 & 5.8615 & TRN & & \\
\hline CHEMBL3927984 & 1637967 & 7.7447 & 7.7247 & TRN & & \\
\hline CHEMBL3894999 & 1637967 & 7.0605 & 6.2717 & TST & & \\
\hline CHEMBL3898428 & 1637967 & 5.8539 & 5.8281 & TRN & & \\
\hline CHEMBL3987014 & 1637967 & 6.3726 & 6.4127 & TRN & & \\
\hline CHEMBL3902000 & 1637967 & 6.0 & 6.0088 & TRN & & \\
\hline CHEMBL3919545 & 1637967 & 5.8239 & 5.88299 & 9999999999 & & TRN \\
\hline CHEMBL3980816 & 1637967 & 4.0862 & 4.1144 & TRN & & \\
\hline CHEMBL3931019 & 1637967 & 6.9031 & 6.8158 & TRN & & \\
\hline CHEMBL3975705 & 1637967 & 6.2741 & 6.3324 & TST & & \\
\hline CHEMBL3964451 & 1637967 & 5.1367 & 5.1585 & TRN & & \\
\hline CHEMBL3946793 & 1637967 & 6.3487 & 6.3516 & TRN & & \\
\hline
\end{tabular}


Supplemental Table S2.txt

\begin{tabular}{|c|c|c|c|c|c|c|}
\hline CHEMBL3963803 & 1637967 & 5.9431 & 5.9508 & TRN & & \\
\hline CHEMBL 3922274 & 1637967 & 6.82100 & 0000000 & 21 & 6.8967 & TRN \\
\hline CHEMBL 3970483 & 1637967 & 6.8601 & 6.8368 & TRN & & \\
\hline CHEMBL 3972710 & 1637967 & 6.71 & 6.6874 & TRN & & \\
\hline CHEMBL3928912 & 1637967 & 6.0044 & 6.6401 & TST & & \\
\hline CHEMBL3976748 & 1637967 & 6.5072 & 6.479 & TRN & & \\
\hline CHEMBL3953845 & 1637967 & 7.0969 & 7.0692 & TRN & & \\
\hline CHEMBL3912858 & 1637967 & 6.3979 & 6.4704 & TRN & & \\
\hline CHEMBL 3937879 & 1637967 & 7.5528 & 6.3251 & TST & & \\
\hline CHEMBL3932994 & 1637967 & 7.1675 & 7.1772 & TRN & & \\
\hline CHEMBL 3909445 & 1637967 & 6.7595 & 6.7919 & TRN & & \\
\hline CHEMBL3911742 & 1637967 & 5.5376 & 6.66799 & 9999999999 & & TST \\
\hline CHEMBL3916120 & 1637967 & 6.644 & 6.6844 & TRN & & \\
\hline CHEMBL 3985823 & 1637967 & 4.7959 & 4.8539 & TRN & & \\
\hline CHEMBL538361 & 1637967 & 7.699 & 7.0429 & TST & & \\
\hline CHEMBL 3900024 & 1637967 & 5.9586 & 6.4805 & TST & & \\
\hline CHEMBL3915562 & 1637967 & 4.0 & 4.0051 & TRN & & \\
\hline CHEMBL3936535 & 1637967 & 4.9586 & 4.965 & TRN & & \\
\hline CHEMBL3901866 & 1637967 & 5.041 & 6.3629 & TST & & \\
\hline CHEMBL 3957803 & 1637967 & 7.8447 & 7.8949 & TRN & & \\
\hline CHEMBL3935733 & 1637967 & 7.1079 & 7.5936 & TST & & \\
\hline CHEMBL3979719 & 1637967 & 5.8539 & 5.3504 & TST & & \\
\hline CHEMBL 3945754 & 1637967 & 6.8539 & 6.8935 & TRN & & \\
\hline CHEMBL3983182 & 1637967 & 6.983 & 6.9742 & TRN & & \\
\hline CHEMBL3909023 & 1637967 & 5.8861 & 5.8958 & TRN & & \\
\hline CHEMBL 387810 & 818494 & 7.9547 & 8.0762 & TRN & & \\
\hline CHEMBL 2031789 & 818494 & 8.7959 & 8.5378 & TRN & & \\
\hline CHEMBL 2032042 & 818494 & 8.2147 & 7.7994 & TRN & & \\
\hline CHEMBL477247 & 818494 & 7.9101 & 8.014 & TRN & & \\
\hline CHEMBL477238 & 818494 & 8.3565 & 8.1551 & TRN & & \\
\hline CHEMBL 2032044 & 818494 & 7.1296 & 7.4039 & TRN & & \\
\hline CHEMBL 2031928 & 818494 & 8.585 & 8.9924 & TST & & \\
\hline CHEMBL 2032043 & 818494 & 8.6383 & 7.8366 & TRN & & \\
\hline CHEMBL192273 & 818494 & 6.7986 & 7.818 & TST & & \\
\hline CHEMBL 1818384 & 818494 & 9.3979 & 8.0561 & TST & & \\
\hline CHEMBL 2031797 & 818494 & 9.301 & 8.4754 & TRN & & \\
\hline CHEMBL2031929 & 818494 & 7.1772 & 8.0396 & TRN & & \\
\hline CHEMBL476668 & 818494 & 7.8697 & 7.6004 & TRN & & \\
\hline CHEMBL 2031807 & 818494 & 8.8861 & 7.7908 & TRN & & \\
\hline CHEMBL 242470 & 818494 & 6.0 & 7.5638 & TRN & & \\
\hline CHEMBL 2031941 & 818494 & 8.9208 & 8.2941 & TRN & & \\
\hline CHEMBL 388004 & 818494 & 7.5317 & 8.2771 & TRN & & \\
\hline CHEMBL476614 & 818494 & 8.5528 & 8.0608 & TRN & & \\
\hline CHEMBL244192 & 818494 & 6.0 & 7.1487 & TRN & & \\
\hline CHEMBL515028 & 818494 & 7.6091 & 7.1785 & TRN & & \\
\hline CHEMBL 2031950 & 818494 & 9.0 & 8.5026 & TRN & & \\
\hline CHEMBL476057 & 818494 & 8.2924 & 8.5551 & TRN & & \\
\hline CHEMBL 2031800 & 818494 & 8.7696 & 7.9057 & TRN & & \\
\hline
\end{tabular}

Page 3949 


\begin{tabular}{|c|c|c|c|c|c|c|}
\hline & & \multicolumn{5}{|c|}{ Supplemental Table S2.txt } \\
\hline CHEMBL2031814 & 818494 & 8.7959 & 8.6728 & TRN & & \\
\hline CHEMBL10835 & 818494 & 7.5513 & 8.5037 & TST & & \\
\hline CHEMBL 2031933 & 818494 & 8.4202 & 8.2439 & TRN & & \\
\hline CHEMBL 2031796 & 818494 & 8.3768 & 8.7123 & TST & & \\
\hline CHEMBL477237 & 818494 & 8.699 & 8.2341 & TRN & & \\
\hline CHEMBL 2031812 & 818494 & 9.301 & 9.286 & TRN & & \\
\hline CHEMBL245148 & 818494 & 8.7696 & 8.6918 & TRN & & \\
\hline CHEMBL222160 & 818494 & 6.8477 & 8.7973 & TST & & \\
\hline CHEMBL1535088 & 818494 & 6.2144 & 7.0673 & TRN & & \\
\hline CHEMBL2031923 & 818494 & 9.0 & 8.0197 & TRN & & \\
\hline CHEMBL397693 & 818494 & 8.3188 & 8.9288 & TRN & & \\
\hline CHEMBL2031944 & 818494 & 7.9172 & 7.6293 & TRN & & \\
\hline CHEMBL396760 & 818494 & 8.9586 & 8.9096 & TRN & & \\
\hline CHEMBL 2031801 & 818494 & 8.2147 & 8.1474 & TRN & & \\
\hline CHEMBL1360431 & 818494 & 8.7696 & 9.0484 & TST & & \\
\hline CHEMBL 2031938 & 818494 & 7.0458 & 9.1011 & TST & & \\
\hline CHEMBL2031816 & 818494 & 9.0458 & 8.9302 & TRN & & \\
\hline CHEMBL 2032041 & 818494 & 8.28399 & 99999999 & 99 & 7.3771 & TRN \\
\hline CHEMBL 2029374 & 818494 & 8.4089 & 9.2077 & TST & & \\
\hline CHEMBL388015 & 818494 & 8.7447 & 8.7491 & TRN & & \\
\hline CHEMBL223281 & 818494 & 9.0969 & 8.4249 & TRN & & \\
\hline CHEMBL 2031932 & 818494 & 8.7447 & 9.424 & TST & & \\
\hline CHEMBL 243125 & 818494 & 8.9586 & 8.5836 & TRN & & \\
\hline CHEMBL 2031791 & 818494 & 8.5086 & 8.9897 & TRN & & \\
\hline CHEMBL 2031948 & 818494 & 7.1739 & 8.1401 & TRN & & \\
\hline CHEMBL 2031947 & 818494 & 8.2076 & 8.5316 & TRN & & \\
\hline CHEMBL242459 & 818494 & 8.8239 & 8.3751 & TRN & & \\
\hline CHEMBL 2031936 & 818494 & 7.8239 & 8.8316 & TST & & \\
\hline CHEMBL2031817 & 818494 & 8.5686 & 8.2073 & TRN & & \\
\hline CHEMBL 2031945 & 818494 & 7.9666 & 8.4005 & TRN & & \\
\hline CHEMBL 2031940 & 818494 & 8.3279 & 8.7752 & TRN & & \\
\hline CHEMBL2031804 & 818494 & 8.2007 & 8.3027 & TRN & & \\
\hline CHEMBL2031795 & 818494 & 8.6021 & 8.1009 & TRN & & \\
\hline CHEMBL2032046 & 818494 & 8.6198 & 8.3929 & TRN & & \\
\hline CHEMBL 2031798 & 818494 & 8.585 & 8.5497 & TRN & & \\
\hline CHEMBL2031951 & 818494 & 8.8861 & 8.8856 & TRN & & \\
\hline CHEMBL2032045 & 818494 & 9.2218 & 8.9553 & TRN & & \\
\hline CHEMBL 245142 & 818494 & 8.3872 & 8.337 & TRN & & \\
\hline CHEMBL242899 & 818494 & 7.9101 & 8.8497 & TRN & & \\
\hline CHEMBL 2031942 & 818494 & 8.2924 & 8.8891 & TST & & \\
\hline CHEMBL 2031946 & 818494 & 8.3872 & 8.3228 & TRN & & \\
\hline CHEMBL 2031802 & 818494 & 8.8239 & 9.1695 & TRN & & \\
\hline CHEMBL 2031808 & 818494 & 9.0969 & 9.1388 & TRN & & \\
\hline CHEMBL 2031924 & 818494 & 8.7959 & 9.0451 & TRN & & \\
\hline CHEMBL 2031927 & 818494 & 8.9586 & 8.9702 & TST & & \\
\hline CHEMBL 2031939 & 818494 & 7.9101 & 8.4096 & TST & & \\
\hline CHEMBL395714 & 818494 & 7.8996 & 7.8482 & TRN & & \\
\hline CHEMBL2031926 & 818494 & 8.9208 & 9.0004 & TRN & & \\
\hline
\end{tabular}




\begin{tabular}{|c|c|c|c|c|c|}
\hline \multirow[b]{2}{*}{ CHEMBL1610486 } & \multirow[b]{2}{*}{818494} & \multicolumn{4}{|c|}{ Supplemental Table s2.txt } \\
\hline & & \multicolumn{2}{|c|}{\begin{tabular}{lc}
\multicolumn{2}{c}{ supplement } \\
8.0605 & 9.1154
\end{tabular}} & \multicolumn{2}{|l|}{ TST } \\
\hline CHEMBL 243521 & 818494 & 6.8928 & 7.3173 & \multicolumn{2}{|l|}{ TRN } \\
\hline CHEMBL2032040 & 818494 & 8.0862 & 7.6448 & \multicolumn{2}{|l|}{ TRN } \\
\hline CHEMBL395988 & 818494 & 8.9586 & 8.6763 & \multicolumn{2}{|l|}{ TRN } \\
\hline CHEMBL1736995 & 818494 & 4.8918 & 6.4694 & \multicolumn{2}{|l|}{ TRN } \\
\hline CHEMBL 2031806 & 818494 & 8.2924 & 8.6741 & \multicolumn{2}{|l|}{ TRN } \\
\hline CHEMBL 2031931 & 818494 & 9.0969 & 9.4992 & \multicolumn{2}{|l|}{ TST } \\
\hline CHEMBL2031949 & 818494 & 8.7447 & 8.4359 & \multicolumn{2}{|l|}{ TRN } \\
\hline CHEMBL478322 & 818494 & 7.5421 & 7.4338 & \multicolumn{2}{|l|}{ TRN } \\
\hline CHEMBL2031935 & 818494 & 8.4202 & 8.6343 & \multicolumn{2}{|l|}{ TST } \\
\hline CHEMBL2031937 & 818494 & 8.0177 & 8.9631 & \multicolumn{2}{|l|}{ TST } \\
\hline CHEMBL1632490 & 818494 & 7.8356 & 9.0262 & \multicolumn{2}{|l|}{ TRN } \\
\hline CHEMBL2031803 & 818494 & 8.7959 & 8.5315 & \multicolumn{2}{|l|}{ TRN } \\
\hline CHEMBL 2031790 & 818494 & 7.5884 & 7.4411 & \multicolumn{2}{|l|}{ TRN } \\
\hline CHEMBL2031918 & 818494 & 7.2373 & 7.4014 & \multicolumn{2}{|l|}{ TRN } \\
\hline CHEMBL 2031788 & 818494 & 7.8665 & 8.0099 & \multicolumn{2}{|l|}{ TRN } \\
\hline CHEMBL477067 & 818494 & 7.8539 & 7.2104 & \multicolumn{2}{|l|}{ TRN } \\
\hline CHEMBL395738 & 818494 & 8.8539 & 8.8038 & TRN & \\
\hline CHEMBL 2031930 & 818494 & 9.0969 & 9.596 & TRN & \\
\hline CHEMBL397669 & 818494 & 8.3188 & 8.8872 & TST & \\
\hline CHEMBL438867 & 818494 & 8.7447 & 9.0471 & TST & \\
\hline CHEMBL2031799 & 818494 & 8.6198 & 8.8438 & TST & \\
\hline CHEMBL 2031943 & 818494 & 8.4815 & 9.3059 & TST & \\
\hline CHEMBL242655 & 818494 & 7.8508 & 8.2941 & TST & \\
\hline CHEMBL245159 & 818494 & 8.0269 & 8.5281 & TST & \\
\hline CHEMBL 2349538 & 951534 & 8.4318 & 8.3761 & TRN & \\
\hline CHEMBL2346737 & 951534 & 7.3936 & 6.8313 & TRN & \\
\hline CHEMBL 2346729 & 951534 & 7.3354 & 7.081 & TRN & \\
\hline CHEMBL 2346716 & 951534 & 6.7352 & 6.71700 & 00000000005 & TRN \\
\hline CHEMBL2346723 & 951534 & 5.5686 & 6.475 & TRN & \\
\hline CHEMBL 2349543 & 951534 & 7.7696 & 7.7753 & TRN & \\
\hline CHEMBL2346736 & 951534 & 7.05399 & 99999999 & 6.528 & TRN \\
\hline CHEMBL 2346713 & 951534 & 7.5528 & 7.5618 & TRN & \\
\hline CHEMBL2349542 & 951534 & 7.4202 & 7.6413 & TRN & \\
\hline CHEMBL292065 & 951534 & 7.9208 & 5.71200 & 0000000001 & TST \\
\hline CHEMBL2349545 & 951534 & 7.1487 & 7.5868 & TRN & \\
\hline CHEMBL2349544 & 951534 & 6.1904 & 7.44600 & 0000000001 & TRN \\
\hline CHEMBL2349535 & 951534 & 8.4202 & 8.3297 & TRN & \\
\hline CHEMBL2346717 & 951534 & 6.5222 & 6.5153 & TRN & \\
\hline CHEMBL2346712 & 951534 & 6.8861 & 7.3246 & TRN & \\
\hline CHEMBL 2349529 & 951534 & 7.5686 & 7.2465 & TST & \\
\hline CHEMBL2346732 & 951534 & 6.76200 & 00000000 & 6.6669 & TRN \\
\hline CHEMBL2346722 & 951534 & 7.7852 & 7.7085 & TRN & \\
\hline CHEMBL2346711 & 951534 & 7.7852 & 7.9287 & TRN & \\
\hline CHEMBL2349527 & 951534 & 6.4283 & 7.1648 & TST & \\
\hline CHEMBL 2349547 & 951534 & 7.0362 & 6.9464 & TRN & \\
\hline CHEMBL2349539 & 951534 & 8.2757 & 8.4001 & TRN & \\
\hline CHEMBL2349546 & 951534 & 7.6021 & 7.61600 & 00000000005 & TRN \\
\hline & & & & 3951 & \\
\hline
\end{tabular}


Supplemental Table S2.txt

\begin{tabular}{|c|c|c|c|c|}
\hline CHEMBL 2349540 & 951534 & 8.6383 & 8.9945 & TRN \\
\hline CHEMBL 2346720 & 951534 & 7.3809 & 6.8638 & TRN \\
\hline CHEMBL 2349528 & 951534 & 7.2007 & 7.0153 & TST \\
\hline CHEMBL 2349553 & 951534 & 7.0846 & 6.9021 & TRN \\
\hline CHEMBL 2349530 & 951534 & 5.0 & 6.9721 & TST \\
\hline CHEMBL 2346726 & 951534 & 8.2366 & 8.307 & TRN \\
\hline CHEMBL 2349548 & 951534 & 5.8861 & 6.2614 & TRN \\
\hline CHEMBL 2346714 & 951534 & 6.71 & 7.1079 & TRN \\
\hline CHEMBL 2349532 & 951534 & 7.0223 & 7.9019 & TST \\
\hline CHEMBL 2346715 & 951534 & 7.9872 & 6.846 & TRN \\
\hline CHEMBL 2349533 & 951534 & 8.3565 & 8.0631 & TRN \\
\hline CHEMBL 2346733 & 951534 & 7.1135 & 6.6752 & TRN \\
\hline CHEMBL 2349551 & 951534 & 6.0405 & 6.2478 & TRN \\
\hline CHEMBL 2346724 & 951534 & 7.9208 & 5.8 & TST \\
\hline CHEMBL 2349552 & 951534 & 7.0419 & 6.8312 & TRN \\
\hline CHEMBL 2346731 & 951534 & 7.6162 & 7.1061 & TST \\
\hline CHEMBL 2346718 & 951534 & 7.0246 & 6.9124 & TRN \\
\hline CHEMBL 2346730 & 951534 & 7.767 & 7.6814 & TST \\
\hline CHEMBL 2349541 & 951534 & 8.2757 & 8.147 & TRN \\
\hline CHEMBL2346719 & 951534 & 7.2495 & 7.1089 & TRN \\
\hline CHEMBL 2349534 & 951534 & 8.9586 & 8.0167 & TRN \\
\hline CHEMBL 2346728 & 951534 & 6.8327 & 7.1396 & TST \\
\hline CHEMBL 2346735 & 951534 & 7.2076 & \multicolumn{2}{|c|}{6.7989999999999995} \\
\hline CHEMBL 2349531 & 951534 & 5.0 & 6.0511 & TRN \\
\hline CHEMBL 2349537 & 951534 & 8.3665 & 8.4797 & TRN \\
\hline CHEMBL 2346721 & 951534 & 8.1487 & 7.4273 & TRN \\
\hline CHEMBL 2346734 & 951534 & 6.857 & 6.9875 & TST \\
\hline CHEMBL 2346739 & 951534 & 7.5686 & 7.7252 & TRN \\
\hline CHEMBL 2346725 & 951534 & 7.8861 & 7.4441 & TST \\
\hline CHEMBL 2346727 & 951534 & 7.8386 & 8.1633 & TST \\
\hline CHEMBL 2349536 & 951534 & 8.3279 & 8.6473 & TRN \\
\hline CHEMBL 366508 & 158347 & 8.8539 & 8.9179 & TRN \\
\hline CHEMBL352872 & 158347 & 7.3188 & 8.4582 & TST \\
\hline CHEMBL170398 & 158347 & 8.3979 & 8.3168 & TRN \\
\hline CHEMBL173104 & 158347 & 5.0 & 5.5054 & TRN \\
\hline CHEMBL426579 & 158347 & 6.7447 & 6.6459 & TRN \\
\hline CHEMBL172949 & 158347 & 7.9586 & 7.5264 & TRN \\
\hline CHEMBL172484 & 158347 & 8.699 & 8.6745 & TST \\
\hline CHEMBL173122 & 158347 & 8.8861 & 9.0159 & TRN \\
\hline CHEMBL170370 & 158347 & 7.9586 & 8.0777 & TRN \\
\hline CHEMBL174198 & 158347 & 9.0362 & 9.0116 & TRN \\
\hline CHEMBL367393 & 158347 & 8.301 & 8.1617 & TRN \\
\hline CHEMBL174262 & 158347 & 8.2218 & 8.817 & TST \\
\hline CHEMBL366553 & 158347 & 9.041 & 9.1097 & TRN \\
\hline CHEMBL173586 & 158347 & 8.9586 & 9.0912 & TRN \\
\hline CHEMBL367673 & 158347 & 7.9586 & 7.9337 & TRN \\
\hline CHEMBL369854 & 158347 & 9.1079 & 9.2868 & TRN \\
\hline CHEMBL369233 & 158347 & 9.1739 & 9.1883 & TRN \\
\hline
\end{tabular}


Supplemental Table S2.txt

\begin{tabular}{|c|c|c|c|c|}
\hline CHEMBL 367786 & 158347 & 8.0862 & 8.0804 & TRN \\
\hline CHEMBL 368292 & 158347 & 7.9208 & 9.4664 & TST \\
\hline CHEMBL366998 & 158347 & 8.8239 & 8.6931 & TRN \\
\hline CHEMBL369395 & 158347 & 8.8239 & 8.962 & TRN \\
\hline CHEMBL368162 & 158347 & 8.3665 & 8.248 & TRN \\
\hline CHEMBL174618 & 158347 & 7.5086 & 7.672999 & э999999999 \\
\hline CHEMBL 367130 & 158347 & 7.6383 & 7.5432 & TRN \\
\hline CHEMBL 367530 & 158347 & 7.9586 & 8.0828 & TRN \\
\hline CHEMBL173742 & 158347 & 7.8539 & 7.7067 & TRN \\
\hline CHEMBL369411 & 158347 & 7.2924 & 7.3415 & TRN \\
\hline CHEMBL354819 & 158347 & 8.7447 & 8.4582 & TRN \\
\hline CHEMBL133197 & 158347 & 7.2757 & 7.3231 & TRN \\
\hline CHEMBL173471 & 158347 & 7.7959 & 7.5764 & TRN \\
\hline CHEMBL172859 & 158347 & 9.2007 & 7.8739 & TST \\
\hline CHEMBL353618 & 158347 & 7.9208 & 8.0644 & TRN \\
\hline CHEMBL424947 & 158347 & 9.2924 & 9.5592 & TST \\
\hline CHEMBL 367160 & 158347 & 6.2147 & 6.7011 & TRN \\
\hline CHEMBL173191 & 158347 & 8.5376 & 8.7843 & TRN \\
\hline CHEMBL173571 & 158347 & 7.9586 & 8.2069 & TRN \\
\hline CHEMBL176797 & 158347 & 9.0605 & 9.0174 & TST \\
\hline CHEMBL174454 & 158347 & 7.1249 & 7.8677 & TST \\
\hline CHEMBL174550 & 158347 & 8.4685 & 8.6692 & TRN \\
\hline CHEMBL 367295 & 158347 & 8.2924 & 8.4616 & TRN \\
\hline CHEMBL174104 & 158347 & 8.4437 & 8.2414 & TRN \\
\hline CHEMBL427121 & 158347 & 8.1675 & 8.5218 & TRN \\
\hline CHEMBL 367418 & 158347 & 8.4949 & 8.2555 & TRN \\
\hline CHEMBL 367964 & 158347 & 8.8861 & 8.5544 & TST \\
\hline CHEMBL 275912 & 158347 & 7.4089 & 7.4031 & TRN \\
\hline CHEMBL173584 & 158347 & 9.0458 & 8.9349 & TRN \\
\hline CHEMBL174668 & 158347 & 8.9208 & 8.6026 & TRN \\
\hline CHEMBL 367085 & 158347 & 9.0706 & 8.582 & TRN \\
\hline CHEMBL 369225 & 158347 & 9.0 & 8.705 & TRN \\
\hline CHEMBL174859 & 158347 & 8.6576 & 8.6315 & TRN \\
\hline CHEMBL174479 & 158347 & 8.28399 & 99999999 & 8.2924 \\
\hline CHEMBL173304 & 158347 & 8.2147 & 8.1193 & TRN \\
\hline CHEMBL 367941 & 158347 & 8.0 & 7.9426 & TRN \\
\hline CHEMBL174592 & 158347 & 9.8239 & 9.6615 & TRN \\
\hline CHEMBL173157 & 158347 & 8.3279 & 8.5957 & TRN \\
\hline CHEMBL 368657 & 158347 & 6.9208 & 6.8718 & TRN \\
\hline CHEMBL170749 & 158347 & 5.0 & 7.8641 & TST \\
\hline CHEMBL176678 & 158347 & 6.8539 & 6.5854 & TRN \\
\hline CHEMBL368923 & 158347 & 8.5376 & 9.1141 & TST \\
\hline CHEMBL 368586 & 158347 & 6.9586 & 6.7968 & TRN \\
\hline CHEMBL174402 & 158347 & 8.699 & 8.8722 & TRN \\
\hline CHEMBL174183 & 158347 & 8.0 & 8.1178 & TRN \\
\hline CHEMBL 367011 & 158347 & 6.7212 & 7.1903 & TRN \\
\hline CHEMBL427307 & 158347 & 9.0655 & 9.2906 & TRN \\
\hline CHEMBL173497 & 158347 & 8.8239 & 9.029 & TRN \\
\hline
\end{tabular}




\begin{tabular}{|c|c|c|c|c|c|}
\hline \multicolumn{6}{|c|}{ Supplemental Table S2.txt } \\
\hline CHEMBL 368410 & 158347 & 7.7212 & 7.6489 & TRN & \\
\hline CHEMBL368185 & 158347 & 8.6198 & 7.7985 & TST & \\
\hline CHEMBL367425 & 158347 & 8.0269 & 8.1193 & TRN & \\
\hline CHEMBL172697 & 158347 & 8.2676 & 8.555 & TRN & \\
\hline CHEMBL433795 & 158347 & 9.2007 & 9.18799 & 9999999999 & TRN \\
\hline CHEMBL366987 & 158347 & 5.0 & 7.0027 & TST & \\
\hline CHEMBL173318 & 158347 & 7.4089 & 7.4829 & TRN & \\
\hline CHEMBL172819 & 158347 & 8.8861 & 8.9529 & TRN & \\
\hline CHEMBL369614 & 158347 & 8.699 & 8.632 & TRN & \\
\hline CHEMBL435115 & 158347 & 8.2147 & 8.3119 & TRN & \\
\hline CHEMBL173531 & 158347 & 7.8239 & 8.9489 & TST & \\
\hline CHEMBL174989 & 158347 & 6.9208 & 6.7549 & TRN & \\
\hline CHEMBL425688 & 158347 & 8.7696 & 8.6489 & TRN & \\
\hline CHEMBL176725 & 158347 & 8.6383 & 7.7605 & TRN & \\
\hline CHEMBL367398 & 158347 & 9.0862 & 9.0177 & TRN & \\
\hline CHEMBL369643 & 158347 & 8.5376 & 8.908 & TST & \\
\hline CHEMBL 367922 & 158347 & 9.0223 & 9.4769 & TST & \\
\hline CHEMBL171294 & 158347 & 7.7212 & 8.31299 & 9999999999 & TST \\
\hline CHEMBL 368113 & 158347 & 9.7212 & 8.9447 & TST & \\
\hline CHEMBL173642 & 158347 & 8.6021 & 8.0545 & TST & \\
\hline CHEMBL173215 & 158347 & 6.585 & 7.1304 & TST & \\
\hline CHEMBL 369578 & 158347 & 8.3565 & 8.3896 & TST & \\
\hline CHEMBL174192 & 158347 & 7.8861 & 8.0408 & TST & \\
\hline CHEMBL557915 & 1640194 & 8.6882 & 8.6629 & TRN & \\
\hline CHEMBL48813 & 1640194 & 8.7375 & 8.6073 & TST & \\
\hline CHEMBL3972799 & 1640194 & 9.0737 & 9.044 & TRN & \\
\hline CHEMBL196669 & 1640194 & 5.1931 & 5.20200 & 0000000001 & TRN \\
\hline CHEMBL3959350 & 1640194 & 7.5058 & 7.3796 & TRN & \\
\hline CHEMBL381866 & 1640194 & 8.3019 & 8.4642 & TRN & \\
\hline CHEMBL3961484 & 1640194 & 9.0691 & 8.8067 & TRN & \\
\hline CHEMBL 3974641 & 1640194 & 7.6108 & 7.1855 & TST & \\
\hline CHEMBL194810 & 1640194 & 7.8239 & 8.0919 & TRN & \\
\hline CHEMBL3972969 & 1640194 & 8.1215 & 8.2756 & TRN & \\
\hline CHEMBL196162 & 1640194 & 8.4737 & 7.8463 & TRN & \\
\hline CHEMBL371106 & 1640194 & 7.4789 & 7.559 & TRN & \\
\hline CHEMBL3957468 & 1640194 & 7.857 & 7.9987 & TRN & \\
\hline CHEMBL196539 & 1640194 & 9.104 & 9.0986 & TRN & \\
\hline CHEMBL316053 & 1640194 & 7.3757 & 7.4305 & TST & \\
\hline CHEMBL3304291 & 1640194 & 8.2503 & 8.3982 & TRN & \\
\hline CHEMBL3907419 & 1640194 & 8.5817 & 8.4562 & TRN & \\
\hline CHEMBL190142 & 1640194 & 8.7825 & 8.6265 & TRN & \\
\hline CHEMBL197377 & 1640194 & 9.1397 & 9.0471 & TRN & \\
\hline CHEMBL1235423 & 1640194 & 7.556 & 7.5029 & TST & \\
\hline CHEMBL197624 & 1640194 & 7.4214 & 7.5734 & TRN & \\
\hline CHEMBL3305961 & 1640194 & 7.6778 & 7.6596 & TRN & \\
\hline CHEMBL194186 & 1640194 & 9.0788 & 9.0897 & TRN & \\
\hline CHEMBL3928201 & 1640194 & 7.5003 & 7.7149 & TST & \\
\hline CHEMBL372568 & 1640194 & 6.3686 & 6.4379 & TRN & \\
\hline
\end{tabular}


Supplemental Table S2.txt

\begin{tabular}{|c|c|c|c|c|}
\hline CHEMBL564248 & 1640194 & 8.762 & 8.7924 & TRN \\
\hline CHEMBL383361 & 1640194 & 8.9914 & 8.9542 & TRN \\
\hline CHEMBL3904655 & 1640194 & 8.5751 & 8.6584 & TRN \\
\hline CHEMBL3979386 & 1640194 & 8.9172 & 9.002 & TRN \\
\hline CHEMBL550453 & 1640194 & 8.0205 & 8.1809 & TRN \\
\hline CHEMBL194889 & 1640194 & 6.2941 & 6.2168 & TRN \\
\hline CHEMBL3942651 & 1640194 & 5.1537 & 6.0565 & TST \\
\hline CHEMBL3955803 & 1640194 & 8.7852 & 8.6672 & TRN \\
\hline CHEMBL3956658 & 1640194 & 8.0391 & 8.1457 & TRN \\
\hline CHEMBL370176 & 1640194 & \multicolumn{3}{|c|}{6.757000000000001} \\
\hline CHEMBL364284 & 1640194 & 9.6253 & 9.7794 & TRN \\
\hline CHEMBL3968842 & 1640194 & 8.5622 & 8.7706 & TRN \\
\hline CHEMBL3912108 & 1640194 & 8.7932 & 8.6836 & TRN \\
\hline CHEMBL370614 & 1640194 & 8.9393 & 8.8502 & TRN \\
\hline CHEMBL3966335 & 1640194 & 5.8665 & 6.2767 & TST \\
\hline CHEMBL372956 & 1640194 & 8.7645 & 8.7427 & TRN \\
\hline CHEMBL196589 & 1640194 & 6.9355 & 7.1236 & TRN \\
\hline CHEMBL3986101 & 1640194 & 8.9245 & 8.9537 & TRN \\
\hline CHEMBL3910588 & 1640194 & 9.0501 & 8.9082 & TRN \\
\hline CHEMBL3960154 & 1640194 & 9.1421 & 8.7369 & TST \\
\hline CHEMBL436293 & 1640194 & 7.1273 & \multicolumn{2}{|c|}{6.867999999999999} \\
\hline CHEMBL198421 & 1640194 & 6.5719 & 6.6276 & TRN \\
\hline CHEMBL198654 & 1640194 & 8.3036 & 8.259 & TRN \\
\hline CHEMBL196551 & 1640194 & 8.1141 & 7.8515 & TST \\
\hline CHEMBL3958789 & 1640194 & 8.4724 & 8.414 & TST \\
\hline CHEMBL196492 & 1640194 & 8.262 & 7.893 & TST \\
\hline CHEMBL197547 & 1640194 & 7.3298 & 7.2414 & TST \\
\hline CHEMBL93087 & 1640194 & 7.1694 & 7.4205 & TST \\
\hline CHEMBL120413 & 1640194 & 7.1945 & 7.3499 & TST \\
\hline CHEMBL590311 & 609123 & 5.4815 & 5.7574 & TRN \\
\hline CHEMBL590399 & 609123 & 3.0 & 2.6888 & TRN \\
\hline CHEMBL600456 & 609123 & 6.4318 & 5.8188 & TRN \\
\hline CHEMBL590562 & 609123 & 6.4089 & 4.4876 & TST \\
\hline CHEMBL589835 & 609123 & 7.0177 & \multicolumn{2}{|c|}{5.843999999999999} \\
\hline CHEMBL602926 & 609123 & 5.4559 & 4.0347 & TRN \\
\hline CHEMBL607082 & 609123 & 7.5229 & 7.9042 & TRN \\
\hline CHEMBL590090 & 609123 & 5.8861 & 5.9615 & TST \\
\hline CHEMBL599773 & 609123 & 7.1938 & 7.3533 & TRN \\
\hline CHEMBL602529 & 609123 & 6.3468 & 5.3477 & TRN \\
\hline CHEMBL592780 & 609123 & 6.301 & 5.6531 & TRN \\
\hline CHEMBL591983 & 609123 & 6.2596 & 3.9765 & TST \\
\hline CHEMBL597543 & 609123 & 6.6198 & 7.3257 & TRN \\
\hline CHEMBL590634 & 609123 & 6.8861 & 6.7956 & TRN \\
\hline CHEMBL592698 & 609123 & 5.4202 & 5.0665 & TST \\
\hline CHEMBL597726 & 609123 & 7.1427 & 7.3278 & TRN \\
\hline CHEMBL591984 & 609123 & 5.3872 & 5.6473 & TRN \\
\hline CHEMBL600649 & 609123 & 4.4949 & 5.3177 & TRN \\
\hline CHEMBL598127 & 609123 & 7.3872 & 7.5121 & TRN \\
\hline
\end{tabular}




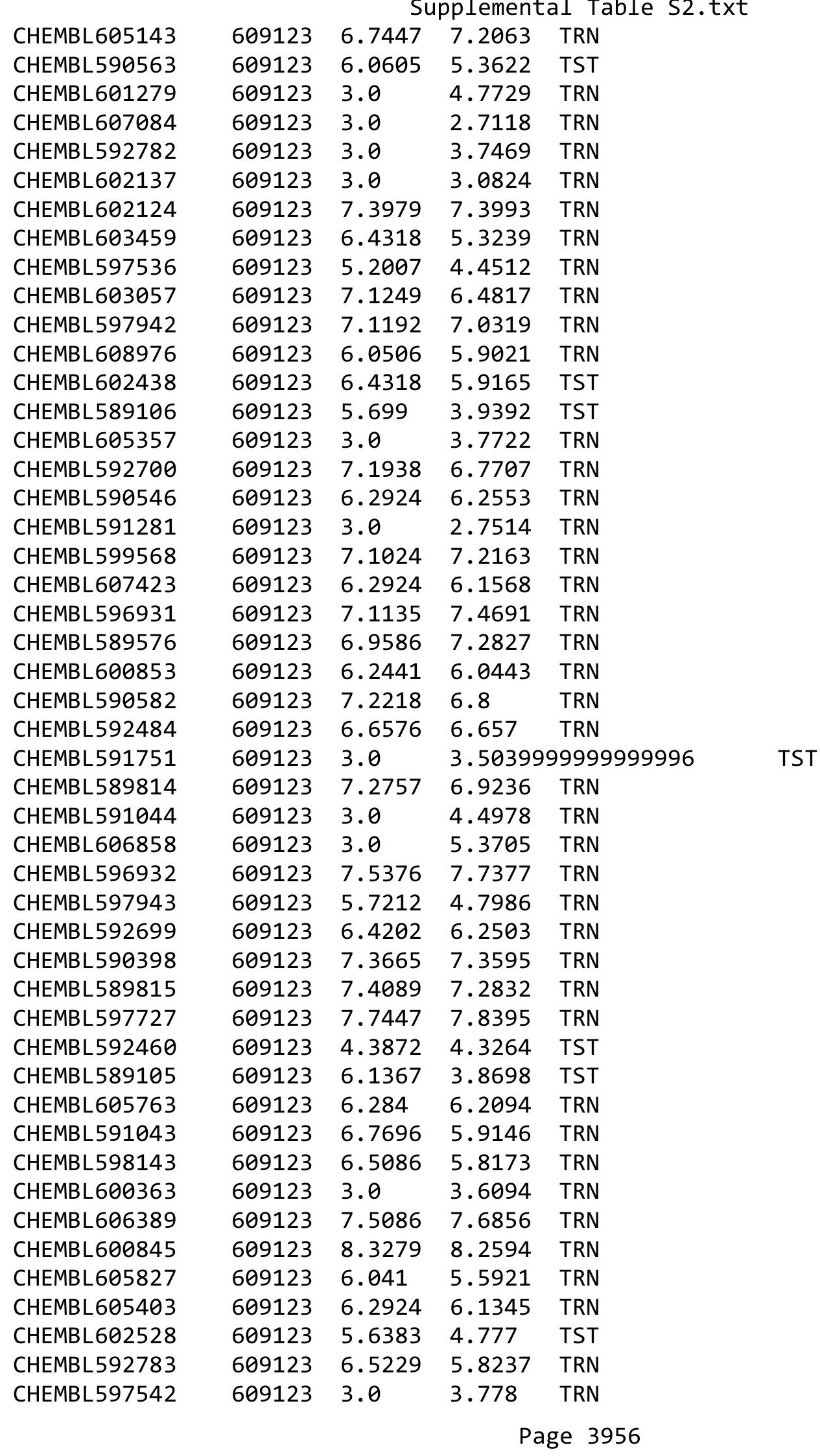




\begin{tabular}{|c|c|c|c|c|c|c|}
\hline \multirow[b]{2}{*}{ CHEMBL600846 } & \multicolumn{6}{|c|}{ Supplemental Table S2.txt } \\
\hline & 609123 & 3.0 & 1.3368 & TST & & \\
\hline CHEMBL597323 & 609123 & 6.6576 & 6.3068 & TRN & & \\
\hline CHEMBL589406 & 609123 & 7.4437 & 7.2163 & TRN & & \\
\hline CHEMBL605148 & 609123 & 7.5086 & 7.9595 & TRN & & \\
\hline CHEMBL597333 & 609123 & 3.0 & 4.32100 & 000000000 & & TST \\
\hline CHEMBL591749 & 609123 & 5.8539 & 5.473 & TST & & \\
\hline CHEMBL597535 & 609123 & 6.1487 & 4.6514 & TST & & \\
\hline CHEMBL591519 & 609123 & 5.8861 & 5.5993 & TST & & \\
\hline CHEMBL590633 & 609123 & 6.8539 & 6.6601 & TST & & \\
\hline CHEMBL603456 & 609123 & 5.8239 & 5.9688 & TST & & \\
\hline CHEMBL597322 & 609123 & 6.4685 & 6.3671 & TST & & \\
\hline CHEMBL1079686 & 621599 & 7.284 & 7.2107 & TRN & & \\
\hline CHEMBL1082039 & 621599 & 5.0 & 5.5524 & TST & & \\
\hline CHEMBL1077723 & 621599 & 5.0 & 5.4213 & TRN & & \\
\hline CHEMBL1078896 & 621599 & 6.7399 & 6.4385 & TRN & & \\
\hline CHEMBL1078956 & 621599 & 5.0 & 4.9977 & TRN & & \\
\hline CHEMBL1077877 & 621599 & 6.3125 & 6.5603 & TRN & & \\
\hline CHEMBL1078745 & 621599 & 6.7011 & 6.9707 & TST & & \\
\hline CHEMBL1079313 & 621599 & 6.7077 & 6.545 & TRN & & \\
\hline CHEMBL391951 & 621599 & 6.5331 & 6.5193 & TRN & & \\
\hline CHEMBL1080950 & 621599 & 6.5986 & 6.8048 & TRN & & \\
\hline CHEMBL1079171 & 621599 & 5.0 & 5.3662 & TST & & \\
\hline CHEMBL1079007 & 621599 & 5.0 & 5.103 & TST & & \\
\hline CHEMBL1082037 & 621599 & 5.0 & 5.4322 & TST & & \\
\hline CHEMBL1077887 & 621599 & 6.2807 & 6.442 & TRN & & \\
\hline CHEMBL 393718 & 621599 & 6.2765 & 6.9332 & TRN & & \\
\hline CHEMBL1078528 & 621599 & 6.6459 & 6.5782 & TRN & & \\
\hline CHEMBL1078173 & 621599 & 5.0 & 6.1333 & TRN & & \\
\hline CHEMBL1080951 & 621599 & 6.6216 & 7.0219 & TRN & & \\
\hline CHEMBL1079874 & 621599 & 7.7447 & 7.704 & TRN & & \\
\hline CHEMBL236587 & 621599 & 6.9172 & 6.2231 & TRN & & \\
\hline CHEMBL1078903 & 621599 & 6.4815 & 5.2434 & TST & & \\
\hline CHEMBL1082038 & 621599 & 5.0 & 5.6829 & TST & & \\
\hline CHEMBL1078215 & 621599 & 6.45100 & 30000000 & 005 & 6.0485 & TRN \\
\hline CHEMBL1080584 & 621599 & 8.0969 & 7.8645 & TRN & & \\
\hline CHEMBL1079180 & 621599 & 6.5986 & 6.8147 & TRN & & \\
\hline CHEMBL1078240 & 621599 & 6.4647 & 6.4625 & TRN & & \\
\hline CHEMBL1078283 & 621599 & 6.4473 & 6.5956 & TRN & & \\
\hline CHEMBL1077908 & 621599 & 6.6882 & 6.5823 & TRN & & \\
\hline CHEMBL1079314 & 621599 & 6.5986 & 6.615 & TRN & & \\
\hline CHEMBL1078904 & 621599 & 5.0 & 5.2874 & TST & & \\
\hline CHEMBL1081133 & 621599 & 6.75700 & 00000000 & $\partial 1$ & 6.544 & TRN \\
\hline CHEMBL1078841 & 621599 & 6.4306 & 6.5703 & TRN & & \\
\hline CHEMBL1078449 & 621599 & 7.4815 & 7.2123 & TRN & & \\
\hline CHEMBL236588 & 621599 & 7.6383 & 7.0662 & TRN & & \\
\hline CHEMBL1077724 & 621599 & 5.0 & 5.0755 & TRN & & \\
\hline CHEMBL393436 & 621599 & 6.7122 & 6.2001 & TRN & & \\
\hline CHEMBL1082036 & 621599 & 7.2596 & 7.3738 & TST & & \\
\hline
\end{tabular}




\begin{tabular}{|c|c|c|c|c|c|}
\hline \multirow[b]{2}{*}{ CHEMBL237660 } & \multicolumn{5}{|c|}{ Supplemental Table S2.txt } \\
\hline & 621599 & 7.1805 & 7.0417 & TRN & \\
\hline CHEMBL1081317 & 621599 & 6.51 & 5.3035 & TST & \\
\hline CHEMBL236788 & 621599 & 7.8861 & 7.773 & TRN & \\
\hline CHEMBL1077722 & 621599 & 6.1427 & 5.876 & TRN & \\
\hline CHEMBL1077721 & 621599 & 6.1986 & 5.8082 & TRN & \\
\hline CHEMBL1080585 & 621599 & 8.5229 & 8.6772 & TRN & \\
\hline CHEMBL1078895 & 621599 & 7.5086 & 7.5227 & TRN & \\
\hline CHEMBL1078799 & 621599 & 5.0 & 4.8998 & TRN & \\
\hline CHEMBL1077742 & 621599 & 6.3261 & 7.0825 & TRN & \\
\hline CHEMBL236611 & 621599 & 7.4318 & 7.0457 & TRN & \\
\hline CHEMBL393333 & 621599 & 7.0809 & 7.0638 & TRN & \\
\hline CHEMBL1078081 & 621599 & 6.27 & 6.6361 & TRN & \\
\hline CHEMBL1079006 & 621599 & 5.0 & 5.782 & TST & \\
\hline CHEMBL1078451 & 621599 & 6.7496 & 6.2315 & TRN & \\
\hline CHEMBL236610 & 621599 & 6.9469 & 7.0263 & TRN & \\
\hline CHEMBL1078438 & 621599 & 5.0 & 5.4028 & TRN & \\
\hline CHEMBL1079312 & 621599 & 6.7122 & 6.4374 & TST & \\
\hline CHEMBL1082040 & 621599 & 6.4425 & 5.803 & TST & \\
\hline CHEMBL1080586 & 621599 & 7.6383 & 8.4658 & TST & \\
\hline CHEMBL1078450 & 621599 & 6.8069 & 7.4158 & TST & \\
\hline CHEMBL3665172 & 1536270 & 10.4353 & 10.0989 & TST & \\
\hline CHEMBL3665158 & 1536270 & 9.0 & 9.3113 & TRN & \\
\hline CHEMBL3665140 & 1536270 & 9.8147 & 8.7947 & TRN & \\
\hline CHEMBL3665173 & 1536270 & 10.4157 & 9.9822 & TST & \\
\hline CHEMBL3665151 & 1536270 & 11.0506 & 9.3344 & TRN & \\
\hline CHEMBL3665215 & 1536270 & 10.0768 & 10.1437 & TRN & \\
\hline CHEMBL3665121 & 1536270 & 6.0 & 7.2579 & TRN & \\
\hline CHEMBL 3665144 & 1536270 & 9.6525 & 9.8665 & TRN & \\
\hline CHEMBL 3665125 & 1536270 & 10.1163 & 8.6841 & TRN & \\
\hline CHEMBL 3665149 & 1536270 & 9.7775 & 9.943999 & 9999999999 & TRN \\
\hline CHEMBL3665203 & 1536270 & 9.8623 & 10.0471 & TRN & \\
\hline CHEMBL 3665167 & 1536270 & 10.0985 & 10.1373 & TRN & \\
\hline CHEMBL3665207 & 1536270 & 9.8371 & 10.1832 & TRN & \\
\hline CHEMBL3665196 & 1536270 & 9.5933 & 9.9134 & TRN & \\
\hline CHEMBL3665212 & 1536270 & 9.6726 & 9.9122 & TRN & \\
\hline CHEMBL3665219 & 1536270 & 9.334 & 9.6275 & TRN & \\
\hline CHEMBL 3665160 & 1536270 & 9.0 & 8.697000 & 0000000001 & TST \\
\hline CHEMBL 3665143 & 1536270 & 9.0911 & 9.0893 & TRN & \\
\hline CHEMBL 3665208 & 1536270 & 9.7567 & 9.6804 & TRN & \\
\hline CHEMBL3665199 & 1536270 & 10.6556 & 10.3706 & TRN & \\
\hline CHEMBL3665188 & 1536270 & 10.5331 & 10.6131 & TRN & \\
\hline CHEMBL3665205 & 1536270 & 6.0 & 7.502000 & 0000000001 & TRN \\
\hline CHEMBL3665159 & 1536270 & 9.5084 & 8.8907 & TRN & \\
\hline CHEMBL3665182 & 1536270 & 10.1898 & 10.7511 & TRN & \\
\hline CHEMBL3665176 & 1536270 & 10.6968 & $10.0170 e$ & 00000000001 & TRN \\
\hline CHEMBL3665175 & 1536270 & 10.0458 & 10.2669 & TRN & \\
\hline CHEMBL 3665134 & 1536270 & 9.465 & 9.106 & TRN & \\
\hline CHEMBL3665195 & 1536270 & 9.7523 & 9.9195 & TRN & \\
\hline
\end{tabular}


Supplemental Table S2.txt

CHEMBL3665174

CHEMBL 3665165

CHEMBL 3665139

CHEMBL 3665213

CHEMBL3665178

CHEMBL3665124

CHEMBL3665201

CHEMBL3665141

CHEMBL3665223

CHEMBL3335698

CHEMBL3665138

CHEMBL3335695

CHEMBL 3665210

CHEMBL3665119

CHEMBL3665120

CHEMBL3665218

CHEMBL3665179

CHEMBL3665217

CHEMBL3665214

CHEMBL 3335690

CHEMBL 3665145

CHEMBL 3665150

CHEMBL3665197

CHEMBL 3665216

CHEMBL3665131

CHEMBL3665168

CHEMBL 3665135

CHEMBL3335691

CHEMBL3665123

CHEMBL3665191

CHEMBL3665189

CHEMBL3665169

CHEMBL 3665154

CHEMBL3665147

CHEMBL3665198

CHEMBL 3665209

CHEMBL3665157

CHEMBL 3665186

CHEMBL3665190

CHEMBL 3665130

CHEMBL 3665133

CHEMBL3665136

CHEMBL3665142

CHEMBL 3639640

CHEMBL3665152

CHEMBL 3665177

CHEMBL3665192

CHEMBL 3665132 $\begin{array}{lll}1536270 & 10.4001 & 10.1978 \text { TST }\end{array}$

$\begin{array}{llll}1536270 & 8.9101 & 8.2647 & \text { TRN }\end{array}$

$\begin{array}{lllll}1536270 & 9.7737 & 8.8822 & \text { TST }\end{array}$

$\begin{array}{llll}1536270 & 10.15 & 9.8427 & \text { TRN }\end{array}$

$\begin{array}{llll}1536270 & 9.6546 & 9.5374 & \text { TRN }\end{array}$

$\begin{array}{lll}1536270 & 10.3279 & 8.6085\end{array}$

$\begin{array}{lll}1536270 & 9.965 & 10.0102 \\ 15 R N\end{array}$

$\begin{array}{lll}1536270 & 9.8536 & 9.7116\end{array}$ TRN

$\begin{array}{lll}1536270 & 9.6373 & 9.2396\end{array}$ TST

$\begin{array}{lll}1536270 & 9.9889 & 10.1117 \text { TRN }\end{array}$

$\begin{array}{llll}1536270 & 9.9158 & 8.8848 & \text { TST }\end{array}$

$\begin{array}{lll}1536270 & 9.8881 & 10.0822 \text { TRN }\end{array}$

$\begin{array}{llll}1536270 & 9.1952 & 9.6419 & \text { TST }\end{array}$

$\begin{array}{llll}1536270 & 6.0 & 7.6688 & \text { TRN }\end{array}$

$\begin{array}{llll}1536270 & 6.0 & 7.3714 & \text { TST }\end{array}$

$\begin{array}{lll}1536270 & 9.255 \quad 9.2716 \text { TRN }\end{array}$

$\begin{array}{lll}1536270 & 10.2358 & 10.664000000000001\end{array}$

$\begin{array}{lll}1536270 & 9.6639 & 10.0619\end{array}$

$\begin{array}{lll}1536270 & 10.2328 & 10.4448 \text { TRN }\end{array}$

$\begin{array}{lll}1536270 & 10.6108 & 10.3201 \\ 10 R N\end{array}$

$\begin{array}{llll}1536270 & 10.0575 & 9.6937 & \text { TST }\end{array}$

$\begin{array}{lll}1536270 & 9.8735 & 10.1926 \text { TRN }\end{array}$

$\begin{array}{lll}1536270 & 9.9718 \quad 10.0082 & \text { TRN }\end{array}$

$\begin{array}{lll}1536270 & 10.1068 & 10.4798 \text { TRN }\end{array}$

$\begin{array}{llll}1536270 & 10.6799 & 8.9946 & \text { TRN }\end{array}$

$\begin{array}{llll}1536270 & 9.7178 & 9.0057 & \text { TRN }\end{array}$

$\begin{array}{llll}1536270 & 9.242 & 9.0029 & \text { TRN }\end{array}$

$\begin{array}{lll}1536270 & 10.0555 & 10.5907 \text { TRN }\end{array}$

$\begin{array}{lll}1536270 & 10.6421 & 9.7163\end{array}$

$\begin{array}{llll}1536270 & 9.8499 & 9.955 & \text { TRN }\end{array}$

$\begin{array}{lll}1536270 & 10.1445 \quad 9.9908 & \text { TRN }\end{array}$

$\begin{array}{llll}1536270 & 8.0 & 9.2795 & \text { TST }\end{array}$

$\begin{array}{llll}1536270 & 8.7077 & 8.5642 & \text { TST }\end{array}$

$\begin{array}{llll}1536270 & 10.4559 & 9.4051 & \text { TST }\end{array}$

$\begin{array}{llll}1536270 & 9.7786 & 9.9558 & \text { TRN }\end{array}$

$\begin{array}{lll}1536270 & 9.9465 & 10.0979 \\ 15 R N\end{array}$

$\begin{array}{llll}1536270 & 9.0793 & 9.3854 & \text { TRN }\end{array}$

$\begin{array}{lllll}1536270 & 9.8623 & 9.834 & \text { TRN }\end{array}$

$\begin{array}{lllll}1536270 & 9.8814 & 9.8786 & \text { TRN }\end{array}$

$\begin{array}{lll}1536270 & 10.9747 & 9.3124 \\ \text { TST }\end{array}$

$\begin{array}{llll}1536270 & 9.6075 & 9.312999999999999 & \text { TRN }\end{array}$

$\begin{array}{lllll}1536270 & 9.1791 & 9.0598 & \text { TRN }\end{array}$

$\begin{array}{lll}1536270 & 10.1701 & 10.2467 \text { TRN }\end{array}$

$\begin{array}{llll}1536270 & 9.8339 & 9.6478 & \text { TST }\end{array}$

$\begin{array}{lll}1536270 & 10.3841 & 10.0795 \text { TRN }\end{array}$

$\begin{array}{llll}1536270 & 9.9527 & 9.5249 & \text { TRN }\end{array}$

$\begin{array}{lll}1536270 & 10.1752 & 10.2871 \text { TRN }\end{array}$

$\begin{array}{llll}1536270 & 9.1376 & 8.9915 & \text { TRN }\end{array}$ 


\begin{tabular}{|c|c|c|c|c|c|c|}
\hline \multicolumn{7}{|c|}{ Supplemental Table S2.txt } \\
\hline CHEMBL3665162 & 1536270 & 9.0 & 8.8939 & TRN & & \\
\hline CHEMBL3665137 & 1536270 & 10.0721 & 9.0487 & TST & & \\
\hline CHEMBL3335692 & 1536270 & 10.1549 & 10.2296 & TRN & & \\
\hline CHEMBL 3665220 & 1536270 & 9.6605 & 9.4947 & TST & & \\
\hline CHEMBL3665184 & 1536270 & 10.3098 & 10.3952 & TRN & & \\
\hline CHEMBL3665171 & 1536270 & 9.908 & 9.9401 & TST & & \\
\hline CHEMBL3335693 & 1536270 & 9.7433 & 9.849 & TRN & & \\
\hline CHEMBL3335699 & 1536270 & 10.2197 & 10.0854 & TRN & & \\
\hline CHEMBL 3665222 & 1536270 & 10.4789 & 10.4904 & TRN & & \\
\hline CHEMBL3665148 & 1536270 & 9.7926 & 9.9047 & TRN & & \\
\hline CHEMBL3335694 & 1536270 & 10.1469 & 10.1795 & TRN & & \\
\hline CHEMBL3665166 & 1536270 & 8.0 & 8.9326 & TST & & \\
\hline CHEMBL3665185 & 1536270 & $9.85700 e$ & 900000006 & & .887 & TRN \\
\hline CHEMBL3665129 & 1536270 & $10.7190 e$ & 0000000 & 001 & .455 & TST \\
\hline CHEMBL3665221 & 1536270 & 9.2911 & 9.4236 & TST & & \\
\hline CHEMBL3665183 & 1536270 & 10.1169 & 10.4331 & TRN & & \\
\hline CHEMBL3665146 & 1536270 & 10.3335 & 9.861 & TRN & & \\
\hline CHEMBL3665206 & 1536270 & 10.3143 & 10.1545 & TRN & & \\
\hline CHEMBL3665181 & 1536270 & 10.2604 & 10.557 & TRN & & \\
\hline CHEMBL3665163 & 1536270 & 8.5229 & 8.9566 & TRN & & \\
\hline CHEMBL3665164 & 1536270 & 8.0 & 9.3677 & TST & & \\
\hline CHEMBL3665204 & 1536270 & 9.2086 & 9.6747 & TRN & & \\
\hline CHEMBL3665180 & 1536270 & 10.7077 & 10.8661 & TRN & & \\
\hline CHEMBL3665193 & 1536270 & 10.1175 & 10.2511 & TRN & & \\
\hline CHEMBL3665187 & 1536270 & 9.4102 & 9.3435 & TST & & \\
\hline CHEMBL3665194 & 1536270 & 9.6517 & 9.3142 & TST & & \\
\hline CHEMBL3665202 & 1536270 & 10.7645 & 10.7062 & TRN & & \\
\hline CHEMBL3665153 & 1536270 & 9.8116 & 9.8936 & TST & & \\
\hline CHEMBL 3665156 & 1536270 & 9.0662 & 9.0987 & TRN & & \\
\hline CHEMBL3665211 & 1536270 & 9.7165 & 9.9706 & TRN & & \\
\hline CHEMBL3335689 & 1536270 & 9.967 & 9.8257 & TRN & & \\
\hline CHEMBL3357978 & 1536270 & 10.4449 & 9.5292 & TRN & & \\
\hline CHEMBL3665161 & 1536270 & 9.2364 & 8.9192 & TST & & \\
\hline CHEMBL1086860 & 619940 & 7.1249 & 5.9775 & TST & & \\
\hline CHEMBL1076466 & 619940 & 5.4248 & 5.4895 & TRN & & \\
\hline CHEMBL1086731 & 619940 & 8.3979 & $6.80200 t$ & 00000000005 & & TST \\
\hline CHEMBL1076193 & 619940 & 5.1174 & 5.3828 & TRN & & \\
\hline CHEMBL1080299 & 619940 & 5.8259 & 5.8553 & TRN & & \\
\hline CHEMBL1076473 & 619940 & 5.8407 & 6.2952 & TRN & & \\
\hline CHEMBL1076198 & 619940 & 5.9133 & 5.4543 & TRN & & \\
\hline CHEMBL1087636 & 619940 & 5.8033 & 5.5686 & TRN & & \\
\hline CHEMBL1076194 & 619940 & 5.5804 & 5.5042 & TRN & & \\
\hline CHEMBL1076437 & 619940 & 6.2306 & 6.177006 & 00000000005 & & TRN \\
\hline CHEMBL1076480 & 619940 & 4.0 & 4.5373 & TRN & & \\
\hline CHEMBL1076474 & 619940 & 5.7924 & 6.0747 & TRN & & \\
\hline CHEMBL1076478 & 619940 & 5.5 & 5.5064 & TRN & & \\
\hline CHEMBL1076475 & 619940 & 4.0 & 4.2599 & TRN & & \\
\hline CHEMBL1076469 & 619940 & 5.5074 & 5.3888 & TRN & & \\
\hline
\end{tabular}




\begin{tabular}{|c|c|c|c|c|c|}
\hline & & & 110 & & \\
\hline CHEMBL1076433 & 619940 & 7.2007 & 6.041 & TST & \\
\hline CHEMBL1076202 & 619940 & 5.9618 & 5.6708 & TRN & \\
\hline CHEMBL1075628 & 619940 & 6.0872 & 5.9147 & TST & \\
\hline CHEMBL1076436 & 619940 & 6.3883 & 6.2807 & TRN & \\
\hline CHEMBL1076196 & 619940 & 5.4577 & 5.6532 & TRN & \\
\hline CHEMBL1079424 & 619940 & 4.0 & 3.9105 & TRN & \\
\hline CHEMBL1088429 & 619940 & 5.4773 & 5.2001 & TRN & \\
\hline CHEMBL1087524 & 619940 & 4.0 & 4.6745 & TRN & \\
\hline CHEMBL1088027 & 619940 & 4.0 & 3.9077 & TRN & \\
\hline CHEMBL1088153 & 619940 & 5.7075 & 5.6276 & TST & \\
\hline CHEMBL1076465 & 619940 & 5.5578 & 5.405 & TRN & \\
\hline CHEMBL1087513 & 619940 & 4.0 & 4.0009 & TRN & \\
\hline CHEMBL1087127 & 619940 & 7.5376 & 7.7443 & TRN & \\
\hline CHEMBL1076471 & 619940 & 5.3813 & 5.1853 & TRN & \\
\hline CHEMBL1076203 & 619940 & 5.8649 & 5.7545 & TRN & \\
\hline CHEMBL1088028 & 619940 & 5.2496 & 5.2195 & TRN & \\
\hline CHEMBL1080294 & 619940 & 4.0 & 4.0305 & TRN & \\
\hline CHEMBL1076468 & 619940 & 5.9427 & 5.8813 & TRN & \\
\hline CHEMBL1076195 & 619940 & 5.6453 & 5.9048 & TRN & \\
\hline CHEMBL1087128 & 619940 & 5.9122 & 5.8806 & TRN & \\
\hline CHEMBL1076476 & 619940 & 4.0 & 4.0926 & TRN & \\
\hline CHEMBL1081090 & 619940 & 5.2648 & 4.5023 & TRN & \\
\hline CHEMBL1081436 & 619940 & 5.2435 & 5.1318 & TRN & \\
\hline CHEMBL1076432 & 619940 & 6.1273 & 6.2914 & TRN & \\
\hline CHEMBL1076197 & 619940 & 5.4957 & 5.4304 & TRN & \\
\hline CHEMBL1079945 & 619940 & 6.1798 & 5.8444 & TRN & \\
\hline CHEMBL1076477 & 619940 & 5.8431 & 5.688 & TRN & \\
\hline CHEMBL1079422 & 619940 & 5.7016 & 5.5821 & TRN & \\
\hline CHEMBL1076200 & 619940 & 5.8222 & 5.6714 & TRN & \\
\hline CHEMBL1079946 & 619940 & 4.0 & 4.5578 & TRN & \\
\hline CHEMBL1087638 & 619940 & 5.3564 & 4.9297 & TST & \\
\hline CHEMBL1076472 & 619940 & 5.9638 & 5.66299 & 9999999999 & TST \\
\hline CHEMBL1076470 & 619940 & 5.5211 & 6.0028 & TST & \\
\hline CHEMBL1076199 & 619940 & 5.7428 & 5.876 & TST & \\
\hline CHEMBL1087002 & 619940 & 5.1475 & 5.2117 & TST & \\
\hline CHEMBL1076201 & 619940 & 5.7314 & 5.5201 & TST & \\
\hline CHEMBL1076533 & 619940 & 5.2266 & 4.9641 & TST & \\
\hline CHEMBL1087649 & 619940 & 4.0 & 4.6225 & TST & \\
\hline CHEMBL1080930 & 619940 & 4.0 & 4.7285 & TST & \\
\hline CHEMBL395226 & 447747 & 8.6576 & 8.7682 & TRN & \\
\hline CHEMBL 232584 & 447747 & 8.3768 & 8.4862 & TRN & \\
\hline CHEMBL 233371 & 447747 & 8.5376 & 7.6442 & TST & \\
\hline CHEMBL430165 & 447747 & 8.1367 & 8.3669 & TRN & \\
\hline CHEMBL 232386 & 447747 & 8.0555 & 7.9267 & TRN & \\
\hline CHEMBL 233758 & 447747 & 8.4815 & 8.5768 & TRN & \\
\hline CHEMBL 232774 & 447747 & 7.5086 & 7.6061 & TRN & \\
\hline CHEMBL429943 & 447747 & 8.301 & 8.1895 & TRN & \\
\hline CHEMBL394167 & 447747 & 8.1024 & 8.205 & TRN & \\
\hline
\end{tabular}




\begin{tabular}{|c|c|c|c|c|c|}
\hline & & & & & \\
\hline CHEMBL232186 & 447747 & 8.0809 & 8.0764 & TRN & \\
\hline CHEMBL 232388 & 447747 & 6.0 & 5.9881 & TRN & \\
\hline CHEMBL393903 & 447747 & 8.2366 & 8.0548 & TRN & \\
\hline CHEMBL 232724 & 447747 & 7.9208 & 7.8523 & TRN & \\
\hline CHEMBL393134 & 447747 & 7.2924 & 6.957006 & 0000000001 & TRN \\
\hline CHEMBL 392092 & 447747 & 9.0177 & 8.6533 & TRN & \\
\hline CHEMBL232387 & 447747 & 8.1249 & 8.1066 & TRN & \\
\hline CHEMBL391664 & 447747 & 8.4949 & 7.5449 & TST & \\
\hline CHEMBL 232723 & 447747 & 6.8861 & 6.8094 & TRN & \\
\hline CHEMBL 232532 & 447747 & 7.2218 & 6.8486 & TRN & \\
\hline CHEMBL 232972 & 447747 & 7.699 & 7.696006 & 0000000001 & TRN \\
\hline CHEMBL 232162 & 447747 & 8.7696 & 8.8214 & TRN & \\
\hline CHEMBL233135 & 447747 & 8.699 & 8.5589 & TRN & \\
\hline CHEMBL 396940 & 447747 & 7.3468 & 7.3496 & TRN & \\
\hline CHEMBL395227 & 447747 & 8.28399 & 99999999 & 8.3411 & TRN \\
\hline CHEMBL 233336 & 447747 & 7.4815 & 7.4433 & TRN & \\
\hline CHEMBL 233544 & 447747 & 6.1367 & 6.06 & TST & \\
\hline CHEMBL233757 & 447747 & 8.5686 & 8.7457 & TRN & \\
\hline CHEMBL 397140 & 447747 & 4.0 & 3.7313 & TRN & \\
\hline CHEMBL233756 & 447747 & 5.6383 & 6.228 & TRN & \\
\hline CHEMBL 232533 & 447747 & 6.6576 & 6.699 & TRN & \\
\hline CHEMBL232161 & 447747 & 8.6778 & 8.6648 & TRN & \\
\hline CHEMBL401027 & 447747 & 6.1135 & 6.0944 & TRN & \\
\hline CHEMBL233357 & 447747 & 6.9586 & 7.0751 & TRN & \\
\hline CHEMBL233809 & 447747 & 4.7696 & 5.3357 & TRN & \\
\hline CHEMBL439020 & 447747 & 8.3098 & 8.3626 & TRN & \\
\hline CHEMBL391665 & 447747 & 7.5528 & 7.5104 & TRN & \\
\hline CHEMBL428014 & 447747 & 6.3768 & 6.2042 & TRN & \\
\hline CHEMBL233175 & 447747 & 7.3468 & 7.136 & TRN & \\
\hline CHEMBL 233176 & 447747 & 8.1549 & 7.2917 & TST & \\
\hline CHEMBL232951 & 447747 & 8.4318 & 8.5053 & TRN & \\
\hline CHEMBL393133 & 447747 & 6.1938 & 6.2369 & TRN & \\
\hline CHEMBL232164 & 447747 & 8.1871 & 8.2133 & TRN & \\
\hline CHEMBL232163 & 447747 & 8.0132 & 8.0523 & TRN & \\
\hline CHEMBL 232775 & 447747 & 7.1079 & 7.3639 & TST & \\
\hline CHEMBL 232327 & 447747 & 4.9586 & 5.4775 & TST & \\
\hline CHEMBL 232773 & 447747 & 7.7447 & 8.0745 & TST & \\
\hline CHEMBL232585 & 447747 & 7.4815 & 7.9546 & TST & \\
\hline CHEMBL233156 & 447747 & 8.3468 & 8.0639 & TST & \\
\hline CHEMBL450577 & 447747 & 7.301 & 7.0353 & TST & \\
\hline CHEMBL 233372 & 447747 & 8.4089 & 7.8324 & TST & \\
\hline CHEMBL393948 & 447747 & 7.8539 & 7.2793 & TST & \\
\hline CHEMBL233559 & 447747 & 9.0458 & 7.9911 & TST & \\
\hline CHEMBL232973 & 447747 & 7.4318 & 7.4518 & TST & \\
\hline CHEMBL307077 & 63874 & 8.2518 & 8.2829 & TRN & \\
\hline CHEMBL77033 & 63874 & 7.5528 & 7.9369 & TST & \\
\hline CHEMBL308815 & 63874 & 8.6778 & 8.6522 & TRN & \\
\hline CHEMBL2304016 & 63874 & 7.2757 & 7.2909 & TRN & \\
\hline
\end{tabular}


Supplemental Table S2.txt

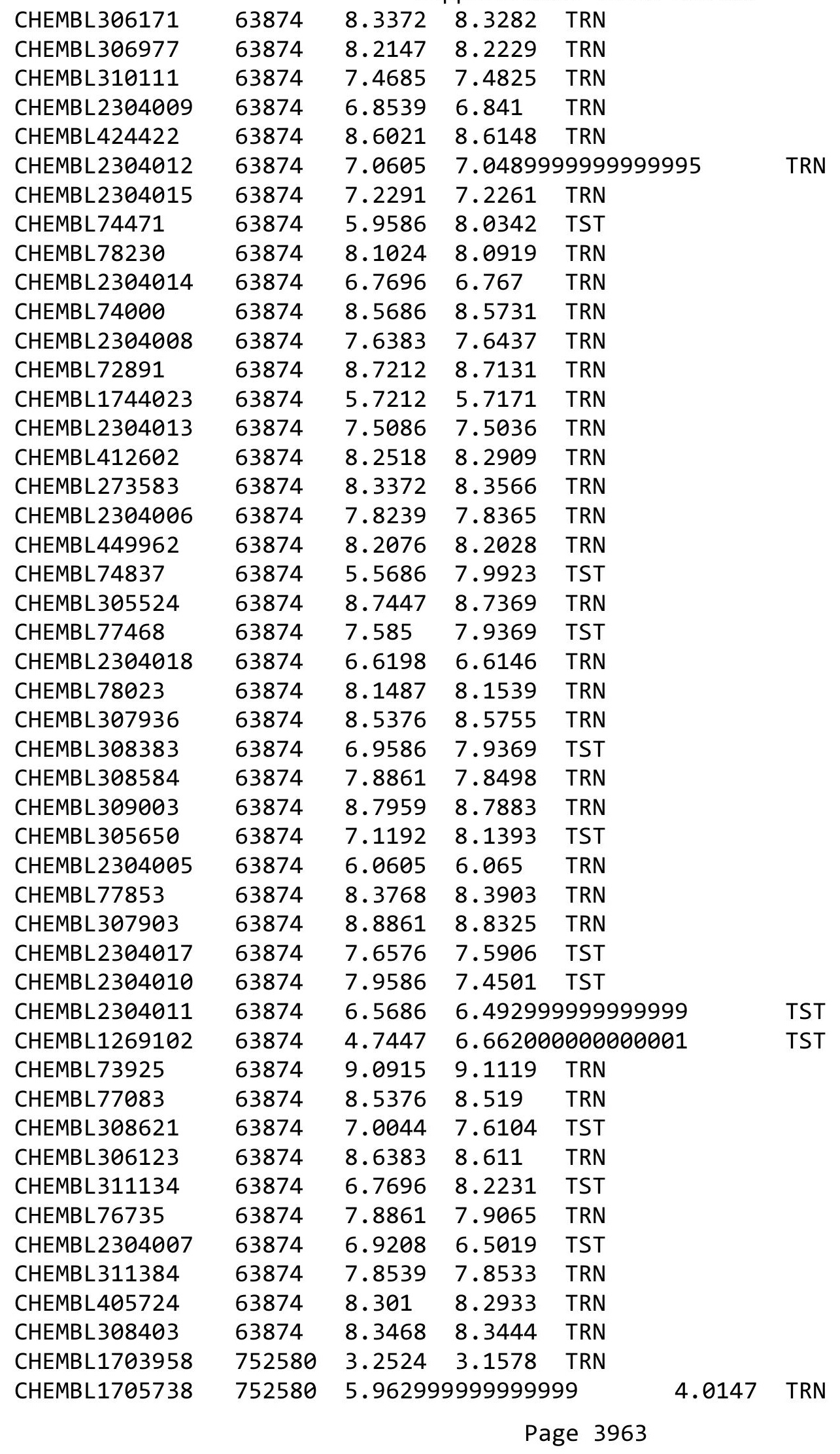




\begin{tabular}{|c|c|c|c|c|c|}
\hline \\
\hline CHEMBL1713873 & 752580 & 3.2527 & 3.3612 & TRN & \\
\hline CHEMBL1547938 & 752580 & 3.2618 & 4.4597 & TRN & \\
\hline CHEMBL1986183 & 752580 & 3.2621 & 3.0648 & TST & \\
\hline CHEMBL1610752 & 752580 & 3.2524 & 3.1486 & TRN & \\
\hline CHEMBL1504972 & 752580 & 3.2621 & 3.5731 & TRN & \\
\hline CHEMBL1392848 & 752580 & 3.2618 & 4.3307 & TRN & \\
\hline CHEMBL1575701 & 752580 & 4.4929 & 3.8474 & TST & \\
\hline CHEMBL1388543 & 752580 & 3.2619 & 3.2152 & TRN & \\
\hline CHEMBL1611041 & 752580 & 3.262 & 3.3515 & TST & \\
\hline CHEMBL86464 & 752580 & 3.2621 & 3.3189 & TRN & \\
\hline CHEMBL1361924 & 752580 & 3.2619 & 2.9941 & TRN & \\
\hline CHEMBL1979061 & 752580 & 3.2527 & 3.6373 & TRN & \\
\hline CHEMBL1353338 & 752580 & 3.2523 & 3.2779 & TRN & \\
\hline CHEMBL1707833 & 752580 & 3.2523 & 3.5385 & TRN & \\
\hline CHEMBL1331010 & 752580 & 3.2621 & 3.216 & TRN & \\
\hline CHEMBL1415720 & 752580 & 3.2526 & 3.20899 & 99999999996 & TRN \\
\hline CHEMBL1313831 & 752580 & 3.2619 & 3.661 & TRN & \\
\hline CHEMBL1545021 & 752580 & 3.2623 & 3.307 & TST & \\
\hline CHEMBL1473205 & 752580 & 3.2627 & 4.0434 & TST & \\
\hline CHEMBL1572055 & 752580 & 3.2524 & 3.2659 & TRN & \\
\hline CHEMBL1500686 & 752580 & 3.262 & 3.0895 & TRN & \\
\hline CHEMBL1730051 & 752580 & 3.262 & 4.2368 & TST & \\
\hline CHEMBL1995720 & 752580 & 3.2521 & 2.9711 & TST & \\
\hline CHEMBL1486690 & 752580 & 5.6809 & 3.7971 & TST & \\
\hline CHEMBL1452296 & 752580 & 3.2523 & 3.4976 & TST & \\
\hline CHEMBL3196438 & 752580 & 3.2523 & 3.5154 & TRN & \\
\hline CHEMBL1496705 & 752580 & 3.2523 & 3.4686 & TRN & \\
\hline CHEMBL1381946 & 752580 & 3.2523 & 3.2994 & TRN & \\
\hline CHEMBL1485551 & 752580 & 3.2522 & 3.1046 & TRN & \\
\hline CHEMBL1361615 & 752580 & 3.2524 & 3.4142 & TRN & \\
\hline CHEMBL1448906 & 752580 & 3.7294 & 3.96 & TRN & \\
\hline CHEMBL1328504 & 752580 & 3.2624 & 3.6863 & TRN & \\
\hline CHEMBL1966241 & 752580 & 3.2621 & 3.6736 & TST & \\
\hline CHEMBL1331195 & 752580 & 3.2618 & 4.2544 & TRN & \\
\hline CHEMBL1973159 & 752580 & 3.2524 & 3.0061 & TST & \\
\hline CHEMBL1979800 & 752580 & 3.262 & 3.431 & TST & \\
\hline CHEMBL 1455530 & 752580 & 3.2524 & 3.3264 & TRN & \\
\hline CHEMBL1412077 & 752580 & 5.3057 & 4.0095 & TRN & \\
\hline CHEMBL1880132 & 752580 & 3.262 & 3.8473 & TRN & \\
\hline CHEMBL1398001 & 752580 & 3.2523 & 3.3004 & TRN & \\
\hline CHEMBL1391773 & 752580 & 3.2619 & 3.8967 & TRN & \\
\hline CHEMBL1510317 & 752580 & 4.7684 & 4.1041 & TRN & \\
\hline CHEMBL1587031 & 752580 & 3.2521 & 3.1899 & TRN & \\
\hline CHEMBL1553368 & 752580 & 7.3468 & 4.3612 & TRN & \\
\hline CHEMBL1474759 & 752580 & 3.2624 & 3.3223 & TRN & \\
\hline CHEMBL1393633 & 752580 & 4.2316 & 3.6671 & TRN & \\
\hline CHEMBL1370456 & 752580 & 4.2705 & 3.8795 & TST & \\
\hline CHEMBL1464261 & 752580 & 3.2522 & 3.13 & TRN & \\
\hline
\end{tabular}




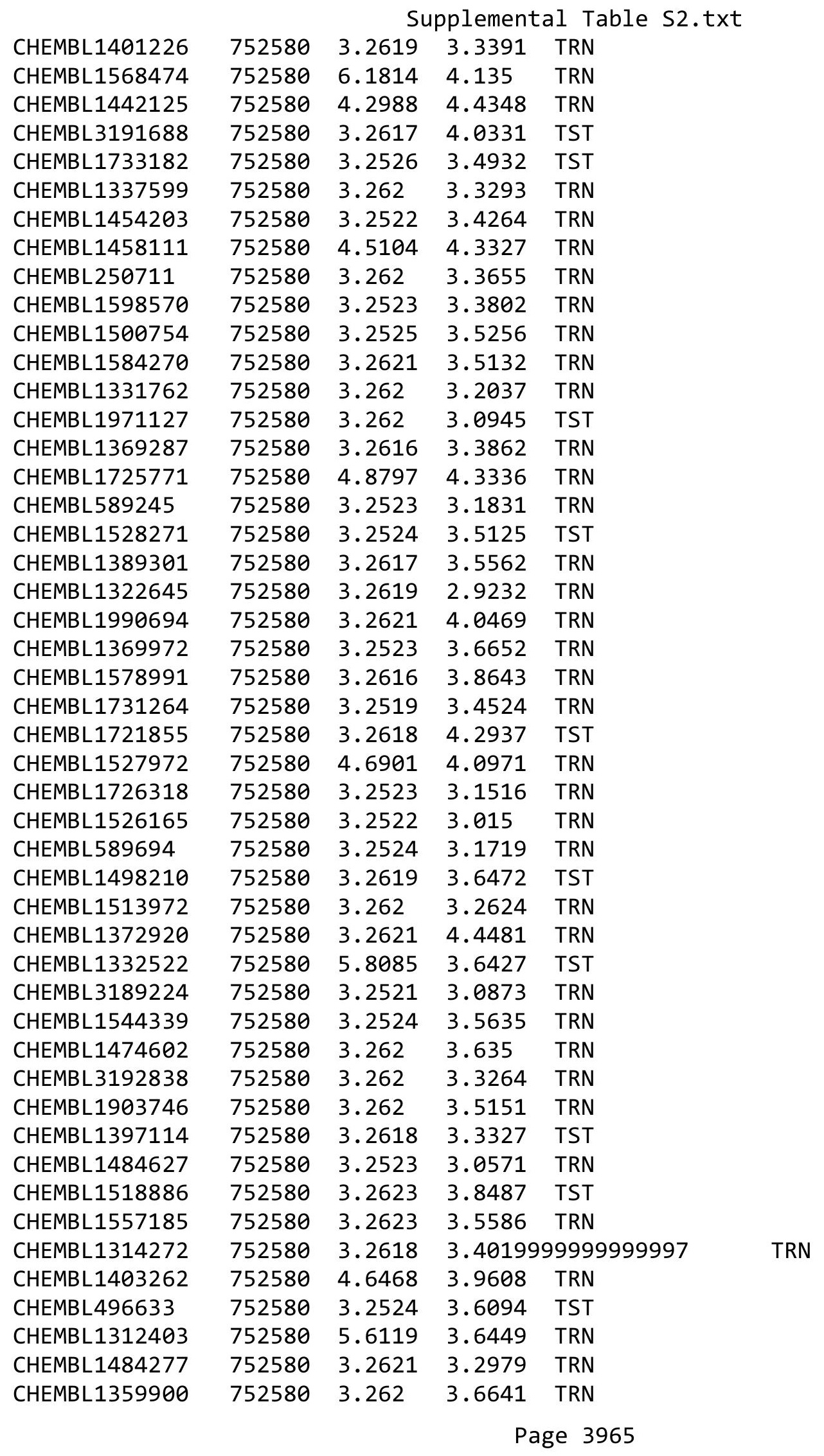




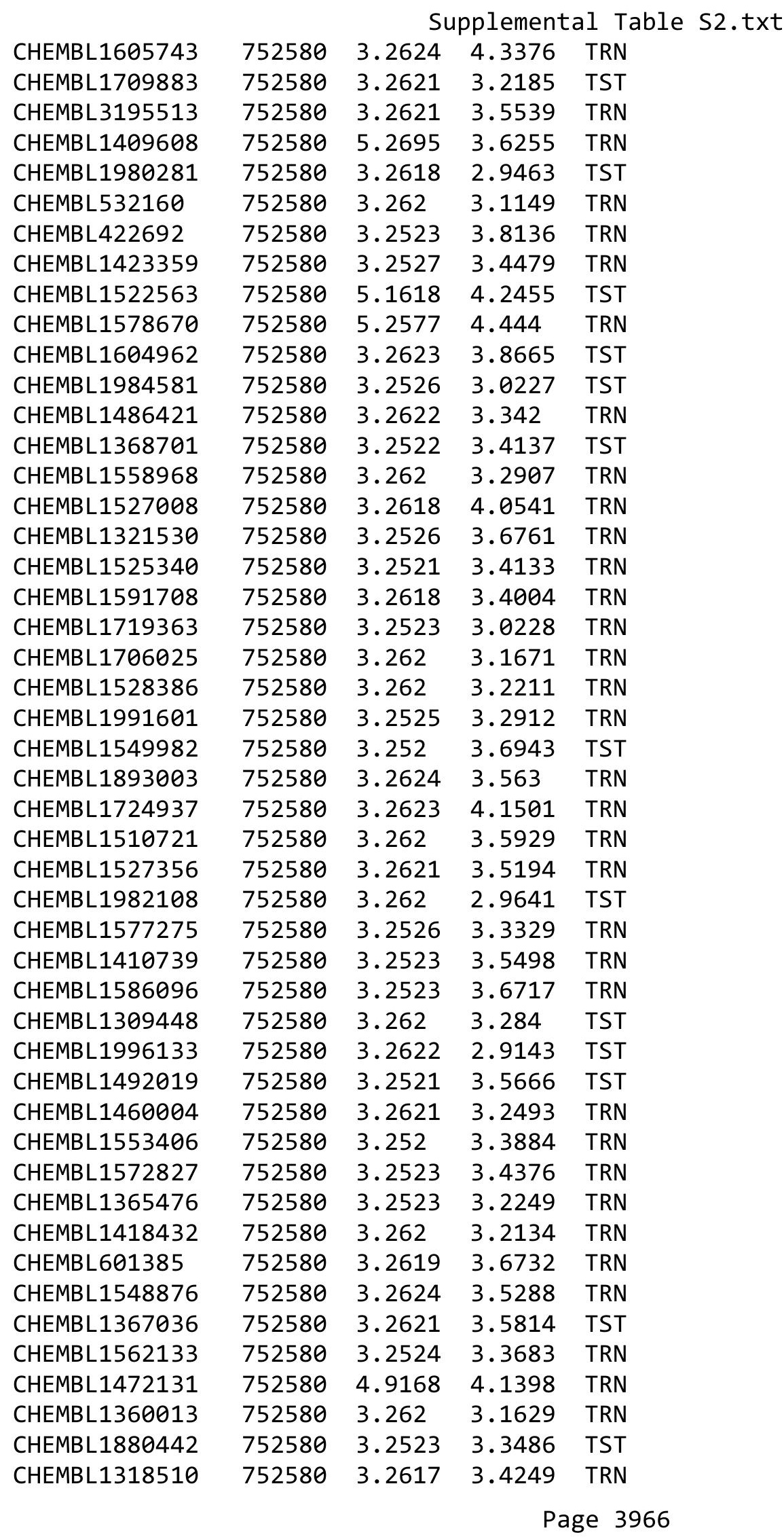




\begin{tabular}{|c|c|c|c|c|}
\hline \multicolumn{5}{|c|}{ Supplemental Table s2.txt } \\
\hline CHEMBL1429269 & 752580 & 3.2619 & 3.0655 & TRN \\
\hline CHEMBL1708021 & 752580 & 3.2621 & 3.3521 & TRN \\
\hline CHEMBL1497597 & 752580 & 3.2619 & 3.1823 & TRN \\
\hline CHEMBL1360535 & 752580 & 3.262 & 3.6919 & TST \\
\hline CHEMBL1393761 & 752580 & 3.262 & 3.2167 & TST \\
\hline CHEMBL1542526 & 752580 & 3.2619 & 3.1329 & TRN \\
\hline CHEMBL1419164 & 752580 & 3.2622 & 4.3281 & TRN \\
\hline CHEMBL1491750 & 752580 & 3.262 & 4.0178 & TST \\
\hline CHEMBL1355072 & 752580 & 3.2523 & 3.2644 & TRN \\
\hline CHEMBL1723816 & 752580 & 3.2621 & 3.4932 & TRN \\
\hline CHEMBL1387366 & 752580 & 5.1827 & 4.4654 & TRN \\
\hline CHEMBL1303641 & 752580 & 3.2621 & 3.8029 & TRN \\
\hline CHEMBL1341102 & 752580 & 3.2619 & 3.1709 & TRN \\
\hline CHEMBL1571034 & 752580 & 4.2066 & 4.2268 & TRN \\
\hline CHEMBL1418096 & 752580 & 3.2617 & 4.1723 & TRN \\
\hline CHEMBL1376516 & 752580 & 3.2523 & 3.0927 & TRN \\
\hline CHEMBL1545734 & 752580 & 3.2619 & 3.2263 & TRN \\
\hline CHEMBL1302748 & 752580 & 3.2618 & 3.7368 & TRN \\
\hline CHEMBL1704902 & 752580 & 3.2525 & 3.2196 & TRN \\
\hline CHEMBL1370322 & 752580 & 3.2523 & 3.4336 & TRN \\
\hline CHEMBL1452571 & 752580 & 3.2524 & 3.4687 & TRN \\
\hline CHEMBL3198737 & 752580 & 3.2527 & 3.4357 & TRN \\
\hline CHEMBL1345866 & 752580 & 3.2621 & 3.5887 & TRN \\
\hline CHEMBL1497642 & 752580 & 3.2624 & 3.0755 & TRN \\
\hline CHEMBL1492044 & 752580 & 3.2619 & 3.773 & TRN \\
\hline CHEMBL1367989 & 752580 & 3.2523 & 3.1946 & TRN \\
\hline CHEMBL1378294 & 752580 & 5.3371 & 4.1034 & TRN \\
\hline CHEMBL1503093 & 752580 & 3.2524 & 3.0181 & TRN \\
\hline CHEMBL1303339 & 752580 & 3.2524 & 3.1661 & TRN \\
\hline CHEMBL1576297 & 752580 & 3.252 & 3.4689 & TRN \\
\hline CHEMBL1729450 & 752580 & 3.262 & 3.0586 & TRN \\
\hline CHEMBL1497035 & 752580 & 3.2621 & 3.1772 & TRN \\
\hline CHEMBL1208858 & 752580 & 3.2619 & 3.2349 & TST \\
\hline CHEMBL1394552 & 752580 & 3.2624 & 3.6859 & TST \\
\hline CHEMBL1530087 & 752580 & 3.2621 & 3.2738 & TRN \\
\hline CHEMBL1232381 & 752580 & 4.9249 & 3.8935 & TRN \\
\hline CHEMBL1471509 & 752580 & 3.2523 & 3.5394 & TST \\
\hline CHEMBL1349596 & 752580 & 3.2526 & 3.8805 & TST \\
\hline CHEMBL1992490 & 752580 & 3.2523 & 2.9936 & TST \\
\hline CHEMBL1576059 & 752580 & 3.2522 & 3.3038 & TRN \\
\hline CHEMBL1390912 & 752580 & 3.2523 & 3.4019 & TRN \\
\hline CHEMBL1462480 & 752580 & 3.262 & 3.2542 & TRN \\
\hline CHEMBL1605224 & 752580 & 3.262 & 3.2282 & TRN \\
\hline CHEMBL1491847 & 752580 & 3.2523 & 3.1092 & TRN \\
\hline CHEMBL1418754 & 752580 & 3.2524 & 3.4913 & TRN \\
\hline CHEMBL1707076 & 752580 & 3.2621 & 3.0816 & TRN \\
\hline CHEMBL1511114 & 752580 & 3.2621 & 3.3787 & TRN \\
\hline CHEMBL1713654 & 752580 & 3.262 & 4.1998 & TST \\
\hline
\end{tabular}




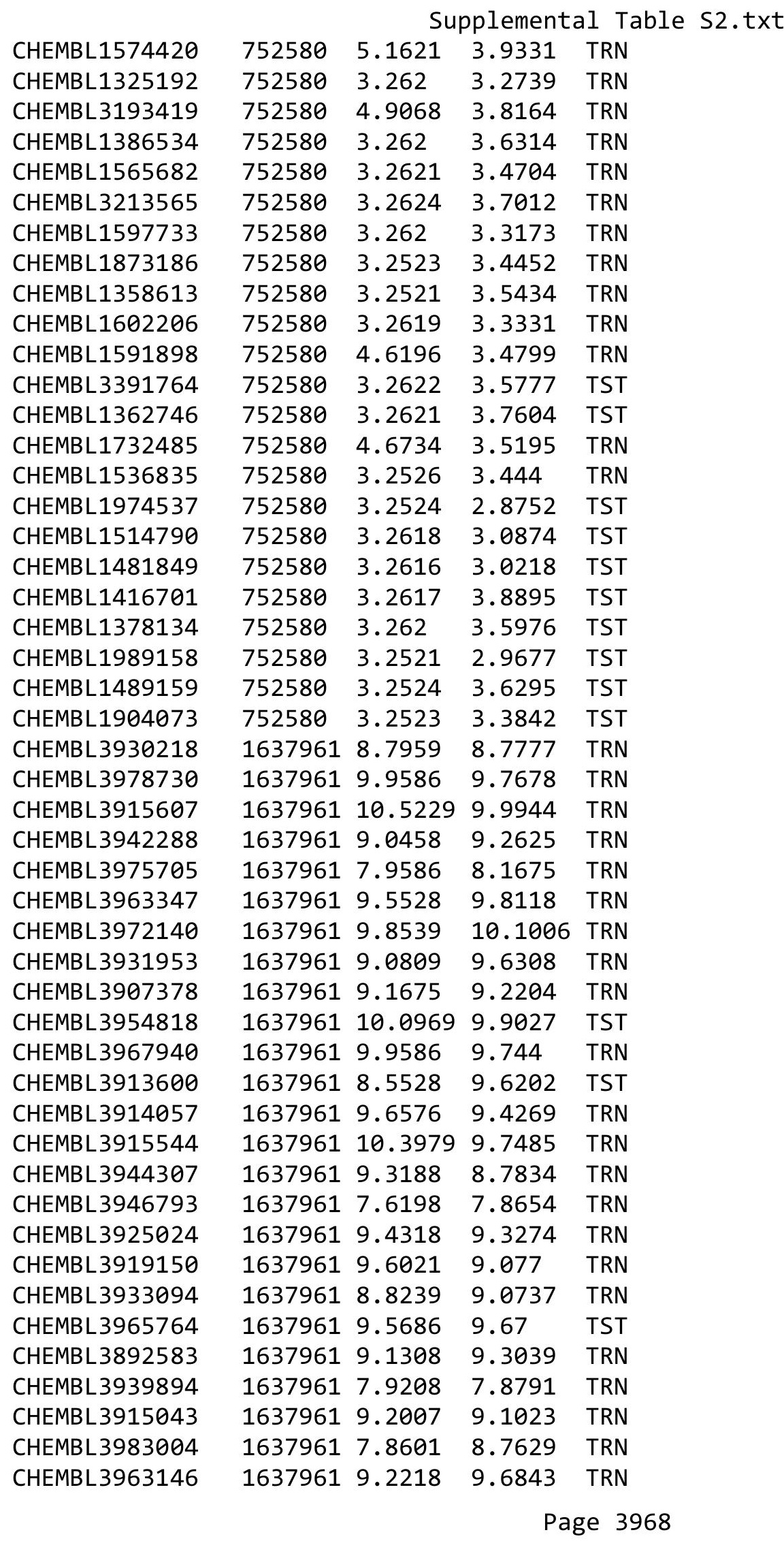




\begin{tabular}{|c|c|c|c|c|c|c|}
\hline \multirow[b]{2}{*}{ CHEMBL3891392 } & \multicolumn{6}{|c|}{ Supplemental Table S2.txt } \\
\hline & 1637961 & 8.4318 & 8.4532 & TST & & \\
\hline CHEMBL3894732 & 1637961 & 10.0315 & 9.9937 & TRN & & \\
\hline CHEMBL3985867 & 1637961 & 8.8861 & 9.0755 & TRN & & \\
\hline CHEMBL 3927752 & 1637961 & 8.7959 & 8.8333 & TRN & & \\
\hline CHEMBL3986713 & 1637961 & 8.585 & 9.3388 & TRN & & \\
\hline CHEMBL3984370 & 1637961 & 10.2076 & 9.6383 & TRN & & \\
\hline CHEMBL3891135 & 1637961 & 10.0 & 9.9669 & TRN & & \\
\hline CHEMBL3969695 & 1637961 & 10.30099 & Э9999999 & 998 & 10.0346 & TRN \\
\hline CHEMBL3967039 & 1637961 & 7.3979 & 8.4633 & TST & & \\
\hline CHEMBL 3899067 & 1637961 & 7.5376 & 8.7067 & TRN & & \\
\hline CHEMBL3938361 & 1637961 & 9.1805 & 9.9779 & TST & & \\
\hline CHEMBL 3891895 & 1637961 & 10.2218 & 9.9836 & TRN & & \\
\hline CHEMBL3935733 & 1637961 & 8.8539 & 8.5761 & TST & & \\
\hline CHEMBL 3923888 & 1637961 & 9.5229 & 8.4656 & TST & & \\
\hline CHEMBL3901866 & 1637961 & 8.0458 & 8.0272 & TRN & & \\
\hline CHEMBL3956618 & 1637961 & 9.585 & 9.7923 & TRN & & \\
\hline CHEMBL3907423 & 1637961 & 8.7696 & 9.5655 & TST & & \\
\hline CHEMBL3891979 & 1637961 & 9.6576 & 9.7429 & TRN & & \\
\hline CHEMBL3925826 & 1637961 & 9.4318 & 9.2969 & TST & & \\
\hline CHEMBL 3944594 & 1637961 & 7.9031 & 8.1388 & TRN & & \\
\hline CHEMBL3907574 & 1637961 & 9.0809 & 9.3672 & TRN & & \\
\hline CHEMBL3947303 & 1637961 & 5.585 & 8.3368 & TST & & \\
\hline CHEMBL3930504 & 1637961 & 8.3372 & 8.0006 & TRN & & \\
\hline CHEMBL3951790 & 1637961 & 9.4685 & 9.3544 & TST & & \\
\hline CHEMBL 3975092 & 1637961 & 8.4949 & 7.8153 & TRN & & \\
\hline CHEMBL3925855 & 1637961 & 10.69900 & 300000006 & 002 & 9.9426 & TRN \\
\hline CHEMBL 3947822 & 1637961 & 9.1938 & 8.914 & TRN & & \\
\hline CHEMBL3895731 & 1637961 & 7.3979 & 8.3128 & TST & & \\
\hline CHEMBL3984623 & 1637961 & 8.8861 & 9.3018 & TST & & \\
\hline CHEMBL 3901827 & 1637961 & 7.0 & 9.9906 & TRN & & \\
\hline CHEMBL3930485 & 1637961 & 9.8861 & 9.8775 & TRN & & \\
\hline CHEMBL3891951 & 1637961 & 8.5302 & 9.7503 & TST & & \\
\hline CHEMBL3899609 & 1637961 & 10.3979 & 9.7061 & TRN & & \\
\hline CHEMBL3978209 & 1637961 & 7.7447 & 7.8396 & TRN & & \\
\hline CHEMBL 3922242 & 1637961 & 9.6383 & 9.9005 & TRN & & \\
\hline CHEMBL3912858 & 1637961 & 8.6198 & 8.0604 & TRN & & \\
\hline CHEMBL3896103 & 1637961 & 9.4089 & 9.2657 & TRN & & \\
\hline CHEMBL3915562 & 1637961 & 8.585 & 7.9401 & TRN & & \\
\hline CHEMBL3918357 & 1637961 & 9.1249 & 9.9141 & TRN & & \\
\hline CHEMBL3922509 & 1637961 & 9.4815 & 9.3017 & TRN & & \\
\hline CHEMBL3959522 & 1637961 & 8.7696 & 9.4295 & TRN & & \\
\hline CHEMBL 3899200 & 1637961 & 9.6576 & 10.009 & TRN & & \\
\hline CHEMBL3889841 & 1637961 & 10.0969 & 9.2029 & TST & & \\
\hline CHEMBL3972427 & 1637961 & 8.0969 & 9.6251 & TST & & \\
\hline CHEMBL3904637 & 1637961 & 11.0 & 9.9969 & TRN & & \\
\hline CHEMBL3956824 & 1637961 & 9.7447 & 9.3291 & TRN & & \\
\hline CHEMBL3959310 & 1637961 & 9.9586 & 9.8414 & TRN & & \\
\hline CHEMBL3961315 & 1637961 & 9.1871 & 9.1723 & TRN & & \\
\hline
\end{tabular}


Supplemental Table S2.txt

\begin{tabular}{|c|c|c|c|c|c|}
\hline CHEMBL3896803 & 1637961 & 6.5229 & 8.2058 & TST & \\
\hline CHEMBL 3898428 & 1637961 & 8.6576 & 8.2457 & TST & \\
\hline CHEMBL3948411 & 1637961 & 9.1427 & 9.3857 & TRN & \\
\hline CHEMBL 3941907 & 1637961 & 9.3098 & 9.0478 & TRN & \\
\hline CHEMBL 3960830 & 1637961 & 9.9586 & 9.6026 & TST & \\
\hline CHEMBL3954085 & 1637961 & 9.4559 & 9.3485 & TST & \\
\hline CHEMBL3915626 & 1637961 & 9.699 & 10.0499 & TRN & \\
\hline CHEMBL3980816 & 1637961 & 7.9586 & 7.9441 & TRN & \\
\hline CHEMBL3949546 & 1637961 & 11.0 & 10.0331 & TRN & \\
\hline CHEMBL3952496 & 1637961 & 10.3372 & 9.718 & TRN & \\
\hline CHEMBL3899567 & 1637961 & 8.9586 & 9.355 & TST & \\
\hline CHEMBL 3898789 & 1637961 & 10.5229 & 9.3788 & TRN & \\
\hline CHEMBL3958130 & 1637961 & 7.8239 & 7.944 & TRN & \\
\hline CHEMBL3926057 & 1637961 & 7.1427 & 8.1428 & TRN & \\
\hline CHEMBL3945318 & 1637961 & 9.2676 & 9.5421 & TRN & \\
\hline CHEMBL3966821 & 1637961 & 9.6576 & 9.2577 & TST & \\
\hline CHEMBL3982880 & 1637961 & 9.4318 & 10.0107 & TRN & \\
\hline CHEMBL3959357 & 1637961 & 11.0 & 9.7531 & TRN & \\
\hline CHEMBL 3889849 & 1637961 & 8.7696 & 9.6121 & TST & \\
\hline CHEMBL3960801 & 1637961 & 8.7959 & 9.1137 & TRN & \\
\hline CHEMBL3904168 & 1637961 & 10.2218 & 9.9803 & TRN & \\
\hline CHEMBL3953791 & 1637961 & 8.7447 & 8.6723 & TRN & \\
\hline CHEMBL3912174 & 1637961 & 10.0969 & 9.9644 & TRN & \\
\hline CHEMBL3906996 & 1637961 & 9.3665 & 9.4552 & TST & \\
\hline CHEMBL 3921873 & 1637961 & 9.5376 & 9.8033 & TRN & \\
\hline CHEMBL1422572 & 737209 & 3.0969 & 2.7906 & TRN & \\
\hline CHEMBL581868 & 737209 & 3.0969 & 4.5386 & TRN & \\
\hline CHEMBL1472773 & 737209 & 3.0969 & 3.3312 & TST & \\
\hline CHEMBL1543215 & 737209 & 6.1605 & 6.3089 & TRN & \\
\hline CHEMBL530291 & 737209 & 3.0969 & 4.2257 & TRN & \\
\hline CHEMBL1363219 & 737209 & 6.6596 & 6.17299 & 9999999999 & TRN \\
\hline CHEMBL1490503 & 737209 & 3.0969 & 2.5526 & TRN & \\
\hline CHEMBL1338060 & 737209 & 3.0969 & 3.5879 & TRN & \\
\hline CHEMBL1589677 & 737209 & 3.0969 & 4.4529 & TRN & \\
\hline CHEMBL1978117 & 737209 & 4.6676 & 5.0324 & TRN & \\
\hline CHEMBL1481733 & 737209 & 3.0969 & 3.4116 & TRN & \\
\hline CHEMBL1440954 & 737209 & 7.7959 & 7.5529 & TRN & \\
\hline CHEMBL1562983 & 737209 & 5.8041 & 4.6607 & TRN & \\
\hline CHEMBL1511219 & 737209 & 7.7959 & 6.9269 & TRN & \\
\hline CHEMBL1985582 & 737209 & 5.9914 & 5.0904 & TRN & \\
\hline CHEMBL290077 & 737209 & 5.8633 & 5.9735 & TST & \\
\hline CHEMBL1703043 & 737209 & 7.7959 & 7.2081 & TRN & \\
\hline CHEMBL1371706 & 737209 & 3.0969 & 3.0558 & TST & \\
\hline CHEMBL1333449 & 737209 & 3.0969 & 3.8494 & TRN & \\
\hline CHEMBL1516365 & 737209 & 3.0969 & 4.398 & TST & \\
\hline CHEMBL1462900 & 737209 & 6.5986 & 6.0863 & TRN & \\
\hline CHEMBL3185655 & 737209 & 7.7959 & 7.5269 & TRN & \\
\hline CHEMBL1360997 & 737209 & 3.0969 & 2.7654 & TRN & \\
\hline
\end{tabular}


Supplemental Table S2.txt

\begin{tabular}{|c|c|c|c|c|c|}
\hline CHEMBL1729737 & 737209 & 6.5735 & 7.0793 & TRN & \\
\hline CHEMBL1389543 & 737209 & 3.0969 & 3.5502 & TRN & \\
\hline CHEMBL1562575 & 737209 & 7.7959 & 8.4768 & TRN & \\
\hline CHEMBL1415885 & 737209 & 4.4921 & 4.3064 & TST & \\
\hline CHEMBL1339737 & 737209 & 3.0969 & 3.3917 & TRN & \\
\hline CHEMBL1566610 & 737209 & 6.4237 & 6.3211 & TRN & \\
\hline CHEMBL590706 & 737209 & 3.0969 & 3.3917 & TRN & \\
\hline CHEMBL533602 & 737209 & 3.0969 & 4.4457 & TST & \\
\hline CHEMBL1531328 & 737209 & 4.2495 & 2.8447 & TRN & \\
\hline CHEMBL1316828 & 737209 & 5.2076 & 4.7975 & TST & \\
\hline CHEMBL 3191989 & 737209 & 7.7959 & 7.3038 & TRN & \\
\hline CHEMBL609027 & 737209 & 3.0969 & 3.1949 & TRN & \\
\hline CHEMBL1597669 & 737209 & 5.6536 & 5.4397 & TRN & \\
\hline CHEMBL1425552 & 737209 & 3.0969 & 3.16 & TRN & \\
\hline CHEMBL1430094 & 737209 & 6.5607 & 6.9897 & TRN & \\
\hline CHEMBL1383664 & 737209 & 6.3206 & 5.681 & TRN & \\
\hline CHEMBL1378232 & 737209 & 6.4365 & 6.3631 & TRN & \\
\hline CHEMBL994 & 737209 & 3.0969 & 4.016999 & 99999999995 & TRN \\
\hline CHEMBL584442 & 737209 & 3.0969 & 4.7876 & TRN & \\
\hline CHEMBL1456751 & 737209 & 4.9469 & 4.9797 & TRN & \\
\hline CHEMBL 3189250 & 737209 & 6.2269 & 5.6813 & TST & \\
\hline CHEMBL1565349 & 737209 & 5.1445 & 4.3359 & TRN & \\
\hline CHEMBL1403484 & 737209 & 3.0969 & 3.1481 & TRN & \\
\hline CHEMBL1569724 & 737209 & 3.0969 & 2.6792 & TRN & \\
\hline CHEMBL1485727 & 737209 & 3.0969 & 3.19 & TRN & \\
\hline CHEMBL 300389 & 737209 & 7.7959 & 7.3359 & TRN & \\
\hline CHEMBL1349146 & 737209 & 5.2411 & 4.5872 & TRN & \\
\hline CHEMBL1358722 & 737209 & 6.51 & 5.252000 & 000000001 & 151 \\
\hline CHEMBL601933 & 737209 & 4.3354 & 3.3917 & TRN & \\
\hline CHEMBL1441604 & 737209 & 4.15300 & 000000000 & 4.0954 & TRN \\
\hline CHEMBL1527341 & 737209 & 3.0969 & 4.6249 & TRN & \\
\hline CHEMBL1438881 & 737209 & 5.05699 & 999999999 & 4.7799 & TRN \\
\hline CHEMBL1544743 & 737209 & 3.0969 & 3.1001 & TRN & \\
\hline CHEMBL338474 & 737209 & 3.0969 & 5.5038 & TRN & \\
\hline CHEMBL1319304 & 737209 & 3.0969 & 2.8568 & TRN & \\
\hline CHEMBL1428735 & 737209 & 5.8761 & 6.3597 & TRN & \\
\hline CHEMBL1980982 & 737209 & 6.3107 & 5.8959 & TRN & \\
\hline CHEMBL1301042 & 737209 & 7.7959 & 7.4551 & TRN & \\
\hline CHEMBL1304342 & 737209 & 3.0969 & 4.0786 & TRN & \\
\hline CHEMBL1521023 & 737209 & 7.7959 & 6.6514 & TRN & \\
\hline CHEMBL1453858 & 737209 & 3.0969 & 3.2222 & TRN & \\
\hline CHEMBL1513566 & 737209 & 6.1831 & 6.2861 & TRN & \\
\hline CHEMBL328834 & 737209 & 7.7959 & 6.7516 & TST & \\
\hline CHEMBL1721226 & 737209 & 3.0969 & 3.3709 & TRN & \\
\hline CHEMBL 270297 & 737209 & 3.0969 & 5.7367 & TRN & \\
\hline CHEMBL1524484 & 737209 & 6.7033 & 5.642 & TRN & \\
\hline CHEMBL548619 & 737209 & 3.0969 & 3.3917 & TRN & \\
\hline CHEMBL1729353 & 737209 & 6.3605 & 5.6308 & TRN & \\
\hline
\end{tabular}


Supplemental Table S2.txt

\begin{tabular}{|c|c|c|c|c|}
\hline CHEMBL1400379 & 737209 & 6.6757 & 6.9076 & TRN \\
\hline CHEMBL1511555 & 737209 & 3.0969 & 2.9801 & TRN \\
\hline CHEMBL405317 & 737209 & 6.0146 & 6.1092 & TRN \\
\hline CHEMBL 81782 & 737209 & 4.9393 & 5.0655 & TRN \\
\hline CHEMBL1420829 & 737209 & 5.0685 & 4.4591 & TRN \\
\hline CHEMBL1505813 & 737209 & 3.0969 & 4.0853 & TRN \\
\hline CHEMBL1423660 & 737209 & 4.1113 & 2.9256 & TRN \\
\hline CHEMBL1409554 & 737209 & 3.0969 & 3.5536 & TST \\
\hline CHEMBL507237 & 737209 & 5.1537 & 5.4762 & TST \\
\hline CHEMBL1490293 & 737209 & 6.6799 & 6.059 & TRN \\
\hline CHEMBL1518672 & 737209 & 5.8761 & 5.8592 & TRN \\
\hline CHEMBL1382191 & 737209 & 3.0969 & 4.4695 & TRN \\
\hline CHEMBL1559529 & 737209 & 5.9431 & 5.2502 & TRN \\
\hline CHEMBL1340715 & 737209 & 3.0969 & 2.8745 & TRN \\
\hline CHEMBL1597245 & 737209 & 6.2076 & 5.9615 & TRN \\
\hline CHEMBL 3193058 & 737209 & 6.6536 & 6.4384 & TRN \\
\hline CHEMBL1971760 & 737209 & 6.1537 & 5.8954 & TST \\
\hline CHEMBL1563943 & 737209 & 3.0969 & 3.2935 & TRN \\
\hline CHEMBL1499501 & 737209 & 3.0969 & 3.1624 & TRN \\
\hline CHEMBL1699881 & 737209 & 6.4802 & 6.7299 & TRN \\
\hline CHEMBL1519965 & 737209 & 6.17200 & 00000000 & 5.4428 \\
\hline CHEMBL1521681 & 737209 & 6.5969 & 5.4138 & TST \\
\hline CHEMBL1430096 & 737209 & 7.7959 & 6.6019 & TST \\
\hline CHEMBL1375648 & 737209 & 5.7905 & 5.4044 & TRN \\
\hline CHEMBL568092 & 737209 & 5.0367 & 3.3917 & TRN \\
\hline CHEMBL1386804 & 737209 & 6.5229 & 6.1044 & TRN \\
\hline CHEMBL1711914 & 737209 & 3.0969 & 4.2023 & TRN \\
\hline CHEMBL1382917 & 737209 & 3.0969 & 4.31 & TRN \\
\hline CHEMBL1491705 & 737209 & 6.1101 & 6.1868 & TRN \\
\hline CHEMBL1310617 & 737209 & 5.3872 & 6.4763 & TRN \\
\hline CHEMBL1730045 & 737209 & 7.7959 & 7.0642 & TST \\
\hline CHEMBL1329446 & 737209 & 6.6946 & 7.446006 & 0000000001 \\
\hline CHEMBL581880 & 737209 & 4.6517 & 4.8423 & TRN \\
\hline CHEMBL1613147 & 737209 & 6.2976 & 5.8276 & TRN \\
\hline CHEMBL598263 & 737209 & 7.7959 & 6.9288 & TRN \\
\hline CHEMBL1552210 & 737209 & 3.0969 & 4.2035 & TRN \\
\hline CHEMBL1394722 & 737209 & 3.0969 & 3.1218 & TRN \\
\hline CHEMBL1486109 & 737209 & 6.0595 & 5.7963 & TRN \\
\hline CHEMBL17639 & 737209 & 3.0969 & 5.444 & TST \\
\hline CHEMBL1361461 & 737209 & 3.0969 & 3.5725 & TRN \\
\hline CHEMBL1603001 & 737209 & 4.4763 & 3.5712 & TRN \\
\hline CHEMBL1437030 & 737209 & 3.0969 & 2.7108 & TRN \\
\hline CHEMBL1549500 & 737209 & 3.0969 & 3.9973 & TRN \\
\hline CHEMBL1489605 & 737209 & 7.7959 & 6.8623 & TRN \\
\hline CHEMBL1404493 & 737209 & 3.0969 & 4.423 & TRN \\
\hline CHEMBL1450527 & 737209 & 3.0969 & 2.5911 & TRN \\
\hline CHEMBL1462745 & 737209 & 5.3883 & 3.9313 & TRN \\
\hline CHEMBL1313542 & 737209 & 3.0969 & 4.4552 & TST \\
\hline
\end{tabular}


Supplemental Table S2.txt

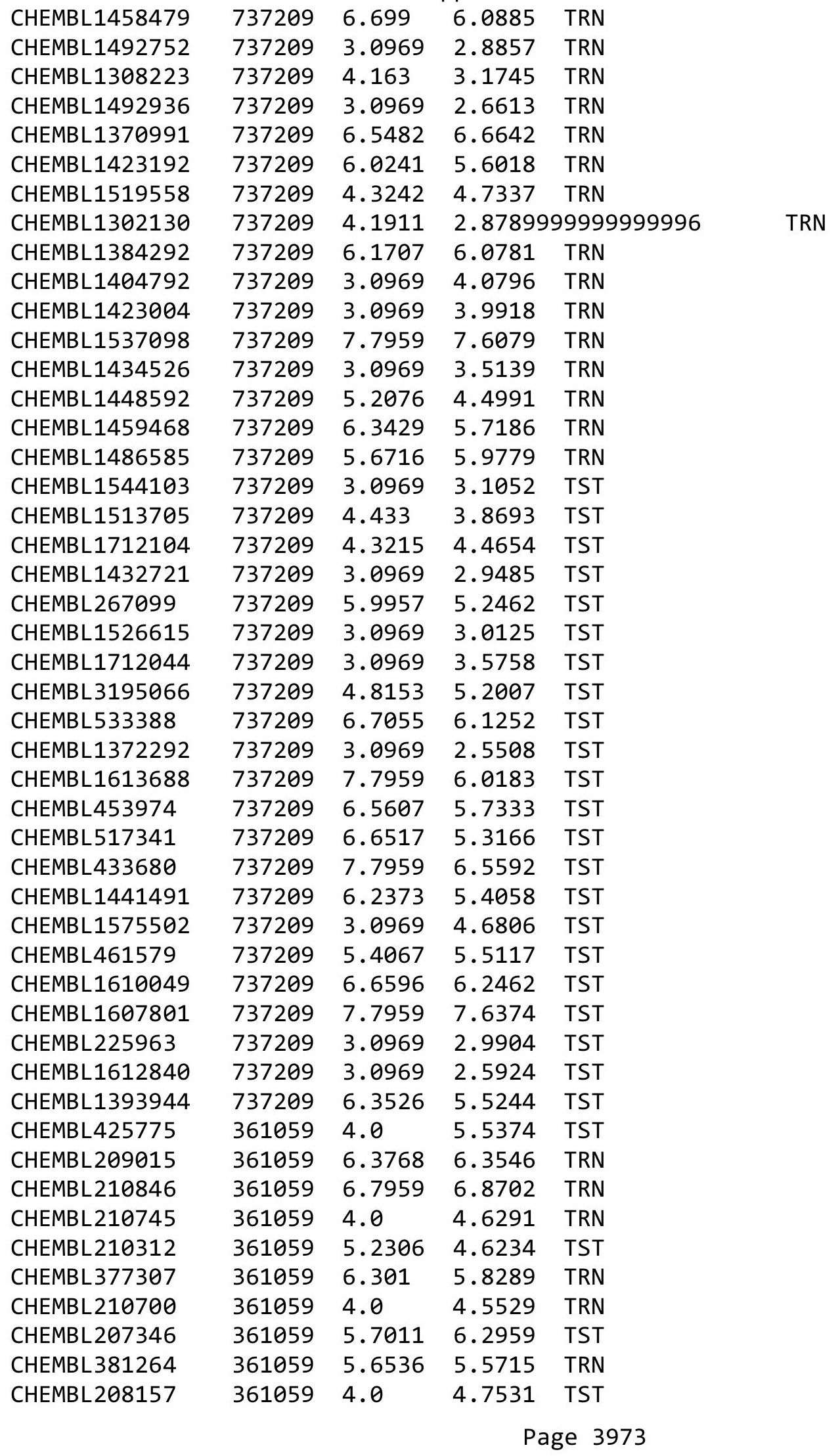




\begin{tabular}{|c|c|c|c|c|c|}
\hline \multirow{3}{*}{$\begin{array}{l}\text { CHEMBL } 208090 \\
\text { CHEMBL } 377636\end{array}$} & & \multicolumn{4}{|c|}{ Supplemental Table S2.txt } \\
\hline & 361059 & 5.6778 & \multicolumn{2}{|c|}{5.587999999999999} & TRN \\
\hline & 361059 & 4.0 & 5.7263 & TRN & \\
\hline CHEMBL210572 & 361059 & 5.8894 & 5.9105 & TRN & \\
\hline CHEMBL190270 & 361059 & 5.4248 & 5.3745 & TRN & \\
\hline CHEMBL382766 & 361059 & 4.0 & 4.2047 & TRN & \\
\hline CHEMBL365409 & 361059 & 6.1079 & 6.3934 & TRN & \\
\hline CHEMBL378841 & 361059 & 5.3497 & 5.1078 & TRN & \\
\hline CHEMBL378559 & 361059 & 4.9355 & 4.8494 & TST & \\
\hline CHEMBL210627 & 361059 & 4.0 & 4.1438 & TRN & \\
\hline CHEMBL208899 & 361059 & 5.4584 & 5.2487 & TRN & \\
\hline CHEMBL445149 & 361059 & 5.4949 & 5.6471 & TRN & \\
\hline CHEMBL382231 & 361059 & 4.0 & 4.4631 & TRN & \\
\hline CHEMBL411221 & 361059 & 6.6021 & \multicolumn{2}{|c|}{5.6610000000000005} & TRN \\
\hline CHEMBL 383200 & 361059 & 4.0 & 4.4449 & TST & \\
\hline CHEMBL208633 & 361059 & 4.0 & 3.7746 & TRN & \\
\hline CHEMBL378129 & 361059 & 5.5686 & 5.7773 & TRN & \\
\hline CHEMBL438063 & 361059 & 4.994 & 4.9182 & TST & \\
\hline CHEMBL378624 & 361059 & 4.0 & 5.1955 & TRN & \\
\hline CHEMBL209185 & 361059 & 5.5157 & 5.6405 & TRN & \\
\hline CHEMBL210488 & 361059 & 5.9208 & 5.7607 & TRN & \\
\hline CHEMBL207334 & 361059 & 6.9586 & 6.9521 & TRN & \\
\hline CHEMBL207814 & 361059 & 4.0 & 3.6744 & TRN & \\
\hline CHEMBL208105 & 361059 & 6.6383 & 6.3279 & TRN & \\
\hline CHEMBL190326 & 361059 & 6.0044 & 5.9775 & TRN & \\
\hline CHEMBL379178 & 361059 & 4.0 & 3.9135 & TRN & \\
\hline CHEMBL379553 & 361059 & 5.4067 & 5.2685 & TST & \\
\hline CHEMBL206992 & 361059 & 6.9208 & 6.5794 & TRN & \\
\hline CHEMBL207181 & 361059 & 5.2815 & 5.9642 & TST & \\
\hline CHEMBL207107 & 361059 & 6.3665 & 5.9979 & TRN & \\
\hline CHEMBL379923 & 361059 & 4.0 & 5.5388 & TST & \\
\hline CHEMBL378550 & 361059 & 4.0 & 4.876 & TRN & \\
\hline CHEMBL207475 & 361059 & 5.585 & 5.4628 & TRN & \\
\hline CHEMBL191039 & 361059 & 5.3788 & 4.4494 & TRN & \\
\hline CHEMBL209183 & 361059 & 5.7423 & 5.6184 & TRN & \\
\hline CHEMBL206574 & 361059 & 5.9318 & 4.7113 & TRN & \\
\hline CHEMBL211040 & 361059 & 6.5768 & 6.9258 & TRN & \\
\hline CHEMBL379515 & 361059 & 6.7959 & 6.1453 & TRN & \\
\hline CHEMBL210573 & 361059 & 5.7825 & 6.2481 & TST & \\
\hline CHEMBL207624 & 361059 & 6.6383 & 6.4975 & TST & \\
\hline CHEMBL378434 & 361059 & 5.8069 & 5.4326 & TST & \\
\hline CHEMBL14267 & 88905 & 7.5 & 7.4789 & TRN & \\
\hline CHEMBL268734 & 88905 & 8.2 & 8.2356 & TRN & \\
\hline CHEMBL13938 & 88905 & 5.0 & 6.2883 & TST & \\
\hline CHEMBL13569 & 88905 & 7.1 & 7.11 & TRN & \\
\hline CHEMBL14210 & 88905 & 8.6 & 8.6172 & TRN & \\
\hline CHEMBL14242 & 88905 & 7.2 & 7.2258 & TRN & \\
\hline CHEMBL 266386 & 88905 & 8.0 & 8.1722 & TST & \\
\hline CHEMBL276868 & 88905 & 6.3 & 6.2818 & TRN & \\
\hline
\end{tabular}




\begin{tabular}{|c|c|c|c|c|c|}
\hline \multicolumn{6}{|c|}{ Supplemental Table S2.txt } \\
\hline CHEMBL13892 & 88905 & 8.4 & 8.4074 & TRN & \\
\hline CHEMBL280022 & 88905 & 6.0 & 6.0001 & TRN & \\
\hline CHEMBL278221 & 88905 & 8.0 & 8.0182 & TRN & \\
\hline CHEMBL14049 & 88905 & 5.9 & 5.9262 & TRN & \\
\hline CHEMBL14641 & 88905 & 5.1 & 5.0868 & TRN & \\
\hline CHEMBL13721 & 88905 & 5.1 & 6.4649 & TST & \\
\hline CHEMBL13896 & 88905 & 6.8 & 6.7612 & TRN & \\
\hline CHEMBL275502 & 88905 & 7.1 & 7.1519 & TRN & \\
\hline CHEMBL13639 & 88905 & 7.3 & 7.2902 & TRN & \\
\hline CHEMBL14135 & 88905 & 6.7 & 6.6852 & TRN & \\
\hline CHEMBL13940 & 88905 & 6.8 & 6.7952 & TRN & \\
\hline CHEMBL14015 & 88905 & 7.3 & 7.3165 & TRN & \\
\hline CHEMBL14028 & 88905 & 8.1 & 8.0142 & TRN & \\
\hline CHEMBL276487 & 88905 & 8.3 & 8.1938 & TRN & \\
\hline CHEMBL275118 & 88905 & 7.2 & 7.21399 & 99999999995 & TRN \\
\hline CHEMBL267801 & 88905 & 8.5 & 8.525 & TRN & \\
\hline CHEMBL13887 & 88905 & 8.6 & 8.6375 & TRN & \\
\hline CHEMBL274315 & 88905 & 7.2 & 7.2186 & TRN & \\
\hline CHEMBL14056 & 88905 & 5.1 & 5.8486 & TST & \\
\hline CHEMBL13845 & 88905 & 6.4 & 7.723 & TST & \\
\hline CHEMBL275613 & 88905 & 5.5 & 5.4715 & TRN & \\
\hline CHEMBL275777 & 88905 & 5.4 & 5.4856 & TRN & \\
\hline CHEMBL14448 & 88905 & 5.2 & 5.1781 & TRN & \\
\hline CHEMBL13925 & 88905 & 6.7 & 6.7172 & TRN & \\
\hline CHEMBL277570 & 88905 & 7.1 & 7.1178 & TRN & \\
\hline CHEMBL 275403 & 88905 & 6.6 & 6.0439 & TST & \\
\hline CHEMBL14208 & 88905 & 5.6 & 5.6253 & TRN & \\
\hline CHEMBL275774 & 88905 & 6.8 & 6.8587 & TRN & \\
\hline CHEMBL14235 & 88905 & 7.4 & 8.1968 & TST & \\
\hline CHEMBL268035 & 88905 & 5.3 & 5.2651 & TRN & \\
\hline CHEMBL14189 & 88905 & 5.9 & 5.6909 & TST & \\
\hline CHEMBL13670 & 88905 & 6.2 & 5.8673 & TRN & \\
\hline CHEMBL13789 & 88905 & 6.5 & 6.5233 & TRN & \\
\hline CHEMBL13879 & 88905 & 6.8 & 6.7533 & TRN & \\
\hline CHEMBL13858 & 88905 & 6.1 & 5.8734 & TST & \\
\hline CHEMBL269631 & 88905 & 7.2 & 7.193 & TRN & \\
\hline CHEMBL13810 & 88905 & 6.8 & 6.8152 & TRN & \\
\hline CHEMBL266613 & 88905 & 5.3 & 5.3017 & TRN & \\
\hline CHEMBL14140 & 88905 & 5.0 & 4.9985 & TRN & \\
\hline CHEMBL13893 & 88905 & 5.8 & 5.8036 & TRN & \\
\hline CHEMBL1255832 & 88905 & 8.8 & 8.7989 & TRN & \\
\hline CHEMBL13620 & 88905 & 7.1 & 7.1326 & TRN & \\
\hline CHEMBL274784 & 88905 & 8.0 & 8.0207 & TRN & \\
\hline CHEMBL274889 & 88905 & 6.8 & 8.1326 & TST & \\
\hline CHEMBL416893 & 88905 & 5.5 & 5.487 & TRN & \\
\hline CHEMBL441589 & 88905 & 5.0 & 5.0074 & TRN & \\
\hline CHEMBL279394 & 88905 & 6.4 & 9.3051 & TST & \\
\hline CHEMBL14016 & 88905 & 5.7 & 5.6958 & TRN & \\
\hline
\end{tabular}




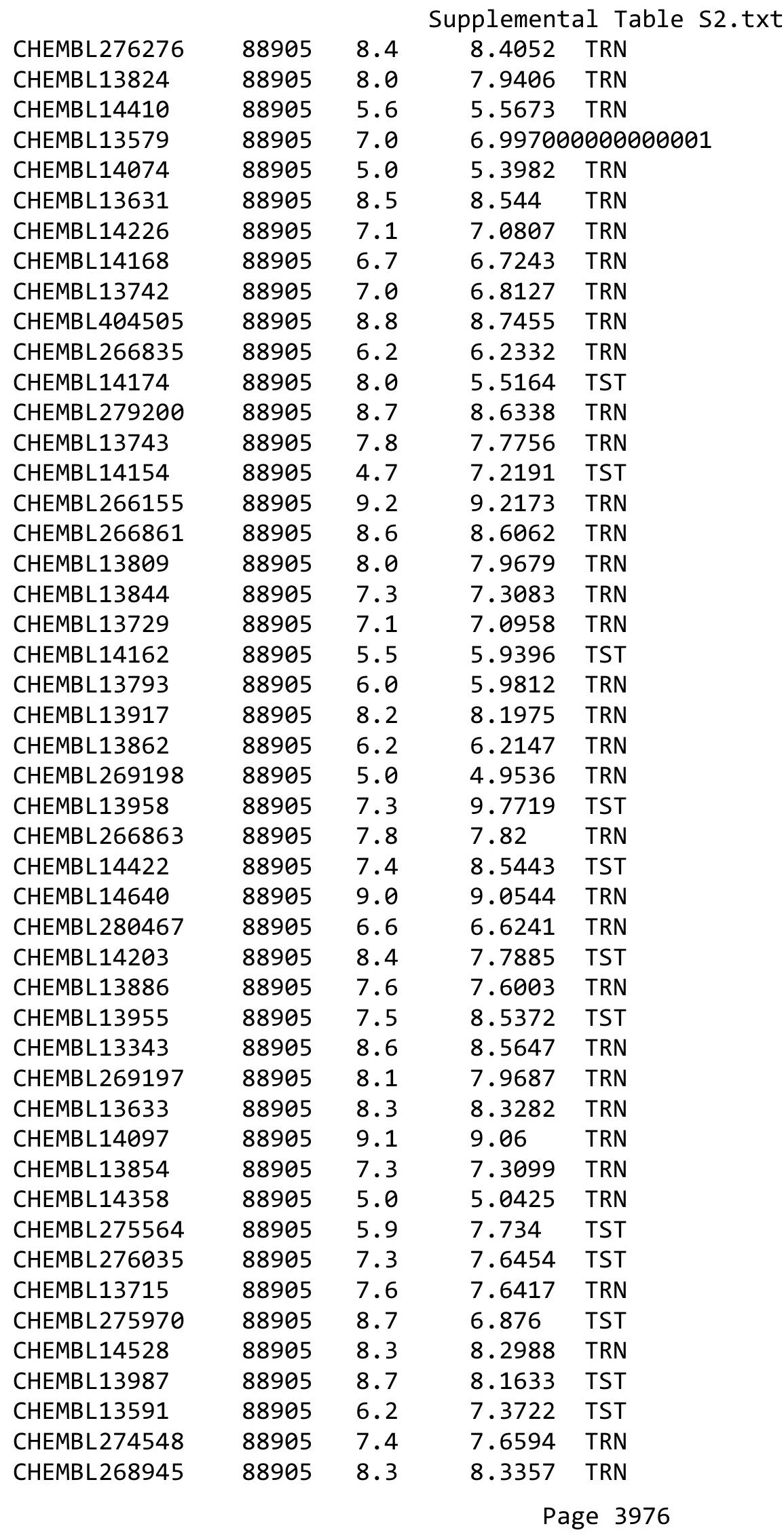

TRN 


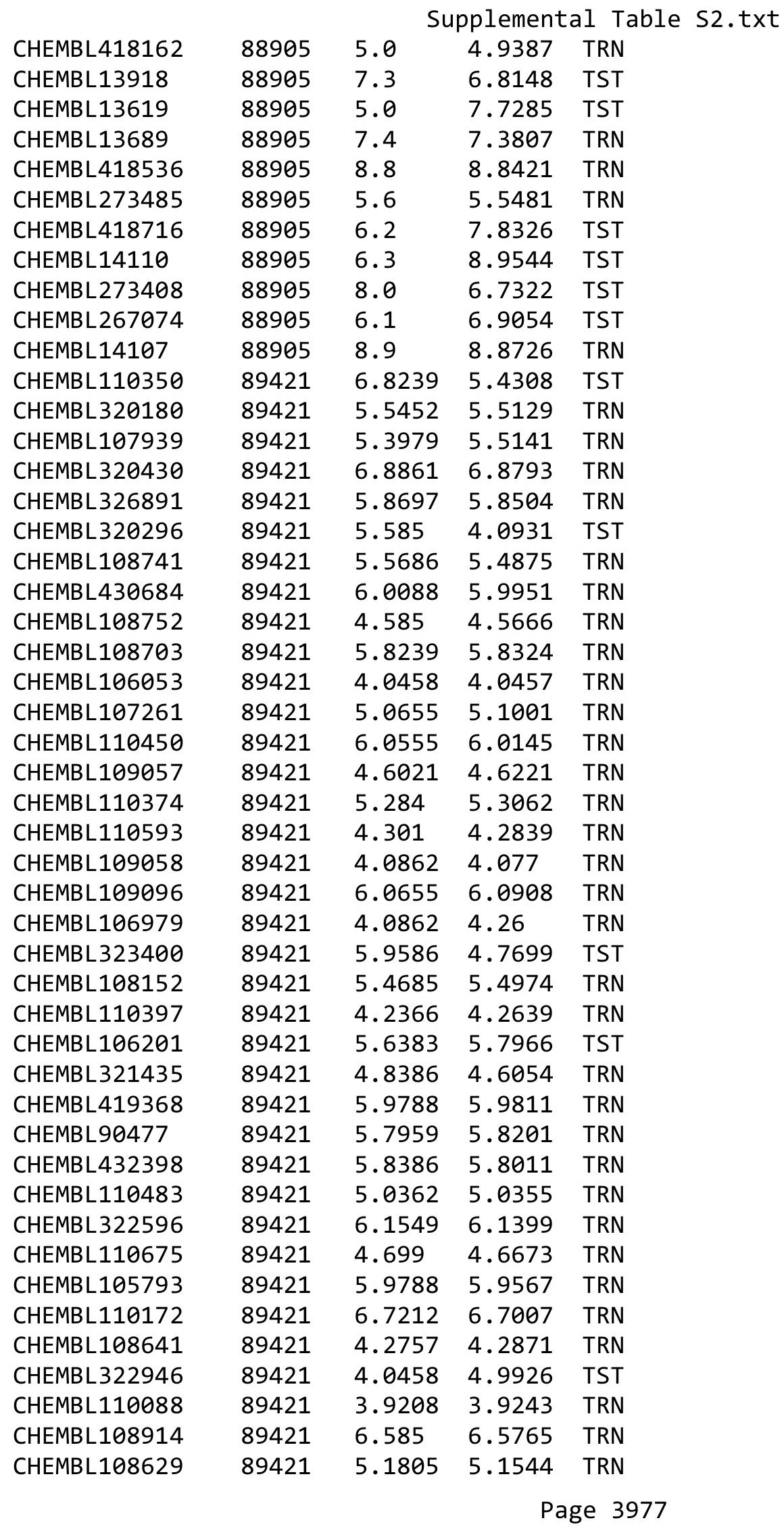




\begin{tabular}{|c|c|c|c|c|}
\hline & & & pplement & al $\mathrm{Ta}$ \\
\hline CHEMBL107034 & 89421 & 6.0 & 6.0201 & TRN \\
\hline CHEMBL108913 & 89421 & 6.4089 & 6.4426 & TRN \\
\hline CHEMBL108365 & 89421 & 5.7212 & 5.7907 & TRN \\
\hline CHEMBL262661 & 89421 & 5.7212 & 5.7504 & TRN \\
\hline CHEMBL106922 & 89421 & 6.7447 & 6.755 & TRN \\
\hline CHEMBL110087 & 89421 & 5.4437 & 5.4584 & TRN \\
\hline CHEMBL 324011 & 89421 & 6.9788 & 6.9562 & TRN \\
\hline CHEMBL110620 & 89421 & 3.8239 & 3.8062 & TRN \\
\hline CHEMBL105948 & 89421 & 5.1549 & 5.1597 & TRN \\
\hline CHEMBL109149 & 89421 & 6.5376 & 6.5387 & TRN \\
\hline CHEMBL110173 & 89421 & 6.0 & 5.9803 & TRN \\
\hline CHEMBL108876 & 89421 & 6.301 & 6.2942 & TRN \\
\hline CHEMBL108603 & 89421 & 6.0 & 5.9832 & TRN \\
\hline CHEMBL110484 & 89421 & 6.3768 & 6.4133 & TRN \\
\hline CHEMBL109052 & 89421 & 4.3279 & 3.8861 & TST \\
\hline CHEMBL321600 & 89421 & 6.6021 & 6.7007 & TST \\
\hline CHEMBL109062 & 89421 & 5.3979 & 5.4875 & TST \\
\hline CHEMBL110218 & 89421 & 4.6021 & 4.7084 & TST \\
\hline CHEMBL 323174 & 89421 & 5.3372 & 5.7504 & TST \\
\hline CHEMBL110338 & 89421 & 5.7696 & 5.4872 & TST \\
\hline CHEMBL107651 & 89421 & 6.7959 & 6.2273 & TST \\
\hline CHEMBL323383 & 89421 & 4.2218 & 5.0266 & TST \\
\hline CHEMBL110734 & 89421 & 6.0 & 5.0522 & TST \\
\hline CHEMBL323494 & 89421 & 5.0 & 5.3638 & TST \\
\hline CHEMBL110499 & 89421 & 5.3665 & 4.6085 & TST \\
\hline CHEMBL1532352 & 688855 & 5.1994 & 4.3444 & TRN \\
\hline CHEMBL1416015 & 688855 & 4.8562 & 4.5362 & TRN \\
\hline CHEMBL1317919 & 688855 & 2.9208 & 3.0645 & TRN \\
\hline CHEMBL1566735 & 688855 & 4.9609 & 4.3135 & TRN \\
\hline CHEMBL1329938 & 688855 & 5.6611 & 4.4771 & TRN \\
\hline CHEMBL1551741 & 688855 & 4.739 & 4.2433 & TRN \\
\hline CHEMBL 3212098 & 688855 & 4.0587 & 5.0533 & TST \\
\hline CHEMBL1486710 & 688855 & 4.8811 & 3.1093 & TST \\
\hline CHEMBL3198976 & 688855 & 5.0196 & 5.3688 & TRN \\
\hline CHEMBL1506183 & 688855 & 2.9208 & 3.8175 & TRN \\
\hline CHEMBL1446641 & 688855 & 2.9208 & 5.1353 & TRN \\
\hline CHEMBL1526362 & 688855 & 4.8593 & 4.8855 & TRN \\
\hline CHEMBL1406346 & 688855 & 6.8794 & 5.9346 & TRN \\
\hline CHEMBL1372085 & 688855 & 4.8034 & 5.0082 & TRN \\
\hline CHEMBL1421850 & 688855 & 2.9208 & 3.7294 & TRN \\
\hline CHEMBL1586605 & 688855 & 4.6593 & 3.6132 & TRN \\
\hline CHEMBL1560260 & 688855 & 5.2346 & 3.8809 & TRN \\
\hline CHEMBL1598916 & 688855 & 5.0881 & 4.7251 & TRN \\
\hline CHEMBL1522801 & 688855 & 5.0247 & 5.065 & TRN \\
\hline CHEMBL1410615 & 688855 & 4.955 & 4.3736 & TRN \\
\hline CHEMBL1390469 & 688855 & 2.9208 & 4.5422 & TST \\
\hline CHEMBL3213784 & 688855 & 5.0421 & 5.0141 & TRN \\
\hline CHEMBL1386412 & 688855 & 2.9208 & 3.2316 & TRN \\
\hline
\end{tabular}


Supplemental Table S2.txt

\begin{tabular}{|c|c|c|c|c|}
\hline HEN & & 208 & & \\
\hline HEMBL1537737 & & .3781 & 4.9563 & \\
\hline 751 & & & & \\
\hline AEMBL1 & & & & Ne \\
\hline AEMBL3195910 & & 863 & 104 & \\
\hline HEMBL1605898 & 38855 & 9208 & 5872 & \\
\hline HEMBL1352 & 8855 & 804 & & \\
\hline IEMBI 1333794 & & & & \\
\hline AEMBL1583715 & 88855 & 2343 & & \\
\hline HEMBL1359952 & 38855 & 07 & 3266 & \\
\hline HEMBL1337152 & 88855 & 94 & & \\
\hline IEMBL155e & & 85 & & \\
\hline AEMBL1339672 & & & & \\
\hline HEMBL1537451 & 88855 & 775 & & \\
\hline AEMBL1543 & 5 & & & \\
\hline AEMBL1556013 & 3 & 08 & 371 & \\
\hline IEMBL144€ & & & & \\
\hline HEMBL140 & & & & \\
\hline AEMBL1427 & 5 & & & \\
\hline IEMBL32 & & & & \\
\hline HBMLISSE & 5 & & & NIV \\
\hline AEMBL15 & & & & 传 \\
\hline JEMBL10 & 5 & & & \\
\hline AFMRI 13 & & & & \\
\hline AEMBL 3193 & & & & res \\
\hline HEMBL1 & 5 & & & KIV \\
\hline HEMBLI & & & & RN \\
\hline AFMRI 1 & 5 & & & \\
\hline HEMBL156 & & & & IRIV \\
\hline HEMBL1548850 & 5 & & & IRIV \\
\hline HEMBL151 & 5 & & & SI \\
\hline HEMBL & & 8 & & TRN \\
\hline HEMPI & 5 & & & TRN \\
\hline HEMBL3196976 & & & & ISI \\
\hline HEMBL1531764 & 88855 & & & TRN \\
\hline HEMBL319 & 5 & & & TRN \\
\hline HCMD - & & & & $\Gamma \mathrm{RN}$ \\
\hline HEMBL1 & & & 166 & TRN \\
\hline HEMBL483137 & 88855 & & 7323 & TRN \\
\hline AEMBL15685 & 88855 & & & $\Gamma \mathrm{RN}$ \\
\hline HEMBL15365 & 88855 & & 935 & 80 \\
\hline HEMBL140 & & & & TRN \\
\hline HEMBL1389755 & 55 & & 7039 & RN \\
\hline AEMBL1305278 & 38855 & & 917 & TRN \\
\hline AEMBL14228 & & & & $T$ \\
\hline HEMBL 32145 & 000 & & & \\
\hline HEMBL1327719 & & 4.82 & .8883 & \\
\hline HEMBL1341336 & 688855 & 4.7718 & 4.6363 & ГRN \\
\hline
\end{tabular}

Page 3979 


\begin{tabular}{|c|c|c|c|c|c|c|}
\hline & & \multicolumn{5}{|c|}{ Supplemental Table S2.txt } \\
\hline CHEMBL1380397 & 688855 & 4.6248 & 4.4693 & TRN & & \\
\hline CHEMBL1467284 & 688855 & 2.9208 & 3.0195 & TRN & & \\
\hline CHEMBL1322183 & 688855 & 4.7651 & 4.9824 & TRN & & \\
\hline CHEMBL1502465 & 688855 & 8.0 & 5.3962 & TRN & & \\
\hline CHEMBL131037 & 688855 & 2.9208 & 3.5726 & TST & & \\
\hline CHEMBL1965956 & 688855 & 2.9208 & 4.673 & TRN & & \\
\hline CHEMBL1467438 & 688855 & 5.0367 & 4.4747 & TRN & & \\
\hline CHEMBL1485860 & 688855 & \multicolumn{3}{|c|}{5.492000000000001} & 5.2543 & TRN \\
\hline CHEMBL1424555 & 688855 & 6.7773 & 5.7859 & TRN & & \\
\hline CHEMBL1531960 & 688855 & 4.6478 & \multicolumn{3}{|c|}{4.553999999999999} & TRN \\
\hline CHEMBL1567107 & 688855 & 6.5884 & 4.4211 & TRN & & \\
\hline CHEMBL1200717 & 688855 & 2.9208 & 3.3936 & TST & & \\
\hline CHEMBL1308898 & 688855 & 4.4652 & 5.5071 & TRN & & \\
\hline CHEMBL3192121 & 688855 & 4.7542 & 6.2175 & TRN & & \\
\hline CHEMBL1550861 & 688855 & 5.476 & 5.3017 & TRN & & \\
\hline CHEMBL3211206 & 688855 & 4.7278 & 4.6617 & TRN & & \\
\hline CHEMBL1306817 & 688855 & 4.4375 & 4.8498 & TRN & & \\
\hline CHEMBL1441326 & 688855 & 4.6984 & 4.8191 & TRN & & \\
\hline CHEMBL1511456 & 688855 & 4.614 & 5.0648 & TRN & & \\
\hline CHEMBL1610870 & 688855 & 5.2783 & 4.4036 & TRN & & \\
\hline CHEMBL 3197741 & 688855 & 8.0 & 7.0613 & TRN & & \\
\hline CHEMBL1595573 & 688855 & 5.1752 & 4.6897 & TRN & & \\
\hline CHEMBL1439444 & 688855 & 5.0132 & 3.4904 & TRN & & \\
\hline CHEMBL1411907 & 688855 & 2.9208 & 4.2969 & TRN & & \\
\hline CHEMBL1482571 & 688855 & 6.684 & 5.5186 & TRN & & \\
\hline CHEMBL1612547 & 688855 & 2.9208 & 3.3961 & TRN & & \\
\hline CHEMBL1569541 & 688855 & 6.2503 & 4.7771 & TRN & & \\
\hline CHEMBL1387204 & 688855 & 2.9208 & 3.61 & TRN & & \\
\hline CHEMBL1338359 & 688855 & 4.7163 & 4.8309 & TRN & & \\
\hline CHEMBL1384739 & 688855 & 6.104 & 5.6486 & TRN & & \\
\hline CHEMBL1582035 & 688855 & 5.0884 & 4.8663 & TRN & & \\
\hline CHEMBL1601835 & 688855 & 2.9208 & 4.1092 & TRN & & \\
\hline CHEMBL1589378 & 688855 & 5.0126 & 4.8696 & TRN & & \\
\hline CHEMBL1549700 & 688855 & 4.8767 & 5.0385 & TRN & & \\
\hline CHEMBL1327643 & 688855 & 4.8505 & 4.9957 & TRN & & \\
\hline CHEMBL1582469 & 688855 & 4.8325 & 4.8561 & TST & & \\
\hline CHEMBL240333 & 688855 & 7.0 & 5.9129 & TRN & & \\
\hline CHEMBL1597773 & 688855 & 2.9208 & 3.2284 & TRN & & \\
\hline CHEMBL1420382 & 688855 & \multicolumn{3}{|c|}{4.7330000000000005} & 5.0591 & TRN \\
\hline CHEMBL1453471 & 688855 & 5.2568 & 3.8821 & TRN & & \\
\hline CHEMBL1377341 & 688855 & 4.7196 & 5.7673 & TRN & & \\
\hline CHEMBL1380549 & 688855 & 2.9208 & 3.6418 & TRN & & \\
\hline CHEMBL1320349 & 688855 & 2.9208 & 4.4642 & TRN & & \\
\hline CHEMBL1477844 & 688855 & \multicolumn{3}{|c|}{ 4. 3469999999999995} & 4.4812 & TRN \\
\hline CHEMBL1325503 & 688855 & 6.4401 & 5.362 & TRN & & \\
\hline CHEMBL1455144 & 688855 & 4.5503 & 4.6605 & TRN & & \\
\hline CHEMBL1567309 & 688855 & 2.9208 & 3.7906 & TRN & & \\
\hline CHEMBL1376513 & 688855 & 5.2715 & 4.8403 & TRN & & \\
\hline
\end{tabular}




\begin{tabular}{|c|c|c|c|c|}
\hline \multicolumn{5}{|c|}{ Supplemental Table s2.txt } \\
\hline CHEMBL1541465 & 688855 & 2.9208 & 3.9943 & TST \\
\hline CHEMBL1383194 & 688855 & 4.7638 & 4.3167 & TRN \\
\hline CHEMBL1571239 & 688855 & 6.7328 & 6.8863 & TRN \\
\hline CHEMBL3197566 & 688855 & 2.9208 & 4.0944 & TST \\
\hline CHEMBL1525320 & 688855 & 4.7646 & 4.6551 & TRN \\
\hline CHEMBL1528629 & 688855 & 2.9208 & 3.4543 & TRN \\
\hline CHEMBL1525755 & 688855 & 8.0 & 4.6026 & TST \\
\hline CHEMBL1531774 & 688855 & 4.8591 & 4.7903 & TRN \\
\hline CHEMBL1531116 & 688855 & 2.9208 & 3.3996 & TRN \\
\hline CHEMBL1552473 & 688855 & 4.5466 & 4.9446 & TRN \\
\hline CHEMBL1452680 & 688855 & 5.0395 & 4.6954 & TRN \\
\hline CHEMBL1535599 & 688855 & 4.8277 & 4.4897 & TRN \\
\hline CHEMBL1520273 & 688855 & 8.0 & 6.8839 & TRN \\
\hline CHEMBL1531245 & 688855 & 2.9208 & 3.0524 & TRN \\
\hline CHEMBL1602826 & 688855 & 5.4194 & 4.7969 & TRN \\
\hline CHEMBL1601460 & 688855 & 4.8831 & 4.2852 & TRN \\
\hline CHEMBL1424754 & 688855 & 8.0 & 5.3871 & TRN \\
\hline CHEMBL1343279 & 688855 & 4.3771 & 4.4641 & TRN \\
\hline CHEMBL1570117 & 688855 & 4.2855 & 5.1129 & TRN \\
\hline CHEMBL1339702 & 688855 & 4.6695 & 6.5399 & TRN \\
\hline CHEMBL1320382 & 688855 & 4.0205 & 4.7437 & TRN \\
\hline CHEMBL1534302 & 688855 & 6.4881 & 4.7021 & TRN \\
\hline CHEMBL3191413 & 688855 & 4.6134 & 4.9902 & TRN \\
\hline CHEMBL3191391 & 688855 & 2.9208 & 5.1781 & TRN \\
\hline CHEMBL1542242 & 688855 & 5.9682 & 5.831 & TRN \\
\hline CHEMBL1389746 & 688855 & 4.8759 & 4.1828 & TRN \\
\hline CHEMBL1330446 & 688855 & 6.6402 & 6.0523 & TRN \\
\hline CHEMBL1391325 & 688855 & 6.9393 & 5.3881 & TRN \\
\hline CHEMBL1582517 & 688855 & 4.8645 & 4.2284 & TRN \\
\hline CHEMBL1561777 & 688855 & 6.7282 & 4.5926 & TST \\
\hline CHEMBL1326044 & 688855 & 2.9208 & 4.3363 & TRN \\
\hline CHEMBL1351765 & 688855 & 4.3347 & 4.8441 & TRN \\
\hline CHEMBL3208019 & 688855 & 4.6267 & 5.0144 & TRN \\
\hline CHEMBL3213703 & 688855 & 4.2715 & 4.1734 & TRN \\
\hline CHEMBL1601639 & 688855 & 2.9208 & 5.1472 & TRN \\
\hline CHEMBL1505790 & 688855 & 2.9208 & 3.4277 & TRN \\
\hline CHEMBL1339310 & 688855 & 5.1699 & 5.1295 & TRN \\
\hline CHEMBL1384746 & 688855 & 4.2716 & 5.7577 & TRN \\
\hline CHEMBL1574581 & 688855 & 2.9208 & 3.6851 & TRN \\
\hline CHEMBL1414419 & 688855 & 5.3349 & 4.5679 & TST \\
\hline CHEMBL1588307 & 688855 & 4.8195 & 4.6244 & TRN \\
\hline CHEMBL1524916 & 688855 & 2.9208 & 4.7443 & TST \\
\hline CHEMBL1349626 & 688855 & 4.6737 & 3.937 & TRN \\
\hline CHEMBL1568905 & 688855 & 4.78 & 5.3106 & TRN \\
\hline CHEMBL1606863 & 688855 & 4.6933 & 4.8129 & TST \\
\hline CHEMBL1518652 & 688855 & 5.091 & 4.4178 & TRN \\
\hline CHEMBL1467999 & 688855 & 4.8227 & 4.7678 & TRN \\
\hline CHEMBL1422573 & 688855 & 6.8894 & 6.1941 & TRN \\
\hline
\end{tabular}




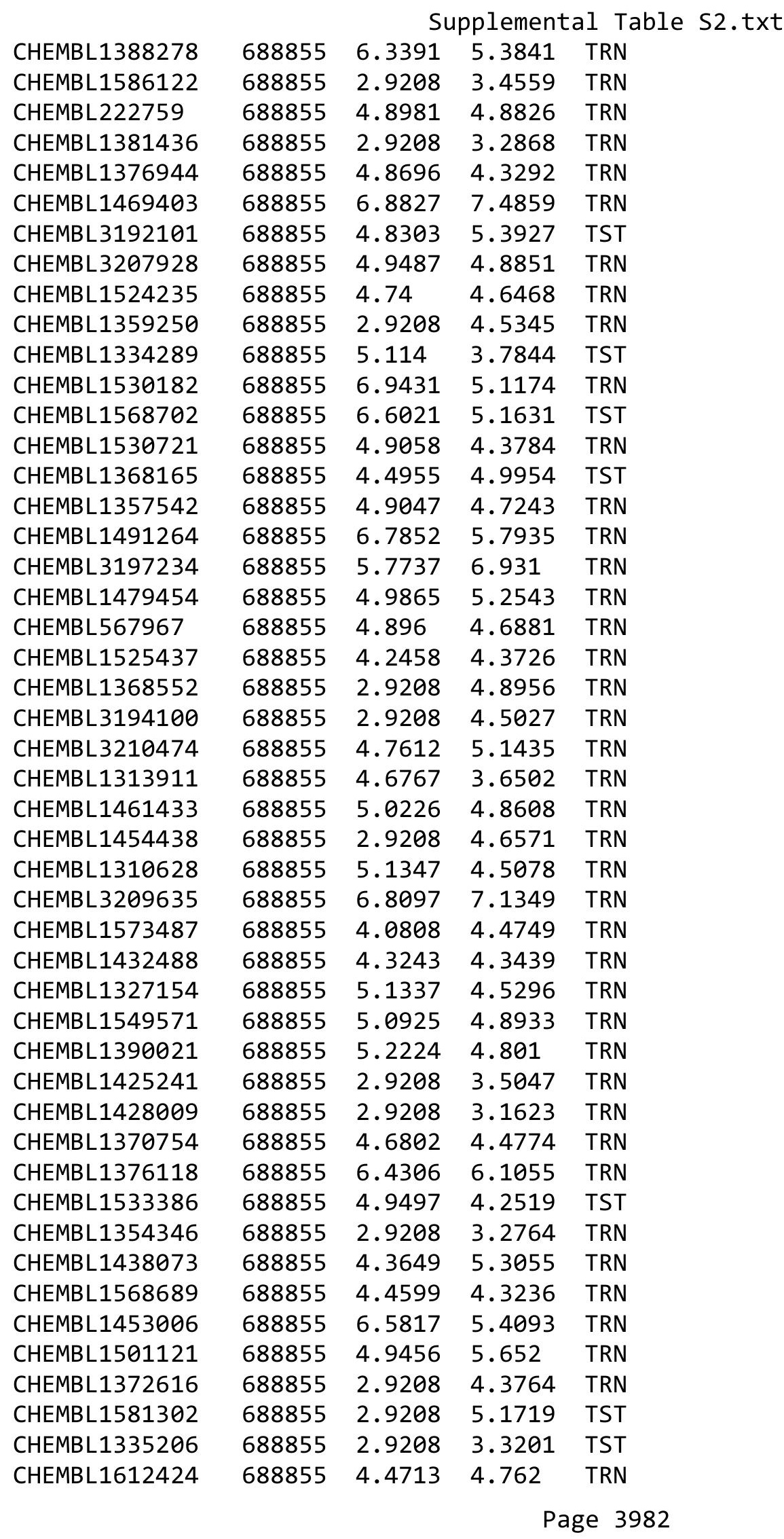




\begin{tabular}{|c|c|c|c|c|}
\hline \multicolumn{5}{|c|}{ Supplemental Table } \\
\hline CHEMBL584883 & 688855 & 4.7948 & 4.0413 & TST \\
\hline CHEMBL1336874 & 688855 & 2.9208 & 4.9584 & TRN \\
\hline CHEMBL1395051 & 688855 & 4.8168 & 4.6467 & TRN \\
\hline CHEMBL3193521 & 688855 & 6.1463 & 4.3067 & TRN \\
\hline CHEMBL1543843 & 688855 & 4.2987 & 4.4797 & TRN \\
\hline CHEMBL1384906 & 688855 & 4.8582 & 4.7187 & TRN \\
\hline CHEMBL1441799 & 688855 & 5.2906 & 4.0443 & TRN \\
\hline CHEMBL1544498 & 688855 & 4.835 & 4.7901 & TRN \\
\hline CHEMBL1479116 & 688855 & 4.6666 & 4.7767 & TRN \\
\hline CHEMBL1483048 & 688855 & 6.1831 & 5.184 & TRN \\
\hline CHEMBL1418545 & 688855 & 4.6911 & 4.5476 & TRN \\
\hline CHEMBL3199114 & 688855 & 4.8824 & 5.6544 & TRN \\
\hline CHEMBL1578141 & 688855 & 4.7524 & 4.4948 & TRN \\
\hline CHEMBL1405704 & 688855 & 4.8873 & 3.4693 & TRN \\
\hline CHEMBL1399142 & 688855 & 2.9208 & 3.3091 & TRN \\
\hline CHEMBL1321895 & 688855 & 4.6251 & 3.8469 & TRN \\
\hline CHEMBL139250 & 688855 & 4.9131 & 3.647 & TRN \\
\hline CHEMBL1530257 & 688855 & 5.0238 & 4.6986 & TRN \\
\hline CHEMBL1499681 & 688855 & 8.0 & 4.7672 & TRN \\
\hline CHEMBL1554017 & 688855 & 2.9208 & 3.3316 & TRN \\
\hline CHEMBL1557142 & 688855 & 4.6492 & 6.6065 & TRN \\
\hline CHEMBL1576496 & 688855 & 4.5377 & 4.4532 & TRN \\
\hline CHEMBL1610276 & 688855 & 4.8422 & 4.8666 & TRN \\
\hline CHEMBL1360965 & 688855 & 4.6846 & 4.7553 & TRN \\
\hline CHEMBL1556906 & 688855 & 4.8124 & 4.75 & TRN \\
\hline CHEMBL1545721 & 688855 & 4.5597 & 4.9432 & TRN \\
\hline CHEMBL1575523 & 688855 & 2.9208 & 4.2666 & TRN \\
\hline CHEMBL1557196 & 688855 & 2.9208 & 3.5298 & TRN \\
\hline CHEMBL1315908 & 688855 & 5.6041 & 5.4653 & TRN \\
\hline CHEMBL3211529 & 688855 & 2.9208 & 3.6356 & TRN \\
\hline CHEMBL 1427857 & 688855 & 4.8263 & 4.9768 & TRN \\
\hline CHEMBL1584686 & 688855 & 2.9208 & 4.4863 & TRN \\
\hline CHEMBL1458318 & 688855 & 4.7729 & 4.5405 & TST \\
\hline CHEMBL1583812 & 688855 & 2.9208 & 3.4511 & TRN \\
\hline CHEMBL1468383 & 688855 & 4.9566 & 5.0153 & TRN \\
\hline CHEMBL1509837 & 688855 & 2.9208 & 4.2872 & TRN \\
\hline CHEMBL1423707 & 688855 & 5.2797 & 4.2396 & TRN \\
\hline CHEMBL1488108 & 688855 & 6.4921 & 4.9194 & TRN \\
\hline CHEMBL1374157 & 688855 & 4.6991 & 4.928 & TRN \\
\hline CHEMBL527677 & 688855 & 4.8692 & 4.4846 & TRN \\
\hline CHEMBL1611839 & 688855 & 2.9208 & 4.1315 & TRN \\
\hline CHEMBL1564952 & 688855 & 5.3616 & 4.7358 & TRN \\
\hline CHEMBL1337580 & 688855 & 2.9208 & 5.1124 & TRN \\
\hline CHEMBL1481951 & 688855 & 5.2443 & 4.0992 & TST \\
\hline CHEMBL1170485 & 688855 & 2.9208 & 3.7925 & TST \\
\hline CHEMBL1566120 & 688855 & 4.8827 & 4.4723 & TRN \\
\hline CHEMBL1506611 & 688855 & 4.8068 & 4.7184 & TRN \\
\hline CHEMBL1490334 & 688855 & 6.5143 & 7.2041 & TRN \\
\hline
\end{tabular}


Supplemental Table S2.txt

\begin{tabular}{|c|c|c|c|c|c|}
\hline CHEMBL1454225 & 688855 & 5.1961 & 4.6641 & TRN & \\
\hline CHEMBL1509216 & 688855 & 6.6073 & 5.6663 & TRN & \\
\hline CHEMBL1578490 & 688855 & 4.8309 & 5.0071 & TRN & \\
\hline CHEMBL 3197088 & 688855 & 2.9208 & 3.4562 & TRN & \\
\hline CHEMBL528734 & 688855 & 5.1061 & 4.8122 & TRN & \\
\hline CHEMBL1435015 & 688855 & 2.9208 & 4.7165 & TRN & \\
\hline CHEMBL3208571 & 688855 & 4.8652 & 4.6011 & TRN & \\
\hline CHEMBL3194650 & 688855 & 4.81800 & 00000000 & 4.7807 & TRN \\
\hline CHEMBL1414223 & 688855 & 6.5784 & 4.2327 & TST & \\
\hline CHEMBL492116 & 688855 & 4.5406 & 4.305 & TRN & \\
\hline CHEMBL1454258 & 688855 & 4.8608 & 4.0999 & TRN & \\
\hline CHEMBL1460831 & 688855 & 2.9208 & 3.1648 & TRN & \\
\hline CHEMBL1384659 & 688855 & 2.9208 & 3.5438 & TST & \\
\hline CHEMBL1302976 & 688855 & 4.6924 & 4.5831 & TRN & \\
\hline CHEMBL 3208063 & 688855 & 4.4076 & 5.0593 & TRN & \\
\hline CHEMBL1351823 & 688855 & 2.9208 & 3.1907 & TRN & \\
\hline CHEMBL1423670 & 688855 & 4.8856 & 5.00899 & 99999999995 & TRN \\
\hline CHEMBL1315795 & 688855 & 4.8432 & 4.8076 & TST & \\
\hline CHEMBL1468618 & 688855 & 8.0 & 4.73300 & 00000000005 & TRN \\
\hline CHEMBL1423344 & 688855 & 4.1924 & 4.5254 & TRN & \\
\hline CHEMBL1575609 & 688855 & 2.9208 & 3.4001 & TRN & \\
\hline CHEMBL1308583 & 688855 & 4.8708 & 4.415 & TRN & \\
\hline CHEMBL1605328 & 688855 & 2.9208 & 4.3828 & TST & \\
\hline CHEMBL1486570 & 688855 & 4.9257 & 4.6214 & TRN & \\
\hline CHEMBL1416018 & 688855 & 2.9208 & 3.4179 & TRN & \\
\hline CHEMBL1535700 & 688855 & 5.1394 & 5.131 & TRN & \\
\hline CHEMBL1385946 & 688855 & 6.857 & 5.7764 & TRN & \\
\hline CHEMBL1414244 & 688855 & 2.9208 & 3.9783 & TRN & \\
\hline CHEMBL1371482 & 688855 & 4.5555 & 4.8793 & TRN & \\
\hline CHEMBL1381002 & 688855 & 5.1151 & 4.2429 & TRN & \\
\hline CHEMBL1413214 & 688855 & 4.3134 & 4.4085 & TRN & \\
\hline CHEMBL1373880 & 688855 & 2.9208 & 3.4058 & TST & \\
\hline CHEMBL1504204 & 688855 & 2.9208 & 4.3275 & TRN & \\
\hline CHEMBL1457697 & 688855 & 2.9208 & 4.8504 & TRN & \\
\hline CHEMBL1518828 & 688855 & \multicolumn{2}{|c|}{6.2620000000000005} & 4.7113 & TST \\
\hline CHEMBL1353405 & 688855 & 4.8283 & 4.4208 & TRN & \\
\hline CHEMBL1459418 & 688855 & 6.0419 & 4.7559 & TRN & \\
\hline CHEMBL1520096 & 688855 & 4.56 & 5.0327 & TRN & \\
\hline CHEMBL1488930 & 688855 & 2.9208 & 4.7312 & TRN & \\
\hline CHEMBL1326068 & 688855 & 5.4423 & 5.0056 & TRN & \\
\hline CHEMBL1364610 & 688855 & 4.363 & 4.8016 & TRN & \\
\hline CHEMBL1350667 & 688855 & 4.7218 & 4.2632 & TRN & \\
\hline CHEMBL1462536 & 688855 & 4.7517 & 4.7016 & TRN & \\
\hline CHEMBL1510805 & 688855 & 4.8338 & 4.7344 & TRN & \\
\hline CHEMBL1493546 & 688855 & 5.0975 & 4.0335 & TST & \\
\hline CHEMBL1391282 & 688855 & 4.872 & 4.2078 & TRN & \\
\hline CHEMBL3190048 & 688855 & 4.2281 & 5.0364 & TST & \\
\hline CHEMBL1586474 & 688855 & 4.5952 & 4.9806 & TRN & \\
\hline
\end{tabular}


Supplemental Table S2.txt

\begin{tabular}{|c|c|c|c|c|c|}
\hline CHEMBL1596598 & 688855 & 4.8902 & 4.7886 & TRN & \\
\hline CHEMBL1381979 & 688855 & 4.6229 & 4.7909 & TRN & \\
\hline CHEMBL1419183 & 688855 & 5.0517 & 4.6322 & TST & \\
\hline CHEMBL1588752 & 688855 & 5.0551 & 4.6452 & TRN & \\
\hline CHEMBL1501925 & 688855 & 5.0712 & 4.5364 & TRN & \\
\hline CHEMBL1597364 & 688855 & 2.9208 & 4.6457 & TRN & \\
\hline CHEMBL1467146 & 688855 & 4.9668 & 4.4274 & TST & \\
\hline CHEMBL1536258 & 688855 & 4.6093 & 6.1878 & TST & \\
\hline CHEMBL1352816 & 688855 & 4.2248 & 4.2746 & TRN & \\
\hline CHEMBL1453224 & 688855 & 4.936 & 4.5499 & TST & \\
\hline CHEMBL1585189 & 688855 & 4.8157 & 4.0968 & TRN & \\
\hline CHEMBL1347160 & 688855 & 4.9954 & 4.8988 & TRN & \\
\hline CHEMBL1549548 & 688855 & 2.9208 & 4.1563 & TRN & \\
\hline CHEMBL1597587 & 688855 & 2.9208 & 3.7025 & TRN & \\
\hline CHEMBL1320994 & 688855 & 2.9208 & 3.2126 & TRN & \\
\hline CHEMBL1347288 & 688855 & 6.9393 & 5.2203 & TRN & \\
\hline CHEMBL1401099 & 688855 & 5.2822 & 5.66100 & 00000000005 & TRN \\
\hline CHEMBL1532225 & 688855 & 2.9208 & 4.1483 & TRN & \\
\hline CHEMBL1491707 & 688855 & 2.9208 & 4.9404 & TRN & \\
\hline CHEMBL1371851 & 688855 & 2.9208 & 5.0793 & TRN & \\
\hline CHEMBL1446080 & 688855 & 4.1092 & 4.47 & TRN & \\
\hline CHEMBL1309143 & 688855 & 4.8027 & 4.6945 & TST & \\
\hline CHEMBL1518669 & 688855 & 2.9208 & 3.7963 & TRN & \\
\hline CHEMBL1559717 & 688855 & 4.7004 & 5.2812 & TRN & \\
\hline CHEMBL1602646 & 688855 & 2.9208 & 3.2815 & TRN & \\
\hline CHEMBL1487137 & 688855 & 4.2495 & 4.4478 & TRN & \\
\hline CHEMBL1347002 & 688855 & 4.636 & 4.7657 & TRN & \\
\hline CHEMBL1336959 & 688855 & 2.9208 & 4.4652 & TRN & \\
\hline CHEMBL1575576 & 688855 & 4.4589 & 4.71399 & & TRN \\
\hline CHEMBL1520703 & 688855 & 6.5258 & 6.0441 & TRN & \\
\hline CHEMBL1466165 & 688855 & 4.8425 & 3.2707 & TRN & \\
\hline CHEMBL1310007 & 688855 & 4.9152 & 4.9179 & TRN & \\
\hline CHEMBL1461102 & 688855 & 4.4875 & 4.2793 & TRN & \\
\hline CHEMBL1347104 & 688855 & 4.7429 & 3.6354 & TRN & \\
\hline CHEMBL1520621 & 688855 & 4.782 & 3.9439 & TRN & \\
\hline CHEMBL1565105 & 688855 & 4.8024 & 4.3631 & TRN & \\
\hline CHEMBL1410534 & 688855 & 4.468 & 4.5798 & TRN & \\
\hline CHEMBL585622 & 688855 & 2.9208 & 4.2151 & TRN & \\
\hline CHEMBL1364646 & 688855 & 6.9136 & 6.75299 & & TRN \\
\hline CHEMBL1547409 & 688855 & 4.8281 & 4.8286 & TRN & \\
\hline CHEMBL1557320 & 688855 & 6.8447 & 4.5695 & TRN & \\
\hline CHEMBL1396533 & 688855 & 5.3684 & 5.0552 & TRN & \\
\hline CHEMBL1301421 & 688855 & 4.4842 & 5.358 & TRN & \\
\hline CHEMBL1313750 & 688855 & \multicolumn{3}{|c|}{4.7989999999999995} & TS \\
\hline CHEMBL1603708 & 688855 & 5.1384 & 4.7268 & TRN & \\
\hline CHEMBL1313467 & 688855 & 4.7901 & 4.4653 & TRN & \\
\hline CHEMBL1558912 & 688855 & 4.0794 & 4.3022 & TRN & \\
\hline CHEMBL1613402 & 688855 & 4.8512 & 4.2155 & TRN & \\
\hline
\end{tabular}




\begin{tabular}{|c|c|c|c|c|c|}
\hline \multicolumn{6}{|c|}{ Supplemental Table S2.txt } \\
\hline CHEMBL1527546 & 688855 & 4.4183 & 4.7211 & TRN & \\
\hline CHEMBL3198682 & 688855 & 2.9208 & 4.7475 & TRN & \\
\hline CHEMBL1392365 & 688855 & 2.9208 & 4.2439 & TRN & \\
\hline CHEMBL1534465 & 688855 & 4.8752 & 4.3849 & TRN & \\
\hline CHEMBL1581881 & 688855 & 4.8335 & 3.7497 & TRN & \\
\hline CHEMBL1324465 & 688855 & 5.3201 & 5.0962 & TRN & \\
\hline CHEMBL1587454 & 688855 & 4.7284 & 4.5037 & TRN & \\
\hline CHEMBL1415834 & 688855 & 4.8252 & 4.9315 & TRN & \\
\hline CHEMBL1253586 & 688855 & 4.8663 & 4.967 & TST & \\
\hline CHEMBL1382183 & 688855 & 2.9208 & 3.3518 & TRN & \\
\hline CHEMBL1306731 & 688855 & 4.6222 & 4.7387 & TRN & \\
\hline CHEMBL1536255 & 688855 & 4.9802 & 5.3616 & TRN & \\
\hline CHEMBL1197872 & 688855 & 2.9208 & 4.187 & TST & \\
\hline CHEMBL1588575 & 688855 & 6.2692 & 5.144 & TRN & \\
\hline CHEMBL1569728 & 688855 & 5.1337 & 4.9583 & TRN & \\
\hline CHEMBL1998940 & 688855 & 4.8848 & 3.5732 & TRN & \\
\hline CHEMBL1575033 & 688855 & 4.8581 & 5.2603 & TRN & \\
\hline CHEMBL1491252 & 688855 & 2.9208 & 3.4843 & TST & \\
\hline CHEMBL1526806 & 688855 & $5.1270 e$ & 0000000 & 4.6133 & TRN \\
\hline CHEMBL1389262 & 688855 & 5.3171 & 5.5985 & TRN & \\
\hline CHEMBL1392472 & 688855 & 4.7157 & 4.0771 & TRN & \\
\hline CHEMBL1503386 & 688855 & 4.8362 & 5.0892 & TST & \\
\hline CHEMBL1374465 & 688855 & 4.8029 & 4.2529 & TST & \\
\hline CHEMBL1340051 & 688855 & 2.9208 & 3.3871 & TRN & \\
\hline CHEMBL1581385 & 688855 & 5.107 & 5.0365 & TRN & \\
\hline CHEMBL1480985 & 688855 & 2.9208 & 3.4782 & TRN & \\
\hline CHEMBL1387251 & 688855 & 8.0 & 5.0958 & TRN & \\
\hline CHEMBL1462785 & 688855 & 2.9208 & 3.44100 & 00000000003 & TRN \\
\hline CHEMBL1581554 & 688855 & 4.3739 & 4.5522 & TRN & \\
\hline CHEMBL1596703 & 688855 & 2.9208 & 5.0334 & TRN & \\
\hline CHEMBL 3208320 & 688855 & 2.9208 & 4.4899 & TRN & \\
\hline CHEMBL1608645 & 688855 & 4.7069 & 4.2804 & TRN & \\
\hline CHEMBL1414067 & 688855 & 6.9136 & 4.9374 & TST & \\
\hline CHEMBL3194597 & 688855 & 4.4568 & 4.6749 & TRN & \\
\hline CHEMBL1459112 & 688855 & 4.8868 & 5.0469 & TRN & \\
\hline CHEMBL1366112 & 688855 & 4.952 & 4.9342 & TRN & \\
\hline CHEMBL1418678 & 688855 & 2.9208 & 5.2552 & TRN & \\
\hline CHEMBL1583314 & 688855 & 2.9208 & 4.202 & TRN & \\
\hline CHEMBL1526338 & 688855 & 4.6096 & 4.3337 & TRN & \\
\hline CHEMBL1469600 & 688855 & 4.5759 & 4.9183 & TST & \\
\hline CHEMBL1440361 & 688855 & 2.9208 & 3.4464 & TRN & \\
\hline CHEMBL1557898 & 688855 & 6.7328 & 6.8874 & TRN & \\
\hline CHEMBL1465534 & 688855 & 2.9208 & 4.8343 & TRN & \\
\hline CHEMBL1492000 & 688855 & 4.8402 & 4.9859 & TST & \\
\hline CHEMBL1572244 & 688855 & 2.9208 & 4.7378 & TRN & \\
\hline CHEMBL1347564 & 688855 & 4.6557 & 4.7246 & TRN & \\
\hline CHEMBL1432814 & 688855 & 4.8306 & 4.6319 & TRN & \\
\hline CHEMBL1997288 & 688855 & 2.9208 & 4.4618 & TRN & \\
\hline
\end{tabular}




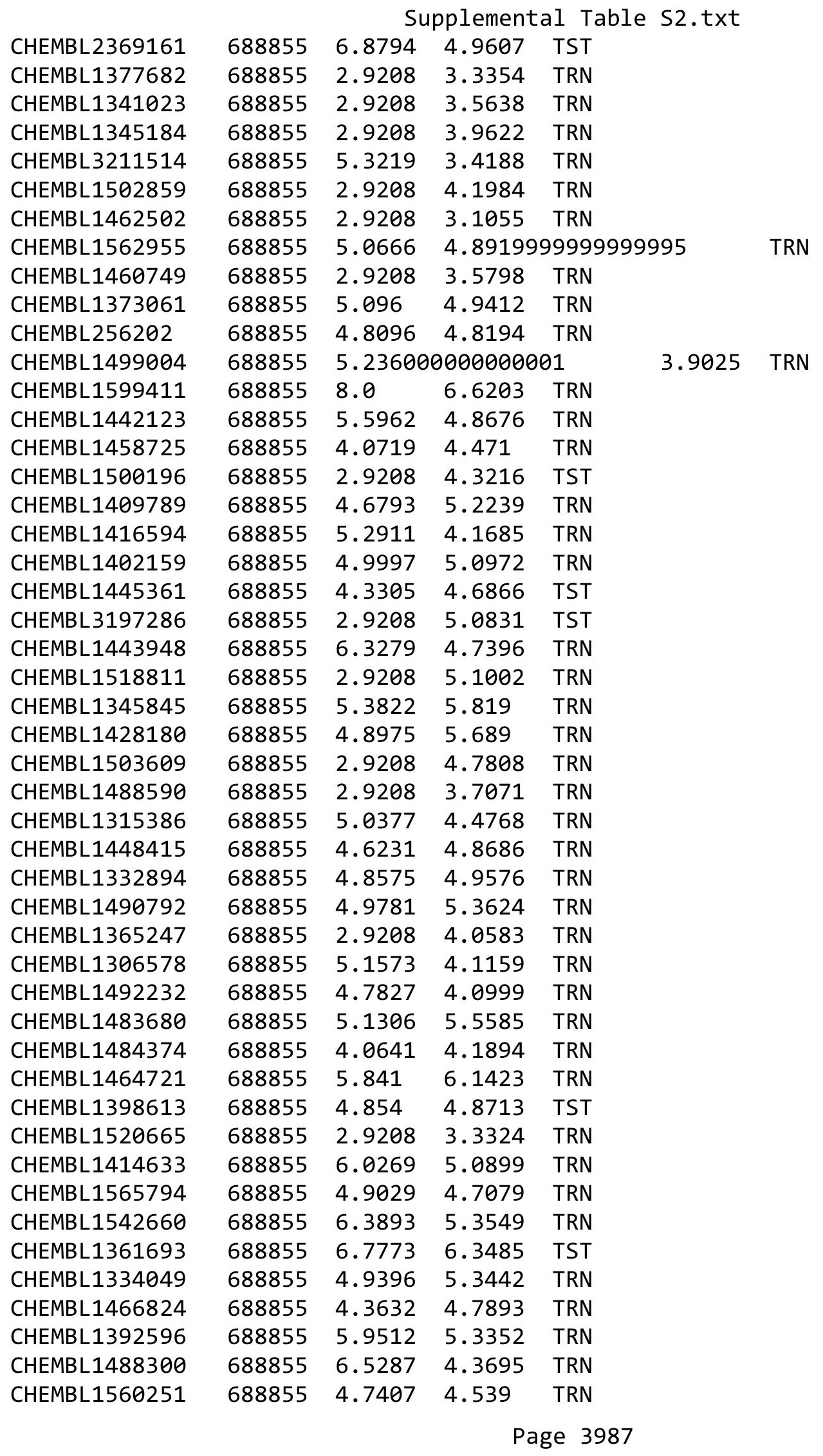




\begin{tabular}{|c|c|c|c|c|c|}
\hline \multicolumn{6}{|c|}{ Supplemental Table S2.txt } \\
\hline CHEMBL1556289 & 688855 & 6.7825 & 4.2067 & TRN & \\
\hline CHEMBL1339785 & 688855 & 8.0 & 4.1999 & TST & \\
\hline CHEMBL1991311 & 688855 & 4.8724 & 5.4603 & TRN & \\
\hline CHEMBL1510630 & 688855 & 2.9208 & 4.4558 & TRN & \\
\hline CHEMBL 1478726 & 688855 & 5.2084 & 4.8888 & TRN & \\
\hline CHEMBL1467543 & 688855 & 4.8358 & 4.6898 & TRN & \\
\hline CHEMBL1426292 & 688855 & 4.4019 & 4.5012 & TRN & \\
\hline CHEMBL1335650 & 688855 & 4.782 & 3.8025 & TST & \\
\hline CHEMBL1459415 & 688855 & 2.9208 & 3.4785 & TRN & \\
\hline CHEMBL1465298 & 688855 & 4.8941 & 5.0437 & TRN & \\
\hline CHEMBL1577329 & 688855 & 5.1948 & 5.0905 & TRN & \\
\hline CHEMBL1387115 & 688855 & 4.8724 & 4.9376 & TRN & \\
\hline CHEMBL1573961 & 688855 & 4.9339 & 5.5793 & TRN & \\
\hline CHEMBL1536037 & 688855 & 2.9208 & 3.7453 & TRN & \\
\hline CHEMBL1501741 & 688855 & 4.2389 & 5.0615 & TRN & \\
\hline CHEMBL3190857 & 688855 & 2.9208 & 4.5442 & TRN & \\
\hline CHEMBL1362914 & 688855 & 4.4636 & 4.3223 & TRN & \\
\hline CHEMBL1323962 & 688855 & 4.9172 & 4.7705 & TRN & \\
\hline CHEMBL1533823 & 688855 & 3.2218 & 4.5311 & TRN & \\
\hline CHEMBL1499905 & 688855 & 6.433 & 6.2529 & TRN & \\
\hline CHEMBL1367400 & 688855 & 4.1755 & 5.0432 & TRN & \\
\hline CHEMBL1336412 & 688855 & 2.9208 & 4.8913 & TRN & \\
\hline CHEMBL1403377 & 688855 & 4.7352 & 4.4924 & TRN & \\
\hline CHEMBL3198668 & 688855 & 6.7033 & 5.1715 & TRN & \\
\hline CHEMBL1582426 & 688855 & 4.7799 & 3.2131 & TRN & \\
\hline CHEMBL1450420 & 688855 & 3.9829 & 4.5064 & TRN & \\
\hline CHEMBL1415813 & 688855 & 5.4525 & 4.5108 & TRN & \\
\hline CHEMBL1517230 & 688855 & 4.9719 & 3.89399 & 99999999997 & TRN \\
\hline CHEMBL1347694 & 688855 & 2.9208 & 4.6661 & TRN & \\
\hline CHEMBL1379181 & 688855 & 2.9208 & 5.0074 & TRN & \\
\hline CHEMBL1446875 & 688855 & 4.2733 & 4.9929 & TST & \\
\hline CHEMBL1562944 & 688855 & 5.2787 & 4.7022 & TRN & \\
\hline CHEMBL1597879 & 688855 & 2.9208 & 3.3729 & TRN & \\
\hline CHEMBL1569976 & 688855 & 5.1834 & 4.5619 & TRN & \\
\hline CHEMBL1416745 & 688855 & 4.9139 & 4.7955 & TRN & \\
\hline CHEMBL1377188 & 688855 & 8.0 & 4.365 & TRN & \\
\hline CHEMBL1439902 & 688855 & 6.9747 & 5.6931 & TST & \\
\hline CHEMBL1564911 & 688855 & 5.0246 & 4.26399 & э999999999 & TRN \\
\hline CHEMBL1602105 & 688855 & 2.9208 & 3.3971 & TRN & \\
\hline CHEMBL1308386 & 688855 & 4.3451 & 4.8909 & TRN & \\
\hline CHEMBL1415140 & 688855 & 6.9101 & 4.7687 & TRN & \\
\hline CHEMBL3199639 & 688855 & 6.7423 & 6.9092 & TRN & \\
\hline CHEMBL1401958 & 688855 & 2.9208 & 4.1034 & TRN & \\
\hline CHEMBL3191741 & 688855 & 4.8126 & 5.3944 & TRN & \\
\hline CHEMBL1547901 & 688855 & 2.9208 & 5.845 & TRN & \\
\hline CHEMBL1556354 & 688855 & 4.8277 & 4.4987 & TRN & \\
\hline CHEMBL1484631 & 688855 & 2.9208 & 3.8102 & TRN & \\
\hline CHEMBL1586235 & 688855 & 5.2689 & 5.1967 & TRN & \\
\hline
\end{tabular}




\begin{tabular}{|c|c|c|c|c|c|}
\hline & & \multicolumn{4}{|c|}{ Supplemental Table S2.txt } \\
\hline CHEMBL1436348 & 688855 & 4.8296 & 4.0474 & TRN & \\
\hline CHEMBL1370259 & 688855 & 5.95 & 5.1716 & TRN & \\
\hline CHEMBL1421119 & 688855 & 2.9208 & 3.8557 & TRN & \\
\hline CHEMBL1350591 & 688855 & 2.9208 & 4.2787 & TRN & \\
\hline CHEMBL1551926 & 688855 & 5.0978 & 4.9212 & TST & \\
\hline CHEMBL1304553 & 688855 & 4.7524 & 5.2066 & TRN & \\
\hline CHEMBL1299603 & 688855 & 4.1948 & 4.8405 & TRN & \\
\hline CHEMBL1535025 & 688855 & 2.9208 & 4.7569 & TRN & \\
\hline CHEMBL1977683 & 688855 & 6.3862 & 4.8903 & TRN & \\
\hline CHEMBL1528931 & 688855 & 4.7158 & 4.7095 & TRN & \\
\hline CHEMBL1603505 & 688855 & 4.959 & 4.8233 & TRN & \\
\hline CHEMBL3194157 & 688855 & 4.9237 & 4.497 & TRN & \\
\hline CHEMBL1517603 & 688855 & 6.1163 & 6.3233 & TRN & \\
\hline CHEMBL1401270 & 688855 & \multicolumn{3}{|c|}{4.0680000000000005} & TRN \\
\hline CHEMBL3194314 & 688855 & 4.9577 & 5.0307 & TRN & \\
\hline CHEMBL1370907 & 688855 & 4.8161 & 4.9128 & TRN & \\
\hline CHEMBL1588037 & 688855 & 4.7569 & 4.9615 & TRN & \\
\hline CHEMBL1575735 & 688855 & 4.6956 & 4.2045 & TRN & \\
\hline CHEMBL1328741 & 688855 & 5.3579 & 4.3856 & TRN & \\
\hline CHEMBL1510632 & 688855 & 2.9208 & 4.3834 & TRN & \\
\hline CHEMBL1323437 & 688855 & 2.9208 & 3.63199 & 99999999997 & TRN \\
\hline CHEMBL1548929 & 688855 & 5.0303 & 5.6996 & TRN & \\
\hline CHEMBL1476311 & 688855 & 8.0 & 5.3414 & TRN & \\
\hline CHEMBL1586145 & 688855 & 8.0 & 6.5487 & TRN & \\
\hline CHEMBL1450173 & 688855 & 4.928 & 4.9308 & TRN & \\
\hline CHEMBL1482199 & 688855 & 4.3756 & 4.5164 & TRN & \\
\hline CHEMBL3190267 & 688855 & 5.1801 & 5.099 & TRN & \\
\hline CHEMBL1439775 & 688855 & 5.2022 & 4.9389 & TRN & \\
\hline CHEMBL1358960 & 688855 & 4.2749 & 4.9145 & TRN & \\
\hline CHEMBL1449093 & 688855 & 4.8208 & 4.7155 & TRN & \\
\hline CHEMBL1567527 & 688855 & 4.638 & 4.1711 & TRN & \\
\hline CHEMBL3199242 & 688855 & 4.8436 & 5.0008 & TRN & \\
\hline CHEMBL1488263 & 688855 & 4.3473 & 5.5994 & TRN & \\
\hline CHEMBL1321519 & 688855 & 6.5654 & 6.0865 & TRN & \\
\hline CHEMBL1331973 & 688855 & 2.9208 & 3.44 & TRN & \\
\hline CHEMBL1320060 & 688855 & 4.8286 & 4.4378 & TRN & \\
\hline CHEMBL1325798 & 688855 & 5.2521 & 4.7657 & TST & \\
\hline CHEMBL1496209 & 688855 & 2.9208 & 5.0541 & TRN & \\
\hline CHEMBL1541650 & 688855 & 2.9208 & 4.645 & TRN & \\
\hline CHEMBL3191418 & 688855 & 8.0 & 4.7418 & TRN & \\
\hline CHEMBL1323478 & 688855 & 5.0947 & 4.83 & TRN & \\
\hline CHEMBL3211892 & 688855 & 4.7177 & 3.3341 & TST & \\
\hline CHEMBL1572722 & 688855 & 6.2958 & 5.0421 & TRN & \\
\hline CHEMBL1386822 & 688855 & 6.4012 & 6.1577 & TRN & \\
\hline CHEMBL3208065 & 688855 & 4.738 & 4.9348 & TRN & \\
\hline CHEMBL476190 & 688855 & 5.2224 & 4.5921 & TRN & \\
\hline CHEMBL1411474 & 688855 & 2.9208 & 3.7242 & TRN & \\
\hline CHEMBL1306554 & 688855 & 4.2444 & 4.9533 & TRN & \\
\hline
\end{tabular}




\begin{tabular}{|c|c|c|c|c|c|c|}
\hline & & \multicolumn{5}{|c|}{ Supplemental Table S2.txt } \\
\hline CHEMBL1342148 & 688855 & 4.926 & 5.1431 & TRN & & \\
\hline CHEMBL1613430 & 688855 & 2.9208 & 5.1305 & TST & & \\
\hline CHEMBL1362521 & 688855 & 4.0374 & 3.812 & TRN & & \\
\hline CHEMBL1600643 & 688855 & 2.9208 & 3.4295 & TRN & & \\
\hline CHEMBL1423521 & 688855 & 4.9904 & 4.8872 & TRN & & \\
\hline CHEMBL1606899 & 688855 & 4.9415 & 4.6347 & TST & & \\
\hline CHEMBL1539762 & 688855 & 4.8075 & 4.7862 & TRN & & \\
\hline CHEMBL3212478 & 688855 & 4.7208 & 6.2883 & TRN & & \\
\hline CHEMBL1308677 & 688855 & 5.4078 & 4.5732 & TRN & & \\
\hline CHEMBL1484081 & 688855 & 5.1446 & 4.9355 & TRN & & \\
\hline CHEMBL1417174 & 688855 & 8.0 & 5.8519 & TRN & & \\
\hline CHEMBL1395615 & 688855 & 6.1129 & 5.3278 & TST & & \\
\hline CHEMBL1555525 & 688855 & 6.4089 & 4.4542 & TRN & & \\
\hline CHEMBL1574660 & 688855 & 4.7471 & 4.4955 & TRN & & \\
\hline CHEMBL1409246 & 688855 & 6.8928 & 5.6981 & TRN & & \\
\hline CHEMBL1588679 & 688855 & 2.9208 & 3.6402 & TST & & \\
\hline CHEMBL1516666 & 688855 & 6.9208 & 6.0004 & TRN & & \\
\hline CHEMBL1511276 & 688855 & 2.9208 & 4.2147 & TRN & & \\
\hline CHEMBL1464329 & 688855 & 4.8031 & 4.3068 & TRN & & \\
\hline CHEMBL1511867 & 688855 & 2.9208 & 4.0285 & TRN & & \\
\hline CHEMBL1342363 & 688855 & 2.9208 & 3.3786 & TRN & & \\
\hline CHEMBL3198096 & 688855 & 2.9208 & 3.4041 & TRN & & \\
\hline CHEMBL1364203 & 688855 & 2.9208 & 4.8727 & TRN & & \\
\hline CHEMBL1497725 & 688855 & 5.7775 & 4.2298 & TRN & & \\
\hline CHEMBL1355755 & 688855 & $6.7520 e$ & 000000000 & 01 & 7.4944 & TRN \\
\hline CHEMBL1463521 & 688855 & 2.9208 & 3.6775 & TRN & & \\
\hline CHEMBL1607064 & 688855 & 2.9208 & 3.3971 & TRN & & \\
\hline CHEMBL1435486 & 688855 & 5.5552 & 5.5086 & TRN & & \\
\hline CHEMBL1380103 & 688855 & 6.71899 & 999999999 & & 5.6092 & TRN \\
\hline CHEMBL1424562 & 688855 & 5.0604 & 4.678999 & 9999999999 & & TRN \\
\hline CHEMBL1588778 & 688855 & 4.397 & 4.3262 & TRN & & \\
\hline CHEMBL1580472 & 688855 & 2.9208 & 3.3943 & TRN & & \\
\hline CHEMBL1381492 & 688855 & 4.6816 & 4.3199 & TST & & \\
\hline CHEMBL3190074 & 688855 & 2.9208 & 5.3381 & TRN & & \\
\hline CHEMBL1409494 & 688855 & 2.9208 & 3.4295 & TRN & & \\
\hline CHEMBL1500007 & 688855 & 4.5636 & 4.9932 & TRN & & \\
\hline CHEMBL1563027 & 688855 & 2.9208 & 3.4079 & TST & & \\
\hline CHEMBL1334962 & 688855 & 4.8177 & 4.4287 & TRN & & \\
\hline CHEMBL3190599 & 688855 & 2.9208 & 3.323 & TRN & & \\
\hline CHEMBL1497338 & 688855 & 2.9208 & 3.5384 & TRN & & \\
\hline CHEMBL1449627 & 688855 & 8.0 & 6.0047 & TRN & & \\
\hline CHEMBL1485369 & 688855 & 2.9208 & 3.6718 & TRN & & \\
\hline CHEMBL1381236 & 688855 & 4.8049 & 4.4679 & TST & & \\
\hline CHEMBL1531932 & 688855 & 2.9208 & 5.1297 & TRN & & \\
\hline CHEMBL1350313 & 688855 & 2.9208 & 4.4564 & TRN & & \\
\hline CHEMBL1326529 & 688855 & 4.5382 & 4.7472 & TRN & & \\
\hline CHEMBL1319703 & 688855 & 5.7916 & 5.7364 & TRN & & \\
\hline CHEMBL1611417 & 688855 & 2.9208 & 4.6899 & TRN & & \\
\hline
\end{tabular}


Supplemental Table S2.txt

\begin{tabular}{|c|c|c|c|c|}
\hline AEMBL 3213109 & 8855 & 4.5845 & & \\
\hline HEMBL1379067 & & 2.9208 & & \\
\hline & & & & \\
\hline IEMBL578716 & & & & \\
\hline AEMBL1 & 855 & 9208 & 788 & \\
\hline AEMBL3190926 & 38855 & .9208 & 721 & \\
\hline IEMBL: & 855 & & & \\
\hline EMBL & & & & \\
\hline AEMBL & 3855 & 9208 & $\partial 29$ & \\
\hline AEMBL1522037 & 8855 & .4004 & 111 & \\
\hline AEMBL1 & 8855 & 96 & 483 & \\
\hline IEMBL: & 855 & 73 & 936 & \\
\hline EMBL & 855 & & & \\
\hline AEMBL & 855 & 5.9516 & 372 & \\
\hline IEMBL] & 855 & .7273 & 207 & \\
\hline EMBL: & 855 & $4.6 \varepsilon$ & & \\
\hline AEMBL & 855 & .0 & 06 & \\
\hline AEMBL & 855 & & & \\
\hline AEMBL & 855 & 4.5445 & & \\
\hline IEMBL & 855 & & & \\
\hline IEMBL & b - r r r & 5 . & & \\
\hline EMB & 55 & 5 & & \\
\hline EMB & 855 & 4. & & \\
\hline 00 & 855 & & 205 & \\
\hline IEMBL: & 55 & & & \\
\hline IEMBL & 855 & 4. & & \\
\hline EMBI & 55 & I & 03 & \\
\hline 66 & 355 & & 67 & \\
\hline 20 & & & & \\
\hline IEMBL3 & 55 & $4 . \varepsilon$ & & \\
\hline AEMBL: & 855 & 4.5 & & \\
\hline 30 & 355 & & & \\
\hline 54 & 55 & & & NIV \\
\hline AEMBL & & & & \\
\hline AEMBL1312428 & 855 & 5.4 & & \\
\hline 53 & 55 & & & \\
\hline 7 & 55 & 3 & & \\
\hline & & & & \\
\hline AEMBL1 & 8855 & 4.7 & & \\
\hline IEMBL: & 8855 & 5.2 & 64 & \\
\hline 61 & 855 & & & \\
\hline & & 4.56 & 892 & \\
\hline HEMBL: & 8855 & 4.2004 & 027 & \\
\hline IEMBL: & 8855 & 4.2816 & 182 & \\
\hline AEMBL & 8855 & 4.5 & 71 & \\
\hline CHEMBL & & 4.7 & & \\
\hline CHEMBL: & & 5.2714 & 4.7891 & \\
\hline CHEMBL1445085 & 688855 & 4.8513 & 3.661 & \\
\hline
\end{tabular}

Page 3991 


\begin{tabular}{|c|c|c|c|c|c|c|}
\hline & & \multicolumn{5}{|c|}{ Supplemental Table S2.txt } \\
\hline CHEMBL1362125 & 688855 & 2.9208 & 3.8703 & TRN & & \\
\hline CHEMBL495063 & 688855 & 6.5622 & 5.0412 & TST & & \\
\hline CHEMBL1367297 & 688855 & 4.7413 & 4.1756 & TST & & \\
\hline CHEMBL1459714 & 688855 & 8.0 & 4.7459 & TRN & & \\
\hline CHEMBL1392187 & 688855 & 4.6598 & 4.8437 & TRN & & \\
\hline CHEMBL1424179 & 688855 & 3.2218 & 4.5899 & TRN & & \\
\hline CHEMBL1450952 & 688855 & 4.5856 & 5.0354 & TRN & & \\
\hline CHEMBL1489179 & 688855 & 8.0 & 6.21 & TST & & \\
\hline CHEMBL1498481 & 688855 & 6.6696 & 5.6611 & TRN & & \\
\hline CHEMBL1352868 & 688855 & 4.8798 & 4.6269 & TRN & & \\
\hline CHEMBL1444545 & 688855 & 5.6262 & 4.9439 & TST & & \\
\hline CHEMBL1302081 & 688855 & 5.8477 & 4.8267 & TRN & & \\
\hline CHEMBL1374559 & 688855 & 2.9208 & 3.8191 & TRN & & \\
\hline CHEMBL1371175 & 688855 & 4.6641 & 5.5714 & TRN & & \\
\hline CHEMBL1374228 & 688855 & 3.2218 & 4.9405 & TRN & & \\
\hline CHEMBL1375390 & 688855 & 4.4485 & 4.334 & TRN & & \\
\hline CHEMBL1483099 & 688855 & 4.5254 & 4.572 & TRN & & \\
\hline CHEMBL1385987 & 688855 & 4.1323 & 5.1308 & TRN & & \\
\hline CHEMBL1308593 & 688855 & 4.9157 & 5.1497 & TRN & & \\
\hline CHEMBL1445899 & 688855 & 2.9208 & 3.2038 & TRN & & \\
\hline CHEMBL1519639 & 688855 & 8.0 & 6.1087 & TRN & & \\
\hline CHEMBL3194933 & 688855 & 5.6554 & 4.7311 & TRN & & \\
\hline CHEMBL1478305 & 688855 & 2.9208 & 4.993 & TRN & & \\
\hline CHEMBL1402596 & 688855 & 4.8463 & 5.0582 & TRN & & \\
\hline CHEMBL1561135 & 688855 & 6.7328 & 6.2787 & TRN & & \\
\hline CHEMBL3211325 & 688855 & 4.8631 & 5.1125 & TRN & & \\
\hline CHEMBL3197987 & 688855 & 5.21399 & 79999999 & 995 & 5.1049 & TRN \\
\hline CHEMBL1524702 & 688855 & 4.7509 & 4.3776 & TST & & \\
\hline CHEMBL1419590 & 688855 & 5.1316 & 5.2541 & TRN & & \\
\hline CHEMBL1589770 & 688855 & 2.9208 & 4.593 & TRN & & \\
\hline CHEMBL1414311 & 688855 & 2.9208 & 3.3851 & TRN & & \\
\hline CHEMBL1336722 & 688855 & 4.0483 & 4.8693 & TRN & & \\
\hline CHEMBL1534523 & 688855 & 5.5222 & 4.5471 & TST & & \\
\hline CHEMBL1517251 & 688855 & 5.0141 & 5.1995 & TRN & & \\
\hline CHEMBL1369424 & 688855 & 6.9747 & 4.822 & TST & & \\
\hline CHEMBL1579841 & 688855 & 6.2027 & 5.349 & TRN & & \\
\hline CHEMBL1496585 & 688855 & 4.6322 & 4.5009 & TRN & & \\
\hline CHEMBL1375823 & 688855 & 4.8138 & 5.0271 & TRN & & \\
\hline CHEMBL1464980 & 688855 & 4.9463 & 4.5835 & TRN & & \\
\hline CHEMBL1561067 & 688855 & 2.9208 & 3.4682 & TRN & & \\
\hline CHEMBL1470577 & 688855 & 4.3472 & 4.4491 & TRN & & \\
\hline CHEMBL585071 & 688855 & 2.9208 & 3.9573 & TRN & & \\
\hline CHEMBL1550851 & 688855 & 2.9208 & 3.7241 & TRN & & \\
\hline CHEMBL1367860 & 688855 & 4.7761 & 4.7213 & TST & & \\
\hline CHEMBL1564468 & 688855 & 2.9208 & 4.7949 & TRN & & \\
\hline CHEMBL1570236 & 688855 & 4.9405 & 4.6181 & TRN & & \\
\hline CHEMBL1974351 & 688855 & 4.7575 & 4.3193 & TRN & & \\
\hline CHEMBL3196904 & 688855 & 4.9596 & 4.7778 & TRN & & \\
\hline
\end{tabular}




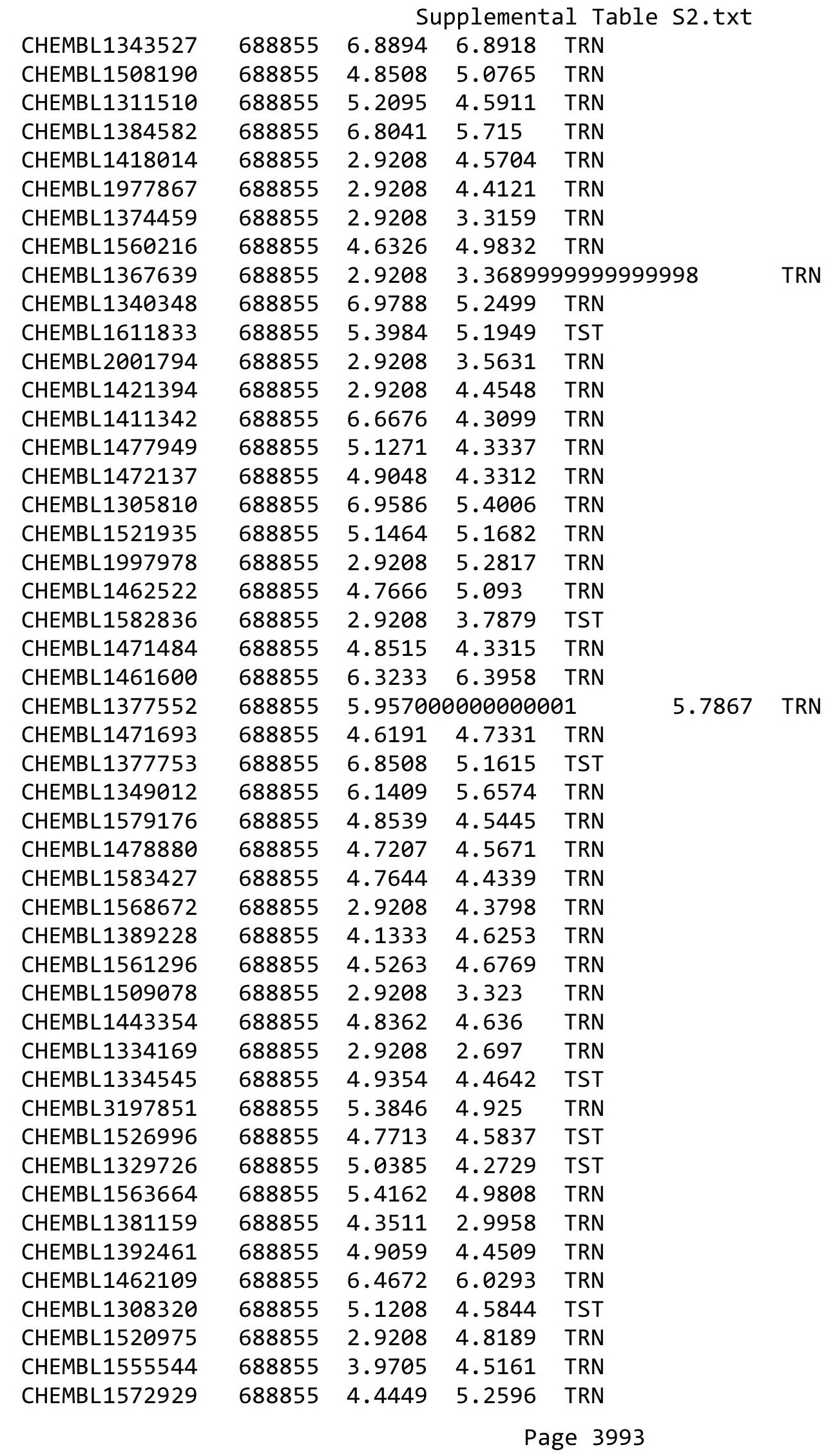


Supplemental Table S2.txt

\begin{tabular}{|c|c|c|c|c|}
\hline CHEMBL473613 & 688855 & 2.9208 & 4.643 & TST \\
\hline CHEMBL1451064 & 688855 & 5.4656 & 4.7653 & TRN \\
\hline CHEMBL1457445 & 688855 & 5.6844 & 4.3764 & TRN \\
\hline CHEMBL1371059 & 688855 & 5.3477 & 5.4997 & TRN \\
\hline CHEMBL1602676 & 688855 & 5.0537 & 4.3626 & TST \\
\hline CHEMBL1548458 & 688855 & 4.467 & 4.867 & TRN \\
\hline CHEMBL1460850 & 688855 & 5.3033 & 5.3182 & TRN \\
\hline CHEMBL1427687 & 688855 & 2.9208 & 5.3205 & TRN \\
\hline CHEMBL1501596 & 688855 & 4.5168 & 5.0319 & TRN \\
\hline CHEMBL1559721 & 688855 & 4.7238 & 5.0102 & TRN \\
\hline CHEMBL1493135 & 688855 & 5.0738 & 4.73 & TRN \\
\hline CHEMBL1307447 & 688855 & 4.8901 & 5.0307 & TRN \\
\hline CHEMBL1322727 & 688855 & 8.0 & 5.0601 & TRN \\
\hline CHEMBL1577017 & 688855 & 4.6067 & 4.6929 & TST \\
\hline CHEMBL1609144 & 688855 & 2.9208 & 4.5722 & TRN \\
\hline CHEMBL1442956 & 688855 & 4.7338 & 4.5795 & TRN \\
\hline CHEMBL1581345 & 688855 & 4.6594 & 5.3606 & TRN \\
\hline CHEMBL1468965 & 688855 & 2.9208 & 4.4528 & TRN \\
\hline CHEMBL1539579 & 688855 & 2.9208 & 4.8245 & TRN \\
\hline CHEMBL1410469 & 688855 & 5.1755 & 5.0443 & TRN \\
\hline CHEMBL1375414 & 688855 & 2.9208 & 4.3602 & TRN \\
\hline CHEMBL1368806 & 688855 & 2.9208 & 4.5626 & TRN \\
\hline CHEMBL473162 & 688855 & 6.5391 & 6.2745 & TRN \\
\hline CHEMBL1502624 & 688855 & 5.4012 & 5.2971 & TRN \\
\hline CHEMBL1530766 & 688855 & 2.9208 & 3.2847 & TRN \\
\hline CHEMBL1402346 & 688855 & 5.1403 & 4.9729 & TRN \\
\hline CHEMBL1987082 & 688855 & 8.0 & 6.8005 & TRN \\
\hline CHEMBL1401280 & 688855 & 2.9208 & 5.1017 & TRN \\
\hline CHEMBL1581155 & 688855 & 4.0187 & 4.1472 & TST \\
\hline CHEMBL1488333 & 688855 & 6.3344 & 4.8064 & TRN \\
\hline CHEMBL1341522 & 688855 & 4.5176 & 4.7737 & TRN \\
\hline CHEMBL1505273 & 688855 & 4.9092 & 5.2465 & TRN \\
\hline CHEMBL1998566 & 688855 & 5.0857 & 4.0236 & TRN \\
\hline CHEMBL1446387 & 688855 & 2.9208 & 3.3051 & TRN \\
\hline CHEMBL1080213 & 688855 & 6.6635 & \multicolumn{2}{|c|}{5.507000000000001} \\
\hline CHEMBL1364848 & 688855 & 2.9208 & 3.5555 & TST \\
\hline CHEMBL3190070 & 688855 & 4.955 & 5.2721 & TRN \\
\hline CHEMBL1503105 & 688855 & 4.0248 & 4.9363 & TRN \\
\hline CHEMBL1605139 & 688855 & 4.7705 & 4.5088 & TRN \\
\hline CHEMBL1404286 & 688855 & 5.0161 & 4.9919 & TRN \\
\hline CHEMBL1377335 & 688855 & 4.8987 & 5.2271 & TST \\
\hline CHEMBL1303143 & 688855 & 4.9048 & 5.3414 & TST \\
\hline CHEMBL1331200 & 688855 & 4.8576 & 4.7142 & TRN \\
\hline CHEMBL1445389 & 688855 & 5.0015 & 4.7421 & TRN \\
\hline CHEMBL1441404 & 688855 & 2.9208 & 3.9112 & TRN \\
\hline CHEMBL1535460 & 688855 & 5.0185 & 4.7934 & TRN \\
\hline CHEMBL1600990 & 688855 & 4.346 & \multicolumn{2}{|c|}{3.7110000000000003} \\
\hline CHEMBL1607650 & 688855 & 2.9208 & 4.7366 & TRN \\
\hline
\end{tabular}

Page 3994 


\begin{tabular}{|c|c|c|c|c|c|}
\hline \multirow[b]{2}{*}{ CHEMBL3210009 } & \multicolumn{5}{|c|}{ Supplemental Table S2.txt } \\
\hline & 688855 & 5.2913 & 5.0941 & TRN & \\
\hline CHEMBL 1450360 & 688855 & 4.0066 & 5.36600 & 00000000005 & TST \\
\hline CHEMBL1376011 & 688855 & 6.9355 & 5.7483 & TRN & \\
\hline CHEMBL1422056 & 688855 & 2.9208 & 5.1783 & TRN & \\
\hline CHEMBL 2000947 & 688855 & 2.9208 & 4.4606 & TRN & \\
\hline CHEMBL1318940 & 688855 & 2.9208 & 5.1785 & TRN & \\
\hline CHEMBL1387889 & 688855 & 2.9208 & 4.5918 & TRN & \\
\hline CHEMBL1574589 & 688855 & 3.2218 & 4.4166 & TRN & \\
\hline CHEMBL1383152 & 688855 & 5.0241 & 4.3754 & TRN & \\
\hline CHEMBL1491745 & 688855 & 8.0 & 3.9621 & TRN & \\
\hline CHEMBL1350621 & 688855 & 6.8508 & 6.17 & TRN & \\
\hline CHEMBL3208511 & 688855 & 4.9594 & 4.0468 & TRN & \\
\hline CHEMBL1508580 & 688855 & 2.9208 & 3.7102 & TRN & \\
\hline CHEMBL1502176 & 688855 & 2.9208 & 3.6436 & TRN & \\
\hline CHEMBL1310278 & 688855 & 4.8083 & 4.2341 & TRN & \\
\hline CHEMBL1416732 & 688855 & 4.4071 & 4.6548 & TRN & \\
\hline CHEMBL1579931 & 688855 & 4.8803 & 4.711 & TRN & \\
\hline CHEMBL1315161 & 688855 & 2.9208 & 4.5296 & TRN & \\
\hline CHEMBL1378325 & 688855 & 2.9208 & 3.6 & TRN & \\
\hline CHEMBL1466288 & 688855 & 4.8551 & 3.9127 & TRN & \\
\hline CHEMBL1335197 & 688855 & 4.3507 & 4.5524 & TRN & \\
\hline CHEMBL3208442 & 688855 & 4.8979 & 4.5049 & TST & \\
\hline CHEMBL1390595 & 688855 & 2.9208 & 4.9999 & TRN & \\
\hline CHEMBL1984604 & 688855 & 5.1492 & 4.7208 & TRN & \\
\hline CHEMBL1472505 & 688855 & 2.9208 & 4.121 & TRN & \\
\hline CHEMBL1327494 & 688855 & 4.8643 & 4.7163 & TRN & \\
\hline CHEMBL1389025 & 688855 & 4.8696 & 4.9261 & TRN & \\
\hline CHEMBL1549222 & 688855 & 2.9208 & 5.0521 & TST & \\
\hline CHEMBL1427062 & 688855 & 5.1409 & 6.3627 & TRN & \\
\hline CHEMBL3191360 & 688855 & 5.0228 & 4.9774 & TRN & \\
\hline CHEMBL3199635 & 688855 & 4.6794 & 4.6181 & TRN & \\
\hline CHEMBL1577430 & 688855 & 5.0233 & 5.1521 & TRN & \\
\hline CHEMBL1335318 & 688855 & 8.0 & 6.5435 & TRN & \\
\hline CHEMBL449336 & 688855 & 4.7948 & 4.8564 & TST & \\
\hline CHEMBL1484314 & 688855 & 4.4882 & 4.5901 & TRN & \\
\hline CHEMBL1390359 & 688855 & 4.8685 & 4.6776 & TRN & \\
\hline CHEMBL1559477 & 688855 & 4.5403 & 4.6666 & TRN & \\
\hline CHEMBL1514916 & 688855 & 4.1476 & 3.49300 & 00000000003 & TST \\
\hline CHEMBL1505540 & 688855 & 2.9208 & 3.3461 & TST & \\
\hline CHEMBL1565236 & 688855 & 5.1622 & 4.9671 & TRN & \\
\hline CHEMBL1971532 & 688855 & 6.6596 & 5.5831 & TRN & \\
\hline CHEMBL1566881 & 688855 & 6.9666 & 5.1987 & TRN & \\
\hline CHEMBL1423459 & 688855 & 2.9208 & 4.6162 & TRN & \\
\hline CHEMBL1471595 & 688855 & 2.9208 & 3.3481 & TST & \\
\hline CHEMBL1310486 & 688855 & 2.9208 & 4.0896 & TRN & \\
\hline CHEMBL1311224 & 688855 & 5.0569 & 4.8192 & TST & \\
\hline CHEMBL1378535 & 688855 & 5.0354 & 5.2752 & TRN & \\
\hline CHEMBL1562181 & 688855 & 4.9155 & 4.4097 & TST & \\
\hline
\end{tabular}


Supplemental Table S2.txt

\begin{tabular}{|c|c|c|c|c|}
\hline CHEMBL1409618 & 688855 & 6.5591 & 5.6151 & TRN \\
\hline CHEMBL1387546 & 688855 & 4.9996 & 4.941 & TRN \\
\hline CHEMBL1428012 & 688855 & 2.9208 & 3.71 & TRN \\
\hline CHEMBL1332476 & 688855 & 4.6673 & 4.7164 & TRN \\
\hline CHEMBL1977963 & 688855 & 2.9208 & 3.7925 & TRN \\
\hline CHEMBL1456045 & 688855 & 4.3858 & 5.17 & TRN \\
\hline CHEMBL1535087 & 688855 & 5.9957 & 5.7853 & TRN \\
\hline CHEMBL1487591 & 688855 & 4.7968 & 5.3134 & TRN \\
\hline CHEMBL1366133 & 688855 & 4.8872 & 4.7974 & TRN \\
\hline CHEMBL1303649 & 688855 & 4.8662 & 4.309 & TRN \\
\hline CHEMBL546475 & 688855 & 2.9208 & 4.1541 & TRN \\
\hline CHEMBL1443303 & 688855 & 2.9208 & 3.4008 & TRN \\
\hline CHEMBL1494085 & 688855 & 4.5812 & 4.3456 & TRN \\
\hline CHEMBL1494477 & 688855 & 4.6305 & 4.6521 & TRN \\
\hline CHEMBL1343460 & 688855 & 8.0 & 4.8686 & TST \\
\hline CHEMBL1517515 & 688855 & 4.4206 & 4.6997 & TRN \\
\hline CHEMBL1522322 & 688855 & 4.6463 & 4.3625 & TRN \\
\hline CHEMBL1605642 & 688855 & 4.5718 & 4.9518 & TRN \\
\hline CHEMBL249931 & 688855 & 4.8525 & 4.8057 & TST \\
\hline CHEMBL1462073 & 688855 & 4.8876 & 4.6139 & TRN \\
\hline CHEMBL1342518 & 688855 & 4.1735 & 4.0065 & TST \\
\hline CHEMBL1534724 & 688855 & 5.5411 & 4.6126 & TRN \\
\hline CHEMBL1974926 & 688855 & 2.9208 & 6.0412 & TRN \\
\hline CHEMBL1401683 & 688855 & 4.2102 & 4.8792 & TRN \\
\hline CHEMBL1460013 & 688855 & 4.8708 & 5.0927 & TRN \\
\hline CHEMBL1407379 & 688855 & 5.4171 & 4.5726 & TST \\
\hline CHEMBL1458423 & 688855 & 4.519 & 4.7897 & TRN \\
\hline CHEMBL1496663 & 688855 & 5.1599 & 3.313 & TRN \\
\hline CHEMBL1506367 & 688855 & 2.9208 & 3.7431 & TRN \\
\hline CHEMBL1402339 & 688855 & 4.0464 & 4.4972 & TRN \\
\hline CHEMBL1506291 & 688855 & 5.32 & 4.7695 & TRN \\
\hline CHEMBL1340446 & 688855 & 4.8441 & 4.8505 & TRN \\
\hline CHEMBL1337140 & 688855 & 4.7809 & 4.5395 & TRN \\
\hline CHEMBL1402372 & 688855 & 4.8602 & 4.756 & TRN \\
\hline CHEMBL1378090 & 688855 & 4.5909 & 5.0491 & TRN \\
\hline CHEMBL1424783 & 688855 & 2.9208 & 3.3294 & TRN \\
\hline CHEMBL1519624 & 688855 & 5.0995 & 4.9081 & TRN \\
\hline CHEMBL1544075 & 688855 & 5.1897 & 4.6477 & TST \\
\hline CHEMBL 3211154 & 688855 & 8.0 & 7.417999 & 9999999999 \\
\hline CHEMBL1443669 & 688855 & 4.9803 & 4.5004 & TRN \\
\hline CHEMBL1366110 & 688855 & 2.9208 & 3.3471 & TRN \\
\hline CHEMBL1527590 & 688855 & 4.5302 & 4.6577 & TST \\
\hline CHEMBL1417043 & 688855 & 5.2646 & 4.9722 & TRN \\
\hline CHEMBL1550661 & 688855 & 5.1522 & 4.2718 & TRN \\
\hline CHEMBL1610045 & 688855 & 4.581 & 4.2449 & TRN \\
\hline CHEMBL1466758 & 688855 & 5.461 & 4.737 & TRN \\
\hline CHEMBL1454540 & 688855 & 4.9305 & 4.6824 & TRN \\
\hline CHEMBL1467994 & 688855 & 2.9208 & 4.4058 & TST \\
\hline
\end{tabular}


Supplemental Table S2.txt

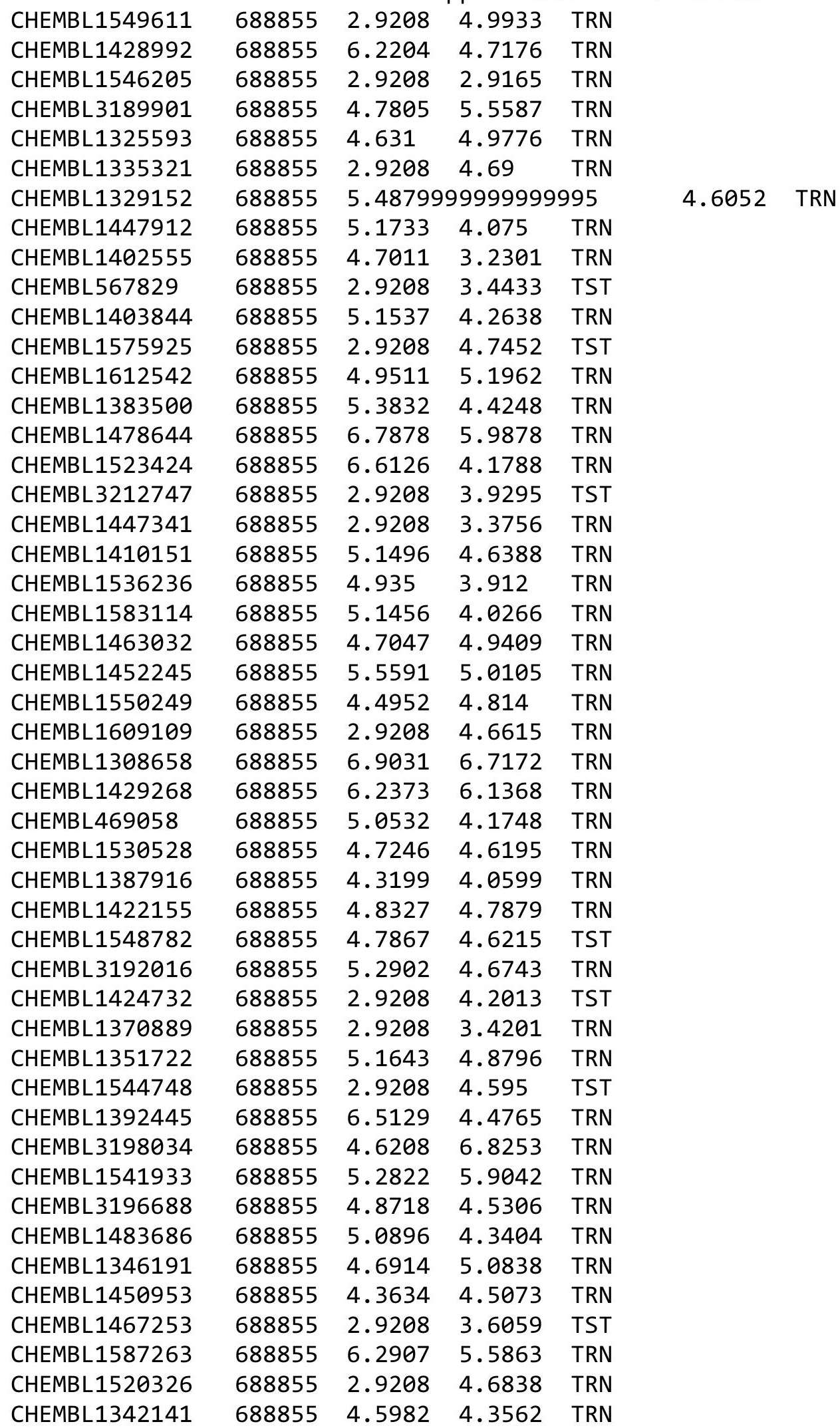

Page 3997 
Supplemental Table S2.txt

\begin{tabular}{|c|c|c|c|c|}
\hline HEMBL: & & & 32 & \\
\hline HEMRI 1531350 & 38855 & 2194 & 4.4566 & \\
\hline HEMBL1 & 3855 & 257 & & \\
\hline AEMBL1375371 & 8855 & 719 & 35 & \\
\hline HEMBL3212742 & 88855 & .8465 & 0544 & \\
\hline HEMBL1509760 & 38855 & 374 & 9987 & \\
\hline AEMBL1 & 8855 & 208 & & \\
\hline HEMBL1302741 & 88855 & 3097 & 56 & \\
\hline HEMBL3197123 & 88855 & 8.0 & 9569 & \\
\hline HEMBL1590783 & 88855 & 4.6609 & 1698 & \\
\hline HEMBL15 & 8855 & 386 & 142 & \\
\hline HEMBL] & 855 & 208 & & \\
\hline HEMBL1 & 855 & 924 & 7088 & \\
\hline AEMBL31 & 8855 & 147 & 749 & \\
\hline AEMBL160S & 855 & .7545 & 4.2527 & \\
\hline AEMBL1 & 55 & 208 & 26 & \\
\hline HEMBLI & & & & \\
\hline HEMBLI & 5 & 528 & & \\
\hline AEMBL1 & & 449 & & \\
\hline AEMBL16 & 55 & 208 & 01 & $\mathrm{NIN}$ \\
\hline EMBL & & 43 & & $\mathrm{RN}$ \\
\hline AEME & & & & RIV \\
\hline HEMBL1 & 5 & 278 & & \\
\hline AEMBL1 & & 62 & & \\
\hline AEMBL1 & 55 & 685 & & RIN \\
\hline IEMBL1 & & 08 & & ST \\
\hline FM & & & & $\mathrm{RN}$ \\
\hline STM & & & & $\mathrm{RN}$ \\
\hline AEMBL1 & & & & 「RN \\
\hline AEMBL157 & 55 & 271 & & RN \\
\hline AEMBL 1 & & 547 & & RN \\
\hline$\Gamma M$ & & 72 & & ГRN \\
\hline & & & & RN \\
\hline AEMBL158 & & & & 「RN \\
\hline AEMBL2e & 8855 & 38 & & RN \\
\hline AFMRI 1 & & 38 & & 「RN \\
\hline & & & & 「RN \\
\hline & & & & RN \\
\hline AEMBL152 & 8855 & 173 & & $\Gamma R$ \\
\hline EMBL & 855 & 352 & & 「RN \\
\hline HEMBL1 & 55 & 545 & & \\
\hline & & & & $\mathrm{RN}$ \\
\hline HEMBL15 & & 4.4088 & & IST \\
\hline IEMBL15 & 38855 & 667 & 82 & TR \\
\hline HEMBL13752 & & & & \\
\hline HEMBL1412 & 88855 & 4.8101 & & \\
\hline CHEMBL1321322 & & 4.6205 & & \\
\hline CHEMBL141013 & 688855 & 5.9674 & 4.577 & \\
\hline
\end{tabular}

Page 3998 
Supplemental Table S2.txt

\begin{tabular}{|c|c|c|c|c|}
\hline 720 & & .9208 & 7534 & \\
\hline HEMBL1538034 & & 367 & & \\
\hline AEMR I - & 5 & & & \\
\hline EMBL & 8855 & 97 & & \\
\hline AEMBL3195155 & 38855 & 1236 & 4377 & \\
\hline HEMBL152: & 88855 & 9208 & 3856 & \\
\hline HEMBL1 & 3855 & 592 & 15 & \\
\hline HEMBL134 & 855 & & & \\
\hline HEMBL1609703 & 88855 & 9208 & 2057 & \\
\hline HEMBL1600748 & 88855 & 208 & 5729 & \\
\hline HEMBL1405 & 855 & & & \\
\hline IEMBL & 855 & 74 & 414 & \\
\hline AEMBL3 & 855 & & & \\
\hline HEMBL1390438 & 88855 & 547 & 1123 & \\
\hline AEMBL1536 & 88855 & & & \\
\hline AEMBL1 & 55 & 12 & & \\
\hline AEMBL & & & & 促 \\
\hline HEMBL1 & 55 & & & \\
\hline AFMBL 3 & 855 & & & \\
\hline HEMBL1538 & 855 & & & \\
\hline HEMBL & 5 & & & NIV \\
\hline HEM & & & & ST \\
\hline AEMBL & 55 & & & \\
\hline AEMBL1 & 55 & & & \\
\hline HEMBL151 & 55 & 3 & 81 & I RN \\
\hline HEMBL1 & 855 & & & RN \\
\hline HEM & & & & RN \\
\hline HEMRI & & & & \\
\hline AEMBL1 & & & & IRN \\
\hline AEMBL156e & 38855 & & & TRN \\
\hline EMBL: & 55 & & & ST \\
\hline HFM & & & & 「RN \\
\hline 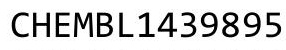 & & & & RN \\
\hline AEMBL150 & & & & ГST \\
\hline AEMBL154C & 8855 & & & RN \\
\hline IEMPI. & & & & ГST \\
\hline 3 & & & & TRN \\
\hline HEMBL1 & & & & TST \\
\hline HEMBL160 & 55 & & & TRN \\
\hline EMB & 55 & & & RN \\
\hline HEMBL1 & 55 & & 89 & TRN \\
\hline HEMBL1 & 55 & 4. & 27 & ST \\
\hline HEMBL1479133 & & & & TRN \\
\hline HEMBL137 & 55 & & & TR \\
\hline СНГMDI 120 & & & & \\
\hline HEMBL147 & & & & \\
\hline HEMBL1328903 & & 4. & 526 & \\
\hline CHEMBL1485166 & 688855 & 4.8409 & 4.4657 & $\mathrm{~K}$ \\
\hline
\end{tabular}

Page 3999 


\begin{tabular}{|c|c|c|c|c|c|c|}
\hline & & \multicolumn{5}{|c|}{ Supplemental Table S2.txt } \\
\hline CHEMBL1364200 & 688855 & 4.9391 & 4.4922 & TRN & & \\
\hline CHEMBL1599460 & 688855 & 5.1244 & 4.8732 & TRN & & \\
\hline CHEMBL560553 & 688855 & 4.7863 & 4.5417 & TRN & & \\
\hline CHEMBL1528986 & 688855 & 4.8817 & 4.5824 & TRN & & \\
\hline CHEMBL1542537 & 688855 & 4.5212 & 3.9545 & TRN & & \\
\hline CHEMBL1532364 & 688855 & 4.9358 & 4.6421 & TRN & & \\
\hline CHEMBL1440263 & 688855 & 4.5935 & 4.5681 & TRN & & \\
\hline CHEMBL1389557 & 688855 & 2.9208 & 4.838 & TST & & \\
\hline CHEMBL1313565 & 688855 & 5.4104 & 4.6188 & TRN & & \\
\hline CHEMBL1529862 & 688855 & 2.9208 & 3.909 & TRN & & \\
\hline CHEMBL1579339 & 688855 & 8.0 & 7.0145 & TRN & & \\
\hline CHEMBL1463025 & 688855 & 6.3325 & 6.0065 & TRN & & \\
\hline CHEMBL1594846 & 688855 & 2.9208 & 2.6981 & TRN & & \\
\hline CHEMBL1401589 & 688855 & 5.1955 & 4.745 & TRN & & \\
\hline CHEMBL1408191 & 688855 & 6.7799 & 4.8658 & TRN & & \\
\hline CHEMBL1549607 & 688855 & 4.878 & 4.6193 & TRN & & \\
\hline CHEMBL1312512 & 688855 & 4.9058 & 4.1927 & TRN & & \\
\hline CHEMBL1384726 & 688855 & 2.9208 & 3.4108 & TRN & & \\
\hline CHEMBL 1600446 & 688855 & 4.8833 & 4.6284 & TRN & & \\
\hline CHEMBL1490834 & 688855 & 2.9208 & 4.6079 & TRN & & \\
\hline CHEMBL1539301 & 688855 & 5.0727 & 4.1869 & TST & & \\
\hline CHEMBL1463302 & 688855 & 4.9058 & 4.1739 & TRN & & \\
\hline CHEMBL1386310 & 688855 & 6.7212 & 6.9614 & TRN & & \\
\hline CHEMBL3211496 & 688855 & 4.8244 & 4.4874 & TRN & & \\
\hline CHEMBL1517447 & 688855 & 4.9952 & 4.98 & TRN & & \\
\hline CHEMBL1462769 & 688855 & 4.9681 & 4.7853 & TRN & & \\
\hline CHEMBL1481964 & 688855 & 2.9208 & 3.4178 & TST & & \\
\hline CHEMBL1453532 & 688855 & 4.9236 & 4.1954 & TRN & & \\
\hline CHEMBL1544192 & 688855 & 5.3270 & 00000000 & $\partial 1$ & 4.45 & TRN \\
\hline CHEMBL1589689 & 688855 & 4.7387 & 4.6562 & TRN & & \\
\hline CHEMBL1419764 & 688855 & 4.9214 & 4.7553 & TRN & & \\
\hline CHEMBL1346887 & 688855 & 4.1473 & 4.874 & TRN & & \\
\hline CHEMBL1545433 & 688855 & 4.8761 & 5.3758 & TRN & & \\
\hline CHEMBL1870966 & 688855 & 2.9208 & 4.8552 & TRN & & \\
\hline CHEMBL1470903 & 688855 & 6.9872 & 6.3766 & TRN & & \\
\hline CHEMBL1583892 & 688855 & 4.3822 & 4.6081 & TRN & & \\
\hline CHEMBL1507946 & 688855 & 4.8234 & 4.7289 & TST & & \\
\hline CHEMBL1388766 & 688855 & 2.9208 & 3.4926 & TRN & & \\
\hline CHEMBL1455218 & 688855 & 6.5817 & 4.4643 & TRN & & \\
\hline CHEMBL3198486 & 688855 & 2.9208 & 4.5314 & TRN & & \\
\hline CHEMBL1501303 & 688855 & 5.3696 & 5.0366 & TRN & & \\
\hline CHEMBL1428141 & 688855 & 4.9963 & 4.4883 & TRN & & \\
\hline CHEMBL1449685 & 688855 & 6.3706 & 5.4445 & TRN & & \\
\hline CHEMBL3211169 & 688855 & 2.9208 & 3.4475 & TRN & & \\
\hline CHEMBL1534639 & 688855 & 5.1555 & 4.5524 & TRN & & \\
\hline CHEMBL1368839 & 688855 & 4.896 & 4.7821 & TRN & & \\
\hline CHEMBL1517682 & 688855 & 2.9208 & 4.2323 & TRN & & \\
\hline CHEMBL1610160 & 688855 & 4.6497 & 4.9277 & TRN & & \\
\hline
\end{tabular}




\begin{tabular}{|c|c|c|c|c|c|c|}
\hline \multicolumn{7}{|c|}{ Supplemental Table S2.txt } \\
\hline CHEMBL1977589 & 688855 & 8.0 & 6.8369 & TRN & & \\
\hline CHEMBL1578674 & 688855 & 2.9208 & 5.2197 & TRN & & \\
\hline CHEMBL1528180 & 688855 & 4.9613 & 4.3819 & TRN & & \\
\hline CHEMBL1502638 & 688855 & 2.9208 & 4.8859 & TRN & & \\
\hline CHEMBL1537753 & 688855 & 2.9208 & 4.583 & TRN & & \\
\hline CHEMBL1584711 & 688855 & 4.9675 & 4.6983 & TRN & & \\
\hline CHEMBL1513595 & 688855 & 5.9223 & 4.867 & TST & & \\
\hline CHEMBL1576324 & 688855 & 4.9213 & 4.5953 & TST & & \\
\hline CHEMBL1344260 & 688855 & 4.831 & 4.8372 & TRN & & \\
\hline CHEMBL1358797 & 688855 & 4.3647 & 4.5077 & TRN & & \\
\hline CHEMBL1448583 & 688855 & 4.8727 & 4.6168 & TRN & & \\
\hline CHEMBL1976271 & 688855 & 6.7721 & 3.9385 & TRN & & \\
\hline CHEMBL1388701 & 688855 & 4.7434 & 4.3459 & TRN & & \\
\hline CHEMBL1520035 & 688855 & 8.0 & 6.091 & TRN & & \\
\hline CHEMBL1344387 & 688855 & 4.9922 & 5.1532 & TRN & & \\
\hline CHEMBL1558072 & 688855 & 4.9028 & 4.4861 & TRN & & \\
\hline CHEMBL1486214 & 688855 & 2.9208 & 3.8184 & TRN & & \\
\hline CHEMBL1539263 & 688855 & $4.9110 e$ & 00000000 & 205 & 3077 & TRN \\
\hline CHEMBL1405274 & 688855 & 2.9208 & 3.9742 & TRN & & \\
\hline CHEMBL1307120 & 688855 & 4.7497 & 5.1099 & TRN & & \\
\hline CHEMBL1573309 & 688855 & 4.9935 & 4.149 & TRN & & \\
\hline CHEMBL1438259 & 688855 & 6.2612 & 4.8036 & TRN & & \\
\hline CHEMBL3211742 & 688855 & 4.8174 & 4.6305 & TRN & & \\
\hline CHEMBL1530830 & 688855 & 4.8059 & 4.6297 & TRN & & \\
\hline CHEMBL1381292 & 688855 & 4.9022 & 4.7275 & TRN & & \\
\hline CHEMBL1579395 & 688855 & 5.0252 & 4.899 & TRN & & \\
\hline CHEMBL1490486 & 688855 & 2.9208 & 3.6017 & TST & & \\
\hline CHEMBL3184145 & 688855 & 4.982 & 3.4563 & TRN & & \\
\hline CHEMBL1383700 & 688855 & 6.0376 & 4.9741 & TRN & & \\
\hline CHEMBL1501871 & 688855 & 3.9908 & 4.2675 & TRN & & \\
\hline CHEMBL1308668 & 688855 & 4.5039 & 5.3004 & TRN & & \\
\hline CHEMBL3195749 & 688855 & 2.9208 & 4.4428 & TRN & & \\
\hline CHEMBL1464193 & 688855 & 4.9009 & 4.4283 & TST & & \\
\hline CHEMBL1566477 & 688855 & 4.868 & 4.197 & TRN & & \\
\hline CHEMBL1554847 & 688855 & 6.7328 & 6.5423 & TRN & & \\
\hline CHEMBL1439137 & 688855 & 2.9208 & 5.4779 & TRN & & \\
\hline CHEMBL3192004 & 688855 & 5.8193 & 4.5242 & TRN & & \\
\hline CHEMBL1325363 & 688855 & 2.9208 & 3.71 & TRN & & \\
\hline CHEMBL1402410 & 688855 & 2.9208 & 4.0794 & TRN & & \\
\hline CHEMBL1505310 & 688855 & 6.556 & 4.952 & TRN & & \\
\hline CHEMBL1337171 & 688855 & 4.7494 & 4.7887 & TRN & & \\
\hline CHEMBL1596117 & 688855 & 4.8199 & 6.0905 & TRN & & \\
\hline CHEMBL1439783 & 688855 & 2.9208 & 3.6918 & TRN & & \\
\hline CHEMBL1379768 & 688855 & 4.8363 & 4.6173 & TRN & & \\
\hline CHEMBL1486199 & 688855 & 5.08 & 4.556 & TRN & & \\
\hline CHEMBL1346228 & 688855 & 2.9208 & 4.9568 & TST & & \\
\hline CHEMBL1571645 & 688855 & 4.9916 & 4.8755 & TST & & \\
\hline CHEMBL3198658 & 688855 & 5.0831 & 5.0064 & TRN & & \\
\hline
\end{tabular}




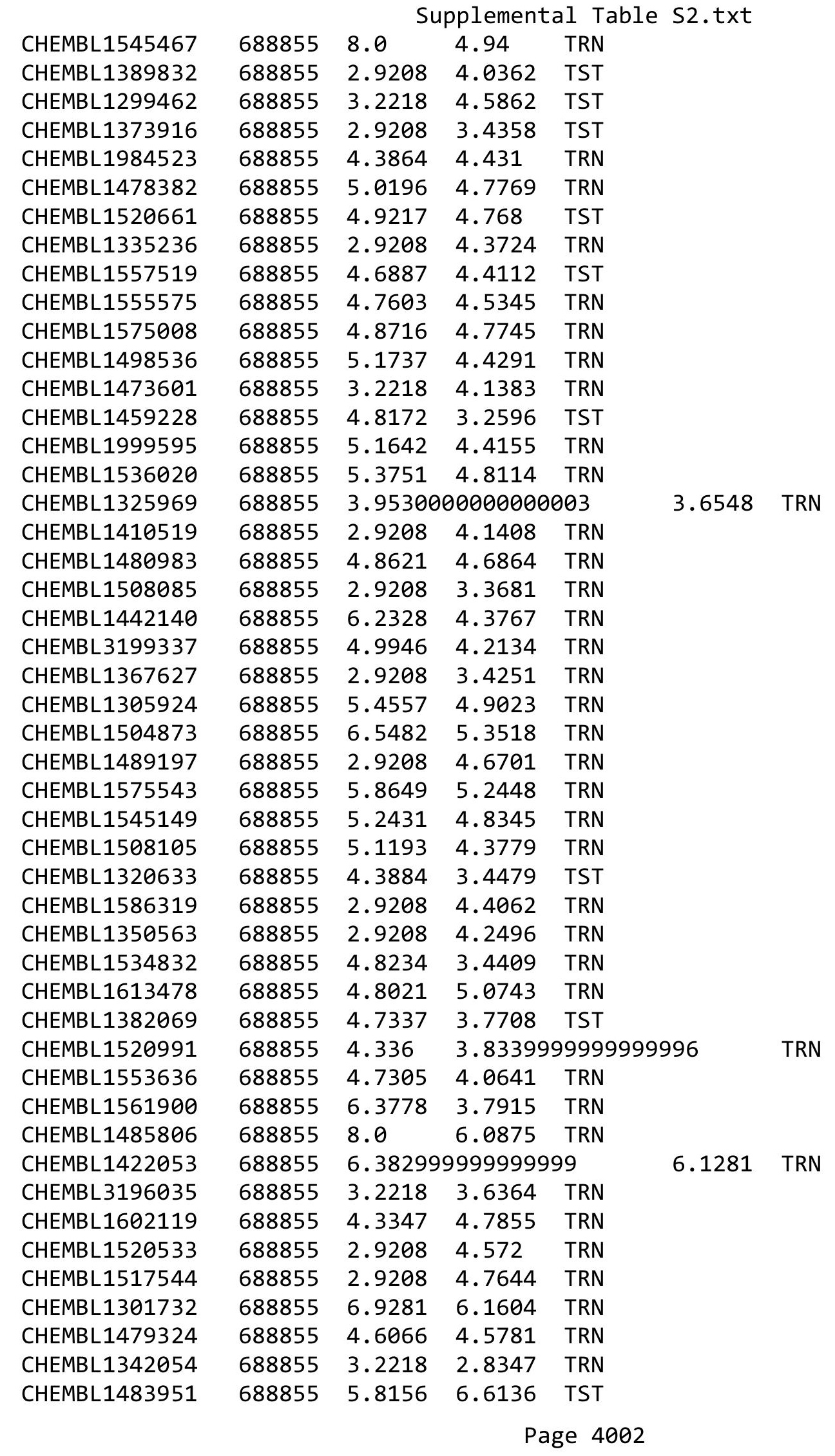


Supplemental Table S2.txt

\begin{tabular}{|c|c|c|c|c|c|}
\hline CHEMBL1369984 & 688855 & 6.7077 & 4.4018 & TRN & \\
\hline CHEMBL1346199 & 688855 & 4.7311 & 4.6412 & TRN & \\
\hline CHEMBL1340076 & 688855 & 4.3923 & 3.7966 & TRN & \\
\hline CHEMBL1464300 & 688855 & 5.087 & 4.795 & TRN & \\
\hline CHEMBL1338990 & 688855 & 2.9208 & 3.4743 & TST & \\
\hline CHEMBL1362566 & 688855 & 4.9029 & 4.1012 & TRN & \\
\hline CHEMBL1583898 & 688855 & 4.5368 & 4.8175 & TRN & \\
\hline CHEMBL1447796 & 688855 & 2.9208 & 3.466 & TRN & \\
\hline CHEMBL1495908 & 688855 & 4.9702 & 4.6744 & TRN & \\
\hline CHEMBL3196435 & 688855 & 4.005 & 5.2702 & TRN & \\
\hline CHEMBL1301035 & 688855 & 4.4306 & 4.1421 & TST & \\
\hline CHEMBL1464256 & 688855 & 6.5935 & 4.7489 & TRN & \\
\hline CHEMBL1568474 & 688855 & 6.399 & 4.4022 & TST & \\
\hline CHEMBL1579833 & 688855 & 6.3279 & 4.7911 & TST & \\
\hline CHEMBL1542533 & 688855 & 8.0 & 6.1426 & TRN & \\
\hline CHEMBL1586872 & 688855 & 5.2272 & 4.7506 & TRN & \\
\hline CHEMBL1450011 & 688855 & 5.0118 & 4.5075 & TRN & \\
\hline CHEMBL1373917 & 688855 & 4.7227 & 5.0903 & TST & \\
\hline CHEMBL1337770 & 688855 & 5.3557 & 5.16799 & 9999999999 & TRN \\
\hline CHEMBL1304189 & 688855 & 4.7378 & 4.4563 & TST & \\
\hline CHEMBL1342306 & 688855 & 4.1406 & 4.6553 & TRN & \\
\hline CHEMBL 3197511 & 688855 & 2.9208 & 3.5467 & TRN & \\
\hline CHEMBL1425445 & 688855 & 5.1976 & 4.1159 & TRN & \\
\hline CHEMBL1576454 & 688855 & 5.0777 & 4.8759 & TRN & \\
\hline CHEMBL1426951 & 688855 & 4.8733 & 4.9399 & TRN & \\
\hline CHEMBL1470281 & 688855 & 5.768 & 3.8112 & TST & \\
\hline CHEMBL1337145 & 688855 & 4.7693 & 5.204 & TRN & \\
\hline CHEMBL1359655 & 688855 & 2.9208 & 3.2701 & TRN & \\
\hline CHEMBL1378700 & 688855 & 6.4389 & 4.0128 & TST & \\
\hline CHEMBL1335336 & 688855 & 4.7537 & 5.2415 & TRN & \\
\hline CHEMBL1574074 & 688855 & 6.4449 & 4.7234 & TRN & \\
\hline CHEMBL1555816 & 688855 & 5.2541 & 4.6051 & TRN & \\
\hline CHEMBL1584746 & 688855 & 5.1432 & 5.0382 & TRN & \\
\hline CHEMBL 3190273 & 688855 & 6.6596 & 5.9375 & TRN & \\
\hline CHEMBL1401292 & 688855 & 2.9208 & 4.5924 & TRN & \\
\hline CHEMBL1459195 & 688855 & 4.7192 & 4.6597 & TRN & \\
\hline CHEMBL1584117 & 688855 & 2.9208 & 3.4322 & TRN & \\
\hline CHEMBL1592550 & 688855 & 4.9434 & 5.4274 & TRN & \\
\hline CHEMBL1507676 & 688855 & 7.0 & 7.5912 & TRN & \\
\hline CHEMBL1542591 & 688855 & 5.0471 & 4.8575 & TRN & \\
\hline CHEMBL1464924 & 688855 & 6.3778 & 4.899 & TRN & \\
\hline CHEMBL1465725 & 688855 & 4.8608 & 5.2953 & TRN & \\
\hline CHEMBL1393965 & 688855 & 4.9144 & 5.1727 & TRN & \\
\hline CHEMBL1343994 & 688855 & 5.3292 & 4.8168 & TRN & \\
\hline CHEMBL1556113 & 688855 & 4.9351 & 4.4179 & TRN & \\
\hline CHEMBL1378221 & 688855 & 5.1944 & 4.86 & TRN & \\
\hline CHEMBL1578551 & 688855 & 2.9208 & 4.3707 & TST & \\
\hline CHEMBL1405368 & 688855 & 6.0878 & 4.8666 & TRN & \\
\hline
\end{tabular}




\begin{tabular}{|c|c|c|c|c|c|c|}
\hline & & \multicolumn{5}{|c|}{ Supplemental Table S2.txt } \\
\hline CHEMBL1566972 & 688855 & 6.4168 & 4.8928 & TRN & & \\
\hline CHEMBL1566459 & 688855 & 5.3334 & 5.9344 & TRN & & \\
\hline CHEMBL1420870 & 688855 & 2.9208 & 4.2669 & TRN & & \\
\hline CHEMBL1305698 & 688855 & 3.2218 & 5.3247 & TRN & & \\
\hline CHEMBL1432801 & 688855 & 5.0117 & 5.4876 & TRN & & \\
\hline CHEMBL3211758 & 688855 & 2.9208 & 3.4956 & TRN & & \\
\hline CHEMBL1523761 & 688855 & 4.0696 & 4.1756 & TRN & & \\
\hline CHEMBL1330543 & 688855 & 4.5429 & 5.1263 & TRN & & \\
\hline CHEMBL1528010 & 688855 & 4.7133 & 4.7533 & TRN & & \\
\hline CHEMBL1427219 & 688855 & 2.9208 & 4.9917 & TRN & & \\
\hline CHEMBL1453649 & 688855 & 4.8644 & 4.5319 & TRN & & \\
\hline CHEMBL1304741 & 688855 & 2.9208 & 4.3192 & TRN & & \\
\hline CHEMBL1542766 & 688855 & 2.9208 & 4.4193 & TST & & \\
\hline CHEMBL1363818 & 688855 & 2.9208 & 3.2951 & TRN & & \\
\hline CHEMBL1302420 & 688855 & 5.1459 & 4.3796 & TRN & & \\
\hline CHEMBL1583182 & 688855 & 4.8359 & 4.2365 & TRN & & \\
\hline CHEMBL1366559 & 688855 & 4.9552 & 5.0079 & TRN & & \\
\hline CHEMBL1486606 & 688855 & 2.9208 & 4.1074 & TRN & & \\
\hline CHEMBL1345705 & 688855 & 2.9208 & 4.6963 & TRN & & \\
\hline CHEMBL1489593 & 688855 & 6.9355 & 4.337 & TRN & & \\
\hline CHEMBL1485099 & 688855 & 5.0148 & 4.3928 & TRN & & \\
\hline CHEMBL1549899 & 688855 & 5.0885 & 4.5385 & TRN & & \\
\hline CHEMBL1508749 & 688855 & \multicolumn{3}{|c|}{4.8180000000000005} & 4.5423 & \\
\hline CHEMBL3191398 & 688855 & 8.0 & 5.8063 & TRN & & \\
\hline CHEMBL1527152 & 688855 & 2.9208 & 4.421 & TRN & & \\
\hline CHEMBL1525026 & 688855 & 4.0836 & 4.8292 & TRN & & \\
\hline CHEMBL1535665 & 688855 & 2.9208 & 3.2338 & TRN & & \\
\hline CHEMBL1481541 & 688855 & 6.4179 & 5.0662 & TRN & & \\
\hline CHEMBL1368046 & 688855 & 2.9208 & 3.2411 & TRN & & \\
\hline CHEMBL1305543 & 688855 & 2.9208 & 3.9642 & TRN & & \\
\hline CHEMBL1588715 & 688855 & 5.1639 & 4.6983 & TRN & & \\
\hline CHEMBL1491767 & 688855 & 4.7807 & 5.0658 & TRN & & \\
\hline CHEMBL1467750 & 688855 & 2.9208 & 3.4674 & TST & & \\
\hline CHEMBL1498996 & 688855 & 5.3087 & 4.5683 & TRN & & \\
\hline CHEMBL3192267 & 688855 & 4.8456 & 4.8373 & TST & & \\
\hline CHEMBL1599076 & 688855 & 5.0438 & 5.6569 & TRN & & \\
\hline CHEMBL1425046 & 688855 & 6.3251 & 6.0801 & TRN & & \\
\hline CHEMBL3198603 & 688855 & 4.9368 & 5.0286 & TST & & \\
\hline CHEMBL3193974 & 688855 & 5.2463 & 5.5785 & TRN & & \\
\hline CHEMBL1444579 & 688855 & 4.8958 & 4.404 & TRN & & \\
\hline CHEMBL1353083 & 688855 & 4.3216 & 4.8567 & TRN & & \\
\hline CHEMBL1977995 & 688855 & 2.9208 & 3.1832 & TRN & & \\
\hline CHEMBL1403313 & 688855 & 2.9208 & 4.4638 & TRN & & \\
\hline CHEMBL1322536 & 688855 & 4.604 & 3.8656 & TST & & \\
\hline CHEMBL1362757 & 688855 & 2.9208 & 3.5572 & TRN & & \\
\hline CHEMBL1530653 & 688855 & 2.9208 & 4.9811 & TRN & & \\
\hline CHEMBL1416166 & 688855 & 6.6003 & 5.1872 & TRN & & \\
\hline CHEMBL1422337 & 688855 & 5.1556 & 5.1735 & TRN & & \\
\hline
\end{tabular}


Supplemental Table S2.txt

\begin{tabular}{|c|c|c|c|c|}
\hline CHEMBL1540417 & 688855 & 6.9208 & 6.4526 & TRN \\
\hline CHEMBL1535680 & 688855 & 5.343 & 4.8028 & TRN \\
\hline CHEMBL1578816 & 688855 & 4.7506 & 4.3367 & TRN \\
\hline CHEMBL1981770 & 688855 & 2.9208 & 3.4849 & TST \\
\hline CHEMBL1386396 & 688855 & 6.0752 & 4.4492 & TRN \\
\hline CHEMBL1561085 & 688855 & 4.8459 & 3.5502 & TST \\
\hline CHEMBL1513113 & 688855 & 5.4113 & 4.4612 & TRN \\
\hline CHEMBL1443936 & 688855 & 6.3072 & 6.4564 & TRN \\
\hline CHEMBL 3213940 & 688855 & 4.0344 & 4.5594 & TRN \\
\hline CHEMBL3193057 & 688855 & 4.9454 & 4.8974 & TRN \\
\hline CHEMBL1348831 & 688855 & 5.4455 & 5.0025 & TRN \\
\hline CHEMBL1399973 & 688855 & 5.4999 & 5.7876 & TRN \\
\hline CHEMBL1440725 & 688855 & 5.0985 & 4.5144 & TRN \\
\hline CHEMBL1301526 & 688855 & 4.5218 & 5.245 & TRN \\
\hline CHEMBL1413789 & 688855 & 4.9629 & 4.5705 & TRN \\
\hline CHEMBL1446574 & 688855 & 8.0 & 5.8388 & TRN \\
\hline CHEMBL1352852 & 688855 & 2.9208 & 3.0804 & TRN \\
\hline CHEMBL1362093 & 688855 & 2.9208 & 3.7708 & TRN \\
\hline CHEMBL1457432 & 688855 & 2.9208 & 4.2502 & TRN \\
\hline CHEMBL1454113 & 688855 & 5.8877 & 5.2513 & TST \\
\hline CHEMBL1543194 & 688855 & 4.5964 & 4.598 & TRN \\
\hline CHEMBL1447118 & 688855 & 4.84 & 4.7317 & TRN \\
\hline CHEMBL1494242 & 688855 & 4.7081 & 4.3945 & TRN \\
\hline CHEMBL1521723 & 688855 & 4.9227 & 4.6302 & TRN \\
\hline CHEMBL1358035 & 688855 & 6.4123 & 5.0542 & TRN \\
\hline CHEMBL1344382 & 688855 & 2.9208 & 4.7172 & TST \\
\hline CHEMBL1451747 & 688855 & 2.9208 & 3.3633 & TRN \\
\hline CHEMBL3191975 & 688855 & 5.0016 & 6.5046 & TST \\
\hline CHEMBL1582073 & 688855 & 4.9449 & 4.7505 & TST \\
\hline CHEMBL1491779 & 688855 & 5.0665 & 3.4442 & TRN \\
\hline CHEMBL1602816 & 688855 & 5.1057 & 4.4178 & TRN \\
\hline CHEMBL1349194 & 688855 & 2.9208 & 4.1846 & TRN \\
\hline CHEMBL1439149 & 688855 & 4.9041 & 3.8609 & TRN \\
\hline CHEMBL1415109 & 688855 & 4.8421 & 4.0485 & TRN \\
\hline CHEMBL1595927 & 688855 & 5.2146 & 5.1936 & TRN \\
\hline CHEMBL1994673 & 688855 & 6.9747 & 5.401 & TRN \\
\hline CHEMBL 3193472 & 688855 & 4.5388 & 3.56100 & 00000000004 \\
\hline CHEMBL1517426 & 688855 & 2.9208 & 3.2872 & TRN \\
\hline CHEMBL1540046 & 688855 & 2.9208 & 3.1366 & TRN \\
\hline CHEMBL1529438 & 688855 & 4.4739 & 4.7004 & TST \\
\hline CHEMBL1343061 & 688855 & 4.7475 & 4.9751 & TRN \\
\hline CHEMBL1521031 & 688855 & 6.5467 & 4.3902 & TRN \\
\hline CHEMBL1307534 & 688855 & 2.9208 & 3.3273 & TRN \\
\hline CHEMBL1377181 & 688855 & 4.2595 & 4.5335 & TST \\
\hline CHEMBL1378580 & 688855 & 4.7811 & 5.083 & TRN \\
\hline CHEMBL1495474 & 688855 & 8.0 & 6.4024 & TRN \\
\hline CHEMBL1321786 & 688855 & 4.2538 & 3.9939 & TRN \\
\hline CHEMBL1540638 & 688855 & 5.4839 & 5.2117 & TRN \\
\hline
\end{tabular}




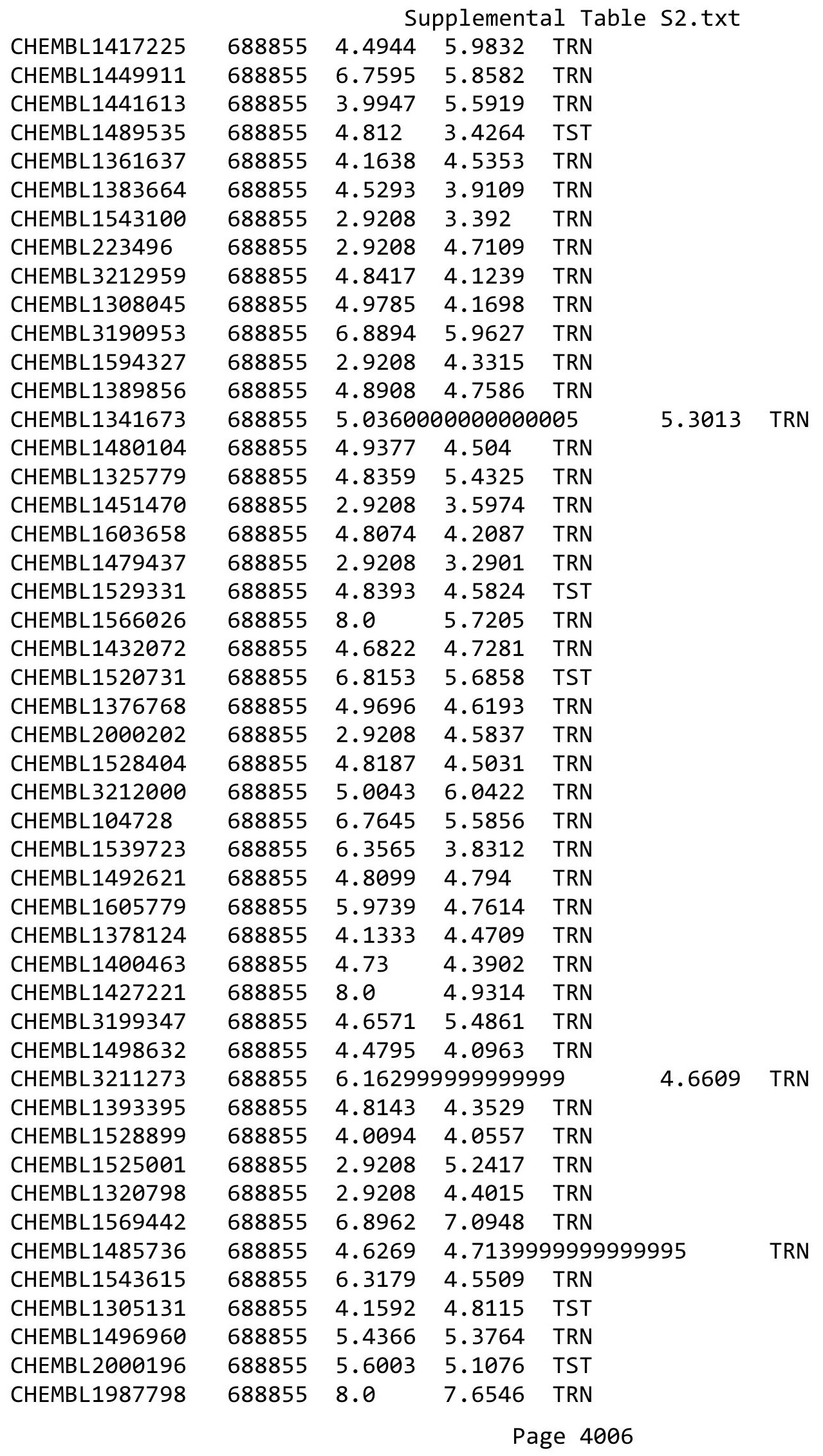




\begin{tabular}{|c|c|c|c|c|c|c|}
\hline & & \multicolumn{5}{|c|}{ Supplemental Table S2.txt } \\
\hline CHEMBL1446233 & 688855 & 5.513 & 5.6291 & TRN & & \\
\hline CHEMBL1501282 & 688855 & 4.4478 & 6.0761 & TRN & & \\
\hline CHEMBL1599132 & 688855 & 5.0034 & 3.5684 & TRN & & \\
\hline CHEMBL1464966 & 688855 & 5.5804 & 5.9067 & TRN & & \\
\hline CHEMBL1522903 & 688855 & 8.0 & 4.3454 & TRN & & \\
\hline CHEMBL1387150 & 688855 & 2.9208 & 5.9088 & TRN & & \\
\hline CHEMBL1511429 & 688855 & 2.9208 & 4.2038 & TRN & & \\
\hline CHEMBL1560476 & 688855 & 4.6621 & 4.8313 & TRN & & \\
\hline CHEMBL 1324770 & 688855 & 4.8806 & 4.5692 & TRN & & \\
\hline CHEMBL1407407 & 688855 & 4.9706 & 4.9283 & TST & & \\
\hline CHEMBL1411542 & 688855 & 5.4097 & 5.6553 & TRN & & \\
\hline CHEMBL1303960 & 688855 & \multicolumn{3}{|c|}{4.888999999999999} & 4.4856 & TRN \\
\hline CHEMBL1479214 & 688855 & 5.3696 & 4.8037 & TRN & & \\
\hline CHEMBL1518379 & 688855 & 4.9048 & 4.3305 & TRN & & \\
\hline CHEMBL1428107 & 688855 & 4.8387 & 4.9099 & TRN & & \\
\hline CHEMBL3210221 & 688855 & 2.9208 & 4.3635 & TST & & \\
\hline CHEMBL1382098 & 688855 & 5.2513 & 4.2727 & TRN & & \\
\hline CHEMBL3195413 & 688855 & 2.9208 & 3.3183 & TRN & & \\
\hline CHEMBL512649 & 688855 & 2.9208 & 4.3919 & TST & & \\
\hline CHEMBL1511747 & 688855 & 4.9344 & 5.2642 & TRN & & \\
\hline CHEMBL1304331 & 688855 & 4.9149 & 4.7418 & TRN & & \\
\hline CHEMBL1412704 & 688855 & 4.9349 & 4.8106 & TRN & & \\
\hline CHEMBL1406155 & 688855 & 5.2853 & 5.6545 & TRN & & \\
\hline CHEMBL3189326 & 688855 & \multicolumn{3}{|c|}{4.7989999999999995} & 3.6646 & TST \\
\hline CHEMBL1323910 & 688855 & 4.8767 & 4.4092 & TST & & \\
\hline CHEMBL3191856 & 688855 & 6.4547 & 5.3444 & TRN & & \\
\hline CHEMBL1433770 & 688855 & 4.9071 & 4.8634 & TRN & & \\
\hline CHEMBL1399126 & 688855 & 2.9208 & 4.1092 & TST & & \\
\hline CHEMBL1531035 & 688855 & 4.8259 & 4.7825 & TRN & & \\
\hline CHEMBL1541632 & 688855 & 4.8097 & 4.9668 & TST & & \\
\hline CHEMBL1468717 & 688855 & 4.8122 & 4.4123 & TRN & & \\
\hline CHEMBL1427626 & 688855 & 2.9208 & 5.2619 & TRN & & \\
\hline CHEMBL3196868 & 688855 & 6.8356 & 5.9937 & TST & & \\
\hline CHEMBL1328740 & 688855 & 5.2263 & 4.4613 & TRN & & \\
\hline CHEMBL1369590 & 688855 & 2.9208 & 4.5774 & TRN & & \\
\hline CHEMBL1428468 & 688855 & 3.2218 & 5.2881 & TRN & & \\
\hline CHEMBL1437043 & 688855 & 4.8761 & 4.4658 & TRN & & \\
\hline CHEMBL1362558 & 688855 & 4.8934 & 4.8577 & TRN & & \\
\hline CHEMBL1335434 & 688855 & 5.1938 & 3.9253 & TRN & & \\
\hline CHEMBL1342491 & 688855 & 5.9614 & 3.8169 & TST & & \\
\hline CHEMBL1424980 & 688855 & 5.2873 & 4.5959 & TRN & & \\
\hline CHEMBL1564290 & 688855 & 4.7991 & 4.3698 & TRN & & \\
\hline CHEMBL1574508 & 688855 & 4.3831 & 4.6206 & TRN & & \\
\hline CHEMBL1395312 & 688855 & 6.3439 & 4.1365 & TRN & & \\
\hline CHEMBL1547757 & 688855 & 5.0975 & 4.8607 & TRN & & \\
\hline CHEMBL1544322 & 688855 & 4.027 & 4.7521 & TRN & & \\
\hline CHEMBL1589285 & 688855 & 4.4483 & 4.4403 & TRN & & \\
\hline CHEMBL1530139 & 688855 & 5.1393 & 4.5038 & TRN & & \\
\hline
\end{tabular}




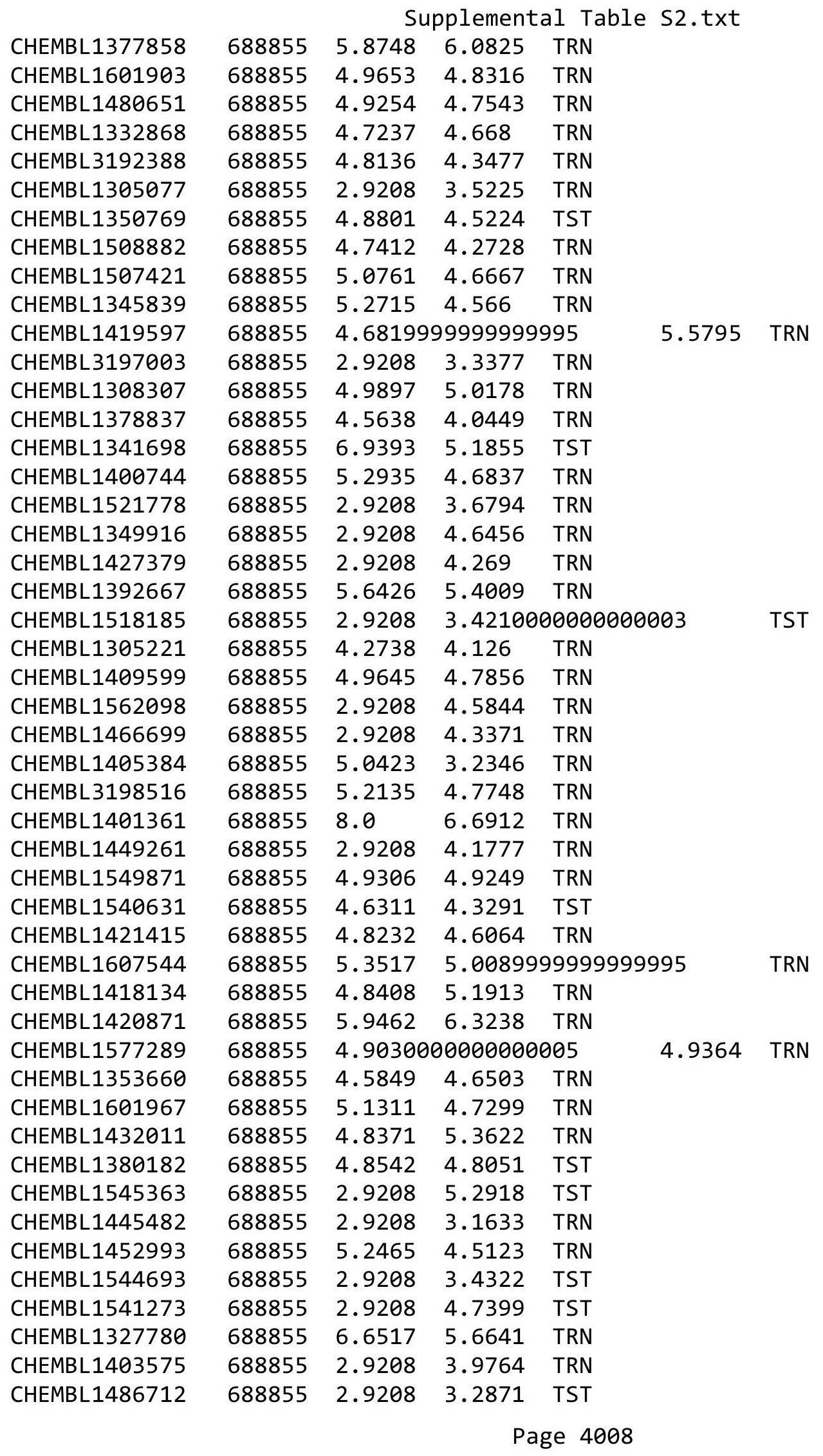


Supplemental Table S2.txt

\begin{tabular}{|c|c|c|c|c|c|c|}
\hline CHEMBL1534490 & 688855 & 2.9208 & 3.4004 & TST & & \\
\hline CHEMBL1491711 & 688855 & 4.8575 & 3.2071 & TRN & & \\
\hline CHEMBL1306090 & 688855 & 5.5504 & 5.2567 & TRN & & \\
\hline CHEMBL1385806 & 688855 & 2.9208 & 4.3656 & TRN & & \\
\hline CHEMBL3199616 & 688855 & 4.8331 & 4.3402 & TRN & & \\
\hline CHEMBL1403095 & 688855 & 3.9281 & 4.8679 & TRN & & \\
\hline CHEMBL1325354 & 688855 & 8.0 & 5.3205 & TRN & & \\
\hline CHEMBL1347531 & 688855 & 6.9914 & 5.6973 & TRN & & \\
\hline CHEMBL1412792 & 688855 & 4.9567 & 3.7798 & TRN & & \\
\hline CHEMBL1393076 & 688855 & 2.9208 & 4.5324 & TRN & & \\
\hline CHEMBL1515973 & 688855 & 2.9208 & 4.4954 & TRN & & \\
\hline CHEMBL1471358 & 688855 & 2.9208 & 5.039 & TRN & & \\
\hline CHEMBL1438797 & 688855 & 2.9208 & 3.3865 & TRN & & \\
\hline CHEMBL1333661 & 688855 & 4.5656 & 4.4959 & TRN & & \\
\hline CHEMBL1580910 & 688855 & 2.9208 & 3.1727 & TRN & & \\
\hline CHEMBL1303140 & 688855 & 5.1289 & 4.7357 & TRN & & \\
\hline CHEMBL1369567 & 688855 & 4.8933 & 4.6267 & TST & & \\
\hline CHEMBL 3190220 & 688855 & 4.7602 & 3.3264 & TST & & \\
\hline CHEMBL1364299 & 688855 & 4.99 & 4.2331 & TST & & \\
\hline CHEMBL1312335 & 688855 & \multicolumn{3}{|c|}{4.7010000000000005} & 4.0719 & TST \\
\hline CHEMBL3210132 & 688855 & 4.7611 & 4.699 & TST & & \\
\hline CHEMBL1481769 & 688855 & 6.7167 & 4.1643 & TST & & \\
\hline CHEMBL 3190842 & 688855 & 4.7819 & 4.5563 & TST & & \\
\hline CHEMBL1360493 & 688855 & 2.9208 & 5.1117 & TST & & \\
\hline CHEMBL1350122 & 688855 & 4.702 & 4.0447 & TST & & \\
\hline CHEMBL1584502 & 688855 & 2.9208 & 3.4862 & TST & & \\
\hline CHEMBL 3192482 & 688855 & 2.9208 & 4.9765 & TST & & \\
\hline CHEMBL1310825 & 688855 & 5.1191 & 5.1755 & TST & & \\
\hline CHEMBL1434993 & 688855 & 4.9229 & 4.2279 & TST & & \\
\hline CHEMBL1543038 & 688855 & 5.2529 & 4.4896 & TST & & \\
\hline CHEMBL1371038 & 688855 & 2.9208 & 4.713 & TST & & \\
\hline CHEMBL1610086 & 688855 & 5.4423 & 4.2358 & TST & & \\
\hline CHEMBL1480762 & 688855 & 4.8953 & 4.5198 & TST & & \\
\hline CHEMBL1535290 & 688855 & 4.603 & 5.2834 & TST & & \\
\hline CHEMBL1380651 & 688855 & 6.4225 & 5.2761 & TST & & \\
\hline CHEMBL1393834 & 688855 & 6.6073 & 5.3119 & TST & & \\
\hline CHEMBL1375907 & 688855 & 5.1036 & 4.5814 & TST & & \\
\hline CHEMBL1530088 & 688855 & 6.8041 & 6.1786 & TST & & \\
\hline CHEMBL1343552 & 688855 & 4.8723 & 4.8309 & TST & & \\
\hline CHEMBL1343030 & 688855 & 2.9208 & 4.5699 & TST & & \\
\hline CHEMBL 2007400 & 688855 & 2.9208 & 4.4318 & TST & & \\
\hline CHEMBL1477333 & 688855 & 6.8697 & 4.9957 & TST & & \\
\hline CHEMBL1427637 & 688855 & 2.9208 & 3.3814 & TST & & \\
\hline CHEMBL1589458 & 688855 & 4.8806 & 4.5036 & TST & & \\
\hline CHEMBL1326481 & 688855 & 6.6126 & 5.0231 & TST & & \\
\hline CHEMBL1399096 & 688855 & 2.9208 & 4.6758 & TST & & \\
\hline CHEMBL1453005 & 688855 & 5.8677 & 5.2733 & TST & & \\
\hline CHEMBL3198073 & 688855 & 4.7082 & 4.8639 & TST & & \\
\hline
\end{tabular}

Page 4009 


\begin{tabular}{|c|c|c|c|c|c|c|}
\hline \multirow[b]{2}{*}{ CHEMBL1558301 } & & \multicolumn{5}{|c|}{ Supplemental Table S2.txt } \\
\hline & 688855 & 4.6559 & 4.9249 & TST & & \\
\hline CHEMBL3213314 & 688855 & 8.0 & 5.6407 & TST & & \\
\hline CHEMBL1410857 & 688855 & 2.9208 & 3.2427 & TST & & \\
\hline CHEMBL3195471 & 688855 & \multicolumn{3}{|c|}{5.2860000000000005} & 5.2475 & TST \\
\hline CHEMBL1396449 & 688855 & 5.3702 & 4.7222 & TST & & \\
\hline CHEMBL1492589 & 688855 & 4.245 & 4.5105 & TST & & \\
\hline CHEMBL1385055 & 688855 & 5.0981 & 3.4378 & TST & & \\
\hline CHEMBL1331702 & 688855 & 5.4441 & 4.7005 & TST & & \\
\hline CHEMBL1343099 & 688855 & 5.6209 & 5.2769 & TST & & \\
\hline CHEMBL1531389 & 688855 & 5.4307 & 4.5632 & TST & & \\
\hline CHEMBL1490429 & 688855 & 8.0 & 6.489 & TST & & \\
\hline CHEMBL1526067 & 688855 & 2.9208 & 3.7578 & TST & & \\
\hline CHEMBL1986090 & 688855 & 8.0 & 5.9989 & TST & & \\
\hline CHEMBL1561328 & 688855 & 2.9208 & 3.6792 & TST & & \\
\hline CHEMBL1393134 & 688855 & 2.9208 & 3.5701 & TST & & \\
\hline CHEMBL1479392 & 688855 & 2.9208 & 4.1437 & TST & & \\
\hline CHEMBL3212956 & 688855 & 4.2446 & 4.6851 & TST & & \\
\hline CHEMBL1329655 & 688855 & \multicolumn{3}{|c|}{4.9110000000000005} & 4.7871 & TST \\
\hline CHEMBL1331466 & 688855 & 2.9208 & 5.0781 & TST & & \\
\hline CHEMBL1484894 & 688855 & 4.4231 & 4.5273 & TST & & \\
\hline CHEMBL1486332 & 688855 & 2.9208 & 4.2559 & TST & & \\
\hline CHEMBL1600400 & 688855 & 2.9208 & 3.5611 & TST & & \\
\hline CHEMBL1598791 & 688855 & 5.8102 & 4.6173 & TST & & \\
\hline CHEMBL1092508 & 688855 & 4.4981 & 4.9277 & TST & & \\
\hline CHEMBL1538347 & 688855 & 2.9208 & 3.3888 & TST & & \\
\hline CHEMBL1306342 & 688855 & 4.3226 & 4.0021 & TST & & \\
\hline CHEMBL1428897 & 688855 & 6.6326 & 6.0054 & TST & & \\
\hline CHEMBL1327417 & 688855 & 2.9208 & 3.452 & TST & & \\
\hline CHEMBL1607974 & 688855 & 2.9208 & 4.7825 & TST & & \\
\hline CHEMBL1459184 & 688855 & 4.4043 & 4.5543 & TST & & \\
\hline CHEMBL1532369 & 688855 & 2.9208 & 3.6538 & TST & & \\
\hline CHEMBL1311838 & 688855 & 4.8209 & 5.1646 & TST & & \\
\hline CHEMBL1559258 & 688855 & 4.8277 & 3.3217 & TST & & \\
\hline CHEMBL1381275 & 688855 & 4.8099 & 4.1706 & TST & & \\
\hline CHEMBL1530057 & 688855 & 4.7883 & 4.6181 & TST & & \\
\hline CHEMBL1424944 & 688855 & 4.9596 & 4.4535 & TST & & \\
\hline CHEMBL1523841 & 688855 & 2.9208 & 3.9058 & TST & & \\
\hline CHEMBL1341924 & 688855 & 4.8888 & 4.9053 & TST & & \\
\hline CHEMBL1334134 & 688855 & 3.2218 & 4.4648 & TST & & \\
\hline CHEMBL1303339 & 688855 & 2.9208 & 4.6122 & TST & & \\
\hline CHEMBL1392554 & 688855 & 5.2025 & 4.18 & TST & & \\
\hline CHEMBL1478376 & 688855 & 5.2587 & 4.868 & TST & & \\
\hline CHEMBL3212230 & 688855 & 5.147 & 5.0121 & TST & & \\
\hline CHEMBL1444341 & 688855 & 4.8319 & 4.6633 & TST & & \\
\hline CHEMBL1425355 & 688855 & 4.7608 & 4.6534 & TST & & \\
\hline CHEMBL1478232 & 688855 & 8.0 & 5.7316 & TST & & \\
\hline CHEMBL1457749 & 688855 & 4.6955 & 3.9563 & TST & & \\
\hline CHEMBL1570658 & 688855 & 4.5815 & 5.1933 & TST & & \\
\hline
\end{tabular}




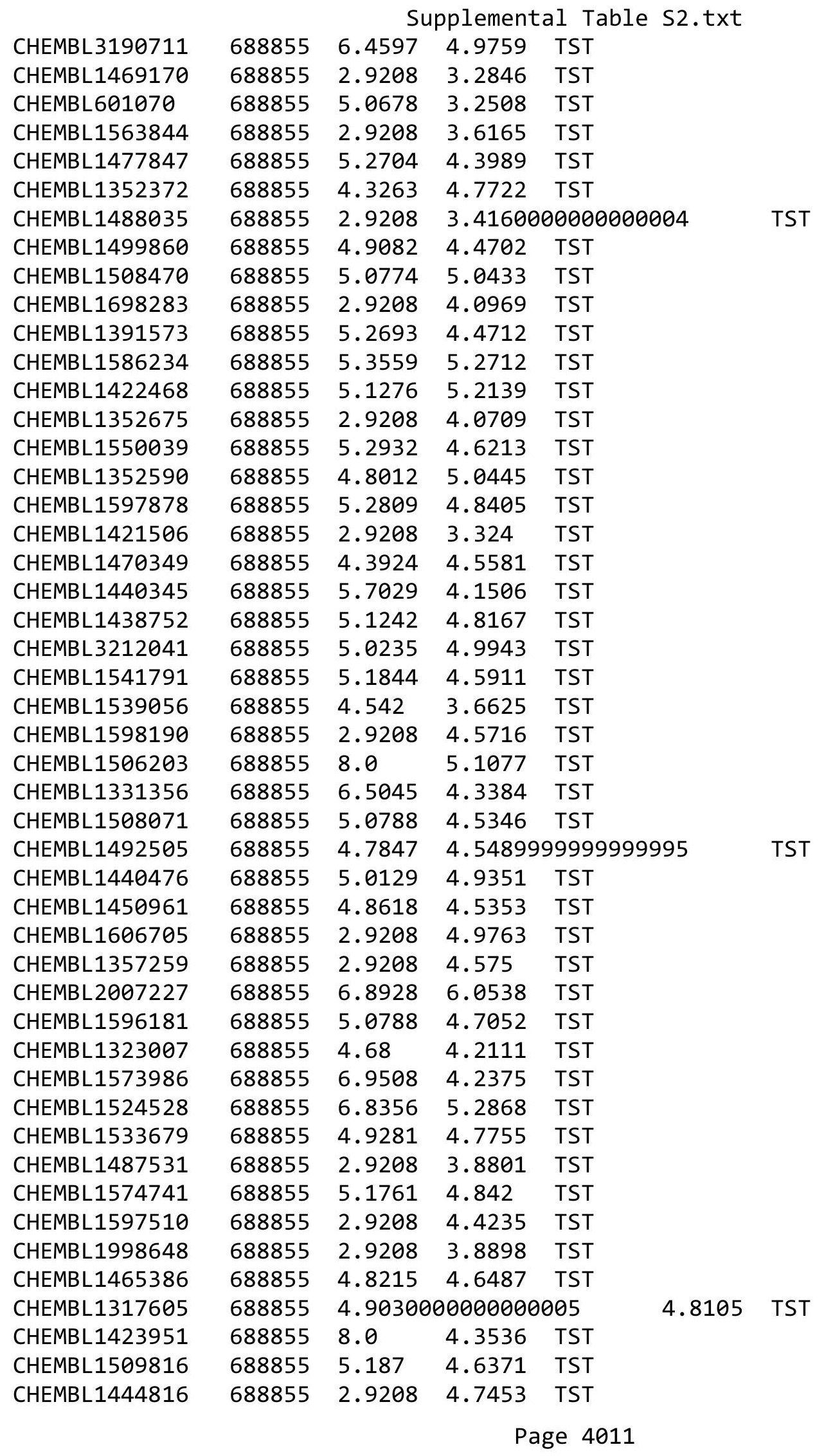


Supplemental Table S2.txt

\begin{tabular}{|c|c|c|c|c|}
\hline CHEMBL1335068 & 688855 & 2.9208 & 2.8989 & TST \\
\hline CHEMBL1585531 & 688855 & 6.2218 & 5.1692 & TST \\
\hline CHEMBL1508330 & 688855 & 2.9208 & 4.705 & TST \\
\hline CHEMBL1571941 & 688855 & 2.9208 & 4.8826 & TST \\
\hline CHEMBL1578912 & 688855 & 2.9208 & 3.1406 & TST \\
\hline CHEMBL1462286 & 688855 & 6.7799 & 5.0095 & TST \\
\hline CHEMBL1493226 & 688855 & 6.8861 & 5.1785 & TST \\
\hline CHEMBL1321472 & 688855 & 6.5817 & 5.1678 & TST \\
\hline CHEMBL1609490 & 688855 & 2.9208 & 4.2168 & TST \\
\hline CHEMBL372840 & 688855 & 4.8143 & 3.5916 & TST \\
\hline CHEMBL1523917 & 688855 & 5.0522 & 4.503 & TST \\
\hline CHEMBL1498971 & 688855 & 4.6372 & 5.141 & TST \\
\hline CHEMBL1347452 & 688855 & 2.9208 & 4.5578 & TST \\
\hline CHEMBL1342952 & 688855 & 4.8094 & 5.2473 & TST \\
\hline CHEMBL1423926 & 688855 & 2.9208 & 5.1171 & TST \\
\hline CHEMBL1415012 & 688855 & 4.7888 & 5.0635 & TST \\
\hline CHEMBL1588123 & 688855 & 5.2846 & 4.9511 & TST \\
\hline CHEMBL1340584 & 688855 & 4.7067 & 4.4775 & TST \\
\hline CHEMBL1526676 & 688855 & 3.9449 & 5.3206 & TST \\
\hline CHEMBL1472807 & 688855 & 4.7827 & 5.1752 & TST \\
\hline CHEMBL1382917 & 688855 & 4.8049 & 4.7112 & TST \\
\hline CHEMBL1443086 & 688855 & 4.5578 & 5.3199 & TST \\
\hline CHEMBL1571228 & 688855 & 4.9843 & 4.4334 & TST \\
\hline CHEMBL547833 & 688855 & 2.9208 & 4.4619 & TST \\
\hline CHEMBL1460534 & 688855 & 8.0 & 5.9429 & TST \\
\hline CHEMBL1347487 & 688855 & 4.618 & 4.5135 & TST \\
\hline CHEMBL1585599 & 688855 & 4.8675 & 4.879 & TST \\
\hline CHEMBL1550457 & 688855 & 6.4976 & 4.7807 & TST \\
\hline CHEMBL1530303 & 688855 & 4.42 & 4.6653 & TST \\
\hline CHEMBL1585789 & 688855 & 2.9208 & 3.7904 & TST \\
\hline CHEMBL1311739 & 688855 & 4.5236 & 4.5333 & TST \\
\hline CHEMBL1491863 & 688855 & 4.6549 & 4.0938 & TST \\
\hline CHEMBL1376590 & 688855 & 5.7284 & 5.1682 & TST \\
\hline CHEMBL1490718 & 688855 & 6.0269 & 6.0907 & TST \\
\hline CHEMBL1448363 & 688855 & 4.8301 & 4.7706 & TST \\
\hline CHEMBL1495198 & 688855 & 6.2487 & 4.5966 & TST \\
\hline CHEMBL3192157 & 688855 & 5.1735 & 4.7274 & TST \\
\hline CHEMBL1488450 & 688855 & 4.9524 & 5.1757 & TST \\
\hline CHEMBL1497673 & 688855 & 4.5096 & 4.8122 & TST \\
\hline CHEMBL1448605 & 688855 & 6.6326 & 5.7879 & TST \\
\hline CHEMBL1446575 & 688855 & 5.0556 & 4.6037 & TST \\
\hline CHEMBL1543489 & 688855 & 6.5591 & 4.9387 & TST \\
\hline CHEMBL3212409 & 688855 & 5.2682 & 4.7812 & TST \\
\hline CHEMBL1539171 & 688855 & 4.7792 & 4.7412 & TST \\
\hline CHEMBL1373732 & 688855 & 4.8402 & 5.0273 & TST \\
\hline CHEMBL1349964 & 688855 & 6.6635 & 6.08299 & 9999999999 \\
\hline CHEMBL1329596 & 688855 & 6.7305 & 5.7463 & TST \\
\hline CHEMBL1305128 & 688855 & 4.8856 & 3.7935 & TST \\
\hline
\end{tabular}




\begin{tabular}{|c|c|c|c|c|}
\hline & & & pplement & al $\mathrm{T}$ \\
\hline CHEMBL1568646 & 688855 & 6.767 & 5.9263 & TST \\
\hline CHEMBL1443457 & 688855 & 4.8023 & 4.8245 & TST \\
\hline CHEMBL1556666 & 688855 & 2.9208 & 4.426 & TST \\
\hline CHEMBL1490778 & 688855 & 5.3143 & 4.3842 & TST \\
\hline CHEMBL1541456 & 688855 & 4.8176 & 4.3292 & TST \\
\hline CHEMBL1452771 & 688855 & 4.849 & 4.6991 & TST \\
\hline CHEMBL1537269 & 688855 & 4.8072 & 3.6053 & TST \\
\hline CHEMBL1397547 & 688855 & 5.2393 & 4.2211 & TST \\
\hline CHEMBL1499023 & 688855 & 4.9723 & 4.8995 & TST \\
\hline CHEMBL1563059 & 688855 & 5.2049 & 4.4019 & TST \\
\hline CHEMBL1370978 & 688855 & 4.7186 & 4.5557 & TST \\
\hline CHEMBL1501969 & 688855 & 4.811 & 4.5412 & TST \\
\hline CHEMBL1604106 & 688855 & 2.9208 & 4.9864 & TST \\
\hline CHEMBL3189244 & 688855 & 2.9208 & 4.0074 & TST \\
\hline CHEMBL1491320 & 688855 & 4.9338 & 4.6684 & TST \\
\hline CHEMBL 3207881 & 688855 & 2.9208 & 3.9009 & TST \\
\hline CHEMBL3209422 & 688855 & 4.1694 & 3.4039 & TST \\
\hline CHEMBL1564117 & 688855 & 3.2218 & 3.3696 & TST \\
\hline CHEMBL1493792 & 688855 & 4.8029 & 4.5751 & TST \\
\hline CHEMBL252901 & 688855 & 6.7799 & 5.2186 & TST \\
\hline CHEMBL1534933 & 688855 & 3.2218 & 4.2547 & TST \\
\hline CHEMBL1361072 & 688855 & 2.9208 & 3.1738 & TST \\
\hline CHEMBL3211314 & 688855 & 4.7658 & 4.6297 & TST \\
\hline CHEMBL1491031 & 688855 & 4.8609 & 5.0442 & TST \\
\hline CHEMBL1604258 & 688855 & 4.8483 & 4.9558 & TST \\
\hline CHEMBL1384623 & 688855 & 2.9208 & 5.2902 & TST \\
\hline CHEMBL1567874 & 688855 & 4.266 & 4.9299 & TST \\
\hline CHEMBL1324703 & 688855 & 6.7747 & 6.6452 & TST \\
\hline CHEMBL1588880 & 688855 & 6.9747 & 5.8405 & TST \\
\hline CHEMBL1612481 & 688855 & 4.4239 & 5.3111 & TST \\
\hline CHEMBL1609019 & 688855 & 4.5841 & 4.8078 & TST \\
\hline CHEMBL1404510 & 688855 & 5.6694 & 4.1189 & TST \\
\hline CHEMBL1455567 & 688855 & 2.9208 & 3.8449 & TST \\
\hline CHEMBL1417316 & 688855 & 4.8701 & 4.0118 & TST \\
\hline CHEMBL1507040 & 688855 & 4.8375 & 3.7961 & TST \\
\hline CHEMBL1321104 & 688855 & 8.0 & 7.0588 & TST \\
\hline CHEMBL1349074 & 688855 & 5.0935 & 4.0843 & TST \\
\hline CHEMBL1308206 & 688855 & 4.9693 & 4.6867 & TST \\
\hline CHEMBL1599365 & 688855 & 2.9208 & 3.3716 & TST \\
\hline CHEMBL1401735 & 688855 & 4.8835 & 4.3708 & TST \\
\hline CHEMBL1400312 & 688855 & 4.732 & 4.9621 & TST \\
\hline CHEMBL1431044 & 688855 & 4.4998 & 4.9531 & TST \\
\hline CHEMBL1575467 & 688855 & 2.9208 & 5.0539 & TST \\
\hline CHEMBL1409330 & 688855 & 6.6904 & 4.4313 & TST \\
\hline CHEMBL1608887 & 688855 & 4.3287 & 4.9865 & TST \\
\hline CHEMBL1364267 & 688855 & 4.852 & 4.8138 & TST \\
\hline CHEMBL1518960 & 688746 & 4.4 & 4.8812 & TRN \\
\hline CHEMBL1331498 & 688746 & 4.6 & 4.9165 & TRN \\
\hline
\end{tabular}




\begin{tabular}{|c|c|c|c|c|}
\hline & & & upplement & al Ta \\
\hline CHEMBL1986805 & 688746 & 4.9 & 4.7628 & TRN \\
\hline CHEMBL1311185 & 688746 & 4.4 & 4.7439 & TRN \\
\hline CHEMBL1503512 & 688746 & 4.55 & 5.0034 & TRN \\
\hline CHEMBL1509101 & 688746 & 6.1 & 5.0015 & TRN \\
\hline CHEMBL1491594 & 688746 & 4.55 & 4.939 & TRN \\
\hline CHEMBL1574562 & 688746 & 4.4 & 4.9013 & TRN \\
\hline CHEMBL1345685 & 688746 & 4.45 & 4.8503 & TRN \\
\hline CHEMBL1571752 & 688746 & 4.4 & 4.9016 & TST \\
\hline CHEMBL1403373 & 688746 & 4.4 & 4.8218 & TRN \\
\hline CHEMBL1596249 & 688746 & 4.4 & 4.8348 & TST \\
\hline CHEMBL1520736 & 688746 & 4.6 & 4.8336 & TRN \\
\hline CHEMBL1546072 & 688746 & 6.5 & 4.9117 & TRN \\
\hline CHEMBL1400143 & 688746 & 4.8 & 4.7843 & TRN \\
\hline CHEMBL1345574 & 688746 & 4.55 & 4.9039 & TST \\
\hline CHEMBL1529046 & 688746 & 4.55 & 4.7541 & TRN \\
\hline CHEMBL1459594 & 688746 & 4.75 & 4.8893 & TRN \\
\hline CHEMBL1345081 & 688746 & 4.8 & 4.8903 & TRN \\
\hline CHEMBL1534941 & 688746 & 4.8 & 4.7951 & TRN \\
\hline CHEMBL1400320 & 688746 & 6.9 & 4.9746 & TRN \\
\hline CHEMBL1386835 & 688746 & 4.55 & 4.8957 & TRN \\
\hline CHEMBL1534012 & 688746 & 5.6 & 4.93 & TRN \\
\hline CHEMBL1384645 & 688746 & 4.4 & 4.8384 & TRN \\
\hline CHEMBL1549532 & 688746 & 4.45 & 4.8695 & TRN \\
\hline CHEMBL1449338 & 688746 & 5.0 & 4.8624 & TRN \\
\hline CHEMBL1469720 & 688746 & 4.8 & 4.8753 & TRN \\
\hline CHEMBL1603643 & 688746 & 5.05 & 4.7368 & TRN \\
\hline CHEMBL1309316 & 688746 & 4.4 & 4.8405 & TST \\
\hline CHEMBL1399724 & 688746 & 5.2 & 4.851 & TRN \\
\hline CHEMBL1311280 & 688746 & 4.9 & 4.8593 & TRN \\
\hline CHEMBL1495929 & 688746 & 6.1 & 4.7696 & TRN \\
\hline CHEMBL1485289 & 688746 & 6.3 & 4.9845 & TRN \\
\hline CHEMBL1608377 & 688746 & 5.15 & 4.8781 & TRN \\
\hline CHEMBL1320043 & 688746 & 4.45 & 4.8873 & TRN \\
\hline CHEMBL1084441 & 688746 & 4.55 & 4.7754 & TRN \\
\hline CHEMBL 3198870 & 688746 & 4.65 & 4.7847 & TRN \\
\hline CHEMBL599013 & 688746 & 4.6 & 4.7086 & TRN \\
\hline CHEMBL1390419 & 688746 & 4.4 & 4.8359 & TST \\
\hline CHEMBL1412811 & 688746 & 5.15 & 4.8429 & TRN \\
\hline CHEMBL1309333 & 688746 & 4.4 & 4.9512 & TRN \\
\hline CHEMBL1563504 & 688746 & 4.45 & 4.8903 & TRN \\
\hline CHEMBL1471955 & 688746 & 5.2 & 5.007 & TRN \\
\hline CHEMBL1391042 & 688746 & 4.45 & 4.8227 & TRN \\
\hline CHEMBL1583758 & 688746 & 4.8 & 4.8746 & TRN \\
\hline CHEMBL1464554 & 688746 & 4.65 & 4.8671 & TRN \\
\hline CHEMBL1389881 & 688746 & 4.5 & 4.8306 & TST \\
\hline CHEMBL1312622 & 688746 & 4.65 & 4.8827 & TRN \\
\hline CHEMBL1333960 & 688746 & 4.5 & 4.8467 & TRN \\
\hline CHEMBL1358604 & 688746 & 4.45 & 4.8949 & TRN \\
\hline
\end{tabular}




\begin{tabular}{|c|c|c|c|c|c|}
\hline & & \multicolumn{4}{|c|}{ Supplemental Table S2.txt } \\
\hline CHEMBL1600737 & 688746 & 4.55 & 4.8502 & TRN & \\
\hline CHEMBL1338645 & 688746 & 4.85 & 4.8452 & TRN & \\
\hline CHEMBL1470313 & 688746 & 4.5 & 4.9572 & TRN & \\
\hline CHEMBL1412313 & 688746 & 4.65 & 4.9055 & TRN & \\
\hline CHEMBL1450659 & 688746 & 4.6 & 4.9424 & TRN & \\
\hline CHEMBL1303347 & 688746 & 5.5 & 4.966 & TRN & \\
\hline CHEMBL1530741 & 688746 & 4.7 & 4.9058 & TRN & \\
\hline CHEMBL1455821 & 688746 & 4.45 & 4.7883 & TST & \\
\hline CHEMBL1573013 & 688746 & 4.6 & 4.8948 & TRN & \\
\hline CHEMBL1486438 & 688746 & 4.9 & 4.8261 & TRN & \\
\hline CHEMBL421088 & 688746 & 5.05 & 4.7657 & TRN & \\
\hline CHEMBL1533962 & 688746 & 5.15 & 4.8547 & TRN & \\
\hline CHEMBL1346975 & 688746 & 4.4 & 4.8483 & TRN & \\
\hline CHEMBL1542269 & 688746 & 4.45 & 4.8987 & TST & \\
\hline CHEMBL1464645 & 688746 & 4.85 & 4.7283 & TRN & \\
\hline CHEMBL1510651 & 688746 & 4.6 & 4.8477 & TRN & \\
\hline CHEMBL1975516 & 688746 & 4.85 & 4.76399 & 9999999999 & TRN \\
\hline CHEMBL1504875 & 688746 & 4.65 & 4.787 & TRN & \\
\hline CHEMBL1482651 & 688746 & 4.45 & 4.9105 & TRN & \\
\hline CHEMBL1605212 & 688746 & 4.5 & 4.9216 & TRN & \\
\hline CHEMBL1504353 & 688746 & 5.15 & 4.9545 & TRN & \\
\hline CHEMBL1440902 & 688746 & 4.55 & 4.8302 & TRN & \\
\hline CHEMBL1313597 & 688746 & 4.4 & 4.8668 & TRN & \\
\hline CHEMBL1610680 & 688746 & 4.6 & 4.8057 & TRN & \\
\hline CHEMBL1388790 & 688746 & 5.25 & 4.7695 & TRN & \\
\hline CHEMBL1368677 & 688746 & 4.75 & 4.9888 & TRN & \\
\hline CHEMBL3197422 & 688746 & 4.6 & 4.7832 & TRN & \\
\hline CHEMBL1478187 & 688746 & 6.1 & 4.9075 & TST & \\
\hline CHEMBL1488320 & 688746 & 4.6 & 4.9641 & TRN & \\
\hline CHEMBL1348588 & 688746 & 5.35 & 4.9165 & TRN & \\
\hline CHEMBL1467957 & 688746 & 4.4 & 4.8589 & TRN & \\
\hline CHEMBL1471249 & 688746 & 4.75 & 4.9868 & TRN & \\
\hline CHEMBL1493127 & 688746 & 4.75 & 4.8227 & TRN & \\
\hline CHEMBL1533880 & 688746 & 4.6 & 4.8591 & TRN & \\
\hline CHEMBL1379976 & 688746 & 4.4 & 4.7884 & TRN & \\
\hline CHEMBL1538753 & 688746 & 4.55 & 4.7831 & TRN & \\
\hline CHEMBL1510463 & 688746 & 4.65 & 4.9876 & TRN & \\
\hline CHEMBL1585268 & 688746 & 6.05 & 4.8807 & TST & \\
\hline CHEMBL1378417 & 688746 & 4.75 & 4.8525 & TRN & \\
\hline CHEMBL1429429 & 688746 & 5.0 & 4.8776 & TST & \\
\hline CHEMBL2000529 & 688746 & 4.85 & 4.7527 & TRN & \\
\hline CHEMBL1504876 & 688746 & 4.5 & 4.857 & TRN & \\
\hline CHEMBL1359931 & 688746 & 5.05 & 4.8496 & TST & \\
\hline CHEMBL1427072 & 688746 & 4.85 & 4.7328 & TRN & \\
\hline CHEMBL1458226 & 688746 & 4.4 & 4.8341 & TRN & \\
\hline CHEMBL3214508 & 688746 & 4.5 & 4.789 & TRN & \\
\hline CHEMBL1505050 & 688746 & 5.35 & 4.8733 & TRN & \\
\hline CHEMBL1602447 & 688746 & 4.45 & 4.8873 & TST & \\
\hline
\end{tabular}




\begin{tabular}{|c|c|c|c|c|c|}
\hline \multicolumn{6}{|c|}{ Supplemental Table S2.txt } \\
\hline CHEMBL1598317 & 688746 & 6.05 & 4.863 & TRN & \\
\hline CHEMBL1456623 & 688746 & 4.45 & 4.7955 & TRN & \\
\hline CHEMBL1607306 & 688746 & 4.9 & 4.783 & TRN & \\
\hline CHEMBL1514207 & 688746 & 5.15 & 4.8893 & TST & \\
\hline CHEMBL1385027 & 688746 & 4.8 & 4.8358 & TRN & \\
\hline CHEMBL1537744 & 688746 & 4.7 & 4.8152 & TRN & \\
\hline CHEMBL1374522 & 688746 & 5.25 & 4.792 & TST & \\
\hline CHEMBL260213 & 688746 & 4.5 & 4.8221 & TRN & \\
\hline CHEMBL1440532 & 688746 & 5.5 & 4.8481 & TST & \\
\hline CHEMBL1428228 & 688746 & 5.1 & 4.942 & TRN & \\
\hline CHEMBL1536196 & 688746 & 6.3 & 4.8503 & TST & \\
\hline CHEMBL1964405 & 688746 & 4.5 & 4.7211 & TRN & \\
\hline CHEMBL1554982 & 688746 & 5.05 & 4.9256 & TST & \\
\hline CHEMBL1387514 & 688746 & 4.55 & 4.8406 & TRN & \\
\hline CHEMBL1543339 & 688746 & 4.6 & 4.82600 & 00000000005 & TRN \\
\hline CHEMBL1370260 & 688746 & 6.45 & 4.917 & TRN & \\
\hline CHEMBL1508694 & 688746 & 4.4 & 4.8094 & TRN & \\
\hline CHEMBL1576166 & 688746 & 4.75 & 4.7831 & TRN & \\
\hline CHEMBL1577064 & 688746 & 5.25 & 4.8721 & TST & \\
\hline CHEMBL1466699 & 688746 & 4.55 & 4.782 & TRN & \\
\hline CHEMBL1504361 & 688746 & 5.05 & 4.8927 & TRN & \\
\hline CHEMBL1593709 & 688746 & 5.2 & 4.9206 & TST & \\
\hline CHEMBL1345933 & 688746 & 6.1 & 4.8774 & TRN & \\
\hline CHEMBL1485148 & 688746 & 4.6 & 4.7554 & TRN & \\
\hline CHEMBL1584469 & 688746 & 4.55 & 4.7905 & TST & \\
\hline CHEMBL1506274 & 688746 & 4.5 & 4.7382 & TRN & \\
\hline CHEMBL1559112 & 688746 & 5.05 & 4.9529 & TRN & \\
\hline CHEMBL1431163 & 688746 & 4.4 & 4.886 & TRN & \\
\hline CHEMBL3198811 & 688746 & 4.75 & 4.7946 & TRN & \\
\hline CHEMBL1988731 & 688746 & 5.95 & 4.8609 & TRN & \\
\hline CHEMBL3192383 & 688746 & 4.75 & 4.9003 & TRN & \\
\hline CHEMBL1382910 & 688746 & 4.6 & 4.9234 & TRN & \\
\hline CHEMBL1573686 & 688746 & 4.6 & 4.9657 & TRN & \\
\hline CHEMBL1433058 & 688746 & 4.85 & 4.8777 & TRN & \\
\hline CHEMBL1413930 & 688746 & 4.65 & 4.9921 & TRN & \\
\hline CHEMBL1348638 & 688746 & 4.8 & 4.8631 & TRN & \\
\hline CHEMBL3210195 & 688746 & 4.75 & 4.9057 & TRN & \\
\hline CHEMBL1578341 & 688746 & 4.8 & 4.8477 & TRN & \\
\hline CHEMBL1323587 & 688746 & 4.8 & 4.9595 & TRN & \\
\hline CHEMBL1539359 & 688746 & 4.55 & 4.7545 & TRN & \\
\hline CHEMBL 3190400 & 688746 & 4.95 & 4.7188 & TRN & \\
\hline CHEMBL1327251 & 688746 & 4.6 & 4.8794 & TST & \\
\hline CHEMBL1539520 & 688746 & 4.9 & 4.92399 & 99999999995 & TRN \\
\hline CHEMBL1312751 & 688746 & 4.45 & 4.8344 & TRN & \\
\hline CHEMBL1568871 & 688746 & 5.1 & 5.0086 & TRN & \\
\hline CHEMBL1385105 & 688746 & 4.95 & 4.9122 & TRN & \\
\hline CHEMBL1344077 & 688746 & 4.8 & 4.8711 & TRN & \\
\hline CHEMBL1527095 & 688746 & 4.4 & 4.7168 & TRN & \\
\hline
\end{tabular}




\begin{tabular}{|c|c|c|c|c|c|}
\hline \multirow[b]{2}{*}{ CHEMBL1362296 } & \multirow[b]{2}{*}{688746} & \\
\hline & & 4.4 & 4.8028 & TST & \\
\hline CHEMBL1382651 & 688746 & 4.85 & 4.8082 & TRN & \\
\hline CHEMBL1348757 & 688746 & 4.4 & 4.7561 & TRN & \\
\hline CHEMBL1570355 & 688746 & 4.4 & 4.8446 & TRN & \\
\hline CHEMBL1301074 & 688746 & 4.85 & 4.8415 & TRN & \\
\hline CHEMBL 2000264 & 688746 & 4.5 & 4.7631 & TRN & \\
\hline CHEMBL3199340 & 688746 & 5.5 & 4.8909 & TRN & \\
\hline CHEMBL1525076 & 688746 & 4.55 & \multicolumn{2}{|c|}{5.0169999999999995} & TRN \\
\hline CHEMBL1392776 & 688746 & 4.6 & 4.8928 & TRN & \\
\hline CHEMBL1453201 & 688746 & 4.4 & 4.8511 & TST & \\
\hline CHEMBL1330058 & 688746 & 4.85 & 4.6881 & TRN & \\
\hline CHEMBL1560618 & 688746 & 5.45 & 4.8771 & TRN & \\
\hline CHEMBL1521330 & 688746 & 4.45 & 4.7289 & TRN & \\
\hline CHEMBL1323335 & 688746 & 4.4 & 4.8346 & TRN & \\
\hline CHEMBL1578449 & 688746 & 5.0 & 4.8042 & TRN & \\
\hline CHEMBL1426164 & 688746 & 6.6 & 4.9692 & TRN & \\
\hline CHEMBL1545263 & 688746 & 4.4 & 4.9267 & TST & \\
\hline CHEMBL1330063 & 688746 & 5.05 & 4.6975 & TRN & \\
\hline CHEMBL1305197 & 688746 & 5.2 & 4.8904 & TRN & \\
\hline CHEMBL1322646 & 688746 & 5.55 & 5.0297 & TRN & \\
\hline CHEMBL1613477 & 688746 & 5.2 & 4.755 & TST & \\
\hline CHEMBL1504074 & 688746 & 4.55 & 4.9609 & TRN & \\
\hline CHEMBL1588809 & 688746 & 4.4 & 4.9159 & TRN & \\
\hline CHEMBL608699 & 688746 & 5.65 & 4.8039 & TRN & \\
\hline CHEMBL1577027 & 688746 & 4.85 & 4.8962 & TRN & \\
\hline CHEMBL1347204 & 688746 & 4.65 & 4.739 & TRN & \\
\hline CHEMBL1318813 & 688746 & 4.5 & 4.8347 & TRN & \\
\hline CHEMBL1535268 & 688746 & 4.4 & 4.8531 & TRN & \\
\hline CHEMBL1582486 & 688746 & 6.25 & 4.9089 & TRN & \\
\hline CHEMBL1518723 & 688746 & 4.85 & 4.8174 & TRN & \\
\hline CHEMBL1973383 & 688746 & 4.7 & 4.7772 & TST & \\
\hline CHEMBL1574042 & 688746 & 5.75 & 5.0081 & TRN & \\
\hline CHEMBL1354000 & 688746 & 6.7501 & 4.7804 & TRN & \\
\hline CHEMBL1502149 & 688746 & 4.4 & 4.7835 & TRN & \\
\hline CHEMBL1496173 & 688746 & 5.0 & 4.7832 & TRN & \\
\hline CHEMBL1084625 & 688746 & 6.95 & 4.8942 & TST & \\
\hline CHEMBL3211820 & 688746 & 4.5 & 4.7795 & TRN & \\
\hline CHEMBL1368535 & 688746 & 4.4 & 4.73300 & 00000000005 & TST \\
\hline CHEMBL1334552 & 688746 & 4.4 & 4.8868 & TRN & \\
\hline CHEMBL1413495 & 688746 & 4.8 & 4.813 & TST & \\
\hline CHEMBL1486454 & 688746 & 4.65 & 4.9997 & TRN & \\
\hline CHEMBL1360939 & 688746 & 4.55 & 4.7839 & TRN & \\
\hline CHEMBL1543169 & 688746 & 4.6 & 4.8831 & TRN & \\
\hline CHEMBL1612222 & 688746 & 4.55 & 4.9521 & TRN & \\
\hline CHEMBL1486834 & 688746 & 4.6 & 4.8767 & TRN & \\
\hline CHEMBL1570148 & 688746 & 4.55 & 4.8227 & TRN & \\
\hline CHEMBL1303437 & 688746 & 4.75 & 4.9281 & TRN & \\
\hline \multirow[t]{2}{*}{ CHEMBL1530341 } & 688746 & 4.85 & 4.7513 & TRN & \\
\hline & & \multicolumn{4}{|c|}{ Page 4017} \\
\hline
\end{tabular}




\begin{tabular}{|c|c|c|c|c|}
\hline \\
\hline CHEMBL1546698 & 688746 & 4.9 & 4.8526 & TRN \\
\hline CHEMBL1349506 & 688746 & 4.4 & 4.9218 & TRN \\
\hline CHEMBL1589085 & 688746 & 4.8 & 4.8798 & TST \\
\hline CHEMBL1412990 & 688746 & 4.7 & 4.9062 & TRN \\
\hline CHEMBL1510141 & 688746 & 4.4 & 4.8805 & TRN \\
\hline CHEMBL1509858 & 688746 & 7.4001 & 4.9257 & TST \\
\hline CHEMBL1603125 & 688746 & 4.65 & 4.8814 & TRN \\
\hline CHEMBL 2005973 & 688746 & 4.5 & 4.8245 & TST \\
\hline CHEMBL1400136 & 688746 & 4.55 & 4.8849 & TRN \\
\hline CHEMBL1539144 & 688746 & 4.4 & 4.9028 & TRN \\
\hline CHEMBL1518053 & 688746 & 4.75 & 4.9455 & TST \\
\hline CHEMBL1448834 & 688746 & 5.1 & 4.8436 & TRN \\
\hline CHEMBL1387192 & 688746 & 5.05 & 4.8006 & TST \\
\hline CHEMBL1382017 & 688746 & 5.2 & 4.8454 & TRN \\
\hline CHEMBL1573529 & 688746 & 6.0 & 4.8642 & TST \\
\hline CHEMBL1501515 & 688746 & 4.9 & 4.7819 & TRN \\
\hline CHEMBL1362691 & 688746 & 4.6 & 4.8143 & TRN \\
\hline CHEMBL1416262 & 688746 & 4.6 & 4.8971 & TST \\
\hline CHEMBL1573413 & 688746 & 4.9 & 4.8786 & TRN \\
\hline CHEMBL1610067 & 688746 & 5.5 & 4.9795 & TRN \\
\hline CHEMBL1421179 & 688746 & 4.6 & 4.838 & TRN \\
\hline CHEMBL1404301 & 688746 & 4.7 & 4.8614 & TRN \\
\hline CHEMBL1338432 & 688746 & 4.7 & 4.9527 & TRN \\
\hline CHEMBL1492697 & 688746 & 7.0 & 4.7999 & TST \\
\hline CHEMBL1359564 & 688746 & 4.45 & 4.8506 & TRN \\
\hline CHEMBL1500913 & 688746 & 4.85 & 4.8747 & TRN \\
\hline CHEMBL1440291 & 688746 & 5.05 & 4.945 & TRN \\
\hline CHEMBL1562712 & 688746 & 4.9 & 4.8041 & TRN \\
\hline CHEMBL3190736 & 688746 & 4.75 & 4.8806 & TRN \\
\hline CHEMBL1970615 & 688746 & 4.55 & 4.9106 & TRN \\
\hline CHEMBL1389485 & 688746 & 4.65 & 4.8953 & TST \\
\hline CHEMBL1542039 & 688746 & 4.85 & 4.8316 & TRN \\
\hline CHEMBL 1400220 & 688746 & 4.8 & 4.8199 & TRN \\
\hline CHEMBL1401431 & 688746 & 4.75 & 4.8859 & TRN \\
\hline CHEMBL1425380 & 688746 & 4.65 & 4.7999 & TRN \\
\hline CHEMBL1495269 & 688746 & 5.1 & 4.9661 & TRN \\
\hline CHEMBL1374291 & 688746 & 4.75 & 4.9068 & TRN \\
\hline CHEMBL1402998 & 688746 & 4.45 & 4.9177 & TRN \\
\hline CHEMBL1419375 & 688746 & 4.6 & 4.8361 & TRN \\
\hline CHEMBL1590282 & 688746 & 4.85 & 4.9036 & TRN \\
\hline CHEMBL1526382 & 688746 & 4.8 & 4.8208 & TST \\
\hline CHEMBL3192998 & 688746 & 4.8 & 4.8542 & TRN \\
\hline CHEMBL1421073 & 688746 & 4.55 & 4.8577 & TRN \\
\hline CHEMBL1335725 & 688746 & 5.4 & 4.9056 & TRN \\
\hline CHEMBL1494617 & 688746 & 5.15 & 4.8741 & TRN \\
\hline CHEMBL1352775 & 688746 & 5.5 & 4.989 & TRN \\
\hline CHEMBL1489534 & 688746 & 6.0 & 4.9993 & TRN \\
\hline CHEMBL1327648 & 688746 & 4.85 & 4.8707 & TRN \\
\hline
\end{tabular}




\begin{tabular}{|c|c|c|c|c|}
\hline \multirow[b]{2}{*}{ CHEMBL1510948 } & \multicolumn{4}{|c|}{ Supplemental Table S2.txt } \\
\hline & 688746 & 4.5 & 4.8806 & TRN \\
\hline CHEMBL1544528 & 688746 & 4.75 & 4.8004 & TRN \\
\hline CHEMBL 3196877 & 688746 & 4.95 & 4.8197 & TST \\
\hline CHEMBL 3190025 & 688746 & 4.45 & 4.7794 & TRN \\
\hline CHEMBL1542792 & 688746 & 5.0 & 4.8629 & TST \\
\hline CHEMBL1463706 & 688746 & 4.75 & 4.8107 & TRN \\
\hline CHEMBL3191239 & 688746 & 4.65 & 4.7748 & TRN \\
\hline CHEMBL1424122 & 688746 & 5.05 & 5.0261 & TRN \\
\hline CHEMBL1611479 & 688746 & 5.5 & 4.8724 & TRN \\
\hline CHEMBL1501396 & 688746 & 5.05 & 4.9098 & TRN \\
\hline CHEMBL1520283 & 688746 & 4.4 & 4.8195 & TRN \\
\hline CHEMBL1613021 & 688746 & 4.6 & 4.981 & TRN \\
\hline CHEMBL1518586 & 688746 & 4.8 & 5.0408 & TRN \\
\hline CHEMBL1562961 & 688746 & 4.85 & 4.9417 & TRN \\
\hline CHEMBL1393447 & 688746 & 4.4 & 4.7977 & TRN \\
\hline CHEMBL1428973 & 688746 & 4.4 & 4.9429 & TRN \\
\hline CHEMBL1579532 & 688746 & 4.7 & 4.8863 & TRN \\
\hline CHEMBL1575021 & 688746 & 5.35 & 4.814 & TST \\
\hline CHEMBL1539900 & 688746 & 5.35 & 4.8001 & TST \\
\hline CHEMBL1486109 & 688746 & 5.45 & 4.7093 & TRN \\
\hline CHEMBL1343858 & 688746 & 5.75 & 4.8569 & TST \\
\hline CHEMBL1560185 & 688746 & 4.75 & 4.9182 & TRN \\
\hline CHEMBL1500766 & 688746 & 4.8 & 4.8241 & TRN \\
\hline CHEMBL1386349 & 688746 & 4.6 & 4.798 & TRN \\
\hline CHEMBL1350152 & 688746 & 4.95 & 4.7436 & TRN \\
\hline CHEMBL1367163 & 688746 & 5.8 & 4.9287 & TRN \\
\hline CHEMBL1411499 & 688746 & 4.65 & 4.9908 & TRN \\
\hline CHEMBL1359468 & 688746 & 4.65 & 4.8717 & TRN \\
\hline CHEMBL1612474 & 688746 & 5.75 & 4.7837 & TRN \\
\hline CHEMBL1336534 & 688746 & 6.45 & 4.8941 & TRN \\
\hline CHEMBL1346882 & 688746 & 4.4 & 4.8453 & TST \\
\hline CHEMBL1491944 & 688746 & 4.4 & 4.841 & TRN \\
\hline CHEMBL1385413 & 688746 & 4.65 & 4.7903 & TRN \\
\hline CHEMBL1511872 & 688746 & 5.4 & 4.7384 & TRN \\
\hline CHEMBL1374651 & 688746 & 4.75 & 4.9853 & TRN \\
\hline CHEMBL1573856 & 688746 & 4.5 & 4.8193 & TRN \\
\hline CHEMBL1299519 & 688746 & 5.25 & 4.8048 & TRN \\
\hline CHEMBL1401232 & 688746 & 4.8 & 4.8974 & TST \\
\hline CHEMBL1430263 & 688746 & 4.85 & 4.9367 & TRN \\
\hline CHEMBL 3191674 & 688746 & 4.45 & 4.8496 & TRN \\
\hline CHEMBL1424486 & 688746 & 4.65 & 4.7146 & TRN \\
\hline CHEMBL1330331 & 688746 & 4.65 & 4.8456 & TRN \\
\hline CHEMBL1402717 & 688746 & 4.5 & 4.9617 & TRN \\
\hline CHEMBL1381730 & 688746 & 4.75 & 4.8613 & TRN \\
\hline CHEMBL1387407 & 688746 & 4.4 & 4.8953 & TRN \\
\hline CHEMBL1302078 & 688746 & 4.6 & 4.8434 & TRN \\
\hline CHEMBL1452851 & 688746 & 5.5 & 4.8147 & TRN \\
\hline CHEMBL1529842 & 688746 & 4.45 & 4.8551 & TRN \\
\hline
\end{tabular}




\begin{tabular}{|c|c|c|c|c|}
\hline \multicolumn{5}{|c|}{ Supplemental Table S2.txt } \\
\hline CHEMBL1331231 & 688746 & 4.8 & 4.8007 & TRN \\
\hline CHEMBL1420775 & 688746 & 4.8 & 4.878 & TRN \\
\hline CHEMBL1360500 & 688746 & 5.2 & 4.7683 & TRN \\
\hline CHEMBL 3214413 & 688746 & 6.0 & 4.806 & TST \\
\hline CHEMBL1498228 & 688746 & 5.2 & 4.833 & TRN \\
\hline CHEMBL1376737 & 688746 & 4.85 & 4.8565 & TRN \\
\hline CHEMBL1351526 & 688746 & 4.45 & 4.8188 & TRN \\
\hline CHEMBL1557499 & 688746 & 4.6 & 4.7978 & TRN \\
\hline CHEMBL1529233 & 688746 & 5.15 & 4.817 & TRN \\
\hline CHEMBL1333254 & 688746 & 4.65 & 4.7902 & TRN \\
\hline CHEMBL1417534 & 688746 & 5.2 & 4.9413 & TRN \\
\hline CHEMBL1531439 & 688746 & 5.05 & 4.9452 & TRN \\
\hline CHEMBL1417210 & 688746 & 4.6 & 4.7763 & TRN \\
\hline CHEMBL1307526 & 688746 & 5.05 & 4.8934 & TRN \\
\hline CHEMBL1381810 & 688746 & 5.4 & 4.8147 & TRN \\
\hline CHEMBL1587263 & 688746 & 4.65 & 4.8851 & TRN \\
\hline CHEMBL3196042 & 688746 & 4.7 & 4.7951 & TRN \\
\hline CHEMBL1459475 & 688746 & 5.05 & 4.8911 & TRN \\
\hline CHEMBL1537835 & 688746 & 6.1 & 4.8513 & TST \\
\hline CHEMBL1491543 & 688746 & 4.85 & 4.9731 & TRN \\
\hline CHEMBL1992394 & 688746 & 4.5 & 4.8197 & TRN \\
\hline CHEMBL1385260 & 688746 & 4.8 & 4.8645 & TRN \\
\hline CHEMBL1504712 & 688746 & 4.65 & 4.8598 & TRN \\
\hline CHEMBL1379710 & 688746 & 5.25 & 5.0307 & TRN \\
\hline CHEMBL1386269 & 688746 & 4.65 & 4.9819 & TRN \\
\hline CHEMBL1560782 & 688746 & 4.6 & 4.9136 & TRN \\
\hline CHEMBL1480628 & 688746 & 6.25 & 5.0099 & TRN \\
\hline CHEMBL 3195377 & 688746 & 4.45 & 4.885 & TRN \\
\hline CHEMBL1313352 & 688746 & 4.65 & 4.9757 & TRN \\
\hline CHEMBL1495389 & 688746 & 4.4 & 4.9353 & TRN \\
\hline CHEMBL1603691 & 688746 & 4.6 & 4.859 & TRN \\
\hline CHEMBL3191719 & 688746 & 4.45 & 4.8302 & TRN \\
\hline CHEMBL1482208 & 688746 & 4.4 & 4.8997 & TRN \\
\hline CHEMBL1529871 & 688746 & 4.85 & 4.8864 & TST \\
\hline CHEMBL1550006 & 688746 & 6.1 & 4.8382 & TRN \\
\hline CHEMBL1431326 & 688746 & 4.4 & 4.7166 & TRN \\
\hline CHEMBL235586 & 688746 & 5.2 & 4.8007 & TRN \\
\hline CHEMBL1479572 & 688746 & 8.1487 & 4.8546 & TRN \\
\hline CHEMBL1387495 & 688746 & 4.65 & 4.83 & TST \\
\hline CHEMBL1347937 & 688746 & 5.05 & 4.9048 & TRN \\
\hline CHEMBL1493333 & 688746 & 4.95 & 4.8526 & TRN \\
\hline CHEMBL1547901 & 688746 & 4.55 & 4.8043 & TRN \\
\hline CHEMBL1490747 & 688746 & 5.35 & 4.8722 & TRN \\
\hline CHEMBL1510030 & 688746 & 4.65 & 4.8161 & TRN \\
\hline CHEMBL1462021 & 688746 & 4.65 & 4.9033 & TRN \\
\hline CHEMBL1456526 & 688746 & 4.4 & 4.8859 & TRN \\
\hline CHEMBL1595843 & 688746 & 4.4 & 4.8759 & TST \\
\hline CHEMBL1489618 & 688746 & 5.1 & 4.9028 & TRN \\
\hline
\end{tabular}




\begin{tabular}{|c|c|c|c|c|}
\hline \multicolumn{5}{|c|}{ plemental T } \\
\hline CHEMBL1540072 & 688746 & 4.6 & 4.9167 & TRN \\
\hline CHEMBL1578700 & 688746 & 4.95 & 4.9668 & TRN \\
\hline CHEMBL1372372 & 688746 & 4.65 & 4.8757 & TRN \\
\hline CHEMBL1547774 & 688746 & 4.4 & 4.8378 & TRN \\
\hline CHEMBL1986111 & 688746 & 5.05 & 4.7224 & TRN \\
\hline CHEMBL1353220 & 688746 & 5.6 & 4.8719 & TRN \\
\hline CHEMBL1311834 & 688746 & 4.65 & 4.8957 & TRN \\
\hline CHEMBL1538576 & 688746 & 4.85 & 4.9229 & TRN \\
\hline CHEMBL1410337 & 688746 & 5.95 & 4.914 & TRN \\
\hline CHEMBL1428076 & 688746 & 4.6 & 4.8168 & TST \\
\hline CHEMBL1344131 & 688746 & 4.6 & 4.757 & TRN \\
\hline CHEMBL1426302 & 688746 & 4.75 & 4.8386 & TRN \\
\hline CHEMBL1589046 & 688746 & 4.55 & 4.8515 & TRN \\
\hline CHEMBL1450797 & 688746 & 5.1 & 4.7586 & TRN \\
\hline CHEMBL1392753 & 688746 & 4.7 & 4.8377 & TST \\
\hline CHEMBL1496457 & 688746 & 4.4 & 4.8415 & TST \\
\hline CHEMBL1565500 & 688746 & 5.3 & 4.8857 & TRN \\
\hline CHEMBL1506801 & 688746 & 5.35 & 4.9173 & TRN \\
\hline CHEMBL1433135 & 688746 & 4.4 & 4.9255 & TRN \\
\hline CHEMBL1443180 & 688746 & 4.5 & 4.8242 & TRN \\
\hline CHEMBL1383531 & 688746 & 4.6 & 4.8335 & TRN \\
\hline CHEMBL1500411 & 688746 & 5.15 & 5.0047 & TRN \\
\hline CHEMBL1431917 & 688746 & 4.5 & 4.9047 & TRN \\
\hline CHEMBL591412 & 688746 & 4.5 & 4.8384 & TRN \\
\hline CHEMBL 260342 & 688746 & 4.4 & 4.7651 & TRN \\
\hline CHEMBL1331249 & 688746 & 4.9 & 4.908 & TRN \\
\hline CHEMBL1530581 & 688746 & 4.85 & 4.7743 & TRN \\
\hline CHEMBL514760 & 688746 & 5.45 & 4.8591 & TRN \\
\hline CHEMBL432044 & 688746 & 4.5 & 4.789 & TRN \\
\hline CHEMBL1495025 & 688746 & 4.6 & 4.7703 & TRN \\
\hline CHEMBL1497780 & 688746 & 4.55 & 4.8415 & TRN \\
\hline CHEMBL1539501 & 688746 & 4.75 & 4.9926 & TRN \\
\hline CHEMBL1564388 & 688746 & 4.55 & 4.7826 & TRN \\
\hline CHEMBL1410716 & 688746 & 4.55 & 4.7966 & TRN \\
\hline CHEMBL1440565 & 688746 & 4.45 & 4.916 & TRN \\
\hline CHEMBL1303051 & 688746 & 5.8 & 5.0156 & TRN \\
\hline CHEMBL1493103 & 688746 & 4.65 & 4.9163 & TST \\
\hline CHEMBL1395505 & 688746 & 4.45 & 4.9678 & TRN \\
\hline CHEMBL1366681 & 688746 & 4.85 & 4.7298 & TST \\
\hline CHEMBL1496425 & 688746 & 5.45 & 4.8119 & TST \\
\hline CHEMBL3212127 & 688746 & 4.8 & 4.7645 & TRN \\
\hline CHEMBL1353221 & 688746 & 4.55 & 4.8569 & TST \\
\hline CHEMBL1527136 & 688746 & 5.15 & 4.9425 & TST \\
\hline CHEMBL1399557 & 688746 & 4.55 & 5.024 & TRN \\
\hline CHEMBL1336680 & 688746 & 4.45 & 4.8187 & TRN \\
\hline CHEMBL1566719 & 688746 & 4.6 & 4.8845 & TST \\
\hline CHEMBL1974613 & 688746 & 5.15 & 4.7565 & TRN \\
\hline CHEMBL1546667 & 688746 & 4.55 & 4.8721 & TRN \\
\hline
\end{tabular}




\begin{tabular}{|c|c|c|c|c|}
\hline \multicolumn{5}{|c|}{ Supplemental Table S2.txt } \\
\hline CHEMBL1381310 & 688746 & 5.25 & 4.8013 & TRN \\
\hline CHEMBL1427456 & 688746 & 5.0 & 4.9315 & TRN \\
\hline CHEMBL1966921 & 688746 & 4.85 & 4.7548 & TRN \\
\hline CHEMBL1350146 & 688746 & 4.55 & 4.8819 & TRN \\
\hline CHEMBL1544221 & 688746 & 4.55 & 4.8203 & TRN \\
\hline CHEMBL1329322 & 688746 & 4.4 & 4.7368 & TST \\
\hline CHEMBL1323280 & 688746 & 4.8 & 4.9388 & TRN \\
\hline CHEMBL1484173 & 688746 & 4.45 & 4.791 & TRN \\
\hline CHEMBL1329799 & 688746 & 4.4 & 4.8381 & TRN \\
\hline CHEMBL1338624 & 688746 & 4.5 & 4.8223 & TST \\
\hline CHEMBL1519501 & 688746 & 4.95 & 4.7255 & TRN \\
\hline CHEMBL1462443 & 688746 & 5.15 & 4.8501 & TRN \\
\hline CHEMBL1313682 & 688746 & 5.45 & 4.8017 & TST \\
\hline CHEMBL1345696 & 688746 & 4.6 & 4.8695 & TRN \\
\hline CHEMBL3207941 & 688746 & 4.7 & 4.8447 & TRN \\
\hline CHEMBL1605978 & 688746 & 4.45 & 4.8863 & TST \\
\hline CHEMBL1562525 & 688746 & 4.85 & 4.9634 & TRN \\
\hline CHEMBL1437634 & 688746 & 5.7 & 4.9818 & TRN \\
\hline CHEMBL1470729 & 688746 & 4.6 & 4.8502 & TRN \\
\hline CHEMBL1441314 & 688746 & 4.6 & 4.8317 & TRN \\
\hline CHEMBL1604007 & 688746 & 4.85 & 4.809 & TRN \\
\hline CHEMBL1449708 & 688746 & 4.55 & 4.8745 & TRN \\
\hline CHEMBL1340416 & 688746 & 5.35 & 4.8615 & TRN \\
\hline CHEMBL1364176 & 688746 & 4.4 & 4.7862 & TRN \\
\hline CHEMBL1502008 & 688746 & 4.55 & 4.8811 & TRN \\
\hline CHEMBL1312552 & 688746 & 5.45 & 4.9295 & TRN \\
\hline CHEMBL1482609 & 688746 & 6.8499 & 4.8153 & TRN \\
\hline CHEMBL1494938 & 688746 & 5.05 & 4.8842 & TRN \\
\hline CHEMBL1418847 & 688746 & 4.4 & 4.9057 & TRN \\
\hline CHEMBL1467766 & 688746 & 5.85 & 4.8967 & TRN \\
\hline CHEMBL1458567 & 688746 & 4.4 & 4.979 & TRN \\
\hline CHEMBL1346114 & 688746 & 4.55 & 4.7712 & TST \\
\hline CHEMBL1467277 & 688746 & 4.6 & 4.8756 & TRN \\
\hline CHEMBL1589404 & 688746 & 4.85 & 4.8725 & TRN \\
\hline CHEMBL1605232 & 688746 & 4.4 & 4.8432 & TRN \\
\hline CHEMBL1387000 & 688746 & 4.65 & 4.8941 & TRN \\
\hline CHEMBL1447218 & 688746 & 4.55 & 4.9111 & TST \\
\hline CHEMBL1087863 & 688746 & 4.4 & 4.7943 & TRN \\
\hline CHEMBL1363849 & 688746 & 4.45 & 4.8261 & TRN \\
\hline CHEMBL1302238 & 688746 & 4.55 & 4.8094 & TRN \\
\hline CHEMBL1388509 & 688746 & 4.95 & 4.8744 & TRN \\
\hline CHEMBL1461891 & 688746 & 4.55 & 4.8076 & TRN \\
\hline CHEMBL1533390 & 688746 & 4.8 & 4.9931 & TRN \\
\hline CHEMBL1490445 & 688746 & 6.1 & 4.9183 & TRN \\
\hline CHEMBL1325943 & 688746 & 4.9 & 4.79 & TRN \\
\hline CHEMBL1548680 & 688746 & 4.45 & 4.8207 & TRN \\
\hline CHEMBL1573120 & 688746 & 4.95 & 4.8013 & TRN \\
\hline CHEMBL1386571 & 688746 & 4.65 & 4.8772 & TRN \\
\hline
\end{tabular}




\begin{tabular}{|c|c|c|c|c|}
\hline \multicolumn{5}{|c|}{ lemental T } \\
\hline CHEMBL1429437 & 688746 & 5.5 & 4.8753 & TRN \\
\hline CHEMBL1369983 & 688746 & 5.0 & 4.8259 & TRN \\
\hline CHEMBL1526690 & 688746 & 4.9 & 4.8581 & TRN \\
\hline CHEMBL1487306 & 688746 & 4.55 & 4.8691 & TRN \\
\hline CHEMBL1510683 & 688746 & 5.7 & 4.8574 & TRN \\
\hline CHEMBL1517628 & 688746 & 4.4 & 4.8414 & TRN \\
\hline CHEMBL1418209 & 688746 & 5.1 & 4.8756 & TRN \\
\hline CHEMBL1483103 & 688746 & 4.8 & 4.8642 & TRN \\
\hline CHEMBL1374460 & 688746 & 4.8 & 4.8344 & TRN \\
\hline CHEMBL1510034 & 688746 & 4.75 & 4.9472 & TRN \\
\hline CHEMBL1548653 & 688746 & 4.5 & 4.8695 & TRN \\
\hline CHEMBL1357580 & 688746 & 5.45 & 5.0258 & TST \\
\hline CHEMBL1324093 & 688746 & 4.75 & 4.8489 & TRN \\
\hline CHEMBL1423690 & 688746 & 6.45 & 5.0183 & TRN \\
\hline CHEMBL1393638 & 688746 & 5.5 & 4.8687 & TRN \\
\hline CHEMBL1299725 & 688746 & 4.6 & 4.8694 & TRN \\
\hline CHEMBL1480798 & 688746 & 5.55 & 4.8193 & TRN \\
\hline CHEMBL322036 & 688746 & 4.5 & 4.823 & TST \\
\hline CHEMBL1579449 & 688746 & 4.4 & 4.9608 & TRN \\
\hline CHEMBL1503366 & 688746 & 4.6 & 4.8816 & TRN \\
\hline CHEMBL1384436 & 688746 & 5.0 & 4.8454 & TST \\
\hline CHEMBL1390650 & 688746 & 4.75 & 4.7648 & TRN \\
\hline CHEMBL1570329 & 688746 & 4.65 & 4.9117 & TST \\
\hline CHEMBL1385743 & 688746 & 4.65 & 4.7907 & TRN \\
\hline CHEMBL1480254 & 688746 & 4.55 & 4.9508 & TRN \\
\hline CHEMBL1542326 & 688746 & 4.35 & 4.7762 & TRN \\
\hline CHEMBL1511596 & 688746 & 4.6 & 4.9123 & TRN \\
\hline CHEMBL1453446 & 688746 & 6.25 & 4.8889 & TRN \\
\hline CHEMBL1402302 & 688746 & 5.05 & 4.8691 & TST \\
\hline CHEMBL3189607 & 688746 & 4.7 & 4.7074 & TRN \\
\hline CHEMBL1575442 & 688746 & 5.0 & 4.8436 & TRN \\
\hline CHEMBL1448663 & 688746 & 5.0 & 5.0231 & TRN \\
\hline CHEMBL1567815 & 688746 & 4.8 & 4.9308 & TRN \\
\hline CHEMBL1585547 & 688746 & 4.8 & 4.8404 & TRN \\
\hline CHEMBL1462373 & 688746 & 4.85 & 4.8146 & TRN \\
\hline CHEMBL1420082 & 688746 & 4.45 & 4.8126 & TRN \\
\hline CHEMBL1584844 & 688746 & 5.3 & 4.8843 & TST \\
\hline CHEMBL252417 & 688746 & 4.65 & 4.8173 & TST \\
\hline CHEMBL1414273 & 688746 & 4.9 & 4.8176 & TRN \\
\hline CHEMBL3212590 & 688746 & 4.45 & 4.8264 & TRN \\
\hline CHEMBL1585103 & 688746 & 4.85 & 4.8947 & TRN \\
\hline CHEMBL1331531 & 688746 & 4.65 & 4.8843 & TRN \\
\hline CHEMBL1379512 & 688746 & 4.65 & 4.8398 & TST \\
\hline CHEMBL1449108 & 688746 & 4.8 & 4.9228 & TRN \\
\hline CHEMBL1405834 & 688746 & 4.6 & 4.789 & TRN \\
\hline CHEMBL154580 & 688746 & 5.0 & 4.7862 & TST \\
\hline CHEMBL1331491 & 688746 & 4.65 & 4.8481 & TRN \\
\hline CHEMBL1471125 & 688746 & 4.6 & 4.8783 & TRN \\
\hline
\end{tabular}




\begin{tabular}{|c|c|c|c|c|c|}
\hline \\
\hline CHEMBL1588818 & 688746 & 4.55 & 4.8427 & TRN & \\
\hline CHEMBL1401799 & 688746 & 4.5 & 4.7555 & TRN & \\
\hline CHEMBL1388304 & 688746 & 6.2 & 4.8335 & TRN & \\
\hline CHEMBL3193168 & 688746 & 5.15 & 4.8272 & TST & \\
\hline CHEMBL3207673 & 688746 & 4.4 & 4.831 & TRN & \\
\hline CHEMBL1374141 & 688746 & 4.9 & 4.8174 & TRN & \\
\hline CHEMBL1339618 & 688746 & 4.75 & 4.9705 & TRN & \\
\hline CHEMBL1576939 & 688746 & 4.4 & 4.9458 & TRN & \\
\hline CHEMBL219778 & 688746 & 4.85 & 4.88399 & 99999999995 & TRN \\
\hline CHEMBL1421640 & 688746 & 4.55 & 4.8517 & TST & \\
\hline CHEMBL1386547 & 688746 & 4.55 & 4.8881 & TRN & \\
\hline CHEMBL1372889 & 688746 & 4.5 & 4.8091 & TST & \\
\hline CHEMBL1541779 & 688746 & 4.7 & 4.8638 & TRN & \\
\hline CHEMBL1438903 & 688746 & 4.55 & 4.8369 & TRN & \\
\hline CHEMBL1588293 & 688746 & 4.7 & 4.8226 & TRN & \\
\hline CHEMBL1495096 & 688746 & 4.8 & 4.7918 & TRN & \\
\hline CHEMBL1311881 & 688746 & 4.65 & 4.9125 & TST & \\
\hline CHEMBL1501898 & 688746 & 4.4 & 4.8141 & TST & \\
\hline CHEMBL1580372 & 688746 & 4.65 & 4.8182 & TRN & \\
\hline CHEMBL1519965 & 688746 & 5.4 & 4.8192 & TRN & \\
\hline CHEMBL1517332 & 688746 & 4.8 & 4.7025 & TRN & \\
\hline CHEMBL1338317 & 688746 & 5.45 & 5.0245 & TRN & \\
\hline CHEMBL1432648 & 688746 & 4.65 & 4.9917 & TRN & \\
\hline CHEMBL1324867 & 688746 & 4.8 & 4.7998 & TST & \\
\hline CHEMBL1612994 & 688746 & 4.5 & 4.9047 & TRN & \\
\hline CHEMBL1561230 & 688746 & 4.6 & 4.7798 & TST & \\
\hline CHEMBL1464133 & 688746 & 5.3 & 4.8212 & TRN & \\
\hline CHEMBL1350960 & 688746 & 4.5 & 4.8256 & TRN & \\
\hline CHEMBL1586813 & 688746 & 5.25 & 4.9253 & TRN & \\
\hline CHEMBL1532843 & 688746 & 5.8 & 4.8381 & TST & \\
\hline CHEMBL3209541 & 688746 & 4.75 & 4.8895 & TRN & \\
\hline CHEMBL1419054 & 688746 & 4.45 & 4.7956 & TRN & \\
\hline CHEMBL1417083 & 688746 & 4.4 & 4.7345 & TRN & \\
\hline CHEMBL1549297 & 688746 & 4.4 & 4.883 & TRN & \\
\hline CHEMBL1415821 & 688746 & 4.85 & 5.0351 & TRN & \\
\hline CHEMBL3194460 & 688746 & 4.65 & 4.7893 & TRN & \\
\hline CHEMBL1464751 & 688746 & 4.9 & 4.9383 & TRN & \\
\hline CHEMBL1581007 & 688746 & 5.55 & 4.8424 & TRN & \\
\hline CHEMBL1426863 & 688746 & 4.4 & 4.7845 & TRN & \\
\hline CHEMBL1349769 & 688746 & 4.95 & 4.8903 & TRN & \\
\hline CHEMBL1457071 & 688746 & 4.65 & 4.9083 & TRN & \\
\hline CHEMBL1503160 & 688746 & 5.35 & 4.812 & TRN & \\
\hline CHEMBL1556805 & 688746 & 4.55 & 4.789 & TST & \\
\hline CHEMBL1460141 & 688746 & 4.85 & 4.8475 & TRN & \\
\hline CHEMBL1304678 & 688746 & 4.55 & 4.9551 & TRN & \\
\hline CHEMBL3197462 & 688746 & 4.6 & 4.7782 & TRN & \\
\hline CHEMBL1364752 & 688746 & 4.5 & 4.8581 & TRN & \\
\hline CHEMBL1326546 & 688746 & 5.15 & 4.8096 & TRN & \\
\hline
\end{tabular}




\begin{tabular}{|c|c|c|c|c|}
\hline & & & pplemen & \\
\hline CHEMBL1373873 & 688746 & 4.75 & 4.9487 & TRN \\
\hline CHEMBL1558284 & 688746 & 4.6 & 4.8365 & TRN \\
\hline CHEMBL1999049 & 688746 & 4.8 & 4.8932 & TST \\
\hline CHEMBL 2003887 & 688746 & 5.1 & 4.8045 & TRN \\
\hline CHEMBL1524713 & 688746 & 6.1 & 4.9933 & TRN \\
\hline CHEMBL1302946 & 688746 & 4.65 & 4.8381 & TRN \\
\hline CHEMBL1424737 & 688746 & 5.15 & 4.9777 & TRN \\
\hline CHEMBL1336173 & 688746 & 4.45 & 4.8348 & TRN \\
\hline CHEMBL1485879 & 688746 & 5.2 & 4.8764 & TRN \\
\hline CHEMBL1321132 & 688746 & 4.8 & 4.9034 & TRN \\
\hline CHEMBL1613091 & 688746 & 4.55 & 4.845 & TRN \\
\hline CHEMBL1442553 & 688746 & 4.55 & 4.8668 & TRN \\
\hline CHEMBL1345032 & 688746 & 4.55 & 4.8962 & TRN \\
\hline CHEMBL1304086 & 688746 & 4.55 & 4.9896 & TRN \\
\hline CHEMBL1498564 & 688746 & 4.6 & 4.795 & TRN \\
\hline CHEMBL1386849 & 688746 & 4.4 & 4.8581 & TRN \\
\hline CHEMBL3210270 & 688746 & 4.4 & 4.8231 & TRN \\
\hline CHEMBL1550617 & 688746 & 4.4 & 4.8875 & TRN \\
\hline CHEMBL1607527 & 688746 & 5.15 & 4.8582 & TRN \\
\hline CHEMBL1422578 & 688746 & 5.0 & 4.9451 & TRN \\
\hline CHEMBL1588814 & 688746 & 4.6 & 4.9796 & TRN \\
\hline CHEMBL1342326 & 688746 & 4.4 & 4.9677 & TRN \\
\hline CHEMBL1569481 & 688746 & 4.4 & 4.8839 & TRN \\
\hline CHEMBL 3199842 & 688746 & 4.4 & 4.8206 & TRN \\
\hline CHEMBL1364716 & 688746 & 4.4 & 4.7629 & TST \\
\hline CHEMBL1419849 & 688746 & 5.4 & 4.8314 & TRN \\
\hline CHEMBL1526870 & 688746 & 5.45 & 4.8512 & TRN \\
\hline CHEMBL1456719 & 688746 & 4.45 & 4.8749 & TRN \\
\hline CHEMBL1383340 & 688746 & 4.8 & 4.8365 & TST \\
\hline CHEMBL1559317 & 688746 & 4.6 & 4.8836 & TRN \\
\hline CHEMBL1592493 & 688746 & 5.05 & 4.7708 & TRN \\
\hline CHEMBL1480031 & 688746 & 4.55 & 4.8594 & TRN \\
\hline CHEMBL1456371 & 688746 & 5.4 & 4.8318 & TRN \\
\hline CHEMBL1385074 & 688746 & 4.55 & 4.8317 & TRN \\
\hline CHEMBL3197737 & 688746 & 4.4 & 4.7874 & TRN \\
\hline CHEMBL1493929 & 688746 & 4.85 & 4.8576 & TRN \\
\hline CHEMBL1404231 & 688746 & 4.5 & 4.8198 & TRN \\
\hline CHEMBL193627 & 688746 & 5.35 & 4.8347 & TST \\
\hline CHEMBL1543104 & 688746 & 5.0 & 4.8388 & TRN \\
\hline CHEMBL1345135 & 688746 & 5.45 & 4.7836 & TRN \\
\hline CHEMBL1580398 & 688746 & 4.8 & 4.8834 & TRN \\
\hline CHEMBL1450826 & 688746 & 5.0 & 4.949 & TRN \\
\hline CHEMBL1575306 & 688746 & 4.8 & 4.8987 & TST \\
\hline CHEMBL1504339 & 688746 & 4.55 & 4.9551 & TRN \\
\hline CHEMBL1535836 & 688746 & 5.05 & 4.9124 & TRN \\
\hline CHEMBL1414041 & 688746 & 5.15 & 4.8806 & TRN \\
\hline CHEMBL1431126 & 688746 & 4.6 & 4.754 & TRN \\
\hline CHEMBL1564212 & 688746 & 4.75 & 4.8079 & TRN \\
\hline
\end{tabular}




\begin{tabular}{|c|c|c|c|c|}
\hline \multicolumn{5}{|c|}{ Supplemental Table S2.txt } \\
\hline CHEMBL1407667 & 688746 & 6.95 & 4.8595 & TRN \\
\hline CHEMBL1577863 & 688746 & 4.55 & 4.8756 & TRN \\
\hline CHEMBL1451828 & 688746 & 4.9 & 5.0107 & TRN \\
\hline CHEMBL1368547 & 688746 & 5.05 & 4.8043 & TRN \\
\hline CHEMBL1521940 & 688746 & 4.75 & 4.9781 & TRN \\
\hline CHEMBL1485133 & 688746 & 4.9 & 4.9255 & TRN \\
\hline CHEMBL3210340 & 688746 & 4.6 & 4.8053 & TRN \\
\hline CHEMBL1610930 & 688746 & 4.5 & 4.8763 & TST \\
\hline CHEMBL3192106 & 688746 & 4.4 & 4.7968 & TST \\
\hline CHEMBL1382734 & 688746 & 4.5 & 4.795 & TRN \\
\hline CHEMBL3192009 & 688746 & 4.6 & 4.8105 & TRN \\
\hline CHEMBL1410119 & 688746 & 4.5 & 4.8346 & TRN \\
\hline CHEMBL1489861 & 688746 & 5.0 & 4.9522 & TST \\
\hline CHEMBL1326803 & 688746 & 4.9 & 4.7974 & TRN \\
\hline CHEMBL1390064 & 688746 & 5.15 & 4.9868 & TRN \\
\hline CHEMBL1461451 & 688746 & 4.4 & 4.8651 & TRN \\
\hline CHEMBL1301103 & 688746 & 4.45 & 4.7836 & TRN \\
\hline CHEMBL1967185 & 688746 & 4.85 & 4.8112 & TRN \\
\hline CHEMBL1568933 & 688746 & 4.45 & 4.7554 & TRN \\
\hline CHEMBL1588534 & 688746 & 4.65 & 4.8607 & TRN \\
\hline CHEMBL1303693 & 688746 & 4.4 & 4.9322 & TRN \\
\hline CHEMBL1528965 & 688746 & 6.95 & 4.7688 & TRN \\
\hline CHEMBL1413213 & 688746 & 4.55 & 4.8798 & TRN \\
\hline CHEMBL1309568 & 688746 & 4.5 & 4.9119 & TRN \\
\hline CHEMBL1413479 & 688746 & 5.3 & 4.8499 & TRN \\
\hline CHEMBL1413662 & 688746 & 6.1 & 4.8437 & TRN \\
\hline CHEMBL3199413 & 688746 & 4.7 & 4.7805 & TRN \\
\hline CHEMBL1542492 & 688746 & 4.85 & 4.8114 & TRN \\
\hline CHEMBL1491354 & 688746 & 5.25 & 4.8489 & TRN \\
\hline CHEMBL1549373 & 688746 & 4.5 & 4.8546 & TST \\
\hline CHEMBL1587424 & 688746 & 4.55 & 4.9124 & TRN \\
\hline CHEMBL1466868 & 688746 & 4.6 & 4.7831 & TRN \\
\hline CHEMBL1310732 & 688746 & 4.5 & 4.8497 & TST \\
\hline CHEMBL1504463 & 688746 & 4.5 & 5.0077 & TRN \\
\hline CHEMBL1989750 & 688746 & 4.4 & 4.7181 & TRN \\
\hline CHEMBL1567793 & 688746 & 4.55 & 4.7845 & TRN \\
\hline CHEMBL1457260 & 688746 & 4.5 & 4.837 & TRN \\
\hline CHEMBL1441042 & 688746 & 4.9 & 4.7183 & TRN \\
\hline CHEMBL1604245 & 688746 & 4.9 & 4.7445 & TRN \\
\hline CHEMBL307893 & 688746 & 4.95 & 4.8791 & TST \\
\hline CHEMBL1382293 & 688746 & 5.1 & 5.0491 & TRN \\
\hline CHEMBL1549079 & 688746 & 4.55 & 4.8592 & TRN \\
\hline CHEMBL1447568 & 688746 & 5.1 & 4.8471 & TRN \\
\hline CHEMBL 3190169 & 688746 & 4.95 & 4.8216 & TRN \\
\hline CHEMBL1429161 & 688746 & 5.4 & 5.0044 & TRN \\
\hline CHEMBL1496495 & 688746 & 5.2 & 4.9839 & TRN \\
\hline CHEMBL1571685 & 688746 & 5.2 & 4.852 & TRN \\
\hline CHEMBL1505806 & 688746 & 4.45 & 4.6945 & TRN \\
\hline
\end{tabular}




\begin{tabular}{|c|c|c|c|c|c|}
\hline \multicolumn{6}{|c|}{ Supplemental Table S2.txt } \\
\hline CHEMBL1550342 & 688746 & 4.65 & 4.9379 & TST & \\
\hline CHEMBL3194871 & 688746 & 4.55 & 4.7638 & TRN & \\
\hline CHEMBL1545934 & 688746 & 4.5 & 4.8776 & TST & \\
\hline CHEMBL1332882 & 688746 & 4.55 & 4.7402 & TRN & \\
\hline CHEMBL3195761 & 688746 & 5.1 & 4.7713 & TRN & \\
\hline CHEMBL1304395 & 688746 & 4.7 & 5.0182 & TRN & \\
\hline CHEMBL1370420 & 688746 & 5.5 & 4.7783 & TRN & \\
\hline CHEMBL1304177 & 688746 & 4.4 & 4.785 & TRN & \\
\hline CHEMBL1421117 & 688746 & 4.55 & 4.8554 & TRN & \\
\hline CHEMBL1387916 & 688746 & 5.15 & 4.9067 & TRN & \\
\hline CHEMBL1430356 & 688746 & 4.45 & 4.8843 & TRN & \\
\hline CHEMBL1423192 & 688746 & 4.55 & 4.7535 & TRN & \\
\hline CHEMBL1504964 & 688746 & 4.45 & 4.8336 & TRN & \\
\hline CHEMBL3214466 & 688746 & 4.4 & 4.7327 & TST & \\
\hline CHEMBL1580421 & 688746 & 4.85 & 4.8893 & TRN & \\
\hline CHEMBL1353714 & 688746 & 4.4 & 4.8001 & TRN & \\
\hline CHEMBL1382945 & 688746 & 4.9 & 4.8724 & TST & \\
\hline CHEMBL1574472 & 688746 & 4.4 & 4.8384 & TST & \\
\hline CHEMBL1393085 & 688746 & 4.55 & 4.8982 & TRN & \\
\hline CHEMBL1493784 & 688746 & 4.45 & 4.9132 & TST & \\
\hline CHEMBL1527727 & 688746 & 4.55 & 4.6842 & TRN & \\
\hline CHEMBL1495685 & 688746 & 5.65 & 4.7968 & TRN & \\
\hline CHEMBL1414231 & 688746 & 4.8 & 4.8864 & TRN & \\
\hline CHEMBL1353674 & 688746 & 6.0 & 4.9951 & TRN & \\
\hline CHEMBL1303178 & 688746 & 5.35 & 4.9248 & TRN & \\
\hline CHEMBL1469505 & 688746 & 4.8 & 4.9037 & TRN & \\
\hline CHEMBL1443464 & 688746 & 4.5 & 4.8001 & TRN & \\
\hline CHEMBL1481603 & 688746 & 6.05 & 4.8429 & TST & \\
\hline CHEMBL1308688 & 688746 & 6.0 & 5.0091 & TRN & \\
\hline CHEMBL1423747 & 688746 & 5.1 & 4.8321 & TRN & \\
\hline CHEMBL1526308 & 688746 & 4.95 & 5.0271 & TRN & \\
\hline CHEMBL1978730 & 688746 & 5.0 & 4.7789 & TRN & \\
\hline CHEMBL1307692 & 688746 & 5.5 & 4.7816 & TRN & \\
\hline CHEMBL1501394 & 688746 & 4.5 & 4.8311 & TRN & \\
\hline CHEMBL1420849 & 688746 & 4.6 & 4.8813 & TRN & \\
\hline CHEMBL1417563 & 688746 & 4.45 & 4.9239 & TRN & \\
\hline CHEMBL1335413 & 688746 & 5.6 & 4.8931 & TRN & \\
\hline CHEMBL1392244 & 688746 & 4.4 & 4.8294 & TRN & \\
\hline CHEMBL1536179 & 688746 & 5.0 & 4.9478 & TRN & \\
\hline CHEMBL1535553 & 688746 & 5.55 & 4.8818 & TRN & \\
\hline CHEMBL1389829 & 688746 & 4.9 & 4.8356 & TRN & \\
\hline CHEMBL1544495 & 688746 & 5.4 & 4.9342 & TRN & \\
\hline CHEMBL1416184 & 688746 & 5.4 & 4.7964 & TRN & \\
\hline CHEMBL1527937 & 688746 & 4.8 & 4.9259 & TRN & \\
\hline CHEMBL1381407 & 688746 & 4.45 & 4.776 & TRN & \\
\hline CHEMBL1535345 & 688746 & 5.3 & 4.81800 & 00000000005 & TRN \\
\hline CHEMBL3193861 & 688746 & 4.55 & 4.8378 & TRN & \\
\hline CHEMBL1439557 & 688746 & 4.9 & 4.8677 & TRN & \\
\hline
\end{tabular}




\begin{tabular}{|c|c|c|c|c|}
\hline & & & & al T \\
\hline CHEMBL161957 & 688746 & 4.6 & 4.8413 & TST \\
\hline CHEMBL1430687 & 688746 & 5.15 & 4.8466 & TRN \\
\hline CHEMBL1340987 & 688746 & 4.4 & 4.8039 & TST \\
\hline CHEMBL1582442 & 688746 & 4.45 & 4.8151 & TRN \\
\hline CHEMBL 3194443 & 688746 & 4.4 & 4.7462 & TRN \\
\hline CHEMBL1321993 & 688746 & 4.4 & 4.8715 & TST \\
\hline CHEMBL1484231 & 688746 & 4.85 & 4.8747 & TST \\
\hline CHEMBL1336523 & 688746 & 4.55 & 4.9817 & TRN \\
\hline CHEMBL1576155 & 688746 & 4.85 & 5.0138 & TRN \\
\hline CHEMBL1408430 & 688746 & 5.3 & 4.8576 & TRN \\
\hline CHEMBL1995193 & 688746 & 4.55 & 4.718 & TRN \\
\hline CHEMBL1360965 & 688746 & 4.6 & 4.8743 & TRN \\
\hline CHEMBL1408233 & 688746 & 4.4 & 4.8702 & TRN \\
\hline CHEMBL1586003 & 688746 & 5.8 & 5.0391 & TRN \\
\hline CHEMBL1567873 & 688746 & 6.0 & 4.8532 & TRN \\
\hline CHEMBL1486262 & 688746 & 4.4 & 4.7834 & TRN \\
\hline CHEMBL1542404 & 688746 & 4.7 & 4.8189 & TRN \\
\hline CHEMBL1462145 & 688746 & 4.4 & 4.8522 & TRN \\
\hline CHEMBL1351806 & 688746 & 4.9 & 4.8589 & TRN \\
\hline CHEMBL1403448 & 688746 & 4.7 & 4.8281 & TRN \\
\hline CHEMBL1569308 & 688746 & 4.55 & 4.9384 & TRN \\
\hline CHEMBL1532772 & 688746 & 5.45 & 4.9285 & TRN \\
\hline CHEMBL1505334 & 688746 & 4.5 & 4.7919 & TRN \\
\hline CHEMBL1323432 & 688746 & 5.4 & 4.8431 & TRN \\
\hline CHEMBL1449037 & 688746 & 4.45 & 4.7671 & TRN \\
\hline CHEMBL3197721 & 688746 & 5.2 & 4.7683 & TST \\
\hline CHEMBL1506811 & 688746 & 4.95 & 4.9585 & TRN \\
\hline CHEMBL1556644 & 688746 & 4.7 & 4.9928 & TRN \\
\hline CHEMBL3145305 & 688746 & 4.9 & 4.86 & TRN \\
\hline CHEMBL1577971 & 688746 & 4.8 & 4.8763 & TRN \\
\hline CHEMBL1565221 & 688746 & 4.5 & 4.7486 & TRN \\
\hline CHEMBL1529411 & 688746 & 4.7 & 4.8057 & TRN \\
\hline CHEMBL1534695 & 688746 & 4.9 & 4.8668 & TRN \\
\hline CHEMBL1430386 & 688746 & 4.85 & 4.802 & TST \\
\hline CHEMBL1372206 & 688746 & 4.5 & 4.927 & TRN \\
\hline CHEMBL1369045 & 688746 & 4.75 & 4.7922 & TRN \\
\hline CHEMBL1597766 & 688746 & 4.85 & 4.8247 & TRN \\
\hline CHEMBL1529066 & 688746 & 5.0 & 4.8992 & TRN \\
\hline CHEMBL1430344 & 688746 & 5.05 & 4.8691 & TRN \\
\hline CHEMBL1602624 & 688746 & 4.4 & 4.8585 & TRN \\
\hline CHEMBL1486510 & 688746 & 4.5 & 4.8513 & TRN \\
\hline CHEMBL1422133 & 688746 & 5.0 & 4.9452 & TST \\
\hline CHEMBL1429456 & 688746 & 5.35 & 4.9026 & TRN \\
\hline CHEMBL1401798 & 688746 & 4.55 & 4.8311 & TRN \\
\hline CHEMBL1369199 & 688746 & 4.5 & 5.0031 & TRN \\
\hline CHEMBL1323490 & 688746 & 4.55 & 4.7446 & TRN \\
\hline CHEMBL1596675 & 688746 & 5.05 & 4.8726 & TST \\
\hline CHEMBL1344484 & 688746 & 4.9 & 4.8602 & TRN \\
\hline
\end{tabular}




\begin{tabular}{|c|c|c|c|c|}
\hline & & & ient & al T \\
\hline CHEMBL1566877 & 688746 & 5.0 & 4.7385 & TRN \\
\hline CHEMBL1449644 & 688746 & 4.45 & 4.8775 & TRN \\
\hline CHEMBL1448856 & 688746 & 4.8 & 4.8184 & TRN \\
\hline CHEMBL1372387 & 688746 & 4.4 & 4.8845 & TRN \\
\hline CHEMBL1568631 & 688746 & 4.7 & 4.7994 & TST \\
\hline CHEMBL1585623 & 688746 & 4.5 & 4.828 & TRN \\
\hline CHEMBL1510345 & 688746 & 5.95 & 5.0273 & TRN \\
\hline CHEMBL1462274 & 688746 & 5.0 & 4.7826 & TRN \\
\hline CHEMBL1599057 & 688746 & 4.4 & 4.855 & TST \\
\hline CHEMBL1481651 & 688746 & 4.8 & 4.8366 & TRN \\
\hline CHEMBL1371083 & 688746 & 5.15 & 5.0437 & TRN \\
\hline CHEMBL1499433 & 688746 & 4.95 & 4.9028 & TRN \\
\hline CHEMBL1489151 & 688746 & 4.85 & 4.8024 & TRN \\
\hline CHEMBL1522184 & 688746 & 6.05 & 4.8124 & TST \\
\hline CHEMBL1385230 & 688746 & 4.65 & 4.8123 & TRN \\
\hline CHEMBL1574759 & 688746 & 4.4 & 4.8647 & TRN \\
\hline CHEMBL1400003 & 688746 & 4.75 & 4.8655 & TST \\
\hline CHEMBL1562605 & 688746 & 5.45 & 4.7827 & TRN \\
\hline CHEMBL1506281 & 688746 & 4.7 & 4.9231 & TRN \\
\hline CHEMBL1537383 & 688746 & 4.45 & 4.8701 & TRN \\
\hline CHEMBL 140425 & 688746 & 4.45 & 4.7951 & TRN \\
\hline CHEMBL1376387 & 688746 & 4.45 & 4.7831 & TRN \\
\hline CHEMBL1547130 & 688746 & 5.95 & 4.8557 & TRN \\
\hline CHEMBL1462244 & 688746 & 4.5 & 4.6999 & TRN \\
\hline CHEMBL1342141 & 688746 & 4.5 & 4.8232 & TRN \\
\hline CHEMBL 1543750 & 688746 & 4.4 & 4.9639 & TRN \\
\hline CHEMBL564979 & 688746 & 4.9 & 4.8577 & TRN \\
\hline CHEMBL1965471 & 688746 & 4.45 & 4.8039 & TRN \\
\hline CHEMBL1570008 & 688746 & 5.1 & 4.797 & TRN \\
\hline CHEMBL1403634 & 688746 & 4.65 & 4.8084 & TRN \\
\hline CHEMBL1429799 & 688746 & 5.0 & 4.8456 & TRN \\
\hline CHEMBL1432947 & 688746 & 4.4 & 4.9631 & TRN \\
\hline CHEMBL1530743 & 688746 & 4.45 & 4.7608 & TRN \\
\hline CHEMBL1444315 & 688746 & 4.5 & 4.9175 & TRN \\
\hline CHEMBL1405197 & 688746 & 4.55 & 4.8846 & TRN \\
\hline CHEMBL1350157 & 688746 & 5.1 & 4.8302 & TRN \\
\hline CHEMBL1495059 & 688746 & 5.2 & 5.0241 & TRN \\
\hline CHEMBL1411673 & 688746 & 4.85 & 4.823 & TRN \\
\hline CHEMBL1366069 & 688746 & 4.4 & 4.9121 & TRN \\
\hline CHEMBL1381321 & 688746 & 4.5 & 4.9592 & TRN \\
\hline CHEMBL1464304 & 688746 & 4.5 & 4.837 & TRN \\
\hline CHEMBL1605885 & 688746 & 4.55 & 4.7643 & TRN \\
\hline CHEMBL1492719 & 688746 & 4.75 & 4.8966 & TRN \\
\hline CHEMBL1319910 & 688746 & 4.7 & 4.8589 & TRN \\
\hline CHEMBL1393406 & 688746 & 4.5 & 4.8994 & TRN \\
\hline CHEMBL1568810 & 688746 & 5.25 & 4.8053 & TRN \\
\hline CHEMBL1537146 & 688746 & 4.85 & 5.0455 & TRN \\
\hline CHEMBL1430732 & 688746 & 4.4 & 4.9451 & TRN \\
\hline
\end{tabular}




\begin{tabular}{|c|c|c|c|c|c|}
\hline \\
\hline CHEMBL1422394 & 688746 & 4.4 & 4.832 & TRN & \\
\hline CHEMBL1340455 & 688746 & 5.2 & 4.846 & TRN & \\
\hline CHEMBL1392651 & 688746 & 5.05 & 4.9016 & TST & \\
\hline CHEMBL1312579 & 688746 & 4.4 & 4.8293 & TRN & \\
\hline CHEMBL1329272 & 688746 & 4.9 & 4.766999 & 79999999995 & TRN \\
\hline CHEMBL1585117 & 688746 & 4.55 & 4.8575 & TRN & \\
\hline CHEMBL1328778 & 688746 & 5.65 & 4.9312 & TRN & \\
\hline CHEMBL1509705 & 688746 & 4.75 & 4.8813 & TRN & \\
\hline CHEMBL1484144 & 688746 & 5.35 & 4.8652 & TST & \\
\hline CHEMBL1511520 & 688746 & 4.95 & 4.8178 & TRN & \\
\hline CHEMBL1557775 & 688746 & 4.9 & 4.8746 & TRN & \\
\hline CHEMBL1375190 & 688746 & 4.45 & 4.9071 & TRN & \\
\hline CHEMBL1441838 & 688746 & 4.45 & 4.8321 & TRN & \\
\hline CHEMBL1587985 & 688746 & 4.55 & 4.8035 & TRN & \\
\hline CHEMBL1349189 & 688746 & 4.6 & 4.8828 & TRN & \\
\hline CHEMBL1422908 & 688746 & 4.85 & 4.8887 & TRN & \\
\hline CHEMBL1383533 & 688746 & 4.45 & 4.8416 & TRN & \\
\hline CHEMBL1508076 & 688746 & 4.6 & 4.8143 & TRN & \\
\hline CHEMBL1576494 & 688746 & 4.55 & 4.8647 & TRN & \\
\hline CHEMBL1386216 & 688746 & 4.65 & 4.9555 & TRN & \\
\hline CHEMBL1370032 & 688746 & 4.85 & 4.8591 & TST & \\
\hline CHEMBL1467033 & 688746 & 4.75 & 4.8195 & TRN & \\
\hline CHEMBL1330064 & 688746 & 6.1 & 4.7949 & TST & \\
\hline CHEMBL1423475 & 688746 & 4.4 & 4.8733 & TRN & \\
\hline CHEMBL1480722 & 688746 & 4.6 & 4.8714 & TRN & \\
\hline CHEMBL1581172 & 688746 & 4.85 & 5.0423 & TRN & \\
\hline CHEMBL1978279 & 688746 & 4.55 & 4.775 & TRN & \\
\hline CHEMBL1407450 & 688746 & 4.55 & 5.0173 & TRN & \\
\hline CHEMBL1440300 & 688746 & 4.95 & 4.8055 & TRN & \\
\hline CHEMBL1308009 & 688746 & 4.65 & 4.8334 & TRN & \\
\hline CHEMBL453291 & 688746 & 4.6 & 4.8651 & TST & \\
\hline CHEMBL1320234 & 688746 & 5.8 & 4.7859 & TRN & \\
\hline CHEMBL3194911 & 688746 & 5.4 & 4.8106 & TRN & \\
\hline CHEMBL1424694 & 688746 & 4.7 & 4.846 & TRN & \\
\hline CHEMBL1596599 & 688746 & 4.7 & 4.8635 & TRN & \\
\hline CHEMBL1466350 & 688746 & 5.15 & 5.0028 & TRN & \\
\hline CHEMBL1495592 & 688746 & 5.25 & 4.8198 & TST & \\
\hline CHEMBL1372229 & 688746 & 4.85 & 4.7818 & TRN & \\
\hline CHEMBL1299882 & 688746 & 5.15 & 4.8048 & TRN & \\
\hline CHEMBL1570417 & 688746 & 4.65 & 4.8204 & TRN & \\
\hline CHEMBL1542102 & 688746 & 4.4 & 4.9464 & TRN & \\
\hline CHEMBL1504797 & 688746 & 4.6 & 5.0043 & TRN & \\
\hline CHEMBL1531298 & 688746 & 4.5 & 4.8352 & TST & \\
\hline CHEMBL1485349 & 688746 & 6.25 & 4.8703 & TRN & \\
\hline CHEMBL1302662 & 688746 & 5.05 & 4.9422 & TRN & \\
\hline CHEMBL154358 & 688746 & 4.5 & 4.9164 & TST & \\
\hline CHEMBL1601994 & 688746 & 4.85 & 4.9451 & TRN & \\
\hline CHEMBL1353776 & 688746 & 4.75 & 4.8992 & TRN & \\
\hline & & & & 4030 & \\
\hline
\end{tabular}




\begin{tabular}{|c|c|c|c|c|}
\hline \multicolumn{5}{|c|}{ Supplemental Table S2.txt } \\
\hline CHEMBL1563798 & 688746 & 4.75 & 4.9035 & TRN \\
\hline CHEMBL1594411 & 688746 & 4.45 & 4.7926 & TST \\
\hline CHEMBL3195808 & 688746 & 5.75 & 4.8057 & TRN \\
\hline CHEMBL1319307 & 688746 & 4.85 & 4.8816 & TRN \\
\hline CHEMBL1336959 & 688746 & 4.4 & 4.8269 & TRN \\
\hline CHEMBL1608259 & 688746 & 5.4 & 4.9076 & TRN \\
\hline CHEMBL1596108 & 688746 & 4.65 & 4.9687 & TRN \\
\hline CHEMBL1305647 & 688746 & 5.45 & 4.7989 & TRN \\
\hline CHEMBL1409488 & 688746 & 4.55 & 4.7577 & TRN \\
\hline CHEMBL1564130 & 688746 & 4.4 & 4.9526 & TST \\
\hline CHEMBL1388194 & 688746 & 4.55 & 4.8538 & TRN \\
\hline CHEMBL3210215 & 688746 & 4.4 & 4.8944 & TRN \\
\hline CHEMBL1372781 & 688746 & 5.3 & 4.9494 & TRN \\
\hline CHEMBL3190792 & 688746 & 4.4 & 4.7842 & TRN \\
\hline CHEMBL1305721 & 688746 & 4.85 & 4.8522 & TST \\
\hline CHEMBL3197841 & 688746 & 4.55 & 4.8325 & TRN \\
\hline CHEMBL1359820 & 688746 & 4.4 & 4.9611 & TRN \\
\hline CHEMBL1430777 & 688746 & 4.6 & 5.0459 & TRN \\
\hline CHEMBL1588874 & 688746 & 4.65 & 4.9588 & TRN \\
\hline CHEMBL1346909 & 688746 & 4.45 & 4.8438 & TST \\
\hline CHEMBL1516704 & 688746 & 5.55 & 4.9137 & TRN \\
\hline CHEMBL1562273 & 688746 & 4.75 & 4.9868 & TRN \\
\hline CHEMBL1442687 & 688746 & 5.7 & 4.9319 & TRN \\
\hline CHEMBL1494784 & 688746 & 4.4 & 4.9611 & TST \\
\hline CHEMBL1382917 & 688746 & 5.3 & 4.8743 & TST \\
\hline CHEMBL1313003 & 688746 & 4.4 & 4.7621 & TRN \\
\hline CHEMBL1323361 & 688746 & 4.4 & 4.7793 & TRN \\
\hline CHEMBL1567444 & 688746 & 4.55 & 4.9528 & TRN \\
\hline CHEMBL1568043 & 688746 & 5.15 & 4.8347 & TRN \\
\hline CHEMBL1424094 & 688746 & 4.75 & 4.8466 & TRN \\
\hline CHEMBL1563581 & 688746 & 4.5 & 4.7163 & TRN \\
\hline CHEMBL1360977 & 688746 & 4.85 & 4.713 & TRN \\
\hline CHEMBL1344752 & 688746 & 4.6 & 5.0341 & TRN \\
\hline CHEMBL1508458 & 688746 & 4.55 & 4.7694 & TRN \\
\hline CHEMBL3196684 & 688746 & 4.6 & 4.7864 & TRN \\
\hline CHEMBL1528095 & 688746 & 4.7 & 4.9284 & TRN \\
\hline CHEMBL1480901 & 688746 & 5.25 & 4.9924 & TRN \\
\hline CHEMBL1432977 & 688746 & 4.8 & 4.8278 & TST \\
\hline CHEMBL1428932 & 688746 & 4.85 & 4.7812 & TRN \\
\hline CHEMBL1310318 & 688746 & 4.45 & 4.8651 & TRN \\
\hline CHEMBL1571518 & 688746 & 4.5 & 4.9081 & TRN \\
\hline CHEMBL3211460 & 688746 & 4.75 & 4.7691 & TRN \\
\hline CHEMBL 227447 & 688746 & 5.2 & 4.9885 & TRN \\
\hline CHEMBL1323805 & 688746 & 4.45 & 4.9691 & TRN \\
\hline CHEMBL1417271 & 688746 & 4.55 & 4.723 & TRN \\
\hline CHEMBL1488204 & 688746 & 4.75 & 4.7383 & TRN \\
\hline CHEMBL1312341 & 688746 & 5.4 & 4.9088 & TRN \\
\hline CHEMBL1343919 & 688746 & 4.65 & 4.8243 & TST \\
\hline
\end{tabular}




\begin{tabular}{|c|c|c|c|c|}
\hline \multicolumn{5}{|c|}{ Supplemental Table } \\
\hline CHEMBL1407293 & 688746 & 5.35 & 4.8256 & TRN \\
\hline CHEMBL1559414 & 688746 & 4.7 & 4.8249 & TRN \\
\hline CHEMBL1335155 & 688746 & 5.15 & 4.9284 & TST \\
\hline CHEMBL1494871 & 688746 & 5.2 & 4.8672 & TRN \\
\hline CHEMBL1302030 & 688746 & 5.0 & 4.9582 & TRN \\
\hline CHEMBL1494029 & 688746 & 4.75 & 4.8937 & TRN \\
\hline CHEMBL1455116 & 688746 & 4.4 & 4.9432 & TRN \\
\hline CHEMBL1562713 & 688746 & 4.4 & 4.7454 & TRN \\
\hline CHEMBL3193124 & 688746 & 4.7 & 4.7408 & TRN \\
\hline CHEMBL1605356 & 688746 & 5.15 & 4.9128 & TST \\
\hline CHEMBL1457836 & 688746 & 4.6 & 4.879 & TRN \\
\hline CHEMBL1492651 & 688746 & 4.9 & 4.9758 & TRN \\
\hline CHEMBL1538938 & 688746 & 4.7 & 4.8891 & TRN \\
\hline CHEMBL1604473 & 688746 & 4.8 & 5.0006 & TRN \\
\hline CHEMBL1359354 & 688746 & 5.05 & 4.8093 & TRN \\
\hline CHEMBL1338958 & 688746 & 4.55 & 4.9476 & TST \\
\hline CHEMBL1300266 & 688746 & 4.75 & 4.8335 & TRN \\
\hline CHEMBL1539417 & 688746 & 4.45 & 4.9574 & TRN \\
\hline CHEMBL1522554 & 688746 & 4.4 & 4.827 & TRN \\
\hline CHEMBL1332177 & 688746 & 5.25 & 4.8702 & TST \\
\hline CHEMBL1522139 & 688746 & 4.95 & 4.8764 & TRN \\
\hline CHEMBL1381157 & 688746 & 4.8 & 4.8882 & TRN \\
\hline CHEMBL1585474 & 688746 & 4.8 & 4.8364 & TRN \\
\hline CHEMBL1501005 & 688746 & 5.65 & 4.8422 & TRN \\
\hline CHEMBL1448738 & 688746 & 4.55 & 4.7959 & TRN \\
\hline CHEMBL1412104 & 688746 & 4.85 & 4.9423 & TRN \\
\hline CHEMBL1556669 & 688746 & 5.3 & 4.8358 & TRN \\
\hline CHEMBL1453131 & 688746 & 4.55 & 4.9715 & TRN \\
\hline CHEMBL1487084 & 688746 & 5.6 & 4.9584 & TRN \\
\hline CHEMBL1581251 & 688746 & 4.95 & 4.8329 & TRN \\
\hline CHEMBL1407791 & 688746 & 5.45 & 4.8885 & TRN \\
\hline CHEMBL1302041 & 688746 & 4.55 & 4.7784 & TRN \\
\hline CHEMBL1559741 & 688746 & 4.7 & 4.891 & TRN \\
\hline CHEMBL1555729 & 688746 & 4.65 & 4.8176 & TRN \\
\hline CHEMBL1561101 & 688746 & 4.4 & 4.7932 & TRN \\
\hline CHEMBL1309198 & 688746 & 4.75 & 4.7939 & TRN \\
\hline CHEMBL1354063 & 688746 & 5.0 & 4.797 & TST \\
\hline CHEMBL1495442 & 688746 & 6.15 & 4.8578 & TRN \\
\hline CHEMBL1558729 & 688746 & 4.6 & 4.8455 & TRN \\
\hline CHEMBL1493847 & 688746 & 4.4 & 4.8296 & TRN \\
\hline CHEMBL1370933 & 688746 & 4.4 & 4.8291 & TRN \\
\hline CHEMBL1610008 & 688746 & 4.4 & 4.7915 & TRN \\
\hline CHEMBL1359257 & 688746 & 5.45 & 4.7801 & TST \\
\hline CHEMBL1358996 & 688746 & 4.8 & 4.9933 & TRN \\
\hline CHEMBL1993190 & 688746 & 4.6 & 4.7424 & TRN \\
\hline CHEMBL1401695 & 688746 & 4.55 & 4.8317 & TRN \\
\hline CHEMBL1390753 & 688746 & 4.4 & 4.789 & TRN \\
\hline CHEMBL1573181 & 688746 & 6.6 & 4.9173 & TRN \\
\hline
\end{tabular}




\begin{tabular}{|c|c|c|c|c|}
\hline \multicolumn{5}{|c|}{ splemental Table S } \\
\hline CHEMBL1353101 & 688746 & 5.2 & 4.9193 & TRN \\
\hline CHEMBL1488914 & 688746 & 4.5 & 4.9536 & TRN \\
\hline CHEMBL1332946 & 688746 & 4.85 & 5.0096 & TRN \\
\hline CHEMBL3209946 & 688746 & 5.15 & 4.9443 & TRN \\
\hline CHEMBL1497684 & 688746 & 4.5 & 4.8496 & TRN \\
\hline CHEMBL1313410 & 688746 & 4.5 & 4.8383 & TST \\
\hline CHEMBL1420244 & 688746 & 5.05 & 4.8931 & TRN \\
\hline CHEMBL1463463 & 688746 & 5.15 & 4.9143 & TRN \\
\hline CHEMBL1405786 & 688746 & 4.5 & 4.7723 & TRN \\
\hline CHEMBL3211672 & 688746 & 4.4 & 4.7896 & TRN \\
\hline CHEMBL1505314 & 688746 & 5.35 & 4.8351 & TRN \\
\hline CHEMBL1500324 & 688746 & 4.4 & 4.8488 & TRN \\
\hline CHEMBL1369727 & 688746 & 5.15 & 4.7731 & TRN \\
\hline CHEMBL1496624 & 688746 & 4.9 & 4.7933 & TRN \\
\hline CHEMBL1461002 & 688746 & 5.25 & 4.9202 & TRN \\
\hline CHEMBL1494908 & 688746 & 4.7 & 4.8139 & TST \\
\hline CHEMBL1419366 & 688746 & 5.0 & 4.8928 & TST \\
\hline CHEMBL1574905 & 688746 & 4.75 & 4.8682 & TRN \\
\hline CHEMBL1380122 & 688746 & 4.6 & 4.888 & TRN \\
\hline CHEMBL1578534 & 688746 & 4.9 & 4.9713 & TRN \\
\hline CHEMBL1539369 & 688746 & 5.4 & 4.9414 & TRN \\
\hline CHEMBL1362291 & 688746 & 4.55 & 4.8795 & TRN \\
\hline CHEMBL1518446 & 688746 & 4.55 & 4.8284 & TRN \\
\hline CHEMBL585265 & 688746 & 5.25 & 4.8981 & TRN \\
\hline CHEMBL1562132 & 688746 & 5.9 & 4.8891 & TRN \\
\hline CHEMBL1531526 & 688746 & 4.6 & 4.8139 & TST \\
\hline CHEMBL1421232 & 688746 & 5.25 & 4.78 & TRN \\
\hline CHEMBL1370895 & 688746 & 4.85 & 4.9812 & TRN \\
\hline CHEMBL1419505 & 688746 & 4.8 & 4.9129 & TRN \\
\hline CHEMBL1412821 & 688746 & 4.5 & 4.9026 & TST \\
\hline CHEMBL1455130 & 688746 & 4.45 & 5.0299 & TRN \\
\hline CHEMBL1461167 & 688746 & 4.4 & 4.8929 & TRN \\
\hline CHEMBL1596755 & 688746 & 4.55 & 4.8734 & TRN \\
\hline CHEMBL1564713 & 688746 & 4.65 & 4.7723 & TRN \\
\hline CHEMBL 3193575 & 688746 & 4.55 & 4.8241 & TRN \\
\hline CHEMBL1549138 & 688746 & 5.05 & 4.885 & TST \\
\hline CHEMBL1452865 & 688746 & 4.4 & 4.8331 & TST \\
\hline CHEMBL1423005 & 688746 & 4.6 & 4.8682 & TRN \\
\hline CHEMBL1368665 & 688746 & 4.5 & 4.8589 & TRN \\
\hline CHEMBL1604546 & 688746 & 4.95 & 4.8662 & TST \\
\hline CHEMBL1401692 & 688746 & 4.4 & 4.8828 & TST \\
\hline CHEMBL1548864 & 688746 & 6.0 & 4.89199 & 99999999995 \\
\hline CHEMBL1497552 & 688746 & 4.6 & 4.9218 & TRN \\
\hline CHEMBL1392956 & 688746 & 4.65 & 4.9158 & TRN \\
\hline CHEMBL1461897 & 688746 & 4.7 & 4.7639 & TRN \\
\hline CHEMBL1536511 & 688746 & 4.5 & 4.8527 & TST \\
\hline CHEMBL1572533 & 688746 & 6.0 & 4.8126 & TRN \\
\hline CHEMBL1521425 & 688746 & 4.4 & 4.8541 & TRN \\
\hline
\end{tabular}




\begin{tabular}{|c|c|c|c|c|c|}
\hline \\
\hline CHEMBL1304007 & 688746 & 4.55 & 4.9073 & TRN & \\
\hline CHEMBL1575701 & 688746 & 5.1 & 4.8293 & TST & \\
\hline CHEMBL1580408 & 688746 & 5.4 & 4.8962 & TRN & \\
\hline CHEMBL1338094 & 688746 & 5.8 & 4.8943 & TRN & \\
\hline CHEMBL1480652 & 688746 & 4.9 & 4.8701 & TRN & \\
\hline CHEMBL1349466 & 688746 & 5.05 & 5.00899 & 99999999995 & TRN \\
\hline CHEMBL3210746 & 688746 & 5.2 & 4.9739 & TRN & \\
\hline CHEMBL1330583 & 688746 & 4.75 & 4.7866 & TRN & \\
\hline CHEMBL1417838 & 688746 & 4.65 & 4.75899 & 99999999995 & TRN \\
\hline CHEMBL1547455 & 688746 & 4.5 & 4.8653 & TRN & \\
\hline CHEMBL1445156 & 688746 & 4.5 & 5.0205 & TRN & \\
\hline CHEMBL1349565 & 688746 & 5.1 & 4.9553 & TRN & \\
\hline CHEMBL1575954 & 688746 & 4.55 & 4.9762 & TRN & \\
\hline CHEMBL1410738 & 688746 & 4.55 & 4.8649 & TRN & \\
\hline CHEMBL1586957 & 688746 & 4.8 & 4.8946 & TST & \\
\hline CHEMBL1612480 & 688746 & 5.0 & 4.9935 & TRN & \\
\hline CHEMBL1364723 & 688746 & 4.95 & 4.9588 & TRN & \\
\hline CHEMBL1403855 & 688746 & 4.9 & 4.7974 & TRN & \\
\hline CHEMBL1522914 & 688746 & 4.4 & 4.832 & TRN & \\
\hline CHEMBL1481192 & 688746 & 4.75 & 4.8163 & TRN & \\
\hline CHEMBL 3194340 & 688746 & 4.45 & 4.7712 & TRN & \\
\hline CHEMBL3213103 & 688746 & 4.8 & 4.8747 & TST & \\
\hline CHEMBL1330727 & 688746 & 5.15 & 4.8845 & TRN & \\
\hline CHEMBL1469246 & 688746 & 4.45 & 4.95 & TST & \\
\hline CHEMBL1599180 & 688746 & 4.4 & 4.8305 & TST & \\
\hline CHEMBL1302252 & 688746 & 4.5 & 4.8708 & TRN & \\
\hline CHEMBL 202131 & 688746 & 4.5 & 4.8181 & TRN & \\
\hline CHEMBL1446202 & 688746 & 5.4 & 4.8477 & TRN & \\
\hline CHEMBL3196996 & 688746 & 4.95 & 4.8906 & TST & \\
\hline CHEMBL1342598 & 688746 & 4.5 & 4.7925 & TRN & \\
\hline CHEMBL1529230 & 688746 & 4.4 & 4.8636 & TST & \\
\hline CHEMBL1307532 & 688746 & 4.9 & 4.8826 & TRN & \\
\hline CHEMBL1564396 & 688746 & 4.75 & 4.7629 & TRN & \\
\hline CHEMBL1530245 & 688746 & 4.5 & 4.8121 & TRN & \\
\hline CHEMBL1459728 & 688746 & 4.45 & 4.9911 & TRN & \\
\hline CHEMBL1446871 & 688746 & 4.4 & 4.9039 & TRN & \\
\hline CHEMBL1391815 & 688746 & 4.85 & 4.8696 & TRN & \\
\hline CHEMBL1568902 & 688746 & 4.4 & 4.8166 & TRN & \\
\hline CHEMBL1607313 & 688746 & 5.9 & 4.8641 & TRN & \\
\hline CHEMBL1461444 & 688746 & 4.8 & 5.0165 & TRN & \\
\hline CHEMBL1607959 & 688746 & 5.5 & 4.9455 & TRN & \\
\hline CHEMBL1483838 & 688746 & 4.5 & 4.8859 & TRN & \\
\hline CHEMBL1305663 & 688746 & 4.7 & 4.8246 & TRN & \\
\hline CHEMBL3194726 & 688746 & 5.05 & 4.7481 & TRN & \\
\hline CHEMBL1383055 & 688746 & 4.65 & 4.8379 & TRN & \\
\hline CHEMBL1503314 & 688746 & 5.0 & 4.9452 & TRN & \\
\hline CHEMBL1301806 & 688746 & 5.1 & 4.8133 & TRN & \\
\hline CHEMBL1386015 & 688746 & 4.4 & 4.7992 & TRN & \\
\hline
\end{tabular}




\begin{tabular}{|c|c|c|c|c|}
\hline \multicolumn{5}{|c|}{ Supplemental Table S2.txt } \\
\hline CHEMBL1352990 & 688746 & 4.65 & 4.9616 & TRN \\
\hline CHEMBL1408535 & 688746 & 4.55 & 4.761 & TRN \\
\hline CHEMBL1579367 & 688746 & 4.85 & 4.8248 & TRN \\
\hline CHEMBL1530441 & 688746 & 4.55 & 4.8269 & TRN \\
\hline CHEMBL1533166 & 688746 & 4.8 & 4.7815 & TRN \\
\hline CHEMBL1540218 & 688746 & 5.0 & 4.9661 & TRN \\
\hline CHEMBL1411451 & 688746 & 4.65 & 4.8499 & TRN \\
\hline CHEMBL1560698 & 688746 & 4.6 & 4.772 & TRN \\
\hline CHEMBL1444437 & 688746 & 4.4 & 4.7931 & TRN \\
\hline CHEMBL1418145 & 688746 & 4.65 & 4.8412 & TRN \\
\hline CHEMBL1338544 & 688746 & 4.9 & 4.8162 & TST \\
\hline CHEMBL3195233 & 688746 & 4.4 & 4.8178 & TST \\
\hline CHEMBL3208023 & 688746 & 4.7 & 4.8239 & TRN \\
\hline CHEMBL448847 & 688746 & 6.1 & 4.9198 & TRN \\
\hline CHEMBL3189381 & 688746 & 4.8 & 4.7679 & TRN \\
\hline CHEMBL1363304 & 688746 & 4.65 & 4.9282 & TRN \\
\hline CHEMBL1346164 & 688746 & 5.15 & 4.8513 & TRN \\
\hline CHEMBL1458013 & 688746 & 4.45 & 4.8339 & TST \\
\hline CHEMBL1533547 & 688746 & 4.45 & 4.8337 & TRN \\
\hline CHEMBL1481675 & 688746 & 4.55 & 4.7722 & TRN \\
\hline CHEMBL1404910 & 688746 & 4.5 & 4.8105 & TRN \\
\hline CHEMBL1319191 & 688746 & 4.6 & 4.8359 & TRN \\
\hline CHEMBL1470956 & 688746 & 4.4 & 5.069 & TRN \\
\hline CHEMBL3196467 & 688746 & 4.9 & 4.8238 & TRN \\
\hline CHEMBL1564201 & 688746 & 5.1 & 4.8547 & TRN \\
\hline CHEMBL1583794 & 688746 & 5.3 & 4.9205 & TRN \\
\hline CHEMBL1524870 & 688746 & 5.55 & 4.8963 & TRN \\
\hline CHEMBL1558484 & 688746 & 4.8 & 4.9712 & TRN \\
\hline CHEMBL1409874 & 688746 & 4.85 & 4.9161 & TRN \\
\hline CHEMBL1403436 & 688746 & 4.8 & 4.7893 & TRN \\
\hline CHEMBL1455421 & 688746 & 4.95 & 4.7884 & TRN \\
\hline CHEMBL1418645 & 688746 & 5.35 & 4.928 & TRN \\
\hline CHEMBL1458929 & 688746 & 4.55 & 4.8167 & TRN \\
\hline CHEMBL1466405 & 688746 & 4.55 & 4.8334 & TRN \\
\hline CHEMBL1501015 & 688746 & 5.9 & 4.9356 & TRN \\
\hline CHEMBL3212687 & 688746 & 4.5 & 4.7328 & TRN \\
\hline CHEMBL1369041 & 688746 & 4.7 & 4.9355 & TRN \\
\hline CHEMBL1597895 & 688746 & 4.7 & 4.8652 & TRN \\
\hline CHEMBL1392095 & 688746 & 4.8 & 4.8597 & TRN \\
\hline CHEMBL1329531 & 688746 & 4.4 & 4.787 & TRN \\
\hline CHEMBL1406966 & 688746 & 4.4 & 4.9118 & TRN \\
\hline CHEMBL1351033 & 688746 & 5.2 & 4.9066 & TST \\
\hline CHEMBL1332281 & 688746 & 4.9 & 4.936 & TRN \\
\hline CHEMBL1469488 & 688746 & 4.75 & 5.0158 & TRN \\
\hline CHEMBL1460199 & 688746 & 4.45 & 4.8305 & TRN \\
\hline CHEMBL1530379 & 688746 & 4.85 & 4.7457 & TRN \\
\hline CHEMBL1340915 & 688746 & 4.65 & 4.7871 & TRN \\
\hline CHEMBL1367726 & 688746 & 4.4 & 4.9477 & TRN \\
\hline
\end{tabular}




\begin{tabular}{|c|c|c|c|c|}
\hline \multicolumn{5}{|c|}{ Supplemental Table S2.txt } \\
\hline CHEMBL1559164 & 688746 & 4.7 & 4.9886 & TRN \\
\hline CHEMBL1538180 & 688746 & 4.75 & 4.9812 & TRN \\
\hline CHEMBL1465175 & 688746 & 4.45 & 4.8656 & TRN \\
\hline CHEMBL1486489 & 688746 & 4.4 & 4.8693 & TRN \\
\hline CHEMBL1564712 & 688746 & 5.05 & 4.8576 & TRN \\
\hline CHEMBL1350072 & 688746 & 5.45 & 4.8489 & TRN \\
\hline CHEMBL1608398 & 688746 & 4.65 & 4.8566 & TRN \\
\hline CHEMBL1348456 & 688746 & 5.1 & 4.7904 & TST \\
\hline CHEMBL1571665 & 688746 & 4.6 & 4.8488 & TRN \\
\hline CHEMBL1412033 & 688746 & 4.85 & 4.8655 & TRN \\
\hline CHEMBL1492205 & 688746 & 4.9 & 4.9471 & TST \\
\hline CHEMBL1589007 & 688746 & 4.55 & 4.8308 & TRN \\
\hline CHEMBL1369205 & 688746 & 5.45 & 4.8214 & TST \\
\hline CHEMBL1508243 & 688746 & 4.4 & 4.9409 & TRN \\
\hline CHEMBL1393432 & 688746 & 5.2 & 4.9309 & TRN \\
\hline CHEMBL1326482 & 688746 & 4.85 & 4.8504 & TST \\
\hline CHEMBL1366050 & 688746 & 4.85 & 4.8308 & TRN \\
\hline CHEMBL1417633 & 688746 & 5.35 & 4.8798 & TST \\
\hline CHEMBL1302800 & 688746 & 4.45 & 4.8558 & TRN \\
\hline CHEMBL1354100 & 688746 & 4.8 & 4.8322 & TRN \\
\hline CHEMBL1305430 & 688746 & 4.45 & 4.8417 & TRN \\
\hline CHEMBL1465339 & 688746 & 4.75 & 4.8487 & TST \\
\hline CHEMBL1586720 & 688746 & 4.45 & 4.8073 & TRN \\
\hline CHEMBL1519247 & 688746 & 4.4 & 4.9105 & TRN \\
\hline CHEMBL1469551 & 688746 & 4.95 & 4.8218 & TRN \\
\hline CHEMBL1393144 & 688746 & 5.3 & 4.9317 & TRN \\
\hline CHEMBL1484796 & 688746 & 5.85 & 4.8482 & TST \\
\hline CHEMBL1517934 & 688746 & 4.45 & 4.919 & TRN \\
\hline CHEMBL1338333 & 688746 & 5.1 & 4.7675 & TST \\
\hline CHEMBL1308182 & 688746 & 6.1 & 4.9319 & TRN \\
\hline CHEMBL1330909 & 688746 & 4.6 & 5.0346 & TRN \\
\hline CHEMBL1466997 & 688746 & 4.75 & 4.7281 & TRN \\
\hline CHEMBL1310766 & 688746 & 4.45 & 4.9039 & TST \\
\hline CHEMBL1301238 & 688746 & 4.6 & 4.7912 & TRN \\
\hline CHEMBL1601475 & 688746 & 5.75 & 4.8904 & TST \\
\hline CHEMBL1242180 & 688746 & 5.05 & 4.7673 & TST \\
\hline CHEMBL1441854 & 688746 & 4.65 & 4.9058 & TRN \\
\hline CHEMBL1340736 & 688746 & 6.5 & 4.8622 & TRN \\
\hline CHEMBL1522989 & 688746 & 4.65 & 4.6747 & TRN \\
\hline CHEMBL3194770 & 688746 & 4.8 & 4.7939 & TRN \\
\hline CHEMBL3207312 & 688746 & 4.65 & 4.8134 & TRN \\
\hline CHEMBL1545203 & 688746 & 4.65 & 4.745 & TRN \\
\hline CHEMBL1300246 & 688746 & 4.5 & 4.8762 & TRN \\
\hline CHEMBL1410096 & 688746 & 4.85 & 4.9005 & TRN \\
\hline CHEMBL1551004 & 688746 & 4.45 & 4.8071 & TRN \\
\hline CHEMBL1517700 & 688746 & 4.45 & 4.8408 & TRN \\
\hline CHEMBL1341893 & 688746 & 4.65 & 4.9341 & TRN \\
\hline CHEMBL1446067 & 688746 & 6.9 & 4.8089 & TRN \\
\hline
\end{tabular}




\begin{tabular}{|c|c|c|c|c|c|}
\hline \\
\hline CHEMBL1457543 & 688746 & 4.5 & 4.8921 & TST & \\
\hline CHEMBL1441713 & 688746 & 4.7 & 4.9271 & TRN & \\
\hline CHEMBL1374573 & 688746 & 5.35 & 4.8937 & TRN & \\
\hline CHEMBL1607720 & 688746 & 4.4 & 4.8011 & TRN & \\
\hline CHEMBL1518866 & 688746 & 4.7 & 4.7295 & TRN & \\
\hline CHEMBL1310872 & 688746 & 4.8 & 4.9596 & TRN & \\
\hline CHEMBL1307669 & 688746 & 4.45 & 4.8656 & TRN & \\
\hline CHEMBL1495991 & 688746 & 5.2 & 4.9071 & TST & \\
\hline CHEMBL1561218 & 688746 & 4.5 & 4.8467 & TRN & \\
\hline CHEMBL1479571 & 688746 & 4.65 & 4.9233 & TRN & \\
\hline CHEMBL1567992 & 688746 & 5.3 & 4.96 & TRN & \\
\hline CHEMBL1528096 & 688746 & 4.45 & 4.9226 & TRN & \\
\hline CHEMBL1526561 & 688746 & 4.55 & 4.8201 & TRN & \\
\hline CHEMBL1569712 & 688746 & 4.85 & 4.8712 & TRN & \\
\hline CHEMBL1607304 & 688746 & 4.65 & 4.8413 & TRN & \\
\hline CHEMBL1460681 & 688746 & 4.8 & 4.9792 & TRN & \\
\hline CHEMBL3197785 & 688746 & 4.65 & 4.71 & TRN & \\
\hline CHEMBL1399243 & 688746 & 4.65 & 4.935 & TRN & \\
\hline CHEMBL1458581 & 688746 & 6.95 & 4.8292 & TST & \\
\hline CHEMBL1495167 & 688746 & 4.45 & 4.9036 & TRN & \\
\hline CHEMBL1557072 & 688746 & 5.25 & 4.998 & TRN & \\
\hline CHEMBL1427218 & 688746 & 4.65 & 4.7042 & TRN & \\
\hline CHEMBL1416326 & 688746 & 4.6 & 4.8856 & TST & \\
\hline CHEMBL1336339 & 688746 & 8.2007 & 4.89199 & 99999999995 & TST \\
\hline CHEMBL1447002 & 688746 & 5.0 & 4.8517 & TRN & \\
\hline CHEMBL1556561 & 688746 & 5.4 & 4.8921 & TRN & \\
\hline CHEMBL1339149 & 688746 & 5.55 & 4.934 & TRN & \\
\hline CHEMBL1531759 & 688746 & 5.15 & 4.8511 & TRN & \\
\hline CHEMBL1499494 & 688746 & 5.45 & 4.8706 & TST & \\
\hline CHEMBL1507723 & 688746 & 4.4 & 4.8619 & TRN & \\
\hline CHEMBL1302232 & 688746 & 4.7 & 4.7712 & TRN & \\
\hline CHEMBL1545891 & 688746 & 4.55 & 4.9427 & TRN & \\
\hline CHEMBL1305439 & 688746 & 4.45 & 4.8645 & TRN & \\
\hline CHEMBL112597 & 688746 & 4.8 & 4.70100 & 00000000005 & TRN \\
\hline CHEMBL1419714 & 688746 & 4.4 & 4.8129 & TRN & \\
\hline CHEMBL1332208 & 688746 & 4.45 & 4.8482 & TRN & \\
\hline CHEMBL3213506 & 688746 & 4.55 & 4.8065 & TRN & \\
\hline CHEMBL1454030 & 688746 & 4.85 & 4.7527 & TRN & \\
\hline CHEMBL1402084 & 688746 & 5.05 & 4.8267 & TST & \\
\hline CHEMBL1336444 & 688746 & 4.8 & 4.9303 & TRN & \\
\hline CHEMBL1426320 & 688746 & 4.6 & 4.9159 & TRN & \\
\hline CHEMBL1584878 & 688746 & 4.4 & 4.8595 & TST & \\
\hline CHEMBL1446015 & 688746 & 8.0 & 5.0362 & TRN & \\
\hline CHEMBL1984816 & 688746 & 4.5 & 4.845 & TRN & \\
\hline CHEMBL1345692 & 688746 & 4.6 & 4.8682 & TST & \\
\hline CHEMBL1561540 & 688746 & 4.4 & 4.8192 & TRN & \\
\hline CHEMBL1470050 & 688746 & 4.55 & 4.978 & TRN & \\
\hline CHEMBL1546694 & 688746 & 4.55 & 4.878 & TRN & \\
\hline
\end{tabular}




\begin{tabular}{|c|c|c|c|c|}
\hline & & & upplement & al $\mathrm{T}$ \\
\hline CHEMBL1408102 & 688746 & 4.8 & 4.8367 & TRN \\
\hline CHEMBL1569897 & 688746 & 4.45 & 4.9235 & TRN \\
\hline CHEMBL1301438 & 688746 & 4.8 & 4.8732 & TRN \\
\hline CHEMBL1339591 & 688746 & 4.8 & 4.8173 & TST \\
\hline CHEMBL1389013 & 688746 & 4.5 & 4.9316 & TRN \\
\hline CHEMBL1368231 & 688746 & 5.5 & 4.9564 & TRN \\
\hline CHEMBL1548465 & 688746 & 5.05 & 4.8732 & TRN \\
\hline CHEMBL1431067 & 688746 & 4.4 & 4.859 & TRN \\
\hline CHEMBL585804 & 688746 & 4.5 & 4.7851 & TRN \\
\hline CHEMBL1461913 & 688746 & 4.65 & 4.8811 & TST \\
\hline CHEMBL1489522 & 688746 & 4.6 & 4.923 & TRN \\
\hline CHEMBL1246 & 688746 & 5.05 & 4.8536 & TRN \\
\hline CHEMBL1598253 & 688746 & 4.35 & 4.9746 & TRN \\
\hline CHEMBL1350287 & 688746 & 4.4 & 4.7942 & TRN \\
\hline CHEMBL1413956 & 688746 & 4.85 & 4.8626 & TRN \\
\hline CHEMBL1563859 & 688746 & 4.45 & 4.9 & TRN \\
\hline CHEMBL3196699 & 688746 & 4.6 & 4.7347 & TRN \\
\hline CHEMBL1420886 & 688746 & 4.4 & 4.9163 & TRN \\
\hline CHEMBL1561034 & 688746 & 4.5 & 4.8974 & TRN \\
\hline CHEMBL1377501 & 688746 & 4.8 & 4.8169 & TRN \\
\hline CHEMBL1385690 & 688746 & 4.85 & 4.9167 & TRN \\
\hline CHEMBL1351175 & 688746 & 4.5 & 4.8766 & TRN \\
\hline CHEMBL1595525 & 688746 & 4.5 & 4.7217 & TRN \\
\hline CHEMBL1329642 & 688746 & 4.8 & 4.8086 & TRN \\
\hline CHEMBL1509543 & 688746 & 5.0 & 4.8585 & TRN \\
\hline CHEMBL3212312 & 688746 & 5.0 & 4.8202 & TRN \\
\hline CHEMBL1418103 & 688746 & 4.55 & 4.7409 & TRN \\
\hline CHEMBL1418618 & 688746 & 4.65 & 4.8777 & TST \\
\hline CHEMBL1463529 & 688746 & 5.05 & 4.7129 & TRN \\
\hline CHEMBL1601553 & 688746 & 4.5 & 4.8799 & TRN \\
\hline CHEMBL1349445 & 688746 & 4.6 & 4.9142 & TRN \\
\hline CHEMBL1333915 & 688746 & 4.85 & 4.8469 & TRN \\
\hline CHEMBL1470256 & 688746 & 4.85 & 4.8542 & TST \\
\hline CHEMBL1536928 & 688746 & 4.4 & 4.8115 & TST \\
\hline CHEMBL1299362 & 688746 & 4.4 & 4.9036 & TRN \\
\hline CHEMBL1576056 & 688746 & 5.85 & 4.859 & TRN \\
\hline CHEMBL1414963 & 688746 & 4.5 & 4.9007 & TRN \\
\hline CHEMBL 3207632 & 688746 & 4.4 & 4.8389 & TRN \\
\hline CHEMBL1610689 & 688746 & 5.5 & 4.843 & TRN \\
\hline CHEMBL3194663 & 688746 & 4.65 & 4.8725 & TST \\
\hline CHEMBL1424060 & 688746 & 4.5 & 4.7454 & TRN \\
\hline CHEMBL1588458 & 688746 & 5.3 & 4.7808 & TST \\
\hline CHEMBL1595988 & 688746 & 5.35 & 4.8888 & TRN \\
\hline CHEMBL1306711 & 688746 & 4.8 & 4.8882 & TST \\
\hline CHEMBL1327488 & 688746 & 4.9 & 4.8586 & TST \\
\hline CHEMBL1479248 & 688746 & 4.6 & 4.8073 & TRN \\
\hline CHEMBL1392155 & 688746 & 5.05 & 4.8426 & TRN \\
\hline CHEMBL1424381 & 688746 & 4.55 & 4.8209 & TRN \\
\hline
\end{tabular}




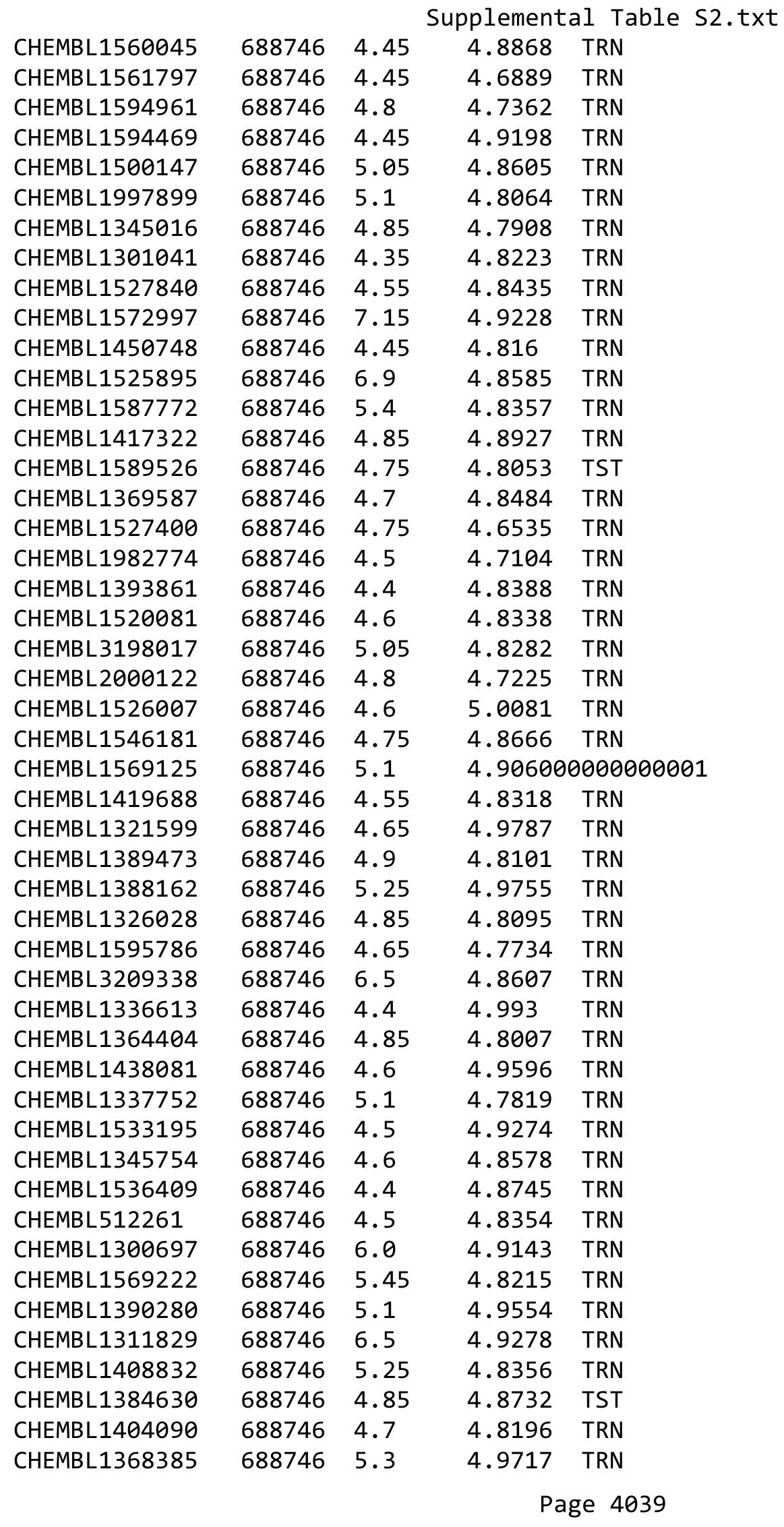

TRN 


\begin{tabular}{|c|c|c|c|c|}
\hline \multicolumn{5}{|c|}{ emental T } \\
\hline CHEMBL1364635 & 688746 & 4.4 & 4.8014 & TRN \\
\hline CHEMBL1312606 & 688746 & 4.5 & 4.8245 & TRN \\
\hline CHEMBL1599401 & 688746 & 4.4 & 4.8326 & TRN \\
\hline CHEMBL1381590 & 688746 & 4.45 & 4.8362 & TRN \\
\hline CHEMBL1339860 & 688746 & 5.05 & 4.813 & TRN \\
\hline CHEMBL1331931 & 688746 & 4.85 & 4.9663 & TRN \\
\hline CHEMBL1348749 & 688746 & 4.55 & 4.7977 & TST \\
\hline CHEMBL1484782 & 688746 & 5.15 & 4.9076 & TRN \\
\hline CHEMBL1541140 & 688746 & 4.45 & 4.8873 & TRN \\
\hline CHEMBL1577277 & 688746 & 4.7 & 4.8204 & TST \\
\hline CHEMBL1522755 & 688746 & 5.35 & 4.875 & TRN \\
\hline CHEMBL1535845 & 688746 & 5.4 & 4.9836 & TRN \\
\hline CHEMBL1360182 & 688746 & 5.5 & 4.8273 & TRN \\
\hline CHEMBL1305165 & 688746 & 5.4 & 4.9663 & TRN \\
\hline CHEMBL1452082 & 688746 & 4.65 & 4.8382 & TRN \\
\hline CHEMBL1457285 & 688746 & 4.6 & 4.9139 & TRN \\
\hline CHEMBL1494120 & 688746 & 4.55 & 4.8246 & TRN \\
\hline CHEMBL235541 & 688746 & 4.7 & 4.9627 & TRN \\
\hline CHEMBL1572006 & 688746 & 5.9 & 4.8944 & TRN \\
\hline CHEMBL1342229 & 688746 & 4.5 & 4.8745 & TRN \\
\hline CHEMBL1457014 & 688746 & 5.0 & 4.8757 & TRN \\
\hline CHEMBL1525946 & 688746 & 4.4 & 4.8399 & TRN \\
\hline CHEMBL1328356 & 688746 & 4.85 & 4.8352 & TRN \\
\hline CHEMBL1322241 & 688746 & 4.55 & 4.9185 & TRN \\
\hline CHEMBL1373095 & 688746 & 4.55 & 4.8694 & TRN \\
\hline CHEMBL1333479 & 688746 & 4.5 & 4.8954 & TRN \\
\hline CHEMBL1344481 & 688746 & 4.4 & 4.9367 & TRN \\
\hline CHEMBL1382435 & 688746 & 4.4 & 4.9591 & TST \\
\hline CHEMBL1368351 & 688746 & 4.45 & 4.7596 & TST \\
\hline CHEMBL1502432 & 688746 & 4.4 & 4.8587 & TST \\
\hline CHEMBL1538509 & 688746 & 4.45 & 4.92 & TRN \\
\hline CHEMBL1368206 & 688746 & 4.7 & 4.7921 & TRN \\
\hline CHEMBL1420432 & 688746 & 4.75 & 4.8354 & TRN \\
\hline CHEMBL3197152 & 688746 & 4.5 & 4.7268 & TRN \\
\hline CHEMBL1353231 & 688746 & 4.5 & 4.8443 & TRN \\
\hline CHEMBL1587813 & 688746 & 5.0 & 4.8985 & TRN \\
\hline CHEMBL1378232 & 688746 & 4.65 & 4.7991 & TRN \\
\hline CHEMBL1425317 & 688746 & 5.1 & 4.9159 & TRN \\
\hline CHEMBL 3184468 & 688746 & 4.4 & 4.9131 & TST \\
\hline CHEMBL1544213 & 688746 & 4.45 & 4.8326 & TST \\
\hline CHEMBL1353400 & 688746 & 4.55 & 4.8532 & TRN \\
\hline CHEMBL1606132 & 688746 & 4.85 & 4.8995 & TRN \\
\hline CHEMBL1312950 & 688746 & 4.45 & 4.8777 & TST \\
\hline CHEMBL1350956 & 688746 & 4.45 & 4.834 & TRN \\
\hline CHEMBL1503937 & 688746 & 4.4 & 4.7815 & TST \\
\hline CHEMBL1360155 & 688746 & 4.6 & 4.7794 & TRN \\
\hline CHEMBL1551975 & 688746 & 4.4 & 4.8171 & TST \\
\hline CHEMBL1330120 & 688746 & 4.85 & 4.824 & TST \\
\hline
\end{tabular}




\begin{tabular}{|c|c|c|c|c|c|}
\hline & & \multicolumn{4}{|c|}{ Supplemental Table S2.txt } \\
\hline CHEMBL1362048 & 688746 & 4.55 & 4.8185 & TRN & \\
\hline CHEMBL1580767 & 688746 & 4.45 & 4.9259 & TRN & \\
\hline CHEMBL1613015 & 688746 & 4.7 & 4.856 & TRN & \\
\hline CHEMBL1381692 & 688746 & 4.75 & 4.8361 & TRN & \\
\hline CHEMBL1507084 & 688746 & 4.4 & 4.9242 & TRN & \\
\hline CHEMBL1305166 & 688746 & 4.65 & 4.9404 & TST & \\
\hline CHEMBL1504431 & 688746 & 4.5 & 4.8121 & TRN & \\
\hline CHEMBL1507747 & 688746 & 5.55 & 4.9242 & TRN & \\
\hline CHEMBL1389044 & 688746 & 5.15 & 4.8943 & TST & \\
\hline CHEMBL1525534 & 688746 & 5.3 & 4.8548 & TRN & \\
\hline CHEMBL1462286 & 688746 & 4.45 & 4.8677 & TRN & \\
\hline CHEMBL1562684 & 688746 & 4.8 & 4.758 & TRN & \\
\hline CHEMBL1410009 & 688746 & 5.6 & 4.8742 & TRN & \\
\hline CHEMBL1375820 & 688746 & 4.6 & 4.9053 & TRN & \\
\hline CHEMBL1402473 & 688746 & 4.85 & 4.8123 & TRN & \\
\hline CHEMBL1377241 & 688746 & 4.4 & 4.8862 & TRN & \\
\hline CHEMBL3190131 & 688746 & 4.8 & 4.7248 & TRN & \\
\hline CHEMBL1479010 & 688746 & 4.9 & 4.7592 & TRN & \\
\hline CHEMBL1329846 & 688746 & 4.8 & 4.865 & TRN & \\
\hline CHEMBL3208841 & 688746 & 4.45 & 4.8535 & TST & \\
\hline CHEMBL1608128 & 688746 & 5.0 & 4.9599 & TRN & \\
\hline CHEMBL1576394 & 688746 & 5.0 & 4.99 & TRN & \\
\hline CHEMBL1366431 & 688746 & 4.4 & 4.7678 & TRN & \\
\hline CHEMBL1410068 & 688746 & 4.8 & 4.8164 & TST & \\
\hline CHEMBL1300487 & 688746 & 4.4 & 4.859 & TRN & \\
\hline CHEMBL32793 & 688746 & 5.45 & 4.8286 & TST & \\
\hline CHEMBL1471615 & 688746 & 4.4 & 4.7909 & TRN & \\
\hline CHEMBL1507061 & 688746 & 5.2 & 4.8548 & TRN & \\
\hline CHEMBL1543745 & 688746 & 4.75 & 4.9658 & TRN & \\
\hline CHEMBL1455335 & 688746 & 4.85 & 4.854 & TRN & \\
\hline CHEMBL1588299 & 688746 & 5.45 & 4.79899 & 99999999995 & TRN \\
\hline CHEMBL1555617 & 688746 & 4.65 & 4.7895 & TRN & \\
\hline CHEMBL1336549 & 688746 & 4.5 & 4.8471 & TRN & \\
\hline CHEMBL1575495 & 688746 & 5.15 & 4.865 & TRN & \\
\hline CHEMBL 261693 & 688746 & 4.9 & 4.8044 & TRN & \\
\hline CHEMBL1387775 & 688746 & 4.5 & 4.7273 & TRN & \\
\hline CHEMBL1535729 & 688746 & 5.15 & 4.832 & TRN & \\
\hline CHEMBL1603556 & 688746 & 4.45 & 4.8763 & TRN & \\
\hline CHEMBL1507287 & 688746 & 4.55 & 4.771 & TRN & \\
\hline CHEMBL1348360 & 688746 & 6.95 & 4.8405 & TRN & \\
\hline CHEMBL1444893 & 688746 & 4.5 & 4.9709 & TRN & \\
\hline CHEMBL467987 & 688746 & 6.45 & 4.8874 & TST & \\
\hline CHEMBL3198342 & 688746 & 4.8 & 4.7986 & TRN & \\
\hline CHEMBL1419692 & 688746 & 6.05 & 4.8784 & TST & \\
\hline CHEMBL1465278 & 688746 & 4.55 & 4.8173 & TRN & \\
\hline CHEMBL1542358 & 688746 & 5.15 & 4.8116 & TST & \\
\hline CHEMBL595111 & 688746 & 4.55 & 4.9907 & TRN & \\
\hline CHEMBL3193211 & 688746 & 5.3 & 4.7726 & TRN & \\
\hline
\end{tabular}




\begin{tabular}{|c|c|c|c|c|}
\hline \multicolumn{5}{|c|}{ Supplemental Table } \\
\hline CHEMBL1560337 & 688746 & 4.85 & 4.9022 & TRN \\
\hline CHEMBL1550170 & 688746 & 5.2 & 4.8934 & TRN \\
\hline CHEMBL1299632 & 688746 & 4.5 & 4.9593 & TST \\
\hline CHEMBL1966168 & 688746 & 4.9 & 4.8129 & TRN \\
\hline CHEMBL1504532 & 688746 & 6.35 & 4.9201 & TRN \\
\hline CHEMBL1307207 & 688746 & 4.85 & 4.9072 & TRN \\
\hline CHEMBL1548588 & 688746 & 4.6 & 4.9677 & TRN \\
\hline CHEMBL1520121 & 688746 & 4.9 & 4.7579 & TRN \\
\hline CHEMBL1987173 & 688746 & 4.5 & 4.7777 & TRN \\
\hline CHEMBL1557846 & 688746 & 5.35 & 4.9669 & TRN \\
\hline CHEMBL1373860 & 688746 & 6.2 & 4.8873 & TRN \\
\hline CHEMBL1391916 & 688746 & 4.75 & 4.8852 & TRN \\
\hline CHEMBL1457174 & 688746 & 4.5 & 4.8929 & TST \\
\hline CHEMBL1478591 & 688746 & 4.45 & 4.7825 & TRN \\
\hline CHEMBL1334168 & 688746 & 5.45 & 5.0324 & TRN \\
\hline CHEMBL1359363 & 688746 & 5.15 & 5.0403 & TRN \\
\hline CHEMBL1338441 & 688746 & 5.55 & 4.8577 & TRN \\
\hline CHEMBL1502133 & 688746 & 4.75 & 4.777 & TRN \\
\hline CHEMBL1568173 & 688746 & 4.4 & 4.9152 & TRN \\
\hline CHEMBL1361913 & 688746 & 4.55 & 4.7647 & TST \\
\hline CHEMBL1331376 & 688746 & 4.45 & 4.8444 & TRN \\
\hline CHEMBL3189794 & 688746 & 5.05 & 4.8676 & TRN \\
\hline CHEMBL1346893 & 688746 & 6.7501 & 4.8538 & TRN \\
\hline CHEMBL1470176 & 688746 & 4.9 & 4.8998 & TRN \\
\hline CHEMBL1611871 & 688746 & 4.75 & 4.864 & TRN \\
\hline CHEMBL1428733 & 688746 & 4.75 & 4.8489 & TRN \\
\hline CHEMBL1469974 & 688746 & 5.1 & 4.8831 & TRN \\
\hline CHEMBL1368151 & 688746 & 4.45 & 4.9365 & TRN \\
\hline CHEMBL1352516 & 688746 & 5.35 & 4.8737 & TRN \\
\hline CHEMBL1501018 & 688746 & 4.95 & 4.8087 & TRN \\
\hline CHEMBL1407399 & 688746 & 4.55 & 4.9009 & TRN \\
\hline CHEMBL1352194 & 688746 & 4.4 & 4.9192 & TST \\
\hline CHEMBL1507679 & 688746 & 4.75 & 4.9006 & TST \\
\hline CHEMBL1483419 & 688746 & 4.4 & 4.7637 & TRN \\
\hline CHEMBL1468300 & 688746 & 4.4 & 4.8354 & TRN \\
\hline CHEMBL3214202 & 688746 & 4.4 & 4.8464 & TRN \\
\hline CHEMBL1413729 & 688746 & 5.05 & 4.9846 & TRN \\
\hline CHEMBL1560540 & 688746 & 4.6 & 4.8633 & TST \\
\hline CHEMBL1510601 & 688746 & 4.7 & 4.9183 & TRN \\
\hline CHEMBL1362507 & 688746 & 4.7 & 4.8409 & TRN \\
\hline CHEMBL1327498 & 688746 & 4.55 & 4.8811 & TRN \\
\hline CHEMBL1400751 & 688746 & 4.6 & 4.886 & TRN \\
\hline CHEMBL1523461 & 688746 & 4.7 & 4.8677 & TRN \\
\hline CHEMBL1477912 & 688746 & 5.1 & 4.8792 & TRN \\
\hline CHEMBL1391720 & 688746 & 4.55 & 4.9091 & TST \\
\hline CHEMBL473313 & 688746 & 6.15 & 4.8708 & TRN \\
\hline CHEMBL1580946 & 688746 & 4.85 & 4.8679 & TRN \\
\hline CHEMBL1479729 & 688746 & 4.7 & 4.9211 & TRN \\
\hline
\end{tabular}




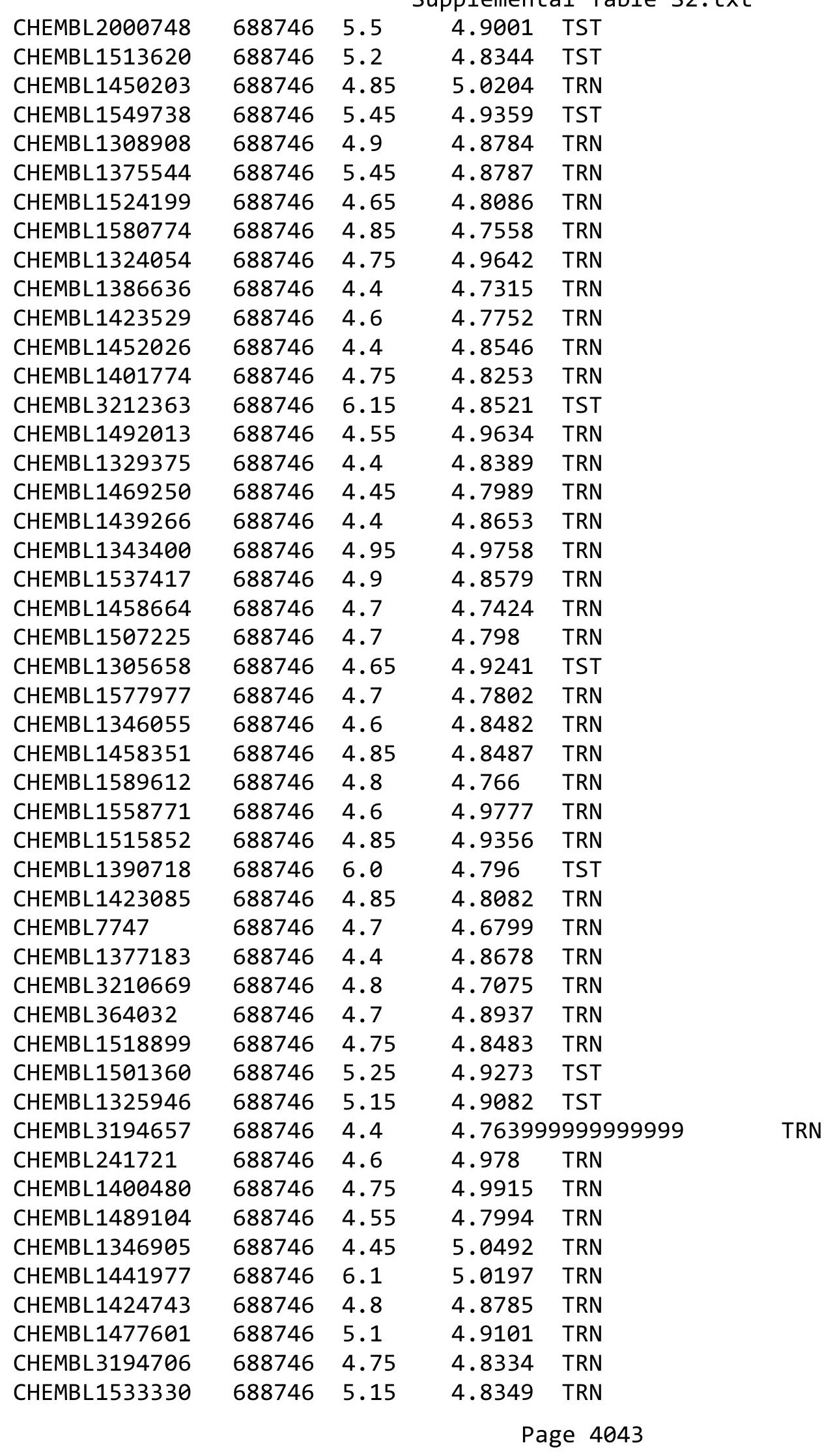




\begin{tabular}{|c|c|c|c|c|}
\hline \multicolumn{5}{|c|}{ Supplemental Table S2.txt } \\
\hline CHEMBL1565866 & 688746 & 4.8 & 4.7256 & TRN \\
\hline CHEMBL1555772 & 688746 & 5.55 & 4.9889 & TRN \\
\hline CHEMBL1488671 & 688746 & 4.4 & 4.8186 & TRN \\
\hline CHEMBL3197861 & 688746 & 4.8 & 4.7703 & TRN \\
\hline CHEMBL3199923 & 688746 & 4.55 & 4.8446 & TRN \\
\hline CHEMBL1393326 & 688746 & 4.75 & 4.9286 & TRN \\
\hline CHEMBL3190998 & 688746 & 4.8 & 4.7918 & TRN \\
\hline CHEMBL1328841 & 688746 & 5.4 & 4.8998 & TRN \\
\hline CHEMBL1376309 & 688746 & 4.65 & 4.8331 & TRN \\
\hline CHEMBL567622 & 688746 & 5.5 & 4.7919 & TRN \\
\hline CHEMBL1465541 & 688746 & 4.8 & 4.9126 & TRN \\
\hline CHEMBL1549752 & 688746 & 4.45 & 4.9379 & TST \\
\hline CHEMBL1423715 & 688746 & 4.8 & 4.8953 & TRN \\
\hline CHEMBL1386461 & 688746 & 4.5 & 4.8377 & TRN \\
\hline CHEMBL1301494 & 688746 & 5.1 & 4.8498 & TST \\
\hline CHEMBL1439929 & 688746 & 4.55 & 4.7312 & TRN \\
\hline CHEMBL3209511 & 688746 & 5.5 & 4.9051 & TRN \\
\hline CHEMBL1337277 & 688746 & 4.4 & 4.8693 & TRN \\
\hline CHEMBL1539167 & 688746 & 4.6 & 4.7631 & TST \\
\hline CHEMBL1600669 & 688746 & 4.55 & 4.9293 & TST \\
\hline CHEMBL1529249 & 688746 & 5.55 & 4.8804 & TRN \\
\hline CHEMBL1380297 & 688746 & 4.5 & 4.8664 & TRN \\
\hline CHEMBL1455935 & 688746 & 8.301 & 4.9214 & TRN \\
\hline CHEMBL1364833 & 688746 & 4.45 & 4.7701 & TRN \\
\hline CHEMBL1343102 & 688746 & 4.8 & 4.9824 & TRN \\
\hline CHEMBL1377687 & 688746 & 6.15 & 4.9292 & TRN \\
\hline CHEMBL1088762 & 688746 & 6.6499 & 5.0207 & TRN \\
\hline CHEMBL1587782 & 688746 & 5.15 & 4.8248 & TST \\
\hline CHEMBL1405082 & 688746 & 4.5 & 4.8779 & TRN \\
\hline CHEMBL1524907 & 688746 & 4.5 & 4.862 & TRN \\
\hline CHEMBL 373481 & 688746 & 6.05 & 4.8169 & TST \\
\hline CHEMBL1511424 & 688746 & 4.55 & 4.8343 & TRN \\
\hline CHEMBL1300171 & 688746 & 6.25 & 4.9663 & TRN \\
\hline CHEMBL1455919 & 688746 & 5.5 & 4.8751 & TRN \\
\hline CHEMBL1509990 & 688746 & 5.0 & 5.0267 & TRN \\
\hline CHEMBL1381152 & 688746 & 5.1 & 4.8482 & TST \\
\hline CHEMBL1415420 & 688746 & 4.55 & 4.9941 & TRN \\
\hline CHEMBL3145316 & 688746 & 5.05 & 4.8526 & TRN \\
\hline CHEMBL1419031 & 688746 & 5.05 & 4.7972 & TRN \\
\hline CHEMBL1346108 & 688746 & 5.2 & 4.8361 & TRN \\
\hline CHEMBL1373015 & 688746 & 4.55 & 4.7915 & TRN \\
\hline CHEMBL1506622 & 688746 & 6.1 & 4.7714 & TRN \\
\hline CHEMBL1413358 & 688746 & 6.2 & 4.8466 & TRN \\
\hline CHEMBL1607759 & 688746 & 6.7501 & 4.9451 & TRN \\
\hline CHEMBL1579959 & 688746 & 4.8 & 4.8572 & TRN \\
\hline CHEMBL1392039 & 688746 & 4.85 & 4.8657 & TRN \\
\hline CHEMBL1507433 & 688746 & 4.45 & 4.9537 & TRN \\
\hline CHEMBL1519434 & 688746 & 5.1 & 4.8017 & TRN \\
\hline
\end{tabular}




\begin{tabular}{|c|c|c|c|c|}
\hline \multicolumn{5}{|c|}{ Supplemental Table S2.txt } \\
\hline CHEMBL1468919 & 688746 & 4.9 & 4.8412 & TRN \\
\hline CHEMBL1496996 & 688746 & 4.4 & 4.8678 & TST \\
\hline CHEMBL3194037 & 688746 & 5.2 & 4.8555 & TST \\
\hline CHEMBL1369716 & 688746 & 4.55 & 4.9143 & TRN \\
\hline CHEMBL1379862 & 688746 & 4.85 & 4.8127 & TRN \\
\hline CHEMBL1983323 & 688746 & 4.55 & 4.7465 & TRN \\
\hline CHEMBL1985649 & 688746 & 4.5 & 4.8181 & TST \\
\hline CHEMBL1556151 & 688746 & 4.4 & 4.8929 & TRN \\
\hline CHEMBL1506112 & 688746 & 4.75 & 4.8242 & TRN \\
\hline CHEMBL1469904 & 688746 & 5.3 & 4.7263 & TRN \\
\hline CHEMBL1411962 & 688746 & 4.95 & 4.7519 & TST \\
\hline CHEMBL1520679 & 688746 & 4.65 & 5.0246 & TRN \\
\hline CHEMBL1421330 & 688746 & 4.65 & 4.8305 & TST \\
\hline CHEMBL1415410 & 688746 & 4.85 & 4.8916 & TRN \\
\hline CHEMBL1428605 & 688746 & 5.05 & 4.9332 & TRN \\
\hline CHEMBL1431566 & 688746 & 4.75 & 4.7446 & TRN \\
\hline CHEMBL1562983 & 688746 & 6.15 & 4.8565 & TRN \\
\hline CHEMBL1381289 & 688746 & 4.7 & 4.9563 & TRN \\
\hline CHEMBL1398572 & 688746 & 4.8 & 4.7385 & TRN \\
\hline CHEMBL1399612 & 688746 & 6.7501 & 4.7996 & TRN \\
\hline CHEMBL1544926 & 688746 & 4.5 & 4.8945 & TRN \\
\hline CHEMBL1335489 & 688746 & 5.05 & 4.7372 & TRN \\
\hline CHEMBL1357090 & 688746 & 5.5 & 4.8117 & TRN \\
\hline CHEMBL1448412 & 688746 & 6.1 & 4.865 & TST \\
\hline CHEMBL 1327610 & 688746 & 4.45 & 4.8328 & TRN \\
\hline CHEMBL3198227 & 688746 & 4.45 & 4.8212 & TRN \\
\hline CHEMBL1327333 & 688746 & 4.7 & 4.8354 & TRN \\
\hline CHEMBL1511198 & 688746 & 4.6 & 4.7999 & TRN \\
\hline CHEMBL1429711 & 688746 & 4.5 & 4.7529 & TRN \\
\hline CHEMBL1347477 & 688746 & 4.95 & 4.7096 & TRN \\
\hline CHEMBL1419870 & 688746 & 4.55 & 4.6619 & TRN \\
\hline CHEMBL1611507 & 688746 & 4.6 & 4.9034 & TRN \\
\hline CHEMBL1511484 & 688746 & 4.4 & 4.9514 & TRN \\
\hline CHEMBL1580141 & 688746 & 5.55 & 4.9517 & TRN \\
\hline CHEMBL1470471 & 688746 & 4.5 & 4.7705 & TRN \\
\hline CHEMBL1585756 & 688746 & 4.4 & 4.9069 & TRN \\
\hline CHEMBL1517299 & 688746 & 4.8 & 4.8823 & TST \\
\hline CHEMBL1574363 & 688746 & 4.95 & 4.8323 & TRN \\
\hline CHEMBL1574062 & 688746 & 6.15 & 4.8343 & TRN \\
\hline CHEMBL1324828 & 688746 & 5.0 & 5.0475 & TRN \\
\hline CHEMBL1388026 & 688746 & 4.45 & 4.9661 & TRN \\
\hline CHEMBL1409431 & 688746 & 5.4 & 4.8273 & TRN \\
\hline CHEMBL1502957 & 688746 & 4.75 & 4.8851 & TRN \\
\hline CHEMBL1451130 & 688746 & 6.45 & 4.8769 & TRN \\
\hline CHEMBL1340066 & 688746 & 6.1 & 4.8139 & TRN \\
\hline CHEMBL1303506 & 688746 & 4.6 & 4.7973 & TRN \\
\hline CHEMBL1345128 & 688746 & 4.75 & 4.8213 & TRN \\
\hline CHEMBL1388130 & 688746 & 6.0 & 4.9499 & TRN \\
\hline
\end{tabular}




\begin{tabular}{|c|c|c|c|c|c|}
\hline \multicolumn{6}{|c|}{ oplemental la } \\
\hline CHEMBL1573273 & 688746 & 4.65 & 4.8042 & TRN & \\
\hline CHEMBL1333174 & 688746 & 5.05 & 4.9156 & TRN & \\
\hline CHEMBL1577070 & 688746 & 4.45 & 4.808 & TRN & \\
\hline CHEMBL1508610 & 688746 & 4.6 & 4.7657 & TRN & \\
\hline CHEMBL1497352 & 688746 & 4.6 & 4.8677 & TRN & \\
\hline CHEMBL1375934 & 688746 & 4.55 & 4.7566 & TRN & \\
\hline CHEMBL1522025 & 688746 & 4.55 & 4.8103 & TRN & \\
\hline CHEMBL3191795 & 688746 & 4.6 & 4.7337 & TRN & \\
\hline CHEMBL1359627 & 688746 & 5.55 & 4.8308 & TRN & \\
\hline CHEMBL1331605 & 688746 & 4.5 & 4.8612 & TST & \\
\hline CHEMBL1468756 & 688746 & 4.95 & 4.8815 & TRN & \\
\hline CHEMBL1464517 & 688746 & 4.55 & 4.948 & TRN & \\
\hline CHEMBL 229359 & 688746 & 4.4 & 4.7581 & TRN & \\
\hline CHEMBL1328980 & 688746 & 4.6 & 4.8306 & TRN & \\
\hline CHEMBL1299879 & 688746 & 4.55 & 4.8109 & TRN & \\
\hline CHEMBL1501676 & 688746 & 4.85 & 4.8406 & TRN & \\
\hline CHEMBL1458486 & 688746 & 4.5 & 4.7556 & TRN & \\
\hline CHEMBL1388312 & 688746 & 4.6 & 4.873 & TRN & \\
\hline CHEMBL1374966 & 688746 & 4.55 & 4.8428 & TRN & \\
\hline CHEMBL376896 & 688746 & 4.9 & 4.8897 & TRN & \\
\hline CHEMBL 3211445 & 688746 & 4.6 & 4.8503 & TRN & \\
\hline CHEMBL1503644 & 688746 & 4.4 & 4.7754 & TRN & \\
\hline CHEMBL1381944 & 688746 & 4.7 & 4.8797 & TRN & \\
\hline CHEMBL1370137 & 688746 & 4.5 & 4.8374 & TRN & \\
\hline CHEMBL1612557 & 688746 & 4.4 & 4.9108 & TRN & \\
\hline CHEMBL1979849 & 688746 & 5.9 & 4.7782 & TRN & \\
\hline CHEMBL1599090 & 688746 & 4.9 & 4.7781 & TRN & \\
\hline CHEMBL1389195 & 688746 & 4.75 & 4.9244 & TRN & \\
\hline CHEMBL1374900 & 688746 & 4.4 & 4.8218 & TRN & \\
\hline CHEMBL1395885 & 688746 & 4.4 & 4.8883 & TRN & \\
\hline CHEMBL1575881 & 688746 & 4.4 & 4.8359 & TRN & \\
\hline CHEMBL1530922 & 688746 & 5.05 & 4.7877 & TRN & \\
\hline CHEMBL1470006 & 688746 & 4.4 & 4.8002 & TRN & \\
\hline CHEMBL1527183 & 688746 & 4.55 & 4.8827 & TST & \\
\hline CHEMBL1490676 & 688746 & 6.15 & 4.9013 & TRN & \\
\hline CHEMBL1313786 & 688746 & 4.4 & 4.899 & TRN & \\
\hline CHEMBL1214407 & 688746 & 4.85 & 4.8018 & TRN & \\
\hline CHEMBL1341970 & 688746 & 4.65 & 4.89199 & 99999999995 & TRN \\
\hline CHEMBL1325840 & 688746 & 4.55 & 4.8917 & TRN & \\
\hline CHEMBL1379776 & 688746 & 5.5 & 4.8061 & TRN & \\
\hline CHEMBL1972405 & 688746 & 4.75 & 4.7691 & TRN & \\
\hline CHEMBL1484883 & 688746 & 5.5 & 4.9797 & TRN & \\
\hline CHEMBL1442981 & 688746 & 4.5 & 4.7839 & TRN & \\
\hline CHEMBL1352154 & 688746 & 4.5 & 4.8058 & TRN & \\
\hline CHEMBL265686 & 688746 & 4.65 & 4.7113 & TRN & \\
\hline CHEMBL602259 & 688746 & 5.1 & 4.8244 & TRN & \\
\hline CHEMBL1492443 & 688746 & 4.85 & 4.8421 & TRN & \\
\hline CHEMBL1489812 & 688746 & 4.5 & 4.7844 & TRN & \\
\hline
\end{tabular}




\begin{tabular}{|c|c|c|c|c|c|}
\hline \multirow[b]{2}{*}{ CHEMBL1371020 } & \multirow{2}{*}{688746} & \\
\hline & & 4.5 & 4.7914 & TST & \\
\hline CHEMBL1562501 & 688746 & 5.3 & 4.8329 & TRN & \\
\hline CHEMBL1449846 & 688746 & 4.5 & 4.774 & TRN & \\
\hline CHEMBL1325035 & 688746 & 4.4 & 4.8829 & TRN & \\
\hline CHEMBL1373057 & 688746 & 5.05 & 4.8083 & TRN & \\
\hline CHEMBL1599007 & 688746 & 4.4 & 4.9626 & TST & \\
\hline CHEMBL1522148 & 688746 & 4.75 & 4.8298 & TRN & \\
\hline CHEMBL1346768 & 688746 & 4.4 & 4.8321 & TRN & \\
\hline CHEMBL405110 & 688746 & 4.4 & 4.7917 & TST & \\
\hline CHEMBL1524331 & 688746 & 4.95 & 4.8873 & TST & \\
\hline CHEMBL1987472 & 688746 & 4.45 & 4.8162 & TRN & \\
\hline CHEMBL1602006 & 688746 & 4.75 & 4.8798 & TRN & \\
\hline CHEMBL1588050 & 688746 & 4.55 & 4.8105 & TRN & \\
\hline CHEMBL1366826 & 688746 & 4.65 & 4.7671 & TRN & \\
\hline CHEMBL1484325 & 688746 & 4.4 & 4.7529 & TST & \\
\hline CHEMBL1392711 & 688746 & 5.45 & 4.8177 & TST & \\
\hline CHEMBL1529950 & 688746 & 4.95 & 4.7886 & TRN & \\
\hline CHEMBL1424333 & 688746 & 5.65 & 4.8402 & TRN & \\
\hline CHEMBL1573994 & 688746 & 4.85 & 4.8374 & TRN & \\
\hline CHEMBL1360905 & 688746 & 5.7 & 4.7972 & TRN & \\
\hline CHEMBL1338776 & 688746 & 4.9 & 4.8394 & TRN & \\
\hline CHEMBL1498260 & 688746 & 4.65 & 4.9294 & TST & \\
\hline CHEMBL1446971 & 688746 & 6.9 & 4.8625 & TRN & \\
\hline CHEMBL1402494 & 688746 & 5.85 & 4.8826 & TRN & \\
\hline CHEMBL1326359 & 688746 & 6.05 & 4.7979 & TRN & \\
\hline CHEMBL1311761 & 688746 & 5.45 & 4.8921 & TST & \\
\hline CHEMBL1486369 & 688746 & 6.15 & 5.0249 & TRN & \\
\hline CHEMBL1498952 & 688746 & 4.7 & 4.848 & TRN & \\
\hline CHEMBL1500106 & 688746 & 4.6 & 4.7444 & TRN & \\
\hline CHEMBL1387563 & 688746 & 4.55 & 4.8087 & TRN & \\
\hline CHEMBL1576076 & 688746 & 4.7 & 4.9217 & TRN & \\
\hline CHEMBL1313428 & 688746 & 4.85 & 4.7769 & TRN & \\
\hline CHEMBL1576795 & 688746 & 5.75 & 4.76699 & 99999999995 & TRN \\
\hline CHEMBL1332073 & 688746 & 4.9 & 4.8238 & TRN & \\
\hline CHEMBL1523263 & 688746 & 4.8 & 4.7604 & TST & \\
\hline CHEMBL1407407 & 688746 & 4.7 & 4.8116 & TST & \\
\hline CHEMBL1464053 & 688746 & 5.1 & 4.8485 & TRN & \\
\hline CHEMBL3193134 & 688746 & 5.0 & 4.8506 & TRN & \\
\hline CHEMBL179024 & 688746 & 4.45 & 4.7977 & TRN & \\
\hline CHEMBL1336240 & 688746 & 4.4 & 4.9133 & TRN & \\
\hline CHEMBL1488674 & 688746 & 5.2 & 4.8804 & TRN & \\
\hline CHEMBL3197650 & 688746 & 4.4 & 4.8682 & TRN & \\
\hline CHEMBL127579 & 688746 & 4.85 & 4.6774 & TRN & \\
\hline CHEMBL1415670 & 688746 & 4.5 & 5.0204 & TRN & \\
\hline CHEMBL1605713 & 688746 & 4.65 & 4.8463 & TRN & \\
\hline CHEMBL1320787 & 688746 & 4.45 & 4.874 & TRN & \\
\hline CHEMBL1344115 & 688746 & 4.45 & 4.8658 & TST & \\
\hline CHEMBL1394517 & 688746 & 5.3 & 4.8395 & TRN & \\
\hline & & & & 1047 & \\
\hline
\end{tabular}




\begin{tabular}{|c|c|c|c|c|c|}
\hline \\
\hline CHEMBL1482475 & 688746 & 4.75 & 4.8246 & TRN & \\
\hline CHEMBL1474206 & 688746 & 4.4 & 4.9062 & TRN & \\
\hline CHEMBL1549055 & 688746 & 6.5 & 4.9433 & TRN & \\
\hline CHEMBL1300237 & 688746 & 4.8 & 4.7805 & TRN & \\
\hline CHEMBL1530991 & 688746 & 5.2 & 4.8114 & TST & \\
\hline CHEMBL1549120 & 688746 & 5.4 & 4.7348 & TRN & \\
\hline CHEMBL1558216 & 688746 & 5.3 & 4.9263 & TRN & \\
\hline CHEMBL1469891 & 688746 & 4.75 & 4.7778 & TST & \\
\hline CHEMBL1516758 & 688746 & 4.4 & 4.9268 & TRN & \\
\hline CHEMBL3195177 & 688746 & 5.0 & 4.8207 & TST & \\
\hline CHEMBL1544171 & 688746 & 5.1 & 4.9997 & TRN & \\
\hline CHEMBL1463582 & 688746 & 4.8 & 4.8434 & TRN & \\
\hline CHEMBL1500231 & 688746 & 5.85 & 4.9289 & TST & \\
\hline CHEMBL1457996 & 688746 & 4.4 & 4.904 & TRN & \\
\hline CHEMBL1445917 & 688746 & 4.85 & 4.894 & TRN & \\
\hline CHEMBL1407169 & 688746 & 4.5 & 4.7651 & TST & \\
\hline CHEMBL1578235 & 688746 & 4.45 & 4.864 & TRN & \\
\hline CHEMBL 3208054 & 688746 & 5.9 & 4.73300 & 00000000005 & TRN \\
\hline CHEMBL1468476 & 688746 & 5.35 & 4.8937 & TST & \\
\hline CHEMBL1586350 & 688746 & 4.65 & 4.8665 & TRN & \\
\hline CHEMBL1540416 & 688746 & 4.4 & 4.8828 & TRN & \\
\hline CHEMBL1339312 & 688746 & 4.5 & 4.8629 & TRN & \\
\hline CHEMBL1401157 & 688746 & 4.5 & 4.8653 & TRN & \\
\hline CHEMBL1311895 & 688746 & 4.55 & 4.8642 & TRN & \\
\hline CHEMBL1393976 & 688746 & 4.7 & 4.8457 & TRN & \\
\hline CHEMBL1579972 & 688746 & 4.4 & 4.8731 & TRN & \\
\hline CHEMBL1343121 & 688746 & 4.4 & 4.8527 & TRN & \\
\hline CHEMBL1549324 & 688746 & 5.0 & 4.8879 & TRN & \\
\hline CHEMBL1536977 & 688746 & 4.8 & 4.8564 & TRN & \\
\hline CHEMBL1388858 & 688746 & 4.6 & 4.9809 & TRN & \\
\hline CHEMBL1467213 & 688746 & 5.0 & 4.9325 & TRN & \\
\hline CHEMBL 1424364 & 688746 & 5.05 & 4.7675 & TRN & \\
\hline CHEMBL1537100 & 688746 & 4.65 & 4.8921 & TRN & \\
\hline CHEMBL3209639 & 688746 & 4.9 & 4.9568 & TST & \\
\hline CHEMBL1507267 & 688746 & 4.4 & 4.9589 & TRN & \\
\hline CHEMBL1561273 & 688746 & 5.05 & 4.9067 & TRN & \\
\hline CHEMBL 1430606 & 688746 & 4.5 & 4.9127 & TRN & \\
\hline CHEMBL1392030 & 688746 & 4.6 & 4.811 & TRN & \\
\hline CHEMBL1430306 & 688746 & 4.55 & 4.9289 & TRN & \\
\hline CHEMBL1381318 & 688746 & 6.15 & 4.791 & TRN & \\
\hline CHEMBL 1504320 & 688746 & 4.6 & 4.8889 & TRN & \\
\hline CHEMBL3209080 & 688746 & 7.0 & 4.886 & TRN & \\
\hline CHEMBL1309719 & 688746 & 5.15 & 4.9183 & TST & \\
\hline CHEMBL1556394 & 688746 & 4.8 & 4.8661 & TRN & \\
\hline CHEMBL1529334 & 688746 & 4.55 & 4.9144 & TRN & \\
\hline CHEMBL1431222 & 688746 & 5.2 & 5.0 & TRN & \\
\hline CHEMBL1362099 & 688746 & 5.4 & 4.7987 & TRN & \\
\hline CHEMBL1564088 & 688746 & 7.0501 & 4.8709 & TRN & \\
\hline
\end{tabular}




\begin{tabular}{|c|c|c|c|c|}
\hline \multicolumn{5}{|c|}{ Supplemental Table S2.txt } \\
\hline CHEMBL1381659 & 688746 & 4.85 & 5.0606 & TRN \\
\hline CHEMBL1454433 & 688746 & 5.15 & 4.9145 & TRN \\
\hline CHEMBL1345201 & 688746 & 4.4 & 4.9097 & TRN \\
\hline CHEMBL1503755 & 688746 & 4.75 & 4.859 & TRN \\
\hline CHEMBL1594574 & 688746 & 4.55 & 4.8945 & TRN \\
\hline CHEMBL1364876 & 688746 & 4.6 & 4.8385 & TRN \\
\hline CHEMBL1473119 & 688746 & 4.85 & 4.9554 & TST \\
\hline CHEMBL1458733 & 688746 & 4.65 & 4.8418 & TRN \\
\hline CHEMBL1557772 & 688746 & 4.4 & 4.897 & TRN \\
\hline CHEMBL1540219 & 688746 & 4.5 & 4.9324 & TRN \\
\hline CHEMBL1608121 & 688746 & 4.7 & 4.9192 & TRN \\
\hline CHEMBL1527433 & 688746 & 4.8 & 4.749 & TRN \\
\hline CHEMBL1434136 & 688746 & 5.15 & 4.93 & TRN \\
\hline CHEMBL1326112 & 688746 & 5.35 & 4.8802 & TST \\
\hline CHEMBL1416897 & 688746 & 5.7 & 4.9708 & TRN \\
\hline CHEMBL1547628 & 688746 & 4.4 & 4.7728 & TRN \\
\hline CHEMBL1572756 & 688746 & 4.75 & 4.8476 & TRN \\
\hline CHEMBL1508870 & 688746 & 5.45 & 4.953 & TST \\
\hline CHEMBL1547278 & 688746 & 4.8 & 4.8297 & TRN \\
\hline CHEMBL1585168 & 688746 & 4.7 & 4.9639 & TRN \\
\hline CHEMBL1333533 & 688746 & 4.6 & 4.8564 & TRN \\
\hline CHEMBL1351253 & 688746 & 5.2 & 4.8282 & TRN \\
\hline CHEMBL1441840 & 688746 & 6.1 & 4.8933 & TRN \\
\hline CHEMBL1417751 & 688746 & 4.4 & 4.7386 & TRN \\
\hline CHEMBL1563328 & 688746 & 4.5 & 5.0195 & TRN \\
\hline CHEMBL1402279 & 688746 & 4.6 & 4.9326 & TRN \\
\hline CHEMBL1340563 & 688746 & 5.15 & 4.8926 & TST \\
\hline CHEMBL3212061 & 688746 & 4.5 & 4.8548 & TRN \\
\hline CHEMBL1538371 & 688746 & 4.4 & 4.8118 & TRN \\
\hline CHEMBL1489741 & 688746 & 5.0 & 4.9115 & TRN \\
\hline CHEMBL1492391 & 688746 & 4.6 & 4.8613 & TRN \\
\hline CHEMBL1325367 & 688746 & 4.4 & 4.7927 & TST \\
\hline CHEMBL1536193 & 688746 & 4.4 & 4.8842 & TST \\
\hline CHEMBL1462301 & 688746 & 4.9 & 4.7759 & TRN \\
\hline CHEMBL1600311 & 688746 & 4.45 & 4.8084 & TRN \\
\hline CHEMBL1544407 & 688746 & 4.55 & 4.8134 & TRN \\
\hline CHEMBL 232508 & 688746 & 4.6 & 4.8191 & TRN \\
\hline CHEMBL1324556 & 688746 & 4.45 & 4.8408 & TRN \\
\hline CHEMBL1518380 & 688746 & 4.55 & 4.9098 & TRN \\
\hline CHEMBL1380653 & 688746 & 4.4 & 4.9084 & TRN \\
\hline CHEMBL1349067 & 688746 & 4.75 & 4.7764 & TRN \\
\hline CHEMBL1304120 & 688746 & 4.55 & 4.8944 & TRN \\
\hline CHEMBL1561889 & 688746 & 4.35 & 4.896 & TRN \\
\hline CHEMBL1530932 & 688746 & 4.6 & 4.794 & TRN \\
\hline CHEMBL1465935 & 688746 & 4.4 & 4.9539 & TRN \\
\hline CHEMBL1452608 & 688746 & 4.6 & 4.8922 & TRN \\
\hline CHEMBL1583337 & 688746 & 4.4 & 4.8127 & TST \\
\hline CHEMBL1335690 & 688746 & 5.5 & 4.8718 & TRN \\
\hline
\end{tabular}




\begin{tabular}{|c|c|c|c|c|}
\hline \multicolumn{5}{|c|}{ Supplemental Table S2.txt } \\
\hline CHEMBL1427781 & 688746 & 5.35 & 4.9171 & TRN \\
\hline CHEMBL1307636 & 688746 & 4.6 & 4.9355 & TRN \\
\hline CHEMBL1393499 & 688746 & 4.5 & 4.8424 & TRN \\
\hline CHEMBL 3189420 & 688746 & 4.55 & 4.8041 & TRN \\
\hline CHEMBL 1459786 & 688746 & 4.4 & 4.7803 & TRN \\
\hline CHEMBL 2003587 & 688746 & 4.4 & 4.8355 & TRN \\
\hline CHEMBL1441142 & 688746 & 4.7 & 4.8718 & TRN \\
\hline CHEMBL1510344 & 688746 & 4.55 & 4.8241 & TRN \\
\hline CHEMBL1302635 & 688746 & 4.95 & 4.9651 & TRN \\
\hline CHEMBL3192631 & 688746 & 4.65 & 4.7913 & TRN \\
\hline CHEMBL1601509 & 688746 & 5.15 & 4.8147 & TRN \\
\hline CHEMBL1318381 & 688746 & 4.4 & 5.0022 & TRN \\
\hline CHEMBL1335758 & 688746 & 4.4 & 4.8512 & TST \\
\hline CHEMBL1449174 & 688746 & 4.75 & 4.9651 & TRN \\
\hline CHEMBL1517936 & 688746 & 4.45 & 4.9296 & TRN \\
\hline CHEMBL1556821 & 688746 & 4.4 & 4.8324 & TRN \\
\hline CHEMBL1523465 & 688746 & 4.6 & 4.9935 & TRN \\
\hline CHEMBL1537794 & 688746 & 4.45 & 4.8595 & TRN \\
\hline CHEMBL1541807 & 688746 & 4.85 & 4.8456 & TRN \\
\hline CHEMBL1601562 & 688746 & 5.35 & 4.816 & TRN \\
\hline CHEMBL1610587 & 688746 & 5.3 & 4.7868 & TST \\
\hline CHEMBL1477258 & 688746 & 4.65 & 4.9344 & TRN \\
\hline CHEMBL211969 & 688746 & 4.4 & 4.8977 & TST \\
\hline CHEMBL1557468 & 688746 & 4.6 & 4.8416 & TRN \\
\hline CHEMBL1411018 & 688746 & 4.4 & 4.9314 & TRN \\
\hline CHEMBL1558817 & 688746 & 5.5 & 5.0158 & TRN \\
\hline CHEMBL1469745 & 688746 & 4.4 & 4.8115 & TRN \\
\hline CHEMBL1365612 & 688746 & 4.65 & 4.9499 & TRN \\
\hline CHEMBL1527911 & 688746 & 4.7 & 5.0635 & TRN \\
\hline CHEMBL1390155 & 688746 & 4.4 & 4.7447 & TRN \\
\hline CHEMBL1561590 & 688746 & 4.4 & 4.9042 & TRN \\
\hline CHEMBL1469774 & 688746 & 5.15 & 4.8776 & TRN \\
\hline CHEMBL1464122 & 688746 & 4.65 & 4.8334 & TST \\
\hline CHEMBL1707275 & 688746 & 4.5 & 4.7956 & TST \\
\hline CHEMBL3191304 & 688746 & 4.8 & 4.8501 & TRN \\
\hline CHEMBL1543735 & 688746 & 4.5 & 4.8657 & TRN \\
\hline CHEMBL1467259 & 688746 & 4.6 & 4.8734 & TRN \\
\hline CHEMBL3198440 & 688746 & 4.45 & 4.8312 & TRN \\
\hline CHEMBL1550137 & 688746 & 5.05 & 5.0037 & TRN \\
\hline CHEMBL1467360 & 688746 & 4.5 & 4.8194 & TRN \\
\hline CHEMBL1556737 & 688746 & 4.55 & 4.8206 & TRN \\
\hline CHEMBL1547449 & 688746 & 5.15 & 4.8657 & TRN \\
\hline CHEMBL1333805 & 688746 & 4.4 & 4.8641 & TRN \\
\hline CHEMBL1604678 & 688746 & 4.8 & 4.8406 & TRN \\
\hline CHEMBL1566926 & 688746 & 4.4 & 4.9306 & TRN \\
\hline CHEMBL1447306 & 688746 & 5.35 & 4.7845 & TRN \\
\hline CHEMBL1567647 & 688746 & 4.55 & 4.8678 & TRN \\
\hline CHEMBL1511369 & 688746 & 4.85 & 4.9421 & TRN \\
\hline
\end{tabular}




\begin{tabular}{|c|c|c|c|c|}
\hline \multicolumn{5}{|c|}{ Supplemental Table S2.txt } \\
\hline CHEMBL1332483 & 688746 & 4.55 & 4.7802 & TRN \\
\hline CHEMBL1583998 & 688746 & 4.55 & 4.8419 & TST \\
\hline CHEMBL1544309 & 688746 & 4.9 & 4.8359 & TRN \\
\hline CHEMBL1447353 & 688746 & 5.6 & 5.0197 & TRN \\
\hline CHEMBL1581238 & 688746 & 4.5 & 4.8865 & TST \\
\hline CHEMBL1371969 & 688746 & 5.05 & 4.9563 & TRN \\
\hline CHEMBL1597459 & 688746 & 4.75 & 4.7866 & TST \\
\hline CHEMBL460517 & 688746 & 4.85 & 4.6803 & TRN \\
\hline CHEMBL1369096 & 688746 & 5.3 & 4.9317 & TRN \\
\hline CHEMBL1559997 & 688746 & 6.6 & 4.8977 & TST \\
\hline CHEMBL1352152 & 688746 & 4.85 & 4.957 & TRN \\
\hline CHEMBL1489771 & 688746 & 4.6 & 4.9773 & TST \\
\hline CHEMBL1241452 & 688746 & 4.4 & 4.7714 & TRN \\
\hline CHEMBL1520595 & 688746 & 4.4 & 4.7454 & TRN \\
\hline CHEMBL1359608 & 688746 & 4.6 & 4.8514 & TRN \\
\hline CHEMBL1504504 & 688746 & 5.05 & 4.9245 & TRN \\
\hline CHEMBL1455163 & 688746 & 4.6 & 4.7994 & TST \\
\hline CHEMBL1346130 & 688746 & 4.65 & 5.0131 & TRN \\
\hline CHEMBL1403919 & 688746 & 4.95 & 4.8107 & TRN \\
\hline CHEMBL1498566 & 688746 & 5.0 & 4.9567 & TRN \\
\hline CHEMBL1429590 & 688746 & 6.6499 & 5.0213 & TRN \\
\hline CHEMBL1494543 & 688746 & 4.75 & 4.9549 & TRN \\
\hline CHEMBL3199590 & 688746 & 6.0 & 4.7372 & TRN \\
\hline CHEMBL1600475 & 688746 & 4.5 & 4.842 & TRN \\
\hline CHEMBL1413356 & 688746 & 4.4 & 5.0075 & TRN \\
\hline CHEMBL1351070 & 688746 & 5.2 & 4.8502 & TRN \\
\hline CHEMBL1525678 & 688746 & 4.5 & 4.7278 & TRN \\
\hline CHEMBL1464128 & 688746 & 4.5 & 4.882 & TST \\
\hline CHEMBL1370557 & 688746 & 6.2 & 4.7898 & TRN \\
\hline CHEMBL1490043 & 688746 & 5.0 & 4.7769 & TRN \\
\hline CHEMBL1998221 & 688746 & 4.4 & 4.8802 & TST \\
\hline CHEMBL1550078 & 688746 & 4.4 & 4.7093 & TRN \\
\hline CHEMBL1504592 & 688746 & 4.6 & 4.7687 & TRN \\
\hline CHEMBL1361349 & 688746 & 4.95 & 4.8471 & TRN \\
\hline CHEMBL1375576 & 688746 & 5.0 & 4.8934 & TST \\
\hline CHEMBL530609 & 688746 & 4.8 & 4.787 & TRN \\
\hline CHEMBL1488730 & 688746 & 4.8 & 4.8304 & TRN \\
\hline CHEMBL1456792 & 688746 & 4.6 & 4.8242 & TRN \\
\hline CHEMBL 3196993 & 688746 & 5.0 & 4.849 & TRN \\
\hline CHEMBL1309573 & 688746 & 4.5 & 4.7047 & TRN \\
\hline CHEMBL1328707 & 688746 & 5.2 & 4.7473 & TRN \\
\hline CHEMBL1326120 & 688746 & 5.05 & 4.9555 & TRN \\
\hline CHEMBL1520245 & 688746 & 5.1 & 4.8508 & TRN \\
\hline CHEMBL1461937 & 688746 & 4.65 & 4.7735 & TRN \\
\hline CHEMBL3190011 & 688746 & 4.5 & 4.7835 & TRN \\
\hline CHEMBL1303333 & 688746 & 4.85 & 4.808 & TRN \\
\hline CHEMBL1515601 & 688746 & 4.4 & 5.0233 & TRN \\
\hline CHEMBL1549672 & 688746 & 4.95 & 4.9677 & TRN \\
\hline
\end{tabular}




\begin{tabular}{|c|c|c|c|c|}
\hline & & & pplement & al $\mathrm{Ta}$ \\
\hline CHEMBL1376212 & 688746 & 4.4 & 4.7676 & TRN \\
\hline CHEMBL1561215 & 688746 & 5.1 & 4.8436 & TST \\
\hline CHEMBL1339868 & 688746 & 4.4 & 4.7485 & TRN \\
\hline CHEMBL1302721 & 688746 & 4.55 & 4.8658 & TRN \\
\hline CHEMBL1556511 & 688746 & 4.65 & 4.8079 & TRN \\
\hline CHEMBL1472283 & 688746 & 4.65 & 4.724 & TRN \\
\hline CHEMBL1300714 & 688746 & 5.15 & 4.8994 & TRN \\
\hline CHEMBL1545016 & 688746 & 4.85 & 4.9688 & TRN \\
\hline CHEMBL1313234 & 688746 & 5.25 & 4.9257 & TRN \\
\hline CHEMBL1321827 & 688746 & 6.1 & 4.8724 & TRN \\
\hline CHEMBL1422601 & 688746 & 4.65 & 4.8636 & TRN \\
\hline CHEMBL1341892 & 688746 & 5.55 & 5.0066 & TRN \\
\hline CHEMBL1583508 & 688746 & 5.8 & 4.8729 & TRN \\
\hline CHEMBL1477375 & 688746 & 4.45 & 4.8211 & TRN \\
\hline CHEMBL1497281 & 688746 & 4.4 & 4.815 & TST \\
\hline CHEMBL1423546 & 688746 & 4.7 & 4.8495 & TRN \\
\hline CHEMBL1350634 & 688746 & 4.4 & 4.8675 & TRN \\
\hline CHEMBL1416853 & 688746 & 4.85 & 4.8176 & TST \\
\hline CHEMBL1459913 & 688746 & 4.95 & 4.8946 & TRN \\
\hline CHEMBL1508848 & 688746 & 4.5 & 4.8646 & TRN \\
\hline CHEMBL1521348 & 688746 & 4.6 & 4.8297 & TRN \\
\hline CHEMBL 2005284 & 688746 & 4.85 & 4.75 & TRN \\
\hline CHEMBL1453880 & 688746 & 4.7 & 4.9365 & TRN \\
\hline CHEMBL1454440 & 688746 & 4.4 & 4.9029 & TRN \\
\hline CHEMBL1388408 & 688746 & 4.55 & 4.7679 & TST \\
\hline CHEMBL1310511 & 688746 & 7.6003 & 4.8672 & TST \\
\hline CHEMBL1335008 & 688746 & 4.6 & 4.8349 & TRN \\
\hline CHEMBL1612553 & 688746 & 4.55 & 4.9279 & TRN \\
\hline CHEMBL1531256 & 688746 & 4.65 & 4.8288 & TRN \\
\hline CHEMBL1399979 & 688746 & 5.1 & 4.8219 & TRN \\
\hline CHEMBL1386151 & 688746 & 4.4 & 4.9061 & TRN \\
\hline CHEMBL1363706 & 688746 & 5.5 & 4.8198 & TRN \\
\hline CHEMBL1579329 & 688746 & 4.45 & 4.8606 & TST \\
\hline CHEMBL1362928 & 688746 & 4.4 & 4.9549 & TRN \\
\hline CHEMBL1416550 & 688746 & 5.9 & 4.9028 & TRN \\
\hline CHEMBL1384365 & 688746 & 4.75 & 4.7754 & TRN \\
\hline CHEMBL1594607 & 688746 & 5.1 & 4.8517 & TRN \\
\hline CHEMBL1362870 & 688746 & 5.7 & 4.8374 & TRN \\
\hline CHEMBL1606993 & 688746 & 5.25 & 4.9248 & TRN \\
\hline CHEMBL1350240 & 688746 & 4.45 & 4.7232 & TRN \\
\hline CHEMBL1320620 & 688746 & 4.8 & 4.7797 & TST \\
\hline CHEMBL1978101 & 688746 & 4.65 & 4.8078 & TRN \\
\hline CHEMBL1528524 & 688746 & 6.05 & 4.9657 & TRN \\
\hline CHEMBL1493396 & 688746 & 5.4 & 4.7571 & TST \\
\hline CHEMBL1545209 & 688746 & 4.6 & 4.8541 & TST \\
\hline CHEMBL1386109 & 688746 & 4.45 & 4.8577 & TRN \\
\hline CHEMBL1498720 & 688746 & 4.85 & 4.9482 & TRN \\
\hline CHEMBL1445900 & 688746 & 4.7 & 4.8844 & TRN \\
\hline
\end{tabular}




\begin{tabular}{|c|c|c|c|c|}
\hline \multicolumn{5}{|c|}{ Supplemental Table S2.txt } \\
\hline CHEMBL1612281 & 688746 & 4.95 & 4.8566 & TRN \\
\hline CHEMBL1459239 & 688746 & 5.05 & 4.8703 & TRN \\
\hline CHEMBL1450071 & 688746 & 5.5 & 4.89 & TRN \\
\hline CHEMBL1346456 & 688746 & 4.95 & 4.8574 & TST \\
\hline CHEMBL1581987 & 688746 & 4.4 & 4.8661 & TRN \\
\hline CHEMBL1404385 & 688746 & 4.4 & 5.0039 & TRN \\
\hline CHEMBL1579763 & 688746 & 4.4 & 4.9149 & TRN \\
\hline CHEMBL1504637 & 688746 & 4.55 & 4.9827 & TRN \\
\hline CHEMBL 3208140 & 688746 & 4.5 & 4.7548 & TRN \\
\hline CHEMBL1454363 & 688746 & 4.5 & 4.9003 & TRN \\
\hline CHEMBL1461499 & 688746 & 4.4 & 4.9107 & TST \\
\hline CHEMBL1604032 & 688746 & 5.4 & 4.8415 & TRN \\
\hline CHEMBL1549097 & 688746 & 5.45 & 4.9246 & TRN \\
\hline CHEMBL1526836 & 688746 & 4.5 & 5.0106 & TRN \\
\hline CHEMBL1544412 & 688746 & 4.6 & 4.9271 & TRN \\
\hline CHEMBL1422426 & 688746 & 5.85 & 4.9736 & TRN \\
\hline CHEMBL1999046 & 688746 & 5.05 & 4.8787 & TST \\
\hline CHEMBL1500013 & 688746 & 4.4 & 4.8249 & TRN \\
\hline CHEMBL1384916 & 688746 & 4.85 & 4.945 & TRN \\
\hline CHEMBL1352413 & 688746 & 4.75 & 4.846 & TRN \\
\hline CHEMBL1391063 & 688746 & 6.95 & 4.8704 & TST \\
\hline CHEMBL1491626 & 688746 & 5.45 & 4.9217 & TRN \\
\hline CHEMBL1544420 & 688746 & 4.6 & 4.9214 & TRN \\
\hline CHEMBL1342579 & 688746 & 5.1 & 5.0125 & TRN \\
\hline CHEMBL1555519 & 688746 & 4.75 & 4.8806 & TRN \\
\hline CHEMBL1323575 & 688746 & 4.55 & 4.8032 & TST \\
\hline CHEMBL1326084 & 688746 & 5.55 & 5.0091 & TRN \\
\hline CHEMBL1500340 & 688746 & 4.4 & 4.9661 & TRN \\
\hline CHEMBL 3195878 & 688746 & 4.5 & 4.7364 & TRN \\
\hline CHEMBL1602614 & 688746 & 4.65 & 4.8217 & TRN \\
\hline CHEMBL1316971 & 688746 & 8.1487 & 4.9373 & TRN \\
\hline CHEMBL1603187 & 688746 & 4.65 & 4.9029 & TRN \\
\hline CHEMBL3194966 & 688746 & 4.4 & 4.8882 & TRN \\
\hline CHEMBL3192131 & 688746 & 5.15 & 4.7183 & TRN \\
\hline CHEMBL1440032 & 688746 & 5.15 & 4.909 & TST \\
\hline CHEMBL1371592 & 688746 & 4.55 & 4.9886 & TRN \\
\hline CHEMBL1338767 & 688746 & 5.4 & 4.8052 & TRN \\
\hline CHEMBL1543588 & 688746 & 4.6 & 4.7879 & TRN \\
\hline CHEMBL1544252 & 688746 & 4.4 & 4.7828 & TRN \\
\hline CHEMBL1366347 & 688746 & 4.9 & 4.7299 & TRN \\
\hline CHEMBL1603776 & 688746 & 5.95 & 4.8698 & TST \\
\hline CHEMBL1369431 & 688746 & 4.6 & 4.8878 & TRN \\
\hline CHEMBL1587933 & 688746 & 5.4 & 4.8151 & TRN \\
\hline CHEMBL1462302 & 688746 & 4.75 & 4.7539 & TRN \\
\hline CHEMBL1527992 & 688746 & 5.5 & 4.7861 & TST \\
\hline CHEMBL1517046 & 688746 & 5.4 & 4.9924 & TRN \\
\hline CHEMBL1486335 & 688746 & 4.6 & 4.8269 & TRN \\
\hline CHEMBL1517374 & 688746 & 5.05 & 4.8551 & TRN \\
\hline
\end{tabular}




\begin{tabular}{|c|c|c|c|c|}
\hline \multicolumn{5}{|c|}{ oplemental } \\
\hline CHEMBL1372513 & 688746 & 4.6 & 4.8919 & TRN \\
\hline CHEMBL1600826 & 688746 & 5.35 & 4.8848 & TRN \\
\hline CHEMBL1300471 & 688746 & 4.65 & 4.8978 & TRN \\
\hline CHEMBL1575708 & 688746 & 4.6 & 4.7401 & TRN \\
\hline CHEMBL1362955 & 688746 & 4.4 & 4.8737 & TRN \\
\hline CHEMBL1323049 & 688746 & 4.4 & 4.8414 & TRN \\
\hline CHEMBL1387816 & 688746 & 4.6 & 4.8533 & TRN \\
\hline CHEMBL1432332 & 688746 & 4.8 & 4.9207 & TRN \\
\hline CHEMBL1537133 & 688746 & 4.7 & 4.8114 & TRN \\
\hline CHEMBL1587145 & 688746 & 4.5 & 4.7855 & TRN \\
\hline CHEMBL1325757 & 688746 & 4.55 & 4.7818 & TRN \\
\hline CHEMBL1481920 & 688746 & 4.4 & 5.016 & TRN \\
\hline CHEMBL1302917 & 688746 & 5.35 & 4.8461 & TRN \\
\hline CHEMBL1421842 & 688746 & 4.55 & 5.0216 & TRN \\
\hline CHEMBL1576421 & 688746 & 4.95 & 4.7899 & TST \\
\hline CHEMBL1562641 & 688746 & 4.7 & 5.0342 & TRN \\
\hline CHEMBL1996833 & 688746 & 4.75 & 4.7726 & TRN \\
\hline CHEMBL1421390 & 688746 & 4.85 & 5.0474 & TRN \\
\hline CHEMBL1304259 & 688746 & 4.55 & 4.8855 & TRN \\
\hline CHEMBL1379838 & 688746 & 6.2 & 4.9291 & TRN \\
\hline CHEMBL1588624 & 688746 & 5.15 & 4.9957 & TRN \\
\hline CHEMBL1577182 & 688746 & 4.4 & 4.9006 & TRN \\
\hline CHEMBL1594867 & 688746 & 4.6 & 4.7003 & TRN \\
\hline CHEMBL1425504 & 688746 & 4.6 & 4.8899 & TST \\
\hline CHEMBL1377115 & 688746 & 4.85 & 4.8132 & TRN \\
\hline CHEMBL1518799 & 688746 & 4.4 & 4.8517 & TRN \\
\hline CHEMBL3198900 & 688746 & 5.65 & 4.7963 & TRN \\
\hline CHEMBL1342575 & 688746 & 5.35 & 4.8945 & TRN \\
\hline CHEMBL1351391 & 688746 & 4.55 & 4.9867 & TRN \\
\hline CHEMBL1303621 & 688746 & 4.8 & 4.8415 & TST \\
\hline CHEMBL1445307 & 688746 & 4.55 & 4.8896 & TRN \\
\hline CHEMBL1323648 & 688746 & 5.9 & 4.7756 & TST \\
\hline CHEMBL1388186 & 688746 & 4.85 & 4.8206 & TST \\
\hline CHEMBL1527410 & 688746 & 4.85 & 4.8783 & TRN \\
\hline CHEMBL1409407 & 688746 & 5.3 & 4.883 & TRN \\
\hline CHEMBL1333451 & 688746 & 5.05 & 4.84 & TST \\
\hline CHEMBL1488712 & 688746 & 5.0 & 4.7454 & TRN \\
\hline CHEMBL1333618 & 688746 & 4.85 & 4.8521 & TRN \\
\hline CHEMBL1533620 & 688746 & 5.1 & 4.8244 & TRN \\
\hline CHEMBL1588741 & 688746 & 4.75 & 4.9362 & TRN \\
\hline CHEMBL1309345 & 688746 & 4.45 & 4.9505 & TST \\
\hline CHEMBL3194445 & 688746 & 4.75 & 4.8435 & TST \\
\hline CHEMBL3207648 & 688746 & 4.85 & 4.879 & TRN \\
\hline CHEMBL1306435 & 688746 & 4.65 & 4.9566 & TRN \\
\hline CHEMBL 3198478 & 688746 & 4.4 & 4.7758 & TRN \\
\hline CHEMBL1386036 & 688746 & 4.7 & 4.8374 & TRN \\
\hline CHEMBL1539023 & 688746 & 4.45 & 4.7576 & TRN \\
\hline CHEMBL1577927 & 688746 & 6.05 & 4.8095 & TRN \\
\hline
\end{tabular}




\begin{tabular}{|c|c|c|c|c|c|}
\hline \multicolumn{6}{|c|}{ Supplemental Table S2.txt } \\
\hline CHEMBL1974432 & 688746 & 4.55 & 4.7231 & TRN & \\
\hline CHEMBL1452894 & 688746 & 5.5 & 4.9733 & TST & \\
\hline CHEMBL1539826 & 688746 & 5.15 & 4.7257 & TRN & \\
\hline CHEMBL1332402 & 688746 & 4.45 & 4.8607 & TRN & \\
\hline CHEMBL1349002 & 688746 & 5.2 & 4.7699 & TRN & \\
\hline CHEMBL1446929 & 688746 & 4.45 & 4.8649 & TST & \\
\hline CHEMBL1547025 & 688746 & 4.45 & 4.7597 & TRN & \\
\hline CHEMBL1421517 & 688746 & 4.55 & 4.8878 & TRN & \\
\hline CHEMBL1469653 & 688746 & 4.8 & 4.8765 & TRN & \\
\hline CHEMBL3189629 & 688746 & 5.1 & 4.7722 & TRN & \\
\hline CHEMBL1347753 & 688746 & 4.6 & 4.8816 & TRN & \\
\hline CHEMBL1471645 & 688746 & 4.4 & 4.8224 & TST & \\
\hline CHEMBL1535157 & 688746 & 4.55 & 4.8363 & TRN & \\
\hline CHEMBL1525069 & 688746 & 4.75 & 4.9563 & TRN & \\
\hline CHEMBL1301935 & 688746 & 4.85 & 4.8469 & TRN & \\
\hline CHEMBL1438074 & 688746 & 4.85 & 5.0115 & TRN & \\
\hline CHEMBL1498639 & 688746 & 4.8 & 4.6848 & TRN & \\
\hline CHEMBL1400779 & 688746 & 4.4 & 4.8785 & TST & \\
\hline CHEMBL1976049 & 688746 & 4.55 & 4.8259 & TRN & \\
\hline CHEMBL175266 & 688746 & 5.0 & 4.8742 & TST & \\
\hline CHEMBL1333773 & 688746 & 4.45 & 4.8835 & TRN & \\
\hline CHEMBL1454380 & 688746 & 4.85 & 4.8833 & TRN & \\
\hline CHEMBL1536637 & 688746 & 4.8 & 4.8417 & TRN & \\
\hline CHEMBL1465313 & 688746 & 4.4 & 4.8952 & TRN & \\
\hline CHEMBL1340903 & 688746 & 5.25 & 4.918 & TRN & \\
\hline CHEMBL1580357 & 688746 & 4.5 & 4.8232 & TRN & \\
\hline CHEMBL1343458 & 688746 & 4.75 & 4.7502 & TRN & \\
\hline CHEMBL1352624 & 688746 & 4.8 & 4.7282 & TRN & \\
\hline CHEMBL1597705 & 688746 & 4.55 & 4.80699 & 99999999995 & TRN \\
\hline CHEMBL1504492 & 688746 & 4.75 & 4.8144 & TRN & \\
\hline CHEMBL1386796 & 688746 & 4.5 & 4.8725 & TRN & \\
\hline CHEMBL1498310 & 688746 & 6.7001 & 4.8833 & TRN & \\
\hline CHEMBL1381128 & 688746 & 4.6 & 4.8077 & TST & \\
\hline CHEMBL1611199 & 688746 & 4.4 & 4.8334 & TRN & \\
\hline CHEMBL1575075 & 688746 & 4.75 & 4.8479 & TRN & \\
\hline CHEMBL1555787 & 688746 & 5.05 & 4.8654 & TST & \\
\hline CHEMBL1478445 & 688746 & 4.6 & 4.872 & TRN & \\
\hline CHEMBL1318728 & 688746 & 4.85 & 4.9371 & TRN & \\
\hline CHEMBL1432944 & 688746 & 5.75 & 4.956 & TRN & \\
\hline CHEMBL1448475 & 688746 & 4.7 & 4.7359 & TRN & \\
\hline CHEMBL1356592 & 688746 & 5.3 & 4.9413 & TRN & \\
\hline CHEMBL1969298 & 688746 & 4.85 & 4.6798 & TRN & \\
\hline CHEMBL1708832 & 688746 & 4.9 & 4.81 & TRN & \\
\hline CHEMBL1328560 & 688746 & 4.45 & 4.8465 & TRN & \\
\hline CHEMBL1581297 & 688746 & 5.45 & 4.8104 & TRN & \\
\hline CHEMBL1353716 & 688746 & 4.5 & 4.765 & TRN & \\
\hline CHEMBL1565179 & 688746 & 5.05 & 4.8388 & TRN & \\
\hline CHEMBL1544192 & 688746 & 5.35 & 4.7876 & TRN & \\
\hline
\end{tabular}




\begin{tabular}{|c|c|c|c|c|}
\hline \multicolumn{5}{|c|}{ Supplemental T } \\
\hline CHEMBL1304644 & 688746 & 4.8 & 4.8552 & TRN \\
\hline CHEMBL1372906 & 688746 & 6.4 & 4.8713 & TST \\
\hline CHEMBL1308870 & 688746 & 5.5 & 4.837 & TRN \\
\hline CHEMBL3196363 & 688746 & 4.55 & 4.8298 & TRN \\
\hline CHEMBL1378661 & 688746 & 4.5 & 4.9306 & TRN \\
\hline CHEMBL1518374 & 688746 & 4.8 & 4.8125 & TRN \\
\hline CHEMBL1604258 & 688746 & 4.4 & 4.9213 & TRN \\
\hline CHEMBL1530509 & 688746 & 4.4 & 4.9787 & TRN \\
\hline CHEMBL1482740 & 688746 & 5.45 & 4.8111 & TRN \\
\hline CHEMBL1377067 & 688746 & 4.45 & 4.8099 & TRN \\
\hline CHEMBL1376192 & 688746 & 4.55 & 4.8612 & TRN \\
\hline CHEMBL1605029 & 688746 & 4.5 & 4.8669 & TRN \\
\hline CHEMBL1336490 & 688746 & 5.85 & 4.9138 & TST \\
\hline CHEMBL1569759 & 688746 & 5.2 & 4.827 & TRN \\
\hline CHEMBL1443354 & 688746 & 4.85 & 4.9042 & TST \\
\hline CHEMBL1444187 & 688746 & 5.0 & 4.942 & TRN \\
\hline CHEMBL1582818 & 688746 & 4.4 & 4.9081 & TRN \\
\hline CHEMBL1381066 & 688746 & 4.55 & 4.8414 & TST \\
\hline CHEMBL1492233 & 688746 & 4.5 & 4.8143 & TRN \\
\hline CHEMBL1367504 & 688746 & 5.65 & 4.9119 & TRN \\
\hline CHEMBL1511645 & 688746 & 4.85 & 4.8168 & TRN \\
\hline CHEMBL1319703 & 688746 & 4.65 & 4.8172 & TRN \\
\hline CHEMBL1982658 & 688746 & 4.6 & 4.8149 & TRN \\
\hline CHEMBL1506712 & 688746 & 4.55 & 4.742 & TRN \\
\hline CHEMBL1594431 & 688746 & 4.4 & 4.8701 & TRN \\
\hline CHEMBL1609413 & 688746 & 4.6 & 4.9151 & TRN \\
\hline CHEMBL1490587 & 688746 & 4.45 & 4.8134 & TRN \\
\hline CHEMBL164103 & 688746 & 4.65 & 4.7544 & TRN \\
\hline CHEMBL1516719 & 688746 & 4.55 & 4.8454 & TRN \\
\hline CHEMBL1406708 & 688746 & 4.65 & 4.895 & TST \\
\hline CHEMBL1567147 & 688746 & 4.55 & 4.9916 & TRN \\
\hline CHEMBL1378605 & 688746 & 4.4 & 4.876 & TRN \\
\hline CHEMBL1404745 & 688746 & 4.4 & 4.9282 & TRN \\
\hline CHEMBL1333190 & 688746 & 4.6 & 4.8133 & TRN \\
\hline CHEMBL1461268 & 688746 & 5.95 & 4.9075 & TRN \\
\hline CHEMBL1496609 & 688746 & 4.4 & 4.9102 & TST \\
\hline CHEMBL1423778 & 688746 & 4.4 & 4.8896 & TRN \\
\hline CHEMBL1350884 & 688746 & 4.7 & 4.9778 & TRN \\
\hline CHEMBL1336775 & 688746 & 4.4 & 4.8566 & TST \\
\hline CHEMBL3196120 & 688746 & 4.55 & 4.8246 & TRN \\
\hline CHEMBL1480640 & 688746 & 4.4 & 4.9028 & TRN \\
\hline CHEMBL1483344 & 688746 & 6.0 & 4.8828 & TRN \\
\hline CHEMBL1523920 & 688746 & 5.05 & 4.775 & TRN \\
\hline CHEMBL1370171 & 688746 & 4.7 & 5.0094 & TRN \\
\hline CHEMBL2094339 & 688746 & 4.4 & 4.7733 & TRN \\
\hline CHEMBL1497782 & 688746 & 5.25 & 4.8532 & TRN \\
\hline CHEMBL1588058 & 688746 & 4.6 & 4.7846 & TRN \\
\hline CHEMBL1353457 & 688746 & 5.15 & 4.7991 & TRN \\
\hline
\end{tabular}




\begin{tabular}{|c|c|c|c|c|}
\hline \multicolumn{5}{|c|}{ Supplemental Table S2.txt } \\
\hline CHEMBL1578083 & 688746 & 5.25 & 4.8765 & TST \\
\hline CHEMBL1377737 & 688746 & 4.8 & 4.8246 & TRN \\
\hline CHEMBL3213485 & 688746 & 4.4 & 4.8645 & TRN \\
\hline CHEMBL1334110 & 688746 & 6.05 & 4.9909 & TRN \\
\hline CHEMBL1307858 & 688746 & 6.35 & 4.8534 & TRN \\
\hline CHEMBL1445881 & 688746 & 5.2 & 4.7776 & TRN \\
\hline CHEMBL1487173 & 688746 & 4.55 & 4.8563 & TRN \\
\hline CHEMBL1440220 & 688746 & 4.4 & 4.8304 & TRN \\
\hline CHEMBL3193193 & 688746 & 4.4 & 4.8092 & TST \\
\hline CHEMBL1466902 & 688746 & 4.5 & 4.8946 & TRN \\
\hline CHEMBL1560628 & 688746 & 4.7 & 4.8435 & TST \\
\hline CHEMBL3191288 & 688746 & 4.4 & 4.8471 & TRN \\
\hline CHEMBL1714415 & 688746 & 4.45 & 4.8343 & TST \\
\hline CHEMBL1471694 & 688746 & 4.45 & 4.9219 & TRN \\
\hline CHEMBL1399096 & 688746 & 4.4 & 4.8118 & TRN \\
\hline CHEMBL1496119 & 688746 & 4.85 & 4.8223 & TRN \\
\hline CHEMBL1568385 & 688746 & 4.6 & 4.8349 & TRN \\
\hline CHEMBL1373732 & 688746 & 4.7 & 4.8677 & TRN \\
\hline CHEMBL1535216 & 688746 & 4.85 & 4.8661 & TRN \\
\hline CHEMBL1337329 & 688746 & 6.6499 & 4.7143 & TRN \\
\hline CHEMBL1459718 & 688746 & 4.55 & 4.8832 & TRN \\
\hline CHEMBL1336716 & 688746 & 4.65 & 4.8218 & TRN \\
\hline CHEMBL1447309 & 688746 & 5.0 & 4.8444 & TRN \\
\hline CHEMBL1550085 & 688746 & 5.0 & 4.8214 & TRN \\
\hline CHEMBL1350860 & 688746 & 5.0 & 4.8792 & TRN \\
\hline CHEMBL1567664 & 688746 & 4.4 & 4.8113 & TRN \\
\hline CHEMBL1312788 & 688746 & 6.0 & 4.7716 & TRN \\
\hline CHEMBL1580777 & 688746 & 5.05 & 4.8734 & TRN \\
\hline CHEMBL1549290 & 688746 & 4.55 & 4.8228 & TRN \\
\hline CHEMBL1983871 & 688746 & 5.0 & 4.8126 & TRN \\
\hline CHEMBL1404347 & 688746 & 4.4 & 4.8145 & TRN \\
\hline CHEMBL1572340 & 688746 & 4.4 & 4.9212 & TRN \\
\hline CHEMBL1372096 & 688746 & 4.65 & 4.8596 & TRN \\
\hline CHEMBL1404137 & 688746 & 4.7 & 4.776 & TRN \\
\hline CHEMBL1511096 & 688746 & 5.8 & 4.9518 & TRN \\
\hline CHEMBL1305881 & 688746 & 4.45 & 4.8528 & TRN \\
\hline CHEMBL1606007 & 688746 & 4.6 & 4.8553 & TST \\
\hline CHEMBL1403570 & 688746 & 4.6 & 4.8276 & TRN \\
\hline CHEMBL1364292 & 688746 & 4.4 & 4.8409 & TST \\
\hline CHEMBL1504838 & 688746 & 4.8 & 4.9619 & TRN \\
\hline CHEMBL1470321 & 688746 & 4.75 & 4.8912 & TST \\
\hline CHEMBL1444114 & 688746 & 5.4 & 4.8041 & TRN \\
\hline CHEMBL1310138 & 688746 & 4.6 & 4.8107 & TST \\
\hline CHEMBL1320219 & 688746 & 4.9 & 4.8393 & TRN \\
\hline CHEMBL1543516 & 688746 & 4.65 & 4.8303 & TST \\
\hline CHEMBL1429403 & 688746 & 4.4 & 4.8169 & TRN \\
\hline CHEMBL1491858 & 688746 & 6.15 & 4.7688 & TST \\
\hline CHEMBL1555930 & 688746 & 4.85 & 4.7709 & TRN \\
\hline
\end{tabular}




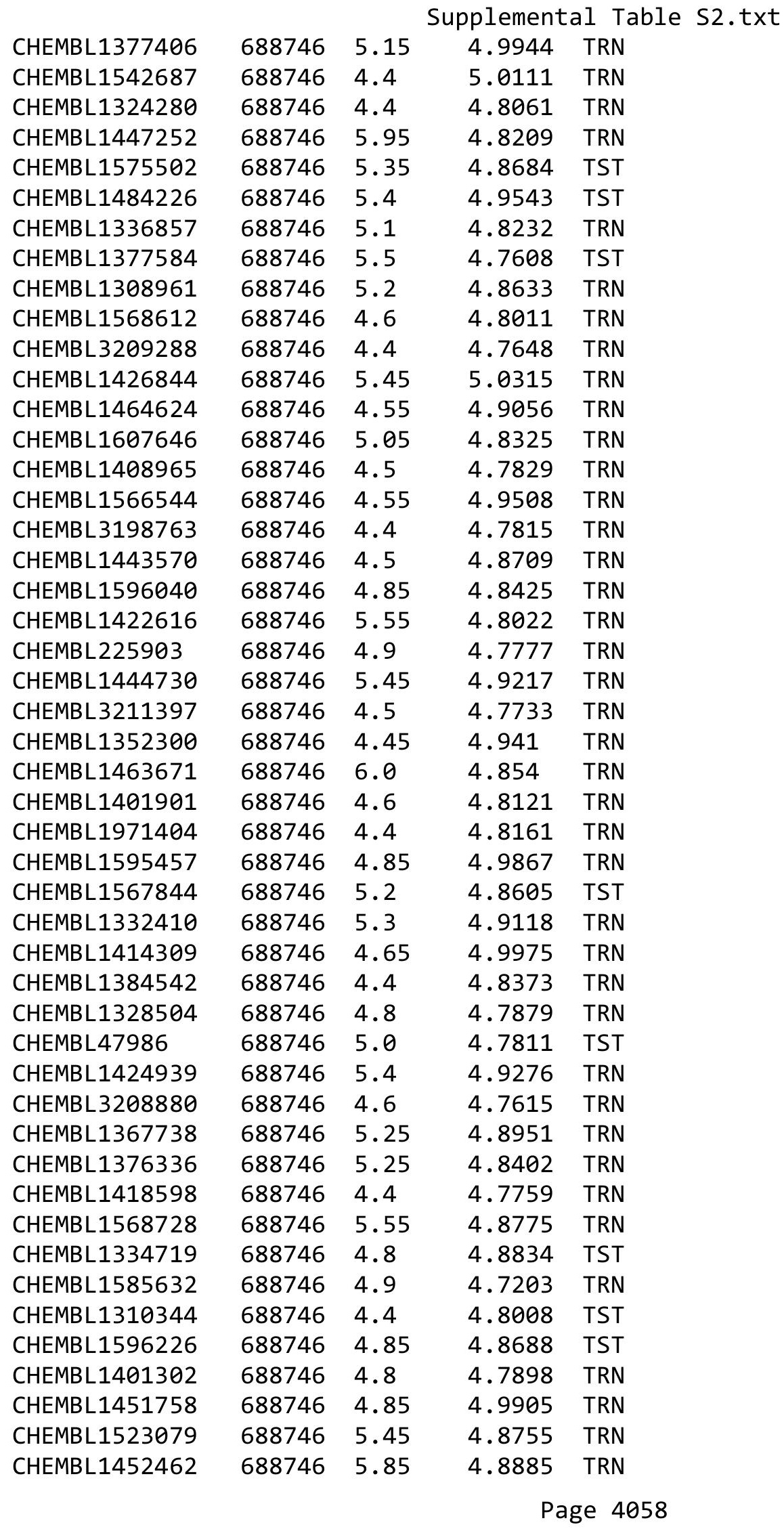




\begin{tabular}{|c|c|c|c|c|c|}
\hline \multicolumn{6}{|c|}{ oplemental İ } \\
\hline CHEMBL1564490 & 688746 & 4.65 & 4.8296 & TRN & \\
\hline CHEMBL1350800 & 688746 & 5.65 & 4.8163 & TST & \\
\hline CHEMBL1383728 & 688746 & 4.9 & 5.0032 & TRN & \\
\hline CHEMBL1364030 & 688746 & 5.25 & 4.8537 & TRN & \\
\hline CHEMBL1549704 & 688746 & 5.3 & 5.0201 & TRN & \\
\hline CHEMBL1500050 & 688746 & 4.5 & 4.9014 & TST & \\
\hline CHEMBL1480448 & 688746 & 5.15 & 4.878 & TRN & \\
\hline CHEMBL1505673 & 688746 & 6.5 & 4.8771 & TRN & \\
\hline CHEMBL1550895 & 688746 & 4.65 & 4.7995 & TRN & \\
\hline CHEMBL1390938 & 688746 & 4.75 & 4.891 & TRN & \\
\hline CHEMBL1582121 & 688746 & 4.7 & 4.8579 & TRN & \\
\hline CHEMBL1483711 & 688746 & 4.55 & 4.8541 & TRN & \\
\hline CHEMBL1457955 & 688746 & 4.5 & 4.824 & TRN & \\
\hline CHEMBL1477842 & 688746 & 5.55 & 4.9315 & TRN & \\
\hline CHEMBL1441449 & 688746 & 4.95 & 4.8969 & TST & \\
\hline CHEMBL1439730 & 688746 & 4.8 & 4.7735 & TRN & \\
\hline CHEMBL1565445 & 688746 & 4.5 & 4.9 & TRN & \\
\hline CHEMBL1520048 & 688746 & 4.5 & 4.8289 & TRN & \\
\hline CHEMBL1527417 & 688746 & 4.55 & 4.8652 & TRN & \\
\hline CHEMBL1600256 & 688746 & 4.6 & 4.806 & TRN & \\
\hline CHEMBL1509092 & 688746 & 4.6 & 4.901 & TRN & \\
\hline CHEMBL52347 & 688746 & 4.9 & 4.7795 & TST & \\
\hline CHEMBL1300864 & 688746 & 7.0 & 4.8272 & TST & \\
\hline CHEMBL1378013 & 688746 & 4.4 & 4.7401 & TRN & \\
\hline CHEMBL1430211 & 688746 & 4.5 & 4.92399 & 79999999995 & TRN \\
\hline CHEMBL1584013 & 688746 & 4.55 & 4.8723 & TRN & \\
\hline CHEMBL1318998 & 688746 & 5.55 & 4.9099 & TRN & \\
\hline CHEMBL1481616 & 688746 & 4.65 & 4.871 & TRN & \\
\hline CHEMBL1549166 & 688746 & 4.5 & 4.934 & TRN & \\
\hline CHEMBL1538161 & 688746 & 4.7 & 4.8678 & TRN & \\
\hline CHEMBL1565168 & 688746 & 5.45 & 4.9974 & TRN & \\
\hline CHEMBL1566787 & 688746 & 5.25 & 4.9471 & TRN & \\
\hline CHEMBL1553586 & 688746 & 4.45 & 4.9377 & TST & \\
\hline CHEMBL1470840 & 688746 & 6.0 & 4.9873 & TRN & \\
\hline CHEMBL1431644 & 688746 & 4.6 & 4.8269 & TST & \\
\hline CHEMBL1430467 & 688746 & 4.85 & 4.8524 & TST & \\
\hline CHEMBL1325580 & 688746 & 5.45 & 5.0316 & TRN & \\
\hline CHEMBL1442065 & 688746 & 5.55 & 4.8854 & TRN & \\
\hline CHEMBL1433203 & 688746 & 4.4 & 4.7337 & TRN & \\
\hline CHEMBL1516723 & 688746 & 4.95 & 4.9281 & TRN & \\
\hline CHEMBL1484517 & 688746 & 4.95 & 4.8901 & TRN & \\
\hline CHEMBL1540526 & 688746 & 4.8 & 4.8559 & TRN & \\
\hline CHEMBL1334170 & 688746 & 4.7 & 4.9442 & TRN & \\
\hline CHEMBL1542422 & 688746 & 6.2 & 4.8782 & TRN & \\
\hline CHEMBL1361502 & 688746 & 4.55 & 4.8699 & TRN & \\
\hline CHEMBL1562056 & 688746 & 4.65 & 4.8923 & TRN & \\
\hline CHEMBL1568398 & 688746 & 4.4 & 4.814 & TRN & \\
\hline CHEMBL1388639 & 688746 & 4.55 & 4.8463 & TRN & \\
\hline
\end{tabular}




\begin{tabular}{|c|c|c|c|c|}
\hline \multicolumn{5}{|c|}{ emen } \\
\hline CHEMBL1340016 & 688746 & 4.5 & 4.8915 & TRN \\
\hline CHEMBL1402679 & 688746 & 5.2 & 4.8134 & TRN \\
\hline CHEMBL3190104 & 688746 & 4.6 & 4.7205 & TRN \\
\hline CHEMBL1563423 & 688746 & 4.4 & 4.8217 & TRN \\
\hline CHEMBL1520392 & 688746 & 4.7 & 4.7626 & TRN \\
\hline CHEMBL1586614 & 688746 & 4.4 & 4.9202 & TRN \\
\hline CHEMBL1422250 & 688746 & 4.6 & 4.8082 & TRN \\
\hline CHEMBL1405767 & 688746 & 4.4 & 4.8949 & TRN \\
\hline CHEMBL1594316 & 688746 & 4.85 & 4.7547 & TRN \\
\hline CHEMBL1574932 & 688746 & 5.7 & 4.8109 & TST \\
\hline CHEMBL1432275 & 688746 & 4.7 & 4.8518 & TRN \\
\hline CHEMBL1385491 & 688746 & 4.6 & 4.8711 & TRN \\
\hline CHEMBL1610697 & 688746 & 4.65 & 4.956 & TRN \\
\hline CHEMBL1370669 & 688746 & 4.65 & 4.7985 & TRN \\
\hline CHEMBL1341050 & 688746 & 4.7 & 4.9921 & TRN \\
\hline CHEMBL1371188 & 688746 & 4.55 & 4.8428 & TRN \\
\hline CHEMBL1612578 & 688746 & 4.65 & 4.9193 & TRN \\
\hline CHEMBL1507144 & 688746 & 5.0 & 4.755 & TRN \\
\hline CHEMBL1541334 & 688746 & 4.8 & 4.7176 & TRN \\
\hline CHEMBL1432691 & 688746 & 4.4 & 4.973 & TRN \\
\hline CHEMBL578257 & 688746 & 5.5 & 4.8213 & TST \\
\hline CHEMBL1541964 & 688746 & 4.4 & 4.8787 & TRN \\
\hline CHEMBL1567662 & 688746 & 4.8 & 4.8163 & TRN \\
\hline CHEMBL1606465 & 688746 & 4.55 & 4.8297 & TRN \\
\hline CHEMBL1600395 & 688746 & 4.65 & 4.8032 & TRN \\
\hline CHEMBL1396422 & 688746 & 5.3 & 4.9731 & TRN \\
\hline CHEMBL1540850 & 688746 & 5.5 & 5.0474 & TRN \\
\hline CHEMBL1577844 & 688746 & 4.4 & 4.8248 & TRN \\
\hline CHEMBL1506512 & 688746 & 4.45 & 4.8455 & TRN \\
\hline CHEMBL1321367 & 688746 & 4.65 & 5.0111 & TRN \\
\hline CHEMBL1608197 & 688746 & 5.45 & 4.9165 & TRN \\
\hline CHEMBL3209151 & 688746 & 4.5 & 4.8749 & TRN \\
\hline CHEMBL1576791 & 688746 & 5.6 & 4.8884 & TRN \\
\hline CHEMBL1314094 & 688746 & 4.85 & 4.7679 & TRN \\
\hline CHEMBL1600818 & 688746 & 6.05 & 4.8945 & TRN \\
\hline CHEMBL1313663 & 688746 & 4.9 & 4.8469 & TRN \\
\hline CHEMBL1545660 & 688746 & 4.65 & 4.7898 & TRN \\
\hline CHEMBL1573483 & 688746 & 6.0 & 5.0031 & TRN \\
\hline CHEMBL1367975 & 688746 & 4.65 & 5.0275 & TRN \\
\hline CHEMBL1566495 & 688746 & 5.1 & 4.8358 & TRN \\
\hline CHEMBL1574847 & 688746 & 5.95 & 4.9366 & TRN \\
\hline CHEMBL1595536 & 688746 & 4.4 & 4.8378 & TRN \\
\hline CHEMBL1449527 & 688746 & 5.4 & 4.8696 & TRN \\
\hline CHEMBL1337986 & 688746 & 4.9 & 4.868 & TRN \\
\hline CHEMBL1387866 & 688746 & 5.2 & 4.8524 & TRN \\
\hline CHEMBL1493395 & 688746 & 5.45 & 4.9835 & TRN \\
\hline CHEMBL1522726 & 688746 & 4.7 & 4.7202 & TRN \\
\hline CHEMBL1541866 & 688746 & 4.6 & 4.9953 & TRN \\
\hline
\end{tabular}




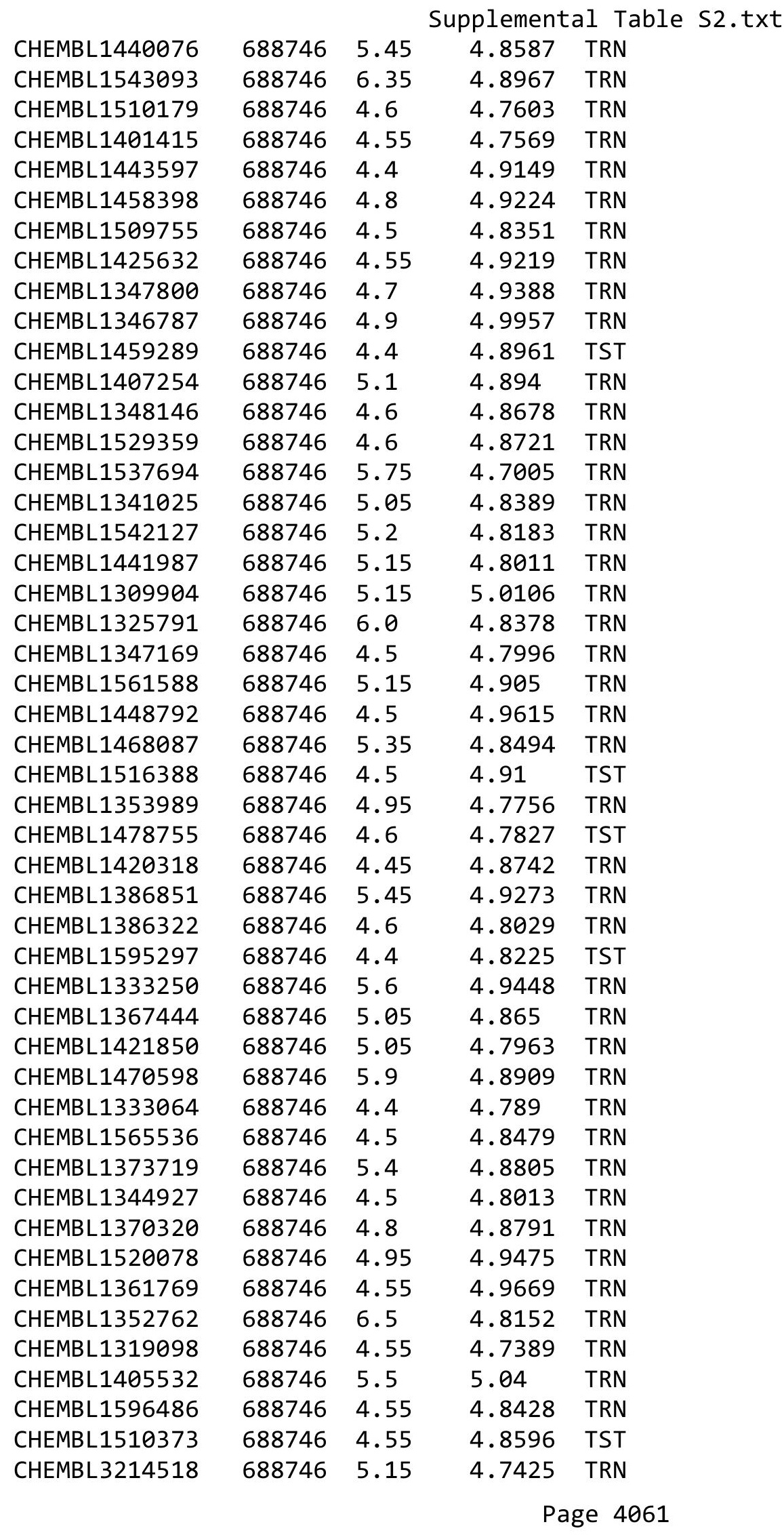




\begin{tabular}{|c|c|c|c|c|}
\hline \multicolumn{5}{|c|}{ Supplemental Table S2.txt } \\
\hline CHEMBL1597013 & 688746 & 5.2 & 4.8652 & TRN \\
\hline CHEMBL1586326 & 688746 & 5.35 & 4.8534 & TST \\
\hline CHEMBL1547519 & 688746 & 4.4 & 4.7995 & TRN \\
\hline CHEMBL3197629 & 688746 & 4.6 & 4.8629 & TRN \\
\hline CHEMBL1534974 & 688746 & 4.45 & 4.8306 & TRN \\
\hline CHEMBL 3207620 & 688746 & 4.55 & 4.806 & TRN \\
\hline CHEMBL1334320 & 688746 & 4.4 & 4.8762 & TRN \\
\hline CHEMBL1388580 & 688746 & 4.6 & 4.9069 & TRN \\
\hline CHEMBL1581079 & 688746 & 8.2518 & 4.9337 & TRN \\
\hline CHEMBL1579034 & 688746 & 4.8 & 4.8162 & TRN \\
\hline CHEMBL1613238 & 688746 & 4.7 & 4.8105 & TST \\
\hline CHEMBL1427185 & 688746 & 4.75 & 4.8916 & TRN \\
\hline CHEMBL3197099 & 688746 & 4.9 & 4.78 & TRN \\
\hline CHEMBL1486726 & 688746 & 4.85 & 4.7329 & TRN \\
\hline CHEMBL1569790 & 688746 & 4.45 & 4.8254 & TRN \\
\hline CHEMBL1536044 & 688746 & 5.45 & 4.8865 & TRN \\
\hline CHEMBL1520438 & 688746 & 4.4 & 4.9171 & TST \\
\hline CHEMBL1343993 & 688746 & 4.55 & 4.7979 & TRN \\
\hline CHEMBL1582561 & 688746 & 4.6 & 4.862 & TRN \\
\hline CHEMBL1308799 & 688746 & 4.55 & 4.8326 & TST \\
\hline CHEMBL1602160 & 688746 & 6.0 & 4.8771 & TRN \\
\hline CHEMBL1491228 & 688746 & 4.55 & 4.824 & TRN \\
\hline CHEMBL1369784 & 688746 & 4.75 & 4.8263 & TRN \\
\hline CHEMBL1499202 & 688746 & 4.95 & 4.8001 & TRN \\
\hline CHEMBL1428731 & 688746 & 4.6 & 4.8868 & TRN \\
\hline CHEMBL1383026 & 688746 & 4.4 & 4.8956 & TRN \\
\hline CHEMBL1502482 & 688746 & 4.55 & 4.9244 & TRN \\
\hline CHEMBL1403469 & 688746 & 4.4 & 4.85 & TRN \\
\hline CHEMBL1465439 & 688746 & 5.1 & 5.0413 & TRN \\
\hline CHEMBL1584634 & 688746 & 4.85 & 4.7915 & TRN \\
\hline CHEMBL3197464 & 688746 & 4.9 & 4.8056 & TRN \\
\hline CHEMBL1607549 & 688746 & 4.85 & 4.9638 & TRN \\
\hline CHEMBL1412113 & 688746 & 5.95 & 4.8366 & TRN \\
\hline CHEMBL3145140 & 688746 & 4.4 & 4.8623 & TST \\
\hline CHEMBL1446502 & 688746 & 4.85 & 4.8489 & TRN \\
\hline CHEMBL1460869 & 688746 & 4.75 & 4.7862 & TRN \\
\hline CHEMBL1402243 & 688746 & 4.6 & 4.8925 & TST \\
\hline CHEMBL1556051 & 688746 & 4.35 & 4.8757 & TRN \\
\hline CHEMBL1573366 & 688746 & 4.6 & 4.7636 & TRN \\
\hline CHEMBL 2000172 & 688746 & 4.5 & 4.6524 & TRN \\
\hline CHEMBL 243651 & 688746 & 5.2 & 4.8243 & TRN \\
\hline CHEMBL1587152 & 688746 & 4.9 & 4.8479 & TST \\
\hline CHEMBL1463647 & 688746 & 4.4 & 4.8528 & TST \\
\hline CHEMBL1377220 & 688746 & 4.4 & 4.8128 & TRN \\
\hline CHEMBL3210421 & 688746 & 4.45 & 4.7763 & TRN \\
\hline CHEMBL1430473 & 688746 & 6.2 & 4.8768 & TST \\
\hline CHEMBL1523936 & 688746 & 7.5498 & 4.8774 & TRN \\
\hline CHEMBL1439938 & 688746 & 4.55 & 4.8907 & TRN \\
\hline
\end{tabular}




\begin{tabular}{|c|c|c|c|c|c|}
\hline \multirow{2}{*}{\multicolumn{2}{|c|}{ CHEMBL1488925 }} & \\
\hline & & 4.4 & 4.79 & TRN & \\
\hline CHEMBL1375660 & 688746 & 5.15 & 4.8448 & TRN & \\
\hline CHEMBL1311408 & 688746 & 4.55 & 5.0101 & TRN & \\
\hline CHEMBL1585691 & 688746 & 4.65 & 4.8191 & TRN & \\
\hline CHEMBL1365522 & 688746 & 4.65 & 4.8817 & TRN & \\
\hline CHEMBL1562026 & 688746 & 4.85 & 4.9679 & TRN & \\
\hline CHEMBL1608489 & 688746 & 4.55 & 4.8886 & TRN & \\
\hline CHEMBL1433022 & 688746 & 5.4 & 4.8859 & TRN & \\
\hline CHEMBL 3194151 & 688746 & 4.9 & 4.8767 & TRN & \\
\hline CHEMBL1509104 & 688746 & 4.55 & 4.832 & TRN & \\
\hline CHEMBL1596248 & 688746 & 4.5 & 4.6986 & TRN & \\
\hline CHEMBL1374167 & 688746 & 4.5 & 4.8301 & TST & \\
\hline CHEMBL1477227 & 688746 & 4.4 & 4.9064 & TST & \\
\hline CHEMBL1585891 & 688746 & 4.4 & 4.9121 & TST & \\
\hline CHEMBL1343677 & 688746 & 5.2 & 4.8923 & TRN & \\
\hline CHEMBL1379970 & 688746 & 4.4 & 4.80699 & 99999999995 & TST \\
\hline CHEMBL1577174 & 688746 & 4.75 & 4.774 & TRN & \\
\hline CHEMBL1509292 & 688746 & 4.8 & 4.9585 & TRN & \\
\hline CHEMBL1477100 & 688746 & 4.85 & 4.8183 & TRN & \\
\hline CHEMBL1363666 & 688746 & 4.6 & 4.85800 & 00000000005 & TRN \\
\hline CHEMBL1308724 & 688746 & 4.8 & 4.8323 & TRN & \\
\hline CHEMBL1383181 & 688746 & 4.8 & 4.7964 & TRN & \\
\hline CHEMBL1314037 & 688746 & 4.7 & 4.8189 & TRN & \\
\hline CHEMBL1981539 & 688746 & 6.4 & 4.8997 & TST & \\
\hline CHEMBL1342514 & 688746 & 4.75 & 4.8608 & TRN & \\
\hline CHEMBL1309192 & 688746 & 4.95 & 4.9729 & TRN & \\
\hline CHEMBL1433838 & 688746 & 5.0 & 4.8769 & TRN & \\
\hline CHEMBL2139212 & 688746 & 4.85 & 4.919 & TRN & \\
\hline CHEMBL1496782 & 688746 & 4.5 & 4.8058 & TRN & \\
\hline CHEMBL1587981 & 688746 & 4.6 & 4.9763 & TRN & \\
\hline CHEMBL1558588 & 688746 & 4.65 & 4.8537 & TRN & \\
\hline CHEMBL1391741 & 688746 & 5.3 & 4.8438 & TRN & \\
\hline CHEMBL1467501 & 688746 & 4.4 & 4.8257 & TRN & \\
\hline CHEMBL1538355 & 688746 & 4.75 & 4.8803 & TRN & \\
\hline CHEMBL1478140 & 688746 & 4.55 & 4.8381 & TRN & \\
\hline CHEMBL1430311 & 688746 & 4.45 & 4.8363 & TRN & \\
\hline CHEMBL1456295 & 688746 & 5.85 & 4.8737 & TRN & \\
\hline CHEMBL1548669 & 688746 & 4.5 & 4.8938 & TRN & \\
\hline CHEMBL1470907 & 688746 & 4.5 & 4.8782 & TRN & \\
\hline CHEMBL1454233 & 688746 & 5.0 & 4.9619 & TRN & \\
\hline CHEMBL1540497 & 688746 & 4.95 & 4.9209 & TRN & \\
\hline CHEMBL1527176 & 688746 & 5.15 & 4.743 & TRN & \\
\hline CHEMBL1460100 & 688746 & 5.15 & 4.8833 & TRN & \\
\hline CHEMBL1597798 & 688746 & 4.85 & 4.9406 & TRN & \\
\hline CHEMBL1465644 & 688746 & 4.8 & 4.8741 & TRN & \\
\hline CHEMBL1347304 & 688746 & 4.9 & 5.0425 & TRN & \\
\hline CHEMBL1309107 & 688746 & 5.0 & 4.8374 & TST & \\
\hline CHEMBL1379300 & 688746 & 5.6 & 4.9493 & TRN & \\
\hline & & & & 4063 & \\
\hline
\end{tabular}




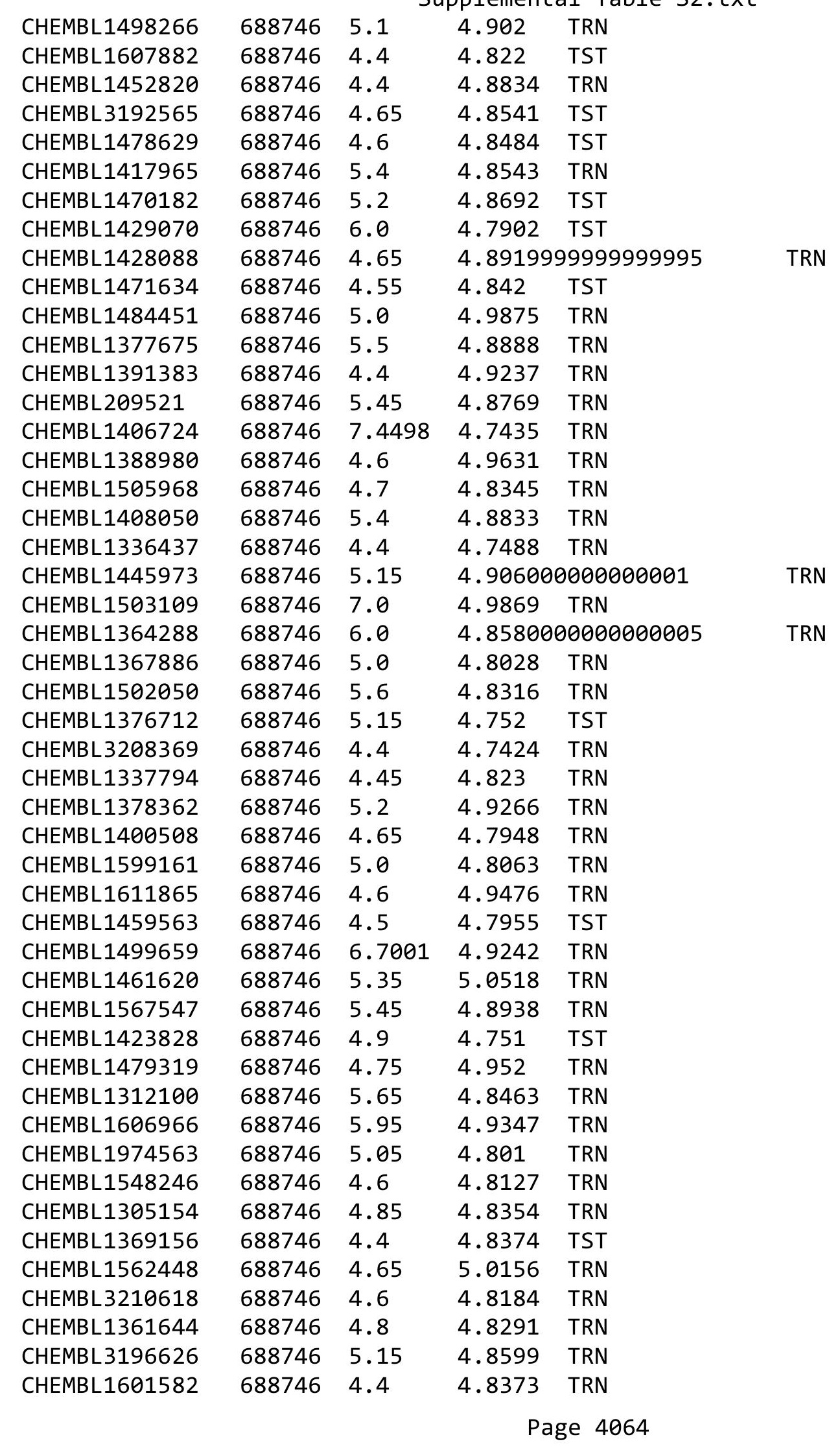




\begin{tabular}{|c|c|c|c|c|}
\hline \multicolumn{5}{|c|}{ Supplemental Table } \\
\hline CHEMBL1577618 & 688746 & 4.45 & 4.9181 & TRN \\
\hline CHEMBL1380732 & 688746 & 4.5 & 4.875 & TRN \\
\hline CHEMBL1497301 & 688746 & 4.5 & 4.7526 & TRN \\
\hline CHEMBL1420399 & 688746 & 4.6 & 4.8755 & TRN \\
\hline CHEMBL1393628 & 688746 & 4.5 & 4.8267 & TRN \\
\hline CHEMBL1382702 & 688746 & 5.0 & 4.8661 & TRN \\
\hline CHEMBL1351853 & 688746 & 4.6 & 4.8403 & TRN \\
\hline CHEMBL1420325 & 688746 & 4.85 & 4.8799 & TST \\
\hline CHEMBL1347854 & 688746 & 5.05 & 4.8411 & TRN \\
\hline CHEMBL1431841 & 688746 & 4.45 & 4.8807 & TRN \\
\hline CHEMBL1310280 & 688746 & 4.55 & 4.8382 & TRN \\
\hline CHEMBL3189395 & 688746 & 4.5 & 4.8397 & TRN \\
\hline CHEMBL1376147 & 688746 & 4.6 & 4.838 & TRN \\
\hline CHEMBL1416914 & 688746 & 5.0 & 4.9708 & TRN \\
\hline CHEMBL1342297 & 688746 & 5.5 & 4.9055 & TRN \\
\hline CHEMBL 260311 & 688746 & 4.7 & 4.703 & TRN \\
\hline CHEMBL1572287 & 688746 & 4.75 & 4.9917 & TRN \\
\hline CHEMBL1559336 & 688746 & 6.45 & 4.8487 & TST \\
\hline CHEMBL1608391 & 688746 & 4.85 & 4.8289 & TST \\
\hline CHEMBL1503930 & 688746 & 4.8 & 4.8036 & TRN \\
\hline CHEMBL1416847 & 688746 & 4.55 & 4.7905 & TRN \\
\hline CHEMBL1539059 & 688746 & 4.55 & 4.9016 & TRN \\
\hline CHEMBL1403065 & 688746 & 4.6 & 4.7735 & TRN \\
\hline CHEMBL1421754 & 688746 & 4.6 & 4.8756 & TRN \\
\hline CHEMBL393296 & 688746 & 4.8 & 4.9234 & TRN \\
\hline CHEMBL1496280 & 688746 & 4.55 & 4.8017 & TRN \\
\hline CHEMBL1519022 & 688746 & 4.8 & 4.9115 & TRN \\
\hline CHEMBL1469921 & 688746 & 8.2518 & 4.8227 & TRN \\
\hline CHEMBL1391168 & 688746 & 5.55 & 5.0562 & TRN \\
\hline CHEMBL1561492 & 688746 & 6.15 & 4.9698 & TRN \\
\hline CHEMBL1508326 & 688746 & 5.55 & 4.8608 & TRN \\
\hline CHEMBL1541005 & 688746 & 4.4 & 4.7619 & TRN \\
\hline CHEMBL1458531 & 688746 & 4.45 & 4.8832 & TST \\
\hline CHEMBL1523068 & 688746 & 4.4 & 4.8101 & TRN \\
\hline CHEMBL1367860 & 688746 & 4.9 & 4.8113 & TST \\
\hline CHEMBL1340573 & 688746 & 4.45 & 4.8665 & TST \\
\hline CHEMBL1309228 & 688746 & 4.6 & 4.8566 & TRN \\
\hline CHEMBL1518905 & 688746 & 4.75 & 4.8368 & TST \\
\hline CHEMBL1533940 & 688746 & 5.5 & 4.7946 & TRN \\
\hline CHEMBL 3210064 & 688746 & 4.6 & 4.84 & TST \\
\hline CHEMBL1352217 & 688746 & 4.4 & 4.8892 & TRN \\
\hline CHEMBL1597738 & 688746 & 5.1 & 4.9969 & TRN \\
\hline CHEMBL1604544 & 688746 & 6.4 & 4.9007 & TRN \\
\hline CHEMBL1359029 & 688746 & 4.8 & 4.7914 & TRN \\
\hline CHEMBL1522846 & 688746 & 4.4 & 4.8787 & TST \\
\hline CHEMBL1539166 & 688746 & 5.6 & 4.8343 & TRN \\
\hline CHEMBL1311053 & 688746 & 4.65 & 4.9085 & TST \\
\hline CHEMBL1533950 & 688746 & 4.6 & 4.9847 & TRN \\
\hline
\end{tabular}




\begin{tabular}{|c|c|c|c|c|}
\hline & & & & \\
\hline CHEMBL1506582 & 688746 & 4.4 & 4.8992 & TST \\
\hline CHEMBL1506176 & 688746 & 4.5 & 4.9155 & TRN \\
\hline CHEMBL566068 & 688746 & 4.4 & 4.7796 & TST \\
\hline CHEMBL1462723 & 688746 & 5.4 & 4.8996 & TRN \\
\hline CHEMBL1613469 & 688746 & 4.65 & 4.8915 & TST \\
\hline CHEMBL1610025 & 688746 & 5.45 & 4.8268 & TRN \\
\hline CHEMBL1411373 & 688746 & 4.5 & 4.8916 & TRN \\
\hline CHEMBL1302697 & 688746 & 4.8 & 4.8653 & TRN \\
\hline CHEMBL 3208262 & 688746 & 5.15 & 4.8504 & TRN \\
\hline CHEMBL1499740 & 688746 & 5.05 & 4.902 & TRN \\
\hline CHEMBL3190416 & 688746 & 4.95 & 4.7667 & TRN \\
\hline CHEMBL1413188 & 688746 & 5.5 & 4.8272 & TRN \\
\hline CHEMBL1608303 & 688746 & 4.8 & 4.7718 & TRN \\
\hline CHEMBL1570958 & 688746 & 5.15 & 4.9084 & TRN \\
\hline CHEMBL1418583 & 688746 & 6.1 & 4.9213 & TRN \\
\hline CHEMBL1335855 & 688746 & 4.95 & 4.7721 & TRN \\
\hline CHEMBL1984271 & 688746 & 4.7 & 4.8183 & TST \\
\hline CHEMBL1516017 & 688746 & 6.3 & 4.9833 & TRN \\
\hline CHEMBL1340531 & 688746 & 5.5 & 4.8761 & TRN \\
\hline CHEMBL1584444 & 688746 & 4.65 & 4.7517 & TST \\
\hline CHEMBL1478351 & 688746 & 5.55 & 4.8914 & TRN \\
\hline CHEMBL3195360 & 688746 & 4.85 & 4.8741 & TST \\
\hline CHEMBL1543238 & 688746 & 4.85 & 4.7324 & TRN \\
\hline CHEMBL1375672 & 688746 & 4.6 & 4.8257 & TRN \\
\hline CHEMBL3145329 & 688746 & 4.65 & 4.8372 & TRN \\
\hline CHEMBL1346913 & 688746 & 4.9 & 4.8594 & TRN \\
\hline CHEMBL1313977 & 688746 & 4.7 & 4.8694 & TRN \\
\hline CHEMBL1391803 & 688746 & 4.45 & 4.9043 & TST \\
\hline CHEMBL1341762 & 688746 & 4.9 & 4.9142 & TRN \\
\hline CHEMBL1538098 & 688746 & 5.6 & 5.0221 & TRN \\
\hline CHEMBL1376200 & 688746 & 7.0 & 4.7951 & TRN \\
\hline CHEMBL1478124 & 688746 & 5.25 & 4.9011 & TRN \\
\hline CHEMBL1318815 & 688746 & 4.5 & 4.9033 & TRN \\
\hline CHEMBL589101 & 688746 & 4.85 & 4.885 & TRN \\
\hline CHEMBL1428884 & 688746 & 4.9 & 4.9048 & TRN \\
\hline CHEMBL1577640 & 688746 & 4.8 & 4.8577 & TRN \\
\hline CHEMBL1534118 & 688746 & 4.45 & 4.8604 & TRN \\
\hline CHEMBL1504589 & 688746 & 4.65 & 5.0284 & TRN \\
\hline CHEMBL3191796 & 688746 & 6.05 & 4.9064 & TST \\
\hline CHEMBL1523184 & 688746 & 5.3 & 4.9803 & TRN \\
\hline CHEMBL1466454 & 688746 & 4.8 & 4.9712 & TRN \\
\hline CHEMBL1357104 & 688746 & 4.8 & 5.0058 & TRN \\
\hline CHEMBL1583325 & 688746 & 4.45 & 4.865 & TRN \\
\hline CHEMBL1480330 & 688746 & 5.0 & 4.8036 & TRN \\
\hline CHEMBL1570643 & 688746 & 6.2 & 4.8793 & TRN \\
\hline CHEMBL1419913 & 688746 & 5.15 & 4.8811 & TRN \\
\hline CHEMBL1612433 & 688746 & 4.45 & 4.8608 & TRN \\
\hline CHEMBL1333524 & 688746 & 5.4 & 4.9859 & TRN \\
\hline
\end{tabular}




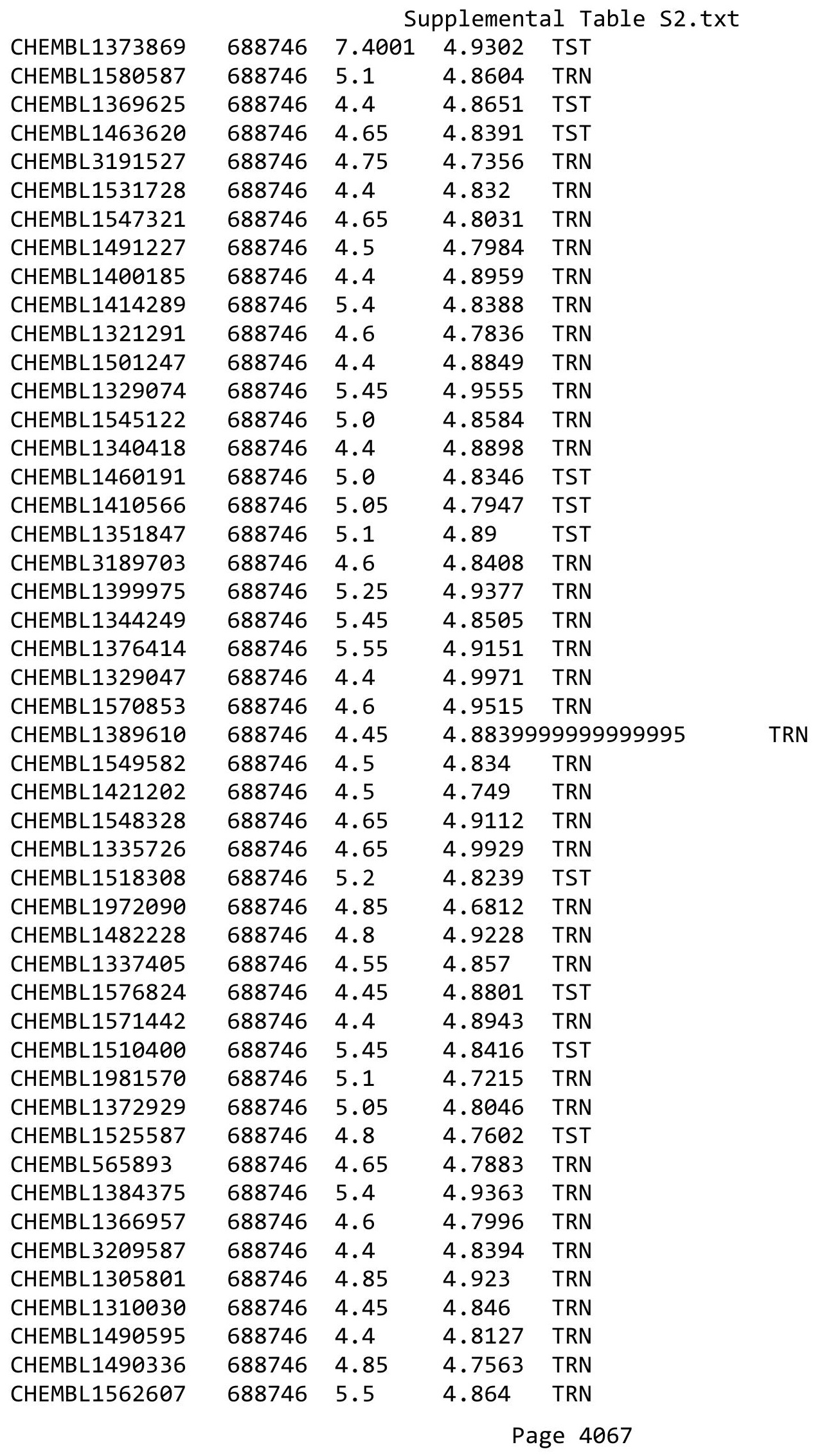




\begin{tabular}{|c|c|c|c|c|c|}
\hline \multicolumn{6}{|c|}{ oplemental Ia } \\
\hline CHEMBL3190678 & 688746 & 4.4 & 4.7534 & TRN & \\
\hline CHEMBL1438466 & 688746 & 5.55 & 4.9995 & TRN & \\
\hline CHEMBL1558913 & 688746 & 6.05 & 4.9078 & TST & \\
\hline CHEMBL1306433 & 688746 & 4.85 & 5.0263 & TRN & \\
\hline CHEMBL1454917 & 688746 & 4.95 & 4.8894 & TRN & \\
\hline CHEMBL1542970 & 688746 & 5.55 & 4.9663 & TRN & \\
\hline CHEMBL1552575 & 688746 & 6.15 & 4.9064 & TRN & \\
\hline CHEMBL1385122 & 688746 & 4.6 & 4.8939 & TRN & \\
\hline CHEMBL1567159 & 688746 & 4.75 & 4.8089 & TRN & \\
\hline CHEMBL1498070 & 688746 & 4.4 & 4.8937 & TRN & \\
\hline CHEMBL1446094 & 688746 & 4.85 & 4.8767 & TRN & \\
\hline CHEMBL1371053 & 688746 & 4.55 & 4.8583 & TRN & \\
\hline CHEMBL1384966 & 688746 & 4.4 & 4.8572 & TRN & \\
\hline CHEMBL1540929 & 688746 & 4.4 & 4.9144 & TRN & \\
\hline CHEMBL1544484 & 688746 & 4.95 & 4.9376 & TST & \\
\hline CHEMBL1388544 & 688746 & 4.55 & 4.813 & TRN & \\
\hline CHEMBL1348969 & 688746 & 5.05 & 4.8229 & TRN & \\
\hline CHEMBL1490429 & 688746 & 5.45 & 4.7616 & TRN & \\
\hline CHEMBL1503795 & 688746 & 4.45 & 4.8928 & TRN & \\
\hline CHEMBL1325882 & 688746 & 4.4 & 4.8656 & TST & \\
\hline CHEMBL1445810 & 688746 & 4.8 & 4.8284 & TRN & \\
\hline CHEMBL1511784 & 688746 & 4.4 & 4.8369 & TRN & \\
\hline CHEMBL1588990 & 688746 & 5.4 & 4.8515 & TRN & \\
\hline CHEMBL1471306 & 688746 & 5.1 & 4.90300 & 00000000005 & TST \\
\hline CHEMBL1506369 & 688746 & 6.0 & 4.9126 & TRN & \\
\hline CHEMBL1359182 & 688746 & 4.8 & 4.8808 & TRN & \\
\hline CHEMBL1380546 & 688746 & 4.5 & 4.817 & TRN & \\
\hline CHEMBL1443516 & 688746 & 4.85 & 4.8412 & TRN & \\
\hline CHEMBL1492631 & 688746 & 5.45 & 4.833 & TRN & \\
\hline CHEMBL1561189 & 688746 & 4.4 & 4.8573 & TRN & \\
\hline CHEMBL1567704 & 688746 & 4.85 & 4.9326 & TRN & \\
\hline CHEMBL1577228 & 688746 & 6.1 & 4.9293 & TRN & \\
\hline CHEMBL1583797 & 688746 & 4.8 & 4.8691 & TRN & \\
\hline CHEMBL473314 & 688746 & 5.15 & 4.8153 & TRN & \\
\hline CHEMBL3199938 & 688746 & 4.55 & 4.7677 & TRN & \\
\hline CHEMBL1558699 & 688746 & 4.4 & 4.8027 & TRN & \\
\hline CHEMBL1556975 & 688746 & 4.7 & 4.80399 & 9999999999 & TST \\
\hline CHEMBL1489786 & 688746 & 4.65 & 4.7729 & TRN & \\
\hline CHEMBL1502878 & 688746 & 5.05 & 4.8829 & TST & \\
\hline CHEMBL1431572 & 688746 & 4.45 & 4.9372 & TRN & \\
\hline CHEMBL1537049 & 688746 & 4.5 & 4.9418 & TST & \\
\hline CHEMBL1329363 & 688746 & 6.4 & 4.9333 & TRN & \\
\hline CHEMBL1492094 & 688746 & 5.2 & 4.9222 & TRN & \\
\hline CHEMBL1455854 & 688746 & 4.55 & 4.8526 & TRN & \\
\hline CHEMBL1466080 & 688746 & 4.45 & 4.8754 & TRN & \\
\hline CHEMBL1404792 & 688746 & 5.5 & 4.8806 & TST & \\
\hline CHEMBL3191375 & 688746 & 5.35 & 4.7091 & TRN & \\
\hline CHEMBL1335290 & 688746 & 4.5 & 4.7788 & TST & \\
\hline
\end{tabular}




\begin{tabular}{|c|c|c|c|c|}
\hline \multicolumn{5}{|c|}{ Supplemental Table } \\
\hline CHEMBL1402056 & 688746 & 4.55 & 4.9217 & TST \\
\hline CHEMBL45152 & 688746 & 4.4 & 4.7901 & TRN \\
\hline CHEMBL1602297 & 688746 & 4.55 & 4.8181 & TRN \\
\hline CHEMBL1455957 & 688746 & 4.45 & 4.8208 & TST \\
\hline CHEMBL3210689 & 688746 & 4.6 & 4.8365 & TST \\
\hline CHEMBL1500343 & 688746 & 4.75 & 4.9839 & TRN \\
\hline CHEMBL1410448 & 688746 & 5.1 & 4.842 & TRN \\
\hline CHEMBL1572440 & 688746 & 4.55 & 4.8725 & TRN \\
\hline CHEMBL1580880 & 688746 & 4.85 & 4.8296 & TRN \\
\hline CHEMBL1519157 & 688746 & 5.65 & 4.9151 & TRN \\
\hline CHEMBL1436306 & 688746 & 4.5 & 4.9533 & TRN \\
\hline CHEMBL 3197525 & 688746 & 5.6 & 4.8922 & TRN \\
\hline CHEMBL1362102 & 688746 & 6.0 & 4.798 & TST \\
\hline CHEMBL1565995 & 688746 & 5.05 & 4.9264 & TRN \\
\hline CHEMBL1403024 & 688746 & 5.25 & 4.7258 & TRN \\
\hline CHEMBL3194093 & 688746 & 5.0 & 4.683 & TRN \\
\hline CHEMBL1515585 & 688746 & 6.15 & 4.9129 & TRN \\
\hline CHEMBL1463212 & 688746 & 4.85 & 4.9321 & TRN \\
\hline CHEMBL1321329 & 688746 & 4.85 & 4.8041 & TST \\
\hline CHEMBL1569585 & 688746 & 4.8 & 4.8697 & TST \\
\hline CHEMBL1566887 & 688746 & 4.6 & 4.8231 & TRN \\
\hline CHEMBL1571435 & 688746 & 6.1 & 4.8226 & TRN \\
\hline CHEMBL1603676 & 688746 & 4.75 & 4.8953 & TRN \\
\hline CHEMBL 3856092 & 688746 & 5.3 & 4.8093 & TST \\
\hline CHEMBL1442810 & 688746 & 4.4 & 4.9029 & TRN \\
\hline CHEMBL1417745 & 688746 & 4.9 & 4.8627 & TRN \\
\hline CHEMBL1559930 & 688746 & 4.9 & 4.9641 & TRN \\
\hline CHEMBL1413585 & 688746 & 5.65 & 4.794 & TRN \\
\hline CHEMBL448490 & 688746 & 4.4 & 4.7983 & TST \\
\hline CHEMBL1399009 & 688746 & 4.55 & 4.9267 & TRN \\
\hline CHEMBL1429669 & 688746 & 4.55 & 4.8918 & TRN \\
\hline CHEMBL1501199 & 688746 & 4.9 & 4.8728 & TRN \\
\hline CHEMBL1380684 & 688746 & 6.0 & 4.8548 & TST \\
\hline CHEMBL1418949 & 688746 & 4.55 & 4.8847 & TRN \\
\hline CHEMBL1363389 & 688746 & 4.8 & 4.8165 & TRN \\
\hline CHEMBL1414312 & 688746 & 4.55 & 4.9948 & TRN \\
\hline CHEMBL1396181 & 688746 & 4.55 & 4.887 & TST \\
\hline CHEMBL1483809 & 688746 & 4.85 & 4.8459 & TST \\
\hline CHEMBL1440346 & 688746 & 4.75 & 4.8983 & TRN \\
\hline CHEMBL1576113 & 688746 & 4.55 & 4.9016 & TRN \\
\hline CHEMBL1340704 & 688746 & 4.55 & 4.7381 & TRN \\
\hline CHEMBL3212361 & 688746 & 4.5 & 4.7654 & TRN \\
\hline CHEMBL1510658 & 688746 & 6.4 & 4.846 & TST \\
\hline CHEMBL1562577 & 688746 & 4.55 & 4.8531 & TRN \\
\hline CHEMBL1469135 & 688746 & 4.55 & 4.8959 & TRN \\
\hline CHEMBL1530789 & 688746 & 4.85 & 4.8445 & TRN \\
\hline CHEMBL1565124 & 688746 & 4.45 & 4.8183 & TRN \\
\hline CHEMBL1431345 & 688746 & 4.85 & 4.8792 & TRN \\
\hline
\end{tabular}




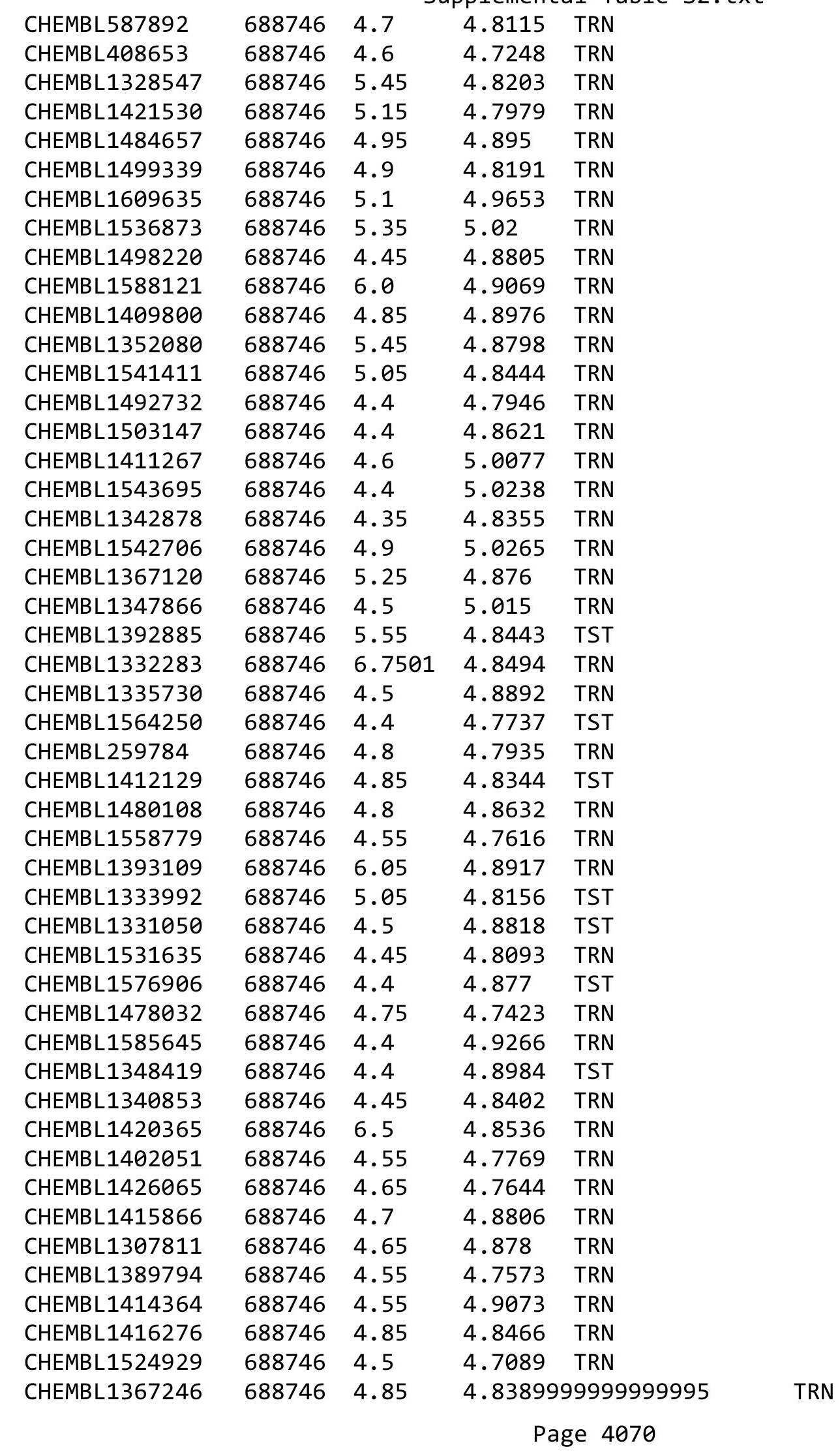




\begin{tabular}{|c|c|c|c|c|}
\hline \multicolumn{5}{|c|}{ plemental T } \\
\hline CHEMBL1556849 & 688746 & 4.4 & 4.8278 & TRN \\
\hline CHEMBL1461530 & 688746 & 5.1 & 4.8553 & TST \\
\hline CHEMBL1495038 & 688746 & 4.95 & 4.9511 & TRN \\
\hline CHEMBL1384172 & 688746 & 4.8 & 4.7024 & TRN \\
\hline CHEMBL1340178 & 688746 & 4.4 & 4.8585 & TRN \\
\hline CHEMBL1533287 & 688746 & 4.4 & 4.8909 & TRN \\
\hline CHEMBL1581261 & 688746 & 5.05 & 4.8083 & TRN \\
\hline CHEMBL201325 & 688746 & 4.85 & 4.727 & TRN \\
\hline CHEMBL3198600 & 688746 & 4.4 & 4.8019 & TST \\
\hline CHEMBL1336295 & 688746 & 4.65 & 4.8514 & TRN \\
\hline CHEMBL1541859 & 688746 & 4.55 & 4.9269 & TRN \\
\hline CHEMBL1598011 & 688746 & 4.8 & 4.7966 & TRN \\
\hline CHEMBL1384113 & 688746 & 5.45 & 4.9258 & TRN \\
\hline CHEMBL1522230 & 688746 & 4.4 & 4.8473 & TRN \\
\hline CHEMBL1557668 & 688746 & 4.7 & 4.8822 & TRN \\
\hline CHEMBL584883 & 688746 & 4.85 & 4.79 & TST \\
\hline CHEMBL1352895 & 688746 & 6.4 & 4.8633 & TRN \\
\hline CHEMBL1380239 & 688746 & 4.8 & 5.0522 & TRN \\
\hline CHEMBL1581173 & 688746 & 4.8 & 4.7976 & TRN \\
\hline CHEMBL1335370 & 688746 & 6.0 & 4.9 & TRN \\
\hline CHEMBL1609703 & 688746 & 5.2 & 4.8039 & TST \\
\hline CHEMBL1501799 & 688746 & 4.6 & 4.8535 & TRN \\
\hline CHEMBL1580274 & 688746 & 5.05 & 4.8606 & TRN \\
\hline CHEMBL1578173 & 688746 & 4.45 & 4.883 & TRN \\
\hline CHEMBL1459912 & 688746 & 4.65 & 4.8551 & TRN \\
\hline CHEMBL1416417 & 688746 & 4.75 & 4.8972 & TST \\
\hline CHEMBL1376704 & 688746 & 5.0 & 4.7971 & TRN \\
\hline CHEMBL1457634 & 688746 & 5.05 & 4.7693 & TRN \\
\hline CHEMBL1567329 & 688746 & 4.6 & 4.9956 & TRN \\
\hline CHEMBL1511083 & 688746 & 4.5 & 4.8551 & TRN \\
\hline CHEMBL1578616 & 688746 & 6.2 & 4.8985 & TST \\
\hline CHEMBL1308902 & 688746 & 4.4 & 4.8325 & TRN \\
\hline CHEMBL594707 & 688746 & 4.6 & 4.7964 & TST \\
\hline CHEMBL1347936 & 688746 & 4.75 & 4.796 & TRN \\
\hline CHEMBL1502092 & 688746 & 5.8 & 4.9455 & TRN \\
\hline CHEMBL1563127 & 688746 & 4.4 & 4.7883 & TRN \\
\hline CHEMBL1464373 & 688746 & 4.85 & 4.8247 & TRN \\
\hline CHEMBL1571713 & 688746 & 4.85 & 4.997 & TRN \\
\hline CHEMBL1560384 & 688746 & 4.7 & 5.0171 & TRN \\
\hline CHEMBL1333718 & 688746 & 5.55 & 4.8694 & TRN \\
\hline CHEMBL1419721 & 688746 & 4.65 & 4.9161 & TRN \\
\hline CHEMBL1562548 & 688746 & 4.75 & 4.8719 & TRN \\
\hline CHEMBL 2171381 & 688746 & 4.75 & 4.7393 & TRN \\
\hline CHEMBL1510477 & 688746 & 5.05 & 4.9371 & TRN \\
\hline CHEMBL1394971 & 688746 & 6.05 & 5.0393 & TRN \\
\hline CHEMBL1450393 & 688746 & 5.45 & 4.8952 & TST \\
\hline CHEMBL1498328 & 688746 & 5.4 & 4.852 & TRN \\
\hline CHEMBL1606600 & 688746 & 6.1 & 4.8554 & TRN \\
\hline
\end{tabular}




\begin{tabular}{|c|c|c|c|c|}
\hline \multicolumn{5}{|c|}{ Supplemental Table S2.txt } \\
\hline CHEMBL1304602 & 688746 & 4.5 & 4.8776 & TST \\
\hline CHEMBL1324328 & 688746 & 4.85 & 4.7927 & TRN \\
\hline CHEMBL1328069 & 688746 & 4.85 & 4.8362 & TRN \\
\hline CHEMBL1426521 & 688746 & 5.35 & 4.9687 & TRN \\
\hline CHEMBL1368593 & 688746 & 4.7 & 4.8801 & TRN \\
\hline CHEMBL1313560 & 688746 & 4.85 & 4.8237 & TST \\
\hline CHEMBL1519576 & 688746 & 4.4 & 4.8377 & TRN \\
\hline CHEMBL1313891 & 688746 & 4.85 & 4.7303 & TRN \\
\hline CHEMBL1384974 & 688746 & 4.45 & 4.8577 & TRN \\
\hline CHEMBL1442202 & 688746 & 4.45 & 4.9438 & TRN \\
\hline CHEMBL1541785 & 688746 & 4.6 & 4.8789 & TRN \\
\hline CHEMBL1363166 & 688746 & 5.3 & 4.7842 & TRN \\
\hline CHEMBL1309436 & 688746 & 4.55 & 4.8444 & TRN \\
\hline CHEMBL1531424 & 688746 & 4.55 & 4.7948 & TRN \\
\hline CHEMBL1401060 & 688746 & 4.4 & 4.7939 & TRN \\
\hline CHEMBL1213862 & 688746 & 4.65 & 4.7619 & TST \\
\hline CHEMBL3198550 & 688746 & 4.7 & 4.7947 & TRN \\
\hline CHEMBL 3145169 & 688746 & 4.45 & 4.7939 & TRN \\
\hline CHEMBL1547184 & 688746 & 5.45 & 4.9303 & TST \\
\hline CHEMBL1368651 & 688746 & 4.45 & 4.8284 & TRN \\
\hline CHEMBL1596228 & 688746 & 5.4 & 4.8407 & TRN \\
\hline CHEMBL1398992 & 688746 & 4.7 & 4.8523 & TRN \\
\hline CHEMBL1319158 & 688746 & 4.7 & 4.8243 & TRN \\
\hline CHEMBL 3210521 & 688746 & 4.45 & 4.823 & TRN \\
\hline CHEMBL1338232 & 688746 & 4.6 & 4.8822 & TRN \\
\hline CHEMBL1404641 & 688746 & 4.4 & 4.9188 & TRN \\
\hline CHEMBL1463453 & 688746 & 6.8 & 4.9215 & TRN \\
\hline CHEMBL1340144 & 688746 & 5.3 & 4.8454 & TRN \\
\hline CHEMBL1598769 & 688746 & 4.85 & 4.7948 & TRN \\
\hline CHEMBL1572154 & 688746 & 6.2 & 4.8732 & TRN \\
\hline CHEMBL1486272 & 688746 & 4.8 & 4.888 & TRN \\
\hline CHEMBL1423466 & 688746 & 4.85 & 4.7862 & TRN \\
\hline CHEMBL1480419 & 688746 & 5.15 & 4.9548 & TRN \\
\hline CHEMBL1375740 & 688746 & 5.05 & 4.72 & TRN \\
\hline CHEMBL1572540 & 688746 & 4.55 & 4.894 & TST \\
\hline CHEMBL1596427 & 688746 & 4.75 & 4.7909 & TRN \\
\hline CHEMBL1538199 & 688746 & 4.6 & 4.916 & TRN \\
\hline CHEMBL1338879 & 688746 & 4.6 & 4.8612 & TRN \\
\hline CHEMBL1989500 & 688746 & 4.95 & 4.7567 & TRN \\
\hline CHEMBL1532822 & 688746 & 6.05 & 4.9068 & TRN \\
\hline CHEMBL1542456 & 688746 & 4.65 & 5.0384 & TRN \\
\hline CHEMBL1594272 & 688746 & 4.65 & 4.9304 & TRN \\
\hline CHEMBL1386409 & 688746 & 4.4 & 4.7908 & TRN \\
\hline CHEMBL1421820 & 688746 & 4.9 & 4.8774 & TRN \\
\hline CHEMBL1483015 & 688746 & 4.75 & 4.8 & TRN \\
\hline CHEMBL1468732 & 688746 & 4.45 & 4.7599 & TRN \\
\hline CHEMBL1335311 & 688746 & 4.4 & 5.0306 & TRN \\
\hline CHEMBL1506926 & 688746 & 4.75 & 4.7137 & TRN \\
\hline
\end{tabular}




\begin{tabular}{|c|c|c|c|c|c|}
\hline \multicolumn{6}{|c|}{ 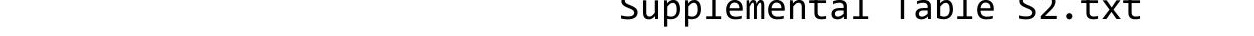 } \\
\hline CHEMBL1565838 & 688746 & 4.95 & 5.0172 & TRN & \\
\hline CHEMBL1603224 & 688746 & 6.45 & 4.7775 & TRN & \\
\hline CHEMBL1347835 & 688746 & 6.05 & 4.7686 & TRN & \\
\hline CHEMBL3213802 & 688746 & 4.9 & 4.9744 & TRN & \\
\hline CHEMBL1342372 & 688746 & 4.95 & 4.9961 & TRN & \\
\hline CHEMBL1500083 & 688746 & 4.4 & 4.8383 & TRN & \\
\hline CHEMBL1460445 & 688746 & 4.8 & 4.8069 & TRN & \\
\hline CHEMBL3192897 & 688746 & 4.8 & 4.8313 & TST & \\
\hline CHEMBL1565717 & 688746 & 6.0 & 4.8618 & TRN & \\
\hline CHEMBL1478052 & 688746 & 4.95 & 4.8769 & TRN & \\
\hline CHEMBL1545353 & 688746 & 4.65 & 4.891 & TRN & \\
\hline CHEMBL383475 & 688746 & 4.6 & 4.8405 & TRN & \\
\hline CHEMBL1377716 & 688746 & 8.2007 & 4.9731 & TRN & \\
\hline CHEMBL1439777 & 688746 & 4.85 & 4.8585 & TRN & \\
\hline CHEMBL1425290 & 688746 & 4.45 & 4.8173 & TRN & \\
\hline CHEMBL1555664 & 688746 & 4.6 & 4.8988 & TRN & \\
\hline CHEMBL1369040 & 688746 & 4.4 & 4.81800 & 00000000005 & TRN \\
\hline CHEMBL1586704 & 688746 & 4.5 & 4.8781 & TRN & \\
\hline CHEMBL1596317 & 688746 & 4.4 & 4.84 & TRN & \\
\hline CHEMBL1606956 & 688746 & 4.6 & 4.768 & TRN & \\
\hline CHEMBL1387390 & 688746 & 5.3 & 4.8453 & TRN & \\
\hline CHEMBL1319488 & 688746 & 5.75 & 4.8994 & TRN & \\
\hline CHEMBL1505478 & 688746 & 5.1 & 4.8663 & TRN & \\
\hline CHEMBL1478589 & 688746 & 5.05 & 4.8491 & TRN & \\
\hline CHEMBL3194427 & 688746 & 5.0 & 4.7419 & TRN & \\
\hline CHEMBL1346477 & 688746 & 4.4 & 4.925 & TRN & \\
\hline CHEMBL1976507 & 688746 & 4.65 & 4.7227 & TRN & \\
\hline CHEMBL1995823 & 688746 & 4.6 & 4.8097 & TRN & \\
\hline CHEMBL1449253 & 688746 & 4.4 & 4.841 & TRN & \\
\hline CHEMBL1521810 & 688746 & 5.55 & 4.9789 & TRN & \\
\hline CHEMBL1555941 & 688746 & 4.4 & 4.9275 & TST & \\
\hline CHEMBL1586936 & 688746 & 5.4 & 4.8439 & TRN & \\
\hline CHEMBL1395526 & 688746 & 5.15 & 4.9117 & TRN & \\
\hline CHEMBL1335571 & 688746 & 4.5 & 4.7313 & TRN & \\
\hline CHEMBL3209405 & 688746 & 7.0 & 4.814 & TST & \\
\hline CHEMBL1329390 & 688746 & 4.5 & 4.979 & TRN & \\
\hline CHEMBL1341981 & 688746 & 4.6 & 4.9098 & TST & \\
\hline CHEMBL1573673 & 688746 & 4.4 & 4.8168 & TRN & \\
\hline CHEMBL3199216 & 688746 & 4.6 & 4.7193 & TRN & \\
\hline CHEMBL1606568 & 688746 & 4.4 & 4.7767 & TRN & \\
\hline CHEMBL1375285 & 688746 & 6.0 & 4.8502 & TRN & \\
\hline CHEMBL1370145 & 688746 & 4.6 & 4.7619 & TRN & \\
\hline CHEMBL1322308 & 688746 & 4.4 & 4.7777 & TRN & \\
\hline CHEMBL1333162 & 688746 & 4.9 & 4.8254 & TRN & \\
\hline CHEMBL1443210 & 688746 & 5.65 & 4.7625 & TRN & \\
\hline CHEMBL1605397 & 688746 & 4.4 & 4.8627 & TRN & \\
\hline CHEMBL1447343 & 688746 & 4.7 & 4.8337 & TRN & \\
\hline CHEMBL 3212373 & 688746 & 4.65 & 4.7801 & TRN & \\
\hline
\end{tabular}




\begin{tabular}{|c|c|c|c|c|c|}
\hline & & \multicolumn{4}{|c|}{ Supplemental Table S2.txt } \\
\hline CHEMBL1362013 & 688746 & 4.85 & 4.7531 & TRN & \\
\hline CHEMBL1409648 & 688746 & 4.85 & 4.9217 & TRN & \\
\hline CHEMBL1448216 & 688746 & 4.55 & 4.8746 & TST & \\
\hline CHEMBL512048 & 688746 & 4.9 & 4.7128 & TRN & \\
\hline CHEMBL1389633 & 688746 & 5.85 & 4.8307 & TRN & \\
\hline CHEMBL1481543 & 688746 & 5.1 & 4.7604 & TRN & \\
\hline CHEMBL1430617 & 688746 & 5.2 & 4.9216 & TRN & \\
\hline CHEMBL1588627 & 688746 & 4.4 & 4.7242 & TRN & \\
\hline CHEMBL1499376 & 688746 & 4.4 & 4.8603 & TRN & \\
\hline CHEMBL1428218 & 688746 & 4.55 & 4.8243 & TRN & \\
\hline CHEMBL1600326 & 688746 & 5.0 & 4.8707 & TST & \\
\hline CHEMBL1610124 & 688746 & 4.65 & 4.8562 & TRN & \\
\hline CHEMBL1366622 & 688746 & 4.5 & 4.8807 & TST & \\
\hline CHEMBL1448181 & 688746 & 4.8 & 4.8263 & TRN & \\
\hline CHEMBL1544730 & 688746 & 4.6 & 4.9682 & TRN & \\
\hline CHEMBL1303738 & 688746 & 4.8 & 4.8925 & TRN & \\
\hline CHEMBL1372555 & 688746 & 5.85 & 4.8831 & TRN & \\
\hline CHEMBL1353443 & 688746 & 4.4 & 4.8188 & TRN & \\
\hline CHEMBL1509287 & 688746 & 4.75 & 4.7768 & TRN & \\
\hline CHEMBL3209768 & 688746 & 4.7 & 4.8532 & TST & \\
\hline CHEMBL1398981 & 688746 & 4.9 & 4.9486 & TRN & \\
\hline CHEMBL1432901 & 688746 & 4.55 & 4.8536 & TRN & \\
\hline CHEMBL1534723 & 688746 & 4.55 & 4.9213 & TRN & \\
\hline CHEMBL1410545 & 688746 & 4.45 & 4.9493 & TRN & \\
\hline CHEMBL1966984 & 688746 & 5.35 & 4.841 & TRN & \\
\hline CHEMBL1310529 & 688746 & 4.6 & 4.9594 & TRN & \\
\hline CHEMBL 3210268 & 688746 & 4.8 & 4.8672 & TST & \\
\hline CHEMBL1482310 & 688746 & 5.05 & 4.9136 & TRN & \\
\hline CHEMBL1489717 & 688746 & 4.6 & 4.8854 & TRN & \\
\hline CHEMBL1441086 & 688746 & 4.65 & 4.9268 & TRN & \\
\hline CHEMBL3196335 & 688746 & 4.6 & 4.71899 & 9999999999 & TRN \\
\hline CHEMBL1534789 & 688746 & 4.4 & 4.7713 & TRN & \\
\hline CHEMBL1393847 & 688746 & 4.45 & 4.9193 & TRN & \\
\hline CHEMBL1389916 & 688746 & 5.15 & 5.0097 & TRN & \\
\hline CHEMBL1483246 & 688746 & 5.35 & 4.8804 & TRN & \\
\hline CHEMBL1472138 & 688746 & 5.25 & 4.8399 & TST & \\
\hline CHEMBL1556627 & 688746 & 5.0 & 4.9348 & TRN & \\
\hline CHEMBL3209977 & 688746 & 5.15 & 4.9095 & TRN & \\
\hline CHEMBL1465011 & 688746 & 4.45 & 4.8114 & TRN & \\
\hline CHEMBL1484539 & 688746 & 4.4 & 4.8324 & TST & \\
\hline CHEMBL1493066 & 688746 & 4.7 & 4.7657 & TRN & \\
\hline CHEMBL1526476 & 688746 & 4.45 & 4.7444 & TRN & \\
\hline CHEMBL408850 & 688746 & 4.8 & 4.7519 & TRN & \\
\hline CHEMBL1526645 & 688746 & 4.65 & 4.8526 & TRN & \\
\hline CHEMBL1429951 & 688746 & 4.65 & 4.8604 & TST & \\
\hline CHEMBL1416770 & 688746 & 5.35 & 4.805 & TRN & \\
\hline CHEMBL1429805 & 688746 & 5.45 & 4.7819 & TRN & \\
\hline CHEMBL1505924 & 688746 & 4.95 & 4.878 & TST & \\
\hline
\end{tabular}




\begin{tabular}{|c|c|c|c|c|c|}
\hline \\
\hline CHEMBL1599120 & 688746 & 5.1 & 4.878 & TST & \\
\hline CHEMBL1364777 & 688746 & 5.3 & 4.882 & TST & \\
\hline CHEMBL57978 & 688746 & 4.6 & 4.7225 & TRN & \\
\hline CHEMBL1964843 & 688746 & 4.7 & 4.7173 & TRN & \\
\hline CHEMBL1417859 & 688746 & 4.45 & 4.7589 & TRN & \\
\hline CHEMBL1570845 & 688746 & 5.1 & 4.841 & TRN & \\
\hline CHEMBL3196976 & 688746 & 4.85 & 4.8739 & TRN & \\
\hline CHEMBL1426649 & 688746 & 4.9 & 4.9578 & TRN & \\
\hline CHEMBL1365539 & 688746 & 5.45 & 5.0417 & TRN & \\
\hline CHEMBL1600150 & 688746 & 5.55 & 5.0032 & TRN & \\
\hline CHEMBL1410401 & 688746 & 5.55 & 4.9403 & TRN & \\
\hline CHEMBL3145322 & 688746 & 4.85 & 4.761 & TRN & \\
\hline CHEMBL1485168 & 688746 & 4.55 & 4.8423 & TRN & \\
\hline CHEMBL3191143 & 688746 & 4.6 & 4.8938 & TST & \\
\hline CHEMBL1510979 & 688746 & 4.7 & 4.8525 & TRN & \\
\hline CHEMBL593944 & 688746 & 4.55 & 4.9468 & TRN & \\
\hline CHEMBL1310319 & 688746 & 4.8 & 4.8299 & TST & \\
\hline CHEMBL1400473 & 688746 & 4.4 & 4.785 & TRN & \\
\hline CHEMBL1331600 & 688746 & 4.6 & 4.8421 & TRN & \\
\hline CHEMBL1300753 & 688746 & 4.7 & 4.8307 & TRN & \\
\hline CHEMBL1574851 & 688746 & 4.9 & 4.9012 & TRN & \\
\hline CHEMBL1322905 & 688746 & 4.45 & 4.8702 & TRN & \\
\hline CHEMBL1380740 & 688746 & 4.55 & 4.8577 & TRN & \\
\hline CHEMBL1464370 & 688746 & 6.05 & 4.8722 & TRN & \\
\hline CHEMBL1330951 & 688746 & 5.15 & 4.9214 & TST & \\
\hline CHEMBL1890899 & 688746 & 4.65 & 4.8769 & TRN & \\
\hline CHEMBL1581231 & 688746 & 4.55 & 4.9868 & TRN & \\
\hline CHEMBL1381187 & 688746 & 4.4 & 4.9492 & TRN & \\
\hline CHEMBL1411689 & 688746 & 4.8 & 4.89199 & 99999999995 & TRN \\
\hline CHEMBL1452028 & 688746 & 4.4 & 4.8462 & TRN & \\
\hline CHEMBL1598513 & 688746 & 4.45 & 4.8592 & TRN & \\
\hline CHEMBL1332528 & 688746 & 4.6 & 4.912 & TRN & \\
\hline CHEMBL1518715 & 688746 & 4.55 & 4.8483 & TRN & \\
\hline CHEMBL1971376 & 688746 & 4.6 & 4.8273 & TRN & \\
\hline CHEMBL1300548 & 688746 & 4.8 & 4.8957 & TRN & \\
\hline CHEMBL1365746 & 688746 & 5.2 & 4.8681 & TRN & \\
\hline CHEMBL1325966 & 688746 & 4.7 & 4.8993 & TRN & \\
\hline CHEMBL 1443550 & 688746 & 4.85 & 4.9206 & TRN & \\
\hline CHEMBL1419251 & 688746 & 4.7 & 4.8303 & TRN & \\
\hline CHEMBL1448479 & 688746 & 5.2 & 4.8786 & TST & \\
\hline CHEMBL1326309 & 688746 & 4.8 & 4.9518 & TRN & \\
\hline CHEMBL1532680 & 688746 & 5.35 & 4.8832 & TRN & \\
\hline CHEMBL1411780 & 688746 & 5.9 & 4.8932 & TRN & \\
\hline CHEMBL1302231 & 688746 & 4.7 & 4.8362 & TRN & \\
\hline CHEMBL1556089 & 688746 & 4.7 & 4.822 & TRN & \\
\hline CHEMBL1331416 & 688746 & 4.55 & 4.8346 & TRN & \\
\hline CHEMBL1610118 & 688746 & 5.75 & 4.9222 & TRN & \\
\hline CHEMBL1450240 & 688746 & 4.4 & 4.9897 & TRN & \\
\hline
\end{tabular}




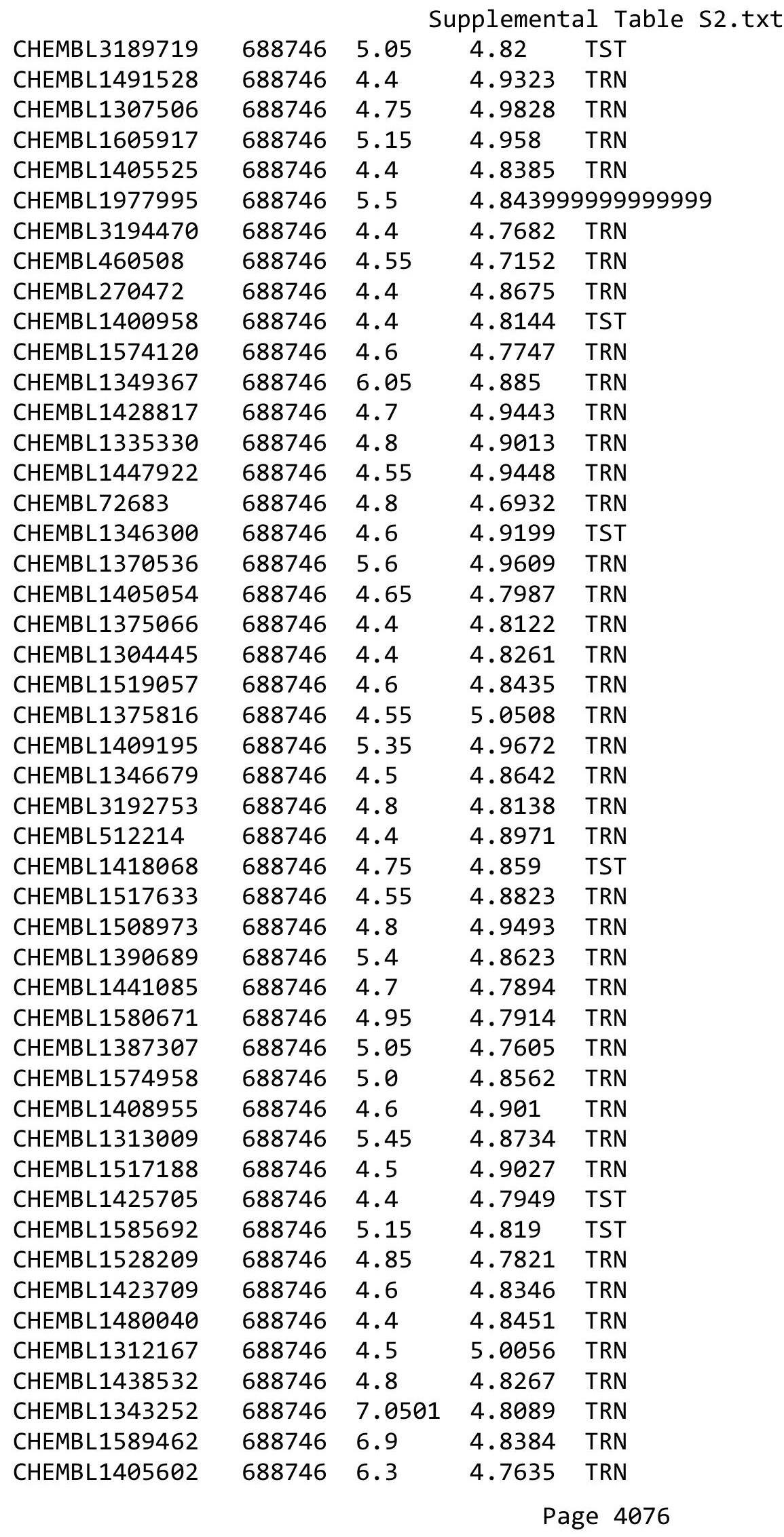




\begin{tabular}{|c|c|c|c|c|c|}
\hline & & \\
\hline CHEMBL1524790 & 688746 & 4.9 & 4.8663 & TRN & \\
\hline CHEMBL1403131 & 688746 & 6.9 & 5.0112 & TRN & \\
\hline CHEMBL1448617 & 688746 & 4.4 & 4.9782 & TRN & \\
\hline CHEMBL1399453 & 688746 & 4.85 & 4.8441 & TRN & \\
\hline CHEMBL1587401 & 688746 & 5.1 & 4.9518 & TST & \\
\hline CHEMBL1994973 & 688746 & 5.15 & 4.7977 & TRN & \\
\hline CHEMBL1569080 & 688746 & 5.0 & 4.987 & TRN & \\
\hline CHEMBL1421009 & 688746 & 6.7001 & 4.8073 & TRN & \\
\hline CHEMBL3214148 & 688746 & 4.55 & 4.7641 & TRN & \\
\hline CHEMBL1585304 & 688746 & 4.85 & 4.9354 & TRN & \\
\hline CHEMBL1577121 & 688746 & 4.55 & 4.8289 & TRN & \\
\hline CHEMBL1438559 & 688746 & 5.85 & 4.8643 & TST & \\
\hline CHEMBL1464352 & 688746 & 4.45 & 4.8055 & TRN & \\
\hline CHEMBL1344731 & 688746 & 4.5 & 4.817 & TRN & \\
\hline CHEMBL1497539 & 688746 & 5.55 & 4.7593 & TRN & \\
\hline CHEMBL1578930 & 688746 & 4.4 & 4.7848 & TRN & \\
\hline CHEMBL1424027 & 688746 & 4.55 & 4.9582 & TST & \\
\hline CHEMBL1369599 & 688746 & 5.4 & 4.9962 & TRN & \\
\hline CHEMBL1383769 & 688746 & 4.65 & 4.9768 & TRN & \\
\hline CHEMBL1499853 & 688746 & 4.95 & 4.8704 & TRN & \\
\hline CHEMBL1964407 & 688746 & 4.85 & 4.863 & TST & \\
\hline CHEMBL1330751 & 688746 & 4.65 & 4.8393 & TRN & \\
\hline CHEMBL1381080 & 688746 & 4.8 & 4.9289 & TRN & \\
\hline CHEMBL1407312 & 688746 & 5.45 & 4.8861 & TST & \\
\hline CHEMBL1464182 & 688746 & 5.45 & 4.8714 & TRN & \\
\hline CHEMBL1563303 & 688746 & 5.5 & 4.9081 & TRN & \\
\hline CHEMBL1387695 & 688746 & 4.5 & 4.9428 & TRN & \\
\hline CHEMBL1369079 & 688746 & 6.95 & 4.8611 & TST & \\
\hline CHEMBL1406315 & 688746 & 4.45 & 4.961 & TRN & \\
\hline CHEMBL1413180 & 688746 & 6.6 & 4.9054 & TST & \\
\hline CHEMBL1531315 & 688746 & 4.75 & 4.8229 & TRN & \\
\hline CHEMBL3197055 & 688746 & 5.1 & 4.8995 & TRN & \\
\hline CHEMBL1449695 & 688746 & 5.35 & 5.0088 & TRN & \\
\hline CHEMBL1430608 & 688746 & 4.65 & 4.7482 & TRN & \\
\hline CHEMBL1322713 & 688746 & 4.45 & 4.8417 & TRN & \\
\hline CHEMBL1540207 & 688746 & 5.25 & 4.79899 & 99999999995 & TRN \\
\hline CHEMBL1585426 & 688746 & 4.4 & 4.7961 & TRN & \\
\hline CHEMBL3207705 & 688746 & 4.6 & 4.9399 & TRN & \\
\hline CHEMBL3211234 & 688746 & 4.4 & 4.8055 & TST & \\
\hline CHEMBL1583482 & 688746 & 4.4 & 4.8325 & TRN & \\
\hline CHEMBL1321021 & 688746 & 4.4 & 4.7961 & TRN & \\
\hline CHEMBL1527751 & 688746 & 4.6 & 4.7518 & TST & \\
\hline CHEMBL1510527 & 688746 & 4.55 & 4.9304 & TRN & \\
\hline CHEMBL1428820 & 688746 & 4.4 & 4.8581 & TRN & \\
\hline CHEMBL3191233 & 688746 & 5.4 & 4.8706 & TRN & \\
\hline CHEMBL1533502 & 688746 & 4.9 & 4.7885 & TRN & \\
\hline CHEMBL1384912 & 688746 & 4.6 & 4.9105 & TRN & \\
\hline CHEMBL1506697 & 688746 & 4.5 & 4.7827 & TRN & \\
\hline & & & & 0 & \\
\hline
\end{tabular}




\begin{tabular}{|c|c|c|c|c|}
\hline \multicolumn{5}{|c|}{ Supplemental Table S2.txt } \\
\hline CHEMBL3198261 & 688746 & 5.2 & 4.8166 & TRN \\
\hline CHEMBL1353591 & 688746 & 4.75 & 4.824 & TRN \\
\hline CHEMBL1607918 & 688746 & 4.8 & 4.8077 & TRN \\
\hline CHEMBL1609697 & 688746 & 4.6 & 4.9125 & TRN \\
\hline CHEMBL1557752 & 688746 & 4.95 & 4.9045 & TRN \\
\hline CHEMBL3199008 & 688746 & 4.75 & 4.783 & TRN \\
\hline CHEMBL1543305 & 688746 & 4.4 & 4.8764 & TRN \\
\hline CHEMBL1556578 & 688746 & 4.7 & 4.9604 & TRN \\
\hline CHEMBL1322637 & 688746 & 4.6 & 4.848 & TRN \\
\hline CHEMBL1563622 & 688746 & 4.65 & 4.9918 & TRN \\
\hline CHEMBL1412308 & 688746 & 4.7 & 4.9515 & TRN \\
\hline CHEMBL1427047 & 688746 & 4.65 & 4.7946 & TRN \\
\hline CHEMBL1365457 & 688746 & 4.5 & 4.8556 & TRN \\
\hline CHEMBL1402596 & 688746 & 4.45 & 4.9074 & TST \\
\hline CHEMBL1346444 & 688746 & 4.6 & 4.9049 & TRN \\
\hline CHEMBL1598843 & 688746 & 4.8 & 4.8479 & TRN \\
\hline CHEMBL379179 & 688746 & 4.9 & 4.7521 & TRN \\
\hline CHEMBL1606160 & 688746 & 5.05 & 4.89 & TRN \\
\hline CHEMBL1604603 & 688746 & 6.8 & 4.8411 & TRN \\
\hline CHEMBL1524034 & 688746 & 4.4 & 4.7806 & TRN \\
\hline CHEMBL1610657 & 688746 & 5.15 & 4.795 & TRN \\
\hline CHEMBL1462847 & 688746 & 4.95 & 4.9407 & TRN \\
\hline CHEMBL1384800 & 688746 & 4.4 & 4.7678 & TRN \\
\hline CHEMBL1528450 & 688746 & 4.95 & 4.8144 & TST \\
\hline CHEMBL1464148 & 688746 & 4.85 & 4.8574 & TRN \\
\hline CHEMBL1528959 & 688746 & 4.6 & 4.9487 & TRN \\
\hline CHEMBL1985333 & 688746 & 4.85 & 4.7599 & TRN \\
\hline CHEMBL1392842 & 688746 & 4.5 & 4.7438 & TRN \\
\hline CHEMBL1354458 & 688746 & 5.15 & 4.925 & TRN \\
\hline CHEMBL1375217 & 688746 & 4.4 & 4.8632 & TRN \\
\hline CHEMBL1540825 & 688746 & 6.15 & 4.9767 & TRN \\
\hline CHEMBL1418340 & 688746 & 5.5 & 4.9948 & TRN \\
\hline CHEMBL1451493 & 688746 & 4.85 & 4.9185 & TRN \\
\hline CHEMBL1437976 & 688746 & 4.65 & 4.7603 & TRN \\
\hline CHEMBL1585000 & 688746 & 4.8 & 4.8793 & TRN \\
\hline CHEMBL1338543 & 688746 & 4.45 & 4.9806 & TRN \\
\hline CHEMBL1580318 & 688746 & 4.45 & 4.7726 & TRN \\
\hline CHEMBL1304507 & 688746 & 4.8 & 4.9956 & TRN \\
\hline CHEMBL1555207 & 688746 & 4.5 & 4.9109 & TST \\
\hline CHEMBL1988883 & 688746 & 4.5 & 4.7763 & TRN \\
\hline CHEMBL145558 & 688746 & 4.75 & 4.8838 & TRN \\
\hline CHEMBL1443090 & 688746 & 6.35 & 4.8901 & TST \\
\hline CHEMBL1448596 & 688746 & 5.3 & 4.9573 & TRN \\
\hline CHEMBL1486877 & 688746 & 4.8 & 4.7689 & TRN \\
\hline CHEMBL1376115 & 688746 & 4.65 & 4.7855 & TST \\
\hline CHEMBL1340713 & 688746 & 4.8 & 4.8291 & TST \\
\hline CHEMBL1492932 & 688746 & 4.55 & 4.8201 & TRN \\
\hline CHEMBL1445153 & 688746 & 4.75 & 4.9531 & TRN \\
\hline
\end{tabular}




\begin{tabular}{|c|c|c|c|c|c|}
\hline \multicolumn{6}{|c|}{ Supplemental Table S2.txt } \\
\hline CHEMBL1327169 & 688746 & 4.75 & 4.7631 & TRN & \\
\hline CHEMBL1320241 & 688746 & 4.6 & 5.0386 & TRN & \\
\hline CHEMBL1557110 & 688746 & 4.85 & 5.0068 & TRN & \\
\hline CHEMBL1393735 & 688746 & 4.65 & 4.8868 & TRN & \\
\hline CHEMBL1483234 & 688746 & 4.4 & 4.8909 & TRN & \\
\hline CHEMBL3208993 & 688746 & 4.5 & 4.82600 & 00000000005 & TRN \\
\hline CHEMBL1389673 & 688746 & 4.8 & 4.8496 & TRN & \\
\hline CHEMBL1507790 & 688746 & 4.6 & 4.9846 & TRN & \\
\hline CHEMBL 3197831 & 688746 & 5.45 & 4.9309 & TRN & \\
\hline CHEMBL 3856088 & 688746 & 5.15 & 4.85 & TST & \\
\hline CHEMBL1499136 & 688746 & 4.65 & 4.8935 & TRN & \\
\hline CHEMBL1547301 & 688746 & 4.55 & 4.8709 & TRN & \\
\hline CHEMBL1480772 & 688746 & 4.45 & 4.8603 & TRN & \\
\hline CHEMBL1404424 & 688746 & 5.15 & 4.8115 & TST & \\
\hline CHEMBL1332725 & 688746 & 4.4 & 4.9151 & TRN & \\
\hline CHEMBL1489390 & 688746 & 4.6 & 4.8755 & TRN & \\
\hline CHEMBL1300561 & 688746 & 4.45 & 4.8869 & TRN & \\
\hline CHEMBL1529634 & 688746 & 4.4 & 4.872 & TRN & \\
\hline CHEMBL1483641 & 688746 & 5.15 & 4.9661 & TST & \\
\hline CHEMBL1982222 & 688746 & 5.65 & 4.8381 & TRN & \\
\hline CHEMBL1391969 & 688746 & 4.4 & 4.8843 & TRN & \\
\hline CHEMBL1414382 & 688746 & 5.1 & 4.9162 & TRN & \\
\hline CHEMBL1408919 & 688746 & 4.6 & 4.7618 & TRN & \\
\hline CHEMBL1600380 & 688746 & 4.95 & 4.7453 & TRN & \\
\hline CHEMBL1556069 & 688746 & 4.65 & 4.917 & TRN & \\
\hline CHEMBL1482416 & 688746 & 4.8 & 4.9513 & TRN & \\
\hline CHEMBL1571906 & 688746 & 4.4 & 4.7548 & TST & \\
\hline CHEMBL1599550 & 688746 & 4.45 & 4.9006 & TRN & \\
\hline CHEMBL1373831 & 688746 & 4.4 & 4.7615 & TRN & \\
\hline CHEMBL1305805 & 688746 & 4.55 & 4.9367 & TRN & \\
\hline CHEMBL1530545 & 688746 & 5.35 & 4.8412 & TRN & \\
\hline CHEMBL1337949 & 688746 & 4.55 & 4.9385 & TRN & \\
\hline CHEMBL1510399 & 688746 & 4.65 & 4.7701 & TRN & \\
\hline CHEMBL1501356 & 688746 & 4.45 & 4.7735 & TRN & \\
\hline CHEMBL1578473 & 688746 & 4.6 & 4.7869 & TST & \\
\hline CHEMBL1361074 & 688746 & 5.5 & 4.8184 & TRN & \\
\hline CHEMBL 3214200 & 688746 & 4.4 & 4.8197 & TRN & \\
\hline CHEMBL1511203 & 688746 & 5.6 & 4.913 & TRN & \\
\hline CHEMBL1303373 & 688746 & 4.7 & 4.8343 & TRN & \\
\hline CHEMBL1611083 & 688746 & 4.5 & 4.879 & TRN & \\
\hline CHEMBL1312400 & 688746 & 4.9 & 5.0164 & TRN & \\
\hline CHEMBL1382864 & 688746 & 4.4 & 4.9134 & TRN & \\
\hline CHEMBL1407374 & 688746 & 4.45 & 4.9214 & TRN & \\
\hline CHEMBL3213292 & 688746 & 4.3 & 4.8041 & TRN & \\
\hline CHEMBL 3195910 & 688746 & 4.55 & 4.7477 & TRN & \\
\hline CHEMBL1379623 & 688746 & 4.95 & 5.0094 & TRN & \\
\hline CHEMBL1373584 & 688746 & 5.45 & 4.7848 & TRN & \\
\hline CHEMBL1500301 & 688746 & 4.4 & 4.8101 & TRN & \\
\hline
\end{tabular}




\begin{tabular}{|c|c|c|c|c|}
\hline \\
\hline CHEMBL1368822 & 688746 & 4.4 & 4.8343 & TRN \\
\hline CHEMBL1309035 & 688746 & 4.95 & 4.8011 & TRN \\
\hline CHEMBL1393072 & 688746 & 7.0501 & 4.8273 & TRN \\
\hline CHEMBL1984804 & 688746 & 4.55 & 4.784 & TRN \\
\hline CHEMBL1441794 & 688746 & 5.1 & 4.8686 & TRN \\
\hline CHEMBL1547533 & 688746 & 4.4 & 4.8643 & TST \\
\hline CHEMBL1533652 & 688746 & 6.7001 & 4.9217 & TRN \\
\hline CHEMBL1479362 & 688746 & 5.3 & 4.8288 & TRN \\
\hline CHEMBL1548229 & 688746 & 4.8 & 4.8643 & TST \\
\hline CHEMBL1450977 & 688746 & 4.8 & 4.9115 & TRN \\
\hline CHEMBL1482425 & 688746 & 4.65 & 4.8662 & TRN \\
\hline CHEMBL1467325 & 688746 & 4.8 & 4.8469 & TRN \\
\hline CHEMBL1346677 & 688746 & 4.8 & 4.8179 & TRN \\
\hline CHEMBL1423169 & 688746 & 4.6 & 5.0081 & TRN \\
\hline CHEMBL1392999 & 688746 & 4.4 & 4.824 & TRN \\
\hline CHEMBL1341684 & 688746 & 4.7 & 4.8925 & TRN \\
\hline CHEMBL1579691 & 688746 & 4.55 & 4.8668 & TRN \\
\hline CHEMBL1447137 & 688746 & 4.6 & 4.8741 & TRN \\
\hline CHEMBL1523603 & 688746 & 5.1 & 4.8314 & TRN \\
\hline CHEMBL1419425 & 688746 & 4.4 & 4.9268 & TRN \\
\hline CHEMBL1550795 & 688746 & 5.15 & 4.8424 & TRN \\
\hline CHEMBL1491047 & 688746 & 4.9 & 4.9619 & TRN \\
\hline CHEMBL1509029 & 688746 & 4.6 & 4.958 & TRN \\
\hline CHEMBL1525789 & 688746 & 4.75 & 4.7803 & TRN \\
\hline CHEMBL1384304 & 688746 & 5.4 & 4.8752 & TRN \\
\hline CHEMBL1348802 & 688746 & 4.4 & 4.8075 & TST \\
\hline CHEMBL1558540 & 688746 & 4.45 & 4.7538 & TRN \\
\hline CHEMBL1589041 & 688746 & 4.4 & 4.8752 & TRN \\
\hline CHEMBL1539535 & 688746 & 4.5 & 4.905 & TRN \\
\hline CHEMBL1499554 & 688746 & 4.4 & 4.9341 & TRN \\
\hline CHEMBL1377036 & 688746 & 4.55 & 4.8355 & TST \\
\hline CHEMBL1443259 & 688746 & 5.65 & 4.9123 & TRN \\
\hline CHEMBL1336077 & 688746 & 4.55 & 4.9552 & TRN \\
\hline CHEMBL1301150 & 688746 & 5.85 & 4.9039 & TRN \\
\hline CHEMBL1566656 & 688746 & 4.4 & 4.803 & TRN \\
\hline CHEMBL1576145 & 688746 & 6.7501 & 4.9662 & TRN \\
\hline CHEMBL1359212 & 688746 & 6.2 & 4.7864 & TRN \\
\hline CHEMBL 1337876 & 688746 & 4.8 & 5.0019 & TRN \\
\hline CHEMBL 2374034 & 688746 & 5.15 & 4.8968 & TST \\
\hline CHEMBL1532981 & 688746 & 4.6 & 4.9418 & TRN \\
\hline CHEMBL1498009 & 688746 & 5.15 & 4.876 & TST \\
\hline CHEMBL1502828 & 688746 & 4.85 & 4.9029 & TST \\
\hline CHEMBL1373347 & 688746 & 4.55 & 4.7949 & TRN \\
\hline CHEMBL1441827 & 688746 & 5.8 & 4.8741 & TRN \\
\hline CHEMBL1449208 & 688746 & 4.6 & 4.8584 & TRN \\
\hline CHEMBL1577118 & 688746 & 4.45 & 4.9433 & TRN \\
\hline CHEMBL 3214275 & 688746 & 8.1024 & 4.7429 & TRN \\
\hline CHEMBL1533268 & 688746 & 6.05 & 4.9485 & TRN \\
\hline
\end{tabular}




\begin{tabular}{|c|c|c|c|c|}
\hline \multicolumn{5}{|c|}{ Supplemental Table } \\
\hline CHEMBL1374795 & 688746 & 4.8 & 4.7854 & TRN \\
\hline CHEMBL1299791 & 688746 & 5.25 & 4.9823 & TRN \\
\hline CHEMBL1504526 & 688746 & 4.6 & 4.8729 & TRN \\
\hline CHEMBL1482063 & 688746 & 6.3 & 4.8222 & TRN \\
\hline CHEMBL1324278 & 688746 & 4.55 & 4.9651 & TRN \\
\hline CHEMBL1440753 & 688746 & 5.0 & 4.8118 & TRN \\
\hline CHEMBL1331981 & 688746 & 6.05 & 5.0104 & TRN \\
\hline CHEMBL1481492 & 688746 & 5.5 & 4.8563 & TST \\
\hline CHEMBL1565157 & 688746 & 5.4 & 5.0564 & TRN \\
\hline CHEMBL1303763 & 688746 & 4.7 & 5.0392 & TRN \\
\hline CHEMBL1461939 & 688746 & 4.65 & 4.8611 & TRN \\
\hline CHEMBL1410592 & 688746 & 5.7 & 4.9071 & TRN \\
\hline CHEMBL1576143 & 688746 & 4.55 & 4.8029 & TRN \\
\hline CHEMBL3197242 & 688746 & 4.85 & 4.8176 & TST \\
\hline CHEMBL3209672 & 688746 & 4.7 & 4.7908 & TRN \\
\hline CHEMBL1359534 & 688746 & 5.2 & 4.8947 & TST \\
\hline CHEMBL1574105 & 688746 & 5.35 & 4.7846 & TRN \\
\hline CHEMBL1420782 & 688746 & 4.4 & 4.9444 & TRN \\
\hline CHEMBL1428274 & 688746 & 4.4 & 4.9157 & TRN \\
\hline CHEMBL602880 & 688746 & 4.75 & 4.8917 & TRN \\
\hline CHEMBL1451410 & 688746 & 4.5 & 5.0655 & TRN \\
\hline CHEMBL1351372 & 688746 & 5.4 & 4.8815 & TST \\
\hline CHEMBL1538069 & 688746 & 4.4 & 4.8165 & TRN \\
\hline CHEMBL193872 & 688746 & 4.85 & 4.8163 & TST \\
\hline CHEMBL1570233 & 688746 & 4.4 & 4.7558 & TRN \\
\hline CHEMBL1309088 & 688746 & 5.1 & 4.8407 & TRN \\
\hline CHEMBL3211204 & 688746 & 4.55 & 4.7593 & TRN \\
\hline CHEMBL1517790 & 688746 & 5.95 & 4.9188 & TRN \\
\hline CHEMBL3193206 & 688746 & 4.4 & 4.9608 & TST \\
\hline CHEMBL1529307 & 688746 & 4.55 & 4.8976 & TRN \\
\hline CHEMBL1484458 & 688746 & 4.4 & 4.9908 & TRN \\
\hline CHEMBL1546959 & 688746 & 5.15 & 5.0328 & TRN \\
\hline CHEMBL1425641 & 688746 & 4.45 & 4.8951 & TST \\
\hline CHEMBL1529946 & 688746 & 4.85 & 4.8009 & TRN \\
\hline CHEMBL1420642 & 688746 & 4.6 & 4.8786 & TST \\
\hline CHEMBL1491855 & 688746 & 5.3 & 4.8215 & TRN \\
\hline CHEMBL1544874 & 688746 & 4.75 & 4.9404 & TRN \\
\hline CHEMBL1611106 & 688746 & 4.5 & 4.7883 & TRN \\
\hline CHEMBL1489025 & 688746 & 4.7 & 4.8855 & TST \\
\hline CHEMBL1584479 & 688746 & 5.35 & 4.8179 & TRN \\
\hline CHEMBL1459767 & 688746 & 4.4 & 4.8763 & TRN \\
\hline CHEMBL3197115 & 688746 & 4.8 & 4.8159 & TST \\
\hline CHEMBL1587260 & 688746 & 4.4 & 4.897 & TRN \\
\hline CHEMBL1599855 & 688746 & 4.8 & 4.9696 & TRN \\
\hline CHEMBL1501859 & 688746 & 4.7 & 4.8261 & TRN \\
\hline CHEMBL1507072 & 688746 & 4.4 & 4.8708 & TRN \\
\hline CHEMBL1464024 & 688746 & 4.95 & 4.9952 & TRN \\
\hline CHEMBL1487834 & 688746 & 5.35 & 4.8503 & TRN \\
\hline
\end{tabular}




\begin{tabular}{|c|c|c|c|c|c|}
\hline \multicolumn{6}{|c|}{ Supplemental Table S2.txt } \\
\hline CHEMBL1389160 & 688746 & 4.4 & 4.8991 & TRN & \\
\hline CHEMBL1417917 & 688746 & 4.85 & 4.7656 & TRN & \\
\hline CHEMBL1369433 & 688746 & 4.55 & 4.7995 & TRN & \\
\hline CHEMBL1495934 & 688746 & 5.05 & 4.8751 & TRN & \\
\hline CHEMBL1459802 & 688746 & 6.95 & 4.9165 & TRN & \\
\hline CHEMBL1468487 & 688746 & 4.45 & 4.8139 & TRN & \\
\hline CHEMBL1597808 & 688746 & 6.3 & 4.8013 & TRN & \\
\hline CHEMBL1331388 & 688746 & 5.25 & 4.9516 & TST & \\
\hline CHEMBL1390591 & 688746 & 4.9 & 4.9824 & TRN & \\
\hline CHEMBL1300767 & 688746 & 4.45 & 4.8513 & TRN & \\
\hline CHEMBL1369296 & 688746 & 4.6 & 4.7498 & TRN & \\
\hline CHEMBL284742 & 688746 & 4.65 & 4.6641 & TRN & \\
\hline CHEMBL3195108 & 688746 & 4.7 & 4.708 & TRN & \\
\hline CHEMBL3190501 & 688746 & 4.9 & 4.9112 & TRN & \\
\hline CHEMBL1542548 & 688746 & 4.5 & 4.9801 & TRN & \\
\hline CHEMBL1301457 & 688746 & 6.1 & 4.9008 & TRN & \\
\hline CHEMBL1611239 & 688746 & 4.45 & 4.8518 & TST & \\
\hline CHEMBL1421182 & 688746 & 4.55 & 4.8175 & TRN & \\
\hline CHEMBL1586047 & 688746 & 5.3 & 4.8526 & TRN & \\
\hline CHEMBL1353266 & 688746 & 4.4 & 4.7978 & TRN & \\
\hline CHEMBL1422691 & 688746 & 4.7 & 4.8758 & TRN & \\
\hline CHEMBL1300312 & 688746 & 4.7 & 4.7645 & TRN & \\
\hline CHEMBL3207890 & 688746 & 4.7 & 4.8391 & TST & \\
\hline CHEMBL1411922 & 688746 & 4.65 & 4.8802 & TRN & \\
\hline CHEMBL1312377 & 688746 & 5.5 & 4.8584 & TRN & \\
\hline CHEMBL1533598 & 688746 & 6.8 & 4.8787 & TRN & \\
\hline CHEMBL1360260 & 688746 & 4.45 & 4.705 & TRN & \\
\hline CHEMBL199925 & 688746 & 5.45 & 4.7316 & TRN & \\
\hline CHEMBL1393209 & 688746 & 4.55 & 4.83899 & 99999999995 & TRN \\
\hline CHEMBL1302148 & 688746 & 4.8 & 4.8408 & TRN & \\
\hline CHEMBL1603269 & 688746 & 4.85 & 4.8806 & TRN & \\
\hline CHEMBL1351903 & 688746 & 4.6 & 4.9258 & TRN & \\
\hline CHEMBL1313735 & 688746 & 4.45 & 4.8401 & TST & \\
\hline CHEMBL1529652 & 688746 & 4.55 & 4.8317 & TRN & \\
\hline CHEMBL1494595 & 688746 & 4.65 & 4.8023 & TST & \\
\hline CHEMBL51085 & 688746 & 5.2 & 4.8094 & TRN & \\
\hline CHEMBL1537273 & 688746 & 4.9 & 4.9894 & TRN & \\
\hline CHEMBL1561801 & 688746 & 4.55 & 4.8781 & TRN & \\
\hline CHEMBL1398944 & 688746 & 4.9 & 4.823 & TRN & \\
\hline CHEMBL1581846 & 688746 & 4.55 & 4.8798 & TRN & \\
\hline CHEMBL1501537 & 688746 & 4.7 & 4.8848 & TRN & \\
\hline CHEMBL1518761 & 688746 & 4.45 & 4.8978 & TRN & \\
\hline CHEMBL1541244 & 688746 & 4.55 & 4.7231 & TRN & \\
\hline CHEMBL1363178 & 688746 & 4.95 & 4.855 & TRN & \\
\hline CHEMBL1546098 & 688746 & 4.4 & 4.8337 & TST & \\
\hline CHEMBL1418809 & 688746 & 4.55 & 4.8247 & TRN & \\
\hline CHEMBL1421552 & 688746 & 4.55 & 4.8763 & TRN & \\
\hline CHEMBL1539744 & 688746 & 4.85 & 4.8808 & TRN & \\
\hline
\end{tabular}




\begin{tabular}{|c|c|c|c|c|}
\hline & & & upplement & $d \perp 1$ \\
\hline CHEMBL1427288 & 688746 & 4.4 & 4.9004 & TRN \\
\hline CHEMBL1504113 & 688746 & 5.4 & 4.9682 & TST \\
\hline CHEMBL1397295 & 688746 & 4.85 & 5.0016 & TRN \\
\hline CHEMBL 3207423 & 688746 & 4.5 & 4.8612 & TRN \\
\hline CHEMBL1982852 & 688746 & 5.15 & 4.8527 & TRN \\
\hline CHEMBL1428934 & 688746 & 5.65 & 4.9346 & TRN \\
\hline CHEMBL3192879 & 688746 & 4.9 & 4.8612 & TRN \\
\hline CHEMBL1531761 & 688746 & 4.5 & 4.9314 & TRN \\
\hline CHEMBL1360928 & 688746 & 4.65 & 4.7601 & TRN \\
\hline CHEMBL1565638 & 688746 & 4.4 & 4.8207 & TRN \\
\hline CHEMBL1455663 & 688746 & 4.65 & 4.8413 & TRN \\
\hline CHEMBL1986443 & 688746 & 4.85 & 4.7554 & TRN \\
\hline CHEMBL1507455 & 688746 & 4.8 & 4.94 & TRN \\
\hline CHEMBL1547751 & 688746 & 4.6 & 4.8535 & TST \\
\hline CHEMBL1425837 & 688746 & 4.95 & 4.9035 & TRN \\
\hline CHEMBL1480498 & 688746 & 4.55 & 4.865 & TRN \\
\hline CHEMBL1524020 & 688746 & 5.05 & 4.7585 & TRN \\
\hline CHEMBL1557911 & 688746 & 6.1 & 5.0453 & TRN \\
\hline CHEMBL1406362 & 688746 & 4.8 & 4.8668 & TRN \\
\hline CHEMBL1489627 & 688746 & 4.4 & 4.7848 & TRN \\
\hline CHEMBL1469265 & 688746 & 4.55 & 4.8283 & TRN \\
\hline CHEMBL1349109 & 688746 & 6.2 & 5.0064 & TRN \\
\hline CHEMBL1525053 & 688746 & 4.55 & 4.8885 & TRN \\
\hline CHEMBL1456349 & 688746 & 5.15 & 4.9414 & TST \\
\hline CHEMBL1429106 & 688746 & 4.45 & 4.7597 & TST \\
\hline CHEMBL3213454 & 688746 & 4.6 & 4.7847 & TRN \\
\hline CHEMBL1574374 & 688746 & 4.75 & 4.7953 & TST \\
\hline CHEMBL1550743 & 688746 & 5.5 & 4.9717 & TRN \\
\hline CHEMBL1462603 & 688746 & 5.7 & 4.7775 & TRN \\
\hline CHEMBL1381627 & 688746 & 4.7 & 4.9062 & TST \\
\hline CHEMBL1335226 & 688746 & 5.0 & 4.8926 & TRN \\
\hline CHEMBL1306204 & 688746 & 5.75 & 4.9099 & TRN \\
\hline CHEMBL1603175 & 688746 & 4.8 & 4.9198 & TRN \\
\hline CHEMBL1467973 & 688746 & 5.0 & 4.9859 & TRN \\
\hline CHEMBL1583697 & 688746 & 5.4 & 4.7951 & TRN \\
\hline CHEMBL1588105 & 688746 & 4.4 & 4.8762 & TRN \\
\hline CHEMBL 1440920 & 688746 & 5.4 & 4.7872 & TRN \\
\hline CHEMBL1576311 & 688746 & 5.45 & 4.9703 & TRN \\
\hline CHEMBL1532306 & 688746 & 4.75 & 5.0197 & TRN \\
\hline CHEMBL1377380 & 688746 & 4.5 & 4.9404 & TRN \\
\hline CHEMBL1483968 & 688746 & 4.7 & 4.9419 & TRN \\
\hline CHEMBL1546250 & 688746 & 4.6 & 4.8712 & TRN \\
\hline CHEMBL3208593 & 688746 & 4.9 & 4.7424 & TRN \\
\hline CHEMBL1585974 & 688746 & 4.4 & 4.7728 & TRN \\
\hline CHEMBL19954 & 688746 & 4.45 & 4.8466 & TRN \\
\hline CHEMBL1586246 & 688746 & 4.55 & 4.7814 & TRN \\
\hline CHEMBL1445957 & 688746 & 5.4 & 4.8528 & TRN \\
\hline CHEMBL1299579 & 688746 & 4.4 & 4.8545 & TRN \\
\hline
\end{tabular}




\begin{tabular}{|c|c|c|c|c|c|}
\hline \multicolumn{6}{|c|}{ Supplemental Table S2.txt } \\
\hline CHEMBL1310508 & 688746 & 5.45 & 4.9542 & TRN & \\
\hline CHEMBL1458268 & 688746 & 4.7 & 4.8398 & TRN & \\
\hline CHEMBL1538515 & 688746 & 4.4 & 4.8088 & TRN & \\
\hline CHEMBL1506843 & 688746 & 4.55 & 4.8653 & TRN & \\
\hline CHEMBL1351374 & 688746 & 5.4 & 4.8835 & TRN & \\
\hline CHEMBL1368166 & 688746 & 4.45 & 4.8934 & TRN & \\
\hline CHEMBL1978830 & 688746 & 4.85 & 4.8616 & TRN & \\
\hline CHEMBL1457990 & 688746 & 4.4 & 4.8962 & TST & \\
\hline CHEMBL1576312 & 688746 & 5.35 & 4.788 & TRN & \\
\hline CHEMBL1391263 & 688746 & 4.85 & 4.882 & TRN & \\
\hline CHEMBL1979957 & 688746 & 4.7 & 4.7938 & TST & \\
\hline CHEMBL1516252 & 688746 & 4.75 & 4.86600 & 00000000005 & TRN \\
\hline CHEMBL1604434 & 688746 & 4.8 & 4.9227 & TRN & \\
\hline CHEMBL1500237 & 688746 & 4.7 & 4.8649 & TRN & \\
\hline CHEMBL1527186 & 688746 & 4.8 & 4.7948 & TRN & \\
\hline CHEMBL1580105 & 688746 & 6.25 & 4.9293 & TRN & \\
\hline CHEMBL1483664 & 688746 & 5.45 & 4.9257 & TRN & \\
\hline CHEMBL1387716 & 688746 & 4.85 & 4.9815 & TRN & \\
\hline CHEMBL 3210177 & 688746 & 4.75 & 4.7796 & TST & \\
\hline CHEMBL1501311 & 688746 & 4.4 & 4.8515 & TST & \\
\hline CHEMBL1457794 & 688746 & 4.75 & 4.9159 & TRN & \\
\hline CHEMBL1608945 & 688746 & 4.55 & 4.9914 & TRN & \\
\hline CHEMBL1424604 & 688746 & 4.9 & 4.9991 & TRN & \\
\hline CHEMBL1600079 & 688746 & 4.45 & 4.8214 & TRN & \\
\hline CHEMBL1415344 & 688746 & 4.5 & 4.7865 & TRN & \\
\hline CHEMBL1345956 & 688746 & 4.55 & 4.8547 & TRN & \\
\hline CHEMBL1312988 & 688746 & 4.65 & 4.8406 & TRN & \\
\hline CHEMBL1538822 & 688746 & 6.6 & 4.8771 & TRN & \\
\hline CHEMBL1608486 & 688746 & 4.6 & 4.7701 & TRN & \\
\hline CHEMBL1334484 & 688746 & 5.25 & 4.7182 & TST & \\
\hline CHEMBL1557806 & 688746 & 4.7 & 4.9384 & TRN & \\
\hline CHEMBL1573754 & 688746 & 4.45 & 4.9043 & TST & \\
\hline CHEMBL1520497 & 688746 & 4.8 & 4.8579 & TRN & \\
\hline CHEMBL1366110 & 688746 & 4.45 & 4.8909 & TST & \\
\hline CHEMBL1584476 & 688746 & 4.9 & 4.8704 & TRN & \\
\hline CHEMBL1447350 & 688746 & 4.7 & 4.8507 & TRN & \\
\hline CHEMBL1573371 & 688746 & 4.75 & 4.9012 & TRN & \\
\hline CHEMBL1508505 & 688746 & 4.85 & 4.8468 & TRN & \\
\hline CHEMBL1428832 & 688746 & 4.5 & 4.999 & TRN & \\
\hline CHEMBL 3198100 & 688746 & 4.95 & 4.8028 & TRN & \\
\hline CHEMBL1406688 & 688746 & 5.5 & 4.8648 & TRN & \\
\hline CHEMBL1384214 & 688746 & 4.55 & 4.8071 & TRN & \\
\hline CHEMBL1350132 & 688746 & 5.1 & 4.854 & TRN & \\
\hline CHEMBL1411168 & 688746 & 5.05 & 4.933 & TRN & \\
\hline CHEMBL1572289 & 688746 & 4.75 & 5.0098 & TRN & \\
\hline CHEMBL1566563 & 688746 & 4.45 & 4.9071 & TRN & \\
\hline CHEMBL1600412 & 688746 & 4.4 & 4.9997 & TRN & \\
\hline CHEMBL1351338 & 688746 & 4.75 & 4.8942 & TRN & \\
\hline
\end{tabular}




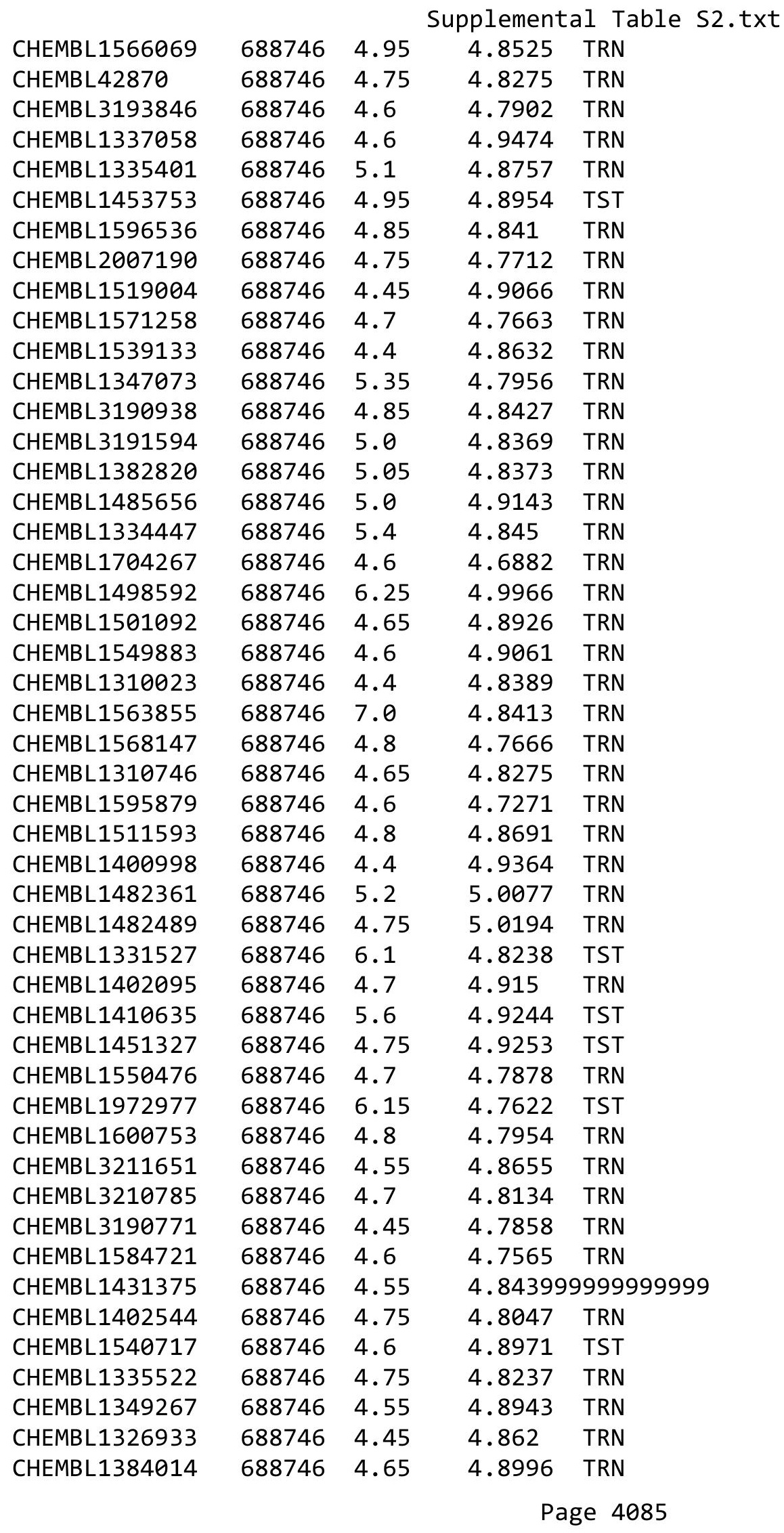

TRN 


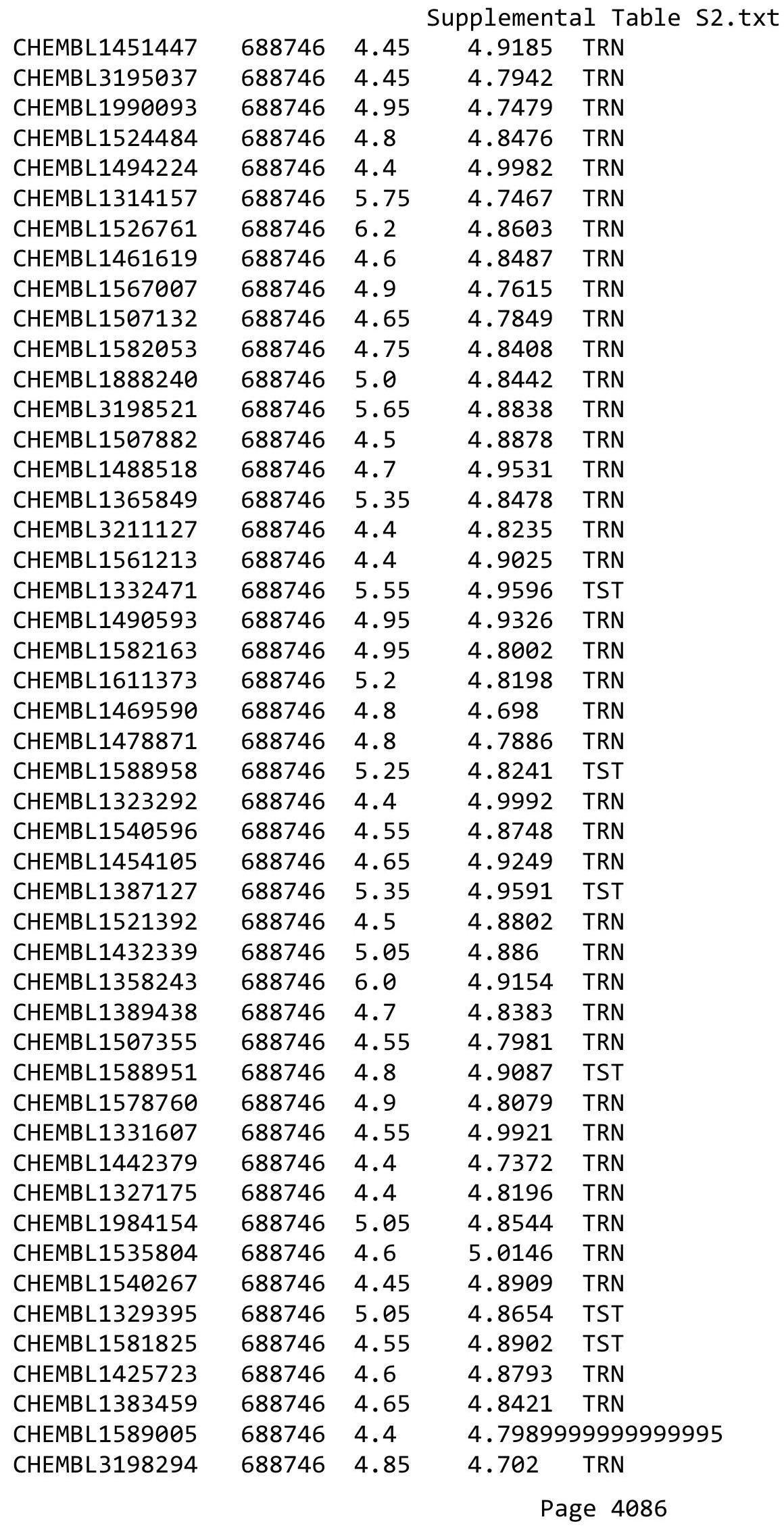

TRN 


\begin{tabular}{|c|c|c|c|c|}
\hline \multicolumn{5}{|c|}{ Supplemental Table S2.txt } \\
\hline CHEMBL1384116 & 688746 & 4.45 & 4.8511 & TRN \\
\hline CHEMBL1320162 & 688746 & 4.4 & 4.8979 & TRN \\
\hline CHEMBL1495992 & 688746 & 4.45 & 4.8641 & TRN \\
\hline CHEMBL1339512 & 688746 & 4.4 & 4.8775 & TRN \\
\hline CHEMBL1532262 & 688746 & 4.45 & 4.8912 & TST \\
\hline CHEMBL1432351 & 688746 & 4.5 & 4.8603 & TRN \\
\hline CHEMBL1573167 & 688746 & 5.1 & 4.8187 & TRN \\
\hline CHEMBL1577952 & 688746 & 5.55 & 4.7765 & TST \\
\hline CHEMBL 3190112 & 688746 & 4.5 & 4.7531 & TRN \\
\hline CHEMBL1499996 & 688746 & 4.5 & 4.9871 & TRN \\
\hline CHEMBL1358802 & 688746 & 4.8 & 4.9191 & TRN \\
\hline CHEMBL1342873 & 688746 & 5.85 & 4.7862 & TRN \\
\hline CHEMBL1558355 & 688746 & 4.6 & 4.8819 & TRN \\
\hline CHEMBL1558080 & 688746 & 4.45 & 4.8372 & TRN \\
\hline CHEMBL1503840 & 688746 & 4.5 & 4.8779 & TST \\
\hline CHEMBL3211753 & 688746 & 4.4 & 4.8516 & TRN \\
\hline CHEMBL1455750 & 688746 & 4.7 & 4.7568 & TRN \\
\hline CHEMBL1586827 & 688746 & 5.15 & 4.9288 & TRN \\
\hline CHEMBL1462469 & 688746 & 4.5 & 4.8731 & TRN \\
\hline CHEMBL3199090 & 688746 & 4.5 & 4.7891 & TRN \\
\hline CHEMBL1412667 & 688746 & 5.45 & 4.8903 & TRN \\
\hline CHEMBL3194954 & 688746 & 5.0 & 4.7681 & TRN \\
\hline CHEMBL 3191282 & 688746 & 4.55 & 4.9276 & TRN \\
\hline CHEMBL1372556 & 688746 & 4.4 & 4.8325 & TRN \\
\hline CHEMBL1488020 & 688746 & 4.85 & 4.806 & TRN \\
\hline CHEMBL1501488 & 688746 & 5.4 & 4.935 & TRN \\
\hline CHEMBL1460926 & 688746 & 4.4 & 4.9597 & TST \\
\hline CHEMBL1599320 & 688746 & 4.5 & 4.8335 & TRN \\
\hline CHEMBL1313965 & 688746 & 4.45 & 4.8265 & TRN \\
\hline CHEMBL 1471242 & 688746 & 4.6 & 5.0025 & TRN \\
\hline CHEMBL1608798 & 688746 & 4.4 & 4.7937 & TRN \\
\hline CHEMBL1595473 & 688746 & 4.9 & 4.8107 & TRN \\
\hline CHEMBL1371377 & 688746 & 4.4 & 4.796 & TRN \\
\hline CHEMBL1327993 & 688746 & 5.55 & 4.901 & TRN \\
\hline CHEMBL1369932 & 688746 & 5.3 & 4.8598 & TST \\
\hline CHEMBL1358266 & 688746 & 4.6 & 4.878 & TST \\
\hline CHEMBL1433028 & 688746 & 4.4 & 4.8091 & TRN \\
\hline CHEMBL3192455 & 688746 & 5.35 & 4.9774 & TRN \\
\hline CHEMBL1346930 & 688746 & 7.4001 & 4.897 & TRN \\
\hline CHEMBL1532453 & 688746 & 5.1 & 4.8092 & TRN \\
\hline CHEMBL1543789 & 688746 & 4.6 & 4.8615 & TST \\
\hline CHEMBL1522443 & 688746 & 5.05 & 4.862 & TRN \\
\hline CHEMBL1487422 & 688746 & 4.4 & 4.9007 & TRN \\
\hline CHEMBL1504747 & 688746 & 4.55 & 4.9239 & TRN \\
\hline CHEMBL1304273 & 688746 & 4.85 & 4.7781 & TST \\
\hline CHEMBL3213419 & 688746 & 4.7 & 4.7898 & TRN \\
\hline CHEMBL1577829 & 688746 & 5.0 & 4.9127 & TST \\
\hline CHEMBL1511194 & 688746 & 4.4 & 4.9473 & TRN \\
\hline
\end{tabular}




\begin{tabular}{|c|c|c|c|c|c|}
\hline \multicolumn{6}{|c|}{ Supplemental Table S2.txt } \\
\hline CHEMBL1348181 & 688746 & 5.75 & 4.779 & TRN & \\
\hline CHEMBL1579853 & 688746 & 4.85 & 4.8606 & TRN & \\
\hline CHEMBL339561 & 688746 & 4.7 & 4.8212 & TRN & \\
\hline CHEMBL1440572 & 688746 & 4.8 & 4.8403 & TRN & \\
\hline CHEMBL398765 & 688746 & 5.25 & 4.7924 & TRN & \\
\hline CHEMBL1387313 & 688746 & 4.45 & 4.8008 & TST & \\
\hline CHEMBL1412664 & 688746 & 5.05 & 4.8258 & TRN & \\
\hline CHEMBL1480601 & 688746 & 4.4 & 4.9736 & TRN & \\
\hline CHEMBL1325917 & 688746 & 4.65 & 4.9127 & TRN & \\
\hline CHEMBL1344976 & 688746 & 4.45 & 4.9073 & TRN & \\
\hline CHEMBL1305224 & 688746 & 5.05 & 5.0148 & TRN & \\
\hline CHEMBL 3210893 & 688746 & 4.4 & 4.8093 & TRN & \\
\hline CHEMBL378679 & 688746 & 5.15 & 4.84399 & 9999999999 & TRN \\
\hline CHEMBL1418459 & 688746 & 5.2 & 4.7389 & TRN & \\
\hline CHEMBL1928491 & 688746 & 5.0 & 4.7462 & TRN & \\
\hline CHEMBL1492897 & 688746 & 4.5 & 4.9565 & TRN & \\
\hline CHEMBL1442040 & 688746 & 4.4 & 4.94 & TRN & \\
\hline CHEMBL1369110 & 688746 & 4.4 & 5.0592 & TRN & \\
\hline CHEMBL1443637 & 688746 & 5.15 & 4.8467 & TRN & \\
\hline CHEMBL 2002465 & 688746 & 5.2 & 4.777 & TRN & \\
\hline CHEMBL 2002140 & 688746 & 4.85 & 4.7731 & TRN & \\
\hline CHEMBL1589334 & 688746 & 4.85 & 4.7487 & TRN & \\
\hline CHEMBL1469451 & 688746 & 5.35 & 4.912 & TRN & \\
\hline CHEMBL1378209 & 688746 & 4.9 & 4.8541 & TRN & \\
\hline CHEMBL1575124 & 688746 & 4.85 & 4.7949 & TRN & \\
\hline CHEMBL1479759 & 688746 & 4.4 & 4.8697 & TST & \\
\hline CHEMBL1532268 & 688746 & 4.4 & 4.8545 & TRN & \\
\hline CHEMBL1313964 & 688746 & 4.9 & 4.9087 & TRN & \\
\hline CHEMBL1580740 & 688746 & 4.6 & 4.8027 & TRN & \\
\hline CHEMBL1344703 & 688746 & 5.25 & 4.7596 & TST & \\
\hline CHEMBL1359384 & 688746 & 6.0 & 4.9228 & TRN & \\
\hline CHEMBL1390996 & 688746 & 4.6 & 4.8676 & TRN & \\
\hline CHEMBL3199145 & 688746 & 5.15 & 4.8738 & TST & \\
\hline CHEMBL1423143 & 688746 & 5.3 & 4.9963 & TRN & \\
\hline CHEMBL1600459 & 688746 & 4.6 & 4.7851 & TRN & \\
\hline CHEMBL1339763 & 688746 & 5.4 & 4.8714 & TRN & \\
\hline CHEMBL1612912 & 688746 & 4.65 & 4.7747 & TRN & \\
\hline CHEMBL1986348 & 688746 & 4.6 & 4.8459 & TRN & \\
\hline CHEMBL1472108 & 688746 & 5.0 & 4.8282 & TRN & \\
\hline CHEMBL1481478 & 688746 & 4.65 & 4.9536 & TRN & \\
\hline CHEMBL1365359 & 688746 & 4.85 & 4.7827 & TRN & \\
\hline CHEMBL1370950 & 688746 & 5.35 & 4.8939 & TRN & \\
\hline CHEMBL395296 & 688746 & 6.5 & 4.7522 & TST & \\
\hline CHEMBL1571776 & 688746 & 4.8 & 4.9296 & TRN & \\
\hline CHEMBL1427053 & 688746 & 4.8 & 4.9908 & TRN & \\
\hline CHEMBL1470847 & 688746 & 4.4 & 4.9959 & TST & \\
\hline CHEMBL1502269 & 688746 & 5.55 & 4.9242 & TST & \\
\hline CHEMBL1423198 & 688746 & 4.7 & 4.79899 & 99999999995 & TST \\
\hline & & & & 4088 & \\
\hline
\end{tabular}




\begin{tabular}{|c|c|c|c|c|}
\hline \multicolumn{5}{|c|}{ Supplemental Table S2.txt } \\
\hline CHEMBL1480310 & 688746 & 4.7 & 4.8096 & TRN \\
\hline CHEMBL1366236 & 688746 & 4.4 & 4.784 & TRN \\
\hline CHEMBL1576687 & 688746 & 4.65 & 4.8571 & TRN \\
\hline CHEMBL1444521 & 688746 & 4.65 & 5.0121 & TRN \\
\hline CHEMBL1345860 & 688746 & 4.55 & 5.0207 & TRN \\
\hline CHEMBL1461962 & 688746 & 5.45 & 4.9153 & TRN \\
\hline CHEMBL1420623 & 688746 & 4.55 & 4.8467 & TRN \\
\hline CHEMBL1366759 & 688746 & 4.4 & 4.9023 & TRN \\
\hline CHEMBL1324792 & 688746 & 5.1 & 4.8398 & TRN \\
\hline CHEMBL305978 & 688746 & 4.6 & 4.672 & TRN \\
\hline CHEMBL1459809 & 688746 & 4.6 & 4.7802 & TRN \\
\hline CHEMBL1338974 & 688746 & 4.4 & 4.8843 & TRN \\
\hline CHEMBL1596938 & 688746 & 4.7 & 4.9863 & TRN \\
\hline CHEMBL1343392 & 688746 & 4.4 & 4.8656 & TRN \\
\hline CHEMBL1391552 & 688746 & 4.4 & 4.7775 & TRN \\
\hline CHEMBL1444240 & 688746 & 4.4 & 4.7608 & TRN \\
\hline CHEMBL1470495 & 688746 & 4.85 & 4.8326 & TRN \\
\hline CHEMBL1493460 & 688746 & 4.45 & 4.9898 & TRN \\
\hline CHEMBL1524968 & 688746 & 4.55 & 4.9757 & TRN \\
\hline CHEMBL1611831 & 688746 & 4.4 & 4.9108 & TRN \\
\hline CHEMBL1324571 & 688746 & 4.65 & 4.8035 & TRN \\
\hline CHEMBL1493791 & 688746 & 4.4 & 4.8591 & TRN \\
\hline CHEMBL1491315 & 688746 & 4.8 & 4.7425 & TRN \\
\hline CHEMBL1381099 & 688746 & 5.5 & 4.7462 & TRN \\
\hline CHEMBL1583967 & 688746 & 6.0 & 4.8395 & TRN \\
\hline CHEMBL1383301 & 688746 & 4.75 & 4.9875 & TRN \\
\hline CHEMBL1418479 & 688746 & 4.4 & 5.0097 & TRN \\
\hline CHEMBL3191022 & 688746 & 5.5 & 4.8455 & TRN \\
\hline CHEMBL376426 & 688746 & 5.2 & 4.7524 & TRN \\
\hline CHEMBL1539905 & 688746 & 5.5 & 4.8364 & TRN \\
\hline CHEMBL1335336 & 688746 & 4.4 & 4.7706 & TRN \\
\hline CHEMBL1498693 & 688746 & 5.4 & 4.9301 & TRN \\
\hline CHEMBL1331952 & 688746 & 5.35 & 4.8937 & TRN \\
\hline CHEMBL1523296 & 688746 & 4.5 & 4.9282 & TRN \\
\hline CHEMBL1399191 & 688746 & 4.6 & 4.9102 & TRN \\
\hline CHEMBL1445681 & 688746 & 4.95 & 4.8844 & TRN \\
\hline CHEMBL1305014 & 688746 & 4.95 & 4.785 & TRN \\
\hline CHEMBL1419929 & 688746 & 4.55 & 4.8862 & TRN \\
\hline CHEMBL1574853 & 688746 & 4.4 & 4.9468 & TST \\
\hline CHEMBL1322212 & 688746 & 5.45 & 4.8476 & TRN \\
\hline CHEMBL1471865 & 688746 & 4.8 & 4.9313 & TRN \\
\hline CHEMBL1471488 & 688746 & 4.85 & 4.9642 & TST \\
\hline CHEMBL1377717 & 688746 & 5.5 & 4.8903 & TRN \\
\hline CHEMBL1359860 & 688746 & 4.45 & 4.8442 & TRN \\
\hline CHEMBL1453291 & 688746 & 4.4 & 4.7073 & TRN \\
\hline CHEMBL1504774 & 688746 & 4.4 & 4.8313 & TST \\
\hline CHEMBL1450354 & 688746 & 4.6 & 4.9307 & TRN \\
\hline CHEMBL1394003 & 688746 & 4.4 & 4.9105 & TRN \\
\hline
\end{tabular}




\begin{tabular}{|c|c|c|c|c|}
\hline \multicolumn{5}{|c|}{ Supplemental Table S2.txt } \\
\hline CHEMBL1411321 & 688746 & 4.85 & 4.9158 & TRN \\
\hline CHEMBL1372272 & 688746 & 5.0 & 4.8312 & TRN \\
\hline CHEMBL1376122 & 688746 & 4.4 & 4.8532 & TRN \\
\hline CHEMBL1429164 & 688746 & 4.75 & 4.8248 & TRN \\
\hline CHEMBL1537858 & 688746 & 5.0 & 4.8464 & TRN \\
\hline CHEMBL1532988 & 688746 & 4.45 & 4.9582 & TRN \\
\hline CHEMBL1545491 & 688746 & 4.45 & 4.9952 & TRN \\
\hline CHEMBL1318802 & 688746 & 5.3 & 4.7843 & TST \\
\hline CHEMBL1470267 & 688746 & 4.85 & 5.0201 & TRN \\
\hline CHEMBL1340110 & 688746 & 4.4 & 5.0552 & TRN \\
\hline CHEMBL1505645 & 688746 & 4.85 & 4.7913 & TRN \\
\hline CHEMBL1576814 & 688746 & 4.5 & 4.7874 & TRN \\
\hline CHEMBL1546215 & 688746 & 4.4 & 4.7829 & TRN \\
\hline CHEMBL1509613 & 688746 & 4.4 & 4.8017 & TRN \\
\hline CHEMBL1343203 & 688746 & 4.5 & 4.8065 & TRN \\
\hline CHEMBL1428462 & 688746 & 4.85 & 4.8644 & TRN \\
\hline CHEMBL1507274 & 688746 & 5.1 & 4.7179 & TRN \\
\hline CHEMBL1478044 & 688746 & 4.4 & 4.9118 & TRN \\
\hline CHEMBL1404559 & 688746 & 4.9 & 4.8653 & TRN \\
\hline CHEMBL1583788 & 688746 & 4.6 & 4.8458 & TRN \\
\hline CHEMBL1458095 & 688746 & 4.45 & 4.9875 & TRN \\
\hline CHEMBL1539226 & 688746 & 5.45 & 4.9641 & TRN \\
\hline CHEMBL 2001904 & 688746 & 5.5 & 4.9064 & TST \\
\hline CHEMBL1427171 & 688746 & 5.05 & 4.893 & TRN \\
\hline CHEMBL1417787 & 688746 & 4.4 & 4.8281 & TST \\
\hline CHEMBL1598199 & 688746 & 5.0 & 5.0523 & TRN \\
\hline CHEMBL1545984 & 688746 & 5.25 & 4.7699 & TRN \\
\hline CHEMBL1405428 & 688746 & 4.85 & 4.8735 & TRN \\
\hline CHEMBL3191911 & 688746 & 4.6 & 4.8684 & TRN \\
\hline CHEMBL1384638 & 688746 & 5.0 & 4.877 & TRN \\
\hline CHEMBL1547769 & 688746 & 4.55 & 4.7493 & TRN \\
\hline CHEMBL1319154 & 688746 & 5.0 & 4.9198 & TRN \\
\hline CHEMBL 3213214 & 688746 & 4.85 & 4.8242 & TST \\
\hline CHEMBL1486214 & 688746 & 4.85 & 4.7732 & TRN \\
\hline CHEMBL1320613 & 688746 & 5.4 & 4.8408 & TRN \\
\hline CHEMBL1403460 & 688746 & 4.8 & 4.8264 & TRN \\
\hline CHEMBL1567872 & 688746 & 4.6 & 4.7696 & TRN \\
\hline CHEMBL1305050 & 688746 & 4.4 & 4.8189 & TRN \\
\hline CHEMBL1482623 & 688746 & 4.95 & 4.9897 & TRN \\
\hline CHEMBL1313200 & 688746 & 4.7 & 4.9117 & TST \\
\hline CHEMBL1589581 & 688746 & 4.4 & 4.8078 & TRN \\
\hline CHEMBL1465995 & 688746 & 4.55 & 4.7863 & TRN \\
\hline CHEMBL1545601 & 688746 & 4.7 & 4.8841 & TRN \\
\hline CHEMBL1369845 & 688746 & 4.65 & 4.8197 & TRN \\
\hline CHEMBL1319113 & 688746 & 4.5 & 4.8295 & TRN \\
\hline CHEMBL1367599 & 688746 & 4.6 & 4.9183 & TRN \\
\hline CHEMBL560919 & 688746 & 4.7 & 4.8102 & TRN \\
\hline CHEMBL1407306 & 688746 & 4.65 & 4.9096 & TRN \\
\hline
\end{tabular}




\begin{tabular}{|c|c|c|c|c|c|}
\hline \\
\hline CHEMBL1326479 & 688746 & 4.4 & 4.7846 & TRN & \\
\hline CHEMBL1466907 & 688746 & 4.65 & 4.9124 & TRN & \\
\hline CHEMBL1587849 & 688746 & 4.85 & 4.7995 & TRN & \\
\hline CHEMBL1595161 & 688746 & 4.6 & 4.7955 & TRN & \\
\hline CHEMBL1310972 & 688746 & 4.65 & 4.7912 & TRN & \\
\hline CHEMBL1312092 & 688746 & 4.6 & 5.0507 & TRN & \\
\hline CHEMBL1385946 & 688746 & 6.15 & 4.8923 & TRN & \\
\hline CHEMBL1404414 & 688746 & 5.0 & 4.7908 & TRN & \\
\hline CHEMBL1563218 & 688746 & 4.45 & 4.7622 & TRN & \\
\hline CHEMBL1568012 & 688746 & 5.75 & 4.8862 & TRN & \\
\hline CHEMBL1429234 & 688746 & 5.45 & 4.8528 & TRN & \\
\hline CHEMBL1324032 & 688746 & 4.85 & 4.8021 & TST & \\
\hline CHEMBL179161 & 688746 & 5.3 & 4.8384 & TRN & \\
\hline CHEMBL1347084 & 688746 & 5.15 & 4.8835 & TRN & \\
\hline CHEMBL1378309 & 688746 & 4.6 & 4.8362 & TST & \\
\hline CHEMBL1338027 & 688746 & 4.75 & 4.8626 & TST & \\
\hline CHEMBL1377248 & 688746 & 5.2 & 4.935 & TST & \\
\hline CHEMBL1269508 & 688746 & 4.4 & 4.7044 & TRN & \\
\hline CHEMBL1506667 & 688746 & 5.6 & 4.8872 & TRN & \\
\hline CHEMBL1422767 & 688746 & 4.6 & 4.9434 & TST & \\
\hline CHEMBL1337387 & 688746 & 6.0 & 4.9034 & TRN & \\
\hline CHEMBL1369699 & 688746 & 4.4 & 4.7827 & TRN & \\
\hline CHEMBL1369177 & 688746 & 4.8 & 4.8017 & TRN & \\
\hline CHEMBL3193885 & 688746 & 4.4 & 4.6927 & TRN & \\
\hline CHEMBL1540570 & 688746 & 4.65 & 4.841 & TST & \\
\hline CHEMBL1431984 & 688746 & 4.75 & 4.9108 & TRN & \\
\hline CHEMBL1534717 & 688746 & 4.55 & 4.8878 & TRN & \\
\hline CHEMBL1468748 & 688746 & 4.4 & 4.9065 & TRN & \\
\hline CHEMBL1486129 & 688746 & 4.9 & 4.84399 & 9999999999 & TRN \\
\hline CHEMBL1335541 & 688746 & 5.15 & 4.7983 & TRN & \\
\hline CHEMBL3197734 & 688746 & 5.4 & 4.8223 & TST & \\
\hline CHEMBL1343960 & 688746 & 4.8 & 4.8283 & TRN & \\
\hline CHEMBL1365977 & 688746 & 4.85 & 4.9209 & TRN & \\
\hline CHEMBL1422851 & 688746 & 4.4 & 4.8807 & TRN & \\
\hline CHEMBL1537287 & 688746 & 5.05 & 4.862 & TRN & \\
\hline CHEMBL1500066 & 688746 & 4.3 & 4.8027 & TRN & \\
\hline CHEMBL1408705 & 688746 & 4.65 & 4.8026 & TRN & \\
\hline CHEMBL1399813 & 688746 & 4.55 & 4.9307 & TST & \\
\hline CHEMBL1428443 & 688746 & 4.95 & 4.8107 & TRN & \\
\hline CHEMBL1570600 & 688746 & 6.25 & 4.8074 & TST & \\
\hline CHEMBL1348245 & 688746 & 5.4 & 4.9504 & TRN & \\
\hline CHEMBL1525935 & 688746 & 5.25 & 4.9537 & TRN & \\
\hline CHEMBL1407267 & 688746 & 4.4 & 4.8369 & TRN & \\
\hline CHEMBL1588910 & 688746 & 5.15 & 4.8433 & TRN & \\
\hline CHEMBL1463199 & 688746 & 4.45 & 4.85800 & 00000000005 & TST \\
\hline CHEMBL1483915 & 688746 & 5.05 & 4.9182 & TRN & \\
\hline CHEMBL3199673 & 688746 & 4.85 & 4.7477 & TRN & \\
\hline CHEMBL1577872 & 688746 & 4.45 & 4.9714 & TRN & \\
\hline
\end{tabular}




\begin{tabular}{|c|c|c|c|c|c|}
\hline \\
\hline CHEMBL1324516 & 688746 & 4.85 & 4.8714 & TRN & \\
\hline CHEMBL1300897 & 688746 & 4.4 & 4.8495 & TRN & \\
\hline CHEMBL1342289 & 688746 & 4.6 & 4.8204 & TRN & \\
\hline CHEMBL1540680 & 688746 & 4.4 & 4.8389 & TRN & \\
\hline CHEMBL1407890 & 688746 & 4.7 & 4.8379 & TRN & \\
\hline CHEMBL1470880 & 688746 & 5.2 & 4.8707 & TST & \\
\hline CHEMBL1456838 & 688746 & 4.4 & 4.98300 & 20000000005 & TRN \\
\hline CHEMBL1561207 & 688746 & 4.55 & 4.9703 & TRN & \\
\hline CHEMBL1500385 & 688746 & 4.45 & 4.9994 & TRN & \\
\hline CHEMBL1541183 & 688746 & 4.7 & 4.71 & TRN & \\
\hline CHEMBL1333831 & 688746 & 4.65 & 4.8398 & TRN & \\
\hline CHEMBL1492811 & 688746 & 4.5 & 4.8985 & TRN & \\
\hline CHEMBL1588436 & 688746 & 4.6 & 4.8361 & TRN & \\
\hline CHEMBL1401915 & 688746 & 6.0 & 5.0062 & TRN & \\
\hline CHEMBL1302750 & 688746 & 4.75 & 4.9288 & TST & \\
\hline CHEMBL1547597 & 688746 & 4.9 & 4.8846 & TST & \\
\hline CHEMBL1335822 & 688746 & 4.75 & 5.0026 & TRN & \\
\hline CHEMBL1468337 & 688746 & 4.5 & 4.8079 & TST & \\
\hline CHEMBL1501824 & 688746 & 4.55 & 4.8674 & TRN & \\
\hline CHEMBL1468152 & 688746 & 4.4 & 4.8513 & TRN & \\
\hline CHEMBL3194554 & 688746 & 4.45 & 4.8535 & TRN & \\
\hline CHEMBL1360618 & 688746 & 5.55 & 4.7357 & TST & \\
\hline CHEMBL1308496 & 688746 & 4.4 & 4.8629 & TST & \\
\hline CHEMBL1576662 & 688746 & 4.75 & 4.9157 & TST & \\
\hline CHEMBL1494130 & 688746 & 5.3 & 4.9004 & TST & \\
\hline CHEMBL1318462 & 688746 & 5.0 & 4.8921 & TRN & \\
\hline CHEMBL1421976 & 688746 & 4.75 & 4.878 & TRN & \\
\hline CHEMBL1324618 & 688746 & 4.8 & 4.6996 & TRN & \\
\hline CHEMBL1495687 & 688746 & 6.25 & 4.9772 & TRN & \\
\hline CHEMBL1503961 & 688746 & 4.55 & 4.8371 & TST & \\
\hline CHEMBL1492553 & 688746 & 4.5 & 4.8349 & TRN & \\
\hline CHEMBL1576679 & 688746 & 4.4 & 4.8716 & TST & \\
\hline CHEMBL1431953 & 688746 & 5.05 & 4.869 & TST & \\
\hline CHEMBL1311954 & 688746 & 5.55 & 4.9154 & TRN & \\
\hline CHEMBL1581989 & 688746 & 4.75 & 4.8532 & TRN & \\
\hline CHEMBL1493646 & 688746 & 4.6 & 4.8619 & TST & \\
\hline CHEMBL1400638 & 688746 & 4.6 & 4.8893 & TST & \\
\hline CHEMBL1504286 & 688746 & 5.5 & 4.9205 & TRN & \\
\hline CHEMBL1993627 & 688746 & 4.6 & 4.7632 & TRN & \\
\hline CHEMBL1598397 & 688746 & 4.9 & 4.7916 & TRN & \\
\hline CHEMBL1330354 & 688746 & 4.75 & 4.9692 & TRN & \\
\hline CHEMBL1380792 & 688746 & 4.4 & 4.7989 & TRN & \\
\hline CHEMBL 1447678 & 688746 & 4.65 & 4.8068 & TRN & \\
\hline CHEMBL1454487 & 688746 & 5.2 & 4.8696 & TST & \\
\hline CHEMBL1427722 & 688746 & 5.8 & 4.8506 & TRN & \\
\hline CHEMBL1583534 & 688746 & 5.85 & 4.8677 & TST & \\
\hline CHEMBL1982520 & 688746 & 4.8 & 4.9265 & TRN & \\
\hline CHEMBL1487489 & 688746 & 4.6 & 4.8544 & TST & \\
\hline
\end{tabular}




\begin{tabular}{|c|c|c|c|c|}
\hline \multicolumn{5}{|c|}{ Supplemental Table } \\
\hline CHEMBL1339662 & 688746 & 4.85 & 4.9834 & TRN \\
\hline CHEMBL1431036 & 688746 & 4.65 & 4.9438 & TRN \\
\hline CHEMBL1521673 & 688746 & 6.7001 & 5.0515 & TRN \\
\hline CHEMBL1508584 & 688746 & 5.4 & 4.7166 & TRN \\
\hline CHEMBL1374050 & 688746 & 6.2 & 4.9724 & TRN \\
\hline CHEMBL1429330 & 688746 & 4.4 & 4.688 & TRN \\
\hline CHEMBL1478043 & 688746 & 5.3 & 4.8784 & TRN \\
\hline CHEMBL1409450 & 688746 & 4.6 & 4.8041 & TRN \\
\hline CHEMBL1329475 & 688746 & 5.15 & 4.8194 & TRN \\
\hline CHEMBL1310850 & 688746 & 4.5 & 4.9164 & TRN \\
\hline CHEMBL1564756 & 688746 & 4.8 & 4.9437 & TRN \\
\hline CHEMBL1492319 & 688746 & 5.05 & 4.8635 & TRN \\
\hline CHEMBL1452978 & 688746 & 4.85 & 4.77 & TRN \\
\hline CHEMBL1324015 & 688746 & 5.1 & 4.797 & TST \\
\hline CHEMBL1301667 & 688746 & 4.4 & 4.8339 & TST \\
\hline CHEMBL1429559 & 688746 & 4.4 & 4.7025 & TST \\
\hline CHEMBL1445585 & 688746 & 5.35 & 4.9489 & TRN \\
\hline CHEMBL1387797 & 688746 & 4.65 & 4.8584 & TRN \\
\hline CHEMBL1303948 & 688746 & 4.95 & 4.8401 & TRN \\
\hline CHEMBL1384567 & 688746 & 4.75 & 4.7797 & TST \\
\hline CHEMBL3196551 & 688746 & 5.2 & 4.7415 & TRN \\
\hline CHEMBL1402510 & 688746 & 4.55 & 4.779 & TRN \\
\hline CHEMBL1541153 & 688746 & 4.8 & 4.9055 & TRN \\
\hline CHEMBL 3235884 & 688746 & 4.45 & 4.8464 & TRN \\
\hline CHEMBL1574220 & 688746 & 4.4 & 4.9623 & TRN \\
\hline CHEMBL3190207 & 688746 & 4.6 & 4.8004 & TRN \\
\hline CHEMBL1540012 & 688746 & 4.4 & 4.7902 & TRN \\
\hline CHEMBL1347979 & 688746 & 4.4 & 4.8318 & TRN \\
\hline CHEMBL1560315 & 688746 & 4.65 & 4.8794 & TRN \\
\hline CHEMBL1421468 & 688746 & 4.75 & 4.8163 & TRN \\
\hline CHEMBL1571107 & 688746 & 4.4 & 4.8687 & TRN \\
\hline CHEMBL1328065 & 688746 & 5.55 & 4.7693 & TRN \\
\hline CHEMBL1444884 & 688746 & 5.05 & 4.8106 & TRN \\
\hline CHEMBL1371795 & 688746 & 5.4 & 4.8437 & TRN \\
\hline CHEMBL1398938 & 688746 & 4.6 & 4.8923 & TRN \\
\hline CHEMBL1336887 & 688746 & 5.1 & 4.7855 & TRN \\
\hline CHEMBL601528 & 688746 & 4.75 & 4.8821 & TRN \\
\hline CHEMBL1343228 & 688746 & 4.9 & 5.0593 & TRN \\
\hline CHEMBL1447901 & 688746 & 4.6 & 4.8706 & TST \\
\hline CHEMBL1506006 & 688746 & 4.95 & 5.0158 & TRN \\
\hline CHEMBL1609070 & 688746 & 4.55 & 4.7821 & TRN \\
\hline CHEMBL1611799 & 688746 & 5.35 & 5.0132 & TRN \\
\hline CHEMBL1607974 & 688746 & 4.4 & 4.7949 & TST \\
\hline CHEMBL1516533 & 688746 & 4.5 & 4.8438 & TRN \\
\hline CHEMBL1544144 & 688746 & 4.55 & 4.8717 & TRN \\
\hline CHEMBL1488923 & 688746 & 4.8 & 4.7959 & TRN \\
\hline CHEMBL1457179 & 688746 & 4.55 & 4.8541 & TRN \\
\hline CHEMBL1449441 & 688746 & 4.4 & 4.9329 & TRN \\
\hline
\end{tabular}




\begin{tabular}{|c|c|c|c|c|}
\hline \multicolumn{5}{|c|}{ plemental T } \\
\hline CHEMBL1383482 & 688746 & 4.6 & 4.801 & TRN \\
\hline CHEMBL1381824 & 688746 & 4.8 & 4.7969 & TRN \\
\hline CHEMBL1332712 & 688746 & 4.4 & 4.9088 & TRN \\
\hline CHEMBL1985932 & 688746 & 4.4 & 4.8606 & TST \\
\hline CHEMBL1303464 & 688746 & 4.8 & 5.0491 & TRN \\
\hline CHEMBL1306132 & 688746 & 4.9 & 4.8158 & TST \\
\hline CHEMBL1413901 & 688746 & 4.6 & 4.7457 & TRN \\
\hline CHEMBL1598791 & 688746 & 4.45 & 4.8472 & TST \\
\hline CHEMBL1417991 & 688746 & 4.85 & 4.8823 & TRN \\
\hline CHEMBL1602793 & 688746 & 5.4 & 4.8485 & TRN \\
\hline CHEMBL1416822 & 688746 & 4.45 & 4.9817 & TRN \\
\hline CHEMBL1369358 & 688746 & 4.6 & 4.7513 & TRN \\
\hline CHEMBL1300047 & 688746 & 4.75 & 4.8738 & TST \\
\hline CHEMBL1345994 & 688746 & 4.55 & 4.8585 & TRN \\
\hline CHEMBL1567210 & 688746 & 4.4 & 4.9379 & TRN \\
\hline CHEMBL1556843 & 688746 & 5.15 & 4.855 & TRN \\
\hline CHEMBL1330336 & 688746 & 4.4 & 4.8879 & TST \\
\hline CHEMBL1547206 & 688746 & 4.65 & 4.8496 & TST \\
\hline CHEMBL1501764 & 688746 & 4.4 & 4.8637 & TST \\
\hline CHEMBL1477044 & 688746 & 4.4 & 4.8295 & TRN \\
\hline CHEMBL1560223 & 688746 & 4.9 & 4.7564 & TRN \\
\hline CHEMBL1303587 & 688746 & 4.55 & 4.7933 & TRN \\
\hline CHEMBL1469463 & 688746 & 4.5 & 4.8203 & TRN \\
\hline CHEMBL1587045 & 688746 & 5.5 & 4.8905 & TRN \\
\hline CHEMBL1444354 & 688746 & 4.65 & 4.9039 & TRN \\
\hline CHEMBL3193188 & 688746 & 4.85 & 4.9353 & TST \\
\hline CHEMBL1384158 & 688746 & 4.45 & 4.7411 & TST \\
\hline CHEMBL1426411 & 688746 & 5.55 & 4.8289 & TRN \\
\hline CHEMBL1577645 & 688746 & 5.25 & 4.8459 & TRN \\
\hline CHEMBL1556953 & 688746 & 4.4 & 4.8077 & TRN \\
\hline CHEMBL1532627 & 688746 & 4.75 & 5.012 & TRN \\
\hline CHEMBL1527768 & 688746 & 4.65 & 4.8312 & TRN \\
\hline CHEMBL1536612 & 688746 & 4.6 & 4.9818 & TST \\
\hline CHEMBL1496184 & 688746 & 4.85 & 4.8939 & TRN \\
\hline CHEMBL1323348 & 688746 & 6.05 & 4.9003 & TRN \\
\hline CHEMBL1613115 & 688746 & 4.45 & 4.9686 & TRN \\
\hline CHEMBL1508182 & 688746 & 4.85 & 4.85 & TST \\
\hline CHEMBL 1438570 & 688746 & 4.4 & 4.8442 & TRN \\
\hline CHEMBL1328634 & 688746 & 4.9 & 4.8832 & TST \\
\hline CHEMBL1494965 & 688746 & 5.9 & 4.8724 & TRN \\
\hline CHEMBL1359902 & 688746 & 5.1 & 4.9687 & TRN \\
\hline CHEMBL1579203 & 688746 & 4.55 & 4.8891 & TRN \\
\hline CHEMBL1445966 & 688746 & 5.15 & 4.8942 & TST \\
\hline CHEMBL1349446 & 688746 & 4.95 & 4.8402 & TRN \\
\hline CHEMBL1388726 & 688746 & 4.7 & 4.8282 & TRN \\
\hline CHEMBL1551361 & 688746 & 5.5 & 4.8973 & TRN \\
\hline CHEMBL1376477 & 688746 & 5.45 & 4.902 & TRN \\
\hline CHEMBL1323985 & 688746 & 4.6 & 4.7599 & TRN \\
\hline
\end{tabular}




\begin{tabular}{|c|c|c|c|c|}
\hline \multicolumn{5}{|c|}{ Supplemental Table S2.txt } \\
\hline CHEMBL1465338 & 688746 & 4.95 & 4.7671 & TRN \\
\hline CHEMBL1422043 & 688746 & 6.25 & 4.9217 & TST \\
\hline CHEMBL1483437 & 688746 & 4.4 & 4.8403 & TRN \\
\hline CHEMBL1300610 & 688746 & 5.4 & 4.7797 & TRN \\
\hline CHEMBL1561507 & 688746 & 4.7 & 4.8568 & TRN \\
\hline CHEMBL 3198740 & 688746 & 4.4 & 4.8237 & TRN \\
\hline CHEMBL1351514 & 688746 & 6.0 & 4.842 & TRN \\
\hline CHEMBL1584920 & 688746 & 4.65 & 4.9531 & TRN \\
\hline CHEMBL1519182 & 688746 & 5.35 & 4.8669 & TRN \\
\hline CHEMBL1321642 & 688746 & 4.5 & 4.8003 & TRN \\
\hline CHEMBL1370870 & 688746 & 4.6 & 4.827 & TRN \\
\hline CHEMBL1598907 & 688746 & 4.4 & 4.7987 & TRN \\
\hline CHEMBL1449995 & 688746 & 5.65 & 4.7532 & TRN \\
\hline CHEMBL1349179 & 688746 & 4.85 & 4.8142 & TRN \\
\hline CHEMBL1372228 & 688746 & 4.85 & 4.9863 & TRN \\
\hline CHEMBL1440713 & 688746 & 4.65 & 4.895 & TRN \\
\hline CHEMBL1505003 & 688746 & 4.7 & 4.8905 & TRN \\
\hline CHEMBL1307360 & 688746 & 4.5 & 4.8526 & TRN \\
\hline CHEMBL1352005 & 688746 & 4.7 & 4.8151 & TRN \\
\hline CHEMBL1409158 & 688746 & 5.0 & 4.9883 & TRN \\
\hline CHEMBL1404458 & 688746 & 4.85 & 4.8273 & TRN \\
\hline CHEMBL1403890 & 688746 & 5.05 & 4.9241 & TRN \\
\hline CHEMBL1526637 & 688746 & 5.15 & 4.7238 & TRN \\
\hline CHEMBL1385659 & 688746 & 4.55 & 4.8424 & TST \\
\hline CHEMBL1383710 & 688746 & 4.4 & 4.8187 & TRN \\
\hline CHEMBL1454761 & 688746 & 4.55 & 4.9023 & TRN \\
\hline CHEMBL1401101 & 688746 & 4.8 & 4.7919 & TRN \\
\hline CHEMBL1411788 & 688746 & 7.3497 & 4.9376 & TST \\
\hline CHEMBL1973156 & 688746 & 5.85 & 4.7527 & TST \\
\hline CHEMBL1334593 & 688746 & 8.1487 & 4.8849 & TRN \\
\hline CHEMBL1322645 & 688746 & 4.55 & 4.8551 & TRN \\
\hline CHEMBL1583295 & 688746 & 4.5 & 4.7091 & TRN \\
\hline CHEMBL1457157 & 688746 & 4.95 & 4.8315 & TRN \\
\hline CHEMBL1596611 & 688746 & 4.4 & 4.7872 & TRN \\
\hline CHEMBL1416391 & 688746 & 6.95 & 4.8404 & TRN \\
\hline CHEMBL1543163 & 688746 & 4.45 & 4.8842 & TST \\
\hline CHEMBL1301383 & 688746 & 7.0 & 4.9279 & TST \\
\hline CHEMBL1304052 & 688746 & 4.7 & 4.8332 & TST \\
\hline CHEMBL1536303 & 688746 & 4.9 & 4.9135 & TRN \\
\hline CHEMBL1490141 & 688746 & 5.2 & 4.9263 & TST \\
\hline CHEMBL1565308 & 688746 & 4.8 & 4.9036 & TRN \\
\hline CHEMBL1555806 & 688746 & 4.55 & 4.8886 & TRN \\
\hline CHEMBL3190951 & 688746 & 4.45 & 4.8489 & TRN \\
\hline CHEMBL1393692 & 688746 & 4.8 & 4.9829 & TRN \\
\hline CHEMBL1466466 & 688746 & 4.5 & 4.829 & TRN \\
\hline CHEMBL1351433 & 688746 & 4.8 & 4.7389 & TRN \\
\hline CHEMBL1324188 & 688746 & 4.9 & 4.8721 & TST \\
\hline CHEMBL1419590 & 688746 & 4.6 & 4.7994 & TRN \\
\hline
\end{tabular}




\begin{tabular}{|c|c|c|c|c|}
\hline \multicolumn{5}{|c|}{ Supplemental Table S2.txt } \\
\hline CHEMBL1367314 & 688746 & 5.05 & 4.8956 & TRN \\
\hline CHEMBL1606486 & 688746 & 4.55 & 4.817 & TRN \\
\hline CHEMBL1560724 & 688746 & 6.5 & 4.9369 & TRN \\
\hline CHEMBL1456422 & 688746 & 4.4 & 4.8984 & TST \\
\hline CHEMBL1472193 & 688746 & 5.4 & 4.9384 & TRN \\
\hline CHEMBL1383322 & 688746 & 4.75 & 4.9095 & TRN \\
\hline CHEMBL1357907 & 688746 & 4.4 & 4.8935 & TRN \\
\hline CHEMBL1427749 & 688746 & 4.75 & 4.9409 & TRN \\
\hline CHEMBL1498834 & 688746 & 4.85 & 4.8237 & TRN \\
\hline CHEMBL1497186 & 688746 & 6.1 & 4.8844 & TRN \\
\hline CHEMBL1463892 & 688746 & 4.4 & 4.8909 & TST \\
\hline CHEMBL3196729 & 688746 & 4.9 & 4.7009 & TRN \\
\hline CHEMBL1442935 & 688746 & 4.8 & 4.8962 & TRN \\
\hline CHEMBL1330005 & 688746 & 4.5 & 4.8196 & TRN \\
\hline CHEMBL1455535 & 688746 & 4.9 & 4.8905 & TRN \\
\hline CHEMBL1595853 & 688746 & 4.4 & 4.8842 & TRN \\
\hline CHEMBL1561809 & 688746 & 5.05 & 4.7402 & TRN \\
\hline CHEMBL1471193 & 688746 & 4.75 & 4.8208 & TRN \\
\hline CHEMBL1540099 & 688746 & 4.8 & 4.8145 & TRN \\
\hline CHEMBL1559001 & 688746 & 5.5 & 4.8263 & TRN \\
\hline CHEMBL1481374 & 688746 & 8.1024 & 4.9152 & TST \\
\hline CHEMBL1992641 & 688746 & 4.55 & 4.8206 & TST \\
\hline CHEMBL1310224 & 688746 & 4.8 & 4.8636 & TRN \\
\hline CHEMBL1497097 & 688746 & 4.4 & 4.9087 & TST \\
\hline CHEMBL 297453 & 688746 & 5.4 & 4.8486 & TST \\
\hline CHEMBL1359006 & 688746 & 4.55 & 4.8224 & TRN \\
\hline CHEMBL3194929 & 688746 & 4.6 & 4.8372 & TRN \\
\hline CHEMBL1373563 & 688746 & 5.15 & 4.8651 & TRN \\
\hline CHEMBL1377664 & 688746 & 5.2 & 4.7867 & TRN \\
\hline CHEMBL1385535 & 688746 & 4.55 & 4.8615 & TRN \\
\hline CHEMBL3194210 & 688746 & 4.95 & 4.8749 & TRN \\
\hline CHEMBL1560714 & 688746 & 5.1 & 4.9915 & TRN \\
\hline CHEMBL1413879 & 688746 & 6.5 & 4.8739 & TST \\
\hline CHEMBL1309510 & 688746 & 5.05 & 4.8254 & TRN \\
\hline CHEMBL1504371 & 688746 & 4.6 & 4.891 & TRN \\
\hline CHEMBL1428256 & 688746 & 4.85 & 4.8644 & TRN \\
\hline CHEMBL1507757 & 688746 & 4.65 & 4.6588 & TRN \\
\hline CHEMBL1366175 & 688746 & 4.9 & 4.8022 & TRN \\
\hline CHEMBL1527083 & 688746 & 4.4 & 4.8479 & TST \\
\hline CHEMBL1457320 & 688746 & 4.4 & 4.8985 & TRN \\
\hline CHEMBL1321058 & 688746 & 4.55 & 4.8729 & TRN \\
\hline CHEMBL3195816 & 688746 & 5.4 & 4.8583 & TRN \\
\hline CHEMBL1458383 & 688746 & 5.0 & 4.8825 & TRN \\
\hline CHEMBL1454772 & 688746 & 5.15 & 4.8142 & TST \\
\hline CHEMBL542493 & 688746 & 4.5 & 4.8476 & TST \\
\hline CHEMBL1531320 & 688746 & 4.95 & 4.7786 & TRN \\
\hline CHEMBL1486092 & 688746 & 4.8 & 4.962 & TRN \\
\hline CHEMBL1506921 & 688746 & 4.45 & 4.8557 & TRN \\
\hline
\end{tabular}




\begin{tabular}{|c|c|c|c|c|}
\hline \\
\hline CHEMBL3145314 & 688746 & 4.8 & 4.8975 & TRN \\
\hline CHEMBL1544352 & 688746 & 4.4 & 4.9004 & TST \\
\hline CHEMBL1448774 & 688746 & 4.5 & 4.7736 & TRN \\
\hline CHEMBL1589490 & 688746 & 4.4 & 4.9324 & TRN \\
\hline CHEMBL1379643 & 688746 & 4.5 & 4.8943 & TRN \\
\hline CHEMBL1499676 & 688746 & 4.55 & 4.9404 & TRN \\
\hline CHEMBL1371396 & 688746 & 4.4 & 4.9077 & TST \\
\hline CHEMBL1306924 & 688746 & 4.45 & 4.9946 & TRN \\
\hline CHEMBL1465400 & 688746 & 5.45 & 4.9023 & TRN \\
\hline CHEMBL1351285 & 688746 & 6.05 & 4.9072 & TRN \\
\hline CHEMBL1431002 & 688746 & 4.6 & 4.9332 & TRN \\
\hline CHEMBL1507028 & 688746 & 4.4 & 4.8288 & TRN \\
\hline CHEMBL1998940 & 688746 & 5.5 & 4.8688 & TRN \\
\hline CHEMBL1361621 & 688746 & 4.5 & 4.8674 & TRN \\
\hline CHEMBL1363581 & 688746 & 4.4 & 4.9062 & TST \\
\hline CHEMBL1443366 & 688746 & 5.15 & 4.9593 & TST \\
\hline CHEMBL1300958 & 688746 & 4.65 & 4.8507 & TRN \\
\hline CHEMBL1302160 & 688746 & 4.7 & 4.848 & TRN \\
\hline CHEMBL1446963 & 688746 & 5.75 & 4.8975 & TRN \\
\hline CHEMBL1543562 & 688746 & 7.0 & 5.0246 & TRN \\
\hline CHEMBL1451755 & 688746 & 4.65 & 4.8413 & TRN \\
\hline CHEMBL1339009 & 688746 & 4.85 & 4.9666 & TRN \\
\hline CHEMBL1518987 & 688746 & 5.15 & 4.8289 & TRN \\
\hline CHEMBL1606718 & 688746 & 4.9 & 4.9849 & TRN \\
\hline CHEMBL1539824 & 688746 & 5.45 & 4.8072 & TRN \\
\hline CHEMBL1548783 & 688746 & 4.5 & 5.0179 & TRN \\
\hline CHEMBL3213151 & 688746 & 4.8 & 4.914 & TRN \\
\hline CHEMBL1581017 & 688746 & 8.2518 & 5.0087 & TRN \\
\hline CHEMBL1318061 & 688746 & 4.45 & 4.9616 & TRN \\
\hline CHEMBL1608430 & 688746 & 5.0 & 4.7805 & TRN \\
\hline CHEMBL1502693 & 688746 & 4.6 & 4.9043 & TRN \\
\hline CHEMBL1457735 & 688746 & 4.55 & 4.8172 & TRN \\
\hline CHEMBL1550108 & 688746 & 4.6 & 4.8772 & TRN \\
\hline CHEMBL1417385 & 688746 & 4.4 & 4.947 & TRN \\
\hline CHEMBL1353259 & 688746 & 4.55 & 4.9192 & TRN \\
\hline CHEMBL1598274 & 688746 & 7.0501 & 5.0165 & TRN \\
\hline CHEMBL1456676 & 688746 & 4.85 & 4.8481 & TST \\
\hline CHEMBL1367222 & 688746 & 4.55 & 4.9609 & TST \\
\hline CHEMBL66966 & 688746 & 6.0 & 4.8205 & TRN \\
\hline CHEMBL1606284 & 688746 & 4.75 & 4.8088 & TRN \\
\hline CHEMBL1388719 & 688746 & 4.6 & 4.9754 & TRN \\
\hline CHEMBL1438064 & 688746 & 4.5 & 4.9455 & TRN \\
\hline CHEMBL1349072 & 688746 & 4.7 & 4.7348 & TRN \\
\hline CHEMBL1471775 & 688746 & 4.8 & 4.8325 & TRN \\
\hline CHEMBL1312852 & 688746 & 4.55 & 4.9608 & TRN \\
\hline CHEMBL1504221 & 688746 & 6.5501 & 4.8857 & TRN \\
\hline CHEMBL1385541 & 688746 & 4.5 & 4.9349 & TRN \\
\hline CHEMBL1567019 & 688746 & 4.85 & 4.7601 & TRN \\
\hline
\end{tabular}




\begin{tabular}{|c|c|c|c|c|c|}
\hline \multicolumn{6}{|c|}{ Supplemental Table s2.txt } \\
\hline CHEMBL1546956 & 688746 & 4.55 & 4.8126 & TRN & \\
\hline CHEMBL 244889 & 688746 & 4.65 & 4.8764 & TRN & \\
\hline CHEMBL1471450 & 688746 & 4.75 & 4.7885 & TRN & \\
\hline CHEMBL1555873 & 688746 & 4.4 & 4.6766 & TRN & \\
\hline CHEMBL1502580 & 688746 & 4.5 & 4.8313 & TRN & \\
\hline CHEMBL1457033 & 688746 & 4.55 & 4.9213 & TRN & \\
\hline CHEMBL1313196 & 688746 & 4.4 & 4.9436 & TST & \\
\hline CHEMBL1585075 & 688746 & 6.6499 & 4.8841 & TRN & \\
\hline CHEMBL1519846 & 688746 & 5.45 & 4.9116 & TRN & \\
\hline CHEMBL1456961 & 688746 & 4.4 & 4.8792 & TRN & \\
\hline CHEMBL1595607 & 688746 & 4.85 & 4.9312 & TRN & \\
\hline CHEMBL1992631 & 688746 & 4.95 & 4.802 & TRN & \\
\hline CHEMBL1536935 & 688746 & 4.45 & 4.8539 & TST & \\
\hline CHEMBL1373360 & 688746 & 5.35 & 4.8014 & TRN & \\
\hline CHEMBL1504792 & 688746 & 4.8 & 4.8891 & TST & \\
\hline CHEMBL1600924 & 688746 & 4.8 & 4.9797 & TRN & \\
\hline CHEMBL1383493 & 688746 & 6.8 & 4.8763 & TST & \\
\hline CHEMBL1507720 & 688746 & 5.2 & 4.8561 & TRN & \\
\hline CHEMBL1481018 & 688746 & 4.4 & 4.8504 & TRN & \\
\hline CHEMBL1380662 & 688746 & 4.85 & 4.7631 & TRN & \\
\hline CHEMBL1516092 & 688746 & 4.4 & 4.8734 & TRN & \\
\hline CHEMBL1368046 & 688746 & 4.6 & 4.9344 & TRN & \\
\hline CHEMBL1565408 & 688746 & 4.6 & 4.8688 & TRN & \\
\hline CHEMBL1213769 & 688746 & 5.45 & 4.8055 & TRN & \\
\hline CHEMBL1583390 & 688746 & 5.45 & 4.8437 & TRN & \\
\hline CHEMBL3192508 & 688746 & 4.8 & 4.9894 & TRN & \\
\hline CHEMBL1978103 & 688746 & 4.6 & 4.7717 & TRN & \\
\hline CHEMBL1521542 & 688746 & 4.85 & 4.9985 & TRN & \\
\hline CHEMBL1411280 & 688746 & 4.45 & 4.846 & TRN & \\
\hline CHEMBL 3199737 & 688746 & 4.7 & 4.7735 & TST & \\
\hline CHEMBL1566375 & 688746 & 6.1 & 4.8762 & TRN & \\
\hline CHEMBL1575130 & 688746 & 4.55 & 4.8158 & TRN & \\
\hline CHEMBL1307093 & 688746 & 5.05 & 4.9094 & TRN & \\
\hline CHEMBL1359537 & 688746 & 4.65 & 4.8239 & TST & \\
\hline CHEMBL1387248 & 688746 & 5.05 & 4.9015 & TST & \\
\hline CHEMBL1450104 & 688746 & 5.15 & 4.8972 & TRN & \\
\hline CHEMBL1540164 & 688746 & 4.6 & 4.8164 & TRN & \\
\hline CHEMBL1439679 & 688746 & 4.85 & 4.78600 & 00000000005 & TRN \\
\hline CHEMBL1594920 & 688746 & 4.55 & 4.817 & TRN & \\
\hline CHEMBL1467560 & 688746 & 5.05 & 4.9117 & TRN & \\
\hline CHEMBL1457597 & 688746 & 5.55 & 4.8637 & TRN & \\
\hline CHEMBL1321179 & 688746 & 4.85 & 4.916 & TRN & \\
\hline CHEMBL1401801 & 688746 & 4.4 & 4.7305 & TRN & \\
\hline CHEMBL1302354 & 688746 & 5.5 & 4.9577 & TRN & \\
\hline CHEMBL1367279 & 688746 & 4.7 & 4.9345 & TRN & \\
\hline CHEMBL1406193 & 688746 & 4.5 & 4.8778 & TRN & \\
\hline CHEMBL125044 & 688746 & 4.8 & 4.8109 & TRN & \\
\hline CHEMBL1527565 & 688746 & 4.4 & 4.8184 & TST & \\
\hline
\end{tabular}




\begin{tabular}{|c|c|c|c|c|}
\hline \multicolumn{5}{|c|}{ Supplemental Table S2.txt } \\
\hline CHEMBL1546363 & 688746 & 4.55 & 4.8479 & TST \\
\hline CHEMBL1432734 & 688746 & 5.9 & 4.8411 & TST \\
\hline CHEMBL1612046 & 688746 & 5.15 & 4.7986 & TRN \\
\hline CHEMBL1312351 & 688746 & 5.05 & 4.9692 & TRN \\
\hline CHEMBL1390297 & 688746 & 4.45 & 4.9361 & TRN \\
\hline CHEMBL1429003 & 688746 & 4.7 & 4.8162 & TRN \\
\hline CHEMBL1383509 & 688746 & 4.4 & 4.9964 & TRN \\
\hline CHEMBL3211771 & 688746 & 4.4 & 4.8942 & TRN \\
\hline CHEMBL1368944 & 688746 & 5.8 & 4.9084 & TRN \\
\hline CHEMBL1965453 & 688746 & 4.4 & 4.7958 & TRN \\
\hline CHEMBL1445020 & 688746 & 4.85 & 5.0165 & TRN \\
\hline CHEMBL3210209 & 688746 & 4.6 & 4.9444 & TST \\
\hline CHEMBL1613473 & 688746 & 4.7 & 4.7658 & TRN \\
\hline CHEMBL1428448 & 688746 & 4.8 & 4.9285 & TRN \\
\hline CHEMBL1388171 & 688746 & 4.65 & 4.9023 & TST \\
\hline CHEMBL1597654 & 688746 & 8.1024 & 4.8349 & TRN \\
\hline CHEMBL1472102 & 688746 & 5.05 & 4.8129 & TRN \\
\hline CHEMBL1596116 & 688746 & 4.45 & 4.9667 & TRN \\
\hline CHEMBL1599175 & 688746 & 4.45 & 4.803 & TRN \\
\hline CHEMBL1607603 & 688746 & 5.7 & 4.9726 & TRN \\
\hline CHEMBL1403316 & 688746 & 4.4 & 4.7979 & TRN \\
\hline CHEMBL1596529 & 688746 & 4.6 & 4.9731 & TRN \\
\hline CHEMBL3213354 & 688746 & 4.6 & 4.9292 & TST \\
\hline CHEMBL1375830 & 688746 & 4.4 & 4.8988 & TST \\
\hline CHEMBL3189605 & 688746 & 5.5 & 4.7884 & TRN \\
\hline CHEMBL1406041 & 688746 & 5.8 & 4.9078 & TRN \\
\hline CHEMBL1557373 & 688746 & 5.3 & 4.8881 & TRN \\
\hline CHEMBL1335968 & 688746 & 4.8 & 4.9682 & TRN \\
\hline CHEMBL1456355 & 688746 & 5.1 & 4.8416 & TST \\
\hline CHEMBL1390727 & 688746 & 4.6 & 4.9257 & TRN \\
\hline CHEMBL1607488 & 688746 & 5.45 & 4.9019 & TRN \\
\hline CHEMBL1389249 & 688746 & 5.1 & 4.8599 & TST \\
\hline CHEMBL1579363 & 688746 & 4.7 & 4.8686 & TRN \\
\hline CHEMBL1566092 & 688746 & 5.35 & 4.8281 & TRN \\
\hline CHEMBL1596329 & 688746 & 4.5 & 4.7744 & TRN \\
\hline CHEMBL1510817 & 688746 & 4.65 & 4.8582 & TRN \\
\hline CHEMBL1371792 & 688746 & 4.95 & 5.0066 & TRN \\
\hline CHEMBL1490031 & 688746 & 4.8 & 4.7879 & TST \\
\hline CHEMBL1344163 & 688746 & 4.85 & 4.8299 & TRN \\
\hline CHEMBL1585677 & 688746 & 4.4 & 4.8633 & TRN \\
\hline CHEMBL1524283 & 688746 & 5.15 & 4.8622 & TRN \\
\hline CHEMBL1533221 & 688746 & 4.7 & 5.0094 & TRN \\
\hline CHEMBL1399492 & 688746 & 5.2 & 4.7897 & TRN \\
\hline CHEMBL1421887 & 688746 & 6.6 & 4.9441 & TRN \\
\hline CHEMBL1584451 & 688746 & 5.2 & 4.8957 & TRN \\
\hline CHEMBL1386455 & 688746 & 4.45 & 4.7398 & TRN \\
\hline CHEMBL1404156 & 688746 & 5.45 & 5.0207 & TRN \\
\hline CHEMBL1549187 & 688746 & 5.2 & 4.9661 & TRN \\
\hline
\end{tabular}




\begin{tabular}{|c|c|c|c|c|c|}
\hline & & \multicolumn{4}{|c|}{ Supplemental Table S2.txt } \\
\hline CHEMBL 2005446 & 688746 & 5.05 & 4.8007 & TRN & \\
\hline CHEMBL1508701 & 688746 & 4.65 & 4.8221 & TRN & \\
\hline CHEMBL1457591 & 688746 & 4.65 & 4.8515 & TRN & \\
\hline CHEMBL1536211 & 688746 & 4.4 & 4.9892 & TRN & \\
\hline CHEMBL1482025 & 688746 & 5.0 & 4.7707 & TRN & \\
\hline CHEMBL1586233 & 688746 & 4.65 & 4.8243 & TRN & \\
\hline CHEMBL1388207 & 688746 & 4.6 & 4.8409 & TRN & \\
\hline CHEMBL1604664 & 688746 & 5.15 & 4.8771 & TRN & \\
\hline CHEMBL1367933 & 688746 & 5.15 & 4.8139 & TST & \\
\hline CHEMBL1582887 & 688746 & 4.8 & 4.8377 & TST & \\
\hline CHEMBL1562631 & 688746 & 4.8 & 4.8879 & TRN & \\
\hline CHEMBL1434324 & 688746 & 5.35 & 4.9341 & TRN & \\
\hline CHEMBL1390445 & 688746 & 4.55 & 4.8357 & TRN & \\
\hline CHEMBL1430020 & 688746 & 4.4 & 4.8971 & TRN & \\
\hline CHEMBL1461491 & 688746 & 6.25 & 4.8256 & TST & \\
\hline CHEMBL3210051 & 688746 & 5.2 & 4.8748 & TRN & \\
\hline CHEMBL1363865 & 688746 & 4.55 & 4.8194 & TRN & \\
\hline CHEMBL1443459 & 688746 & 4.4 & 4.8534 & TST & \\
\hline CHEMBL1391246 & 688746 & 4.4 & 4.881 & TST & \\
\hline CHEMBL1531120 & 688746 & 4.75 & 4.84699 & 99999999995 & TRN \\
\hline CHEMBL1542511 & 688746 & 4.6 & 4.7607 & TRN & \\
\hline CHEMBL1587654 & 688746 & 4.65 & 4.8898 & TRN & \\
\hline CHEMBL1310283 & 688746 & 6.5 & 4.7953 & TRN & \\
\hline CHEMBL1301692 & 688746 & 5.0 & 4.8804 & TRN & \\
\hline CHEMBL1520399 & 688746 & 4.45 & 4.7761 & TRN & \\
\hline CHEMBL1558563 & 688746 & 4.95 & 4.7879 & TRN & \\
\hline CHEMBL1301861 & 688746 & 4.55 & 4.8516 & TRN & \\
\hline CHEMBL1544661 & 688746 & 4.6 & 4.8906 & TRN & \\
\hline CHEMBL1382028 & 688746 & 4.8 & 4.8115 & TRN & \\
\hline CHEMBL1404547 & 688746 & 5.0 & 4.7993 & TRN & \\
\hline CHEMBL1367149 & 688746 & 5.45 & 4.9176 & TRN & \\
\hline CHEMBL 210730 & 688746 & 4.85 & 4.6947 & TRN & \\
\hline CHEMBL1409366 & 688746 & 4.9 & 4.9707 & TRN & \\
\hline CHEMBL1382240 & 688746 & 4.6 & 4.9452 & TRN & \\
\hline CHEMBL1352743 & 688746 & 4.55 & 4.8831 & TRN & \\
\hline CHEMBL1531691 & 688746 & 4.75 & 4.9871 & TRN & \\
\hline CHEMBL1478464 & 688746 & 4.6 & 4.914 & TRN & \\
\hline CHEMBL512387 & 688746 & 5.0 & 4.6945 & TRN & \\
\hline CHEMBL1459140 & 688746 & 6.0 & 4.8258 & TRN & \\
\hline CHEMBL1371936 & 688746 & 4.55 & 4.8579 & TRN & \\
\hline CHEMBL1376356 & 688746 & 5.0 & 4.852 & TRN & \\
\hline CHEMBL1597486 & 688746 & 4.4 & 4.8117 & TST & \\
\hline CHEMBL1459940 & 688746 & 5.05 & 5.0278 & TRN & \\
\hline CHEMBL1604319 & 688746 & 4.6 & 4.952 & TRN & \\
\hline CHEMBL1414534 & 688746 & 5.05 & 4.8051 & TRN & \\
\hline CHEMBL1376411 & 688746 & 4.75 & 4.8094 & TRN & \\
\hline CHEMBL1423257 & 688746 & 4.9 & 4.6937 & TRN & \\
\hline CHEMBL1412685 & 688746 & 4.4 & 4.7827 & TRN & \\
\hline
\end{tabular}




\begin{tabular}{|c|c|c|c|c|c|}
\hline \multicolumn{6}{|c|}{ Supplemental Table s2.txt } \\
\hline CHEMBL1389241 & 688746 & 4.45 & 4.8608 & TRN & \\
\hline CHEMBL1456260 & 688746 & 4.8 & 4.8562 & TRN & \\
\hline CHEMBL1389600 & 688746 & 4.6 & 4.8746 & TRN & \\
\hline CHEMBL1566018 & 688746 & 4.4 & 4.8743 & TRN & \\
\hline CHEMBL1449697 & 688746 & 4.45 & 4.82600 & 00000000005 & TRN \\
\hline CHEMBL 3207833 & 688746 & 5.35 & 4.965 & TST & \\
\hline CHEMBL1575045 & 688746 & 4.35 & 4.9038 & TRN & \\
\hline CHEMBL1332143 & 688746 & 4.45 & 4.8454 & TRN & \\
\hline CHEMBL1542470 & 688746 & 5.45 & 4.9513 & TRN & \\
\hline CHEMBL1403896 & 688746 & 4.8 & 4.9074 & TRN & \\
\hline CHEMBL1428889 & 688746 & 4.55 & 4.8108 & TRN & \\
\hline CHEMBL1338998 & 688746 & 4.85 & 4.7448 & TRN & \\
\hline CHEMBL1367689 & 688746 & 4.4 & 4.8049 & TRN & \\
\hline CHEMBL1613205 & 688746 & 4.4 & 4.934 & TST & \\
\hline CHEMBL1336116 & 688746 & 4.7 & 4.9836 & TRN & \\
\hline CHEMBL1567218 & 688746 & 4.85 & 4.9528 & TRN & \\
\hline CHEMBL3212937 & 688746 & 5.7 & 4.8236 & TRN & \\
\hline CHEMBL1375360 & 688746 & 5.2 & 4.8119 & TRN & \\
\hline CHEMBL1335616 & 688746 & 4.55 & 4.7247 & TRN & \\
\hline CHEMBL1311519 & 688746 & 4.65 & 4.9326 & TRN & \\
\hline CHEMBL1388871 & 688746 & 4.4 & 4.8251 & TST & \\
\hline CHEMBL1571040 & 688746 & 4.4 & 4.8068 & TRN & \\
\hline CHEMBL3196816 & 688746 & 4.5 & 4.8317 & TRN & \\
\hline CHEMBL1549548 & 688746 & 4.7 & 4.7814 & TRN & \\
\hline CHEMBL1387610 & 688746 & 5.05 & 4.7264 & TRN & \\
\hline CHEMBL1327413 & 688746 & 4.9 & 4.7713 & TRN & \\
\hline CHEMBL1370361 & 688746 & 5.2 & 4.7914 & TRN & \\
\hline CHEMBL3194619 & 688746 & 4.8 & 4.8633 & TST & \\
\hline CHEMBL1443467 & 688746 & 4.4 & 4.944 & TRN & \\
\hline CHEMBL1595110 & 688746 & 4.85 & 4.8934 & TRN & \\
\hline CHEMBL1562333 & 688746 & 5.1 & 4.80699 & 99999999995 & TRN \\
\hline CHEMBL1399802 & 688746 & 4.95 & 4.9409 & TRN & \\
\hline CHEMBL1578953 & 688746 & 5.0 & 4.6939 & TRN & \\
\hline CHEMBL1413321 & 688746 & 4.85 & 4.8575 & TRN & \\
\hline CHEMBL1369930 & 688746 & 4.85 & 4.8307 & TRN & \\
\hline CHEMBL1498309 & 688746 & 4.6 & 4.9064 & TRN & \\
\hline CHEMBL1607815 & 688746 & 4.4 & 4.8662 & TRN & \\
\hline CHEMBL1350315 & 688746 & 4.45 & 4.9344 & TRN & \\
\hline CHEMBL 3213377 & 688746 & 4.5 & 4.8373 & TRN & \\
\hline CHEMBL1610101 & 688746 & 5.3 & 4.9107 & TRN & \\
\hline CHEMBL1453548 & 688746 & 6.1 & 4.852 & TRN & \\
\hline CHEMBL1468394 & 688746 & 4.4 & 4.6963 & TRN & \\
\hline CHEMBL1533351 & 688746 & 4.45 & 4.9136 & TRN & \\
\hline CHEMBL1377322 & 688746 & 4.65 & 4.8603 & TRN & \\
\hline CHEMBL1420885 & 688746 & 4.4 & 4.8767 & TRN & \\
\hline CHEMBL1530214 & 688746 & 4.8 & 4.8523 & TRN & \\
\hline CHEMBL1335718 & 688746 & 4.6 & 4.9579 & TRN & \\
\hline CHEMBL3199771 & 688746 & 5.2 & 4.8687 & TRN & \\
\hline
\end{tabular}




\begin{tabular}{|c|c|c|c|c|c|}
\hline \multicolumn{6}{|c|}{ Supplemental Table S2.txt } \\
\hline CHEMBL1301244 & 688746 & 5.25 & 4.8759 & TRN & \\
\hline CHEMBL1369101 & 688746 & 5.05 & 4.8179 & TRN & \\
\hline CHEMBL1305453 & 688746 & 4.5 & 4.8988 & TRN & \\
\hline CHEMBL1350161 & 688746 & 5.55 & 4.9391 & TRN & \\
\hline CHEMBL1485923 & 688746 & 4.5 & 4.7997 & TRN & \\
\hline CHEMBL1351274 & 688746 & 4.4 & 5.0084 & TRN & \\
\hline CHEMBL1546386 & 688746 & 4.45 & 4.8393 & TRN & \\
\hline CHEMBL3193139 & 688746 & 5.05 & 4.7204 & TRN & \\
\hline CHEMBL1534535 & 688746 & 5.4 & 5.0323 & TRN & \\
\hline CHEMBL1420323 & 688746 & 4.6 & 4.8061 & TRN & \\
\hline CHEMBL1511458 & 688746 & 4.5 & 4.8182 & TRN & \\
\hline CHEMBL 3196587 & 688746 & 4.5 & 4.8357 & TST & \\
\hline CHEMBL1366006 & 688746 & 5.6 & 4.8997 & TRN & \\
\hline CHEMBL1493615 & 688746 & 4.5 & 4.8303 & TRN & \\
\hline CHEMBL1612163 & 688746 & 5.0 & 4.9219 & TRN & \\
\hline CHEMBL1312303 & 688746 & 4.4 & 4.7814 & TRN & \\
\hline CHEMBL1347116 & 688746 & 5.2 & 4.82 & TRN & \\
\hline CHEMBL1378111 & 688746 & 4.45 & 4.8634 & TRN & \\
\hline CHEMBL3191199 & 688746 & 4.4 & 4.8356 & TRN & \\
\hline CHEMBL1605369 & 688746 & 5.3 & 4.872 & TRN & \\
\hline CHEMBL1342767 & 688746 & 4.4 & 4.7424 & TRN & \\
\hline CHEMBL3197723 & 688746 & 4.75 & 4.8274 & TRN & \\
\hline CHEMBL1404932 & 688746 & 4.6 & 4.8372 & TST & \\
\hline CHEMBL1533794 & 688746 & 5.05 & 4.9432 & TRN & \\
\hline CHEMBL1535051 & 688746 & 4.5 & 4.8601 & TRN & \\
\hline CHEMBL1611131 & 688746 & 4.6 & 4.9411 & TRN & \\
\hline CHEMBL1442910 & 688746 & 4.65 & 4.8615 & TST & \\
\hline CHEMBL1384322 & 688746 & 4.8 & 4.8613 & TRN & \\
\hline CHEMBL1510438 & 688746 & 4.55 & 5.0391 & TRN & \\
\hline CHEMBL515252 & 688746 & 5.1 & 4.8236 & TST & \\
\hline CHEMBL 3190083 & 688746 & 5.15 & 4.7691 & TST & \\
\hline CHEMBL1507023 & 688746 & 4.85 & 4.7151 & TRN & \\
\hline CHEMBL1601647 & 688746 & 4.6 & 4.8005 & TRN & \\
\hline CHEMBL1604456 & 688746 & 4.4 & 4.7692 & TRN & \\
\hline CHEMBL334707 & 688746 & 4.4 & 4.77800 & 00000000005 & TRN \\
\hline CHEMBL1535021 & 688746 & 5.0 & 4.7676 & TRN & \\
\hline CHEMBL1323110 & 688746 & 5.45 & 4.8658 & TRN & \\
\hline CHEMBL1502229 & 688746 & 4.5 & 4.7695 & TST & \\
\hline CHEMBL1345944 & 688746 & 4.4 & 4.9286 & TRN & \\
\hline CHEMBL1350832 & 688746 & 4.65 & 4.8752 & TRN & \\
\hline CHEMBL1301436 & 688746 & 4.4 & 4.8719 & TRN & \\
\hline CHEMBL11326 & 688746 & 4.6 & 4.8512 & TRN & \\
\hline CHEMBL1346172 & 688746 & 5.35 & 4.7382 & TRN & \\
\hline CHEMBL1327682 & 688746 & 4.55 & 4.8273 & TRN & \\
\hline CHEMBL1561302 & 688746 & 4.85 & 4.935 & TRN & \\
\hline CHEMBL3145285 & 688746 & 5.0 & 4.8234 & TRN & \\
\hline CHEMBL1505737 & 688746 & 4.55 & 4.7902 & TRN & \\
\hline CHEMBL1567981 & 688746 & 5.4 & 4.9159 & TRN & \\
\hline
\end{tabular}




\begin{tabular}{|c|c|c|c|c|}
\hline \multicolumn{5}{|c|}{ Supplemental Table S2.txt } \\
\hline CHEMBL3211930 & 688746 & 4.65 & 4.7683 & TRN \\
\hline CHEMBL1307064 & 688746 & 4.4 & 4.8924 & TRN \\
\hline CHEMBL544115 & 688746 & 4.8 & 4.8911 & TST \\
\hline CHEMBL567422 & 688746 & 5.0 & 4.8251 & TST \\
\hline CHEMBL1381479 & 688746 & 5.4 & 5.0335 & TRN \\
\hline CHEMBL1330647 & 688746 & 4.5 & 4.8378 & TRN \\
\hline CHEMBL1563443 & 688746 & 4.5 & 4.838 & TRN \\
\hline CHEMBL1378903 & 688746 & 5.1 & 4.7581 & TRN \\
\hline CHEMBL1446833 & 688746 & 4.8 & 5.0385 & TRN \\
\hline CHEMBL1388715 & 688746 & 4.85 & 4.8433 & TRN \\
\hline CHEMBL1563888 & 688746 & 4.7 & 4.8449 & TST \\
\hline CHEMBL1370876 & 688746 & 4.55 & 4.9151 & TRN \\
\hline CHEMBL1498250 & 688746 & 4.6 & 4.939 & TRN \\
\hline CHEMBL1305116 & 688746 & 4.4 & 4.8803 & TRN \\
\hline CHEMBL1996490 & 688746 & 4.6 & 4.6777 & TRN \\
\hline CHEMBL1533819 & 688746 & 5.6 & 4.8314 & TRN \\
\hline CHEMBL1556188 & 688746 & 6.1 & 4.9034 & TRN \\
\hline CHEMBL1427529 & 688746 & 4.6 & 4.8614 & TRN \\
\hline CHEMBL1532278 & 688746 & 4.4 & 4.7537 & TRN \\
\hline CHEMBL1305289 & 688746 & 4.4 & 4.8347 & TST \\
\hline CHEMBL1467714 & 688746 & 4.5 & 4.8514 & TRN \\
\hline CHEMBL3193119 & 688746 & 4.7 & 4.7693 & TRN \\
\hline CHEMBL1469513 & 688746 & 4.5 & 4.8657 & TST \\
\hline CHEMBL1330807 & 688746 & 4.55 & 4.8487 & TRN \\
\hline CHEMBL1489570 & 688746 & 4.75 & 5.0118 & TRN \\
\hline CHEMBL1455138 & 688746 & 5.05 & 4.8532 & TRN \\
\hline CHEMBL1506088 & 688746 & 4.4 & 4.8395 & TRN \\
\hline CHEMBL3193749 & 688746 & 4.4 & 4.8045 & TRN \\
\hline CHEMBL1472389 & 688746 & 4.4 & 4.886 & TST \\
\hline CHEMBL1390185 & 688746 & 5.35 & 4.908 & TRN \\
\hline CHEMBL1496857 & 688746 & 4.95 & 4.8097 & TRN \\
\hline CHEMBL1603358 & 688746 & 4.45 & 4.859 & TST \\
\hline CHEMBL 75412 & 688746 & 4.5 & 4.7903 & TST \\
\hline CHEMBL1469024 & 688746 & 5.15 & 4.8363 & TST \\
\hline CHEMBL1345816 & 688746 & 4.4 & 4.8649 & TST \\
\hline CHEMBL239398 & 688746 & 4.85 & 4.92 & TRN \\
\hline CHEMBL1349125 & 688746 & 4.45 & 4.8275 & TST \\
\hline CHEMBL1303972 & 688746 & 4.4 & 4.9172 & TRN \\
\hline CHEMBL1383312 & 688746 & 4.8 & 4.7661 & TRN \\
\hline CHEMBL1537869 & 688746 & 5.35 & 4.806 & TRN \\
\hline CHEMBL1370700 & 688746 & 4.6 & 4.8321 & TRN \\
\hline CHEMBL1478008 & 688746 & 4.6 & 4.8473 & TRN \\
\hline CHEMBL1411084 & 688746 & 4.5 & 4.8403 & TRN \\
\hline CHEMBL1597899 & 688746 & 5.35 & 4.8472 & TST \\
\hline CHEMBL1443052 & 688746 & 4.8 & 4.8807 & TRN \\
\hline CHEMBL1499574 & 688746 & 4.45 & 4.8163 & TRN \\
\hline CHEMBL1494495 & 688746 & 5.55 & 4.9066 & TRN \\
\hline CHEMBL1407000 & 688746 & 4.5 & 4.8867 & TRN \\
\hline
\end{tabular}




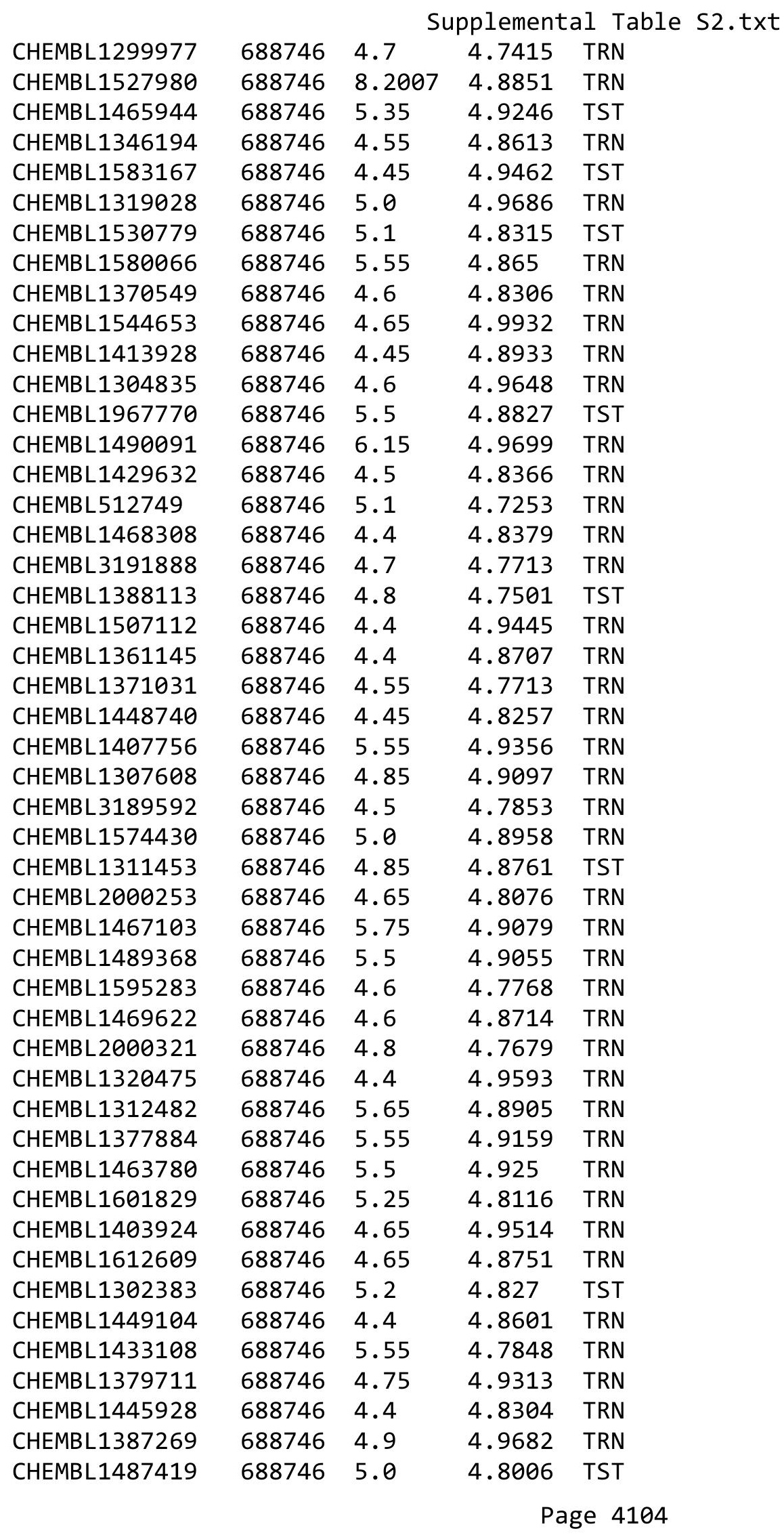




\begin{tabular}{|c|c|c|c|c|c|}
\hline \multirow{2}{*}{ CHEMBL1449378 } & \multirow{2}{*}{688746} & \\
\hline & & 4.4 & 4.875 & TRN & \\
\hline CHEMBL1379998 & 688746 & 4.65 & 5.0212 & TRN & \\
\hline CHEMBL1490438 & 688746 & 4.4 & 4.853 & TRN & \\
\hline CHEMBL3214470 & 688746 & 5.4 & 4.8683 & TST & \\
\hline CHEMBL1373608 & 688746 & 5.35 & 4.8553 & TRN & \\
\hline CHEMBL1599202 & 688746 & 5.1 & 4.9217 & TRN & \\
\hline CHEMBL1504898 & 688746 & 4.5 & 4.8495 & TRN & \\
\hline CHEMBL1374125 & 688746 & 5.0 & 4.8742 & TRN & \\
\hline CHEMBL1441778 & 688746 & 5.45 & 4.8243 & TST & \\
\hline CHEMBL1529281 & 688746 & 4.6 & 4.8171 & TRN & \\
\hline CHEMBL1545099 & 688746 & 4.75 & 4.8486 & TRN & \\
\hline CHEMBL1587816 & 688746 & 4.4 & 4.8239 & TRN & \\
\hline CHEMBL1393020 & 688746 & 4.4 & 4.7709 & TRN & \\
\hline CHEMBL1429956 & 688746 & 5.1 & 4.9307 & TRN & \\
\hline CHEMBL1469770 & 688746 & 4.75 & 4.7942 & TST & \\
\hline CHEMBL1577267 & 688746 & 5.05 & 4.8037 & TST & \\
\hline CHEMBL1545768 & 688746 & 5.5 & 4.8539 & TRN & \\
\hline CHEMBL1493936 & 688746 & 5.4 & 4.8099 & TRN & \\
\hline CHEMBL3214502 & 688746 & 5.1 & 4.7109 & TRN & \\
\hline CHEMBL1525234 & 688746 & 4.55 & 4.8358 & TST & \\
\hline CHEMBL1310496 & 688746 & 4.55 & 4.7499 & TRN & \\
\hline CHEMBL1560371 & 688746 & 4.6 & 4.828 & TST & \\
\hline CHEMBL1360844 & 688746 & 5.2 & 4.8066 & TST & \\
\hline CHEMBL1504878 & 688746 & 4.7 & 4.856 & TRN & \\
\hline CHEMBL1449670 & 688746 & 4.5 & 4.8764 & TRN & \\
\hline CHEMBL8883 & 688746 & 4.4 & 4.9152 & TRN & \\
\hline CHEMBL1392052 & 688746 & 4.4 & 4.8048 & TRN & \\
\hline CHEMBL1566422 & 688746 & 5.3 & 4.9427 & TRN & \\
\hline CHEMBL1573915 & 688746 & 4.55 & 4.8486 & TRN & \\
\hline CHEMBL1589244 & 688746 & 4.65 & 4.7229 & TRN & \\
\hline CHEMBL1399087 & 688746 & 4.4 & 4.8278 & TRN & \\
\hline CHEMBL1377333 & 688746 & 4.75 & 4.8358 & TRN & \\
\hline CHEMBL1382516 & 688746 & 4.4 & 4.927 & TRN & \\
\hline CHEMBL1382616 & 688746 & 4.5 & 4.7823 & TRN & \\
\hline CHEMBL1995156 & 688746 & 4.4 & 4.8035 & TRN & \\
\hline CHEMBL1991779 & 688746 & 4.85 & 4.763 & TRN & \\
\hline CHEMBL1991610 & 688746 & 4.55 & 4.6476 & TRN & \\
\hline CHEMBL1333796 & 688746 & 4.4 & 4.8811 & TST & \\
\hline CHEMBL 230143 & 688746 & 6.6 & 4.8842 & TRN & \\
\hline CHEMBL1426076 & 688746 & 4.6 & 4.8621 & TST & \\
\hline CHEMBL3208915 & 688746 & 6.35 & 4.7916 & TST & \\
\hline CHEMBL1491586 & 688746 & 4.85 & 4.9488 & TRN & \\
\hline CHEMBL1556628 & 688746 & 6.7501 & 4.9534 & TRN & \\
\hline CHEMBL1566723 & 688746 & 5.2 & 4.9573 & TRN & \\
\hline CHEMBL1493429 & 688746 & 4.85 & 4.726 & TRN & \\
\hline CHEMBL1989090 & 688746 & 4.85 & 4.70100 & 00000000005 & TRN \\
\hline CHEMBL1383991 & 688746 & 4.85 & 4.71899 & 9999999999 & TRN \\
\hline CHEMBL1570876 & 688746 & 4.7 & 5.0728 & TRN & \\
\hline
\end{tabular}




\begin{tabular}{|c|c|c|c|c|}
\hline & & & pplemen & al $\mathrm{T}$ \\
\hline CHEMBL3189148 & 688746 & 6.05 & 4.8109 & TST \\
\hline CHEMBL1412922 & 688746 & 4.4 & 4.8246 & TRN \\
\hline CHEMBL1464803 & 688746 & 4.7 & 4.8373 & TRN \\
\hline CHEMBL1483315 & 688746 & 4.95 & 4.8728 & TRN \\
\hline CHEMBL1326999 & 688746 & 4.5 & 4.7734 & TST \\
\hline CHEMBL243644 & 688746 & 4.75 & 4.8438 & TRN \\
\hline CHEMBL1574004 & 688746 & 4.5 & 4.9386 & TRN \\
\hline CHEMBL1455950 & 688746 & 4.85 & 4.8403 & TRN \\
\hline CHEMBL1409317 & 688746 & 6.1 & 4.8364 & TST \\
\hline CHEMBL1522245 & 688746 & 4.45 & 4.9932 & TRN \\
\hline CHEMBL1344582 & 688746 & 5.1 & 4.7597 & TRN \\
\hline CHEMBL 2000877 & 688746 & 4.6 & 4.8193 & TRN \\
\hline CHEMBL1344438 & 688746 & 5.3 & 4.9512 & TRN \\
\hline CHEMBL1549038 & 688746 & 4.55 & 4.9208 & TRN \\
\hline CHEMBL1302266 & 688746 & 4.9 & 4.8116 & TRN \\
\hline CHEMBL1585026 & 688746 & 5.35 & 4.8461 & TRN \\
\hline CHEMBL1593082 & 688746 & 4.45 & 4.9213 & TST \\
\hline CHEMBL1401167 & 688746 & 4.55 & 4.7025 & TRN \\
\hline CHEMBL1586236 & 688746 & 5.4 & 5.0115 & TRN \\
\hline CHEMBL1538294 & 688746 & 4.4 & 4.9269 & TST \\
\hline CHEMBL1533068 & 688746 & 4.8 & 4.8223 & TRN \\
\hline CHEMBL1319436 & 688746 & 4.45 & 4.971 & TRN \\
\hline CHEMBL1467905 & 688746 & 4.9 & 5.0 & TRN \\
\hline CHEMBL1519992 & 688746 & 4.55 & 4.8227 & TRN \\
\hline CHEMBL1531806 & 688746 & 4.55 & 4.7512 & TRN \\
\hline CHEMBL1522275 & 688746 & 5.0 & 4.8938 & TST \\
\hline CHEMBL1424468 & 688746 & 4.4 & 4.8076 & TRN \\
\hline CHEMBL1454092 & 688746 & 4.9 & 4.9604 & TRN \\
\hline CHEMBL1467087 & 688746 & 6.25 & 4.9221 & TST \\
\hline CHEMBL1359815 & 688746 & 4.85 & 5.0165 & TRN \\
\hline CHEMBL1326847 & 688746 & 6.1 & 4.7906 & TST \\
\hline CHEMBL1433946 & 688746 & 4.5 & 4.9398 & TRN \\
\hline CHEMBL1483351 & 688746 & 4.6 & 4.9699 & TST \\
\hline CHEMBL1389550 & 688746 & 4.8 & 5.0161 & TRN \\
\hline CHEMBL139935 & 688746 & 4.4 & 4.769 & TRN \\
\hline CHEMBL1431490 & 688746 & 4.65 & 4.7624 & TRN \\
\hline CHEMBL1444916 & 688746 & 4.7 & 4.9809 & TRN \\
\hline CHEMBL1542155 & 688746 & 5.6 & 4.9933 & TRN \\
\hline CHEMBL1448776 & 688746 & 5.7 & 4.8117 & TRN \\
\hline CHEMBL1484071 & 688746 & 4.55 & 4.9207 & TST \\
\hline CHEMBL1997422 & 688746 & 4.4 & 4.8248 & TRN \\
\hline CHEMBL1418518 & 688746 & 5.0 & 4.7972 & TRN \\
\hline CHEMBL1350856 & 688746 & 4.8 & 4.8481 & TRN \\
\hline CHEMBL1381618 & 688746 & 6.15 & 4.9663 & TRN \\
\hline CHEMBL1585127 & 688746 & 4.5 & 4.789 & TRN \\
\hline CHEMBL1363037 & 688746 & 4.4 & 4.842 & TRN \\
\hline CHEMBL1406687 & 688746 & 4.45 & 4.8181 & TRN \\
\hline CHEMBL3199450 & 688746 & 4.6 & 4.8007 & TRN \\
\hline
\end{tabular}




\begin{tabular}{|c|c|c|c|c|c|}
\hline \\
\hline CHEMBL1555400 & 688746 & 5.9 & 4.8187 & TRN & \\
\hline CHEMBL1368371 & 688746 & 5.7 & 4.8862 & TRN & \\
\hline CHEMBL1321057 & 688746 & 6.1 & 4.8696 & TRN & \\
\hline CHEMBL1411661 & 688746 & 4.4 & 4.8658 & TRN & \\
\hline CHEMBL1491698 & 688746 & 5.1 & 4.7853 & TST & \\
\hline CHEMBL3189792 & 688746 & 5.5 & 4.8221 & TRN & \\
\hline CHEMBL1460863 & 688746 & 4.4 & 4.8435 & TRN & \\
\hline CHEMBL1367579 & 688746 & 4.4 & 4.9352 & TRN & \\
\hline CHEMBL1585028 & 688746 & 6.15 & 4.8226 & TRN & \\
\hline CHEMBL3193108 & 688746 & 5.2 & 4.8438 & TRN & \\
\hline CHEMBL1413557 & 688746 & 4.75 & 4.7712 & TRN & \\
\hline CHEMBL1310777 & 688746 & 4.65 & 4.8374 & TRN & \\
\hline CHEMBL1359359 & 688746 & 6.2 & 4.8511 & TST & \\
\hline CHEMBL1340139 & 688746 & 5.45 & 4.8777 & TRN & \\
\hline CHEMBL1377073 & 688746 & 4.4 & 4.79899 & 79999999995 & TRN \\
\hline CHEMBL1381005 & 688746 & 4.55 & 4.9101 & TRN & \\
\hline CHEMBL1561738 & 688746 & 5.0 & 4.811 & TRN & \\
\hline CHEMBL1447319 & 688746 & 5.1 & 4.9511 & TRN & \\
\hline CHEMBL1563111 & 688746 & 6.0 & 4.8818 & TRN & \\
\hline CHEMBL1609556 & 688746 & 4.4 & 4.8083 & TST & \\
\hline CHEMBL1550554 & 688746 & 5.45 & 4.848 & TRN & \\
\hline CHEMBL1538625 & 688746 & 4.6 & 4.8223 & TRN & \\
\hline CHEMBL1415568 & 688746 & 4.65 & 4.8041 & TRN & \\
\hline CHEMBL1304552 & 688746 & 4.55 & 4.7947 & TRN & \\
\hline CHEMBL1611067 & 688746 & 4.45 & 4.7141 & TRN & \\
\hline CHEMBL1504810 & 688746 & 4.4 & 4.893 & TST & \\
\hline CHEMBL1339103 & 688746 & 4.75 & 4.7547 & TRN & \\
\hline CHEMBL1509369 & 688746 & 4.7 & 4.8412 & TST & \\
\hline CHEMBL1307117 & 688746 & 4.8 & 4.7983 & TRN & \\
\hline CHEMBL1547684 & 688746 & 5.0 & 4.7922 & TRN & \\
\hline CHEMBL1471293 & 688746 & 4.5 & 4.9159 & TRN & \\
\hline CHEMBL1471326 & 688746 & 4.7 & 4.8431 & TRN & \\
\hline CHEMBL1343727 & 688746 & 6.1 & 4.9396 & TRN & \\
\hline CHEMBL1324416 & 688746 & 6.1 & 4.8141 & TST & \\
\hline CHEMBL1301917 & 688746 & 4.65 & 4.8947 & TST & \\
\hline CHEMBL1324717 & 688746 & 4.4 & 4.8959 & TST & \\
\hline CHEMBL1390472 & 688746 & 4.4 & 4.9201 & TST & \\
\hline CHEMBL1447458 & 688746 & 4.7 & 4.8449 & TRN & \\
\hline CHEMBL1485940 & 688746 & 4.4 & 4.8321 & TRN & \\
\hline CHEMBL1557115 & 688746 & 4.6 & 4.8494 & TRN & \\
\hline CHEMBL1470203 & 688746 & 4.4 & 4.9652 & TRN & \\
\hline CHEMBL3194236 & 688746 & 4.6 & 4.8484 & TRN & \\
\hline CHEMBL1529084 & 688746 & 4.6 & 4.8941 & TRN & \\
\hline CHEMBL1539342 & 688746 & 6.15 & 4.7457 & TST & \\
\hline CHEMBL1612139 & 688746 & 4.55 & 4.7709 & TRN & \\
\hline CHEMBL1547700 & 688746 & 4.4 & 4.8257 & TRN & \\
\hline CHEMBL1569543 & 688746 & 4.45 & 4.8068 & TRN & \\
\hline CHEMBL1424010 & 688746 & 4.4 & 4.9573 & TRN & \\
\hline
\end{tabular}




\begin{tabular}{|c|c|c|c|c|}
\hline \multicolumn{5}{|c|}{ Supplemental Table S2.txt } \\
\hline CHEMBL1596828 & 688746 & 5.05 & 4.8245 & TRN \\
\hline CHEMBL1320850 & 688746 & 5.45 & 4.9407 & TRN \\
\hline CHEMBL1386035 & 688746 & 4.8 & 5.0159 & TRN \\
\hline CHEMBL1530670 & 688746 & 6.1 & 4.8414 & TST \\
\hline CHEMBL1610730 & 688746 & 5.5 & 4.9305 & TRN \\
\hline CHEMBL1544857 & 688746 & 4.8 & 5.0048 & TRN \\
\hline CHEMBL1549112 & 688746 & 4.8 & 4.8875 & TST \\
\hline CHEMBL1382320 & 688746 & 4.6 & 4.9565 & TRN \\
\hline CHEMBL1378098 & 688746 & 4.6 & 4.8481 & TRN \\
\hline CHEMBL1389973 & 688746 & 4.8 & 4.9559 & TRN \\
\hline CHEMBL1569057 & 688746 & 4.6 & 4.9681 & TRN \\
\hline CHEMBL1586970 & 688746 & 4.75 & 4.7777 & TRN \\
\hline CHEMBL1548458 & 688746 & 4.4 & 4.7721 & TRN \\
\hline CHEMBL1413985 & 688746 & 5.0 & 4.8779 & TRN \\
\hline CHEMBL3190023 & 688746 & 4.55 & 4.7466 & TRN \\
\hline CHEMBL1527266 & 688746 & 4.95 & 4.8352 & TRN \\
\hline CHEMBL1413450 & 688746 & 4.45 & 4.8951 & TRN \\
\hline CHEMBL1585654 & 688746 & 4.6 & 4.8003 & TRN \\
\hline CHEMBL1392222 & 688746 & 4.5 & 4.8508 & TRN \\
\hline CHEMBL1469517 & 688746 & 4.6 & 4.8452 & TRN \\
\hline CHEMBL1587117 & 688746 & 4.65 & 4.7839 & TRN \\
\hline CHEMBL1338266 & 688746 & 5.7 & 4.8296 & TRN \\
\hline CHEMBL1428165 & 688746 & 4.7 & 4.9243 & TRN \\
\hline CHEMBL1441583 & 688746 & 4.4 & 4.7175 & TRN \\
\hline CHEMBL 222709 & 688746 & 4.8 & 4.9168 & TRN \\
\hline CHEMBL1579447 & 688746 & 4.4 & 4.9505 & TRN \\
\hline CHEMBL1422502 & 688746 & 4.55 & 4.8853 & TST \\
\hline CHEMBL1481813 & 688746 & 4.4 & 4.9597 & TST \\
\hline CHEMBL1361076 & 688746 & 5.5 & 4.9299 & TRN \\
\hline CHEMBL1421334 & 688746 & 4.95 & 4.8453 & TRN \\
\hline CHEMBL1422975 & 688746 & 5.35 & 4.9062 & TRN \\
\hline CHEMBL1352955 & 688746 & 4.65 & 4.8054 & TRN \\
\hline CHEMBL1492677 & 688746 & 4.6 & 4.8872 & TST \\
\hline CHEMBL3145301 & 688746 & 4.9 & 4.9596 & TRN \\
\hline CHEMBL1402010 & 688746 & 4.85 & 4.8156 & TRN \\
\hline CHEMBL1303913 & 688746 & 4.8 & 4.8707 & TRN \\
\hline CHEMBL1386067 & 688746 & 5.25 & 4.8439 & TRN \\
\hline CHEMBL1327627 & 688746 & 4.8 & 4.8557 & TRN \\
\hline CHEMBL1505082 & 688746 & 4.5 & 4.9387 & TRN \\
\hline CHEMBL1525300 & 688746 & 4.8 & 4.8248 & TRN \\
\hline CHEMBL3191637 & 688746 & 5.05 & 4.8473 & TRN \\
\hline CHEMBL1428677 & 688746 & 4.5 & 4.9849 & TRN \\
\hline CHEMBL1528386 & 688746 & 6.8 & 4.939 & TST \\
\hline CHEMBL1416655 & 688746 & 4.6 & 4.7744 & TRN \\
\hline CHEMBL3195785 & 688746 & 4.95 & 4.7694 & TRN \\
\hline CHEMBL1347592 & 688746 & 5.7 & 4.9676 & TRN \\
\hline CHEMBL1538769 & 688746 & 6.35 & 4.8869 & TRN \\
\hline CHEMBL1320370 & 688746 & 4.45 & 4.895 & TRN \\
\hline
\end{tabular}




\begin{tabular}{|c|c|c|c|c|}
\hline & & & & al Table \\
\hline CHEMBL1481785 & 688746 & 4.55 & 5.0254 & TRN \\
\hline CHEMBL1498077 & 688746 & 4.55 & 4.8404 & TST \\
\hline CHEMBL1440607 & 688746 & 5.05 & 4.7542 & TRN \\
\hline CHEMBL1485466 & 688746 & 4.9 & 4.9047 & TRN \\
\hline CHEMBL1529994 & 688746 & 4.4 & 4.7742 & TRN \\
\hline CHEMBL1488848 & 688746 & 4.4 & 4.7902 & TRN \\
\hline CHEMBL1582718 & 688746 & 4.4 & 5.0013 & TRN \\
\hline CHEMBL1456254 & 688746 & 5.35 & 4.9369 & TRN \\
\hline CHEMBL1574662 & 688746 & 5.5 & 4.7656 & TRN \\
\hline CHEMBL1346584 & 688746 & 5.7 & \multicolumn{2}{|c|}{4.906000000000001} \\
\hline CHEMBL1507702 & 688746 & 4.85 & 4.8576 & TRN \\
\hline CHEMBL1475708 & 688746 & 4.6 & 4.9338 & TRN \\
\hline CHEMBL1503518 & 688746 & 4.45 & 4.9388 & TRN \\
\hline CHEMBL1495775 & 688746 & 4.4 & 4.8416 & TRN \\
\hline CHEMBL1368942 & 688746 & 4.55 & 4.9512 & TST \\
\hline CHEMBL1558488 & 688746 & 5.15 & 4.955 & TRN \\
\hline CHEMBL1510258 & 688746 & 5.2 & 4.8204 & TST \\
\hline CHEMBL1344687 & 688746 & 4.75 & 4.8767 & TST \\
\hline CHEMBL1394811 & 688746 & 4.4 & 4.9861 & TRN \\
\hline CHEMBL3191238 & 688746 & 4.75 & 4.7387 & TRN \\
\hline CHEMBL1388848 & 688746 & 5.1 & 4.9823 & TRN \\
\hline CHEMBL1344071 & 688746 & 5.15 & 4.8306 & TRN \\
\hline CHEMBL1375704 & 688746 & 6.2 & 4.9222 & TRN \\
\hline CHEMBL2001895 & 688746 & 4.4 & 4.7857 & TST \\
\hline CHEMBL1427265 & 688746 & 4.6 & 4.7734 & TRN \\
\hline CHEMBL1532377 & 688746 & 5.2 & 4.7961 & TRN \\
\hline CHEMBL1422656 & 688746 & 4.4 & 5.0043 & TRN \\
\hline CHEMBL1342337 & 688746 & 5.55 & 4.9467 & TRN \\
\hline CHEMBL1465125 & 688746 & 4.45 & 4.8713 & TRN \\
\hline CHEMBL1450131 & 688746 & 5.6 & 4.9082 & TRN \\
\hline CHEMBL1560434 & 688746 & 4.45 & 4.7616 & TRN \\
\hline CHEMBL1494057 & 688746 & 4.85 & 4.9159 & TRN \\
\hline CHEMBL1544136 & 688746 & 5.05 & 4.9603 & TRN \\
\hline CHEMBL1311694 & 688746 & 4.55 & 4.8182 & TST \\
\hline CHEMBL1342038 & 688746 & 5.25 & 4.7408 & TRN \\
\hline CHEMBL1382438 & 688746 & 4.85 & 4.8375 & TRN \\
\hline CHEMBL1351283 & 688746 & 5.85 & 4.7898 & TRN \\
\hline CHEMBL1419133 & 688746 & 4.45 & 4.9016 & TRN \\
\hline CHEMBL1519680 & 688746 & 6.15 & 5.0081 & TRN \\
\hline CHEMBL1439954 & 688746 & 4.75 & 4.7542 & TRN \\
\hline CHEMBL1505255 & 688746 & 4.7 & 5.0023 & TRN \\
\hline CHEMBL1500903 & 688746 & 4.9 & 4.9204 & TRN \\
\hline CHEMBL1456624 & 688746 & 4.7 & 4.8875 & TRN \\
\hline CHEMBL1980574 & 688746 & 4.7 & 4.7707 & TRN \\
\hline CHEMBL1543208 & 688746 & 4.7 & 5.0264 & TRN \\
\hline CHEMBL1521930 & 688746 & 4.55 & 4.881 & TRN \\
\hline CHEMBL1483173 & 688746 & 4.85 & 4.8245 & TRN \\
\hline CHEMBL1409348 & 688746 & 4.4 & 4.8141 & TRN \\
\hline
\end{tabular}




\begin{tabular}{|c|c|c|c|c|}
\hline \multicolumn{5}{|c|}{ Supplemental Table S2.txt } \\
\hline CHEMBL1349938 & 688746 & 5.2 & 4.8815 & TRN \\
\hline CHEMBL1529266 & 688746 & 4.55 & 4.9176 & TRN \\
\hline CHEMBL1301379 & 688746 & 4.45 & 5.0626 & TRN \\
\hline CHEMBL1344369 & 688746 & 5.05 & 5.066 & TRN \\
\hline CHEMBL3194192 & 688746 & 4.7 & 4.7857 & TRN \\
\hline CHEMBL1572850 & 688746 & 4.65 & 4.9023 & TRN \\
\hline CHEMBL1402390 & 688746 & 4.8 & 4.7412 & TRN \\
\hline CHEMBL1335988 & 688746 & 5.5 & 4.8159 & TST \\
\hline CHEMBL1361191 & 688746 & 4.5 & 4.7994 & TRN \\
\hline CHEMBL1517538 & 688746 & 4.95 & 4.7959 & TRN \\
\hline CHEMBL1499414 & 688746 & 4.8 & 4.8971 & TRN \\
\hline CHEMBL75913 & 688746 & 4.6 & 4.8374 & TST \\
\hline CHEMBL1525814 & 688746 & 7.0 & 4.9095 & TST \\
\hline CHEMBL1519690 & 688746 & 5.0 & 4.8928 & TRN \\
\hline CHEMBL1424798 & 688746 & 4.6 & 4.8013 & TST \\
\hline CHEMBL1501868 & 688746 & 4.8 & 4.8133 & TRN \\
\hline CHEMBL1375679 & 688746 & 4.6 & 4.9056 & TRN \\
\hline CHEMBL116548 & 688746 & 4.55 & 4.869 & TST \\
\hline CHEMBL1340058 & 688746 & 4.55 & 4.8159 & TRN \\
\hline CHEMBL3193859 & 688746 & 4.4 & 4.7808 & TRN \\
\hline CHEMBL3192197 & 688746 & 5.3 & 4.7106 & TRN \\
\hline CHEMBL1501349 & 688746 & 4.4 & 4.8449 & TRN \\
\hline CHEMBL1478632 & 688746 & 6.1 & 4.8573 & TST \\
\hline CHEMBL1612932 & 688746 & 5.45 & 4.8853 & TRN \\
\hline CHEMBL1440986 & 688746 & 4.9 & 4.7654 & TRN \\
\hline CHEMBL1596719 & 688746 & 4.5 & 4.7232 & TRN \\
\hline CHEMBL1471580 & 688746 & 4.5 & 4.8849 & TRN \\
\hline CHEMBL1384592 & 688746 & 4.4 & 4.7526 & TRN \\
\hline CHEMBL1596106 & 688746 & 4.4 & 4.9009 & TRN \\
\hline CHEMBL1565830 & 688746 & 4.75 & 4.822 & TRN \\
\hline CHEMBL1329071 & 688746 & 4.85 & 4.859 & TRN \\
\hline CHEMBL1598532 & 688746 & 6.8499 & 4.7356 & TST \\
\hline CHEMBL1329984 & 688746 & 5.05 & 4.9602 & TRN \\
\hline CHEMBL1488643 & 688746 & 5.3 & 4.886 & TST \\
\hline CHEMBL1546760 & 688746 & 4.85 & 4.8348 & TRN \\
\hline CHEMBL1489339 & 688746 & 5.05 & 4.966 & TRN \\
\hline CHEMBL1990418 & 688746 & 4.9 & 4.9255 & TST \\
\hline CHEMBL1387436 & 688746 & 4.8 & 4.7858 & TRN \\
\hline CHEMBL1369309 & 688746 & 5.75 & 4.9777 & TRN \\
\hline CHEMBL1303824 & 688746 & 4.5 & 4.9151 & TRN \\
\hline CHEMBL1444465 & 688746 & 4.4 & 4.9456 & TRN \\
\hline CHEMBL1491312 & 688746 & 4.4 & 4.792 & TRN \\
\hline CHEMBL1420785 & 688746 & 4.65 & 4.9456 & TRN \\
\hline CHEMBL1972652 & 688746 & 5.5 & 4.8364 & TRN \\
\hline CHEMBL1598010 & 688746 & 4.4 & 4.7984 & TST \\
\hline CHEMBL1332207 & 688746 & 5.15 & 4.7624 & TRN \\
\hline CHEMBL1547034 & 688746 & 4.8 & 4.7518 & TRN \\
\hline CHEMBL1996724 & 688746 & 4.4 & 4.8152 & TST \\
\hline
\end{tabular}




\begin{tabular}{|c|c|c|c|c|c|}
\hline \multicolumn{6}{|c|}{ Supplemental Table s2.txt } \\
\hline CHEMBL1408241 & 688746 & 4.85 & 4.8654 & TRN & \\
\hline CHEMBL1471762 & 688746 & 4.7 & 4.8032 & TRN & \\
\hline CHEMBL1495170 & 688746 & 5.55 & 4.8518 & TRN & \\
\hline CHEMBL1384821 & 688746 & 4.45 & 4.9741 & TRN & \\
\hline CHEMBL1449317 & 688746 & 5.45 & 4.9205 & TRN & \\
\hline CHEMBL1521770 & 688746 & 4.75 & 4.8537 & TRN & \\
\hline CHEMBL1415572 & 688746 & 5.35 & 4.8599 & TRN & \\
\hline CHEMBL1380781 & 688746 & 5.2 & 4.8159 & TRN & \\
\hline CHEMBL1967540 & 688746 & 5.3 & 4.7843 & TRN & \\
\hline CHEMBL3187659 & 688746 & 4.85 & 4.7711 & TRN & \\
\hline CHEMBL1571222 & 688746 & 4.65 & 4.9175 & TRN & \\
\hline CHEMBL1533055 & 688746 & 4.9 & 4.8307 & TRN & \\
\hline CHEMBL1965873 & 688746 & 5.15 & 4.7707 & TRN & \\
\hline CHEMBL1430953 & 688746 & 4.7 & 4.8758 & TST & \\
\hline CHEMBL1613669 & 688746 & 5.6 & 4.9981 & TRN & \\
\hline CHEMBL1526851 & 688746 & 5.5 & 4.7449 & TRN & \\
\hline CHEMBL1500443 & 688746 & 5.15 & 4.9133 & TST & \\
\hline CHEMBL1485491 & 688746 & 6.7001 & 4.8009 & TRN & \\
\hline CHEMBL1197556 & 688746 & 4.85 & 4.8368 & TST & \\
\hline CHEMBL1386301 & 688746 & 4.65 & 4.886 & TRN & \\
\hline CHEMBL1321480 & 688746 & 4.55 & 4.7799 & TRN & \\
\hline CHEMBL1366410 & 688746 & 4.65 & 4.9355 & TRN & \\
\hline CHEMBL1556882 & 688746 & 4.5 & 4.8455 & TRN & \\
\hline CHEMBL1458720 & 688746 & 4.95 & 4.8289 & TRN & \\
\hline CHEMBL1597701 & 688746 & 5.1 & 4.8796 & TRN & \\
\hline CHEMBL1441707 & 688746 & 4.45 & 4.9103 & TRN & \\
\hline CHEMBL1467247 & 688746 & 4.55 & 4.8204 & TRN & \\
\hline CHEMBL1556391 & 688746 & 6.7001 & 4.9012 & TST & \\
\hline CHEMBL1406791 & 688746 & 6.05 & 4.8404 & TRN & \\
\hline CHEMBL225951 & 688746 & 4.9 & 4.7432 & TRN & \\
\hline CHEMBL1333161 & 688746 & 5.4 & 4.9456 & TRN & \\
\hline CHEMBL1439985 & 688746 & 5.3 & 4.6945 & TRN & \\
\hline CHEMBL590660 & 688746 & 4.45 & 4.7821 & TRN & \\
\hline CHEMBL1343915 & 688746 & 4.4 & 4.8825 & TRN & \\
\hline CHEMBL3190456 & 688746 & 4.4 & 4.7511 & TRN & \\
\hline CHEMBL1338936 & 688746 & 4.6 & 4.8006 & TRN & \\
\hline CHEMBL1982913 & 688746 & 4.65 & 4.7952 & TRN & \\
\hline CHEMBL1377249 & 688746 & 4.65 & 4.886 & TRN & \\
\hline CHEMBL1498877 & 688746 & 4.45 & 4.9531 & TRN & \\
\hline CHEMBL1333963 & 688746 & 5.0 & 4.8121 & TRN & \\
\hline CHEMBL1449305 & 688746 & 5.2 & 4.859 & TRN & \\
\hline CHEMBL1542219 & 688746 & 4.4 & 4.8631 & TRN & \\
\hline CHEMBL1588560 & 688746 & 4.6 & 4.82600 & 00000000005 & TST \\
\hline CHEMBL1466389 & 688746 & 5.35 & 4.80399 & 9999999999 & TRN \\
\hline CHEMBL1575115 & 688746 & 4.95 & 4.9396 & TRN & \\
\hline CHEMBL3192436 & 688746 & 4.5 & 4.7643 & TRN & \\
\hline CHEMBL1461225 & 688746 & 4.5 & 4.8999 & TRN & \\
\hline CHEMBL1574389 & 688746 & 4.4 & 4.8457 & TRN & \\
\hline
\end{tabular}




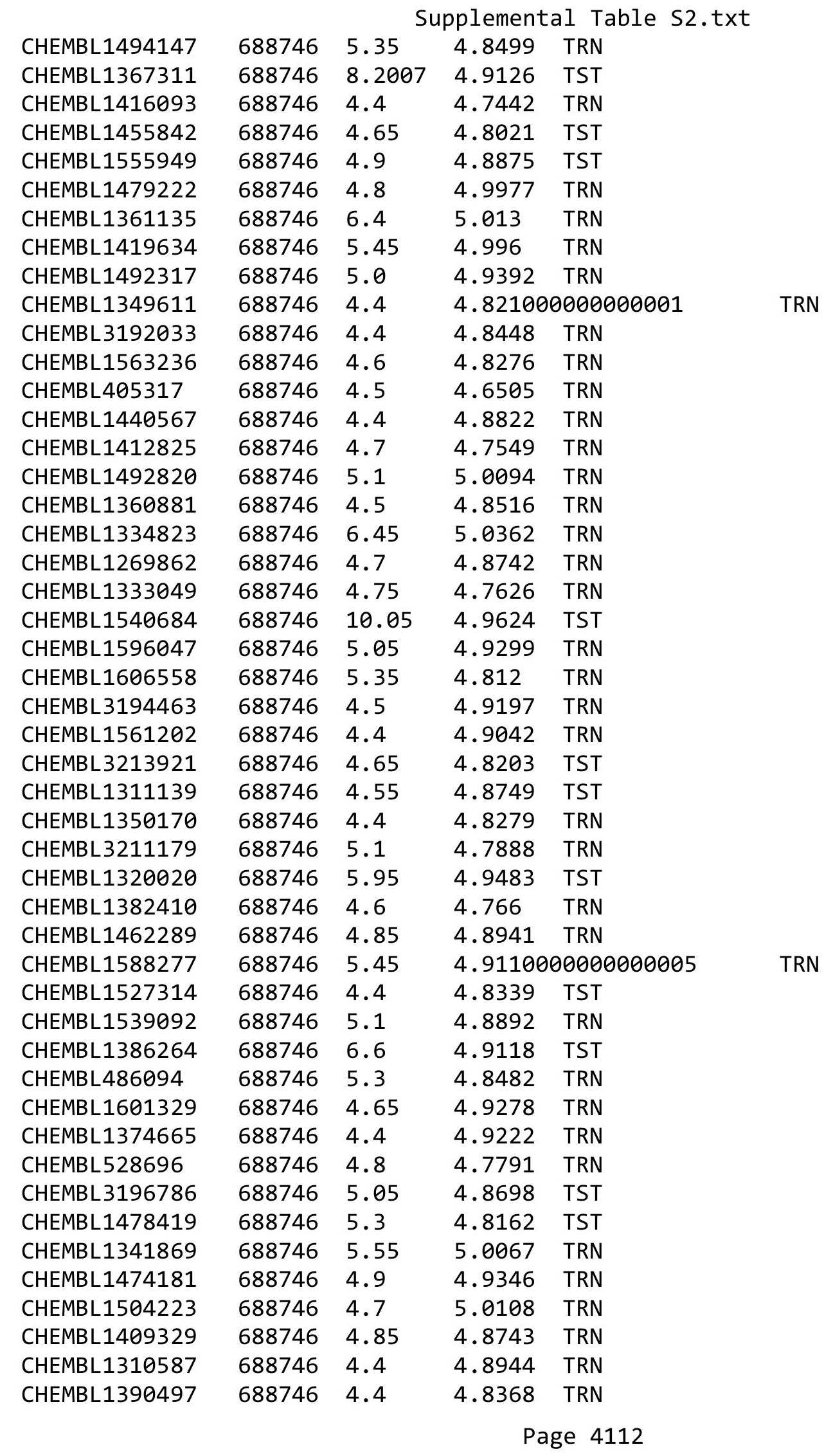




\begin{tabular}{|c|c|c|c|c|}
\hline \multicolumn{5}{|c|}{ Supplemental Table S2.txt } \\
\hline CHEMBL1423901 & 688746 & 4.85 & 4.9172 & TRN \\
\hline CHEMBL1406872 & 688746 & 5.0 & 4.9565 & TRN \\
\hline CHEMBL1498728 & 688746 & 4.5 & 4.7763 & TRN \\
\hline CHEMBL1348026 & 688746 & 4.6 & 4.8624 & TRN \\
\hline CHEMBL1477218 & 688746 & 4.4 & 4.8348 & TST \\
\hline CHEMBL1448433 & 688746 & 5.95 & 4.7631 & TST \\
\hline CHEMBL3197268 & 688746 & 4.45 & 4.7612 & TRN \\
\hline CHEMBL1595606 & 688746 & 5.85 & 4.8857 & TRN \\
\hline CHEMBL1558265 & 688746 & 4.55 & 4.8322 & TRN \\
\hline CHEMBL1353151 & 688746 & 4.7 & 4.9209 & TRN \\
\hline CHEMBL1402928 & 688746 & 4.7 & 4.8787 & TRN \\
\hline CHEMBL1428912 & 688746 & 4.45 & 4.7835 & TRN \\
\hline CHEMBL1582131 & 688746 & 5.45 & 4.8532 & TST \\
\hline CHEMBL1560985 & 688746 & 4.5 & 4.8587 & TRN \\
\hline CHEMBL1313761 & 688746 & 4.75 & 4.8356 & TRN \\
\hline CHEMBL3210794 & 688746 & 4.55 & 4.8767 & TRN \\
\hline CHEMBL1319476 & 688746 & 4.4 & 4.9369 & TST \\
\hline CHEMBL3192160 & 688746 & 5.15 & 4.7782 & TRN \\
\hline CHEMBL1994635 & 688746 & 4.8 & 4.7249 & TRN \\
\hline CHEMBL1554376 & 688746 & 4.4 & 4.9678 & TRN \\
\hline CHEMBL1306254 & 688746 & 4.6 & 4.8905 & TRN \\
\hline CHEMBL1605869 & 688746 & 4.55 & 4.8231 & TRN \\
\hline CHEMBL1350028 & 688746 & 4.6 & 4.8011 & TRN \\
\hline CHEMBL1526855 & 688746 & 5.45 & 4.9011 & TRN \\
\hline CHEMBL1588221 & 688746 & 6.0 & 4.8273 & TRN \\
\hline CHEMBL1582195 & 688746 & 4.65 & 4.758 & TST \\
\hline CHEMBL1584875 & 688746 & 4.65 & 4.7797 & TRN \\
\hline CHEMBL1325338 & 688746 & 4.4 & 4.9478 & TRN \\
\hline CHEMBL3192853 & 688746 & 5.4 & 4.8369 & TRN \\
\hline CHEMBL1504914 & 688746 & 5.5 & 4.8768 & TRN \\
\hline CHEMBL1329610 & 688746 & 4.85 & 4.842 & TRN \\
\hline CHEMBL1372655 & 688746 & 4.5 & 4.9029 & TST \\
\hline CHEMBL1479132 & 688746 & 4.4 & 4.7004 & TRN \\
\hline CHEMBL1508240 & 688746 & 4.85 & 4.8036 & TRN \\
\hline CHEMBL1412068 & 688746 & 4.45 & 4.7074 & TRN \\
\hline CHEMBL1463482 & 688746 & 4.5 & 4.8113 & TRN \\
\hline CHEMBL1469080 & 688746 & 5.0 & 4.9443 & TRN \\
\hline CHEMBL1423456 & 688746 & 4.65 & 4.8408 & TRN \\
\hline CHEMBL1556579 & 688746 & 4.85 & 4.8454 & TRN \\
\hline CHEMBL1495778 & 688746 & 4.55 & 4.8095 & TRN \\
\hline CHEMBL1451245 & 688746 & 4.6 & 4.7645 & TRN \\
\hline CHEMBL1536418 & 688746 & 4.8 & 4.7513 & TST \\
\hline CHEMBL1443470 & 688746 & 4.4 & 4.8782 & TST \\
\hline CHEMBL1489268 & 688746 & 4.4 & 4.8667 & TST \\
\hline CHEMBL1571315 & 688746 & 4.8 & 4.7476 & TRN \\
\hline CHEMBL1312319 & 688746 & 4.45 & 4.8642 & TST \\
\hline CHEMBL1542617 & 688746 & 4.45 & 4.9254 & TST \\
\hline CHEMBL1467060 & 688746 & 5.45 & 4.8618 & TRN \\
\hline
\end{tabular}




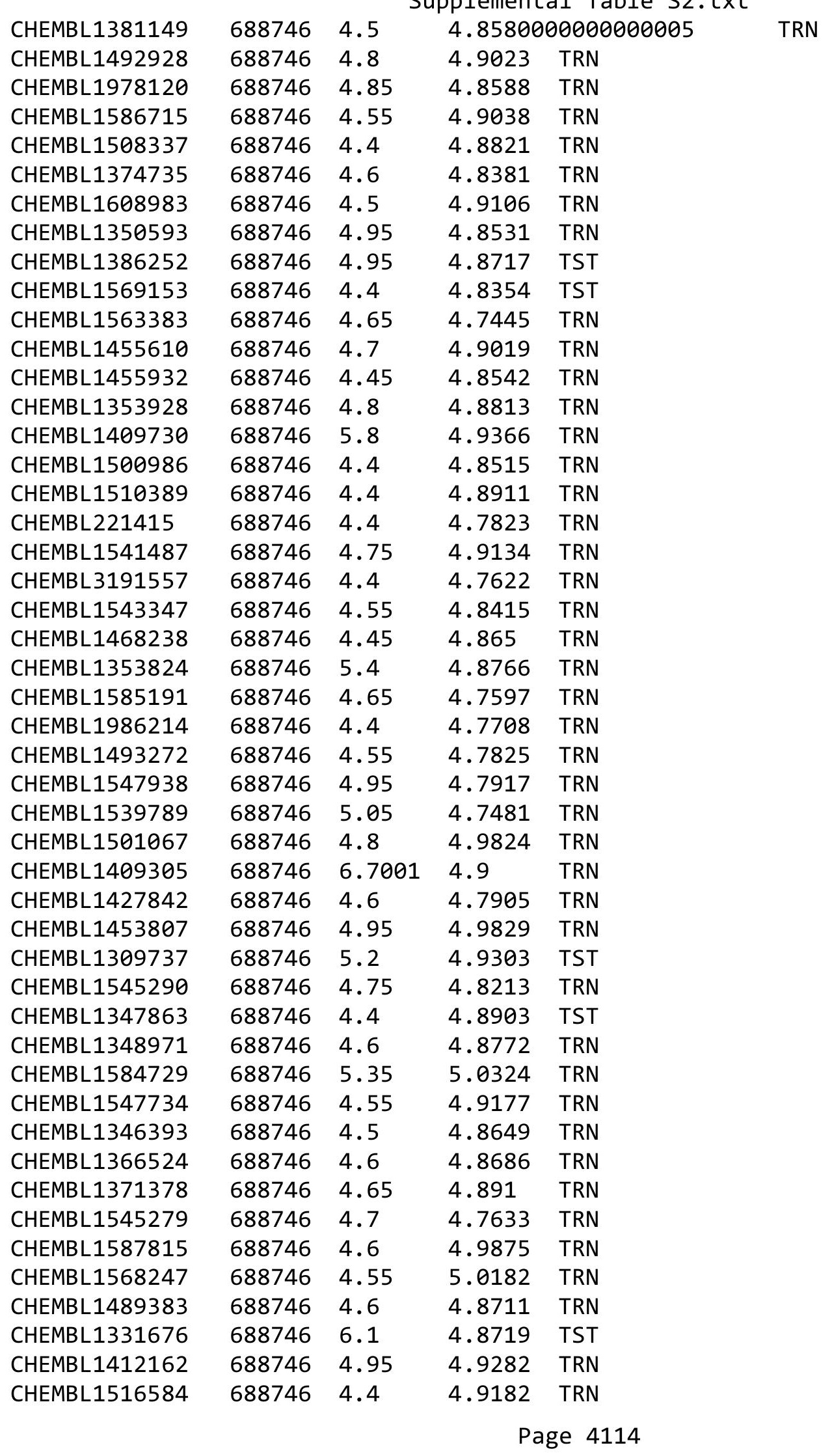




\begin{tabular}{|c|c|c|c|c|}
\hline \multicolumn{5}{|c|}{ Supplemental Table S2.txt } \\
\hline CHEMBL1489449 & 688746 & 5.0 & 4.7874 & TRN \\
\hline CHEMBL1581440 & 688746 & 4.65 & 4.806 & TRN \\
\hline CHEMBL1348251 & 688746 & 5.45 & 4.8981 & TRN \\
\hline CHEMBL1478561 & 688746 & 5.0 & 4.88 & TRN \\
\hline CHEMBL1448089 & 688746 & 5.4 & 4.8537 & TRN \\
\hline CHEMBL1586765 & 688746 & 5.1 & 4.967 & TRN \\
\hline CHEMBL1382074 & 688746 & 4.5 & 4.9486 & TST \\
\hline CHEMBL1411856 & 688746 & 4.6 & 4.987 & TRN \\
\hline CHEMBL1409863 & 688746 & 4.5 & 4.8311 & TRN \\
\hline CHEMBL1447108 & 688746 & 4.65 & 4.8614 & TRN \\
\hline CHEMBL1457771 & 688746 & 5.25 & 4.9687 & TRN \\
\hline CHEMBL1595274 & 688746 & 4.85 & 4.8876 & TST \\
\hline CHEMBL3211187 & 688746 & 4.55 & 4.9303 & TRN \\
\hline CHEMBL1471809 & 688746 & 5.4 & 4.8689 & TST \\
\hline CHEMBL1583893 & 688746 & 5.95 & 4.92 & TRN \\
\hline CHEMBL1392192 & 688746 & 4.6 & 4.9653 & TRN \\
\hline CHEMBL1375021 & 688746 & 4.95 & 5.0703 & TRN \\
\hline CHEMBL3191895 & 688746 & 4.55 & 4.8817 & TRN \\
\hline CHEMBL1535701 & 688746 & 5.15 & 5.0256 & TRN \\
\hline CHEMBL1386949 & 688746 & 4.4 & 4.9301 & TRN \\
\hline CHEMBL1417732 & 688746 & 5.0 & 4.788 & TRN \\
\hline CHEMBL1521752 & 688746 & 5.15 & 4.9326 & TRN \\
\hline CHEMBL1305421 & 688746 & 4.65 & 4.8587 & TRN \\
\hline CHEMBL1519554 & 688746 & 4.8 & 4.7382 & TRN \\
\hline CHEMBL1345420 & 688746 & 5.1 & 4.8432 & TRN \\
\hline CHEMBL1374938 & 688746 & 5.45 & 4.8956 & TRN \\
\hline CHEMBL3213197 & 688746 & 5.8 & 4.9702 & TRN \\
\hline CHEMBL1545058 & 688746 & 4.45 & 4.8004 & TRN \\
\hline CHEMBL1531944 & 688746 & 4.65 & 4.803 & TRN \\
\hline CHEMBL1401363 & 688746 & 6.05 & 4.9627 & TRN \\
\hline CHEMBL1523417 & 688746 & 4.6 & 4.9367 & TRN \\
\hline CHEMBL1511219 & 688746 & 4.8 & 4.7559 & TRN \\
\hline CHEMBL1304837 & 688746 & 4.55 & 4.9561 & TRN \\
\hline CHEMBL1332375 & 688746 & 4.75 & 4.8335 & TRN \\
\hline CHEMBL1454081 & 688746 & 4.6 & 4.8423 & TRN \\
\hline CHEMBL1482787 & 688746 & 4.4 & 4.8924 & TRN \\
\hline CHEMBL1301962 & 688746 & 5.65 & 4.9138 & TRN \\
\hline CHEMBL1322728 & 688746 & 5.15 & 4.9419 & TRN \\
\hline CHEMBL1350435 & 688746 & 4.95 & 4.8321 & TRN \\
\hline CHEMBL1416266 & 688746 & 4.8 & 4.8595 & TRN \\
\hline CHEMBL3208408 & 688746 & 4.95 & 4.8017 & TRN \\
\hline CHEMBL3213264 & 688746 & 4.4 & 4.7477 & TRN \\
\hline CHEMBL1559143 & 688746 & 4.65 & 4.8886 & TRN \\
\hline CHEMBL1982901 & 688746 & 4.65 & 4.6994 & TRN \\
\hline CHEMBL1389341 & 688746 & 4.75 & 4.9717 & TRN \\
\hline CHEMBL1393275 & 688746 & 4.9 & 4.9566 & TRN \\
\hline CHEMBL1457590 & 688746 & 4.8 & 4.9333 & TRN \\
\hline CHEMBL1562068 & 688746 & 4.5 & 4.947 & TRN \\
\hline
\end{tabular}




\begin{tabular}{|c|c|c|c|c|c|}
\hline & & \\
\hline CHEMBL1341923 & 688746 & 6.1 & 4.9095 & TRN & \\
\hline CHEMBL1401954 & 688746 & 5.4 & 4.8793 & TRN & \\
\hline CHEMBL140 & 688746 & 4.55 & 4.8189 & TRN & \\
\hline CHEMBL1585250 & 688746 & 5.75 & 4.8873 & TRN & \\
\hline CHEMBL1499803 & 688746 & 4.45 & 4.7536 & TRN & \\
\hline CHEMBL1563327 & 688746 & 4.4 & 4.8146 & TST & \\
\hline CHEMBL1487563 & 688746 & 4.55 & 4.7766 & TRN & \\
\hline CHEMBL1465518 & 688746 & 4.85 & 4.8363 & TRN & \\
\hline CHEMBL1344651 & 688746 & 4.85 & 4.85 & TRN & \\
\hline CHEMBL1418601 & 688746 & 4.8 & 4.8498 & TRN & \\
\hline CHEMBL1464547 & 688746 & 4.8 & 4.8738 & TRN & \\
\hline CHEMBL1471458 & 688746 & 4.4 & 4.8587 & TRN & \\
\hline CHEMBL1446064 & 688746 & 4.55 & 4.899 & TRN & \\
\hline CHEMBL1455820 & 688746 & 4.7 & 4.9992 & TRN & \\
\hline CHEMBL1313485 & 688746 & 5.25 & 4.8338 & TST & \\
\hline CHEMBL1099177 & 688746 & 4.65 & 4.8005 & TST & \\
\hline CHEMBL1376836 & 688746 & 4.4 & 4.8607 & TST & \\
\hline CHEMBL1495505 & 688746 & 4.6 & 4.6902 & TRN & \\
\hline CHEMBL1516134 & 688746 & 5.6 & 4.9611 & TRN & \\
\hline CHEMBL1441511 & 688746 & 5.35 & 4.8088 & TRN & \\
\hline CHEMBL1423069 & 688746 & 5.3 & 4.7816 & TRN & \\
\hline CHEMBL1427289 & 688746 & 4.55 & 4.773 & TRN & \\
\hline CHEMBL1443863 & 688746 & 4.45 & 4.896 & TRN & \\
\hline CHEMBL3214355 & 688746 & 4.55 & 4.8329 & TRN & \\
\hline CHEMBL1522734 & 688746 & 5.35 & 4.8714 & TST & \\
\hline CHEMBL1406720 & 688746 & 4.4 & 4.8166 & TRN & \\
\hline CHEMBL 2000888 & 688746 & 5.05 & 4.8043 & TRN & \\
\hline CHEMBL1611573 & 688746 & 5.05 & 4.8189 & TRN & \\
\hline CHEMBL1367356 & 688746 & 4.65 & 4.8675 & TRN & \\
\hline CHEMBL1584030 & 688746 & 4.55 & 4.7842 & TRN & \\
\hline CHEMBL1335132 & 688746 & 6.05 & 4.8277 & TST & \\
\hline CHEMBL1398991 & 688746 & 4.6 & 5.022 & TRN & \\
\hline CHEMBL1392671 & 688746 & 4.9 & 4.8942 & TRN & \\
\hline CHEMBL1306203 & 688746 & 4.4 & 4.7732 & TRN & \\
\hline CHEMBL1374474 & 688746 & 4.4 & 4.8476 & TRN & \\
\hline CHEMBL1499070 & 688746 & 4.6 & 4.878 & TRN & \\
\hline CHEMBL1356213 & 688746 & 5.4 & 4.9382 & TRN & \\
\hline CHEMBL1408307 & 688746 & 4.85 & 4.7758 & TRN & \\
\hline CHEMBL1488194 & 688746 & 5.4 & 4.8384 & TST & \\
\hline CHEMBL1300595 & 688746 & 4.5 & 4.9114 & TRN & \\
\hline CHEMBL1393926 & 688746 & 4.9 & 4.8177 & TRN & \\
\hline CHEMBL1477027 & 688746 & 5.4 & 4.8537 & TST & \\
\hline CHEMBL1449935 & 688746 & 5.05 & 4.8868 & TRN & \\
\hline CHEMBL1586973 & 688746 & 4.6 & 4.8259 & TRN & \\
\hline CHEMBL1968361 & 688746 & 4.75 & 4.76399 & 9999999999 & TRN \\
\hline CHEMBL1345831 & 688746 & 4.45 & 4.8147 & TRN & \\
\hline CHEMBL 1486212 & 688746 & 4.4 & 4.7989 & TRN & \\
\hline CHEMBL1441918 & 688746 & 4.4 & 4.8259 & TRN & \\
\hline & & & & 4116 & \\
\hline
\end{tabular}




\begin{tabular}{|c|c|c|c|c|}
\hline \multicolumn{5}{|c|}{ Supplemental Table S2.txt } \\
\hline CHEMBL1319111 & 688746 & 4.4 & 4.8697 & TRN \\
\hline CHEMBL1348393 & 688746 & 4.55 & 4.784 & TRN \\
\hline CHEMBL1494470 & 688746 & 4.5 & 4.8084 & TRN \\
\hline CHEMBL1339466 & 688746 & 4.7 & 4.7372 & TRN \\
\hline CHEMBL1422477 & 688746 & 4.7 & 4.9135 & TRN \\
\hline CHEMBL1588629 & 688746 & 4.4 & 4.7757 & TRN \\
\hline CHEMBL1600495 & 688746 & 4.85 & 5.0234 & TRN \\
\hline CHEMBL1502908 & 688746 & 4.6 & 4.7768 & TRN \\
\hline CHEMBL 2004475 & 688746 & 4.95 & 4.8802 & TST \\
\hline CHEMBL1324654 & 688746 & 4.6 & 4.8756 & TST \\
\hline CHEMBL1353518 & 688746 & 4.75 & 4.9484 & TRN \\
\hline CHEMBL1584343 & 688746 & 4.5 & 5.0438 & TRN \\
\hline CHEMBL1388616 & 688746 & 4.75 & 4.9096 & TRN \\
\hline CHEMBL1332045 & 688746 & 4.4 & 4.9096 & TRN \\
\hline CHEMBL1548591 & 688746 & 4.65 & 4.9072 & TRN \\
\hline CHEMBL1368202 & 688746 & 4.4 & 4.8638 & TRN \\
\hline CHEMBL1388088 & 688746 & 4.65 & 4.8196 & TRN \\
\hline CHEMBL3189818 & 688746 & 6.1 & 4.811 & TST \\
\hline CHEMBL1453592 & 688746 & 4.4 & 4.8857 & TRN \\
\hline CHEMBL1313708 & 688746 & 4.5 & 4.9109 & TRN \\
\hline CHEMBL1309877 & 688746 & 4.7 & 4.8803 & TRN \\
\hline CHEMBL1379875 & 688746 & 5.15 & 4.872 & TST \\
\hline CHEMBL3197141 & 688746 & 4.55 & 4.7835 & TRN \\
\hline CHEMBL1520214 & 688746 & 4.9 & 4.852 & TRN \\
\hline CHEMBL1491747 & 688746 & 4.4 & 4.823 & TST \\
\hline CHEMBL1372429 & 688746 & 5.8 & 5.0226 & TRN \\
\hline CHEMBL1535709 & 688746 & 4.4 & 4.8734 & TRN \\
\hline CHEMBL1541664 & 688746 & 4.85 & 4.9442 & TRN \\
\hline CHEMBL1410575 & 688746 & 4.5 & 4.8751 & TRN \\
\hline CHEMBL1359204 & 688746 & 7.2 & 4.85 & TST \\
\hline CHEMBL1586204 & 688746 & 4.45 & 4.8676 & TRN \\
\hline CHEMBL1347345 & 688746 & 4.45 & 4.9563 & TRN \\
\hline CHEMBL1970272 & 688746 & 4.95 & 4.9098 & TST \\
\hline CHEMBL1385516 & 688746 & 4.6 & 4.7857 & TRN \\
\hline CHEMBL 3212751 & 688746 & 4.85 & 4.8843 & TRN \\
\hline CHEMBL1493886 & 688746 & 4.75 & 4.7479 & TRN \\
\hline CHEMBL1474864 & 688746 & 5.15 & 4.8698 & TST \\
\hline CHEMBL1320254 & 688746 & 4.4 & 4.8025 & TST \\
\hline CHEMBL1309000 & 688746 & 4.6 & 4.8688 & TST \\
\hline CHEMBL1531023 & 688746 & 4.45 & 4.9289 & TRN \\
\hline CHEMBL1989440 & 688746 & 4.8 & 4.7509 & TRN \\
\hline CHEMBL1503962 & 688746 & 4.75 & 4.8329 & TST \\
\hline CHEMBL1525337 & 688746 & 4.75 & 4.9434 & TST \\
\hline CHEMBL1323968 & 688746 & 4.6 & 4.7904 & TRN \\
\hline CHEMBL1430987 & 688746 & 4.5 & 4.8895 & TRN \\
\hline CHEMBL373909 & 688746 & 5.35 & 4.7559 & TRN \\
\hline CHEMBL1584578 & 688746 & 4.75 & 4.8588 & TST \\
\hline CHEMBL1405454 & 688746 & 4.5 & 4.8942 & TRN \\
\hline
\end{tabular}




\begin{tabular}{|c|c|c|c|c|c|}
\hline & & & & & \\
\hline CHEMBL1581374 & 688746 & 4.7 & 4.86 & TRN & \\
\hline CHEMBL1507307 & 688746 & 4.5 & 4.8544 & TST & \\
\hline CHEMBL3194700 & 688746 & 4.8 & 4.8956 & TST & \\
\hline CHEMBL1501901 & 688746 & 6.4 & 4.8983 & TRN & \\
\hline CHEMBL1307518 & 688746 & 4.95 & 5.043 & TRN & \\
\hline CHEMBL1471965 & 688746 & 4.6 & 4.7874 & TRN & \\
\hline CHEMBL1426233 & 688746 & 4.95 & 4.8269 & TRN & \\
\hline CHEMBL3195494 & 688746 & 5.45 & 4.8023 & TST & \\
\hline CHEMBL1403417 & 688746 & 4.4 & 4.7848 & TRN & \\
\hline CHEMBL1581734 & 688746 & 4.85 & 4.9165 & TRN & \\
\hline CHEMBL1502268 & 688746 & 5.45 & 4.8375 & TRN & \\
\hline CHEMBL1447124 & 688746 & 5.4 & 4.8742 & TRN & \\
\hline CHEMBL1559523 & 688746 & 4.65 & 4.8292 & TRN & \\
\hline CHEMBL1582563 & 688746 & 4.55 & 4.8341 & TRN & \\
\hline CHEMBL1522035 & 688746 & 5.0 & 4.8727 & TRN & \\
\hline CHEMBL1353907 & 688746 & 4.6 & 4.81800 & 00000000005 & TRN \\
\hline CHEMBL1608610 & 688746 & 5.0 & 4.8134 & TRN & \\
\hline CHEMBL1418029 & 688746 & 4.55 & 4.9849 & TRN & \\
\hline CHEMBL1544306 & 688746 & 4.55 & 4.8136 & TRN & \\
\hline CHEMBL1520315 & 688746 & 4.6 & 5.0075 & TRN & \\
\hline CHEMBL1543184 & 688746 & 4.6 & 4.8907 & TRN & \\
\hline CHEMBL1537058 & 688746 & 4.7 & 4.8546 & TRN & \\
\hline CHEMBL1300772 & 688746 & 4.5 & 4.7754 & TRN & \\
\hline CHEMBL1610636 & 688746 & 4.4 & 4.814 & TRN & \\
\hline CHEMBL1403156 & 688746 & 4.6 & 4.8122 & TRN & \\
\hline CHEMBL1548953 & 688746 & 4.4 & 4.9476 & TRN & \\
\hline CHEMBL1340905 & 688746 & 4.85 & 4.782 & TRN & \\
\hline CHEMBL1350891 & 688746 & 4.4 & 4.8906 & TRN & \\
\hline CHEMBL1347748 & 688746 & 4.4 & 4.8821 & TRN & \\
\hline CHEMBL1342736 & 688746 & 4.65 & 4.8361 & TRN & \\
\hline CHEMBL1415509 & 688746 & 4.8 & 4.9728 & TRN & \\
\hline CHEMBL1994596 & 688746 & 4.75 & 4.7242 & TRN & \\
\hline CHEMBL 3198821 & 688746 & 4.75 & 4.7818 & TRN & \\
\hline CHEMBL1525623 & 688746 & 4.7 & 4.8998 & TRN & \\
\hline CHEMBL1480398 & 688746 & 4.75 & 4.8882 & TST & \\
\hline CHEMBL1490305 & 688746 & 4.9 & 4.8279 & TRN & \\
\hline CHEMBL1503633 & 688746 & 4.45 & 4.8373 & TRN & \\
\hline CHEMBL1532070 & 688746 & 4.95 & 4.9586 & TRN & \\
\hline CHEMBL1538717 & 688746 & 5.15 & 4.8796 & TRN & \\
\hline CHEMBL1398955 & 688746 & 4.85 & 5.0431 & TRN & \\
\hline CHEMBL1540427 & 688746 & 4.85 & 4.8094 & TRN & \\
\hline CHEMBL3194561 & 688746 & 4.8 & 4.7867 & TRN & \\
\hline CHEMBL1538023 & 688746 & 4.45 & 4.8277 & TRN & \\
\hline CHEMBL1478109 & 688746 & 6.9 & 4.9206 & TRN & \\
\hline CHEMBL1507972 & 688746 & 4.95 & 4.7451 & TRN & \\
\hline CHEMBL1510655 & 688746 & 4.95 & 4.8304 & TRN & \\
\hline CHEMBL1543847 & 688746 & 4.6 & 4.7902 & TRN & \\
\hline CHEMBL1460632 & 688746 & 8.2007 & 4.9666 & TRN & \\
\hline
\end{tabular}




\begin{tabular}{|c|c|c|c|c|}
\hline \multicolumn{5}{|c|}{ Supplemental Table S2.txt } \\
\hline CHEMBL3199770 & 688746 & 6.0 & 4.8491 & TRN \\
\hline CHEMBL1499870 & 688746 & 4.4 & 4.8088 & TRN \\
\hline CHEMBL1509692 & 688746 & 4.6 & 4.9097 & TRN \\
\hline CHEMBL1432130 & 688746 & 4.8 & 4.9024 & TST \\
\hline CHEMBL1536609 & 688746 & 4.6 & 4.8968 & TRN \\
\hline CHEMBL1481493 & 688746 & 4.4 & 4.8384 & TRN \\
\hline CHEMBL1583838 & 688746 & 4.45 & 4.7991 & TRN \\
\hline CHEMBL1410025 & 688746 & 5.05 & 4.8631 & TRN \\
\hline CHEMBL1613708 & 688746 & 4.55 & 4.8425 & TRN \\
\hline CHEMBL1431940 & 688746 & 4.4 & 4.8729 & TRN \\
\hline CHEMBL1609746 & 688746 & 4.65 & 4.8804 & TRN \\
\hline CHEMBL1547610 & 688746 & 4.4 & 4.8451 & TRN \\
\hline CHEMBL1321639 & 688746 & 5.2 & 4.8518 & TRN \\
\hline CHEMBL1407743 & 688746 & 5.65 & 4.8647 & TST \\
\hline CHEMBL1299987 & 688746 & 4.55 & 4.8682 & TRN \\
\hline CHEMBL1445387 & 688746 & 4.4 & 4.908 & TST \\
\hline CHEMBL1468505 & 688746 & 4.7 & 4.8969 & TRN \\
\hline CHEMBL1300836 & 688746 & 4.4 & 4.8069 & TRN \\
\hline CHEMBL1608758 & 688746 & 4.45 & 4.775 & TRN \\
\hline CHEMBL1470463 & 688746 & 5.5 & 4.8295 & TRN \\
\hline CHEMBL1578479 & 688746 & 5.0 & 4.794 & TRN \\
\hline CHEMBL1604448 & 688746 & 4.45 & 4.9095 & TRN \\
\hline CHEMBL355318 & 688746 & 5.15 & 4.8034 & TRN \\
\hline CHEMBL1368420 & 688746 & 6.0 & 4.871 & TRN \\
\hline CHEMBL 2000670 & 688746 & 4.85 & 4.721 & TRN \\
\hline CHEMBL1471879 & 688746 & 4.7 & 4.8856 & TRN \\
\hline CHEMBL1495417 & 688746 & 4.85 & 4.8637 & TRN \\
\hline CHEMBL1347042 & 688746 & 5.0 & 4.7851 & TRN \\
\hline CHEMBL1341526 & 688746 & 5.8 & 4.8228 & TST \\
\hline CHEMBL1334194 & 688746 & 4.55 & 4.9489 & TST \\
\hline CHEMBL1382674 & 688746 & 4.6 & 4.8861 & TST \\
\hline CHEMBL1381607 & 688746 & 4.9 & 4.995 & TRN \\
\hline CHEMBL1498604 & 688746 & 5.5 & 4.8197 & TRN \\
\hline CHEMBL1380522 & 688746 & 4.65 & 4.7963 & TST \\
\hline CHEMBL1578299 & 688746 & 4.75 & 4.7852 & TRN \\
\hline CHEMBL1312800 & 688746 & 4.55 & 4.8862 & TRN \\
\hline CHEMBL1368898 & 688746 & 5.5 & 4.7403 & TRN \\
\hline CHEMBL1339846 & 688746 & 4.45 & 4.9271 & TRN \\
\hline CHEMBL1424454 & 688746 & 4.45 & 4.8734 & TRN \\
\hline CHEMBL1308240 & 688746 & 5.35 & 4.8789 & TRN \\
\hline CHEMBL1461649 & 688746 & 4.45 & 4.7912 & TRN \\
\hline CHEMBL1328731 & 688746 & 4.85 & 5.0274 & TRN \\
\hline CHEMBL1376835 & 688746 & 4.4 & 4.7715 & TRN \\
\hline CHEMBL1386652 & 688746 & 6.7001 & 4.9744 & TRN \\
\hline CHEMBL1509096 & 688746 & 4.85 & 4.9207 & TRN \\
\hline CHEMBL1408737 & 688746 & 4.6 & 4.8665 & TRN \\
\hline CHEMBL 290914 & 688746 & 4.75 & 4.8101 & TST \\
\hline CHEMBL1376724 & 688746 & 9.1549 & 4.9116 & TRN \\
\hline
\end{tabular}




\begin{tabular}{|c|c|c|c|c|}
\hline & & & ient & al Ta \\
\hline CHEMBL1541353 & 688746 & 4.6 & 4.8871 & TRN \\
\hline CHEMBL1459695 & 688746 & 4.45 & 4.8997 & TST \\
\hline CHEMBL1305242 & 688746 & 4.6 & 4.8372 & TRN \\
\hline CHEMBL1386764 & 688746 & 4.65 & 4.9687 & TRN \\
\hline CHEMBL1539710 & 688746 & 4.6 & 4.8441 & TST \\
\hline CHEMBL1543309 & 688746 & 5.05 & 4.8757 & TRN \\
\hline CHEMBL1444814 & 688746 & 4.55 & 4.8315 & TST \\
\hline CHEMBL1367161 & 688746 & 4.6 & 4.9148 & TRN \\
\hline CHEMBL 2002162 & 688746 & 4.95 & 4.8574 & TST \\
\hline CHEMBL1601897 & 688746 & 4.85 & 4.8473 & TRN \\
\hline CHEMBL1557816 & 688746 & 4.5 & 4.8855 & TRN \\
\hline CHEMBL1506936 & 688746 & 4.4 & 4.8385 & TRN \\
\hline CHEMBL1556289 & 688746 & 5.0 & 4.824 & TRN \\
\hline CHEMBL1578178 & 688746 & 5.0 & 4.8853 & TST \\
\hline CHEMBL1350319 & 688746 & 5.2 & 4.9593 & TRN \\
\hline CHEMBL1607035 & 688746 & 4.85 & 4.9156 & TRN \\
\hline CHEMBL3212636 & 688746 & 5.0 & 4.8062 & TRN \\
\hline CHEMBL473721 & 688746 & 4.85 & 4.6707 & TRN \\
\hline CHEMBL1493497 & 688746 & 4.6 & 4.8041 & TRN \\
\hline CHEMBL1302144 & 688746 & 4.55 & 4.8608 & TRN \\
\hline CHEMBL 373167 & 688746 & 4.6 & 4.9406 & TRN \\
\hline CHEMBL1401998 & 688746 & 5.25 & 4.8285 & TRN \\
\hline CHEMBL1378295 & 688746 & 4.6 & 4.8921 & TRN \\
\hline CHEMBL1415437 & 688746 & 4.9 & 4.9744 & TRN \\
\hline CHEMBL1411344 & 688746 & 4.65 & 4.7921 & TRN \\
\hline CHEMBL1379137 & 688746 & 4.65 & 4.9141 & TRN \\
\hline CHEMBL3192752 & 688746 & 5.35 & 4.8475 & TRN \\
\hline CHEMBL1507021 & 688746 & 4.5 & 4.9918 & TRN \\
\hline CHEMBL1425309 & 688746 & 4.45 & 4.7288 & TRN \\
\hline CHEMBL3208605 & 688746 & 4.8 & 4.7896 & TRN \\
\hline CHEMBL 1405660 & 688746 & 4.7 & 4.8845 & TRN \\
\hline CHEMBL1444565 & 688746 & 5.1 & 4.8934 & TRN \\
\hline CHEMBL 3189384 & 688746 & 4.85 & 4.8986 & TRN \\
\hline CHEMBL1386684 & 688746 & 5.25 & 4.8128 & TRN \\
\hline CHEMBL1376138 & 688746 & 6.45 & 5.0393 & TRN \\
\hline CHEMBL1986514 & 688746 & 4.6 & 4.7779 & TRN \\
\hline CHEMBL1348144 & 688746 & 4.5 & 4.8185 & TRN \\
\hline CHEMBL 3191554 & 688746 & 4.55 & 4.9038 & TST \\
\hline CHEMBL1367634 & 688746 & 6.95 & 4.8063 & TST \\
\hline CHEMBL1532794 & 688746 & 4.65 & 4.8403 & TST \\
\hline CHEMBL1586093 & 688746 & 4.5 & 4.8501 & TRN \\
\hline CHEMBL1557069 & 688746 & 4.5 & 4.8891 & TRN \\
\hline CHEMBL1607263 & 688746 & 4.85 & 4.9595 & TRN \\
\hline CHEMBL1302616 & 688746 & 4.5 & 4.9607 & TRN \\
\hline CHEMBL1324817 & 688746 & 5.35 & 4.775 & TRN \\
\hline CHEMBL1423209 & 688746 & 4.4 & 4.8277 & TRN \\
\hline CHEMBL1452409 & 688746 & 4.8 & 4.7039 & TRN \\
\hline CHEMBL1353664 & 688746 & 4.65 & 4.9154 & TRN \\
\hline
\end{tabular}




\begin{tabular}{|c|c|c|c|c|c|}
\hline & & \multicolumn{4}{|c|}{ Supplemental Table S2.txt } \\
\hline CHEMBL1525060 & 688746 & 4.55 & 4.922 & TRN & \\
\hline CHEMBL1440612 & 688746 & 4.9 & 4.8993 & TRN & \\
\hline CHEMBL1493565 & 688746 & 4.85 & 4.8057 & TRN & \\
\hline CHEMBL1455229 & 688746 & 4.65 & 4.7777 & TRN & \\
\hline CHEMBL1537403 & 688746 & 4.6 & 4.9721 & TRN & \\
\hline CHEMBL592314 & 688746 & 4.85 & 4.7736 & TRN & \\
\hline CHEMBL1467626 & 688746 & 4.8 & 4.9388 & TRN & \\
\hline CHEMBL1422415 & 688746 & 4.4 & 4.8109 & TST & \\
\hline CHEMBL3210365 & 688746 & 6.1 & 4.7631 & TRN & \\
\hline CHEMBL1612619 & 688746 & 4.6 & 4.8302 & TRN & \\
\hline CHEMBL1570003 & 688746 & 4.8 & 4.9223 & TRN & \\
\hline CHEMBL1309580 & 688746 & 4.85 & 4.7802 & TRN & \\
\hline CHEMBL1577138 & 688746 & 5.45 & 4.8906 & TRN & \\
\hline CHEMBL1370165 & 688746 & 4.45 & 4.8576 & TRN & \\
\hline CHEMBL1496651 & 688746 & 4.7 & 4.7582 & TRN & \\
\hline CHEMBL1429795 & 688746 & 4.85 & 4.9044 & TRN & \\
\hline CHEMBL1506395 & 688746 & 6.4 & 4.9726 & TRN & \\
\hline CHEMBL1385562 & 688746 & 4.45 & 4.97199 & 99999999995 & TRN \\
\hline CHEMBL1330558 & 688746 & 4.55 & 4.7698 & TRN & \\
\hline CHEMBL1521317 & 688746 & 4.9 & 4.7968 & TRN & \\
\hline CHEMBL1573693 & 688746 & 4.6 & 4.8899 & TRN & \\
\hline CHEMBL2007313 & 688746 & 4.45 & 4.899 & TST & \\
\hline CHEMBL1974389 & 688746 & 5.65 & 4.9167 & TRN & \\
\hline CHEMBL1411437 & 688746 & 4.4 & 4.8835 & TRN & \\
\hline CHEMBL1563161 & 688746 & 4.6 & 4.8429 & TRN & \\
\hline CHEMBL1306740 & 688746 & 5.5 & 4.9911 & TRN & \\
\hline CHEMBL3191921 & 688746 & 4.55 & 4.7279 & TRN & \\
\hline CHEMBL1417064 & 688746 & 4.4 & 4.7713 & TRN & \\
\hline CHEMBL1391714 & 688746 & 4.8 & 4.9175 & TRN & \\
\hline CHEMBL1504575 & 688746 & 4.4 & 4.6656 & TRN & \\
\hline CHEMBL1402278 & 688746 & 5.25 & 4.9085 & TRN & \\
\hline CHEMBL1509919 & 688746 & 4.85 & 4.8191 & TRN & \\
\hline CHEMBL1332544 & 688746 & 4.65 & 4.8951 & TRN & \\
\hline CHEMBL1459468 & 688746 & 4.8 & 4.734 & TRN & \\
\hline CHEMBL1459938 & 688746 & 4.8 & 4.9529 & TRN & \\
\hline CHEMBL1523086 & 688746 & 4.45 & 4.9301 & TST & \\
\hline CHEMBL1390100 & 688746 & 5.4 & 4.7986 & TST & \\
\hline CHEMBL1532186 & 688746 & 5.45 & 4.8622 & TRN & \\
\hline CHEMBL1360298 & 688746 & 4.6 & 4.7595 & TRN & \\
\hline CHEMBL1369640 & 688746 & 4.45 & 5.013 & TRN & \\
\hline CHEMBL1432327 & 688746 & 4.8 & 4.8762 & TRN & \\
\hline CHEMBL1588056 & 688746 & 4.6 & 4.8505 & TRN & \\
\hline CHEMBL1506630 & 688746 & 5.4 & 4.9193 & TRN & \\
\hline CHEMBL1560067 & 688746 & 4.4 & 4.8443 & TST & \\
\hline CHEMBL1385595 & 688746 & 4.85 & 4.9078 & TRN & \\
\hline CHEMBL1301673 & 688746 & 4.9 & 4.8744 & TST & \\
\hline CHEMBL1336922 & 688746 & 4.4 & 4.8416 & TRN & \\
\hline CHEMBL252403 & 688746 & 5.15 & 4.7535 & TRN & \\
\hline
\end{tabular}




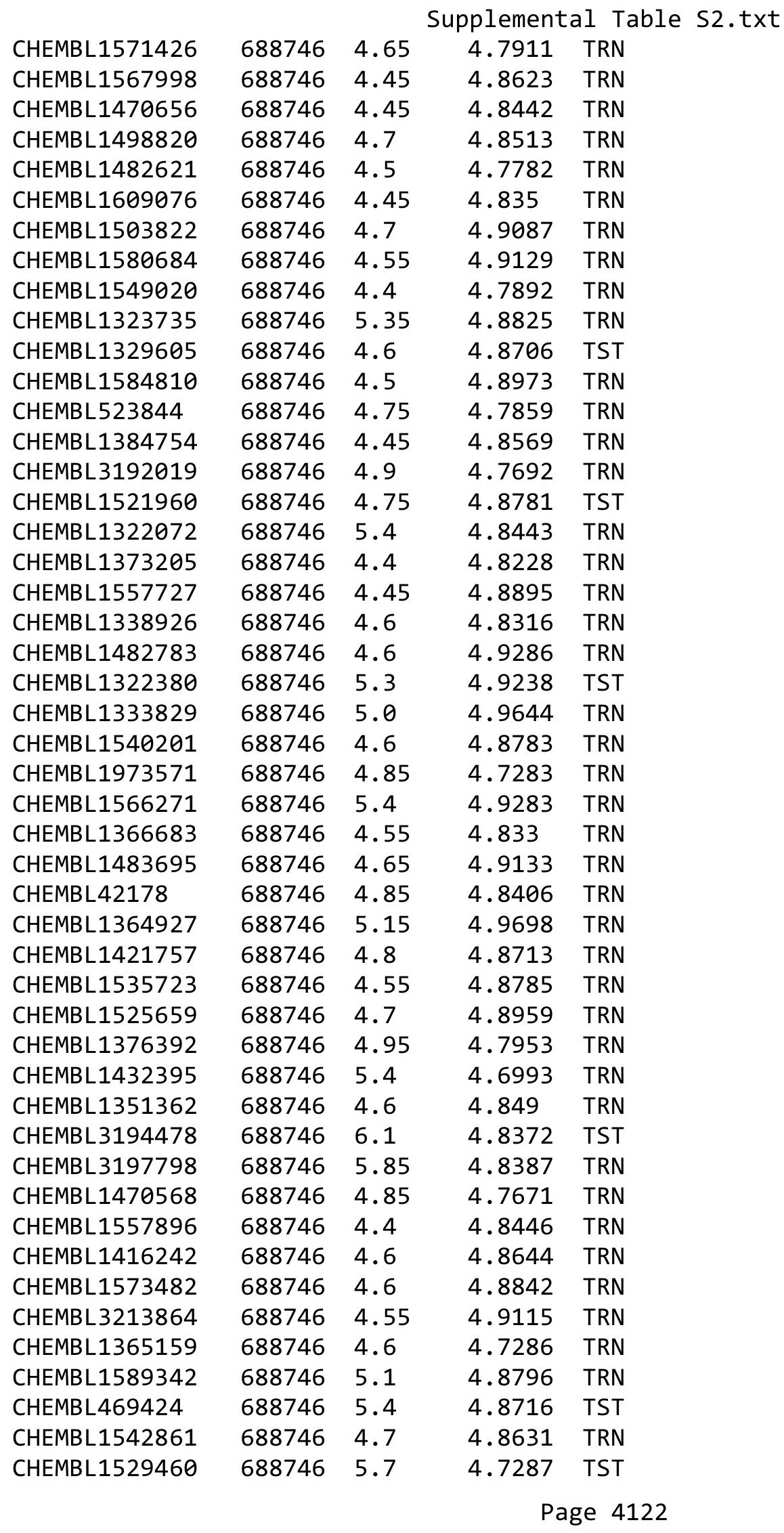




\begin{tabular}{|c|c|c|c|c|c|}
\hline \multicolumn{6}{|c|}{ Supplemental Table S2.txt } \\
\hline CHEMBL1444201 & 688746 & 4.65 & 4.8751 & TRN & \\
\hline CHEMBL1544731 & 688746 & 4.4 & 4.7942 & TRN & \\
\hline CHEMBL1542740 & 688746 & 4.65 & 4.9101 & TRN & \\
\hline CHEMBL1576135 & 688746 & 4.4 & 4.8473 & TRN & \\
\hline CHEMBL1597481 & 688746 & 4.85 & 4.822 & TRN & \\
\hline CHEMBL3191913 & 688746 & 5.0 & 4.8675 & TRN & \\
\hline CHEMBL1561033 & 688746 & 4.4 & 4.8744 & TRN & \\
\hline CHEMBL1560638 & 688746 & 4.95 & 4.8651 & TRN & \\
\hline CHEMBL1384332 & 688746 & 4.4 & 4.8461 & TRN & \\
\hline CHEMBL1524978 & 688746 & 4.5 & 4.9429 & TRN & \\
\hline CHEMBL1994078 & 688746 & 5.25 & 4.7602 & TRN & \\
\hline CHEMBL1457077 & 688746 & 4.85 & 4.8879 & TRN & \\
\hline CHEMBL1562478 & 688746 & 5.5 & 4.82 & TRN & \\
\hline CHEMBL1599297 & 688746 & 5.35 & 4.8401 & TST & \\
\hline CHEMBL3198681 & 688746 & 4.55 & 4.8787 & TRN & \\
\hline CHEMBL1424911 & 688746 & 5.15 & 4.8196 & TRN & \\
\hline CHEMBL1481924 & 688746 & 4.55 & 4.8545 & TRN & \\
\hline CHEMBL1411418 & 688746 & 4.6 & 4.8469 & TRN & \\
\hline CHEMBL1363938 & 688746 & 4.5 & 4.8184 & TRN & \\
\hline CHEMBL3191094 & 688746 & 4.8 & 4.72199 & 99999999995 & TRN \\
\hline CHEMBL1574150 & 688746 & 4.5 & 4.8435 & TRN & \\
\hline CHEMBL1505688 & 688746 & 4.4 & 4.7631 & TRN & \\
\hline CHEMBL3213089 & 688746 & 4.45 & 4.7728 & TRN & \\
\hline CHEMBL1540198 & 688746 & 4.95 & 5.0394 & TRN & \\
\hline CHEMBL1459399 & 688746 & 4.4 & 4.8646 & TRN & \\
\hline CHEMBL568739 & 688746 & 4.4 & 4.8254 & TST & \\
\hline CHEMBL1540359 & 688746 & 4.85 & 4.9155 & TRN & \\
\hline CHEMBL1333669 & 688746 & 4.45 & 4.995 & TRN & \\
\hline CHEMBL1577547 & 688746 & 4.8 & 4.8946 & TST & \\
\hline CHEMBL1348188 & 688746 & 4.4 & 5.002 & TRN & \\
\hline CHEMBL3193355 & 688746 & 4.4 & 4.7917 & TRN & \\
\hline CHEMBL1990081 & 688746 & 4.75 & 4.8306 & TRN & \\
\hline CHEMBL1507392 & 688746 & 4.6 & 4.8965 & TRN & \\
\hline CHEMBL1405653 & 688746 & 4.65 & 4.9658 & TRN & \\
\hline CHEMBL1337583 & 688746 & 4.55 & 4.8856 & TRN & \\
\hline CHEMBL1589658 & 688746 & 4.65 & 4.8722 & TRN & \\
\hline CHEMBL1496461 & 688746 & 4.4 & 4.8548 & TST & \\
\hline CHEMBL1307806 & 688746 & 4.55 & 4.8473 & TRN & \\
\hline CHEMBL1200717 & 688746 & 4.6 & 4.9684 & TST & \\
\hline CHEMBL1577985 & 688746 & 4.4 & 4.8375 & TRN & \\
\hline CHEMBL1584631 & 688746 & 4.8 & 4.8396 & TRN & \\
\hline CHEMBL1406930 & 688746 & 5.0 & 4.9416 & TRN & \\
\hline CHEMBL1360927 & 688746 & 4.5 & 4.8808 & TRN & \\
\hline CHEMBL1339588 & 688746 & 4.6 & 4.9879 & TRN & \\
\hline CHEMBL1333697 & 688746 & 4.75 & 4.8386 & TRN & \\
\hline CHEMBL1411616 & 688746 & 5.05 & 4.8336 & TST & \\
\hline CHEMBL3195079 & 688746 & 4.8 & 4.8822 & TRN & \\
\hline CHEMBL1585140 & 688746 & 4.5 & 4.9406 & TRN & \\
\hline
\end{tabular}




\begin{tabular}{|c|c|c|c|c|}
\hline & & & pplement & al $\mathrm{Ta}$ \\
\hline CHEMBL1526378 & 688746 & 4.55 & 4.9516 & TRN \\
\hline CHEMBL1382570 & 688746 & 4.5 & 4.8608 & TRN \\
\hline CHEMBL1528469 & 688746 & 4.65 & 4.8201 & TRN \\
\hline CHEMBL1554411 & 688746 & 4.8 & 4.8262 & TRN \\
\hline CHEMBL1501551 & 688746 & 4.55 & 4.8732 & TST \\
\hline CHEMBL1458057 & 688746 & 5.3 & 4.9806 & TRN \\
\hline CHEMBL1531074 & 688746 & 5.65 & 5.05 & TRN \\
\hline CHEMBL1313152 & 688746 & 4.6 & 4.8125 & TRN \\
\hline CHEMBL1347028 & 688746 & 5.35 & 4.8006 & TRN \\
\hline CHEMBL1370875 & 688746 & 4.65 & 4.9005 & TST \\
\hline CHEMBL1326967 & 688746 & 4.55 & 4.6978 & TRN \\
\hline CHEMBL1488741 & 688746 & 5.45 & 4.9515 & TRN \\
\hline CHEMBL1345029 & 688746 & 4.45 & 4.8822 & TST \\
\hline CHEMBL1560117 & 688746 & 4.8 & 4.8932 & TRN \\
\hline CHEMBL1538833 & 688746 & 4.6 & 5.0259 & TRN \\
\hline CHEMBL1421806 & 688746 & 4.55 & 4.8314 & TRN \\
\hline CHEMBL1458288 & 688746 & 4.65 & 4.8773 & TRN \\
\hline CHEMBL3197156 & 688746 & 4.6 & 4.8036 & TRN \\
\hline CHEMBL1446030 & 688746 & 5.05 & 4.812 & TRN \\
\hline CHEMBL1303028 & 688746 & 5.35 & 4.878 & TRN \\
\hline CHEMBL1378230 & 688746 & 4.4 & 4.7839 & TRN \\
\hline CHEMBL1986893 & 688746 & 4.45 & 4.7504 & TRN \\
\hline CHEMBL1577672 & 688746 & 4.7 & 4.8325 & TRN \\
\hline CHEMBL1431573 & 688746 & 4.5 & 4.8655 & TRN \\
\hline CHEMBL1977570 & 688746 & 5.5 & 4.7562 & TRN \\
\hline CHEMBL1321369 & 688746 & 4.85 & 4.9342 & TRN \\
\hline CHEMBL1333510 & 688746 & 4.45 & 4.8367 & TRN \\
\hline CHEMBL1430919 & 688746 & 4.4 & 4.7505 & TRN \\
\hline CHEMBL1300515 & 688746 & 4.8 & 5.0198 & TRN \\
\hline CHEMBL1459325 & 688746 & 4.65 & 4.9513 & TRN \\
\hline CHEMBL1359521 & 688746 & 4.75 & 4.7085 & TRN \\
\hline CHEMBL1463423 & 688746 & 4.4 & 4.8343 & TST \\
\hline CHEMBL1361919 & 688746 & 4.85 & 4.8734 & TRN \\
\hline CHEMBL1556777 & 688746 & 4.5 & 4.8643 & TRN \\
\hline CHEMBL1386691 & 688746 & 4.85 & 4.8069 & TRN \\
\hline CHEMBL1604606 & 688746 & 5.65 & 4.9207 & TRN \\
\hline CHEMBL1603741 & 688746 & 6.5501 & 4.9254 & TST \\
\hline CHEMBL1378869 & 688746 & 4.55 & 4.8984 & TRN \\
\hline CHEMBL1309234 & 688746 & 5.45 & 4.9437 & TRN \\
\hline CHEMBL1429510 & 688746 & 4.6 & 4.8949 & TRN \\
\hline CHEMBL1611408 & 688746 & 4.7 & 4.8686 & TRN \\
\hline CHEMBL1564138 & 688746 & 4.4 & 4.963 & TRN \\
\hline CHEMBL1412489 & 688746 & 6.95 & 4.8724 & TST \\
\hline CHEMBL1432279 & 688746 & 4.85 & 4.9273 & TRN \\
\hline CHEMBL1305526 & 688746 & 5.0 & 4.8312 & TST \\
\hline CHEMBL1557191 & 688746 & 4.9 & 4.7878 & TRN \\
\hline CHEMBL1350609 & 688746 & 4.75 & 4.8061 & TRN \\
\hline CHEMBL1559777 & 688746 & 4.4 & 4.852 & TST \\
\hline
\end{tabular}




\begin{tabular}{|c|c|c|c|c|}
\hline \multicolumn{5}{|c|}{ Supplemental Ta } \\
\hline CHEMBL1381070 & 688746 & 5.1 & 4.8579 & TRN \\
\hline CHEMBL1301001 & 688746 & 4.4 & 4.9105 & TST \\
\hline CHEMBL1341192 & 688746 & 4.85 & 4.8115 & TRN \\
\hline CHEMBL1481804 & 688746 & 4.55 & 4.9791 & TRN \\
\hline CHEMBL1482567 & 688746 & 4.55 & 4.94 & TRN \\
\hline CHEMBL301507 & 688746 & 4.55 & 4.7772 & TRN \\
\hline CHEMBL1540894 & 688746 & 4.9 & 4.8112 & TRN \\
\hline CHEMBL1571615 & 688746 & 4.55 & 4.7994 & TRN \\
\hline CHEMBL1523322 & 688746 & 4.5 & 4.9731 & TRN \\
\hline CHEMBL1303801 & 688746 & 8.4949 & 5.0381 & TRN \\
\hline CHEMBL1517608 & 688746 & 4.9 & 4.7494 & TRN \\
\hline CHEMBL1543574 & 688746 & 4.4 & 4.7568 & TRN \\
\hline CHEMBL1333817 & 688746 & 4.6 & 4.7841 & TRN \\
\hline CHEMBL1084720 & 688746 & 4.4 & 4.9146 & TRN \\
\hline CHEMBL1529827 & 688746 & 5.3 & 4.8828 & TRN \\
\hline CHEMBL1969647 & 688746 & 4.65 & 4.7353 & TRN \\
\hline CHEMBL1340952 & 688746 & 4.55 & 4.9828 & TRN \\
\hline CHEMBL1414939 & 688746 & 4.6 & 4.8417 & TRN \\
\hline CHEMBL1306395 & 688746 & 4.65 & 4.8691 & TRN \\
\hline CHEMBL1519037 & 688746 & 4.55 & 4.923 & TRN \\
\hline CHEMBL1368141 & 688746 & 4.85 & 4.8951 & TRN \\
\hline CHEMBL3193004 & 688746 & 4.45 & 4.8141 & TRN \\
\hline CHEMBL1385030 & 688746 & 5.5 & 4.8811 & TRN \\
\hline CHEMBL1583713 & 688746 & 4.4 & 4.8224 & TRN \\
\hline CHEMBL1587583 & 688746 & 4.65 & 4.7858 & TRN \\
\hline CHEMBL1600919 & 688746 & 4.95 & 4.6915 & TRN \\
\hline CHEMBL3193229 & 688746 & 4.45 & 4.7387 & TRN \\
\hline CHEMBL1575294 & 688746 & 4.6 & 4.8024 & TRN \\
\hline CHEMBL1511579 & 688746 & 5.35 & 5.0346 & TRN \\
\hline CHEMBL1602085 & 688746 & 4.9 & 4.7792 & TRN \\
\hline CHEMBL3196706 & 688746 & 4.65 & 4.7577 & TRN \\
\hline CHEMBL1543801 & 688746 & 4.75 & 4.8718 & TRN \\
\hline CHEMBL1548422 & 688746 & 4.7 & 4.8218 & TRN \\
\hline CHEMBL1425516 & 688746 & 4.65 & 4.8159 & TRN \\
\hline CHEMBL1589770 & 688746 & 4.85 & 4.9896 & TRN \\
\hline CHEMBL1484182 & 688746 & 4.75 & 4.8602 & TRN \\
\hline CHEMBL1435620 & 688746 & 4.5 & 5.0161 & TRN \\
\hline CHEMBL1365290 & 688746 & 4.75 & 4.8347 & TRN \\
\hline CHEMBL1311880 & 688746 & 5.4 & 4.9954 & TRN \\
\hline CHEMBL1458701 & 688746 & 4.85 & 4.8389 & TRN \\
\hline CHEMBL3189345 & 688746 & 4.4 & 4.8309 & TRN \\
\hline CHEMBL1402355 & 688746 & 4.4 & 4.9388 & TST \\
\hline CHEMBL1303816 & 688746 & 4.8 & 4.7911 & TRN \\
\hline CHEMBL1481187 & 688746 & 5.2 & 4.9186 & TRN \\
\hline CHEMBL1344936 & 688746 & 5.1 & 4.886 & TRN \\
\hline CHEMBL1525529 & 688746 & 4.55 & 4.8237 & TRN \\
\hline CHEMBL1465516 & 688746 & 4.9 & 4.7968 & TRN \\
\hline CHEMBL1335770 & 688746 & 4.85 & 4.9259 & TRN \\
\hline
\end{tabular}




\begin{tabular}{|c|c|c|c|c|c|}
\hline \multirow[b]{2}{*}{ CHEMBL1416449 } & \multirow[b]{2}{*}{688746} & \\
\hline & & 6.8 & 4.9024 & TST & \\
\hline CHEMBL1326881 & 688746 & 4.85 & 4.7999 & TRN & \\
\hline CHEMBL1322028 & 688746 & 4.8 & 4.9031 & TRN & \\
\hline CHEMBL1307290 & 688746 & 5.55 & 5.0125 & TRN & \\
\hline CHEMBL1400641 & 688746 & 6.1 & 4.8578 & TRN & \\
\hline CHEMBL1373059 & 688746 & 5.2 & 4.8413 & TRN & \\
\hline CHEMBL1428053 & 688746 & 4.55 & 4.8504 & TRN & \\
\hline CHEMBL1471258 & 688746 & 5.45 & 4.9227 & TRN & \\
\hline CHEMBL1485672 & 688746 & 4.4 & 4.9123 & TRN & \\
\hline CHEMBL1467772 & 688746 & 4.95 & 4.9543 & TRN & \\
\hline CHEMBL1408237 & 688746 & 6.0 & 4.9061 & TRN & \\
\hline CHEMBL1538883 & 688746 & 4.55 & 4.835 & TST & \\
\hline CHEMBL1508581 & 688746 & 4.65 & 4.9959 & TRN & \\
\hline CHEMBL1319748 & 688746 & 4.8 & 4.8725 & TRN & \\
\hline CHEMBL1419553 & 688746 & 5.2 & 4.9059 & TST & \\
\hline CHEMBL1557926 & 688746 & 4.4 & 4.8185 & TRN & \\
\hline CHEMBL1546232 & 688746 & 4.65 & 4.8033 & TRN & \\
\hline CHEMBL251998 & 688746 & 4.4 & 4.8957 & TRN & \\
\hline CHEMBL1339678 & 688746 & 4.8 & 4.7836 & TRN & \\
\hline CHEMBL1498682 & 688746 & 4.9 & 4.9632 & TRN & \\
\hline CHEMBL3211047 & 688746 & 4.4 & 4.8244 & TRN & \\
\hline CHEMBL1310714 & 688746 & 4.45 & 4.8074 & TRN & \\
\hline CHEMBL1508177 & 688746 & 5.5 & 4.8692 & TRN & \\
\hline CHEMBL245962 & 688746 & 5.3 & 4.8015 & TRN & \\
\hline CHEMBL1302845 & 688746 & 4.65 & 4.9164 & TRN & \\
\hline CHEMBL1527818 & 688746 & 5.1 & 4.8654 & TRN & \\
\hline CHEMBL1411125 & 688746 & 4.6 & 4.8669 & TRN & \\
\hline CHEMBL1470485 & 688746 & 4.5 & 4.8125 & TRN & \\
\hline CHEMBL2003508 & 688746 & 4.6 & 4.7098 & TRN & \\
\hline CHEMBL1378036 & 688746 & 4.65 & 4.8367 & TRN & \\
\hline CHEMBL1360913 & 688746 & 4.6 & 4.8595 & TRN & \\
\hline CHEMBL1462296 & 688746 & 5.05 & 4.82100 & 0000000001 & TST \\
\hline CHEMBL1321932 & 688746 & 4.45 & 4.9756 & TRN & \\
\hline CHEMBL3192497 & 688746 & 4.6 & 4.7139 & TRN & \\
\hline CHEMBL1301740 & 688746 & 4.45 & 4.8482 & TRN & \\
\hline CHEMBL1311879 & 688746 & 4.6 & 4.7393 & TRN & \\
\hline CHEMBL1459404 & 688746 & 5.35 & 4.9151 & TRN & \\
\hline CHEMBL1505567 & 688746 & 4.9 & 4.8897 & TRN & \\
\hline CHEMBL1587959 & 688746 & 4.55 & 4.8897 & TST & \\
\hline CHEMBL1562840 & 688746 & 5.55 & 4.9019 & TRN & \\
\hline CHEMBL1474701 & 688746 & 4.75 & 4.7847 & TST & \\
\hline CHEMBL1367305 & 688746 & 5.45 & 4.8963 & TRN & \\
\hline CHEMBL1328177 & 688746 & 4.5 & 4.894 & TRN & \\
\hline CHEMBL1588332 & 688746 & 4.65 & 4.8955 & TST & \\
\hline CHEMBL1409204 & 688746 & 4.4 & 4.8031 & TRN & \\
\hline CHEMBL1389029 & 688746 & 4.8 & 4.8228 & TRN & \\
\hline CHEMBL1300722 & 688746 & 4.55 & 4.9854 & TRN & \\
\hline CHEMBL1538326 & 688746 & 4.4 & 4.8812 & TRN & \\
\hline & & & & 4126 & \\
\hline
\end{tabular}




\begin{tabular}{|c|c|c|c|c|}
\hline \multicolumn{5}{|c|}{ Supplemental Table S2.txt } \\
\hline CHEMBL1241371 & 688746 & 4.45 & 4.7573 & TRN \\
\hline CHEMBL1575110 & 688746 & 6.05 & 4.8892 & TRN \\
\hline CHEMBL1522155 & 688746 & 4.55 & 4.8513 & TST \\
\hline CHEMBL1399826 & 688746 & 5.45 & 4.9519 & TRN \\
\hline CHEMBL3207897 & 688746 & 4.4 & 4.8422 & TRN \\
\hline CHEMBL1390047 & 688746 & 4.85 & 4.868 & TRN \\
\hline CHEMBL1529766 & 688746 & 4.45 & 4.8605 & TST \\
\hline CHEMBL1347047 & 688746 & 5.1 & 4.9012 & TST \\
\hline CHEMBL1589216 & 688746 & 4.45 & 4.9603 & TRN \\
\hline CHEMBL1448625 & 688746 & 4.75 & 4.7916 & TRN \\
\hline CHEMBL1338606 & 688746 & 4.6 & 4.9024 & TST \\
\hline CHEMBL3212167 & 688746 & 5.25 & 4.8741 & TST \\
\hline CHEMBL1609239 & 688746 & 4.4 & 4.7924 & TRN \\
\hline CHEMBL1363540 & 688746 & 4.45 & 4.8425 & TRN \\
\hline CHEMBL1422342 & 688746 & 4.65 & 4.8733 & TRN \\
\hline CHEMBL1505441 & 688746 & 4.65 & 4.7386 & TRN \\
\hline CHEMBL1504800 & 688746 & 5.4 & 4.7936 & TST \\
\hline CHEMBL1452136 & 688746 & 4.8 & 4.8747 & TST \\
\hline CHEMBL1533269 & 688746 & 5.3 & 4.7981 & TRN \\
\hline CHEMBL1420149 & 688746 & 4.5 & 4.7991 & TST \\
\hline CHEMBL1442773 & 688746 & 6.7501 & 4.8415 & TST \\
\hline CHEMBL1341399 & 688746 & 4.75 & 4.8414 & TRN \\
\hline CHEMBL1379592 & 688746 & 4.8 & 4.8161 & TST \\
\hline CHEMBL1510922 & 688746 & 4.55 & 4.9295 & TRN \\
\hline CHEMBL1482760 & 688746 & 4.85 & 4.8403 & TRN \\
\hline CHEMBL3191940 & 688746 & 4.85 & 4.8604 & TST \\
\hline CHEMBL1490970 & 688746 & 6.0 & 4.8096 & TRN \\
\hline CHEMBL1302032 & 688746 & 4.4 & 4.8363 & TRN \\
\hline CHEMBL 234338 & 688746 & 4.4 & 4.7985 & TST \\
\hline CHEMBL1502774 & 688746 & 5.35 & 4.8954 & TRN \\
\hline CHEMBL1549059 & 688746 & 4.95 & 4.9732 & TRN \\
\hline CHEMBL1503727 & 688746 & 4.85 & 4.7539 & TRN \\
\hline CHEMBL1414867 & 688746 & 4.45 & 4.8556 & TRN \\
\hline CHEMBL1601251 & 688746 & 5.05 & 5.0446 & TRN \\
\hline CHEMBL1510493 & 688746 & 6.6499 & 4.914 & TRN \\
\hline CHEMBL1610169 & 688746 & 5.25 & 4.7775 & TST \\
\hline CHEMBL 2001433 & 688746 & 4.65 & 4.8008 & TRN \\
\hline CHEMBL1477308 & 688746 & 6.4 & 4.9895 & TRN \\
\hline CHEMBL1516879 & 688746 & 4.7 & 4.8069 & TRN \\
\hline CHEMBL1459949 & 688746 & 4.8 & 4.8474 & TRN \\
\hline CHEMBL1370195 & 688746 & 4.7 & 5.0207 & TRN \\
\hline CHEMBL1365347 & 688746 & 4.85 & 4.8734 & TRN \\
\hline CHEMBL1462892 & 688746 & 4.7 & 4.9127 & TRN \\
\hline CHEMBL1447939 & 688746 & 4.4 & 4.9627 & TRN \\
\hline CHEMBL1539431 & 688746 & 4.65 & 4.9543 & TRN \\
\hline CHEMBL1511141 & 688746 & 4.4 & 4.881 & TST \\
\hline CHEMBL1393636 & 688746 & 4.8 & 4.8754 & TRN \\
\hline CHEMBL1324726 & 688746 & 4.65 & 4.9092 & TRN \\
\hline
\end{tabular}




\begin{tabular}{|c|c|c|c|c|}
\hline \multicolumn{5}{|c|}{ plemental T } \\
\hline CHEMBL1327614 & 688746 & 5.8 & 4.8793 & TRN \\
\hline CHEMBL1335221 & 688746 & 6.25 & 4.9053 & TRN \\
\hline CHEMBL1399262 & 688746 & 4.75 & 4.9114 & TRN \\
\hline CHEMBL1441041 & 688746 & 4.4 & 4.8034 & TRN \\
\hline CHEMBL1603695 & 688746 & 5.55 & 4.7074 & TRN \\
\hline CHEMBL1364527 & 688746 & 4.5 & 4.815 & TRN \\
\hline CHEMBL1597120 & 688746 & 5.15 & 4.8693 & TRN \\
\hline CHEMBL1367267 & 688746 & 4.55 & 4.8843 & TRN \\
\hline CHEMBL1506328 & 688746 & 4.8 & 5.0022 & TRN \\
\hline CHEMBL1524083 & 688746 & 6.1 & 4.9074 & TRN \\
\hline CHEMBL1419127 & 688746 & 4.95 & 4.9558 & TRN \\
\hline CHEMBL3194740 & 688746 & 5.0 & 4.9534 & TRN \\
\hline CHEMBL1402037 & 688746 & 4.9 & 4.9202 & TRN \\
\hline CHEMBL1605989 & 688746 & 4.5 & 4.9377 & TRN \\
\hline CHEMBL1303712 & 688746 & 4.35 & 4.8591 & TRN \\
\hline CHEMBL1377992 & 688746 & 4.7 & 4.8131 & TRN \\
\hline CHEMBL1520726 & 688746 & 4.55 & 4.8442 & TRN \\
\hline CHEMBL1481546 & 688746 & 5.55 & 4.9425 & TRN \\
\hline CHEMBL1497483 & 688746 & 4.45 & 4.8826 & TRN \\
\hline CHEMBL1440626 & 688746 & 4.65 & 4.8343 & TRN \\
\hline CHEMBL1447031 & 688746 & 4.9 & 4.9282 & TRN \\
\hline CHEMBL1486044 & 688746 & 4.85 & 4.9403 & TST \\
\hline CHEMBL392723 & 688746 & 4.7 & 4.8589 & TRN \\
\hline CHEMBL1463953 & 688746 & 4.9 & 4.8121 & TRN \\
\hline CHEMBL1347165 & 688746 & 5.35 & 4.8927 & TRN \\
\hline CHEMBL1968732 & 688746 & 4.6 & 4.8613 & TST \\
\hline CHEMBL1540922 & 688746 & 4.6 & 4.8689 & TRN \\
\hline CHEMBL3189499 & 688746 & 7.0 & 4.8168 & TRN \\
\hline CHEMBL3208220 & 688746 & 4.4 & 4.8889 & TRN \\
\hline CHEMBL1530550 & 688746 & 4.75 & 4.8613 & TST \\
\hline CHEMBL1480193 & 688746 & 4.4 & 4.8438 & TRN \\
\hline CHEMBL1485571 & 688746 & 5.4 & 4.9242 & TRN \\
\hline CHEMBL1340397 & 688746 & 4.6 & 4.755 & TST \\
\hline CHEMBL1510526 & 688746 & 4.95 & 4.8987 & TRN \\
\hline CHEMBL1530117 & 688746 & 4.4 & 4.9043 & TST \\
\hline CHEMBL1576392 & 688746 & 4.45 & 4.9297 & TRN \\
\hline CHEMBL1601571 & 688746 & 4.9 & 4.8682 & TRN \\
\hline CHEMBL1309987 & 688746 & 4.8 & 4.84 & TST \\
\hline CHEMBL1384492 & 688746 & 4.4 & 4.9349 & TRN \\
\hline CHEMBL1534039 & 688746 & 5.05 & 4.93 & TRN \\
\hline CHEMBL1307126 & 688746 & 4.65 & 4.8837 & TRN \\
\hline CHEMBL1550726 & 688746 & 4.75 & 4.8469 & TRN \\
\hline CHEMBL1372330 & 688746 & 4.65 & 4.8751 & TRN \\
\hline CHEMBL1309417 & 688746 & 4.45 & 4.7915 & TST \\
\hline CHEMBL1418929 & 688746 & 5.0 & 4.8816 & TRN \\
\hline CHEMBL1530001 & 688746 & 4.8 & 4.8233 & TRN \\
\hline CHEMBL1375545 & 688746 & 5.1 & 4.9841 & TRN \\
\hline CHEMBL1392228 & 688746 & 4.7 & 4.7798 & TRN \\
\hline
\end{tabular}




\begin{tabular}{|c|c|c|c|c|}
\hline \multicolumn{5}{|c|}{ Supplemental Table } \\
\hline CHEMBL1380592 & 688746 & 4.45 & 4.8727 & TRN \\
\hline CHEMBL1387768 & 688746 & 5.0 & 4.8854 & TRN \\
\hline CHEMBL1410761 & 688746 & 5.3 & 4.8449 & TRN \\
\hline CHEMBL1418183 & 688746 & 4.5 & 4.9247 & TRN \\
\hline CHEMBL1549762 & 688746 & 4.7 & 4.9334 & TRN \\
\hline CHEMBL1471686 & 688746 & 5.15 & 4.9018 & TRN \\
\hline CHEMBL 256098 & 688746 & 4.4 & 4.883 & TRN \\
\hline CHEMBL1608754 & 688746 & 5.4 & 4.9182 & TRN \\
\hline CHEMBL1569079 & 688746 & 4.65 & 4.8768 & TRN \\
\hline CHEMBL1406170 & 688746 & 4.5 & 4.8577 & TST \\
\hline CHEMBL1486939 & 688746 & 4.45 & 4.7575 & TRN \\
\hline CHEMBL1586674 & 688746 & 4.85 & 4.8803 & TRN \\
\hline CHEMBL1471095 & 688746 & 4.85 & 4.8246 & TRN \\
\hline CHEMBL1352070 & 688746 & 4.85 & 4.9432 & TRN \\
\hline CHEMBL1387519 & 688746 & 4.7 & 4.8553 & TRN \\
\hline CHEMBL1489621 & 688746 & 4.5 & 4.9163 & TRN \\
\hline CHEMBL1431603 & 688746 & 5.3 & 4.874 & TRN \\
\hline CHEMBL1392389 & 688746 & 5.1 & 4.8799 & TRN \\
\hline CHEMBL1442224 & 688746 & 5.4 & 4.7323 & TRN \\
\hline CHEMBL1561773 & 688746 & 4.5 & 4.9652 & TRN \\
\hline CHEMBL1524298 & 688746 & 4.85 & 4.8065 & TST \\
\hline CHEMBL1380305 & 688746 & 4.85 & 4.9798 & TRN \\
\hline CHEMBL1598034 & 688746 & 4.4 & 4.8443 & TRN \\
\hline CHEMBL1496638 & 688746 & 4.4 & 4.8034 & TST \\
\hline CHEMBL399121 & 688746 & 4.4 & 4.913 & TST \\
\hline CHEMBL1304195 & 688746 & 4.5 & 4.9432 & TRN \\
\hline CHEMBL1426023 & 688746 & 4.55 & 4.9265 & TRN \\
\hline CHEMBL1418951 & 688746 & 4.4 & 4.9284 & TRN \\
\hline CHEMBL1543251 & 688746 & 4.55 & 4.8291 & TRN \\
\hline CHEMBL1516620 & 688746 & 4.4 & 4.8781 & TRN \\
\hline CHEMBL3209663 & 688746 & 5.15 & 4.8072 & TST \\
\hline CHEMBL3193557 & 688746 & 4.8 & 4.8114 & TRN \\
\hline CHEMBL3212666 & 688746 & 4.45 & 4.8486 & TRN \\
\hline CHEMBL1359872 & 688746 & 4.55 & 4.7864 & TRN \\
\hline CHEMBL1410425 & 688746 & 4.5 & 4.8924 & TRN \\
\hline CHEMBL1533638 & 688746 & 4.4 & 4.9039 & TRN \\
\hline CHEMBL1541592 & 688746 & 4.6 & 4.6792 & TRN \\
\hline CHEMBL1974425 & 688746 & 4.6 & 4.8253 & TRN \\
\hline CHEMBL1578952 & 688746 & 4.65 & 4.7743 & TRN \\
\hline CHEMBL1600668 & 688746 & 4.6 & 4.7787 & TRN \\
\hline CHEMBL1589562 & 688746 & 6.1 & 4.838 & TRN \\
\hline CHEMBL1497335 & 688746 & 4.4 & 4.8647 & TST \\
\hline CHEMBL1388410 & 688746 & 4.7 & 4.8996 & TRN \\
\hline CHEMBL1359782 & 688746 & 4.7 & 4.8339 & TRN \\
\hline CHEMBL2001743 & 688746 & 5.55 & 4.8234 & TRN \\
\hline CHEMBL1459930 & 688746 & 4.9 & 4.7041 & TRN \\
\hline CHEMBL1587018 & 688746 & 4.8 & 4.8349 & TRN \\
\hline CHEMBL388959 & 688746 & 4.85 & 4.7774 & TRN \\
\hline
\end{tabular}




\begin{tabular}{|c|c|c|c|c|c|}
\hline \\
\hline CHEMBL1303955 & 688746 & 4.5 & 4.8955 & TST & \\
\hline CHEMBL1333135 & 688746 & 5.0 & 4.8556 & TRN & \\
\hline CHEMBL1987655 & 688746 & 4.8 & 4.71 & TRN & \\
\hline CHEMBL1534959 & 688746 & 4.85 & 4.7582 & TRN & \\
\hline CHEMBL3213495 & 688746 & 4.4 & 4.7612 & TRN & \\
\hline CHEMBL1975615 & 688746 & 4.6 & 4.8663 & TRN & \\
\hline CHEMBL3189882 & 688746 & 6.7501 & 4.8959 & TRN & \\
\hline CHEMBL1604119 & 688746 & 4.95 & 4.8388 & TRN & \\
\hline CHEMBL1570504 & 688746 & 6.2 & 4.7597 & TRN & \\
\hline CHEMBL1362784 & 688746 & 4.45 & 4.913 & TRN & \\
\hline CHEMBL3198730 & 688746 & 4.5 & 4.8031 & TRN & \\
\hline CHEMBL1348538 & 688746 & 5.35 & 4.8768 & TRN & \\
\hline CHEMBL1495878 & 688746 & 4.45 & 4.8569 & TRN & \\
\hline CHEMBL1536321 & 688746 & 4.55 & 4.9066 & TRN & \\
\hline CHEMBL1470421 & 688746 & 4.9 & 4.7839 & TRN & \\
\hline CHEMBL1540529 & 688746 & 4.8 & 4.9749 & TRN & \\
\hline CHEMBL1612225 & 688746 & 8.2007 & 4.8754 & TRN & \\
\hline CHEMBL1302884 & 688746 & 4.4 & 4.8951 & TRN & \\
\hline CHEMBL1466323 & 688746 & 4.5 & 4.8663 & TRN & \\
\hline CHEMBL1359123 & 688746 & 4.7 & 4.8242 & TRN & \\
\hline CHEMBL1384851 & 688746 & 5.25 & 4.8758 & TRN & \\
\hline CHEMBL1416895 & 688746 & 5.45 & 4.9342 & TRN & \\
\hline CHEMBL1488864 & 688746 & 4.95 & 4.9456 & TRN & \\
\hline CHEMBL1345786 & 688746 & 4.6 & 4.8612 & TRN & \\
\hline CHEMBL1507701 & 688746 & 4.55 & 4.8955 & TRN & \\
\hline CHEMBL1531802 & 688746 & 5.35 & 4.8859 & TRN & \\
\hline CHEMBL1324343 & 688746 & 5.4 & 4.8461 & TRN & \\
\hline CHEMBL1523699 & 688746 & 4.5 & 4.8518 & TST & \\
\hline CHEMBL1347749 & 688746 & 4.7 & 4.8347 & TRN & \\
\hline CHEMBL1507009 & 688746 & 4.6 & 4.8544 & TST & \\
\hline CHEMBL1549129 & 688746 & 4.4 & 4.83899 & 99999999995 & TST \\
\hline CHEMBL1509449 & 688746 & 4.7 & 4.8546 & TST & \\
\hline CHEMBL1458812 & 688746 & 4.45 & 4.8695 & TST & \\
\hline CHEMBL1347089 & 688746 & 4.4 & 4.824 & TST & \\
\hline CHEMBL1340027 & 688746 & 4.85 & 4.8453 & TST & \\
\hline CHEMBL1415222 & 688746 & 4.6 & 5.0256 & TST & \\
\hline CHEMBL3199175 & 688746 & 5.5 & 4.7686 & TST & \\
\hline CHEMBL1566498 & 688746 & 5.2 & 4.8718 & TST & \\
\hline CHEMBL1402614 & 688746 & 4.6 & 4.8717 & TST & \\
\hline CHEMBL1993746 & 688746 & 4.95 & 4.8926 & TST & \\
\hline CHEMBL1611655 & 688746 & 4.55 & 4.8698 & TST & \\
\hline CHEMBL 257856 & 688746 & 4.45 & 5.0141 & TST & \\
\hline CHEMBL1562443 & 688746 & 5.05 & 4.9175 & TST & \\
\hline CHEMBL1387360 & 688746 & 4.6 & 4.8563 & TST & \\
\hline CHEMBL1331809 & 688746 & 5.3 & 4.8494 & TST & \\
\hline CHEMBL1533248 & 688746 & 4.9 & 4.8238 & TST & \\
\hline CHEMBL1541234 & 688746 & 5.1 & 5.0493 & TST & \\
\hline CHEMBL1330965 & 688746 & 4.45 & 4.8209 & TST & \\
\hline & & & & 4130 & \\
\hline
\end{tabular}




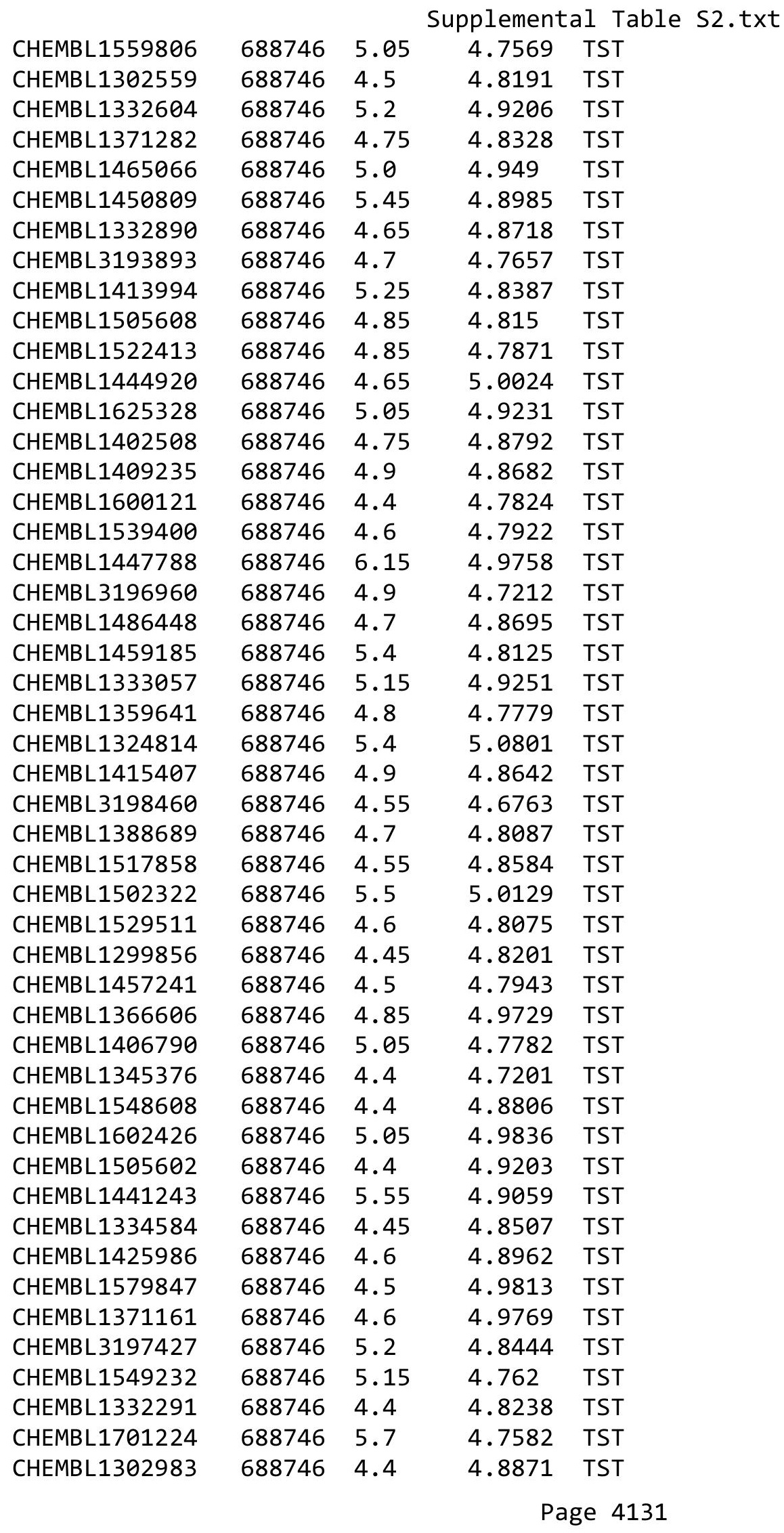




\begin{tabular}{|c|c|c|c|c|c|}
\hline \\
\hline CHEMBL1583644 & 688746 & 4.4 & 4.888 & TST & \\
\hline CHEMBL1362523 & 688746 & 4.4 & 4.942 & TST & \\
\hline CHEMBL1400830 & 688746 & 5.15 & 5.0288 & TST & \\
\hline CHEMBL1329764 & 688746 & 4.75 & 4.7918 & TST & \\
\hline CHEMBL1524009 & 688746 & 4.9 & 4.8664 & TST & \\
\hline CHEMBL1462913 & 688746 & 6.15 & 4.9515 & TST & \\
\hline CHEMBL1341511 & 688746 & 4.55 & 4.942 & TST & \\
\hline CHEMBL1381008 & 688746 & 4.4 & 4.9022 & TST & \\
\hline CHEMBL1561877 & 688746 & 4.45 & 4.7909 & TST & \\
\hline CHEMBL1490610 & 688746 & 4.4 & 4.8161 & TST & \\
\hline CHEMBL1544493 & 688746 & 4.4 & 4.9028 & TST & \\
\hline CHEMBL1547448 & 688746 & 5.15 & 4.9078 & TST & \\
\hline CHEMBL1432352 & 688746 & 4.55 & 4.7919 & TST & \\
\hline CHEMBL1613424 & 688746 & 4.8 & 4.8913 & TST & \\
\hline CHEMBL1446575 & 688746 & 4.85 & 4.8295 & TST & \\
\hline CHEMBL1407548 & 688746 & 4.6 & 4.9061 & TST & \\
\hline CHEMBL1425566 & 688746 & 4.45 & 5.005 & TST & \\
\hline CHEMBL1610783 & 688746 & 4.8 & 4.71899 & 9999999999 & TST \\
\hline CHEMBL1456164 & 688746 & 4.4 & 4.8866 & TST & \\
\hline CHEMBL1504133 & 688746 & 5.55 & 4.9589 & TST & \\
\hline CHEMBL1372543 & 688746 & 4.6 & 4.94 & TST & \\
\hline CHEMBL1416657 & 688746 & 5.3 & 4.7961 & TST & \\
\hline CHEMBL1521232 & 688746 & 4.85 & 4.9245 & TST & \\
\hline CHEMBL1493198 & 688746 & 4.4 & 4.9963 & TST & \\
\hline CHEMBL1408743 & 688746 & 4.8 & 5.0129 & TST & \\
\hline CHEMBL3212154 & 688746 & 4.6 & 4.8297 & TST & \\
\hline CHEMBL1478754 & 688746 & 4.75 & 4.882 & TST & \\
\hline CHEMBL1385366 & 688746 & 4.4 & 4.7872 & TST & \\
\hline CHEMBL1454509 & 688746 & 4.6 & 5.0139 & TST & \\
\hline CHEMBL1479488 & 688746 & 4.65 & 4.84699 & 99999999995 & TST \\
\hline CHEMBL1374875 & 688746 & 4.4 & 4.913 & TST & \\
\hline CHEMBL429335 & 688746 & 4.75 & 4.7159 & TST & \\
\hline CHEMBL1447433 & 688746 & 5.3 & 4.8381 & TST & \\
\hline CHEMBL1402525 & 688746 & 4.55 & 4.8259 & TST & \\
\hline CHEMBL1421889 & 688746 & 5.15 & 4.9995 & TST & \\
\hline CHEMBL1519934 & 688746 & 4.4 & 4.8751 & TST & \\
\hline CHEMBL1556063 & 688746 & 4.4 & 4.8462 & TST & \\
\hline CHEMBL1468947 & 688746 & 4.8 & 4.8866 & TST & \\
\hline CHEMBL1445736 & 688746 & 4.45 & 4.8443 & TST & \\
\hline CHEMBL1463789 & 688746 & 5.1 & 4.8587 & TST & \\
\hline CHEMBL3210364 & 688746 & 4.85 & 4.8599 & TST & \\
\hline CHEMBL1349827 & 688746 & 5.2 & 4.9277 & TST & \\
\hline CHEMBL1536340 & 688746 & 5.05 & 4.8858 & TST & \\
\hline CHEMBL1501238 & 688746 & 4.95 & 4.79899 & 99999999995 & TST \\
\hline CHEMBL 1487498 & 688746 & 4.95 & 4.8632 & TST & \\
\hline CHEMBL1527520 & 688746 & 5.5 & 4.8122 & TST & \\
\hline CHEMBL1561963 & 688746 & 5.3 & 4.8642 & TST & \\
\hline CHEMBL1388241 & 688746 & 4.4 & 4.9501 & TST & \\
\hline
\end{tabular}




\begin{tabular}{|c|c|c|c|c|c|}
\hline \\
\hline CHEMBL1414010 & 688746 & 4.4 & 4.8274 & TST & \\
\hline CHEMBL1493400 & 688746 & 5.6 & 4.875 & TST & \\
\hline CHEMBL1454397 & 688746 & 4.65 & 4.8638 & TST & \\
\hline CHEMBL1497939 & 688746 & 5.0 & 4.6951 & TST & \\
\hline CHEMBL1304859 & 688746 & 4.65 & 4.8525 & TST & \\
\hline CHEMBL1494838 & 688746 & 4.45 & 4.8383 & TST & \\
\hline CHEMBL1500987 & 688746 & 4.75 & 4.809 & TST & \\
\hline CHEMBL1381560 & 688746 & 7.5003 & 4.9006 & TST & \\
\hline CHEMBL3196906 & 688746 & 6.0 & 4.8311 & TST & \\
\hline CHEMBL3212480 & 688746 & 5.5 & 4.7974 & TST & \\
\hline CHEMBL1331554 & 688746 & 4.4 & 4.8301 & TST & \\
\hline CHEMBL1789996 & 688746 & 4.4 & 4.8153 & TST & \\
\hline CHEMBL1539020 & 688746 & 4.5 & 4.8401 & TST & \\
\hline CHEMBL1536562 & 688746 & 4.65 & 4.8509 & TST & \\
\hline CHEMBL1472383 & 688746 & 6.05 & 4.9839 & TST & \\
\hline CHEMBL1311094 & 688746 & 4.95 & 4.79 & TST & \\
\hline CHEMBL3191523 & 688746 & 6.15 & 4.8497 & TST & \\
\hline CHEMBL1570433 & 688746 & 4.5 & 4.9113 & TST & \\
\hline CHEMBL1410147 & 688746 & 5.0 & 4.699 & TST & \\
\hline CHEMBL1545556 & 688746 & 4.85 & 4.8014 & TST & \\
\hline CHEMBL1410598 & 688746 & 4.7 & 4.7885 & TST & \\
\hline CHEMBL 3198235 & 688746 & 5.1 & 4.7937 & TST & \\
\hline CHEMBL1302981 & 688746 & 4.4 & 4.8687 & TST & \\
\hline CHEMBL1494296 & 688746 & 5.95 & 4.8667 & TST & \\
\hline CHEMBL1490561 & 688746 & 4.4 & 4.8593 & TST & \\
\hline CHEMBL1446859 & 688746 & 6.2 & 4.8718 & TST & \\
\hline CHEMBL1420119 & 688746 & 4.9 & 4.8093 & TST & \\
\hline CHEMBL1528535 & 688746 & 4.65 & 4.7619 & TST & \\
\hline CHEMBL1332967 & 688746 & 5.35 & 5.0099 & TST & \\
\hline CHEMBL1405264 & 688746 & 4.6 & 4.7469 & TST & \\
\hline CHEMBL1382203 & 688746 & 4.7 & 4.8068 & TST & \\
\hline CHEMBL1333118 & 688746 & 4.9 & 4.8511 & TST & \\
\hline CHEMBL3191433 & 688746 & 4.4 & 4.9223 & TST & \\
\hline CHEMBL1604679 & 688746 & 5.0 & 4.8881 & TST & \\
\hline CHEMBL602418 & 688746 & 5.5 & 4.8549 & TST & \\
\hline CHEMBL1479701 & 688746 & 4.5 & 4.843 & TST & \\
\hline CHEMBL1349365 & 688746 & 4.45 & 4.7711 & TST & \\
\hline CHEMBL1349193 & 688746 & 5.45 & 4.8775 & TST & \\
\hline CHEMBL1460536 & 688746 & 4.7 & 4.8282 & TST & \\
\hline CHEMBL1439220 & 688746 & 4.65 & 4.99100 & 00000000005 & TST \\
\hline CHEMBL1421941 & 688746 & 4.65 & 4.77800 & 00000000005 & TST \\
\hline CHEMBL1309716 & 688746 & 4.85 & 4.9266 & TST & \\
\hline CHEMBL1422612 & 688746 & 4.6 & 4.8548 & TST & \\
\hline CHEMBL1542765 & 688746 & 4.7 & 4.8863 & TST & \\
\hline CHEMBL1612297 & 688746 & 6.05 & 4.8708 & TST & \\
\hline CHEMBL1342418 & 688746 & 4.4 & 4.8704 & TST & \\
\hline CHEMBL503470 & 688746 & 4.4 & 4.806 & TST & \\
\hline CHEMBL1334140 & 688746 & 4.45 & 4.9646 & TST & \\
\hline
\end{tabular}




\begin{tabular}{|c|c|c|c|c|}
\hline \multicolumn{5}{|c|}{ Supplemental Table } \\
\hline CHEMBL1302912 & 688746 & 4.6 & 4.8846 & TST \\
\hline CHEMBL572994 & 688746 & 5.3 & 4.8083 & TST \\
\hline CHEMBL1579526 & 688746 & 4.7 & 4.8931 & TST \\
\hline CHEMBL1429172 & 688746 & 4.5 & 4.9471 & TST \\
\hline CHEMBL1543036 & 688746 & 5.25 & 4.8515 & TST \\
\hline CHEMBL1487538 & 688746 & 6.7501 & 4.8078 & TST \\
\hline CHEMBL1521187 & 688746 & 5.2 & 4.7449 & TST \\
\hline CHEMBL1362658 & 688746 & 4.55 & 4.8688 & TST \\
\hline CHEMBL1399990 & 688746 & 4.55 & 4.8632 & TST \\
\hline CHEMBL1500580 & 688746 & 4.7 & 4.8288 & TST \\
\hline CHEMBL1605264 & 688746 & 4.45 & 4.8249 & TST \\
\hline CHEMBL1573636 & 688746 & 4.55 & 4.7083 & TST \\
\hline CHEMBL1513046 & 688746 & 4.4 & 4.8394 & TST \\
\hline CHEMBL1349743 & 688746 & 4.6 & 4.8612 & TST \\
\hline CHEMBL1306725 & 688746 & 4.5 & 4.8588 & TST \\
\hline CHEMBL1510194 & 688746 & 4.6 & 5.0177 & TST \\
\hline CHEMBL1452710 & 688746 & 5.45 & 4.8245 & TST \\
\hline CHEMBL1330368 & 688746 & 5.05 & 4.886 & TST \\
\hline CHEMBL1584288 & 688746 & 4.4 & 4.8453 & TST \\
\hline CHEMBL1531853 & 688746 & 4.65 & 4.8596 & TST \\
\hline CHEMBL1528486 & 688746 & 5.05 & 5.0036 & TST \\
\hline CHEMBL1309122 & 688746 & 4.55 & 4.8553 & TST \\
\hline CHEMBL1468887 & 688746 & 4.85 & 4.9719 & TST \\
\hline CHEMBL1372760 & 688746 & 4.85 & 4.7814 & TST \\
\hline CHEMBL1544921 & 688746 & 4.6 & 4.8337 & TST \\
\hline CHEMBL1985165 & 688746 & 4.55 & 4.754 & TST \\
\hline CHEMBL1418027 & 688746 & 4.6 & 4.8448 & TST \\
\hline CHEMBL1447412 & 688746 & 4.55 & 4.789 & TST \\
\hline CHEMBL1339825 & 688746 & 4.5 & 4.9196 & TST \\
\hline CHEMBL1584300 & 688746 & 4.65 & 4.8552 & TST \\
\hline CHEMBL1406076 & 688746 & 5.05 & 4.7772 & TST \\
\hline CHEMBL1599937 & 688746 & 4.4 & 4.8917 & TST \\
\hline CHEMBL1302502 & 688746 & 4.7 & 4.9036 & TST \\
\hline CHEMBL1340474 & 688746 & 5.45 & 4.9269 & TST \\
\hline CHEMBL3199171 & 688746 & 4.4 & 4.7696 & TST \\
\hline CHEMBL1464595 & 688746 & 4.6 & 4.8084 & TST \\
\hline CHEMBL1451630 & 688746 & 4.4 & 4.829 & TST \\
\hline CHEMBL1314518 & 688746 & 5.1 & 4.805 & TST \\
\hline CHEMBL1477957 & 688746 & 4.85 & 4.7546 & TST \\
\hline CHEMBL1560245 & 688746 & 4.45 & 4.8297 & TST \\
\hline CHEMBL1343883 & 688746 & 4.8 & 4.9192 & TST \\
\hline CHEMBL1330201 & 688746 & 4.5 & 4.7657 & TST \\
\hline CHEMBL1493097 & 688746 & 4.9 & 4.9143 & TST \\
\hline CHEMBL1319210 & 688746 & 4.4 & 4.8266 & TST \\
\hline CHEMBL1452731 & 688746 & 4.8 & 4.9428 & TST \\
\hline CHEMBL1487205 & 688746 & 5.25 & 4.8066 & TST \\
\hline CHEMBL1502401 & 688746 & 4.7 & 4.8417 & TST \\
\hline CHEMBL1533549 & 688746 & 4.65 & 4.6682 & TST \\
\hline
\end{tabular}




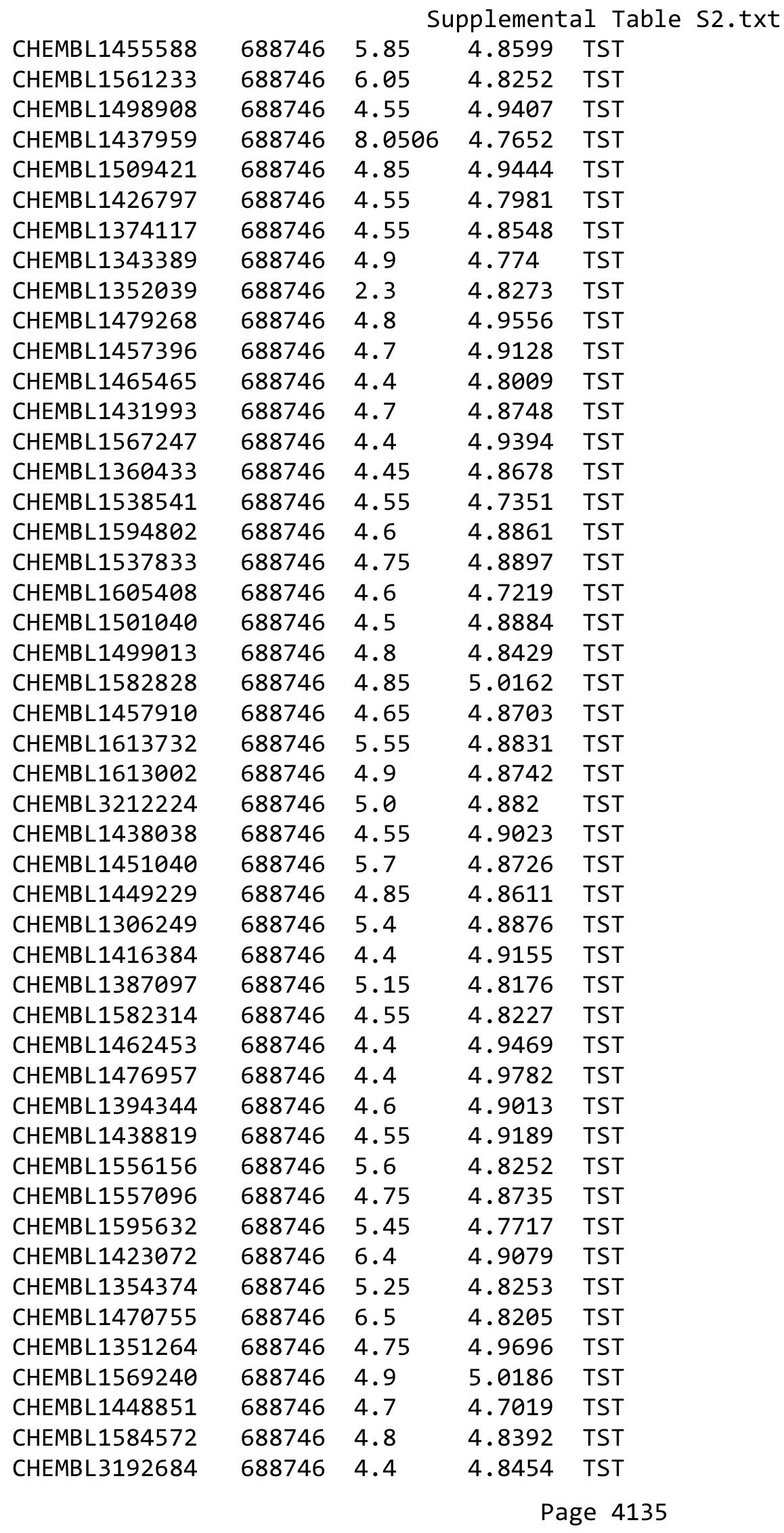




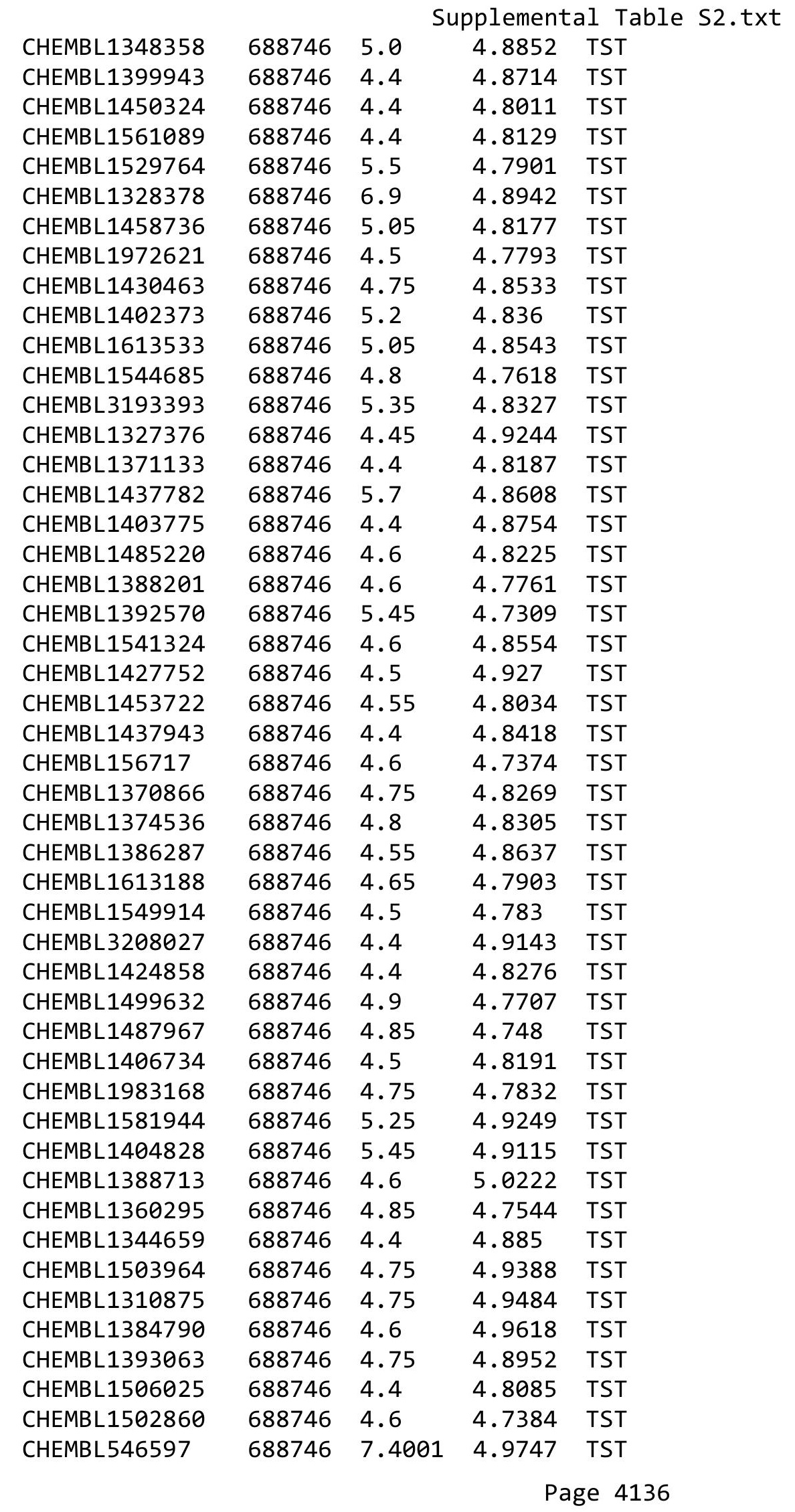




\begin{tabular}{|c|c|c|c|c|c|}
\hline & & \multicolumn{4}{|c|}{ Supplemental Table s2.txt } \\
\hline CHEMBL512216 & 688746 & 5.85 & 4.8236 & TST & \\
\hline CHEMBL146842 & 688746 & 5.5 & 4.8804 & TST & \\
\hline CHEMBL1352586 & 688746 & 5.0 & 4.8608 & TST & \\
\hline CHEMBL1536344 & 688746 & 5.3 & 4.9169 & TST & \\
\hline CHEMBL3194724 & 688746 & 4.5 & 4.8636 & TST & \\
\hline CHEMBL1382266 & 688746 & 4.55 & 4.897 & TST & \\
\hline CHEMBL1420105 & 688746 & 4.5 & 4.9322 & TST & \\
\hline CHEMBL1452695 & 688746 & 4.4 & 4.8298 & TST & \\
\hline CHEMBL1477411 & 688746 & 4.4 & 4.8619 & TST & \\
\hline CHEMBL1378566 & 688746 & 4.6 & 4.9063 & TST & \\
\hline CHEMBL1611168 & 688746 & 4.4 & 4.8492 & TST & \\
\hline CHEMBL1490044 & 688746 & 4.7 & 4.9176 & TST & \\
\hline CHEMBL1567878 & 688746 & 4.9 & 4.8673 & TST & \\
\hline CHEMBL1510045 & 688746 & 4.65 & 4.9524 & TST & \\
\hline CHEMBL1444643 & 688746 & 4.4 & 4.8359 & TST & \\
\hline CHEMBL1537348 & 688746 & 4.7 & 4.7781 & TST & \\
\hline CHEMBL1508252 & 688746 & 4.85 & 4.8665 & TST & \\
\hline CHEMBL1373194 & 688746 & 4.95 & 4.7495 & TST & \\
\hline CHEMBL1360026 & 688746 & 4.6 & 4.9188 & TST & \\
\hline CHEMBL1439145 & 688746 & 4.5 & 4.7656 & TST & \\
\hline CHEMBL1421878 & 688746 & 4.5 & 4.8653 & TST & \\
\hline CHEMBL1320230 & 688746 & 5.35 & 4.7585 & TST & \\
\hline CHEMBL1489200 & 688746 & 4.55 & 4.7873 & TST & \\
\hline CHEMBL1577159 & 688746 & 4.4 & 4.8249 & TST & \\
\hline CHEMBL1524121 & 688746 & 5.2 & 4.8911 & TST & \\
\hline CHEMBL1486767 & 688746 & 4.4 & 4.82600 & 00000000005 & TST \\
\hline CHEMBL1431524 & 688746 & 4.8 & 4.9002 & TST & \\
\hline CHEMBL1372910 & 688746 & 4.4 & 4.8603 & TST & \\
\hline CHEMBL1354033 & 688746 & 4.5 & 4.9814 & TST & \\
\hline CHEMBL1427726 & 688746 & 4.55 & 4.8486 & TST & \\
\hline CHEMBL1351515 & 688746 & 4.4 & 4.7909 & TST & \\
\hline CHEMBL1393451 & 688746 & 5.0 & 4.8763 & TST & \\
\hline CHEMBL1416049 & 688746 & 4.55 & 4.7837 & TST & \\
\hline CHEMBL1468195 & 688746 & 4.75 & 4.9385 & TST & \\
\hline CHEMBL1480163 & 688746 & 5.05 & 4.8124 & TST & \\
\hline CHEMBL1533294 & 688746 & 4.45 & 4.8441 & TST & \\
\hline CHEMBL1558111 & 688746 & 4.9 & 5.0048 & TST & \\
\hline CHEMBL1482032 & 688746 & 4.75 & 4.8323 & TST & \\
\hline CHEMBL1510300 & 688746 & 4.55 & 4.9636 & TST & \\
\hline CHEMBL1387862 & 688746 & 4.75 & 4.8933 & TST & \\
\hline CHEMBL1448704 & 688746 & 4.55 & 4.8386 & TST & \\
\hline CHEMBL1489478 & 688746 & 4.9 & 4.9522 & TST & \\
\hline CHEMBL1471308 & 688746 & 5.4 & 4.8398 & TST & \\
\hline CHEMBL1539778 & 688746 & 4.6 & 4.9013 & TST & \\
\hline CHEMBL1582865 & 688746 & 4.55 & 4.8639 & TST & \\
\hline CHEMBL1331907 & 688746 & 4.6 & 4.7999 & TST & \\
\hline CHEMBL1373256 & 688746 & 4.55 & 4.7947 & TST & \\
\hline CHEMBL1325167 & 688746 & 5.4 & 4.9145 & TST & \\
\hline
\end{tabular}




\begin{tabular}{|c|c|c|c|c|}
\hline \multicolumn{5}{|c|}{ oplemental T } \\
\hline CHEMBL1383557 & 688746 & 4.6 & 4.8135 & TST \\
\hline CHEMBL1419161 & 688746 & 4.8 & 4.8244 & TST \\
\hline CHEMBL1374227 & 688746 & 5.45 & 4.9502 & TST \\
\hline CHEMBL1988416 & 688746 & 4.75 & 4.8755 & TST \\
\hline CHEMBL1380145 & 688746 & 4.5 & 4.7836 & TST \\
\hline CHEMBL1540480 & 688746 & 4.55 & 4.9662 & TST \\
\hline CHEMBL1429002 & 688746 & 4.5 & 4.7924 & TST \\
\hline CHEMBL1330405 & 688746 & 4.55 & 4.9404 & TST \\
\hline CHEMBL1561282 & 688746 & 4.4 & 4.7999 & TST \\
\hline CHEMBL1504412 & 688746 & 6.7001 & 4.8126 & TST \\
\hline CHEMBL1341444 & 688746 & 4.6 & 4.8044 & TST \\
\hline CHEMBL3194422 & 688746 & 4.7 & 4.7505 & TST \\
\hline CHEMBL1485473 & 688746 & 4.6 & 4.8627 & TST \\
\hline CHEMBL1543984 & 688746 & 4.4 & 4.8819 & TST \\
\hline CHEMBL1470614 & 688746 & 4.45 & 4.9372 & TST \\
\hline CHEMBL3199264 & 688746 & 5.05 & 4.8686 & TST \\
\hline CHEMBL1386565 & 688746 & 4.8 & 4.7135 & TST \\
\hline CHEMBL1539103 & 688746 & 5.4 & 4.7627 & TST \\
\hline CHEMBL1610435 & 688746 & 5.4 & 4.8872 & TST \\
\hline CHEMBL1337744 & 688746 & 4.45 & 4.9393 & TST \\
\hline CHEMBL1610275 & 688746 & 4.65 & 4.9826 & TST \\
\hline CHEMBL1537703 & 688746 & 4.55 & 4.957 & TST \\
\hline CHEMBL 1408546 & 688746 & 5.3 & 4.9545 & TST \\
\hline CHEMBL3199911 & 688746 & 4.4 & 4.8907 & TST \\
\hline CHEMBL1479542 & 688746 & 5.05 & 4.8014 & TST \\
\hline CHEMBL1371918 & 688746 & 4.65 & 4.8494 & TST \\
\hline CHEMBL1522691 & 688746 & 4.4 & 4.9364 & TST \\
\hline CHEMBL1528393 & 688746 & 4.8 & 4.98 & TST \\
\hline CHEMBL602413 & 688746 & 4.5 & 4.8251 & TST \\
\hline CHEMBL1448309 & 688746 & 4.7 & 4.8258 & TST \\
\hline CHEMBL1469079 & 688746 & 4.65 & 4.91 & TST \\
\hline CHEMBL1482758 & 688746 & 5.0 & 4.8204 & TST \\
\hline CHEMBL607524 & 688746 & 4.45 & 4.9524 & TST \\
\hline CHEMBL1613265 & 688746 & 5.05 & 4.8966 & TST \\
\hline CHEMBL1543818 & 688746 & 4.75 & 4.7628 & TST \\
\hline CHEMBL1391824 & 688746 & 4.7 & 5.0605 & TST \\
\hline CHEMBL1430809 & 688746 & 4.7 & 4.9846 & TST \\
\hline CHEMBL1487360 & 688746 & 4.65 & 4.8741 & TST \\
\hline CHEMBL1372662 & 688746 & 4.75 & 4.9581 & TST \\
\hline CHEMBL1973921 & 688746 & 4.7 & 4.7606 & TST \\
\hline CHEMBL1373596 & 688746 & 4.75 & 4.8729 & TST \\
\hline CHEMBL1302934 & 688746 & 6.8 & 4.8496 & TST \\
\hline CHEMBL1391474 & 688746 & 4.75 & 4.7547 & TST \\
\hline CHEMBL1462765 & 688746 & 5.35 & 4.9485 & TST \\
\hline CHEMBL1304754 & 688746 & 5.2 & 4.9084 & TST \\
\hline CHEMBL1465234 & 688746 & 4.4 & 4.8741 & TST \\
\hline CHEMBL 365161 & 688746 & 5.85 & 4.8424 & TST \\
\hline CHEMBL1605011 & 688746 & 4.4 & 4.9237 & TST \\
\hline
\end{tabular}




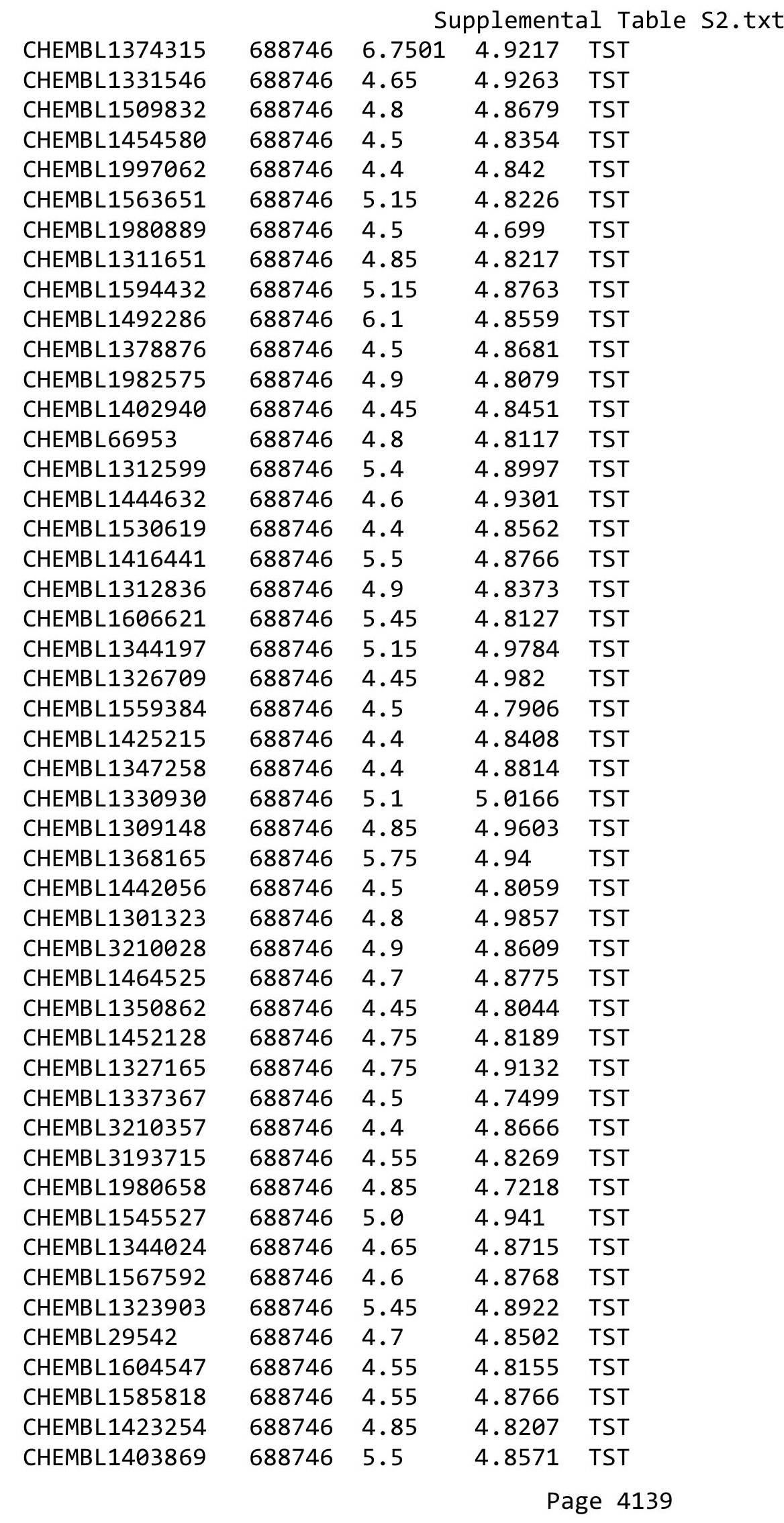




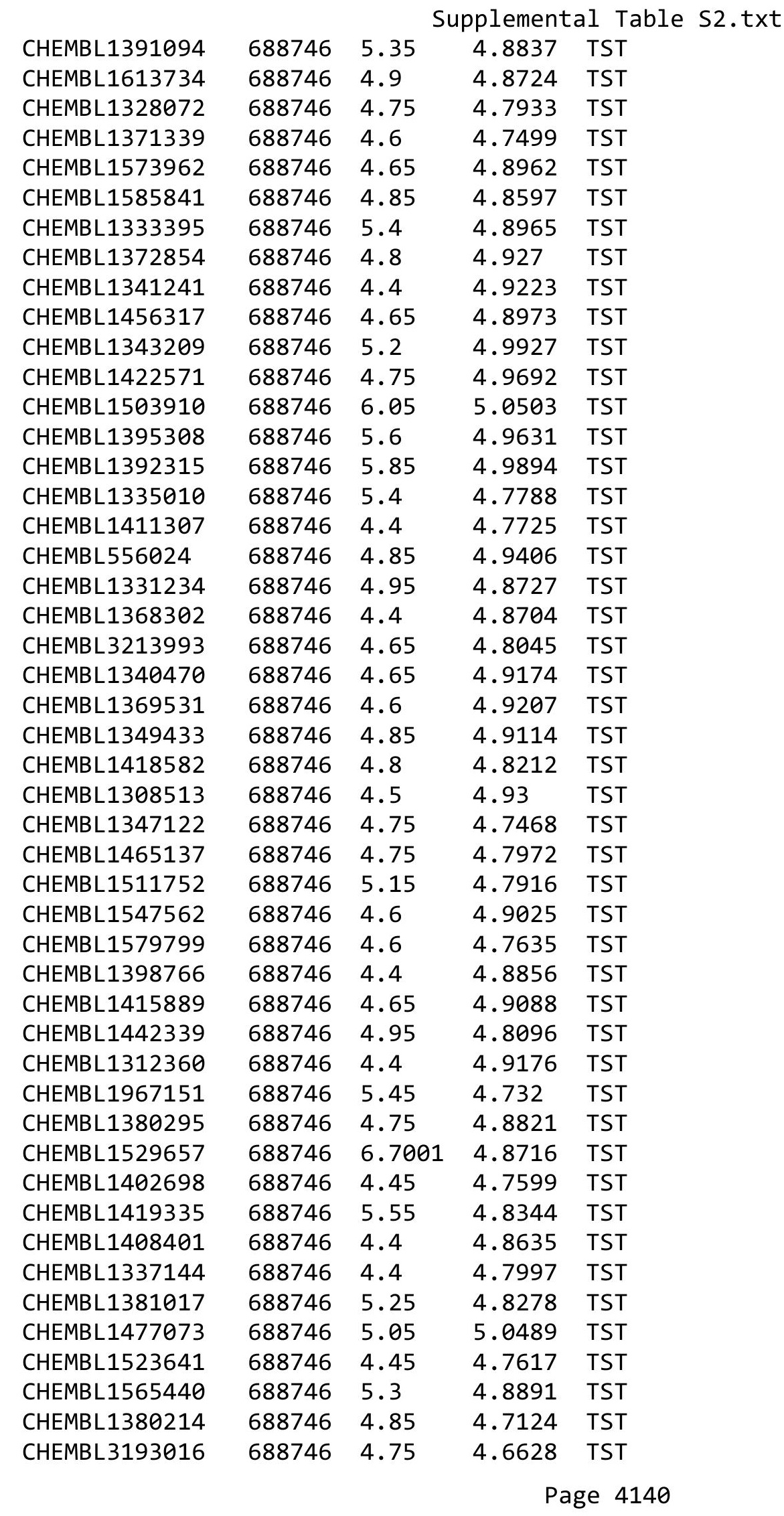




\begin{tabular}{|c|c|c|c|c|}
\hline & & & pplement & al $\mathrm{Ta}$ \\
\hline CHEMBL199194 & 688746 & 4.5 & 4.7557 & TST \\
\hline CHEMBL1497863 & 688746 & 4.6 & 4.8143 & TST \\
\hline CHEMBL1381708 & 688746 & 4.4 & 4.9012 & TST \\
\hline CHEMBL1505764 & 688746 & 6.0 & 4.921 & TST \\
\hline CHEMBL1588365 & 688746 & 4.9 & 4.9663 & TST \\
\hline CHEMBL1505628 & 688746 & 5.15 & 4.9344 & TST \\
\hline CHEMBL1465645 & 688746 & 4.4 & 4.9647 & TST \\
\hline CHEMBL1428758 & 688746 & 4.85 & 4.8429 & TST \\
\hline CHEMBL1409288 & 688746 & 4.9 & 4.7829 & TST \\
\hline CHEMBL1328401 & 688746 & 6.15 & 4.9539 & TST \\
\hline CHEMBL1442928 & 688746 & 5.0 & 4.8567 & TST \\
\hline CHEMBL1523555 & 688746 & 4.8 & 4.8522 & TST \\
\hline CHEMBL1417251 & 688746 & 4.8 & 4.9 & TST \\
\hline CHEMBL1438123 & 688746 & 4.6 & 5.0386 & TST \\
\hline CHEMBL1362264 & 688746 & 5.85 & 4.9239 & TST \\
\hline CHEMBL1587826 & 688746 & 4.65 & 4.9086 & TST \\
\hline CHEMBL1406745 & 688746 & 4.4 & 4.8498 & TST \\
\hline CHEMBL1302931 & 688746 & 4.5 & 4.9653 & TST \\
\hline CHEMBL1490692 & 688746 & 4.9 & 4.8205 & TST \\
\hline CHEMBL1483790 & 688746 & 4.8 & 4.9581 & TST \\
\hline CHEMBL592124 & 688746 & 4.45 & 4.875 & TST \\
\hline CHEMBL1492001 & 688746 & 4.75 & 4.8191 & TST \\
\hline CHEMBL1349983 & 688746 & 5.25 & 4.8417 & TST \\
\hline CHEMBL1477550 & 688746 & 4.95 & 4.7299 & TST \\
\hline CHEMBL1585855 & 688746 & 5.0 & 4.9109 & TST \\
\hline CHEMBL1517045 & 688746 & 4.9 & 4.7372 & TST \\
\hline CHEMBL 3192083 & 688746 & 4.6 & 4.8497 & TST \\
\hline CHEMBL1338774 & 688746 & 5.95 & 4.7522 & TST \\
\hline CHEMBL1308357 & 688746 & 4.6 & 4.7434 & TST \\
\hline CHEMBL259805 & 688746 & 4.6 & 4.7702 & TST \\
\hline CHEMBL1600417 & 688746 & 4.4 & 4.9478 & TST \\
\hline CHEMBL1433158 & 688746 & 5.45 & 4.8813 & TST \\
\hline CHEMBL1344025 & 688746 & 4.4 & 4.9796 & TST \\
\hline CHEMBL1599381 & 688746 & 4.6 & 5.0143 & TST \\
\hline CHEMBL3199318 & 688746 & 5.15 & 4.7719 & TST \\
\hline CHEMBL1422590 & 688746 & 4.7 & 4.8955 & TST \\
\hline CHEMBL1500193 & 688746 & 5.35 & 4.726 & TST \\
\hline CHEMBL1970478 & 688746 & 5.05 & 4.7554 & TST \\
\hline CHEMBL1318643 & 688746 & 6.0 & 4.8127 & TST \\
\hline CHEMBL1541798 & 688746 & 4.45 & 4.9651 & TST \\
\hline CHEMBL1452558 & 688746 & 6.25 & 4.912 & TST \\
\hline CHEMBL1597238 & 688746 & 6.05 & 4.9553 & TST \\
\hline CHEMBL1469532 & 688746 & 4.4 & 4.788 & TST \\
\hline CHEMBL1458771 & 688746 & 5.45 & 4.8433 & TST \\
\hline CHEMBL1332728 & 688746 & 4.85 & 4.7794 & TST \\
\hline CHEMBL 1400050 & 688746 & 4.5 & 4.9391 & TST \\
\hline CHEMBL1368725 & 688746 & 4.4 & 4.8521 & TST \\
\hline CHEMBL1299210 & 688746 & 4.8 & 4.8214 & TST \\
\hline
\end{tabular}




\begin{tabular}{|c|c|c|c|c|}
\hline & & & & al Table \\
\hline CHEMBL1574550 & 688746 & 4.4 & 4.8591 & TST \\
\hline CHEMBL1301481 & 688746 & 4.5 & 4.8026 & TST \\
\hline CHEMBL1381637 & 688746 & 6.15 & 4.9054 & TST \\
\hline CHEMBL1334746 & 688746 & 4.6 & 4.9624 & TST \\
\hline CHEMBL1340454 & 688746 & 5.9 & 4.8594 & TST \\
\hline CHEMBL1517424 & 688746 & 4.75 & 4.9915 & TST \\
\hline CHEMBL1606229 & 688746 & 4.55 & 4.9989 & TST \\
\hline CHEMBL1471698 & 688746 & 4.4 & 4.8696 & TST \\
\hline CHEMBL1384621 & 688746 & 4.45 & 4.8013 & TST \\
\hline CHEMBL1603148 & 688746 & 4.4 & \multicolumn{2}{|c|}{4.906000000000001} \\
\hline CHEMBL1600114 & 688746 & 5.0 & 4.7789 & TST \\
\hline CHEMBL1586224 & 688746 & 4.8 & 4.8515 & TST \\
\hline CHEMBL1344433 & 688746 & 4.65 & 4.9862 & TST \\
\hline CHEMBL1603542 & 688746 & 4.9 & 4.8853 & TST \\
\hline CHEMBL1505230 & 688746 & 4.75 & 4.8845 & TST \\
\hline CHEMBL1342147 & 688746 & 4.9 & 4.7271 & TST \\
\hline CHEMBL1500060 & 688746 & 4.65 & 4.8179 & TST \\
\hline CHEMBL3213588 & 688746 & 4.4 & 4.7766 & TST \\
\hline CHEMBL1575265 & 688746 & 6.2 & 4.8514 & TST \\
\hline CHEMBL1588389 & 688746 & 5.0 & 4.8198 & TST \\
\hline CHEMBL1487067 & 688746 & 4.7 & 4.9302 & TST \\
\hline CHEMBL1379686 & 688746 & 4.6 & 5.0008 & TST \\
\hline CHEMBL1385209 & 688746 & 5.2 & 4.9814 & TST \\
\hline CHEMBL1529716 & 688746 & 4.65 & 4.8537 & TST \\
\hline CHEMBL127757 & 688746 & 4.85 & 4.7719 & TST \\
\hline CHEMBL1369416 & 688746 & 4.75 & 4.7899 & TST \\
\hline CHEMBL1465990 & 688746 & 4.75 & 5.0231 & TST \\
\hline CHEMBL1570020 & 688746 & 4.55 & 4.925 & TST \\
\hline CHEMBL1525074 & 688746 & 4.5 & 4.9162 & TST \\
\hline CHEMBL1447167 & 688746 & 4.8 & 4.9158 & TST \\
\hline CHEMBL561936 & 688746 & 5.1 & 4.7893 & TST \\
\hline CHEMBL1347914 & 688746 & 5.45 & 4.7546 & TST \\
\hline CHEMBL1439981 & 688746 & 6.6 & 4.8696 & TST \\
\hline CHEMBL1549066 & 688746 & 5.0 & 4.8734 & TST \\
\hline CHEMBL1415522 & 688746 & 4.55 & 4.8883 & TST \\
\hline CHEMBL1607586 & 688746 & 4.5 & 4.7652 & TST \\
\hline CHEMBL1386149 & 688746 & 4.65 & 4.7058 & TST \\
\hline CHEMBL1377108 & 688746 & 4.85 & 4.7824 & TST \\
\hline CHEMBL1471899 & 688746 & 4.6 & 4.8107 & TST \\
\hline CHEMBL1493226 & 688746 & 4.8 & 4.8402 & TST \\
\hline CHEMBL1371578 & 688746 & 4.8 & 4.8938 & TST \\
\hline CHEMBL1494650 & 688746 & 4.45 & 4.8901 & TST \\
\hline CHEMBL1470914 & 688746 & 4.6 & 4.8346 & TST \\
\hline CHEMBL1336655 & 688746 & 5.65 & 4.9584 & TST \\
\hline CHEMBL1400583 & 688746 & 4.4 & 4.834 & TST \\
\hline CHEMBL1440527 & 688746 & 4.8 & 4.914 & TST \\
\hline CHEMBL1579755 & 688746 & 4.85 & 4.8905 & TST \\
\hline CHEMBL1370828 & 688746 & 5.35 & 4.9094 & TST \\
\hline
\end{tabular}




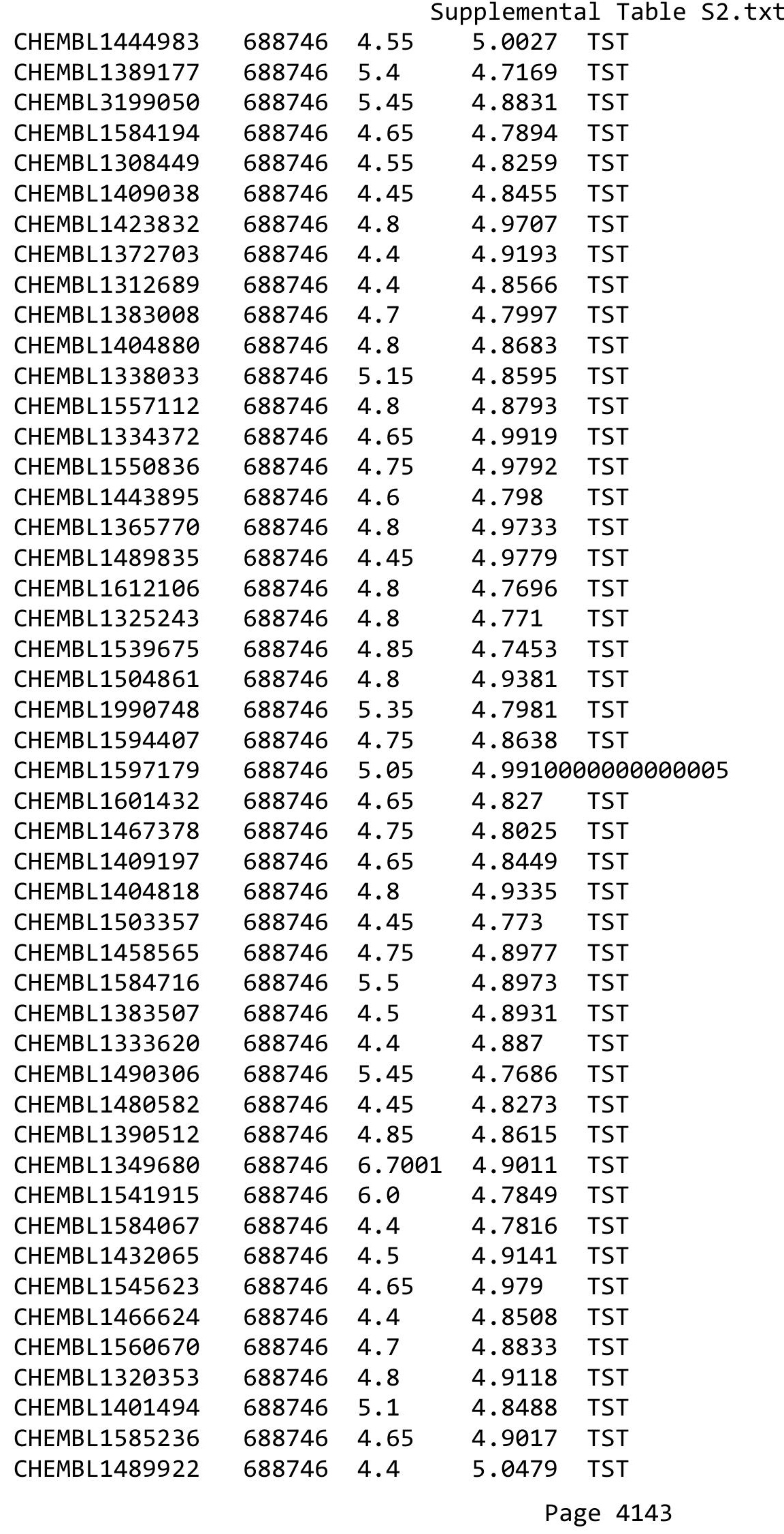




\begin{tabular}{|c|c|c|c|c|}
\hline & & & upplement & al \\
\hline CHEMBL1431271 & 688746 & 5.45 & 4.8946 & TST \\
\hline CHEMBL1319607 & 688746 & 4.4 & 4.8122 & TST \\
\hline CHEMBL1509528 & 688746 & 4.4 & 4.9278 & TST \\
\hline CHEMBL1304955 & 688746 & 4.4 & 4.7311 & TST \\
\hline CHEMBL1585699 & 688746 & 4.4 & 4.8728 & TST \\
\hline CHEMBL1407624 & 688746 & 5.15 & 4.8519 & TST \\
\hline CHEMBL1538241 & 688746 & 4.75 & 4.9107 & TST \\
\hline CHEMBL1603864 & 688746 & 4.4 & 4.8944 & TST \\
\hline CHEMBL1323764 & 688746 & 4.4 & 4.7245 & TST \\
\hline CHEMBL1418000 & 688746 & 4.85 & 4.9385 & TST \\
\hline CHEMBL1600851 & 688746 & 4.4 & 4.8509 & TST \\
\hline CHEMBL1383892 & 688746 & 4.65 & 4.753 & TST \\
\hline CHEMBL1305475 & 688746 & 4.45 & 4.822 & TST \\
\hline CHEMBL3209570 & 688746 & 4.55 & 4.8506 & TST \\
\hline CHEMBL1537373 & 688746 & 4.55 & 4.9522 & TST \\
\hline CHEMBL1570727 & 688746 & 4.5 & 4.8848 & TST \\
\hline CHEMBL1337712 & 688746 & 4.4 & 4.8089 & TST \\
\hline CHEMBL1349597 & 688746 & 5.2 & 4.8661 & TST \\
\hline CHEMBL1429218 & 688746 & 4.8 & 4.7093 & TST \\
\hline CHEMBL1402097 & 688746 & 4.45 & 4.8579 & TST \\
\hline CHEMBL1560984 & 688746 & 4.85 & 5.0005 & TST \\
\hline CHEMBL1491241 & 688746 & 5.15 & 4.9063 & TST \\
\hline CHEMBL1427476 & 688746 & 4.65 & 4.8104 & TST \\
\hline CHEMBL1383569 & 688746 & 4.8 & 4.8331 & TST \\
\hline CHEMBL1438789 & 688746 & 4.65 & 4.7791 & TST \\
\hline CHEMBL3194220 & 688746 & 5.1 & 4.8085 & TST \\
\hline CHEMBL460518 & 688746 & 4.7 & 4.6589 & TST \\
\hline CHEMBL1458556 & 688746 & 5.5 & 4.8894 & TST \\
\hline CHEMBL1522100 & 688746 & 4.85 & 4.8456 & TST \\
\hline CHEMBL1581132 & 688746 & 4.4 & 4.8068 & TST \\
\hline CHEMBL1339579 & 688746 & 4.4 & 4.7786 & TST \\
\hline CHEMBL1571842 & 688746 & 4.85 & 4.8671 & TST \\
\hline CHEMBL1400070 & 688746 & 4.4 & 4.8978 & TST \\
\hline CHEMBL1463990 & 688746 & 4.6 & 4.7994 & TST \\
\hline CHEMBL1407401 & 688746 & 4.65 & 4.8975 & TST \\
\hline CHEMBL1492431 & 688746 & 4.65 & 4.8612 & TST \\
\hline CHEMBL1556096 & 688746 & 4.5 & 4.9259 & TST \\
\hline CHEMBL1575179 & 688746 & 4.65 & 5.0164 & TST \\
\hline CHEMBL1313249 & 688746 & 5.45 & 4.8231 & TST \\
\hline CHEMBL1347052 & 688746 & 4.7 & 4.8935 & TST \\
\hline CHEMBL1379740 & 688746 & 4.85 & 4.8036 & TST \\
\hline CHEMBL1599932 & 688746 & 4.9 & 4.894 & TST \\
\hline CHEMBL1507328 & 688746 & 4.4 & 4.9069 & TST \\
\hline CHEMBL1441439 & 688746 & 4.4 & 4.823 & TST \\
\hline CHEMBL1511238 & 688746 & 4.65 & 4.7481 & TST \\
\hline CHEMBL3199462 & 688746 & 4.45 & 4.8174 & TST \\
\hline CHEMBL1429058 & 688746 & 4.4 & 4.8412 & TST \\
\hline CHEMBL1387670 & 688746 & 4.65 & 4.8619 & TST \\
\hline
\end{tabular}




\begin{tabular}{|c|c|c|c|c|c|}
\hline & & & & & \\
\hline CHEMBL1413748 & 688746 & 4.4 & 4.7887 & TST & \\
\hline CHEMBL1344952 & 688716 & 4.3 & 4.2925 & TRN & \\
\hline CHEMBL445957 & 688716 & 4.4 & 4.4435 & TRN & \\
\hline CHEMBL1526319 & 688716 & 4.3 & 4.3398 & TRN & \\
\hline CHEMBL1565705 & 688716 & 4.3 & 4.3349 & TRN & \\
\hline CHEMBL85811 & 688716 & 4.3 & 4.1677 & TRN & \\
\hline CHEMBL1561876 & 688716 & 4.3 & 4.4632 & TRN & \\
\hline CHEMBL1325964 & 688716 & 4.1 & 4.5154 & TRN & \\
\hline CHEMBL196537 & 688716 & 4.1 & 4.2775 & TRN & \\
\hline CHEMBL1366408 & 688716 & 4.4 & 4.6202 & TRN & \\
\hline CHEMBL57394 & 688716 & 4.4 & 4.4295 & TRN & \\
\hline CHEMBL1471289 & 688716 & 4.8 & 4.4561 & TRN & \\
\hline CHEMBL468037 & 688716 & 4.3 & 4.582 & TRN & \\
\hline CHEMBL36296 & 688716 & 4.3 & 4.351 & TRN & \\
\hline CHEMBL1448387 & 688716 & 4.5 & 4.5408 & TRN & \\
\hline CHEMBL1569493 & 688716 & 6.0 & 5.943 & TRN & \\
\hline CHEMBL1602699 & 688716 & 5.3 & 5.2319 & TRN & \\
\hline CHEMBL8320 & 688716 & 4.3 & 4.4231 & TRN & \\
\hline CHEMBL1338613 & 688716 & 4.4 & 4.3055 & TRN & \\
\hline CHEMBL1517425 & 688716 & 4.3 & 4.18199 & 99999999995 & TRN \\
\hline CHEMBL1447588 & 688716 & 4.9 & 4.9959 & TST & \\
\hline CHEMBL1450607 & 688716 & 4.6 & 4.5994 & TRN & \\
\hline CHEMBL1430204 & 688716 & 4.4 & 4.3662 & TRN & \\
\hline CHEMBL418068 & 688716 & 4.3 & 4.4793 & TRN & \\
\hline CHEMBL167423 & 688716 & 4.2 & 4.2293 & TRN & \\
\hline CHEMBL1531716 & 688716 & 4.3 & 4.3762 & TRN & \\
\hline CHEMBL402063 & 688716 & 6.0 & 5.2815 & TST & \\
\hline CHEMBL454173 & 688716 & 6.0 & 4.7921 & TRN & \\
\hline CHEMBL1371297 & 688716 & 4.1 & 4.3682 & TRN & \\
\hline CHEMBL1569226 & 688716 & 5.5 & 5.1357 & TRN & \\
\hline CHEMBL440287 & 688716 & 4.3 & 4.5583 & TRN & \\
\hline CHEMBL175193 & 688716 & 4.1 & 4.2128 & TRN & \\
\hline CHEMBL486193 & 688716 & 4.3 & 4.7058 & TST & \\
\hline CHEMBL1452158 & 688716 & 4.4 & 4.3233 & TRN & \\
\hline CHEMBL1496957 & 688716 & 4.7 & 4.6825 & TRN & \\
\hline CHEMBL1485974 & 688716 & 4.5 & 4.3534 & TRN & \\
\hline CHEMBL1600998 & 688716 & 5.2 & 5.3908 & TRN & \\
\hline CHEMBL1309179 & 688716 & 5.1 & 4.7588 & TRN & \\
\hline CHEMBL1330518 & 688716 & 4.3 & 4.3399 & TRN & \\
\hline CHEMBL1609459 & 688716 & 4.9 & 5.0859 & TRN & \\
\hline CHEMBL8739 & 688716 & 4.3 & 4.2825 & TRN & \\
\hline CHEMBL 28 & 688716 & 4.3 & 4.3656 & TRN & \\
\hline CHEMBL1408847 & 688716 & 5.3 & 5.2072 & TRN & \\
\hline CHEMBL1529759 & 688716 & 4.1 & 4.4666 & TST & \\
\hline CHEMBL1559341 & 688716 & 4.6 & 4.385 & TRN & \\
\hline CHEMBL194399 & 688716 & 4.3 & 4.3101 & TRN & \\
\hline CHEMBL1526721 & 688716 & 5.2 & 4.9981 & TRN & \\
\hline CHEMBL192627 & 688716 & 4.7 & 4.5885 & TRN & \\
\hline & & & & 4145 & \\
\hline
\end{tabular}




\begin{tabular}{|c|c|c|c|c|c|}
\hline & & & & & \\
\hline CHEMBL389950 & 688716 & 4.1 & 4.3062 & TST & \\
\hline CHEMBL1200471 & 688716 & 6.6 & 6.6517 & TRN & \\
\hline CHEMBL1308088 & 688716 & 4.8 & 4.8044 & TRN & \\
\hline CHEMBL1142 & 688716 & 4.4 & 4.3138 & TRN & \\
\hline CHEMBL1585396 & 688716 & 4.4 & 4.3871 & TRN & \\
\hline CHEMBL1545634 & 688716 & 6.3 & 6.5388 & TRN & \\
\hline CHEMBL 230156 & 688716 & 4.3 & 4.2725 & TRN & \\
\hline CHEMBL1518369 & 688716 & 4.3 & 4.4307 & TRN & \\
\hline CHEMBL1489064 & 688716 & 4.3 & 4.21399 & 99999999995 & TRN \\
\hline CHEMBL1451833 & 688716 & 4.5 & 4.468 & TST & \\
\hline CHEMBL220845 & 688716 & 4.4 & 4.2221 & TRN & \\
\hline CHEMBL1462419 & 688716 & 4.4 & 4.4733 & TST & \\
\hline CHEMBL1409985 & 688716 & 5.4 & 5.2004 & TRN & \\
\hline CHEMBL1562104 & 688716 & 5.4 & 5.4219 & TRN & \\
\hline CHEMBL1319452 & 688716 & 4.5 & 4.4876 & TRN & \\
\hline CHEMBL1393325 & 688716 & 4.1 & 4.4868 & TRN & \\
\hline CHEMBL58835 & 688716 & 4.4 & 4.4624 & TRN & \\
\hline CHEMBL1364985 & 688716 & 4.3 & 4.5929 & TRN & \\
\hline CHEMBL1414154 & 688716 & 4.3 & 4.1972 & TRN & \\
\hline CHEMBL509531 & 688716 & 4.6 & 4.8916 & TST & \\
\hline CHEMBL1519327 & 688716 & 6.5 & 6.2727 & TRN & \\
\hline CHEMBL1304981 & 688716 & 4.1 & 4.251 & TRN & \\
\hline CHEMBL242080 & 688716 & 4.3 & 4.474 & TRN & \\
\hline CHEMBL195953 & 688716 & 4.3 & 4.2542 & TRN & \\
\hline CHEMBL1612246 & 688716 & 4.4 & 4.6032 & TRN & \\
\hline CHEMBL1579130 & 688716 & 6.0 & 5.5466 & TST & \\
\hline CHEMBL1558796 & 688716 & 4.3 & 4.6159 & TRN & \\
\hline CHEMBL1578983 & 688716 & 4.4 & 4.3638 & TRN & \\
\hline CHEMBL40274 & 688716 & 4.3 & 4.5565 & TRN & \\
\hline CHEMBL105712 & 688716 & 5.0 & 4.96899 & 9999999999 & TRN \\
\hline CHEMBL1514512 & 688716 & 4.3 & 4.2914 & TRN & \\
\hline CHEMBL1492729 & 688716 & 4.7 & 4.6825 & TRN & \\
\hline CHEMBL1527567 & 688716 & 4.5 & 4.2942 & TRN & \\
\hline CHEMBL1449018 & 688716 & 4.6 & 4.6233 & TRN & \\
\hline CHEMBL1524617 & 688716 & 5.3 & 5.0973 & TST & \\
\hline CHEMBL935 & 688716 & 4.3 & 4.3691 & TRN & \\
\hline CHEMBL1528479 & 688716 & 4.1 & 4.194 & TRN & \\
\hline CHEMBL1499545 & 688716 & 5.1 & 5.3103 & TRN & \\
\hline CHEMBL1535689 & 688716 & 4.5 & 4.305 & TRN & \\
\hline CHEMBL224282 & 688716 & 4.3 & 4.2131 & TRN & \\
\hline CHEMBL1492884 & 688716 & 4.4 & 4.3567 & TRN & \\
\hline CHEMBL329673 & 688716 & 4.4 & 4.4135 & TRN & \\
\hline CHEMBL144530 & 688716 & 4.5 & 4.2617 & TRN & \\
\hline CHEMBL194400 & 688716 & 4.3 & 4.2456 & TRN & \\
\hline CHEMBL1456906 & 688716 & 4.4 & 4.6644 & TST & \\
\hline CHEMBL1418603 & 688716 & 4.4 & 4.1959 & TRN & \\
\hline CHEMBL1522486 & 688716 & 4.6 & 4.6344 & TRN & \\
\hline CHEMBL140 & 688716 & 4.4 & 4.376 & TRN & \\
\hline & & & & 4146 & \\
\hline
\end{tabular}




\begin{tabular}{|c|c|c|c|c|}
\hline \multicolumn{5}{|c|}{ Supplemental Table S2.txt } \\
\hline CHEMBL334255 & 688716 & 4.6 & 5.0801 & TST \\
\hline CHEMBL1530684 & 688716 & 4.4 & 4.3945 & TST \\
\hline CHEMBL84685 & 688716 & 4.3 & 4.4398 & TST \\
\hline CHEMBL162598 & 688716 & 4.4 & 4.3902 & TST \\
\hline CHEMBL443949 & 688716 & 4.5 & 4.5118 & TST \\
\hline CHEMBL1562553 & 688716 & 4.3 & 4.4621 & TST \\
\hline CHEMBL1485360 & 688716 & 4.4 & 4.6059 & TST \\
\hline CHEMBL1549844 & 688716 & 4.9 & 4.6216 & TST \\
\hline CHEMBL1492104 & 688716 & 4.8 & 4.7814 & TST \\
\hline CHEMBL1566504 & 688716 & 4.3 & 4.3718 & TST \\
\hline CHEMBL1407826 & 688716 & 4.6 & 4.7851 & TST \\
\hline CHEMBL1303139 & 688716 & 5.4 & 5.0533 & TST \\
\hline CHEMBL44072 & 688716 & 4.4 & 4.3554 & TST \\
\hline CHEMBL1484480 & 688716 & 4.1 & 4.1161 & TST \\
\hline CHEMBL1576086 & 688716 & 4.5 & 4.4799 & TST \\
\hline CHEMBL538146 & 688716 & 4.4 & 4.7709 & TST \\
\hline CHEMBL1331245 & 688716 & 4.3 & 4.2417 & TST \\
\hline CHEMBL289277 & 688716 & 4.4 & 4.4026 & TST \\
\hline CHEMBL 3685719 & 1537553 & 6.0458 & 5.4583 & TRN \\
\hline CHEMBL3685724 & 1537553 & 5.7959 & 6.2127 & TRN \\
\hline CHEMBL 3685686 & 1537553 & 6.2218 & 6.4954 & TRN \\
\hline CHEMBL3681007 & 1537553 & 8.1549 & 7.4703 & TRN \\
\hline CHEMBL3681001 & 1537553 & 6.0458 & 6.3876 & TST \\
\hline CHEMBL 3680993 & 1537553 & 7.1549 & 7.2542 & TST \\
\hline CHEMBL 3685730 & 1537553 & 5.301 & 6.2385 & TST \\
\hline CHEMBL 3681014 & 1537553 & 6.699 & 6.5474 & TRN \\
\hline CHEMBL3685732 & 1537553 & 6.1549 & 6.1057 & TRN \\
\hline CHEMBL3685713 & 1537553 & 7.0 & 6.5622 & TRN \\
\hline CHEMBL 3685668 & 1537553 & 6.699 & 6.2709 & TRN \\
\hline CHEMBL3730661 & 1537553 & 5.4559 & 5.9779 & TST \\
\hline CHEMBL3681012 & 1537553 & 6.5229 & 6.4234 & TRN \\
\hline CHEMBL3681024 & 1537553 & 7.0458 & 6.5728 & TRN \\
\hline CHEMBL3685687 & 1537553 & 6.0969 & 6.4888 & TRN \\
\hline CHEMBL3685711 & 1537553 & 5.4685 & 6.1361 & TRN \\
\hline CHEMBL3681006 & 1537553 & 6.8239 & 6.8954 & TRN \\
\hline CHEMBL 3681010 & 1537553 & 6.699 & 6.6097 & TRN \\
\hline CHEMBL3681015 & 1537553 & 6.2218 & 6.188 & TRN \\
\hline CHEMBL 3685662 & 1537553 & 5.4318 & 6.267 & TRN \\
\hline CHEMBL 3685700 & 1537553 & 6.301 & 6.33 & TRN \\
\hline CHEMBL3685677 & 1537553 & 5.5376 & 6.0466 & TRN \\
\hline CHEMBL 3685655 & 1537553 & 5.6383 & 6.0297 & TRN \\
\hline CHEMBL 3681021 & 1537553 & 6.0969 & 5.8272 & TRN \\
\hline CHEMBL3685681 & 1537553 & 6.699 & 6.6205 & TRN \\
\hline CHEMBL 3685632 & 1537553 & 6.3979 & 6.2133 & TRN \\
\hline CHEMBL 3685628 & 1537553 & 6.5229 & 6.5986 & TRN \\
\hline CHEMBL 3685725 & 1537553 & 6.1549 & 6.2748 & TRN \\
\hline CHEMBL 3685651 & 1537553 & 6.5229 & 6.0741 & TRN \\
\hline CHEMBL 3685664 & 1537553 & 6.699 & 7.2862 & TRN \\
\hline
\end{tabular}


Supplemental Table S2.txt

\begin{tabular}{|c|c|c|c|c|}
\hline 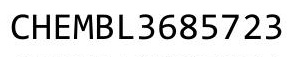 & & & 92 & \\
\hline HEMBL3685634 & 537553 & 7.0 & 1346 & \\
\hline HEMBL3680990 & & 6.0458 & 2149 & \\
\hline 23 & & & 1946 & \\
\hline EMBL: & 3 & 61 & 8906 & PN \\
\hline HEMBL3685653 & 537553 & 7.0 & 2586 & \\
\hline HEMBL3685663 & 537553 & 5.9586 & 6696 & \\
\hline HEMBL3685693 & & & 7688 & \\
\hline HEMBL3685702 & & 6.1549 & 8999 & \\
\hline AEMBL3 & 537 & 59 & 4855 & \\
\hline HEMBL3685680 & 537 & 6.1549 & 6801 & \\
\hline HEMBL3685704 & 53 & 6.5229 & 2176 & \\
\hline HEMBL3685692 & וכבע & 12 & 4438 & \\
\hline HEMBL3685729 & 3 & 6.699 & 4301 & \\
\hline HEMBI & 3 & & 3311 & \\
\hline HEMBL3685642 & 537 & 6.0 & 5009 & \\
\hline HEMBL3685688 & $-2-7$ & 7.0 & 4836 & \\
\hline HEMBL3681002 & 53 & 5 . & 632 & \\
\hline 701 & & & 536 & NIV \\
\hline 629 & 3 & & 054 & \\
\hline HEMBL3680999 & 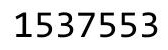 & & 3571 & \\
\hline HEMBL3685689 & $537-2 \cdot 1-2 \cdot$ & & 534 & \\
\hline HEMBL3680988 & 53 & 7 & 17 & RN \\
\hline HEMBL36 & & & 559 & RN \\
\hline 998 & 3 & 7. & 823 & RN \\
\hline HEMBL36 & & & 505 & RN \\
\hline HEMBL 3685648 & 53 & & 3942 & TST \\
\hline HEMBL3685691 & 53 & & 431 & RN \\
\hline 717 & & & 275 & $\mathrm{RN}$ \\
\hline HEMBL & 3 & & 2643 & RN \\
\hline HEMBL3685712 & 537 & 8.0 & 272 & IRN \\
\hline HEMBL 3730049 & 537 & & 459 & TST \\
\hline HEMBL3 & & & & RN \\
\hline 9 & 3 & & 59 & RN \\
\hline 95 & 2 & 7. & 2176 & RN \\
\hline HEMBL3685636 & 537 & & 1902 & 「RN \\
\hline HEMBL3685667 & 5375 & 6. & 2405 & ГRN \\
\hline 00 & & 9 & 3322 & RN \\
\hline 22 & דרי & 9 & 148 & RN \\
\hline HEMBL3685631 & 537553 & 7.30 & 1379 & 「RN \\
\hline HEMBL3685699 & 537553 & 6. & 154 & ГST \\
\hline CHEMBL 3685676 & 1537 & 6 . & 669 & IST \\
\hline 35 & רכזי & & 611 & \\
\hline CHEMBL 3685658 & 537 & & 3024 & RIN \\
\hline HEMBL3685659 & 537553 & 7.301 & .1907 & ST \\
\hline HEMBL3685633 & 53755 & 5. & 8169 & ST \\
\hline HEMBL 3685643 & 53 & & 21 & \\
\hline HEMPI 368561 & & .615 & & \\
\hline
\end{tabular}

Page 4148 
Supplemental Table S2.txt

\begin{tabular}{|c|c|c|c|c|c|}
\hline CHEMBL3685678 & 1537553 & 5.5376 & 5.811 & TRN & \\
\hline CHEMBL3685682 & 1537553 & 7.699 & 6.6558 & TRN & \\
\hline CHEMBL3681011 & 1537553 & 5.7212 & 6.6905 & TRN & \\
\hline CHEMBL3685673 & 1537553 & 6.699 & 6.2291 & TRN & \\
\hline CHEMBL3681018 & 1537553 & 6.0458 & 6.1538 & TRN & \\
\hline CHEMBL3680992 & 1537553 & 6.301 & 6.9096 & TST & \\
\hline CHEMBL3685690 & 1537553 & 5.9586 & 6.6202 & TRN & \\
\hline CHEMBL3685641 & 1537553 & 6.3979 & 6.9484 & TST & \\
\hline CHEMBL3685647 & 1537553 & 5.6383 & 6.1506 & TST & \\
\hline CHEMBL3685660 & 1537553 & 6.5229 & 7.209 & TRN & \\
\hline CHEMBL 3685720 & 1537553 & 5.301 & 5.1743 & TRN & \\
\hline CHEMBL3681013 & 1537553 & 8.0 & 6.9148 & TRN & \\
\hline CHEMBL3681019 & 1537553 & 6.0 & 5.7285 & TRN & \\
\hline CHEMBL3680997 & 1537553 & 6.5229 & 6.1662 & TRN & \\
\hline CHEMBL3728784 & 1537553 & 5.7696 & 6.242006 & 0000000001 & TRN \\
\hline CHEMBL3685707 & 1537553 & 5.5686 & 6.1081 & TRN & \\
\hline CHEMBL3685665 & 1537553 & 6.3979 & 6.6367 & TRN & \\
\hline CHEMBL3681005 & 1537553 & 7.3979 & 7.3607 & TRN & \\
\hline CHEMBL 3685652 & 1537553 & 7.3979 & 6.1469 & TST & \\
\hline CHEMBL3685646 & 1537553 & 5.6778 & 5.8192 & TRN & \\
\hline CHEMBL 3685640 & 1537553 & 5.4685 & 6.3367 & TST & \\
\hline CHEMBL3685733 & 1537553 & 6.1549 & 6.1736 & TST & \\
\hline CHEMBL1368744 & 1537553 & 5.4815 & 6.41 & TST & \\
\hline CHEMBL3681026 & 1537553 & 6.2218 & 6.1886 & TRN & \\
\hline CHEMBL3685637 & 1537553 & 6.301 & 6.2977 & TRN & \\
\hline CHEMBL3639845 & 1537553 & 5.3979 & 6.2191 & TST & \\
\hline CHEMBL 3681020 & 1537553 & 6.0969 & 5.7306 & TRN & \\
\hline CHEMBL3685670 & 1537553 & 6.3979 & 6.7843 & TRN & \\
\hline CHEMBL 3685638 & 1537553 & 6.0969 & 6.0366 & TRN & \\
\hline CHEMBL3681017 & 1537553 & 5.7696 & 6.1905 & TRN & \\
\hline CHEMBL 3727684 & 1537553 & 5.5376 & \multicolumn{2}{|c|}{6.037000000000001} & TRN \\
\hline CHEMBL3681027 & 1537553 & 7.3979 & \multicolumn{2}{|c|}{6.537999999999999} & TRN \\
\hline CHEMBL 3685674 & 1537553 & 5.4685 & 6.5977 & TST & \\
\hline CHEMBL 3685697 & 1537553 & 6.0458 & 6.5198 & TRN & \\
\hline CHEMBL3685654 & 1537553 & 7.2218 & 6.6048 & TRN & \\
\hline CHEMBL3685716 & 1537553 & 5.5528 & 6.5614 & TRN & \\
\hline CHEMBL3685726 & 1537553 & 5.7447 & \multicolumn{2}{|c|}{6.242000000000001} & TRN \\
\hline CHEMBL3730229 & 1537553 & 5.7696 & 6.6351 & TST & \\
\hline CHEMBL 3685721 & 1537553 & 5.3098 & 5.6289 & TRN & \\
\hline CHEMBL3685715 & 1537553 & 6.699 & 7.1991 & TST & \\
\hline CHEMBL3685706 & 1537553 & 5.4815 & 5.9068 & TRN & \\
\hline CHEMBL3685657 & 1537553 & 6.699 & 6.6772 & TST & \\
\hline CHEMBL3685656 & 1537553 & 7.1549 & 6.4754 & TRN & \\
\hline CHEMBL3681025 & 1537553 & 6.699 & 6.4888 & TRN & \\
\hline CHEMBL3685669 & 1537553 & 6.699 & 6.9147 & TST & \\
\hline CHEMBL3685685 & 1537553 & 5.3979 & 6.2266 & TRN & \\
\hline CHEMBL3685679 & 1537553 & 6.5229 & 6.6664 & TST & \\
\hline CHEMBL3681008 & 1537553 & 7.301 & 7.1513 & TRN & \\
\hline
\end{tabular}


Supplemental Table S2.txt

\begin{tabular}{|c|c|c|c|c|}
\hline AEMBL3685727 & 537553 & 7.699 & 6.5342 & TF \\
\hline HEMBL 3685731 & 537553 & 6.2218 & 6.0519 & \\
\hline 695 & 53 & 7.0 & & \\
\hline AEMBL3685671 & 537553 & 6.301 & & \\
\hline HEMBL3685684 & 537553 & 7.0 & & \\
\hline HEMBL3680994 & 537553 & 7.2218 & 7782 & \\
\hline HEMBL3680996 & 5 & 5.9586 & & \\
\hline IEMBL: & 553 & 7.2218 & & \\
\hline HEMBL3685696 & 537553 & 5.4318 & & ST \\
\hline HEMBL3685650 & 537553 & 5.699 & 3024 & ST \\
\hline HEMBL3639798 & 537553 & 7.699 & 396 & \\
\hline AEMBL3681003 & 537553 & 6.301 & 73 & ST \\
\hline AEMBL & & 6.2218 & & RN \\
\hline 35661 & 553 & 7.3979 & & \\
\hline 585714 & 537553 & 6.0 & & rRN \\
\hline AEMBL3732995 & 553 & 7.5229 & & ST \\
\hline HEMBL3681016 & 3 & 5.3188 & 63 & RN \\
\hline HEMBL & 53 & 6.4685 & & RN \\
\hline 35698 & 553 & 5.6021 & & $\mathrm{RN}$ \\
\hline AEMBL: & 553 & 6.1549 & & ST \\
\hline AEMBL3685718 & 1537553 & 6.301 & 5 . & TRN \\
\hline HEMBL3685675 & 53 & 6. & & ST \\
\hline HEMBL & 53 & 5.7212 & & $\mathrm{RN}$ \\
\hline AEMBL & 53 & 6.3979 & & RN \\
\hline IEMBL: & 53 & 5.7212 & & TST \\
\hline 580986 & 553 & 6.699 & 6. & ST \\
\hline AEMBL: & $\theta 0$ & 5.5086 & & rRN \\
\hline AEMBL & $\partial 0$ & 7.3979 & & $\mathrm{RN}$ \\
\hline AEMB & 30 & 686 & & RN \\
\hline IEMBL & $\partial 0$ & 208 & & TST \\
\hline IEMBL: & 5100 & .5376 & & RN \\
\hline AEMBL: & 00 & 2.6778 & & IST \\
\hline AEMBL & $\partial 0$ & 5.1549 & & $\mathrm{RN}$ \\
\hline AEMB & & & & TRN \\
\hline IEMBL: & 25100 & 4.1308 & & TRN \\
\hline IEMBL: & 25100 & 5.1487 & & RN \\
\hline HEMBL: & $\partial 5100$ & 269 & & TRN \\
\hline יחנזM & $\partial 0$ & 99 & & $\mathrm{RN}$ \\
\hline HEMBL: & 25100 & 5.0 & & TRN \\
\hline AEMBL & 25100 & 3.6198 & 3 . & TRN \\
\hline AEMBL & 35100 & 4.0223 & & rRN \\
\hline CHEMBL & 05100 & 7.2218 & & TRN \\
\hline CHEMBL & & 2.7959 & & TRN \\
\hline HEMBL: & 25100 & 4.4318 & 607 & TRN \\
\hline AEMBL364001 & 25100 & 6.7959 & 6.5729 & $T R$ \\
\hline CHEMBL & 05100 & 5.9586 & & niv \\
\hline CHEMBL191288 & 05100 & 3.5528 & 3.2995 & TRN \\
\hline CHEMBL534923 & 305100 & 3.2441 & 4.9753 & \\
\hline
\end{tabular}

Page 4150 


\begin{tabular}{|c|c|c|c|c|}
\hline & & & oplement & al Table S \\
\hline CHEMBL365924 & 305100 & 2.9208 & 3.3775 & TRN \\
\hline CHEMBL362121 & 305100 & 5.1805 & 5.4535 & TRN \\
\hline CHEMBL366209 & 305100 & 5.6778 & 5.3353 & TRN \\
\hline CHEMBL433959 & 305100 & 5.301 & 5.1981 & TRN \\
\hline CHEMBL191519 & 305100 & 3.6778 & 3.4516 & TRN \\
\hline CHEMBL189876 & 305100 & 3.301 & 3.2733 & TRN \\
\hline CHEMBL536272 & 305100 & 6.3372 & 6.4619 & TST \\
\hline CHEMBL364858 & 305100 & 4.2007 & 4.6529 & TRN \\
\hline CHEMBL363174 & 305100 & 7.301 & 7.3182 & TRN \\
\hline CHEMBL443048 & 305100 & 3.5686 & 4.2958 & TST \\
\hline CHEMBL188346 & 305100 & 2.8539 & 5.6289 & TST \\
\hline CHEMBL372269 & 305100 & 3.0809 & 2.9919 & TRN \\
\hline CHEMBL187352 & 305100 & 5.0 & 4.6967 & TRN \\
\hline CHEMBL190738 & 305100 & 4.8861 & 4.9179 & TRN \\
\hline CHEMBL 370283 & 305100 & 5.6778 & 5.2846 & TRN \\
\hline CHEMBL425550 & 305100 & 3.3188 & 3.053 & TRN \\
\hline CHEMBL366237 & 305100 & 3.3188 & 3.5265 & TRN \\
\hline CHEMBL191547 & 305100 & 4.3188 & 4.1124 & TRN \\
\hline CHEMBL1790020 & 305100 & 6.2291 & 1.8123 & TST \\
\hline CHEMBL372698 & 305100 & 4.4318 & 4.6951 & TRN \\
\hline CHEMBL362075 & 305100 & 5.5229 & 5.3442 & TRN \\
\hline CHEMBL189332 & 305100 & 5.1675 & 5.0863 & TRN \\
\hline CHEMBL187816 & 305100 & 7.0969 & 7.2425 & TRN \\
\hline CHEMBL435693 & 305100 & 4.8239 & 4.7077 & TRN \\
\hline CHEMBL188662 & 305100 & 2.7447 & 2.7437 & TRN \\
\hline CHEMBL187873 & 305100 & 3.5686 & 4.7998 & TST \\
\hline CHEMBL436284 & 305100 & 4.6576 & 4.5455 & TRN \\
\hline CHEMBL190887 & 305100 & 3.6576 & 3.728 & TRN \\
\hline CHEMBL187811 & 305100 & 4.4437 & 4.5019 & TRN \\
\hline CHEMBL189333 & 305100 & 5.2757 & 5.3644 & TRN \\
\hline CHEMBL187433 & 305100 & 5.5376 & 5.5817 & TRN \\
\hline CHEMBL188251 & 305100 & 3.9586 & 4.7171 & TRN \\
\hline CHEMBL190789 & 305100 & 4.6778 & 4.7066 & TRN \\
\hline CHEMBL190323 & 305100 & 4.9586 & 4.7175 & TRN \\
\hline CHEMBL364226 & 305100 & 4.6778 & 5.0122 & TRN \\
\hline CHEMBL364435 & 305100 & 5.6198 & 5.6601 & TRN \\
\hline CHEMBL191462 & 305100 & 4.3565 & 4.6651 & TRN \\
\hline CHEMBL373307 & 305100 & 2.699 & 4.1802 & TST \\
\hline CHEMBL190091 & 305100 & 5.0132 & 4.935 & TRN \\
\hline CHEMBL362323 & 305100 & 2.7959 & 2.9694 & TRN \\
\hline CHEMBL433590 & 305100 & 5.7696 & 5.8718 & TRN \\
\hline CHEMBL188650 & 305100 & 5.699 & 5.6419 & TRN \\
\hline CHEMBL418203 & 305100 & 7.0458 & 5.53100 & 0000000001 \\
\hline CHEMBL190483 & 305100 & 4.6021 & 4.4722 & TRN \\
\hline CHEMBL363679 & 305100 & 5.5686 & 5.1166 & TRN \\
\hline CHEMBL363689 & 305100 & 5.0969 & 5.1093 & TRN \\
\hline CHEMBL187984 & 305100 & 7.699 & 7.3174 & TRN \\
\hline CHEMBL187353 & 305100 & 5.3665 & 5.5459 & TRN \\
\hline
\end{tabular}




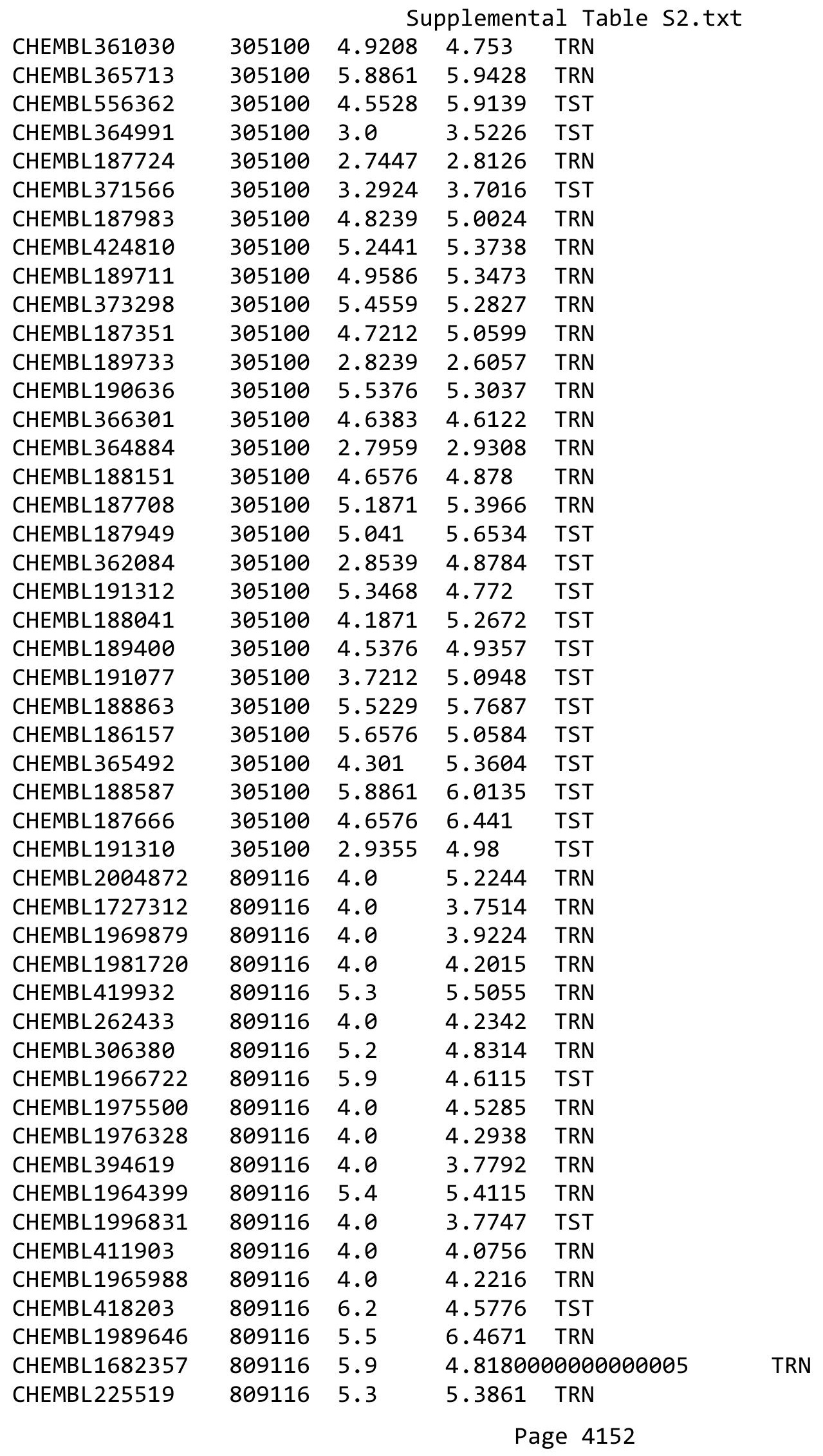




\begin{tabular}{|c|c|c|c|c|c|}
\hline \multicolumn{6}{|c|}{ Supplemental Table S2.txt } \\
\hline CHEMBL209534 & 809116 & 4.0 & 3.8168 & TRN & \\
\hline CHEMBL1978200 & 809116 & 4.0 & 4.1412 & TRN & \\
\hline CHEMBL 2006631 & 809116 & 5.3 & 4.8189 & TRN & \\
\hline CHEMBL1970522 & 809116 & 4.0 & 3.8515 & TRN & \\
\hline CHEMBL402846 & 809116 & 4.0 & 3.8795 & TRN & \\
\hline CHEMBL1990415 & 809116 & 4.0 & 4.1076 & TRN & \\
\hline CHEMBL1966087 & 809116 & 4.0 & 4.2413 & TRN & \\
\hline CHEMBL1964692 & 809116 & 4.0 & 4.0084 & TRN & \\
\hline CHEMBL1996931 & 809116 & 4.0 & 4.2209 & TRN & \\
\hline CHEMBL1964413 & 809116 & 4.0 & 4.3691 & TRN & \\
\hline CHEMBL1973483 & 809116 & 4.0 & 4.2044 & TRN & \\
\hline CHEMBL1984432 & 809116 & 6.1 & 4.7513 & TRN & \\
\hline CHEMBL1970735 & 809116 & 4.0 & 4.0229 & TRN & \\
\hline CHEMBL219722 & 809116 & 4.0 & 3.969 & TRN & \\
\hline CHEMBL1997340 & 809116 & 4.0 & 3.6781 & TRN & \\
\hline CHEMBL 2004365 & 809116 & 5.2 & 4.5473 & TST & \\
\hline CHEMBL1522508 & 809116 & 4.0 & 3.6653 & TRN & \\
\hline CHEMBL1989474 & 809116 & 4.0 & 3.9247 & TRN & \\
\hline CHEMBL1090360 & 809116 & 4.0 & 4.1645 & TRN & \\
\hline CHEMBL 210887 & 809116 & 4.0 & 3.9894 & TST & \\
\hline CHEMBL458997 & 809116 & 4.0 & 3.90100 & 00000000002 & TRN \\
\hline CHEMBL1971021 & 809116 & 4.0 & 4.3577 & TRN & \\
\hline CHEMBL 227271 & 809116 & 7.4 & 8.0408 & TRN & \\
\hline CHEMBL583144 & 809116 & 5.3 & 4.1298 & TST & \\
\hline CHEMBL1974310 & 809116 & 4.0 & 4.2634 & TRN & \\
\hline CHEMBL1982660 & 809116 & 4.0 & 3.8179 & TRN & \\
\hline CHEMBL1994693 & 809116 & 4.0 & 4.1518 & TRN & \\
\hline CHEMBL1982957 & 809116 & 6.1 & 5.1964 & TRN & \\
\hline CHEMBL1725279 & 809116 & 4.0 & 4.0623 & TST & \\
\hline CHEMBL1975138 & 809116 & 5.4 & 4.5529 & TST & \\
\hline CHEMBL424872 & 809116 & 4.0 & 3.6949 & TRN & \\
\hline CHEMBL 2006836 & 809116 & 4.0 & 3.95300 & 00000000003 & TST \\
\hline CHEMBL1971947 & 809116 & 4.0 & 3.7924 & TRN & \\
\hline CHEMBL412142 & 809116 & 4.0 & 4.6023 & TST & \\
\hline CHEMBL1980704 & 809116 & 4.0 & 4.7011 & TST & \\
\hline CHEMBL 2003271 & 809116 & 5.2 & 4.598 & TST & \\
\hline CHEMBL1966808 & 809116 & 4.0 & 4.6864 & TST & \\
\hline CHEMBL 2004447 & 809116 & 5.4 & 4.3469 & TRN & \\
\hline CHEMBL1983111 & 809116 & 5.7 & 5.3972 & TST & \\
\hline CHEMBL1973860 & 809116 & 4.0 & 3.6468 & TRN & \\
\hline CHEMBL1977713 & 809116 & 4.0 & 4.0167 & TRN & \\
\hline CHEMBL 260135 & 809116 & 4.0 & 4.2806 & TRN & \\
\hline CHEMBL220241 & 809116 & 6.8 & 6.0224 & TST & \\
\hline CHEMBL 2004544 & 809116 & 4.0 & 4.2081 & TST & \\
\hline CHEMBL1982610 & 809116 & 4.0 & 3.7795 & TST & \\
\hline CHEMBL1999496 & 809116 & 4.0 & 4.4938 & TRN & \\
\hline CHEMBL 2006933 & 809116 & 5.6 & 4.8499 & TST & \\
\hline CHEMBL1988300 & 809116 & 4.0 & 3.3949 & TRN & \\
\hline
\end{tabular}




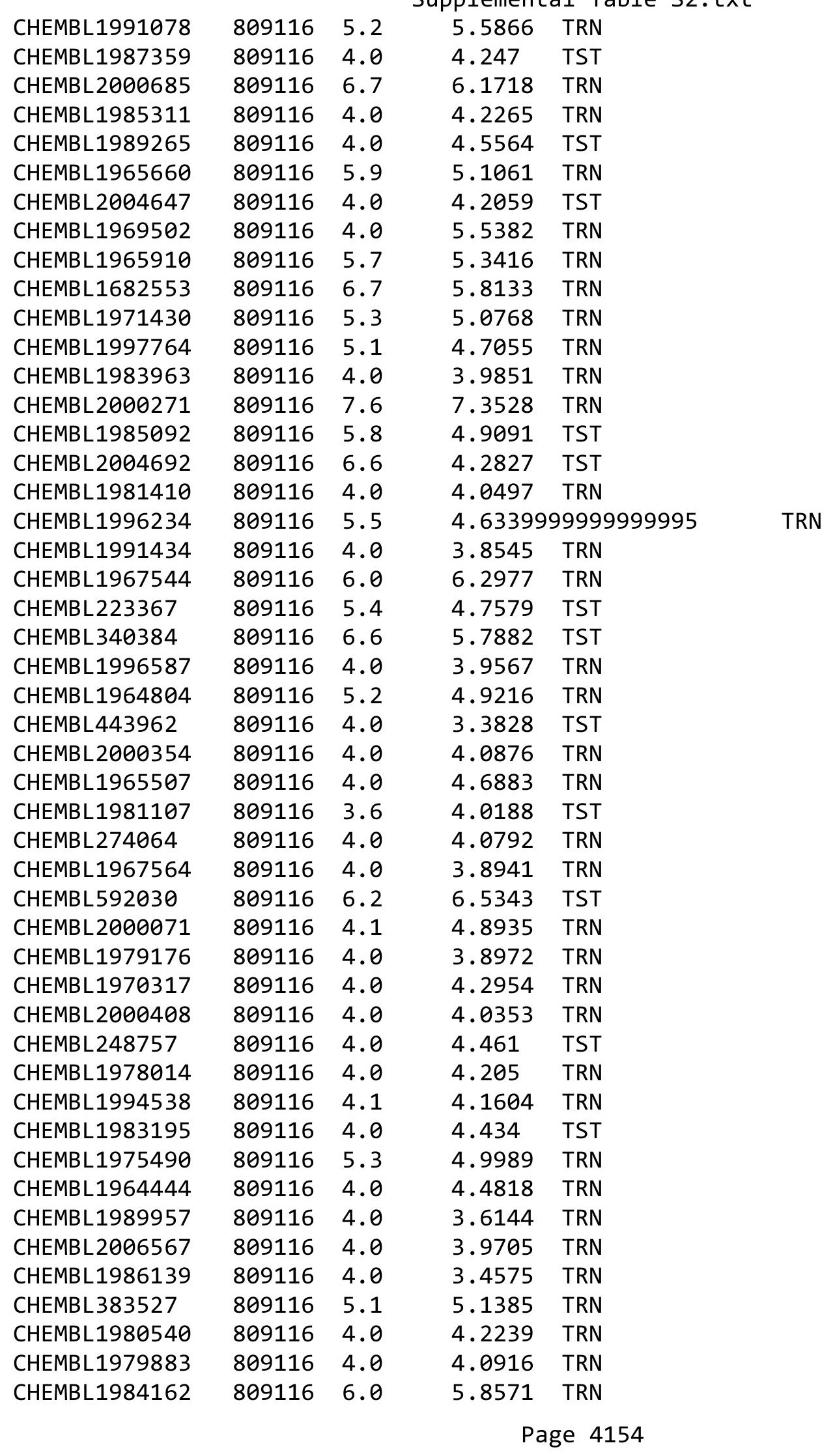




\begin{tabular}{|c|c|c|c|c|c|}
\hline \\
\hline CHEMBL491758 & 809116 & 4.0 & 3.7129 & TRN & \\
\hline CHEMBL549730 & 809116 & 6.2 & 5.6294 & TRN & \\
\hline CHEMBL1682360 & 809116 & 4.0 & 4.4293 & TRN & \\
\hline CHEMBL1970189 & 809116 & 4.0 & 3.9398 & TRN & \\
\hline CHEMBL1996791 & 809116 & 4.0 & 4.0733 & TRN & \\
\hline CHEMBL371206 & 809116 & 4.0 & 4.0327 & TRN & \\
\hline CHEMBL1974664 & 809116 & 4.0 & 4.41 & TST & \\
\hline CHEMBL1970104 & 809116 & 4.0 & 4.6265 & TRN & \\
\hline CHEMBL1974288 & 809116 & 5.3 & 5.4371 & TRN & \\
\hline CHEMBL196363 & 809116 & 4.0 & 3.6206 & TRN & \\
\hline CHEMBL1190711 & 809116 & 4.0 & 4.3766 & TRN & \\
\hline CHEMBL1990346 & 809116 & 4.0 & 4.4015 & TRN & \\
\hline CHEMBL1968705 & 809116 & 6.0 & 4.8653 & TRN & \\
\hline CHEMBL404367 & 809116 & 4.0 & 3.7095 & TRN & \\
\hline CHEMBL1966343 & 809116 & 5.1 & 5.0135 & TRN & \\
\hline CHEMBL1967887 & 809116 & 6.2 & 5.9829 & TRN & \\
\hline CHEMBL 2000568 & 809116 & 4.0 & 4.2739 & TRN & \\
\hline CHEMBL 2000335 & 809116 & 4.0 & 4.5887 & TRN & \\
\hline CHEMBL1977604 & 809116 & 4.0 & 4.485 & TST & \\
\hline CHEMBL1988717 & 809116 & 4.0 & 4.0323 & TRN & \\
\hline CHEMBL1974328 & 809116 & 5.7 & 5.4363 & TST & \\
\hline CHEMBL509032 & 809116 & 5.4 & 5.9521 & TRN & \\
\hline CHEMBL573339 & 809116 & 4.0 & 3.7104 & TRN & \\
\hline CHEMBL1973808 & 809116 & 4.0 & 3.9007 & TRN & \\
\hline CHEMBL 2000429 & 809116 & 4.0 & 4.1341 & TRN & \\
\hline CHEMBL1972576 & 809116 & 5.4 & 4.5292 & TRN & \\
\hline CHEMBL1992555 & 809116 & 4.0 & 4.4143 & TST & \\
\hline CHEMBL1992342 & 809116 & 4.0 & 4.6071 & TRN & \\
\hline CHEMBL1988173 & 809116 & 5.7 & 5.1054 & TST & \\
\hline CHEMBL535331 & 809116 & 4.0 & 3.8046 & TRN & \\
\hline CHEMBL1989805 & 809116 & 4.0 & 4.30699 & 99999999995 & TST \\
\hline CHEMBL1982980 & 809116 & 4.0 & 4.3921 & TST & \\
\hline CHEMBL1965423 & 809116 & 4.0 & 4.3927 & TRN & \\
\hline CHEMBL1983025 & 809116 & 4.0 & 4.197 & TRN & \\
\hline CHEMBL 205415 & 809116 & 6.5 & 5.6504 & TRN & \\
\hline CHEMBL1977135 & 809116 & 5.0 & 4.9084 & TRN & \\
\hline CHEMBL 2001920 & 809116 & 4.0 & 4.3984 & TRN & \\
\hline CHEMBL 2002322 & 809116 & 4.0 & 4.164 & TRN & \\
\hline CHEMBL2002323 & 809116 & 4.0 & 4.0288 & TST & \\
\hline CHEMBL1241473 & 809116 & 6.1 & 5.7125 & TRN & \\
\hline CHEMBL1978448 & 809116 & 5.7 & 4.6902 & TST & \\
\hline CHEMBL 2004513 & 809116 & 4.0 & 4.18199 & 99999999995 & TRN \\
\hline CHEMBL1972258 & 809116 & 4.0 & 4.2182 & TRN & \\
\hline CHEMBL 2001257 & 809116 & 4.0 & 4.0743 & TRN & \\
\hline CHEMBL 2005548 & 809116 & 4.0 & 5.2229 & TRN & \\
\hline CHEMBL1987793 & 809116 & 5.6 & 4.7781 & TST & \\
\hline CHEMBL1992536 & 809116 & 4.0 & 5.2943 & TRN & \\
\hline CHEMBL1992740 & 809116 & 4.0 & 4.0197 & TRN & \\
\hline
\end{tabular}




\begin{tabular}{|c|c|c|c|c|c|}
\hline \multicolumn{6}{|c|}{ Supplemental Table S2.txt } \\
\hline CHEMBL 2002373 & 809116 & 4.0 & 3.8396 & TRN & \\
\hline CHEMBL439340 & 809116 & 4.0 & 3.9983 & TRN & \\
\hline CHEMBL 2006188 & 809116 & 6.0 & 6.0727 & TRN & \\
\hline CHEMBL1967531 & 809116 & 4.0 & 3.6268 & TRN & \\
\hline CHEMBL1970913 & 809116 & 4.0 & 4.1555 & TRN & \\
\hline CHEMBL1973893 & 809116 & 4.0 & 3.891 & TRN & \\
\hline CHEMBL1995736 & 809116 & 4.0 & 4.0077 & TRN & \\
\hline CHEMBL1997534 & 809116 & 7.6 & 6.1972 & TRN & \\
\hline CHEMBL1996500 & 809116 & 4.0 & 4.1064 & TRN & \\
\hline CHEMBL1985095 & 809116 & 5.4 & 5.4909 & TST & \\
\hline CHEMBL1998551 & 809116 & 4.0 & 4.1518 & TRN & \\
\hline CHEMBL1977374 & 809116 & 4.0 & 4.3257 & TRN & \\
\hline CHEMBL1991180 & 809116 & 5.5 & 5.5337 & TST & \\
\hline CHEMBL1989708 & 809116 & 4.0 & 4.2551 & TRN & \\
\hline CHEMBL1682540 & 809116 & 4.0 & 4.4575 & TRN & \\
\hline CHEMBL1978656 & 809116 & 4.0 & 3.8483 & TRN & \\
\hline CHEMBL1976420 & 809116 & 4.0 & 4.2047 & TST & \\
\hline CHEMBL1994864 & 809116 & 6.8 & 6.3014 & TRN & \\
\hline CHEMBL413779 & 809116 & 5.3 & 4.7104 & TST & \\
\hline CHEMBL 2002446 & 809116 & 5.2 & 4.5505 & TST & \\
\hline CHEMBL497151 & 809116 & 6.3 & 4.9598 & TRN & \\
\hline CHEMBL246970 & 809116 & 4.0 & 4.6213 & TRN & \\
\hline CHEMBL1980497 & 809116 & 5.2 & 4.7706 & TRN & \\
\hline CHEMBL340921 & 809116 & 5.7 & 5.3856 & TST & \\
\hline CHEMBL373598 & 809116 & 5.2 & 4.632 & TST & \\
\hline CHEMBL1999718 & 809116 & 4.0 & 3.95600 & 00000000004 & TRN \\
\hline CHEMBL1276446 & 809116 & 4.0 & 5.393 & TST & \\
\hline CHEMBL1977346 & 809116 & 4.0 & 3.7241 & TRN & \\
\hline CHEMBL1971649 & 809116 & 4.0 & 4.0528 & TRN & \\
\hline CHEMBL 2003657 & 809116 & 5.0 & 4.35 & TRN & \\
\hline CHEMBL1998435 & 809116 & 4.0 & 3.8708 & TRN & \\
\hline CHEMBL 2006439 & 809116 & 6.9 & 6.9039 & TRN & \\
\hline CHEMBL 2006156 & 809116 & 4.0 & 4.2227 & TST & \\
\hline CHEMBL1969190 & 809116 & 4.0 & 4.348 & TRN & \\
\hline CHEMBL1973937 & 809116 & 5.1 & 4.30399 & 9999999999 & TRN \\
\hline CHEMBL1991674 & 809116 & 7.7 & 7.4429 & TRN & \\
\hline CHEMBL1982711 & 809116 & 5.7 & 5.3404 & TRN & \\
\hline CHEMBL1987982 & 809116 & 4.0 & 4.61100 & 0000000001 & TST \\
\hline CHEMBL1984842 & 809116 & 4.0 & 3.9307 & TRN & \\
\hline CHEMBL1969102 & 809116 & 4.0 & 4.24 & TRN & \\
\hline CHEMBL1682346 & 809116 & 5.2 & 5.3951 & TRN & \\
\hline CHEMBL 2007044 & 809116 & 4.0 & 4.4361 & TST & \\
\hline CHEMBL 2001998 & 809116 & 4.0 & 4.0651 & TST & \\
\hline CHEMBL1994241 & 809116 & 4.0 & 4.1732 & TRN & \\
\hline CHEMBL 223460 & 809116 & 4.0 & 4.7746 & TST & \\
\hline CHEMBL1998829 & 809116 & 4.0 & 4.4524 & TRN & \\
\hline CHEMBL50894 & 809116 & 6.7 & 5.9799 & TRN & \\
\hline CHEMBL1988838 & 809116 & 4.0 & 4.1213 & TRN & \\
\hline
\end{tabular}




\begin{tabular}{|c|c|c|c|c|}
\hline & & & & $a \perp 1$ \\
\hline CHEMBL1981725 & 809116 & 6.5 & 5.5782 & TRN \\
\hline CHEMBL375284 & 809116 & 4.0 & 3.9804 & TRN \\
\hline CHEMBL1982866 & 809116 & 4.0 & 3.8575 & TRN \\
\hline CHEMBL 2005792 & 809116 & 4.0 & 3.8617 & TRN \\
\hline CHEMBL1968926 & 809116 & 4.0 & 4.2062 & TRN \\
\hline CHEMBL 2006609 & 809116 & 5.0 & 4.5743 & TST \\
\hline CHEMBL1984206 & 809116 & 4.0 & 4.0419 & TRN \\
\hline CHEMBL462120 & 809116 & 5.2 & 4.3081 & TST \\
\hline CHEMBL1991577 & 809116 & 5.4 & 5.3079 & TRN \\
\hline CHEMBL1965570 & 809116 & 4.0 & 3.8689 & TRN \\
\hline CHEMBL 2007592 & 809116 & 4.0 & 4.2119 & TST \\
\hline CHEMBL 210963 & 809116 & 4.0 & 3.9102 & TRN \\
\hline CHEMBL1082440 & 809116 & 4.0 & 5.3421 & TST \\
\hline CHEMBL1614705 & 809116 & 4.0 & 3.9358 & TRN \\
\hline CHEMBL1972362 & 809116 & 4.0 & 4.1692 & TRN \\
\hline CHEMBL1984633 & 809116 & 4.0 & 5.2871 & TRN \\
\hline CHEMBL2007372 & 809116 & 4.0 & 3.7122 & TRN \\
\hline CHEMBL1965845 & 809116 & 7.1 & 6.7859 & TRN \\
\hline CHEMBL1982167 & 809116 & 4.0 & 3.9464 & TRN \\
\hline CHEMBL2006715 & 809116 & 6.2 & 5.4296 & TRN \\
\hline CHEMBL1986597 & 809116 & 4.0 & 3.8842 & TRN \\
\hline CHEMBL1971017 & 809116 & 5.1 & 4.8407 & TRN \\
\hline CHEMBL1990482 & 809116 & 4.0 & 4.3079 & TRN \\
\hline CHEMBL1990904 & 809116 & 4.0 & 3.7185 & TRN \\
\hline CHEMBL2005475 & 809116 & 4.0 & 4.0054 & TRN \\
\hline CHEMBL 2000104 & 809116 & 4.0 & 4.0873 & TRN \\
\hline CHEMBL1997349 & 809116 & 4.0 & 4.53600 & 00000000005 \\
\hline CHEMBL183844 & 809116 & 4.0 & 4.166 & TRN \\
\hline CHEMBL220057 & 809116 & 4.0 & 4.0636 & TRN \\
\hline CHEMBL1682545 & 809116 & 4.0 & 4.2537 & TRN \\
\hline CHEMBL 383541 & 809116 & 5.4 & 5.5809 & TRN \\
\hline CHEMBL 2001224 & 809116 & 4.0 & 4.3709 & TRN \\
\hline CHEMBL10 & 809116 & 4.0 & 4.1407 & TRN \\
\hline CHEMBL1976732 & 809116 & 4.0 & 4.315 & TRN \\
\hline CHEMBL1969506 & 809116 & 4.0 & 4.4827 & TRN \\
\hline CHEMBL1964937 & 809116 & 5.7 & 6.1375 & TRN \\
\hline CHEMBL1980163 & 809116 & 4.0 & 3.7978 & TRN \\
\hline CHEMBL590109 & 809116 & 5.5 & 6.2206 & TST \\
\hline CHEMBL1970879 & 809116 & 6.8 & 6.5373 & TRN \\
\hline CHEMBL1989856 & 809116 & 4.0 & 3.8622 & TST \\
\hline CHEMBL2005899 & 809116 & 6.1 & 5.4451 & TRN \\
\hline CHEMBL1682552 & 809116 & 5.8 & 5.465 & TRN \\
\hline CHEMBL 259850 & 809116 & 4.0 & 3.8936 & TRN \\
\hline CHEMBL1972568 & 809116 & 4.0 & 4.1908 & TRN \\
\hline CHEMBL1996155 & 809116 & 5.5 & 4.5885 & TRN \\
\hline CHEMBL229799 & 809116 & 8.1 & 8.0643 & TRN \\
\hline CHEMBL1682359 & 809116 & 4.0 & 4.4529 & TRN \\
\hline CHEMBL105739 & 809116 & 4.0 & 4.2644 & TRN \\
\hline
\end{tabular}




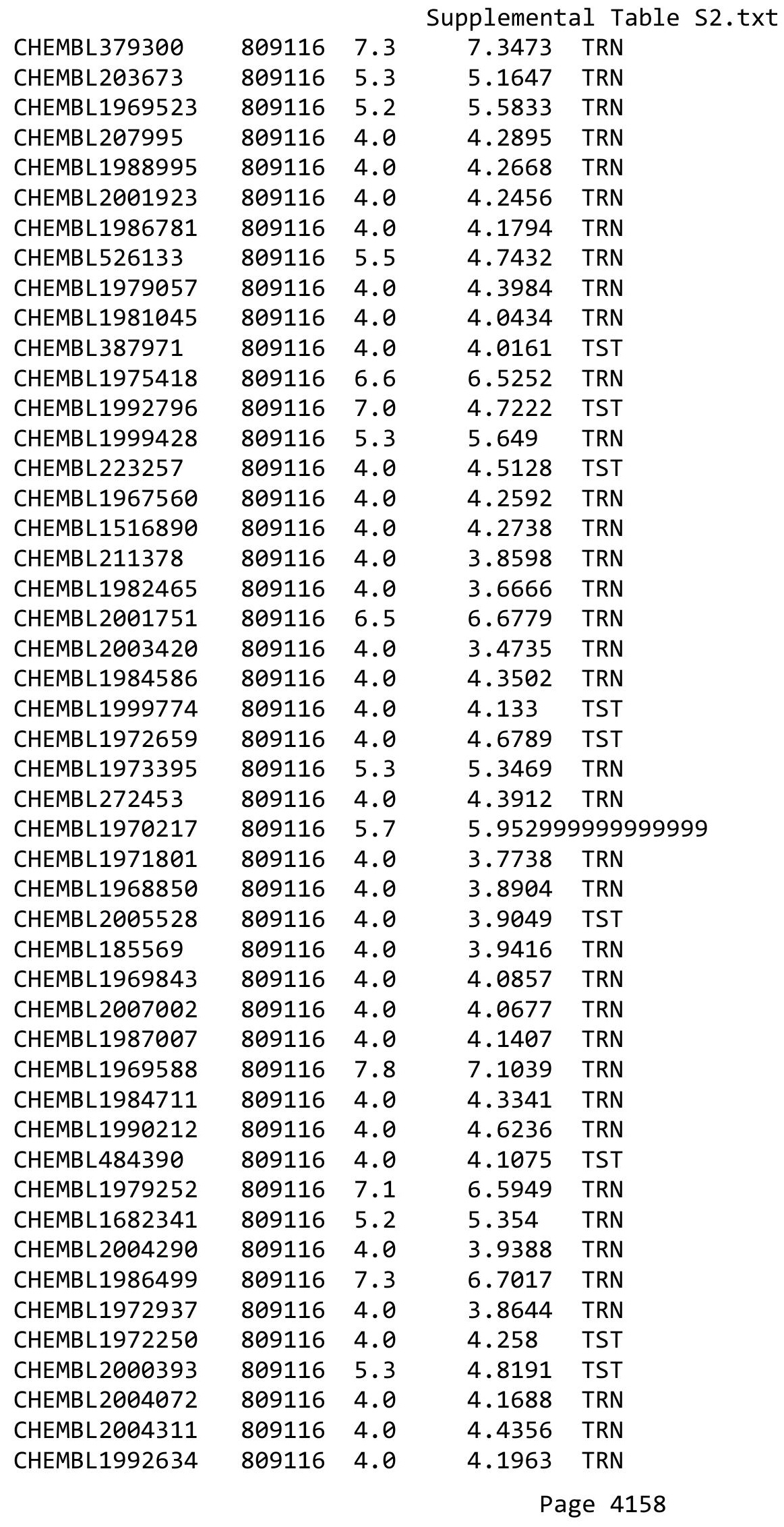

TRN 


\begin{tabular}{|c|c|c|c|c|c|}
\hline \multicolumn{6}{|c|}{ Supplemental Table S2.txt } \\
\hline CHEMBL1242373 & 809116 & 4.0 & 4.3349 & TRN & \\
\hline CHEMBL 2000433 & 809116 & 4.0 & 4.1271 & TST & \\
\hline CHEMBL56543 & 809116 & 4.0 & 3.8676 & TRN & \\
\hline CHEMBL316264 & 809116 & 4.0 & 3.8966 & TRN & \\
\hline CHEMBL1988075 & 809116 & 4.0 & 4.0874 & TRN & \\
\hline CHEMBL1991678 & 809116 & 4.0 & 4.0386 & TRN & \\
\hline CHEMBL 2001239 & 809116 & 5.4 & 5.2907 & TST & \\
\hline CHEMBL1988594 & 809116 & 4.0 & 4.3821 & TRN & \\
\hline CHEMBL 2001288 & 809116 & 4.0 & 3.4694 & TRN & \\
\hline CHEMBL260092 & 809116 & 4.0 & 4.0564 & TRN & \\
\hline CHEMBL1999811 & 809116 & 4.0 & 4.4009 & TST & \\
\hline CHEMBL1965495 & 809116 & 4.0 & 4.4316 & TRN & \\
\hline CHEMBL1985074 & 809116 & 4.0 & 4.1779 & TST & \\
\hline CHEMBL1982874 & 809116 & 4.0 & 4.1832 & TRN & \\
\hline CHEMBL 2000481 & 809116 & 4.0 & 4.851 & TRN & \\
\hline CHEMBL1991725 & 809116 & 5.6 & 5.2566 & TRN & \\
\hline CHEMBL1992242 & 809116 & 4.0 & 3.69 & TRN & \\
\hline CHEMBL 2007296 & 809116 & 4.0 & 5.3948 & TRN & \\
\hline CHEMBL208637 & 809116 & 4.0 & 4.07100 & 0000000001 & TRN \\
\hline CHEMBL396523 & 809116 & 4.0 & 4.963 & TRN & \\
\hline CHEMBL 2007138 & 809116 & 3.6 & 3.9891 & TRN & \\
\hline CHEMBL1970203 & 809116 & 4.0 & 4.4371 & TRN & \\
\hline CHEMBL1986530 & 809116 & 4.0 & 3.911 & TST & \\
\hline CHEMBL1965351 & 809116 & 4.0 & 4.0492 & TST & \\
\hline CHEMBL1999321 & 809116 & 4.0 & 4.5511 & TRN & \\
\hline CHEMBL1968590 & 809116 & 4.0 & 3.8254 & TRN & \\
\hline CHEMBL1999749 & 809116 & 4.0 & 4.4737 & TRN & \\
\hline CHEMBL 2005375 & 809116 & 4.0 & 4.2905 & TRN & \\
\hline CHEMBL1984191 & 809116 & 4.0 & 4.2444 & TRN & \\
\hline CHEMBL1983006 & 809116 & 4.0 & 3.9661 & TRN & \\
\hline CHEMBL1972183 & 809116 & 4.0 & 4.0544 & TRN & \\
\hline CHEMBL1971029 & 809116 & 6.3 & 5.414 & TRN & \\
\hline CHEMBL1995391 & 809116 & 3.6 & 3.9813 & TRN & \\
\hline CHEMBL 394790 & 809116 & 4.0 & 3.7712 & TRN & \\
\hline CHEMBL226471 & 809116 & 4.0 & 4.0639 & TRN & \\
\hline CHEMBL1974702 & 809116 & 4.0 & 3.7596 & TST & \\
\hline CHEMBL1996111 & 809116 & 6.7 & 6.6873 & TRN & \\
\hline CHEMBL1965589 & 809116 & 4.0 & 4.0609 & TRN & \\
\hline CHEMBL1998193 & 809116 & 4.0 & 3.5835 & TRN & \\
\hline CHEMBL474432 & 809116 & 4.0 & 4.6056 & TST & \\
\hline CHEMBL1988153 & 809116 & 4.0 & 4.2019 & TRN & \\
\hline CHEMBL1972584 & 809116 & 5.1 & 6.1422 & TRN & \\
\hline CHEMBL1999556 & 809116 & 4.0 & 4.5001 & TRN & \\
\hline CHEMBL1988437 & 809116 & 4.0 & 4.1862 & TST & \\
\hline CHEMBL1968245 & 809116 & 5.4 & 5.3269 & TRN & \\
\hline CHEMBL1998121 & 809116 & 6.3 & 6.5589 & TRN & \\
\hline CHEMBL1979577 & 809116 & 4.0 & 4.4374 & TRN & \\
\hline CHEMBL1991800 & 809116 & 4.0 & 3.8437 & TRN & \\
\hline
\end{tabular}




\begin{tabular}{|c|c|c|c|c|}
\hline \multicolumn{5}{|c|}{ Supplemental Table S2.txt } \\
\hline CHEMBL1985566 & 809116 & 4.0 & 4.1693 & TRN \\
\hline CHEMBL52387 & 809116 & 4.0 & 3.8382 & TST \\
\hline CHEMBL379835 & 809116 & 4.0 & 4.0138 & TST \\
\hline CHEMBL1979357 & 809116 & 5.3 & 5.1959 & TRN \\
\hline CHEMBL1980802 & 809116 & 4.0 & 3.9973 & TST \\
\hline CHEMBL1979554 & 809116 & 7.0 & 6.0711 & TRN \\
\hline CHEMBL1996817 & 809116 & 5.9 & 5.5982 & TRN \\
\hline CHEMBL 3197315 & 809116 & 6.2 & 4.2348 & TST \\
\hline CHEMBL 2004355 & 809116 & 4.0 & 3.6236 & TRN \\
\hline CHEMBL468280 & 809116 & 4.0 & 4.2859 & TST \\
\hline CHEMBL1990884 & 809116 & 4.0 & 4.4202 & TRN \\
\hline CHEMBL3109278 & 809116 & 4.0 & 4.9118 & TRN \\
\hline CHEMBL 256835 & 809116 & 4.0 & 4.194 & TRN \\
\hline CHEMBL1970006 & 809116 & 4.0 & 4.564 & TST \\
\hline CHEMBL1980142 & 809116 & 4.0 & 4.5094 & TRN \\
\hline CHEMBL41783 & 809116 & 4.0 & 4.1215 & TRN \\
\hline CHEMBL 2004438 & 809116 & 4.0 & 3.887 & TRN \\
\hline CHEMBL 2006276 & 809116 & 5.9 & 5.5333 & TRN \\
\hline CHEMBL 271381 & 809116 & 4.0 & 4.0744 & TRN \\
\hline CHEMBL 2006785 & 809116 & 4.0 & 3.8159 & TST \\
\hline CHEMBL1982466 & 809116 & 4.0 & 4.0304 & TRN \\
\hline CHEMBL1995740 & 809116 & 5.5 & 4.99 & TRN \\
\hline CHEMBL1996390 & 809116 & 4.0 & 3.8592 & TRN \\
\hline CHEMBL1986943 & 809116 & 7.5 & 7.6249 & TRN \\
\hline CHEMBL 234085 & 809116 & 4.0 & 4.2678 & TRN \\
\hline CHEMBL1995832 & 809116 & 4.0 & 4.0431 & TRN \\
\hline CHEMBL1998414 & 809116 & 4.0 & 3.8383 & TRN \\
\hline CHEMBL1969042 & 809116 & 4.0 & 4.6476 & TST \\
\hline CHEMBL 2000345 & 809116 & 4.0 & 4.4058 & TRN \\
\hline CHEMBL1999931 & 809116 & 5.8 & 5.7402 & TRN \\
\hline CHEMBL1991640 & 809116 & 4.0 & 5.3838 & TST \\
\hline CHEMBL1375418 & 809116 & 4.0 & 4.3325 & TRN \\
\hline CHEMBL 302449 & 809116 & 4.0 & 6.0011 & TST \\
\hline CHEMBL 2007064 & 809116 & 4.0 & 4.143 & TRN \\
\hline CHEMBL1981047 & 809116 & 4.0 & 4.2936 & TST \\
\hline CHEMBL229968 & 809116 & 8.1 & 7.8114 & TRN \\
\hline CHEMBL1976240 & 809116 & 6.5 & 6.2583 & TRN \\
\hline CHEMBL1979093 & 809116 & 4.0 & 4.5536 & TRN \\
\hline CHEMBL1968151 & 809116 & 4.0 & 4.5304 & TST \\
\hline CHEMBL1381197 & 809116 & 4.0 & 4.1908 & TRN \\
\hline CHEMBL1987009 & 809116 & 4.0 & 4.3384 & TRN \\
\hline CHEMBL379218 & 809116 & 7.1 & 7.6972 & TRN \\
\hline CHEMBL 2003817 & 809116 & 4.0 & 3.7736 & TRN \\
\hline CHEMBL336961 & 809116 & 4.0 & 4.6091 & TRN \\
\hline CHEMBL1994830 & 809116 & 4.0 & 3.9768 & TRN \\
\hline CHEMBL1987054 & 809116 & 5.0 & 5.7919 & TRN \\
\hline CHEMBL1970083 & 809116 & 4.0 & 4.1515 & TRN \\
\hline CHEMBL 226403 & 809116 & 4.0 & 3.8081 & TRN \\
\hline
\end{tabular}




\begin{tabular}{|c|c|c|c|c|c|}
\hline \multicolumn{6}{|c|}{ Supplemental Table S2.txt } \\
\hline CHEMBL 2005631 & 809116 & 4.0 & 3.7408 & TRN & \\
\hline CHEMBL1994938 & 809116 & 5.4 & 4.1517 & TRN & \\
\hline CHEMBL1825138 & 809116 & 4.0 & 4.5169 & TST & \\
\hline CHEMBL1977223 & 809116 & 4.0 & 4.9154 & TRN & \\
\hline CHEMBL1236126 & 809116 & 4.0 & 4.1646 & TST & \\
\hline CHEMBL1966279 & 809116 & 4.0 & 4.6665 & TRN & \\
\hline CHEMBL1997846 & 809116 & 7.4 & 7.1452 & TRN & \\
\hline CHEMBL 2004419 & 809116 & 4.0 & 4.4408 & TRN & \\
\hline CHEMBL1991728 & 809116 & 6.5 & 6.0023 & TRN & \\
\hline CHEMBL1975787 & 809116 & 4.1 & 4.5543 & TRN & \\
\hline CHEMBL 2002407 & 809116 & 4.0 & 3.8731 & TRN & \\
\hline CHEMBL1972489 & 809116 & 4.0 & 3.4517 & TRN & \\
\hline CHEMBL1994074 & 809116 & 4.0 & 3.99300 & 00000000003 & TRN \\
\hline CHEMBL1992937 & 809116 & 4.0 & 3.9741 & TST & \\
\hline CHEMBL536151 & 809116 & 4.0 & 3.8638 & TST & \\
\hline CHEMBL1972119 & 809116 & 4.0 & 4.0093 & TRN & \\
\hline CHEMBL1986328 & 809116 & 4.0 & 4.2959 & TST & \\
\hline CHEMBL95692 & 809116 & 4.0 & 4.1281 & TRN & \\
\hline CHEMBL1090356 & 809116 & 4.0 & 4.1672 & TRN & \\
\hline CHEMBL1976455 & 809116 & 4.0 & 4.0444 & TRN & \\
\hline CHEMBL1983923 & 809116 & 4.0 & 4.0334 & TST & \\
\hline CHEMBL1983534 & 809116 & 4.0 & 4.8662 & TRN & \\
\hline CHEMBL1982361 & 809116 & 7.2 & 6.7179 & TRN & \\
\hline CHEMBL1999112 & 809116 & 4.0 & 4.3192 & TST & \\
\hline CHEMBL1982122 & 809116 & 5.4 & 5.1838 & TRN & \\
\hline CHEMBL 2000801 & 809116 & 4.0 & 3.694 & TRN & \\
\hline CHEMBL1682546 & 809116 & 4.0 & 4.7614 & TRN & \\
\hline CHEMBL1991395 & 809116 & 4.0 & 3.6685 & TRN & \\
\hline CHEMBL1971245 & 809116 & 4.0 & 4.1598 & TRN & \\
\hline CHEMBL1987648 & 809116 & 4.0 & 3.8442 & TRN & \\
\hline CHEMBL1996780 & 809116 & 6.6 & 5.2276 & TST & \\
\hline CHEMBL1972142 & 809116 & 4.0 & 4.173 & TRN & \\
\hline CHEMBL1966514 & 809116 & 4.0 & 3.6588 & TRN & \\
\hline CHEMBL 2003638 & 809116 & 5.2 & 5.4749 & TRN & \\
\hline CHEMBL 296586 & 809116 & 5.3 & 5.1971 & TRN & \\
\hline CHEMBL1996066 & 809116 & 4.0 & 3.568 & TST & \\
\hline CHEMBL516429 & 809116 & 6.7 & 6.1367 & TRN & \\
\hline CHEMBL1972152 & 809116 & 4.0 & 4.2653 & TST & \\
\hline CHEMBL1993722 & 809116 & 4.0 & 4.1982 & TRN & \\
\hline CHEMBL1970806 & 809116 & 4.0 & 4.2078 & TST & \\
\hline CHEMBL202635 & 809116 & 4.0 & 4.2986 & TRN & \\
\hline CHEMBL1375640 & 809116 & 4.0 & 4.394 & TST & \\
\hline CHEMBL1979970 & 809116 & 4.0 & 3.7505 & TRN & \\
\hline CHEMBL249282 & 809116 & 4.0 & 3.9335 & TST & \\
\hline CHEMBL1969264 & 809116 & 4.0 & 4.1079 & TRN & \\
\hline CHEMBL1973711 & 809116 & 4.0 & 4.0502 & TST & \\
\hline CHEMBL 2006237 & 809116 & 4.0 & 3.7019 & TRN & \\
\hline CHEMBL1967720 & 809116 & 4.0 & 4.3533 & TRN & \\
\hline
\end{tabular}




\begin{tabular}{|c|c|c|c|c|c|}
\hline \multicolumn{6}{|c|}{ Supplemental Table S2.txt } \\
\hline CHEMBL1572266 & 809116 & 4.0 & 3.8765 & TST & \\
\hline CHEMBL1991138 & 809116 & 4.0 & 4.9877 & TRN & \\
\hline CHEMBL1969755 & 809116 & 4.0 & 4.6198 & TRN & \\
\hline CHEMBL1979516 & 809116 & 4.0 & 3.9035 & TRN & \\
\hline CHEMBL1605605 & 809116 & 5.2 & 5.3853 & TRN & \\
\hline CHEMBL1972820 & 809116 & 4.0 & 3.5997 & TST & \\
\hline CHEMBL1996208 & 809116 & 4.0 & 3.634 & TST & \\
\hline CHEMBL1989029 & 809116 & 4.0 & 4.1445 & TRN & \\
\hline CHEMBL392642 & 809116 & 4.0 & 4.711 & TRN & \\
\hline CHEMBL514499 & 809116 & 4.0 & 4.2155 & TST & \\
\hline CHEMBL1965631 & 809116 & 4.0 & 4.8122 & TRN & \\
\hline CHEMBL1980144 & 809116 & 5.3 & 5.1317 & TRN & \\
\hline CHEMBL1991188 & 809116 & 6.4 & 6.1338 & TRN & \\
\hline CHEMBL1972849 & 809116 & 4.0 & 4.1303 & TRN & \\
\hline CHEMBL 377408 & 809116 & 4.0 & 4.26 & TRN & \\
\hline CHEMBL 215152 & 809116 & 4.0 & 4.2698 & TRN & \\
\hline CHEMBL231209 & 809116 & 4.0 & 3.8142 & TRN & \\
\hline CHEMBL1975357 & 809116 & 4.0 & 4.3375 & TST & \\
\hline CHEMBL1976220 & 809116 & 4.0 & 3.8248 & TRN & \\
\hline CHEMBL259922 & 809116 & 4.0 & 4.2639 & TST & \\
\hline CHEMBL1997617 & 809116 & 5.8 & 5.1628 & TRN & \\
\hline CHEMBL1982383 & 809116 & 4.0 & 3.8742 & TRN & \\
\hline CHEMBL1969301 & 809116 & 4.0 & 4.3298 & TST & \\
\hline CHEMBL17370 & 809116 & 5.2 & 4.4261 & TRN & \\
\hline CHEMBL1987910 & 809116 & 4.0 & 3.9695 & TRN & \\
\hline CHEMBL1983932 & 809116 & 4.0 & 3.74300 & 00000000003 & TRN \\
\hline CHEMBL1966069 & 809116 & 5.4 & 5.398 & TRN & \\
\hline CHEMBL1997822 & 809116 & 4.0 & 4.0809 & TRN & \\
\hline CHEMBL1991285 & 809116 & 4.0 & 4.0678 & TRN & \\
\hline CHEMBL 243088 & 809116 & 4.0 & 4.3715 & TRN & \\
\hline CHEMBL1984038 & 809116 & 4.0 & 4.5032 & TRN & \\
\hline CHEMBL1993661 & 809116 & 7.0 & 6.1306 & TRN & \\
\hline CHEMBL1974416 & 809116 & 5.7 & 5.1961 & TRN & \\
\hline CHEMBL2004615 & 809116 & 4.0 & 4.2058 & TST & \\
\hline CHEMBL1984039 & 809116 & 4.0 & 4.5589 & TST & \\
\hline CHEMBL1997872 & 809116 & 4.0 & 3.5547 & TRN & \\
\hline CHEMBL1964290 & 809116 & 5.3 & 5.1854 & TRN & \\
\hline CHEMBL 2003768 & 809116 & 6.1 & 5.7086 & TRN & \\
\hline CHEMBL213505 & 809116 & 4.0 & 4.0205 & TRN & \\
\hline CHEMBL1982880 & 809116 & 5.0 & 4.426 & TRN & \\
\hline CHEMBL1987034 & 809116 & 5.3 & 4.6478 & TRN & \\
\hline CHEMBL1993941 & 809116 & 4.0 & 4.2804 & TRN & \\
\hline CHEMBL 377383 & 809116 & 4.0 & 3.572 & TRN & \\
\hline CHEMBL578061 & 809116 & 3.6 & 4.0705 & TRN & \\
\hline CHEMBL 2005886 & 809116 & 5.3 & 5.2572 & TRN & \\
\hline CHEMBL481491 & 809116 & 4.0 & 4.0347 & TST & \\
\hline CHEMBL1682345 & 809116 & 6.3 & 5.2451 & TRN & \\
\hline CHEMBL1973142 & 809116 & 4.0 & 4.6992 & TST & \\
\hline
\end{tabular}




\begin{tabular}{|c|c|c|c|c|}
\hline \multicolumn{5}{|c|}{ Supplemental Table S2.txt } \\
\hline CHEMBL1973145 & 809116 & 4.0 & 3.2528 & TRN \\
\hline CHEMBL1982924 & 809116 & 4.0 & 5.0845 & TRN \\
\hline CHEMBL 2005936 & 809116 & 6.7 & 6.3013 & TRN \\
\hline CHEMBL1971141 & 809116 & 4.0 & 3.9125 & TRN \\
\hline CHEMBL1995813 & 809116 & 7.2 & 7.0658 & TRN \\
\hline CHEMBL1979718 & 809116 & 6.4 & 4.974 & TRN \\
\hline CHEMBL206236 & 809116 & 5.4 & 5.1346 & TRN \\
\hline CHEMBL523823 & 809116 & 4.0 & 4.0533 & TST \\
\hline CHEMBL1562756 & 809116 & 4.0 & 4.0955 & TST \\
\hline CHEMBL244378 & 809116 & 5.3 & 4.9086 & TRN \\
\hline CHEMBL 2001957 & 809116 & 4.0 & 3.8636 & TRN \\
\hline CHEMBL1969372 & 809116 & 4.0 & 3.7007 & TRN \\
\hline CHEMBL1990583 & 809116 & 4.0 & 4.885 & TRN \\
\hline CHEMBL 2006263 & 809116 & 4.0 & 4.6747 & TST \\
\hline CHEMBL 2001646 & 809116 & 5.1 & 4.8729 & TST \\
\hline CHEMBL1993584 & 809116 & 5.6 & 5.0586 & TRN \\
\hline CHEMBL1986263 & 809116 & 4.0 & 4.5077 & TRN \\
\hline CHEMBL 2000114 & 809116 & 4.0 & 4.2584 & TRN \\
\hline CHEMBL210618 & 809116 & 4.0 & 3.8816 & TRN \\
\hline CHEMBL1975647 & 809116 & 4.0 & 4.2809 & TRN \\
\hline CHEMBL1968380 & 809116 & 5.1 & 4.4157 & TRN \\
\hline CHEMBL1964644 & 809116 & 4.0 & 3.8991 & TRN \\
\hline CHEMBL1981782 & 809116 & 5.1 & 5.4922 & TRN \\
\hline CHEMBL1977681 & 809116 & 4.0 & 4.2904 & TRN \\
\hline CHEMBL1970142 & 809116 & 4.0 & 4.1077 & TRN \\
\hline CHEMBL1990912 & 809116 & 4.0 & 3.6261 & TRN \\
\hline CHEMBL1988163 & 809116 & 4.0 & 4.3757 & TRN \\
\hline CHEMBL1995592 & 809116 & 5.9 & 5.0803 & TST \\
\hline CHEMBL1975128 & 809116 & 6.6 & 6.8953 & TRN \\
\hline CHEMBL 2006493 & 809116 & 4.0 & 4.2364 & TST \\
\hline CHEMBL1982541 & 809116 & 4.0 & 4.312 & TRN \\
\hline CHEMBL1996923 & 809116 & 4.0 & 3.8945 & TST \\
\hline CHEMBL1983449 & 809116 & 6.7 & 6.5284 & TRN \\
\hline CHEMBL1992323 & 809116 & 4.0 & 3.7467 & TST \\
\hline CHEMBL1969735 & 809116 & 4.0 & 3.9929 & TRN \\
\hline CHEMBL 2003524 & 809116 & 4.0 & 4.6126 & TST \\
\hline CHEMBL 2002649 & 809116 & 4.0 & 4.2957 & TRN \\
\hline CHEMBL437747 & 809116 & 5.4 & 4.9409 & TRN \\
\hline CHEMBL1995172 & 809116 & 4.0 & 3.7949 & TST \\
\hline CHEMBL104264 & 809116 & 4.0 & 5.267 & TST \\
\hline CHEMBL1994321 & 809116 & 4.0 & 3.9747 & TRN \\
\hline CHEMBL1997129 & 809116 & 5.1 & 4.7944 & TRN \\
\hline CHEMBL1984788 & 809116 & 4.0 & 4.0584 & TRN \\
\hline CHEMBL451964 & 809116 & 4.0 & 4.0614 & TRN \\
\hline CHEMBL1996604 & 809116 & 4.0 & 4.141 & TRN \\
\hline CHEMBL1964307 & 809116 & 4.0 & 4.3449 & TRN \\
\hline CHEMBL 2000508 & 809116 & 4.0 & 4.0473 & TRN \\
\hline CHEMBL1971694 & 809116 & 4.0 & 4.1547 & TST \\
\hline
\end{tabular}




\begin{tabular}{|c|c|c|c|c|c|}
\hline \multicolumn{6}{|c|}{ Supplemental Table S2.txt } \\
\hline CHEMBL 2001547 & 809116 & 4.0 & 3.9851 & TRN & \\
\hline CHEMBL210928 & 809116 & 4.0 & 3.85 & TRN & \\
\hline CHEMBL1994361 & 809116 & 4.0 & 4.4904 & TRN & \\
\hline CHEMBL1986603 & 809116 & 4.0 & 3.7575 & TST & \\
\hline CHEMBL1972840 & 809116 & 5.8 & 5.7714 & TRN & \\
\hline CHEMBL1977148 & 809116 & 4.0 & 3.6521 & TRN & \\
\hline CHEMBL 2003286 & 809116 & 4.0 & 3.5893 & TRN & \\
\hline CHEMBL1992306 & 809116 & 4.0 & 3.9334 & TRN & \\
\hline CHEMBL 2002165 & 809116 & 5.0 & 4.4285 & TRN & \\
\hline CHEMBL 2001668 & 809116 & 4.0 & 3.7710 & 00000000004 & TST \\
\hline CHEMBL1979318 & 809116 & 4.0 & 3.9739 & 99999999998 & TRN \\
\hline CHEMBL206382 & 809116 & 4.0 & 4.2896 & TRN & \\
\hline CHEMBL1998585 & 809116 & 4.0 & 3.9275 & TRN & \\
\hline CHEMBL127898 & 809116 & 4.0 & 4.5923 & TST & \\
\hline CHEMBL519697 & 809116 & 4.0 & 4.1701 & TST & \\
\hline CHEMBL 2004934 & 809116 & 5.8 & 6.1125 & TRN & \\
\hline CHEMBL1981947 & 809116 & 5.2 & 4.3697 & TST & \\
\hline CHEMBL1970369 & 809116 & 4.0 & 3.7947 & TRN & \\
\hline CHEMBL 2001485 & 809116 & 4.0 & 4.3055 & TRN & \\
\hline CHEMBL504950 & 809116 & 5.1 & 4.7625 & TRN & \\
\hline CHEMBL1966425 & 809116 & 5.4 & 5.4386 & TRN & \\
\hline CHEMBL1984363 & 809116 & 4.0 & 4.6541 & TRN & \\
\hline CHEMBL1978099 & 809116 & 4.0 & 3.5674 & TRN & \\
\hline CHEMBL1977041 & 809116 & 4.0 & 4.5489 & TRN & \\
\hline CHEMBL1968070 & 809116 & 4.0 & 3.9381 & TRN & \\
\hline CHEMBL1988608 & 809116 & 7.0 & 6.6327 & TRN & \\
\hline CHEMBL184847 & 809116 & 4.0 & 4.8877 & TRN & \\
\hline CHEMBL1984367 & 809116 & 4.0 & 4.1594 & TRN & \\
\hline CHEMBL178737 & 809116 & 4.0 & 4.0852 & TST & \\
\hline CHEMBL1982563 & 809116 & 4.0 & 4.0632 & TRN & \\
\hline CHEMBL539474 & 809116 & 4.0 & 4.8905 & TST & \\
\hline CHEMBL575824 & 809116 & 5.3 & 5.4318 & TRN & \\
\hline CHEMBL1988387 & 809116 & 4.0 & 4.3146 & TRN & \\
\hline CHEMBL1997759 & 809116 & 4.0 & 4.0876 & TRN & \\
\hline CHEMBL1974803 & 809116 & 5.1 & 3.6081 & TST & \\
\hline CHEMBL1970074 & 809116 & 4.0 & 4.0035 & TRN & \\
\hline CHEMBL1986970 & 809116 & 6.8 & 6.5539 & 9999999999 & TRN \\
\hline CHEMBL 2005112 & 809116 & 4.0 & 4.0747 & TST & \\
\hline CHEMBL1958401 & 809116 & 5.5 & 4.8583 & TRN & \\
\hline CHEMBL1984044 & 809116 & 4.0 & 3.6915 & TRN & \\
\hline CHEMBL 2003456 & 809116 & 4.0 & 4.0843 & TRN & \\
\hline CHEMBL1966816 & 809116 & 4.0 & 4.3099 & TRN & \\
\hline CHEMBL 2002992 & 809116 & 5.4 & 5.6874 & TRN & \\
\hline CHEMBL560813 & 809116 & 4.0 & 3.6247 & TRN & \\
\hline CHEMBL207253 & 809116 & 4.0 & 4.0873 & TST & \\
\hline CHEMBL1890036 & 809116 & 6.1 & 4.6688 & TST & \\
\hline CHEMBL1990635 & 809116 & 5.1 & 5.0343 & TST & \\
\hline CHEMBL1968791 & 809116 & 5.4 & 5.5448 & TRN & \\
\hline
\end{tabular}




\begin{tabular}{|c|c|c|c|c|}
\hline & & & plement & \\
\hline CHEMBL326282 & 809116 & 4.0 & 3.9594 & TST \\
\hline CHEMBL 2002682 & 809116 & 5.5 & 5.0565 & TST \\
\hline CHEMBL1992732 & 809116 & 4.0 & 4.42 & TST \\
\hline CHEMBL1971186 & 809116 & 4.0 & 3.9004 & TRN \\
\hline CHEMBL 2003482 & 809116 & 4.0 & 4.1449 & TRN \\
\hline CHEMBL1973211 & 809116 & 4.0 & 4.1837 & TRN \\
\hline CHEMBL1984700 & 809116 & 4.0 & 4.1372 & TRN \\
\hline CHEMBL 2007151 & 809116 & 5.9 & 5.4583 & TRN \\
\hline CHEMBL1972125 & 809116 & 4.0 & 4.0452 & TRN \\
\hline CHEMBL1461728 & 809116 & 4.0 & 4.1242 & TRN \\
\hline CHEMBL1976134 & 809116 & 5.2 & 4.2009 & TRN \\
\hline CHEMBL1965131 & 809116 & 4.0 & 4.6534 & TST \\
\hline CHEMBL1995448 & 809116 & 5.5 & 4.4635 & TRN \\
\hline CHEMBL1972158 & 809116 & 6.7 & 6.8316 & TRN \\
\hline CHEMBL1974457 & 809116 & 4.0 & 3.9695 & TRN \\
\hline CHEMBL 2006580 & 809116 & 4.0 & 3.3992 & TRN \\
\hline CHEMBL 2006581 & 809116 & 4.0 & 3.8299 & TRN \\
\hline CHEMBL 2006481 & 809116 & 4.0 & 3.5607 & TRN \\
\hline CHEMBL1979855 & 809116 & 4.0 & 4.8472 & TRN \\
\hline CHEMBL1970340 & 809116 & 4.0 & 4.2742 & TRN \\
\hline CHEMBL 2005186 & 809116 & 4.0 & 4.3126 & TRN \\
\hline CHEMBL1995927 & 809116 & 4.0 & 4.2265 & TST \\
\hline CHEMBL1975534 & 809116 & 4.0 & 3.9747 & TRN \\
\hline CHEMBL1993424 & 809116 & 4.0 & 3.7543 & TRN \\
\hline CHEMBL1966703 & 809116 & 4.0 & 4.6309 & TST \\
\hline CHEMBL1969561 & 809116 & 7.5 & 6.9133 & TRN \\
\hline CHEMBL1997023 & 809116 & 5.1 & 4.494 & TST \\
\hline CHEMBL1964687 & 809116 & 5.2 & 4.3445 & TRN \\
\hline CHEMBL1971943 & 809116 & 7.1 & 6.5237 & TRN \\
\hline CHEMBL1999918 & 809116 & 6.2 & 5.1009 & TRN \\
\hline CHEMBL1974254 & 809116 & 5.1 & 4.0186 & TRN \\
\hline CHEMBL1988537 & 809116 & 4.0 & 4.2491 & TST \\
\hline CHEMBL1969049 & 809116 & 5.7 & 6.1884 & TRN \\
\hline CHEMBL 2005828 & 809116 & 4.0 & 4.2131 & TRN \\
\hline CHEMBL 2002240 & 809116 & 4.0 & 4.1087 & TRN \\
\hline CHEMBL1991143 & 809116 & 4.0 & 4.1428 & TST \\
\hline CHEMBL1998611 & 809116 & 4.0 & 4.4161 & TST \\
\hline CHEMBL485556 & 809116 & 4.0 & 4.0249 & TST \\
\hline CHEMBL1975900 & 809116 & 6.9 & 6.7347 & TRN \\
\hline CHEMBL 255822 & 809116 & 4.0 & 3.6057 & TRN \\
\hline CHEMBL1972221 & 809116 & 4.0 & 3.7709 & TRN \\
\hline CHEMBL 2006778 & 809116 & 4.0 & 3.9502 & TRN \\
\hline CHEMBL378627 & 809116 & 4.0 & 4.1883 & TRN \\
\hline CHEMBL1996979 & 809116 & 6.0 & 5.3414 & TRN \\
\hline CHEMBL1997025 & 809116 & 4.0 & 4.0332 & TRN \\
\hline CHEMBL1968406 & 809116 & 5.2 & 4.4619 & TRN \\
\hline CHEMBL1982476 & 809116 & 4.0 & 4.0093 & TRN \\
\hline CHEMBL1984274 & 809116 & 5.1 & 4.5556 & TST \\
\hline
\end{tabular}




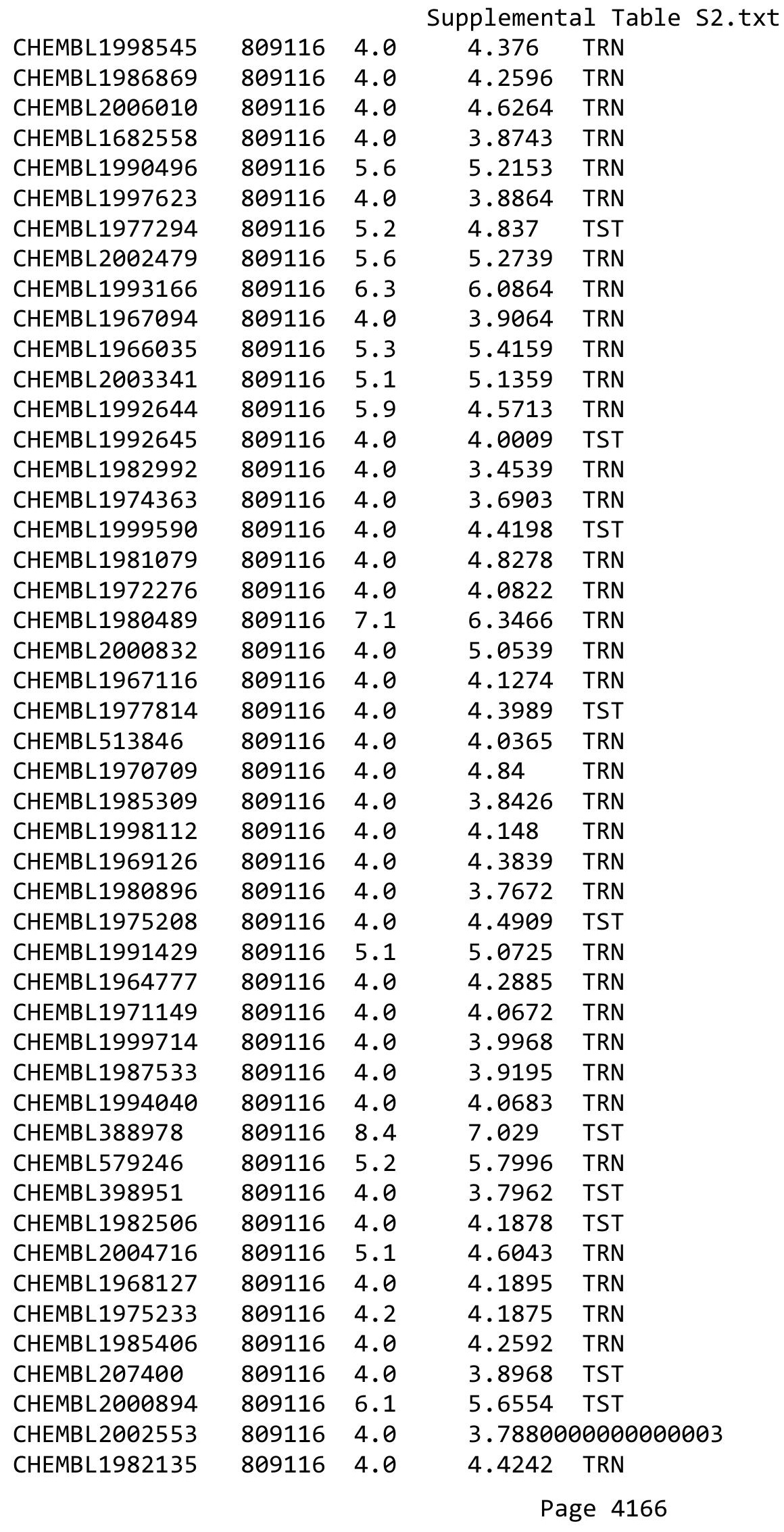




\begin{tabular}{|c|c|c|c|c|c|}
\hline \multirow[b]{2}{*}{ CHEMBL1976090 } & \multicolumn{5}{|c|}{ Supplemental Table s2.txt } \\
\hline & 809116 & 4.0 & 4.2885 & TRN & \\
\hline CHEMBL1993243 & 809116 & 4.0 & 3.8864 & TRN & \\
\hline CHEMBL1992922 & 809116 & 5.1 & 4.9903 & TRN & \\
\hline CHEMBL2004771 & 809116 & 4.0 & 4.7545 & TRN & \\
\hline CHEMBL 399021 & 809116 & 5.8 & 5.466 & TRN & \\
\hline CHEMBL1997597 & 809116 & 4.0 & 4.50899 & 99999999995 & TST \\
\hline CHEMBL1969537 & 809116 & 4.0 & 4.6471 & TST & \\
\hline CHEMBL1976093 & 809116 & 4.0 & 4.0602 & TST & \\
\hline CHEMBL210032 & 809116 & 4.0 & 4.0432 & TST & \\
\hline CHEMBL1996543 & 809116 & 4.0 & 4.8034 & TST & \\
\hline CHEMBL1975256 & 809116 & 7.2 & 4.3876 & TST & \\
\hline CHEMBL508928 & 809116 & 4.0 & 4.1241 & TST & \\
\hline CHEMBL1991356 & 809116 & 4.0 & 4.17 & TST & \\
\hline CHEMBL1983309 & 809116 & 4.0 & 3.9648 & TST & \\
\hline CHEMBL 2004892 & 809116 & 4.0 & 4.5226 & TST & \\
\hline CHEMBL1999126 & 809116 & 4.0 & 3.9824 & TST & \\
\hline CHEMBL1997503 & 809116 & 4.0 & 4.1759 & TST & \\
\hline CHEMBL116070 & 809116 & 5.3 & 4.2277 & TST & \\
\hline CHEMBL1990821 & 809116 & 5.0 & 4.7052 & TST & \\
\hline CHEMBL1970314 & 809116 & 4.0 & 3.9299 & TST & \\
\hline CHEMBL 2004871 & 809116 & 5.1 & 3.6775 & TST & \\
\hline CHEMBL454402 & 566940 & 6.6576 & 6.6583 & TRN & \\
\hline CHEMBL464209 & 566940 & 6.7959 & 6.8088 & TRN & \\
\hline CHEMBL463424 & 566940 & 7.4202 & 7.2262 & TST & \\
\hline CHEMBL463423 & 566940 & 6.9586 & 7.5083 & TST & \\
\hline CHEMBL510083 & 566940 & 6.7447 & 6.569 & TST & \\
\hline CHEMBL508045 & 566940 & 6.5086 & 6.4199 & TST & \\
\hline CHEMBL460748 & 566940 & 7.4437 & 7.4475 & TRN & \\
\hline CHEMBL454631 & 566940 & 6.3979 & 6.4078 & TRN & \\
\hline CHEMBL517578 & 566940 & 7.8861 & 7.88 & TRN & \\
\hline CHEMBL463614 & 566940 & 7.8239 & 7.8298 & TRN & \\
\hline CHEMBL461170 & 566940 & 7.4685 & 7.4393 & TRN & \\
\hline CHEMBL506391 & 566940 & 6.3279 & 6.3221 & TRN & \\
\hline CHEMBL463027 & 566940 & 6.8239 & 6.8215 & TRN & \\
\hline CHEMBL452595 & 566940 & 7.7959 & 7.3486 & TST & \\
\hline CHEMBL453626 & 566940 & 8.0 & 7.9961 & TRN & \\
\hline CHEMBL459690 & 566940 & 8.0458 & 8.0511 & TRN & \\
\hline CHEMBL518695 & 566940 & 7.8861 & 7.8818 & TRN & \\
\hline CHEMBL454630 & 566940 & 7.2007 & 8.2097 & TST & \\
\hline CHEMBL464412 & 566940 & 5.3565 & 5.3447 & TRN & \\
\hline CHEMBL508274 & 566940 & 8.0 & 7.9944 & TRN & \\
\hline CHEMBL460540 & 566940 & 7.0132 & 7.0133 & TRN & \\
\hline CHEMBL463419 & 566940 & 8.0969 & 8.0969 & TRN & \\
\hline CHEMBL460920 & 566940 & 7.2518 & 7.2532 & TRN & \\
\hline CHEMBL462833 & 566940 & 7.6778 & 7.6775 & TRN & \\
\hline CHEMBL462834 & 566940 & 7.2518 & 7.2573 & TRN & \\
\hline CHEMBL474356 & 566940 & 7.0088 & 7.0134 & TRN & \\
\hline CHEMBL460747 & 566940 & 7.3665 & 7.9579 & TST & \\
\hline & & & & 4167 & \\
\hline
\end{tabular}




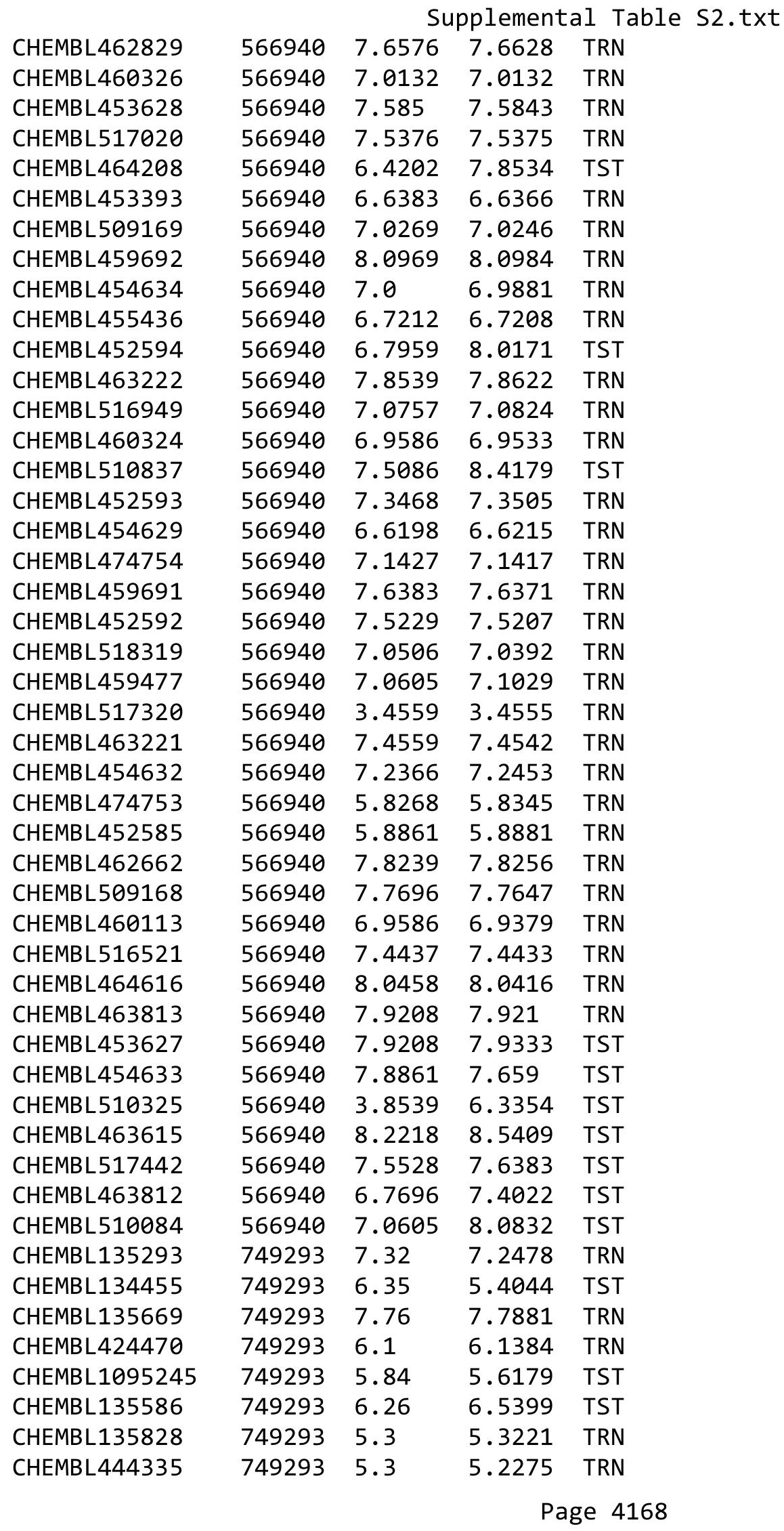




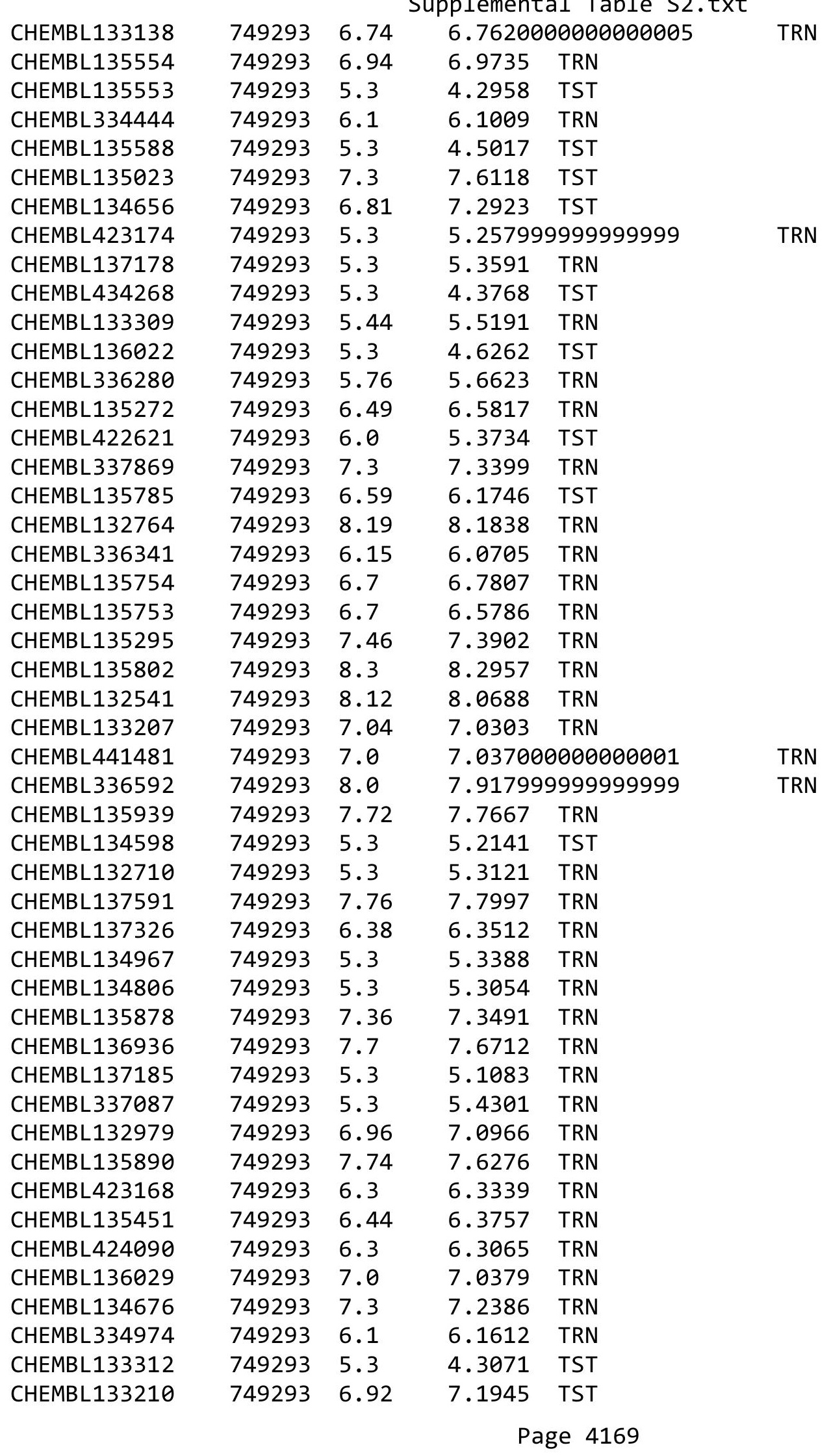




\begin{tabular}{|c|c|c|c|c|c|}
\hline \multicolumn{6}{|c|}{ Supplemental Table S2.txt } \\
\hline CHEMBL135922 & 749293 & 5.8 & 5.3837 & TST & \\
\hline CHEMBL133139 & 749293 & 5.8 & 5.5673 & TST & \\
\hline CHEMBL1785010 & 749293 & 6.07 & 6.0374 & TRN & \\
\hline CHEMBL132916 & 749293 & 7.8 & 7.8114 & TRN & \\
\hline CHEMBL135379 & 749293 & 5.56 & 5.5816 & TRN & \\
\hline CHEMBL334407 & 749293 & 7.92 & 7.9434 & TRN & \\
\hline CHEMBL336562 & 749293 & 7.47 & 7.5088 & TRN & \\
\hline CHEMBL135585 & 749293 & 6.47 & 6.529 & TRN & \\
\hline CHEMBL132532 & 749293 & 6.6 & 6.6039 & TRN & \\
\hline CHEMBL135770 & 749293 & 6.3 & 6.2323 & TST & \\
\hline CHEMBL 3955810 & 1641176 & 8.1656 & 7.0665 & TRN & \\
\hline CHEMBL 3897820 & 1641176 & 9.6556 & 9.0953 & TRN & \\
\hline CHEMBL3892850 & 1641176 & 5.9136 & 7.4848 & TST & \\
\hline CHEMBL3896529 & 1641176 & 7.9172 & 7.5823 & TRN & \\
\hline CHEMBL 3893851 & 1641176 & 8.4425 & 8.1149 & TST & \\
\hline CHEMBL 3902723 & 1641176 & 7.4023 & 6.2323 & TRN & \\
\hline CHEMBL3958878 & 1641176 & 8.6861 & 8.6152 & TRN & \\
\hline CHEMBL 3977514 & 1641176 & 7.4609 & 7.8159 & TRN & \\
\hline CHEMBL3919020 & 1641176 & 6.1079 & 7.5139 & TST & \\
\hline CHEMBL 3915271 & 1641176 & 9.1851 & 9.19399 & 9999999999 & TRN \\
\hline CHEMBL 3917060 & 1641176 & 6.6904 & 6.8937 & TRN & \\
\hline CHEMBL 3889607 & 1641176 & 8.5735 & 8.3025 & TST & \\
\hline CHEMBL 3967841 & 1641176 & 7.5986 & 8.1539 & TRN & \\
\hline CHEMBL3962206 & 1641176 & 5.8729 & 7.8501 & TST & \\
\hline CHEMBL 3894824 & 1641176 & 6.0 & 9.3042 & TRN & \\
\hline CHEMBL 3981646 & 1641176 & 8.4425 & 7.9905 & TRN & \\
\hline CHEMBL3916989 & 1641176 & 8.4473 & 9.0331 & TRN & \\
\hline CHEMBL3909058 & 1641176 & 8.7423 & 8.5194 & TRN & \\
\hline CHEMBL3944591 & 1641176 & 8.8665 & 8.9457 & TRN & \\
\hline CHEMBL 3939841 & 1641176 & 8.8539 & 8.1743 & TRN & \\
\hline CHEMBL3924859 & 1641176 & 8.9245 & 8.4254 & TRN & \\
\hline CHEMBL 3975849 & 1641176 & 9.5969 & 8.2994 & TRN & \\
\hline CHEMBL 3898867 & 1641176 & 6.9066 & 7.87299 & 9999999999 & TRN \\
\hline CHEMBL3895636 & 1641176 & 7.266 & 8.0017 & TST & \\
\hline CHEMBL 3894160 & 1641176 & 9.5901 & 9.5298 & TRN & \\
\hline CHEMBL3927532 & 1641176 & 8.8697 & 8.0587 & TRN & \\
\hline CHEMBL3915385 & 1641176 & 7.7258 & 7.8433 & TRN & \\
\hline CHEMBL 3902354 & 1641176 & 8.8297 & 8.6366 & TRN & \\
\hline CHEMBL 3930360 & 1641176 & 7.8996 & 6.6739 & TRN & \\
\hline CHEMBL 3917319 & 1641176 & 7.3382 & 8.2297 & TST & \\
\hline CHEMBL3896499 & 1641176 & 7.8729 & 7.8715 & TRN & \\
\hline CHEMBL3950736 & 1641176 & 6.5622 & 7.0957 & TST & \\
\hline CHEMBL 3960363 & 1641176 & 7.5186 & 7.5164 & TRN & \\
\hline CHEMBL3978287 & 1641176 & 8.2899 & 8.6915 & TRN & \\
\hline CHEMBL 3914654 & 1641176 & 9.2097 & 9.4085 & TRN & \\
\hline CHEMBL3911331 & 1641176 & 9.4225 & 9.6035 & TRN & \\
\hline CHEMBL 3948464 & 1641176 & 6.0 & 7.4794 & TRN & \\
\hline CHEMBL3916284 & 1641176 & 8.8182 & 8.0589 & TST & \\
\hline
\end{tabular}


Supplemental Table S2.txt

\begin{tabular}{|c|c|c|c|c|}
\hline 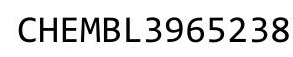 & 176 & & & \\
\hline HEMBL3941372 & 641176 & 8.7878 & 8.0269 & \\
\hline & & & & \\
\hline 84 & 176 & 429 & & \\
\hline AEMBL3910460 & 641176 & 6.0 & 1063 & \\
\hline AEMBL3931366 & 641176 & 9.2255 & 9897 & \\
\hline HEMBL393 & 176 & 6.0 & & \\
\hline L398 & 76 & 235 & 47 & \\
\hline IEMBL 394 & 176 & & 47 & \\
\hline AEMBL3928996 & 176 & 7.7545 & .5676 & \\
\hline HEMBL3953651 & 176 & 6.8508 & .8596 & \\
\hline AEMBL396 & 176 & 8.9626 & .8911 & \\
\hline AEMBL3S & & & & \\
\hline HEMBL39 & & & & \\
\hline AEMBL3953962 & 76 & 06 & & \\
\hline AEMBL3935720 & & 6.6946 & 8553 & \\
\hline HEMBL38 & 76 & 686 & 88 & \\
\hline HEMBL39 & & $\partial 89$ & & \\
\hline HEMBL 394 & & & & \\
\hline HEMBL 397 & & & & RN \\
\hline EMBL 390 & 6 & 197 & 53 & \\
\hline HEMBL39 & 6 & 498 & 64 & \\
\hline HEMBL39 & & 857 & & \\
\hline 96 & & 326 & & 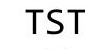 \\
\hline AEMBL39 & & 52 & 79 & SI \\
\hline L38 & 6 & 71 & 8. & ГRN \\
\hline HEMBL 38 & & 13 & 76 & - \\
\hline HEM & & 58 & & RN \\
\hline AEMBL3S & & & & RN \\
\hline AEMBL39 & 6 & & & RN \\
\hline AEMBL39 & & 14 & 7. & RN \\
\hline 130 & & 25 & 24 & RN \\
\hline 6 & & & & ST \\
\hline HEMBL 396 & & & & RN \\
\hline AEMBL3955988 & 6 & 73 & & RN \\
\hline HEMBL39 & & 31 & & \\
\hline HEMRI 3 & & 35 & & RN \\
\hline & & & & RN \\
\hline HEMBL3949305 & 76 & 9.9393 & 8.7421 & TRN \\
\hline IEMBL 389 & 6 & 8. & 8.8075 & RN \\
\hline HEMBL 3940393 & 16 & 009 & 9. 2132 & 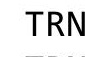 \\
\hline HEMBL 395 & & & & RN \\
\hline HEMBL3958429 & 76 & 8.0101 & 8.546 & TST \\
\hline HEMBL3890768 & 76 & 9.1238 & .5941 & TRN \\
\hline EMBL39. & & & 39 & $\mathrm{~K}$ \\
\hline HEMBL 3899872 & & & 8.1804 & \\
\hline HEMBL 396 & & 9.4647 & 8.2633 & \\
\hline CHEMBL395257 & 1641176 & 8.8508 & 8.7786 & \\
\hline
\end{tabular}

Page 4171 
Supplemental Table S2.txt

\begin{tabular}{|c|c|c|c|c|c|}
\hline CHEMBL3963858 & 1641176 & 7.2034 & 6.6424 & TRN & \\
\hline CHEMBL3938607 & 1641176 & 6.0 & 6.3506 & TRN & \\
\hline CHEMBL3926768 & 1641176 & 5.9626 & 6.6798 & TST & \\
\hline CHEMBL 3948642 & 1641176 & 9.6144 & 9.19399 & 9999999999 & TRN \\
\hline CHEMBL3985297 & 1641176 & 9.4012 & 8.2579 & TRN & \\
\hline CHEMBL3924582 & 1641176 & 5.2197 & 6.6517 & TST & \\
\hline CHEMBL3892015 & 1641176 & 9.3125 & 8.0652 & TRN & \\
\hline CHEMBL 3933774 & 1641176 & 9.98299 & 99999999 & 9.3785 & TRN \\
\hline CHEMBL 3962596 & 1641176 & 8.4828 & 8.327 & TST & \\
\hline CHEMBL3931798 & 1641176 & 8.9066 & 8.5794 & TRN & \\
\hline CHEMBL3931992 & 1641176 & 6.0 & 6.3861 & TRN & \\
\hline CHEMBL 3977655 & 1641176 & 7.5768 & 8.3908 & TST & \\
\hline CHEMBL 3907549 & 1641176 & 6.0 & 8.2109 & TST & \\
\hline CHEMBL 3955695 & 1641176 & 9.8268 & 9.3964 & TST & \\
\hline CHEMBL 3890881 & 1641176 & 8.9245 & 8.2093 & TRN & \\
\hline CHEMBL 3970876 & 1641176 & 8.4089 & 7.7898 & TRN & \\
\hline CHEMBL3907613 & 1641176 & 6.45100 & 0000000 & 8.2084 & TRN \\
\hline CHEMBL 3953213 & 1641176 & 8.7471 & 8.5874 & TRN & \\
\hline CHEMBL 3962705 & 1641176 & 8.4789 & 8.257 & TRN & \\
\hline CHEMBL 3984311 & 1641176 & 8.7212 & 8.5211 & TRN & \\
\hline CHEMBL 3940811 & 1641176 & 6.0 & 7.7119 & TRN & \\
\hline CHEMBL 3907752 & 1641176 & 8.8508 & 8.4502 & TRN & \\
\hline CHEMBL3897480 & 1641176 & 6.0 & 6.8414 & TRN & \\
\hline CHEMBL 3957964 & 1641176 & 8.9281 & 7.9309 & TRN & \\
\hline CHEMBL 3910171 & 1641176 & 8.2644 & 8.0701 & TRN & \\
\hline CHEMBL3911903 & 1641176 & 9.0783 & 9.1585 & TRN & \\
\hline CHEMBL 3898890 & 1641176 & 8.9666 & 9.3093 & TRN & \\
\hline CHEMBL3925911 & 1641176 & 9.7721 & 9.522 & TRN & \\
\hline CHEMBL 3933434 & 1641176 & 8.9469 & 8.4304 & TRN & \\
\hline CHEMBL 3902331 & 1641176 & 9.8894 & 9.251 & TRN & \\
\hline CHEMBL3953306 & 1641176 & 6.8097 & 6.9922 & TST & \\
\hline CHEMBL3931406 & 1641176 & 9.6596 & 9.0518 & TRN & \\
\hline CHEMBL3906700 & 1641176 & 4.9101 & 7.7304 & TST & \\
\hline CHEMBL3935098 & 1641176 & 6.0 & 6.8105 & TST & \\
\hline CHEMBL 3926750 & 1641176 & 6.0 & 7.5464 & TRN & \\
\hline CHEMBL 3934174 & 1641176 & 6.4425 & 6.6576 & TRN & \\
\hline CHEMBL 3893730 & 1641176 & 9.3809 & 8.2694 & TRN & \\
\hline CHEMBL3893186 & 1641176 & 6.4815 & 6.4477 & TRN & \\
\hline CHEMBL 3924117 & 1641176 & 9.8013 & 9.4676 & TRN & \\
\hline CHEMBL 3943007 & 1641176 & 7.5751 & 7.9109 & TRN & \\
\hline CHEMBL 3899894 & 1641176 & 7.7773 & 7.2446 & TST & \\
\hline CHEMBL 3955088 & 1641176 & 7.8761 & 7.9011 & TST & \\
\hline CHEMBL3924521 & 1641176 & 7.5452 & 7.892 & TRN & \\
\hline CHEMBL3929111 & 1641176 & 9.8327 & 8.7213 & TRN & \\
\hline CHEMBL 3890021 & 1641176 & 6.0 & 8.2631 & TRN & \\
\hline CHEMBL3895516 & 1641176 & 8.4698 & 8.2889 & TST & \\
\hline CHEMBL 3964967 & 1641176 & 7.9066 & 7.9524 & TRN & \\
\hline CHEMBL3946384 & 1641176 & 8.4101 & 8.0852 & TRN & \\
\hline
\end{tabular}


Supplemental Table S2.txt

\begin{tabular}{|c|c|c|c|c|c|}
\hline CHEMBL3948665 & 1641176 & 9.8386 & 9.3408 & TRN & \\
\hline CHEMBL3895586 & 1641176 & 6.0 & 8.3828 & TRN & \\
\hline CHEMBL3983287 & 1641176 & 6.0 & 7.9051 & TRN & \\
\hline CHEMBL3928112 & 1641176 & 8.7799 & 9.1094 & TRN & \\
\hline CHEMBL3953615 & 1641176 & 9.3125 & 9.1488 & TRN & \\
\hline CHEMBL3930809 & 1641176 & 8.5031 & 9.0621 & TRN & \\
\hline CHEMBL3968040 & 1641176 & 8.8297 & 9.3125 & TRN & \\
\hline CHEMBL3891146 & 1641176 & 9.7721 & 9.4924 & TRN & \\
\hline CHEMBL3953627 & 1641176 & 9.6421 & 9.3717 & TRN & \\
\hline CHEMBL3963581 & 1641176 & 9.4868 & 9.0498 & TRN & \\
\hline CHEMBL3938025 & 1641176 & 5.5834 & 8.176 & TST & \\
\hline CHEMBL3983726 & 1641176 & 8.9666 & 8.6944 & TST & \\
\hline CHEMBL3944902 & 1641176 & 8.71 & 9.0442 & TRN & \\
\hline CHEMBL3892625 & 1641176 & 6.4535 & 8.3674 & TST & \\
\hline CHEMBL3960925 & 1641176 & 9.719 & 9.3098 & TRN & \\
\hline CHEMBL3984803 & 1641176 & 6.0 & 8.484 & TRN & \\
\hline CHEMBL3916673 & 1641176 & 9.0424 & 8.8625 & TRN & \\
\hline CHEMBL 3919473 & 1641176 & 7.9172 & 8.2031 & TRN & \\
\hline CHEMBL3978049 & 1641176 & 9.4685 & 8.232000 & 0000000001 & TRN \\
\hline CHEMBL3974992 & 1641176 & 8.1524 & 7.5726 & TRN & \\
\hline CHEMBL3960615 & 1641176 & 10.0391 & 9.023 & TRN & \\
\hline CHEMBL 3978744 & 1641176 & 6.0 & 6.6784 & TRN & \\
\hline CHEMBL3974723 & 1641176 & 8.0762 & 8.1435 & TRN & \\
\hline CHEMBL3949143 & 1641176 & 6.0 & 7.5181 & TRN & \\
\hline CHEMBL3944658 & 1641176 & 8.0996 & 8.3764 & TST & \\
\hline CHEMBL3896812 & 1641176 & 9.6162 & 8.3234 & TRN & \\
\hline CHEMBL 3927504 & 1641176 & 9.2984 & 9.1499 & TRN & \\
\hline CHEMBL3891814 & 1641176 & 8.9706 & 9.2524 & TRN & \\
\hline CHEMBL3928360 & 1641176 & 6.0 & 7.2451 & TRN & \\
\hline CHEMBL3942336 & 1641176 & 7.1931 & 7.5786 & TRN & \\
\hline CHEMBL3915682 & 1641176 & 9.4559 & 8.624 & TRN & \\
\hline CHEMBL3951606 & 1641176 & 8.6021 & 8.7984 & TRN & \\
\hline CHEMBL3970580 & 1641176 & \multicolumn{2}{|c|}{6.821000000000001} & 8.0618 & TRN \\
\hline CHEMBL3953599 & 1641176 & 5.5735 & 6.8354 & TST & \\
\hline CHEMBL3916271 & 1641176 & 7.5143 & 7.4772 & TRN & \\
\hline CHEMBL3951655 & 1641176 & 6.9706 & 7.7887 & TST & \\
\hline CHEMBL3970097 & 1641176 & 9.6635 & 9.6195 & TRN & \\
\hline CHEMBL3936721 & 1641176 & \multicolumn{2}{|c|}{6.718999999999999} & 6.8479 & TRN \\
\hline CHEMBL3925976 & 1641176 & 8.289 & 9.052 & TRN & \\
\hline CHEMBL3930173 & 1641176 & 6.0 & 7.7567 & TRN & \\
\hline CHEMBL3931760 & 1641176 & 6.0 & 8.0689 & TRN & \\
\hline CHEMBL3931917 & 1641176 & 8.3851 & 8.103 & TRN & \\
\hline CHEMBL3972085 & 1641176 & 6.0 & 6.9904 & TST & \\
\hline CHEMBL3977849 & 1641176 & 9.4202 & 8.7168 & TRN & \\
\hline CHEMBL3904718 & 1641176 & \multicolumn{3}{|c|}{6.752000000000001} & TRN \\
\hline CHEMBL3933514 & 1641176 & 9.1002 & 8.6372 & TRN & \\
\hline CHEMBL3983720 & 1641176 & 7.9101 & 8.0653 & TRN & \\
\hline CHEMBL 3899467 & 1641176 & 9.104 & 8.6787 & TRN & \\
\hline
\end{tabular}


Supplemental Table S2.txt

\begin{tabular}{|c|c|c|c|c|}
\hline 04 & 176 & & & \\
\hline & 641176 & & & \\
\hline & 176 & & & \\
\hline 98768 & & & & \\
\hline 982225 & 176 & & & \\
\hline HEMBL3939882 & 176 & 46 & 9477 & \\
\hline & 76 & & 481 & \\
\hline & & & & \\
\hline IEMBL3970 & & & 1514 & \\
\hline AEMBL3939292 & 176 & & 9.2921 & \\
\hline HEMBL3896899 & 176 & & .2367 & \\
\hline 41 & 76 & & 2372 & \\
\hline 53 & & & & \\
\hline HEMBL392 & & & 7.1702 & \\
\hline IEMBL3930 & 176 & & 8.729 & \\
\hline IEMBL 395 & & 82 & .5543 & \\
\hline 91 & & & .5198 & \\
\hline 7 & & & .2773 & ST \\
\hline 38 & & & 8.0636 & \\
\hline 42 & & & 048 & \\
\hline IEIMLL 234 & & & . 1417 & TII \\
\hline 34 & & & 4.0681 & R \\
\hline 9 & & & 5.3339 & . \\
\hline 3 & & & 5.9702 & \\
\hline 39 & & & 568 & \\
\hline MBL234 & & & 927 & KI \\
\hline L234c & & & 006 & RN \\
\hline 3 & & & 6.1487 & RN \\
\hline 1 & & & & \\
\hline & & & & RN \\
\hline BBL2349 & & & 961 & $\mathrm{RI}$ \\
\hline LL234C & & & 3928 & 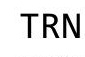 \\
\hline 7 & & & & \\
\hline & & & & \\
\hline IEMBL 2349 & & & 29 & 'RI \\
\hline BBL234 & & & 386 & RI \\
\hline 7 & & & 37 & 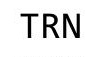 \\
\hline & & & & 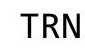 \\
\hline 8 & & & 169 & ST \\
\hline EMBL234C & & & & $\mathrm{R}$ \\
\hline MBL234 & & & 5.8346 & $S$ \\
\hline 9 & & & 5.2523 & \\
\hline & & & & RI \\
\hline HEMBL 2349 & & & 6.0405 & RI \\
\hline MBL 2349 & & & 5.1457 & $\mathrm{R}$ \\
\hline 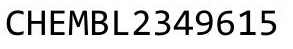 & & & 4236 & $\mathrm{~K}$ \\
\hline CHEMBL234 & & & 5.6286 & \\
\hline CHEMBL234 & 54242 & 4.3133 & 5.1739 & \\
\hline
\end{tabular}

Page 4174 
Supplemental Table S2.txt

\begin{tabular}{|c|c|c|c|c|}
\hline 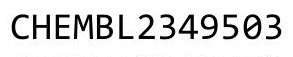 & & 3036 & & \\
\hline HEMBL 2349472 & 54242 & 6.3215 & 6.4111 & \\
\hline HEMBL2349608 & 4242 & 5484 & 5735 & \\
\hline 02 & 4242 & & 371 & \\
\hline HEMBL 234 & 242 & & 305 & \\
\hline AEMBL2349498 & 54242 & .5998 & .6135 & \\
\hline HEMBL 2349505 & 54242 & .6842 & .6894 & \\
\hline HEMBL2349492 & 54242 & & 6.3531 & \\
\hline AEMBL234 & 54242 & 68 & .5827 & \\
\hline IEMBL 234 & & & & \\
\hline HEMBL2349469 & 54242 & 6.0 & 5.8693 & \\
\hline HEMBL 2349490 & 54242 & 5.9872 & 6.0423 & \\
\hline HEMBL 234 & 54 & & 5.0509 & \\
\hline HEMBL 23 & 42 & $\partial 2$ & .5523 & \\
\hline JEMBL 234 & 42 & & .1177 & \\
\hline HEMBL2349479 & 54242 & 26 & 5.3949 & \\
\hline HEMBL2349619 & 42 & 38 & & \\
\hline HEMBL 234 & 5 & 19 & 6.1064 & \\
\hline L23 & & & 109 & \\
\hline AEMBL23 & & & 483 & \\
\hline HEMBL2349486 & 42 & & 6.3837 & \\
\hline HEMBL 234 & 42 & & & ST \\
\hline HEMBL17 & 9 & & 7.7103 & \\
\hline HEM & & & 33 & \\
\hline 66 & & 7. & 98 & ST \\
\hline L177 & & & 219 & not \\
\hline AEMBL1532595 & & & & RN \\
\hline HEMBL17 & 9 & & 219 & \\
\hline HEN & & & & RN \\
\hline 147 & & & 667 & RN \\
\hline AEMBL1542183 & & & & $\mathrm{RN}$ \\
\hline HEMBL1775050 & 9 & & 73 & RN \\
\hline AEMBL1 & & & & RN \\
\hline 9 & & 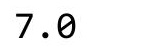 & 33 & RN \\
\hline 45 & & & 279 & $\mathrm{RN}$ \\
\hline AEMBL1775161 & & & 333 & RN \\
\hline AEMBL1775120 & & & 6.5 & $\mathrm{RN}$ \\
\hline 8 & & & 48 & RIN \\
\hline НᄃМР 17 & & & 992 & RIN \\
\hline AEMBL17 & & & & $\mathrm{RN}$ \\
\hline AEMBL1775115 & 19 & & 105 & RN \\
\hline AEMBL17 & & & & RN \\
\hline HEMBL1775116 & & & & \\
\hline HEMBL1775156 & & & & RIN \\
\hline HEMBL1775051 & & 7.5086 & 7.3843 & RN \\
\hline IEMBL1775124 & & 5.7 & .2469 & \\
\hline & & & & \\
\hline & 746 & 6.3468 & & \\
\hline
\end{tabular}

Page 4175 


\begin{tabular}{|c|c|c|c|c|c|c|}
\hline \multicolumn{7}{|c|}{ Supplemental Table S2.txt } \\
\hline CHEMBL1775146 & 746119 & 7.1024 & 6.7555 & TRN & & \\
\hline CHEMBL1775139 & 746119 & 7.0 & 7.6685 & TRN & & \\
\hline CHEMBL1775127 & 746119 & 5.0 & 4.0187 & TRN & & \\
\hline CHEMBL1775167 & 746119 & 3.5003 & 3.5253 & TRN & & \\
\hline CHEMBL1775126 & 746119 & 4.9393 & 5.0792 & TST & & \\
\hline CHEMBL1775136 & 746119 & 7.7959 & 7.1657 & TRN & & \\
\hline CHEMBL1775132 & 746119 & 7.3979 & 7.7872 & TRN & & \\
\hline CHEMBL1775150 & 746119 & 7.1549 & 7.1649 & TRN & & \\
\hline CHEMBL1775157 & 746119 & 4.6003 & 4.1976 & TRN & & \\
\hline CHEMBL1775142 & 746119 & 7.5086 & 7.5949 & TRN & & \\
\hline CHEMBL1775141 & 746119 & 5.9031 & 6.1288 & TRN & & \\
\hline CHEMBL1358782 & 746119 & 7.2007 & 7.2511 & TRN & & \\
\hline CHEMBL1775148 & 746119 & 7.301 & 7.2216 & TRN & & \\
\hline CHEMBL1775122 & 746119 & 7.0458 & 6.5077 & TRN & & \\
\hline CHEMBL1775128 & 746119 & 3.5003 & 3.7298 & TRN & & \\
\hline CHEMBL1578785 & 746119 & 3.5003 & 3.5034 & TRN & & \\
\hline CHEMBL1775114 & 746119 & 7.0 & 7.3712 & TRN & & \\
\hline CHEMBL1775123 & 746119 & 4.7399 & 5.8239 & TST & & \\
\hline CHEMBL1451935 & 746119 & 6.301 & 6.3732 & TRN & & \\
\hline CHEMBL1775159 & 746119 & 7.4089 & 7.4764 & TRN & & \\
\hline CHEMBL1775164 & 746119 & 5.301 & 5.06 & TRN & & \\
\hline CHEMBL1558336 & 746119 & 7.5086 & 7.2478 & TRN & & \\
\hline CHEMBL1775119 & 746119 & 6.5376 & 6.359 & TRN & & \\
\hline CHEMBL1775140 & 746119 & 7.4089 & 6.9121 & TRN & & \\
\hline CHEMBL1775131 & 746119 & 6.9508 & 7.4283 & TRN & & \\
\hline CHEMBL1775135 & 746119 & 7.7212 & 7.1167 & TRN & & \\
\hline CHEMBL1775153 & 746119 & 5.2403 & 5.8079 & TRN & & \\
\hline CHEMBL1773093 & 746119 & 7.1024 & 7.0161 & TRN & & \\
\hline CHEMBL 1775118 & 746119 & 6.4318 & 6.8307 & TRN & & \\
\hline CHEMBL1775154 & 746119 & 5.82100 & 00000000 & 5.7 & . 7379999999999995. & TRN \\
\hline CHEMBL1775125 & 746119 & 3.5003 & 3.5527 & TST & & \\
\hline CHEMBL1775112 & 746119 & 6.8539 & 7.1507 & TRN & & \\
\hline CHEMBL1775129 & 746119 & 3.5003 & 4.1972 & TRN & & \\
\hline CHEMBL1775143 & 746119 & 7.5086 & 7.4898 & TST & & \\
\hline CHEMBL1775144 & 746119 & 7.4089 & 7.0582 & TST & & \\
\hline CHEMBL1775162 & 746119 & 3.5003 & 3.9128 & TST & & \\
\hline CHEMBL1775113 & 746119 & 5.8013 & 5.4328 & TST & & \\
\hline CHEMBL 1775165 & 746119 & 3.5003 & 4.0882 & TST & & \\
\hline CHEMBL1775134 & 746119 & 7.0 & 6.101 & TST & & \\
\hline CHEMBL1775138 & 746119 & 7.5086 & 6.6824 & TST & & \\
\hline CHEMBL 1775130 & 746119 & 3.5003 & 4.0173 & TST & & \\
\hline CHEMBL1775121 & 746119 & 6.3979 & 6.3053 & TST & & \\
\hline CHEMBL 1775137 & 746119 & 7.5528 & 7.3972 & TST & & \\
\hline CHEMBL1775155 & 746119 & 8.0 & 7.7987 & TST & & \\
\hline CHEMBL67468 & 70360 & 3.96 & 3.96100 & 00000000003 & TRN & \\
\hline CHEMBL63177 & 70360 & 5.28 & 5.0128 & TRN & & \\
\hline CHEMBL68449 & 70360 & 6.52 & 6.4693 & TRN & & \\
\hline CHEMBL67717 & 70360 & 4.48 & 4.6995 & TRN & & \\
\hline
\end{tabular}




\begin{tabular}{|c|c|c|c|c|c|}
\hline \multicolumn{6}{|c|}{ Supplemental Table S2.txt } \\
\hline CHEMBL431177 & 70360 & 6.9 & 6.4816 & TST & \\
\hline CHEMBL68130 & 70360 & 6.44 & 6.42 & TST & \\
\hline CHEMBL67626 & 70360 & 6.62 & 6.9428 & TST & \\
\hline CHEMBL443527 & 70360 & 5.04 & 5.0012 & TRN & \\
\hline CHEMBL172100 & 70360 & 7.12 & 7.2773 & TRN & \\
\hline CHEMBL355010 & 70360 & 5.78 & 6.1449 & TRN & \\
\hline CHEMBL171831 & 70360 & 7.1 & 7.3047 & TRN & \\
\hline CHEMBL353150 & 70360 & 6.48 & 6.3637 & TRN & \\
\hline CHEMBL67606 & 70360 & 4.28 & 2.8445 & TST & \\
\hline CHEMBL170607 & 70360 & 7.39 & 7.3015 & TRN & \\
\hline CHEMBL169139 & 70360 & 7.43 & 7.3375 & TRN & \\
\hline CHEMBL169215 & 70360 & 7.35 & 7.2685 & TRN & \\
\hline CHEMBL63143 & 70360 & 5.46 & 5.9552 & TST & \\
\hline CHEMBL355090 & 70360 & 6.15 & 6.7002 & TST & \\
\hline CHEMBL66470 & 70360 & 3.15 & 3.1984 & TRN & \\
\hline CHEMBL66905 & 70360 & 3.22 & 5.9109 & TST & \\
\hline CHEMBL170108 & 70360 & 6.9 & 7.0283 & TRN & \\
\hline CHEMBL169671 & 70360 & 7.1 & 7.1078 & TRN & \\
\hline CHEMBL64969 & 70360 & 5.6 & 5.32600 & 00000000005 & TRN \\
\hline CHEMBL63360 & 70360 & 6.68 & 5.7278 & TST & \\
\hline CHEMBL169585 & 70360 & 7.39 & 7.1653 & TRN & \\
\hline CHEMBL169928 & 70360 & 7.62 & 7.4221 & TRN & \\
\hline CHEMBL355638 & 70360 & 4.48 & 4.617 & TRN & \\
\hline CHEMBL172627 & 70360 & 7.42 & 7.4077 & TRN & \\
\hline CHEMBL302613 & 70360 & 4.52 & 4.6157 & TRN & \\
\hline CHEMBL65025 & 70360 & 4.04 & 3.844 & TRN & \\
\hline CHEMBL169493 & 70360 & 7.37 & 7.3258 & TRN & \\
\hline CHEMBL168328 & 70360 & 7.42 & 7.5218 & TRN & \\
\hline CHEMBL355201 & 70360 & 6.3 & 6.1974 & TRN & \\
\hline CHEMBL424205 & 70360 & 7.51 & 7.3533 & TRN & \\
\hline CHEMBL67254 & 70360 & 6.89 & 6.4756 & TST & \\
\hline CHEMBL63665 & 70360 & 5.12 & 4.1691 & TST & \\
\hline CHEMBL169760 & 70360 & 3.48 & 3.7849 & TST & \\
\hline CHEMBL306913 & 70360 & 3.12 & 3.2084 & TRN & \\
\hline CHEMBL68074 & 70360 & 6.24 & 6.3529 & TRN & \\
\hline CHEMBL169477 & 70360 & 4.74 & 4.9149 & TRN & \\
\hline CHEMBL68343 & 70360 & 3.12 & 2.7868 & TST & \\
\hline CHEMBL424570 & 70360 & 6.82 & 6.6247 & TRN & \\
\hline CHEMBL294057 & 70360 & 5.3 & 5.1725 & TRN & \\
\hline CHEMBL169984 & 70360 & 6.94 & 7.0078 & TRN & \\
\hline CHEMBL353902 & 70360 & 7.44 & 7.3939 & TRN & \\
\hline CHEMBL172679 & 70360 & 7.39 & 7.4518 & TRN & \\
\hline CHEMBL63841 & 70360 & 3.13 & 3.1367 & TRN & \\
\hline CHEMBL66379 & 70360 & 3.7 & 3.8178 & TRN & \\
\hline CHEMBL63562 & 70360 & 5.72 & 5.6746 & TRN & \\
\hline CHEMBL169547 & 70360 & 7.39 & 7.325 & TRN & \\
\hline CHEMBL352388 & 70360 & 7.66 & 7.5079 & TRN & \\
\hline CHEMBL68291 & 70360 & 4.0 & 2.2059 & TST & \\
\hline
\end{tabular}




\begin{tabular}{|c|c|c|c|c|c|}
\hline \multicolumn{6}{|c|}{ Supplemental Table s2.txt } \\
\hline CHEMBL172270 & 70360 & 6.96 & 7.0678 & TRN & \\
\hline CHEMBL169819 & 70360 & 7.4 & 7.6134 & TRN & \\
\hline CHEMBL351620 & 70360 & 6.87 & 6.4608 & TST & \\
\hline CHEMBL66386 & 70360 & 6.1 & 6.7005 & TST & \\
\hline CHEMBL66261 & 70360 & 6.2 & 5.9779 & TRN & \\
\hline CHEMBL367194 & 70360 & 6.72 & 6.8286 & TRN & \\
\hline CHEMBL350415 & 70360 & 6.73 & 6.8839 & TRN & \\
\hline CHEMBL307082 & 70360 & 5.39 & 5.2325 & TRN & \\
\hline CHEMBL67124 & 70360 & 5.19 & \multicolumn{2}{|c|}{4.3660000000000005} & TST \\
\hline CHEMBL171053 & 70360 & 7.07 & 7.0953 & TRN & \\
\hline CHEMBL354325 & 70360 & 7.1 & 7.3493 & TRN & \\
\hline CHEMBL88405 & 214499 & 3.301 & 4.3675 & TRN & \\
\hline CHEMBL87810 & 214499 & 5.1192 & 4.4795 & TRN & \\
\hline CHEMBL 87746 & 214499 & 4.3316 & 3.1265 & TRN & \\
\hline CHEMBL86943 & 214499 & 7.1549 & 6.693 & TRN & \\
\hline CHEMBL86480 & 214499 & 5.6021 & 5.4745 & TRN & \\
\hline CHEMBL85403 & 214499 & 4.5086 & 5.3162 & TRN & \\
\hline CHEMBL330321 & 214499 & 6.0 & 5.8539 & TRN & \\
\hline CHEMBL313578 & 214499 & 5.5686 & 5.4414 & TRN & \\
\hline CHEMBL89505 & 214499 & 5.0757 & 4.3236 & TRN & \\
\hline CHEMBL86432 & 214499 & 3.0 & 4.6182 & TRN & \\
\hline CHEMBL312826 & 214499 & 3.0 & 4.2927 & TRN & \\
\hline CHEMBL86837 & 214499 & 3.0 & 3.5825 & TRN & \\
\hline CHEMBL 86944 & 214499 & 3.0 & 2.4277 & TRN & \\
\hline CHEMBL87325 & 214499 & 3.0 & 4.898 & TRN & \\
\hline CHEMBL313433 & 214499 & 6.8539 & 6.8699 & TRN & \\
\hline CHEMBL 87324 & 214499 & 7.1079 & \multicolumn{2}{|c|}{7.138999999999999} & TRN \\
\hline CHEMBL89040 & 214499 & 5.6021 & 5.8096 & TRN & \\
\hline CHEMBL314146 & 214499 & 5.4685 & 5.2281 & TRN & \\
\hline CHEMBL48760 & 214499 & 5.284 & 5.2562 & TRN & \\
\hline CHEMBL316020 & 214499 & 5.5686 & 5.6217 & TST & \\
\hline CHEMBL89809 & 214499 & 5.5229 & 5.3125 & TRN & \\
\hline CHEMBL314021 & 214499 & 3.0 & 3.1551 & TST & \\
\hline CHEMBL420411 & 214499 & 3.0 & \multicolumn{2}{|c|}{6.747999999999999} & TST \\
\hline CHEMBL87783 & 214499 & 4.8125 & 3.9966 & TRN & \\
\hline CHEMBL315701 & 214499 & 5.3468 & 5.0694 & TRN & \\
\hline CHEMBL85021 & 214499 & 5.0706 & 5.4353 & TRN & \\
\hline CHEMBL421548 & 214499 & 5.3872 & 4.5972 & TRN & \\
\hline CHEMBL90277 & 214499 & 5.6778 & 5.6969 & TRN & \\
\hline CHEMBL87080 & 214499 & 4.0 & 4.0676 & TRN & \\
\hline CHEMBL431025 & 214499 & 5.5229 & 4.7288 & TRN & \\
\hline CHEMBL89721 & 214499 & 5.6308 & 4.6019 & TST & \\
\hline CHEMBL86755 & 214499 & 6.4089 & 5.6475 & TRN & \\
\hline CHEMBL89646 & 214499 & 3.0 & 4.3999 & TST & \\
\hline CHEMBL316008 & 214499 & 6.7447 & 5.9217 & TST & \\
\hline CHEMBL89363 & 214499 & 6.3979 & 6.3259 & TST & \\
\hline CHEMBL86921 & 214499 & 4.6459 & 4.7336 & TST & \\
\hline CHEMBL89697 & 214499 & 4.1331 & 4.9751 & TST & \\
\hline
\end{tabular}




\begin{tabular}{|c|c|c|c|c|c|c|}
\hline \multirow[b]{2}{*}{ CHEMBL89723 } & \multicolumn{6}{|c|}{ Supplemental Table S2.txt } \\
\hline & 214499 & 5.3665 & 4.5452 & TRN & & \\
\hline CHEMBL328710 & 214499 & 6.0969 & 5.63200 & 000000000 & & TRN \\
\hline CHEMBL86631 & 214499 & 4.6904 & 4.9794 & TST & & \\
\hline CHEMBL86326 & 214499 & 3.0 & 2.5373 & TRN & & \\
\hline CHEMBL314217 & 214499 & 5.5229 & 5.0336 & TRN & & \\
\hline CHEMBL86945 & 214499 & 3.0 & 3.3079 & TRN & & \\
\hline CHEMBL313259 & 214499 & 3.0 & 4.3951 & TRN & & \\
\hline CHEMBL329367 & 214499 & 5.3372 & 5.8959 & TRN & & \\
\hline CHEMBL314798 & 214499 & 3.0 & 5.0634 & TST & & \\
\hline CHEMBL87208 & 214499 & 7.1079 & 6.3448 & TRN & & \\
\hline CHEMBL315546 & 214499 & 5.7959 & 5.722 & TRN & & \\
\hline CHEMBL328452 & 214499 & 4.3851 & 5.3198 & TST & & \\
\hline CHEMBL87402 & 214499 & 5.1302 & 4.3579 & TST & & \\
\hline CHEMBL316268 & 214499 & 3.0 & 3.7743 & TRN & & \\
\hline CHEMBL89483 & 214499 & 6.5229 & 6.5404 & TRN & & \\
\hline CHEMBL316009 & 214499 & 5.2007 & 5.9855 & TST & & \\
\hline CHEMBL 2170597 & 862367 & 8.0 & 7.9402 & TRN & & \\
\hline CHEMBL 2170412 & 862367 & 7.6345 & 7.3906 & TST & & \\
\hline CHEMBL 2170431 & 862367 & 8.3979 & 8.1263 & TRN & & \\
\hline CHEMBL 2170441 & 862367 & 7.7282 & 7.7745 & TRN & & \\
\hline CHEMBL 2170426 & 862367 & 3.301 & 5.5865 & TST & & \\
\hline CHEMBL 2170407 & 862367 & 6.5003 & 6.9459 & TST & & \\
\hline CHEMBL 2170433 & 862367 & 6.2518 & 6.2034 & TRN & & \\
\hline CHEMBL 2170595 & 862367 & 4.6091 & 5.2755 & TRN & & \\
\hline CHEMBL 2170416 & 862367 & 8.5086 & 6.9646 & TST & & \\
\hline CHEMBL 2170600 & 862367 & 3.301 & 5.6 & TST & & \\
\hline CHEMBL 2170420 & 862367 & 7.7011 & 7.895 & TRN & & \\
\hline CHEMBL 2170418 & 862367 & 8.5229 & 7.1411 & TST & & \\
\hline CHEMBL 2170435 & 862367 & 8.6778 & 8.4707 & TRN & & \\
\hline CHEMBL 2170417 & 862367 & 7.76200 & 00000000 & 005 & 7.5964 & TST \\
\hline CHEMBL 2170587 & 862367 & 8.0706 & 7.1789 & TST & & \\
\hline CHEMBL 2170442 & 862367 & 7.52 & 8.001 & TRN & & \\
\hline CHEMBL 2170423 & 862367 & 5.8268 & 5.5715 & TRN & & \\
\hline CHEMBL 244839 & 862367 & 7.1002 & 7.3411 & TRN & & \\
\hline CHEMBL 2170410 & 862367 & 6.5969 & 6.9549 & TRN & & \\
\hline CHEMBL 2170591 & 862367 & 7.5513 & 7.7369 & TRN & & \\
\hline CHEMBL578061 & 862367 & 6.3737 & 6.1336 & TRN & & \\
\hline CHEMBL 2170589 & 862367 & 8.3468 & 8.1791 & TRN & & \\
\hline CHEMBL 2170436 & 862367 & 8.4815 & 8.5869 & TRN & & \\
\hline CHEMBL 2170593 & 862367 & 5.0458 & 4.4671 & TRN & & \\
\hline CHEMBL 244793 & 862367 & 7.9469 & 7.7161 & TRN & & \\
\hline CHEMBL 2170404 & 862367 & 7.7447 & 7.6195 & TRN & & \\
\hline CHEMBL 2170596 & 862367 & 7.4179 & 7.1058 & TRN & & \\
\hline CHEMBL 2170429 & 862367 & 8.699 & 8.3937 & TRN & & \\
\hline CHEMBL 2170408 & 862367 & 6.9337 & 7.2938 & TRN & & \\
\hline CHEMBL 2170415 & 862367 & 7.6737 & 7.6896 & TRN & & \\
\hline CHEMBL 2170425 & 862367 & 6.4248 & 6.7453 & TRN & & \\
\hline CHEMBL 2170437 & 862367 & 8.1805 & 7.7791 & TRN & & \\
\hline
\end{tabular}




\begin{tabular}{|c|c|c|c|c|}
\hline & & & oplement & al $\mathrm{T}$ \\
\hline CHEMBL 2170438 & 862367 & 6.5467 & 7.1679 & TRN \\
\hline CHEMBL 2170430 & 862367 & 7.5528 & 7.8861 & TRN \\
\hline CHEMBL2170406 & 862367 & 7.1475 & 6.8725 & TRN \\
\hline CHEMBL2170409 & 862367 & 7.5686 & 7.1285 & TRN \\
\hline CHEMBL 2170601 & 862367 & 8.6021 & 8.4165 & TRN \\
\hline CHEMBL 2170602 & 862367 & 8.4089 & 8.1825 & TRN \\
\hline CHEMBL 2170594 & 862367 & 4.5045 & 4.6313 & TRN \\
\hline CHEMBL2170598 & 862367 & 6.5918 & 6.9676 & TRN \\
\hline CHEMBL394816 & 862367 & 7.2396 & 7.3756 & TRN \\
\hline CHEMBL 2170411 & 862367 & 7.6696 & 7.8512 & TST \\
\hline CHEMBL2170428 & 862367 & 5.7513 & 5.8059 & TRN \\
\hline CHEMBL 2170414 & 862367 & 7.8416 & 8.5802 & TST \\
\hline CHEMBL2170427 & 862367 & 8.4318 & 8.5815 & TRN \\
\hline CHEMBL 2170405 & 862367 & 7.3478 & 7.0396 & TRN \\
\hline CHEMBL2170590 & 862367 & 6.6655 & 6.8967 & TRN \\
\hline CHEMBL 2170440 & 862367 & 7.3665 & 7.4374 & TRN \\
\hline CHEMBL2170599 & 862367 & 6.5513 & 7.0622 & TST \\
\hline CHEMBL2169893 & 862367 & 8.5376 & 7.5138 & TST \\
\hline CHEMBL 2170421 & 862367 & 7.7375 & 7.5157 & TRN \\
\hline CHEMBL2170419 & 862367 & 9.0969 & 8.8422 & TST \\
\hline CHEMBL 2170586 & 862367 & 6.8268 & 7.1771 & TRN \\
\hline CHEMBL 2170432 & 862367 & 7.3316 & 6.8848 & TRN \\
\hline CHEMBL2170424 & 862367 & 8.4989 & 7.808 & TST \\
\hline CHEMBL2170413 & 862367 & 7.9101 & 7.8931 & TRN \\
\hline CHEMBL2170588 & 862367 & 7.2993 & 7.3605 & TST \\
\hline CHEMBL2170439 & 862367 & 7.4559 & 7.8743 & TRN \\
\hline CHEMBL2170592 & 862367 & 8.2147 & 8.0138 & TRN \\
\hline CHEMBL2170434 & 862367 & 7.4547 & 7.1375 & TRN \\
\hline CHEMBL2170422 & 862367 & 8.2924 & 7.6201 & TST \\
\hline CHEMBL395808 & 688877 & 4.85 & 5.1797 & TRN \\
\hline CHEMBL1406879 & 688877 & 6.15 & 5.6695 & TRN \\
\hline CHEMBL1596499 & 688877 & 5.5 & 5.5207 & TRN \\
\hline CHEMBL198159 & 688877 & 5.05 & 4.9349 & TRN \\
\hline CHEMBL517986 & 688877 & 4.4 & 5.3078 & TST \\
\hline CHEMBL523167 & 688877 & 4.85 & 5.0484 & TRN \\
\hline CHEMBL1394829 & 688877 & 4.5 & 4.9611 & TRN \\
\hline CHEMBL1327243 & 688877 & 5.2 & 5.5444 & TST \\
\hline CHEMBL1373259 & 688877 & 5.55 & 6.0172 & TRN \\
\hline CHEMBL406834 & 688877 & 4.8 & 5.7434 & TRN \\
\hline CHEMBL1590855 & 688877 & 4.65 & 5.468 & TRN \\
\hline CHEMBL1592964 & 688877 & 6.15 & 6.1248 & TRN \\
\hline CHEMBL18701 & 688877 & 6.0 & 5.3055 & TRN \\
\hline CHEMBL1255664 & 688877 & 5.3 & 5.1267 & TRN \\
\hline CHEMBL1394477 & 688877 & 6.95 & 5.7824 & TRN \\
\hline CHEMBL1317009 & 688877 & 6.35 & 5.9977 & TRN \\
\hline CHEMBL1370480 & 688877 & 6.6499 & 6.0323 & TRN \\
\hline CHEMBL88961 & 688877 & 4.65 & 5.7411 & TRN \\
\hline CHEMBL90769 & 688877 & 4.8 & 5.4962 & TST \\
\hline
\end{tabular}




\begin{tabular}{|c|c|c|c|c|c|}
\hline \multicolumn{6}{|c|}{ Supplemental Table s2.txt } \\
\hline CHEMBL1377111 & 688877 & 5.0 & 5.4983 & TST & \\
\hline CHEMBL9352 & 688877 & 4.5 & 4.6684 & TRN & \\
\hline CHEMBL1552100 & 688877 & 5.4 & 4.7803 & TRN & \\
\hline CHEMBL166161 & 688877 & 4.95 & 5.5958 & TRN & \\
\hline CHEMBL50267 & 688877 & 4.8 & 5.1437 & TST & \\
\hline CHEMBL134291 & 688877 & 5.65 & 5.3625 & TRN & \\
\hline CHEMBL1437002 & 688877 & 4.4 & 6.1243 & TRN & \\
\hline CHEMBL1596756 & 688877 & 6.1 & 6.2967 & TRN & \\
\hline CHEMBL52 & 688877 & 6.0 & 4.5779 & TRN & \\
\hline CHEMBL1318509 & 688877 & 6.45 & 5.979 & TRN & \\
\hline CHEMBL1338870 & 688877 & 4.95 & 5.0776 & TRN & \\
\hline CHEMBL1515366 & 688877 & 5.8 & 5.9429 & TRN & \\
\hline CHEMBL1453911 & 688877 & 5.55 & 6.1615 & TRN & \\
\hline CHEMBL1357894 & 688877 & 6.15 & 5.0849 & TST & \\
\hline CHEMBL1315690 & 688877 & 5.4 & 5.6724 & TRN & \\
\hline CHEMBL 543 & 688877 & 5.45 & 5.6787 & TST & \\
\hline CHEMBL168 & 688877 & 4.8 & 5.3254 & TST & \\
\hline CHEMBL1554826 & 688877 & 6.25 & 6.0599 & TRN & \\
\hline CHEMBL1593370 & 688877 & 5.3 & 5.5203 & TRN & \\
\hline CHEMBL419815 & 688877 & 4.4 & 4.8762 & TRN & \\
\hline CHEMBL497781 & 688877 & 5.65 & 5.2335 & TRN & \\
\hline CHEMBL1514486 & 688877 & 4.45 & 4.851 & TST & \\
\hline CHEMBL1318064 & 688877 & 5.8 & 5.6929 & TRN & \\
\hline CHEMBL19439 & 688877 & 4.8 & 5.4854 & TRN & \\
\hline CHEMBL 310310 & 688877 & 4.45 & 4.84399 & 9999999999 & TRN \\
\hline CHEMBL1528565 & 688877 & 4.4 & 5.2552 & TST & \\
\hline CHEMBL392394 & 688877 & 4.95 & 5.5036 & TST & \\
\hline CHEMBL1357018 & 688877 & 7.8508 & 6.5926 & TRN & \\
\hline CHEMBL63154 & 688877 & 5.45 & 5.4155 & TRN & \\
\hline CHEMBL58033 & 688877 & 6.0 & 5.3647 & TRN & \\
\hline CHEMBL1607885 & 688877 & 7.1002 & 6.822 & TRN & \\
\hline CHEMBL1445893 & 688877 & 6.05 & 6.3672 & TRN & \\
\hline CHEMBL1563566 & 688877 & 6.1 & 5.9616 & TRN & \\
\hline CHEMBL1396377 & 688877 & 5.95 & 6.0201 & TRN & \\
\hline CHEMBL 258893 & 688877 & 4.85 & 5.8317 & TRN & \\
\hline CHEMBL117 & 688877 & 4.45 & 5.0912 & TRN & \\
\hline CHEMBL1407 & 688877 & 4.8 & 5.223 & TRN & \\
\hline CHEMBL1329927 & 688877 & 4.9 & 4.9801 & TST & \\
\hline CHEMBL12014 & 688877 & 6.0 & 5.4841 & TRN & \\
\hline CHEMBL1394638 & 688877 & 5.05 & 5.6905 & TRN & \\
\hline CHEMBL 30024 & 688877 & 4.6 & 4.7448 & TST & \\
\hline CHEMBL1473149 & 688877 & 4.9 & 5.4464 & TRN & \\
\hline CHEMBL87285 & 688877 & 8.0506 & 5.3818 & TRN & \\
\hline CHEMBL1394923 & 688877 & 5.55 & 5.563 & TRN & \\
\hline CHEMBL1591956 & 688877 & 7.0 & 5.91700 & 0000000001 & TRN \\
\hline CHEMBL1553741 & 688877 & 6.5501 & 5.7223 & TRN & \\
\hline CHEMBL1591971 & 688877 & 7.6003 & 5.6141 & TRN & \\
\hline CHEMBL1591556 & 688877 & 4.9 & 5.4622 & TRN & \\
\hline
\end{tabular}




\begin{tabular}{|c|c|c|c|c|c|}
\hline \multicolumn{6}{|c|}{ Supplemental Table s2.txt } \\
\hline CHEMBL1564194 & 688877 & 5.95 & 5.6204 & TRN & \\
\hline CHEMBL479014 & 688877 & 6.0 & 5.3647 & TRN & \\
\hline CHEMBL1377526 & 688877 & 5.35 & 6.107 & TRN & \\
\hline CHEMBL489534 & 688877 & 4.9 & 5.864 & TRN & \\
\hline CHEMBL303579 & 688877 & 5.45 & 4.9246 & TRN & \\
\hline CHEMBL1368511 & 688877 & 4.6 & 5.6228 & TRN & \\
\hline CHEMBL1317853 & 688877 & 5.2 & 6.0205 & TRN & \\
\hline CHEMBL1516331 & 688877 & 5.0 & 5.7408 & TRN & \\
\hline CHEMBL1435028 & 688877 & 6.25 & 5.671 & TRN & \\
\hline CHEMBL1256697 & 688877 & 5.25 & 4.7612 & TRN & \\
\hline CHEMBL1441415 & 688877 & 4.7 & 6.319 & TRN & \\
\hline CHEMBL1255941 & 688877 & 4.85 & 4.8169 & TRN & \\
\hline CHEMBL1396792 & 688877 & 6.05 & 6.1845 & TRN & \\
\hline CHEMBL1554935 & 688877 & 5.4 & 5.6387 & TRN & \\
\hline CHEMBL1526068 & 688877 & 5.55 & 5.3602 & TRN & \\
\hline CHEMBL1314324 & 688877 & 7.5498 & 5.9001 & TRN & \\
\hline CHEMBL1475951 & 688877 & 6.1 & 5.9311 & TRN & \\
\hline CHEMBL1395415 & 688877 & 4.4 & 4.965 & TRN & \\
\hline CHEMBL1434111 & 688877 & 5.75 & 5.5928 & TRN & \\
\hline CHEMBL1611225 & 688877 & 4.45 & 4.6914 & TST & \\
\hline CHEMBL1514416 & 688877 & 5.05 & 6.0478 & TRN & \\
\hline CHEMBL1517884 & 688877 & 4.65 & 5.1637 & TRN & \\
\hline CHEMBL1355896 & 688877 & 6.6 & 6.1137 & TRN & \\
\hline CHEMBL1592584 & 688877 & 5.6 & 5.7906 & TRN & \\
\hline CHEMBL1521453 & 688877 & 5.05 & 5.2562 & TST & \\
\hline CHEMBL1596170 & 688877 & 6.05 & 6.234 & TRN & \\
\hline CHEMBL1553808 & 688877 & 5.5 & 5.6719 & TRN & \\
\hline CHEMBL1529009 & 688877 & 4.45 & 5.5275 & TRN & \\
\hline CHEMBL1354600 & 688877 & 6.05 & 5.4686 & TRN & \\
\hline CHEMBL1497006 & 688877 & 5.8 & 5.4383 & TRN & \\
\hline CHEMBL1318041 & 688877 & 5.5 & 5.3507 & TRN & \\
\hline CHEMBL183 & 688877 & 4.85 & 5.6568 & TRN & \\
\hline CHEMBL1356346 & 688877 & 4.45 & 4.9396 & TRN & \\
\hline CHEMBL1359291 & 688877 & 6.8499 & 5.8051 & TRN & \\
\hline CHEMBL1551064 & 688877 & 4.8 & 5.7645 & TRN & \\
\hline CHEMBL 227744 & 688877 & 5.5 & 5.0244 & TRN & \\
\hline CHEMBL7257 & 688877 & 5.1 & 5.8688 & TRN & \\
\hline CHEMBL6640 & 688877 & 4.4 & 5.29700 & 0000000001 & TRN \\
\hline CHEMBL1529490 & 688877 & 6.0 & 5.5346 & TRN & \\
\hline CHEMBL1256667 & 688877 & 6.0 & 5.5302 & TST & \\
\hline CHEMBL53898 & 688877 & 6.0 & 5.3311 & TRN & \\
\hline CHEMBL1493037 & 688877 & 4.95 & 5.2095 & TST & \\
\hline CHEMBL1315145 & 688877 & 4.65 & 5.9231 & TRN & \\
\hline CHEMBL1256661 & 688877 & 4.45 & 5.2537 & TRN & \\
\hline CHEMBL1789998 & 688877 & 4.4 & 4.9204 & TST & \\
\hline CHEMBL1554308 & 688877 & 4.75 & 5.9185 & TRN & \\
\hline CHEMBL1553173 & 688877 & 6.0 & 5.9634 & TRN & \\
\hline CHEMBL1396782 & 688877 & 8.1024 & 6.2225 & TRN & \\
\hline
\end{tabular}




\begin{tabular}{|c|c|c|c|c|c|}
\hline & & & & & \\
\hline CHEMBL 275809 & 688877 & 4.6 & 5.7361 & TRN & \\
\hline CHEMBL1554579 & 688877 & 5.8 & 6.4609 & TRN & \\
\hline CHEMBL1394140 & 688877 & 5.4 & 5.9379 & TRN & \\
\hline CHEMBL1394490 & 688877 & 5.45 & 5.1168 & TRN & \\
\hline CHEMBL1568086 & 688877 & 5.75 & 5.8405 & TRN & \\
\hline CHEMBL1317344 & 688877 & 7.1002 & 6.01399 & 9999999999 & TRN \\
\hline CHEMBL1594058 & 688877 & 5.85 & 5.9402 & TRN & \\
\hline CHEMBL1476049 & 688877 & 5.35 & 5.8172 & TRN & \\
\hline CHEMBL1434625 & 688877 & 5.4 & 5.864 & TRN & \\
\hline CHEMBL1407670 & 688877 & 7.15 & 5.7714 & TRN & \\
\hline CHEMBL10 & 688877 & 6.0 & 6.1301 & TRN & \\
\hline CHEMBL1318067 & 688877 & 6.0 & 5.6877 & TRN & \\
\hline CHEMBL1531899 & 688877 & 6.1 & 6.0764 & TRN & \\
\hline CHEMBL1354864 & 688877 & 6.7001 & 5.6437 & TRN & \\
\hline CHEMBL598952 & 688877 & 4.8 & 5.4879 & TST & \\
\hline CHEMBL1572915 & 688877 & 6.95 & 5.3905 & TRN & \\
\hline CHEMBL510009 & 688877 & 5.7 & 5.9439 & TRN & \\
\hline CHEMBL1404451 & 688877 & 7.3002 & 6.5465 & TRN & \\
\hline CHEMBL1455369 & 688877 & 4.9 & 5.5517 & TRN & \\
\hline CHEMBL165 & 688877 & 6.0 & 4.9161 & TRN & \\
\hline CHEMBL1523957 & 688877 & 5.55 & 5.9421 & TRN & \\
\hline CHEMBL3186408 & 688877 & 6.0 & 5.4711 & TST & \\
\hline CHEMBL1326787 & 688877 & 5.45 & 5.5362 & TRN & \\
\hline CHEMBL1554588 & 688877 & 6.5501 & 6.0975 & TRN & \\
\hline CHEMBL1318847 & 688877 & 5.4 & 5.7529 & TRN & \\
\hline CHEMBL346516 & 688877 & 4.65 & 5.3792 & TRN & \\
\hline CHEMBL1410676 & 688877 & 6.25 & 6.4662 & TRN & \\
\hline CHEMBL1603820 & 688877 & 4.8 & 5.2826 & TRN & \\
\hline CHEMBL75035 & 688877 & 4.85 & 5.4606 & TRN & \\
\hline CHEMBL3392050 & 688877 & 5.1 & 4.6259 & TST & \\
\hline CHEMBL1414126 & 688877 & 5.15 & 5.5077 & TST & \\
\hline CHEMBL1394939 & 688877 & 4.75 & 5.6154 & TRN & \\
\hline CHEMBL1573862 & 688877 & 6.7001 & 6.0985 & TRN & \\
\hline CHEMBL1474318 & 688877 & 4.8 & 5.6629 & TRN & \\
\hline CHEMBL1551133 & 688877 & 5.85 & 6.1088 & TRN & \\
\hline CHEMBL1316760 & 688877 & 5.35 & 5.8416 & TRN & \\
\hline CHEMBL1328324 & 688877 & 4.85 & 5.2808 & TST & \\
\hline CHEMBL1475166 & 688877 & 4.4 & 5.0448 & TRN & \\
\hline CHEMBL1489016 & 688877 & 5.5 & 5.4736 & TRN & \\
\hline CHEMBL 280074 & 688877 & 5.65 & 5.506 & TRN & \\
\hline CHEMBL267014 & 688877 & 4.45 & 5.38200 & 2000000001 & TRN \\
\hline CHEMBL1593153 & 688877 & 6.1 & 5.7052 & TRN & \\
\hline CHEMBL1414452 & 688877 & 4.45 & 4.6493 & TST & \\
\hline CHEMBL1476348 & 688877 & 4.95 & 5.7426 & TRN & \\
\hline CHEMBL412010 & 688877 & 4.65 & 5.55 & TRN & \\
\hline CHEMBL1435248 & 688877 & 5.85 & 5.6491 & TRN & \\
\hline CHEMBL50378 & 688877 & 4.85 & 4.97 & TRN & \\
\hline CHEMBL1595282 & 688877 & 6.45 & 5.8085 & TRN & \\
\hline
\end{tabular}




\begin{tabular}{|c|c|c|c|c|c|}
\hline & & \multicolumn{4}{|c|}{ Supplemental Table S2.txt } \\
\hline CHEMBL278755 & 688877 & 7.3497 & 4.9429 & TST & \\
\hline CHEMBL37312 & 688877 & 6.4 & 5.4536 & TRN & \\
\hline CHEMBL1315380 & 688877 & 7.15 & 5.8752 & TRN & \\
\hline CHEMBL 52030 & 688877 & 5.4 & 5.5759 & TRN & \\
\hline CHEMBL3084891 & 688877 & 5.15 & 4.8667 & TRN & \\
\hline CHEMBL1394765 & 688877 & 6.35 & 5.7863 & TRN & \\
\hline CHEMBL1435916 & 688877 & 6.3 & 5.9013 & TRN & \\
\hline CHEMBL1569001 & 688877 & 5.0 & 5.4115 & TRN & \\
\hline CHEMBL1315528 & 688877 & 4.85 & 5.4485 & TRN & \\
\hline CHEMBL1255749 & 688877 & 4.4 & 4.5971 & TST & \\
\hline CHEMBL1592975 & 688877 & 4.4 & 5.2408 & TST & \\
\hline CHEMBL1360916 & 688877 & 4.5 & 4.9971 & TRN & \\
\hline CHEMBL1553218 & 688877 & 6.05 & 5.8469 & TRN & \\
\hline CHEMBL1593068 & 688877 & 6.2 & 5.4494 & TRN & \\
\hline CHEMBL107251 & 688877 & 5.15 & 5.2299 & TST & \\
\hline CHEMBL1394302 & 688877 & 6.6499 & 5.99100 & 00000000005 & TST \\
\hline CHEMBL1435604 & 688877 & 5.55 & 5.8135 & TRN & \\
\hline CHEMBL1433752 & 688877 & 8.0 & 6.3736 & TRN & \\
\hline CHEMBL1356135 & 688877 & 4.4 & 5.6258 & TRN & \\
\hline CHEMBL1361750 & 688877 & 5.4 & 5.3591 & TRN & \\
\hline CHEMBL1355242 & 688877 & 5.5 & 5.4243 & TRN & \\
\hline CHEMBL1314422 & 688877 & 6.1 & 6.1746 & TRN & \\
\hline CHEMBL447001 & 688877 & 4.4 & 5.539 & TST & \\
\hline CHEMBL1316424 & 688877 & 6.5501 & 5.8926 & TRN & \\
\hline CHEMBL13097 & 688877 & 5.65 & 5.6405 & TRN & \\
\hline CHEMBL1558621 & 688877 & 4.4 & 4.8671 & TST & \\
\hline CHEMBL9843 & 688877 & 4.7 & 5.5351 & TRN & \\
\hline CHEMBL1536007 & 688877 & 4.85 & 4.8412 & TRN & \\
\hline CHEMBL1372363 & 688877 & 6.4 & 5.8425 & TRN & \\
\hline CHEMBL1513669 & 688877 & 5.45 & 6.2188 & TRN & \\
\hline CHEMBL1512250 & 688877 & 6.0 & 5.8067 & TRN & \\
\hline CHEMBL1417503 & 688877 & 5.6 & 5.8253 & TRN & \\
\hline CHEMBL1496664 & 688877 & 5.4 & 5.6426 & TRN & \\
\hline CHEMBL440084 & 688877 & 6.95 & 6.5513 & TRN & \\
\hline CHEMBL1256851 & 688877 & 4.4 & 5.5429 & TRN & \\
\hline CHEMBL1357157 & 688877 & 6.25 & 5.9947 & TRN & \\
\hline CHEMBL1256775 & 688877 & 5.35 & 5.5235 & TST & \\
\hline CHEMBL56331 & 688877 & 4.75 & 4.953 & TRN & \\
\hline CHEMBL1396203 & 688877 & 4.4 & 6.2154 & TRN & \\
\hline CHEMBL243664 & 688877 & 4.75 & 5.4866 & TRN & \\
\hline CHEMBL1255837 & 688877 & 6.0 & 5.0412 & TST & \\
\hline CHEMBL1552294 & 688877 & 5.5 & 6.0022 & TRN & \\
\hline CHEMBL1574924 & 688877 & 5.95 & 5.319 & TRN & \\
\hline CHEMBL113142 & 688877 & 5.35 & 5.4536 & TST & \\
\hline CHEMBL1562786 & 688877 & 4.55 & 5.7908 & TRN & \\
\hline CHEMBL 247378 & 688877 & 6.0 & 5.3239 & TRN & \\
\hline CHEMBL34704 & 688877 & 4.4 & 5.2504 & TST & \\
\hline CHEMBL1413280 & 688877 & 4.9 & 5.2151 & TRN & \\
\hline
\end{tabular}




\begin{tabular}{|c|c|c|c|c|c|}
\hline \multicolumn{6}{|c|}{ Supplemental Table s2.txt } \\
\hline CHEMBL1496560 & 688877 & 5.85 & 5.9566 & TRN & \\
\hline CHEMBL1418387 & 688877 & 4.95 & 5.5841 & TRN & \\
\hline CHEMBL164660 & 688877 & 5.05 & 5.4249 & TRN & \\
\hline CHEMBL1334321 & 688877 & 4.7 & 5.5778 & TRN & \\
\hline CHEMBL276140 & 688877 & 5.85 & 5.5861 & TRN & \\
\hline CHEMBL1358796 & 688877 & 5.45 & 6.2273 & TRN & \\
\hline CHEMBL483835 & 688877 & 4.8 & 5.2897 & TRN & \\
\hline CHEMBL1593374 & 688877 & 5.95 & 6.0444 & TRN & \\
\hline CHEMBL1473809 & 688877 & 5.2 & 5.7313 & TRN & \\
\hline CHEMBL181633 & 688877 & 6.25 & 5.8064 & TRN & \\
\hline CHEMBL333985 & 688877 & 6.6 & 5.3931 & TST & \\
\hline CHEMBL1416055 & 688877 & 4.5 & 4.9804 & TRN & \\
\hline CHEMBL1490528 & 688877 & 5.15 & 5.3363 & TRN & \\
\hline CHEMBL1474241 & 688877 & 4.95 & 5.1172 & TRN & \\
\hline CHEMBL1493369 & 688877 & 4.45 & 5.0699 & TST & \\
\hline CHEMBL1606727 & 688877 & 6.15 & 6.4313 & TRN & \\
\hline CHEMBL1558843 & 688877 & 6.45 & 6.2725 & TRN & \\
\hline CHEMBL72365 & 688877 & 4.9 & 5.10800 & 00000000005 & TST \\
\hline CHEMBL1489708 & 688877 & 5.45 & 6.1752 & TRN & \\
\hline CHEMBL1376158 & 688877 & 5.05 & 5.5981 & TRN & \\
\hline CHEMBL1449187 & 688877 & 7.4001 & 5.8031 & TRN & \\
\hline CHEMBL295316 & 688877 & 6.0 & 4.6548 & TRN & \\
\hline CHEMBL1609896 & 688877 & 7.1002 & 5.8616 & TRN & \\
\hline CHEMBL1333783 & 688877 & 5.85 & 5.7663 & TRN & \\
\hline CHEMBL1369871 & 688877 & 6.7501 & 6.2162 & TRN & \\
\hline CHEMBL151 & 688877 & 6.0 & 4.9706 & TRN & \\
\hline CHEMBL1365427 & 688877 & 5.45 & 6.0656 & TRN & \\
\hline CHEMBL1320765 & 688877 & 5.0 & 5.357 & TRN & \\
\hline CHEMBL1315461 & 688877 & 5.3 & 5.8231 & TRN & \\
\hline CHEMBL449329 & 688877 & 4.6 & 5.5842 & TRN & \\
\hline CHEMBL1612620 & 688877 & 6.15 & 5.8804 & TRN & \\
\hline CHEMBL1512049 & 688877 & 5.65 & 5.5295 & TRN & \\
\hline CHEMBL23194 & 688877 & 5.8 & 5.1323 & TST & \\
\hline CHEMBL1322597 & 688877 & 4.8 & 5.3219 & TRN & \\
\hline CHEMBL1482759 & 688877 & 5.45 & 5.5837 & TRN & \\
\hline CHEMBL1369515 & 688877 & 5.25 & 5.6114 & TRN & \\
\hline CHEMBL1372635 & 688877 & 4.5 & 6.0789 & TRN & \\
\hline CHEMBL1316056 & 688877 & 6.4 & 6.2021 & TRN & \\
\hline CHEMBL1512454 & 688877 & 6.35 & 6.1332 & TRN & \\
\hline CHEMBL1520292 & 688877 & 5.55 & 5.5928 & TRN & \\
\hline CHEMBL1533572 & 688877 & 5.75 & 6.15799 & 99999999995 & TRN \\
\hline CHEMBL 2374266 & 688877 & 5.15 & 5.1296 & TRN & \\
\hline CHEMBL1357598 & 688877 & 5.0 & 5.8371 & TRN & \\
\hline CHEMBL 254348 & 688877 & 5.65 & 5.3221 & TRN & \\
\hline CHEMBL317869 & 688877 & 4.85 & 4.9981 & TRN & \\
\hline CHEMBL1519435 & 688877 & 6.95 & 6.5143 & TRN & \\
\hline CHEMBL1316470 & 688877 & 4.85 & 4.7077 & TRN & \\
\hline CHEMBL 259388 & 688877 & 4.85 & 5.41200 & 0000000001 & TRN \\
\hline & & & & 4185 & \\
\hline
\end{tabular}




\begin{tabular}{|c|c|c|c|c|c|}
\hline \multicolumn{6}{|c|}{ Supplemental Table S2.txt } \\
\hline CHEMBL1552150 & 688877 & 6.7501 & 5.9863 & TRN & \\
\hline CHEMBL1435077 & 688877 & 6.45 & 6.1382 & TRN & \\
\hline CHEMBL1594421 & 688877 & 4.4 & 5.6762 & TRN & \\
\hline CHEMBL1366297 & 688877 & 7.4498 & 5.5052 & TRN & \\
\hline CHEMBL449690 & 688877 & 4.9 & 5.1964 & TRN & \\
\hline CHEMBL1398425 & 688877 & 5.1 & 5.9018 & TRN & \\
\hline CHEMBL1333061 & 688877 & 5.55 & 5.6802 & TRN & \\
\hline CHEMBL1256923 & 688877 & 4.4 & 4.6471 & TST & \\
\hline CHEMBL1560118 & 688877 & 4.95 & 5.5733 & TST & \\
\hline CHEMBL1315268 & 688877 & 5.85 & 5.7169 & TRN & \\
\hline CHEMBL399491 & 688877 & 4.8 & 5.274 & TST & \\
\hline CHEMBL 375270 & 688877 & 6.0 & 5.1708 & TST & \\
\hline CHEMBL1513648 & 688877 & 5.15 & 5.9992 & TRN & \\
\hline CHEMBL1397079 & 688877 & 5.75 & 5.5368 & TRN & \\
\hline CHEMBL1096400 & 688877 & 4.5 & 5.9922 & TRN & \\
\hline CHEMBL1592556 & 688877 & 6.9 & 6.0606 & TRN & \\
\hline CHEMBL39317 & 688877 & 4.75 & 5.7504 & TRN & \\
\hline CHEMBL1409689 & 688877 & 6.1 & 5.7673 & TRN & \\
\hline CHEMBL 286615 & 688877 & 4.9 & 5.7348 & TRN & \\
\hline CHEMBL1443163 & 688877 & 4.65 & 4.806 & TST & \\
\hline CHEMBL1355634 & 688877 & 4.65 & 5.564 & TRN & \\
\hline CHEMBL 34730 & 688877 & 4.95 & 5.6652 & TRN & \\
\hline CHEMBL1571679 & 688877 & 4.85 & 5.8622 & TRN & \\
\hline CHEMBL1321398 & 688877 & 4.7 & 5.2411 & TST & \\
\hline CHEMBL1482184 & 688877 & 8.0 & 4.7426 & TST & \\
\hline CHEMBL48449 & 688877 & 6.0 & 5.2172 & TST & \\
\hline CHEMBL1315318 & 688877 & 8.1024 & 6.5725 & TRN & \\
\hline CHEMBL490745 & 688877 & 5.35 & 5.7835 & TRN & \\
\hline CHEMBL1374271 & 688877 & 5.4 & 5.2968 & TRN & \\
\hline CHEMBL1378755 & 688877 & 6.35 & 5.5359 & TRN & \\
\hline CHEMBL1516276 & 688877 & 5.6 & 5.7974 & TRN & \\
\hline CHEMBL1373326 & 688877 & 5.45 & 5.9013 & TRN & \\
\hline CHEMBL1515802 & 688877 & 4.5 & 5.0061 & TRN & \\
\hline CHEMBL574985 & 688877 & 5.35 & 4.8495 & TST & \\
\hline CHEMBL1325369 & 688877 & 7.8013 & 5.8306 & TRN & \\
\hline CHEMBL1316656 & 688877 & 5.55 & 6.2253 & TRN & \\
\hline CHEMBL490744 & 688877 & 4.5 & 5.936 & TRN & \\
\hline CHEMBL1397654 & 688877 & 8.1024 & 5.972 & TRN & \\
\hline CHEMBL1317498 & 688877 & 5.7 & 5.7414 & TRN & \\
\hline CHEMBL1552332 & 688877 & 8.301 & 5.53799 & 9999999999 & TRN \\
\hline CHEMBL1567020 & 688877 & 5.9 & 5.0021 & TST & \\
\hline CHEMBL1322959 & 688877 & 6.0 & 5.0638 & TRN & \\
\hline CHEMBL305195 & 688877 & 4.85 & 4.5522 & TRN & \\
\hline CHEMBL 243676 & 688877 & 5.6 & 5.1696 & TRN & \\
\hline CHEMBL268609 & 688877 & 5.55 & 5.2384 & TRN & \\
\hline CHEMBL1535372 & 688877 & 5.6 & 5.8311 & TRN & \\
\hline CHEMBL1592186 & 688877 & 5.45 & 5.9858 & TRN & \\
\hline CHEMBL1435917 & 688877 & 7.8508 & 5.7195 & TRN & \\
\hline
\end{tabular}




\begin{tabular}{|c|c|c|c|c|c|}
\hline \multicolumn{6}{|c|}{ Supplemental Table S2.txt } \\
\hline CHEMBL1370925 & 688877 & 4.85 & 5.6104 & TST & \\
\hline CHEMBL1517935 & 688877 & 5.65 & 6.0041 & TRN & \\
\hline CHEMBL140 & 688877 & 5.85 & 5.0129 & TRN & \\
\hline CHEMBL77971 & 688877 & 4.95 & 5.5497 & TST & \\
\hline CHEMBL1358983 & 688877 & 6.1 & 6.2589 & TRN & \\
\hline CHEMBL1601630 & 688877 & 6.2 & 6.0221 & TRN & \\
\hline CHEMBL311158 & 688877 & 4.35 & 4.8195 & TRN & \\
\hline CHEMBL1531108 & 688877 & 6.25 & 6.0664 & TRN & \\
\hline CHEMBL1446539 & 688877 & 5.7 & 5.5542 & TRN & \\
\hline CHEMBL1315083 & 688877 & 5.4 & 6.2907 & TRN & \\
\hline CHEMBL1592760 & 688877 & 6.35 & 5.8507 & TRN & \\
\hline CHEMBL1513848 & 688877 & 7.4498 & 5.6809 & TRN & \\
\hline CHEMBL113830 & 688877 & 4.5 & 4.8318 & TRN & \\
\hline CHEMBL1317924 & 688877 & 5.6 & 5.5753 & TRN & \\
\hline CHEMBL1553785 & 688877 & 6.0 & 5.8805 & TRN & \\
\hline CHEMBL1524650 & 688877 & 6.15 & 5.8723 & TRN & \\
\hline CHEMBL1595377 & 688877 & 5.5 & 5.6481 & TRN & \\
\hline CHEMBL 86676 & 688877 & 5.5 & 5.3895 & TST & \\
\hline CHEMBL1396989 & 688877 & 5.15 & 5.626 & TRN & \\
\hline CHEMBL1512919 & 688877 & 4.7 & 5.726 & TRN & \\
\hline CHEMBL1570196 & 688877 & 4.85 & 5.4517 & TRN & \\
\hline CHEMBL2373626 & 688877 & 4.45 & 5.6456 & TST & \\
\hline CHEMBL1256289 & 688877 & 5.15 & 5.2321 & TST & \\
\hline CHEMBL1396310 & 688877 & 7.0501 & 6.2378 & TRN & \\
\hline CHEMBL334378 & 688877 & 4.5 & 5.2642 & TRN & \\
\hline CHEMBL582444 & 688877 & 4.8 & 4.6818 & TST & \\
\hline CHEMBL259389 & 688877 & 5.3 & 5.6315 & TRN & \\
\hline CHEMBL1591272 & 688877 & 5.45 & 5.4814 & TRN & \\
\hline CHEMBL1551009 & 688877 & 5.75 & 5.8389 & TRN & \\
\hline CHEMBL1332929 & 688877 & 8.301 & 5.7269 & TRN & \\
\hline CHEMBL1555884 & 688877 & 7.9508 & 4.91 & TST & \\
\hline CHEMBL1396384 & 688877 & 7.6498 & 6.8253 & TRN & \\
\hline CHEMBL1562663 & 688877 & 4.4 & 5.541 & TRN & \\
\hline CHEMBL1607868 & 688877 & 4.9 & 5.8032 & TRN & \\
\hline CHEMBL1320469 & 688877 & 6.6499 & 5.9222 & TRN & \\
\hline CHEMBL1256186 & 688877 & 5.15 & 5.2096 & TST & \\
\hline CHEMBL118109 & 688877 & 4.8 & 5.2172 & TRN & \\
\hline CHEMBL1257014 & 688877 & 5.0 & 5.7782 & TRN & \\
\hline CHEMBL1322478 & 688877 & 4.8 & 4.8395 & TRN & \\
\hline CHEMBL1358743 & 688877 & 4.8 & 5.1667 & TST & \\
\hline CHEMBL1553941 & 688877 & 4.95 & 5.6384 & TRN & \\
\hline CHEMBL1552854 & 688877 & 8.2518 & 6.53700 & 0000000001 & TRN \\
\hline CHEMBL1255659 & 688877 & 5.05 & 5.3933 & TRN & \\
\hline CHEMBL1412847 & 688877 & 5.35 & 5.222 & TRN & \\
\hline CHEMBL1395605 & 688877 & 5.8 & 5.5365 & TRN & \\
\hline CHEMBL1334874 & 688877 & 4.4 & 5.0767 & TST & \\
\hline CHEMBL1495954 & 688877 & 4.45 & 5.0667 & TRN & \\
\hline CHEMBL1329499 & 688877 & 7.3002 & 6.1211 & TRN & \\
\hline
\end{tabular}




\begin{tabular}{|c|c|c|c|c|}
\hline \multicolumn{5}{|c|}{ Supplemental Table S2.txt } \\
\hline CHEMBL1535431 & 688877 & 5.45 & 5.8633 & TRN \\
\hline CHEMBL1315417 & 688877 & 4.45 & 5.4568 & TST \\
\hline CHEMBL1552329 & 688877 & 6.0 & 5.4902 & TRN \\
\hline CHEMBL1318278 & 688877 & 6.45 & 6.0929 & TRN \\
\hline CHEMBL 1474326 & 688877 & 6.5 & 5.7667 & TRN \\
\hline CHEMBL 2448558 & 688877 & 4.4 & 5.2471 & TRN \\
\hline CHEMBL1551200 & 688877 & 6.5501 & 6.1747 & TRN \\
\hline CHEMBL1411094 & 688877 & 6.5 & 6.0779 & TRN \\
\hline CHEMBL1396040 & 688877 & 5.35 & 6.0415 & TRN \\
\hline CHEMBL 1437226 & 688877 & 6.1 & 6.4881 & TRN \\
\hline CHEMBL1480779 & 688877 & 5.05 & 5.4683 & TRN \\
\hline CHEMBL1439882 & 688877 & 7.6498 & 5.8302 & TRN \\
\hline CHEMBL1401859 & 688877 & 5.95 & 5.6322 & TRN \\
\hline CHEMBL1433785 & 688877 & 7.8508 & 5.843 & TRN \\
\hline CHEMBL1403562 & 688877 & 6.25 & 5.4847 & TRN \\
\hline CHEMBL1484127 & 688877 & 5.7 & 5.9684 & TRN \\
\hline CHEMBL1256668 & 688877 & 4.6 & 4.6738 & TST \\
\hline CHEMBL1358671 & 688877 & 5.85 & 5.6032 & TRN \\
\hline CHEMBL1355701 & 688877 & 5.3 & 5.6765 & TRN \\
\hline CHEMBL1256740 & 688877 & 4.4 & 5.06 & TRN \\
\hline CHEMBL1474169 & 688877 & 6.05 & 5.8128 & TRN \\
\hline CHEMBL1398810 & 688877 & 5.8 & 5.7124 & TRN \\
\hline CHEMBL1356733 & 688877 & 6.0 & 5.8704 & TRN \\
\hline CHEMBL1457544 & 688877 & 5.7 & 5.8153 & TRN \\
\hline CHEMBL 1605700 & 688877 & 4.55 & 4.9484 & TRN \\
\hline CHEMBL 221300 & 688877 & 5.35 & 5.4885 & TRN \\
\hline CHEMBL1595910 & 688877 & 6.25 & 5.475 & TRN \\
\hline CHEMBL 269366 & 688877 & 4.5 & 5.3018 & TST \\
\hline CHEMBL461903 & 688877 & 4.45 & 5.1147 & TST \\
\hline CHEMBL 286721 & 688877 & 4.7 & 5.2304 & TRN \\
\hline CHEMBL37081 & 688877 & 4.85 & 5.1094 & TRN \\
\hline CHEMBL1552540 & 688877 & 5.0 & 5.3047 & TRN \\
\hline CHEMBL1161461 & 688877 & 6.8 & 4.993 & TST \\
\hline CHEMBL 280065 & 688877 & 4.4 & 4.9257 & TRN \\
\hline CHEMBL1355963 & 688877 & 4.8 & 4.8509 & TST \\
\hline CHEMBL1533853 & 688877 & 5.9 & 5.9536 & TRN \\
\hline CHEMBL1256686 & 688877 & 5.55 & 5.2942 & TST \\
\hline CHEMBL1365978 & 688877 & 4.7 & 5.2127 & TST \\
\hline CHEMBL554041 & 688877 & 6.0 & 4.8618 & TST \\
\hline CHEMBL1403134 & 688877 & 5.45 & 5.3363 & TRN \\
\hline CHEMBL45281 & 688877 & 5.5 & 5.1542 & TST \\
\hline CHEMBL1513392 & 688877 & 4.45 & 5.0725 & TST \\
\hline CHEMBL18132 & 688877 & 6.0 & 5.4676 & TRN \\
\hline CHEMBL1376290 & 688877 & 5.65 & 5.9363 & TRN \\
\hline CHEMBL 280563 & 688877 & 6.15 & 4.8979 & TST \\
\hline CHEMBL1593511 & 688877 & 5.15 & 5.9524 & TRN \\
\hline CHEMBL1339209 & 688877 & 6.0 & 6.506 & TRN \\
\hline CHEMBL1323549 & 688877 & 6.45 & 5.5577 & TRN \\
\hline
\end{tabular}




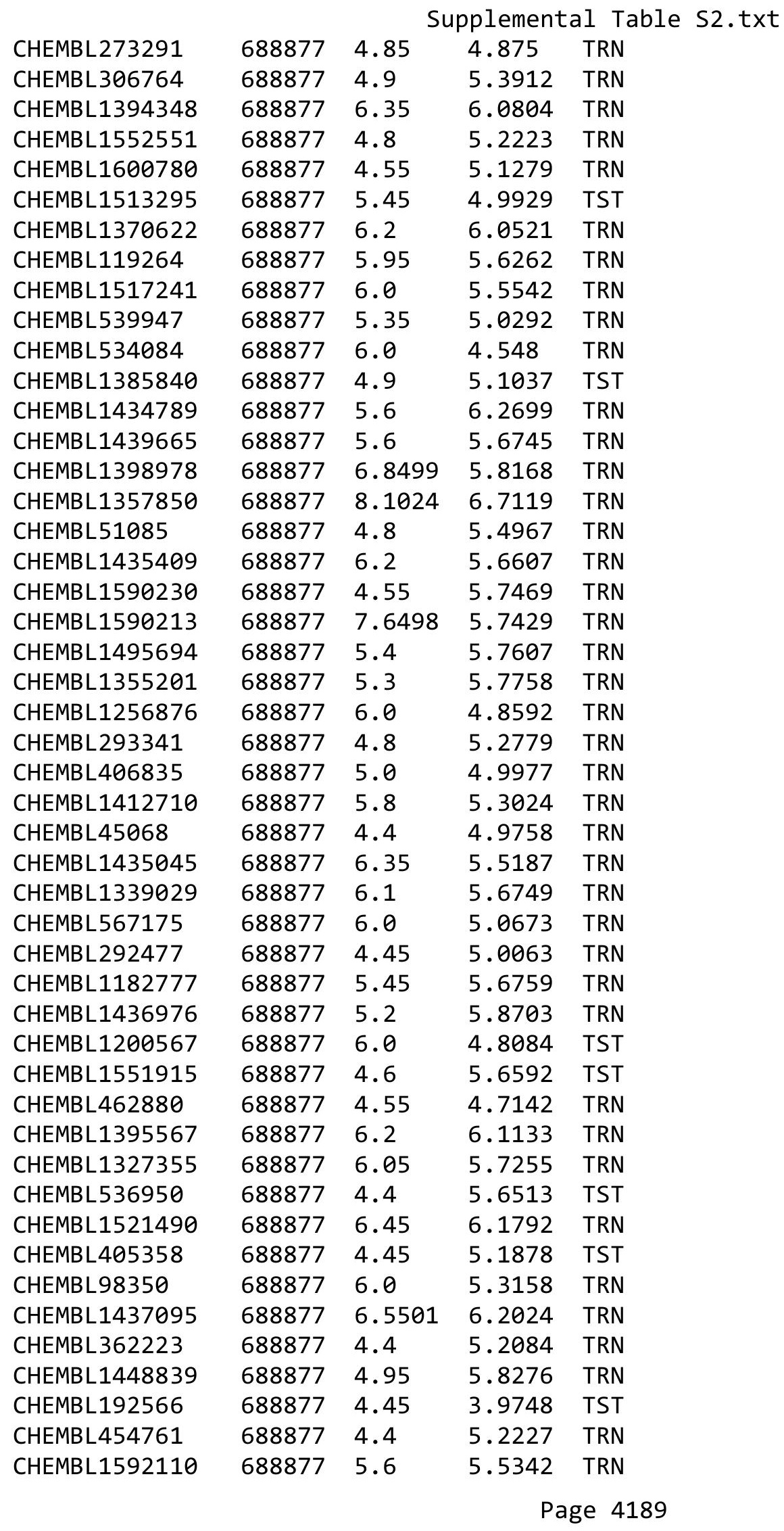




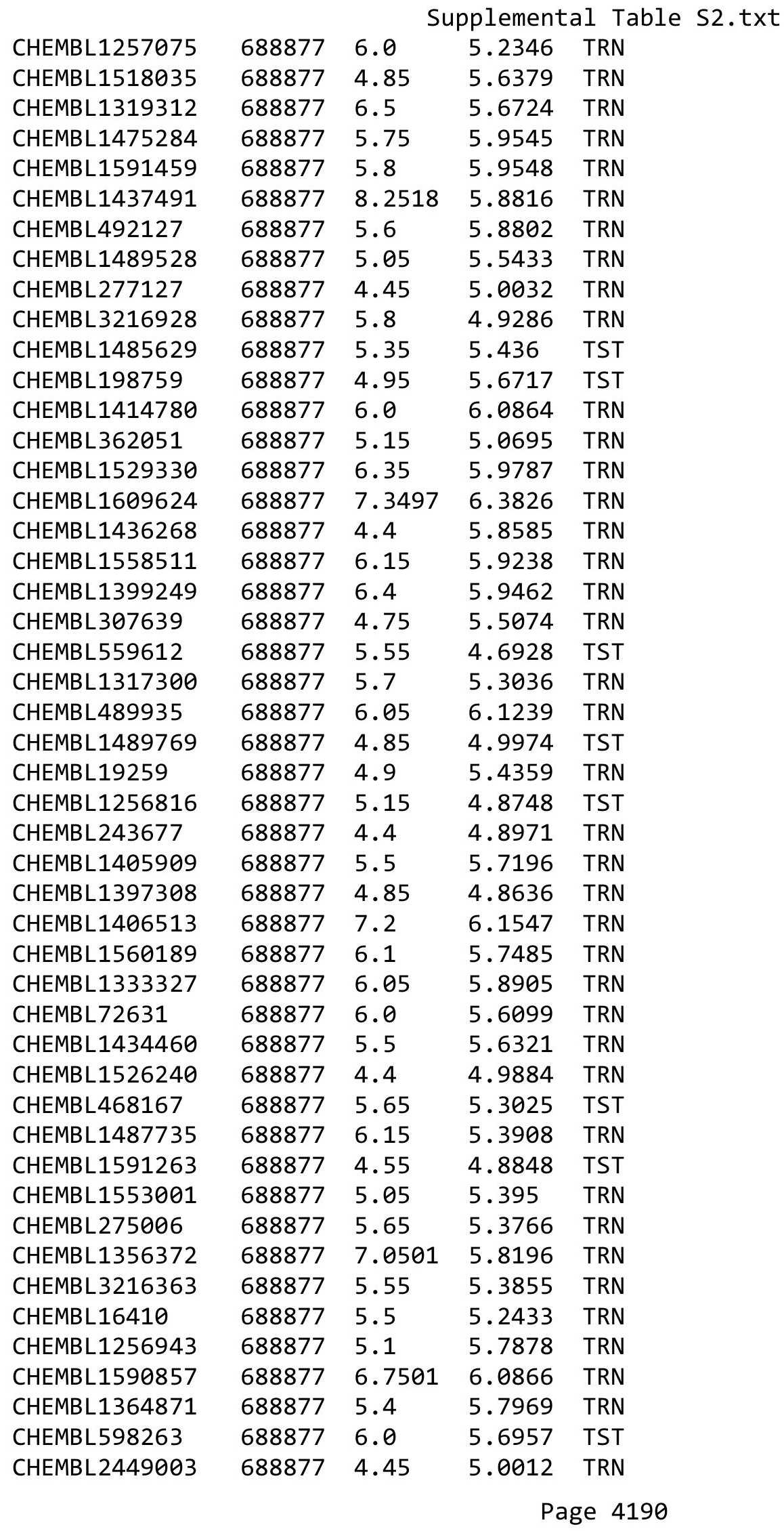




\begin{tabular}{|c|c|c|c|c|c|}
\hline \\
\hline CHEMBL1591258 & 688877 & 4.6 & 5.0575 & TRN & \\
\hline CHEMBL1436054 & 688877 & 5.9 & 5.5893 & TRN & \\
\hline CHEMBL1528531 & 688877 & 4.8 & 5.345 & TST & \\
\hline CHEMBL1200938 & 688877 & 4.85 & 5.1466 & TST & \\
\hline CHEMBL1451058 & 688877 & 4.9 & 5.2256 & TRN & \\
\hline CHEMBL 294018 & 688877 & 4.65 & 5.4181 & TST & \\
\hline CHEMBL 2374058 & 688877 & 6.0 & 4.9087 & TST & \\
\hline CHEMBL1396783 & 688877 & 5.4 & 6.1555 & TRN & \\
\hline CHEMBL1452881 & 688877 & 4.5 & 5.0213 & TST & \\
\hline CHEMBL1555713 & 688877 & 5.85 & 5.9668 & TRN & \\
\hline CHEMBL29197 & 688877 & 5.95 & 5.7739 & TRN & \\
\hline CHEMBL1329517 & 688877 & 5.95 & 5.1033 & TST & \\
\hline CHEMBL1317177 & 688877 & 5.0 & 5.6181 & TRN & \\
\hline CHEMBL453797 & 688877 & 4.8 & 4.6111 & TST & \\
\hline CHEMBL1330459 & 688877 & 4.85 & 5.86799 & 9999999999 & TRN \\
\hline CHEMBL478 & 688877 & 6.0 & 4.97 & TRN & \\
\hline CHEMBL1451087 & 688877 & 4.85 & 5.1121 & TRN & \\
\hline CHEMBL1712082 & 688877 & 4.85 & 5.037 & TST & \\
\hline CHEMBL1436075 & 688877 & 5.3 & 5.775 & TRN & \\
\hline CHEMBL1592376 & 688877 & 6.2 & 6.2831 & TRN & \\
\hline CHEMBL1440302 & 688877 & 5.8 & 5.5097 & TRN & \\
\hline CHEMBL1516211 & 688877 & 4.45 & 5.6464 & TRN & \\
\hline CHEMBL 63426 & 688877 & 5.5 & 5.1883 & TST & \\
\hline CHEMBL1230270 & 688877 & 7.5003 & 5.1366 & TRN & \\
\hline CHEMBL1439401 & 688877 & 5.9 & 6.4857 & TRN & \\
\hline CHEMBL1399702 & 688877 & 5.5 & 5.9631 & TRN & \\
\hline CHEMBL1357067 & 688877 & 6.0 & 6.1201 & TRN & \\
\hline CHEMBL1316491 & 688877 & 5.5 & 6.2055 & TRN & \\
\hline CHEMBL175858 & 688877 & 6.25 & 5.5486 & TST & \\
\hline CHEMBL 244707 & 688877 & 4.55 & 4.7921 & TRN & \\
\hline CHEMBL1558834 & 688877 & 5.4 & 5.7594 & TRN & \\
\hline CHEMBL1325701 & 688877 & 5.35 & 5.9326 & TRN & \\
\hline CHEMBL1472880 & 688877 & 7.0501 & 6.0665 & TRN & \\
\hline CHEMBL1590262 & 688877 & 5.75 & 5.9387 & TRN & \\
\hline CHEMBL1395850 & 688877 & 5.2 & 5.4885 & TRN & \\
\hline CHEMBL1483855 & 688877 & 6.5 & 6.2686 & TRN & \\
\hline CHEMBL1479741 & 688877 & 6.15 & 5.8416 & TRN & \\
\hline CHEMBL1360011 & 688877 & 6.6 & 5.6207 & TRN & \\
\hline CHEMBL1434747 & 688877 & 6.45 & 5.843 & TRN & \\
\hline CHEMBL 305881 & 688877 & 5.15 & 5.1812 & TRN & \\
\hline CHEMBL1552071 & 688877 & 5.7 & 5.9473 & TRN & \\
\hline CHEMBL1593056 & 688877 & 6.15 & 5.7358 & TRN & \\
\hline CHEMBL1436925 & 688877 & 7.3002 & 6.41200 & 0000000001 & TRN \\
\hline CHEMBL1476146 & 688877 & 6.25 & 5.7713 & TRN & \\
\hline CHEMBL338115 & 688877 & 4.8 & 6.0137 & TRN & \\
\hline CHEMBL1357162 & 688877 & 4.4 & 5.0897 & TST & \\
\hline CHEMBL1354941 & 688877 & 6.05 & 5.7691 & TRN & \\
\hline CHEMBL1414943 & 688877 & 5.5 & 5.8145 & TRN & \\
\hline
\end{tabular}




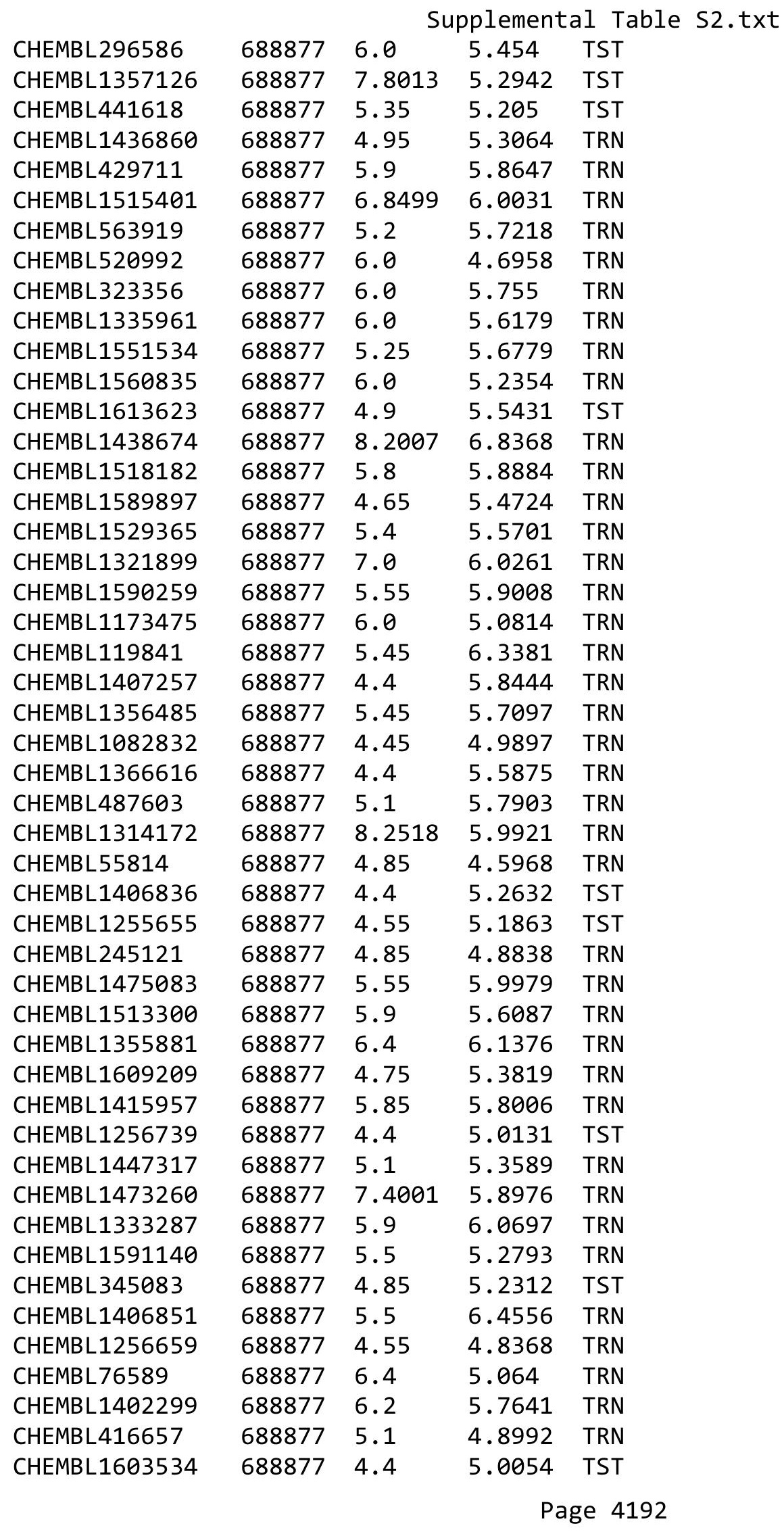




\begin{tabular}{|c|c|c|c|c|c|}
\hline \multirow[b]{2}{*}{ CHEMBL1513936 } & \multicolumn{5}{|c|}{ plemental Table S2. } \\
\hline & 688877 & 5.0 & 5.5406 & TRN & \\
\hline CHEMBL 22304 & 688877 & 4.8 & 5.09699 & 99999999995 & TRN \\
\hline CHEMBL1448979 & 688877 & 5.5 & 5.6481 & TRN & \\
\hline CHEMBL1451377 & 688877 & 4.65 & 4.8977 & TST & \\
\hline CHEMBL1394887 & 688877 & 5.35 & 5.8359 & TRN & \\
\hline CHEMBL8145 & 688877 & 5.2 & 5.1755 & TRN & \\
\hline CHEMBL1591896 & 688877 & 5.45 & 5.9798 & TRN & \\
\hline CHEMBL168279 & 688877 & 7.9508 & 5.3918 & TRN & \\
\hline CHEMBL 222838 & 688877 & 4.85 & 4.8482 & TST & \\
\hline CHEMBL1316265 & 688877 & 4.4 & 4.585 & TRN & \\
\hline CHEMBL490718 & 688877 & 4.6 & 5.7985 & TRN & \\
\hline CHEMBL1570633 & 688877 & 5.5 & 5.9788 & TRN & \\
\hline CHEMBL1472955 & 688877 & 6.9 & 6.3716 & TRN & \\
\hline CHEMBL1972346 & 688877 & 4.55 & 4.6784 & TRN & \\
\hline CHEMBL470881 & 688877 & 6.5 & 5.5815 & TST & \\
\hline CHEMBL542493 & 688877 & 6.7001 & 4.5972 & TRN & \\
\hline CHEMBL1256996 & 688877 & 4.65 & 4.7447 & TRN & \\
\hline CHEMBL1355323 & 688877 & 6.15 & 5.16 & TST & \\
\hline CHEMBL542448 & 688877 & 4.4 & 5.1597 & TST & \\
\hline CHEMBL540851 & 688877 & 5.15 & 5.4794 & TST & \\
\hline CHEMBL1474313 & 688877 & 4.6 & 5.9714 & TRN & \\
\hline CHEMBL1335406 & 688877 & 4.4 & 5.3211 & TRN & \\
\hline CHEMBL1316979 & 688877 & 7.3497 & 6.7834 & TRN & \\
\hline CHEMBL1592804 & 688877 & 4.4 & 5.9459 & TRN & \\
\hline CHEMBL404313 & 688877 & 4.5 & 5.1718 & TST & \\
\hline CHEMBL393136 & 688877 & 4.4 & 4.8224 & TRN & \\
\hline CHEMBL 277525 & 688877 & 5.35 & 5.4391 & TRN & \\
\hline CHEMBL1566442 & 688877 & 6.5 & 5.794 & TRN & \\
\hline CHEMBL1354355 & 688877 & 5.55 & 5.5578 & TRN & \\
\hline CHEMBL1327681 & 688877 & 5.6 & 6.2586 & TRN & \\
\hline CHEMBL1603418 & 688877 & 5.5 & 5.9163 & TRN & \\
\hline CHEMBL1514748 & 688877 & 5.5 & 5.4658 & TRN & \\
\hline CHEMBL1440509 & 688877 & 7.2 & 6.13899 & 9999999999 & TRN \\
\hline CHEMBL1360944 & 688877 & 5.7 & 5.5526 & TST & \\
\hline CHEMBL1518338 & 688877 & 6.6 & 5.8775 & TRN & \\
\hline CHEMBL20562 & 688877 & 5.15 & 5.2519 & TST & \\
\hline CHEMBL1473099 & 688877 & 5.6 & 5.6111 & TRN & \\
\hline CHEMBL1452868 & 688877 & 6.5 & 5.3579 & TRN & \\
\hline CHEMBL1513347 & 688877 & 7.2 & 5.8707 & TRN & \\
\hline CHEMBL1569529 & 688877 & 4.75 & 5.7638 & TRN & \\
\hline CHEMBL1256776 & 688877 & 7.8013 & 5.1755 & TRN & \\
\hline CHEMBL1409572 & 688877 & 6.1 & 5.9302 & TRN & \\
\hline CHEMBL1403505 & 688877 & 6.7001 & 6.1916 & TRN & \\
\hline CHEMBL1397089 & 688877 & 5.3 & 5.3674 & TST & \\
\hline CHEMBL56543 & 688877 & 4.5 & 5.152 & TRN & \\
\hline CHEMBL1398537 & 688877 & 4.8 & 5.849 & TRN & \\
\hline CHEMBL1551981 & 688877 & 5.75 & 5.3206 & TRN & \\
\hline CHEMBL1255867 & 688877 & 4.85 & 5.0606 & TRN & \\
\hline
\end{tabular}




\begin{tabular}{|c|c|c|c|c|c|}
\hline \multirow{3}{*}{$\begin{array}{l}\text { CHEMBL1435994 } \\
\text { CHEMBL1435481 }\end{array}$} & & \multicolumn{4}{|c|}{ Supplemental Table s2.txt } \\
\hline & 688877 & 4.85 & \multicolumn{2}{|c|}{5.9110000000000005} & TRN \\
\hline & 688877 & 5.75 & 5.6964 & TRN & \\
\hline CHEMBL310798 & 688877 & 5.45 & 4.8676 & TRN & \\
\hline CHEMBL221137 & 688877 & 4.8 & 4.7755 & TST & \\
\hline CHEMBL1441453 & 688877 & 5.95 & 5.6919 & TRN & \\
\hline CHEMBL1314022 & 688877 & 4.9 & 5.4673 & TST & \\
\hline CHEMBL1315920 & 688877 & 6.45 & 6.1625 & TRN & \\
\hline CHEMBL1475642 & 688877 & 4.85 & 5.7497 & TRN & \\
\hline CHEMBL1437056 & 688877 & 5.55 & 5.5434 & TRN & \\
\hline CHEMBL1553804 & 688877 & 7.8508 & 6.0146 & TRN & \\
\hline CHEMBL1454920 & 688877 & 4.95 & 5.7352 & TRN & \\
\hline CHEMBL1317066 & 688877 & 5.8 & 6.0145 & TRN & \\
\hline CHEMBL1590048 & 688877 & 5.9 & 5.4453 & TRN & \\
\hline CHEMBL1473429 & 688877 & 4.85 & 5.5305 & TST & \\
\hline CHEMBL334255 & 688877 & 5.0 & 5.0004 & TST & \\
\hline CHEMBL326958 & 688877 & 7.6003 & 6.0644 & TRN & \\
\hline CHEMBL131171 & 688877 & 5.4 & 5.4782 & TRN & \\
\hline CHEMBL1437713 & 688877 & 7.15 & 6.1049 & TRN & \\
\hline CHEMBL 21241 & 688877 & 4.45 & 5.1162 & TST & \\
\hline CHEMBL1512385 & 688877 & 5.85 & 5.9792 & TRN & \\
\hline CHEMBL1555267 & 688877 & 4.4 & 5.2464 & TST & \\
\hline CHEMBL1436521 & 688877 & 5.8 & 5.83700 & 0000000001 & TRN \\
\hline CHEMBL323542 & 688877 & 4.3 & 5.0084 & TST & \\
\hline CHEMBL1556654 & 688877 & 5.8 & 5.6282 & TST & \\
\hline CHEMBL1449651 & 688877 & 4.4 & 5.3145 & TST & \\
\hline CHEMBL1433686 & 688877 & 4.45 & 5.0446 & TST & \\
\hline CHEMBL1593765 & 688877 & 4.85 & 5.0435 & TRN & \\
\hline CHEMBL1555567 & 688877 & 6.1 & 5.8641 & TRN & \\
\hline CHEMBL 274844 & 688877 & 4.45 & 5.1186 & TRN & \\
\hline CHEMBL1515004 & 688877 & 4.9 & 5.3103 & TRN & \\
\hline CHEMBL1371525 & 688877 & 4.9 & 5.6768 & TST & \\
\hline CHEMBL1396354 & 688877 & 7.0501 & 6.2937 & TRN & \\
\hline CHEMBL1354325 & 688877 & 8.699 & 5.1418 & TST & \\
\hline CHEMBL1256998 & 688877 & 4.4 & 4.9063 & TRN & \\
\hline CHEMBL1257002 & 688877 & 4.95 & 5.647 & TST & \\
\hline CHEMBL243250 & 688877 & 5.1 & 5.5134 & TRN & \\
\hline CHEMBL1338229 & 688877 & 4.45 & 5.3007 & TRN & \\
\hline CHEMBL90882 & 688877 & 4.55 & 4.7047 & TRN & \\
\hline CHEMBL1356657 & 688877 & 5.85 & 5.6163 & TRN & \\
\hline CHEMBL1452250 & 688877 & 6.05 & 6.0517 & TRN & \\
\hline CHEMBL1316075 & 688877 & 5.8 & 6.022 & TRN & \\
\hline CHEMBL491978 & 688877 & 6.05 & 6.0643 & TRN & \\
\hline CHEMBL1317302 & 688877 & 6.8 & 5.7612 & TRN & \\
\hline CHEMBL1476580 & 688877 & 4.75 & 5.7005 & TRN & \\
\hline CHEMBL1474471 & 688877 & 7.3497 & 5.9955 & TRN & \\
\hline CHEMBL1315968 & 688877 & 8.301 & 5.7549 & TRN & \\
\hline CHEMBL1601908 & 688877 & 6.5 & 6.1249 & TRN & \\
\hline CHEMBL1395252 & 688877 & 4.55 & 5.4725 & TRN & \\
\hline
\end{tabular}




\begin{tabular}{|c|c|c|c|c|c|}
\hline \multicolumn{6}{|c|}{ Supplemental Table S2.txt } \\
\hline CHEMBL1316516 & 688877 & 5.1 & 5.3573 & TRN & \\
\hline CHEMBL 32590 & 688877 & 4.4 & 4.7535 & TRN & \\
\hline CHEMBL1599378 & 688877 & 5.6 & 5.9795 & TRN & \\
\hline CHEMBL158507 & 688877 & 5.75 & 6.0054 & TRN & \\
\hline CHEMBL1395792 & 688877 & 6.1 & 6.0523 & TRN & \\
\hline CHEMBL1593001 & 688877 & 6.35 & 5.7814 & TRN & \\
\hline CHEMBL606675 & 688877 & 4.4 & 5.1092 & TRN & \\
\hline CHEMBL13647 & 688877 & 4.8 & 5.425 & TRN & \\
\hline CHEMBL1394944 & 688877 & 5.5 & 5.9063 & TRN & \\
\hline CHEMBL1515449 & 688877 & 6.05 & 6.0576 & TRN & \\
\hline CHEMBL1079227 & 688877 & 4.8 & 5.2431 & TRN & \\
\hline CHEMBL1354388 & 688877 & 5.8 & 5.6396 & TRN & \\
\hline CHEMBL88402 & 688877 & 4.4 & 5.0305 & TRN & \\
\hline CHEMBL1487191 & 688877 & 5.3 & 5.8817 & TRN & \\
\hline CHEMBL1316831 & 688877 & 4.95 & 5.0226 & TST & \\
\hline CHEMBL42485 & 688877 & 5.35 & 5.3872 & TST & \\
\hline CHEMBL1489392 & 688877 & 6.0 & 5.2008 & TST & \\
\hline CHEMBL 2374063 & 688877 & 4.95 & 4.7131 & TST & \\
\hline CHEMBL1567944 & 688877 & 6.25 & 5.2011 & TRN & \\
\hline CHEMBL1602568 & 688877 & 6.0 & 5.9732 & TRN & \\
\hline CHEMBL 79140 & 688877 & 4.45 & 4.8978 & TRN & \\
\hline CHEMBL244746 & 688877 & 4.5 & 5.20700 & 0000000001 & TRN \\
\hline CHEMBL 302213 & 688877 & 4.4 & 4.7448 & TRN & \\
\hline CHEMBL1406485 & 688877 & 4.55 & 5.3777 & TRN & \\
\hline CHEMBL1243269 & 688877 & 6.0 & 5.402 & TRN & \\
\hline CHEMBL1366754 & 688877 & 6.25 & 5.7109 & TRN & \\
\hline CHEMBL1416207 & 688877 & 4.9 & 5.5504 & TRN & \\
\hline CHEMBL1591600 & 688877 & 6.45 & 6.1383 & TRN & \\
\hline CHEMBL250711 & 688877 & 4.45 & 4.7995 & TRN & \\
\hline CHEMBL1512614 & 688877 & 5.8 & 5.5851 & TRN & \\
\hline CHEMBL1395355 & 688877 & 4.75 & 5.3567 & TRN & \\
\hline CHEMBL1400575 & 688877 & 6.7501 & 5.704 & TRN & \\
\hline CHEMBL1520681 & 688877 & 5.3 & 5.5435 & TRN & \\
\hline CHEMBL1317761 & 688877 & 4.95 & 5.691 & TRN & \\
\hline CHEMBL1591673 & 688877 & 5.6 & 5.3517 & TRN & \\
\hline CHEMBL1596872 & 688877 & 5.05 & 5.70100 & 00000000005 & TRN \\
\hline CHEMBL1476791 & 688877 & 6.25 & 5.8847 & TRN & \\
\hline CHEMBL490742 & 688877 & 5.2 & 5.8485 & TRN & \\
\hline CHEMBL1316616 & 688877 & 5.15 & 5.5254 & TRN & \\
\hline CHEMBL441282 & 688877 & 6.45 & 5.2646 & TST & \\
\hline CHEMBL498770 & 688877 & 4.55 & 5.3336 & TST & \\
\hline CHEMBL1592452 & 688877 & 6.45 & 5.8395 & TRN & \\
\hline CHEMBL1526572 & 688877 & 6.45 & 6.0946 & TRN & \\
\hline CHEMBL40157 & 688877 & 6.7501 & 4.9881 & TST & \\
\hline CHEMBL 1484120 & 688877 & 6.1 & 5.8976 & TRN & \\
\hline CHEMBL251647 & 688877 & 4.55 & 5.49700 & 0000000001 & TRN \\
\hline CHEMBL1253351 & 688877 & 5.05 & 5.4397 & TST & \\
\hline CHEMBL1572280 & 688877 & 4.4 & 5.3841 & TST & \\
\hline
\end{tabular}




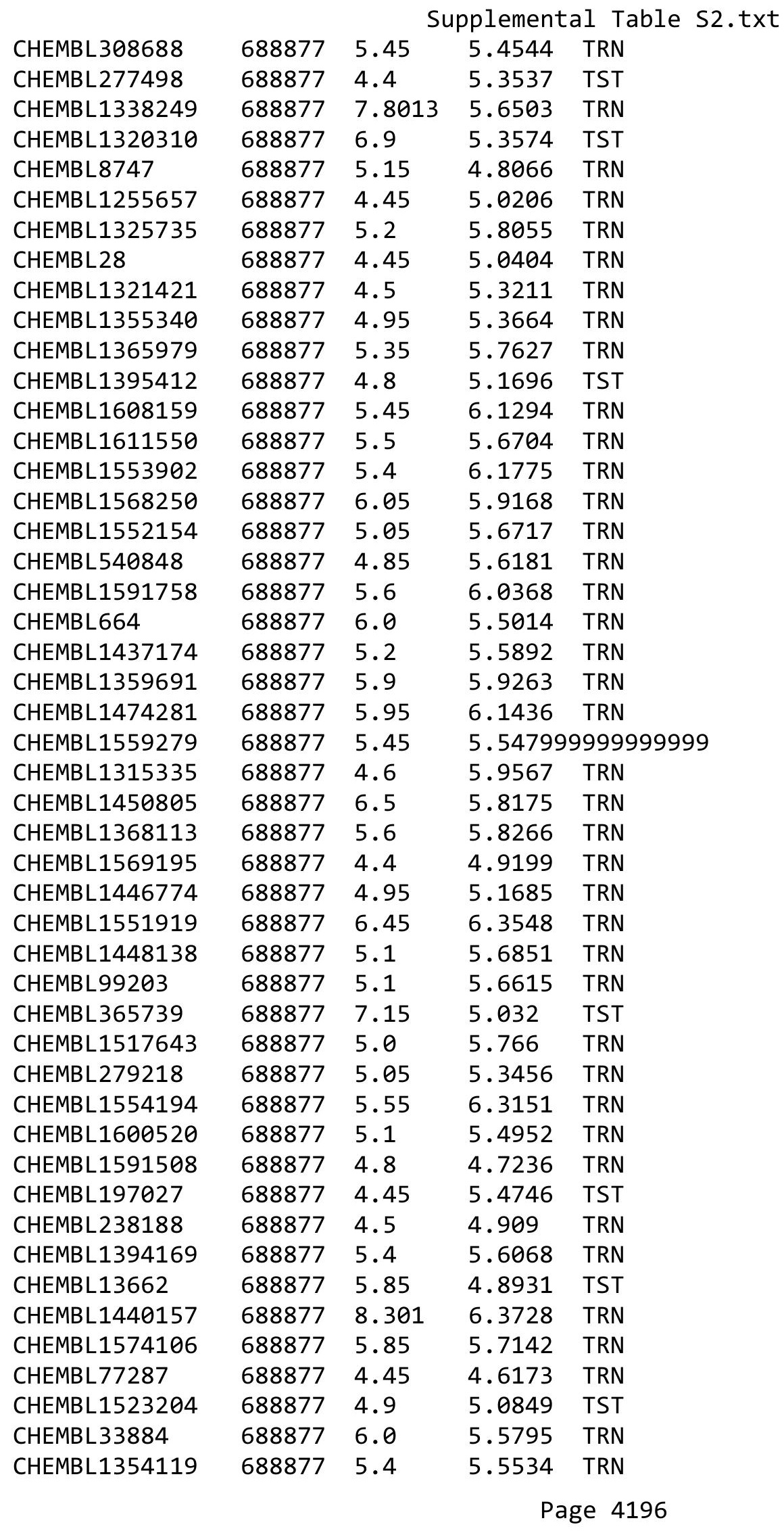




\begin{tabular}{|c|c|c|c|c|c|}
\hline \multirow{3}{*}{$\begin{array}{l}\text { CHEMBL1437657 } \\
\text { CHEMBL1479912 }\end{array}$} & \multirow{3}{*}{$\begin{array}{l}688877 \\
688877\end{array}$} & \multicolumn{4}{|c|}{ Supplemental Table S2.txt } \\
\hline & & 7.6498 & \multicolumn{2}{|c|}{5.9510000000000005} & TRN \\
\hline & & 7.2 & 5.9476 & TRN & \\
\hline CHEMBL1394118 & 688877 & 5.6 & 5.9713 & TRN & \\
\hline CHEMBL1474695 & 688877 & 5.5 & 5.8359 & TRN & \\
\hline CHEMBL1476108 & 688877 & 5.15 & 5.4466 & TST & \\
\hline CHEMBL446315 & 688877 & 4.8 & 5.0649 & TST & \\
\hline CHEMBL1158 & 688877 & 7.3497 & 5.6791 & TST & \\
\hline CHEMBL65 & 688877 & 4.65 & 4.4052 & TST & \\
\hline CHEMBL1484422 & 688877 & 5.5 & 5.5631 & TRN & \\
\hline CHEMBL75773 & 688877 & 4.8 & 5.55200 & 00000000005 & TRN \\
\hline CHEMBL60859 & 688877 & 4.9 & 4.9053 & TRN & \\
\hline CHEMBL1456346 & 688877 & 4.4 & 4.7794 & TST & \\
\hline CHEMBL258767 & 688877 & 6.0 & 4.987 & TRN & \\
\hline CHEMBL444309 & 688877 & 6.1 & 5.2008 & TRN & \\
\hline CHEMBL1533537 & 688877 & 7.1002 & 5.915 & TRN & \\
\hline CHEMBL23731 & 688877 & 4.95 & 5.3175 & TRN & \\
\hline CHEMBL86931 & 688877 & 5.2 & 4.823 & TRN & \\
\hline CHEMBL481537 & 688877 & 4.9 & 4.9864 & TRN & \\
\hline CHEMBL430893 & 688877 & 6.0 & 5.4444 & TRN & \\
\hline CHEMBL1314255 & 688877 & 5.45 & 5.4238 & TRN & \\
\hline CHEMBL 7162 & 688877 & 4.45 & 5.3098 & TST & \\
\hline CHEMBL1593443 & 688877 & 5.9 & 5.3133 & TRN & \\
\hline CHEMBL521971 & 688877 & 5.2 & 6.0623 & TRN & \\
\hline CHEMBL1488010 & 688877 & 5.3 & 5.6183 & TRN & \\
\hline CHEMBL514432 & 688877 & 7.15 & 5.0146 & TST & \\
\hline CHEMBL1482953 & 688877 & 5.15 & 5.4035 & TRN & \\
\hline CHEMBL1398683 & 688877 & 5.85 & 5.3631 & TST & \\
\hline CHEMBL1400342 & 688877 & 6.4 & 6.0366 & TRN & \\
\hline CHEMBL1452413 & 688877 & 5.2 & 5.7326 & TRN & \\
\hline CHEMBL1437831 & 688877 & 4.4 & 5.1741 & TST & \\
\hline CHEMBL391997 & 688877 & 6.0 & 4.9131 & TRN & \\
\hline CHEMBL1591107 & 688877 & 5.55 & 5.5848 & TRN & \\
\hline CHEMBL1436763 & 688877 & 5.3 & 5.0707 & TRN & \\
\hline CHEMBL 287045 & 688877 & 4.45 & 5.001 & TRN & \\
\hline CHEMBL1314799 & 688877 & 5.8 & 5.7935 & TRN & \\
\hline CHEMBL23957 & 688877 & 4.4 & 5.2029 & TST & \\
\hline CHEMBL1397825 & 688877 & 5.2 & 5.8069 & TRN & \\
\hline CHEMBL1452049 & 688877 & 6.2 & 6.101 & TRN & \\
\hline CHEMBL1592212 & 688877 & 4.6 & 5.4346 & TRN & \\
\hline CHEMBL543467 & 688877 & 4.75 & 5.5427 & TRN & \\
\hline CHEMBL1555389 & 688877 & 4.8 & 5.1829 & TRN & \\
\hline CHEMBL1400491 & 688877 & 6.3 & 6.2427 & TRN & \\
\hline CHEMBL432527 & 688877 & 4.8 & 4.6207 & TRN & \\
\hline CHEMBL1394353 & 688877 & 4.85 & 5.9088 & TRN & \\
\hline CHEMBL 1721226 & 688877 & 6.5501 & 5.2878 & TRN & \\
\hline CHEMBL1592754 & 688877 & 5.8 & 5.5773 & TRN & \\
\hline CHEMBL291057 & 688877 & 4.7 & 5.0136 & TST & \\
\hline CHEMBL1361596 & 688877 & 5.1 & 5.0689 & TST & \\
\hline
\end{tabular}




\begin{tabular}{|c|c|c|c|c|c|}
\hline \multicolumn{6}{|c|}{ Supplemental Table s2.txt } \\
\hline CHEMBL497170 & 688877 & 5.6 & 5.0011 & TRN & \\
\hline CHEMBL1568854 & 688877 & 6.35 & 6.0304 & TRN & \\
\hline CHEMBL1235001 & 688877 & 4.7 & 4.8364 & TST & \\
\hline CHEMBL 289233 & 688877 & 5.45 & 6.0344 & TRN & \\
\hline CHEMBL1256390 & 688877 & 5.15 & 4.8911 & TST & \\
\hline CHEMBL1567194 & 688877 & 4.7 & 5.664 & TRN & \\
\hline CHEMBL508494 & 688877 & 4.45 & 5.3365 & TRN & \\
\hline CHEMBL1417789 & 688877 & 6.5501 & 5.7657 & TRN & \\
\hline CHEMBL1354287 & 688877 & 5.55 & 5.447 & TRN & \\
\hline CHEMBL1315373 & 688877 & 5.45 & 5.9356 & TRN & \\
\hline CHEMBL1256484 & 688877 & 5.1 & 4.9639 & TRN & \\
\hline CHEMBL1593269 & 688877 & 6.4 & 5.642 & TRN & \\
\hline CHEMBL371811 & 688877 & 4.85 & 5.1833 & TRN & \\
\hline CHEMBL 22870 & 688877 & 5.3 & 4.981 & TRN & \\
\hline CHEMBL1318553 & 688877 & 4.8 & 5.4136 & TST & \\
\hline CHEMBL1440857 & 688877 & 8.6576 & 5.279 & TST & \\
\hline CHEMBL1475541 & 688877 & 5.0 & 5.7482 & TRN & \\
\hline CHEMBL1558569 & 688877 & 5.25 & 4.9786 & TRN & \\
\hline CHEMBL1512797 & 688877 & 4.85 & 5.1808 & TRN & \\
\hline CHEMBL 269733 & 688877 & 4.4 & 4.8026 & TRN & \\
\hline CHEMBL541847 & 688877 & 6.6 & 6.2664 & TRN & \\
\hline CHEMBL1592506 & 688877 & 5.95 & 5.9851 & TRN & \\
\hline CHEMBL1415569 & 688877 & 6.15 & 5.4366 & TRN & \\
\hline CHEMBL1433683 & 688877 & 4.85 & 5.4483 & TRN & \\
\hline CHEMBL1626274 & 688877 & 6.0 & 5.1527 & TRN & \\
\hline CHEMBL1512540 & 688877 & 7.15 & 5.1474 & TRN & \\
\hline CHEMBL54804 & 688877 & 4.7 & 5.1589 & TST & \\
\hline CHEMBL543876 & 688877 & 4.35 & 5.0535 & TRN & \\
\hline CHEMBL1316156 & 688877 & 4.8 & 4.7602 & TRN & \\
\hline CHEMBL1413770 & 688877 & 5.45 & 5.7114 & TRN & \\
\hline CHEMBL1513578 & 688877 & 6.1 & 6.3175 & TRN & \\
\hline CHEMBL33171 & 688877 & 6.0 & 5.709 & TRN & \\
\hline CHEMBL1329108 & 688877 & 5.5 & 5.8627 & TRN & \\
\hline CHEMBL269550 & 688877 & 4.85 & 5.0612 & TRN & \\
\hline CHEMBL1437325 & 688877 & 7.5498 & 5.9076 & TRN & \\
\hline CHEMBL1606751 & 688877 & 5.9 & 5.0973 & TRN & \\
\hline CHEMBL1491313 & 688877 & 4.85 & 5.5689 & TRN & \\
\hline CHEMBL1367789 & 688877 & 5.95 & 5.394 & TRN & \\
\hline CHEMBL 388054 & 688877 & 4.8 & 5.1145 & TST & \\
\hline CHEMBL1490195 & 688877 & 5.2 & 5.4347 & TRN & \\
\hline CHEMBL1552095 & 688877 & 5.5 & 5.1898 & TST & \\
\hline CHEMBL1433687 & 688877 & 5.75 & 5.98799 & 99999999995 & TRN \\
\hline CHEMBL63102 & 688877 & 5.45 & 5.3602 & TST & \\
\hline CHEMBL258405 & 688877 & 6.0 & 5.1173 & TST & \\
\hline CHEMBL1590458 & 688877 & 6.15 & 5.8175 & TRN & \\
\hline CHEMBL1435053 & 688877 & 6.0 & 5.4776 & TST & \\
\hline CHEMBL1417135 & 688877 & 5.35 & 5.5374 & TRN & \\
\hline CHEMBL1402028 & 688877 & 4.85 & 6.3024 & TRN & \\
\hline
\end{tabular}




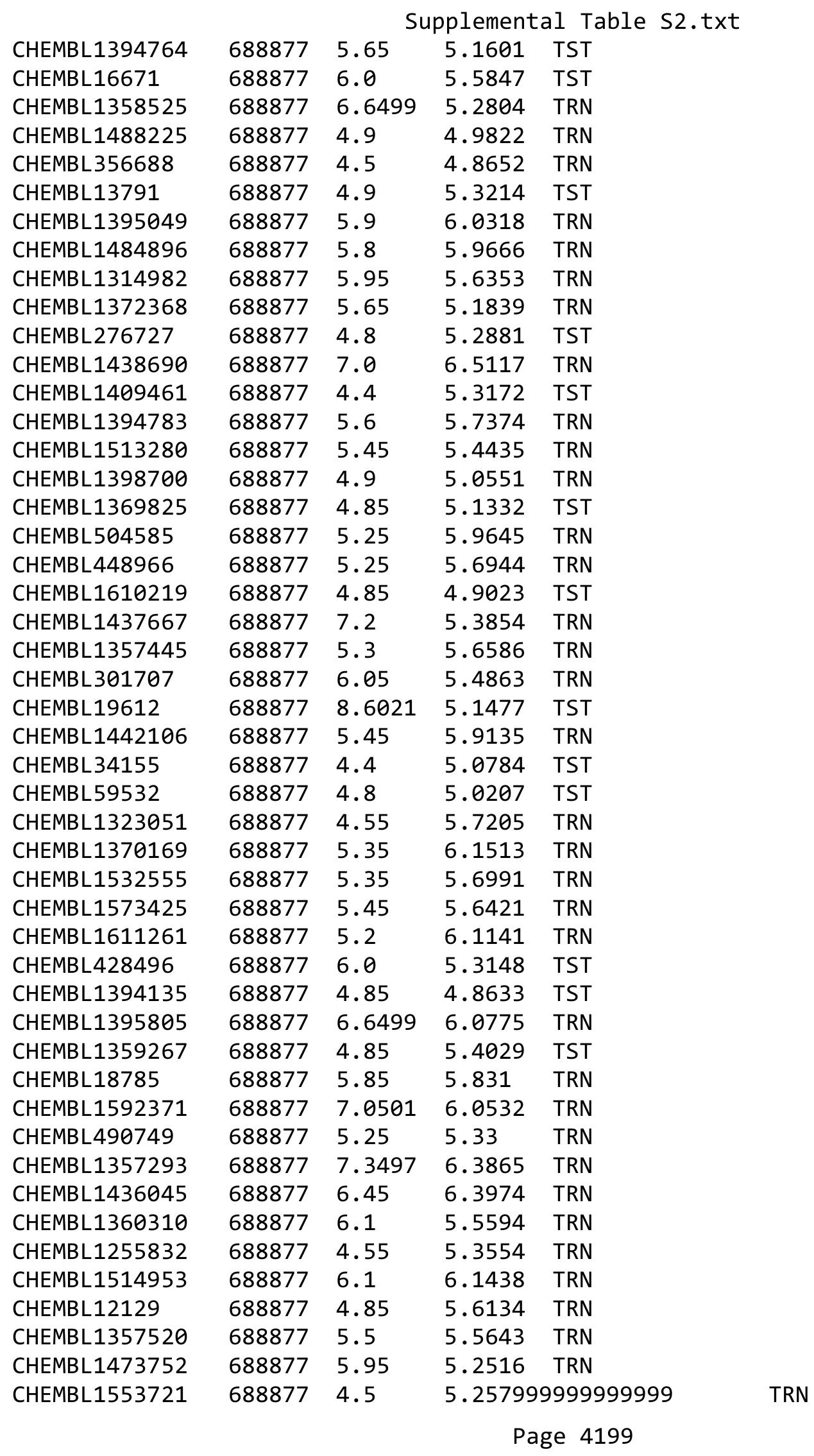




\begin{tabular}{|c|c|c|c|c|c|}
\hline & & & & & \\
\hline CHEMBL1357401 & 688877 & 4.4 & 4.7447 & TRN & \\
\hline CHEMBL1516476 & 688877 & 6.0 & 5.4856 & TRN & \\
\hline CHEMBL1572834 & 688877 & 6.0 & 5.2781 & TRN & \\
\hline CHEMBL1357247 & 688877 & 6.0 & 5.7626 & TST & \\
\hline CHEMBL16751 & 688877 & 4.5 & 5.5164 & TRN & \\
\hline CHEMBL1329110 & 688877 & 6.45 & 5.9527 & TRN & \\
\hline CHEMBL1590059 & 688877 & 5.85 & 5.0418 & TRN & \\
\hline CHEMBL1358628 & 688877 & 4.95 & 5.33200 & 0000000001 & TRN \\
\hline CHEMBL332898 & 688877 & 6.05 & 5.5445 & TRN & \\
\hline CHEMBL71851 & 688877 & 4.5 & 5.1955 & TRN & \\
\hline CHEMBL1476851 & 688877 & 4.5 & 5.1853 & TRN & \\
\hline CHEMBL313737 & 688877 & 6.4 & 5.2667 & TST & \\
\hline CHEMBL1591674 & 688877 & 4.95 & 5.8201 & TRN & \\
\hline CHEMBL338066 & 688877 & 4.5 & 4.7946 & TRN & \\
\hline CHEMBL1528842 & 688877 & 4.7 & 5.2054 & TRN & \\
\hline CHEMBL1358807 & 688877 & 7.6498 & 6.0463 & TRN & \\
\hline CHEMBL1555320 & 688877 & 6.6499 & 6.1266 & TRN & \\
\hline CHEMBL1374710 & 688877 & 5.7 & 6.1109 & TRN & \\
\hline CHEMBL1524520 & 688877 & 6.0 & 5.6302 & TRN & \\
\hline CHEMBL1489988 & 688877 & 5.7 & 5.395 & TRN & \\
\hline CHEMBL1436024 & 688877 & 5.4 & 5.6784 & TRN & \\
\hline CHEMBL1594086 & 688877 & 6.5501 & 5.8721 & TRN & \\
\hline CHEMBL1188431 & 688877 & 4.9 & 5.2118 & TRN & \\
\hline CHEMBL1318480 & 688877 & 4.7 & 5.5816 & TRN & \\
\hline CHEMBL15060 & 688877 & 6.1 & 6.1194 & TRN & \\
\hline CHEMBL1435447 & 688877 & 5.7 & 5.7104 & TRN & \\
\hline CHEMBL1406175 & 688877 & 4.8 & 5.8327 & TRN & \\
\hline CHEMBL1314371 & 688877 & 5.6 & 5.7677 & TRN & \\
\hline CHEMBL1481127 & 688877 & 5.5 & 5.7178 & TRN & \\
\hline CHEMBL1358614 & 688877 & 5.6 & 5.94600 & 0000000001 & TRN \\
\hline CHEMBL1361513 & 688877 & 5.05 & 5.6911 & TRN & \\
\hline CHEMBL182310 & 688877 & 4.6 & 5.1202 & TRN & \\
\hline CHEMBL444422 & 688877 & 4.6 & 5.2487 & TRN & \\
\hline CHEMBL1516701 & 688877 & 6.1 & 5.9724 & TRN & \\
\hline CHEMBL1397704 & 688877 & 5.0 & 5.7393 & TRN & \\
\hline CHEMBL1533335 & 688877 & 5.2 & 6.0685 & TRN & \\
\hline CHEMBL1484360 & 688877 & 5.6 & 5.8524 & TRN & \\
\hline CHEMBL1318340 & 688877 & 4.4 & 5.8554 & TRN & \\
\hline CHEMBL1589925 & 688877 & 5.45 & 5.4391 & TRN & \\
\hline CHEMBL1256360 & 688877 & 5.55 & 4.4993 & TRN & \\
\hline CHEMBL1490139 & 688877 & 4.85 & 5.6004 & TRN & \\
\hline CHEMBL1398050 & 688877 & 7.0501 & 6.1205 & TRN & \\
\hline CHEMBL1591815 & 688877 & 5.6 & 5.7807 & TRN & \\
\hline CHEMBL1314956 & 688877 & 5.6 & 5.5921 & TRN & \\
\hline CHEMBL344127 & 688877 & 4.5 & 5.7516 & TRN & \\
\hline CHEMBL1473996 & 688877 & 6.15 & 5.8707 & TRN & \\
\hline CHEMBL286722 & 688877 & 5.45 & 4.9261 & TRN & \\
\hline CHEMBL38576 & 688877 & 5.5 & 5.0418 & TRN & \\
\hline & & & & 4200 & \\
\hline
\end{tabular}




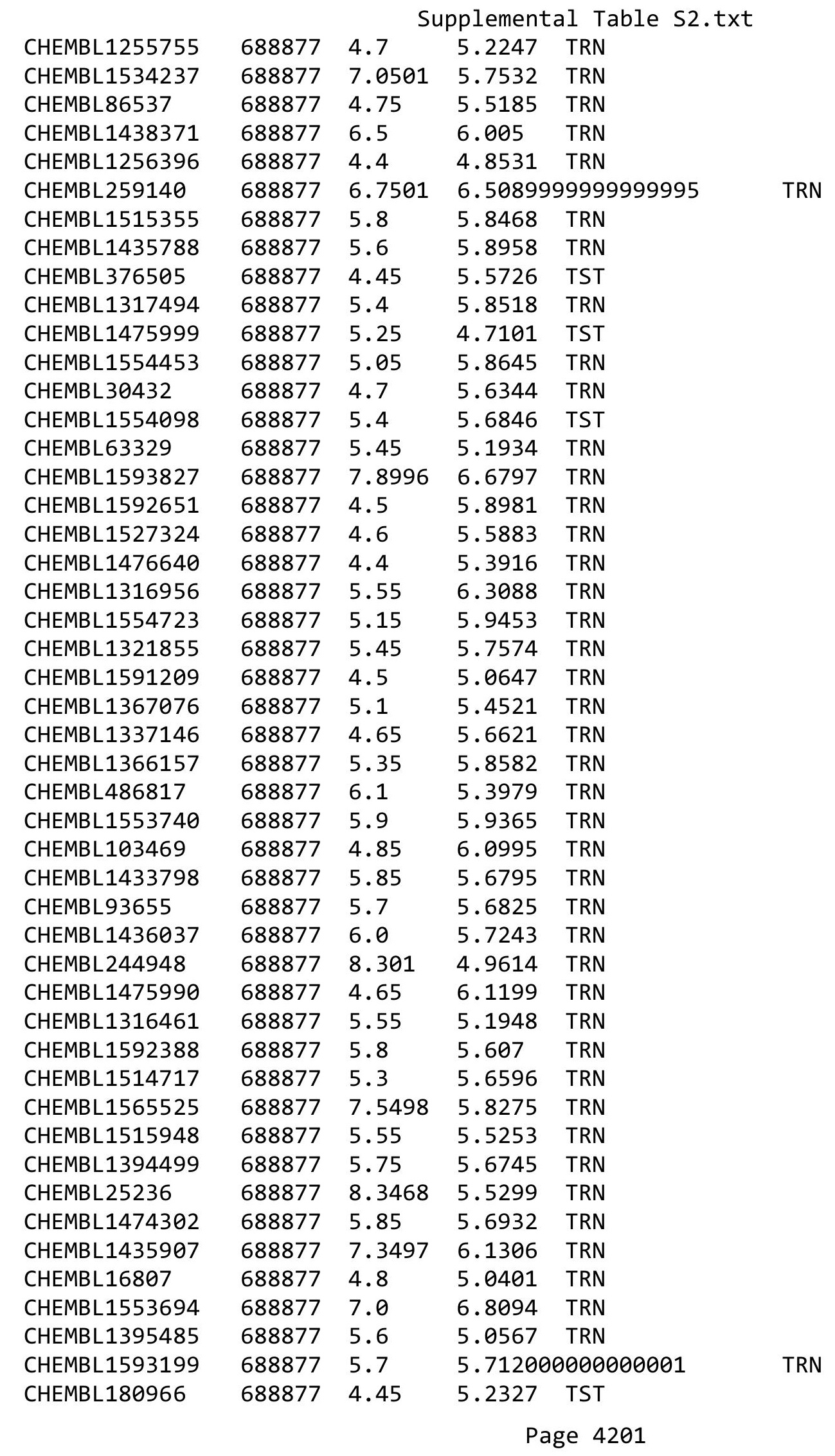




\begin{tabular}{|c|c|c|c|c|}
\hline & & & oplement & al $\mathrm{Tc}$ \\
\hline CHEMBL 294590 & 688877 & 8.6021 & 5.5672 & TRN \\
\hline CHEMBL1314906 & 688877 & 4.4 & 5.4183 & TRN \\
\hline CHEMBL1554717 & 688877 & 8.6576 & 5.3241 & TRN \\
\hline CHEMBL1552752 & 688877 & 7.0501 & 6.374 & TRN \\
\hline CHEMBL33103 & 688877 & 5.25 & 5.5724 & TRN \\
\hline CHEMBL1453208 & 688877 & 6.0 & 4.5838 & TRN \\
\hline CHEMBL 36148 & 688877 & 4.6 & 5.1506 & TRN \\
\hline CHEMBL1512782 & 688877 & 4.4 & 5.9877 & TRN \\
\hline CHEMBL1601121 & 688877 & 5.7 & 5.9738 & TRN \\
\hline CHEMBL1597474 & 688877 & 5.95 & 5.8471 & TRN \\
\hline CHEMBL1476170 & 688877 & 6.0 & 5.1375 & TST \\
\hline CHEMBL491943 & 688877 & 5.05 & 5.9512 & TRN \\
\hline CHEMBL1322233 & 688877 & 5.65 & 5.8046 & TRN \\
\hline CHEMBL1533843 & 688877 & 5.55 & 5.733 & TRN \\
\hline CHEMBL294747 & 688877 & 4.85 & 5.5135 & TRN \\
\hline CHEMBL489943 & 688877 & 5.6 & 5.4924 & TRN \\
\hline CHEMBL1418420 & 688877 & 7.0501 & 6.3814 & TRN \\
\hline CHEMBL1435296 & 688877 & 5.35 & 5.4573 & TRN \\
\hline CHEMBL 208484 & 688877 & 6.4 & 5.5172 & TRN \\
\hline CHEMBL1396809 & 688877 & 5.75 & 6.1155 & TRN \\
\hline CHEMBL1443796 & 688877 & 4.45 & 5.0094 & TRN \\
\hline CHEMBL1526543 & 688877 & 5.7 & 5.419 & TST \\
\hline CHEMBL1519472 & 688877 & 5.5 & 5.4142 & TRN \\
\hline CHEMBL1590242 & 688877 & 5.9 & 5.397 & TRN \\
\hline CHEMBL1436228 & 688877 & 4.4 & 5.4887 & TRN \\
\hline CHEMBL1449417 & 688877 & 5.55 & 5.6397 & TRN \\
\hline CHEMBL1406410 & 688877 & 6.0 & 5.6127 & TRN \\
\hline CHEMBL1514431 & 688877 & 5.45 & 5.8695 & TRN \\
\hline CHEMBL 1455462 & 688877 & 4.6 & 5.8495 & TRN \\
\hline CHEMBL1315845 & 688877 & 7.0 & 5.5541 & TRN \\
\hline CHEMBL294264 & 688877 & 4.8 & 4.4961 & TRN \\
\hline CHEMBL1398013 & 688877 & 6.2 & 5.723 & TRN \\
\hline CHEMBL1355216 & 688877 & 5.5 & 5.5061 & TRN \\
\hline CHEMBL11458 & 688877 & 4.95 & 5.9281 & TRN \\
\hline CHEMBL69367 & 688877 & 4.7 & 5.5063 & TRN \\
\hline CHEMBL1255935 & 688877 & 4.8 & 5.3533 & TRN \\
\hline CHEMBL1314225 & 688877 & 5.4 & 6.0761 & TRN \\
\hline CHEMBL16312 & 688877 & 7.9508 & 5.8074 & TRN \\
\hline CHEMBL1523613 & 688877 & 5.9 & 5.8172 & TRN \\
\hline CHEMBL1256180 & 688877 & 4.8 & 5.0066 & TST \\
\hline CHEMBL1461491 & 688877 & 4.4 & 5.0956 & TRN \\
\hline CHEMBL1517986 & 688877 & 4.85 & 5.1159 & TRN \\
\hline CHEMBL1255839 & 688877 & 6.0 & 5.2111 & TST \\
\hline CHEMBL1553136 & 688877 & 4.4 & 5.9995 & TRN \\
\hline CHEMBL1318114 & 688877 & 5.95 & 6.4089 & TRN \\
\hline CHEMBL1450334 & 688877 & 4.8 & 5.0544 & TRN \\
\hline CHEMBL1321846 & 688877 & 5.6 & 5.7493 & TRN \\
\hline CHEMBL1523450 & 688877 & 5.8 & 5.8652 & TRN \\
\hline
\end{tabular}




\begin{tabular}{|c|c|c|c|c|c|}
\hline \\
\hline CHEMBL566899 & 688877 & 5.2 & 6.0583 & TRN & \\
\hline CHEMBL1553247 & 688877 & 5.8 & 6.2135 & TRN & \\
\hline CHEMBL1475902 & 688877 & 5.95 & 5.9866 & TRN & \\
\hline CHEMBL10347 & 688877 & 6.0 & 5.704 & TST & \\
\hline CHEMBL1364717 & 688877 & 5.4 & 6.348 & TRN & \\
\hline CHEMBL1396773 & 688877 & 5.75 & 5.9824 & TRN & \\
\hline CHEMBL1533516 & 688877 & 5.5 & 5.7486 & TRN & \\
\hline CHEMBL39947 & 688877 & 5.1 & 5.1403 & TST & \\
\hline CHEMBL92708 & 688877 & 4.9 & 4.65600 & 0000000001 & TRN \\
\hline CHEMBL1560685 & 688877 & 4.9 & 5.227 & TRN & \\
\hline CHEMBL148296 & 688877 & 6.25 & 5.5561 & TRN & \\
\hline CHEMBL1403488 & 688877 & 4.4 & 5.2941 & TRN & \\
\hline CHEMBL1256885 & 688877 & 4.6 & 4.7136 & TRN & \\
\hline CHEMBL283196 & 688877 & 6.6499 & 5.3784 & TRN & \\
\hline CHEMBL1316463 & 688877 & 6.4 & 5.9317 & TRN & \\
\hline CHEMBL1593365 & 688877 & 4.95 & 4.9763 & TRN & \\
\hline CHEMBL1314286 & 688877 & 4.9 & 4.8781 & TST & \\
\hline CHEMBL 242384 & 688877 & 5.1 & 5.1749 & TRN & \\
\hline CHEMBL1562420 & 688877 & 5.05 & 5.41299 & 9999999999 & TRN \\
\hline CHEMBL1355387 & 688877 & 5.65 & 5.9126 & TRN & \\
\hline CHEMBL1515508 & 688877 & 4.75 & 5.3918 & TRN & \\
\hline CHEMBL1566571 & 688877 & 4.85 & 5.5279 & TRN & \\
\hline CHEMBL299683 & 688877 & 6.95 & 5.2327 & TRN & \\
\hline CHEMBL1256869 & 688877 & 4.8 & 5.6168 & TRN & \\
\hline CHEMBL77030 & 688877 & 5.1 & 5.07600 & 00000000005 & TRN \\
\hline CHEMBL1354281 & 688877 & 5.45 & 6.2544 & TRN & \\
\hline CHEMBL1255646 & 688877 & 5.5 & 5.2565 & TST & \\
\hline CHEMBL1474211 & 688877 & 5.15 & 6.0822 & TRN & \\
\hline CHEMBL50112 & 688877 & 4.85 & 5.3396 & TRN & \\
\hline CHEMBL1590975 & 688877 & 5.8 & 5.7118 & TRN & \\
\hline CHEMBL115225 & 688877 & 4.8 & 5.2856 & TRN & \\
\hline CHEMBL 330320 & 688877 & 6.0 & 5.447 & TRN & \\
\hline CHEMBL604119 & 688877 & 4.4 & 4.9156 & TST & \\
\hline CHEMBL1610995 & 688877 & 7.2503 & 5.9864 & TRN & \\
\hline CHEMBL68423 & 688877 & 6.05 & 5.9994 & TRN & \\
\hline CHEMBL1513063 & 688877 & 6.1 & 5.4029 & TRN & \\
\hline CHEMBL1395137 & 688877 & 4.4 & 5.6058 & TRN & \\
\hline CHEMBL1590831 & 688877 & 4.8 & 5.4007 & TRN & \\
\hline CHEMBL137803 & 688877 & 4.9 & 5.2767 & TST & \\
\hline CHEMBL1457262 & 688877 & 4.8 & 4.7143 & TRN & \\
\hline CHEMBL1443695 & 688877 & 5.45 & 6.0631 & TRN & \\
\hline CHEMBL1354154 & 688877 & 4.8 & 6.0514 & TRN & \\
\hline CHEMBL1374610 & 688877 & 4.9 & 4.8755 & TRN & \\
\hline CHEMBL1358562 & 688877 & 4.4 & 5.7425 & TRN & \\
\hline CHEMBL1316953 & 688877 & 4.4 & 5.151 & TST & \\
\hline CHEMBL1593867 & 688877 & 6.5501 & 5.7503 & TRN & \\
\hline CHEMBL15594 & 688877 & 4.5 & 4.905 & TRN & \\
\hline CHEMBL23327 & 688877 & 5.9 & 5.175 & TRN & \\
\hline
\end{tabular}




\begin{tabular}{|c|c|c|c|c|}
\hline \multicolumn{5}{|c|}{ Supplemental Table S2.txt } \\
\hline CHEMBL1397671 & 688877 & 5.7 & 5.8012 & TRN \\
\hline CHEMBL465843 & 688877 & 6.0 & 5.3339 & TRN \\
\hline CHEMBL66675 & 688877 & 4.8 & 5.2996 & TST \\
\hline CHEMBL1593545 & 688877 & 6.05 & 5.8857 & TRN \\
\hline CHEMBL1595111 & 688877 & 4.65 & 5.6009 & TRN \\
\hline CHEMBL1321655 & 688877 & 4.85 & 5.5094 & TRN \\
\hline CHEMBL445102 & 688877 & 4.45 & 5.1452 & TRN \\
\hline CHEMBL1609142 & 688877 & 6.0 & 6.1148 & TRN \\
\hline CHEMBL1512833 & 688877 & 6.45 & 6.4224 & TRN \\
\hline CHEMBL1079460 & 688877 & 4.6 & 5.23 & TST \\
\hline CHEMBL1318104 & 688877 & 5.7 & 5.5797 & TRN \\
\hline CHEMBL1329033 & 688877 & 4.9 & 5.0248 & TRN \\
\hline CHEMBL1553939 & 688877 & 4.65 & 5.6513 & TRN \\
\hline CHEMBL 252909 & 688877 & 4.4 & 5.4171 & TST \\
\hline CHEMBL1372037 & 688877 & 6.95 & 6.4633 & TRN \\
\hline CHEMBL 260629 & 688877 & 5.55 & 5.1077 & TRN \\
\hline CHEMBL1441843 & 688877 & 4.85 & 5.4548 & TRN \\
\hline CHEMBL1437046 & 688877 & 5.45 & 5.6467 & TRN \\
\hline CHEMBL1412163 & 688877 & 6.3 & 5.3827 & TRN \\
\hline CHEMBL16687 & 688877 & 6.0 & 5.5201 & TST \\
\hline CHEMBL1413097 & 688877 & 4.45 & 5.0091 & TST \\
\hline CHEMBL45244 & 688877 & 4.85 & 5.6736 & TRN \\
\hline CHEMBL126077 & 688877 & 6.0 & 5.2869 & TST \\
\hline CHEMBL 1256760 & 688877 & 5.15 & 5.3996 & TRN \\
\hline CHEMBL1318425 & 688877 & 4.85 & 5.8 & TST \\
\hline CHEMBL54909 & 688877 & 4.5 & 5.0723 & TRN \\
\hline CHEMBL1433805 & 688877 & 5.25 & 5.6039 & TRN \\
\hline CHEMBL 278041 & 688877 & 5.5 & 5.7541 & TRN \\
\hline CHEMBL1513119 & 688877 & 5.1 & 5.3145 & TST \\
\hline CHEMBL1591121 & 688877 & 6.5 & 6.4061 & TRN \\
\hline CHEMBL1552249 & 688877 & 5.3 & 4.5482 & TRN \\
\hline CHEMBL66 & 688877 & 4.4 & 4.7417 & TRN \\
\hline CHEMBL1590354 & 688877 & 5.45 & 5.7122 & TRN \\
\hline CHEMBL1455018 & 688877 & 5.5 & 5.8428 & TRN \\
\hline CHEMBL1356115 & 688877 & 4.45 & 4.7356 & TST \\
\hline CHEMBL1531837 & 688877 & 5.05 & 5.311 & TRN \\
\hline CHEMBL429023 & 688877 & 6.0 & 5.5516 & TRN \\
\hline CHEMBL1589893 & 688877 & 5.75 & 5.7925 & TRN \\
\hline CHEMBL1417771 & 688877 & 6.8499 & 6.8407 & TRN \\
\hline CHEMBL1362892 & 688877 & 5.95 & 5.2971 & TRN \\
\hline CHEMBL 250053 & 688877 & 4.85 & 5.3932 & TST \\
\hline CHEMBL1363513 & 688877 & 4.6 & 6.0912 & TRN \\
\hline CHEMBL1327772 & 688877 & 5.35 & 5.5078 & TRN \\
\hline CHEMBL1317712 & 688877 & 5.1 & 5.7488 & TRN \\
\hline CHEMBL1520394 & 688877 & 5.55 & 4.747 & TRN \\
\hline CHEMBL1364366 & 688877 & 5.35 & 6.0154 & TRN \\
\hline CHEMBL1474578 & 688877 & 6.1 & 5.4039 & TRN \\
\hline CHEMBL1417025 & 688877 & 5.25 & 5.6347 & TRN \\
\hline
\end{tabular}




\begin{tabular}{|c|c|c|c|c|c|}
\hline \multicolumn{6}{|c|}{ Supplemental Table s2.txt } \\
\hline CHEMBL1474261 & 688877 & 5.2 & 5.526 & TRN & \\
\hline CHEMBL1376543 & 688877 & 4.5 & 4.9209 & TST & \\
\hline CHEMBL1605510 & 688877 & 7.4498 & 5.9383 & TRN & \\
\hline CHEMBL1568735 & 688877 & 5.75 & 5.966 & TRN & \\
\hline CHEMBL1488918 & 688877 & 6.15 & 5.8597 & TRN & \\
\hline CHEMBL1476021 & 688877 & 7.4001 & 5.6771 & TRN & \\
\hline CHEMBL1516005 & 688877 & 6.2 & 5.8371 & TRN & \\
\hline CHEMBL1316055 & 688877 & 7.0 & 6.4474 & TRN & \\
\hline CHEMBL 88584 & 688877 & 8.6021 & 5.5884 & TST & \\
\hline CHEMBL1593547 & 688877 & 6.35 & 5.6447 & TRN & \\
\hline CHEMBL1324889 & 688877 & 4.85 & 5.931 & TRN & \\
\hline CHEMBL1474532 & 688877 & 4.45 & 4.6117 & TRN & \\
\hline CHEMBL1551284 & 688877 & 8.0506 & 5.9539 & TRN & \\
\hline CHEMBL 94990 & 688877 & 4.4 & 4.9823 & TRN & \\
\hline CHEMBL1512756 & 688877 & 5.75 & 5.3948 & TRN & \\
\hline CHEMBL61605 & 688877 & 4.85 & 4.9418 & TST & \\
\hline CHEMBL1442538 & 688877 & 5.55 & 5.8892 & TRN & \\
\hline CHEMBL611494 & 688877 & 4.8 & 5.706 & TRN & \\
\hline CHEMBL1590378 & 688877 & 4.45 & 4.8435 & TRN & \\
\hline CHEMBL1593128 & 688877 & 5.45 & 5.8617 & TRN & \\
\hline CHEMBL1396463 & 688877 & 5.15 & 5.2314 & TST & \\
\hline CHEMBL1358090 & 688877 & 7.2503 & 5.8543 & TRN & \\
\hline CHEMBL1395089 & 688877 & 6.9 & 6.45200 & 0000000001 & TRN \\
\hline CHEMBL1356808 & 688877 & 5.75 & 5.955 & TRN & \\
\hline CHEMBL1513223 & 688877 & 5.15 & 5.8669 & TRN & \\
\hline CHEMBL1355224 & 688877 & 4.4 & 5.1859 & TRN & \\
\hline CHEMBL1433776 & 688877 & 5.5 & 5.8768 & TRN & \\
\hline CHEMBL1608125 & 688877 & 5.45 & 6.2203 & TRN & \\
\hline CHEMBL1473753 & 688877 & 4.4 & 5.7107 & TRN & \\
\hline CHEMBL1534347 & 688877 & 5.0 & 5.3468 & TRN & \\
\hline CHEMBL1256746 & 688877 & 6.0 & 4.7311 & TRN & \\
\hline CHEMBL 250428 & 688877 & 5.6 & 5.6519 & TRN & \\
\hline CHEMBL1302867 & 688877 & 4.6 & 5.1132 & TST & \\
\hline CHEMBL489737 & 688877 & 5.75 & 5.984 & TRN & \\
\hline CHEMBL1354678 & 688877 & 4.4 & 5.6547 & TRN & \\
\hline CHEMBL410063 & 688877 & 5.2 & 5.5275 & TST & \\
\hline CHEMBL1558777 & 688877 & 6.7001 & 5.6954 & TRN & \\
\hline CHEMBL 272005 & 688877 & 5.15 & 5.5107 & TRN & \\
\hline CHEMBL1591874 & 688877 & 6.7501 & 5.7746 & TRN & \\
\hline CHEMBL66654 & 688877 & 5.2 & 5.7266 & TST & \\
\hline CHEMBL448741 & 688877 & 4.55 & 4.5378 & TRN & \\
\hline CHEMBL 291536 & 688877 & 5.7 & 5.9735 & TRN & \\
\hline CHEMBL15927 & 688877 & 4.5 & 4.802 & TRN & \\
\hline CHEMBL1604095 & 688877 & 5.6 & 5.7039 & TRN & \\
\hline CHEMBL1559654 & 688877 & 7.6498 & 6.1921 & TRN & \\
\hline CHEMBL1255934 & 688877 & 5.55 & 5.5916 & TST & \\
\hline CHEMBL1317172 & 688877 & 8.301 & 5.6116 & TRN & \\
\hline CHEMBL267458 & 688877 & 4.5 & 5.4907 & TRN & \\
\hline
\end{tabular}




\begin{tabular}{|c|c|c|c|c|c|}
\hline \multirow[b]{2}{*}{ CHEMBL1515717 } & \multicolumn{5}{|c|}{ Supplemental Table S2.txt } \\
\hline & 688877 & 7.4498 & 6.3115 & TRN & \\
\hline CHEMBL1552727 & 688877 & 5.6 & 5.8629 & TRN & \\
\hline CHEMBL125569 & 688877 & 4.8 & 5.4843 & TST & \\
\hline CHEMBL1397192 & 688877 & 6.7001 & 5.54799 & 9999999999 & TRN \\
\hline CHEMBL1478 & 688877 & 4.4 & 4.9656 & TRN & \\
\hline CHEMBL1483625 & 688877 & 5.5 & 5.83700 & 0000000001 & TRN \\
\hline CHEMBL1527923 & 688877 & 5.2 & 5.8374 & TRN & \\
\hline CHEMBL1600347 & 688877 & 4.7 & 4.8664 & TRN & \\
\hline CHEMBL1323714 & 688877 & 4.8 & 5.1278 & TST & \\
\hline CHEMBL25230 & 688877 & 4.55 & 4.9963 & TST & \\
\hline CHEMBL1474890 & 688877 & 6.35 & 6.2606 & TRN & \\
\hline CHEMBL1565133 & 688877 & 4.8 & 5.7501 & TRN & \\
\hline CHEMBL1481399 & 688877 & 4.55 & 5.6631 & TRN & \\
\hline CHEMBL41680 & 688877 & 8.6576 & 5.1978 & TST & \\
\hline CHEMBL1524760 & 688877 & 4.5 & 4.9824 & TST & \\
\hline CHEMBL1397636 & 688877 & 6.3 & 6.2086 & TRN & \\
\hline CHEMBL1449133 & 688877 & 4.45 & 5.0632 & TST & \\
\hline CHEMBL1475338 & 688877 & 7.1002 & 6.8417 & TRN & \\
\hline CHEMBL1400043 & 688877 & 5.45 & 6.0058 & TRN & \\
\hline CHEMBL1408703 & 688877 & 6.8499 & 6.2413 & TRN & \\
\hline CHEMBL 1256514 & 688877 & 4.4 & 5.4322 & TST & \\
\hline CHEMBL1552277 & 688877 & 6.05 & 6.2029 & TRN & \\
\hline CHEMBL1515829 & 688877 & 4.85 & 5.7322 & TRN & \\
\hline CHEMBL1443745 & 688877 & 4.45 & 5.1022 & TST & \\
\hline CHEMBL1400637 & 688877 & 6.8 & 5.7213 & TRN & \\
\hline CHEMBL47529 & 688877 & 5.6 & 5.5208 & TRN & \\
\hline CHEMBL1316808 & 688877 & 5.6 & 5.5707 & TRN & \\
\hline CHEMBL 74913 & 688877 & 4.45 & 5.732 & TRN & \\
\hline CHEMBL1435259 & 688877 & 6.1 & 6.1151 & TRN & \\
\hline CHEMBL398673 & 688877 & 4.5 & 5.3609 & TST & \\
\hline CHEMBL1479817 & 688877 & 6.45 & 5.9989 & TRN & \\
\hline CHEMBL1396907 & 688877 & 4.45 & 5.4283 & TRN & \\
\hline CHEMBL1395431 & 688877 & 4.7 & 5.7712 & TRN & \\
\hline CHEMBL39 & 688877 & 4.35 & 5.1404 & TRN & \\
\hline CHEMBL 285843 & 688877 & 4.8 & 4.9754 & TRN & \\
\hline CHEMBL1415231 & 688877 & 6.0 & 6.2431 & TRN & \\
\hline CHEMBL269521 & 688877 & 4.8 & 5.3004 & TRN & \\
\hline CHEMBL 284895 & 688877 & 4.4 & 4.99100 & 00000000005 & TRN \\
\hline CHEMBL1318042 & 688877 & 6.3 & 5.6472 & TRN & \\
\hline CHEMBL340807 & 688877 & 6.0 & 5.9766 & TRN & \\
\hline CHEMBL1398456 & 688877 & 5.6 & 4.9749 & TRN & \\
\hline CHEMBL1452716 & 688877 & 4.9 & 5.9189 & TST & \\
\hline CHEMBL1496590 & 688877 & 6.35 & 5.7709 & TRN & \\
\hline CHEMBL1355909 & 688877 & 4.7 & 5.2344 & TRN & \\
\hline CHEMBL1590598 & 688877 & 6.2 & 6.1605 & TRN & \\
\hline CHEMBL1256875 & 688877 & 6.9 & 5.44 & TRN & \\
\hline CHEMBL1437176 & 688877 & 5.3 & 5.6614 & TRN & \\
\hline CHEMBL1370891 & 688877 & 4.4 & 4.7697 & TRN & \\
\hline
\end{tabular}




\begin{tabular}{|c|c|c|c|c|}
\hline \multicolumn{5}{|c|}{ Supplemental Table S2.txt } \\
\hline CHEMBL1475657 & 688877 & 5.75 & 5.6033 & TRN \\
\hline CHEMBL1605255 & 688877 & 5.95 & 5.7115 & TRN \\
\hline CHEMBL1527221 & 688877 & 5.4 & 5.6787 & TRN \\
\hline CHEMBL1435912 & 688877 & 5.85 & 6.0048 & TRN \\
\hline CHEMBL1455570 & 688877 & 5.9 & 6.0182 & TRN \\
\hline CHEMBL1434817 & 688877 & 5.9 & 5.5236 & TRN \\
\hline CHEMBL1434550 & 688877 & 5.2 & 4.8416 & TRN \\
\hline CHEMBL1322743 & 688877 & 8.301 & 5.8739 & TRN \\
\hline CHEMBL322970 & 688877 & 4.8 & 4.8944 & TST \\
\hline CHEMBL243663 & 688877 & 4.55 & 5.1663 & TRN \\
\hline CHEMBL1585944 & 688877 & 4.8 & 4.7902 & TRN \\
\hline CHEMBL1398528 & 688877 & 5.25 & 5.959 & TRN \\
\hline CHEMBL1444141 & 688877 & 5.5 & 5.6463 & TRN \\
\hline CHEMBL1357956 & 688877 & 5.65 & 5.5964 & TRN \\
\hline CHEMBL1396862 & 688877 & 5.7 & 5.6206 & TRN \\
\hline CHEMBL1323290 & 688877 & 4.65 & 5.1651 & TRN \\
\hline CHEMBL1523594 & 688877 & 6.6 & 5.8139 & TRN \\
\hline CHEMBL 85251 & 688877 & 4.8 & 4.7134 & TRN \\
\hline CHEMBL1437488 & 688877 & 4.9 & 5.5072 & TRN \\
\hline CHEMBL1593859 & 688877 & 6.8499 & 5.6356 & TRN \\
\hline CHEMBL169233 & 688877 & 5.75 & 5.1319 & TST \\
\hline CHEMBL1441787 & 688877 & 5.25 & 5.6465 & TRN \\
\hline CHEMBL1315530 & 688877 & 7.4498 & 5.6178 & TRN \\
\hline CHEMBL1606199 & 688877 & 6.2 & 5.6775 & TRN \\
\hline CHEMBL1256749 & 688877 & 6.0 & 5.0051 & TST \\
\hline CHEMBL502044 & 688877 & 5.2 & 4.83 & TST \\
\hline CHEMBL1255936 & 688877 & 5.0 & 5.345 & TRN \\
\hline CHEMBL1378208 & 688877 & 5.45 & 5.749 & TRN \\
\hline CHEMBL1314469 & 688877 & 4.15 & 5.1397 & TST \\
\hline CHEMBL1363481 & 688877 & 5.7 & 5.6477 & TRN \\
\hline CHEMBL1435120 & 688877 & 8.4949 & 5.6582 & TRN \\
\hline CHEMBL1534413 & 688877 & 5.75 & 5.5902 & TRN \\
\hline CHEMBL168276 & 688877 & 4.6 & 4.7513 & TRN \\
\hline CHEMBL1457390 & 688877 & 5.5 & 5.9804 & TRN \\
\hline CHEMBL1401031 & 688877 & 7.0501 & 5.8569 & TRN \\
\hline CHEMBL1476712 & 688877 & 4.4 & 5.3405 & TRN \\
\hline CHEMBL1592966 & 688877 & 6.4 & 5.9689 & TRN \\
\hline CHEMBL1357338 & 688877 & 6.2 & 5.8271 & TRN \\
\hline CHEMBL1476504 & 688877 & 5.75 & 5.6913 & TRN \\
\hline CHEMBL1485984 & 688877 & 4.8 & 4.7534 & TST \\
\hline CHEMBL1592160 & 688877 & 5.1 & 5.3162 & TRN \\
\hline CHEMBL1408808 & 688877 & 4.55 & 5.1335 & TST \\
\hline CHEMBL1593337 & 688877 & 5.25 & 5.4769 & TRN \\
\hline CHEMBL1336803 & 688877 & 6.95 & 6.0378 & TRN \\
\hline CHEMBL1551847 & 688877 & 4.4 & 5.1266 & TRN \\
\hline CHEMBL1436726 & 688877 & 6.05 & 5.4302 & TRN \\
\hline CHEMBL1327619 & 688877 & 4.85 & 5.5257 & TRN \\
\hline CHEMBL1514910 & 688877 & 4.9 & 5.6943 & TST \\
\hline
\end{tabular}




\begin{tabular}{|c|c|c|c|c|c|}
\hline \multicolumn{6}{|c|}{ Supplemental Table S2.txt } \\
\hline CHEMBL222334 & 688877 & 5.2 & 4.5138 & TRN & \\
\hline CHEMBL317757 & 688877 & 6.1 & 5.1247 & TRN & \\
\hline CHEMBL1355227 & 688877 & 5.3 & 5.7728 & TRN & \\
\hline CHEMBL1558135 & 688877 & 6.0 & 5.6439 & TRN & \\
\hline CHEMBL7463 & 688877 & 4.8 & 5.3763 & TRN & \\
\hline CHEMBL1436917 & 688877 & 4.55 & 5.7602 & TRN & \\
\hline CHEMBL318779 & 688877 & 5.25 & 5.0156 & TRN & \\
\hline CHEMBL1366926 & 688877 & 5.1 & 5.3457 & TRN & \\
\hline CHEMBL275084 & 688877 & 7.6498 & 5.4487 & TRN & \\
\hline CHEMBL123433 & 688877 & 4.45 & 5.5811 & TST & \\
\hline CHEMBL1318045 & 688877 & 8.2518 & 6.2545 & TRN & \\
\hline CHEMBL1728023 & 688877 & 4.5 & 5.0526 & TRN & \\
\hline CHEMBL1591757 & 688877 & 6.8499 & 5.7512 & TRN & \\
\hline CHEMBL1396822 & 688877 & 4.8 & 5.0427 & TST & \\
\hline CHEMBL1531250 & 688877 & 5.85 & 5.6296 & TRN & \\
\hline CHEMBL 260374 & 688877 & 5.4 & 5.7725 & TST & \\
\hline CHEMBL1473055 & 688877 & 5.95 & 5.5731 & TRN & \\
\hline CHEMBL1334465 & 688877 & 5.95 & 5.6742 & TRN & \\
\hline CHEMBL1403333 & 688877 & 6.0 & 5.705 & TRN & \\
\hline CHEMBL1551090 & 688877 & 6.5501 & 5.7596 & TRN & \\
\hline CHEMBL1590645 & 688877 & 4.9 & 5.885 & TRN & \\
\hline CHEMBL1512701 & 688877 & 6.8499 & 6.3983 & TRN & \\
\hline CHEMBL67535 & 688877 & 5.3 & 5.1653 & TRN & \\
\hline CHEMBL 8165 & 688877 & 7.0 & 5.8147 & TRN & \\
\hline CHEMBL1256656 & 688877 & 5.1 & 5.6471 & TRN & \\
\hline CHEMBL1433950 & 688877 & 6.4 & 5.5939 & TRN & \\
\hline CHEMBL1514359 & 688877 & 5.0 & 5.8097 & TRN & \\
\hline CHEMBL1710 & 688877 & 4.5 & 4.541 & TRN & \\
\hline CHEMBL1317884 & 688877 & 4.75 & 5.7999 & TRN & \\
\hline CHEMBL369142 & 688877 & 5.75 & 5.2069 & TRN & \\
\hline CHEMBL1477081 & 688877 & 4.55 & 4.8615 & TRN & \\
\hline CHEMBL1516028 & 688877 & 5.8 & 6.0116 & TRN & \\
\hline CHEMBL1551962 & 688877 & 6.35 & 5.9891 & TRN & \\
\hline CHEMBL18879 & 688877 & 4.8 & 4.9849 & TST & \\
\hline CHEMBL1568575 & 688877 & 8.1024 & 6.3109 & TRN & \\
\hline CHEMBL1554246 & 688877 & 4.85 & 5.3691 & TRN & \\
\hline CHEMBL399249 & 688877 & 4.55 & 4.6517 & TRN & \\
\hline CHEMBL1434369 & 688877 & 5.65 & 5.6888 & TRN & \\
\hline CHEMBL1593663 & 688877 & 7.8013 & 6.12700 & 0000000001 & TRN \\
\hline CHEMBL1600620 & 688877 & 6.5501 & 5.9129 & TRN & \\
\hline CHEMBL1373007 & 688877 & 5.0 & 5.8242 & TST & \\
\hline CHEMBL1356497 & 688877 & 5.35 & 5.2902 & TRN & \\
\hline CHEMBL1516388 & 688877 & 6.0 & 4.8374 & TST & \\
\hline CHEMBL1474479 & 688877 & 5.8 & 5.0886 & TRN & \\
\hline CHEMBL112362 & 688877 & 4.45 & 5.0586 & TST & \\
\hline CHEMBL1553766 & 688877 & 6.05 & 5.6233 & TRN & \\
\hline CHEMBL1480903 & 688877 & 4.85 & 5.7323 & TRN & \\
\hline CHEMBL1472765 & 688877 & 5.45 & 5.8256 & TRN & \\
\hline
\end{tabular}




\begin{tabular}{|c|c|c|c|c|}
\hline \multirow[b]{2}{*}{ CHEMBL1314446 } & \multicolumn{4}{|c|}{ Supplemental Table S2.txt } \\
\hline & 688877 & 7.4001 & 6.0311 & TRN \\
\hline CHEMBL1395297 & 688877 & 8.0 & 5.4583 & TRN \\
\hline CHEMBL1592803 & 688877 & 5.5 & 6.3792 & TRN \\
\hline CHEMBL1552519 & 688877 & 5.25 & 5.669 & TRN \\
\hline CHEMBL109037 & 688877 & 4.7 & 4.7751 & TRN \\
\hline CHEMBL1494177 & 688877 & 5.55 & 5.7792 & TRN \\
\hline CHEMBL1480806 & 688877 & 5.55 & 5.6444 & TRN \\
\hline CHEMBL1477140 & 688877 & 5.45 & 5.8028 & TRN \\
\hline CHEMBL1335889 & 688877 & 5.5 & 6.2935 & TRN \\
\hline CHEMBL1323759 & 688877 & 7.2 & 5.8346 & TRN \\
\hline CHEMBL1397913 & 688877 & 4.9 & 4.9485 & TRN \\
\hline CHEMBL1412842 & 688877 & 6.0 & 5.709 & TRN \\
\hline CHEMBL1551503 & 688877 & 5.85 & 6.0063 & TRN \\
\hline CHEMBL1411146 & 688877 & 5.35 & 5.2893 & TRN \\
\hline CHEMBL1473448 & 688877 & 5.3 & 5.2343 & TRN \\
\hline CHEMBL1361725 & 688877 & 5.95 & 5.5085 & TRN \\
\hline CHEMBL1435079 & 688877 & 5.1 & 5.4675 & TRN \\
\hline CHEMBL1591080 & 688877 & 5.3 & 5.5226 & TRN \\
\hline CHEMBL 294649 & 688877 & 4.9 & 5.4962 & TRN \\
\hline CHEMBL1360434 & 688877 & 6.1 & 5.6254 & TRN \\
\hline CHEMBL1475381 & 688877 & 4.75 & 5.8858 & TRN \\
\hline CHEMBL56731 & 688877 & 5.75 & 5.3729 & TRN \\
\hline CHEMBL1454284 & 688877 & 9.0458 & 5.1422 & TST \\
\hline CHEMBL409024 & 688877 & 4.65 & 4.7739 & TRN \\
\hline CHEMBL1357231 & 688877 & 5.95 & 5.284 & TRN \\
\hline CHEMBL1372371 & 688877 & 5.4 & 5.7093 & TRN \\
\hline CHEMBL 225513 & 688877 & 4.7 & 4.8609 & TRN \\
\hline CHEMBL252721 & 688877 & 6.5501 & 5.9951 & TRN \\
\hline CHEMBL1597812 & 688877 & 5.1 & 4.7104 & TRN \\
\hline CHEMBL1442458 & 688877 & 5.35 & 5.4969 & TRN \\
\hline CHEMBL1521167 & 688877 & 4.7 & 5.17899 & 9999999999 \\
\hline CHEMBL1555153 & 688877 & 4.8 & 5.2099 & TST \\
\hline CHEMBL1407217 & 688877 & 6.0 & 5.858 & TRN \\
\hline CHEMBL26320 & 688877 & 4.85 & 4.8886 & TRN \\
\hline CHEMBL1358208 & 688877 & 5.55 & 5.6921 & TRN \\
\hline CHEMBL1355089 & 688877 & 7.0 & 5.6193 & TRN \\
\hline CHEMBL1474684 & 688877 & 4.55 & 4.7505 & TST \\
\hline CHEMBL1450004 & 688877 & 4.5 & 4.9927 & TST \\
\hline CHEMBL1440619 & 688877 & 5.5 & 6.0748 & TRN \\
\hline CHEMBL1395030 & 688877 & 5.2 & 4.8948 & TRN \\
\hline CHEMBL27403 & 688877 & 4.45 & 4.9435 & TRN \\
\hline CHEMBL1604283 & 688877 & 5.15 & 5.0943 & TST \\
\hline CHEMBL1514016 & 688877 & 7.3002 & 5.6831 & TRN \\
\hline CHEMBL1402957 & 688877 & 4.5 & 5.2176 & TST \\
\hline CHEMBL 1255746 & 688877 & 4.45 & 5.1988 & TST \\
\hline CHEMBL1592464 & 688877 & 5.6 & 6.1018 & TRN \\
\hline CHEMBL375629 & 688877 & 4.5 & 4.9275 & TRN \\
\hline CHEMBL85194 & 688877 & 5.6 & 6.0962 & TRN \\
\hline
\end{tabular}




\begin{tabular}{|c|c|c|c|c|}
\hline \multicolumn{5}{|c|}{ Supplemental Table s2.txt } \\
\hline CHEMBL1443376 & 688877 & 5.1 & 5.6034 & TST \\
\hline CHEMBL1336787 & 688877 & 6.25 & 5.7295 & TRN \\
\hline CHEMBL1725279 & 688877 & 5.4 & 5.1118 & TST \\
\hline CHEMBL434063 & 688877 & 6.0 & 5.6454 & TST \\
\hline CHEMBL1318512 & 688877 & 5.35 & 6.0294 & TRN \\
\hline CHEMBL1593096 & 688877 & 5.15 & 5.0436 & TRN \\
\hline CHEMBL1475428 & 688877 & 5.5 & 5.7795 & TRN \\
\hline CHEMBL1610003 & 688877 & 5.8 & 5.3565 & TRN \\
\hline CHEMBL1256865 & 688877 & 4.7 & 5.3072 & TRN \\
\hline CHEMBL1513985 & 688877 & 4.55 & 5.3957 & TRN \\
\hline CHEMBL267179 & 688877 & 5.4 & 4.9933 & TRN \\
\hline CHEMBL1357463 & 688877 & 5.05 & 6.2181 & TRN \\
\hline CHEMBL1551925 & 688877 & 4.8 & 5.6714 & TRN \\
\hline CHEMBL24909 & 688877 & 4.9 & 5.8964 & TRN \\
\hline CHEMBL1526852 & 688877 & 5.1 & 4.9216 & TRN \\
\hline CHEMBL1325335 & 688877 & 5.8 & 5.4722 & TRN \\
\hline CHEMBL1479792 & 688877 & 5.25 & 5.1708 & TRN \\
\hline CHEMBL1482446 & 688877 & 4.55 & 5.5183 & TRN \\
\hline CHEMBL1551477 & 688877 & 5.55 & 5.9957 & TRN \\
\hline CHEMBL1552984 & 688877 & 4.6 & 5.2205 & TRN \\
\hline CHEMBL1514976 & 688877 & 6.5501 & 5.6698 & TRN \\
\hline CHEMBL 285241 & 688877 & 4.8 & 4.9222 & TRN \\
\hline CHEMBL520107 & 688877 & 4.5 & 5.2505 & TST \\
\hline CHEMBL395827 & 688877 & 4.4 & 4.8255 & TST \\
\hline CHEMBL45176 & 688877 & 5.95 & 5.6736 & TRN \\
\hline CHEMBL522121 & 688877 & 5.45 & 6.1668 & TRN \\
\hline CHEMBL1514517 & 688877 & 5.6 & 5.5384 & TRN \\
\hline CHEMBL1438719 & 688877 & 4.8 & 4.7652 & TST \\
\hline CHEMBL1255841 & 688877 & 6.0 & 4.8587 & TRN \\
\hline CHEMBL1256024 & 688877 & 4.4 & 5.0161 & TST \\
\hline CHEMBL1358297 & 688877 & 4.5 & 5.2545 & TST \\
\hline CHEMBL1609528 & 688877 & 5.5 & 5.6169 & TRN \\
\hline CHEMBL1317537 & 688877 & 6.3 & 5.6902 & TRN \\
\hline CHEMBL1476009 & 688877 & 5.3 & 5.9211 & TRN \\
\hline CHEMBL1590266 & 688877 & 5.3 & 5.9111 & TRN \\
\hline CHEMBL1514719 & 688877 & 5.45 & 5.6493 & TRN \\
\hline CHEMBL491977 & 688877 & 5.4 & 5.4894 & TRN \\
\hline CHEMBL1559246 & 688877 & 5.6 & 6.1723 & TRN \\
\hline CHEMBL1315292 & 688877 & 5.4 & 5.7057 & TRN \\
\hline CHEMBL1610375 & 688877 & 5.7 & 6.2479 & TRN \\
\hline CHEMBL1474195 & 688877 & 6.0 & 6.1765 & TRN \\
\hline CHEMBL1314182 & 688877 & 4.65 & 5.7466 & TRN \\
\hline CHEMBL1315109 & 688877 & 5.15 & 5.669 & TRN \\
\hline CHEMBL1417552 & 688877 & 5.2 & 5.8218 & TRN \\
\hline CHEMBL172064 & 688877 & 4.85 & 5.2459 & TST \\
\hline CHEMBL1531754 & 688877 & 5.5 & 5.6189 & TRN \\
\hline CHEMBL107131 & 688877 & 5.35 & 5.1494 & TRN \\
\hline CHEMBL1405546 & 688877 & 5.95 & 5.9611 & TRN \\
\hline
\end{tabular}




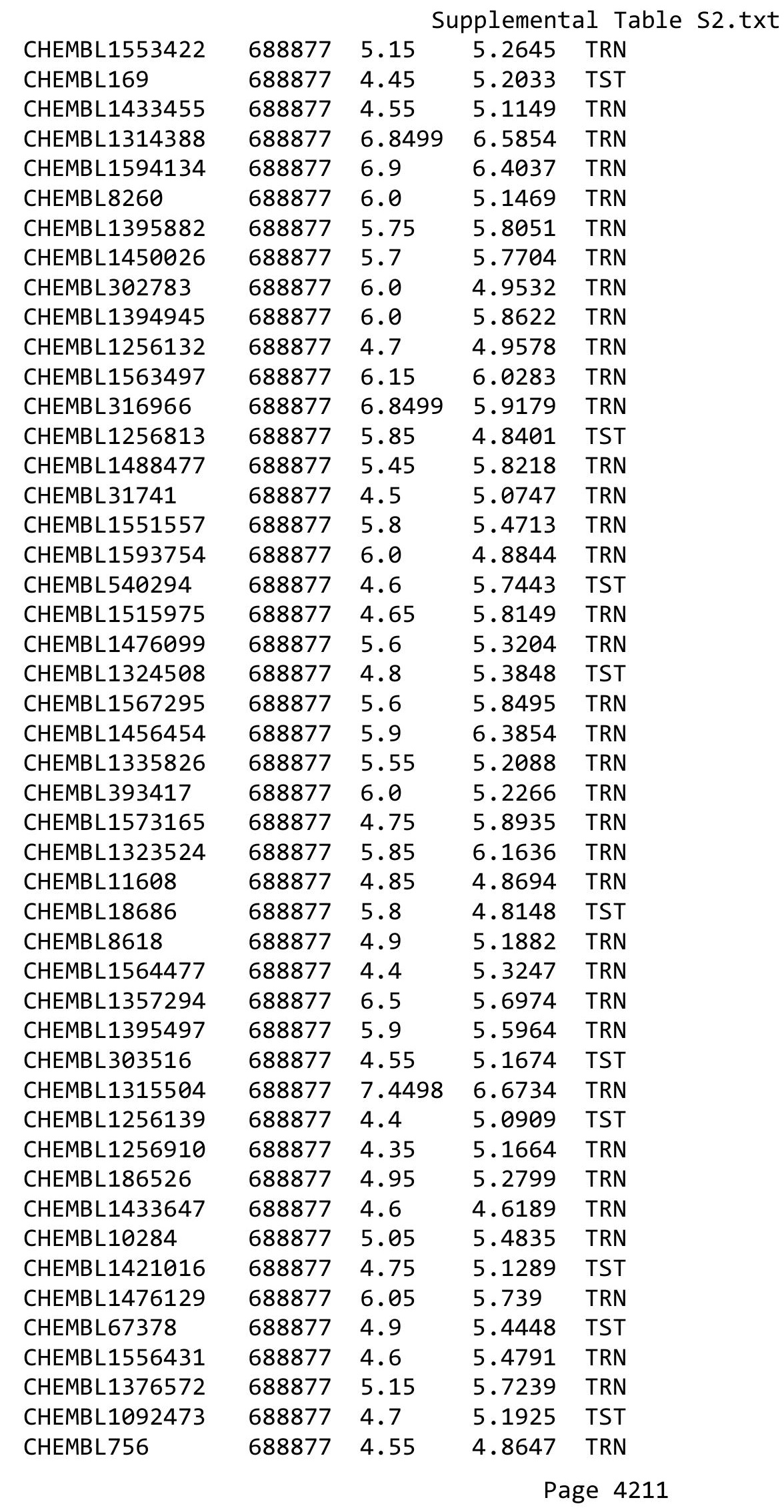




\begin{tabular}{|c|c|c|c|c|c|}
\hline & & \multicolumn{4}{|c|}{ Supplemental Table S2.txt } \\
\hline CHEMBL1513654 & 688877 & 6.8499 & 5.0595 & TST & \\
\hline CHEMBL 1456076 & 688877 & 5.7 & 5.8968 & TRN & \\
\hline CHEMBL596674 & 688877 & 6.0 & 5.1449 & TST & \\
\hline CHEMBL1396010 & 688877 & 6.05 & 5.8914 & TRN & \\
\hline CHEMBL1775009 & 688877 & 4.5 & 5.6558 & TRN & \\
\hline CHEMBL1364995 & 688877 & 5.35 & 5.7767 & TRN & \\
\hline CHEMBL1373796 & 688877 & 6.2 & 5.6038 & TRN & \\
\hline CHEMBL286204 & 688877 & 5.05 & 5.5996 & TST & \\
\hline CHEMBL1572855 & 688877 & 7.0501 & 5.8161 & TRN & \\
\hline CHEMBL 2374027 & 688877 & 4.35 & 4.7953 & TRN & \\
\hline CHEMBL1315374 & 688877 & 4.4 & 5.4694 & TRN & \\
\hline CHEMBL1484738 & 688877 & 5.15 & \multicolumn{2}{|c|}{5.2410000000000005} & TST \\
\hline CHEMBL1414073 & 688877 & 8.2518 & 6.0722 & TRN & \\
\hline CHEMBL1434715 & 688877 & 5.8 & 5.4598 & TRN & \\
\hline CHEMBL 242172 & 688877 & 5.35 & 5.224 & TRN & \\
\hline CHEMBL1472753 & 688877 & 6.25 & 5.9409 & TRN & \\
\hline CHEMBL1473205 & 688877 & 5.0 & 5.3271 & TRN & \\
\hline CHEMBL465339 & 688877 & 7.15 & 5.1353 & TRN & \\
\hline CHEMBL1551639 & 688877 & 5.15 & 5.5531 & TRN & \\
\hline CHEMBL1316337 & 688877 & 5.5 & 5.9871 & TRN & \\
\hline CHEMBL60718 & 688877 & 4.45 & 5.0215 & TRN & \\
\hline CHEMBL1495665 & 688877 & 5.9 & 5.8918 & TRN & \\
\hline CHEMBL1516054 & 688877 & 7.2 & 6.2873 & TRN & \\
\hline CHEMBL 388342 & 688877 & 4.8 & 4.9436 & TRN & \\
\hline CHEMBL1532517 & 688877 & 5.75 & 5.5778 & TRN & \\
\hline CHEMBL1256663 & 688877 & 5.4 & 5.4079 & TRN & \\
\hline CHEMBL1330317 & 688877 & 6.05 & \multicolumn{2}{|c|}{5.167999999999999} & TRN \\
\hline CHEMBL1450521 & 688877 & 5.6 & 6.0127 & TRN & \\
\hline CHEMBL1314749 & 688877 & 4.5 & 4.7636 & TRN & \\
\hline CHEMBL1395417 & 688877 & 5.35 & 5.7118 & TRN & \\
\hline CHEMBL1237212 & 688877 & 4.8 & 5.2986 & TST & \\
\hline CHEMBL1374585 & 688877 & 5.2 & 5.2253 & TRN & \\
\hline CHEMBL1554577 & 688877 & 6.15 & 6.2397 & TRN & \\
\hline CHEMBL1316828 & 688877 & 5.1 & 4.6806 & TRN & \\
\hline CHEMBL1512562 & 688877 & 5.75 & 6.1117 & TRN & \\
\hline CHEMBL1436438 & 688877 & 6.0 & 5.9363 & TRN & \\
\hline CHEMBL920 & 688877 & 5.3 & 5.1972 & TST & \\
\hline CHEMBL294989 & 688877 & 4.85 & 4.7903 & TRN & \\
\hline CHEMBL1612062 & 688877 & 4.4 & 5.2196 & TST & \\
\hline CHEMBL 242383 & 688877 & 4.4 & 5.1729 & TRN & \\
\hline CHEMBL1513050 & 688877 & 4.8 & 5.2348 & TST & \\
\hline CHEMBL568379 & 688877 & 5.45 & 5.5229 & TRN & \\
\hline CHEMBL1474151 & 688877 & 4.4 & 5.9645 & TRN & \\
\hline CHEMBL1444856 & 688877 & 5.4 & 5.1494 & TRN & \\
\hline CHEMBL1358284 & 688877 & 5.6 & 5.2355 & TRN & \\
\hline CHEMBL1416476 & 688877 & 7.4001 & 6.5508 & TRN & \\
\hline CHEMBL1551884 & 688877 & 4.5 & 5.3903 & TRN & \\
\hline CHEMBL1318495 & 688877 & 6.15 & 5.9379 & TRN & \\
\hline
\end{tabular}




\begin{tabular}{|c|c|c|c|c|c|}
\hline \\
\hline CHEMBL1515559 & 688877 & 5.5 & 5.8901 & TRN & \\
\hline CHEMBL1316314 & 688877 & 4.4 & 5.1376 & TST & \\
\hline CHEMBL1327256 & 688877 & 4.45 & 5.1585 & TRN & \\
\hline CHEMBL1366408 & 688877 & 5.0 & 4.9275 & TST & \\
\hline CHEMBL476833 & 688877 & 5.25 & 5.4538 & TST & \\
\hline CHEMBL1256695 & 688877 & 4.65 & 5.1899 & TST & \\
\hline CHEMBL1356652 & 688877 & 5.95 & 5.9056 & TRN & \\
\hline CHEMBL93353 & 688877 & 4.45 & 5.5107 & TRN & \\
\hline CHEMBL1376253 & 688877 & 5.75 & 5.7938 & TRN & \\
\hline CHEMBL 92387 & 688877 & 4.65 & 5.3712 & TST & \\
\hline CHEMBL242171 & 688877 & 4.9 & 4.8755 & TRN & \\
\hline CHEMBL 271023 & 688877 & 5.15 & 5.3587 & TST & \\
\hline CHEMBL1354424 & 688877 & 4.45 & 4.63399 & 99999999995 & TST \\
\hline CHEMBL325238 & 688877 & 4.45 & 5.1454 & TRN & \\
\hline CHEMBL1356138 & 688877 & 5.65 & 5.8443 & TRN & \\
\hline CHEMBL321820 & 688877 & 4.65 & 5.1243 & TST & \\
\hline CHEMBL1367094 & 688877 & 4.85 & 5.0518 & TRN & \\
\hline CHEMBL1475686 & 688877 & 7.4001 & 5.7842 & TRN & \\
\hline CHEMBL1554910 & 688877 & 6.7501 & 5.9232 & TRN & \\
\hline CHEMBL1571785 & 688877 & 5.75 & 5.3553 & TRN & \\
\hline CHEMBL153036 & 688877 & 4.4 & 4.8925 & TST & \\
\hline CHEMBL1339015 & 688877 & 4.85 & 5.4967 & TRN & \\
\hline CHEMBL1440715 & 688877 & 4.9 & 5.5415 & TRN & \\
\hline CHEMBL480626 & 688877 & 4.8 & 4.7595 & TRN & \\
\hline CHEMBL 297784 & 688877 & 5.7 & 5.9841 & TRN & \\
\hline CHEMBL556001 & 688877 & 4.85 & 5.5519 & TRN & \\
\hline CHEMBL 270299 & 688877 & 6.0 & 5.2955 & TRN & \\
\hline CHEMBL1474498 & 688877 & 4.85 & 5.4582 & TST & \\
\hline CHEMBL210868 & 688877 & 4.55 & 4.9994 & TST & \\
\hline CHEMBL1377727 & 688877 & 7.8508 & 5.9515 & TRN & \\
\hline CHEMBL489525 & 688877 & 4.4 & 5.0006 & TRN & \\
\hline CHEMBL539507 & 688877 & 4.95 & 4.809 & TST & \\
\hline CHEMBL293749 & 688877 & 4.4 & 5.3845 & TRN & \\
\hline CHEMBL1514307 & 688877 & 6.05 & 5.4158 & TRN & \\
\hline CHEMBL1516103 & 688877 & 4.4 & 5.9165 & TRN & \\
\hline CHEMBL1555028 & 688877 & 7.0 & 5.7825 & TRN & \\
\hline CHEMBL1368062 & 688877 & 6.45 & 5.845 & TRN & \\
\hline CHEMBL1515945 & 688877 & 5.7 & 5.9973 & TRN & \\
\hline CHEMBL1515804 & 688877 & 5.75 & 5.9869 & TRN & \\
\hline CHEMBL1354841 & 688877 & 7.2 & 5.8845 & TRN & \\
\hline CHEMBL1565564 & 688877 & 5.25 & 5.3699 & TRN & \\
\hline CHEMBL8739 & 688877 & 4.85 & 4.9447 & TRN & \\
\hline CHEMBL16685 & 688877 & 5.05 & 5.3924 & TRN & \\
\hline CHEMBL 2373666 & 688877 & 7.0 & 5.12 & TRN & \\
\hline CHEMBL1476333 & 688877 & 4.45 & 5.206 & TST & \\
\hline CHEMBL407232 & 688877 & 4.9 & 5.3529 & TST & \\
\hline CHEMBL513116 & 688877 & 4.45 & 5.0371 & TRN & \\
\hline CHEMBL137743 & 688877 & 7.8508 & 5.1382 & TRN & \\
\hline
\end{tabular}




\begin{tabular}{|c|c|c|c|c|}
\hline & & & oplement & al $\mathrm{Ta}$ \\
\hline CHEMBL1357167 & 688877 & 6.5 & 5.9008 & TRN \\
\hline CHEMBL88147 & 688877 & 6.15 & 5.7465 & TST \\
\hline CHEMBL1494832 & 688877 & 7.0 & 5.7853 & TRN \\
\hline CHEMBL1492411 & 688877 & 4.6 & 5.5354 & TRN \\
\hline CHEMBL1475255 & 688877 & 7.6003 & 6.1552 & TRN \\
\hline CHEMBL242385 & 688877 & 5.25 & 4.8536 & TRN \\
\hline CHEMBL1559783 & 688877 & 5.6 & 5.9418 & TRN \\
\hline CHEMBL1433489 & 688877 & 5.1 & 5.3183 & TRN \\
\hline CHEMBL1380684 & 688877 & 4.6 & 4.7505 & TRN \\
\hline CHEMBL1473317 & 688877 & 5.8 & 5.5446 & TRN \\
\hline CHEMBL1515348 & 688877 & 4.7 & 6.1713 & TRN \\
\hline CHEMBL1314674 & 688877 & 5.75 & 5.5862 & TRN \\
\hline CHEMBL1396326 & 688877 & 5.1 & 5.8746 & TRN \\
\hline CHEMBL1330357 & 688877 & 4.75 & 4.751 & TST \\
\hline CHEMBL1410006 & 688877 & 5.25 & 5.8537 & TRN \\
\hline CHEMBL1534738 & 688877 & 4.4 & 5.4426 & TRN \\
\hline CHEMBL1593134 & 688877 & 6.3 & 6.1569 & TRN \\
\hline CHEMBL1316779 & 688877 & 8.0 & 6.1652 & TRN \\
\hline CHEMBL44 & 688877 & 6.0 & 5.1168 & TRN \\
\hline CHEMBL1591714 & 688877 & 4.9 & 5.7673 & TRN \\
\hline CHEMBL1395974 & 688877 & 5.7 & 5.8821 & TRN \\
\hline CHEMBL1563501 & 688877 & 6.15 & 5.5961 & TRN \\
\hline CHEMBL605003 & 688877 & 4.55 & 5.2628 & TST \\
\hline CHEMBL98572 & 688877 & 4.9 & 5.1912 & TRN \\
\hline CHEMBL1553863 & 688877 & 8.2518 & 5.9808 & TRN \\
\hline CHEMBL1553352 & 688877 & 6.45 & 5.9303 & TRN \\
\hline CHEMBL1490209 & 688877 & 6.3 & 5.4659 & TRN \\
\hline CHEMBL1316759 & 688877 & 6.0 & 5.9183 & TRN \\
\hline CHEMBL1571692 & 688877 & 4.4 & 5.0832 & TST \\
\hline CHEMBL1316190 & 688877 & 6.1 & 5.541 & TRN \\
\hline CHEMBL453019 & 688877 & 4.75 & 5.474 & TRN \\
\hline CHEMBL1256716 & 688877 & 4.5 & 5.2335 & TRN \\
\hline CHEMBL1474402 & 688877 & 8.301 & 6.3829 & TRN \\
\hline CHEMBL17331 & 688877 & 4.55 & 5.9602 & TRN \\
\hline CHEMBL 76904 & 688877 & 5.05 & 4.9318 & TRN \\
\hline CHEMBL1354988 & 688877 & 4.4 & 5.2174 & TST \\
\hline CHEMBL504722 & 688877 & 4.45 & 5.2511 & TRN \\
\hline CHEMBL1317125 & 688877 & 8.1487 & 5.9581 & TST \\
\hline CHEMBL1394854 & 688877 & 5.6 & 5.8966 & TST \\
\hline CHEMBL1375046 & 688877 & 7.3002 & 5.8182 & TST \\
\hline CHEMBL1397088 & 688877 & 5.3 & 5.5689 & TST \\
\hline CHEMBL 7917 & 688877 & 6.0 & 5.5475 & TST \\
\hline CHEMBL1603371 & 688877 & 5.75 & 5.8164 & TST \\
\hline CHEMBL1373818 & 688877 & 4.5 & 4.8243 & TST \\
\hline CHEMBL1356834 & 688877 & 5.05 & 5.6052 & TST \\
\hline CHEMBL1434441 & 688877 & 4.7 & 4.9389 & TST \\
\hline CHEMBL402468 & 688877 & 5.1 & 5.1243 & TST \\
\hline CHEMBL1416812 & 688877 & 6.0 & 5.2321 & TST \\
\hline
\end{tabular}




\begin{tabular}{|c|c|c|c|c|}
\hline \multicolumn{5}{|c|}{ Supplemental Table S2.txt } \\
\hline CHEMBL1594612 & 688877 & 6.3 & 5.6528 & TST \\
\hline CHEMBL1531863 & 688877 & 5.25 & 5.0789 & TST \\
\hline CHEMBL845 & 688877 & 4.6 & 4.8868 & TST \\
\hline CHEMBL1337479 & 688877 & 5.55 & 5.7252 & TST \\
\hline CHEMBL236789 & 688877 & 4.9 & 5.0283 & TST \\
\hline CHEMBL1356775 & 688877 & 5.4 & 5.3181 & TST \\
\hline CHEMBL1324494 & 688877 & 5.45 & 5.7155 & TST \\
\hline CHEMBL1484261 & 688877 & 6.35 & 6.3091 & TST \\
\hline CHEMBL1486734 & 688877 & 5.45 & 5.7493 & TST \\
\hline CHEMBL1256577 & 688877 & 4.4 & 5.2593 & TST \\
\hline CHEMBL1314376 & 688877 & 4.45 & 5.1794 & TST \\
\hline CHEMBL137498 & 688877 & 5.5 & 5.2774 & TST \\
\hline CHEMBL484662 & 688877 & 4.55 & 4.9494 & TST \\
\hline CHEMBL1473760 & 688877 & 6.5 & 6.3934 & TST \\
\hline CHEMBL1356094 & 688877 & 6.3 & 4.9018 & TST \\
\hline CHEMBL580421 & 688877 & 4.55 & 4.7533 & TST \\
\hline CHEMBL66966 & 688877 & 4.8 & 4.5625 & TST \\
\hline CHEMBL164841 & 688877 & 4.9 & 5.3 & TST \\
\hline CHEMBL1554131 & 688877 & 4.65 & 5.8708 & TST \\
\hline CHEMBL1201091 & 688877 & 4.55 & 5.7169 & TST \\
\hline CHEMBL1314367 & 688877 & 6.05 & 5.6067 & TST \\
\hline CHEMBL1558420 & 688877 & 5.8 & 5.8353 & TST \\
\hline CHEMBL1457550 & 688877 & 4.45 & 5.4118 & TST \\
\hline CHEMBL1556035 & 688877 & 5.1 & 5.0654 & TST \\
\hline CHEMBL1332033 & 688877 & 5.45 & 5.4736 & TST \\
\hline CHEMBL1408176 & 688877 & 6.15 & 5.6895 & TST \\
\hline CHEMBL1435086 & 688877 & 7.0501 & 5.9977 & TST \\
\hline CHEMBL1330729 & 688877 & 4.6 & 4.6378 & TST \\
\hline CHEMBL544115 & 688877 & 5.1 & 4.6134 & TST \\
\hline CHEMBL1493002 & 688877 & 5.9 & 5.7039 & TST \\
\hline CHEMBL 2374050 & 688877 & 5.2 & 5.2033 & TST \\
\hline CHEMBL1314416 & 688877 & 5.85 & 5.8013 & TST \\
\hline CHEMBL1590974 & 688877 & 7.8013 & 5.8627 & TST \\
\hline CHEMBL1356342 & 688877 & 4.8 & 4.8266 & TST \\
\hline CHEMBL1314647 & 688877 & 5.5 & 5.9964 & TST \\
\hline CHEMBL1357674 & 688877 & 5.2 & 5.2272 & TST \\
\hline CHEMBL1551445 & 688877 & 6.2 & 6.0456 & TST \\
\hline CHEMBL1561363 & 688877 & 5.45 & 5.6255 & TST \\
\hline CHEMBL1358722 & 688877 & 6.0 & 4.8075 & TST \\
\hline CHEMBL1355135 & 688877 & 5.85 & 5.8458 & TST \\
\hline CHEMBL155265 & 688877 & 5.05 & 5.1662 & TST \\
\hline CHEMBL140220 & 688877 & 5.6 & 6.0361 & TST \\
\hline CHEMBL1567176 & 688877 & 6.05 & 5.7953 & TST \\
\hline CHEMBL1595371 & 688877 & 7.3002 & 5.8414 & TST \\
\hline CHEMBL502242 & 688877 & 4.8 & 4.9083 & TST \\
\hline CHEMBL21396 & 688877 & 6.8499 & 5.769 & TST \\
\hline CHEMBL1317913 & 688877 & 5.4 & 5.3682 & TST \\
\hline CHEMBL1320206 & 688877 & 4.65 & 5.6125 & TST \\
\hline
\end{tabular}




\begin{tabular}{|c|c|c|c|c|c|}
\hline \multicolumn{6}{|c|}{ plemental } \\
\hline CHEMBL1196026 & 688877 & 4.7 & 5.3475 & TST & \\
\hline CHEMBL491976 & 688877 & 5.2 & 5.7473 & TST & \\
\hline CHEMBL1514153 & 688877 & 5.2 & 4.8534 & TST & \\
\hline CHEMBL1360725 & 688877 & 4.45 & 5.2552 & TST & \\
\hline CHEMBL1332361 & 688877 & 4.85 & 5.2353 & TST & \\
\hline CHEMBL1590982 & 688877 & 6.45 & 5.8955 & TST & \\
\hline CHEMBL137648 & 688877 & 5.35 & 5.3431 & TST & \\
\hline CHEMBL1554486 & 688877 & 4.65 & 6.0637 & TST & \\
\hline CHEMBL602375 & 688877 & 4.6 & 5.0049 & TST & \\
\hline CHEMBL448515 & 688877 & 4.55 & 5.3022 & TST & \\
\hline CHEMBL1256835 & 688877 & 4.5 & 5.1829 & TST & \\
\hline CHEMBL1434006 & 688877 & 5.3 & 5.5897 & TST & \\
\hline CHEMBL1317802 & 688877 & 5.7 & 5.689 & TST & \\
\hline CHEMBL1434895 & 688877 & 5.5 & 5.8881 & TST & \\
\hline CHEMBL491742 & 688877 & 4.9 & 5.3232 & TST & \\
\hline CHEMBL1442250 & 688877 & 5.05 & 5.832006 & 0000000001 & TST \\
\hline CHEMBL602575 & 688877 & 6.5 & 5.1581 & TST & \\
\hline CHEMBL1317823 & 688877 & 4.85 & 5.33299 & 9999999999 & TST \\
\hline CHEMBL1526411 & 688877 & 6.5 & 5.5084 & TST & \\
\hline CHEMBL1473554 & 688877 & 5.85 & 5.5684 & TST & \\
\hline CHEMBL1315754 & 688877 & 4.85 & 5.0253 & TST & \\
\hline CHEMBL1607905 & 688877 & 4.9 & 4.9896 & TST & \\
\hline CHEMBL1559404 & 688877 & 5.45 & 5.8632 & TST & \\
\hline CHEMBL1472899 & 688877 & 8.301 & 5.6179 & TST & \\
\hline CHEMBL1331037 & 688877 & 6.15 & 6.2353 & TST & \\
\hline CHEMBL1512693 & 688877 & 5.9 & 5.3875 & TST & \\
\hline CHEMBL1613441 & 688877 & 5.2 & 5.4532 & TST & \\
\hline CHEMBL1395915 & 688877 & 7.699 & 5.706 & TST & \\
\hline CHEMBL1329790 & 688877 & 4.7 & 4.864 & TST & \\
\hline CHEMBL1396462 & 688877 & 5.4 & 5.7133 & TST & \\
\hline CHEMBL1356844 & 688877 & 5.6 & 5.8783 & TST & \\
\hline CHEMBL1314582 & 688877 & 6.4 & 4.8511 & TST & \\
\hline CHEMBL1443323 & 688877 & 6.7001 & 6.0286 & TST & \\
\hline CHEMBL1484944 & 688877 & 4.4 & 5.8629 & TST & \\
\hline CHEMBL1491966 & 688877 & 6.6 & 5.6668 & TST & \\
\hline CHEMBL1331521 & 688877 & 5.6 & 5.81 & TST & \\
\hline CHEMBL1596743 & 688877 & 5.55 & 5.7598 & TST & \\
\hline CHEMBL1553114 & 688877 & 5.8 & 5.4591 & TST & \\
\hline CHEMBL54277 & 688877 & 4.8 & 5.3544 & TST & \\
\hline CHEMBL1366732 & 688877 & 5.0 & 5.7506 & TST & \\
\hline CHEMBL1317400 & 688877 & 6.0 & 5.9429 & TST & \\
\hline CHEMBL14276 & 688877 & 5.85 & 5.6885 & TST & \\
\hline CHEMBL1356439 & 688877 & 6.4 & 5.9868 & TST & \\
\hline CHEMBL 2373651 & 688877 & 5.55 & 5.0713 & TST & \\
\hline CHEMBL1414236 & 688877 & 4.4 & 5.3187 & TST & \\
\hline CHEMBL1355408 & 688877 & 6.8499 & 6.6095 & TST & \\
\hline CHEMBL 34241 & 688877 & 6.0 & 4.7034 & TST & \\
\hline CHEMBL1535897 & 688877 & 4.95 & 4.8647 & TST & \\
\hline
\end{tabular}




\begin{tabular}{|c|c|c|c|c|c|}
\hline \multicolumn{6}{|c|}{ Supplemental Table S2.txt } \\
\hline CHEMBL1180496 & 688877 & 4.5 & 5.4579 & TST & \\
\hline CHEMBL342375 & 688877 & 5.65 & 5.3519 & TST & \\
\hline CHEMBL1606591 & 688877 & 5.15 & 6.2521 & TST & \\
\hline CHEMBL528080 & 688877 & 5.0 & 4.9265 & TST & \\
\hline CHEMBL1336932 & 688877 & 8.2007 & 5.67 & TST & \\
\hline CHEMBL429095 & 688877 & 6.0 & 4.8414 & TST & \\
\hline CHEMBL1327247 & 688877 & 4.8 & 5.5143 & TST & \\
\hline CHEMBL1522486 & 688877 & 4.4 & 5.5584 & TST & \\
\hline CHEMBL1489211 & 688877 & 5.45 & 5.7019 & TST & \\
\hline CHEMBL1489432 & 688877 & 5.45 & 5.3667 & TST & \\
\hline CHEMBL1590818 & 688877 & 5.8 & 5.8369 & TST & \\
\hline CHEMBL1256283 & 688877 & 4.4 & 5.3283 & TST & \\
\hline CHEMBL1512780 & 688877 & 8.2518 & 5.8799 & TST & \\
\hline CHEMBL1358234 & 688877 & 5.9 & 6.0869 & TST & \\
\hline CHEMBL1482155 & 688877 & 4.95 & 5.9606 & TST & \\
\hline CHEMBL323197 & 688877 & 6.0 & 5.2274 & TST & \\
\hline CHEMBL1475789 & 688877 & 5.6 & 5.6632 & TST & \\
\hline CHEMBL1554433 & 688877 & 6.45 & 5.7139 & TST & \\
\hline CHEMBL1591893 & 688877 & 6.05 & 6.4943 & TST & \\
\hline CHEMBL1366812 & 688877 & 4.4 & 4.8981 & TST & \\
\hline CHEMBL1730100 & 688877 & 5.0 & 4.8208 & TST & \\
\hline CHEMBL1594405 & 688877 & 6.3 & 5.4035 & TST & \\
\hline CHEMBL102714 & 688877 & 5.55 & 5.45299 & 9999999999 & TST \\
\hline CHEMBL 36028 & 688877 & 5.15 & 5.6035 & TST & \\
\hline CHEMBL1477982 & 688877 & 5.65 & 5.8413 & TST & \\
\hline CHEMBL1255831 & 688877 & 5.55 & 5.2653 & TST & \\
\hline CHEMBL68908 & 688877 & 4.6 & 5.4119 & TST & \\
\hline CHEMBL1325833 & 688877 & 6.05 & 5.9895 & TST & \\
\hline CHEMBL559934 & 688877 & 5.95 & 5.2341 & TST & \\
\hline CHEMBL1398260 & 688877 & 5.45 & 5.2349 & TST & \\
\hline CHEMBL1551139 & 688877 & 5.65 & 5.57299 & 99999999995 & TST \\
\hline CHEMBL1436821 & 688877 & 5.65 & 5.4741 & TST & \\
\hline CHEMBL1473755 & 688877 & 6.1 & 6.3452 & TST & \\
\hline CHEMBL1366061 & 688877 & 4.9 & 5.9751 & TST & \\
\hline CHEMBL1450499 & 688877 & 4.5 & 5.5393 & TST & \\
\hline CHEMBL1256147 & 688877 & 6.8499 & 5.1268 & TST & \\
\hline CHEMBL 281622 & 688877 & 6.2 & 4.9361 & TST & \\
\hline CHEMBL1512444 & 688877 & 7.2503 & 5.6761 & TST & \\
\hline CHEMBL1492215 & 688877 & 7.4001 & 6.0318 & TST & \\
\hline CHEMBL1357941 & 688877 & 5.35 & 5.1415 & TST & \\
\hline CHEMBL1474272 & 688877 & 6.4 & 6.19 & TST & \\
\hline CHEMBL1479372 & 688877 & 4.7 & 5.7788 & TST & \\
\hline CHEMBL490706 & 688877 & 5.15 & 5.8356 & TST & \\
\hline CHEMBL1591635 & 688877 & 6.05 & 5.8516 & TST & \\
\hline CHEMBL1513825 & 688877 & 4.8 & 5.7377 & TST & \\
\hline CHEMBL517040 & 688877 & 4.45 & 5.1021 & TST & \\
\hline CHEMBL71492 & 688877 & 5.25 & 5.2457 & TST & \\
\hline CHEMBL1315129 & 688877 & 5.05 & 5.899 & TST & \\
\hline
\end{tabular}




\begin{tabular}{|c|c|c|c|c|c|c|}
\hline \multirow[b]{2}{*}{ CHEMBL573107 } & & \multicolumn{5}{|c|}{ Supplemental Table S2.txt } \\
\hline & 954994 & 3.7508 & 3.7446 & TRN & & \\
\hline CHEMBL1673039 & 954994 & 4.9641 & 4.96899 & 999999999 & & TRN \\
\hline CHEMBL92309 & 954994 & 3.3848 & 2.553 & TST & & \\
\hline CHEMBL259181 & 954994 & 5.4881 & 5.4912 & TRN & & \\
\hline CHEMBL 2005886 & 954994 & 6.6377 & 6.6342 & TRN & & \\
\hline CHEMBL1256459 & 954994 & 7.1221 & 7.1217 & TRN & & \\
\hline CHEMBL483849 & 954994 & 2.1756 & 1.9346 & TST & & \\
\hline CHEMBL 240954 & 954994 & 2.8387 & 3.4623 & TST & & \\
\hline CHEMBL1404918 & 954994 & 3.0004 & 2.9949 & TRN & & \\
\hline CHEMBL412142 & 954994 & 3.6618 & 3.6689 & TRN & & \\
\hline CHEMBL209148 & 954994 & 4.8764 & 4.8687 & TRN & & \\
\hline CHEMBL 9470 & 954994 & 4.6822 & 5.4909 & TST & & \\
\hline CHEMBL379975 & 954994 & 5.2249 & 5.228 & TRN & & \\
\hline CHEMBL399530 & 954994 & 4.617 & 4.6165 & TRN & & \\
\hline CHEMBL449158 & 954994 & 6.5344 & 6.901 & TST & & \\
\hline CHEMBL191334 & 954994 & 3.0796 & 3.0786 & TRN & & \\
\hline CHEMBL 258844 & 954994 & 4.7068 & 4.7041 & TRN & & \\
\hline CHEMBL515416 & 954994 & 4.1741 & 4.1764 & TRN & & \\
\hline CHEMBL1516890 & 954994 & 4.9334 & 4.9367 & TRN & & \\
\hline CHEMBL3186408 & 954994 & 3.31600 & 30000000 & 003 & 3.6466 & TST \\
\hline CHEMBL1186585 & 954994 & 4.7281 & 4.7243 & TRN & & \\
\hline CHEMBL373751 & 954994 & 3.5728 & 3.572 & TRN & & \\
\hline CHEMBL192566 & 954994 & 7.193 & 7.5455 & TST & & \\
\hline CHEMBL217354 & 954994 & 6.78 & 6.7887 & TRN & & \\
\hline CHEMBL2363137 & 954994 & 5.6492 & 5.6465 & TRN & & \\
\hline CHEMBL 2134202 & 954994 & 3.4709 & 3.4756 & TRN & & \\
\hline CHEMBL1909414 & 954994 & 3.8329 & 3.8336 & TRN & & \\
\hline CHEMBL188678 & 954994 & 4.07600 & 30000000 & 005 & 4.0701 & TRN \\
\hline CHEMBL1230020 & 954994 & 4.0072 & 4.0042 & TRN & & \\
\hline CHEMBL 2144069 & 954994 & 4.0179 & 4.0165 & TRN & & \\
\hline CHEMBL 210618 & 954994 & 3.0186 & 3.0061 & TRN & & \\
\hline CHEMBL 213100 & 954994 & 4.5553 & 4.5598 & TRN & & \\
\hline CHEMBL1788116 & 954994 & 4.5978 & 4.5986 & TRN & & \\
\hline CHEMBL1190711 & 954994 & 4.8271 & 4.8306 & TRN & & \\
\hline CHEMBL65 & 954994 & 6.7059 & 6.7064 & TRN & & \\
\hline CHEMBL3349342 & 954994 & 3.7453 & 3.7423 & TRN & & \\
\hline CHEMBL 221137 & 954994 & 4.1843 & 4.5113 & TST & & \\
\hline CHEMBL483847 & 954994 & 4.3067 & 4.3186 & TRN & & \\
\hline CHEMBL 300389 & 954994 & 6.7943 & 6.7976 & TRN & & \\
\hline CHEMBL558642 & 954994 & 3.7741 & 3.7711 & TRN & & \\
\hline CHEMBL392695 & 954994 & 5.7097 & 5.7017 & TRN & & \\
\hline CHEMBL514499 & 954994 & 7.2219 & 7.2214 & TRN & & \\
\hline CHEMBL1970879 & 954994 & 5.0209 & 5.0131 & TRN & & \\
\hline CHEMBL189584 & 954994 & 3.5771 & 3.576 & TRN & & \\
\hline CHEMBL1357247 & 954994 & 3.5017 & 3.5096 & TRN & & \\
\hline CHEMBL509032 & 954994 & 6.0469 & 6.0488 & TRN & & \\
\hline CHEMBL 222102 & 954994 & 3.0916 & 3.1042 & TRN & & \\
\hline CHEMBL379300 & 954994 & 6.6529 & 6.6512 & TRN & & \\
\hline
\end{tabular}




\begin{tabular}{|c|c|c|c|c|c|c|}
\hline & & \multicolumn{5}{|c|}{ Supplemental Table S2.txt } \\
\hline CHEMBL135561 & 954994 & 4.4105 & 4.4094 & TRN & & \\
\hline CHEMBL472940 & 954994 & 2.3777 & 2.381 & TRN & & \\
\hline CHEMBL202721 & 954994 & 4.5283 & 4.522 & TRN & & \\
\hline CHEMBL3199475 & 954994 & 3.5174 & 3.5195 & TRN & & \\
\hline CHEMBL577784 & 954994 & 3.5834 & 3.5823 & TRN & & \\
\hline CHEMBL102714 & 954994 & 4.0296 & 4.027 & TRN & & \\
\hline CHEMBL255342 & 954994 & \multicolumn{3}{|c|}{3.8369999999999997} & 3.8363 & TRN \\
\hline CHEMBL393929 & 954994 & 3.1969 & 3.2016 & TRN & & \\
\hline CHEMBL1242367 & 954994 & 4.0683 & 4.0474 & TST & & \\
\hline CHEMBL585951 & 954994 & 7.1094 & 6.3633 & TST & & \\
\hline CHEMBL220241 & 954994 & 4.0192 & 3.9235 & TST & & \\
\hline CHEMBL180127 & 954994 & 4.6266 & 4.6058 & TST & & \\
\hline CHEMBL3392440 & 954994 & 3.8094 & 4.1917 & TST & & \\
\hline CHEMBL1590308 & 954994 & 3.3167 & 3.4151 & TST & & \\
\hline CHEMBL 2137530 & 954994 & 4.398 & 4.5863 & TST & & \\
\hline CHEMBL512504 & 954994 & 4.7741 & 4.3792 & TST & & \\
\hline CHEMBL1643959 & 954994 & 3.7327 & 3.4079 & TST & & \\
\hline CHEMBL 2323513 & 941824 & 5.8416 & 6.183 & TRN & & \\
\hline CHEMBL 2323521 & 941824 & 5.3288 & 5.3533 & TRN & & \\
\hline CHEMBL 2323524 & 941824 & 5.295 & 5.6314 & TST & & \\
\hline CHEMBL 2323478 & 941824 & 5.1226 & 4.8275 & TRN & & \\
\hline CHEMBL 2323491 & 941824 & 4.9066 & 5.1149 & TRN & & \\
\hline CHEMBL 2323511 & 941824 & 6.4685 & 5.7087 & TRN & & \\
\hline CHEMBL 2323517 & 941824 & 5.9547 & 5.8474 & TRN & & \\
\hline CHEMBL 2323520 & 941824 & 5.5768 & 5.6482 & TRN & & \\
\hline CHEMBL 2323475 & 941824 & 5.6126 & 5.9106 & TRN & & \\
\hline CHEMBL 2323510 & 941824 & 6.5376 & 6.3716 & TRN & & \\
\hline CHEMBL 2323502 & 941824 & 5.9547 & 5.8981 & TRN & & \\
\hline CHEMBL 2323515 & 941824 & 5.5952 & 5.7552 & TRN & & \\
\hline CHEMBL 2323488 & 941824 & 6.301 & 5.9389 & TST & & \\
\hline CHEMBL 2323509 & 941824 & 6.9208 & 6.9183 & TRN & & \\
\hline CHEMBL2323503 & 941824 & 5.4012 & 5.5147 & TRN & & \\
\hline CHEMBL 2323482 & 941824 & 6.5376 & 6.434 & TRN & & \\
\hline CHEMBL 2323523 & 941824 & 6.5544 & 5.4549 & TST & & \\
\hline CHEMBL 2323525 & 941824 & 6.4685 & 6.3099 & TST & & \\
\hline CHEMBL 2323481 & 941824 & 6.1308 & 6.20799 & 9999999999 & & TRN \\
\hline CHEMBL 2323484 & 941824 & 4.9454 & 4.8577 & TRN & & \\
\hline CHEMBL 2323483 & 941824 & 5.4486 & 6.07700 & 0000000001 & & TST \\
\hline CHEMBL 2323485 & 941824 & 5.3045 & 5.4119 & TRN & & \\
\hline CHEMBL2323492 & 941824 & 5.9245 & 5.6337 & TRN & & \\
\hline CHEMBL 2323512 & 941824 & 5.2573 & 5.3021 & TRN & & \\
\hline CHEMBL 2323505 & 941824 & 5.6198 & 5.7324 & TST & & \\
\hline CHEMBL 2323473 & 941824 & 6.8539 & 6.6614 & TRN & & \\
\hline CHEMBL1058 & 941824 & 3.0 & 6.0136 & TST & & \\
\hline CHEMBL2323486 & 941824 & 5.9666 & 5.9905 & TRN & & \\
\hline CHEMBL 2323493 & 941824 & 5.0545 & 5.1048 & TRN & & \\
\hline CHEMBL 2323514 & 941824 & 5.5072 & 5.4699 & TRN & & \\
\hline CHEMBL 2323506 & 941824 & 4.6424 & 5.0081 & TST & & \\
\hline
\end{tabular}




\begin{tabular}{|c|c|c|c|c|c|}
\hline & & \multicolumn{4}{|c|}{ Supplemental Table S2.txt } \\
\hline CHEMBL 2323494 & 941824 & 5.684 & 5.6614 & TRN & \\
\hline CHEMBL503179 & 941824 & 6.0177 & 6.1524 & TRN & \\
\hline CHEMBL 2323496 & 941824 & 5.4283 & 5.4904 & TRN & \\
\hline CHEMBL 2323501 & 941824 & 5.5986 & 5.6886 & TRN & \\
\hline CHEMBL 2323477 & 941824 & 5.6517 & 5.6063 & TRN & \\
\hline CHEMBL 2323500 & 941824 & 5.1046 & 5.1212 & TRN & \\
\hline CHEMBL 2323518 & 941824 & 5.6021 & 5.7724 & TRN & \\
\hline CHEMBL 2323504 & 941824 & 5.7122 & 5.7047 & TRN & \\
\hline CHEMBL178687 & 941824 & 6.6576 & 6.7595 & TRN & \\
\hline CHEMBL 2323490 & 941824 & 6.6778 & 5.9958 & TRN & \\
\hline CHEMBL178499 & 941824 & 6.1487 & 6.1641 & TRN & \\
\hline CHEMBL 2323487 & 941824 & 5.2832 & 5.26399 & 9999999999 & TRN \\
\hline CHEMBL 2323508 & 941824 & 7.0458 & 7.057 & TRN & \\
\hline CHEMBL 2323522 & 941824 & 6.7959 & 6.3513 & TST & \\
\hline CHEMBL 2323516 & 941824 & 5.4881 & 5.4079 & TRN & \\
\hline CHEMBL 2323480 & 941824 & 5.1198 & 5.0247 & TRN & \\
\hline CHEMBL2323479 & 941824 & 4.8038 & 5.1131 & TRN & \\
\hline CHEMBL73572 & 941824 & 5.2464 & 5.1718 & TRN & \\
\hline CHEMBL 2323497 & 941824 & 5.6799 & 5.4895 & TRN & \\
\hline CHEMBL 2323495 & 941824 & 5.5768 & 5.5862 & TRN & \\
\hline CHEMBL 2323474 & 941824 & 6.5686 & 6.67700 & 00000000005 & TRN \\
\hline CHEMBL 2323489 & 941824 & 4.9208 & 5.5563 & TRN & \\
\hline CHEMBL 2172787 & 941824 & 5.6498 & 5.7803 & TRN & \\
\hline CHEMBL2323499 & 941824 & 5.2366 & 5.535 & TST & \\
\hline CHEMBL 2323476 & 941824 & 6.6021 & 6.4557 & TST & \\
\hline CHEMBL 2323472 & 941824 & 6.9208 & 6.5069 & TST & \\
\hline CHEMBL 2323498 & 941824 & 5.1979 & 5.2524 & TST & \\
\hline CHEMBL179587 & 941824 & 6.7959 & 6.3234 & TST & \\
\hline CHEMBL 2323507 & 941824 & 6.8861 & 6.8058 & TST & \\
\hline CHEMBL 2314893 & 936910 & 4.2495 & 5.2887 & TRN & \\
\hline CHEMBL 2314908 & 936910 & 3.0 & 3.5976 & TRN & \\
\hline CHEMBL1164885 & 936910 & 5.585 & 5.8039 & TRN & \\
\hline CHEMBL 2314886 & 936910 & 4.0521 & 4.0235 & TRN & \\
\hline CHEMBL 2314672 & 936910 & 4.6073 & 3.9915 & TRN & \\
\hline CHEMBL 2314903 & 936910 & 5.5086 & 5.3432 & TRN & \\
\hline CHEMBL 2314888 & 936910 & 4.1543 & 4.2542 & TRN & \\
\hline CHEMBL1199825 & 936910 & 4.1391 & 3.9058 & TRN & \\
\hline CHEMBL 2314907 & 936910 & 3.0 & 3.8404 & TRN & \\
\hline CHEMBL1165622 & 936910 & 5.6576 & 5.4388 & TRN & \\
\hline CHEMBL 2314671 & 936910 & 3.0 & 3.6313 & TRN & \\
\hline CHEMBL1200104 & 936910 & 3.0 & 3.989 & TRN & \\
\hline CHEMBL1593867 & 936910 & 4.2218 & 3.8483 & TST & \\
\hline CHEMBL 2314887 & 936910 & 3.0 & 4.183 & TRN & \\
\hline CHEMBL 2314892 & 936910 & 5.3098 & 5.6502 & TRN & \\
\hline CHEMBL 2314899 & 936910 & 5.7959 & 5.7704 & TRN & \\
\hline CHEMBL 2314889 & 936910 & 3.0 & 4.0259 & TST & \\
\hline CHEMBL 2314670 & 936910 & 4.3279 & 3.9193 & TRN & \\
\hline CHEMBL2314905 & 936910 & 4.5346 & 3.9453 & TRN & \\
\hline
\end{tabular}




\begin{tabular}{|c|c|c|c|c|c|}
\hline \multicolumn{6}{|c|}{ Supplemental Table S2.txt } \\
\hline CHEMBL1199577 & 936910 & 3.0 & 3.8068 & TRN & \\
\hline CHEMBL2314667 & 936910 & 4.5498 & 4.1731 & TRN & \\
\hline CHEMBL2314898 & 936910 & 5.6778 & 5.7714 & TRN & \\
\hline CHEMBL1165565 & 936910 & 5.6576 & 5.3719 & TRN & \\
\hline CHEMBL2314891 & 936910 & 5.6198 & 5.4476 & TST & \\
\hline CHEMBL1199528 & 936910 & 4.2967 & 4.3434 & TRN & \\
\hline CHEMBL1178003 & 936910 & 4.6819 & 4.3469 & TRN & \\
\hline CHEMBL2314909 & 936910 & 4.52 & 4.0359 & TRN & \\
\hline CHEMBL 2314895 & 936910 & 5.4089 & 5.6339 & TST & \\
\hline CHEMBL1164886 & 936910 & 4.9066 & 5.6904 & TST & \\
\hline CHEMBL2314884 & 936910 & 5.699 & 4.1431 & TRN & \\
\hline CHEMBL2314894 & 936910 & 5.6576 & 5.4192 & TST & \\
\hline CHEMBL2314668 & 936910 & 3.0 & 4.0891 & TST & \\
\hline CHEMBL1199576 & 936910 & 4.6737 & 4.2173 & TRN & \\
\hline CHEMBL2314900 & 936910 & 5.8539 & 5.7298 & TST & \\
\hline CHEMBL2314896 & 936910 & 5.3979 & 5.4253 & TST & \\
\hline CHEMBL2314890 & 936910 & 3.0 & 3.8666 & TRN & \\
\hline CHEMBL2314901 & 936910 & 5.4089 & 5.4087 & TST & \\
\hline CHEMBL1199529 & 936910 & 4.3134 & 4.2773 & TRN & \\
\hline CHEMBL2314897 & 936910 & 5.6576 & 5.3251 & TST & \\
\hline CHEMBL1199961 & 936910 & 4.7595 & 3.8941 & TRN & \\
\hline CHEMBL1199533 & 936910 & 3.0 & 3.8817 & TRN & \\
\hline CHEMBL1199575 & 936910 & 4.4935 & 3.9718 & TRN & \\
\hline CHEMBL 2314883 & 936910 & 4.4908 & 4.3042 & TRN & \\
\hline CHEMBL2314885 & 936910 & 4.5591 & 4.3414 & TRN & \\
\hline CHEMBL2314669 & 936910 & 3.0 & 3.8068 & TRN & \\
\hline CHEMBL1199532 & 936910 & 4.5129 & 3.9767 & TRN & \\
\hline CHEMBL2314904 & 936910 & 4.5591 & 4.164 & TRN & \\
\hline CHEMBL1199826 & 936910 & 4.1337 & 3.8327 & TRN & \\
\hline CHEMBL2314906 & 936910 & 4.6326 & 4.2246 & TRN & \\
\hline CHEMBL2314902 & 936910 & 5.8239 & 5.6552 & TST & \\
\hline CHEMBL2314666 & 936910 & 4.3904 & 4.1951 & TRN & \\
\hline CHEMBL1164796 & 936910 & 6.0315 & 5.2542 & TST & \\
\hline CHEMBL1080532 & 620648 & 5.5817 & 6.1383 & TRN & \\
\hline CHEMBL1080368 & 620648 & 8.5229 & 8.4441 & TRN & \\
\hline CHEMBL1079962 & 620648 & 4.0 & 4.3643 & TRN & \\
\hline CHEMBL1079505 & 620648 & 8.0969 & 7.5972 & TRN & \\
\hline CHEMBL1080366 & 620648 & 6.0315 & 5.3403 & TRN & \\
\hline CHEMBL1080363 & 620648 & 6.9208 & 7.24700 & 0000000001 & TRN \\
\hline CHEMBL1075893 & 620648 & 6.8861 & 6.38200 & 2000000001 & TRN \\
\hline CHEMBL1075706 & 620648 & 7.3468 & 7.8601 & TRN & \\
\hline CHEMBL1079961 & 620648 & 4.0 & 4.3045 & TRN & \\
\hline CHEMBL1079503 & 620648 & 6.4559 & 6.5392 & TRN & \\
\hline CHEMBL1079982 & 620648 & 4.0 & 5.0669 & TRN & \\
\hline CHEMBL1080140 & 620648 & 4.0 & 4.4471 & TRN & \\
\hline CHEMBL1081749 & 620648 & 7.3979 & 6.3595 & TRN & \\
\hline CHEMBL1079981 & 620648 & 4.0 & 5.6054 & TRN & \\
\hline CHEMBL1080184 & 620648 & 7.8539 & 7.9096 & TRN & \\
\hline
\end{tabular}




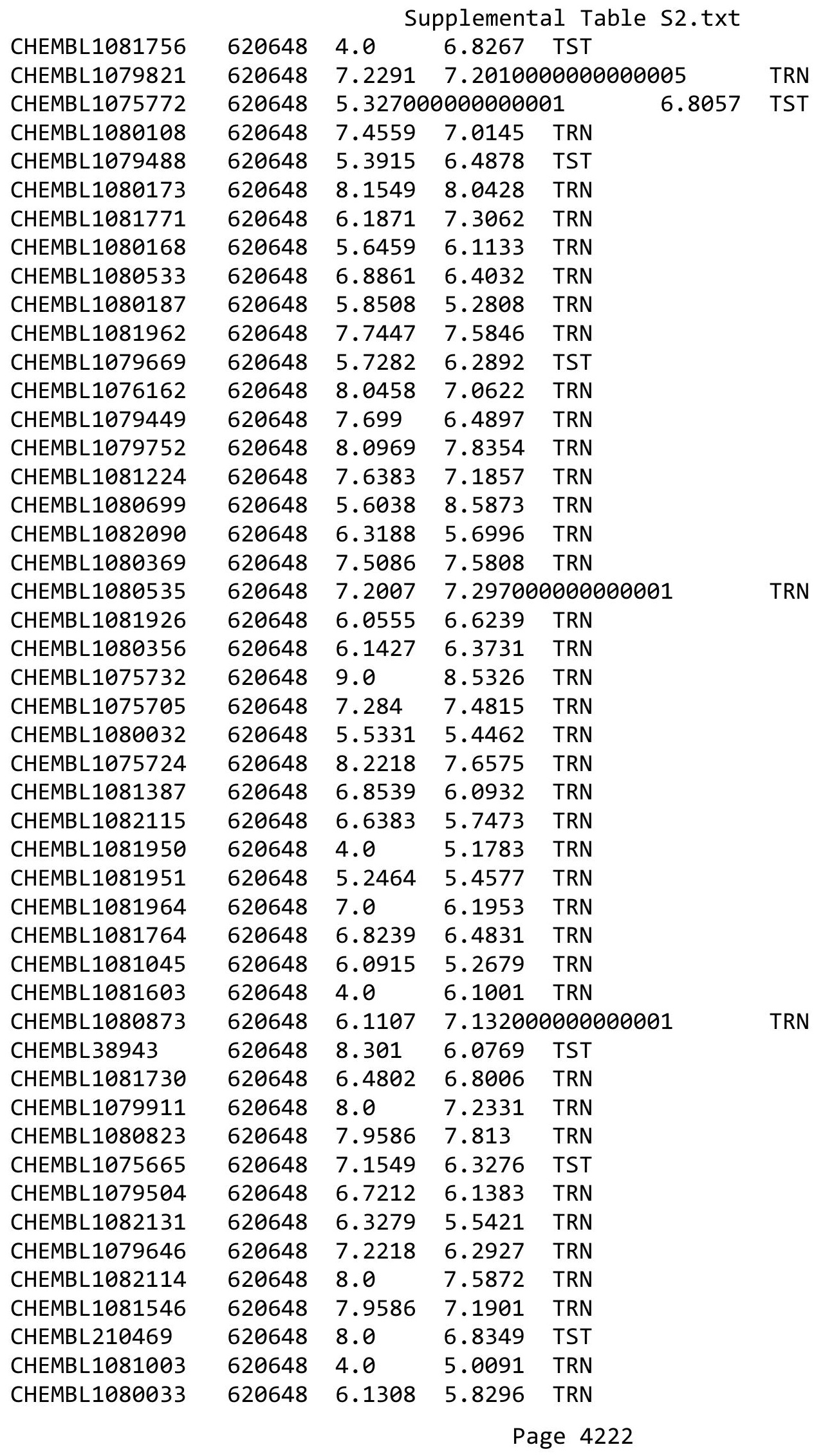


Supplemental Table S2.txt

\begin{tabular}{|c|c|c|c|c|c|}
\hline CHEMBL1079826 & 620648 & 7.699 & 6.4826 & TRN & \\
\hline CHEMBL1081380 & 620648 & 5.8861 & 5.5366 & TRN & \\
\hline CHEMBL1080355 & 620648 & 6.2924 & 6.9716 & TRN & \\
\hline CHEMBL1075856 & 620648 & 5.1993 & \multicolumn{2}{|c|}{6.417000000000001} & TRN \\
\hline CHEMBL1081004 & 620648 & 6.9208 & 6.5674 & TRN & \\
\hline CHEMBL1081206 & 620648 & 4.0 & 6.2775 & TST & \\
\hline CHEMBL1081601 & 620648 & 8.0 & 7.3699 & TRN & \\
\hline CHEMBL1082089 & 620648 & 6.9586 & 7.6737 & TRN & \\
\hline CHEMBL1079677 & 620648 & 6.8539 & 6.2519 & TRN & \\
\hline CHEMBL1081207 & 620648 & 6.3372 & 6.6116 & TST & \\
\hline CHEMBL1080534 & 620648 & 6.1805 & 6.602 & TRN & \\
\hline CHEMBL1081751 & 620648 & 4.0 & 6.2377 & TRN & \\
\hline CHEMBL1079983 & 620648 & 7.7696 & 6.8463 & TRN & \\
\hline CHEMBL1080822 & 620648 & 8.0458 & 7.3647 & TRN & \\
\hline CHEMBL1079910 & 620648 & 8.0 & 7.9433 & TRN & \\
\hline CHEMBL1081729 & 620648 & 7.1549 & 7.2212 & TRN & \\
\hline CHEMBL1075683 & 620648 & 8.3979 & 8.4582 & TRN & \\
\hline CHEMBL1080172 & 620648 & 8.2218 & 7.7924 & TRN & \\
\hline CHEMBL1075835 & 620648 & 7.7447 & 8.2053 & TRN & \\
\hline CHEMBL1075704 & 620648 & 6.3872 & 7.4697 & TRN & \\
\hline CHEMBL1079489 & 620648 & 6.4685 & 6.7437 & TST & \\
\hline CHEMBL1080349 & 620648 & 8.1549 & \multicolumn{2}{|c|}{7.428999999999999} & TRN \\
\hline CHEMBL1080025 & 620648 & 4.0 & 6.2766 & TRN & \\
\hline CHEMBL1081241 & 620648 & 6.6021 & 6.1564 & TST & \\
\hline CHEMBL1081591 & 620648 & 5.6198 & 6.6741 & TRN & \\
\hline CHEMBL1080821 & 620648 & 7.2518 & 6.8255 & TRN & \\
\hline CHEMBL1081391 & 620648 & 7.1675 & 7.0225 & TRN & \\
\hline CHEMBL1081917 & 620648 & 8.5229 & 7.0133 & TST & \\
\hline CHEMBL1079618 & 620648 & 7.301 & 7.1133 & TRN & \\
\hline CHEMBL1082116 & 620648 & 6.7212 & 6.7506 & TRN & \\
\hline CHEMBL1081044 & 620648 & 5.1965 & 4.8707 & TST & \\
\hline CHEMBL1080361 & 620648 & 5.4949 & 5.0485 & TST & \\
\hline CHEMBL1079925 & 620648 & 7.4949 & 7.1051 & TRN & \\
\hline CHEMBL1075836 & 620648 & 8.5229 & 8.1308 & TRN & \\
\hline CHEMBL1081600 & 620648 & 7.301 & 7.2852 & TRN & \\
\hline CHEMBL1080365 & 620648 & 9.0 & 8.6217 & TRN & \\
\hline CHEMBL1081949 & 620648 & 6.4949 & 6.3968 & TRN & \\
\hline CHEMBL1080143 & 620648 & 7.5229 & 7.2261 & TRN & \\
\hline CHEMBL 279053 & 620648 & 7.9208 & 6.4533 & TST & \\
\hline CHEMBL1079965 & 620648 & 7.7696 & 7.5113 & TRN & \\
\hline CHEMBL1079668 & 620648 & 6.8861 & 6.25299 & 9999999999 & TRN \\
\hline CHEMBL1080013 & 620648 & 6.4202 & 5.8606 & TRN & \\
\hline CHEMBL1080540 & 620648 & 6.4685 & 5.9951 & TST & \\
\hline CHEMBL1081963 & 620648 & 6.8861 & 6.6269 & TST & \\
\hline CHEMBL1081763 & 620648 & 7.699 & 6.5968 & TRN & \\
\hline CHEMBL1082118 & 620648 & 8.0969 & 7.8554 & TRN & \\
\hline CHEMBL1076175 & 620648 & 6.7959 & 6.7664 & TRN & \\
\hline CHEMBL1081424 & 620648 & 5.857 & 6.8873 & TST & \\
\hline
\end{tabular}




\begin{tabular}{|c|c|c|c|c|c|c|}
\hline \multicolumn{6}{|c|}{ Supplemental Table S2.txt } & \\
\hline CHEMBL1079739 & 620648 & 6.9586 & 6.4225 & TRN & & \\
\hline CHEMBL1075682 & 620648 & 8.0 & 7.4247 & TRN & & \\
\hline CHEMBL1081046 & 620648 & 7.5229 & 5.1674 & TST & & \\
\hline CHEMBL1079617 & 620648 & 7.0969 & 6.6931 & TRN & & \\
\hline CHEMBL1082117 & 620648 & 7.2596 & 7.9969 & TRN & & \\
\hline CHEMBL1076163 & 620648 & 7.7447 & 7.5393 & TRN & & \\
\hline CHEMBL1079382 & 620648 & 7.2076 & 5.6306 & TST & & \\
\hline CHEMBL1075894 & 620648 & 8.699 & 8.9507 & TRN & & \\
\hline CHEMBL1075725 & 620648 & 7.7447 & 8.5914 & TRN & & \\
\hline CHEMBL1081602 & 620648 & 5.2291 & 6.4032 & TRN & & \\
\hline CHEMBL1080109 & 620648 & 8.0458 & 8.2434 & TRN & & \\
\hline CHEMBL1080708 & 620648 & 4.0 & 6.3615 & TST & & \\
\hline CHEMBL1081410 & 620648 & 5.9208 & 5.4395 & TST & & \\
\hline CHEMBL1080312 & 620648 & 5.4815 & 4.7005 & TST & & \\
\hline CHEMBL1080026 & 620648 & 6.2924 & 6.4591 & TST & & \\
\hline CHEMBL1081786 & 620648 & 4.0 & 5.0666 & TST & & \\
\hline CHEMBL1075723 & 620648 & 8.699 & 7.5508 & TST & & \\
\hline CHEMBL1075895 & 620648 & 9.0 & 8.9224 & TST & & \\
\hline CHEMBL1080188 & 620648 & 7.585 & 6.9858 & TST & & \\
\hline CHEMBL1082137 & 620648 & 8.0 & 6.195 & TST & & \\
\hline CHEMBL1076151 & 620648 & 6.6021 & 6.3585 & TST & & \\
\hline CHEMBL1075703 & 620648 & 7.8861 & 7.5528 & TST & & \\
\hline CHEMBL1079984 & 620648 & 7.4685 & 7.0591 & TST & & \\
\hline CHEMBL1081223 & 620648 & 6.2644 & 7.3822 & TST & & \\
\hline CHEMBL1081750 & 620648 & 7.1549 & 6.2736 & TST & & \\
\hline CHEMBL1584180 & 737424 & 4.2575 & 4.5109 & TRN & & \\
\hline CHEMBL1995726 & 737424 & 3.3032 & 4.493 & TRN & & \\
\hline CHEMBL1375038 & 737424 & 5.5092 & 5.7904 & TRN & & \\
\hline CHEMBL1582623 & 737424 & 4.8394 & 4.9134 & TRN & & \\
\hline CHEMBL1438796 & 737424 & 5.2187 & 4.7539 & TRN & & \\
\hline CHEMBL1612190 & 737424 & 5.4724 & 4.6656 & TRN & & \\
\hline CHEMBL1997993 & 737424 & 5.5508 & 5.1102 & TRN & & \\
\hline CHEMBL1334210 & 737424 & 5.215 & 4.623 & TRN & & \\
\hline CHEMBL1399190 & 737424 & 4.8331 & 4.9247 & TST & & \\
\hline CHEMBL1342888 & 737424 & 5.2583 & 4.9837 & TST & & \\
\hline CHEMBL1720383 & 737424 & 5.1196 & 4.8098 & TRN & & \\
\hline CHEMBL1557141 & 737424 & 4.7872 & 5.1214 & TRN & & \\
\hline CHEMBL1980584 & 737424 & 5.0017 & 4.9289 & TRN & & \\
\hline CHEMBL 2004183 & 737424 & 5.3143 & 5.1757 & TRN & & \\
\hline CHEMBL1501678 & 737424 & 6.41799 & 99999999 & & 5.4005 TRN & \\
\hline CHEMBL1528787 & 737424 & 5.24200 & 00000000 & 01 & 5.202999999999999 & TRN \\
\hline CHEMBL1977808 & 737424 & 5.3481 & 5.2904 & TRN & & \\
\hline CHEMBL1466856 & 737424 & 5.398 & 5.3818 & TRN & & \\
\hline CHEMBL1409773 & 737424 & 5.0136 & 4.6909 & TRN & & \\
\hline CHEMBL1426481 & 737424 & 5.0179 & 4.5288 & TRN & & \\
\hline CHEMBL1416951 & 737424 & 5.8365 & 5.2356 & TRN & & \\
\hline CHEMBL1548353 & 737424 & 5.4585 & 4.7824 & TRN & & \\
\hline CHEMBL1571807 & 737424 & 4.2574 & 4.3462 & TRN & & \\
\hline
\end{tabular}


Supplemental Table S2.txt

\begin{tabular}{|c|c|c|c|c|c|}
\hline CHEMBL1363571 & 737424 & 3.3033 & 4.5731 & TRN & \\
\hline CHEMBL1466997 & 737424 & 5.263 & 4.5621 & TRN & \\
\hline CHEMBL1369963 & 737424 & 3.3029 & 5.2815 & TRN & \\
\hline CHEMBL1440953 & 737424 & 5.3658 & 4.9576 & TRN & \\
\hline CHEMBL1724205 & 737424 & 4.8826 & 4.9554 & TRN & \\
\hline CHEMBL1327065 & 737424 & 4.8786 & 5.3498 & TRN & \\
\hline CHEMBL1422276 & 737424 & 4.4871 & 4.7473 & TRN & \\
\hline CHEMBL1516768 & 737424 & 3.3028 & 4.9211 & TRN & \\
\hline CHEMBL1344555 & 737424 & 3.3033 & 4.4333 & TRN & \\
\hline CHEMBL1526729 & 737424 & 4.6925 & 4.4552 & TRN & \\
\hline CHEMBL1386871 & 737424 & 4.4827 & 4.9648 & TRN & \\
\hline CHEMBL1302355 & 737424 & 5.0872 & 5.5532 & TRN & \\
\hline CHEMBL1556254 & 737424 & 4.8763 & 4.5349 & TRN & \\
\hline CHEMBL1503548 & 737424 & 5.2077 & 4.8093 & TRN & \\
\hline CHEMBL1714761 & 737424 & 5.3685 & 5.3639 & TRN & \\
\hline CHEMBL1438621 & 737424 & 5.192 & 4.6437 & TRN & \\
\hline CHEMBL1360282 & 737424 & 5.5116 & 5.49100 & 00000000005 & TRN \\
\hline CHEMBL1433931 & 737424 & 5.4903 & 5.4348 & TST & \\
\hline CHEMBL1966472 & 737424 & 3.3035 & 4.4413 & TRN & \\
\hline CHEMBL1715597 & 737424 & 5.3736 & 5.2837 & TRN & \\
\hline CHEMBL1542157 & 737424 & 4.9044 & 4.926 & TRN & \\
\hline CHEMBL1348119 & 737424 & 4.5165 & 4.3438 & TRN & \\
\hline CHEMBL1498924 & 737424 & 5.7913 & 4.9521 & TST & \\
\hline CHEMBL1979607 & 737424 & 4.506 & 4.7287 & TRN & \\
\hline CHEMBL1485238 & 737424 & 5.1461 & 5.2891 & TRN & \\
\hline CHEMBL1330781 & 737424 & 4.6478 & 4.8549 & TST & \\
\hline CHEMBL1727648 & 737424 & 5.5239 & 5.5265 & TRN & \\
\hline CHEMBL1536442 & 737424 & 5.2545 & 4.912 & TRN & \\
\hline CHEMBL1400350 & 737424 & 5.1814 & 5.12200 & $\partial 000000001$ & TRN \\
\hline CHEMBL1335116 & 737424 & 5.2134 & 5.2916 & TRN & \\
\hline CHEMBL1476308 & 737424 & 4.9058 & 5.5516 & TST & \\
\hline CHEMBL1367648 & 737424 & 5.1155 & 4.5005 & TRN & \\
\hline CHEMBL1733477 & 737424 & 4.2578 & 4.8422 & TRN & \\
\hline CHEMBL1588363 & 737424 & 5.2725 & 4.9132 & TRN & \\
\hline CHEMBL1532928 & 737424 & 5.3702 & 4.6915 & TRN & \\
\hline CHEMBL1539105 & 737424 & 5.37200 & 00000000 & 4.7453 & 10 \\
\hline CHEMBL1351110 & 737424 & 4.9007 & 4.7348 & TRN & \\
\hline CHEMBL1326648 & 737424 & 5.965 & 5.8592 & TRN & \\
\hline CHEMBL1481716 & 737424 & 5.2525 & 5.6184 & TRN & \\
\hline CHEMBL1560993 & 737424 & 4.8757 & 5.2155 & TRN & \\
\hline CHEMBL1727586 & 737424 & 4.9511 & 5.3977 & TST & \\
\hline CHEMBL1588229 & 737424 & 4.7844 & 4.8476 & TST & \\
\hline CHEMBL1342119 & 737424 & 5.0279 & 4.738 & TRN & \\
\hline CHEMBL1485217 & 737424 & 5.0437 & 5.176 & TRN & \\
\hline CHEMBL1307031 & 737424 & 4.8605 & 5.0693 & TST & \\
\hline CHEMBL1270809 & 737424 & 4.8536 & 5.22 & TRN & \\
\hline CHEMBL1594672 & 737424 & 5.9485 & 5.5333 & TRN & \\
\hline CHEMBL1380649 & 737424 & 5.518 & 5.3405 & TRN & \\
\hline
\end{tabular}


Supplemental Table S2.txt

\begin{tabular}{|c|c|c|c|c|c|c|}
\hline CHEMBL1576843 & 737424 & 5.1629 & 4.9528 & TRN & & \\
\hline CHEMBL1716146 & 737424 & 5.0075 & 5.5576 & TRN & & \\
\hline CHEMBL1583817 & 737424 & 6.065 & 5.4447 & TRN & & \\
\hline CHEMBL1461147 & 737424 & 4.9791 & 5.1607 & TRN & & \\
\hline CHEMBL1572480 & 737424 & 4.8838 & 4.6952 & TRN & & \\
\hline CHEMBL3214429 & 737424 & 5.6338 & 5.2509 & TST & & \\
\hline CHEMBL1714525 & 737424 & 5.188 & 5.0376 & TRN & & \\
\hline CHEMBL1572095 & 737424 & 5.3057 & 5.0656 & TRN & & \\
\hline CHEMBL1341758 & 737424 & 4.4633 & 4.87 & TST & & \\
\hline CHEMBL1328144 & 737424 & 5.3132 & 5.6457 & TRN & & \\
\hline CHEMBL1524484 & 737424 & 4.3178 & 4.9405 & TRN & & \\
\hline CHEMBL1521046 & 737424 & 4.4774 & 4.9161 & TRN & & \\
\hline CHEMBL1343392 & 737424 & 5.2129 & 5.1689 & TRN & & \\
\hline CHEMBL1379934 & 737424 & 5.626 & 5.1853 & TRN & & \\
\hline CHEMBL1409330 & 737424 & 5.9918 & 4.5292 & TRN & & \\
\hline CHEMBL1546895 & 737424 & 5.4449 & 4.9766 & TRN & & \\
\hline CHEMBL1459180 & 737424 & 6.1154 & 5.1931 & TRN & & \\
\hline CHEMBL1313229 & 737424 & 4.8978 & 5.3624 & TST & & \\
\hline CHEMBL1967431 & 737424 & 5.1324 & 4.987 & TRN & & \\
\hline CHEMBL1355104 & 737424 & 5.4084 & 5.1857 & TRN & & \\
\hline CHEMBL1481095 & 737424 & 5.1094 & 4.811 & TRN & & \\
\hline CHEMBL 2003606 & 737424 & 5.2269 & 5.4858 & TRN & & \\
\hline CHEMBL1571574 & 737424 & 4.869 & 5.2346 & TRN & & \\
\hline CHEMBL1342815 & 737424 & 4.7248 & 5.0349 & TRN & & \\
\hline CHEMBL1540815 & 737424 & 5.1367 & 5.1213 & TRN & & \\
\hline CHEMBL1979844 & 737424 & 5.1822 & 4.9846 & TRN & & \\
\hline CHEMBL1562279 & 737424 & 6.3702 & 6.0736 & TRN & & \\
\hline CHEMBL1536921 & 737424 & 3.3032 & 4.8213 & TRN & & \\
\hline CHEMBL1572758 & 737424 & 5.2756 & 4.7197 & TRN & & \\
\hline CHEMBL1351929 & 737424 & 5.1866 & 5.218 & TRN & & \\
\hline CHEMBL1595403 & 737424 & 3.7802 & 4.8181 & TRN & & \\
\hline CHEMBL1706285 & 737424 & 5.4593 & 4.9724 & TRN & & \\
\hline CHEMBL1333148 & 737424 & 5.5025 & 5.604 & TRN & & \\
\hline CHEMBL1378896 & 737424 & 3.303 & 4.7283 & TRN & & \\
\hline CHEMBL1583293 & 737424 & 4.8054 & 4.8179 & TRN & & \\
\hline CHEMBL1533279 & 737424 & 5.5065 & 4.7049 & TST & & \\
\hline CHEMBL1494796 & 737424 & 4.8409 & 5.0954 & TST & & \\
\hline CHEMBL1502109 & 737424 & 4.2574 & 4.982 & TRN & & \\
\hline CHEMBL1330907 & 737424 & 5.0626 & 4.9043 & TRN & & \\
\hline CHEMBL1459603 & 737424 & 5.1935 & 5.3261 & TRN & & \\
\hline CHEMBL1541192 & 737424 & 5.4733 & 5.2663 & TRN & & \\
\hline CHEMBL1605702 & 737424 & 5.45299 & 99999999 & 99 & 5.4125 & TST \\
\hline CHEMBL1527445 & 737424 & 5.2486 & 4.8411 & TRN & & \\
\hline CHEMBL1577537 & 737424 & 4.8328 & 4.995 & TST & & \\
\hline CHEMBL1709502 & 737424 & 5.3052 & 5.416 & TRN & & \\
\hline CHEMBL1418095 & 737424 & 5.8592 & 5.505 & TRN & & \\
\hline CHEMBL1421498 & 737424 & 5.0615 & 5.1201 & TRN & & \\
\hline CHEMBL1735531 & 737424 & 4.8348 & 5.2485 & TRN & & \\
\hline
\end{tabular}


Supplemental Table S2.txt

\begin{tabular}{|c|c|c|c|c|}
\hline CHEMBL1565236 & 737424 & 5.9094 & 4.8841 & TRN \\
\hline CHEMBL1456018 & 737424 & 5.5424 & 5.0371 & TRN \\
\hline CHEMBL1512498 & 737424 & 5.0904 & 4.852 & TRN \\
\hline CHEMBL1514800 & 737424 & 5.7711 & 5.1825 & TRN \\
\hline CHEMBL1365949 & 737424 & 5.2169 & 4.9731 & TRN \\
\hline CHEMBL1468272 & 737424 & 4.7539 & 4.9055 & TRN \\
\hline CHEMBL1590375 & 737424 & 5.0268 & 4.9244 & TST \\
\hline CHEMBL1967103 & 737424 & 6.2791 & 5.4205 & TRN \\
\hline CHEMBL1301892 & 737424 & 5.5879 & 5.6821 & TRN \\
\hline CHEMBL1731389 & 737424 & 5.6994 & 5.3098 & TRN \\
\hline CHEMBL1549099 & 737424 & 4.2572 & 4.402 & TRN \\
\hline CHEMBL1559065 & 737424 & 4.3471 & 4.9525 & TRN \\
\hline CHEMBL1502107 & 737424 & 4.8702 & 4.9358 & TRN \\
\hline CHEMBL1604928 & 737424 & 5.1753 & 4.8691 & TST \\
\hline CHEMBL1364699 & 737424 & 3.3032 & 4.9889 & TRN \\
\hline CHEMBL1388463 & 737424 & 3.303 & 4.4015 & TRN \\
\hline CHEMBL1445904 & 737424 & 4.8142 & 5.504 & TRN \\
\hline CHEMBL 3199868 & 737424 & $5.1110 e$ & 00000000 & 4.8717 \\
\hline CHEMBL1337585 & 737424 & 5.4925 & 5.7764 & TRN \\
\hline CHEMBL1970286 & 737424 & 5.4357 & 5.0553 & TRN \\
\hline CHEMBL1418678 & 737424 & 4.824 & 4.7817 & TST \\
\hline CHEMBL1487872 & 737424 & 4.9818 & 4.852 & TRN \\
\hline CHEMBL1330311 & 737424 & 4.9833 & 4.8765 & TRN \\
\hline CHEMBL1978193 & 737424 & 4.6251 & 4.4776 & TRN \\
\hline CHEMBL1331281 & 737424 & 5.6623 & 5.5126 & TRN \\
\hline CHEMBL1464571 & 737424 & 4.5793 & 4.8286 & TRN \\
\hline CHEMBL1702133 & 737424 & 4.6389 & 5.045 & TRN \\
\hline CHEMBL1534057 & 737424 & 5.0453 & 5.1362 & TRN \\
\hline CHEMBL1419029 & 737424 & 5.6169 & 5.7143 & TRN \\
\hline CHEMBL1432793 & 737424 & 4.7763 & 4.90300 & 30000000005 \\
\hline CHEMBL1458511 & 737424 & 4.8895 & 4.6176 & TRN \\
\hline CHEMBL1354074 & 737424 & 4.8456 & 5.3546 & TRN \\
\hline CHEMBL1552334 & 737424 & 5.4835 & 5.5101 & TRN \\
\hline CHEMBL1588256 & 737424 & 4.8679 & 5.0079 & TRN \\
\hline CHEMBL1335338 & 737424 & 5.4824 & 5.1031 & TRN \\
\hline CHEMBL1406761 & 737424 & 5.4445 & 5.041 & TRN \\
\hline CHEMBL1704083 & 737424 & 4.9221 & 5.1518 & TRN \\
\hline CHEMBL1478565 & 737424 & 5.6602 & 4.6721 & TRN \\
\hline CHEMBL1458435 & 737424 & 5.6498 & 5.09399 & э999999999 \\
\hline CHEMBL1434457 & 737424 & 4.8212 & 5.4051 & TRN \\
\hline CHEMBL1399289 & 737424 & 4.2574 & 4.602 & TRN \\
\hline CHEMBL199868 & 737424 & 5.3945 & 4.8757 & TRN \\
\hline CHEMBL1402931 & 737424 & 6.0563 & 5.0133 & TST \\
\hline CHEMBL1532403 & 737424 & 5.4183 & 5.117 & TRN \\
\hline CHEMBL1512619 & 737424 & 5.6287 & 5.1716 & TRN \\
\hline CHEMBL1357156 & 737424 & 5.755 & 5.1942 & TRN \\
\hline CHEMBL1978117 & 737424 & 5.3986 & 5.0813 & TRN \\
\hline CHEMBL1977763 & 737424 & 5.605 & 4.7383 & TRN \\
\hline
\end{tabular}


Supplemental Table S2.txt

\begin{tabular}{|c|c|c|c|c|c|}
\hline CHEMBL1460004 & 737424 & 5.0612 & 5.3406 & TST & \\
\hline CHEMBL1477093 & 737424 & 4.8997 & 4.6371 & TRN & \\
\hline CHEMBL1520346 & 737424 & \multicolumn{2}{|c|}{5.752000000000001} & 5.2401 & TRN \\
\hline CHEMBL 2006840 & 737424 & 5.4795 & 5.1189 & TRN & \\
\hline CHEMBL1721724 & 737424 & 4.7074 & 5.1623 & TRN & \\
\hline CHEMBL1556270 & 737424 & 3.3033 & 4.4348 & TRN & \\
\hline CHEMBL1981638 & 737424 & 5.0324 & 4.9382 & TRN & \\
\hline CHEMBL1304258 & 737424 & 5.2623 & 4.9439 & TRN & \\
\hline CHEMBL1438417 & 737424 & 4.2574 & 4.6621 & TRN & \\
\hline CHEMBL1983843 & 737424 & 5.4908 & 4.7506 & TRN & \\
\hline CHEMBL1722330 & 737424 & 5.4851 & 5.1803 & TRN & \\
\hline CHEMBL1511752 & 737424 & 3.3031 & 4.3478 & TRN & \\
\hline CHEMBL1377656 & 737424 & 4.7651 & 4.5602 & TRN & \\
\hline CHEMBL1513765 & 737424 & 5.2311 & 5.1806 & TRN & \\
\hline CHEMBL1590005 & 737424 & 5.114 & 5.2736 & TRN & \\
\hline CHEMBL1333250 & 737424 & 5.1145 & 5.0874 & TRN & \\
\hline CHEMBL1988282 & 737424 & 5.2253 & 5.4918 & TRN & \\
\hline CHEMBL1372776 & 737424 & 5.1856 & 5.2146 & TRN & \\
\hline CHEMBL1966014 & 737424 & 5.56 & 5.0446 & TRN & \\
\hline CHEMBL1973904 & 737424 & 5.0616 & 4.9386 & TRN & \\
\hline CHEMBL1518032 & 737424 & 4.2574 & 4.9474 & TRN & \\
\hline CHEMBL1493493 & 737424 & 3.3032 & 4.93199 & 9999999 & TRN \\
\hline CHEMBL1585859 & 737424 & 5.8745 & 5.2904 & TRN & \\
\hline CHEMBL1401331 & 737424 & 5.1387 & 5.1173 & TRN & \\
\hline CHEMBL1713886 & 737424 & 4.6949 & 5.035 & TRN & \\
\hline CHEMBL1327720 & 737424 & 4.6278 & 4.6732 & TRN & \\
\hline CHEMBL1493746 & 737424 & 4.9494 & 4.9477 & TRN & \\
\hline CHEMBL1491556 & 737424 & 5.3004 & 4.9348 & TST & \\
\hline CHEMBL1606494 & 737424 & 5.2018 & 5.006 & TRN & \\
\hline CHEMBL1476869 & 737424 & 5.2034 & 5.2575 & TST & \\
\hline CHEMBL1440341 & 737424 & 5.6889 & 4.9846 & TRN & \\
\hline CHEMBL1575559 & 737424 & 5.1487 & 5.1456 & TRN & \\
\hline CHEMBL1964878 & 737424 & 5.5485 & 5.1603 & TST & \\
\hline CHEMBL1465216 & 737424 & 5.3677 & 5.1374 & TST & \\
\hline CHEMBL1480014 & 737424 & 4.7585 & 4.5644 & TRN & \\
\hline CHEMBL1720286 & 737424 & 4.6214 & 4.9339 & TST & \\
\hline CHEMBL1706330 & 737424 & 5.3369 & 5.1693 & TRN & \\
\hline CHEMBL1714024 & 737424 & 5.4885 & 5.2451 & TRN & \\
\hline CHEMBL3199892 & 737424 & 5.2412 & 5.307 & TRN & \\
\hline CHEMBL1582357 & 737424 & 5.6398 & 5.2091 & TRN & \\
\hline CHEMBL1501952 & 737424 & 3.3032 & 5.3819 & TRN & \\
\hline CHEMBL1336039 & 737424 & 5.0228 & 5.091 & TRN & \\
\hline CHEMBL3667549 & 737424 & 6.0968 & 5.5214 & TRN & \\
\hline CHEMBL1722206 & 737424 & 4.8018 & 4.5699 & TRN & \\
\hline CHEMBL1579404 & 737424 & 5.4618 & 5.269 & TRN & \\
\hline CHEMBL1344470 & 737424 & 4.7753 & 4.6489 & TST & \\
\hline CHEMBL1699081 & 737424 & 4.8598 & 5.2582 & TST & \\
\hline CHEMBL1463349 & 737424 & 5.1639 & 4.8573 & TST & \\
\hline
\end{tabular}


Supplemental Table S2.txt

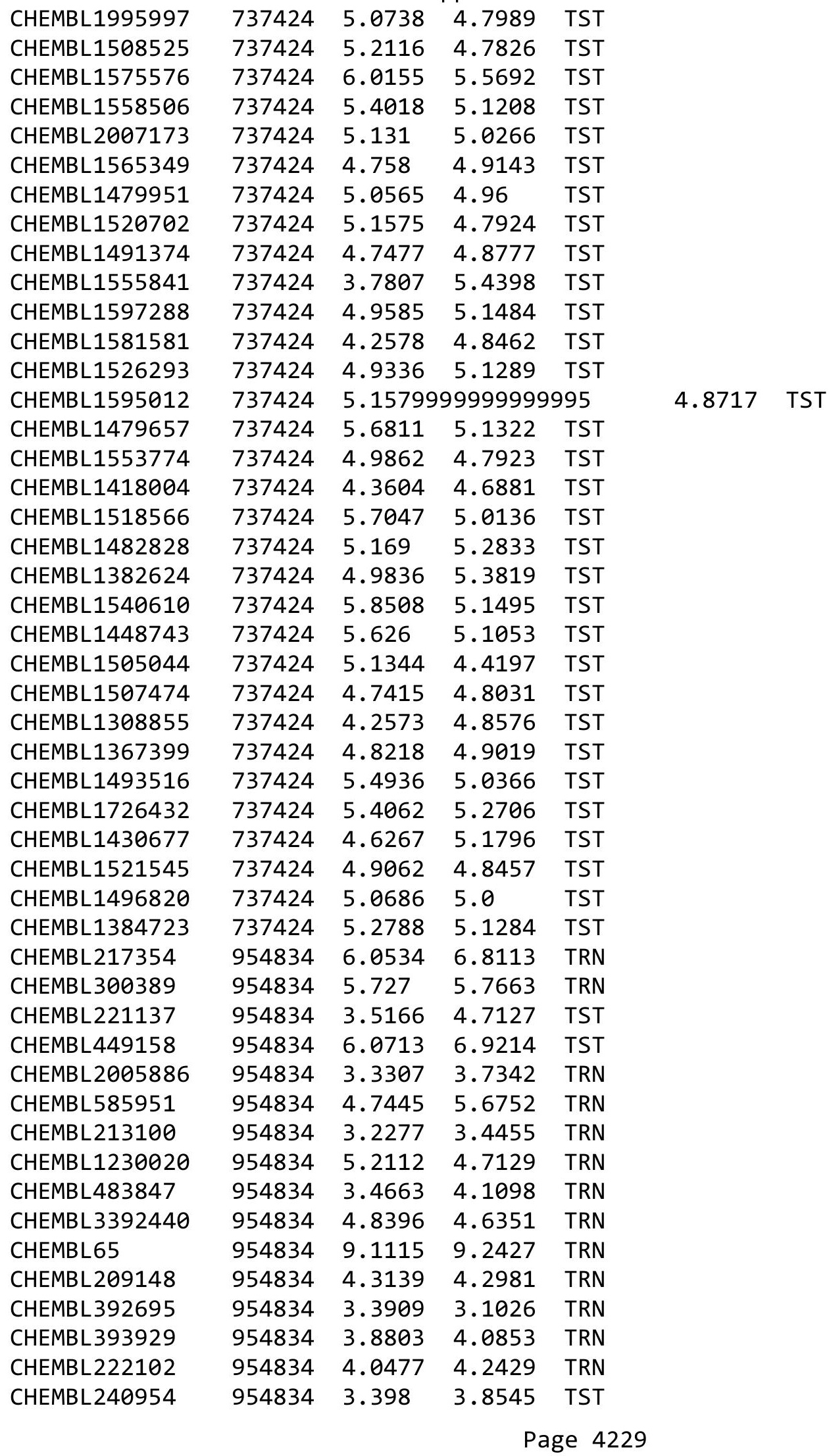


Supplemental Table S2.txt

\begin{tabular}{|c|c|c|c|c|c|}
\hline CHEMBL1788116 & 954834 & 5.1807 & 4.6598 & TRN & \\
\hline CHEMBL210618 & 954834 & 3.2239 & 3.5518 & TRN & \\
\hline CHEMBL180127 & 954834 & 2.5553 & 2.9936 & TRN & \\
\hline CHEMBL1357247 & 954834 & 3.8844 & 3.5256 & TRN & \\
\hline CHEMBL512504 & 954834 & 4.8138 & 3.9073 & TRN & \\
\hline CHEMBL1190711 & 954834 & 5.0097 & \multicolumn{2}{|c|}{5.1370000000000005} & TRN \\
\hline CHEMBL558642 & 954834 & 2.7005 & 3.0636 & TRN & \\
\hline CHEMBL483849 & 954834 & 2.3558 & 2.7425 & TST & \\
\hline CHEMBL1590308 & 954834 & 2.5684 & 3.0835 & TST & \\
\hline CHEMBL1256459 & 954834 & 5.0212 & 4.5468 & TRN & \\
\hline CHEMBL514499 & 954834 & 3.8527 & 3.9618 & TRN & \\
\hline CHEMBL1242367 & 954834 & 3.2106 & 3.3624 & TRN & \\
\hline CHEMBL1404918 & 954834 & 3.0067 & 3.5319 & TRN & \\
\hline CHEMBL 2137530 & 954834 & 4.7052 & 4.7655 & TRN & \\
\hline CHEMBL379975 & 954834 & 5.4545 & 5.5492 & TRN & \\
\hline CHEMBL1186585 & 954834 & 4.1534 & 4.2049 & TRN & \\
\hline CHEMBL1970879 & 954834 & 2.9739 & 3.2731 & TRN & \\
\hline CHEMBL399530 & 954834 & 4.917 & 4.511 & TRN & \\
\hline CHEMBL255342 & 954834 & 3.5204 & 3.405 & TRN & \\
\hline CHEMBL 2134202 & 954834 & 3.7274 & 3.7189 & TRN & \\
\hline CHEMBL192566 & 954834 & 4.7361 & 8.6896 & TST & \\
\hline CHEMBL1909414 & 954834 & 4.1277 & 4.0976 & TRN & \\
\hline CHEMBL220241 & 954834 & 2.5923 & 3.2697 & TRN & \\
\hline CHEMBL515416 & 954834 & 3.8269 & \multicolumn{2}{|c|}{3.9610000000000003} & TRN \\
\hline CHEMBL412142 & 954834 & 3.6108 & 3.8489 & TRN & \\
\hline CHEMBL189584 & 954834 & 5.4161 & 4.6215 & TRN & \\
\hline CHEMBL92309 & 954834 & 1.3733 & 2.4599 & TST & \\
\hline CHEMBL259181 & 954834 & 4.3397 & 4.4865 & TRN & \\
\hline CHEMBL1643959 & 954834 & 2.6443 & 2.9544 & TRN & \\
\hline CHEMBL509032 & 954834 & 4.5211 & 4.6079 & TRN & \\
\hline CHEMBL202721 & 954834 & 5.9989 & 5.2815 & TRN & \\
\hline CHEMBL573107 & 954834 & 5.6505 & 5.7985 & TRN & \\
\hline CHEMBL191334 & 954834 & 4.1659 & 4.4419 & TRN & \\
\hline CHEMBL1673039 & 954834 & 4.7771 & 3.8235 & TRN & \\
\hline CHEMBL188678 & 954834 & 4.8815 & 4.5051 & TRN & \\
\hline CHEMBL373751 & 954834 & 2.9193 & 3.3091 & TRN & \\
\hline CHEMBL 2144069 & 954834 & 4.8556 & 4.626 & TRN & \\
\hline CHEMBL472940 & 954834 & 4.9106 & 4.3278 & TRN & \\
\hline CHEMBL1516890 & 954834 & 5.1014 & 4.104 & TRN & \\
\hline CHEMBL3199475 & 954834 & 4.7172 & 4.8242 & TST & \\
\hline CHEMBL379300 & 954834 & 5.0962 & 4.6108 & TST & \\
\hline CHEMBL135561 & 954834 & 5.0592 & 4.237 & TST & \\
\hline CHEMBL9470 & 954834 & 5.5793 & 5.6308 & TST & \\
\hline CHEMBL3349342 & 954834 & 4.1656 & 5.1234 & TST & \\
\hline CHEMBL577784 & 954834 & 5.9232 & 5.6267 & TST & \\
\hline CHEMBL3186408 & 954834 & 3.0573 & 3.0825 & TST & \\
\hline CHEMBL 2363137 & 954834 & 3.5877 & 4.7817 & TST & \\
\hline CHEMBL258844 & 954834 & 4.3134 & 4.8676 & TST & \\
\hline
\end{tabular}




$$
\text { Supplemental Table S2.txt }
$$

\begin{tabular}{|c|c|c|c|c|c|}
\hline CHEMBL102714 & 954834 & 3.8714 & 3.943 & TST & \\
\hline CHEMBL3325950 & 1457669 & 4.9586 & 4.9557 & TRN & \\
\hline CHEMBL418899 & 1457669 & 4.699 & 3.4038 & TST & \\
\hline CHEMBL3325674 & 1457669 & 3.0 & 2.9368 & TRN & \\
\hline CHEMBL3325947 & 1457669 & 3.0 & 2.9692 & TRN & \\
\hline CHEMBL1526476 & 1457669 & 3.0 & 3.0539 & TRN & \\
\hline CHEMBL3325680 & 1457669 & 3.0 & 3.0226 & TRN & \\
\hline CHEMBL1922082 & 1457669 & 3.0 & 3.0402 & TRN & \\
\hline CHEMBL3325954 & 1457669 & 3.0 & 2.9587 & TRN & \\
\hline CHEMBL3325945 & 1457669 & 3.0 & 2.9681 & TRN & \\
\hline CHEMBL3325936 & 1457669 & 3.0 & 2.9961 & TRN & \\
\hline CHEMBL3325839 & 1457669 & 3.0 & 3.0448 & TRN & \\
\hline CHEMBL3325825 & 1457669 & 4.8861 & 4.7071 & TRN & \\
\hline CHEMBL3325837 & 1457669 & 3.0 & 2.9478 & TRN & \\
\hline CHEMBL3325821 & 1457669 & 4.5528 & 4.6246 & TRN & \\
\hline CHEMBL3325834 & 1457669 & 4.699 & 4.6042 & TRN & \\
\hline CHEMBL3325840 & 1457669 & 3.0 & 3.1712 & TRN & \\
\hline CHEMBL3325820 & 1457669 & 4.7696 & 4.7602 & TRN & \\
\hline CHEMBL3325937 & 1457669 & 4.9208 & 4.8831 & TRN & \\
\hline CHEMBL3325682 & 1457669 & 3.0 & 2.912 & TRN & \\
\hline CHEMBL3325938 & 1457669 & 4.9208 & 4.8735 & TRN & \\
\hline CHEMBL3325948 & 1457669 & 4.3279 & 4.248 & TRN & \\
\hline CHEMBL2112432 & 1457669 & 3.0 & 3.2758 & TST & \\
\hline CHEMBL3325669 & 1457669 & 4.0969 & 4.0352 & TRN & \\
\hline CHEMBL3325941 & 1457669 & 3.0 & 3.0252 & TRN & \\
\hline CHEMBL3325944 & 1457669 & 3.0 & 3.0611 & TRN & \\
\hline CHEMBL3325953 & 1457669 & 4.6778 & 4.6885 & TRN & \\
\hline CHEMBL3325451 & 1457669 & 4.4815 & 4.5026 & TRN & \\
\hline CHEMBL3325685 & 1457669 & 4.1367 & 4.2193 & TRN & \\
\hline CHEMBL3325835 & 1457669 & 4.9586 & 5.1757 & TRN & \\
\hline CHEMBL351569 & 1457669 & 3.0 & 2.9675 & TRN & \\
\hline CHEMBL564201 & 1457669 & 3.0 & 2.627 & TST & \\
\hline CHEMBL3325675 & 1457669 & 4.8539 & 4.9561 & TRN & \\
\hline CHEMBL3325681 & 1457669 & 3.0 & 3.0375 & TRN & \\
\hline CHEMBL3325946 & 1457669 & 3.0 & 2.9749 & TRN & \\
\hline CHEMBL3325687 & 1457669 & 4.4949 & 4.558 & TRN & \\
\hline CHEMBL3325827 & 1457669 & 3.0 & 3.10699 & 99999999998 & TRN \\
\hline CHEMBL3325833 & 1457669 & 4.585 & 4.5084 & TRN & \\
\hline CHEMBL3325676 & 1457669 & 3.0 & 3.0222 & TRN & \\
\hline CHEMBL3325689 & 1457669 & 3.0 & 2.9729 & TRN & \\
\hline CHEMBL3325832 & 1457669 & 4.7696 & 4.7422 & TRN & \\
\hline CHEMBL3325935 & 1457669 & 4.9208 & 4.742 & TRN & \\
\hline CHEMBL3327379 & 1457669 & 3.0 & 2.9662 & TRN & \\
\hline CHEMBL573352 & 1457669 & 4.5229 & 4.1254 & TST & \\
\hline CHEMBL3325951 & 1457669 & 3.0 & 3.0779 & TRN & \\
\hline CHEMBL3325684 & 1457669 & 3.0 & 4.0634 & TST & \\
\hline CHEMBL3325668 & 1457669 & 4.0969 & 4.0645 & TRN & \\
\hline CHEMBL3325670 & 1457669 & 6.0 & 6.0953 & TRN & \\
\hline
\end{tabular}




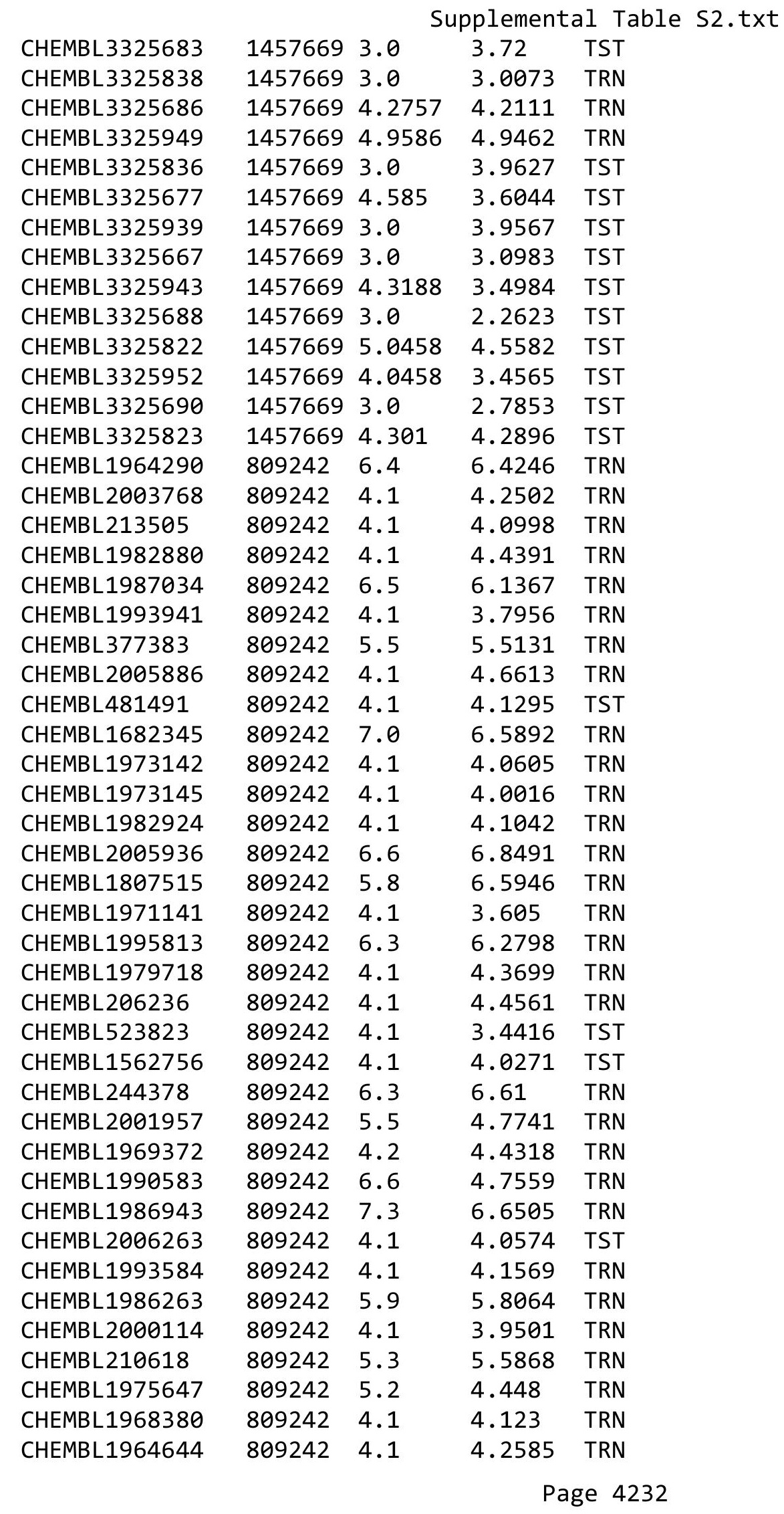




\begin{tabular}{|c|c|c|c|c|c|}
\hline & & & & & \\
\hline CHEMBL1981782 & 809242 & 6.5 & 5.657 & TRN & \\
\hline CHEMBL1977681 & 809242 & 5.3 & 5.3109 & TRN & \\
\hline CHEMBL1970142 & 809242 & 4.1 & 4.2024 & TRN & \\
\hline CHEMBL1990912 & 809242 & 5.3 & 4.0936 & TRN & \\
\hline CHEMBL1988163 & 809242 & 5.2 & 5.2488 & TRN & \\
\hline CHEMBL1995592 & 809242 & 4.1 & 4.5462 & TST & \\
\hline CHEMBL 2006493 & 809242 & 4.1 & 3.6293 & TST & \\
\hline CHEMBL1996923 & 809242 & 4.1 & 3.9996 & TST & \\
\hline CHEMBL1983449 & 809242 & 4.1 & 4.2205 & TRN & \\
\hline CHEMBL1992323 & 809242 & 4.1 & $3.6510 e$ & 00000000002 & TRN \\
\hline CHEMBL1969735 & 809242 & 4.1 & 4.5005 & TRN & \\
\hline CHEMBL 2003524 & 809242 & 4.1 & 4.3796 & TST & \\
\hline CHEMBL 2002649 & 809242 & 6.3 & 5.0966 & TRN & \\
\hline CHEMBL437747 & 809242 & 7.1 & 6.2094 & TRN & \\
\hline CHEMBL1995172 & 809242 & 4.1 & 3.9897 & TST & \\
\hline CHEMBL507936 & 809242 & 4.1 & 3.761 & TRN & \\
\hline CHEMBL104264 & 809242 & 5.1 & 4.198 & TST & \\
\hline CHEMBL1994321 & 809242 & 4.1 & 4.1305 & TRN & \\
\hline CHEMBL1997129 & 809242 & 6.3 & 6.6059 & TRN & \\
\hline CHEMBL1984788 & 809242 & 4.1 & 4.1708 & TRN & \\
\hline CHEMBL451964 & 809242 & 4.1 & 4.0474 & TRN & \\
\hline CHEMBL1964307 & 809242 & 4.1 & 4.6473 & TRN & \\
\hline CHEMBL 2000508 & 809242 & 4.1 & 4.3822 & TRN & \\
\hline CHEMBL1971694 & 809242 & 4.1 & 3.4994 & TST & \\
\hline CHEMBL 2001547 & 809242 & 4.1 & 4.0238 & TRN & \\
\hline CHEMBL 210928 & 809242 & 4.1 & 4.8491 & TRN & \\
\hline CHEMBL1994361 & 809242 & 4.1 & 4.5032 & TRN & \\
\hline CHEMBL1986603 & 809242 & 4.1 & 4.0291 & TST & \\
\hline CHEMBL1972840 & 809242 & 5.8 & 5.6032 & TRN & \\
\hline CHEMBL1977148 & 809242 & 4.1 & 3.8079 & TRN & \\
\hline CHEMBL 2003286 & 809242 & 4.1 & 3.9571 & TRN & \\
\hline CHEMBL1992306 & 809242 & 4.1 & 4.0055 & TRN & \\
\hline CHEMBL2002165 & 809242 & 4.1 & 4.4909 & TRN & \\
\hline CHEMBL 2001668 & 809242 & 4.1 & 4.1523 & TST & \\
\hline CHEMBL1979318 & 809242 & 4.1 & 4.2151 & TRN & \\
\hline CHEMBL206382 & 809242 & 4.1 & 3.6264 & TRN & \\
\hline CHEMBL1998585 & 809242 & 4.1 & 4.4475 & TRN & \\
\hline CHEMBL127898 & 809242 & 4.1 & 4.1791 & TST & \\
\hline CHEMBL519697 & 809242 & 4.1 & 3.9414 & TST & \\
\hline CHEMBL 2004934 & 809242 & 6.1 & 6.0575 & TRN & \\
\hline CHEMBL1970369 & 809242 & 4.1 & 4.3854 & TRN & \\
\hline CHEMBL 2001485 & 809242 & 4.1 & 4.1084 & TRN & \\
\hline CHEMBL504950 & 809242 & 4.1 & 4.5143 & TRN & \\
\hline CHEMBL1966425 & 809242 & 4.1 & 3.7914 & TRN & \\
\hline CHEMBL1984363 & 809242 & 4.1 & 4.5328 & TRN & \\
\hline CHEMBL1978099 & 809242 & 4.1 & 4.9171 & TRN & \\
\hline CHEMBL1977041 & 809242 & 4.1 & 4.6045 & TRN & \\
\hline CHEMBL1968070 & 809242 & 4.1 & 4.6726 & TRN & \\
\hline & & & & 4233 & \\
\hline
\end{tabular}




\begin{tabular}{|c|c|c|c|c|c|}
\hline \\
\hline CHEMBL1988608 & 809242 & 6.2 & 5.2046 & TRN & \\
\hline CHEMBL184847 & 809242 & 4.1 & 3.8593 & TRN & \\
\hline CHEMBL1984367 & 809242 & 5.3 & 5.6408 & TRN & \\
\hline CHEMBL178737 & 809242 & 4.1 & 3.99899 & 99999999997 & TST \\
\hline CHEMBL226898 & 809242 & 6.2 & 6.3666 & TRN & \\
\hline CHEMBL1982563 & 809242 & 4.1 & 4.5941 & TRN & \\
\hline CHEMBL539474 & 809242 & 4.1 & 4.63899 & 9999999999 & TST \\
\hline CHEMBL575824 & 809242 & 4.2 & 4.7786 & TRN & \\
\hline CHEMBL1988387 & 809242 & 4.1 & 4.1851 & TRN & \\
\hline CHEMBL1997759 & 809242 & 4.1 & 4.5195 & TRN & \\
\hline CHEMBL1989708 & 809242 & 4.1 & 4.4569 & TRN & \\
\hline CHEMBL1974803 & 809242 & 4.1 & 3.6236 & TST & \\
\hline CHEMBL1970074 & 809242 & 4.1 & 4.1927 & TRN & \\
\hline CHEMBL1986970 & 809242 & 6.1 & 6.5188 & TRN & \\
\hline CHEMBL2005112 & 809242 & 4.1 & 3.9389 & TST & \\
\hline CHEMBL1958401 & 809242 & 5.1 & 4.9142 & TRN & \\
\hline CHEMBL1984044 & 809242 & 4.1 & 3.7854 & TRN & \\
\hline CHEMBL2003456 & 809242 & 4.1 & 4.1034 & TRN & \\
\hline CHEMBL1966816 & 809242 & 4.1 & 4.3219 & TRN & \\
\hline CHEMBL1972584 & 809242 & 4.1 & 4.69300 & 00000000005 & TRN \\
\hline CHEMBL560813 & 809242 & 4.1 & 3.5113 & TRN & \\
\hline CHEMBL 207253 & 809242 & 4.1 & 3.4805 & TST & \\
\hline CHEMBL1890036 & 809242 & 4.1 & 4.8271 & TST & \\
\hline CHEMBL1968791 & 809242 & 4.1 & 4.0639 & TRN & \\
\hline CHEMBL326282 & 809242 & 4.1 & 3.7401 & TST & \\
\hline CHEMBL 2002682 & 809242 & 4.1 & 4.2135 & TST & \\
\hline CHEMBL1992732 & 809242 & 4.1 & 3.9719 & TST & \\
\hline CHEMBL1971186 & 809242 & 5.9 & 5.5249 & TRN & \\
\hline CHEMBL 2003482 & 809242 & 5.3 & 4.4495 & TRN & \\
\hline CHEMBL1973211 & 809242 & 4.1 & 4.2083 & TRN & \\
\hline CHEMBL1984700 & 809242 & 4.2 & 4.6051 & TRN & \\
\hline CHEMBL 2007151 & 809242 & 4.1 & 4.0831 & TRN & \\
\hline CHEMBL1972125 & 809242 & 4.1 & 4.0769 & TRN & \\
\hline CHEMBL1461728 & 809242 & 4.1 & 3.9713 & TRN & \\
\hline CHEMBL1976134 & 809242 & 5.3 & 4.7959 & TRN & \\
\hline CHEMBL1965131 & 809242 & 4.1 & 4.0809 & TRN & \\
\hline CHEMBL1995448 & 809242 & 4.1 & 3.9729 & TRN & \\
\hline CHEMBL1972158 & 809242 & 7.0 & 6.7417 & TRN & \\
\hline CHEMBL1974457 & 809242 & 4.1 & 4.0732 & TRN & \\
\hline CHEMBL 2006580 & 809242 & 4.1 & 3.6149 & TRN & \\
\hline CHEMBL 2006581 & 809242 & 5.8 & 5.4307 & TRN & \\
\hline CHEMBL 2006481 & 809242 & 4.1 & 4.2641 & TRN & \\
\hline CHEMBL1979855 & 809242 & 4.1 & 3.937 & TRN & \\
\hline CHEMBL1970340 & 809242 & 4.1 & 3.7207 & TRN & \\
\hline CHEMBL 2005186 & 809242 & 4.1 & 4.4451 & TRN & \\
\hline CHEMBL1995927 & 809242 & 4.1 & 4.0392 & TST & \\
\hline CHEMBL1975534 & 809242 & 4.1 & 4.333 & TRN & \\
\hline CHEMBL1993424 & 809242 & 4.1 & 4.7375 & TRN & \\
\hline
\end{tabular}




\begin{tabular}{|c|c|c|c|c|c|}
\hline \multicolumn{6}{|c|}{ Supplemental Table s2.txt } \\
\hline CHEMBL1966703 & 809242 & 4.1 & 4.5629 & TST & \\
\hline CHEMBL1997023 & 809242 & 4.1 & 3.9723 & TST & \\
\hline CHEMBL1964687 & 809242 & 4.1 & 4.3816 & TRN & \\
\hline CHEMBL1971943 & 809242 & 4.1 & 4.2687 & TRN & \\
\hline CHEMBL1999918 & 809242 & 6.2 & 5.1736 & TRN & \\
\hline CHEMBL1974254 & 809242 & 4.1 & 3.6321 & TRN & \\
\hline CHEMBL1988537 & 809242 & 4.1 & 4.742 & TST & \\
\hline CHEMBL1969049 & 809242 & 6.2 & 6.0832 & TRN & \\
\hline CHEMBL 2005828 & 809242 & 4.1 & 4.1595 & TRN & \\
\hline CHEMBL 2002240 & 809242 & 4.1 & 4.4884 & TRN & \\
\hline CHEMBL1991143 & 809242 & 4.1 & 4.2836 & TST & \\
\hline CHEMBL1998611 & 809242 & 4.1 & 4.6445 & TRN & \\
\hline CHEMBL485556 & 809242 & 4.1 & 3.7667 & TST & \\
\hline CHEMBL1975900 & 809242 & 5.2 & 4.9057 & TRN & \\
\hline CHEMBL255822 & 809242 & 4.1 & 4.2082 & TRN & \\
\hline CHEMBL1972221 & 809242 & 5.7 & 4.6923 & TRN & \\
\hline CHEMBL 2006778 & 809242 & 4.1 & 3.7171 & TRN & \\
\hline CHEMBL 378627 & 809242 & 5.4 & 5.4035 & TRN & \\
\hline CHEMBL1996979 & 809242 & 4.1 & 4.31 & TRN & \\
\hline CHEMBL1997025 & 809242 & 4.1 & 4.3712 & TRN & \\
\hline CHEMBL1968406 & 809242 & 4.1 & 4.3802 & TRN & \\
\hline CHEMBL1982476 & 809242 & 4.1 & 4.3636 & TRN & \\
\hline CHEMBL1984274 & 809242 & 4.1 & 3.8609 & TST & \\
\hline CHEMBL1998545 & 809242 & 5.8 & 5.0753 & TRN & \\
\hline CHEMBL1986869 & 809242 & 4.1 & 4.487 & TRN & \\
\hline CHEMBL 2006010 & 809242 & 4.1 & 4.1879 & TRN & \\
\hline CHEMBL1682558 & 809242 & 4.1 & 3.7801 & TRN & \\
\hline CHEMBL1990496 & 809242 & 4.1 & 4.4804 & TRN & \\
\hline CHEMBL1997623 & 809242 & 4.1 & 3.9235 & TRN & \\
\hline CHEMBL 2002479 & 809242 & 4.1 & 4.1477 & TRN & \\
\hline CHEMBL1993166 & 809242 & 4.1 & 3.99399 & 99999999998 & TRN \\
\hline CHEMBL1967094 & 809242 & 6.8 & 6.0851 & TRN & \\
\hline CHEMBL1966035 & 809242 & 4.1 & 4.71 & TRN & \\
\hline CHEMBL 2003341 & 809242 & 6.0 & 5.1452 & TRN & \\
\hline CHEMBL1992645 & 809242 & 4.1 & 3.8533 & TST & \\
\hline CHEMBL1982992 & 809242 & 4.1 & 3.7301 & TRN & \\
\hline CHEMBL1999590 & 809242 & 4.1 & 4.1259 & TST & \\
\hline CHEMBL1981079 & 809242 & 6.8 & 6.5953 & TRN & \\
\hline CHEMBL1972276 & 809242 & 4.1 & 4.0044 & TRN & \\
\hline CHEMBL1980489 & 809242 & 4.1 & 4.4168 & TRN & \\
\hline CHEMBL1967116 & 809242 & 4.1 & 4.1788 & TRN & \\
\hline CHEMBL 2000832 & 809242 & 4.1 & 5.0075 & TRN & \\
\hline CHEMBL1977814 & 809242 & 4.1 & 3.8636 & TST & \\
\hline CHEMBL513846 & 809242 & 4.1 & 4.0924 & TRN & \\
\hline CHEMBL1970709 & 809242 & 4.1 & 4.984 & TRN & \\
\hline CHEMBL1965660 & 809242 & 7.5 & 6.9181 & TRN & \\
\hline CHEMBL1998112 & 809242 & 4.1 & 4.5559 & TRN & \\
\hline CHEMBL1969126 & 809242 & 4.1 & 4.4553 & TRN & \\
\hline
\end{tabular}




\begin{tabular}{|c|c|c|c|c|c|}
\hline \multicolumn{6}{|c|}{ splemental lá } \\
\hline CHEMBL1980896 & 809242 & 4.2 & 3.9709 & TRN & \\
\hline CHEMBL1975208 & 809242 & 4.1 & 4.2631 & TST & \\
\hline CHEMBL1970104 & 809242 & 4.1 & 4.7612 & TRN & \\
\hline CHEMBL1991429 & 809242 & 4.1 & 4.5999 & TRN & \\
\hline CHEMBL1964777 & 809242 & 4.1 & 4.2683 & TRN & \\
\hline CHEMBL1971149 & 809242 & 4.1 & 4.2697 & TRN & \\
\hline CHEMBL1999714 & 809242 & 4.1 & 4.1346 & TRN & \\
\hline CHEMBL1987533 & 809242 & 4.1 & 4.2031 & TRN & \\
\hline CHEMBL1994040 & 809242 & 4.1 & 4.3128 & TRN & \\
\hline CHEMBL388978 & 809242 & 6.3 & 6.4952 & TST & \\
\hline CHEMBL579246 & 809242 & 5.8 & 5.3379 & TRN & \\
\hline CHEMBL398951 & 809242 & 4.1 & 3.37399 & 99999999997 & TST \\
\hline CHEMBL1982506 & 809242 & 4.1 & 4.2888 & TST & \\
\hline CHEMBL 2004716 & 809242 & 4.1 & 4.029 & TRN & \\
\hline CHEMBL1968127 & 809242 & 4.1 & 4.4752 & TRN & \\
\hline CHEMBL1975233 & 809242 & 4.1 & 4.3429 & TRN & \\
\hline CHEMBL1985406 & 809242 & 4.1 & 4.9905 & TRN & \\
\hline CHEMBL 207400 & 809242 & 4.1 & 3.8412 & TST & \\
\hline CHEMBL 2000894 & 809242 & 4.1 & 4.6378 & TST & \\
\hline CHEMBL2002553 & 809242 & 4.1 & 4.1465 & TST & \\
\hline CHEMBL1982135 & 809242 & 4.1 & 4.092 & TRN & \\
\hline CHEMBL1976090 & 809242 & 4.1 & 4.55 & TRN & \\
\hline CHEMBL1993243 & 809242 & 4.1 & 3.8939 & TRN & \\
\hline CHEMBL1992922 & 809242 & 5.4 & 4.6656 & TRN & \\
\hline CHEMBL2004771 & 809242 & 4.1 & 3.8922 & TRN & \\
\hline CHEMBL 399021 & 809242 & 4.1 & 4.2131 & TRN & \\
\hline CHEMBL1997597 & 809242 & 4.1 & 4.1499 & TRN & \\
\hline CHEMBL1969537 & 809242 & 4.1 & 4.3398 & TST & \\
\hline CHEMBL1976093 & 809242 & 4.1 & 4.0935 & TRN & \\
\hline CHEMBL210032 & 809242 & 4.1 & 4.4717 & TRN & \\
\hline CHEMBL1996543 & 809242 & 4.1 & 4.5638 & TRN & \\
\hline CHEMBL1975256 & 809242 & 4.1 & 4.4066 & TST & \\
\hline CHEMBL508928 & 809242 & 4.1 & 3.8744 & TRN & \\
\hline CHEMBL1991356 & 809242 & 4.1 & 4.3299 & TST & \\
\hline CHEMBL1983309 & 809242 & 4.1 & 4.3991 & TRN & \\
\hline CHEMBL2004892 & 809242 & 4.1 & 4.231 & TRN & \\
\hline CHEMBL1999126 & 809242 & 4.1 & 3.9044 & TST & \\
\hline CHEMBL1997503 & 809242 & 4.1 & 4.478 & TST & \\
\hline CHEMBL116070 & 809242 & 4.1 & 4.2599 & TRN & \\
\hline CHEMBL1990821 & 809242 & 4.1 & 3.9268 & TST & \\
\hline CHEMBL1970314 & 809242 & 4.1 & 4.0899 & TRN & \\
\hline CHEMBL 2004871 & 809242 & 4.1 & 3.8248 & TRN & \\
\hline CHEMBL 2004872 & 809242 & 5.7 & 6.0028 & TRN & \\
\hline CHEMBL1727312 & 809242 & 4.1 & 3.7647 & TRN & \\
\hline CHEMBL1969879 & 809242 & 4.1 & 4.0284 & TST & \\
\hline CHEMBL419932 & 809242 & 4.1 & 4.3282 & TRN & \\
\hline CHEMBL 262433 & 809242 & 4.1 & 3.9794 & TRN & \\
\hline CHEMBL 306380 & 809242 & 4.1 & 4.275 & TRN & \\
\hline
\end{tabular}




\begin{tabular}{|c|c|c|c|c|c|}
\hline & & & & & \\
\hline CHEMBL1966722 & 809242 & 4.1 & 4.2391 & TST & \\
\hline CHEMBL1975500 & 809242 & 4.1 & 4.4462 & TRN & \\
\hline CHEMBL1976328 & 809242 & 4.1 & 4.1324 & TRN & \\
\hline CHEMBL394619 & 809242 & 4.1 & 4.1819 & 99999999995 & TRN \\
\hline CHEMBL1964399 & 809242 & 6.7 & 5.92290 & 9999999999 & TRN \\
\hline CHEMBL1996831 & 809242 & 4.1 & 4.4796 & TST & \\
\hline CHEMBL411903 & 809242 & 4.1 & 4.6089 & TRN & \\
\hline CHEMBL1965988 & 809242 & 4.1 & 4.4141 & TRN & \\
\hline CHEMBL418203 & 809242 & 4.1 & 4.7449 & TST & \\
\hline CHEMBL1989646 & 809242 & 6.9 & 6.5914 & TRN & \\
\hline CHEMBL1682357 & 809242 & 5.9 & 5.4827 & TRN & \\
\hline CHEMBL225519 & 809242 & 5.6 & 6.0112 & TRN & \\
\hline CHEMBL209534 & 809242 & 6.5 & 5.8057 & TRN & \\
\hline CHEMBL1978200 & 809242 & 4.1 & 4.2871 & TRN & \\
\hline CHEMBL 2006631 & 809242 & 4.1 & 4.1012 & TRN & \\
\hline CHEMBL1970522 & 809242 & 4.1 & 4.323 & TRN & \\
\hline CHEMBL1990415 & 809242 & 4.1 & 4.101 & TRN & \\
\hline CHEMBL1966087 & 809242 & 4.1 & 4.1704 & TRN & \\
\hline CHEMBL1964692 & 809242 & 4.1 & 3.8854 & TRN & \\
\hline CHEMBL1996931 & 809242 & 4.1 & 4.7462 & TRN & \\
\hline CHEMBL1964413 & 809242 & 5.8 & 5.1958 & TRN & \\
\hline CHEMBL1973483 & 809242 & 4.1 & 4.1153 & TRN & \\
\hline CHEMBL1984432 & 809242 & 6.2 & 5.5558 & TRN & \\
\hline CHEMBL1970735 & 809242 & 4.1 & 4.1555 & TRN & \\
\hline CHEMBL219722 & 809242 & 4.1 & 4.3427 & TRN & \\
\hline CHEMBL1997340 & 809242 & 4.1 & 4.4497 & TRN & \\
\hline CHEMBL 2004365 & 809242 & 4.1 & 4.3929 & TST & \\
\hline CHEMBL1522508 & 809242 & 4.1 & 3.799 & TRN & \\
\hline CHEMBL1989474 & 809242 & 4.1 & 4.0757 & TRN & \\
\hline CHEMBL1090360 & 809242 & 4.1 & 4.03106 & 0000000001 & TRN \\
\hline CHEMBL210887 & 809242 & 4.1 & 3.7227 & TST & \\
\hline CHEMBL458997 & 809242 & 6.6 & 6.273 & TRN & \\
\hline CHEMBL1971021 & 809242 & 4.1 & 4.3476 & TRN & \\
\hline CHEMBL 227271 & 809242 & 6.6 & 6.6869 & TRN & \\
\hline CHEMBL583144 & 809242 & 4.1 & 4.2292 & TRN & \\
\hline CHEMBL1974310 & 809242 & 5.1 & 4.601 & TRN & \\
\hline CHEMBL1982660 & 809242 & 4.1 & 4.5002 & TRN & \\
\hline CHEMBL1994693 & 809242 & 4.1 & 4.2915 & TRN & \\
\hline CHEMBL1982957 & 809242 & 5.7 & 4.9864 & TRN & \\
\hline CHEMBL1725279 & 809242 & 5.3 & 4.9741 & TST & \\
\hline CHEMBL1975138 & 809242 & 4.1 & 4.1036 & TST & \\
\hline CHEMBL424872 & 809242 & 6.2 & 5.7914 & TRN & \\
\hline CHEMBL 2006836 & 809242 & 4.1 & 3.7619 & TST & \\
\hline CHEMBL1971947 & 809242 & 4.1 & 3.8414 & TRN & \\
\hline CHEMBL412142 & 809242 & 4.1 & 4.3305 & TST & \\
\hline CHEMBL1980704 & 809242 & 4.1 & 4.2465 & TST & \\
\hline CHEMBL 2003271 & 809242 & 4.1 & 3.9594 & TRN & \\
\hline CHEMBL1966808 & 809242 & 5.5 & 3.9381 & TST & \\
\hline & & & & 4237 & \\
\hline
\end{tabular}




\begin{tabular}{|c|c|c|c|c|}
\hline \multicolumn{5}{|c|}{ emental T } \\
\hline CHEMBL 2004447 & 809242 & 4.1 & 3.9456 & TRN \\
\hline CHEMBL1983111 & 809242 & 6.5 & 5.6097 & TST \\
\hline CHEMBL1973860 & 809242 & 4.1 & 3.9273 & TRN \\
\hline CHEMBL1977713 & 809242 & 4.1 & 4.5138 & TRN \\
\hline CHEMBL 260135 & 809242 & 4.1 & 4.4614 & TRN \\
\hline CHEMBL220241 & 809242 & 4.1 & 4.1101 & TRN \\
\hline CHEMBL 2004544 & 809242 & 4.1 & 4.3212 & TST \\
\hline CHEMBL1982610 & 809242 & 4.1 & 4.1245 & TST \\
\hline CHEMBL1999496 & 809242 & 4.1 & 4.2368 & TRN \\
\hline CHEMBL2006933 & 809242 & 6.0 & 4.8682 & TST \\
\hline CHEMBL1988300 & 809242 & 4.1 & 3.8073 & TRN \\
\hline CHEMBL1991078 & 809242 & 7.0 & 7.4826 & TRN \\
\hline CHEMBL1987359 & 809242 & 4.1 & 3.717 & TST \\
\hline CHEMBL 2000685 & 809242 & 4.1 & 4.4831 & TRN \\
\hline CHEMBL1985311 & 809242 & 4.1 & 4.439 & TRN \\
\hline CHEMBL1989265 & 809242 & 4.1 & 3.804 & TST \\
\hline CHEMBL 2004647 & 809242 & 4.1 & 4.3468 & TST \\
\hline CHEMBL1969502 & 809242 & 6.6 & 5.5374 & TRN \\
\hline CHEMBL1965910 & 809242 & 4.1 & 4.1994 & TRN \\
\hline CHEMBL1682553 & 809242 & 5.7 & 5.8565 & TRN \\
\hline CHEMBL1971430 & 809242 & 4.1 & 4.4451 & TRN \\
\hline CHEMBL1997764 & 809242 & 4.1 & 4.0535 & TRN \\
\hline CHEMBL1983963 & 809242 & 4.1 & 4.2657 & TRN \\
\hline CHEMBL 2000271 & 809242 & 5.9 & 6.2585 & TRN \\
\hline CHEMBL1985092 & 809242 & 5.2 & 4.5816 & TST \\
\hline CHEMBL 2004692 & 809242 & 4.1 & 4.3019 & TST \\
\hline CHEMBL1981410 & 809242 & 4.1 & 4.2393 & TRN \\
\hline CHEMBL1996234 & 809242 & 4.1 & 4.5589 & TRN \\
\hline CHEMBL1991434 & 809242 & 4.1 & 4.1984 & TST \\
\hline CHEMBL1967544 & 809242 & 5.1 & 4.5569 & TRN \\
\hline CHEMBL223367 & 809242 & 4.1 & 3.8569 & TST \\
\hline CHEMBL340384 & 809242 & 4.2 & 5.087 & TST \\
\hline CHEMBL1996587 & 809242 & 4.1 & 4.0574 & TRN \\
\hline CHEMBL1964804 & 809242 & 4.1 & 4.3334 & TRN \\
\hline CHEMBL443962 & 809242 & 4.1 & 4.6719 & TST \\
\hline CHEMBL 2000354 & 809242 & 4.1 & 4.2035 & TRN \\
\hline CHEMBL1965507 & 809242 & 4.1 & 4.4272 & TRN \\
\hline CHEMBL274064 & 809242 & 5.5 & 4.7738 & TRN \\
\hline CHEMBL1967564 & 809242 & 4.1 & 4.2828 & TRN \\
\hline CHEMBL592030 & 809242 & 5.3 & 6.1282 & TST \\
\hline CHEMBL 2000071 & 809242 & 4.1 & 4.1184 & TRN \\
\hline CHEMBL1979176 & 809242 & 4.1 & 4.1281 & TRN \\
\hline CHEMBL1970317 & 809242 & 4.1 & 4.1079 & TRN \\
\hline CHEMBL 2000408 & 809242 & 4.1 & 4.3472 & TRN \\
\hline CHEMBL 248757 & 809242 & 4.1 & 3.6678 & TST \\
\hline CHEMBL1978014 & 809242 & 5.1 & 5.2182 & TRN \\
\hline CHEMBL1994538 & 809242 & 4.1 & 4.4219 & TRN \\
\hline CHEMBL1983195 & 809242 & 4.1 & 4.02 & TST \\
\hline
\end{tabular}




\begin{tabular}{|c|c|c|c|c|c|}
\hline \multirow[b]{2}{*}{ CHEMBL1975490 } & \multirow[b]{2}{*}{809242} & \\
\hline & & 4.1 & 3.7737 & TRN & \\
\hline CHEMBL1964444 & 809242 & 4.1 & 4.4349 & TRN & \\
\hline CHEMBL1989957 & 809242 & 4.1 & 3.9663 & TRN & \\
\hline CHEMBL 2006567 & 809242 & 4.1 & 4.4737 & TRN & \\
\hline CHEMBL1986139 & 809242 & 4.1 & 3.6623 & TRN & \\
\hline CHEMBL 383527 & 809242 & 4.1 & 4.005 & TRN & \\
\hline CHEMBL1980540 & 809242 & 4.1 & 4.1205 & TRN & \\
\hline CHEMBL1979883 & 809242 & 4.1 & 4.0817 & TRN & \\
\hline CHEMBL549730 & 809242 & 4.1 & 4.1696 & TRN & \\
\hline CHEMBL1682360 & 809242 & 4.1 & 4.4422 & TRN & \\
\hline CHEMBL1970189 & 809242 & 4.1 & 4.1131 & TRN & \\
\hline CHEMBL1996791 & 809242 & 5.5 & 4.5439 & TRN & \\
\hline CHEMBL371206 & 809242 & 4.1 & 4.3042 & TRN & \\
\hline CHEMBL1974664 & 809242 & 4.1 & 4.0743 & TST & \\
\hline CHEMBL1974288 & 809242 & 6.6 & 5.7724 & TRN & \\
\hline CHEMBL196363 & 809242 & 4.1 & 4.2864 & TRN & \\
\hline CHEMBL1190711 & 809242 & 5.5 & 4.9585 & TRN & \\
\hline CHEMBL1990346 & 809242 & 4.1 & 4.4259 & TRN & \\
\hline CHEMBL1968705 & 809242 & 4.1 & 3.6422 & TRN & \\
\hline CHEMBL404367 & 809242 & 4.1 & 4.012 & TRN & \\
\hline CHEMBL1966343 & 809242 & 5.5 & 5.5326 & TRN & \\
\hline CHEMBL1967887 & 809242 & 5.5 & 5.0826 & TRN & \\
\hline CHEMBL 2000568 & 809242 & 4.1 & 4.0849 & TRN & \\
\hline CHEMBL 2000335 & 809242 & 4.1 & 4.6004 & TRN & \\
\hline CHEMBL1977604 & 809242 & 4.1 & 4.0438 & TST & \\
\hline CHEMBL1988717 & 809242 & 4.1 & 3.8734 & TRN & \\
\hline CHEMBL1974328 & 809242 & 5.9 & 5.3376 & TRN & \\
\hline CHEMBL509032 & 809242 & 6.7 & 6.859 & TRN & \\
\hline CHEMBL1973808 & 809242 & 4.1 & 3.8764 & TRN & \\
\hline CHEMBL 2000429 & 809242 & 5.6 & 4.8875 & TRN & \\
\hline CHEMBL1972576 & 809242 & 4.1 & 4.4495 & TRN & \\
\hline CHEMBL1992555 & 809242 & 4.1 & 3.9521 & TST & \\
\hline CHEMBL1992342 & 809242 & 4.1 & 4.3313 & TRN & \\
\hline CHEMBL1988173 & 809242 & 4.1 & 4.6577 & TST & \\
\hline CHEMBL535331 & 809242 & 4.1 & 3.5316 & TRN & \\
\hline CHEMBL1989805 & 809242 & 4.1 & 4.5123 & TST & \\
\hline CHEMBL1965423 & 809242 & 4.1 & 4.3367 & TRN & \\
\hline CHEMBL1982980 & 809242 & 4.1 & 3.8224 & TST & \\
\hline CHEMBL1983025 & 809242 & 4.1 & 4.2617 & TRN & \\
\hline CHEMBL205415 & 809242 & 4.1 & 4.292 & TRN & \\
\hline CHEMBL1977135 & 809242 & 5.9 & $5.2410 e$ & 00000000005 & TRN \\
\hline CHEMBL 2001920 & 809242 & 4.1 & 4.2072 & TRN & \\
\hline CHEMBL 2002322 & 809242 & 4.1 & 4.0437 & TRN & \\
\hline CHEMBL 2002323 & 809242 & 4.1 & 3.7909 & TRN & \\
\hline CHEMBL1241473 & 809242 & 6.9 & 6.36799 & 9999999999 & TRN \\
\hline CHEMBL1978448 & 809242 & 4.1 & 4.6325 & TST & \\
\hline CHEMBL 2004513 & 809242 & 4.1 & 4.4929 & TRN & \\
\hline CHEMBL1972258 & 809242 & 4.1 & 3.4328 & TRN & \\
\hline & & & & 4239 & \\
\hline
\end{tabular}




\begin{tabular}{|c|c|c|c|c|}
\hline & & & plemen & \\
\hline CHEMBL 2001257 & 809242 & 4.1 & 4.0175 & TRN \\
\hline CHEMBL 2005548 & 809242 & 4.1 & 3.9316 & TRN \\
\hline CHEMBL1992536 & 809242 & 4.1 & 4.6284 & TRN \\
\hline CHEMBL1987793 & 809242 & 4.1 & 3.8937 & TST \\
\hline CHEMBL1992740 & 809242 & 4.1 & 4.0805 & TRN \\
\hline CHEMBL 2002373 & 809242 & 4.1 & 4.0899 & TRN \\
\hline CHEMBL439340 & 809242 & 4.1 & 3.9844 & TRN \\
\hline CHEMBL 2006188 & 809242 & 5.4 & 5.8335 & TRN \\
\hline CHEMBL1967531 & 809242 & 4.1 & 4.3172 & TRN \\
\hline CHEMBL1970913 & 809242 & 4.1 & 4.2257 & TRN \\
\hline CHEMBL1973893 & 809242 & 4.1 & 4.2399 & TRN \\
\hline CHEMBL1995736 & 809242 & 4.1 & 4.4166 & TRN \\
\hline CHEMBL1997534 & 809242 & 6.3 & 6.1351 & TRN \\
\hline CHEMBL1996500 & 809242 & 4.1 & 4.0338 & TRN \\
\hline CHEMBL1985095 & 809242 & 4.1 & 6.0733 & TST \\
\hline CHEMBL1998551 & 809242 & 4.1 & 4.2179 & TRN \\
\hline CHEMBL1977374 & 809242 & 4.1 & 4.3605 & TRN \\
\hline CHEMBL1991180 & 809242 & 4.1 & 4.8945 & TST \\
\hline CHEMBL1682540 & 809242 & 4.1 & 5.2398 & TRN \\
\hline CHEMBL1978656 & 809242 & 4.1 & 4.192 & TRN \\
\hline CHEMBL1976420 & 809242 & 4.1 & 4.4346 & TST \\
\hline CHEMBL1994864 & 809242 & 4.1 & 4.3932 & TRN \\
\hline CHEMBL413779 & 809242 & 5.6 & 4.0456 & TST \\
\hline CHEMBL 2002446 & 809242 & 4.1 & 4.4125 & TST \\
\hline CHEMBL497151 & 809242 & 4.1 & 4.3122 & TRN \\
\hline CHEMBL246970 & 809242 & 4.1 & 4.5551 & TRN \\
\hline CHEMBL340921 & 809242 & 4.1 & 4.546 & TST \\
\hline CHEMBL373598 & 809242 & 5.1 & 3.7546 & TST \\
\hline CHEMBL1999718 & 809242 & 4.1 & 4.1619 & TRN \\
\hline CHEMBL1276446 & 809242 & 6.8 & 5.5262 & TST \\
\hline CHEMBL1977346 & 809242 & 4.1 & 4.3758 & TRN \\
\hline CHEMBL1971649 & 809242 & 4.1 & 3.7787 & TRN \\
\hline CHEMBL 2003657 & 809242 & 5.1 & 4.5291 & TRN \\
\hline CHEMBL1998435 & 809242 & 4.1 & 3.8888 & TRN \\
\hline CHEMBL 2006439 & 809242 & 6.4 & 5.9635 & TRN \\
\hline CHEMBL 2006156 & 809242 & 4.1 & 4.447 & TST \\
\hline CHEMBL1969190 & 809242 & 4.1 & 4.0474 & TRN \\
\hline CHEMBL1973937 & 809242 & 4.1 & 4.3796 & TRN \\
\hline CHEMBL1991674 & 809242 & 4.3 & 5.5125 & TRN \\
\hline CHEMBL1982711 & 809242 & 4.1 & 5.0285 & TRN \\
\hline CHEMBL1987982 & 809242 & 4.1 & 4.2892 & TST \\
\hline CHEMBL1984842 & 809242 & 5.2 & 4.8573 & TRN \\
\hline CHEMBL1969102 & 809242 & 4.1 & 4.2546 & TRN \\
\hline CHEMBL1682346 & 809242 & 5.9 & 6.6111 & TRN \\
\hline CHEMBL 2007044 & 809242 & 4.1 & 3.9248 & TST \\
\hline CHEMBL 2001998 & 809242 & 4.1 & 3.9356 & TST \\
\hline CHEMBL1994241 & 809242 & 4.1 & 4.5875 & TRN \\
\hline CHEMBL223460 & 809242 & 4.1 & 3.6226 & TST \\
\hline
\end{tabular}




\begin{tabular}{|c|c|c|c|c|}
\hline & & & 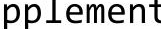 & al Ta \\
\hline CHEMBL1998829 & 809242 & 4.1 & 3.4064 & TRN \\
\hline CHEMBL50894 & 809242 & 5.6 & 4.619 & TRN \\
\hline CHEMBL1988838 & 809242 & 5.8 & 5.3068 & TRN \\
\hline CHEMBL1981725 & 809242 & 4.1 & 4.1105 & TRN \\
\hline CHEMBL375284 & 809242 & 4.1 & 4.1784 & TRN \\
\hline CHEMBL1982866 & 809242 & 4.1 & 4.0087 & TRN \\
\hline CHEMBL 2005792 & 809242 & 5.4 & 4.7552 & TRN \\
\hline CHEMBL1968926 & 809242 & 4.1 & 4.3033 & TRN \\
\hline CHEMBL462120 & 809242 & 5.1 & 3.8427 & TST \\
\hline CHEMBL1984206 & 809242 & 5.7 & 5.73 & TRN \\
\hline CHEMBL1991577 & 809242 & 4.1 & 4.2448 & TRN \\
\hline CHEMBL1965570 & 809242 & 4.1 & 3.9463 & TRN \\
\hline CHEMBL 2007592 & 809242 & 4.1 & 4.0805 & TST \\
\hline CHEMBL210963 & 809242 & 5.2 & 5.1711 & TRN \\
\hline CHEMBL1082440 & 809242 & 4.1 & 4.8061 & TST \\
\hline CHEMBL1614705 & 809242 & 4.1 & 4.4169 & TRN \\
\hline CHEMBL1972362 & 809242 & 4.1 & 4.3988 & TRN \\
\hline CHEMBL1984633 & 809242 & 6.1 & 5.9602 & TRN \\
\hline CHEMBL 2007372 & 809242 & 4.1 & 4.2413 & TRN \\
\hline CHEMBL1965845 & 809242 & 6.7 & 6.5366 & TRN \\
\hline CHEMBL1982167 & 809242 & 4.1 & 4.756 & TRN \\
\hline CHEMBL 2006715 & 809242 & 5.8 & 4.5838 & TRN \\
\hline CHEMBL1986597 & 809242 & 4.1 & 3.5849 & TRN \\
\hline CHEMBL1971017 & 809242 & 5.3 & 4.8169 & TRN \\
\hline CHEMBL1990482 & 809242 & 4.1 & 4.3608 & TRN \\
\hline CHEMBL1990904 & 809242 & 5.6 & 4.7665 & TRN \\
\hline CHEMBL 2005475 & 809242 & 6.6 & 6.0417 & TRN \\
\hline CHEMBL 2000104 & 809242 & 4.1 & 4.4862 & TRN \\
\hline CHEMBL402846 & 809242 & 4.1 & 3.8093 & TRN \\
\hline CHEMBL1997349 & 809242 & 4.1 & 4.3324 & TST \\
\hline CHEMBL183844 & 809242 & 4.1 & 4.0956 & TRN \\
\hline CHEMBL220057 & 809242 & 4.1 & 4.387 & TRN \\
\hline CHEMBL1682545 & 809242 & 4.1 & 4.363 & TRN \\
\hline CHEMBL 383541 & 809242 & 5.1 & 4.6679 & TRN \\
\hline CHEMBL 2001224 & 809242 & 4.1 & 4.2471 & TRN \\
\hline CHEMBL10 & 809242 & 4.1 & 4.0444 & TRN \\
\hline CHEMBL1976732 & 809242 & 4.1 & 4.1082 & TRN \\
\hline CHEMBL1969506 & 809242 & 4.1 & 3.8143 & TRN \\
\hline CHEMBL1964937 & 809242 & 6.2 & 5.8425 & TRN \\
\hline CHEMBL1980163 & 809242 & 4.1 & 3.4549 & TRN \\
\hline CHEMBL590109 & 809242 & 4.1 & 6.1171 & TST \\
\hline CHEMBL1970879 & 809242 & 5.4 & 5.0088 & TRN \\
\hline CHEMBL1989856 & 809242 & 4.1 & 4.0298 & TST \\
\hline CHEMBL 2005899 & 809242 & 4.1 & 4.3763 & TRN \\
\hline CHEMBL1682552 & 809242 & 5.3 & 5.7308 & TRN \\
\hline CHEMBL259850 & 809242 & 4.1 & 4.3079 & TRN \\
\hline CHEMBL1972568 & 809242 & 4.1 & 3.9664 & TRN \\
\hline CHEMBL1996155 & 809242 & 4.1 & 4.2331 & TRN \\
\hline
\end{tabular}




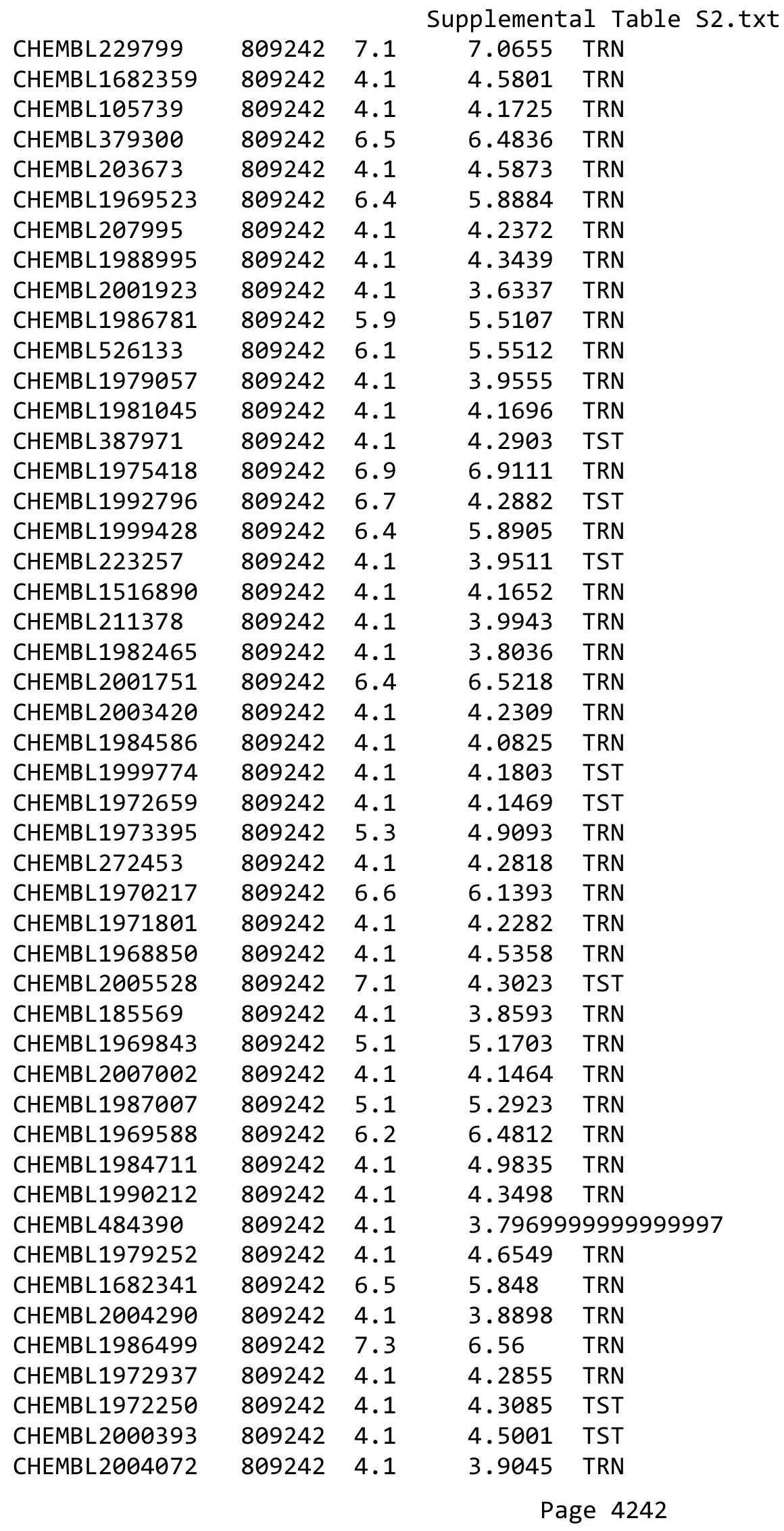




\begin{tabular}{|c|c|c|c|c|c|}
\hline \multicolumn{6}{|c|}{ Supplemental Table S2.txt } \\
\hline CHEMBL 2004311 & 809242 & 4.1 & 3.9972 & TRN & \\
\hline CHEMBL1992634 & 809242 & 4.1 & 4.0773 & TRN & \\
\hline CHEMBL1242373 & 809242 & 4.1 & 4.4517 & TRN & \\
\hline CHEMBL 2000433 & 809242 & 4.1 & 4.2138 & TST & \\
\hline CHEMBL1988075 & 809242 & 4.1 & 4.0763 & TRN & \\
\hline CHEMBL316264 & 809242 & 4.1 & 4.0484 & TRN & \\
\hline CHEMBL 2001239 & 809242 & 5.2 & 4.6222 & TST & \\
\hline CHEMBL1988594 & 809242 & 4.1 & 4.5014 & TRN & \\
\hline CHEMBL 2001288 & 809242 & 4.1 & 3.9835 & TRN & \\
\hline CHEMBL260092 & 809242 & 4.1 & 4.6442 & TRN & \\
\hline CHEMBL1999811 & 809242 & 4.1 & 4.1894 & TST & \\
\hline CHEMBL1965495 & 809242 & 4.1 & 4.4769 & TRN & \\
\hline CHEMBL1985074 & 809242 & 4.1 & 4.1257 & TST & \\
\hline CHEMBL1982874 & 809242 & 4.1 & 4.3976 & TRN & \\
\hline CHEMBL 2000481 & 809242 & 4.1 & 3.5927 & TRN & \\
\hline CHEMBL1991725 & 809242 & 4.1 & 5.1055 & TRN & \\
\hline CHEMBL1992242 & 809242 & 4.1 & 3.8813 & TRN & \\
\hline CHEMBL 2007296 & 809242 & 4.1 & 5.3221 & TRN & \\
\hline CHEMBL208637 & 809242 & 4.1 & 4.6109 & TRN & \\
\hline CHEMBL396523 & 809242 & 5.8 & 6.6218 & TRN & \\
\hline CHEMBL1970203 & 809242 & 4.1 & 4.3565 & TRN & \\
\hline CHEMBL1986530 & 809242 & 4.1 & 4.2206 & TST & \\
\hline CHEMBL1965351 & 809242 & 4.1 & 3.9892 & TST & \\
\hline CHEMBL1999321 & 809242 & 4.1 & 3.6222 & TRN & \\
\hline CHEMBL1968590 & 809242 & 4.1 & 3.8326 & TRN & \\
\hline CHEMBL1999749 & 809242 & 4.1 & 3.9731 & TRN & \\
\hline CHEMBL 2005375 & 809242 & 4.1 & 4.2331 & TRN & \\
\hline CHEMBL1984191 & 809242 & 4.1 & 4.5392 & TRN & \\
\hline CHEMBL1983006 & 809242 & 4.1 & 4.28600 & 30000000005 & TRN \\
\hline CHEMBL1972183 & 809242 & 4.1 & 4.2928 & TRN & \\
\hline CHEMBL1971029 & 809242 & 6.9 & 6.3346 & TRN & \\
\hline CHEMBL394790 & 809242 & 4.1 & 4.0794 & TRN & \\
\hline CHEMBL226471 & 809242 & 5.8 & 5.8092 & TRN & \\
\hline CHEMBL1974702 & 809242 & 4.1 & 3.9568 & TRN & \\
\hline CHEMBL1996111 & 809242 & 6.3 & 6.6073 & TRN & \\
\hline CHEMBL1965589 & 809242 & 4.1 & 4.3516 & TRN & \\
\hline CHEMBL1998193 & 809242 & 4.1 & 3.6469 & TRN & \\
\hline CHEMBL474432 & 809242 & 5.3 & 4.9598 & TST & \\
\hline CHEMBL1988153 & 809242 & 4.1 & 3.9759 & TRN & \\
\hline CHEMBL1999556 & 809242 & 5.2 & 4.9901 & TRN & \\
\hline CHEMBL1988437 & 809242 & 4.1 & 4.7719 & TST & \\
\hline CHEMBL1968245 & 809242 & 4.1 & 4.4099 & TRN & \\
\hline CHEMBL1998121 & 809242 & 6.7 & 6.3239 & TRN & \\
\hline CHEMBL1979577 & 809242 & 4.1 & 4.29 & TRN & \\
\hline CHEMBL1991800 & 809242 & 5.2 & 4.55 & TRN & \\
\hline CHEMBL52387 & 809242 & 4.2 & 5.33 & TST & \\
\hline CHEMBL379835 & 809242 & 4.1 & 4.2818 & TST & \\
\hline CHEMBL1979357 & 809242 & 4.1 & 4.2566 & TRN & \\
\hline
\end{tabular}




\begin{tabular}{|c|c|c|c|c|}
\hline & & & & $a \perp \mid a b \perp$ \\
\hline CHEMBL1980802 & 809242 & 4.1 & 3.7817 & TST \\
\hline CHEMBL1979554 & 809242 & 4.1 & 4.698 & TRN \\
\hline CHEMBL1996817 & 809242 & 5.2 & 4.4073 & TRN \\
\hline CHEMBL3197315 & 809242 & 4.1 & 4.207 & TST \\
\hline CHEMBL2004355 & 809242 & 6.2 & 5.8647 & TRN \\
\hline CHEMBL468280 & 809242 & 4.1 & 3.4691 & TST \\
\hline CHEMBL1990884 & 809242 & 4.1 & 4.3736 & TST \\
\hline CHEMBL3109278 & 809242 & 4.1 & 4.296 & TRN \\
\hline CHEMBL256835 & 809242 & 4.1 & 4.6749 & TRN \\
\hline CHEMBL1970006 & 809242 & 4.1 & 4.4519 & TST \\
\hline CHEMBL1980142 & 809242 & 4.1 & 4.3156 & TRN \\
\hline CHEMBL41783 & 809242 & 4.1 & 4.131 & TRN \\
\hline CHEMBL 2004438 & 809242 & 4.1 & 3.7253 & TRN \\
\hline CHEMBL 2006276 & 809242 & 4.1 & 3.9794 & TRN \\
\hline CHEMBL271381 & 809242 & 4.1 & 3.9617 & TRN \\
\hline CHEMBL2006785 & 809242 & 4.1 & 3.5934 & TRN \\
\hline CHEMBL1982466 & 809242 & 4.1 & 3.7133 & TRN \\
\hline CHEMBL1996390 & 809242 & 4.1 & 4.308 & TRN \\
\hline CHEMBL1995832 & 809242 & 4.1 & 4.7295 & TRN \\
\hline CHEMBL1998414 & 809242 & 5.2 & 4.988 & TRN \\
\hline CHEMBL1969042 & 809242 & 4.1 & 4.2199 & TST \\
\hline CHEMBL2000345 & 809242 & 4.1 & 4.5861 & TRN \\
\hline CHEMBL1999931 & 809242 & 8.0 & 7.7677 & TRN \\
\hline CHEMBL1991640 & 809242 & 4.1 & 4.586 & TST \\
\hline CHEMBL1375418 & 809242 & 4.1 & 4.171 & TRN \\
\hline CHEMBL 302449 & 809242 & 7.0 & 5.4176 & TST \\
\hline CHEMBL2007064 & 809242 & 4.1 & 4.416 & TRN \\
\hline CHEMBL1981047 & 809242 & 4.1 & 5.2366 & TST \\
\hline CHEMBL229968 & 809242 & 7.4 & 6.981 & TRN \\
\hline CHEMBL1976240 & 809242 & 5.8 & 6.1819 & TRN \\
\hline CHEMBL1979093 & 809242 & 4.1 & 3.8668 & TRN \\
\hline CHEMBL1968151 & 809242 & 4.1 & 3.7996 & TST \\
\hline CHEMBL1381197 & 809242 & 4.1 & 3.9762 & TRN \\
\hline CHEMBL1987009 & 809242 & 6.3 & 6.6174 & TRN \\
\hline CHEMBL379218 & 809242 & 6.4 & 6.5493 & TRN \\
\hline CHEMBL2003817 & 809242 & 4.1 & 4.2624 & TRN \\
\hline CHEMBL336961 & 809242 & 4.1 & 4.0934 & TRN \\
\hline CHEMBL1994830 & 809242 & 4.1 & 4.0169 & TRN \\
\hline CHEMBL1987054 & 809242 & 4.1 & 4.7294 & TRN \\
\hline CHEMBL1970083 & 809242 & 4.1 & 4.0268 & TRN \\
\hline CHEMBL226403 & 809242 & 6.4 & 5.8366 & TRN \\
\hline CHEMBL2005631 & 809242 & 4.1 & 4.0756 & TRN \\
\hline CHEMBL1994938 & 809242 & 4.1 & 3.6313 & TRN \\
\hline CHEMBL1825138 & 809242 & 4.1 & 4.92899 & 9999999999 \\
\hline CHEMBL1977223 & 809242 & 7.9 & 7.1333 & TRN \\
\hline CHEMBL1236126 & 809242 & 4.1 & 3.2595 & TST \\
\hline CHEMBL1966279 & 809242 & 4.1 & 3.3782 & TRN \\
\hline CHEMBL1997846 & 809242 & 5.1 & 5.2433 & TRN \\
\hline
\end{tabular}




\begin{tabular}{|c|c|c|c|c|c|}
\hline \multirow{3}{*}{$\begin{array}{l}\text { CHEMBL } 2004419 \\
\text { CHEMBL1991728 }\end{array}$} & \multirow{3}{*}{$\begin{array}{l}809242 \\
809242\end{array}$} & \multicolumn{4}{|c|}{ Supplemental Table S2.txt } \\
\hline & & 4.1 & \multicolumn{2}{|c|}{4.5089999999999995} & TRN \\
\hline & & 4.1 & 4.1715 & TRN & \\
\hline CHEMBL1975787 & 809242 & 4.2 & 4.7909 & TRN & \\
\hline CHEMBL 2002407 & 809242 & 4.1 & 4.2023 & TRN & \\
\hline CHEMBL1972489 & 809242 & 4.1 & 3.5803 & TRN & \\
\hline CHEMBL1994074 & 809242 & 4.1 & 4.3208 & TRN & \\
\hline CHEMBL1992937 & 809242 & 4.1 & 4.3665 & TST & \\
\hline CHEMBL1985566 & 809242 & 4.1 & 3.9026 & TRN & \\
\hline CHEMBL536151 & 809242 & 4.1 & 3.9509 & TST & \\
\hline CHEMBL1972119 & 809242 & 4.1 & 4.1824 & TRN & \\
\hline CHEMBL1986328 & 809242 & 4.1 & 4.061 & TST & \\
\hline CHEMBL95692 & 809242 & 4.1 & 4.6079 & TRN & \\
\hline CHEMBL1090356 & 809242 & 4.1 & 4.25 & TRN & \\
\hline CHEMBL1976455 & 809242 & 4.1 & 4.3766 & TRN & \\
\hline CHEMBL1983923 & 809242 & 4.1 & 4.1966 & TST & \\
\hline CHEMBL1983534 & 809242 & 4.1 & 4.4639 & TRN & \\
\hline CHEMBL1982361 & 809242 & 4.1 & 4.3821 & TRN & \\
\hline CHEMBL1999112 & 809242 & 4.1 & 3.9247 & TST & \\
\hline CHEMBL1982122 & 809242 & 5.2 & 4.9789 & TRN & \\
\hline CHEMBL 2000801 & 809242 & 4.1 & 3.9488 & TRN & \\
\hline CHEMBL1682546 & 809242 & 5.7 & 5.1047 & TRN & \\
\hline CHEMBL1991395 & 809242 & 4.1 & 4.3262 & TRN & \\
\hline CHEMBL1971245 & 809242 & 4.1 & 4.4478 & TRN & \\
\hline CHEMBL1987648 & 809242 & 4.1 & 4.3614 & TRN & \\
\hline CHEMBL1996780 & 809242 & 4.1 & 4.3559 & TST & \\
\hline CHEMBL1972142 & 809242 & 4.1 & 4.5138 & TRN & \\
\hline CHEMBL1966514 & 809242 & 4.1 & 4.1007 & TRN & \\
\hline CHEMBL 2003638 & 809242 & 7.1 & 7.4965 & TRN & \\
\hline CHEMBL296586 & 809242 & 4.1 & 4.3699 & TRN & \\
\hline CHEMBL1996066 & 809242 & 4.1 & 4.5495 & TST & \\
\hline CHEMBL516429 & 809242 & 6.6 & 6.0823 & TRN & \\
\hline CHEMBL1972152 & 809242 & 4.1 & 4.6388 & TST & \\
\hline CHEMBL1993722 & 809242 & 4.1 & 4.0683 & TRN & \\
\hline CHEMBL1970806 & 809242 & 4.1 & 3.8303 & TST & \\
\hline CHEMBL 202635 & 809242 & 4.1 & 4.2898 & TRN & \\
\hline CHEMBL1375640 & 809242 & 4.1 & 4.8547 & TST & \\
\hline CHEMBL1979970 & 809242 & 5.2 & 4.4823 & TRN & \\
\hline CHEMBL249282 & 809242 & 4.1 & 3.3348 & TST & \\
\hline CHEMBL1969264 & 809242 & 4.1 & 4.0724 & TRN & \\
\hline CHEMBL1973711 & 809242 & 4.1 & 3.6684 & TRN & \\
\hline CHEMBL 2006237 & 809242 & 4.1 & 4.0196 & TRN & \\
\hline CHEMBL1967720 & 809242 & 4.1 & 4.0672 & TRN & \\
\hline CHEMBL1572266 & 809242 & 4.1 & 4.0444 & TST & \\
\hline CHEMBL1991138 & 809242 & 4.1 & 4.0963 & TRN & \\
\hline CHEMBL1969755 & 809242 & 5.8 & 5.1396 & TRN & \\
\hline CHEMBL1979516 & 809242 & 4.1 & 3.9081 & TRN & \\
\hline CHEMBL1605605 & 809242 & 4.1 & 4.4518 & TRN & \\
\hline CHEMBL1972820 & 809242 & 4.1 & 4.356 & TST & \\
\hline
\end{tabular}




\begin{tabular}{|c|c|c|c|c|}
\hline \multicolumn{5}{|c|}{ Tetrlat } \\
\hline CHEMBL1996208 & 809242 & 4.1 & 3.9063 & TST \\
\hline CHEMBL1989029 & 809242 & 4.1 & 3.85100 & 00000000004 \\
\hline CHEMBL392642 & 809242 & 4.1 & 4.8868 & TRN \\
\hline CHEMBL514499 & 809242 & 4.1 & 4.6253 & TST \\
\hline CHEMBL1965631 & 809242 & 6.8 & 6.4341 & TRN \\
\hline CHEMBL1980144 & 809242 & 4.1 & 4.4925 & TRN \\
\hline CHEMBL1991188 & 809242 & 7.0 & 6.2627 & TST \\
\hline CHEMBL1972849 & 809242 & 4.1 & 3.9093 & TST \\
\hline CHEMBL377408 & 809242 & 6.7 & 5.8425 & TST \\
\hline CHEMBL215152 & 809242 & 4.1 & 3.4429 & TST \\
\hline CHEMBL231209 & 809242 & 4.1 & 4.0707 & TST \\
\hline CHEMBL1975357 & 809242 & 4.1 & 4.1981 & TST \\
\hline CHEMBL1976220 & 809242 & 4.1 & 4.1136 & TST \\
\hline CHEMBL 259922 & 809242 & 4.1 & 3.7394 & TST \\
\hline CHEMBL1997617 & 809242 & 4.1 & 4.4328 & TST \\
\hline CHEMBL1982383 & 809242 & 4.1 & 4.2409 & TST \\
\hline CHEMBL1969301 & 809242 & 4.1 & 3.7441 & TST \\
\hline CHEMBL17370 & 809242 & 4.1 & 4.3016 & TST \\
\hline CHEMBL1987910 & 809242 & 4.1 & 4.3595 & TST \\
\hline CHEMBL1983932 & 809242 & 4.1 & 4.3592 & TST \\
\hline CHEMBL 1966069 & 809242 & 6.1 & 5.4548 & TST \\
\hline CHEMBL1997822 & 809242 & 4.1 & 3.76 & TST \\
\hline CHEMBL1991285 & 809242 & 4.1 & 4.1791 & TST \\
\hline CHEMBL243088 & 809242 & 5.3 & 5.9278 & TST \\
\hline CHEMBL1984038 & 809242 & 4.1 & 4.1662 & TST \\
\hline CHEMBL1993661 & 809242 & 8.4 & 6.0661 & TST \\
\hline CHEMBL1974416 & 809242 & 4.1 & 4.1879 & TST \\
\hline CHEMBL 2004615 & 809242 & 4.1 & 4.3173 & TST \\
\hline CHEMBL1984039 & 809242 & 4.1 & 4.0567 & TST \\
\hline CHEMBL1997872 & 809242 & 4.1 & 3.6867 & TST \\
\hline CHEMBL101998 & 195374 & 6.3372 & 6.3421 & TRN \\
\hline CHEMBL318982 & 195374 & 7.0458 & 7.0564 & TRN \\
\hline CHEMBL101834 & 195374 & 6.4815 & 6.4802 & TRN \\
\hline CHEMBL330416 & 195374 & 7.301 & 7.329 & TRN \\
\hline CHEMBL101501 & 195374 & 7.0458 & 7.0559 & TRN \\
\hline CHEMBL101938 & 195374 & 6.8239 & 6.8131 & TRN \\
\hline CHEMBL100056 & 195374 & 6.9208 & 6.9088 & TRN \\
\hline CHEMBL322869 & 195374 & 7.2218 & 7.2059 & TRN \\
\hline CHEMBL101845 & 195374 & 7.699 & 7.6602 & TRN \\
\hline CHEMBL102163 & 195374 & 6.9586 & 6.9701 & TRN \\
\hline CHEMBL102056 & 195374 & 6.7212 & 6.7391 & TRN \\
\hline CHEMBL100844 & 195374 & 6.5229 & 6.5164 & TRN \\
\hline CHEMBL37343 & 195374 & 7.0458 & 7.0335 & TRN \\
\hline CHEMBL330602 & 195374 & 6.7959 & 6.8204 & TRN \\
\hline CHEMBL100352 & 195374 & 7.301 & 7.3023 & TRN \\
\hline CHEMBL321765 & 195374 & 6.3665 & 6.3692 & TRN \\
\hline CHEMBL421210 & 195374 & 7.0969 & 7.1427 & TRN \\
\hline CHEMBL317130 & 195374 & 7.0 & 7.0063 & TRN \\
\hline
\end{tabular}

TRN 


\begin{tabular}{|c|c|c|c|c|c|}
\hline \multirow[b]{2}{*}{ CHEMBL101670 } & \multicolumn{5}{|c|}{ Supplemental Table S2.txt } \\
\hline & 195374 & 6.6383 & 6.6335 & TRN & \\
\hline CHEMBL330597 & 195374 & 6.9208 & 6.9338 & TRN & \\
\hline CHEMBL318952 & 195374 & 7.0969 & 7.0755 & TRN & \\
\hline CHEMBL102192 & 195374 & 7.301 & 7.311 & TRN & \\
\hline CHEMBL100833 & 195374 & 7.301 & 7.3162 & TRN & \\
\hline CHEMBL319762 & 195374 & 6.699 & 6.6947 & TRN & \\
\hline CHEMBL319091 & 195374 & 7.5229 & 7.4874 & TRN & \\
\hline CHEMBL318646 & 195374 & 6.6778 & 6.6617 & TRN & \\
\hline CHEMBL 317072 & 195374 & 6.2076 & 6.19 & TRN & \\
\hline CHEMBL103716 & 195374 & 6.2291 & 6.8568 & TST & \\
\hline CHEMBL327744 & 195374 & 6.7959 & 6.7783 & TRN & \\
\hline CHEMBL318720 & 195374 & 6.9208 & 6.9096 & TRN & \\
\hline CHEMBL100934 & 195374 & 7.2218 & 7.2345 & TRN & \\
\hline CHEMBL100629 & 195374 & 6.6021 & 6.6375 & TST & \\
\hline CHEMBL101944 & 195374 & 6.8861 & 6.8882 & TRN & \\
\hline CHEMBL102113 & 195374 & 7.699 & 7.699 & TRN & \\
\hline CHEMBL318635 & 195374 & 7.0 & 7.0278 & TRN & \\
\hline CHEMBL100136 & 195374 & 7.2218 & 7.2072 & TRN & \\
\hline CHEMBL100968 & 195374 & 6.2676 & 6.2688 & TRN & \\
\hline CHEMBL420460 & 195374 & 5.9586 & 6.6666 & TST & \\
\hline CHEMBL318343 & 195374 & 5.8239 & 5.8251 & TRN & \\
\hline CHEMBL71766 & 195374 & 6.2676 & 6.2795 & TRN & \\
\hline CHEMBL327938 & 195374 & 6.8539 & 6.8482 & TRN & \\
\hline CHEMBL100568 & 195374 & 5.0 & 6.683 & TST & \\
\hline CHEMBL100942 & 195374 & 6.1249 & 6.1111 & TRN & \\
\hline CHEMBL101412 & 195374 & 7.301 & 7.3001 & TRN & \\
\hline CHEMBL328848 & 195374 & 7.3979 & 7.4004 & TRN & \\
\hline CHEMBL103953 & 195374 & 7.5229 & 7.5431 & TST & \\
\hline CHEMBL101946 & 195374 & 7.3979 & 6.9467 & TST & \\
\hline CHEMBL329938 & 195374 & 5.0 & 6.7237 & TST & \\
\hline CHEMBL 328408 & 195374 & 5.0 & 6.6002 & TST & \\
\hline CHEMBL318562 & 195374 & 5.9914 & 7.2719 & TST & \\
\hline CHEMBL103593 & 195374 & 7.0969 & 7.2576 & TST & \\
\hline CHEMBL99844 & 195374 & 5.5229 & 6.7995 & TST & \\
\hline CHEMBL321544 & 195374 & 7.0969 & 7.0802 & TST & \\
\hline CHEMBL102960 & 195374 & 6.9208 & 7.19799 & 99999999995 & TST \\
\hline CHEMBL319032 & 195374 & 6.9586 & 6.9343 & TST & \\
\hline CHEMBL1951672 & 803068 & 5.0 & 5.066 & TRN & \\
\hline CHEMBL1951665 & 803068 & 7.9586 & 7.8458 & TST & \\
\hline CHEMBL1951675 & 803068 & 7.3768 & 7.3201 & TRN & \\
\hline CHEMBL1951882 & 803068 & 8.4815 & 8.425 & TRN & \\
\hline CHEMBL1951678 & 803068 & 6.109 & 5.4935 & TST & \\
\hline CHEMBL1951687 & 803068 & 7.2007 & 7.7397 & TRN & \\
\hline CHEMBL1951667 & 803068 & 7.7212 & 7.9652 & TRN & \\
\hline CHEMBL1951682 & 803068 & 7.6198 & 7.336 & TRN & \\
\hline CHEMBL1951663 & 803068 & 7.2518 & 7.4476 & TRN & \\
\hline CHEMBL1951877 & 803068 & 8.0177 & 7.8201 & TRN & \\
\hline CHEMBL1951683 & 803068 & 8.28399 & 79999999 & 8.0309 & TRN \\
\hline
\end{tabular}




\begin{tabular}{|c|c|c|c|c|c|}
\hline & & \multicolumn{4}{|c|}{ Supplemental Table S2.txt } \\
\hline CHEMBL1951889 & 803068 & 7.284 & 7.3712 & TRN & \\
\hline CHEMBL1951670 & 803068 & 8.1871 & 7.8147 & TRN & \\
\hline CHEMBL1951685 & 803068 & 6.9666 & 7.013 & TRN & \\
\hline CHEMBL1951664 & 803068 & 7.7447 & 7.9662 & TRN & \\
\hline CHEMBL1951885 & 803068 & 7.4949 & 7.4115 & TRN & \\
\hline CHEMBL1951874 & 803068 & 7.3979 & 7.1662 & TRN & \\
\hline CHEMBL1951876 & 803068 & 7.1487 & 7.1093 & TST & \\
\hline CHEMBL1951661 & 803068 & 8.7212 & 8.8919 & TRN & \\
\hline CHEMBL1951676 & 803068 & 6.9245 & 7.0141 & TRN & \\
\hline CHEMBL1951658 & 803068 & 7.7696 & 8.4495 & TRN & \\
\hline CHEMBL1951673 & 803068 & 6.6904 & 6.4177 & TRN & \\
\hline CHEMBL1951680 & 803068 & 7.7447 & 7.5457 & TRN & \\
\hline CHEMBL1951884 & 803068 & 7.1135 & 7.3275 & TRN & \\
\hline CHEMBL1951681 & 803068 & 8.0757 & 7.6955 & TRN & \\
\hline CHEMBL1951684 & 803068 & 6.8665 & 6.8731 & TRN & \\
\hline CHEMBL1951660 & 803068 & 7.5376 & 8.0086 & TRN & \\
\hline CHEMBL1951679 & 803068 & 5.0 & 5.5573 & TRN & \\
\hline CHEMBL1951879 & 803068 & 8.0269 & 8.1127 & TRN & \\
\hline CHEMBL1951886 & 803068 & 7.8861 & 7.8349 & TRN & \\
\hline CHEMBL1951666 & 803068 & 7.8861 & 8.283 & TRN & \\
\hline CHEMBL1951890 & 803068 & 7.6576 & 7.61799 & 9999999999 & TRN \\
\hline CHEMBL1951686 & 803068 & 7.0655 & 6.8632 & TRN & \\
\hline CHEMBL1951880 & 803068 & 8.1367 & 8.1868 & TRN & \\
\hline CHEMBL1951689 & 803068 & 6.5686 & 6.8959 & TRN & \\
\hline CHEMBL1951875 & 803068 & 7.4949 & 6.9918 & TRN & \\
\hline CHEMBL1951659 & 803068 & 8.7212 & 8.3009 & TRN & \\
\hline CHEMBL1951677 & 803068 & 7.8539 & 7.4439 & TST & \\
\hline CHEMBL1951662 & 803068 & 9.3979 & 8.3774 & TRN & \\
\hline CHEMBL1951881 & 803068 & 8.1367 & 8.3538 & TRN & \\
\hline CHEMBL1951669 & 803068 & 7.9208 & 8.1626 & TST & \\
\hline CHEMBL1951887 & 803068 & 7.5528 & 7.9126 & TST & \\
\hline CHEMBL1951883 & 803068 & 7.7212 & 8.0659 & TST & \\
\hline CHEMBL1951688 & 803068 & 7.7959 & 7.78 & TRN & \\
\hline CHEMBL1951690 & 803068 & 7.8861 & 8.0917 & TRN & \\
\hline CHEMBL1951873 & 803068 & 6.51 & 6.2777 & TRN & \\
\hline CHEMBL1951668 & 803068 & 7.9586 & 8.0988 & TST & \\
\hline CHEMBL1951671 & 803068 & 6.2472 & 6.8638 & TST & \\
\hline CHEMBL1951888 & 803068 & 7.0132 & 7.3019 & TST & \\
\hline CHEMBL1951674 & 803068 & 7.4949 & 7.1654 & TST & \\
\hline CHEMBL1951872 & 803068 & 8.2147 & 8.4425 & TST & \\
\hline CHEMBL1951878 & 803068 & 7.9208 & 7.9346 & TST & \\
\hline CHEMBL148225 & 158653 & 5.857 & 5.7722 & TRN & \\
\hline CHEMBL146078 & 158653 & 6.4815 & 6.1899 & TRN & \\
\hline CHEMBL147917 & 158653 & 7.0 & 6.6549 & TRN & \\
\hline CHEMBL359007 & 158653 & 7.1549 & 6.6488 & TRN & \\
\hline CHEMBL102346 & 158653 & 7.0969 & 7.4732 & TRN & \\
\hline CHEMBL344561 & 158653 & 5.8239 & 3.6691 & TST & \\
\hline CHEMBL144078 & 158653 & 6.7212 & 6.6322 & TRN & \\
\hline
\end{tabular}




\begin{tabular}{|c|c|c|c|c|c|}
\hline \multicolumn{6}{|c|}{ Supplemental Table S } \\
\hline CHEMBL144076 & 158653 & 6.4089 & 6.3597 & TRN & \\
\hline CHEMBL147325 & 158653 & 3.5229 & 4.0662 & TRN & \\
\hline CHEMBL359194 & 158653 & 6.2596 & 6.3767 & TRN & \\
\hline CHEMBL101127 & 158653 & 3.5229 & 3.9312 & TRN & \\
\hline CHEMBL144574 & 158653 & 3.5229 & 5.6705 & TST & \\
\hline CHEMBL411229 & 158653 & 7.0 & 6.8926 & TRN & \\
\hline CHEMBL144369 & 158653 & 4.8761 & 4.8842 & TRN & \\
\hline CHEMBL144368 & 158653 & 4.9872 & 4.6806 & TRN & \\
\hline CHEMBL145179 & 158653 & 3.5229 & 3.9305 & TRN & \\
\hline CHEMBL146876 & 158653 & 6.0915 & 6.3657 & TRN & \\
\hline CHEMBL144622 & 158653 & 6.5686 & 6.7902 & TRN & \\
\hline CHEMBL342515 & 158653 & 7.301 & 6.9153 & TRN & \\
\hline CHEMBL434262 & 158653 & 6.8539 & 5.4493 & TST & \\
\hline CHEMBL103179 & 158653 & 3.5229 & 3.7225 & TRN & \\
\hline CHEMBL147841 & 158653 & 5.4868 & 6.596 & TST & \\
\hline CHEMBL143986 & 158653 & 6.3098 & 4.7535 & TST & \\
\hline CHEMBL144990 & 158653 & 3.5229 & 4.2085 & TRN & \\
\hline CHEMBL144816 & 158653 & 3.5229 & 3.2227 & TST & \\
\hline CHEMBL359204 & 158653 & 3.5229 & 3.9678 & TRN & \\
\hline CHEMBL147052 & 158653 & 4.0 & 3.2553 & TST & \\
\hline CHEMBL144593 & 158653 & 3.5229 & 3.8939 & TRN & \\
\hline CHEMBL421206 & 158653 & 3.5229 & 3.8816 & TRN & \\
\hline CHEMBL144296 & 158653 & 6.5229 & 6.6945 & TRN & \\
\hline CHEMBL342280 & 158653 & 4.6778 & 4.8461 & TRN & \\
\hline CHEMBL148382 & 158653 & 7.0969 & 7.2648 & TRN & \\
\hline CHEMBL147916 & 158653 & 6.7447 & 7.61700 & 0000000001 & TRN \\
\hline CHEMBL144862 & 158653 & 3.5229 & 5.1014 & TST & \\
\hline CHEMBL145259 & 158653 & 6.2924 & 6.2272 & TRN & \\
\hline CHEMBL342999 & 158653 & 3.5229 & 3.7329 & TRN & \\
\hline CHEMBL147837 & 158653 & 3.5229 & 3.3672 & TRN & \\
\hline CHEMBL100305 & 158653 & 4.9626 & 4.6279 & TRN & \\
\hline CHEMBL448729 & 158653 & 7.2218 & 7.1596 & TRN & \\
\hline CHEMBL144390 & 158653 & 6.5376 & 6.5196 & TRN & \\
\hline CHEMBL100734 & 158653 & 3.5229 & 2.9891 & TRN & \\
\hline CHEMBL100542 & 158653 & 5.8416 & 5.8773 & TRN & \\
\hline CHEMBL344091 & 158653 & 7.1549 & 7.1882 & TRN & \\
\hline CHEMBL103490 & 158653 & 6.8239 & 7.2479 & TRN & \\
\hline CHEMBL319894 & 158653 & 7.0458 & 6.6011 & TRN & \\
\hline CHEMBL144860 & 158653 & 5.5686 & 4.5906 & TST & \\
\hline CHEMBL144077 & 158653 & 7.0458 & 6.9463 & TRN & \\
\hline CHEMBL146020 & 158653 & 6.1938 & 6.4442 & TRN & \\
\hline CHEMBL100736 & 158653 & 7.3979 & 7.7299 & TRN & \\
\hline CHEMBL103776 & 158653 & 3.5229 & 3.5228 & TRN & \\
\hline CHEMBL144340 & 158653 & 3.5229 & 3.7175 & TRN & \\
\hline CHEMBL356129 & 158653 & 5.8125 & 5.7111 & TST & \\
\hline CHEMBL100735 & 158653 & 6.2076 & 7.2479 & TST & \\
\hline CHEMBL103447 & 158653 & 3.5229 & 4.7019 & TST & \\
\hline CHEMBL144749 & 158653 & 7.0458 & 6.5586 & TRN & \\
\hline
\end{tabular}




\begin{tabular}{|c|c|c|c|c|c|}
\hline & & \multicolumn{4}{|c|}{ Supplemental Table S2.txt } \\
\hline CHEMBL424129 & 158653 & 6.5376 & 6.6322 & TRN & \\
\hline CHEMBL99729 & 158653 & 6.699 & 4.637 & TST & \\
\hline CHEMBL343209 & 158653 & 7.699 & 7.3606 & TRN & \\
\hline CHEMBL144109 & 158653 & 4.9914 & 6.2406 & TST & \\
\hline CHEMBL148221 & 158653 & 3.5229 & 3.9685 & TRN & \\
\hline CHEMBL103326 & 158653 & 3.5229 & 3.667 & TRN & \\
\hline CHEMBL144279 & 158653 & 5.2161 & 4.9265 & TRN & \\
\hline CHEMBL144054 & 158653 & 5.8861 & 4.9089 & TST & \\
\hline CHEMBL356715 & 158653 & 6.8861 & 6.5121 & TRN & \\
\hline CHEMBL359229 & 158653 & 6.7447 & 6.4142 & TRN & \\
\hline CHEMBL102911 & 158653 & 8.0 & 7.7299 & TRN & \\
\hline CHEMBL144307 & 158653 & 3.5229 & 5.4968 & TST & \\
\hline CHEMBL344962 & 158653 & 7.0 & 6.9153 & TRN & \\
\hline CHEMBL339685 & 158653 & 8.0 & 8.0626 & TRN & \\
\hline CHEMBL104325 & 158653 & 5.9586 & 6.4012 & TRN & \\
\hline CHEMBL147277 & 158653 & 7.0969 & 7.2648 & TST & \\
\hline CHEMBL147001 & 158653 & 6.7696 & 4.4285 & TST & \\
\hline CHEMBL144725 & 158653 & 7.699 & 8.0626 & TRN & \\
\hline CHEMBL148259 & 158653 & 7.1549 & 7.1596 & TRN & \\
\hline CHEMBL147056 & 158653 & 3.5229 & 5.1029 & TST & \\
\hline CHEMBL 264182 & 158653 & 3.5229 & 3.7885 & TRN & \\
\hline CHEMBL148084 & 158653 & 6.5086 & 6.7403 & TST & \\
\hline CHEMBL102301 & 158653 & 7.0458 & 6.3554 & TST & \\
\hline CHEMBL143892 & 158653 & 4.0 & 3.6503 & TRN & \\
\hline CHEMBL106966 & 158653 & 6.0706 & 5.6799 & TRN & \\
\hline CHEMBL103487 & 158653 & 6.4202 & 6.1824 & TRN & \\
\hline CHEMBL148047 & 158653 & 3.5229 & 2.85100 & 00000000004 & TRN \\
\hline CHEMBL146993 & 158653 & 6.1871 & 5.7722 & TRN & \\
\hline CHEMBL144433 & 158653 & 3.5229 & 2.9851 & TRN & \\
\hline CHEMBL144687 & 158653 & 7.0969 & 7.1575 & TRN & \\
\hline CHEMBL424502 & 158653 & 6.1079 & 5.8031 & TRN & \\
\hline CHEMBL 99743 & 158653 & 6.1549 & 5.9306 & TRN & \\
\hline CHEMBL423752 & 158653 & 3.5229 & 5.461 & TST & \\
\hline CHEMBL343241 & 158653 & 5.3382 & 5.3379 & TRN & \\
\hline CHEMBL357673 & 158653 & 7.0458 & 6.8972 & TST & \\
\hline CHEMBL146114 & 158653 & 3.5229 & 3.5485 & TRN & \\
\hline CHEMBL 350094 & 75756 & 5.5784 & 6.4153 & TRN & \\
\hline CHEMBL163353 & 75756 & 6.3279 & 6.7093 & TRN & \\
\hline CHEMBL163457 & 75756 & 6.3298 & 5.3889 & TST & \\
\hline CHEMBL424343 & 75756 & 6.2882 & 5.7514 & TST & \\
\hline CHEMBL163594 & 75756 & 7.3098 & 6.976 & TRN & \\
\hline CHEMBL162318 & 75756 & 7.4685 & 7.3668 & TRN & \\
\hline CHEMBL162309 & 75756 & 6.3605 & 6.4874 & TRN & \\
\hline CHEMBL349901 & 75756 & 6.9172 & 7.1214 & TRN & \\
\hline CHEMBL162926 & 75756 & 6.9318 & 6.8312 & TRN & \\
\hline CHEMBL 350316 & 75756 & 7.6778 & 7.311 & TST & \\
\hline CHEMBL 350370 & 75756 & 6.224 & 6.0825 & TST & \\
\hline CHEMBL162440 & 75756 & 6.3851 & 6.485 & TRN & \\
\hline
\end{tabular}




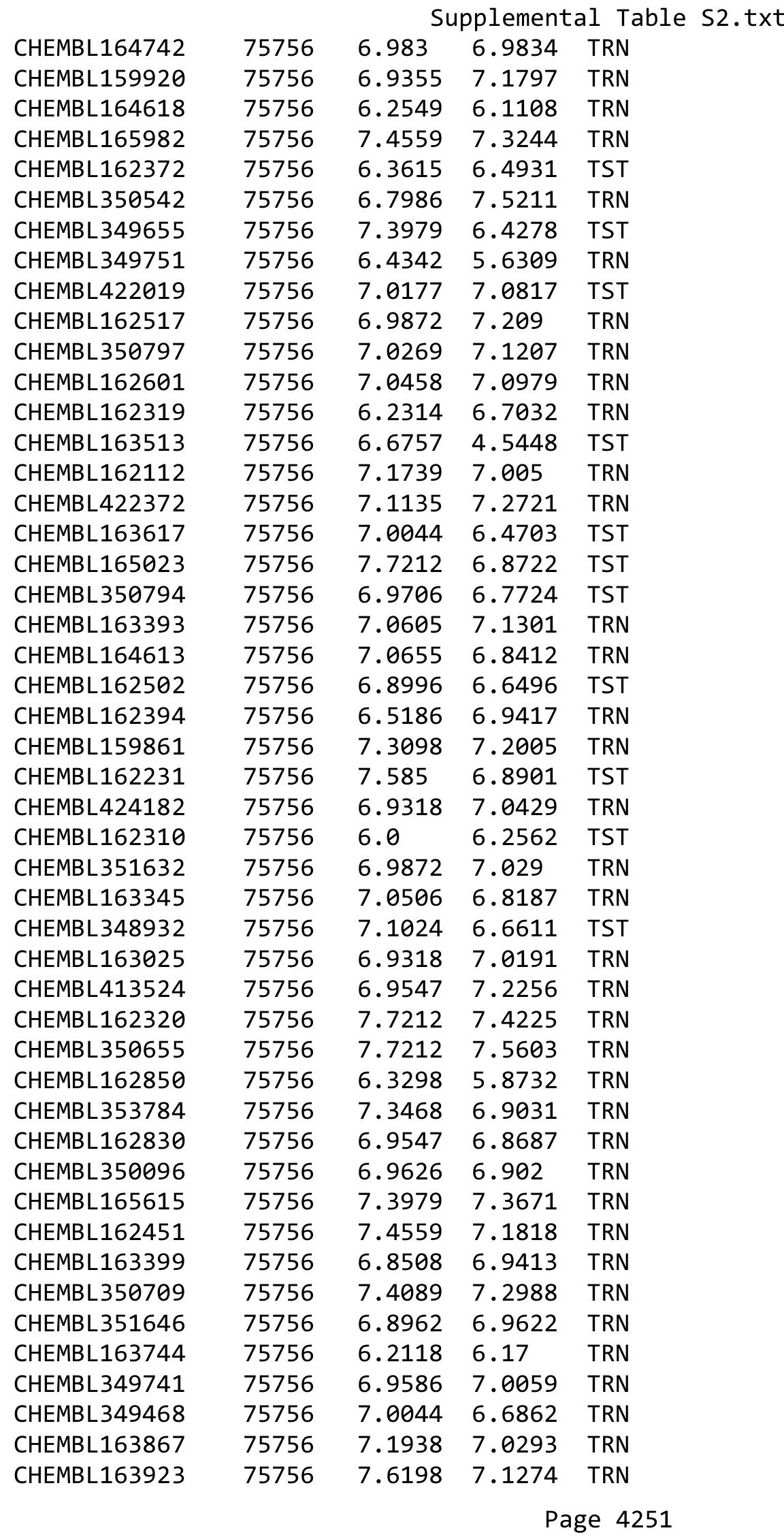




\begin{tabular}{|c|c|c|c|c|c|}
\hline & & \multicolumn{4}{|c|}{ Supplemental Table S2.txt } \\
\hline CHEMBL163534 & 75756 & 5.8652 & 5.9739 & TRN & \\
\hline CHEMBL163873 & 75756 & 6.3206 & 5.9609 & TST & \\
\hline CHEMBL354691 & 75756 & 5.6702 & 5.4273 & TRN & \\
\hline CHEMBL163681 & 75756 & 7.699 & 7.55399 & 9999999999 & TRN \\
\hline CHEMBL348746 & 75756 & 5.4152 & 5.3317 & TRN & \\
\hline CHEMBL163031 & 75756 & 6.9872 & 6.9306 & TRN & \\
\hline CHEMBL423463 & 75756 & 5.671 & 5.9943 & TRN & \\
\hline CHEMBL162233 & 75756 & 6.3768 & 6.5559 & TRN & \\
\hline CHEMBL162384 & 75756 & 6.8069 & 6.2428 & TST & \\
\hline CHEMBL163139 & 75756 & 4.301 & 4.8408 & TRN & \\
\hline CHEMBL162169 & 75756 & 7.5528 & 7.3955 & TRN & \\
\hline CHEMBL 274023 & 75756 & 6.109 & 6.5139 & TST & \\
\hline CHEMBL162448 & 75756 & 6.9957 & 6.782 & TST & \\
\hline CHEMBL3675556 & 1535880 & 4.0 & 3.9385 & TRN & \\
\hline CHEMBL3675573 & 1535880 & 7.4685 & 5.8866 & TST & \\
\hline CHEMBL3675579 & 1535880 & 6.9355 & 5.5844 & TRN & \\
\hline CHEMBL3675588 & 1535880 & 4.0 & 4.4686 & TRN & \\
\hline CHEMBL3639695 & 1535880 & 7.0706 & 6.9068 & TRN & \\
\hline CHEMBL3670714 & 1535880 & 4.0 & 4.3654 & TRN & \\
\hline CHEMBL3675582 & 1535880 & 4.0 & 4.4576 & TRN & \\
\hline CHEMBL3675551 & 1535880 & 4.301 & 5.8686 & TRN & \\
\hline CHEMBL3675594 & 1535880 & 5.0 & 6.0427 & TRN & \\
\hline CHEMBL3675568 & 1535880 & 6.6234 & 5.7008 & TRN & \\
\hline CHEMBL3675587 & 1535880 & 4.0 & 3.8657 & TRN & \\
\hline CHEMBL3670708 & 1535880 & 6.3372 & 6.5254 & TRN & \\
\hline CHEMBL 3675570 & 1535880 & 6.9666 & 5.8686 & TRN & \\
\hline CHEMBL3675555 & 1535880 & 5.0 & 4.3013 & TRN & \\
\hline CHEMBL3670709 & 1535880 & 5.0 & 4.3268 & TST & \\
\hline CHEMBL 3675576 & 1535880 & 6.5986 & 5.4298 & TRN & \\
\hline CHEMBL3670717 & 1535880 & 5.0 & 4.4233 & TRN & \\
\hline CHEMBL3675559 & 1535880 & 4.0 & 4.3355 & TRN & \\
\hline CHEMBL3675543 & 1535880 & 7.0555 & 6.4849 & TRN & \\
\hline CHEMBL3675607 & 1535880 & 5.0 & 4.8019 & TRN & \\
\hline CHEMBL3675590 & 1535880 & 3.0 & 3.8628 & TST & \\
\hline CHEMBL 3675574 & 1535880 & 6.5229 & 5.3074 & TRN & \\
\hline CHEMBL3675592 & 1535880 & 5.0 & 5.4524 & TRN & \\
\hline CHEMBL3675597 & 1535880 & 4.0 & 3.9806 & TRN & \\
\hline CHEMBL 3675583 & 1535880 & 4.0 & 4.07100 & 0000000001 & TRN \\
\hline CHEMBL3670718 & 1535880 & 4.0 & 4.8874 & TST & \\
\hline CHEMBL3670696 & 1535880 & 6.4191 & 6.70200 & 0000000001 & TRN \\
\hline CHEMBL3675542 & 1535880 & 6.4724 & 5.6582 & TRN & \\
\hline CHEMBL 3675584 & 1535880 & 4.0 & 4.4311 & TRN & \\
\hline CHEMBL3675585 & 1535880 & 4.301 & 4.6764 & TRN & \\
\hline CHEMBL3675541 & 1535880 & 4.301 & 5.0369 & TRN & \\
\hline CHEMBL3675580 & 1535880 & 6.6925 & 5.405 & TRN & \\
\hline CHEMBL 3675554 & 1535880 & 4.301 & 5.8866 & TST & \\
\hline CHEMBL3675601 & 1535880 & 4.301 & 4.5871 & TRN & \\
\hline CHEMBL3675547 & 1535880 & 4.0 & 5.3074 & TRN & \\
\hline
\end{tabular}




$$
\text { Supplemental Table S2.txt }
$$

\begin{tabular}{|c|c|c|c|c|}
\hline EMBL 3675572 & & 5364 & & TST \\
\hline -HFMBI 3670710 & .535880 & 4.301 & & \\
\hline IEMBL3675600 & 535880 & 4.0 & & \\
\hline AEMBL 3675595 & 535880 & 5.0 & 4831 & \\
\hline HEMBL3670701 & 535880 & 7.107 & .7894 & \\
\hline AEMBL3670719 & 535880 & 5.0 & 46 & \\
\hline EMBL & 535880 & 7.7959 & & \\
\hline AEMBL3670698 & 535880 & 6.8894 & & \\
\hline HEMBL3675546 & 535880 & 5.0 & 5.6854 & \\
\hline HEMBL3670695 & 535880 & 6.6144 & 6.7836 & \\
\hline AEMBL3675577 & 535880 & 6.8477 & 5.607 & \\
\hline AEMBL & 535880 & 5.0 & & \\
\hline 75571 & 535880 & 6.5884 & 5.3886 & \\
\hline 575605 & 535880 & 6.2373 & 5.4846 & \\
\hline AEMBL3675545 & 535880 & 4.301 & 5174 & \\
\hline AEMBL & 535880 & 4.0 & 209 & \\
\hline AEMBL & 880 & 4.0 & 36 & \\
\hline HEMBL & 535880 & 4.301 & 08 & \\
\hline IEMBL: & 535880 & 4.301 & 4278 & \\
\hline AEMBL & 5880 & 4.0 & & \\
\hline AEMBL & 880 & & & \\
\hline AEMBL & 30 & 5.0 & & \\
\hline AEMBL. & 535880 & 4.0 & 384 & \\
\hline IEMBL: & 535880 & 5.0 & & \\
\hline IEMBL3 & 380 & & & \\
\hline AEMBL & 5880 & 6 . & & SI \\
\hline AEMBL & 5880 & 4. & & \\
\hline 99 & 80 & 6.24 & 39 & \\
\hline IEMBL & 80 & 6. & & TRI \\
\hline IEMBL 3639744 & 5880 & 4.301 & & 8 \\
\hline 64 & 880 & 6 . & & ГRN \\
\hline 81 & 30 & 5.0 & 33 & \\
\hline 707 & 30 & 4.0 & & \\
\hline IEMBL: & 535880 & 6.056 & & $\Gamma \mathrm{RI}$ \\
\hline AEMBL 3675591 & 535880 & 5. & 4. & TST \\
\hline 53 & 380 & 4 . & & \\
\hline 91 & 0 & 1 & & \\
\hline 720 & 30 & 6.5513 & & RN \\
\hline 575598 & 535880 & 5 . & & $\mathrm{R}$ \\
\hline AEMBL & 535880 & 4. & & $\mathrm{RI}$ \\
\hline HEMBL & 1535880 & & & \\
\hline HEMBL & .535880 & 6.1555 & 6.5203 & \\
\hline HEMBL3675566 & & 6.7747 & & RI \\
\hline 570706 & 535886 & 6.9788 & 88 & $s$ \\
\hline HEMBL & 535881 & 4.0 & & \\
\hline CHEMBL & 535880 & 5.0 & 4.8922 & \\
\hline CHEMBL 3675549 & 535880 & 4.0 & 5.7008 & \\
\hline CHEMBL 3675596 & 1535880 & 4.0 & 3.9806 & \\
\hline
\end{tabular}


Supplemental Table S2.txt

\begin{tabular}{|c|c|c|c|c|}
\hline AEMB & 880 & 301 & 5.3886 & TR \\
\hline HEMBL 3670711 & .535880 & 4.301 & 4.6404 & \\
\hline HEMBL $]$ & 535880 & 4.0 & 605 & \\
\hline HEMBL3670712 & 535880 & 5.0 & 6076 & \\
\hline HEMBL3675567 & 535880 & 6.2076 & . 7209 & \\
\hline HEMBL3670703 & 535880 & 6.3565 & 7.0356 & \\
\hline HEMBL3675604 & 535880 & 4.0 & .4169 & \\
\hline HEMBL3675569 & 535880 & 6.4724 & 5.3599 & \\
\hline HEMBL3675544 & 535880 & 4.301 & 5.7114 & \\
\hline HEMBL3675560 & 535880 & 5.0 & 4.8249 & \\
\hline HEMBL3675599 & 535880 & 4.301 & 4.8282 & \\
\hline HEMBL3675561 & 535880 & 4.0 & .5873 & \\
\hline HEMBL 36 & 535880 & 6.52 & 5.4531 & \\
\hline HEMBL561783 & 79311 & 7.0458 & 6.7197 & \\
\hline HEMBL539400 & 79311 & 8.0458 & 7.1615 & ST \\
\hline HEMBL 561982 & 79311 & 6.3872 & 6.5696 & \\
\hline AEMBL55 & 311 & 7.5229 & 7.9737 & \\
\hline HEMBL56 & 311 & 5.6498 & 6.1513 & \\
\hline HEMBL55 & 79311 & 6.0969 & 5.9637 & \\
\hline HEMBL550 & 311 & 8.0458 & & ST \\
\hline HEMBL56 & 11 & 7.0458 & 45 & KIV \\
\hline HEMBL56 & 311 & 6.5229 & 7928 & RN \\
\hline HEMBL56 & 311 & 58 & 7.6215 & $\mathrm{RN}$ \\
\hline HEMBL564188 & 79311 & 8.0969 & 6.9052 & RN \\
\hline HEMBL561859 & 311 & 5.9245 & 6.5567 & RN \\
\hline HEMBL55 & 311 & 7.5229 & 7.0022 & ST \\
\hline HEMBL5 & 311 & 7.699 & 6.4255 & RN \\
\hline HEMBL5€ & 311 & 6.1675 & 323 & RN \\
\hline HEMBL551518 & 79311 & 6.0605 & 6.6993 & TRN \\
\hline HEMBL562588 & 79311 & 6.5528 & 7.0587 & TRN \\
\hline HEMBL552192 & 9311 & 7.301 & 7.1844 & TST \\
\hline HEMBL 5 & 11 & 5.5817 & 6.8115 & TST \\
\hline HEMBL5 & 11 & 6.1487 & 6.5479 & TST \\
\hline HEMBL563459 & 79311 & 8.2218 & 7.6349 & TRN \\
\hline HEMBL561923 & 79311 & 5.9031 & 6.4045 & TRN \\
\hline HEMBL551257 & 79311 & 6.585 & 6.7879 & TRN \\
\hline CHEMBL 5 & 11 & 69 & 6.9802 & RN \\
\hline THEMBL563562 & 79311 & 5.5686 & 6.7352 & ГST \\
\hline HEMBL556417 & 79311 & 7.9208 & 7.6671 & TRN \\
\hline HEMBL5519 & 9311 & 6.6383 & 6.7419 & TRN \\
\hline CHEMBL558404 & 9311 & 6.7447 & 7.0266 & TST \\
\hline CHEMBL563418 & 79311 & 6.8239 & & RN \\
\hline CHEMBL549981 & 79311 & 7.301 & 6.9834 & TRN \\
\hline CHEMBL562602 & 79311 & 7.699 & 6.7828 & TRN \\
\hline HEMBL55 & 9311 & 7.0969 & 6.6989 & 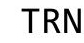 \\
\hline CHEMBL560783 & 79311 & 8.0458 & 8.0977 & \\
\hline CHEMBL549428 & 79311 & 7.1549 & 7.7874 & RIN \\
\hline CHEMBL554520 & 579311 & 6.6021 & 7.0914 & 「RN \\
\hline
\end{tabular}




\begin{tabular}{|c|c|c|c|c|c|c|}
\hline & & \multicolumn{5}{|c|}{ Supplemental Table s2.txt } \\
\hline CHEMBL551798 & 579311 & 7.301 & 6.9368 & TRN & & \\
\hline CHEMBL560180 & 579311 & 7.301 & 7.6966 & TRN & & \\
\hline CHEMBL557435 & 579311 & 5.5331 & 6.0147 & TRN & & \\
\hline CHEMBL560576 & 579311 & 6.6198 & 6.8542 & TRN & & \\
\hline CHEMBL559788 & 579311 & 8.0458 & 7.4735 & TRN & & \\
\hline CHEMBL563355 & 579311 & 6.7447 & 7.6474 & TST & & \\
\hline CHEMBL564797 & 579311 & 7.9586 & 6.91799 & 999999999 & & TST \\
\hline CHEMBL557710 & 579311 & 5.585 & 7.0038 & TST & & \\
\hline CHEMBL564867 & 579311 & 6.5686 & 7.4341 & TRN & & \\
\hline CHEMBL560259 & 579311 & 7.5229 & 6.9821 & TST & & \\
\hline CHEMBL565097 & 579311 & 8.0458 & 7.0652 & TST & & \\
\hline CHEMBL539429 & 579311 & 6.9586 & 7.1567 & TRN & & \\
\hline CHEMBL556182 & 579311 & 6.8539 & 7.1296 & TRN & & \\
\hline CHEMBL558947 & 579311 & 6.585 & 6.5044 & TRN & & \\
\hline CHEMBL561784 & 579311 & 7.0458 & 6.5022 & TRN & & \\
\hline CHEMBL550918 & 579311 & 7.2218 & 7.0245 & TRN & & \\
\hline CHEMBL551661 & 579311 & 6.3188 & 6.7799 & TRN & & \\
\hline CHEMBL562879 & 579311 & 7.2218 & 6.9215 & TRN & & \\
\hline CHEMBL540490 & 579311 & 7.699 & 6.8943 & TRN & & \\
\hline CHEMBL559529 & 579311 & 7.0969 & 7.2518 & TST & & \\
\hline CHEMBL559924 & 579311 & 8.0458 & 7.2556 & TST & & \\
\hline CHEMBL549900 & 579311 & 6.0862 & 6.313 & TRN & & \\
\hline CHEMBL550386 & 579311 & 7.8539 & 6.6749 & TRN & & \\
\hline CHEMBL562570 & 579311 & 8.0458 & 7.0307 & TST & & \\
\hline CHEMBL558116 & 579311 & 7.2218 & 7.696006 & 000000000 & & TRN \\
\hline CHEMBL549839 & 579311 & 5.71 & 6.2542 & TRN & & \\
\hline CHEMBL562061 & 579311 & 6.5686 & 6.9719 & TRN & & \\
\hline CHEMBL559864 & 579311 & 7.5229 & 7.0973 & TST & & \\
\hline CHEMBL551516 & 579311 & 5.6289 & 6.4496 & TRN & & \\
\hline CHEMBL553470 & 579311 & 8.2218 & 7.6127 & TRN & & \\
\hline CHEMBL564915 & 579311 & 7.0969 & 7.3277 & TST & & \\
\hline CHEMBL549360 & 579311 & 6.585 & 7.1901 & TRN & & \\
\hline CHEMBL551459 & 579311 & 6.6383 & 6.8311 & TRN & & \\
\hline CHEMBL550916 & 579311 & 8.0458 & 7.7713 & TRN & & \\
\hline CHEMBL563010 & 579311 & 7.0969 & 6.4147 & TRN & & \\
\hline CHEMBL549977 & 579311 & 5.8928 & 6.5692 & TRN & & \\
\hline CHEMBL556699 & 579311 & 6.0757 & 6.6744 & TRN & & \\
\hline CHEMBL559468 & 579311 & 7.1549 & 6.6554 & TRN & & \\
\hline CHEMBL559205 & 579311 & 6.9586 & 7.187 & TST & & \\
\hline CHEMBL3950905 & 1642271 & 3.7721 & 4.1963 & TRN & & \\
\hline CHEMBL3895211 & 1642271 & 3.75699 & 99999999 & 997 & 3.7825 & TRN \\
\hline CHEMBL3932835 & 1642271 & 4.9172 & 5.294 & TRN & & \\
\hline CHEMBL3958682 & 1642271 & 5.4225 & 5.3119 & TRN & & \\
\hline CHEMBL3898577 & 1642271 & 4.8633 & 4.3647 & TRN & & \\
\hline CHEMBL3955067 & 1642271 & 6.0 & 5.7866 & TRN & & \\
\hline CHEMBL3984179 & 1642271 & 5.983 & 5.8772 & TRN & & \\
\hline CHEMBL3907190 & 1642271 & 6.6055 & 6.5399 & TRN & & \\
\hline CHEMBL3936734 & 1642271 & 5.9318 & 5.9622 & TRN & & \\
\hline
\end{tabular}


Supplemental Table S2.txt

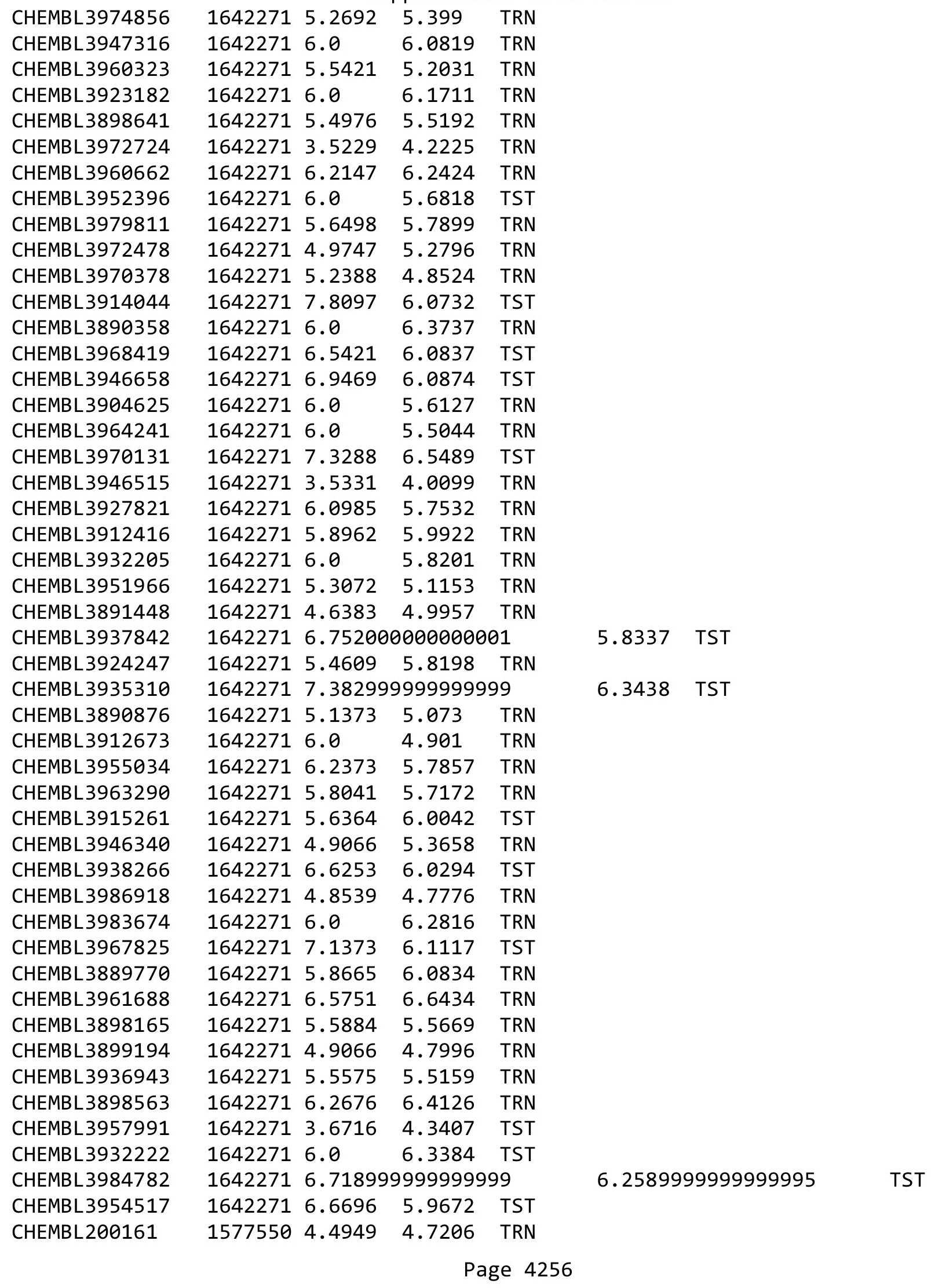


Supplemental Table S2.txt

\begin{tabular}{|c|c|c|c|c|}
\hline 1975 & 577550 & 5.9101 & & \\
\hline & 577550 & 5.4815 & 5.3013 & \\
\hline HFMRI & 77550 & 08 & & \\
\hline IEMBL 200427 & 550 & 815 & & \\
\hline HEMBL 200005 & 577550 & 815 & 3321 & \\
\hline HEMBL 200160 & 50 & 4.0269 & .7631 & \\
\hline HEMBL3806324 & & & & \\
\hline HEMBL 383584 & 50 & & & 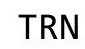 \\
\hline HEMBL197130 & 577550 & 5.4815 & .3052 & \\
\hline HEMBL3806077 & 550 & 5.4815 & 3775 & \\
\hline HEMBL3805560 & 50 & & & \\
\hline HEMBL 2 & 50 & & & RN \\
\hline HEMBL197181 & 50 & & & \\
\hline HEMBL 371499 & 577550 & 865 & 8454 & \\
\hline HEMBL3805060 & & 77 & & \\
\hline HEMBL 200577 & 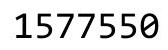 & 5. & 42 & RIN \\
\hline HEMBL2 & ש & & 02 & KIV \\
\hline HEMBL1651358 & 50 & & & $\mathrm{RN}$ \\
\hline HEMBL 381847 & 50 & & & \\
\hline HEMBL 200151 & & & & 131 \\
\hline HEMBL & שמ & & & RN \\
\hline HEME & & & & RN \\
\hline HEMBL & 50 & & & RN \\
\hline HEMBL 370188 & & & & I RIV \\
\hline HEMBL 200004 & & & 53 & I RN \\
\hline HEMBL 38058 & ש & & 49 & RN \\
\hline HEM & 00 & & & RN \\
\hline 69 & 50 & & & 「RN \\
\hline HEMBL3 & & & & IRIN \\
\hline HEMBL 198570 & 50 & 5. & 97 & TRN \\
\hline HEMBL. & 50 & & & RN \\
\hline HFM & & & & 「RN \\
\hline נ & & & & 「RN \\
\hline HEMBL3806165 & 50 & & & 「RN \\
\hline HEMBL 3805078 & 50 & 3. & & ГST \\
\hline AFMR I & 50 & & & TRN \\
\hline 6 & & & & ГRN \\
\hline HEMBL380594e & 50 & & & RN \\
\hline HEMBL200006 & 50 & & & $\Gamma R$ \\
\hline AEMBL & 50 & & & IST \\
\hline HEMBL1651359 & שנ & & 44 & TRN \\
\hline HEMBL 2 & 50 & 5.2 & 5.4482 & IST \\
\hline HEMBL 380512 & .577550 & 5.2 & 5.5789 & TRN \\
\hline HEMBL 38049 & 550 & & & TS \\
\hline CHEMBL371466 & & & & $\mathrm{N}$ \\
\hline HEMBL 3805032 & 1577 & 5.4815 & 5.5984 & \\
\hline CHEMBL3805682 & 1577550 & 5.4815 & 5.8517 & ST \\
\hline CHEMBL3805885 & 1577550 & 7.585 & 6.2271 & $\Gamma \mathrm{ST}$ \\
\hline
\end{tabular}

Page 4257 
Supplemental Table S2.txt

\begin{tabular}{|c|c|c|c|c|c|}
\hline CHEMBL 3805198 & 1577550 & 5.4815 & 4.9588 & TST & \\
\hline CHEMBL595637 & 1577550 & 5.4815 & 5.4843 & TRN & \\
\hline CHEMBL 200743 & 1577550 & 5.4815 & 5.4785 & TRN & \\
\hline CHEMBL 371285 & 1577550 & 5.4815 & 5.258999 & 99999999995 & TRN \\
\hline CHEMBL 3805261 & 1577550 & 5.4389 & 6.2138 & TST & \\
\hline CHEMBL 200836 & 1577550 & 5.4815 & 5.4091 & TRN & \\
\hline CHEMBL 3805093 & 1577550 & 7.38399 & 999999999 & 6.2402 & TST \\
\hline CHEMBL 200635 & 1577550 & 5.4815 & 5.2887 & TRN & \\
\hline CHEMBL 3805941 & 1577550 & 5.4815 & 5.5918 & TRN & \\
\hline CHEMBL344174 & 1577550 & 5.4815 & 5.3661 & TRN & \\
\hline CHEMBL 200574 & 1577550 & 5.4815 & 5.4102 & TST & \\
\hline CHEMBL 3806204 & 1577550 & 5.4815 & 5.3764 & TST & \\
\hline CHEMBL424669 & 1577550 & 5.4815 & 5.4699 & TST & \\
\hline CHEMBL1967887 & 809192 & 5.8 & 6.7268 & TRN & \\
\hline CHEMBL 213505 & 809192 & 4.7 & 5.2623 & TRN & \\
\hline CHEMBL 2000568 & 809192 & 4.7 & 4.3038 & TRN & \\
\hline CHEMBL 2000335 & 809192 & 7.1 & 6.5184 & TRN & \\
\hline CHEMBL1974328 & 809192 & 6.0 & 5.0519 & TRN & \\
\hline CHEMBL1988717 & 809192 & 4.7 & 5.0455 & TRN & \\
\hline CHEMBL509032 & 809192 & 4.7 & 5.085 & TRN & \\
\hline CHEMBL1987034 & 809192 & 7.0 & 5.9882 & TRN & \\
\hline CHEMBL1993941 & 809192 & 4.7 & 5.6558 & TRN & \\
\hline CHEMBL 377383 & 809192 & 4.7 & 4.7896 & TRN & \\
\hline CHEMBL 2005886 & 809192 & 4.7 & 4.7916 & TST & \\
\hline CHEMBL 1973808 & 809192 & 4.7 & 4.6125 & TRN & \\
\hline CHEMBL 2000429 & 809192 & 4.7 & 4.8039 & TRN & \\
\hline CHEMBL481491 & 809192 & 4.7 & 4.8027 & TST & \\
\hline CHEMBL1973142 & 809192 & 4.7 & 4.9163 & TST & \\
\hline CHEMBL1972576 & 809192 & 5.8 & 5.0892 & TRN & \\
\hline CHEMBL1990254 & 809192 & 8.1 & 6.7615 & TRN & \\
\hline CHEMBL1973145 & 809192 & 4.7 & 5.5263 & TRN & \\
\hline CHEMBL1982924 & 809192 & 4.7 & 5.2101 & TRN & \\
\hline CHEMBL1992342 & 809192 & 4.7 & 5.1945 & TRN & \\
\hline CHEMBL 2005936 & 809192 & 7.1 & 6.6243 & TRN & \\
\hline CHEMBL1988173 & 809192 & 6.9 & 5.3373 & TST & \\
\hline CHEMBL1971141 & 809192 & 4.7 & 5.3369 & TRN & \\
\hline CHEMBL 1989805 & 809192 & 6.2 & 5.2877 & TST & \\
\hline CHEMBL206236 & 809192 & 5.8 & 5.8733 & TRN & \\
\hline CHEMBL1965423 & 809192 & 4.7 & 4.8398 & TRN & \\
\hline CHEMBL 2001957 & 809192 & 4.7 & 4.6947 & TRN & \\
\hline CHEMBL1969372 & 809192 & 4.7 & 4.5442 & TRN & \\
\hline CHEMBL 1983025 & 809192 & 7.1 & 6.9321 & TRN & \\
\hline CHEMBL205415 & 809192 & 6.6 & \multicolumn{2}{|c|}{6.202000000000001} & TRN \\
\hline CHEMBL1977135 & 809192 & 6.5 & 6.247000 & 0000000001 & TR \\
\hline CHEMBL 2001920 & 809192 & 4.7 & 4.9875 & TST & \\
\hline CHEMBL 2006263 & 809192 & 6.2 & 5.9036 & TRN & \\
\hline CHEMBL 1241473 & 809192 & 4.7 & 5.0542 & TRN & \\
\hline CHEMBL1993584 & 809192 & 4.7 & 5.5003 & TRN & \\
\hline
\end{tabular}




\begin{tabular}{|c|c|c|c|c|c|}
\hline \multicolumn{6}{|c|}{ Supplemental Table S2.txt } \\
\hline CHEMBL1986263 & 809192 & 4.7 & 4.8558 & TRN & \\
\hline CHEMBL 2000114 & 809192 & 4.7 & 5.0122 & TRN & \\
\hline CHEMBL 2001257 & 809192 & 7.5 & 6.869 & TRN & \\
\hline CHEMBL210618 & 809192 & 4.7 & 4.715 & TRN & \\
\hline CHEMBL1975647 & 809192 & 4.7 & 4.5375 & TRN & \\
\hline CHEMBL1992536 & 809192 & 4.7 & 5.3376 & TRN & \\
\hline CHEMBL1968380 & 809192 & 4.7 & 4.8173 & TRN & \\
\hline CHEMBL1964644 & 809192 & 4.7 & 4.5432 & TRN & \\
\hline CHEMBL1992740 & 809192 & 4.7 & 4.7703 & TRN & \\
\hline CHEMBL1977681 & 809192 & 4.7 & 4.617 & TRN & \\
\hline CHEMBL1970142 & 809192 & 4.7 & 5.4149 & TRN & \\
\hline CHEMBL1990912 & 809192 & 4.7 & 4.3916 & TRN & \\
\hline CHEMBL2002373 & 809192 & 4.7 & 4.522 & TRN & \\
\hline CHEMBL439340 & 809192 & 4.7 & 5.4679 & TRN & \\
\hline CHEMBL1970913 & 809192 & 4.7 & 4.5541 & TRN & \\
\hline CHEMBL1988163 & 809192 & 4.7 & 4.5926 & TRN & \\
\hline CHEMBL1985095 & 809192 & 4.7 & 6.2858 & TST & \\
\hline CHEMBL1996500 & 809192 & 4.7 & 4.5234 & TRN & \\
\hline CHEMBL2006493 & 809192 & 4.7 & 4.7147 & TST & \\
\hline CHEMBL1682540 & 809192 & 4.7 & 4.7964 & TRN & \\
\hline CHEMBL1983449 & 809192 & 4.7 & 5.7822 & TRN & \\
\hline CHEMBL1992323 & 809192 & 4.7 & 4.6488 & TST & \\
\hline CHEMBL1969735 & 809192 & 4.7 & 4.9767 & TRN & \\
\hline CHEMBL1976420 & 809192 & 4.7 & 4.8346 & TST & \\
\hline CHEMBL 2002649 & 809192 & 4.7 & 4.8298 & TRN & \\
\hline CHEMBL1994864 & 809192 & 4.7 & 5.6043 & TRN & \\
\hline CHEMBL 2002446 & 809192 & 5.8 & 5.4757 & TRN & \\
\hline CHEMBL497151 & 809192 & 5.8 & 5.1307 & TRN & \\
\hline CHEMBL246970 & 809192 & 4.7 & 5.4384 & TRN & \\
\hline CHEMBL1994321 & 809192 & 6.9 & 6.641 & TRN & \\
\hline CHEMBL340921 & 809192 & 6.3 & 6.24799 & 9999999999 & TST \\
\hline CHEMBL1997129 & 809192 & 4.7 & 4.2897 & TST & \\
\hline CHEMBL1999718 & 809192 & 4.7 & 4.7039 & TRN & \\
\hline CHEMBL1276446 & 809192 & 6.1 & 5.2717 & TST & \\
\hline CHEMBL1977346 & 809192 & 4.7 & 4.3564 & TRN & \\
\hline CHEMBL1971649 & 809192 & 4.7 & 5.1818 & TRN & \\
\hline CHEMBL 2000508 & 809192 & 4.7 & 4.5874 & TRN & \\
\hline CHEMBL1971694 & 809192 & 4.7 & 4.2699 & TST & \\
\hline CHEMBL2001547 & 809192 & 4.7 & 4.4969 & TRN & \\
\hline CHEMBL 210928 & 809192 & 4.7 & 4.7437 & TRN & \\
\hline CHEMBL1986603 & 809192 & 4.7 & 4.6416 & TST & \\
\hline CHEMBL1969190 & 809192 & 6.0 & 5.4217 & TRN & \\
\hline CHEMBL1977148 & 809192 & 5.8 & 5.6033 & TRN & \\
\hline CHEMBL1973937 & 809192 & 6.6 & 6.1781 & TRN & \\
\hline CHEMBL1992306 & 809192 & 4.7 & 4.8744 & TRN & \\
\hline CHEMBL 2002165 & 809192 & 4.7 & 5.6699 & TRN & \\
\hline CHEMBL1982711 & 809192 & 4.7 & 6.421 & TRN & \\
\hline CHEMBL206382 & 809192 & 5.7 & 5.32799 & 9999999999 & TRN \\
\hline & & & & 4259 & \\
\hline
\end{tabular}




\begin{tabular}{|c|c|c|c|c|c|}
\hline \\
\hline CHEMBL1998585 & 809192 & 6.2 & 6.2806 & TRN & \\
\hline CHEMBL519697 & 809192 & 4.7 & 4.4065 & TST & \\
\hline CHEMBL2004934 & 809192 & 6.3 & 6.4478 & TRN & \\
\hline CHEMBL1994241 & 809192 & 4.7 & 4.4821 & TST & \\
\hline CHEMBL 2007044 & 809192 & 4.7 & 5.3412 & TRN & \\
\hline CHEMBL 223460 & 809192 & 4.7 & 5.2748 & TST & \\
\hline CHEMBL1975128 & 809192 & 7.7 & 6.8291 & TRN & \\
\hline CHEMBL1998829 & 809192 & 4.7 & 4.8833 & TRN & \\
\hline CHEMBL50894 & 809192 & 4.8 & 4.9009 & TRN & \\
\hline CHEMBL1988838 & 809192 & 4.7 & 5.3923 & TRN & \\
\hline CHEMBL 2001485 & 809192 & 4.7 & 5.6119 & TRN & \\
\hline CHEMBL1981725 & 809192 & 4.7 & 5.13299 & 9999999999 & TRN \\
\hline CHEMBL1984363 & 809192 & 6.7 & 6.1649 & TRN & \\
\hline CHEMBL1978099 & 809192 & 4.7 & 5.0825 & TRN & \\
\hline CHEMBL1988608 & 809192 & 4.7 & 5.7852 & TRN & \\
\hline CHEMBL1982866 & 809192 & 4.7 & 4.6409 & TRN & \\
\hline CHEMBL1984367 & 809192 & 4.7 & 4.7754 & TRN & \\
\hline CHEMBL2007592 & 809192 & 4.7 & 4.3879 & TST & \\
\hline CHEMBL1965570 & 809192 & 5.9 & 4.9912 & TRN & \\
\hline CHEMBL226898 & 809192 & 7.1 & 7.7481 & TRN & \\
\hline CHEMBL1982563 & 809192 & 4.7 & 4.9851 & TRN & \\
\hline CHEMBL575824 & 809192 & 5.0 & 6.3907 & TRN & \\
\hline CHEMBL210963 & 809192 & 4.7 & 4.6226 & TRN & \\
\hline CHEMBL1988387 & 809192 & 4.7 & 5.7597 & TRN & \\
\hline CHEMBL1082440 & 809192 & 4.7 & 5.0414 & TST & \\
\hline CHEMBL1614705 & 809192 & 4.7 & 4.9051 & TRN & \\
\hline CHEMBL1990288 & 809192 & 4.7 & 4.8579 & TRN & \\
\hline CHEMBL1970074 & 809192 & 6.1 & 5.6115 & TRN & \\
\hline CHEMBL1965845 & 809192 & 4.7 & 5.5925 & TRN & \\
\hline CHEMBL1986970 & 809192 & 7.0 & 6.3569 & TRN & \\
\hline CHEMBL2006715 & 809192 & 4.7 & 5.0537 & TRN & \\
\hline CHEMBL1990482 & 809192 & 5.7 & 5.2438 & TRN & \\
\hline CHEMBL1990904 & 809192 & 4.7 & 4.6609 & TRN & \\
\hline CHEMBL2005475 & 809192 & 4.7 & 4.4327 & TRN & \\
\hline CHEMBL2003456 & 809192 & 4.7 & 4.5121 & TRN & \\
\hline CHEMBL402846 & 809192 & 6.0 & 5.7084 & TRN & \\
\hline CHEMBL2002992 & 809192 & 6.2 & 5.5759 & TRN & \\
\hline CHEMBL1997349 & 809192 & 5.7 & 4.7541 & TST & \\
\hline CHEMBL183844 & 809192 & 4.7 & 5.1833 & TRN & \\
\hline CHEMBL560813 & 809192 & 4.7 & 4.4937 & TRN & \\
\hline CHEMBL1682545 & 809192 & 4.7 & 4.891 & TRN & \\
\hline CHEMBL 220057 & 809192 & 6.5 & 6.5652 & TRN & \\
\hline CHEMBL383541 & 809192 & 6.8 & 6.5808 & TRN & \\
\hline CHEMBL 2001224 & 809192 & 4.7 & 5.0868 & TRN & \\
\hline CHEMBL1968791 & 809192 & 4.7 & 5.6813 & TRN & \\
\hline CHEMBL10 & 809192 & 4.7 & 4.7079 & TRN & \\
\hline CHEMBL1969506 & 809192 & 4.7 & 5.2595 & TRN & \\
\hline CHEMBL1964937 & 809192 & 6.6 & 5.45 & TRN & \\
\hline & & & & 4260 & \\
\hline
\end{tabular}




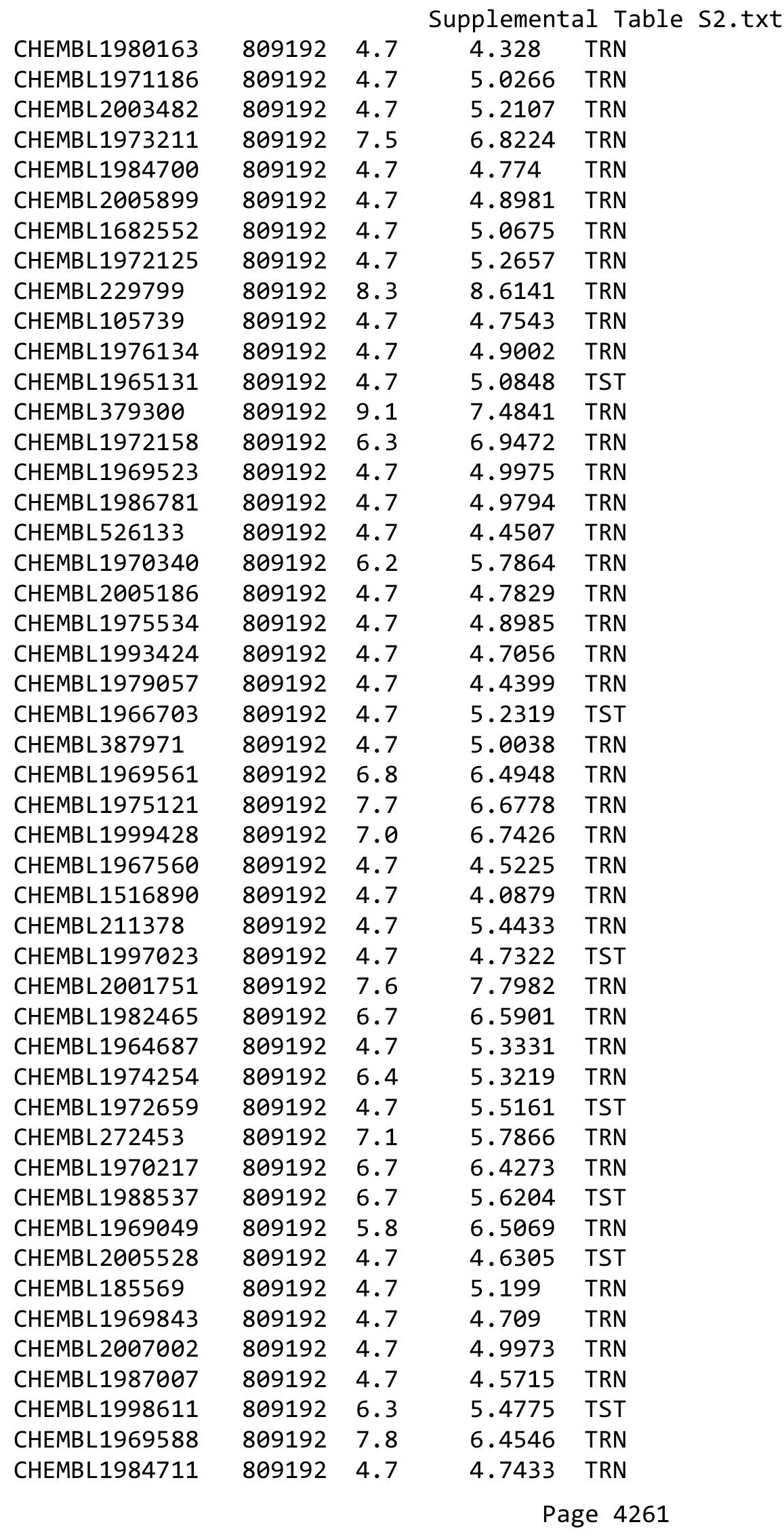




\begin{tabular}{|c|c|c|c|c|}
\hline & & & & $a+1 a$ \\
\hline CHEMBL1975900 & 809192 & 7.8 & 6.0907 & TRN \\
\hline CHEMBL2006778 & 809192 & 4.7 & 5.3086 & TRN \\
\hline CHEMBL484390 & 809192 & 4.7 & 4.2793 & TST \\
\hline CHEMBL1979252 & 809192 & 5.8 & 5.3764 & TRN \\
\hline CHEMBL378627 & 809192 & 4.7 & 4.643 & TRN \\
\hline CHEMBL1996979 & 809192 & 4.7 & 5.1385 & TRN \\
\hline CHEMBL1968406 & 809192 & 4.7 & 5.0825 & TRN \\
\hline CHEMBL 2004290 & 809192 & 4.7 & 5.2312 & TRN \\
\hline CHEMBL 2000393 & 809192 & 6.2 & 4.80399 & 9999999999 \\
\hline CHEMBL2004311 & 809192 & 4.7 & 4.7262 & TRN \\
\hline CHEMBL1992634 & 809192 & 4.7 & 4.6066 & TRN \\
\hline CHEMBL1242373 & 809192 & 4.7 & 5.1826 & TRN \\
\hline CHEMBL1998545 & 809192 & 5.8 & 6.0144 & TRN \\
\hline CHEMBL1986869 & 809192 & 4.7 & 4.974 & TRN \\
\hline CHEMBL316264 & 809192 & 4.7 & 4.5719 & TRN \\
\hline CHEMBL1988075 & 809192 & 4.7 & 5.1968 & TRN \\
\hline CHEMBL1991678 & 809192 & 4.7 & 4.6353 & TRN \\
\hline CHEMBL1682558 & 809192 & 4.7 & 4.7238 & TRN \\
\hline CHEMBL2001239 & 809192 & 6.0 & 5.7932 & TRN \\
\hline CHEMBL1990496 & 809192 & 4.7 & 5.2712 & TRN \\
\hline CHEMBL1988594 & 809192 & 4.7 & 4.4907 & TRN \\
\hline CHEMBL 2001288 & 809192 & 4.7 & 4.297 & TRN \\
\hline CHEMBL1999811 & 809192 & 4.7 & 4.8625 & TST \\
\hline CHEMBL1985074 & 809192 & 4.7 & 4.2961 & TST \\
\hline CHEMBL1982874 & 809192 & 4.7 & 4.6518 & TRN \\
\hline CHEMBL1992242 & 809192 & 4.7 & 5.0711 & TRN \\
\hline CHEMBL1991725 & 809192 & 4.7 & 5.5876 & TRN \\
\hline CHEMBL208637 & 809192 & 4.7 & 4.5134 & TRN \\
\hline CHEMBL1967094 & 809192 & 4.7 & 4.8543 & TRN \\
\hline CHEMBL 2003341 & 809192 & 6.8 & 6.3872 & TRN \\
\hline CHEMBL1970203 & 809192 & 4.7 & 4.4836 & TRN \\
\hline CHEMBL1986530 & 809192 & 4.7 & 3.9972 & TRN \\
\hline CHEMBL1968590 & 809192 & 4.7 & 4.8778 & TRN \\
\hline CHEMBL1984191 & 809192 & 4.7 & 5.1121 & TRN \\
\hline CHEMBL1982992 & 809192 & 4.7 & 4.7256 & TRN \\
\hline CHEMBL1999590 & 809192 & 4.7 & 5.0509 & TST \\
\hline CHEMBL1971029 & 809192 & 4.7 & 4.6949 & TRN \\
\hline CHEMBL1967116 & 809192 & 6.6 & 5.8213 & TRN \\
\hline CHEMBL 2000832 & 809192 & 6.6 & 6.0204 & TRN \\
\hline CHEMBL1980489 & 809192 & 4.7 & 5.6816 & TRN \\
\hline CHEMBL 394790 & 809192 & 6.0 & 5.5939 & TRN \\
\hline CHEMBL1970709 & 809192 & 7.3 & 6.1619 & TRN \\
\hline CHEMBL226471 & 809192 & 4.7 & 4.2433 & TST \\
\hline CHEMBL1974702 & 809192 & 4.7 & 4.6922 & TST \\
\hline CHEMBL1998112 & 809192 & 4.7 & 4.3768 & TRN \\
\hline CHEMBL1969126 & 809192 & 4.7 & 4.9366 & TRN \\
\hline CHEMBL1965589 & 809192 & 4.7 & 4.7617 & TRN \\
\hline CHEMBL1980896 & 809192 & 4.7 & 5.2788 & TRN \\
\hline
\end{tabular}




\begin{tabular}{|c|c|c|c|c|c|}
\hline \multicolumn{6}{|c|}{ Supplemental Table S2.txt } \\
\hline CHEMBL1970104 & 809192 & 4.7 & 4.5256 & TRN & \\
\hline CHEMBL1991429 & 809192 & 5.8 & 4.9063 & TRN & \\
\hline CHEMBL474432 & 809192 & 4.7 & 4.265 & TST & \\
\hline CHEMBL1971149 & 809192 & 4.7 & 4.7752 & TRN & \\
\hline CHEMBL1994040 & 809192 & 4.7 & 4.5253 & TRN & \\
\hline CHEMBL1988153 & 809192 & 4.7 & 4.9572 & TRN & \\
\hline CHEMBL579246 & 809192 & 7.5 & 7.0607 & TRN & \\
\hline CHEMBL1972584 & 809192 & 6.3 & 4.8735 & TRN & \\
\hline CHEMBL398951 & 809192 & 4.7 & 5.4171 & TRN & \\
\hline CHEMBL1982506 & 809192 & 4.7 & 4.5607 & TST & \\
\hline CHEMBL 2004716 & 809192 & 6.3 & 6.4525 & TRN & \\
\hline CHEMBL1968127 & 809192 & 4.7 & 4.8136 & TRN & \\
\hline CHEMBL1975233 & 809192 & 5.8 & 5.1791 & TRN & \\
\hline CHEMBL1988437 & 809192 & 4.7 & 4.9229 & TST & \\
\hline CHEMBL1985406 & 809192 & 4.7 & 5.0286 & TRN & \\
\hline CHEMBL207400 & 809192 & 4.7 & 4.3987 & TST & \\
\hline CHEMBL 2000894 & 809192 & 6.4 & 6.5209 & TST & \\
\hline CHEMBL1979577 & 809192 & 7.4 & 6.79899 & 99999999995 & TRN \\
\hline CHEMBL1998121 & 809192 & 6.9 & 6.612 & TRN & \\
\hline CHEMBL1982135 & 809192 & 4.7 & 4.5935 & TRN & \\
\hline CHEMBL1991800 & 809192 & 4.7 & 4.6558 & TRN & \\
\hline CHEMBL1976090 & 809192 & 4.7 & 4.8583 & TRN & \\
\hline CHEMBL52387 & 809192 & 4.7 & 4.1743 & TST & \\
\hline CHEMBL1993243 & 809192 & 4.7 & 5.056 & TRN & \\
\hline CHEMBL1992922 & 809192 & 5.8 & 5.4097 & TRN & \\
\hline CHEMBL379835 & 809192 & 4.7 & 4.5214 & TST & \\
\hline CHEMBL1969537 & 809192 & 6.3 & 5.2593 & TST & \\
\hline CHEMBL1976093 & 809192 & 4.7 & 4.4872 & TRN & \\
\hline CHEMBL1979357 & 809192 & 4.7 & 5.318 & TRN & \\
\hline CHEMBL1996817 & 809192 & 4.7 & 5.5377 & TRN & \\
\hline CHEMBL1975256 & 809192 & 4.7 & 5.3001 & TST & \\
\hline CHEMBL508928 & 809192 & 4.7 & 5.4137 & TRN & \\
\hline CHEMBL3197315 & 809192 & 5.9 & 5.3204 & TST & \\
\hline CHEMBL1991356 & 809192 & 4.7 & 4.5589 & TST & \\
\hline CHEMBL 2004892 & 809192 & 4.7 & 5.2235 & TRN & \\
\hline CHEMBL468280 & 809192 & 4.7 & 4.702 & TST & \\
\hline CHEMBL116070 & 809192 & 4.7 & 4.7264 & TRN & \\
\hline CHEMBL1990884 & 809192 & 4.7 & 5.2306 & TRN & \\
\hline CHEMBL3109278 & 809192 & 6.4 & 5.5056 & TRN & \\
\hline CHEMBL 256835 & 809192 & 4.7 & 4.5803 & TRN & \\
\hline CHEMBL1970314 & 809192 & 4.7 & 4.5329 & TRN & \\
\hline CHEMBL 2004871 & 809192 & 4.7 & 4.512 & TRN & \\
\hline CHEMBL1969879 & 809192 & 4.7 & 4.5448 & TRN & \\
\hline CHEMBL1980142 & 809192 & 4.7 & 5.0719 & TRN & \\
\hline CHEMBL 2006276 & 809192 & 4.7 & 4.4029 & TRN & \\
\hline CHEMBL1981720 & 809192 & 4.7 & 4.3042 & TRN & \\
\hline CHEMBL419932 & 809192 & 7.1 & 6.2796 & TRN & \\
\hline CHEMBL271381 & 809192 & 6.5 & 5.8223 & TRN & \\
\hline
\end{tabular}




\begin{tabular}{|c|c|c|c|c|c|}
\hline \multicolumn{6}{|c|}{ Supplemental Table S2.txt } \\
\hline CHEMBL262433 & 809192 & 6.4 & 5.3961 & TRN & \\
\hline CHEMBL1982466 & 809192 & 4.7 & 5.1924 & TRN & \\
\hline CHEMBL306380 & 809192 & 4.7 & 5.5488 & TRN & \\
\hline CHEMBL1995740 & 809192 & 6.0 & 5.8028 & TRN & \\
\hline CHEMBL1975500 & 809192 & 4.7 & 5.5304 & TRN & \\
\hline CHEMBL394619 & 809192 & 6.6 & 5.9283 & TRN & \\
\hline CHEMBL1996831 & 809192 & 4.7 & 4.9766 & TST & \\
\hline CHEMBL411903 & 809192 & 5.9 & 5.1521 & TRN & \\
\hline CHEMBL234085 & 809192 & 4.7 & 4.8104 & TRN & \\
\hline CHEMBL1965988 & 809192 & 7.3 & 6.9472 & TRN & \\
\hline CHEMBL1995832 & 809192 & 4.7 & 4.7705 & TRN & \\
\hline CHEMBL418203 & 809192 & 4.7 & 5.5452 & TST & \\
\hline CHEMBL1969042 & 809192 & 4.7 & 5.9156 & TST & \\
\hline CHEMBL1989646 & 809192 & 6.8 & 6.6212 & TRN & \\
\hline CHEMBL 2000345 & 809192 & 4.7 & 4.5525 & TST & \\
\hline CHEMBL225519 & 809192 & 6.0 & 5.4421 & TST & \\
\hline CHEMBL1999931 & 809192 & 4.7 & 5.7772 & TRN & \\
\hline CHEMBL1978200 & 809192 & 4.7 & 4.7107 & TRN & \\
\hline CHEMBL1970522 & 809192 & 4.7 & 4.2805 & TRN & \\
\hline CHEMBL1375418 & 809192 & 4.7 & 4.897 & TRN & \\
\hline CHEMBL 2007064 & 809192 & 4.7 & 4.78 & TRN & \\
\hline CHEMBL1964692 & 809192 & 4.7 & 5.3984 & TRN & \\
\hline CHEMBL1964413 & 809192 & 4.7 & 4.9992 & TRN & \\
\hline CHEMBL1981047 & 809192 & 4.7 & 4.3659 & TST & \\
\hline CHEMBL 229968 & 809192 & 8.9 & 8.4164 & TRN & \\
\hline CHEMBL1973483 & 809192 & 4.7 & 4.5584 & TRN & \\
\hline CHEMBL1976240 & 809192 & 7.6 & 7.0185 & TRN & \\
\hline CHEMBL1522508 & 809192 & 4.7 & 4.4254 & TRN & \\
\hline CHEMBL1968151 & 809192 & 4.7 & 4.55699 & 99999999995 & TST \\
\hline CHEMBL1979093 & 809192 & 6.6 & 5.8084 & TRN & \\
\hline CHEMBL1989474 & 809192 & 4.7 & 4.4023 & TRN & \\
\hline CHEMBL1090360 & 809192 & 4.7 & 4.46899 & 9999999999 & TRN \\
\hline CHEMBL1987009 & 809192 & 4.7 & 4.8099 & TRN & \\
\hline CHEMBL379218 & 809192 & 7.0 & 7.7585 & TRN & \\
\hline CHEMBL 2003817 & 809192 & 4.7 & 4.3734 & TRN & \\
\hline CHEMBL1994830 & 809192 & 4.7 & 4.9779 & TRN & \\
\hline CHEMBL210887 & 809192 & 5.8 & 4.3114 & TST & \\
\hline CHEMBL226403 & 809192 & 4.7 & 4.2029 & TST & \\
\hline CHEMBL227271 & 809192 & 7.3 & 8.247 & TRN & \\
\hline CHEMBL1971021 & 809192 & 4.7 & 4.9483 & TRN & \\
\hline CHEMBL583144 & 809192 & 6.1 & 5.0437 & TST & \\
\hline CHEMBL1974310 & 809192 & 4.7 & 4.7803 & TRN & \\
\hline CHEMBL1982660 & 809192 & 4.7 & 3.9061 & TRN & \\
\hline CHEMBL1994693 & 809192 & 4.7 & 4.7982 & TRN & \\
\hline CHEMBL 2005631 & 809192 & 6.7 & 5.6577 & TRN & \\
\hline CHEMBL1994938 & 809192 & 4.7 & 5.0328 & TRN & \\
\hline CHEMBL1825138 & 809192 & 4.7 & 4.8631 & TST & \\
\hline CHEMBL1982957 & 809192 & 5.9 & 5.896 & TRN & \\
\hline
\end{tabular}




\begin{tabular}{|c|c|c|c|c|c|}
\hline & & \multicolumn{4}{|c|}{ Supplemental Table S2.txt } \\
\hline CHEMBL1977223 & 809192 & 4.7 & \multicolumn{2}{|c|}{5.1160000000000005} & TRN \\
\hline CHEMBL1236126 & 809192 & 4.7 & 4.2247 & TST & \\
\hline CHEMBL1975138 & 809192 & 5.8 & 4.6838 & TST & \\
\hline CHEMBL424872 & 809192 & 4.7 & 4.7288 & TRN & \\
\hline CHEMBL412142 & 809192 & 4.7 & 5.2943 & TST & \\
\hline CHEMBL1980704 & 809192 & 4.7 & 4.7221 & TST & \\
\hline CHEMBL1966808 & 809192 & 4.7 & 4.4068 & TST & \\
\hline CHEMBL 2004447 & 809192 & 4.7 & 4.8226 & TST & \\
\hline CHEMBL1973860 & 809192 & 5.9 & 4.8501 & TRN & \\
\hline CHEMBL1972489 & 809192 & 4.7 & 4.6618 & TRN & \\
\hline CHEMBL260135 & 809192 & 5.9 & \multicolumn{2}{|c|}{5.0360000000000005} & TRN \\
\hline CHEMBL1994074 & 809192 & 4.7 & 4.4636 & TRN & \\
\hline CHEMBL220241 & 809192 & 7.2 & 6.6789 & TRN & \\
\hline CHEMBL1992937 & 809192 & 4.7 & 4.4275 & TST & \\
\hline CHEMBL1982610 & 809192 & 4.7 & 4.3346 & TST & \\
\hline CHEMBL1999496 & 809192 & 4.7 & 5.1384 & TRN & \\
\hline CHEMBL1988300 & 809192 & 4.7 & 4.9482 & TRN & \\
\hline CHEMBL1972119 & 809192 & 4.7 & 4.6469 & TRN & \\
\hline CHEMBL1986328 & 809192 & 4.7 & 5.0578 & TST & \\
\hline CHEMBL95692 & 809192 & 4.7 & 4.758 & TRN & \\
\hline CHEMBL1090356 & 809192 & 4.7 & 4.5698 & TRN & \\
\hline CHEMBL1983534 & 809192 & 4.7 & 4.9665 & TRN & \\
\hline CHEMBL1982361 & 809192 & 5.8 & 5.5301 & TRN & \\
\hline CHEMBL1999112 & 809192 & 4.7 & 4.8268 & TST & \\
\hline CHEMBL 2000801 & 809192 & 4.7 & 4.9683 & TRN & \\
\hline CHEMBL1982122 & 809192 & 4.7 & 5.3495 & TRN & \\
\hline CHEMBL1682546 & 809192 & 4.7 & 5.2696 & TRN & \\
\hline CHEMBL1991395 & 809192 & 4.7 & 4.5539 & TRN & \\
\hline CHEMBL1971245 & 809192 & 4.7 & 4.6613 & TRN & \\
\hline CHEMBL1972142 & 809192 & 4.7 & 4.2177 & TRN & \\
\hline CHEMBL1969502 & 809192 & 4.7 & 5.6868 & TRN & \\
\hline CHEMBL1682553 & 809192 & 6.0 & 5.4837 & TRN & \\
\hline CHEMBL1966514 & 809192 & 5.9 & \multicolumn{2}{|c|}{5.297000000000001} & TRN \\
\hline CHEMBL1971430 & 809192 & 4.7 & 4.9517 & TRN & \\
\hline CHEMBL 2003638 & 809192 & 6.5 & 5.8473 & TRN & \\
\hline CHEMBL1983963 & 809192 & 5.9 & 5.6304 & TRN & \\
\hline CHEMBL1997764 & 809192 & 4.7 & 4.958 & TRN & \\
\hline CHEMBL1996066 & 809192 & 4.7 & 4.0843 & TST & \\
\hline CHEMBL1981410 & 809192 & 4.7 & 4.6515 & TRN & \\
\hline CHEMBL1970806 & 809192 & 4.7 & 4.4069 & TST & \\
\hline CHEMBL1993722 & 809192 & 7.4 & 6.1859 & TRN & \\
\hline CHEMBL1996234 & 809192 & 4.7 & 4.7372 & TRN & \\
\hline CHEMBL1991434 & 809192 & 4.7 & 4.9194 & TRN & \\
\hline CHEMBL1967544 & 809192 & 6.5 & 6.2438 & TRN & \\
\hline CHEMBL1375640 & 809192 & 4.7 & 4.921 & TST & \\
\hline CHEMBL1979970 & 809192 & 4.7 & 4.7446 & TRN & \\
\hline CHEMBL223367 & 809192 & 4.7 & 5.8145 & TST & \\
\hline CHEMBL249282 & 809192 & 4.7 & 5.3294 & TRN & \\
\hline
\end{tabular}




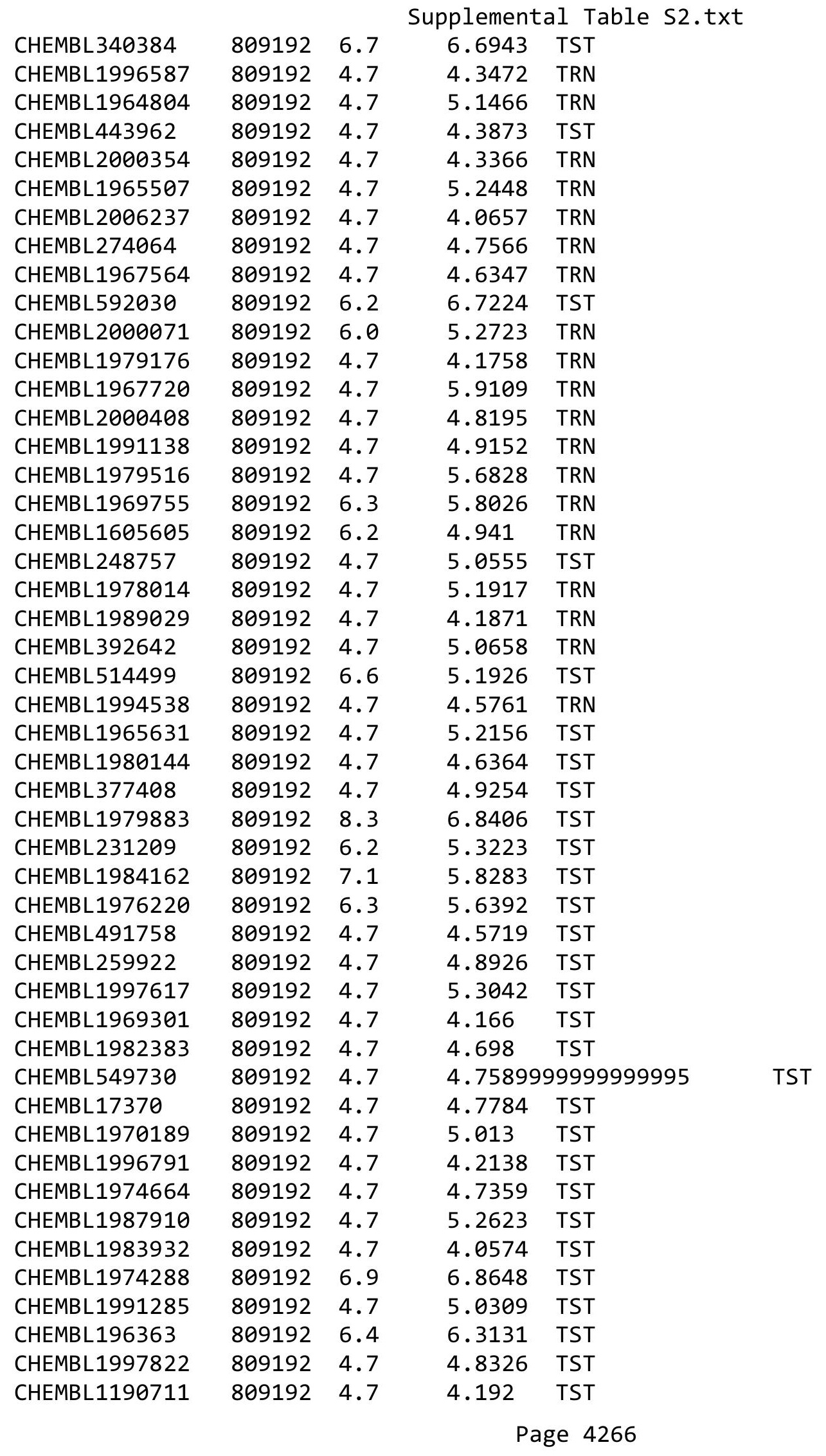




\begin{tabular}{|c|c|c|c|c|}
\hline \multicolumn{5}{|c|}{ Supplemental Tab. } \\
\hline CHEMBL1974416 & 809192 & 4.7 & 5.1855 & TST \\
\hline CHEMBL1993661 & 809192 & 6.5 & 5.7968 & TST \\
\hline CHEMBL2004615 & 809192 & 5.8 & 4.5601 & TST \\
\hline CHEMBL1997872 & 809192 & 4.7 & 4.0564 & TST \\
\hline CHEMBL1966343 & 809192 & 4.7 & 6.1119 & TST \\
\hline CHEMBL404367 & 809192 & 5.8 & 5.5874 & TST \\
\hline CHEMBL3342269 & 1436204 & 7.4202 & 7.358 & TRN \\
\hline CHEMBL3342302 & 1436204 & 4.0 & 3.9856 & TRN \\
\hline CHEMBL3342308 & 1436204 & 4.301 & 4.4007 & TRN \\
\hline CHEMBL3342270 & 1436204 & 5.4089 & 5.4531 & TRN \\
\hline CHEMBL 3342323 & 1436204 & 5.7011 & 5.6246 & TST \\
\hline CHEMBL 3342273 & 1436204 & 4.0 & 4.106 & TRN \\
\hline CHEMBL3342304 & 1436204 & 6.5575 & 6.6202 & TRN \\
\hline CHEMBL3342293 & 1436204 & 4.0 & 3.9651 & TRN \\
\hline CHEMBL3342295 & 1436204 & 4.301 & 4.2507 & TRN \\
\hline CHEMBL 3342274 & 1436204 & 4.0 & 4.0964 & TRN \\
\hline CHEMBL3342288 & 1436204 & 4.301 & 4.3194 & TRN \\
\hline CHEMBL3342315 & 1436204 & 4.0 & 3.9697 & TRN \\
\hline CHEMBL3342318 & 1436204 & 6.9788 & 7.2149 & TRN \\
\hline CHEMBL3342292 & 1436204 & 4.301 & 4.3581 & TRN \\
\hline CHEMBL 3342282 & 1436204 & 6.2676 & 6.1148 & TST \\
\hline CHEMBL3342305 & 1436204 & 4.0 & 4.0059 & TRN \\
\hline CHEMBL3342289 & 1436204 & 4.0 & 3.5668 & TRN \\
\hline CHEMBL239767 & 1436204 & 7.5229 & 5.6842 & TST \\
\hline CHEMBL3342287 & 1436204 & 4.0 & 3.9218 & TRN \\
\hline CHEMBL3342299 & 1436204 & 4.301 & 4.2136 & TRN \\
\hline CHEMBL 3342278 & 1436204 & 4.0 & 4.2458 & TST \\
\hline CHEMBL3342297 & 1436204 & 4.301 & 4.0816 & TRN \\
\hline CHEMBL 3342272 & 1436204 & 4.301 & 4.2636 & TRN \\
\hline CHEMBL 3342300 & 1436204 & 4.0 & 3.9386 & TRN \\
\hline CHEMBL3342317 & 1436204 & 6.284 & 6.2795 & TRN \\
\hline CHEMBL3342320 & 1436204 & 7.1079 & 6.7671 & TST \\
\hline CHEMBL3342294 & 1436204 & 4.0 & 4.2435 & TRN \\
\hline CHEMBL 3342280 & 1436204 & 4.0 & 4.2291 & TRN \\
\hline CHEMBL 3342277 & 1436204 & 4.301 & 4.4559 & TRN \\
\hline CHEMBL3342281 & 1436204 & 4.301 & 4.3356 & TRN \\
\hline CHEMBL3342311 & 1436204 & 5.8297 & 5.6673 & TRN \\
\hline CHEMBL 3342307 & 1436204 & 4.0 & 4.3705 & TRN \\
\hline CHEMBL3342309 & 1436204 & 5.6737 & 5.4971 & TRN \\
\hline CHEMBL3342283 & 1436204 & 4.301 & 4.0745 & TST \\
\hline CHEMBL3342310 & 1436204 & 6.1198 & 6.1566 & TRN \\
\hline CHEMBL3342276 & 1436204 & 4.0 & 3.8763 & TRN \\
\hline CHEMBL3342275 & 1436204 & 4.301 & 5.1522 & TST \\
\hline CHEMBL 3342322 & 1436204 & 4.301 & 4.7107 & TST \\
\hline CHEMBL3342296 & 1436204 & 4.0 & 3.9975 & TRN \\
\hline CHEMBL 3354644 & 1436204 & 4.301 & 4.8403 & TST \\
\hline CHEMBL3342285 & 1436204 & 4.301 & 4.3339 & TRN \\
\hline CHEMBL39835 & 1436204 & 4.301 & 4.3415 & TRN \\
\hline
\end{tabular}


Supplemental Table S2.txt

\begin{tabular}{|c|c|c|c|c|}
\hline CHEMBL3342312 & 1436204 & 6.7696 & 6.6169 & TRN \\
\hline CHEMBL3342319 & 1436204 & 6.5317 & 6.523 & TRN \\
\hline CHEMBL3342301 & 1436204 & 4.0 & 4.1266 & TRN \\
\hline CHEMBL3342316 & 1436204 & 4.0 & 4.0683 & TRN \\
\hline CHEMBL3342314 & 1436204 & 6.556 & 6.4607 & TRN \\
\hline CHEMBL3342290 & 1436204 & 4.301 & 4.6061 & TRN \\
\hline CHEMBL3342286 & 1436204 & 4.301 & 4.2161 & TRN \\
\hline CHEMBL3342321 & 1436204 & 6.0506 & 6.3026 & TST \\
\hline CHEMBL3342306 & 1436204 & 4.0 & 3.7772 & TRN \\
\hline CHEMBL3342291 & 1436204 & 6.4089 & 6.1834 & TRN \\
\hline CHEMBL3342284 & 1436204 & 4.301 & 4.6922 & TST \\
\hline CHEMBL3342298 & 1436204 & 4.0 & 3.8165 & TST \\
\hline CHEMBL3342303 & 1436204 & 5.7932 & 5.4101 & TST \\
\hline CHEMBL3342279 & 1436204 & 4.301 & 4.3339 & TST \\
\hline CHEMBL3342313 & 1436204 & 6.5607 & 7.0095 & TST \\
\hline CHEMBL187582 & 302753 & 8.9208 & 8.7966 & TRN \\
\hline CHEMBL184748 & 302753 & 6.0 & 6.2613 & TST \\
\hline CHEMBL365863 & 302753 & 7.1487 & 7.7873 & TRN \\
\hline CHEMBL185778 & 302753 & 8.0269 & 7.3177 & TST \\
\hline CHEMBL186530 & 302753 & 8.9208 & 8.5754 & TRN \\
\hline CHEMBL366285 & 302753 & 6.0 & 6.4293 & TRN \\
\hline CHEMBL187114 & 302753 & 7.2076 & 7.1241 & TRN \\
\hline CHEMBL426801 & 302753 & 7.9208 & 7.8796 & TRN \\
\hline CHEMBL361720 & 302753 & 9.2291 & 8.9905 & TRN \\
\hline CHEMBL185229 & 302753 & 8.7696 & 8.4732 & TRN \\
\hline CHEMBL434903 & 302753 & 8.7212 & 8.9262 & TRN \\
\hline CHEMBL185687 & 302753 & 8.4437 & 7.1698 & TST \\
\hline CHEMBL185728 & 302753 & 6.3188 & 6.5549 & TRN \\
\hline CHEMBL186041 & 302753 & 8.5086 & 8.2339 & TRN \\
\hline CHEMBL186742 & 302753 & 8.8861 & 8.748 & TRN \\
\hline CHEMBL186183 & 302753 & 8.8239 & 8.8278 & TRN \\
\hline CHEMBL185668 & 302753 & 8.1739 & 8.1783 & TRN \\
\hline CHEMBL187179 & 302753 & 8.9586 & 8.6171 & TRN \\
\hline CHEMBL365886 & 302753 & 8.585 & 8.1336 & TRN \\
\hline CHEMBL187306 & 302753 & 7.0809 & 6.8317 & TRN \\
\hline CHEMBL185980 & 302753 & 6.0 & 6.7942 & TRN \\
\hline CHEMBL364649 & 302753 & 7.3468 & 7.7286 & TRN \\
\hline CHEMBL425713 & 302753 & 8.0044 & 8.0909 & TRN \\
\hline CHEMBL363287 & 302753 & 9.0915 & 8.6934 & TRN \\
\hline CHEMBL184453 & 302753 & 8.5229 & 8.4927 & TRN \\
\hline CHEMBL363550 & 302753 & 7.1427 & 8.1341 & TRN \\
\hline CHEMBL363265 & 302753 & 8.3872 & 8.8117 & TRN \\
\hline CHEMBL187376 & 302753 & 8.4318 & 8.7699 & TRN \\
\hline CHEMBL434542 & 302753 & 6.0 & 6.5482 & TST \\
\hline CHEMBL184130 & 302753 & 8.8861 & 7.6457 & TRN \\
\hline CHEMBL186549 & 302753 & 7.9208 & 8.276 & TRN \\
\hline CHEMBL184744 & 302753 & 8.4815 & \multicolumn{2}{|c|}{8.761000000000001} \\
\hline CHEMBL414659 & 302753 & 7.2924 & 8.0511 & TRN \\
\hline
\end{tabular}




\begin{tabular}{|c|c|c|c|c|c|}
\hline \multicolumn{6}{|c|}{ Supplemental Table S2.txt } \\
\hline CHEMBL187806 & 302753 & 8.1612 & 8.2968 & TRN & \\
\hline CHEMBL187260 & 302753 & 7.7212 & 8.215 & TRN & \\
\hline CHEMBL363677 & 302753 & 8.3979 & 7.6498 & TST & \\
\hline CHEMBL427331 & 302753 & 9.0969 & 8.8754 & TRN & \\
\hline CHEMBL186281 & 302753 & 7.301 & 7.91799 & 9999999999 & TRN \\
\hline CHEMBL424987 & 302753 & 5.8239 & 7.3612 & TRN & \\
\hline CHEMBL361483 & 302753 & 6.0 & 5.6394 & TRN & \\
\hline CHEMBL361456 & 302753 & 8.6576 & 8.111 & TRN & \\
\hline CHEMBL185780 & 302753 & 8.6021 & 7.1641 & TRN & \\
\hline CHEMBL363015 & 302753 & 8.7696 & 8.7786 & TRN & \\
\hline CHEMBL362331 & 302753 & 9.585 & 7.6847 & TRN & \\
\hline CHEMBL185782 & 302753 & 8.2218 & 7.5574 & TST & \\
\hline CHEMBL184944 & 302753 & 5.041 & 7.4216 & TST & \\
\hline CHEMBL 264290 & 302753 & 8.8539 & 8.3581 & TST & \\
\hline CHEMBL186741 & 302753 & 6.9586 & 7.187 & TST & \\
\hline CHEMBL364395 & 302753 & 8.7447 & 8.3555 & TST & \\
\hline CHEMBL365068 & 302753 & 8.8861 & 7.9087 & TST & \\
\hline CHEMBL187590 & 302753 & 7.5528 & 8.0447 & TST & \\
\hline CHEMBL184820 & 302753 & 8.2007 & 7.6747 & TST & \\
\hline CHEMBL412142 & 954468 & 3.8704 & 4.3433 & TRN & \\
\hline CHEMBL379975 & 954468 & 5.1934 & 4.9992 & TRN & \\
\hline CHEMBL 379300 & 954468 & 7.028 & 7.3982 & TRN & \\
\hline CHEMBL 255342 & 954468 & 3.3258 & 3.5523 & TRN & \\
\hline CHEMBL 2005886 & 954468 & 7.1284 & 6.9931 & TRN & \\
\hline CHEMBL1230020 & 954468 & 4.9647 & 4.461 & TRN & \\
\hline CHEMBL 259181 & 954468 & 4.7091 & 5.3077 & TRN & \\
\hline CHEMBL1242367 & 954468 & 5.4872 & 5.3518 & TRN & \\
\hline CHEMBL1357247 & 954468 & 3.2983 & 3.565 & TRN & \\
\hline CHEMBL1190711 & 954468 & 6.3176 & 5.7791 & TRN & \\
\hline CHEMBL221137 & 954468 & 5.3305 & 5.0054 & TST & \\
\hline CHEMBL1256459 & 954468 & 8.6171 & 8.0482 & TRN & \\
\hline CHEMBL392695 & 954468 & 6.013 & 5.5893 & TRN & \\
\hline CHEMBL180127 & 954468 & 4.7932 & 4.952 & TRN & \\
\hline CHEMBL512504 & 954468 & 4.7357 & 4.5272 & TRN & \\
\hline CHEMBL3392440 & 954468 & 5.3567 & 4.7677 & TRN & \\
\hline CHEMBL1673039 & 954468 & 5.4478 & 5.8484 & TRN & \\
\hline CHEMBL9470 & 954468 & 3.5494 & 6.0242 & TST & \\
\hline CHEMBL188678 & 954468 & 5.4373 & 4.5879 & TRN & \\
\hline CHEMBL483847 & 954468 & 6.2436 & 5.1151 & TRN & \\
\hline CHEMBL1970879 & 954468 & 6.7073 & 6.5392 & TRN & \\
\hline CHEMBL 240954 & 954468 & 3.3335 & 4.1411 & TST & \\
\hline CHEMBL558642 & 954468 & 4.7219 & 5.227 & TRN & \\
\hline CHEMBL135561 & 954468 & 4.6789 & 5.0824 & TRN & \\
\hline CHEMBL 2134202 & 954468 & 4.1695 & 4.6345 & TRN & \\
\hline CHEMBL192566 & 954468 & 10.0837 & 8.2562 & TST & \\
\hline CHEMBL585951 & 954468 & 6.5133 & 6.4042 & TRN & \\
\hline CHEMBL 209148 & 954468 & 5.8872 & 5.61 & TRN & \\
\hline CHEMBL483849 & 954468 & 3.2808 & 2.9667 & TST & \\
\hline
\end{tabular}




\begin{tabular}{|c|c|c|c|c|c|c|}
\hline & & \multicolumn{5}{|c|}{ Supplemental Table S2.txt } \\
\hline CHEMBL189584 & 954468 & 5.2419 & 5.0403 & TRN & & \\
\hline CHEMBL393929 & 954468 & 3.9542 & 4.1271 & TRN & & \\
\hline CHEMBL472940 & 954468 & 4.9313 & 3.9908 & TRN & & \\
\hline CHEMBL1788116 & 954468 & 5.2254 & 5.0588 & TRN & & \\
\hline CHEMBL509032 & 954468 & 6.9874 & 7.2827 & TRN & & \\
\hline CHEMBL3186408 & 954468 & 3.5044 & 4.3265 & TST & & \\
\hline CHEMBL92309 & 954468 & 3.1123 & 3.5332 & TST & & \\
\hline CHEMBL202721 & 954468 & 4.8692 & 5.2695 & TRN & & \\
\hline CHEMBL3349342 & 954468 & 5.0089 & 5.6329 & TRN & & \\
\hline CHEMBL258844 & 954468 & 5.8634 & 5.2094 & TRN & & \\
\hline CHEMBL1186585 & 954468 & 4.523 & 4.6066 & TRN & & \\
\hline CHEMBL 2137530 & 954468 & 5.2257 & 4.9957 & TRN & & \\
\hline CHEMBL373751 & 954468 & 3.6412 & 4.4028 & TRN & & \\
\hline CHEMBL102714 & 954468 & \multicolumn{3}{|c|}{3.4730000000000003} & 3.6114 & TRN \\
\hline CHEMBL 2363137 & 954468 & 5.6865 & 5.12 & TRN & & \\
\hline CHEMBL399530 & 954468 & 4.9641 & 4.8005 & TRN & & \\
\hline CHEMBL3199475 & 954468 & 5.2246 & 4.9594 & TRN & & \\
\hline CHEMBL220241 & 954468 & 5.2349 & 5.4543 & TRN & & \\
\hline CHEMBL1404918 & 954468 & 2.9492 & 3.3767 & TRN & & \\
\hline CHEMBL577784 & 954468 & 5.2579 & 5.7499 & TRN & & \\
\hline CHEMBL1590308 & 954468 & 4.4648 & 4.1603 & TST & & \\
\hline CHEMBL1643959 & 954468 & 4.7905 & 5.1703 & TRN & & \\
\hline CHEMBL65 & 954468 & 7.0369 & 7.4043 & TRN & & \\
\hline CHEMBL222102 & 954468 & 4.104 & 4.065 & TRN & & \\
\hline CHEMBL213100 & 954468 & 6.0221 & 6.5303 & TRN & & \\
\hline CHEMBL191334 & 954468 & 4.0095 & 4.4597 & TRN & & \\
\hline CHEMBL 217354 & 954468 & 6.6286 & 6.4968 & TRN & & \\
\hline CHEMBL300389 & 954468 & 7.7082 & 7.2008 & TST & & \\
\hline CHEMBL210618 & 954468 & 3.2177 & 3.7333 & TST & & \\
\hline CHEMBL 2144069 & 954468 & 7.0332 & 5.5828 & TST & & \\
\hline CHEMBL1909414 & 954468 & 4.4399 & 4.16 & TST & & \\
\hline CHEMBL573107 & 954468 & 5.1424 & 5.5029 & TST & & \\
\hline CHEMBL1516890 & 954468 & 4.8105 & 4.5666 & TST & & \\
\hline CHEMBL514499 & 954468 & 7.7807 & 7.481 & TST & & \\
\hline CHEMBL449158 & 954468 & 6.5017 & 7.1894 & TST & & \\
\hline CHEMBL515416 & 954468 & 4.1545 & 5.2559 & TST & & \\
\hline CHEMBL3885499 & 1633657 & 3.0 & 2.8638 & TRN & & \\
\hline CHEMBL3885401 & 1633657 & 4.8697 & 4.8881 & TRN & & \\
\hline CHEMBL 3884056 & 1633657 & 6.1593 & 6.1134 & TRN & & \\
\hline CHEMBL3885357 & 1633657 & 5.7144 & 5.6993 & TRN & & \\
\hline CHEMBL3885229 & 1633657 & 5.5086 & 5.624 & TRN & & \\
\hline CHEMBL3883521 & 1633657 & 3.0 & 3.0035 & TRN & & \\
\hline CHEMBL3884172 & 1633657 & 3.0 & 3.2197 & TRN & & \\
\hline CHEMBL 3884862 & 1633657 & 4.2396 & 4.9277 & TST & & \\
\hline CHEMBL3884809 & 1633657 & 6.4802 & 6.5136 & TRN & & \\
\hline CHEMBL 3883471 & 1633657 & 5.9586 & 5.8982 & TRN & & \\
\hline CHEMBL3883998 & 1633657 & 5.5901 & 5.6338 & TRN & & \\
\hline CHEMBL3884038 & 1633657 & 6.699 & 6.7552 & TRN & & \\
\hline
\end{tabular}




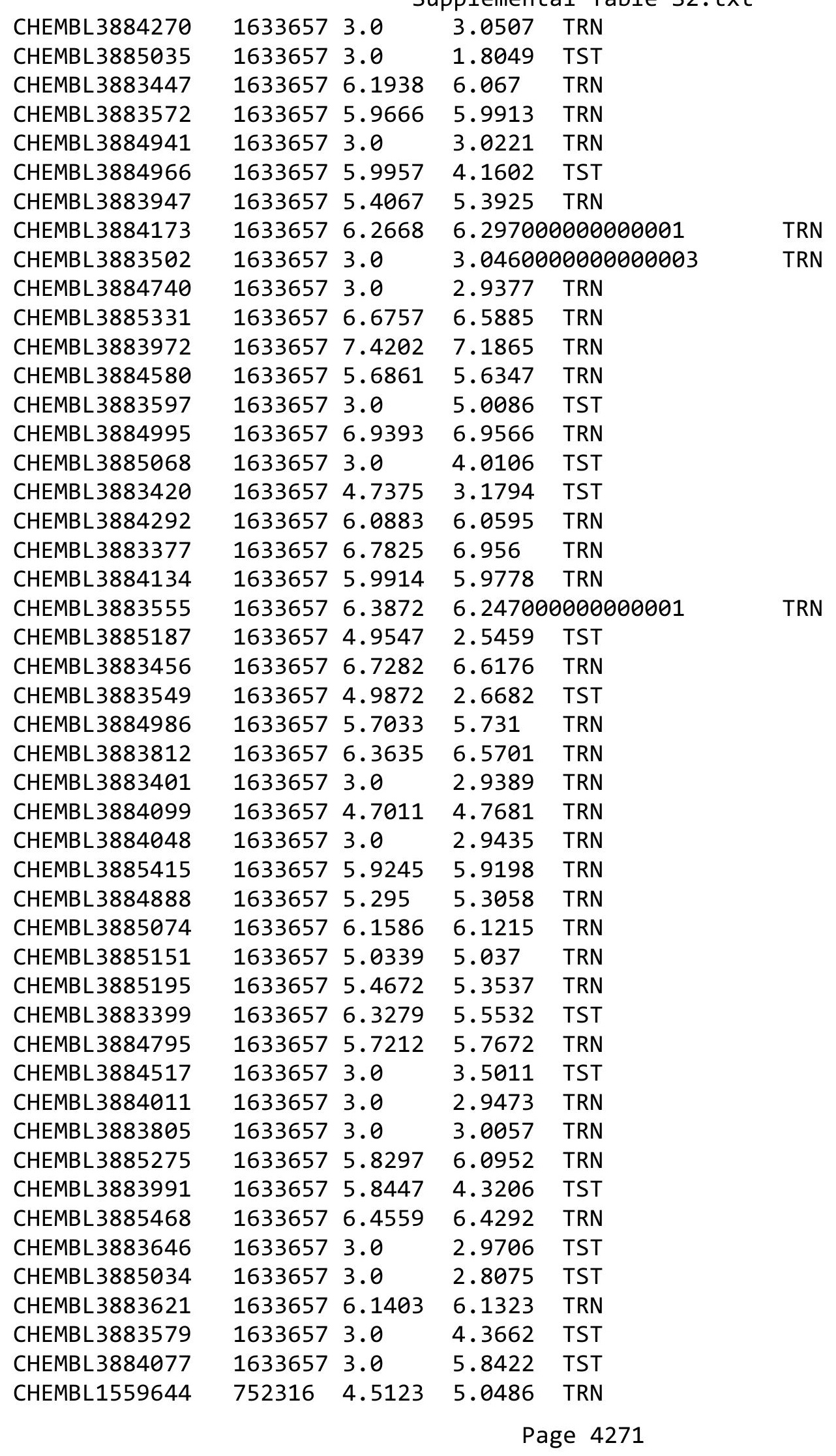


Supplemental Table S2.txt

\begin{tabular}{|c|c|c|c|c|c|}
\hline CHEMBL1299470 & 752316 & 4.9733 & 5.0033 & TRN & \\
\hline CHEMBL1608635 & 752316 & 4.6334 & 4.8763 & TRN & \\
\hline CHEMBL1718825 & 752316 & 6.0009 & 4.7967 & TRN & \\
\hline CHEMBL1609219 & 752316 & 4.7775 & 4.8728 & TST & \\
\hline CHEMBL1524403 & 752316 & 4.5124 & 4.6086 & TRN & \\
\hline CHEMBL1883309 & 752316 & 5.4142 & 5.1124 & TST & \\
\hline CHEMBL1978733 & 752316 & 5.4594 & 5.2019 & TRN & \\
\hline CHEMBL1460869 & 752316 & 5.5799 & 5.3568 & TRN & \\
\hline CHEMBL 2359467 & 752316 & 5.6558 & 4.7474 & TRN & \\
\hline CHEMBL1896407 & 752316 & 5.3762 & 4.2884 & TRN & \\
\hline CHEMBL1731017 & 752316 & 5.8665 & 5.2995 & TRN & \\
\hline CHEMBL1867591 & 752316 & 7.1675 & 6.5002 & TRN & \\
\hline CHEMBL580955 & 752316 & 5.7605 & 5.7285 & TRN & \\
\hline CHEMBL1902169 & 752316 & 5.0447 & 5.0623 & TRN & \\
\hline CHEMBL1864040 & 752316 & 5.3943 & 5.1259 & TRN & \\
\hline CHEMBL116919 & 752316 & 4.191 & 4.624 & TRN & \\
\hline CHEMBL1526148 & 752316 & 4.5815 & 4.7792 & TRN & \\
\hline CHEMBL1698316 & 752316 & 6.5702 & 6.6383 & TRN & \\
\hline CHEMBL1304363 & 752316 & 5.8735 & 4.8472 & TRN & \\
\hline CHEMBL1494159 & 752316 & 4.1158 & 4.4508 & TRN & \\
\hline CHEMBL1501483 & 752316 & 4.4688 & 4.4343 & TRN & \\
\hline CHEMBL 225903 & 752316 & 5.484 & 5.4952 & TRN & \\
\hline CHEMBL3213965 & 752316 & 6.45100 & 00000006 & 05 & 5.5856 \\
\hline CHEMBL3199428 & 752316 & 4.7705 & 5.2211 & TRN & \\
\hline CHEMBL1705854 & 752316 & 5.0985 & 5.0054 & TRN & \\
\hline CHEMBL 314090 & 752316 & 4.9297 & 4.5551 & TST & \\
\hline CHEMBL1417732 & 752316 & 4.6095 & 4.859 & TRN & \\
\hline CHEMBL1557619 & 752316 & 5.6131 & 4.4916 & TST & \\
\hline CHEMBL1607086 & 752316 & 4.598 & 4.2839 & TRN & \\
\hline CHEMBL1529190 & 752316 & 5.1597 & 5.4694 & TRN & \\
\hline CHEMBL1491194 & 752316 & 4.6264 & 4.9829 & TRN & \\
\hline CHEMBL1893344 & 752316 & 5.1347 & 5.2525 & TST & \\
\hline CHEMBL1535532 & 752316 & 5.3925 & 4.9239 & TRN & \\
\hline CHEMBL1384771 & 752316 & 5.5962 & 4.9727 & TRN & \\
\hline CHEMBL1567738 & 752316 & 4.6619 & 4.6816 & TRN & \\
\hline CHEMBL1541177 & 752316 & 4.4399 & 5.1435 & TRN & \\
\hline CHEMBL1487619 & 752316 & 5.2162 & 5.2513 & TRN & \\
\hline CHEMBL1392776 & 752316 & 6.4214 & 4.5344 & TRN & \\
\hline CHEMBL1335944 & 752316 & 5.1117 & 5.2705 & TRN & \\
\hline CHEMBL602218 & 752316 & 4.978 & 5.0892 & TRN & \\
\hline CHEMBL1724732 & 752316 & 4.7916 & 4.5928 & TRN & \\
\hline CHEMBL591363 & 752316 & 5.9165 & 6.0574 & TRN & \\
\hline CHEMBL1441042 & 752316 & 4.2777 & 4.7892 & TRN & \\
\hline CHEMBL1708568 & 752316 & 5.4966 & 5.3117 & TRN & \\
\hline CHEMBL1530911 & 752316 & 5.6525 & 4.9757 & TRN & \\
\hline CHEMBL1603731 & 752316 & 4.5823 & 4.8399 & TRN & \\
\hline CHEMBL 600778 & 752316 & 5.8066 & 5.9599 & TRN & \\
\hline CHEMBL1998863 & 752316 & 5.4286 & 5.3781 & TRN & \\
\hline
\end{tabular}




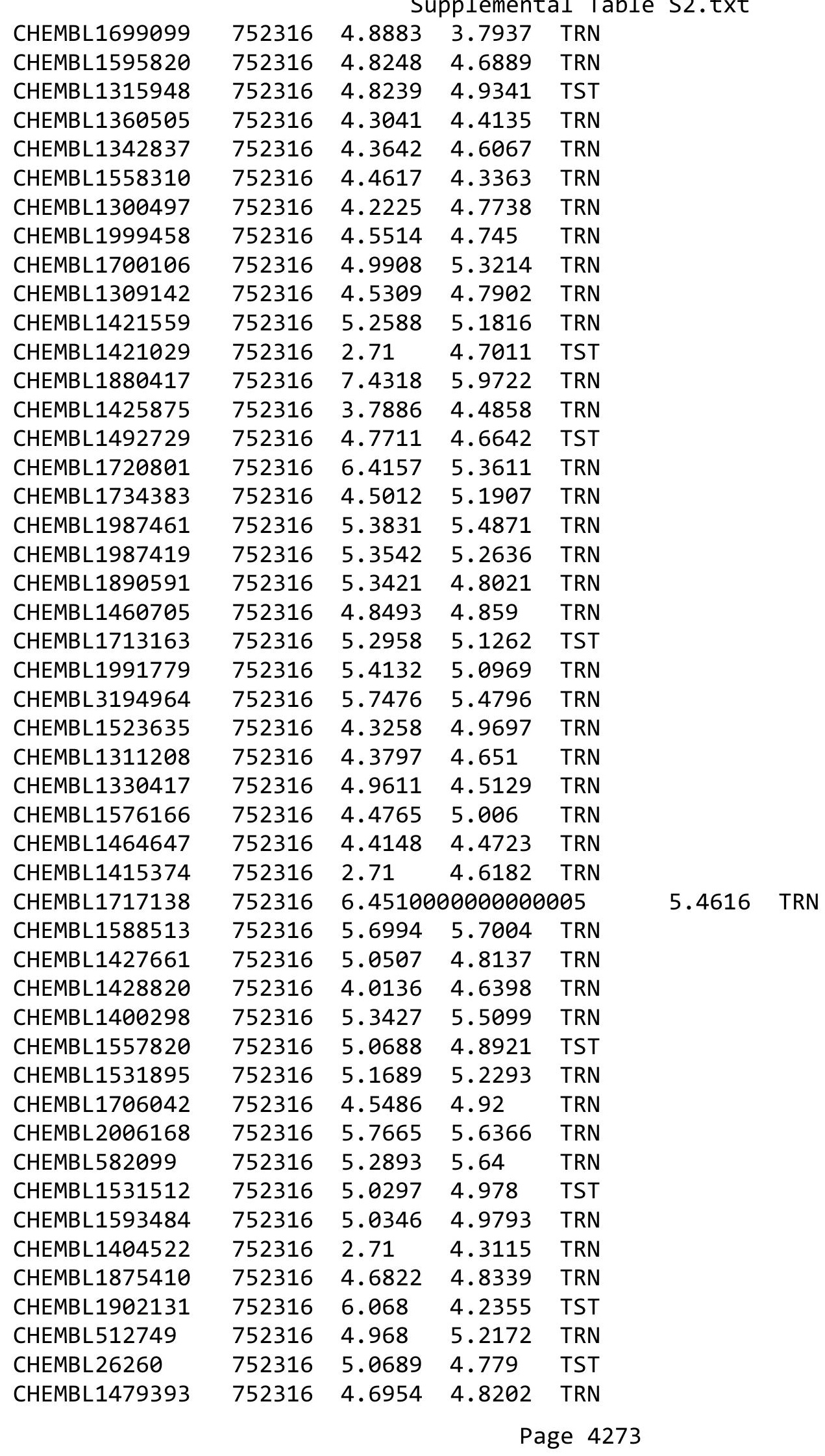


Supplemental Table S2.txt

\begin{tabular}{|c|c|c|c|c|c|}
\hline CHEMBL1544409 & 752316 & 5.1573 & 4.5235 & TST & \\
\hline CHEMBL1608194 & 752316 & 4.382 & 4.3935 & TRN & \\
\hline CHEMBL1705535 & 752316 & 6.4413 & 5.296 & TRN & \\
\hline CHEMBL1978830 & 752316 & 5.1809 & 5.4862 & TRN & \\
\hline CHEMBL3190712 & 752316 & 4.8978 & 4.8713 & TRN & \\
\hline CHEMBL1894615 & 752316 & 6.1707 & 5.0695 & TRN & \\
\hline CHEMBL 225951 & 752316 & 4.8578 & 5.3058 & TRN & \\
\hline CHEMBL1589625 & 752316 & 4.5364 & 4.8708 & TST & \\
\hline CHEMBL1365550 & 752316 & 3.8574 & 4.6292 & TRN & \\
\hline CHEMBL 1883210 & 752316 & 6.3449 & 5.757999 & & TRN \\
\hline CHEMBL265699 & 752316 & 5.9747 & 5.2261 & TRN & \\
\hline CHEMBL1899001 & 752316 & 5.9385 & 5.4179 & TRN & \\
\hline CHEMBL1347449 & 752316 & 2.71 & 4.546 & TRN & \\
\hline CHEMBL 3189519 & 752316 & 5.4962 & 5.4614 & TRN & \\
\hline CHEMBL 3145303 & 752316 & 6.0809 & 5.3768 & TRN & \\
\hline CHEMBL1990258 & 752316 & 4.3947 & 4.7695 & TRN & \\
\hline CHEMBL1522827 & 752316 & 5.7093 & 4.6647 & TRN & \\
\hline CHEMBL1577174 & 752316 & 4.6455 & 4.7314 & TRN & \\
\hline CHEMBL1329129 & 752316 & 5.8236 & 5.0049 & TRN & \\
\hline CHEMBL 3198886 & 752316 & 5.3176 & 4.9363 & TRN & \\
\hline CHEMBL1563149 & 752316 & 4.6636 & 4.5884 & TRN & \\
\hline CHEMBL1573366 & 752316 & 4.6023 & 4.8466 & TRN & \\
\hline CHEMBL1894539 & 752316 & 5.2639 & 4.8645 & TRN & \\
\hline CHEMBL 3199168 & 752316 & 4.4422 & 4.5531 & TRN & \\
\hline CHEMBL1400132 & 752316 & 2.71 & 4.9469 & TRN & \\
\hline CHEMBL1889367 & 752316 & 4.7532 & 5.3389 & TRN & \\
\hline CHEMBL1991388 & 752316 & 4.5629 & 4.2022 & TRN & \\
\hline CHEMBL1583665 & 752316 & 5.7165 & 5.3988 & TRN & \\
\hline CHEMBL1905020 & 752316 & 5.8047 & 5.6 & TRN & \\
\hline CHEMBL 1576722 & 752316 & 5.0837 & 4.8453 & TRN & \\
\hline CHEMBL1730953 & 752316 & 4.5663 & 4.5345 & TST & \\
\hline CHEMBL 1442280 & 752316 & 5.3264 & 5.3063 & TRN & \\
\hline CHEMBL1531914 & 752316 & \multicolumn{3}{|c|}{5.507000000000001} & TRN \\
\hline CHEMBL1706381 & 752316 & 5.2495 & 5.5159 & TRN & \\
\hline CHEMBL590665 & 752316 & 5.5933 & 5.6844 & TRN & \\
\hline CHEMBL1983939 & 752316 & 5.2063 & 5.1724 & TRN & \\
\hline CHEMBL 1537781 & 752316 & 4.6118 & 4.9166 & TST & \\
\hline CHEMBL 3196193 & 752316 & 2.71 & 5.1313 & TRN & \\
\hline CHEMBL1898104 & 752316 & \multicolumn{3}{|c|}{5.212999999999999} & TRN \\
\hline CHEMBL1504701 & 752316 & 6.5258 & 5.2649 & TRN & \\
\hline CHEMBL1721075 & 752316 & 6.0074 & 5.1204 & TRN & \\
\hline CHEMBL 1981002 & 752316 & 5.0379 & 4.8173 & TRN & \\
\hline CHEMBL1306800 & 752316 & 4.5249 & 4.4823 & TRN & \\
\hline CHEMBL 3192616 & 752316 & 4.9691 & 5.2071 & TRN & \\
\hline CHEMBL1980322 & 752316 & 5.1737 & 5.3627 & TRN & \\
\hline CHEMBL1406568 & 752316 & 4.6334 & 4.7794 & TRN & \\
\hline CHEMBL600862 & 752316 & 4.4807 & 5.8999 & TRN & \\
\hline CHEMBL548615 & 752316 & 5.8884 & 4.817 & TRN & \\
\hline
\end{tabular}


Supplemental Table S2.txt

\begin{tabular}{|c|c|c|c|c|c|c|}
\hline CHEMBL1455993 & 752316 & 4.7123 & 4.7263 & TRN & & \\
\hline CHEMBL1964614 & 752316 & 5.3461 & 5.4041 & TRN & & \\
\hline CHEMBL1345167 & 752316 & 4.5924 & 4.7436 & TST & & \\
\hline CHEMBL1448442 & 752316 & 4.6997 & 4.6739 & TRN & & \\
\hline CHEMBL1322650 & 752316 & 4.5971 & 4.5218 & TRN & & \\
\hline CHEMBL1597459 & 752316 & 4.7742 & 5.2836 & TRN & & \\
\hline CHEMBL1373096 & 752316 & 5.7149 & 5.9809 & TRN & & \\
\hline CHEMBL1423387 & 752316 & 5.2458 & 5.0885 & TRN & & \\
\hline CHEMBL1571157 & 752316 & 4.7565 & 5.0852 & TRN & & \\
\hline CHEMBL1354085 & 752316 & 5.9147 & 4.8253 & TST & & \\
\hline CHEMBL1866510 & 752316 & 5.983 & 4.7175 & TRN & & \\
\hline CHEMBL1499202 & 752316 & 4.6701 & 4.8022 & TRN & & \\
\hline CHEMBL1899528 & 752316 & 4.886 & 5.3287 & TRN & & \\
\hline CHEMBL429335 & 752316 & 4.5358 & 3.8312 & TRN & & \\
\hline CHEMBL3196960 & 752316 & 4.68199 & 99999999 & 995 & 4.8355 & TRN \\
\hline CHEMBL1505247 & 752316 & 4.231 & 5.1048 & TRN & & \\
\hline CHEMBL3196134 & 752316 & 5.3995 & 5.2777 & TRN & & \\
\hline CHEMBL3195997 & 752316 & 5.516 & 5.3135 & TRN & & \\
\hline CHEMBL3199139 & 752316 & 2.71 & 4.7524 & TST & & \\
\hline CHEMBL 3192578 & 752316 & 5.421 & 5.2459 & TRN & & \\
\hline CHEMBL2004978 & 752316 & 4.7455 & 4.7687 & TRN & & \\
\hline CHEMBL1497295 & 752316 & 5.4755 & 5.4878 & TRN & & \\
\hline CHEMBL1487901 & 752316 & 5.0734 & 4.4234 & TST & & \\
\hline CHEMBL1580272 & 752316 & 4.7264 & 4.6431 & TRN & & \\
\hline CHEMBL1865393 & 752316 & 5.5862 & 5.0799 & TRN & & \\
\hline CHEMBL1427463 & 752316 & 4.3746 & 4.4434 & TRN & & \\
\hline CHEMBL1450526 & 752316 & 5.1531 & 5.3057 & TRN & & \\
\hline CHEMBL1547350 & 752316 & 2.71 & 4.4761 & TRN & & \\
\hline CHEMBL494326 & 752316 & 3.8905 & 4.4635 & TRN & & \\
\hline CHEMBL89445 & 752316 & 5.7729 & 5.4999 & TRN & & \\
\hline CHEMBL1565344 & 752316 & 4.802 & 4.6373 & TST & & \\
\hline CHEMBL1698608 & 752316 & 6.3675 & 5.5722 & TRN & & \\
\hline CHEMBL1312275 & 752316 & 5.4332 & 4.7593 & TRN & & \\
\hline CHEMBL1502883 & 752316 & 5.605 & 3.6333 & TRN & & \\
\hline CHEMBL591876 & 752316 & 5.6419 & 5.7767 & TRN & & \\
\hline CHEMBL1317322 & 752316 & 5.3545 & 5.0871 & TRN & & \\
\hline CHEMBL1904727 & 752316 & 4.9779 & 5.2034 & TRN & & \\
\hline CHEMBL1515267 & 752316 & 5.1287 & 4.7696 & TRN & & \\
\hline CHEMBL1379178 & 752316 & 4.9585 & 4.6826 & TST & & \\
\hline CHEMBL1585578 & 752316 & 3.9422 & 4.4931 & TRN & & \\
\hline CHEMBL1441122 & 752316 & 5.8508 & 4.7259 & TRN & & \\
\hline CHEMBL1331851 & 752316 & 5.4289 & 4.6561 & TRN & & \\
\hline CHEMBL 3189712 & 752316 & 5.4451 & 4.7271 & TRN & & \\
\hline CHEMBL1900730 & 752316 & 5.4157 & 5.3872 & TST & & \\
\hline CHEMBL1527433 & 752316 & 4.709 & 5.0356 & TRN & & \\
\hline CHEMBL1464261 & 752316 & 5.187 & 4.6137 & TST & & \\
\hline CHEMBL1867789 & 752316 & 5.6377 & 4.7465 & TRN & & \\
\hline CHEMBL199194 & 752316 & 4.6117 & 4.5329 & TST & & \\
\hline
\end{tabular}




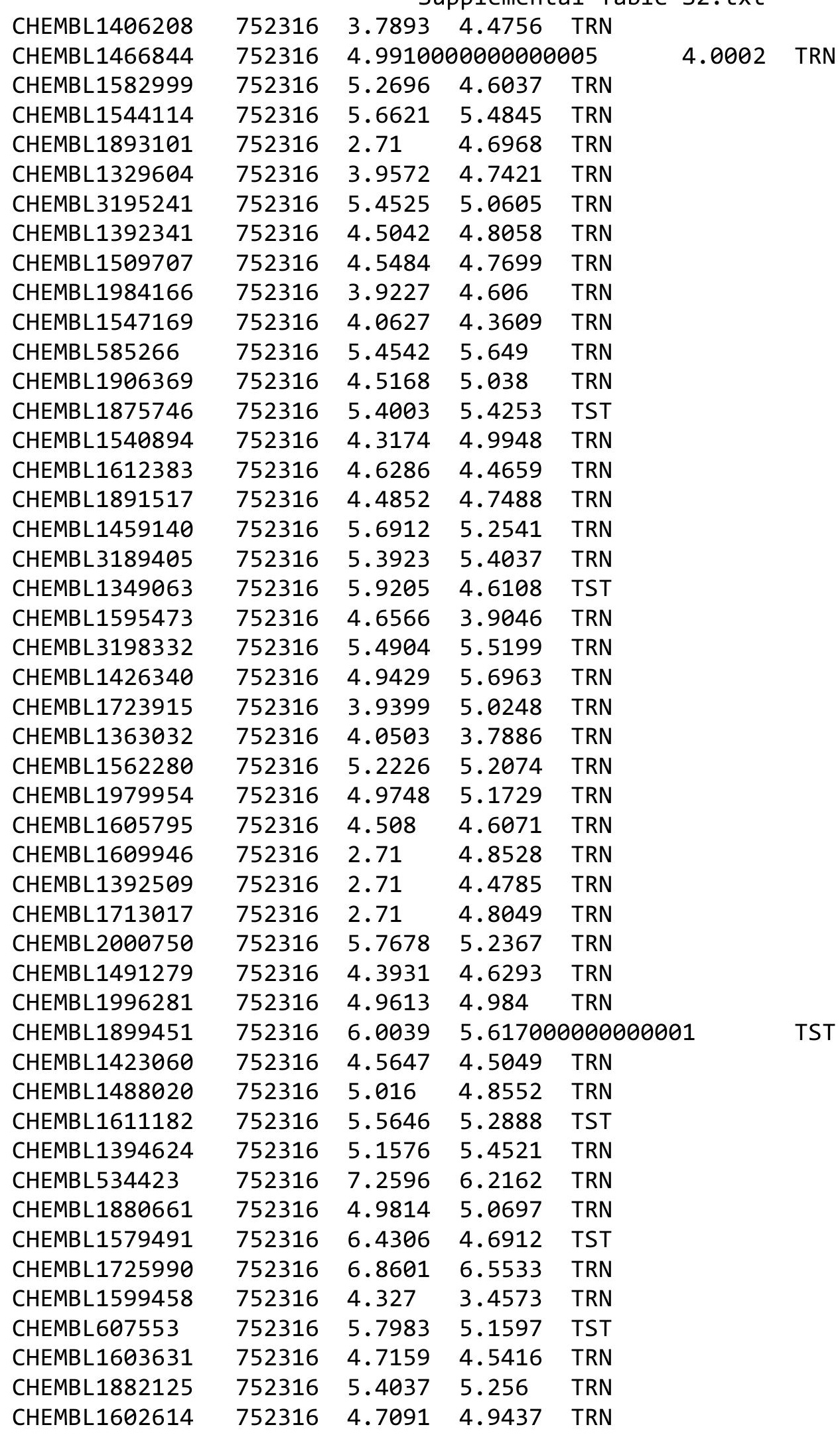




\begin{tabular}{|c|c|c|c|c|c|}
\hline & & & & & \\
\hline CHEMBL1505474 & 752316 & 5.4218 & 4.6762 & TST & \\
\hline CHEMBL1980018 & 752316 & 5.8179 & 4.8375 & TRN & \\
\hline CHEMBL3192181 & 752316 & 5.5629 & 5.485 & TRN & \\
\hline CHEMBL1472117 & 752316 & 4.8348 & 4.5827 & TRN & \\
\hline CHEMBL1580774 & 752316 & 4.9257 & 4.8942 & TST & \\
\hline CHEMBL3190911 & 752316 & 5.3072 & 5.4409 & TRN & \\
\hline CHEMBL3191632 & 752316 & 5.4798 & 4.8633 & TRN & \\
\hline CHEMBL1417731 & 752316 & 4.1405 & 4.0019 & TRN & \\
\hline CHEMBL 3196324 & 752316 & 5.9805 & 5.9348 & TRN & \\
\hline CHEMBL2358182 & 752316 & 4.9723 & 5.11600 & 00000000005 & TRN \\
\hline CHEMBL1339433 & 752316 & 5.0133 & 5.0871 & TRN & \\
\hline CHEMBL1343490 & 752316 & 5.1182 & 5.0225 & TST & \\
\hline CHEMBL1484158 & 752316 & 2.71 & 3.7656 & TRN & \\
\hline CHEMBL1989897 & 752316 & 5.2016 & 5.3305 & TRN & \\
\hline CHEMBL1984876 & 752316 & 6.0953 & 5.8594 & TRN & \\
\hline CHEMBL1514530 & 752316 & 5.4376 & 5.6384 & TRN & \\
\hline CHEMBL1530152 & 752316 & 4.6042 & 4.7722 & TRN & \\
\hline CHEMBL1986514 & 752316 & 4.6717 & 4.9497 & TRN & \\
\hline CHEMBL1550518 & 752316 & 4.5206 & 4.8352 & TRN & \\
\hline CHEMBL1570364 & 752316 & 4.8163 & 4.8 & TST & \\
\hline CHEMBL1575124 & 752316 & 4.6587 & 4.5922 & TST & \\
\hline CHEMBL530049 & 752316 & 5.1974 & 5.2291 & TST & \\
\hline CHEMBL1521187 & 752316 & 2.71 & 3.7338 & TST & \\
\hline CHEMBL45281 & 752316 & 4.4705 & 4.9836 & TST & \\
\hline CHEMBL 2354875 & 752316 & 4.797 & 4.7465 & TST & \\
\hline CHEMBL1421358 & 752316 & 4.342 & 4.4605 & TST & \\
\hline CHEMBL3189416 & 752316 & 4.9713 & 4.9209 & TST & \\
\hline CHEMBL1558462 & 752316 & 5.3443 & 5.2975 & TST & \\
\hline CHEMBL1566488 & 752316 & 4.3498 & 4.8341 & TST & \\
\hline CHEMBL3192341 & 752316 & 4.5796 & 4.7473 & TST & \\
\hline CHEMBL1527400 & 752316 & 5.0352 & 5.0907 & TST & \\
\hline CHEMBL1576130 & 752316 & 4.1373 & 4.9272 & TST & \\
\hline CHEMBL455284 & 752316 & 6.8861 & 6.2354 & TST & \\
\hline CHEMBL1594286 & 752316 & 4.4894 & 4.6009 & TST & \\
\hline CHEMBL1518085 & 752316 & 4.5381 & 5.5386 & TST & \\
\hline CHEMBL3199467 & 752316 & 5.0821 & 5.4263 & TST & \\
\hline CHEMBL1993020 & 752316 & 2.71 & 4.6618 & TST & \\
\hline CHEMBL1864760 & 752316 & 5.4198 & 5.3225 & TST & \\
\hline CHEMBL1474014 & 752316 & 4.9576 & 4.6862 & TST & \\
\hline CHEMBL1589790 & 752316 & 4.5949 & 4.4918 & TST & \\
\hline CHEMBL1611300 & 752316 & 3.98 & 3.6981 & TST & \\
\hline CHEMBL1573883 & 752316 & 5.105 & 4.8671 & TST & \\
\hline CHEMBL1486726 & 752316 & 4.4598 & 4.7814 & TST & \\
\hline CHEMBL1878035 & 752316 & 5.2695 & 5.5413 & TST & \\
\hline CHEMBL1708343 & 752316 & 5.6251 & 4.1768 & TST & \\
\hline CHEMBL1701797 & 752316 & 6.8125 & 6.2763 & TST & \\
\hline CHEMBL1354361 & 752316 & 4.5847 & 4.4865 & TST & \\
\hline CHEMBL1864112 & 752316 & 3.9996 & 4.843 & TST & \\
\hline & & & & 4277 & \\
\hline
\end{tabular}




\begin{tabular}{|c|c|c|c|c|c|}
\hline \multicolumn{6}{|c|}{ Supplemental Table S2.txt } \\
\hline CHEMBL3195688 & 752316 & 5.4803 & 5.1895 & TST & \\
\hline CHEMBL3198912 & 752316 & 5.5154 & 5.3153 & TST & \\
\hline CHEMBL1699228 & 752316 & 5.2893 & 4.9471 & TST & \\
\hline CHEMBL1311453 & 752316 & 4.8592 & 4.7672 & TST & \\
\hline CHEMBL1426226 & 752316 & 4.5596 & 4.3852 & TST & \\
\hline CHEMBL1577983 & 752316 & 2.71 & 4.9815 & TST & \\
\hline CHEMBL1547261 & 752316 & 4.6769 & 4.5337 & TST & \\
\hline CHEMBL1713327 & 752316 & 5.4069 & 5.4989 & TST & \\
\hline CHEMBL1987820 & 752316 & 5.9747 & 5.3894 & TST & \\
\hline CHEMBL1469251 & 752316 & 4.3962 & 4.6949 & TST & \\
\hline CHEMBL1481616 & 752316 & 4.2503 & 4.7128 & TST & \\
\hline CHEMBL151176 & 954790 & 6.7186 & 4.9144 & TRN & \\
\hline CHEMBL 2137530 & 954790 & 4.479 & 4.7696 & TRN & \\
\hline CHEMBL220241 & 954790 & 5.8445 & 6.2833 & TRN & \\
\hline CHEMBL180127 & 954790 & 4.3426 & 4.5694 & TRN & \\
\hline CHEMBL135561 & 954790 & 4.5744 & 4.6568 & TRN & \\
\hline CHEMBL373751 & 954790 & 3.5128 & 4.0077 & TRN & \\
\hline CHEMBL558642 & 954790 & 3.8718 & 3.43399 & 99999999997 & TRN \\
\hline CHEMBL1909414 & 954790 & 3.5136 & 3.5053 & TRN & \\
\hline CHEMBL1230020 & 954790 & 3.6488 & 3.8646 & TRN & \\
\hline CHEMBL393929 & 954790 & 3.845 & 3.7945 & TRN & \\
\hline CHEMBL449158 & 954790 & 6.0076 & 7.181 & TST & \\
\hline CHEMBL188678 & 954790 & 4.4279 & 4.2439 & TRN & \\
\hline CHEMBL65 & 954790 & 7.7513 & 7.9196 & TRN & \\
\hline CHEMBL1404918 & 954790 & 2.9266 & 2.5882 & TRN & \\
\hline CHEMBL210618 & 954790 & 3.3474 & 3.3071 & TRN & \\
\hline CHEMBL192566 & 954790 & 5.5038 & 6.938 & TST & \\
\hline CHEMBL 2363137 & 954790 & 3.8662 & 4.2298 & TRN & \\
\hline CHEMBL577784 & 954790 & 5.1431 & 5.3716 & TRN & \\
\hline CHEMBL1788116 & 954790 & 4.8887 & 4.9564 & TRN & \\
\hline CHEMBL189584 & 954790 & 4.1567 & 4.4576 & TRN & \\
\hline CHEMBL573107 & 954790 & 4.8501 & 4.8944 & TRN & \\
\hline CHEMBL1590308 & 954790 & 4.3955 & 4.1003 & TST & \\
\hline CHEMBL259181 & 954790 & 2.7652 & 2.7731 & TRN & \\
\hline CHEMBL240954 & 954790 & 3.7537 & 3.5082 & TST & \\
\hline CHEMBL483849 & 954790 & 1.8233 & 1.5601 & TST & \\
\hline CHEMBL191334 & 954790 & 5.0692 & 5.1477 & TRN & \\
\hline CHEMBL585951 & 954790 & 5.7154 & 5.9121 & TRN & \\
\hline CHEMBL3349342 & 954790 & 4.5231 & 4.7337 & TRN & \\
\hline CHEMBL 2144069 & 954790 & 6.4485 & 6.0681 & TRN & \\
\hline CHEMBL102714 & 954790 & 3.3298 & 3.7987 & TRN & \\
\hline CHEMBL3186408 & 954790 & 4.3148 & 4.0855 & TST & \\
\hline CHEMBL3199475 & 954790 & 3.6161 & 3.5489 & TRN & \\
\hline CHEMBL412142 & 954790 & 5.2603 & 5.1131 & TRN & \\
\hline CHEMBL512504 & 954790 & 4.1632 & 4.1697 & TRN & \\
\hline CHEMBL1357247 & 954790 & 2.9096 & 3.0887 & TRN & \\
\hline CHEMBL1190711 & 954790 & 3.8566 & 4.1285 & TRN & \\
\hline CHEMBL221137 & 954790 & 4.7806 & 4.2241 & TRN & \\
\hline
\end{tabular}




\begin{tabular}{|c|c|c|c|c|c|}
\hline \multirow[b]{2}{*}{ CHEMBL 222102} & & \multicolumn{4}{|c|}{ Supplemental Table S2.txt } \\
\hline & 954790 & 2.9681 & \multicolumn{2}{|c|}{3.3939999999999997} & TRN \\
\hline CHEMBL472940 & 954790 & 2.5819 & 2.5197 & TRN & \\
\hline CHEMBL 2134202 & 954790 & 4.1808 & 4.1862 & TRN & \\
\hline CHEMBL1186585 & 954790 & 3.992 & 4.3377 & TRN & \\
\hline CHEMBL 258844 & 954790 & 4.5068 & 4.2154 & TRN & \\
\hline CHEMBL379975 & 954790 & 5.6083 & 5.0938 & TRN & \\
\hline CHEMBL9470 & 954790 & 6.0384 & 5.8018 & TRN & \\
\hline CHEMBL92309 & 954790 & 2.8029 & \multicolumn{2}{|c|}{2.6060000000000003} & TST \\
\hline CHEMBL202721 & 954790 & \multicolumn{3}{|c|}{4.531000000000001} & TST \\
\hline CHEMBL399530 & 954790 & 4.6927 & 4.1824 & TST & \\
\hline CHEMBL1516890 & 954790 & 4.9511 & 4.0524 & TST & \\
\hline CHEMBL217354 & 954790 & 5.8478 & 6.1713 & TST & \\
\hline CHEMBL 255342 & 954790 & 3.8624 & 3.6162 & TST & \\
\hline CHEMBL1673039 & 954790 & 5.025 & 5.322 & TST & \\
\hline CHEMBL441942 & 147797 & 7.0458 & 6.7097 & TRN & \\
\hline CHEMBL384047 & 147797 & 2.0 & 1.6555 & TST & \\
\hline CHEMBL410749 & 147797 & 5.7471 & 5.8951 & TRN & \\
\hline CHEMBL440613 & 147797 & 6.1612 & 6.6958 & TRN & \\
\hline CHEMBL 280472 & 147797 & 2.0 & 1.1443 & TST & \\
\hline CHEMBL406777 & 147797 & 6.3468 & 5.9137 & TRN & \\
\hline CHEMBL428821 & 147797 & 6.2291 & \multicolumn{2}{|c|}{6.4670000000000005} & TRN \\
\hline CHEMBL214619 & 147797 & 2.0 & 1.8439 & TRN & \\
\hline CHEMBL 265747 & 147797 & 6.1024 & 6.3908 & TRN & \\
\hline CHEMBL411097 & 147797 & 5.5017 & 5.3558 & TRN & \\
\hline CHEMBL441924 & 147797 & 6.7959 & 6.4809 & TRN & \\
\hline CHEMBL409392 & 147797 & 5.4437 & \multicolumn{2}{|c|}{5.827999999999999} & TRN \\
\hline CHEMBL 267350 & 147797 & 2.0 & 1.6604 & TST & \\
\hline CHEMBL425940 & 147797 & 6.3098 & 6.1881 & TRN & \\
\hline CHEMBL 204810 & 147797 & 6.3872 & 6.0258 & TRN & \\
\hline CHEMBL429376 & 147797 & 5.6198 & 5.6488 & TRN & \\
\hline CHEMBL409269 & 147797 & 5.6003 & 6.1857 & TRN & \\
\hline CHEMBL428626 & 147797 & 6.2291 & 6.0338 & TRN & \\
\hline CHEMBL439123 & 147797 & 6.3979 & 6.3312 & TRN & \\
\hline CHEMBL437920 & 147797 & 6.1487 & 6.4035 & TRN & \\
\hline CHEMBL408467 & 147797 & 6.5229 & 6.4035 & TRN & \\
\hline CHEMBL384249 & 147797 & 2.0 & 2.2293 & TRN & \\
\hline CHEMBL 268346 & 147797 & 5.3565 & 5.4343 & TRN & \\
\hline CHEMBL409323 & 147797 & 5.9872 & 6.1322 & TRN & \\
\hline CHEMBL440826 & 147797 & 7.2218 & 6.1029 & TST & \\
\hline CHEMBL 276022 & 147797 & 6.1938 & 5.6657 & TRN & \\
\hline CHEMBL439167 & 147797 & 2.0 & 1.5004 & TST & \\
\hline CHEMBL407866 & 147797 & 6.1675 & 5.8951 & TRN & \\
\hline CHEMBL411914 & 147797 & 5.6326 & 6.3611 & TRN & \\
\hline CHEMBL441585 & 147797 & 6.7212 & 5.8951 & TRN & \\
\hline CHEMBL 386724 & 147797 & 2.0 & 1.44099 & 99999999998 & TST \\
\hline CHEMBL437533 & 147797 & 6.1024 & 5.8951 & TRN & \\
\hline CHEMBL409291 & 147797 & 5.6421 & 6.3611 & TRN & \\
\hline CHEMBL430345 & 147797 & 2.0 & 1.7976 & TST & \\
\hline
\end{tabular}




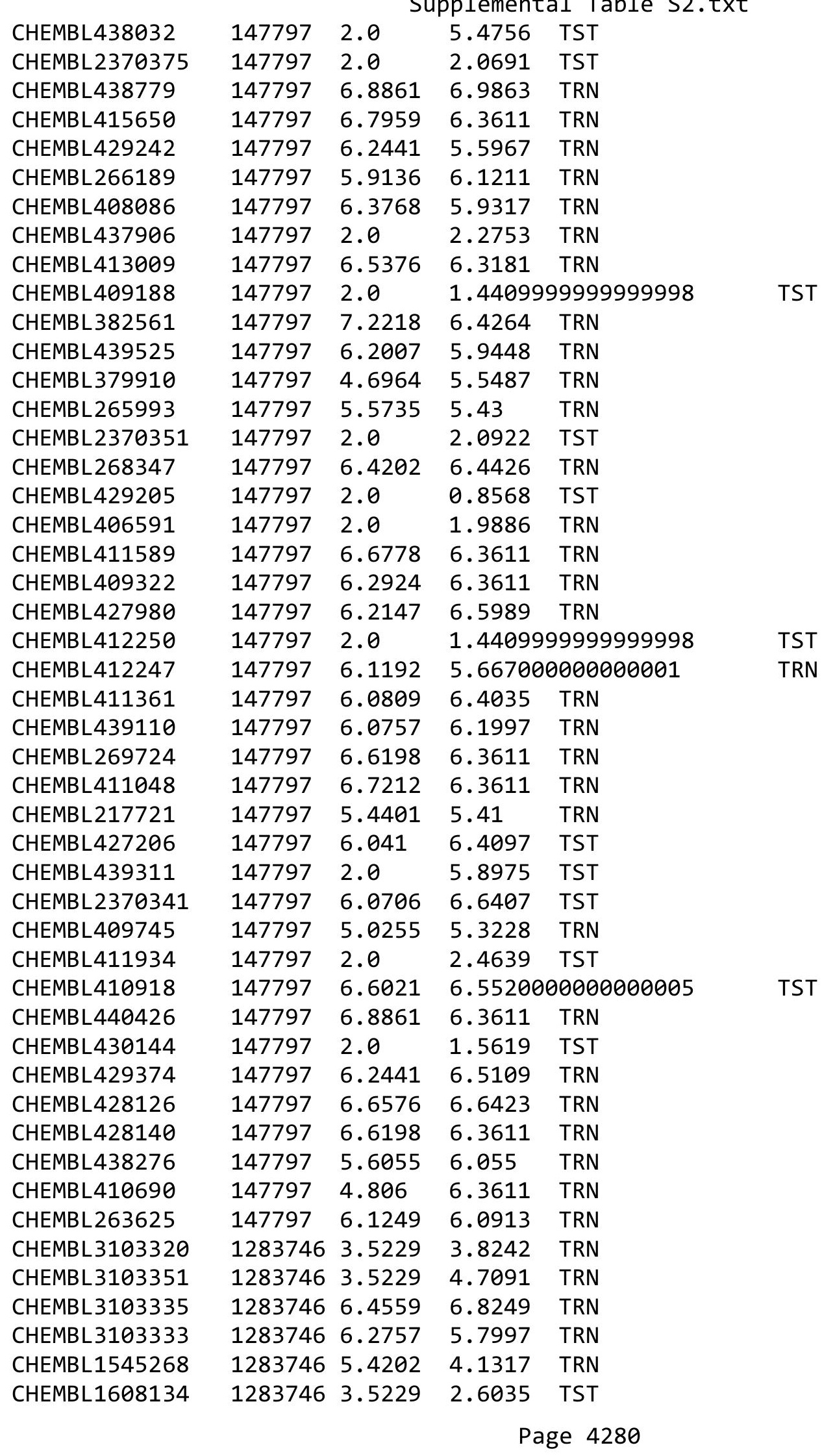


Supplemental Table S2.txt

\begin{tabular}{|c|c|c|c|c|c|}
\hline CHEMBL3103332 & 1283746 & 6.7959 & 6.9446 & TRN & \\
\hline CHEMBL3103329 & 1283746 & 3.5229 & 3.3 & TRN & \\
\hline CHEMBL3103355 & 1283746 & 5.2581 & 5.019 & TRN & \\
\hline CHEMBL3103347 & 1283746 & 6.9586 & 5.5957 & TRN & \\
\hline CHEMBL3103330 & 1283746 & 7.6021 & 7.197 & TRN & \\
\hline CHEMBL3103364 & 1283746 & 3.5229 & 4.6951 & TRN & \\
\hline CHEMBL3103324 & 1283746 & 6.4559 & 3.4588 & TST & \\
\hline CHEMBL1447127 & 1283746 & 5.2147 & 5.3227 & TRN & \\
\hline CHEMBL3103334 & 1283746 & 7.0 & 7.4588 & TRN & \\
\hline CHEMBL3103338 & 1283746 & 3.5229 & 3.0277 & TRN & \\
\hline CHEMBL3103340 & 1283746 & 4.8996 & 3.7292 & TST & \\
\hline CHEMBL3103348 & 1283746 & 6.8539 & 6.1255 & TRN & \\
\hline CHEMBL3103323 & 1283746 & 6.3372 & 4.5717 & TRN & \\
\hline CHEMBL3103352 & 1283746 & 3.5229 & 4.3203 & TRN & \\
\hline CHEMBL3103339 & 1283746 & 3.5229 & 1.7129 & TST & \\
\hline CHEMBL3103357 & 1283746 & 4.9172 & 6.20100 & 30000000005 & TRN \\
\hline CHEMBL3103360 & 1283746 & 5.2757 & 5.9977 & TRN & \\
\hline CHEMBL3103326 & 1283746 & 3.5229 & 5.1482 & TRN & \\
\hline CHEMBL3103346 & 1283746 & 7.1675 & 6.4101 & TRN & \\
\hline CHEMBL3103328 & 1283746 & 5.4318 & 5.4143 & TST & \\
\hline CHEMBL1865699 & 1283746 & 4.6925 & 5.5738 & TRN & \\
\hline CHEMBL3103345 & 1283746 & 6.1805 & 5.7726 & TRN & \\
\hline CHEMBL3103365 & 1283746 & 5.3098 & 5.0415 & TRN & \\
\hline CHEMBL3103362 & 1283746 & 6.4437 & 5.4215 & TRN & \\
\hline CHEMBL3103321 & 1283746 & 3.5229 & 3.9631 & TRN & \\
\hline CHEMBL3103350 & 1283746 & 3.5229 & 3.8957 & TRN & \\
\hline CHEMBL1499626 & 1283746 & 3.5229 & 3.0785 & TRN & \\
\hline CHEMBL3103353 & 1283746 & 3.5229 & 3.6812 & TRN & \\
\hline CHEMBL3103349 & 1283746 & 7.1739 & 5.7904 & TRN & \\
\hline CHEMBL3103337 & 1283746 & 3.5229 & 4.0732 & TRN & \\
\hline CHEMBL3103361 & 1283746 & 3.5229 & 4.3964 & TRN & \\
\hline CHEMBL1418164 & 1283746 & 6.301 & 6.3876 & TRN & \\
\hline CHEMBL3103341 & 1283746 & 5.041 & 4.4707 & TRN & \\
\hline CHEMBL3102863 & 1283746 & 3.5229 & 3.3394 & TRN & \\
\hline CHEMBL3103342 & 1283746 & 3.5229 & 4.2933 & TRN & \\
\hline CHEMBL3103325 & 1283746 & 3.5229 & 5.0021 & TST & \\
\hline CHEMBL3103356 & 1283746 & 6.2441 & 5.8531 & TRN & \\
\hline CHEMBL3103359 & 1283746 & 6.1549 & 6.5137 & TRN & \\
\hline CHEMBL3103344 & 1283746 & 5.5376 & 5.2847 & TRN & \\
\hline CHEMBL3103331 & 1283746 & 6.9586 & 6.7773 & TST & \\
\hline CHEMBL3103358 & 1283746 & 5.6383 & 6.2101 & TST & \\
\hline CHEMBL3103336 & 1283746 & 6.3188 & 6.1115 & TST & \\
\hline CHEMBL3103343 & 1283746 & 3.5229 & 4.0455 & TST & \\
\hline CHEMBL3103327 & 1283746 & 4.5229 & 5.0854 & TST & \\
\hline CHEMBL3103354 & 1283746 & 3.5229 & 4.4839 & TST & \\
\hline CHEMBL3103363 & 1283746 & 6.4559 & 4.762 & TST & \\
\hline CHEMBL3103322 & 1283746 & 4.6596 & 3.6353 & TST & \\
\hline CHEMBL129538 & 3965 & 4.4949 & 4.5525 & TRN & \\
\hline
\end{tabular}




\begin{tabular}{|c|c|c|c|c|c|}
\hline & & \multicolumn{4}{|c|}{ Supplemental Table s2.txt } \\
\hline CHEMBL338785 & 3965 & 5.2596 & 5.1454 & TRN & \\
\hline CHEMBL339537 & 3965 & 5.4089 & 5.4574 & TRN & \\
\hline CHEMBL126135 & 3965 & 5.5528 & 5.4995 & TRN & \\
\hline CHEMBL129670 & 3965 & 4.8861 & 4.9929 & TRN & \\
\hline CHEMBL6415 & 3965 & 4.4949 & 4.4259 & TRN & \\
\hline CHEMBL129369 & 3965 & 4.5229 & 4.7118 & TRN & \\
\hline CHEMBL126191 & 3965 & 5.2218 & 5.0628 & TRN & \\
\hline CHEMBL30110 & 3965 & 5.3665 & 4.9334 & TST & \\
\hline CHEMBL126910 & 3965 & 4.7212 & 4.716 & TRN & \\
\hline CHEMBL126950 & 3965 & 4.7212 & 5.0239 & TRN & \\
\hline CHEMBL338084 & 3965 & 3.5229 & 3.5884 & TRN & \\
\hline CHEMBL128138 & 3965 & 5.041 & 5.0275 & TRN & \\
\hline CHEMBL128869 & 3965 & 4.8539 & 4.7468 & TRN & \\
\hline CHEMBL129260 & 3965 & 5.6198 & 5.7271 & TRN & \\
\hline CHEMBL129325 & 3965 & 5.0862 & 5.2868 & TRN & \\
\hline CHEMBL340693 & 3965 & 4.4949 & 4.8803 & TST & \\
\hline CHEMBL129441 & 3965 & 5.2596 & 5.1496 & TRN & \\
\hline CHEMBL340896 & 3965 & 5.8239 & 5.8258 & TRN & \\
\hline CHEMBL338620 & 3965 & 4.4949 & 4.6555 & TST & \\
\hline CHEMBL129154 & 3965 & 4.6576 & 4.8141 & TRN & \\
\hline CHEMBL338692 & 3965 & 4.3979 & 4.5106 & TRN & \\
\hline CHEMBL341498 & 3965 & 4.4949 & 4.5829 & TST & \\
\hline CHEMBL126672 & 3965 & 5.5686 & 5.4089 & TRN & \\
\hline CHEMBL129799 & 3965 & 5.0223 & 4.8901 & TRN & \\
\hline CHEMBL129428 & 3965 & 5.1805 & 5.2061 & TRN & \\
\hline CHEMBL129531 & 3965 & 5.1675 & 4.7933 & TST & \\
\hline CHEMBL129818 & 3965 & 4.9586 & 4.984 & TRN & \\
\hline CHEMBL128664 & 3965 & 5.3098 & 5.3074 & TRN & \\
\hline CHEMBL340217 & 3965 & 4.3279 & 4.3368 & TRN & \\
\hline CHEMBL340927 & 3965 & 5.1675 & 5.2374 & TRN & \\
\hline CHEMBL126290 & 3965 & 5.2757 & 5.0406 & TRN & \\
\hline CHEMBL126969 & 3965 & 3.4134 & 3.4477 & TRN & \\
\hline CHEMBL126326 & 3965 & 4.3098 & 4.2622 & TRN & \\
\hline CHEMBL128429 & 3965 & 5.0506 & 5.0965 & TRN & \\
\hline CHEMBL339239 & 3965 & 5.3098 & 5.17700 & 00000000005 & TRN \\
\hline CHEMBL7660 & 3965 & 5.7212 & 4.8347 & TST & \\
\hline CHEMBL127110 & 3965 & 5.4202 & 5.3553 & TRN & \\
\hline CHEMBL128663 & 3965 & 4.8239 & 4.6145 & TRN & \\
\hline CHEMBL129798 & 3965 & 5.4559 & 5.4625 & TRN & \\
\hline CHEMBL341253 & 3965 & 4.7696 & 4.7868 & TRN & \\
\hline CHEMBL338563 & 3965 & 4.4949 & 4.4014 & TRN & \\
\hline CHEMBL127109 & 3965 & 5.9586 & 5.96 & TRN & \\
\hline CHEMBL128308 & 3965 & 5.1612 & 5.1234 & TRN & \\
\hline CHEMBL126460 & 3965 & 4.5229 & 4.5237 & TRN & \\
\hline CHEMBL338350 & 3965 & 4.9208 & 4.9449 & TRN & \\
\hline CHEMBL341302 & 3965 & 4.4559 & 4.6426 & TRN & \\
\hline CHEMBL128758 & 3965 & 5.0757 & 5.1191 & TRN & \\
\hline CHEMBL340341 & 3965 & 4.6778 & 4.5866 & TRN & \\
\hline
\end{tabular}




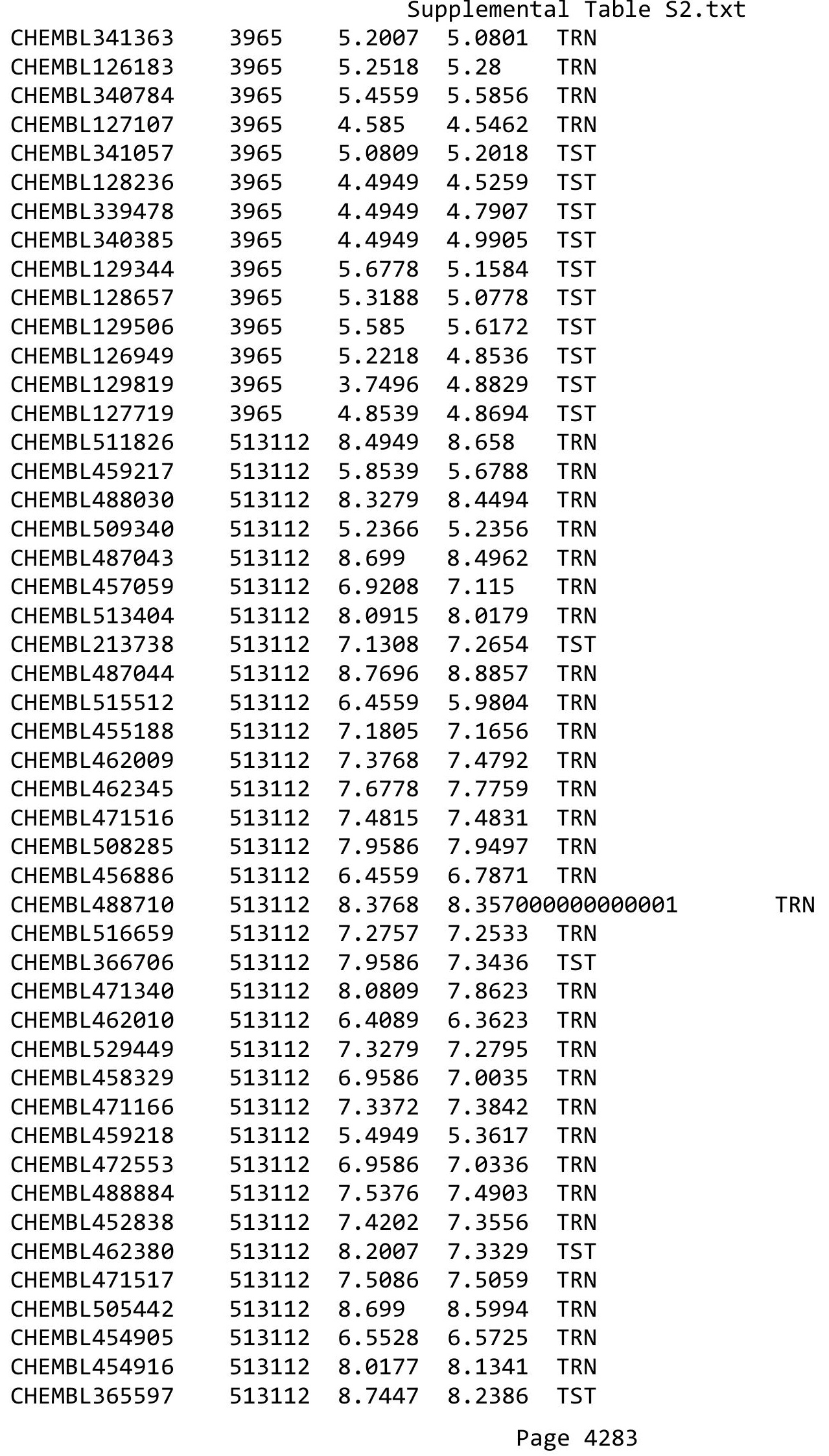




\begin{tabular}{|c|c|c|c|c|c|}
\hline \multicolumn{6}{|c|}{ Supplemental Table S2.txt } \\
\hline CHEMBL508293 & 513112 & 7.4949 & 7.416 & TRN & \\
\hline CHEMBL507347 & 513112 & 6.6383 & 6.4697 & TRN & \\
\hline CHEMBL454918 & 513112 & 7.585 & 7.7698 & TRN & \\
\hline CHEMBL471167 & 513112 & 7.6778 & 7.442 & TRN & \\
\hline CHEMBL470301 & 513112 & 7.041 & 7.1042 & TRN & \\
\hline CHEMBL503909 & 513112 & 6.9586 & 6.9823 & TRN & \\
\hline CHEMBL488719 & 513112 & 6.9586 & 7.0686 & TRN & \\
\hline CHEMBL455393 & 513112 & 4.0 & 4.4307 & TRN & \\
\hline CHEMBL462346 & 513112 & 7.8239 & 7.8797 & TST & \\
\hline CHEMBL528329 & 513112 & 7.585 & 7.609 & TRN & \\
\hline CHEMBL508641 & 513112 & 7.8861 & 7.7886 & TRN & \\
\hline CHEMBL454663 & 513112 & 7.9586 & 8.0126 & TRN & \\
\hline CHEMBL457058 & 513112 & 5.9208 & 5.7159 & TRN & \\
\hline CHEMBL455394 & 513112 & 6.8239 & 6.5677 & TST & \\
\hline CHEMBL462559 & 513112 & 7.0506 & 6.7756 & TST & \\
\hline CHEMBL452084 & 513112 & 4.0 & 3.9665 & TRN & \\
\hline CHEMBL384138 & 513112 & 6.3098 & 6.233 & TST & \\
\hline CHEMBL444749 & 513112 & 7.0809 & 7.1276 & TRN & \\
\hline CHEMBL507776 & 513112 & 5.7696 & 5.5551 & TRN & \\
\hline CHEMBL183434 & 513112 & 6.4202 & 7.2254 & TST & \\
\hline CHEMBL447298 & 513112 & 7.6383 & 7.6006 & TRN & \\
\hline CHEMBL515542 & 513112 & 4.0 & 4.1864 & TRN & \\
\hline CHEMBL455189 & 513112 & 7.1805 & 7.155 & TRN & \\
\hline CHEMBL462379 & 513112 & 6.4815 & 6.7111 & TRN & \\
\hline CHEMBL454917 & 513112 & 7.3098 & 7.1875 & TST & \\
\hline CHEMBL528108 & 513112 & 8.1135 & 8.0207 & TRN & \\
\hline CHEMBL460942 & 513112 & 7.6198 & 7.6596 & TRN & \\
\hline CHEMBL461132 & 513112 & 6.4202 & 6.4408 & TRN & \\
\hline CHEMBL454670 & 513112 & 6.2518 & 6.1357 & TST & \\
\hline CHEMBL519729 & 513112 & 7.2676 & 7.1527 & TST & \\
\hline CHEMBL340355 & 513112 & 6.5686 & 7.3841 & TST & \\
\hline CHEMBL454900 & 513112 & 8.0269 & 8.0931 & TST & \\
\hline CHEMBL452323 & 513112 & 4.0 & 4.2687 & TST & \\
\hline CHEMBL514603 & 513112 & 7.585 & 7.6053 & TST & \\
\hline CHEMBL488716 & 513112 & 6.0605 & 7.4726 & TST & \\
\hline CHEMBL512496 & 513112 & 7.7959 & 7.9528 & TST & \\
\hline CHEMBL3361325 & 1444281 & 4.0 & 4.5429 & TRN & \\
\hline CHEMBL3353269 & 1444281 & 5.5686 & 5.42899 & 9999999999 & TRN \\
\hline CHEMBL3361323 & 1444281 & 5.2366 & 4.4988 & TRN & \\
\hline CHEMBL3353267 & 1444281 & 5.2596 & 5.4588 & TRN & \\
\hline CHEMBL3361334 & 1444281 & 4.0 & 4.6728 & TST & \\
\hline CHEMBL3353279 & 1444281 & 5.7959 & 5.5189 & TRN & \\
\hline CHEMBL3353266 & 1444281 & 5.4815 & 5.40600 & 0000000001 & TRN \\
\hline CHEMBL3361330 & 1444281 & 5.6778 & 4.6451 & TST & \\
\hline CHEMBL3361319 & 1444281 & 6.1024 & 5.2353 & TRN & \\
\hline CHEMBL 3353280 & 1444281 & 6.0458 & 5.5785 & TRN & \\
\hline CHEMBL3361331 & 1444281 & 5.6198 & 4.6354 & TST & \\
\hline CHEMBL3361321 & 1444281 & 4.0 & 4.7401 & TRN & \\
\hline
\end{tabular}


Supplemental Table S2.txt

\begin{tabular}{|c|c|c|c|c|}
\hline HEMBL & 444281 & 6.0 & 4.7754 & TS \\
\hline & 444281 & 6.0706 & 5.0523 & \\
\hline $\mathrm{HFN}$ & 281 & 4.0 & 1925 & \\
\hline HEMBL & 281 & 5.6576 & 9781 & $2 \mathrm{~N}$ \\
\hline HEMBL3353276 & 281 & 5.8539 & 5099 & \\
\hline HEMBL3361336 & .444281 & 4.0 & 3112 & \\
\hline 1316 & 81 & 5.1805 & 2845 & \\
\hline 361333 & 281 & & 6388 & \\
\hline HEMBL3353288 & & 5.1938 & 9177 & PN \\
\hline HEMBL3353287 & 81 & 5.8861 & 7444 & \\
\hline HEMBL3361335 & 281 & 4.0 & .4871 & \\
\hline IEMBL3: & 81 & 188 & 155 & \\
\hline AEMBL3 & & & & \\
\hline HEMBL 33 & & 5.2596 & 3718 & \\
\hline AEMBL33 & 81 & 5.6198 & 737 & \\
\hline AEMBL3353285 & 31 & 5.4815 & 9091 & \\
\hline HEMBL33 & 31 & 29 & 825 & \\
\hline HEMBL33 & & 586 & 1089 & \\
\hline HEMBL33 & & 5.7212 & 306 & \\
\hline AEMBL3 & & 3 . & 588 & \\
\hline HEMBL3 & 1 & 51 & 266 & RIN \\
\hline HEMBL: & 1 & 7 & 543 & RN \\
\hline HEMBL3 & 31 & 4.0 & 473 & \\
\hline HEMBL3361328 & & 5.8861 & 2586 & \\
\hline AEMBL3361315 & & & & TST \\
\hline HEMBL3 & 4 & 4 & 352 & SI \\
\hline HEMBL; & 4 & & 523 & RN \\
\hline HFMBI 3 & 31 & 51 & 284 & $C T$ \\
\hline HEMBL3361324 & & 4.0 & 583 & IS \\
\hline HEMBL3353284 & & 5 . & 7431 & IK \\
\hline HEMBL3 & -4 & 5. & 675 & $\mathrm{RN}$ \\
\hline HEMBL & 14 & 4 & 89 & RN \\
\hline HEMBL3 & & 5. & 781 & RN \\
\hline HEMBL3361338 & & 5 . & & IRN \\
\hline HEMBL3353264 & 4 & 3.5229 & 236 & TRN \\
\hline HEMBL3 & 1 & 59 & 376 & ГST \\
\hline HFMRI $=$ & & 17 & 81 & TST \\
\hline HEMBL3 & & 5.3872 & & TST \\
\hline HEMBL 313021 & 6 & 9.0 & 211 & TRN \\
\hline IEMBL8 & & & 107 & IRN \\
\hline HEMBL $8 \varepsilon$ & & 861 & 921 & \\
\hline CHEMBL92205 & & & 3.6408 & TRN \\
\hline HEMBL329248 & & 7.699 & 7.1583 & TRN \\
\hline HEMBL 90380 & & 8.5229 & 9326 & {$\left[R_{2}>-1\right.$} \\
\hline MBL & & & 114 & Tru \\
\hline HEMBL9 & & 9.2218 & 3.8737 & \\
\hline CHEMBL43108 & & 9.1549 & 8.4707 & \\
\hline CHEMBL327786 & 216496 & 8.2218 & 9.4303 & - \\
\hline
\end{tabular}

Page 4285 


\begin{tabular}{|c|c|c|c|c|c|}
\hline \multirow[b]{2}{*}{ CHEMBL90183 } & \multicolumn{5}{|c|}{ Supplemental Table S2.txt } \\
\hline & 216496 & 7.5229 & 7.2082 & TRN & \\
\hline CHEMBL91388 & 216496 & 9.3979 & 9.0629 & TRN & \\
\hline CHEMBL89276 & 216496 & 6.5229 & 6.83799 & 9999999999 & TRN \\
\hline CHEMBL 329412 & 216496 & 8.1549 & 8.3236 & TRN & \\
\hline CHEMBL92381 & 216496 & 7.3979 & 7.6965 & TRN & \\
\hline CHEMBL92202 & 216496 & 7.5229 & 8.1931 & TST & \\
\hline CHEMBL90876 & 216496 & 9.1549 & 8.736 & TRN & \\
\hline CHEMBL91724 & 216496 & 7.3979 & 7.5612 & TRN & \\
\hline CHEMBL432057 & 216496 & 9.3979 & 9.7603 & TRN & \\
\hline CHEMBL91249 & 216496 & 9.0458 & 8.9175 & TRN & \\
\hline CHEMBL91715 & 216496 & 9.2218 & 10.087 & TRN & \\
\hline CHEMBL91014 & 216496 & 9.0458 & 8.9753 & TRN & \\
\hline CHEMBL329573 & 216496 & 9.1549 & 9.2636 & TRN & \\
\hline CHEMBL314949 & 216496 & 8.0458 & 9.2256 & TRN & \\
\hline CHEMBL329173 & 216496 & 9.699 & 9.5952 & TRN & \\
\hline CHEMBL91503 & 216496 & 9.5229 & 9.7966 & TRN & \\
\hline CHEMBL330737 & 216496 & 8.699 & 8.9775 & TRN & \\
\hline CHEMBL89820 & 216496 & 8.301 & 8.3916 & TRN & \\
\hline CHEMBL88797 & 216496 & 7.0969 & 9.1591 & TST & \\
\hline CHEMBL329788 & 216496 & 9.3979 & 9.1869 & TRN & \\
\hline CHEMBL330086 & 216496 & 9.1549 & 8.9347 & TRN & \\
\hline CHEMBL92169 & 216496 & 8.301 & 8.3735 & TRN & \\
\hline CHEMBL90176 & 216496 & 9.0 & 8.9012 & TRN & \\
\hline CHEMBL90877 & 216496 & 9.699 & 9.7603 & TRN & \\
\hline CHEMBL90849 & 216496 & 6.2218 & 6.7075 & TRN & \\
\hline CHEMBL 90230 & 216496 & 8.1549 & 8.1817 & TRN & \\
\hline CHEMBL90515 & 216496 & 8.3468 & 7.7663 & TST & \\
\hline CHEMBL 330240 & 216496 & 7.3979 & 7.9874 & TST & \\
\hline CHEMBL93730 & 216496 & 8.699 & 8.9913 & TRN & \\
\hline CHEMBL328711 & 216496 & 8.3979 & 8.2945 & TST & \\
\hline CHEMBL 327882 & 216496 & 8.5229 & 8.5267 & TRN & \\
\hline CHEMBL327234 & 216496 & 10.5229 & 10.087 & TRN & \\
\hline CHEMBL 89395 & 216496 & 6.5229 & 7.1938 & TST & \\
\hline CHEMBL91010 & 216496 & 8.1549 & 7.9223 & TRN & \\
\hline CHEMBL92165 & 216496 & 9.301 & 9.5413 & TRN & \\
\hline CHEMBL 329344 & 216496 & 7.301 & 7.0172 & TST & \\
\hline CHEMBL328987 & 216496 & 6.5229 & 6.62700 & 0000000001 & TST \\
\hline CHEMBL433183 & 216496 & 9.1549 & 9.0709 & TRN & \\
\hline CHEMBL328279 & 216496 & 7.699 & 7.9674 & TST & \\
\hline CHEMBL90546 & 216496 & 8.699 & 9.0757 & TRN & \\
\hline CHEMBL 279859 & 216496 & 5.301 & 6.8724 & TST & \\
\hline CHEMBL90647 & 216496 & 9.5229 & 9.0767 & TRN & \\
\hline CHEMBL88787 & 216496 & 10.0969 & 9.4261 & TRN & \\
\hline CHEMBL 88182 & 216496 & 7.699 & 6.6676 & TST & \\
\hline CHEMBL 327808 & 216496 & 8.0969 & 8.7998 & TST & \\
\hline CHEMBL89810 & 216496 & 8.699 & 8.362 & TRN & \\
\hline CHEMBL1405769 & 688573 & 5.1 & 5.1176 & TRN & \\
\hline CHEMBL1303244 & 688573 & 5.3 & 5.3003 & TRN & \\
\hline
\end{tabular}




\begin{tabular}{|c|c|c|c|c|c|}
\hline & & & & & \\
\hline CHEMBL1350581 & 688573 & 6.1 & 6.1071 & TRN & \\
\hline CHEMBL1326366 & 688573 & 5.85 & 5.1935 & TST & \\
\hline CHEMBL1573401 & 688573 & 5.3 & 5.3087 & TRN & \\
\hline CHEMBL1597014 & 688573 & 4.9 & 4.9026 & TRN & \\
\hline CHEMBL1612870 & 688573 & 6.1 & 6.104 & TRN & \\
\hline CHEMBL1502125 & 688573 & 4.9 & 4.8947 & TRN & \\
\hline CHEMBL1420689 & 688573 & 5.3 & 5.2942 & TRN & \\
\hline CHEMBL1469621 & 688573 & 5.3 & 5.2992 & TRN & \\
\hline CHEMBL1342646 & 688573 & 4.9 & 4.4651 & TST & \\
\hline CHEMBL1535448 & 688573 & 5.4 & 5.3935 & TRN & \\
\hline CHEMBL1565991 & 688573 & 6.2 & 6.1951 & TRN & \\
\hline CHEMBL 7033 & 688573 & 4.9 & 4.8924 & TRN & \\
\hline CHEMBL1304777 & 688573 & 5.4 & 5.38899 & 9999999999 & TRN \\
\hline CHEMBL1482555 & 688573 & 4.9 & 4.90300 & 00000000005 & TRN \\
\hline CHEMBL1973866 & 688573 & 6.0 & 5.6724 & TST & \\
\hline CHEMBL1365395 & 688573 & 5.5 & 5.5968 & TST & \\
\hline CHEMBL1607475 & 688573 & 4.9 & 5.1599 & TST & \\
\hline CHEMBL1561287 & 688573 & 5.35 & 5.3309 & TRN & \\
\hline CHEMBL1578026 & 688573 & 4.9 & 4.9096 & TRN & \\
\hline CHEMBL1391856 & 688573 & 5.85 & 5.1851 & TST & \\
\hline CHEMBL1568538 & 688573 & 4.9 & 4.891 & TRN & \\
\hline CHEMBL1308942 & 688573 & 5.2 & 5.1865 & TRN & \\
\hline CHEMBL1511519 & 688573 & 5.3 & 5.3049 & TRN & \\
\hline CHEMBL1372818 & 688573 & 5.3 & 5.3349 & TRN & \\
\hline CHEMBL1387624 & 688573 & 5.45 & 5.4576 & TRN & \\
\hline CHEMBL1582549 & 688573 & 4.9 & 5.0191 & TST & \\
\hline CHEMBL1524849 & 688573 & 4.8 & 4.7867 & TRN & \\
\hline CHEMBL1579418 & 688573 & 6.1 & 6.1069 & TRN & \\
\hline CHEMBL1310978 & 688573 & 4.85 & 4.8837 & TRN & \\
\hline CHEMBL1536015 & 688573 & 5.0 & 5.0038 & TRN & \\
\hline CHEMBL1595155 & 688573 & 5.0 & 4.9836 & TRN & \\
\hline CHEMBL1585266 & 688573 & 5.1 & 5.1053 & TRN & \\
\hline CHEMBL1389117 & 688573 & 6.4 & 5.6936 & TST & \\
\hline CHEMBL1449096 & 688573 & 5.1 & 5.0945 & TRN & \\
\hline CHEMBL1341815 & 688573 & 5.8 & 5.7954 & TRN & \\
\hline CHEMBL1508848 & 688573 & 5.2 & 6.216 & TST & \\
\hline CHEMBL1574971 & 688573 & 6.0 & 5.974 & TRN & \\
\hline CHEMBL1546773 & 688573 & 5.0 & 5.3405 & TST & \\
\hline CHEMBL1508330 & 688573 & 5.55 & 5.5563 & TRN & \\
\hline CHEMBL1311029 & 688573 & 5.5 & 5.5052 & TRN & \\
\hline CHEMBL1374249 & 688573 & 5.0 & 4.995 & TRN & \\
\hline CHEMBL1347130 & 688573 & 5.9 & 5.9039 & TRN & \\
\hline CHEMBL1407256 & 688573 & 5.4 & 5.3865 & TRN & \\
\hline CHEMBL16687 & 688573 & 4.8 & 4.7947 & TRN & \\
\hline CHEMBL1550717 & 688573 & 5.9 & 5.9091 & TST & \\
\hline CHEMBL1526559 & 688573 & 5.3 & 5.2932 & TRN & \\
\hline CHEMBL1558852 & 688573 & 4.9 & 4.9135 & TRN & \\
\hline CHEMBL1463711 & 688573 & 5.0 & 5.2624 & TST & \\
\hline & & & & 4287 & \\
\hline
\end{tabular}




\begin{tabular}{|c|c|c|c|c|c|}
\hline \multicolumn{6}{|c|}{ Supplemental Table S2.txt } \\
\hline CHEMBL1414660 & 688573 & 5.8 & 5.814 & TRN & \\
\hline CHEMBL1538833 & 688573 & 4.9 & 4.8961 & TRN & \\
\hline CHEMBL1455600 & 688573 & 5.9 & 5.8903 & TRN & \\
\hline CHEMBL395808 & 688573 & 5.5 & 5.4935 & TRN & \\
\hline CHEMBL1527817 & 688573 & 6.0 & 6.0151 & TRN & \\
\hline CHEMBL1353216 & 688573 & 5.55 & 5.5417 & TRN & \\
\hline CHEMBL1419089 & 688573 & 4.6 & 4.6086 & TRN & \\
\hline CHEMBL1509321 & 688573 & 6.2 & 6.2047 & TRN & \\
\hline CHEMBL1497712 & 688573 & 6.15 & 6.1657 & TRN & \\
\hline CHEMBL470881 & 688573 & 6.8 & 5.9776 & TST & \\
\hline CHEMBL1419387 & 688573 & 5.4 & 5.3917 & TRN & \\
\hline CHEMBL1577585 & 688573 & 5.8 & 5.8101 & TRN & \\
\hline CHEMBL1568610 & 688573 & 5.5 & 5.5058 & TRN & \\
\hline CHEMBL 3208184 & 688573 & 5.35 & 5.3618 & TST & \\
\hline CHEMBL1337016 & 688573 & 4.9 & 4.8977 & TRN & \\
\hline CHEMBL430893 & 688573 & 7.5498 & 7.5478 & TRN & \\
\hline CHEMBL1332683 & 688573 & 6.2 & 6.2014 & TRN & \\
\hline CHEMBL1602246 & 688573 & 5.0 & 4.9994 & TRN & \\
\hline CHEMBL1479324 & 688573 & 4.9 & 5.558 & TST & \\
\hline CHEMBL1548490 & 688573 & 5.4 & 5.3693 & TRN & \\
\hline CHEMBL1530911 & 688573 & 5.85 & 5.751 & TST & \\
\hline CHEMBL1599589 & 688573 & 5.7 & 5.6946 & TRN & \\
\hline CHEMBL1377679 & 688573 & 4.9 & 5.6631 & TST & \\
\hline CHEMBL1304099 & 688573 & 4.9 & 5.1862 & TST & \\
\hline CHEMBL1560552 & 688573 & 4.9 & 4.9026 & TRN & \\
\hline CHEMBL1324221 & 688573 & 5.4 & 5.4027 & TRN & \\
\hline CHEMBL1305639 & 688573 & 5.65 & 5.6396 & TRN & \\
\hline CHEMBL88147 & 688573 & 8.0506 & 8.0463 & TRN & \\
\hline CHEMBL1412930 & 688573 & 6.5 & 6.5 & TRN & \\
\hline CHEMBL1449105 & 688573 & 8.1487 & 5.4376 & TST & \\
\hline CHEMBL1550165 & 688573 & 5.9 & 5.8842 & TRN & \\
\hline CHEMBL1537654 & 688573 & 5.7 & 5.7187 & TRN & \\
\hline CHEMBL1391454 & 688573 & 4.9 & 5.7572 & TST & \\
\hline CHEMBL1469864 & 688573 & 5.35 & 5.3492 & TRN & \\
\hline CHEMBL1452841 & 688573 & 4.85 & 4.5213 & TST & \\
\hline CHEMBL1524804 & 688573 & 5.5 & 5.5212 & TRN & \\
\hline CHEMBL1457951 & 688573 & 4.9 & 4.9031 & TRN & \\
\hline CHEMBL1344072 & 688573 & 4.9 & 4.9213 & TRN & \\
\hline CHEMBL1564501 & 688573 & 6.3 & 5.2256 & TST & \\
\hline CHEMBL1325911 & 688573 & 5.5 & 5.49799 & 9999999999 & TRN \\
\hline CHEMBL1416062 & 688573 & 6.9 & 6.9015 & TRN & \\
\hline CHEMBL1599856 & 688573 & 4.9 & 4.9031 & TRN & \\
\hline CHEMBL1600958 & 688573 & 5.9 & 5.1737 & TST & \\
\hline CHEMBL1360283 & 688573 & 5.2 & 5.1784 & TRN & \\
\hline CHEMBL1441893 & 688573 & 4.9 & 4.8899 & TRN & \\
\hline CHEMBL1303907 & 688573 & 4.85 & 4.8475 & TRN & \\
\hline CHEMBL1541227 & 688573 & 4.8 & 5.3948 & TST & \\
\hline CHEMBL1604912 & 688573 & 5.35 & 5.6044 & TST & \\
\hline
\end{tabular}




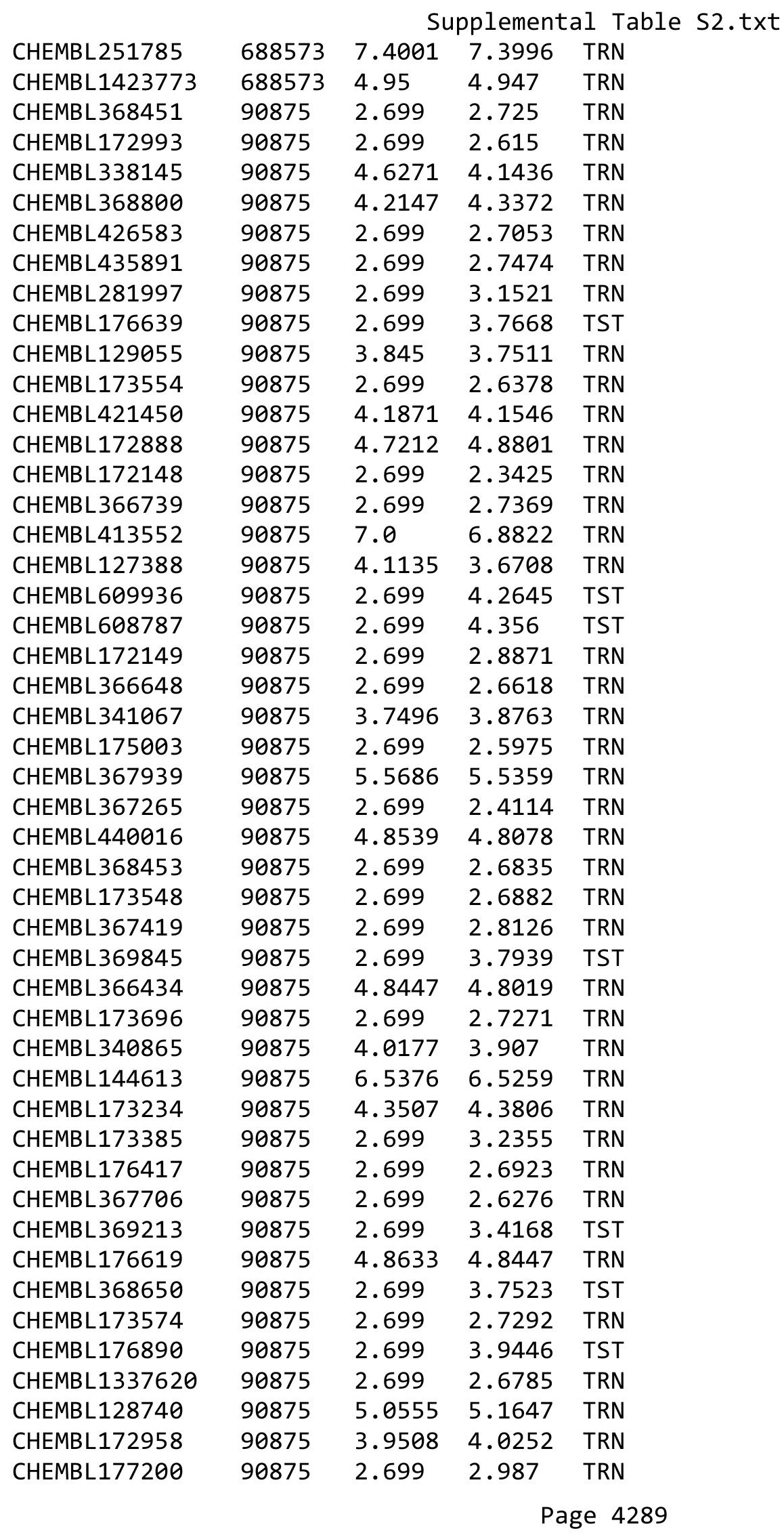




\begin{tabular}{|c|c|c|c|c|}
\hline & & & pplement & al Table S \\
\hline CHEMBL538398 & 90875 & 2.699 & 2.7339 & TRN \\
\hline CHEMBL176555 & 90875 & 2.699 & 2.6764 & TRN \\
\hline CHEMBL369592 & 90875 & 2.699 & 2.7218 & TRN \\
\hline CHEMBL175107 & 90875 & 2.699 & 2.656 & TRN \\
\hline CHEMBL319244 & 90875 & 5.0 & 5.1152 & TRN \\
\hline CHEMBL173691 & 90875 & 2.699 & 2.5631 & TST \\
\hline CHEMBL176775 & 90875 & 2.699 & 2.8378 & TST \\
\hline CHEMBL368602 & 90875 & 2.699 & 4.0552 & TST \\
\hline CHEMBL173097 & 90875 & 2.699 & 4.4526 & TST \\
\hline CHEMBL367557 & 90875 & 2.699 & 3.8321 & TST \\
\hline CHEMBL366634 & 90875 & 2.699 & 1.5588 & TST \\
\hline CHEMBL366481 & 90875 & 2.699 & 3.9241 & TST \\
\hline CHEMBL174460 & 90875 & 4.0969 & 4.1809 & TST \\
\hline CHEMBL391444 & 456072 & 3.1681 & 2.8663 & TRN \\
\hline CHEMBL239056 & 456072 & 4.0 & 3.8343 & TRN \\
\hline CHEMBL240753 & 456072 & 3.0 & 3.0721 & TRN \\
\hline CHEMBL240512 & 456072 & 3.7077 & 3.5829 & TST \\
\hline CHEMBL239274 & 456072 & 4.1079 & 4.0205 & TST \\
\hline CHEMBL401051 & 456072 & 3.0 & 3.1309 & TRN \\
\hline CHEMBL391729 & 456072 & 3.8239 & 3.7431 & TRN \\
\hline CHEMBL239244 & 456072 & 4.1938 & 3.9984 & TRN \\
\hline CHEMBL240548 & 456072 & 3.0 & 3.5151 & TRN \\
\hline CHEMBL394683 & 456072 & 3.0 & 3.8914 & TRN \\
\hline CHEMBL240975 & 456072 & 3.0 & 3.2084 & TRN \\
\hline CHEMBL240712 & 456072 & 3.7932 & 3.7139 & TST \\
\hline CHEMBL239275 & 456072 & 3.0 & 3.6934 & TST \\
\hline CHEMBL240547 & 456072 & 4.7212 & 4.3821 & TRN \\
\hline CHEMBL240974 & 456072 & 4.0 & 3.6639 & TRN \\
\hline CHEMBL 240543 & 456072 & 4.041 & 3.9852 & TRN \\
\hline CHEMBL240330 & 456072 & 3.0 & 3.658 & TRN \\
\hline CHEMBL276600 & 456072 & 3.0 & 2.506 & TRN \\
\hline CHEMBL239485 & 456072 & 4.7447 & 4.5067 & TRN \\
\hline CHEMBL399211 & 456072 & 3.0 & 3.1797 & TRN \\
\hline CHEMBL391423 & 456072 & 4.0969 & 3.6966 & TRN \\
\hline CHEMBL395448 & 456072 & 4.284 & 4.1554 & TRN \\
\hline CHEMBL240511 & 456072 & 4.0757 & 4.0174 & TRN \\
\hline CHEMBL241184 & 456072 & 3.0 & 3.6931 & TRN \\
\hline CHEMBL241597 & 456072 & 5.4815 & 5.5006 & TRN \\
\hline CHEMBL 240331 & 456072 & 4.0605 & 3.7546 & TRN \\
\hline CHEMBL239696 & 456072 & 4.4949 & 4.4149 & TRN \\
\hline CHEMBL240329 & 456072 & 4.3768 & 4.40600 & 0000000001 \\
\hline CHEMBL395590 & 456072 & 2.0 & 3.1991 & TRN \\
\hline CHEMBL401049 & 456072 & 4.7959 & 4.7255 & TRN \\
\hline CHEMBL 238632 & 456072 & 3.0 & 3.5218 & TRN \\
\hline CHEMBL240332 & 456072 & 3.71 & 3.903 & TST \\
\hline CHEMBL239483 & 456072 & 4.1308 & 4.1543 & TRN \\
\hline CHEMBL394650 & 456072 & 4.5376 & 4.494 & TRN \\
\hline CHEMBL239484 & 456072 & 4.0223 & 3.6702 & TRN \\
\hline
\end{tabular}




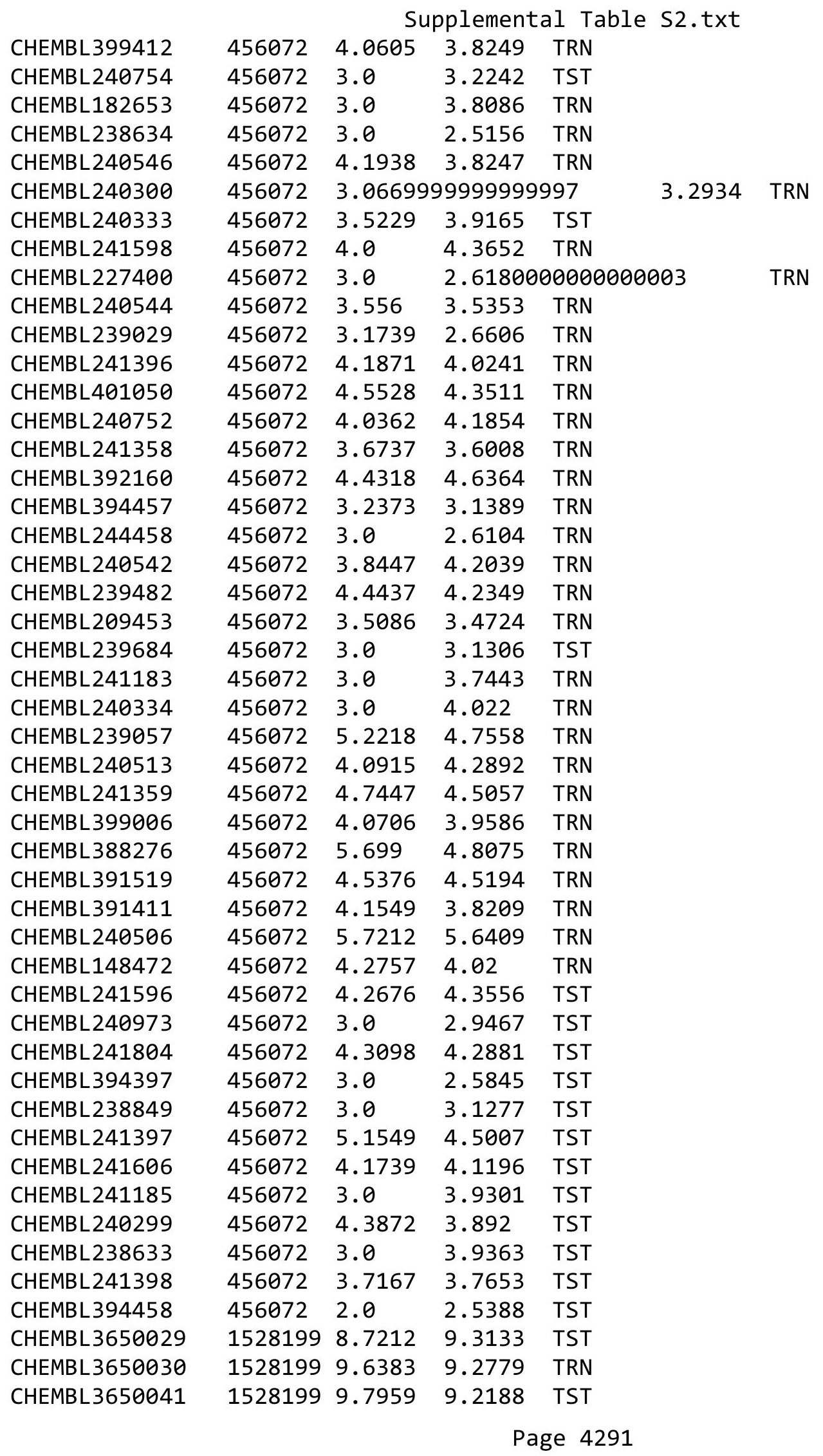


Supplemental Table S2.txt

\begin{tabular}{|c|c|c|c|c|}
\hline . & 28199 & & & \\
\hline & 528199 & 9.0706 & 9.4868 & \\
\hline 7287 & & & & \\
\hline AEMBL & 99 & & & \\
\hline HEMBL364 & 528199 & 586 & & \\
\hline HEMBL3650032 & 528199 & 9.4949 & 0966 & \\
\hline HEMBL & 199 & & 9766 & \\
\hline 73 & & 539 & & \\
\hline HEMBL36 & 528199 & 8.699 & 0566 & \\
\hline HEMBL 365 & 528199 & 559 & 3074 & \\
\hline AEMBL364 & 528199 & 9.4202 & 5302 & \\
\hline IEMBL36 & 99 & 85 & 841 & \\
\hline AEMBL3 & & & & \\
\hline HEMBL36 & 528199 & 938 & 1986 & \\
\hline AEMBL36 & 99 & 8 & 7716 & \\
\hline AEMBL36 & 99 & 9. & 01 & \\
\hline AEMBL3 & 9 & 9. & 37 & \\
\hline HEMBL36 & & & & \\
\hline HEMBL3E & 99 & 8. & & \\
\hline AEMBL36 & 99 & & & \\
\hline HEMBL= & 99 & 7 & 67 & RIV \\
\hline HEMBL: & 9 & 9. & 33 & RN \\
\hline HEMBL & & 78 & & \\
\hline 82 & & 9.3768 & & \\
\hline AEMBL36 & & & & I RIV \\
\hline HEMBL3 & 99 & & 35 & RN \\
\hline HEMBL & & & 27 & 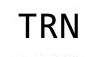 \\
\hline HFMRI & 99 & 65 & 58 & \\
\hline HEMBL36 & & & & in \\
\hline HEMBL 365 & 52 & & & I RN \\
\hline HEMBL36 & & & 01 & RN \\
\hline HEMBL & 9 & 51 & 72 & TRN \\
\hline HEMBL. & 9 & & 71 & TRN \\
\hline HEMBL 36 & & & 431 & IR \\
\hline HEMBL 364 & 528 & 8.8861 & 711 & 「RN \\
\hline HEMBL3 & 9 & & 16 & 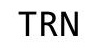 \\
\hline HCMP - & & & & \\
\hline & & & 3965 & IR \\
\hline HEMBL 36 & 528199 & 9.2291 & 3347 & $\mathrm{TR}$ \\
\hline AEMBL3 & 528 & & 612 & -7 \\
\hline HEMBL36 & 9 & 861 & 365 & \\
\hline CHEMBL 36 & & & & ГST \\
\hline HEMBL36 & 99 & 8.8861 & 8.7986 & TST \\
\hline AEMBL36 & 528199 & 8.3768 & 0078 & TS \\
\hline 1 & 99 & & 1411 & TS \\
\hline HEMBL3 & & 9.0044 & 3302 & \\
\hline HEMBL 36 & 5281 & 9.6383 & 9.7066 & \\
\hline THEMBL3650031 & 152819 & 10.1938 & 9.7138 & ГST \\
\hline
\end{tabular}

Page 4292 
Supplemental Table S2.txt

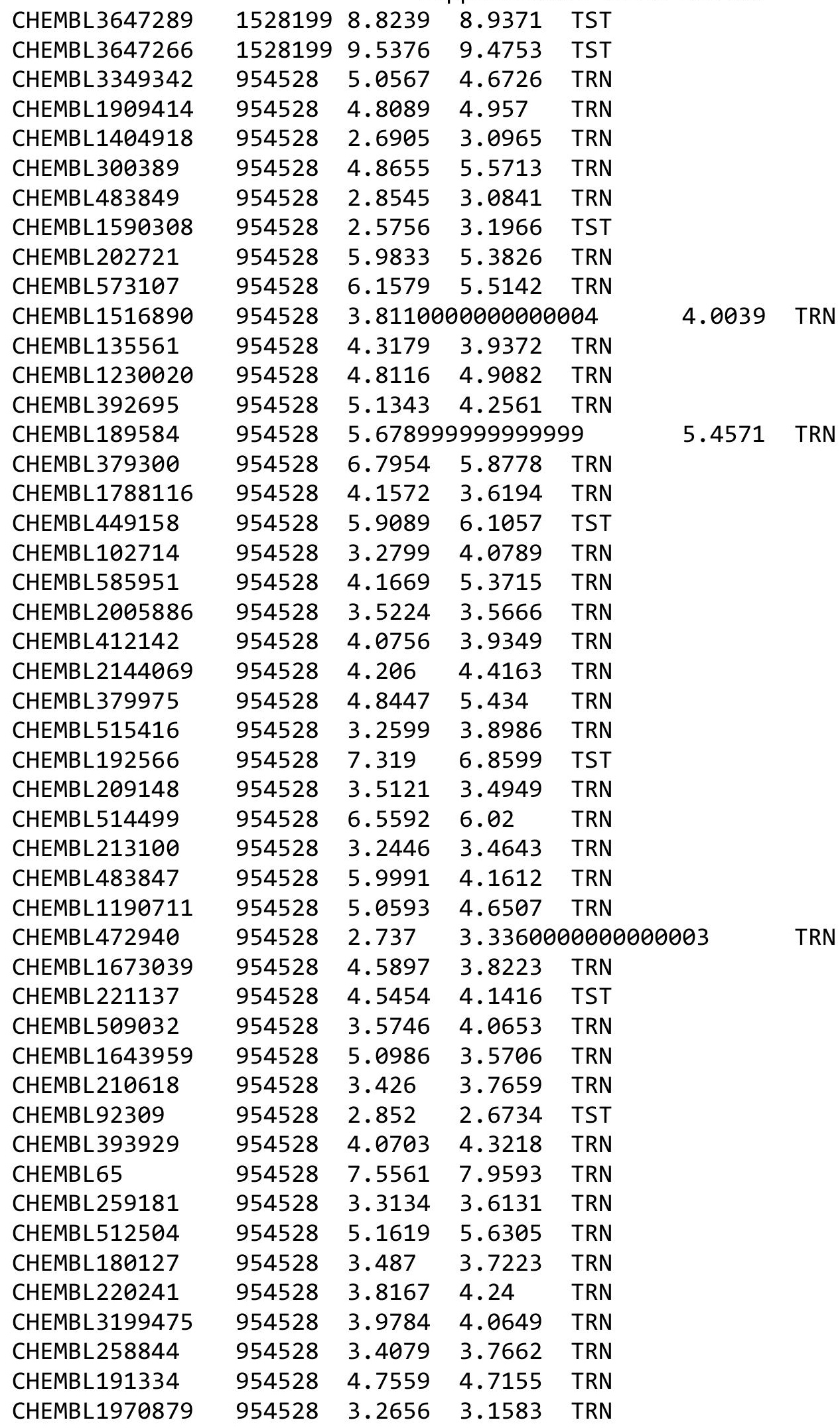

Page 4293 


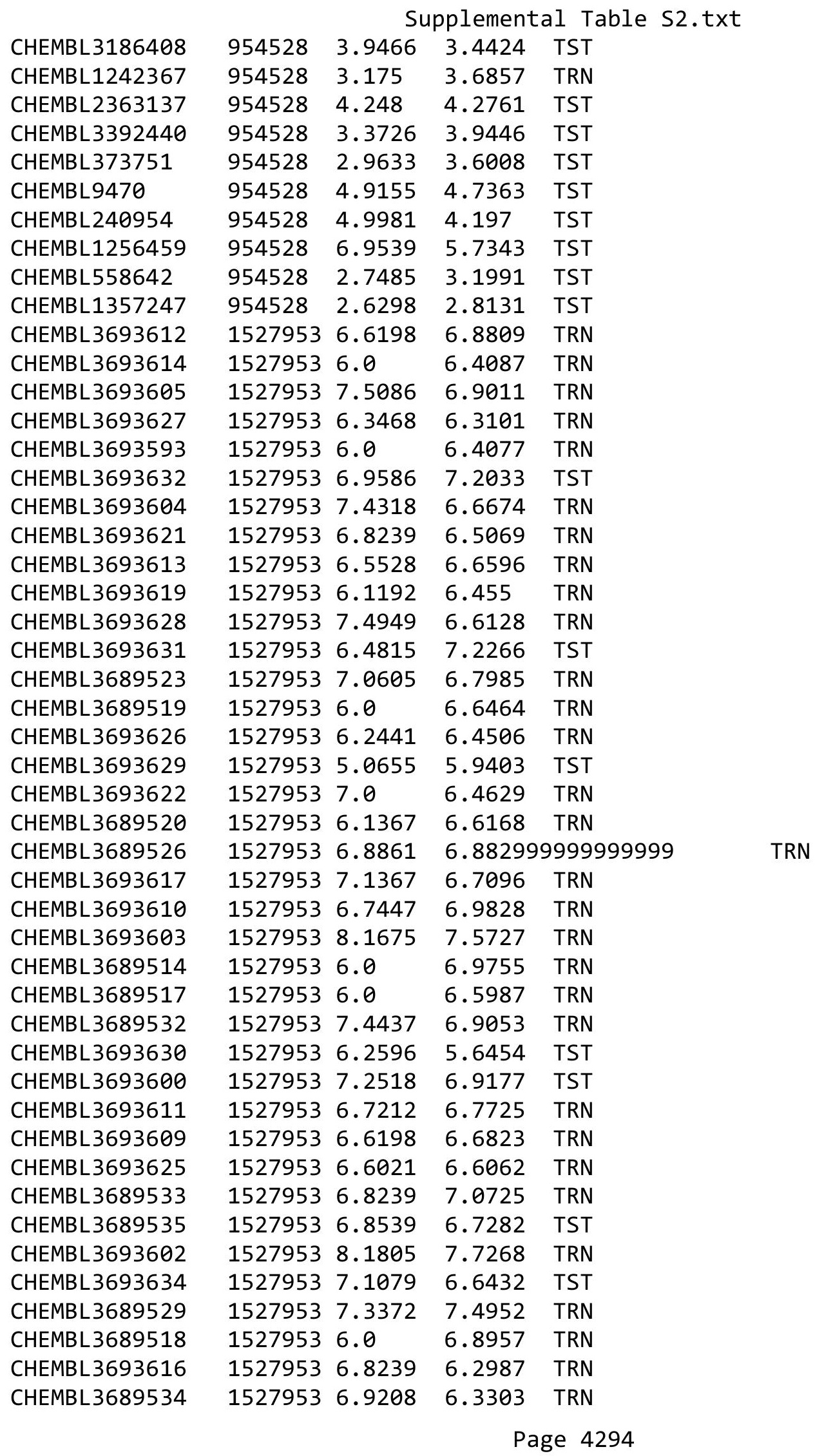


Supplemental Table S2.txt

\begin{tabular}{|c|c|c|c|c|c|}
\hline CHEMBL 3689527 & 1527953 & 7.3279 & 6.5906 & TRN & \\
\hline CHEMBL 3693599 & 1527953 & 8.0 & 7.0044 & TRN & \\
\hline CHEMBL 3693623 & 1527953 & 6.3372 & 6.5069 & TRN & \\
\hline CHEMBL 3693633 & 1527953 & 6.4559 & 6.8192 & TST & \\
\hline CHEMBL3689516 & 1527953 & 6.0 & 6.7602 & TRN & \\
\hline CHEMBL 3693592 & 1527953 & 7.1739 & 6.3408 & TRN & \\
\hline CHEMBL 3689515 & 1527953 & 6.0 & 6.7527 & TRN & \\
\hline CHEMBL 3689531 & 1527953 & 6.0 & 6.7338 & TRN & \\
\hline CHEMBL 3693595 & 1527953 & 6.9586 & 6.5882 & TRN & \\
\hline CHEMBL 3693598 & 1527953 & 6.6383 & 6.6558 & TRN & \\
\hline CHEMBL 3693608 & 1527953 & 6.8861 & 7.0177 & TRN & \\
\hline CHEMBL 3693615 & 1527953 & 6.6021 & 7.1959 & TRN & \\
\hline CHEMBL 3689522 & 1527953 & 7.2366 & 7.337999 & 9999999999 & TRN \\
\hline CHEMBL 3693607 & 1527953 & 6.1871 & 6.3769 & TRN & \\
\hline CHEMBL 3689525 & 1527953 & 6.8861 & 7.0135 & TRN & \\
\hline CHEMBL 3693606 & 1527953 & 7.8539 & 7.3576 & TRN & \\
\hline CHEMBL 3689524 & 1527953 & 6.3872 & 6.696000 & 0000000001 & TRN \\
\hline CHEMBL 3689530 & 1527953 & 6.3098 & 6.5366 & TST & \\
\hline CHEMBL 3693596 & 1527953 & 6.7696 & 5.7255 & TST & \\
\hline CHEMBL 3689536 & 1527953 & 7.0458 & 7.2179 & TST & \\
\hline CHEMBL 3693597 & 1527953 & 7.0362 & 6.6645 & TST & \\
\hline CHEMBL 3693618 & 1527953 & 6.7447 & 6.5375 & TST & \\
\hline CHEMBL 3693620 & 1527953 & 7.3188 & 6.5039 & TST & \\
\hline CHEMBL 3693601 & 1527953 & 6.0 & 7.2436 & TST & \\
\hline CHEMBL 3693624 & 1527953 & 7.8861 & 6.5375 & TST & \\
\hline CHEMBL1796968 & 752640 & 3.64399 & 999999999 & 4.1943 & TST \\
\hline CHEMBL1796932 & 752640 & 5.3468 & 5.2285 & TRN & \\
\hline CHEMBL1796784 & 752640 & 4.699 & 4.57 & TRN & \\
\hline CHEMBL1796959 & 752640 & 4.7447 & 5.4182 & TST & \\
\hline CHEMBL 1796950 & 752640 & 5.4437 & 5.5198 & TRN & \\
\hline CHEMBL1796964 & 752640 & 6.6198 & 6.6057 & TRN & \\
\hline CHEMBL1796970 & 752640 & 5.3768 & 5.8268 & TST & \\
\hline CHEMBL1796796 & 752640 & 4.7696 & 4.9535 & TRN & \\
\hline CHEMBL1796936 & 752640 & 5.1024 & 5.0263 & TRN & \\
\hline CHEMBL1796967 & 752640 & 7.2218 & 5.196000 & 0000000001 & TS \\
\hline CHEMBL1796942 & 752640 & 5.7447 & 5.7055 & TRN & \\
\hline CHEMBL1796956 & 752640 & 6.5686 & 6.6607 & TRN & \\
\hline CHEMBL1796789 & 752640 & 4.699 & 4.7431 & TRN & \\
\hline CHEMBL1796798 & 752640 & 5.1675 & 5.3212 & TRN & \\
\hline CHEMBL1796962 & 752640 & 5.6021 & 5.3813 & TRN & \\
\hline CHEMBL1796797 & 752640 & 4.9586 & 5.0867 & TRN & \\
\hline CHEMBL1796790 & 752640 & 6.0 & 5.7382 & TRN & \\
\hline CHEMBL1796794 & 752640 & 4.5086 & 4.3211 & TRN & \\
\hline CHEMBL1796957 & 752640 & 4.3872 & 4.2883 & TRN & \\
\hline CHEMBL1796947 & 752640 & 3.2076 & 3.4333 & TRN & \\
\hline CHEMBL1796965 & 752640 & 3.6478 & 3.4706 & TRN & \\
\hline CHEMBL1796785 & 752640 & 4.4815 & 4.5298 & TRN & \\
\hline CHEMBL1796955 & 752640 & 5.699 & 5.7628 & TRN & \\
\hline
\end{tabular}


Supplemental Table S2.txt

\begin{tabular}{|c|c|c|c|c|}
\hline IEN & 0 & 6 & & \\
\hline HEMBL1796969 & 52640 & 5.6778 & 5.6641 & \\
\hline HEMBL1796944 & 2640 & 8239 & & \\
\hline HEMBL1796946 & 2640 & 6021 & & \\
\hline HEMBL1796960 & 52640 & 6.0 & & \\
\hline AEMBL1795346 & 52640 & 4.8861 & 9016 & \\
\hline HEMBL1796938 & 52640 & & 355 & \\
\hline AEMBL1796939 & 52640 & & & \\
\hline AEMBL1796953 & 52640 & 5.1805 & 1339 & \\
\hline HEMBL1796954 & 52640 & 3665 & .4329 & \\
\hline HEMBL1796933 & 52640 & 4.2924 & 4.379 & \\
\hline HEMBL1796792 & 52640 & .2291 & 12 & \\
\hline HEMBL1796949 & & 5.5229 & & \\
\hline HEMBL1796971 & 52640 & 5.2924 & 5.2009 & \\
\hline HEMBL1796786 & 52640 & 4.3872 & 25 & \\
\hline HEMBL1796787 & 52640 & 4.7696 & 85 & \\
\hline AEMBL1796961 & 52640 & 576 & 13 & \\
\hline HEMBL1796963 & 52640 & 815 & & \\
\hline AEMBL1796795 & 52640 & 4.4685 & 4.6087 & \\
\hline HEMBL1796791 & 640 & 24 & & \\
\hline HEMBL1 & 40 & 924 & 33 & \\
\hline HEMBL1 & 540 & 229 & 04 & \\
\hline HEMBL1 & 40 & 4. & 86 & \\
\hline HEMBL1796952 & 52640 & 3.8861 & 3.7583 & \\
\hline HEMBL1796966 & & & & \\
\hline HEMBL1796788 & 52640 & 4.8861 & 494 & \\
\hline HEMBL1796793 & 640 & 57 & 65 & \\
\hline HEMBL 2440523 & 92728 & 2 . & 89 & \\
\hline HEMBL2440562 & 92728 & 4.3947 & & \\
\hline HEMBL2440544 & 28 & 2.9031 & 284 & \\
\hline HEMBL2334498 & 92728 & 655 & 635 & \\
\hline HEMBL 2440 & 92728 & 4. & 49 & \\
\hline HEMBL2440560 & 92728 & 3 . & 549 & \\
\hline HEMBL 313833 & 92728 & 4.556 & 0903 & \\
\hline HEMBL2440522 & 92728 & 2.9031 & 3.1079 & \\
\hline HEMBL2440552 & 92728 & 2.9031 & 5907 & \\
\hline HEMBL2440538 & 992728 & 4 . & 4.2915 & \\
\hline HEMBL2440574 & 992728 & 4.8239 & 4.2836 & \\
\hline HEMBL2440531 & 92728 & 2.9031 & 2.9998 & \\
\hline HEMBL2334484 & 92728 & 4.4841 & 3.9992 & \\
\hline HEMBL2440550 & 992728 & 2.9031 & 4.1964 & \\
\hline CHEMBL 2440575 & 992728 & 4.52 & 3.7058 & \\
\hline CHEMBL2440576 & 992728 & 4.327 & 3.6279 & \\
\hline HEMBL2440546 & 992728 & 2.9031 & 4.3693 & \\
\hline EMBL2 & 992728 & 2.9031 & 3.4215 & \\
\hline HEMBL 2440570 & 992728 & 4.2588 & 3.6073 & \\
\hline CHEMBL 2440528 & 992728 & 2.9031 & 3.0884 & \\
\hline CHEMBL2334191 & 992728 & 4.71 & 3.7106 & \\
\hline
\end{tabular}

Page 4296 
Supplemental Table S2.txt

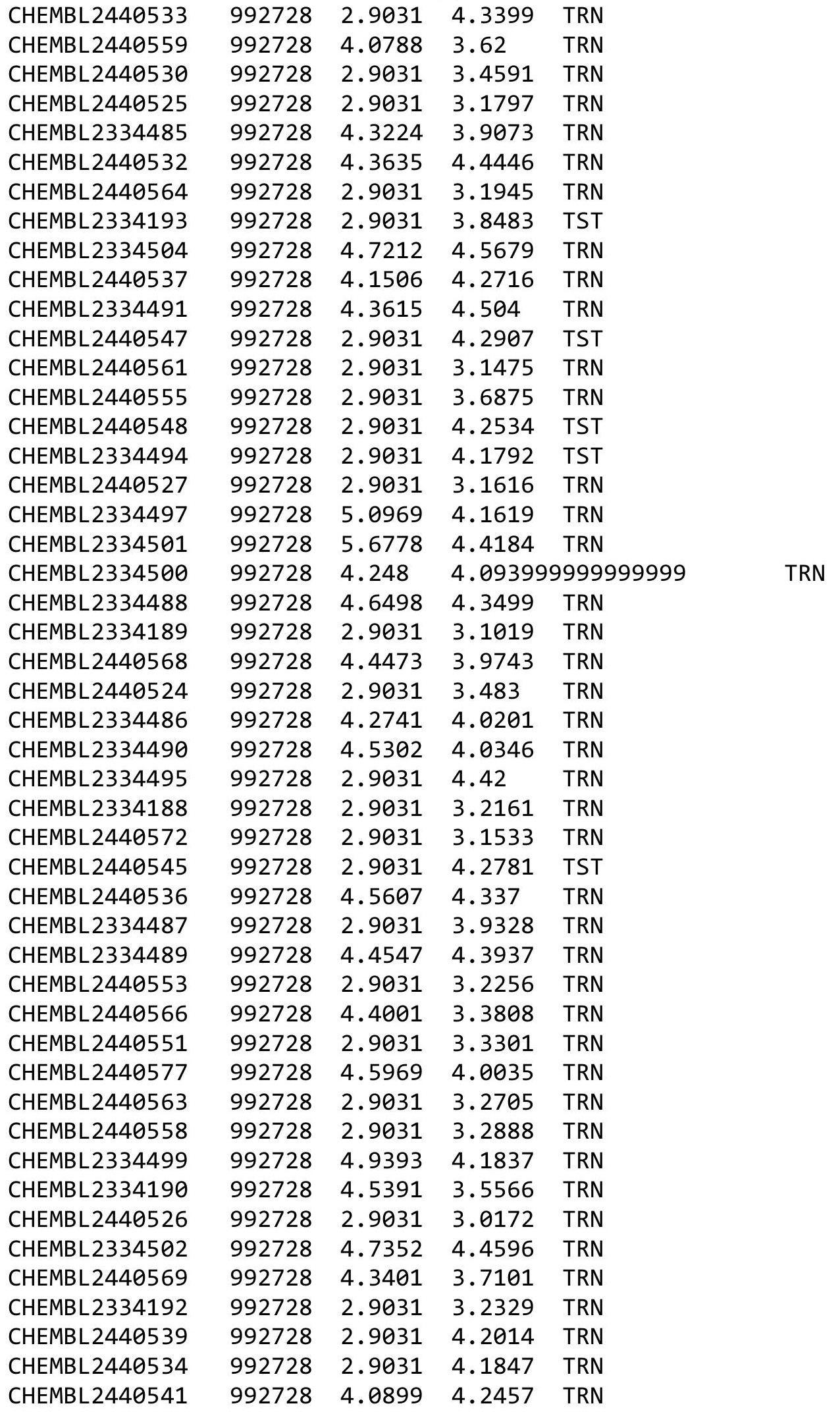

Page 4297 


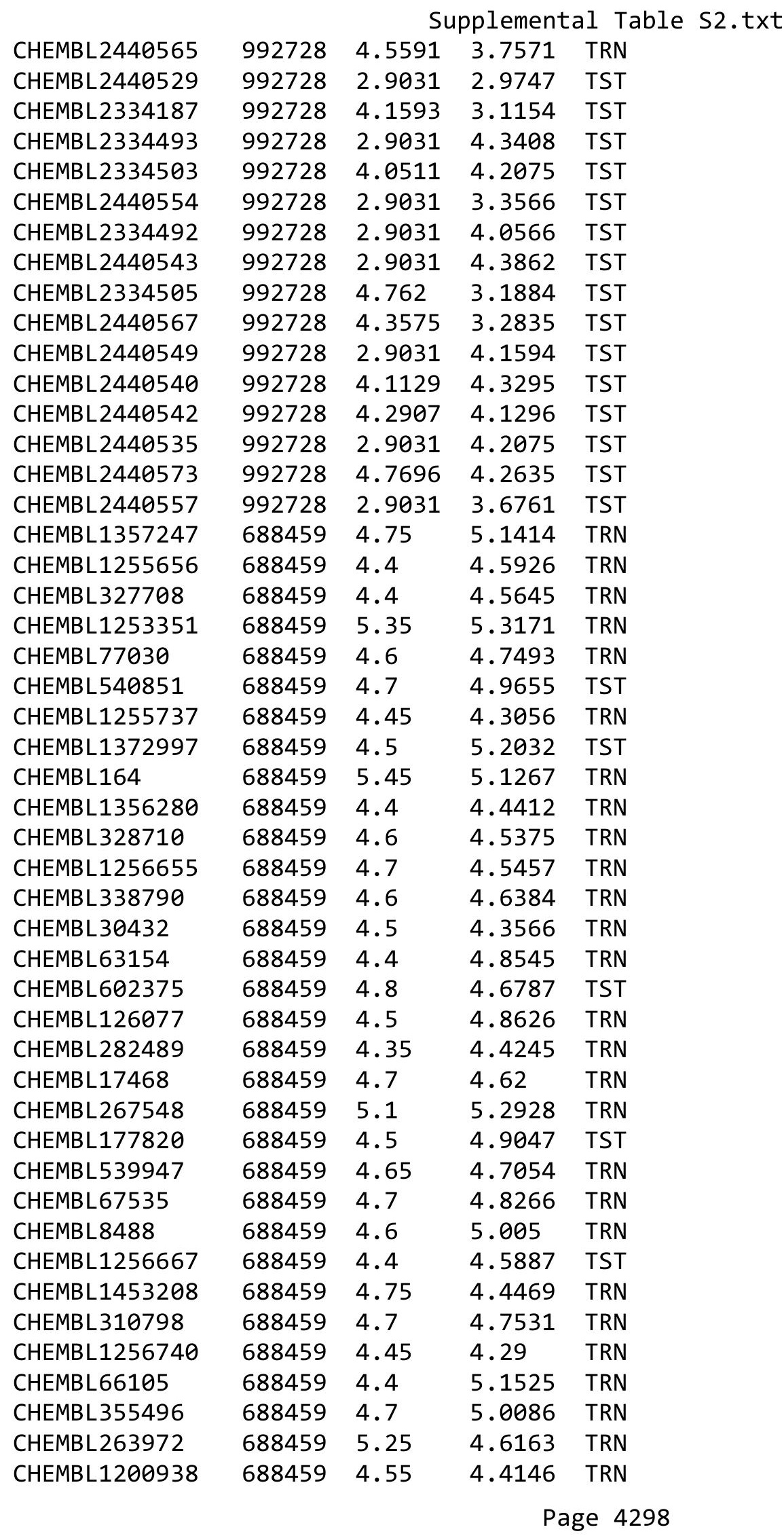




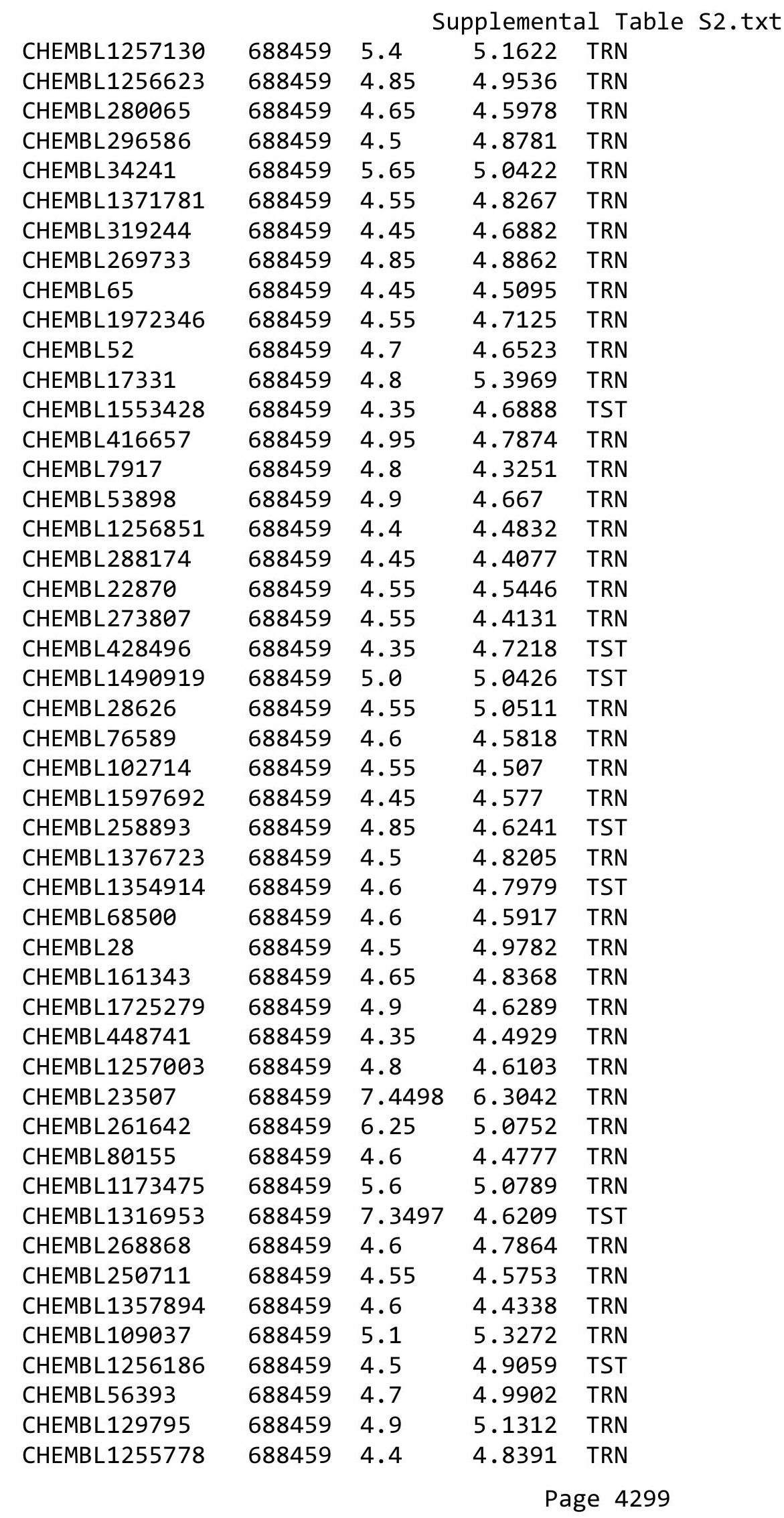




\begin{tabular}{|c|c|c|c|c|c|}
\hline \multicolumn{6}{|c|}{ Supplemental Table S2.txt } \\
\hline CHEMBL68534 & 688459 & 5.35 & 4.8867 & TRN & \\
\hline CHEMBL1256148 & 688459 & 5.1 & 4.4819 & TRN & \\
\hline CHEMBL97760 & 688459 & 4.55 & 4.8068 & TRN & \\
\hline CHEMBL1365553 & 688459 & 5.05 & 4.8545 & TRN & \\
\hline CHEMBL1255653 & 688459 & 4.65 & 4.9237 & TST & \\
\hline CHEMBL1435381 & 688459 & 7.3497 & 4.5746 & TST & \\
\hline CHEMBL546257 & 688459 & 4.55 & 4.2603 & TST & \\
\hline CHEMBL418333 & 688459 & 4.6 & 4.8614 & TST & \\
\hline CHEMBL 26138 & 688459 & 4.7 & 4.6116 & TST & \\
\hline CHEMBL605003 & 688459 & 5.0 & 4.9019 & TST & \\
\hline CHEMBL1605916 & 688459 & 5.15 & 4.6112 & TST & \\
\hline CHEMBL578741 & 688459 & 4.6 & 4.7229 & TST & \\
\hline CHEMBL 2374058 & 688459 & 4.75 & 4.5565 & TST & \\
\hline CHEMBL1256813 & 688459 & 4.35 & 4.9757 & TST & \\
\hline CHEMBL288096 & 688459 & 4.7 & 4.5284 & TST & \\
\hline CHEMBL289277 & 688459 & 4.55 & 4.9666 & TST & \\
\hline CHEMBL1593765 & 688459 & 7.4001 & 4.4622 & TST & \\
\hline CHEMBL 207062 & 370710 & 8.5376 & 8.3347 & TRN & \\
\hline CHEMBL208496 & 370710 & 5.5229 & 5.4981 & TRN & \\
\hline CHEMBL211517 & 370710 & 6.8125 & 6.2576 & TST & \\
\hline CHEMBL209589 & 370710 & 5.5229 & 5.5447 & TRN & \\
\hline CHEMBL 208830 & 370710 & 7.6234 & 7.9319 & TRN & \\
\hline CHEMBL208691 & 370710 & 7.3872 & 7.3371 & TRN & \\
\hline CHEMBL 377975 & 370710 & 7.3737 & 7.5171 & TRN & \\
\hline CHEMBL 212222 & 370710 & 8.9957 & 8.93100 & 0000000001 & TRN \\
\hline CHEMBL 207078 & 370710 & 9.585 & 9.5909 & TRN & \\
\hline CHEMBL 212278 & 370710 & 5.5229 & 6.194 & TST & \\
\hline CHEMBL 209565 & 370710 & 5.5229 & 5.5 & TRN & \\
\hline CHEMBL211351 & 370710 & 9.2676 & 9.2349 & TRN & \\
\hline CHEMBL 212730 & 370710 & 9.2757 & 9.4029 & TRN & \\
\hline CHEMBL209664 & 370710 & 9.1427 & 9.2345 & TRN & \\
\hline CHEMBL209057 & 370710 & 9.2218 & 9.2133 & TRN & \\
\hline CHEMBL209098 & 370710 & 7.0214 & 7.0917 & TRN & \\
\hline CHEMBL 378760 & 370710 & 5.5229 & 5.5755 & TRN & \\
\hline CHEMBL 210908 & 370710 & 9.4559 & 9.2337 & TRN & \\
\hline CHEMBL 210410 & 370710 & 8.1308 & 8.485 & TRN & \\
\hline CHEMBL209932 & 370710 & 5.5229 & 5.1443 & TST & \\
\hline CHEMBL 208610 & 370710 & 9.4685 & 9.3007 & TRN & \\
\hline CHEMBL 208650 & 370710 & 9.7696 & 9.7564 & TRN & \\
\hline CHEMBL 211738 & 370710 & 7.0747 & 6.6259 & TST & \\
\hline CHEMBL 379172 & 370710 & 5.5229 & 5.4457 & TRN & \\
\hline CHEMBL 379741 & 370710 & 7.8125 & 6.2285 & TST & \\
\hline CHEMBL 210503 & 370710 & 6.8508 & 5.1341 & TST & \\
\hline CHEMBL380261 & 370710 & 7.2291 & 6.6631 & TST & \\
\hline CHEMBL 378842 & 370710 & 9.2757 & 8.8406 & TRN & \\
\hline CHEMBL209099 & 370710 & 7.767 & 7.9816 & TRN & \\
\hline CHEMBL210346 & 370710 & 6.7282 & 6.8623 & TRN & \\
\hline CHEMBL208564 & 370710 & 6.8894 & 8.5575 & TST & \\
\hline
\end{tabular}




\begin{tabular}{|c|c|c|c|c|}
\hline \multicolumn{5}{|c|}{ Supplemental Table } \\
\hline CHEMBL210291 & 370710 & 7.9355 & 7.7599 & TRN \\
\hline CHEMBL210051 & 370710 & 9.699 & 9.835 & TRN \\
\hline CHEMBL210761 & 370710 & 6.8069 & 6.7616 & TRN \\
\hline CHEMBL210401 & 370710 & 8.0915 & 8.4442 & TRN \\
\hline CHEMBL211290 & 370710 & 7.7122 & 7.8184 & TRN \\
\hline CHEMBL208611 & 370710 & 9.699 & 9.8583 & TRN \\
\hline CHEMBL210997 & 370710 & 5.5229 & 6.3139 & TST \\
\hline CHEMBL209120 & 370710 & 7.9172 & 7.7366 & TRN \\
\hline CHEMBL209362 & 370710 & 5.5229 & 5.5303 & TRN \\
\hline CHEMBL209188 & 370710 & 5.5229 & 6.475 & TST \\
\hline CHEMBL208892 & 370710 & 7.7447 & 7.8452 & TRN \\
\hline CHEMBL210252 & 370710 & 7.5086 & 7.4849 & TRN \\
\hline CHEMBL211289 & 370710 & 5.5229 & 5.3071 & TST \\
\hline CHEMBL208829 & 370710 & 8.3098 & 8.0429 & TRN \\
\hline CHEMBL208626 & 370710 & 7.6459 & 7.7352 & TRN \\
\hline CHEMBL378072 & 370710 & 9.4685 & 9.5119 & TRN \\
\hline CHEMBL209139 & 370710 & 8.1367 & 8.075 & TRN \\
\hline CHEMBL441527 & 370710 & 7.2676 & 8.8108 & TST \\
\hline CHEMBL212516 & 370710 & 5.5229 & 5.2974 & TST \\
\hline CHEMBL377099 & 370710 & 8.6778 & 8.2343 & TRN \\
\hline CHEMBL11458 & 91168 & 7.35 & 4.9568 & TST \\
\hline CHEMBL3138548 & 91168 & 6.74 & 6.8704 & TRN \\
\hline CHEMBL3138601 & 91168 & 5.48 & 6.3379 & TRN \\
\hline CHEMBL3138567 & 91168 & 5.69 & 6.0597 & TRN \\
\hline CHEMBL3138559 & 91168 & 6.0 & 6.0 & TRN \\
\hline CHEMBL3138589 & 91168 & 5.82 & 6.4056 & TRN \\
\hline CHEMBL324190 & 91168 & 6.67 & 6.2386 & TRN \\
\hline CHEMBL3138596 & 91168 & 7.26 & 6.8232 & TRN \\
\hline CHEMBL3138557 & 91168 & 5.23 & 5.5399 & TRN \\
\hline CHEMBL 3138585 & 91168 & 6.0 & 5.7097 & TRN \\
\hline CHEMBL321982 & 91168 & 6.35 & 6.7823 & TRN \\
\hline CHEMBL3138592 & 91168 & 6.81 & 6.1992 & TRN \\
\hline CHEMBL3138555 & 91168 & 6.67 & 6.0235 & TRN \\
\hline CHEMBL3138593 & 91168 & 7.82 & 5.8211 & TST \\
\hline CHEMBL3138594 & 91168 & 6.3 & 6.4247 & TRN \\
\hline CHEMBL 2062142 & 91168 & 6.6 & 5.8364 & TST \\
\hline CHEMBL420483 & 91168 & 6.47 & 6.7612 & TRN \\
\hline CHEMBL3138605 & 91168 & 5.88 & 6.3369 & TRN \\
\hline CHEMBL3138550 & 91168 & 6.0 & 5.6814 & TRN \\
\hline CHEMBL3138581 & 91168 & 6.86 & 6.2896 & TRN \\
\hline CHEMBL3138556 & 91168 & 5.62 & 6.0251 & TRN \\
\hline CHEMBL3138554 & 91168 & 6.55 & 6.1625 & TRN \\
\hline CHEMBL 2052025 & 91168 & 5.42 & 5.2528 & TRN \\
\hline CHEMBL70996 & 91168 & 6.41 & 4.7821 & TST \\
\hline CHEMBL3138590 & 91168 & 4.92 & 4.9612 & TRN \\
\hline CHEMBL3138602 & 91168 & 6.0 & 5.3689 & TRN \\
\hline CHEMBL3138604 & 91168 & 6.33 & 6.1481 & TRN \\
\hline CHEMBL3138569 & 91168 & 6.0 & 5.4111 & TRN \\
\hline
\end{tabular}




\begin{tabular}{|c|c|c|c|c|c|}
\hline \multicolumn{6}{|c|}{ Supplemental Table S2.txt } \\
\hline CHEMBL3138546 & 91168 & 4.21 & 4.9304 & TRN & \\
\hline CHEMBL3138582 & 91168 & 6.67 & 6.2932 & TRN & \\
\hline CHEMBL3138563 & 91168 & 6.0 & 6.6045 & TRN & \\
\hline CHEMBL11684 & 91168 & 6.37 & 5.7155 & TST & \\
\hline CHEMBL 3138584 & 91168 & 5.64 & 5.8466 & TRN & \\
\hline CHEMBL 3138571 & 91168 & 6.0 & 5.5887 & TST & \\
\hline CHEMBL108586 & 91168 & 7.56 & 6.8866 & TRN & \\
\hline CHEMBL110710 & 91168 & 6.0 & 6.4008 & TRN & \\
\hline CHEMBL109159 & 91168 & 5.74 & 6.2973 & TRN & \\
\hline CHEMBL3138583 & 91168 & 5.59 & 6.0561 & TRN & \\
\hline CHEMBL3138597 & 91168 & 5.65 & 6.2423 & TRN & \\
\hline CHEMBL3138568 & 91168 & 6.66 & 6.8962 & TRN & \\
\hline CHEMBL3138547 & 91168 & 5.55 & 6.0455 & TRN & \\
\hline CHEMBL 3138545 & 91168 & 7.55 & 6.3535 & TRN & \\
\hline CHEMBL3138549 & 91168 & 7.59 & 7.0759 & TRN & \\
\hline CHEMBL3138565 & 91168 & 6.57 & 6.28700 & 0000000001 & TRN \\
\hline CHEMBL3138552 & 91168 & 5.5 & 5.646 & TRN & \\
\hline CHEMBL 3138572 & 91168 & 6.13 & 6.3635 & TST & \\
\hline CHEMBL 3138580 & 91168 & 5.98 & 5.7294 & TRN & \\
\hline CHEMBL3138570 & 91168 & 5.87 & 5.9951 & TRN & \\
\hline CHEMBL325805 & 91168 & 5.5 & 6.4375 & TST & \\
\hline CHEMBL 3138588 & 91168 & 6.68 & 6.2658 & TST & \\
\hline CHEMBL3138591 & 91168 & 6.24 & 6.3819 & TST & \\
\hline CHEMBL3138606 & 91168 & 7.27 & 6.6109 & TST & \\
\hline CHEMBL3138564 & 91168 & 6.62 & 5.7842 & TST & \\
\hline CHEMBL3138598 & 91168 & 5.73 & 6.4545 & TST & \\
\hline CHEMBL3138587 & 91168 & 7.66 & 6.3234 & TST & \\
\hline CHEMBL 225093 & 830577 & 4.757 & 4.6417 & TRN & \\
\hline CHEMBL427251 & 830577 & 4.3188 & 4.6417 & TRN & \\
\hline CHEMBL 2059695 & 830577 & 2.9547 & 2.9488 & TRN & \\
\hline CHEMBL 2059428 & 830577 & 2.9547 & 2.9526 & TRN & \\
\hline CHEMBL 2057330 & 830577 & 2.9547 & 3.0968 & TST & \\
\hline CHEMBL 2059752 & 830577 & 2.9547 & 2.9515 & TRN & \\
\hline CHEMBL 2059694 & 830577 & 2.9547 & 2.9549 & TRN & \\
\hline CHEMBL 2059751 & 830577 & 2.9547 & 2.9515 & TRN & \\
\hline CHEMBL 2059279 & 830577 & 2.9547 & 2.9526 & TRN & \\
\hline CHEMBL 2059754 & 830577 & 2.9547 & 2.9515 & TRN & \\
\hline CHEMBL 2059760 & 830577 & 2.9547 & 3.1069 & TST & \\
\hline CHEMBL 2059429 & 830577 & 2.9547 & 2.9783 & TRN & \\
\hline CHEMBL 2059753 & 830577 & 2.9547 & 2.9515 & TRN & \\
\hline CHEMBL187863 & 830577 & 4.6517 & 4.6103 & TRN & \\
\hline CHEMBL 2059539 & 830577 & 2.9547 & 2.9549 & TRN & \\
\hline CHEMBL333363 & 830577 & 4.5302 & 4.5056 & TRN & \\
\hline CHEMBL 2057323 & 830577 & 5.8182 & 2.9963 & TST & \\
\hline CHEMBL223773 & 830577 & 4.8508 & 4.6417 & TRN & \\
\hline CHEMBL 2059284 & 830577 & 2.9547 & 2.9526 & TRN & \\
\hline CHEMBL 2059277 & 830577 & 2.9547 & 2.9652 & TRN & \\
\hline CHEMBL 2059280 & 830577 & 2.9547 & 2.9526 & TST & \\
\hline
\end{tabular}




\begin{tabular}{|c|c|c|c|c|c|}
\hline \multirow[b]{2}{*}{ CHEMBL2059691 } & & \multicolumn{4}{|c|}{ Supplemental Table S2.txt } \\
\hline & 830577 & 2.9547 & 2.9549 & TRN & \\
\hline CHEMBL 2059538 & 830577 & 2.9547 & 2.9531 & TRN & \\
\hline CHEMBL 2059755 & 830577 & 2.9547 & 2.9515 & TRN & \\
\hline CHEMBL 2057320 & 830577 & 2.9547 & 2.9508 & TRN & \\
\hline CHEMBL 2059693 & 830577 & 2.9547 & 2.9549 & TRN & \\
\hline CHEMBL139888 & 830577 & 2.9547 & 2.9611 & TRN & \\
\hline CHEMBL 2057319 & 830577 & 2.9547 & 2.9168 & TST & \\
\hline CHEMBL 2059282 & 830577 & 2.9547 & 2.9526 & TST & \\
\hline CHEMBL123218 & 830577 & 2.9547 & 2.945 & TRN & \\
\hline CHEMBL 2059749 & 830577 & 2.9547 & 2.9574 & TRN & \\
\hline CHEMBL 2057329 & 830577 & 2.9547 & 3.0968 & TST & \\
\hline CHEMBL 2059692 & 830577 & 2.9547 & 2.9549 & TRN & \\
\hline CHEMBL 2057326 & 830577 & 2.9547 & 3.1015 & TST & \\
\hline CHEMBL 2059750 & 830577 & 2.9547 & 2.9515 & TRN & \\
\hline CHEMBL121622 & 830577 & 2.9547 & 2.9518 & TRN & \\
\hline CHEMBL 2057328 & 830577 & 2.9547 & 3.0968 & TST & \\
\hline CHEMBL 2059431 & 830577 & 2.9547 & 2.9552 & TRN & \\
\hline CHEMBL 2057324 & 830577 & 2.9547 & 2.9565 & TRN & \\
\hline CHEMBL 2059535 & 830577 & 2.9547 & 2.9652 & TRN & \\
\hline CHEMBL 2059761 & 830577 & 2.9547 & 3.1237 & TST & \\
\hline CHEMBL 2059430 & 830577 & 2.9547 & 2.9542 & TRN & \\
\hline CHEMBL 2059530 & 830577 & 2.9547 & 2.9552 & TRN & \\
\hline CHEMBL 2059534 & 830577 & 2.9547 & 2.9315 & TRN & \\
\hline CHEMBL 2059757 & 830577 & 2.9547 & 2.9515 & TRN & \\
\hline CHEMBL188130 & 830577 & 4.2573 & 4.306 & TRN & \\
\hline CHEMBL 2059758 & 830577 & 2.9547 & 3.1488 & TST & \\
\hline CHEMBL225390 & 830577 & 4.5406 & 4.6417 & TRN & \\
\hline CHEMBL388801 & 830577 & $4.8210 e$ & 0000000 & 4.6417 & TRN \\
\hline CHEMBL 2059532 & 830577 & 2.9547 & 2.9552 & TRN & \\
\hline CHEMBL 2059434 & 830577 & 2.9547 & 2.9552 & TRN & \\
\hline CHEMBL 2059427 & 830577 & 2.9547 & 2.9526 & TST & \\
\hline CHEMBL2057321 & 830577 & 2.9547 & 2.9508 & TRN & \\
\hline CHEMBL 2057327 & 830577 & 2.9547 & 3.1021 & TST & \\
\hline CHEMBL 2059537 & 830577 & 2.9547 & 2.9549 & TRN & \\
\hline CHEMBL 2059531 & 830577 & 2.9547 & 2.9552 & TRN & \\
\hline CHEMBL141955 & 830577 & 2.9547 & 2.9565 & TRN & \\
\hline CHEMBL2059759 & 830577 & 2.9547 & 3.1191 & TST & \\
\hline CHEMBL 2059536 & 830577 & 2.9547 & 2.95600 & 00000000004 & TRN \\
\hline CHEMBL390611 & 830577 & 4.6021 & 4.6417 & TRN & \\
\hline CHEMBL 2059281 & 830577 & 2.9547 & 2.9526 & TST & \\
\hline CHEMBL 2059748 & 830577 & 2.9547 & 2.9732 & TRN & \\
\hline CHEMBL 2057322 & 830577 & 2.9547 & 2.9508 & TRN & \\
\hline CHEMBL 2059433 & 830577 & 2.9547 & 2.9552 & TRN & \\
\hline CHEMBL 2057325 & 830577 & 2.9547 & 2.9565 & TRN & \\
\hline CHEMBL 2059283 & 830577 & 2.9547 & 2.9526 & TST & \\
\hline CHEMBL 2057231 & 830577 & 2.9547 & 2.9499 & TRN & \\
\hline CHEMBL 2059756 & 830577 & 2.9547 & 2.9515 & TRN & \\
\hline CHEMBL 2059276 & 830577 & 2.9547 & 2.9318 & TST & \\
\hline
\end{tabular}




\begin{tabular}{|c|c|c|c|c|c|}
\hline \multicolumn{6}{|c|}{ Supplemental Table S2.txt } \\
\hline CHEMBL1512328 & 830577 & 5.1135 & 3.4662 & TST & \\
\hline CHEMBL 223545 & 830577 & 4.8928 & 4.6417 & TRN & \\
\hline CHEMBL2059533 & 830577 & 2.9547 & 2.9552 & TRN & \\
\hline CHEMBL 2059278 & 830577 & 2.9547 & 2.9522 & TST & \\
\hline CHEMBL376179 & 830577 & 4.3279 & 4.6417 & TRN & \\
\hline CHEMBL 2059690 & 830577 & 2.9547 & 2.9549 & TRN & \\
\hline CHEMBL 2059432 & 830577 & 2.9547 & 2.9552 & TRN & \\
\hline CHEMBL3314591 & 1454591 & 7.2924 & 7.4158 & TRN & \\
\hline CHEMBL 3314565 & 1454591 & 7.1367 & 7.3215 & TRN & \\
\hline CHEMBL3314574 & 1454591 & 6.9586 & 7.1202 & TRN & \\
\hline CHEMBL3314549 & 1454591 & 7.1871 & 6.8911 & TRN & \\
\hline CHEMBL3314563 & 1454591 & 6.9208 & 7.0969 & TRN & \\
\hline CHEMBL3314586 & 1454591 & 7.1024 & 7.2706 & TRN & \\
\hline CHEMBL 3314530 & 1454591 & 6.7212 & 6.565 & TRN & \\
\hline CHEMBL3314554 & 1454591 & 6.3768 & 6.8778 & TRN & \\
\hline CHEMBL3314541 & 1454591 & 6.1549 & 6.0718 & TST & \\
\hline CHEMBL3314540 & 1454591 & 7.0132 & 6.5395 & TRN & \\
\hline CHEMBL 3314580 & 1454591 & 9.1549 & 8.1238 & TRN & \\
\hline CHEMBL 3314532 & 1454591 & 7.6198 & 6.6359 & TRN & \\
\hline CHEMBL3314590 & 1454591 & 7.3468 & 7.6135 & TRN & \\
\hline CHEMBL3314560 & 1454591 & 6.4318 & 6.6694 & TRN & \\
\hline CHEMBL3314572 & 1454591 & 7.2757 & 7.2393 & TRN & \\
\hline CHEMBL 3314567 & 1454591 & 7.2924 & 7.2792 & TRN & \\
\hline CHEMBL3314557 & 1454591 & 6.7959 & 7.0856 & TRN & \\
\hline CHEMBL3314588 & 1454591 & 7.4559 & 7.3274 & TST & \\
\hline CHEMBL3314585 & 1454591 & 9.9208 & 8.456 & TRN & \\
\hline CHEMBL3314539 & 1454591 & 7.3098 & 6.6699 & TRN & \\
\hline CHEMBL3314589 & 1454591 & 7.3979 & 7.6616 & TRN & \\
\hline CHEMBL3314548 & 1454591 & 6.7696 & 5.9788 & TST & \\
\hline CHEMBL3314543 & 1454591 & 6.699 & 5.9751 & TST & \\
\hline CHEMBL1923433 & 1454591 & 5.1079 & 5.2684 & TRN & \\
\hline CHEMBL 3314582 & 1454591 & 6.9208 & 7.699 & TRN & \\
\hline CHEMBL3314579 & 1454591 & 7.1675 & 7.2972 & TRN & \\
\hline CHEMBL3314553 & 1454591 & 7.1427 & 7.2039 & TRN & \\
\hline CHEMBL3314578 & 1454591 & 7.3665 & 7.5601 & TRN & \\
\hline CHEMBL3314584 & 1454591 & 7.0605 & 7.4061 & TRN & \\
\hline CHEMBL 3314550 & 1454591 & 7.8539 & 6.982 & TST & \\
\hline CHEMBL3314546 & 1454591 & 6.8861 & 5.9035 & TST & \\
\hline CHEMBL3314538 & 1454591 & 7.3279 & 6.5911 & TRN & \\
\hline CHEMBL3313938 & 1454591 & 6.9208 & 7.1109 & TRN & \\
\hline CHEMBL3314542 & 1454591 & 5.7447 & 5.968 & TST & \\
\hline CHEMBL 3314568 & 1454591 & 7.3768 & 7.2137 & TRN & \\
\hline CHEMBL3314571 & 1454591 & 6.7447 & 7.1726 & TRN & \\
\hline CHEMBL3314581 & 1454591 & 7.1487 & 7.54200 & 0000000001 & TRN \\
\hline CHEMBL3314577 & 1454591 & 7.1675 & 7.4062 & TRN & \\
\hline CHEMBL3314537 & 1454591 & 7.2291 & 6.4031 & TST & \\
\hline CHEMBL3314529 & 1454591 & 5.7447 & 6.2666 & TST & \\
\hline CHEMBL 3314570 & 1454591 & 7.0 & 7.1298 & TRN & \\
\hline
\end{tabular}


Supplemental Table S2.txt

\begin{tabular}{|c|c|c|c|c|c|}
\hline CHEMBL3314573 & 1454591 & 7.2291 & 7.062 & TRN & \\
\hline CHEMBL 3314569 & 1454591 & 7.4437 & 7.0729 & TRN & \\
\hline CHEMBL 3314583 & 1454591 & 7.2076 & 7.6316 & TRN & \\
\hline CHEMBL 3314534 & 1454591 & 5.9586 & 6.3969 & TST & \\
\hline CHEMBL 3314564 & 1454591 & 7.2757 & 7.0282 & TRN & \\
\hline CHEMBL 3314533 & 1454591 & 6.7212 & 6.8095 & TST & \\
\hline CHEMBL3314575 & 1454591 & 7.2676 & 7.5136 & TRN & \\
\hline CHEMBL 3314531 & 1454591 & 6.8239 & 6.7735 & TST & \\
\hline CHEMBL1923440 & 1454591 & 6.7959 & 6.2592 & TST & \\
\hline CHEMBL3314576 & 1454591 & 7.0706 & 7.5871 & TRN & \\
\hline CHEMBL 3314547 & 1454591 & 7.3872 & 6.1408 & TST & \\
\hline CHEMBL3314566 & 1454591 & 7.3665 & 7.5394 & TRN & \\
\hline CHEMBL1703699 & 737136 & 5.5622 & 4.58 & TRN & \\
\hline CHEMBL1577942 & 737136 & 3.0 & 3.7194 & TRN & \\
\hline CHEMBL1428441 & 737136 & 3.0 & 3.9533 & TRN & \\
\hline CHEMBL1722484 & 737136 & 3.0 & 3.6724 & TRN & \\
\hline CHEMBL1411252 & 737136 & 4.0214 & 3.8201 & TRN & \\
\hline CHEMBL1387505 & 737136 & 3.0 & 2.826 & TRN & \\
\hline CHEMBL1321207 & 737136 & 4.063 & 3.6457 & TRN & \\
\hline CHEMBL1700771 & 737136 & 3.0 & 2.8745 & TRN & \\
\hline CHEMBL1713539 & 737136 & 3.0 & 3.0872 & TRN & \\
\hline CHEMBL1464460 & 737136 & 5.0339 & 5.8711 & TRN & \\
\hline CHEMBL1463019 & 737136 & 5.21399 & 79999999 & 995 & 5.4357 \\
\hline CHEMBL1416302 & 737136 & 5.1379 & 4.5583 & TST & \\
\hline CHEMBL1313635 & 737136 & 5.1891 & 4.1841 & TRN & \\
\hline CHEMBL1705486 & 737136 & 3.0 & 4.1718 & TRN & \\
\hline CHEMBL1732622 & 737136 & 3.0 & 2.8082 & TRN & \\
\hline CHEMBL1540272 & 737136 & 5.266 & 4.7137 & TRN & \\
\hline CHEMBL1422967 & 737136 & 4.2441 & 3.9382 & TRN & \\
\hline CHEMBL1715163 & 737136 & 3.0 & 3.6294 & TRN & \\
\hline CHEMBL1718734 & 737136 & 5.2857 & 3.9226 & TRN & \\
\hline CHEMBL1572009 & 737136 & 4.684 & 5.1392 & TST & \\
\hline CHEMBL1734711 & 737136 & 3.0 & 3.2976 & TRN & \\
\hline CHEMBL1518235 & 737136 & 4.757 & 4.5581 & TST & \\
\hline CHEMBL 3207758 & 737136 & 3.0 & 3.0937 & TRN & \\
\hline CHEMBL1730395 & 737136 & 3.0 & 3.5576 & TRN & \\
\hline CHEMBL1709549 & 737136 & 4.7471 & 4.3075 & TRN & \\
\hline CHEMBL1550902 & 737136 & 3.0 & 4.0713 & TRN & \\
\hline CHEMBL1349022 & 737136 & 3.0 & 4.1136 & TST & \\
\hline CHEMBL1462740 & 737136 & 4.7932 & 5.6202 & TRN & \\
\hline CHEMBL1983083 & 737136 & 5.2366 & 3.7721 & TRN & \\
\hline CHEMBL1587882 & 737136 & 3.0 & 4.2722 & TST & \\
\hline CHEMBL1711550 & 737136 & 3.0 & 3.3229 & TRN & \\
\hline CHEMBL1709821 & 737136 & 3.0 & 3.6204 & TRN & \\
\hline CHEMBL1447764 & 737136 & 3.0 & 3.7529 & TRN & \\
\hline CHEMBL1497773 & 737136 & 5.9431 & 5.8185 & TST & \\
\hline CHEMBL1699486 & 737136 & 3.0 & 3.2041 & TRN & \\
\hline CHEMBL1699657 & 737136 & 3.0 & 4.4238 & TST & \\
\hline
\end{tabular}




\begin{tabular}{|c|c|c|c|c|c|c|}
\hline \multicolumn{7}{|c|}{ Supplemental Table S2.txt } \\
\hline CHEMBL1524163 & 737136 & 3.0 & 3.6114 & TRN & & \\
\hline CHEMBL1339593 & 737136 & 4.1457 & 3.8425 & TRN & & \\
\hline CHEMBL3213237 & 737136 & 4.0926 & 3.1396 & TRN & & \\
\hline CHEMBL1547939 & 737136 & 4.3224 & 4.1921 & TRN & & \\
\hline CHEMBL1303289 & 737136 & 4.6778 & 5.0908 & TST & & \\
\hline CHEMBL1426560 & 737136 & 4.3125 & 3.8784 & TRN & & \\
\hline CHEMBL286404 & 737136 & 3.0 & 4.1111 & TST & & \\
\hline CHEMBL1577371 & 737136 & 3.0 & 4.0086 & TST & & \\
\hline CHEMBL1578367 & 737136 & 4.6021 & 3.7987 & TRN & & \\
\hline CHEMBL1530246 & 737136 & 4.2027 & 3.7354 & TRN & & \\
\hline CHEMBL1335091 & 737136 & 3.0 & 3.4328 & TRN & & \\
\hline CHEMBL1563010 & 737136 & 3.0 & 2.8668 & TRN & & \\
\hline CHEMBL1545487 & 737136 & 3.0 & 5.3069 & TST & & \\
\hline CHEMBL1505905 & 737136 & 4.9751 & 4.0988 & TST & & \\
\hline CHEMBL1599517 & 737136 & 4.5591 & 5.1094 & TST & & \\
\hline CHEMBL1522300 & 737136 & 5.8447 & 5.5825 & TRN & & \\
\hline CHEMBL1709023 & 737136 & 3.0 & 3.0558 & TRN & & \\
\hline CHEMBL1731262 & 737136 & 3.0 & 3.1819 & TRN & & \\
\hline CHEMBL1715789 & 737136 & 4.4609 & 4.2851 & TRN & & \\
\hline CHEMBL1363678 & 737136 & $4.1530 e$ & 00000006 & 205 & 3.7968 & TRN \\
\hline CHEMBL1991440 & 737136 & 5.61799 & 99999999 & 99 & 4.8253 & TRN \\
\hline CHEMBL3191738 & 737136 & 3.0 & 3.0687 & TRN & & \\
\hline CHEMBL1389680 & 737136 & 3.0 & 3.7968 & TRN & & \\
\hline CHEMBL1581190 & 737136 & 4.1586 & 3.6889 & TRN & & \\
\hline CHEMBL1458928 & 737136 & 3.0 & 2.8321 & TRN & & \\
\hline CHEMBL1385027 & 737136 & 5.0438 & 4.6591 & TRN & & \\
\hline CHEMBL1583797 & 737136 & 5.3354 & 4.1393 & TRN & & \\
\hline CHEMBL1993711 & 737136 & 3.0 & 4.3388 & TRN & & \\
\hline CHEMBL1495764 & 737136 & 4.5072 & 3.7152 & TRN & & \\
\hline CHEMBL1731046 & 737136 & 3.0 & 3.5521 & TRN & & \\
\hline CHEMBL1548422 & 737136 & 5.2097 & 4.6613 & TRN & & \\
\hline CHEMBL1703558 & 737136 & 3.0 & 3.5446 & TRN & & \\
\hline CHEMBL1340905 & 737136 & 4.0737 & 3.8114 & TRN & & \\
\hline CHEMBL1466225 & 737136 & 4.1319 & 3.90199 & 99999 & 97 & TRN \\
\hline CHEMBL 3207500 & 737136 & 3.0 & 3.1 & TRN & & \\
\hline CHEMBL1312519 & 737136 & 4.5599 & 4.8306 & TST & & \\
\hline CHEMBL1704868 & 737136 & 3.0 & 3.0143 & TRN & & \\
\hline CHEMBL1349518 & 737136 & 3.0 & 4.846 & TST & & \\
\hline CHEMBL1700837 & 737136 & 3.0 & 3.9512 & TRN & & \\
\hline CHEMBL1359322 & 737136 & 4.3516 & 4.1342 & TST & & \\
\hline CHEMBL1508177 & 737136 & 3.0 & 3.8002 & TRN & & \\
\hline CHEMBL1367248 & 737136 & 5.0778 & 4.0982 & TST & & \\
\hline CHEMBL1726321 & 737136 & 4.6696 & 3.8902 & TRN & & \\
\hline CHEMBL1582492 & 737136 & 4.9318 & 4.93 & TST & & \\
\hline CHEMBL1445700 & 737136 & 5.3737 & 4.8762 & TST & & \\
\hline CHEMBL1485592 & 737136 & 4.4566 & 4.9498 & TST & & \\
\hline CHEMBL1602385 & 737136 & 3.0 & 4.9259 & TST & & \\
\hline CHEMBL1588650 & 737136 & 3.0 & 4.797 & TST & & \\
\hline
\end{tabular}




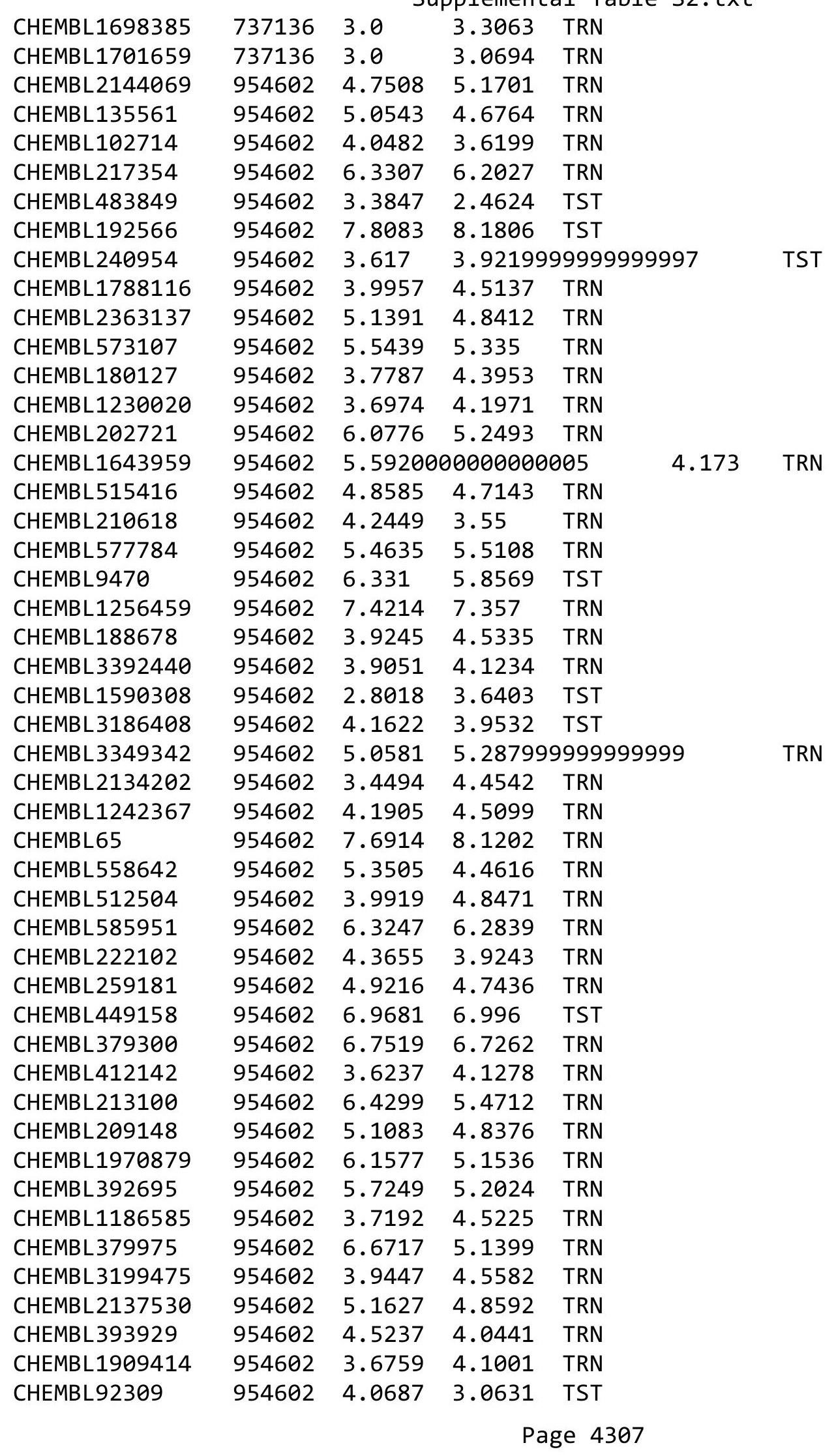




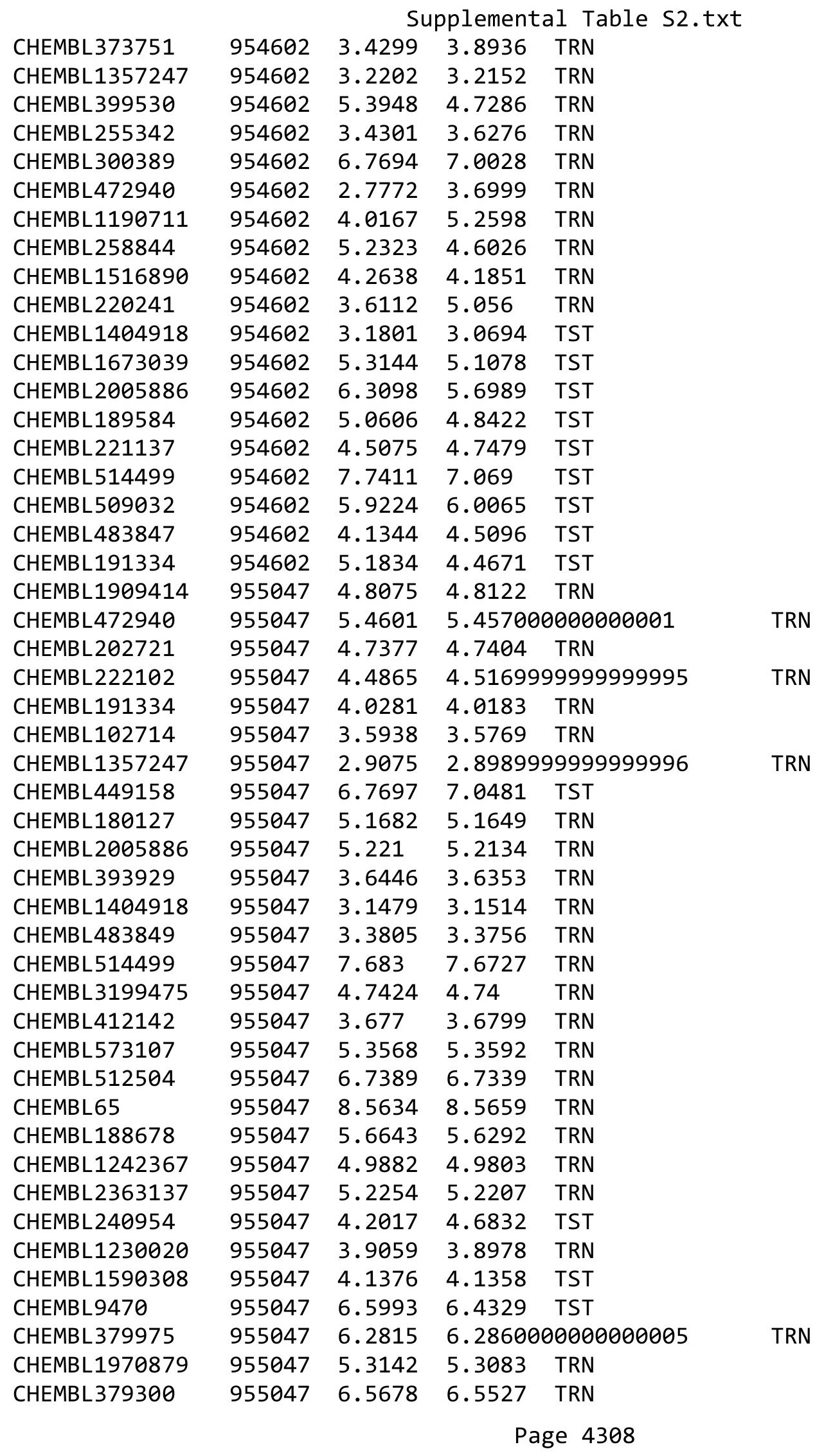




\begin{tabular}{|c|c|c|c|c|c|c|}
\hline \multirow[b]{2}{*}{ CHEMBL1256459 } & \multicolumn{6}{|c|}{ Supplemental Table S2.txt } \\
\hline & 955047 & 7.7404 & 7.7324 & TRN & & \\
\hline CHEMBL1673039 & 955047 & 5.4151 & 5.4293 & TRN & & \\
\hline CHEMBL1516890 & 955047 & 4.2815 & 4.3031 & TRN & & \\
\hline CHEMBL577784 & 955047 & 5.55200 & 00000000 & 005 & 5.5716 & TRN \\
\hline CHEMBL 300389 & 955047 & 7.2339 & 7.2405 & TRN & & \\
\hline CHEMBL92309 & 955047 & 3.8634 & 3.5199 & TST & & \\
\hline CHEMBL483847 & 955047 & 4.0658 & 4.0659 & TRN & & \\
\hline CHEMBL220241 & 955047 & 4.0228 & 4.0353 & TRN & & \\
\hline CHEMBL1190711 & 955047 & 5.5937 & 5.6055 & TRN & & \\
\hline CHEMBL192566 & 955047 & 7.8986 & 8.668 & TST & & \\
\hline CHEMBL259181 & 955047 & 4.6365 & 4.6397 & TRN & & \\
\hline CHEMBL585951 & 955047 & 6.3664 & 6.3799 & TRN & & \\
\hline CHEMBL221137 & 955047 & 4.9642 & 5.6247 & TST & & \\
\hline CHEMBL 209148 & 955047 & 4.9505 & 4.947 & TRN & & \\
\hline CHEMBL2144069 & 955047 & 4.5535 & 4.5483 & TRN & & \\
\hline CHEMBL213100 & 955047 & 4.5815 & 4.5778 & TRN & & \\
\hline CHEMBL515416 & 955047 & 5.405 & 5.4185 & TRN & & \\
\hline CHEMBL1788116 & 955047 & 5.0907 & 5.0889 & TRN & & \\
\hline CHEMBL558642 & 955047 & 4.7462 & 4.7494 & TRN & & \\
\hline CHEMBL392695 & 955047 & 5.1892 & 5.1992 & TRN & & \\
\hline CHEMBL509032 & 955047 & 5.0356 & 5.0231 & TRN & & \\
\hline CHEMBL189584 & 955047 & 4.8771 & 4.8861 & TRN & & \\
\hline CHEMBL 210618 & 955047 & 3.1657 & 3.4987 & TST & & \\
\hline CHEMBL 373751 & 955047 & 3.2351 & 4.0076 & TST & & \\
\hline CHEMBL 3392440 & 955047 & 3.5509 & 4.0808 & TST & & \\
\hline CHEMBL 258844 & 955047 & 4.5709 & 4.7518 & TST & & \\
\hline CHEMBL3349342 & 955047 & 3.4213 & 4.9181 & TST & & \\
\hline CHEMBL3186408 & 955047 & 4.8406 & 4.4074 & TST & & \\
\hline CHEMBL1643959 & 955047 & 4.6338 & 4.1153 & TST & & \\
\hline CHEMBL135561 & 955047 & 3.7395 & 4.4812 & TST & & \\
\hline CHEMBL3715502 & 1536718 & 9.3279 & 9.2447 & TRN & & \\
\hline CHEMBL3719375 & 1536718 & 9.301 & 9.1668 & TRN & & \\
\hline CHEMBL3717419 & 1536718 & 9.4949 & 9.1564 & TRN & & \\
\hline CHEMBL3718657 & 1536718 & 9.3768 & 9.131 & TRN & & \\
\hline CHEMBL 3717779 & 1536718 & 9.1675 & 9.0832 & TRN & & \\
\hline CHEMBL3718803 & 1536718 & 9.0555 & 9.2155 & TRN & & \\
\hline CHEMBL 3718231 & 1536718 & 8.8861 & 9.1763 & TRN & & \\
\hline CHEMBL3718313 & 1536718 & 9.2924 & 9.0973 & TRN & & \\
\hline CHEMBL3718827 & 1536718 & 9.2147 & 9.125 & TRN & & \\
\hline CHEMBL 3714842 & 1536718 & 9.5086 & 9.1161 & TRN & & \\
\hline CHEMBL3716066 & 1536718 & 9.3279 & 9.1248 & TRN & & \\
\hline CHEMBL 3717858 & 1536718 & 9.0362 & 9.1617 & TRN & & \\
\hline CHEMBL3715336 & 1536718 & 5.459 & 8.6818 & TST & & \\
\hline CHEMBL3719215 & 1536718 & 9.2147 & 9.0975 & TRN & & \\
\hline CHEMBL3716956 & 1536718 & 9.0655 & 9.1345 & TRN & & \\
\hline CHEMBL3716160 & 1536718 & 9.4949 & 9.1993 & TRN & & \\
\hline CHEMBL3717972 & 1536718 & 9.3468 & 9.009 & TST & & \\
\hline CHEMBL3715736 & 1536718 & 8.8539 & 8.6528 & TRN & & \\
\hline
\end{tabular}


Supplemental Table S2.txt

\begin{tabular}{|c|c|c|c|c|c|}
\hline CHEMBL3716819 & 1536718 & 9.041 & 8.9916 & TRN & \\
\hline CHEMBL 3719060 & 1536718 & 9.0 & 9.23299 & 9999999999 & TRN \\
\hline CHEMBL3716780 & 1536718 & 8.7696 & 9.1121 & TST & \\
\hline CHEMBL 3715066 & 1536718 & 9.4202 & 9.0543 & TRN & \\
\hline CHEMBL3718689 & 1536718 & 9.1805 & 8.7851 & TRN & \\
\hline CHEMBL3717982 & 1536718 & 9.2147 & 8.6389 & TRN & \\
\hline CHEMBL 3716534 & 1536718 & 8.2076 & 8.6876 & TRN & \\
\hline CHEMBL 3719133 & 1536718 & 8.4089 & 8.898 & TST & \\
\hline CHEMBL 3719018 & 1536718 & 8.2757 & 8.9065 & TST & \\
\hline CHEMBL3716212 & 1536718 & 9.4202 & 9.2306 & TRN & \\
\hline CHEMBL 3715945 & 1536718 & 9.3098 & 9.1711 & TRN & \\
\hline CHEMBL 3717235 & 1536718 & 9.585 & 9.1951 & TRN & \\
\hline CHEMBL3717535 & 1536718 & 9.1612 & 9.0586 & TRN & \\
\hline CHEMBL3719105 & 1536718 & 8.8861 & 8.7803 & TRN & \\
\hline CHEMBL3717413 & 1536718 & 8.7212 & 9.067 & TST & \\
\hline CHEMBL 3718220 & 1536718 & 9.0605 & 9.0895 & TST & \\
\hline CHEMBL3715590 & 1536718 & 9.1938 & 9.1184 & TRN & \\
\hline CHEMBL3718893 & 1536718 & 7.6198 & 8.8908 & TST & \\
\hline CHEMBL3718059 & 1536718 & 9.3665 & 9.0952 & TRN & \\
\hline CHEMBL3716290 & 1536718 & 9.4437 & 9.2448 & TRN & \\
\hline CHEMBL3718462 & 1536718 & 8.6021 & 8.6532 & TST & \\
\hline CHEMBL3715215 & 1536718 & 9.0862 & 9.1178 & TRN & \\
\hline CHEMBL3718829 & 1536718 & 9.2366 & 9.1501 & TRN & \\
\hline CHEMBL3717386 & 1536718 & 9.1192 & 8.7482 & TRN & \\
\hline CHEMBL3718490 & 1536718 & 9.0757 & 9.1718 & TRN & \\
\hline CHEMBL3715042 & 1536718 & 7.4949 & 8.6746 & TRN & \\
\hline CHEMBL 3717116 & 1536718 & 9.1612 & 9.0998 & TST & \\
\hline CHEMBL3714932 & 1536718 & 8.1612 & 8.7156 & TRN & \\
\hline CHEMBL 3719238 & 1536718 & 8.9586 & 9.1046 & TRN & \\
\hline CHEMBL3718433 & 1536718 & 9.3372 & 9.2137 & TRN & \\
\hline CHEMBL3717259 & 1536718 & 8.9208 & 9.1641 & TRN & \\
\hline CHEMBL3719267 & 1536718 & 8.3768 & 8.6486 & TST & \\
\hline CHEMBL 3715947 & 1536718 & 8.8861 & 9.1495 & TRN & \\
\hline CHEMBL3714991 & 1536718 & 8.7696 & 8.6877 & TRN & \\
\hline CHEMBL3716211 & 1536718 & 9.2676 & 8.8684 & TRN & \\
\hline CHEMBL3715642 & 1536718 & 8.7447 & 9.0291 & TRN & \\
\hline CHEMBL3714934 & 1536718 & 9.3188 & 9.1681 & TRN & \\
\hline CHEMBL3718254 & 1536718 & 9.2007 & 9.1432 & TRN & \\
\hline CHEMBL 3717023 & 1536718 & 8.9208 & 9.1214 & TRN & \\
\hline CHEMBL3717802 & 1536718 & 8.8539 & 9.0973 & TRN & \\
\hline CHEMBL3716539 & 1536718 & 8.8861 & 9.0499 & TST & \\
\hline CHEMBL3718629 & 1536718 & 9.1249 & 8.7652 & TRN & \\
\hline CHEMBL3718346 & 1536718 & 8.7696 & 9.128 & TRN & \\
\hline CHEMBL3716402 & 1536718 & 9.0132 & 9.0386 & TST & \\
\hline CHEMBL3715853 & 1536718 & 9.5086 & 9.1175 & TRN & \\
\hline CHEMBL3717127 & 1536718 & 9.6021 & 9.0939 & TRN & \\
\hline CHEMBL3715852 & 1536718 & 9.1938 & 9.0454 & TRN & \\
\hline CHEMBL3715716 & 1536718 & 9.1427 & 8.7216 & TST & \\
\hline
\end{tabular}


Supplemental Table S2.txt

\begin{tabular}{|c|c|c|c|c|}
\hline 784 & & & & \\
\hline HEMBL3715374 & 536718 & 8.1249 & & \\
\hline & & 1612 & & \\
\hline 00 & 718 & 3979 & & \\
\hline |EMB| & 718 & 1949 & & \\
\hline EMBL3717544 & 536718 & 1938 & 1982 & \\
\hline AEMBL3 & 718 & 8861 & 737 & \\
\hline & 118 & 279 & & \\
\hline 529 & 536718 & 2596 & & $a^{-1}+2$ \\
\hline IEMBL3718867 & 536718 & 2007 & 9.0181 & \\
\hline AEMBL 37 & 536718 & 318 & 1083 & \\
\hline IEMBL3 & 18 & 212 & 786 & \\
\hline EMBL & & & & RN \\
\hline IEMBL & 718 & 007 & & \\
\hline AEMBL37 & 536718 & 686 & 2207 & \\
\hline IEMBL37 & 18 & 539 & 84 & \\
\hline IEMBL37 & 8 & 318 & 62 & \\
\hline EMBL37 & & 28 & & \\
\hline AEMBL & 18 & 586 & & \\
\hline IEMBL3 & 18 & 372 & & \\
\hline 642 & 8 & 85 & 79 & \\
\hline IEMBL3 & 8 & 366 & & \\
\hline IEMBL3 & & & & \\
\hline 763 & & 318 & & \\
\hline IEMBL3 & 18 & 77 & 38 & RN \\
\hline EMBL3 & 8 & 5 & 33 & RI \\
\hline EMBL3 & L8 & 44 & & $x^{2}+2+$ \\
\hline 5 & & & & \\
\hline IEMBL3 & & & & RN \\
\hline IEMBL3 & 8 & & & RN \\
\hline IEMBL3 & 8 & 24 & 93 & S \\
\hline FMRI 3 & & & & $\cdots$ \\
\hline 39 & & & & RIV \\
\hline EMBL37 & & & & ST \\
\hline IEMBL37 & 8 & 815 & 69 & RI \\
\hline IEMBL3 & & 565 & & \\
\hline 28 & & & & NIV \\
\hline & & & & $\mathrm{RN}$ \\
\hline IEMBL37 & 8 & 685 & 89 & RN \\
\hline EMBL37 & 536 & 223 & & RI \\
\hline IEMBL37 & 36 & 861 & 91 & \\
\hline 182 & & & & RIV \\
\hline HEMBL37 & L8 & 3872 & 9.2326 & RN \\
\hline EMBL37 & 36718 & 8.4559 & 8.9585 & S \\
\hline EBL3 & 2 & 291 & & R \\
\hline CHEMBL 37 & & 367 & & \\
\hline 年 & . & 861 & 8.6284 & \\
\hline CHEMBL3719034 & 1536718 & 9.4437 & 9.1232 & $R$ \\
\hline
\end{tabular}

Page 4311 
Supplemental Table S2.txt

\begin{tabular}{|c|c|c|c|c|c|}
\hline CHEMBL 3716144 & 1536718 & 9.4318 & 9.1607 & TRN & \\
\hline CHEMBL3717527 & 1536718 & 7.6198 & 8.6344 & TRN & \\
\hline CHEMBL3715170 & 1536718 & 9.0088 & 9.0325 & TRN & \\
\hline CHEMBL3716844 & 1536718 & 9.3979 & 9.1741 & TST & \\
\hline CHEMBL3719044 & 1536718 & 9.2291 & 8.7325 & TRN & \\
\hline CHEMBL3714821 & 1536718 & 9.1938 & 9.0604 & TST & \\
\hline CHEMBL3718248 & 1536718 & 7.7959 & 8.6735 & TST & \\
\hline CHEMBL3719385 & 1536718 & 8.1079 & 8.6745 & TST & \\
\hline CHEMBL3715312 & 1536718 & 7.3188 & 8.7031 & TST & \\
\hline CHEMBL3714914 & 1536718 & 9.1427 & 8.771 & TRN & \\
\hline CHEMBL 3717425 & 1536718 & 9.28399 & 99999999 & 99 & 9.2003 \\
\hline CHEMBL3718293 & 1536718 & 9.0862 & 8.8285 & TRN & \\
\hline CHEMBL3716552 & 1536718 & 9.3468 & 9.2074 & TRN & \\
\hline CHEMBL3716037 & 1536718 & 8.1367 & 8.6439 & TRN & \\
\hline CHEMBL3716498 & 1536718 & 8.8861 & 9.0873 & TST & \\
\hline CHEMBL3718755 & 1536718 & 8.8539 & 9.1501 & TRN & \\
\hline CHEMBL3718860 & 1536718 & 8.6778 & 9.0191 & TRN & \\
\hline CHEMBL3717160 & 1536718 & 9.3665 & 9.0986 & TRN & \\
\hline CHEMBL3715093 & 1536718 & 9.0915 & 9.1788 & TRN & \\
\hline CHEMBL3716103 & 1536718 & 8.7959 & 9.0812 & TRN & \\
\hline CHEMBL3717467 & 1536718 & 9.3565 & 8.6927 & TRN & \\
\hline CHEMBL3715161 & 1536718 & 8.9208 & 9.0122 & TST & \\
\hline CHEMBL 3718540 & 1536718 & 9.4089 & 9.1454 & TRN & \\
\hline CHEMBL 3717407 & 1536718 & 9.0655 & 8.7936 & TRN & \\
\hline CHEMBL3715876 & 1536718 & 9.4815 & 9.0704 & TST & \\
\hline CHEMBL3719223 & 1536718 & 9.1612 & 9.1829 & TRN & \\
\hline CHEMBL3718108 & 1536718 & 8.6576 & 9.2089 & TRN & \\
\hline CHEMBL3716525 & 1536718 & 9.0223 & 9.1021 & TRN & \\
\hline CHEMBL 3714802 & 1536718 & 9.0269 & 9.1349 & TRN & \\
\hline CHEMBL3718641 & 1536718 & 9.3768 & 8.7011 & TRN & \\
\hline CHEMBL3717891 & 1536718 & 9.1249 & 9.1568 & TRN & \\
\hline CHEMBL3717638 & 1536718 & 9.3468 & 9.1893 & TRN & \\
\hline CHEMBL 3717580 & 1536718 & 8.8239 & 9.021 & TST & \\
\hline CHEMBL 3714814 & 1536718 & 9.2518 & 8.6819 & TRN & \\
\hline CHEMBL3717186 & 1536718 & 9.3768 & 9.2131 & TRN & \\
\hline CHEMBL3719316 & 1536718 & 8.9586 & 9.145 & TRN & \\
\hline CHEMBL3718335 & 1536718 & 6.9586 & 8.6398 & TST & \\
\hline CHEMBL 3717136 & 1536718 & 9.1427 & 9.2389 & TRN & \\
\hline CHEMBL3717633 & 1536718 & 7.3665 & 8.895 & TST & \\
\hline CHEMBL3716150 & 1536718 & 8.8861 & 9.0195 & TRN & \\
\hline CHEMBL3717785 & 1536718 & 9.0706 & 9.1102 & TRN & \\
\hline CHEMBL3717332 & 1536718 & 8.7959 & 9.1561 & TRN & \\
\hline CHEMBL3714888 & 1536718 & 9.3188 & 9.2392 & TRN & \\
\hline CHEMBL3716723 & 1536718 & 9.4815 & 9.0903 & TRN & \\
\hline CHEMBL3716096 & 1536718 & 9.2924 & 9.1676 & TRN & \\
\hline CHEMBL3718840 & 1536718 & 8.9208 & 9.125 & TRN & \\
\hline CHEMBL3715516 & 1536718 & 9.0706 & 9.1571 & TRN & \\
\hline CHEMBL3714921 & 1536718 & 9.1024 & 9.0934 & TRN & \\
\hline
\end{tabular}


Supplemental Table S2.txt

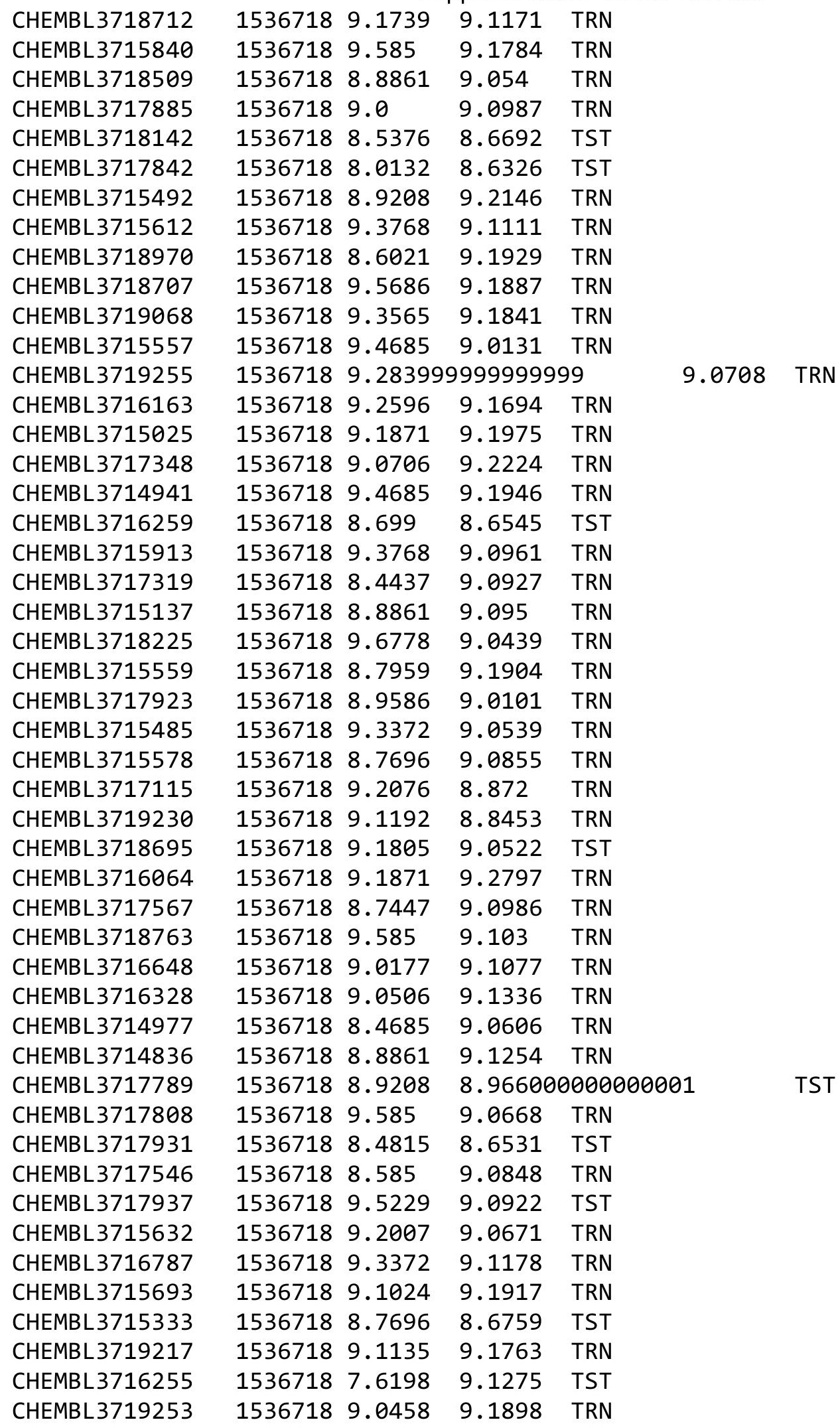

Page 4313 
Supplemental Table S2.txt

\begin{tabular}{|c|c|c|c|c|}
\hline th & 36718 & 427 & & \\
\hline & & 8.6021 & 9.1529 & \\
\hline & 18 & 08 & & \\
\hline AEMBL3 & & & & $\mathrm{MI}$ \\
\hline AEMBL37 & 36718 & & 7755 & \\
\hline HEMBL 3718380 & 536718 & 9.1427 & 1257 & \\
\hline HEMBL; & 36718 & 75 & & \\
\hline |FMRI & & & & \\
\hline AEMBL3 & 718 & 9.1739 & 973 & \\
\hline HEMBL37 & 536718 & 9.3979 & 2803 & \\
\hline AEMBL3 & 536718 & 9.0 & 8281 & \\
\hline IEMBL: & 718 & 9. & 234 & \\
\hline AEMBL & & & & \\
\hline HEMBL3 & 718 & & 5603 & \\
\hline AEMBL3 & 718 & 67 & & \\
\hline AEMBL3 & 18 & 18 & 97 & \\
\hline HEMBL & & & 17 & \\
\hline HEMBL; & & & & \\
\hline HEMBL3 & & & 9985 & \\
\hline AEMBL3 & & & & \\
\hline AEMBL & 8 & 9 . & 991 & | IS \\
\hline HEMBL & & & & RN \\
\hline HEMBL & & & 143 & \\
\hline 87 & & & 661 & \\
\hline AEMBL3 & & & & $\Gamma \mathrm{RN}$ \\
\hline HEMBL & & & 59 & RIV \\
\hline HEMBL & & & 87 & וד וכ \\
\hline HFMBL & 18 & & 88 & \\
\hline HEMBL3 & & & & RIV \\
\hline HEMBL3 & & & 166 & I RN \\
\hline HEMBL3 & 8 & & 995 & RN \\
\hline HEMBL & & & 28 & RN \\
\hline HЕMPI & 18 & & 92 & \\
\hline HEMBL3 & & & & $\mathrm{IR}$ \\
\hline HEMBL37 & 36718 & & 224 & TRN \\
\hline HEMBL & 718 & & 392 & ST \\
\hline HEMRI & & & 187 & ST \\
\hline HEMBL & & & & TRN \\
\hline HEMBL3 & 536718 & 9. & 5294 & TST \\
\hline AEMBL3 & 536718 & & 7738 & TST \\
\hline HEMBL & 18 & & 523 & \\
\hline CHEMBL3 & & & 633 & \\
\hline HEMBL3 & 536718 & & 9.1338 & ГST \\
\hline HEMBL3 & 536718 & 9. & 3261 & TR \\
\hline . & & & 662 & $\mathrm{~N}$ \\
\hline HEMBL & ר & & 5567 & \\
\hline HEMBL3 & & 9.2366 & 8.7561 & \\
\hline CHEMBL3717974 & 1536718 & 9.3665 & 9.2782 & ГRN \\
\hline
\end{tabular}

Page 4314 
Supplemental Table S2.txt

\begin{tabular}{|c|c|c|c|c|}
\hline CHEMBL 3717706 & 1536718 & 9.5528 & 9.0589 & TST \\
\hline CHEMBL 3717814 & 1536718 & 8.9208 & 8.8369 & TRN \\
\hline CHEMBL3718352 & 1536718 & 8.9586 & 8.6557 & TST \\
\hline CHEMBL 3716823 & 1536718 & 8.9586 & 9.0565 & TST \\
\hline CHEMBL3717188 & 1536718 & 8.6383 & 9.1097 & TRN \\
\hline CHEMBL 3715839 & 1536718 & 8.8861 & 9.1474 & TRN \\
\hline CHEMBL 3716059 & 1536718 & 9.5376 & 9.0531 & TST \\
\hline CHEMBL 3714962 & 1536718 & 7.0362 & 9.1596 & TRN \\
\hline CHEMBL 3719245 & 1536718 & 9.0132 & 9.1234 & TRN \\
\hline CHEMBL3717028 & 1536718 & 9.0 & 9.0665 & TRN \\
\hline CHEMBL 3715995 & 1536718 & 9.3098 & 9.1659 & TRN \\
\hline CHEMBL 3716324 & 1536718 & 8.5086 & 8.6452 & TST \\
\hline CHEMBL 3716420 & 1536718 & 9.6383 & 9.1633 & TRN \\
\hline CHEMBL 3715043 & 1536718 & 9.5229 & 9.2265 & TRN \\
\hline CHEMBL3718885 & 1536718 & 8.9208 & 8.7318 & TRN \\
\hline CHEMBL 3718267 & 1536718 & 9.4949 & 9.0768 & TST \\
\hline CHEMBL3719156 & 1536718 & 9.0044 & 9.2318 & TRN \\
\hline CHEMBL 3717630 & 1536718 & 9.28399 & 999999999 & 9.1153 \\
\hline CHEMBL 3718801 & 1536718 & 9.5086 & 8.8195 & TRN \\
\hline CHEMBL 3717042 & 1536718 & 9.585 & 9.1001 & TRN \\
\hline CHEMBL 3714807 & 1536718 & 8.5376 & 9.0426 & TST \\
\hline CHEMBL 3715264 & 1536718 & 8.9586 & 8.9947 & TST \\
\hline CHEMBL 3717364 & 1536718 & 8.9586 & 8.6702 & TST \\
\hline CHEMBL 3716189 & 1536718 & 7.9586 & 8.6776 & TST \\
\hline CHEMBL 3717746 & 1536718 & 9.2518 & 9.1138 & TRN \\
\hline CHEMBL 3715406 & 1536718 & 9.2218 & 9.2016 & TRN \\
\hline CHEMBL 3714777 & 1536718 & 8.7212 & 8.6657 & TST \\
\hline CHEMBL 3717571 & 1536718 & 9.1427 & 9.1489 & TRN \\
\hline CHEMBL 3715391 & 1536718 & 9.3468 & 9.1516 & TRN \\
\hline CHEMBL 3715367 & 1536718 & 9.1308 & 9.1486 & TRN \\
\hline CHEMBL 3715465 & 1536718 & 9.0 & 9.1319 & TRN \\
\hline CHEMBL 3716572 & 1536718 & 8.9208 & 8.6791 & TST \\
\hline CHEMBL 3718333 & 1536718 & 8.1549 & 8.6497 & TST \\
\hline CHEMBL 3715686 & 1536718 & 8.4559 & 8.6766 & TRN \\
\hline CHEMBL 3716372 & 1536718 & 9.3872 & 9.1425 & TRN \\
\hline CHEMBL 3716524 & 1536718 & 7.8239 & 8.687000 & 0000000001 \\
\hline CHEMBL 3719070 & 1536718 & 8.4437 & 8.7114 & TST \\
\hline CHEMBL 3715762 & 1536718 & 8.9208 & 8.7604 & TRN \\
\hline CHEMBL 3715600 & 1536718 & 8.6021 & 9.13 & TRN \\
\hline CHEMBL 3715912 & 1536718 & 9.3665 & 9.1302 & TST \\
\hline CHEMBL 3715726 & 1536718 & 8.9586 & 9.0907 & TRN \\
\hline CHEMBL 3716676 & 1536718 & 9.2676 & 9.2334 & TRN \\
\hline CHEMBL 3718733 & 1536718 & 6.684 & 8.6203 & TST \\
\hline CHEMBL 3718853 & 1536718 & 9.301 & 9.1491 & TRN \\
\hline CHEMBL 3715442 & 1536718 & 9.5376 & 8.7166 & TRN \\
\hline CHEMBL3719069 & 1536718 & 8.9208 & 9.1265 & TRN \\
\hline CHEMBL 3717486 & 1536718 & 8.8861 & 9.0628 & TRN \\
\hline CHEMBL 3716019 & 1536718 & 9.1871 & 9.1712 & TRN \\
\hline
\end{tabular}


Supplemental Table S2.txt

\begin{tabular}{|c|c|c|c|c|}
\hline CHEMBL3719053 & 1536718 & 9.1871 & 8.7838 & TRN \\
\hline CHEMBL3716197 & 1536718 & 9.3279 & 9.1232 & TRN \\
\hline CHEMBL3974732 & 1639957 & 8.0 & 7.9818 & TST \\
\hline CHEMBL3959845 & 1639957 & 7.0 & 7.145 & TST \\
\hline CHEMBL3956883 & 1639957 & 8.0 & 8.0366 & TRN \\
\hline CHEMBL3957247 & 1639957 & 7.0 & 6.8708 & TRN \\
\hline CHEMBL3975414 & 1639957 & 8.0 & 7.8286 & TRN \\
\hline CHEMBL3965793 & 1639957 & 7.0 & 7.1086 & TRN \\
\hline CHEMBL3919707 & 1639957 & 7.0 & 7.7821 & TRN \\
\hline CHEMBL3951798 & 1639957 & 6.0 & 5.715 & TST \\
\hline CHEMBL3986550 & 1639957 & 8.0 & 7.7584 & TRN \\
\hline CHEMBL3967114 & 1639957 & 8.0 & 7.6858 & TRN \\
\hline CHEMBL3927630 & 1639957 & 8.0 & 8.0506 & TRN \\
\hline CHEMBL3939157 & 1639957 & 8.0 & 7.7525 & TRN \\
\hline CHEMBL3938550 & 1639957 & 6.0 & 6.2999 & TRN \\
\hline CHEMBL3906492 & 1639957 & 8.0 & 7.9738 & TRN \\
\hline CHEMBL3942727 & 1639957 & 8.0 & 7.7328 & TRN \\
\hline CHEMBL3919359 & 1639957 & 6.0 & 6.4385 & TRN \\
\hline CHEMBL3983372 & 1639957 & 8.0 & 7.8666 & TST \\
\hline CHEMBL 3983876 & 1639957 & 8.0 & 7.8856 & TRN \\
\hline CHEMBL3934007 & 1639957 & 6.0 & 6.2068 & TRN \\
\hline CHEMBL3958040 & 1639957 & 7.0 & 6.9153 & TRN \\
\hline CHEMBL3958236 & 1639957 & 7.0 & 6.5296 & TST \\
\hline CHEMBL3915704 & 1639957 & 6.0 & 6.1159 & TST \\
\hline CHEMBL3903726 & 1639957 & 8.0 & 7.9431 & TST \\
\hline CHEMBL3930109 & 1639957 & 8.0 & 8.0454 & TRN \\
\hline CHEMBL 3942022 & 1639957 & 8.0 & 7.5968 & TRN \\
\hline CHEMBL3983242 & 1639957 & 8.0 & 7.9337 & TRN \\
\hline CHEMBL3952417 & 1639957 & 8.0 & 7.7199 & TRN \\
\hline CHEMBL3948278 & 1639957 & 8.0 & 7.8837 & TRN \\
\hline CHEMBL3969729 & 1639957 & 6.0 & 6.942 & TRN \\
\hline CHEMBL3891390 & 1639957 & 7.0 & 7.7388 & TRN \\
\hline CHEMBL3966631 & 1639957 & 8.0 & 7.7578 & TRN \\
\hline CHEMBL3896685 & 1639957 & 8.0 & 7.9668 & TRN \\
\hline CHEMBL3986486 & 1639957 & 7.0 & 6.8524 & TRN \\
\hline CHEMBL3953389 & 1639957 & 8.0 & 7.91700 & 0000000001 \\
\hline CHEMBL3931348 & 1639957 & 8.0 & 7.7643 & TRN \\
\hline CHEMBL3915663 & 1639957 & 8.0 & 7.9271 & TST \\
\hline CHEMBL3948829 & 1639957 & 7.0 & 6.9709 & TRN \\
\hline CHEMBL3934557 & 1639957 & 7.0 & 7.8671 & TRN \\
\hline CHEMBL3966039 & 1639957 & 7.0 & 6.8456 & TRN \\
\hline CHEMBL3906243 & 1639957 & 6.0 & 5.79899 & 99999999995 \\
\hline CHEMBL3905821 & 1639957 & 8.0 & 7.7575 & TST \\
\hline CHEMBL3978301 & 1639957 & 7.0 & 6.9658 & TRN \\
\hline CHEMBL3915100 & 1639957 & 7.0 & 7.1407 & TRN \\
\hline CHEMBL3910022 & 1639957 & 8.0 & 7.855 & TRN \\
\hline CHEMBL3955601 & 1639957 & 6.0 & 5.971 & TST \\
\hline CHEMBL3959587 & 1639957 & 8.0 & 8.0138 & TRN \\
\hline
\end{tabular}




\begin{tabular}{|c|c|c|c|c|}
\hline & & & ient & al Ta \\
\hline CHEMBL3909290 & 1639957 & 7.0 & 6.8983 & TRN \\
\hline CHEMBL3936743 & 1639957 & 8.0 & 8.0394 & TRN \\
\hline CHEMBL3902706 & 1639957 & 8.0 & 7.8814 & TRN \\
\hline CHEMBL3967151 & 1639957 & 6.0 & 6.1063 & TRN \\
\hline CHEMBL3919524 & 1639957 & 8.0 & 7.9885 & TRN \\
\hline CHEMBL3925179 & 1639957 & 8.0 & 7.8517 & TRN \\
\hline CHEMBL3971008 & 1639957 & 7.0 & 7.1611 & TRN \\
\hline CHEMBL3973612 & 1639957 & 7.0 & 7.7843 & TRN \\
\hline CHEMBL3938334 & 1639957 & 6.0 & 6.1967 & TRN \\
\hline CHEMBL3969486 & 1639957 & 8.0 & 8.0452 & TRN \\
\hline CHEMBL 3922084 & 1639957 & 8.0 & 8.0025 & TRN \\
\hline CHEMBL3950687 & 1639957 & 8.0 & 7.9096 & TRN \\
\hline CHEMBL 3896503 & 1639957 & 6.0 & 6.0061 & TST \\
\hline CHEMBL3965479 & 1639957 & 7.0 & 6.9484 & TRN \\
\hline CHEMBL 3955346 & 1639957 & 7.0 & 7.1626 & TRN \\
\hline CHEMBL 3979837 & 1639957 & 7.0 & 7.6647 & TST \\
\hline CHEMBL 3892588 & 1639957 & 6.0 & 6.9112 & TST \\
\hline CHEMBL 3906764 & 1639957 & 7.0 & 7.7749 & TRN \\
\hline CHEMBL3911804 & 1639957 & 8.0 & 7.9644 & TRN \\
\hline CHEMBL 3910002 & 1639957 & 6.0 & 6.3952 & TRN \\
\hline CHEMBL3903694 & 1639957 & 8.0 & 7.809 & TRN \\
\hline CHEMBL 3980924 & 1639957 & 7.0 & 7.2876 & TRN \\
\hline CHEMBL3921763 & 1639957 & 8.0 & 7.7758 & TRN \\
\hline CHEMBL3953985 & 1639957 & 8.0 & 7.2878 & TRN \\
\hline CHEMBL 3950710 & 1639957 & 8.0 & 7.9981 & TST \\
\hline CHEMBL3927351 & 1639957 & 7.0 & 7.1054 & TRN \\
\hline CHEMBL3939322 & 1639957 & 8.0 & 6.9657 & TRN \\
\hline CHEMBL 3946402 & 1639957 & 8.0 & 7.5779 & TST \\
\hline CHEMBL3976089 & 1639957 & 8.0 & 8.0175 & TRN \\
\hline CHEMBL3967092 & 1639957 & 7.0 & 7.0481 & TRN \\
\hline CHEMBL3970317 & 1639957 & 8.0 & 7.6789 & TRN \\
\hline CHEMBL 3899187 & 1639957 & 8.0 & 7.7823 & TRN \\
\hline CHEMBL 3912449 & 1639957 & 8.0 & 8.0451 & TRN \\
\hline CHEMBL3934045 & 1639957 & 8.0 & 7.7225 & TRN \\
\hline CHEMBL3920191 & 1639957 & 8.0 & 7.8958 & TRN \\
\hline CHEMBL3975985 & 1639957 & 8.0 & 8.036 & TRN \\
\hline CHEMBL3962643 & 1639957 & 8.0 & 8.0428 & TRN \\
\hline CHEMBL3953149 & 1639957 & 7.0 & 8.0214 & TRN \\
\hline CHEMBL3972256 & 1639957 & 8.0 & 7.7875 & TRN \\
\hline CHEMBL 3894764 & 1639957 & 7.0 & 6.9913 & TST \\
\hline CHEMBL3941852 & 1639957 & 7.0 & 6.9689 & TRN \\
\hline CHEMBL3922446 & 1639957 & 8.0 & 7.8875 & TRN \\
\hline CHEMBL3950917 & 1639957 & 8.0 & 8.0069 & TST \\
\hline CHEMBL3903125 & 1639957 & 8.0 & 7.6694 & TRN \\
\hline CHEMBL3948598 & 1639957 & 7.0 & 7.0009 & TST \\
\hline CHEMBL 3893223 & 1639957 & 8.0 & 8.0121 & TRN \\
\hline CHEMBL3910786 & 1639957 & 8.0 & 8.0166 & TRN \\
\hline CHEMBL3957159 & 1639957 & 7.0 & 7.8513 & TST \\
\hline
\end{tabular}




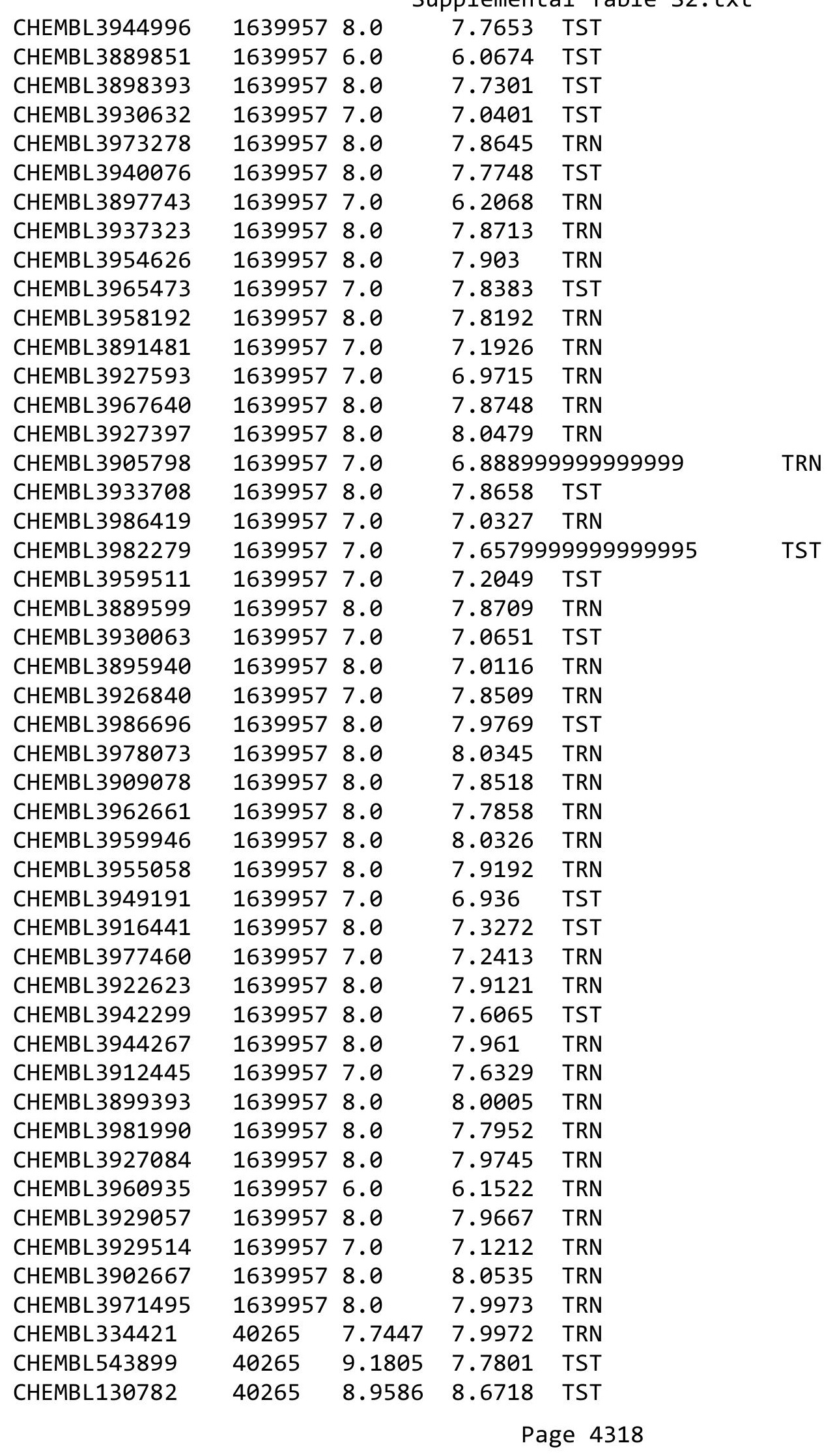




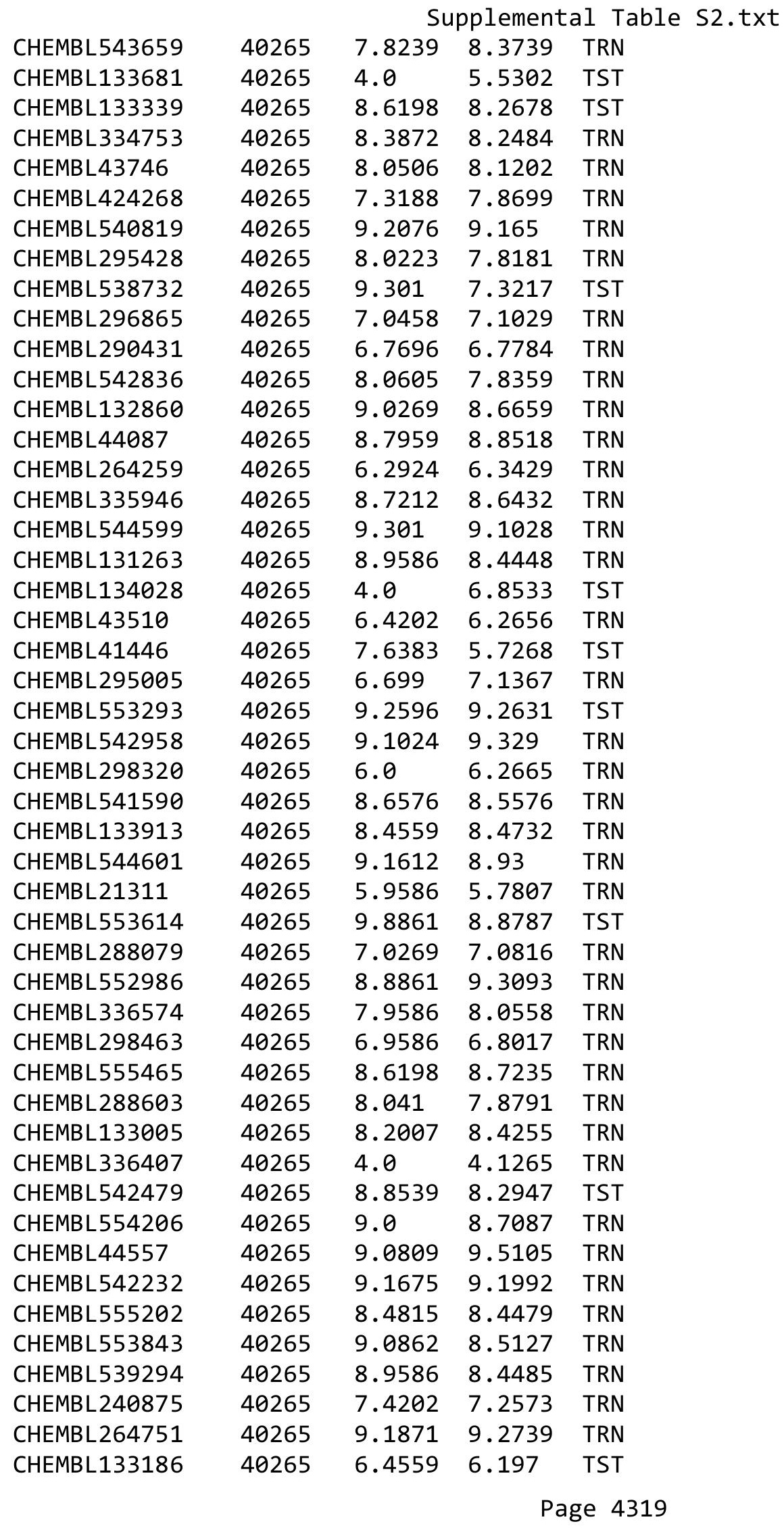




\begin{tabular}{|c|c|c|c|c|c|}
\hline \multicolumn{6}{|c|}{ Supplemental Table S2.txt } \\
\hline CHEMBL130436 & 40265 & 9.1192 & 9.3437 & TRN & \\
\hline CHEMBL552543 & 40265 & 9.3279 & 8.8656 & TST & \\
\hline CHEMBL543781 & 40265 & 9.0132 & 8.9817 & TRN & \\
\hline CHEMBL542096 & 40265 & 9.2924 & 9.2836 & TST & \\
\hline CHEMBL130517 & 40265 & 9.3372 & 8.9793 & TST & \\
\hline CHEMBL132510 & 40265 & 9.0269 & 9.5572 & TST & \\
\hline CHEMBL1880647 & 752555 & 3.0969 & 3.1068 & TRN & \\
\hline CHEMBL1867264 & 752555 & 3.0969 & 3.0769 & TRN & \\
\hline CHEMBL1877088 & 752555 & 3.0969 & 3.0826 & TRN & \\
\hline CHEMBL1492662 & 752555 & 3.0969 & 3.03800 & 00000000003 & TRN \\
\hline CHEMBL1881953 & 752555 & 3.0969 & 3.3794 & TRN & \\
\hline CHEMBL1884740 & 752555 & 3.0969 & 3.2148 & TRN & \\
\hline CHEMBL1877532 & 752555 & 4.9431 & 5.1144 & TRN & \\
\hline CHEMBL1564699 & 752555 & 5.0506 & 5.0705 & TRN & \\
\hline CHEMBL1889188 & 752555 & 3.0969 & 3.762 & TST & \\
\hline CHEMBL1505625 & 752555 & 3.0969 & 3.8501 & TST & \\
\hline CHEMBL1447097 & 752555 & 3.0969 & 3.7384 & TST & \\
\hline CHEMBL1871173 & 752555 & 3.0969 & 3.5503 & TST & \\
\hline CHEMBL1865285 & 752555 & 3.0969 & 2.955 & TRN & \\
\hline CHEMBL1877469 & 752555 & 3.0969 & 3.4061 & TRN & \\
\hline CHEMBL1903537 & 752555 & 3.0969 & 3.1596 & TRN & \\
\hline CHEMBL1879859 & 752555 & 3.0969 & 2.9885 & TRN & \\
\hline CHEMBL1895627 & 752555 & 3.0969 & 3.4682 & TST & \\
\hline CHEMBL1867414 & 752555 & 3.0969 & 3.0988 & TRN & \\
\hline CHEMBL1865517 & 752555 & 5.3152 & 5.0501 & TRN & \\
\hline CHEMBL1877571 & 752555 & 3.0969 & 3.3308 & TST & \\
\hline CHEMBL1893231 & 752555 & 3.0969 & 3.2102 & TRN & \\
\hline CHEMBL1334787 & 752555 & 4.9208 & 3.4311 & TRN & \\
\hline CHEMBL1880882 & 752555 & 3.0969 & 3.1096 & TRN & \\
\hline CHEMBL1903920 & 752555 & 3.0969 & 3.1489 & TRN & \\
\hline CHEMBL1896660 & 752555 & 3.0969 & 3.0403 & TRN & \\
\hline CHEMBL1883114 & 752555 & 5.0044 & 4.9811 & TRN & \\
\hline CHEMBL1342410 & 752555 & 4.9914 & 4.9311 & TRN & \\
\hline CHEMBL1868199 & 752555 & 3.0969 & 4.0967 & TST & \\
\hline CHEMBL1902190 & 752555 & 3.0969 & 3.0932 & TRN & \\
\hline CHEMBL1347253 & 752555 & 5.4698 & 4.1942 & TST & \\
\hline CHEMBL1466110 & 752555 & 3.0969 & 4.0442 & TST & \\
\hline CHEMBL1872727 & 752555 & 3.0969 & 2.9761 & TRN & \\
\hline CHEMBL1898021 & 752555 & 3.0969 & 3.2431 & TRN & \\
\hline CHEMBL1465938 & 752555 & 4.9788 & 4.9774 & TRN & \\
\hline CHEMBL1895705 & 752555 & 3.0969 & 3.0458 & TRN & \\
\hline CHEMBL1417992 & 752555 & 4.3645 & 4.1869 & TST & \\
\hline CHEMBL1882018 & 752555 & 3.0969 & 3.0556 & TRN & \\
\hline CHEMBL1866012 & 752555 & 3.0969 & 3.1439 & TRN & \\
\hline CHEMBL1904169 & 752555 & 3.0969 & 3.1344 & TRN & \\
\hline CHEMBL1889670 & 752555 & 3.0969 & 3.3646 & TRN & \\
\hline CHEMBL1890081 & 752555 & 3.0969 & 3.2356 & TRN & \\
\hline CHEMBL1567670 & 752555 & 3.0969 & 2.9585 & TRN & \\
\hline
\end{tabular}


Supplemental Table S2.txt

\begin{tabular}{|c|c|c|c|c|}
\hline and & & & & \\
\hline $\mathrm{CHFl}$ & 2555 & 3.0969 & & \\
\hline HEMBL1887735 & 2555 & 969 & 2049 & \\
\hline HEMBL1875709 & 52555 & 1824 & 5443 & \\
\hline HEMBL187 & 52555 & 0969 & 0804 & \\
\hline HEMBL1899387 & 2555 & 969 & 016 & \\
\hline HEMBL187 & 52555 & $\partial 969$ & 3.4515 & \\
\hline HEMBL1900041 & 52555 & 969 & 3.089 & \\
\hline HEMBL1888094 & 52555 & .0969 & 3.1934 & \\
\hline HEMBL1882595 & 525 & 969 & .1323 & \\
\hline AEMBL1887151 & & 969 & 2.9107 & \\
\hline HEMBL1898878 & 52555 & 5.0061 & 4.7861 & \\
\hline HEMBL1904466 & 5 & 969 & 4.2786 & \\
\hline HEMBL1871292 & 525 & 969 & 3.0193 & \\
\hline AEMBL1880360 & 5 & 969 & 1995 & \\
\hline 929 & & & .1637 & \\
\hline 940 & 55 & 69 & 3.0369 & \\
\hline 086 & & 69 & 2457 & \\
\hline AEMBL1896481 & 52555 & 69 & 2.9692 & \\
\hline 270 & 5 & 59 & 5966 & \\
\hline 268 & & & 2334 & \\
\hline 709 & 5 & & 3.1299 & \\
\hline 333 & & & & \\
\hline 038 & 5 & 69 & 1072 & \\
\hline 793 & 5 & & 598 & RN \\
\hline 307 & & & 312 & \\
\hline 978 & 52555 & & 0208 & \\
\hline 48 & & & 337 & \\
\hline AEMBL29 & 52555 & 59 & 3.2348 & ГRN \\
\hline 037 & 5 & 5 & 665 & RN \\
\hline 949 & 5 & & 49 & \\
\hline 21 & & & & \\
\hline HEMBL1889695 & & & & ST \\
\hline HEMBL1870195 & 52555 & & 29 & RN \\
\hline HEMBL19 & 5 & & 684 & ST \\
\hline & 5 & & 998 & $\mathrm{RN}$ \\
\hline 677 & & & & RN \\
\hline HEMBL1901046 & 52555 & & 133 & $\mathrm{RN}$ \\
\hline HEMBL12: & 52555 & & 1139 & RN \\
\hline 611 & 5 & & 537 & RIN \\
\hline 308 & & & 111 & ST \\
\hline HEMBL1590966 & 71801 & & 3.7344 & ГST \\
\hline HEMBL 2402627 & 71801 & & 4329 & RN \\
\hline HEMBL2402641 & 971801 & & 9929 & ST \\
\hline HEMBL 2402672 & 971801 & & 4.8478 & \\
\hline CHEMBL2338066 & 71801 & & 5.2865 & ST \\
\hline HEMBL2402657 & 71801 & 4.721 & 4.7416 & $\mathrm{RN}$ \\
\hline HEMBL 2402640 & 971801 & 3. & 3.1757 & $\mathrm{RN}$ \\
\hline
\end{tabular}




\begin{tabular}{|c|c|c|c|c|c|}
\hline \multirow[b]{2}{*}{ CHEMBL 2402799} & \multicolumn{5}{|c|}{ Supplemental Table S2.txt } \\
\hline & 971801 & 3.301 & 2.8577 & TST & \\
\hline CHEMBL 2402646 & 971801 & 3.301 & 3.1735 & TRN & \\
\hline CHEMBL 2402654 & 971801 & 4.75899 & 99999999 & 4.6075 & TRN \\
\hline CHEMBL2402664 & 971801 & 3.301 & 3.5455 & TRN & \\
\hline CHEMBL 2402796 & 971801 & 4.4865 & 3.7048 & TST & \\
\hline CHEMBL 2402663 & 971801 & 4.6966 & 4.2373 & TRN & \\
\hline CHEMBL 2402798 & 971801 & 3.301 & 3.5591 & TRN & \\
\hline CHEMBL518707 & 971801 & 3.301 & 3.14399 & 99999999997 & TRN \\
\hline CHEMBL 2402644 & 971801 & 4.7557 & 4.4626 & TST & \\
\hline CHEMBL 2402649 & 971801 & 4.7174 & 4.4937 & TRN & \\
\hline CHEMBL 2402651 & 971801 & 4.6676 & 4.4641 & TRN & \\
\hline CHEMBL 2402632 & 971801 & 3.301 & 3.3453 & TST & \\
\hline CHEMBL 2402675 & 971801 & 4.8024 & 4.6071 & TRN & \\
\hline CHEMBL 2402626 & 971801 & 3.301 & 3.4214 & TRN & \\
\hline CHEMBL 2402631 & 971801 & 3.301 & 2.9941 & TRN & \\
\hline CHEMBL 2402673 & 971801 & 4.768 & 4.7221 & TRN & \\
\hline CHEMBL 2402802 & 971801 & 3.301 & 3.3349 & TRN & \\
\hline CHEMBL 2402645 & 971801 & 3.301 & 4.1029 & TRN & \\
\hline CHEMBL 2402629 & 971801 & 4.8642 & 4.7439 & TRN & \\
\hline CHEMBL 2402643 & 971801 & 3.301 & 4.4083 & TST & \\
\hline CHEMBL 2402655 & 971801 & 4.5764 & 4.4967 & TRN & \\
\hline CHEMBL 2402650 & 971801 & 4.6509 & 4.5765 & TRN & \\
\hline CHEMBL 2402670 & 971801 & 3.301 & 3.3496 & TRN & \\
\hline CHEMBL 2402660 & 971801 & 4.3734 & 4.2043 & TST & \\
\hline CHEMBL 2402659 & 971801 & 4.7258 & 4.8246 & TRN & \\
\hline CHEMBL 2402674 & 971801 & 4.9278 & 5.1465 & TRN & \\
\hline CHEMBL 2402668 & 971801 & 4.4794 & 4.5795 & TRN & \\
\hline CHEMBL 2402795 & 971801 & 4.5478 & 3.6651 & TRN & \\
\hline CHEMBL 2402628 & 971801 & 3.301 & 3.4249 & TRN & \\
\hline CHEMBL 2402639 & 971801 & 3.301 & 3.0359 & TRN & \\
\hline CHEMBL 2402652 & 971801 & 4.5491 & 4.4733 & TRN & \\
\hline CHEMBL 2402797 & 971801 & 3.301 & 3.3652 & TRN & \\
\hline CHEMBL 2402636 & 971801 & 3.301 & 3.1066 & TST & \\
\hline CHEMBL2402666 & 971801 & 5.4976 & 5.1232 & TRN & \\
\hline CHEMBL 2402667 & 971801 & 3.301 & 3.4507 & TRN & \\
\hline CHEMBL 2402794 & 971801 & 3.301 & 3.4427 & TRN & \\
\hline CHEMBL 2402661 & 971801 & 3.301 & 3.4841 & TRN & \\
\hline CHEMBL 2402665 & 971801 & 3.301 & 3.3535 & TRN & \\
\hline CHEMBL 2402648 & 971801 & 4.5688 & 4.2884 & TRN & \\
\hline CHEMBL 2402671 & 971801 & 4.7406 & 4.7951 & TRN & \\
\hline CHEMBL 2402638 & 971801 & 4.9367 & 3.1357 & TST & \\
\hline CHEMBL 2402653 & 971801 & 4.4522 & 4.7002 & TRN & \\
\hline CHEMBL2402647 & 971801 & 4.5955 & 5.0624 & TRN & \\
\hline CHEMBL 2402656 & 971801 & 4.6356 & 4.5398 & TRN & \\
\hline CHEMBL 2402669 & 971801 & 3.301 & 3.5484 & TRN & \\
\hline CHEMBL2402658 & 971801 & 4.908 & 4.7683 & TRN & \\
\hline CHEMBL 2402801 & 971801 & 3.301 & 3.4266 & TRN & \\
\hline CHEMBL 2402633 & 971801 & 3.301 & 3.219 & TST & \\
\hline
\end{tabular}




\begin{tabular}{|c|c|c|c|c|c|c|}
\hline & & \multicolumn{5}{|c|}{ Supplemental Table S2.txt } \\
\hline CHEMBL 2402642 & 971801 & 3.301 & 4.1117 & TST & & \\
\hline CHEMBL 2402800 & 971801 & 3.301 & 3.3476 & TRN & & \\
\hline CHEMBL 2402635 & 971801 & 3.301 & 2.8463 & TST & & \\
\hline CHEMBL 2402637 & 971801 & 3.301 & 2.8161 & TST & & \\
\hline CHEMBL 2402634 & 971801 & 4.6944 & 3.0306 & TST & & \\
\hline CHEMBL 2402662 & 971801 & 3.301 & 3.5144 & TRN & & \\
\hline CHEMBL 2402630 & 971801 & 4.7486 & 4.8729 & TRN & & \\
\hline CHEMBL3799073 & 1572641 & 7.9431 & 8.0631 & TRN & & \\
\hline CHEMBL3799679 & 1572641 & 8.3768 & 8.255 & TRN & & \\
\hline CHEMBL3797571 & 1572641 & 8.6198 & 8.7535 & TRN & & \\
\hline CHEMBL3798987 & 1572641 & 8.6198 & 8.6242 & TRN & & \\
\hline CHEMBL3799212 & 1572641 & 8.6383 & 8.8413 & TRN & & \\
\hline CHEMBL3799824 & 1572641 & 8.5528 & 8.1789 & TST & & \\
\hline CHEMBL3797558 & 1572641 & 8.301 & 8.1624 & TRN & & \\
\hline CHEMBL3798886 & 1572641 & 7.983 & 7.9631 & TST & & \\
\hline CHEMBL3408213 & 1572641 & 8.1427 & 8.1463 & TRN & & \\
\hline CHEMBL3799307 & 1572641 & 8.6383 & 8.5445 & TRN & & \\
\hline CHEMBL3798611 & 1572641 & $7.7570 e$ & 00000000 & 01 & 7.9297 & TRN \\
\hline CHEMBL3799742 & 1572641 & 7.9666 & 7.9469 & TRN & & \\
\hline CHEMBL 3800533 & 1572641 & 7.2668 & 7.2256 & TRN & & \\
\hline CHEMBL3798804 & 1572641 & 8.5528 & 8.3281 & TRN & & \\
\hline CHEMBL3800210 & 1572641 & 8.1549 & 8.218 & TRN & & \\
\hline CHEMBL3797472 & 1572641 & 8.0223 & 7.9742 & TRN & & \\
\hline CHEMBL3798294 & 1572641 & 7.5528 & 7.6279 & TRN & & \\
\hline CHEMBL 3800432 & 1572641 & 7.8477 & 7.9127 & TRN & & \\
\hline CHEMBL3798726 & 1572641 & 8.4815 & 8.5287 & TRN & & \\
\hline CHEMBL3799592 & 1572641 & 8.4949 & 8.3376 & TST & & \\
\hline CHEMBL3797212 & 1572641 & 7.8327 & 7.8034 & TRN & & \\
\hline CHEMBL3798712 & 1572641 & 6.2557 & 7.6607 & TST & & \\
\hline CHEMBL3800399 & 1572641 & 6.8508 & 7.8137 & TST & & \\
\hline CHEMBL3797823 & 1572641 & 7.5302 & 7.3669 & TRN & & \\
\hline CHEMBL3798778 & 1572641 & 7.308 & 7.8691 & TST & & \\
\hline CHEMBL3798419 & 1572641 & 7.7852 & 8.3879 & TRN & & \\
\hline CHEMBL3798382 & 1572641 & 8.6383 & 8.2663 & TRN & & \\
\hline CHEMBL3798568 & 1572641 & 7.9172 & 7.7522 & TRN & & \\
\hline CHEMBL3798632 & 1572641 & 8.4089 & 8.2439 & TRN & & \\
\hline CHEMBL3797689 & 1572641 & 6.1537 & 7.2792 & TST & & \\
\hline CHEMBL3798129 & 1572641 & 7.9208 & 8.061 & TRN & & \\
\hline CHEMBL3798663 & 1572641 & 8.2596 & 8.2793 & TRN & & \\
\hline CHEMBL3797656 & 1572641 & 8.2596 & 8.2276 & TRN & & \\
\hline CHEMBL3797440 & 1572641 & 8.4815 & 8.491 & TRN & & \\
\hline CHEMBL 3800037 & 1572641 & 8.3665 & 8.1123 & TRN & & \\
\hline CHEMBL3798318 & 1572641 & 7.5702 & 7.6157 & TRN & & \\
\hline CHEMBL3797317 & 1572641 & 8.4318 & 8.6124 & TRN & & \\
\hline CHEMBL3798587 & 1572641 & 7.4271 & 8.0617 & TST & & \\
\hline CHEMBL 3798944 & 1572641 & 8.7959 & 8.4225 & TRN & & \\
\hline CHEMBL3800311 & 1572641 & 8.6198 & 8.6891 & TRN & & \\
\hline CHEMBL3799116 & 1572641 & 8.4202 & 8.3078 & TRN & & \\
\hline
\end{tabular}


Supplemental Table S2.txt

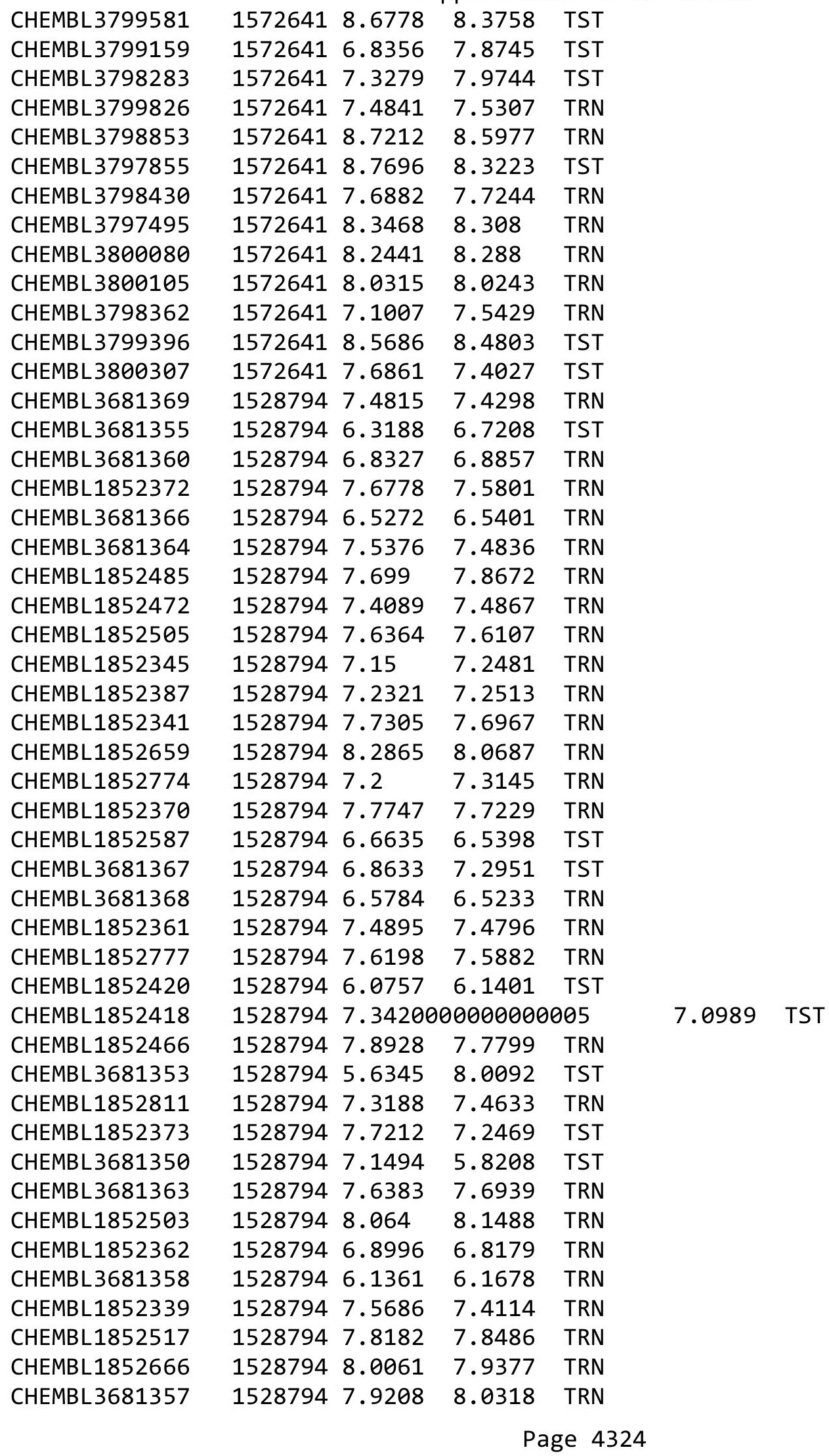


Supplemental Table S2.txt

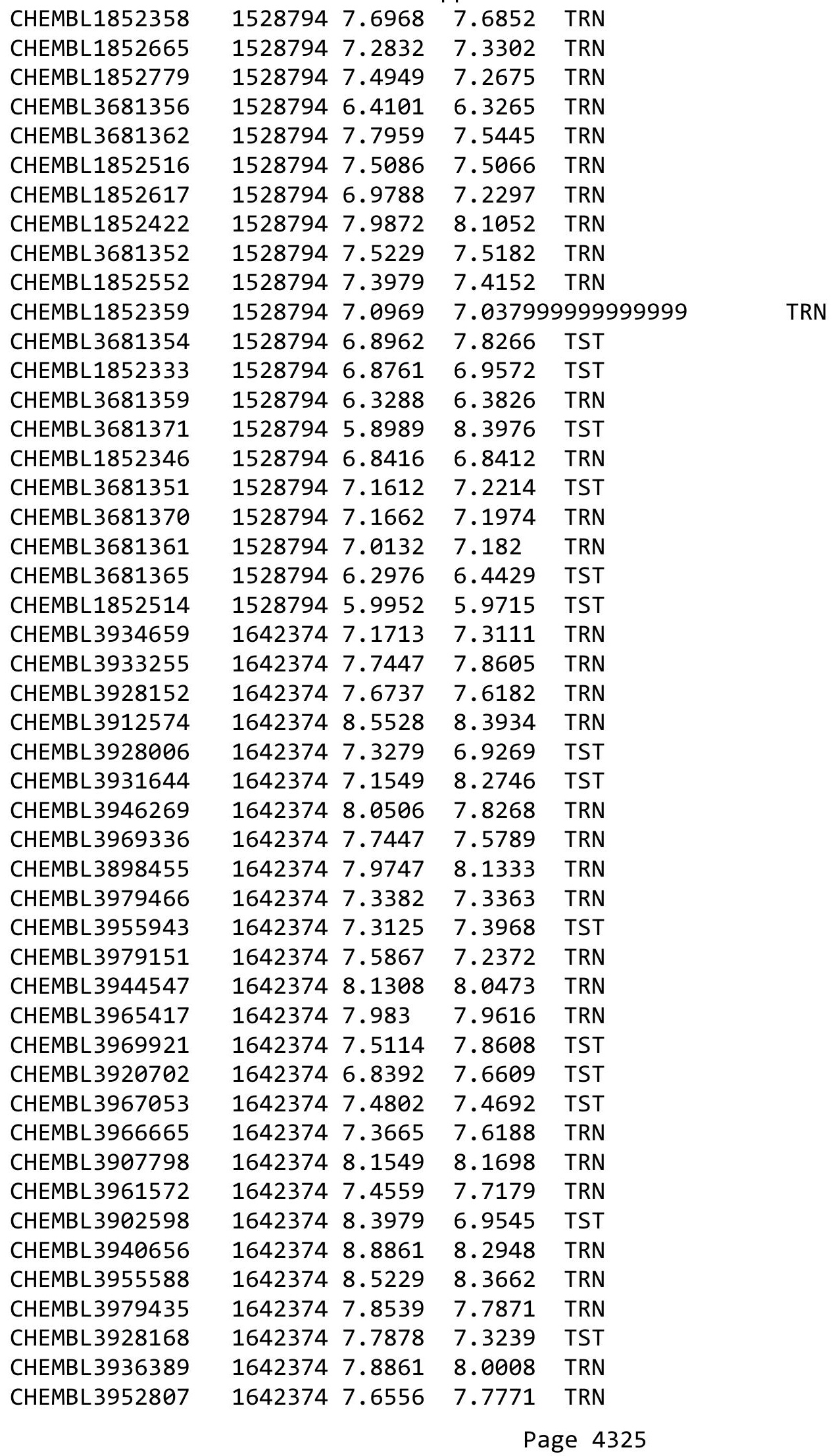




$$
\text { Supplemental Table S2.txt }
$$

\begin{tabular}{|c|c|c|c|c|c|}
\hline CHEMBL 3936348 & 1642374 & 8.1549 & 7.9167 & TRN & \\
\hline CHEMBL 3914538 & 1642374 & 7.1938 & 7.2895 & TRN & \\
\hline CHEMBL3901450 & 1642374 & 7.983 & 7.8024 & TRN & \\
\hline CHEMBL 3972740 & 1642374 & 7.0706 & 7.0956 & TRN & \\
\hline CHEMBL3969648 & 1642374 & 8.2676 & 8.157 & TRN & \\
\hline CHEMBL 3893031 & 1642374 & 9.0 & 8.7883 & TRN & \\
\hline CHEMBL 3928289 & 1642374 & 8.4089 & 8.0882 & TRN & \\
\hline CHEMBL 3904759 & 1642374 & 7.8996 & 7.6831 & TRN & \\
\hline CHEMBL3946375 & 1642374 & 7.8097 & 8.0934 & TRN & \\
\hline CHEMBL3973109 & 1642374 & 7.0555 & 7.2457 & TST & \\
\hline CHEMBL3952102 & 1642374 & 7.2596 & 8.2306 & TST & \\
\hline CHEMBL3909269 & 1642374 & 8.3372 & 8.0465 & TRN & \\
\hline CHEMBL 3967131 & 1642374 & 8.301 & 8.4408 & TRN & \\
\hline CHEMBL3957771 & 1642374 & 7.8861 & 7.8817 & TRN & \\
\hline CHEMBL3953877 & 1642374 & 7.8539 & 8.3116 & TST & \\
\hline CHEMBL3890739 & 1642374 & 7.71899 & 79999999 & 7.8025 & TRN \\
\hline CHEMBL3930512 & 1642374 & 8.7696 & 8.6335 & TRN & \\
\hline CHEMBL3954996 & 1642374 & 6.7349 & 7.0555 & TRN & \\
\hline CHEMBL3927474 & 1642374 & 7.0711 & 7.8061 & TST & \\
\hline CHEMBL3905151 & 1642374 & 8.1192 & $8.31200 t$ & 0000000001 & TRN \\
\hline CHEMBL3966867 & 1642374 & 7.1079 & 7.1248 & TRN & \\
\hline CHEMBL 3984701 & 1642374 & 7.2007 & 7.1337 & TRN & \\
\hline CHEMBL 3966421 & 1642374 & 7.7447 & 7.9413 & TRN & \\
\hline CHEMBL3974426 & 1642374 & 7.6198 & 7.4808 & TRN & \\
\hline CHEMBL 3921547 & 1642374 & 7.767 & 7.4539 & TRN & \\
\hline CHEMBL3936921 & 1642374 & 6.9136 & 7.2838 & TRN & \\
\hline CHEMBL3940353 & 1642374 & 7.1662 & 7.2089 & TST & \\
\hline CHEMBL 3970420 & 1642374 & 8.5528 & 8.1615 & TRN & \\
\hline CHEMBL3913949 & 1642374 & 7.0757 & 7.2458 & TRN & \\
\hline CHEMBL 3917390 & 1642374 & 7.5376 & 7.2143 & TRN & \\
\hline CHEMBL 3902655 & 1642374 & 7.6003 & 8.0266 & TST & \\
\hline CHEMBL3899847 & 1642374 & 7.9666 & $8.57200 t$ & 0000000001 & TST \\
\hline CHEMBL 3968086 & 1642374 & 8.8861 & 8.7433 & TRN & \\
\hline CHEMBL3955615 & 1642374 & 8.0 & 8.1662 & TRN & \\
\hline CHEMBL 3952002 & 1642374 & 7.82100 & 00000000 & 8.0005 & TRN \\
\hline CHEMBL 3923782 & 1642374 & 7.8539 & 8.1489 & TRN & \\
\hline CHEMBL3929832 & 1642374 & 7.9586 & 8.436 & TST & \\
\hline CHEMBL3955881 & 1642374 & 7.8861 & 7.8218 & TRN & \\
\hline CHEMBL3913668 & 1642374 & 7.8239 & 8.0011 & TRN & \\
\hline CHEMBL3959819 & 1642374 & 8.1308 & 8.5706 & TST & \\
\hline CHEMBL3959332 & 1642374 & 7.6308 & 7.3382 & TST & \\
\hline CHEMBL3898139 & 1642374 & 7.0083 & 7.3247 & TST & \\
\hline CHEMBL3905220 & 1642374 & 8.699 & 8.6333 & TRN & \\
\hline CHEMBL3907478 & 1642374 & 6.8601 & 7.1229 & TRN & \\
\hline CHEMBL 3956002 & 1642374 & 8.7447 & 8.4589 & TRN & \\
\hline CHEMBL3943193 & 1642374 & 7.3565 & 7.5889 & TRN & \\
\hline CHEMBL3940833 & 1642374 & 7.0074 & 7.2369 & TRN & \\
\hline CHEMBL3944276 & 1642374 & 8.1427 & 7.5124 & TST & \\
\hline
\end{tabular}


Supplemental Table S2.txt

\begin{tabular}{|c|c|c|c|c|}
\hline CHEMBL 3892851 & 1642374 & 8.3979 & 8.4486 & TRN \\
\hline CHEMBL3917243 & 1642374 & 7.4089 & 7.6327 & TST \\
\hline CHEMBL3955050 & 1642374 & 7.2565 & 7.1602 & TRN \\
\hline CHEMBL3907747 & 1642374 & 7.7423 & 8.4059 & TST \\
\hline CHEMBL3949642 & 1642374 & 8.4949 & 7.5727 & TST \\
\hline CHEMBL3935003 & 1642374 & 8.4089 & 8.27700 & 3000000001 \\
\hline CHEMBL3963871 & 1642374 & 7.2434 & 7.4667 & TRN \\
\hline CHEMBL3962625 & 1642374 & 7.0177 & 7.0855 & TST \\
\hline CHEMBL3918971 & 1642374 & 9.0 & 8.8691 & TRN \\
\hline CHEMBL3949816 & 1642374 & 7.1024 & 6.8608 & TRN \\
\hline CHEMBL3923518 & 1642374 & 7.7212 & 7.9452 & TRN \\
\hline CHEMBL3960450 & 1642374 & 7.7212 & 7.6498 & TRN \\
\hline CHEMBL 3941752 & 1642374 & 7.7375 & 7.9762 & TRN \\
\hline CHEMBL3908105 & 1642374 & 9.0969 & 8.362 & TRN \\
\hline CHEMBL3957206 & 1642374 & 7.1838 & 6.5917 & TST \\
\hline CHEMBL3971036 & 1642374 & 7.0996 & 7.0596 & TRN \\
\hline CHEMBL3950293 & 1642374 & 7.9586 & 8.0587 & TRN \\
\hline CHEMBL 3934357 & 1642374 & 7.8182 & 7.7469 & TRN \\
\hline CHEMBL3950386 & 1642374 & 7.8239 & 7.6167 & TST \\
\hline CHEMBL3976176 & 1642374 & 8.1549 & 7.8521 & TST \\
\hline CHEMBL3915886 & 1642374 & 7.7258 & 7.835 & TRN \\
\hline CHEMBL3977538 & 1642374 & 7.4413 & 8.0335 & TRN \\
\hline CHEMBL 3941913 & 1642374 & 8.6576 & 8.5001 & TRN \\
\hline CHEMBL3948573 & 1642374 & 7.1675 & 7.5986 & TST \\
\hline CHEMBL3980530 & 1642374 & 8.3468 & 7.7206 & TRN \\
\hline CHEMBL3895859 & 1642374 & 8.3768 & 8.2279 & TRN \\
\hline CHEMBL 3930378 & 1642374 & 7.0132 & 7.5879 & TRN \\
\hline CHEMBL 3979412 & 1642374 & 8.0 & 8.7523 & TRN \\
\hline CHEMBL3950459 & 1642374 & 7.3979 & 7.6914 & TRN \\
\hline CHEMBL3902002 & 1642374 & 8.1192 & 8.2184 & TST \\
\hline CHEMBL3921459 & 1642374 & 7.4815 & 7.3315 & TRN \\
\hline CHEMBL3911198 & 1642374 & 7.27 & 8.2873 & TST \\
\hline CHEMBL3980645 & 1642374 & 7.8508 & 8.1224 & TRN \\
\hline CHEMBL3916609 & 1642374 & 7.4342 & 8.0072 & TST \\
\hline CHEMBL3944628 & 1642374 & 7.7645 & 7.5486 & TRN \\
\hline CHEMBL3931787 & 1642374 & 7.4089 & 7.4602 & TRN \\
\hline CHEMBL 3917244 & 1642374 & 7.5376 & 7.6025 & TRN \\
\hline CHEMBL3970872 & 1642374 & 7.6326 & 7.7006 & TRN \\
\hline CHEMBL3939319 & 1642374 & 7.27 & 8.0059 & TST \\
\hline CHEMBL3974817 & 1642374 & 7.6021 & 7.4003 & TRN \\
\hline CHEMBL3905958 & 1642374 & 8.0506 & 8.2285 & TRN \\
\hline CHEMBL3949759 & 1642374 & 7.5935 & 7.2225 & TRN \\
\hline CHEMBL3894517 & 1642374 & 7.6198 & 7.5016 & TRN \\
\hline CHEMBL3983475 & 1642374 & 7.7212 & 7.9817 & TRN \\
\hline CHEMBL3954465 & 1642374 & 8.0132 & 8.0562 & TRN \\
\hline CHEMBL 3932487 & 1642374 & 8.0458 & 8.1812 & TRN \\
\hline CHEMBL 3983690 & 1642374 & 7.9208 & 7.8491 & TRN \\
\hline CHEMBL3929247 & 1642374 & 8.3979 & 8.5345 & TRN \\
\hline
\end{tabular}


Supplemental Table S2.txt

\begin{tabular}{|c|c|c|c|c|c|}
\hline CHEMBL 3974529 & 1642374 & 9.0969 & 8.6794 & TRN & \\
\hline CHEMBL 3937463 & 1642374 & 9.0458 & 7.6807 & TST & \\
\hline CHEMBL3963990 & 1642374 & 8.1427 & 7.9833 & TRN & \\
\hline CHEMBL 3907967 & 1642374 & 8.6383 & 8.59 & TRN & \\
\hline CHEMBL 3932918 & 1642374 & 7.983 & 7.4813 & TST & \\
\hline CHEMBL 3967138 & 1642374 & 7.0757 & 7.3143 & TRN & \\
\hline CHEMBL 3948724 & 1642374 & 6.6925 & 6.872000 & 0000000001 & TRN \\
\hline CHEMBL 3975533 & 1642374 & 7.1824 & 7.877000 & 0000000001 & TRN \\
\hline CHEMBL 3943385 & 1642374 & 8.5229 & 8.1905 & TRN & \\
\hline CHEMBL 3907445 & 1642374 & 7.7447 & 7.3821 & TRN & \\
\hline CHEMBL 3925618 & 1642374 & 7.9872 & 7.7062 & TRN & \\
\hline CHEMBL3916171 & 1642374 & 8.301 & 8.5754 & TRN & \\
\hline CHEMBL 3941244 & 1642374 & 7.3526 & 7.5714 & TRN & \\
\hline CHEMBL 3958469 & 1642374 & 7.6576 & 7.8051 & TRN & \\
\hline CHEMBL 3921157 & 1642374 & 6.6402 & 6.91 & TRN & \\
\hline CHEMBL 3971861 & 1642374 & 8.0969 & 8.1815 & TRN & \\
\hline CHEMBL 3944918 & 1642374 & 7.2916 & 8.3773 & TST & \\
\hline CHEMBL 3952414 & 1642374 & 8.3098 & 8.0568 & TRN & \\
\hline CHEMBL 3978543 & 1642374 & 7.2007 & 7.1913 & TST & \\
\hline CHEMBL 3920412 & 1642374 & 7.8239 & 7.7098 & TRN & \\
\hline CHEMBL 3940338 & 1642374 & 8.1938 & 8.0154 & TRN & \\
\hline CHEMBL3891101 & 1642374 & 7.4949 & 7.7239 & TRN & \\
\hline CHEMBL 3947781 & 1642374 & 7.284 & 7.2064 & TRN & \\
\hline CHEMBL 3974612 & 1642374 & 8.2924 & 8.2954 & TRN & \\
\hline CHEMBL 3900143 & 1642374 & 7.6198 & 7.6093 & TRN & \\
\hline CHEMBL 3893135 & 1642374 & 7.1024 & 7.2947 & TST & \\
\hline CHEMBL3968699 & 1642374 & 8.7447 & 8.828 & TRN & \\
\hline CHEMBL 3975952 & 1642374 & 7.4559 & 7.4987 & TST & \\
\hline CHEMBL 3968385 & 1642374 & 7.1308 & 7.5092 & TRN & \\
\hline CHEMBL 3961748 & 1642374 & 7.8539 & 7.5213 & TRN & \\
\hline CHEMBL 3935423 & 1642374 & 7.4486 & 7.5047 & TRN & \\
\hline CHEMBL 3964760 & 1642374 & 8.0555 & 7.9456 & TST & \\
\hline CHEMBL 3913853 & 1642374 & 7.3279 & 8.005 & TRN & \\
\hline CHEMBL 3920862 & 1642374 & 8.699 & 8.9476 & TRN & \\
\hline CHEMBL 3979269 & 1642374 & 8.699 & 8.3165 & TRN & \\
\hline CHEMBL3922796 & 1642374 & 7.6198 & 8.2452 & TRN & \\
\hline CHEMBL 3909766 & 1642374 & 7.8539 & 8.4522 & TST & \\
\hline CHEMBL 3909187 & 1642374 & 7.1549 & 7.263999 & 9999999999 & TRI \\
\hline CHEMBL 3943123 & 1642374 & 7.0362 & 7.0172 & TRN & \\
\hline CHEMBL 3951576 & 1642374 & 8.301 & 8.2809 & TRN & \\
\hline CHEMBL 3910384 & 1642374 & 7.3696 & 7.3005 & TRN & \\
\hline CHEMBL 3926827 & 1642374 & 7.5719 & 7.5669 & TRN & \\
\hline CHEMBL 3950935 & 1642374 & 8.4089 & 8.4044 & TRN & \\
\hline CHEMBL 3896477 & 1642374 & 7.3979 & 7.7462 & TRN & \\
\hline CHEMBL 3898546 & 1642374 & 8.1549 & 8.1486 & TRN & \\
\hline CHEMBL 3891885 & 1642374 & 7.4318 & 7.7926 & TRN & \\
\hline CHEMBL 3979527 & 1642374 & 7.617999 & 999999999 & 7.6594 & KI \\
\hline CHEMBL 3966385 & 1642374 & 7.3665 & 7.2946 & TRN & \\
\hline
\end{tabular}


Supplemental Table S2.txt

\begin{tabular}{|c|c|c|c|c|}
\hline CHEMBL3961302 & 1642374 & 8.2441 & 7.8575 & TRN \\
\hline CHEMBL3935813 & 1642374 & 8.2218 & 7.9216 & TRN \\
\hline CHEMBL3969844 & 1642374 & 8.4089 & 8.4842 & TRN \\
\hline CHEMBL3932315 & 1642374 & 7.6904 & 8.0348 & TST \\
\hline CHEMBL3921793 & 1642374 & 7.2774 & 7.4114 & TST \\
\hline CHEMBL3931412 & 1642374 & 9.0 & 8.968 & TRN \\
\hline CHEMBL3962048 & 1642374 & 7.5817 & 7.5897 & TRN \\
\hline CHEMBL3982205 & 1642374 & 7.5376 & 7.7461 & TRN \\
\hline CHEMBL3978081 & 1642374 & 8.3872 & 8.2834 & TRN \\
\hline CHEMBL3900288 & 1642374 & 7.6556 & 7.9568 & TRN \\
\hline CHEMBL3960336 & 1642374 & 7.7696 & 7.7772 & TST \\
\hline CHEMBL3924807 & 1642374 & 8.5229 & 8.1612 & TRN \\
\hline CHEMBL3957612 & 1642374 & 8.5229 & 8.1583 & TRN \\
\hline CHEMBL3894946 & 1642374 & 8.2218 & 8.2892 & TRN \\
\hline CHEMBL3895088 & 1642374 & 8.0458 & 8.2536 & TST \\
\hline CHEMBL3900199 & 1642374 & 7.5086 & 7.3373 & TRN \\
\hline CHEMBL3944648 & 1642374 & 8.1308 & 8.0085 & TRN \\
\hline CHEMBL3891712 & 1642374 & 8.1308 & 7.8232 & TST \\
\hline CHEMBL 3982100 & 1642374 & 7.6478 & 7.7727 & TRN \\
\hline CHEMBL3969993 & 1642374 & 9.0 & 8.7772 & TRN \\
\hline CHEMBL3969449 & 1642374 & 7.4318 & 7.3626 & TRN \\
\hline CHEMBL3935580 & 1642374 & 8.7212 & 8.2592 & TRN \\
\hline CHEMBL3896487 & 1642374 & 7.7258 & 7.3457 & TRN \\
\hline CHEMBL3963717 & 1642374 & 7.8125 & 7.277 & TST \\
\hline CHEMBL 3922757 & 1642374 & 7.3251 & 7.2995 & TRN \\
\hline CHEMBL3964852 & 1642374 & 8.6198 & 8.02799 & 9999999999 \\
\hline CHEMBL3958934 & 1642374 & 8.0 & 8.2041 & TRN \\
\hline CHEMBL3977992 & 1642374 & 7.1938 & 7.9113 & TST \\
\hline CHEMBL3956334 & 1642374 & 7.3872 & 7.7294 & TST \\
\hline CHEMBL3913784 & 1642374 & 8.1549 & 8.0275 & TRN \\
\hline CHEMBL3937425 & 1642374 & 8.1549 & 8.2497 & TRN \\
\hline CHEMBL3969014 & 1642374 & 8.1079 & 8.3869 & TRN \\
\hline CHEMBL3932824 & 1642374 & 7.6576 & 7.1796 & TRN \\
\hline CHEMBL3967521 & 1642374 & 7.3372 & 7.7683 & TST \\
\hline CHEMBL3353610 & 1642374 & 9.3979 & 9.0954 & TRN \\
\hline CHEMBL3909177 & 1642374 & 8.699 & 8.4781 & TRN \\
\hline CHEMBL3930421 & 1642374 & 7.6556 & 7.5381 & TRN \\
\hline CHEMBL3918677 & 1642374 & 7.9469 & 7.9609 & TRN \\
\hline CHEMBL 3938527 & 1642374 & 8.7959 & 8.7068 & TRN \\
\hline CHEMBL3929507 & 1642374 & 8.1367 & 7.9092 & TRN \\
\hline CHEMBL3944001 & 1642374 & 8.0458 & 8.054 & TRN \\
\hline CHEMBL3970000 & 1642374 & 7.9208 & 7.4582 & TRN \\
\hline CHEMBL3899786 & 1642374 & 7.8861 & 7.8763 & TRN \\
\hline CHEMBL3950639 & 1642374 & 7.0026 & 7.3641 & TRN \\
\hline CHEMBL3940620 & 1642374 & 7.5986 & 7.8507 & TRN \\
\hline CHEMBL3959660 & 1642374 & 8.3188 & 7.8626 & TRN \\
\hline CHEMBL3968398 & 1642374 & 6.8928 & 7.6229 & TST \\
\hline CHEMBL3937816 & 1642374 & 7.6021 & 7.9256 & TRN \\
\hline
\end{tabular}


Supplemental Table S2.txt

\begin{tabular}{|c|c|c|c|c|c|}
\hline CHEMBL3937106 & 1642374 & 6.9355 & 6.5237 & TST & \\
\hline CHEMBL 3984021 & 1642374 & 8.1938 & 7.7618 & TRN & \\
\hline CHEMBL3930785 & 1642374 & 7.8239 & \multicolumn{2}{|c|}{7.212000000000001} & TRN \\
\hline CHEMBL3910568 & 1642374 & 7.9508 & 7.8605 & TRN & \\
\hline CHEMBL 3944870 & 1642374 & 9.0 & 8.8356 & TRN & \\
\hline CHEMBL 3970583 & 1642374 & 7.5317 & 7.7283 & TRN & \\
\hline CHEMBL3936788 & 1642374 & 7.1938 & 6.8934 & TRN & \\
\hline CHEMBL 3963427 & 1642374 & 8.0 & 6.0707 & TST & \\
\hline CHEMBL 3937528 & 1642374 & 7.6345 & 8.0206 & TRN & \\
\hline CHEMBL 3922279 & 1642374 & 8.8539 & 8.3896 & TRN & \\
\hline CHEMBL 3922914 & 1642374 & 7.317 & 7.6205 & TST & \\
\hline CHEMBL3916657 & 1642374 & 7.2924 & 7.1963 & TRN & \\
\hline CHEMBL 3945276 & 1642374 & 7.6198 & 7.4611 & TRN & \\
\hline CHEMBL 3896764 & 1642374 & 7.4815 & 7.6957 & TRN & \\
\hline CHEMBL 3957386 & 1642374 & 7.6576 & 7.6634 & TRN & \\
\hline CHEMBL 3913583 & 1642374 & 7.1561 & 7.3457 & TRN & \\
\hline CHEMBL3958038 & 1642374 & 7.2984 & 7.9774 & TST & \\
\hline CHEMBL 3892123 & 1642374 & 7.4949 & 7.5408 & TRN & \\
\hline CHEMBL 3975568 & 1642374 & 7.1739 & 7.5121 & TRN & \\
\hline CHEMBL 3981838 & 1642374 & 8.2757 & 7.8249 & TRN & \\
\hline CHEMBL 3904802 & 1642374 & 7.8539 & \multicolumn{2}{|c|}{7.946000000000001} & TRN \\
\hline CHEMBL3965618 & 1642374 & 7.9586 & 7.6055 & TRN & \\
\hline CHEMBL 3984551 & 1642374 & 7.4001 & 7.4309 & TST & \\
\hline CHEMBL 3897724 & 1642374 & 8.6778 & 8.3734 & TRN & \\
\hline CHEMBL3964989 & 1642374 & 7.7447 & 8.0062 & TRN & \\
\hline CHEMBL 3909503 & 1642374 & 7.2596 & 7.0848 & TRN & \\
\hline CHEMBL3969643 & 1642374 & 7.5528 & 7.3172 & TRN & \\
\hline CHEMBL3927693 & 1642374 & 8.0458 & 7.7993 & TRN & \\
\hline CHEMBL3956595 & 1642374 & 7.7986 & 7.4744 & TRN & \\
\hline CHEMBL 3927978 & 1642374 & 8.699 & 8.1427 & TRN & \\
\hline CHEMBL 3971345 & 1642374 & 7.6198 & 8.0617 & TRN & \\
\hline CHEMBL3899016 & 1642374 & 7.8239 & 8.6584 & TRN & \\
\hline CHEMBL3942913 & 1642374 & 7.5654 & 7.6927 & TRN & \\
\hline CHEMBL 3958967 & 1642374 & 7.4179 & 7.0926 & TRN & \\
\hline CHEMBL 3919278 & 1642374 & 7.9547 & 7.8892 & TRN & \\
\hline CHEMBL3964645 & 1642374 & 8.2218 & 7.5002 & TST & \\
\hline CHEMBL 3911457 & 1642374 & 8.0969 & 7.892 & TST & \\
\hline CHEMBL 3894711 & 1642374 & 7.4437 & 7.8594 & TRN & \\
\hline CHEMBL3932016 & 1642374 & 7.3979 & 7.6488 & TST & \\
\hline CHEMBL3973219 & 1642374 & 7.0315 & 7.1052 & TRN & \\
\hline CHEMBL 3960390 & 1642374 & 8.1308 & 7.9082 & TRN & \\
\hline CHEMBL 3932465 & 1642374 & 6.9927 & 6.4571 & TST & \\
\hline CHEMBL3958957 & 1642374 & 8.1675 & 8.2227 & TRN & \\
\hline CHEMBL 3909013 & 1642374 & 7.2373 & 7.3581 & TRN & \\
\hline CHEMBL 3895783 & 1642374 & 6.971 & 7.2435 & TST & \\
\hline CHEMBL 3970408 & 1642374 & 8.1739 & 7.8634 & TST & \\
\hline CHEMBL 3950238 & 1642374 & 7.3372 & 7.3049 & TRN & \\
\hline CHEMBL 3983615 & 1642374 & 7.2411 & 7.3459 & TRN & \\
\hline
\end{tabular}

Page 4330 
Supplemental Table S2.txt

\begin{tabular}{|c|c|c|c|c|}
\hline CHEMBL 3911471 & 1642374 & 8.0458 & 8.0375 & TRN \\
\hline CHEMBL 3890977 & 1642374 & 6.8742 & 6.9908 & TST \\
\hline CHEMBL3962662 & 1642374 & 7.5575 & 7.5439 & TRN \\
\hline CHEMBL 3903323 & 1642374 & 8.6198 & 8.6128 & TRN \\
\hline CHEMBL 3891366 & 1642374 & 8.585 & 8.0849 & TRN \\
\hline CHEMBL 3959394 & 1642374 & 8.0 & 8.0661 & TRN \\
\hline CHEMBL 3970806 & 1642374 & 7.6271 & 7.8652 & TRN \\
\hline CHEMBL 3943905 & 1642374 & 7.9245 & 7.6985 & TST \\
\hline CHEMBL 3908026 & 1642374 & 7.301 & 7.2228 & TRN \\
\hline CHEMBL 3892603 & 1642374 & 8.1427 & 8.1425 & TRN \\
\hline CHEMBL 3943660 & 1642374 & 7.6576 & 7.8262 & TRN \\
\hline CHEMBL3910839 & 1642374 & 7.7212 & 7.6961 & TST \\
\hline CHEMBL 3956893 & 1642374 & 7.6576 & 7.47 & TRN \\
\hline CHEMBL3973714 & 1642374 & 6.4711 & 6.9357 & TRN \\
\hline CHEMBL 3903515 & 1642374 & 7.5867 & 7.4828 & TRN \\
\hline CHEMBL 3891607 & 1642374 & 8.699 & 9.0175 & TRN \\
\hline CHEMBL 3902332 & 1642374 & 7.8356 & 8.3348 & TST \\
\hline CHEMBL 3931912 & 1642374 & 8.4318 & 8.5267 & TRN \\
\hline CHEMBL 3978460 & 1642374 & 7.4437 & 7.5339 & TST \\
\hline CHEMBL 3917776 & 1642374 & 7.4622 & 7.3028 & TRN \\
\hline CHEMBL3951668 & 1642374 & 8.2757 & 8.0869 & TRN \\
\hline CHEMBL 3975249 & 1642374 & 6.0 & 7.0584 & TST \\
\hline CHEMBL 3959641 & 1642374 & 7.1805 & 6.9451 & TST \\
\hline CHEMBL 3916903 & 1642374 & 7.7696 & 7.8098 & TST \\
\hline CHEMBL 3982029 & 1642374 & 8.2218 & 8.5447 & TRN \\
\hline CHEMBL 3980536 & 1642374 & 8.2366 & 8.1025 & TRN \\
\hline CHEMBL 3933365 & 1642374 & 7.6383 & 7.6263 & TRN \\
\hline CHEMBL 3897547 & 1642374 & 7.3188 & 7.3846 & TRN \\
\hline CHEMBL 3926237 & 1642374 & 7.1739 & 7.808 & TST \\
\hline CHEMBL 3948983 & 1642374 & 7.4815 & 7.3773 & TST \\
\hline CHEMBL 3982493 & 1642374 & 7.4123 & 7.3188 & TST \\
\hline CHEMBL 3928181 & 1642374 & 8.2218 & 8.1784 & TRN \\
\hline CHEMBL 3938371 & 1642374 & 7.8477 & 7.3105 & TST \\
\hline CHEMBL 3889923 & 1642374 & 8.5528 & 8.9865 & TRN \\
\hline CHEMBL 3900214 & 1642374 & 7.8239 & 8.0977 & TRN \\
\hline CHEMBL3910621 & 1642374 & 7.4609 & 7.1981 & TST \\
\hline CHEMBL 3922704 & 1642374 & 6.9666 & 7.2103 & TRN \\
\hline CHEMBL 3930405 & 1642374 & 7.8894 & 8.0027 & TRN \\
\hline CHEMBL 3923064 & 1642374 & 8.0969 & 7.5431 & TST \\
\hline CHEMBL3958989 & 1642374 & 7.8539 & 7.856 & TRN \\
\hline CHEMBL 3892209 & 1642374 & 8.4318 & 8.0278 & TRN \\
\hline CHEMBL 3975143 & 1642374 & 8.0969 & 7.704 & TRN \\
\hline CHEMBL 3979247 & 1642374 & 8.3979 & 8.3776 & TST \\
\hline CHEMBL 3984570 & 1642374 & 6.8386 & 7.1968 & TRN \\
\hline CHEMBL 3932130 & 1642374 & 6.7696 & 6.84399 & 9999999999 \\
\hline CHEMBL 3958244 & 1642374 & 8.1079 & 7.9483 & TRN \\
\hline CHEMBL 3949330 & 1642374 & 8.301 & 8.2859 & TRN \\
\hline CHEMBL 3893165 & 1642374 & 7.7212 & 7.6515 & TRN \\
\hline
\end{tabular}

Page 4331 
Supplemental Table S2.txt

\begin{tabular}{|c|c|c|c|c|}
\hline CHEMBL3983099 & 1642374 & 7.5528 & 7.558 & TST \\
\hline CHEMBL 3892297 & 1642374 & 7.7696 & 7.8708 & TRN \\
\hline CHEMBL3917842 & 1642374 & 7.9872 & 8.0028 & TRN \\
\hline CHEMBL3947628 & 1642374 & 7.9318 & 8.189 & TRN \\
\hline CHEMBL3907818 & 1642374 & 7.4949 & 7.3612 & TRN \\
\hline CHEMBL3930345 & 1642374 & 8.5229 & 8.2254 & TRN \\
\hline CHEMBL3947073 & 1642374 & 7.7144 & 7.4419 & TST \\
\hline CHEMBL3954466 & 1642374 & 8.0458 & 7.7904 & TST \\
\hline CHEMBL3935289 & 1642374 & 7.2218 & 7.73799 & 99999999995 \\
\hline CHEMBL3971419 & 1642374 & 7.8665 & 7.7297 & TRN \\
\hline CHEMBL3905918 & 1642374 & 7.6778 & 7.8315 & TRN \\
\hline CHEMBL3950226 & 1642374 & 8.3979 & 8.3022 & TRN \\
\hline CHEMBL3961019 & 1642374 & 7.8239 & 8.0628 & TRN \\
\hline CHEMBL3900519 & 1642374 & 7.2291 & 7.4062 & TST \\
\hline CHEMBL3926236 & 1642374 & 8.5229 & 8.2112 & TRN \\
\hline CHEMBL3906912 & 1642374 & 8.3979 & 8.2427 & TRN \\
\hline CHEMBL3956828 & 1642374 & 7.1308 & 7.7604 & TRN \\
\hline CHEMBL3932913 & 1642374 & 8.0809 & 8.0607 & TRN \\
\hline CHEMBL3986368 & 1642374 & 7.0434 & 7.2716 & TRN \\
\hline CHEMBL3971289 & 1642374 & 8.0 & 7.9632 & TRN \\
\hline CHEMBL3940954 & 1642374 & 8.1487 & 8.1573 & TRN \\
\hline CHEMBL3917337 & 1642374 & 7.5376 & 7.6409 & TRN \\
\hline CHEMBL3918275 & 1642374 & 7.1129 & 7.0267 & TRN \\
\hline CHEMBL3939794 & 1642374 & 8.1675 & 8.1209 & TRN \\
\hline CHEMBL3946360 & 1642374 & 7.9208 & 7.9379 & TRN \\
\hline CHEMBL3909466 & 1642374 & 6.4962 & 7.4825 & TST \\
\hline CHEMBL3983047 & 1642374 & 8.2218 & 8.5046 & TST \\
\hline CHEMBL3928206 & 1642374 & 7.0362 & 8.4475 & TST \\
\hline CHEMBL3950426 & 1642374 & 6.9867 & 7.1315 & TST \\
\hline CHEMBL3908715 & 1642374 & 8.699 & 8.7627 & TRN \\
\hline CHEMBL3942188 & 1642374 & 7.3279 & 7.715 & TRN \\
\hline CHEMBL3942886 & 1642374 & 7.585 & 8.0289 & TST \\
\hline CHEMBL3946907 & 1642374 & 7.5482 & 7.3866 & TRN \\
\hline CHEMBL3906829 & 1642374 & 8.2757 & 8.3884 & TRN \\
\hline CHEMBL3959815 & 1642374 & 8.1079 & 7.414 & TST \\
\hline CHEMBL3942280 & 1642374 & 8.7447 & 8.4965 & TRN \\
\hline CHEMBL3957966 & 1642374 & 7.5258 & 7.3083 & TRN \\
\hline CHEMBL3947106 & 1642374 & 8.1805 & 8.4618 & TRN \\
\hline CHEMBL3939574 & 1642374 & 7.7852 & 7.6627 & TRN \\
\hline CHEMBL3920912 & 1642374 & 7.4672 & 8.0268 & TRN \\
\hline CHEMBL3914970 & 1642374 & 7.7932 & 8.5902 & TST \\
\hline CHEMBL3960220 & 1642374 & 8.301 & 7.4856 & TST \\
\hline CHEMBL3933607 & 1642374 & 8.2218 & 8.135 & TRN \\
\hline CHEMBL3908832 & 1642374 & 7.0443 & 7.9217 & TST \\
\hline CHEMBL3975056 & 1642374 & 8.6576 & 8.2634 & TRN \\
\hline CHEMBL3929362 & 1642374 & 8.1079 & 8.1907 & TRN \\
\hline CHEMBL3967439 & 1642374 & 7.7799 & 8.0813 & TST \\
\hline CHEMBL3940168 & 1642374 & 7.8861 & 7.3516 & TST \\
\hline
\end{tabular}


Supplemental Table S2.txt

\begin{tabular}{|c|c|c|c|c|c|c|}
\hline CHEMBL3935271 & 1642374 & 7.7959 & 7.6491 & TRN & & \\
\hline CHEMBL 3938084 & 1642374 & 8.0458 & 7.9857 & TRN & & \\
\hline CHEMBL3903826 & 1642374 & 7.8633 & 8.1751 & TRN & & \\
\hline CHEMBL3962046 & 1642374 & 8.4318 & 8.0138 & TST & & \\
\hline CHEMBL 3967665 & 1642374 & 8.2218 & 7.8362 & TRN & & \\
\hline CHEMBL3981147 & 1642374 & 7.8861 & 7.9756 & TRN & & \\
\hline CHEMBL3949997 & 1642374 & 7.2924 & 7.5262 & TST & & \\
\hline CHEMBL3971293 & 1642374 & 8.1549 & 7.8995 & TST & & \\
\hline CHEMBL3973817 & 1642374 & 8.3768 & 7.598 & TST & & \\
\hline CHEMBL3927369 & 1642374 & 7.8861 & 8.2283 & TRN & & \\
\hline CHEMBL 3948933 & 1642374 & 7.7986 & 7.9823 & TST & & \\
\hline CHEMBL 3921173 & 1642374 & 7.3372 & 8.2984 & TST & & \\
\hline CHEMBL3938411 & 1642374 & 7.8928 & 7.7578 & TRN & & \\
\hline CHEMBL3914217 & 1642374 & 7.3188 & 7.7791 & TST & & \\
\hline CHEMBL3926381 & 1642374 & 7.4089 & 7.2047 & TRN & & \\
\hline CHEMBL3944758 & 1642374 & 8.0 & 7.9855 & TRN & & \\
\hline CHEMBL3904208 & 1642374 & 7.2218 & 7.8235 & TRN & & \\
\hline CHEMBL3915414 & 1642374 & 8.699 & 8.2645 & TST & & \\
\hline CHEMBL 3890587 & 1642374 & 7.6162 & 7.819 & TRN & & \\
\hline CHEMBL 3955774 & 1642374 & 8.0655 & 8.1244 & TRN & & \\
\hline CHEMBL3975504 & 1642374 & 8.0555 & 7.9662 & TRN & & \\
\hline CHEMBL3962132 & 1642374 & 6.9101 & 7.4476 & TRN & & \\
\hline CHEMBL 3904494 & 1642374 & 7.6778 & 7.932 & TST & & \\
\hline CHEMBL3961490 & 1642374 & 7.8729 & 8.0698 & TRN & & \\
\hline CHEMBL3986992 & 1642374 & 7.1487 & 7.6196 & TRN & & \\
\hline CHEMBL 3980374 & 1642374 & 7.4949 & 7.4368 & TRN & & \\
\hline CHEMBL 3936060 & 1642374 & 9.0458 & 8.8146 & TRN & & \\
\hline CHEMBL3967016 & 1642374 & 7.7212 & 8.1811 & TRN & & \\
\hline CHEMBL3934733 & 1642374 & 7.5229 & 7.3776 & TRN & & \\
\hline CHEMBL3977728 & 1642374 & 9.0 & 8.9138 & TRN & & \\
\hline CHEMBL3896063 & 1642374 & 7.27 & 7.2133 & TRN & & \\
\hline CHEMBL3959124 & 1642374 & \multicolumn{3}{|c|}{7.3420000000000005} & 7.4903 & TRN \\
\hline CHEMBL3966112 & 1642374 & 8.8539 & 8.5628 & TRN & & \\
\hline CHEMBL3908931 & 1642374 & 8.699 & 8.6337 & TRN & & \\
\hline CHEMBL3960710 & 1642374 & 7.4559 & 7.6325 & TRN & & \\
\hline CHEMBL3906578 & 1642374 & 8.301 & 8.4513 & TRN & & \\
\hline CHEMBL 3930154 & 1642374 & 8.1427 & 8.4947 & TRN & & \\
\hline CHEMBL3913463 & 1642374 & 7.7696 & 7.7836 & TRN & & \\
\hline CHEMBL3930767 & 1642374 & 7.0496 & 8.161 & TST & & \\
\hline CHEMBL3933787 & 1642374 & 7.6055 & 7.3301 & TST & & \\
\hline CHEMBL 3900150 & 1642374 & 7.585 & 7.8354 & TST & & \\
\hline CHEMBL3941205 & 1642374 & 7.9355 & 7.6953 & TRN & & \\
\hline CHEMBL3928697 & 1642374 & 8.2218 & 8.0334 & TRN & & \\
\hline CHEMBL3902375 & 1642374 & 7.8861 & 8.3507 & TST & & \\
\hline CHEMBL 3947152 & 1642374 & 7.3188 & 7.4799 & TRN & & \\
\hline CHEMBL 3890105 & 1642374 & 7.5969 & 7.2339 & TRN & & \\
\hline CHEMBL 3964284 & 1642374 & 7.3958 & 7.138 & TRN & & \\
\hline CHEMBL3934931 & 1642374 & 7.2449 & 7.7456 & TST & & \\
\hline
\end{tabular}

Page 4333 
Supplemental Table S2.txt

CHEMBL3965415

CHEMBL3918593

CHEMBL 3971733

CHEMBL3969834

CHEMBL3984365

CHEMBL2324349

CHEMBL3955533

CHEMBL3936205

CHEMBL3932355

CHEMBL3927921

CHEMBL3903572

CHEMBL3940530

CHEMBL3912341

CHEMBL3926053

CHEMBL3981467

CHEMBL3976458

CHEMBL3946234

CHEMBL3957165

CHEMBL3898598

CHEMBL3959343

CHEMBL3936707

CHEMBL3956570

CHEMBL3912579

CHEMBL3906987

CHEMBL3919428

CHEMBL3919170

CHEMBL3909632

CHEMBL3931405

CHEMBL 3908860

CHEMBL3948498

CHEMBL3971483

CHEMBL3912841

CHEMBL3918427

CHEMBL3972310

CHEMBL3960827

CHEMBL3925666

CHEMBL3971501

CHEMBL3959205

CHEMBL3931699

CHEMBL3900167

CHEMBL3966054

CHEMBL3947192

CHEMBL3903952

CHEMBL 3903646

CHEMBL3892495

CHEMBL3976364

CHEMBL3901138

CHEMBL3982988
16423747.6364

16423747.585

16423748.1739

16423748.3279

16423748.0

16423749.0969

16423748.2218

16423747.4202

16423748.2218

16423748.699

16423747.2807

16423747.9208

16423747.6091

16423746.5834

16423747.699

16423747.3585

16423748.2441

16423747.8239

16423747.0555

16423747.6596

16423747.7212

16423747.3188

16423747.8962

16423747.2204

16423747.4437

16423747.699

16423747.7212

16423749.0

16423748.1549

16423747.5884

16423748.1367

16423748.5229

16423747.5129

16423747.5287

16423747.7447

16423747.7212

16423747.8125

16423748.6021

16423747.6778

16423749.2218

16423747.3072

16423747.5045

16423747.2907

16423747.4202

16423747.4461

16423748.0862

16423747.8539

16423748.2218
7.8619 TRN

7.7616 TRN

8.033999999999999

7.9513 TRN

8.2268 TRN

8.7211 TRN

8.3121 TRN

7.0842 TST

7.9316 TRN

8.5818 TRN

7.5806 TRN

8.3207 TRN

7.4572 TRN

6.6871 TRN

7.66 TRN

7.5223 TRN

8.3182 TRN

7.5419 TST

7.2661 TST

7.733 TRN

7.9292 TRN

7.0832 TST

7.8629 TRN

7.1587 TST

7.9831 TRN

7.6909 TRN

7.9491 TST

8.6184 TRN

7.814 TRN

7.6452 TRN

7.8976 TRN

8.7874 TRN

8.2464 TST

7.6908 TST

7.7289 TST

7.5395 TRN

7.6807 TST

8.2859 TRN

7.843 TRN

8.8557 TRN

7.6649 TRN

7.7136 TST

7.5472 TRN

8.142999999999999

TST

7.5357 TRN

7.8954 TRN

8.4467 TST

8.0023 TRN 
Supplemental Table S2.txt

\begin{tabular}{|c|c|c|c|c|c|}
\hline CHEMBL3969092 & 1642374 & 7.7986 & 8.3208 & TST & \\
\hline CHEMBL3983589 & 1642374 & 8.0969 & 7.6697 & TRN & \\
\hline CHEMBL3920697 & 1642374 & 7.2596 & 7.58799 & 9999999999 & TRN \\
\hline CHEMBL 3977753 & 1642374 & 7.5157 & 7.2374 & TST & \\
\hline CHEMBL3922837 & 1642374 & 8.0458 & 7.5264 & TRN & \\
\hline CHEMBL3909493 & 1642374 & 8.0506 & 7.7828 & TRN & \\
\hline CHEMBL3921139 & 1642374 & 7.5229 & 7.3729 & TRN & \\
\hline CHEMBL3907134 & 1642374 & 8.2218 & 8.3706 & TRN & \\
\hline CHEMBL3924036 & 1642374 & 8.3979 & 8.254 & TRN & \\
\hline CHEMBL3967313 & 1642374 & 7.6091 & 7.5065 & TRN & \\
\hline CHEMBL3900471 & 1642374 & 8.0969 & 7.7726 & TRN & \\
\hline CHEMBL3895715 & 1642374 & 6.9731 & 7.2858 & TST & \\
\hline CHEMBL3928321 & 1642374 & 7.6003 & 7.3835 & TRN & \\
\hline CHEMBL 3974276 & 1642374 & 7.1101 & 7.6518 & TRN & \\
\hline CHEMBL3926732 & 1642374 & 7.7959 & 7.9278 & TRN & \\
\hline CHEMBL3947210 & 1642374 & 8.5229 & 8.5246 & TRN & \\
\hline CHEMBL3915874 & 1642374 & 7.2076 & 7.4561 & TRN & \\
\hline CHEMBL3967314 & 1642374 & 8.1249 & 8.1657 & TRN & \\
\hline CHEMBL3954503 & 1642374 & 8.6778 & 8.3113 & TRN & \\
\hline CHEMBL3931443 & 1642374 & 7.6778 & 7.6558 & TST & \\
\hline CHEMBL3927795 & 1642374 & 7.2076 & 7.2844 & TST & \\
\hline CHEMBL3920911 & 1642374 & 8.3979 & 8.1805 & TST & \\
\hline CHEMBL3986281 & 1642374 & 7.6198 & 7.6488 & TRN & \\
\hline CHEMBL3926165 & 1642374 & 7.4989 & 7.4508 & TRN & \\
\hline CHEMBL3934639 & 1642374 & 7.2588 & 7.8569 & TRN & \\
\hline CHEMBL3980487 & 1642374 & 8.0969 & 8.291 & TRN & \\
\hline CHEMBL3918985 & 1642374 & 7.4449 & 7.5091 & TRN & \\
\hline CHEMBL3973730 & 1642374 & 8.2218 & 8.2961 & TRN & \\
\hline CHEMBL3941464 & 1642374 & 7.6778 & 7.8662 & TST & \\
\hline CHEMBL3916559 & 1642374 & 7.5686 & \multicolumn{2}{|c|}{7.218999999999999} & TRN \\
\hline CHEMBL3915898 & 1642374 & 8.0 & 8.5017 & TRN & \\
\hline CHEMBL 3979023 & 1642374 & 7.5735 & 7.4706 & TRN & \\
\hline CHEMBL3953690 & 1642374 & 6.6882 & 7.9008 & TST & \\
\hline CHEMBL3952661 & 1642374 & 7.2757 & 7.7393 & TST & \\
\hline CHEMBL3936273 & 1642374 & 7.9666 & 7.8404 & TRN & \\
\hline CHEMBL3945392 & 1642374 & 7.7696 & 7.6598 & TST & \\
\hline CHEMBL 3980034 & 1642374 & 7.4815 & 7.5972 & TST & \\
\hline CHEMBL3923562 & 1642374 & 7.7696 & 7.9607 & TRN & \\
\hline CHEMBL3921991 & 1642374 & 8.0555 & \multicolumn{2}{|c|}{7.986000000000001} & TRN \\
\hline CHEMBL3976483 & 1642374 & 7.9586 & 7.4869 & TST & \\
\hline CHEMBL3979624 & 1642374 & 8.4815 & 8.6498 & TRN & \\
\hline CHEMBL 3892419 & 1642374 & 8.1549 & 7.9677 & TRN & \\
\hline CHEMBL3904436 & 1642374 & 7.2757 & 7.8793 & TRN & \\
\hline CHEMBL3926105 & 1642374 & 8.1079 & 7.9226 & TRN & \\
\hline CHEMBL3928126 & 1642374 & 7.3516 & 7.2097 & TRN & \\
\hline CHEMBL3971103 & 1642374 & 7.0362 & 6.9651 & TRN & \\
\hline CHEMBL3897829 & 1642374 & 9.0969 & 8.8053 & TRN & \\
\hline CHEMBL3940385 & 1642374 & 7.9208 & 7.7586 & TRN & \\
\hline
\end{tabular}


Supplemental Table S2.txt

\begin{tabular}{|c|c|c|c|c|c|}
\hline CHEMBL3921819 & 1642374 & 7.7773 & 7.5621 & TST & \\
\hline CHEMBL3982130 & 1642374 & 8.301 & 7.931 & TRN & \\
\hline CHEMBL3945697 & 1642374 & 7.9547 & \multicolumn{2}{|c|}{7.9270000000000005} & TST \\
\hline CHEMBL3986632 & 1642374 & 7.699 & 7.6965 & TST & \\
\hline CHEMBL3955147 & 1642374 & 7.4318 & 7.2599 & TRN & \\
\hline CHEMBL3904290 & 1642374 & 7.6778 & 7.4674 & TRN & \\
\hline CHEMBL3965675 & 1642374 & 7.8761 & 7.3528 & TRN & \\
\hline CHEMBL3900555 & 1642374 & \multicolumn{2}{|c|}{7.7620000000000005} & 7.9462 & TRN \\
\hline CHEMBL3945128 & 1642374 & 6.9747 & 7.4014 & TST & \\
\hline CHEMBL3982001 & 1642374 & 7.5391 & 7.7318 & TRN & \\
\hline CHEMBL3935547 & 1642374 & 8.1549 & 7.9734 & TRN & \\
\hline CHEMBL3909554 & 1642374 & 7.6021 & 7.8345 & TRN & \\
\hline CHEMBL3959297 & 1642374 & 7.5768 & 7.6705 & TRN & \\
\hline CHEMBL 3895871 & 1642374 & 7.4202 & 7.9403 & TRN & \\
\hline CHEMBL 3891282 & 1642374 & 7.4437 & \multicolumn{2}{|c|}{7.827999999999999} & TRN \\
\hline CHEMBL3975619 & 1642374 & 8.5229 & 8.254 & TRN & \\
\hline CHEMBL3965259 & 1642374 & 8.0458 & 7.9794 & TRN & \\
\hline CHEMBL3891896 & 1642374 & 7.1612 & 7.4778 & TRN & \\
\hline CHEMBL3971016 & 1642374 & 7.9136 & 8.2196 & TST & \\
\hline CHEMBL3986327 & 1642374 & 6.9101 & 7.1686 & TRN & \\
\hline CHEMBL3897869 & 1642374 & 7.5243 & 7.8339 & TRN & \\
\hline CHEMBL3974078 & 1642374 & 7.4685 & 6.7482 & TST & \\
\hline CHEMBL3959912 & 1642374 & 7.3809 & 7.419 & TST & \\
\hline CHEMBL3979038 & 1642374 & 9.0969 & 8.6329 & TRN & \\
\hline CHEMBL 3908052 & 1642374 & 8.699 & 8.2295 & TRN & \\
\hline CHEMBL3936784 & 1642374 & 7.8508 & 7.7115 & TRN & \\
\hline CHEMBL 3987048 & 1642374 & 7.0419 & 8.2764 & TST & \\
\hline CHEMBL3943765 & 1642374 & 7.3516 & 7.6551 & TRN & \\
\hline CHEMBL 3952502 & 1642374 & 7.4962 & 7.6801 & TRN & \\
\hline CHEMBL3918709 & 1642374 & 7.9136 & 8.1652 & TRN & \\
\hline CHEMBL3923600 & 1642374 & 9.1549 & 8.7734 & TRN & \\
\hline CHEMBL3969214 & 1642374 & 6.9318 & 7.3887 & TRN & \\
\hline CHEMBL3896309 & 1642374 & 7.9136 & 8.4008 & TST & \\
\hline CHEMBL3972603 & 1642374 & 9.0458 & 8.6017 & TRN & \\
\hline CHEMBL3911243 & 1642374 & 8.2218 & 8.3218 & TRN & \\
\hline CHEMBL3975548 & 1642374 & 7.4498 & 7.4421 & TRN & \\
\hline CHEMBL3952718 & 1642374 & 7.699 & 7.37200 & 0000000001 & TRN \\
\hline CHEMBL 3898580 & 1642374 & 7.6778 & 7.8072 & TST & \\
\hline CHEMBL3982038 & 1642374 & 8.7447 & 8.5514 & TRN & \\
\hline CHEMBL3948035 & 1642374 & 7.4949 & 7.9501 & TRN & \\
\hline CHEMBL3925583 & 1642374 & 6.9508 & 6.6864 & TST & \\
\hline CHEMBL 3943402 & 1642374 & 7.1135 & 7.8021 & TST & \\
\hline CHEMBL3903745 & 1642374 & 8.0757 & 8.0158 & TRN & \\
\hline CHEMBL3923721 & 1642374 & 7.6778 & 7.7957 & TST & \\
\hline CHEMBL3953334 & 1642374 & 7.2076 & 7.4019 & TRN & \\
\hline CHEMBL3898195 & 1642374 & 7.0655 & 7.5006 & TRN & \\
\hline CHEMBL3964363 & 1642374 & 7.301 & 7.0662 & TRN & \\
\hline CHEMBL3961110 & 1642374 & 7.3372 & 7.2798 & TRN & \\
\hline
\end{tabular}


Supplemental Table S2.txt

\begin{tabular}{|c|c|c|c|c|}
\hline - & 374 & & & \\
\hline HEMBL3937327 & 642374 & 7.5467 & & \\
\hline & 374 & & & \\
\hline 65 & 374 & $\theta$ & 878 & \\
\hline IEMBL: & 374 & 699 & 398 & \\
\hline EMBL3942214 & 542374 & 1068 & 1659 & \\
\hline IEMBL39 & 374 & .2076 & 451 & \\
\hline & 374 & 3539 & 347 & \\
\hline 385 & 374 & 7696 & 7932 & \\
\hline IEMBL3959445 & 374 & 7.7959 & 0387 & \\
\hline AEMBL 3952196 & 374 & 7.4559 & 6465 & \\
\hline IEMBL38 & 374 & 458 & 126 & \\
\hline EMBL: & & & 728 & \\
\hline IEMBL: & 374 & 5778 & 8062 & \\
\hline IEMBL3959258 & 374 & 5383 & 6901 & \\
\hline EMBL3889773 & 74 & 089 & 5481 & \\
\hline IEMBL3S & 74 & 928 & 084 & \\
\hline IEMBL3 3 & 74 & 172 & 506 & \\
\hline IEMBL & 374 & 655 & 204 & \\
\hline IEMBL 388 & 374 & 565 & 647 & \\
\hline IEMBL 38 & 74 & 962 & 511 & \\
\hline EMBL3S & 74 & +27 & 503 & \\
\hline 29 & & 36 & 995 & \\
\hline 46 & 374 & 208 & & \\
\hline EMBL39 & 74 & 33 & 88 & RN \\
\hline EMBL3S & 74 & 22 & 94 & \\
\hline EMBL 39 & 74 & 18 & 17 & $x^{2}+2+$ \\
\hline 1 & & 98 & 92 & \\
\hline 59 & 74 & 79 & 197 & RN \\
\hline IEMBL3S & 74 & 38 & 81 & RN \\
\hline EMBL39 & 74 & 218 & .71 & 5 \\
\hline FMBI $3 c$ & 74 & & & RI \\
\hline & 74 & & & \\
\hline EMBL 391 & 74 & & 083 & RN \\
\hline IEMBL397 & 74 & 161 & 891 & RI \\
\hline EMBL3C & 74 & 932 & 945 & \\
\hline 13 & & 18 & 588 & D \\
\hline & 74 & 73 & 376 & RIN \\
\hline AEMBL3975346 & 374 & 852 & 184 & $\mathrm{RI}$ \\
\hline EMBL39 & 74 & 069 & 222 & $S$ \\
\hline IEMBL390 & 74 & 218 & 921 & RI \\
\hline & & & & RIN \\
\hline AEMBL3908076 & 374 & 8.3979 & 8.3441 & RN \\
\hline EMBL3912633 & 374 & 8.1805 & 8.7294 & S \\
\hline 97 & & & 753 & \\
\hline CHEMBL389 & & 229 & 7.6613 & \\
\hline ל & 374 & 3.2147 & 8.1721 & \\
\hline CHEMBL3898797 & 1642374 & 7.7959 & 7.8484 & \\
\hline
\end{tabular}

Page 4337 
Supplemental Table S2.txt

\begin{tabular}{|c|c|c|c|c|c|}
\hline CHEMBL3921470 & 1642374 & 8.0969 & 8.0825 & TRN & \\
\hline CHEMBL3923886 & 1642374 & 8.301 & 7.8298 & TRN & \\
\hline CHEMBL3890058 & 1642374 & 7.7447 & 7.4829 & TRN & \\
\hline CHEMBL3932253 & 1642374 & 7.8729 & 7.6477 & TRN & \\
\hline CHEMBL3972627 & 1642374 & 7.8508 & 7.5099 & TRN & \\
\hline CHEMBL3950342 & 1642374 & 7.8239 & 7.637006 & 00000000005 & TRN \\
\hline CHEMBL3895865 & 1642374 & 8.0 & 7.7241 & TRN & \\
\hline CHEMBL3926274 & 1642374 & 6.9031 & 7.0675 & TRN & \\
\hline CHEMBL3927379 & 1642374 & 7.0526 & 7.2212 & TRN & \\
\hline CHEMBL3928513 & 1642374 & 7.2418 & 7.3468 & TRN & \\
\hline CHEMBL3933921 & 1642374 & 7.7447 & 7.4684 & TRN & \\
\hline CHEMBL3953167 & 1642374 & 6.4622 & 7.0649 & TRN & \\
\hline CHEMBL3957897 & 1642374 & 7.6778 & 7.8215 & TRN & \\
\hline CHEMBL3901973 & 1642374 & 8.1549 & 7.739 & TRN & \\
\hline CHEMBL3964437 & 1642374 & 8.301 & 8.2898 & TRN & \\
\hline CHEMBL3974419 & 1642374 & 7.699 & 7.7852 & TRN & \\
\hline CHEMBL3981015 & 1642374 & 7.0555 & 7.3608 & TRN & \\
\hline CHEMBL3933605 & 1642374 & 8.0269 & 7.6562 & TRN & \\
\hline CHEMBL3916958 & 1642374 & 8.5229 & 8.2202 & TRN & \\
\hline CHEMBL3899297 & 1642374 & 7.7447 & 7.8812 & TRN & \\
\hline CHEMBL3912572 & 1642374 & 7.8861 & 7.9155 & TRN & \\
\hline CHEMBL3902650 & 1642374 & 7.4559 & 6.9911 & TST & \\
\hline CHEMBL3926731 & 1642374 & 7.1319 & 7.3038 & TRN & \\
\hline CHEMBL3920893 & 1642374 & 8.3979 & 7.9294 & TRN & \\
\hline CHEMBL3889921 & 1642374 & 7.9208 & 7.8313 & TST & \\
\hline CHEMBL3942832 & 1642374 & 8.0458 & 8.1008 & TRN & \\
\hline CHEMBL3904559 & 1642374 & 8.0 & 8.1887 & TRN & \\
\hline CHEMBL3978362 & 1642374 & 6.7696 & 6.7831 & TRN & \\
\hline CHEMBL3912726 & 1642374 & 8.0 & 7.7158 & TRN & \\
\hline CHEMBL3964077 & 1642374 & 8.1612 & 8.3407 & TST & \\
\hline CHEMBL3899718 & 1642374 & 8.1805 & 8.1583 & TST & \\
\hline CHEMBL3939493 & 1642374 & 9.0 & 8.3295 & TRN & \\
\hline CHEMBL3932972 & 1642374 & 7.5086 & 7.8273 & TRN & \\
\hline CHEMBL3919072 & 1642374 & 6.8297 & 7.1686 & TRN & \\
\hline CHEMBL3927920 & 1642374 & 7.7696 & 8.1016 & TRN & \\
\hline CHEMBL3978015 & 1642374 & 7.1367 & 6.7416 & TST & \\
\hline CHEMBL3895023 & 1642374 & 7.5214 & 7.6375 & TRN & \\
\hline CHEMBL3935044 & 1642374 & 6.983 & 6.4632 & TST & \\
\hline CHEMBL3955503 & 1642374 & 7.8239 & 8.0834 & TST & \\
\hline CHEMBL3923368 & 1642374 & 7.58 & 7.6573 & TRN & \\
\hline CHEMBL3891193 & 1642374 & 7.8386 & 7.7244 & TRN & \\
\hline CHEMBL3934730 & 1642374 & 8.2218 & 8.134 & TRN & \\
\hline CHEMBL3981278 & 1642374 & 7.1945 & 7.0845 & TRN & \\
\hline CHEMBL3954317 & 1642374 & 7.0915 & \multicolumn{2}{|c|}{7.6979999999999995} & TRN \\
\hline CHEMBL3935676 & 1642374 & 8.5229 & 8.7402 & TRN & \\
\hline CHEMBL3962589 & 1642374 & 7.3279 & 7.1458 & TRN & \\
\hline CHEMBL3943479 & 1642374 & 7.0458 & 7.6454 & TRN & \\
\hline CHEMBL3952006 & 1642374 & 8.301 & 8.1403 & TRN & \\
\hline
\end{tabular}


Supplemental Table S2.txt

\begin{tabular}{|c|c|c|c|c|}
\hline - & 374 & & & \\
\hline HEMBL3894800 & 642374 & 7.6576 & 8345 & \\
\hline & 374 & & & \\
\hline 422 & 374 & 39 & 7258 & \\
\hline AEMBL3957656 & 542374 & 6383 & 3818 & \\
\hline AEMBL3945966 & 642374 & 7.52 & 6166 & \\
\hline HEMBL3916148 & 642374 & 9.0 & .1602 & \\
\hline HEMBL391 & 374 & & 858 & \\
\hline AEMBL3940446 & & & .3183 & \\
\hline AEMBL3911841 & 374 & 7.9208 & 3898 & \\
\hline AEMBL3975526 & 374 & 7.8729 & 1107 & \\
\hline AEMBL3920291 & 374 & 3872 & 7248 & \\
\hline AEMBL3924959 & & & .0203 & \\
\hline AEMBL3950165 & & 376 & 5117 & \\
\hline AEMBL3977653 & 74 & 268 & 354 & \\
\hline AEMBL3983116 & 74 & 7.9431 & 65 & \\
\hline HEMBL3908684 & 74 & 8.0 & 111 & \\
\hline HEMBL3938693 & & & 82 & \\
\hline HEMBL3904680 & & & 3477 & \\
\hline AEMBL3944256 & 74 & & 514 & RN \\
\hline AEMBL3932811 & 74 & $81 /$ & 5124 & \\
\hline HEMBL3959962 & 74 & 7. & 756 & \\
\hline HEMBL3904038 & & & 828 & RN \\
\hline 7359 & & & 289 & RN \\
\hline AEMBL3925910 & 74 & & 77 & II \\
\hline 66990 & 74 & 31 & 94 & RN \\
\hline L3961407 & 74 & 99 & 74 & $\mathrm{RN}$ \\
\hline 19 & & & 479 & RN \\
\hline AEMBL3969317 & & & 5011 & ו \\
\hline AEMBL3931 & 74 & 8 . & 935 & RN \\
\hline AEMBL 393 & & 7. & 569 & RN \\
\hline 15 & & & 43 & RIV \\
\hline 44 & & & 773 & RN \\
\hline HEMBL3892494 & & & 278 & 51 \\
\hline JEMBL 3977231 & 74 & 7. & 884 & RN \\
\hline HEMBL 394 & 74 & & 087 & \\
\hline HEMRI 2 & & & 392 & ST \\
\hline HEMBL3964790 & & & 313 & RN \\
\hline HEMBL3982157 & 374 & 9. & 494 & TRN \\
\hline AEMBL3958303 & 74 & & 418 & RN \\
\hline HEMBL3982280 & 74 & 7. & 143 & I \\
\hline HEMBL 3973994 & & & & RN \\
\hline HEMBL3919006 & 374 & 7.4881 & 7.5541 & TST \\
\hline HEMBL 383565 & 82 & 5.3665 & 4836 & $\Gamma R$ \\
\hline EMBL365998 & & & 3822 & \\
\hline HEMBL195228 & & & 3.5882 & \\
\hline HEMBL 36 & 82 & 5.4318 & 4.0417 & ST \\
\hline CHEMBL195421 & 310682 & 6.6021 & 6.6527 & ГRN \\
\hline
\end{tabular}

Page 4339 


\begin{tabular}{|c|c|c|c|c|c|}
\hline \multicolumn{6}{|c|}{ Supplemental Table S2.txt } \\
\hline CHEMBL195084 & 310682 & 7.0 & 7.0137 & TRN & \\
\hline CHEMBL364497 & 310682 & 4.6383 & 4.7294 & TRN & \\
\hline CHEMBL195048 & 310682 & 6.2218 & 6.2823 & TRN & \\
\hline CHEMBL425007 & 310682 & 3.0 & 2.987 & TRN & \\
\hline CHEMBL195162 & 310682 & 5.7696 & 3.8588 & TST & \\
\hline CHEMBL192529 & 310682 & 4.6778 & 4.6088 & TRN & \\
\hline CHEMBL191660 & 310682 & 5.0655 & 3.6643 & TST & \\
\hline CHEMBL191673 & 310682 & 7.5229 & 7.4662 & TRN & \\
\hline CHEMBL370094 & 310682 & 6.2218 & 3.5134 & TST & \\
\hline CHEMBL192015 & 310682 & 4.9586 & 4.9543 & TRN & \\
\hline CHEMBL191644 & 310682 & 5.301 & 5.2733 & TRN & \\
\hline CHEMBL195839 & 310682 & 6.5229 & 6.6035 & TRN & \\
\hline CHEMBL192067 & 310682 & 6.301 & 6.3007 & TRN & \\
\hline CHEMBL543611 & 310682 & 7.699 & 3.2441 & TST & \\
\hline CHEMBL195736 & 310682 & 5.301 & 5.29299 & & TRN \\
\hline CHEMBL194655 & 310682 & 5.6198 & 5.5679 & TRN & \\
\hline CHEMBL195108 & 310682 & 6.8861 & 6.8598 & TRN & \\
\hline CHEMBL435303 & 310682 & 6.699 & 6.6764 & TRN & \\
\hline CHEMBL195325 & 310682 & 5.5229 & 5.5796 & TRN & \\
\hline CHEMBL195109 & 310682 & 5.4318 & 5.7097 & TRN & \\
\hline CHEMBL192093 & 310682 & 8.0 & 6.4366 & TST & \\
\hline CHEMBL191961 & 310682 & 6.8539 & 6.8687 & TRN & \\
\hline CHEMBL364701 & 310682 & 5.6383 & 4.1076 & TST & \\
\hline CHEMBL194926 & 310682 & 4.8861 & 4.729 & TRN & \\
\hline CHEMBL370605 & 310682 & 3.0 & 3.0065 & TRN & \\
\hline CHEMBL373329 & 310682 & 7.3979 & 7.3606 & TRN & \\
\hline CHEMBL371605 & 310682 & 7.1549 & 5.9563 & TST & \\
\hline CHEMBL191190 & 310682 & 7.5229 & 7.6267 & TRN & \\
\hline CHEMBL191655 & 310682 & 5.9208 & 5.7518 & TRN & \\
\hline CHEMBL195817 & 310682 & 7.699 & 7.6002 & TRN & \\
\hline CHEMBL194654 & 310682 & 6.5229 & 6.3829 & TRN & \\
\hline CHEMBL191659 & 310682 & 7.301 & 6.1891 & TST & \\
\hline CHEMBL371652 & 310682 & 5.1549 & 5.2139 & TRN & \\
\hline CHEMBL195161 & 310682 & 7.0 & 6.9645 & TRN & \\
\hline CHEMBL 364489 & 310682 & 5.585 & 5.3781 & TRN & \\
\hline CHEMBL363399 & 310682 & 4.3872 & 4.7028 & TST & \\
\hline CHEMBL195360 & 310682 & 7.0 & 7.011 & TRN & \\
\hline CHEMBL194230 & 310682 & 5.5229 & 5.5513 & TRN & \\
\hline CHEMBL192297 & 310682 & 5.3979 & 5.5028 & TRN & \\
\hline CHEMBL427545 & 310682 & 7.0969 & 7.2493 & TRN & \\
\hline CHEMBL193950 & 310682 & 5.8539 & 5.9088 & TRN & \\
\hline CHEMBL192618 & 310682 & 6.3979 & 6.519 & TRN & \\
\hline CHEMBL191910 & 310682 & 7.699 & 7.6314 & TRN & \\
\hline CHEMBL364021 & 310682 & 6.5229 & 3.2699 & TST & \\
\hline CHEMBL192168 & 310682 & 4.4437 & 3.9072 & TST & \\
\hline CHEMBL 382540 & 310682 & 4.3665 & 3.6165 & TST & \\
\hline CHEMBL195131 & 310682 & 5.8239 & 5.8816 & TRN & \\
\hline CHEMBL364518 & 310682 & 7.3979 & 7.0315 & TRN & \\
\hline
\end{tabular}




\begin{tabular}{|c|c|c|c|c|}
\hline & & & & \\
\hline CHEMBL365370 & 310682 & 5.2518 & 3.7225 & 15 \\
\hline CHEMBL195733 & 310682 & 6.301 & 6.2599 & \\
\hline CHEMBL371992 & 10682 & 3.0 & 4958 & \\
\hline CHEMBL195848 & 10682 & 7.301 & 4.8888 & \\
\hline CHEMBL 365741 & 10682 & 7.1549 & 7.2969 & \\
\hline CHEMBL191970 & 310682 & 7.0 & 6.9511 & \\
\hline HEMBL363585 & 10682 & 6.301 & 6.2725 & \\
\hline CHEMBL364921 & 10682 & 3.0 & 2.858 & \\
\hline CHEMBL370878 & 10682 & 5.0269 & 5.2297 & \\
\hline CHEMBL371780 & 10682 & 4.1871 & 5.2163 & \\
\hline CHEMBL191141 & 310682 & 7.3979 & 7.5945 & \\
\hline CHEMBL192610 & 10682 & 5.1871 & 5.2554 & \\
\hline CHEMBL195526 & 310682 & 3.3468 & 3.2662 & \\
\hline CHEMBL 1 & 10682 & 4.5686 & 4.5431 & \\
\hline CHEMBL1 & 32 & 4.7696 & 3367 & \\
\hline CHEMBL 3 & 310682 & 5.6383 & 5.4444 & \\
\hline CHEMBL192322 & 10682 & 5.699 & 233 & \\
\hline CHEMBL1S & 3106 & 3.0 & 3.283 & \\
\hline CHEMBL: & 10 & 4.1675 & 3.8668 & \\
\hline CHEMBL 1 & 2 & 3.0 & 3.0918 & \\
\hline CHEMBL3 & 310 & 5.699 & 5.6568 & TRA \\
\hline CHEMBL 1 & 2 & 4.3188 & 502 & \\
\hline CHEMBL 1 & 3106 & 4.7212 & 4.6344 & $\mathrm{TR}$ \\
\hline CHEMBL & $1 e$ & 3. & 837 & \\
\hline CHEMBL & 2 & 5.5229 & 353 & \\
\hline CHEMBL 1 & 2 & 5.1549 & 28 & \\
\hline CHEMBL3 & 2 & 4.1871 & 943 & $\mathrm{Tr}$ \\
\hline CHEMBL 3 & 3106 & 3.0 & 2.9977 & TRI \\
\hline CHEMBL & 2 & 7.6021 & 7.5972 & \\
\hline CHEMBL 1 & 2 & 4.8861 & 4.93 & $1 \mathrm{~N}$ \\
\hline CHEMBL & 2 & 6.2218 & 005 & TRI \\
\hline CHEMBL3 & 106 & 7.3979 & 774 & TR \\
\hline CHEMBL 3 & 775 & 3.9393 & 4.3862 & $\mathrm{TR}$ \\
\hline CHEMBL 2 & 775 & 6.0218 & 6.5914 & $\mathrm{TR}$ \\
\hline CHEMBL & 977511 & 5.1215 & 4.8562 & TRN \\
\hline CHEMBL3217253 & 977511 & 5.475 & 4.5585 & $\mathrm{TR}$ \\
\hline CHEMBL 2418029 & 977511 & 7.284 & 7.3723 & $\mathrm{TR}$ \\
\hline CHEMBL 3 & 9775 & 4.0246 & 4.6227 & $\mathrm{TR}$ \\
\hline CHEMBL2 & 977511 & 7.6021 & 7.4104 & $\mathrm{TR}$ \\
\hline CHEMBL 2 & 977511 & 7.2924 & 7.3678 & TRN \\
\hline CHEMBL 3217251 & 977511 & 4.1487 & 4.707 & $\mathrm{TR}$ \\
\hline CHEMBL 2417998 & 977511 & 7.1778 & 7.6892 & $\mathrm{TR}$ \\
\hline CHEMBL & 9775 & 3.9914 & 983 & $\mathrm{TR}$ \\
\hline CHEMBL2418011 & 977511 & 6.9172 & 7.1735 & $\mathrm{TR}$ \\
\hline CHEMBL2418018 & 977511 & 7.8539 & 7.3632 & $\mathrm{TR}$ \\
\hline CHEMBL3707184 & 977511 & 7.6108 & 7.433 & $\mathrm{TR}$ \\
\hline CHEMBL3216142 & 977511 & 7.7447 & 7.0005 & TS \\
\hline CHEMBL 2418034 & 977511 & 7.5086 & 7.1599 & $\mathrm{R}$ \\
\hline
\end{tabular}

Page 4341 
Supplemental Table S2.txt

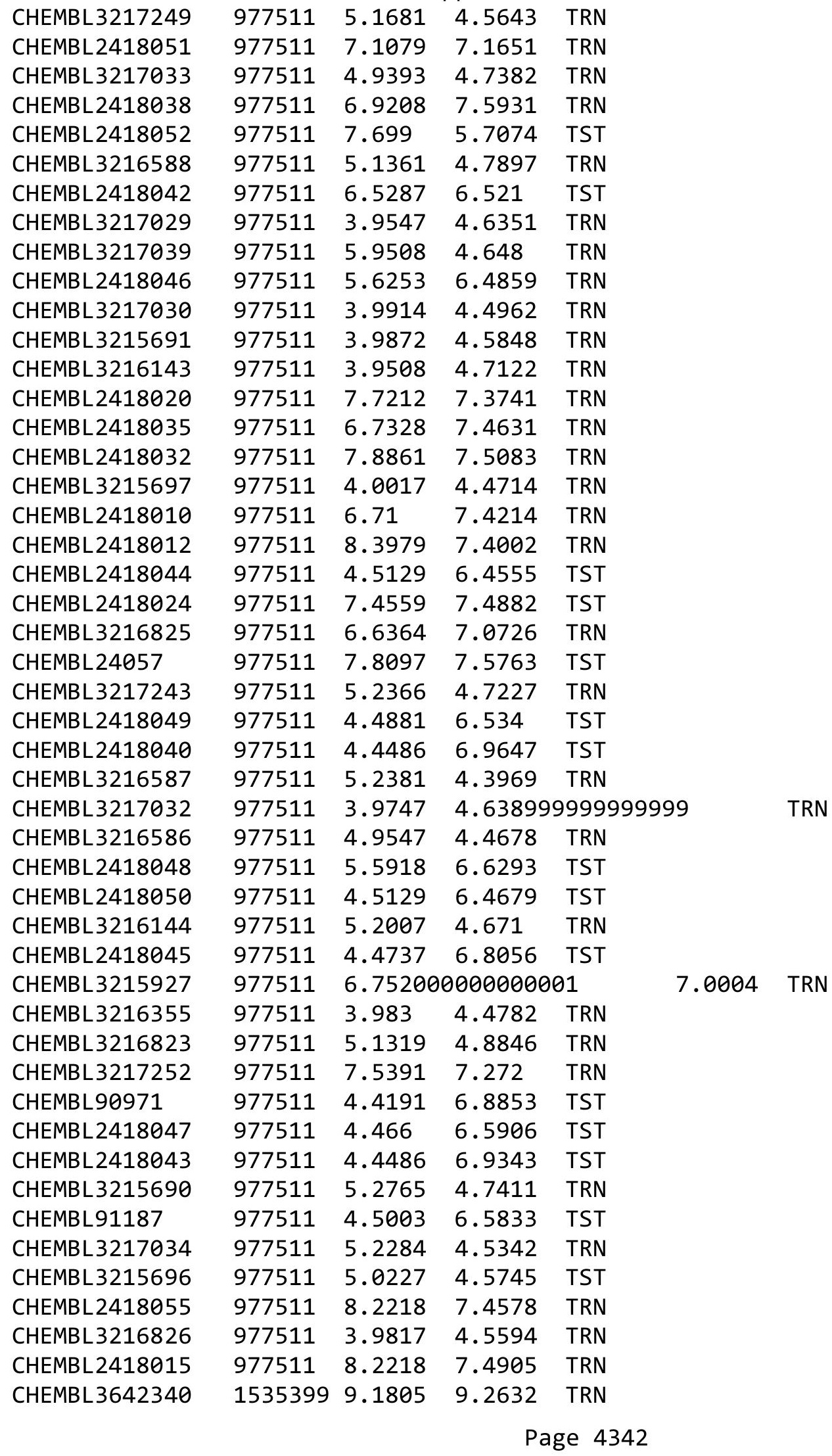


Supplemental Table S2.txt

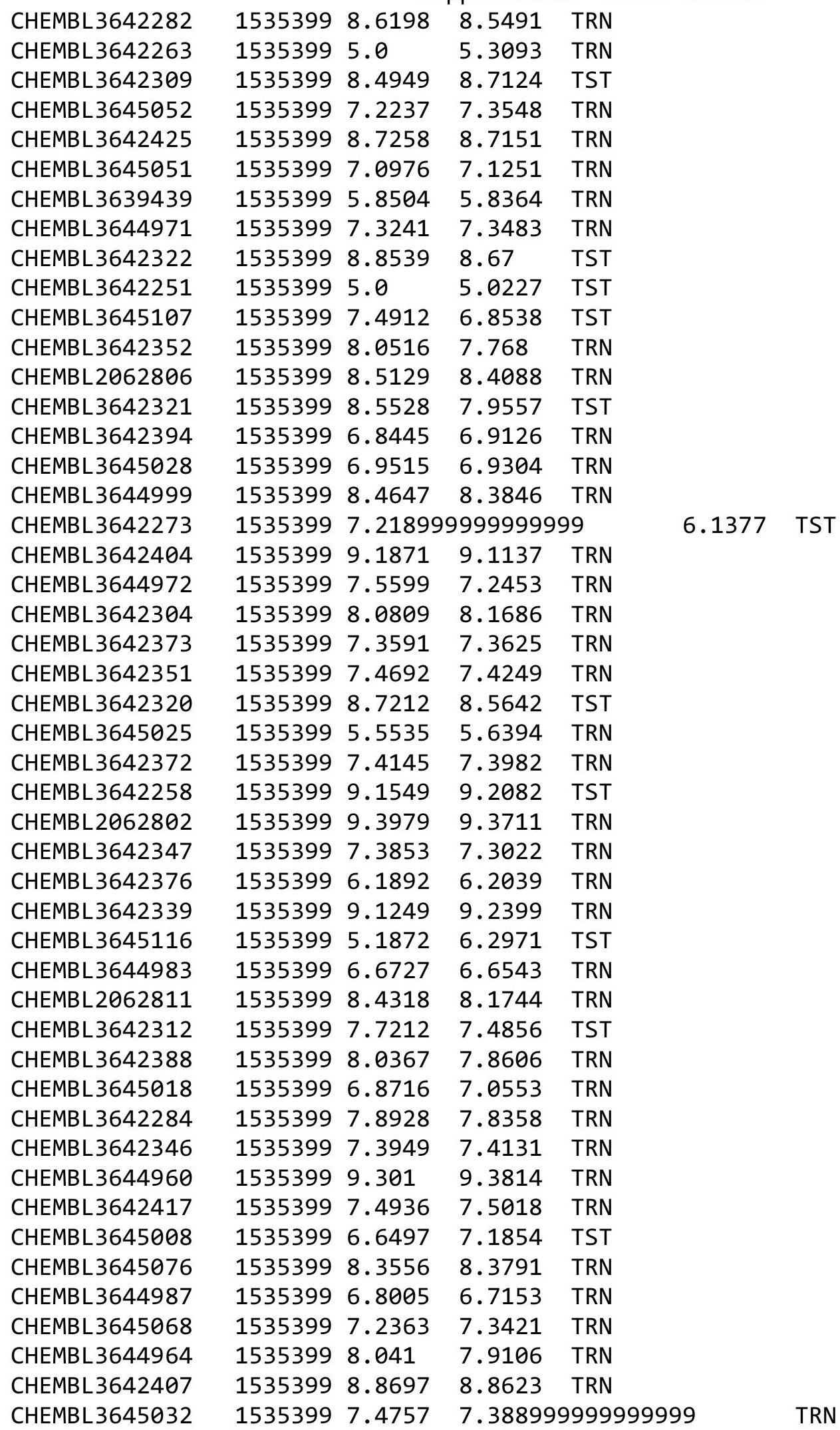

Page 4343 


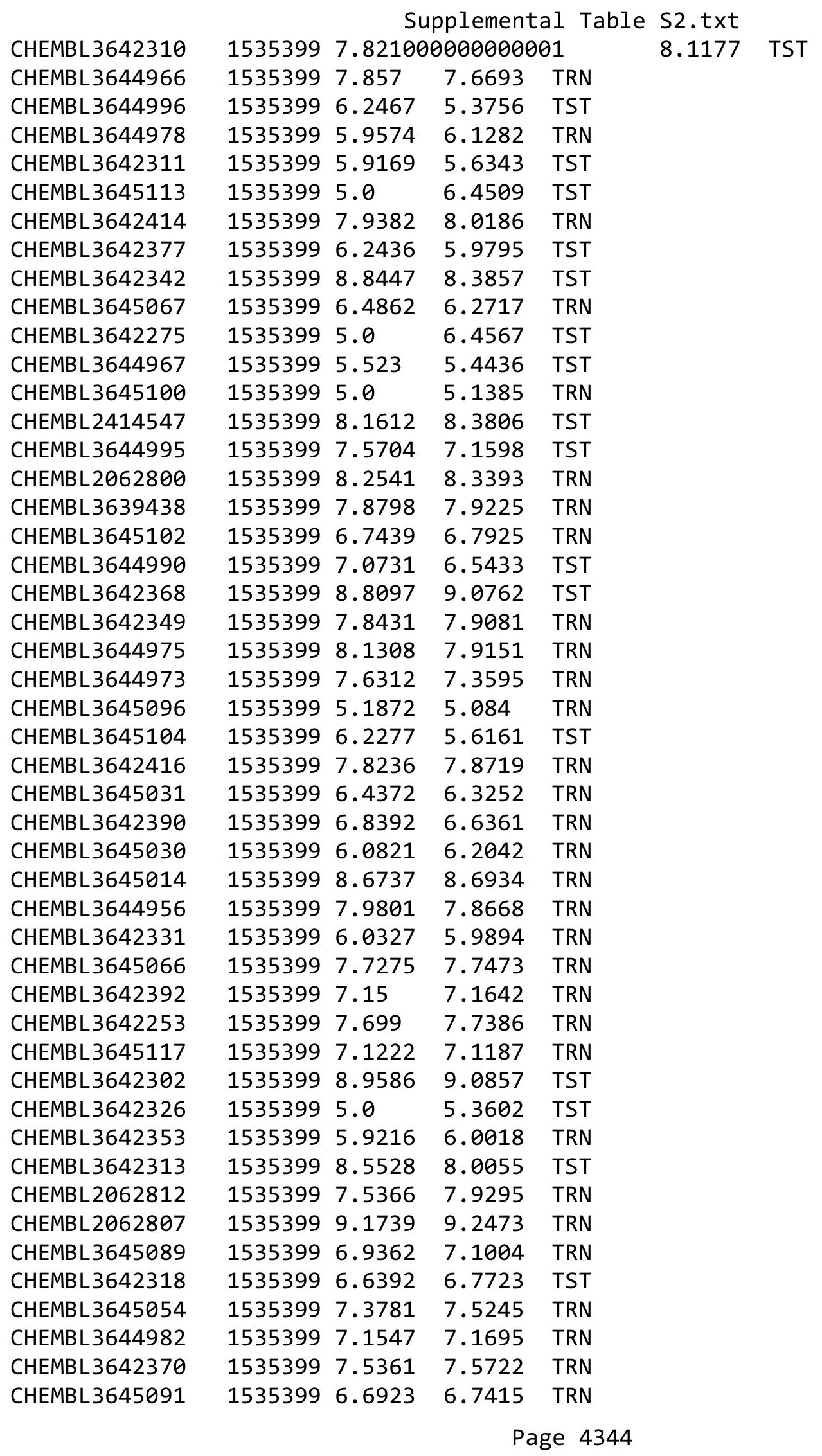


Supplemental Table S2.txt

\begin{tabular}{|c|c|c|c|c|c|}
\hline CHEMBL 3642344 & 1535399 & 9.2596 & 9.1671 & TST & \\
\hline CHEMBL3642386 & 1535399 & 7.3991 & 7.2623 & TRN & \\
\hline CHEMBL3935745 & 1535399 & 6.4848 & 5.047 & TST & \\
\hline CHEMBL 3642296 & 1535399 & 9.2218 & 9.244 & TRN & \\
\hline CHEMBL 3645080 & 1535399 & 6.7063 & 6.4351 & TRN & \\
\hline CHEMBL 3642396 & 1535399 & 8.0996 & 8.1875 & TRN & \\
\hline CHEMBL3642345 & 1535399 & 7.6834 & 7.7212 & TRN & \\
\hline CHEMBL 3645062 & 1535399 & 8.1192 & 7.9881 & TRN & \\
\hline CHEMBL 3644989 & 1535399 & 7.5388 & 7.2229 & TRN & \\
\hline CHEMBL 3642361 & 1535399 & 7.8781 & 7.9204 & TRN & \\
\hline CHEMBL 3642303 & 1535399 & 9.0969 & 8.5911 & TST & \\
\hline CHEMBL3642269 & 1535399 & 7.5575 & 7.5693 & TRN & \\
\hline CHEMBL 3642308 & 1535399 & 8.1805 & 8.0859 & TST & \\
\hline CHEMBL 3642363 & 1535399 & 7.6461 & 7.7992 & TRN & \\
\hline CHEMBL 3642408 & 1535399 & 8.3072 & 8.3832 & TRN & \\
\hline CHEMBL 3645106 & 1535399 & 6.0005 & 5.7808 & TST & \\
\hline CHEMBL3645046 & 1535399 & 6.4996 & 6.3011 & TRN & \\
\hline CHEMBL 3642413 & 1535399 & 7.6218 & 7.6946 & TRN & \\
\hline CHEMBL 3642279 & 1535399 & 6.4261 & 5.3779 & TST & \\
\hline CHEMBL3642359 & 1535399 & 7.1125 & 7.2845 & TRN & \\
\hline CHEMBL 3642338 & 1535399 & 7.22 & 7.1114 & TRN & \\
\hline CHEMBL 2062798 & 1535399 & 9.0 & 9.1298 & TRN & \\
\hline CHEMBL 2062797 & 1535399 & 5.8791 & 5.7306 & TRN & \\
\hline CHEMBL 3642379 & 1535399 & 7.4505 & 7.3244 & TRN & \\
\hline CHEMBL 3645016 & 1535399 & 5.8264 & 5.6687 & TRN & \\
\hline CHEMBL 3644998 & 1535399 & 6.8453 & 6.8747 & TST & \\
\hline CHEMBL 3645063 & 1535399 & 7.971 & 8.1445 & TRN & \\
\hline CHEMBL3642336 & 1535399 & 6.48600 & 000000000 & 31 & 6.2981 \\
\hline CHEMBL 3642332 & 1535399 & 6.4893 & 6.2567 & TST & \\
\hline CHEMBL 3644974 & 1535399 & 7.5737 & 7.7835 & TRN & \\
\hline CHEMBL 3642307 & 1535399 & 5.0 & 5.7788 & TST & \\
\hline CHEMBL 3642333 & 1535399 & 7.5003 & 7.2046 & TRN & \\
\hline CHEMBL3645098 & 1535399 & 5.5197 & 5.4325 & TRN & \\
\hline CHEMBL 3644958 & 1535399 & 5.523 & 5.5155 & TRN & \\
\hline CHEMBL3642329 & 1535399 & 5.0 & 5.1337 & TRN & \\
\hline CHEMBL3642315 & 1535399 & 8.7696 & 8.5141 & TST & \\
\hline CHEMBL 3642399 & 1535399 & 8.1421 & 8.1124 & TRN & \\
\hline CHEMBL 3645015 & 1535399 & 8.9747 & 8.7033 & TRN & \\
\hline CHEMBL 3642323 & 1535399 & 8.0315 & 7.7513 & TST & \\
\hline CHEMBL 3642280 & 1535399 & 8.5229 & 8.7165 & TST & \\
\hline CHEMBL 3642299 & 1535399 & 5.6027 & 5.5533 & TRN & \\
\hline CHEMBL 3645053 & 1535399 & 5.9399 & 5.7994 & TRN & \\
\hline CHEMBL 3642362 & 1535399 & 7.5797 & 7.5019 & TRN & \\
\hline CHEMBL 3645057 & 1535399 & 7.4725 & 7.421 & TRN & \\
\hline CHEMBL 3645114 & 1535399 & 5.704 & 7.7471 & TST & \\
\hline CHEMBL 3645017 & 1535399 & 7.1322 & 7.0514 & TST & \\
\hline CHEMBL 3644970 & 1535399 & 5.0 & 5.3549 & TRN & \\
\hline CHEMBL 3645019 & 1535399 & 5.7721 & 5.8803 & TRN & \\
\hline
\end{tabular}

Page 4345 
Supplemental Table S2.txt

\begin{tabular}{|c|c|c|c|c|c|}
\hline CHEMBL 3642274 & 1535399 & 9.0 & 7.3726 & TST & \\
\hline CHEMBL3642380 & 1535399 & 6.6583 & 6.73 & TRN & \\
\hline CHEMBL3645022 & 1535399 & 5.523 & 5.5566 & TRN & \\
\hline CHEMBL3644991 & 1535399 & 7.1323 & 6.5889 & TST & \\
\hline CHEMBL3642267 & 1535399 & 5.0 & 4.8649 & TRN & \\
\hline CHEMBL3642261 & 1535399 & 8.0706 & 8.2536 & TRN & \\
\hline CHEMBL2062529 & 1535399 & 8.8239 & 8.666 & TRN & \\
\hline CHEMBL3645044 & 1535399 & 6.2804 & 6.1724 & TRN & \\
\hline CHEMBL3642397 & 1535399 & 8.2262 & 7.9879 & TRN & \\
\hline CHEMBL3642402 & 1535399 & 9.0132 & 9.1288 & TRN & \\
\hline CHEMBL3645041 & 1535399 & 7.3282 & 7.3003 & TRN & \\
\hline CHEMBL3644965 & 1535399 & 5.523 & 5.6567 & TRN & \\
\hline CHEMBL3642295 & 1535399 & 9.2218 & 9.2878 & TRN & \\
\hline CHEMBL3645087 & 1535399 & 5.9673 & 5.9995 & TRN & \\
\hline CHEMBL3644968 & 1535399 & 6.1869 & 6.206 & TRN & \\
\hline CHEMBL3645105 & 1535399 & 6.0881 & 5.9747 & TST & \\
\hline CHEMBL3645088 & 1535399 & 5.523 & 5.8991 & TRN & \\
\hline CHEMBL3645118 & 1535399 & 8.7905 & 8.7183 & TRN & \\
\hline CHEMBL 3642420 & 1535399 & 6.8714 & 7.4996 & TST & \\
\hline CHEMBL3645003 & 1535399 & 6.1708 & 6.1031 & TRN & \\
\hline CHEMBL3642256 & 1535399 & 9.0 & 8.9624 & TRN & \\
\hline CHEMBL3645112 & 1535399 & 5.9922 & 6.2216 & TST & \\
\hline CHEMBL3645099 & 1535399 & 5.523 & 5.5914 & TRN & \\
\hline CHEMBL3642278 & 1535399 & 7.4868 & 7.1051 & TST & \\
\hline CHEMBL3642421 & 1535399 & 6.9349 & 7.0613 & TRN & \\
\hline CHEMBL3642405 & 1535399 & 9.3872 & 9.5298 & TRN & \\
\hline CHEMBL3645064 & 1535399 & 6.2761 & 6.1949 & TRN & \\
\hline CHEMBL3642354 & 1535399 & 7.9427 & 8.0755 & TRN & \\
\hline CHEMBL3645010 & 1535399 & 6.8771 & 7.1127 & TRN & \\
\hline CHEMBL3644980 & 1535399 & 5.6748 & 6.0336 & TST & \\
\hline CHEMBL3642271 & 1535399 & 6.356 & 5.6071 & TST & \\
\hline CHEMBL3642343 & 1535399 & 9.5686 & 9.3016 & TRN & \\
\hline CHEMBL3642298 & 1535399 & 5.8774 & 5.5926 & TRN & \\
\hline CHEMBL3642412 & 1535399 & 9.2596 & 9.1899 & TRN & \\
\hline CHEMBL3645043 & 1535399 & 5.9187 & 6.2307 & TRN & \\
\hline CHEMBL3645024 & 1535399 & 7.4862 & 7.4118 & TRN & \\
\hline CHEMBL3645090 & 1535399 & 6.7029 & 6.7987 & TRN & \\
\hline CHEMBL3645059 & 1535399 & 8.0904 & 8.0474 & TRN & \\
\hline CHEMBL3645083 & 1535399 & 6.29700 & 200000000 & 6.1592 & TRN \\
\hline CHEMBL3642418 & 1535399 & 6.3787 & 6.3493 & TRN & \\
\hline CHEMBL3642411 & 1535399 & 9.3372 & 9.0135 & TRN & \\
\hline CHEMBL2062804 & 1535399 & 8.8861 & 8.9379 & TRN & \\
\hline CHEMBL3644988 & 1535399 & 5.0 & 5.337999 & 9999999999 & TRN \\
\hline CHEMBL3642257 & 1535399 & 8.2596 & 8.0812 & TRN & \\
\hline CHEMBL 3642378 & 1535399 & 7.4431 & 7.5171 & TRN & \\
\hline CHEMBL3644969 & 1535399 & 5.0 & 5.0284 & TST & \\
\hline CHEMBL3645065 & 1535399 & 7.5164 & 7.4116 & TRN & \\
\hline CHEMBL3645040 & 1535399 & 7.9473 & 7.9197 & TRN & \\
\hline
\end{tabular}

Page 4346 
Supplemental Table S2.txt

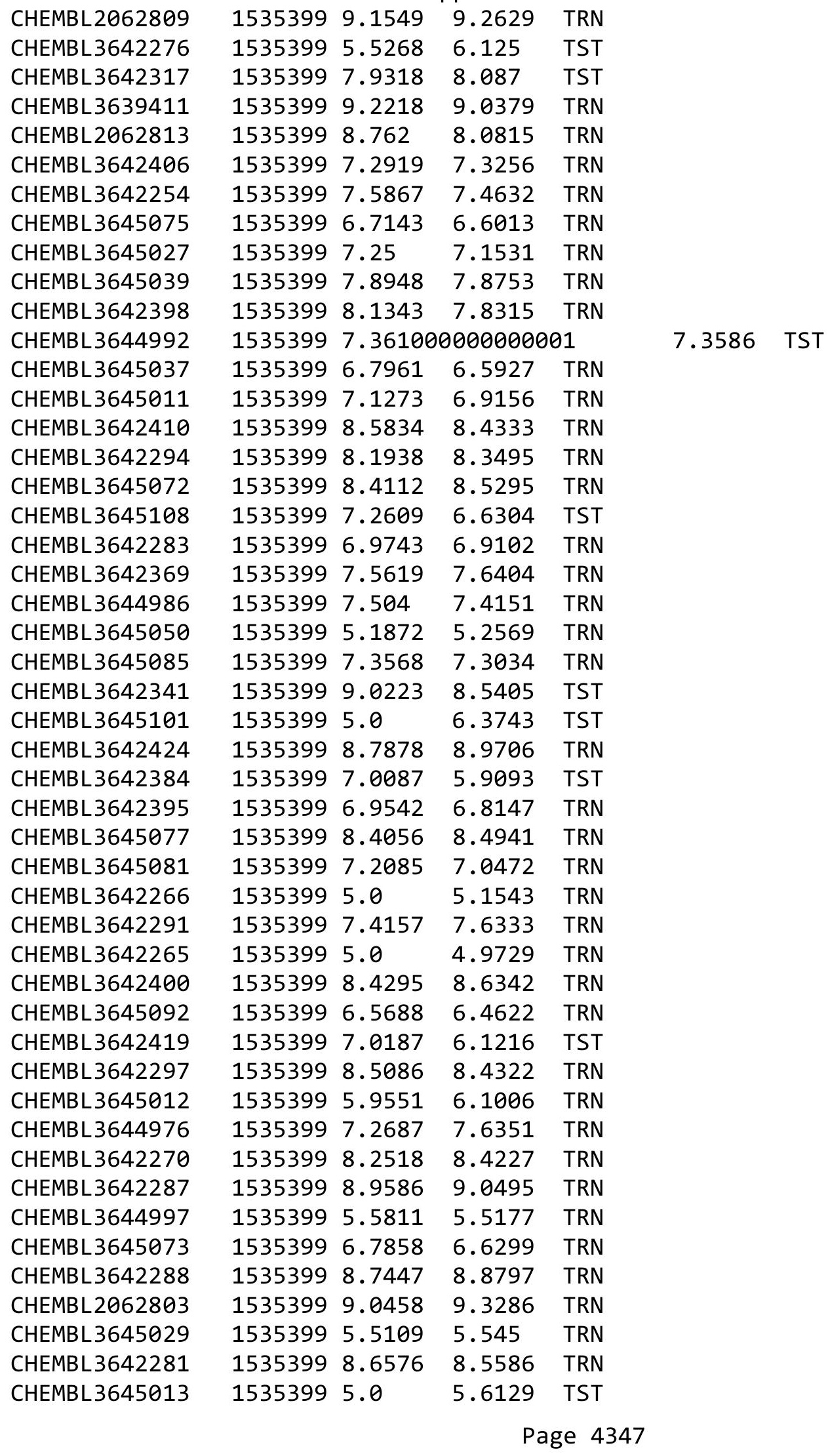




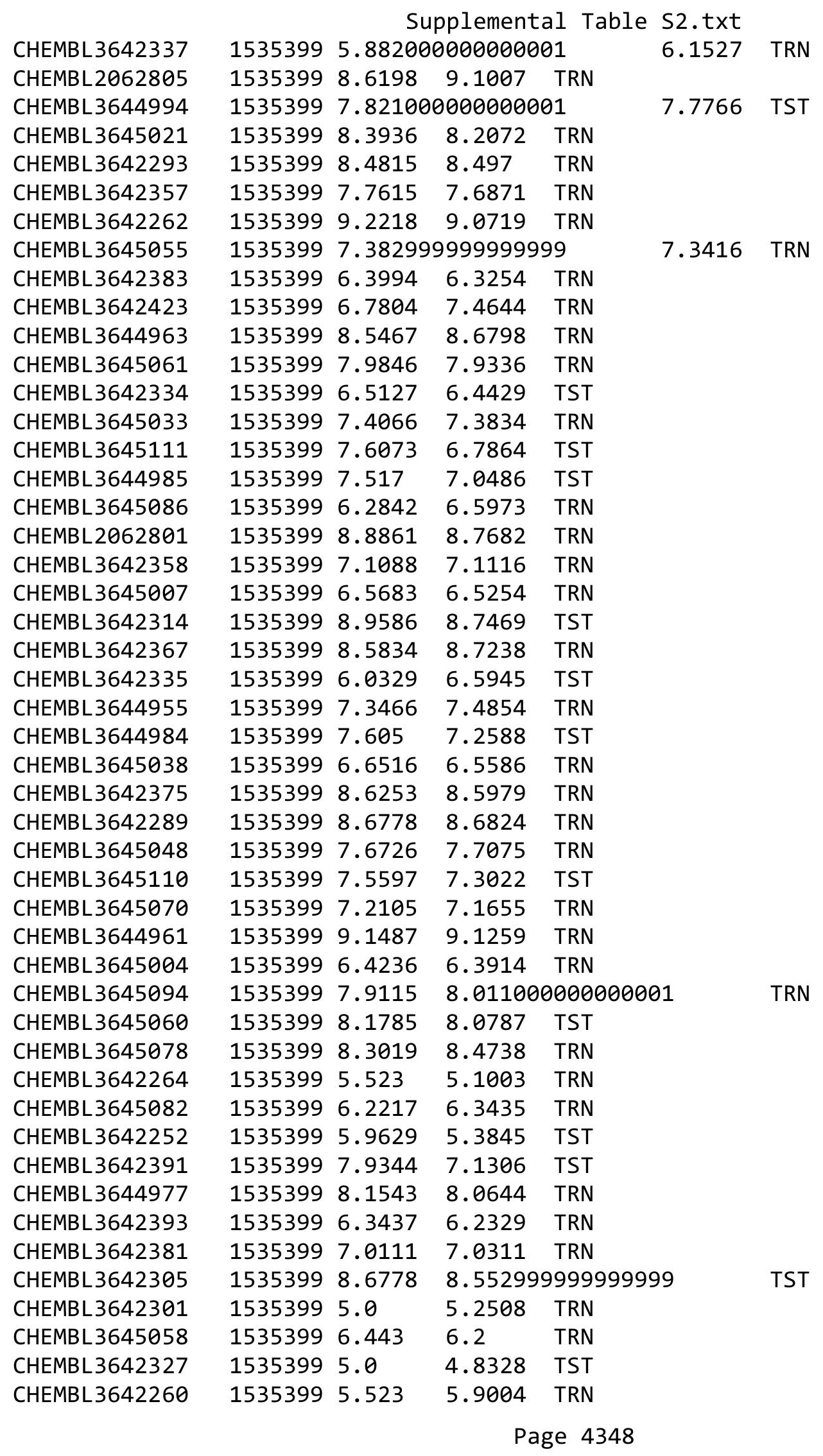


Supplemental Table S2.txt

\begin{tabular}{|c|c|c|c|c|c|}
\hline CHEMBL3642300 & 1535399 & 7.5376 & 7.5603 & TRN & \\
\hline CHEMBL3642328 & 1535399 & 5.0 & 5.4606 & TST & \\
\hline CHEMBL3645095 & 1535399 & 7.3377 & 7.3107 & TRN & \\
\hline CHEMBL3645005 & 1535399 & 6.5998 & 6.6961 & TRN & \\
\hline CHEMBL3642364 & 1535399 & 7.8213 & 7.8642 & TRN & \\
\hline CHEMBL3645023 & 1535399 & 5.7466 & 5.6155 & TRN & \\
\hline CHEMBL3642350 & 1535399 & 7.7286 & 7.8407 & TRN & \\
\hline CHEMBL3642355 & 1535399 & 7.4806 & 7.3608 & TRN & \\
\hline CHEMBL3639412 & 1535399 & 6.581 & 6.6824 & TRN & \\
\hline CHEMBL3645006 & 1535399 & 6.7169 & 7.1055 & TST & \\
\hline CHEMBL3642259 & 1535399 & 8.5229 & 8.4513 & TRN & \\
\hline CHEMBL3645097 & 1535399 & 5.8731 & 5.9865 & TRN & \\
\hline CHEMBL3645034 & 1535399 & 7.7506 & 7.5461 & TRN & \\
\hline CHEMBL3642272 & 1535399 & 6.2457 & 6.3885 & TST & \\
\hline CHEMBL3642330 & 1535399 & 5.0 & 5.1066 & TRN & \\
\hline CHEMBL3642415 & 1535399 & 6.6615 & 6.6655 & TRN & \\
\hline CHEMBL3642277 & 1535399 & 6.3277 & 6.3259 & TRN & \\
\hline CHEMBL3642360 & 1535399 & 5.523 & 5.5762 & TRN & \\
\hline CHEMBL 2414545 & 1535399 & 8.0362 & 8.2754 & TST & \\
\hline CHEMBL3642382 & 1535399 & 6.9367 & 6.9754 & TRN & \\
\hline CHEMBL3645074 & 1535399 & 8.0438 & 8.0905 & TRN & \\
\hline CHEMBL3642356 & 1535399 & 7.75899 & 99999999 & 995 & 7.7825 \\
\hline CHEMBL3645036 & 1535399 & 6.8647 & 6.9337 & TRN & \\
\hline CHEMBL3645049 & 1535399 & 7.8173 & 7.5655 & TRN & \\
\hline CHEMBL3645093 & 1535399 & 7.524 & 6.5803 & TST & \\
\hline CHEMBL3644959 & 1535399 & 5.9367 & 6.1975 & TRN & \\
\hline CHEMBL3645079 & 1535399 & 6.8867 & 6.7814 & TRN & \\
\hline CHEMBL3644957 & 1535399 & 8.7258 & 8.6042 & TRN & \\
\hline CHEMBL3642374 & 1535399 & 6.3117 & 6.3003 & TRN & \\
\hline CHEMBL3645000 & 1535399 & 7.7737 & 7.9437 & TRN & \\
\hline CHEMBL 2062810 & 1535399 & 8.8861 & 8.8617 & TRN & \\
\hline CHEMBL 3645071 & 1535399 & 8.2358 & 8.4082 & TRN & \\
\hline CHEMBL3642268 & 1535399 & 8.8861 & 8.8151 & TRN & \\
\hline CHEMBL3642387 & 1535399 & 7.8921 & 8.0261 & TRN & \\
\hline CHEMBL3642292 & 1535399 & 7.5719 & 7.4942 & TRN & \\
\hline CHEMBL3642285 & 1535399 & 9.1549 & 9.0477 & TRN & \\
\hline CHEMBL 3645045 & 1535399 & 6.5893 & 6.5994 & TRN & \\
\hline CHEMBL3645002 & 1535399 & 8.1169 & 8.0605 & TRN & \\
\hline CHEMBL3642324 & 1535399 & 9.0 & 8.6837 & TST & \\
\hline CHEMBL3642389 & 1535399 & 9.1367 & 9.0836 & TRN & \\
\hline CHEMBL3645103 & 1535399 & 5.8432 & 5.7238 & TRN & \\
\hline CHEMBL3645056 & 1535399 & 7.1814 & 7.3097 & TRN & \\
\hline CHEMBL3645047 & 1535399 & 7.4305 & 7.6372 & TRN & \\
\hline CHEMBL3645020 & 1535399 & 8.2487 & 8.2211 & TRN & \\
\hline CHEMBL3642306 & 1535399 & 8.8861 & 9.2132 & TST & \\
\hline CHEMBL3645035 & 1535399 & 7.2638 & 7.1842 & TRN & \\
\hline CHEMBL3645026 & 1535399 & 7.7815 & 7.7602 & TST & \\
\hline CHEMBL3642319 & 1535399 & 5.8148 & 6.4071 & TST & \\
\hline
\end{tabular}


Supplemental Table S2.txt

\begin{tabular}{|c|c|c|c|c|c|c|}
\hline CHEMBL 3642371 & 1535399 & 7.178 & 7.0714 & TRN & & \\
\hline CHEMBL 3642348 & 1535399 & 8.1805 & 8.104 & TRN & & \\
\hline CHEMBL 3642255 & 1535399 & 7.8729 & 7.7477 & TST & & \\
\hline CHEMBL 3645042 & 1535399 & 8.0716 & 8.0168 & TRN & & \\
\hline CHEMBL 3642385 & 1535399 & 7.6556 & 7.5827 & TRN & & \\
\hline CHEMBL3642365 & 1535399 & 6.0 & 5.9823 & TRN & & \\
\hline CHEMBL 3642316 & 1535399 & 8.3098 & 8.3914 & TST & & \\
\hline CHEMBL 3642422 & 1535399 & 6.2431 & 6.1935 & TRN & & \\
\hline CHEMBL 3645069 & 1535399 & 7.3406 & 7.5498 & TRN & & \\
\hline CHEMBL 3644993 & 1535399 & 7.0021 & 6.9145 & TST & & \\
\hline CHEMBL 3642401 & 1535399 & 8.7212 & 8.6367 & TRN & & \\
\hline CHEMBL 3642290 & 1535399 & 8.7696 & 8.8378 & TRN & & \\
\hline CHEMBL 2062799 & 1535399 & 9.0 & 8.9648 & TRN & & \\
\hline CHEMBL 3644962 & 1535399 & 5.7834 & 5.7439 & TRN & & \\
\hline CHEMBL 3642409 & 1535399 & 8.8447 & 8.7777 & TST & & \\
\hline CHEMBL 3645084 & 1535399 & 7.3714 & 7.7506 & TRN & & \\
\hline CHEMBL3644981 & 1535399 & 7.3604 & 7.0263 & TST & & \\
\hline CHEMBL 3645109 & 1535399 & 7.37 & 7.4848 & TST & & \\
\hline CHEMBL 3645001 & 1535399 & 6.2321 & 6.0072 & TRN & & \\
\hline CHEMBL 3645115 & 1535399 & 5.5594 & 7.1821 & TST & & \\
\hline CHEMBL 3642325 & 1535399 & 5.0 & 5.2695 & TST & & \\
\hline CHEMBL3931778 & 1642518 & 7.4895 & 6.6967 & TST & & \\
\hline CHEMBL 3979405 & 1642518 & 5.64 & 7.0906 & TRN & & \\
\hline CHEMBL3934050 & 1642518 & 5.8 & 6.0878 & TRN & & \\
\hline CHEMBL 3942250 & 1642518 & 6.14 & 6.2273 & TRN & & \\
\hline CHEMBL 3890699 & 1642518 & \multicolumn{3}{|c|}{6.787000000000001} & 7.0823 & TRN \\
\hline CHEMBL 3964243 & 1642518 & 5.354 & 6.3142 & TRN & & \\
\hline CHEMBL 3947638 & 1642518 & \multicolumn{3}{|c|}{4.861000000000001} & 5.2504 & TRN \\
\hline CHEMBL 3906207 & 1642518 & 8.0223 & 6.7032 & TST & & \\
\hline CHEMBL 3936866 & 1642518 & 5.189 & 6.3026 & TRN & & \\
\hline CHEMBL 3928215 & 1642518 & \multicolumn{3}{|c|}{5.7170000000000005} & 6.0895 & TRN \\
\hline CHEMBL 3951030 & 1642518 & 6.0 & 5.4768 & TRN & & \\
\hline CHEMBL3906769 & 1642518 & \multicolumn{3}{|c|}{5.917999999999999} & 6.9619 & TRN \\
\hline CHEMBL3950911 & 1642518 & 6.0 & 5.3418 & TRN & & \\
\hline CHEMBL 3948603 & 1642518 & 5.062 & 5.9734 & TRN & & \\
\hline CHEMBL 3938002 & 1642518 & 6.23 & 6.2404 & TST & & \\
\hline CHEMBL3928756 & 1642518 & 5.9 & 6.1064 & TRN & & \\
\hline CHEMBL 3923235 & 1642518 & 6.6 & 7.0169 & TRN & & \\
\hline CHEMBL 3974838 & 1642518 & 8.1871 & 6.8 & TRN & & \\
\hline CHEMBL 3949272 & 1642518 & 5.7935 & 6.1052 & TRN & & \\
\hline CHEMBL 3958089 & 1642518 & 5.475 & 5.765 & TRN & & \\
\hline CHEMBL 3961941 & 1642518 & 5.811 & 5.8835 & TRN & & \\
\hline CHEMBL 3915054 & 1642518 & 6.8 & 5.9649 & TRN & & \\
\hline CHEMBL3934526 & 1642518 & 4.0 & 5.5529 & TST & & \\
\hline CHEMBL 3975636 & 1642518 & 6.7469 & 6.1905 & TRN & & \\
\hline CHEMBL 3954268 & 1642518 & 6.341 & 6.1223 & TRN & & \\
\hline CHEMBL 3928889 & 1642518 & 6.0 & 5.3673 & TRN & & \\
\hline CHEMBL 3898553 & 1642518 & 6.9 & 6.561 & TRN & & \\
\hline
\end{tabular}




\begin{tabular}{|c|c|c|c|c|c|c|c|}
\hline \multicolumn{8}{|c|}{ Supplemental Table s2.txt } \\
\hline CHEMBL 3899670 & 1642518 & 6.358 & 6.7567 & TST & & & \\
\hline CHEMBL 3935464 & 1642518 & 5.8 & 5.8364 & TRN & & & \\
\hline CHEMBL3926483 & 1642518 & 7.2882 & 7.0592 & TRN & & & \\
\hline CHEMBL 3986774 & 1642518 & 4.0 & 4.7207 & TST & & & \\
\hline CHEMBL3945387 & 1642518 & 6.0 & 5.3793 & TRN & & & \\
\hline CHEMBL3952160 & 1642518 & 6.9682 & 6.2985 & TST & & & \\
\hline CHEMBL3901985 & 1642518 & 6.8111 & 6.7397 & TST & & & \\
\hline CHEMBL3959416 & 1642518 & 6.21899 & 999999999 & & 6.1945 & TRN & \\
\hline CHEMBL 3952765 & 1642518 & 5.371 & 6.197999 & 9999999999 & 95 & TRN & \\
\hline CHEMBL3938984 & 1642518 & 5.612 & 6.6717 & TRN & & & \\
\hline CHEMBL3955511 & 1642518 & 6.8979 & 6.684 & TST & & & \\
\hline CHEMBL3891835 & 1642518 & 6.0 & 6.3613 & TRN & & & \\
\hline CHEMBL3981471 & 1642518 & 5.87700 & 000000000 & & 6.8217 & TRN & \\
\hline CHEMBL 3953197 & 1642518 & 5.159 & 6.297000 & 0000000001 & & TRN & \\
\hline CHEMBL3914720 & 1642518 & 6.586 & 6.6272 & TST & & & \\
\hline CHEMBL3945189 & 1642518 & 5.684 & 5.8255 & TST & & & \\
\hline CHEMBL3919300 & 1642518 & 5.604 & 6.2213 & TRN & & & \\
\hline CHEMBL3914545 & 1642518 & 6.0 & 5.5376 & TRN & & & \\
\hline CHEMBL3984595 & 1642518 & 6.401 & 6.3086 & TRN & & & \\
\hline CHEMBL3897182 & 1642518 & 6.04200 & 000000000 & & 6.9385 & TST & \\
\hline CHEMBL3913899 & 1642518 & 5.794 & 6.1801 & TRN & & & \\
\hline CHEMBL 3918171 & 1642518 & 6.0 & 5.3419 & TRN & & & \\
\hline CHEMBL3946989 & 1642518 & 6.0 & 5.5574 & TRN & & & \\
\hline CHEMBL3905914 & 1642518 & 7.1029 & 6.9876 & TRN & & & \\
\hline CHEMBL3943500 & 1642518 & 5.7 & 5.797000 & 0000000001 & & TST & \\
\hline CHEMBL3934656 & 1642518 & 8.0605 & 7.021 & TRN & & & \\
\hline CHEMBL3946841 & 1642518 & 6.8661 & 6.6531 & TST & & & \\
\hline CHEMBL3914354 & 1642518 & 6.11600 & 000000000 & 005 & 6.61700 & 0000000001 & TST \\
\hline CHEMBL 3894854 & 1642518 & 4.607 & 5.3761 & TST & & & \\
\hline CHEMBL3929472 & 1642518 & 4.0 & 4.3309 & TRN & & & \\
\hline CHEMBL3933222 & 1642518 & 4.0 & 4.0519 & TRN & & & \\
\hline CHEMBL3981370 & 1642518 & 6.0 & 5.5609 & TRN & & & \\
\hline CHEMBL3951416 & 1642518 & 5.625 & 5.5114 & TRN & & & \\
\hline CHEMBL3965629 & 1642518 & 6.1 & 6.6974 & TRN & & & \\
\hline CHEMBL3922208 & 1642518 & 6.5 & 5.8316 & TRN & & & \\
\hline CHEMBL3936551 & 1642518 & 6.0 & 5.4453 & TRN & & & \\
\hline CHEMBL3976763 & 1642518 & 8.0809 & 6.4275 & TRN & & & \\
\hline CHEMBL3930601 & 1642518 & 4.0 & 5.6126 & TRN & & & \\
\hline CHEMBL 3948827 & 1642518 & 4.0 & 5.3527 & TRN & & & \\
\hline CHEMBL3914669 & 1642518 & 4.0 & 4.4406 & TRN & & & \\
\hline CHEMBL3980994 & 1642518 & 4.0 & 6.1676 & TST & & & \\
\hline CHEMBL3936619 & 1642518 & 6.0 & 5.5168 & TRN & & & \\
\hline CHEMBL3917725 & 1642518 & 8.2007 & 6.8808 & TRN & & & \\
\hline CHEMBL3922442 & 1642518 & 5.5 & 5.8031 & TRN & & & \\
\hline CHEMBL3984854 & 1642518 & 5.665 & 5.7228 & TRN & & & \\
\hline CHEMBL3891612 & 1642518 & 6.0 & 5.3545 & TRN & & & \\
\hline CHEMBL3921656 & 1642518 & 6.8111 & 6.9217 & TRN & & & \\
\hline CHEMBL3984318 & 1642518 & 6.7104 & 6.8668 & TST & & & \\
\hline
\end{tabular}




$$
\text { Supplemental Table S2.txt }
$$

\begin{tabular}{|c|c|c|c|c|c|c|}
\hline CHEMBL 3954936 & 1642518 & 8.4202 & 6.3454 & TRN & & \\
\hline CHEMBL 3897237 & 1642518 & 6.0 & 5.3508 & TRN & & \\
\hline CHEMBL 3923377 & 1642518 & \multicolumn{3}{|c|}{5.247999999999999} & 5.5911 & TRN \\
\hline CHEMBL 3938917 & 1642518 & 5.52 & 5.7056 & TRN & & \\
\hline CHEMBL 3946132 & 1642518 & 5.815 & 6.2666 & TST & & \\
\hline CHEMBL 3921541 & 1642518 & \multicolumn{3}{|c|}{5.428999999999999} & 5.8909 & TST \\
\hline CHEMBL 3951020 & 1642518 & 6.0 & 5.5564 & TRN & & \\
\hline CHEMBL 3964899 & 1642518 & 6.8941 & 6.7376 & TRN & & \\
\hline CHEMBL 3947197 & 1642518 & 8.5528 & 6.432 & TRN & & \\
\hline CHEMBL 3945829 & 1642518 & 5.285 & 4.95 & TST & & \\
\hline CHEMBL 3964371 & 1642518 & \multicolumn{3}{|c|}{5.212000000000001} & 5.4646 & TRN \\
\hline CHEMBL 3946102 & 1642518 & 6.0 & 5.5552 & TRN & & \\
\hline CHEMBL 3903983 & 1642518 & 7.8996 & 6.5901 & TST & & \\
\hline CHEMBL 3890005 & 1642518 & 8.1135 & 6.6009 & TRN & & \\
\hline CHEMBL 3956010 & 1642518 & \multicolumn{3}{|c|}{5.712000000000001} & 6.6524 & TRN \\
\hline CHEMBL 3938026 & 1642518 & 5.909 & 6.2151 & TRN & & \\
\hline CHEMBL3956614 & 1642518 & 8.2007 & 6.0137 & TRN & & \\
\hline CHEMBL 3920065 & 1642518 & 5.684 & 6.1951 & TRN & & \\
\hline CHEMBL 3904138 & 1642518 & 7.3737 & 6.774 & TRN & & \\
\hline CHEMBL 3896451 & 1642518 & 5.223 & 5.0162 & TST & & \\
\hline CHEMBL 3971321 & 1642518 & 4.869 & 5.4019 & TST & & \\
\hline CHEMBL 3907767 & 1642518 & 4.0 & 4.1024 & TRN & & \\
\hline CHEMBL 3958578 & 1642518 & 4.0 & 5.5211 & TRN & & \\
\hline CHEMBL 3928785 & 1642518 & 5.369 & 6.3314 & TRN & & \\
\hline CHEMBL 3950699 & 1642518 & 6.0 & 5.4088 & TRN & & \\
\hline CHEMBL 3941856 & 1642518 & 5.9 & 6.2633 & TST & & \\
\hline CHEMBL3969664 & 1642518 & 4.0 & 5.4882 & TST & & \\
\hline CHEMBL 3952152 & 1642518 & 6.357 & 6.7776 & TRN & & \\
\hline CHEMBL 3904743 & 1642518 & 6.0 & 5.7069 & TRN & & \\
\hline CHEMBL 3966695 & 1642518 & 6.0 & 5.1237 & TRN & & \\
\hline CHEMBL 3983427 & 1642518 & 7.9914 & 6.4433 & TRN & & \\
\hline CHEMBL 3932769 & 1642518 & 5.086 & 5.2179 & TST & & \\
\hline CHEMBL 3891750 & 1642518 & 5.9 & 5.8661 & TRN & & \\
\hline CHEMBL3910372 & 1642518 & 7.0429 & 6.2527 & TRN & & \\
\hline CHEMBL 3938418 & 1642518 & 6.0 & 5.3459 & TRN & & \\
\hline CHEMBL 3895558 & 1642518 & 7.7825 & 6.6392 & TRN & & \\
\hline CHEMBL3960396 & 1642518 & \multicolumn{3}{|c|}{5.617999999999999} & 5.3594 & TST \\
\hline CHEMBL 3933252 & 1642518 & \multicolumn{3}{|c|}{6.0120000000000005} & 6.8246 & TST \\
\hline CHEMBL3964916 & 1642518 & 6.4 & 6.6389 & TST & & \\
\hline CHEMBL 3954147 & 1642518 & 6.0 & 5.4167 & TRN & & \\
\hline CHEMBL 3904251 & 1642518 & 6.7279 & 6.4224 & TRN & & \\
\hline CHEMBL 3911143 & 1642518 & 6.0 & 5.3258 & TRN & & \\
\hline CHEMBL 3932188 & 1642518 & 6.0 & 5.5722 & TRN & & \\
\hline CHEMBL 3900089 & 1642518 & 5.386 & 6.1946 & TST & & \\
\hline CHEMBL 3924602 & 1642518 & 5.305 & 5.6959 & TST & & \\
\hline CHEMBL 3935159 & 1642518 & 6.249 & 5.9906 & TST & & \\
\hline CHEMBL3911481 & 1642518 & 5.8365 & 6.297999 & 9999999999 & & TRN \\
\hline CHEMBL3915469 & 1642518 & 6.0 & 5.5485 & TRN & & \\
\hline
\end{tabular}




\begin{tabular}{|c|c|c|c|c|c|c|}
\hline \multicolumn{7}{|c|}{ Supplemental Table S2.txt } \\
\hline CHEMBL 3909675 & 1642518 & 6.49 & 6.7587 & TRN & & \\
\hline CHEMBL 3890441 & 1642518 & 6.1 & 6.5182 & TRN & & \\
\hline CHEMBL3901310 & 1642518 & 5.879 & 6.5685 & TRN & & \\
\hline CHEMBL3965542 & 1642518 & 4.0 & 5.2095 & TRN & & \\
\hline CHEMBL3936653 & 1642518 & 7.0348 & 6.755 & TRN & & \\
\hline CHEMBL3909983 & 1642518 & 7.466 & 6.4216 & TRN & & \\
\hline CHEMBL3968133 & 1642518 & 6.6851 & 6.6734 & TRN & & \\
\hline CHEMBL3964565 & 1642518 & 4.97199 & 99999999 & 995 & 4.3512 & TRN \\
\hline CHEMBL3967077 & 1642518 & 6.7729 & 6.9892 & TST & & \\
\hline CHEMBL3940065 & 1642518 & 7.1838 & 6.5008 & TRN & & \\
\hline CHEMBL 3923168 & 1642518 & 6.0 & 5.5188 & TRN & & \\
\hline CHEMBL 3947652 & 1642518 & 6.96899 & 99999999 & 99 & 6.0021 & TRN \\
\hline CHEMBL3914857 & 1642518 & 8.0862 & 6.7596 & TRN & & \\
\hline CHEMBL3965486 & 1642518 & 5.914 & 5.755 & TST & & \\
\hline CHEMBL3969399 & 1642518 & 7.0501 & 6.5997 & TRN & & \\
\hline CHEMBL3982821 & 1642518 & 7.9914 & 6.6394 & TRN & & \\
\hline CHEMBL3980975 & 1642518 & 6.65799 & 99999999 & 995 & 5.7437 & TST \\
\hline CHEMBL3976605 & 1642518 & 6.3 & 6.1135 & TST & & \\
\hline CHEMBL 3942735 & 1642518 & 6.261 & 7.0086 & TST & & \\
\hline CHEMBL3904840 & 1642518 & 6.0 & 5.5588 & TRN & & \\
\hline CHEMBL 3967385 & 1642518 & 6.0 & 5.4585 & TRN & & \\
\hline CHEMBL3890552 & 1642518 & 4.0 & 5.7032 & TRN & & \\
\hline CHEMBL3928620 & 1642518 & 5.4 & 6.0672 & TRN & & \\
\hline CHEMBL3899349 & 1642518 & 4.0 & 5.0571 & TRN & & \\
\hline CHEMBL3957535 & 1642518 & 7.2549 & 6.5927 & TRN & & \\
\hline CHEMBL 3963279 & 1642518 & 6.8771 & 6.8216 & TRN & & \\
\hline CHEMBL 3907060 & 1642518 & 5.349 & 6.16299 & 999999999 & & TRN \\
\hline CHEMBL 3920897 & 1642518 & 5.96399 & 99999999 & 995 & 7.1181 & TRN \\
\hline CHEMBL 3894510 & 1642518 & 4.0 & 5.2671 & TRN & & \\
\hline CHEMBL3891830 & 1642518 & 6.278 & 5.8387 & TRN & & \\
\hline CHEMBL 3931652 & 1642518 & 5.86 & 6.5206 & TRN & & \\
\hline CHEMBL3981846 & 1642518 & 4.0 & 4.1447 & TRN & & \\
\hline CHEMBL 3970209 & 1642518 & 5.78299 & 99999999 & 995 & 6.2756 & TRN \\
\hline CHEMBL3970054 & 1642518 & 5.9 & 6.836 & TST & & \\
\hline CHEMBL3916735 & 1642518 & 4.694 & 5.7111 & TRN & & \\
\hline CHEMBL3961849 & 1642518 & 5.59 & 6.3557 & TRN & & \\
\hline CHEMBL3889556 & 1642518 & 7.9547 & 6.7606 & TRN & & \\
\hline CHEMBL 3973480 & 1642518 & 7.1487 & 6.6111 & TRN & & \\
\hline CHEMBL3902545 & 1642518 & 5.48600 & 00000000 & & 6.0458 & TRN \\
\hline CHEMBL3891197 & 1642518 & 5.909 & 5.6233 & TRN & & \\
\hline CHEMBL3906564 & 1642518 & 6.0 & 5.5719 & TRN & & \\
\hline CHEMBL3896213 & 1642518 & 6.17200 & $\partial 0000000$ & 01 & 6.3416 & TST \\
\hline CHEMBL 3960245 & 1642518 & 5.185 & 5.8027 & TST & & \\
\hline CHEMBL3962858 & 1642518 & 6.0 & 5.5367 & TRN & & \\
\hline CHEMBL3961280 & 1642518 & 6.716 & 6.8207 & TST & & \\
\hline CHEMBL 3967670 & 1642518 & 4.997 & 5.2956 & TRN & & \\
\hline CHEMBL3986264 & 1642518 & 7.6861 & 6.6725 & TRN & & \\
\hline CHEMBL3973475 & 1642518 & 6.734 & 6.7507 & TRN & & \\
\hline
\end{tabular}




\begin{tabular}{|c|c|c|c|c|c|c|}
\hline \multicolumn{7}{|c|}{ Supplemental Table s2.txt } \\
\hline CHEMBL 3967445 & 1642518 & 6.061 & 6.9685 & TRN & & \\
\hline CHEMBL3966375 & 1642518 & 5.726 & 6.2298 & TST & & \\
\hline CHEMBL3919823 & 1642518 & 4.0 & 5.6383 & TRN & & \\
\hline CHEMBL 3946254 & 1642518 & 5.0405 & 5.8599 & TRN & & \\
\hline CHEMBL 3950348 & 1642518 & 5.723 & 6.0012 & TRN & & \\
\hline CHEMBL3936355 & 1642518 & 4.0 & 4.6025 & TST & & \\
\hline CHEMBL3935995 & 1642518 & 6.7481 & 7.2073 & TST & & \\
\hline CHEMBL3923816 & 1642518 & 6.17399 & 99999999 & 995 & 6.5154 & TRN \\
\hline CHEMBL 3907793 & 1642518 & 5.774 & 6.5936 & TRN & & \\
\hline CHEMBL 3924464 & 1642518 & 5.82600 & 00000000 & 005 & 7.1413 & TRN \\
\hline CHEMBL 3916556 & 1642518 & 5.21 & 5.7184 & TRN & & \\
\hline CHEMBL 3936758 & 1642518 & 5.854 & 6.9682 & TRN & & \\
\hline CHEMBL3921944 & 1642518 & 4.418 & 5.7045 & TRN & & \\
\hline CHEMBL 3912077 & 1642518 & 6.8781 & 6.6245 & TRN & & \\
\hline CHEMBL 3897781 & 1642518 & 7.063 & 6.806 & TST & & \\
\hline CHEMBL 3899300 & 1642518 & 4.0 & 4.0182 & TRN & & \\
\hline CHEMBL3929261 & 1642518 & 4.0 & 5.24200 & 0000000001 & & TRN \\
\hline CHEMBL3898513 & 1642518 & 7.0799 & 6.7227 & TRN & & \\
\hline CHEMBL 3960075 & 1642518 & 6.0 & 5.6013 & TRN & & \\
\hline CHEMBL3924275 & 1642518 & 4.0 & 4.4082 & TST & & \\
\hline CHEMBL 3953783 & 1642518 & 6.8511 & 6.3222 & TRN & & \\
\hline CHEMBL3947089 & 1642518 & 5.749 & 6.8585 & TRN & & \\
\hline CHEMBL3954397 & 1642518 & 6.9101 & 6.8112 & TST & & \\
\hline CHEMBL3906194 & 1642518 & 6.401 & 5.9936 & TRN & & \\
\hline CHEMBL3890561 & 1642518 & 6.0 & 5.6931 & TRN & & \\
\hline CHEMBL 3975084 & 1642518 & 7.21899 & 99999999 & & 5.9479 & TRN \\
\hline CHEMBL3976490 & 1642518 & 6.36799 & 99999999 & & 5.9639 & TRN \\
\hline CHEMBL3943013 & 1642518 & 5.8505 & 6.1895 & TRN & & \\
\hline CHEMBL3955703 & 1642518 & 5.7855 & 6.6334 & TST & & \\
\hline CHEMBL3946826 & 1642518 & 5.902 & 6.3617 & TRN & & \\
\hline CHEMBL 3906045 & 1642518 & 5.785 & 6.1081 & TST & & \\
\hline CHEMBL3896271 & 1642518 & 5.36700 & 000000006 & & 5.9868 & TST \\
\hline CHEMBL3978377 & 1642518 & 5.078 & 5.7132 & TRN & & \\
\hline CHEMBL3427365 & 1476694 & 2.699 & 2.9657 & TST & & \\
\hline CHEMBL 3427320 & 1476694 & 4.0969 & 4.0557 & TRN & & \\
\hline CHEMBL2094513 & 1476694 & 3.9586 & 3.9005 & TRN & & \\
\hline CHEMBL3427341 & 1476694 & 2.699 & 2.7405 & TRN & & \\
\hline CHEMBL3427355 & 1476694 & 2.699 & 2.7447 & TRN & & \\
\hline CHEMBL 3427361 & 1476694 & 2.699 & 2.6834 & TRN & & \\
\hline CHEMBL3427359 & 1476694 & 2.699 & 2.6439 & TRN & & \\
\hline CHEMBL 3427349 & 1476694 & 3.8539 & 3.8162 & TRN & & \\
\hline CHEMBL 3427322 & 1476694 & 4.1549 & 4.3845 & TRN & & \\
\hline CHEMBL3427357 & 1476694 & 2.699 & 2.6596 & TRN & & \\
\hline CHEMBL 3427353 & 1476694 & 2.699 & 2.7952 & TRN & & \\
\hline CHEMBL 3427331 & 1476694 & 2.699 & 2.7565 & TRN & & \\
\hline CHEMBL 3427337 & 1476694 & 2.699 & 2.7509 & TRN & & \\
\hline CHEMBL 3427338 & 1476694 & 2.699 & 2.6947 & TRN & & \\
\hline CHEMBL3427350 & 1476694 & 2.699 & 2.7271 & TRN & & \\
\hline
\end{tabular}


Supplemental Table S2.txt

\begin{tabular}{|c|c|c|c|c|c|}
\hline CHEMBL3427356 & 1476694 & 2.699 & 2.6994 & TRN & \\
\hline CHEMBL 3427328 & 1476694 & 2.699 & 2.7949 & TRN & \\
\hline CHEMBL3427344 & 1476694 & 2.699 & 2.6471 & TRN & \\
\hline CHEMBL 3427364 & 1476694 & 2.699 & 3.108 & TST & \\
\hline CHEMBL 3427346 & 1476694 & 3.8861 & 3.8773 & TRN & \\
\hline CHEMBL 3427343 & 1476694 & 2.699 & 2.6005 & TRN & \\
\hline CHEMBL 3427336 & 1476694 & 4.301 & 4.3085 & TRN & \\
\hline CHEMBL 3427330 & 1476694 & 4.1249 & 4.0746 & TRN & \\
\hline CHEMBL 3427345 & 1476694 & 3.699 & 3.2552 & TST & \\
\hline CHEMBL3427319 & 1476694 & 4.0 & 3.9355 & TRN & \\
\hline CHEMBL 3427333 & 1476694 & 3.7447 & 3.8075 & TRN & \\
\hline CHEMBL 3427340 & 1476694 & 2.699 & 2.7872 & TRN & \\
\hline CHEMBL 3427347 & 1476694 & 2.699 & 2.6163 & TRN & \\
\hline CHEMBL 3427342 & 1476694 & 2.699 & 2.6394 & TRN & \\
\hline CHEMBL3427325 & 1476694 & 5.0 & 4.7201 & TRN & \\
\hline CHEMBL 3427360 & 1476694 & 4.3979 & 4.506 & TRN & \\
\hline CHEMBL3427321 & 1476694 & 4.2218 & 4.1847 & TRN & \\
\hline CHEMBL 3427335 & 1476694 & 3.9208 & 3.8278 & TRN & \\
\hline CHEMBL 3427352 & 1476694 & 3.699 & 3.6943 & TRN & \\
\hline CHEMBL3427323 & 1476694 & 4.1249 & 4.3788 & TRN & \\
\hline CHEMBL3427367 & 1476694 & 3.9208 & 0.8074 & TST & \\
\hline CHEMBL3427339 & 1476694 & 2.699 & \multicolumn{2}{|c|}{2.7110000000000003} & TRN \\
\hline CHEMBL 3427327 & 1476694 & 2.699 & 2.6677 & TRN & \\
\hline CHEMBL 3427332 & 1476694 & 2.699 & 2.6826 & TRN & \\
\hline CHEMBL 3427354 & 1476694 & 4.301 & 4.2196 & TRN & \\
\hline CHEMBL3427366 & 1476694 & 3.9586 & 3.3631 & TST & \\
\hline CHEMBL 3427348 & 1476694 & 2.699 & 2.6033 & TRN & \\
\hline CHEMBL 3427351 & 1476694 & 2.699 & 2.8264 & TRN & \\
\hline CHEMBL 3211065 & 1476694 & 2.699 & 3.4201 & TST & \\
\hline CHEMBL 3427324 & 1476694 & 4.301 & 5.0356 & TST & \\
\hline CHEMBL3427334 & 1476694 & 2.8239 & 3.447 & TST & \\
\hline CHEMBL 3427326 & 1476694 & 2.699 & 2.0183 & TST & \\
\hline CHEMBL 3427358 & 1476694 & 2.699 & 2.5955 & TST & \\
\hline CHEMBL3427329 & 1476694 & 2.699 & \multicolumn{2}{|c|}{3.8139999999999996} & TST \\
\hline CHEMBL 3427362 & 1476694 & 2.699 & 4.488 & TST & \\
\hline CHEMBL3427363 & 1476694 & 2.699 & 3.0148 & TST & \\
\hline CHEMBL 3781298 & 1565263 & 3.5229 & 4.5644 & TST & \\
\hline CHEMBL 3780426 & 1565263 & 3.5229 & 4.3107 & TRN & \\
\hline CHEMBL 3781755 & 1565263 & 6.5229 & 6.2548 & TRN & \\
\hline CHEMBL 3234253 & 1565263 & 5.4976 & 5.2147 & TRN & \\
\hline CHEMBL 3780901 & 1565263 & 6.1367 & 6.2486 & TRN & \\
\hline CHEMBL 3781898 & 1565263 & 5.9172 & 5.4106 & TRN & \\
\hline CHEMBL 3780508 & 1565263 & 5.983 & 5.8598 & TRN & \\
\hline CHEMBL 3780233 & 1565263 & 4.857 & 5.1262 & TST & \\
\hline CHEMBL 3780262 & 1565263 & 3.5229 & 4.7593 & TRN & \\
\hline CHEMBL3781556 & 1565263 & 5.3152 & \multicolumn{2}{|c|}{5.8420000000000005} & TRN \\
\hline CHEMBL 3780560 & 1565263 & 6.2757 & 5.5992 & TRN & \\
\hline CHEMBL3779914 & 1565263 & 4.6751 & 4.7397 & TRN & \\
\hline
\end{tabular}

Page 4355 
Supplemental Table S2.txt

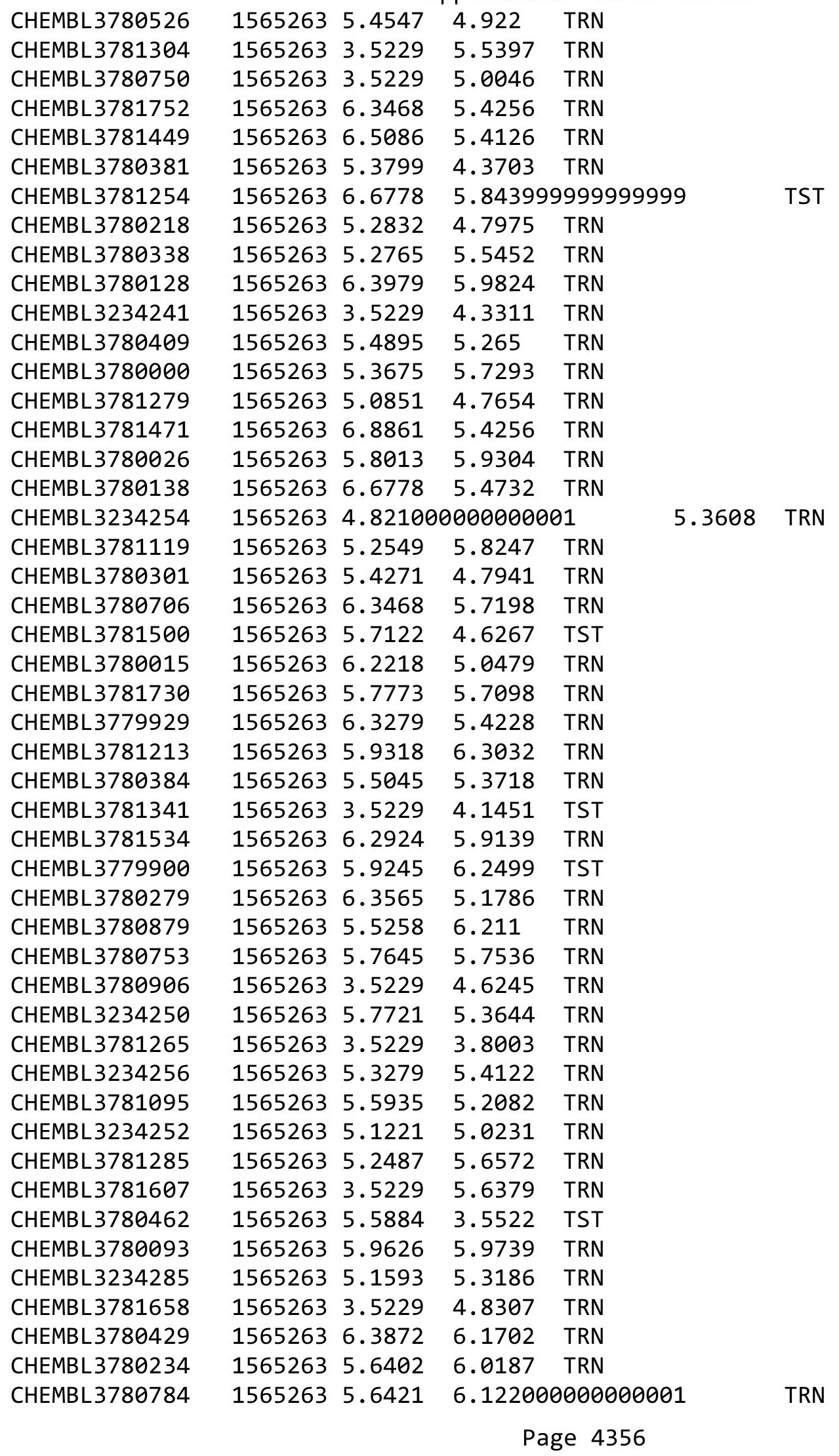


Supplemental Table S2.txt

\begin{tabular}{|c|c|c|c|c|c|}
\hline CHEMBL3781484 & 1565263 & 6.3372 & 5.8954 & TST & \\
\hline CHEMBL 3780735 & 1565263 & 3.5229 & 5.1244 & TRN & \\
\hline CHEMBL3781570 & 1565263 & 5.4123 & 6.0648 & TRN & \\
\hline CHEMBL 3782048 & 1565263 & 5.9355 & 4.9107 & TRN & \\
\hline CHEMBL 3780143 & 1565263 & 5.3179 & 5.7342 & TRN & \\
\hline CHEMBL3780059 & 1565263 & 6.9208 & 6.0257 & TRN & \\
\hline CHEMBL3781513 & 1565263 & 5.8239 & 5.1487 & TRN & \\
\hline CHEMBL3781951 & 1565263 & 5.7077 & 5.0916 & TRN & \\
\hline CHEMBL1957266 & 1565263 & 6.9208 & 5.3967 & TST & \\
\hline CHEMBL 3781084 & 1565263 & 5.3872 & 5.4132 & TST & \\
\hline CHEMBL 3780491 & 1565263 & 5.3098 & 6.0722 & TST & \\
\hline CHEMBL 3779921 & 1565263 & 3.5229 & 5.1396 & TST & \\
\hline CHEMBL 3780017 & 1565263 & 6.2076 & 6.2193 & TST & \\
\hline CHEMBL1485571 & 1565263 & 6.0 & 4.9321 & TST & \\
\hline CHEMBL 3780398 & 1565263 & 5.8153 & 5.4801 & TST & \\
\hline CHEMBL 3780518 & 1565263 & 3.5229 & 4.5517 & TST & \\
\hline CHEMBL3781093 & 1565263 & 5.9508 & 5.2182 & TST & \\
\hline CHEMBL 3780115 & 1565263 & 5.3696 & 6.5575 & TST & \\
\hline CHEMBL3780650 & 1565263 & 5.2291 & 3.7955 & TST & \\
\hline CHEMBL 3780992 & 1565263 & 5.4634 & 4.4166 & TST & \\
\hline CHEMBL3780310 & 1565263 & 5.1878 & 4.0271 & TST & \\
\hline CHEMBL 275307 & 48248 & 8.2366 & 8.2628 & TRN & \\
\hline CHEMBL8997 & 48248 & 7.8539 & 7.83299 & 9999999999 & TRN \\
\hline CHEMBL 9010 & 48248 & 5.9318 & 5.9443 & TRN & \\
\hline CHEMBL9406 & 48248 & 8.301 & 8.2885 & TRN & \\
\hline CHEMBL 9492 & 48248 & 6.5817 & 6.5731 & TRN & \\
\hline CHEMBL 266557 & 48248 & 8.6198 & 8.6279 & TRN & \\
\hline CHEMBL9311 & 48248 & 7.6021 & 7.61100 & 0000000001 & TRN \\
\hline CHEMBL9195 & 48248 & 7.6383 & 4.5108 & TST & \\
\hline CHEMBL 267023 & 48248 & 7.5376 & 7.5455 & TRN & \\
\hline CHEMBL9501 & 48248 & 7.585 & 7.57700 & 3000000001 & TRN \\
\hline CHEMBL9465 & 48248 & 6.6596 & 6.6673 & TRN & \\
\hline CHEMBL 269662 & 48248 & 7.2441 & 7.2648 & TRN & \\
\hline CHEMBL415965 & 48248 & 7.4202 & 7.4255 & TRN & \\
\hline CHEMBL 9287 & 48248 & 7.1367 & 7.14 & TRN & \\
\hline CHEMBL 9083 & 48248 & 7.8539 & 7.8449 & TRN & \\
\hline CHEMBL 8921 & 48248 & 6.4962 & 6.4724 & TRN & \\
\hline CHEMBL 266376 & 48248 & 6.699 & 6.7165 & TRN & \\
\hline CHEMBL9336 & 48248 & 6.8182 & 6.858 & TRN & \\
\hline CHEMBL 269123 & 48248 & 7.4815 & 7.4911 & TRN & \\
\hline CHEMBL9405 & 48248 & 8.9208 & 8.9112 & TRN & \\
\hline CHEMBL 8890 & 48248 & 8.7212 & 8.72 & TRN & \\
\hline CHEMBL9267 & 48248 & 8.301 & 8.301 & TRN & \\
\hline CHEMBL9377 & 48248 & 7.3468 & 7.318 & TRN & \\
\hline CHEMBL 70380 & 48248 & 8.0706 & 4.3868 & TST & \\
\hline CHEMBL 9230 & 48248 & \multicolumn{3}{|c|}{6.2139999999999995} & TRN \\
\hline CHEMBL9535 & 48248 & 7.0132 & 7.0095 & TRN & \\
\hline CHEMBL275789 & 48248 & 5.6757 & 5.6855 & TRN & \\
\hline
\end{tabular}




\begin{tabular}{|c|c|c|c|c|}
\hline \multirow[b]{2}{*}{ CHEMBL9319 } & \multicolumn{4}{|c|}{ Supplemental Table S2.txt } \\
\hline & 48248 & 8.0 & 7.9954 & TRN \\
\hline CHEMBL8954 & 48248 & 8.0969 & 8.0943 & TRN \\
\hline CHEMBL 276627 & 48248 & 8.2291 & 8.2456 & TRN \\
\hline CHEMBL9291 & 48248 & 7.8239 & 7.8303 & TRN \\
\hline CHEMBL 9888 & 48248 & 7.0555 & 7.0539 & TRN \\
\hline CHEMBL9171 & 48248 & 7.2007 & 7.2213 & TRN \\
\hline CHEMBL9459 & 48248 & 7.7959 & 5.8082 & TST \\
\hline CHEMBL266819 & 48248 & 5.3686 & 5.3883 & TRN \\
\hline CHEMBL264087 & 48248 & 5.0 & 5.0073 & TRN \\
\hline CHEMBL8922 & 48248 & 7.6576 & 7.6352 & TRN \\
\hline CHEMBL266598 & 48248 & 6.2328 & 4.6787 & TST \\
\hline CHEMBL269606 & 48248 & 6.9666 & 7.0923 & TST \\
\hline CHEMBL 2051984 & 48248 & 5.9052 & 5.9094 & TRN \\
\hline CHEMBL 273693 & 48248 & 6.8539 & 5.904 & TST \\
\hline CHEMBL 9532 & 48248 & 5.4483 & 5.4349 & TRN \\
\hline CHEMBL 266523 & 48248 & 6.0386 & 6.0384 & TRN \\
\hline CHEMBL 269142 & 48248 & 6.6478 & 6.6297 & TRN \\
\hline CHEMBL418700 & 48248 & 5.1152 & 5.1121 & TRN \\
\hline CHEMBL 8920 & 48248 & 6.2277 & 6.2129 & TRN \\
\hline CHEMBL 9449 & 48248 & 8.0969 & 5.989 & TST \\
\hline CHEMBL8905 & 48248 & 5.9654 & 5.942 & TRN \\
\hline CHEMBL 9422 & 48248 & 7.8539 & 7.8443 & TRN \\
\hline CHEMBL262569 & 48248 & 7.301 & 8.3574 & TST \\
\hline CHEMBL 9188 & 48248 & 8.8239 & 7.9999 & TST \\
\hline CHEMBL 266120 & 48248 & 7.9586 & 7.6488 & TST \\
\hline CHEMBL 9203 & 48248 & 9.0 & 8.4846 & TST \\
\hline CHEMBL9524 & 48248 & 7.8539 & 6.7184 & TST \\
\hline CHEMBL9026 & 48248 & 8.0315 & 6.6021 & TST \\
\hline CHEMBL 9354 & 48248 & 7.8239 & 7.1376 & TST \\
\hline CHEMBL 9534 & 48248 & 8.0969 & 4.7877 & TST \\
\hline CHEMBL1078765 & 619859 & 3.9136 & 4.1635 & TRN \\
\hline CHEMBL1078729 & 619859 & 3.2588 & 3.4295 & TRN \\
\hline CHEMBL1078035 & 619859 & 4.8539 & 5.426 & TRN \\
\hline CHEMBL1079054 & 619859 & 3.1367 & 3.5752 & TRN \\
\hline CHEMBL1077574 & 619859 & 3.4365 & 4.4427 & TRN \\
\hline CHEMBL1078728 & 619859 & 3.3089 & 3.4582 & TRN \\
\hline CHEMBL1080233 & 619859 & 3.5528 & 3.6015 & TRN \\
\hline CHEMBL1077960 & 619859 & 5.0 & 4.2009 & TRN \\
\hline CHEMBL1078296 & 619859 & 3.9393 & 3.7265 & TRN \\
\hline CHEMBL1078034 & 619859 & 5.1871 & 5.254 & TRN \\
\hline CHEMBL1079253 & 619859 & 4.4815 & 5.4852 & TRN \\
\hline CHEMBL1079284 & 619859 & 5.5229 & 5.2802 & TRN \\
\hline CHEMBL1078483 & 619859 & 3.5143 & 4.2828 & TST \\
\hline CHEMBL1078898 & 619859 & 3.8041 & 4.0527 & TST \\
\hline CHEMBL1078877 & 619859 & 3.1158 & 3.7761 & TST \\
\hline CHEMBL1078227 & 619859 & 3.6861 & 4.3843 & TRN \\
\hline CHEMBL1077581 & 619859 & 3.8356 & 4.1811 & TRN \\
\hline CHEMBL1077971 & 619859 & 4.1871 & 4.2264 & TRN \\
\hline
\end{tabular}




\begin{tabular}{|c|c|c|c|c|c|}
\hline \multicolumn{6}{|c|}{ supplemental } \\
\hline CHEMBL1078200 & 619859 & 4.7447 & 4.3807 & TRN & \\
\hline CHEMBL1078727 & 619859 & 4.5686 & 5.3104 & TRN & \\
\hline CHEMBL1082219 & 619859 & 3.6635 & 3.5572 & TRN & \\
\hline CHEMBL1080943 & 619859 & 3.2924 & 3.8526 & TRN & \\
\hline CHEMBL1079276 & 619859 & 3.8996 & 3.9516 & TRN & \\
\hline CHEMBL1080224 & 619859 & 3.0128 & 3.4988 & TRN & \\
\hline CHEMBL1079336 & 619859 & 3.0283 & 3.8175 & TRN & \\
\hline CHEMBL1078295 & 619859 & 3.8153 & 3.7502 & TRN & \\
\hline CHEMBL1079216 & 619859 & 3.2941 & 3.81100 & 00000000004 & TRN \\
\hline CHEMBL1077373 & 619859 & 4.4202 & 4.1077 & TRN & \\
\hline CHEMBL1078590 & 619859 & 4.1612 & 4.0579 & TRN & \\
\hline CHEMBL1078802 & 619859 & 5.1549 & 3.7146 & TST & \\
\hline CHEMBL1079155 & 619859 & 5.9586 & 4.3843 & TRN & \\
\hline CHEMBL1079337 & 619859 & 3.2676 & 3.7091 & TRN & \\
\hline CHEMBL1077404 & 619859 & 3.5622 & 3.6911 & TRN & \\
\hline CHEMBL1079093 & 619859 & 4.1249 & 4.0379 & TRN & \\
\hline CHEMBL1077539 & 619859 & 3.3401 & 3.99899 & 99999999997 & TST \\
\hline CHEMBL1078294 & 619859 & 4.041 & 4.1739 & TRN & \\
\hline CHEMBL1080234 & 619859 & 4.1549 & 4.0951 & TRN & \\
\hline CHEMBL1077958 & 619859 & 4.2757 & 3.9716 & TRN & \\
\hline CHEMBL1078655 & 619859 & 3.4034 & 4.2018 & TRN & \\
\hline CHEMBL1078673 & 619859 & 5.1805 & 3.8446 & TRN & \\
\hline CHEMBL1079218 & 619859 & 4.2518 & 3.7466 & TST & \\
\hline CHEMBL1078334 & 619859 & 3.5229 & 4.2235 & TRN & \\
\hline CHEMBL1078603 & 619859 & 3.5003 & 3.6473 & TRN & \\
\hline CHEMBL1078833 & 619859 & 3.2055 & 3.8396 & TRN & \\
\hline CHEMBL1079096 & 619859 & 3.3635 & 3.6793 & TRN & \\
\hline CHEMBL1078379 & 619859 & 4.1427 & 4.2446 & TRN & \\
\hline CHEMBL1078943 & 619859 & 3.8356 & 3.7682 & TRN & \\
\hline CHEMBL1078967 & 619859 & 3.9031 & 4.024 & TRN & \\
\hline CHEMBL1079250 & 619859 & 4.9586 & 4.3561 & TRN & \\
\hline CHEMBL1082215 & 619859 & 3.5391 & 3.6278 & TRN & \\
\hline CHEMBL1079219 & 619859 & 3.2503 & 4.1561 & TST & \\
\hline CHEMBL1079002 & 619859 & 3.1898 & 3.6674 & TRN & \\
\hline CHEMBL1078399 & 619859 & 3.4237 & 3.9886 & TRN & \\
\hline CHEMBL1080942 & 619859 & 3.6402 & 3.9491 & TRN & \\
\hline CHEMBL1078431 & 619859 & 3.9281 & 3.6414 & TRN & \\
\hline CHEMBL1078987 & 619859 & 3.1871 & 3.4726 & TRN & \\
\hline CHEMBL1078593 & 619859 & 3.1931 & 3.7551 & TST & \\
\hline CHEMBL1078656 & 619859 & 4.6778 & 3.9088 & TRN & \\
\hline CHEMBL1078278 & 619859 & 5.8861 & 4.1897 & TRN & \\
\hline CHEMBL1077382 & 619859 & 4.2924 & 4.0078 & TRN & \\
\hline CHEMBL1077473 & 619859 & 3.3458 & 3.7532 & TST & \\
\hline CHEMBL1077456 & 619859 & 3.4789 & 4.1065 & TST & \\
\hline CHEMBL1078832 & 619859 & 4.8539 & 3.8759 & TRN & \\
\hline CHEMBL1081129 & 619859 & 3.9101 & 3.7836 & TRN & \\
\hline CHEMBL1077502 & 619859 & 3.8601 & 3.9518 & TST & \\
\hline CHEMBL1079251 & 619859 & 3.1904 & 4.2484 & TRN & \\
\hline
\end{tabular}




\begin{tabular}{|c|c|c|c|c|c|c|}
\hline & & \multicolumn{5}{|c|}{ Supplemental Table S2.txt } \\
\hline CHEMBL1077410 & 619859 & 3.7932 & 3.9814 & TRN & & \\
\hline CHEMBL1079010 & 619859 & 3.3526 & 3.6435 & TRN & & \\
\hline CHEMBL1078485 & 619859 & 3.8697 & 3.6355 & TRN & & \\
\hline CHEMBL1077601 & 619859 & 5.4089 & 3.8718 & TRN & & \\
\hline CHEMBL1078199 & 619859 & 4.6778 & 4.3237 & TRN & & \\
\hline CHEMBL1077573 & 619859 & 3.7212 & 4.0393 & TRN & & \\
\hline CHEMBL1077970 & 619859 & 3.6478 & 4.121 & TRN & & \\
\hline CHEMBL1078645 & 619859 & 5.3872 & 4.4462 & TRN & & \\
\hline CHEMBL1077576 & 619859 & 3.8477 & 3.9311 & TRN & & \\
\hline CHEMBL1078046 & 619859 & 4.6021 & 4.1565 & TRN & & \\
\hline CHEMBL1080235 & 619859 & 3.7447 & 3.9115 & TRN & & \\
\hline CHEMBL1078201 & 619859 & 4.6576 & 3.9021 & TRN & & \\
\hline CHEMBL1078931 & 619859 & 3.9469 & 4.1384 & TRN & & \\
\hline CHEMBL1079164 & 619859 & 3.6091 & 3.9539 & TST & & \\
\hline CHEMBL1077546 & 619859 & 3.2557 & 3.8724 & TRN & & \\
\hline CHEMBL1079321 & 619859 & 5.4318 & 4.3347 & TRN & & \\
\hline CHEMBL1077444 & 619859 & 4.4318 & 3.9989 & TRN & & \\
\hline CHEMBL1079252 & 619859 & 6.1135 & 5.5994 & TRN & & \\
\hline CHEMBL1078858 & 619859 & 4.0088 & 4.0763 & TST & & \\
\hline CHEMBL1078674 & 619859 & 3.062 & 4.1539 & TRN & & \\
\hline CHEMBL1077714 & 619859 & 5.2596 & 5.2413 & TRN & & \\
\hline CHEMBL1078192 & 619859 & 5.7447 & 4.2248 & TRN & & \\
\hline CHEMBL1078941 & 619859 & 3.2573 & 3.3512 & TRN & & \\
\hline CHEMBL1078644 & 619859 & 4.3098 & 4.2739 & TRN & & \\
\hline CHEMBL1077969 & 619859 & 3.2104 & 3.7534 & TRN & & \\
\hline CHEMBL1079281 & 619859 & 4.1192 & 4.085 & TRN & & \\
\hline CHEMBL1080042 & 619859 & 3.8827 & 4.0635 & TST & & \\
\hline CHEMBL1079283 & 619859 & 5.0706 & 5.3262 & TST & & \\
\hline CHEMBL1078430 & 619859 & 3.68399 & 9999999 & 997 & 3.9477 & TST \\
\hline CHEMBL1080946 & 619859 & 3.4202 & 3.5727 & TST & & \\
\hline CHEMBL1078646 & 619859 & 3.6904 & 4.2515 & TST & & \\
\hline CHEMBL1078888 & 619859 & 3.6498 & 3.9143 & TST & & \\
\hline CHEMBL1078764 & 619859 & 4.2924 & 4.0589 & TST & & \\
\hline CHEMBL1078482 & 619859 & 4.3279 & 4.3615 & TST & & \\
\hline CHEMBL1079053 & 619859 & 3.1524 & 3.7823 & TST & & \\
\hline CHEMBL1078381 & 619859 & 5.0 & 4.0375 & TST & & \\
\hline CHEMBL1078202 & 619859 & 4.1612 & 3.8644 & TST & & \\
\hline CHEMBL1080043 & 619859 & 3.9666 & 4.1648 & TST & & \\
\hline CHEMBL1082221 & 619859 & 4.041 & 3.9944 & TST & & \\
\hline CHEMBL1077614 & 619859 & 3.2314 & 3.7695 & TST & & \\
\hline CHEMBL610989 & 29318 & 5.5686 & 5.4969 & TRN & & \\
\hline CHEMBL609049 & 29318 & 5.6778 & 5.6636 & TRN & & \\
\hline CHEMBL604851 & 29318 & 7.5622 & 7.1415 & TRN & & \\
\hline CHEMBL607613 & 29318 & 6.7212 & 6.4335 & TRN & & \\
\hline CHEMBL608298 & 29318 & 6.5045 & 6.5189 & TST & & \\
\hline CHEMBL606230 & 29318 & 6.7305 & 7.3757 & TRN & & \\
\hline CHEMBL611582 & 29318 & 6.8996 & 7.1943 & TRN & & \\
\hline CHEMBL57706 & 29318 & 5.8225 & 6.4247 & TST & & \\
\hline
\end{tabular}




\begin{tabular}{|c|c|c|c|c|c|}
\hline & & \multicolumn{4}{|c|}{ Supplemental Table s2.txt } \\
\hline CHEMBL611900 & 29318 & 5.4559 & 5.5959 & TRN & \\
\hline CHEMBL285819 & 29318 & 8.1739 & 8.1849 & TRN & \\
\hline CHEMBL608650 & 29318 & 6.2218 & 5.6288 & TRN & \\
\hline CHEMBL608947 & 29318 & 6.6126 & 6.6891 & TRN & \\
\hline CHEMBL612215 & 29318 & 5.6383 & 5.3837 & TRN & \\
\hline CHEMBL611583 & 29318 & 9.0757 & 7.1248 & TST & \\
\hline CHEMBL608463 & 29318 & 6.1192 & 6.1591 & TRN & \\
\hline CHEMBL611586 & 29318 & 5.9266 & 5.7408 & TRN & \\
\hline CHEMBL605685 & 29318 & 6.301 & 6.7917 & TRN & \\
\hline CHEMBL60860 & 29318 & 5.3716 & 5.6927 & TST & \\
\hline CHEMBL608063 & 29318 & 5.301 & 5.8372 & TRN & \\
\hline CHEMBL608948 & 29318 & 7.8539 & 6.9303 & TST & \\
\hline CHEMBL610651 & 29318 & 6.6819 & 6.8321 & TST & \\
\hline CHEMBL604023 & 29318 & 6.2226 & 6.291 & TRN & \\
\hline CHEMBL611291 & 29318 & 5.9007 & 5.8836 & TRN & \\
\hline CHEMBL608180 & 29318 & 6.129 & 5.6117 & TRN & \\
\hline CHEMBL608461 & 29318 & 7.3098 & 6.8748 & TRN & \\
\hline CHEMBL605264 & 29318 & 5.7951 & 6.2168 & TRN & \\
\hline CHEMBL607901 & 29318 & 5.0653 & 5.4127 & TRN & \\
\hline CHEMBL606318 & 29318 & 6.9431 & 6.8816 & TRN & \\
\hline CHEMBL612214 & 29318 & 5.7959 & 5.5795 & TRN & \\
\hline CHEMBL611288 & 29318 & 7.5513 & 6.7215 & TST & \\
\hline CHEMBL 2113504 & 29318 & 7.0555 & 6.9528 & TST & \\
\hline CHEMBL609544 & 29318 & 5.585 & 5.7006 & TRN & \\
\hline CHEMBL 2113450 & 29318 & 6.6799 & 6.7632 & TRN & \\
\hline CHEMBL607614 & 29318 & 5.5229 & 5.2067 & TRN & \\
\hline CHEMBL611899 & 29318 & 6.3372 & 5.9774 & TRN & \\
\hline CHEMBL608182 & 29318 & 6.0506 & 5.9474 & TRN & \\
\hline CHEMBL607775 & 29318 & 6.8125 & 7.4496 & TRN & \\
\hline CHEMBL612216 & 29318 & 6.5346 & 6.5843 & TST & \\
\hline CHEMBL 374685 & 29318 & 6.8861 & 6.3702 & TRN & \\
\hline CHEMBL604849 & 29318 & 6.38299 & 99999999 & 6.2622 & TRN \\
\hline CHEMBL604647 & 29318 & 5.614 & 5.4581 & TRN & \\
\hline CHEMBL609543 & 29318 & 7.7328 & 7.136 & TRN & \\
\hline CHEMBL611585 & 29318 & 7.1427 & 6.2645 & TRN & \\
\hline CHEMBL604234 & 29318 & 6.0458 & 6.2355 & TRN & \\
\hline CHEMBL607728 & 29318 & 6.5654 & 7.246 & TST & \\
\hline CHEMBL223846 & 29318 & 5.8861 & 5.98799 & 99999999995 & TRN \\
\hline CHEMBL610362 & 29318 & 6.8665 & 6.7825 & TST & \\
\hline CHEMBL2113499 & 29318 & 6.7905 & 7.0316 & TST & \\
\hline CHEMBL331372 & 29318 & 5.7447 & 6.00799 & 9999999999 & TST \\
\hline CHEMBL464859 & 29318 & 7.8761 & 7.6433 & TST & \\
\hline CHEMBL 2113507 & 29318 & 6.7696 & 6.9033 & TST & \\
\hline CHEMBL609825 & 29318 & 6.8928 & 7.0344 & TRN & \\
\hline CHEMBL387324 & 29318 & 5.6198 & 5.8883 & TRN & \\
\hline CHEMBL610988 & 29318 & 6.0177 & 6.04700 & 0000000001 & TRN \\
\hline CHEMBL611289 & 29318 & 6.8539 & 6.6717 & TRN & \\
\hline CHEMBL606319 & 29318 & 6.7496 & 6.9375 & TST & \\
\hline
\end{tabular}




\begin{tabular}{|c|c|c|c|c|c|}
\hline \multicolumn{6}{|c|}{ Supplemental Table S2.txt } \\
\hline CHEMBL607773 & 29318 & 6.4202 & 6.3332 & TRN & \\
\hline CHEMBL603602 & 29318 & 6.3036 & 6.5911 & TRN & \\
\hline CHEMBL611290 & 29318 & 6.3468 & 6.7174 & TRN & \\
\hline CHEMBL608460 & 29318 & 7.4191 & 7.0873 & TRN & \\
\hline CHEMBL605265 & 29318 & 7.0685 & 6.5845 & TRN & \\
\hline CHEMBL605691 & 29318 & 5.4799 & 6.0928 & TRN & \\
\hline CHEMBL605473 & 29318 & 5.1634 & 5.6302 & TRN & \\
\hline CHEMBL605055 & 29318 & 5.8431 & 6.0359 & TRN & \\
\hline CHEMBL609244 & 29318 & 6.3251 & 5.9338 & TRN & \\
\hline CHEMBL605056 & 29318 & 6.5086 & 6.0257 & TRN & \\
\hline CHEMBL610992 & 29318 & 5.5528 & 5.6832 & TRN & \\
\hline CHEMBL608753 & 29318 & 7.9957 & 7.36600 & 00000000005 & TRN \\
\hline CHEMBL 2113500 & 29318 & 6.3979 & 6.8647 & TST & \\
\hline CHEMBL608918 & 29318 & 6.6946 & 6.7803 & TRN & \\
\hline CHEMBL604440 & 29318 & 7.0434 & 6.6743 & TST & \\
\hline CHEMBL610993 & 29318 & 4.9172 & 5.7716 & TRN & \\
\hline CHEMBL426928 & 29318 & 6.301 & 6.3076 & TRN & \\
\hline CHEMBL603389 & 29318 & 6.3686 & 6.3902 & TRN & \\
\hline CHEMBL 223270 & 29318 & 6.1561 & 6.3606 & TRN & \\
\hline CHEMBL603812 & 29318 & 6.857 & 6.5205 & TRN & \\
\hline CHEMBL608949 & 29318 & 6.6021 & 6.4119 & TRN & \\
\hline CHEMBL611293 & 29318 & 5.6021 & 5.9031 & TRN & \\
\hline CHEMBL609493 & 29318 & 6.8601 & 6.8735 & TST & \\
\hline CHEMBL 345286 & 29318 & 5.7959 & 5.1693 & TRN & \\
\hline CHEMBL 387354 & 29318 & 5.7959 & 5.6383 & TRN & \\
\hline CHEMBL 374151 & 29318 & 5.4437 & 5.6242 & TRN & \\
\hline CHEMBL607772 & 29318 & 5.9208 & 6.2386 & TRN & \\
\hline CHEMBL610990 & 29318 & 5.3116 & 5.6313 & TRN & \\
\hline CHEMBL 3350613 & 29318 & 6.8861 & 4.4167 & TST & \\
\hline CHEMBL605057 & 29318 & 5.3504 & 6.2615 & TST & \\
\hline CHEMBL608464 & 29318 & 5.9586 & 5.6754 & TRN & \\
\hline CHEMBL608462 & 29318 & 4.699 & 5.1658 & TRN & \\
\hline CHEMBL610138 & 29318 & 6.3188 & 6.3176 & TRN & \\
\hline CHEMBL606315 & 29318 & 5.1251 & 6.405 & TST & \\
\hline CHEMBL608181 & 29318 & 7.0894 & 7.2716 & TRN & \\
\hline CHEMBL 375190 & 29318 & 6.1543 & 6.8627 & TST & \\
\hline CHEMBL1807815 & 29318 & 4.8539 & 5.3628 & TRN & \\
\hline CHEMBL604649 & 29318 & 6.224 & 6.2975 & TST & \\
\hline CHEMBL608177 & 29318 & 5.8268 & 5.8115 & TRN & \\
\hline CHEMBL608351 & 29318 & 6.284 & 6.456 & TRN & \\
\hline CHEMBL 3675583 & 1535383 & 7.3565 & 7.6072 & TRN & \\
\hline CHEMBL 3670700 & 1535383 & 6.4001 & 6.7954 & TRN & \\
\hline CHEMBL3675559 & 1535383 & 7.2441 & 6.7025 & TRN & \\
\hline CHEMBL 3675565 & 1535383 & 7.8447 & 7.2438 & TRN & \\
\hline CHEMBL3670702 & 1535383 & 7.2757 & 7.1784 & TRN & \\
\hline CHEMBL 3675586 & 1535383 & 7.5918 & 8.0955 & TRN & \\
\hline CHEMBL 3675546 & 1535383 & 6.5143 & 7.2989 & TRN & \\
\hline CHEMBL3670711 & 1535383 & 5.0 & 6.2428 & TST & \\
\hline
\end{tabular}


Supplemental Table S2.txt

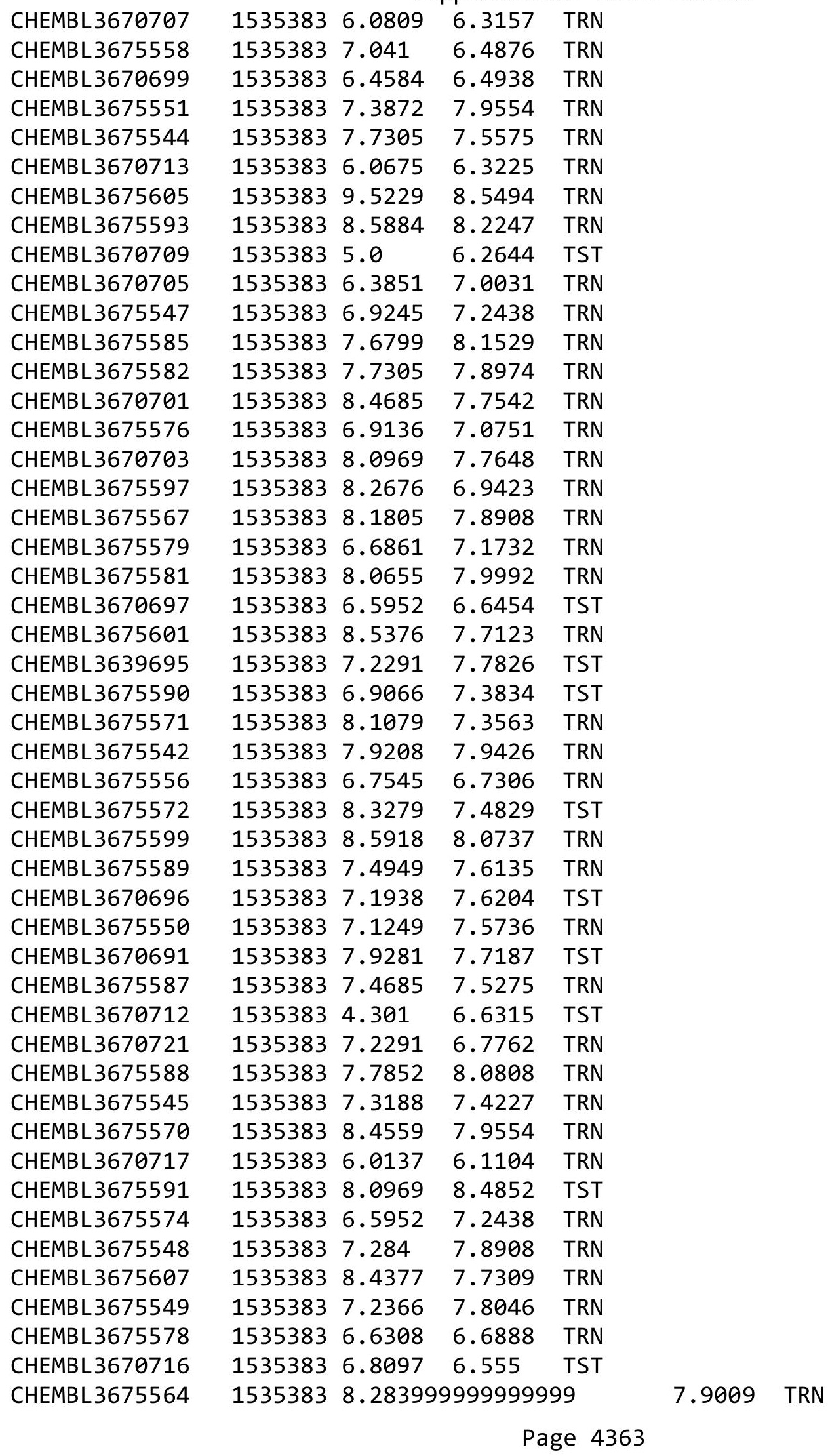


Supplemental Table S2.txt

\begin{tabular}{|c|c|c|c|c|c|}
\hline CHEMBL3675584 & 1535383 & 7.8477 & 8.1649 & TRN & \\
\hline CHEMBL 3675595 & 1535383 & 7.6576 & 7.4891 & TRN & \\
\hline CHEMBL3675602 & 1535383 & 7.3979 & 6.8777 & TRN & \\
\hline CHEMBL1232492 & 1535383 & 6.0 & 7.4922 & TRN & \\
\hline CHEMBL 3675577 & 1535383 & 6.6003 & 6.9584 & TRN & \\
\hline CHEMBL3675569 & 1535383 & 7.9914 & 7.5736 & TRN & \\
\hline CHEMBL 3670715 & 1535383 & 6.8125 & 6.6725 & TRN & \\
\hline CHEMBL3670706 & 1535383 & 8.2676 & 7.0031 & TST & \\
\hline CHEMBL 3675560 & 1535383 & 7.2518 & 6.7698 & TRN & \\
\hline CHEMBL 3675594 & 1535383 & 7.7696 & $8.44700 e$ & 0000000001 & TRN \\
\hline CHEMBL3670698 & 1535383 & 8.0862 & 7.6473 & TST & \\
\hline CHEMBL 3675568 & 1535383 & 8.6576 & 7.8046 & TRN & \\
\hline CHEMBL 3675566 & 1535383 & 8.4815 & 8.0842 & TRN & \\
\hline CHEMBL3670720 & 1535383 & 6.8013 & 7.7307 & TRN & \\
\hline CHEMBL 3675596 & 1535383 & 6.4989 & 6.9423 & TRN & \\
\hline CHEMBL3675554 & 1535383 & 7.8962 & 8.618 & TST & \\
\hline CHEMBL3675562 & 1535383 & 7.284 & 6.7934 & TRN & \\
\hline CHEMBL 3675541 & 1535383 & 6.433 & 6.8912 & TRN & \\
\hline CHEMBL3675600 & 1535383 & 7.2518 & 6.877999 & 9999999999 & TRN \\
\hline CHEMBL 3675553 & 1535383 & 6.5867 & 7.4829 & TST & \\
\hline CHEMBL 3675603 & 1535383 & 8.3665 & 8.5081 & TST & \\
\hline CHEMBL3675557 & 1535383 & 7.1367 & 7.0311 & TRN & \\
\hline CHEMBL 3675575 & 1535383 & 7.9788 & 7.898 & TRN & \\
\hline CHEMBL 3675604 & 1535383 & 7.0757 & 7.1378 & TST & \\
\hline CHEMBL 3670710 & 1535383 & 6.7959 & 6.7162 & TST & \\
\hline CHEMBL 3675580 & 1535383 & 5.0 & 6.9698 & TRN & \\
\hline CHEMBL 3670708 & 1535383 & 7.9508 & 7.7413 & TST & \\
\hline CHEMBL3675552 & 1535383 & 7.1192 & 7.3563 & TRN & \\
\hline CHEMBL3675573 & 1535383 & 8.9788 & 8.618 & TST & \\
\hline CHEMBL 3639744 & 1535383 & 7.4318 & 8.0842 & TRN & \\
\hline CHEMBL3670695 & 1535383 & 7.9586 & 7.9651 & TST & \\
\hline CHEMBL 3675555 & 1535383 & 6.7212 & 6.8479 & TRN & \\
\hline CHEMBL3670719 & 1535383 & 6.0521 & 6.7052 & TST & \\
\hline CHEMBL3675592 & 1535383 & 8.7352 & 8.2563 & TRN & \\
\hline CHEMBL3675561 & 1535383 & 7.4559 & 6.6678 & TRN & \\
\hline CHEMBL3670704 & 1535383 & 7.2676 & 7.4709 & TST & \\
\hline CHEMBL 3670718 & 1535383 & 6.0985 & 6.6442 & TST & \\
\hline CHEMBL 3675598 & 1535383 & \multicolumn{3}{|c|}{7.821000000000001} & TRN \\
\hline CHEMBL1232489 & 1535383 & 6.9245 & 6.8376 & TST & \\
\hline CHEMBL3670714 & 1535383 & 6.3288 & 6.1265 & TRN & \\
\hline CHEMBL 3675543 & 1535383 & 8.6576 & 8.4382 & TRN & \\
\hline CHEMBL409669 & 770827 & 8.31 & 8.1532 & TST & \\
\hline CHEMBL410677 & 770827 & 8.8 & 8.8041 & TRN & \\
\hline CHEMBL410676 & 770827 & 8.52 & 8.51 & TRN & \\
\hline CHEMBL 259463 & 770827 & 8.18 & 8.1812 & TRN & \\
\hline CHEMBL411674 & 770827 & 8.6 & 8.6109 & TRN & \\
\hline CHEMBL271838 & 770827 & 9.19 & 9.1969 & TRN & \\
\hline CHEMBL271839 & 770827 & 9.83 & 9.8285 & TRN & \\
\hline
\end{tabular}




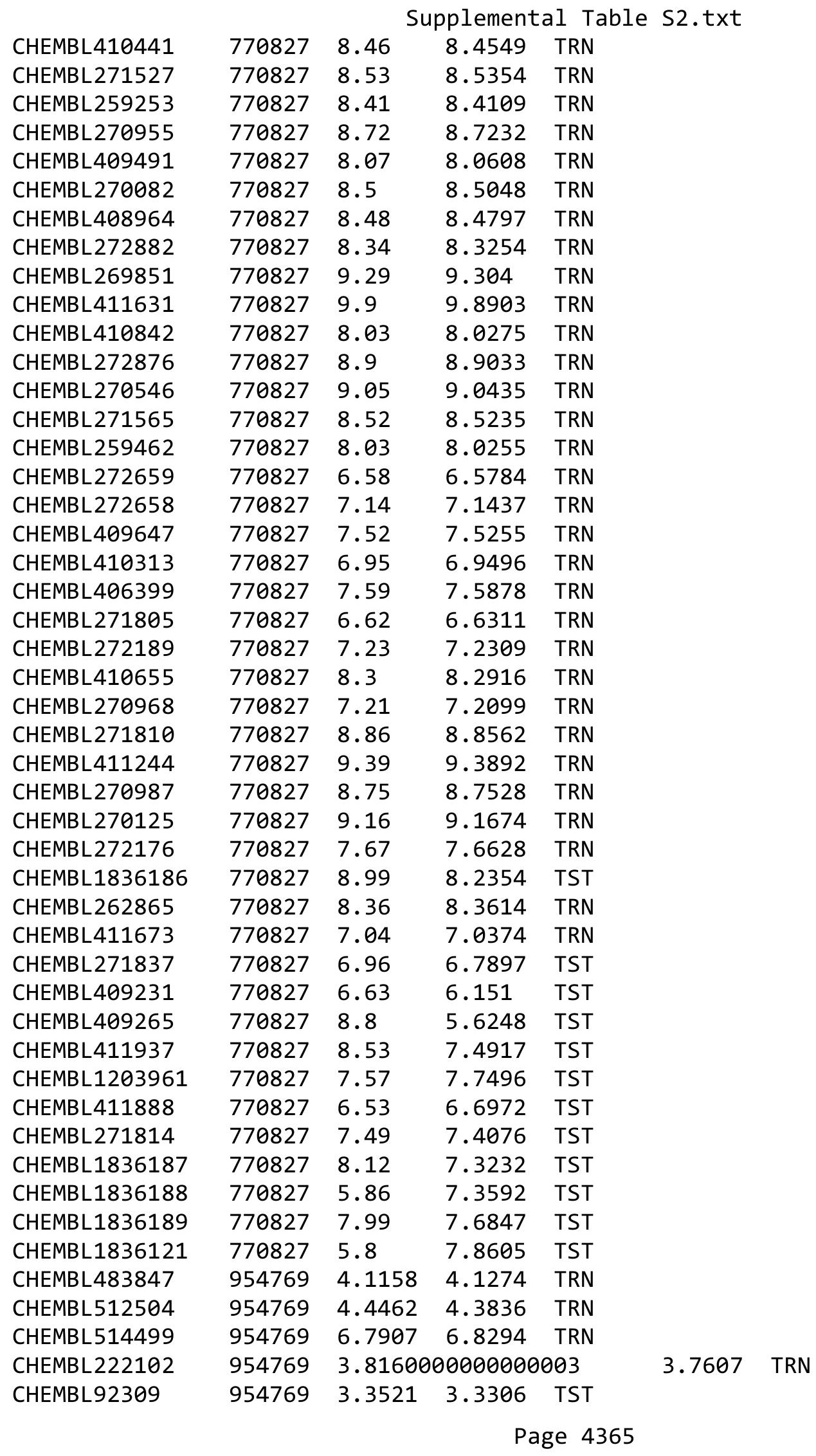




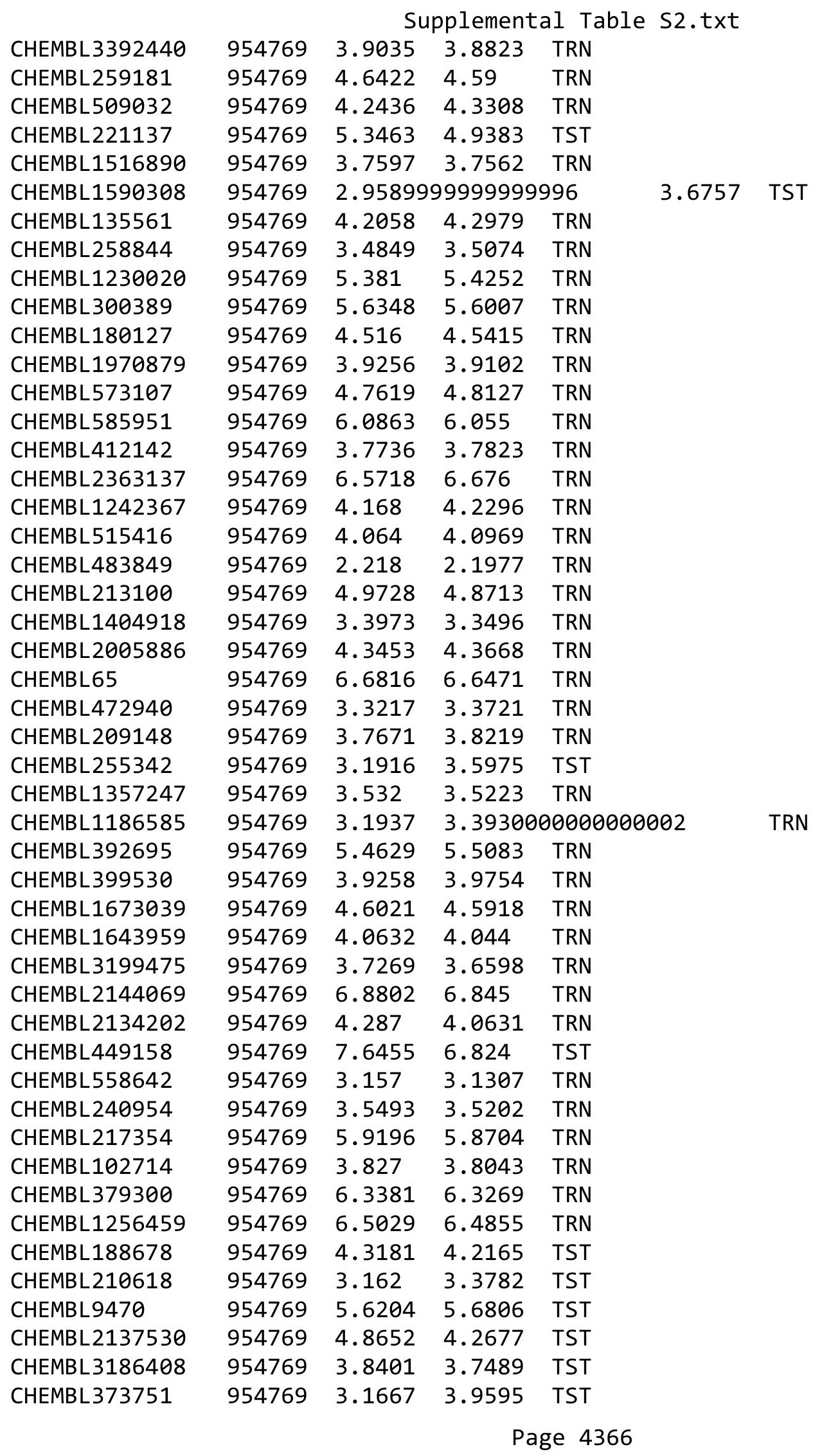




\begin{tabular}{|c|c|c|c|c|c|}
\hline \multirow[b]{2}{*}{ CHEMBL1788116 } & \multicolumn{5}{|c|}{ Supplemental Table S2.txt } \\
\hline & 954769 & 4.1209 & 4.0332 & TST & \\
\hline CHEMBL192566 & 954769 & 8.4442 & 7.9737 & TST & \\
\hline CHEMBL1190711 & 954769 & 3.1017 & 4.245 & TST & \\
\hline CHEMBL 220241 & 954769 & 4.4371 & 4.6936 & TST & \\
\hline CHEMBL338743 & 688675 & 4.5 & 4.635 & TRN & \\
\hline CHEMBL1422299 & 688675 & 4.4 & 4.6768 & TST & \\
\hline CHEMBL375107 & 688675 & 7.8996 & 4.958 & TRN & \\
\hline CHEMBL1489064 & 688675 & 4.3 & 4.5035 & TRN & \\
\hline CHEMBL1612246 & 688675 & 4.5 & 4.6993 & TRN & \\
\hline CHEMBL1451833 & 688675 & 4.8 & 4.6695 & TST & \\
\hline CHEMBL1600998 & 688675 & 5.1 & 5.5447 & TRN & \\
\hline CHEMBL1221925 & 688675 & 4.3 & 4.5537 & TRN & \\
\hline CHEMBL1364985 & 688675 & 4.4 & 4.8119 & TRN & \\
\hline CHEMBL1569493 & 688675 & 6.1 & 5.9969 & TRN & \\
\hline CHEMBL194400 & 688675 & 4.4 & 4.4801 & TST & \\
\hline CHEMBL1330518 & 688675 & 4.3 & 4.5048 & TRN & \\
\hline CHEMBL1519327 & 688675 & 6.3 & 6.3666 & TRN & \\
\hline CHEMBL31561 & 688675 & 4.3 & 4.5247 & TRN & \\
\hline CHEMBL1319452 & 688675 & 5.0 & 4.6451 & TRN & \\
\hline CHEMBL1527567 & 688675 & 4.5 & 4.5425 & TRN & \\
\hline CHEMBL 28319 & 688675 & 4.5 & 4.5715 & TRN & \\
\hline CHEMBL1419151 & 688675 & 4.3 & 4.7355 & TRN & \\
\hline CHEMBL1514512 & 688675 & 4.4 & 4.5173 & TRN & \\
\hline CHEMBL553181 & 688675 & 4.4 & 4.7018 & TRN & \\
\hline CHEMBL8739 & 688675 & 4.3 & 4.4684 & TRN & \\
\hline CHEMBL 1448387 & 688675 & 4.5 & 4.7695 & TRN & \\
\hline CHEMBL1559341 & 688675 & 4.6 & 4.6626 & TRN & \\
\hline CHEMBL1399151 & 688675 & 4.4 & 4.7808 & TRN & \\
\hline CHEMBL89295 & 688675 & 4.5 & 4.6824 & TST & \\
\hline CHEMBL1562553 & 688675 & 4.2 & 4.6124 & TRN & \\
\hline CHEMBL1602127 & 688675 & 4.3 & 4.7191 & TRN & \\
\hline CHEMBL1200471 & 688675 & 6.6 & 6.63200 & 0000000001 & TRN \\
\hline CHEMBL1569226 & 688675 & 5.2 & 5.3945 & TRN & \\
\hline CHEMBL85811 & 688675 & 4.4 & 4.4109 & TRN & \\
\hline CHEMBL192627 & 688675 & 4.8 & 4.8032 & TRN & \\
\hline CHEMBL1576086 & 688675 & 4.5 & 4.6108 & TRN & \\
\hline CHEMBL1518369 & 688675 & 4.4 & 4.5885 & TRN & \\
\hline CHEMBL9113 & 688675 & 4.1 & 4.5772 & TRN & \\
\hline CHEMBL 242080 & 688675 & 6.0 & 4.7198 & TRN & \\
\hline CHEMBL1532013 & 688675 & 5.9 & 4.7947 & TRN & \\
\hline CHEMBL 1484480 & 688675 & 4.1 & 4.3675 & TRN & \\
\hline CHEMBL1407826 & 688675 & 4.5 & 4.8895 & TST & \\
\hline CHEMBL1303139 & 688675 & 5.3 & 5.36 & TRN & \\
\hline CHEMBL196537 & 688675 & 4.3 & 4.5062 & TST & \\
\hline CHEMBL70971 & 688675 & 4.9 & 4.7657 & TRN & \\
\hline CHEMBL1391678 & 688675 & 4.1 & 4.4819 & TRN & \\
\hline CHEMBL1545634 & 688675 & 6.5 & 6.4888 & TRN & \\
\hline CHEMBL1375124 & 688675 & 4.3 & 4.7376 & TRN & \\
\hline
\end{tabular}




\begin{tabular}{|c|c|c|c|c|c|}
\hline \multirow[b]{2}{*}{ CHEMBL1524617 } & \multirow[b]{2}{*}{688675} & \\
\hline & & 5.2 & 5.3035 & TST & \\
\hline CHEMBL1585396 & 688675 & 4.3 & 4.5457 & TRN & \\
\hline CHEMBL1531716 & 688675 & 4.1 & 4.6195 & TRN & \\
\hline CHEMBL1561876 & 688675 & 5.4 & \multicolumn{2}{|c|}{4.6419999999999995} & TRN \\
\hline CHEMBL1447588 & 688675 & 5.1 & 5.1674 & TST & \\
\hline CHEMBL1489405 & 688675 & 4.1 & 4.8026 & TRN & \\
\hline CHEMBL105712 & 688675 & 5.0 & 5.1992 & TRN & \\
\hline CHEMBL486193 & 688675 & 4.3 & 4.8043 & TRN & \\
\hline CHEMBL1452158 & 688675 & 4.4 & 4.5064 & TRN & \\
\hline CHEMBL1469099 & 688675 & 4.3 & 4.7223 & TRN & \\
\hline CHEMBL230156 & 688675 & 4.3 & 4.4698 & TRN & \\
\hline CHEMBL195953 & 688675 & 4.4 & 4.463 & TST & \\
\hline CHEMBL1393325 & 688675 & 4.3 & 4.5611 & TRN & \\
\hline CHEMBL1430204 & 688675 & 4.4 & 4.6589 & TRN & \\
\hline CHEMBL1409985 & 688675 & 5.2 & 5.44 & TRN & \\
\hline CHEMBL1414154 & 688675 & 4.4 & 4.3992 & TRN & \\
\hline CHEMBL1566504 & 688675 & 4.4 & 4.5886 & TST & \\
\hline CHEMBL468582 & 688675 & 5.3 & 4.5369 & TST & \\
\hline CHEMBL408049 & 688675 & 4.1 & 4.7033 & TRN & \\
\hline CHEMBL1492884 & 688675 & 4.4 & 4.6014 & TRN & \\
\hline CHEMBL558459 & 688675 & 4.3 & 4.7339 & TRN & \\
\hline CHEMBL82492 & 688675 & 5.9 & 4.6457 & TRN & \\
\hline CHEMBL1450607 & 688675 & 4.9 & 4.8249 & TRN & \\
\hline CHEMBL44072 & 688675 & 4.7 & 4.5555 & TST & \\
\hline CHEMBL45462 & 688675 & 4.8 & 4.7972 & TRN & \\
\hline CHEMBL388676 & 688675 & 6.0 & 4.9016 & TST & \\
\hline CHEMBL1142 & 688675 & 4.6 & 4.5995 & TRN & \\
\hline CHEMBL319398 & 688675 & 5.2 & 4.6292 & TRN & \\
\hline CHEMBL1403227 & 688675 & 4.1 & 4.665 & TRN & \\
\hline CHEMBL1526319 & 688675 & 4.5 & 4.5962 & TRN & \\
\hline CHEMBL1602699 & 688675 & 5.6 & 5.3963 & TRN & \\
\hline CHEMBL334255 & 688675 & 4.5 & 5.0928 & TRN & \\
\hline CHEMBL157427 & 688675 & 7.8013 & 4.5898 & TST & \\
\hline CHEMBL1495381 & 688675 & 4.9 & 5.1996 & TST & \\
\hline CHEMBL552741 & 688675 & 5.0 & 4.7267 & TRN & \\
\hline CHEMBL21015 & 688675 & 4.6 & 4.7243 & TRN & \\
\hline CHEMBL162598 & 688675 & 4.5 & 4.5533 & TST & \\
\hline CHEMBL1570502 & 688675 & 4.1 & 4.5999 & TST & \\
\hline CHEMBL1496957 & 688675 & 5.0 & 4.8754 & TRN & \\
\hline CHEMBL194399 & 688675 & 4.5 & 4.5537 & TST & \\
\hline CHEMBL1308088 & 688675 & 4.9 & 5.0188 & TRN & \\
\hline CHEMBL1450123 & 688675 & 4.7 & 4.5422 & TRN & \\
\hline CHEMBL140 & 688675 & 4.5 & 4.6036 & TRN & \\
\hline CHEMBL1609459 & 688675 & 4.9 & 5.28 & TRN & \\
\hline CHEMBL1418603 & 688675 & 4.7 & 4.4048 & TRN & \\
\hline CHEMBL1085946 & 688675 & 5.9 & 4.6763 & TRN & \\
\hline CHEMBL487187 & 688675 & 6.7001 & 4.9345 & TRN & \\
\hline CHEMBL1564920 & 688675 & 4.7 & 4.5587 & TRN & \\
\hline & & & & 4368 & \\
\hline
\end{tabular}




\begin{tabular}{|c|c|c|c|c|}
\hline \multicolumn{5}{|c|}{ Supplemental Table S2.txt } \\
\hline CHEMBL8320 & 688675 & 4.5 & 4.6003 & TRN \\
\hline CHEMBL509531 & 688675 & 4.9 & 5.0087 & TST \\
\hline CHEMBL1535689 & 688675 & 4.5 & 4.5522 & TRN \\
\hline CHEMBL16435 & 688675 & 4.4 & 4.7274 & TRN \\
\hline CHEMBL1558796 & 688675 & 4.6 & 4.7662 & TRN \\
\hline CHEMBL185885 & 688675 & 4.4 & 4.7696 & TRN \\
\hline CHEMBL1580759 & 688675 & 5.1 & 4.6678 & TRN \\
\hline CHEMBL443949 & 688675 & 4.3 & 4.6224 & TRN \\
\hline CHEMBL1309179 & 688675 & 4.6 & 4.9994 & TRN \\
\hline CHEMBL1517425 & 688675 & 4.4 & 4.3991 & TRN \\
\hline CHEMBL220845 & 688675 & 5.1 & 4.4781 & TRN \\
\hline CHEMBL1566491 & 688675 & 4.1 & 4.6923 & TRN \\
\hline CHEMBL1449018 & 688675 & 4.4 & 4.7967 & TRN \\
\hline CHEMBL470671 & 688675 & 7.699 & 4.7306 & TRN \\
\hline CHEMBL1408847 & 688675 & 5.4 & 5.4703 & TRN \\
\hline CHEMBL1528164 & 688675 & 6.9 & 4.9093 & TRN \\
\hline CHEMBL1331245 & 688675 & 4.3 & 4.4436 & TRN \\
\hline CHEMBL36296 & 688675 & 4.3 & 4.4676 & TRN \\
\hline CHEMBL1499545 & 688675 & 5.1 & 5.4163 & TRN \\
\hline CHEMBL280998 & 688675 & 4.9 & 4.6362 & TRN \\
\hline CHEMBL530115 & 688675 & 4.1 & 4.9563 & TRN \\
\hline CHEMBL402063 & 688675 & 4.4 & 5.6399 & TST \\
\hline CHEMBL510309 & 688675 & 4.6 & 4.7832 & TRN \\
\hline CHEMBL1562104 & 688675 & 5.4 & 5.4952 & TRN \\
\hline CHEMBL1530684 & 688675 & 4.4 & 4.6054 & TRN \\
\hline CHEMBL1366408 & 688675 & 4.6 & 4.777 & TST \\
\hline CHEMBL440287 & 688675 & 4.4 & 4.6936 & TRN \\
\hline CHEMBL70582 & 688675 & 4.5 & 4.7123 & TRN \\
\hline CHEMBL1549844 & 688675 & 4.7 & 4.8022 & TST \\
\hline CHEMBL14068 & 688675 & 4.6 & 4.547 & TRN \\
\hline CHEMBL1304981 & 688675 & 4.3 & 4.4529 & TST \\
\hline CHEMBL348399 & 688675 & 4.1 & 4.5633 & TST \\
\hline CHEMBL 1372143 & 688675 & 4.9 & 4.6757 & TST \\
\hline CHEMBL1579130 & 688675 & 6.0 & 5.5806 & TST \\
\hline CHEMBL1545045 & 688675 & 4.9 & 4.7224 & TST \\
\hline CHEMBL224282 & 688675 & 4.3 & 4.4326 & TST \\
\hline CHEMBL1338613 & 688675 & 4.7 & 4.5578 & TST \\
\hline CHEMBL1319257 & 688675 & 4.2 & 4.9145 & TST \\
\hline CHEMBL1605493 & 688675 & 5.2 & 4.5349 & TST \\
\hline CHEMBL144530 & 688675 & 4.3 & 4.5244 & TST \\
\hline CHEMBL3391990 & 688675 & 4.3 & 4.7074 & TST \\
\hline CHEMBL1522486 & 688675 & 4.6 & 4.8153 & TST \\
\hline CHEMBL 220315 & 517306 & 7.5302 & 7.3644 & TRN \\
\hline CHEMBL456280 & 517306 & 10.0757 & 10.1372 & TRN \\
\hline CHEMBL445983 & 517306 & 9.6345 & 10.627 & TRN \\
\hline CHEMBL477420 & 517306 & 9.6778 & 9.3443 & TRN \\
\hline CHEMBL219748 & 517306 & 11.3979 & 10.7046 & TRN \\
\hline CHEMBL465382 & 517306 & 10.4437 & 10.5371 & TRN \\
\hline
\end{tabular}

Page 4369 


\begin{tabular}{|c|c|c|c|c|c|}
\hline \multicolumn{6}{|c|}{ le s2.txt } \\
\hline CHEMBL458887 & 517306 & 4.0 & 7.296 & TST & \\
\hline CHEMBL219696 & 517306 & 10.0809 & 10.2121 & TRN & \\
\hline CHEMBL475964 & 517306 & 6.215 & 6.3733 & TST & \\
\hline CHEMBL456067 & 517306 & 9.9318 & 10.0336 & TRN & \\
\hline CHEMBL465796 & 517306 & 10.4202 & 10.1875 & TRN & \\
\hline CHEMBL455855 & 517306 & 4.8351 & 6.8242 & TST & \\
\hline CHEMBL478058 & 517306 & 9.1549 & 9.2473 & TRN & \\
\hline CHEMBL220455 & 517306 & 6.724 & 6.6888 & TRN & \\
\hline CHEMBL456929 & 517306 & 7.2366 & 7.1584 & TST & \\
\hline CHEMBL415592 & 517306 & 9.2366 & 9.1655 & TRN & \\
\hline CHEMBL473047 & 517306 & 9.4202 & 9.3036 & TRN & \\
\hline CHEMBL 384440 & 517306 & 10.3768 & 10.38906 & 00000000001 & TRN \\
\hline CHEMBL458675 & 517306 & 6.2653 & 7.8245 & TST & \\
\hline CHEMBL478893 & 517306 & 9.5376 & 9.4447 & TRN & \\
\hline CHEMBL476802 & 517306 & 9.762 & 9.6802 & TRN & \\
\hline CHEMBL459101 & 517306 & 9.9208 & 9.8654 & TRN & \\
\hline CHEMBL 385790 & 517306 & 10.1427 & 10.3511 & TRN & \\
\hline CHEMBL515826 & 517306 & 7.6216 & 6.8204 & TST & \\
\hline CHEMBL514587 & 517306 & 4.0 & 7.1235 & TST & \\
\hline CHEMBL457782 & 517306 & 9.8539 & 9.7256 & TRN & \\
\hline CHEMBL516737 & 517306 & 8.7258 & 8.8578 & TRN & \\
\hline CHEMBL220076 & 517306 & 9.7352 & 10.0505 & TRN & \\
\hline CHEMBL516262 & 517306 & 9.9393 & 9.9976 & TRN & \\
\hline CHEMBL266949 & 517306 & 10.1549 & 9.7346 & TRN & \\
\hline CHEMBL458886 & 517306 & 5.6937 & 7.2832 & TST & \\
\hline CHEMBL473461 & 517306 & 5.9401 & 6.3908 & TST & \\
\hline CHEMBL457330 & 517306 & 8.7905 & 9.1078 & TRN & \\
\hline CHEMBL514175 & 517306 & 7.4815 & 7.4177 & TST & \\
\hline CHEMBL414056 & 517306 & 9.4647 & 9.6054 & TRN & \\
\hline CHEMBL374709 & 517306 & 9.6383 & 9.6755 & TRN & \\
\hline CHEMBL476407 & 517306 & 9.4318 & 9.666 & TRN & \\
\hline CHEMBL269291 & 517306 & 6.7755 & 7.0469 & TRN & \\
\hline CHEMBL473667 & 517306 & 6.2348 & 6.3725 & TST & \\
\hline CHEMBL477415 & 517306 & 9.1024 & 9.0007 & TRN & \\
\hline CHEMBL474876 & 517306 & 5.627006 & 00000006 & 5.7966 & TST \\
\hline CHEMBL458000 & 517306 & 8.8386 & 8.8892 & TRN & \\
\hline CHEMBL461495 & 517306 & 6.8239 & 6.9607 & TRN & \\
\hline CHEMBL477231 & 517306 & 10.1739 & 10.0648 & TRN & \\
\hline CHEMBL266948 & 517306 & 9.9706 & 10.2342 & TRN & \\
\hline CHEMBL 266950 & 517306 & 8.4202 & 8.5931 & TRN & \\
\hline CHEMBL477032 & 517306 & 9.4685 & 9.7197 & TRN & \\
\hline CHEMBL516102 & 517306 & 4.5797 & 7.0156 & TST & \\
\hline CHEMBL266947 & 517306 & 10.4949 & 10.1349 & TRN & \\
\hline CHEMBL373518 & 517306 & 10.7959 & 10.9223 & TRN & \\
\hline CHEMBL 3349444 & 517306 & 9.4089 & 9.399 & TRN & \\
\hline CHEMBL 219913 & 517306 & 9.7696 & 9.7505 & TRN & \\
\hline CHEMBL220078 & 517306 & 11.2218 & 10.7365 & TRN & \\
\hline CHEMBL268117 & 517306 & 6.6221 & 6.7367 & TRN & \\
\hline
\end{tabular}




\begin{tabular}{|c|c|c|c|c|c|c|}
\hline \multicolumn{7}{|c|}{ Supplemental Table s2.txt } \\
\hline CHEMBL413489 & 517306 & 9.5901 & 9.2113 & TRN & & \\
\hline CHEMBL476582 & 517306 & 9.0862 & 9.4191 & TRN & & \\
\hline CHEMBL476379 & 517306 & 8.6055 & 8.961 & TRN & & \\
\hline CHEMBL514030 & 517306 & 10.4815 & 10.3648 & TRN & & \\
\hline CHEMBL465381 & 517306 & 9.51 & 9.5014 & TRN & & \\
\hline CHEMBL515498 & 517306 & 4.8784 & 7.9342 & TST & & \\
\hline CHEMBL220077 & 517306 & 10.0706 & 10.139 & TRN & & \\
\hline CHEMBL515772 & 517306 & 10.3372 & 10.0179 & TRN & & \\
\hline CHEMBL477214 & 517306 & 10.0315 & 9.4157 & TST & & \\
\hline CHEMBL475991 & 517306 & 9.0655 & 8.8531 & TRN & & \\
\hline CHEMBL385789 & 517306 & 10.7959 & 10.6246 & TRN & & \\
\hline CHEMBL477630 & 517306 & 9.6778 & 9.8929 & TRN & & \\
\hline CHEMBL475484 & 517306 & 10.2441 & 10.554 & TRN & & \\
\hline CHEMBL456046 & 517306 & 10.2007 & 10.0166 & TRN & & \\
\hline CHEMBL514288 & 517306 & 10.2076 & 9.7558 & TRN & & \\
\hline CHEMBL474877 & 517306 & 6.2885 & 5.5428 & TST & & \\
\hline CHEMBL218403 & 517306 & 9.2757 & 9.5302 & TRN & & \\
\hline CHEMBL503050 & 517306 & 10.7212 & 10.8846 & TRN & & \\
\hline CHEMBL465795 & 517306 & 10.0044 & 10.3765 & TRN & & \\
\hline CHEMBL459099 & 517306 & 6.587006 & 000000006 & $\partial 1$ & 8.0003 & TST \\
\hline CHEMBL415591 & 517306 & 9.0757 & 9.1553 & TRN & & \\
\hline CHEMBL 375664 & 517306 & 6.7953 & 6.7752 & TRN & & \\
\hline CHEMBL477001 & 517306 & 9.2097 & 9.0858 & TRN & & \\
\hline CHEMBL472844 & 517306 & 7.2993 & 6.1958 & TST & & \\
\hline CHEMBL475076 & 517306 & 5.9729 & 6.1775 & TST & & \\
\hline CHEMBL459100 & 517306 & 9.6198 & 9.4934 & TRN & & \\
\hline CHEMBL515309 & 517306 & 10.2007 & 9.5794 & TRN & & \\
\hline CHEMBL514810 & 517306 & 10.8539 & 10.34 & TRN & & \\
\hline CHEMBL475279 & 517306 & 7.3936 & 6.3992 & TST & & \\
\hline CHEMBL457806 & 517306 & 8.3799 & 8.7893 & TRN & & \\
\hline CHEMBL3349445 & 517306 & 7.279 & 6.8395 & TST & & \\
\hline CHEMBL475963 & 517306 & 9.7696 & 9.6075 & TRN & & \\
\hline CHEMBL458664 & 517306 & 9.9318 & 9.8769 & TRN & & \\
\hline CHEMBL457127 & 517306 & 4.0 & 7.7712 & TST & & \\
\hline CHEMBL476611 & 517306 & 9.8729 & 10.0761 & TRN & & \\
\hline CHEMBL385345 & 517306 & 10.0969 & 9.9818 & TRN & & \\
\hline CHEMBL 220454 & 517306 & 9.0969 & 9.6459 & TRN & & \\
\hline CHEMBL510313 & 517306 & 7.3768 & 7.1671 & TRN & & \\
\hline CHEMBL412998 & 517306 & 6.769 & 6.4803 & TRN & & \\
\hline CHEMBL 382400 & 517306 & 11.2218 & 10.9214 & TRN & & \\
\hline CHEMBL384438 & 517306 & 12.0969 & 10.6523 & TST & & \\
\hline CHEMBL538160 & 517306 & 9.8794 & 10.2158 & TRN & & \\
\hline CHEMBL457783 & 517306 & 10.5686 & 10.3959 & TRN & & \\
\hline CHEMBL515549 & 517306 & 10.4815 & 10.5811 & TRN & & \\
\hline CHEMBL 384437 & 517306 & 10.1805 & 10.2047 & TST & & \\
\hline CHEMBL384436 & 517306 & 10.0 & 10.1752 & TST & & \\
\hline CHEMBL3952936 & 1642536 & 7.2441 & 7.4547 & TRN & & \\
\hline CHEMBL3913622 & 1642536 & 7.3468 & 7.3652 & TRN & & \\
\hline
\end{tabular}


Supplemental Table S2.txt

\begin{tabular}{|c|c|c|c|c|}
\hline - & & 7.1739 & & \\
\hline & & 7.3872 & 7.233 & \\
\hline & & & & \\
\hline HEMBL3 & & & 4997 & \\
\hline AEMBL3896236 & م30 & 676 & 1636 & \\
\hline HEMBL3967370 & 642536 & 7.4318 & 5464 & \\
\hline & & & .6264 & \\
\hline IFMRI 393 & & & 1605 & \\
\hline HEMBL 394 & & & 5034 & \\
\hline HEMBL 389 & 36 & 5576 & 5428 & \\
\hline HEMBL 394 & 62 & 5.0 & .0898 & \\
\hline IEMBL398 & & 367 & 2352 & \\
\hline AEMBL39 & & & & \\
\hline HEMBL 390 & 36 & & 3.0398 & \\
\hline HEMBL398 & 36 & 85 & 3978 & \\
\hline AEMBL391 & 0 & 7.8861 & 8684 & \\
\hline HEMBL39L & 0 & 55 & 4897 & \\
\hline HEMBL 391 & & & & \\
\hline HEMBL 391 & & 7.7447 & 7.7666 & \\
\hline AEMBL39 & & 98 & & \\
\hline HEIMBLSS & 62 & 2 & 63 & 1 \\
\hline AEMBL3S & & & 12 & 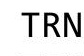 \\
\hline HEMBL3S & & & 37 & \\
\hline HFMRI 39 & & & 278 & \\
\hline AEMBL38ऽ & & & & (3) \\
\hline HEMBL39 & 6 & 39 & 38 & KIV \\
\hline HEMBL3 & & 76 & 92 & Niv \\
\hline HFMBI $3 c$ & & 47 & 184 & \\
\hline HEMBL395 & & & & IRIV \\
\hline HEMBL 392 & & & 28 & 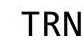 \\
\hline HEMBL39 & & & 308 & RIV \\
\hline HEMBL3 & & 12 & 27 & ST \\
\hline HEMBL3 & & 76 & & $\mathrm{RN}$ \\
\hline HEMBL 389 & & 6.3872 & 614 & ISI \\
\hline HEMBL3903817 & 6 & 7.6576 & 5353 & TRN \\
\hline HEMBL 39 & & 98 & 223 & \\
\hline HEMPI 2 & & & 555 & Niv \\
\hline HEMBL39 & & & 3904 & RN \\
\hline HEMBL396 & & 372 & 3903 & TRN \\
\hline IEMBL39 & 36 & & 3836 & RN \\
\hline HEMBL 389 & 0 & 18 & 452 & \\
\hline CHEMBL397 & & & & RIV \\
\hline HEMBL389 & 36 & 8.3098 & 8.1964 & $\Gamma \mathrm{RN}$ \\
\hline HEMBL 389 & 36 & 7.6383 & 1733 & TRN \\
\hline 2 & & & & \\
\hline HEMBL 39 & & .3768 & & \\
\hline CHEMBL393. & & .301 & 7.3089 & \\
\hline LHEMBL3986613 & 1642536 & 7.6198 & 8.4478 & ГST \\
\hline
\end{tabular}

Page 4372 
Supplemental Table S2.txt

\begin{tabular}{|c|c|c|c|c|}
\hline The & & 7.4815 & & \\
\hline HEMBL3984749 & & 7.8539 & & \\
\hline 247 & & & & \\
\hline AEMBL & & 2291 & & 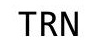 \\
\hline AEMBL3980883 & 30 & 5.0 & & \\
\hline HEMBL3963389 & b36 & 7.4318 & 342 & \\
\hline HEMBL; & & & 859 & \\
\hline 38 & & & & \\
\hline AEMBL3901392 & & 7959 & 5924 & \\
\hline HEMBL3892634 & 36 & 7696 & 6411 & \\
\hline HEMBL3907106 & 0 & 1367 & 7.1 & \\
\hline IEMBL39 & & 528 & & \\
\hline IEMBL3 & & & & RN \\
\hline HEMBL 394 & & 676 & 8.2149 & \\
\hline HEMBL397 & 36 & 3665 & & \\
\hline AEMBL396 & & 949 & 7.6313 & \\
\hline HEMBL38 & 36 & 58 & & \\
\hline HEMBL13 & & & & \\
\hline HEMBL14 & & 2541 & 3.3819 & \\
\hline AEMBL15 & & & & \\
\hline HEMBLI & & & 96 & \\
\hline HEMBL1: & & & & RN \\
\hline HEMBL1 & & & 76 & \\
\hline AFMRI 5 & & 541 & 5798 & \\
\hline JEMBL13 & & & & $\Gamma \mathrm{RN}$ \\
\hline HEMBL1C & & 3. & 37 & RN \\
\hline HEMBL1 & & 541 & 72 & Niv \\
\hline HFMBI 1 & & & 36 & \\
\hline HEMBL14 & & & & TRN \\
\hline HEMBL1319229 & & 3 & & TST \\
\hline HEMBL1: & & & 647 & RN \\
\hline HEMBL1 & & 1 & 26 & ST \\
\hline HFMRI 1 & & & & ST \\
\hline HEMBL14€ & & & & IR \\
\hline HEMBL1366712 & & 4.5805 & 4.0475 & TRN \\
\hline HEMBL1: & & 541 & 1036 & RN \\
\hline HFMRI & & 11 & 51 & KIV \\
\hline HEMBL1: & & 3 & 423 & RN \\
\hline HEMBL1325226 & 37 & 541 & 7193 & TRN \\
\hline AEMBL13 & & 541 & 537 & TRN \\
\hline HEMBL13 & & 424 & 4.2873 & \\
\hline CHEMBL13 & & & & TRN \\
\hline HEMBL 145 & & & 4.0978 & TRN \\
\hline AEMBL1536636 & 37 & 3.2541 & 3.7474 & TS \\
\hline HEMBL1 & 00 & $\perp$ & 3.4962 & \\
\hline HEMBL158 & & $r$ & & \\
\hline CHEMBL160 & & 3.2541 & 3.2442 & \\
\hline CHEMBL 319974 & 688187 & 3.2541 & 3.5652 & ГST \\
\hline
\end{tabular}

Page 4373 


\begin{tabular}{|c|c|c|c|c|}
\hline & & & oplement & al $\mathrm{T}$ \\
\hline CHEMBL1459929 & 688187 & 4.9303 & 4.1049 & TRN \\
\hline CHEMBL1442663 & 688187 & 3.2541 & 3.9153 & TRN \\
\hline CHEMBL1545677 & 688187 & 3.2541 & 3.2091 & TRN \\
\hline CHEMBL1518163 & 688187 & 3.2541 & 3.1234 & TRN \\
\hline CHEMBL1327627 & 688187 & 3.2541 & 3.0696 & TRN \\
\hline CHEMBL1407286 & 688187 & 3.2541 & 3.3263 & TRN \\
\hline CHEMBL1447188 & 688187 & 3.2541 & 3.7921 & TRN \\
\hline CHEMBL1498999 & 688187 & 4.7926 & 4.4246 & TRN \\
\hline CHEMBL1588771 & 688187 & 3.2541 & 3.207 & TRN \\
\hline CHEMBL1455974 & 688187 & 3.2541 & 3.4439 & TRN \\
\hline CHEMBL1478316 & 688187 & 3.2541 & 3.7658 & TRN \\
\hline CHEMBL1966497 & 688187 & 3.2541 & 3.7642 & TRN \\
\hline CHEMBL1477419 & 688187 & 3.2541 & 4.0685 & TRN \\
\hline CHEMBL3196880 & 688187 & 4.4869 & 3.9876 & TRN \\
\hline CHEMBL1499456 & 688187 & 3.2541 & 3.2521 & TRN \\
\hline CHEMBL1605293 & 688187 & 3.2541 & 4.0963 & TRN \\
\hline CHEMBL1588702 & 688187 & 3.2541 & 3.48 & TRN \\
\hline CHEMBL1510023 & 688187 & 3.2541 & 3.1888 & TRN \\
\hline CHEMBL1427458 & 688187 & 3.2541 & 3.3107 & TRN \\
\hline CHEMBL1467999 & 688187 & 4.945 & 3.2234 & TRN \\
\hline CHEMBL1503513 & 688187 & 3.2541 & 3.3006 & TST \\
\hline CHEMBL3195322 & 688187 & 3.2541 & 4.0591 & TRN \\
\hline CHEMBL1341040 & 688187 & 3.2541 & 3.5379 & TRN \\
\hline CHEMBL1393007 & 688187 & 3.2541 & 3.4887 & TRN \\
\hline CHEMBL1488466 & 688187 & 3.2541 & 3.2181 & TRN \\
\hline CHEMBL1548815 & 688187 & 3.2541 & 3.5652 & TRN \\
\hline CHEMBL1352525 & 688187 & 3.2541 & 3.2507 & TRN \\
\hline CHEMBL 372840 & 688187 & 3.2541 & 3.4895 & TST \\
\hline CHEMBL1386065 & 688187 & 3.2541 & 3.3371 & TRN \\
\hline CHEMBL1523501 & 688187 & 4.761 & 4.4691 & TRN \\
\hline CHEMBL1501859 & 688187 & 4.7014 & 3.6738 & TRN \\
\hline CHEMBL1428891 & 688187 & 3.2541 & 3.3988 & TRN \\
\hline CHEMBL1350141 & 688187 & 4.3217 & 3.2174 & TRN \\
\hline CHEMBL1563220 & 688187 & 3.2541 & 3.2899 & TRN \\
\hline CHEMBL1425718 & 688187 & 3.2541 & 3.3935 & TRN \\
\hline CHEMBL3190201 & 688187 & 3.2541 & 3.3783 & TRN \\
\hline CHEMBL1420649 & 688187 & 3.2541 & 3.1862 & TRN \\
\hline CHEMBL1463780 & 688187 & 3.2541 & 3.3419 & TRN \\
\hline CHEMBL1320353 & 688187 & 3.2541 & 3.3493 & TRN \\
\hline CHEMBL1575333 & 688187 & 3.2541 & 3.1943 & TRN \\
\hline CHEMBL1575557 & 688187 & 3.2541 & 3.3034 & TST \\
\hline CHEMBL1542483 & 688187 & 3.2541 & 3.062 & TRN \\
\hline CHEMBL1419744 & 688187 & 3.2541 & 3.1291 & TRN \\
\hline CHEMBL1563149 & 688187 & 4.9307 & 4.0237 & TRN \\
\hline CHEMBL1339432 & 688187 & 3.2541 & 3.3886 & TRN \\
\hline CHEMBL1608301 & 688187 & 4.7989 & 4.4991 & TRN \\
\hline CHEMBL1468344 & 688187 & 3.2541 & 3.1534 & TRN \\
\hline CHEMBL1510582 & 688187 & 3.2541 & 3.0678 & TRN \\
\hline
\end{tabular}




\begin{tabular}{|c|c|c|c|c|c|}
\hline & & & & & \\
\hline CHEMBL1365679 & 688187 & 3.2541 & 3.3094 & TST & \\
\hline CHEMBL1380192 & 688187 & 3.2541 & 3.7632 & TRN & \\
\hline CHEMBL1482965 & 688187 & 3.2541 & 3.3195 & TRN & \\
\hline CHEMBL1596496 & 688187 & 3.2541 & 3.4676 & TRN & \\
\hline CHEMBL1472244 & 688187 & 3.2541 & 3.3925 & TRN & \\
\hline CHEMBL1492655 & 688187 & 3.2541 & 3.5558 & TST & \\
\hline CHEMBL1501238 & 688187 & 4.8891 & 3.6024 & TRN & \\
\hline CHEMBL1482188 & 688187 & 3.2541 & 3.3125 & TRN & \\
\hline CHEMBL1560530 & 688187 & 3.2541 & 3.49899 & 99999999997 & TRN \\
\hline CHEMBL1530735 & 688187 & 3.2541 & 3.7226 & TRN & \\
\hline CHEMBL1489401 & 688187 & 3.2541 & 3.60399 & 99999999996 & TRN \\
\hline CHEMBL1604945 & 688187 & 3.2541 & 3.7257 & TRN & \\
\hline CHEMBL1449103 & 688187 & 3.2541 & 3.4095 & TRN & \\
\hline CHEMBL1300536 & 688187 & 3.2541 & 3.4723 & TRN & \\
\hline CHEMBL1464371 & 688187 & 3.2541 & 3.6284 & TRN & \\
\hline CHEMBL1370479 & 688187 & 3.2541 & 3.4123 & TRN & \\
\hline CHEMBL1607115 & 688187 & 3.2541 & 3.2262 & TRN & \\
\hline CHEMBL1546405 & 688187 & 4.7493 & 3.9757 & TRN & \\
\hline CHEMBL1453320 & 688187 & 3.2541 & 3.3763 & TST & \\
\hline CHEMBL1544478 & 688187 & 3.2541 & 3.4218 & TST & \\
\hline CHEMBL1603921 & 688187 & 3.2541 & 3.4675 & TST & \\
\hline CHEMBL1338375 & 688187 & 4.7228 & 3.292 & TST & \\
\hline CHEMBL1526413 & 688187 & 3.2541 & 3.2997 & TST & \\
\hline CHEMBL1509244 & 688187 & 3.2541 & 3.3257 & TST & \\
\hline CHEMBL1539607 & 688187 & 3.2541 & 3.1794 & TST & \\
\hline CHEMBL1603032 & 688187 & 3.2541 & 3.2701 & TST & \\
\hline CHEMBL1404788 & 688187 & 4.7385 & 3.6321 & TST & \\
\hline CHEMBL1476319 & 688187 & 3.2541 & 3.4271 & TST & \\
\hline CHEMBL1547757 & 688187 & 3.2541 & 3.2635 & TST & \\
\hline CHEMBL1300956 & 688187 & 3.2541 & 3.2985 & TST & \\
\hline CHEMBL1573523 & 688187 & 3.2541 & 3.2178 & TST & \\
\hline CHEMBL1344478 & 688187 & 3.2541 & 3.2182 & TST & \\
\hline CHEMBL1598614 & 688187 & 4.5065 & 4.5621 & TST & \\
\hline CHEMBL1329661 & 688187 & 3.2541 & 3.4739 & TST & \\
\hline CHEMBL1718884 & 752504 & 4.6533 & 4.4917 & TRN & \\
\hline CHEMBL3189539 & 752504 & 4.4218 & 4.4555 & TRN & \\
\hline CHEMBL1521014 & 752504 & 4.3826 & 4.3025 & TRN & \\
\hline CHEMBL1333537 & 752504 & 6.1904 & 5.2333 & TRN & \\
\hline CHEMBL1470045 & 752504 & 4.5456 & 4.3272 & TRN & \\
\hline CHEMBL1483375 & 752504 & 4.6159 & 4.4426 & TRN & \\
\hline CHEMBL1528954 & 752504 & 4.603 & 4.5857 & TRN & \\
\hline CHEMBL1427209 & 752504 & 4.3575 & 4.4421 & TRN & \\
\hline CHEMBL1383968 & 752504 & 2.8239 & 4.4813 & TST & \\
\hline CHEMBL1310632 & 752504 & 5.0474 & 5.4518 & TRN & \\
\hline CHEMBL1314093 & 752504 & 4.2389 & 4.3397 & TRN & \\
\hline CHEMBL1555855 & 752504 & 4.466 & 4.4475 & TRN & \\
\hline CHEMBL1556865 & 752504 & 2.8239 & 4.3542 & TRN & \\
\hline CHEMBL1390112 & 752504 & 4.4092 & 4.2834 & TRN & \\
\hline
\end{tabular}


Supplemental Table S2.txt

\begin{tabular}{|c|c|c|c|c|c|}
\hline CHEMBL1423423 & 752504 & 4.5144 & 4.2787 & TRN & \\
\hline CHEMBL1336277 & 752504 & 2.8239 & 4.4211 & TRN & \\
\hline CHEMBL1505834 & 752504 & 4.4966 & 4.466 & TST & \\
\hline CHEMBL1584992 & 752504 & 4.5065 & 4.5439 & TST & \\
\hline CHEMBL1368680 & 752504 & 4.6354 & 4.4484 & TRN & \\
\hline CHEMBL1461863 & 752504 & 4.3522 & 4.2931 & TRN & \\
\hline CHEMBL1879475 & 752504 & 2.8239 & 4.687 & TST & \\
\hline CHEMBL1457353 & 752504 & 4.4985 & 4.4395 & TRN & \\
\hline CHEMBL1603448 & 752504 & 4.1263 & 4.5873 & TRN & \\
\hline CHEMBL1578973 & 752504 & 4.5432 & 4.3599 & TRN & \\
\hline CHEMBL1370750 & 752504 & 4.9055 & 4.4317 & TRN & \\
\hline CHEMBL1556466 & 752504 & 4.2376 & 4.4051 & TRN & \\
\hline CHEMBL1539551 & 752504 & 3.9513 & 4.3066 & TRN & \\
\hline CHEMBL1599034 & 752504 & 4.3352 & 4.462 & TRN & \\
\hline CHEMBL1474116 & 752504 & 4.4694 & 4.2992 & TRN & \\
\hline CHEMBL1704905 & 752504 & 4.4045 & 4.2843 & TRN & \\
\hline CHEMBL3199212 & 752504 & 4.5863 & 4.4455 & TRN & \\
\hline CHEMBL1484377 & 752504 & 4.5355 & 4.4128 & TRN & \\
\hline CHEMBL1712308 & 752504 & 4.5584 & 4.4063 & TRN & \\
\hline CHEMBL1556305 & 752504 & 4.1004 & 4.2783 & TST & \\
\hline CHEMBL1700444 & 752504 & 4.2438 & 4.3476 & TRN & \\
\hline CHEMBL1328882 & 752504 & 4.4986 & 4.578 & TRN & \\
\hline CHEMBL1558097 & 752504 & 2.8239 & 4.3314 & TRN & \\
\hline CHEMBL1389697 & 752504 & 3.883 & 4.3673 & TRN & \\
\hline CHEMBL1353499 & 752504 & 4.6253 & 4.258999 & 99999999995 & TRN \\
\hline CHEMBL1468813 & 752504 & 4.4416 & 4.4695 & TRN & \\
\hline CHEMBL1311513 & 752504 & 3.9789 & 4.5252 & TRN & \\
\hline CHEMBL1389092 & 752504 & 4.0134 & 4.6265 & TST & \\
\hline CHEMBL1589398 & 752504 & 4.6137 & 4.426 & TRN & \\
\hline CHEMBL1531367 & 752504 & 4.5267 & 4.4737 & TRN & \\
\hline CHEMBL1499330 & 752504 & 4.6736 & 4.3468 & TRN & \\
\hline CHEMBL1322395 & 752504 & 4.9023 & 4.5864 & TRN & \\
\hline CHEMBL3196945 & 752504 & 4.6305 & 4.4789 & TRN & \\
\hline CHEMBL1390738 & 752504 & 4.582 & 4.237 & TRN & \\
\hline CHEMBL1388706 & 752504 & 4.6318 & 4.5745 & TRN & \\
\hline CHEMBL1867757 & 752504 & 4.5901 & 4.4433 & TST & \\
\hline CHEMBL1387086 & 752504 & 4.5339 & 4.3906 & TST & \\
\hline CHEMBL1722825 & 752504 & 3.8953 & 4.3369 & TRN & \\
\hline CHEMBL3199003 & 752504 & 4.0712 & 4.3809 & TST & \\
\hline CHEMBL1307371 & 752504 & 4.4393 & 4.4028 & TRN & \\
\hline CHEMBL1563828 & 752504 & 4.6185 & 4.5758 & TRN & \\
\hline CHEMBL1539755 & 752504 & 4.567 & 4.6234 & TRN & \\
\hline CHEMBL1489954 & 752504 & 4.2762 & 4.4392 & TRN & \\
\hline CHEMBL1457864 & 752504 & 4.5933 & 4.4772 & TRN & \\
\hline CHEMBL1723844 & 752504 & 4.6404 & 4.2907 & TRN & \\
\hline CHEMBL3193517 & 752504 & 4.5782 & 4.5281 & TST & \\
\hline CHEMBL1563833 & 752504 & 4.2945 & 4.5503 & TRN & \\
\hline CHEMBL1456220 & 752504 & 4.6265 & 4.4068 & TRN & \\
\hline
\end{tabular}


Supplemental Table S2.txt

\begin{tabular}{|c|c|c|c|c|c|}
\hline CHEMBL1507366 & 752504 & 4.6102 & 4.5025 & TRN & \\
\hline CHEMBL1409110 & 752504 & 4.6294 & 4.3509 & TRN & \\
\hline CHEMBL1520209 & 752504 & 4.5893 & 4.3907 & TRN & \\
\hline CHEMBL1501653 & 752504 & 5.6893 & 5.3331 & TRN & \\
\hline CHEMBL1510680 & 752504 & 4.5316 & 4.3034 & TRN & \\
\hline CHEMBL1583992 & 752504 & 4.5767 & 4.3598 & TRN & \\
\hline CHEMBL1313468 & 752504 & 4.4524 & 4.4146 & TRN & \\
\hline CHEMBL1559861 & 752504 & 4.1856 & 4.3227 & TRN & \\
\hline CHEMBL1489965 & 752504 & 4.5675 & 4.2764 & TRN & \\
\hline CHEMBL1580552 & 752504 & 4.5173 & 4.3865 & TRN & \\
\hline CHEMBL1546729 & 752504 & 4.6236 & 4.393 & TRN & \\
\hline CHEMBL1320011 & 752504 & 2.8239 & 4.1875 & TRN & \\
\hline CHEMBL1256291 & 752504 & 4.0225 & 4.6067 & TRN & \\
\hline CHEMBL1876343 & 752504 & 4.5633 & 4.2951 & TRN & \\
\hline CHEMBL1901333 & 752504 & 4.5504 & 4.31 & TRN & \\
\hline CHEMBL1398809 & 752504 & 4.5102 & 4.33899 & э99999999995 & TRN \\
\hline CHEMBL1461121 & 752504 & 4.6159 & 4.5498 & TRN & \\
\hline CHEMBL1574539 & 752504 & 4.2346 & 4.5091 & TRN & \\
\hline CHEMBL1611445 & 752504 & 4.4935 & 4.2702 & TRN & \\
\hline CHEMBL1712708 & 752504 & 4.6589 & 4.4942 & TRN & \\
\hline CHEMBL1581561 & 752504 & 2.8239 & 4.5523 & TRN & \\
\hline CHEMBL1418599 & 752504 & 4.3261 & 4.4127 & TRN & \\
\hline CHEMBL1319128 & 752504 & 4.5822 & 4.6446 & TRN & \\
\hline CHEMBL1542959 & 752504 & 6.2857 & 5.8126 & TRN & \\
\hline CHEMBL1423502 & 752504 & 4.4011 & 4.5052 & TRN & \\
\hline CHEMBL1491484 & 752504 & 4.5253 & 4.3638 & TRN & \\
\hline CHEMBL1413315 & 752504 & 4.6135 & 4.5596 & TRN & \\
\hline CHEMBL1313744 & 752504 & 4.694 & 4.3923 & TRN & \\
\hline CHEMBL1412452 & 752504 & 4.5583 & 4.4481 & TRN & \\
\hline CHEMBL1712503 & 752504 & 4.4116 & 4.4729 & TRN & \\
\hline CHEMBL1442788 & 752504 & 5.1864 & 4.5774 & TRN & \\
\hline CHEMBL1341573 & 752504 & 4.5277 & 4.412 & TRN & \\
\hline CHEMBL1309316 & 752504 & 4.4935 & 4.3878 & TRN & \\
\hline CHEMBL1429388 & 752504 & 3.8723 & 4.4749 & TRN & \\
\hline CHEMBL1256917 & 752504 & 4.7128 & 4.4455 & TST & \\
\hline CHEMBL1886604 & 752504 & 4.0501 & 4.4595 & TRN & \\
\hline CHEMBL1363008 & 752504 & 4.3766 & 4.3671 & TRN & \\
\hline CHEMBL1548626 & 752504 & 4.0143 & 4.39199 & 99999999995 & $\mathrm{NT}$ \\
\hline CHEMBL1363459 & 752504 & 4.6117 & 4.5422 & TRN & \\
\hline CHEMBL1540065 & 752504 & 4.3606 & 4.3898 & TRN & \\
\hline CHEMBL1427897 & 752504 & 4.0021 & 4.39 & TRN & \\
\hline CHEMBL1433202 & 752504 & 4.3673 & 4.4453 & TRN & \\
\hline CHEMBL1388427 & 752504 & 4.4135 & 4.6261 & TRN & \\
\hline CHEMBL1353170 & 752504 & 5.0863 & 5.3734 & TRN & \\
\hline CHEMBL1331793 & 752504 & \multicolumn{3}{|c|}{4.5489999999999995} & $\mathrm{n}$ \\
\hline CHEMBL1604283 & 752504 & 2.8239 & 5.8617 & TST & \\
\hline CHEMBL1878940 & 752504 & 4.6486 & 4.4522 & TST & \\
\hline CHEMBL505670 & 752504 & 5.0705 & 4.657 & TRN & \\
\hline
\end{tabular}


Supplemental Table S2.txt

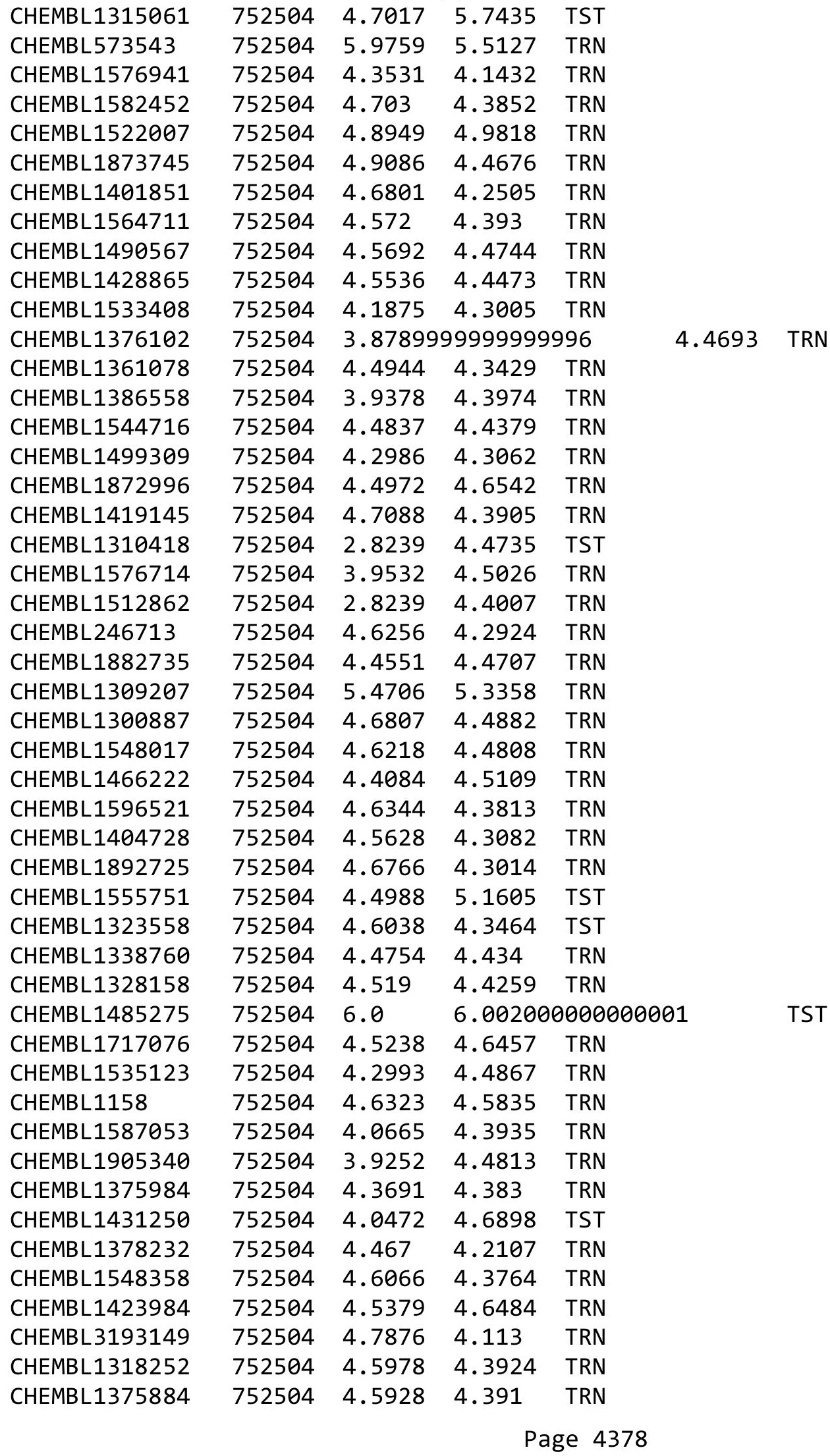


Supplemental Table S2.txt

\begin{tabular}{|c|c|c|c|c|c|}
\hline CHEMBL1537344 & 752504 & 4.328 & 5.7086 & TST & \\
\hline CHEMBL1875647 & 752504 & 4.5957 & 4.4347 & TRN & \\
\hline CHEMBL1328408 & 752504 & 4.3234 & 4.5313 & TRN & \\
\hline CHEMBL1711359 & 752504 & 5.3706 & 4.3094 & TST & \\
\hline CHEMBL1885238 & 752504 & 4.0944 & 4.2942 & TRN & \\
\hline CHEMBL1874665 & 752504 & 4.5457 & 4.4757 & TRN & \\
\hline CHEMBL1727741 & 752504 & 4.3972 & 4.3409 & TRN & \\
\hline CHEMBL1332738 & 752504 & 4.4386 & 4.2665 & TRN & \\
\hline CHEMBL1438105 & 752504 & 4.6184 & 4.5071 & TRN & \\
\hline CHEMBL1498183 & 752504 & 4.5167 & 4.3354 & TRN & \\
\hline CHEMBL 3210079 & 752504 & 4.3508 & 4.3877 & TRN & \\
\hline CHEMBL1310859 & 752504 & 4.183 & 4.3578 & TRN & \\
\hline CHEMBL 3208642 & 752504 & 4.0646 & 4.4548 & TRN & \\
\hline CHEMBL1478658 & 752504 & 3.9865 & 4.5054 & TRN & \\
\hline CHEMBL1608786 & 752504 & 4.4007 & 4.4882 & TRN & \\
\hline CHEMBL1533847 & 752504 & 4.4063 & 4.3348 & TRN & \\
\hline CHEMBL 283849 & 752504 & 5.5894 & 6.3368 & TRN & \\
\hline CHEMBL1583266 & 752504 & 2.8239 & 4.46899 & 9999999999 & TRN \\
\hline CHEMBL1308570 & 752504 & 2.8239 & 4.3592 & TRN & \\
\hline CHEMBL1445139 & 752504 & 4.0846 & 4.3157 & TRN & \\
\hline CHEMBL1364320 & 752504 & 4.4899 & 4.3226 & TRN & \\
\hline CHEMBL1374440 & 752504 & 4.4751 & 4.5245 & TRN & \\
\hline CHEMBL1431887 & 752504 & 4.4104 & 4.53600 & 00000000005 & TRN \\
\hline CHEMBL1568014 & 752504 & 4.4705 & 4.3738 & TRN & \\
\hline CHEMBL1391932 & 752504 & 4.1472 & 4.2091 & TRN & \\
\hline CHEMBL1410177 & 752504 & 4.5421 & 4.4704 & TRN & \\
\hline CHEMBL1372839 & 752504 & 4.6295 & 4.4115 & TRN & \\
\hline CHEMBL1871463 & 752504 & 4.5574 & 4.6399 & TST & \\
\hline CHEMBL1865281 & 752504 & 4.5334 & 4.5029 & TRN & \\
\hline CHEMBL1565507 & 752504 & 4.5865 & 4.2532 & TRN & \\
\hline CHEMBL1428093 & 752504 & 4.6029 & 4.3358 & TRN & \\
\hline CHEMBL1578127 & 752504 & 4.4733 & 4.398 & TST & \\
\hline CHEMBL1400550 & 752504 & 4.3977 & 4.3067 & TRN & \\
\hline CHEMBL1317300 & 752504 & 4.266 & 4.4021 & TST & \\
\hline CHEMBL1733262 & 752504 & \multicolumn{3}{|c|}{6.202000000000001} & TRN \\
\hline CHEMBL1873673 & 752504 & 4.3136 & 4.526 & TRN & \\
\hline CHEMBL1441196 & 752504 & 5.7773 & 5.5934 & TRN & \\
\hline CHEMBL1453993 & 752504 & 4.3699 & 4.3737 & TRN & \\
\hline CHEMBL1604947 & 752504 & 5.6017 & 5.2843 & TRN & \\
\hline CHEMBL1499810 & 752504 & 4.5442 & 4.3962 & TRN & \\
\hline CHEMBL1590902 & 752504 & 4.8279 & 4.5789 & TST & \\
\hline CHEMBL1558767 & 752504 & 4.6784 & 4.4689 & TRN & \\
\hline CHEMBL1348169 & 752504 & 4.2969 & 4.449 & TRN & \\
\hline CHEMBL1454617 & 752504 & 4.6704 & 4.4261 & TRN & \\
\hline CHEMBL1526014 & 752504 & 4.6162 & 4.5793 & TRN & \\
\hline CHEMBL1707535 & 752504 & 3.948 & 4.3052 & TRN & \\
\hline CHEMBL1557373 & 752504 & 3.8249 & 4.5513 & TRN & \\
\hline CHEMBL1360103 & 752504 & 3.9738 & 4.4183 & TRN & \\
\hline
\end{tabular}

Page 4379 
Supplemental Table S2.txt

\begin{tabular}{|c|c|c|c|c|}
\hline CHEMBL1528530 & 752504 & 4.588 & 4.3928 & TRN \\
\hline CHEMBL1409629 & 752504 & 4.7004 & 4.3897 & TST \\
\hline CHEMBL1510810 & 752504 & 4.2072 & 4.3739 & TRN \\
\hline CHEMBL1530469 & 752504 & 4.5492 & 4.2865 & TST \\
\hline CHEMBL1422619 & 752504 & 4.4992 & 4.4668 & TST \\
\hline CHEMBL1401659 & 752504 & 4.4309 & 4.4018 & TRN \\
\hline CHEMBL1323480 & 752504 & 4.5061 & 4.3564 & TST \\
\hline CHEMBL1716797 & 752504 & 4.6017 & 4.2638 & TRN \\
\hline CHEMBL1728109 & 752504 & 4.5466 & 4.3608 & TRN \\
\hline CHEMBL1330727 & 752504 & 4.5273 & 4.3393 & TRN \\
\hline CHEMBL1559551 & 752504 & 4.6611 & 4.3712 & TRN \\
\hline CHEMBL1542522 & 752504 & 4.18 & 4.3827 & TST \\
\hline CHEMBL1344171 & 752504 & 4.5245 & 4.2758 & TRN \\
\hline CHEMBL1339592 & 752504 & 4.4218 & 4.333 & TRN \\
\hline CHEMBL1326371 & 752504 & 5.5777 & 5.5252 & TRN \\
\hline CHEMBL1388716 & 752504 & 4.2028 & 4.2386 & TRN \\
\hline CHEMBL1415164 & 752504 & 4.5849 & 4.3107 & TRN \\
\hline CHEMBL1576581 & 752504 & 5.8431 & 5.4865 & TRN \\
\hline CHEMBL1717177 & 752504 & 4.7085 & 4.4545 & TRN \\
\hline CHEMBL1312839 & 752504 & 4.5473 & 4.2813 & TRN \\
\hline CHEMBL1548962 & 752504 & 4.07100 & 00000000 & 4.36 \\
\hline CHEMBL1438391 & 752504 & 4.2313 & 4.2945 & TRN \\
\hline CHEMBL1711244 & 752504 & 4.5993 & 4.5305 & TST \\
\hline CHEMBL1873133 & 752504 & 4.5764 & 4.3961 & TST \\
\hline CHEMBL1453127 & 752504 & 4.2698 & 4.4439 & TRN \\
\hline CHEMBL1486066 & 752504 & 4.4561 & 4.3496 & TRN \\
\hline CHEMBL1351621 & 752504 & 4.419 & 4.2592 & TRN \\
\hline CHEMBL1546781 & 752504 & 4.637 & 4.4884 & TRN \\
\hline CHEMBL1540425 & 752504 & 4.4131 & 4.3489 & TRN \\
\hline CHEMBL1351670 & 752504 & 4.6524 & 4.3679 & TRN \\
\hline CHEMBL1508942 & 752504 & 4.1281 & 4.1824 & TRN \\
\hline CHEMBL1389507 & 752504 & 4.5458 & 4.55699 & 99999999995 \\
\hline CHEMBL1332667 & 752504 & 4.4579 & 4.5053 & TST \\
\hline CHEMBL1413415 & 752504 & 4.1265 & 4.3946 & TRN \\
\hline CHEMBL1571514 & 752504 & 4.6462 & 4.446006 & $\partial 000000001$ \\
\hline CHEMBL1522925 & 752504 & 4.6208 & 4.5485 & TRN \\
\hline CHEMBL1733450 & 752504 & 4.6461 & 4.3983 & TRN \\
\hline CHEMBL1445249 & 752504 & 4.6117 & 4.4579 & TST \\
\hline CHEMBL1209369 & 752504 & 4.6334 & 4.56800 & $\partial 0000000005$ \\
\hline CHEMBL1472223 & 752504 & 2.8239 & 4.2809 & TRN \\
\hline CHEMBL1888741 & 752504 & 3.9338 & 4.4619 & TRN \\
\hline CHEMBL1583582 & 752504 & 4.6024 & 4.3688 & TRN \\
\hline CHEMBL1358776 & 752504 & 4.4621 & 4.4746 & TRN \\
\hline CHEMBL1345251 & 752504 & 3.9091 & 4.3014 & TRN \\
\hline CHEMBL1348591 & 752504 & 4.3925 & 4.4172 & TRN \\
\hline CHEMBL1700479 & 752504 & 3.9483 & 4.5951 & TST \\
\hline CHEMBL1528010 & 752504 & 4.3833 & 4.383 & TRN \\
\hline CHEMBL1721644 & 752504 & 4.635 & 4.295 & TRN \\
\hline
\end{tabular}




\begin{tabular}{|c|c|c|c|c|c|c|}
\hline & & & & & & \\
\hline CHEMBL1452397 & 752504 & 4.2459 & 4.3771 & TRN & & \\
\hline CHEMBL1393680 & 752504 & 4.2048 & 4.3297 & TRN & & \\
\hline CHEMBL1384697 & 752504 & 4.3777 & 4.3885 & TRN & & \\
\hline CHEMBL1728268 & 752504 & 4.1818 & 4.3735 & TRN & & \\
\hline CHEMBL1306450 & 752504 & 4.609 & 4.4187 & TRN & & \\
\hline CHEMBL1543147 & 752504 & 4.3627 & 4.4124 & TRN & & \\
\hline CHEMBL1342690 & 752504 & 4.7347 & 4.4171 & TRN & & \\
\hline CHEMBL1326535 & 752504 & 4.6582 & 4.4976 & TRN & & \\
\hline CHEMBL 3194387 & 752504 & 4.414 & 4.3223 & TRN & & \\
\hline CHEMBL1875335 & 752504 & 4.6274 & 4.5197 & TRN & & \\
\hline CHEMBL1736770 & 752504 & 4.5014 & 4.2474 & TRN & & \\
\hline CHEMBL1428987 & 752504 & 2.8239 & 4.3933 & TST & & \\
\hline CHEMBL1500823 & 752504 & 4.2341 & 4.4808 & TRN & & \\
\hline CHEMBL568415 & 752504 & 4.4129 & 4.2274 & TRN & & \\
\hline CHEMBL1366040 & 752504 & 4.5937 & 4.2793 & TRN & & \\
\hline CHEMBL1716119 & 752504 & 4.8062 & 4.6425 & TST & & \\
\hline CHEMBL1566900 & 752504 & 4.5824 & 4.373 & TRN & & \\
\hline CHEMBL1864672 & 752504 & 4.368 & 4.5225 & TRN & & \\
\hline CHEMBL1712785 & 752504 & 4.5507 & 4.3368 & TRN & & \\
\hline CHEMBL1491742 & 752504 & 4.4799 & 4.5565 & TRN & & \\
\hline CHEMBL1509665 & 752504 & 4.6275 & 4.4175 & TRN & & \\
\hline CHEMBL1418374 & 752504 & 4.3609 & 4.4621 & TRN & & \\
\hline CHEMBL1725295 & 752504 & 4.5615 & 4.2775 & TRN & & \\
\hline CHEMBL1429397 & 752504 & 4.5161 & 4.3741 & TRN & & \\
\hline CHEMBL3195484 & 752504 & 2.8239 & 4.8672 & TST & & \\
\hline CHEMBL1586310 & 752504 & 4.4478 & 4.4558 & TRN & & \\
\hline CHEMBL1547122 & 752504 & 4.6237 & 4.3098 & TST & & \\
\hline CHEMBL1489416 & 752504 & 4.5451 & 4.3855 & TRN & & \\
\hline CHEMBL1346731 & 752504 & 4.5746 & 4.4855 & TRN & & \\
\hline CHEMBL1490513 & 752504 & 4.6512 & 4.5984 & TST & & \\
\hline CHEMBL1478936 & 752504 & 4.5848 & 4.4902 & TST & & \\
\hline CHEMBL1476255 & 752504 & 4.2113 & 4.5922 & TRN & & \\
\hline CHEMBL3209660 & 752504 & 4.6654 & 4.5047 & TRN & & \\
\hline CHEMBL1597270 & 752504 & 4.4301 & 4.3252 & TRN & & \\
\hline CHEMBL1708261 & 752504 & 4.6349 & 4.5473 & TRN & & \\
\hline CHEMBL1425316 & 752504 & 5.4116 & 5.3371 & TRN & & \\
\hline CHEMBL1332193 & 752504 & 4.27800 & 000000000 & 205 & 4.3333 & TRN \\
\hline CHEMBL1872656 & 752504 & 4.6202 & 4.6228 & TST & & \\
\hline CHEMBL1302630 & 752504 & 4.71899 & 999999999 & 99 & 4.2738 & TRN \\
\hline CHEMBL1558826 & 752504 & 4.9288 & 5.0541 & TST & & \\
\hline CHEMBL1076257 & 752504 & 4.4712 & 4.633 & TST & & \\
\hline CHEMBL1420042 & 752504 & 4.4784 & 4.3147 & TRN & & \\
\hline CHEMBL1964361 & 752504 & 4.4203 & 4.4581 & TST & & \\
\hline CHEMBL1307929 & 752504 & 4.5032 & 4.5458 & TRN & & \\
\hline CHEMBL1413184 & 752504 & 4.5682 & 4.2798 & TRN & & \\
\hline CHEMBL1442980 & 752504 & 4.569 & 4.2572 & TRN & & \\
\hline CHEMBL1328100 & 752504 & 4.5878 & 4.3076 & TRN & & \\
\hline CHEMBL1447470 & 752504 & 4.5193 & 4.5602 & TST & & \\
\hline
\end{tabular}




\begin{tabular}{|c|c|c|c|c|c|}
\hline & & & & & \\
\hline CHEMBL1341449 & 752504 & 4.7345 & 4.4762 & TRN & \\
\hline CHEMBL1400909 & 752504 & 4.5384 & 4.3192 & TST & \\
\hline CHEMBL1486570 & 752504 & 4.7374 & 4.4591 & TRN & \\
\hline CHEMBL1343369 & 752504 & 4.7335 & 4.26699 & 99999999995 & TRN \\
\hline CHEMBL1573632 & 752504 & 4.9114 & 5.0474 & TST & \\
\hline CHEMBL1372703 & 752504 & 4.5715 & 4.3737 & TRN & \\
\hline CHEMBL1363272 & 752504 & 4.292 & 4.3724 & TRN & \\
\hline CHEMBL1527199 & 752504 & 4.6222 & 4.4523 & TRN & \\
\hline CHEMBL1541910 & 752504 & 4.6244 & 4.6345 & TRN & \\
\hline CHEMBL1466809 & 752504 & 3.9399 & 4.4095 & TRN & \\
\hline CHEMBL1576118 & 752504 & 4.439 & 4.4755 & TRN & \\
\hline CHEMBL1890672 & 752504 & 2.8239 & 4.2693 & TST & \\
\hline CHEMBL1323647 & 752504 & 4.1524 & 4.3681 & TST & \\
\hline CHEMBL1301600 & 752504 & 4.6828 & 4.4586 & TST & \\
\hline CHEMBL1370799 & 752504 & 4.48 & 4.3684 & TST & \\
\hline CHEMBL1410311 & 752504 & 4.6433 & 4.5945 & TST & \\
\hline CHEMBL518494 & 752504 & 6.3045 & 4.6226 & TST & \\
\hline CHEMBL1384463 & 752504 & 4.1361 & 4.3968 & TST & \\
\hline CHEMBL1411058 & 752504 & 4.6667 & 4.3794 & TST & \\
\hline CHEMBL1487758 & 752504 & 3.9697 & 4.5154 & TST & \\
\hline CHEMBL 3190868 & 752504 & 4.5909 & 4.5117 & TST & \\
\hline CHEMBL1499371 & 752504 & 4.021 & 4.3156 & TST & \\
\hline CHEMBL1430871 & 752504 & 4.4788 & 4.5677 & TST & \\
\hline CHEMBL1505275 & 752504 & 5.5995 & 5.7139 & TST & \\
\hline CHEMBL3189350 & 752504 & 4.6558 & 4.4048 & TST & \\
\hline CHEMBL1868251 & 752504 & 4.6732 & 4.3881 & TST & \\
\hline CHEMBL1501384 & 752504 & 4.5935 & 4.4017 & TST & \\
\hline CHEMBL3192399 & 752504 & 4.5071 & 4.5005 & TST & \\
\hline CHEMBL1906323 & 752504 & 4.5558 & 4.4997 & TST & \\
\hline CHEMBL1477236 & 752504 & 2.8239 & 4.44300 & 00000000005 & TST \\
\hline CHEMBL1347215 & 752504 & 2.8239 & 4.27 & TST & \\
\hline CHEMBL1536659 & 752504 & 2.8239 & 4.5564 & TST & \\
\hline CHEMBL1878964 & 752504 & 4.4163 & 4.2674 & TST & \\
\hline CHEMBL1385486 & 752504 & 4.5842 & 4.3169 & TST & \\
\hline CHEMBL1547542 & 752504 & 4.6255 & 4.4419 & TST & \\
\hline CHEMBL1506420 & 752504 & 4.6015 & 4.2819 & TST & \\
\hline CHEMBL1733751 & 752504 & 4.6008 & 4.333 & TST & \\
\hline CHEMBL1377917 & 752504 & 4.3881 & 4.3414 & TST & \\
\hline CHEMBL1528375 & 752504 & 4.6436 & 4.5229 & TST & \\
\hline CHEMBL 3145042 & 752504 & 4.3355 & 4.4986 & TST & \\
\hline CHEMBL1383540 & 752504 & 4.5661 & 4.3373 & TST & \\
\hline CHEMBL1516953 & 752504 & 4.5655 & 4.4503 & TST & \\
\hline CHEMBL325681 & 752504 & 4.5502 & 4.2329 & TST & \\
\hline CHEMBL1524986 & 752504 & 4.63399 & 99999999 & 4.7878 & TST \\
\hline CHEMBL1558814 & 752504 & 4.2902 & 4.3886 & TST & \\
\hline CHEMBL1609689 & 752504 & 4.3683 & 4.5067 & TST & \\
\hline CHEMBL1200567 & 752504 & 4.6822 & 5.609 & TST & \\
\hline CHEMBL1095804 & 752504 & 4.5953 & 4.1669 & TST & \\
\hline
\end{tabular}


Supplemental Table S2.txt

\begin{tabular}{|c|c|c|c|c|}
\hline CHEMBL1345440 & 752504 & 2.8239 & 4.4443 & TST \\
\hline CHEMBL1356238 & 752504 & 5.0428 & 4.6525 & TST \\
\hline CHEMBL1502079 & 752504 & 4.4025 & 4.3014 & TST \\
\hline CHEMBL1722902 & 752504 & 4.3499 & 4.316 & TST \\
\hline CHEMBL 3960029 & 1641197 & 6.7011 & 6.9217 & TRN \\
\hline CHEMBL3899975 & 1641197 & 6.8477 & 7.0629 & TRN \\
\hline CHEMBL3927937 & 1641197 & 8.699 & 8.5664 & TRN \\
\hline CHEMBL 3896872 & 1641197 & 8.5229 & 8.3412 & TRN \\
\hline CHEMBL3932522 & 1641197 & 7.8539 & 6.4833 & TST \\
\hline CHEMBL3936935 & 1641197 & 8.699 & 8.8518 & TRN \\
\hline CHEMBL3946614 & 1641197 & 7.4949 & 6.6602 & TST \\
\hline CHEMBL3958384 & 1641197 & 7.1249 & 6.7152 & TRN \\
\hline CHEMBL3980630 & 1641197 & 8.0458 & 8.0578 & TRN \\
\hline CHEMBL 3967247 & 1641197 & 8.301 & 8.2156 & TRN \\
\hline CHEMBL 3986904 & 1641197 & 10.0 & 9.2304 & TRN \\
\hline CHEMBL 3900304 & 1641197 & 10.0 & 8.8641 & TST \\
\hline CHEMBL3949420 & 1641197 & 8.0 & 7.7668 & TRN \\
\hline CHEMBL3920935 & 1641197 & 8.0458 & 8.3572 & TRN \\
\hline CHEMBL3918561 & 1641197 & 7.0315 & 7.2796 & TRN \\
\hline CHEMBL3944099 & 1641197 & 7.7959 & 7.9415 & TRN \\
\hline CHEMBL 3975188 & 1641197 & 8.301 & 8.3149 & TST \\
\hline CHEMBL3926692 & 1641197 & 7.6198 & 7.7728 & TRN \\
\hline CHEMBL3897917 & 1641197 & 7.301 & 6.7553 & TRN \\
\hline CHEMBL 3925985 & 1641197 & 10.0 & 8.9082 & TST \\
\hline CHEMBL3955192 & 1641197 & 7.0362 & 6.5209 & TRN \\
\hline CHEMBL 3978244 & 1641197 & 6.1215 & 6.5863 & TRN \\
\hline CHEMBL3933021 & 1641197 & 8.1549 & 9.1644 & TRN \\
\hline CHEMBL3960541 & 1641197 & 8.3979 & 8.5934 & TRN \\
\hline CHEMBL3920172 & 1641197 & 7.8239 & 8.3299 & TST \\
\hline CHEMBL3891402 & 1641197 & 8.301 & 8.1101 & TRN \\
\hline CHEMBL3961674 & 1641197 & 8.5229 & 8.48200 & 2000000001 \\
\hline CHEMBL3935126 & 1641197 & 7.9208 & 7.5507 & TRN \\
\hline CHEMBL3949262 & 1641197 & 7.7447 & 7.7217 & TST \\
\hline CHEMBL 3894106 & 1641197 & 7.6198 & 7.1145 & TRN \\
\hline CHEMBL3907109 & 1641197 & 6.7447 & 6.8399 & TRN \\
\hline CHEMBL3921959 & 1641197 & 6.1733 & 5.8376 & TRN \\
\hline CHEMBL3969828 & 1641197 & 8.0458 & 8.1856 & TRN \\
\hline CHEMBL3936603 & 1641197 & 9.0 & 9.0007 & TRN \\
\hline CHEMBL3958095 & 1641197 & 7.5528 & 7.5724 & TRN \\
\hline CHEMBL3943340 & 1641197 & 6.7399 & 6.9587 & TRN \\
\hline CHEMBL 3921640 & 1641197 & 8.3979 & 7.9554 & TRN \\
\hline CHEMBL3958297 & 1641197 & 7.2441 & 6.9778 & TRN \\
\hline CHEMBL3975927 & 1641197 & 8.2218 & 5.9329 & TST \\
\hline CHEMBL3919242 & 1641197 & 4.7959 & 6.2816 & TRN \\
\hline CHEMBL 3924003 & 1641197 & 10.0 & 9.1291 & TRN \\
\hline CHEMBL 3958914 & 1641197 & 4.8069 & 5.3415 & TRN \\
\hline CHEMBL3912970 & 1641197 & 7.4089 & 7.6957 & TRN \\
\hline CHEMBL 3964270 & 1641197 & 6.5528 & 6.3527 & TRN \\
\hline
\end{tabular}

Page 4383 
Supplemental Table S2.txt

\begin{tabular}{|c|c|c|c|c|}
\hline 5 & 1197 & & 2904 & \\
\hline & 641197 & 6.7905 & & \\
\hline AEM & 197 & 376 & & \\
\hline IEMBL & 197 & 5229 & 339 & \\
\hline AEMBL3976445 & 641197 & 6.8508 & 119 & \\
\hline HEMBL3695569 & 97 & 7.3768 & 6028 & \\
\hline HEMBL & 97 & 7.6576 & $\partial 256$ & \\
\hline HEMBL390 & & 212 & 0774 & \\
\hline HEMBL3950258 & 197 & 8.5229 & 5007 & \\
\hline HEMBL3890213 & 197 & 8.0 & 0307 & \\
\hline HEMBL3928618 & 97 & 71 & & \\
\hline AEMBL3S & 97 & & 3658 & S \\
\hline HEMBL3 & & 539 & 2119 & \\
\hline HEMBL3979828 & 97 & 7.6021 & 6.8611 & \\
\hline AEMBL3909641 & 97 & & 8516 & \\
\hline HEMBL3 & 6 & & 7038 & RIV \\
\hline HEMBL3 & & & 877 & RN \\
\hline HEMBL3 & & & 773 & \\
\hline HEMBL3 & & 15 & 5663 & \\
\hline HEMBL393 & & & & I KIV \\
\hline HEMBL; & 6 & & 143 & RN \\
\hline HEM & & & 134 & RN \\
\hline HEMBL & 97 & 16 & 1784 & BN \\
\hline HEMBL & & 7 & 7237 & | \\
\hline HEMBL393 & & 7. & 542 & IRIN \\
\hline HEMBL3 & & & 434 & $\mathrm{RN}$ \\
\hline HEME & & & 819 & $\mathrm{RN}$ \\
\hline 98 & & 15 & 034 & 「RN \\
\hline AEMBL3 & & & 626 & IK \\
\hline HEMBL 395 & & 7.6778 & 265 & TRN \\
\hline AEMBL. & & & 559 & RN \\
\hline HEM & & & 18 & 「RN \\
\hline מיח & & & 5568 & TST \\
\hline HEMBL3 & & & 828 & 「RN \\
\hline HEMBL 397 & 97 & & 1692 & ГRN \\
\hline JIMDI 2 & & 59 & 753 & TRN \\
\hline 10 & & & 337 & ST \\
\hline HEMBL3S & & & & TST \\
\hline HEMBL 395 & & 7. & 406 & $\Gamma R$ \\
\hline IEMBL & & 7. & 542 & IST \\
\hline HEMDI 3 & & 7. & 389 & IST \\
\hline HEMBL3 & & 7.7447 & 9185 & IST \\
\hline HEMBL3 & & 7.8539 & 1373 & TST \\
\hline HEMBL 395 & & 7.7696 & 185 & TS \\
\hline CHFMRI 3915395 & & & & 3 \\
\hline HEMBL 3912657 & & 7.8239 & 5433 & \\
\hline CHEMBL3915981 & 197 & 8.699 & 5453 & ST \\
\hline CHEMBL440287 & 688827 & 4.4 & 4.4145 & $\mathrm{R}$ \\
\hline
\end{tabular}

Page 4384 


\begin{tabular}{|c|c|c|c|c|c|}
\hline \\
\hline CHEMBL1414154 & 688827 & 4.1 & 4.1242 & TRN & \\
\hline CHEMBL1569493 & 688827 & 5.8 & 5.8544 & TRN & \\
\hline CHEMBL1456906 & 688827 & 4.2 & 4.4622 & TRN & \\
\hline CHEMBL1370662 & 688827 & 4.3 & 4.3807 & TRN & \\
\hline CHEMBL230156 & 688827 & 4.3 & 4.22199 & 99999999995 & TRN \\
\hline CHEMBL1409985 & 688827 & 5.3 & 5.3197 & TRN & \\
\hline CHEMBL1579130 & 688827 & 6.0 & 5.5584 & TRN & \\
\hline CHEMBL1600998 & 688827 & 5.2 & 5.4224 & TRN & \\
\hline CHEMBL443949 & 688827 & 4.3 & 4.3725 & TRN & \\
\hline CHEMBL144530 & 688827 & 4.5 & 4.2867 & TRN & \\
\hline CHEMBL1519327 & 688827 & 6.3 & 6.2161 & TRN & \\
\hline CHEMBL1526721 & 688827 & 5.2 & 5.0955 & TST & \\
\hline CHEMBL1308088 & 688827 & 5.0 & 4.7621 & TRN & \\
\hline CHEMBL1200471 & 688827 & 6.5 & 6.3919 & TRN & \\
\hline CHEMBL1517425 & 688827 & 4.1 & 4.1196 & TRN & \\
\hline CHEMBL1492884 & 688827 & 4.4 & 4.3303 & TRN & \\
\hline CHEMBL1529759 & 688827 & 4.1 & 4.3077 & TST & \\
\hline CHEMBL1451833 & 688827 & 4.4 & 4.3907 & TST & \\
\hline CHEMBL1471289 & 688827 & 4.6 & 4.3848 & TRN & \\
\hline CHEMBL1602699 & 688827 & 5.3 & 5.2205 & TRN & \\
\hline CHEMBL1569226 & 688827 & 5.3 & 5.2372 & TRN & \\
\hline CHEMBL 28 & 688827 & 4.1 & 4.1618 & TRN & \\
\hline CHEMBL1485974 & 688827 & 4.4 & 4.317 & TRN & \\
\hline CHEMBL3391990 & 688827 & 4.3 & 4.4251 & TRN & \\
\hline CHEMBL1449018 & 688827 & 4.5 & 4.6009 & TRN & \\
\hline CHEMBL1585396 & 688827 & 4.3 & 4.2636 & TST & \\
\hline CHEMBL509531 & 688827 & 4.6 & 4.7951 & TRN & \\
\hline CHEMBL1407826 & 688827 & 4.4 & 4.6131 & TST & \\
\hline CHEMBL468582 & 688827 & 4.3 & 4.2847 & TST & \\
\hline CHEMBL 334255 & 688827 & 4.8 & 4.8181 & TRN & \\
\hline CHEMBL1485360 & 688827 & 4.6 & 4.5058 & TST & \\
\hline CHEMBL346918 & 688827 & 4.1 & 4.3671 & TST & \\
\hline CHEMBL1524617 & 688827 & 5.1 & 5.03100 & 0000000001 & TST \\
\hline CHEMBL 224282 & 688827 & 4.1 & 4.1761 & TRN & \\
\hline CHEMBL1527567 & 688827 & 4.4 & 4.3052 & TRN & \\
\hline CHEMBL1549844 & 688827 & 4.7 & 4.5656 & TST & \\
\hline CHEMBL935 & 688827 & 4.3 & 4.3048 & TRN & \\
\hline CHEMBL1522486 & 688827 & 4.6 & 4.4933 & TRN & \\
\hline CHEMBL192627 & 688827 & 4.6 & 4.5547 & TST & \\
\hline CHEMBL1450607 & 688827 & 4.6 & 4.5318 & TST & \\
\hline CHEMBL1559341 & 688827 & 4.4 & 4.3622 & TRN & \\
\hline CHEMBL1304981 & 688827 & 4.3 & 4.126 & TRN & \\
\hline CHEMBL1545634 & 688827 & 6.3 & 6.3787 & TRN & \\
\hline CHEMBL 140 & 688827 & 4.4 & 4.2557 & TRN & \\
\hline CHEMBL1309179 & 688827 & 4.8 & 4.7823 & TRN & \\
\hline CHEMBL1612246 & 688827 & 4.4 & 4.4401 & TRN & \\
\hline CHEMBL162598 & 688827 & 4.3 & 4.2217 & TST & \\
\hline CHEMBL389950 & 688827 & 4.1 & 4.1565 & TST & \\
\hline
\end{tabular}




\begin{tabular}{|c|c|c|c|c|c|}
\hline \multicolumn{6}{|c|}{ Supplemental Table s2.txt } \\
\hline CHEMBL1430204 & 688827 & 4.3 & 4.3947 & TRN & \\
\hline CHEMBL1338613 & 688827 & 4.6 & 4.2882 & TRN & \\
\hline CHEMBL1303139 & 688827 & 5.1 & 5.1837 & TRN & \\
\hline CHEMBL1142 & 688827 & 4.3 & 4.3504 & TRN & \\
\hline CHEMBL1492104 & 688827 & 4.8 & 4.7421 & TST & \\
\hline CHEMBL1447588 & 688827 & 4.8 & 4.9099 & TRN & \\
\hline CHEMBL44072 & 688827 & 4.3 & 4.268 & TST & \\
\hline CHEMBL1496957 & 688827 & 4.7 & 4.61 & TRN & \\
\hline CHEMBL1576086 & 688827 & 4.3 & 4.3357 & TRN & \\
\hline CHEMBL1566504 & 688827 & 4.3 & 4.2965 & TST & \\
\hline CHEMBL105712 & 688827 & 5.0 & 5.008 & TRN & \\
\hline CHEMBL402063 & 688827 & 6.0 & 5.2562 & TST & \\
\hline CHEMBL1448387 & 688827 & 4.4 & 4.4723 & TRN & \\
\hline CHEMBL1562104 & 688827 & 5.2 & 5.2849 & TRN & \\
\hline CHEMBL1408847 & 688827 & 5.1 & 5.3034 & TRN & \\
\hline CHEMBL1526319 & 688827 & 4.3 & 4.3342 & TRN & \\
\hline CHEMBL195953 & 688827 & 4.3 & 4.1711 & TST & \\
\hline CHEMBL1393325 & 688827 & 4.1 & 4.3286 & TRN & \\
\hline CHEMBL486193 & 688827 & 4.3 & 4.5914 & TRN & \\
\hline CHEMBL1366408 & 688827 & 4.3 & 4.4317 & TRN & \\
\hline CHEMBL1499545 & 688827 & 5.3 & 5.2078 & TRN & \\
\hline CHEMBL1609459 & 688827 & 5.1 & 5.0966 & TRN & \\
\hline CHEMBL462576 & 688827 & 4.1 & 4.4229 & TST & \\
\hline CHEMBL1489064 & 688827 & 4.2 & 4.1727 & TRN & \\
\hline CHEMBL1452158 & 688827 & 4.3 & 4.2399 & TRN & \\
\hline CHEMBL1530684 & 688827 & 4.4 & 4.3923 & TRN & \\
\hline CHEMBL8739 & 688827 & 4.3 & 4.2062 & TRN & \\
\hline CHEMBL 36296 & 688827 & 4.1 & 4.2125 & TRN & \\
\hline CHEMBL1331245 & 688827 & 4.3 & 4.1656 & TRN & \\
\hline CHEMBL1535689 & 688827 & 4.5 & 4.2463 & TRN & \\
\hline CHEMBL 242080 & 688827 & 4.3 & 4.32100 & 0000000001 & TRN \\
\hline CHEMBL 289277 & 688827 & 4.3 & 4.3253 & TRN & \\
\hline CHEMBL1489568 & 688827 & 3.9 & 4.2498 & TRN & \\
\hline CHEMBL220845 & 688827 & 4.3 & 4.2143 & TRN & \\
\hline CHEMBL1558796 & 688827 & 4.3 & 4.5435 & TST & \\
\hline CHEMBL1341889 & 688469 & 2.9208 & 4.5262 & TRN & \\
\hline CHEMBL1344339 & 688469 & 4.8488 & 3.8002 & TST & \\
\hline CHEMBL1336728 & 688469 & 4.6267 & 3.5492 & TRN & \\
\hline CHEMBL1361645 & 688469 & 2.9208 & 3.9461 & TRN & \\
\hline CHEMBL1467993 & 688469 & 4.7226 & 3.6433 & TST & \\
\hline CHEMBL267099 & 688469 & 8.0 & 6.3782 & TST & \\
\hline CHEMBL1302027 & 688469 & 2.9208 & 3.4058 & TRN & \\
\hline CHEMBL1520497 & 688469 & 2.9208 & 3.3944 & TRN & \\
\hline CHEMBL1352812 & 688469 & 2.9208 & 3.3308 & TRN & \\
\hline CHEMBL1477635 & 688469 & 2.9208 & 3.3709 & TRN & \\
\hline CHEMBL1600977 & 688469 & 2.9208 & 3.7922 & TRN & \\
\hline CHEMBL1540717 & 688469 & 4.6564 & 4.4903 & TST & \\
\hline CHEMBL1429139 & 688469 & 4.8156 & 3.3503 & TRN & \\
\hline
\end{tabular}




\begin{tabular}{|c|c|c|c|c|}
\hline & & & pplement & al $\mathrm{T}$ \\
\hline CHEMBL1448535 & 688469 & 2.9208 & 3.4542 & TST \\
\hline CHEMBL1334550 & 688469 & 2.9208 & 4.7594 & TRN \\
\hline CHEMBL1525789 & 688469 & 6.684 & 6.7621 & TRN \\
\hline CHEMBL 3196824 & 688469 & 4.5815 & 3.6072 & TRN \\
\hline CHEMBL1545422 & 688469 & 2.9208 & 3.7255 & TRN \\
\hline CHEMBL1372163 & 688469 & 5.7615 & 6.9983 & TRN \\
\hline CHEMBL1533541 & 688469 & 2.9208 & 4.3695 & TRN \\
\hline CHEMBL1441654 & 688469 & 2.9208 & 3.5057 & TST \\
\hline CHEMBL1420007 & 688469 & 4.9527 & 4.9979 & TST \\
\hline CHEMBL1491222 & 688469 & 6.699 & 5.9624 & TRN \\
\hline CHEMBL1576132 & 688469 & 5.0588 & 5.3549 & TRN \\
\hline CHEMBL1374907 & 688469 & 4.8395 & 4.4283 & TRN \\
\hline CHEMBL1383626 & 688469 & 2.9208 & 3.8389 & TRN \\
\hline CHEMBL1326102 & 688469 & 2.9208 & 3.8669 & TRN \\
\hline CHEMBL581152 & 688469 & 2.9208 & 3.3943 & TRN \\
\hline CHEMBL1531769 & 688469 & 2.9208 & 3.2382 & TRN \\
\hline CHEMBL599255 & 688469 & 4.9164 & 4.0033 & TRN \\
\hline CHEMBL1404049 & 688469 & 4.7263 & 4.1879 & TRN \\
\hline CHEMBL1585777 & 688469 & 2.9208 & 4.4332 & TRN \\
\hline CHEMBL1323774 & 688469 & 2.9208 & 6.4022 & TRN \\
\hline CHEMBL1572212 & 688469 & 2.9208 & 3.4287 & TRN \\
\hline CHEMBL1303404 & 688469 & 5.0117 & 5.0729 & TRN \\
\hline CHEMBL1331520 & 688469 & 5.126 & 5.1862 & TRN \\
\hline CHEMBL1408236 & 688469 & 4.886 & 4.9097 & TRN \\
\hline CHEMBL606532 & 688469 & 4.8776 & 4.2553 & TRN \\
\hline CHEMBL1510156 & 688469 & 5.0679 & 3.9797 & TRN \\
\hline CHEMBL1582334 & 688469 & 2.9208 & 3.5026 & TRN \\
\hline CHEMBL1323569 & 688469 & 4.8776 & 4.4675 & TRN \\
\hline CHEMBL1429793 & 688469 & 4.7761 & 3.6842 & TRN \\
\hline CHEMBL1603826 & 688469 & 4.7759 & 3.7772 & TRN \\
\hline CHEMBL3199325 & 688469 & 4.8828 & 3.9777 & TRN \\
\hline CHEMBL1321326 & 688469 & 2.9208 & 6.3116 & TRN \\
\hline CHEMBL1310382 & 688469 & 2.9208 & 3.5043 & TRN \\
\hline CHEMBL1305809 & 688469 & 2.9208 & 3.9827 & TRN \\
\hline CHEMBL1343773 & 688469 & 4.8686 & 3.6765 & TRN \\
\hline CHEMBL1443177 & 688469 & 5.6817 & 4.9225 & TRN \\
\hline CHEMBL1605021 & 688469 & 6.7055 & 6.6655 & TST \\
\hline CHEMBL1386669 & 688469 & 2.9208 & 3.1931 & TRN \\
\hline CHEMBL1449669 & 688469 & 4.934 & 5.3242 & TRN \\
\hline CHEMBL1494829 & 688469 & 4.8469 & 4.6936 & TRN \\
\hline CHEMBL601351 & 688469 & 2.9208 & 3.4879 & TST \\
\hline CHEMBL1486733 & 688469 & 4.8908 & 4.0364 & TST \\
\hline CHEMBL2369172 & 688469 & 5.0566 & 4.1679 & TRN \\
\hline CHEMBL1398622 & 688469 & 2.9208 & 3.4676 & TRN \\
\hline CHEMBL1349403 & 688469 & 4.9418 & 4.3051 & TRN \\
\hline CHEMBL1584470 & 688469 & 2.9208 & 3.5887 & TRN \\
\hline CHEMBL1568414 & 688469 & 5.0417 & 4.2761 & TRN \\
\hline CHEMBL1450526 & 688469 & 5.0153 & 5.435 & TRN \\
\hline
\end{tabular}




\begin{tabular}{|c|c|c|c|c|c|c|}
\hline \multirow[b]{2}{*}{ CHEMBL1492266 } & & \multicolumn{5}{|c|}{ Supplemental Table S2.txt } \\
\hline & 688469 & 4.8259 & \multicolumn{3}{|c|}{4.0969999999999995} & TRN \\
\hline CHEMBL1490293 & 688469 & 8.0 & 6.3963 & TRN & & \\
\hline CHEMBL1391811 & 688469 & 4.6568 & 3.4852 & TRN & & \\
\hline CHEMBL1344256 & 688469 & 4.8242 & 4.6958 & TRN & & \\
\hline CHEMBL1389225 & 688469 & 4.9073 & 4.6457 & TST & & \\
\hline CHEMBL1395907 & 688469 & 2.9208 & 4.6778 & TRN & & \\
\hline CHEMBL1387436 & 688469 & 5.374 & 5.0401 & TRN & & \\
\hline CHEMBL1507833 & 688469 & 2.9208 & 3.3924 & TST & & \\
\hline CHEMBL1426792 & 688469 & 5.1418 & 5.5415 & TRN & & \\
\hline CHEMBL1416020 & 688469 & 2.9208 & 3.5857 & TRN & & \\
\hline CHEMBL1333294 & 688469 & 6.8894 & 6.4356 & TRN & & \\
\hline CHEMBL 259784 & 688469 & 5.7762 & 5.5702 & TRN & & \\
\hline CHEMBL1372889 & 688469 & 7.71 & 6.8442 & TRN & & \\
\hline CHEMBL1470919 & 688469 & 4.874 & 3.3979 & TRN & & \\
\hline CHEMBL1452636 & 688469 & 4.7171 & 4.0487 & TRN & & \\
\hline CHEMBL1459471 & 688469 & 4.7401 & 4.4227 & TRN & & \\
\hline CHEMBL3196703 & 688469 & 4.6344 & 5.1043 & TRN & & \\
\hline CHEMBL1327738 & 688469 & 2.9208 & 4.3218 & TRN & & \\
\hline CHEMBL1473464 & 688469 & 5.325 & 5.1089 & TRN & & \\
\hline CHEMBL1493561 & 688469 & 2.9208 & 4.0762 & TRN & & \\
\hline CHEMBL1991327 & 688469 & 4.9147 & 4.686 & TRN & & \\
\hline CHEMBL1579708 & 688469 & 2.9208 & 3.9888 & TRN & & \\
\hline CHEMBL1427106 & 688469 & 2.9208 & 4.0455 & TRN & & \\
\hline CHEMBL1560708 & 688469 & 2.9208 & 3.8486 & TST & & \\
\hline CHEMBL1431607 & 688469 & 4.7857 & 3.4484 & TRN & & \\
\hline CHEMBL1383331 & 688469 & 4.94 & 3.2917 & TRN & & \\
\hline CHEMBL1396209 & 688469 & 8.0 & 5.7803 & TRN & & \\
\hline CHEMBL1389609 & 688469 & 2.9208 & 3.3176 & TRN & & \\
\hline CHEMBL1505359 & 688469 & 4.7153 & 3.9627 & TRN & & \\
\hline CHEMBL1493861 & 688469 & 4.6375 & 3.7879 & TRN & & \\
\hline CHEMBL1453857 & 688469 & 4.7838 & 3.9402 & TRN & & \\
\hline CHEMBL1516767 & 688469 & 4.5531 & 3.3286 & TRN & & \\
\hline CHEMBL1428850 & 688469 & 3.2218 & 4.7596 & TRN & & \\
\hline CHEMBL1345404 & 688469 & 4.6008 & 4.7416 & TRN & & \\
\hline CHEMBL1359026 & 688469 & 4.7576 & 3.3181 & TRN & & \\
\hline CHEMBL3209142 & 688469 & 4.6949 & 4.0048 & TRN & & \\
\hline CHEMBL1469689 & 688469 & 2.9208 & 3.4094 & TRN & & \\
\hline CHEMBL1384963 & 688469 & 4.78600 & 30000000 & 005 & 3.4557 & \\
\hline CHEMBL1490356 & 688469 & 2.9208 & 3.5533 & TRN & & \\
\hline CHEMBL1430180 & 688469 & 2.9208 & 3.6555 & TRN & & \\
\hline CHEMBL1309839 & 688469 & 2.9208 & 4.234 & TRN & & \\
\hline CHEMBL1349509 & 688469 & 2.9208 & 3.3939 & TRN & & \\
\hline CHEMBL1360539 & 688469 & 5.17200 & 30000000 & & 5.0743 & 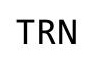 \\
\hline CHEMBL3199401 & 688469 & 4.7272 & 4.482 & TRN & & \\
\hline CHEMBL1540594 & 688469 & 2.9208 & 4.3716 & TRN & & \\
\hline CHEMBL1340698 & 688469 & 5.0715 & 4.8937 & TRN & & \\
\hline CHEMBL1983311 & 688469 & 4.827 & 4.4815 & TRN & & \\
\hline CHEMBL1572157 & 688469 & 4.922 & 3.5722 & TRN & & \\
\hline
\end{tabular}




\begin{tabular}{|c|c|c|c|c|c|}
\hline & & \multicolumn{4}{|c|}{ Supplemental Table S2.txt } \\
\hline CHEMBL1547785 & 688469 & 2.9208 & 4.1696 & TRN & \\
\hline CHEMBL1466251 & 688469 & 2.9208 & 3.6491 & TRN & \\
\hline CHEMBL1562664 & 688469 & 4.9877 & 4.5802 & TRN & \\
\hline CHEMBL1459916 & 688469 & 4.7831 & 4.3492 & TRN & \\
\hline CHEMBL1462970 & 688469 & 4.3701 & 4.127 & TST & \\
\hline CHEMBL1476556 & 688469 & 4.5388 & 4.2182 & TRN & \\
\hline CHEMBL1563424 & 688469 & 4.7215 & 3.3026 & TRN & \\
\hline CHEMBL1562575 & 688469 & 8.0 & 7.57700 & 0000000001 & TRN \\
\hline CHEMBL1536437 & 688469 & 4.8816 & 4.7569 & TRN & \\
\hline CHEMBL1342029 & 688469 & 2.9208 & 4.73 & TRN & \\
\hline CHEMBL1370744 & 688469 & 5.1138 & 4.8106 & TRN & \\
\hline CHEMBL1338624 & 688469 & 2.9208 & 4.4787 & TST & \\
\hline CHEMBL1544011 & 688469 & 2.9208 & 3.5586 & TRN & \\
\hline CHEMBL1336914 & 688469 & 2.9208 & 4.3473 & TRN & \\
\hline CHEMBL1306265 & 688469 & 2.9208 & 4.3836 & TRN & \\
\hline CHEMBL1453067 & 688469 & 4.8428 & 4.4414 & TRN & \\
\hline CHEMBL1328529 & 688469 & 2.9208 & 3.9063 & TST & \\
\hline CHEMBL1476264 & 688469 & 5.0215 & 5.9707 & TRN & \\
\hline CHEMBL1612267 & 688469 & 2.9208 & 4.2575 & TRN & \\
\hline CHEMBL1508668 & 688469 & 4.6567 & 4.558 & TRN & \\
\hline CHEMBL1546992 & 688469 & 2.9208 & 3.3995 & TST & \\
\hline CHEMBL181930 & 688469 & 2.9208 & 3.6537 & TRN & \\
\hline CHEMBL1547760 & 688469 & 6.5331 & 6.0137 & TRN & \\
\hline CHEMBL1468683 & 688469 & 4.7377 & 3.4506 & TRN & \\
\hline CHEMBL1418158 & 688469 & 4.953 & 4.2779 & TRN & \\
\hline CHEMBL1567908 & 688469 & 2.9208 & 3.2116 & TRN & \\
\hline CHEMBL1321622 & 688469 & 6.5482 & 6.3176 & TRN & \\
\hline CHEMBL1539413 & 688469 & 2.9208 & 4.1836 & TRN & \\
\hline CHEMBL1424898 & 688469 & 2.9208 & 4.6038 & TRN & \\
\hline CHEMBL1438210 & 688469 & 5.0076 & 4.5179 & TRN & \\
\hline CHEMBL1987454 & 688469 & 5.0681 & 4.6017 & TRN & \\
\hline CHEMBL3189243 & 688469 & 4.9595 & 5.0214 & TRN & \\
\hline CHEMBL1497865 & 688469 & 2.9208 & 3.4183 & TST & \\
\hline CHEMBL 2000750 & 688469 & 4.9754 & 4.9041 & TRN & \\
\hline CHEMBL1558287 & 688469 & 4.8005 & 3.9556 & TRN & \\
\hline CHEMBL1353271 & 688469 & 5.1005 & 4.6006 & TRN & \\
\hline CHEMBL1584186 & 688469 & 4.8883 & 4.2884 & TRN & \\
\hline CHEMBL1526910 & 688469 & 5.0834 & 4.5351 & TRN & \\
\hline CHEMBL373137 & 688469 & 8.0 & 6.3186 & TRN & \\
\hline CHEMBL1426435 & 688469 & 4.8428 & 4.7687 & TRN & \\
\hline CHEMBL1597706 & 688469 & 2.9208 & 3.5569 & TRN & \\
\hline CHEMBL1507179 & 688469 & 2.9208 & 3.5354 & TRN & \\
\hline CHEMBL1499914 & 688469 & 2.9208 & 3.9641 & TRN & \\
\hline CHEMBL1560034 & 688469 & 4.4068 & 3.3597 & TRN & \\
\hline CHEMBL1332878 & 688469 & 6.8356 & 6.5755 & TRN & \\
\hline CHEMBL1462204 & 688469 & 4.7637 & 3.603 & TRN & \\
\hline CHEMBL1409219 & 688469 & 2.9208 & 4.6129 & TRN & \\
\hline CHEMBL1392176 & 688469 & 4.8254 & 4.1184 & TRN & \\
\hline
\end{tabular}




\begin{tabular}{|c|c|c|c|c|}
\hline & & & oplement & al Ta \\
\hline CHEMBL1508373 & 688469 & 2.9208 & 3.6854 & TRN \\
\hline CHEMBL1606524 & 688469 & 4.8487 & 4.1105 & TRN \\
\hline CHEMBL1562190 & 688469 & 4.7574 & 4.8913 & TRN \\
\hline CHEMBL3199020 & 688469 & 5.5278 & 5.8021 & TRN \\
\hline CHEMBL1537509 & 688469 & 8.0 & 6.6229 & TST \\
\hline CHEMBL1600287 & 688469 & 4.7965 & 3.4078 & TRN \\
\hline CHEMBL3196324 & 688469 & 5.4256 & 5.9599 & TRN \\
\hline CHEMBL1477200 & 688469 & 2.9208 & 3.4653 & TRN \\
\hline CHEMBL1967256 & 688469 & 4.8519 & 4.4481 & TRN \\
\hline CHEMBL1333035 & 688469 & 2.9208 & 5.0646 & TRN \\
\hline CHEMBL1465741 & 688469 & 3.2218 & 4.68 & TRN \\
\hline CHEMBL3192890 & 688469 & 2.9208 & 4.1562 & TRN \\
\hline CHEMBL1504569 & 688469 & 5.0411 & 4.9117 & TRN \\
\hline CHEMBL1358906 & 688469 & 2.9208 & 4.3847 & TST \\
\hline CHEMBL1555935 & 688469 & 8.0 & 6.9969 & TRN \\
\hline CHEMBL1397452 & 688469 & 5.0654 & 4.8278 & TRN \\
\hline CHEMBL1412554 & 688469 & 2.9208 & 3.4015 & TRN \\
\hline CHEMBL1600399 & 688469 & 5.1744 & 4.3215 & TRN \\
\hline CHEMBL578502 & 688469 & 4.9648 & 4.6551 & TRN \\
\hline CHEMBL1380862 & 688469 & 4.8221 & 3.9651 & TRN \\
\hline CHEMBL581225 & 688469 & 2.9208 & 4.7061 & TST \\
\hline CHEMBL1446341 & 688469 & 4.8729 & 3.764 & TRN \\
\hline CHEMBL1563221 & 688469 & 4.6754 & 4.7644 & TRN \\
\hline CHEMBL1401272 & 688469 & 6.0074 & 4.8222 & TRN \\
\hline CHEMBL1490905 & 688469 & 4.5138 & 3.6298 & TRN \\
\hline CHEMBL1580848 & 688469 & 6.8477 & 6.2576 & TRN \\
\hline CHEMBL1579636 & 688469 & 5.3648 & 5.6788 & TRN \\
\hline CHEMBL1317745 & 688469 & 2.9208 & 3.5264 & TRN \\
\hline CHEMBL1556805 & 688469 & 4.3602 & 5.494 & TST \\
\hline CHEMBL1361196 & 688469 & 4.834 & 4.4571 & TRN \\
\hline CHEMBL3199243 & 688469 & 2.9208 & 3.6108 & TRN \\
\hline CHEMBL1301573 & 688469 & 5.0082 & 5.2048 & TRN \\
\hline CHEMBL1535361 & 688469 & 4.9258 & 5.0034 & TRN \\
\hline CHEMBL1505277 & 688469 & 2.9208 & 3.5628 & TRN \\
\hline CHEMBL1393183 & 688469 & 2.9208 & 3.8677 & TRN \\
\hline CHEMBL1545196 & 688469 & 2.9208 & 3.6051 & TRN \\
\hline CHEMBL 3212407 & 688469 & 2.9208 & 3.4781 & TRN \\
\hline CHEMBL1354093 & 688469 & 4.9381 & 5.7718 & TRN \\
\hline CHEMBL1503756 & 688469 & 2.9208 & 3.2498 & TRN \\
\hline CHEMBL1555681 & 688469 & 2.9208 & 3.23 & TRN \\
\hline CHEMBL1420030 & 688469 & 2.9208 & 3.4429 & TRN \\
\hline CHEMBL1571181 & 688469 & 2.9208 & 3.3332 & TRN \\
\hline CHEMBL1587732 & 688469 & 2.9208 & 3.3385 & TRN \\
\hline CHEMBL1376657 & 688469 & 4.9553 & 4.5556 & TRN \\
\hline CHEMBL1353180 & 688469 & 2.9208 & 4.2471 & TST \\
\hline CHEMBL1350432 & 688469 & 5.0892 & 4.8393 & TST \\
\hline CHEMBL1576248 & 688469 & 4.1606 & 4.2435 & TRN \\
\hline CHEMBL1496342 & 688469 & 2.9208 & 4.4357 & TRN \\
\hline
\end{tabular}


Supplemental Table S2.txt

\begin{tabular}{|c|c|c|c|c|}
\hline 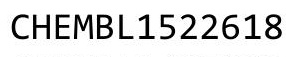 & & 208 & 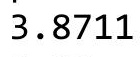 & \\
\hline HEMBL1497289 & 88469 & 2729 & 4.32 & \\
\hline HEMBL1497230 & 88469 & .5708 & 8088 & \\
\hline IEMBL1989858 & & & & \\
\hline IEMBL13 & 469 & 208 & 1 & \\
\hline HEMBL1599796 & 88469 & 7382 & 3545 & \\
\hline HEMBL1310861 & 88469 & 2.9208 & .7117 & \\
\hline HEMBL16e & 88469 & & 2528 & \\
\hline IEMBL16e & 8469 & 208 & 4543 & \\
\hline IEMBL14 & 69 & & 5679 & \\
\hline HEMBL1388599 & 88469 & 8.0 & 4619 & \\
\hline HEMBL1538625 & 88469 & 97 & 2112 & \\
\hline HEMBL132 & 88469 & & 5449 & \\
\hline HEMBL14 & 59 & & 256 & \\
\hline HEMBL15 & 59 & & & \\
\hline HEMBL 206 & 88469 & & & \\
\hline HEMBL198 & 88469 & & .7601 & \\
\hline HEMBL155 & 59 & & 07 & \\
\hline HEMBL14 & 9 & & & \\
\hline HEMBL 32 & 59 & & & \\
\hline HEMBL13 & 59 & 12 & & \\
\hline HEMBL158 & 88 & & 16 & RN \\
\hline HEMBL14 & 9 & & 17 & RN \\
\hline HEMBL13 & & & & \\
\hline HEME & 59 & & & RN \\
\hline HEMBL14 & 59 & & & ST \\
\hline JEMBL16. & 884 & 38 & 904 & RN \\
\hline HEMBL13 & 9 & 49 & 706 & RN \\
\hline HEME & 9 & & & RN \\
\hline HEMBL13 & 59 & & & ST \\
\hline HEMBL142 & 9 & & & RN \\
\hline HEMBL149 & 88469 & $r$ & 36 & RN \\
\hline HEMBL15€ & 9 & & 03 & RN \\
\hline IFM & 9 & & & RN \\
\hline HEMBL14 & & & & RN \\
\hline HEMBL133 & 884 & & & RN \\
\hline HEMBL149 & 88469 & & & ST \\
\hline HEMBL15 & 9 & & & RN \\
\hline IIM & & & & RN \\
\hline HEMBL131 & & & & RN \\
\hline HEMBL138 & 88469 & & 205 & ST \\
\hline HEMBL319 & 59 & & & ST \\
\hline HEMBL146 & & 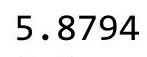 & & \\
\hline LHEMBL136 & 88469 & & & RN \\
\hline HEMBL1595516 & & & & RN \\
\hline HEMBL14 & 88469 & 4. & 58 & $\mathrm{~N}$ \\
\hline 14 & & & & \\
\hline רי 19 & & & & \\
\hline
\end{tabular}

Page 4391 


\begin{tabular}{|c|c|c|c|c|c|c|}
\hline & & & oplement & & s2.txt & \\
\hline CHEMBL1314284 & 688469 & 3.98199 & 99999999 & 998 & 5.9948 & TRN \\
\hline CHEMBL3145088 & 688469 & 5.4722 & 5.1597 & TRN & & \\
\hline CHEMBL1444874 & 688469 & 4.5387 & 4.1487 & TST & & \\
\hline CHEMBL504142 & 688469 & 4.8956 & 4.8621 & TST & & \\
\hline CHEMBL1430182 & 688469 & 2.9208 & 3.6479 & TRN & & \\
\hline CHEMBL1503764 & 688469 & 2.9208 & 5.0463 & TRN & & \\
\hline CHEMBL1598196 & 688469 & 2.9208 & 3.318 & TRN & & \\
\hline CHEMBL1427281 & 688469 & $4.7780 e$ & 00000000 & 205 & 3.4263 & TRN \\
\hline CHEMBL 2002849 & 688469 & 2.9208 & 4.1 & TRN & & \\
\hline CHEMBL1308497 & 688469 & 2.9208 & 3.4604 & TRN & & \\
\hline CHEMBL1330626 & 688469 & 4.7517 & 4.4929 & TRN & & \\
\hline CHEMBL1530184 & 688469 & 2.9208 & 3.4945 & TRN & & \\
\hline CHEMBL1565969 & 688469 & 2.9208 & 4.356 & TST & & \\
\hline CHEMBL1451300 & 688469 & 2.9208 & 3.9559 & TRN & & \\
\hline CHEMBL1320566 & 688469 & 5.0065 & 4.7667 & TST & & \\
\hline CHEMBL3191745 & 688469 & 2.9208 & 3.5553 & TRN & & \\
\hline CHEMBL606675 & 688469 & 4.862 & 4.4036 & TST & & \\
\hline CHEMBL1348251 & 688469 & 4.635 & 4.0605 & TRN & & \\
\hline CHEMBL1401175 & 688469 & 5.0339 & 4.7276 & TRN & & \\
\hline CHEMBL1561676 & 688469 & 4.9409 & 4.8345 & TRN & & \\
\hline CHEMBL1376974 & 688469 & 8.0 & 5.71 & TST & & \\
\hline CHEMBL1335000 & 688469 & 4.0799 & 3.7252 & TRN & & \\
\hline CHEMBL1351542 & 688469 & 4.9783 & 4.9383 & TRN & & \\
\hline CHEMBL1407944 & 688469 & 5.1285 & 5.6677 & TRN & & \\
\hline CHEMBL1491827 & 688469 & 4.7565 & 3.925 & TRN & & \\
\hline CHEMBL1590547 & 688469 & 5.0807 & 4.7105 & TST & & \\
\hline CHEMBL3197990 & 688469 & 8.0 & 5.6185 & TRN & & \\
\hline CHEMBL1611191 & 688469 & 6.224 & 5.4496 & TRN & & \\
\hline CHEMBL1480952 & 688469 & 4.7409 & 3.4036 & TRN & & \\
\hline CHEMBL1595169 & 688469 & 8.0 & 6.9419 & TRN & & \\
\hline CHEMBL1441228 & 688469 & 2.9208 & 4.48 & TRN & & \\
\hline CHEMBL1928491 & 688469 & 5.149 & 5.1529 & TRN & & \\
\hline CHEMBL1544655 & 688469 & 2.9208 & 3.9743 & TRN & & \\
\hline CHEMBL1397089 & 688469 & 5.2879 & 6.3245 & TST & & \\
\hline CHEMBL1306460 & 688469 & 5.1331 & 6.0792 & TRN & & \\
\hline CHEMBL 2000517 & 688469 & 5.5411 & 5.5054 & TRN & & \\
\hline CHEMBL1363955 & 688469 & 5.6275 & 4.4133 & TRN & & \\
\hline CHEMBL1541717 & 688469 & 2.9208 & 3.5178 & TRN & & \\
\hline CHEMBL1335553 & 688469 & 2.9208 & 4.3734 & TRN & & \\
\hline CHEMBL586029 & 688469 & 2.9208 & 4.6898 & TRN & & \\
\hline CHEMBL3192625 & 688469 & 4.8776 & 4.0324 & TRN & & \\
\hline CHEMBL1465671 & 688469 & 2.9208 & 4.7278 & TRN & & \\
\hline CHEMBL1557954 & 688469 & 4.9297 & 4.06 & TRN & & \\
\hline CHEMBL1544095 & 688469 & 2.9208 & 3.3294 & TRN & & \\
\hline CHEMBL1446095 & 688469 & 4.9223 & 3.7779 & TRN & & \\
\hline CHEMBL1575389 & 688469 & 4.9142 & 4.5017 & TRN & & \\
\hline CHEMBL1590016 & 688469 & 5.3515 & 5.1855 & TRN & & \\
\hline CHEMBL1503983 & 688469 & 2.9208 & 3.6984 & TRN & & \\
\hline
\end{tabular}




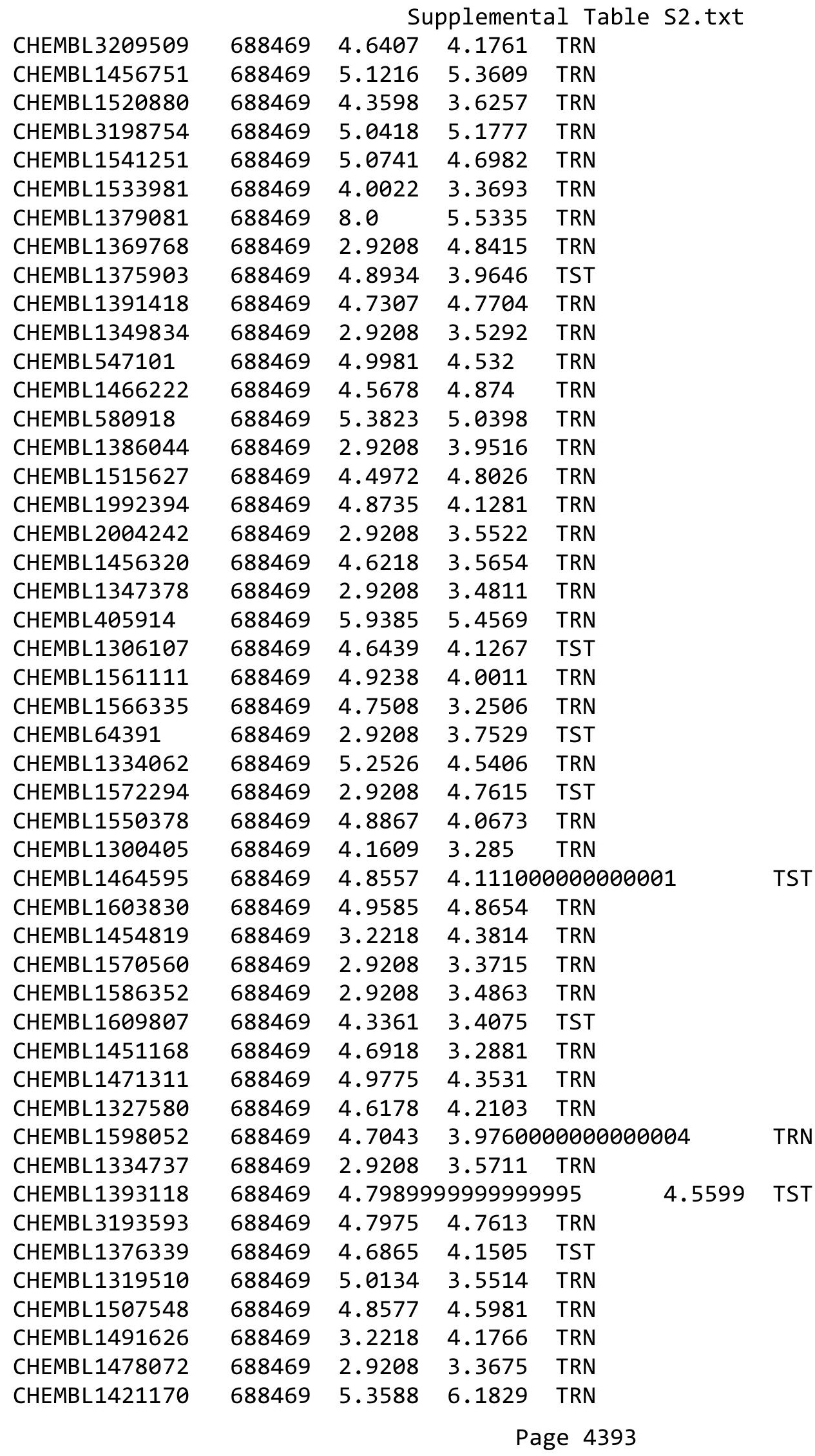




\begin{tabular}{|c|c|c|c|c|c|}
\hline & & & & & \\
\hline CHEMBL1324197 & 688469 & 8.0 & 6.7372 & TRN & \\
\hline CHEMBL1324125 & 688469 & 8.0 & 6.2024 & TRN & \\
\hline CHEMBL1402900 & 688469 & 4.9793 & 4.998 & TRN & \\
\hline CHEMBL1457419 & 688469 & 4.9339 & 4.2803 & TRN & \\
\hline CHEMBL1545656 & 688469 & 4.7919 & 4.6048 & TRN & \\
\hline CHEMBL1335176 & 688469 & 2.9208 & 5.1426 & TST & \\
\hline CHEMBL1419114 & 688469 & 4.8586 & 4.67399 & 99999999995 & TRN \\
\hline CHEMBL1427494 & 688469 & 6.0269 & 3.9671 & TRN & \\
\hline CHEMBL1972651 & 688469 & 4.9633 & 5.0393 & TRN & \\
\hline CHEMBL1390234 & 688469 & 2.9208 & 3.3902 & TRN & \\
\hline CHEMBL1309450 & 688469 & 4.7672 & 4.6216 & TRN & \\
\hline CHEMBL1506791 & 688469 & 2.9208 & 3.4656 & TST & \\
\hline CHEMBL1528067 & 688469 & 5.0402 & 5.1246 & TRN & \\
\hline CHEMBL1404086 & 688469 & 4.856 & 4.1845 & TRN & \\
\hline CHEMBL1355541 & 688469 & 8.0 & 6.3717 & TST & \\
\hline CHEMBL1562712 & 688469 & 5.6142 & 6.7202 & TRN & \\
\hline CHEMBL 2006221 & 688469 & 5.0356 & 4.8817 & TRN & \\
\hline CHEMBL1585682 & 688469 & 8.0 & 5.8051 & TRN & \\
\hline CHEMBL1343081 & 688469 & 4.6833 & 3.2584 & TRN & \\
\hline CHEMBL1537452 & 688469 & 6.8297 & 6.1795 & TRN & \\
\hline CHEMBL1379405 & 688469 & 2.9208 & 3.41399 & 99999999997 & TRN \\
\hline CHEMBL3190649 & 688469 & 4.7507 & 4.01 & TRN & \\
\hline CHEMBL1536679 & 688469 & 2.9208 & 3.436006 & 00000000004 & TRN \\
\hline CHEMBL1332007 & 688469 & 5.0114 & 4.4691 & TRN & \\
\hline CHEMBL1469827 & 688469 & 4.926 & 4.7961 & TRN & \\
\hline CHEMBL1570491 & 688469 & 5.103 & 4.9289 & TRN & \\
\hline CHEMBL530291 & 688469 & 5.0957 & 4.9879 & TRN & \\
\hline CHEMBL1416108 & 688469 & 2.9208 & 4.1253 & TRN & \\
\hline CHEMBL1299644 & 688469 & 2.9208 & 4.1423 & TRN & \\
\hline CHEMBL1309897 & 688469 & 4.879 & 4.4483 & TST & \\
\hline CHEMBL1974613 & 688469 & 2.9208 & 4.3054 & TRN & \\
\hline CHEMBL1460225 & 688469 & 5.013 & 4.7311 & TRN & \\
\hline CHEMBL1505799 & 688469 & 4.8001 & 3.8108 & TRN & \\
\hline CHEMBL1584564 & 688469 & 4.9739 & 6.7544 & TRN & \\
\hline CHEMBL1613639 & 688469 & 6.6655 & 5.7866 & TRN & \\
\hline CHEMBL1510690 & 688469 & 5.3852 & 5.3977 & TRN & \\
\hline CHEMBL1322293 & 688469 & 4.8333 & 4.1987 & TRN & \\
\hline CHEMBL1995692 & 688469 & 6.5171 & 5.9199 & TRN & \\
\hline CHEMBL1301531 & 688469 & 4.4356 & 4.1985 & TRN & \\
\hline CHEMBL1585423 & 688469 & 4.8809 & 4.1447 & TRN & \\
\hline CHEMBL1611882 & 688469 & 2.9208 & 3.2053 & TRN & \\
\hline CHEMBL1572031 & 688469 & 2.9208 & 4.5464 & TRN & \\
\hline CHEMBL1330516 & 688469 & 4.9442 & 4.9993 & TRN & \\
\hline CHEMBL1585625 & 688469 & 2.9208 & 3.3042 & TRN & \\
\hline CHEMBL1381392 & 688469 & 6.3019 & 5.9282 & TRN & \\
\hline CHEMBL1418885 & 688469 & 4.936 & 3.54699 & 99999999997 & TRN \\
\hline CHEMBL1422286 & 688469 & 2.9208 & 3.4928 & TST & \\
\hline CHEMBL1593484 & 688469 & 6.3726 & 4.7979 & TRN & \\
\hline
\end{tabular}




\begin{tabular}{|c|c|c|c|c|c|}
\hline & & \multicolumn{4}{|c|}{ Supplemental Table S2.txt } \\
\hline CHEMBL1506364 & 688469 & 4.8144 & 3.5227 & TST & \\
\hline CHEMBL1496595 & 688469 & 4.9037 & 4.5828 & TRN & \\
\hline CHEMBL486504 & 688469 & 8.0 & 6.5641 & TST & \\
\hline CHEMBL1456201 & 688469 & 2.9208 & 3.6005 & TST & \\
\hline CHEMBL1459841 & 688469 & 6.8861 & 6.53600 & 00000000005 & TRN \\
\hline CHEMBL1484632 & 688469 & 5.265 & 5.1683 & TST & \\
\hline CHEMBL1506879 & 688469 & 2.9208 & 3.7435 & TRN & \\
\hline CHEMBL3211356 & 688469 & 4.8974 & 5.1117 & TRN & \\
\hline CHEMBL1330793 & 688469 & 5.3769 & 5.6282 & TST & \\
\hline CHEMBL1328553 & 688469 & 4.8232 & 4.6191 & TST & \\
\hline CHEMBL1494423 & 688469 & 3.2218 & 4.2116 & TRN & \\
\hline CHEMBL1452379 & 688469 & 3.5229 & 4.5576 & TRN & \\
\hline CHEMBL1416848 & 688469 & 5.3605 & 5.2457 & TRN & \\
\hline CHEMBL1578124 & 688469 & 2.9208 & 3.3903 & TST & \\
\hline CHEMBL1391387 & 688469 & 5.3037 & 5.88200 & 0000000001 & TRN \\
\hline CHEMBL1489856 & 688469 & 4.9003 & 4.2762 & TRN & \\
\hline CHEMBL1538880 & 688469 & 2.9208 & 3.7029 & TRN & \\
\hline CHEMBL1337990 & 688469 & 2.9208 & 4.4052 & TRN & \\
\hline CHEMBL1305138 & 688469 & 2.9208 & 3.2464 & TRN & \\
\hline CHEMBL1406488 & 688469 & 4.8034 & 3.6017 & TRN & \\
\hline CHEMBL1350589 & 688469 & 4.9366 & 4.5355 & TRN & \\
\hline CHEMBL1437623 & 688469 & 4.8726 & 4.252 & TRN & \\
\hline CHEMBL1481574 & 688469 & 2.9208 & 3.9305 & TRN & \\
\hline CHEMBL1342336 & 688469 & 8.0 & 6.8067 & TRN & \\
\hline CHEMBL1510332 & 688469 & 4.8202 & 4.4983 & TRN & \\
\hline CHEMBL1487609 & 688469 & 3.2218 & 4.8056 & TRN & \\
\hline CHEMBL1560901 & 688469 & 4.9896 & 4.0224 & TRN & \\
\hline CHEMBL1328795 & 688469 & 4.8213 & 3.8448 & TRN & \\
\hline CHEMBL1468355 & 688469 & 2.9208 & 5.20299 & 9999999999 & TRN \\
\hline CHEMBL1509021 & 688469 & 2.9208 & 3.4755 & TRN & \\
\hline CHEMBL1463699 & 688469 & 4.7269 & 4.3219 & TRN & \\
\hline CHEMBL1381920 & 688469 & 2.9208 & 4.5977 & TST & \\
\hline CHEMBL1340058 & 688469 & 6.6021 & 6.305 & TRN & \\
\hline CHEMBL1585825 & 688469 & 3.2218 & 5.0524 & TRN & \\
\hline CHEMBL1471899 & 688469 & 5.5758 & 5.32 & TRN & \\
\hline CHEMBL1443802 & 688469 & 4.9432 & 4.4093 & TRN & \\
\hline CHEMBL1487794 & 688469 & 2.9208 & 3.4527 & TRN & \\
\hline CHEMBL1367089 & 688469 & 2.9208 & 4.7371 & TRN & \\
\hline CHEMBL1347556 & 688469 & 5.0887 & 4.4262 & TRN & \\
\hline CHEMBL1382361 & 688469 & 4.3872 & 4.4939 & TRN & \\
\hline CHEMBL1491004 & 688469 & 5.0752 & 4.9802 & TRN & \\
\hline CHEMBL3190314 & 688469 & 5.0052 & 4.9744 & TRN & \\
\hline CHEMBL1541771 & 688469 & 4.949 & 5.0241 & TRN & \\
\hline CHEMBL 2138014 & 688469 & 2.9208 & 4.7062 & TRN & \\
\hline CHEMBL1424697 & 688469 & 5.2626 & 5.1608 & TST & \\
\hline CHEMBL1586862 & 688469 & 5.1215 & 6.5722 & TRN & \\
\hline CHEMBL3196105 & 688469 & 2.9208 & 4.4617 & TRN & \\
\hline CHEMBL1567568 & 688469 & 5.1042 & 5.272 & TST & \\
\hline
\end{tabular}




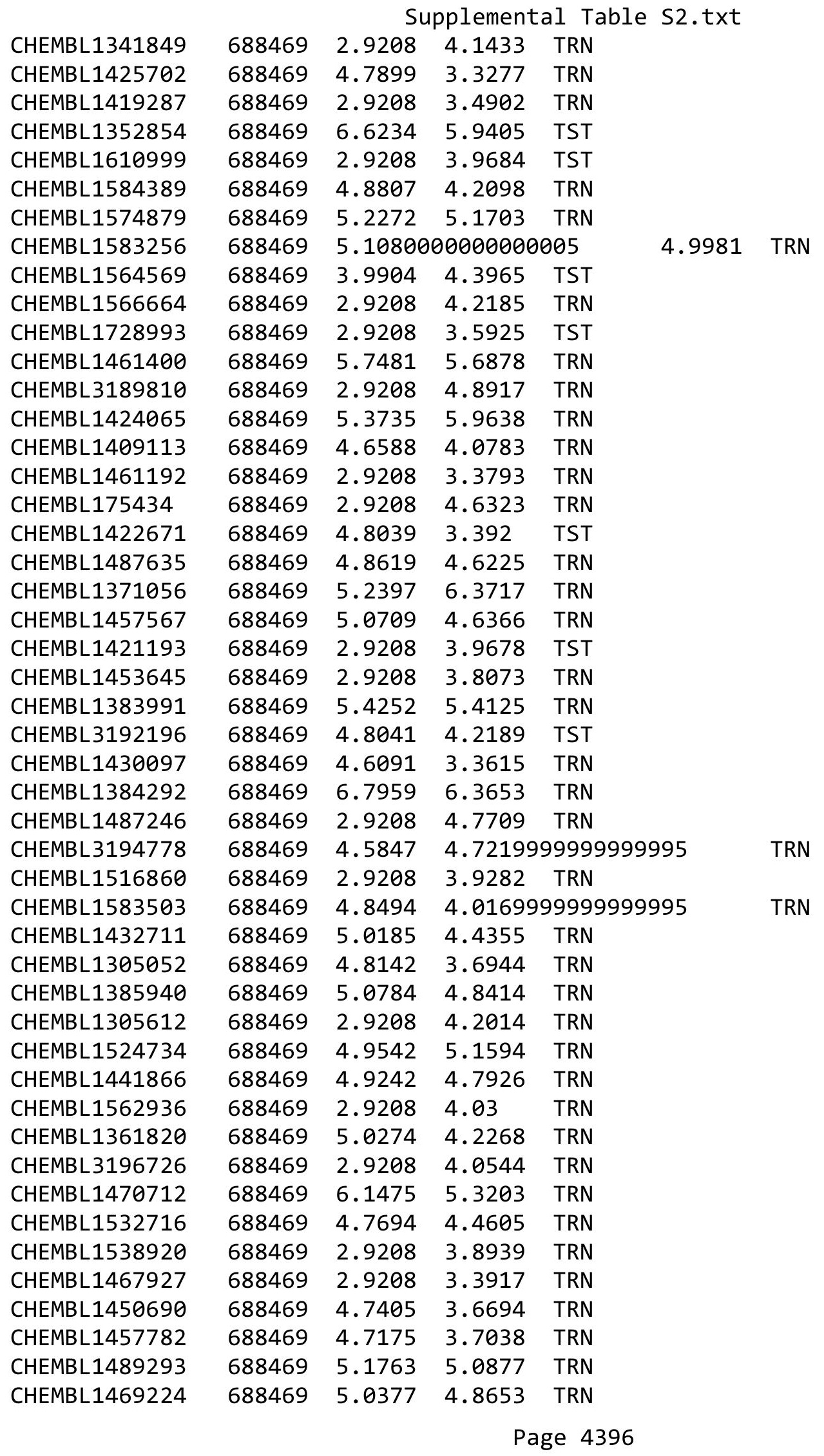




\begin{tabular}{|c|c|c|c|c|c|}
\hline & & \multicolumn{4}{|c|}{ Supplemental Table S2.txt } \\
\hline CHEMBL1467383 & 688469 & 2.9208 & 4.5914 & TRN & \\
\hline CHEMBL3190786 & 688469 & 4.9576 & 4.8419 & TRN & \\
\hline CHEMBL1572278 & 688469 & 5.3254 & 6.353 & TRN & \\
\hline CHEMBL1561439 & 688469 & 4.9131 & 4.8468 & TRN & \\
\hline CHEMBL1484622 & 688469 & 4.9971 & 5.02 & TRN & \\
\hline CHEMBL3196936 & 688469 & 4.9035 & 5.1038 & TRN & \\
\hline CHEMBL3190012 & 688469 & 4.8918 & 5.0425 & TRN & \\
\hline CHEMBL1502526 & 688469 & 2.9208 & 3.3835 & TRN & \\
\hline CHEMBL1402510 & 688469 & 6.5157 & 7.2911 & TRN & \\
\hline CHEMBL1606813 & 688469 & 6.0752 & 5.024 & TRN & \\
\hline CHEMBL1384253 & 688469 & 5.52 & 5.7105 & TRN & \\
\hline CHEMBL1412681 & 688469 & 2.9208 & 3.2459 & TRN & \\
\hline CHEMBL1500168 & 688469 & 2.9208 & 3.1316 & TRN & \\
\hline CHEMBL1378768 & 688469 & 2.9208 & 4.5903 & TST & \\
\hline CHEMBL1412184 & 688469 & 4.8603 & 3.5963 & TRN & \\
\hline CHEMBL1341384 & 688469 & 4.7959 & 3.8828 & TRN & \\
\hline CHEMBL1545881 & 688469 & 2.9208 & 3.7762 & TRN & \\
\hline CHEMBL3191770 & 688469 & 4.8684 & 4.7733 & TRN & \\
\hline CHEMBL1519030 & 688469 & 2.9208 & 3.7152 & TST & \\
\hline CHEMBL1341872 & 688469 & 2.9208 & 3.3956 & TST & \\
\hline CHEMBL1532657 & 688469 & 2.9208 & 3.9057 & TRN & \\
\hline CHEMBL1312166 & 688469 & 2.9208 & 3.47899 & 99999999996 & TRN \\
\hline CHEMBL1400298 & 688469 & 4.9653 & 5.4329 & TRN & \\
\hline CHEMBL1335812 & 688469 & 4.9326 & 4.2987 & TRN & \\
\hline CHEMBL15968 & 688469 & 5.6153 & 5.6065 & TRN & \\
\hline CHEMBL1545679 & 688469 & 5.1046 & 4.6544 & TRN & \\
\hline CHEMBL1332013 & 688469 & 5.38 & 5.0436 & TRN & \\
\hline CHEMBL1529883 & 688469 & 5.6299 & 5.6628 & TRN & \\
\hline CHEMBL1557372 & 688469 & 4.8679 & 4.3413 & TRN & \\
\hline CHEMBL1995152 & 688469 & 5.0512 & 4.4731 & TRN & \\
\hline CHEMBL1301665 & 688469 & 4.7272 & 3.6844 & TRN & \\
\hline CHEMBL470881 & 688469 & 2.9208 & 4.8744 & TST & \\
\hline CHEMBL1349613 & 688469 & 2.9208 & 3.4761 & TRN & \\
\hline CHEMBL1341270 & 688469 & 6.4168 & 5.046 & TRN & \\
\hline CHEMBL1386760 & 688469 & 2.9208 & 4.5095 & TRN & \\
\hline CHEMBL3190770 & 688469 & 2.9208 & 4.4619 & TRN & \\
\hline CHEMBL3212546 & 688469 & 2.9208 & 3.8104 & TRN & \\
\hline CHEMBL1494117 & 688469 & 5.0221 & 4.6166 & TRN & \\
\hline CHEMBL1558822 & 688469 & 2.9208 & 4.2551 & TRN & \\
\hline CHEMBL1606712 & 688469 & 4.8081 & 3.3636 & TRN & \\
\hline CHEMBL1545747 & 688469 & 4.6476 & 3.7278 & TRN & \\
\hline CHEMBL2001216 & 688469 & 3.5229 & 4.0303 & TRN & \\
\hline CHEMBL1349387 & 688469 & 4.9679 & 4.4877 & TRN & \\
\hline CHEMBL1497562 & 688469 & 4.7821 & 5.1522 & TRN & \\
\hline CHEMBL1506428 & 688469 & 2.9208 & 3.9466 & TRN & \\
\hline CHEMBL1312291 & 688469 & 2.9208 & 4.6067 & TRN & \\
\hline CHEMBL1593562 & 688469 & 4.7643 & 4.4598 & TST & \\
\hline CHEMBL1521660 & 688469 & 2.9208 & 4.1862 & TRN & \\
\hline
\end{tabular}




\begin{tabular}{|c|c|c|c|c|c|}
\hline & & \multicolumn{4}{|c|}{ Supplemental Table S2.txt } \\
\hline CHEMBL3191884 & 688469 & 4.7379 & 3.4721 & TRN & \\
\hline CHEMBL1400196 & 688469 & 2.9208 & 5.2564 & TRN & \\
\hline CHEMBL1312906 & 688469 & 4.7886 & 4.3309 & TRN & \\
\hline CHEMBL1504859 & 688469 & 5.0613 & 4.665 & TRN & \\
\hline CHEMBL1403917 & 688469 & 4.8222 & 4.6366 & TRN & \\
\hline CHEMBL1537246 & 688469 & 4.7 & 4.2591 & TRN & \\
\hline CHEMBL1978534 & 688469 & 2.9208 & 3.4055 & TST & \\
\hline CHEMBL1342933 & 688469 & 2.9208 & 3.4258 & TRN & \\
\hline CHEMBL1398603 & 688469 & 2.9208 & 3.4441 & TRN & \\
\hline CHEMBL1412855 & 688469 & 5.0152 & 4.934 & TRN & \\
\hline CHEMBL1603662 & 688469 & 5.0226 & 5.3061 & TRN & \\
\hline CHEMBL3209368 & 688469 & 5.0196 & 4.21399 & 99999999995 & TRN \\
\hline CHEMBL1467873 & 688469 & 4.7964 & 4.2178 & TST & \\
\hline CHEMBL1611300 & 688469 & 5.0583 & 5.3989 & TRN & \\
\hline CHEMBL1521456 & 688469 & 2.9208 & 3.7005 & TRN & \\
\hline CHEMBL1542868 & 688469 & 2.9208 & 3.5134 & TRN & \\
\hline CHEMBL3211923 & 688469 & 4.8334 & 4.8039 & TRN & \\
\hline CHEMBL1524034 & 688469 & 8.0 & 6.1067 & TRN & \\
\hline CHEMBL1321427 & 688469 & 8.0 & 7.1176 & TRN & \\
\hline CHEMBL3191765 & 688469 & 8.0 & 4.6579 & TRN & \\
\hline CHEMBL1528660 & 688469 & 8.0 & 6.6049 & TRN & \\
\hline CHEMBL1374384 & 688469 & 5.2493 & 4.8131 & TRN & \\
\hline CHEMBL1303609 & 688469 & 4.4179 & 4.0971 & TRN & \\
\hline CHEMBL1504701 & 688469 & 6.4045 & 5.7344 & TRN & \\
\hline CHEMBL1534592 & 688469 & 2.9208 & 3.8454 & TRN & \\
\hline CHEMBL1319615 & 688469 & 5.095 & 4.579 & TRN & \\
\hline CHEMBL1967697 & 688469 & 4.9699 & 4.6222 & TRN & \\
\hline CHEMBL1459440 & 688469 & 2.9208 & 3.1772 & TRN & \\
\hline CHEMBL1399388 & 688469 & 4.8228 & 4.3454 & TRN & \\
\hline CHEMBL1334861 & 688469 & 2.9208 & 3.3445 & TRN & \\
\hline CHEMBL1518680 & 688469 & 4.4011 & 3.52399 & 99999999996 & TST \\
\hline CHEMBL1430043 & 688469 & 4.7767 & 4.9376 & TRN & \\
\hline CHEMBL487356 & 688469 & 4.9993 & 4.8585 & TRN & \\
\hline CHEMBL1561380 & 688469 & 2.9208 & 4.1488 & TRN & \\
\hline CHEMBL1573212 & 688469 & 2.9208 & 3.3259 & TRN & \\
\hline CHEMBL1570624 & 688469 & 5.2823 & 5.3189 & TST & \\
\hline CHEMBL1523361 & 688469 & 2.9208 & 3.5073 & TRN & \\
\hline CHEMBL1452898 & 688469 & 4.4618 & 3.22899 & 99999999996 & TRN \\
\hline CHEMBL1379401 & 688469 & 4.8686 & 3.6431 & TRN & \\
\hline CHEMBL1567469 & 688469 & 2.9208 & 3.4116 & TST & \\
\hline CHEMBL1609770 & 688469 & 5.473 & 5.3339 & TRN & \\
\hline CHEMBL1506300 & 688469 & 2.9208 & 3.5617 & TST & \\
\hline CHEMBL166209 & 688469 & 5.6057 & 5.2187 & TRN & \\
\hline CHEMBL1405648 & 688469 & 2.9208 & 3.5031 & TRN & \\
\hline CHEMBL1333930 & 688469 & 8.0 & 6.8049 & TRN & \\
\hline CHEMBL1587323 & 688469 & 4.649 & 3.4038 & TRN & \\
\hline CHEMBL1355233 & 688469 & 5.2806 & 4.673 & TRN & \\
\hline CHEMBL1364172 & 688469 & 2.9208 & 5.0399 & TRN & \\
\hline
\end{tabular}


Supplemental Table S2.txt

\begin{tabular}{|c|c|c|c|c|c|}
\hline CHEMBL1558095 & 688469 & 2.9208 & 3.3842 & TRN & \\
\hline CHEMBL1313644 & 688469 & 2.9208 & 4.2321 & TRN & \\
\hline CHEMBL1345432 & 688469 & 2.9208 & 3.4191 & TST & \\
\hline CHEMBL1528487 & 688469 & 2.9208 & 4.5187 & TRN & \\
\hline CHEMBL1467943 & 688469 & 5.6353 & 5.4935 & TRN & \\
\hline CHEMBL1387528 & 688469 & 2.9208 & 3.3999 & TST & \\
\hline CHEMBL1422161 & 688469 & 2.9208 & 6.279 & TRN & \\
\hline CHEMBL1420309 & 688469 & 4.5741 & 4.1201 & TRN & \\
\hline CHEMBL1469597 & 688469 & 2.9208 & 3.3322 & TRN & \\
\hline CHEMBL1598374 & 688469 & 2.9208 & 4.5339 & TRN & \\
\hline CHEMBL1466656 & 688469 & 2.9208 & 3.3973 & TRN & \\
\hline CHEMBL1400593 & 688469 & 4.9407 & 3.8671 & TRN & \\
\hline CHEMBL1386406 & 688469 & 2.9208 & 3.5564 & TRN & \\
\hline CHEMBL1310355 & 688469 & 4.9825 & 4.8323 & TRN & \\
\hline CHEMBL1375248 & 688469 & 2.9208 & 3.5724 & TRN & \\
\hline CHEMBL1576251 & 688469 & 8.0 & 6.4722 & TRN & \\
\hline CHEMBL1548803 & 688469 & 4.9348 & 4.0495 & TRN & \\
\hline CHEMBL1522803 & 688469 & 5.0402 & 4.9258 & TRN & \\
\hline CHEMBL 237214 & 688469 & 2.9208 & 4.152 & TRN & \\
\hline CHEMBL1385210 & 688469 & 2.9208 & 4.69600 & 3000000001 & TRN \\
\hline CHEMBL1507852 & 688469 & 4.8838 & 4.0832 & TRN & \\
\hline CHEMBL1575124 & 688469 & 5.5502 & 5.1987 & TRN & \\
\hline CHEMBL1569525 & 688469 & 2.9208 & 3.8431 & TRN & \\
\hline CHEMBL 3145303 & 688469 & 6.1349 & 5.8946 & TRN & \\
\hline CHEMBL1439222 & 688469 & 2.9208 & 3.282 & TST & \\
\hline CHEMBL 3210088 & 688469 & 5.0429 & 5.3916 & TRN & \\
\hline CHEMBL1578880 & 688469 & 4.6816 & 4.5646 & TRN & \\
\hline CHEMBL1323461 & 688469 & 4.9214 & 4.5133 & TRN & \\
\hline CHEMBL1374644 & 688469 & 4.8661 & 4.4307 & TRN & \\
\hline CHEMBL1484886 & 688469 & 5.0901 & 4.6037 & TRN & \\
\hline CHEMBL1594680 & 688469 & 4.6741 & 4.1346 & TRN & \\
\hline CHEMBL1321166 & 688469 & 4.6431 & 4.0705 & TST & \\
\hline CHEMBL1403276 & 688469 & 5.3971 & 6.195 & TRN & \\
\hline CHEMBL1443472 & 688469 & 2.9208 & 3.3536 & TST & \\
\hline CHEMBL1572746 & 688469 & 6.4078 & 6.0563 & TRN & \\
\hline CHEMBL586602 & 688469 & 5.1744 & 5.0398 & TRN & \\
\hline CHEMBL1488760 & 688469 & 6.8729 & 6.7362 & TRN & \\
\hline CHEMBL1500397 & 688469 & 2.9208 & 4.6183 & TRN & \\
\hline CHEMBL1398647 & 688469 & 2.9208 & 3.4148 & TRN & \\
\hline CHEMBL1506283 & 688469 & 4.7842 & 3.7552 & TRN & \\
\hline CHEMBL1499095 & 688469 & 2.9208 & 3.3039 & TRN & \\
\hline CHEMBL1423270 & 688469 & 4.9029 & 3.9967 & TRN & \\
\hline CHEMBL3190651 & 688469 & 4.8086 & 4.6235 & TRN & \\
\hline CHEMBL1546566 & 688469 & 4.9428 & 3.9246 & TRN & \\
\hline CHEMBL1316831 & 688469 & 8.0 & 6.4946 & TST & \\
\hline CHEMBL1371339 & 688469 & 6.2596 & 5.1081 & TRN & \\
\hline CHEMBL1302099 & 688469 & 2.9208 & 4.3022 & TRN & \\
\hline CHEMBL1506962 & 688469 & 4.9972 & 4.8455 & TRN & \\
\hline
\end{tabular}

Page 4399 


\begin{tabular}{|c|c|c|c|c|}
\hline \multicolumn{5}{|c|}{ Supplemental Table S2.txt } \\
\hline CHEMBL1572139 & 688469 & 4.8394 & 5.8611 & TRN \\
\hline CHEMBL1307031 & 688469 & 4.0996 & 3.5192 & TST \\
\hline CHEMBL1442323 & 688469 & 2.9208 & 3.3237 & TRN \\
\hline CHEMBL1526462 & 688469 & 4.7516 & 3.4489 & TRN \\
\hline CHEMBL1526298 & 688469 & 4.8273 & 3.6769 & TRN \\
\hline CHEMBL1452595 & 688469 & 2.9208 & 3.4065 & TRN \\
\hline CHEMBL1389541 & 688469 & 2.9208 & 3.1636 & TRN \\
\hline CHEMBL1314195 & 688469 & 4.9297 & 3.9662 & TRN \\
\hline CHEMBL1423192 & 688469 & 8.0 & 6.6353 & TRN \\
\hline CHEMBL533226 & 688469 & 6.2899 & 4.9813 & TRN \\
\hline CHEMBL1577495 & 688469 & 4.9881 & 3.4532 & TRN \\
\hline CHEMBL3192156 & 688469 & 4.6494 & 4.0167 & TRN \\
\hline CHEMBL1420777 & 688469 & 2.9208 & 3.3277 & TST \\
\hline CHEMBL1586489 & 688469 & 4.9802 & 5.987 & TRN \\
\hline CHEMBL602997 & 688469 & 2.9208 & 4.8189 & TRN \\
\hline CHEMBL1502608 & 688469 & 2.9208 & 3.5489 & TRN \\
\hline CHEMBL 3194554 & 688469 & 2.9208 & 4.0476 & TST \\
\hline CHEMBL1454000 & 688469 & 5.0148 & 4.8251 & TRN \\
\hline CHEMBL460601 & 688469 & 8.0 & 6.6364 & TST \\
\hline CHEMBL1495092 & 688469 & 8.0 & 5.9616 & TST \\
\hline CHEMBL1497910 & 688469 & 4.7336 & 3.6637 & TRN \\
\hline CHEMBL1385414 & 688469 & 2.9208 & 3.5871 & TRN \\
\hline CHEMBL1329237 & 688469 & 6.5317 & 6.4739 & TRN \\
\hline CHEMBL1539864 & 688469 & 4.9017 & 4.3742 & TRN \\
\hline CHEMBL 259103 & 688469 & 8.0 & 6.3231 & TRN \\
\hline CHEMBL 3190805 & 688469 & 4.7321 & 5.215 & TRN \\
\hline CHEMBL1560324 & 688469 & 2.9208 & 4.8806 & TRN \\
\hline CHEMBL3197433 & 688469 & 4.2766 & 5.3289 & TRN \\
\hline CHEMBL1478486 & 688469 & 4.7597 & 4.704 & TRN \\
\hline CHEMBL1307395 & 688469 & 2.9208 & 3.1564 & TRN \\
\hline CHEMBL1471808 & 688469 & 4.9587 & 4.6692 & TRN \\
\hline CHEMBL1331904 & 688469 & 5.2623 & 5.8202 & TRN \\
\hline CHEMBL1309679 & 688469 & 2.9208 & 4.1979 & TRN \\
\hline CHEMBL1500722 & 688469 & 2.9208 & 3.4697 & TRN \\
\hline CHEMBL1303463 & 688469 & 4.7337 & 4.4919 & TRN \\
\hline CHEMBL1602344 & 688469 & 2.9208 & 4.1458 & TRN \\
\hline CHEMBL1485006 & 688469 & 2.9208 & 3.4045 & TRN \\
\hline CHEMBL1300952 & 688469 & 8.0 & 5.5726 & TRN \\
\hline CHEMBL3199752 & 688469 & 4.8307 & 4.9061 & TRN \\
\hline CHEMBL3208365 & 688469 & 5.0303 & 5.1167 & TRN \\
\hline CHEMBL1536119 & 688469 & 2.9208 & 3.3251 & TRN \\
\hline CHEMBL1484547 & 688469 & 5.3124 & 5.2627 & TRN \\
\hline CHEMBL1463463 & 688469 & 4.8965 & 4.4551 & TRN \\
\hline CHEMBL1526550 & 688469 & 2.9208 & 3.6502 & TRN \\
\hline CHEMBL3191879 & 688469 & 5.0707 & 5.0084 & TRN \\
\hline CHEMBL1375884 & 688469 & 4.9144 & 4.7534 & TRN \\
\hline CHEMBL 251785 & 688469 & 8.0 & 6.1547 & TRN \\
\hline CHEMBL1573496 & 688469 & 2.9208 & 3.8491 & TRN \\
\hline
\end{tabular}


Supplemental Table S2.txt

\begin{tabular}{|c|c|c|c|c|}
\hline IE & & 8 & & \\
\hline UГMDI 1100510 & & .9208 & 4.0857 & \\
\hline & & & & \\
\hline IEMBL15908 & & & & \\
\hline AEMBL1547087 & & 9208 & 208 & \\
\hline HEMBL1575038 & 88469 & 7628 & 5196 & \\
\hline HEMBL 193872 & 8469 & & & \\
\hline AEMBL157 & & & & \\
\hline AEMBL1979106 & 69 & & & \\
\hline HEMBL1603164 & 88469 & 208 & 1524 & \\
\hline AEMBL1570761 & 88469 & 815 & & \\
\hline EMBL319 & 59 & & 65 & \\
\hline HEMBL156 & & & & \\
\hline AEMBL1341999 & 59 & & & \\
\hline AEMBL158 & 88469 & 37 & & \\
\hline AEMBL134 & 88469 & 98 & 72 & \\
\hline IEMBL155 & 9 & & & \\
\hline HEMBL154 & & & & \\
\hline HEMBL155 & 59 & & & \\
\hline AEMBL158 & 59 & & & II \\
\hline EMBLI42 & 59 & & & \\
\hline AEMBL13 & & & & \\
\hline AEMBL14 & & & & RN \\
\hline HEMBL199 & & & & MM \\
\hline IEMBL141 & & & & \\
\hline AEMBL1S & 9 & & & \\
\hline AEMBL: & & & & res \\
\hline AFMBI 14 & & & & RN \\
\hline HEMBL134 & & & & KIV \\
\hline HEMBL 3194 & & & & RN \\
\hline HEMBL138e & & & & $2 \mathrm{~N}$ \\
\hline HEMBL: & & & & RN \\
\hline AEMBL14 & 59 & & & ST \\
\hline HEMBL1329255 & & & & RN \\
\hline HEMBL1098875 & 88469 & & 775 & TRN \\
\hline AEMBL158 & 59 & & 144 & ST \\
\hline HEMPI 1 & & & & RN \\
\hline HEMBL13 & & & & RN \\
\hline HEMBL1460757 & 88469 & & & TRN \\
\hline IEMBL14 & 88 & & & RN \\
\hline HEMBL146 & 59 & 37 & & \\
\hline HEMBL1351532 & & & & TRN \\
\hline HEMBL1494220 & & & 4758 & RN \\
\hline AEMBL1329662 & 88469 & 08 & 139 & TRN \\
\hline MBL1 & & & & I \\
\hline HEMBL1501 & 59 & & & \\
\hline CHEMBL1431314 & 88469 & 2.9208 & .1166 & \\
\hline HEMBL1415642 & 688469 & 4.7672 & 3.5264 & \\
\hline
\end{tabular}

Page 4401 
Supplemental Table S2.txt

\begin{tabular}{|c|c|c|c|c|}
\hline CHEMBL1407961 & 688469 & 4.9525 & 4.7967 & TRN \\
\hline CHEMBL1515483 & 688469 & 2.9208 & 3.3186 & TRN \\
\hline CHEMBL1414850 & 688469 & 4.7962 & 3.4507 & TRN \\
\hline CHEMBL1496478 & 688469 & 4.8973 & 4.5996 & TRN \\
\hline CHEMBL 3198692 & 688469 & 4.5345 & 4.3732 & TRN \\
\hline CHEMBL1466243 & 688469 & 5.215 & 4.4888 & TRN \\
\hline CHEMBL1339546 & 688469 & 6.0851 & 5.0872 & TRN \\
\hline CHEMBL1503359 & 688469 & 5.2271 & 4.987 & TRN \\
\hline CHEMBL1302130 & 688469 & 2.9208 & 3.4482 & TST \\
\hline CHEMBL1323412 & 688469 & 5.2226 & 4.6269 & TRN \\
\hline CHEMBL1408368 & 688469 & 4.8231 & 4.7613 & TRN \\
\hline CHEMBL1521149 & 688469 & 2.9208 & 3.9832 & TRN \\
\hline CHEMBL1400322 & 688469 & 3.2218 & 5.3767 & TST \\
\hline CHEMBL1341290 & 688469 & 5.117 & 4.8517 & TRN \\
\hline CHEMBL1549525 & 688469 & 5.6302 & 5.6969 & TST \\
\hline CHEMBL1496138 & 688469 & 2.9208 & 4.6847 & TST \\
\hline CHEMBL1302495 & 688469 & 2.9208 & 4.5205 & TST \\
\hline CHEMBL1365398 & 688469 & 2.9208 & 4.8199 & TRN \\
\hline CHEMBL1572375 & 688469 & 4.8735 & 4.1984 & TRN \\
\hline CHEMBL1377889 & 688469 & 2.9208 & 3.5735 & TRN \\
\hline CHEMBL1498834 & 688469 & 4.6257 & 3.4148 & TRN \\
\hline CHEMBL1587516 & 688469 & 4.7142 & 4.4707 & TRN \\
\hline CHEMBL1538534 & 688469 & 4.7752 & 3.2064 & TRN \\
\hline CHEMBL1378991 & 688469 & 4.6876 & 3.2974 & TRN \\
\hline CHEMBL1310101 & 688469 & 3.9799 & 3.9202 & TRN \\
\hline CHEMBL1525220 & 688469 & 5.0055 & 4.7378 & TRN \\
\hline CHEMBL1442500 & 688469 & 5.044 & 5.2292 & TRN \\
\hline CHEMBL1987820 & 688469 & 5.2935 & 4.9906 & TRN \\
\hline CHEMBL1353693 & 688469 & 4.9048 & 4.7011 & TRN \\
\hline CHEMBL1468313 & 688469 & 4.2632 & 3.571 & TRN \\
\hline CHEMBL1584336 & 688469 & 2.9208 & 3.323 & TRN \\
\hline CHEMBL1488591 & 688469 & 2.9208 & 4.76699 & 99999999995 \\
\hline CHEMBL1460047 & 688469 & 4.3 & 3.3335 & TRN \\
\hline CHEMBL1523792 & 688469 & 5.1141 & 5.037 & TRN \\
\hline CHEMBL1538446 & 688469 & 4.6166 & 4.3123 & TRN \\
\hline CHEMBL1488730 & 688469 & 6.6216 & 6.2691 & TRN \\
\hline CHEMBL1485890 & 688469 & 4.9904 & 4.8275 & TRN \\
\hline CHEMBL1303719 & 688469 & 5.2437 & 5.1519 & TRN \\
\hline CHEMBL1557615 & 688469 & 4.9605 & 4.6209 & TRN \\
\hline CHEMBL193627 & 688469 & 6.8477 & 6.1101 & TST \\
\hline CHEMBL1457201 & 688469 & 5.2589 & 4.5992 & TRN \\
\hline CHEMBL1464973 & 688469 & 4.7118 & 4.1025 & TRN \\
\hline CHEMBL1595938 & 688469 & 4.7641 & 4.0677 & TRN \\
\hline CHEMBL 3210297 & 688469 & 4.8948 & 3.5439 & TRN \\
\hline CHEMBL1560772 & 688469 & 2.9208 & 3.9199 & TRN \\
\hline CHEMBL1373207 & 688469 & 2.9208 & 3.9877 & TST \\
\hline CHEMBL1401973 & 688469 & 2.9208 & 3.9889 & TRN \\
\hline CHEMBL1445707 & 688469 & 5.119 & 5.4728 & TRN \\
\hline
\end{tabular}


Supplemental Table S2.txt

\begin{tabular}{|c|c|c|c|c|}
\hline CHEMBL1486267 & 688469 & 2.9208 & 4.2124 & TST \\
\hline CHEMBL1377507 & 688469 & 2.9208 & 3.9945 & TST \\
\hline CHEMBL3189393 & 688469 & 4.7686 & 3.9425 & TRN \\
\hline CHEMBL1471211 & 688469 & 3.5229 & \multicolumn{2}{|c|}{4.0360000000000005} \\
\hline CHEMBL1365261 & 688469 & 2.9208 & 3.3326 & TRN \\
\hline CHEMBL1324061 & 688469 & 5.1469 & 6.1303 & TRN \\
\hline CHEMBL1430657 & 688469 & 2.9208 & 3.7959 & TRN \\
\hline CHEMBL1420325 & 688469 & 2.9208 & 4.8131 & TRN \\
\hline CHEMBL1989817 & 688469 & 2.9208 & 4.178 & TRN \\
\hline CHEMBL517645 & 688469 & 8.0 & 6.9462 & TST \\
\hline CHEMBL1452391 & 688469 & 5.0722 & 5.0949 & TRN \\
\hline CHEMBL1583867 & 688469 & 2.9208 & 3.5977 & TRN \\
\hline CHEMBL1332139 & 688469 & 8.0 & 6.6075 & TRN \\
\hline CHEMBL1329006 & 688469 & 2.9208 & 3.6654 & TRN \\
\hline CHEMBL1452116 & 688469 & 5.093 & 4.6914 & TRN \\
\hline CHEMBL1576489 & 688469 & 2.9208 & 4.2512 & TRN \\
\hline CHEMBL1326215 & 688469 & 4.6969 & 3.7183 & TRN \\
\hline CHEMBL1543742 & 688469 & 5.0917 & 4.8755 & TRN \\
\hline CHEMBL1977930 & 688469 & 2.9208 & 4.6766 & TRN \\
\hline CHEMBL1557333 & 688469 & 4.8839 & 4.3807 & TRN \\
\hline CHEMBL1310439 & 688469 & 2.9208 & 3.207 & TRN \\
\hline CHEMBL1418611 & 688469 & 2.9208 & 4.9488 & TRN \\
\hline CHEMBL1601647 & 688469 & 5.5124 & 5.5405 & TRN \\
\hline CHEMBL1369269 & 688469 & 4.8081 & 4.4238 & TRN \\
\hline CHEMBL1304245 & 688469 & 2.9208 & 3.5707 & TRN \\
\hline CHEMBL1429850 & 688469 & 6.1238 & 5.7229 & TRN \\
\hline CHEMBL1320542 & 688469 & 2.9208 & 4.6075 & TRN \\
\hline CHEMBL3212551 & 688469 & 5.0361 & 5.0305 & TRN \\
\hline CHEMBL1360484 & 688469 & 8.0 & 5.7397 & TRN \\
\hline CHEMBL3195226 & 688469 & 4.8754 & 4.4054 & TRN \\
\hline CHEMBL1383035 & 688469 & 4.8352 & 3.4076 & TRN \\
\hline CHEMBL505209 & 688469 & 4.6113 & 4.7875 & TRN \\
\hline CHEMBL1576870 & 688469 & 8.0 & 6.5896 & TRN \\
\hline CHEMBL1562367 & 688469 & 4.7322 & 3.3647 & TRN \\
\hline CHEMBL1477197 & 688469 & 5.0697 & 3.8349 & TRN \\
\hline CHEMBL1600065 & 688469 & 4.5934 & 4.8691 & TRN \\
\hline CHEMBL1495451 & 688469 & 2.9208 & 4.2289 & TST \\
\hline CHEMBL1476215 & 688469 & 5.4827 & 6.2943 & TRN \\
\hline CHEMBL1522289 & 688469 & 4.8912 & 5.6887 & TRN \\
\hline CHEMBL1411830 & 688469 & 2.9208 & 4.3047 & TRN \\
\hline CHEMBL 2006844 & 688469 & 5.0404 & 4.5625 & TRN \\
\hline CHEMBL1430581 & 688469 & 2.9208 & 4.4723 & TRN \\
\hline CHEMBL3208398 & 688469 & 2.9208 & 4.1416 & TRN \\
\hline CHEMBL1407046 & 688469 & 2.9208 & 3.3381 & TRN \\
\hline CHEMBL1313520 & 688469 & 8.0 & 7.0219 & TRN \\
\hline CHEMBL1367325 & 688469 & 5.3839 & 4.9997 & TRN \\
\hline CHEMBL3212783 & 688469 & 2.9208 & 3.4552 & TST \\
\hline CHEMBL1320808 & 688469 & 2.9208 & 4.9559 & TRN \\
\hline
\end{tabular}


Supplemental Table S2.txt

\begin{tabular}{|c|c|c|c|c|c|}
\hline CHEMBL1423970 & 688469 & 2.9208 & 4.6665 & TST & \\
\hline CHEMBL1415368 & 688469 & 2.9208 & 3.3566 & TRN & \\
\hline CHEMBL1504509 & 688469 & 4.9974 & 4.6363 & TRN & \\
\hline CHEMBL1362507 & 688469 & 8.0 & 5.5726 & TRN & \\
\hline CHEMBL1334578 & 688469 & 2.9208 & 3.4462 & TRN & \\
\hline CHEMBL1359973 & 688469 & 2.9208 & 3.4696 & TST & \\
\hline CHEMBL1572800 & 688469 & 4.9221 & 3.3373 & TRN & \\
\hline CHEMBL1610036 & 688469 & 4.9746 & 4.8571 & TRN & \\
\hline CHEMBL 3199157 & 688469 & 2.9208 & 4.27 & TRN & \\
\hline CHEMBL1485377 & 688469 & 2.9208 & 3.8497 & TRN & \\
\hline CHEMBL1388595 & 688469 & 5.0791 & 4.6526 & TRN & \\
\hline CHEMBL1611686 & 688469 & 2.9208 & 4.247 & TRN & \\
\hline CHEMBL1543238 & 688469 & 6.1878 & 6.2276 & TRN & \\
\hline CHEMBL1517849 & 688469 & 2.9208 & 3.5117 & TRN & \\
\hline CHEMBL1517243 & 688469 & 4.6119 & 3.7612 & TRN & \\
\hline CHEMBL1579084 & 688469 & 4.9463 & 5.1435 & TRN & \\
\hline CHEMBL1456768 & 688469 & 4.9463 & 4.3035 & TRN & \\
\hline CHEMBL1589670 & 688469 & 4.8814 & 4.7458 & TRN & \\
\hline CHEMBL1468700 & 688469 & 2.9208 & 4.2338 & TRN & \\
\hline CHEMBL1454614 & 688469 & 5.0774 & 4.328 & TRN & \\
\hline CHEMBL1428986 & 688469 & 4.7681 & 3.978 & TRN & \\
\hline CHEMBL1561738 & 688469 & 4.6798 & 3.4895 & TRN & \\
\hline CHEMBL1600769 & 688469 & 4.5607 & 3.324 & TRN & \\
\hline CHEMBL1386546 & 688469 & 4.9952 & 4.9622 & TRN & \\
\hline CHEMBL1299526 & 688469 & 5.0923 & 3.993000 & 30000000003 & TRN \\
\hline CHEMBL602722 & 688469 & 5.2761 & 5.9737 & TRN & \\
\hline CHEMBL1359890 & 688469 & 2.9208 & 4.1713 & TRN & \\
\hline CHEMBL1973669 & 688469 & 4.961 & 5.0044 & TRN & \\
\hline CHEMBL1301700 & 688469 & 2.9208 & 4.8486 & TST & \\
\hline CHEMBL1310553 & 688469 & 2.9208 & 4.2906 & TST & \\
\hline CHEMBL1999193 & 688469 & 2.9208 & 3.6972 & TRN & \\
\hline CHEMBL1367134 & 688469 & 2.9208 & 3.3188 & TST & \\
\hline CHEMBL1549738 & 688469 & 4.9633 & 3.8426 & TST & \\
\hline CHEMBL1409039 & 688469 & 6.3851 & 5.4853 & TRN & \\
\hline CHEMBL 3194623 & 688469 & 5.67299 & 999999999 & 4.9457 & TRN \\
\hline CHEMBL1400888 & 688469 & 2.9208 & 4.2083 & TRN & \\
\hline CHEMBL1343705 & 688469 & 4.8158 & 4.7195 & TRN & \\
\hline CHEMBL1417944 & 688469 & 2.9208 & 3.3645 & TRN & \\
\hline CHEMBL1606115 & 688469 & 3.2218 & 4.6785 & TRN & \\
\hline CHEMBL1442176 & 688469 & 2.9208 & 4.0481 & TRN & \\
\hline CHEMBL1401141 & 688469 & 2.9208 & 3.4326 & TRN & \\
\hline CHEMBL1318757 & 688469 & 4.8612 & 3.3637 & TRN & \\
\hline CHEMBL 3197250 & 688469 & 4.9553 & 4.7549 & TRN & \\
\hline CHEMBL1363839 & 688469 & 4.8962 & 4.7783 & TRN & \\
\hline CHEMBL1978733 & 688469 & 5.052 & 4.9327 & TRN & \\
\hline CHEMBL591126 & 688469 & 5.2234 & 5.2828 & TRN & \\
\hline CHEMBL1575284 & 688469 & 4.5933 & 4.4683 & TRN & \\
\hline CHEMBL1424691 & 688469 & 2.9208 & 3.4447 & TRN & \\
\hline
\end{tabular}




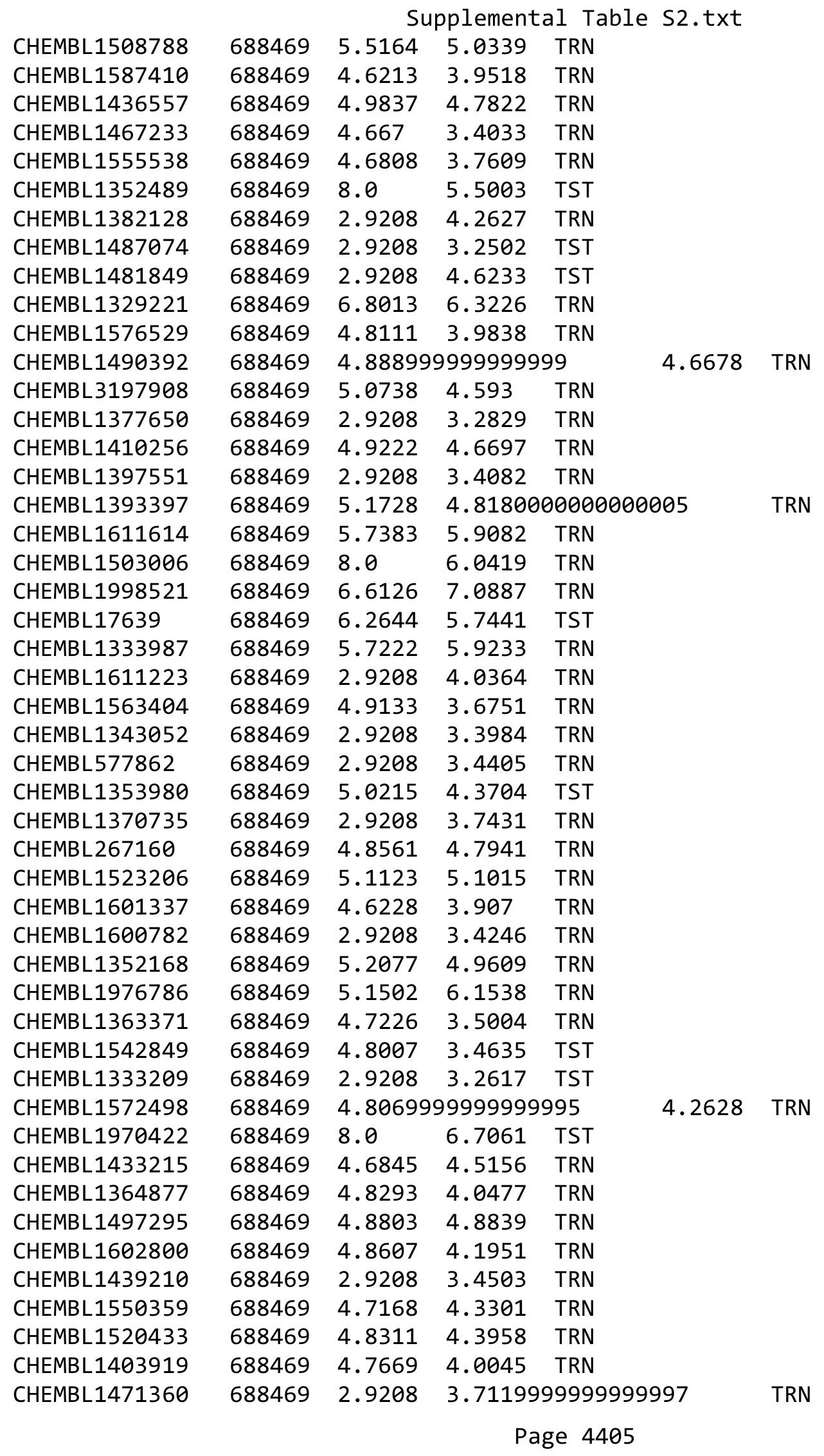




\begin{tabular}{|c|c|c|c|c|c|c|}
\hline & & \multicolumn{5}{|c|}{ Supplemental Table S2.txt } \\
\hline CHEMBL1320019 & 688469 & 2.9208 & 4.4536 & TRN & & \\
\hline CHEMBL1410483 & 688469 & 4.762 & 3.7735 & TRN & & \\
\hline CHEMBL492468 & 688469 & 2.9208 & 4.6148 & TST & & \\
\hline CHEMBL1489123 & 688469 & 8.0 & 4.8014 & TRN & & \\
\hline CHEMBL1985582 & 688469 & 5.5817 & 5.4833 & TRN & & \\
\hline CHEMBL1447556 & 688469 & 4.8078 & 3.341 & TRN & & \\
\hline CHEMBL1588626 & 688469 & 4.5852 & 3.4815 & TRN & & \\
\hline CHEMBL1599438 & 688469 & 2.9208 & 4.9697 & TRN & & \\
\hline CHEMBL1320095 & 688469 & 2.9208 & 4.7719 & TRN & & \\
\hline CHEMBL1504565 & 688469 & 4.3663 & 3.2237 & TRN & & \\
\hline CHEMBL1306186 & 688469 & 2.9208 & 3.4242 & TRN & & \\
\hline CHEMBL1377218 & 688469 & 2.9208 & 3.8334 & TRN & & \\
\hline CHEMBL1426800 & 688469 & 4.9017 & 3.8232 & TST & & \\
\hline CHEMBL1427089 & 688469 & 4.6703 & 4.2578 & TRN & & \\
\hline CHEMBL1575194 & 688469 & 2.9208 & 3.7229 & TRN & & \\
\hline CHEMBL1506641 & 688469 & 4.9371 & 4.8755 & TRN & & \\
\hline CHEMBL1462745 & 688469 & 8.0 & 5.7685 & TRN & & \\
\hline CHEMBL1384920 & 688469 & \multicolumn{3}{|c|}{5.0489999999999995} & 4.2693 & TRN \\
\hline CHEMBL 1542780 & 688469 & 8.0 & 5.3666 & TRN & & \\
\hline CHEMBL1453061 & 688469 & 4.8574 & 4.1509 & TRN & & \\
\hline CHEMBL1421347 & 688469 & 4.7676 & 4.3354 & TST & & \\
\hline CHEMBL1489585 & 688469 & 4.841 & 4.6616 & TRN & & \\
\hline CHEMBL1348840 & 688469 & 4.7177 & 3.2623 & TRN & & \\
\hline CHEMBL1999480 & 688469 & 5.2397 & 4.9543 & TRN & & \\
\hline CHEMBL1304897 & 688469 & 2.9208 & 3.832 & TST & & \\
\hline CHEMBL1503892 & 688469 & 4.4728 & 4.2134 & TRN & & \\
\hline CHEMBL1404578 & 688469 & 4.9135 & 4.4489 & TRN & & \\
\hline CHEMBL463763 & 688469 & 8.0 & 6.6 & TST & & \\
\hline CHEMBL1469852 & 688469 & 4.7839 & 3.2106 & TRN & & \\
\hline CHEMBL1456943 & 688469 & 2.9208 & 3.6145 & TRN & & \\
\hline CHEMBL1358782 & 688469 & 5.3559 & 6.28700 & 0000000001 & & TRN \\
\hline CHEMBL1419582 & 688469 & 2.9208 & 3.7335 & TRN & & \\
\hline CHEMBL1466833 & 688469 & 2.9208 & 3.4195 & TRN & & \\
\hline CHEMBL1491327 & 688469 & 5.4963 & 5.2119 & TRN & & \\
\hline CHEMBL1422586 & 688469 & 4.9631 & 4.1312 & TRN & & \\
\hline CHEMBL1537552 & 688469 & 2.9208 & 3.4495 & TRN & & \\
\hline CHEMBL3199311 & 688469 & 5.3363 & 6.2906 & TRN & & \\
\hline CHEMBL1993165 & 688469 & 5.0107 & 5.1369 & TRN & & \\
\hline CHEMBL1386429 & 688469 & 4.7163 & 4.6345 & TRN & & \\
\hline CHEMBL3213635 & 688469 & 2.9208 & 3.4859 & TRN & & \\
\hline CHEMBL1384729 & 688469 & 4.5629 & 4.5959 & TRN & & \\
\hline CHEMBL1586623 & 688469 & 5.0135 & 4.4711 & TRN & & \\
\hline CHEMBL1536753 & 688469 & 2.9208 & 3.2276 & TRN & & \\
\hline CHEMBL1301721 & 688469 & 4.8713 & 3.7908 & TRN & & \\
\hline CHEMBL1594613 & 688469 & 2.9208 & 3.3767 & TRN & & \\
\hline CHEMBL 6742 & 688469 & 5.1952 & 4.9049 & TRN & & \\
\hline CHEMBL1981103 & 688469 & 2.9208 & 4.8006 & TST & & \\
\hline CHEMBL3190974 & 688469 & 4.9589 & 4.7337 & TRN & & \\
\hline
\end{tabular}


Supplemental Table S2.txt

\begin{tabular}{|c|c|c|c|c|}
\hline CHEMBL1311547 & 688469 & 4.989 & 4.7933 & TRN \\
\hline CHEMBL1588263 & 688469 & 4.8793 & 4.0846 & TST \\
\hline CHEMBL1487444 & 688469 & 5.0891 & 4.6487 & TRN \\
\hline CHEMBL1481780 & 688469 & 2.9208 & 3.9464 & TRN \\
\hline CHEMBL1539359 & 688469 & 3.2218 & 5.0365 & TRN \\
\hline CHEMBL1467399 & 688469 & 2.9208 & 3.6275 & TRN \\
\hline CHEMBL1990258 & 688469 & 5.0642 & 5.2213 & TRN \\
\hline CHEMBL1324224 & 688469 & 2.9208 & 4.7441 & TRN \\
\hline CHEMBL1539642 & 688469 & 2.9208 & 3.4219 & TRN \\
\hline CHEMBL1608722 & 688469 & 8.0 & 4.7001 & TRN \\
\hline CHEMBL1320575 & 688469 & 4.5224 & 3.9374 & TRN \\
\hline CHEMBL1604761 & 688469 & 4.7978 & 4.3321 & TRN \\
\hline CHEMBL1492289 & 688469 & 4.9759 & 3.6451 & TRN \\
\hline CHEMBL1401566 & 688469 & 4.7926 & 3.4526 & TST \\
\hline CHEMBL1985330 & 688469 & 4.9989 & 5.0886 & TRN \\
\hline CHEMBL1496771 & 688469 & 4.5536 & 3.4168 & TRN \\
\hline CHEMBL1459746 & 688469 & 6.4271 & 5.2303 & TRN \\
\hline CHEMBL1563001 & 688469 & 4.7673 & 3.6397 & TRN \\
\hline CHEMBL1382960 & 688469 & 2.9208 & 3.4275 & TST \\
\hline CHEMBL3198554 & 688469 & 4.935 & 4.7771 & TRN \\
\hline CHEMBL1434686 & 688469 & 4.6473 & 3.486 & TRN \\
\hline CHEMBL53260 & 688469 & 2.9208 & 3.7485 & TST \\
\hline CHEMBL1607180 & 688469 & 4.6024 & 4.4208 & TRN \\
\hline CHEMBL1521023 & 688469 & 8.0 & 7.1415 & TRN \\
\hline CHEMBL 37570 & 688469 & 6.4737 & 5.8086 & TRN \\
\hline CHEMBL1456821 & 688469 & 4.8898 & 3.8951 & TRN \\
\hline CHEMBL1546607 & 688469 & 2.9208 & 4.6929 & TRN \\
\hline CHEMBL1497019 & 688469 & 6.1669 & 6.0126 & TRN \\
\hline CHEMBL1495001 & 688469 & 4.7895 & 3.46199 & 99999999997 \\
\hline CHEMBL3211050 & 688469 & 2.9208 & 4.7282 & TRN \\
\hline CHEMBL1589009 & 688469 & 2.9208 & 3.2455 & TRN \\
\hline CHEMBL1460544 & 688469 & 4.9255 & 4.0453 & TRN \\
\hline CHEMBL603129 & 688469 & 5.8511 & 6.1 & TRN \\
\hline CHEMBL3191011 & 688469 & 4.9416 & 4.6906 & TRN \\
\hline CHEMBL1490339 & 688469 & 6.5751 & 6.4282 & TRN \\
\hline CHEMBL1306095 & 688469 & 2.9208 & 3.4975 & TRN \\
\hline CHEMBL1580002 & 688469 & 2.9208 & 3.5203 & TST \\
\hline CHEMBL1278035 & 688469 & 5.0422 & 4.6509 & TST \\
\hline CHEMBL3211859 & 688469 & 5.0024 & 4.8633 & TRN \\
\hline CHEMBL1310617 & 688469 & 5.6317 & 5.7694 & TRN \\
\hline CHEMBL1593640 & 688469 & 2.9208 & 3.7376 & TRN \\
\hline CHEMBL1463249 & 688469 & 4.9419 & 4.6115 & TST \\
\hline CHEMBL1392228 & 688469 & 8.0 & 7.0267 & TRN \\
\hline CHEMBL1591171 & 688469 & 2.9208 & 4.4579 & TST \\
\hline CHEMBL1320068 & 688469 & 4.7013 & 4.033 & TRN \\
\hline CHEMBL3209229 & 688469 & 4.9917 & 4.5262 & TRN \\
\hline CHEMBL1406974 & 688469 & 2.9208 & 3.3527 & TRN \\
\hline CHEMBL1347346 & 688469 & 8.0 & 6.4635 & TRN \\
\hline
\end{tabular}




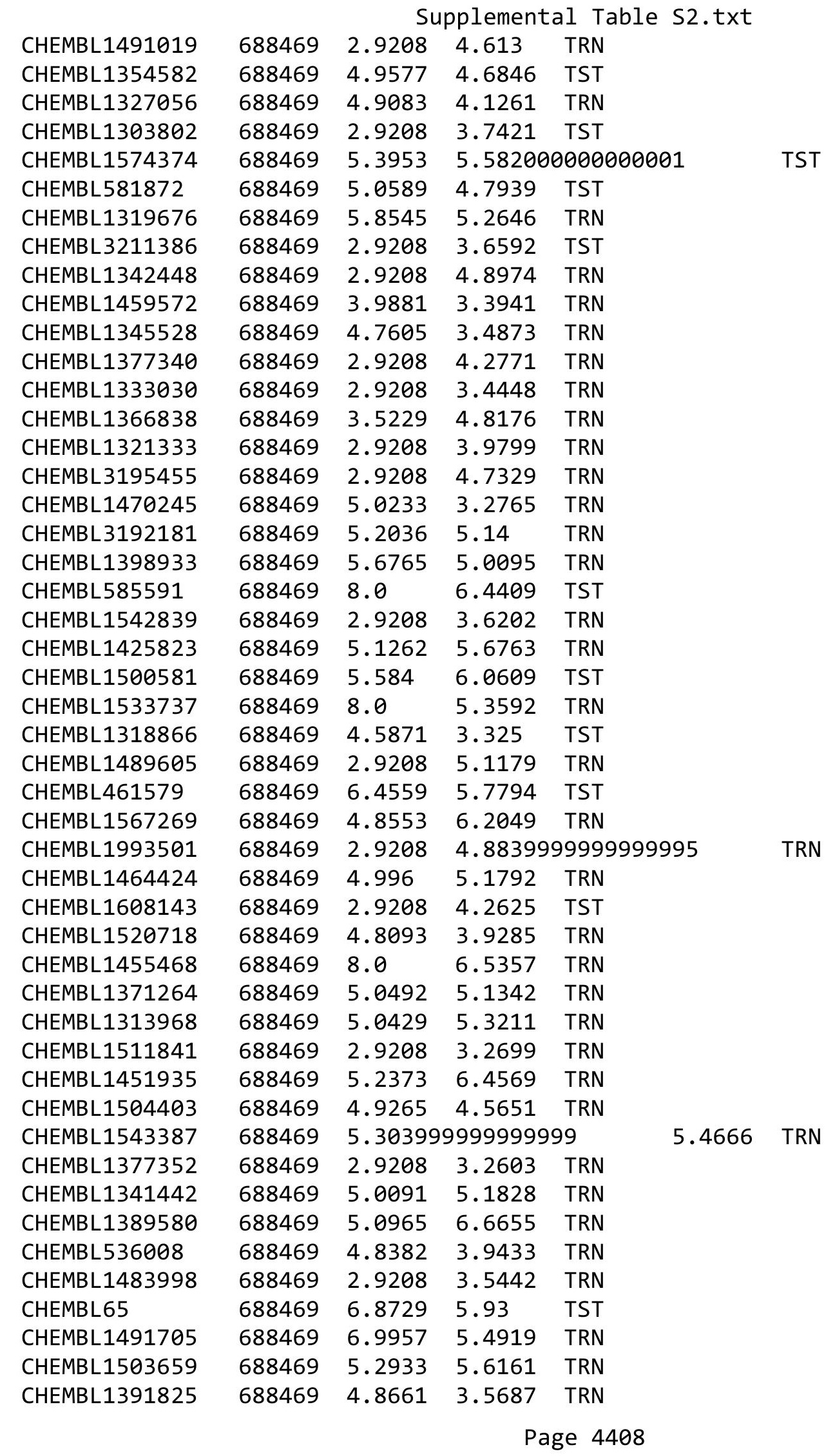




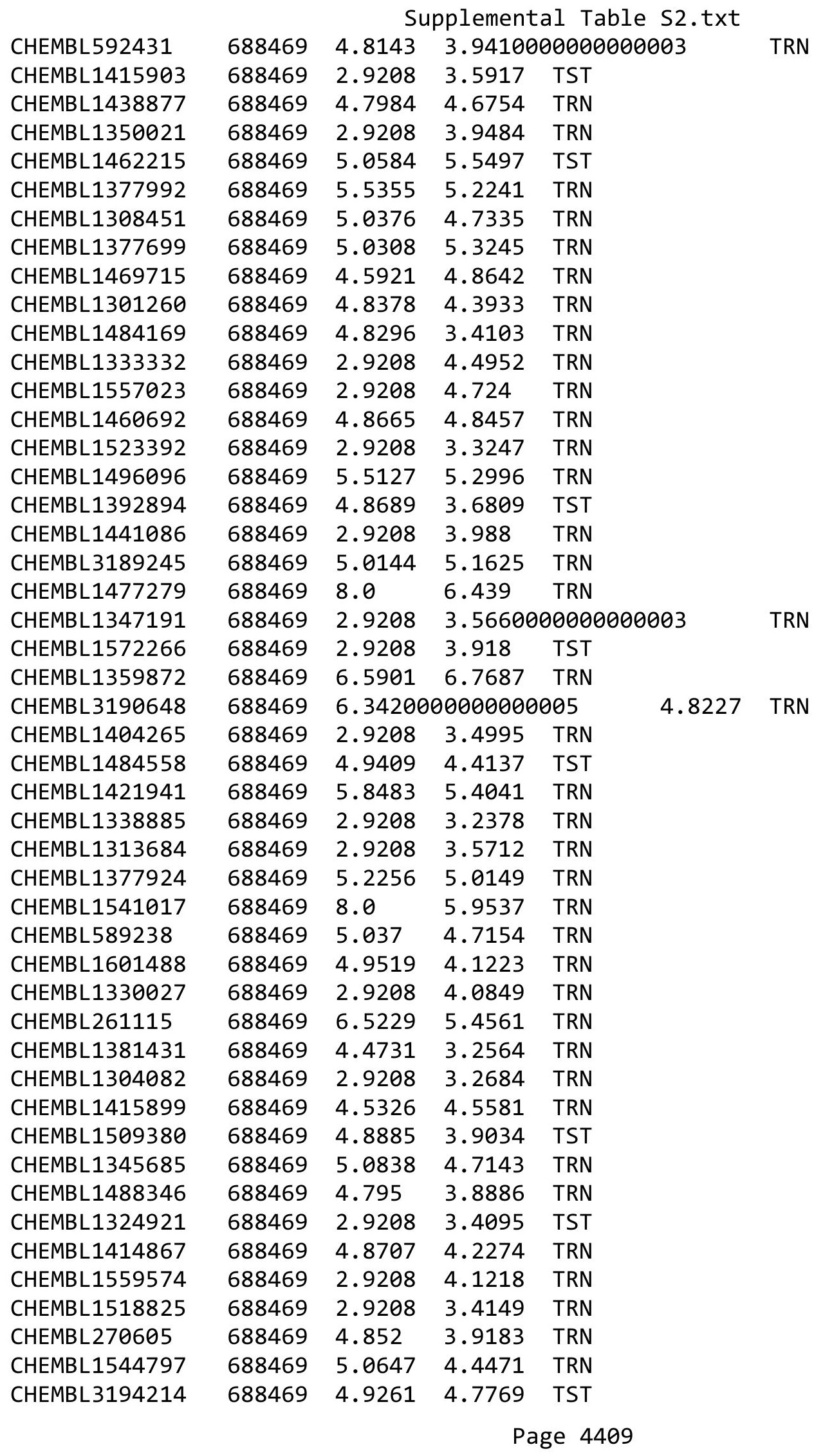




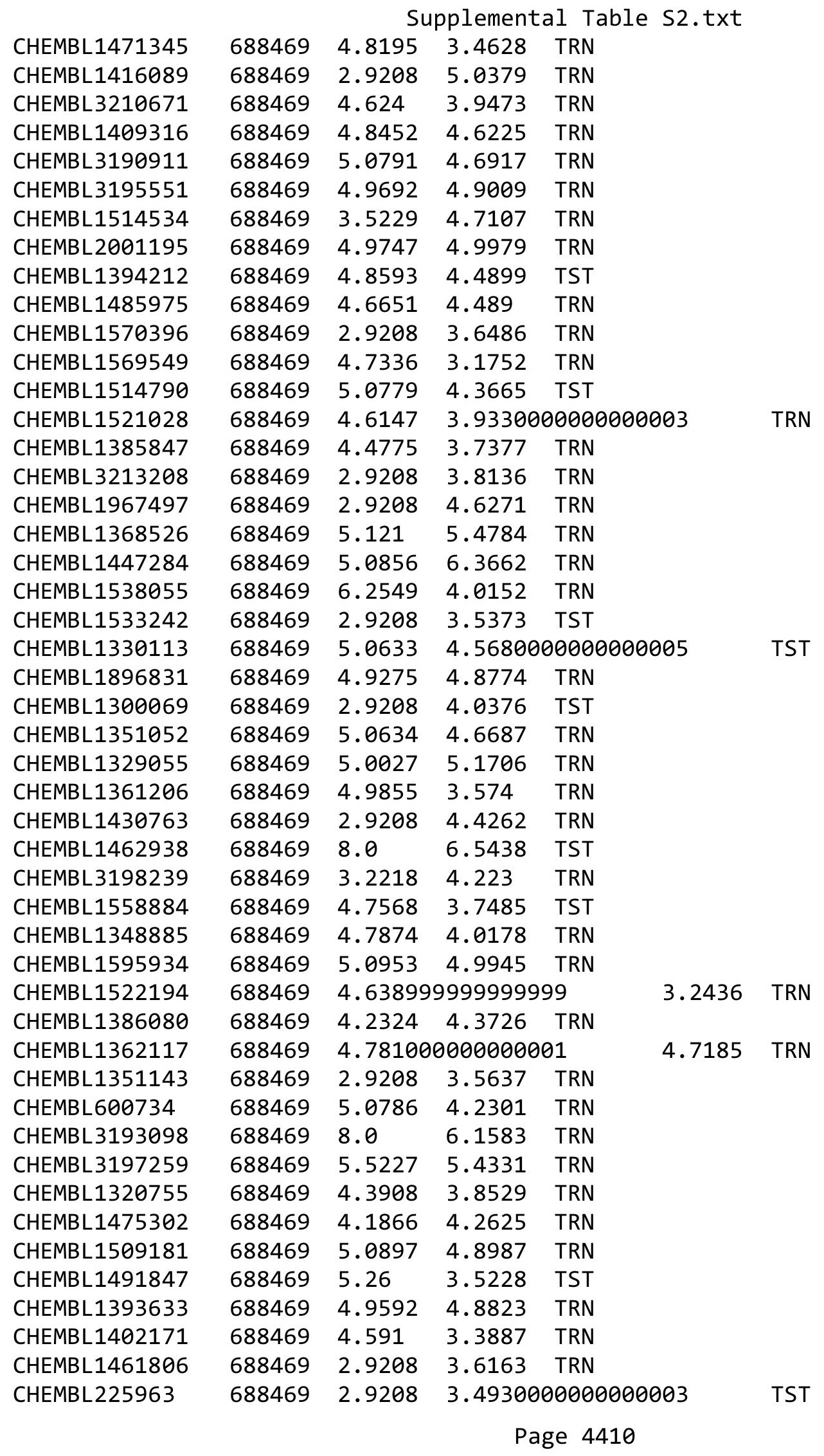


Supplemental Table S2.txt

\begin{tabular}{|c|c|c|c|c|}
\hline CHEMBL1325260 & 688469 & 4.8879 & 4.6825 & TRN \\
\hline CHEMBL1374924 & 688469 & 2.9208 & 4.2216 & TRN \\
\hline CHEMBL1404030 & 688469 & 2.9208 & 3.5045 & TST \\
\hline CHEMBL601757 & 688469 & 6.6289 & 5.6496 & TRN \\
\hline CHEMBL 3195273 & 688469 & 6.6402 & 5.6751 & TRN \\
\hline CHEMBL1493848 & 688469 & 4.4492 & 3.8126 & TRN \\
\hline CHEMBL1362086 & 688469 & 2.9208 & 4.0804 & TRN \\
\hline CHEMBL1573311 & 688469 & 4.8332 & 4.2815 & TRN \\
\hline CHEMBL 3194400 & 688469 & 2.9208 & 3.563 & TRN \\
\hline CHEMBL1488229 & 688469 & 5.2022 & 5.0818 & TRN \\
\hline CHEMBL1546588 & 688469 & 4.6001 & 4.2758 & TRN \\
\hline CHEMBL222409 & 688469 & 8.0 & 6.6538 & TRN \\
\hline CHEMBL543876 & 688469 & 5.0171 & 3.2368 & TRN \\
\hline CHEMBL1326180 & 688469 & 4.6697 & 3.6828 & TRN \\
\hline CHEMBL 3209663 & 688469 & 4.9544 & 4.7028 & TST \\
\hline CHEMBL1567944 & 688469 & 8.0 & 7.1354 & TST \\
\hline CHEMBL607309 & 688469 & 4.9959 & 4.7577 & TRN \\
\hline CHEMBL1539531 & 688469 & 4.6488 & 3.3734 & TRN \\
\hline CHEMBL1567841 & 688469 & 5.4393 & 5.8754 & TRN \\
\hline CHEMBL1428589 & 688469 & 4.5475 & 3.8699 & TRN \\
\hline CHEMBL1524994 & 688469 & 4.7749 & 4.7359 & TRN \\
\hline CHEMBL1565674 & 688469 & 5.0913 & 3.6243 & TST \\
\hline CHEMBL1462368 & 688469 & 4.7947 & 4.4266 & TRN \\
\hline CHEMBL 3189712 & 688469 & 5.124 & 6.1911 & TRN \\
\hline CHEMBL1365411 & 688469 & 5.013 & 4.5286 & TRN \\
\hline CHEMBL1331514 & 688469 & 7.71 & 6.66200 & 000000001 \\
\hline CHEMBL1383414 & 688469 & 4.9327 & 3.9719 & TRN \\
\hline CHEMBL1588660 & 688469 & 4.936 & 4.1442 & TRN \\
\hline CHEMBL1313978 & 688469 & 2.9208 & 4.3512 & TRN \\
\hline CHEMBL1613695 & 688469 & 5.1986 & 4.7481 & TST \\
\hline CHEMBL 1471080 & 688469 & 4.9321 & 4.0219 & TRN \\
\hline CHEMBL1334442 & 688469 & 4.8485 & 4.1161 & TRN \\
\hline CHEMBL1305304 & 688469 & 8.0 & 6.8219 & TRN \\
\hline CHEMBL1541313 & 688469 & 2.9208 & 3.3585 & TRN \\
\hline CHEMBL1601627 & 688469 & 4.7184 & 4.0622 & TRN \\
\hline CHEMBL1598769 & 688469 & 5.6221 & 6.0258 & TRN \\
\hline CHEMBL1611593 & 688469 & 4.6129 & 3.3134 & TRN \\
\hline CHEMBL1601912 & 688469 & 8.0 & 6.4655 & TRN \\
\hline CHEMBL1308199 & 688469 & 4.3287 & 4.4016 & TRN \\
\hline CHEMBL1468954 & 688469 & 3.2218 & 3.5492 & TRN \\
\hline CHEMBL1301542 & 688469 & 4.6773 & 3.4093 & TRN \\
\hline CHEMBL1315224 & 688469 & 4.8375 & 5.256 & TRN \\
\hline CHEMBL1464327 & 688469 & 4.846 & 4.4829 & TST \\
\hline CHEMBL1997659 & 688469 & 2.9208 & 3.6343 & TRN \\
\hline CHEMBL1525719 & 688469 & 4.8983 & 3.6879 & TRN \\
\hline CHEMBL1576605 & 688469 & 4.7545 & 3.5338 & TRN \\
\hline CHEMBL1422597 & 688469 & 5.1129 & 5.6526 & TRN \\
\hline CHEMBL1554602 & 688469 & 4.8631 & 4.6483 & TRN \\
\hline
\end{tabular}




\begin{tabular}{|c|c|c|c|c|c|c|}
\hline & & \multicolumn{5}{|c|}{ Supplemental Table s2.txt } \\
\hline CHEMBL1978354 & 688469 & 5.056 & 5.1159 & TRN & & \\
\hline CHEMBL1570765 & 688469 & 6.8633 & 5.4556 & TRN & & \\
\hline CHEMBL1548478 & 688469 & 4.7883 & 3.4593 & TRN & & \\
\hline CHEMBL 3199362 & 688469 & 4.8195 & 4.663 & TRN & & \\
\hline CHEMBL546170 & 688469 & 4.0751 & 5.7847 & TRN & & \\
\hline CHEMBL1559726 & 688469 & 2.9208 & 3.8711 & TRN & & \\
\hline CHEMBL532160 & 688469 & 2.9208 & 3.4498 & TRN & & \\
\hline CHEMBL3213030 & 688469 & 2.9208 & 3.5716 & TRN & & \\
\hline CHEMBL1327496 & 688469 & 5.9614 & 6.5104 & TRN & & \\
\hline CHEMBL1307769 & 688469 & 8.0 & 6.3913 & TRN & & \\
\hline CHEMBL1491402 & 688469 & \multicolumn{3}{|c|}{5.0760000000000005} & 4.9692 & TRN \\
\hline CHEMBL1545086 & 688469 & 4.9034 & 4.2769 & TRN & & \\
\hline CHEMBL1309796 & 688469 & 2.9208 & 3.6568 & TRN & & \\
\hline CHEMBL1309980 & 688469 & 4.6047 & 3.8995 & TRN & & \\
\hline CHEMBL1389184 & 688469 & 2.9208 & 3.4154 & TRN & & \\
\hline CHEMBL1351441 & 688469 & 6.8447 & 4.4577 & TRN & & \\
\hline CHEMBL1602637 & 688469 & 6.7011 & 6.1305 & TRN & & \\
\hline CHEMBL1467877 & 688469 & 8.0 & 5.94 & TST & & \\
\hline CHEMBL1433424 & 688469 & 4.9426 & 4.6042 & TRN & & \\
\hline CHEMBL1351758 & 688469 & 5.2168 & 5.473 & TRN & & \\
\hline CHEMBL1386622 & 688469 & 5.0879 & 5.035 & TRN & & \\
\hline CHEMBL1417099 & 688469 & 5.0377 & 5.0964 & TST & & \\
\hline CHEMBL1332395 & 688469 & 4.6437 & 3.4231 & TRN & & \\
\hline CHEMBL1600709 & 688469 & 4.6572 & 3.2664 & TRN & & \\
\hline CHEMBL1588363 & 688469 & 4.7871 & 3.7 & TRN & & \\
\hline CHEMBL1560237 & 688469 & 5.0023 & 6.2563 & TST & & \\
\hline CHEMBL1604735 & 688469 & 2.9208 & 4.3005 & TRN & & \\
\hline CHEMBL1400850 & 688469 & 2.9208 & 3.3559 & TRN & & \\
\hline CHEMBL1328214 & 688469 & 4.7547 & 4.3429 & TRN & & \\
\hline CHEMBL567323 & 688469 & 4.3866 & 4.0097 & TRN & & \\
\hline CHEMBL1399127 & 688469 & 4.2179 & 4.3185 & TST & & \\
\hline CHEMBL1572961 & 688469 & 2.9208 & 3.5353 & TRN & & \\
\hline CHEMBL1355327 & 688469 & 2.9208 & 3.2169 & TRN & & \\
\hline CHEMBL1423338 & 688469 & 5.0458 & 4.3777 & TST & & \\
\hline CHEMBL1522352 & 688469 & 4.5304 & 4.0673 & TRN & & \\
\hline CHEMBL1420056 & 688469 & 4.829 & 3.3223 & TST & & \\
\hline CHEMBL1311526 & 688469 & 4.8055 & 4.7431 & TRN & & \\
\hline CHEMBL192984 & 688469 & 4.971 & 5.1203 & TRN & & \\
\hline CHEMBL1985479 & 688469 & 4.9008 & 4.7404 & TRN & & \\
\hline CHEMBL1335177 & 688469 & 4.9639 & 4.5877 & TRN & & \\
\hline CHEMBL1424729 & 688469 & 5.15600 & 000000006 & 01 & 4.7977 & TST \\
\hline CHEMBL1356472 & 688469 & 4.9521 & 4.2221 & TRN & & \\
\hline CHEMBL1586266 & 688469 & 4.887 & 4.2917 & TRN & & \\
\hline CHEMBL1437052 & 688469 & 4.8325 & 4.3456 & TRN & & \\
\hline CHEMBL1525771 & 688469 & 4.9346 & 4.6948 & TRN & & \\
\hline CHEMBL3192670 & 688469 & 5.0132 & 4.7275 & TRN & & \\
\hline CHEMBL1607474 & 688469 & 2.9208 & 3.486 & TRN & & \\
\hline CHEMBL1576754 & 688469 & 2.9208 & 4.215 & TRN & & \\
\hline
\end{tabular}




\begin{tabular}{|c|c|c|c|c|c|}
\hline & & \multicolumn{4}{|c|}{ Supplemental Table S2.txt } \\
\hline CHEMBL1329685 & 688469 & 2.9208 & 3.2792 & TRN & \\
\hline CHEMBL1975487 & 688469 & 4.909 & 4.8773 & TRN & \\
\hline CHEMBL2004417 & 688469 & 5.0141 & 5.2052 & TRN & \\
\hline CHEMBL1380781 & 688469 & 5.6992 & 4.9715 & TRN & \\
\hline CHEMBL1483913 & 688469 & 4.3445 & 4.377 & TST & \\
\hline CHEMBL1979574 & 688469 & 5.1851 & 5.0436 & TRN & \\
\hline CHEMBL469036 & 688469 & 5.25 & 3.3894 & TST & \\
\hline CHEMBL1403165 & 688469 & 2.9208 & 3.4587 & TRN & \\
\hline CHEMBL1500190 & 688469 & 4.925 & \multicolumn{2}{|c|}{5.638999999999999} & TRN \\
\hline CHEMBL1452295 & 688469 & 4.9609 & 4.5679 & TRN & \\
\hline CHEMBL 248654 & 688469 & 2.9208 & 3.9312 & TRN & \\
\hline CHEMBL1488001 & 688469 & 4.9911 & 4.3299 & TRN & \\
\hline CHEMBL1256686 & 688469 & 6.5331 & 5.7833 & TST & \\
\hline CHEMBL 3190445 & 688469 & 2.9208 & 3.9409 & TRN & \\
\hline CHEMBL1546687 & 688469 & 4.5337 & \multicolumn{2}{|c|}{3.7030000000000003} & TRN \\
\hline CHEMBL1548748 & 688469 & 4.8867 & 4.476 & TRN & \\
\hline CHEMBL1366321 & 688469 & 5.2017 & 4.8178 & TRN & \\
\hline CHEMBL1375597 & 688469 & 2.9208 & 4.2608 & TRN & \\
\hline CHEMBL1407294 & 688469 & 2.9208 & 3.3271 & TRN & \\
\hline CHEMBL1533271 & 688469 & 2.9208 & 3.3566 & TRN & \\
\hline CHEMBL1555435 & 688469 & 4.8788 & 4.4797 & TRN & \\
\hline CHEMBL1424269 & 688469 & 6.2782 & 5.6145 & TRN & \\
\hline CHEMBL1412543 & 688469 & 2.9208 & 3.3295 & TRN & \\
\hline CHEMBL1468419 & 688469 & 2.9208 & 3.1828 & TRN & \\
\hline CHEMBL 1432560 & 688469 & 4.8324 & 4.0209 & TRN & \\
\hline CHEMBL1464261 & 688469 & 4.6186 & 4.2793 & TRN & \\
\hline CHEMBL 1494050 & 688469 & 4.5897 & 3.6797 & TRN & \\
\hline CHEMBL 3189161 & 688469 & 4.9534 & 4.6152 & TRN & \\
\hline CHEMBL1304177 & 688469 & 2.9208 & 4.6508 & TRN & \\
\hline CHEMBL 1557240 & 688469 & 2.9208 & 3.5657 & TRN & \\
\hline CHEMBL 259507 & 688469 & 4.5503 & 3.8285 & TRN & \\
\hline CHEMBL1496165 & 688469 & 4.7515 & 4.3128 & TRN & \\
\hline CHEMBL1497549 & 688469 & 6.5751 & 5.8404 & TRN & \\
\hline CHEMBL1312371 & 688469 & 2.9208 & 3.4246 & TST & \\
\hline CHEMBL1463184 & 688469 & 4.8472 & 3.9279 & TRN & \\
\hline CHEMBL1601997 & 688469 & 5.0686 & 4.2948 & TST & \\
\hline CHEMBL 1480024 & 688469 & 4.976 & 3.5535 & TRN & \\
\hline CHEMBL417727 & 688469 & 2.9208 & 4.1111 & TRN & \\
\hline CHEMBL1349435 & 688469 & 4.9039 & 4.2175 & TRN & \\
\hline CHEMBL1402745 & 688469 & 4.813 & 4.1817 & TRN & \\
\hline CHEMBL3212655 & 688469 & 4.5884 & 5.0234 & TRN & \\
\hline CHEMBL1391313 & 688469 & 4.9419 & 6.166 & TRN & \\
\hline CHEMBL1537098 & 688469 & 8.0 & 6.4477 & TRN & \\
\hline CHEMBL1506951 & 688469 & 5.104 & 4.7916 & TRN & \\
\hline CHEMBL1467326 & 688469 & 4.6809 & 4.3228 & TRN & \\
\hline CHEMBL1459795 & 688469 & 4.845 & 4.5575 & TRN & \\
\hline CHEMBL1996189 & 688469 & 4.9921 & 6.4509 & TRN & \\
\hline CHEMBL1535730 & 688469 & 2.9208 & 4.1848 & TRN & \\
\hline
\end{tabular}




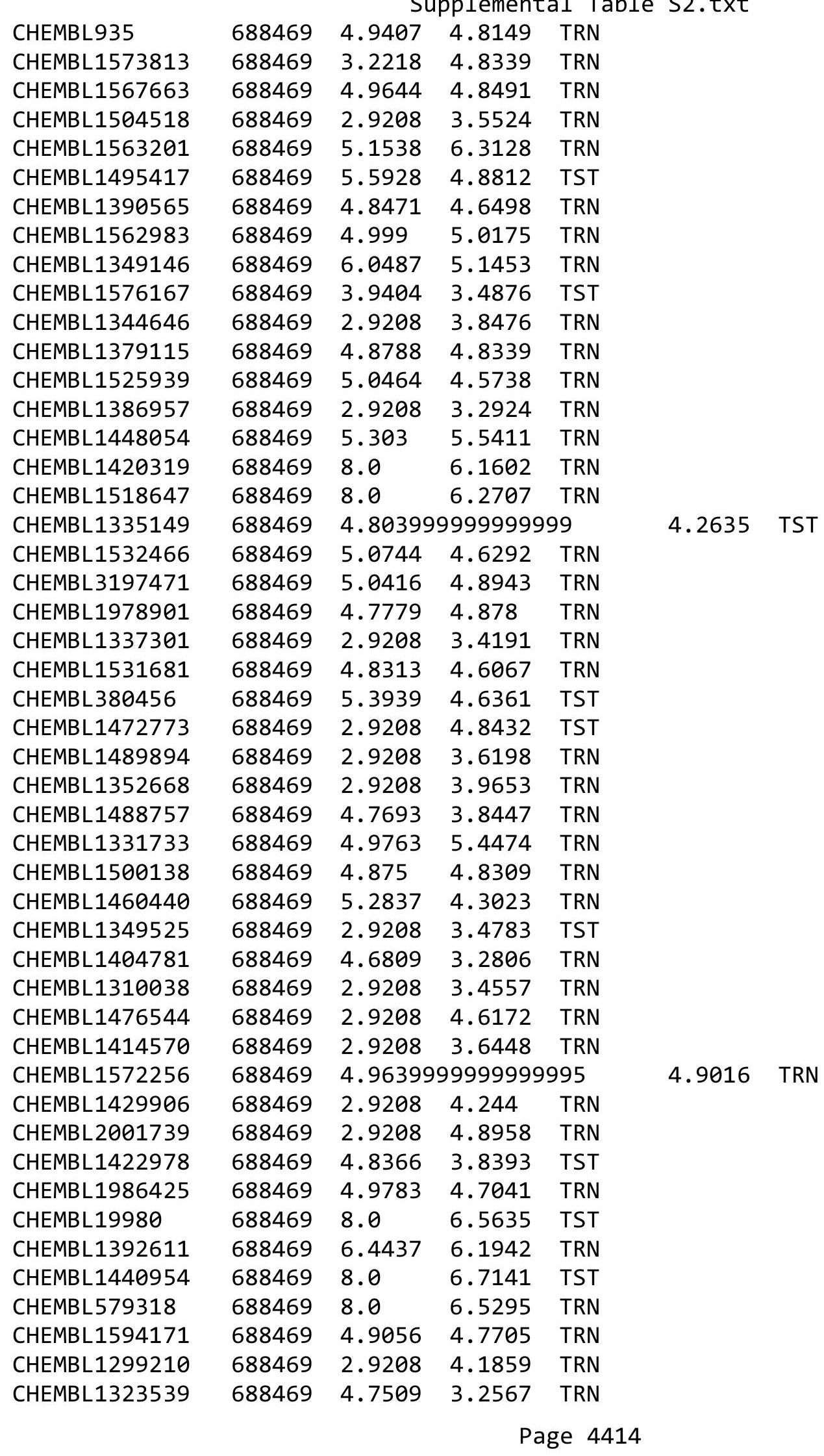




\begin{tabular}{|c|c|c|c|c|c|c|}
\hline & & \multicolumn{5}{|c|}{ Supplemental Table S2.txt } \\
\hline CHEMBL1439666 & 688469 & 4.1595 & 3.2465 & TRN & & \\
\hline CHEMBL1613644 & 688469 & 4.6641 & 4.0108 & TRN & & \\
\hline CHEMBL1389427 & 688469 & 5.035 & 4.6278 & TRN & & \\
\hline CHEMBL1485659 & 688469 & 2.9208 & 3.4945 & TRN & & \\
\hline CHEMBL1407086 & 688469 & 2.9208 & 3.4151 & TRN & & \\
\hline CHEMBL528791 & 688469 & 2.9208 & 4.7771 & TRN & & \\
\hline CHEMBL1569107 & 688469 & 2.9208 & 3.9383 & TRN & & \\
\hline CHEMBL1511499 & 688469 & 2.9208 & 3.6222 & TST & & \\
\hline CHEMBL1608294 & 688469 & 4.7717 & 3.9256 & TRN & & \\
\hline CHEMBL1485785 & 688469 & 2.9208 & 3.4937 & TRN & & \\
\hline CHEMBL1305231 & 688469 & 2.9208 & 4.1858 & TRN & & \\
\hline CHEMBL1312088 & 688469 & 2.9208 & 4.1202 & TST & & \\
\hline CHEMBL1412636 & 688469 & 4.622 & 3.3984 & TRN & & \\
\hline CHEMBL1483475 & 688469 & 4.9993 & 4.4577 & TRN & & \\
\hline CHEMBL1376166 & 688469 & 6.1669 & 6.4687 & TRN & & \\
\hline CHEMBL1522486 & 688469 & 5.15799 & 99999999 & 995 & 4.9114 & TRN \\
\hline CHEMBL1461748 & 688469 & 2.9208 & 3.8148 & TRN & & \\
\hline CHEMBL1415958 & 688469 & 8.0 & 5.055 & TRN & & \\
\hline CHEMBL1500296 & 688469 & 4.7931 & 3.3382 & TRN & & \\
\hline CHEMBL1517147 & 688469 & 4.8344 & 3.7746 & TRN & & \\
\hline CHEMBL1606328 & 688469 & 4.9503 & 4.7543 & TRN & & \\
\hline CHEMBL3197793 & 688469 & 2.9208 & 3.7328 & TRN & & \\
\hline CHEMBL1574553 & 688469 & 6.9706 & 5.692 & TST & & \\
\hline CHEMBL 1322272 & 688469 & 5.325 & 6.0999 & TRN & & \\
\hline CHEMBL1464513 & 688469 & 2.9208 & 3.3757 & TRN & & \\
\hline CHEMBL1493942 & 688469 & 5.1637 & 5.0798 & TRN & & \\
\hline CHEMBL1563176 & 688469 & 2.9208 & 4.6301 & TRN & & \\
\hline CHEMBL1410689 & 688469 & 4.4432 & 3.4837 & TRN & & \\
\hline CHEMBL1436569 & 688469 & 4.81 & 4.5081 & TRN & & \\
\hline CHEMBL3211755 & 688469 & 2.9208 & 3.7819 & TST & & \\
\hline CHEMBL1558947 & 688469 & 2.9208 & 3.2835 & TRN & & \\
\hline CHEMBL1487952 & 688469 & 2.9208 & 4.7953 & TRN & & \\
\hline CHEMBL1587117 & 688469 & 8.0 & 7.6272 & TRN & & \\
\hline CHEMBL1550934 & 688469 & 4.9913 & 4.7982 & TRN & & \\
\hline CHEMBL1389886 & 688469 & 4.3732 & 4.1763 & TRN & & \\
\hline CHEMBL3197126 & 688469 & 5.2679 & 5.602 & TRN & & \\
\hline CHEMBL1586416 & 688469 & 4.9786 & 4.5158 & TRN & & \\
\hline CHEMBL1322601 & 688469 & 2.9208 & 4.0868 & TRN & & \\
\hline CHEMBL1580220 & 688469 & 4.8869 & 3.8559 & TRN & & \\
\hline CHEMBL1451921 & 688469 & 6.9957 & 6.2385 & TRN & & \\
\hline CHEMBL1300239 & 688469 & 4.8184 & 5.0727 & TRN & & \\
\hline CHEMBL1386838 & 688469 & 2.9208 & 4.7027 & TST & & \\
\hline CHEMBL1546084 & 688469 & 4.5961 & 3.3049 & TRN & & \\
\hline CHEMBL3210051 & 688469 & 4.9446 & 4.7982 & TRN & & \\
\hline CHEMBL1423927 & 688469 & 6.9469 & 6.0136 & TRN & & \\
\hline CHEMBL2369309 & 688469 & 2.9208 & 4.3324 & TRN & & \\
\hline CHEMBL1334514 & 688469 & 6.6968 & 5.8843 & TRN & & \\
\hline CHEMBL1213281 & 688469 & 4.888 & 4.7992 & TRN & & \\
\hline
\end{tabular}




\begin{tabular}{|c|c|c|c|c|c|}
\hline & & \multicolumn{4}{|c|}{ Supplemental Table S2.txt } \\
\hline CHEMBL1384373 & 688469 & 2.9208 & 3.8551 & TRN & \\
\hline CHEMBL3189613 & 688469 & 5.2326 & 4.9567 & TRN & \\
\hline CHEMBL1301576 & 688469 & 4.8059 & 4.7881 & TRN & \\
\hline CHEMBL1460352 & 688469 & 5.0632 & 4.8426 & TRN & \\
\hline CHEMBL1472341 & 688469 & 2.9208 & 3.6888 & TRN & \\
\hline CHEMBL1588846 & 688469 & 2.9208 & 4.5111 & TRN & \\
\hline CHEMBL1359285 & 688469 & 3.2218 & 4.2921 & TRN & \\
\hline CHEMBL3190257 & 688469 & 4.9198 & 4.4805 & TRN & \\
\hline CHEMBL 1305436 & 688469 & 4.8044 & 3.50600 & 00000000002 & TRN \\
\hline CHEMBL1329507 & 688469 & 4.9813 & 4.7398 & TRN & \\
\hline CHEMBL1528118 & 688469 & 5.0961 & 5.3414 & TRN & \\
\hline CHEMBL1586200 & 688469 & 2.9208 & 4.3584 & TRN & \\
\hline CHEMBL1413629 & 688469 & 6.6055 & 5.0099 & TRN & \\
\hline CHEMBL1482663 & 688469 & 2.9208 & 5.0286 & TST & \\
\hline CHEMBL1540713 & 688469 & 2.9208 & 3.5631 & TRN & \\
\hline CHEMBL1577719 & 688469 & 2.9208 & 3.5462 & TRN & \\
\hline CHEMBL3197102 & 688469 & 4.9969 & 4.9937 & TRN & \\
\hline CHEMBL1610585 & 688469 & 4.9114 & 4.2693 & TST & \\
\hline CHEMBL1315921 & 688469 & 4.959 & 4.176 & TRN & \\
\hline CHEMBL1532825 & 688469 & 2.9208 & 4.7085 & TRN & \\
\hline CHEMBL1981200 & 688469 & 5.1487 & 5.0898 & TRN & \\
\hline CHEMBL484744 & 688469 & 2.9208 & 4.3421 & TRN & \\
\hline CHEMBL1570797 & 688469 & 4.8455 & 4.5847 & TRN & \\
\hline CHEMBL1431944 & 688469 & 2.9208 & 4.3935 & TRN & \\
\hline CHEMBL3192138 & 688469 & 8.0 & 6.8497 & TRN & \\
\hline CHEMBL1456009 & 688469 & 2.9208 & 4.176 & TRN & \\
\hline CHEMBL1468277 & 688469 & 4.9512 & 4.8006 & TRN & \\
\hline CHEMBL1450889 & 688469 & 2.9208 & 4.2319 & TRN & \\
\hline CHEMBL1368458 & 688469 & 2.9208 & 4.2468 & TST & \\
\hline CHEMBL3189905 & 688469 & 2.9208 & 3.645 & TRN & \\
\hline CHEMBL1443750 & 688469 & 4.5821 & 4.8197 & TRN & \\
\hline CHEMBL1478187 & 688469 & 2.9208 & 3.4861 & TST & \\
\hline CHEMBL3195760 & 688469 & 4.9925 & 5.2959 & TRN & \\
\hline CHEMBL3193076 & 688469 & 4.9592 & 4.7372 & TST & \\
\hline CHEMBL1609686 & 688469 & 5.0755 & 5.2826 & TRN & \\
\hline CHEMBL1542907 & 688469 & 2.9208 & 4.4171 & TRN & \\
\hline CHEMBL1344206 & 688469 & 2.9208 & 4.5378 & TRN & \\
\hline CHEMBL1508845 & 688469 & 2.9208 & 3.54100 & 00000000004 & TRN \\
\hline CHEMBL1361507 & 688469 & 5.091 & 4.3225 & TRN & \\
\hline CHEMBL1980322 & 688469 & 2.9208 & 4.6087 & TRN & \\
\hline CHEMBL3195189 & 688469 & 6.767 & 6.277 & TRN & \\
\hline CHEMBL1542614 & 688469 & 4.7567 & 4.061 & TRN & \\
\hline CHEMBL1413355 & 688469 & 2.9208 & 3.7458 & TRN & \\
\hline CHEMBL1457644 & 688469 & 4.9235 & 4.9368 & TRN & \\
\hline CHEMBL1568933 & 688469 & 4.9604 & 5.0848 & TRN & \\
\hline CHEMBL1420659 & 688469 & 4.8296 & 4.1291 & TRN & \\
\hline CHEMBL1420837 & 688469 & 5.2168 & 4.7409 & TRN & \\
\hline CHEMBL1461934 & 688469 & 2.9208 & 4.7355 & TRN & \\
\hline
\end{tabular}




\begin{tabular}{|c|c|c|c|c|}
\hline \multicolumn{5}{|c|}{ Supplemental Table S2.txt } \\
\hline CHEMBL1404398 & 688469 & 5.0221 & 4.8105 & TRN \\
\hline CHEMBL3209921 & 688469 & 2.9208 & 3.6089 & TRN \\
\hline CHEMBL1353133 & 688469 & 4.8107 & 4.6862 & TRN \\
\hline CHEMBL1493731 & 688469 & 5.1519 & 6.5457 & TRN \\
\hline CHEMBL1491037 & 688469 & 4.7418 & 3.7473 & TRN \\
\hline CHEMBL1556891 & 688469 & 4.9775 & 4.2496 & TRN \\
\hline CHEMBL1326584 & 688469 & 4.9522 & 4.8019 & TRN \\
\hline CHEMBL1541657 & 688469 & 2.9208 & 4.2624 & TST \\
\hline CHEMBL1513553 & 688469 & 2.9208 & 3.668 & TST \\
\hline CHEMBL1400785 & 688469 & 5.0282 & 4.7295 & TRN \\
\hline CHEMBL1399858 & 688469 & 2.9208 & 4.1233 & TRN \\
\hline CHEMBL3211971 & 688469 & 4.7336 & 4.595 & TRN \\
\hline CHEMBL1339565 & 688469 & 4.8391 & 3.3848 & TRN \\
\hline CHEMBL3198929 & 688469 & 2.9208 & 4.374 & TRN \\
\hline CHEMBL1310514 & 688469 & 4.6706 & 4.0408 & TRN \\
\hline CHEMBL590706 & 688469 & 4.8864 & 4.5802 & TRN \\
\hline CHEMBL1380482 & 688469 & 5.0794 & 3.4574 & TRN \\
\hline CHEMBL1574778 & 688469 & 5.8133 & 4.8799 & TRN \\
\hline CHEMBL1507600 & 688469 & 4.8106 & 4.2685 & TRN \\
\hline CHEMBL1394270 & 688469 & 4.9472 & 3.4344 & TRN \\
\hline CHEMBL1393195 & 688469 & 6.4763 & 5.7675 & TRN \\
\hline CHEMBL486706 & 688469 & 2.9208 & 4.6079 & TRN \\
\hline CHEMBL1333449 & 688469 & 6.2055 & 6.3291 & TRN \\
\hline CHEMBL1414112 & 688469 & 5.744 & 6.4287 & TRN \\
\hline CHEMBL1529404 & 688469 & 5.3952 & 5.7593 & TRN \\
\hline CHEMBL1320400 & 688469 & 8.0 & 4.4319 & TRN \\
\hline CHEMBL1544256 & 688469 & 4.9574 & 4.8007 & TRN \\
\hline CHEMBL1992943 & 688469 & 4.8177 & 4.1255 & TST \\
\hline CHEMBL1495991 & 688469 & 2.9208 & 3.2871 & TST \\
\hline CHEMBL1994068 & 688469 & 4.923 & 4.7461 & TRN \\
\hline CHEMBL3194303 & 688469 & 4.9495 & 4.9146 & TRN \\
\hline CHEMBL1550442 & 688469 & 4.8467 & 4.5744 & TRN \\
\hline CHEMBL1538336 & 688469 & 2.9208 & 3.5895 & TRN \\
\hline CHEMBL1606583 & 688469 & 5.5989 & 6.3164 & TRN \\
\hline CHEMBL1493118 & 688469 & 4.7769 & 4.4535 & TRN \\
\hline CHEMBL1516044 & 688469 & 2.9208 & 3.8665 & TRN \\
\hline CHEMBL1457139 & 688469 & 4.926 & 5.2289 & TRN \\
\hline CHEMBL1516671 & 688469 & 4.8421 & 3.6771 & TRN \\
\hline CHEMBL1432420 & 688469 & 5.6959 & 5.7211 & TRN \\
\hline CHEMBL1305287 & 688469 & 5.0947 & 6.7295 & TRN \\
\hline CHEMBL1542001 & 688469 & 4.8714 & 4.5934 & TRN \\
\hline CHEMBL1344340 & 688469 & 2.9208 & 3.3848 & TRN \\
\hline CHEMBL1361866 & 688469 & 4.8895 & 4.5732 & TRN \\
\hline CHEMBL3197055 & 688469 & 2.9208 & 3.4707 & TRN \\
\hline CHEMBL1469553 & 688469 & 2.9208 & 3.3482 & TRN \\
\hline CHEMBL1528280 & 688469 & 2.9208 & 4.2503 & TRN \\
\hline CHEMBL1341553 & 688469 & 4.7177 & 4.4505 & TRN \\
\hline CHEMBL1506317 & 688469 & 5.4066 & 4.8715 & TRN \\
\hline
\end{tabular}




\begin{tabular}{|c|c|c|c|c|c|c|}
\hline & & \multicolumn{5}{|c|}{ Supplemental Table S2.txt } \\
\hline CHEMBL189584 & 688469 & 2.9208 & 4.7726 & TST & & \\
\hline CHEMBL1379970 & 688469 & 8.0 & 6.9196 & TRN & & \\
\hline CHEMBL1355887 & 688469 & 4.6323 & 4.0172 & TRN & & \\
\hline CHEMBL1313954 & 688469 & 5.6743 & 5.3212 & TRN & & \\
\hline CHEMBL1336402 & 688469 & 4.3747 & 3.2894 & TRN & & \\
\hline CHEMBL1312349 & 688469 & 2.9208 & 4.5057 & TST & & \\
\hline CHEMBL1368347 & 688469 & 2.9208 & 3.3988 & TST & & \\
\hline CHEMBL1340220 & 688469 & 4.7713 & 4.6155 & TRN & & \\
\hline CHEMBL1557894 & 688469 & 2.9208 & 3.3902 & TST & & \\
\hline CHEMBL 2028186 & 688469 & 4.8827 & 4.74 & TST & & \\
\hline CHEMBL1336644 & 688469 & 4.2107 & 4.5036 & TRN & & \\
\hline CHEMBL1323796 & 688469 & 2.9208 & 3.4651 & TRN & & \\
\hline CHEMBL1412667 & 688469 & 2.9208 & 4.4485 & TRN & & \\
\hline CHEMBL 3194887 & 688469 & 2.9208 & 3.5436 & TRN & & \\
\hline CHEMBL1522827 & 688469 & 5.2056 & 5.0371 & TRN & & \\
\hline CHEMBL1363982 & 688469 & 4.1891 & 3.3248 & TRN & & \\
\hline CHEMBL1319204 & 688469 & 2.9208 & 3.9589 & TRN & & \\
\hline CHEMBL1371395 & 688469 & 5.0768 & 4.835 & TRN & & \\
\hline CHEMBL1428004 & 688469 & 4.8262 & 4.2762 & TRN & & \\
\hline CHEMBL1312101 & 688469 & 4.4076 & 3.2986 & TRN & & \\
\hline CHEMBL1463050 & 688469 & 6.1707 & 5.3758 & TRN & & \\
\hline CHEMBL1988416 & 688469 & 3.2218 & 4.3778 & TST & & \\
\hline CHEMBL1576851 & 688469 & 5.3298 & 5.0561 & TRN & & \\
\hline CHEMBL1514238 & 688469 & 5.0517 & 3.5487 & TRN & & \\
\hline CHEMBL1613218 & 688469 & 4.7622 & 4.6076 & TRN & & \\
\hline CHEMBL1426865 & 688469 & 4.7405 & 4.9787 & TST & & \\
\hline CHEMBL1400375 & 688469 & $5.7020 e$ & 00000000 & $\partial 1$ & 4.9795 & Tा \\
\hline CHEMBL1332512 & 688469 & 6.0737 & 4.8028 & TRN & & \\
\hline CHEMBL 1352348 & 688469 & 5.1371 & 5.2135 & TRN & & \\
\hline CHEMBL1321442 & 688469 & 2.9208 & 3.3471 & TRN & & \\
\hline CHEMBL34137 & 688469 & 4.3209 & 4.7781 & TRN & & \\
\hline CHEMBL1408311 & 688469 & 4.7996 & 4.6822 & TRN & & \\
\hline CHEMBL1591302 & 688469 & 2.9208 & 3.3843 & TST & & \\
\hline CHEMBL338474 & 688469 & 5.3349 & 4.6799 & TST & & \\
\hline CHEMBL1520166 & 688469 & 2.9208 & 3.4455 & TRN & & \\
\hline CHEMBL1345123 & 688469 & 2.9208 & 3.385 & TRN & & \\
\hline CHEMBL1301968 & 688469 & 4.6316 & 4.2189 & TRN & & \\
\hline CHEMBL1603905 & 688469 & 4.6318 & 3.3437 & TRN & & \\
\hline CHEMBL1375406 & 688469 & 4.5682 & 3.6466 & TST & & \\
\hline CHEMBL1341518 & 688469 & 5.0243 & 4.3452 & TST & & \\
\hline CHEMBL1530743 & 688469 & 5.4353 & 5.1486 & TRN & & \\
\hline CHEMBL1343198 & 688469 & 4.6715 & 3.8883 & TRN & & \\
\hline CHEMBL1478412 & 688469 & 2.9208 & 3.2547 & TRN & & \\
\hline CHEMBL1255733 & 688469 & 6.6003 & 6.1233 & TST & & \\
\hline CHEMBL1526855 & 688469 & 5.022 & 3.8248 & TRN & & \\
\hline CHEMBL1612177 & 688469 & 5.2162 & 4.9587 & TRN & & \\
\hline CHEMBL1358278 & 688469 & 5.0048 & 5.5835 & TRN & & \\
\hline CHEMBL1392356 & 688469 & 4.8358 & 3.4844 & TRN & & \\
\hline
\end{tabular}




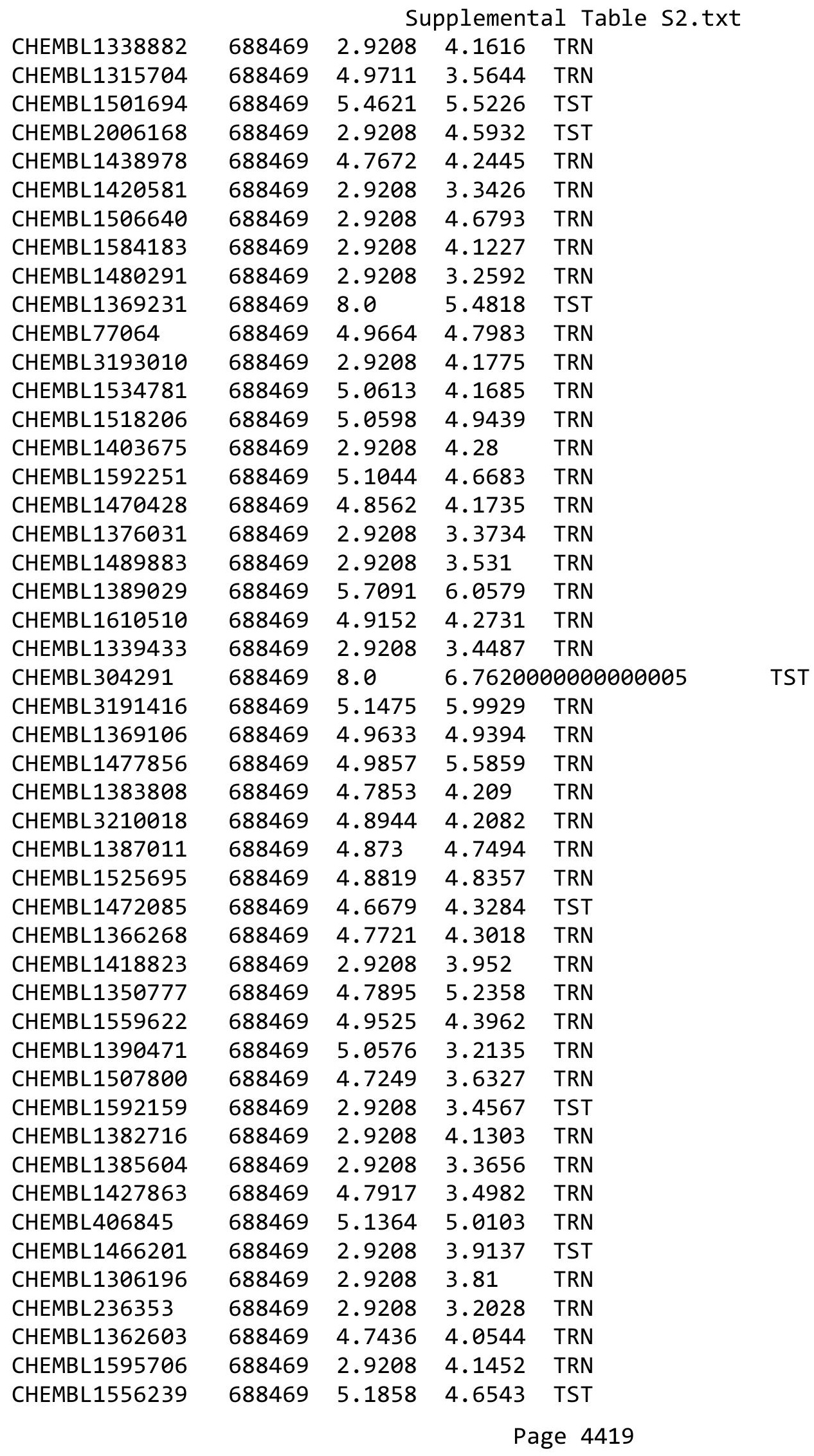




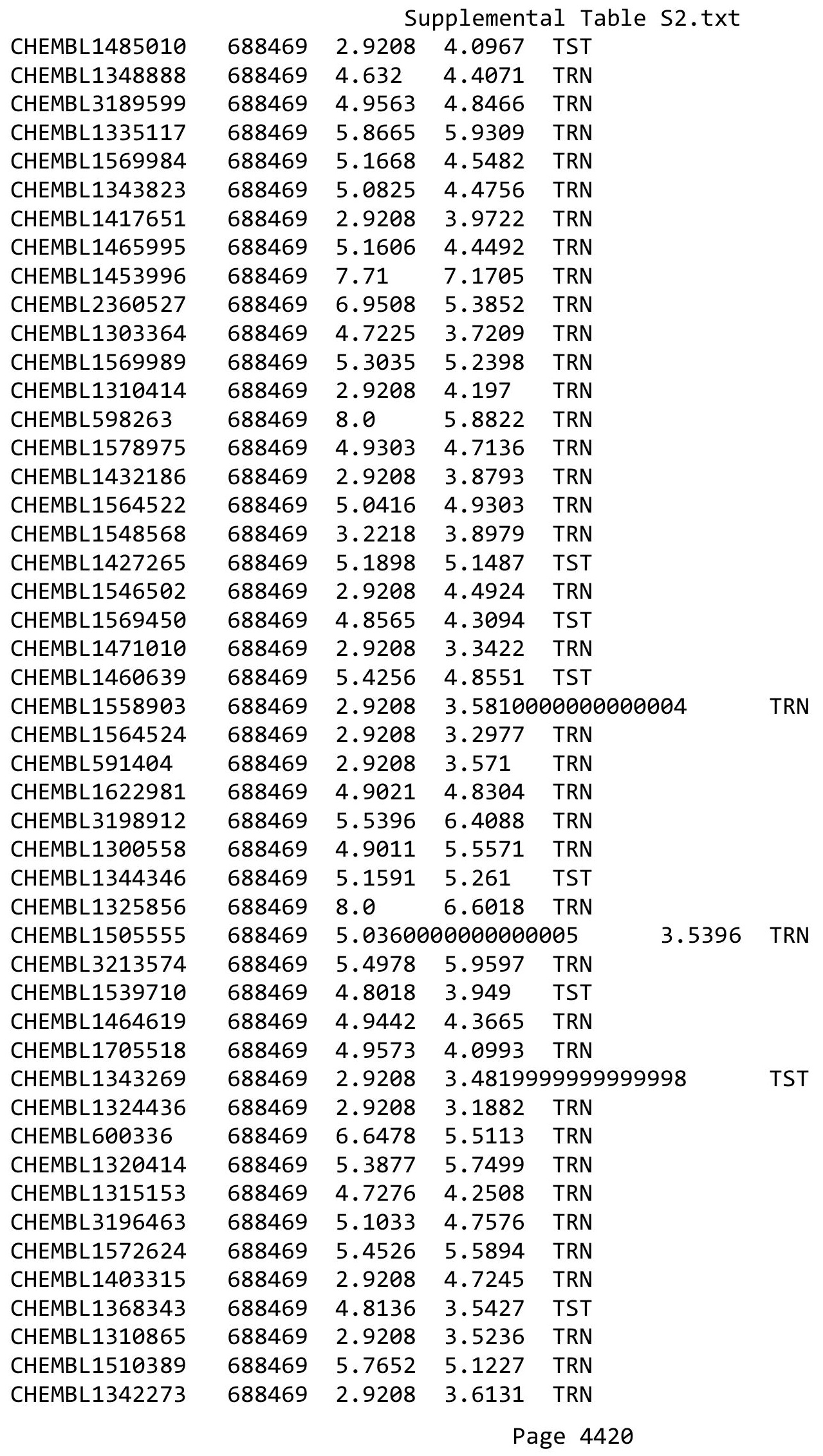




\begin{tabular}{|c|c|c|c|c|c|}
\hline \multicolumn{6}{|c|}{ Supplemental Table S2.txt } \\
\hline CHEMBL1430866 & 688469 & 4.7486 & 3.515 & TRN & \\
\hline CHEMBL1518705 & 688469 & 2.9208 & 4.7634 & TST & \\
\hline CHEMBL1486216 & 688469 & 4.7743 & 4.442 & TRN & \\
\hline CHEMBL1333534 & 688469 & 2.9208 & 4.9328 & TRN & \\
\hline CHEMBL1499698 & 688469 & 4.9735 & 4.0964 & TRN & \\
\hline CHEMBL1452890 & 688469 & 2.9208 & 3.5944 & TRN & \\
\hline CHEMBL1513325 & 688469 & 5.2033 & 6.1448 & TRN & \\
\hline CHEMBL1599566 & 688469 & 5.1409 & 4.7631 & TRN & \\
\hline CHEMBL 3145296 & 688469 & 5.1022 & 5.2623 & TRN & \\
\hline CHEMBL1505866 & 688469 & 2.9208 & 4.16 & TRN & \\
\hline CHEMBL1495567 & 688469 & 4.7893 & 4.0222 & TRN & \\
\hline CHEMBL587801 & 688469 & 2.9208 & 4.7882 & TRN & \\
\hline CHEMBL1440659 & 688469 & 2.9208 & 4.6687 & TRN & \\
\hline CHEMBL1989673 & 688469 & 4.7684 & 4.6205 & TRN & \\
\hline CHEMBL3197825 & 688469 & 4.9326 & 4.9456 & TRN & \\
\hline CHEMBL1580124 & 688469 & 4.7184 & 4.4452 & TRN & \\
\hline CHEMBL1558285 & 688469 & 4.952 & 4.9142 & TRN & \\
\hline CHEMBL1481301 & 688469 & 4.9412 & 4.6021 & TRN & \\
\hline CHEMBL1597655 & 688469 & 8.0 & 5.3795 & TRN & \\
\hline CHEMBL1366690 & 688469 & 2.9208 & 3.5155 & TRN & \\
\hline CHEMBL1347534 & 688469 & 2.9208 & 4.6021 & TRN & \\
\hline CHEMBL1412113 & 688469 & 4.7714 & 3.3616 & TRN & \\
\hline CHEMBL1500204 & 688469 & 2.9208 & 3.6723 & TRN & \\
\hline CHEMBL1544633 & 688469 & 5.0625 & 4.9932 & TRN & \\
\hline CHEMBL1418884 & 688469 & 2.9208 & 3.5855 & TST & \\
\hline CHEMBL1995314 & 688469 & 2.9208 & 3.5206 & TRN & \\
\hline CHEMBL1577399 & 688469 & 4.5743 & 4.0629 & TRN & \\
\hline CHEMBL1581343 & 688469 & 2.9208 & 3.4244 & TST & \\
\hline CHEMBL1406301 & 688469 & 4.5881 & 4.1862 & TST & \\
\hline CHEMBL1318795 & 688469 & 2.9208 & 3.2426 & TRN & \\
\hline CHEMBL1366573 & 688469 & 2.9208 & 4.0052 & TRN & \\
\hline CHEMBL1530673 & 688469 & 5.2629 & 6.383999 & 99999999995 & TST \\
\hline CHEMBL1368875 & 688469 & 2.9208 & 3.4156 & TRN & \\
\hline CHEMBL1481034 & 688469 & 4.5253 & 3.4266 & TRN & \\
\hline CHEMBL1464984 & 688469 & 2.9208 & 4.9283 & TRN & \\
\hline CHEMBL1352257 & 688469 & 4.6995 & 4.1345 & TRN & \\
\hline CHEMBL1422078 & 688469 & 5.2357 & 5.5743 & TRN & \\
\hline CHEMBL3189156 & 688469 & 2.9208 & 4.9439 & TRN & \\
\hline CHEMBL1603890 & 688469 & 5.0868 & 4.7179 & TST & \\
\hline CHEMBL1335915 & 688469 & 4.7174 & 4.2589 & TRN & \\
\hline CHEMBL1412300 & 688469 & 4.8522 & 3.985 & TRN & \\
\hline CHEMBL1514474 & 688469 & 2.9208 & 4.6874 & TRN & \\
\hline CHEMBL1497821 & 688469 & 2.9208 & 3.3248 & TRN & \\
\hline CHEMBL1545701 & 688469 & 4.8822 & 4.5036 & TRN & \\
\hline CHEMBL1421670 & 688469 & 4.9431 & 4.8796 & TRN & \\
\hline CHEMBL3195389 & 688469 & 8.0 & 7.3189 & TRN & \\
\hline CHEMBL3192140 & 688469 & 6.8356 & 5.9542 & TST & \\
\hline CHEMBL1332955 & 688469 & 2.9208 & 4.3665 & TRN & \\
\hline
\end{tabular}




\begin{tabular}{|c|c|c|c|c|c|}
\hline \multicolumn{6}{|c|}{ Supplemental Table S2.txt } \\
\hline CHEMBL1548023 & 688469 & 2.9208 & 3.6212 & TRN & \\
\hline CHEMBL1375094 & 688469 & 4.6582 & 3.4901 & TRN & \\
\hline CHEMBL3214332 & 688469 & 4.7647 & 4.5043 & TRN & \\
\hline CHEMBL1468961 & 688469 & 2.9208 & 3.2933 & TRN & \\
\hline CHEMBL1308576 & 688469 & 2.9208 & 4.0855 & TST & \\
\hline CHEMBL1307622 & 688469 & 4.6674 & 3.6982 & TRN & \\
\hline CHEMBL1362250 & 688469 & 2.9208 & 3.6129 & TST & \\
\hline CHEMBL1500185 & 688469 & 4.7016 & 3.4134 & TRN & \\
\hline CHEMBL1544557 & 688469 & 3.2218 & 5.21399 & 99999999995 & TRN \\
\hline CHEMBL1567326 & 688469 & 4.6664 & 4.40600 & 0000000001 & TRN \\
\hline CHEMBL1459254 & 688469 & 5.0166 & 4.7144 & TST & \\
\hline CHEMBL1312298 & 688469 & 4.8422 & 4.2147 & TRN & \\
\hline CHEMBL1572558 & 688469 & 5.1503 & 5.4334 & TRN & \\
\hline CHEMBL1890591 & 688469 & 4.9442 & 5.1545 & TRN & \\
\hline CHEMBL1415650 & 688469 & 2.9208 & 3.4749 & TST & \\
\hline CHEMBL1502189 & 688469 & 2.9208 & 4.6025 & TRN & \\
\hline CHEMBL1342143 & 688469 & 4.7852 & 4.5274 & TRN & \\
\hline CHEMBL89445 & 688469 & 8.0 & 6.7596 & TRN & \\
\hline CHEMBL1539440 & 688469 & 4.7212 & 3.4813 & TST & \\
\hline CHEMBL3193702 & 688469 & 4.9192 & 4.44600 & 0000000001 & TRN \\
\hline CHEMBL1539808 & 688469 & 3.2218 & 4.5913 & TRN & \\
\hline CHEMBL1404987 & 688469 & 4.97 & 4.6226 & TRN & \\
\hline CHEMBL 76887 & 688469 & 4.9463 & 4.7635 & TRN & \\
\hline CHEMBL1332356 & 688469 & 2.9208 & 3.4013 & TRN & \\
\hline CHEMBL1427989 & 688469 & 2.9208 & 3.7237 & TRN & \\
\hline CHEMBL1310501 & 688469 & 2.9208 & 3.4079 & TRN & \\
\hline CHEMBL1467220 & 688469 & 2.9208 & 3.6953 & TST & \\
\hline CHEMBL1430123 & 688469 & 4.9329 & 4.0868 & TRN & \\
\hline CHEMBL1612884 & 688469 & 2.9208 & 3.6116 & TRN & \\
\hline CHEMBL1335978 & 688469 & 2.9208 & 4.4421 & TRN & \\
\hline CHEMBL1986081 & 688469 & 5.246 & 4.9141 & TRN & \\
\hline CHEMBL1445776 & 688469 & 2.9208 & 3.72 & TRN & \\
\hline CHEMBL1362687 & 688469 & 5.0058 & 5.4645 & TRN & \\
\hline CHEMBL1519703 & 688469 & 4.6919 & 4.2706 & TRN & \\
\hline CHEMBL1429312 & 688469 & 2.9208 & 4.9081 & TRN & \\
\hline CHEMBL1498588 & 688469 & 4.454 & 4.5261 & TRN & \\
\hline CHEMBL1581822 & 688469 & 2.9208 & 3.7607 & TRN & \\
\hline CHEMBL1333962 & 688469 & 4.8527 & 3.7356 & TRN & \\
\hline CHEMBL1348389 & 688469 & 4.7798 & 4.8027 & TRN & \\
\hline CHEMBL1479301 & 688469 & 8.0 & 7.0727 & TST & \\
\hline CHEMBL1987461 & 688469 & 5.4753 & 5.1233 & TRN & \\
\hline CHEMBL1520802 & 688469 & 4.4555 & 3.5015 & TRN & \\
\hline CHEMBL1338349 & 688469 & 2.9208 & 3.3881 & TST & \\
\hline CHEMBL1573187 & 688469 & 4.8004 & 4.5821 & TRN & \\
\hline CHEMBL1405749 & 688469 & 8.0 & 5.8695 & TRN & \\
\hline CHEMBL3191713 & 688469 & 6.5143 & 6.3466 & TRN & \\
\hline CHEMBL3196217 & 688469 & 2.9208 & 4.2328 & TRN & \\
\hline CHEMBL1308609 & 688469 & 2.9208 & 3.2803 & TRN & \\
\hline
\end{tabular}




\begin{tabular}{|c|c|c|c|c|c|}
\hline \multicolumn{6}{|c|}{ Supplemental Table S2.txt } \\
\hline CHEMBL1535546 & 688469 & 2.9208 & 4.8205 & TRN & \\
\hline CHEMBL1547706 & 688469 & 5.3463 & 5.7789 & TRN & \\
\hline CHEMBL1509754 & 688469 & 4.8243 & 3.6092 & TRN & \\
\hline CHEMBL1448808 & 688469 & 4.9155 & 3.5567 & TST & \\
\hline CHEMBL1460783 & 688469 & 2.9208 & 3.7671 & TST & \\
\hline CHEMBL1608629 & 688469 & 5.131 & 4.7995 & TRN & \\
\hline CHEMBL1329450 & 688469 & 2.9208 & 4.0892 & TRN & \\
\hline CHEMBL1578850 & 688469 & 2.9208 & 3.4525 & TRN & \\
\hline CHEMBL1311021 & 688469 & 2.9208 & 3.2536 & TRN & \\
\hline CHEMBL1536637 & 688469 & 3.2218 & 4.5005 & TRN & \\
\hline CHEMBL1383790 & 688469 & 2.9208 & 3.3464 & TRN & \\
\hline CHEMBL1494106 & 688469 & 2.9208 & 3.3887 & TRN & \\
\hline CHEMBL 2006655 & 688469 & 2.9208 & 3.5695 & TRN & \\
\hline CHEMBL1507107 & 688469 & 2.9208 & 4.0211 & TRN & \\
\hline CHEMBL1332853 & 688469 & 2.9208 & 3.4467 & TRN & \\
\hline CHEMBL1365426 & 688469 & 2.9208 & 3.2689 & TRN & \\
\hline CHEMBL1487901 & 688469 & 4.9351 & 4.7954 & TST & \\
\hline CHEMBL1558695 & 688469 & 4.9856 & 5.0917 & TRN & \\
\hline CHEMBL1972216 & 688469 & 5.6925 & 5.56 & TRN & \\
\hline CHEMBL1585663 & 688469 & 4.5004 & 3.7518 & TRN & \\
\hline CHEMBL1518428 & 688469 & 4.9294 & 4.8608 & TRN & \\
\hline CHEMBL1392142 & 688469 & 8.0 & 7.4384 & TST & \\
\hline CHEMBL1301556 & 688469 & 2.9208 & 3.43399 & 99999999997 & TST \\
\hline CHEMBL 3198763 & 688469 & 5.3139 & 5.2476 & TST & \\
\hline CHEMBL1603001 & 688469 & 2.9208 & 3.5053 & TST & \\
\hline CHEMBL1487099 & 688469 & 5.9884 & 5.9246 & TST & \\
\hline CHEMBL1497927 & 688469 & 4.547 & 4.1345 & TST & \\
\hline CHEMBL1370024 & 688469 & 5.063 & 4.9662 & TST & \\
\hline CHEMBL1372738 & 688469 & 2.9208 & 3.6026 & TST & \\
\hline CHEMBL1463373 & 688469 & 4.871 & 3.7837 & TST & \\
\hline CHEMBL1573902 & 688469 & 2.9208 & 3.82800 & 00000000003 & TST \\
\hline CHEMBL1300237 & 688469 & 5.4721 & 5.4508 & TST & \\
\hline CHEMBL1498913 & 688469 & 2.9208 & 3.3049 & TST & \\
\hline CHEMBL1560066 & 688469 & 4.9301 & 4.8514 & TST & \\
\hline CHEMBL1392640 & 688469 & 2.9208 & 4.5153 & TST & \\
\hline CHEMBL1988121 & 688469 & 2.9208 & 5.0011 & TST & \\
\hline CHEMBL 1582620 & 688469 & 2.9208 & 3.3593 & TST & \\
\hline CHEMBL1327749 & 688469 & 8.0 & 5.803 & TST & \\
\hline CHEMBL1549357 & 688469 & 4.2608 & 5.016 & TST & \\
\hline CHEMBL3197771 & 688469 & 5.4645 & 4.583 & TST & \\
\hline CHEMBL1525098 & 688469 & 4.8099 & 4.3168 & TST & \\
\hline CHEMBL 1423060 & 688469 & 5.0632 & 4.9366 & TST & \\
\hline CHEMBL1486651 & 688469 & 4.8387 & 4.7623 & TST & \\
\hline CHEMBL 3185655 & 688469 & 8.0 & 6.9091 & TST & \\
\hline CHEMBL3213929 & 688469 & 4.6686 & 3.4983 & TST & \\
\hline CHEMBL1446892 & 688469 & 2.9208 & 3.9254 & TST & \\
\hline CHEMBL 1476358 & 688469 & 5.0391 & 3.8737 & TST & \\
\hline CHEMBL3196364 & 688469 & 5.2229 & 4.8835 & TST & \\
\hline
\end{tabular}




\begin{tabular}{|c|c|c|c|c|c|c|}
\hline & & \multicolumn{5}{|c|}{ Supplemental Table S2.txt } \\
\hline CHEMBL1578539 & 688469 & 2.9208 & 3.3297 & TST & & \\
\hline CHEMBL1306565 & 688469 & 4.9315 & 4.7151 & TST & & \\
\hline CHEMBL1360028 & 688469 & 4.9114 & 4.7671 & TST & & \\
\hline CHEMBL1323668 & 688469 & 5.5173 & 6.7303 & TST & & \\
\hline CHEMBL1388151 & 688469 & 2.9208 & 3.3937 & TST & & \\
\hline CHEMBL1560092 & 688469 & 2.9208 & 4.0194 & TST & & \\
\hline CHEMBL1547470 & 688469 & 4.7783 & 3.4944 & TST & & \\
\hline CHEMBL1562033 & 688469 & 4.4145 & 6.4813 & TST & & \\
\hline CHEMBL563577 & 688469 & 8.0 & 6.0639 & TST & & \\
\hline CHEMBL1603615 & 688469 & \multicolumn{3}{|c|}{5.167000000000001} & 4.8156 & TST \\
\hline CHEMBL1604296 & 688469 & 5.0431 & 4.8987 & TST & & \\
\hline CHEMBL1417732 & 688469 & 5.0903 & 4.8189 & TST & & \\
\hline CHEMBL1399543 & 688469 & 4.833 & 5.3683 & TST & & \\
\hline CHEMBL1307091 & 688469 & 8.0 & 6.6435 & TST & & \\
\hline CHEMBL1450165 & 688469 & 2.9208 & 3.6249 & TST & & \\
\hline CHEMBL1431241 & 688469 & 2.9208 & 4.6337 & TST & & \\
\hline CHEMBL1601295 & 688469 & 5.0509 & 4.7004 & TST & & \\
\hline CHEMBL1572510 & 688469 & 4.9304 & 4.6833 & TST & & \\
\hline CHEMBL1432507 & 688469 & 8.0 & 5.6933 & TST & & \\
\hline CHEMBL1511653 & 688469 & 2.9208 & 3.3021 & TST & & \\
\hline CHEMBL1483593 & 688469 & 8.0 & 6.3143 & TST & & \\
\hline CHEMBL1528420 & 688469 & 2.9208 & 4.1235 & TST & & \\
\hline CHEMBL1564302 & 688469 & 2.9208 & 4.1724 & TST & & \\
\hline CHEMBL285932 & 688469 & 4.9458 & 4.2495 & TST & & \\
\hline CHEMBL1523348 & 688469 & 4.1189 & 3.0999 & TST & & \\
\hline CHEMBL1328784 & 688469 & 2.9208 & 3.5208 & TST & & \\
\hline CHEMBL1304997 & 688469 & 2.9208 & 3.8785 & TST & & \\
\hline CHEMBL1428777 & 688469 & 4.7883 & 3.9828 & TST & & \\
\hline CHEMBL1984454 & 688469 & 4.9549 & 4.6248 & TST & & \\
\hline CHEMBL1408486 & 688469 & 5.334 & 5.8878 & TST & & \\
\hline CHEMBL 290077 & 688469 & 6.6162 & 6.8589 & TST & & \\
\hline CHEMBL1574752 & 688469 & 2.9208 & 3.7251 & TST & & \\
\hline CHEMBL1458306 & 688469 & 4.8201 & 4.1051 & TST & & \\
\hline CHEMBL1364056 & 688469 & 2.9208 & 4.0615 & TST & & \\
\hline CHEMBL1334041 & 688469 & 4.8496 & 3.8808 & TST & & \\
\hline CHEMBL1464180 & 688469 & 5.0203 & 4.8989 & TST & & \\
\hline CHEMBL1327172 & 688469 & 4.9182 & 4.873 & TST & & \\
\hline CHEMBL1444941 & 688469 & 4.7126 & 3.6922 & TST & & \\
\hline CHEMBL1466170 & 688469 & 2.9208 & 3.603 & TST & & \\
\hline CHEMBL1388529 & 688469 & 5.2267 & 5.2731 & TST & & \\
\hline CHEMBL 3039774 & 688469 & 2.9208 & 3.8539 & TST & & \\
\hline CHEMBL1381585 & 688469 & 2.9208 & 3.5974 & TST & & \\
\hline CHEMBL1365210 & 688469 & 4.7951 & 4.6892 & TST & & \\
\hline CHEMBL1413931 & 688469 & 2.9208 & 4.8158 & TST & & \\
\hline CHEMBL1572214 & 688469 & 8.0 & 5.9714 & TST & & \\
\hline CHEMBL1536981 & 688469 & 8.0 & 6.5147 & TST & & \\
\hline CHEMBL1532762 & 688469 & 4.5178 & 3.7214 & TST & & \\
\hline CHEMBL1455309 & 688469 & 2.9208 & 3.4535 & TST & & \\
\hline
\end{tabular}


Supplemental Table S2.txt

\begin{tabular}{|c|c|c|c|c|}
\hline 年 & & & ד & \\
\hline HEMBL1584226 & & .9145 & 4.7707 & \\
\hline 52 & & & & \\
\hline EMPI 1 & 9 & & & \\
\hline EMBL1458390 & 88469 & 558 & & \\
\hline AEMBL579322 & 88469 & 9337 & 7542 & \\
\hline AEMBL1466871 & 88469 & 314 & & \\
\hline EME & & & & \\
\hline EMBL129 & 88 & 7551 & & \\
\hline AEMBL1312738 & 384 & .0 & 93 & \\
\hline AEMBL1405413 & 884 & 9208 & & \\
\hline EMBL320 & 384 & 81 & 97 & \\
\hline EM & & & & \\
\hline IEMBL143 & 9 & 208 & & \\
\hline EMBL1557701 & 9 & 9208 & 71 & \\
\hline EMBL & 59 & 8958 & 36 & \\
\hline EMBL1 & 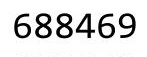 & 876 & & \\
\hline AEMBL1 & 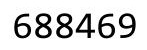 & 634 & & \\
\hline AEMBL 154 & 9 & 674 & & \\
\hline EMBL1 & 9 & 799 & 88 & S \\
\hline EMIBL 145 & 9 & 99 & 9 & \\
\hline EME & 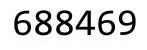 & 944 & & \\
\hline 27 & 9 & 904 & & \\
\hline 61 & 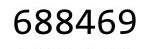 & 208 & & \\
\hline EMBL1 & 9 & & & S \\
\hline EME & 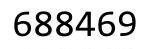 & & & \\
\hline EM & & 8 & & \\
\hline 1 & & 88 & & \\
\hline 44 & & & & ST \\
\hline EMBL138 & 38 & & & S \\
\hline 82 & 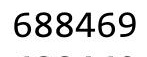 & & & \\
\hline 98 & & 8 & & \\
\hline & & & & ST \\
\hline EMBL1596468 & & & & ST \\
\hline EMBL1528 & 88 & 059 & & ST \\
\hline EMBL149: & $88>2>$ & 208 & & \\
\hline 2 & & & & \\
\hline & & & & ST \\
\hline IEMBL1490480 & 884 & 208 & 17 & $\mathrm{~S}$ \\
\hline EMBL1979 & 88 & 942 & & $S$ \\
\hline HEMBL1390428 & 88 & 208 & & \\
\hline & & & & S \\
\hline IEMBL1417160 & 9 & 3211 & & ST \\
\hline EMBL1351309 & 88469 & 917 & 77 & $\mathrm{~s}$ \\
\hline 12 & 00 & & & IS \\
\hline HEMBL1447563 & 688 & & & \\
\hline HEMBL1572920 & - & 9553 & 4.7111 & \\
\hline CHEMBL1491927 & 688469 & 4.6285 & 4.5904 & TS \\
\hline
\end{tabular}

Page 4425 
Supplemental Table S2.txt

\begin{tabular}{|c|c|c|c|c|}
\hline CHEMBL1548907 & 688469 & 4.6049 & 4.4847 & TST \\
\hline CHEMBL1452941 & 688469 & 2.9208 & 3.4684 & TST \\
\hline CHEMBL1393602 & 688469 & 4.6862 & 3.3127 & TST \\
\hline CHEMBL1609081 & 688469 & 4.8003 & 4.5184 & TST \\
\hline CHEMBL1887153 & 688469 & 6.2676 & 5.7757 & TST \\
\hline CHEMBL1544486 & 688469 & 5.3029 & 5.0395 & TST \\
\hline CHEMBL525103 & 688469 & 2.9208 & 4.8355 & TST \\
\hline CHEMBL1403718 & 688469 & 2.9208 & 3.6599 & TST \\
\hline CHEMBL1484090 & 688469 & 4.5312 & 4.0653 & TST \\
\hline CHEMBL1423097 & 688469 & 2.9208 & 4.4136 & TST \\
\hline CHEMBL1380296 & 688469 & 4.9731 & 4.7055 & TST \\
\hline CHEMBL1581013 & 688469 & 4.9836 & 4.8218 & TST \\
\hline CHEMBL1525080 & 688469 & 2.9208 & 4.6565 & TST \\
\hline CHEMBL1463234 & 688469 & 3.2218 & 3.5812 & TST \\
\hline CHEMBL1409963 & 688469 & 5.1096 & 4.8775 & TST \\
\hline CHEMBL1451109 & 688469 & 2.9208 & 3.7664 & TST \\
\hline CHEMBL1542833 & 688469 & 5.1418 & 5.0418 & TST \\
\hline CHEMBL 3207792 & 688469 & 2.9208 & 4.6316 & TST \\
\hline CHEMBL1380880 & 688469 & 2.9208 & 3.4755 & TST \\
\hline CHEMBL1505057 & 688469 & 2.9208 & 4.5837 & TST \\
\hline CHEMBL1340423 & 688469 & 4.8983 & 4.2595 & TST \\
\hline CHEMBL1322645 & 688469 & 5.0818 & 3.8179 & TST \\
\hline CHEMBL1542809 & 688469 & 5.0841 & 4.5908 & TST \\
\hline CHEMBL1425426 & 688469 & 4.6563 & 4.2437 & TST \\
\hline CHEMBL1324569 & 688469 & 4.7875 & 4.6697 & TST \\
\hline CHEMBL1480997 & 688469 & 2.9208 & 3.3782 & TST \\
\hline CHEMBL1442185 & 688469 & 2.9208 & 3.4105 & TST \\
\hline CHEMBL1502410 & 688469 & 2.9208 & $4.70100 e$ & 00000000005 \\
\hline CHEMBL1365689 & 688469 & 5.1797 & 5.2222 & TST \\
\hline CHEMBL1588275 & 688469 & 5.0689 & 4.7808 & TST \\
\hline CHEMBL1332529 & 688469 & 4.1776 & 4.2528 & TST \\
\hline CHEMBL1496396 & 688469 & 5.0042 & 4.5471 & TST \\
\hline CHEMBL1415306 & 688469 & 4.8999 & 3.6641 & TST \\
\hline CHEMBL1605138 & 688469 & 2.9208 & 3.7511 & TST \\
\hline CHEMBL1563337 & 688469 & 4.6908 & 4.5797 & TST \\
\hline CHEMBL3193600 & 688469 & 4.9557 & 4.8948 & TST \\
\hline CHEMBL1450354 & 688469 & 4.7917 & 3.4431 & TST \\
\hline CHEMBL1331692 & 688469 & 2.9208 & 4.6579 & TST \\
\hline CHEMBL1585345 & 688469 & 5.3192 & 6.0243 & TST \\
\hline CHEMBL1602385 & 688469 & 8.0 & 6.5247 & TST \\
\hline CHEMBL1336428 & 688469 & 4.8309 & 4.6093 & TST \\
\hline CHEMBL1582355 & 688469 & 4.9692 & 4.582 & TST \\
\hline CHEMBL1388002 & 688469 & 4.6658 & 3.8124 & TST \\
\hline CHEMBL1523552 & 688469 & 4.8018 & 4.4578 & TST \\
\hline CHEMBL1466145 & 688469 & 2.9208 & 4.4077 & TST \\
\hline CHEMBL1483161 & 688469 & 2.9208 & 4.387 & TST \\
\hline CHEMBL1576383 & 688469 & 2.9208 & 4.0761 & TST \\
\hline CHEMBL1471547 & 688469 & 4.8021 & 4.1308 & TST \\
\hline
\end{tabular}




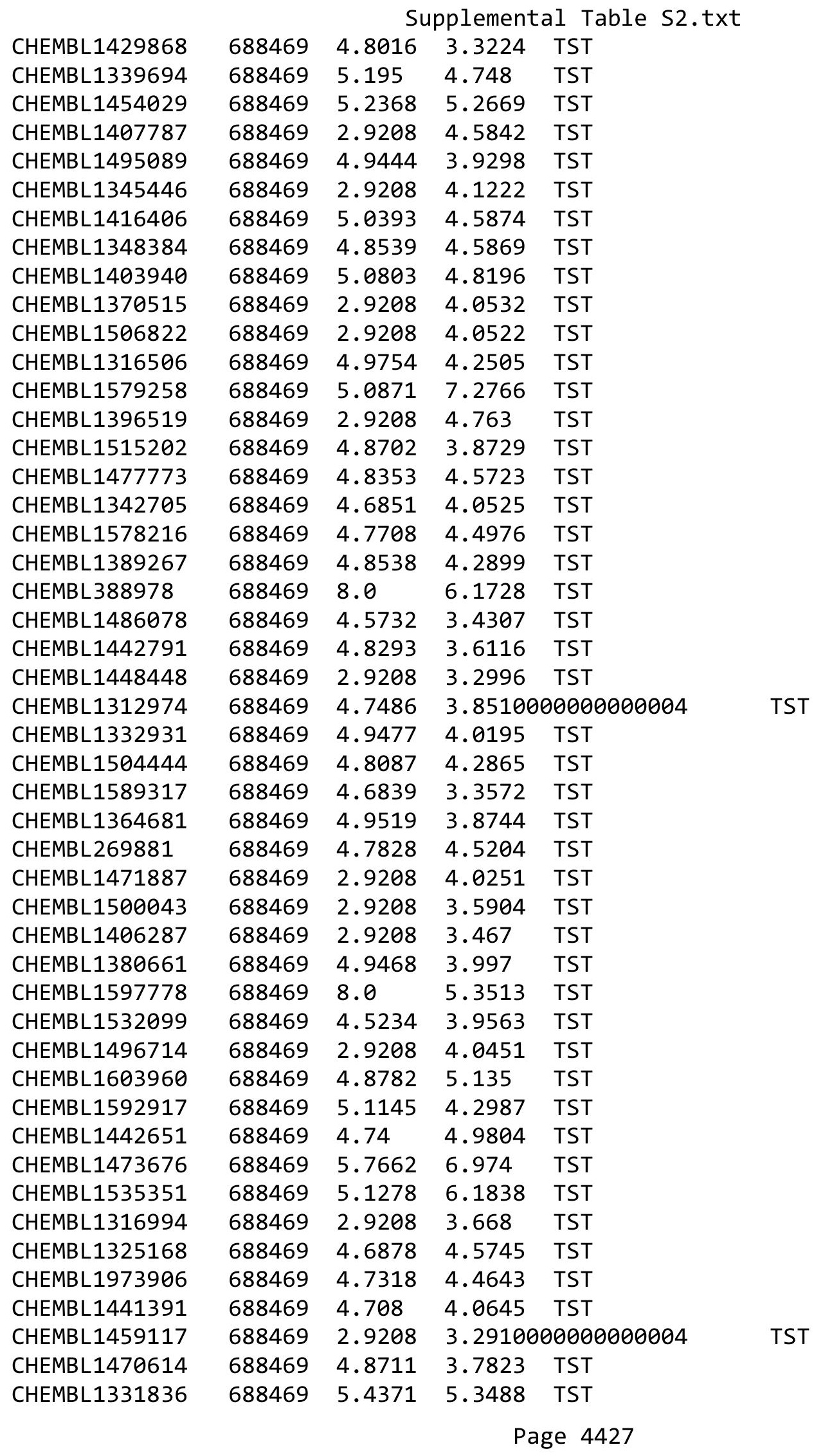




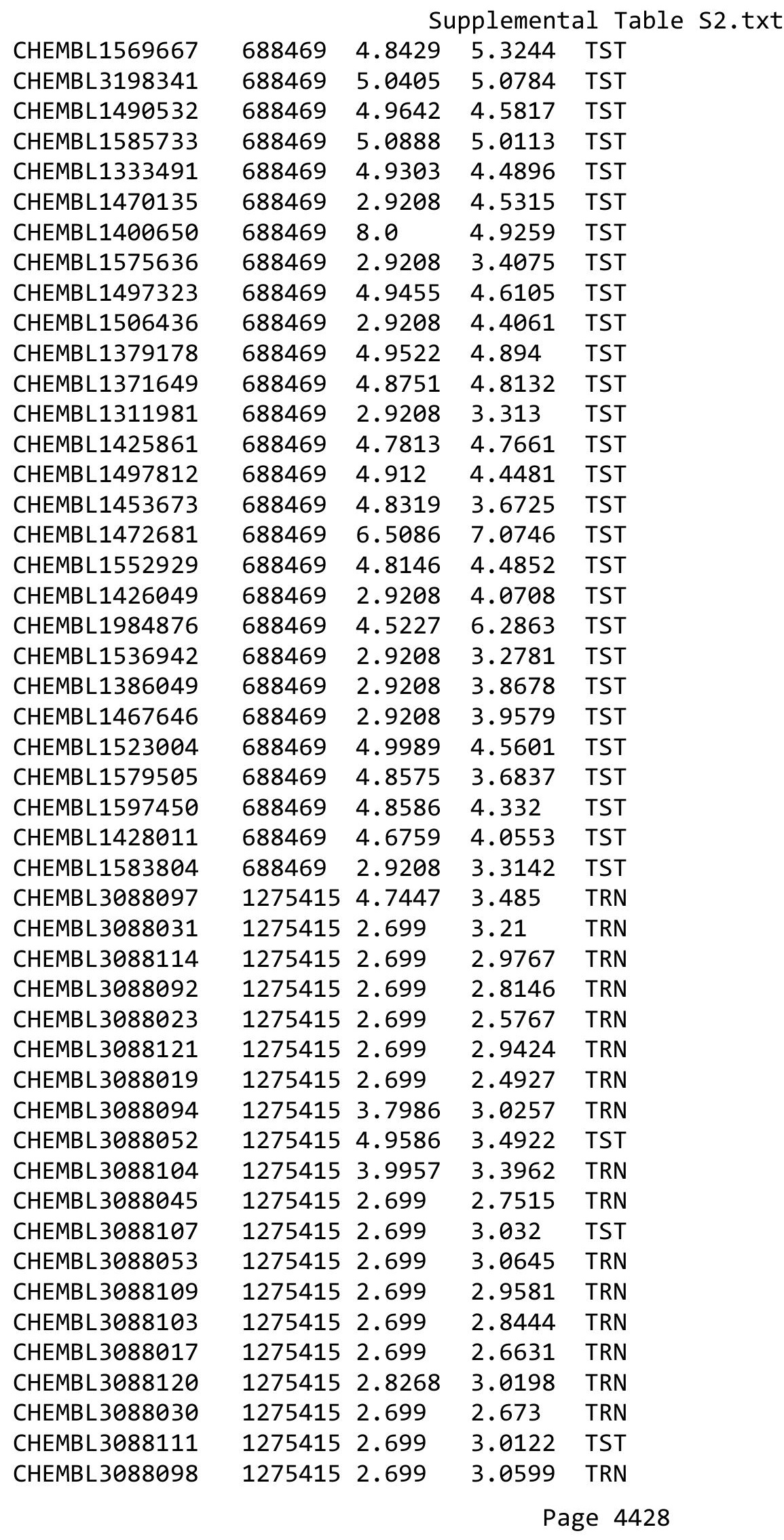


Supplemental Table S2.txt

\begin{tabular}{|c|c|c|c|c|}
\hline CHEMBL 3085800 & 1275415 & 2.699 & 2.8331 & TRN \\
\hline CHEMBL 3088018 & 1275415 & 2.699 & 2.5748 & TRN \\
\hline CHEMBL 3088037 & 1275415 & 2.699 & 2.5812 & TRN \\
\hline CHEMBL 3088112 & 1275415 & 2.699 & 2.7656 & TRN \\
\hline CHEMBL 3088101 & 1275415 & 2.699 & 2.8169 & TRN \\
\hline CHEMBL 3088105 & 1275415 & 4.7212 & 3.3827 & TST \\
\hline CHEMBL 3088038 & 1275415 & 2.699 & 2.499 & TRN \\
\hline CHEMBL 3088093 & 1275415 & 3.699 & 2.9249 & TRN \\
\hline CHEMBL 3088099 & 1275415 & 3.8894 & 3.1391 & TST \\
\hline CHEMBL3088095 & 1275415 & 2.699 & 2.9499 & TRN \\
\hline CHEMBL 3088022 & 1275415 & 2.699 & 2.4608 & TRN \\
\hline CHEMBL 3088116 & 1275415 & 2.699 & 3.4127 & TST \\
\hline CHEMBL 3088113 & 1275415 & 2.699 & 2.8704 & TRN \\
\hline CHEMBL 3088043 & 1275415 & 2.699 & 2.5503 & TRN \\
\hline CHEMBL 3085801 & 1275415 & 3.7645 & 3.4476 & TRN \\
\hline CHEMBL 3088028 & 1275415 & 2.699 & 2.6981 & TRN \\
\hline CHEMBL 3088115 & 1275415 & 2.699 & 2.9008 & TRN \\
\hline CHEMBL 3088039 & 1275415 & 2.699 & 3.0088 & TRN \\
\hline CHEMBL 3088118 & 1275415 & 2.699 & 2.8191 & TRN \\
\hline CHEMBL 3088035 & 1275415 & 2.699 & 2.3662 & TRN \\
\hline CHEMBL 3088119 & 1275415 & 2.699 & 2.9136 & TRN \\
\hline CHEMBL 3088044 & 1275415 & 2.699 & 2.6489 & TRN \\
\hline CHEMBL 3088051 & 1275415 & 4.3768 & 3.4931 & TRN \\
\hline CHEMBL 3088108 & 1275415 & 2.699 & 3.1216 & TST \\
\hline CHEMBL 3088040 & 1275415 & 2.699 & 3.029 & TST \\
\hline CHEMBL 3088100 & 1275415 & 2.699 & 2.7101 & TRN \\
\hline CHEMBL 3088048 & 1275415 & 4.0132 & 3.2088 & TST \\
\hline CHEMBL 3088117 & 1275415 & 3.0506 & 3.2271 & TST \\
\hline CHEMBL 3088049 & 1275415 & 2.699 & 2.7878 & TRN \\
\hline CHEMBL 3088042 & 1275415 & 2.699 & 2.9903 & TST \\
\hline CHEMBL 3088036 & 1275415 & 2.699 & 2.4751 & TRN \\
\hline CHEMBL 3088033 & 1275415 & 2.699 & 3.0134 & TRN \\
\hline CHEMBL 3088041 & 1275415 & 2.699 & 2.6063 & TRN \\
\hline CHEMBL 3088025 & 1275415 & 2.699 & 2.5992 & TRN \\
\hline CHEMBL 3088106 & 1275415 & 2.699 & 2.9538 & TRN \\
\hline CHEMBL 3088032 & 1275415 & 2.699 & 2.8988 & TST \\
\hline CHEMBL 3088027 & 1275415 & 2.699 & 3.1096 & TST \\
\hline CHEMBL 3088046 & 1275415 & 2.699 & 2.6777 & TRN \\
\hline CHEMBL 3088029 & 1275415 & 2.699 & 2.9913 & TST \\
\hline CHEMBL 3088016 & 1275415 & 2.699 & 2.9657 & TST \\
\hline CHEMBL 3088024 & 1275415 & 2.699 & 2.6839 & TRN \\
\hline CHEMBL 3088102 & 1275415 & 2.699 & 2.9188 & TRN \\
\hline CHEMBL 3088021 & 1275415 & 2.699 & 2.9063 & TST \\
\hline CHEMBL 3088034 & 1275415 & 2.699 & 2.7977 & TST \\
\hline CHEMBL 3088096 & 1275415 & 2.699 & 3.4919 & TRN \\
\hline CHEMBL 3088047 & 1275415 & 2.8239 & 3.2103 & TRN \\
\hline CHEMBL 3088050 & 1275415 & 2.699 & 2.663999 & 99999999997 \\
\hline CHEMBL 3088020 & 1275415 & 2.699 & 2.7387 & TST \\
\hline
\end{tabular}


Supplemental Table S2.txt

\begin{tabular}{|c|c|c|c|c|c|}
\hline CHEMBL 3088110 & 1275415 & 2.699 & 2.8005 & TRN & \\
\hline CHEMBL 3088026 & 1275415 & 2.699 & 3.1143 & TRN & \\
\hline CHEMBL 3648289 & 1527833 & 7.1871 & 6.566 & TRN & \\
\hline CHEMBL 3645371 & 1527833 & 6.5436 & 6.3633 & TRN & \\
\hline CHEMBL 3648307 & 1527833 & 6.8633 & 6.0763 & TST & \\
\hline CHEMBL 3648315 & 1527833 & 5.9136 & 5.9381 & TRN & \\
\hline CHEMBL 3648316 & 1527833 & 6.7077 & 6.7023 & TRN & \\
\hline CHEMBL461173 & 1527833 & 4.3093 & 5.3757 & TRN & \\
\hline CHEMBL 3974687 & 1527833 & \multicolumn{2}{|c|}{6.7620000000000005} & 6.4656 & TST \\
\hline CHEMBL491316 & 1527833 & 7.284 & 6.8213 & TRN & \\
\hline CHEMBL 3648270 & 1527833 & 6.4306 & 6.5061 & TRN & \\
\hline CHEMBL 3648274 & 1527833 & 5.9431 & 6.6633 & TST & \\
\hline CHEMBL522269 & 1527833 & 6.6615 & 6.6094 & TRN & \\
\hline CHEMBL 3648310 & 1527833 & 6.7959 & 6.3521 & TST & \\
\hline CHEMBL 3645370 & 1527833 & 5.8182 & 5.9459 & TRN & \\
\hline CHEMBL442585 & 1527833 & 6.7825 & 6.2155 & TRN & \\
\hline CHEMBL 3648301 & 1527833 & 5.9872 & 6.7035 & TRN & \\
\hline CHEMBL 3911671 & 1527833 & 7.0 & 6.0373 & TST & \\
\hline CHEMBL 3648276 & 1527833 & 5.8996 & 6.6195 & TRN & \\
\hline CHEMBL 3648303 & 1527833 & 5.7328 & 6.059 & TST & \\
\hline CHEMBL489330 & 1527833 & 6.5171 & 6.6766 & TRN & \\
\hline CHEMBL 3648282 & 1527833 & 6.3979 & 6.8539 & TRN & \\
\hline CHEMBL 3648304 & 1527833 & 3.0 & 6.2614 & TRN & \\
\hline CHEMBL491687 & 1527833 & 6.3478 & 6.6235 & TRN & \\
\hline CHEMBL 3648308 & 1527833 & 6.8356 & 6.2314 & TRN & \\
\hline CHEMBL3953192 & 1527833 & 7.2147 & 6.3518 & TST & \\
\hline CHEMBL490722 & 1527833 & 5.6556 & 6.5586 & TRN & \\
\hline CHEMBL489124 & 1527833 & 6.0575 & 6.5904 & TRN & \\
\hline CHEMBL 3648271 & 1527833 & 6.0472 & 6.0099 & TRN & \\
\hline CHEMBL 3918186 & 1527833 & 6.2865 & 6.4808 & TST & \\
\hline CHEMBL523646 & 1527833 & 6.71 & 6.6879 & TRN & \\
\hline CHEMBL 3648279 & 1527833 & 7.1487 & 6.9028 & TRN & \\
\hline CHEMBL 3648292 & 1527833 & 6.9031 & 6.4924 & TRN & \\
\hline CHEMBL 3648277 & 1527833 & 5.7721 & 6.3904 & TRN & \\
\hline CHEMBL 3648265 & 1527833 & 5.8775 & 6.2121 & TRN & \\
\hline CHEMBL475145 & 1527833 & 7.1938 & 5.661006 & 00000000005 & TRN \\
\hline CHEMBL 3645366 & 1527833 & 6.5719 & 6.7183 & TST & \\
\hline CHEMBL 3648305 & 1527833 & 7.2076 & 6.59399 & 9999999999 & וS1 \\
\hline CHEMBL 3648295 & 1527833 & 6.4306 & 6.7527 & TRN & \\
\hline CHEMBL 3648263 & 1527833 & 6.4145 & 5.9316 & TRN & \\
\hline CHEMBL460963 & 1527833 & 7.6198 & 6.9542 & TRN & \\
\hline CHEMBL 3648290 & 1527833 & 7.284 & 6.7361 & TRN & \\
\hline CHEMBL 3645368 & 1527833 & 5.3645 & 5.6248 & TRN & \\
\hline CHEMBL 3648266 & 1527833 & 5.8794 & 6.4234 & TRN & \\
\hline CHEMBL491490 & 1527833 & 6.6091 & 6.6227 & TRN & \\
\hline CHEMBL 3645373 & 1527833 & 5.5751 & 5.6678 & TRN & \\
\hline CHEMBL 3648285 & 1527833 & 6.9355 & 6.8707 & TRN & \\
\hline CHEMBL474547 & 1527833 & 5.7773 & 5.5965 & TRN & \\
\hline
\end{tabular}

Page 4430 
Supplemental Table S2.txt

\begin{tabular}{|c|c|c|c|c|c|}
\hline CHEMBL 3648306 & 1527833 & 6.9355 & 6.6424 & TRN & \\
\hline CHEMBL 3648313 & 1527833 & 6.0237 & 6.0174 & TRN & \\
\hline CHEMBL 3648284 & 1527833 & 6.5272 & 6.5979 & TRN & \\
\hline CHEMBL474350 & 1527833 & 5.4895 & 5.7927 & TRN & \\
\hline CHEMBL491688 & 1527833 & 7.585 & 6.7514 & TRN & \\
\hline CHEMBL489331 & 1527833 & 6.7905 & 6.7151 & TRN & \\
\hline CHEMBL 3645369 & 1527833 & 5.8601 & 5.5491 & TRN & \\
\hline CHEMBL 3648294 & 1527833 & 6.5317 & 6.7757 & TRN & \\
\hline CHEMBL464718 & 1527833 & 5.4815 & 5.994 & TRN & \\
\hline CHEMBL 3648298 & 1527833 & 6.2441 & 6.4312 & TRN & \\
\hline CHEMBL 3648311 & 1527833 & 6.7773 & 6.4749 & TST & \\
\hline CHEMBL 3645374 & 1527833 & 6.0726 & 5.5532 & TRN & \\
\hline CHEMBL 3645367 & 1527833 & 5.8633 & 6.1788 & TRN & \\
\hline CHEMBL474152 & 1527833 & 6.767 & 6.3087 & TRN & \\
\hline CHEMBL 3648278 & 1527833 & 5.7959 & 6.5781 & TRN & \\
\hline CHEMBL489706 & 1527833 & 6.7122 & 6.6318 & TRN & \\
\hline CHEMBL 3648269 & 1527833 & 5.8356 & 6.4065 & TRN & \\
\hline CHEMBL 3648272 & 1527833 & 6.4486 & 6.5936 & TST & \\
\hline CHEMBL 3648297 & 1527833 & 6.2518 & 6.585 & TRN & \\
\hline CHEMBL 3648317 & 1527833 & 5.8539 & 6.1907 & TST & \\
\hline CHEMBL 3648286 & 1527833 & 6.7799 & 6.1968 & TRN & \\
\hline CHEMBL 3645372 & 1527833 & 5.8729 & 5.9652 & TRN & \\
\hline CHEMBL 3648280 & 1527833 & 7.2676 & 6.6074 & TRN & \\
\hline CHEMBL 3648268 & 1527833 & 6.6861 & 6.6776 & TRN & \\
\hline CHEMBL 3648267 & 1527833 & 7.0362 & 6.7581 & TRN & \\
\hline CHEMBL 3648296 & 1527833 & 6.4179 & 6.6107 & TST & \\
\hline CHEMBL 3648302 & 1527833 & 5.9626 & 5.9641 & TST & \\
\hline CHEMBL 3916325 & 1527833 & 7.5229 & 6.7791 & TST & \\
\hline CHEMBL 3648309 & 1527833 & 6.8153 & 6.7604 & TST & \\
\hline CHEMBL491491 & 1527833 & 7.1427 & 6.7513 & TRN & \\
\hline CHEMBL1377382 & 1527833 & 6.71 & 5.8371 & TST & \\
\hline CHEMBL 3648288 & 1527833 & 6.7747 & 6.6563 & TRN & \\
\hline CHEMBL 3648293 & 1527833 & 6.5376 & 6.5524 & TST & \\
\hline CHEMBL 3648264 & 1527833 & 6.3585 & 6.597 & TRN & \\
\hline CHEMBL 3648314 & 1527833 & 5.8729 & 5.9157 & TRN & \\
\hline CHEMBL521909 & 1527833 & 6.6861 & 6.4883 & TRN & \\
\hline CHEMBL489332 & 1527833 & 7.4089 & 6.8195 & TRN & \\
\hline CHEMBL 3648299 & 1527833 & 6.0477 & 6.1119 & TST & \\
\hline CHEMBL 3648312 & 1527833 & 6.7773 & 6.7477 & TRN & \\
\hline CHEMBL 3648318 & 1527833 & 6.6308 & 6.2022 & TRN & \\
\hline CHEMBL 3966516 & 1527833 & 6.8827 & 6.1939 & TST & \\
\hline CHEMBL 3648275 & 1527833 & 6.6383 & 6.2407 & TST & \\
\hline CHEMBL 3648300 & 1527833 & 6.0348 & 6.5705 & TST & \\
\hline CHEMBL523601 & 1527833 & 6.8013 & 6.593 & TRN & \\
\hline CHEMBL474546 & 1527833 & 5.71899 & 999999999 & 99 & 5.5283 \\
\hline CHEMBL 3892688 & 1527833 & 6.3197 & 6.2095 & TST & \\
\hline CHEMBL489125 & 1527833 & 6.644 & 6.606 & TRN & \\
\hline CHEMBL474746 & 1527833 & 7.2924 & 6.0788 & TRN & \\
\hline
\end{tabular}




\begin{tabular}{|c|c|c|c|c|}
\hline & & & oplement & al Ta \\
\hline CHEMBL364450 & 305419 & 4.5768 & 4.4319 & TRN \\
\hline CHEMBL190438 & 305419 & 2.3979 & 2.3926 & TRN \\
\hline CHEMBL190439 & 305419 & 3.71 & 3.5452 & TRN \\
\hline CHEMBL191601 & 305419 & 4.3224 & 4.507 & TRN \\
\hline CHEMBL192647 & 305419 & 5.041 & 5.0774 & TRN \\
\hline CHEMBL191835 & 305419 & 2.8239 & 2.6102 & TRN \\
\hline CHEMBL192013 & 305419 & 4.2182 & 4.0381 & TRN \\
\hline CHEMBL372013 & 305419 & 3.9031 & 3.8155 & TRN \\
\hline CHEMBL371570 & 305419 & 2.8239 & 3.2574 & TRN \\
\hline CHEMBL364239 & 305419 & 3.8327 & 3.8324 & TRN \\
\hline CHEMBL191268 & 305419 & 4.6421 & 4.7257 & TRN \\
\hline CHEMBL191920 & 305419 & 4.58 & 4.8911 & TRN \\
\hline CHEMBL370286 & 305419 & 4.1249 & 4.1153 & TRN \\
\hline CHEMBL191641 & 305419 & 4.0531 & 3.9464 & TRN \\
\hline CHEMBL190518 & 305419 & 4.6517 & 4.2115 & TRN \\
\hline CHEMBL161992 & 305419 & 4.8327 & 4.8058 & TRN \\
\hline CHEMBL371372 & 305419 & 4.0132 & 3.7996 & TRN \\
\hline CHEMBL426086 & 305419 & 4.3497 & 4.3957 & TRN \\
\hline CHEMBL364272 & 305419 & 3.9136 & 4.1989 & TST \\
\hline CHEMBL192145 & 305419 & 5.8386 & 6.0389 & TRN \\
\hline CHEMBL193892 & 305419 & 2.3979 & 2.7106 & TRN \\
\hline CHEMBL424824 & 305419 & 4.4067 & 3.9635 & TRN \\
\hline CHEMBL191786 & 305419 & 5.6576 & 5.5897 & TRN \\
\hline CHEMBL192937 & 305419 & 4.9066 & 4.5422 & TST \\
\hline CHEMBL193282 & 305419 & 5.8861 & 5.5734 & TRN \\
\hline CHEMBL195096 & 305419 & 3.0 & 3.7427 & TRN \\
\hline CHEMBL365118 & 305419 & 3.4498 & 3.3614 & TRN \\
\hline CHEMBL363196 & 305419 & 4.2343 & 4.1028 & TRN \\
\hline CHEMBL415775 & 305419 & 3.5031 & 3.7373 & TST \\
\hline CHEMBL192761 & 305419 & 3.9574 & 3.9603 & TST \\
\hline CHEMBL352683 & 305419 & 4.5421 & 4.8384 & TRN \\
\hline CHEMBL370247 & 305419 & 4.8601 & 5.146 & TRN \\
\hline CHEMBL427169 & 305419 & 3.8041 & 4.0331 & TST \\
\hline CHEMBL365159 & 305419 & 6.5229 & 6.1179 & TST \\
\hline CHEMBL112953 & 305419 & 5.8239 & 5.8763 & TRN \\
\hline CHEMBL192480 & 305419 & 4.2366 & 4.2249 & TRN \\
\hline CHEMBL189537 & 305419 & 4.4976 & 4.4898 & TST \\
\hline CHEMBL349231 & 305419 & 4.9788 & 5.1947 & TRN \\
\hline CHEMBL193310 & 305419 & 3.9788 & 3.7676 & TST \\
\hline CHEMBL194716 & 305419 & 4.3206 & 3.685 & TST \\
\hline CHEMBL439852 & 305419 & 4.6289 & 4.5621 & TRN \\
\hline CHEMBL370092 & 305419 & 4.3575 & 4.4195 & TST \\
\hline CHEMBL193259 & 305419 & 4.6799 & 4.4971 & TRN \\
\hline CHEMBL362972 & 305419 & 3.7696 & 4.0665 & TST \\
\hline CHEMBL273986 & 305419 & 5.4949 & 4.9762 & TRN \\
\hline CHEMBL364730 & 305419 & 3.5072 & 3.6299 & TRN \\
\hline CHEMBL191635 & 305419 & 6.0915 & 5.9438 & TRN \\
\hline CHEMBL191241 & 305419 & 4.5482 & 4.4815 & TRN \\
\hline
\end{tabular}




\begin{tabular}{|c|c|c|c|c|c|c|}
\hline \multicolumn{7}{|c|}{ Supplemental Table S2.txt } \\
\hline CHEMBL193056 & 305419 & 4.0 & 4.041 & TRN & & \\
\hline CHEMBL364456 & 305419 & 4.4449 & 4.7654 & TRN & & \\
\hline CHEMBL190654 & 305419 & 3.5017 & 3.5614 & TST & & \\
\hline CHEMBL193313 & 305419 & 2.301 & 3.8646 & TST & & \\
\hline CHEMBL192062 & 305419 & 5.4559 & 5.4875 & TRN & & \\
\hline CHEMBL193672 & 305419 & 4.15300 & 00000000 & 205 & 4.426 & TST \\
\hline CHEMBL195869 & 305419 & 4.27 & 4.1938 & TRN & & \\
\hline CHEMBL192649 & 305419 & 4.2426 & 4.1276 & TST & & \\
\hline CHEMBL191668 & 305419 & 4.1851 & 4.2382 & TRN & & \\
\hline CHEMBL363860 & 305419 & 2.8239 & 2.7614 & TRN & & \\
\hline CHEMBL277718 & 37966 & 6.8697 & 6.8284 & TRN & & \\
\hline CHEMBL267335 & 37966 & 7.6778 & 7.6336 & TRN & & \\
\hline CHEMBL281645 & 37966 & 6.9031 & 7.1978 & TRN & & \\
\hline CHEMBL21251 & 37966 & 7.0 & 4.203 & TST & & \\
\hline CHEMBL20297 & 37966 & 6.8697 & 6.8606 & TRN & & \\
\hline CHEMBL 20984 & 37966 & 6.3665 & 6.307 & TRN & & \\
\hline CHEMBL21087 & 37966 & 6.7959 & 5.2571 & TST & & \\
\hline CHEMBL20530 & 37966 & 7.7959 & 7.8212 & TRN & & \\
\hline CHEMBL 20411 & 37966 & 7.0 & 4.4904 & TST & & \\
\hline CHEMBL21030 & 37966 & 6.0 & 5.9172 & TRN & & \\
\hline CHEMBL20519 & 37966 & 5.0 & 5.0192 & TRN & & \\
\hline CHEMBL538650 & 37966 & 7.0177 & 7.1052 & TRN & & \\
\hline CHEMBL280399 & 37966 & 6.2716 & 6.3769 & TRN & & \\
\hline CHEMBL280125 & 37966 & 5.3979 & 3.6749 & TST & & \\
\hline CHEMBL21222 & 37966 & 8.0 & 7.935 & TRN & & \\
\hline CHEMBL 20765 & 37966 & 7.0706 & 7.1076 & TRN & & \\
\hline CHEMBL21202 & 37966 & 5.8239 & 7.3218 & TST & & \\
\hline CHEMBL20049 & 37966 & 7.4318 & 7.4564 & TRN & & \\
\hline CHEMBL277007 & 37966 & 8.1549 & 8.1858 & TRN & & \\
\hline CHEMBL19981 & 37966 & 6.4685 & 6.3884 & TRN & & \\
\hline CHEMBL277450 & 37966 & 7.0 & 7.0247 & TRN & & \\
\hline CHEMBL 20082 & 37966 & 7.3279 & 7.3131 & TRN & & \\
\hline CHEMBL 20221 & 37966 & 6.7328 & 6.6024 & TRN & & \\
\hline CHEMBL 280674 & 37966 & 4.0 & 5.7411 & TST & & \\
\hline CHEMBL21262 & 37966 & 8.0969 & 8.09799 & 9999999999 & & TRN \\
\hline CHEMBL277617 & 37966 & 6.9706 & 7.0705 & TRN & & \\
\hline CHEMBL20121 & 37966 & 7.3768 & 7.2995 & TRN & & \\
\hline CHEMBL 20983 & 37966 & 8.0458 & 8.2183 & TRN & & \\
\hline CHEMBL282678 & 37966 & 4.0 & 4.3775 & TRN & & \\
\hline CHEMBL428362 & 37966 & 8.0458 & 8.0624 & TRN & & \\
\hline CHEMBL20529 & 37966 & 7.699 & 7.7154 & TRN & & \\
\hline CHEMBL20214 & 37966 & 7.4685 & 7.3449 & TRN & & \\
\hline CHEMBL278760 & 37966 & 7.2218 & 5.63200 & 0000000001 & & TST \\
\hline CHEMBL20055 & 37966 & 6.2716 & 6.2527 & TRN & & \\
\hline CHEMBL20113 & 37966 & 7.9208 & 7.885 & TRN & & \\
\hline CHEMBL20268 & 37966 & 6.7212 & 6.8366 & TRN & & \\
\hline CHEMBL21169 & 37966 & 6.699 & 6.584 & TRN & & \\
\hline CHEMBL20346 & 37966 & 7.6198 & 7.5823 & TRN & & \\
\hline
\end{tabular}




\begin{tabular}{|c|c|c|c|c|c|}
\hline & & \multicolumn{4}{|c|}{ Supplemental Table S2.txt } \\
\hline CHEMBL 277461 & 37966 & 7.4559 & 7.3197 & TRN & \\
\hline CHEMBL416549 & 37966 & 7.7212 & 7.671 & TRN & \\
\hline CHEMBL 20980 & 37966 & 7.6198 & 7.6516 & TRN & \\
\hline CHEMBL279517 & 37966 & 7.301 & 6.0779 & TST & \\
\hline CHEMBL442335 & 37966 & 7.0506 & 6.9966 & TRN & \\
\hline CHEMBL 20349 & 37966 & 5.3979 & 5.2065 & TRN & \\
\hline CHEMBL20037 & 37966 & 6.5302 & 6.5351 & TRN & \\
\hline CHEMBL276991 & 37966 & 7.3768 & 7.3007 & TRN & \\
\hline CHEMBL281643 & 37966 & 7.0706 & 5.3436 & TST & \\
\hline CHEMBL20695 & 37966 & 7.5229 & 7.6022 & TRN & \\
\hline CHEMBL 279969 & 37966 & 5.7328 & 5.7236 & TRN & \\
\hline CHEMBL 20078 & 37966 & 4.0 & 4.0735 & TRN & \\
\hline CHEMBL21029 & 37966 & 7.3468 & 7.4095 & TRN & \\
\hline CHEMBL20638 & 37966 & 6.3279 & 4.1375 & TST & \\
\hline CHEMBL281824 & 37966 & 6.0969 & 6.086 & TRN & \\
\hline CHEMBL19874 & 37966 & 7.4685 & 7.5813 & TRN & \\
\hline CHEMBL20584 & 37966 & 7.8539 & 7.8787 & TRN & \\
\hline CHEMBL20473 & 37966 & 6.1308 & 5.8868 & TST & \\
\hline CHEMBL21144 & 37966 & 5.699 & 5.3981 & TRN & \\
\hline CHEMBL21089 & 37966 & 5.8861 & 5.9468 & TRN & \\
\hline CHEMBL 277407 & 37966 & 5.1487 & 5.0392 & TST & \\
\hline CHEMBL 20478 & 37966 & 6.8697 & 6.8382 & TRN & \\
\hline CHEMBL 279087 & 37966 & 6.9208 & 4.0516 & TST & \\
\hline CHEMBL 20077 & 37966 & 7.6021 & 7.5956 & TRN & \\
\hline CHEMBL 274076 & 37966 & 7.0 & 5.2075 & TST & \\
\hline CHEMBL20120 & 37966 & 7.1192 & 7.5169 & TST & \\
\hline CHEMBL 280208 & 37966 & 7.2147 & 7.5165 & TST & \\
\hline CHEMBL 20908 & 37966 & 4.0 & 5.4468 & TST & \\
\hline CHEMBL277406 & 37966 & 7.2441 & 7.147 & TRN & \\
\hline CHEMBL198421 & 1640195 & 6.5884 & 6.8546 & TRN & \\
\hline CHEMBL194186 & 1640195 & 9.0991 & 9.2875 & TRN & \\
\hline CHEMBL3968842 & 1640195 & 8.6716 & 8.7744 & TRN & \\
\hline CHEMBL190142 & 1640195 & 8.7905 & 8.4822 & TRN & \\
\hline CHEMBL383361 & 1640195 & 9.0737 & 9.2097 & TRN & \\
\hline CHEMBL198654 & 1640195 & 8.3615 & 8.4203 & TRN & \\
\hline CHEMBL196539 & 1640195 & 9.1163 & 9.1902 & TRN & \\
\hline CHEMBL3959350 & 1640195 & 7.5058 & 7.2922 & TRN & \\
\hline CHEMBL1235423 & 1640195 & 7.5622 & 7.3114 & TST & \\
\hline CHEMBL370614 & 1640195 & 9.1085 & 8.9308 & TRN & \\
\hline CHEMBL3966335 & 1640195 & 5.9626 & 6.2264 & TST & \\
\hline CHEMBL 3958789 & 1640195 & 8.5482 & 8.4918 & TRN & \\
\hline CHEMBL3304291 & 1640195 & 8.28399 & 99999999 & 8.3991 & TRN \\
\hline CHEMBL196669 & 1640195 & 5.1959 & 5.2504 & TRN & \\
\hline CHEMBL3956658 & 1640195 & 8.1221 & 8.2494 & TRN & \\
\hline CHEMBL196492 & 1640195 & 8.3536 & 8.0819 & TRN & \\
\hline CHEMBL372568 & 1640195 & 6.4365 & 6.4261 & TRN & \\
\hline CHEMBL197547 & 1640195 & 7.3778 & 7.2312 & TRN & \\
\hline CHEMBL196589 & 1640195 & 6.9393 & 7.38399 & 99999999995 & TRN \\
\hline
\end{tabular}


Supplemental Table S2.txt

\begin{tabular}{|c|c|c|c|c|c|}
\hline CHEMBL436293 & 1640195 & 7.0434 & 6.9559 & TRN & \\
\hline CHEMBL564248 & 1640195 & 8.7645 & 8.9308 & TRN & \\
\hline CHEMBL196162 & 1640195 & 8.4802 & 7.7784 & TRN & \\
\hline CHEMBL 3957468 & 1640195 & 7.8729 & 7.8168 & TRN & \\
\hline CHEMBL196551 & 1640195 & 8.2388 & 8.1052 & TRN & \\
\hline CHEMBL557915 & 1640195 & 8.757 & 8.7504 & TRN & \\
\hline CHEMBL3986101 & 1640195 & 8.9172 & 9.1077 & TRN & \\
\hline CHEMBL3928201 & 1640195 & 7.4763 & 7.3324 & TST & \\
\hline CHEMBL364284 & 1640195 & 9.6696 & 9.7248 & TRN & \\
\hline CHEMBL 3960154 & 1640195 & 9.1824 & 8.9668 & TST & \\
\hline CHEMBL120413 & 1640195 & 7.2161 & 7.0904 & TST & \\
\hline CHEMBL371106 & 1640195 & 7.4949 & 7.7811 & TRN & \\
\hline CHEMBL93087 & 1640195 & 7.1904 & 7.19600 & 0000000001 & TST \\
\hline CHEMBL370176 & 1640195 & 6.7959 & 6.9735 & TRN & \\
\hline CHEMBL194889 & 1640195 & 6.3478 & 6.3155 & TRN & \\
\hline CHEMBL3907419 & 1640195 & 8.7212 & 8.6406 & TRN & \\
\hline CHEMBL381866 & 1640195 & 8.3788 & 8.4022 & TRN & \\
\hline CHEMBL 3979386 & 1640195 & 8.9393 & 9.0103 & TRN & \\
\hline CHEMBL3972799 & 1640195 & 9.0958 & 9.1209 & TRN & \\
\hline CHEMBL197377 & 1640195 & 9.1986 & 9.1202 & TRN & \\
\hline CHEMBL48813 & 1640195 & 8.7721 & 8.6568 & TST & \\
\hline CHEMBL197624 & 1640195 & 7.4672 & 7.5763 & TRN & \\
\hline CHEMBL372956 & 1640195 & 8.7799 & 8.5002 & TRN & \\
\hline CHEMBL550453 & 1640195 & 8.0867 & 8.3095 & TRN & \\
\hline CHEMBL 3974641 & 1640195 & 7.7033 & 7.3211 & TST & \\
\hline CHEMBL3910588 & 1640195 & 9.0675 & 9.06299 & 9999999999 & TRN \\
\hline CHEMBL 3961484 & 1640195 & 9.1051 & 8.9207 & TRN & \\
\hline CHEMBL316053 & 1640195 & 7.3595 & 7.1853 & TST & \\
\hline CHEMBL3955803 & 1640195 & 8.8508 & 8.7859 & TRN & \\
\hline CHEMBL 3904655 & 1640195 & \multicolumn{2}{|c|}{8.767000000000001} & 8.5227 & TST \\
\hline CHEMBL194810 & 1640195 & 7.8327 & 7.9825 & TST & \\
\hline CHEMBL 3972969 & 1640195 & 8.1701 & 8.2417 & TST & \\
\hline CHEMBL3305961 & 1640195 & 7.7055 & 7.8201 & TST & \\
\hline CHEMBL3912108 & 1640195 & 8.7447 & 8.4837 & TST & \\
\hline CHEMBL 367188 & 4285 & 6.7959 & 6.9524 & TRN & \\
\hline CHEMBL154517 & 4285 & 5.2218 & 5.3736 & TRN & \\
\hline CHEMBL175903 & 4285 & 5.3372 & 5.5267 & TRN & \\
\hline CHEMBL177392 & 4285 & 6.3098 & 5.9975 & TRN & \\
\hline CHEMBL154574 & 4285 & 4.9208 & 4.8039 & TRN & \\
\hline CHEMBL174161 & 4285 & 5.5686 & 5.419 & TRN & \\
\hline CHEMBL368604 & 4285 & 6.1427 & 6.2097 & TRN & \\
\hline CHEMBL156835 & 4285 & 4.2147 & 4.3874 & TST & \\
\hline CHEMBL 366714 & 4285 & 6.5528 & 7.149 & TRN & \\
\hline CHEMBL 309339 & 4285 & 4.5229 & 4.5693 & TST & \\
\hline CHEMBL175908 & 4285 & 5.1024 & 4.7536 & TRN & \\
\hline CHEMBL177702 & 4285 & 6.3872 & 6.3703 & TRN & \\
\hline CHEMBL65654 & 4285 & 7.1938 & 7.0218 & TRN & \\
\hline CHEMBL154827 & 4285 & 5.699 & 5.5454 & TRN & \\
\hline
\end{tabular}




\begin{tabular}{|c|c|c|c|c|c|}
\hline & & \multicolumn{4}{|c|}{ Supplemental Table s2.txt } \\
\hline CHEMBL176849 & 4285 & 5.1871 & 5.6886 & TRN & \\
\hline CHEMBL174051 & 4285 & 6.4437 & 6.8623 & TRN & \\
\hline CHEMBL434171 & 4285 & 4.2147 & 5.1368 & TST & \\
\hline CHEMBL351785 & 4285 & 6.2924 & 6.0722 & TRN & \\
\hline CHEMBL175134 & 4285 & 6.6778 & 7.0011 & TRN & \\
\hline CHEMBL152665 & 4285 & 3.5229 & 5.0369 & TST & \\
\hline CHEMBL367336 & 4285 & 5.7447 & 5.4193 & TRN & \\
\hline CHEMBL155611 & 4285 & 6.9208 & 6.593 & TRN & \\
\hline CHEMBL175410 & 4285 & 5.2757 & 5.0381 & TRN & \\
\hline CHEMBL304443 & 4285 & 6.5376 & 6.1717 & TRN & \\
\hline CHEMBL65655 & 4285 & 7.6576 & 7.6185 & TRN & \\
\hline CHEMBL16300 & 4285 & 3.9586 & 4.228 & TRN & \\
\hline CHEMBL177246 & 4285 & 5.1871 & 5.1718 & TRN & \\
\hline CHEMBL115468 & 4285 & 4.3665 & 5.7385 & TST & \\
\hline CHEMBL177989 & 4285 & 6.1079 & 5.3301 & TST & \\
\hline CHEMBL368826 & 4285 & 6.5229 & 6.6511 & TRN & \\
\hline CHEMBL367643 & 4285 & 5.7447 & 5.8644 & TRN & \\
\hline CHEMBL 307568 & 4285 & 6.4089 & 6.256 & TRN & \\
\hline CHEMBL155319 & 4285 & 4.5686 & 5.5214 & TST & \\
\hline CHEMBL156887 & 4285 & 6.7447 & 6.4493 & TRN & \\
\hline CHEMBL101043 & 4285 & 4.8539 & 5.2256 & TRN & \\
\hline CHEMBL154008 & 4285 & 6.4815 & 6.3108 & TRN & \\
\hline CHEMBL175117 & 4285 & 5.2757 & 5.9927 & TRN & \\
\hline CHEMBL154585 & 4285 & 5.3872 & 5.3506 & TRN & \\
\hline CHEMBL146477 & 4285 & 6.2291 & 6.1794 & TRN & \\
\hline CHEMBL178065 & 4285 & 6.0506 & 5.8911 & TRN & \\
\hline CHEMBL369436 & 4285 & 5.3372 & 5.8132 & TST & \\
\hline CHEMBL152162 & 4285 & 4.0605 & 5.2464 & TST & \\
\hline CHEMBL69110 & 4285 & 6.5528 & 6.2302 & TRN & \\
\hline CHEMBL367924 & 4285 & 6.3665 & 6.5157 & TRN & \\
\hline CHEMBL155287 & 4285 & 4.8239 & 4.3952 & TRN & \\
\hline CHEMBL154302 & 4285 & 4.1871 & 4.8425 & TRN & \\
\hline CHEMBL 303033 & 4285 & 6.1135 & 6.0701 & TRN & \\
\hline CHEMBL177084 & 4285 & 5.0809 & 5.6382 & TST & \\
\hline CHEMBL175932 & 4285 & 5.4437 & 5.5334 & TST & \\
\hline CHEMBL176288 & 4285 & 5.5376 & 5.8829 & TST & \\
\hline CHEMBL175319 & 4285 & 6.0088 & 5.2118 & TRN & \\
\hline CHEMBL158240 & 4285 & 3.7212 & 3.6876 & TRN & \\
\hline CHEMBL65946 & 4285 & 5.4318 & 5.5786 & TRN & \\
\hline CHEMBL351337 & 4285 & 4.8539 & 4.0239 & TRN & \\
\hline CHEMBL446362 & 4285 & 7.0 & 6.6032 & TRN & \\
\hline CHEMBL67940 & 4285 & 6.3468 & 6.4999 & TRN & \\
\hline CHEMBL55895 & 4285 & 4.5686 & 5.3984 & TST & \\
\hline CHEMBL155033 & 4285 & 7.0862 & 6.96700 & 00000000005 & TRN \\
\hline CHEMBL174898 & 4285 & 7.0 & 7.2825 & TRN & \\
\hline CHEMBL177476 & 4285 & 6.8861 & 6.4316 & TRN & \\
\hline CHEMBL176285 & 4285 & 5.7212 & 5.7202 & TRN & \\
\hline CHEMBL67411 & 4285 & 6.3872 & 5.8231 & TRN & \\
\hline
\end{tabular}




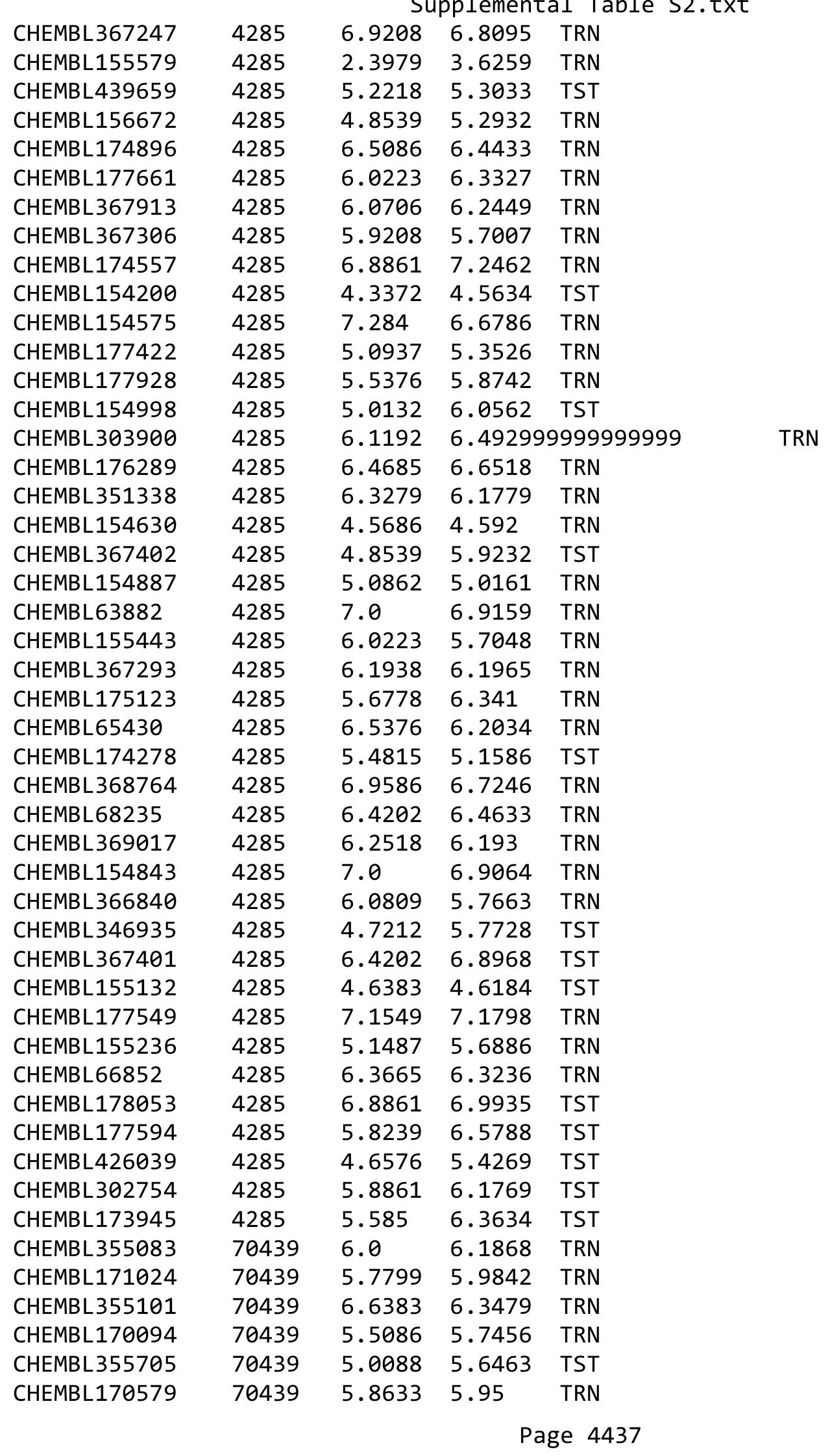




\begin{tabular}{|c|c|c|c|c|c|c|}
\hline & & \multicolumn{5}{|c|}{ Supplemental Table s2.txt } \\
\hline CHEMBL171544 & 70439 & 5.9031 & 5.6538 & TRN & & \\
\hline CHEMBL369265 & 70439 & 6.4815 & 6.3162 & TRN & & \\
\hline CHEMBL172109 & 70439 & 5.6021 & 5.6192 & TRN & & \\
\hline CHEMBL171463 & 70439 & 6.3979 & 6.3857 & TRN & & \\
\hline CHEMBL172580 & 70439 & 6.0 & 5.7413 & TRN & & \\
\hline CHEMBL353280 & 70439 & 5.3665 & 5.3865 & TRN & & \\
\hline CHEMBL170428 & 70439 & 6.983 & 6.7565 & TRN & & \\
\hline CHEMBL355058 & 70439 & 4.3468 & 5.7204 & TST & & \\
\hline CHEMBL366550 & 70439 & 7.2218 & 7.1202 & TST & & \\
\hline CHEMBL172097 & 70439 & 7.0 & 6.9827 & TRN & & \\
\hline CHEMBL169160 & 70439 & 5.6778 & 5.52 & TRN & & \\
\hline CHEMBL170445 & 70439 & 4.5884 & 5.6877 & TST & & \\
\hline CHEMBL171164 & 70439 & 7.2676 & 7.4072 & TRN & & \\
\hline CHEMBL171751 & 70439 & 6.041 & 5.8592 & TRN & & \\
\hline CHEMBL353038 & 70439 & 5.1549 & 5.2854 & TRN & & \\
\hline CHEMBL338910 & 70439 & 4.4168 & 6.3365 & TST & & \\
\hline CHEMBL354331 & 70439 & 5.6778 & 5.9314 & TRN & & \\
\hline CHEMBL354945 & 70439 & 4.4202 & 6.3332 & TST & & \\
\hline CHEMBL355483 & 70439 & 6.5229 & 6.4719 & TRN & & \\
\hline CHEMBL354427 & 70439 & 5.9626 & 5.8654 & TRN & & \\
\hline CHEMBL336597 & 70439 & 6.0458 & 5.9671 & TRN & & \\
\hline CHEMBL353421 & 70439 & 5.6576 & 5.5904 & TRN & & \\
\hline CHEMBL354131 & 70439 & 6.4685 & 6.7443 & TRN & & \\
\hline CHEMBL445917 & 70439 & 5.556 & 5.5297 & TST & & \\
\hline CHEMBL171939 & 70439 & 4.4949 & 5.5244 & TST & & \\
\hline CHEMBL169500 & 70439 & 5.8894 & 6.0289 & TRN & & \\
\hline CHEMBL171097 & 70439 & 7.0362 & 7.1719 & TRN & & \\
\hline CHEMBL169435 & 70439 & \multicolumn{3}{|c|}{5.757000000000001} & 5.4176 & TRN \\
\hline CHEMBL170014 & 70439 & 6.3468 & 6.4124 & TRN & & \\
\hline CHEMBL170955 & 70439 & 6.0969 & 5.8133 & TRN & & \\
\hline CHEMBL170652 & 70439 & 6.9666 & 6.88899 & 9999999999 & & TRN \\
\hline CHEMBL366497 & 70439 & 4.4559 & 5.1146 & TRN & & \\
\hline CHEMBL171597 & 70439 & 5.6576 & 5.7669 & TRN & & \\
\hline CHEMBL171938 & 70439 & 5.6021 & 5.7895 & TST & & \\
\hline CHEMBL367708 & 70439 & 5.9788 & 5.9573 & TRN & & \\
\hline CHEMBL144031 & 70439 & 6.0 & 6.5906 & TRN & & \\
\hline CHEMBL311310 & 70439 & 6.0 & 6.195 & TRN & & \\
\hline CHEMBL355262 & 70439 & 5.7447 & 6.2035 & TST & & \\
\hline CHEMBL305798 & 70439 & 6.0 & 6.6862 & TRN & & \\
\hline CHEMBL170860 & 70439 & 6.0555 & 5.8922 & TRN & & \\
\hline CHEMBL171005 & 70439 & 6.0 & 5.975 & TRN & & \\
\hline CHEMBL172561 & 70439 & 5.7235 & 5.74700 & 0000000001 & & TRN \\
\hline CHEMBL170525 & 70439 & 6.0555 & 6.1414 & TRN & & \\
\hline CHEMBL354591 & 70439 & 5.8861 & 5.6251 & TRN & & \\
\hline CHEMBL422723 & 70439 & 5.9066 & 5.7836 & TRN & & \\
\hline CHEMBL352727 & 70439 & 6.5528 & 6.3517 & TRN & & \\
\hline CHEMBL369047 & 70439 & 7.301 & 6.8958 & TRN & & \\
\hline CHEMBL355717 & 70439 & 6.0 & 6.106 & TRN & & \\
\hline
\end{tabular}




\begin{tabular}{|c|c|c|c|c|c|}
\hline \multicolumn{6}{|c|}{ Supplemental Table S2.txt } \\
\hline CHEMBL172779 & 70439 & 6.0 & 5.8355 & TRN & \\
\hline CHEMBL336370 & 70439 & 6.0223 & 6.1358 & TRN & \\
\hline CHEMBL352918 & 70439 & 6.0 & 6.4751 & TRN & \\
\hline CHEMBL352997 & 70439 & 5.9586 & 5.8147 & TRN & \\
\hline CHEMBL170455 & 70439 & 7.0809 & 7.1889 & TRN & \\
\hline CHEMBL170887 & 70439 & 6.6778 & 6.61299 & 99999999995 & TRN \\
\hline CHEMBL354071 & 70439 & 5.3372 & 5.6417 & TST & \\
\hline CHEMBL352930 & 70439 & 6.0 & 5.9256 & TRN & \\
\hline CHEMBL171785 & 70439 & 6.4089 & 6.4402 & TRN & \\
\hline CHEMBL171046 & 70439 & 4.9136 & 4.8103 & TRN & \\
\hline CHEMBL170456 & 70439 & 4.7212 & 4.6273 & TRN & \\
\hline CHEMBL171073 & 70439 & 5.5086 & 5.7255 & TRN & \\
\hline CHEMBL171451 & 70439 & 4.6383 & 6.2294 & TST & \\
\hline CHEMBL354588 & 70439 & 7.4685 & 7.0177 & TST & \\
\hline CHEMBL169934 & 70439 & 6.5086 & 6.0767 & TRN & \\
\hline CHEMBL171441 & 70439 & 5.8996 & 5.7457 & TRN & \\
\hline CHEMBL354716 & 70439 & 4.4202 & 6.0509 & TST & \\
\hline CHEMBL352653 & 70439 & 7.3872 & 7.4056 & TRN & \\
\hline CHEMBL172397 & 70439 & 5.6126 & 5.397 & TRN & \\
\hline CHEMBL172823 & 70439 & 5.7447 & 5.76399 & 9999999999 & TRN \\
\hline CHEMBL171443 & 70439 & 5.6904 & 5.9447 & TRN & \\
\hline CHEMBL171484 & 70439 & 6.4202 & 6.4231 & TRN & \\
\hline CHEMBL354747 & 70439 & 6.9914 & 7.0309 & TRN & \\
\hline CHEMBL355453 & 70439 & 6.7696 & 6.33200 & 0000000001 & TRN \\
\hline CHEMBL172387 & 70439 & 7.0 & 6.8438 & TRN & \\
\hline CHEMBL354717 & 70439 & 4.8239 & 5.4982 & TST & \\
\hline CHEMBL171788 & 70439 & 5.8962 & 5.8348 & TRN & \\
\hline CHEMBL352560 & 70439 & 4.6946 & 4.6697 & TRN & \\
\hline CHEMBL355252 & 70439 & 4.8761 & 4.8827 & TRN & \\
\hline CHEMBL169966 & 70439 & 5.585 & 5.6063 & TRN & \\
\hline CHEMBL368752 & 70439 & 5.4815 & 5.6471 & TRN & \\
\hline CHEMBL367735 & 70439 & 5.3872 & 5.2614 & TRN & \\
\hline CHEMBL169647 & 70439 & 6.0555 & 6.0419 & TRN & \\
\hline CHEMBL355879 & 70439 & 5.3098 & 5.8384 & TST & \\
\hline CHEMBL 367172 & 70439 & 7.5528 & 7.3838 & TRN & \\
\hline CHEMBL354221 & 70439 & 6.0555 & 6.1 & TRN & \\
\hline CHEMBL171186 & 70439 & 5.4202 & 5.5724 & TRN & \\
\hline CHEMBL169863 & 70439 & 5.1308 & 5.1538 & TRN & \\
\hline CHEMBL353495 & 70439 & 7.3468 & 7.2647 & TRN & \\
\hline CHEMBL117406 & 70439 & 4.5186 & 4.4918 & TRN & \\
\hline CHEMBL170211 & 70439 & 5.6021 & 5.5924 & TRN & \\
\hline CHEMBL341393 & 70439 & 6.4437 & 6.5232 & TRN & \\
\hline CHEMBL352489 & 70439 & 5.3468 & 5.8902 & TST & \\
\hline CHEMBL353906 & 70439 & 6.5229 & 6.2633 & TST & \\
\hline CHEMBL171165 & 70439 & 5.8539 & 6.2677 & TST & \\
\hline CHEMBL170891 & 70439 & 6.0 & 5.7182 & TRN & \\
\hline CHEMBL425133 & 70439 & 6.6778 & 6.4848 & TST & \\
\hline CHEMBL355335 & 70439 & 6.0 & 5.8433 & TST & \\
\hline
\end{tabular}




\begin{tabular}{|c|c|c|c|c|c|}
\hline \multicolumn{6}{|c|}{ Supplemental Table S2.txt } \\
\hline CHEMBL355534 & 70439 & 6.0706 & 5.7156 & TST & \\
\hline CHEMBL171605 & 70439 & 6.0862 & 5.7627 & TRN & \\
\hline CHEMBL369442 & 70439 & 5.9586 & 6.0412 & TRN & \\
\hline CHEMBL169130 & 70439 & 6.6198 & 6.4611 & TST & \\
\hline CHEMBL352569 & 70439 & 4.6383 & 4.58899 & 99999999995 & TST \\
\hline CHEMBL368295 & 70439 & 7.9208 & 7.0487 & TST & \\
\hline CHEMBL334749 & 70439 & 6.0 & 5.8517 & TST & \\
\hline CHEMBL170414 & 70439 & 5.1675 & 5.3451 & TRN & \\
\hline CHEMBL 3085290 & 70439 & 5.1549 & 5.5093 & TRN & \\
\hline CHEMBL352309 & 70439 & 4.3188 & 6.055 & TST & \\
\hline CHEMBL170921 & 70439 & 7.1612 & 7.0344 & TRN & \\
\hline CHEMBL170436 & 70439 & 5.6778 & 5.8203 & TRN & \\
\hline CHEMBL171210 & 70439 & 6.3279 & 6.3578 & TRN & \\
\hline CHEMBL354742 & 70439 & 5.3188 & 5.0288 & TST & \\
\hline CHEMBL352634 & 70439 & 4.9469 & 5.2539 & TRN & \\
\hline CHEMBL335871 & 70439 & 5.5638 & 5.7562 & TST & \\
\hline CHEMBL353225 & 70439 & 6.1805 & 6.3934 & TRN & \\
\hline CHEMBL353223 & 70439 & 6.0362 & 5.9341 & TRN & \\
\hline CHEMBL172565 & 70439 & 5.7595 & 5.8147 & TST & \\
\hline CHEMBL170295 & 70439 & 6.0862 & 5.7085 & TST & \\
\hline CHEMBL355632 & 70439 & 6.0 & 5.8617 & TRN & \\
\hline CHEMBL353647 & 70439 & 4.699 & 4.7573 & TRN & \\
\hline CHEMBL169867 & 70439 & 7.5686 & 7.364 & TRN & \\
\hline CHEMBL171232 & 70439 & $5.7520 e$ & 30000000 & 6.4743 & 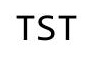 \\
\hline CHEMBL3947507 & 1641005 & 10.0 & 9.9149 & TRN & \\
\hline CHEMBL3902740 & 1641005 & 8.3188 & 8.2559 & TRN & \\
\hline CHEMBL3893279 & 1641005 & 8.7212 & 8.8102 & TRN & \\
\hline CHEMBL3917488 & 1641005 & 7.6635 & 7.8202 & TRN & \\
\hline CHEMBL 3900604 & 1641005 & 8.9208 & 8.9357 & TRN & \\
\hline CHEMBL3981668 & 1641005 & 7.2487 & 7.2406 & TRN & \\
\hline CHEMBL3974100 & 1641005 & 9.699 & 9.5449 & TRN & \\
\hline CHEMBL3912711 & 1641005 & 9.0969 & 9.2373 & TST & \\
\hline CHEMBL3927103 & 1641005 & 7.9469 & 8.6961 & TST & \\
\hline CHEMBL3892999 & 1641005 & 8.8861 & 8.8908 & TST & \\
\hline CHEMBL3953953 & 1641005 & 9.301 & 9.4534 & TRN & \\
\hline CHEMBL3954314 & 1641005 & 9.0969 & 9.0968 & TRN & \\
\hline CHEMBL3935425 & 1641005 & 7.8928 & 7.9819 & TRN & \\
\hline CHEMBL3971441 & 1641005 & 7.3862 & 7.4392 & TRN & \\
\hline CHEMBL3894021 & 1641005 & 8.2924 & 8.3977 & TRN & \\
\hline CHEMBL3963048 & 1641005 & 7.2154 & 7.1136 & TRN & \\
\hline CHEMBL3946768 & 1641005 & 9.1549 & 8.1455 & TST & \\
\hline CHEMBL3929899 & 1641005 & 7.8729 & 7.86600 & 00000000005 & T \\
\hline CHEMBL3934837 & 1641005 & 7.7905 & 7.8206 & TRN & \\
\hline CHEMBL3913892 & 1641005 & 8.6383 & 8.6832 & TRN & \\
\hline CHEMBL 3964173 & 1641005 & 8.585 & 8.5709 & TRN & \\
\hline CHEMBL3961172 & 1641005 & 9.699 & 9.617 & TRN & \\
\hline CHEMBL3982409 & 1641005 & 6.1655 & 6.186 & TRN & \\
\hline CHEMBL3978108 & 1641005 & 9.5229 & 9.5381 & TRN & \\
\hline
\end{tabular}


Supplemental Table S2.txt

\begin{tabular}{|c|c|c|c|c|c|}
\hline CHEMBL3950956 & 1641005 & 9.5229 & 9.4159 & TRN & \\
\hline CHEMBL3917047 & 1641005 & 8.2518 & 8.2295 & TRN & \\
\hline CHEMBL3971297 & 1641005 & 6.4044 & 9.0542 & TST & \\
\hline CHEMBL3892630 & 1641005 & 8.0 & 7.9666 & TRN & \\
\hline CHEMBL3966792 & 1641005 & 8.6576 & 8.6724 & TRN & \\
\hline CHEMBL3982629 & 1641005 & 8.9586 & 8.882 & TRN & \\
\hline CHEMBL3894114 & 1641005 & 8.4318 & 8.4194 & TRN & \\
\hline CHEMBL3890838 & 1641005 & 7.2132 & 9.4173 & TST & \\
\hline CHEMBL3908132 & 1641005 & 6.5248 & 6.5289 & TRN & \\
\hline CHEMBL3890109 & 1641005 & 8.3768 & 8.4867 & TST & \\
\hline CHEMBL3937458 & 1641005 & 8.6021 & 8.4656 & TRN & \\
\hline CHEMBL3963030 & 1641005 & 8.2596 & 8.2616 & TRN & \\
\hline CHEMBL3954250 & 1641005 & 7.0585 & 7.0219 & TRN & \\
\hline CHEMBL3920034 & 1641005 & 9.5229 & 9.4397 & TRN & \\
\hline CHEMBL3986049 & 1641005 & 8.9586 & 8.8993 & TRN & \\
\hline CHEMBL3932046 & 1641005 & 8.6383 & 8.6071 & TRN & \\
\hline CHEMBL3911616 & 1641005 & 8.1308 & 8.1451 & TST & \\
\hline CHEMBL3908191 & 1641005 & 8.8861 & 8.8149 & TRN & \\
\hline CHEMBL3979469 & 1641005 & 9.301 & 9.4016 & TST & \\
\hline CHEMBL3945295 & 1641005 & 7.7328 & 7.6378 & TRN & \\
\hline CHEMBL3970655 & 1641005 & 9.0 & 8.9735 & TRN & \\
\hline CHEMBL3915778 & 1641005 & 6.1965 & 6.2916 & TRN & \\
\hline CHEMBL3922028 & 1641005 & 8.7959 & 8.7807 & TRN & \\
\hline CHEMBL3978912 & 1641005 & 8.585 & 8.4337 & TRN & \\
\hline CHEMBL3892069 & 1641005 & 6.1234 & 8.0264 & TST & \\
\hline CHEMBL3974617 & 1641005 & 6.5112 & 7.0732 & TST & \\
\hline CHEMBL3910867 & 1641005 & 9.0 & 8.9416 & TRN & \\
\hline CHEMBL3949361 & 1641005 & 7.8894 & 7.8903 & TRN & \\
\hline CHEMBL3914203 & 1641005 & 8.6778 & 8.5553 & TRN & \\
\hline CHEMBL3959194 & 1641005 & 8.8239 & 8.873 & TRN & \\
\hline CHEMBL3978199 & 1641005 & 9.3979 & 9.5242 & TRN & \\
\hline CHEMBL3930371 & 1641005 & 9.0 & 8.8811 & TST & \\
\hline CHEMBL3908540 & 1641005 & 9.301 & 9.3796 & TRN & \\
\hline CHEMBL3914303 & 1641005 & 7.0097 & 6.9923 & TST & \\
\hline CHEMBL3949067 & 1641005 & 8.1871 & 8.21 & TRN & \\
\hline CHEMBL3903436 & 1641005 & 9.699 & 9.8769 & TRN & \\
\hline CHEMBL3902113 & 1641005 & 9.3979 & 9.3853 & TRN & \\
\hline CHEMBL3894091 & 1641005 & 9.2218 & 9.35799 & & TRN \\
\hline CHEMBL 3970287 & 1641005 & 8.1192 & 8.1669 & TRN & \\
\hline CHEMBL3945675 & 1641005 & 9.1549 & 9.2362 & TRN & \\
\hline CHEMBL3918166 & 1641005 & 9.5229 & 9.1782 & TST & \\
\hline CHEMBL3900323 & 1641005 & 7.6596 & 7.7223 & TRN & \\
\hline CHEMBL3916552 & 1641005 & 6.9263 & 7.1921 & TST & \\
\hline CHEMBL 3893785 & 1641005 & 8.9586 & 8.9991 & TRN & \\
\hline CHEMBL3921277 & 1641005 & 6.7557 & 8.7299 & TST & \\
\hline CHEMBL3918250 & 1641005 & 8.7696 & 8.6568 & TRN & \\
\hline CHEMBL3928155 & 1641005 & 9.0969 & 9.1658 & TRN & \\
\hline CHEMBL3893720 & 1641005 & 8.8861 & 8.9406 & TRN & \\
\hline
\end{tabular}


Supplemental Table S2.txt

\begin{tabular}{|c|c|c|c|c|}
\hline CHEMBL3963810 & 1641005 & 8.3098 & \multicolumn{2}{|c|}{8.283999999999999} \\
\hline CHEMBL3908461 & 1641005 & 8.0132 & 8.0361 & TRN \\
\hline CHEMBL3944509 & 1641005 & 8.6021 & 8.72206 & 0000000001 \\
\hline CHEMBL3901506 & 1641005 & 7.1759 & 9.2865 & TST \\
\hline CHEMBL3899086 & 1641005 & 8.8861 & 8.9264 & TRN \\
\hline CHEMBL3910476 & 1641005 & 6.8099 & 7.8477 & TST \\
\hline CHEMBL3907441 & 1641005 & 8.8861 & 8.7733 & TRN \\
\hline CHEMBL3937889 & 1641005 & 6.5418 & 6.5019 & TRN \\
\hline CHEMBL3913517 & 1641005 & 8.4318 & 8.3659 & TRN \\
\hline CHEMBL3975045 & 1641005 & 8.2924 & 8.2147 & TRN \\
\hline CHEMBL3903045 & 1641005 & 8.9208 & 8.9204 & TRN \\
\hline CHEMBL3930547 & 1641005 & 8.6383 & 8.6102 & TRN \\
\hline CHEMBL3970604 & 1641005 & 6.4008 & 6.9867 & TST \\
\hline CHEMBL3958283 & 1641005 & 9.301 & 9.1957 & TRN \\
\hline CHEMBL3940456 & 1641005 & 8.0706 & 8.2051 & TRN \\
\hline CHEMBL3965834 & 1641005 & 8.0605 & 8.0364 & TRN \\
\hline CHEMBL3954491 & 1641005 & 8.7696 & 8.8245 & TRN \\
\hline CHEMBL3903702 & 1641005 & 9.1549 & 9.4815 & TST \\
\hline CHEMBL3966347 & 1641005 & 7.0685 & 7.11 & TRN \\
\hline CHEMBL3920928 & 1641005 & 8.9586 & 9.0036 & TRN \\
\hline CHEMBL3945777 & 1641005 & 9.3979 & 9.4492 & TRN \\
\hline CHEMBL3899406 & 1641005 & 9.0458 & 8.9175 & TRN \\
\hline CHEMBL3959548 & 1641005 & 8.7447 & 8.7869 & TRN \\
\hline CHEMBL3920626 & 1641005 & 7.7352 & 7.8691 & TST \\
\hline CHEMBL3922640 & 1641005 & 6.4688 & 8.7208 & TST \\
\hline CHEMBL3952865 & 1641005 & 8.8539 & 8.8375 & TST \\
\hline CHEMBL3941857 & 1641005 & 7.9066 & 7.8769 & TST \\
\hline CHEMBL3930948 & 1641005 & 8.2441 & 8.103 & TST \\
\hline CHEMBL3902653 & 1641005 & 9.0969 & 9.3121 & TST \\
\hline CHEMBL601486 & 609034 & 8.699 & 8.024 & TRN \\
\hline CHEMBL602110 & 609034 & 7.7959 & 8.1639 & TRN \\
\hline CHEMBL601693 & 609034 & 7.9208 & 8.249 & TRN \\
\hline CHEMBL601270 & 609034 & 7.5086 & 7.5269 & TRN \\
\hline CHEMBL602112 & 609034 & 8.2291 & 8.2375 & TRN \\
\hline CHEMBL590008 & 609034 & 8.7696 & 8.2704 & TRN \\
\hline CHEMBL539733 & 609034 & 7.8239 & 8.2533 & TRN \\
\hline CHEMBL590007 & 609034 & 8.3468 & 8.0914 & TRN \\
\hline CHEMBL590009 & 609034 & 8.2007 & 8.3704 & TRN \\
\hline CHEMBL589930 & 609034 & 7.6576 & 8.1014 & TRN \\
\hline CHEMBL602108 & 609034 & 8.2291 & 7.9008 & TRN \\
\hline CHEMBL601489 & 609034 & 9.1938 & 8.3584 & TRN \\
\hline CHEMBL589597 & 609034 & 7.8861 & 7.9719 & TRN \\
\hline CHEMBL590001 & 609034 & 7.9586 & 8.2382 & TRN \\
\hline CHEMBL589897 & 609034 & 8.1871 & 8.6065 & TRN \\
\hline CHEMBL601271 & 609034 & 8.2596 & 7.6051 & TRN \\
\hline CHEMBL602111 & 609034 & 8.5528 & 8.2058 & TRN \\
\hline CHEMBL601276 & 609034 & 7.6778 & 7.8516 & TRN \\
\hline CHEMBL590258 & 609034 & 7.8861 & 7.9015 & TRN \\
\hline
\end{tabular}


Supplemental Table S2.txt

\begin{tabular}{|c|c|c|c|c|}
\hline CHEMBL590261 & 609034 & 8.2596 & 8.1308 & TST \\
\hline CHEMBL589519 & 509034 & 8.8239 & 8.4108 & \\
\hline HEMBL589298 & 09034 & 8239 & 0294 & $3 \mathrm{~N}$ \\
\hline HEMBL601272 & 09034 & 7.9586 & 7007 & ST \\
\hline HEMBL 589824 & 09034 & 8.5528 & 3924 & N \\
\hline HEMBL589927 & 509034 & 8.0757 & 7.9092 & \\
\hline HEMBL601484 & 09034 & 6.0 & 7.5118 & \\
\hline HEMBL601485 & 509034 & & 7.7183 & RN \\
\hline HEMBL 589804 & 609034 & 8.8239 & 8.4901 & RN \\
\hline HEMBL590114 & 509034 & 8.301 & 7.9895 & ST \\
\hline HEMBL590006 & 609034 & 7.5376 & 7.9832 & \\
\hline HEMBL601697 & 09034 & .3665 & 8.8354 & \\
\hline HEMBL589889 & 509034 & 979 & 0482 & \\
\hline HEMBL601695 & 609034 & 9.1024 & 8.5099 & \\
\hline HEMBL601447 & 09034 & 7.9208 & 9124 & \\
\hline HEMBL 589828 & 609034 & 8.2218 & 8.4816 & \\
\hline HEMBL601696 & 09034 & 9.2366 & 046 & KIV \\
\hline HEMBL601273 & 09034 & 8.1367 & 7.7992 & \\
\hline HEMBL589961 & 609034 & 8.1249 & 8.6 & $\mathrm{RN}$ \\
\hline CHEMBL590254 & 509034 & 8.0 & 122 & \\
\hline HEMBL590146 & 609034 & 7696 & 3422 & IV \\
\hline HEMBL590257 & 09034 & .0044 & 7.7033 & RN \\
\hline HEMBL601910 & 09034 & 8.3098 & 8.1609 & \\
\hline HEMBL589697 & 509034 & 8.2007 & 8.0678 & N \\
\hline HEMBL589584 & 509034 & .4949 & 8.7364 & TRN \\
\hline HEMBL601905 & 609034 & 9208 & 8.3223 & RN \\
\hline HEMBL5 & 09034 & .6021 & 1882 & $\Gamma \mathrm{RN}$ \\
\hline CHEMBL590005 & 09034 & 8.1871 & 8.362 & TRN \\
\hline CHEMBL601906 & 609034 & 8.6778 & 8.6609 & IRIV \\
\hline CHEMBL589616 & 509034 & 8.0809 & 9356 & TRN \\
\hline HEMBL589520 & 609034 & 8.4202 & 8.8327 & TST \\
\hline HEMBL6 & 09034 & 7. & 1896 & TRN \\
\hline CHEMBL 601908 & 509034 & 8.0706 & 7.9259 & TRN \\
\hline CHEMBL601909 & 609034 & 8.0506 & 7.9245 & TRN \\
\hline HEMBL590087 & 609034 & 7.7696 & 7.8821 & TRN \\
\hline CHEMBL590004 & 609034 & & 8.8364 & TRN \\
\hline CHEMBL6 & 609034 & 7.6021 & 8.4254 & TST \\
\hline CHEMBL601698 & 609034 & 9.0088 & 8.4825 & TRN \\
\hline CHEMBL539734 & 609034 & 7.8239 & 8.3829 & TST \\
\hline CHEMBL601907 & 609034 & 8.5528 & 8.316 & TRN \\
\hline CHEMBL589335 & 609034 & 8.7212 & 8.3876 & TST \\
\hline CHEMBL590256 & 609034 & 7.6576 & 7.5766 & TST \\
\hline CHEMBL589901 & 609034 & 8.699 & 8.7159 & TRN \\
\hline CHEMBL590003 & 609034 & 8.1024 & 8.6719 & TRN \\
\hline CHEMBL590069 & 609034 & 8.4559 & 7.7741 & TST \\
\hline CHEMBL601274 & 609034 & 8.0 & 7.6275 & TST \\
\hline CHEMBL590259 & 609034 & 7.5086 & 7.8927 & SI \\
\hline CHEMBL601692 & 609034 & 8.9586 & 8.3611 & TST \\
\hline
\end{tabular}

Page 4443 


\begin{tabular}{|c|c|c|c|c|c|c|c|}
\hline \multicolumn{8}{|c|}{ sup } \\
\hline CHEMBL589971 & 609034 & 8.3979 & 8.2578 & TST & & & \\
\hline CHEMBL601478 & 609034 & 8.8239 & 8.6999 & TST & & & \\
\hline CHEMBL602109 & 609034 & 8.28399 & 999999999 & & 8.176 & TRN & \\
\hline CHEMBL601487 & 609034 & 8.4815 & 8.0395 & TST & & & \\
\hline CHEMBL601275 & 609034 & 7.585 & 7.1928 & TRN & & & \\
\hline CHEMBL589518 & 609034 & 8.3979 & 8.7619 & TST & & & \\
\hline CHEMBL590002 & 609034 & 8.0969 & 8.0215 & TST & & & \\
\hline CHEMBL570295 & 609034 & 9.1675 & 9.4009 & TRN & & & \\
\hline CHEMBL601903 & 609034 & 8.9586 & 8.3974 & TRN & & & \\
\hline CHEMBL601904 & 609034 & 8.3188 & 8.0007 & TRN & & & \\
\hline CHEMBL601488 & 609034 & 8.1487 & 8.2154 & TST & & & \\
\hline CHEMBL1430113 & 688709 & 5.69799 & 999999999 & 995 & 6.3655 & TRN & \\
\hline CHEMBL1560775 & 688709 & 6.19799 & 999999999 & 995 & 5.3526 & TRN & \\
\hline CHEMBL1507962 & 688709 & 4.598 & 5.4748 & TRN & & & \\
\hline CHEMBL1548278 & 688709 & 4.548 & 6.1703 & TRN & & & \\
\hline CHEMBL1545632 & 688709 & 5.94799 & 999999999 & 995 & 5.6565 & TRN & \\
\hline CHEMBL1449916 & 688709 & 6.04799 & 999999999 & & 5.6116 & TRN & \\
\hline CHEMBL1304236 & 688709 & 4.948 & 5.3931 & TRN & & & \\
\hline CHEMBL1420642 & 688709 & 4.648 & 5.3102 & TRN & & & \\
\hline CHEMBL1462297 & 688709 & 4.798 & 6.1973 & TRN & & & \\
\hline CHEMBL1340442 & 688709 & 7.3478 & 6.0173 & TST & & & \\
\hline CHEMBL1461129 & 688709 & 5.398 & 6.1474 & TRN & & & \\
\hline CHEMBL1538052 & 688709 & 5.648 & 6.1441 & TRN & & & \\
\hline CHEMBL1493557 & 688709 & 4.548 & 5.0922 & TRN & & & \\
\hline CHEMBL1545938 & 688709 & 7.2976 & 5.642 & TST & & & \\
\hline CHEMBL1608489 & 688709 & 4.648 & 5.5432 & TRN & & & \\
\hline CHEMBL1585579 & 688709 & 5.54799 & 999999999 & & 5.88399 & 99999999995 & TRN \\
\hline CHEMBL1304114 & 688709 & 9.2218 & 6.1589 & TRN & & & \\
\hline CHEMBL1584829 & 688709 & 5.048 & 5.1501 & TRN & & & \\
\hline CHEMBL 368036 & 688709 & 4.948 & 5.0276 & TRN & & & \\
\hline CHEMBL1560873 & 688709 & 5.29799 & 999999999 & & 4.9333 & TRN & \\
\hline CHEMBL1529493 & 688709 & 5.348 & 6.1257 & TRN & & & \\
\hline CHEMBL1312463 & 688709 & 5.098 & 5.8836 & TRN & & & \\
\hline CHEMBL1574073 & 688709 & 4.998 & 5.4196 & TRN & & & \\
\hline CHEMBL1497461 & 688709 & 4.998 & 5.1727 & TRN & & & \\
\hline CHEMBL1571821 & 688709 & 6.5479 & 5.796 & TRN & & & \\
\hline CHEMBL1401342 & 688709 & 4.648 & 5.8807 & TRN & & & \\
\hline CHEMBL1361184 & 688709 & 8.7959 & 6.1191 & TRN & & & \\
\hline CHEMBL1613126 & 688709 & 4.998 & 4.7586 & TRN & & & \\
\hline CHEMBL1351877 & 688709 & 6.5979 & 4.898 & TRN & & & \\
\hline CHEMBL1310194 & 688709 & 7.699 & 5.5077 & TRN & & & \\
\hline CHEMBL1299367 & 688709 & 7.6478 & 5.6753 & TRN & & & \\
\hline CHEMBL1343071 & 688709 & 7.0482 & 5.7063 & TRN & & & \\
\hline CHEMBL1323187 & 688709 & 5.29799 & 999999999 & & 5.2007 & TRN & \\
\hline CHEMBL479898 & 688709 & 4.948 & 5.9085 & TST & & & \\
\hline CHEMBL1536491 & 688709 & 4.698 & 5.8634 & TRN & & & \\
\hline CHEMBL1428906 & 688709 & 6.24799 & 999999999 & 99 & 5.9287 & TRN & \\
\hline CHEMBL1324970 & 688709 & 8.0 & 6.0686 & TRN & & & \\
\hline
\end{tabular}




\begin{tabular}{|c|c|c|c|c|c|c|c|}
\hline \multicolumn{8}{|c|}{ Supplemental Table s2.txt } \\
\hline CHEMBL1367369 & 688709 & 4.898 & 5.6384 & TRN & & & \\
\hline CHEMBL1428066 & 688709 & 9.0458 & 5.4646 & TST & & & \\
\hline CHEMBL1596419 & 688709 & 4.748 & 5.6889 & TRN & & & \\
\hline CHEMBL1563997 & 688709 & 8.0 & 6.327006 & 000000000 & & TST & \\
\hline CHEMBL1368803 & 688709 & 4.848 & 5.6616 & TRN & & & \\
\hline CHEMBL1334600 & 688709 & 5.048 & 5.815 & TRN & & & \\
\hline CHEMBL42867 & 688709 & 5.49799 & 99999999 & & 5.0023 & TRN & \\
\hline CHEMBL1442547 & 688709 & 4.798 & 5.1037 & TRN & & & \\
\hline CHEMBL1351375 & 688709 & 7.699 & 5.9266 & TRN & & & \\
\hline CHEMBL1531514 & 688709 & 6.19799 & 99999999 & 995 & 5.4096 & TRN & \\
\hline CHEMBL1384138 & 688709 & 8.0458 & 5.8696 & TRN & & & \\
\hline CHEMBL1400284 & 688709 & 4.548 & 5.2313 & TRN & & & \\
\hline CHEMBL1559690 & 688709 & 4.548 & 5.551 & TRN & & & \\
\hline CHEMBL1309832 & 688709 & 5.49799 & 99999999 & & 5.7759 & TRN & \\
\hline CHEMBL1343837 & 688709 & 5.19799 & 99999999 & 995 & 5.9727 & TRN & \\
\hline CHEMBL1366764 & 688709 & 4.798 & 5.8865 & TRN & & & \\
\hline CHEMBL1535527 & 688709 & 5.048 & 5.536006 & 000000000 & 05 & TRN & \\
\hline CHEMBL1602147 & 688709 & 4.898 & 5.2131 & TRN & & & \\
\hline CHEMBL1528710 & 688709 & 5.54799 & 79999999 & & 6.08700 & 0000000001 & TRN \\
\hline CHEMBL1309096 & 688709 & 5.348 & 5.9862 & TRN & & & \\
\hline CHEMBL1368374 & 688709 & 4.748 & 5.4236 & TRN & & & \\
\hline CHEMBL1378761 & 688709 & 4.648 & 5.5816 & TRN & & & \\
\hline CHEMBL1490317 & 688709 & 7.4486 & 5.8707 & TRN & & & \\
\hline CHEMBL1404418 & 688709 & 5.99799 & 79999999 & & 5.1453 & TRN & \\
\hline CHEMBL1452432 & 688709 & 7.6478 & 6.7848 & TRN & & & \\
\hline CHEMBL1543867 & 688709 & 9.301 & 5.8632 & TRN & & & \\
\hline CHEMBL1558158 & 688709 & 4.898 & 4.887 & TRN & & & \\
\hline CHEMBL1411820 & 688709 & 4.948 & 5.7379 & TRN & & & \\
\hline CHEMBL1391772 & 688709 & 4.598 & 5.4585 & TRN & & & \\
\hline CHEMBL1538901 & 688709 & 8.4949 & 5.7173 & TRN & & & \\
\hline CHEMBL1306670 & 688709 & 6.8979 & 6.8059 & TRN & & & \\
\hline CHEMBL1585197 & 688709 & 4.798 & 4.7753 & TRN & & & \\
\hline CHEMBL1570173 & 688709 & 4.698 & 5.6629 & TRN & & & \\
\hline CHEMBL1505661 & 688709 & 4.648 & 5.55 & TRN & & & \\
\hline CHEMBL1373362 & 688709 & 4.548 & 5.4802 & TRN & & & \\
\hline CHEMBL1576675 & 688709 & 6.8979 & 6.0429 & TRN & & & \\
\hline CHEMBL1445840 & 688709 & 4.748 & 5.8037 & TRN & & & \\
\hline CHEMBL1427854 & 688709 & 6.9481 & 5.982 & TRN & & & \\
\hline CHEMBL1520809 & 688709 & 5.048 & 5.9144 & TRN & & & \\
\hline CHEMBL525826 & 688709 & 7.6478 & 5.3323 & TRN & & & \\
\hline CHEMBL1313828 & 688709 & 5.74799 & 99999999 & 99 & 5.689 & TRN & \\
\hline CHEMBL1546517 & 688709 & 8.6021 & 6.6375 & TRN & & & \\
\hline CHEMBL1371417 & 688709 & 8.4437 & 6.1431 & TST & & & \\
\hline CHEMBL3192897 & 688709 & 4.548 & 5.23 & TRN & & & \\
\hline CHEMBL1465498 & 688709 & 4.648 & 5.2927 & TRN & & & \\
\hline CHEMBL1534547 & 688709 & 7.098 & 5.6448 & TST & & & \\
\hline CHEMBL1523375 & 688709 & 5.648 & 5.1355 & TRN & & & \\
\hline CHEMBL1520654 & 688709 & 4.648 & 5.7536 & TRN & & & \\
\hline
\end{tabular}




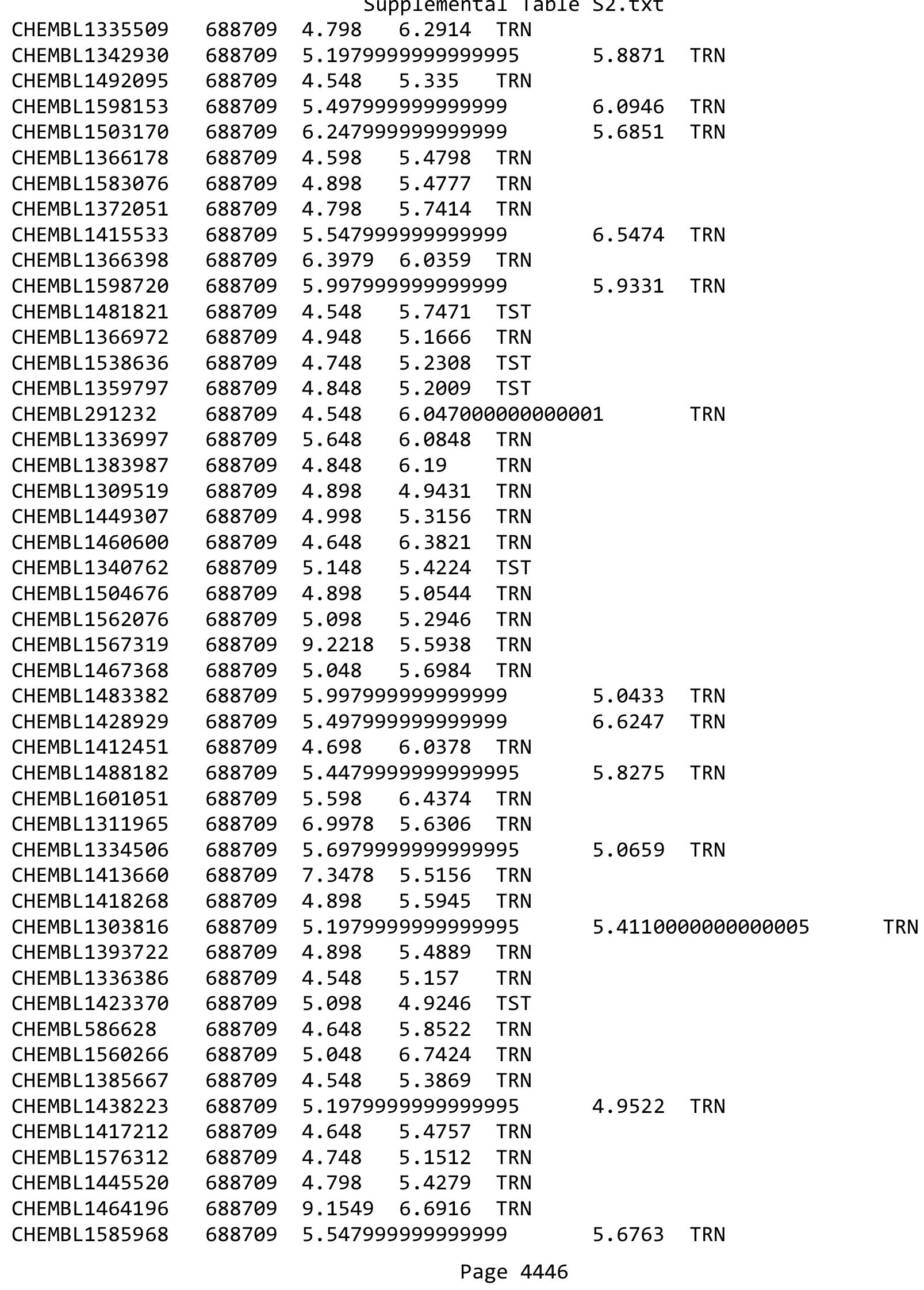




\begin{tabular}{|c|c|c|c|c|c|c|c|}
\hline \multicolumn{7}{|c|}{ Supplemental Table s2.txt } & \\
\hline CHEMBL1585506 & 688709 & 4.898 & 5.8667 & TRN & & & \\
\hline CHEMBL1458212 & 688709 & 4.648 & 5.7494 & TRN & & & \\
\hline CHEMBL1342911 & 688709 & 5.44799 & $79999999 \subseteq$ & 995 & 6.1658 & TRN & \\
\hline CHEMBL1389531 & 688709 & 5.49799 & 99999999 & & 5.2861 & TRN & \\
\hline CHEMBL1331866 & 688709 & 4.998 & 6.1735 & TST & & & \\
\hline CHEMBL1567986 & 688709 & 5.148 & 5.9295 & TRN & & & \\
\hline CHEMBL1530423 & 688709 & 7.4976 & 5.2438 & TRN & & & \\
\hline CHEMBL1408140 & 688709 & 4.548 & 6.3253 & TRN & & & \\
\hline CHEMBL1535711 & 688709 & 4.798 & 6.1128 & TRN & & & \\
\hline CHEMBL1308791 & 688709 & 4.698 & 5.8857 & TRN & & & \\
\hline CHEMBL516029 & 688709 & 8.7447 & 6.3761 & TRN & & & \\
\hline CHEMBL1417054 & 688709 & 6.3479 & 4.8975 & TRN & & & \\
\hline CHEMBL1322434 & 688709 & 4.498 & 5.7041 & TRN & & & \\
\hline CHEMBL1345083 & 688709 & 5.098 & 5.5267 & TRN & & & \\
\hline CHEMBL1327431 & 688709 & 5.94799 & 99999999 & 995 & 5.772 & TRN & \\
\hline CHEMBL1408592 & 688709 & 4.998 & 6.0051 & TRN & & & \\
\hline CHEMBL1539267 & 688709 & 7.699 & 6.0179 & TRN & & & \\
\hline CHEMBL1492087 & 688709 & 7.5482 & 6.6656 & TRN & & & \\
\hline CHEMBL1582463 & 688709 & 5.048 & 5.3654 & TRN & & & \\
\hline CHEMBL1560928 & 688709 & 4.648 & 5.9857 & TRN & & & \\
\hline CHEMBL1516882 & 688709 & 5.29799 & 99999999 & & 5.6092 & TRN & \\
\hline CHEMBL1568271 & 688709 & 5.74799 & 99999999 & & 5.9542 & TRN & \\
\hline CHEMBL1411111 & 688709 & 5.098 & 5.1627 & TST & & & \\
\hline CHEMBL1440200 & 688709 & 4.548 & 5.9511 & TRN & & & \\
\hline CHEMBL1488009 & 688709 & 4.598 & 5.6224 & TRN & & & \\
\hline CHEMBL1337702 & 688709 & 4.748 & 5.9753 & TST & & & \\
\hline CHEMBL1308451 & 688709 & 6.3479 & 5.8869 & TRN & & & \\
\hline CHEMBL1505637 & 688709 & 9.301 & 5.9761 & TST & & & \\
\hline CHEMBL1410286 & 688709 & 7.098 & 5.9037 & TRN & & & \\
\hline CHEMBL1708334 & 688709 & 4.948 & 5.3192 & TST & & & \\
\hline CHEMBL1367260 & 688709 & 4.798 & 6.0183 & TRN & & & \\
\hline CHEMBL1470168 & 688709 & 4.998 & 6.5045 & TRN & & & \\
\hline CHEMBL1426158 & 688709 & 4.898 & 6.149 & TRN & & & \\
\hline CHEMBL1577606 & 688709 & 7.3979 & 6.4931 & TRN & & & \\
\hline CHEMBL1415528 & 688709 & 4.948 & 6.1173 & TRN & & & \\
\hline CHEMBL1586526 & 688709 & 8.0458 & 5.6455 & TST & & & \\
\hline CHEMBL1307848 & 688709 & 7.4486 & 5.9663 & TRN & & & \\
\hline CHEMBL1535793 & 688709 & 4.598 & 4.9341 & TRN & & & \\
\hline CHEMBL1337587 & 688709 & 6.29799 & 79999999 & & 5.2989 & 99999999995 & TRN \\
\hline CHEMBL1405039 & 688709 & 5.398 & 5.3049 & TRN & & & \\
\hline CHEMBL1328700 & 688709 & 5.348 & 5.6795 & TST & & & \\
\hline CHEMBL1548635 & 688709 & 4.848 & 5.2597 & TRN & & & \\
\hline CHEMBL19980 & 688709 & 6.24799 & 79999999 & & 6.1553 & TST & \\
\hline CHEMBL1544956 & 688709 & 9.5229 & 6.3688 & TRN & & & \\
\hline CHEMBL1326167 & 688709 & 6.5479 & 5.0757 & TST & & & \\
\hline CHEMBL1607241 & 688709 & 5.098 & 5.7013 & TRN & & & \\
\hline CHEMBL1335492 & 688709 & 5.148 & 5.0111 & TRN & & & \\
\hline CHEMBL1480122 & 688709 & 6.9978 & 6.2709 & TRN & & & \\
\hline
\end{tabular}




\begin{tabular}{|c|c|c|c|c|c|c|}
\hline & & \multicolumn{5}{|c|}{ Supplemental Table s2.txt } \\
\hline CHEMBL1484256 & 688709 & 4.748 & 6.1928 & TRN & & \\
\hline CHEMBL1583432 & 688709 & 4.648 & 4.8798 & TRN & & \\
\hline CHEMBL1430979 & 688709 & 5.898 & 5.3385 & TRN & & \\
\hline CHEMBL 1417725 & 688709 & 4.598 & 5.2197 & TRN & & \\
\hline CHEMBL1341514 & 688709 & 8.2007 & 5.9497 & TRN & & \\
\hline CHEMBL1594533 & 688709 & 5.598 & 6.2786 & TRN & & \\
\hline CHEMBL1575724 & 688709 & 7.4976 & 5.9692 & TST & & \\
\hline CHEMBL1332999 & 688709 & 4.698 & 5.2438 & TRN & & \\
\hline CHEMBL1421860 & 688709 & 5.148 & 6.36799 & 9999999999 & & TRN \\
\hline CHEMBL1391364 & 688709 & 7.0482 & 5.7676 & TRN & & \\
\hline CHEMBL1355079 & 688709 & 6.3479 & 6.2696 & TRN & & \\
\hline CHEMBL 1416140 & 688709 & 8.0969 & 6.1175 & TRN & & \\
\hline CHEMBL1601356 & 688709 & 4.748 & 5.7669 & TRN & & \\
\hline CHEMBL1541983 & 688709 & 6.1479 & 6.0352 & TRN & & \\
\hline CHEMBL1408884 & 688709 & 5.148 & 5.3372 & TRN & & \\
\hline CHEMBL1479206 & 688709 & 6.19799 & 79999999 & 995 & 5.1177 & TRN \\
\hline CHEMBL1595776 & 688709 & 4.548 & 5.19 & TRN & & \\
\hline CHEMBL1537826 & 688709 & 7.2976 & 5.3552 & TRN & & \\
\hline CHEMBL1427549 & 688709 & 5.598 & 6.1163 & TRN & & \\
\hline CHEMBL1467481 & 688709 & 4.948 & 5.4465 & TRN & & \\
\hline CHEMBL1422036 & 688709 & 8.1487 & 6.6696 & TRN & & \\
\hline CHEMBL1346356 & 688709 & 8.0458 & 6.07 & TRN & & \\
\hline CHEMBL1584468 & 688709 & 4.948 & 5.6908 & TRN & & \\
\hline CHEMBL1575103 & 688709 & 7.098 & 5.6049 & TRN & & \\
\hline CHEMBL1509991 & 688709 & 5.148 & 5.7499 & TRN & & \\
\hline CHEMBL1338620 & 688709 & 7.6478 & 6.1668 & TRN & & \\
\hline CHEMBL1613499 & 688709 & 4.848 & 5.3101 & TRN & & \\
\hline CHEMBL1335055 & 688709 & 6.6979 & 6.556 & TRN & & \\
\hline CHEMBL1555623 & 688709 & 6.0979 & 5.2022 & TRN & & \\
\hline CHEMBL1312013 & 688709 & 7.699 & 5.74700 & 0000000001 & & TRN \\
\hline CHEMBL1572330 & 688709 & 7.9469 & 5.2496 & TST & & \\
\hline CHEMBL1556927 & 688709 & 5.24799 & 99999999 & 99 & 6.6816 & TRN \\
\hline CHEMBL1299612 & 688709 & 5.048 & 5.7062 & TRN & & \\
\hline CHEMBL1385640 & 688709 & 9.2218 & 6.6066 & TRN & & \\
\hline CHEMBL1587587 & 688709 & 4.898 & 6.0262 & TRN & & \\
\hline CHEMBL377295 & 688709 & 5.048 & 5.4594 & TRN & & \\
\hline CHEMBL1541417 & 688709 & 9.3979 & 6.1813 & TRN & & \\
\hline CHEMBL1428572 & 688709 & 4.948 & 5.5995 & TRN & & \\
\hline CHEMBL1517590 & 688709 & 7.5986 & 6.5739 & TRN & & \\
\hline CHEMBL1498602 & 688709 & 8.8861 & 6.0805 & TRN & & \\
\hline CHEMBL1561813 & 688709 & 6.24799 & 99999999 & 99 & 6.015 & TRN \\
\hline CHEMBL1369015 & 688709 & 4.698 & 5.5215 & TRN & & \\
\hline CHEMBL1486214 & 688709 & 5.048 & 5.2577 & TRN & & \\
\hline CHEMBL1336660 & 688709 & 4.898 & 5.5814 & TST & & \\
\hline CHEMBL1500986 & 688709 & 6.1479 & 5.4253 & TRN & & \\
\hline CHEMBL1336749 & 688709 & 5.24799 & 99999999 & & 5.1267 & TRN \\
\hline CHEMBL1421437 & 688709 & 6.6979 & 6.3473 & TRN & & \\
\hline CHEMBL1348386 & 688709 & 5.24799 & 79999999ऽ & & 5.5409 & TRN \\
\hline
\end{tabular}




\begin{tabular}{|c|c|c|c|c|c|c|}
\hline \multirow[b]{2}{*}{ CHEMBL1364782 } & \multirow[b]{2}{*}{688709} & \multicolumn{5}{|c|}{ Supplemental Table s2.txt } \\
\hline & & 4.798 & 5.1454 & TRN & \multirow{3}{*}{5.6727} & \multirow[b]{2}{*}{ TST } \\
\hline CHEMBL155563 & 688709 & \multicolumn{3}{|c|}{$\begin{array}{ll}4.798 & 5.1454 \\
5.497999999999999\end{array}$} & & \\
\hline CHEMBL1372941 & 688709 & 6.8979 & 5.7165 & TRN & & \\
\hline CHEMBL1448207 & 688709 & 5.048 & 5.8729 & TRN & & \\
\hline CHEMBL1462014 & 688709 & 4.598 & 5.7061 & TRN & & \\
\hline CHEMBL1568268 & 688709 & 4.748 & 5.4534 & TRN & & \\
\hline CHEMBL1363752 & 688709 & 5.048 & 5.4828 & TST & & \\
\hline CHEMBL1533162 & 688709 & \multicolumn{3}{|c|}{5.4479999999999995} & 6.5004 & TRN \\
\hline CHEMBL1419074 & 688709 & 4.648 & 6.3251 & TRN & & \\
\hline CHEMBL1367374 & 688709 & 4.998 & 5.9167 & TRN & & \\
\hline CHEMBL1589457 & 688709 & 4.698 & 5.6822 & TRN & & \\
\hline CHEMBL1303620 & 688709 & 4.948 & 5.1735 & TRN & & \\
\hline CHEMBL1303173 & 688709 & 5.048 & 6.0317 & TRN & & \\
\hline CHEMBL1401860 & 688709 & 4.698 & 5.5255 & TRN & & \\
\hline CHEMBL1405409 & 688709 & \multicolumn{3}{|c|}{5.1979999999999995} & 5.9043 & TRN \\
\hline CHEMBL1541792 & 688709 & 7.1979 & 6.4232 & TST & & \\
\hline CHEMBL1486763 & 688709 & 4.598 & 5.8417 & TRN & & \\
\hline CHEMBL1430012 & 688709 & 4.948 & 5.3532 & TRN & & \\
\hline CHEMBL1570272 & 688709 & 4.848 & 5.9624 & TRN & & \\
\hline CHEMBL97453 & 688709 & 5.098 & 5.3492 & TST & & \\
\hline CHEMBL1469093 & 688709 & 4.598 & 5.8645 & TST & & \\
\hline CHEMBL1326432 & 688709 & 4.748 & 5.1123 & TRN & & \\
\hline CHEMBL486422 & 688709 & 4.648 & 5.4511 & TST & & \\
\hline CHEMBL1522250 & 688709 & \multicolumn{3}{|c|}{5.1979999999999995} & 5.8039 & TRN \\
\hline CHEMBL1463109 & 688709 & 6.6979 & \multicolumn{3}{|c|}{5.202999999999999} & TRN \\
\hline CHEMBL1503923 & 688709 & 4.598 & \multicolumn{3}{|c|}{5.382999999999999} & TRN \\
\hline CHEMBL1558572 & 688709 & 4.548 & 5.2859 & TRN & & \\
\hline CHEMBL1492862 & 688709 & 8.4949 & 5.4411 & TRN & & \\
\hline CHEMBL1446285 & 688709 & 4.548 & 5.8999 & TRN & & \\
\hline CHEMBL1596633 & 688709 & 4.848 & 5.9509 & TRN & & \\
\hline CHEMBL1432275 & 688709 & 4.598 & 5.4011 & TRN & & \\
\hline CHEMBL1419877 & 688709 & \multicolumn{3}{|c|}{5.1979999999999995} & 6.2066 & TST \\
\hline CHEMBL1400652 & 688709 & 5.898 & \multicolumn{3}{|c|}{5.8229999999999995} & TRN \\
\hline CHEMBL1447645 & 688709 & 4.698 & 5.5057 & TRN & & \\
\hline CHEMBL1450015 & 688709 & \multicolumn{3}{|c|}{6.297999999999999} & 5.7468 & TST \\
\hline CHEMBL1419472 & 688709 & 4.648 & 5.6081 & TRN & & \\
\hline CHEMBL1457420 & 688709 & 5.098 & 6.2263 & TST & & \\
\hline CHEMBL1525872 & 688709 & 4.598 & 5.9408 & TRN & & \\
\hline CHEMBL1589287 & 688709 & 6.3479 & \multicolumn{3}{|c|}{5.712999999999999} & TRN \\
\hline CHEMBL1447034 & 688709 & \multicolumn{3}{|c|}{5.547999999999999} & 6.0876 & TST \\
\hline CHEMBL1400827 & 688709 & 5.048 & \multicolumn{3}{|c|}{5.832999999999999} & TRN \\
\hline CHEMBL1578480 & 688709 & \multicolumn{3}{|c|}{5.6979999999999995} & 6.2924 & TRN \\
\hline CHEMBL1430908 & 688709 & 4.848 & \multicolumn{3}{|c|}{5.2989999999999995} & TRN \\
\hline CHEMBL1546087 & 688709 & \multicolumn{3}{|c|}{ 7.247999999999999 } & 6.0751 & TRN \\
\hline CHEMBL1336931 & 688709 & \multicolumn{3}{|c|}{5.497999999999999} & 5.5766 & TRN \\
\hline CHEMBL1487887 & 688709 & 4.698 & 4.6723 & TRN & & \\
\hline CHEMBL1412328 & 688709 & 5.398 & 5.7863 & TRN & & \\
\hline CHEMBL1612937 & 688709 & 5.54799 & 99999999 & & 5.3046 & TRN \\
\hline
\end{tabular}




\begin{tabular}{|c|c|c|c|c|c|c|}
\hline \multirow[b]{2}{*}{ CHEMBL1346679 } & & \multicolumn{5}{|c|}{ oplemental Table } \\
\hline & 688709 & 4.548 & 5.6214 & TRN & & \\
\hline CHEMBL1488213 & 688709 & 5.44799 & 999999999 & 995 & 5.3809 & TRN \\
\hline CHEMBL1536155 & 688709 & 4.798 & 5.3835 & TRN & & \\
\hline CHEMBL1377746 & 688709 & 6.19799 & 999999999 & 995 & 5.3494 & TST \\
\hline CHEMBL1312168 & 688709 & 4.898 & 5.3428 & TST & & \\
\hline CHEMBL 1557874 & 688709 & 5.098 & 5.8758 & TRN & & \\
\hline CHEMBL1300696 & 688709 & 4.548 & 5.1705 & TRN & & \\
\hline CHEMBL1380947 & 688709 & 5.24799 & 999999999 & & 5.8314 & TRN \\
\hline CHEMBL1300878 & 688709 & 5.54799 & 999999999 & & 5.0666 & TRN \\
\hline CHEMBL1409876 & 688709 & 5.69799 & 999999999 & 995 & 6.5671 & TRN \\
\hline CHEMBL1388159 & 688709 & 6.24799 & 999999999 & & 5.2651 & TRN \\
\hline CHEMBL1488232 & 688709 & 4.548 & 6.4107 & TRN & & \\
\hline CHEMBL1434331 & 688709 & 4.548 & 5.4623 & TST & & \\
\hline CHEMBL1430425 & 688709 & 4.548 & 5.1864 & TRN & & \\
\hline CHEMBL1372045 & 688709 & 4.548 & 5.9175 & TRN & & \\
\hline CHEMBL1399899 & 688709 & 4.948 & 5.5008 & TRN & & \\
\hline CHEMBL1371252 & 688709 & 4.798 & 4.8959 & TRN & & \\
\hline CHEMBL1300286 & 688709 & 5.398 & 5.8244 & TRN & & \\
\hline CHEMBL1560888 & 688709 & 9.5229 & 6.1602 & TRN & & \\
\hline CHEMBL1472219 & 688709 & 6.7981 & 5.8508 & TST & & \\
\hline CHEMBL1324890 & 688709 & 4.948 & 5.5999 & TRN & & \\
\hline CHEMBL1369630 & 688709 & 6.49799 & 999999999 & 99 & 6.6856 & TRN \\
\hline CHEMBL1471752 & 688709 & 8.0 & 5.3583 & TRN & & \\
\hline CHEMBL1495724 & 688709 & 6.7981 & 6.7264 & TRN & & \\
\hline CHEMBL1545850 & 688709 & 9.0969 & 6.2725 & TRN & & \\
\hline CHEMBL1378209 & 688709 & 6.3479 & 5.6338 & TRN & & \\
\hline CHEMBL1334239 & 688709 & 6.19799 & 999999999 & 995 & 5.8831 & $T$ \\
\hline CHEMBL1387505 & 688709 & 6.0979 & 6.3503 & TRN & & \\
\hline CHEMBL1422481 & 688709 & 5.098 & 5.0956 & TST & & \\
\hline CHEMBL1550931 & 688709 & 4.998 & 5.2069 & TRN & & \\
\hline CHEMBL1509483 & 688709 & 4.598 & 5.4926 & TRN & & \\
\hline CHEMBL1575600 & 688709 & 4.998 & 5.9464 & TRN & & \\
\hline CHEMBL1379593 & 688709 & 4.998 & 5.652 & TRN & & \\
\hline CHEMBL1362247 & 688709 & 5.048 & 5.6194 & TRN & & \\
\hline CHEMBL1548084 & 688709 & 6.9978 & 5.5387 & TST & & \\
\hline CHEMBL1518566 & 688709 & 4.748 & 5.0157 & TRN & & \\
\hline CHEMBL376643 & 688709 & 8.0458 & 5.8371 & TRN & & \\
\hline CHEMBL 1496374 & 688709 & 6.49799 & 999999999 & & 5.4271 & \\
\hline CHEMBL1338902 & 688709 & 5.54799 & 999999999 & & & \\
\hline CHEMBL1468046 & 688709 & 4.848 & 5.6039 & TRN & & \\
\hline CHEMBL1302464 & 688709 & 8.1487 & 5.8338 & TRN & & \\
\hline CHEMBL1401456 & 688709 & 5.098 & 5.0252 & TRN & & \\
\hline CHEMBL1418519 & 688709 & 7.5482 & 5.8378 & TRN & & \\
\hline CHEMBL1336147 & 688709 & 6.848 & 5.6492 & TRN & & \\
\hline CHEMBL1534310 & 688709 & 6.0979 & 5.9571 & TRN & & \\
\hline CHEMBL1565709 & 688709 & 4.548 & 5.6805 & TRN & & \\
\hline CHEMBL1575708 & 688709 & 6.648 & 5.0778 & TRN & & \\
\hline CHEMBL1432290 & 688709 & 4.748 & 5.4323 & TRN & & \\
\hline
\end{tabular}




\begin{tabular}{|c|c|c|c|c|c|c|}
\hline & & \multicolumn{5}{|c|}{ Supplemental Table s2.txt } \\
\hline CHEMBL1430891 & 688709 & \multicolumn{3}{|c|}{5.1979999999999995} & 5.6777 & TRN \\
\hline CHEMBL1479911 & 688709 & \multicolumn{3}{|c|}{5.797999999999999} & 5.0102 & TRN \\
\hline CHEMBL1525712 & 688709 & 5.098 & 4.9823 & TRN & & \\
\hline CHEMBL1591909 & 688709 & 4.648 & 5.9179 & TST & & \\
\hline CHEMBL1351231 & 688709 & 4.898 & 5.4258 & TST & & \\
\hline CHEMBL1481499 & 688709 & \multicolumn{3}{|c|}{5.497999999999999} & 5.4141 & TRN \\
\hline CHEMBL1363853 & 688709 & 9.2218 & 6.3936 & TRN & & \\
\hline CHEMBL1377884 & 688709 & 5.148 & 5.5827 & TRN & & \\
\hline CHEMBL1332471 & 688709 & 6.0979 & 5.5266 & TST & & \\
\hline CHEMBL1541535 & 688709 & 5.098 & 5.119 & TRN & & \\
\hline CHEMBL1493938 & 688709 & 4.548 & 5.7273 & TRN & & \\
\hline CHEMBL1583060 & 688709 & \multicolumn{3}{|c|}{5.1979999999999995} & 5.1011 & TRN \\
\hline CHEMBL1347092 & 688709 & 4.898 & 5.1183 & TRN & & \\
\hline CHEMBL1372590 & 688709 & 4.698 & 5.1813 & TRN & & \\
\hline CHEMBL1364363 & 688709 & \multicolumn{3}{|c|}{5.997999999999999} & 5.3581 & TRN \\
\hline CHEMBL1361834 & 688709 & \multicolumn{3}{|c|}{5.4479999999999995} & 5.688 & TRN \\
\hline CHEMBL1302567 & 688709 & 4.998 & 5.2848 & TRN & & \\
\hline CHEMBL1603834 & 688709 & \multicolumn{3}{|c|}{5.1979999999999995} & 5.1904 & TRN \\
\hline CHEMBL1612684 & 688709 & 5.398 & 5.9318 & TRN & & \\
\hline CHEMBL1332825 & 688709 & 4.698 & 5.4538 & TRN & & \\
\hline CHEMBL14120 & 688709 & 7.1481 & 4.921 & TRN & & \\
\hline CHEMBL1310014 & 688709 & 7.5986 & 6.3525 & TRN & & \\
\hline CHEMBL1504527 & 688709 & 5.048 & 5.3182 & TRN & & \\
\hline CHEMBL1381841 & 688709 & 5.598 & 5.2714 & TRN & & \\
\hline CHEMBL1542882 & 688709 & 6.1479 & 5.7841 & TRN & & \\
\hline CHEMBL1462761 & 688709 & 9.0458 & 6.1234 & TRN & & \\
\hline CHEMBL1594687 & 688709 & 5.098 & 5.3763 & TST & & \\
\hline CHEMBL1381933 & 688709 & 4.898 & 5.7633 & TST & & \\
\hline CHEMBL1319906 & 688709 & \multicolumn{3}{|c|}{6.1979999999999995} & 5.6525 & TST \\
\hline CHEMBL1582855 & 688709 & \multicolumn{3}{|c|}{5.1979999999999995} & 5.9446 & TST \\
\hline CHEMBL1499130 & 688709 & \multicolumn{3}{|c|}{5.247999999999999} & 5.9573 & TST \\
\hline CHEMBL1563074 & 688709 & 4.998 & 6.0514 & TST & & \\
\hline CHEMBL1530236 & 688709 & 4.648 & 5.7334 & TST & & \\
\hline CHEMBL1389823 & 688709 & \multicolumn{3}{|c|}{5.297999999999999} & 5.4387 & TST \\
\hline CHEMBL1528449 & 688709 & 8.6021 & 5.9966 & TST & & \\
\hline CHEMBL1462202 & 688709 & \multicolumn{3}{|c|}{5.247999999999999} & 5.0302 & TST \\
\hline CHEMBL1605953 & 688709 & \multicolumn{3}{|c|}{5.997999999999999} & 5.401 & TST \\
\hline CHEMBL1510327 & 688709 & 6.5979 & 5.1819 & TST & & \\
\hline CHEMBL1582152 & 688709 & 7.8477 & 5.1821 & TST & & \\
\hline CHEMBL1402510 & 688709 & 7.4486 & 5.1163 & TST & & \\
\hline CHEMBL1368484 & 688709 & 4.748 & 5.6862 & TST & & \\
\hline CHEMBL1422022 & 688709 & 5.398 & 5.3227 & TST & & \\
\hline CHEMBL1432580 & 688709 & \multicolumn{3}{|c|}{5.997999999999999} & 5.4623 & TST \\
\hline CHEMBL1453590 & 688709 & 5.148 & 6.0407 & TST & & \\
\hline CHEMBL1461629 & 688709 & 4.998 & 5.4588 & TST & & \\
\hline CHEMBL1598126 & 688709 & 4.548 & 5.5891 & TST & & \\
\hline CHEMBL1365557 & 688709 & 4.898 & 6.206 & TST & & \\
\hline CHEMBL1403305 & 688709 & 4.848 & 5.3812 & TST & & \\
\hline
\end{tabular}




\begin{tabular}{|c|c|c|c|c|c|c|}
\hline & & \multicolumn{5}{|c|}{ Supplemental Table S2.txt } \\
\hline CHEMBL1581632 & 688709 & 4.648 & 6.1586 & TST & & \\
\hline CHEMBL 98245 & 688709 & 4.948 & 5.7117 & TST & & \\
\hline CHEMBL1420187 & 688709 & 6.7479 & 6.8676 & TST & & \\
\hline CHEMBL1589089 & 688709 & 7.3979 & 6.9664 & TST & & \\
\hline CHEMBL1550705 & 688709 & 4.998 & 5.7685 & TST & & \\
\hline CHEMBL1538501 & 688709 & 7.8996 & 6.4534 & TST & & \\
\hline CHEMBL1411649 & 688709 & 8.699 & 5.9787 & TST & & \\
\hline CHEMBL1493348 & 688709 & \multicolumn{3}{|c|}{5.4479999999999995} & 5.5025 & TST \\
\hline CHEMBL1343712 & 688709 & 6.6979 & 5.7384 & TST & & \\
\hline CHEMBL1456786 & 688709 & 4.898 & 5.5908 & TST & & \\
\hline CHEMBL1363865 & 688709 & 5.148 & 5.3843 & TST & & \\
\hline CHEMBL1577017 & 688709 & 4.548 & 5.7207 & TST & & \\
\hline CHEMBL1432679 & 688709 & 7.4976 & 6.2272 & TST & & \\
\hline CHEMBL1487884 & 688709 & 4.548 & 5.7198 & TST & & \\
\hline CHEMBL1303507 & 688709 & 8.6576 & 5.4166 & TST & & \\
\hline CHEMBL1440850 & 688709 & 7.5482 & 6.4013 & TST & & \\
\hline CHEMBL601559 & 688709 & 4.998 & 6.1987 & TST & & \\
\hline CHEMBL1489742 & 688709 & 4.998 & 4.8199 & TST & & \\
\hline CHEMBL1303840 & 688709 & 4.798 & 5.2981 & TST & & \\
\hline CHEMBL1441819 & 688709 & 4.548 & 5.3973 & TST & & \\
\hline CHEMBL1408902 & 688709 & 4.748 & 5.3967 & TST & & \\
\hline CHEMBL1491104 & 688709 & 5.048 & 5.3355 & TST & & \\
\hline CHEMBL1585445 & 688709 & 5.098 & 5.2127 & TST & & \\
\hline CHEMBL1424514 & 688709 & \multicolumn{3}{|c|}{6.247999999999999} & 6.2221 & TST \\
\hline CHEMBL1453566 & 688709 & 4.698 & 5.8067 & TST & & \\
\hline CHEMBL1603944 & 688709 & 7.2976 & 5.4488 & TST & & \\
\hline CHEMBL1331972 & 688709 & 4.898 & 5.4412 & TST & & \\
\hline CHEMBL1354424 & 688709 & 4.648 & 6.04799 & 9999999999 & & TST \\
\hline CHEMBL1383755 & 688709 & 4.748 & 5.8949 & TST & & \\
\hline CHEMBL1495939 & 688709 & 4.898 & 5.4519 & TST & & \\
\hline CHEMBL1345518 & 688709 & 8.0458 & 6.1041 & TST & & \\
\hline CHEMBL1613688 & 688709 & 4.698 & 5.8912 & TST & & \\
\hline CHEMBL1341282 & 688709 & 4.598 & 5.4151 & TST & & \\
\hline CHEMBL1510099 & 688709 & 9.301 & 5.5902 & TST & & \\
\hline CHEMBL1501098 & 688709 & 4.948 & 5.1782 & TST & & \\
\hline CHEMBL1359489 & 688709 & 5.098 & 5.4632 & TST & & \\
\hline CHEMBL1314708 & 688709 & 4.748 & 5.8128 & TST & & \\
\hline CHEMBL1610690 & 688709 & 4.998 & 6.2314 & TST & & \\
\hline CHEMBL3650685 & 1528150 & 6.0458 & 6.0639 & TRN & & \\
\hline CHEMBL3650703 & 1528150 & 7.5229 & 7.5227 & TRN & & \\
\hline CHEMBL3650722 & 1528150 & 7.5229 & 7.8957 & TST & & \\
\hline CHEMBL3650739 & 1528150 & 8.5229 & 8.4974 & TRN & & \\
\hline CHEMBL3650733 & 1528150 & 7.5229 & 7.5322 & TRN & & \\
\hline CHEMBL3650714 & 1528150 & 6.0458 & 6.0348 & TRN & & \\
\hline CHEMBL3650717 & 1528150 & 8.5229 & 8.5484 & TRN & & \\
\hline CHEMBL3650699 & 1528150 & 8.5229 & 7.9926 & TST & & \\
\hline CHEMBL3650755 & 1528150 & 8.5229 & 8.5037 & TRN & & \\
\hline CHEMBL3650753 & 1528150 & 8.5229 & 8.4775 & TRN & & \\
\hline
\end{tabular}


Supplemental Table S2.txt

\begin{tabular}{|c|c|c|c|c|}
\hline HEMBL: & & & 6 & \\
\hline HEMRI 3659715 & & 7.5229 & & \\
\hline HEMBL & & 5229 & & \\
\hline AEMBL3650693 & 528150 & 5229 & & \\
\hline HEMBL3650738 & 528150 & 8.5229 & 4952 & \\
\hline HEMBL & 150 & 58 & & \\
\hline AFMBI: & & & & \\
\hline HEMBL3 & 50 & & & \\
\hline HEMBL3650754 & 528150 & 8.5229 & 5649 & \\
\hline HEMBL3650737 & 528150 & 8.5229 & .5684 & \\
\hline AEMBL36 & 150 & 29 & & \\
\hline AEMBL36 & & & & \\
\hline HEMBL36 & 50 & 29 & & \\
\hline HEMBL 365 & 50 & 29 & & \\
\hline AEMBL3650 & 50 & 8. & & \\
\hline AEMBL & 50 & & & \\
\hline HEMBL & & & & \\
\hline HEMBL3 & 50 & 29 & & \\
\hline AEMBL36 & & & & \\
\hline AEMBL 365 & 50 & 8. & 75 & KIV \\
\hline AEMBL3 & $\theta$ & & & I \\
\hline AEMBL: & & & & RN \\
\hline HEMBL; & 50 & 7 & & RN \\
\hline AEMBL3 & & & & \\
\hline HEMBL 365 & 50 & 6. & & RN \\
\hline AEMBL3 & $\theta$ & & & RN \\
\hline AEME & & & & RN \\
\hline 2 & & & & $C T-1$ \\
\hline AEMBL3 & & & & $|S|$ \\
\hline HEMBL 365 & 50 & & & RN \\
\hline AEMBL: & $\theta$ & & & RN \\
\hline$I 5 M$ & & & & ST \\
\hline & & & & $\mathrm{RN}$ \\
\hline HEMBL 365 & & & & 「RN \\
\hline HEMBL 365 & 50 & & & RN \\
\hline AFMRI 3 & $\theta$ & & & RN \\
\hline & & & & RN \\
\hline HEMBL36 & & & & RN \\
\hline AEMBL 3656 & 90 & 8 . & & $\Gamma R$ \\
\hline EMBL3 & 6 & & & IST \\
\hline HEMBL36 & & & & TRN \\
\hline HEMBL 36 & & & & RN \\
\hline HEMBL 365 & & & 5366 & 「RN \\
\hline AEMBL 365 & 50 & 29 & 71 & TR \\
\hline EMBL3 & & & & \\
\hline HEMBL 3650713 & & & & \\
\hline CHEMBL3650688 & $=2$ & .5229 & 8.5241 & \\
\hline CHEMBL3650728 & 1528150 & 7.5229 & 7.5947 & \\
\hline
\end{tabular}

Page 4453 
Supplemental Table S2.txt

\begin{tabular}{|c|c|c|c|c|c|c|}
\hline CHEMBL 3650697 & 1528150 & 8.5229 & 8.2713 & TST & & \\
\hline CHEMBL3650729 & 1528150 & 7.5229 & 7.4878 & TRN & & \\
\hline CHEMBL3650689 & 1528150 & 8.5229 & 7.8352 & TST & & \\
\hline CHEMBL3650695 & 1528150 & 6.0458 & 7.8869 & TST & & \\
\hline CHEMBL3650725 & 1528150 & 8.5229 & 8.394 & TST & & \\
\hline CHEMBL3650692 & 1528150 & 8.5229 & 8.274 & TST & & \\
\hline CHEMBL3650707 & 1528150 & 7.5229 & 7.7538 & TST & & \\
\hline CHEMBL3892112 & 1528150 & 6.0458 & 7.3187 & TST & & \\
\hline CHEMBL3650735 & 1528150 & 8.5229 & 8.6586 & TST & & \\
\hline CHEMBL3650740 & 1528150 & 7.5229 & 8.1175 & TST & & \\
\hline CHEMBL3650705 & 1528150 & 7.5229 & $7.19600 t$ & 000000000 & & TST \\
\hline CHEMBL26836 & 1513 & 7.21 & 7.2085 & TRN & & \\
\hline CHEMBL 27025 & 1513 & 7.19 & 7.19 & TRN & & \\
\hline CHEMBL417470 & 1513 & 7.6 & 7.6025 & TRN & & \\
\hline CHEMBL27719 & 1513 & \multicolumn{3}{|c|}{7.712000000000001} & \multicolumn{2}{|c|}{ 7.712999999999999 } \\
\hline CHEMBL26972 & 1513 & \multicolumn{3}{|c|}{7.1610000000000005} & 7.1611 & TRN \\
\hline CHEMBL27998 & 1513 & 7.09 & 7.0919 & TRN & & \\
\hline CHEMBL128544 & 1513 & 6.86 & 7.237 & TST & & \\
\hline CHEMBL 285777 & 1513 & 7.676 & 7.6803 & TRN & & \\
\hline CHEMBL26868 & 1513 & \multicolumn{3}{|c|}{6.4239999999999995} & 6.4258 & TRN \\
\hline CHEMBL283397 & 1513 & 6.955 & 6.9536 & TRN & & \\
\hline CHEMBL281434 & 1513 & 7.638 & 7.6369 & TRN & & \\
\hline CHEMBL 26655 & 1513 & 6.836 & 6.8334 & TRN & & \\
\hline CHEMBL28105 & 1513 & 6.98 & 6.979 & TRN & & \\
\hline CHEMBL283185 & 1513 & 6.723 & 6.7226 & TRN & & \\
\hline CHEMBL 25812 & 1513 & 6.44 & 6.4405 & TRN & & \\
\hline CHEMBL281432 & 1513 & 7.77 & 7.7751 & TRN & & \\
\hline CHEMBL 26850 & 1513 & \multicolumn{3}{|c|}{5.747999999999999} & 5.7526 & TRN \\
\hline CHEMBL130159 & 1513 & \multicolumn{3}{|c|}{5.257000000000001} & 6.7773 & TST \\
\hline CHEMBL282799 & 1513 & 7.13 & 7.1258 & TRN & & \\
\hline CHEMBL 285157 & 1513 & 6.035 & 6.0338 & TRN & & \\
\hline CHEMBL26322 & 1513 & 7.11 & 7.1117 & TRN & & \\
\hline CHEMBL 283257 & 1513 & 7.19 & 7.1909 & TRN & & \\
\hline CHEMBL283398 & 1513 & 8.276 & 8.2715 & TRN & & \\
\hline CHEMBL27643 & 1513 & 7.721 & 7.7197 & TRN & & \\
\hline CHEMBL287576 & 1513 & 7.638 & 7.6417 & TRN & & \\
\hline CHEMBL287655 & 1513 & 6.726 & 6.726 & TRN & & \\
\hline CHEMBL131203 & 1513 & 6.416 & 6.4144 & TRN & & \\
\hline CHEMBL26900 & 1513 & 7.6 & 7.6 & TRN & & \\
\hline CHEMBL341485 & 1513 & 6.29 & 6.6256 & TST & & \\
\hline CHEMBL 287441 & 1513 & 6.9 & 6.9019 & TRN & & \\
\hline CHEMBL340175 & 1513 & 7.056 & 7.0556 & TRN & & \\
\hline CHEMBL283899 & 1513 & 7.26 & 7.2575 & TRN & & \\
\hline CHEMBL337381 & 1513 & 6.26 & 6.7945 & TST & & \\
\hline CHEMBL 280779 & 1513 & \multicolumn{3}{|c|}{6.656000000000001} & 6.657 & TRN \\
\hline CHEMBL 26921 & 1513 & 6.255 & 6.2528 & TRN & & \\
\hline CHEMBL27227 & 1513 & 7.96 & 7.9581 & TRN & & \\
\hline CHEMBL18785 & 1513 & 7.96 & 7.9596 & TRN & & \\
\hline
\end{tabular}




\begin{tabular}{|c|c|c|c|c|c|c|}
\hline & & \multicolumn{5}{|c|}{ Supplemental Table S2.txt } \\
\hline CHEMBL 287097 & 1513 & 7.432 & 7.4305 & TRN & & \\
\hline CHEMBL128288 & 1513 & 6.78299 & 99999999 & 995 & 6.7843 & TRN \\
\hline CHEMBL 26311 & 1513 & 7.442 & 7.4417 & TRN & & \\
\hline CHEMBL 281937 & 1513 & 5.0 & 5.7782 & TST & & \\
\hline CHEMBL284107 & 1513 & 7.26 & 7.2627 & TRN & & \\
\hline CHEMBL 284447 & 1513 & \multicolumn{3}{|c|}{6.462000000000001} & 6.4572 & TRN \\
\hline CHEMBL 27811 & 1513 & 6.723 & 7.1718 & TST & & \\
\hline CHEMBL442534 & 1513 & 6.836 & 7.1675 & TST & & \\
\hline CHEMBL 283416 & 1513 & 7.676 & 6.8603 & TST & & \\
\hline CHEMBL26980 & 1513 & 6.16 & 6.5772 & TST & & \\
\hline CHEMBL539159 & 1513 & 6.699 & 6.8831 & TST & & \\
\hline CHEMBL436568 & 1513 & 5.63 & 6.2123 & TST & & \\
\hline CHEMBL 281716 & 1513 & 6.519 & 6.6105 & TST & & \\
\hline CHEMBL 286264 & 1513 & 6.728 & 6.9684 & TST & & \\
\hline CHEMBL 188962 & 304989 & 5.1163 & 5.6704 & TRN & & \\
\hline CHEMBL187495 & 304989 & 5.4841 & 5.2376 & TRN & & \\
\hline CHEMBL188162 & 304989 & 5.684 & 5.414 & TST & & \\
\hline CHEMBL190849 & 304989 & 7.3979 & 7.0057 & TRN & & \\
\hline CHEMBL187436 & 304989 & 5.5654 & 5.0649 & TRN & & \\
\hline CHEMBL188332 & 304989 & 5.2083 & 5.4016 & TST & & \\
\hline CHEMBL424817 & 304989 & 6.1675 & 5.8531 & TRN & & \\
\hline CHEMBL 366212 & 304989 & 6.3665 & 5.9105 & TRN & & \\
\hline CHEMBL188971 & 304989 & 5.0575 & 5.7419 & TRN & & \\
\hline CHEMBL191335 & 304989 & 5.7447 & 5.351 & TRN & & \\
\hline CHEMBL190948 & 304989 & 6.1024 & 5.8592 & TST & & \\
\hline CHEMBL189656 & 304989 & 5.4672 & 6.0719 & TRN & & \\
\hline CHEMBL190263 & 304989 & 5.0665 & 4.9365 & TRN & & \\
\hline CHEMBL189958 & 304989 & 5.5086 & 5.3811 & TRN & & \\
\hline CHEMBL191443 & 304989 & 5.5751 & 5.8064 & TRN & & \\
\hline CHEMBL187496 & 304989 & 5.2882 & 5.5111 & TRN & & \\
\hline CHEMBL361691 & 304989 & 5.2503 & 5.7683 & TRN & & \\
\hline CHEMBL 190787 & 304989 & 6.7212 & 6.7826 & TRN & & \\
\hline CHEMBL 363511 & 304989 & 5.6716 & 5.7809 & TRN & & \\
\hline CHEMBL188334 & 304989 & 5.6162 & 6.0781 & TRN & & \\
\hline CHEMBL 362370 & 304989 & 5.8928 & 6.066 & TST & & \\
\hline CHEMBL190376 & 304989 & 5.6576 & 5.73600 & 0000000001 & & \\
\hline CHEMBL 363889 & 304989 & 6.0362 & 6.1846 & TRN & & \\
\hline CHEMBL188960 & 304989 & 5.5003 & 5.4262 & TST & & \\
\hline CHEMBL 363734 & 304989 & 5.9066 & 5.7309 & TRN & & \\
\hline CHEMBL 361448 & 304989 & 5.5884 & 5.3373 & TST & & \\
\hline CHEMBL189520 & 304989 & 6.0809 & 6.5095 & TRN & & \\
\hline CHEMBL 365214 & 304989 & 5.2041 & 5.0495 & TRN & & \\
\hline CHEMBL185650 & 304989 & 5.0241 & 5.4465 & TRN & & \\
\hline CHEMBL 370308 & 304989 & 5.1752 & 5.3715 & TRN & & \\
\hline CHEMBL 364482 & 304989 & 5.4881 & 5.5572 & TRN & & \\
\hline CHEMBL188333 & 304989 & 6.8539 & 6.058 & TRN & & \\
\hline CHEMBL 370238 & 304989 & 5.0 & 4.647 & TRN & & \\
\hline CHEMBL 360645 & 304989 & 5.7352 & 5.5179 & TRN & & \\
\hline
\end{tabular}




\begin{tabular}{|c|c|c|c|c|c|c|}
\hline \multirow[b]{2}{*}{ CHEMBL 371587} & & \multicolumn{5}{|c|}{ Supplemental Table S2.txt } \\
\hline & 304989 & 5.1215 & \multicolumn{3}{|c|}{5.132000000000001} & TRN \\
\hline CHEMBL188677 & 304989 & 5.0742 & 5.3227 & TRN & & \\
\hline CHEMBL187548 & 304989 & 7.3979 & 6.6765 & TRN & & \\
\hline CHEMBL189182 & 304989 & 5.4949 & 5.7957 & TRN & & \\
\hline CHEMBL188292 & 304989 & 7.0177 & 5.6704 & TRN & & \\
\hline CHEMBL188647 & 304989 & 5.7721 & 6.0715 & TRN & & \\
\hline CHEMBL 362512 & 304989 & 7.1308 & 6.8243 & TRN & & \\
\hline CHEMBL 363301 & 304989 & 5.6038 & 5.735 & TRN & & \\
\hline CHEMBL 363903 & 304989 & 5.4962 & 5.5843 & TRN & & \\
\hline CHEMBL188030 & 304989 & 5.0506 & 5.7174 & TRN & & \\
\hline CHEMBL 362755 & 304989 & 6.8861 & 5.9435 & TRN & & \\
\hline CHEMBL439667 & 304989 & 6.6383 & 6.3949 & TRN & & \\
\hline CHEMBL188628 & 304989 & 6.0506 & 6.0922 & TRN & & \\
\hline CHEMBL185697 & 304989 & 5.4342 & 5.6195 & TRN & & \\
\hline CHEMBL187497 & 304989 & 5.5784 & 5.3115 & TRN & & \\
\hline CHEMBL191328 & 304989 & 5.0057 & 5.4367 & TRN & & \\
\hline CHEMBL190364 & 304989 & 6.1871 & 5.6913 & TRN & & \\
\hline CHEMBL187341 & 304989 & 5.0325 & 4.7991 & TRN & & \\
\hline CHEMBL 366287 & 304989 & 5.3019 & 5.7045 & TRN & & \\
\hline CHEMBL 365618 & 304989 & 5.7212 & 5.9649 & TRN & & \\
\hline CHEMBL186673 & 304989 & \multicolumn{3}{|c|}{5.821000000000001} & 5.4267 & TRN \\
\hline CHEMBL185798 & 304989 & 6.5686 & 6.6252 & TRN & & \\
\hline CHEMBL188108 & 304989 & 5.0 & 6.0273 & TRN & & \\
\hline CHEMBL 363185 & 304989 & 5.2154 & 5.6555 & TRN & & \\
\hline CHEMBL188397 & 304989 & 5.3391 & 5.0592 & TRN & & \\
\hline CHEMBL191119 & 304989 & 5.0501 & 5.5683 & TRN & & \\
\hline CHEMBL189566 & 304989 & 6.1135 & 6.1224 & TRN & & \\
\hline CHEMBL34816 & 304989 & 6.0 & 5.9889 & TRN & & \\
\hline CHEMBL190365 & 304989 & 5.2168 & 5.3926 & TRN & & \\
\hline CHEMBL362871 & 304989 & 6.5686 & 5.7857 & TRN & & \\
\hline CHEMBL 361476 & 304989 & 5.2226 & 5.2501 & TST & & \\
\hline CHEMBL188598 & 304989 & 5.0424 & 5.0748 & TRN & & \\
\hline CHEMBL 365147 & 304989 & 5.9586 & 5.7684 & TRN & & \\
\hline CHEMBL188233 & 304989 & 5.8327 & 6.0834 & TRN & & \\
\hline CHEMBL187442 & 304989 & 5.0255 & 5.6398 & TRN & & \\
\hline CHEMBL365857 & 304989 & 5.3716 & 5.5342 & TST & & \\
\hline CHEMBL363668 & 304989 & 7.7696 & 6.8243 & TST & & \\
\hline CHEMBL190906 & 304989 & \multicolumn{3}{|c|}{5.2620000000000005} & 5.5193 & 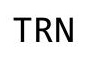 \\
\hline CHEMBL189498 & 304989 & 5.5331 & 5.4601 & TST & & \\
\hline CHEMBL190423 & 304989 & 6.2007 & 5.8745 & TST & & \\
\hline CHEMBL189008 & 304989 & 5.1878 & 5.0509 & TRN & & \\
\hline CHEMBL189007 & 304989 & 5.4191 & 5.2769 & TRN & & \\
\hline CHEMBL263749 & 304989 & 5.475 & 5.4842 & TST & & \\
\hline CHEMBL366107 & 304989 & 5.4962 & 5.8428 & TST & & \\
\hline CHEMBL 35970 & 304989 & 6.5686 & 5.6423 & TST & & \\
\hline CHEMBL189519 & 304989 & 5.0 & 5.1394 & TRN & & \\
\hline CHEMBL 364888 & 304989 & 5.7375 & 5.391 & TRN & & \\
\hline \multirow[t]{2}{*}{ CHEMBL365694 } & 304989 & 6.4949 & \multicolumn{3}{|c|}{5.861000000000001} & \\
\hline & & & & 4456 & & \\
\hline
\end{tabular}




\begin{tabular}{|c|c|c|c|c|c|}
\hline \multicolumn{6}{|c|}{ supplementa } \\
\hline CHEMBL370720 & 304989 & 5.1068 & 5.5225 & TST & \\
\hline CHEMBL187632 & 304989 & 5.4559 & 6.1276 & TST & \\
\hline CHEMBL189281 & 304989 & 6.4559 & 6.3872 & TST & \\
\hline CHEMBL366118 & 304989 & 7.585 & 6.5757 & TST & \\
\hline CHEMBL190307 & 304989 & 5.8386 & 5.6076 & TST & \\
\hline CHEMBL188461 & 304989 & 7.1308 & 5.6704 & TST & \\
\hline CHEMBL187486 & 304989 & 5.0645 & 5.8892 & TST & \\
\hline CHEMBL188211 & 304989 & 7.8861 & 7.3849 & TRN & \\
\hline CHEMBL362528 & 304989 & 5.9172 & 5.1599 & TST & \\
\hline CHEMBL188241 & 304989 & 5.3449 & 5.5152 & TRN & \\
\hline CHEMBL362580 & 304989 & 6.2076 & 6.3185 & TRN & \\
\hline CHEMBL363231 & 304989 & 5.4815 & 5.167006 & 0000000001 & TST \\
\hline CHEMBL189772 & 304989 & 5.0 & 4.8229 & TRN & \\
\hline CHEMBL361481 & 304989 & 6.284 & 6.4184 & TRN & \\
\hline CHEMBL202068 & 331786 & 4.7959 & 4.0911 & TRN & \\
\hline CHEMBL202580 & 331786 & 6.699 & 6.4765 & TRN & \\
\hline CHEMBL201237 & 331786 & 3.5229 & 3.5908 & TRN & \\
\hline CHEMBL425754 & 331786 & 4.6021 & 5.3129 & TRN & \\
\hline CHEMBL380899 & 331786 & 3.5229 & 3.9277 & TRN & \\
\hline CHEMBL201999 & 331786 & 6.0 & 5.2285 & TRN & \\
\hline CHEMBL382825 & 331786 & 5.7696 & 5.7148 & TRN & \\
\hline CHEMBL201236 & 331786 & 6.2218 & 6.2491 & TST & \\
\hline CHEMBL202133 & 331786 & 4.5686 & 6.4018 & TST & \\
\hline CHEMBL382505 & 331786 & 5.1549 & 4.8172 & TRN & \\
\hline CHEMBL372075 & 331786 & 6.0 & 6.0754 & TRN & \\
\hline CHEMBL202173 & 331786 & 3.5229 & 3.9571 & TRN & \\
\hline CHEMBL202264 & 331786 & 6.0458 & 5.8535 & TRN & \\
\hline CHEMBL371882 & 331786 & 5.5229 & 5.5832 & TRN & \\
\hline CHEMBL 382504 & 331786 & 3.5229 & 3.613 & TRN & \\
\hline CHEMBL382763 & 331786 & 5.699 & 6.2872 & TRN & \\
\hline CHEMBL202494 & 331786 & 4.5229 & 5.0603 & TRN & \\
\hline CHEMBL202338 & 331786 & 3.5229 & 3.5015 & TRN & \\
\hline CHEMBL382345 & 331786 & 5.301 & 4.8145 & TRN & \\
\hline CHEMBL201887 & 331786 & 3.5229 & 3.7291 & TST & \\
\hline CHEMBL440573 & 331786 & 6.699 & 5.9956 & TRN & \\
\hline CHEMBL202263 & 331786 & 5.699 & 6.2253 & TRN & \\
\hline CHEMBL380825 & 331786 & 3.5229 & 4.1209 & TST & \\
\hline CHEMBL66064 & 331786 & 4.6576 & 5.3088 & TST & \\
\hline CHEMBL201501 & 331786 & 6.699 & 5.8286 & TRN & \\
\hline CHEMBL435117 & 331786 & 5.1871 & 5.5603 & TRN & \\
\hline CHEMBL381101 & 331786 & 7.0 & 7.2445 & TRN & \\
\hline CHEMBL200986 & 331786 & 5.5229 & 5.9014 & TRN & \\
\hline CHEMBL197649 & 331786 & 4.8239 & 5.2767 & TRN & \\
\hline CHEMBL370137 & 331786 & 5.301 & 5.068006 & 00000000005 & TRN \\
\hline CHEMBL201942 & 331786 & 5.0969 & 5.3922 & TRN & \\
\hline CHEMBL202934 & 331786 & 6.1549 & 6.4025 & TRN & \\
\hline CHEMBL201533 & 331786 & 4.5229 & 5.2272 & TRN & \\
\hline CHEMBL201550 & 331786 & 6.699 & 6.6614 & TRN & \\
\hline
\end{tabular}




\begin{tabular}{|c|c|c|c|c|c|}
\hline \multicolumn{6}{|c|}{ Supplemental Table S2.txt } \\
\hline CHEMBL 377720 & 331786 & 5.8239 & 5.2623 & TRN & \\
\hline CHEMBL201469 & 331786 & 3.5229 & 3.9744 & TRN & \\
\hline CHEMBL 202043 & 331786 & 6.0 & 5.6143 & TRN & \\
\hline CHEMBL 381033 & 331786 & 6.699 & 5.3956 & TRN & \\
\hline CHEMBL 200965 & 331786 & 6.1549 & 5.7309 & TRN & \\
\hline CHEMBL 264217 & 331786 & 6.1549 & 7.13200 & 0000000001 & TST \\
\hline CHEMBL372998 & 331786 & 6.301 & 6.6467 & TST & \\
\hline CHEMBL 202498 & 331786 & 6.2218 & 6.4925 & TST & \\
\hline CHEMBL 201797 & 331786 & 5.2218 & 6.3516 & TST & \\
\hline CHEMBL380960 & 331786 & 5.0 & 4.9007 & TRN & \\
\hline CHEMBL 373014 & 331786 & 5.1549 & 4.5087 & TST & \\
\hline CHEMBL197761 & 331786 & 4.8239 & 5.3904 & TRN & \\
\hline CHEMBL 372777 & 331786 & 4.9586 & 6.5531 & TST & \\
\hline CHEMBL 201467 & 331786 & 3.5229 & 4.1693 & TST & \\
\hline CHEMBL199930 & 331786 & 5.7212 & 5.7599 & TRN & \\
\hline CHEMBL199809 & 331786 & 6.0 & 5.8476 & TRN & \\
\hline CHEMBL 202032 & 331786 & 6.0969 & 6.2395 & TST & \\
\hline CHEMBL372836 & 331786 & 6.0 & 6.3136 & TRN & \\
\hline CHEMBL 380788 & 331786 & 6.699 & 6.5128 & TST & \\
\hline CHEMBL3361355 & 1459647 & 5.7055 & 5.6954 & TRN & \\
\hline CHEMBL3361359 & 1459647 & 7.3098 & 7.0906 & TST & \\
\hline CHEMBL 3360789 & 1459647 & 7.3372 & 7.3856 & TRN & \\
\hline CHEMBL3361350 & 1459647 & 6.1261 & 6.0978 & TRN & \\
\hline CHEMBL 3361379 & 1459647 & 8.2041 & 8.2093 & TRN & \\
\hline CHEMBL3361378 & 1459647 & 7.4473 & 7.4823 & TRN & \\
\hline CHEMBL3361394 & 1459647 & 9.2204 & 9.2424 & TRN & \\
\hline CHEMBL3361390 & 1459647 & 8.4271 & 8.5263 & TRN & \\
\hline CHEMBL 3361389 & 1459647 & 9.5058 & 9.4284 & TRN & \\
\hline CHEMBL 3361357 & 1459647 & 7.1439 & 6.7532 & TST & \\
\hline CHEMBL3361386 & 1459647 & 8.1238 & 8.1668 & TRN & \\
\hline CHEMBL3361374 & 1459647 & 7.9747 & 8.0025 & TRN & \\
\hline CHEMBL 3361383 & 1459647 & 6.8041 & 6.7843 & TRN & \\
\hline CHEMBL3360795 & 1459647 & 6.8928 & 6.9087 & TRN & \\
\hline CHEMBL 3361352 & 1459647 & 7.466 & 7.1797 & TST & \\
\hline CHEMBL 3360794 & 1459647 & 6.1261 & 6.1149 & TRN & \\
\hline CHEMBL 3361377 & 1459647 & 7.58 & 7.46299 & 9999999999 & TRN \\
\hline CHEMBL3361351 & 1459647 & 5.8013 & 6.1499 & TST & \\
\hline CHEMBL3360792 & 1459647 & 7.1752 & 7.154 & TRN & \\
\hline CHEMBL 3361393 & 1459647 & 7.1343 & 7.1322 & TRN & \\
\hline CHEMBL 3361360 & 1459647 & 7.2676 & 7.2918 & TRN & \\
\hline CHEMBL3361353 & 1459647 & 7.8761 & 7.8521 & TRN & \\
\hline CHEMBL3361385 & 1459647 & 8.1124 & 7.9596 & TRN & \\
\hline CHEMBL3361349 & 1459647 & 5.5243 & 5.5357 & TRN & \\
\hline CHEMBL 3361367 & 1459647 & 5.7235 & 5.7587 & TRN & \\
\hline CHEMBL3360793 & 1459647 & 6.0325 & 6.0325 & TRN & \\
\hline CHEMBL3361372 & 1459647 & 8.7496 & 8.6676 & TRN & \\
\hline CHEMBL3361382 & 1459647 & 6.7122 & 6.6777 & TRN & \\
\hline CHEMBL1257903 & 1459647 & 7.5817 & 7.7592 & TRN & \\
\hline
\end{tabular}


Supplemental Table S2.txt

\begin{tabular}{|c|c|c|c|c|c|}
\hline CHEMBL3361369 & 1459647 & 6.5884 & 6.5873 & TRN & \\
\hline CHEMBL3361391 & 1459647 & 8.1113 & 8.2339 & TRN & \\
\hline CHEMBL3361356 & 1459647 & 6.8761 & 6.4599 & TST & \\
\hline CHEMBL3360791 & 1459647 & 8.1772 & 8.1866 & TRN & \\
\hline CHEMBL3361371 & 1459647 & 6.8125 & 6.8048 & TRN & \\
\hline CHEMBL3361364 & 1459647 & 6.2865 & 6.2567 & TRN & \\
\hline CHEMBL3361368 & 1459647 & 5.5436 & 5.5683 & TRN & \\
\hline CHEMBL3361384 & 1459647 & 6.3536 & 6.3334 & TRN & \\
\hline CHEMBL 3361363 & 1459647 & 6.1096 & 6.0724 & TRN & \\
\hline CHEMBL3361380 & 1459647 & 5.7747 & 5.8182 & TRN & \\
\hline CHEMBL 3361366 & 1459647 & 7.2168 & 7.2296 & TRN & \\
\hline CHEMBL3361361 & 1459647 & 7.2336 & 7.2034 & TRN & \\
\hline CHEMBL3360787 & 1459647 & 7.6108 & 7.6016 & TRN & \\
\hline CHEMBL3361354 & 1459647 & 5.9747 & 5.8598 & TST & \\
\hline CHEMBL3361358 & 1459647 & \multicolumn{3}{|c|}{6.7620000000000005} & 6.796 \\
\hline CHEMBL3361370 & 1459647 & 5.2676 & 5.216 & TRN & \\
\hline CHEMBL3361365 & 1459647 & 7.6478 & 7.6825 & TRN & \\
\hline CHEMBL3361373 & 1459647 & 8.6198 & 8.6729 & TRN & \\
\hline CHEMBL3361362 & 1459647 & 5.2581 & 5.2737 & TRN & \\
\hline CHEMBL3361375 & 1459647 & 8.8861 & 8.7585 & TRN & \\
\hline CHEMBL3361388 & 1459647 & 8.6946 & 9.3419 & TST & \\
\hline CHEMBL3361395 & 1459647 & 9.1637 & 8.271 & TST & \\
\hline CHEMBL3360790 & 1459647 & 7.2097 & 7.1052 & TST & \\
\hline CHEMBL3361376 & 1459647 & 7.6819 & 7.2004 & TST & \\
\hline CHEMBL 3360786 & 1459647 & 8.2343 & 8.4052 & TST & \\
\hline CHEMBL3361392 & 1459647 & 8.2857 & 7.8805 & TST & \\
\hline CHEMBL 3361387 & 1459647 & 7.8477 & 8.4713 & TST & \\
\hline CHEMBL3360788 & 1459647 & 8.0386 & 8.8257 & TST & \\
\hline CHEMBL3361381 & 1459647 & 7.6696 & 8.5799 & TST & \\
\hline CHEMBL336506 & 97604 & 4.5607 & 4.3566 & TST & \\
\hline CHEMBL337455 & 97604 & 4.9586 & 5.0429 & TRN & \\
\hline CHEMBL341453 & 97604 & 4.3487 & 4.1854 & TST & \\
\hline CHEMBL339857 & 97604 & 4.4908 & 4.7044 & TST & \\
\hline CHEMBL1213547 & 97604 & 5.1249 & 4.9355 & TRN & \\
\hline CHEMBL130225 & 97604 & 5.3098 & 5.2549 & TRN & \\
\hline CHEMBL423164 & 97604 & 4.7595 & 5.1047 & TRN & \\
\hline CHEMBL341454 & 97604 & 3.6914 & 4.0748 & TST & \\
\hline CHEMBL1213590 & 97604 & 4.8416 & 5.2291 & TRN & \\
\hline CHEMBL1213626 & 97604 & 4.3036 & 4.9118 & TRN & \\
\hline CHEMBL 2367467 & 97604 & 4.3316 & 4.1479 & TRN & \\
\hline CHEMBL136952 & 97604 & 5.3279 & 5.1384 & TRN & \\
\hline CHEMBL1213548 & 97604 & 5.4318 & 5.1781 & TRN & \\
\hline CHEMBL317528 & 97604 & 4.3925 & 4.0352 & TRN & \\
\hline CHEMBL1213503 & 97604 & 5.0706 & 4.4936 & TRN & \\
\hline CHEMBL99717 & 97604 & 4.9547 & 4.8859 & TRN & \\
\hline CHEMBL134674 & 97604 & 5.7447 & 5.5341 & TRN & \\
\hline CHEMBL335105 & 97604 & 4.7799 & 5.3481 & TRN & \\
\hline CHEMBL98210 & 97604 & 5.3468 & 4.8277 & TRN & \\
\hline
\end{tabular}




\begin{tabular}{|c|c|c|c|c|c|}
\hline \multicolumn{6}{|c|}{ Supplemental Table S2.txt } \\
\hline CHEMBL99929 & 97604 & 3.5889 & 4.0776 & TRN & \\
\hline CHEMBL133878 & 97604 & 4.308 & 4.0381 & TRN & \\
\hline CHEMBL132641 & 97604 & 5.5376 & 5.4232 & TRN & \\
\hline CHEMBL301028 & 97604 & 3.8814 & 4.2997 & TST & \\
\hline CHEMBL1213092 & 97604 & 3.6156 & 4.0733 & TRN & \\
\hline CHEMBL134789 & 97604 & 3.8187 & 4.0318 & TRN & \\
\hline CHEMBL132436 & 97604 & 4.3947 & 4.8358 & TRN & \\
\hline CHEMBL335987 & 97604 & 3.7317 & 4.2558 & TST & \\
\hline CHEMBL337614 & 97604 & 4.8153 & 4.7188 & TRN & \\
\hline CHEMBL337636 & 97604 & 3.8297 & 3.9833 & TST & \\
\hline CHEMBL1213501 & 97604 & 4.7496 & 4.3182 & TRN & \\
\hline CHEMBL335298 & 97604 & 4.58 & 4.5685 & TRN & \\
\hline CHEMBL318045 & 97604 & 4.5086 & 4.1464 & TRN & \\
\hline CHEMBL335031 & 97604 & 5.6383 & 5.3279 & TRN & \\
\hline CHEMBL1213502 & 97604 & 4.9101 & 4.2801 & TRN & \\
\hline CHEMBL423716 & 97604 & 4.2518 & 4.7 & TST & \\
\hline CHEMBL318450 & 97604 & 3.7518 & 4.0422 & TRN & \\
\hline CHEMBL336114 & 97604 & 4.4815 & 4.93 & TRN & \\
\hline CHEMBL133958 & 97604 & 4.4237 & 4.63899 & 9999999999 & TRN \\
\hline CHEMBL539296 & 97604 & 4.4437 & 4.9819 & TRN & \\
\hline CHEMBL335410 & 97604 & 3.9948 & 4.19300 & 00000000005 & TRN \\
\hline CHEMBL1213589 & 97604 & 4.3497 & 4.8047 & TRN & \\
\hline CHEMBL100210 & 97604 & 4.4498 & 4.2028 & TRN & \\
\hline CHEMBL136006 & 97604 & 4.5935 & 4.7978 & TST & \\
\hline CHEMBL1213504 & 97604 & 4.1007 & 4.5911 & TRN & \\
\hline CHEMBL337399 & 97604 & 4.4101 & 4.2994 & TRN & \\
\hline CHEMBL136943 & 97604 & 3.4169 & 4.2254 & TRN & \\
\hline CHEMBL336784 & 97604 & 6.5229 & 5.36700 & 0000000001 & TRN \\
\hline CHEMBL133162 & 97604 & 4.15 & 3.9791 & TRN & \\
\hline CHEMBL341399 & 97604 & 4.3516 & 4.1713 & TST & \\
\hline CHEMBL1213093 & 97604 & 4.2168 & 4.1817 & TRN & \\
\hline CHEMBL99340 & 97604 & 4.8996 & 4.6317 & TRN & \\
\hline CHEMBL135406 & 97604 & 5.4318 & 5.4599 & TRN & \\
\hline CHEMBL1213550 & 97604 & 4.9208 & 4.9739 & TRN & \\
\hline CHEMBL135194 & 97604 & 4.3526 & 4.0508 & TRN & \\
\hline CHEMBL1213588 & 97604 & 4.2692 & 4.8141 & TST & \\
\hline CHEMBL1213587 & 97604 & 5.8539 & 4.9195 & TST & \\
\hline CHEMBL1213549 & 97604 & 4.9245 & 5.117 & TST & \\
\hline CHEMBL1213464 & 97604 & 4.7747 & 4.2353 & TST & \\
\hline CHEMBL100740 & 97604 & 3.8005 & 4.0915 & TST & \\
\hline CHEMBL 2001398 & 809249 & 4.2 & 4.5174 & TRN & \\
\hline CHEMBL213505 & 809249 & 5.9 & 5.4186 & TRN & \\
\hline CHEMBL202721 & 809249 & 4.2 & 4.7822 & TRN & \\
\hline CHEMBL1987034 & 809249 & 7.0 & 7.3531 & TRN & \\
\hline CHEMBL1993941 & 809249 & 6.5 & 6.0689 & TRN & \\
\hline CHEMBL377383 & 809249 & 4.8 & 4.4966 & TRN & \\
\hline CHEMBL 2005886 & 809249 & 6.9 & 6.6199 & TRN & \\
\hline CHEMBL481491 & 809249 & 4.8 & 4.7745 & TST & \\
\hline
\end{tabular}




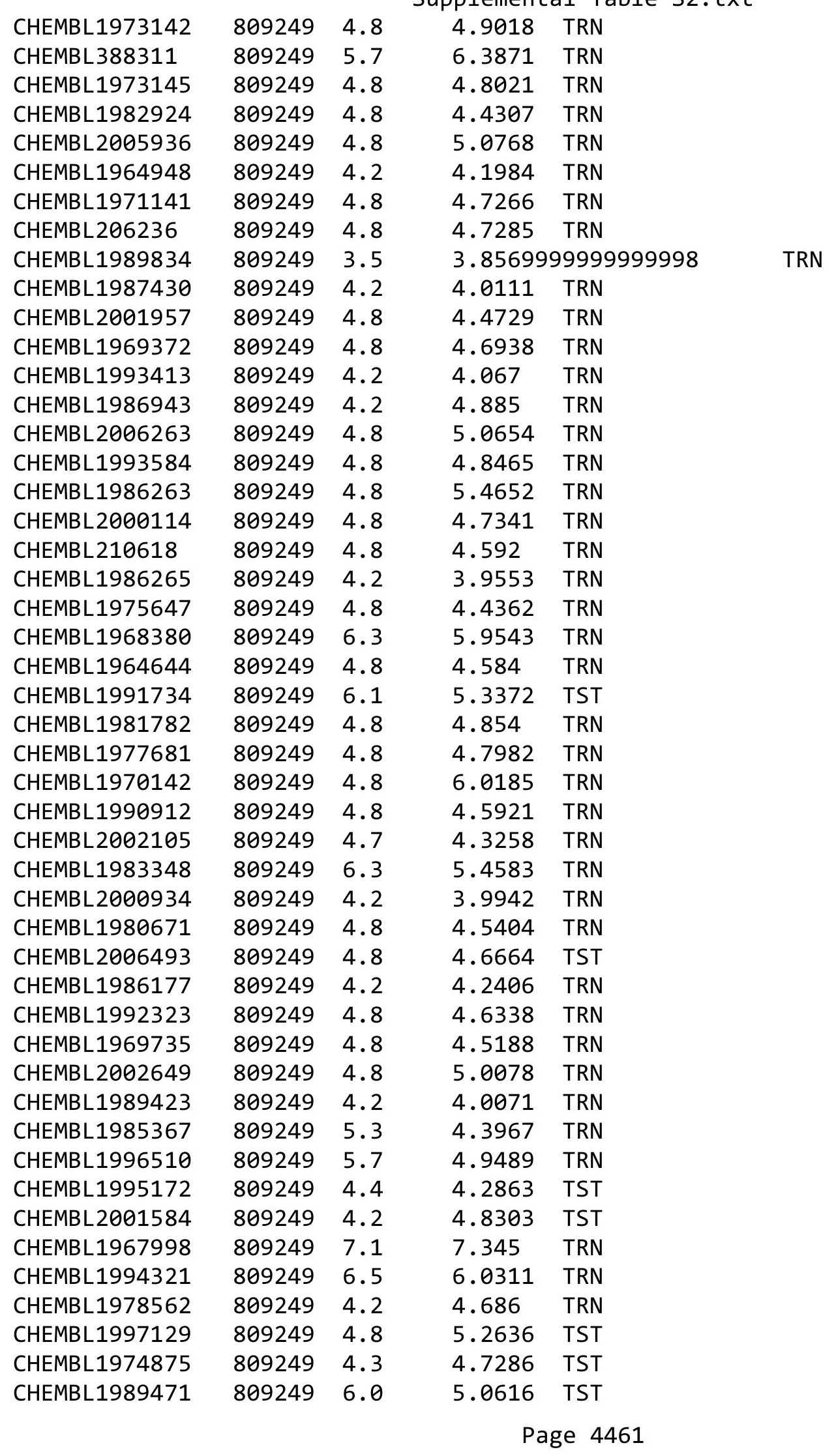




\begin{tabular}{|c|c|c|c|c|c|}
\hline \\
\hline CHEMBL2000508 & 809249 & 4.8 & 4.5897 & TRN & \\
\hline CHEMBL2001547 & 809249 & 4.8 & 4.5008 & TRN & \\
\hline CHEMBL210928 & 809249 & 4.8 & 4.7184 & TRN & \\
\hline CHEMBL1978195 & 809249 & 4.2 & 4.7886 & TRN & \\
\hline CHEMBL1977148 & 809249 & 4.8 & 5.3305 & TRN & \\
\hline CHEMBL1966842 & 809249 & 4.5 & 4.7001 & TRN & \\
\hline CHEMBL 2003286 & 809249 & 4.8 & 4.981 & TRN & \\
\hline CHEMBL1992306 & 809249 & 4.8 & 5.2351 & TRN & \\
\hline CHEMBL 2002165 & 809249 & 6.8 & 6.4341 & TRN & \\
\hline CHEMBL206382 & 809249 & 4.8 & 4.6278 & TRN & \\
\hline CHEMBL1998585 & 809249 & 7.1 & 6.4643 & TRN & \\
\hline CHEMBL519697 & 809249 & 4.8 & 5.1762 & TRN & \\
\hline CHEMBL1973516 & 809249 & 6.6 & 6.8968 & TRN & \\
\hline CHEMBL1996345 & 809249 & 4.2 & 4.5025 & TST & \\
\hline CHEMBL1975128 & 809249 & 4.8 & 5.5454 & TRN & \\
\hline CHEMBL 2004025 & 809249 & 4.2 & 4.9648 & TRN & \\
\hline CHEMBL1996048 & 809249 & 6.1 & 4.8138 & TRN & \\
\hline CHEMBL1976158 & 809249 & 4.5 & 4.7069 & TST & \\
\hline CHEMBL461876 & 809249 & 7.4 & 6.817 & TRN & \\
\hline CHEMBL1965033 & 809249 & 4.2 & 4.4587 & TRN & \\
\hline CHEMBL 2001485 & 809249 & 6.3 & 6.07799 & 9999999999 & TRN \\
\hline CHEMBL1971519 & 809249 & 4.7 & 4.0453 & TRN & \\
\hline CHEMBL1997335 & 809249 & 6.1 & 5.4634 & TRN & \\
\hline CHEMBL1984363 & 809249 & 4.8 & 4.8285 & TRN & \\
\hline CHEMBL1978099 & 809249 & 4.8 & 6.5045 & TRN & \\
\hline CHEMBL1988608 & 809249 & 4.8 & 5.2383 & TRN & \\
\hline CHEMBL184847 & 809249 & 4.8 & 4.6215 & TRN & \\
\hline CHEMBL1971132 & 809249 & 4.2 & 3.9878 & TRN & \\
\hline CHEMBL1984367 & 809249 & 4.8 & 4.4788 & TRN & \\
\hline CHEMBL226898 & 809249 & 4.8 & 5.1194 & TRN & \\
\hline CHEMBL1982563 & 809249 & 4.8 & 4.5735 & TRN & \\
\hline CHEMBL1991377 & 809249 & 4.2 & 4.4052 & TRN & \\
\hline CHEMBL575824 & 809249 & 4.8 & 5.1384 & TRN & \\
\hline CHEMBL1988387 & 809249 & 7.1 & 6.4455 & TRN & \\
\hline CHEMBL1973868 & 809249 & 4.2 & 4.4065 & TRN & \\
\hline CHEMBL1972462 & 809249 & 4.2 & 4.3883 & TRN & \\
\hline CHEMBL1990288 & 809249 & 4.8 & 4.7222 & TRN & \\
\hline CHEMBL1970074 & 809249 & 4.8 & 5.0943 & TRN & \\
\hline CHEMBL1986970 & 809249 & 4.8 & 5.0553 & TRN & \\
\hline CHEMBL 2003456 & 809249 & 4.8 & 4.232 & TRN & \\
\hline CHEMBL1972584 & 809249 & 4.8 & 6.0157 & TRN & \\
\hline CHEMBL 2002992 & 809249 & 4.5 & 4.9432 & TRN & \\
\hline CHEMBL560813 & 809249 & 4.8 & 4.7657 & TRN & \\
\hline CHEMBL1982700 & 809249 & 4.2 & 4.471 & TST & \\
\hline CHEMBL1968791 & 809249 & 4.8 & 5.0122 & TRN & \\
\hline CHEMBL1977634 & 809249 & 4.2 & 4.1951 & TRN & \\
\hline CHEMBL1971186 & 809249 & 4.8 & 4.9631 & TRN & \\
\hline CHEMBL 2003482 & 809249 & 4.8 & 4.6118 & TRN & \\
\hline
\end{tabular}




\begin{tabular}{|c|c|c|c|c|}
\hline & & & ient & al Ta \\
\hline CHEMBL1973211 & 809249 & 6.4 & 6.0176 & TRN \\
\hline CHEMBL1984700 & 809249 & 4.8 & 4.6038 & TRN \\
\hline CHEMBL1998953 & 809249 & 4.2 & 4.2154 & TRN \\
\hline CHEMBL1971606 & 809249 & 4.2 & 4.2935 & TRN \\
\hline CHEMBL1972125 & 809249 & 4.8 & 4.9165 & TRN \\
\hline CHEMBL1999120 & 809249 & 4.1 & 4.5288 & TST \\
\hline CHEMBL1976134 & 809249 & 4.8 & 5.1163 & TRN \\
\hline CHEMBL1965131 & 809249 & 4.8 & 4.8077 & TRN \\
\hline CHEMBL1981215 & 809249 & 4.2 & 4.372 & TRN \\
\hline CHEMBL1999414 & 809249 & 5.6 & 5.8288 & TRN \\
\hline CHEMBL1967336 & 809249 & 4.2 & 4.1798 & TRN \\
\hline CHEMBL 2001228 & 809249 & 4.2 & 5.0392 & TRN \\
\hline CHEMBL1970340 & 809249 & 3.4 & 3.8897 & TRN \\
\hline CHEMBL1967992 & 809249 & 4.2 & 4.3615 & TRN \\
\hline CHEMBL2005186 & 809249 & 4.8 & 4.6124 & TRN \\
\hline CHEMBL1981671 & 809249 & 4.2 & 4.2452 & TRN \\
\hline CHEMBL 2006450 & 809249 & 4.2 & 4.1157 & TRN \\
\hline CHEMBL1975534 & 809249 & 4.8 & 4.6905 & TRN \\
\hline CHEMBL1966703 & 809249 & 4.8 & 4.8965 & TST \\
\hline CHEMBL 2001987 & 809249 & 4.2 & 4.1994 & TRN \\
\hline CHEMBL1969561 & 809249 & 4.8 & 5.114 & TRN \\
\hline CHEMBL1994555 & 809249 & 5.3 & 4.8898 & TRN \\
\hline CHEMBL1975121 & 809249 & 4.2 & 4.2384 & TRN \\
\hline CHEMBL1983640 & 809249 & 6.5 & 5.2505 & TRN \\
\hline CHEMBL1997023 & 809249 & 4.8 & 4.8847 & TST \\
\hline CHEMBL1964687 & 809249 & 5.8 & 5.9006 & TRN \\
\hline CHEMBL1971943 & 809249 & 4.2 & 4.1944 & TRN \\
\hline CHEMBL1974254 & 809249 & 4.8 & 5.8165 & TRN \\
\hline CHEMBL1997924 & 809249 & 8.3 & 6.3303 & TRN \\
\hline CHEMBL1988537 & 809249 & 4.8 & 4.7731 & TST \\
\hline CHEMBL 2005828 & 809249 & 4.8 & 4.6229 & TRN \\
\hline CHEMBL1978267 & 809249 & 5.7 & 4.3288 & TRN \\
\hline CHEMBL1971485 & 809249 & 4.2 & 4.6769 & TRN \\
\hline CHEMBL1998611 & 809249 & 4.8 & 4.871 & TRN \\
\hline CHEMBL1975900 & 809249 & 4.8 & 4.9725 & TRN \\
\hline CHEMBL1992334 & 809249 & 4.2 & 4.2776 & TRN \\
\hline CHEMBL 255822 & 809249 & 4.8 & 5.1358 & TRN \\
\hline CHEMBL1972221 & 809249 & 4.8 & 5.1232 & TRN \\
\hline CHEMBL 2006778 & 809249 & 4.8 & 5.3904 & TRN \\
\hline CHEMBL 378627 & 809249 & 4.8 & 4.8272 & TRN \\
\hline CHEMBL1996979 & 809249 & 4.8 & 5.1182 & TRN \\
\hline CHEMBL1968406 & 809249 & 6.7 & 5.8236 & TRN \\
\hline CHEMBL1975921 & 809249 & 4.5 & 4.3085 & TRN \\
\hline CHEMBL1998545 & 809249 & 4.8 & 4.5448 & TRN \\
\hline CHEMBL1986869 & 809249 & 4.8 & 4.5918 & TRN \\
\hline CHEMBL1975923 & 809249 & 4.5 & 4.9525 & TST \\
\hline CHEMBL 2005449 & 809249 & 5.9 & 5.6771 & TRN \\
\hline CHEMBL1987998 & 809249 & 4.2 & 4.0439 & TRN \\
\hline
\end{tabular}




\begin{tabular}{|c|c|c|c|c|}
\hline & & & pplement & al lable S2 \\
\hline CHEMBL1992527 & 809249 & 7.5 & 6.4893 & TRN \\
\hline CHEMBL1682558 & 809249 & 4.8 & 4.8068 & TRN \\
\hline CHEMBL1971534 & 809249 & 4.0 & 4.6264 & TRN \\
\hline CHEMBL1990496 & 809249 & 4.3 & 4.47199 & 99999999995 \\
\hline CHEMBL 2002799 & 809249 & 4.2 & 4.4998 & TST \\
\hline CHEMBL 242865 & 809249 & 6.9 & 6.4292 & TRN \\
\hline CHEMBL 2002480 & 809249 & 4.0 & 4.4432 & TRN \\
\hline CHEMBL1967094 & 809249 & 4.8 & 4.749 & TRN \\
\hline CHEMBL 2003341 & 809249 & 4.8 & 4.6272 & TRN \\
\hline CHEMBL1982992 & 809249 & 4.8 & 4.6989 & TRN \\
\hline CHEMBL1998110 & 809249 & 4.2 & 4.104 & TRN \\
\hline CHEMBL1999590 & 809249 & 4.8 & 4.7636 & TST \\
\hline CHEMBL1978166 & 809249 & 6.2 & 6.0089 & TRN \\
\hline CHEMBL1980489 & 809249 & 4.8 & 4.6823 & TRN \\
\hline CHEMBL2000832 & 809249 & 4.8 & 5.1578 & TRN \\
\hline CHEMBL1967116 & 809249 & 7.4 & 6.3884 & TRN \\
\hline CHEMBL1990590 & 809249 & 4.2 & 4.035 & TRN \\
\hline CHEMBL1977814 & 809249 & 4.2 & 4.5817 & TST \\
\hline CHEMBL1974617 & 809249 & 4.2 & 4.5762 & TRN \\
\hline CHEMBL1970709 & 809249 & 4.8 & 4.6951 & TRN \\
\hline CHEMBL1965660 & 809249 & 4.2 & 5.1605 & TRN \\
\hline CHEMBL1992125 & 809249 & 5.6 & 5.4996 & TRN \\
\hline CHEMBL1969126 & 809249 & 4.8 & 4.6879 & TRN \\
\hline CHEMBL1980896 & 809249 & 4.8 & 4.9582 & TRN \\
\hline CHEMBL1970104 & 809249 & 4.8 & 5.4698 & TRN \\
\hline CHEMBL1967612 & 809249 & 4.1 & 4.4755 & TST \\
\hline CHEMBL1971149 & 809249 & 4.8 & 4.5019 & TRN \\
\hline CHEMBL1999714 & 809249 & 4.8 & 4.45 & TRN \\
\hline CHEMBL1994040 & 809249 & 4.8 & 4.6045 & TRN \\
\hline CHEMBL 388978 & 809249 & 7.0 & 7.3281 & TST \\
\hline CHEMBL579246 & 809249 & 4.8 & 5.064 & TRN \\
\hline CHEMBL398951 & 809249 & 4.3 & 4.5202 & TRN \\
\hline CHEMBL1982506 & 809249 & 4.8 & 4.5587 & TST \\
\hline CHEMBL 2004716 & 809249 & 6.6 & 6.0829 & TRN \\
\hline CHEMBL1968127 & 809249 & 4.8 & 4.6963 & TRN \\
\hline CHEMBL1975233 & 809249 & 4.8 & 4.8486 & TRN \\
\hline CHEMBL1985406 & 809249 & 4.8 & 4.9533 & TRN \\
\hline CHEMBL 2007603 & 809249 & 4.2 & 4.0794 & TRN \\
\hline CHEMBL 207400 & 809249 & 4.8 & 4.5574 & TST \\
\hline CHEMBL 2000894 & 809249 & 4.8 & 4.9653 & TST \\
\hline CHEMBL1421720 & 809249 & 4.2 & 4.9177 & TRN \\
\hline CHEMBL1968130 & 809249 & 4.6 & 4.3264 & TST \\
\hline CHEMBL1982135 & 809249 & 4.8 & 5.2109 & TRN \\
\hline CHEMBL1976090 & 809249 & 4.8 & 4.6642 & TRN \\
\hline CHEMBL1993243 & 809249 & 4.8 & 5.1616 & TRN \\
\hline CHEMBL1992922 & 809249 & 4.8 & 4.7673 & TRN \\
\hline CHEMBL399021 & 809249 & 5.1 & 4.877 & TRN \\
\hline CHEMBL1997597 & 809249 & 4.8 & 4.9202 & TRN \\
\hline
\end{tabular}

TRN 


\begin{tabular}{|c|c|c|c|c|}
\hline & & & & al \\
\hline CHEMBL1969537 & 809249 & 4.8 & 5.2196 & TST \\
\hline CHEMBL1972466 & 809249 & 5.6 & 5.0737 & TRN \\
\hline CHEMBL576113 & 809249 & 4.2 & 4.5719 & TRN \\
\hline CHEMBL1976093 & 809249 & 4.8 & 4.67 & TRN \\
\hline CHEMBL1975256 & 809249 & 4.8 & 4.7974 & TST \\
\hline CHEMBL508928 & 809249 & 4.8 & 5.1223 & TRN \\
\hline CHEMBL 2004892 & 809249 & 4.8 & 5.0328 & TRN \\
\hline CHEMBL1949855 & 809249 & 4.9 & 4.6103 & TRN \\
\hline CHEMBL116070 & 809249 & 4.8 & 4.915 & TRN \\
\hline CHEMBL1970314 & 809249 & 4.8 & 4.7935 & TRN \\
\hline CHEMBL 2004871 & 809249 & 4.8 & 4.548 & TRN \\
\hline CHEMBL1727312 & 809249 & 3.4 & 4.1165 & TRN \\
\hline CHEMBL1990223 & 809249 & 4.2 & 4.0369 & TRN \\
\hline CHEMBL 2006149 & 809249 & 4.2 & 4.1712 & TRN \\
\hline CHEMBL1964382 & 809249 & 4.2 & 4.4243 & TST \\
\hline CHEMBL101311 & 809249 & 6.1 & 5.6307 & TRN \\
\hline CHEMBL1981720 & 809249 & 4.8 & 4.2238 & TRN \\
\hline CHEMBL419932 & 809249 & 4.8 & 4.9127 & TRN \\
\hline CHEMBL262433 & 809249 & 4.8 & 5.3364 & TRN \\
\hline CHEMBL 306380 & 809249 & 4.8 & 5.0707 & TRN \\
\hline CHEMBL1966722 & 809249 & 4.8 & 5.1351 & TRN \\
\hline CHEMBL1988581 & 809249 & 6.8 & 6.1206 & TST \\
\hline CHEMBL2005699 & 809249 & 4.2 & 4.1722 & TRN \\
\hline CHEMBL1975500 & 809249 & 4.8 & 5.2492 & TRN \\
\hline CHEMBL394619 & 809249 & 4.8 & 5.1094 & TRN \\
\hline CHEMBL 2006564 & 809249 & 6.4 & 6.6148 & TRN \\
\hline CHEMBL1996831 & 809249 & 4.8 & 4.9735 & TST \\
\hline CHEMBL411903 & 809249 & 6.7 & 6.1947 & TRN \\
\hline CHEMBL1978167 & 809249 & 5.3 & 4.357 & TRN \\
\hline CHEMBL1965988 & 809249 & 6.1 & 6.0401 & TRN \\
\hline CHEMBL418203 & 809249 & 4.4 & 5.3595 & TST \\
\hline CHEMBL225519 & 809249 & 4.3 & 4.9174 & TST \\
\hline CHEMBL1978200 & 809249 & 4.8 & 4.5741 & TRN \\
\hline CHEMBL1970522 & 809249 & 4.8 & 4.9481 & TRN \\
\hline CHEMBL1964692 & 809249 & 7.0 & 5.6338 & TRN \\
\hline CHEMBL1996931 & 809249 & 4.8 & 4.5073 & TRN \\
\hline CHEMBL1964413 & 809249 & 4.8 & 4.7348 & TRN \\
\hline CHEMBL1998470 & 809249 & 4.2 & 4.3274 & TRN \\
\hline CHEMBL1995428 & 809249 & 5.5 & 4.5656 & TRN \\
\hline CHEMBL1975903 & 809249 & 4.2 & 4.7613 & TRN \\
\hline CHEMBL1997340 & 809249 & 4.8 & 4.8291 & TRN \\
\hline CHEMBL1522508 & 809249 & 3.4 & 3.9172 & TRN \\
\hline CHEMBL1989474 & 809249 & 4.8 & 4.5556 & TRN \\
\hline CHEMBL1090360 & 809249 & 6.3 & 4.9212 & TRN \\
\hline CHEMBL 210887 & 809249 & 4.8 & 4.8201 & TRN \\
\hline CHEMBL1988805 & 809249 & 4.2 & 4.5129 & TST \\
\hline CHEMBL458997 & 809249 & 8.8 & 7.65 & TRN \\
\hline CHEMBL1971021 & 809249 & 4.8 & 5.5382 & TRN \\
\hline
\end{tabular}




\begin{tabular}{|c|c|c|c|c|}
\hline \multicolumn{5}{|c|}{ Supplemental Table S2.txt } \\
\hline CHEMBL227271 & 809249 & 4.8 & 5.1701 & TRN \\
\hline CHEMBL583144 & 809249 & 4.8 & 5.1686 & TRN \\
\hline CHEMBL1974310 & 809249 & 4.8 & 4.9713 & TRN \\
\hline CHEMBL1969942 & 809249 & 4.2 & 4.216 & TRN \\
\hline CHEMBL1978567 & 809249 & 4.2 & 4.104 & TRN \\
\hline CHEMBL1982660 & 809249 & 4.2 & 4.8563 & TRN \\
\hline CHEMBL1994693 & 809249 & 4.8 & 5.4242 & TRN \\
\hline CHEMBL1982957 & 809249 & 4.8 & 5.1314 & TRN \\
\hline CHEMBL1975138 & 809249 & 4.8 & 4.9604 & TRN \\
\hline CHEMBL424872 & 809249 & 4.3 & 4.2333 & TRN \\
\hline CHEMBL412142 & 809249 & 4.8 & 4.9716 & TST \\
\hline CHEMBL1980704 & 809249 & 4.8 & 4.6757 & TST \\
\hline CHEMBL 2003271 & 809249 & 4.8 & 4.8255 & TRN \\
\hline CHEMBL 2004447 & 809249 & 4.8 & 4.6955 & TST \\
\hline CHEMBL1983111 & 809249 & 8.1 & 7.0813 & TRN \\
\hline CHEMBL1973860 & 809249 & 4.8 & 4.612 & TRN \\
\hline CHEMBL260135 & 809249 & 4.8 & 4.4283 & TRN \\
\hline CHEMBL1988141 & 809249 & 5.4 & 5.4807 & TST \\
\hline CHEMBL1982610 & 809249 & 4.8 & 4.7581 & TST \\
\hline CHEMBL1977134 & 809249 & 4.2 & 4.7832 & TRN \\
\hline CHEMBL1985206 & 809249 & 4.2 & 4.1297 & TRN \\
\hline CHEMBL1988300 & 809249 & 4.8 & 4.8804 & TRN \\
\hline CHEMBL1991078 & 809249 & 4.2 & 5.4768 & TRN \\
\hline CHEMBL1977749 & 809249 & 5.7 & 5.3815 & TST \\
\hline CHEMBL 2001613 & 809249 & 4.5 & 4.516 & TRN \\
\hline CHEMBL1997275 & 809249 & 4.2 & 4.2809 & TRN \\
\hline CHEMBL1993904 & 809249 & 4.2 & 4.9449 & TRN \\
\hline CHEMBL1967513 & 809249 & 4.2 & 3.9623 & TRN \\
\hline CHEMBL 2000724 & 809249 & 4.2 & 4.1218 & TRN \\
\hline CHEMBL1982413 & 809249 & 4.2 & 4.5346 & TRN \\
\hline CHEMBL1969502 & 809249 & 4.8 & 5.682 & TST \\
\hline CHEMBL1682553 & 809249 & 4.8 & 4.718 & TRN \\
\hline CHEMBL1983963 & 809249 & 4.8 & 5.3605 & TRN \\
\hline CHEMBL1997764 & 809249 & 4.8 & 4.3546 & TRN \\
\hline CHEMBL1981792 & 809249 & 4.2 & 4.19 & TRN \\
\hline CHEMBL1987535 & 809249 & 4.2 & 4.3877 & TRN \\
\hline CHEMBL1985092 & 809249 & 4.8 & 4.6997 & TRN \\
\hline CHEMBL1981410 & 809249 & 4.8 & 4.9908 & TRN \\
\hline CHEMBL 2002586 & 809249 & 6.0 & 5.4247 & TRN \\
\hline CHEMBL 383264 & 809249 & 8.7 & 4.9408 & TRN \\
\hline CHEMBL 2007421 & 809249 & 7.5 & 6.5651 & TRN \\
\hline CHEMBL1991434 & 809249 & 4.8 & 5.1018 & TRN \\
\hline CHEMBL1967544 & 809249 & 4.8 & 4.7999 & TRN \\
\hline CHEMBL1973138 & 809249 & 4.2 & 4.6468 & TST \\
\hline CHEMBL223367 & 809249 & 4.8 & 4.9974 & TST \\
\hline CHEMBL340384 & 809249 & 4.8 & 5.2022 & TST \\
\hline CHEMBL1969151 & 809249 & 4.2 & 4.6518 & TRN \\
\hline CHEMBL1981492 & 809249 & 4.1 & 4.5302 & TST \\
\hline
\end{tabular}




\begin{tabular}{|c|c|c|c|c|c|}
\hline \\
\hline CHEMBL1993335 & 809249 & 5.3 & 4.7723 & TRN & \\
\hline CHEMBL1988692 & 809249 & 4.2 & 5.1446 & TRN & \\
\hline CHEMBL2007574 & 809249 & 4.2 & 4.3483 & TRN & \\
\hline CHEMBL1964804 & 809249 & 4.8 & 4.8025 & TRN & \\
\hline CHEMBL443962 & 809249 & 4.8 & 5.02 & TRN & \\
\hline CHEMBL 2000354 & 809249 & 4.8 & 4.984 & TRN & \\
\hline CHEMBL1965507 & 809249 & 4.8 & 4.809 & TRN & \\
\hline CHEMBL274064 & 809249 & 4.8 & 4.51 & TRN & \\
\hline CHEMBL1998680 & 809249 & 4.2 & 4.159 & TRN & \\
\hline CHEMBL1967564 & 809249 & 4.8 & 4.5401 & TRN & \\
\hline CHEMBL592030 & 809249 & 4.3 & 4.711 & TRN & \\
\hline CHEMBL2000071 & 809249 & 4.8 & 4.5978 & TRN & \\
\hline CHEMBL1970317 & 809249 & 6.0 & 5.8706 & TRN & \\
\hline CHEMBL2000408 & 809249 & 4.8 & 4.4488 & TRN & \\
\hline CHEMBL248757 & 809249 & 4.8 & 4.8839 & TST & \\
\hline CHEMBL1978014 & 809249 & 4.8 & 4.936 & TRN & \\
\hline CHEMBL2002736 & 809249 & 4.2 & 4.3801 & TRN & \\
\hline CHEMBL1997007 & 809249 & 5.5 & 4.973 & TRN & \\
\hline CHEMBL1994538 & 809249 & 4.8 & 4.5522 & TRN & \\
\hline CHEMBL1964444 & 809249 & 4.2 & 3.9774 & TRN & \\
\hline CHEMBL2002690 & 809249 & 4.2 & 4.3854 & TRN & \\
\hline CHEMBL1986139 & 809249 & 4.8 & 4.5577 & TRN & \\
\hline CHEMBL 278041 & 809249 & 4.4 & 4.2929 & TRN & \\
\hline CHEMBL1979883 & 809249 & 6.6 & 6.15600 & 0000000001 & TRN \\
\hline CHEMBL1984162 & 809249 & 7.4 & 6.4987 & TRN & \\
\hline CHEMBL1997051 & 809249 & 4.4 & 4.874 & TRN & \\
\hline CHEMBL491758 & 809249 & 6.0 & 6.0864 & TRN & \\
\hline CHEMBL1986590 & 809249 & 4.2 & 4.5068 & TRN & \\
\hline CHEMBL549730 & 809249 & 4.8 & 4.963 & TRN & \\
\hline CHEMBL1970189 & 809249 & 4.8 & 4.9906 & TST & \\
\hline CHEMBL1870106 & 809249 & 4.2 & 4.7456 & TST & \\
\hline CHEMBL1996791 & 809249 & 4.8 & 5.2704 & TRN & \\
\hline CHEMBL371206 & 809249 & 4.8 & 5.4599 & TRN & \\
\hline CHEMBL1974664 & 809249 & 4.8 & 5.0028 & TRN & \\
\hline CHEMBL406845 & 809249 & 4.2 & 4.482 & TRN & \\
\hline CHEMBL482538 & 809249 & 5.2 & 4.2977 & TRN & \\
\hline CHEMBL1974288 & 809249 & 4.8 & 4.6959 & TRN & \\
\hline CHEMBL1984296 & 809249 & 5.5 & 4.7882 & TRN & \\
\hline CHEMBL196363 & 809249 & 4.8 & 5.5412 & TRN & \\
\hline CHEMBL1964718 & 809249 & 4.1 & 4.7468 & TST & \\
\hline CHEMBL1968705 & 809249 & 4.2 & 4.5147 & TRN & \\
\hline CHEMBL1964441 & 809249 & 5.9 & 5.66200 & 2000000001 & TRN \\
\hline CHEMBL1991410 & 809249 & 4.2 & 4.1076 & TRN & \\
\hline CHEMBL546797 & 809249 & 4.2 & 4.4362 & TST & \\
\hline CHEMBL404367 & 809249 & 4.8 & 5.1526 & TRN & \\
\hline CHEMBL1966343 & 809249 & 4.8 & 5.2706 & TRN & \\
\hline CHEMBL1978271 & 809249 & 4.3 & 4.1894 & TRN & \\
\hline CHEMBL1967887 & 809249 & 4.8 & 4.8886 & TRN & \\
\hline
\end{tabular}




\begin{tabular}{|c|c|c|c|c|}
\hline & & & lement & al Ta \\
\hline CHEMBL 2007266 & 809249 & 4.2 & 4.2346 & TRN \\
\hline CHEMBL 2000568 & 809249 & 4.6 & 4.5768 & TRN \\
\hline CHEMBL1985469 & 809249 & 4.2 & 4.4101 & TST \\
\hline CHEMBL 2000335 & 809249 & 4.8 & 5.6992 & TRN \\
\hline CHEMBL1994308 & 809249 & 4.2 & 4.3544 & TRN \\
\hline CHEMBL1090363 & 809249 & 5.8 & 4.6401 & TRN \\
\hline CHEMBL1988717 & 809249 & 4.8 & 5.2756 & TRN \\
\hline CHEMBL1974328 & 809249 & 6.5 & 5.7746 & TRN \\
\hline CHEMBL1973808 & 809249 & 4.8 & 4.6771 & TRN \\
\hline CHEMBL 2000429 & 809249 & 4.8 & 4.638 & TRN \\
\hline CHEMBL1972576 & 809249 & 4.8 & 4.8757 & TRN \\
\hline CHEMBL1992342 & 809249 & 4.8 & 5.0185 & TRN \\
\hline CHEMBL1988173 & 809249 & 4.8 & 5.2403 & TRN \\
\hline CHEMBL1973013 & 809249 & 5.8 & 5.6886 & TRN \\
\hline CHEMBL1164265 & 809249 & 6.7 & 5.8597 & TST \\
\hline CHEMBL1965423 & 809249 & 4.8 & 4.5426 & TRN \\
\hline CHEMBL1983025 & 809249 & 5.9 & 5.9101 & TRN \\
\hline CHEMBL1975927 & 809249 & 5.9 & 6.1781 & TRN \\
\hline CHEMBL205415 & 809249 & 4.4 & 4.6245 & TRN \\
\hline CHEMBL1977135 & 809249 & 4.8 & 4.436 & TRN \\
\hline CHEMBL 2001920 & 809249 & 4.8 & 4.8412 & TRN \\
\hline CHEMBL1977138 & 809249 & 6.9 & 6.3665 & TST \\
\hline CHEMBL1241473 & 809249 & 8.2 & 7.3218 & TRN \\
\hline CHEMBL 2000879 & 809249 & 4.3 & 4.4847 & TST \\
\hline CHEMBL1978448 & 809249 & 4.2 & 4.8154 & TST \\
\hline CHEMBL1969483 & 809249 & 4.2 & 4.421 & TRN \\
\hline CHEMBL 2001257 & 809249 & 6.0 & 5.6171 & TRN \\
\hline CHEMBL 2004515 & 809249 & 5.2 & 5.0392 & TRN \\
\hline CHEMBL1980329 & 809249 & 4.2 & 5.9161 & TRN \\
\hline CHEMBL1992042 & 809249 & 4.2 & 4.5595 & TST \\
\hline CHEMBL1992536 & 809249 & 4.8 & 4.7423 & TRN \\
\hline CHEMBL21156 & 809249 & 6.1 & 5.4178 & TST \\
\hline CHEMBL1992740 & 809249 & 4.8 & 4.9654 & TRN \\
\hline CHEMBL1994724 & 809249 & 4.2 & 4.2947 & TRN \\
\hline CHEMBL1989267 & 809249 & 5.7 & 5.3318 & TRN \\
\hline CHEMBL1970290 & 809249 & 5.7 & 5.0803 & TRN \\
\hline CHEMBL1974574 & 809249 & 4.2 & 4.3864 & TST \\
\hline CHEMBL1967531 & 809249 & 4.8 & 4.8678 & TRN \\
\hline CHEMBL1970913 & 809249 & 4.8 & 4.6467 & TRN \\
\hline CHEMBL1973893 & 809249 & 4.8 & 5.1617 & TRN \\
\hline CHEMBL1993877 & 809249 & 5.5 & 5.294 & TRN \\
\hline CHEMBL1996500 & 809249 & 4.3 & 4.2677 & TRN \\
\hline CHEMBL1985095 & 809249 & 4.8 & 4.8562 & TRN \\
\hline CHEMBL1682540 & 809249 & 4.8 & 4.7929 & TRN \\
\hline CHEMBL1976420 & 809249 & 5.8 & 5.1726 & TRN \\
\hline CHEMBL1998253 & 809249 & 4.2 & 4.0915 & TST \\
\hline CHEMBL1981744 & 809249 & 4.2 & 4.091 & TRN \\
\hline CHEMBL1994864 & 809249 & 4.8 & 4.672 & TRN \\
\hline
\end{tabular}




\begin{tabular}{|c|c|c|c|c|}
\hline & & & ient & al Ta \\
\hline CHEMBL 2002446 & 809249 & 4.8 & 4.9747 & TRN \\
\hline CHEMBL497151 & 809249 & 4.8 & 5.1143 & TRN \\
\hline CHEMBL 2000029 & 809249 & 5.5 & 5.02 & TRN \\
\hline CHEMBL1973961 & 809249 & 6.2 & 5.8605 & TRN \\
\hline CHEMBL 246970 & 809249 & 4.8 & 4.9894 & TRN \\
\hline CHEMBL340921 & 809249 & 4.8 & 4.9527 & TST \\
\hline CHEMBL1994977 & 809249 & 4.4 & 4.093 & TRN \\
\hline CHEMBL 2001149 & 809249 & 4.2 & 4.3761 & TRN \\
\hline CHEMBL 2000078 & 809249 & 5.3 & 4.6481 & TRN \\
\hline CHEMBL 2005478 & 809249 & 4.2 & 4.6165 & TRN \\
\hline CHEMBL1276446 & 809249 & 4.8 & 6.1785 & TST \\
\hline CHEMBL1996646 & 809249 & 4.2 & 5.1915 & TRN \\
\hline CHEMBL1979773 & 809249 & 4.2 & 4.0731 & TRN \\
\hline CHEMBL1977346 & 809249 & 4.8 & 5.0228 & TRN \\
\hline CHEMBL1971649 & 809249 & 4.8 & 4.5863 & TRN \\
\hline CHEMBL 2005482 & 809249 & 5.7 & 4.9183 & TRN \\
\hline CHEMBL1996702 & 809249 & 5.3 & 5.3863 & TRN \\
\hline CHEMBL1997909 & 809249 & 4.2 & 4.4118 & TRN \\
\hline CHEMBL 2007124 & 809249 & 4.2 & 4.552 & TRN \\
\hline CHEMBL2006439 & 809249 & 4.2 & 4.1579 & TRN \\
\hline CHEMBL 2006156 & 809249 & 5.9 & 5.1306 & TRN \\
\hline CHEMBL1985681 & 809249 & 5.2 & 5.0793 & TST \\
\hline CHEMBL1969190 & 809249 & 6.4 & 5.3202 & TRN \\
\hline CHEMBL 2002660 & 809249 & 4.2 & 4.1806 & TRN \\
\hline CHEMBL1973937 & 809249 & 6.2 & 5.5551 & TRN \\
\hline CHEMBL1991674 & 809249 & 4.2 & 4.155 & TRN \\
\hline CHEMBL1982711 & 809249 & 4.4 & 4.8129 & TRN \\
\hline CHEMBL1984842 & 809249 & 4.2 & 4.3909 & TRN \\
\hline CHEMBL 2004118 & 809249 & 5.3 & 5.2068 & TRN \\
\hline CHEMBL1996795 & 809249 & 4.2 & 4.5684 & TST \\
\hline CHEMBL 2007044 & 809249 & 4.8 & 4.7067 & TRN \\
\hline CHEMBL1994241 & 809249 & 4.8 & 4.8725 & TST \\
\hline CHEMBL223460 & 809249 & 4.8 & 5.0101 & TST \\
\hline CHEMBL1998829 & 809249 & 4.8 & 4.5821 & TRN \\
\hline CHEMBL50894 & 809249 & 4.5 & 4.1024 & TRN \\
\hline CHEMBL1995211 & 809249 & 5.6 & 4.5987 & TRN \\
\hline CHEMBL1988838 & 809249 & 6.3 & 6.874 & TRN \\
\hline CHEMBL1982753 & 809249 & 5.4 & 4.9983 & TRN \\
\hline CHEMBL2006299 & 809249 & 4.2 & 4.1438 & TRN \\
\hline CHEMBL1972346 & 809249 & 6.1 & 5.5754 & TST \\
\hline CHEMBL1965169 & 809249 & 4.2 & 4.1699 & TRN \\
\hline CHEMBL1991818 & 809249 & 4.2 & 4.7227 & TST \\
\hline CHEMBL1081312 & 809249 & 5.9 & 5.7473 & TRN \\
\hline CHEMBL1965170 & 809249 & 4.2 & 5.3153 & TRN \\
\hline CHEMBL1982866 & 809249 & 4.8 & 4.5906 & TRN \\
\hline CHEMBL 2005792 & 809249 & 4.2 & 4.3311 & TRN \\
\hline CHEMBL1986503 & 809249 & 4.2 & 4.2322 & TST \\
\hline CHEMBL1965570 & 809249 & 5.9 & 5.6474 & TRN \\
\hline
\end{tabular}




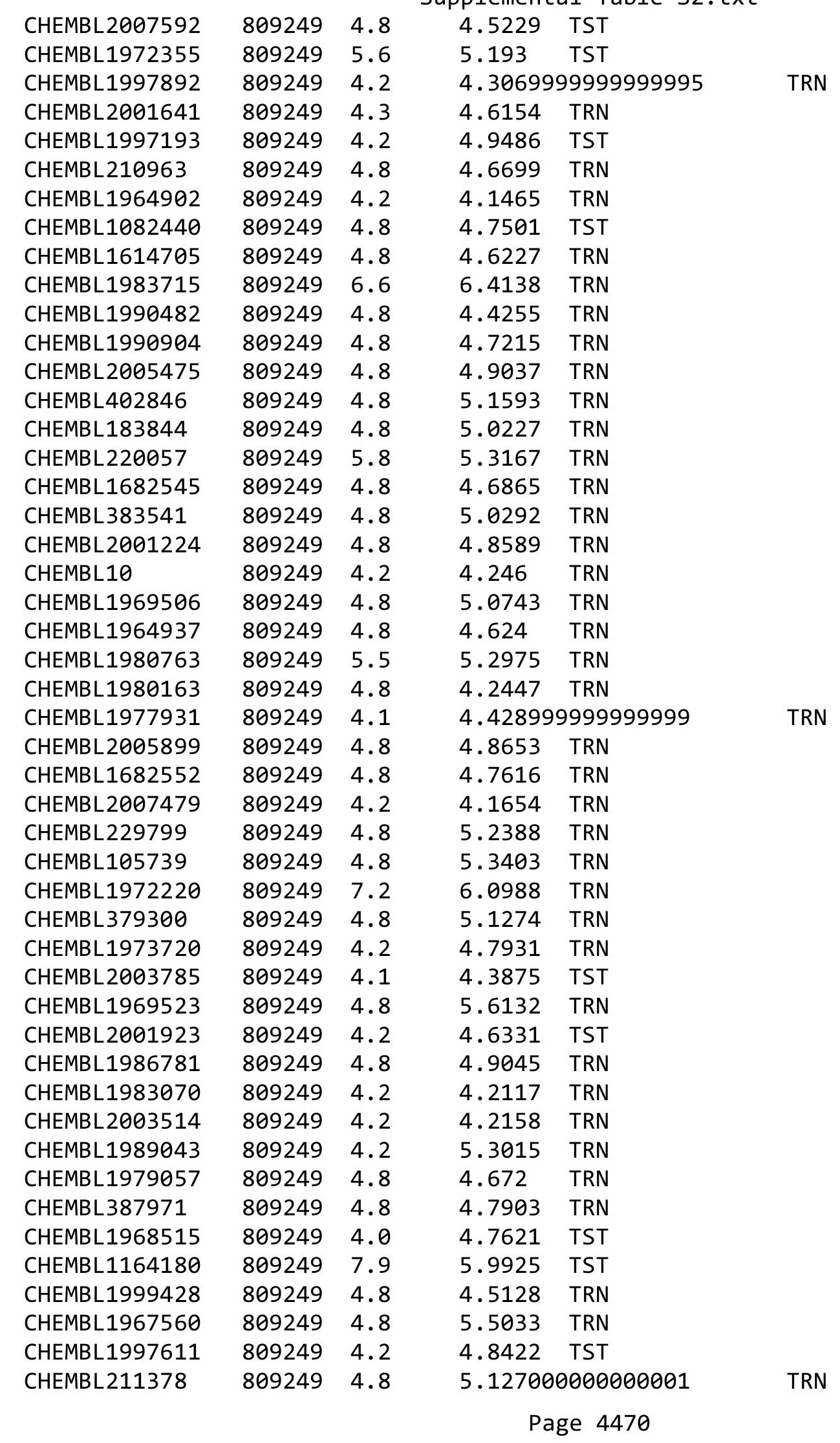




\begin{tabular}{|c|c|c|c|c|}
\hline & & & & \\
\hline CHEMBL1987104 & 809249 & 6.2 & 5.0738 & TRN \\
\hline CHEMBL1982465 & 809249 & 6.3 & 5.9531 & TRN \\
\hline CHEMBL2001751 & 809249 & 4.8 & 5.5505 & TRN \\
\hline CHEMBL1984586 & 809249 & 4.8 & 4.5728 & TRN \\
\hline CHEMBL1972659 & 809249 & 4.8 & 4.5969 & TST \\
\hline CHEMBL 2002723 & 809249 & 5.3 & 5.2006 & TST \\
\hline CHEMBL 272453 & 809249 & 4.8 & 4.9222 & TRN \\
\hline CHEMBL2005528 & 809249 & 4.8 & 4.8396 & TST \\
\hline CHEMBL1984686 & 809249 & 4.2 & 4.4725 & TRN \\
\hline CHEMBL185569 & 809249 & 4.8 & 5.0734 & TRN \\
\hline CHEMBL1969843 & 809249 & 4.8 & 4.8828 & TRN \\
\hline CHEMBL 2007002 & 809249 & 4.8 & 4.9132 & TRN \\
\hline CHEMBL1987007 & 809249 & 4.8 & 4.6705 & TRN \\
\hline CHEMBL1973793 & 809249 & 4.2 & 4.7693 & TST \\
\hline CHEMBL1984711 & 809249 & 7.0 & 6.0984 & TRN \\
\hline CHEMBL1992073 & 809249 & 4.2 & 5.3364 & TRN \\
\hline CHEMBL484390 & 809249 & 4.8 & 5.1781 & TRN \\
\hline CHEMBL1986143 & 809249 & 4.2 & 4.2504 & TRN \\
\hline CHEMBL1979252 & 809249 & 4.8 & 4.8095 & TRN \\
\hline CHEMBL 2007559 & 809249 & 4.2 & 4.8281 & TRN \\
\hline CHEMBL1992581 & 809249 & 4.2 & 5.0676 & TRN \\
\hline CHEMBL 2004290 & 809249 & 5.7 & 5.4633 & TRN \\
\hline CHEMBL1972937 & 809249 & 4.8 & 4.6589 & TRN \\
\hline CHEMBL 2000393 & 809249 & 6.5 & 5.9235 & TST \\
\hline CHEMBL 2004311 & 809249 & 4.8 & 5.4918 & TRN \\
\hline CHEMBL1992634 & 809249 & 4.8 & 4.8039 & TRN \\
\hline CHEMBL1242373 & 809249 & 6.2 & 5.9914 & TRN \\
\hline CHEMBL1984847 & 809249 & 4.2 & 4.566 & TRN \\
\hline CHEMBL316264 & 809249 & 4.8 & 4.3933 & TRN \\
\hline CHEMBL1988075 & 809249 & 6.1 & 5.3604 & TRN \\
\hline CHEMBL1996576 & 809249 & 4.2 & 4.3498 & TST \\
\hline CHEMBL1988076 & 809249 & 4.2 & 4.577 & TRN \\
\hline CHEMBL1991678 & 809249 & 4.2 & 4.2657 & TRN \\
\hline CHEMBL 2001239 & 809249 & 4.8 & 4.9355 & TST \\
\hline CHEMBL1988594 & 809249 & 4.8 & 4.6979 & TRN \\
\hline CHEMBL 2001288 & 809249 & 4.8 & 4.9798 & TRN \\
\hline CHEMBL1999811 & 809249 & 4.8 & 5.2477 & TRN \\
\hline CHEMBL 235157 & 809249 & 4.2 & 4.5211 & TRN \\
\hline CHEMBL1985074 & 809249 & 4.8 & 4.7814 & TST \\
\hline CHEMBL1982874 & 809249 & 4.8 & 4.628 & TRN \\
\hline CHEMBL1991725 & 809249 & 4.8 & 4.8365 & TRN \\
\hline CHEMBL1992242 & 809249 & 4.8 & 4.873 & TRN \\
\hline CHEMBL2004159 & 809249 & 4.2 & 4.1351 & TRN \\
\hline CHEMBL1978371 & 809249 & 4.2 & 4.745 & TST \\
\hline CHEMBL1970203 & 809249 & 4.8 & 4.8001 & TRN \\
\hline CHEMBL440084 & 809249 & 4.2 & 4.17899 & 9999999999 \\
\hline CHEMBL1968590 & 809249 & 4.8 & 4.9202 & TRN \\
\hline CHEMBL 2005375 & 809249 & 6.0 & 5.621 & TRN \\
\hline
\end{tabular}

TRN 


\begin{tabular}{|c|c|c|c|c|}
\hline & & & ient & al Ta \\
\hline CHEMBL1984191 & 809249 & 4.8 & 4.5226 & TRN \\
\hline CHEMBL1966501 & 809249 & 4.2 & 4.0937 & TRN \\
\hline CHEMBL1971029 & 809249 & 8.6 & 7.8402 & TRN \\
\hline CHEMBL 394790 & 809249 & 4.8 & 4.939 & TRN \\
\hline CHEMBL 2001451 & 809249 & 4.2 & 4.3553 & TRN \\
\hline CHEMBL226471 & 809249 & 4.8 & 4.8143 & TST \\
\hline CHEMBL1974702 & 809249 & 4.8 & 5.0044 & TRN \\
\hline CHEMBL1996111 & 809249 & 4.8 & 5.0468 & TRN \\
\hline CHEMBL1966175 & 809249 & 4.2 & 4.8829 & TRN \\
\hline CHEMBL1965589 & 809249 & 4.8 & 4.5741 & TRN \\
\hline CHEMBL 2007375 & 809249 & 4.2 & 4.0225 & TRN \\
\hline CHEMBL379975 & 809249 & 4.2 & 4.6122 & TST \\
\hline CHEMBL474432 & 809249 & 4.8 & 5.7363 & TST \\
\hline CHEMBL1973016 & 809249 & 4.2 & 4.4641 & TRN \\
\hline CHEMBL1965387 & 809249 & 4.2 & 3.8777 & TRN \\
\hline CHEMBL2001539 & 809249 & 4.6 & 4.0629 & TST \\
\hline CHEMBL1997041 & 809249 & 4.9 & 4.5963 & TRN \\
\hline CHEMBL1988153 & 809249 & 4.8 & 4.7273 & TRN \\
\hline CHEMBL550418 & 809249 & 5.8 & 4.8899 & TRN \\
\hline CHEMBL1971289 & 809249 & 4.2 & 4.494 & TRN \\
\hline CHEMBL1988437 & 809249 & 4.4 & 4.9526 & TST \\
\hline CHEMBL1998121 & 809249 & 4.8 & 5.3842 & TRN \\
\hline CHEMBL1979577 & 809249 & 5.9 & 6.0116 & TRN \\
\hline CHEMBL1991800 & 809249 & 4.8 & 4.6228 & TRN \\
\hline CHEMBL2003689 & 809249 & 4.2 & 4.2099 & TRN \\
\hline CHEMBL1979357 & 809249 & 4.8 & 4.6398 & TRN \\
\hline CHEMBL1996649 & 809249 & 4.2 & 5.4368 & TRN \\
\hline CHEMBL1996817 & 809249 & 4.8 & 4.7561 & TRN \\
\hline CHEMBL1986756 & 809249 & 4.2 & 4.1816 & TRN \\
\hline CHEMBL468280 & 809249 & 4.8 & 4.5536 & TST \\
\hline CHEMBL1990884 & 809249 & 4.8 & 5.095 & TRN \\
\hline CHEMBL3109278 & 809249 & 6.5 & 4.3282 & TRN \\
\hline CHEMBL256835 & 809249 & 4.8 & 4.6076 & TRN \\
\hline CHEMBL1974998 & 809249 & 4.2 & 4.1836 & TRN \\
\hline CHEMBL41783 & 809249 & 4.8 & 4.833 & TRN \\
\hline CHEMBL 2004438 & 809249 & 4.2 & 4.2048 & TRN \\
\hline CHEMBL 2006276 & 809249 & 4.8 & 4.6004 & TRN \\
\hline CHEMBL191003 & 809249 & 4.4 & 5.3848 & TRN \\
\hline CHEMBL271381 & 809249 & 7.6 & 6.3539 & TRN \\
\hline CHEMBL 2006785 & 809249 & 4.8 & 4.7408 & TRN \\
\hline CHEMBL1982466 & 809249 & 4.8 & 5.854 & TRN \\
\hline CHEMBL1973359 & 809249 & 6.5 & 5.6727 & TST \\
\hline CHEMBL1995740 & 809249 & 4.8 & 5.0415 & TRN \\
\hline CHEMBL1979690 & 809249 & 7.2 & 7.4371 & TRN \\
\hline CHEMBL234085 & 809249 & 4.2 & 4.6904 & TRN \\
\hline CHEMBL1995832 & 809249 & 4.8 & 4.5067 & TRN \\
\hline CHEMBL1969042 & 809249 & 4.8 & 4.7611 & TRN \\
\hline CHEMBL 2005714 & 809249 & 4.8 & 5.9393 & TRN \\
\hline
\end{tabular}




\begin{tabular}{|c|c|c|c|c|}
\hline & & & ient & al Ta \\
\hline CHEMBL 2000345 & 809249 & 4.8 & 4.8989 & TST \\
\hline CHEMBL1976376 & 809249 & 4.2 & 4.6917 & TRN \\
\hline CHEMBL1983575 & 809249 & 5.8 & 5.6393 & TRN \\
\hline CHEMBL1968868 & 809249 & 4.2 & 4.2715 & TRN \\
\hline CHEMBL 2007064 & 809249 & 4.8 & 5.6707 & TRN \\
\hline CHEMBL1981047 & 809249 & 7.6 & 6.9326 & TRN \\
\hline CHEMBL 229968 & 809249 & 4.8 & 5.4263 & TRN \\
\hline CHEMBL1976196 & 809249 & 4.2 & 4.4785 & TST \\
\hline CHEMBL1976240 & 809249 & 4.8 & 4.6701 & TRN \\
\hline CHEMBL1997197 & 809249 & 4.2 & 4.353 & TRN \\
\hline CHEMBL1979093 & 809249 & 4.8 & 5.3109 & TRN \\
\hline CHEMBL1987009 & 809249 & 4.8 & 4.8063 & TRN \\
\hline CHEMBL379218 & 809249 & 4.8 & 5.0224 & TRN \\
\hline CHEMBL 2003817 & 809249 & 4.8 & 4.5716 & TRN \\
\hline CHEMBL1994830 & 809249 & 4.8 & 4.9043 & TRN \\
\hline CHEMBL 226403 & 809249 & 4.8 & 4.8586 & TST \\
\hline CHEMBL 2005631 & 809249 & 6.1 & 6.231 & TRN \\
\hline CHEMBL1994938 & 809249 & 4.8 & 5.475 & TRN \\
\hline CHEMBL1977223 & 809249 & 4.8 & 5.1823 & TST \\
\hline CHEMBL1995765 & 809249 & 4.4 & 4.3577 & TST \\
\hline CHEMBL1236126 & 809249 & 4.8 & 4.8615 & TST \\
\hline CHEMBL1984760 & 809249 & 5.7 & 5.1012 & TST \\
\hline CHEMBL1997846 & 809249 & 4.2 & 3.9278 & TST \\
\hline CHEMBL 2004419 & 809249 & 4.8 & 4.6282 & TST \\
\hline CHEMBL 360847 & 809249 & 4.2 & 4.9178 & TST \\
\hline CHEMBL 2007073 & 809249 & 4.2 & 4.1092 & TST \\
\hline CHEMBL1995811 & 809249 & 4.2 & 5.0526 & TST \\
\hline CHEMBL1994074 & 809249 & 4.8 & 4.4684 & TST \\
\hline CHEMBL1992937 & 809249 & 4.3 & 4.4827 & TST \\
\hline CHEMBL451401 & 809249 & 4.6 & 3.9898 & TST \\
\hline CHEMBL95692 & 809249 & 4.8 & 4.5717 & TST \\
\hline CHEMBL1090356 & 809249 & 4.8 & 5.0635 & TST \\
\hline CHEMBL1976455 & 809249 & 4.8 & 4.5892 & TST \\
\hline CHEMBL261849 & 809249 & 4.2 & 4.3139 & TST \\
\hline CHEMBL1983923 & 809249 & 5.5 & 5.7359 & TST \\
\hline CHEMBL1982361 & 809249 & 4.8 & 4.8885 & TST \\
\hline CHEMBL1999112 & 809249 & 4.8 & 5.0018 & TST \\
\hline CHEMBL 2000801 & 809249 & 4.8 & 4.6965 & TST \\
\hline CHEMBL1682546 & 809249 & 4.8 & 4.6493 & TST \\
\hline CHEMBL1991395 & 809249 & 4.8 & 4.6228 & TST \\
\hline CHEMBL1988872 & 809249 & 4.2 & 4.7088 & TST \\
\hline CHEMBL1993634 & 809249 & 4.2 & 4.4045 & TST \\
\hline CHEMBL1972142 & 809249 & 4.8 & 4.6697 & TST \\
\hline CHEMBL1966514 & 809249 & 6.1 & 5.8094 & TST \\
\hline CHEMBL1983393 & 809249 & 4.2 & 4.3101 & TST \\
\hline CHEMBL1993722 & 809249 & 4.8 & 4.9175 & TST \\
\hline CHEMBL 2006674 & 809249 & 4.2 & 4.5501 & TST \\
\hline CHEMBL1984236 & 809249 & 4.2 & 4.244 & TST \\
\hline
\end{tabular}




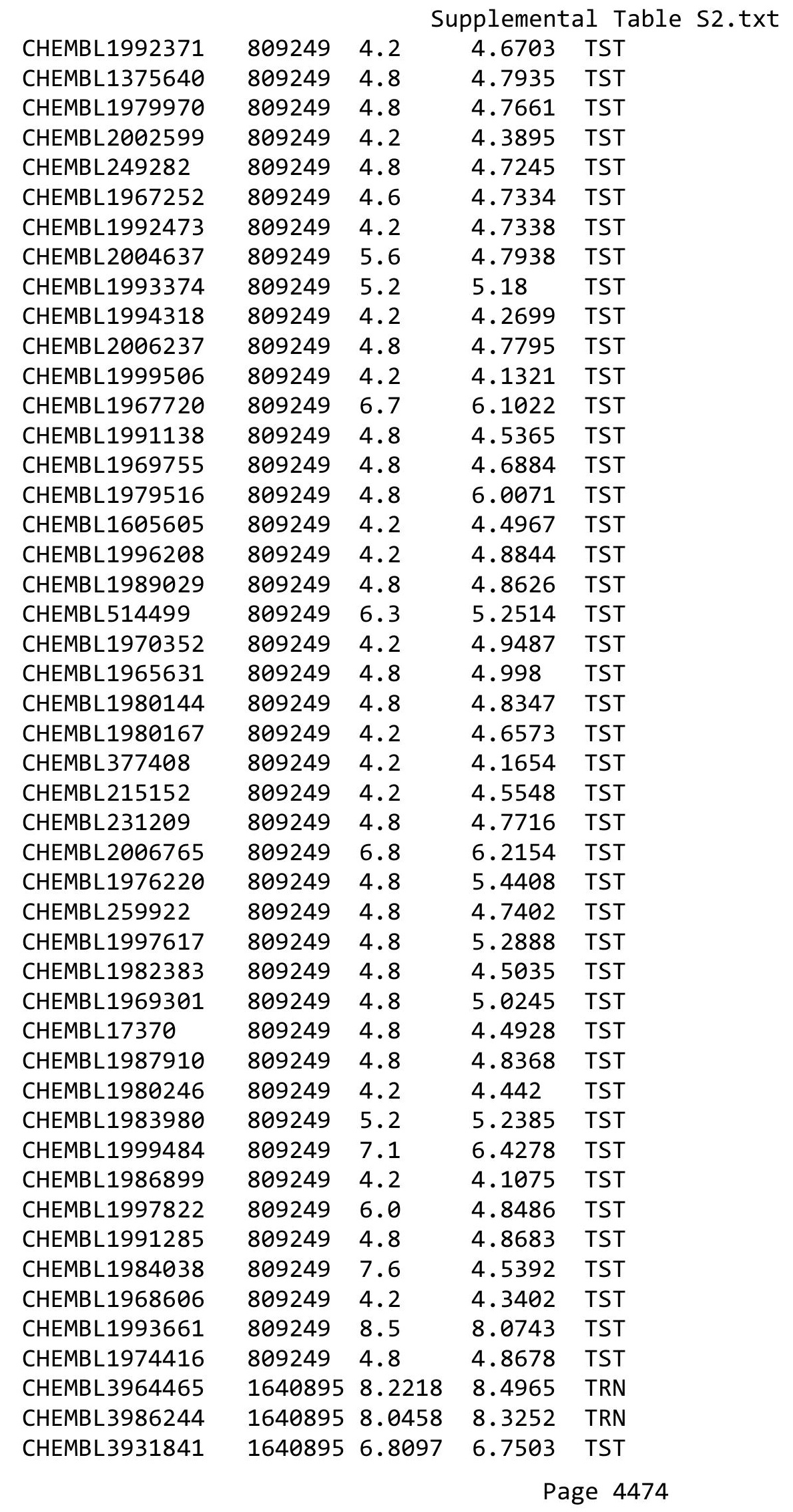


Supplemental Table S2.txt

\begin{tabular}{|c|c|c|c|c|}
\hline HEMB & 640895 & & 8.1534 & $\cdots$ \\
\hline 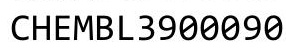 & & & 8.229 & \\
\hline HFMRI & 95 & & 1404 & \\
\hline IEMBL & 895 & 5229 & 9013 & \\
\hline AEMBL3922911 & 640895 & 3979 & 2214 & \\
\hline HEMBL3980574 & 895 & 8.699 & .8033 & \\
\hline HEMBL3 & 9 & & 2098 & \\
\hline AEMBL3S & & & 1536 & \\
\hline HEMBL3933143 & 640895 & 8.2218 & 8.3381 & \\
\hline HEMBL3936785 & 640895 & 7.3665 & .4323 & \\
\hline HEMBL3S & 64 & 8.5229 & 8.3225 & \\
\hline IEMBL3 & 95 & 01 & .8249 & $\mathrm{RN}$ \\
\hline AEMBL3 & & & .5612 & \\
\hline HEMBL3891196 & 895 & 8.3979 & 8.2783 & \\
\hline HEMBL3985604 & 64 & 10.0 & 9.8264 & \\
\hline HEMBL3 & 6 & 6. & 5.8078 & (2) \\
\hline HEMBL3 & 95 & & 68 & s \\
\hline HEMBL3 & 95 & 9. & 8.2828 & $\mathrm{RN}$ \\
\hline HEMBL3 & 95 & & .3132 & \\
\hline HEMBL3933833 & 64 & & 9.6212 & I KIV \\
\hline HEMBL & 62 & 8. & 958 & 31 \\
\hline HEM & 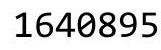 & 9 & 538 & ST \\
\hline HEMBL & 5 & & 8.3939 & RN \\
\hline HEMBL & & & 7226 & ST \\
\hline AEMBL3 & & 7. & 8.2972 & 15 \\
\hline HEMBL3 & 62 & & 349 & SI \\
\hline HEME & כ & & 225 & ST \\
\hline HEME & 6 & 229 & 8.5979 & 「RN \\
\hline AEMBL3 & & 9. & 1006 & IRIN \\
\hline HEMBL3932080 & 54 & 7. & 7.8926 & TRN \\
\hline AEMBL & & & 389 & 「RN \\
\hline HFN & & & 17 & 「RN \\
\hline - - & & 8 . & 8.4006 & TRN \\
\hline HEMBL3S & & & & ГST \\
\hline HEMBL 3954844 & 64 & & 7.9998 & ГRN \\
\hline JIMDI 2 & 6 & & 3079 & TRN \\
\hline 1 & & 8 & 35 & TRN \\
\hline HEMBL 39 & & 8.221 & 8.2173 & TRN \\
\hline HEMBL 396 & $\sigma$ & 9. & 474 & $\Gamma R$ \\
\hline EIMDL & $0^{2}$ & & & RN \\
\hline HEMBL3 & 61 & 7. & 7.4448 & TRN \\
\hline HEMBL 390 & & 7.699 & 7.4611 & 「RN \\
\hline HEMBL396 & & 7.6576 & 8.305 & RN \\
\hline HEMBL3 & 6 & 7. & 8102 & TS \\
\hline CHEMBL391 & & & 3921 & I \\
\hline HEMBL3 & & $2+0$ & 9.1706 & RIN \\
\hline HEMBL 3906042 & 16 & 8.301 & 8.3798 & TRN \\
\hline CHEMBL3955596 & 164089 & 9.0 & 9.1764 & 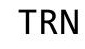 \\
\hline
\end{tabular}




\begin{tabular}{|c|c|c|c|c|c|}
\hline \multicolumn{6}{|c|}{ Supplemental Table S2.txt } \\
\hline CHEMBL3948175 & 1640895 & 10.0 & 8.9388 & TRN & \\
\hline CHEMBL3947599 & 1640895 & 10.0 & 9.5793 & TRN & \\
\hline CHEMBL3913039 & 1640895 & 7.1427 & 7.6794 & TRN & \\
\hline CHEMBL3951558 & 1640895 & 8.3979 & 8.6494 & TRN & \\
\hline CHEMBL3919436 & 1640895 & 8.699 & 8.5614 & TRN & \\
\hline CHEMBL3956294 & 1640895 & 8.1549 & 8.1228 & TRN & \\
\hline CHEMBL3900043 & 1640895 & 7.9586 & 9.0693 & TRN & \\
\hline CHEMBL3962865 & 1640895 & 9.0 & 8.5529 & TST & \\
\hline CHEMBL3944218 & 1640895 & 8.699 & 8.433 & TRN & \\
\hline CHEMBL3905815 & 1640895 & 7.4089 & 7.6783 & TST & \\
\hline CHEMBL3894953 & 1640895 & 9.0 & 8.8614 & TRN & \\
\hline CHEMBL 3955884 & 1640895 & 8.1549 & 8.3664 & TST & \\
\hline CHEMBL3932412 & 1640895 & 7.699 & 7.33700 & 0000000001 & TRN \\
\hline CHEMBL3972697 & 1640895 & 8.699 & 8.5235 & TRN & \\
\hline CHEMBL3948177 & 1640895 & 8.0969 & 8.2787 & TRN & \\
\hline CHEMBL3983768 & 1640895 & 7.7447 & 8.0844 & TRN & \\
\hline CHEMBL3902049 & 1640895 & 8.301 & 8.2717 & TRN & \\
\hline CHEMBL3901349 & 1640895 & 7.8861 & 7.9116 & TRN & \\
\hline CHEMBL 3897734 & 1640895 & 7.9208 & 8.0391 & TRN & \\
\hline CHEMBL3972303 & 1640895 & 7.2366 & 7.76399 & 9999999999 & TRN \\
\hline CHEMBL3941093 & 1640895 & 8.5229 & 8.5513 & TRN & \\
\hline CHEMBL 3942055 & 1640895 & 10.0 & 8.9113 & TRN & \\
\hline CHEMBL3893921 & 1640895 & 8.699 & 8.3429 & TST & \\
\hline CHEMBL3974562 & 1640895 & 10.0 & 9.6317 & TST & \\
\hline CHEMBL3919110 & 1640895 & 8.301 & 8.3767 & TRN & \\
\hline CHEMBL3956070 & 1640895 & 7.8239 & 7.8652 & TRN & \\
\hline CHEMBL3972283 & 1640895 & 8.301 & 9.2562 & TRN & \\
\hline CHEMBL3972528 & 1640895 & 8.0 & 7.896 & TRN & \\
\hline CHEMBL3910507 & 1640895 & 9.0 & 8.7755 & TRN & \\
\hline CHEMBL3967258 & 1640895 & 8.301 & 8.3682 & TRN & \\
\hline CHEMBL3961313 & 1640895 & 10.0 & 9.4719 & TRN & \\
\hline CHEMBL3957754 & 1640895 & 7.9208 & 7.8092 & TRN & \\
\hline CHEMBL3904950 & 1640895 & 8.699 & 8.5119 & TRN & \\
\hline CHEMBL3929596 & 1640895 & 8.3979 & 8.2309 & TRN & \\
\hline CHEMBL3926917 & 1640895 & 8.2218 & 8.1682 & TRN & \\
\hline CHEMBL3944823 & 1640895 & 9.0 & 8.5197 & TRN & \\
\hline CHEMBL3941002 & 1640895 & 10.0 & 9.7547 & TRN & \\
\hline CHEMBL3962697 & 1640895 & 8.0969 & 8.2102 & TRN & \\
\hline CHEMBL3957157 & 1640895 & 8.5229 & 8.1011 & TST & \\
\hline CHEMBL3980460 & 1640895 & 8.5229 & 8.2247 & TRN & \\
\hline CHEMBL3943736 & 1640895 & 8.2218 & 8.1404 & TRN & \\
\hline CHEMBL3961195 & 1640895 & 9.0 & 8.8344 & TRN & \\
\hline CHEMBL3910489 & 1640895 & 9.0 & 9.0858 & TST & \\
\hline CHEMBL3966154 & 1640895 & 8.2218 & 8.1501 & TST & \\
\hline CHEMBL3985502 & 1640895 & 7.3872 & 7.6419 & TRN & \\
\hline CHEMBL3967231 & 1640895 & 7.6576 & 7.971 & TRN & \\
\hline CHEMBL3925892 & 1640895 & 8.3979 & 8.2652 & TRN & \\
\hline CHEMBL3947191 & 1640895 & 6.1198 & 6.4271 & TST & \\
\hline
\end{tabular}


Supplemental Table S2.txt

\begin{tabular}{|c|c|c|c|c|}
\hline CHEMBL3916906 & 1640895 & 8.699 & 8.4644 & TRN \\
\hline CHEMBL 3895234 & 1640895 & 8.2218 & 8.176 & TRN \\
\hline CHEMBL3978469 & 1640895 & 8.699 & 8.1528 & TRN \\
\hline CHEMBL 3970908 & 1640895 & 8.301 & 8.5894 & TRN \\
\hline CHEMBL3917292 & 1640895 & 7.9208 & 8.3877 & TST \\
\hline CHEMBL 3895963 & 1640895 & 7.6576 & 7.9914 & TRN \\
\hline CHEMBL 3919818 & 1640895 & 10.0 & 9.7114 & TRN \\
\hline CHEMBL3918307 & 1640895 & 7.2757 & 7.5724 & TST \\
\hline CHEMBL3965547 & 1640895 & 8.699 & \multicolumn{2}{|c|}{8.767000000000001} \\
\hline CHEMBL3892340 & 1640895 & 8.699 & 8.9183 & TRN \\
\hline CHEMBL 3924561 & 1640895 & 7.6778 & 7.5602 & TRN \\
\hline CHEMBL 3889938 & 1640895 & 8.0969 & 8.0789 & TRN \\
\hline CHEMBL3896816 & 1640895 & 7.7212 & 8.104 & TRN \\
\hline CHEMBL 3977413 & 1640895 & 8.2218 & 8.3998 & TRN \\
\hline CHEMBL3945948 & 1640895 & 8.301 & 8.2572 & TRN \\
\hline CHEMBL 3948002 & 1640895 & 9.0 & 9.0973 & TST \\
\hline CHEMBL 3897208 & 1640895 & 8.3979 & 8.6827 & TRN \\
\hline CHEMBL 3902868 & 1640895 & 8.699 & 8.4092 & TST \\
\hline CHEMBL 3977248 & 1640895 & 6.6108 & 6.8629 & TRN \\
\hline CHEMBL3976547 & 1640895 & 9.0 & 9.0068 & TRN \\
\hline CHEMBL 3984507 & 1640895 & 9.0 & 8.8696 & TRN \\
\hline CHEMBL 3915787 & 1640895 & 8.3979 & 8.2095 & TRN \\
\hline CHEMBL 3916260 & 1640895 & 8.0 & 8.1086 & TRN \\
\hline CHEMBL 3950774 & 1640895 & 10.0 & 8.4559 & TRN \\
\hline CHEMBL3901162 & 1640895 & 9.0 & 9.5123 & TRN \\
\hline CHEMBL 3985334 & 1640895 & 8.2218 & 8.1753 & TRN \\
\hline CHEMBL3907959 & 1640895 & 6.1599 & 6.394 & TRN \\
\hline CHEMBL3893218 & 1640895 & 7.8539 & 7.9471 & TRN \\
\hline CHEMBL3928461 & 1640895 & 8.5229 & 8.2533 & TRN \\
\hline CHEMBL3944569 & 1640895 & 8.3979 & 8.1914 & TRN \\
\hline CHEMBL 3972556 & 1640895 & 9.0 & 9.4513 & TRN \\
\hline CHEMBL3956297 & 1640895 & 8.3979 & 8.0607 & TRN \\
\hline CHEMBL 3966593 & 1640895 & 8.3979 & 8.1461 & TRN \\
\hline CHEMBL3937143 & 1640895 & 8.5229 & 8.3797 & TST \\
\hline CHEMBL3959329 & 1640895 & 6.8996 & 6.3237 & TRN \\
\hline CHEMBL3977862 & 1640895 & 9.0 & 9.1366 & TRN \\
\hline CHEMBL3951313 & 1640895 & 6.2197 & 6.3422 & TRN \\
\hline CHEMBL3964785 & 1640895 & 7.284 & 7.4882 & TRN \\
\hline CHEMBL 3943804 & 1640895 & 6.1701 & 6.6781 & TST \\
\hline CHEMBL3951727 & 1640895 & 8.699 & 8.5232 & TRN \\
\hline CHEMBL3949801 & 1640895 & 10.0 & 7.9814 & TST \\
\hline CHEMBL3974282 & 1640895 & 8.3979 & 8.5275 & TST \\
\hline CHEMBL3910240 & 1640895 & 8.3979 & 8.4047 & TRN \\
\hline CHEMBL3950046 & 1640895 & 8.0458 & 9.4669 & TRN \\
\hline CHEMBL 3964851 & 1640895 & 8.699 & 8.6519 & TST \\
\hline CHEMBL3980594 & 1640895 & 8.699 & 8.7764 & TRN \\
\hline CHEMBL3948570 & 1640895 & 10.0 & 9.9655 & TRN \\
\hline CHEMBL3972103 & 1640895 & 8.1549 & 7.9628 & TRN \\
\hline
\end{tabular}


Supplemental Table S2.txt

\begin{tabular}{|c|c|c|c|c|}
\hline 199 & 16 & 699 & 32 & TRN \\
\hline CHEMRI 3962236 & 1640895 & 8.5229 & 8.7355 & \\
\hline AEMBL3922895 & 540895 & 6.9393 & $\partial 193$ & \\
\hline AEMBL 3914577 & 540895 & 7.2596 & 1656 & \\
\hline HEMBL3903434 & 640895 & 9.0 & 9351 & \\
\hline HEMBL 394 & 540895 & 9.0 & 617 & \\
\hline IEMBL397 & 640895 & 9.0 & 985 & \\
\hline HEMBL3925279 & 640895 & 8.5229 & 854 & \\
\hline HEMBL3966136 & 640895 & 8.5229 & 8.4865 & \\
\hline HEMBL3962426 & 640895 & 8.1549 & 3585 & \\
\hline AEMBL3890317 & 640895 & 8.5229 & 925 & \\
\hline AEMBL393 & 640895 & 8.2218 & & \\
\hline HEMBL3924860 & 640895 & 10.0 & 9.8418 & \\
\hline AEMBL3901148 & 640895 & 8.301 & 9.0766 & \\
\hline HEMBL602946 & 369323 & 5.0685 & 909 & \\
\hline AEMBL & 323 & 4.8579 & 19 & \\
\hline AEMBL & 323 & & & \\
\hline HEMBL & 369323 & 5.4191 & 309 & \\
\hline AEMBL531 & 369323 & 3024 & & \\
\hline HEMBL 534 & 23 & 4.8353 & 673 & \\
\hline AEMBL & 23 & 038 & 272 & RI \\
\hline AEMBL & & 26 & & \\
\hline AEMBL & 323 & 5.3098 & 272 & \\
\hline IEMBL: & 323 & 5021 & & \\
\hline HEMBL: & 23 & 6.5171 & 78 & ISI \\
\hline IEMBL & 23 & 431 & 58 & $\mathrm{RN}$ \\
\hline IEMBL & & & & \\
\hline IEMB & & 586 & & \\
\hline EMBL & 23 & & & 2 \\
\hline AEMBL6039 & 323 & 7.1308 & 096 & TRN \\
\hline EMBL & 323 & 71 & 04 & RI \\
\hline IEMB & & 332 & & 的 \\
\hline AEMBL & & 5.4522 & & RN \\
\hline IEMBLC & 23 & 4.8511 & & ГST \\
\hline IEMBL: & 323 & 4.751 & 236 & ГRN \\
\hline IEMBL & 323 & 179 & 91 & 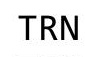 \\
\hline JEMDI & & 94 & & $\mathbf{I N}$ \\
\hline HEMBL & & & & RN \\
\hline HEMBL & 323 & 5.1637 & & IS \\
\hline IEMBL & 323 & 4.9431 & 236 & RI \\
\hline HEMBL: & 136 & 5.6108 & & \\
\hline CHEMBL590 & & 5.3372 & 4.9177 & TRN \\
\hline CHEMBL 2028060 & 369323 & 5.2933 & 5.3889 & RN \\
\hline AEMBL5296 & 323 & 5.5287 & & h \\
\hline CHEMBL & 36 & 5.0991 & & \\
\hline CHEMBL261095 & 136932 & 4.7129 & 4.8888 & \\
\hline CHEMBL601825 & 369323 & 4.8147 & 5.2821 & \\
\hline CHEMBL602586 & 1369323 & 7.3665 & 5.5441 & \\
\hline
\end{tabular}

Page 4478 
Supplemental Table S2.txt

\begin{tabular}{|c|c|c|c|c|}
\hline CHEMBL582070 & 323 & 192 & 5.3958 & TRN \\
\hline HEMBL 529385 & 369323 & 5.5302 & 5.2582 & \\
\hline HEMBL586933 & 369323 & 5.0 & 8069 & \\
\hline HEMBL 581489 & 369323 & 585 & 1015 & \\
\hline HEMBL547488 & 369323 & 4.8318 & .8608 & \\
\hline HEMBL577445 & 369323 & 6.0915 & .405 & \\
\hline HEMBL581475 & 369323 & & .3581 & RN \\
\hline HEMBL588732 & 369323 & 3.6021 & 5.2601 & RN \\
\hline HEMBL585983 & 369323 & 4.6021 & 5.6187 & \\
\hline HEMBL2028046 & 369323 & 4.8327 & 5.2229 & \\
\hline HEMBL2021322 & 369323 & 5.3089 & 5.4174 & \\
\hline HEMBL 528437 & 323 & 696 & 5.4987 & $\mathrm{RN}$ \\
\hline HEMBL579760 & 369323 & 4.8775 & 5.4247 & \\
\hline HEMBL 587288 & 369323 & 5.6882 & 5.0328 & \\
\hline HEMBL525106 & 369323 & 5.3072 & 5.4956 & RN \\
\hline HEMBL 57 & 36 & 933 & 872 & RIV \\
\hline HEMBL5 & 23 & 12 & 978 & ST \\
\hline HEMBL600132 & 365 & 487 & 5.1701 & ST \\
\hline HEMBL589 & 23 & 4.6751 & 3804 & \\
\hline HEMBL579105 & 365 & 7.0 & 5.8831 & RN \\
\hline HEMBL5 & 36 & 817 & 248 & RN \\
\hline HEMBL5 & 3 & 6. & 05 & ST \\
\hline HEMBL5 & 36 & 192 & 5.5012 & RN \\
\hline HEMBL59 & 23 & 4. & 369 & TRN \\
\hline HEMBL 601612 & $36 \varsigma$ & 5.2716 & 5.3062 & ISI \\
\hline HEMBL59 & 36 & 487 & 3211 & RN \\
\hline HEMBL5 & כ. & 5 . & 57 & 「RN \\
\hline HEMBL5 & 23 & 815 & 5.5265 & RN \\
\hline HEMBL527 & 23 & 5.52 & 971 & IRN \\
\hline HEMBL 584237 & 369 & 5.0 & 395 & TRN \\
\hline HEMBL 5 & 36 & & 19 & TRN \\
\hline HEMB & 3 & & 04 & TRN \\
\hline HEMBL6 & & & 2076 & TST \\
\hline HEMBL 590944 & 369 & 7. & 34 & TRN \\
\hline HEMBL579294 & 369323 & 6. & 5.2784 & TRN \\
\hline HEMBL5 & 36 & 5 . & 133 & TRN \\
\hline CHEMBL5 & & & & $\mathrm{RN}$ \\
\hline HEMBL53 & 36 & & 5.5754 & TRN \\
\hline HEMBL549216 & 369323 & 7.1612 & 5.7895 & TRN \\
\hline HEMBL5 & 3693 & 5 . & 5.8265 & TRN \\
\hline CHEMBL592305 & 1369 & 4.6761 & 5.2927 & TST \\
\hline CHEMBL587923 & 12 & 5.3595 & 5.4834 & TRN \\
\hline CHEMBL590919 & 1369323 & 5.1669 & 5.442 & TRN \\
\hline HEMBL533017 & 369323 & 4.716 & 5.1384 & $\mathrm{TR}$ \\
\hline CHEMBL 1 & 1369 & 5.2441 & 5.1853 & TRN \\
\hline CHEMBL547443 & 136932 & 5.3696 & 5.32 & \\
\hline CHEMBL319952 & 136932 & 5.1391 & 5.5538 & \\
\hline CHEMBL528492 & 1369323 & 5.5302 & 5.3826 & rRN \\
\hline
\end{tabular}

Page 4479 
Supplemental Table S2.txt

\begin{tabular}{|c|c|c|c|c|}
\hline CHEMBL527234 & 1369323 & 4.9586 & 5.0137 & TRN \\
\hline CHEMBL535730 & 1369323 & 5.1367 & 5.4536 & TST \\
\hline CHEMBL1623028 & 1369323 & 5.2161 & 5.6285 & TRN \\
\hline CHEMBL547193 & 1369323 & 4.9212 & 5.5027 & TRN \\
\hline CHEMBL528734 & 1369323 & 4.8735 & 5.4046 & TRN \\
\hline CHEMBL579315 & 1369323 & 6.0778 & 4.9947 & TRN \\
\hline CHEMBL590159 & 1369323 & 5.4089 & 5.3139 & TRN \\
\hline CHEMBL532079 & 1369323 & 5.0 & 5.3947 & TRN \\
\hline CHEMBL601566 & 1369323 & 4.6021 & 5.6544 & TST \\
\hline CHEMBL529984 & 1369323 & 3.6021 & 5.0201 & TRN \\
\hline CHEMBL1198307 & 1369323 & 5.1226 & 5.5554 & TRN \\
\hline CHEMBL533999 & 1369323 & 5.3325 & 5.0248 & TRN \\
\hline CHEMBL602312 & 1369323 & 5.2269 & 5.7942 & TRN \\
\hline CHEMBL591183 & 1369323 & 7.1367 & 5.819 & TRN \\
\hline CHEMBL580353 & 1369323 & 4.8837 & 5.0948 & TRN \\
\hline CHEMBL602409 & 1369323 & 6.4437 & 5.3554 & TRN \\
\hline CHEMBL206540 & 1369323 & 4.871 & 5.2903 & TRN \\
\hline CHEMBL601492 & 1369323 & 4.8179 & 5.2851 & TRN \\
\hline CHEMBL600374 & 1369323 & 5.4089 & 5.6692 & TRN \\
\hline CHEMBL607308 & 1369323 & 4.8894 & 5.4689 & TRN \\
\hline CHEMBL524930 & 1369323 & 5.2958 & 5.5202 & TRN \\
\hline CHEMBL601786 & 1369323 & 6.1487 & 5.5803 & TRN \\
\hline CHEMBL590675 & 1369323 & 4.7924 & 5.0806 & TRN \\
\hline CHEMBL591887 & 1369323 & 5.857 & 5.2962 & TRN \\
\hline CHEMBL2028055 & 1369323 & 5.5784 & 5.8898 & TRN \\
\hline CHEMBL586442 & 1369323 & 4.9412 & 4.9783 & TRN \\
\hline CHEMBL590201 & 1369323 & 4.8735 & 5.4296 & TRN \\
\hline CHEMBL1744512 & 1369323 & 4.8775 & 4.9178 & TST \\
\hline CHEMBL530438 & 1369323 & 5.0 & 5.5892 & TST \\
\hline CHEMBL2028063 & 1369323 & 7.1487 & 5.7156 & TRN \\
\hline CHEMBL585966 & 1369323 & 5.2757 & 4.9524 & TRN \\
\hline CHEMBL533917 & 1369323 & 6.2596 & 5.4244 & TRN \\
\hline CHEMBL592786 & 1369323 & 5.1643 & 5.2774 & TRN \\
\hline CHEMBL580140 & 1369323 & 5.2716 & 5.6323 & TRN \\
\hline CHEMBL581240 & 1369323 & 5.1864 & 5.5131 & TRN \\
\hline CHEMBL586704 & 1369323 & 4.8861 & 5.2948 & TRN \\
\hline CHEMBL609156 & 1369323 & 4.8368 & 5.1835 & TRN \\
\hline CHEMBL591890 & 1369323 & 7.1549 & 5.5963 & TST \\
\hline CHEMBL548399 & 1369323 & 4.7981 & 4.8891 & TRN \\
\hline CHEMBL548209 & 1369323 & 6.0 & 5.6067 & TRN \\
\hline CHEMBL585686 & 1369323 & 6.8861 & 5.4779 & TRN \\
\hline CHEMBL549208 & 1369323 & 4.7632 & 4.9321 & TRN \\
\hline CHEMBL546994 & 1369323 & 4.6517 & 4.8885 & TRN \\
\hline CHEMBL536421 & 1369323 & 4.8768 & 4.824 & TRN \\
\hline CHEMBL547269 & 1369323 & 5.2269 & 5.2697 & TRN \\
\hline CHEMBL534319 & 1369323 & 5.2 & 5.7541 & TRN \\
\hline CHEMBL580388 & 1369323 & 5.2175 & 5.5781 & TST \\
\hline CHEMBL597857 & 1369323 & 6.0 & 5.9868 & TRN \\
\hline
\end{tabular}


Supplemental Table S2.txt

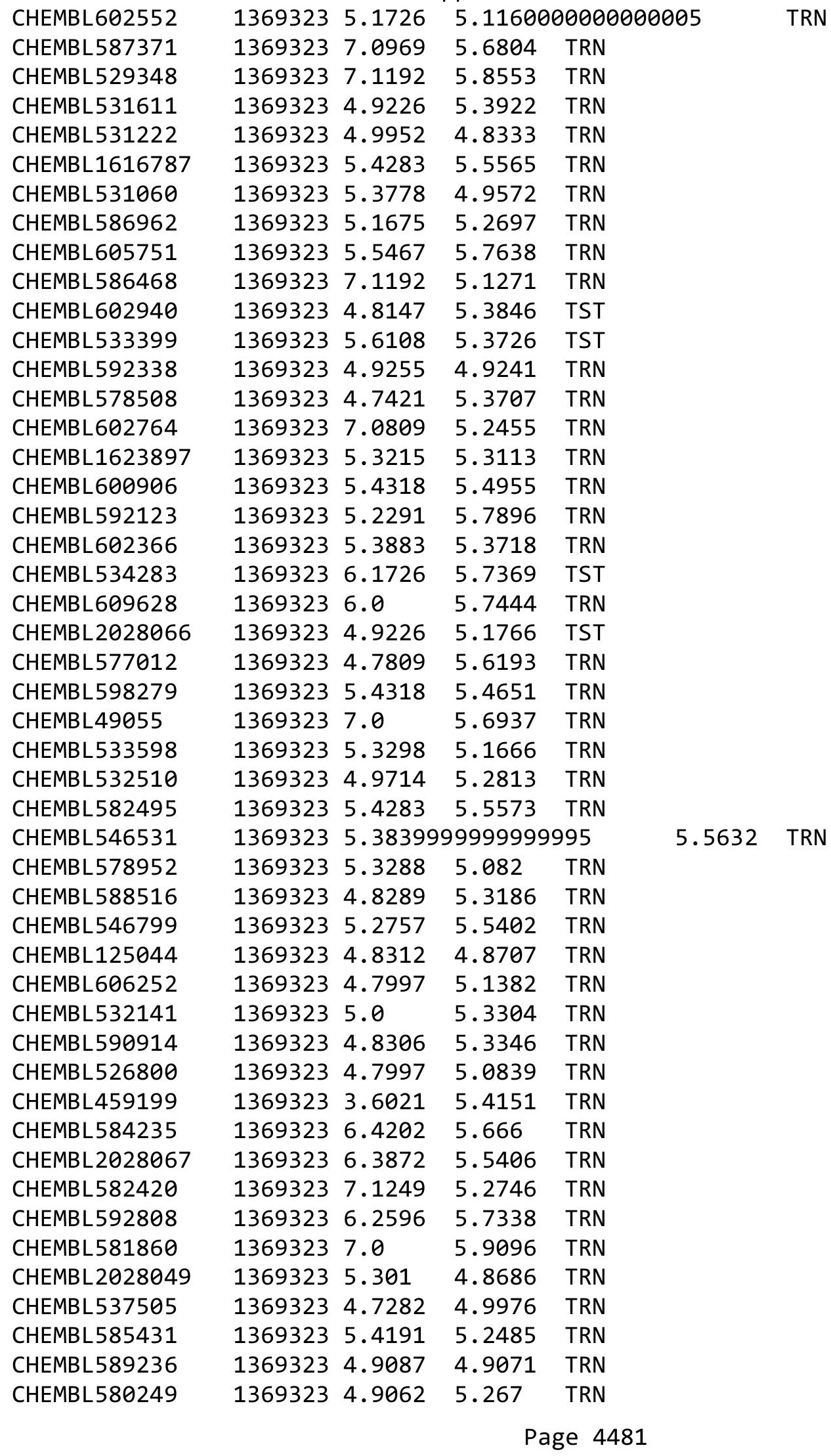




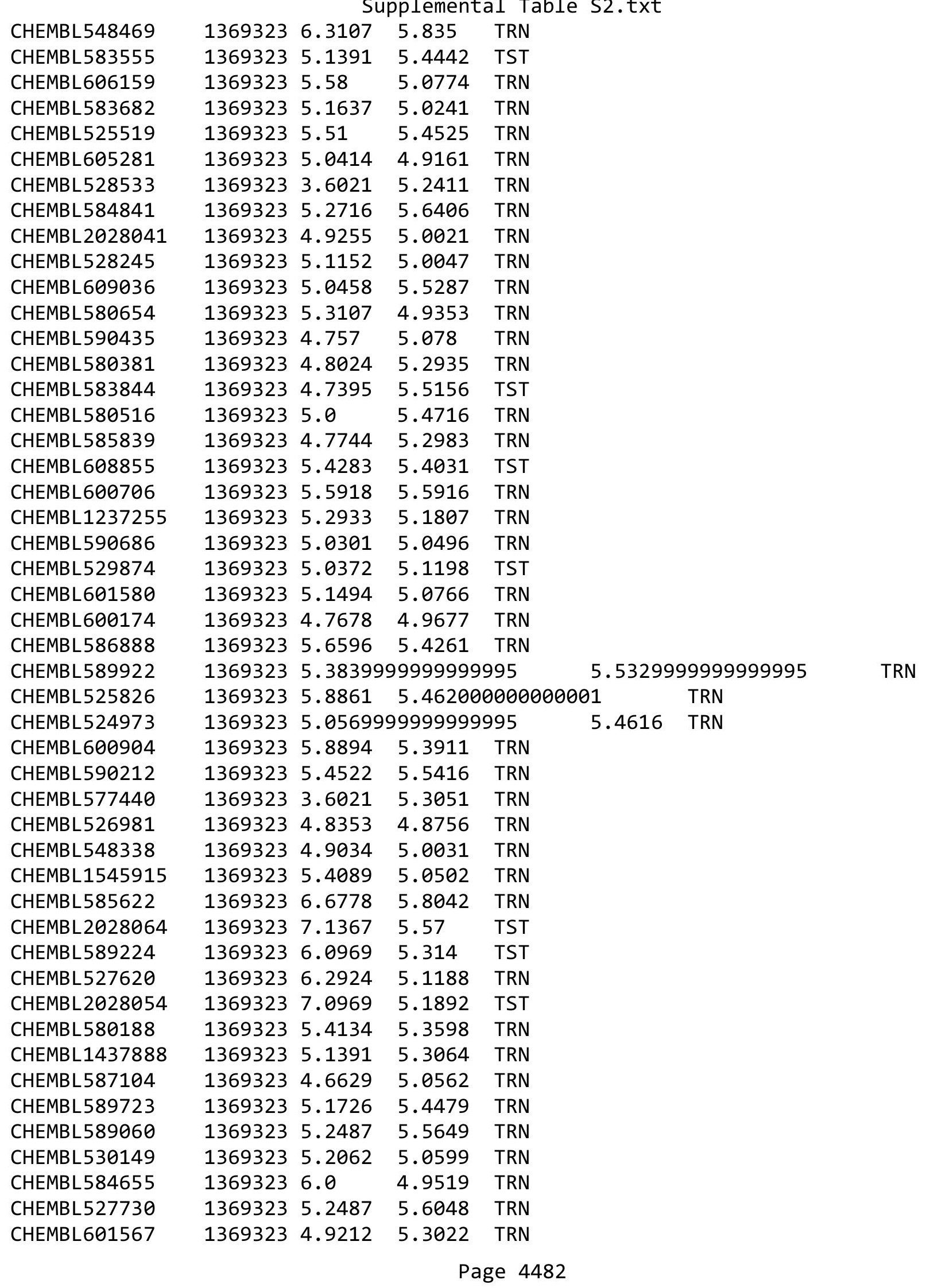


Supplemental Table S2.txt

\begin{tabular}{|c|c|c|c|c|c|c|}
\hline CHEMBL 2028042 & 1369323 & 4.908 & 5.4428 & TRN & & \\
\hline CHEMBL591147 & 1369323 & 5.1864 & 5.367006 & 000000000 & & TRN \\
\hline CHEMBL584015 & 1369323 & 5.3298 & 5.0067 & TRN & & \\
\hline CHEMBL601378 & 1369323 & 5.0996 & 5.3804 & TRN & & \\
\hline CHEMBL589951 & 1369323 & 4.7696 & 5.3604 & TRN & & \\
\hline CHEMBL602127 & 1369323 & 5.2596 & 5.23 & TRN & & \\
\hline CHEMBL592550 & 1369323 & 5.2291 & 5.7539 & TRN & & \\
\hline CHEMBL2028059 & 1369323 & 6.0 & 5.1389 & TRN & & \\
\hline CHEMBL599885 & 1369323 & 5.2596 & 5.2118 & TRN & & \\
\hline CHEMBL598881 & 1369323 & 6.8539 & 5.0148 & TST & & \\
\hline CHEMBL1740701 & 1369323 & 6.0 & 4.9501 & TRN & & \\
\hline CHEMBL580819 & 1369323 & 5.2832 & 5.3825 & TRN & & \\
\hline CHEMBL602179 & 1369323 & 4.8368 & 4.8165 & TRN & & \\
\hline CHEMBL592125 & 1369323 & 5.0 & 5.4879 & TRN & & \\
\hline CHEMBL 2028045 & 1369323 & 5.383999 & 99999999 & 995 & 5.7275 & TRN \\
\hline CHEMBL584676 & 1369323 & 4.9987 & 5.3153 & TRN & & \\
\hline CHEMBL582547 & 1369323 & 4.8368 & 5.5011 & TRN & & \\
\hline CHEMBL 2028047 & 1369323 & 6.3468 & 5.567 & TRN & & \\
\hline CHEMBL537071 & 1369323 & 4.7698 & 5.5498 & TRN & & \\
\hline CHEMBL588155 & 1369323 & 4.8579 & 5.4415 & TRN & & \\
\hline CHEMBL546162 & 1369323 & 4.8589 & 5.5251 & TRN & & \\
\hline CHEMBL592344 & 1369323 & 4.8431 & 5.2005 & TRN & & \\
\hline CHEMBL602234 & 1369323 & 5.2291 & 5.5649 & TRN & & \\
\hline CHEMBL533563 & 1369323 & 4.8468 & 5.2828 & TST & & \\
\hline CHEMBL581187 & 1369323 & 7.1487 & 5.8623 & TRN & & \\
\hline CHEMBL526587 & 1369323 & 5.0 & 5.2599 & TRN & & \\
\hline CHEMBL 2028058 & 1369323 & 5.0453 & 5.3916 & TRN & & \\
\hline CHEMBL582478 & 1369323 & 5.0835 & 5.24 & TRN & & \\
\hline CHEMBL548374 & 1369323 & 4.7491 & 5.1044 & TRN & & \\
\hline CHEMBL546168 & 1369323 & 6.1612 & 5.6404 & TRN & & \\
\hline CHEMBL600439 & 1369323 & 4.87 & 5.4969 & TST & & \\
\hline CHEMBL589946 & 1369323 & 4.9062 & 5.6017 & TRN & & \\
\hline CHEMBL 2028056 & 1369323 & 5.1938 & 5.7911 & TRN & & \\
\hline CHEMBL591395 & 1369323 & 4.8431 & 5.5482 & TRN & & \\
\hline CHEMBL591128 & 1369323 & 4.7129 & 5.1401 & TRN & & \\
\hline CHEMBL532155 & 1369323 & 4.8579 & 5.4304 & TRN & & \\
\hline CHEMBL600356 & 1369323 & 4.7997 & 5.5211 & TST & & \\
\hline CHEMBL581874 & 1369323 & 4.7997 & 5.5212 & TRN & & \\
\hline CHEMBL529968 & 1369323 & 4.782 & 4.871 & TRN & & \\
\hline CHEMBL532015 & 1369323 & 5.4763 & 5.3617 & TRN & & \\
\hline CHEMBL588855 & 1369323 & 4.8837 & 5.7519 & TRN & & \\
\hline CHEMBL537087 & 1369323 & 5.2503 & 5.6883 & TRN & & \\
\hline CHEMBL600488 & 1369323 & 7.0 & 5.4298 & TRN & & \\
\hline CHEMBL604982 & 1369323 & 5.2161 & 5.4812 & TRN & & \\
\hline CHEMBL592332 & 1369323 & 4.9727 & 5.6494 & TRN & & \\
\hline CHEMBL529773 & 1369323 & 6.585 & 5.5041 & TRN & & \\
\hline CHEMBL590933 & 1369323 & 4.7997 & 5.5922 & TRN & & \\
\hline CHEMBL587825 & 1369323 & 5.9788 & 5.5896 & TRN & & \\
\hline
\end{tabular}

Page 4483 


\begin{tabular}{|c|c|c|c|c|c|}
\hline \multicolumn{6}{|c|}{ Supplemental Table S2.txt } \\
\hline CHEMBL547825 & 1369323 & 6.0 & 5.8151 & TRN & \\
\hline CHEMBL586078 & 1369323 & 4.7729 & 5.2556 & TRN & \\
\hline CHEMBL582486 & 1369323 & 4.7881 & 5.55200 & 00000000005 & TST \\
\hline CHEMBL532560 & 1369323 & 5.0857 & 5.6269 & TRN & \\
\hline CHEMBL10835 & 1369323 & 5.3089 & 5.4309 & TRN & \\
\hline CHEMBL596643 & 1369323 & 4.9412 & 5.3112 & TRN & \\
\hline CHEMBL580876 & 1369323 & 5.1938 & 5.0799 & TRN & \\
\hline CHEMBL588481 & 1369323 & 5.4283 & 5.5006 & TRN & \\
\hline CHEMBL600235 & 1369323 & 4.8333 & 5.6402 & TRN & \\
\hline CHEMBL587485 & 1369323 & 5.0443 & 5.1093 & TRN & \\
\hline CHEMBL95606 & 1369323 & 5.3696 & 5.30200 & 00000000005 & TST \\
\hline CHEMBL532525 & 1369323 & 6.5376 & 5.2915 & TRN & \\
\hline CHEMBL579459 & 1369323 & 4.9281 & 4.9025 & TST & \\
\hline CHEMBL581225 & 1369323 & 6.2757 & 5.4212 & TST & \\
\hline CHEMBL 2028062 & 1369323 & 5.2596 & 5.2155 & TRN & \\
\hline CHEMBL534589 & 1369323 & 4.8318 & 4.7915 & TRN & \\
\hline CHEMBL 2028057 & 1369323 & 7.0969 & 5.4541 & TRN & \\
\hline CHEMBL 2028052 & 1369323 & 5.0173 & 5.0234 & TRN & \\
\hline CHEMBL599100 & 1369323 & 4.757 & 5.0288 & TRN & \\
\hline CHEMBL338094 & 1369323 & 4.7418 & 5.2233 & TRN & \\
\hline CHEMBL580159 & 1369323 & 5.0953 & 5.7165 & TRN & \\
\hline CHEMBL533921 & 1369323 & 6.0 & 5.4813 & TRN & \\
\hline CHEMBL530308 & 1369323 & 5.1637 & 5.1851 & TST & \\
\hline CHEMBL590182 & 1369323 & 4.7755 & 4.9741 & TRN & \\
\hline CHEMBL590683 & 1369323 & 4.7924 & 5.0158 & TRN & \\
\hline CHEMBL 2028068 & 1369323 & 6.3872 & 5.3704 & TST & \\
\hline CHEMBL600444 & 1369323 & 5.4134 & 5.6322 & TRN & \\
\hline CHEMBL597262 & 1369323 & 5.2958 & 5.439 & TRN & \\
\hline CHEMBL 2028044 & 1369323 & 7.1675 & 5.5042 & TRN & \\
\hline CHEMBL600305 & 1369323 & 5.0726 & 4.8221 & TRN & \\
\hline CHEMBL537778 & 1369323 & 5.2933 & 5.4854 & TRN & \\
\hline CHEMBL582119 & 1369323 & 4.782 & 5.4107 & TST & \\
\hline CHEMBL582767 & 1369323 & 4.9062 & 5.4666 & TST & \\
\hline CHEMBL529603 & 1369323 & 4.8289 & 5.3935 & TRN & \\
\hline CHEMBL603686 & 1369323 & 4.766 & 5.1593 & TST & \\
\hline CHEMBL591362 & 1369323 & 6.0 & 5.3904 & TRN & \\
\hline CHEMBL588501 & 1369323 & 5.3215 & 5.5846 & TRN & \\
\hline CHEMBL530978 & 1369323 & 4.8655 & 5.1898 & TRN & \\
\hline CHEMBL1738986 & 1369323 & 5.0 & 5.6215 & TRN & \\
\hline CHEMBL2028048 & 1369323 & 5.2291 & 4.8916 & TST & \\
\hline CHEMBL578294 & 1369323 & 4.8368 & 5.4683 & TST & \\
\hline CHEMBL525692 & 1369323 & 5.0742 & 5.0135 & TST & \\
\hline CHEMBL579300 & 1369323 & 4.782 & 5.7655 & TST & \\
\hline CHEMBL586033 & 1369323 & 5.0 & 5.4884 & TST & \\
\hline CHEMBL596652 & 1369323 & 3.6021 & 5.0211 & TST & \\
\hline CHEMBL607688 & 1369323 & 4.6897 & 5.1538 & TST & \\
\hline CHEMBL581349 & 1369323 & 5.0 & 5.6214 & TST & \\
\hline CHEMBL548901 & 1369323 & 4.9062 & 5.3719 & TST & \\
\hline
\end{tabular}




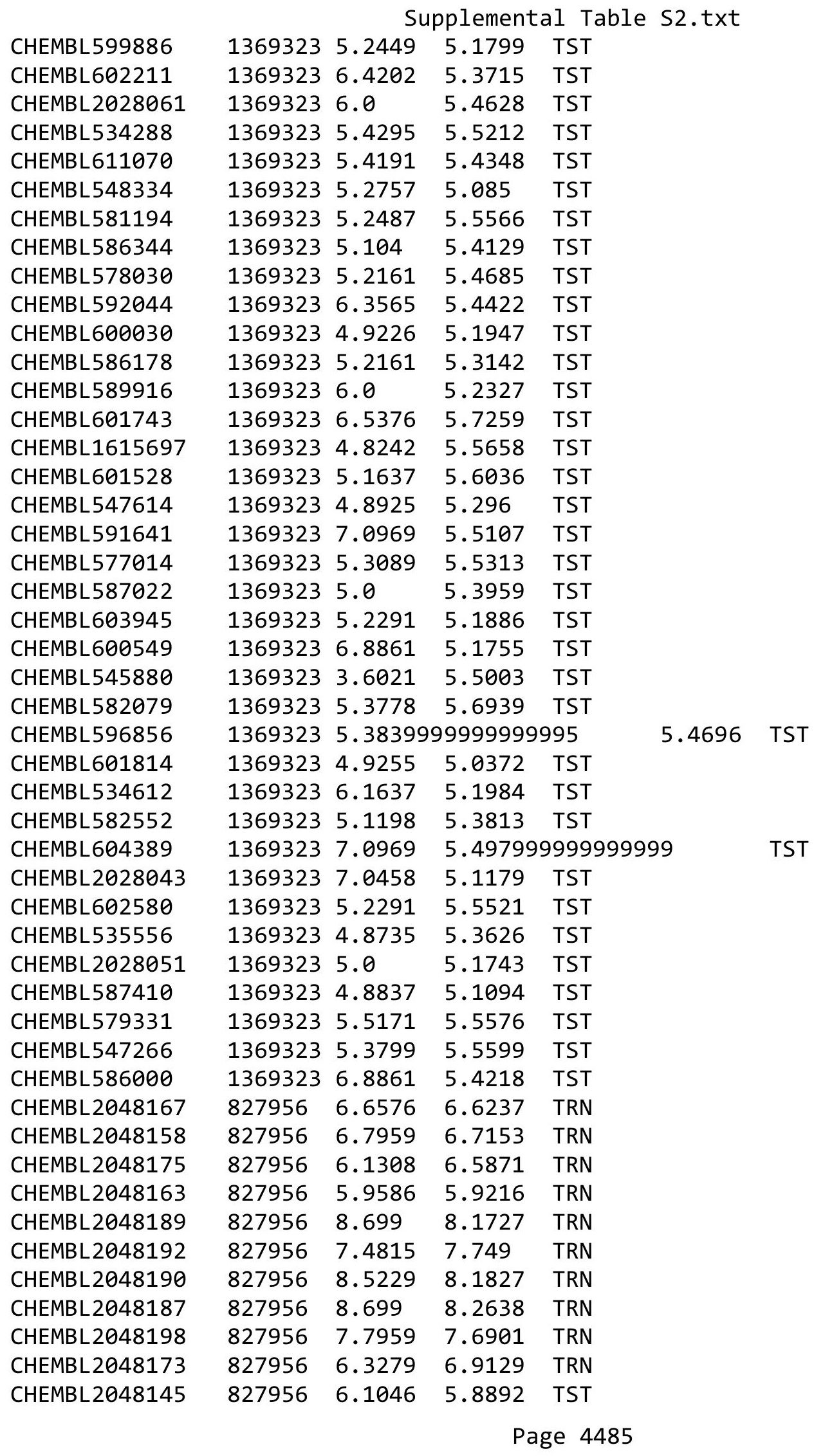




\begin{tabular}{|c|c|c|c|c|c|}
\hline \multicolumn{6}{|c|}{ Supplemental Table S2.txt } \\
\hline CHEMBL 2048183 & 827956 & 8.0969 & 6.9481 & TRN & \\
\hline CHEMBL1881201 & 827956 & 6.2291 & 6.0233 & TST & \\
\hline CHEMBL 2048177 & 827956 & 7.5376 & 6.5214 & TRN & \\
\hline CHEMBL 2048022 & 827956 & 5.699 & 6.2181 & TST & \\
\hline CHEMBL 2048146 & 827956 & 5.8539 & 5.8929 & TST & \\
\hline CHEMBL 2048204 & 827956 & 8.5229 & 7.4094 & TST & \\
\hline CHEMBL 2048166 & 827956 & 6.0915 & 5.9622 & TRN & \\
\hline CHEMBL420315 & 827956 & 6.055 & 5.9942 & TRN & \\
\hline CHEMBL 2048171 & 827956 & 6.284 & 5.7885 & TST & \\
\hline CHEMBL 2048154 & 827956 & 5.3556 & 5.3008 & TRN & \\
\hline CHEMBL 2048200 & 827956 & 7.2291 & 7.3057 & TRN & \\
\hline CHEMBL1549031 & 827956 & 6.4112 & 6.2121 & TRN & \\
\hline CHEMBL 2048147 & 827956 & 6.3233 & 5.8898 & TRN & \\
\hline CHEMBL 2048194 & 827956 & 8.3979 & 8.31299 & 9999999999 & TRN \\
\hline CHEMBL 2048180 & 827956 & 6.4815 & 6.53299 & 99999999995 & TRN \\
\hline CHEMBL 2048151 & 827956 & 5.9066 & 5.5866 & TRN & \\
\hline CHEMBL 2048199 & 827956 & 7.7959 & 7.6673 & TRN & \\
\hline CHEMBL 2048021 & 827956 & 5.6021 & 6.3227 & TST & \\
\hline CHEMBL 2048149 & 827956 & 5.1141 & 6.0904 & TST & \\
\hline CHEMBL 2048172 & 827956 & 6.4202 & 6.8381 & TRN & \\
\hline CHEMBL 2048179 & 827956 & 6.0088 & 6.4039 & TST & \\
\hline CHEMBL 2048174 & 827956 & 5.9208 & 6.1546 & TRN & \\
\hline CHEMBL 2048196 & 827956 & 8.0458 & 8.2741 & TRN & \\
\hline CHEMBL 2048185 & 827956 & 5.6576 & 6.0489 & TRN & \\
\hline CHEMBL 2048188 & 827956 & 7.3468 & 8.161 & TRN & \\
\hline CHEMBL 2048193 & 827956 & 8.3979 & 7.8307 & TRN & \\
\hline CHEMBL 2048202 & 827956 & 6.3054 & 7.0786 & TRN & \\
\hline CHEMBL 2048168 & 827956 & 6.4318 & 6.8147 & TRN & \\
\hline CHEMBL 2048165 & 827956 & 6.9788 & 6.4302 & TRN & \\
\hline CHEMBL 2048164 & 827956 & 6.6576 & 6.2295 & TRN & \\
\hline CHEMBL 2048155 & 827956 & 5.6271 & 5.2321 & TRN & \\
\hline CHEMBL 2048186 & 827956 & 8.301 & 7.7936 & TST & \\
\hline CHEMBL 2046461 & 827956 & 6.3468 & 6.5226 & TRN & \\
\hline CHEMBL 2048156 & 827956 & 5.9957 & 5.2213 & TRN & \\
\hline CHEMBL 2048170 & 827956 & 4.9747 & 6.2749 & TRN & \\
\hline CHEMBL 2048153 & 827956 & 4.9431 & 5.447 & TRN & \\
\hline CHEMBL 2048159 & 827956 & 6.7305 & 6.8627 & TRN & \\
\hline CHEMBL 2048191 & 827956 & 7.3872 & 7.8203 & TRN & \\
\hline CHEMBL 2048176 & 827956 & 5.7959 & 6.0648 & TRN & \\
\hline CHEMBL 2048150 & 827956 & 5.8665 & 5.5723 & TRN & \\
\hline CHEMBL 2048157 & 827956 & 4.0 & 5.2944 & TRN & \\
\hline CHEMBL 2048148 & 827956 & 5.5702 & 5.9483 & TST & \\
\hline CHEMBL 2048160 & 827956 & 6.4318 & 6.4592 & TRN & \\
\hline CHEMBL 2048162 & 827956 & 7.1427 & 6.1663 & TST & \\
\hline CHEMBL 2048184 & 827956 & 6.6383 & 7.0694 & TST & \\
\hline CHEMBL 2048195 & 827956 & 8.301 & 8.3866 & TRN & \\
\hline CHEMBL 2048181 & 827956 & 7.3468 & 6.7587 & TRN & \\
\hline CHEMBL 2048203 & 827956 & 6.9706 & 7.7602 & TRN & \\
\hline
\end{tabular}


Supplemental Table S2.txt

\begin{tabular}{|c|c|c|c|c|}
\hline 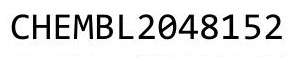 & & 5253 & & \\
\hline HEMBL2048178 & 27956 & 5.5376 & 0672 & \\
\hline HEMBL1400341 & 27956 & .8239 & 4869 & \\
\hline 97 & & & & \\
\hline EMBL20 & & & & \\
\hline HEMBL2048201 & 27956 & 7.1427 & 6108 & \\
\hline HEMBL 2048161 & 27956 & 6.6778 & .9275 & \\
\hline HEMBL 204 & & & & \\
\hline IEMBL34 & 1938 & 4.0 & 899 & \\
\hline IEMBL34 & 7938 & 5.6 & & \\
\hline HEMBL3407866 & 7938 & 9.2218 & .9176 & \\
\hline HEMBL 340 & 938 & 4.0 & .5601 & \\
\hline HEMBL 340 & 938 & 7. & 7.8324 & \\
\hline HEMBL3L & 938 & 18 & & \\
\hline HEMBL34 & 938 & & & \\
\hline HEMBL 34 & 938 & 76 & 276 & \\
\hline HEMBL 34 & 938 & & & \\
\hline HEMBL 34 & 38 & 7. & 84 & \\
\hline HEMBL 34 & & & & \\
\hline HEMBL34 & 38 & 5 . & & \\
\hline HEMBL 34 & 938 & & & \\
\hline HEMBL 34 & & 8. & & \\
\hline HEMBL 34 & 38 & 7. & & \\
\hline HEMBL3L & & & & \\
\hline HEMBL3 & & 5 . & & \\
\hline HEMBL 34 & 938 & & & \\
\hline JEMBL 34 & 38 & & & ST \\
\hline HEMBL3L & 38 & & & \\
\hline HEM & & & & \\
\hline HEMBL3 & 38 & 8. & 52 & RN \\
\hline HEMBL 34 & & & & \\
\hline HEMBL 34 & 38 & 6. & & RN \\
\hline HEMBL3 & 38 & & & NIV \\
\hline 6 & & & & RN \\
\hline HEMBL3 3 & 938 & & & ST \\
\hline HEMBL34e & 938 & & & $\mathrm{RN}$ \\
\hline HEMBL 34 & 938 & 6 . & 353 & ГRN \\
\hline HEM & 38 & & 65 & \\
\hline 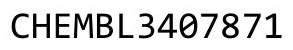 & & & & SI \\
\hline HEMBL34 & 938 & 7. & & TRN \\
\hline HEMBL 34 & 938 & 9.699 & & ГRN \\
\hline HEMBL 34 & 938 & 4. & & IST \\
\hline HEMBL 34 & 938 & 7. & & \\
\hline CHEMBL 34 & 938 & & & ГST \\
\hline HEMBL $34 €$ & 7938 & 7.95 & 3.2476 & RN \\
\hline HEMBL 34 & 938 & 6.8539 & 6.7191 & $N$ \\
\hline HEM & & 4. & & \\
\hline קר נסטזי & 146793 & & & \\
\hline
\end{tabular}

Page 4487 
Supplemental Table S2.txt

\begin{tabular}{|c|c|c|c|c|}
\hline CHEMBL 3407904 & 1467938 & 9.699 & 9.4853 & TRN \\
\hline CHEMBL3407903 & 1467938 & 9.5229 & 9.5 & TRN \\
\hline CHEMBL3407912 & 1467938 & 7.4949 & 7.1593 & TRN \\
\hline CHEMBL 3407881 & 1467938 & 6.585 & 6.0482 & TRN \\
\hline CHEMBL3407925 & 1467938 & 7.9208 & 8.1211 & TRN \\
\hline CHEMBL3407901 & 1467938 & 9.5229 & 9.0029 & TRN \\
\hline CHEMBL3407898 & 1467938 & 4.0 & 3.8196 & TRN \\
\hline CHEMBL3407914 & 1467938 & 9.0458 & 8.8236 & TRN \\
\hline CHEMBL 3407883 & 1467938 & 8.699 & 4.8313 & TST \\
\hline CHEMBL3407890 & 1467938 & 5.7696 & 5.9149 & TRN \\
\hline CHEMBL3407919 & 1467938 & 8.6778 & 8.6516 & TRN \\
\hline CHEMBL3407908 & 1467938 & 8.301 & 8.1654 & TRN \\
\hline CHEMBL3407902 & 1467938 & 9.0458 & 8.9018 & TRN \\
\hline CHEMBL3407928 & 1467938 & 6.3665 & 6.8832 & TRN \\
\hline CHEMBL3407922 & 1467938 & 9.301 & 9.0483 & TRN \\
\hline CHEMBL3407882 & 1467938 & 7.4815 & 7.3978 & TRN \\
\hline CHEMBL3407900 & 1467938 & 7.7212 & 7.7516 & TRN \\
\hline CHEMBL3407927 & 1467938 & 7.2441 & 7.5097 & TRN \\
\hline CHEMBL3407915 & 1467938 & 7.2218 & 7.7476 & TRN \\
\hline CHEMBL3407880 & 1467938 & 8.0 & 8.6432 & TST \\
\hline CHEMBL3407893 & 1467938 & 5.2958 & 5.3813 & TST \\
\hline CHEMBL3407885 & 1467938 & 7.6021 & 6.6237 & TST \\
\hline CHEMBL3407870 & 1467938 & 4.7773 & 5.2216 & TST \\
\hline CHEMBL3407897 & 1467938 & 4.0 & 5.0049 & TST \\
\hline CHEMBL334255 & 688347 & 5.0 & 4.9281 & TRN \\
\hline CHEMBL220845 & 688347 & 4.6 & 4.4167 & TRN \\
\hline CHEMBL28 & 688347 & 4.3 & 4.4663 & TRN \\
\hline CHEMBL1545634 & 688347 & 6.2 & 5.8925 & TRN \\
\hline CHEMBL1495381 & 688347 & 5.8 & 5.3473 & TST \\
\hline CHEMBL1430204 & 688347 & 4.3 & 4.4677 & TRN \\
\hline CHEMBL1456906 & 688347 & 4.3 & 4.5746 & TST \\
\hline CHEMBL165 & 688347 & 4.4 & 4.3634 & TRN \\
\hline CHEMBL433721 & 688347 & 4.9 & 4.7783 & TRN \\
\hline CHEMBL509531 & 688347 & 5.1 & 4.9362 & TST \\
\hline CHEMBL1527567 & 688347 & 4.3 & 4.3317 & TRN \\
\hline CHEMBL1450123 & 688347 & 4.9 & 4.5035 & TRN \\
\hline CHEMBL1499545 & 688347 & 5.5 & 5.1616 & TRN \\
\hline CHEMBL618 & 688347 & 5.3 & 4.583 & TRN \\
\hline CHEMBL1609459 & 688347 & 4.9 & 4.8454 & TRN \\
\hline CHEMBL1517425 & 688347 & 4.3 & 4.3284 & TRN \\
\hline CHEMBL1418603 & 688347 & 4.4 & 4.3857 & TRN \\
\hline CHEMBL1142 & 688347 & 4.4 & 4.3736 & TRN \\
\hline CHEMBL 70971 & 688347 & 5.2 & 4.6435 & TRN \\
\hline CHEMBL1496957 & 688347 & 4.6 & 4.6365 & TRN \\
\hline CHEMBL280998 & 688347 & 5.1 & 4.5799 & TRN \\
\hline CHEMBL105712 & 688347 & 4.3 & 4.7553 & TRN \\
\hline CHEMBL1516868 & 688347 & 4.6 & 4.6687 & TRN \\
\hline CHEMBL1510786 & 688347 & 4.4 & 4.5722 & TRN \\
\hline
\end{tabular}




\begin{tabular}{|c|c|c|c|c|}
\hline & & & ient & al Ta \\
\hline CHEMBL195437 & 688347 & 4.6 & 4.7656 & TRN \\
\hline CHEMBL454173 & 688347 & 6.0 & 6.0718 & TRN \\
\hline CHEMBL1566504 & 688347 & 4.4 & 4.4299 & TST \\
\hline CHEMBL1531716 & 688347 & 4.3 & 4.5398 & TRN \\
\hline CHEMBL1448387 & 688347 & 4.4 & 4.5446 & TRN \\
\hline CHEMBL1366925 & 688347 & 4.3 & 4.6496 & TRN \\
\hline CHEMBL1450607 & 688347 & 4.3 & 4.4286 & TRN \\
\hline CHEMBL1600998 & 688347 & 5.1 & 4.9983 & TRN \\
\hline CHEMBL1558796 & 688347 & 4.5 & 4.5048 & TRN \\
\hline CHEMBL196590 & 688347 & 4.1 & 4.4002 & TRN \\
\hline CHEMBL1303139 & 688347 & 4.6 & 4.7608 & TRN \\
\hline CHEMBL1524617 & 688347 & 4.4 & 4.8051 & TST \\
\hline CHEMBL 327919 & 688347 & 4.9 & 4.802 & TRN \\
\hline CHEMBL1602699 & 688347 & 5.4 & 5.0681 & TRN \\
\hline CHEMBL1489064 & 688347 & 4.3 & 4.362 & TRN \\
\hline CHEMBL1489568 & 688347 & 4.9 & 4.4589 & TRN \\
\hline CHEMBL1530684 & 688347 & 4.4 & 4.4097 & TRN \\
\hline CHEMBL1447588 & 688347 & 5.8 & 5.1119 & TST \\
\hline CHEMBL1381 & 688347 & 4.7 & 4.5073 & TRN \\
\hline CHEMBL1200471 & 688347 & 6.0 & 6.0429 & TRN \\
\hline CHEMBL 83552 & 688347 & 4.6 & 4.6037 & TRN \\
\hline CHEMBL172064 & 688347 & 4.4 & 4.4876 & TST \\
\hline CHEMBL192627 & 688347 & 4.5 & 4.457 & TRN \\
\hline CHEMBL1409985 & 688347 & 5.0 & 4.8762 & TRN \\
\hline CHEMBL1611235 & 688347 & 5.2 & 4.7313 & TRN \\
\hline CHEMBL1492884 & 688347 & 4.4 & 4.4003 & TRN \\
\hline CHEMBL28319 & 688347 & 5.4 & 4.5641 & TRN \\
\hline CHEMBL194400 & 688347 & 4.3 & 4.4166 & TST \\
\hline CHEMBL 70582 & 688347 & 4.4 & 4.6489 & TRN \\
\hline CHEMBL140 & 688347 & 4.4 & 4.4029 & TRN \\
\hline CHEMBL329673 & 688347 & 4.4 & 4.4343 & TRN \\
\hline CHEMBL1514512 & 688347 & 4.4 & 4.5879 & TRN \\
\hline CHEMBL1526319 & 688347 & 4.4 & 4.3815 & TRN \\
\hline CHEMBL1391326 & 688347 & 4.4 & 4.8463 & TRN \\
\hline CHEMBL1561876 & 688347 & 4.3 & 4.6558 & TRN \\
\hline CHEMBL1078384 & 688347 & 4.3 & 4.6794 & TRN \\
\hline CHEMBL 8145 & 688347 & 4.4 & 4.3676 & TRN \\
\hline CHEMBL1535689 & 688347 & 4.4 & 4.4146 & TRN \\
\hline CHEMBL1366408 & 688347 & 4.4 & 4.4809 & TST \\
\hline CHEMBL1330518 & 688347 & 4.3 & 4.4641 & TRN \\
\hline CHEMBL1562104 & 688347 & 4.6 & 5.1146 & TRN \\
\hline CHEMBL1519327 & 688347 & 5.9 & 5.6847 & TRN \\
\hline CHEMBL1578983 & 688347 & 4.4 & 4.4936 & TRN \\
\hline CHEMBL195953 & 688347 & 4.3 & 4.386 & TST \\
\hline CHEMBL1414154 & 688347 & 4.4 & 4.3926 & TRN \\
\hline CHEMBL935 & 688347 & 4.4 & 4.3535 & TRN \\
\hline CHEMBL1308088 & 688347 & 4.7 & 4.7546 & TRN \\
\hline CHEMBL194399 & 688347 & 4.4 & 4.3847 & TST \\
\hline
\end{tabular}




\begin{tabular}{|c|c|c|c|c|}
\hline \multicolumn{5}{|c|}{ Supplemental Table S2.txt } \\
\hline CHEMBL1559341 & 688347 & 4.4 & 4.4596 & TRN \\
\hline CHEMBL 36296 & 688347 & 4.4 & 4.4427 & TRN \\
\hline CHEMBL44072 & 688347 & 5.0 & 4.5107 & TST \\
\hline CHEMBL419564 & 688347 & 4.3 & 4.5072 & TRN \\
\hline CHEMBL224282 & 688347 & 5.6 & 4.4778 & TRN \\
\hline CHEMBL1407826 & 688347 & 4.4 & 4.6073 & TST \\
\hline CHEMBL486193 & 688347 & 4.3 & 5.0884 & TRN \\
\hline CHEMBL1612246 & 688347 & 4.9 & 4.6599 & TRN \\
\hline CHEMBL1569493 & 688347 & 5.4 & 5.4106 & TRN \\
\hline CHEMBL1449018 & 688347 & 4.5 & 4.4753 & TRN \\
\hline CHEMBL388676 & 688347 & 4.7 & 4.9008 & TST \\
\hline CHEMBL1408847 & 688347 & 4.4 & 4.7606 & TRN \\
\hline CHEMBL1565705 & 688347 & 4.1 & 4.3667 & TRN \\
\hline CHEMBL1319452 & 688347 & 4.5 & 4.7099 & TRN \\
\hline CHEMBL1452158 & 688347 & 4.4 & 4.3957 & TRN \\
\hline CHEMBL1304981 & 688347 & 4.4 & 4.503 & TRN \\
\hline CHEMBL8739 & 688347 & 4.3 & 4.3498 & TRN \\
\hline CHEMBL29878 & 688347 & 4.2 & 4.3967 & TRN \\
\hline CHEMBL1471289 & 688347 & 4.4 & 4.4898 & TRN \\
\hline CHEMBL487187 & 688347 & 4.3 & 4.7081 & TST \\
\hline CHEMBL 251389 & 688347 & 6.0 & 4.7671 & TST \\
\hline CHEMBL1522486 & 688347 & 5.1 & 4.6123 & TST \\
\hline CHEMBL3391990 & 688347 & 4.3 & 4.516 & TST \\
\hline CHEMBL242080 & 688347 & 4.8 & 4.3302 & TST \\
\hline CHEMBL402063 & 688347 & 6.0 & 5.3827 & TST \\
\hline CHEMBL1579130 & 688347 & 6.0 & 5.2109 & TST \\
\hline CHEMBL1576086 & 688347 & 4.3 & 4.6043 & TST \\
\hline CHEMBL196537 & 688347 & 4.4 & 4.3247 & TST \\
\hline CHEMBL1604283 & 688347 & 4.3 & 4.6957 & TST \\
\hline CHEMBL440287 & 688347 & 4.5 & 4.4923 & TST \\
\hline CHEMBL1569226 & 688347 & 4.7 & 4.968 & TST \\
\hline CHEMBL1475400 & 809355 & 7.5825 & 7.6782 & TRN \\
\hline CHEMBL1302170 & 809355 & 3.134 & 3.0917 & TRN \\
\hline CHEMBL1901097 & 809355 & 4.4834 & 4.4358 & TRN \\
\hline CHEMBL1736479 & 809355 & 5.8608 & 5.26 & TRN \\
\hline CHEMBL1564695 & 809355 & 4.4974 & 4.5032 & TRN \\
\hline CHEMBL1334802 & 809355 & 4.4985 & 4.4151 & TRN \\
\hline CHEMBL1498082 & 809355 & 3.134 & 3.1191 & TRN \\
\hline CHEMBL1722228 & 809355 & 5.871 & 5.9042 & TRN \\
\hline CHEMBL469424 & 809355 & 4.6843 & 4.7276 & TRN \\
\hline CHEMBL1724488 & 809355 & 4.6832 & 4.7601 & TRN \\
\hline CHEMBL1377099 & 809355 & 5.1078 & 5.1428 & TRN \\
\hline CHEMBL 2006834 & 809355 & 4.4525 & 4.5272 & TRN \\
\hline CHEMBL1521321 & 809355 & 4.9079 & 4.9248 & TRN \\
\hline CHEMBL1340477 & 809355 & 4.2633 & 4.295 & TRN \\
\hline CHEMBL1894967 & 809355 & 5.1882 & 5.5847 & TRN \\
\hline CHEMBL1999018 & 809355 & 4.6853 & 4.7605 & TRN \\
\hline CHEMBL1981481 & 809355 & 4.6999 & 4.8293 & TRN \\
\hline
\end{tabular}




\begin{tabular}{|c|c|c|c|c|c|c|}
\hline & & \multicolumn{5}{|c|}{ Supplemental Table S2.txt } \\
\hline CHEMBL1569081 & 809355 & 5.008 & 4.9519 & TRN & & \\
\hline CHEMBL1369913 & 809355 & 6.2612 & 6.2583 & TRN & & \\
\hline CHEMBL1879480 & 809355 & 3.134 & 3.2097 & TRN & & \\
\hline CHEMBL1514897 & 809355 & 4.7308 & 4.6521 & TRN & & \\
\hline CHEMBL1532033 & 809355 & 5.3228 & 5.263 & TRN & & \\
\hline CHEMBL1972558 & 809355 & 5.5318 & 5.49700 & 000000000 & & TRN \\
\hline CHEMBL1991599 & 809355 & 3.1337 & 3.1626 & TRN & & \\
\hline CHEMBL1889110 & 809355 & 4.8521 & 4.8855 & TRN & & \\
\hline CHEMBL1532466 & 809355 & 4.8618 & 4.9453 & TRN & & \\
\hline CHEMBL1893105 & 809355 & 3.134 & 3.0903 & TRN & & \\
\hline CHEMBL1896885 & 809355 & 5.8969 & 5.9317 & TRN & & \\
\hline CHEMBL1386620 & 809355 & 4.5902 & 4.6606 & TRN & & \\
\hline CHEMBL1563598 & 809355 & 4.5971 & 4.6528 & TRN & & \\
\hline CHEMBL1722341 & 809355 & 4.6539 & 4.6273 & TRN & & \\
\hline CHEMBL1714844 & 809355 & 3.1339 & 3.1502 & TRN & & \\
\hline CHEMBL1303555 & 809355 & 5.8523 & 5.8508 & TRN & & \\
\hline CHEMBL1720406 & 809355 & 4.9517 & 5.2504 & TRN & & \\
\hline CHEMBL1562466 & 809355 & 3.1342 & 3.2872 & TRN & & \\
\hline CHEMBL1504694 & 809355 & 4.6521 & 3.8731 & TST & & \\
\hline CHEMBL1557533 & 809355 & 3.134 & 3.3408 & TRN & & \\
\hline CHEMBL1487433 & 809355 & 4.6877 & 4.6363 & TRN & & \\
\hline CHEMBL1551052 & 809355 & 5.6048 & 5.6657 & TRN & & \\
\hline CHEMBL1403262 & 809355 & 7.7607 & 7.8873 & TRN & & \\
\hline CHEMBL1980259 & 809355 & 3.134 & 3.1271 & TRN & & \\
\hline CHEMBL602772 & 809355 & 4.4954 & 4.5178 & TRN & & \\
\hline CHEMBL1456677 & 809355 & 5.0541 & 4.5007 & TST & & \\
\hline CHEMBL1455014 & 809355 & 6.7169 & 6.3494 & TRN & & \\
\hline CHEMBL1538241 & 809355 & 5.4191 & 5.3843 & TRN & & \\
\hline CHEMBL 1607498 & 809355 & 4.9234 & 4.7947 & TST & & \\
\hline CHEMBL1496456 & 809355 & 4.6008 & 4.6188 & TRN & & \\
\hline CHEMBL1482415 & 809355 & 5.4174 & 5.3723 & TRN & & \\
\hline CHEMBL1438236 & 809355 & 5.3891 & 5.3252 & TRN & & \\
\hline CHEMBL1725439 & 809355 & 4.9777 & 5.0555 & TRN & & \\
\hline CHEMBL1972502 & 809355 & 4.7721 & 4.7902 & TRN & & \\
\hline CHEMBL1584967 & 809355 & 4.7848 & 4.8737 & TRN & & \\
\hline CHEMBL1463143 & 809355 & 4.4091 & 5.2273 & TST & & \\
\hline CHEMBL1562566 & 809355 & 4.7972 & 4.047 & TST & & \\
\hline CHEMBL1506113 & 809355 & 4.9658 & 4.8443 & TRN & & \\
\hline CHEMBL1485830 & 809355 & 5.9893 & 5.9256 & TRN & & \\
\hline CHEMBL1565528 & 809355 & 5.8383 & 5.8734 & TRN & & \\
\hline CHEMBL1345558 & 809355 & 4.5865 & 4.5365 & TRN & & \\
\hline CHEMBL1411575 & 809355 & 4.8504 & 4.9571 & TRN & & \\
\hline CHEMBL156383 & 809355 & 5.6326 & 4.734 & TST & & \\
\hline CHEMBL1399113 & 809355 & 7.82299 & 99999999 & 995 & 7.7923 & TI \\
\hline CHEMBL1698341 & 809355 & 3.6115 & 3.5673 & TRN & & \\
\hline CHEMBL1350056 & 809355 & 4.6824 & 4.6778 & TRN & & \\
\hline CHEMBL1348125 & 809355 & 5.6602 & 5.6924 & TRN & & \\
\hline CHEMBL32579 & 809355 & 3.1339 & 3.2774 & TST & & \\
\hline
\end{tabular}




\begin{tabular}{|c|c|c|c|c|c|}
\hline & & \multicolumn{4}{|c|}{ Supplemental Table s2.txt } \\
\hline CHEMBL1469526 & 809355 & 4.9543 & 4.7978 & TRN & \\
\hline CHEMBL1903124 & 809355 & 4.6282 & 4.6029 & TRN & \\
\hline CHEMBL1888742 & 809355 & 4.8141 & 4.7587 & TRN & \\
\hline CHEMBL1546337 & 809355 & 3.1339 & 3.4328 & TST & \\
\hline CHEMBL1343539 & 809355 & 7.8377 & 7.8283 & TRN & \\
\hline CHEMBL1407551 & 809355 & 5.5815 & 5.603 & TRN & \\
\hline CHEMBL1476849 & 809355 & 4.6493 & 4.9451 & TST & \\
\hline CHEMBL1984216 & 809355 & 4.7629 & 4.5872 & TRN & \\
\hline CHEMBL1999268 & 809355 & 4.7038 & 4.7483 & TRN & \\
\hline CHEMBL1975294 & 809355 & 4.4291 & 4.3947 & TRN & \\
\hline CHEMBL1501990 & 809355 & 4.5929 & 4.5826 & TRN & \\
\hline CHEMBL1866973 & 809355 & 5.1665 & 4.9166 & TRN & \\
\hline CHEMBL1346456 & 809355 & 4.4534 & 4.302 & TST & \\
\hline CHEMBL1882719 & 809355 & 4.3009 & 3.9751 & TRN & \\
\hline CHEMBL1728280 & 809355 & 3.1346 & 4.5699 & TST & \\
\hline CHEMBL1725007 & 809355 & 5.3773 & 5.33 & TRN & \\
\hline CHEMBL1383104 & 809355 & 4.454 & 5.1057 & TST & \\
\hline CHEMBL1868487 & 809355 & 5.7222 & 5.6767 & TRN & \\
\hline CHEMBL1588193 & 809355 & 4.8462 & 4.9392 & TRN & \\
\hline CHEMBL1311154 & 809355 & 7.7284 & 7.7577 & TRN & \\
\hline CHEMBL1376263 & 809355 & 3.1339 & 3.2848 & TRN & \\
\hline CHEMBL1401987 & 809355 & 4.848 & 4.8438 & TRN & \\
\hline CHEMBL1718137 & 809355 & 5.654 & 5.715 & TRN & \\
\hline CHEMBL1494979 & 809355 & 3.1337 & 3.1441 & TRN & \\
\hline CHEMBL1899069 & 809355 & 5.2588 & 5.3708 & TRN & \\
\hline CHEMBL 2001828 & 809355 & 4.6159 & 4.5038 & TRN & \\
\hline CHEMBL1976111 & 809355 & 4.7185 & 4.7816 & TRN & \\
\hline CHEMBL578512 & 809355 & 6.4907 & 4.9573 & TST & \\
\hline CHEMBL1356021 & 809355 & 6.3905 & 5.8969 & TRN & \\
\hline CHEMBL1867098 & 809355 & 4.6586 & 4.6281 & TRN & \\
\hline CHEMBL175266 & 809355 & 6.0785 & 4.3545 & TST & \\
\hline CHEMBL1552356 & 809355 & 5.4007 & 5.33200 & 0000000001 & TRN \\
\hline CHEMBL1495651 & 809355 & 4.7182 & 4.7334 & TRN & \\
\hline CHEMBL 2007329 & 809355 & 3.1339 & 4.2724 & TST & \\
\hline CHEMBL1512846 & 809355 & 6.2089 & 6.1775 & TRN & \\
\hline CHEMBL1504308 & 809355 & 7.8456 & 7.7807 & TRN & \\
\hline CHEMBL1891798 & 809355 & 4.7558 & 4.7022 & TRN & \\
\hline CHEMBL1540298 & 809355 & 5.1623 & 5.1399 & TRN & \\
\hline CHEMBL1325137 & 809355 & 4.8595 & 4.8805 & TRN & \\
\hline CHEMBL1407474 & 809355 & 4.29899 & 99999999 & 4.2613 & TRN \\
\hline CHEMBL1557839 & 809355 & 5.0932 & 5.2687 & TRN & \\
\hline CHEMBL 235504 & 809355 & 5.1809 & 4.9803 & TST & \\
\hline CHEMBL 2000834 & 809355 & 5.4449 & 5.4925 & TRN & \\
\hline CHEMBL1732813 & 809355 & 6.2889 & 6.3665 & TRN & \\
\hline CHEMBL1978670 & 809355 & 3.1339 & 3.158 & TRN & \\
\hline CHEMBL1577193 & 809355 & 4.953 & 4.8451 & TRN & \\
\hline CHEMBL601757 & 809355 & 6.5199 & 5.17700 & 00000000005 & TST \\
\hline CHEMBL1355210 & 809355 & 4.6958 & 4.7067 & TRN & \\
\hline
\end{tabular}




\begin{tabular}{|c|c|c|c|c|c|}
\hline \multicolumn{6}{|c|}{ Supplemental Table S2.txt } \\
\hline CHEMBL1377042 & 809355 & 4.6242 & 4.686 & TRN & \\
\hline CHEMBL1507539 & 809355 & 4.9041 & 4.0659 & TST & \\
\hline CHEMBL1362631 & 809355 & 5.1632 & 5.0984 & TRN & \\
\hline CHEMBL1585699 & 809355 & 5.6223 & 6.0081 & TRN & \\
\hline CHEMBL1309220 & 809355 & 4.6042 & 4.6782 & TRN & \\
\hline CHEMBL1865289 & 809355 & 4.9058 & 4.9808 & TRN & \\
\hline CHEMBL1527083 & 809355 & 6.2768 & 6.20100 & 00000000005 & TRN \\
\hline CHEMBL1342209 & 809355 & 4.9571 & 5.0957 & TRN & \\
\hline CHEMBL1332368 & 809355 & 4.9148 & 4.999 & TRN & \\
\hline CHEMBL1426398 & 809355 & 4.7459 & 4.7728 & TRN & \\
\hline CHEMBL1492247 & 809355 & 4.9263 & 4.8826 & TRN & \\
\hline CHEMBL1325945 & 809355 & 6.2779 & 5.4015 & TST & \\
\hline CHEMBL1975248 & 809355 & 4.3301 & 4.1688 & TRN & \\
\hline CHEMBL1232381 & 809355 & 7.9974 & 7.9932 & TRN & \\
\hline CHEMBL1373522 & 809355 & 4.7447 & 4.6945 & TRN & \\
\hline CHEMBL 2003139 & 809355 & 4.7828 & 4.9311 & TRN & \\
\hline CHEMBL1905325 & 809355 & 4.7784 & 4.6868 & TRN & \\
\hline CHEMBL1554805 & 809355 & 5.6921 & 5.67700 & 00000000005 & TRN \\
\hline CHEMBL1497777 & 809355 & $5.2920 e$ & 30000000 & 5.2383 & TRN \\
\hline CHEMBL1883596 & 809355 & 4.8985 & 5.0375 & TRN & \\
\hline CHEMBL1585740 & 809355 & 3.1337 & 3.0348 & TRN & \\
\hline CHEMBL1709717 & 809355 & 4.9059 & 4.8353 & TRN & \\
\hline CHEMBL1978317 & 809355 & 4.8402 & 4.922 & TRN & \\
\hline CHEMBL1441885 & 809355 & 5.5195 & 5.5364 & TRN & \\
\hline CHEMBL1902526 & 809355 & 4.6728 & 4.9125 & TRN & \\
\hline CHEMBL1999768 & 809355 & 4.9192 & 4.8408 & TRN & \\
\hline CHEMBL1440196 & 809355 & 4.708 & 4.6951 & TRN & \\
\hline CHEMBL1329549 & 809355 & 5.4612 & 5.4496 & TRN & \\
\hline CHEMBL599924 & 809355 & 3.134 & 4.5402 & TST & \\
\hline CHEMBL1894914 & 809355 & 4.6685 & 4.57 & TRN & \\
\hline CHEMBL1336319 & 809355 & 6.0434 & 5.9501 & TRN & \\
\hline CHEMBL2001761 & 809355 & 3.1337 & 3.1196 & TRN & \\
\hline CHEMBL1540093 & 809355 & 4.8167 & 4.9204 & TRN & \\
\hline CHEMBL1968257 & 809355 & 4.511 & 4.417 & TRN & \\
\hline CHEMBL1588205 & 809355 & 4.5725 & 4.5495 & TRN & \\
\hline CHEMBL1987738 & 809355 & 4.5827 & 4.8801 & TRN & \\
\hline CHEMBL1728023 & 809355 & 3.1339 & 2.9848 & TST & \\
\hline CHEMBL1501047 & 809355 & 6.15799 & و9999999 & 6.0836 & TRN \\
\hline CHEMBL3391757 & 809355 & 4.4716 & 5.1268 & TST & \\
\hline CHEMBL1358930 & 809355 & 3.1343 & 3.12600 & 00000000003 & TRN \\
\hline CHEMBL2355890 & 809355 & 5.0142 & 5.0563 & TRN & \\
\hline CHEMBL1481336 & 809355 & 5.2953 & 5.2553 & TRN & \\
\hline CHEMBL1440389 & 809355 & 4.7692 & 4.8344 & TRN & \\
\hline CHEMBL1708562 & 809355 & 4.6684 & 4.8002 & TRN & \\
\hline CHEMBL1367433 & 809355 & 4.8556 & 4.8602 & TRN & \\
\hline CHEMBL1611726 & 809355 & 5.5233 & 5.7127 & TRN & \\
\hline CHEMBL1391220 & 809355 & 4.7591 & 4.7423 & TRN & \\
\hline CHEMBL1432383 & 809355 & 4.6538 & 4.6364 & TRN & \\
\hline
\end{tabular}




\begin{tabular}{|c|c|c|c|c|c|c|}
\hline & & \multicolumn{5}{|c|}{ Supplemental Table S2.txt } \\
\hline CHEMBL1441033 & 809355 & 5.7749 & 5.2 & TST & & \\
\hline CHEMBL1531057 & 809355 & 3.134 & 3.0989 & TRN & & \\
\hline CHEMBL600309 & 809355 & 4.8913 & 4.8902 & TRN & & \\
\hline CHEMBL1892599 & 809355 & 5.8136 & 5.3769 & TRN & & \\
\hline CHEMBL1506655 & 809355 & 4.6766 & 4.6271 & TRN & & \\
\hline CHEMBL1704366 & 809355 & 5.7298 & 5.7693 & TRN & & \\
\hline CHEMBL1905247 & 809355 & 5.4083 & 5.5436 & TRN & & \\
\hline CHEMBL1874848 & 809355 & 4.3885 & 4.3593 & TRN & & \\
\hline CHEMBL1399010 & 809355 & 4.8057 & 4.8058 & TRN & & \\
\hline CHEMBL1608529 & 809355 & 8.0472 & 8.0262 & TRN & & \\
\hline CHEMBL1369512 & 809355 & 6.974 & 6.9133 & TRN & & \\
\hline CHEMBL1417216 & 809355 & 7.0147 & 7.0056 & TRN & & \\
\hline CHEMBL1879781 & 809355 & 4.6884 & 4.8168 & TRN & & \\
\hline CHEMBL1458321 & 809355 & 4.6782 & 4.7512 & TRN & & \\
\hline CHEMBL1343632 & 809355 & 4.837 & 4.8364 & TRN & & \\
\hline CHEMBL1335745 & 809355 & 5.7215 & 5.6951 & TRN & & \\
\hline CHEMBL 2004803 & 809355 & 4.4734 & 5.1589 & TST & & \\
\hline CHEMBL1410512 & 809355 & 4.5792 & 4.6076 & TRN & & \\
\hline CHEMBL1968264 & 809355 & 3.134 & 3.0612 & TRN & & \\
\hline CHEMBL1571034 & 809355 & 6.1402 & 4.8557 & TST & & \\
\hline CHEMBL1498845 & 809355 & 5.239 & 5.2063 & TRN & & \\
\hline CHEMBL1534533 & 809355 & 3.134 & 5.3104 & TST & & \\
\hline CHEMBL1417159 & 809355 & 4.9251 & 5.2852 & TST & & \\
\hline CHEMBL1303511 & 809355 & 5.28799 & 79999999 & 99 & 5.3874 & TRN \\
\hline CHEMBL1985678 & 809355 & 4.7709 & 4.9178 & TRN & & \\
\hline CHEMBL1886710 & 809355 & 4.6334 & 4.4372 & TST & & \\
\hline CHEMBL1467176 & 809355 & 4.2838 & 4.3292 & TRN & & \\
\hline CHEMBL1608891 & 809355 & 4.7842 & 4.7285 & TRN & & \\
\hline CHEMBL1603231 & 809355 & 3.1338 & 3.1432 & TRN & & \\
\hline CHEMBL1347510 & 809355 & 4.4435 & 4.3423 & TRN & & \\
\hline CHEMBL1549912 & 809355 & 5.1612 & 5.1803 & TRN & & \\
\hline CHEMBL1560085 & 809355 & 5.5426 & 5.3155 & TRN & & \\
\hline CHEMBL1969142 & 809355 & 4.5245 & 4.5098 & TRN & & \\
\hline CHEMBL1377692 & 809355 & 4.8523 & 4.8481 & TRN & & \\
\hline CHEMBL1580441 & 809355 & 6.1811 & 6.1646 & TRN & & \\
\hline CHEMBL1710639 & 809355 & 5.2564 & 4.7549 & TST & & \\
\hline CHEMBL1706737 & 809355 & 5.2189 & 4.5329 & TST & & \\
\hline CHEMBL1399443 & 809355 & 4.6705 & 3.6924 & TST & & \\
\hline CHEMBL1865875 & 809355 & 4.7226 & 4.8743 & TST & & \\
\hline CHEMBL1699883 & 809355 & 5.0272 & 5.246 & TST & & \\
\hline CHEMBL1607186 & 809355 & 5.7312 & 5.4729 & TST & & \\
\hline CHEMBL1590190 & 809355 & 4.8435 & 4.5174 & TST & & \\
\hline CHEMBL1879763 & 809355 & 4.5343 & 5.2905 & TST & & \\
\hline CHEMBL1611426 & 809355 & 4.6164 & 5.5142 & TST & & \\
\hline CHEMBL1599263 & 809355 & 4.7121 & 4.7029 & TST & & \\
\hline CHEMBL1966984 & 809355 & 4.7236 & 2.7151 & TST & & \\
\hline CHEMBL1720945 & 809355 & 4.8887 & 5.7723 & TST & & \\
\hline CHEMBL1343866 & 809355 & 5.1073 & 5.4327 & TST & & \\
\hline
\end{tabular}


Supplemental Table S2.txt

\begin{tabular}{|c|c|c|c|c|}
\hline CHEMBL1340528 & 809355 & 5.1896 & 4.3306 & TST \\
\hline CHEMBL1304402 & 809355 & 3.1339 & 5.3689 & TST \\
\hline CHEMBL1981314 & 809355 & 5.2013 & 5.2919 & TST \\
\hline CHEMBL1600581 & 809355 & 4.9594 & 5.671 & TST \\
\hline CHEMBL1863690 & 809355 & 5.5032 & 4.6165 & TST \\
\hline CHEMBL1387987 & 809355 & 4.6507 & 4.3759 & TST \\
\hline CHEMBL1973574 & 809355 & 4.9011 & 4.8742 & TST \\
\hline CHEMBL1901645 & 809355 & 4.8001 & 4.9118 & TST \\
\hline CHEMBL1381661 & 809355 & 4.4672 & 4.2181 & TST \\
\hline CHEMBL1892131 & 809355 & 4.8155 & 5.4689 & TST \\
\hline CHEMBL1344122 & 809355 & 4.8096 & 4.7982 & TST \\
\hline CHEMBL1904492 & 809355 & 4.5806 & 5.0406 & TST \\
\hline CHEMBL1864879 & 809355 & 4.5851 & 3.6121 & TST \\
\hline CHEMBL1350329 & 809355 & 5.4909 & 5.5989 & TST \\
\hline CHEMBL1997922 & 809355 & 4.5654 & 3.0318 & TST \\
\hline CHEMBL1736922 & 809355 & 4.1764 & 4.1153 & TST \\
\hline CHEMBL3645285 & 1642059 & 9.0 & 8.8354 & TRN \\
\hline CHEMBL3645344 & 1642059 & 9.0 & 9.1482 & TRN \\
\hline CHEMBL 3645288 & 1642059 & 9.0 & 8.8831 & TRN \\
\hline CHEMBL 3645328 & 1642059 & 9.0 & 8.9934 & TRN \\
\hline CHEMBL3645348 & 1642059 & 9.0 & 8.9735 & TRN \\
\hline CHEMBL3645292 & 1642059 & 9.0 & 8.8195 & TRN \\
\hline CHEMBL3645293 & 1642059 & 9.0 & 9.0635 & TRN \\
\hline CHEMBL 3645334 & 1642059 & 9.0 & 8.8458 & TRN \\
\hline CHEMBL 3645341 & 1642059 & 6.0 & 6.2661 & TRN \\
\hline CHEMBL3645363 & 1642059 & 9.0 & 8.7692 & TRN \\
\hline CHEMBL3645315 & 1642059 & 9.0 & 6.4249 & TRN \\
\hline CHEMBL3645275 & 1642059 & 9.0 & 8.8323 & TRN \\
\hline CHEMBL 3645281 & 1642059 & 6.0 & 6.3035 & TRN \\
\hline CHEMBL 3645356 & 1642059 & 9.0 & 8.5528 & TRN \\
\hline CHEMBL3645317 & 1642059 & 9.0 & 8.6798 & TRN \\
\hline CHEMBL3645353 & 1642059 & 6.0 & 6.1798 & TRN \\
\hline CHEMBL3645351 & 1642059 & 6.0 & 6.4631 & TRN \\
\hline CHEMBL3645279 & 1642059 & 8.2218 & 8.8272 & TRN \\
\hline CHEMBL 3645296 & 1642059 & 9.0 & 8.8682 & TRN \\
\hline CHEMBL3645324 & 1642059 & 8.5229 & 8.8931 & TRN \\
\hline CHEMBL3645338 & 1642059 & 8.699 & 8.6008 & TRN \\
\hline CHEMBL3645287 & 1642059 & 9.0 & 8.8156 & TRN \\
\hline CHEMBL 3645362 & 1642059 & 8.5229 & 8.7134 & TRN \\
\hline CHEMBL 3645339 & 1642059 & 8.699 & 8.6926 & TRN \\
\hline CHEMBL3645349 & 1642059 & 6.0 & 5.9129 & TRN \\
\hline CHEMBL3645311 & 1642059 & 6.0 & 7.1026 & TRN \\
\hline CHEMBL3645330 & 1642059 & 9.0 & 8.8371 & TRN \\
\hline CHEMBL3645310 & 1642059 & 9.0 & 9.1383 & TRN \\
\hline CHEMBL3645320 & 1642059 & 6.0 & 6.1407 & TRN \\
\hline CHEMBL3645289 & 1642059 & 6.0 & 6.209 & TST \\
\hline CHEMBL 3645337 & 1642059 & 9.0 & 9.2744 & TRN \\
\hline CHEMBL3892141 & 1642059 & 9.0 & 9.5536 & TST \\
\hline
\end{tabular}


Supplemental Table S2.txt

\begin{tabular}{|c|c|c|c|c|c|}
\hline CHEMBL 3426704 & 1642059 & 9.0 & 8.9482 & TST & \\
\hline CHEMBL 3645359 & 1642059 & 9.0 & 8.7949 & TST & \\
\hline CHEMBL 3645329 & 1642059 & 9.0 & 8.6495 & TRN & \\
\hline CHEMBL 3645276 & 1642059 & 8.699 & 8.7766 & TST & \\
\hline CHEMBL3645309 & 1642059 & 9.0 & 8.5174 & TRN & \\
\hline CHEMBL 3645319 & 1642059 & 8.699 & 8.6905 & TRN & \\
\hline CHEMBL 3666068 & 1642059 & 9.0 & 8.8769 & TST & \\
\hline CHEMBL 3645274 & 1642059 & 9.0 & 8.8504 & TST & \\
\hline CHEMBL 3981221 & 1642059 & 9.0 & 9.2148 & TST & \\
\hline CHEMBL3645331 & 1642059 & 9.0 & 9.1482 & TRN & \\
\hline CHEMBL 3645294 & 1642059 & 9.0 & 8.8808 & TRN & \\
\hline CHEMBL 3645312 & 1642059 & 8.5229 & 8.9714 & TRN & \\
\hline CHEMBL 3965175 & 1642059 & 9.0 & 9.3594 & TST & \\
\hline CHEMBL 3645357 & 1642059 & 9.0 & \multicolumn{2}{|c|}{9.011000000000001} & TRN \\
\hline CHEMBL3645358 & 1642059 & 8.5229 & 8.8034 & TRN & \\
\hline CHEMBL 3645322 & 1642059 & 9.0 & 8.4442 & TRN & \\
\hline CHEMBL 3645278 & 1642059 & 9.0 & 8.9624 & TST & \\
\hline CHEMBL 3645336 & 1642059 & 8.3979 & 8.6988 & TRN & \\
\hline CHEMBL 3645298 & 1642059 & 9.0 & 8.8998 & TRN & \\
\hline CHEMBL3645327 & 1642059 & 9.0 & 8.9248 & TRN & \\
\hline CHEMBL 3645283 & 1642059 & 9.0 & 8.9028 & TST & \\
\hline CHEMBL 3645325 & 1642059 & 8.5229 & 8.9313 & TRN & \\
\hline CHEMBL 3952427 & 1642059 & 9.0 & 9.1877 & TST & \\
\hline CHEMBL 3645284 & 1642059 & 9.0 & 8.8925 & TST & \\
\hline CHEMBL 3645280 & 1642059 & 9.0 & 8.7584 & TST & \\
\hline CHEMBL3645277 & 1642059 & 9.0 & 8.8285 & TST & \\
\hline CHEMBL 3645361 & 1642059 & 9.0 & 9.1264 & TRN & \\
\hline CHEMBL 3645326 & 1642059 & 9.0 & 9.0876 & TST & \\
\hline CHEMBL 3645332 & 1642059 & 6.0 & 6.2984 & TRN & \\
\hline CHEMBL 3645295 & 1642059 & 9.0 & 9.0014 & TRN & \\
\hline CHEMBL 3645302 & 1642059 & 9.0 & 8.997 & TRN & \\
\hline CHEMBL 3896828 & 1642059 & 9.0 & 9.2511 & TST & \\
\hline CHEMBL 3645335 & 1642059 & 9.0 & 9.2448 & TRN & \\
\hline CHEMBL3645345 & 1642059 & 6.0 & 6.7244 & TRN & \\
\hline CHEMBL 3645299 & 1642059 & 9.0 & 8.8786 & TRN & \\
\hline CHEMBL 3645340 & 1642059 & 9.0 & 8.638 & TRN & \\
\hline CHEMBL 3645286 & 1642059 & 9.0 & 9.0238 & TST & \\
\hline CHEMBL103413 & 45422 & 7.5086 & 7.4782 & TRN & \\
\hline CHEMBL317249 & 45422 & 7.3372 & 7.3414 & TRN & \\
\hline CHEMBL330413 & 45422 & 7.1739 & 7.2028 & TRN & \\
\hline CHEMBL420096 & 45422 & 7.2291 & 7.2855 & TRN & \\
\hline CHEMBL316576 & 45422 & 6.7212 & 6.617006 & 0000000001 & TRN \\
\hline CHEMBL103392 & 45422 & 7.7696 & 7.707999 & 9999999999 & TRN \\
\hline CHEMBL101190 & 45422 & 7.9208 & 7.9077 & TRN & \\
\hline CHEMBL321795 & 45422 & 7.4437 & 7.3619 & TRN & \\
\hline CHEMBL103415 & 45422 & 7.4815 & 7.4348 & TRN & \\
\hline CHEMBL421200 & 45422 & 7.7212 & 7.6028 & TRN & \\
\hline CHEMBL103802 & 45422 & 7.0132 & 6.9784 & TRN & \\
\hline
\end{tabular}




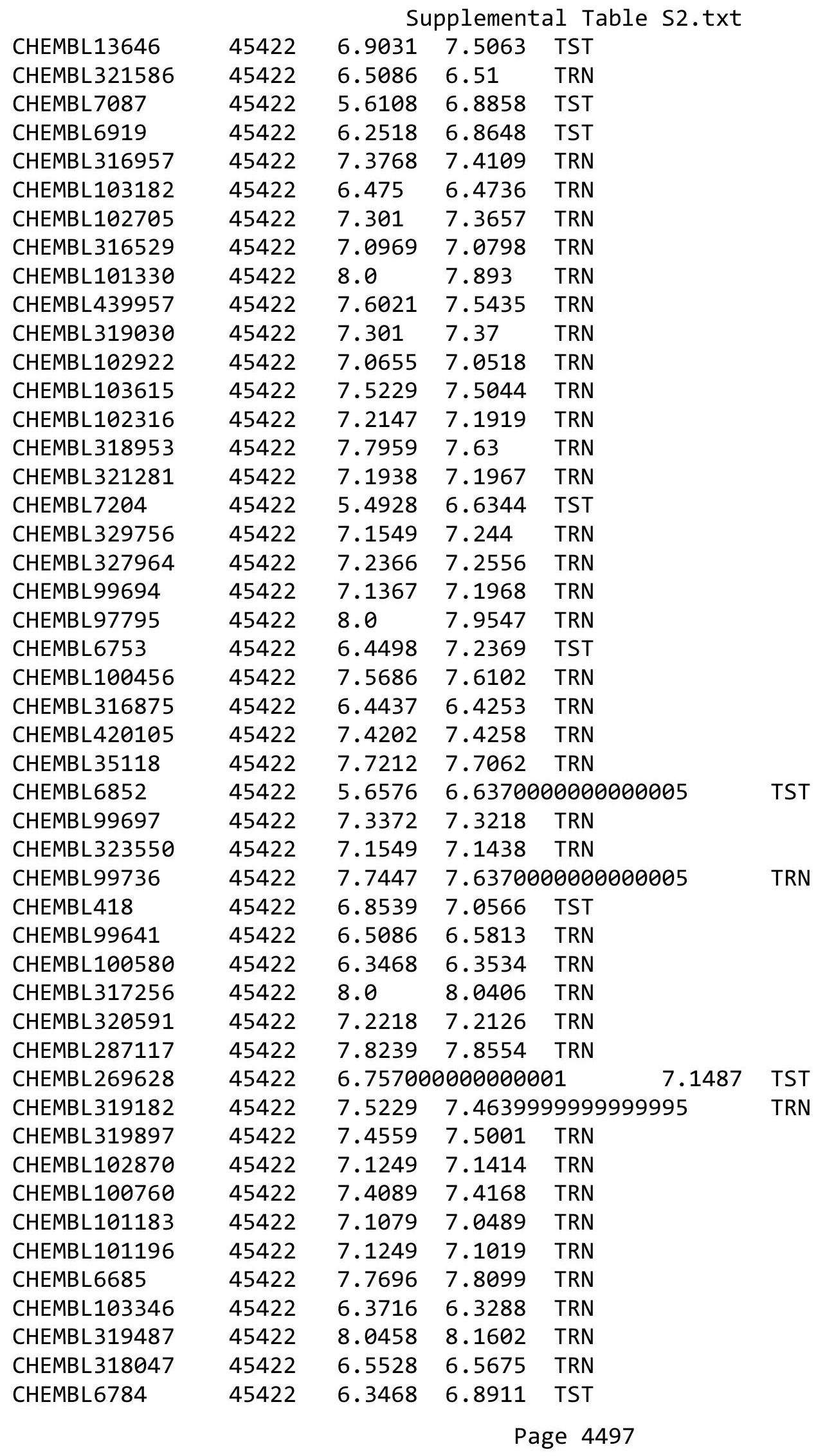




\begin{tabular}{|c|c|c|c|c|}
\hline & & & pplement & al $\mathrm{T}$ \\
\hline CHEMBL102656 & 45422 & 7.1549 & 7.205 & TRN \\
\hline CHEMBL328410 & 45422 & 7.3372 & 7.2927 & TRN \\
\hline CHEMBL6853 & 45422 & 6.7447 & 7.1408 & TST \\
\hline CHEMBL103398 & 45422 & 7.4559 & 7.4004 & TRN \\
\hline CHEMBL103361 & 45422 & 7.2596 & 7.3117 & TRN \\
\hline CHEMBL100860 & 45422 & 8.0 & 7.9434 & TRN \\
\hline CHEMBL103302 & 45422 & 6.8097 & 6.8547 & TRN \\
\hline CHEMBL103325 & 45422 & 6.7696 & 6.7557 & TRN \\
\hline CHEMBL102068 & 45422 & 7.4089 & 7.3851 & TRN \\
\hline CHEMBL431421 & 45422 & 7.5376 & 7.4822 & TRN \\
\hline CHEMBL102401 & 45422 & 7.4437 & 7.5121 & TRN \\
\hline CHEMBL103630 & 45422 & 8.0969 & 8.1368 & TRN \\
\hline CHEMBL411850 & 45422 & 7.1612 & 7.1499 & TRN \\
\hline CHEMBL319364 & 45422 & 6.9393 & 6.9975 & TRN \\
\hline CHEMBL 98673 & 45422 & 7.1427 & 7.1504 & TRN \\
\hline CHEMBL554264 & 45422 & 7.3565 & 7.2987 & TRN \\
\hline CHEMBL269122 & 45422 & 7.301 & 7.399 & TST \\
\hline CHEMBL13630 & 45422 & 9.0969 & 8.4551 & TST \\
\hline CHEMBL319090 & 45422 & 6.7447 & 6.6983 & TRN \\
\hline CHEMBL6705 & 45422 & 5.8827 & 6.5422 & TST \\
\hline CHEMBL317328 & 45422 & 7.2076 & 7.2091 & TRN \\
\hline CHEMBL419536 & 45422 & 7.1938 & 7.1947 & TRN \\
\hline CHEMBL100757 & 45422 & 7.1612 & 7.1667 & TRN \\
\hline CHEMBL100906 & 45422 & 7.7959 & 7.7551 & TRN \\
\hline CHEMBL318014 & 45422 & 7.2518 & 7.3004 & TRN \\
\hline CHEMBL103770 & 45422 & 7.7696 & 7.6898 & TRN \\
\hline CHEMBL103015 & 45422 & 7.7212 & 7.8424 & TRN \\
\hline CHEMBL14182 & 45422 & 7.2757 & 7.3763 & TST \\
\hline CHEMBL100873 & 45422 & 6.4559 & 6.435 & TRN \\
\hline CHEMBL103194 & 45422 & 7.301 & 7.3165 & TRN \\
\hline CHEMBL268177 & 45422 & 6.9031 & 7.0091 & TST \\
\hline CHEMBL102722 & 45422 & 8.0458 & 8.0086 & TRN \\
\hline CHEMBL317015 & 45422 & 7.1249 & 7.1294 & TRN \\
\hline CHEMBL103478 & 45422 & 7.4089 & 7.5197 & TRN \\
\hline CHEMBL320840 & 45422 & 6.4685 & 6.475 & TRN \\
\hline CHEMBL318486 & 45422 & 7.4559 & 7.4012 & TRN \\
\hline CHEMBL430667 & 45422 & 6.8539 & 6.8675 & TRN \\
\hline CHEMBL103757 & 45422 & 7.0757 & 7.0602 & TRN \\
\hline CHEMBL320436 & 45422 & 7.2218 & 7.3283 & TRN \\
\hline CHEMBL319486 & 45422 & 7.2676 & 7.3591 & TRN \\
\hline CHEMBL103407 & 45422 & 7.1487 & 7.1126 & TRN \\
\hline CHEMBL6724 & 45422 & 7.1805 & 7.1136 & TST \\
\hline CHEMBL318969 & 45422 & 7.4202 & 7.4382 & TRN \\
\hline CHEMBL318839 & 45422 & 7.4815 & 7.544 & TRN \\
\hline CHEMBL101174 & 45422 & 6.5376 & 6.5606 & TRN \\
\hline CHEMBL102904 & 45422 & 7.4437 & 7.521 & TRN \\
\hline CHEMBL100733 & 45422 & 7.7959 & 7.7436 & TRN \\
\hline CHEMBL100748 & 45422 & 7.2366 & 7.2538 & TRN \\
\hline
\end{tabular}




\begin{tabular}{|c|c|c|c|c|c|c|}
\hline & & \multicolumn{5}{|c|}{ Supplemental Table s2.txt } \\
\hline CHEMBL319363 & 45422 & 7.1135 & 7.1347 & TRN & & \\
\hline CHEMBL103420 & 45422 & 7.6021 & 7.6584 & TRN & & \\
\hline CHEMBL319297 & 45422 & 7.6021 & 7.58899 & 9999999999 & 95 & TRN \\
\hline CHEMBL99638 & 45422 & 6.8861 & 6.91799 & 9999999999 & & TRN \\
\hline CHEMBL101002 & 45422 & 6.9208 & 6.9175 & TRN & & \\
\hline CHEMBL103825 & 45422 & 7.301 & 7.3604 & TST & & \\
\hline CHEMBL327742 & 45422 & 7.3098 & 7.3556 & TST & & \\
\hline CHEMBL319794 & 45422 & 7.1739 & 7.1788 & TST & & \\
\hline CHEMBL6633 & 45422 & 6.8125 & 7.2652 & TST & & \\
\hline CHEMBL321052 & 45422 & 7.2596 & 7.3064 & TST & & \\
\hline CHEMBL268439 & 45422 & 8.301 & 8.3126 & TST & & \\
\hline CHEMBL7092 & 45422 & 6.4949 & 7.0078 & TST & & \\
\hline CHEMBL103524 & 45422 & 7.4815 & 7.5369 & TST & & \\
\hline CHEMBL265674 & 45422 & 6.2676 & 7.2454 & TST & & \\
\hline CHEMBL266240 & 45422 & 6.7959 & 6.9549 & TST & & \\
\hline CHEMBL102793 & 45422 & 6.4622 & 6.4526 & TST & & \\
\hline CHEMBL318101 & 45422 & 7.1079 & 7.1069 & TST & & \\
\hline CHEMBL103945 & 45422 & 7.2007 & 7.2427 & TST & & \\
\hline CHEMBL100075 & 45422 & 7.5229 & 7.5857 & TST & & \\
\hline CHEMBL99958 & 45422 & 6.3872 & 6.3109 & TST & & \\
\hline CHEMBL99855 & 45422 & 7.8239 & 7.9256 & TST & & \\
\hline CHEMBL519072 & 520159 & 3.0 & 3.0623 & TRN & & \\
\hline CHEMBL488335 & 520159 & 6.6615 & 6.7688 & TRN & & \\
\hline CHEMBL489652 & 520159 & 5.6861 & 5.6665 & TRN & & \\
\hline CHEMBL484698 & 520159 & 5.279 & 5.8924 & TST & & \\
\hline CHEMBL484276 & 520159 & 6.7122 & 6.6779 & TRN & & \\
\hline CHEMBL483471 & 520159 & 7.38200 & 00000000 & $\partial 1$ & 7.4441 & TRN \\
\hline CHEMBL521292 & 520159 & 6.2457 & 6.2703 & TRN & & \\
\hline CHEMBL487102 & 520159 & 6.34200 & 000000006 & 205 & 6.3556 & TRN \\
\hline CHEMBL451609 & 520159 & 6.7825 & 6.7483 & TRN & & \\
\hline CHEMBL482853 & 520159 & 6.5513 & 6.5199 & TRN & & \\
\hline CHEMBL254426 & 520159 & 7.2741 & 7.1802 & TRN & & \\
\hline CHEMBL491262 & 520159 & 7.7305 & 7.78799 & 9999999999 & & TRN \\
\hline CHEMBL492066 & 520159 & 6.4634 & 6.4508 & TRN & & \\
\hline CHEMBL483071 & 520159 & 6.7122 & 6.6595 & TRN & & \\
\hline CHEMBL489005 & 520159 & 6.5031 & 6.479 & TRN & & \\
\hline CHEMBL487300 & 520159 & 7.6737 & 7.7476 & TRN & & \\
\hline CHEMBL519501 & 520159 & 6.9245 & 6.907 & TRN & & \\
\hline CHEMBL482441 & 520159 & 7.0386 & 7.1233 & TRN & & \\
\hline CHEMBL521447 & 520159 & 6.4145 & 6.3116 & TRN & & \\
\hline CHEMBL521464 & 520159 & 5.6968 & 5.6021 & TRN & & \\
\hline CHEMBL488111 & 520159 & 6.1593 & 6.1401 & TRN & & \\
\hline CHEMBL482442 & 520159 & 3.0 & 3.0175 & TRN & & \\
\hline CHEMBL521499 & 520159 & 6.7959 & 6.8603 & TRN & & \\
\hline CHEMBL482848 & 520159 & 7.0696 & 7.2372 & TRN & & \\
\hline CHEMBL485107 & 520159 & 6.6778 & 6.6333 & TRN & & \\
\hline CHEMBL485244 & 520159 & 6.699 & 6.7408 & TRN & & \\
\hline CHEMBL482640 & 520159 & 7.1308 & 7.1317 & TRN & & \\
\hline
\end{tabular}




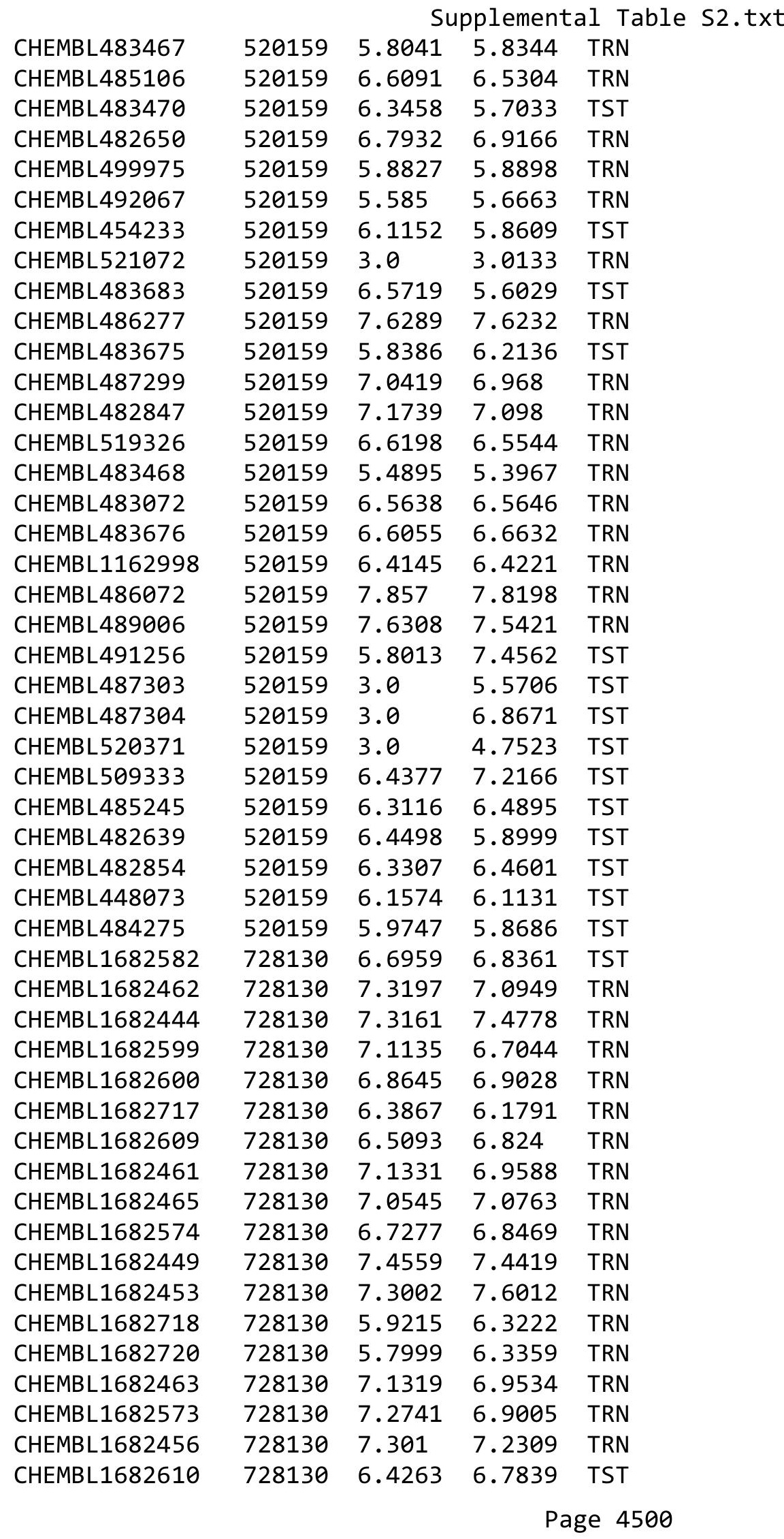


Supplemental Table S2.txt

\begin{tabular}{|c|c|c|c|c|}
\hline CHEMBL1682584 & 728130 & 7.0521 & 6.9246 & TRN \\
\hline CHEMBL1682598 & 728130 & 7.0074 & 6.8342 & TRN \\
\hline CHEMBL1682709 & 728130 & 6.5921 & 6.3246 & TRN \\
\hline CHEMBL1682448 & 728130 & 6.945 & 7.3886 & TRN \\
\hline CHEMBL1682443 & 728130 & 7.4318 & 7.3872 & TST \\
\hline CHEMBL1682710 & 728130 & 6.6908 & 6.2639 & TRN \\
\hline CHEMBL1682705 & 728130 & 6.9215 & 6.545 & TRN \\
\hline CHEMBL1682729 & 728130 & 4.8926 & 5.4282 & TST \\
\hline CHEMBL1682594 & 728130 & 6.7572 & 6.8505 & TRN \\
\hline CHEMBL1682455 & 728130 & 6.7833 & 7.002006 & 0000000001 \\
\hline CHEMBL1682593 & 728130 & 6.7724 & 6.9691 & TRN \\
\hline CHEMBL1682451 & 728130 & 7.1599 & 7.0541 & TRN \\
\hline CHEMBL1682726 & 728130 & 5.6797 & 5.4881 & TRN \\
\hline CHEMBL1682607 & 728130 & 6.9706 & 6.8206 & TST \\
\hline CHEMBL1682452 & 728130 & 7.2757 & 7.2137 & TRN \\
\hline CHEMBL1682588 & 728130 & 6.6778 & 6.7944 & TRN \\
\hline CHEMBL1682719 & 728130 & 6.4316 & 6.0686 & TRN \\
\hline CHEMBL1682580 & 728130 & 7.1314 & 6.8431 & TRN \\
\hline CHEMBL1682608 & 728130 & 6.165 & 6.6445 & TRN \\
\hline CHEMBL1682457 & 728130 & 7.1494 & 7.0977 & TRN \\
\hline CHEMBL1682708 & 728130 & 6.3053 & 6.5901 & TRN \\
\hline CHEMBL1682450 & 728130 & 7.3893 & 7.3315 & TRN \\
\hline CHEMBL1682592 & 728130 & 6.7387 & 6.9363 & TRN \\
\hline CHEMBL1682724 & 728130 & 4.8617 & 5.7076 & TRN \\
\hline CHEMBL1682605 & 728130 & 7.0168 & 6.7751 & TRN \\
\hline CHEMBL1682587 & 728130 & 6.75700 & 00000000 & 6.7183 \\
\hline CHEMBL1682730 & 728130 & 4.8915 & 5.5521 & TRN \\
\hline CHEMBL1682706 & 728130 & 6.7335 & 6.3641 & TRN \\
\hline CHEMBL1682703 & 728130 & 5.9817 & 6.4639 & TST \\
\hline CHEMBL1682575 & 728130 & 7.2007 & 6.9812 & TRN \\
\hline CHEMBL1682447 & 728130 & 7.4237 & 7.2318 & TRN \\
\hline CHEMBL1682458 & 728130 & 7.1273 & 7.1384 & TRN \\
\hline CHEMBL1682577 & 728130 & 6.5626 & 6.7708 & TST \\
\hline CHEMBL1682445 & 728130 & 7.4306 & 7.5227 & TRN \\
\hline CHEMBL1682723 & 728130 & 5.7083 & 6.0197 & TST \\
\hline CHEMBL1682603 & 728130 & 6.5588 & 6.5601 & TST \\
\hline CHEMBL1682454 & 728130 & 6.87 & 7.0571 & TRN \\
\hline CHEMBL1682466 & 728130 & 7.3325 & 7.0723 & TRN \\
\hline CHEMBL1682579 & 728130 & 6.9618 & 6.83 & TRN \\
\hline CHEMBL1682591 & 728130 & 7.1469 & 6.9619 & TRN \\
\hline CHEMBL1682714 & 728130 & 6.1423 & 6.4523 & TST \\
\hline CHEMBL1682464 & 728130 & 6.961 & 7.0686 & TRN \\
\hline CHEMBL1682712 & 728130 & 6.5421 & 6.0691 & TRN \\
\hline CHEMBL1682468 & 728130 & 7.2725 & 7.1087 & TRN \\
\hline CHEMBL1682711 & 728130 & 6.1341 & 6.2929 & TST \\
\hline CHEMBL1682459 & 728130 & 6.6394 & 7.0992 & TRN \\
\hline CHEMBL1682585 & 728130 & 7.0706 & 6.8968 & TRN \\
\hline CHEMBL1682467 & 728130 & 7.1494 & 7.0906 & TRN \\
\hline
\end{tabular}




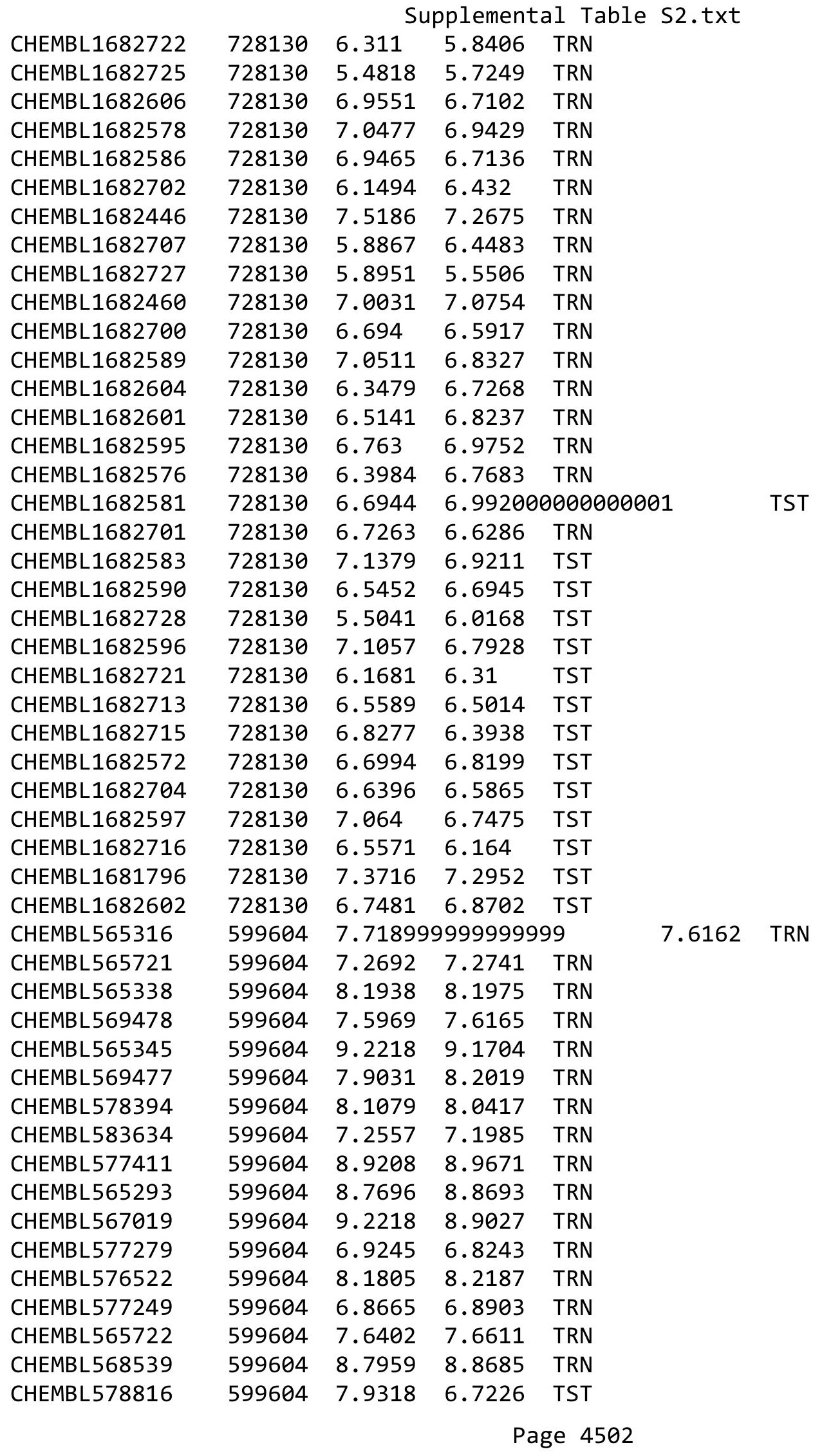




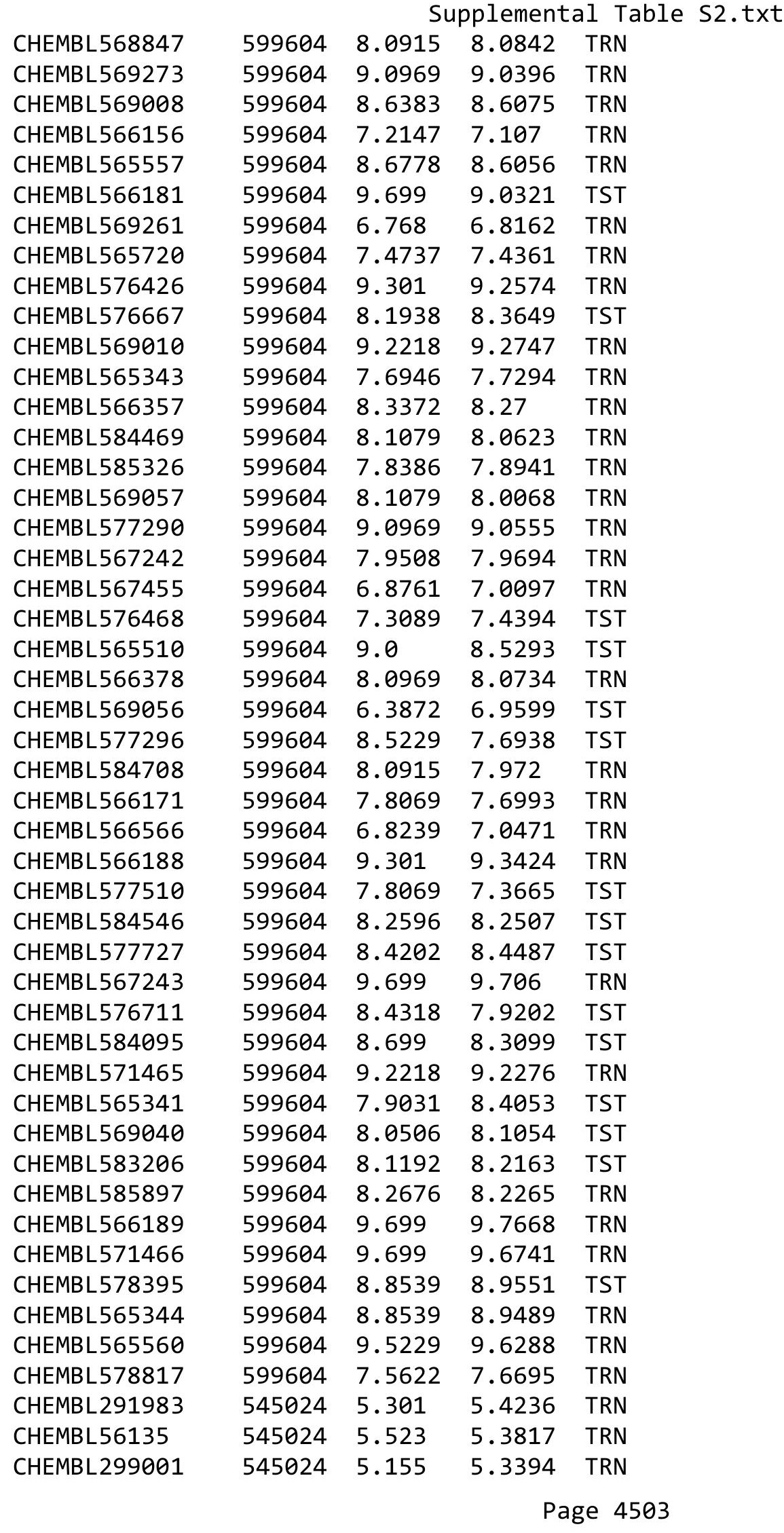




\begin{tabular}{|c|c|c|c|c|c|c|}
\hline & & \multicolumn{5}{|c|}{ Supplemental Table S2.txt } \\
\hline CHEMBL301055 & 545024 & 3.523 & 3.3292 & TRN & & \\
\hline CHEMBL432894 & 545024 & 2.276 & 2.4604 & TRN & & \\
\hline CHEMBL298823 & 545024 & 2.222 & 2.3096 & TRN & & \\
\hline CHEMBL53684 & 545024 & 2.301 & 2.2838 & TRN & & \\
\hline CHEMBL293989 & 545024 & 3.699 & 3.4067 & TRN & & \\
\hline CHEMBL293780 & 545024 & 1.921 & 2.1529 & TRN & & \\
\hline CHEMBL291532 & 545024 & 3.398 & 3.3609 & TRN & & \\
\hline CHEMBL301086 & 545024 & 2.229 & 2.2249 & TRN & & \\
\hline CHEMBL53896 & 545024 & 2.137 & 2.1369 & TRN & & \\
\hline CHEMBL54600 & 545024 & 3.699 & 3.85699 & 9999 & 998 & TRN \\
\hline CHEMBL54444 & 545024 & 2.347 & 2.4387 & TRN & & \\
\hline CHEMBL55043 & 545024 & 1.886 & 1.73699 & 9999 & 999 & TRN \\
\hline CHEMBL55199 & 545024 & 3.222 & 3.2907 & TRN & & \\
\hline CHEMBL55308 & 545024 & 2.8539 & 99999999 & 996 & 2.9028 & TRN \\
\hline CHEMBL55271 & 545024 & 2.161 & 2.2852 & TRN & & \\
\hline CHEMBL55387 & 545024 & 3.0460 & 00000000 & 003 & 2.8183 & TST \\
\hline CHEMBL55862 & 545024 & 3.284 & 3.801 & TST & & \\
\hline CHEMBL292012 & 545024 & 2.208 & 2.0985 & TST & & \\
\hline CHEMBL54318 & 545024 & 3.301 & 3.5418 & TST & & \\
\hline CHEMBL294212 & 545024 & 2.004 & 2.0733 & TST & & \\
\hline CHEMBL55998 & 545024 & 2.319 & 3.1413 & TST & & \\
\hline CHEMBL53893 & 545024 & 2.0 & 2.3007 & TST & & \\
\hline CHEMBL55007 & 545024 & 1.7209 & 99999999 & 999 & 2.1985 & 1 \\
\hline CHEMBL293331 & 545024 & 1.921 & 2.1496 & TST & & \\
\hline CHEMBL54970 & 545024 & 1.886 & 2.6107 & TRN & & \\
\hline CHEMBL292891 & 545024 & 3.8539 & 99999999 & 996 & 3.4258 & TRN \\
\hline CHEMBL56324 & 545024 & 2.77 & 3.385 & TRN & & \\
\hline CHEMBL294179 & 545024 & 3.9210 & $\partial 0000000$ & 003 & 2.952 & TRN \\
\hline CHEMBL294627 & 545024 & 2.9589 & 99999999 & 996 & 3.4611 & TRN \\
\hline CHEMBL54698 & 545024 & 2.456 & 2.2883 & TRN & & \\
\hline CHEMBL293963 & 545024 & 2.149 & 1.9502 & TRN & & \\
\hline CHEMBL293806 & 545024 & 2.9589 & 99999999 & 996 & 2.693 & TRN \\
\hline CHEMBL59586 & 545024 & 2.041 & 2.0397 & TRN & & \\
\hline CHEMBL449041 & 545024 & 1.921 & 2.1018 & TRN & & \\
\hline CHEMBL56465 & 545024 & 1.824 & 2.5246 & TRN & & \\
\hline CHEMBL299271 & 545024 & 2.745 & 2.8805 & TRN & & \\
\hline CHEMBL55599 & 545024 & 1.796 & 2.214 & TRN & & \\
\hline CHEMBL300757 & 545024 & 2.1430 & 20000000 & 002 & 2.0163 & TRN \\
\hline CHEMBL51912 & 545024 & 2.244 & 1.6008 & TRN & & \\
\hline CHEMBL296376 & 545024 & 3.0180 & 00000000 & 002 & 2.6713 & $T N$ \\
\hline CHEMBL51738 & 545024 & 2.824 & 2.5065 & TST & & \\
\hline CHEMBL292464 & 545024 & 2.569 & 2.2936 & TST & & \\
\hline CHEMBL52068 & 545024 & 2.061 & 1.7987 & TST & & \\
\hline CHEMBL55747 & 545024 & 1.921 & 1.9309 & TST & & \\
\hline CHEMBL55187 & 545024 & 5.0 & 5.1452 & TRN & & \\
\hline CHEMBL55186 & 545024 & 4.398 & 4.1361 & TRN & & \\
\hline CHEMBL55997 & 545024 & 3.398 & 3.4297 & TRN & & \\
\hline CHEMBL55951 & 545024 & 5.155 & 4.6436 & TRN & & \\
\hline
\end{tabular}




\begin{tabular}{|c|c|c|c|c|c|}
\hline \multicolumn{6}{|c|}{ Supplemental Table S2.txt } \\
\hline CHEMBL449967 & 557715 & 5.5436 & 5.4267 & TRN & \\
\hline CHEMBL507502 & 557715 & 6.3565 & 6.4342 & TRN & \\
\hline CHEMBL448816 & 557715 & 5.5735 & 5.5628 & TRN & \\
\hline CHEMBL472401 & 557715 & 5.8761 & 5.9261 & TRN & \\
\hline CHEMBL443091 & 557715 & 6.0862 & 6.1888 & TRN & \\
\hline CHEMBL499413 & 557715 & 6.8239 & 6.9005 & TRN & \\
\hline CHEMBL501267 & 557715 & 6.1427 & 6.0817 & TRN & \\
\hline CHEMBL404313 & 557715 & 3.699 & 5.3065 & TST & \\
\hline CHEMBL443663 & 557715 & 6.1805 & 6.0481 & TRN & \\
\hline CHEMBL472896 & 557715 & 5.5834 & 5.1581 & TST & \\
\hline CHEMBL461344 & 557715 & 5.3224 & 5.0985 & TRN & \\
\hline CHEMBL169 & 557715 & 5.5114 & 5.1163 & TST & \\
\hline CHEMBL506556 & 557715 & 6.2076 & 6.3224 & TRN & \\
\hline CHEMBL508834 & 557715 & 4.7865 & 5.1011 & TRN & \\
\hline CHEMBL470029 & 557715 & 5.2741 & 5.1552 & TST & \\
\hline CHEMBL446573 & 557715 & 6.2757 & 6.0167 & TRN & \\
\hline CHEMBL449613 & 557715 & 5.4802 & 5.1001 & TRN & \\
\hline CHEMBL506260 & 557715 & 6.284 & 6.3381 & TRN & \\
\hline CHEMBL504704 & 557715 & 6.3468 & 6.4472 & TRN & \\
\hline CHEMBL461165 & 557715 & 5.0362 & 5.1216 & TRN & \\
\hline CHEMBL452449 & 557715 & 6.2596 & 6.1422 & TRN & \\
\hline CHEMBL504291 & 557715 & 6.0555 & 6.0817 & TRN & \\
\hline CHEMBL445491 & 557715 & 6.1079 & 6.0817 & TRN & \\
\hline CHEMBL481854 & 557715 & 4.9073 & 5.2326 & TST & \\
\hline CHEMBL516988 & 557715 & 3.699 & 4.1245 & TST & \\
\hline CHEMBL447660 & 557715 & 6.2924 & 6.385 & TRN & \\
\hline CHEMBL443398 & 557715 & 6.1871 & 6.2745 & TRN & \\
\hline CHEMBL508831 & 557715 & 6.2676 & 6.1352 & TRN & \\
\hline CHEMBL400074 & 557715 & 3.699 & 3.9818 & TRN & \\
\hline CHEMBL445301 & 557715 & 5.065 & 5.1866 & TRN & \\
\hline CHEMBL510867 & 557715 & 6.2218 & 6.3456 & TRN & \\
\hline CHEMBL457064 & 557715 & 4.8114 & 4.9735 & TRN & \\
\hline CHEMBL437964 & 557715 & 5.0947 & 5.1082 & TST & \\
\hline CHEMBL 301567 & 557715 & 6.2518 & 6.1365 & TRN & \\
\hline CHEMBL509868 & 557715 & 6.2291 & 6.2199 & TRN & \\
\hline CHEMBL502586 & 557715 & 5.3391 & 5.3902 & TRN & \\
\hline CHEMBL449659 & 557715 & 6.2441 & 6.3296 & TRN & \\
\hline CHEMBL443950 & 557715 & 6.2291 & 6.0817 & TRN & \\
\hline CHEMBL211369 & 557715 & 5.6326 & 5.5996 & TRN & \\
\hline CHEMBL472400 & 557715 & 5.6778 & 5.28799 & 9999999999 & TRN \\
\hline CHEMBL511000 & 557715 & 5.4962 & 5.6456 & TRN & \\
\hline CHEMBL462163 & 557715 & 6.2147 & 6.3073 & TRN & \\
\hline CHEMBL391533 & 557715 & 5.2604 & 5.4393 & TST & \\
\hline CHEMBL448797 & 557715 & 6.2007 & 6.2725 & TRN & \\
\hline CHEMBL506934 & 557715 & 5.5391 & 5.6084 & TRN & \\
\hline CHEMBL510912 & 557715 & 5.0915 & 5.0322 & TRN & \\
\hline CHEMBL504397 & 557715 & 5.5654 & 5.487 & TRN & \\
\hline CHEMBL450403 & 557715 & 6.2596 & 6.1601 & TRN & \\
\hline
\end{tabular}


Supplemental Table S2.txt

\begin{tabular}{|c|c|c|c|c|c|}
\hline CHEMBL267225 & 557715 & 3.699 & 5.0345 & TST & \\
\hline CHEMBL446073 & 557715 & 5.224 & 5.6676 & TST & \\
\hline CHEMBL487412 & 557715 & 5.3526 & 5.0037 & TST & \\
\hline CHEMBL446005 & 557715 & 5.3354 & 6.2142 & TST & \\
\hline CHEMBL489670 & 557715 & 5.5452 & 5.2464 & TST & \\
\hline CHEMBL129681 & 557715 & 5.2418 & 5.3059 & TST & \\
\hline CHEMBL1582862 & 688761 & 6.5376 & 5.7878 & TRN & \\
\hline CHEMBL1428673 & 688761 & 6.7033 & 6.5912 & TRN & \\
\hline CHEMBL1501255 & 688761 & 6.6073 & 6.3773 & TRN & \\
\hline CHEMBL1566026 & 688761 & 6.3028 & 6.1491 & TRN & \\
\hline CHEMBL3213314 & 688761 & 6.2487 & 6.3756 & TRN & \\
\hline CHEMBL1545291 & 688761 & 6.5482 & 6.5483 & TRN & \\
\hline CHEMBL1343527 & 688761 & 6.4437 & 6.6547 & TRN & \\
\hline CHEMBL1461878 & 688761 & 6.2757 & 5.3153 & TRN & \\
\hline CHEMBL1448605 & 688761 & 6.6234 & 5.9448 & TRN & \\
\hline CHEMBL1570344 & 688761 & 6.38399 & 99999999 & 995 & 6.1033 \\
\hline CHEMBL1339785 & 688761 & 6.1568 & 5.9368 & TST & \\
\hline CHEMBL1334136 & 688761 & 6.5171 & 6.3075 & TRN & \\
\hline CHEMBL1431361 & 688761 & 6.4935 & 6.4791 & TRN & \\
\hline CHEMBL3210095 & 688761 & 6.3925 & 6.4343 & TST & \\
\hline CHEMBL1557142 & 688761 & 3.9208 & 5.9721 & TST & \\
\hline CHEMBL1491745 & 688761 & 3.9208 & 5.2966 & TRN & \\
\hline CHEMBL1561135 & 688761 & 5.7729 & 5.7828 & TRN & \\
\hline CHEMBL1358014 & 688761 & 5.3014 & 6.2199 & TST & \\
\hline CHEMBL1420428 & 688761 & 6.2534 & 5.9902 & TST & \\
\hline CHEMBL1366816 & 688761 & 6.3298 & 5.9463 & TRN & \\
\hline CHEMBL1520035 & 688761 & 5.4862 & 5.8662 & TRN & \\
\hline CHEMBL1462008 & 688761 & 6.6861 & 6.5287 & TRN & \\
\hline CHEMBL3195196 & 688761 & 6.2358 & 6.6747 & TRN & \\
\hline CHEMBL1357288 & 688761 & 6.4522 & 6.2321 & TRN & \\
\hline CHEMBL1461600 & 688761 & 3.9208 & 5.9077 & TST & \\
\hline CHEMBL1502465 & 688761 & 3.9208 & 5.6438 & TRN & \\
\hline CHEMBL1422573 & 688761 & 6.2125 & 6.2227 & TRN & \\
\hline CHEMBL1547901 & 688761 & 6.3335 & 6.2211 & TRN & \\
\hline CHEMBL3196102 & 688761 & 6.4365 & 6.3736 & TRN & \\
\hline CHEMBL1310825 & 688761 & 6.2284 & 5.6012 & TRN & \\
\hline CHEMBL1991055 & 688761 & 6.556 & 6.6591 & TRN & \\
\hline CHEMBL1575402 & 688761 & 6.699 & 6.7162 & TRN & \\
\hline CHEMBL1541948 & 688761 & 6.2076 & 6.2078 & TRN & \\
\hline CHEMBL3192954 & 688761 & 6.4559 & 6.3014 & TRN & \\
\hline CHEMBL1327517 & 688761 & 3.9208 & 4.678 & TRN & \\
\hline CHEMBL1341119 & 688761 & 6.6421 & 6.1206 & TRN & \\
\hline CHEMBL1468618 & 688761 & 6.3915 & 5.7556 & TRN & \\
\hline CHEMBL3211154 & 688761 & 6.6271 & 5.7977 & TRN & \\
\hline CHEMBL1987798 & 688761 & 6.6421 & 6.7289 & TRN & \\
\hline CHEMBL1386310 & 688761 & 3.9208 & 6.0331 & TRN & \\
\hline CHEMBL1441858 & 688761 & 6.5654 & 5.769 & TRN & \\
\hline CHEMBL473106 & 688761 & 6.5421 & 5.9109 & TST & \\
\hline
\end{tabular}




\begin{tabular}{|c|c|c|c|c|c|}
\hline \multirow[b]{2}{*}{ CHEMBL1393784 } & \multicolumn{5}{|c|}{ Supplemental Table S2.txt } \\
\hline & 688761 & 6.0915 & 5.7101 & TRN & \\
\hline CHEMBL1324123 & 688761 & 6.6778 & 6.33700 & 0000000001 & TRN \\
\hline CHEMBL1545467 & 688761 & 3.9208 & 6.1557 & TST & \\
\hline CHEMBL1557898 & 688761 & 6.4828 & 5.8079 & TRN & \\
\hline CHEMBL1355755 & 688761 & 6.2269 & 6.4634 & TRN & \\
\hline CHEMBL1325762 & 688761 & 6.1818 & 5.30200 & 00000000005 & TRN \\
\hline CHEMBL1564261 & 688761 & 6.6216 & 6.9252 & TRN & \\
\hline CHEMBL1485806 & 688761 & 6.3344 & 5.9665 & TRN & \\
\hline CHEMBL1608506 & 688761 & 5.6234 & 6.2926 & TRN & \\
\hline CHEMBL41384 & 688761 & 6.983 & 6.2026 & TRN & \\
\hline CHEMBL1550861 & 688761 & 6.2366 & 5.9271 & TRN & \\
\hline CHEMBL3198303 & 688761 & 3.9208 & 6.1072 & TRN & \\
\hline CHEMBL1490334 & 688761 & 6.1007 & 6.2717 & TRN & \\
\hline CHEMBL1322727 & 688761 & 3.9208 & 5.441 & TRN & \\
\hline CHEMBL3197741 & 688761 & 6.2757 & 6.05399 & 9999999999 & TRN \\
\hline CHEMBL1431210 & 688761 & 5.171 & 6.5383 & TRN & \\
\hline CHEMBL1581089 & 688761 & 6.4134 & 6.0383 & TRN & \\
\hline CHEMBL1349436 & 688761 & 6.1158 & 6.3839 & TRN & \\
\hline CHEMBL1560147 & 688761 & 6.3615 & 6.1879 & TRN & \\
\hline CHEMBL1312289 & 688761 & 5.7263 & 6.3198 & TRN & \\
\hline CHEMBL1424754 & 688761 & 6.426 & 6.4729 & TRN & \\
\hline CHEMBL1330191 & 688761 & 3.9208 & 5.6457 & TRN & \\
\hline CHEMBL1460534 & 688761 & 6.8508 & 5.9472 & TRN & \\
\hline CHEMBL1525755 & 688761 & 3.9208 & 5.2696 & TST & \\
\hline CHEMBL1384739 & 688761 & 6.2007 & 5.1962 & TRN & \\
\hline CHEMBL1338750 & 688761 & 6.5272 & 6.4814 & TRN & \\
\hline CHEMBL1404163 & 688761 & 5.7289 & 5.8776 & TRN & \\
\hline CHEMBL1607208 & 688761 & 6.4377 & 6.6592 & TRN & \\
\hline CHEMBL 3197234 & 688761 & 6.3726 & 6.4793 & TRN & \\
\hline CHEMBL1556952 & 688761 & 6.4365 & 6.7198 & TST & \\
\hline CHEMBL1519639 & 688761 & 5.8748 & 6.1709 & TRN & \\
\hline CHEMBL1423951 & 688761 & 6.0106 & 5.8739 & TRN & \\
\hline CHEMBL1374706 & 688761 & 6.3507 & 6.249 & TRN & \\
\hline CHEMBL1602928 & 688761 & 6.4647 & 6.5646 & TRN & \\
\hline CHEMBL1586026 & 688761 & 6.5129 & 6.5089 & TRN & \\
\hline CHEMBL1360086 & 688761 & 6.4962 & 6.2754 & TRN & \\
\hline CHEMBL1323133 & 688761 & 6.5918 & 6.5221 & TRN & \\
\hline CHEMBL1328025 & 688761 & 6.4389 & 6.015 & TRN & \\
\hline CHEMBL3190627 & 688761 & 6.1439 & 6.6534 & TRN & \\
\hline CHEMBL1495474 & 688761 & 6.6198 & 5.8277 & TRN & \\
\hline CHEMBL1350043 & 688761 & 6.7595 & 6.1974 & TRN & \\
\hline CHEMBL1507676 & 688761 & 6.5817 & 6.5289 & TRN & \\
\hline CHEMBL1578372 & 688761 & 6.4711 & 6.3293 & TRN & \\
\hline CHEMBL1300939 & 688761 & 6.6038 & 7.07600 & 00000000005 & TST \\
\hline CHEMBL1451684 & 688761 & 5.5507 & 5.8097 & TRN & \\
\hline CHEMBL1408969 & 688761 & 6.5186 & 6.4442 & TRN & \\
\hline CHEMBL1493921 & 688761 & 6.1752 & 6.1556 & TRN & \\
\hline CHEMBL1566003 & 688761 & 6.1898 & 6.5983 & TRN & \\
\hline
\end{tabular}




\begin{tabular}{|c|c|c|c|c|c|}
\hline & & \multicolumn{4}{|c|}{ Supplemental Table s2.txt } \\
\hline CHEMBL1377188 & 688761 & 5.9255 & 5.2159 & TRN & \\
\hline CHEMBL3191975 & 688761 & 6.3706 & 5.919 & TST & \\
\hline CHEMBL1518032 & 688761 & 6.6345 & 6.5219 & TRN & \\
\hline CHEMBL1364646 & 688761 & 6.3335 & 6.5378 & TRN & \\
\hline CHEMBL1327977 & 688761 & 6.3036 & 6.0692 & TRN & \\
\hline CHEMBL1476311 & 688761 & 3.9208 & 6.0929 & TST & \\
\hline CHEMBL1586145 & 688761 & 6.3615 & 6.0285 & TRN & \\
\hline CHEMBL1309788 & 688761 & 6.4634 & 6.4199 & TRN & \\
\hline CHEMBL581251 & 688761 & 5.461 & 5.2769 & TST & \\
\hline CHEMBL1978063 & 688761 & 6.3716 & 6.2893 & TRN & \\
\hline CHEMBL1499250 & 688761 & 6.1337 & 6.3547 & TRN & \\
\hline CHEMBL1411596 & 688761 & 5.5366 & 5.6288 & TRN & \\
\hline CHEMBL1387251 & 688761 & 3.9208 & 4.9378 & TRN & \\
\hline CHEMBL1309378 & 688761 & 6.6596 & 6.4009 & TRN & \\
\hline CHEMBL1311920 & 688761 & 6.6819 & 6.7076 & TRN & \\
\hline CHEMBL1385904 & 688761 & 6.4056 & 6.24 & TRN & \\
\hline CHEMBL1606344 & 688761 & 6.1864 & 5.7882 & TRN & \\
\hline CHEMBL1574671 & 688761 & 6.4724 & 6.4381 & TST & \\
\hline CHEMBL1524533 & 688761 & 6.6253 & 6.3328 & TRN & \\
\hline CHEMBL1401361 & 688761 & 6.3757 & 6.0014 & TRN & \\
\hline CHEMBL1520273 & 688761 & 6.3686 & 6.1798 & TRN & \\
\hline CHEMBL 3214547 & 688761 & 6.3778 & 6.3252 & TRN & \\
\hline CHEMBL1531764 & 688761 & 6.5544 & 6.1971 & TRN & \\
\hline CHEMBL1471700 & 688761 & 6.5528 & 6.0767 & TST & \\
\hline CHEMBL1606705 & 688761 & 6.2557 & 5.8742 & TRN & \\
\hline CHEMBL1597921 & 688761 & 6.4609 & 6.3264 & TRN & \\
\hline CHEMBL1477375 & 688761 & 6.6126 & 6.6683 & TRN & \\
\hline CHEMBL1464721 & 688761 & 3.9208 & 5.7456 & TRN & \\
\hline CHEMBL1533107 & 688761 & 6.5575 & 6.1207 & TRN & \\
\hline CHEMBL1506203 & 688761 & 5.9263 & 5.6863 & TRN & \\
\hline CHEMBL1390789 & 688761 & 6.5243 & 6.8038 & TRN & \\
\hline CHEMBL1501560 & 688761 & 3.9208 & 5.7462 & TRN & \\
\hline CHEMBL1422230 & 688761 & 6.3307 & 6.2844 & TRN & \\
\hline CHEMBL1490976 & 688761 & 6.4535 & 6.7597 & TRN & \\
\hline CHEMBL1504256 & 688761 & 6.4067 & 6.6276 & TRN & \\
\hline CHEMBL1572118 & 688761 & 6.21899 & 99999999 & 6.0449 & TRN \\
\hline CHEMBL3197870 & 688761 & 6.4306 & 6.0048 & TRN & \\
\hline CHEMBL1431253 & 688761 & 6.4935 & 6.1406 & TRN & \\
\hline CHEMBL1530943 & 688761 & 6.4949 & 5.9721 & TRN & \\
\hline CHEMBL1581941 & 688761 & 6.5498 & 6.3903 & TRN & \\
\hline CHEMBL1323422 & 688761 & 6.6383 & 6.5936 & TRN & \\
\hline CHEMBL1605528 & 688761 & 6.1046 & 6.411006 & 00000000005 & TRN \\
\hline CHEMBL1478232 & 688761 & 6.21899 & 99999999 & 6.1156 & TST \\
\hline CHEMBL1363615 & 688761 & 6.9431 & 6.3365 & TRN & \\
\hline CHEMBL1523458 & 688761 & 6.3354 & 6.212006 & 0000000001 & TST \\
\hline CHEMBL3199639 & 688761 & 6.4976 & 6.2155 & TST & \\
\hline CHEMBL1977589 & 688761 & 6.644 & 6.193 & TRN & \\
\hline CHEMBL1494524 & 688761 & 5.9266 & 6.425 & TRN & \\
\hline
\end{tabular}


Supplemental Table S2.txt

\begin{tabular}{|c|c|c|c|c|c|}
\hline CHEMBL1402437 & 688761 & 5.2952 & 5.8806 & TRN & \\
\hline CHEMBL1542533 & 688761 & 6.0334 & 5.896 & TRN & \\
\hline CHEMBL1584476 & 688761 & 6.6003 & 6.188 & TRN & \\
\hline CHEMBL1531037 & 688761 & 5.0824 & 6.0945 & TRN & \\
\hline CHEMBL1543054 & 688761 & 6.5834 & 5.8397 & TRN & \\
\hline CHEMBL240333 & 688761 & 6.1739 & 5.7465 & TRN & \\
\hline CHEMBL1363291 & 688761 & 6.4685 & 6.2235 & TRN & \\
\hline CHEMBL1367908 & 688761 & 6.2434 & 6.1082 & TST & \\
\hline CHEMBL1595774 & 688761 & 6.6003 & 6.4908 & TRN & \\
\hline CHEMBL1382917 & 688761 & 3.9208 & 5.5087 & TST & \\
\hline CHEMBL1569442 & 688761 & 3.9208 & 5.5143 & TRN & \\
\hline CHEMBL3195212 & 688761 & 6.38200 & 00000000 & 11 & 6.4987 \\
\hline CHEMBL1440560 & 688761 & 6.1487 & 5.6472 & TRN & \\
\hline CHEMBL1335404 & 688761 & 6.4202 & 6.489 & TRN & \\
\hline CHEMBL1527038 & 688761 & 6.341 & 6.4937 & TRN & \\
\hline CHEMBL1579339 & 688761 & 6.4672 & 6.2746 & TRN & \\
\hline CHEMBL3197123 & 688761 & 6.1445 & 5.9393 & TRN & \\
\hline CHEMBL1565691 & 688761 & 6.6615 & 6.2381 & TRN & \\
\hline CHEMBL1987082 & 688761 & 6.4935 & 6.4467 & TRN & \\
\hline CHEMBL1588285 & 688761 & 7.1612 & 6.2869 & TRN & \\
\hline CHEMBL1381195 & 688761 & 5.9147 & 6.1094 & TST & \\
\hline CHEMBL1454245 & 688761 & 6.2211 & 6.2934 & TRN & \\
\hline CHEMBL1986090 & 688761 & 6.4895 & 6.0275 & TRN & \\
\hline CHEMBL1501851 & 688761 & 3.9208 & 5.9854 & TRN & \\
\hline CHEMBL1335318 & 688761 & 6.1361 & 6.6161 & TRN & \\
\hline CHEMBL1572929 & 688761 & 3.9208 & 5.506 & TRN & \\
\hline CHEMBL1479595 & 688761 & 6.6635 & 6.2689 & TRN & \\
\hline CHEMBL1600749 & 688761 & 6.5302 & 6.4105 & TRN & \\
\hline CHEMBL3190273 & 688761 & 5.2397 & 5.6964 & TRN & \\
\hline CHEMBL1441319 & 688761 & 6.0106 & 6.2999 & TRN & \\
\hline CHEMBL1485052 & 688761 & 6.0391 & 5.7594 & TRN & \\
\hline CHEMBL1559251 & 688761 & 6.4401 & 6.2504 & TRN & \\
\hline CHEMBL1404912 & 688761 & 6.1325 & 6.0233 & TRN & \\
\hline CHEMBL3193828 & 688761 & 6.2976 & 6.1698 & TST & \\
\hline CHEMBL1587805 & 688761 & 6.6345 & 6.4544 & TRN & \\
\hline CHEMBL1392667 & 688761 & 6.0334 & 6.494 & TRN & \\
\hline CHEMBL580324 & 688761 & 6.3575 & 5.3828 & TRN & \\
\hline CHEMBL1383379 & 688761 & 6.4389 & 7.0371 & TRN & \\
\hline CHEMBL1301732 & 688761 & 6.2807 & 6.3276 & TRN & \\
\hline CHEMBL3191418 & 688761 & 5.9034 & 5.59 & TRN & \\
\hline CHEMBL1608267 & 688761 & 6.6126 & 6.0077 & TRN & \\
\hline CHEMBL1499934 & 688761 & 6.6402 & 5.9346 & TST & \\
\hline CHEMBL1364392 & 688761 & 6.2373 & 6.3386 & TRN & \\
\hline CHEMBL1571509 & 688761 & 6.5072 & 6.2473 & TRN & \\
\hline CHEMBL3213101 & 688761 & 6.5918 & 6.7037 & TRN & \\
\hline CHEMBL3191871 & 688761 & 6.9172 & 5.8937 & TRN & \\
\hline CHEMBL1510400 & 688761 & 6.5072 & 6.5653 & TST & \\
\hline CHEMBL1499681 & 688761 & 3.9208 & 5.24 & TRN & \\
\hline
\end{tabular}


Supplemental Table S2.txt

\begin{tabular}{|c|c|c|c|c|c|}
\hline CHEMBL1427221 & 688761 & 6.1549 & 5.5287 & TRN & \\
\hline CHEMBL1585531 & 688761 & 6.3546 & 5.8689 & TRN & \\
\hline CHEMBL1469403 & 688761 & 6.3716 & 6.3869 & TRN & \\
\hline CHEMBL 3195612 & 688761 & 5.3242 & 5.9258 & TRN & \\
\hline CHEMBL1885024 & 688761 & 6.0255 & 5.38299 & 9999999999 & RN \\
\hline CHEMBL1489179 & 688761 & 6.4437 & 6.3273 & TRN & \\
\hline CHEMBL1599411 & 688761 & 6.5143 & 6.3237 & TRN & \\
\hline CHEMBL1325354 & 688761 & 6.4685 & 5.8318 & TRN & \\
\hline CHEMBL 3208161 & 688761 & 6.4202 & 6.3351 & TRN & \\
\hline CHEMBL1433155 & 688761 & 6.4112 & 6.6191 & TRN & \\
\hline CHEMBL600090 & 688761 & \multicolumn{2}{|c|}{6.2620000000000005} & 5.7931 & TRN \\
\hline CHEMBL1343460 & 688761 & 4.4202 & 4.8844 & TRN & \\
\hline CHEMBL1523841 & 688761 & 5.7953 & 5.9801 & TST & \\
\hline CHEMBL1321104 & 688761 & 5.9496 & 6.0075 & TRN & \\
\hline CHEMBL1511008 & 688761 & 6.4921 & 6.1208 & TRN & \\
\hline CHEMBL 3195432 & 688761 & 6.5017 & 6.0547 & TRN & \\
\hline CHEMBL1361693 & 688761 & 6.4685 & 6.3582 & TST & \\
\hline CHEMBL3191398 & 688761 & 6.0168 & 6.2114 & TST & \\
\hline CHEMBL1545433 & 688761 & 3.9208 & 4.94300 & 00000000005 & \\
\hline CHEMBL1536507 & 688761 & 6.6073 & 6.1955 & TST & \\
\hline CHEMBL1577922 & 688761 & 5.9727 & 6.1322 & TST & \\
\hline CHEMBL 3207793 & 688761 & \multicolumn{3}{|c|}{5.9670000000000005} & \\
\hline CHEMBL1543948 & 688761 & 6.2233 & 5.4291 & TST & \\
\hline CHEMBL1424373 & 688761 & 6.6021 & 6.459 & TST & \\
\hline CHEMBL1405401 & 688761 & 4.97 & 6.0968 & TST & \\
\hline CHEMBL1583879 & 688761 & 6.4023 & 6.8424 & TST & \\
\hline CHEMBL1602693 & 688761 & 6.1158 & 5.6304 & TST & \\
\hline CHEMBL1518080 & 688761 & 6.3726 & 6.2281 & TST & \\
\hline CHEMBL1510913 & 688761 & 6.5986 & 5.9929 & TST & \\
\hline CHEMBL1588860 & 688761 & 6.6198 & 6.1358 & TST & \\
\hline CHEMBL1522903 & 688761 & 6.3478 & 5.8357 & TST & \\
\hline CHEMBL1503325 & 688761 & 6.4056 & 6.3446 & TST & \\
\hline CHEMBL1501185 & 688761 & 6.6271 & 6.1793 & TST & \\
\hline CHEMBL1564332 & 688761 & 6.4123 & 6.6277 & TST & \\
\hline CHEMBL1342667 & 688761 & 6.2581 & 6.2258 & TST & \\
\hline CHEMBL1328527 & 688761 & 6.7932 & 6.0234 & TST & \\
\hline CHEMBL1427062 & 688761 & 6.8601 & 6.4227 & TST & \\
\hline CHEMBL1490429 & 688761 & 6.6364 & 5.9871 & TST & \\
\hline CHEMBL 3209635 & 688761 & 6.4647 & 6.8343 & TST & \\
\hline CHEMBL1417174 & 688761 & 6.4622 & 6.3069 & TST & \\
\hline CHEMBL1984052 & 688761 & 5.5693 & 6.6926 & TST & \\
\hline CHEMBL1577624 & 688761 & 5.765 & 5.5741 & TST & \\
\hline CHEMBL1369483 & 688761 & 6.3325 & 6.3479 & TST & \\
\hline CHEMBL1388901 & 688761 & 6.4306 & 6.2998 & TST & \\
\hline CHEMBL1336531 & 688761 & 6.3261 & 6.1177 & TST & \\
\hline CHEMBL1469054 & 688761 & 5.9481 & 6.2032 & TST & \\
\hline CHEMBL1403922 & 688761 & 6.6655 & 6.3191 & TST & \\
\hline CHEMBL1419233 & 688761 & 6.3726 & 6.6932 & TST & \\
\hline
\end{tabular}




\begin{tabular}{|c|c|c|c|c|}
\hline \multicolumn{5}{|c|}{ Supplemental Table S2.txt } \\
\hline CHEMBL1419848 & 688761 & 6.3233 & 5.8553 & TST \\
\hline CHEMBL 289959 & 468986 & 6.46 & 6.4323 & TRN \\
\hline CHEMBL271408 & 468986 & 8.45 & 8.5252 & TRN \\
\hline CHEMBL410253 & 468986 & 8.25 & 8.1956 & TRN \\
\hline CHEMBL271410 & 468986 & 8.03 & 8.0907 & TRN \\
\hline CHEMBL271587 & 468986 & 8.26 & 8.1649 & TRN \\
\hline CHEMBL 270895 & 468986 & 8.85 & 8.8681 & TRN \\
\hline CHEMBL271113 & 468986 & 7.79 & 7.7487 & TRN \\
\hline CHEMBL 271122 & 468986 & 9.55 & 9.4952 & TRN \\
\hline CHEMBL408399 & 468986 & 9.21 & 9.2535 & TRN \\
\hline CHEMBL405771 & 468986 & 8.82 & 8.8464 & TRN \\
\hline CHEMBL 272187 & 468986 & 9.04 & 9.0515 & TRN \\
\hline CHEMBL 272865 & 468986 & 9.29 & 9.2231 & TRN \\
\hline CHEMBL 272634 & 468986 & 8.14 & 8.1143 & TRN \\
\hline CHEMBL427832 & 468986 & 8.92 & 8.9291 & TRN \\
\hline CHEMBL271623 & 468986 & 8.03 & 8.0109 & TRN \\
\hline CHEMBL271532 & 468986 & 8.3 & 8.3469 & TRN \\
\hline CHEMBL272895 & 468986 & 8.26 & 8.2172 & TRN \\
\hline CHEMBL271334 & 468986 & 8.72 & 8.6681 & TRN \\
\hline CHEMBL405398 & 468986 & 8.49 & 8.5122 & TRN \\
\hline CHEMBL 270966 & 468986 & 7.39 & 7.4281 & TRN \\
\hline CHEMBL411243 & 468986 & 8.07 & 8.1056 & TRN \\
\hline CHEMBL 270501 & 468986 & 8.13 & 8.2078 & TRN \\
\hline CHEMBL408647 & 468986 & 8.05 & 8.0473 & TRN \\
\hline CHEMBL 270713 & 468986 & 7.34 & 7.3137 & TRN \\
\hline CHEMBL406004 & 468986 & 7.92 & 7.9615 & TRN \\
\hline CHEMBL 272477 & 468986 & 7.85 & 7.8264 & TRN \\
\hline CHEMBL410635 & 468986 & 8.49 & 8.4904 & TRN \\
\hline CHEMBL 270695 & 468986 & 9.03 & 9.0548 & TRN \\
\hline CHEMBL408397 & 468986 & 8.58 & 8.565 & TRN \\
\hline CHEMBL270696 & 468986 & 9.61 & 9.6161 & TRN \\
\hline CHEMBL416307 & 468986 & 8.52 & 8.3585 & TST \\
\hline CHEMBL299881 & 468986 & 8.63 & 7.9458 & TST \\
\hline CHEMBL52829 & 468986 & 8.39 & 8.445 & TRN \\
\hline CHEMBL52591 & 468986 & 8.36 & 8.418 & TRN \\
\hline CHEMBL298931 & 468986 & 7.76 & 7.6755 & TRN \\
\hline CHEMBL52823 & 468986 & 6.42 & 6.3332 & TRN \\
\hline CHEMBL271328 & 468986 & 8.63 & 9.1925 & TST \\
\hline CHEMBL53426 & 468986 & 9.6 & 9.3593 & TST \\
\hline CHEMBL417420 & 468986 & 8.53 & 8.8311 & TST \\
\hline CHEMBL 294475 & 468986 & 9.09 & 8.9199 & TST \\
\hline CHEMBL51854 & 468986 & 8.42 & 8.3873 & TRN \\
\hline CHEMBL53777 & 468986 & 9.02 & 8.9694 & TRN \\
\hline CHEMBL 299622 & 468986 & 9.11 & 9.0167 & TRN \\
\hline CHEMBL53831 & 468986 & 8.82 & 8.9387 & TRN \\
\hline CHEMBL53311 & 468986 & 7.08 & 7.1707 & TRN \\
\hline CHEMBL53310 & 468986 & 7.88 & 7.8857 & TRN \\
\hline CHEMBL301549 & 468986 & 6.58 & 6.5488 & TRN \\
\hline
\end{tabular}




\begin{tabular}{|c|c|c|c|c|c|}
\hline \multicolumn{6}{|c|}{ Supplemental Table S2.txt } \\
\hline CHEMBL50245 & 468986 & 6.48 & 6.4825 & TRN & \\
\hline CHEMBL298637 & 468986 & 7.28 & 7.2987 & TRN & \\
\hline CHEMBL291701 & 468986 & 6.16 & 6.1875 & TRN & \\
\hline CHEMBL54474 & 468986 & 6.02 & 6.0214 & TRN & \\
\hline CHEMBL54475 & 468986 & 6.16 & 6.0013 & TST & \\
\hline CHEMBL53299 & 468986 & 8.63 & 7.2161 & TST & \\
\hline CHEMBL53062 & 468986 & 8.58 & 8.6212 & TRN & \\
\hline CHEMBL53121 & 468986 & 6.9 & 6.9137 & TRN & \\
\hline CHEMBL296377 & 468986 & 7.39 & 7.3603 & TRN & \\
\hline CHEMBL51265 & 468986 & 7.29 & 7.3394 & TRN & \\
\hline CHEMBL405772 & 468986 & 7.39 & 7.374 & TRN & \\
\hline CHEMBL402452 & 468986 & 7.15 & 7.1557 & TRN & \\
\hline CHEMBL270975 & 468986 & 6.92 & 6.8904 & TRN & \\
\hline CHEMBL270924 & 468986 & 6.07 & 6.0695 & TRN & \\
\hline CHEMBL 271540 & 468986 & 5.31 & 5.2942 & TRN & \\
\hline CHEMBL406236 & 468986 & 5.74 & 5.7342 & TRN & \\
\hline CHEMBL124618 & 468986 & 5.27 & 7.137000 & 00000000005 & TST \\
\hline CHEMBL407591 & 468986 & 6.17 & 6.1687 & TRN & \\
\hline CHEMBL441335 & 468986 & 6.88 & 6.8742 & TRN & \\
\hline CHEMBL408105 & 468986 & 5.43 & 7.7401 & TST & \\
\hline CHEMBL408351 & 468986 & 5.32 & 5.3261 & TRN & \\
\hline CHEMBL271617 & 468986 & 7.59 & 7.5855 & TRN & \\
\hline CHEMBL258598 & 468986 & 8.0 & 7.9481 & TRN & \\
\hline CHEMBL273116 & 468986 & 6.61 & 8.0942 & TST & \\
\hline CHEMBL441332 & 468986 & 7.39 & 6.3836 & TST & \\
\hline CHEMBL272258 & 468986 & 6.6 & 6.6105 & TRN & \\
\hline CHEMBL441333 & 468986 & 7.4 & 7.4044 & TRN & \\
\hline CHEMBL269889 & 468986 & 7.88 & 7.9709 & TRN & \\
\hline CHEMBL270921 & 468986 & 7.53 & 7.5124 & TRN & \\
\hline CHEMBL52665 & 468986 & 7.45 & 7.4453 & TRN & \\
\hline CHEMBL50519 & 468986 & 8.36 & 8.3593 & TRN & \\
\hline CHEMBL53796 & 468986 & 8.01 & 8.0381 & TRN & \\
\hline CHEMBL53156 & 468986 & 8.5 & 9.0259 & TST & \\
\hline CHEMBL54788 & 468986 & 7.35 & 7.7776 & TST & \\
\hline CHEMBL291496 & 468986 & 7.74 & 7.9347 & TST & \\
\hline CHEMBL300217 & 468986 & 8.11 & 7.7765 & TST & \\
\hline CHEMBL54805 & 468986 & 7.46 & 7.8684 & TST & \\
\hline CHEMBL328106 & 468986 & 10.14 & 8.2394 & TST & \\
\hline CHEMBL418967 & 468986 & 9.76 & 9.176 & TST & \\
\hline CHEMBL35820 & 468986 & 11.22 & 10.1376 & TST & \\
\hline CHEMBL66409 & 468986 & 7.6 & 7.5641 & TRN & \\
\hline CHEMBL65038 & 468986 & 7.82 & 7.8188 & TRN & \\
\hline CHEMBL92936 & 468986 & 7.16 & 7.1687 & TRN & \\
\hline CHEMBL63469 & 468986 & 8.18 & 8.1593 & TRN & \\
\hline CHEMBL96780 & 468986 & 8.42 & 8.3999 & TRN & \\
\hline CHEMBL96489 & 468986 & 6.79 & 6.8069 & TRN & \\
\hline CHEMBL92937 & 468986 & 9.16 & 9.1545 & TRN & \\
\hline CHEMBL90013 & 468986 & 7.95 & 7.9257 & TRN & \\
\hline
\end{tabular}




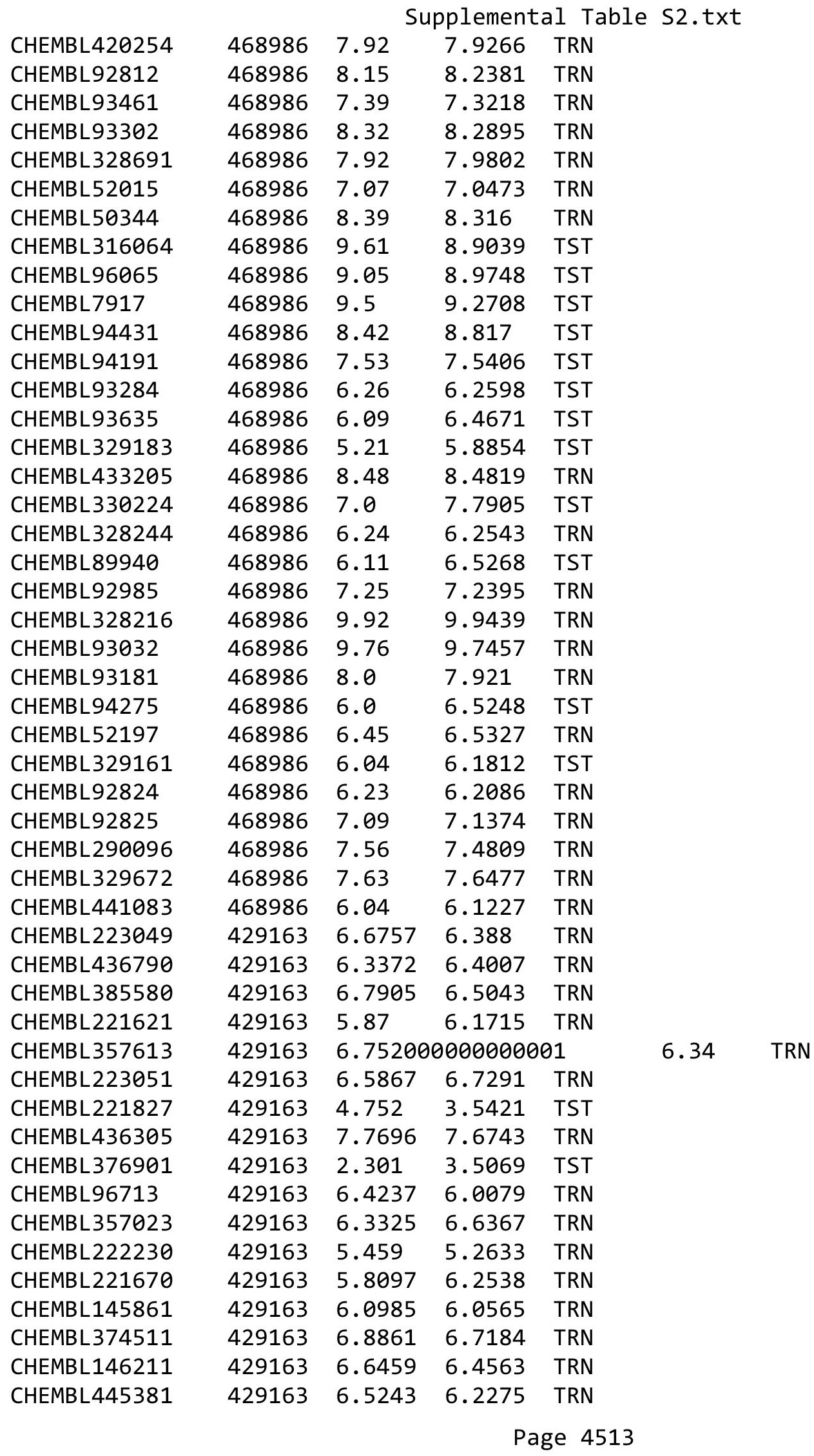




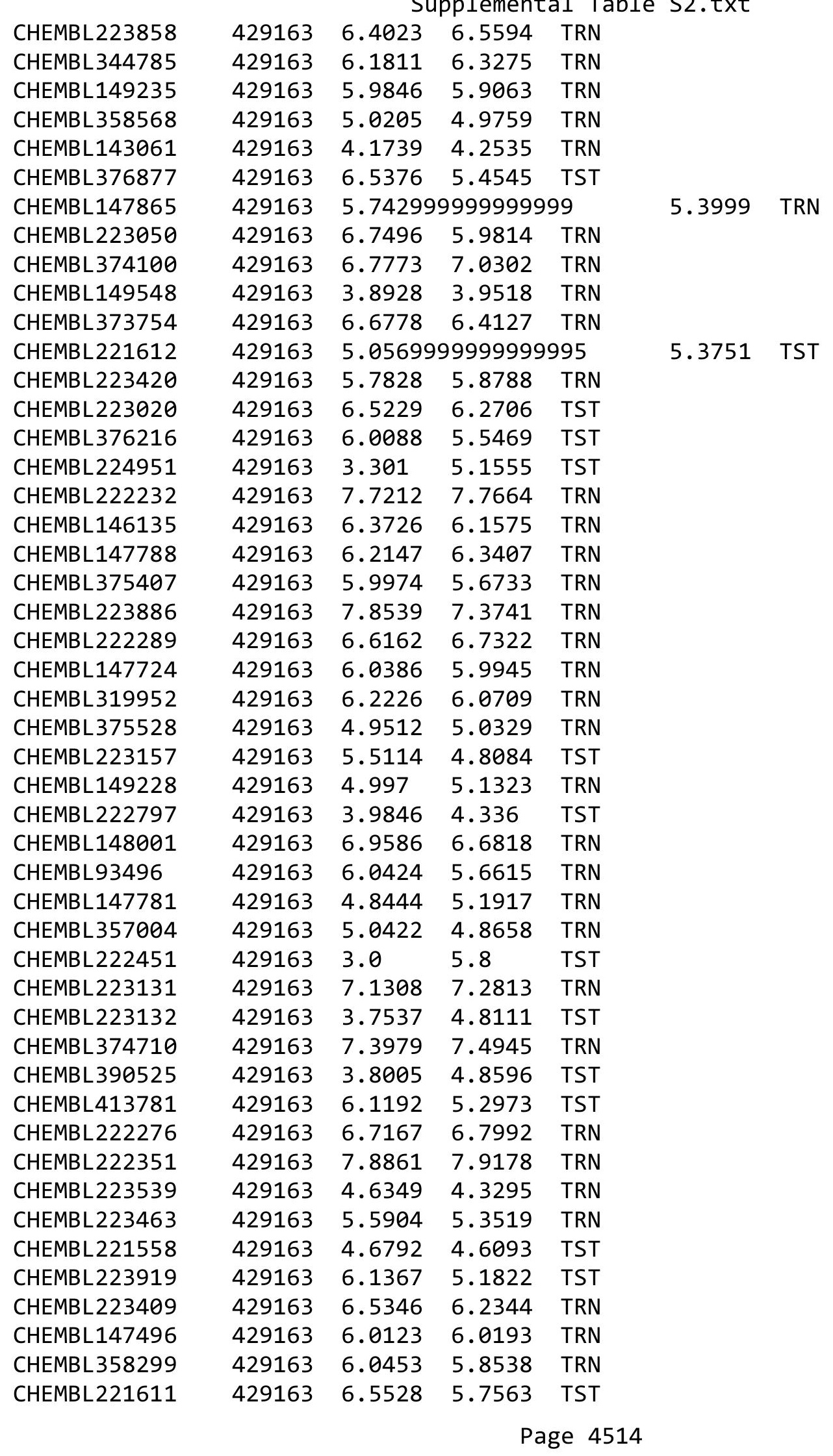




\begin{tabular}{|c|c|c|c|c|c|c|}
\hline \multirow[b]{2}{*}{ CHEMBL142319 } & & \multicolumn{5}{|c|}{ Supplemental Table S2.txt } \\
\hline & 429163 & 5.6057 & 5.4767 & TRN & & \\
\hline CHEMBL222964 & 429163 & 6.8477 & 6.1936 & TRN & & \\
\hline CHEMBL222220 & 429163 & 6.9586 & 6.4778 & TST & & \\
\hline CHEMBL223591 & 429163 & \multicolumn{3}{|c|}{5.837999999999999} & 6.0519 & TRN \\
\hline CHEMBL147055 & 429163 & 7.1249 & 7.5891 & TRN & & \\
\hline CHEMBL221619 & 429163 & 6.8386 & 6.8123 & TRN & & \\
\hline CHEMBL223078 & 429163 & 6.7471 & 6.7322 & TRN & & \\
\hline CHEMBL222687 & 429163 & 6.0 & 4.5853 & TST & & \\
\hline CHEMBL149234 & 429163 & 5.1893 & 5.1532 & TRN & & \\
\hline CHEMBL223462 & 429163 & 6.4737 & 6.209 & TRN & & \\
\hline CHEMBL96597 & 429163 & 7.5686 & 7.4826 & TRN & & \\
\hline CHEMBL341881 & 429163 & 6.7645 & 6.7424 & TRN & & \\
\hline CHEMBL148235 & 429163 & 5.596 & 6.2075 & TRN & & \\
\hline CHEMBL223489 & 429163 & 6.7212 & 6.671 & TRN & & \\
\hline CHEMBL222376 & 429163 & 4.5998 & 5.1916 & TST & & \\
\hline CHEMBL93267 & 429163 & 5.6341 & 5.7026 & TRN & & \\
\hline CHEMBL221986 & 429163 & 6.066 & 6.1318 & TRN & & \\
\hline CHEMBL374988 & 429163 & 6.4214 & 6.0211 & TRN & & \\
\hline CHEMBL426568 & 429163 & 3.0 & 3.9828 & TST & & \\
\hline CHEMBL389268 & 429163 & 7.0132 & 6.2646 & TST & & \\
\hline CHEMBL375089 & 429163 & 6.7471 & 7.0952 & TRN & & \\
\hline CHEMBL375988 & 429163 & \multicolumn{3}{|c|}{5.2620000000000005} & 4.9325 & TRN \\
\hline CHEMBL420815 & 429163 & 6.3809 & 5.9088 & TRN & & \\
\hline CHEMBL141331 & 429163 & 4.9385 & 4.7144 & TST & & \\
\hline CHEMBL387317 & 429163 & 6.1864 & 6.4266 & TRN & & \\
\hline CHEMBL356974 & 429163 & 5.7592 & 5.7628 & TRN & & \\
\hline CHEMBL374871 & 429163 & 6.2967 & 6.6819 & TRN & & \\
\hline CHEMBL95119 & 429163 & 6.5918 & 6.3866 & TRN & & \\
\hline CHEMBL222427 & 429163 & 3.9905 & 3.9147 & TST & & \\
\hline CHEMBL357836 & 429163 & 6.6383 & \multicolumn{3}{|c|}{6.832000000000001} & TRN \\
\hline CHEMBL375192 & 429163 & 4.3105 & 4.4747 & TST & & \\
\hline CHEMBL223354 & 429163 & 6.1238 & 7.0405 & TRN & & \\
\hline CHEMBL376913 & 429163 & 6.9031 & 6.7013 & TRN & & \\
\hline CHEMBL144148 & 429163 & 6.9355 & 7.0481 & TRN & & \\
\hline CHEMBL221671 & 429163 & 6.699 & 6.6123 & TRN & & \\
\hline CHEMBL223352 & 429163 & 5.7731 & 6.2029 & TRN & & \\
\hline CHEMBL147852 & 429163 & 5.8136 & 5.5706 & TRN & & \\
\hline CHEMBL221575 & 429163 & 5.4559 & 6.3387 & TST & & \\
\hline CHEMBL344278 & 429163 & 7.2366 & 6.8339 & TRN & & \\
\hline CHEMBL343400 & 429163 & 6.7645 & 6.8399 & TRN & & \\
\hline CHEMBL223590 & 429163 & 2.7991 & 3.9565 & TRN & & \\
\hline CHEMBL1264 & 429163 & 5.5198 & 5.9392 & TRN & & \\
\hline CHEMBL223537 & 429163 & 6.8633 & 7.4106 & TRN & & \\
\hline CHEMBL376083 & 429163 & 7.585 & 7.5361 & TRN & & \\
\hline CHEMBL146558 & 429163 & \multicolumn{3}{|c|}{6.7620000000000005} & 6.1596 & TRN \\
\hline CHEMBL426728 & 429163 & 7.2291 & 7.7096 & TRN & & \\
\hline CHEMBL223736 & 429163 & 5.7908 & 5.5355 & TST & & \\
\hline \multirow[t]{2}{*}{ CHEMBL146084 } & 429163 & 5.9508 & 6.273 & TRN & & \\
\hline & & \multicolumn{5}{|c|}{ Page 4515} \\
\hline
\end{tabular}




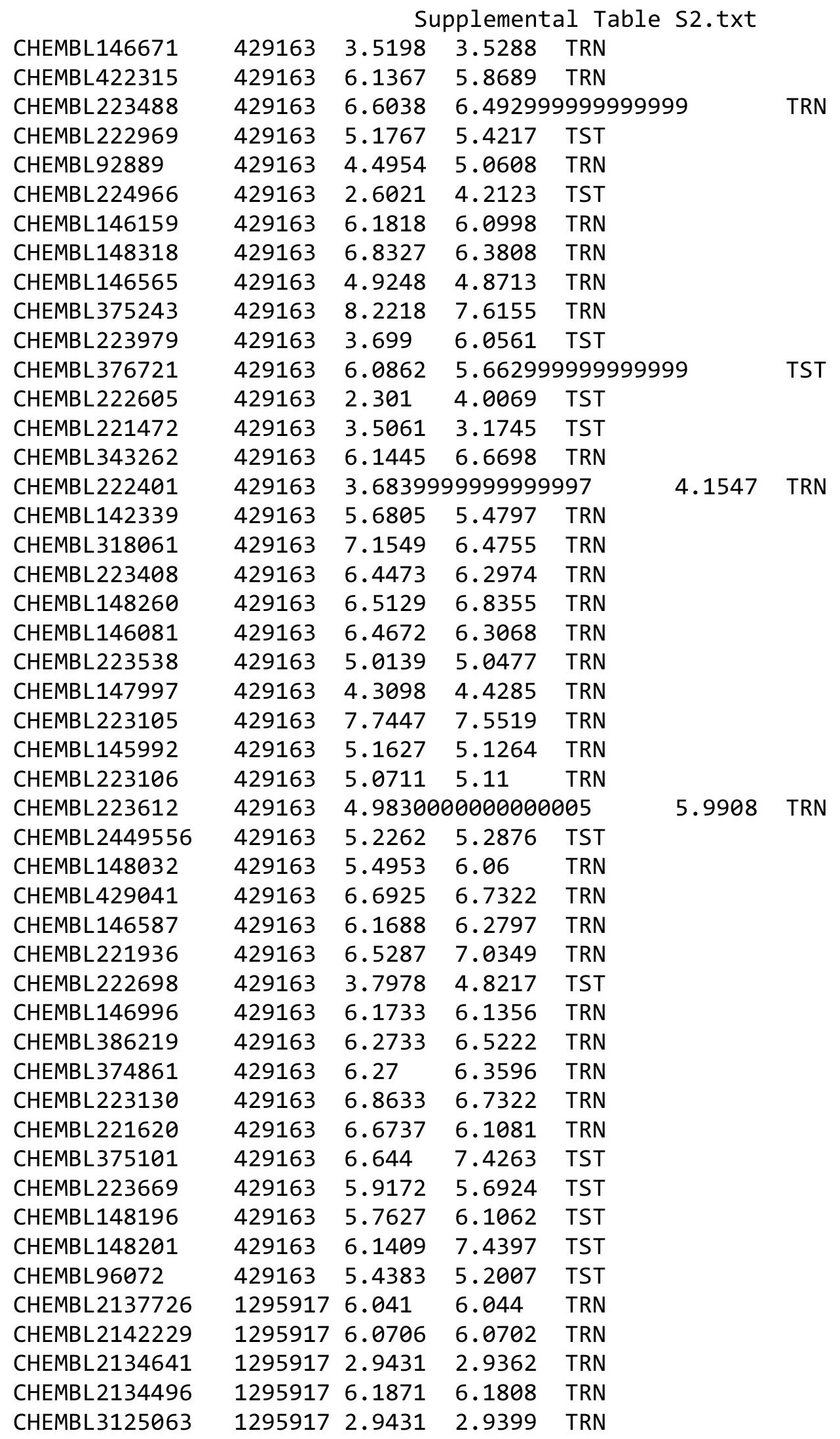

Page 4516 
Supplemental Table S2.txt

\begin{tabular}{|c|c|c|c|c|c|}
\hline CHEMBL 3125074 & 1295917 & 2.9431 & 2.9621 & TRN & \\
\hline CHEMBL 2136769 & 1295917 & 5.8239 & 5.8203 & TRN & \\
\hline CHEMBL 2138934 & 1295917 & 4.9393 & 4.939 & TRN & \\
\hline CHEMBL2136420 & 1295917 & 5.1871 & 5.3131 & TST & \\
\hline CHEMBL 2132174 & 1295917 & 6.2366 & 6.2343 & TRN & \\
\hline CHEMBL 2141810 & 1295917 & 5.9208 & 5.9099 & TRN & \\
\hline CHEMBL 2145195 & 1295917 & 6.1367 & 5.7053 & TST & \\
\hline CHEMBL 2131647 & 1295917 & 6.2924 & 6.3468 & TRN & \\
\hline CHEMBL2130801 & 1295917 & 2.9431 & 2.9397 & TRN & \\
\hline CHEMBL3125061 & 1295917 & 2.9431 & 4.2468 & TST & \\
\hline CHEMBL3125076 & 1295917 & 2.9431 & 3.3074 & TST & \\
\hline CHEMBL 2131241 & 1295917 & 6.1367 & 6.1448 & TRN & \\
\hline CHEMBL2135970 & 1295917 & 6.1367 & 6.1388 & TRN & \\
\hline CHEMBL3125070 & 1295917 & 5.7959 & 5.7922 & TST & \\
\hline CHEMBL3125068 & 1295917 & 6.1367 & 6.1198 & TRN & \\
\hline CHEMBL3125066 & 1295917 & 5.7959 & 5.789 & TRN & \\
\hline CHEMBL3125073 & 1295917 & 6.0 & 6.0024 & TRN & \\
\hline CHEMBL 3125065 & 1295917 & 6.1871 & 6.1926 & TRN & \\
\hline CHEMBL1471788 & 1295917 & 6.1079 & 6.0666 & TRN & \\
\hline CHEMBL 2144006 & 1295917 & 5.7959 & 5.8116 & TRN & \\
\hline CHEMBL 2137247 & 1295917 & 6.041 & 6.039 & TRN & \\
\hline CHEMBL 2131708 & 1295917 & 6.1367 & 6.1315 & TRN & \\
\hline CHEMBL 2134150 & 1295917 & 5.2396 & 5.2287 & TRN & \\
\hline CHEMBL 2135778 & 1295917 & 6.0915 & 6.0937 & TRN & \\
\hline CHEMBL 2140712 & 1295917 & 6.0915 & 6.0991 & TRN & \\
\hline CHEMBL3125062 & 1295917 & 2.9431 & 2.9469 & TRN & \\
\hline CHEMBL3125064 & 1295917 & 5.5376 & 5.5363 & TRN & \\
\hline CHEMBL 2144182 & 1295917 & 6.0915 & 6.0879 & TRN & \\
\hline CHEMBL2135596 & 1295917 & 6.1367 & 6.1421 & TRN & \\
\hline CHEMBL 2135185 & 1295917 & 6.2924 & 6.2799 & TRN & \\
\hline CHEMBL 2132783 & 1295917 & 4.9393 & 4.9487 & TRN & \\
\hline CHEMBL 2137357 & 1295917 & 6.2147 & 6.2264 & TRN & \\
\hline CHEMBL 2136332 & 1295917 & 6.041 & 6.0239 & TRN & \\
\hline CHEMBL2139551 & 1295917 & 5.2366 & 5.2463 & TRN & \\
\hline CHEMBL 3125060 & 1295917 & 2.9431 & 3.9213 & TST & \\
\hline CHEMBL 2144272 & 1295917 & 5.699 & 5.6984 & TRN & \\
\hline CHEMBL 2135885 & 1295917 & 6.5376 & 6.5501 & TRN & \\
\hline CHEMBL3125071 & 1295917 & 2.9431 & 2.943 & TRN & \\
\hline CHEMBL 2142475 & 1295917 & 6.0915 & 6.08899 & 99999999995 & TRN \\
\hline CHEMBL 2138335 & 1295917 & 2.9431 & 2.9391 & TRN & \\
\hline CHEMBL3125075 & 1295917 & 2.9431 & 2.9519 & TRN & \\
\hline CHEMBL3125059 & 1295917 & 6.3872 & 6.3914 & TRN & \\
\hline CHEMBL 2138780 & 1295917 & 5.8861 & 5.8873 & TRN & \\
\hline CHEMBL3125067 & 1295917 & 4.8386 & 5.4912 & TST & \\
\hline CHEMBL 2143378 & 1295917 & 2.9431 & 2.9466 & TRN & \\
\hline CHEMBL3125072 & 1295917 & 2.9431 & 2.9342 & TRN & \\
\hline CHEMBL 2134995 & 1295917 & 4.6402 & 2.6507 & TST & \\
\hline CHEMBL2142819 & 1295917 & 2.9431 & 2.9377 & TRN & \\
\hline
\end{tabular}

Page 4517 
Supplemental Table S2.txt

\begin{tabular}{|c|c|c|c|c|}
\hline CHEMBL 2135147 & 1295917 & 6.2366 & 6.2321 & TRN \\
\hline CHEMBL3125069 & 1295917 & 6.0915 & 6.0814 & TRN \\
\hline CHEMBL2132086 & 1295917 & 6.0 & 6.0035 & TRN \\
\hline CHEMBL 2142358 & 1295917 & 6.0655 & 6.0707 & TRN \\
\hline CHEMBL 2142213 & 1295917 & 6.5376 & 6.5297 & TRN \\
\hline CHEMBL 2144036 & 1295917 & 5.8239 & 4.6491 & TST \\
\hline CHEMBL 2136110 & 1295917 & 6.0915 & 5.8431 & TST \\
\hline CHEMBL2131191 & 1295917 & 6.1367 & 6.3459 & TST \\
\hline CHEMBL 2136415 & 1295917 & 6.1367 & 6.157 & TST \\
\hline CHEMBL 2141221 & 1295917 & 6.0 & 5.6818 & TST \\
\hline CHEMBL 2140870 & 1295917 & 4.9393 & 6.7194 & TST \\
\hline CHEMBL 2140805 & 1295917 & 5.7959 & 5.846 & TST \\
\hline CHEMBL 2140943 & 1295917 & 6.2366 & 6.7457 & TST \\
\hline CHEMBL2137192 & 1295917 & 5.7959 & 6.2639 & TST \\
\hline CHEMBL1257557 & 665507 & 4.5229 & 6.3625 & TST \\
\hline CHEMBL1257330 & 665507 & 6.7447 & 7.0051 & TRN \\
\hline CHEMBL1257799 & 665507 & 7.1249 & 6.343 & TRN \\
\hline CHEMBL1257208 & 665507 & 4.5229 & 5.6768 & TRN \\
\hline CHEMBL1258028 & 665507 & 5.6021 & 6.1177 & TRN \\
\hline CHEMBL1257556 & 665507 & 6.9208 & 6.2841 & TRN \\
\hline CHEMBL1258708 & 665507 & 7.1675 & 6.6235 & TRN \\
\hline CHEMBL1257441 & 665507 & 5.2147 & 5.7924 & TRN \\
\hline CHEMBL1258488 & 665507 & 6.9586 & 7.2079 & TRN \\
\hline CHEMBL1256009 & 665507 & 6.6021 & 6.4673 & TRN \\
\hline CHEMBL1257678 & 665507 & 6.6198 & 6.2288 & TRN \\
\hline CHEMBL1258829 & 665507 & 7.3188 & 7.1242 & TRN \\
\hline CHEMBL1258145 & 665507 & 5.0 & 6.2676 & TRN \\
\hline CHEMBL1258262 & 665507 & 5.0 & 6.1394 & TRN \\
\hline CHEMBL1257328 & 665507 & 6.9208 & 5.7924 & TRN \\
\hline CHEMBL1258374 & 665507 & 7.0915 & 6.38200 & 0000000001 \\
\hline CHEMBL1257327 & 665507 & 5.8665 & 5.7671 & TRN \\
\hline CHEMBL1258601 & 665507 & 6.7447 & 7.0531 & TRN \\
\hline CHEMBL1257918 & 665507 & 6.6576 & 6.4066 & TRN \\
\hline CHEMBL1257802 & 665507 & 4.5229 & 6.0605 & TST \\
\hline CHEMBL1258027 & 665507 & 6.2076 & 6.1579 & TRN \\
\hline CHEMBL1258487 & 665507 & 6.3279 & 6.4636 & TRN \\
\hline CHEMBL1257920 & 665507 & 4.5229 & 6.0766 & TST \\
\hline CHEMBL1258263 & 665507 & 7.1367 & 7.1602 & TRN \\
\hline CHEMBL1256010 & 665507 & 7.2218 & 6.6754 & TRN \\
\hline CHEMBL1257442 & 665507 & 6.0809 & 5.716 & TST \\
\hline CHEMBL1258030 & 665507 & 6.9586 & 7.0889 & TRN \\
\hline CHEMBL1257679 & 665507 & 6.5376 & 6.5405 & TRN \\
\hline CHEMBL1257329 & 665507 & 6.8539 & 6.9406 & TRN \\
\hline CHEMBL1257677 & 665507 & 6.284 & 6.25 & TRN \\
\hline CHEMBL1257800 & 665507 & 6.9586 & 6.4319 & TRN \\
\hline CHEMBL1258709 & 665507 & 6.9208 & 7.20100 & 00000000005 \\
\hline CHEMBL1258828 & 665507 & 6.2441 & 6.4781 & TRN \\
\hline CHEMBL1257558 & 665507 & 6.2441 & 6.4344 & TRN \\
\hline
\end{tabular}


Supplemental Table S2.txt

\begin{tabular}{|c|c|c|c|c|}
\hline CHEMBL1257917 & 665507 & 6.7959 & 6.3559 & TRN \\
\hline CHEMBL1258146 & 665507 & 6.6198 & 6.3492 & TRN \\
\hline CHEMBL1257443 & 665507 & 6.6021 & 6.3081 & TST \\
\hline CHEMBL1258944 & 665507 & 7.2518 & 7.1242 & TRN \\
\hline CHEMBL1258029 & 665507 & 6.4202 & 6.9976 & TRN \\
\hline CHEMBL1258261 & 665507 & 6.5686 & 6.2773 & TRN \\
\hline CHEMBL1257680 & 665507 & 4.5229 & 6.1448 & TST \\
\hline CHEMBL1257801 & 665507 & 4.5229 & 6.3489 & TST \\
\hline CHEMBL1258148 & 665507 & 7.2441 & 7.1629 & TRN \\
\hline CHEMBL1257559 & 665507 & 6.5686 & 6.5177 & TRN \\
\hline CHEMBL1258600 & 665507 & 6.5376 & 6.6942 & TRN \\
\hline CHEMBL1258147 & 665507 & 7.1871 & 7.0353 & TST \\
\hline CHEMBL1257919 & 665507 & 4.5229 & 6.0766 & TST \\
\hline CHEMBL1257207 & 665507 & 6.2007 & 6.481 & TST \\
\hline CHEMBL1257209 & 665507 & 7.0 & 7.0477 & TST \\
\hline CHEMBL1258943 & 665507 & 7.284 & 6.5733 & TST \\
\hline CHEMBL1258375 & 665507 & 7.3188 & 7.0386 & TST \\
\hline CHEMBL295316 & 149344 & 5.6198 & 5.8621 & TST \\
\hline CHEMBL32438 & 149344 & 5.2366 & 5.3065 & TRN \\
\hline CHEMBL 287540 & 149344 & 5.6198 & 5.6376 & TRN \\
\hline CHEMBL44308 & 149344 & 5.7959 & 5.8959 & TST \\
\hline CHEMBL297819 & 149344 & 6.2676 & 6.3916 & TRN \\
\hline CHEMBL296212 & 149344 & 5.1871 & 5.157 & TRN \\
\hline CHEMBL43162 & 149344 & 6.3098 & 6.2856 & TRN \\
\hline CHEMBL43539 & 149344 & 5.5376 & 5.3572 & TRN \\
\hline CHEMBL296919 & 149344 & 5.8239 & 5.5877 & TST \\
\hline CHEMBL440852 & 149344 & 5.6198 & 5.6716 & TRN \\
\hline CHEMBL287272 & 149344 & 5.5229 & 5.5046 & TRN \\
\hline CHEMBL284093 & 149344 & 5.4949 & 5.5419 & TRN \\
\hline CHEMBL291171 & 149344 & 6.7696 & 6.5511 & TRN \\
\hline CHEMBL288764 & 149344 & 7.0177 & 6.8233 & TRN \\
\hline CHEMBL 34027 & 149344 & 5.3979 & 5.5517 & TRN \\
\hline CHEMBL44291 & 149344 & 6.5528 & 6.6092 & TRN \\
\hline CHEMBL288630 & 149344 & 5.4437 & 5.5667 & TRN \\
\hline CHEMBL 36347 & 149344 & 5.1192 & 5.0664 & TRN \\
\hline CHEMBL42151 & 149344 & 5.4318 & 5.3653 & TRN \\
\hline CHEMBL43927 & 149344 & 6.8539 & 6.808 & TRN \\
\hline CHEMBL45038 & 149344 & 5.4685 & 5.4389 & TRN \\
\hline CHEMBL240963 & 149344 & 4.0 & 5.6302 & TST \\
\hline CHEMBL36340 & 149344 & 4.699 & 4.67399 & \\
\hline CHEMBL284496 & 149344 & 5.2218 & 5.4442 & TST \\
\hline CHEMBL 35298 & 149344 & 5.2366 & 5.1968 & TRN \\
\hline CHEMBL43979 & 149344 & 5.3372 & 5.19 & TRN \\
\hline CHEMBL287601 & 149344 & 5.4089 & 5.4222 & TRN \\
\hline CHEMBL 288682 & 149344 & 6.3468 & 6.4669 & TRN \\
\hline CHEMBL441038 & 149344 & 6.6383 & 6.5056 & TRN \\
\hline CHEMBL43041 & 149344 & 5.3565 & 5.2893 & TRN \\
\hline CHEMBL34462 & 149344 & 7.0555 & 6.9078 & TST \\
\hline
\end{tabular}




\begin{tabular}{|c|c|c|c|c|c|}
\hline & & & enco & & \\
\hline CHEMBL41049 & 149344 & 6.3665 & 6.4103 & TRN & \\
\hline CHEMBL42468 & 149344 & 6.2076 & 6.345 & TRN & \\
\hline CHEMBL44443 & 149344 & 5.2676 & 5.4479 & TST & \\
\hline CHEMBL42005 & 149344 & 6.3279 & 6.3545 & TRN & \\
\hline CHEMBL 35665 & 149344 & 5.4685 & 5.4536 & TRN & \\
\hline CHEMBL43926 & 149344 & 7.6198 & 7.2138 & TRN & \\
\hline CHEMBL35363 & 149344 & 5.3979 & 5.8581 & TRN & \\
\hline CHEMBL43049 & 149344 & 6.3098 & 6.3906 & TRN & \\
\hline CHEMBL 289525 & 149344 & 6.4815 & 6.5572 & TRN & \\
\hline CHEMBL 35445 & 149344 & 5.3872 & 5.25700 & 0000000001 & TRN \\
\hline CHEMBL 263420 & 149344 & 6.5376 & 6.7066 & TRN & \\
\hline CHEMBL43907 & 149344 & 5.4089 & 5.4806 & TRN & \\
\hline CHEMBL42106 & 149344 & 5.4318 & 5.7708 & TST & \\
\hline CHEMBL 284304 & 149344 & 6.699 & 6.6803 & TRN & \\
\hline CHEMBL34251 & 149344 & 5.5229 & 5.4181 & TRN & \\
\hline CHEMBL 290452 & 149344 & 5.6576 & 5.709 & TRN & \\
\hline CHEMBL44499 & 149344 & 5.7696 & 5.50299 & & TRN \\
\hline CHEMBL42379 & 149344 & 5.3565 & 5.3527 & TRN & \\
\hline CHEMBL44560 & 149344 & 5.0706 & 5.2507 & TRN & \\
\hline CHEMBL 284247 & 149344 & 5.3372 & 5.3621 & TRN & \\
\hline CHEMBL42238 & 149344 & 5.585 & 5.3948 & TRN & \\
\hline CHEMBL 296697 & 149344 & 6.2757 & 6.51399 & & TRN \\
\hline CHEMBL 285648 & 149344 & 5.7959 & 5.7981 & TST & \\
\hline CHEMBL35618 & 149344 & 5.4949 & 5.5323 & TRN & \\
\hline CHEMBL289457 & 149344 & 5.4318 & 5.4798 & TRN & \\
\hline CHEMBL44507 & 149344 & 6.3279 & 6.3132 & TRN & \\
\hline CHEMBL 295754 & 149344 & 5.585 & 5.2076 & TST & \\
\hline CHEMBL42892 & 149344 & 5.3665 & 5.656006 & 2000000001 & TST \\
\hline CHEMBL36304 & 149344 & 5.5229 & 5.3272 & TST & \\
\hline CHEMBL43001 & 149344 & 6.7959 & 6.7374 & TST & \\
\hline CHEMBL43612 & 149344 & 5.4318 & 5.5878 & TST & \\
\hline CHEMBL434402 & 149344 & 6.7959 & 6.4901 & TST & \\
\hline CHEMBL 297336 & 149344 & 6.8861 & 6.6904 & TST & \\
\hline CHEMBL391533 & 737273 & 3.0969 & 3.2985 & TST & \\
\hline CHEMBL1610008 & 737273 & 3.0969 & 3.2961 & TRN & \\
\hline CHEMBL1481347 & 737273 & 4.6038 & 4.0859 & TST & \\
\hline CHEMBL1491004 & 737273 & 3.0969 & 3.861 & TRN & \\
\hline CHEMBL1347927 & 737273 & 3.0969 & 3.8355 & TRN & \\
\hline CHEMBL1517553 & 737273 & 3.0969 & 3.2688 & TRN & \\
\hline CHEMBL 3210428 & 737273 & 3.0969 & 3.3898 & TRN & \\
\hline CHEMBL1446421 & 737273 & 3.0969 & 3.3049 & TRN & \\
\hline CHEMBL1597580 & 737273 & 3.0969 & 3.8645 & TRN & \\
\hline CHEMBL1573661 & 737273 & 3.0969 & 3.8983 & TRN & \\
\hline CHEMBL1728032 & 737273 & 4.4157 & 4.227 & TRN & \\
\hline CHEMBL3195813 & 737273 & 4.7011 & 3.8455 & TRN & \\
\hline CHEMBL3195562 & 737273 & 4.4056 & 3.6741 & TRN & \\
\hline CHEMBL1716112 & 737273 & 4.8729 & 4.1502 & TST & \\
\hline CHEMBL1735678 & 737273 & 3.0969 & 3.4211 & TRN & \\
\hline
\end{tabular}




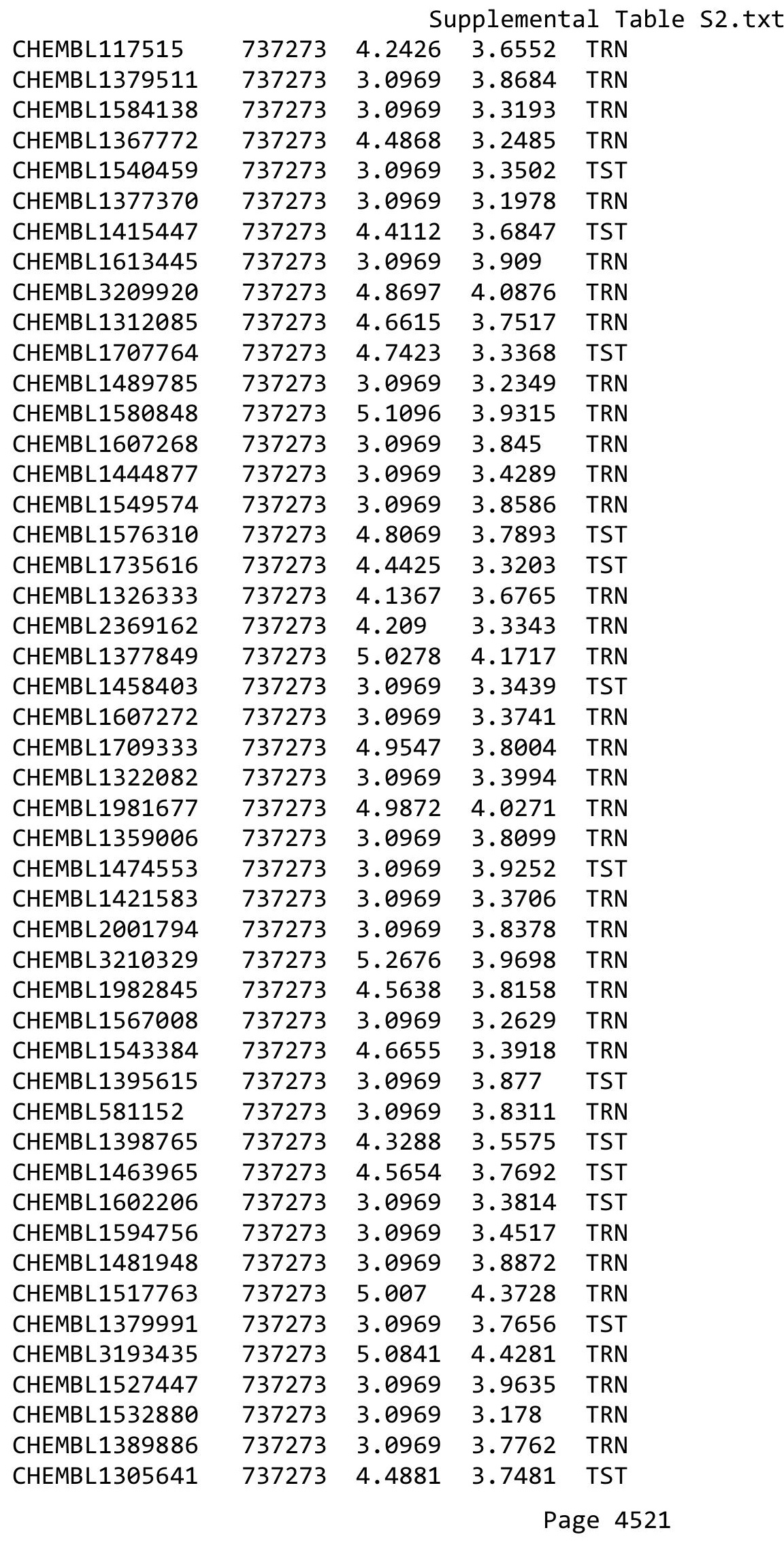




\begin{tabular}{|c|c|c|c|c|}
\hline & & & oplement & al $\mathrm{Ta}$ \\
\hline CHEMBL1526636 & 737273 & 3.0969 & 3.2132 & TRN \\
\hline CHEMBL1341741 & 737273 & 3.0969 & 3.2523 & TRN \\
\hline CHEMBL1722838 & 737273 & 3.0969 & 3.8149 & TRN \\
\hline CHEMBL1480262 & 737273 & 4.4295 & 3.7326 & TRN \\
\hline CHEMBL1307769 & 737273 & 3.0969 & 3.7766 & TRN \\
\hline CHEMBL1443859 & 737273 & 3.0969 & 3.2599 & TRN \\
\hline CHEMBL1422635 & 737273 & 3.0969 & 3.6429 & TST \\
\hline CHEMBL1353750 & 737273 & 3.0969 & 3.7903 & TST \\
\hline CHEMBL1465832 & 737273 & 3.0969 & 3.3613 & TRN \\
\hline CHEMBL1506832 & 737273 & 3.0969 & 3.7529 & TRN \\
\hline CHEMBL1528822 & 737273 & 3.0969 & 3.3494 & TRN \\
\hline CHEMBL1373404 & 737273 & 4.4962 & 3.2257 & TRN \\
\hline CHEMBL1477543 & 737273 & 3.0969 & 3.1875 & TRN \\
\hline CHEMBL3213030 & 737273 & 4.4634 & 4.0137 & TRN \\
\hline CHEMBL1421010 & 737273 & 3.0969 & 3.8281 & TST \\
\hline CHEMBL1339322 & 737273 & 3.0969 & 3.4222 & TRN \\
\hline CHEMBL1320095 & 737273 & 3.0969 & 3.3247 & TRN \\
\hline CHEMBL3212008 & 737273 & 3.0969 & 3.7901 & TRN \\
\hline CHEMBL1431988 & 737273 & 4.5622 & 3.7367 & TRN \\
\hline CHEMBL1431815 & 737273 & 3.0969 & 3.6777 & TRN \\
\hline CHEMBL3198659 & 737273 & 3.0969 & 3.8144 & TRN \\
\hline CHEMBL1461171 & 737273 & 3.0969 & 3.4238 & TRN \\
\hline CHEMBL1518926 & 737273 & 4.6162 & 3.7914 & TRN \\
\hline CHEMBL1525100 & 737273 & 3.0969 & 3.3084 & TRN \\
\hline CHEMBL498436 & 737273 & 3.0969 & 3.8382 & TST \\
\hline CHEMBL1704624 & 737273 & 4.699 & 3.8421 & TST \\
\hline CHEMBL3199020 & 737273 & 3.0969 & 3.3585 & TRN \\
\hline CHEMBL1738986 & 737273 & 3.0969 & 3.1948 & TRN \\
\hline CHEMBL1459240 & 737273 & 4.2299 & 3.6765 & TRN \\
\hline CHEMBL1964776 & 737273 & 3.0969 & 3.3067 & TRN \\
\hline CHEMBL1988829 & 737273 & 4.7055 & 3.2818 & TRN \\
\hline CHEMBL1471146 & 737273 & 3.0969 & 3.5114 & TRN \\
\hline CHEMBL1438402 & 737273 & 3.0969 & 3.3481 & TRN \\
\hline CHEMBL1543331 & 737273 & 4.3516 & 3.6509 & TST \\
\hline CHEMBL1523175 & 737273 & 4.7144 & 3.1906 & TRN \\
\hline CHEMBL1375847 & 737273 & 4.567 & 3.6986 & TRN \\
\hline CHEMBL1517752 & 737273 & 3.0969 & 3.9208 & TRN \\
\hline CHEMBL3192961 & 737273 & 3.0969 & 3.8158 & TST \\
\hline CHEMBL1343952 & 737273 & 3.0969 & 4.2285 & TST \\
\hline CHEMBL3209159 & 737273 & 4.1101 & 4.0416 & TRN \\
\hline CHEMBL3210395 & 737273 & 4.1403 & 3.8535 & TRN \\
\hline CHEMBL3209308 & 737273 & 4.6556 & 4.008 & TRN \\
\hline CHEMBL3197092 & 737273 & 5.061 & 4.3298 & TRN \\
\hline CHEMBL1460440 & 737273 & 3.0969 & 3.7158 & TRN \\
\hline CHEMBL1610943 & 737273 & 3.0969 & 3.8203 & TRN \\
\hline CHEMBL1319009 & 737273 & 3.0969 & 3.3261 & TRN \\
\hline CHEMBL1613230 & 737273 & 3.0969 & 3.4165 & TRN \\
\hline CHEMBL3195171 & 737273 & 3.0969 & 3.3304 & TRN \\
\hline
\end{tabular}




\begin{tabular}{|c|c|c|c|c|c|c|}
\hline & & \multicolumn{5}{|c|}{ Supplemental Table S2.txt } \\
\hline CHEMBL1597446 & 737273 & 3.0969 & 3.6741 & TRN & & \\
\hline CHEMBL 2369184 & 737273 & 5.3915 & 3.7391 & TRN & & \\
\hline CHEMBL1567841 & 737273 & 3.0969 & 3.352 & TRN & & \\
\hline CHEMBL1324224 & 737273 & 3.0969 & 3.79100 & 00000000 & 004 & TRN \\
\hline CHEMBL1532675 & 737273 & 3.0969 & 3.3262 & TRN & & \\
\hline CHEMBL1701527 & 737273 & 4.7258 & 3.8423 & TST & & \\
\hline CHEMBL 3209140 & 737273 & 4.4498 & 3.8782 & TRN & & \\
\hline CHEMBL1372914 & 737273 & 4.5686 & 4.1941 & TRN & & \\
\hline CHEMBL1717612 & 737273 & 3.0969 & 3.7379 & TST & & \\
\hline CHEMBL1453825 & 737273 & 3.0969 & 3.8727 & TRN & & \\
\hline CHEMBL1727260 & 737273 & 4.2211 & 3.8965 & TST & & \\
\hline CHEMBL 1457085 & 737273 & 3.0969 & 3.3122 & TRN & & \\
\hline CHEMBL 201986 & 737273 & 3.0969 & 3.5421 & TRN & & \\
\hline CHEMBL1984130 & 737273 & 3.0969 & 3.7337 & TRN & & \\
\hline CHEMBL1535134 & 737273 & 5.0376 & 3.79 & TRN & & \\
\hline CHEMBL1973127 & 737273 & 3.0969 & 3.6771 & TRN & & \\
\hline CHEMBL1973729 & 737273 & 3.0969 & 3.8165 & TRN & & \\
\hline CHEMBL1736101 & 737273 & 3.0969 & 3.8629 & TST & & \\
\hline CHEMBL1971913 & 737273 & 4.5391 & 3.861 & TST & & \\
\hline CHEMBL1423839 & 737273 & 3.0969 & 3.3512 & TRN & & \\
\hline CHEMBL1611543 & 737273 & 3.0969 & 4.1864 & TRN & & \\
\hline CHEMBL1493254 & 737273 & 4.6968 & 3.8016 & TST & & \\
\hline CHEMBL1583406 & 737273 & 3.0969 & 3.623 & TRN & & \\
\hline CHEMBL 2000633 & 737273 & 4.4191 & 3.9376 & TRN & & \\
\hline CHEMBL1570774 & 737273 & 3.0969 & 3.6494 & TRN & & \\
\hline CHEMBL1405734 & 737273 & 3.0969 & 3.3417 & TST & & \\
\hline CHEMBL1986591 & 737273 & 4.7496 & 3.8441 & TRN & & \\
\hline CHEMBL1541452 & 737273 & 3.0969 & 3.3222 & TRN & & \\
\hline CHEMBL1732128 & 737273 & 4.5186 & 3.7772 & TRN & & \\
\hline CHEMBL1983745 & 737273 & 3.0969 & 3.8115 & TRN & & \\
\hline CHEMBL1580664 & 737273 & 5.0825 & 3.8539 & TRN & & \\
\hline CHEMBL1717433 & 737273 & 3.0969 & 3.4643 & TRN & & \\
\hline CHEMBL 2007390 & 737273 & 4.9586 & 4.1989 & TRN & & \\
\hline CHEMBL1365006 & 737273 & 3.0969 & 3.935 & TST & & \\
\hline CHEMBL1734062 & 737273 & 4.556 & 3.3005 & TRN & & \\
\hline CHEMBL1500059 & 737273 & 4.5528 & 3.4125 & TRN & & \\
\hline CHEMBL1500686 & 737273 & 4.8097 & 3.7878 & TRN & & \\
\hline CHEMBL1992719 & 737273 & 3.0969 & 3.4612 & TRN & & \\
\hline CHEMBL1538986 & 737273 & 4.5346 & 3.6305 & TRN & & \\
\hline CHEMBL1561085 & 737273 & 3.0969 & 3.8773 & TST & & \\
\hline CHEMBL1545927 & 737273 & 4.6696 & 3.6552 & TRN & & \\
\hline CHEMBL1381088 & 737273 & 4.2472 & 3.6407 & TRN & & \\
\hline CHEMBL1447486 & 737273 & 3.0969 & 3.3022 & TST & & \\
\hline CHEMBL1319467 & 737273 & 3.0969 & 3.9057 & TRN & & \\
\hline CHEMBL1433290 & 737273 & 3.0969 & 4.0264 & TST & & \\
\hline CHEMBL1340032 & 737273 & 4.38399 & 99999999 & 995 & 3.7215 & TRN \\
\hline CHEMBL1464261 & 737273 & 3.0969 & 3.3825 & TRN & & \\
\hline CHEMBL1337990 & 737273 & 4.3778 & 3.8031 & TRN & & \\
\hline
\end{tabular}




\begin{tabular}{|c|c|c|c|c|c|}
\hline & & \multicolumn{4}{|c|}{ Supplemental Table S2.txt } \\
\hline CHEMBL1500167 & 737273 & 3.0969 & 3.2517 & TRN & \\
\hline CHEMBL1362687 & 737273 & 4.3958 & 3.6527 & TRN & \\
\hline CHEMBL 2000338 & 737273 & 4.8153 & 4.1749 & TST & \\
\hline CHEMBL511921 & 737273 & 4.2233 & 3.7242 & TRN & \\
\hline CHEMBL1369287 & 737273 & 3.0969 & 3.2809 & TST & \\
\hline CHEMBL1385898 & 737273 & 3.0969 & 3.6335 & TRN & \\
\hline CHEMBL1385436 & 737273 & 3.0969 & 3.8227 & TRN & \\
\hline CHEMBL3197214 & 737273 & 4.5331 & 4.0497 & TRN & \\
\hline CHEMBL 3213830 & 737273 & 4.1818 & 3.8143 & TST & \\
\hline CHEMBL1542833 & 737273 & 4.6576 & 3.7369 & TRN & \\
\hline CHEMBL1481903 & 737273 & 4.7825 & 3.7437 & TRN & \\
\hline CHEMBL1312115 & 737273 & 3.0969 & 3.3714 & TST & \\
\hline CHEMBL1568149 & 737273 & 3.0969 & 3.4273 & TST & \\
\hline CHEMBL3210000 & 737273 & 3.0969 & 3.8469 & TRN & \\
\hline CHEMBL1392765 & 737273 & 4.8794 & 3.7908 & TRN & \\
\hline CHEMBL1418750 & 737273 & 4.699 & 3.2103 & TRN & \\
\hline CHEMBL1344250 & 737273 & 3.0969 & 3.8245 & TRN & \\
\hline CHEMBL1352381 & 737273 & 3.0969 & 3.4961 & TRN & \\
\hline CHEMBL1623028 & 737273 & 4.1314 & 3.6853 & TRN & \\
\hline CHEMBL1328510 & 737273 & 3.0969 & 3.6346 & TRN & \\
\hline CHEMBL1583552 & 737273 & 3.0969 & 3.8233 & TRN & \\
\hline CHEMBL1324256 & 737273 & 4.8069 & 4.146 & TRN & \\
\hline CHEMBL3189689 & 737273 & 3.0969 & 3.4233 & TRN & \\
\hline CHEMBL1454693 & 737273 & 4.4248 & 4.0897 & TRN & \\
\hline CHEMBL 3145282 & 737273 & 3.0969 & 4.1884 & TST & \\
\hline CHEMBL 3193428 & 737273 & 3.0969 & 3.9366 & TRN & \\
\hline CHEMBL1702699 & 737273 & 3.0969 & 3.8555 & TST & \\
\hline CHEMBL1468959 & 737273 & 4.5784 & 3.6929 & TST & \\
\hline CHEMBL1445889 & 737273 & 3.0969 & 3.2993 & TRN & \\
\hline CHEMBL1348774 & 737273 & 3.0969 & 3.319 & TRN & \\
\hline CHEMBL1368384 & 737273 & 3.0969 & 3.3642 & TRN & \\
\hline CHEMBL1467316 & 737273 & 3.0969 & 3.89300 & 00000000002 & TST \\
\hline CHEMBL1722190 & 737273 & 4.8182 & 3.7944 & TRN & \\
\hline CHEMBL1563861 & 737273 & 3.0969 & 4.2078 & TRN & \\
\hline CHEMBL1596903 & 737273 & 3.0969 & 3.7577 & TRN & \\
\hline CHEMBL1728236 & 737273 & 3.0969 & 3.2875 & TRN & \\
\hline CHEMBL1556884 & 737273 & 5.6091 & 4.0229 & TRN & \\
\hline CHEMBL1400243 & 737273 & 4.7545 & 3.7678 & TRN & \\
\hline CHEMBL1373688 & 737273 & 3.0969 & 4.0957 & TRN & \\
\hline CHEMBL1497100 & 737273 & 3.0969 & 3.4766 & TST & \\
\hline CHEMBL1458178 & 737273 & 4.7423 & 3.4907 & TST & \\
\hline CHEMBL1504600 & 737273 & 3.0969 & 3.7427 & TST & \\
\hline CHEMBL1502739 & 737273 & 3.0969 & 3.6863 & TRN & \\
\hline CHEMBL1301278 & 737273 & 3.0969 & 3.9051 & TST & \\
\hline CHEMBL1607280 & 737273 & 3.0969 & 3.8219 & TRN & \\
\hline CHEMBL581860 & 737273 & 3.0969 & 3.8268 & TRN & \\
\hline CHEMBL32147 & 737273 & 3.0969 & 3.8898 & TRN & \\
\hline CHEMBL1990659 & 737273 & 4.7375 & 4.2758 & TRN & \\
\hline
\end{tabular}




\begin{tabular}{|c|c|c|c|c|c|c|}
\hline & & \multicolumn{5}{|c|}{ Supplemental Table S2.txt } \\
\hline CHEMBL1342029 & 737273 & 4.2815 & 3.6968 & TRN & & \\
\hline CHEMBL1411629 & 737273 & 4.5258 & 4.0231 & TRN & & \\
\hline CHEMBL1445171 & 737273 & 4.7305 & 3.4299 & TRN & & \\
\hline CHEMBL1508334 & 737273 & 4.9245 & 3.2402 & TRN & & \\
\hline CHEMBL1522369 & 737273 & 3.0969 & 3.7335 & TRN & & \\
\hline CHEMBL1509317 & 737273 & 3.0969 & 3.3447 & TST & & \\
\hline CHEMBL 2005296 & 737273 & 4.7033 & 3.7953 & TRN & & \\
\hline CHEMBL1365476 & 737273 & 3.0969 & 3.3665 & TRN & & \\
\hline CHEMBL1470946 & 737273 & 3.0969 & 3.8284 & TRN & & \\
\hline CHEMBL1735232 & 737273 & 3.0969 & 3.8501 & TST & & \\
\hline CHEMBL1576784 & 737273 & 4.2899 & 3.7315 & TRN & & \\
\hline CHEMBL1319610 & 737273 & 3.0969 & 3.3723 & TRN & & \\
\hline CHEMBL1335223 & 737273 & 3.0969 & 3.6637 & TST & & \\
\hline CHEMBL1549738 & 737273 & 4.7235 & 3.8339 & TRN & & \\
\hline CHEMBL1580073 & 737273 & 5.3726 & 4.0576 & TRN & & \\
\hline CHEMBL1391484 & 737273 & 4.3487 & 4.0793 & TRN & & \\
\hline CHEMBL1462378 & 737273 & 3.0969 & 3.633 & TRN & & \\
\hline CHEMBL3190724 & 737273 & 4.7167 & 3.9723 & TRN & & \\
\hline CHEMBL1340716 & 737273 & 4.3478 & 3.7968 & TRN & & \\
\hline CHEMBL1411646 & 737273 & 3.0969 & 3.8355 & TRN & & \\
\hline CHEMBL1969303 & 737273 & 4.6737 & 4.0825 & TRN & & \\
\hline CHEMBL1362441 & 737273 & 3.0969 & 3.6082 & TRN & & \\
\hline CHEMBL1336914 & 737273 & 4.6799 & 3.6726 & TRN & & \\
\hline CHEMBL503363 & 737273 & 3.0969 & 3.7863 & TST & & \\
\hline CHEMBL1562968 & 737273 & 3.0969 & 3.2747 & TRN & & \\
\hline CHEMBL3208631 & 737273 & 4.9957 & 4.0129 & TRN & & \\
\hline CHEMBL1568754 & 737273 & 3.0969 & 3.3694 & TRN & & \\
\hline CHEMBL1998521 & 737273 & 3.0969 & 4.1909 & TST & & \\
\hline CHEMBL 3207483 & 737273 & 4.301 & 3.7694 & TST & & \\
\hline CHEMBL1360014 & 737273 & 3.0969 & 3.7019 & TRN & & \\
\hline CHEMBL1335429 & 737273 & 3.0969 & 3.395 & TRN & & \\
\hline CHEMBL1468368 & 737273 & 4.5058 & 3.7911 & TRN & & \\
\hline CHEMBL1410068 & 737273 & 3.0969 & 4.0974 & TST & & \\
\hline CHEMBL3189151 & 737273 & 3.0969 & 4.1006 & TRN & & \\
\hline CHEMBL1312672 & 737273 & 3.0969 & 3.7373 & TRN & & \\
\hline CHEMBL1379816 & 737273 & 4.3261 & 3.7455 & TRN & & \\
\hline CHEMBL1426512 & 737273 & 4.752 & 3.7753 & TRN & & \\
\hline CHEMBL1488408 & 737273 & 3.0969 & 3.8438 & TST & & \\
\hline CHEMBL1515023 & 737273 & 3.0969 & 3.3175 & TRN & & \\
\hline CHEMBL1351044 & 737273 & $4.8210 e$ & 00000000 & 01 & 3.7122 & TRI \\
\hline CHEMBL1438033 & 737273 & 3.0969 & 3.3571 & TRN & & \\
\hline CHEMBL1488591 & 737273 & 3.0969 & 3.3434 & TST & & \\
\hline CHEMBL1428012 & 737273 & 4.9586 & 3.8233 & TRN & & \\
\hline CHEMBL3196472 & 737273 & 3.0969 & 3.8047 & TRN & & \\
\hline CHEMBL1527341 & 737273 & 4.7423 & 3.7521 & TRN & & \\
\hline CHEMBL3209146 & 737273 & 4.7399 & 4.0767 & TRN & & \\
\hline CHEMBL1301480 & 737273 & 4.7496 & 3.3853 & TRN & & \\
\hline CHEMBL1609564 & 737273 & 4.7077 & 3.8446 & TRN & & \\
\hline
\end{tabular}




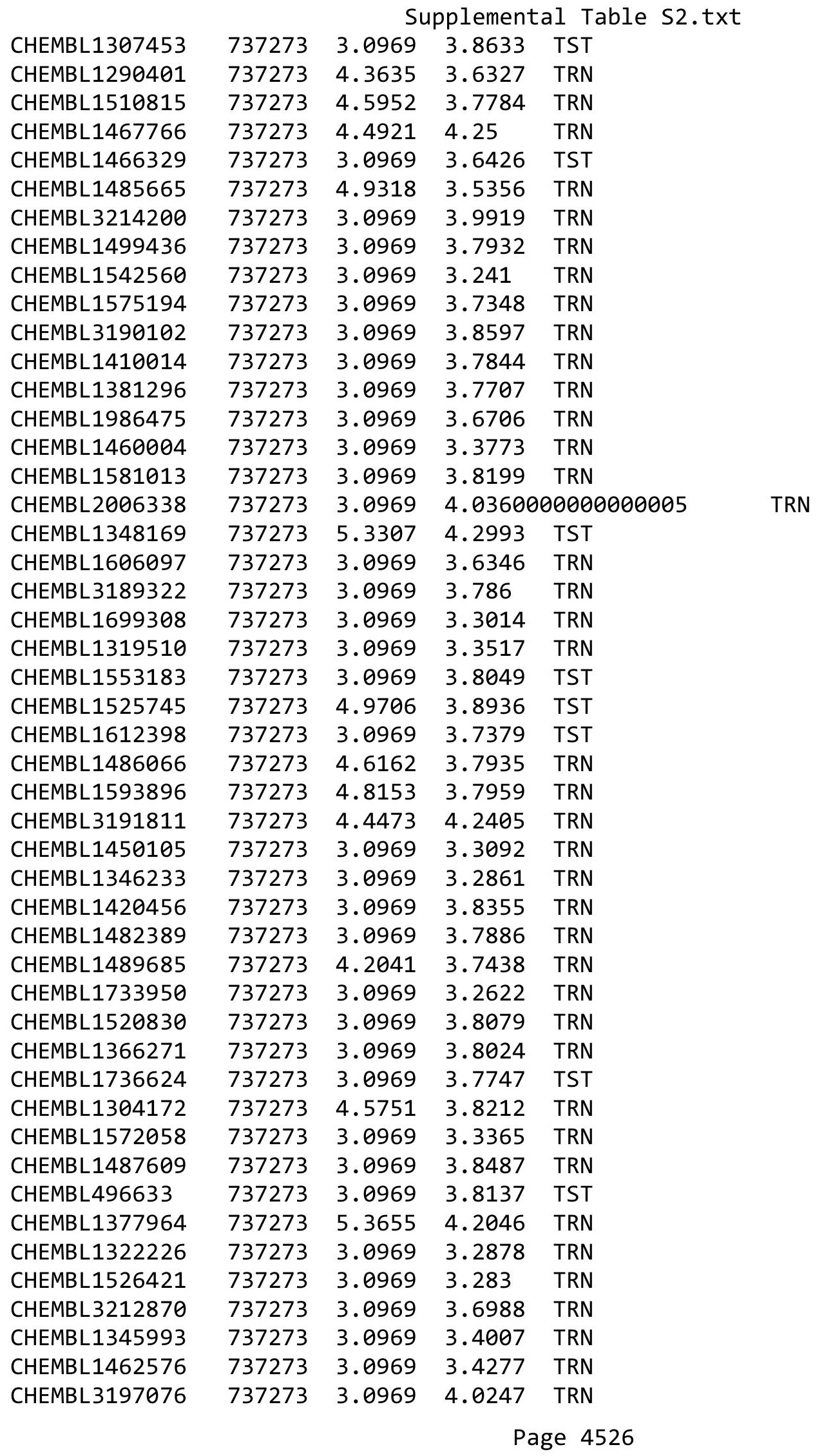


Supplemental Table S2.txt

\begin{tabular}{|c|c|c|c|c|}
\hline & & & & \\
\hline HEMBL 319 & 7273 & $\partial 969$ & 8153 & \\
\hline IEMBL1523563 & 37273 & 969 & & \\
\hline AEMBL1347795 & 37273 & 969 & 9786 & \\
\hline IEMBL1358906 & 7273 & 969 & & \\
\hline IEMBL1353336 & 7273 & 969 & 375 & \\
\hline AEMBL1580604 & 37273 & 969 & 3991 & \\
\hline AEMBL1329069 & 37273 & 056 & 8621 & \\
\hline AEMBL1468543 & 37273 & & 2975 & \\
\hline IEMBL1604286 & 37273 & & 43 & \\
\hline AEMBL1544133 & 37273 & & & \\
\hline AEMBL3198149 & 37273 & 969 & 344 & \\
\hline AEMBL1613318 & 37273 & 97 & 3257 & RI \\
\hline IEMBL15261 & 73 & & & \\
\hline IEMBL1301997 & 37273 & & & \\
\hline AEMBL1336428 & 37273 & & & \\
\hline AEMBL3214431 & 37273 & 969 & 7655 & RN \\
\hline AEMBL1320351 & & 69 & & \\
\hline EMBL1603 & 73 & 26 & & \\
\hline AEMBL3192900 & 7273 & & & \\
\hline AEMBL1715154 & 7273 & & & \\
\hline AEMBL1370810 & 37273 & 423 & & RN \\
\hline AEMBL1495189 & & & & \\
\hline EMBL58 & 73 & & & \\
\hline IEMBL13 & 73 & & & RN \\
\hline AFMRI 131 & 73 & & & RN \\
\hline AEMBL1490379 & & & & RN \\
\hline AEMBL1414 & & & & \\
\hline AEMBL1569 & 73 & & & RN \\
\hline L154 & 73 & & & 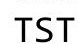 \\
\hline 110 & 73 & & & 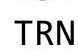 \\
\hline HEMBL3212447 & & & & RN \\
\hline AEMBL1432711 & & & & RI \\
\hline IEMBL1574 & 73 & & & S \\
\hline HEMBL150 & 73 & 3. & 03 & (1) \\
\hline 0 & 73 & & & $\theta$ \\
\hline AEMBL1427492 & 37273 & & & $\mathrm{R}$ \\
\hline AEMBL1608375 & 37273 & & & ST \\
\hline IEMBL1389616 & 3 & & & RI \\
\hline HEMBL 597251 & 73 & & 28 & \\
\hline 148 & 73 & & & RN \\
\hline AEMBL1431385 & 37273 & 3.0969 & 19 & $\mathrm{RN}$ \\
\hline IEMBL1468786 & 73 & & & TS \\
\hline HEMBL157€ & & & & \\
\hline HEMBL1352760 & & & & \\
\hline CHEMBL 1342782 & 737273 & & 667 & RN \\
\hline AEMBL1508274 & 37273 & 3.0969 & .7265 & $\mathrm{TR}$ \\
\hline HFMBI 1985582 & 737273 & 3.0969 & 3.6992 & \\
\hline
\end{tabular}

Page 4527 


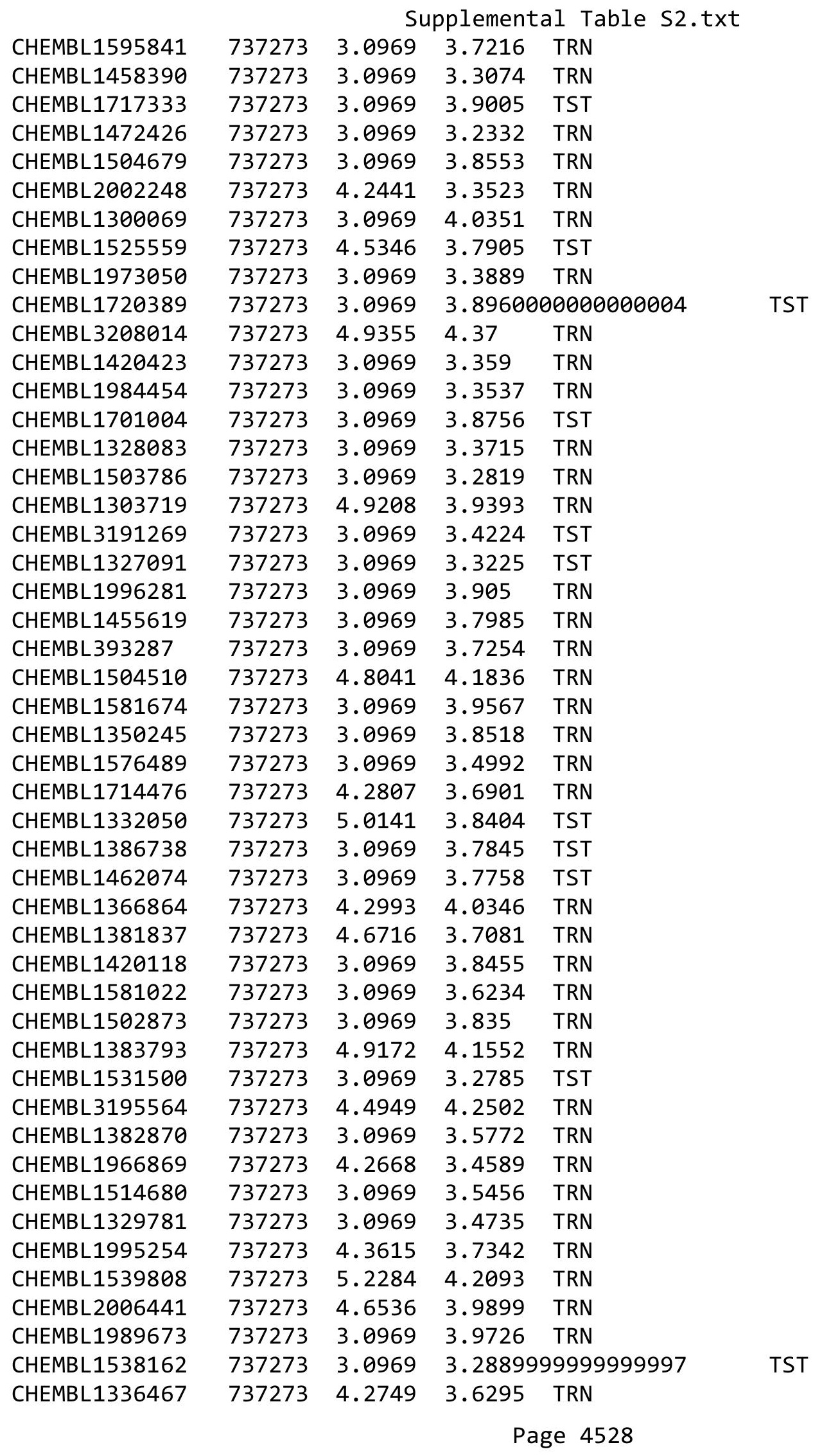




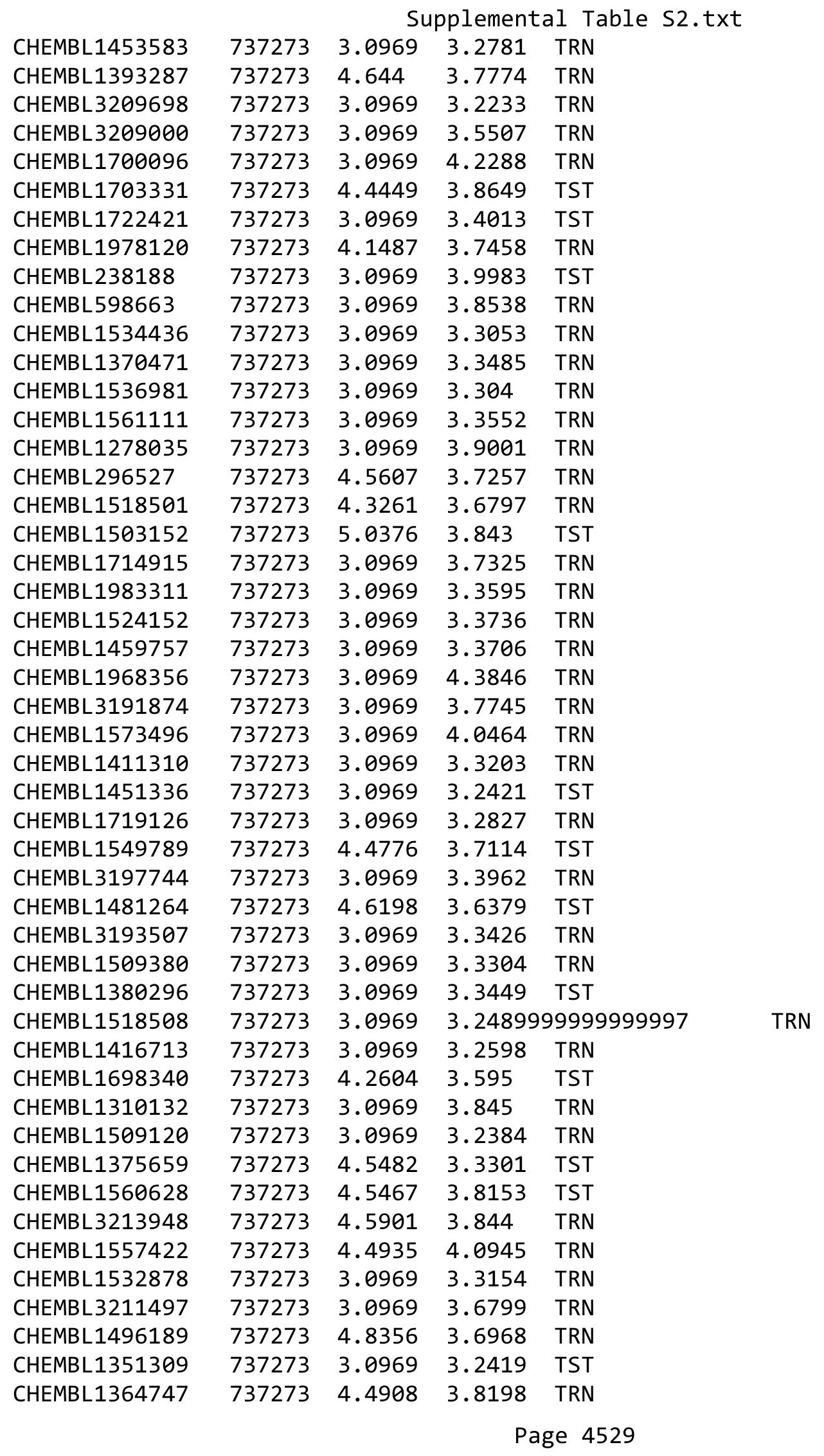




\begin{tabular}{|c|c|c|c|c|c|}
\hline & & \multicolumn{4}{|c|}{ Supplemental Table s2.txt } \\
\hline CHEMBL1518054 & 737273 & 4.9957 & 4.0434 & TRN & \\
\hline CHEMBL3211221 & 737273 & 3.0969 & 3.7772 & TST & \\
\hline CHEMBL1352168 & 737273 & 3.0969 & 3.3914 & TRN & \\
\hline CHEMBL3209897 & 737273 & 4.4306 & 4.0358 & TRN & \\
\hline CHEMBL1362998 & 737273 & 3.0969 & 3.6898 & TRN & \\
\hline CHEMBL1386537 & 737273 & 3.0969 & 3.3633 & TRN & \\
\hline CHEMBL1442176 & 737273 & 3.0969 & 3.2479 & TRN & \\
\hline CHEMBL1455309 & 737273 & 4.5686 & 3.6891 & TRN & \\
\hline CHEMBL1718409 & 737273 & 3.0969 & 3.6838 & TST & \\
\hline CHEMBL1496705 & 737273 & 3.0969 & 3.3435 & TRN & \\
\hline CHEMBL1330510 & 737273 & \multicolumn{3}{|c|}{4.9830000000000005} & TRN \\
\hline CHEMBL1407529 & 737273 & 3.0969 & 3.2544 & TST & \\
\hline CHEMBL1497982 & 737273 & 4.7932 & 4.0467 & TST & \\
\hline CHEMBL1535940 & 737273 & 4.2 & 3.2506 & TRN & \\
\hline CHEMBL1700686 & 737273 & 4.3665 & 3.7889 & TST & \\
\hline CHEMBL1709004 & 737273 & 4.7167 & 4.2633 & TRN & \\
\hline CHEMBL1488623 & 737273 & 3.0969 & 3.2797 & TRN & \\
\hline CHEMBL1396351 & 737273 & 3.0969 & 3.7855 & TST & \\
\hline CHEMBL 1585763 & 737273 & 3.0969 & 3.8837 & TRN & \\
\hline CHEMBL1715461 & 737273 & 3.0969 & 3.3672 & TRN & \\
\hline CHEMBL1976046 & 737273 & 3.0969 & 3.3818 & TRN & \\
\hline CHEMBL3208577 & 737273 & 3.0969 & 3.79100 & 00000000004 & TST \\
\hline CHEMBL1432626 & 737273 & 3.0969 & 3.8915 & TRN & \\
\hline CHEMBL3193227 & 737273 & 4.7852 & 4.3705 & TRN & \\
\hline CHEMBL1995692 & 737273 & 4.4828 & 3.8078 & TRN & \\
\hline CHEMBL3212519 & 737273 & 3.0969 & 4.2689 & TRN & \\
\hline CHEMBL1341399 & 737273 & 4.8729 & 3.9797 & TRN & \\
\hline CHEMBL559384 & 737273 & 3.0969 & 3.2668 & TRN & \\
\hline CHEMBL1460676 & 737273 & 3.0969 & 3.9201 & TRN & \\
\hline CHEMBL1497403 & 737273 & 4.3979 & 3.841 & TRN & \\
\hline CHEMBL1999480 & 737273 & 3.0969 & 3.6891 & TRN & \\
\hline CHEMBL1986090 & 737273 & 4.3979 & 3.9112 & TRN & \\
\hline CHEMBL1610463 & 737273 & 3.0969 & 3.8797 & TRN & \\
\hline CHEMBL1324290 & 737273 & 4.556 & 3.858 & TRN & \\
\hline CHEMBL1310857 & 737273 & 3.0969 & 3.9756 & TRN & \\
\hline CHEMBL1996363 & 737273 & 3.0969 & 3.7217 & TRN & \\
\hline CHEMBL1482979 & 737273 & 3.0969 & 3.6366 & TRN & \\
\hline CHEMBL3198756 & 737273 & 3.0969 & 4.0601 & TRN & \\
\hline CHEMBL1324397 & 737273 & 3.0969 & 3.9018 & TRN & \\
\hline CHEMBL1344927 & 737273 & 3.0969 & 3.8175 & TRN & \\
\hline CHEMBL1500190 & 737273 & 4.5482 & 3.7921 & TRN & \\
\hline CHEMBL1422301 & 737273 & 5.1851 & 3.8471 & TRN & \\
\hline CHEMBL1342448 & 737273 & 3.0969 & 3.7431 & TST & \\
\hline CHEMBL1401373 & 737273 & 4.1296 & 3.5774 & TRN & \\
\hline CHEMBL1417867 & 737273 & 4.1798 & 3.8803 & TRN & \\
\hline CHEMBL1457782 & 737273 & 3.0969 & 3.3249 & TRN & \\
\hline CHEMBL1973341 & 737273 & 4.6073 & 3.9605 & TRN & \\
\hline CHEMBL1509824 & 737273 & 3.0969 & 3.4603 & TRN & \\
\hline
\end{tabular}


Supplemental Table S2.txt

\begin{tabular}{|c|c|c|c|c|}
\hline . & 273 & & & \\
\hline & 37273 & 3.0969 & .7677 & \\
\hline 0816 & 273 & & & \\
\hline AEMBL1351099 & 7273 & 969 & 307 & \\
\hline AEMBL1505153 & 37273 & 969 & 7121 & \\
\hline HEMBL3145321 & 37273 & 969 & 9369 & \\
\hline 06 & 73 & 969 & 164 & \\
\hline 511063 & & & & \\
\hline AEMBL3193533 & 73 & 9136 & 2717 & \\
\hline HEMBL1602157 & 37273 & 969 & 7877 & \\
\hline HEMBL1305307 & 73 & 969 & 8595 & \\
\hline IEMBL602 & 73 & 69 & & \\
\hline HEMBL: & & & & \\
\hline HEMBL1437888 & 73 & 969 & 9114 & \\
\hline AEMBL1525833 & & 59 & 72 & \\
\hline AEMBL1966 & 3 & 969 & 86 & \\
\hline TEMBL1898 & 73 & 59 & & \\
\hline HEMBL1986 & & & & \\
\hline HEMBL1502 & & 969 & 7067 & \\
\hline AEMBL141 & & 59 & & \\
\hline IEMB: & & 59 & 235 & \\
\hline AEMBLI & & 9 & 11 & \\
\hline AEMBL1 & & & 533 & \\
\hline AEMBL1347600 & & 969 & & \\
\hline AEMBL1309 & & 37 & & ( \\
\hline HEMBL1 & & 3 & 664 & KIV \\
\hline HEME & & 9 & 11 & 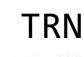 \\
\hline AFMRI & 73 & 69 & 07 & \\
\hline HEMBL151 & & & 1552 & in \\
\hline HEMBL1370 & & & 376 & 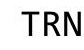 \\
\hline HEMBL1 & & 6 & 885 & RIV \\
\hline HEMBL & & & 13 & RN \\
\hline$\triangle 5 M P$ & & 59 & 59 & \\
\hline HEMBL3208 & & & 017 & T \\
\hline HEMBL1724535 & & 633 & 0477 & ГRN \\
\hline HEMBL & & & 7271 & RN \\
\hline HFMRI 1 & 3 & & 755 & IRIN \\
\hline & & & 524 & RN \\
\hline HEMBL1547873 & & 969 & 1141 & TS \\
\hline AEMBL152 & & & 058 & TRN \\
\hline HEMBL1 & & & 461 & \\
\hline HEMBL3212452 & & 969 & 3067 & \\
\hline HEMBL147 & 73 & .5421 & 2995 & RN \\
\hline HEMBL141716 & 73 & 969 & 168 & TRN \\
\hline HEMBL 319 & & & & $T$ \\
\hline HEMBL1 & & & & \\
\hline CHEMBL1986183 & & & 3.4505 & \\
\hline CHEMBL3209659 & 737273 & 3.0969 & 3.8952 & \\
\hline
\end{tabular}

Page 4531 
Supplemental Table S2.txt

\begin{tabular}{|c|c|c|c|c|c|}
\hline CHEMBL1720448 & 737273 & 5.1805 & 4.4168 & TRN & \\
\hline CHEMBL1538775 & 737273 & 3.0969 & 3.6331 & TRN & \\
\hline CHEMBL3208237 & 737273 & 3.0969 & 4.0261 & TRN & \\
\hline CHEMBL1440293 & 737273 & 3.0969 & 4.2585 & TRN & \\
\hline CHEMBL1527135 & 737273 & 3.0969 & 3.3829 & TRN & \\
\hline CHEMBL1588661 & 737273 & 4.3107 & 3.6164 & TST & \\
\hline CHEMBL1331011 & 737273 & 3.0969 & 3.2814 & TST & \\
\hline CHEMBL1420406 & 737273 & 4.3344 & 3.937 & TRN & \\
\hline CHEMBL1607877 & 737273 & 3.0969 & 3.7785 & TRN & \\
\hline CHEMBL532239 & 737273 & 3.0969 & 4.1756 & TRN & \\
\hline CHEMBL1986073 & 737273 & 4.9281 & 4.2183 & TRN & \\
\hline CHEMBL1446641 & 737273 & 3.0969 & 3.6726 & TRN & \\
\hline CHEMBL1546068 & 737273 & 3.0969 & 3.8214 & TST & \\
\hline CHEMBL1362109 & 737273 & 3.0969 & 3.3993 & TRN & \\
\hline CHEMBL1432772 & 737273 & 3.0969 & 3.3289 & TRN & \\
\hline CHEMBL1986505 & 737273 & 4.3645 & 3.41300 & 30000000003 & TRN \\
\hline CHEMBL1709275 & 737273 & 3.0969 & 3.3403 & TRN & \\
\hline CHEMBL1433088 & 737273 & 4.7645 & 3.9479 & TRN & \\
\hline CHEMBL1493199 & 737273 & 3.0969 & 3.6547 & TRN & \\
\hline CHEMBL1709936 & 737273 & 4.308 & 3.4743 & TST & \\
\hline CHEMBL1497973 & 737273 & 4.3152 & 3.5676 & TRN & \\
\hline CHEMBL1459102 & 737273 & 4.2628 & 3.7203 & TRN & \\
\hline CHEMBL1535457 & 737273 & 4.7986 & 4.0096 & TRN & \\
\hline CHEMBL1976777 & 737273 & 3.0969 & 3.4113 & TST & \\
\hline CHEMBL1370019 & 737273 & 4.7496 & 3.7311 & TRN & \\
\hline CHEMBL1584135 & 737273 & 3.0969 & 3.3446 & TRN & \\
\hline CHEMBL1304831 & 737273 & 4.7122 & 3.8376 & TRN & \\
\hline CHEMBL1563898 & 737273 & 3.0969 & 3.3618 & TRN & \\
\hline CHEMBL1527739 & 737273 & 4.6216 & 3.5565 & TRN & \\
\hline CHEMBL1556958 & 737273 & 4.9666 & 3.9203 & TRN & \\
\hline CHEMBL3191688 & 737273 & 4.4123 & 3.7769 & TRN & \\
\hline CHEMBL1509637 & 737273 & 3.0969 & 3.7209 & TRN & \\
\hline CHEMBL1493290 & 737273 & 3.0969 & 3.3655 & TRN & \\
\hline CHEMBL 3213613 & 737273 & 4.5935 & 3.4221 & TRN & \\
\hline CHEMBL1419117 & 737273 & 4.1427 & 3.2656 & TRN & \\
\hline CHEMBL1347172 & 737273 & 3.0969 & 3.2213 & TRN & \\
\hline CHEMBL1377712 & 737273 & 3.0969 & 3.3068 & TRN & \\
\hline CHEMBL1991601 & 737273 & 3.0969 & 3.7886 & TST & \\
\hline CHEMBL1468403 & 737273 & 3.0969 & 3.7019 & TRN & \\
\hline CHEMBL1503673 & 737273 & 3.0969 & 3.8188 & TRN & \\
\hline CHEMBL1410063 & 737273 & 4.1475 & 3.3856 & TRN & \\
\hline CHEMBL1378768 & 737273 & 4.8013 & 3.3907 & TST & \\
\hline CHEMBL1324894 & 737273 & 4.4449 & 4.0228 & TRN & \\
\hline CHEMBL86104 & 737273 & 3.0969 & 3.3732 & TRN & \\
\hline CHEMBL 1377750 & 737273 & 3.0969 & \multicolumn{2}{|c|}{3.2710000000000004} & TST \\
\hline CHEMBL1310217 & 737273 & 3.0969 & 3.7216 & TST & \\
\hline CHEMBL1450948 & 737273 & 3.0969 & 3.2088 & TST & \\
\hline CHEMBL1720691 & 737273 & 4.301 & 4.0933 & TST & \\
\hline
\end{tabular}




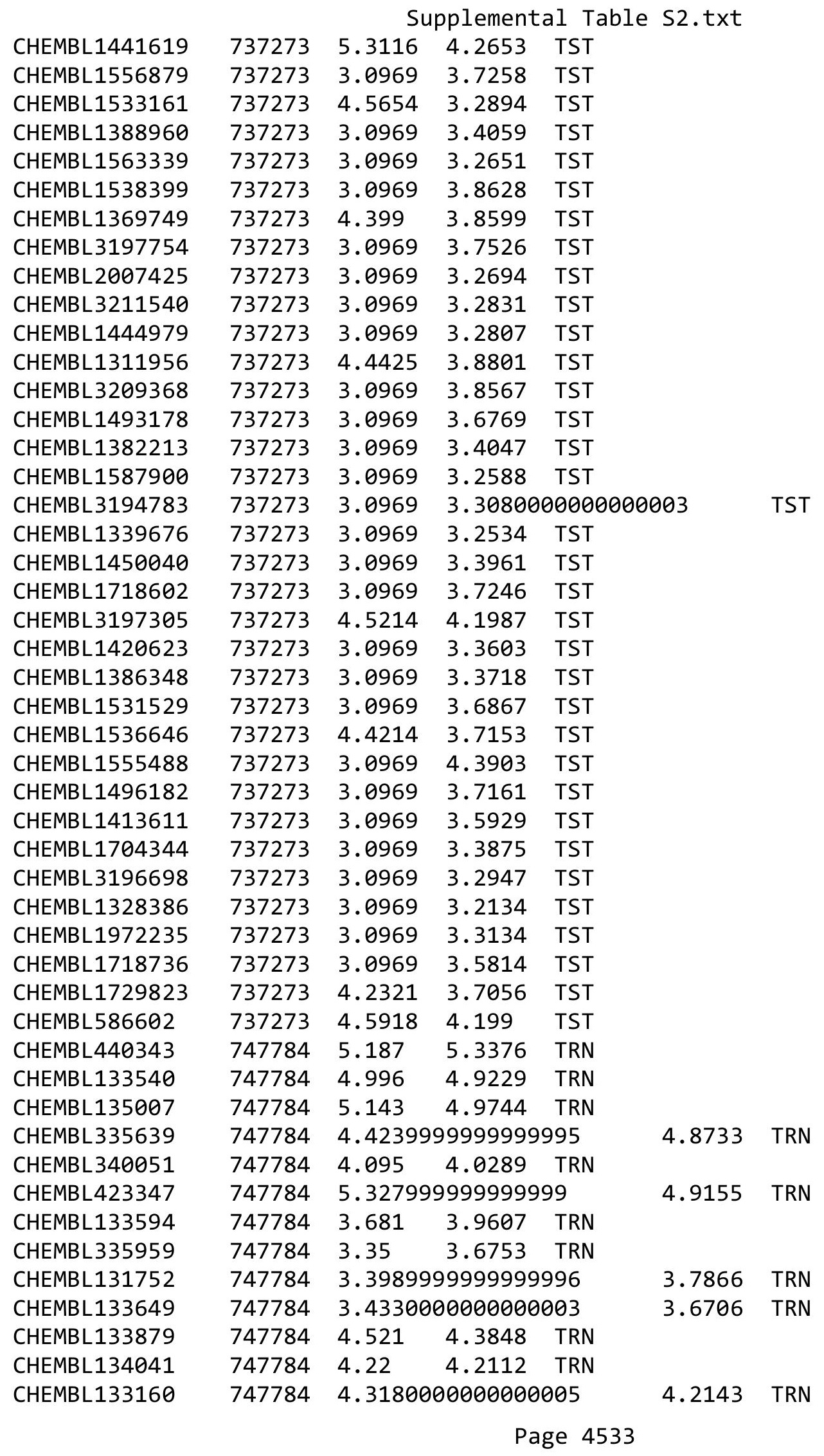




\begin{tabular}{|c|c|c|c|c|c|c|}
\hline \multicolumn{7}{|c|}{ Supplemental Table S2.txt } \\
\hline CHEMBL134014 & 747784 & 4.37 & 3.9666 & TRN & & \\
\hline CHEMBL135362 & 747784 & 3.883 & 4.3985 & TRN & & \\
\hline CHEMBL79143 & 747784 & 4.902 & 4.7611 & TRN & & \\
\hline CHEMBL134672 & 747784 & \multicolumn{3}{|c|}{4.4030000000000005} & 4.0786 & TRN \\
\hline CHEMBL131959 & 747784 & \multicolumn{3}{|c|}{3.4989999999999997} & 3.6195 & TRN \\
\hline CHEMBL450282 & 747784 & \multicolumn{3}{|c|}{4.821000000000001} & 4.7756 & TRN \\
\hline CHEMBL 308340 & 747784 & 4.796 & 4.3908 & TRN & & \\
\hline CHEMBL1777993 & 747784 & 4.83 & 4.8486 & TRN & & \\
\hline CHEMBL609452 & 747784 & 5.119 & 4.386 & TRN & & \\
\hline CHEMBL1178085 & 747784 & 5.027 & 4.6711 & TRN & & \\
\hline CHEMBL1178088 & 747784 & 4.783 & 5.6036 & TRN & & \\
\hline CHEMBL609957 & 747784 & 4.896 & 5.0671 & TRN & & \\
\hline CHEMBL1178069 & 747784 & \multicolumn{3}{|c|}{ 4.5969999999999995 } & 4.8727 & TRN \\
\hline CHEMBL1160840 & 747784 & 5.149 & 4.9842 & TRN & & \\
\hline CHEMBL1178100 & 747784 & \multicolumn{3}{|c|}{5.0360000000000005} & 4.9207 & TRN \\
\hline CHEMBL1777994 & 747784 & \multicolumn{3}{|c|}{5.1080000000000005} & 5.3091 & TRN \\
\hline CHEMBL1777995 & 747784 & 5.069 & 5.1 & TRN & & \\
\hline CHEMBL27651 & 747784 & 4.962 & 4.8289 & TRN & & \\
\hline CHEMBL312418 & 747784 & 4.376 & 4.2397 & TRN & & \\
\hline CHEMBL134824 & 747784 & 3.05 & 3.5443 & TRN & & \\
\hline CHEMBL26666 & 747784 & 4.479 & 4.654 & TRN & & \\
\hline CHEMBL77133 & 747784 & 4.467 & 4.7334 & TRN & & \\
\hline CHEMBL1777996 & 747784 & 5.569 & 4.8171 & TST & & \\
\hline CHEMBL132252 & 747784 & 5.357 & 4.581 & TRN & & \\
\hline CHEMBL132081 & 747784 & 5.268 & 5.051 & TRN & & \\
\hline CHEMBL1777997 & 747784 & 4.55 & 5.2514 & TST & & \\
\hline CHEMBL1777998 & 747784 & 4.492 & 4.8387 & TST & & \\
\hline CHEMBL1777999 & 747784 & 4.975 & 4.3752 & TST & & \\
\hline CHEMBL132189 & 747784 & \multicolumn{3}{|c|}{3.7489999999999997} & 4.0921 & TST \\
\hline CHEMBL1178077 & 747784 & 4.636 & 4.586 & TST & & \\
\hline CHEMBL337647 & 747784 & 3.217 & 3.8869 & TST & & \\
\hline CHEMBL 1778000 & 747784 & 5.481 & 4.9339 & TST & & \\
\hline CHEMBL1178086 & 747784 & \multicolumn{3}{|c|}{5.167000000000001} & 4.681 & TST \\
\hline CHEMBL1778001 & 747784 & 4.315 & 5.0812 & TST & & \\
\hline CHEMBL132717 & 747784 & 3.322 & 4.8413 & TST & & \\
\hline CHEMBL1778002 & 747784 & 4.673 & 4.4237 & TST & & \\
\hline CHEMBL80352 & 747784 & 3.9 & 5.0142 & TST & & \\
\hline CHEMBL205471 & 342731 & 4.6003 & 4.5316 & TRN & & \\
\hline CHEMBL 206858 & 342731 & 5.1249 & 5.0417 & TRN & & \\
\hline CHEMBL 377945 & 342731 & 5.0132 & 4.9384 & TRN & & \\
\hline CHEMBL 207841 & 342731 & 4.7773 & 4.7452 & TRN & & \\
\hline CHEMBL206114 & 342731 & 4.7825 & 4.6022 & TRN & & \\
\hline CHEMBL203231 & 342731 & 3.301 & 3.2721 & TRN & & \\
\hline CHEMBL 204044 & 342731 & 5.0177 & 5.0906 & TRN & & \\
\hline CHEMBL383617 & 342731 & 3.301 & 2.75 & TST & & \\
\hline CHEMBL 203838 & 342731 & 5.1805 & 5.1354 & TRN & & \\
\hline CHEMBL204840 & 342731 & 3.301 & 5.0357 & TST & & \\
\hline CHEMBL203786 & 342731 & 4.5817 & 4.6333 & TRN & & \\
\hline
\end{tabular}




\begin{tabular}{|c|c|c|c|c|c|c|}
\hline \multirow[b]{2}{*}{ CHEMBL206389 } & \multicolumn{6}{|c|}{ Supplemental Table S2.txt } \\
\hline & 342731 & 5.2596 & 5.4175 & TRN & & \\
\hline CHEMBL 204738 & 342731 & 5.0655 & 5.1866 & TRN & & \\
\hline CHEMBL205567 & 342731 & 5.4949 & 5.3987 & TRN & & \\
\hline CHEMBL 383768 & 342731 & 5.1612 & 5.2267 & TRN & & \\
\hline CHEMBL203679 & 342731 & 5.8239 & 6.1695 & TRN & & \\
\hline CHEMBL 205801 & 342731 & 4.7595 & 4.8303 & TRN & & \\
\hline CHEMBL378925 & 342731 & 4.7773 & 4.8075 & TRN & & \\
\hline CHEMBL 383684 & 342731 & 4.7167 & 4.4716 & TRN & & \\
\hline CHEMBL 382801 & 342731 & 3.301 & 3.2266 & TST & & \\
\hline CHEMBL202626 & 342731 & 5.4815 & 5.8793 & TST & & \\
\hline CHEMBL382878 & 342731 & 5.1308 & 5.0655 & TRN & & \\
\hline CHEMBL205878 & 342731 & 5.4437 & 5.4242 & TRN & & \\
\hline CHEMBL202941 & 342731 & 3.301 & 3.4011 & TRN & & \\
\hline CHEMBL 206086 & 342731 & 4.9031 & 4.9874 & TRN & & \\
\hline CHEMBL381925 & 342731 & 5.5528 & 5.6097 & TRN & & \\
\hline CHEMBL203215 & 342731 & 5.4685 & 5.3488 & TRN & & \\
\hline CHEMBL208269 & 342731 & 4.684 & 4.5914 & TRN & & \\
\hline CHEMBL 205370 & 342731 & 4.7258 & 4.6916 & TRN & & \\
\hline CHEMBL383695 & 342731 & 5.6778 & 5.5521 & TRN & & \\
\hline CHEMBL380119 & 342731 & 5.2518 & 5.2069 & TRN & & \\
\hline CHEMBL208403 & 342731 & 5.0223 & 5.0045 & TRN & & \\
\hline CHEMBL206459 & 342731 & 4.3958 & 4.6893 & TRN & & \\
\hline CHEMBL 206080 & 342731 & 5.0315 & 4.9076 & TRN & & \\
\hline CHEMBL205515 & 342731 & 5.4437 & 5.2373 & TRN & & \\
\hline CHEMBL378799 & 342731 & 5.699 & 5.7463 & TRN & & \\
\hline CHEMBL204672 & 342731 & 4.8356 & 4.7478 & TRN & & \\
\hline CHEMBL 383510 & 342731 & 3.301 & 3.4477 & TRN & & \\
\hline CHEMBL 208837 & 342731 & 3.301 & 4.6229 & TST & & \\
\hline CHEMBL205527 & 342731 & 3.301 & 3.3562 & TRN & & \\
\hline CHEMBL382488 & 342731 & 5.699 & 5.7654 & TRN & & \\
\hline CHEMBL381978 & 342731 & 5.2147 & 4.9684 & TRN & & \\
\hline CHEMBL205371 & 342731 & 4.684 & 4.506 & TRN & & \\
\hline CHEMBL380498 & 342731 & 4.5735 & 4.7826 & TRN & & \\
\hline CHEMBL 202888 & 342731 & 3.301 & 3.2246 & TRN & & \\
\hline CHEMBL436769 & 342731 & 3.301 & 4.1588 & TST & & \\
\hline CHEMBL204619 & 342731 & 4.8416 & 4.9347 & TRN & & \\
\hline CHEMBL380130 & 342731 & 3.301 & 3.4318 & TRN & & \\
\hline CHEMBL206063 & 342731 & 3.301 & 3.395 & TRN & & \\
\hline CHEMBL382467 & 342731 & 5.1739 & 5.1286 & TST & & \\
\hline CHEMBL205234 & 342731 & 5.2291 & 6.6285 & TST & & \\
\hline CHEMBL204928 & 342731 & 4.5638 & 5.7195 & TST & & \\
\hline CHEMBL208467 & 342731 & 5.6383 & 5.2626 & TST & & \\
\hline CHEMBL205147 & 342731 & 3.301 & 4.3741 & TST & & \\
\hline CHEMBL 378429 & 342731 & 5.3188 & 4.2922 & TST & & \\
\hline CHEMBL205668 & 342731 & 4.38399 & 99999999 & 995 & 4.52 & TST \\
\hline CHEMBL436751 & 342731 & 3.301 & 4.9374 & TST & & \\
\hline CHEMBL377156 & 342731 & 4.7932 & 5.7484 & TST & & \\
\hline CHEMBL 3780461 & 1564001 & 3.3617 & 3.3599 & TRN & & \\
\hline
\end{tabular}


Supplemental Table s2.txt

\begin{tabular}{|c|c|c|c|c|c|}
\hline CHEMBL3781855 & 1564001 & 3.3617 & 3.88 & TRN & \\
\hline CHEMBL3781955 & 1564001 & 3.3617 & 3.2091 & TRN & \\
\hline CHEMBL3780564 & 1564001 & 3.3617 & 3.2296 & TRN & \\
\hline CHEMBL 3780976 & 1564001 & 3.3617 & 3.1041 & TRN & \\
\hline CHEMBL3781968 & 1564001 & 3.3617 & 4.1902 & TRN & \\
\hline CHEMBL1171902 & 1564001 & 3.3617 & 3.5159 & TRN & \\
\hline CHEMBL 3780873 & 1564001 & 3.3617 & \multicolumn{2}{|c|}{3.5460000000000003} & TRN \\
\hline CHEMBL 3780871 & 1564001 & 3.3617 & 3.6483 & TRN & \\
\hline CHEMBL 3781703 & 1564001 & 3.3617 & 2.8072 & TST & \\
\hline CHEMBL3781000 & 1564001 & 3.3617 & 3.447 & TRN & \\
\hline CHEMBL 3780687 & 1564001 & 3.3617 & 3.156 & TRN & \\
\hline CHEMBL 3781643 & 1564001 & 3.3617 & 3.6412 & TRN & \\
\hline CHEMBL3781646 & 1564001 & 3.3617 & 3.2236 & TRN & \\
\hline CHEMBL 3781038 & 1564001 & 3.3617 & 2.8482 & TST & \\
\hline CHEMBL3781115 & 1564001 & 3.3617 & 3.5014 & TRN & \\
\hline CHEMBL 3781684 & 1564001 & 3.3617 & 3.3428 & TRN & \\
\hline CHEMBL3780905 & 1564001 & 3.3617 & 3.4485 & TRN & \\
\hline CHEMBL405046 & 1564001 & 3.3617 & 3.9198 & TST & \\
\hline CHEMBL 3780313 & 1564001 & 3.3617 & 3.3105 & TRN & \\
\hline CHEMBL3780366 & 1564001 & 5.1245 & 4.4293 & TRN & \\
\hline CHEMBL3781269 & 1564001 & 3.3617 & 3.2971 & TRN & \\
\hline CHEMBL3780814 & 1564001 & 3.3617 & 3.2256 & TRN & \\
\hline CHEMBL 3780875 & 1564001 & 3.3617 & 3.6891 & TRN & \\
\hline CHEMBL 3781816 & 1564001 & 3.3617 & 3.3965 & TRN & \\
\hline CHEMBL 3781904 & 1564001 & 6.0891 & 3.1459 & TST & \\
\hline CHEMBL 3780188 & 1564001 & 3.3617 & 3.1011 & TRN & \\
\hline CHEMBL 3781588 & 1564001 & 3.3617 & 3.4875 & TRN & \\
\hline CHEMBL3781181 & 1564001 & 4.5611 & 2.8411 & TST & \\
\hline CHEMBL 3781421 & 1564001 & 4.7831 & 4.0499 & TRN & \\
\hline CHEMBL3781862 & 1564001 & 4.4437 & 1.9869 & TST & \\
\hline CHEMBL 3780272 & 1564001 & 3.3617 & 3.3654 & TRN & \\
\hline CHEMBL3781647 & 1564001 & 3.3617 & 3.4828 & TRN & \\
\hline CHEMBL3781497 & 1564001 & 3.3617 & 3.5589 & TRN & \\
\hline CHEMBL3781728 & 1564001 & 3.3617 & 3.4735 & TRN & \\
\hline CHEMBL3779925 & 1564001 & 3.3617 & 3.4719 & TRN & \\
\hline CHEMBL 3780834 & 1564001 & 4.6809 & 4.5549 & TRN & \\
\hline CHEMBL3782010 & 1564001 & 3.3617 & 3.847 & TST & \\
\hline CHEMBL3781340 & 1564001 & 3.3617 & 3.31699 & 99999999997 & TRN \\
\hline CHEMBL3781434 & 1564001 & 3.3617 & 3.542 & TRN & \\
\hline CHEMBL3781111 & 1564001 & 3.3617 & 3.9356 & TST & \\
\hline CHEMBL3780201 & 1564001 & 3.3617 & 3.6003 & TRN & \\
\hline CHEMBL3780347 & 1564001 & 3.3617 & 3.3216 & TRN & \\
\hline CHEMBL3781352 & 1564001 & 3.3617 & 3.9071 & TRN & \\
\hline CHEMBL3780514 & 1564001 & 3.3617 & 3.3066 & TRN & \\
\hline CHEMBL3781379 & 1564001 & 3.3617 & 3.1565 & TRN & \\
\hline CHEMBL3782043 & 1564001 & 3.3617 & 3.2771 & TRN & \\
\hline CHEMBL3780964 & 1564001 & 3.3617 & 4.0306 & TST & \\
\hline CHEMBL3780295 & 1564001 & 3.3617 & 3.2796 & TRN & \\
\hline
\end{tabular}


Supplemental Table S2.txt

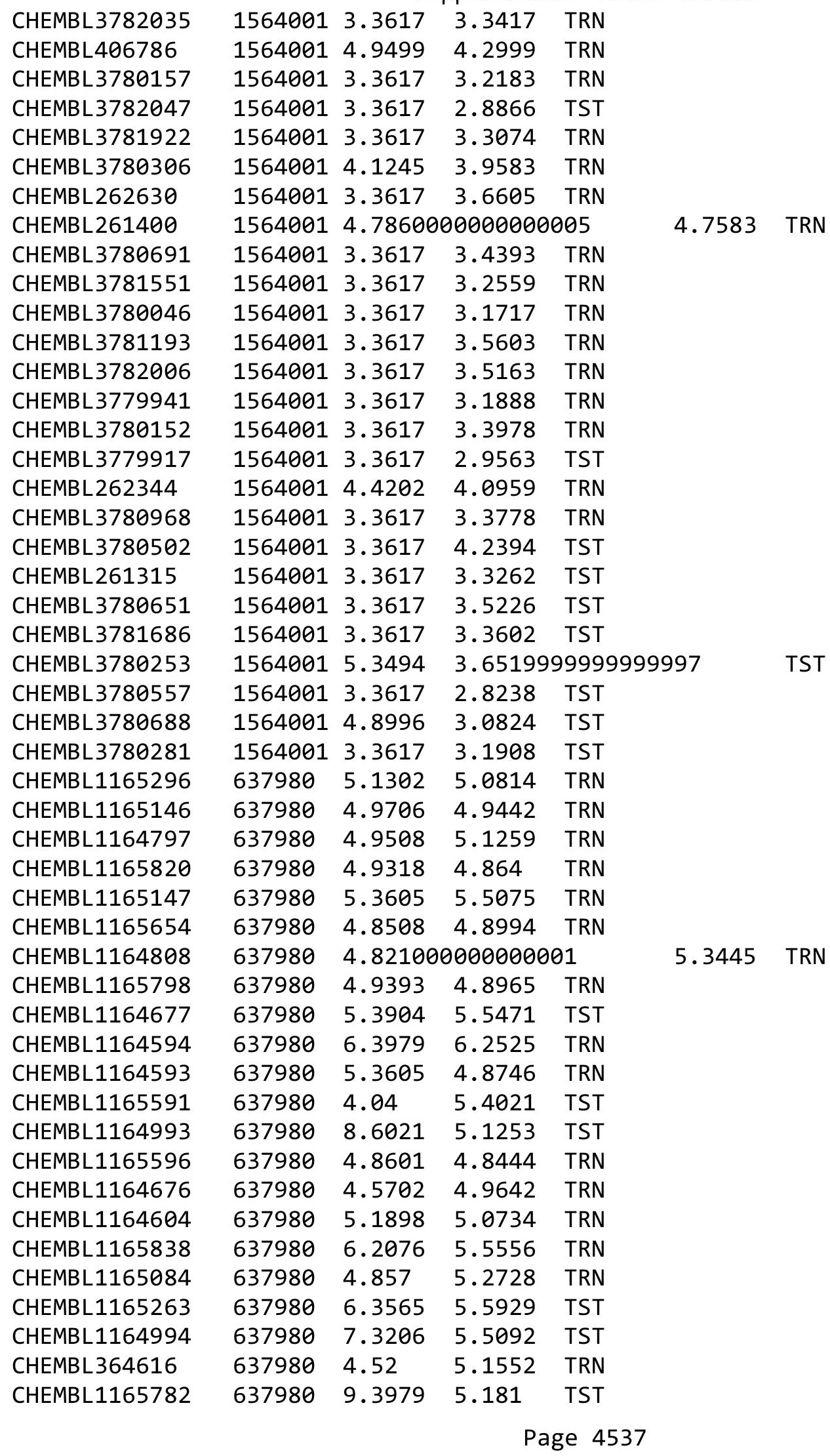


Supplemental Table S2.txt

\begin{tabular}{|c|c|c|c|c|c|}
\hline CHEMBL1165037 & 637980 & 5.3507 & 5.4533 & TRN & \\
\hline CHEMBL185148 & 637980 & 5.2899 & 5.25799 & 9999999999 & TRN \\
\hline CHEMBL462584 & 637980 & 4.7773 & 5.5124 & TST & \\
\hline CHEMBL1165264 & 637980 & 6.2676 & 5.7167 & TST & \\
\hline CHEMBL1165126 & 637980 & 5.7122 & 5.6249 & TRN & \\
\hline CHEMBL1164427 & 637980 & 5.1203 & 5.229 & TRN & \\
\hline CHEMBL1165700 & 637980 & 5.8697 & 5.6969 & TRN & \\
\hline CHEMBL1164804 & 637980 & 5.5498 & 5.2165 & TRN & \\
\hline CHEMBL1165516 & 637980 & 5.9586 & 6.2967 & TRN & \\
\hline CHEMBL279144 & 637980 & 4.6108 & 5.2919 & TST & \\
\hline CHEMBL1165586 & 637980 & 5.2503 & 5.0269 & TRN & \\
\hline CHEMBL1164807 & 637980 & 4.9706 & 5.4977 & TRN & \\
\hline CHEMBL1165611 & 637980 & 5.4401 & 5.5709 & TRN & \\
\hline CHEMBL1164811 & 637980 & 5.0799 & 5.2168 & TRN & \\
\hline CHEMBL1165828 & 637980 & 4.8601 & 4.8668 & TRN & \\
\hline CHEMBL1164102 & 637980 & 6.3565 & 5.9588 & TRN & \\
\hline CHEMBL1164803 & 637980 & 5.27 & 5.114 & TRN & \\
\hline CHEMBL1164195 & 637980 & 6.7447 & 6.4999 & TRN & \\
\hline CHEMBL1165068 & 637980 & 6.0 & 6.1796 & TRN & \\
\hline CHEMBL1165552 & 637980 & 5.3197 & 5.144 & TRN & \\
\hline CHEMBL1165690 & 637980 & 5.1403 & 5.4631 & TRN & \\
\hline CHEMBL1165725 & 637980 & 4.4498 & 4.9259 & TRN & \\
\hline CHEMBL363073 & 637980 & 4.2204 & 5.1003 & TST & \\
\hline CHEMBL1165105 & 637980 & 5.52 & 5.4514 & TRN & \\
\hline CHEMBL1164710 & 637980 & 5.4401 & 5.4445 & TRN & \\
\hline CHEMBL1165749 & 637980 & 4.7696 & 5.0276 & TRN & \\
\hline CHEMBL1165077 & 637980 & 6.5686 & 6.1872 & TRN & \\
\hline CHEMBL282988 & 637980 & 4.2403 & 4.8097 & TST & \\
\hline CHEMBL1165823 & 637980 & 5.71 & 6.3041 & TRN & \\
\hline CHEMBL1164901 & 637980 & 5.4908 & 5.4365 & TRN & \\
\hline CHEMBL1165251 & 637980 & 6.2676 & 5.579 & TRN & \\
\hline CHEMBL1164506 & 637980 & 4.9788 & 4.8933 & TRN & \\
\hline CHEMBL1165592 & 637980 & 4.8794 & 5.0451 & TRN & \\
\hline CHEMBL1164214 & 637980 & 4.6003 & 4.6939 & TRN & \\
\hline CHEMBL1165825 & 637980 & 5.15 & 5.6557 & TRN & \\
\hline CHEMBL1163362 & 637980 & 4.7799 & 5.135 & TRN & \\
\hline CHEMBL1165777 & 637980 & 6.7212 & 6.6002 & TRN & \\
\hline CHEMBL1165560 & 637980 & 5.8013 & 6.0144 & TRN & \\
\hline CHEMBL1164809 & 637980 & 5.1599 & 5.1263 & TRN & \\
\hline CHEMBL1164727 & 637980 & 4.8996 & 4.8429 & TRN & \\
\hline CHEMBL1164669 & 637980 & 7.3429 & 6.1798 & TST & \\
\hline CHEMBL185009 & 637980 & 6.1308 & 5.4634 & TRN & \\
\hline CHEMBL1163795 & 637980 & 5.4698 & 5.2458 & TRN & \\
\hline CHEMBL1164711 & 637980 & 5.8416 & 5.3019 & TRN & \\
\hline CHEMBL1164900 & 637980 & 5.2299 & 5.0128 & TRN & \\
\hline CHEMBL1165830 & 637980 & 5.0501 & 5.1725 & TRN & \\
\hline CHEMBL1165066 & 637980 & 5.4101 & 4.9326 & TRN & \\
\hline CHEMBL1165227 & 637980 & 8.8539 & 6.4679 & TST & \\
\hline
\end{tabular}




\begin{tabular}{|c|c|c|c|c|c|}
\hline & & \multicolumn{4}{|c|}{ Supplemental Table S2.txt } \\
\hline CHEMBL1164494 & 637980 & 5.9586 & 5.7396 & TRN & \\
\hline CHEMBL1165717 & 637980 & 4.6799 & 4.6088 & TRN & \\
\hline CHEMBL1165067 & 637980 & 5.27 & 5.1222 & TRN & \\
\hline CHEMBL1164103 & 637980 & 5.0506 & 5.325 & TRN & \\
\hline CHEMBL1164668 & 637980 & 8.7959 & 5.0477 & TST & \\
\hline CHEMBL1164798 & 637980 & 5.3497 & 5.5722 & TRN & \\
\hline CHEMBL1165127 & 637980 & 5.3799 & 5.3101 & TST & \\
\hline CHEMBL1165096 & 637980 & 5.3904 & 5.2679 & TST & \\
\hline CHEMBL1164964 & 637980 & 5.1203 & 4.9378 & TST & \\
\hline CHEMBL1163863 & 637980 & 6.041 & 5.6843 & TST & \\
\hline CHEMBL1164963 & 637980 & 4.7905 & 4.9616 & TST & \\
\hline CHEMBL1164732 & 637980 & 5.8996 & 5.6406 & TST & \\
\hline CHEMBL1165361 & 637980 & 5.7799 & 5.822 & TST & \\
\hline CHEMBL1517425 & 688501 & 4.3 & 4.1121 & TRN & \\
\hline CHEMBL1462419 & 688501 & 4.3 & 4.3843 & TST & \\
\hline CHEMBL162598 & 688501 & 4.3 & 4.3656 & TST & \\
\hline CHEMBL1485360 & 688501 & 4.8 & 4.5607 & TST & \\
\hline CHEMBL1364985 & 688501 & 4.1 & 4.5927 & TRN & \\
\hline CHEMBL1559341 & 688501 & 4.5 & 4.4066 & TRN & \\
\hline CHEMBL230156 & 688501 & 4.3 & 4.2522 & TRN & \\
\hline CHEMBL440287 & 688501 & 4.3 & 4.6339 & TRN & \\
\hline CHEMBL1449018 & 688501 & 4.5 & 4.6949 & TRN & \\
\hline CHEMBL192627 & 688501 & 4.7 & 4.6942 & TRN & \\
\hline CHEMBL1565705 & 688501 & 4.1 & 4.1772 & TRN & \\
\hline CHEMBL1549844 & 688501 & 4.6 & 4.84399 & 9999999999 & TST \\
\hline CHEMBL57394 & 688501 & 4.4 & 4.2084 & TRN & \\
\hline CHEMBL454173 & 688501 & 4.3 & 4.2221 & TRN & \\
\hline CHEMBL1430204 & 688501 & 4.3 & 4.4794 & TRN & \\
\hline CHEMBL1330518 & 688501 & 4.3 & 4.3978 & TRN & \\
\hline CHEMBL1562104 & 688501 & 5.3 & 5.4319 & TRN & \\
\hline CHEMBL1545634 & 688501 & 6.4 & 6.4931 & TRN & \\
\hline CHEMBL1535689 & 688501 & 4.5 & 4.3011 & TRN & \\
\hline CHEMBL140 & 688501 & 4.6 & 4.289 & TRN & \\
\hline CHEMBL462576 & 688501 & 4.3 & 4.48300 & 00000000005 & TRN \\
\hline CHEMBL36296 & 688501 & 4.3 & 4.1158 & TRN & \\
\hline CHEMBL1331245 & 688501 & 4.3 & 4.1721 & TRN & \\
\hline CHEMBL84685 & 688501 & 4.3 & 4.1655 & TRN & \\
\hline CHEMBL1308088 & 688501 & 5.0 & 4.8941 & TRN & \\
\hline CHEMBL1609459 & 688501 & 5.1 & 5.1123 & TRN & \\
\hline CHEMBL1522486 & 688501 & 4.5 & 4.6181 & TRN & \\
\hline CHEMBL1391326 & 688501 & 4.3 & 4.0607 & TRN & \\
\hline CHEMBL1585396 & 688501 & 4.3 & 4.3381 & TRN & \\
\hline CHEMBL1495381 & 688501 & 4.8 & 4.4838 & TST & \\
\hline CHEMBL1486465 & 688501 & 4.3 & 4.6904 & TRN & \\
\hline CHEMBL1566504 & 688501 & 4.4 & 4.27800 & 00000000005 & TST \\
\hline CHEMBL1492884 & 688501 & 4.4 & 4.3651 & TRN & \\
\hline CHEMBL1518369 & 688501 & 4.1 & 4.3485 & TRN & \\
\hline CHEMBL251389 & 688501 & 4.4 & 4.2839 & TRN & \\
\hline
\end{tabular}




\begin{tabular}{|c|c|c|c|c|c|}
\hline \multicolumn{6}{|c|}{ Supplemental Table S2.txt } \\
\hline CHEMBL105712 & 688501 & 5.0 & 4.9957 & TRN & \\
\hline CHEMBL1304981 & 688501 & 4.1 & 4.1459 & TRN & \\
\hline CHEMBL289277 & 688501 & 4.1 & 4.3479 & TRN & \\
\hline CHEMBL445957 & 688501 & 4.3 & 4.2983 & TRN & \\
\hline CHEMBL1200471 & 688501 & 6.6 & 6.4949 & TRN & \\
\hline CHEMBL263116 & 688501 & 4.3 & 4.7277 & TRN & \\
\hline CHEMBL1499545 & 688501 & 5.4 & 5.191 & TRN & \\
\hline CHEMBL153062 & 688501 & 4.1 & 4.6838 & TRN & \\
\hline CHEMBL1491899 & 688501 & 4.1 & 4.27800 & 00000000005 & TRN \\
\hline CHEMBL1439332 & 688501 & 4.5 & 4.2925 & TRN & \\
\hline CHEMBL1558796 & 688501 & 4.3 & 4.6032 & TRN & \\
\hline CHEMBL1407826 & 688501 & 4.5 & 4.9154 & TST & \\
\hline CHEMBL1579130 & 688501 & 6.0 & 5.7552 & TST & \\
\hline CHEMBL1462995 & 688501 & 4.1 & 4.4826 & TST & \\
\hline CHEMBL8739 & 688501 & 4.3 & 4.3037 & TRN & \\
\hline CHEMBL1421613 & 688501 & 4.1 & 3.9476 & TRN & \\
\hline CHEMBL144530 & 688501 & 4.5 & 4.3285 & TRN & \\
\hline CHEMBL1514512 & 688501 & 4.3 & 4.1086 & TRN & \\
\hline CHEMBL346918 & 688501 & 4.1 & 4.2369 & TRN & \\
\hline CHEMBL418068 & 688501 & 4.1 & 4.4007 & TRN & \\
\hline CHEMBL1569493 & 688501 & 6.0 & 5.7871 & TRN & \\
\hline CHEMBL295652 & 688501 & 2.4 & 3.4399 & TRN & \\
\hline CHEMBL280998 & 688501 & 4.4 & 4.3668 & TRN & \\
\hline CHEMBL1492104 & 688501 & 4.5 & 4.6973 & TRN & \\
\hline CHEMBL1492729 & 688501 & 4.8 & 4.7921 & TRN & \\
\hline CHEMBL220845 & 688501 & 4.4 & 4.1343 & TRN & \\
\hline CHEMBL1319452 & 688501 & 4.6 & 4.3712 & TRN & \\
\hline CHEMBL1600998 & 688501 & 5.1 & 5.4936 & TRN & \\
\hline CHEMBL1309179 & 688501 & 4.9 & 4.8089 & TRN & \\
\hline CHEMBL1496957 & 688501 & 4.7 & 4.7921 & TRN & \\
\hline CHEMBL1338613 & 688501 & 4.4 & 4.2061 & TRN & \\
\hline CHEMBL1448387 & 688501 & 4.4 & 4.6823 & TRN & \\
\hline CHEMBL1526319 & 688501 & 4.3 & 4.4023 & TRN & \\
\hline CHEMBL1529759 & 688501 & 4.1 & 4.2446 & TST & \\
\hline CHEMBL1528479 & 688501 & 4.1 & 4.0705 & TRN & \\
\hline CHEMBL1580759 & 688501 & 4.7 & 4.3187 & TRN & \\
\hline CHEMBL1489064 & 688501 & 4.3 & 4.2375 & TRN & \\
\hline CHEMBL224282 & 688501 & 4.3 & 4.1372 & TRN & \\
\hline CHEMBL1519327 & 688501 & 6.5 & 6.1971 & TRN & \\
\hline CHEMBL 286013 & 688501 & 4.7 & 4.4958 & TRN & \\
\hline CHEMBL1526721 & 688501 & 5.1 & 4.912 & TRN & \\
\hline CHEMBL486193 & 688501 & 4.3 & 4.6172 & TST & \\
\hline CHEMBL1452158 & 688501 & 4.4 & 4.185 & TRN & \\
\hline CHEMBL509531 & 688501 & 4.9 & 4.8001 & TST & \\
\hline CHEMBL1409985 & 688501 & 5.4 & 5.1875 & TRN & \\
\hline CHEMBL1414154 & 688501 & 4.3 & 4.0622 & TRN & \\
\hline CHEMBL1602699 & 688501 & 5.6 & 5.2803 & TRN & \\
\hline CHEMBL 1142 & 688501 & 4.5 & 4.3108 & TRN & \\
\hline
\end{tabular}




\begin{tabular}{|c|c|c|c|c|}
\hline \multicolumn{5}{|c|}{ Supplemental Table s2.txt } \\
\hline CHEMBL1569226 & 688501 & 5.2 & 5.2118 & TRN \\
\hline CHEMBL 28 & 688501 & 4.3 & 4.4456 & TRN \\
\hline CHEMBL1344952 & 688501 & 4.1 & 3.9376 & TRN \\
\hline CHEMBL1471289 & 688501 & 4.4 & 4.4854 & TRN \\
\hline CHEMBL1447588 & 688501 & 4.8 & 4.5812 & TST \\
\hline CHEMBL1612246 & 688501 & 4.4 & 4.3532 & TRN \\
\hline CHEMBL 1484480 & 688501 & 4.1 & 4.1171 & TRN \\
\hline CHEMBL175193 & 688501 & 4.1 & 4.1612 & TRN \\
\hline CHEMBL1418603 & 688501 & 4.4 & 4.0988 & TRN \\
\hline CHEMBL443949 & 688501 & 4.4 & 4.4485 & TRN \\
\hline CHEMBL91732 & 688501 & 4.1 & 4.4611 & TST \\
\hline CHEMBL334255 & 688501 & 4.8 & 5.0771 & TRN \\
\hline CHEMBL1451833 & 688501 & 4.5 & 4.4908 & TST \\
\hline CHEMBL1527567 & 688501 & 4.4 & 4.3412 & TRN \\
\hline CHEMBL44072 & 688501 & 4.4 & 4.3205 & TRN \\
\hline CHEMBL70582 & 688501 & 4.6 & 4.4069 & TRN \\
\hline CHEMBL1524617 & 688501 & 5.3 & 5.2291 & TST \\
\hline CHEMBL1393325 & 688501 & 4.3 & 4.2075 & TRN \\
\hline CHEMBL1450607 & 688501 & 4.6 & 4.6656 & TST \\
\hline CHEMBL1530684 & 688501 & 4.4 & 4.4514 & TST \\
\hline CHEMBL1303139 & 688501 & 5.2 & 5.26399 & 9999999999 \\
\hline CHEMBL538146 & 688501 & 4.4 & 4.6944 & TST \\
\hline CHEMBL 85811 & 688501 & 4.2 & 4.1284 & TST \\
\hline CHEMBL1569358 & 688501 & 4.1 & 4.2857 & TST \\
\hline CHEMBL402063 & 688501 & 4.3 & 5.5258 & TST \\
\hline CHEMBL1408847 & 688501 & 5.2 & 5.2397 & TST \\
\hline CHEMBL8320 & 688501 & 4.3 & 4.3363 & TST \\
\hline CHEMBL1576086 & 688501 & 4.4 & 4.4803 & TST \\
\hline CHEMBL1489568 & 688501 & 4.3 & 4.1636 & TST \\
\hline CHEMBL1366408 & 688501 & 4.4 & 4.7699 & TST \\
\hline CHEMBL389950 & 688501 & 4.1 & 4.2002 & TST \\
\hline CHEMBL3932326 & 1637006 & 8.8861 & 8.8986 & TRN \\
\hline CHEMBL3914721 & 1637006 & 7.2757 & 7.2774 & TRN \\
\hline CHEMBL 3898945 & 1637006 & 5.301 & 5.3121 & TRN \\
\hline CHEMBL3964050 & 1637006 & 7.3468 & 7.3221 & TRN \\
\hline CHEMBL3980067 & 1637006 & 5.4949 & 5.1797 & TST \\
\hline CHEMBL3935046 & 1637006 & 6.585 & 6.5742 & TRN \\
\hline CHEMBL3916933 & 1637006 & 3.5229 & 3.5128 & TRN \\
\hline CHEMBL3971976 & 1637006 & 5.7696 & 6.6651 & TST \\
\hline CHEMBL3950228 & 1637006 & 6.0969 & 6.1016 & TRN \\
\hline CHEMBL3917255 & 1637006 & 7.9208 & 7.9189 & TRN \\
\hline CHEMBL3927277 & 1637006 & 5.6198 & 5.6254 & TRN \\
\hline CHEMBL3968216 & 1637006 & 3.5229 & 3.5114 & TRN \\
\hline CHEMBL 3209049 & 1637006 & 6.1805 & 6.4555 & TST \\
\hline CHEMBL3981183 & 1637006 & 7.2924 & 7.8289 & TST \\
\hline CHEMBL3944040 & 1637006 & 6.3665 & 6.3794 & TRN \\
\hline CHEMBL3899989 & 1637006 & 6.7447 & 6.7421 & TRN \\
\hline CHEMBL3903625 & 1637006 & 5.699 & 5.6989 & TRN \\
\hline
\end{tabular}


Supplemental Table S2.txt

\begin{tabular}{|c|c|c|c|c|}
\hline CHEMBL 3931655 & 1637006 & 6.6778 & 6.6896 & TRN \\
\hline CHEMBL 3965696 & 1637006 & 7.5229 & 7.5042 & TRN \\
\hline CHEMBL 3968083 & 1637006 & 7.3372 & 7.338999 & 99999999995 \\
\hline CHEMBL 3952275 & 1637006 & 7.7696 & 7.7957 & TRN \\
\hline CHEMBL 3900872 & 1637006 & 5.8861 & 5.8785 & TRN \\
\hline CHEMBL3978819 & 1637006 & 6.301 & 6.2713 & TRN \\
\hline CHEMBL 3890861 & 1637006 & 8.301 & 8.3159 & TRN \\
\hline CHEMBL3918456 & 1637006 & 7.4318 & 6.1102 & TST \\
\hline CHEMBL3968112 & 1637006 & 7.2924 & 7.3044 & TRN \\
\hline CHEMBL 3966655 & 1637006 & 6.4685 & 6.4309 & TRN \\
\hline CHEMBL3969447 & 1637006 & 6.2596 & 6.2604 & TRN \\
\hline CHEMBL 3984818 & 1637006 & 8.5229 & 8.522 & TRN \\
\hline CHEMBL 3934275 & 1637006 & 6.0809 & 6.8095 & TST \\
\hline CHEMBL 3974283 & 1637006 & 7.1805 & 7.188 & TRN \\
\hline CHEMBL 3926856 & 1637006 & 8.8539 & 8.854 & TRN \\
\hline CHEMBL 3912469 & 1637006 & 4.301 & 4.3019 & TRN \\
\hline CHEMBL 3980338 & 1637006 & 7.2596 & 7.4194 & TST \\
\hline CHEMBL 3951939 & 1637006 & 6.699 & 7.428 & TST \\
\hline CHEMBL3958181 & 1637006 & 8.0458 & 8.0583 & TRN \\
\hline CHEMBL 3920665 & 1637006 & 8.2218 & 8.2205 & TRN \\
\hline CHEMBL 3910957 & 1637006 & 7.6198 & 7.6223 & TRN \\
\hline CHEMBL 3900353 & 1637006 & 5.7959 & 5.7935 & TRN \\
\hline CHEMBL 3954591 & 1637006 & 7.3979 & 7.5055 & TST \\
\hline CHEMBL3946643 & 1637006 & 3.5229 & 6.3237 & TST \\
\hline CHEMBL 3971765 & 1637006 & 7.0969 & 7.1064 & TRN \\
\hline CHEMBL 3944989 & 1637006 & 7.0458 & 7.053 & TRN \\
\hline CHEMBL3961633 & 1637006 & 5.0 & 5.02 & TRN \\
\hline CHEMBL 3949870 & 1637006 & 7.4202 & 7.4342 & TRN \\
\hline CHEMBL3893648 & 1637006 & 6.9208 & 6.9037 & TRN \\
\hline CHEMBL 3982510 & 1637006 & 6.2147 & 3.6691 & TST \\
\hline CHEMBL3918736 & 1637006 & 7.2218 & 7.2134 & TRN \\
\hline CHEMBL 3907143 & 1637006 & 3.5229 & 6.0588 & TST \\
\hline CHEMBL 3928377 & 1637006 & 6.7696 & 6.7734 & TRN \\
\hline CHEMBL3955559 & 1637006 & 5.8239 & 5.8204 & TRN \\
\hline CHEMBL3921169 & 1637006 & 8.7447 & 8.6964 & TRN \\
\hline CHEMBL 3947573 & 1637006 & 6.1871 & 6.2102 & TRN \\
\hline CHEMBL3971296 & 1637006 & 6.4685 & 6.4773 & TRN \\
\hline CHEMBL 3955382 & 1637006 & 6.2924 & 6.2834 & TRN \\
\hline CHEMBL3898106 & 1637006 & 5.6576 & 5.6673 & TRN \\
\hline CHEMBL 3968552 & 1637006 & 6.1249 & 6.1205 & TRN \\
\hline CHEMBL 3928916 & 1637006 & 6.4318 & 6.4344 & TRN \\
\hline CHEMBL 3942291 & 1637006 & 6.7959 & 6.7912 & TRN \\
\hline CHEMBL 3930285 & 1637006 & 6.3872 & 5.7566 & TST \\
\hline CHEMBL 3952534 & 1637006 & 6.1675 & 6.1881 & TRN \\
\hline CHEMBL 3930579 & 1637006 & 5.2676 & 6.2464 & TST \\
\hline CHEMBL 3965662 & 1637006 & 6.7447 & 6.7411 & TRN \\
\hline CHEMBL 3924129 & 1637006 & 5.699 & 6.8341 & TST \\
\hline CHEMBL3967823 & 1637006 & 5.301 & 5.5185 & TST \\
\hline
\end{tabular}


Supplemental Table S2.txt

\begin{tabular}{|c|c|c|c|c|c|}
\hline CHEMBL3913484 & 1637006 & 6.0915 & \multicolumn{2}{|c|}{6.082999999999999} & TST \\
\hline CHEMBL1788116 & 954488 & 5.3233 & 4.2555 & TRN & \\
\hline CHEMBL509032 & 954488 & 3.8455 & 4.2325 & TRN & \\
\hline CHEMBL240954 & 954488 & 3.3235 & 4.003 & TST & \\
\hline CHEMBL1256459 & 954488 & 3.862 & 4.035 & TRN & \\
\hline CHEMBL220241 & 954488 & 5.1175 & 4.2346 & TRN & \\
\hline CHEMBL1643959 & 954488 & 2.6039 & 3.0136 & TRN & \\
\hline CHEMBL191334 & 954488 & 4.8225 & 4.9916 & TRN & \\
\hline CHEMBL379300 & 954488 & 4.5728 & 4.4451 & TRN & \\
\hline CHEMBL573107 & 954488 & 4.5912 & 5.1217 & TRN & \\
\hline CHEMBL585951 & 954488 & 6.5246 & 6.25700 & 0000000001 & TRN \\
\hline CHEMBL3392440 & 954488 & 3.4 & 3.9458 & TRN & \\
\hline CHEMBL102714 & 954488 & 4.1277 & 4.1155 & TRN & \\
\hline CHEMBL379975 & 954488 & 5.7188 & 5.3678 & TRN & \\
\hline CHEMBL3349342 & 954488 & 3.7572 & 4.1797 & TRN & \\
\hline CHEMBL202721 & 954488 & 4.6023 & 4.8671 & TRN & \\
\hline CHEMBL1673039 & 954488 & 3.5676 & 3.7584 & TRN & \\
\hline CHEMBL412142 & 954488 & 3.4521 & 3.9685 & TRN & \\
\hline CHEMBL 2363137 & 954488 & 4.3145 & 4.5496 & TRN & \\
\hline CHEMBL483849 & 954488 & 3.2666 & 2.5561 & TRN & \\
\hline CHEMBL213100 & 954488 & 2.5744 & 2.8617 & TRN & \\
\hline CHEMBL393929 & 954488 & 3.5953 & 3.925 & TRN & \\
\hline CHEMBL259181 & 954488 & 5.4485 & 4.5259 & TRN & \\
\hline CHEMBL65 & 954488 & 8.5541 & 8.9765 & TRN & \\
\hline CHEMBL392695 & 954488 & 3.4916 & 3.1418 & TRN & \\
\hline CHEMBL210618 & 954488 & 3.0773 & 3.864 & TRN & \\
\hline CHEMBL222102 & 954488 & 3.8965 & 4.1612 & TRN & \\
\hline CHEMBL515416 & 954488 & 4.7671 & 3.8912 & TRN & \\
\hline CHEMBL1190711 & 954488 & 6.3697 & 5.5361 & TRN & \\
\hline CHEMBL180127 & 954488 & 1.3209 & 3.0953 & TRN & \\
\hline CHEMBL 2005886 & 954488 & 3.4811 & 3.9328 & TRN & \\
\hline CHEMBL1404918 & 954488 & 2.6856 & 3.2039 & TRN & \\
\hline CHEMBL472940 & 954488 & 5.0059 & 4.2272 & TRN & \\
\hline CHEMBL189584 & 954488 & 4.1419 & 4.7709 & TRN & \\
\hline CHEMBL258844 & 954488 & 5.3433 & 4.4319 & TRN & \\
\hline CHEMBL1590308 & 954488 & 2.8656 & 2.8399 & TST & \\
\hline CHEMBL558642 & 954488 & 5.2069 & 3.9592 & TRN & \\
\hline CHEMBL1970879 & 954488 & 3.2452 & 3.1185 & TRN & \\
\hline CHEMBL1230020 & 954488 & 4.4187 & 4.072 & TRN & \\
\hline CHEMBL1357247 & 954488 & 3.6187 & 3.1821 & TRN & \\
\hline CHEMBL 9470 & 954488 & 6.6566 & 5.8807 & TST & \\
\hline CHEMBL188678 & 954488 & 4.5331 & 4.8738 & TRN & \\
\hline CHEMBL514499 & 954488 & 4.6074 & 4.1364 & TRN & \\
\hline CHEMBL192566 & 954488 & 8.6819 & 7.9123 & TST & \\
\hline CHEMBL135561 & 954488 & 4.8018 & 4.1875 & TRN & \\
\hline CHEMBL1909414 & 954488 & 3.4951 & 4.1747 & TRN & \\
\hline CHEMBL300389 & 954488 & 5.6284 & 5.5685 & TRN & \\
\hline CHEMBL 2144069 & 954488 & 3.3628 & 4.0279 & TRN & \\
\hline
\end{tabular}




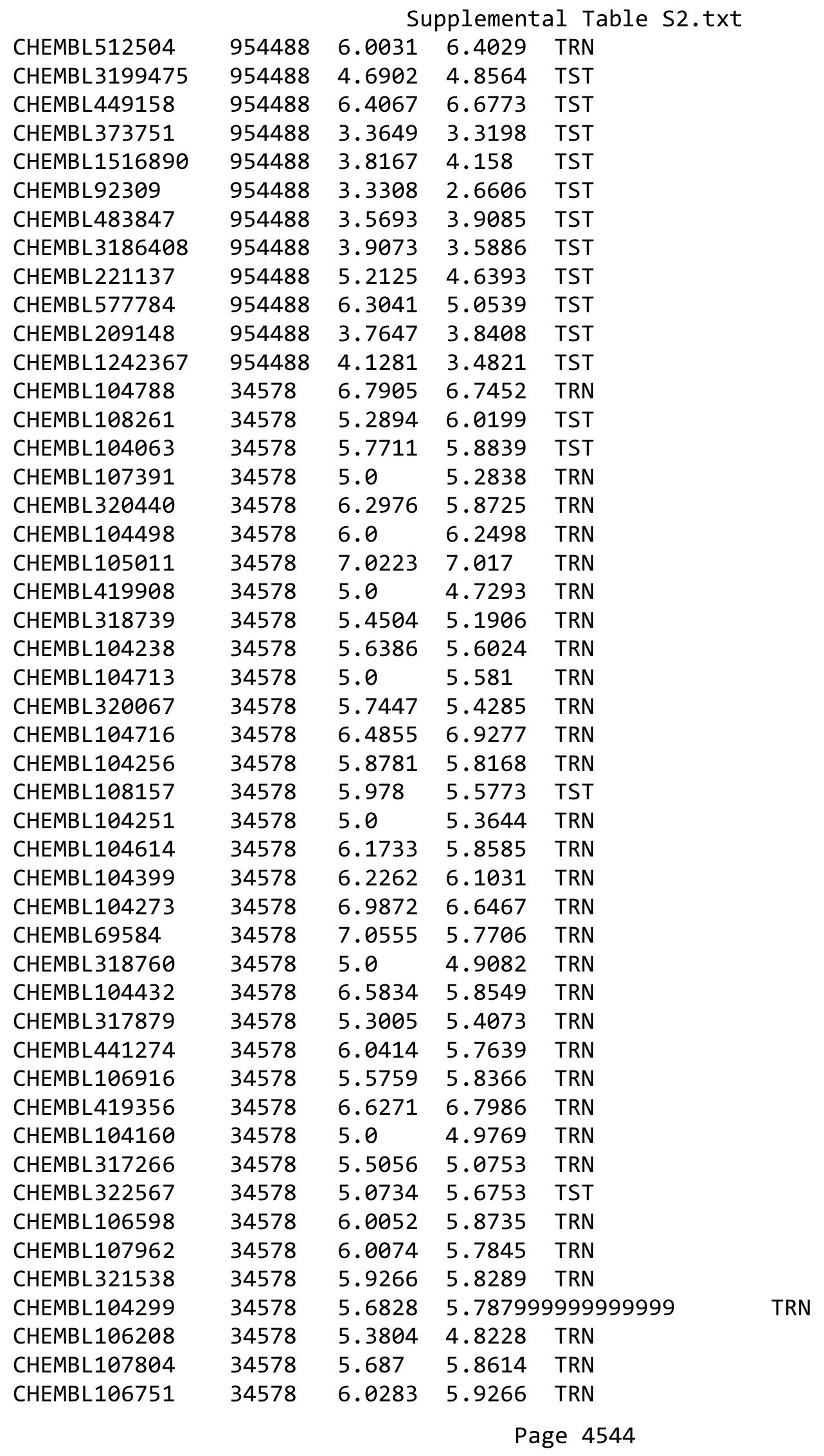




\begin{tabular}{|c|c|c|c|c|c|}
\hline \multicolumn{6}{|c|}{ Supplemental Table s2.txt } \\
\hline CHEMBL107338 & 34578 & 5.0 & 4.9536 & TRN & \\
\hline CHEMBL326250 & 34578 & 5.5476 & 5.5718 & TRN & \\
\hline CHEMBL107793 & 34578 & 5.6572 & 5.7505 & TRN & \\
\hline CHEMBL104719 & 34578 & 6.9281 & 6.8974 & TRN & \\
\hline CHEMBL106917 & 34578 & 5.0 & 5.1804 & TRN & \\
\hline CHEMBL107755 & 34578 & 5.0 & 5.3187 & TST & \\
\hline CHEMBL107384 & 34578 & 5.5459 & 5.3883 & TRN & \\
\hline CHEMBL323525 & 34578 & 6.0595 & 5.8708 & TRN & \\
\hline CHEMBL106170 & 34578 & 4.0 & 5.5455 & TRN & \\
\hline CHEMBL319650 & 34578 & 6.0123 & 5.9366 & TRN & \\
\hline CHEMBL107229 & 34578 & 5.581 & 5.604 & TRN & \\
\hline CHEMBL104138 & 34578 & 6.2941 & 5.9889 & TRN & \\
\hline CHEMBL323537 & 34578 & 4.0 & 5.4478 & TRN & \\
\hline CHEMBL419911 & 34578 & 5.0 & 5.7458 & TRN & \\
\hline CHEMBL323022 & 34578 & 6.9393 & 6.1902 & TRN & \\
\hline CHEMBL107351 & 34578 & 5.8861 & 6.05399 & 9999999999 & TRN \\
\hline CHEMBL321734 & 34578 & 5.0 & 5.6215 & TRN & \\
\hline CHEMBL107742 & 34578 & 5.9007 & 6.011 & TRN & \\
\hline CHEMBL322326 & 34578 & 6.2233 & 5.9117 & TST & \\
\hline CHEMBL104800 & 34578 & 6.7932 & 5.8767 & TST & \\
\hline CHEMBL106742 & 34578 & 6.9281 & 6.9976 & TST & \\
\hline CHEMBL104380 & 34578 & 7.4437 & 5.9371 & TST & \\
\hline CHEMBL105595 & 34578 & 5.5521 & 5.218 & TST & \\
\hline CHEMBL323213 & 34578 & 5.046 & 5.14 & TST & \\
\hline CHEMBL419916 & 34578 & 6.4949 & 5.4071 & TST & \\
\hline CHEMBL104832 & 34578 & 6.8962 & 6.8666 & TST & \\
\hline CHEMBL107020 & 34578 & 5.0 & 5.8183 & TST & \\
\hline CHEMBL104579 & 34578 & 6.8477 & 6.7953 & TST & \\
\hline CHEMBL324867 & 34578 & 5.317 & 5.7375 & TST & \\
\hline CHEMBL104321 & 34578 & 5.1472 & 5.2432 & TST & \\
\hline CHEMBL 3109546 & 1641827 & 6.2967 & 6.0748 & TRN & \\
\hline CHEMBL 3109520 & 1641827 & 6.0 & 6.8405 & TRN & \\
\hline CHEMBL 3109527 & 1641827 & 8.5391 & 8.8139 & TRN & \\
\hline CHEMBL3971881 & 1641827 & 7.2358 & 7.2793 & TRN & \\
\hline CHEMBL 3109556 & 1641827 & 7.8539 & 7.6743 & TRN & \\
\hline CHEMBL3942515 & 1641827 & 7.8268 & 8.8153 & TST & \\
\hline CHEMBL3906925 & 1641827 & 7.9586 & 7.9629 & TRN & \\
\hline CHEMBL3109554 & 1641827 & 7.2588 & 7.3934 & TRN & \\
\hline CHEMBL 3109558 & 1641827 & 8.2218 & 8.0965 & TRN & \\
\hline CHEMBL588662 & 1641827 & 7.9208 & 4.9559 & TST & \\
\hline CHEMBL 3967875 & 1641827 & 8.0315 & 8.441 & TST & \\
\hline CHEMBL3977267 & 1641827 & 6.8996 & 6.898 & TRN & \\
\hline CHEMBL3946545 & 1641827 & 8.0168 & 7.6875 & TST & \\
\hline CHEMBL 3109544 & 1641827 & 6.0 & 6.3803 & TRN & \\
\hline CHEMBL 3978095 & 1641827 & 8.0159 & 7.7913 & TRN & \\
\hline CHEMBL 2012001 & 1641827 & 6.1244 & 5.87200 & 0000000001 & TRN \\
\hline CHEMBL3972112 & 1641827 & 5.1707 & 7.8266 & TST & \\
\hline CHEMBL3109551 & 1641827 & 6.0 & 6.99700 & 0000000001 & TRN \\
\hline & & & & 4545 & \\
\hline
\end{tabular}


Supplemental Table S2.txt

\begin{tabular}{|c|c|c|c|c|c|c|}
\hline CHEMBL 3907442 & 1641827 & 7.0804 & 6.7371 & TRN & & \\
\hline CHEMBL 3109522 & 1641827 & 7.8861 & 7.4761 & TRN & & \\
\hline CHEMBL 3985353 & 1641827 & 6.6757 & 6.9743 & TRN & & \\
\hline CHEMBL 3921372 & 1641827 & 7.3116 & 8.6964 & TST & & \\
\hline CHEMBL 3891237 & 1641827 & 8.2336 & 7.6663 & TRN & & \\
\hline CHEMBL 3983294 & 1641827 & 6.2907 & 6.0504 & TRN & & \\
\hline CHEMBL 3905655 & 1641827 & 6.1945 & 6.3988 & TRN & & \\
\hline CHEMBL 3915894 & 1641827 & 8.7258 & 9.0083 & TST & & \\
\hline CHEMBL 3900873 & 1641827 & 5.5482 & 5.7594 & TRN & & \\
\hline CHEMBL 3109549 & 1641827 & 8.6216 & 8.1333 & TRN & & \\
\hline CHEMBL 3109523 & 1641827 & 8.262 & 8.1332 & TRN & & \\
\hline CHEMBL3976996 & 1641827 & 6.9586 & 6.9298 & TRN & & \\
\hline CHEMBL 3109533 & 1641827 & 7.4802 & 8.2682 & TST & & \\
\hline CHEMBL 3948015 & 1641827 & 7.2865 & 7.0851 & TST & & \\
\hline CHEMBL 3109555 & 1641827 & 8.163 & 8.4601 & TRN & & \\
\hline CHEMBL 3939185 & 1641827 & 7.9431 & 8.1466 & TRN & & \\
\hline CHEMBL3109539 & 1641827 & 6.4067 & 6.0926 & TRN & & \\
\hline CHEMBL 3960162 & 1641827 & 6.3536 & 6.4859 & TRN & & \\
\hline CHEMBL 3109540 & 1641827 & 7.1713 & 6.7563 & TRN & & \\
\hline CHEMBL 2011974 & 1641827 & 5.9957 & 6.4748 & TST & & \\
\hline CHEMBL 3914078 & 1641827 & 6.3706 & 6.5813 & TRN & & \\
\hline CHEMBL 3976714 & 1641827 & 5.7471 & 6.6826 & TRN & & \\
\hline CHEMBL 3109541 & 1641827 & 7.6003 & 7.0935 & TRN & & \\
\hline CHEMBL 3962577 & 1641827 & 8.0044 & 7.2051 & TRN & & \\
\hline CHEMBL 3109526 & 1641827 & 8.6576 & 8.113 & TRN & & \\
\hline CHEMBL 3939240 & 1641827 & 6.6596 & 7.2673 & TRN & & \\
\hline CHEMBL 3109534 & 1641827 & 8.1367 & 8.9521 & TST & & \\
\hline CHEMBL 3924762 & 1641827 & 8.5591 & 7.7769 & TST & & \\
\hline CHEMBL 3913482 & 1641827 & 7.1713 & 7.229 & TRN & & \\
\hline CHEMBL 3947701 & 1641827 & 8.2774 & 7.5536 & TST & & \\
\hline CHEMBL 3109518 & 1641827 & 4.0 & 4.0482 & TRN & & \\
\hline CHEMBL 3109543 & 1641827 & 8.6253 & 7.1757 & TRN & & \\
\hline CHEMBL 3109521 & 1641827 & 7.9208 & 6.8708 & TRN & & \\
\hline CHEMBL 3907570 & 1641827 & 7.26200 & 000000000 & 005 & 7.6135 & TRN \\
\hline CHEMBL 3914640 & 1641827 & 7.0424 & 7.2658 & TRN & & \\
\hline CHEMBL3936611 & 1641827 & 7.9469 & 7.2966 & TRN & & \\
\hline CHEMBL 2011967 & 1641827 & 6.6198 & 7.2083 & TST & & \\
\hline CHEMBL 3985863 & 1641827 & 7.2411 & 8.479 & TST & & \\
\hline CHEMBL 3924123 & 1641827 & 7.8508 & 8.4512 & TRN & & \\
\hline CHEMBL 3966834 & 1641827 & 6.9281 & 7.1407 & TRN & & \\
\hline CHEMBL 3976403 & 1641827 & 7.066 & 7.0059 & TRN & & \\
\hline CHEMBL 3908681 & 1641827 & 7.129 & 6.5223 & TRN & & \\
\hline CHEMBL 3916377 & 1641827 & 7.5528 & 8.9224 & TST & & \\
\hline CHEMBL 3917490 & 1641827 & 7.4802 & 7.9404 & TRN & & \\
\hline CHEMBL 3922940 & 1641827 & 6.983 & 7.4484 & TRN & & \\
\hline CHEMBL 3109547 & 1641827 & 6.0 & 5.8535 & TRN & & \\
\hline CHEMBL 3960302 & 1641827 & 8.699 & 8.1616 & TRN & & \\
\hline CHEMBL582580 & 1641827 & 7.5421 & 4.7172 & TST & & \\
\hline
\end{tabular}


Supplemental Table S2.txt

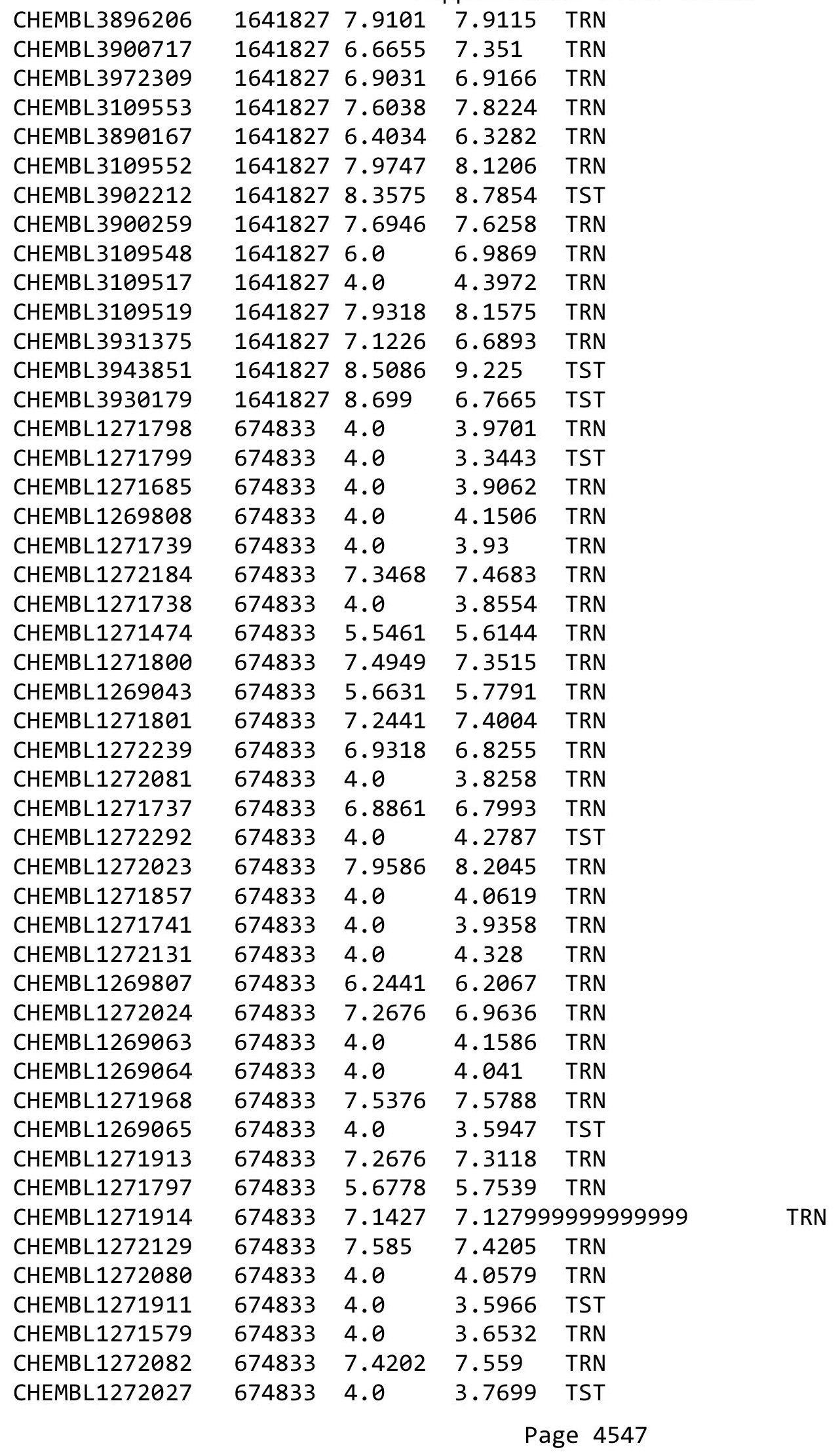




\begin{tabular}{|c|c|c|c|c|c|}
\hline \multicolumn{6}{|c|}{ Supplemental Table S2.txt } \\
\hline CHEMBL1271684 & 674833 & 4.0 & 3.4625 & TST & \\
\hline CHEMBL1271581 & 674833 & 4.0 & 4.0483 & TRN & \\
\hline CHEMBL1271633 & 674833 & 4.0 & 3.2824 & TST & \\
\hline CHEMBL1271912 & 674833 & 7.0915 & 7.1218 & TRN & \\
\hline CHEMBL1271969 & 674833 & 7.3188 & 7.8979 & TST & \\
\hline CHEMBL1271967 & 674833 & 7.4685 & 7.2379 & TRN & \\
\hline CHEMBL1271473 & 674833 & 4.0 & 3.8331 & TRN & \\
\hline CHEMBL1272293 & 674833 & 4.0 & 4.2126 & TRN & \\
\hline CHEMBL1271525 & 674833 & 7.3665 & 7.4483 & TRN & \\
\hline CHEMBL1272183 & 674833 & 7.1739 & 7.2123 & TRN & \\
\hline CHEMBL1271856 & 674833 & 4.0 & 4.0486 & TST & \\
\hline CHEMBL1271854 & 674833 & 4.0 & 4.0518 & TST & \\
\hline CHEMBL1272079 & 674833 & 4.0 & 4.2453 & TRN & \\
\hline CHEMBL1271970 & 674833 & 6.9318 & 6.5598 & TST & \\
\hline CHEMBL1272130 & 674833 & 7.284 & 7.1307 & TRN & \\
\hline CHEMBL1272026 & 674833 & 5.8413 & 5.8125 & TST & \\
\hline CHEMBL1271855 & 674833 & 4.0 & 3.1417 & TST & \\
\hline CHEMBL1271740 & 674833 & 6.2403 & 6.1722 & TST & \\
\hline CHEMBL1271580 & 674833 & 6.9586 & 6.8273 & TRN & \\
\hline CHEMBL3660353 & 1527978 & 5.7852 & 5.7927 & TRN & \\
\hline CHEMBL3660310 & 1527978 & 6.0 & 6.0904 & TRN & \\
\hline CHEMBL 3660412 & 1527978 & 5.7455 & 5.8508 & TRN & \\
\hline CHEMBL3665018 & 1527978 & 6.4101 & 6.5316 & TRN & \\
\hline CHEMBL 3660408 & 1527978 & 6.7011 & 6.6635 & TRN & \\
\hline CHEMBL3660454 & 1527978 & 6.8794 & 6.8715 & TRN & \\
\hline CHEMBL3660406 & 1527978 & 5.4083 & 5.2269 & TRN & \\
\hline CHEMBL3660472 & 1527978 & 6.7645 & 6.7599 & TRN & \\
\hline CHEMBL3660405 & 1527978 & 6.3969 & 6.49299 & 9999999999 & TRN \\
\hline CHEMBL3665039 & 1527978 & 3.699 & 3.5824 & TRN & \\
\hline CHEMBL3665082 & 1527978 & 7.6383 & 7.3962 & TRN & \\
\hline CHEMBL 3660372 & 1527978 & 5.0329 & 5.1387 & TRN & \\
\hline CHEMBL 3665045 & 1527978 & 6.2262 & 6.2635 & TRN & \\
\hline CHEMBL 3660385 & 1527978 & 5.4772 & 6.3385 & TRN & \\
\hline CHEMBL3660365 & 1527978 & 5.1979 & 5.2888 & TRN & \\
\hline CHEMBL491995 & 1527978 & 4.6936 & 4.7666 & TST & \\
\hline CHEMBL3660461 & 1527978 & 6.4547 & 6.3012 & TRN & \\
\hline CHEMBL3660392 & 1527978 & 6.0969 & 6.3036 & TRN & \\
\hline CHEMBL3665054 & 1527978 & 7.3279 & 7.3091 & TRN & \\
\hline CHEMBL 3665101 & 1527978 & 5.8011 & 5.7999 & TRN & \\
\hline CHEMBL3660443 & 1527978 & 6.7167 & 6.6183 & TRN & \\
\hline CHEMBL 3660325 & 1527978 & 6.4202 & 6.3025 & TRN & \\
\hline CHEMBL3660397 & 1527978 & 6.5086 & 6.5312 & TRN & \\
\hline CHEMBL3665051 & 1527978 & 6.8041 & 6.7825 & TRN & \\
\hline CHEMBL 3660337 & 1527978 & 6.1249 & 6.0874 & TRN & \\
\hline CHEMBL3665029 & 1527978 & 7.1308 & 7.081 & TRN & \\
\hline CHEMBL3660453 & 1527978 & 6.8327 & 6.7455 & TRN & \\
\hline CHEMBL3660431 & 1527978 & 6.0996 & 6.1647 & TRN & \\
\hline CHEMBL3660377 & 1527978 & 6.7878 & 6.7713 & TRN & \\
\hline
\end{tabular}




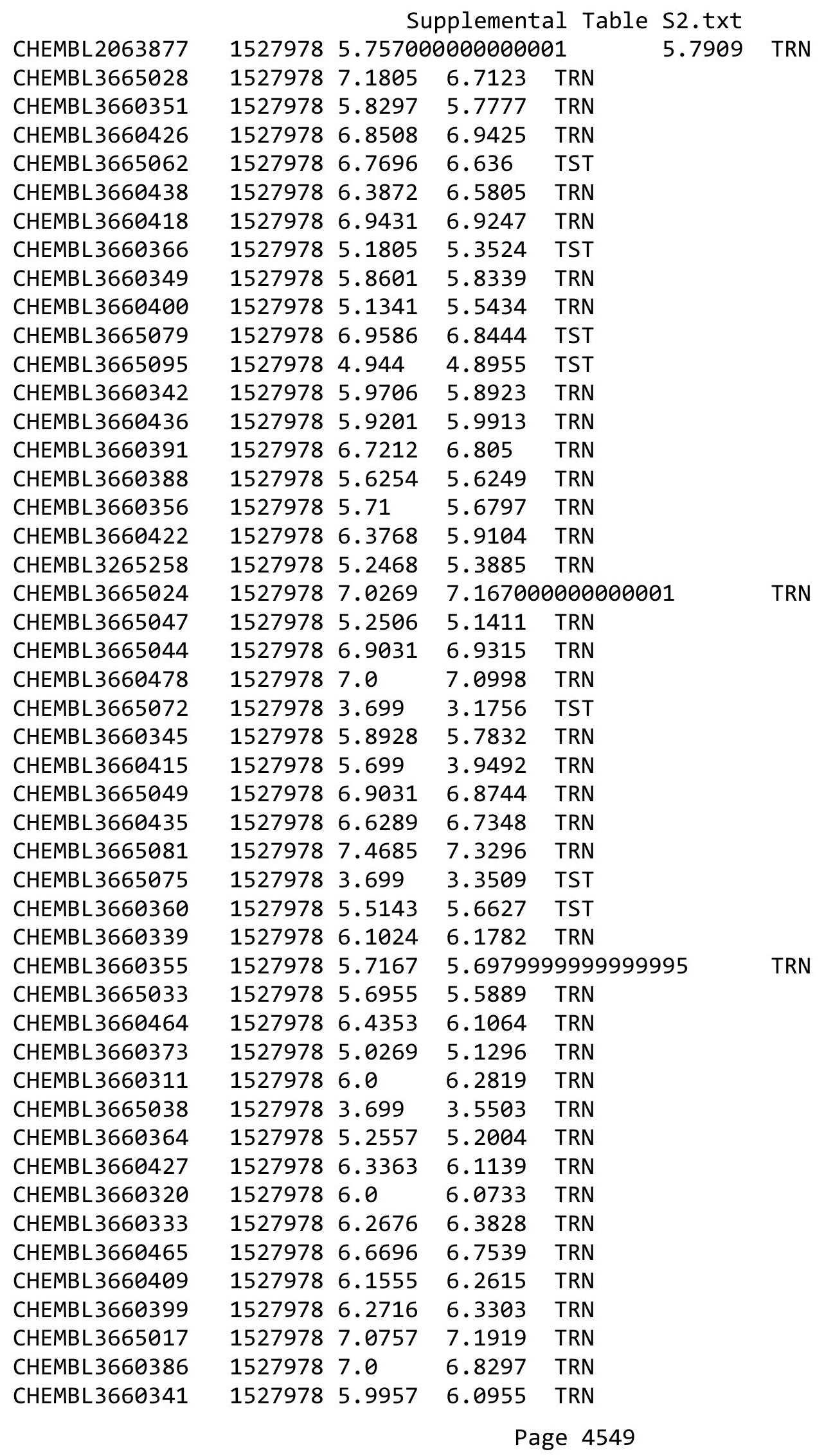




\begin{tabular}{|c|c|c|c|c|c|c|}
\hline \multicolumn{7}{|c|}{ Supplemental Table S2.txt } \\
\hline CHEMBL 3660322 & 1527978 & 6.0 & 6.1911 & TRN & & \\
\hline CHEMBL3660309 & 1527978 & 6.0 & 6.0656 & TRN & & \\
\hline CHEMBL3665061 & 1527978 & 6.82100 & 00000000 & 01 & 6.7014 & TRN \\
\hline CHEMBL 3665094 & 1527978 & 5.8173 & 5.4451 & TST & & \\
\hline CHEMBL3660336 & 1527978 & 6.0 & 6.1551 & TRN & & \\
\hline CHEMBL3665023 & 1527978 & 6.4023 & 6.3617 & TRN & & \\
\hline CHEMBL3660396 & 1527978 & 6.7852 & 6.7726 & TRN & & \\
\hline CHEMBL 3660404 & 1527978 & 6.4547 & 6.0331 & TST & & \\
\hline CHEMBL 3660381 & 1527978 & 7.0132 & 6.9162 & TRN & & \\
\hline CHEMBL 3665026 & 1527978 & 6.1904 & 6.3042 & TRN & & \\
\hline CHEMBL 3665036 & 1527978 & 4.9164 & 5.1596 & TRN & & \\
\hline CHEMBL3665097 & 1527978 & 7.3279 & 7.0623 & TST & & \\
\hline CHEMBL 3660367 & 1527978 & 5.1656 & 5.2518 & TST & & \\
\hline CHEMBL3660469 & 1527978 & 6.3768 & 6.5744 & TRN & & \\
\hline CHEMBL 3665098 & 1527978 & 6.279 & 6.2499 & TST & & \\
\hline CHEMBL3660428 & 1527978 & 7.0862 & 7.0552 & TRN & & \\
\hline CHEMBL3665093 & 1527978 & 3.699 & 3.3977 & TST & & \\
\hline CHEMBL3660423 & 1527978 & 7.0555 & 7.0869 & TRN & & \\
\hline CHEMBL 3665020 & 1527978 & 7.1805 & 7.2582 & TRN & & \\
\hline CHEMBL3665088 & 1527978 & 6.8125 & 6.8457 & TRN & & \\
\hline CHEMBL3665056 & 1527978 & 7.1739 & 7.0898 & TRN & & \\
\hline CHEMBL207194 & 1527978 & 5.8761 & 5.8683 & TST & & \\
\hline CHEMBL3660447 & 1527978 & 6.6383 & 6.5852 & TRN & & \\
\hline CHEMBL 3660467 & 1527978 & 6.1986 & 6.2938 & TRN & & \\
\hline CHEMBL3660369 & 1527978 & 5.0862 & 4.9549 & TST & & \\
\hline CHEMBL3660459 & 1527978 & 6.9957 & 7.0629 & TRN & & \\
\hline CHEMBL3660379 & 1527978 & 6.129 & 6.1106 & TRN & & \\
\hline CHEMBL3660332 & 1527978 & 6.2924 & 5.9505 & TRN & & \\
\hline CHEMBL 3665055 & 1527978 & 6.1904 & 6.4164 & TRN & & \\
\hline CHEMBL3660316 & 1527978 & 6.0 & 6.2076 & TRN & & \\
\hline CHEMBL3660462 & 1527978 & 4.6966 & 4.8738 & TST & & \\
\hline CHEMBL 3665073 & 1527978 & 3.699 & 3.1931 & TST & & \\
\hline CHEMBL3665100 & 1527978 & 6.6556 & 6.7141 & TRN & & \\
\hline CHEMBL 3660334 & 1527978 & 6.2596 & 6.1689 & TST & & \\
\hline CHEMBL3665076 & 1527978 & 3.699 & 3.2246 & TST & & \\
\hline CHEMBL 3665021 & 1527978 & 7.3979 & 7.3735 & TRN & & \\
\hline CHEMBL 3660410 & 1527978 & 5.9952 & 5.9952 & TST & & \\
\hline CHEMBL3660331 & 1527978 & 6.3565 & 6.2753 & TST & & \\
\hline CHEMBL3665019 & 1527978 & 6.4056 & 6.3864 & TRN & & \\
\hline CHEMBL3665065 & 1527978 & 6.3696 & 6.3063 & TST & & \\
\hline CHEMBL3660411 & 1527978 & 5.5144 & 6.1609 & TST & & \\
\hline CHEMBL3660421 & 1527978 & 7.0915 & 7.0493 & TRN & & \\
\hline CHEMBL3660361 & 1527978 & 5.5058 & 5.4582 & TST & & \\
\hline CHEMBL3660315 & 1527978 & 6.7696 & 6.5692 & TST & & \\
\hline CHEMBL 3660384 & 1527978 & 6.5157 & 6.4906 & TRN & & \\
\hline CHEMBL3665052 & 1527978 & 5.5516 & 5.7329 & TRN & & \\
\hline CHEMBL 3660445 & 1527978 & 5.3202 & 5.1834 & TRN & & \\
\hline CHEMBL3660430 & 1527978 & 6.7905 & 6.7364 & TRN & & \\
\hline
\end{tabular}


Supplemental Table S2.txt

\begin{tabular}{|c|c|c|c|c|c|}
\hline CHEMBL3660468 & 1527978 & 6.3757 & 6.3995 & TRN & \\
\hline CHEMBL3660414 & 1527978 & 7.1308 & 7.0776 & TRN & \\
\hline CHEMBL3665074 & 1527978 & 3.699 & 3.4834 & TST & \\
\hline CHEMBL3660354 & 1527978 & 5.7375 & 5.7698 & TRN & \\
\hline CHEMBL3660368 & 1527978 & 6.0 & 5.6845 & TST & \\
\hline CHEMBL3660346 & 1527978 & 5.8861 & 5.8516 & TRN & \\
\hline CHEMBL3660476 & 1527978 & 6.3089 & 6.644 & TRN & \\
\hline CHEMBL3660330 & 1527978 & 6.0 & 6.0674 & TRN & \\
\hline CHEMBL3660362 & 1527978 & 5.3936 & 5.324 & TRN & \\
\hline CHEMBL3665085 & 1527978 & 3.699 & 3.6084 & TST & \\
\hline CHEMBL3660326 & 1527978 & 6.4089 & 6.3393 & TRN & \\
\hline CHEMBL3665035 & 1527978 & 5.0282 & 5.1948 & TRN & \\
\hline CHEMBL3665078 & 1527978 & 6.6556 & 6.582000 & 0000000001 & TRN \\
\hline CHEMBL 3665064 & 1527978 & 5.9066 & 5.834 & TST & \\
\hline CHEMBL 3660442 & 1527978 & 5.4803 & 5.4974 & TRN & \\
\hline CHEMBL3660440 & 1527978 & 6.2676 & 6.3517 & TRN & \\
\hline CHEMBL3665041 & 1527978 & 3.699 & 4.0389 & TRN & \\
\hline CHEMBL3665027 & 1527978 & 7.6383 & 7.2322 & TRN & \\
\hline CHEMBL3660338 & 1527978 & 6.1249 & 6.0068 & TRN & \\
\hline CHEMBL 3660374 & 1527978 & 5.011 & 4.7902 & TST & \\
\hline CHEMBL3660403 & 1527978 & 5.9539 & 6.0232 & TST & \\
\hline CHEMBL3665030 & 1527978 & 7.1024 & 7.0684 & TRN & \\
\hline CHEMBL3660466 & 1527978 & 7.0706 & 7.2111 & TRN & \\
\hline CHEMBL 3660317 & 1527978 & 6.6198 & 6.4765 & TRN & \\
\hline CHEMBL 3660387 & 1527978 & 7.1308 & 7.0149 & TRN & \\
\hline CHEMBL3665092 & 1527978 & 3.699 & 3.6028 & TST & \\
\hline CHEMBL93215 & 1527978 & 7.0969 & 6.8263 & TST & \\
\hline CHEMBL3660323 & 1527978 & 6.4559 & 6.3834 & TRN & \\
\hline CHEMBL3660319 & 1527978 & 6.6021 & 6.5813 & TRN & \\
\hline CHEMBL 3660471 & 1527978 & 6.4001 & 6.4233 & TRN & \\
\hline CHEMBL3665042 & 1527978 & 6.0565 & 6.2056 & TRN & \\
\hline CHEMBL3665063 & 1527978 & 7.3468 & 6.9926 & TST & \\
\hline CHEMBL3660480 & 1527978 & 6.5969 & 6.8546 & TRN & \\
\hline CHEMBL 3660340 & 1527978 & 6.0044 & 5.8521 & TRN & \\
\hline CHEMBL3665032 & 1527978 & 5.3765 & 5.3629 & TRN & \\
\hline CHEMBL3660402 & 1527978 & 6.4802 & 6.5799 & TRN & \\
\hline CHEMBL3660308 & 1527978 & 7.5229 & 7.2385 & TST & \\
\hline CHEMBL3660425 & 1527978 & 6.1524 & 6.0425 & TRN & \\
\hline CHEMBL3903157 & 1527978 & 6.2314 & 6.1483 & TRN & \\
\hline CHEMBL 3660437 & 1527978 & 5.5536 & 5.7121 & TRN & \\
\hline CHEMBL 3660434 & 1527978 & 7.3372 & 7.3608 & TRN & \\
\hline CHEMBL3660473 & 1527978 & 6.34200 & 000000000 & 6.5008 & $1 \mathrm{KT}$ \\
\hline CHEMBL3660416 & 1527978 & 5.3465 & 5.2965 & TRN & \\
\hline CHEMBL3665105 & 1527978 & 6.5186 & 6.541 & TRN & \\
\hline CHEMBL 3660446 & 1527978 & 5.7667 & 5.7736 & TRN & \\
\hline CHEMBL3660390 & 1527978 & 6.0026 & 6.0549 & TST & \\
\hline CHEMBL 3660393 & 1527978 & 7.3372 & 7.2113 & TRN & \\
\hline CHEMBL 3665053 & 1527978 & 8.5229 & 8.2026 & TRN & \\
\hline
\end{tabular}


Supplemental Table S2.txt

\begin{tabular}{|c|c|c|c|c|}
\hline 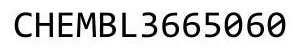 & & & & \\
\hline 398 & 27978 & 6.6271 & 5 & \\
\hline IEMBL3660370 & 527978 & 5.0721 & 0555 & \\
\hline AEMBL & 527978 & 3.699 & 792 & \\
\hline 080 & & & & \\
\hline IEMBL 3660407 & 978 & & & \\
\hline AEMBL3660328 & 527978 & 6.3979 & .2403 & \\
\hline AEMBL3660324 & 527978 & 6.4202 & .3575 & \\
\hline AEMBL3660350 & 78 & & 36 & \\
\hline AEMBL3 & 78 & & & \\
\hline AEMBL3 & & & & \\
\hline AEMBL3660470 & .527978 & 6.1824 & 2617 & \\
\hline AEMBL36 & 978 & & 19 & ST \\
\hline IEMBL 366 & 52 & 5 . & 93 & \\
\hline EMBL & 78 & & & \\
\hline HEMBL; & & & & \\
\hline AEMBL36 & 78 & & 969 & \\
\hline AEMBL3 & 78 & & & \\
\hline IEMBL36 & 8 & & 512 & \\
\hline AEMBL: & 78 & & & \\
\hline HEMBL; & & & & \\
\hline AEMBL3660460 & 78 & & 486 & \\
\hline HEMBL366 & & & 27 & \\
\hline IEMBL36 & 8 & & 33 & $R \mathrm{~N}$ \\
\hline HEMBL: & 78 & & & 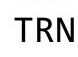 \\
\hline IFMDi. & & & & \\
\hline 3665069 & & & 906 & ST \\
\hline IEMBL 3660 & & & & RN \\
\hline AEMBL3660448 & 52 & 6.8 & 68 & RN \\
\hline 1 & 78 & & 42 & RIV \\
\hline 57 & 78 & & & ST \\
\hline & & & & ST \\
\hline AEMBL3660419 & 52 & & & RI \\
\hline AEMBL3665084 & 52 & & 246 & ST \\
\hline 35 & 52 & & 84 & NIV \\
\hline & & & 86 & $\mathrm{RN}$ \\
\hline AEMBL3665096 & 52 & 4. & 757 & $S$ \\
\hline AEMBL3660318 & 8 & & & RI \\
\hline AEMBL36 & 8 & & & RI \\
\hline 413 & & & 21 & \\
\hline 4 & & & 322 & RN \\
\hline AEMBL3665067 & 78 & 5.05 & 4.7181 & $S$ \\
\hline AEMBL3660420 & 5 & & 87 & TR \\
\hline HEMBL3660329 & & & & \\
\hline & & & .6867 & $\boldsymbol{I}$ \\
\hline CHEMBL3639639 & & & 5633 & $\mathrm{RN}$ \\
\hline AEMBL3665099 & 1527978 & 6.9666 & 6.7997 & $\Gamma R$ \\
\hline HFMRI 3669133 & 1527978 & 6.4214 & 6.2073 & \\
\hline
\end{tabular}

Page 4552 
Supplemental Table S2.txt

\begin{tabular}{|c|c|c|c|c|c|c|}
\hline CHEMBL 3660378 & 1527978 & 6.8268 & 6.8789 & TRN & & \\
\hline CHEMBL3660395 & 1527978 & 6.1226 & 6.3255 & TRN & & \\
\hline CHEMBL3639592 & 1527978 & 6.7696 & 6.7996 & TRN & & \\
\hline CHEMBL3660479 & 1527978 & 6.9747 & 7.2518 & TRN & & \\
\hline CHEMBL3660371 & 1527978 & 5.0531 & 5.1523 & TST & & \\
\hline CHEMBL3660455 & 1527978 & 7.6778 & 7.289 & TRN & & \\
\hline CHEMBL3665048 & 1527978 & 4.8079 & 4.8689 & TRN & & \\
\hline CHEMBL3665071 & 1527978 & 3.699 & 3.2564 & TST & & \\
\hline CHEMBL3660359 & 1527978 & 5.5452 & 5.4553 & TST & & \\
\hline CHEMBL3665089 & 1527978 & 6.1931 & 6.0173 & TST & & \\
\hline CHEMBL3660475 & 1527978 & 5.7122 & 5.8226 & TRN & & \\
\hline CHEMBL3660452 & 1527978 & 6.7055 & 6.9256 & TRN & & \\
\hline CHEMBL3660352 & 1527978 & 5.7986 & 5.7946 & TRN & & \\
\hline CHEMBL3975906 & 1527978 & 6.8041 & 6.1517 & TRN & & \\
\hline CHEMBL3660432 & 1527978 & \multicolumn{3}{|c|}{6.7620000000000005} & 6.9257 & TRN \\
\hline CHEMBL3660474 & 1527978 & 6.0969 & 6.2989 & TRN & & \\
\hline CHEMBL3660457 & 1527978 & 6.8125 & 7.4118 & TRN & & \\
\hline CHEMBL3660383 & 1527978 & 6.0306 & 6.0572 & TRN & & \\
\hline CHEMBL3660313 & 1527978 & 6.9586 & 6.8498 & TRN & & \\
\hline CHEMBL3660451 & 1527978 & 6.3054 & 6.4494 & TRN & & \\
\hline CHEMBL3665083 & 1527978 & 7.8239 & 7.5839 & TRN & & \\
\hline CHEMBL 3660347 & 1527978 & 5.8861 & 5.7569 & TRN & & \\
\hline CHEMBL3665037 & 1527978 & 5.2022 & 5.2986 & TST & & \\
\hline CHEMBL3665057 & 1527978 & 7.3188 & 7.1568 & TRN & & \\
\hline CHEMBL3660358 & 1527978 & 5.5686 & 5.4745 & TRN & & \\
\hline CHEMBL3660450 & 1527978 & \multicolumn{3}{|c|}{6.327000000000001} & 6.4569 & TRN \\
\hline CHEMBL 3660382 & 1527978 & 6.4609 & 6.6511 & TRN & & \\
\hline CHEMBL3660441 & 1527978 & 5.4353 & 5.7117 & TRN & & \\
\hline CHEMBL 3660417 & 1527978 & 6.3556 & 6.4631 & TRN & & \\
\hline CHEMBL3660321 & 1527978 & 6.5528 & 6.4097 & TRN & & \\
\hline CHEMBL3660458 & 1527978 & 5.9059 & 6.0137 & TRN & & \\
\hline CHEMBL3665022 & 1527978 & 7.7212 & 7.6236 & TRN & & \\
\hline CHEMBL229251 & 1527978 & 6.1427 & 6.005 & TST & & \\
\hline CHEMBL3665103 & 1527978 & 6.2933 & 6.1047 & TST & & \\
\hline CHEMBL 3660463 & 1527978 & 6.6517 & 6.7031 & TST & & \\
\hline CHEMBL3665102 & 1527978 & 6.8928 & 6.7832 & TST & & \\
\hline CHEMBL3660363 & 1527978 & 5.2596 & 5.1603 & TST & & \\
\hline CHEMBL3665059 & 1527978 & 6.8041 & 7.0256 & TST & & \\
\hline CHEMBL3660449 & 1527978 & 6.6716 & 6.6092 & TST & & \\
\hline CHEMBL3660376 & 1527978 & 6.8327 & 6.7697 & TST & & \\
\hline CHEMBL3660389 & 1527978 & 7.0862 & 6.8963 & TST & & \\
\hline CHEMBL3665090 & 1527978 & 3.699 & 3.6757 & TST & & \\
\hline CHEMBL3660429 & 1527978 & \multicolumn{3}{|c|}{6.3839999999999995} & 6.3959 & TST \\
\hline CHEMBL3665058 & 1527978 & 6.4101 & 6.5889 & TST & & \\
\hline CHEMBL 3660380 & 1527978 & 6.7747 & 6.8836 & TST & & \\
\hline CHEMBL 3660348 & 1527978 & 5.8827 & 5.8137 & TST & & \\
\hline CHEMBL1230020 & 954655 & 3.8684 & 3.8734 & TRN & & \\
\hline CHEMBL209148 & 954655 & 3.8354 & 3.8271 & TRN & & \\
\hline
\end{tabular}


Supplemental Table S2.txt

\begin{tabular}{|c|c|c|c|c|c|}
\hline CHEMBL 300389 & 954655 & 7.0163 & 7.0286 & TRN & \\
\hline CHEMBL 2137530 & 954655 & 4.8388 & 4.8288 & TRN & \\
\hline CHEMBL449158 & 954655 & 7.2716 & 6.4784 & TST & \\
\hline CHEMBL412142 & 954655 & 3.8315 & 3.8545 & TRN & \\
\hline CHEMBL392695 & 954655 & 3.7341 & 3.7292 & TRN & \\
\hline CHEMBL1788116 & 954655 & 5.8575 & 5.8332 & TRN & \\
\hline CHEMBL393929 & 954655 & 3.2593 & 3.2424 & TRN & \\
\hline CHEMBL255342 & 954655 & 3.2802 & 3.3298 & TRN & \\
\hline CHEMBL1357247 & 954655 & 3.6154 & 3.6357 & TRN & \\
\hline CHEMBL102714 & 954655 & 4.3563 & 4.3535 & TRN & \\
\hline CHEMBL1256459 & 954655 & 6.8669 & 6.8736 & TRN & \\
\hline CHEMBL188678 & 954655 & 4.9642 & 4.9646 & TRN & \\
\hline CHEMBL1190711 & 954655 & 5.4814 & 5.4815 & TRN & \\
\hline CHEMBL 2363137 & 954655 & 4.0529 & 4.0588 & TRN & \\
\hline CHEMBL 3186408 & 954655 & 3.5462 & 3.4971 & TST & \\
\hline CHEMBL577784 & 954655 & 5.1549 & 5.1362 & TRN & \\
\hline CHEMBL259181 & 954655 & 3.1261 & 3.1266 & TRN & \\
\hline CHEMBL 3199475 & 954655 & 3.9258 & 3.9154 & TRN & \\
\hline CHEMBL1242367 & 954655 & 4.9731 & 4.9927 & TRN & \\
\hline CHEMBL191334 & 954655 & 4.2119 & 4.2121 & TRN & \\
\hline CHEMBL509032 & 954655 & 4.4833 & 4.4895 & TRN & \\
\hline CHEMBL221137 & 954655 & 4.1223 & 4.4275 & TST & \\
\hline CHEMBL 2144069 & 954655 & 6.4537 & 6.4448 & TRN & \\
\hline CHEMBL585951 & 954655 & 4.2028 & 4.1898 & TRN & \\
\hline CHEMBL 373751 & 954655 & 3.2146 & 3.2219 & TRN & \\
\hline CHEMBL573107 & 954655 & 4.9267 & 4.9253 & TRN & \\
\hline CHEMBL3349342 & 954655 & 5.2168 & 5.2213 & TRN & \\
\hline CHEMBL1643959 & 954655 & 3.8956 & 3.8751 & TRN & \\
\hline CHEMBL483847 & 954655 & 5.0489 & 5.0454 & TRN & \\
\hline CHEMBL1516890 & 954655 & 3.6629 & 3.6902 & TRN & \\
\hline CHEMBL192566 & 954655 & 4.8664 & 5.4093 & TST & \\
\hline CHEMBL 217354 & 954655 & 5.6958 & 5.7073 & TRN & \\
\hline CHEMBL1673039 & 954655 & 5.0534 & 5.0268 & TRN & \\
\hline CHEMBL1404918 & 954655 & 2.7466 & 2.7243 & TRN & \\
\hline CHEMBL399530 & 954655 & 4.9362 & 4.9423 & TRN & \\
\hline CHEMBL 258844 & 954655 & 4.5301 & 4.522 & TRN & \\
\hline CHEMBL 213100 & 954655 & 5.0015 & 5.0023 & TRN & \\
\hline CHEMBL1970879 & 954655 & 4.5836 & 4.5946 & TRN & \\
\hline CHEMBL 240954 & 954655 & 3.6202 & 3.83 & TST & \\
\hline CHEMBL483849 & 954655 & 2.1094 & 2.3135 & TST & \\
\hline CHEMBL 2005886 & 954655 & 4.7408 & 4.7209 & TRN & \\
\hline CHEMBL514499 & 954655 & 6.247999 & 99999999 & 9 & 6.2641 \\
\hline CHEMBL512504 & 954655 & 4.9192 & 4.918 & TRN & \\
\hline CHEMBL 210618 & 954655 & 3.0373 & 3.0266 & TRN & \\
\hline CHEMBL65 & 954655 & 6.9198 & 6.9131 & TRN & \\
\hline CHEMBL9470 & 954655 & 4.4136 & 4.7601 & TST & \\
\hline CHEMBL379975 & 954655 & 4.5511 & 4.5458 & TRN & \\
\hline CHEMBL515416 & 954655 & 3.7278 & 3.7294 & TRN & \\
\hline
\end{tabular}




\begin{tabular}{|c|c|c|c|c|c|c|}
\hline & & \multicolumn{5}{|c|}{ Supplemental Table S2.txt } \\
\hline CHEMBL 3392440 & 954655 & 4.1555 & 4.1527 & TRN & & \\
\hline CHEMBL 202721 & 954655 & 5.1647 & 5.1848 & TRN & & \\
\hline CHEMBL472940 & 954655 & 4.4342 & 4.436 & TRN & & \\
\hline CHEMBL189584 & 954655 & 4.1676 & 4.1495 & TRN & & \\
\hline CHEMBL135561 & 954655 & 3.9472 & 3.9549 & TRN & & \\
\hline CHEMBL 379300 & 954655 & 5.5191 & 5.9973 & TST & & \\
\hline CHEMBL1186585 & 954655 & 3.3879 & 4.3183 & TST & & \\
\hline CHEMBL 220241 & 954655 & 8.1032 & 4.8653 & TST & & \\
\hline CHEMBL180127 & 954655 & 3.6084 & 4.2064 & TST & & \\
\hline CHEMBL222102 & 954655 & 4.1838 & 3.7373 & TST & & \\
\hline CHEMBL558642 & 954655 & 4.3469 & 3.7485 & TST & & \\
\hline CHEMBL1590308 & 954655 & 2.951 & 3.4021 & TST & & \\
\hline CHEMBL92309 & 954655 & 3.2141 & 2.3717 & TST & & \\
\hline CHEMBL1909414 & 954655 & 3.4152 & 3.5969 & TST & & \\
\hline CHEMBL2134202 & 954655 & 4.3632 & 4.5505 & TST & & \\
\hline CHEMBL544842 & 201737 & 7.9872 & 7.9268 & TRN & & \\
\hline CHEMBL554355 & 201737 & 7.5686 & 7.6581 & TRN & & \\
\hline CHEMBL545777 & 201737 & 5.7106 & 5.7351 & TRN & & \\
\hline CHEMBL543427 & 201737 & 7.8013 & 7.2307 & TST & & \\
\hline CHEMBL542956 & 201737 & 7.4056 & 7.1462 & TST & & \\
\hline CHEMBL542964 & 201737 & 7.3686 & 7.4071 & TRN & & \\
\hline CHEMBL91628 & 201737 & 7.0862 & 7.0671 & TRN & & \\
\hline CHEMBL545537 & 201737 & 6.1221 & 6.1444 & TRN & & \\
\hline CHEMBL545076 & 201737 & \multicolumn{3}{|c|}{6.617999999999999} & 6.7951 & TST \\
\hline CHEMBL545311 & 201737 & 5.9855 & 6.0246 & TRN & & \\
\hline CHEMBL553167 & 201737 & 7.1938 & 7.4965 & TST & & \\
\hline CHEMBL542491 & 201737 & 7.8761 & 7.7706 & TRN & & \\
\hline CHEMBL538052 & 201737 & 6.51 & 6.5662 & TRN & & \\
\hline CHEMBL545542 & 201737 & 7.3958 & 7.3593 & TRN & & \\
\hline CHEMBL543433 & 201737 & 7.8416 & 7.813 & TRN & & \\
\hline CHEMBL543428 & 201737 & 6.9508 & 6.8948 & TRN & & \\
\hline CHEMBL543200 & 201737 & 6.3063 & 6.3427 & TRN & & \\
\hline CHEMBL542730 & 201737 & 7.5129 & 8.02 & TST & & \\
\hline CHEMBL542736 & 201737 & \multicolumn{3}{|c|}{7.7620000000000005} & 7.5872 & TST \\
\hline CHEMBL552605 & 201737 & 6.5834 & 6.5923 & TRN & & \\
\hline CHEMBL554868 & 201737 & 6.8861 & 6.8919 & TRN & & \\
\hline CHEMBL543199 & 201737 & 6.3757 & 6.3916 & TRN & & \\
\hline CHEMBL542487 & 201737 & 8.3468 & 7.5871 & TST & & \\
\hline CHEMBL539299 & 201737 & 7.4377 & 7.3697 & TRN & & \\
\hline CHEMBL543664 & 201737 & 6.6556 & 6.5155 & TRN & & \\
\hline CHEMBL543192 & 201737 & 6.6925 & 6.7628 & TRN & & \\
\hline CHEMBL556043 & 201737 & 7.9666 & 7.9696 & TRN & & \\
\hline CHEMBL543673 & 201737 & 7.5452 & 7.4779 & TRN & & \\
\hline CHEMBL545312 & 201737 & 6.3188 & 6.23600 & 0000000001 & & $1 \mathrm{n}$ \\
\hline CHEMBL538036 & 201737 & 7.7328 & 7.7335 & TRN & & \\
\hline CHEMBL542238 & 201737 & 6.9469 & 6.9967 & TRN & & \\
\hline CHEMBL542486 & 201737 & 6.4191 & 6.9417 & TST & & \\
\hline CHEMBL553034 & 201737 & 8.2441 & 7.5618 & TST & & \\
\hline
\end{tabular}




\begin{tabular}{|c|c|c|c|c|c|}
\hline \multicolumn{6}{|c|}{ Supplemental Table S2.txt } \\
\hline CHEMBL544142 & 201737 & 5.4713 & 5.4278 & TRN & \\
\hline CHEMBL543196 & 201737 & 6.9469 & 6.9735 & TRN & \\
\hline CHEMBL543432 & 201737 & 7.699 & 7.6794 & TRN & \\
\hline CHEMBL552829 & 201737 & 8.1308 & 7.7304 & TST & \\
\hline CHEMBL552831 & 201737 & 8.0969 & 8.0368 & TRN & \\
\hline CHEMBL538283 & 201737 & 7.3979 & 7.4323 & TRN & \\
\hline CHEMBL545079 & 201737 & 6.699 & 6.7794 & TRN & \\
\hline CHEMBL542478 & 201737 & 6.8069 & 7.1755 & TST & \\
\hline CHEMBL543436 & 201737 & 6.9393 & 6.947 & TRN & \\
\hline CHEMBL555091 & 201737 & 7.3615 & 7.3559 & TRN & \\
\hline CHEMBL540326 & 201737 & 6.9586 & 6.8813 & TRN & \\
\hline CHEMBL542959 & 201737 & 7.1555 & 7.1706 & TRN & \\
\hline CHEMBL2093907 & 201737 & 6.5243 & 6.4531 & TRN & \\
\hline CHEMBL540831 & 201737 & 7.1024 & 7.04700 & 0000000001 & TRN \\
\hline CHEMBL544144 & 201737 & 6.6882 & 6.763 & TRN & \\
\hline CHEMBL541848 & 201737 & 6.9469 & 6.90799 & 99999999995 & TRN \\
\hline CHEMBL541860 & 201737 & 7.6861 & 7.7205 & TRN & \\
\hline CHEMBL540841 & 201737 & 7.6216 & 7.7285 & TST & \\
\hline CHEMBL555099 & 201737 & 6.9031 & 6.8941 & TRN & \\
\hline CHEMBL553312 & 201737 & 7.9281 & 8.032 & TRN & \\
\hline CHEMBL540838 & 201737 & 6.7447 & 6.6765 & TRN & \\
\hline CHEMBL545310 & 201737 & 7.7986 & 7.7862 & TRN & \\
\hline CHEMBL545544 & 201737 & 7.3439 & 7.3436 & TRN & \\
\hline CHEMBL 78777 & 201737 & 7.5214 & 7.6117 & TRN & \\
\hline CHEMBL542481 & 201737 & 7.7399 & 8.0983 & TST & \\
\hline CHEMBL555698 & 201737 & 7.0132 & 7.0586 & TRN & \\
\hline CHEMBL554618 & 201737 & 7.1439 & 7.1055 & TRN & \\
\hline CHEMBL538289 & 201737 & 6.4413 & 6.9352 & TST & \\
\hline CHEMBL539549 & 201737 & 7.3401 & 7.3482 & TRN & \\
\hline CHEMBL553747 & 201737 & 6.6498 & 6.7244 & TRN & \\
\hline CHEMBL545769 & 201737 & 6.7852 & 6.8683 & TST & \\
\hline CHEMBL555606 & 201737 & 6.7496 & 6.8609 & TRN & \\
\hline CHEMBL542957 & 201737 & 6.6308 & 6.934 & TST & \\
\hline CHEMBL543431 & 201737 & 7.4976 & 7.4938 & TRN & \\
\hline CHEMBL545545 & 201737 & 7.4089 & 7.0674 & TST & \\
\hline CHEMBL553749 & 201737 & 7.7077 & 7.5193 & TST & \\
\hline CHEMBL369376 & 310453 & 3.5086 & 3.7305 & TRN & \\
\hline CHEMBL369707 & 310453 & 2.699 & 3.79699 & 99999999997 & TST \\
\hline CHEMBL 362661 & 310453 & 5.7447 & 5.4025 & TRN & \\
\hline CHEMBL369009 & 310453 & 3.4948 & 4.121 & TST & \\
\hline CHEMBL 84358 & 310453 & 5.3468 & 5.9041 & TRN & \\
\hline CHEMBL175613 & 310453 & 3.1249 & 3.0816 & TST & \\
\hline CHEMBL368537 & 310453 & 2.699 & 2.5807 & TRN & \\
\hline CHEMBL 313989 & 310453 & 5.8539 & 4.92899 & 9999999999 & TRN \\
\hline CHEMBL360539 & 310453 & 2.699 & 2.9994 & TRN & \\
\hline CHEMBL79826 & 310453 & 5.0458 & 4.498 & TRN & \\
\hline CHEMBL 84208 & 310453 & 5.6383 & 4.9743 & TRN & \\
\hline CHEMBL85059 & 310453 & 8.3979 & 8.4576 & TRN & \\
\hline
\end{tabular}




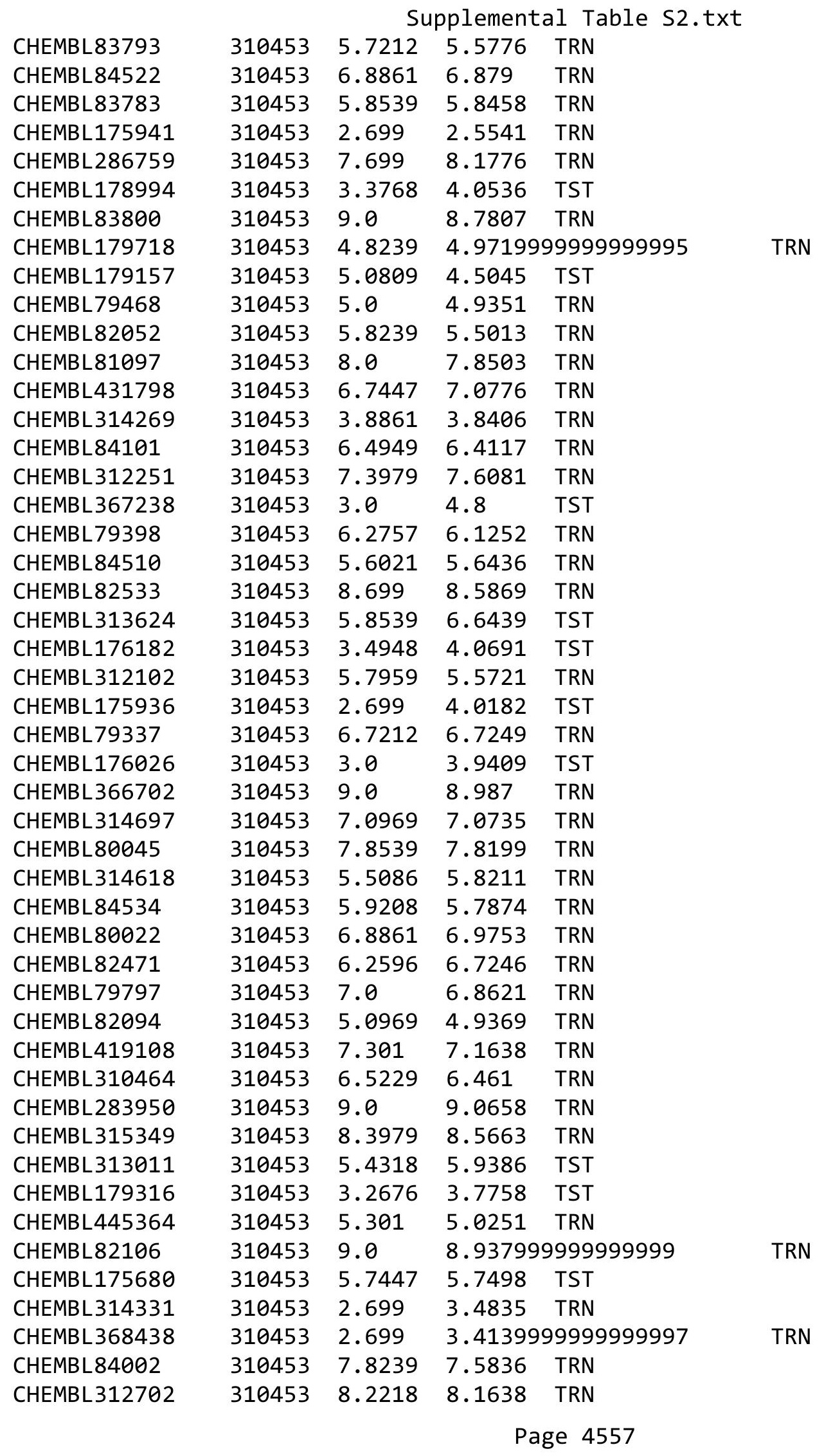




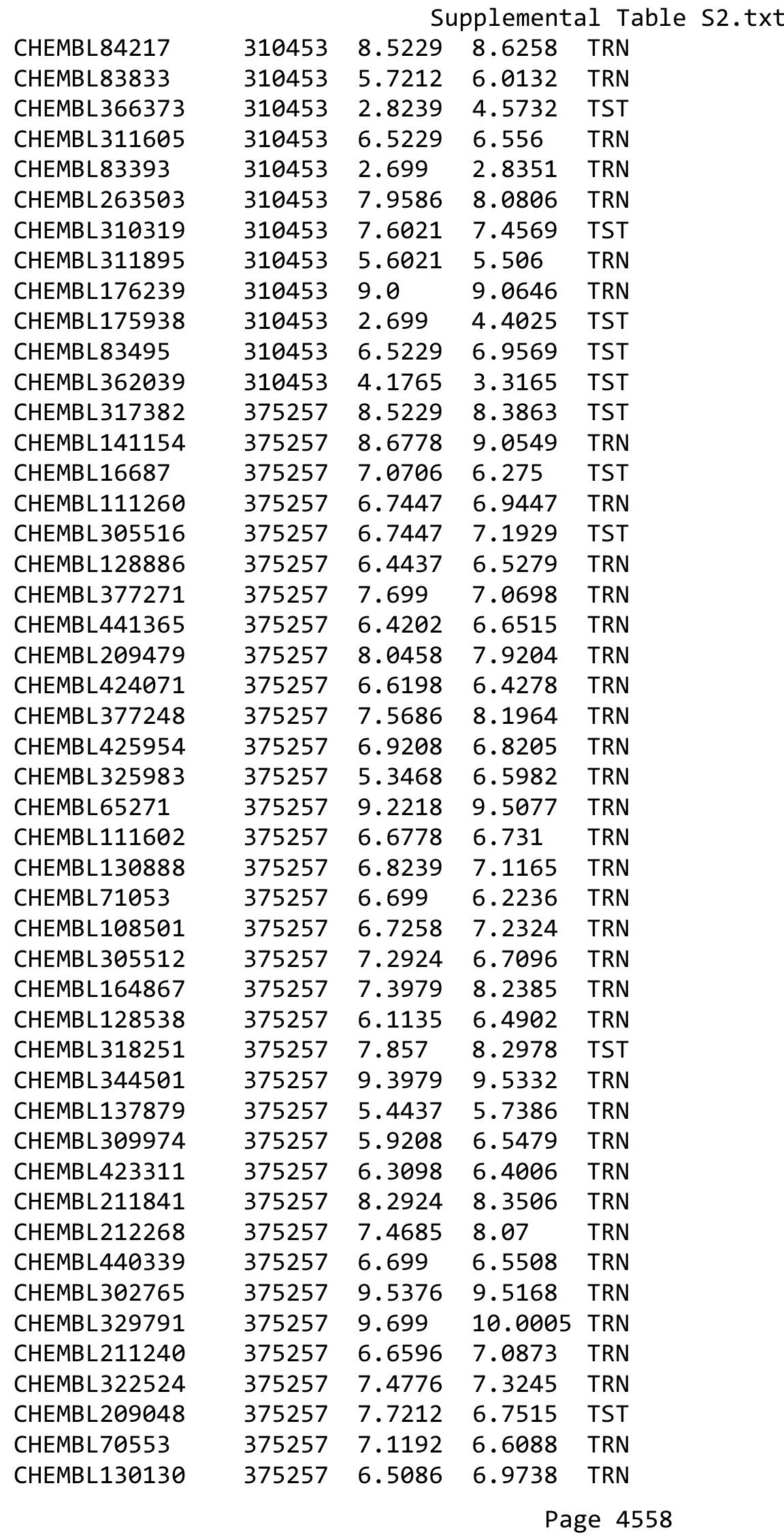


Supplemental Table S2.txt

\begin{tabular}{|c|c|c|c|c|}
\hline HEMBL352345 & 5257 & .5229 & 8.8133 & TRN \\
\hline HEMBL 210351 & 75257 & 8.0809 & 6.9422 & \\
\hline HEMBL 208686 & 5257 & 8539 & 8.1591 & \\
\hline HEMBL 321845 & 5257 & 8729 & 2952 & \\
\hline HEMBL344706 & 75257 & 6.2125 & . 7217 & \\
\hline HEMBL128929 & 75257 & 7.7696 & 7.3266 & \\
\hline HEMBL437685 & 75257 & 8.1024 & 7.3322 & \\
\hline HEMBL 71726 & 75257 & 7.0862 & .9694 & \\
\hline HEMBL 332091 & 75257 & 10.3979 & 9.0955 & RN \\
\hline HEMBL377211 & 375257 & 6.585 & 6.7281 & 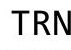 \\
\hline HEMBL165910 & 35257 & 9.1871 & 8.9459 & \\
\hline HEMBL324735 & 75257 & 9.7959 & 9.3749 & \\
\hline HEMBL88147 & 5257 & 9.1871 & 8.1839 & ST \\
\hline HEMBL 211055 & 75257 & 9.0655 & 8.3141 & \\
\hline HEMBL 209992 & 75257 & 9.8539 & 8.3492 & \\
\hline HEMBL 211341 & 375257 & 8.699 & 8.3813 & \\
\hline HEMBL 209332 & 75257 & 9.2518 & 8.2769 & \\
\hline HEMBL127383 & 257 & 7.1612 & 03 & RN \\
\hline HEMBL 329722 & 75257 & 135 & 8.3665 & \\
\hline HEMBL168018 & 75257 & 9.8239 & 8.9974 & RN \\
\hline HEMBL339261 & 35257 & 7.0177 & 6.6091 & KIV \\
\hline HEMBL111423 & 257 & 6.7122 & 7.223 & 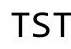 \\
\hline HEMBL 276738 & 257 & 584 & 5.7775 & RN \\
\hline HEMBL350573 & 75257 & 7.5229 & 8.295 & RN \\
\hline HEMBL593058 & 605406 & 893 & 6.4092 & RN \\
\hline HEMBL608093 & 06 & 5.7773 & 5.7945 & RN \\
\hline HEMBL611048 & 05406 & 7.1397 & 7.1328 & RN \\
\hline CHEMBL595844 & 406 & 6.2321 & 6.2292 & RN \\
\hline CHEMBL595365 & 406 & 243 & 6.4793 & RN \\
\hline HEMBL594226 & 06 & 809 & 7.1294 & $\mathrm{RN}$ \\
\hline HEMBL593746 & 25406 & 6.2255 & 6.2177 & ST \\
\hline HEMBL608102 & 05406 & 7.0458 & 6.9862 & TRN \\
\hline CHEMBL596308 & 05406 & 6.5686 & 6.8894 & ST \\
\hline CHEMBL610456 & 406 & 4. & 3.9353 & $\mathrm{RN}$ \\
\hline HEMBL608383 & 25406 & 6.6536 & 6.6782 & TRN \\
\hline HEMBL595363 & 406 & 6.1427 & 6.0801 & $\mathrm{RN}$ \\
\hline CHEMBL594905 & 605406 & 6.6946 & 5.534 & IS \\
\hline CHEMBL593508 & 406 & 269 & 7.181 & RN \\
\hline CHEMBL549885 & 05406 & 6.9136 & 6.8628 & TRN \\
\hline CHEMBL596088 & 25406 & 6.9281 & 6.9334 & TRN \\
\hline CHEMBL595405 & 05406 & 5.8611 & 5.8355 & RN \\
\hline CHEMBL594000 & 605406 & 6.9872 & 6.9957 & I RIN \\
\hline CHEMBL611020 & & 7.0506 & 7.0647 & TRN \\
\hline CHEMBL596291 & 25406 & 6.3206 & 6.369 & TRN \\
\hline CHEMBL608100 & 05406 & 6.0357 & 6.0539 & RN \\
\hline CHEMBL593999 & 605406 & 6.9788 & 5.5204 & \\
\hline CHEMBL611954 & 605406 & 7.3188 & 7.3638 & RN \\
\hline L595174 & 605406 & 6.3344 & 6.5255 & 「RN \\
\hline
\end{tabular}

Page 4559 


\begin{tabular}{|c|c|c|c|c|c|}
\hline & & & & & \\
\hline CHEMBL594454 & 605406 & 6.5575 & 6.3284 & TST & \\
\hline CHEMBL593749 & 605406 & 5.9642 & 5.9746 & TRN & \\
\hline CHEMBL607539 & 605406 & 6.6517 & 6.2897 & TST & \\
\hline CHEMBL611955 & 605406 & 6.2976 & 5.3405 & TST & \\
\hline CHEMBL608980 & 605406 & 7.3979 & 7.3137 & TRN & \\
\hline CHEMBL594662 & 605406 & 5.9539 & 6.4246 & TST & \\
\hline CHEMBL594906 & 605406 & 6.4045 & 6.3494 & TRN & \\
\hline CHEMBL593040 & 605406 & 5.1023 & 5.1446 & TRN & \\
\hline CHEMBL594677 & 605406 & 4.0 & 3.9435 & TRN & \\
\hline CHEMBL593259 & 605406 & 7.1739 & 7.0566 & TRN & \\
\hline CHEMBL595131 & 605406 & 6.5986 & 6.5909 & TRN & \\
\hline CHEMBL596074 & 605406 & 5.9367 & 5.8916 & TRN & \\
\hline CHEMBL594676 & 605406 & 7.0132 & 7.0383 & TRN & \\
\hline CHEMBL607550 & 605406 & 5.9059 & 6.0056 & TRN & \\
\hline CHEMBL609308 & 605406 & 7.2441 & 7.2848 & TRN & \\
\hline CHEMBL595144 & 605406 & 4.0 & 4.078 & TRN & \\
\hline CHEMBL594136 & 605406 & 6.7645 & 7.2438 & TST & \\
\hline CHEMBL609603 & 605406 & 7.3872 & 6.21899 & 9999999999 & TST \\
\hline CHEMBL594197 & 605406 & 6.2396 & 5.7705 & TST & \\
\hline CHEMBL593973 & 605406 & 7.4202 & 7.3766 & TRN & \\
\hline CHEMBL593975 & 605406 & 7.5086 & 7.5365 & TRN & \\
\hline CHEMBL611325 & 605406 & 4.0 & 4.09399 & 9999999999 & TRN \\
\hline CHEMBL607542 & 605406 & 6.82100 & 00000000 & 6.8598 & TRN \\
\hline CHEMBL596075 & 605406 & 6.4034 & 6.4387 & TRN & \\
\hline CHEMBL609578 & 605406 & 6.8761 & 6.8679 & TRN & \\
\hline CHEMBL611964 & 605406 & 5.0376 & 4.9955 & TRN & \\
\hline CHEMBL595843 & 605406 & 6.3883 & 6.3768 & TST & \\
\hline CHEMBL611335 & 605406 & 6.7799 & 7.1588 & TST & \\
\hline CHEMBL596307 & 605406 & 6.5031 & 5.7518 & TST & \\
\hline CHEMBL595132 & 605406 & 7.4202 & 7.3509 & TRN & \\
\hline CHEMBL594455 & 605406 & 6.5686 & 7.1227 & TST & \\
\hline CHEMBL594137 & 605406 & 6.7011 & 6.6533 & TRN & \\
\hline CHEMBL595364 & 605406 & 6.3615 & 5.271 & TST & \\
\hline CHEMBL611337 & 605406 & 5.9179 & 5.9312 & TRN & \\
\hline CHEMBL595845 & 605406 & 7.1805 & 7.2654 & TRN & \\
\hline CHEMBL595146 & 605406 & 5.5943 & 5.5792 & TRN & \\
\hline CHEMBL593986 & 605406 & 7.4202 & 7.446006 & 2000000001 & TRN \\
\hline CHEMBL595863 & 605406 & 6.5591 & 6.4975 & TRN & \\
\hline CHEMBL594907 & 605406 & 7.2518 & 7.2655 & TRN & \\
\hline CHEMBL609304 & 605406 & 6.2976 & 6.2662 & TRN & \\
\hline CHEMBL594363 & 605406 & 6.4342 & 7.0043 & TST & \\
\hline CHEMBL595147 & 605406 & 5.3755 & 5.3226 & TRN & \\
\hline CHEMBL611944 & 605406 & 7.1308 & 6.9691 & TRN & \\
\hline CHEMBL603748 & 605406 & 6.4145 & 6.5237 & TST & \\
\hline CHEMBL610738 & 605406 & 7.1107 & 7.1155 & TRN & \\
\hline CHEMBL595864 & 605406 & 5.8536 & 5.8417 & TRN & \\
\hline CHEMBL399971 & 458907 & 2.08 & 2.1085 & TRN & \\
\hline CHEMBL2372120 & 458907 & 0.439 & 0.4339 & TST & \\
\hline
\end{tabular}




\begin{tabular}{|c|c|c|c|c|c|c|}
\hline \multirow[b]{2}{*}{ CHEMBL403341 } & \multicolumn{6}{|c|}{ Supplemental Table s2.txt } \\
\hline & 458907 & 1.79 & 1.557 & TRN & & \\
\hline CHEMBL429839 & 458907 & 1.489 & 2.1085 & TRN & & \\
\hline CHEMBL2372130 & 458907 & 1.993 & 1.3481 & TRN & & \\
\hline CHEMBL414352 & 458907 & 2.417 & 2.4461 & TRN & & \\
\hline CHEMBL436844 & 458907 & 2.417 & 1.4732 & TRN & & \\
\hline CHEMBL252927 & 458907 & 1.65 & 1.0821 & TRN & & \\
\hline CHEMBL414351 & 458907 & 0.358 & 1.0147 & TRN & & \\
\hline CHEMBL268435 & 458907 & 2.096 & 1.9706 & TRN & & \\
\hline CHEMBL401163 & 458907 & \multicolumn{3}{|c|}{0.21100000000000002} & 1.4804 & TRN \\
\hline CHEMBL252926 & 458907 & 1.173 & 1.2438 & TRN & & \\
\hline CHEMBL 253554 & 458907 & 1.238 & 0.7224 & TRN & & \\
\hline CHEMBL2372129 & 458907 & \multicolumn{3}{|c|}{1.5530000000000002} & 0.8158 & TRN \\
\hline CHEMBL428059 & 458907 & \multicolumn{3}{|c|}{1.3869999999999998} & 0.6958 & TRN \\
\hline CHEMBL398821 & 458907 & 0.105 & 0.8733 & TRN & & \\
\hline CHEMBL 276082 & 458907 & \multicolumn{3}{|c|}{0.022000000000000002} & 0.6705 & TRN \\
\hline CHEMBL412011 & 458907 & 0.708 & 0.6958 & TRN & & \\
\hline CHEMBL266298 & 458907 & 0.721 & 0.7776 & TRN & & \\
\hline CHEMBL 2372128 & 458907 & \multicolumn{3}{|c|}{0.055999999999999994} & 1.0513 & TRN \\
\hline CHEMBL2372127 & 458907 & \multicolumn{3}{|c|}{1.8259999999999998} & 1.3988 & TRN \\
\hline CHEMBL 2372126 & 458907 & \multicolumn{3}{|c|}{1.9509999999999998} & 1.5428 & TRN \\
\hline CHEMBL 2372125 & 458907 & \multicolumn{3}{|c|}{1.5830000000000002} & 1.2485 & TRN \\
\hline CHEMBL442501 & 458907 & \multicolumn{3}{|c|}{1.8259999999999998} & 1.4818 & TRN \\
\hline CHEMBL 2372124 & 458907 & \multicolumn{3}{|c|}{1.6880000000000002} & 1.6206 & TRN \\
\hline CHEMBL252308 & 458907 & \multicolumn{3}{|c|}{1.5830000000000002} & 1.4443 & TST \\
\hline CHEMBL2372123 & 458907 & 1.554 & 1.2003 & TRN & & \\
\hline CHEMBL 2372122 & 458907 & \multirow{2}{*}{\multicolumn{3}{|c|}{$\begin{array}{lcc}1.474 & 1.4338 & \text { TRN } \\
0.47700000000000004\end{array}$}} & & \\
\hline CHEMBL399937 & 458907 & & & & 0.9031 & TRN \\
\hline CHEMBL427660 & 458907 & 0.301 & 0.7501 & TST & & \\
\hline CHEMBL413405 & 458907 & \multicolumn{3}{|c|}{0.17600000000000002} & 0.563 & TRN \\
\hline CHEMBL399729 & 458907 & 0.863 & 0.5581 & TST & & \\
\hline CHEMBL 249850 & 458907 & 0.617 & 0.3573 & TST & & \\
\hline CHEMBL398705 & 458907 & 0.264 & 0.1545 & TRN & & \\
\hline CHEMBL 249849 & 458907 & 0.226 & 0.1705 & TRN & & \\
\hline CHEMBL398704 & 458907 & 0.16 & 0.529 & TRN & & \\
\hline CHEMBL409324 & 458907 & 0.079 & 0.7009 & TRN & & \\
\hline CHEMBL438390 & 458907 & 0.574 & 0.522 & TRN & & \\
\hline CHEMBL439479 & 458907 & 0.319 & -0.0821 & TRN & & \\
\hline CHEMBL 249642 & 458907 & \multicolumn{3}{|c|}{0.6990000000000001} & 0.2506 & TRN \\
\hline CHEMBL413607 & 458907 & 0.456 & 0.5243 & TRN & & \\
\hline CHEMBL264368 & 458907 & 0.084 & 0.5817 & TRN & & \\
\hline CHEMBL413606 & 458907 & 0.617 & 1.0821 & TST & & \\
\hline CHEMBL 2372121 & 458907 & 0.439 & 0.321 & TST & & \\
\hline CHEMBL413605 & 458907 & 0.319 & 0.5061 & TST & & \\
\hline CHEMBL266963 & 458907 & 0.0 & 0.5528 & TST & & \\
\hline CHEMBL437779 & 458907 & \multicolumn{3}{|c|}{0.47700000000000004} & 0.6958 & TST \\
\hline CHEMBL 249641 & 458907 & 0.767 & 0.1796 & TST & & \\
\hline CHEMBL400965 & 458907 & \multicolumn{3}{|c|}{0.09699999999999999} & 0.8164 & TST \\
\hline CHEMBL400780 & 458907 & 0.79 & 0.7342 & TST & & \\
\hline
\end{tabular}




\begin{tabular}{|c|c|c|c|c|c|}
\hline \multicolumn{6}{|c|}{ Supplemental Table S2.txt } \\
\hline CHEMBL256264 & 470053 & 5.2343 & 5.8395 & TST & \\
\hline CHEMBL270564 & 470053 & 6.2441 & 6.2461 & TRN & \\
\hline CHEMBL256272 & 470053 & 6.6576 & 6.6802 & TRN & \\
\hline CHEMBL256271 & 470053 & 6.4949 & 6.4483 & TRN & \\
\hline CHEMBL272523 & 470053 & 6.2218 & 6.2304 & TRN & \\
\hline CHEMBL257452 & 470053 & 6.6198 & 6.6247 & TRN & \\
\hline CHEMBL429419 & 470053 & 7.0458 & 7.0259 & TRN & \\
\hline CHEMBL403728 & 470053 & 7.0458 & 7.0345 & TRN & \\
\hline CHEMBL404033 & 470053 & 6.301 & 6.3156 & TRN & \\
\hline CHEMBL429591 & 470053 & 6.8539 & 6.8541 & TRN & \\
\hline CHEMBL404732 & 470053 & 6.0969 & 6.1104 & TRN & \\
\hline CHEMBL257698 & 470053 & 6.1079 & 6.114 & TRN & \\
\hline CHEMBL402824 & 470053 & 3.5229 & 3.5041 & TRN & \\
\hline CHEMBL256887 & 470053 & 5.9508 & 6.7203 & TST & \\
\hline CHEMBL404301 & 470053 & 6.2218 & 6.2569 & TRN & \\
\hline CHEMBL255338 & 470053 & 6.4559 & 6.46200 & 0000000001 & TRN \\
\hline CHEMBL270419 & 470053 & 5.8962 & 5.9174 & TRN & \\
\hline CHEMBL272097 & 470053 & 6.7959 & 6.6457 & TST & \\
\hline CHEMBL258369 & 470053 & 5.4437 & 5.4427 & TRN & \\
\hline CHEMBL270418 & 470053 & 4.0 & 4.0241 & TRN & \\
\hline CHEMBL256449 & 470053 & 5.8761 & 5.8905 & TRN & \\
\hline CHEMBL403692 & 470053 & 4.0 & 5.0423 & TST & \\
\hline CHEMBL270863 & 470053 & 6.2676 & 6.2768 & TRN & \\
\hline CHEMBL258359 & 470053 & 6.0506 & 6.0571 & TRN & \\
\hline CHEMBL404757 & 470053 & 6.3665 & 6.3503 & TRN & \\
\hline CHEMBL270563 & 470053 & 6.0 & 5.9824 & TRN & \\
\hline CHEMBL 256821 & 470053 & 6.4202 & 6.4274 & TRN & \\
\hline CHEMBL257039 & 470053 & 3.5229 & 3.5379 & TRN & \\
\hline CHEMBL 270358 & 470053 & 5.9318 & 5.9234 & TRN & \\
\hline CHEMBL269956 & 470053 & 6.4318 & 6.4297 & TRN & \\
\hline CHEMBL269957 & 470053 & 6.9586 & 6.9465 & TRN & \\
\hline CHEMBL402327 & 470053 & 5.4473 & 5.8941 & TST & \\
\hline CHEMBL256404 & 470053 & 6.8239 & 6.8291 & TRN & \\
\hline CHEMBL 257508 & 470053 & 4.0 & 3.9812 & TRN & \\
\hline CHEMBL403613 & 470053 & 6.2924 & 6.3157 & TRN & \\
\hline CHEMBL256888 & 470053 & 6.2366 & 6.2169 & TRN & \\
\hline CHEMBL411477 & 470053 & 6.3872 & 6.3903 & TRN & \\
\hline CHEMBL270253 & 470053 & 6.699 & 6.7321 & TRN & \\
\hline CHEMBL 257509 & 470053 & 6.4437 & 6.4204 & TRN & \\
\hline CHEMBL402110 & 470053 & 5.1549 & 5.1348 & TRN & \\
\hline CHEMBL270033 & 470053 & 4.0 & 5.1209 & TST & \\
\hline CHEMBL427834 & 470053 & 6.0 & 6.3564 & TST & \\
\hline CHEMBL258363 & 470053 & 5.0269 & 5.023 & TRN & \\
\hline CHEMBL404195 & 470053 & 4.0 & 4.4606 & TST & \\
\hline CHEMBL258361 & 470053 & 6.4559 & 6.4675 & TRN & \\
\hline CHEMBL404465 & 470053 & 6.3979 & 6.8003 & TST & \\
\hline CHEMBL 271860 & 470053 & 4.0 & 4.1908 & TST & \\
\hline CHEMBL272559 & 470053 & 5.4112 & 5.4067 & TRN & \\
\hline
\end{tabular}




\begin{tabular}{|c|c|c|c|c|c|}
\hline \multicolumn{6}{|c|}{ Supplemental Table S2.txt } \\
\hline CHEMBL271903 & 470053 & 6.3565 & 6.6178 & TST & \\
\hline CHEMBL 258064 & 470053 & 6.3665 & 6.3349 & TRN & \\
\hline CHEMBL257853 & 470053 & 5.3768 & 5.4182 & TST & \\
\hline CHEMBL256889 & 470053 & 6.041 & 6.0635 & TRN & \\
\hline CHEMBL270433 & 470053 & 6.1675 & 6.1666 & TRN & \\
\hline CHEMBL258368 & 470053 & 6.0132 & 5.8296 & TST & \\
\hline CHEMBL271079 & 470053 & 5.9393 & 5.9268 & TRN & \\
\hline CHEMBL270254 & 470053 & 6.3768 & 6.3703 & TST & \\
\hline CHEMBL258065 & 470053 & 6.6021 & 6.5877 & TRN & \\
\hline CHEMBL255587 & 470053 & 3.5229 & 3.6899 & TST & \\
\hline CHEMBL403665 & 470053 & 5.2882 & 5.6805 & TST & \\
\hline CHEMBL411476 & 470053 & 5.7328 & 5.7356 & TRN & \\
\hline CHEMBL270631 & 470053 & 6.5229 & 6.4843 & TRN & \\
\hline CHEMBL258362 & 470053 & 5.0458 & 5.0456 & TRN & \\
\hline CHEMBL258360 & 470053 & 6.2924 & 6.3207 & TRN & \\
\hline CHEMBL255629 & 470053 & 7.0969 & 7.0984 & TRN & \\
\hline CHEMBL1823606 & 766743 & 4.6021 & 4.5628 & TRN & \\
\hline CHEMBL1823865 & 766743 & 7.3468 & 6.4432 & TRN & \\
\hline CHEMBL1823832 & 766743 & 6.4559 & 6.1948 & TRN & \\
\hline CHEMBL1823618 & 766743 & 4.6021 & 6.4287 & TST & \\
\hline CHEMBL1823856 & 766743 & 5.4685 & 6.32600 & 00000000005 & TRN \\
\hline CHEMBL1823836 & 766743 & 5.9586 & 5.7668 & TRN & \\
\hline CHEMBL1821746 & 766743 & 4.6021 & 4.7134 & TRN & \\
\hline CHEMBL1823581 & 766743 & 4.8239 & 5.5638 & TRN & \\
\hline CHEMBL1823612 & 766743 & 5.9586 & 5.2293 & TRN & \\
\hline CHEMBL1823588 & 766743 & 5.2218 & 5.9134 & TST & \\
\hline CHEMBL1823855 & 766743 & 5.5376 & 6.3389 & TRN & \\
\hline CHEMBL1823603 & 766743 & 5.7212 & 5.0164 & TRN & \\
\hline CHEMBL1823591 & 766743 & 6.7696 & 5.9464 & TRN & \\
\hline CHEMBL1823849 & 766743 & 4.6021 & 5.0782 & TRN & \\
\hline CHEMBL1823616 & 766743 & 6.0 & 5.04899 & 99999999995 & TST \\
\hline CHEMBL1823863 & 766743 & 8.5229 & 5.7109 & TST & \\
\hline CHEMBL1823613 & 766743 & 4.6021 & 5.2871 & TRN & \\
\hline CHEMBL1823609 & 766743 & 4.6021 & 4.8914 & TRN & \\
\hline CHEMBL1823608 & 766743 & 4.6021 & 4.702 & TRN & \\
\hline CHEMBL1823589 & 766743 & 5.6778 & 5.9074 & TST & \\
\hline CHEMBL1823827 & 766743 & 5.8539 & 6.04799 & 9999999999 & TRN \\
\hline CHEMBL1823825 & 766743 & 6.6576 & 5.8856 & TRN & \\
\hline CHEMBL1823584 & 766743 & 6.4202 & 5.7824 & TRN & \\
\hline CHEMBL1823861 & 766743 & 6.4559 & 5.6195 & TST & \\
\hline CHEMBL1823592 & 766743 & 4.6021 & 4.582 & TRN & \\
\hline CHEMBL1823601 & 766743 & 4.6021 & 4.7321 & TRN & \\
\hline CHEMBL1823851 & 766743 & 4.6021 & 5.2008 & TRN & \\
\hline CHEMBL1823842 & 766743 & 6.5528 & 6.3079 & TST & \\
\hline CHEMBL1823829 & 766743 & 6.1739 & 6.4108 & TST & \\
\hline CHEMBL1823862 & 766743 & 6.1612 & 5.5703 & TST & \\
\hline CHEMBL1823864 & 766743 & 8.1549 & 5.7954 & TST & \\
\hline CHEMBL1823841 & 766743 & 6.5528 & 6.3593 & TRN & \\
\hline
\end{tabular}


Supplemental Table S2.txt

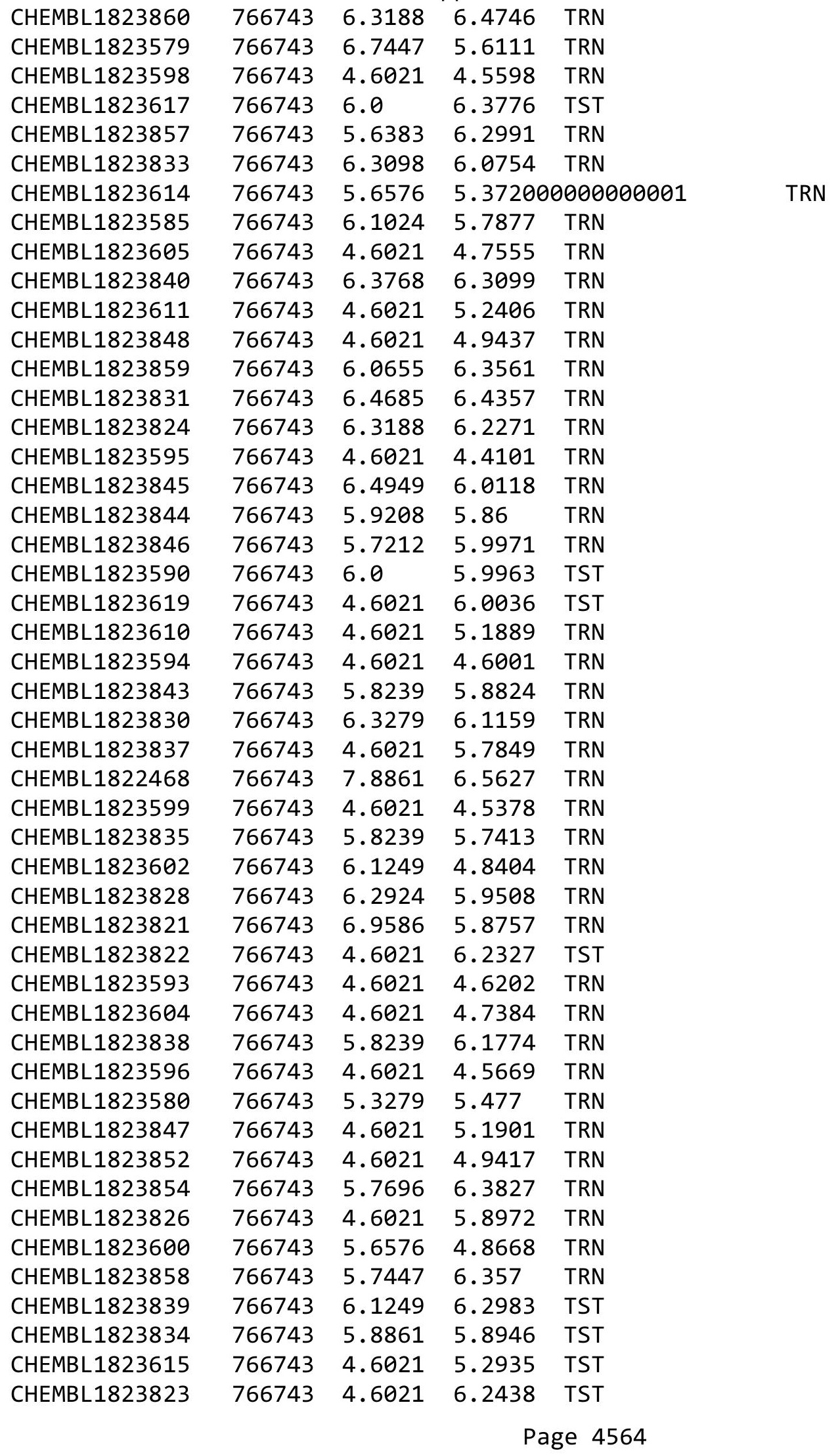


Supplemental Table S2.txt

\begin{tabular}{|c|c|c|c|c|}
\hline CHEMBL1823853 & 766743 & 5.6021 & 6.3607 & TST \\
\hline CHEMBL1823620 & 766743 & 4.6021 & 5.9684 & TST \\
\hline CHEMBL1823850 & 766743 & 5.7447 & 5.2249 & TST \\
\hline CHEMBL 3687123 & 1536328 & 6.5086 & 6.5385 & TRN \\
\hline CHEMBL3682434 & 1536328 & 8.2218 & 8.3715 & TRN \\
\hline CHEMBL3687137 & 1536328 & 7.5229 & 7.8998 & TST \\
\hline CHEMBL3687139 & 1536328 & 6.8539 & 6.3587 & TST \\
\hline CHEMBL3682432 & 1536328 & 7.6778 & 7.5998 & TST \\
\hline CHEMBL 3687158 & 1536328 & 7.6778 & 7.5902 & TRN \\
\hline CHEMBL3682430 & 1536328 & 9.0 & 8.8116 & TRN \\
\hline CHEMBL3687111 & 1536328 & 8.0 & 8.0084 & TRN \\
\hline CHEMBL3687172 & 1536328 & 7.3468 & 7.4647 & TRN \\
\hline CHEMBL 3687175 & 1536328 & 8.2218 & 7.6323 & TST \\
\hline CHEMBL 3682433 & 1536328 & 7.9208 & 7.8479 & TRN \\
\hline CHEMBL3687126 & 1536328 & 7.3979 & 7.4519 & TRN \\
\hline CHEMBL3687177 & 1536328 & 6.8539 & 6.6119 & TRN \\
\hline CHEMBL3687135 & 1536328 & 7.1871 & 7.1236 & TRN \\
\hline CHEMBL 3687110 & 1536328 & 6.6778 & 6.6164 & TRN \\
\hline CHEMBL 3687148 & 1536328 & 7.699 & 7.4521 & TRN \\
\hline CHEMBL3682427 & 1536328 & 8.2218 & 7.976 & TRN \\
\hline CHEMBL3687162 & 1536328 & 7.2924 & 7.3272 & TRN \\
\hline CHEMBL 3687167 & 1536328 & 7.1739 & 7.141 & TRN \\
\hline CHEMBL 3682420 & 1536328 & 8.2218 & 8.5233 & TRN \\
\hline CHEMBL 3687120 & 1536328 & 7.0088 & 6.9679 & TRN \\
\hline CHEMBL 3687141 & 1536328 & 6.699 & 6.9488 & TRN \\
\hline CHEMBL 3687185 & 1536328 & 8.0 & 8.05 & TRN \\
\hline CHEMBL 3687143 & 1536328 & 6.9208 & 6.9511 & TRN \\
\hline CHEMBL3687159 & 1536328 & 8.1549 & 7.7823 & TRN \\
\hline CHEMBL 3687154 & 1536328 & 6.6198 & 6.817 & TRN \\
\hline CHEMBL 3687153 & 1536328 & 7.3665 & 7.5263 & TRN \\
\hline CHEMBL 3687124 & 1536328 & 7.7447 & 7.7146 & TRN \\
\hline CHEMBL 3687122 & 1536328 & 6.0315 & 6.0416 & TST \\
\hline CHEMBL 3687161 & 1536328 & 6.4089 & 6.7719 & TST \\
\hline CHEMBL3687166 & 1536328 & 7.0506 & 7.1329 & TRN \\
\hline CHEMBL 3687144 & 1536328 & 6.1871 & 6.5022 & TST \\
\hline CHEMBL3687186 & 1536328 & 8.699 & 8.5872 & TRN \\
\hline CHEMBL3687136 & 1536328 & 7.3372 & 7.2818 & TRN \\
\hline CHEMBL3687132 & 1536328 & 8.0969 & 7.9736 & TRN \\
\hline CHEMBL 3682431 & 1536328 & 8.3979 & 8.0828 & TRN \\
\hline CHEMBL3687169 & 1536328 & 7.1135 & 6.975 & TRN \\
\hline CHEMBL3687156 & 1536328 & 6.2757 & 6.3186 & TRN \\
\hline CHEMBL 3687130 & 1536328 & 7.4089 & 7.5418 & TRN \\
\hline CHEMBL3687116 & 1536328 & 6.5229 & 6.50899 & 99999999995 \\
\hline CHEMBL 3682424 & 1536328 & 6.699 & 6.7779 & TRN \\
\hline CHEMBL 3687170 & 1536328 & 7.1308 & 7.2606 & TRN \\
\hline CHEMBL 3687182 & 1536328 & 7.6021 & 7.6254 & TRN \\
\hline CHEMBL 3687142 & 1536328 & 7.5229 & 7.6201 & TST \\
\hline CHEMBL 3687171 & 1536328 & 7.0555 & 7.1048 & TRN \\
\hline
\end{tabular}


Supplemental Table S2.txt

\begin{tabular}{|c|c|c|c|c|}
\hline 5 & & & 3782 & \\
\hline & 536328 & 6.7959 & & \\
\hline$E N>$ & 328 & & & \\
\hline IEMBL & 28 & 2147 & 5 & \\
\hline AEMBL3687112 & 536328 & 6.8239 & 7378 & \\
\hline HEMBL3 & 536328 & 8.0969 & 0894 & \\
\hline HEMBL & 328 & 665 & 511 & \\
\hline HEMBL; & & & & \\
\hline HEMBL3687133 & 536328 & 7.6021 & .4621 & \\
\hline HEMBL3 & 536328 & 7.6021 & 4848 & \\
\hline HEMBL3 & 28 & & & \\
\hline HEMBL & 28 & 58 & & \\
\hline HEMBL. & & & & \\
\hline HEMBL3 & 536328 & 7.6778 & 5832 & \\
\hline HEMBL3 & 536328 & 969 & & \\
\hline HEMBL; & 20 & 7 & 21 & \\
\hline HEMBL & & 7 & & ST \\
\hline HEMBL. & & 7. & & \\
\hline HEMBL & 328 & & & \\
\hline AEMBL3 & & & & \\
\hline HEMBL & 0 & 5 & & SI \\
\hline HEM & & & & RN \\
\hline HEMBL & 28 & 49 & & $\mathrm{RN}$ \\
\hline HEMBL & 28 & & & \\
\hline HEMBL3 & 328 & & 56 & ISI \\
\hline HEMBL & & & 41 & ST \\
\hline HEM & & & & RN \\
\hline HEME & 28 & 7 & 99 & \\
\hline HEMBL & & & & IRN \\
\hline HEMBL3 & 28 & 7.0862 & 862 & TRN \\
\hline AEMBL & & 861 & 781 & RN \\
\hline HFM & & & & $\mathrm{RN}$ \\
\hline 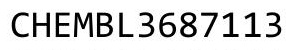 & & & & 「RN \\
\hline HEMBL3 & & & & 「RN \\
\hline HEMBL3 & 28 & 586 & 396 & RN \\
\hline JᄃMPI & & 58 & 25 & TRN \\
\hline 0 & & & & TRN \\
\hline HEMBL & & & & 「RN \\
\hline HEMBL & 28 & 7.5686 & & TS \\
\hline MBL & & 7. & & IST \\
\hline ACMD & & 5. & 68 & \\
\hline HEMBL; & 28 & 6. & 975 & IST \\
\hline HEMBL3 & 536328 & 8.0969 & 7.5507 & TST \\
\hline HEMBL & 28 & 69 & & TS \\
\hline CHEMPI 2 & & & & TST \\
\hline HEMBL3 & & & & \\
\hline CHEMBL3 & 1536328 & 8239 & & ST \\
\hline CHEMBL3687187 & 1536328 & 6.4318 & 6.5516 & - \\
\hline
\end{tabular}

Page 4566 


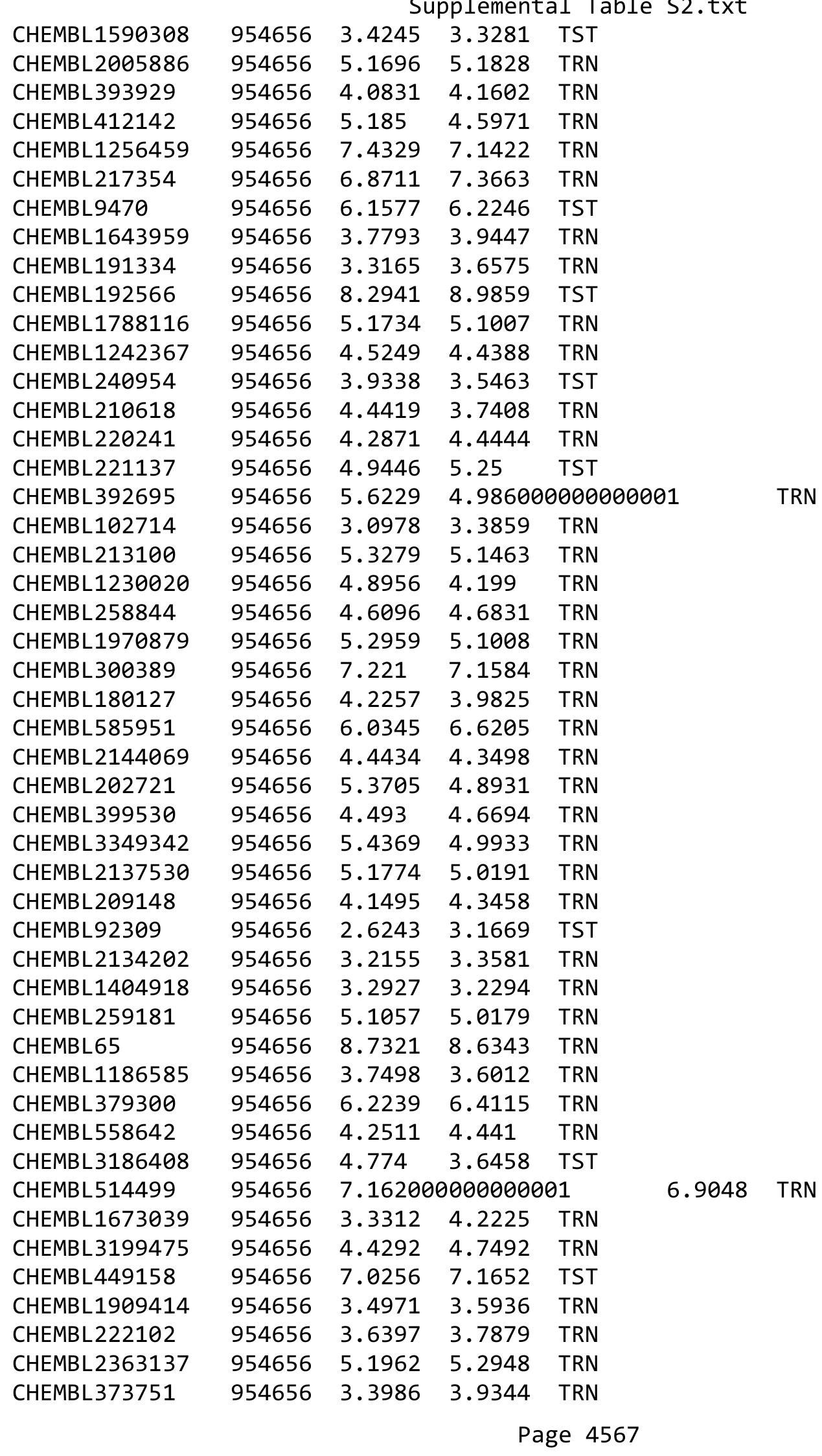




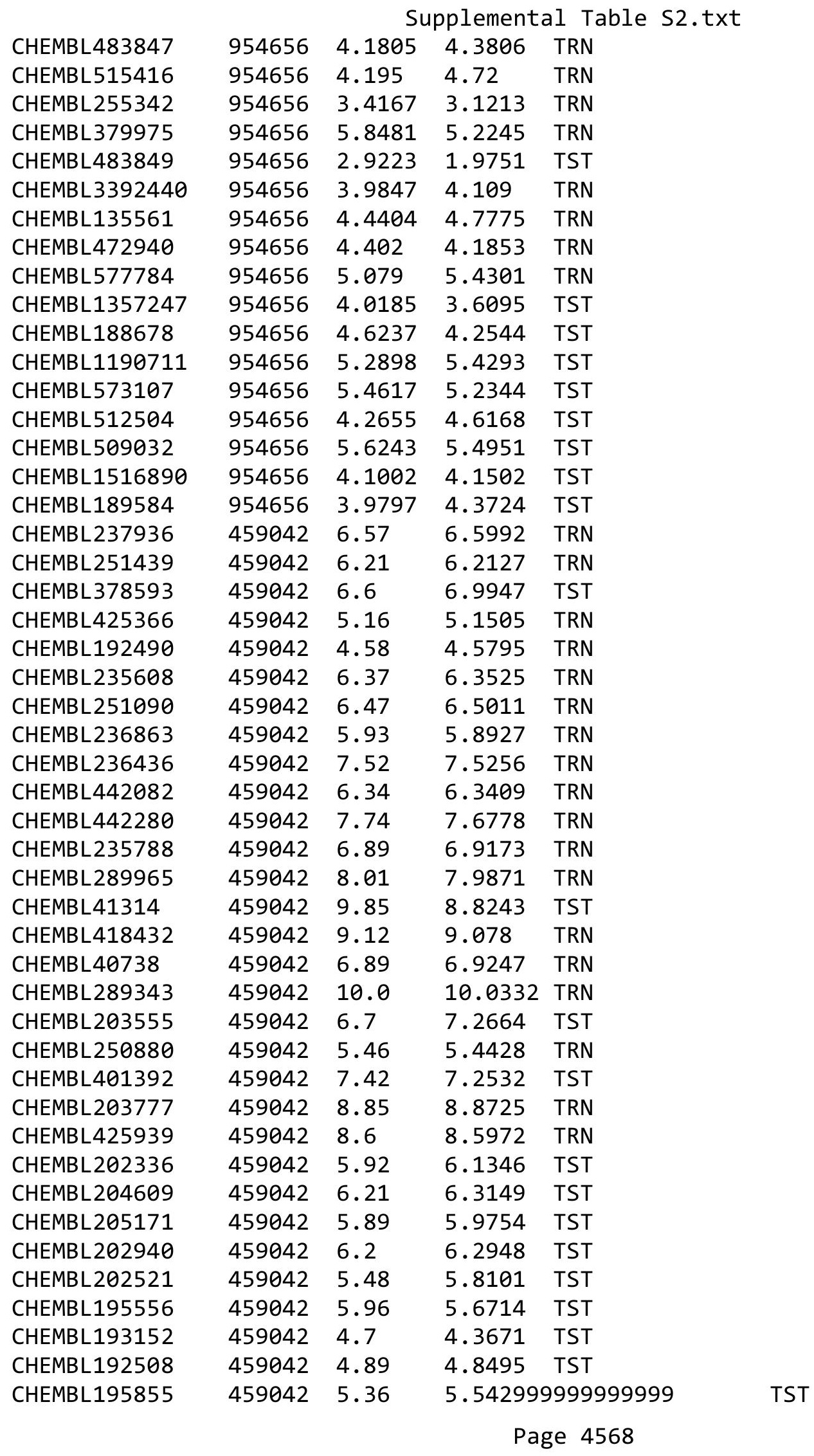




\begin{tabular}{|c|c|c|c|c|}
\hline & & & pplement & al Table S2 \\
\hline CHEMBL 252717 & 459042 & 6.34 & 6.0689 & TST \\
\hline CHEMBL 253123 & 459042 & 5.57 & 5.149 & TST \\
\hline CHEMBL192426 & 459042 & 5.8 & 5.9287 & TST \\
\hline CHEMBL192639 & 459042 & 5.28 & 4.63399 & 99999999995 \\
\hline CHEMBL 236864 & 459042 & 6.07 & 6.0205 & TRN \\
\hline CHEMBL 235385 & 459042 & 6.26 & 6.2778 & TRN \\
\hline CHEMBL 237721 & 459042 & 5.82 & 5.8525 & TRN \\
\hline CHEMBL235177 & 459042 & 7.74 & 7.7125 & TRN \\
\hline CHEMBL 235166 & 459042 & 5.83 & 5.74299 & 9999999999 \\
\hline CHEMBL249445 & 459042 & 7.07 & 7.1234 & TRN \\
\hline CHEMBL392925 & 459042 & 7.02 & 7.0176 & TRN \\
\hline CHEMBL 235607 & 459042 & 6.62 & 6.652 & TRN \\
\hline CHEMBL39174 & 459042 & 8.81 & 8.7608 & TRN \\
\hline CHEMBL 394644 & 459042 & 6.53 & 6.5082 & TRN \\
\hline CHEMBL238178 & 459042 & 7.03 & 7.0477 & TRN \\
\hline CHEMBL429078 & 459042 & 6.55 & 6.5364 & TRN \\
\hline CHEMBL393489 & 459042 & 6.91 & 6.9205 & TRN \\
\hline CHEMBL238179 & 459042 & 5.94 & 5.9618 & TRN \\
\hline CHEMBL 235384 & 459042 & 7.3 & 7.2697 & TRN \\
\hline CHEMBL251456 & 459042 & 7.89 & 7.903 & TRN \\
\hline CHEMBL 237958 & 459042 & 6.64 & 6.6836 & TRN \\
\hline CHEMBL 235383 & 459042 & 6.61 & 6.6644 & TRN \\
\hline CHEMBL442243 & 459042 & 7.4 & 7.4386 & TRN \\
\hline CHEMBL 235165 & 459042 & 6.91 & 6.8557 & TRN \\
\hline CHEMBL254607 & 459042 & 6.9 & 6.8333 & TRN \\
\hline CHEMBL 236438 & 459042 & 7.0 & 7.021 & TRN \\
\hline CHEMBL235609 & 459042 & 7.82 & 7.8109 & TRN \\
\hline CHEMBL 237722 & 459042 & 6.09 & 6.0736 & TRN \\
\hline CHEMBL41036 & 459042 & 7.6 & 7.6153 & TRN \\
\hline CHEMBL235816 & 459042 & 6.69 & 6.7043 & TRN \\
\hline CHEMBL 236648 & 459042 & 5.98 & 6.0293 & TRN \\
\hline CHEMBL235164 & 459042 & 6.25 & 6.2639 & TRN \\
\hline CHEMBL394199 & 459042 & 6.3 & 6.3113 & TRN \\
\hline CHEMBL428729 & 459042 & 6.84 & 6.8318 & TRN \\
\hline CHEMBL1970879 & 809255 & 6.8 & 5.973 & TRN \\
\hline CHEMBL1989856 & 809255 & 5.2 & 5.63899 & 9999999999 \\
\hline CHEMBL2005899 & 809255 & 5.3 & 5.1324 & TRN \\
\hline CHEMBL1682552 & 809255 & 4.2 & 4.4916 & TRN \\
\hline CHEMBL 259850 & 809255 & 5.2 & 4.5863 & TRN \\
\hline CHEMBL1972568 & 809255 & 4.2 & 4.6723 & TRN \\
\hline CHEMBL 2007479 & 809255 & 4.4 & 4.8233 & TRN \\
\hline CHEMBL1996155 & 809255 & 4.2 & 4.3325 & TRN \\
\hline CHEMBL229799 & 809255 & 6.7 & 6.8074 & TRN \\
\hline CHEMBL105739 & 809255 & 7.4 & 6.6636 & TRN \\
\hline CHEMBL1682359 & 809255 & 5.6 & 5.0767 & TRN \\
\hline CHEMBL 379300 & 809255 & 6.2 & 5.9159 & TRN \\
\hline CHEMBL 203673 & 809255 & 4.2 & 4.5891 & TRN \\
\hline CHEMBL 2003785 & 809255 & 4.8 & 4.6979 & TST \\
\hline
\end{tabular}




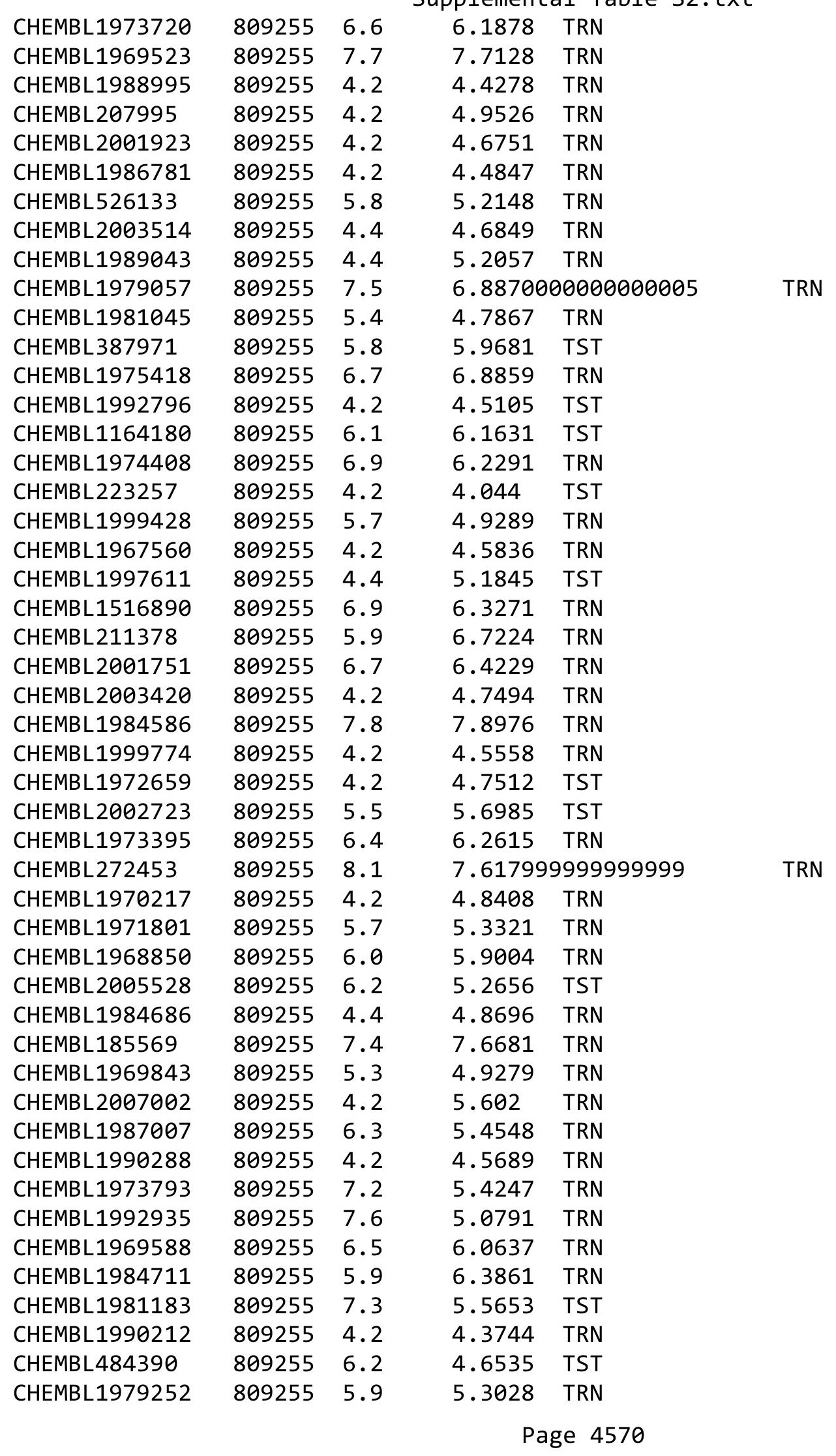




\begin{tabular}{|c|c|c|c|c|c|}
\hline \\
\hline CHEMBL1986143 & 809255 & 4.4 & 4.6585 & TRN & \\
\hline CHEMBL1972934 & 809255 & 4.7 & 4.9103 & TRN & \\
\hline CHEMBL2007559 & 809255 & 4.4 & 5.251 & TRN & \\
\hline CHEMBL1992581 & 809255 & 4.4 & 5.7964 & TRN & \\
\hline CHEMBL1682341 & 809255 & 6.4 & 5.5686 & TRN & \\
\hline CHEMBL1986499 & 809255 & 7.0 & 6.7882 & TRN & \\
\hline CHEMBL1972937 & 809255 & 4.2 & 4.7893 & TRN & \\
\hline CHEMBL1972250 & 809255 & 6.3 & 5.4345 & TST & \\
\hline CHEMBL 2000393 & 809255 & 7.6 & 7.261 & TST & \\
\hline CHEMBL1993510 & 809255 & 8.6 & 6.7962 & TRN & \\
\hline CHEMBL2004072 & 809255 & 5.4 & 5.20100 & 00000000005 & TRN \\
\hline CHEMBL1089101 & 809255 & 5.7 & 4.9713 & TRN & \\
\hline CHEMBL2004311 & 809255 & 6.7 & 6.562 & TRN & \\
\hline CHEMBL1992634 & 809255 & 6.8 & 6.7505 & TRN & \\
\hline CHEMBL1242373 & 809255 & 7.5 & 8.3361 & TRN & \\
\hline CHEMBL 2000433 & 809255 & 5.2 & 5.1688 & TST & \\
\hline CHEMBL1985433 & 809255 & 7.4 & 6.1045 & TRN & \\
\hline CHEMBL56543 & 809255 & 6.2 & 5.6846 & TRN & \\
\hline CHEMBL316264 & 809255 & 4.2 & 4.1785 & TRN & \\
\hline CHEMBL1988075 & 809255 & 8.4 & 8.6895 & TRN & \\
\hline CHEMBL1996576 & 809255 & 4.4 & 5.0659 & TST & \\
\hline CHEMBL1988076 & 809255 & 4.4 & 6.2261 & TRN & \\
\hline CHEMBL1991678 & 809255 & 4.4 & 4.2942 & TRN & \\
\hline CHEMBL2001239 & 809255 & 5.3 & 5.1056 & TRN & \\
\hline CHEMBL1976396 & 809255 & 5.4 & 5.4697 & TRN & \\
\hline CHEMBL 2001288 & 809255 & 4.2 & 5.3153 & TRN & \\
\hline CHEMBL 260092 & 809255 & 8.5 & 8.8362 & TRN & \\
\hline CHEMBL1999811 & 809255 & 6.0 & 6.1448 & TRN & \\
\hline CHEMBL1965495 & 809255 & 6.9 & 6.2107 & TRN & \\
\hline CHEMBL1985074 & 809255 & 5.2 & 4.7258 & TST & \\
\hline CHEMBL 2000481 & 809255 & 7.1 & 5.0711 & TRN & \\
\hline CHEMBL1982874 & 809255 & 4.2 & 5.3573 & TRN & \\
\hline CHEMBL1991725 & 809255 & 5.2 & 5.6119 & TRN & \\
\hline CHEMBL1992242 & 809255 & 4.2 & 5.7447 & TRN & \\
\hline CHEMBL 2007296 & 809255 & 4.2 & 4.6484 & TRN & \\
\hline CHEMBL 208637 & 809255 & 4.2 & 4.3106 & TRN & \\
\hline CHEMBL 396523 & 809255 & 8.4 & 8.2408 & TRN & \\
\hline CHEMBL 2004159 & 809255 & 4.4 & 4.6956 & TRN & \\
\hline CHEMBL1978371 & 809255 & 5.9 & 5.7476 & TST & \\
\hline CHEMBL1986530 & 809255 & 6.4 & 4.9615 & TST & \\
\hline CHEMBL1999321 & 809255 & 4.2 & 5.3128 & TRN & \\
\hline CHEMBL1968590 & 809255 & 6.2 & 6.0261 & TRN & \\
\hline CHEMBL1999749 & 809255 & 4.2 & 4.8985 & TRN & \\
\hline CHEMBL 2005375 & 809255 & 4.2 & 4.5445 & TRN & \\
\hline CHEMBL1984191 & 809255 & 4.2 & 4.4582 & TRN & \\
\hline CHEMBL1983006 & 809255 & 4.2 & 5.1018 & TRN & \\
\hline CHEMBL1972183 & 809255 & 4.2 & 4.7818 & TRN & \\
\hline CHEMBL1971029 & 809255 & 7.2 & 7.9228 & TRN & \\
\hline
\end{tabular}




\begin{tabular}{|c|c|c|c|c|c|}
\hline \multicolumn{6}{|c|}{ Supplemental Table S2.txt } \\
\hline CHEMBL383527 & 809255 & 4.2 & 4.4618 & TRN & \\
\hline CHEMBL394790 & 809255 & 7.9 & 8.1032 & TRN & \\
\hline CHEMBL226471 & 809255 & 5.2 & 5.6064 & TRN & \\
\hline CHEMBL1974702 & 809255 & 5.2 & 5.3263 & TST & \\
\hline CHEMBL1996111 & 809255 & 6.3 & 6.5926 & TRN & \\
\hline CHEMBL1965589 & 809255 & 4.2 & 4.5536 & TRN & \\
\hline CHEMBL 2007375 & 809255 & 4.4 & 4.5827 & TRN & \\
\hline CHEMBL1998193 & 809255 & 4.2 & 4.8566 & TRN & \\
\hline CHEMBL379975 & 809255 & 6.3 & 5.3264 & TST & \\
\hline CHEMBL474432 & 809255 & 6.9 & 6.3856 & TRN & \\
\hline CHEMBL1973016 & 809255 & 4.4 & 4.835 & TST & \\
\hline CHEMBL1965387 & 809255 & 6.6 & 6.2899 & TRN & \\
\hline CHEMBL1970534 & 809255 & 7.3 & 5.5273 & TRN & \\
\hline CHEMBL1988153 & 809255 & 4.2 & 5.2415 & TRN & \\
\hline CHEMBL550418 & 809255 & 5.5 & 5.0293 & TRN & \\
\hline CHEMBL1972584 & 809255 & 8.0 & 7.0123 & TRN & \\
\hline CHEMBL1971289 & 809255 & 4.4 & 5.079 & TRN & \\
\hline CHEMBL1999556 & 809255 & 5.8 & 6.1205 & TRN & \\
\hline CHEMBL1988437 & 809255 & 8.1 & 7.2436 & TRN & \\
\hline CHEMBL1968245 & 809255 & 5.2 & 4.7384 & TRN & \\
\hline CHEMBL1979577 & 809255 & 8.5 & 8.5363 & TRN & \\
\hline CHEMBL1998121 & 809255 & 7.0 & 5.7264 & TRN & \\
\hline CHEMBL1233887 & 809255 & 7.1 & 5.282 & TST & \\
\hline CHEMBL1992607 & 809255 & 4.5 & 5.2188 & TRN & \\
\hline CHEMBL1991800 & 809255 & 4.2 & 4.4017 & TRN & \\
\hline CHEMBL52387 & 809255 & 4.2 & 4.9125 & TST & \\
\hline CHEMBL1985566 & 809255 & 4.2 & 5.0415 & TRN & \\
\hline CHEMBL 2003689 & 809255 & 4.4 & 4.6673 & TRN & \\
\hline CHEMBL379835 & 809255 & 5.2 & 4.9354 & TRN & \\
\hline CHEMBL1969284 & 809255 & 7.8 & 5.6107 & TST & \\
\hline CHEMBL1979357 & 809255 & 5.2 & 4.8292 & TRN & \\
\hline CHEMBL1980802 & 809255 & 4.2 & 4.1678 & TST & \\
\hline CHEMBL1996649 & 809255 & 8.6 & 8.0953 & TRN & \\
\hline CHEMBL1996817 & 809255 & 6.2 & 5.919 & TRN & \\
\hline CHEMBL1979554 & 809255 & 5.2 & 5.0197 & TRN & \\
\hline CHEMBL1986756 & 809255 & 4.4 & 4.6692 & TRN & \\
\hline CHEMBL3197315 & 809255 & 4.2 & 4.7163 & TST & \\
\hline CHEMBL 2004355 & 809255 & 4.2 & 4.5251 & TRN & \\
\hline CHEMBL468280 & 809255 & 4.2 & 4.5211 & TST & \\
\hline CHEMBL1990884 & 809255 & 6.4 & 5.4006 & TRN & \\
\hline CHEMBL 3109278 & 809255 & 6.2 & 5.95700 & 0000000001 & TRN \\
\hline CHEMBL 256835 & 809255 & 4.2 & 4.3937 & TRN & \\
\hline CHEMBL1970006 & 809255 & 6.1 & $5.5360 e$ & 00000000005 & TST \\
\hline CHEMBL1980142 & 809255 & 4.2 & 4.8851 & TRN & \\
\hline CHEMBL41783 & 809255 & 4.2 & 4.452 & TRN & \\
\hline CHEMBL2004438 & 809255 & 5.8 & 6.314 & TRN & \\
\hline CHEMBL 2006276 & 809255 & 4.2 & 5.2629 & TRN & \\
\hline CHEMBL191003 & 809255 & 7.4 & 6.5867 & TRN & \\
\hline
\end{tabular}




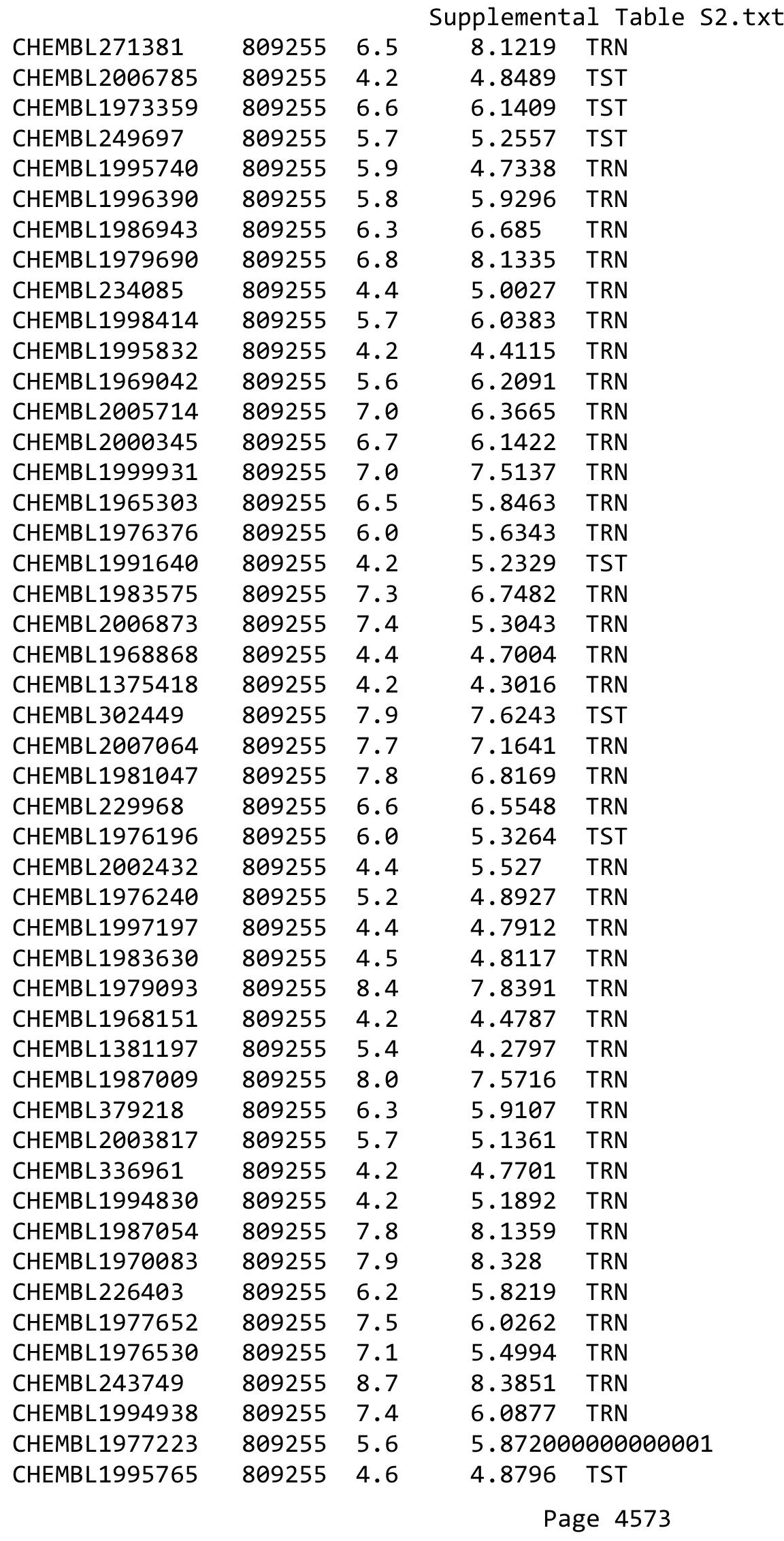

TRN 


\begin{tabular}{|c|c|c|c|c|}
\hline & & & pplement & al $\mathrm{Ta}$ \\
\hline CHEMBL1966279 & 809255 & 7.2 & 5.1134 & TRN \\
\hline CHEMBL1236126 & 809255 & 4.2 & 4.5247 & TST \\
\hline CHEMBL1984760 & 809255 & 6.0 & 6.2606 & TRN \\
\hline CHEMBL1997846 & 809255 & 6.0 & 5.3821 & TRN \\
\hline CHEMBL2004419 & 809255 & 4.2 & 4.6709 & TRN \\
\hline CHEMBL1991728 & 809255 & 5.9 & 5.0944 & TRN \\
\hline CHEMBL 360847 & 809255 & 4.4 & 5.1867 & TST \\
\hline CHEMBL1995811 & 809255 & 4.4 & 5.7617 & TRN \\
\hline CHEMBL1975787 & 809255 & 5.7 & 5.8372 & TRN \\
\hline CHEMBL1995916 & 809255 & 4.2 & 4.4379 & TRN \\
\hline CHEMBL 2002407 & 809255 & 5.8 & 5.4209 & TRN \\
\hline CHEMBL1972489 & 809255 & 4.2 & 4.7129 & TRN \\
\hline CHEMBL1994074 & 809255 & 5.8 & 5.4977 & TRN \\
\hline CHEMBL1992937 & 809255 & 5.8 & 5.0596 & TST \\
\hline CHEMBL1972119 & 809255 & 4.2 & 4.9156 & TRN \\
\hline CHEMBL1986328 & 809255 & 6.0 & 5.2322 & TST \\
\hline CHEMBL95692 & 809255 & 4.2 & 4.4489 & TRN \\
\hline CHEMBL1090356 & 809255 & 7.1 & 6.1981 & TRN \\
\hline CHEMBL1976455 & 809255 & 5.8 & 5.7868 & TRN \\
\hline CHEMBL261849 & 809255 & 4.4 & 4.8711 & TST \\
\hline CHEMBL1983923 & 809255 & 7.3 & 7.1698 & TRN \\
\hline CHEMBL1983534 & 809255 & 5.7 & 5.0967 & TRN \\
\hline CHEMBL1982361 & 809255 & 5.7 & 5.395 & TRN \\
\hline CHEMBL1999112 & 809255 & 5.5 & 4.9406 & TST \\
\hline CHEMBL1982122 & 809255 & 5.8 & 5.0882 & TRN \\
\hline CHEMBL 2000801 & 809255 & 6.0 & 5.8992 & TRN \\
\hline CHEMBL1682546 & 809255 & 5.4 & 5.1076 & TRN \\
\hline CHEMBL1991395 & 809255 & 4.2 & 4.331 & TRN \\
\hline CHEMBL1971245 & 809255 & 7.4 & 5.6773 & TRN \\
\hline CHEMBL1991915 & 809255 & 8.2 & 6.1811 & TRN \\
\hline CHEMBL1987648 & 809255 & 4.2 & 4.1443 & TRN \\
\hline CHEMBL1996780 & 809255 & 4.2 & 4.3014 & TRN \\
\hline CHEMBL1988769 & 809255 & 8.1 & 6.9549 & TRN \\
\hline CHEMBL1972142 & 809255 & 6.8 & 6.4382 & TRN \\
\hline CHEMBL1966514 & 809255 & 8.3 & 8.5068 & TRN \\
\hline CHEMBL 2003638 & 809255 & 6.5 & 7.2845 & TRN \\
\hline CHEMBL 296586 & 809255 & 5.2 & 5.7008 & TRN \\
\hline CHEMBL1996066 & 809255 & 7.3 & 5.7192 & TST \\
\hline CHEMBL1983393 & 809255 & 5.8 & 5.0898 & TRN \\
\hline CHEMBL516429 & 809255 & 6.1 & 6.0344 & TRN \\
\hline CHEMBL1999910 & 809255 & 8.4 & 5.4543 & TRN \\
\hline CHEMBL1972152 & 809255 & 6.1 & 5.0853 & TST \\
\hline CHEMBL1993722 & 809255 & 6.6 & 7.4605 & TRN \\
\hline CHEMBL1970806 & 809255 & 4.2 & 4.5843 & TRN \\
\hline CHEMBL 2006674 & 809255 & 4.4 & 4.8841 & TST \\
\hline CHEMBL1984236 & 809255 & 4.4 & 5.3753 & TST \\
\hline CHEMBL1992371 & 809255 & 4.4 & 5.126 & TRN \\
\hline CHEMBL1375640 & 809255 & 6.1 & 5.5011 & TST \\
\hline
\end{tabular}




\begin{tabular}{|c|c|c|c|c|}
\hline & & & & $\mathrm{al} \mathrm{Ta}$ \\
\hline CHEMBL1979970 & 809255 & 4.2 & 4.2861 & TRN \\
\hline CHEMBL 2002599 & 809255 & 4.4 & 5.2054 & TRN \\
\hline CHEMBL249282 & 809255 & 7.0 & 5.0101 & TST \\
\hline CHEMBL1967252 & 809255 & 5.0 & 5.2931 & TRN \\
\hline CHEMBL1993966 & 809255 & 7.8 & \multicolumn{2}{|c|}{6.94600000000000} \\
\hline CHEMBL1993374 & 809255 & 4.4 & 5.0596 & TRN \\
\hline CHEMBL1969264 & 809255 & 6.5 & 5.9516 & TRN \\
\hline CHEMBL1973711 & 809255 & 5.3 & 5.1898 & TST \\
\hline CHEMBL 2006237 & 809255 & 5.4 & 4.9128 & TRN \\
\hline CHEMBL1572266 & 809255 & 4.2 & 5.1073 & TRN \\
\hline CHEMBL1991138 & 809255 & 5.6 & 4.8213 & TRN \\
\hline CHEMBL1969755 & 809255 & 4.2 & 4.4309 & TRN \\
\hline CHEMBL1972820 & 809255 & 4.2 & 5.2449 & TST \\
\hline CHEMBL1605605 & 809255 & 4.4 & 4.5702 & TRN \\
\hline CHEMBL1996208 & 809255 & 4.2 & 5.0652 & TST \\
\hline CHEMBL1989029 & 809255 & 5.9 & 6.2517 & TRN \\
\hline CHEMBL392642 & 809255 & 4.2 & 4.6832 & TRN \\
\hline CHEMBL514499 & 809255 & 4.2 & 5.6294 & TRN \\
\hline CHEMBL1970352 & 809255 & 4.4 & 5.6089 & TST \\
\hline CHEMBL1965631 & 809255 & 5.2 & 5.2373 & TRN \\
\hline CHEMBL1991188 & 809255 & 4.2 & 4.8253 & TRN \\
\hline CHEMBL1980167 & 809255 & 6.0 & 5.9706 & TST \\
\hline CHEMBL1972849 & 809255 & 4.2 & 4.4603 & TRN \\
\hline CHEMBL 377408 & 809255 & 4.2 & 4.3086 & TRN \\
\hline CHEMBL 2003622 & 809255 & 5.6 & 5.5181 & TRN \\
\hline CHEMBL231209 & 809255 & 8.1 & 7.7306 & TRN \\
\hline CHEMBL1975357 & 809255 & 4.2 & 5.0789 & TST \\
\hline CHEMBL 2006765 & 809255 & 6.7 & 6.9806 & TRN \\
\hline CHEMBL1976220 & 809255 & 7.9 & 8.4082 & TRN \\
\hline CHEMBL 259922 & 809255 & 4.2 & 3.928 & TST \\
\hline CHEMBL1997617 & 809255 & 6.4 & 6.2456 & TRN \\
\hline CHEMBL1969301 & 809255 & 6.7 & 4.9157 & TST \\
\hline CHEMBL1982383 & 809255 & 6.0 & 4.7327 & TRN \\
\hline CHEMBL17370 & 809255 & 4.2 & 4.2216 & TRN \\
\hline CHEMBL1980246 & 809255 & 4.4 & 5.1382 & TRN \\
\hline CHEMBL1987910 & 809255 & 8.2 & 6.8166 & TRN \\
\hline CHEMBL1983932 & 809255 & 7.9 & 5.8171 & TRN \\
\hline CHEMBL1983980 & 809255 & 6.0 & 6.2084 & TRN \\
\hline CHEMBL487402 & 809255 & 7.4 & 5.59 & TRN \\
\hline CHEMBL1999484 & 809255 & 7.5 & 7.6162 & TRN \\
\hline CHEMBL1966069 & 809255 & 6.1 & 5.454 & TRN \\
\hline CHEMBL1986899 & 809255 & 6.1 & 5.6507 & TRN \\
\hline CHEMBL1991285 & 809255 & 4.3 & 5.1836 & TRN \\
\hline CHEMBL1997822 & 809255 & 6.0 & 6.0865 & TRN \\
\hline CHEMBL1985690 & 809255 & 5.2 & 6.5131 & TRN \\
\hline CHEMBL 243088 & 809255 & 8.0 & 8.2282 & TRN \\
\hline CHEMBL1984038 & 809255 & 4.3 & 4.6824 & TRN \\
\hline CHEMBL1968606 & 809255 & 6.2 & 5.8334 & TRN \\
\hline
\end{tabular}




\begin{tabular}{|c|c|c|c|c|c|}
\hline \\
\hline CHEMBL1993661 & 809255 & 6.1 & 8.3422 & TRN & \\
\hline CHEMBL1974416 & 809255 & 4.2 & 5.0133 & TRN & \\
\hline CHEMBL2004615 & 809255 & 5.8 & 5.1588 & TST & \\
\hline CHEMBL1984039 & 809255 & 4.2 & 5.2651 & TRN & \\
\hline CHEMBL1997872 & 809255 & 6.5 & 6.0541 & TRN & \\
\hline CHEMBL1964290 & 809255 & 5.8 & 5.7102 & TRN & \\
\hline CHEMBL 2003768 & 809255 & 5.4 & 4.9841 & TRN & \\
\hline CHEMBL213505 & 809255 & 6.7 & 7.5297 & TRN & \\
\hline CHEMBL 202721 & 809255 & 7.1 & 6.1439 & TRN & \\
\hline CHEMBL1982880 & 809255 & 5.2 & 4.3844 & TRN & \\
\hline CHEMBL1988038 & 809255 & 7.7 & 6.0644 & TRN & \\
\hline CHEMBL1987034 & 809255 & 8.5 & 8.8287 & TRN & \\
\hline CHEMBL377383 & 809255 & 4.2 & 4.4192 & TRN & \\
\hline CHEMBL 2005886 & 809255 & 7.3 & 6.9887 & TRN & \\
\hline CHEMBL481491 & 809255 & 5.5 & 5.2096 & TRN & \\
\hline CHEMBL1682345 & 809255 & 6.2 & 6.182 & TRN & \\
\hline CHEMBL1973142 & 809255 & 6.3 & 5.8259 & TST & \\
\hline CHEMBL388311 & 809255 & 7.4 & 7.7655 & TRN & \\
\hline CHEMBL 2007009 & 809255 & 5.9 & 5.1213 & TRN & \\
\hline CHEMBL1973145 & 809255 & 6.7 & 6.9391 & TRN & \\
\hline CHEMBL1982924 & 809255 & 5.4 & 5.5503 & TRN & \\
\hline CHEMBL2005936 & 809255 & 6.6 & 6.1198 & TRN & \\
\hline CHEMBL1807515 & 809255 & 5.7 & 5.6515 & TRN & \\
\hline CHEMBL1964948 & 809255 & 4.5 & 4.8546 & TRN & \\
\hline CHEMBL1972472 & 809255 & 8.5 & 7.8792 & TRN & \\
\hline CHEMBL1971141 & 809255 & 4.2 & 5.8589 & TRN & \\
\hline CHEMBL1995813 & 809255 & 5.9 & 6.1471 & TRN & \\
\hline CHEMBL1968565 & 809255 & 7.0 & 5.4157 & TST & \\
\hline CHEMBL1979718 & 809255 & 4.2 & 5.38399 & 99999999995 & TRN \\
\hline CHEMBL523823 & 809255 & 4.2 & 4.684 & TST & \\
\hline CHEMBL1562756 & 809255 & 4.2 & 4.6717 & TST & \\
\hline CHEMBL1987430 & 809255 & 4.4 & 4.5462 & TRN & \\
\hline CHEMBL 2001957 & 809255 & 4.2 & 4.5246 & TRN & \\
\hline CHEMBL1969372 & 809255 & 4.2 & 4.3607 & TRN & \\
\hline CHEMBL 289959 & 809255 & 4.6 & 3.7132 & TRN & \\
\hline CHEMBL 2006263 & 809255 & 6.8 & 5.7612 & TST & \\
\hline CHEMBL 2001646 & 809255 & 5.4 & 5.99700 & 0000000001 & TRN \\
\hline CHEMBL1993584 & 809255 & 5.4 & 4.98 & TRN & \\
\hline CHEMBL1986263 & 809255 & 7.3 & 7.3779 & TRN & \\
\hline CHEMBL 2000114 & 809255 & 6.5 & 5.803 & TRN & \\
\hline CHEMBL210618 & 809255 & 4.2 & 4.3464 & TRN & \\
\hline CHEMBL1986265 & 809255 & 4.4 & 4.8648 & TRN & \\
\hline CHEMBL1975647 & 809255 & 5.3 & 5.1115 & TRN & \\
\hline CHEMBL1968380 & 809255 & 4.4 & 4.3447 & TRN & \\
\hline CHEMBL1964644 & 809255 & 4.2 & 4.6883 & TRN & \\
\hline CHEMBL1991734 & 809255 & 6.2 & 6.0315 & TST & \\
\hline CHEMBL1981782 & 809255 & 5.8 & 5.5555 & TRN & \\
\hline CHEMBL1977681 & 809255 & 6.2 & 6.2937 & TRN & \\
\hline
\end{tabular}




\begin{tabular}{|c|c|c|c|c|}
\hline & & & pplement & al $\mathrm{Ta}$ \\
\hline CHEMBL1990912 & 809255 & 6.0 & 5.0149 & TRN \\
\hline CHEMBL1991782 & 809255 & 3.1 & 3.7551 & TRN \\
\hline CHEMBL2002105 & 809255 & 5.8 & 5.0244 & TRN \\
\hline CHEMBL1983348 & 809255 & 6.7 & 6.93 & TRN \\
\hline CHEMBL1988163 & 809255 & 8.6 & 7.4503 & TRN \\
\hline CHEMBL1995592 & 809255 & 5.9 & 6.0855 & TRN \\
\hline CHEMBL2006493 & 809255 & 4.2 & 4.666 & TST \\
\hline CHEMBL1986177 & 809255 & 6.0 & 4.9846 & TRN \\
\hline CHEMBL1996923 & 809255 & 4.2 & 4.4942 & TST \\
\hline CHEMBL1983449 & 809255 & 5.2 & 5.0924 & TRN \\
\hline CHEMBL1992323 & 809255 & 4.2 & 4.5681 & TST \\
\hline CHEMBL1969735 & 809255 & 4.2 & 4.4088 & TRN \\
\hline CHEMBL 2003524 & 809255 & 5.3 & 5.6738 & TST \\
\hline CHEMBL 2002649 & 809255 & 6.6 & 6.1437 & TRN \\
\hline CHEMBL1989423 & 809255 & 5.9 & 3.8992 & TST \\
\hline CHEMBL1985367 & 809255 & 4.4 & 4.8848 & TRN \\
\hline CHEMBL437747 & 809255 & 5.6 & 5.0158 & TRN \\
\hline CHEMBL1995172 & 809255 & 6.6 & 4.4622 & TST \\
\hline CHEMBL 2001584 & 809255 & 4.4 & 4.8145 & TRN \\
\hline CHEMBL507936 & 809255 & 6.5 & 6.4737 & TRN \\
\hline CHEMBL1971227 & 809255 & 5.5 & 5.7294 & TST \\
\hline CHEMBL104264 & 809255 & 6.1 & 5.4712 & TST \\
\hline CHEMBL1994321 & 809255 & 8.6 & 8.6462 & TRN \\
\hline CHEMBL1978562 & 809255 & 6.0 & 6.3807 & TST \\
\hline CHEMBL1997129 & 809255 & 7.8 & 7.2986 & TRN \\
\hline CHEMBL1984788 & 809255 & 6.6 & 5.0605 & TRN \\
\hline CHEMBL451964 & 809255 & 4.2 & 4.3117 & TRN \\
\hline CHEMBL1974875 & 809255 & 4.1 & 4.5926 & TST \\
\hline CHEMBL1964307 & 809255 & 6.8 & 7.5353 & TRN \\
\hline CHEMBL1989471 & 809255 & 6.5 & 5.8968 & TST \\
\hline CHEMBL 2000508 & 809255 & 4.2 & 4.2953 & TRN \\
\hline CHEMBL1971694 & 809255 & 4.2 & 4.825 & TST \\
\hline CHEMBL 2001547 & 809255 & 4.2 & 4.4516 & TRN \\
\hline CHEMBL 210928 & 809255 & 4.2 & 4.2238 & TRN \\
\hline CHEMBL1978195 & 809255 & 4.4 & 5.5831 & TRN \\
\hline CHEMBL1994361 & 809255 & 4.2 & 4.4882 & TRN \\
\hline CHEMBL1986603 & 809255 & 4.2 & 4.8104 & TST \\
\hline CHEMBL 2005800 & 809255 & 8.0 & 5.9778 & TRN \\
\hline CHEMBL1972840 & 809255 & 5.7 & 5.6543 & TRN \\
\hline CHEMBL1966842 & 809255 & 5.7 & 5.8216 & TRN \\
\hline CHEMBL 2003286 & 809255 & 4.2 & 5.2029 & TRN \\
\hline CHEMBL1992306 & 809255 & 6.9 & 6.438 & TRN \\
\hline CHEMBL2001668 & 809255 & 4.2 & 4.7671 & TST \\
\hline CHEMBL1979318 & 809255 & 4.2 & 4.9682 & TRN \\
\hline CHEMBL 206382 & 809255 & 4.2 & 4.4536 & TRN \\
\hline CHEMBL127898 & 809255 & 6.8 & 4.8128 & TST \\
\hline CHEMBL519697 & 809255 & 6.7 & 5.0897 & TST \\
\hline CHEMBL1972851 & 809255 & 8.5 & 8.1498 & TRN \\
\hline
\end{tabular}




\begin{tabular}{|c|c|c|c|c|c|}
\hline \multicolumn{6}{|c|}{ Supplemental Table S2.txt } \\
\hline CHEMBL 2004934 & 809255 & 4.2 & 4.833 & TRN & \\
\hline CHEMBL1996345 & 809255 & 4.4 & 4.9052 & TST & \\
\hline CHEMBL1975128 & 809255 & 7.3 & 7.8236 & TRN & \\
\hline CHEMBL 2004025 & 809255 & 5.8 & 6.1802 & TRN & \\
\hline CHEMBL1996048 & 809255 & 4.8 & 5.3571 & TST & \\
\hline CHEMBL1970369 & 809255 & 4.2 & 4.8917 & TRN & \\
\hline CHEMBL461876 & 809255 & 4.4 & 5.5754 & TRN & \\
\hline CHEMBL1965033 & 809255 & 6.0 & 5.7913 & TRN & \\
\hline CHEMBL504950 & 809255 & 5.7 & 5.80200 & 00000000005 & TRN \\
\hline CHEMBL1997335 & 809255 & 4.4 & 5.4396 & TRN & \\
\hline CHEMBL1966425 & 809255 & 6.2 & 6.0006 & TRN & \\
\hline CHEMBL1984363 & 809255 & 6.9 & 7.6924 & TRN & \\
\hline CHEMBL1978099 & 809255 & 7.1 & 7.9825 & TRN & \\
\hline CHEMBL1968070 & 809255 & 6.0 & 6.0561 & TRN & \\
\hline CHEMBL1988608 & 809255 & 6.7 & 5.7981 & TRN & \\
\hline CHEMBL184847 & 809255 & 7.8 & 6.0811 & TRN & \\
\hline CHEMBL1971132 & 809255 & 4.4 & 4.8835 & TRN & \\
\hline CHEMBL1984367 & 809255 & 6.2 & 5.9937 & TRN & \\
\hline CHEMBL178737 & 809255 & 4.2 & 5.2128 & TST & \\
\hline CHEMBL226898 & 809255 & 5.5 & 5.8535 & TRN & \\
\hline CHEMBL1982563 & 809255 & 4.2 & 4.2931 & TRN & \\
\hline CHEMBL539474 & 809255 & 4.9 & 6.0901 & TST & \\
\hline CHEMBL575824 & 809255 & 4.2 & 4.7603 & TRN & \\
\hline CHEMBL1985523 & 809255 & 8.9 & 8.1284 & TRN & \\
\hline CHEMBL1973868 & 809255 & 4.4 & 4.6631 & TRN & \\
\hline CHEMBL1972462 & 809255 & 4.4 & 4.921 & TRN & \\
\hline CHEMBL1997759 & 809255 & 4.2 & 4.7052 & TRN & \\
\hline CHEMBL1994968 & 809255 & 5.8 & 4.6132 & TRN & \\
\hline CHEMBL1981556 & 809255 & 7.1 & 4.9967 & TST & \\
\hline CHEMBL1974803 & 809255 & 4.2 & 5.4946 & TST & \\
\hline CHEMBL1970074 & 809255 & 6.0 & 6.6907 & TRN & \\
\hline CHEMBL1968103 & 809255 & 5.2 & 4.6939 & TRN & \\
\hline CHEMBL1967620 & 809255 & 6.8 & 5.0295 & TST & \\
\hline CHEMBL1984500 & 809255 & 3.1 & 4.7011 & TRN & \\
\hline CHEMBL1986970 & 809255 & 6.1 & 6.3785 & TRN & \\
\hline CHEMBL 2005112 & 809255 & 5.3 & 5.3431 & TST & \\
\hline CHEMBL1958401 & 809255 & 5.3 & 4.9671 & TRN & \\
\hline CHEMBL206236 & 809255 & 4.2 & 4.6581 & TRN & \\
\hline CHEMBL1984044 & 809255 & 5.5 & 5.1701 & TRN & \\
\hline CHEMBL 2003456 & 809255 & 5.8 & 5.6644 & TRN & \\
\hline CHEMBL1966816 & 809255 & 5.3 & 4.665 & TRN & \\
\hline CHEMBL 2002992 & 809255 & 6.0 & 5.2128 & TRN & \\
\hline CHEMBL560813 & 809255 & 5.6 & 5.4633 & TRN & \\
\hline CHEMBL207253 & 809255 & 4.2 & 4.595 & TRN & \\
\hline CHEMBL1982700 & 809255 & 4.4 & 4.8688 & TST & \\
\hline CHEMBL1980521 & 809255 & 5.9 & 5.6912 & TRN & \\
\hline CHEMBL1968791 & 809255 & 5.3 & 5.4927 & TRN & \\
\hline CHEMBL326282 & 809255 & 4.2 & 4.6715 & TST & \\
\hline
\end{tabular}




\begin{tabular}{|c|c|c|c|c|}
\hline \multicolumn{5}{|c|}{ lemental T } \\
\hline CHEMBL 2002682 & 809255 & 5.2 & 5.3639 & TRN \\
\hline CHEMBL1977634 & 809255 & 4.4 & 4.6912 & TRN \\
\hline CHEMBL1992732 & 809255 & 4.2 & 4.595 & TST \\
\hline CHEMBL1971186 & 809255 & 6.0 & 4.5019 & TRN \\
\hline CHEMBL 2003482 & 809255 & 4.2 & 4.78 & TRN \\
\hline CHEMBL1976872 & 809255 & 4.3 & 3.6118 & TRN \\
\hline CHEMBL1984700 & 809255 & 4.2 & 4.3397 & TRN \\
\hline CHEMBL 2007151 & 809255 & 4.2 & 5.3648 & TRN \\
\hline CHEMBL 2003604 & 809255 & 8.1 & 7.9525 & TRN \\
\hline CHEMBL1972125 & 809255 & 4.2 & 4.5445 & TRN \\
\hline CHEMBL1461728 & 809255 & 4.2 & 5.0929 & TRN \\
\hline CHEMBL1999120 & 809255 & 4.2 & 4.5121 & TST \\
\hline CHEMBL1976134 & 809255 & 6.9 & 6.5208 & TRN \\
\hline CHEMBL1965131 & 809255 & 6.3 & 5.7876 & TST \\
\hline CHEMBL1995448 & 809255 & 4.2 & 5.1278 & TRN \\
\hline CHEMBL1972158 & 809255 & 7.1 & 7.1185 & TRN \\
\hline CHEMBL1981215 & 809255 & 4.4 & 4.8714 & TRN \\
\hline CHEMBL1974457 & 809255 & 5.7 & 5.9343 & TRN \\
\hline CHEMBL 2006580 & 809255 & 6.2 & 5.5176 & TRN \\
\hline CHEMBL1999414 & 809255 & 8.6 & 8.3931 & TRN \\
\hline CHEMBL1967336 & 809255 & 4.4 & 4.8404 & TRN \\
\hline CHEMBL 2001228 & 809255 & 4.4 & 6.4657 & TRN \\
\hline CHEMBL 2006581 & 809255 & 4.2 & 4.2973 & TRN \\
\hline CHEMBL 2006481 & 809255 & 4.2 & 4.8001 & TRN \\
\hline CHEMBL1979855 & 809255 & 4.2 & 4.7407 & TRN \\
\hline CHEMBL1970340 & 809255 & 5.4 & 4.5775 & TRN \\
\hline CHEMBL1967992 & 809255 & 4.4 & 4.6745 & TRN \\
\hline CHEMBL 2005186 & 809255 & 5.3 & 4.8855 & TRN \\
\hline CHEMBL1995927 & 809255 & 4.2 & 4.8669 & TST \\
\hline CHEMBL1981671 & 809255 & 4.4 & 4.9165 & TRN \\
\hline CHEMBL1975534 & 809255 & 4.2 & 5.3103 & TRN \\
\hline CHEMBL1993424 & 809255 & 7.8 & 7.3517 & TRN \\
\hline CHEMBL1966703 & 809255 & 4.2 & 4.7269 & TST \\
\hline CHEMBL 2001987 & 809255 & 4.4 & 4.5505 & TRN \\
\hline CHEMBL 243518 & 809255 & 8.3 & 8.1027 & TRN \\
\hline CHEMBL1969561 & 809255 & 6.9 & 6.8529 & TRN \\
\hline CHEMBL1994555 & 809255 & 5.7 & 5.6653 & TST \\
\hline CHEMBL1972795 & 809255 & 5.5 & 5.3387 & TRN \\
\hline CHEMBL1975121 & 809255 & 4.2 & 4.5866 & TRN \\
\hline CHEMBL1983640 & 809255 & 8.0 & 7.9028 & TRN \\
\hline CHEMBL1997023 & 809255 & 6.3 & 5.2973 & TST \\
\hline CHEMBL1964687 & 809255 & 7.5 & 7.9136 & TRN \\
\hline CHEMBL1971943 & 809255 & 6.7 & 4.643 & TRN \\
\hline CHEMBL1999918 & 809255 & 5.2 & 5.9856 & TRN \\
\hline CHEMBL1987334 & 809255 & 6.7 & 6.6878 & TRN \\
\hline CHEMBL1997924 & 809255 & 6.9 & 6.3916 & TRN \\
\hline CHEMBL1988537 & 809255 & 7.2 & 5.8188 & TST \\
\hline CHEMBL1969049 & 809255 & 4.2 & 4.8147 & TRN \\
\hline
\end{tabular}




\begin{tabular}{|c|c|c|c|c|}
\hline \multicolumn{5}{|c|}{ Supplemental Table S2.txt } \\
\hline CHEMBL2005828 & 809255 & 8.0 & 7.4814 & TRN \\
\hline CHEMBL 2002240 & 809255 & 5.7 & 4.5512 & TRN \\
\hline CHEMBL1982388 & 809255 & 7.1 & 5.3386 & TST \\
\hline CHEMBL231153 & 809255 & 6.7 & 5.7871 & TRN \\
\hline CHEMBL1978267 & 809255 & 6.5 & 6.1085 & TRN \\
\hline CHEMBL1991143 & 809255 & 5.8 & 5.4234 & TRN \\
\hline CHEMBL1998611 & 809255 & 6.0 & 5.5291 & TST \\
\hline CHEMBL485556 & 809255 & 5.9 & 4.787 & TST \\
\hline CHEMBL1975900 & 809255 & 6.0 & 5.334 & TRN \\
\hline CHEMBL 255822 & 809255 & 5.5 & 5.3242 & TRN \\
\hline CHEMBL1972221 & 809255 & 5.2 & 5.8098 & TRN \\
\hline CHEMBL 2006778 & 809255 & 6.8 & 6.6128 & TRN \\
\hline CHEMBL378627 & 809255 & 4.2 & 4.3412 & TRN \\
\hline CHEMBL1996979 & 809255 & 5.7 & 4.9355 & TRN \\
\hline CHEMBL1997025 & 809255 & 6.0 & 4.7533 & TRN \\
\hline CHEMBL1968406 & 809255 & 7.3 & 7.7658 & TRN \\
\hline CHEMBL1966411 & 809255 & 8.0 & 6.091 & TRN \\
\hline CHEMBL1975921 & 809255 & 5.3 & 5.3176 & TRN \\
\hline CHEMBL1984274 & 809255 & 4.2 & 5.0038 & TST \\
\hline CHEMBL1998545 & 809255 & 4.2 & 4.3773 & TRN \\
\hline CHEMBL1986869 & 809255 & 4.2 & 4.6893 & TRN \\
\hline CHEMBL1975923 & 809255 & 5.7 & 5.3194 & TST \\
\hline CHEMBL 2005449 & 809255 & 6.1 & 6.5044 & TRN \\
\hline CHEMBL1987998 & 809255 & 4.4 & 4.7411 & TRN \\
\hline CHEMBL1992527 & 809255 & 7.3 & 6.751 & TRN \\
\hline CHEMBL 2006010 & 809255 & 5.3 & 4.6235 & TRN \\
\hline CHEMBL1682558 & 809255 & 4.2 & 4.6955 & TRN \\
\hline CHEMBL1971534 & 809255 & 4.5 & 4.9751 & TRN \\
\hline CHEMBL1990496 & 809255 & 4.2 & 4.1114 & TRN \\
\hline CHEMBL242865 & 809255 & 6.8 & 7.5809 & TRN \\
\hline CHEMBL1997623 & 809255 & 7.2 & 7.5044 & TRN \\
\hline CHEMBL1978973 & 809255 & 6.8 & 6.2018 & TRN \\
\hline CHEMBL2002479 & 809255 & 7.0 & 6.0475 & TRN \\
\hline CHEMBL1983884 & 809255 & 3.1 & 4.9554 & TST \\
\hline CHEMBL1993166 & 809255 & 5.5 & 4.8264 & TRN \\
\hline CHEMBL1967094 & 809255 & 7.4 & 7.3686 & TRN \\
\hline CHEMBL1966035 & 809255 & 5.2 & 4.8201 & TRN \\
\hline CHEMBL2003341 & 809255 & 4.2 & 4.7373 & TRN \\
\hline CHEMBL1992645 & 809255 & 5.8 & 5.7463 & TST \\
\hline CHEMBL 2000746 & 809255 & 5.8 & 5.4904 & TRN \\
\hline CHEMBL1982992 & 809255 & 5.9 & 5.1437 & TRN \\
\hline CHEMBL1998110 & 809255 & 4.4 & 4.691 & TRN \\
\hline CHEMBL1999590 & 809255 & 4.2 & 4.6768 & TST \\
\hline CHEMBL1981079 & 809255 & 5.4 & 5.6794 & TRN \\
\hline CHEMBL1978166 & 809255 & 7.3 & 8.3799 & TRN \\
\hline CHEMBL1972276 & 809255 & 5.4 & 4.9533 & TRN \\
\hline CHEMBL1980489 & 809255 & 5.9 & 5.1833 & TRN \\
\hline CHEMBL 2000832 & 809255 & 6.2 & 6.0319 & TRN \\
\hline
\end{tabular}




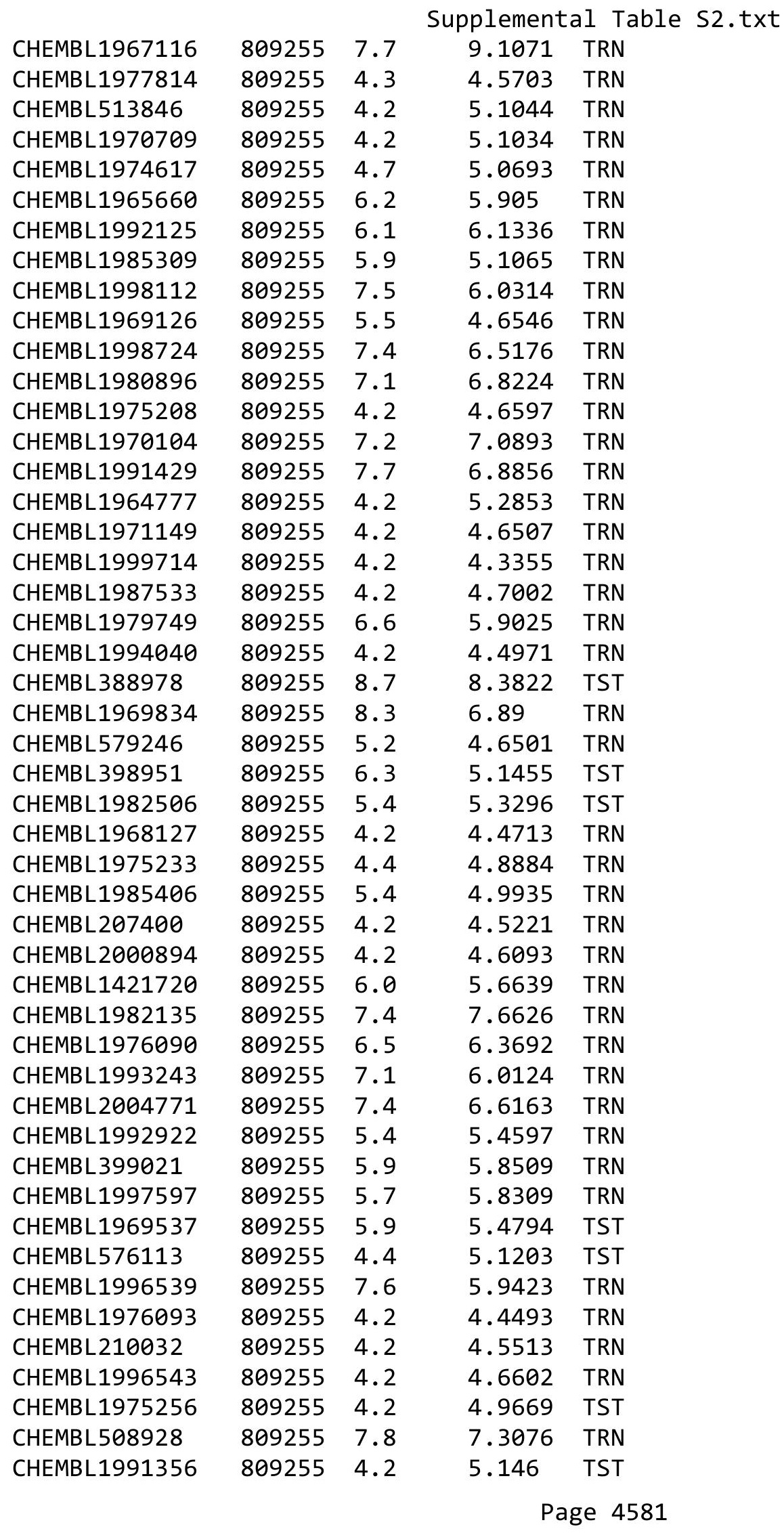




\begin{tabular}{|c|c|c|c|c|c|}
\hline \\
\hline CHEMBL1983309 & 809255 & 6.2 & 5.5271 & TRN & \\
\hline CHEMBL2004892 & 809255 & 5.9 & 5.6667 & TRN & \\
\hline CHEMBL1999126 & 809255 & 5.5 & 5.3429 & TST & \\
\hline CHEMBL1997503 & 809255 & 4.2 & 5.2125 & TST & \\
\hline CHEMBL116070 & 809255 & 4.2 & 4.8373 & TRN & \\
\hline CHEMBL1990821 & 809255 & 5.3 & 5.3738 & TRN & \\
\hline CHEMBL1970314 & 809255 & 6.2 & 5.2181 & TRN & \\
\hline CHEMBL243517 & 809255 & 8.9 & 8.2021 & TRN & \\
\hline CHEMBL 2004871 & 809255 & 5.7 & 4.5377 & TRN & \\
\hline CHEMBL2004872 & 809255 & 4.2 & 4.7156 & TRN & \\
\hline CHEMBL1727312 & 809255 & 4.2 & 3.8414 & TRN & \\
\hline CHEMBL1990223 & 809255 & 4.4 & 4.8624 & TRN & \\
\hline CHEMBL1969879 & 809255 & 5.7 & 4.8988 & TRN & \\
\hline CHEMBL1971463 & 809255 & 5.8 & 5.0644 & TST & \\
\hline CHEMBL1987658 & 809255 & 8.2 & 5.8264 & TRN & \\
\hline CHEMBL1964382 & 809255 & 6.8 & 5.29299 & 9999999999 & TST \\
\hline CHEMBL101311 & 809255 & 5.6 & 5.981 & TRN & \\
\hline CHEMBL1981720 & 809255 & 6.6 & 5.2563 & TRN & \\
\hline CHEMBL419932 & 809255 & 4.2 & 4.9766 & TRN & \\
\hline CHEMBL 262433 & 809255 & 7.8 & 7.609 & TRN & \\
\hline CHEMBL 306380 & 809255 & 5.9 & 4.9365 & TRN & \\
\hline CHEMBL1966722 & 809255 & 6.5 & 5.7978 & TST & \\
\hline CHEMBL1988581 & 809255 & 7.1 & 6.6726 & TST & \\
\hline CHEMBL 2005699 & 809255 & 4.4 & 4.5489 & TRN & \\
\hline CHEMBL1975500 & 809255 & 5.5 & 5.6141 & TRN & \\
\hline CHEMBL1976328 & 809255 & 5.7 & 6.9769 & TRN & \\
\hline CHEMBL394619 & 809255 & 7.9 & 7.994 & TRN & \\
\hline CHEMBL 2006564 & 809255 & 6.9 & 7.1816 & TRN & \\
\hline CHEMBL1964399 & 809255 & 7.3 & 7.7065 & TRN & \\
\hline CHEMBL1996831 & 809255 & 6.3 & 4.8973 & TST & \\
\hline CHEMBL411903 & 809255 & 8.4 & 8.9148 & TRN & \\
\hline CHEMBL1991008 & 809255 & 4.1 & 4.904 & TRN & \\
\hline CHEMBL1978167 & 809255 & 6.5 & 6.706 & TST & \\
\hline CHEMBL1965988 & 809255 & 8.6 & 8.6375 & TRN & \\
\hline CHEMBL418203 & 809255 & 4.3 & 5.1982 & TST & \\
\hline CHEMBL1989646 & 809255 & 6.6 & 6.4418 & TRN & \\
\hline CHEMBL1682357 & 809255 & 5.7 & 5.9977 & TRN & \\
\hline CHEMBL225519 & 809255 & 4.3 & 5.4957 & TRN & \\
\hline CHEMBL 209534 & 809255 & 4.2 & 4.3076 & TRN & \\
\hline CHEMBL1978200 & 809255 & 4.2 & 4.3901 & TRN & \\
\hline CHEMBL1970522 & 809255 & 5.5 & 5.3746 & TRN & \\
\hline CHEMBL1990415 & 809255 & 4.2 & 4.7077 & TRN & \\
\hline CHEMBL1966087 & 809255 & 4.2 & 4.5477 & TRN & \\
\hline CHEMBL1964692 & 809255 & 7.1 & 7.3666 & TRN & \\
\hline CHEMBL1996931 & 809255 & 5.8 & 4.599 & TRN & \\
\hline CHEMBL1964413 & 809255 & 4.2 & 4.9842 & TRN & \\
\hline CHEMBL1973483 & 809255 & 5.7 & 4.7592 & TRN & \\
\hline CHEMBL1984432 & 809255 & 4.2 & 5.5035 & TRN & \\
\hline
\end{tabular}




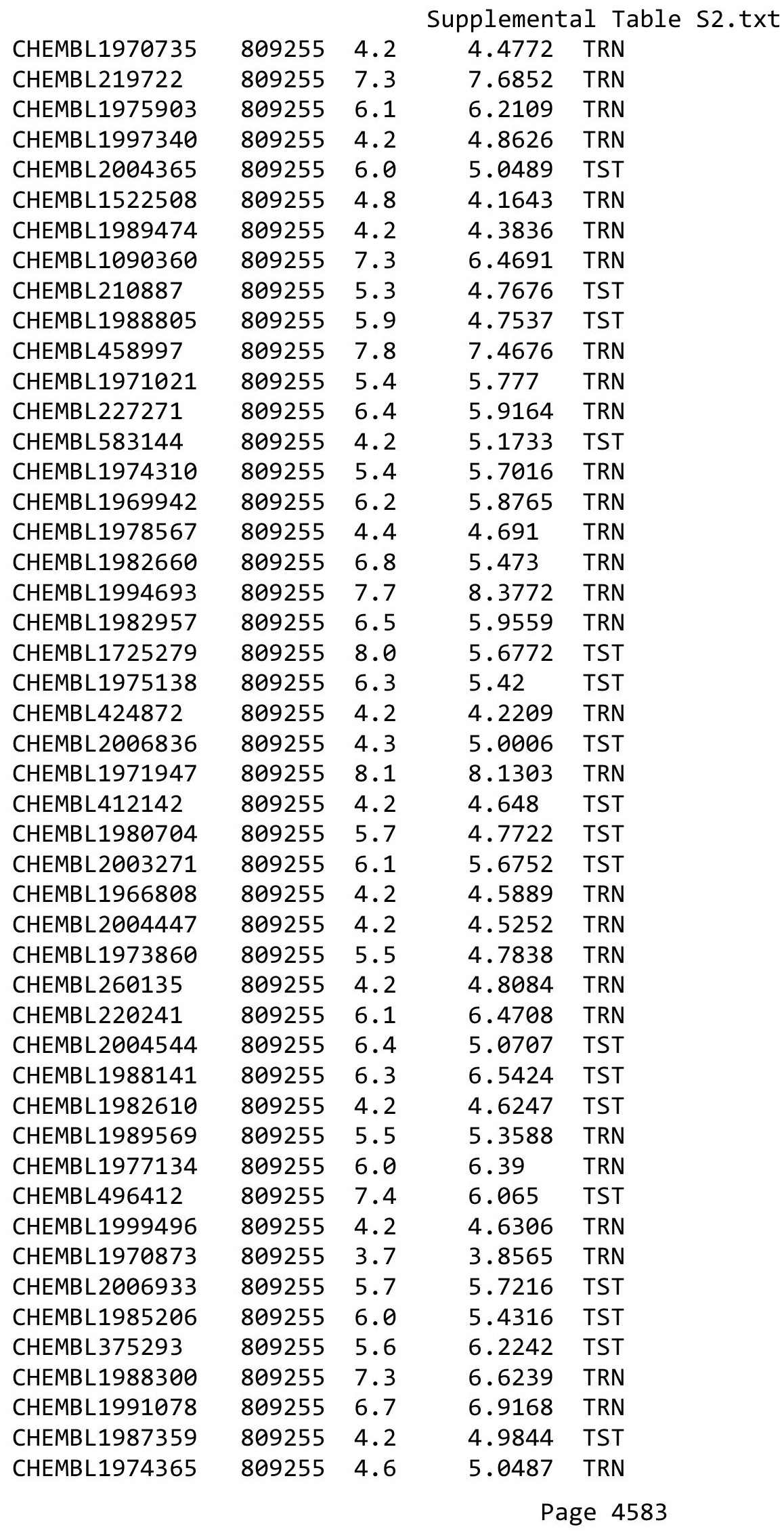




\begin{tabular}{|c|c|c|c|c|c|}
\hline \\
\hline CHEMBL1977749 & 809255 & 6.3 & 5.9694 & TST & \\
\hline CHEMBL1982837 & 809255 & 8.8 & 7.6796 & TRN & \\
\hline CHEMBL2000685 & 809255 & 6.6 & 5.5798 & TRN & \\
\hline CHEMBL2001613 & 809255 & 4.7 & 4.8666 & TRN & \\
\hline CHEMBL1997275 & 809255 & 5.9 & 5.6403 & TRN & \\
\hline CHEMBL1993904 & 809255 & 6.0 & 5.8846 & TRN & \\
\hline CHEMBL1980376 & 809255 & 5.2 & 4.2961 & TRN & \\
\hline CHEMBL1967513 & 809255 & 4.4 & 4.5523 & TRN & \\
\hline CHEMBL1985311 & 809255 & 6.9 & 7.7502 & TRN & \\
\hline CHEMBL1989265 & 809255 & 4.2 & 4.5815 & TRN & \\
\hline CHEMBL1982413 & 809255 & 5.6 & 5.25799 & 9999999999 & TST \\
\hline CHEMBL1965910 & 809255 & 5.6 & 5.7727 & TRN & \\
\hline CHEMBL1682553 & 809255 & 4.2 & 4.2563 & TRN & \\
\hline CHEMBL1971430 & 809255 & 4.2 & 4.2244 & TRN & \\
\hline CHEMBL1997764 & 809255 & 5.3 & 5.4139 & TRN & \\
\hline CHEMBL1983963 & 809255 & 7.7 & 8.246 & TRN & \\
\hline CHEMBL2000271 & 809255 & 6.9 & 6.2882 & TRN & \\
\hline CHEMBL1981792 & 809255 & 4.4 & 4.8303 & TRN & \\
\hline CHEMBL1987535 & 809255 & 4.4 & 5.3284 & TRN & \\
\hline CHEMBL1985092 & 809255 & 5.3 & 5.782 & TRN & \\
\hline CHEMBL2004692 & 809255 & 4.2 & 4.66 & TST & \\
\hline CHEMBL1981410 & 809255 & 5.4 & 7.3044 & TRN & \\
\hline CHEMBL2002586 & 809255 & 4.4 & 5.6534 & TRN & \\
\hline CHEMBL1996234 & 809255 & 6.2 & 5.17200 & 0000000001 & TRN \\
\hline CHEMBL1991434 & 809255 & 4.2 & 4.7065 & TST & \\
\hline CHEMBL1967544 & 809255 & 5.3 & 4.9253 & TRN & \\
\hline CHEMBL1973138 & 809255 & 4.4 & 4.72 & TRN & \\
\hline CHEMBL 223367 & 809255 & 4.2 & 4.1294 & TST & \\
\hline CHEMBL1992673 & 809255 & 4.8 & 4.676 & TST & \\
\hline CHEMBL 340384 & 809255 & 5.5 & 4.9921 & TRN & \\
\hline CHEMBL1969151 & 809255 & 6.1 & 6.0087 & TRN & \\
\hline CHEMBL1996587 & 809255 & 4.2 & 4.6587 & TRN & \\
\hline CHEMBL1981492 & 809255 & 4.8 & 4.2775 & TRN & \\
\hline CHEMBL1993335 & 809255 & 6.6 & 7.0858 & TST & \\
\hline CHEMBL1988692 & 809255 & 6.3 & 6.2735 & TRN & \\
\hline CHEMBL1964804 & 809255 & 5.6 & 5.1232 & TRN & \\
\hline CHEMBL443962 & 809255 & 6.5 & 6.3314 & TST & \\
\hline CHEMBL2000354 & 809255 & 5.4 & 5.4919 & TRN & \\
\hline CHEMBL 274064 & 809255 & 4.2 & 4.7412 & TRN & \\
\hline CHEMBL1998680 & 809255 & 4.4 & 4.6757 & TRN & \\
\hline CHEMBL1967564 & 809255 & 4.2 & 4.352 & TRN & \\
\hline CHEMBL592030 & 809255 & 4.7 & 5.9781 & TST & \\
\hline CHEMBL2000071 & 809255 & 6.0 & 5.9635 & TRN & \\
\hline CHEMBL1979176 & 809255 & 4.2 & 5.5435 & TRN & \\
\hline CHEMBL2000408 & 809255 & 4.2 & 4.3153 & TRN & \\
\hline CHEMBL248757 & 809255 & 5.7 & 4.4501 & TST & \\
\hline CHEMBL1978014 & 809255 & 4.2 & 4.9463 & TRN & \\
\hline CHEMBL1997007 & 809255 & 6.5 & 6.3704 & TRN & \\
\hline
\end{tabular}




\begin{tabular}{|c|c|c|c|c|c|}
\hline \multirow{3}{*}{$\begin{array}{l}\text { CHEMBL1994538 } \\
\text { CHEMBL1983195 }\end{array}$} & \multirow{3}{*}{$\begin{array}{l}809255 \\
809255\end{array}$} & \multicolumn{4}{|c|}{ Supplemental Table S2.txt } \\
\hline & & 4.2 & \multicolumn{2}{|c|}{4.718999999999999} & TRN \\
\hline & & 6.1 & 5.2374 & TST & \\
\hline CHEMBL1975490 & 809255 & 6.0 & 5.9785 & TRN & \\
\hline CHEMBL1964444 & 809255 & 6.6 & 4.6214 & TRN & \\
\hline CHEMBL 2002690 & 809255 & 4.4 & 5.6431 & TRN & \\
\hline CHEMBL 2006567 & 809255 & 5.2 & 4.4201 & TRN & \\
\hline CHEMBL1986139 & 809255 & 5.6 & 5.1911 & TRN & \\
\hline CHEMBL1980540 & 809255 & 4.2 & 4.8565 & TRN & \\
\hline CHEMBL 278041 & 809255 & 4.4 & 4.3619 & TRN & \\
\hline CHEMBL1984162 & 809255 & 8.4 & 8.2742 & TRN & \\
\hline CHEMBL1997051 & 809255 & 5.9 & 5.9258 & TRN & \\
\hline CHEMBL491758 & 809255 & 8.0 & 7.8752 & TRN & \\
\hline CHEMBL1618860 & 809255 & 6.6 & 5.6622 & TST & \\
\hline CHEMBL1986590 & 809255 & 7.1 & 5.6821 & TRN & \\
\hline CHEMBL549730 & 809255 & 4.2 & 5.0494 & TRN & \\
\hline CHEMBL1682360 & 809255 & 4.2 & 5.2605 & TRN & \\
\hline CHEMBL1970189 & 809255 & 4.2 & 4.5871 & TRN & \\
\hline CHEMBL1996791 & 809255 & 5.9 & 5.6099 & TRN & \\
\hline CHEMBL 371206 & 809255 & 8.2 & 8.2148 & TRN & \\
\hline CHEMBL1974664 & 809255 & 7.1 & 4.7136 & TST & \\
\hline CHEMBL406845 & 809255 & 4.4 & 4.7797 & TRN & \\
\hline CHEMBL482538 & 809255 & 5.2 & 4.8303 & TRN & \\
\hline CHEMBL1974288 & 809255 & 4.2 & 4.6254 & TRN & \\
\hline CHEMBL1984296 & 809255 & 5.5 & 5.5398 & TST & \\
\hline CHEMBL196363 & 809255 & 7.6 & 8.5398 & TRN & \\
\hline CHEMBL1190711 & 809255 & 6.6 & 5.6102 & TRN & \\
\hline CHEMBL1990346 & 809255 & 5.9 & 5.6826 & TRN & \\
\hline CHEMBL1964718 & 809255 & 4.1 & 4.5089 & TST & \\
\hline CHEMBL1968705 & 809255 & 6.0 & 5.4122 & TRN & \\
\hline CHEMBL1964441 & 809255 & 8.1 & 8.298 & TRN & \\
\hline CHEMBL546797 & 809255 & 5.6 & 5.6284 & TRN & \\
\hline CHEMBL404367 & 809255 & 6.5 & 7.523 & TRN & \\
\hline CHEMBL1966343 & 809255 & 5.8 & 6.074 & TRN & \\
\hline CHEMBL1967887 & 809255 & 5.4 & 5.0162 & TRN & \\
\hline CHEMBL 2007266 & 809255 & 6.6 & 6.3894 & TRN & \\
\hline CHEMBL 2000568 & 809255 & 6.3 & 5.6777 & TRN & \\
\hline CHEMBL1994308 & 809255 & 4.4 & 5.3836 & TRN & \\
\hline CHEMBL1977604 & 809255 & 4.2 & 4.7009 & TRN & \\
\hline CHEMBL 2007097 & 809255 & 4.2 & 4.6334 & TRN & \\
\hline CHEMBL1988717 & 809255 & 6.9 & 7.0583 & TRN & \\
\hline CHEMBL1974328 & 809255 & 4.7 & 5.9072 & TRN & \\
\hline CHEMBL509032 & 809255 & 6.8 & 7.5028 & TRN & \\
\hline CHEMBL143703 & 809255 & 4.1 & 4.0304 & TRN & \\
\hline CHEMBL1979528 & 809255 & 7.8 & 7.6466 & TRN & \\
\hline CHEMBL1973808 & 809255 & 4.2 & 4.7457 & TRN & \\
\hline CHEMBL 2000429 & 809255 & 4.2 & 4.5172 & TRN & \\
\hline CHEMBL1992555 & 809255 & 4.2 & 5.1342 & TST & \\
\hline CHEMBL1992342 & 809255 & 6.5 & 6.0814 & TRN & \\
\hline
\end{tabular}




\begin{tabular}{|c|c|c|c|c|}
\hline & & & ipplement & al Table S \\
\hline CHEMBL2001535 & 809255 & 8.0 & 7.0259 & TRN \\
\hline CHEMBL1988173 & 809255 & 6.4 & 6.21899 & 9999999999 \\
\hline CHEMBL1973013 & 809255 & 5.8 & 6.056 & TRN \\
\hline CHEMBL1164265 & 809255 & 5.8 & 5.8592 & TST \\
\hline CHEMBL535331 & 809255 & 5.7 & 5.3558 & TRN \\
\hline CHEMBL1989805 & 809255 & 6.6 & 4.717 & TST \\
\hline CHEMBL1982980 & 809255 & 5.2 & 5.3228 & TRN \\
\hline CHEMBL1965423 & 809255 & 4.2 & 4.5805 & TRN \\
\hline CHEMBL1993073 & 809255 & 8.0 & 7.6584 & TRN \\
\hline CHEMBL1983025 & 809255 & 7.8 & 8.1932 & TRN \\
\hline CHEMBL1975927 & 809255 & 5.5 & 6.8693 & TRN \\
\hline CHEMBL 205415 & 809255 & 4.5 & 4.7711 & TRN \\
\hline CHEMBL1977135 & 809255 & 4.2 & 4.6113 & TRN \\
\hline CHEMBL 2001920 & 809255 & 5.6 & 5.8664 & TRN \\
\hline CHEMBL2002322 & 809255 & 4.2 & 4.9017 & TRN \\
\hline CHEMBL1997119 & 809255 & 4.3 & 4.4656 & TST \\
\hline CHEMBL2002323 & 809255 & 4.2 & 4.3017 & TST \\
\hline CHEMBL1241473 & 809255 & 8.2 & 7.152 & TRN \\
\hline CHEMBL1978448 & 809255 & 4.9 & 5.513 & TST \\
\hline CHEMBL1972258 & 809255 & 4.2 & 4.4972 & TRN \\
\hline CHEMBL1969483 & 809255 & 5.9 & 5.7851 & TRN \\
\hline CHEMBL1980329 & 809255 & 7.7 & 6.5826 & TRN \\
\hline CHEMBL2004515 & 809255 & 4.7 & 5.6909 & TRN \\
\hline CHEMBL2001257 & 809255 & 8.0 & 8.0016 & TRN \\
\hline CHEMBL1968271 & 809255 & 7.7 & 5.7215 & TRN \\
\hline CHEMBL1992042 & 809255 & 6.0 & 5.7693 & TRN \\
\hline CHEMBL 2005548 & 809255 & 4.2 & 4.785 & TRN \\
\hline CHEMBL1987793 & 809255 & 4.2 & 5.2384 & TRN \\
\hline CHEMBL1992536 & 809255 & 4.2 & 4.9337 & TRN \\
\hline CHEMBL21156 & 809255 & 7.3 & 5.4951 & TST \\
\hline CHEMBL1992740 & 809255 & 4.2 & 4.4193 & TRN \\
\hline CHEMBL1994724 & 809255 & 6.4 & 5.2048 & TRN \\
\hline CHEMBL1989267 & 809255 & 7.4 & 6.1872 & TRN \\
\hline CHEMBL1964519 & 809255 & 8.3 & 8.012 & TRN \\
\hline CHEMBL 2002373 & 809255 & 4.2 & 4.5249 & TRN \\
\hline CHEMBL439340 & 809255 & 4.2 & 4.4861 & TRN \\
\hline CHEMBL 2003871 & 809255 & 5.6 & 5.0688 & TST \\
\hline CHEMBL1974574 & 809255 & 4.4 & 5.2877 & TST \\
\hline CHEMBL2006188 & 809255 & 4.2 & 4.7724 & TRN \\
\hline CHEMBL1970913 & 809255 & 4.2 & 4.425 & TRN \\
\hline CHEMBL1973893 & 809255 & 5.6 & 5.976 & TRN \\
\hline CHEMBL1995736 & 809255 & 5.3 & 4.9744 & TRN \\
\hline CHEMBL1997534 & 809255 & 6.7 & 5.3675 & TRN \\
\hline CHEMBL1993877 & 809255 & 5.7 & 5.6837 & TRN \\
\hline CHEMBL1996500 & 809255 & 4.3 & 4.4217 & TRN \\
\hline CHEMBL1985095 & 809255 & 5.4 & 6.5546 & TST \\
\hline CHEMBL1998551 & 809255 & 4.2 & 4.54 & TRN \\
\hline CHEMBL1977374 & 809255 & 4.2 & 4.5249 & TRN \\
\hline
\end{tabular}




\begin{tabular}{|c|c|c|c|c|c|}
\hline & & & & & \\
\hline CHEMBL1973363 & 809255 & 5.5 & 5.6517 & TRN & \\
\hline CHEMBL1991180 & 809255 & 5.7 & 6.3328 & TST & \\
\hline CHEMBL1682540 & 809255 & 4.2 & 4.6861 & TRN & \\
\hline CHEMBL1978656 & 809255 & 4.2 & 4.398 & TRN & \\
\hline CHEMBL1976420 & 809255 & 4.8 & 5.7948 & TST & \\
\hline CHEMBL1998253 & 809255 & 4.4 & 4.7761 & TST & \\
\hline CHEMBL413779 & 809255 & 4.2 & 4.6528 & TST & \\
\hline CHEMBL1981744 & 809255 & 4.4 & 4.7071 & TRN & \\
\hline CHEMBL1994864 & 809255 & 5.5 & 5.1206 & TRN & \\
\hline CHEMBL 2002446 & 809255 & 5.9 & 6.0079 & TST & \\
\hline CHEMBL497151 & 809255 & 5.6 & 6.1343 & TRN & \\
\hline CHEMBL 2000029 & 809255 & 5.8 & 6.5765 & TRN & \\
\hline CHEMBL1973961 & 809255 & 4.5 & 5.46899 & 9999999999 & TRN \\
\hline CHEMBL 2001099 & 809255 & 7.7 & 6.0587 & TRN & \\
\hline CHEMBL 246970 & 809255 & 5.6 & 4.5718 & TRN & \\
\hline CHEMBL340921 & 809255 & 4.2 & 4.1771 & TRN & \\
\hline CHEMBL373598 & 809255 & 4.2 & 3.984 & TST & \\
\hline CHEMBL2001149 & 809255 & 5.6 & 5.2431 & TRN & \\
\hline CHEMBL1999718 & 809255 & 4.2 & 4.6655 & TRN & \\
\hline CHEMBL 2000078 & 809255 & 5.9 & 6.171 & TRN & \\
\hline CHEMBL 2005478 & 809255 & 6.2 & 6.6351 & TST & \\
\hline CHEMBL1276446 & 809255 & 8.4 & 7.853 & TST & \\
\hline CHEMBL1996646 & 809255 & 7.7 & 6.7864 & TRN & \\
\hline CHEMBL1979773 & 809255 & 6.1 & 4.915 & TRN & \\
\hline CHEMBL1977346 & 809255 & 5.8 & 6.206 & TRN & \\
\hline CHEMBL 2003657 & 809255 & 5.2 & 4.7175 & TRN & \\
\hline CHEMBL1971649 & 809255 & 6.3 & 6.0925 & TRN & \\
\hline CHEMBL1992723 & 809255 & 4.2 & 3.8964 & TST & \\
\hline CHEMBL 2005482 & 809255 & 4.4 & 6.3605 & TRN & \\
\hline CHEMBL1996702 & 809255 & 5.6 & 5.70299 & 9999999999 & TRN \\
\hline CHEMBL1997909 & 809255 & 4.4 & 6.1843 & TRN & \\
\hline CHEMBL 2007124 & 809255 & 5.5 & 5.8715 & TRN & \\
\hline CHEMBL1998435 & 809255 & 4.2 & 4.6659 & TRN & \\
\hline CHEMBL1995068 & 809255 & 7.9 & 7.9747 & TRN & \\
\hline CHEMBL 2006439 & 809255 & 4.2 & 5.9443 & TRN & \\
\hline CHEMBL 2006156 & 809255 & 6.0 & 5.5588 & TST & \\
\hline CHEMBL1985681 & 809255 & 6.3 & 5.8356 & TST & \\
\hline CHEMBL1969190 & 809255 & 8.5 & 7.8195 & TRN & \\
\hline CHEMBL1973937 & 809255 & 7.2 & 7.6514 & TRN & \\
\hline CHEMBL1991674 & 809255 & 6.5 & 5.847 & TRN & \\
\hline CHEMBL1982711 & 809255 & 6.3 & 5.9896 & TRN & \\
\hline CHEMBL 262623 & 809255 & 5.8 & 5.6837 & TRN & \\
\hline CHEMBL1987982 & 809255 & 4.2 & 5.2844 & TST & \\
\hline CHEMBL1984842 & 809255 & 4.3 & 4.2091 & TRN & \\
\hline CHEMBL 2004118 & 809255 & 6.1 & 6.5341 & TRN & \\
\hline CHEMBL1682346 & 809255 & 6.6 & 6.8557 & TRN & \\
\hline CHEMBL1996795 & 809255 & 5.7 & 5.3503 & TST & \\
\hline CHEMBL2007044 & 809255 & 6.4 & 4.6546 & TST & \\
\hline & & & & 4587 & \\
\hline
\end{tabular}




\begin{tabular}{|c|c|c|c|c|c|}
\hline \multicolumn{6}{|c|}{ plemental lable s2 } \\
\hline CHEMBL2001998 & 809255 & 7.3 & 5.7733 & TST & \\
\hline CHEMBL1994241 & 809255 & 6.0 & 6.11799 & 9999999999 & TRN \\
\hline CHEMBL223460 & 809255 & 4.2 & 4.0991 & TST & \\
\hline CHEMBL1998829 & 809255 & 4.2 & 5.2414 & TRN & \\
\hline CHEMBL50894 & 809255 & 4.7 & 5.291 & TRN & \\
\hline CHEMBL1988838 & 809255 & 7.7 & 7.9563 & TRN & \\
\hline CHEMBL1981725 & 809255 & 8.2 & 7.4697 & TRN & \\
\hline CHEMBL375284 & 809255 & 6.5 & 6.8286 & TST & \\
\hline CHEMBL 2006299 & 809255 & 4.4 & 4.6895 & TST & \\
\hline CHEMBL1965169 & 809255 & 6.1 & 5.511 & TST & \\
\hline CHEMBL1991818 & 809255 & 4.4 & 5.4536 & TST & \\
\hline CHEMBL1081312 & 809255 & 4.4 & 6.1013 & TST & \\
\hline CHEMBL1965170 & 809255 & 9.0 & 8.1037 & TST & \\
\hline CHEMBL1982866 & 809255 & 4.2 & 4.3803 & TST & \\
\hline CHEMBL2005792 & 809255 & 4.3 & 4.2094 & TST & \\
\hline CHEMBL1968926 & 809255 & 5.5 & 4.7276 & TST & \\
\hline CHEMBL1984206 & 809255 & 4.2 & 4.1849 & TST & \\
\hline CHEMBL462120 & 809255 & 4.2 & 4.4283 & TST & \\
\hline CHEMBL1991577 & 809255 & 5.2 & 4.6025 & TST & \\
\hline CHEMBL1991867 & 809255 & 4.3 & 4.7922 & TST & \\
\hline CHEMBL1986503 & 809255 & 4.4 & 4.6713 & TST & \\
\hline CHEMBL 2007592 & 809255 & 4.2 & 4.6293 & TST & \\
\hline CHEMBL1972355 & 809255 & 6.1 & 6.2657 & TST & \\
\hline CHEMBL1997892 & 809255 & 4.4 & 5.4914 & TST & \\
\hline CHEMBL2001641 & 809255 & 4.5 & 4.7825 & TST & \\
\hline CHEMBL1997193 & 809255 & 6.1 & 6.0148 & TST & \\
\hline CHEMBL 210963 & 809255 & 4.2 & 4.245 & TST & \\
\hline CHEMBL1964902 & 809255 & 4.4 & 4.6249 & TST & \\
\hline CHEMBL1082440 & 809255 & 7.4 & 6.1211 & TST & \\
\hline CHEMBL1614705 & 809255 & 4.2 & 4.323 & TST & \\
\hline CHEMBL1972362 & 809255 & 6.4 & 5.7318 & TST & \\
\hline CHEMBL 2003948 & 809255 & 7.1 & 5.6842 & TST & \\
\hline CHEMBL1984633 & 809255 & 5.5 & 4.9319 & TST & \\
\hline CHEMBL1965845 & 809255 & 7.5 & 7.0285 & TST & \\
\hline CHEMBL 2007372 & 809255 & 4.2 & 4.3864 & TST & \\
\hline CHEMBL1998228 & 809255 & 4.6 & 4.7376 & TST & \\
\hline CHEMBL1983715 & 809255 & 7.6 & 7.584 & TST & \\
\hline CHEMBL1982167 & 809255 & 4.2 & 4.476 & TST & \\
\hline CHEMBL1971017 & 809255 & 5.7 & 5.9933 & TST & \\
\hline CHEMBL 2006715 & 809255 & 8.4 & 6.8242 & TST & \\
\hline CHEMBL1986597 & 809255 & 6.4 & 5.9669 & TST & \\
\hline CHEMBL1990482 & 809255 & 5.7 & 4.8823 & TST & \\
\hline CHEMBL1990904 & 809255 & 4.2 & 4.2221 & TST & \\
\hline CHEMBL 2000104 & 809255 & 4.2 & 6.0085 & TST & \\
\hline CHEMBL 2005475 & 809255 & 7.3 & 6.6878 & TST & \\
\hline CHEMBL402846 & 809255 & 6.4 & 7.2963 & TST & \\
\hline CHEMBL1997349 & 809255 & 6.3 & 5.2779 & TST & \\
\hline CHEMBL183844 & 809255 & 6.9 & 6.2094 & TST & \\
\hline
\end{tabular}




\begin{tabular}{|c|c|c|c|c|}
\hline \multicolumn{5}{|c|}{ Supplemental Table S2.txt } \\
\hline CHEMBL220057 & 809255 & 7.2 & 7.9742 & TST \\
\hline CHEMBL1682545 & 809255 & 4.2 & 5.2689 & TST \\
\hline CHEMBL1992195 & 809255 & 9.1 & 5.7758 & TST \\
\hline CHEMBL 383541 & 809255 & 4.2 & 4.769 & TST \\
\hline CHEMBL 2001224 & 809255 & 4.2 & 4.5481 & TST \\
\hline CHEMBL10 & 809255 & 4.3 & 3.9839 & TST \\
\hline CHEMBL1976732 & 809255 & 4.2 & 4.4198 & TST \\
\hline CHEMBL1969506 & 809255 & 5.3 & 4.7884 & TST \\
\hline CHEMBL1980763 & 809255 & 5.8 & 6.6024 & TST \\
\hline CHEMBL1964937 & 809255 & 6.1 & 5.6427 & TST \\
\hline CHEMBL 243297 & 809255 & 8.7 & 7.8854 & TST \\
\hline CHEMBL1980163 & 809255 & 6.3 & 4.8201 & TST \\
\hline CHEMBL590109 & 809255 & 6.1 & 6.1306 & TST \\
\hline CHEMBL42900 & 212895 & 3.8894 & 3.9379 & TRN \\
\hline CHEMBL306622 & 212895 & 2.0 & 3.6499 & TRN \\
\hline CHEMBL310412 & 212895 & 3.8069 & 3.799 & TRN \\
\hline CHEMBL75972 & 212895 & 4.5376 & 4.8552 & TRN \\
\hline CHEMBL 80930 & 212895 & 3.8794 & 3.9379 & TRN \\
\hline CHEMBL 307427 & 212895 & 4.2676 & 4.8816 & TRN \\
\hline CHEMBL306258 & 212895 & 3.8069 & 3.735 & TRN \\
\hline CHEMBL75750 & 212895 & 4.7696 & 4.7916 & TRN \\
\hline CHEMBL 76424 & 212895 & 3.767 & 3.3348 & TST \\
\hline CHEMBL298256 & 212895 & 4.6021 & 3.9029 & TRN \\
\hline CHEMBL77949 & 212895 & 2.0 & 3.4197 & TST \\
\hline CHEMBL431969 & 212895 & 3.6596 & 3.4334 & TRN \\
\hline CHEMBL75635 & 212895 & 3.3516 & 3.2947 & TST \\
\hline CHEMBL308764 & 212895 & 3.1226 & 3.0538 & TST \\
\hline CHEMBL263557 & 212895 & 3.767 & 3.8143 & TRN \\
\hline CHEMBL75624 & 212895 & 2.0 & 3.0241 & TST \\
\hline CHEMBL 77074 & 212895 & 3.7825 & 3.7382 & TRN \\
\hline CHEMBL 77183 & 212895 & 2.0 & 3.0538 & TST \\
\hline CHEMBL307597 & 212895 & 2.0 & 2.8692 & TRN \\
\hline CHEMBL448786 & 212895 & 4.6778 & 3.5562 & TRN \\
\hline CHEMBL43463 & 212895 & 4.3565 & 3.3809 & TRN \\
\hline CHEMBL 76967 & 212895 & 3.8013 & 3.6441 & TRN \\
\hline CHEMBL308632 & 212895 & 4.5528 & 4.4397 & TRN \\
\hline CHEMBL311043 & 212895 & 3.9172 & 3.8898 & TRN \\
\hline CHEMBL263454 & 212895 & 2.0 & 3.2207 & TST \\
\hline CHEMBL 80502 & 212895 & 3.8416 & 3.8143 & TRN \\
\hline CHEMBL 309830 & 212895 & 4.0862 & 3.8637 & TRN \\
\hline CHEMBL 308074 & 212895 & 5.3979 & 4.577 & TRN \\
\hline CHEMBL 307374 & 212895 & 2.0 & 3.0247 & TST \\
\hline CHEMBL 308630 & 212895 & 3.5817 & 3.93 & TRN \\
\hline CHEMBL 307927 & 212895 & 2.0 & 3.0538 & TST \\
\hline CHEMBL76070 & 212895 & 2.0 & 2.9829 & TST \\
\hline CHEMBL307479 & 212895 & 2.0 & 3.2095 & TRN \\
\hline CHEMBL 306620 & 212895 & 4.8239 & 4.5657 & TRN \\
\hline CHEMBL312023 & 212895 & 4.0223 & 3.1495 & TST \\
\hline
\end{tabular}




\begin{tabular}{|c|c|c|c|c|}
\hline \multicolumn{5}{|c|}{ Supplemental Table S2.txt } \\
\hline CHEMBL432172 & 212895 & 4.699 & 4.8988 & TRN \\
\hline CHEMBL311655 & 212895 & 4.4685 & 4.8552 & TRN \\
\hline CHEMBL310760 & 212895 & 4.1805 & 3.5144 & TRN \\
\hline CHEMBL 75679 & 212895 & 2.0 & 2.9167 & TRN \\
\hline CHEMBL77007 & 212895 & 4.8239 & 4.6206 & TRN \\
\hline CHEMBL 77326 & 212895 & 2.0 & 2.9888 & TST \\
\hline CHEMBL 77998 & 212895 & 4.0969 & 3.8724 & TRN \\
\hline CHEMBL307637 & 212895 & 3.8601 & 3.8811 & TRN \\
\hline CHEMBL311482 & 212895 & 4.9586 & 3.7089 & TRN \\
\hline CHEMBL78173 & 212895 & 3.8297 & 3.9706 & TRN \\
\hline CHEMBL 78283 & 212895 & 4.7696 & 4.8957 & TRN \\
\hline CHEMBL 77361 & 212895 & 3.9586 & 3.8224 & TRN \\
\hline CHEMBL406737 & 212895 & 3.8996 & 3.8354 & TRN \\
\hline CHEMBL46809 & 212895 & 4.4089 & 4.0066 & TRN \\
\hline CHEMBL309395 & 212895 & 2.0 & 3.0464 & TST \\
\hline CHEMBL 79655 & 212895 & 3.7399 & 4.005 & TRN \\
\hline CHEMBL77043 & 212895 & 3.0706 & 3.3678 & TST \\
\hline CHEMBL 263244 & 212895 & 3.8827 & 3.6142 & TRN \\
\hline CHEMBL 80878 & 212895 & 3.8996 & 3.9191 & TRN \\
\hline CHEMBL 76883 & 212895 & 4.699 & 4.8552 & TRN \\
\hline CHEMBL 76796 & 212895 & 4.284 & 4.8552 & TRN \\
\hline CHEMBL312463 & 212895 & 3.9547 & 3.9495 & TST \\
\hline CHEMBL3137559 & 1301374 & 6.9108 & 6.2836 & TRN \\
\hline CHEMBL 3137624 & 1301374 & 6.3158 & 6.4971 & TRN \\
\hline CHEMBL 3137647 & 1301374 & 5.1726 & 5.3991 & TRN \\
\hline CHEMBL 3137588 & 1301374 & 5.0 & 4.6156 & TRN \\
\hline CHEMBL3137664 & 1301374 & 5.7395 & 5.7478 & TRN \\
\hline CHEMBL3137628 & 1301374 & 5.0 & 6.6486 & TRN \\
\hline CHEMBL3137617 & 1301374 & 5.4271 & 5.9374 & TRN \\
\hline CHEMBL 3137572 & 1301374 & 5.0773 & 4.5116 & TST \\
\hline CHEMBL 3137570 & 1301374 & 6.7959 & 6.3352 & TRN \\
\hline CHEMBL3137598 & 1301374 & 5.1637 & 6.5058 & TRN \\
\hline CHEMBL3137639 & 1301374 & 7.614 & 7.0749 & TRN \\
\hline CHEMBL 3137567 & 1301374 & 5.0 & 6.1331 & TST \\
\hline CHEMBL 3137577 & 1301374 & 5.0 & 4.3184 & TST \\
\hline CHEMBL3137564 & 1301374 & 6.0761 & 6.1489 & TRN \\
\hline CHEMBL3137625 & 1301374 & 7.7778 & 7.2227 & TRN \\
\hline CHEMBL3137606 & 1301374 & 5.0 & 5.2724 & TRN \\
\hline CHEMBL3137549 & 1301374 & 6.2622 & 5.9655 & TRN \\
\hline CHEMBL3137556 & 1301374 & 6.9948 & 5.9555 & TRN \\
\hline CHEMBL3137586 & 1301374 & 5.58 & 6.1452 & TST \\
\hline CHEMBL 3137566 & 1301374 & 6.2928 & 5.8263 & TRN \\
\hline CHEMBL3137582 & 1301374 & 6.4202 & 5.7226 & TRN \\
\hline CHEMBL 3137554 & 1301374 & 5.7778 & 5.8381 & TRN \\
\hline CHEMBL3137569 & 1301374 & 5.3969 & 6.1387 & TRN \\
\hline CHEMBL 3137563 & 1301374 & 5.1688 & 6.1202 & TRN \\
\hline CHEMBL3137605 & 1301374 & 5.0 & 6.1506 & TST \\
\hline CHEMBL3137632 & 1301374 & 5.0 & 5.4217 & TRN \\
\hline
\end{tabular}




\begin{tabular}{|c|c|c|c|c|c|}
\hline \multicolumn{6}{|c|}{ Supplemental Table s2.txt } \\
\hline CHEMBL3137568 & 1301374 & 5.0 & 5.403 & TST & \\
\hline CHEMBL 3137640 & 1301374 & 5.0 & 6.0888 & TST & \\
\hline CHEMBL3137636 & 1301374 & 6.8526 & 6.3897 & TRN & \\
\hline CHEMBL 3137575 & 1301374 & 6.6021 & 5.8734 & TRN & \\
\hline CHEMBL3137656 & 1301374 & 5.0 & 6.0116 & TST & \\
\hline CHEMBL 3137578 & 1301374 & 5.0 & 5.7485 & TST & \\
\hline CHEMBL 3137645 & 1301374 & 6.5552 & 6.5466 & TRN & \\
\hline CHEMBL3137646 & 1301374 & 6.2444 & 6.3072 & TRN & \\
\hline CHEMBL 3137585 & 1301374 & 5.3045 & 5.3525 & TRN & \\
\hline CHEMBL3137652 & 1301374 & 5.0 & 5.5896 & TRN & \\
\hline CHEMBL 3137622 & 1301374 & 6.0809 & 6.4517 & TST & \\
\hline CHEMBL 3137618 & 1301374 & 6.1871 & 6.0891 & TRN & \\
\hline CHEMBL3137600 & 1301374 & 5.4486 & 5.1743 & TRN & \\
\hline CHEMBL 3137597 & 1301374 & 6.3279 & 6.5276 & TST & \\
\hline CHEMBL3137615 & 1301374 & 6.9586 & 6.2043 & TST & \\
\hline CHEMBL3137589 & 1301374 & 5.0 & 5.0085 & TRN & \\
\hline CHEMBL3137657 & 1301374 & 5.0 & 6.2476 & TST & \\
\hline CHEMBL3137601 & 1301374 & 5.9747 & 5.83700 & 0000000001 & TRN \\
\hline CHEMBL3137565 & 1301374 & 6.761 & 6.2129 & TRN & \\
\hline CHEMBL3137621 & 1301374 & 5.6882 & 6.6181 & TST & \\
\hline CHEMBL3137662 & 1301374 & 5.7881 & 6.1572 & TRN & \\
\hline CHEMBL 3137610 & 1301374 & 6.7447 & 6.0699 & TRN & \\
\hline CHEMBL 3137633 & 1301374 & 5.0161 & 5.4386 & TRN & \\
\hline CHEMBL3137619 & 1301374 & 6.4949 & 6.3236 & TRN & \\
\hline CHEMBL3137552 & 1301374 & 5.2074 & 5.5769 & TRN & \\
\hline CHEMBL3137584 & 1301374 & 6.0706 & 6.1852 & TST & \\
\hline CHEMBL 3137573 & 1301374 & 6.3665 & 5.7825 & TRN & \\
\hline CHEMBL3137595 & 1301374 & 5.0 & 5.4423 & TRN & \\
\hline CHEMBL3137607 & 1301374 & 5.0 & 5.1853 & TRN & \\
\hline CHEMBL3137644 & 1301374 & 6.2238 & 6.521 & TRN & \\
\hline CHEMBL3137635 & 1301374 & 6.5815 & 6.647 & TST & \\
\hline CHEMBL3137665 & 1301374 & 5.0 & 5.4816 & TRN & \\
\hline CHEMBL3137653 & 1301374 & 5.0 & 6.1426 & TST & \\
\hline CHEMBL3137571 & 1301374 & 5.0 & 5.311 & TRN & \\
\hline CHEMBL3137551 & 1301374 & 5.0 & 6.3062 & TRN & \\
\hline CHEMBL3137627 & 1301374 & 5.0 & 5.8715 & TRN & \\
\hline CHEMBL3137609 & 1301374 & 5.1599 & 6.4865 & TST & \\
\hline CHEMBL3137583 & 1301374 & 5.0 & 4.9364 & TRN & \\
\hline CHEMBL3137580 & 1301374 & 5.0 & 5.1808 & TRN & \\
\hline CHEMBL3137650 & 1301374 & 6.4787 & 5.778 & TRN & \\
\hline CHEMBL3137623 & 1301374 & 7.3558 & 7.1957 & TRN & \\
\hline CHEMBL3137579 & 1301374 & 5.0 & 4.2896 & TST & \\
\hline CHEMBL3137611 & 1301374 & 6.5528 & 5.9452 & TRN & \\
\hline CHEMBL3137649 & 1301374 & 5.0 & 5.88399 & 99999999995 & TST \\
\hline CHEMBL3137599 & 1301374 & 5.0 & 5.5586 & TRN & \\
\hline CHEMBL3137561 & 1301374 & 7.1847 & 6.7307 & TRN & \\
\hline CHEMBL3137626 & 1301374 & 6.9404 & 5.9882 & TRN & \\
\hline CHEMBL3137604 & 1301374 & 5.0575 & 4.6419 & TST & \\
\hline
\end{tabular}


Supplemental Table S2.txt

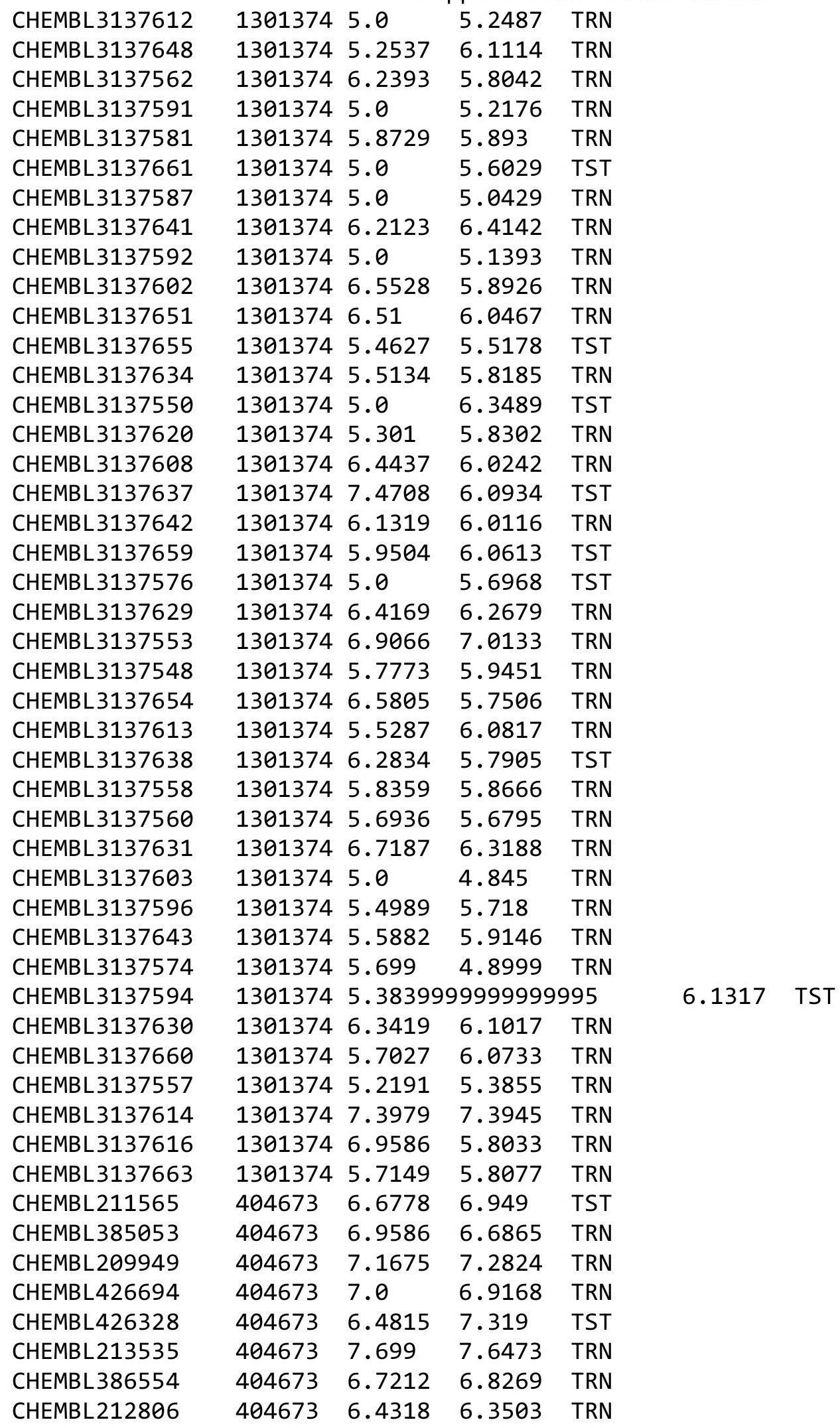

Page 4592 


\begin{tabular}{|c|c|c|c|c|c|}
\hline & & \multicolumn{4}{|c|}{ Supplemental Table s2.txt } \\
\hline CHEMBL213794 & 404673 & 7.9586 & 8.1389 & TRN & \\
\hline CHEMBL378322 & 404673 & 7.1612 & 7.0773 & TRN & \\
\hline CHEMBL386498 & 404673 & 7.3098 & 7.1506 & TRN & \\
\hline CHEMBL 386781 & 404673 & 7.585 & 7.836 & TRN & \\
\hline CHEMBL214196 & 404673 & 5.3768 & 5.5568 & TST & \\
\hline CHEMBL 378755 & 404673 & 7.0506 & 7.5379 & TST & \\
\hline CHEMBL 214060 & 404673 & 6.699 & 6.7144 & TRN & \\
\hline CHEMBL209950 & 404673 & 6.8239 & 7.2261 & TRN & \\
\hline CHEMBL 212343 & 404673 & 8.2218 & 7.8155 & TRN & \\
\hline CHEMBL386782 & 404673 & 6.9586 & 7.1414 & TRN & \\
\hline CHEMBL424702 & 404673 & 6.6198 & 6.8529 & TRN & \\
\hline CHEMBL 209898 & 404673 & 8.3979 & 8.0983 & TRN & \\
\hline CHEMBL451253 & 404673 & 7.0458 & 7.3598 & TST & \\
\hline CHEMBL425061 & 404673 & 6.6198 & 6.5654 & TRN & \\
\hline CHEMBL379857 & 404673 & 6.3188 & 6.7135 & TST & \\
\hline CHEMBL 211305 & 404673 & 6.699 & 6.8014 & TST & \\
\hline CHEMBL380063 & 404673 & 6.699 & 6.813 & TST & \\
\hline CHEMBL 213333 & 404673 & 7.8239 & 7.8267 & TRN & \\
\hline CHEMBL386576 & 404673 & 7.8539 & 7.5838 & TRN & \\
\hline CHEMBL214232 & 404673 & 7.0132 & 6.975 & TRN & \\
\hline CHEMBL 386702 & 404673 & 6.4949 & 6.6045 & TRN & \\
\hline CHEMBL211935 & 404673 & 7.6021 & 7.9175 & TRN & \\
\hline CHEMBL 214490 & 404673 & 7.0 & 7.2434 & TRN & \\
\hline CHEMBL379626 & 404673 & 6.9586 & 7.2376 & TRN & \\
\hline CHEMBL385586 & 404673 & 7.0555 & 7.3657 & TRN & \\
\hline CHEMBL 214589 & 404673 & 6.7959 & 6.7668 & TRN & \\
\hline CHEMBL211987 & 404673 & 7.3872 & 7.5371 & TRN & \\
\hline CHEMBL209529 & 404673 & 7.9208 & 7.2735 & TRN & \\
\hline CHEMBL 380180 & 404673 & 6.7959 & 7.2092 & TST & \\
\hline CHEMBL213182 & 404673 & 5.6198 & 6.08899 & 99999999995 & TRN \\
\hline CHEMBL 214231 & 404673 & 7.2366 & 6.8641 & TST & \\
\hline CHEMBL212387 & 404673 & 8.1549 & 7.6397 & TRN & \\
\hline CHEMBL214306 & 404673 & 6.7447 & 6.4326 & TRN & \\
\hline CHEMBL 213537 & 404673 & 4.0 & 6.4837 & TST & \\
\hline CHEMBL215937 & 404673 & 6.2291 & 6.0556 & TRN & \\
\hline CHEMBL378172 & 404673 & 6.3372 & 6.7055 & TST & \\
\hline CHEMBL210172 & 404673 & 6.1427 & 6.2375 & TST & \\
\hline CHEMBL214249 & 404673 & 7.6576 & 7.1001 & TRN & \\
\hline CHEMBL213900 & 404673 & 6.7212 & 6.4832 & TRN & \\
\hline CHEMBL210112 & 404673 & 8.3979 & 8.3303 & TRN & \\
\hline CHEMBL411713 & 404673 & 7.4559 & 7.9937 & TRN & \\
\hline CHEMBL377047 & 404673 & 5.2441 & 5.3675 & TRN & \\
\hline CHEMBL438252 & 404673 & 6.4089 & 6.7238 & TRN & \\
\hline CHEMBL3903158 & 1640564 & 6.2596 & 6.7396 & TRN & \\
\hline CHEMBL3952030 & 1640564 & 5.0 & 6.2973 & TST & \\
\hline CHEMBL 3898570 & 1640564 & 6.15799 & 99999999 & 5.5024 & TRN \\
\hline CHEMBL3950823 & 1640564 & 5.699 & 5.7252 & TRN & \\
\hline CHEMBL3890779 & 1640564 & 5.7447 & 5.6143 & TRN & \\
\hline
\end{tabular}


Supplemental Table S2.txt

\begin{tabular}{|c|c|c|c|c|}
\hline CHEMBL3908671 & 1640564 & 5.585 & 6.1586 & TRN \\
\hline CHEMBL3891824 & 1640564 & 7.0506 & 6.5248 & TRN \\
\hline CHEMBL3931144 & 1640564 & 6.7696 & 6.0471 & TST \\
\hline CHEMBL3969474 & 1640564 & 6.6778 & 5.6153 & TRN \\
\hline CHEMBL3902499 & 1640564 & 7.0088 & 6.2775 & TRN \\
\hline CHEMBL3980317 & 1640564 & 6.0 & 6.8545 & TRN \\
\hline CHEMBL3940624 & 1640564 & 5.2676 & 6.0477 & TRN \\
\hline CHEMBL3933454 & 1640564 & 5.2291 & 5.551 & TRN \\
\hline CHEMBL3932697 & 1640564 & 6.0 & 4.9477 & TRN \\
\hline CHEMBL3942427 & 1640564 & 6.0 & 6.4262 & TRN \\
\hline CHEMBL3905490 & 1640564 & 6.284 & 6.394 & TRN \\
\hline CHEMBL3948835 & 1640564 & 4.699 & 6.1372 & TST \\
\hline CHEMBL3960835 & 1640564 & 6.1612 & 6.4194 & TRN \\
\hline CHEMBL3945578 & 1640564 & 8.3872 & 6.9831 & TRN \\
\hline CHEMBL3940185 & 1640564 & 6.7212 & 6.269 & TRN \\
\hline CHEMBL3936545 & 1640564 & 6.5376 & 6.6654 & TST \\
\hline CHEMBL3906249 & 1640564 & 4.9208 & 4.8546 & TRN \\
\hline CHEMBL 3939475 & 1640564 & 4.9586 & 5.3048 & TRN \\
\hline CHEMBL3948024 & 1640564 & 5.0 & 5.6663 & TRN \\
\hline CHEMBL3927575 & 1640564 & 6.0 & 5.5182 & TRN \\
\hline CHEMBL3899550 & 1640564 & 5.0 & 5.5205 & TST \\
\hline CHEMBL3925049 & 1640564 & 4.9586 & 6.5787 & TST \\
\hline CHEMBL3933453 & 1640564 & 6.8539 & 7.1177 & TST \\
\hline CHEMBL3899139 & 1640564 & 5.8861 & 5.5047 & TRN \\
\hline CHEMBL3973550 & 1640564 & 6.3098 & 6.1508 & TRN \\
\hline CHEMBL3958598 & 1640564 & 6.3979 & 5.2903 & TRN \\
\hline CHEMBL3916622 & 1640564 & 4.9208 & 5.3846 & TRN \\
\hline CHEMBL3975383 & 1640564 & 5.9208 & 5.6882 & TRN \\
\hline CHEMBL3945508 & 1640564 & 6.1487 & 6.305 & TRN \\
\hline CHEMBL3914472 & 1640564 & 5.0 & 6.1317 & TST \\
\hline CHEMBL3983368 & 1640564 & 5.7959 & 6.2594 & TRN \\
\hline CHEMBL3930070 & 1640564 & 6.6198 & 6.5608 & TRN \\
\hline CHEMBL3903957 & 1640564 & 6.0 & 6.3274 & TRN \\
\hline CHEMBL3946729 & 1640564 & 5.0 & 5.64 & TRN \\
\hline CHEMBL3935990 & 1640564 & 6.585 & 6.3841 & TRN \\
\hline CHEMBL3919249 & 1640564 & 4.6198 & 5.0592 & TRN \\
\hline CHEMBL3929696 & 1640564 & 5.1024 & 6.1238 & TRN \\
\hline CHEMBL3911613 & 1640564 & 5.0 & 5.4904 & TRN \\
\hline CHEMBL3923951 & 1640564 & 5.6383 & 4.9352 & TRN \\
\hline CHEMBL3913745 & 1640564 & 6.0 & 6.5846 & TRN \\
\hline CHEMBL3964767 & 1640564 & 6.8539 & 5.6046 & TRN \\
\hline CHEMBL3922158 & 1640564 & 6.7212 & 5.8393 & TST \\
\hline CHEMBL3954224 & 1640564 & 7.2277 & 6.3802 & TRN \\
\hline CHEMBL3932743 & 1640564 & 7.0605 & 6.5223 & TRN \\
\hline CHEMBL3948252 & 1640564 & 6.4202 & 6.5972 & TRN \\
\hline CHEMBL3963815 & 1640564 & 5.6576 & 6.2006 & TRN \\
\hline CHEMBL3906570 & 1640564 & 6.2441 & 6.0507 & TRN \\
\hline CHEMBL3936671 & 1640564 & 5.0 & 5.4104 & TRN \\
\hline
\end{tabular}


Supplemental Table S2.txt

\begin{tabular}{|c|c|c|c|c|c|}
\hline CHEMBL3890583 & 1640564 & 6.1739 & 5.3823 & TST & \\
\hline CHEMBL3897570 & 1640564 & 6.9208 & 6.4316 & TRN & \\
\hline CHEMBL3921030 & 1640564 & 4.6576 & 5.9856 & TST & \\
\hline CHEMBL3909073 & 1640564 & 6.4089 & 6.9476 & TST & \\
\hline CHEMBL3926661 & 1640564 & 6.585 & 6.4413 & TRN & \\
\hline CHEMBL3983015 & 1640564 & 5.0 & 5.1099 & TRN & \\
\hline CHEMBL 3892344 & 1640564 & 6.058 & 5.5383 & TRN & \\
\hline CHEMBL3927006 & 1640564 & 5.0 & 5.4077 & TST & \\
\hline CHEMBL 3942274 & 1640564 & 6.4437 & 6.2941 & TRN & \\
\hline CHEMBL3964056 & 1640564 & 5.0 & 5.8811 & TST & \\
\hline CHEMBL3912109 & 1640564 & 5.0 & 5.9579 & TRN & \\
\hline CHEMBL3897003 & 1640564 & 6.2924 & 6.2731 & TRN & \\
\hline CHEMBL 3968412 & 1640564 & 6.9208 & 6.6831 & TRN & \\
\hline CHEMBL3969122 & 1640564 & 3.0 & 4.8358 & TRN & \\
\hline CHEMBL3925188 & 1640564 & 6.1675 & 5.5643 & TRN & \\
\hline CHEMBL3955775 & 1640564 & 6.4559 & 6.4253 & TRN & \\
\hline CHEMBL3924538 & 1640564 & 6.0 & 6.6885 & TST & \\
\hline CHEMBL3937044 & 1640564 & 6.4559 & 5.8451 & TST & \\
\hline CHEMBL3920332 & 1640564 & 5.0 & 5.3651 & TRN & \\
\hline CHEMBL3972029 & 1640564 & 5.7959 & 6.3704 & TRN & \\
\hline CHEMBL3912082 & 1640564 & 6.5376 & 6.4127 & TRN & \\
\hline CHEMBL 3974684 & 1640564 & 7.6383 & 6.6292 & TST & \\
\hline CHEMBL3896518 & 1640564 & 8.0915 & 6.677006 & 00000000005 & TST \\
\hline CHEMBL3896544 & 1640564 & 7.0 & 6.7143 & TST & \\
\hline CHEMBL3905526 & 1640564 & 5.5229 & 5.0147 & TRN & \\
\hline CHEMBL3965392 & 1640564 & 5.0 & 5.7026 & TRN & \\
\hline CHEMBL3913156 & 1640564 & 5.0 & 5.2788 & TST & \\
\hline CHEMBL3913550 & 1640564 & 6.4202 & 6.0014 & TRN & \\
\hline CHEMBL3976041 & 1640564 & 5.0 & 5.5815 & TRN & \\
\hline CHEMBL3947957 & 1640564 & 4.2518 & 5.6149 & TRN & \\
\hline CHEMBL3984688 & 1640564 & 5.0 & 5.0911 & TST & \\
\hline CHEMBL3949722 & 1640564 & 6.5376 & 6.4315 & TRN & \\
\hline CHEMBL3921054 & 1640564 & 7.6778 & 6.8377 & TST & \\
\hline CHEMBL 3943330 & 1640564 & 5.0 & 5.0591 & TRN & \\
\hline CHEMBL3972936 & 1640564 & 5.0 & 5.4827 & TRN & \\
\hline CHEMBL3900653 & 1640564 & 6.0 & 6.1276 & TST & \\
\hline CHEMBL3947154 & 1640564 & 6.0 & 5.4855 & TRN & \\
\hline CHEMBL3911505 & 1640564 & 3.0 & 4.851 & TRN & \\
\hline CHEMBL3976946 & 1640564 & 6.0 & 4.7549 & TRN & \\
\hline CHEMBL3947945 & 1640564 & 4.9586 & 4.9538 & TRN & \\
\hline CHEMBL3982148 & 1640564 & 6.433 & 5.8396 & TRN & \\
\hline CHEMBL3916520 & 1640564 & 6.0088 & 5.1016 & TRN & \\
\hline CHEMBL3933947 & 1640564 & 6.6576 & 6.155 & TST & \\
\hline CHEMBL3945270 & 1640564 & 6.7959 & 6.4419 & TST & \\
\hline CHEMBL3981981 & 1640564 & 5.0 & 5.5215 & TRN & \\
\hline CHEMBL3942479 & 1640564 & 6.2381 & 5.8561 & TST & \\
\hline CHEMBL3918934 & 1640564 & 6.1135 & 5.3171 & TRN & \\
\hline CHEMBL3908509 & 1640564 & 6.1871 & 5.8686 & TRN & \\
\hline
\end{tabular}




\begin{tabular}{|c|c|c|c|c|c|}
\hline \multicolumn{6}{|c|}{ Supplemental Table S2.txt } \\
\hline CHEMBL9470 & 954519 & 6.3801 & 6.0186 & TST & \\
\hline CHEMBL1643959 & 954519 & 4.5364 & 4.6009 & TRN & \\
\hline CHEMBL 240954 & 954519 & 4.1709 & 4.5059 & TST & \\
\hline CHEMBL509032 & 954519 & 4.6436 & 4.6754 & TRN & \\
\hline CHEMBL585951 & 954519 & 6.5521 & 6.5793 & TRN & \\
\hline CHEMBL483847 & 954519 & 3.6843 & 3.6237 & TRN & \\
\hline CHEMBL3199475 & 954519 & 5.4636 & 5.4324 & TRN & \\
\hline CHEMBL65 & 954519 & 9.0447 & 9.0406 & TRN & \\
\hline CHEMBL189584 & 954519 & 5.8733 & 5.814 & TRN & \\
\hline CHEMBL379975 & 954519 & 6.0467 & 6.0999 & TRN & \\
\hline CHEMBL 209148 & 954519 & 5.2375 & 5.2451 & TRN & \\
\hline CHEMBL1190711 & 954519 & 5.9085 & 5.8824 & TRN & \\
\hline CHEMBL135561 & 954519 & 4.449 & 4.4355 & TRN & \\
\hline CHEMBL 379300 & 954519 & 6.7736 & 6.8062 & TRN & \\
\hline CHEMBL 213100 & 954519 & 3.4877 & 3.4729 & TRN & \\
\hline CHEMBL 258844 & 954519 & 5.1748 & 5.1445 & TRN & \\
\hline CHEMBL188678 & 954519 & 5.5917 & 5.5862 & TRN & \\
\hline CHEMBL449158 & 954519 & 6.4692 & 6.8385 & TST & \\
\hline CHEMBL 373751 & 954519 & 3.0774 & 3.1758 & TRN & \\
\hline CHEMBL 2363137 & 954519 & 4.8778 & 4.8601 & TRN & \\
\hline CHEMBL412142 & 954519 & 5.709 & 5.6656 & TRN & \\
\hline CHEMBL 2005886 & 954519 & 5.7442 & 5.7798 & TRN & \\
\hline CHEMBL514499 & 954519 & 7.8921 & 7.7721 & TRN & \\
\hline CHEMBL1256459 & 954519 & 7.2264 & 7.2967 & TRN & \\
\hline CHEMBL191334 & 954519 & 5.5648 & 5.54200 & 0000000001 & TRN \\
\hline CHEMBL392695 & 954519 & 5.8873 & 5.8481 & TRN & \\
\hline CHEMBL1242367 & 954519 & 5.4271 & 5.4578 & TRN & \\
\hline CHEMBL1357247 & 954519 & 3.5352 & 3.492 & TRN & \\
\hline CHEMBL1590308 & 954519 & 4.309 & 3.7796 & TST & \\
\hline CHEMBL1909414 & 954519 & 5.1157 & 5.1166 & TRN & \\
\hline CHEMBL1230020 & 954519 & 5.0175 & 5.0078 & TRN & \\
\hline CHEMBL515416 & 954519 & 3.5558 & 3.5555 & TRN & \\
\hline CHEMBL577784 & 954519 & 6.1391 & 6.1928 & TRN & \\
\hline CHEMBL 221137 & 954519 & 4.9775 & 5.2015 & TST & \\
\hline CHEMBL3392440 & 954519 & 2.7407 & 2.6758 & TRN & \\
\hline CHEMBL 210618 & 954519 & 4.7778 & 4.7137 & TRN & \\
\hline CHEMBL3186408 & 954519 & 3.8364 & 4.0123 & TST & \\
\hline CHEMBL393929 & 954519 & 4.9251 & 4.8449 & TRN & \\
\hline CHEMBL 102714 & 954519 & 5.084 & 5.1498 & TRN & \\
\hline CHEMBL512504 & 954519 & 7.0669 & 7.112 & TRN & \\
\hline CHEMBL92309 & 954519 & 4.4662 & 3.7873 & TST & \\
\hline CHEMBL483849 & 954519 & 3.4547 & 3.452 & TRN & \\
\hline CHEMBL3349342 & 954519 & 3.6453 & 3.6525 & TRN & \\
\hline CHEMBL192566 & 954519 & 8.8871 & 8.56 & TST & \\
\hline CHEMBL1673039 & 954519 & 5.4664 & 5.4005 & TRN & \\
\hline CHEMBL 222102 & 954519 & 4.3322 & 4.4469 & TRN & \\
\hline CHEMBL 2144069 & 954519 & 4.0509 & 4.0784 & TRN & \\
\hline CHEMBL300389 & 954519 & 7.1577 & 7.1089 & TRN & \\
\hline
\end{tabular}


Supplemental Table S2.txt

\begin{tabular}{|c|c|c|c|c|}
\hline CHEMBL202721 & 954519 & 6.2562 & 6.3052 & TRN \\
\hline CHEMBL573107 & 954519 & 5.1134 & 5.124 & TRN \\
\hline CHEMBL1970879 & 954519 & 4.9846 & 4.9951 & TRN \\
\hline CHEMBL180127 & 954519 & 4.7215 & 4.7529 & TRN \\
\hline CHEMBL1516890 & 954519 & 3.8696 & 4.2851 & TST \\
\hline CHEMBL1788116 & 954519 & 5.4058 & 5.1877 & TST \\
\hline CHEMBL558642 & 954519 & 5.0476 & 5.1918 & TST \\
\hline CHEMBL1404918 & 954519 & 2.7472 & 3.0419 & TST \\
\hline CHEMBL259181 & 954519 & 4.5847 & 5.096999 & 99999999995 \\
\hline CHEMBL220241 & 954519 & 4.2379 & 4.8251 & TST \\
\hline CHEMBL472940 & 954519 & 4.6339 & 5.0292 & TST \\
\hline CHEMBL3718847 & 1536567 & 4.301 & 4.1987 & TRN \\
\hline CHEMBL3715362 & 1536567 & 7.301 & 6.0232 & TST \\
\hline CHEMBL3718766 & 1536567 & 4.301 & 4.0608 & TRN \\
\hline CHEMBL3715380 & 1536567 & 7.301 & 6.3641 & TST \\
\hline CHEMBL3719326 & 1536567 & 6.301 & 6.3338 & TST \\
\hline CHEMBL3716033 & 1536567 & 4.301 & 4.4424 & TST \\
\hline CHEMBL3716567 & 1536567 & 4.301 & 5.7929 & TRN \\
\hline CHEMBL3718863 & 1536567 & 4.301 & 3.9607 & TRN \\
\hline CHEMBL3715470 & 1536567 & 4.301 & 4.3166 & TRN \\
\hline CHEMBL3718473 & 1536567 & 6.301 & 6.2056 & TRN \\
\hline CHEMBL3717424 & 1536567 & 7.301 & 6.3701 & TRN \\
\hline CHEMBL3715570 & 1536567 & 4.301 & 3.9268 & TRN \\
\hline CHEMBL3716575 & 1536567 & 4.301 & 4.2365 & TRN \\
\hline CHEMBL3718538 & 1536567 & 4.301 & 4.4549 & TST \\
\hline CHEMBL3717846 & 1536567 & 7.301 & 7.0802 & TRN \\
\hline CHEMBL3718595 & 1536567 & 4.301 & 3.8139 & TRN \\
\hline CHEMBL3718459 & 1536567 & 4.301 & 3.8289 & TRN \\
\hline CHEMBL3717643 & 1536567 & 4.301 & 4.8275 & TRN \\
\hline CHEMBL3719083 & 1536567 & 4.301 & 4.6975 & TST \\
\hline CHEMBL3719165 & 1536567 & 6.301 & 5.7509 & TRN \\
\hline CHEMBL3718940 & 1536567 & 6.301 & 5.7042 & TRN \\
\hline CHEMBL 3717484 & 1536567 & 6.301 & 6.24 & TST \\
\hline CHEMBL3716888 & 1536567 & 4.301 & 4.3873 & TRN \\
\hline CHEMBL3716788 & 1536567 & 6.301 & 6.4528 & TRN \\
\hline CHEMBL3719243 & 1536567 & 4.301 & 4.681999 & 99999999995 \\
\hline CHEMBL3716774 & 1536567 & 4.301 & 5.7762 & TRN \\
\hline CHEMBL3717335 & 1536567 & 6.301 & 5.3371 & TRN \\
\hline CHEMBL3717287 & 1536567 & 7.301 & 6.6362 & TRN \\
\hline CHEMBL3717584 & 1536567 & 4.301 & 6.1849 & TST \\
\hline CHEMBL3717713 & 1536567 & 6.301 & 5.6879 & TRN \\
\hline CHEMBL3717227 & 1536567 & 4.301 & 4.1699 & TRN \\
\hline CHEMBL3718891 & 1536567 & 6.301 & 6.0523 & TRN \\
\hline CHEMBL3717373 & 1536567 & 4.301 & 4.9515 & TRN \\
\hline CHEMBL3715292 & 1536567 & 7.301 & 6.9501 & TST \\
\hline CHEMBL3715956 & 1536567 & 7.301 & 5.9697 & TRN \\
\hline CHEMBL3718397 & 1536567 & 6.301 & 6.5946 & TST \\
\hline CHEMBL3716744 & 1536567 & 6.301 & 6.5271 & TRN \\
\hline
\end{tabular}


Supplemental Table S2.txt

\begin{tabular}{|c|c|c|c|c|c|}
\hline CHEMBL 3718622 & 1536567 & 4.301 & 4.497 & TRN & \\
\hline CHEMBL 3719151 & 1536567 & 4.301 & 3.8367 & TRN & \\
\hline CHEMBL 3715969 & 1536567 & 4.301 & 4.1661 & TRN & \\
\hline CHEMBL 3718578 & 1536567 & 4.301 & 4.2041 & TRN & \\
\hline CHEMBL 3716416 & 1536567 & 4.301 & \multicolumn{2}{|c|}{6.002000000000001} & TRN \\
\hline CHEMBL 3715821 & 1536567 & 7.301 & 7.1533 & TRN & \\
\hline CHEMBL3717391 & 1536567 & 7.301 & 6.5719 & TRN & \\
\hline CHEMBL 3718965 & 1536567 & 6.301 & 6.1123 & TRN & \\
\hline CHEMBL 3716968 & 1536567 & 6.301 & 6.6863 & TRN & \\
\hline CHEMBL 3717150 & 1536567 & 4.301 & 4.0891 & TRN & \\
\hline CHEMBL 3717759 & 1536567 & 7.301 & 7.2737 & TRN & \\
\hline CHEMBL3714861 & 1536567 & 7.301 & 6.8704 & TST & \\
\hline CHEMBL 3716849 & 1536567 & 6.301 & 6.4529 & TRN & \\
\hline CHEMBL 3717017 & 1536567 & 7.301 & 7.3113 & TRN & \\
\hline CHEMBL 3715005 & 1536567 & 6.301 & 6.2769 & TST & \\
\hline CHEMBL 3716318 & 1536567 & 4.301 & 5.7352 & TRN & \\
\hline CHEMBL3717117 & 1536567 & 4.301 & 4.4482 & TRN & \\
\hline CHEMBL 3717111 & 1536567 & 6.301 & \multicolumn{2}{|c|}{5.757000000000001} & TRN \\
\hline CHEMBL 3716753 & 1536567 & 7.301 & 6.4815 & TRN & \\
\hline CHEMBL3716321 & 1536567 & 4.301 & 4.0298 & TRN & \\
\hline CHEMBL 3717552 & 1536567 & 4.301 & 5.0191 & TRN & \\
\hline CHEMBL3715050 & 1536567 & 4.301 & 5.9663 & TRN & \\
\hline CHEMBL 3718164 & 1536567 & 6.301 & 6.1046 & TRN & \\
\hline CHEMBL3719286 & 1536567 & 7.301 & \multicolumn{2}{|c|}{6.3660000000000005} & TRN \\
\hline CHEMBL3715806 & 1536567 & 6.301 & 6.5108 & TRN & \\
\hline CHEMBL 3717998 & 1536567 & 8.301 & 6.9902 & TST & \\
\hline CHEMBL 3715887 & 1536567 & 7.301 & 6.8339 & TRN & \\
\hline CHEMBL 3717193 & 1536567 & 6.301 & 6.2058 & TST & \\
\hline CHEMBL 3715150 & 1536567 & 4.301 & 3.9793 & TRN & \\
\hline CHEMBL3719051 & 1536567 & 6.301 & 6.0468 & TRN & \\
\hline CHEMBL 3716742 & 1536567 & 6.301 & 5.8342 & TST & \\
\hline CHEMBL 3718166 & 1536567 & 6.301 & 6.4188 & TST & \\
\hline CHEMBL 3715148 & 1536567 & 7.301 & 6.6108 & TRN & \\
\hline CHEMBL 3717468 & 1536567 & 7.301 & 6.5916 & TRN & \\
\hline CHEMBL3718499 & 1536567 & 4.301 & 5.0049 & TRN & \\
\hline CHEMBL3717933 & 1536567 & 8.301 & 6.9062 & TRN & \\
\hline CHEMBL 3718066 & 1536567 & 6.301 & 6.5846 & TRN & \\
\hline CHEMBL 3715546 & 1536567 & 7.301 & 6.7094 & TST & \\
\hline CHEMBL 3717022 & 1536567 & 8.301 & 6.7788 & TST & \\
\hline CHEMBL3717236 & 1536567 & 6.301 & 6.9193 & TRN & \\
\hline CHEMBL 3716641 & 1536567 & 4.301 & 3.8947 & TRN & \\
\hline CHEMBL 3716358 & 1536567 & 4.301 & 4.0825 & TRN & \\
\hline CHEMBL3715338 & 1536567 & 4.301 & 4.3651 & TST & \\
\hline CHEMBL 3716741 & 1536567 & 7.301 & 6.6861 & TRN & \\
\hline CHEMBL3715872 & 1536567 & 7.301 & 7.1533 & TRN & \\
\hline CHEMBL 3715942 & 1536567 & 4.301 & 5.7468 & TRN & \\
\hline CHEMBL 3717452 & 1536567 & 6.301 & 6.6164 & TRN & \\
\hline CHEMBL 3716666 & 1536567 & 4.301 & 4.2018 & TRN & \\
\hline
\end{tabular}


Supplemental Table S2.txt

\begin{tabular}{|c|c|c|c|c|}
\hline CHEMBL3717276 & 1536567 & 4.301 & 4.6185 & TST \\
\hline CHEMBL3718736 & 1536567 & 6.301 & 6.5926 & TRN \\
\hline CHEMBL3718453 & 1536567 & 7.301 & 6.34399 & 9999999999 \\
\hline CHEMBL3718523 & 1536567 & 7.301 & 6.7778 & TRN \\
\hline CHEMBL3716597 & 1536567 & 6.301 & 6.6362 & TRN \\
\hline CHEMBL3714849 & 1536567 & 4.301 & 5.7167 & TRN \\
\hline CHEMBL3715041 & 1536567 & 4.301 & 5.6899 & TRN \\
\hline CHEMBL3715987 & 1536567 & 7.301 & 6.3538 & TST \\
\hline CHEMBL3715589 & 1536567 & 4.301 & 6.2875 & TST \\
\hline CHEMBL3717761 & 1536567 & 4.301 & 5.3039 & TRN \\
\hline CHEMBL257394 & 461138 & 6.7447 & 6.4328 & TRN \\
\hline CHEMBL404037 & 461138 & 5.1739 & 4.7747 & TRN \\
\hline CHEMBL402735 & 461138 & 5.0862 & 5.0225 & TRN \\
\hline CHEMBL403032 & 461138 & 5.6198 & 5.4471 & TRN \\
\hline CHEMBL401689 & 461138 & 6.2147 & 6.0777 & TRN \\
\hline CHEMBL155208 & 461138 & 6.5686 & 5.8844 & TRN \\
\hline CHEMBL402517 & 461138 & 4.3979 & 4.3282 & TRN \\
\hline CHEMBL 27132 & 461138 & 6.0 & 5.9054 & TST \\
\hline CHEMBL253948 & 461138 & 5.0969 & 4.9042 & TRN \\
\hline CHEMBL 256075 & 461138 & 7.1675 & 6.772 & TRN \\
\hline CHEMBL283489 & 461138 & 6.0 & 5.7369 & TRN \\
\hline CHEMBL417473 & 461138 & 6.0 & 6.159 & TST \\
\hline CHEMBL155352 & 461138 & 6.1427 & 5.5171 & TRN \\
\hline CHEMBL388342 & 461138 & 6.4318 & 6.5242 & TRN \\
\hline CHEMBL118254 & 461138 & 7.1024 & 7.1923 & TRN \\
\hline CHEMBL258372 & 461138 & 7.4089 & 7.2714 & TRN \\
\hline CHEMBL 26907 & 461138 & 3.0 & 2.9699 & TRN \\
\hline CHEMBL253530 & 461138 & 4.699 & 4.9204 & TRN \\
\hline CHEMBL401690 & 461138 & 6.0809 & 6.3055 & TRN \\
\hline CHEMBL 253736 & 461138 & 5.0132 & 5.1343 & TRN \\
\hline CHEMBL253949 & 461138 & 5.3098 & 5.4535 & TRN \\
\hline CHEMBL225853 & 461138 & 6.1308 & 6.5208 & TRN \\
\hline CHEMBL253947 & 461138 & 4.7959 & 4.9731 & TRN \\
\hline CHEMBL253737 & 461138 & 4.8539 & 4.8796 & TRN \\
\hline CHEMBL403844 & 461138 & 7.0809 & 4.5772 & TST \\
\hline CHEMBL154468 & 461138 & 4.0 & 4.4491 & TRN \\
\hline CHEMBL1497070 & 461138 & 5.5528 & 5.4745 & TRN \\
\hline CHEMBL404241 & 461138 & 4.8539 & 4.2945 & TRN \\
\hline CHEMBL253319 & 461138 & 5.2147 & 5.8592 & TST \\
\hline CHEMBL404865 & 461138 & 5.0506 & 5.3119 & TRN \\
\hline CHEMBL345240 & 461138 & 4.0 & 4.3486 & TRN \\
\hline CHEMBL258371 & 461138 & 8.4318 & 8.4707 & TRN \\
\hline CHEMBL253529 & 461138 & 4.8239 & 4.6078 & TRN \\
\hline CHEMBL122485 & 461138 & 6.5686 & 6.1392 & TST \\
\hline CHEMBL332332 & 461138 & 6.0 & 5.4444 & TST \\
\hline CHEMBL401567 & 461138 & 5.3468 & 5.4722 & TRN \\
\hline CHEMBL 27247 & 461138 & 6.0 & 6.3955 & TST \\
\hline CHEMBL253738 & 461138 & 4.8239 & 5.0124 & TRN \\
\hline
\end{tabular}




\begin{tabular}{|c|c|c|c|c|c|}
\hline \multicolumn{6}{|c|}{ Supplemental Table S } \\
\hline CHEMBL225230 & 461138 & 8.0 & 8.2312 & TRN & \\
\hline CHEMBL 254147 & 461138 & 4.8861 & 4.5315 & TRN & \\
\hline CHEMBL255229 & 461138 & 7.1427 & 7.2694 & TRN & \\
\hline CHEMBL404240 & 461138 & 3.699 & 4.2841 & TRN & \\
\hline CHEMBL 28056 & 461138 & 6.0 & 6.1055 & TRN & \\
\hline CHEMBL288096 & 461138 & 10.2757 & 10.0651 & TRN & \\
\hline CHEMBL 281923 & 461138 & 6.0 & 6.5434 & TST & \\
\hline CHEMBL404136 & 461138 & 6.1192 & 6.1051 & TRN & \\
\hline CHEMBL404137 & 461138 & 8.4202 & 6.6539 & TST & \\
\hline CHEMBL119593 & 461138 & 6.6021 & 6.3715 & TRN & \\
\hline CHEMBL155066 & 461138 & 4.0 & 4.6432 & TRN & \\
\hline CHEMBL53294 & 461138 & 9.7696 & 10.0591 & TRN & \\
\hline CHEMBL53510 & 461138 & 5.9706 & 6.2382 & TRN & \\
\hline CHEMBL403550 & 461138 & 7.4685 & 6.5825 & TST & \\
\hline CHEMBL402736 & 461138 & 4.7212 & 4.9224 & TST & \\
\hline CHEMBL253318 & 461138 & 7.2596 & 5.9455 & TST & \\
\hline CHEMBL124419 & 461138 & 6.2676 & 6.0075 & TST & \\
\hline CHEMBL116367 & 461138 & 4.0 & $5.95200 e$ & 0000000001 & TST \\
\hline CHEMBL439639 & 461138 & 5.1871 & 4.9414 & TST & \\
\hline CHEMBL3730446 & 1537597 & 5.0 & 6.6326 & TST & \\
\hline CHEMBL 3729100 & 1537597 & 7.0 & 7.2791 & TRN & \\
\hline CHEMBL3730120 & 1537597 & 6.0 & 6.8702 & TST & \\
\hline CHEMBL 3728774 & 1537597 & 5.0 & 7.4837 & TST & \\
\hline CHEMBL3728968 & 1537597 & 7.0 & 6.9343 & TRN & \\
\hline CHEMBL 3730428 & 1537597 & 5.0 & 5.2226 & TRN & \\
\hline CHEMBL 3732290 & 1537597 & 6.0 & 6.4005 & TRN & \\
\hline CHEMBL3732519 & 1537597 & 7.0 & 6.7897 & TRN & \\
\hline CHEMBL 3731018 & 1537597 & 5.0 & 5.039 & TRN & \\
\hline CHEMBL3730471 & 1537597 & 7.0 & 7.532 & TRN & \\
\hline CHEMBL3727961 & 1537597 & 6.0 & 5.9505 & TRN & \\
\hline CHEMBL 3727903 & 1537597 & 6.0 & 7.3779 & TRN & \\
\hline CHEMBL3732947 & 1537597 & 7.0 & 6.6837 & TRN & \\
\hline CHEMBL 3728863 & 1537597 & 8.0 & 7.9843 & TRN & \\
\hline CHEMBL3731749 & 1537597 & 6.0 & 6.7467 & TRN & \\
\hline CHEMBL3728571 & 1537597 & 7.0 & 6.9791 & TRN & \\
\hline CHEMBL3728051 & 1537597 & 7.0 & 6.0929 & TRN & \\
\hline CHEMBL3729166 & 1537597 & 5.0 & 4.7976 & TRN & \\
\hline CHEMBL 3730828 & 1537597 & 7.0 & 7.0855 & TRN & \\
\hline CHEMBL 3732347 & 1537597 & 7.0 & 7.0858 & TRN & \\
\hline CHEMBL 3730404 & 1537597 & 8.0 & 7.3155 & TRN & \\
\hline CHEMBL3730419 & 1537597 & 8.0 & 7.6795 & TRN & \\
\hline CHEMBL 3732984 & 1537597 & 6.0 & 5.9064 & TST & \\
\hline CHEMBL 3732228 & 1537597 & 5.0 & 5.4836 & TRN & \\
\hline CHEMBL3730511 & 1537597 & 5.0 & 4.4895 & TRN & \\
\hline CHEMBL 3727427 & 1537597 & 8.0 & 7.6946 & TRN & \\
\hline CHEMBL3732117 & 1537597 & 5.0 & 4.6578 & TRN & \\
\hline CHEMBL 3729747 & 1537597 & 6.0 & 5.5907 & TRN & \\
\hline CHEMBL3729595 & 1537597 & 5.0 & 4.3928 & TRN & \\
\hline
\end{tabular}




\begin{tabular}{|c|c|c|c|c|}
\hline & & & pplement & al Ta \\
\hline CHEMBL3732976 & 1537597 & 5.0 & 5.4672 & TRN \\
\hline CHEMBL3728703 & 1537597 & 6.0 & 6.2753 & TRN \\
\hline CHEMBL3730322 & 1537597 & 8.0 & 7.3621 & TRN \\
\hline CHEMBL3728943 & 1537597 & 6.0 & 6.4962 & TRN \\
\hline CHEMBL3733187 & 1537597 & 7.0 & 7.6189 & TRN \\
\hline CHEMBL3730938 & 1537597 & 6.0 & 6.5475 & TRN \\
\hline CHEMBL3730583 & 1537597 & 6.0 & 6.0334 & TST \\
\hline CHEMBL3732003 & 1537597 & 6.0 & 6.0053 & TRN \\
\hline CHEMBL 3728561 & 1537597 & 5.0 & 5.6206 & TST \\
\hline CHEMBL3727836 & 1537597 & 8.0 & 7.9096 & TRN \\
\hline CHEMBL 3727682 & 1537597 & 7.0 & 7.3142 & TRN \\
\hline CHEMBL3729295 & 1537597 & 6.0 & 6.3263 & TRN \\
\hline CHEMBL3730403 & 1537597 & 6.0 & 5.4559 & TRN \\
\hline CHEMBL3729811 & 1537597 & 6.0 & 6.2577 & TST \\
\hline CHEMBL 3730885 & 1537597 & 6.0 & 5.7489 & TRN \\
\hline CHEMBL3732021 & 1537597 & 5.0 & 4.9772 & TRN \\
\hline CHEMBL3731040 & 1537597 & 5.0 & 5.2738 & TRN \\
\hline CHEMBL3733190 & 1537597 & 8.0 & 7.0655 & TRN \\
\hline CHEMBL3729346 & 1537597 & 6.0 & 5.9836 & TRN \\
\hline CHEMBL 3728683 & 1537597 & 6.0 & 6.5906 & TST \\
\hline CHEMBL3729215 & 1537597 & 5.0 & 7.1407 & TST \\
\hline CHEMBL3732491 & 1537597 & 6.0 & 5.7472 & TRN \\
\hline CHEMBL3729210 & 1537597 & 6.0 & 5.4666 & TRN \\
\hline CHEMBL 3729742 & 1537597 & 6.0 & 6.8136 & TRN \\
\hline CHEMBL 3729660 & 1537597 & 7.0 & 6.1537 & TRN \\
\hline CHEMBL 3728254 & 1537597 & 6.0 & 6.718 & TRN \\
\hline CHEMBL3730055 & 1537597 & 6.0 & 6.3546 & TRN \\
\hline CHEMBL3728136 & 1537597 & 5.0 & 6.1856 & TST \\
\hline CHEMBL3730316 & 1537597 & 6.0 & 6.1107 & TRN \\
\hline CHEMBL3731525 & 1537597 & 7.0 & 6.9292 & TRN \\
\hline CHEMBL3729586 & 1537597 & 6.0 & 6.9304 & TST \\
\hline CHEMBL3732659 & 1537597 & 7.0 & 6.5604 & TRN \\
\hline CHEMBL3729173 & 1537597 & 6.0 & 5.7758 & TRN \\
\hline CHEMBL 3729348 & 1537597 & 7.0 & 6.995 & TRN \\
\hline CHEMBL 3728090 & 1537597 & 7.0 & 6.3982 & TRN \\
\hline CHEMBL3731044 & 1537597 & 6.0 & 6.829 & TRN \\
\hline CHEMBL 3728978 & 1537597 & 7.0 & 6.2329 & TRN \\
\hline CHEMBL3732845 & 1537597 & 6.0 & 7.0813 & TST \\
\hline CHEMBL3729239 & 1537597 & 8.0 & 6.8147 & TRN \\
\hline CHEMBL 3732952 & 1537597 & 7.0 & 6.8473 & TRN \\
\hline CHEMBL3730303 & 1537597 & 5.0 & 5.2282 & TST \\
\hline CHEMBL 3727886 & 1537597 & 6.0 & 6.9987 & TRN \\
\hline CHEMBL3730216 & 1537597 & 5.0 & 6.1977 & TST \\
\hline CHEMBL 3727554 & 1537597 & 6.0 & 5.9241 & TRN \\
\hline CHEMBL 3727425 & 1537597 & 6.0 & 5.9848 & TRN \\
\hline CHEMBL3731337 & 1537597 & 8.0 & 7.8655 & TRN \\
\hline CHEMBL 3727923 & 1537597 & 6.0 & 7.0606 & TST \\
\hline CHEMBL 3730501 & 1537597 & 5.0 & 5.1564 & TRN \\
\hline
\end{tabular}




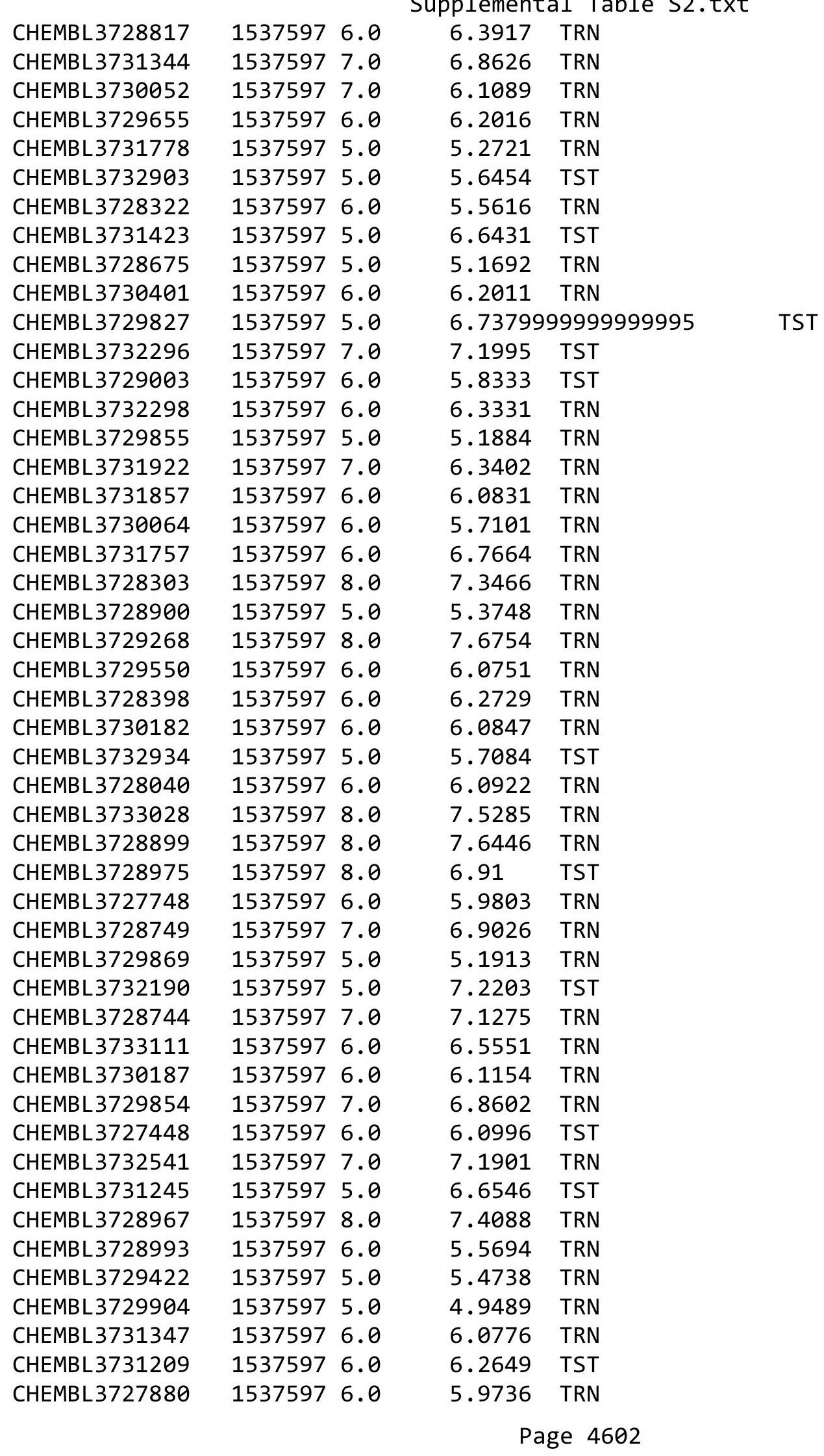




\begin{tabular}{|c|c|c|c|c|}
\hline & & & pplement & al $\mathrm{Ta}$ \\
\hline CHEMBL 3727390 & 1537597 & 7.0 & 6.8622 & TRN \\
\hline CHEMBL3728643 & 1537597 & 5.0 & 5.1094 & TRN \\
\hline CHEMBL3732844 & 1537597 & 8.0 & 7.3821 & TRN \\
\hline CHEMBL3731080 & 1537597 & 6.0 & 5.794 & TRN \\
\hline CHEMBL3729676 & 1537597 & 6.0 & 6.0494 & TRN \\
\hline CHEMBL3730161 & 1537597 & 6.0 & 6.3724 & TRN \\
\hline CHEMBL3729516 & 1537597 & 7.0 & 5.6008 & TST \\
\hline CHEMBL3728958 & 1537597 & 5.0 & 5.9964 & TST \\
\hline CHEMBL 3728060 & 1537597 & 3.2218 & 3.9352 & TST \\
\hline CHEMBL3728132 & 1537597 & 5.0 & 5.4374 & TRN \\
\hline CHEMBL3731282 & 1537597 & 7.0 & 6.2929 & TRN \\
\hline CHEMBL3729783 & 1537597 & 6.0 & 6.6026 & TRN \\
\hline CHEMBL 3727637 & 1537597 & 7.0 & 6.9693 & TST \\
\hline CHEMBL 3727430 & 1537597 & 5.0 & 6.0869 & TST \\
\hline CHEMBL3731776 & 1537597 & 8.0 & 7.9259 & TRN \\
\hline CHEMBL 3730328 & 1537597 & 8.0 & 7.0573 & TST \\
\hline CHEMBL3730147 & 1537597 & 6.0 & 4.9834 & TST \\
\hline CHEMBL3729940 & 1537597 & 7.0 & 6.6956 & TRN \\
\hline CHEMBL3730839 & 1537597 & 7.0 & 7.4933 & TRN \\
\hline CHEMBL3728938 & 1537597 & 8.0 & 7.5877 & TRN \\
\hline CHEMBL3733338 & 1537597 & 5.0 & 4.8598 & TRN \\
\hline CHEMBL3731343 & 1537597 & 5.0 & 4.6626 & TRN \\
\hline CHEMBL3729527 & 1537597 & 7.0 & 7.2238 & TRN \\
\hline CHEMBL 3727431 & 1537597 & 6.0 & 6.2194 & TRN \\
\hline CHEMBL3729853 & 1537597 & 6.0 & 5.3991 & TST \\
\hline CHEMBL3732291 & 1537597 & 6.0 & 6.1205 & TRN \\
\hline CHEMBL3730634 & 1537597 & 6.0 & 6.4345 & TRN \\
\hline CHEMBL3729275 & 1537597 & 7.0 & 6.7214 & TRN \\
\hline CHEMBL 3732486 & 1537597 & 7.0 & 6.8656 & TST \\
\hline CHEMBL3731795 & 1537597 & 7.0 & 6.7077 & TRN \\
\hline CHEMBL3731292 & 1537597 & 6.0 & 6.1308 & TRN \\
\hline CHEMBL 3728075 & 1537597 & 7.0 & 7.1713 & TRN \\
\hline CHEMBL 3729541 & 1537597 & 6.0 & 6.2523 & TRN \\
\hline CHEMBL 3732477 & 1537597 & 7.0 & 6.6802 & TRN \\
\hline CHEMBL3729839 & 1537597 & 6.0 & 6.2215 & TRN \\
\hline CHEMBL3730886 & 1537597 & 5.0 & 4.7901 & TRN \\
\hline CHEMBL3728196 & 1537597 & 7.0 & 6.9318 & TRN \\
\hline CHEMBL3731611 & 1537597 & 6.0 & 6.3996 & TRN \\
\hline CHEMBL 3727409 & 1537597 & 6.0 & 6.3708 & TRN \\
\hline CHEMBL3730628 & 1537597 & 8.0 & 7.0691 & TRN \\
\hline CHEMBL3729472 & 1537597 & 7.0 & 6.4039 & TRN \\
\hline CHEMBL3731713 & 1537597 & 5.0 & 5.103 & TRN \\
\hline CHEMBL3727635 & 1537597 & 5.0 & 4.9724 & TRN \\
\hline CHEMBL 3730568 & 1537597 & 6.0 & 6.3997 & TRN \\
\hline CHEMBL3732205 & 1537597 & 8.0 & 7.6598 & TRN \\
\hline CHEMBL3729908 & 1537597 & 6.0 & 6.9012 & TST \\
\hline CHEMBL3729698 & 1537597 & 7.0 & 6.8276 & TRN \\
\hline CHEMBL3728994 & 1537597 & 5.0 & 4.2611 & TST \\
\hline
\end{tabular}




\begin{tabular}{|c|c|c|c|c|c|}
\hline \multirow{3}{*}{ CHEMBL 3728888} & \multirow{2}{*}{1537597} & \multirow[b]{2}{*}{5.0} & \\
\hline & & & 6.8389 & TST & \\
\hline & 1537597 & 5.0 & 6.8151 & TST & \\
\hline CHEMBL3727866 & 1537597 & 5.0 & 5.4029 & TST & \\
\hline CHEMBL3731386 & 1537597 & 7.0 & 7.1876 & TRN & \\
\hline CHEMBL3730825 & 1537597 & 6.0 & 5.2119 & TRN & \\
\hline CHEMBL3728314 & 1537597 & 6.0 & 6.3972 & TRN & \\
\hline CHEMBL3730153 & 1537597 & 5.0 & 4.4568 & TST & \\
\hline CHEMBL3732216 & 1537597 & 8.0 & \multicolumn{2}{|c|}{7.247000000000001} & TRN \\
\hline CHEMBL3731132 & 1537597 & 7.0 & 6.8781 & TRN & \\
\hline CHEMBL3732834 & 1537597 & 6.0 & 6.5841 & TRN & \\
\hline CHEMBL3732295 & 1537597 & 7.0 & 7.6922 & TRN & \\
\hline CHEMBL3728500 & 1537597 & 6.0 & 6.3502 & TRN & \\
\hline CHEMBL3729368 & 1537597 & 7.0 & 6.7973 & TRN & \\
\hline CHEMBL3732559 & 1537597 & 6.0 & 6.9055 & TST & \\
\hline CHEMBL 3732670 & 1537597 & 6.0 & 5.8372 & TRN & \\
\hline CHEMBL3731054 & 1537597 & 6.0 & 7.3329 & TST & \\
\hline CHEMBL3731582 & 1537597 & 6.0 & 6.4272 & TRN & \\
\hline CHEMBL3729562 & 1537597 & 5.0 & \multicolumn{2}{|c|}{6.617000000000001} & TST \\
\hline CHEMBL3731205 & 1537597 & 6.0 & 6.6428 & TRN & \\
\hline CHEMBL 3727560 & 1537597 & 5.0 & 5.8704 & TST & \\
\hline CHEMBL3730364 & 1537597 & 6.0 & 6.1346 & TRN & \\
\hline CHEMBL3732972 & 1537597 & 7.0 & 7.0485 & TRN & \\
\hline CHEMBL3731806 & 1537597 & 7.0 & 6.9386 & TRN & \\
\hline CHEMBL3728783 & 1537597 & 5.0 & 4.9724 & TRN & \\
\hline CHEMBL3729491 & 1537597 & 7.0 & 7.0102 & TRN & \\
\hline CHEMBL 3728424 & 1537597 & 6.0 & 5.9953 & TRN & \\
\hline CHEMBL3728175 & 1537597 & 7.0 & 6.8787 & TRN & \\
\hline CHEMBL3728881 & 1537597 & 7.0 & 6.9655 & TRN & \\
\hline CHEMBL 3727387 & 1537597 & 5.0 & 5.2118 & TST & \\
\hline CHEMBL3731261 & 1537597 & 6.0 & 6.2605 & TRN & \\
\hline CHEMBL 3732862 & 1537597 & 6.0 & 5.6935 & TRN & \\
\hline CHEMBL3732553 & 1537597 & 6.0 & 4.5944 & TST & \\
\hline CHEMBL3730660 & 1537597 & 7.0 & 7.3236 & TRN & \\
\hline CHEMBL3727941 & 1537597 & 7.0 & 6.9704 & TRN & \\
\hline CHEMBL 3727773 & 1537597 & 6.0 & 6.1947 & TRN & \\
\hline CHEMBL3730395 & 1537597 & 7.0 & 6.6463 & TRN & \\
\hline CHEMBL3732082 & 1537597 & 7.0 & 6.7891 & TST & \\
\hline CHEMBL 3727561 & 1537597 & 7.0 & 6.7004 & TRN & \\
\hline CHEMBL3730731 & 1537597 & 6.0 & 7.0817 & TST & \\
\hline CHEMBL3729212 & 1537597 & 6.0 & \multicolumn{2}{|c|}{6.127000000000001} & TST \\
\hline CHEMBL3729119 & 1537597 & 6.0 & 6.6811 & TRN & \\
\hline CHEMBL3732476 & 1537597 & 5.0 & 4.3512 & TST & \\
\hline CHEMBL3732666 & 1537597 & 5.0 & 4.5711 & TRN & \\
\hline CHEMBL 3728087 & 1537597 & 6.0 & 7.1327 & TST & \\
\hline CHEMBL3728004 & 1537597 & 7.0 & 7.0521 & TRN & \\
\hline CHEMBL 3733296 & 1537597 & 8.0 & 7.3642 & TRN & \\
\hline CHEMBL3731598 & 1537597 & 6.0 & 6.4149 & TRN & \\
\hline \multirow[t]{2}{*}{ CHEMBL3728535 } & 1537597 & 6.0 & \multicolumn{2}{|c|}{5.1370000000000005} & TST \\
\hline & & & & ge 4604 & \\
\hline
\end{tabular}




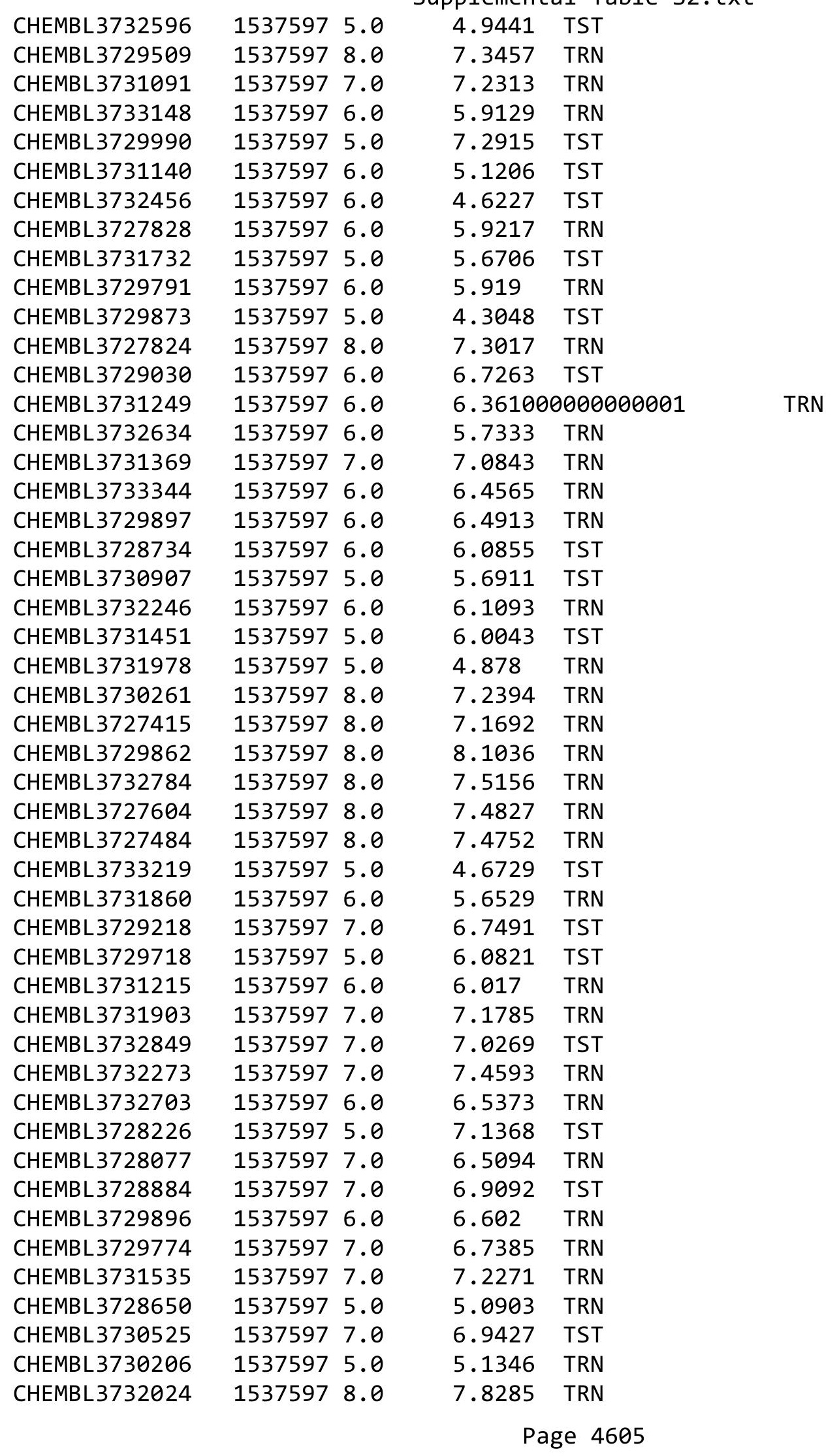




\begin{tabular}{|c|c|c|c|c|}
\hline & & & $p p+e m e$ & al Ta \\
\hline CHEMBL3733268 & 1537597 & 5.0 & 6.4344 & TRN \\
\hline CHEMBL3729501 & 1537597 & 8.0 & 7.5692 & TRN \\
\hline CHEMBL3728045 & 1537597 & 7.0 & 7.0332 & TRN \\
\hline CHEMBL3727913 & 1537597 & 7.0 & 6.95 & TRN \\
\hline CHEMBL 3730943 & 1537597 & 6.0 & 5.9311 & TRN \\
\hline CHEMBL 3732977 & 1537597 & 5.0 & 4.6975 & TST \\
\hline CHEMBL3732193 & 1537597 & 5.0 & 4.9069 & TRN \\
\hline CHEMBL3730158 & 1537597 & 7.0 & 6.6462 & TRN \\
\hline CHEMBL 3728221 & 1537597 & 8.0 & 7.4029 & TRN \\
\hline CHEMBL3731407 & 1537597 & 6.0 & 6.1616 & TRN \\
\hline CHEMBL 3732723 & 1537597 & 6.0 & 6.1725 & TRN \\
\hline CHEMBL3728652 & 1537597 & 7.0 & 6.2949 & TRN \\
\hline CHEMBL3732053 & 1537597 & 6.0 & 7.0717 & TRN \\
\hline CHEMBL3730369 & 1537597 & 5.0 & 6.3613 & TST \\
\hline CHEMBL 3730528 & 1537597 & 6.0 & 6.9245 & TST \\
\hline CHEMBL 3730128 & 1537597 & 6.0 & 6.3586 & TRN \\
\hline CHEMBL3731640 & 1537597 & 7.0 & 6.9432 & TRN \\
\hline CHEMBL3731136 & 1537597 & 7.0 & 7.2393 & TST \\
\hline CHEMBL3729107 & 1537597 & 6.0 & 6.0848 & TRN \\
\hline CHEMBL3730201 & 1537597 & 5.0 & 5.2602 & TRN \\
\hline CHEMBL 3731101 & 1537597 & 7.0 & 6.2741 & TRN \\
\hline CHEMBL3728164 & 1537597 & 6.0 & 5.6137 & TRN \\
\hline CHEMBL 3727971 & 1537597 & 7.0 & 6.7272 & TRN \\
\hline CHEMBL3731899 & 1537597 & 5.0 & 5.4853 & TRN \\
\hline CHEMBL 3730262 & 1537597 & 7.0 & 7.3001 & TRN \\
\hline CHEMBL 3728387 & 1537597 & 7.0 & 6.7626 & TST \\
\hline CHEMBL3729436 & 1537597 & 7.0 & 7.1369 & TRN \\
\hline CHEMBL 3732000 & 1537597 & 6.0 & 6.0102 & TRN \\
\hline CHEMBL 3728567 & 1537597 & 5.0 & 3.9018 & TST \\
\hline CHEMBL3730235 & 1537597 & 5.0 & 6.1365 & TST \\
\hline CHEMBL3728330 & 1537597 & 6.0 & 6.5699 & TRN \\
\hline CHEMBL3729433 & 1537597 & 5.0 & 5.6826 & TRN \\
\hline CHEMBL 3729331 & 1537597 & 7.0 & 7.1869 & TRN \\
\hline CHEMBL3733276 & 1537597 & 6.0 & 6.3693 & TRN \\
\hline CHEMBL 3731000 & 1537597 & 5.0 & 5.0989 & TRN \\
\hline CHEMBL3731177 & 1537597 & 5.0 & 5.0063 & TRN \\
\hline CHEMBL3732355 & 1537597 & 6.0 & 4.9269 & TST \\
\hline CHEMBL 3731902 & 1537597 & 5.0 & 5.7891 & TRN \\
\hline CHEMBL 3732623 & 1537597 & 6.0 & 6.1726 & TRN \\
\hline CHEMBL 3728980 & 1537597 & 8.0 & 7.3561 & TRN \\
\hline CHEMBL3731803 & 1537597 & 5.0 & 4.6425 & TRN \\
\hline CHEMBL3731951 & 1537597 & 6.0 & 6.2077 & TRN \\
\hline CHEMBL 3730412 & 1537597 & 7.0 & 7.4701 & TRN \\
\hline CHEMBL3728039 & 1537597 & 7.0 & 6.6939 & TRN \\
\hline CHEMBL3729396 & 1537597 & 5.0 & 5.9743 & TST \\
\hline CHEMBL3728069 & 1537597 & 5.0 & 6.8748 & TST \\
\hline CHEMBL3730360 & 1537597 & 6.0 & 5.8241 & TRN \\
\hline CHEMBL 3727522 & 1537597 & 7.0 & 7.1877 & TRN \\
\hline
\end{tabular}




\begin{tabular}{|c|c|c|c|c|c|}
\hline \multicolumn{6}{|c|}{ Supplemental Table S2.txt } \\
\hline CHEMBL 3729728 & 1537597 & 6.0 & 6.8102 & TRN & \\
\hline CHEMBL 2048042 & 826120 & 6.9208 & 6.9192 & TRN & \\
\hline CHEMBL 2047888 & 826120 & 6.4559 & 6.4569 & TRN & \\
\hline CHEMBL 2047889 & 826120 & 7.2596 & 7.2558 & TRN & \\
\hline CHEMBL 2048048 & 826120 & 7.0 & 7.0058 & TRN & \\
\hline CHEMBL 2047899 & 826120 & 6.9208 & 6.9237 & TRN & \\
\hline CHEMBL 2047894 & 826120 & 5.7905 & 5.7789 & TRN & \\
\hline CHEMBL 2048053 & 826120 & 8.699 & 8.7184 & TRN & \\
\hline CHEMBL 2047893 & 826120 & 6.8861 & 6.8802 & TRN & \\
\hline CHEMBL2047914 & 826120 & 6.1739 & 6.1885 & TRN & \\
\hline CHEMBL 2048054 & 826120 & 8.3979 & 8.3931 & TRN & \\
\hline CHEMBL2047900 & 826120 & 6.699 & 6.6946 & TRN & \\
\hline CHEMBL 2048040 & 826120 & 7.9586 & 7.9536 & TRN & \\
\hline CHEMBL 2048047 & 826120 & 8.699 & 8.7063 & TRN & \\
\hline CHEMBL 2048056 & 826120 & 4.0 & 7.7502 & TST & \\
\hline CHEMBL 2047912 & 826120 & 7.3098 & 7.3059 & TRN & \\
\hline CHEMBL 2047896 & 826120 & 6.6576 & 6.6564 & TRN & \\
\hline CHEMBL 2047911 & 826120 & 6.8861 & 6.899 & TRN & \\
\hline CHEMBL 2048046 & 826120 & 7.1249 & 7.1134 & TRN & \\
\hline CHEMBL2047915 & 826120 & 7.3468 & 7.34 & TRN & \\
\hline CHEMBL 2047913 & 826120 & 7.1079 & 7.1049 & TRN & \\
\hline CHEMBL2048039 & 826120 & 7.6198 & 7.6126 & TRN & \\
\hline CHEMBL 2048044 & 826120 & 8.2218 & 8.2206 & TRN & \\
\hline CHEMBL 2047908 & 826120 & 7.5528 & 7.5553 & TRN & \\
\hline CHEMBL 2048041 & 826120 & 7.6021 & 7.6181 & TRN & \\
\hline CHEMBL 2047901 & 826120 & 6.8539 & 7.3383 & TST & \\
\hline CHEMBL2047905 & 826120 & 8.0969 & 8.0882 & TRN & \\
\hline CHEMBL 2048063 & 826120 & 8.1549 & 8.1707 & TRN & \\
\hline CHEMBL 2048055 & 826120 & 4.0 & 6.8228 & TST & \\
\hline CHEMBL 2047906 & 826120 & 7.284 & 7.28700 & 0000000001 & TRN \\
\hline CHEMBL 2047892 & 826120 & 6.8861 & 6.8895 & TRN & \\
\hline CHEMBL2047910 & 826120 & 6.8239 & 6.8246 & TRN & \\
\hline CHEMBL 2047898 & 826120 & 7.2596 & 7.2611 & TRN & \\
\hline CHEMBL 2048057 & 826120 & 7.1675 & 7.1594 & TRN & \\
\hline CHEMBL 2048050 & 826120 & 8.5229 & 8.5278 & TRN & \\
\hline CHEMBL 2048049 & 826120 & 7.3665 & 7.3488 & TRN & \\
\hline CHEMBL 2047907 & 826120 & 7.0269 & 7.0238 & TRN & \\
\hline CHEMBL2047909 & 826120 & 7.1024 & 7.1025 & TRN & \\
\hline CHEMBL 2048058 & 826120 & 8.699 & 8.6881 & TRN & \\
\hline CHEMBL 2047890 & 826120 & 6.8539 & 6.8636 & TRN & \\
\hline CHEMBL 2047887 & 826120 & 7.2596 & 7.1898 & TST & \\
\hline CHEMBL 2047897 & 826120 & 5.5607 & 5.5544 & TRN & \\
\hline CHEMBL2048059 & 826120 & 8.699 & 8.68700 & 0000000001 & TRN \\
\hline CHEMBL 2047891 & 826120 & 5.8633 & 5.8722 & TRN & \\
\hline CHEMBL 2048045 & 826120 & 8.2218 & 8.2139 & TRN & \\
\hline CHEMBL 2048038 & 826120 & 7.2518 & 7.2675 & TRN & \\
\hline CHEMBL 2048037 & 826120 & 7.4437 & 7.9032 & TST & \\
\hline CHEMBL 2047895 & 826120 & 5.8386 & 6.3586 & TST & \\
\hline
\end{tabular}




\begin{tabular}{|c|c|c|c|c|c|}
\hline \multirow[b]{2}{*}{ CHEMBL 2048060} & \multicolumn{5}{|c|}{ Supplemental Table S2.txt } \\
\hline & 826120 & 8.2218 & 8.254 & TST & \\
\hline CHEMBL 78946 & 826120 & 8.699 & 6.8527 & TST & \\
\hline CHEMBL 2048062 & 826120 & 7.4437 & 7.4221 & TST & \\
\hline CHEMBL 2048043 & 826120 & 7.3665 & 7.4284 & TST & \\
\hline CHEMBL 2047904 & 826120 & 6.0605 & 6.8622 & TST & \\
\hline CHEMBL 2047903 & 826120 & 7.2147 & 6.4317 & TST & \\
\hline CHEMBL 2048061 & 826120 & 7.3565 & 7.5907 & TST & \\
\hline CHEMBL 2047902 & 826120 & 6.2518 & 7.6587 & TST & \\
\hline CHEMBL554360 & 585475 & 6.66 & 6.4701 & TRN & \\
\hline CHEMBL556155 & 585475 & 7.23 & 7.001 & TRN & \\
\hline CHEMBL555903 & 585475 & 7.38 & 6.9991 & TRN & \\
\hline CHEMBL539463 & 585475 & 7.85 & 7.1901 & TRN & \\
\hline CHEMBL553420 & 585475 & 8.01 & 7.2665 & TRN & \\
\hline CHEMBL541233 & 585475 & 6.2 & 7.8333 & TST & \\
\hline CHEMBL539145 & 585475 & 6.44 & 7.1901 & TRN & \\
\hline CHEMBL539464 & 585475 & 6.76 & 6.8061 & TRN & \\
\hline CHEMBL553339 & 585475 & 7.41 & 7.3265 & TRN & \\
\hline CHEMBL557552 & 585475 & 7.47 & 7.3217 & TRN & \\
\hline CHEMBL553421 & 585475 & 6.66 & 6.8012 & TRN & \\
\hline CHEMBL555686 & 585475 & 7.86 & 7.5059 & TRN & \\
\hline CHEMBL553422 & 585475 & 7.45 & 7.1876 & TST & \\
\hline CHEMBL553253 & 585475 & 5.92 & 6.53700 & 0000000001 & TRN \\
\hline CHEMBL555687 & 585475 & 7.22 & 7.027 & TRN & \\
\hline CHEMBL541996 & 585475 & 7.59 & 7.7001 & TRN & \\
\hline CHEMBL558758 & 585475 & 7.69 & 7.3513 & TRN & \\
\hline CHEMBL558154 & 585475 & 6.28 & 7.0092 & TST & \\
\hline CHEMBL562774 & 585475 & 7.37 & 6.7356 & TST & \\
\hline CHEMBL404613 & 585475 & 8.45 & 7.3456 & TRN & \\
\hline CHEMBL553886 & 585475 & 6.53 & 7.115 & TRN & \\
\hline CHEMBL290484 & 585475 & 7.36 & 7.9606 & TRN & \\
\hline CHEMBL288604 & 585475 & 8.4 & 8.0237 & TRN & \\
\hline CHEMBL43485 & 585475 & 7.92 & 8.0307 & TRN & \\
\hline CHEMBL 288073 & 585475 & 7.67 & 7.9694 & TRN & \\
\hline CHEMBL289602 & 585475 & 7.73 & 7.9379 & TRN & \\
\hline CHEMBL290925 & 585475 & 8.04 & 8.0048 & TRN & \\
\hline CHEMBL405152 & 585475 & 7.92 & 8.0255 & TRN & \\
\hline CHEMBL291252 & 585475 & 7.96 & 7.8847 & TRN & \\
\hline CHEMBL43037 & 585475 & 8.16 & 7.8312 & TRN & \\
\hline CHEMBL44234 & 585475 & 7.31 & 7.8022 & TRN & \\
\hline CHEMBL42446 & 585475 & 7.97 & 7.4802 & TRN & \\
\hline CHEMBL558356 & 585475 & 7.62 & 7.6099 & TRN & \\
\hline CHEMBL559333 & 585475 & 7.77 & 8.0113 & TRN & \\
\hline CHEMBL553254 & 585475 & 8.03 & 7.7366 & TRN & \\
\hline CHEMBL526653 & 585475 & 8.3 & 7.9248 & TRN & \\
\hline CHEMBL553185 & 585475 & 7.59 & 7.8563 & TRN & \\
\hline CHEMBL557972 & 585475 & 6.92 & 8.3863 & TRN & \\
\hline CHEMBL558759 & 585475 & 6.67 & 7.5591 & TST & \\
\hline CHEMBL549879 & 585475 & 4.82 & 6.8 & TST & \\
\hline & & & & 4608 & \\
\hline
\end{tabular}




\begin{tabular}{|c|c|c|c|c|c|}
\hline \multicolumn{6}{|c|}{ Supplemental Table S2.txt } \\
\hline CHEMBL539721 & 585475 & 5.04 & 6.6002 & TRN & \\
\hline CHEMBL289601 & 585475 & 8.77 & 7.7744 & TRN & \\
\hline CHEMBL553626 & 585475 & 9.13 & 8.9674 & TRN & \\
\hline CHEMBL556156 & 585475 & 8.67 & 9.0224 & TRN & \\
\hline CHEMBL553255 & 585475 & 8.94 & 8.5554 & TRN & \\
\hline CHEMBL539017 & 585475 & 8.32 & 7.6459 & TST & \\
\hline CHEMBL563767 & 585475 & 8.48 & 7.9952 & TST & \\
\hline CHEMBL549860 & 585475 & 8.26 & 8.9998 & TST & \\
\hline CHEMBL564254 & 585475 & 8.79 & 8.9117 & TST & \\
\hline CHEMBL562775 & 585475 & 6.34 & 7.8034 & TST & \\
\hline CHEMBL553491 & 585475 & 7.01 & 7.5188 & TST & \\
\hline CHEMBL540230 & 585475 & 7.0 & 7.51399 & 9999999999 & TST \\
\hline CHEMBL24868 & 428967 & 2.699 & 3.8659 & TRN & \\
\hline CHEMBL 375855 & 428967 & 2.699 & 3.6604 & TRN & \\
\hline CHEMBL386932 & 428967 & 2.699 & 2.8781 & TRN & \\
\hline CHEMBL 375857 & 428967 & 5.4949 & 4.0303 & TRN & \\
\hline CHEMBL222681 & 428967 & 2.699 & 2.9502 & TRN & \\
\hline CHEMBL 273401 & 428967 & 2.699 & 3.3667 & TRN & \\
\hline CHEMBL 376637 & 428967 & 2.699 & 2.9144 & TST & \\
\hline CHEMBL222296 & 428967 & 5.0655 & 4.3528 & TRN & \\
\hline CHEMBL341903 & 428967 & 5.2857 & 3.5522 & TRN & \\
\hline CHEMBL221465 & 428967 & 2.699 & 2.5609 & TST & \\
\hline CHEMBL33917 & 428967 & 2.699 & 3.0014 & TRN & \\
\hline CHEMBL 384673 & 428967 & 2.699 & 2.8588 & TRN & \\
\hline CHEMBL222678 & 428967 & 4.5542 & 4.0596 & TST & \\
\hline CHEMBL 223508 & 428967 & 2.699 & 3.1341 & TST & \\
\hline CHEMBL386934 & 428967 & 4.7562 & 4.3499 & TRN & \\
\hline CHEMBL221668 & 428967 & 2.699 & 3.1441 & TRN & \\
\hline CHEMBL 222278 & 428967 & 2.699 & 3.8082 & TST & \\
\hline CHEMBL 222890 & 428967 & 4.02 & 3.8247 & TRN & \\
\hline CHEMBL221932 & 428967 & 2.699 & 4.4072 & TRN & \\
\hline CHEMBL221505 & 428967 & 2.699 & 2.6174 & TRN & \\
\hline CHEMBL 375641 & 428967 & 2.699 & 2.992 & TST & \\
\hline CHEMBL 222962 & 428967 & 2.699 & 3.3275 & TRN & \\
\hline CHEMBL374665 & 428967 & 2.699 & 2.72600 & 30000000004 & TRN \\
\hline CHEMBL223353 & 428967 & 4.8099 & 3.7687 & TRN & \\
\hline CHEMBL221945 & 428967 & 2.699 & 1.7927 & TST & \\
\hline CHEMBL 222305 & 428967 & 2.699 & 2.6855 & TRN & \\
\hline CHEMBL373856 & 428967 & 2.699 & 2.8012 & TRN & \\
\hline CHEMBL373688 & 428967 & 3.9586 & 4.5554 & TRN & \\
\hline CHEMBL222553 & 428967 & 4.0419 & 3.5958 & TRN & \\
\hline CHEMBL 222350 & 428967 & 2.699 & 2.5099 & TRN & \\
\hline CHEMBL 373583 & 428967 & 2.699 & 2.8596 & TRN & \\
\hline CHEMBL 374442 & 428967 & 4.4318 & 4.316 & TRN & \\
\hline CHEMBL222347 & 428967 & 2.699 & 2.9893 & TRN & \\
\hline CHEMBL 375331 & 428967 & 2.699 & 2.48 & TRN & \\
\hline CHEMBL223794 & 428967 & 2.699 & 3.1054 & TRN & \\
\hline CHEMBL 375152 & 428967 & 2.699 & 2.2813 & TRN & \\
\hline
\end{tabular}




\begin{tabular}{|c|c|c|c|c|}
\hline & & & oplement & al Ta \\
\hline CHEMBL 222082 & 428967 & 2.699 & 3.3905 & TRN \\
\hline CHEMBL11762 & 428967 & 2.699 & 2.5292 & TRN \\
\hline CHEMBL223795 & 428967 & 2.699 & 2.4556 & TRN \\
\hline CHEMBL 373471 & 428967 & 4.5745 & 4.209 & TRN \\
\hline CHEMBL222281 & 428967 & 2.699 & 3.2085 & TRN \\
\hline CHEMBL37488 & 428967 & 2.699 & 3.1753 & TST \\
\hline CHEMBL 375151 & 428967 & 4.3979 & 2.0852 & TST \\
\hline CHEMBL376421 & 428967 & 2.699 & 3.3064 & TRN \\
\hline CHEMBL 276888 & 428967 & 2.699 & 2.6771 & TST \\
\hline CHEMBL157159 & 428967 & 2.699 & 2.5273 & TRN \\
\hline CHEMBL 223205 & 428967 & 4.1944 & 4.0709 & TRN \\
\hline CHEMBL376267 & 428967 & 2.699 & 2.3019 & TRN \\
\hline CHEMBL222034 & 428967 & 3.9081 & 4.1218 & TRN \\
\hline CHEMBL222845 & 428967 & 2.699 & 2.9659 & TRN \\
\hline CHEMBL144939 & 428967 & 4.2997 & 3.2378 & TST \\
\hline CHEMBL376474 & 428967 & 2.699 & 2.7654 & TST \\
\hline CHEMBL 373473 & 428967 & 3.8447 & 4.3203 & TRN \\
\hline CHEMBL222571 & 428967 & 2.699 & 2.7949 & TRN \\
\hline CHEMBL221461 & 428967 & 3.9544 & 2.9252 & TST \\
\hline CHEMBL221982 & 428967 & 2.699 & 3.3485 & TRN \\
\hline CHEMBL 221458 & 428967 & 4.2596 & 3.3238 & TST \\
\hline CHEMBL 223308 & 428967 & 3.8928 & 3.2445 & TRN \\
\hline CHEMBL376060 & 428967 & 2.699 & 3.0272 & TRN \\
\hline CHEMBL1162943 & 428967 & 5.7799 & 4.372 & TRN \\
\hline CHEMBL376652 & 428967 & 2.699 & 2.6596 & TRN \\
\hline CHEMBL 222030 & 428967 & 3.9687 & 4.0397 & TRN \\
\hline CHEMBL 222031 & 428967 & 2.699 & 2.5215 & TST \\
\hline CHEMBL436531 & 428967 & 2.699 & 3.5969 & TRN \\
\hline CHEMBL 375608 & 428967 & 2.699 & 3.4739 & TRN \\
\hline CHEMBL 221618 & 428967 & 2.699 & 2.9381 & TRN \\
\hline CHEMBL 223474 & 428967 & 2.699 & 3.0528 & TRN \\
\hline CHEMBL 373876 & 428967 & 2.699 & 3.0991 & TRN \\
\hline CHEMBL 222744 & 428967 & 2.699 & 2.4827 & TST \\
\hline CHEMBL83737 & 428967 & 3.7394 & 4.7289 & TST \\
\hline CHEMBL 299315 & 428967 & 2.699 & 3.8845 & TST \\
\hline CHEMBL384674 & 428967 & 2.699 & 2.4469 & TRN \\
\hline CHEMBL 278418 & 428967 & 2.699 & 2.8899 & TRN \\
\hline CHEMBL419504 & 428967 & 5.3872 & 5.6118 & TRN \\
\hline CHEMBL222279 & 428967 & 2.699 & 3.0013 & TRN \\
\hline CHEMBL222781 & 428967 & 4.4751 & 4.0548 & TST \\
\hline CHEMBL 373370 & 428967 & 2.699 & 1.9799 & TRN \\
\hline CHEMBL 222631 & 428967 & 2.699 & 2.5217 & TRN \\
\hline CHEMBL433881 & 428967 & 3.8036 & 3.0663 & TST \\
\hline CHEMBL221939 & 428967 & 2.699 & 3.8268 & TRN \\
\hline CHEMBL 374499 & 428967 & 2.699 & 3.4981 & TRN \\
\hline CHEMBL 222692 & 428967 & 2.699 & 2.4662 & TRN \\
\hline CHEMBL 222957 & 428967 & 4.4685 & 4.3553 & TST \\
\hline CHEMBL299571 & 428967 & 2.699 & 3.0197 & TST \\
\hline
\end{tabular}




\begin{tabular}{|c|c|c|c|c|}
\hline \multicolumn{5}{|c|}{ Supplemental Table s2.txt } \\
\hline CHEMBL 222779 & 428967 & 2.699 & 3.5002 & TRN \\
\hline CHEMBL 379296 & 428967 & 5.9706 & 3.9799 & TRN \\
\hline CHEMBL 374475 & 428967 & 2.699 & 2.8312 & TRN \\
\hline CHEMBL91024 & 428967 & 4.8894 & 4.2149 & TRN \\
\hline CHEMBL103283 & 428967 & 4.6126 & 3.9133 & TRN \\
\hline CHEMBL436212 & 428967 & 2.699 & 2.6223 & TRN \\
\hline CHEMBL90871 & 428967 & 5.1249 & 4.5735 & TRN \\
\hline CHEMBL 222623 & 428967 & 2.699 & 2.6464 & TRN \\
\hline CHEMBL 374550 & 428967 & 2.699 & 2.4452 & TRN \\
\hline CHEMBL 376278 & 428967 & 5.9208 & 4.3494 & TRN \\
\hline CHEMBL 223521 & 428967 & 2.699 & 3.0521 & TST \\
\hline CHEMBL17559 & 428967 & 2.699 & 2.6253 & TRN \\
\hline CHEMBL 221980 & 428967 & 2.699 & 2.5511 & TRN \\
\hline CHEMBL 222349 & 428967 & 3.9516 & 3.6345 & TRN \\
\hline CHEMBL 374738 & 428967 & 2.699 & 2.213 & TST \\
\hline CHEMBL48266 & 428967 & 4.4233 & 4.1324 & TST \\
\hline CHEMBL 375554 & 428967 & 2.699 & 3.2404 & TST \\
\hline CHEMBL38170 & 428967 & 4.4053 & 4.8212 & TRN \\
\hline CHEMBL 385313 & 428967 & 2.699 & 3.9614 & TRN \\
\hline CHEMBL109792 & 428967 & 2.699 & 3.5582 & TST \\
\hline CHEMBL 223737 & 428967 & 6.2441 & 3.4746 & TST \\
\hline CHEMBL426899 & 428967 & 8.0 & 3.9323 & TST \\
\hline CHEMBL 376876 & 428967 & 5.0372 & 3.8476 & TRN \\
\hline CHEMBL43765 & 428967 & 4.7592 & 3.7723 & TRN \\
\hline CHEMBL 223160 & 428967 & 4.9914 & 3.6174 & TST \\
\hline CHEMBL 373885 & 428967 & 2.699 & 3.5814 & TRN \\
\hline CHEMBL 221624 & 428967 & 4.2676 & 4.5848 & TRN \\
\hline CHEMBL 374664 & 428967 & 4.8668 & 5.4485 & TRN \\
\hline CHEMBL 376217 & 428967 & 4.3008 & 4.0802 & TRN \\
\hline CHEMBL92041 & 428967 & 5.699 & 4.3235 & TRN \\
\hline CHEMBL 221520 & 428967 & 2.699 & 3.6336 & TRN \\
\hline CHEMBL 373690 & 428967 & 2.699 & 3.2306 & TRN \\
\hline CHEMBL 221881 & 428967 & 4.8861 & 3.7394 & TRN \\
\hline CHEMBL 375774 & 428967 & 2.699 & 2.9912 & TRN \\
\hline CHEMBL35179 & 428967 & 2.699 & 3.7527 & TST \\
\hline CHEMBL 221928 & 428967 & 4.8477 & 3.7986 & TRN \\
\hline CHEMBL 374663 & 428967 & 6.0757 & 3.6471 & TST \\
\hline CHEMBL446947 & 428967 & 2.699 & 2.8134 & TRN \\
\hline CHEMBL 222650 & 428967 & 2.699 & 2.8077 & TRN \\
\hline CHEMBL223592 & 428967 & 4.3503 & 3.8174 & TRN \\
\hline CHEMBL328116 & 428967 & 5.1249 & 4.7006 & TRN \\
\hline CHEMBL557811 & 428967 & 2.699 & 2.9388 & TST \\
\hline CHEMBL 222932 & 428967 & 6.4437 & 3.4968 & TRN \\
\hline CHEMBL 374473 & 428967 & 2.699 & 3.1444 & TRN \\
\hline CHEMBL 222624 & 428967 & 2.699 & 2.1692 & TRN \\
\hline CHEMBL 222740 & 428967 & 2.699 & 3.4968 & TST \\
\hline CHEMBL 376780 & 428967 & 2.699 & 2.7441 & TRN \\
\hline CHEMBL 83554 & 428967 & 2.699 & 4.1007 & TST \\
\hline
\end{tabular}




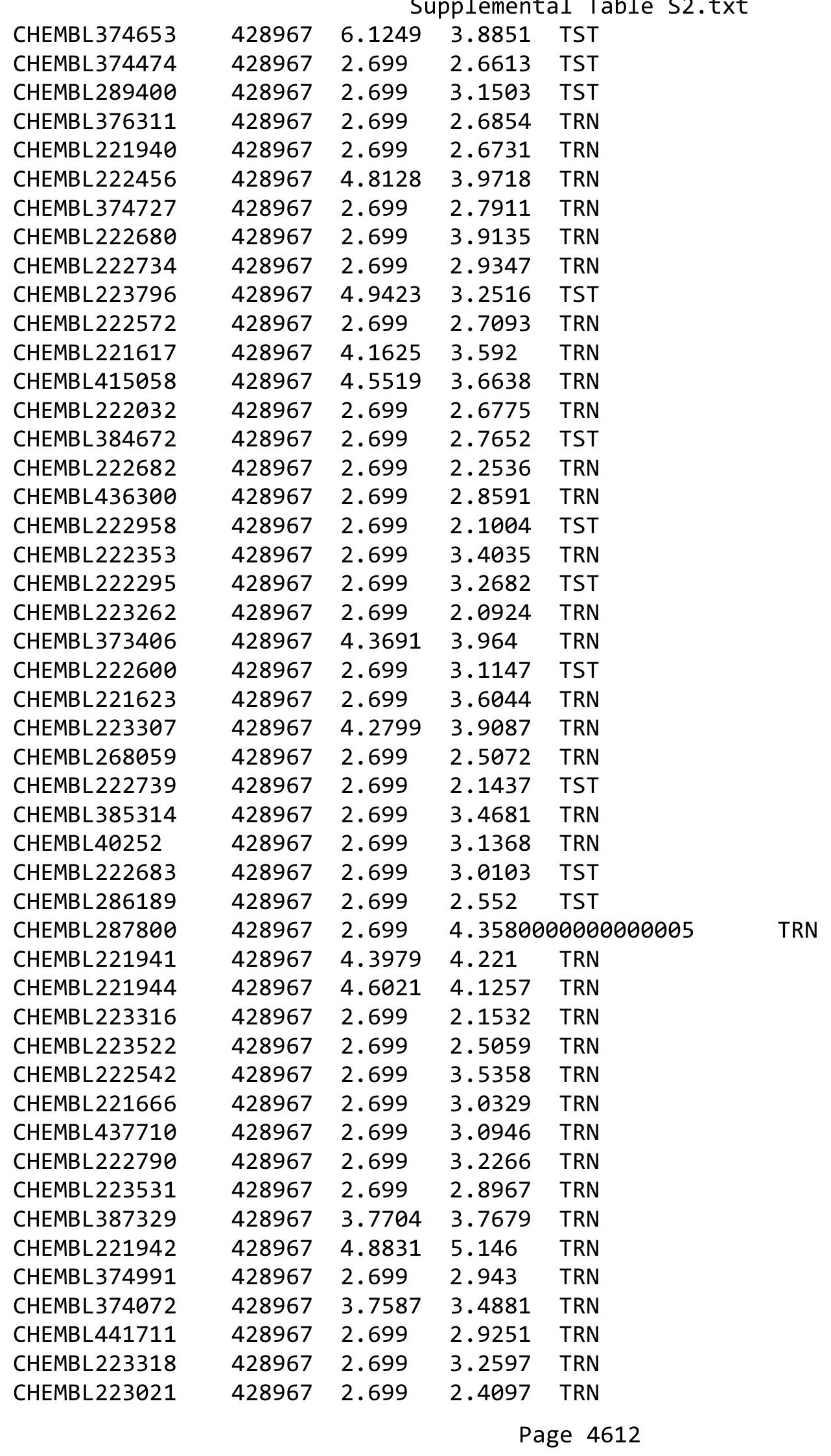




\begin{tabular}{|c|c|c|c|c|c|c|}
\hline & & \multicolumn{5}{|c|}{ Supplemental Table s2.txt } \\
\hline CHEMBL426739 & 428967 & 5.0737 & 5.1698 & TRN & & \\
\hline CHEMBL438462 & 428967 & 4.3665 & 4.0802 & TRN & & \\
\hline CHEMBL222302 & 428967 & 4.1031 & 3.7683 & TRN & & \\
\hline CHEMBL374753 & 428967 & 2.699 & 3.472 & TRN & & \\
\hline CHEMBL222780 & 428967 & 4.8193 & 3.1854 & TST & & \\
\hline CHEMBL222101 & 428967 & 2.699 & 3.0121 & TRN & & \\
\hline CHEMBL222693 & 428967 & 2.699 & 2.9075 & TRN & & \\
\hline CHEMBL426736 & 428967 & 2.699 & 3.965 & TRN & & \\
\hline CHEMBL376074 & 428967 & 2.699 & 2.9696 & TRN & & \\
\hline CHEMBL222643 & 428967 & 2.699 & 2.5694 & TRN & & \\
\hline CHEMBL375987 & 428967 & 2.699 & 3.8291 & TST & & \\
\hline CHEMBL426892 & 428967 & 2.699 & 3.1562 & TRN & & \\
\hline CHEMBL223209 & 428967 & 2.699 & 3.0036 & TRN & & \\
\hline CHEMBL223213 & 428967 & 2.699 & 2.8604 & TRN & & \\
\hline CHEMBL145034 & 428967 & 3.8537 & 3.9815 & TST & & \\
\hline CHEMBL225274 & 428967 & 2.699 & 2.0208 & TST & & \\
\hline CHEMBL88616 & 428967 & 4.9355 & 5.3643 & TRN & & \\
\hline CHEMBL61733 & 428967 & \multicolumn{3}{|c|}{5.7620000000000005} & 3.4245 & TST \\
\hline CHEMBL 88434 & 428967 & 4.9136 & 5.4336 & TRN & & \\
\hline CHEMBL222839 & 428967 & 4.3634 & 4.2917 & TST & & \\
\hline CHEMBL221930 & 428967 & 2.699 & 2.7382 & TRN & & \\
\hline CHEMBL223015 & 428967 & 2.699 & 3.4728 & TRN & & \\
\hline CHEMBL376301 & 428967 & 2.699 & 2.6696 & TRN & & \\
\hline CHEMBL426554 & 428967 & 2.699 & 3.5986 & TRN & & \\
\hline CHEMBL373584 & 428967 & 2.699 & 2.6819 & TRN & & \\
\hline CHEMBL222352 & 428967 & 2.699 & 2.4101 & TRN & & \\
\hline CHEMBL373855 & 428967 & 2.699 & 3.3698 & TRN & & \\
\hline CHEMBL223019 & 428967 & 2.699 & 2.6242 & TST & & \\
\hline CHEMBL221943 & 428967 & 2.699 & 3.074 & TRN & & \\
\hline CHEMBL221466 & 428967 & 2.699 & 2.7915 & TRN & & \\
\hline CHEMBL385319 & 428967 & 2.699 & 2.5803 & TRN & & \\
\hline CHEMBL327570 & 428967 & 5.2924 & 5.1455 & TRN & & \\
\hline CHEMBL373371 & 428967 & 2.699 & 3.1705 & TST & & \\
\hline CHEMBL221622 & 428967 & 2.699 & 2.5316 & TRN & & \\
\hline CHEMBL11591 & 428967 & 2.699 & 2.3695 & TST & & \\
\hline CHEMBL288299 & 428967 & \multicolumn{3}{|c|}{ 3.7889999999999997 } & 4.2562 & $1 \mathrm{~K}$ \\
\hline CHEMBL356046 & 428967 & 2.699 & 2.4324 & TRN & & \\
\hline CHEMBL222000 & 428967 & 2.699 & 2.1302 & TRN & & \\
\hline CHEMBL 38333 & 428967 & 2.699 & 3.5949 & TST & & \\
\hline CHEMBL373407 & 428967 & 3.7696 & 3.7124 & TRN & & \\
\hline CHEMBL374711 & 428967 & 2.699 & 2.0604 & TRN & & \\
\hline CHEMBL222552 & 428967 & 5.2262 & 4.1174 & TRN & & \\
\hline CHEMBL222961 & 428967 & 2.699 & 2.8859 & TRN & & \\
\hline CHEMBL373755 & 428967 & 3.9785 & 3.6779 & TRN & & \\
\hline CHEMBL317488 & 428967 & 2.699 & 3.1468 & TST & & \\
\hline CHEMBL376449 & 428967 & 4.7545 & 3.9772 & TRN & & \\
\hline CHEMBL384669 & 428967 & 2.699 & 2.5397 & TRN & & \\
\hline CHEMBL221467 & 428967 & 2.699 & 2.4233 & TRN & & \\
\hline
\end{tabular}




\begin{tabular}{|c|c|c|c|c|c|}
\hline \multicolumn{6}{|c|}{ Supplemental Table S2.txt } \\
\hline CHEMBL221673 & 428967 & 3.983 & 3.8952 & TRN & \\
\hline CHEMBL 223746 & 428967 & 2.699 & 2.7428 & TRN & \\
\hline CHEMBL 222679 & 428967 & 3.7985 & 3.9578 & TST & \\
\hline CHEMBL 308037 & 428967 & 4.4364 & 4.1412 & TRN & \\
\hline CHEMBL 222730 & 428967 & 2.699 & 2.5984 & TST & \\
\hline CHEMBL435513 & 428967 & 2.699 & 2.7571 & TST & \\
\hline CHEMBL221981 & 428967 & 2.699 & 2.0878 & TST & \\
\hline CHEMBL374759 & 428967 & 3.7753 & 3.5018 & TRN & \\
\hline CHEMBL 222297 & 428967 & 2.699 & 3.464 & TRN & \\
\hline CHEMBL300434 & 428967 & 4.8536 & 4.3202 & TRN & \\
\hline CHEMBL195535 & 428967 & 6.8861 & 4.9062 & TRN & \\
\hline CHEMBL 223557 & 428967 & 2.699 & 3.4111 & TRN & \\
\hline CHEMBL3918978 & 428967 & 2.699 & 2.9513 & TRN & \\
\hline CHEMBL221724 & 428967 & 2.699 & 2.6789 & TRN & \\
\hline CHEMBL3981744 & 1535487 & 6.7447 & 6.7121 & TRN & \\
\hline CHEMBL 3968292 & 1535487 & 7.5376 & 7.6068 & TRN & \\
\hline CHEMBL 3946573 & 1535487 & 7.6021 & 7.6552 & TRN & \\
\hline CHEMBL3903014 & 1535487 & 4.699 & 4.6547 & TST & \\
\hline CHEMBL 3941295 & 1535487 & 4.1024 & 4.4759 & TST & \\
\hline CHEMBL3903501 & 1535487 & 5.8861 & 5.9623 & TRN & \\
\hline CHEMBL3981880 & 1535487 & 6.8539 & 6.8435 & TRN & \\
\hline CHEMBL 3923641 & 1535487 & 5.4318 & 5.1511 & TST & \\
\hline CHEMBL3986243 & 1535487 & 7.6383 & 7.5986 & TRN & \\
\hline CHEMBL 3891118 & 1535487 & 6.0 & 6.0243 & TRN & \\
\hline CHEMBL 3950802 & 1535487 & 6.9586 & 6.9742 & TRN & \\
\hline CHEMBL 3956453 & 1535487 & 4.3768 & 4.3551 & TRN & \\
\hline CHEMBL3979216 & 1535487 & 4.5376 & 4.5799 & TRN & \\
\hline CHEMBL3928910 & 1535487 & 7.8539 & 7.87799 & 9999999999 & TRN \\
\hline CHEMBL 3930255 & 1535487 & 4.5086 & 4.8579 & TST & \\
\hline CHEMBL3939329 & 1535487 & 6.1487 & 6.0779 & TRN & \\
\hline CHEMBL 3949861 & 1535487 & 6.284 & 6.2642 & TRN & \\
\hline CHEMBL 3951863 & 1535487 & 7.1024 & 7.1653 & TRN & \\
\hline CHEMBL3907579 & 1535487 & 6.1367 & 6.7974 & TST & \\
\hline CHEMBL 3965325 & 1535487 & 6.0 & 6.3828 & TST & \\
\hline CHEMBL 3927178 & 1535487 & 6.6021 & 6.7565 & TRN & \\
\hline CHEMBL 3889468 & 1535487 & 6.3188 & 5.949 & TST & \\
\hline CHEMBL 3941780 & 1535487 & 7.3872 & 6.8336 & TST & \\
\hline CHEMBL3931485 & 1535487 & 7.1739 & 7.2524 & TRN & \\
\hline CHEMBL 3956548 & 1535487 & 6.5686 & 6.5628 & TRN & \\
\hline CHEMBL 3889514 & 1535487 & 7.8539 & 7.8974 & TRN & \\
\hline CHEMBL 3897412 & 1535487 & 6.5528 & 6.8537 & TST & \\
\hline CHEMBL3912284 & 1535487 & 7.7447 & 7.7298 & TRN & \\
\hline CHEMBL3962909 & 1535487 & 6.2596 & 6.2829 & TRN & \\
\hline CHEMBL 3936617 & 1535487 & 7.6198 & 7.5174 & TRN & \\
\hline CHEMBL3956681 & 1535487 & 5.8239 & 5.0603 & TST & \\
\hline CHEMBL 3929974 & 1535487 & 7.6383 & 7.6483 & TRN & \\
\hline CHEMBL3899412 & 1535487 & 5.8539 & 5.8927 & TRN & \\
\hline CHEMBL3927839 & 1535487 & 7.3468 & 7.4547 & TRN & \\
\hline
\end{tabular}


Supplemental Table S2.txt

\begin{tabular}{|c|c|c|c|c|}
\hline CHEMBL3891523 & 1535487 & 6.4949 & 6.4473 & TRN \\
\hline CHEMBL3968146 & 1535487 & 8.0 & 7.9045 & TRN \\
\hline CHEMBL3966084 & 1535487 & 4.2441 & 4.317 & TRN \\
\hline CHEMBL 3893033 & 1535487 & 4.4437 & 4.4604 & TRN \\
\hline CHEMBL3980206 & 1535487 & 7.2291 & 7.2739 & TRN \\
\hline CHEMBL 3978292 & 1535487 & 3.7696 & 4.2387 & TST \\
\hline CHEMBL3951354 & 1535487 & 4.7696 & 4.7502 & TST \\
\hline CHEMBL3925189 & 1535487 & 7.9586 & 7.8245 & TRN \\
\hline CHEMBL 3957818 & 1535487 & 6.6198 & 6.5628 & TRN \\
\hline CHEMBL3976545 & 1535487 & 7.4949 & 7.4867 & TRN \\
\hline CHEMBL3913165 & 1535487 & 6.2676 & 6.2364 & TRN \\
\hline CHEMBL3902909 & 1535487 & 6.1871 & 6.1098 & TRN \\
\hline CHEMBL3923762 & 1535487 & 4.8239 & 4.7657 & TST \\
\hline CHEMBL3934591 & 1535487 & 7.6198 & 7.7539 & TRN \\
\hline CHEMBL3944784 & 1535487 & 5.9208 & 5.9226 & TRN \\
\hline CHEMBL 3974086 & 1535487 & 5.0088 & 4.755 & TST \\
\hline CHEMBL3978137 & 1535487 & 6.0862 & 5.9672 & TRN \\
\hline CHEMBL 3890198 & 1535487 & 7.5086 & 7.4274 & TRN \\
\hline CHEMBL3920710 & 1535487 & 7.3468 & 7.3767 & TRN \\
\hline CHEMBL3932028 & 1535487 & 7.0655 & 7.0726 & TRN \\
\hline CHEMBL3891899 & 1535487 & 7.1938 & 7.1871 & TRN \\
\hline CHEMBL3963335 & 1535487 & 7.8539 & 7.874 & TRN \\
\hline CHEMBL3909322 & 1535487 & 6.9586 & 6.76200 & 00000000005 \\
\hline CHEMBL3979774 & 1535487 & 5.8861 & 5.8991 & TRN \\
\hline CHEMBL 3951522 & 1535487 & 7.0177 & 6.9652 & TRN \\
\hline CHEMBL 3898688 & 1535487 & 7.7959 & 7.7335 & TRN \\
\hline CHEMBL3918710 & 1535487 & 7.6778 & 7.7344 & TRN \\
\hline CHEMBL3922666 & 1535487 & 5.8861 & 6.0268 & TRN \\
\hline CHEMBL3918735 & 1535487 & 7.4815 & 7.4153 & TRN \\
\hline CHEMBL 3900532 & 1535487 & 6.8539 & 6.8346 & TRN \\
\hline CHEMBL3973978 & 1535487 & 6.7696 & 6.7355 & TRN \\
\hline CHEMBL 3947960 & 1535487 & 6.301 & 6.3067 & TRN \\
\hline CHEMBL3960559 & 1535487 & 5.7959 & 5.8677 & TRN \\
\hline CHEMBL 3896425 & 1535487 & 7.7696 & 7.8142 & TRN \\
\hline CHEMBL 3975175 & 1535487 & 7.8539 & 7.4962 & TST \\
\hline CHEMBL3896567 & 1535487 & 4.2007 & 4.1802 & TRN \\
\hline CHEMBL3891812 & 1535487 & 6.0 & 5.8461 & TST \\
\hline CHEMBL3917965 & 1535487 & 6.2366 & 6.1803 & TRN \\
\hline CHEMBL3915512 & 1535487 & 6.0605 & 6.0523 & TRN \\
\hline CHEMBL3924539 & 1535487 & 7.9208 & 7.9873 & TRN \\
\hline CHEMBL3927165 & 1535487 & 5.3872 & 5.324 & TRN \\
\hline CHEMBL3890446 & 1535487 & 7.7696 & 7.8255 & TRN \\
\hline CHEMBL3900799 & 1535487 & 5.1024 & 4.9161 & TST \\
\hline CHEMBL3953750 & 1535487 & 4.5686 & 4.4751 & TRN \\
\hline CHEMBL3918246 & 1535487 & 6.2007 & 6.1793 & TRN \\
\hline CHEMBL3967625 & 1535487 & 7.6383 & 7.7181 & TRN \\
\hline CHEMBL3957770 & 1535487 & 5.699 & 5.7072 & TRN \\
\hline CHEMBL3927454 & 1535487 & 6.0862 & 6.1454 & TRN \\
\hline
\end{tabular}


Supplemental Table S2.txt

\begin{tabular}{|c|c|c|c|c|c|}
\hline CHEMBL3943974 & 1535487 & 5.8539 & 6.3159 & TST & \\
\hline CHEMBL3968802 & 1535487 & 5.0862 & 4.9066 & TST & \\
\hline CHEMBL3906236 & 1535487 & 7.9208 & 7.7353 & TRN & \\
\hline CHEMBL3900945 & 1535487 & 6.4815 & 6.5225 & TRN & \\
\hline CHEMBL3911776 & 1535487 & 7.7696 & 7.7246 & TRN & \\
\hline CHEMBL3930995 & 1535487 & 5.4202 & 5.3633 & TRN & \\
\hline CHEMBL3978477 & 1535487 & 4.5686 & 5.1541 & TST & \\
\hline CHEMBL3933237 & 1535487 & 6.2596 & 6.2401 & TRN & \\
\hline CHEMBL3953503 & 1535487 & 6.0 & 6.0156 & TRN & \\
\hline CHEMBL 3973068 & 1535487 & 6.1675 & 6.1637 & TRN & \\
\hline CHEMBL3983024 & 1535487 & 6.5086 & 6.5993 & TRN & \\
\hline CHEMBL3893013 & 1535487 & 7.8539 & 7.8466 & TRN & \\
\hline CHEMBL3968479 & 1535487 & 7.4559 & 7.5529 & TRN & \\
\hline CHEMBL3929540 & 1535487 & 4.2218 & 4.2634 & TRN & \\
\hline CHEMBL3889471 & 1535487 & 7.5376 & 7.5409 & TRN & \\
\hline CHEMBL3902039 & 1535487 & 5.1675 & 5.2367 & TRN & \\
\hline CHEMBL3969866 & 1535487 & 7.7959 & 7.7702 & TRN & \\
\hline CHEMBL3944639 & 1535487 & 5.6778 & 5.7009 & TRN & \\
\hline CHEMBL3916593 & 1535487 & 4.6383 & 4.6304 & TRN & \\
\hline CHEMBL3979534 & 1535487 & 7.9586 & 7.8675 & TRN & \\
\hline CHEMBL3982131 & 1535487 & 5.6778 & 5.2225 & TST & \\
\hline CHEMBL3957412 & 1535487 & 7.7696 & 7.8884 & TRN & \\
\hline CHEMBL3982093 & 1535487 & 5.4949 & 5.50700 & 0000000001 & TRN \\
\hline CHEMBL3937939 & 1535487 & 7.1024 & 6.7593 & TST & \\
\hline CHEMBL3926889 & 1535487 & 4.0223 & 3.9915 & TRN & \\
\hline CHEMBL3898669 & 1535487 & 6.0177 & 6.3625 & TST & \\
\hline CHEMBL3938927 & 1535487 & 6.8239 & 6.9239 & TST & \\
\hline CHEMBL3973548 & 1535487 & 4.9586 & 5.6633 & TST & \\
\hline CHEMBL3927650 & 1535487 & 7.7959 & 7.7841 & TRN & \\
\hline CHEMBL3923665 & 1535487 & 7.1739 & 6.7402 & TST & \\
\hline CHEMBL 3898841 & 1535487 & 4.1079 & 4.42 & TST & \\
\hline CHEMBL3955137 & 1535487 & 7.6778 & 7.6567 & TRN & \\
\hline CHEMBL3986735 & 1535487 & 4.2291 & 4.1831 & TST & \\
\hline CHEMBL3905355 & 1535487 & 6.1675 & 6.1768 & TRN & \\
\hline CHEMBL3892861 & 1535487 & 7.6198 & 7.6874 & TRN & \\
\hline CHEMBL3915350 & 1535487 & 6.2291 & 6.1582 & TRN & \\
\hline CHEMBL 3905294 & 1535487 & 7.6778 & 7.6681 & TRN & \\
\hline CHEMBL3897612 & 1535487 & 7.0044 & 7.0131 & TRN & \\
\hline CHEMBL3980098 & 1535487 & 7.6576 & 7.6242 & TRN & \\
\hline CHEMBL3953188 & 1535487 & 7.3565 & 7.3123 & TRN & \\
\hline CHEMBL3979285 & 1535487 & 7.1135 & 7.0526 & TRN & \\
\hline CHEMBL3902555 & 1535487 & 5.699 & 5.1628 & TST & \\
\hline CHEMBL3909039 & 1535487 & 6.3468 & 5.7994 & TST & \\
\hline CHEMBL3890949 & 1535487 & 7.7212 & 7.7432 & TRN & \\
\hline CHEMBL3974902 & 1535487 & 7.9208 & 7.9187 & TRN & \\
\hline CHEMBL3909957 & 1535487 & 7.8539 & 7.8437 & TRN & \\
\hline CHEMBL3935686 & 1535487 & 6.8861 & 6.7994 & TST & \\
\hline CHEMBL3975033 & 1535487 & 7.4559 & 7.5585 & TRN & \\
\hline
\end{tabular}


Supplemental Table S2.txt

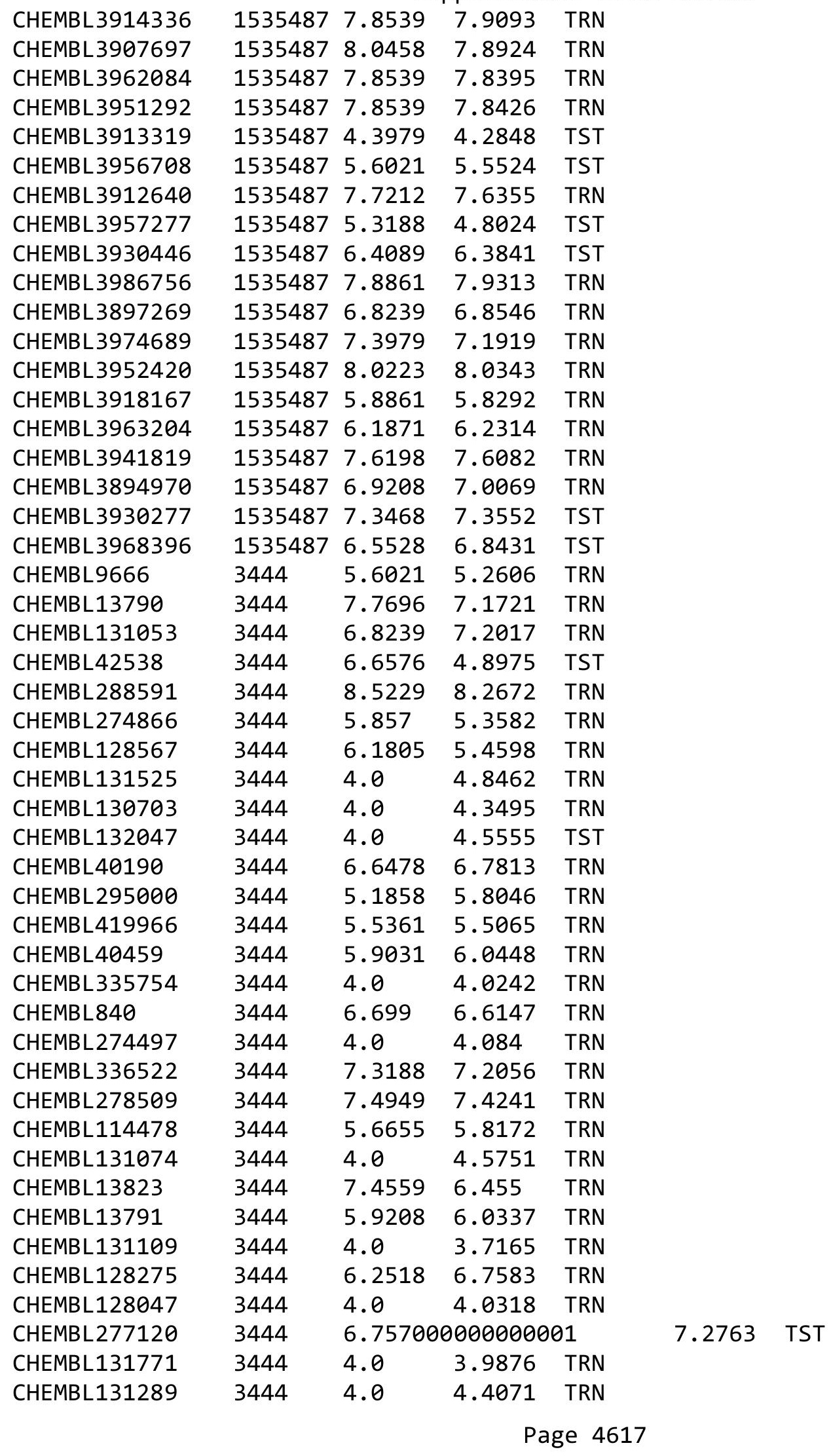




\begin{tabular}{|c|c|c|c|c|c|}
\hline \multirow[b]{2}{*}{ CHEMBL131223 } & \multicolumn{5}{|c|}{ Supplemental Table S2.txt } \\
\hline & 3444 & 5.8386 & 5.1309 & TST & \\
\hline CHEMBL40488 & 3444 & 5.9208 & 6.0142 & TRN & \\
\hline CHEMBL478 & 3444 & 7.2076 & 5.74200 & 0000000001 & TST \\
\hline CHEMBL44236 & 3444 & 5.2441 & 5.4617 & TRN & \\
\hline CHEMBL336107 & 3444 & 4.0 & 3.9415 & TRN & \\
\hline CHEMBL289319 & 3444 & 6.1079 & 5.529 & TRN & \\
\hline CHEMBL14047 & 3444 & 5.6308 & 5.2031 & TRN & \\
\hline CHEMBL42752 & 3444 & 7.2076 & 7.2634 & TRN & \\
\hline CHEMBL129481 & 3444 & 4.0 & 4.793 & TST & \\
\hline CHEMBL41040 & 3444 & 6.4949 & 5.8866 & TRN & \\
\hline CHEMBL20969 & 3444 & 4.0 & 4.3486 & TST & \\
\hline CHEMBL337213 & 3444 & 7.4202 & 7.14 & TST & \\
\hline CHEMBL43798 & 3444 & 7.3979 & 7.0994 & TRN & \\
\hline CHEMBL128071 & 3444 & 4.0 & 4.1844 & TRN & \\
\hline CHEMBL335877 & 3444 & 6.8996 & 3.8726 & TST & \\
\hline CHEMBL334036 & 3444 & 4.0 & 3.9186 & TST & \\
\hline CHEMBL291064 & 3444 & 4.0 & 4.1424 & TRN & \\
\hline CHEMBL45773 & 3444 & 7.8239 & 6.4371 & TST & \\
\hline CHEMBL130698 & 3444 & 4.0 & 3.5272 & TRN & \\
\hline CHEMBL43078 & 3444 & 7.9208 & 8.301 & TRN & \\
\hline CHEMBL131570 & 3444 & 5.9208 & 6.6832 & TRN & \\
\hline CHEMBL 76495 & 3444 & 4.0 & 7.371 & TST & \\
\hline CHEMBL129150 & 3444 & 6.6144 & 6.9167 & TRN & \\
\hline CHEMBL 9434 & 3444 & 5.5229 & 5.5563 & TST & \\
\hline CHEMBL40567 & 3444 & 7.6021 & 7.6605 & TRN & \\
\hline CHEMBL41853 & 3444 & 6.7212 & 6.6034 & TRN & \\
\hline CHEMBL59517 & 3444 & 5.7852 & 5.8718 & TST & \\
\hline CHEMBL131145 & 3444 & 4.0 & 3.9153 & TRN & \\
\hline CHEMBL61778 & 3444 & 7.3979 & 4.7536 & TST & \\
\hline CHEMBL43459 & 3444 & 5.7959 & 5.8941 & TRN & \\
\hline CHEMBL3651102 & 1528716 & 6.5528 & 5.9349 & TRN & \\
\hline CHEMBL3651112 & 1528716 & 6.2596 & 5.983 & TRN & \\
\hline CHEMBL 3651146 & 1528716 & 6.7447 & 6.1985 & TST & \\
\hline CHEMBL3920115 & 1528716 & 5.5528 & 5.7479 & TRN & \\
\hline CHEMBL3651103 & 1528716 & 6.3872 & 6.1948 & TRN & \\
\hline CHEMBL3651117 & 1528716 & 6.7212 & 6.2139 & TST & \\
\hline CHEMBL3651130 & 1528716 & 5.71 & 6.8887 & TRN & \\
\hline CHEMBL3651123 & 1528716 & 6.5229 & 6.2935 & TST & \\
\hline CHEMBL3651098 & 1528716 & 5.3468 & 6.2088 & TST & \\
\hline CHEMBL313833 & 1528716 & 4.6021 & 6.17299 & 9999999999 & TST \\
\hline CHEMBL3639499 & 1528716 & 6.6778 & 6.1279 & TRN & \\
\hline CHEMBL 3651120 & 1528716 & 6.7959 & 6.3168 & TRN & \\
\hline CHEMBL3651129 & 1528716 & 6.4437 & 6.5451 & TRN & \\
\hline CHEMBL3651135 & 1528716 & 6.2924 & 6.814 & TRN & \\
\hline CHEMBL3651127 & 1528716 & 5.3468 & 5.9043 & TRN & \\
\hline CHEMBL3651100 & 1528716 & 5.6383 & 6.1418 & TRN & \\
\hline CHEMBL3651131 & 1528716 & 6.6576 & 6.6059 & TRN & \\
\hline CHEMBL3651113 & 1528716 & 6.8539 & 6.2529 & TRN & \\
\hline
\end{tabular}


Supplemental Table S2.txt

\begin{tabular}{|c|c|c|c|c|}
\hline HEMB I & 28716 & 6.5528 & 6.3882 & \\
\hline & 528716 & 6.5229 & & \\
\hline 143 & 28716 & & & \\
\hline AEMBL & & & & \\
\hline AEMBL3651128 & 528716 & & & \\
\hline HEMBL3651140 & 528716 & 7.3979 & .3134 & \\
\hline 096 & 16 & & & \\
\hline 104 & 716 & & 87 & \\
\hline AEMBL3651151 & 716 & & & \\
\hline HEMBL3651109 & 528716 & & 9379 & \\
\hline AEMBL3651152 & 716 & & & \\
\hline IEMBL36 & 16 & & & \\
\hline AEMBL36 & & & & \\
\hline HEMBL36 & 716 & & & \\
\hline HEMBL365 & 16 & & & \\
\hline AEMBL365 & 16 & & 12 & \\
\hline AEMBL3 & 6 & & & \\
\hline HEMBL36 & & & & \\
\hline HEMBL36 & 16 & & & \\
\hline AEMBL3S & & & & \\
\hline AEMBL3 & 6 & & & II \\
\hline AEMBL & 6 & & & 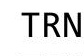 \\
\hline HEMBL & & & & \\
\hline 323 & & & & \\
\hline AEMBL36 & & & & r \\
\hline HEMBL3 & 6 & & & RN \\
\hline HEMBL & & & & 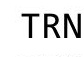 \\
\hline HFMBI 3 & 16 & & & \\
\hline HEMBL36 & & & & r \\
\hline HEMBL3651110 & & & & s \\
\hline HEMBL36 & & & & RN \\
\hline HEMBL; & & & & Niv \\
\hline AEMBL3 & & & & 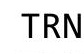 \\
\hline HEMBL3651111 & & & & IR \\
\hline HEMBL3651115 & 6 & & 364 & ГRN \\
\hline HEMBL36 & & & 53 & RN \\
\hline HFMRI 3 & & 9 & & RN \\
\hline HEMBL3 & & & & TRN \\
\hline HEMBL3651101 & 16 & & & $\Gamma R$ \\
\hline AEMBL 365 & 6 & & & TRN \\
\hline HEMBL36 & & & & \\
\hline HEMBL 36 & & & & RN \\
\hline HEMBL36 & & 6.7 & 181 & TST \\
\hline HEMBL3134375 & 16 & 6. & 365 & TST \\
\hline 30 & & & & 13.2 \\
\hline HEMBL36 & & & & \\
\hline LHEMBL3651147 & 716 & : an & 1797 & \\
\hline CHEMBL1600302 & 737068 & 4.9133 & 4.6101 & ГRN \\
\hline
\end{tabular}

Page 4619 


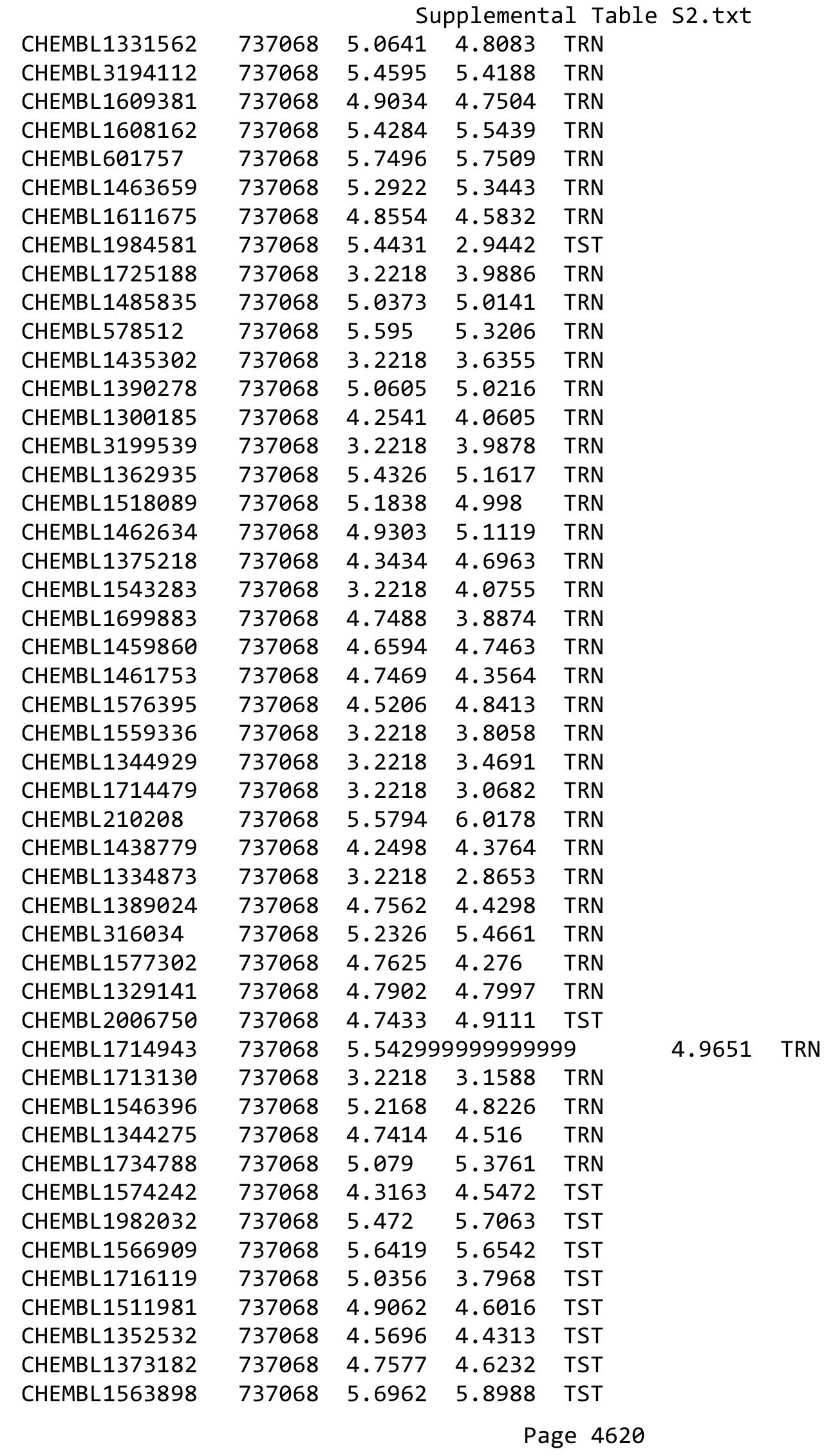




\begin{tabular}{|c|c|c|c|c|}
\hline \multicolumn{5}{|c|}{ Supplemental Table S2.txt } \\
\hline CHEMBL1573966 & 737068 & 5.1813 & 5.0785 & TST \\
\hline CHEMBL1610382 & 737068 & 5.0311 & 4.8773 & TST \\
\hline CHEMBL1525274 & 737068 & 6.1912 & 4.8644 & TST \\
\hline CHEMBL1242288 & 654926 & 5.8827 & 6.4444 & TRN \\
\hline CHEMBL1241771 & 654926 & 5.585 & 5.7519 & TRN \\
\hline CHEMBL1241240 & 654926 & 5.301 & 5.6745 & TST \\
\hline CHEMBL1241483 & 654926 & 6.0841 & 6.2377 & TRN \\
\hline CHEMBL1241104 & 654926 & 5.7959 & 5.6468 & TST \\
\hline CHEMBL1241772 & 654926 & 5.3686 & 5.9653 & TRN \\
\hline CHEMBL1242573 & 654926 & 5.4685 & 6.3755 & TRN \\
\hline CHEMBL1242027 & 654926 & 6.059 & 6.501 & TRN \\
\hline CHEMBL1241269 & 654926 & 6.6021 & 6.1092 & TST \\
\hline CHEMBL1242853 & 654926 & 6.0381 & 6.5278 & TRN \\
\hline CHEMBL1241682 & 654926 & 6.9914 & 6.9301 & TRN \\
\hline CHEMBL1242114 & 654926 & 6.6737 & 7.5893 & TRN \\
\hline CHEMBL1241767 & 654926 & 4.3188 & 6.0973 & TST \\
\hline CHEMBL1242116 & 654926 & 4.0 & 5.4856 & TST \\
\hline CHEMBL1241775 & 654926 & 5.0915 & 5.9331 & TRN \\
\hline CHEMBL1242287 & 654926 & 7.7212 & 7.4089 & TRN \\
\hline CHEMBL1240565 & 654926 & 6.9208 & 6.9017 & TRN \\
\hline CHEMBL1241582 & 654926 & 5.8697 & 6.256 & TRN \\
\hline CHEMBL1242111 & 654926 & 6.7328 & 6.6474 & TST \\
\hline CHEMBL1241675 & 654926 & 7.2757 & 6.1723 & TST \\
\hline CHEMBL1241943 & 654926 & 6.7471 & 6.1653 & TRN \\
\hline CHEMBL1242206 & 654926 & 5.0 & 5.53 & TST \\
\hline CHEMBL1241489 & 654926 & 6.699 & 6.2003 & TRN \\
\hline CHEMBL1242476 & 654926 & 8.0 & 6.7217 & TRN \\
\hline CHEMBL1242024 & 654926 & 6.7212 & 6.5293 & TRN \\
\hline CHEMBL1242110 & 654926 & 6.6003 & 6.6765 & TRN \\
\hline CHEMBL1241301 & 654926 & 6.8239 & 7.1999 & TRN \\
\hline CHEMBL1242202 & 654926 & 6.8097 & 7.2755 & TRN \\
\hline CHEMBL1242566 & 654926 & 6.4737 & 6.605 & TRN \\
\hline CHEMBL1242665 & 654926 & 6.6536 & 5.6213 & TST \\
\hline CHEMBL1240554 & 654926 & 6.6162 & 6.7616 & TRN \\
\hline CHEMBL1242661 & 654926 & 6.585 & 5.5857 & TRN \\
\hline CHEMBL1241492 & 654926 & 5.9208 & 5.8124 & TRN \\
\hline CHEMBL1241482 & 654926 & 5.433 & 5.4039 & TST \\
\hline CHEMBL1242376 & 654926 & 7.5229 & 7.3624 & TRN \\
\hline CHEMBL1242754 & 654926 & 6.4989 & 6.3892 & TRN \\
\hline CHEMBL1242662 & 654926 & 7.0 & 6.9427 & TRN \\
\hline CHEMBL1242201 & 654926 & 6.9547 & 7.4025 & TRN \\
\hline CHEMBL1241858 & 654926 & 5.7144 & 5.9171 & TRN \\
\hline CHEMBL1242757 & 654926 & 6.0209 & 6.1312 & TST \\
\hline CHEMBL1242385 & 654926 & 6.6126 & 6.5789 & TRN \\
\hline CHEMBL1242756 & 654926 & 7.4437 & 6.7092 & TRN \\
\hline CHEMBL1242199 & 654926 & 6.0367 & 6.4287 & TRN \\
\hline CHEMBL1241683 & 654926 & 7.0969 & 7.1569 & TRN \\
\hline CHEMBL1242758 & 654926 & 6.032 & 6.3133 & TST \\
\hline
\end{tabular}


Supplemental Table S2.txt

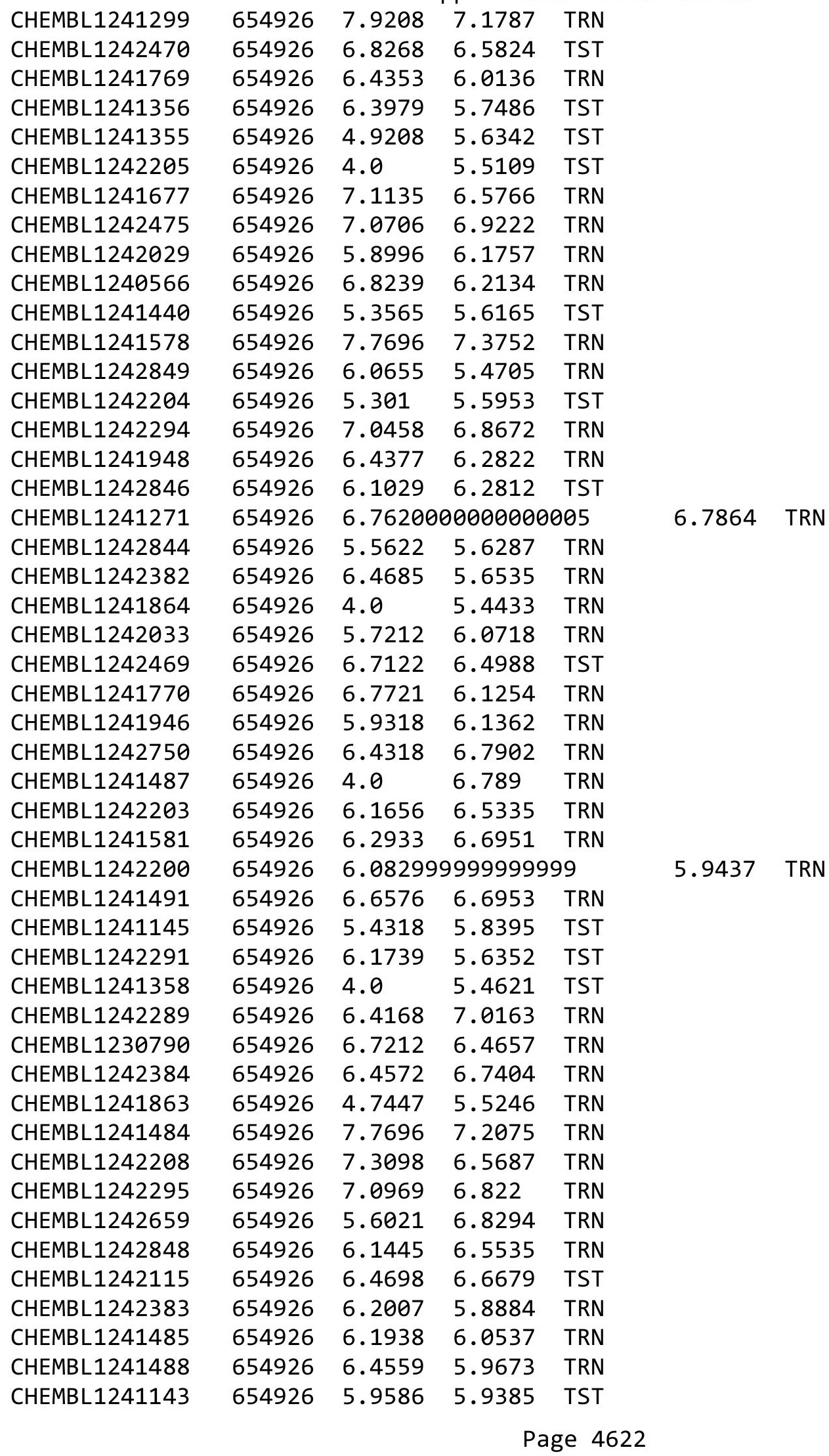


Supplemental Table S2.txt

\begin{tabular}{|c|c|c|c|c|c|}
\hline CHEMBL1242026 & 654926 & 6.6737 & 7.2066 & TRN & \\
\hline CHEMBL1242847 & 654926 & 6.4802 & 6.2039 & TRN & \\
\hline CHEMBL1241587 & 654926 & 6.2628 & 6.4282 & TST & \\
\hline CHEMBL1242569 & 654926 & 6.2549 & 6.3612 & TRN & \\
\hline CHEMBL1241776 & 654926 & 9.301 & 7.2362 & TRN & \\
\hline CHEMBL1241774 & 654926 & 6.8996 & 6.8102 & TRN & \\
\hline CHEMBL1242472 & 654926 & 6.0721 & 6.3331 & TRN & \\
\hline CHEMBL1242381 & 654926 & 6.0 & 6.4744 & TRN & \\
\hline CHEMBL1241585 & 654926 & 5.6778 & 5.5867 & TRN & \\
\hline CHEMBL1241270 & 654926 & 6.3206 & 6.3757 & TST & \\
\hline CHEMBL1242198 & 654926 & 6.1337 & 6.3828 & TRN & \\
\hline CHEMBL1242574 & 654926 & 7.0555 & 6.624 & TRN & \\
\hline CHEMBL1242657 & 654926 & 6.0 & 6.42899 & & TRN \\
\hline CHEMBL1241389 & 654926 & 5.301 & 5.8303 & TST & \\
\hline CHEMBL1242379 & 654926 & 5.8861 & 5.9322 & TRN & \\
\hline CHEMBL1242473 & 654926 & 6.3979 & 5.8895 & TRN & \\
\hline CHEMBL1242113 & 654926 & 6.6696 & 7.2883 & TRN & \\
\hline CHEMBL1241588 & 654926 & 6.3107 & 6.3505 & TST & \\
\hline CHEMBL1242209 & 654926 & 6.4449 & 6.686 & TRN & \\
\hline CHEMBL1241142 & 654926 & 5.8861 & 5.8179 & TST & \\
\hline CHEMBL1241950 & 654926 & 6.5031 & 6.7517 & TRN & \\
\hline CHEMBL1241586 & 654926 & 6.7305 & 6.1294 & TRN & \\
\hline CHEMBL1242117 & 654926 & 6.5482 & 5.7574 & TRN & \\
\hline CHEMBL1233882 & 654926 & 8.0969 & 7.2958 & TRN & \\
\hline CHEMBL1241684 & 654926 & 6.5406 & 6.3221 & TST & \\
\hline CHEMBL1242032 & 654926 & 6.0487 & 6.2022 & TRN & \\
\hline CHEMBL1240594 & 654926 & 7.0706 & 6.1647 & TST & \\
\hline CHEMBL1240567 & 654926 & 6.0555 & 5.9743 & TST & \\
\hline CHEMBL1242851 & 654926 & 6.6778 & 6.0448 & TRN & \\
\hline CHEMBL1241391 & 654926 & 4.9957 & 5.4209 & TRN & \\
\hline CHEMBL1241144 & 654926 & 5.1487 & 5.6982 & TST & \\
\hline CHEMBL1241949 & 654926 & 7.8539 & 7.2849 & TRN & \\
\hline CHEMBL1242028 & 654926 & 7.3188 & 6.9572 & TRN & \\
\hline CHEMBL1241947 & 654926 & 6.7352 & 6.5786 & TST & \\
\hline CHEMBL1242474 & 654926 & 5.9586 & \multicolumn{2}{|c|}{5.843999999999999} & TRN \\
\hline CHEMBL1242570 & 654926 & 5.9586 & 5.8606 & TRN & \\
\hline CHEMBL1242664 & 654926 & 7.2676 & 6.644 & TRN & \\
\hline CHEMBL1242386 & 654926 & 6.9788 & 6.9238 & TRN & \\
\hline CHEMBL1242572 & 654926 & 6.9586 & 6.8172 & TRN & \\
\hline CHEMBL1241580 & 654926 & 7.3665 & 7.0622 & TRN & \\
\hline CHEMBL1242752 & 654926 & 6.2007 & 6.4604 & TRN & \\
\hline CHEMBL1242286 & 654926 & 6.6615 & 6.4525 & TRN & \\
\hline CHEMBL1241486 & 654926 & 5.2366 & 5.7665 & TRN & \\
\hline CHEMBL1242477 & 654926 & 7.1135 & 6.7766 & TRN & \\
\hline CHEMBL1241439 & 654926 & 6.1325 & 6.4948 & TST & \\
\hline CHEMBL1241681 & 654926 & 7.3279 & \multicolumn{2}{|c|}{6.928999999999999} & TRN \\
\hline CHEMBL1241944 & 654926 & 8.0458 & 6.9645 & TRN & \\
\hline CHEMBL1241390 & 654926 & 5.5607 & 6.0369 & TRN & \\
\hline
\end{tabular}




\begin{tabular}{|c|c|c|c|c|c|c|}
\hline & & \multicolumn{5}{|c|}{ Supplemental Table S2.txt } \\
\hline CHEMBL1242207 & 654926 & 5.5686 & 5.994 & TRN & & \\
\hline CHEMBL1242031 & 654926 & 6.1469 & 6.3173 & TRN & & \\
\hline CHEMBL1241861 & 654926 & 4.0 & 5.9078 & TRN & & \\
\hline CHEMBL1242377 & 654926 & 7.0555 & 7.2351 & TRN & & \\
\hline CHEMBL 1241676 & 654926 & 7.8861 & 7.0351 & TRN & & \\
\hline CHEMBL1242748 & 654926 & 6.0 & 6.5062 & TRN & & \\
\hline CHEMBL1233881 & 654926 & 7.3279 & 7.0213 & TRN & & \\
\hline CHEMBL1242109 & 654926 & 6.4737 & 7.2322 & TRN & & \\
\hline CHEMBL1241945 & 654926 & 7.4437 & 7.5439 & TRN & & \\
\hline CHEMBL1241860 & 654926 & 6.6655 & 6.3747 & TRN & & \\
\hline CHEMBL1242751 & 654926 & 5.644 & 5.6649 & TRN & & \\
\hline CHEMBL1241241 & 654926 & 6.2076 & 6.4382 & TRN & & \\
\hline CHEMBL1242852 & 654926 & 6.3665 & 6.574 & TRN & & \\
\hline CHEMBL1231371 & 654926 & 6.3768 & 5.3997 & TRN & & \\
\hline CHEMBL1242293 & 654926 & 7.1487 & 7.1001 & TRN & & \\
\hline CHEMBL1241679 & 654926 & 5.9101 & 5.8722 & TRN & & \\
\hline CHEMBL1242030 & 654926 & 6.0092 & 6.0097 & TRN & & \\
\hline CHEMBL1241242 & 654926 & 6.3565 & 6.0703 & TST & & \\
\hline CHEMBL1242571 & 654926 & 6.5528 & 5.7571 & TRN & & \\
\hline CHEMBL1242034 & 654926 & 5.699 & 6.0959 & TRN & & \\
\hline CHEMBL1242656 & 654926 & 6.9706 & 6.834 & TRN & & \\
\hline CHEMBL1242845 & 654926 & 7.3098 & 5.978 & TST & & \\
\hline CHEMBL1242025 & 654926 & 4.6144 & 6.0554 & TST & & \\
\hline CHEMBL1081312 & 654926 & 7.2218 & 7.6235 & TRN & & \\
\hline CHEMBL 1242378 & 654926 & 6.0 & 6.7055 & TRN & & \\
\hline CHEMBL1242663 & 654926 & 5.9586 & 6.0275 & TST & & \\
\hline CHEMBL1242755 & 654926 & 6.6696 & 6.6843 & TRN & & \\
\hline CHEMBL 1241862 & 654926 & 6.24799 & 999999999 & 99 & 6.3207 & TRN \\
\hline CHEMBL1242850 & 654926 & 4.0 & 5.466 & TST & & \\
\hline CHEMBL1242112 & 654926 & 6.3372 & 6.9039 & TRN & & \\
\hline CHEMBL1242292 & 654926 & 4.0 & 5.4282 & TST & & \\
\hline CHEMBL1241584 & 654926 & 6.1079 & 6.2113 & TRN & & \\
\hline CHEMBL1241674 & 654926 & 6.3872 & 6.9726 & TST & & \\
\hline CHEMBL1242660 & 654926 & 5.4672 & 5.4294 & TRN & & \\
\hline CHEMBL1242753 & 654926 & 5.4157 & 5.9299 & TRN & & \\
\hline CHEMBL1241773 & 654926 & 5.7077 & 5.944 & TRN & & \\
\hline CHEMBL1234815 & 654926 & 7.5376 & 5.8643 & TRN & & \\
\hline CHEMBL1241441 & 654926 & 6.8239 & 6.0451 & TST & & \\
\hline CHEMBL1241357 & 654926 & 5.6198 & 5.7912 & TST & & \\
\hline CHEMBL1242568 & 654926 & 6.9586 & 6.7215 & TRN & & \\
\hline CHEMBL1240553 & 654926 & 6.3344 & 6.8592 & TRN & & \\
\hline CHEMBL1241300 & 654926 & 6.2396 & 6.68 & TST & & \\
\hline CHEMBL1242285 & 654926 & 6.51 & 6.218999 & 9999999999 & & TRN \\
\hline CHEMBL1242666 & 654926 & 7.7212 & 6.9552 & TRN & & \\
\hline CHEMBL1242567 & 654926 & 6.6162 & 6.1543 & TRN & & \\
\hline CHEMBL1241490 & 654926 & 6.5186 & 6.5352 & TRN & & \\
\hline CHEMBL1241583 & 654926 & 6.05399 & 999999999 & 99 & 6.0193 & TRN \\
\hline CHEMBL1241680 & 654926 & 5.2218 & 5.6731 & TRN & & \\
\hline
\end{tabular}




\begin{tabular}{|c|c|c|c|c|c|}
\hline \multirow[b]{2}{*}{242290} & & \\
\hline & 654926 & 6.3575 & 6.6017 & TRN & \\
\hline CHEMBL1242471 & 654926 & 5.6946 & 5.8549 & TST & \\
\hline CHEMBL1240545 & 654926 & 5.5719 & 5.9725 & TRN & \\
\hline CHEMBL1242119 & 654926 & 7.3372 & 6.8367 & TRN & \\
\hline CHEMBL1241859 & 654926 & 6.3893 & 6.1367 & TRN & \\
\hline CHEMBL1242118 & 654926 & 6.585 & 6.3193 & TST & \\
\hline CHEMBL1241481 & 654926 & 5.1938 & 5.5576 & TST & \\
\hline CHEMBL 2327030 & 941545 & 4.6778 & 3.2846 & TRN & \\
\hline CHEMBL 2323897 & 941545 & 5.0 & 3.286 & TRN & \\
\hline CHEMBL 2323888 & 941545 & 4.4318 & 4.5073 & TRN & \\
\hline CHEMBL 2323898 & 941545 & 4.6021 & 4.4212 & TRN & \\
\hline CHEMBL 2323901 & 941545 & 3.0 & 4.1162 & TST & \\
\hline CHEMBL 2327035 & 941545 & 3.0 & 3.1574 & TRN & \\
\hline CHEMBL 2323895 & 941545 & 3.0 & 4.0063 & TRN & \\
\hline CHEMBL 2325807 & 941545 & 4.0655 & 3.658 & TRN & \\
\hline CHEMBL 2327032 & 941545 & 3.0 & 3.1038 & TRN & \\
\hline CHEMBL 2323883 & 941545 & 4.4815 & 3.9624 & TRN & \\
\hline CHEMBL 2323896 & 941545 & 3.0 & 4.0732 & TRN & \\
\hline CHEMBL494725 & 941545 & 4.0862 & 4.1444 & TRN & \\
\hline CHEMBL 2323885 & 941545 & 3.0 & 2.9473 & TRN & \\
\hline CHEMBL 2327028 & 941545 & 3.0 & \multicolumn{2}{|c|}{3.4130000000000003} & TRN \\
\hline CHEMBL 2327036 & 941545 & 3.0 & 3.063 & TRN & \\
\hline CHEMBL 2327041 & 941545 & 4.1612 & 3.9136 & TRN & \\
\hline CHEMBL 2327024 & 941545 & 4.0655 & 3.9706 & TST & \\
\hline CHEMBL 2327038 & 941545 & 3.0 & 3.0264 & TRN & \\
\hline CHEMBL 2323900 & 941545 & 4.7447 & 4.0381 & TST & \\
\hline CHEMBL 2327039 & 941545 & 3.0 & 3.6415 & TRN & \\
\hline CHEMBL 2327026 & 941545 & 4.4089 & \multicolumn{2}{|c|}{3.6180000000000003} & TST \\
\hline CHEMBL 2327040 & 941545 & 4.2924 & 4.2405 & TRN & \\
\hline CHEMBL 2323894 & 941545 & 4.3665 & 4.3152 & TRN & \\
\hline CHEMBL 2327027 & 941545 & 4.7212 & 3.7258 & TRN & \\
\hline CHEMBL 2323899 & 941545 & 4.6778 & 4.6019 & TRN & \\
\hline CHEMBL 2327019 & 941545 & 4.3979 & 4.5373 & TRN & \\
\hline CHEMBL 2327022 & 941545 & 4.301 & 4.1867 & TRN & \\
\hline CHEMBL 2323889 & 941545 & 4.4685 & 4.2446 & TRN & \\
\hline CHEMBL 2327014 & 941545 & 6.6126 & 4.4363 & TST & \\
\hline CHEMBL 2327021 & 941545 & 3.0 & 3.408 & TRN & \\
\hline CHEMBL 2327034 & 941545 & 3.0 & 3.1795 & TRN & \\
\hline CHEMBL 2327025 & 941545 & 3.0 & 3.7329 & TST & \\
\hline CHEMBL 2327013 & 941545 & 6.6819 & 4.3029 & TST & \\
\hline CHEMBL 2323892 & 941545 & 5.1549 & 4.4371 & TRN & \\
\hline CHEMBL 2323879 & 941545 & 3.0 & 3.7027 & TRN & \\
\hline CHEMBL 2327037 & 941545 & 3.0 & 3.1258 & TRN & \\
\hline CHEMBL2325806 & 941545 & 4.1308 & 4.2374 & TRN & \\
\hline CHEMBL 2327016 & 941545 & 3.0 & 3.9226 & TRN & \\
\hline CHEMBL 2323903 & 941545 & 7.3372 & 4.1496 & TST & \\
\hline CHEMBL 2327033 & 941545 & 3.0 & \multicolumn{2}{|c|}{3.3360000000000003} & TRN \\
\hline CHEMBL 2327029 & 941545 & 4.6383 & 3.8123 & TRN & \\
\hline
\end{tabular}




\begin{tabular}{|c|c|c|c|c|}
\hline \multicolumn{5}{|c|}{ Supplemental Table S2.txt } \\
\hline CHEMBL 2327015 & 941545 & 3.0 & 4.3268 & TST \\
\hline CHEMBL 2323890 & 941545 & 4.4559 & 4.474 & TST \\
\hline CHEMBL 2323882 & 941545 & 3.0 & 3.5104 & TRN \\
\hline CHEMBL 2323886 & 941545 & 3.0 & 2.9337 & TST \\
\hline CHEMBL 2327020 & 941545 & 4.4437 & 4.4111 & TRN \\
\hline CHEMBL 2323902 & 941545 & 7.3768 & 4.2825 & TST \\
\hline CHEMBL 2323884 & 941545 & 3.0 & 2.7717 & TST \\
\hline CHEMBL 2323880 & 941545 & 3.0 & 3.594 & TRN \\
\hline CHEMBL 2327031 & 941545 & 3.0 & 3.1803 & TRN \\
\hline CHEMBL 2327017 & 941545 & 4.3279 & 4.4493 & TRN \\
\hline CHEMBL 2323887 & 941545 & 3.0 & 3.3436 & TST \\
\hline CHEMBL 2323881 & 941545 & 3.0 & 3.2159 & TRN \\
\hline CHEMBL 2327018 & 941545 & 4.2924 & 4.3867 & TRN \\
\hline CHEMBL 2327023 & 941545 & 3.0 & 4.0755 & TST \\
\hline CHEMBL 2323891 & 941545 & 4.3768 & 4.5695 & TRN \\
\hline CHEMBL 2325805 & 941545 & 4.3372 & 3.847 & TRN \\
\hline CHEMBL 2323893 & 941545 & 5.0458 & 4.6924 & TRN \\
\hline CHEMBL1543954 & 954294 & 3.0969 & 3.0618 & TRN \\
\hline CHEMBL1444041 & 954294 & 3.0969 & 3.0405 & TRN \\
\hline CHEMBL1563728 & 954294 & 6.3143 & 5.1567 & TRN \\
\hline CHEMBL1565035 & 954294 & 3.0969 & 2.9943 & TRN \\
\hline CHEMBL3198149 & 954294 & 4.1107 & 3.1886 & TST \\
\hline CHEMBL1377901 & 954294 & 3.0969 & 3.3664 & TST \\
\hline CHEMBL1998521 & 954294 & 3.0969 & 3.7235 & TST \\
\hline CHEMBL 1358406 & 954294 & 6.1018 & 5.0588 & TRN \\
\hline CHEMBL 3199720 & 954294 & 3.0969 & 3.2567 & TST \\
\hline CHEMBL3192432 & 954294 & 3.0969 & 3.6158 & TST \\
\hline CHEMBL 1527010 & 954294 & 3.0969 & 3.2127 & TRN \\
\hline CHEMBL1488573 & 954294 & 3.0969 & 3.0556 & TRN \\
\hline CHEMBL1471980 & 954294 & 3.821 & 3.1902 & TRN \\
\hline CHEMBL1875381 & 954294 & 3.0969 & 3.1013 & TRN \\
\hline CHEMBL1369641 & 954294 & 3.0969 & 3.3257 & TRN \\
\hline CHEMBL1580410 & 954294 & 3.0969 & 3.0172 & TRN \\
\hline CHEMBL1307307 & 954294 & 3.0969 & 3.0971 & TRN \\
\hline CHEMBL1611135 & 954294 & 3.0969 & 3.6129 & TST \\
\hline CHEMBL 2361041 & 954294 & 3.0969 & 3.7273 & TST \\
\hline CHEMBL1715400 & 954294 & 3.0969 & 3.2217 & TRN \\
\hline CHEMBL1551497 & 954294 & 3.9281 & 3.1313 & TST \\
\hline CHEMBL1346409 & 954294 & 3.0969 & 3.2397 & TRN \\
\hline CHEMBL1441996 & 954294 & 3.0969 & 3.3245 & TRN \\
\hline CHEMBL1973773 & 954294 & 5.9101 & 3.3344 & TST \\
\hline CHEMBL1348131 & 954294 & 3.0969 & 3.2846 & TST \\
\hline CHEMBL 1352375 & 954294 & 3.0969 & 3.0306 & TRN \\
\hline CHEMBL1309803 & 954294 & 3.0969 & 3.3586 & TRN \\
\hline CHEMBL 1344542 & 954294 & 3.0969 & 3.3489 & TST \\
\hline CHEMBL1390055 & 954294 & 3.0969 & 2.9337 & TRN \\
\hline CHEMBL1604859 & 954294 & 3.0969 & 3.1004 & TRN \\
\hline CHEMBL1576803 & 954294 & 3.0969 & 2.9093 & TRN \\
\hline
\end{tabular}

Page 4626 
Supplemental Table S2.txt

\begin{tabular}{|c|c|c|c|c|}
\hline CHEMBL1366522 & 954294 & 3.0969 & 3.2656 & TRN \\
\hline CHEMBL1389050 & 954294 & 3.0969 & 3.3043 & TST \\
\hline CHEMBL1731619 & 954294 & 3.0969 & 2.7337 & TRN \\
\hline CHEMBL1599495 & 954294 & 3.0969 & 2.8529 & TRN \\
\hline CHEMBL1874169 & 954294 & 3.0969 & 3.4679 & TRN \\
\hline CHEMBL 2132071 & 954294 & 3.0969 & 3.8069 & TST \\
\hline CHEMBL 3209335 & 954294 & 3.0969 & 3.4331 & TRN \\
\hline CHEMBL1537342 & 954294 & 3.0969 & 3.2325 & TRN \\
\hline CHEMBL1465861 & 954294 & 3.0969 & 3.3808 & TST \\
\hline CHEMBL1477073 & 954294 & 3.0969 & 3.1974 & TRN \\
\hline CHEMBL1456727 & 954294 & 3.0969 & 2.9052 & TRN \\
\hline CHEMBL 2143103 & 954294 & 3.9172 & 3.3749 & TST \\
\hline CHEMBL1975294 & 954294 & 3.0969 & 3.9553 & TST \\
\hline CHEMBL1402279 & 954294 & 3.0969 & 2.5768 & TRN \\
\hline CHEMBL1346959 & 954294 & 3.0969 & 3.1378 & TST \\
\hline CHEMBL1397445 & 954294 & 3.0969 & 3.18899 & 99999999996 \\
\hline CHEMBL1430955 & 954294 & 3.0969 & 2.9729 & TRN \\
\hline CHEMBL1700590 & 954294 & 3.0969 & 3.4466 & TRN \\
\hline CHEMBL1304857 & 954294 & 3.0969 & 3.4412 & TRN \\
\hline CHEMBL1448148 & 954294 & 3.0969 & 3.1309 & TRN \\
\hline CHEMBL1736709 & 954294 & 3.0969 & 2.9984 & TST \\
\hline CHEMBL1332181 & 954294 & 3.0969 & 2.9404 & TRN \\
\hline CHEMBL1482497 & 954294 & 3.0969 & 3.34899 & 99999999998 \\
\hline CHEMBL1309171 & 954294 & 4.1798 & 3.2061 & TRN \\
\hline CHEMBL1326873 & 954294 & 3.0969 & 2.9446 & TRN \\
\hline CHEMBL1878561 & 954294 & 3.0969 & 3.2367 & TRN \\
\hline CHEMBL1732391 & 954294 & 3.0969 & 2.9755 & TRN \\
\hline CHEMBL1542947 & 954294 & 3.0969 & 2.9278 & TRN \\
\hline CHEMBL1426758 & 954294 & 3.0969 & 3.13 & TRN \\
\hline CHEMBL1572107 & 954294 & 3.0969 & 3.1599 & TRN \\
\hline CHEMBL1416844 & 954294 & 3.0969 & 3.2363 & TRN \\
\hline CHEMBL1342025 & 954294 & 3.0969 & 3.60399 & 99999999996 \\
\hline CHEMBL1390086 & 954294 & 3.0969 & 3.20899 & \\
\hline CHEMBL1403081 & 954294 & 3.0969 & 3.3847 & TRN \\
\hline CHEMBL1568544 & 954294 & 3.0969 & 3.3421 & TST \\
\hline CHEMBL1300035 & 954294 & 3.0969 & 3.0385 & TRN \\
\hline CHEMBL1596775 & 954294 & 3.0969 & 3.2159 & TRN \\
\hline CHEMBL1439590 & 954294 & 3.0969 & 2.7774 & TRN \\
\hline CHEMBL1497259 & 954294 & 3.0969 & 3.1764 & TRN \\
\hline CHEMBL1974818 & 954294 & 3.0969 & 3.0941 & TRN \\
\hline CHEMBL1381150 & 954294 & 3.0969 & 2.8355 & TRN \\
\hline CHEMBL1391188 & 954294 & 3.0969 & 3.29 & TRN \\
\hline CHEMBL1702042 & 954294 & 3.0969 & 2.8703 & TRN \\
\hline CHEMBL1984876 & 954294 & 3.0969 & 3.5795 & TST \\
\hline CHEMBL1576301 & 954294 & 7.1669 & 3.265 & TST \\
\hline CHEMBL1526732 & 954294 & 3.0969 & 3.1989 & TRN \\
\hline CHEMBL1885508 & 954294 & 3.0969 & 3.0251 & TRN \\
\hline CHEMBL1484341 & 954294 & 3.0969 & 3.1435 & TRN \\
\hline
\end{tabular}


Supplemental Table S2.txt

\begin{tabular}{|c|c|c|c|c|}
\hline 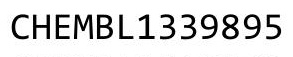 & & & & \\
\hline HEMBL1516503 & 294 & $\partial 969$ & 1373 & \\
\hline HEMBL1558084 & 54294 & 3969 & 213 & \\
\hline 362 & & 969 & 2489 & \\
\hline IEMBL1C & 94 & 969 & 1195 & \\
\hline HEMBL1613131 & 54294 & 969 & 9054 & \\
\hline HEMBL1558203 & 54294 & 969 & .5357 & \\
\hline HEMBL1702144 & 54294 & 969 & 9571 & \\
\hline 304 & 94 & 969 & 8164 & \\
\hline IEMBL1497771 & 94 & 969 & .8651 & \\
\hline HEMBL1536114 & 94 & 969 & 3692 & \\
\hline HEMBL 2358009 & 94 & 969 & 708 & \\
\hline HEMBL1323504 & 94 & 969 & 0312 & \\
\hline HEMBL1706704 & & 969 & 3704 & \\
\hline HEMBL1399754 & 4 & 969 & 4159 & \\
\hline HEMBL1905005 & 94 & 969 & 3741 & \\
\hline HEMBL1460084 & 94 & 969 & 1958 & \\
\hline HEMBL1379055 & 4 & 969 & 5883 & \\
\hline HEMBL1550586 & & 969 & 134 & \\
\hline HEMBL14 & & 969 & 161 & RN \\
\hline HEMBL1352714 & & 969 & 1127 & RN \\
\hline HEMBL1330429 & 4 & 969 & 106 & KIN \\
\hline HEMBL1493465 & 4 & 969 & 782 & 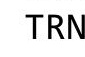 \\
\hline HEMBL1561066 & & 59 & 242 & RN \\
\hline 105 & & 969 & 46 & RN \\
\hline AEMBL1602482 & & 969 & & $M_{2}+2+3$ \\
\hline HEMBL1329663 & 4 & 969 & 757 & RN \\
\hline HEMBL3196324 & & 969 & 1945 & \\
\hline 971 & & 59 & 42 & RN \\
\hline 914 & & 969 & 974 & RN \\
\hline HEMBL1876750 & & 69 & 53 & RN \\
\hline HEMBL1997928 & 4 & 969 & 139 & TRN \\
\hline HEMBL1372213 & & 969 & 771 & ГRN \\
\hline 071 & & 59 & 369 & ST \\
\hline HEMBL1337942 & & 969 & 1056 & RN \\
\hline HEMBL1717545 & & 969 & 1875 & TRN \\
\hline HEMBL1876643 & & 969 & 3097 & ГRN \\
\hline HEMBL1347023 & & 969 & 715 & $\Gamma R N$ \\
\hline 2 & & & 168 & RN \\
\hline HEMBL1383436 & & & $\partial 842$ & RN \\
\hline HEMBL1722417 & & 969 & 1338 & TRN \\
\hline HEMBL1341726 & & 969 & 791 & $\mathrm{~K}$ \\
\hline HEMBL3212216 & & 811 & 258 & \\
\hline CHEMBL1576899 & & & 201 & RN \\
\hline HEMBL1326301 & & .0969 & 052 & RN \\
\hline HEMBL1376534 & 4 & 969 & 03 & 2N \\
\hline I. & & & 828 & \\
\hline & & & & \\
\hline
\end{tabular}


Supplemental Table S2.txt

\begin{tabular}{|c|c|c|c|c|}
\hline & & & & \\
\hline HEMBL2362691 & 54294 & 2969 & 8764 & \\
\hline AEMBL1722821 & 54294 & 51 & 3605 & \\
\hline & 294 & & 602 & \\
\hline AEMBL1384961 & 294 & & 764 & \\
\hline AEMBL1303028 & 54294 & 969 & 3058 & \\
\hline AEMBL1570834 & 54294 & 969 & 8648 & \\
\hline HEMBL1479477 & 294 & & 5546 & \\
\hline AEMBL1587375 & 94 & & 089 & \\
\hline AEMBL1396432 & & & & \\
\hline HEMBL3213414 & 954294 & 69 & 1322 & \\
\hline HEMBL1598299 & 294 & 69 & 8514 & \\
\hline HEMBL1381837 & & & & \\
\hline JEMBL149 & & & & \\
\hline HEMBL 143 & & & & \\
\hline AEMBL1572863 & & & 67 & \\
\hline AEMBL1604425 & & & & \\
\hline HEMBL1477697 & & & 744 & \\
\hline AEMBL1509254 & & & & \\
\hline AEMBL161 & & & & \\
\hline AEMBL1424402 & & & & \\
\hline AEMBL1701884 & & & & \\
\hline HEMBL 235 & & & & \\
\hline HEMBL14C & & & 78 & \\
\hline AFMBI 19 & & & 57 & \\
\hline HEMBL197 & & & & \\
\hline AEMBL1350111 & & & & \\
\hline AEMBL1896036 & & & 41 & \\
\hline AEM & & & & \\
\hline AFMRI 1 & & & & \\
\hline AEMBL1560839 & & & & \\
\hline HEMBL1572624 & & & & \\
\hline & & & & \\
\hline 1 & & & 874 & \\
\hline 30 & & & & $\mathrm{RN}$ \\
\hline AEMBL1580694 & & & & \\
\hline AEMBL1522818 & & & & \\
\hline & & & & \\
\hline קרי & & & & \\
\hline & & & & $\mathrm{RN}$ \\
\hline AEMBL1500793 & & & 599 & 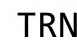 \\
\hline AEMBL1986765 & & & 62 & \\
\hline גו גרזו & & & & \\
\hline HEMBL1488308 & & & & \\
\hline AEMBL1516139 & & & 014 & RN \\
\hline EMBL1974230 & & & 3794 & \\
\hline CMOI 120 & & & & \\
\hline & & & & \\
\hline
\end{tabular}


Supplemental Table S2.txt

\begin{tabular}{|c|c|c|c|c|c|}
\hline CHEMBL1411649 & 954294 & 3.0969 & 3.322 & TRN & \\
\hline CHEMBL1410220 & 954294 & 3.0969 & 3.1092 & TST & \\
\hline CHEMBL1545741 & 954294 & 3.0969 & 2.7944 & TRN & \\
\hline CHEMBL1327921 & 954294 & 3.0969 & 3.2325 & TRN & \\
\hline CHEMBL 3196697 & 954294 & 3.0969 & 3.6738 & TST & \\
\hline CHEMBL 2360167 & 954294 & 3.0969 & 3.1366 & TST & \\
\hline CHEMBL1414376 & 954294 & 3.0969 & 3.2399 & TRN & \\
\hline CHEMBL1506096 & 954294 & 3.0969 & 2.9691 & TRN & \\
\hline CHEMBL1702431 & 954294 & 3.0969 & 3.0003 & TRN & \\
\hline CHEMBL1436264 & 954294 & 3.0969 & 3.783 & TRN & \\
\hline CHEMBL1405676 & 954294 & 3.0969 & 2.8325 & TRN & \\
\hline CHEMBL1447703 & 954294 & 3.0969 & 3.3869 & TRN & \\
\hline CHEMBL1522992 & 954294 & 3.0969 & 2.7001 & TRN & \\
\hline CHEMBL1708006 & 954294 & 3.0969 & 3.0324 & TRN & \\
\hline CHEMBL3191079 & 954294 & 4.0177 & 3.4541 & TST & \\
\hline CHEMBL1377408 & 954294 & 3.0969 & 3.4155 & TRN & \\
\hline CHEMBL1606173 & 954294 & 3.0969 & 2.7123 & TRN & \\
\hline CHEMBL1719799 & 954294 & 4.4067 & 3.332 & TST & \\
\hline CHEMBL1557734 & 954294 & 3.0969 & 2.9372 & TRN & \\
\hline CHEMBL1383320 & 954294 & 3.0969 & 3.2915 & TRN & \\
\hline CHEMBL1380256 & 954294 & 3.0969 & 2.9091 & TRN & \\
\hline CHEMBL1309677 & 954294 & 3.0969 & 2.8997 & TRN & \\
\hline CHEMBL1468767 & 954294 & 3.0969 & 3.0677 & TRN & \\
\hline CHEMBL1724949 & 954294 & 3.0969 & 3.0369 & TRN & \\
\hline CHEMBL1532242 & 954294 & 3.0969 & 3.2628 & TRN & \\
\hline CHEMBL1558970 & 954294 & 3.0969 & 3.0037 & TRN & \\
\hline CHEMBL2138050 & 954294 & 3.0969 & 3.6533 & TRN & \\
\hline CHEMBL1344659 & 954294 & 3.0969 & 3.0256 & TRN & \\
\hline CHEMBL1588973 & 954294 & 3.0969 & 3.0777 & TRN & \\
\hline CHEMBL1418634 & 954294 & 3.0969 & 3.1977 & TRN & \\
\hline CHEMBL1597123 & 954294 & 3.0969 & 2.5713 & TRN & \\
\hline CHEMBL1733584 & 954294 & 3.0969 & 3.0616 & TRN & \\
\hline CHEMBL1307632 & 954294 & 3.0969 & 3.4485 & TST & \\
\hline CHEMBL1721573 & 954294 & 3.0969 & 3.0964 & TRN & \\
\hline CHEMBL1703007 & 954294 & 3.0969 & 3.19199 & 99999999997 & TRN \\
\hline CHEMBL1873621 & 954294 & 3.0969 & 3.1992 & TST & \\
\hline CHEMBL3193792 & 954294 & 3.0969 & 3.0476 & TST & \\
\hline CHEMBL1396872 & 954294 & 3.0969 & 2.9578 & TRN & \\
\hline CHEMBL1552018 & 954294 & 3.0969 & 2.8476 & TRN & \\
\hline CHEMBL1883593 & 954294 & 3.0969 & 2.9374 & TRN & \\
\hline CHEMBL1353090 & 954294 & 3.8827 & 3.12399 & 99999999997 & TRN \\
\hline CHEMBL1475863 & 954294 & 3.0969 & 3.3425 & TRN & \\
\hline CHEMBL1728042 & 954294 & 3.0969 & 3.1482 & TRN & \\
\hline CHEMBL1891367 & 954294 & 5.5952 & 5.0203 & TRN & \\
\hline CHEMBL1699244 & 954294 & 3.0969 & 3.0242 & TRN & \\
\hline CHEMBL1387210 & 954294 & 3.0969 & 3.2905 & TRN & \\
\hline CHEMBL1502747 & 954294 & 3.0969 & 3.5595 & TST & \\
\hline CHEMBL1704801 & 954294 & 3.0969 & 3.2824 & TRN & \\
\hline
\end{tabular}


Supplemental Table S2.txt

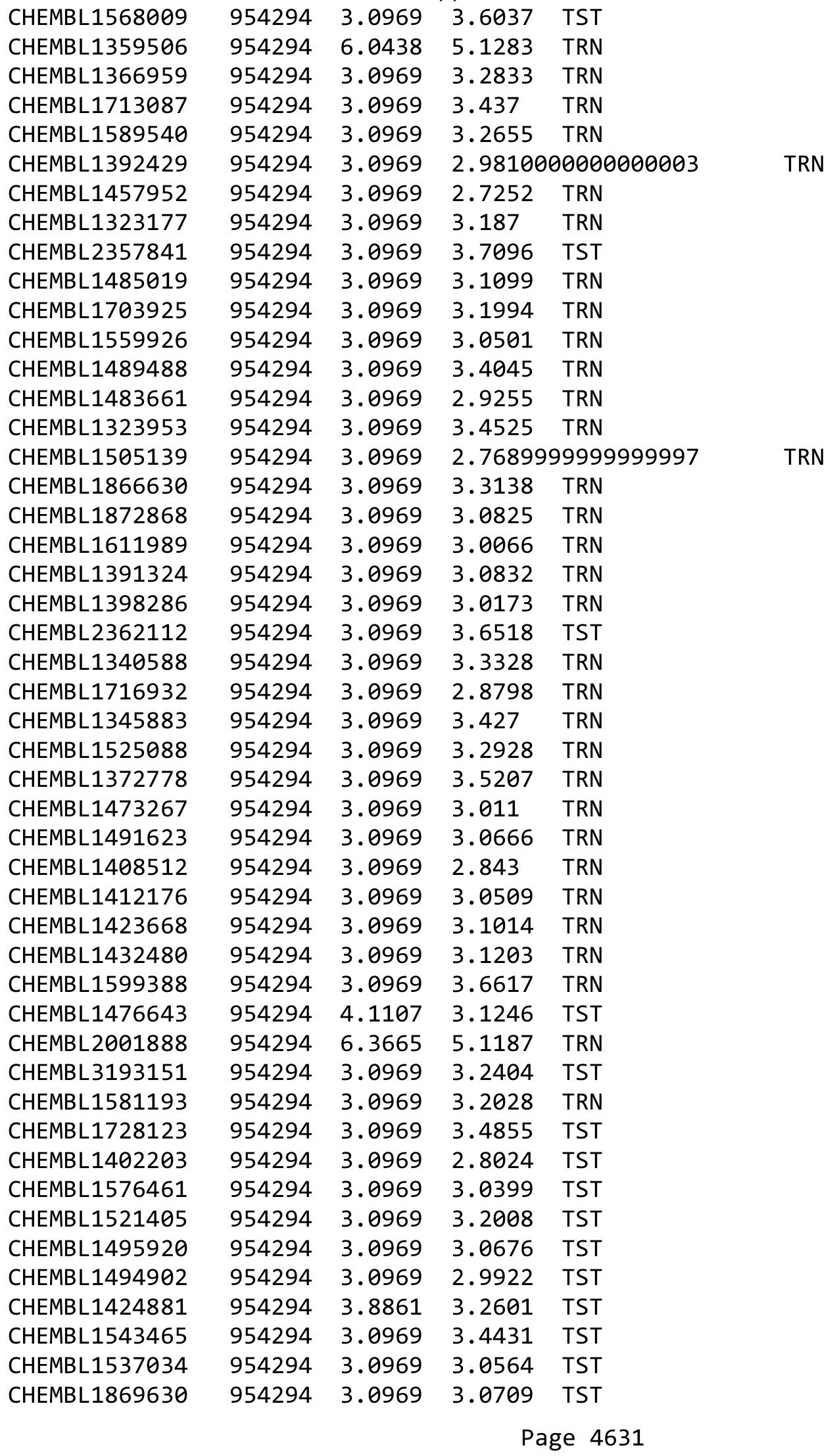


Supplemental Table S2.txt

\begin{tabular}{|c|c|c|c|c|}
\hline CHEMBL1338660 & 954294 & 3.0969 & 3.093 & TST \\
\hline CHEMBL1343337 & 954294 & 3.0969 & 3.2262 & TST \\
\hline CHEMBL1378628 & 954294 & 3.0969 & 2.9124 & TST \\
\hline CHEMBL1387554 & 954294 & 3.0969 & 3.0343 & TST \\
\hline CHEMBL1311965 & 954294 & 3.0969 & 3.2527 & TST \\
\hline CHEMBL1437887 & 954294 & 3.0969 & 2.8796 & TST \\
\hline CHEMBL3673982 & 1528128 & 6.0 & 6.0011 & TRN \\
\hline CHEMBL3673968 & 1528128 & 6.0 & 5.9937 & TRN \\
\hline CHEMBL 3673954 & 1528128 & 6.0 & 5.9992 & TRN \\
\hline CHEMBL3673935 & 1528128 & 6.0 & 5.9778 & TRN \\
\hline CHEMBL3673973 & 1528128 & 8.0 & 8.0003 & TRN \\
\hline CHEMBL3673946 & 1528128 & 6.0 & 5.9915 & TRN \\
\hline CHEMBL3673934 & 1528128 & 6.0 & 6.0287 & TRN \\
\hline CHEMBL3673978 & 1528128 & 6.0 & 6.0046 & TRN \\
\hline CHEMBL3639728 & 1528128 & 6.0 & 5.984 & TRN \\
\hline CHEMBL3673938 & 1528128 & 6.0 & 5.9879 & TRN \\
\hline CHEMBL3673944 & 1528128 & 6.0 & 6.0008 & TRN \\
\hline CHEMBL3673942 & 1528128 & 6.0 & 6.5806 & TST \\
\hline CHEMBL3673969 & 1528128 & 8.0 & 8.0066 & TRN \\
\hline CHEMBL3673959 & 1528128 & 6.0 & 6.0238 & TRN \\
\hline CHEMBL3673940 & 1528128 & 6.0 & 6.0102 & TRN \\
\hline CHEMBL3673939 & 1528128 & 6.0 & 5.9997 & TRN \\
\hline CHEMBL3673941 & 1528128 & 6.0 & 6.462006 & 3000000001 \\
\hline CHEMBL3673956 & 1528128 & 8.0 & 8.0037 & TRN \\
\hline CHEMBL3673975 & 1528128 & 8.0 & 7.9919 & TRN \\
\hline CHEMBL3668998 & 1528128 & 8.0 & 7.9903 & TRN \\
\hline CHEMBL3673945 & 1528128 & 6.0 & 6.0063 & TRN \\
\hline CHEMBL3673972 & 1528128 & 6.0 & 6.0014 & TRN \\
\hline CHEMBL3673947 & 1528128 & 6.0 & 6.0046 & TRN \\
\hline CHEMBL3673957 & 1528128 & 8.0 & 7.9959 & TRN \\
\hline CHEMBL3673932 & 1528128 & 6.0 & 6.0102 & TRN \\
\hline CHEMBL3673981 & 1528128 & 8.0 & 7.9883 & TST \\
\hline CHEMBL3673971 & 1528128 & 6.0 & 5.9963 & TRN \\
\hline CHEMBL 3673977 & 1528128 & 6.0 & 6.0009 & TRN \\
\hline CHEMBL3673943 & 1528128 & 6.0 & 6.0076 & TRN \\
\hline CHEMBL3673964 & 1528128 & 6.0 & 6.0055 & TRN \\
\hline CHEMBL3673966 & 1528128 & 6.0 & 5.9984 & TRN \\
\hline CHEMBL3673976 & 1528128 & 6.0 & 6.5956 & TST \\
\hline CHEMBL3673936 & 1528128 & 6.0 & 5.9864 & TRN \\
\hline CHEMBL3673950 & 1528128 & 6.0 & $6.00200 t$ & 0000000001 \\
\hline CHEMBL3673970 & 1528128 & 6.0 & 6.0034 & TRN \\
\hline CHEMBL3673967 & 1528128 & 8.0 & 7.9971 & TRN \\
\hline CHEMBL3673948 & 1528128 & 8.0 & 8.0173 & TRN \\
\hline CHEMBL3673937 & 1528128 & 6.0 & 6.0034 & TRN \\
\hline CHEMBL3673958 & 1528128 & 6.0 & 6.7894 & TST \\
\hline CHEMBL3669000 & 1528128 & 8.0 & 7.9977 & TRN \\
\hline CHEMBL3669005 & 1528128 & 6.0 & 6.0003 & TRN \\
\hline CHEMBL3673965 & 1528128 & 6.0 & 5.9716 & TRN \\
\hline
\end{tabular}




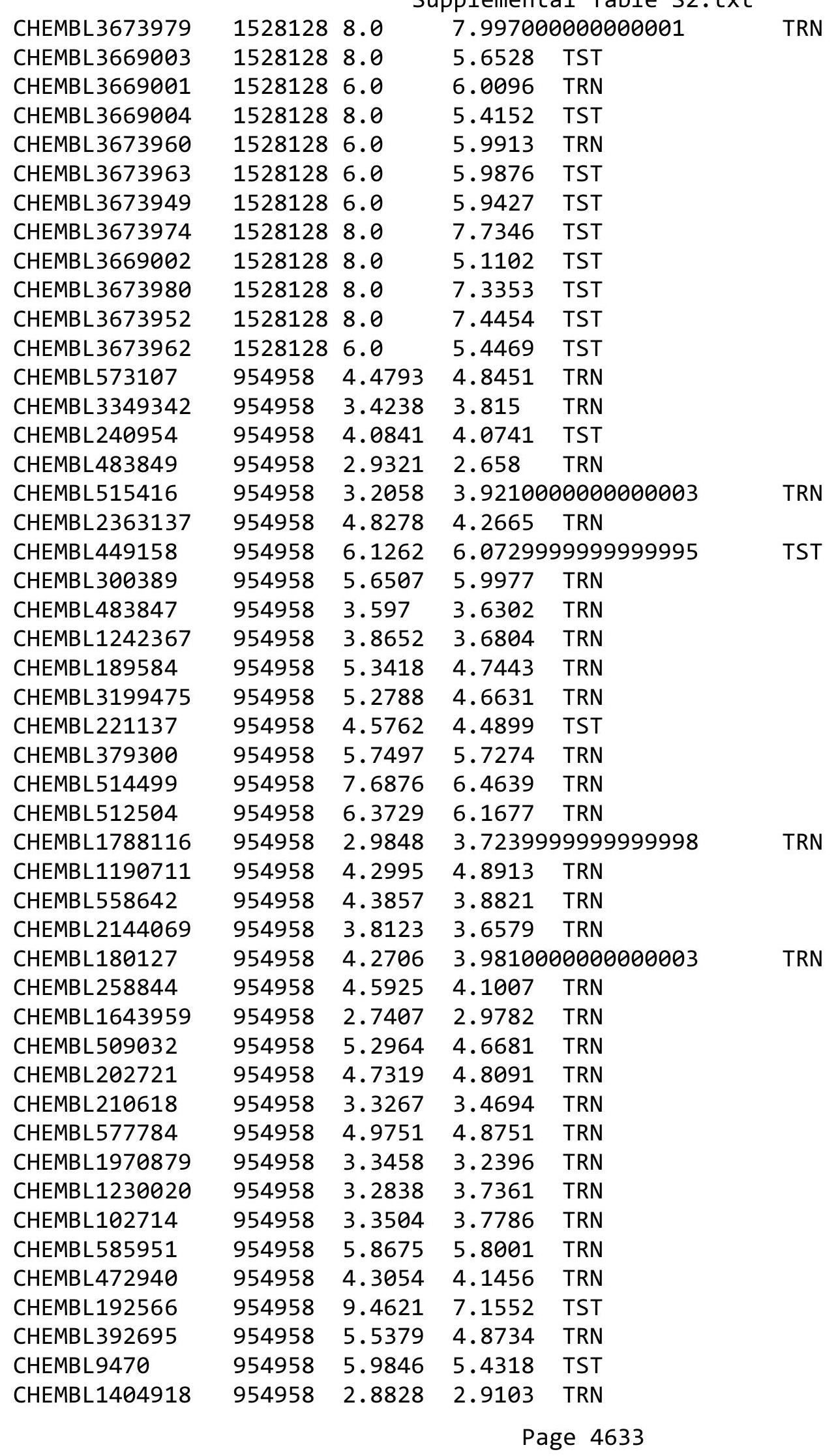




\begin{tabular}{|c|c|c|c|c|c|c|}
\hline & & \multicolumn{5}{|c|}{ Supplemental Table S2.txt } \\
\hline CHEMBL259181 & 954958 & 2.9621 & 4.1646 & TRN & & \\
\hline CHEMBL65 & 954958 & 7.2544 & 7.9191 & TRN & & \\
\hline CHEMBL1256459 & 954958 & 5.4372 & 6.1146 & TRN & & \\
\hline CHEMBL213100 & 954958 & 3.6508 & 3.0153 & TRN & & \\
\hline CHEMBL3392440 & 954958 & 3.424 & 3.5034 & TRN & & \\
\hline CHEMBL373751 & 954958 & 3.0261 & 3.4583 & TRN & & \\
\hline CHEMBL 209148 & 954958 & 4.285 & 3.8571 & TRN & & \\
\hline CHEMBL188678 & 954958 & 4.438 & 4.6096 & TRN & & \\
\hline CHEMBL 2005886 & 954958 & 4.2064 & 4.2837 & TRN & & \\
\hline CHEMBL222102 & 954958 & 3.4857 & 3.9785 & TRN & & \\
\hline CHEMBL393929 & 954958 & 3.6271 & 3.9615 & TRN & & \\
\hline CHEMBL191334 & 954958 & 5.1031 & 4.3043 & TRN & & \\
\hline CHEMBL92309 & 954958 & 2.3792 & 2.9064 & TST & & \\
\hline CHEMBL1357247 & 954958 & 2.8418 & 2.8732 & TRN & & \\
\hline CHEMBL135561 & 954958 & 3.885 & 4.039 & TST & & \\
\hline CHEMBL412142 & 954958 & 3.1555 & 3.5788 & TST & & \\
\hline CHEMBL1673039 & 954958 & 2.9671 & 4.2766 & TST & & \\
\hline CHEMBL1909414 & 954958 & 4.4168 & 4.0743 & TST & & \\
\hline CHEMBL379975 & 954958 & 4.4416 & 5.3558 & TST & & \\
\hline CHEMBL3186408 & 954958 & 3.8796 & 3.6377 & TST & & \\
\hline CHEMBL1590308 & 954958 & 2.8901 & 3.2875 & TST & & \\
\hline CHEMBL1516890 & 954958 & 4.4586 & 3.9376 & TST & & \\
\hline CHEMBL220241 & 954958 & 3.9086 & 4.0794 & TST & & \\
\hline CHEMBL342555 & 307260 & 5.959 & 6.3247 & TRN & & \\
\hline CHEMBL68673 & 307260 & 5.2218 & 4.9938 & TST & & \\
\hline CHEMBL17323 & 307260 & 5.77 & 5.2957 & TST & & \\
\hline CHEMBL17873 & 307260 & 5.854 & 5.3212 & TST & & \\
\hline CHEMBL276734 & 307260 & 5.959 & 5.3734 & TST & & \\
\hline CHEMBL68439 & 307260 & 5.36600 & 000000006 & 205 & 5.0306 & TST \\
\hline CHEMBL283515 & 307260 & 4.721 & 4.2105 & TST & & \\
\hline CHEMBL23846 & 307260 & 4.43199 & 79999999ऽ & 995 & 4.072 & TS \\
\hline CHEMBL279914 & 307260 & 4.4202 & 3.977 & TST & & \\
\hline CHEMBL23960 & 307260 & 4.343 & $3.89600 t$ & 0000000000 & 04 & TST \\
\hline CHEMBL23297 & 307260 & 4.49 & 4.0761 & TST & & \\
\hline CHEMBL22561 & 307260 & 4.627 & 4.258 & TST & & \\
\hline CHEMBL283311 & 307260 & 4.49 & 4.2926 & TST & & \\
\hline CHEMBL 278110 & 307260 & 4.668 & 4.4634 & TST & & \\
\hline CHEMBL292427 & 307260 & 7.2441 & 7.2237 & TRN & & \\
\hline CHEMBL417746 & 307260 & 6.7959 & 6.8276 & TRN & & \\
\hline CHEMBL55928 & 307260 & 7.0458 & 7.1172 & TRN & & \\
\hline CHEMBL54618 & 307260 & 6.8861 & 7.0241 & TRN & & \\
\hline CHEMBL52836 & 307260 & 7.0 & 6.9691 & TRN & & \\
\hline CHEMBL54523 & 307260 & 6.9208 & 6.9959 & TRN & & \\
\hline CHEMBL53165 & 307260 & 6.959 & 7.132006 & 0000000001 & & TKIV \\
\hline CHEMBL55179 & 307260 & 7.398 & 7.3134 & TRN & & \\
\hline CHEMBL415962 & 307260 & 7.7959 & 7.811 & TRN & & \\
\hline CHEMBL54733 & 307260 & 7.07100 & 300000006 & & 7.0941 & TRN \\
\hline CHEMBL53420 & 307260 & 7.06 & 7.1271 & TRN & & \\
\hline
\end{tabular}




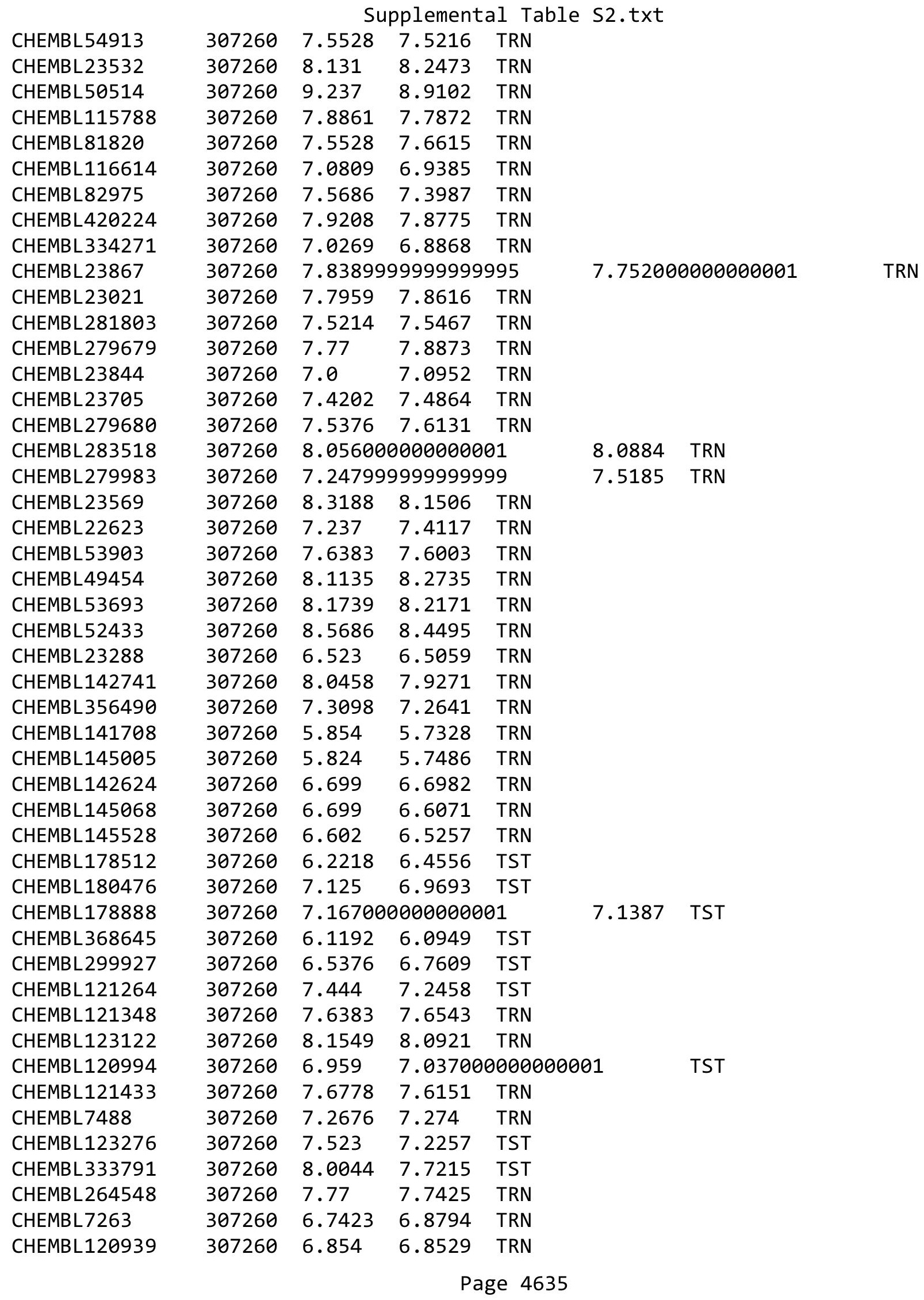




\begin{tabular}{|c|c|c|c|c|c|c|}
\hline \multirow[b]{2}{*}{ CHEMBL121319 } & & \multicolumn{5}{|c|}{ Supplemental Table S2.txt } \\
\hline & 307260 & 7.0132 & 7.0148 & TST & & \\
\hline CHEMBL178904 & 307260 & 7.108 & \multicolumn{3}{|c|}{7.1579999999999995} & TST \\
\hline CHEMBL120826 & 307260 & 7.5686 & 7.5723 & TST & & \\
\hline CHEMBL178684 & 307260 & 6.482 & 6.5521 & TRN & & \\
\hline CHEMBL121868 & 307260 & 7.824 & 7.8925 & TRN & & \\
\hline CHEMBL123043 & 307260 & 7.6576 & 7.6109 & TRN & & \\
\hline CHEMBL121683 & 307260 & 7.77 & 7.6747 & TRN & & \\
\hline CHEMBL120821 & 307260 & 7.9208 & 7.8865 & TRN & & \\
\hline CHEMBL52777 & 307260 & 7.2676 & 7.2255 & TRN & & \\
\hline CHEMBL301105 & 307260 & 7.602 & 7.1191 & TRN & & \\
\hline CHEMBL52947 & 307260 & 6.9208 & 6.9449 & TRN & & \\
\hline CHEMBL51706 & 307260 & 7.3372 & 7.3744 & TRN & & \\
\hline CHEMBL57624 & 307260 & 8.009 & 7.8453 & TRN & & \\
\hline CHEMBL142081 & 307260 & 7.237 & 7.3196 & TST & & \\
\hline CHEMBL137844 & 307260 & 7.3468 & 7.437 & TST & & \\
\hline CHEMBL137981 & 307260 & 7.721 & 7.6575 & TST & & \\
\hline CHEMBL337746 & 307260 & 6.6778 & 6.7595 & TST & & \\
\hline CHEMBL140705 & 307260 & 6.3372 & 6.3896 & TRN & & \\
\hline CHEMBL299174 & 307260 & 7.854 & 7.818 & TRN & & \\
\hline CHEMBL54792 & 307260 & 7.824 & 7.9077 & TRN & & \\
\hline CHEMBL55727 & 307260 & 7.7959 & 7.6457 & TRN & & \\
\hline CHEMBL54538 & 307260 & 7.7447 & 7.7887 & TRN & & \\
\hline CHEMBL53974 & 307260 & 7.585 & 7.6294 & TRN & & \\
\hline CHEMBL300603 & 307260 & 7.5686 & 7.5703 & TRN & & \\
\hline CHEMBL141218 & 307260 & 5.5528 & 5.6843 & TRN & & \\
\hline CHEMBL141585 & 307260 & \multicolumn{3}{|c|}{6.167000000000001} & 6.0415 & TRN \\
\hline CHEMBL141260 & 307260 & 6.1367 & 6.0295 & TRN & & \\
\hline CHEMBL138452 & 307260 & 5.6198 & 5.7103 & TRN & & \\
\hline CHEMBL139188 & 307260 & 6.523 & 6.41100 & 0000000000 & 05 & TRN \\
\hline CHEMBL138252 & 307260 & 6.0809 & 6.1227 & TRN & & \\
\hline CHEMBL55063 & 307260 & 8.076 & 8.7073 & TRN & & \\
\hline CHEMBL52698 & 307260 & 7.4202 & 7.4481 & TRN & & \\
\hline CHEMBL54732 & 307260 & 7.301 & 7.5212 & TRN & & \\
\hline CHEMBL292212 & 307260 & 7.041 & 7.0663 & TRN & & \\
\hline CHEMBL55191 & 307260 & 7.602 & 7.6311 & TRN & & \\
\hline CHEMBL33038 & 307260 & 7.4949 & 7.3601 & TRN & & \\
\hline CHEMBL34337 & 307260 & \multicolumn{3}{|c|}{6.0360000000000005} & 6.1716 & TRN \\
\hline CHEMBL32113 & 307260 & 8.201 & 8.0523 & TRN & & \\
\hline CHEMBL35569 & 307260 & 6.4559 & 6.4601 & TRN & & \\
\hline CHEMBL284849 & 307260 & 6.3188 & \multicolumn{3}{|c|}{6.2989999999999995} & TRN \\
\hline CHEMBL53318 & 307260 & 7.824 & 7.7977 & TRN & & \\
\hline CHEMBL445359 & 307260 & 7.523 & 7.6643 & TRN & & \\
\hline CHEMBL52688 & 307260 & 7.3565 & 7.5596 & TRN & & \\
\hline CHEMBL300886 & 307260 & 6.8861 & 6.9741 & TST & & \\
\hline CHEMBL292634 & 307260 & 7.301 & 7.2759 & TRN & & \\
\hline CHEMBL33208 & 307260 & 6.4559 & 6.4009 & TRN & & \\
\hline CHEMBL32190 & 307260 & 7.854 & 7.8855 & TRN & & \\
\hline CHEMBL32708 & 307260 & 6.5086 & 6.4764 & TRN & & \\
\hline
\end{tabular}




\begin{tabular}{|c|c|c|c|c|c|c|c|}
\hline \multicolumn{7}{|c|}{ Supplemental Table S2.txt } & \\
\hline CHEMBL32754 & 307260 & 6.6383 & 6.4873 & TRN & & & \\
\hline CHEMBL33187 & 307260 & 5.432 & 5.4338 & TRN & & & \\
\hline CHEMBL55656 & 307260 & 7.3098 & 7.2253 & TST & & & \\
\hline CHEMBL292143 & 307260 & 7.3188 & 7.1251 & TST & & & \\
\hline CHEMBL299140 & 307260 & 7.585 & 7.3923 & TRN & & & \\
\hline CHEMBL296382 & 307260 & 6.854 & 6.9543 & TRN & & & \\
\hline CHEMBL278013 & 307260 & 6.0 & 5.6933 & TST & & & \\
\hline CHEMBL278261 & 307260 & 6.06 & 5.6748 & TST & & & \\
\hline CHEMBL 35222 & 307260 & 7.585 & 7.7487 & TRN & & & \\
\hline CHEMBL32769 & 307260 & 6.1367 & 6.13299 & 999999999 & & TRN & \\
\hline CHEMBL36245 & 307260 & 7.5086 & 7.5972 & TRN & & & \\
\hline CHEMBL32266 & 307260 & 5.9208 & 5.9766 & TRN & & & \\
\hline CHEMBL32635 & 307260 & 6.0088 & 5.9741 & TRN & & & \\
\hline CHEMBL32220 & 307260 & 6.4202 & 6.3213 & TRN & & & \\
\hline CHEMBL17430 & 307260 & 4.9355 & 4.662 & TST & & & \\
\hline CHEMBL17431 & 307260 & 5.585 & 5.0106 & TST & & & \\
\hline CHEMBL17479 & 307260 & 6.0915 & 5.4348 & TST & & & \\
\hline CHEMBL275893 & 307260 & 5.03600 & j0000000 & 005 & 4.6174 & TST & \\
\hline CHEMBL113999 & 307260 & 7.0757 & 7.0298 & TRN & & & \\
\hline CHEMBL286700 & 307260 & 6.284 & 5.9962 & TRN & & & \\
\hline CHEMBL32583 & 307260 & 6.74100 & 00000000 & 005 & 6.66299 & 9999999999 & TRN \\
\hline CHEMBL33136 & 307260 & 5.3516 & 5.5464 & TRN & & & \\
\hline CHEMBL116816 & 307260 & 6.7959 & 6.7467 & TRN & & & \\
\hline CHEMBL116815 & 307260 & 6.9208 & 6.8462 & TRN & & & \\
\hline CHEMBL115474 & 307260 & 6.4949 & 6.5693 & TRN & & & \\
\hline CHEMBL116200 & 307260 & 6.77 & 6.7927 & TRN & & & \\
\hline CHEMBL116637 & 307260 & 6.721 & 6.7986 & TRN & & & \\
\hline CHEMBL113816 & 307260 & 8.032 & 7.7128 & TRN & & & \\
\hline CHEMBL178119 & 307260 & 6.0223 & 6.2296 & TRN & & & \\
\hline CHEMBL117750 & 307260 & 7.77 & 7.6105 & TRN & & & \\
\hline CHEMBL179102 & 307260 & 7.0044 & 6.8505 & TRN & & & \\
\hline CHEMBL114833 & 307260 & 6.907 & 6.8264 & TRN & & & \\
\hline CHEMBL367802 & 307260 & 6.6778 & 7.3615 & TRN & & & \\
\hline CHEMBL 325434 & 307260 & 7.523 & 7.4696 & TRN & & & \\
\hline CHEMBL115804 & 307260 & 7.4089 & 7.3769 & TRN & & & \\
\hline CHEMBL80066 & 307260 & 7.959 & 7.8993 & TRN & & & \\
\hline CHEMBL23416 & 307260 & 7.721 & 7.8614 & TRN & & & \\
\hline CHEMBL81119 & 307260 & 8.149 & 8.0352 & TRN & & & \\
\hline CHEMBL 312348 & 307260 & 7.9208 & 8.0219 & TRN & & & \\
\hline CHEMBL80065 & 307260 & 8.0223 & 7.9667 & TRN & & & \\
\hline CHEMBL264386 & 307260 & 8.137 & 7.9744 & TRN & & & \\
\hline CHEMBL179319 & 307260 & 8.201 & 7.9906 & TRN & & & \\
\hline CHEMBL79347 & 307260 & 7.523 & 7.4575 & TRN & & & \\
\hline CHEMBL423560 & 307260 & 7.3098 & 7.2639 & TST & & & \\
\hline CHEMBL358297 & 307260 & 7.11299 & 99999999 & 995 & 7.3097 & TST & \\
\hline CHEMBL147886 & 307260 & 6.959 & 7.1018 & TST & & & \\
\hline CHEMBL179131 & 307260 & 7.482 & 7.1968 & TST & & & \\
\hline CHEMBL561770 & 575604 & 6.0458 & 5.6399 & TRN & & & \\
\hline
\end{tabular}


Supplemental Table S2.txt

\begin{tabular}{|c|c|c|c|c|}
\hline CHEMBL569375 & 575604 & 6.3979 & 6.4569 & TRN \\
\hline CHEMBL550978 & 575604 & 5.3979 & 5.9762 & TRN \\
\hline CHEMBL554974 & 575604 & 4.6021 & 5.2085 & TRN \\
\hline CHEMBL549966 & 575604 & 6.3979 & 6.4341 & TRN \\
\hline CHEMBL551560 & 575604 & 5.699 & 5.9509 & TRN \\
\hline CHEMBL560644 & 575604 & 6.3979 & 6.1311 & TST \\
\hline CHEMBL553173 & 575604 & 6.0969 & 5.9659 & TST \\
\hline CHEMBL540720 & 575604 & 5.2218 & 5.6446 & TRN \\
\hline CHEMBL563552 & 575604 & 6.301 & 6.0572 & TST \\
\hline CHEMBL569376 & 575604 & 6.0458 & 6.4394 & TRN \\
\hline CHEMBL539708 & 575604 & 6.1549 & 5.1941 & TRN \\
\hline CHEMBL556473 & 575604 & 5.699 & 5.9813 & TST \\
\hline CHEMBL560706 & 575604 & 5.3979 & 5.545 & TRN \\
\hline CHEMBL551241 & 575604 & 5.301 & 6.223 & TRN \\
\hline CHEMBL563507 & 575604 & 6.0458 & 5.6238 & TRN \\
\hline CHEMBL555979 & 575604 & 5.3565 & 5.4445 & TRN \\
\hline CHEMBL551568 & 575604 & 6.5086 & 6.1724 & TST \\
\hline CHEMBL551559 & 575604 & 6.3979 & 6.2632 & TRN \\
\hline CHEMBL563783 & 575604 & 6.0458 & 6.4449 & TRN \\
\hline CHEMBL552566 & 575604 & 6.5229 & 6.0351 & TST \\
\hline CHEMBL572334 & 575604 & 6.2218 & 6.2831 & TRN \\
\hline CHEMBL561565 & 575604 & 4.5686 & 5.3397 & TRN \\
\hline CHEMBL564499 & 575604 & 5.8861 & 6.0851 & TST \\
\hline CHEMBL559852 & 575604 & 6.699 & 5.8459 & TST \\
\hline CHEMBL550776 & 575604 & 6.9208 & 6.646 & TRN \\
\hline CHEMBL572338 & 575604 & 6.0 & 6.3496 & TST \\
\hline CHEMBL550838 & 575604 & 5.9208 & 5.5122 & TRN \\
\hline CHEMBL550574 & 575604 & 6.0969 & 6.434 & TRN \\
\hline CHEMBL549415 & 575604 & 5.7447 & 5.9294 & TST \\
\hline CHEMBL560218 & 575604 & 4.699 & 5.2414 & TRN \\
\hline CHEMBL561709 & 575604 & 5.699 & 5.9049 & TST \\
\hline CHEMBL561164 & 575604 & 4.6778 & 5.4339 & TRN \\
\hline CHEMBL561848 & 575604 & 4.7447 & 5.2482 & TRN \\
\hline CHEMBL550494 & 575604 & 6.3979 & 6.2715 & TRN \\
\hline CHEMBL557898 & 575604 & 6.0 & 5.6537 & TRN \\
\hline CHEMBL569371 & 575604 & 5.0506 & 5.2417 & TRN \\
\hline CHEMBL564594 & 575604 & 5.5229 & 5.6329 & TRN \\
\hline CHEMBL557899 & 575604 & 7.0 & 5.8471 & TRN \\
\hline CHEMBL562110 & 575604 & 5.4559 & 5.9815 & TST \\
\hline CHEMBL565197 & 575604 & 4.6021 & 5.2039 & TRN \\
\hline CHEMBL563256 & 575604 & 6.5229 & 5.4448 & TRN \\
\hline CHEMBL560202 & 575604 & 6.301 & 5.3833 & TRN \\
\hline CHEMBL561646 & 575604 & 5.6021 & 5.4226 & TRN \\
\hline CHEMBL562366 & 575604 & 7.0 & 6.4368 & TRN \\
\hline CHEMBL562442 & 575604 & 5.0969 & 5.2108 & TRN \\
\hline CHEMBL561849 & 575604 & 5.3979 & 5.4613 & TRN \\
\hline CHEMBL564147 & 575604 & 6.6383 & 6.025 & TST \\
\hline CHEMBL549886 & 575604 & 5.699 & 5.35 & TRN \\
\hline
\end{tabular}




\begin{tabular}{|c|c|c|c|c|c|}
\hline \multicolumn{6}{|c|}{ Supplemental Table S2.txt } \\
\hline CHEMBL560769 & 575604 & 5.8861 & 5.942 & TST & \\
\hline CHEMBL559284 & 575604 & 6.7696 & 6.5066 & TRN & \\
\hline CHEMBL569135 & 575604 & 5.5686 & 5.3067 & TRN & \\
\hline CHEMBL564630 & 575604 & 6.5229 & 6.2589 & TRN & \\
\hline CHEMBL540719 & 575604 & 5.3979 & 5.6357 & TRN & \\
\hline CHEMBL550086 & 575604 & 5.4318 & 5.3468 & TRN & \\
\hline CHEMBL283996 & 31759 & 8.1612 & 7.8751 & TRN & \\
\hline CHEMBL19759 & 31759 & 7.5528 & 6.8024 & TRN & \\
\hline CHEMBL 20925 & 31759 & 6.3768 & 6.9809 & TRN & \\
\hline CHEMBL19873 & 31759 & 6.6383 & 6.5178 & TRN & \\
\hline CHEMBL 278522 & 31759 & 7.3372 & 7.535 & TRN & \\
\hline CHEMBL283151 & 31759 & 7.4318 & 6.5226 & TST & \\
\hline CHEMBL279673 & 31759 & 5.7447 & 5.5884 & TRN & \\
\hline CHEMBL 20116 & 31759 & 7.4815 & 7.5349 & TRN & \\
\hline CHEMBL20756 & 31759 & 6.2924 & 7.5932 & TRN & \\
\hline CHEMBL 20253 & 31759 & 6.9586 & 7.20700 & 2000000001 & TRN \\
\hline CHEMBL282017 & 31759 & 7.3665 & 7.2375 & TST & \\
\hline CHEMBL21038 & 31759 & 7.8239 & 8.1481 & TRN & \\
\hline CHEMBL 20024 & 31759 & 8.699 & 8.4943 & TRN & \\
\hline CHEMBL 280168 & 31759 & 7.6021 & 7.3212 & TRN & \\
\hline CHEMBL417643 & 31759 & 7.3872 & 7.3534 & TRN & \\
\hline CHEMBL282689 & 31759 & 8.301 & 8.5486 & TRN & \\
\hline CHEMBL20005 & 31759 & 7.4685 & 7.7309 & TRN & \\
\hline CHEMBL 277921 & 31759 & 3.0 & 8.0867 & TST & \\
\hline CHEMBL 20575 & 31759 & 6.7696 & 7.1759 & TRN & \\
\hline CHEMBL19906 & 31759 & 7.585 & 6.7954 & TRN & \\
\hline CHEMBL20199 & 31759 & 5.7696 & 6.2508 & TRN & \\
\hline CHEMBL20885 & 31759 & 5.4949 & 5.6502 & TRN & \\
\hline CHEMBL 20518 & 31759 & 8.301 & 8.1137 & TRN & \\
\hline CHEMBL 21101 & 31759 & 6.3372 & 7.0653 & TST & \\
\hline CHEMBL 20207 & 31759 & 9.0 & 8.397 & TRN & \\
\hline CHEMBL 278991 & 31759 & 8.3979 & 7.5664 & TRN & \\
\hline CHEMBL262701 & 31759 & 5.2596 & 7.4614 & TST & \\
\hline CHEMBL 284018 & 31759 & 7.5686 & 7.5941 & TRN & \\
\hline CHEMBL 20884 & 31759 & 6.9208 & 6.3814 & TRN & \\
\hline CHEMBL 20161 & 31759 & 8.2291 & 7.496 & TRN & \\
\hline CHEMBL 20441 & 31759 & 7.0 & 7.7318 & TRN & \\
\hline CHEMBL19838 & 31759 & 6.3768 & 7.5598 & TRN & \\
\hline CHEMBL 277935 & 31759 & 5.2441 & 7.6583 & TST & \\
\hline CHEMBL21136 & 31759 & 7.0605 & 7.472 & TRN & \\
\hline CHEMBL 20693 & 31759 & 7.9208 & 7.4147 & TRN & \\
\hline CHEMBL416001 & 31759 & 8.2076 & 7.8561 & TRN & \\
\hline CHEMBL 20304 & 31759 & 7.3768 & 7.1964 & TRN & \\
\hline CHEMBL19289 & 31759 & 8.0 & 8.2735 & TRN & \\
\hline CHEMBL283364 & 31759 & 7.0 & 7.409 & TRN & \\
\hline CHEMBL 281620 & 31759 & 6.8539 & 7.6755 & TST & \\
\hline CHEMBL 278832 & 31759 & 6.0 & 6.562 & TRN & \\
\hline CHEMBL 282263 & 31759 & 7.699 & 7.7785 & TRN & \\
\hline
\end{tabular}




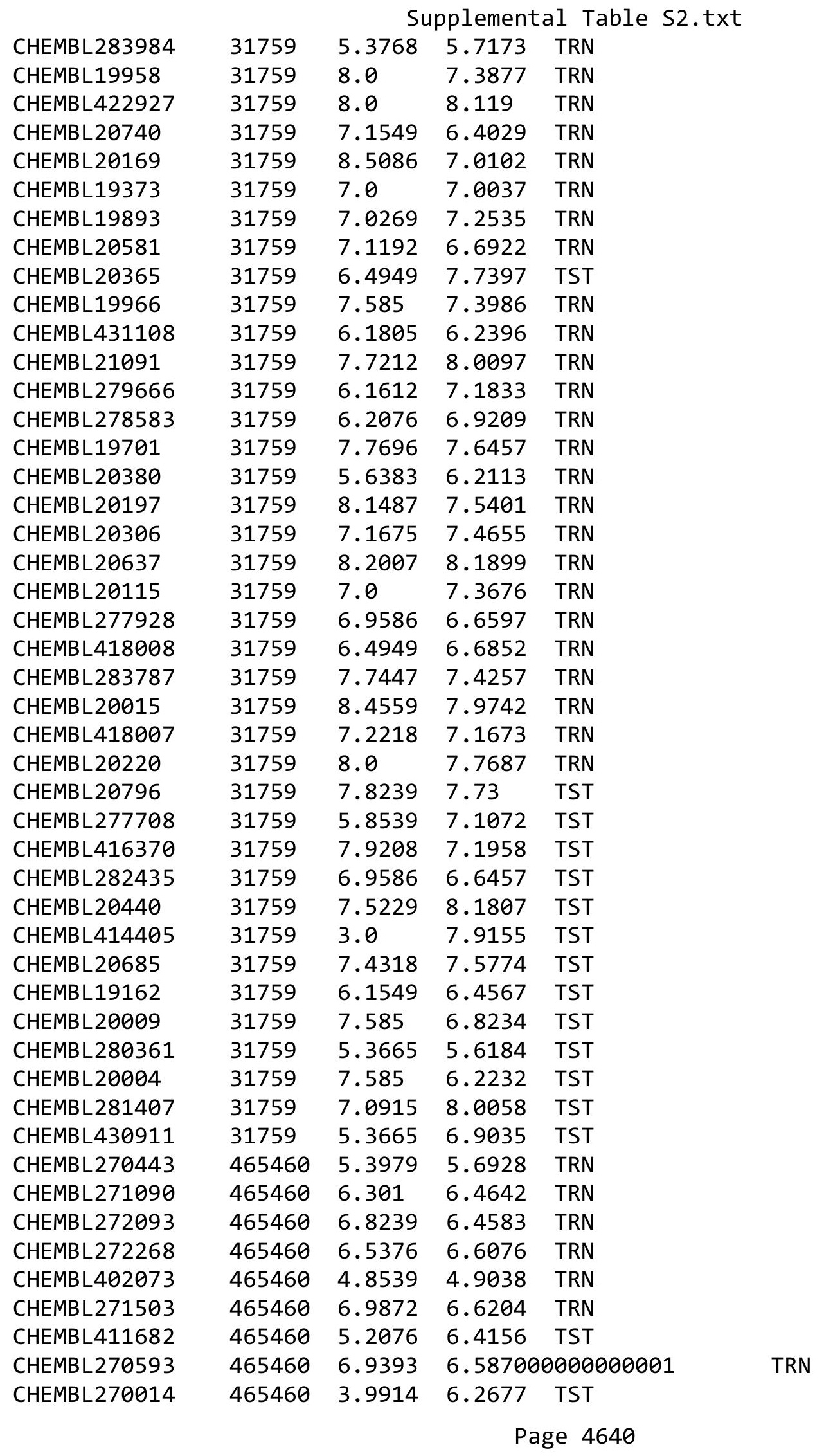




\begin{tabular}{|c|c|c|c|c|c|}
\hline \multirow[b]{2}{*}{ CHEMBL272972 } & & \multicolumn{4}{|c|}{ Supplemental Table S2.txt } \\
\hline & 465460 & 6.4559 & 6.17299 & 9999999999 & TRN \\
\hline CHEMBL270445 & 465460 & 5.4685 & 5.71399 & 99999999995 & TST \\
\hline CHEMBL270823 & 465460 & 5.4202 & 5.4951 & TRN & \\
\hline CHEMBL256860 & 465460 & 6.3279 & 6.2344 & TRN & \\
\hline CHEMBL270413 & 465460 & 6.6383 & 6.5859 & TRN & \\
\hline CHEMBL256859 & 465460 & 6.0315 & 6.0703 & TRN & \\
\hline CHEMBL402581 & 465460 & 5.1367 & 4.2833 & TST & \\
\hline CHEMBL410059 & 465460 & 6.4949 & 6.6015 & TRN & \\
\hline CHEMBL257496 & 465460 & 6.0809 & 5.7907 & TRN & \\
\hline CHEMBL271089 & 465460 & 6.2218 & 6.3818 & TRN & \\
\hline CHEMBL271251 & 465460 & 5.4949 & 5.5643 & TRN & \\
\hline CHEMBL272094 & 465460 & 4.0915 & 4.5679 & TRN & \\
\hline CHEMBL257497 & 465460 & 6.4089 & 6.4195 & TRN & \\
\hline CHEMBL273172 & 465460 & 5.0 & 4.7288 & TRN & \\
\hline CHEMBL411100 & 465460 & 6.3979 & 6.4677 & TRN & \\
\hline CHEMBL404862 & 465460 & 5.4202 & 5.6547 & TST & \\
\hline CHEMBL403112 & 465460 & 6.3872 & 6.2503 & TRN & \\
\hline CHEMBL273159 & 465460 & 5.0458 & 5.1251 & TRN & \\
\hline CHEMBL 273171 & 465460 & 5.4318 & 5.1146 & TRN & \\
\hline CHEMBL401956 & 465460 & 7.0 & 6.6832 & TRN & \\
\hline CHEMBL271897 & 465460 & 6.3768 & 6.4608 & TRN & \\
\hline CHEMBL 257924 & 465460 & 5.5376 & 6.1906 & TRN & \\
\hline CHEMBL401540 & 465460 & 6.5229 & 6.4617 & TRN & \\
\hline CHEMBL271882 & 465460 & 6.4437 & 6.4231 & TRN & \\
\hline CHEMBL271041 & 465460 & 6.585 & 6.4003 & TRN & \\
\hline CHEMBL257925 & 465460 & 6.3665 & 6.5467 & TRN & \\
\hline CHEMBL 258149 & 465460 & 6.3872 & 6.4879 & TRN & \\
\hline CHEMBL313155 & 465460 & 6.4559 & 6.3447 & TRN & \\
\hline CHEMBL 270825 & 465460 & 5.9431 & 6.3952 & TRN & \\
\hline CHEMBL411478 & 465460 & 6.1612 & 5.7564 & TRN & \\
\hline CHEMBL403923 & 465460 & 6.3979 & 6.3913 & TRN & \\
\hline CHEMBL403289 & 465460 & 6.2007 & 6.2435 & TRN & \\
\hline CHEMBL256690 & 465460 & 6.0915 & 6.0848 & TRN & \\
\hline CHEMBL411681 & 465460 & 5.6021 & 5.385 & TRN & \\
\hline CHEMBL401880 & 465460 & 6.5834 & 6.6587 & TRN & \\
\hline CHEMBL271016 & 465460 & 6.3372 & 6.3119 & TRN & \\
\hline CHEMBL 271297 & 465460 & 5.8861 & 6.5189 & TRN & \\
\hline CHEMBL273001 & 465460 & 6.0969 & 6.6143 & TST & \\
\hline CHEMBL402201 & 465460 & 6.0757 & 6.5825 & TST & \\
\hline CHEMBL402755 & 465460 & 5.6576 & 6.3915 & TST & \\
\hline CHEMBL257686 & 465460 & 5.7696 & 6.2368 & TST & \\
\hline CHEMBL402850 & 465460 & 6.699 & 6.6586 & TST & \\
\hline CHEMBL257926 & 465460 & 6.6383 & 6.4701 & TST & \\
\hline CHEMBL402961 & 465460 & 6.8539 & 6.4768 & TST & \\
\hline CHEMBL404478 & 465460 & 6.585 & 5.6641 & TST & \\
\hline CHEMBL271883 & 465460 & 5.6576 & 5.5571 & TST & \\
\hline CHEMBL502400 & 573583 & 9.5229 & 8.9091 & TST & \\
\hline CHEMBL444419 & 573583 & 9.3979 & 9.5147 & TRN & \\
\hline
\end{tabular}




\begin{tabular}{|c|c|c|c|c|c|}
\hline \multicolumn{6}{|c|}{ Supplemental Table S2.txt } \\
\hline CHEMBL556742 & 573583 & 9.3279 & 9.4096 & TRN & \\
\hline CHEMBL553932 & 573583 & 9.4949 & 9.2093 & TRN & \\
\hline CHEMBL537955 & 573583 & 9.3565 & 9.3553 & TRN & \\
\hline CHEMBL501707 & 573583 & 8.8239 & 8.8128 & TST & \\
\hline CHEMBL507683 & 573583 & 9.699 & 9.5811 & TRN & \\
\hline CHEMBL501006 & 573583 & 9.7696 & 8.7683 & TST & \\
\hline CHEMBL555198 & 573583 & 9.2441 & 9.5983 & TRN & \\
\hline CHEMBL452738 & 573583 & 8.699 & 9.4147 & TST & \\
\hline CHEMBL126678 & 573583 & 9.7447 & 9.445 & TRN & \\
\hline CHEMBL557957 & 573583 & 6.4001 & 9.057 & TST & \\
\hline CHEMBL467163 & 573583 & 9.4437 & 9.3316 & TST & \\
\hline CHEMBL553933 & 573583 & 9.5086 & 9.4773 & TRN & \\
\hline CHEMBL502482 & 573583 & 8.8861 & 8.69399 & 9999999999 & TST \\
\hline CHEMBL553663 & 573583 & 10.1079 & 9.7122 & TRN & \\
\hline CHEMBL450955 & 573583 & 9.4437 & 9.477 & TRN & \\
\hline CHEMBL541440 & 573583 & 9.9208 & 9.6849 & TRN & \\
\hline CHEMBL555197 & 573583 & 9.2291 & 9.126 & TRN & \\
\hline CHEMBL442936 & 573583 & 9.0 & 9.2161 & TST & \\
\hline CHEMBL558360 & 573583 & 10.0362 & 9.8968 & TRN & \\
\hline CHEMBL564755 & 573583 & 8.4572 & 8.9459 & TST & \\
\hline CHEMBL551337 & 573583 & 9.8861 & 9.9135 & TRN & \\
\hline CHEMBL564422 & 573583 & 9.585 & 9.3703 & TRN & \\
\hline CHEMBL555142 & 573583 & 9.7696 & 9.5363 & TRN & \\
\hline CHEMBL539891 & 573583 & 9.9208 & 9.9961 & TRN & \\
\hline CHEMBL540215 & 573583 & 9.4685 & 9.3027 & TRN & \\
\hline CHEMBL509534 & 573583 & 9.2218 & 9.4367 & TRN & \\
\hline CHEMBL447645 & 573583 & 8.9586 & 9.25 & TRN & \\
\hline CHEMBL555946 & 573583 & 9.4949 & 9.5174 & TRN & \\
\hline CHEMBL498935 & 573583 & 9.0969 & 9.1261 & TRN & \\
\hline CHEMBL553662 & 573583 & 9.1871 & 9.5747 & TRN & \\
\hline CHEMBL450892 & 573583 & 8.8416 & 8.8269 & TRN & \\
\hline CHEMBL420349 & 573583 & 9.4559 & 9.2991 & TST & \\
\hline CHEMBL506777 & 573583 & 8.8539 & 8.7492 & TRN & \\
\hline CHEMBL502100 & 573583 & 9.0969 & 9.42 & TST & \\
\hline CHEMBL453702 & 573583 & 9.3979 & 8.9113 & TST & \\
\hline CHEMBL510577 & 573583 & 9.3979 & 9.0606 & TST & \\
\hline CHEMBL553898 & 573583 & 9.4685 & 9.5596 & TRN & \\
\hline CHEMBL503845 & 573583 & 9.1549 & 8.896 & TST & \\
\hline CHEMBL126916 & 573583 & 9.699 & 9.65299 & 9999999999 & TRN \\
\hline CHEMBL538439 & 573583 & 8.7721 & 9.2158 & TRN & \\
\hline CHEMBL538133 & 573583 & 9.4318 & 9.3192 & TRN & \\
\hline CHEMBL554777 & 573583 & 9.5086 & 9.3348 & TRN & \\
\hline CHEMBL503307 & 573583 & 8.6383 & 8.8858 & TST & \\
\hline CHEMBL445708 & 573583 & 9.0458 & 9.3597 & TRN & \\
\hline CHEMBL552529 & 573583 & 9.3979 & 9.5922 & TRN & \\
\hline CHEMBL504333 & 573583 & 9.2218 & 9.3646 & TST & \\
\hline CHEMBL447258 & 573583 & 9.301 & 9.1812 & TRN & \\
\hline CHEMBL506225 & 573583 & 9.5229 & 9.0851 & TRN & \\
\hline
\end{tabular}




\begin{tabular}{|c|c|c|c|c|c|c|}
\hline & & \multicolumn{5}{|c|}{ Supplemental Table S2.txt } \\
\hline CHEMBL539196 & 573583 & 9.7212 & 9.4991 & TRN & & \\
\hline CHEMBL556741 & 573583 & 9.2757 & 9.1192 & TRN & & \\
\hline CHEMBL540216 & 573583 & 9.3279 & 9.3903 & TRN & & \\
\hline CHEMBL552530 & 573583 & 9.9208 & 9.7853 & TRN & & \\
\hline CHEMBL538440 & 573583 & 9.4949 & 9.4414 & TRN & & \\
\hline CHEMBL362146 & 573583 & 9.0969 & 9.4966 & TRN & & \\
\hline CHEMBL556740 & 573583 & 9.4949 & 9.235 & TRN & & \\
\hline CHEMBL556751 & 573583 & 9.4202 & 9.3799 & TRN & & \\
\hline CHEMBL554776 & 573583 & 9.3279 & 9.4933 & TST & & \\
\hline CHEMBL502402 & 573583 & 9.0969 & 9.346 & TRN & & \\
\hline CHEMBL537956 & 573583 & 9.3468 & 9.3834 & TRN & & \\
\hline CHEMBL549678 & 573583 & 10.0044 & 9.8414 & TRN & & \\
\hline CHEMBL555945 & 573583 & 9.3979 & 9.3848 & TRN & & \\
\hline CHEMBL502986 & 573583 & 8.8539 & 8.8182 & TRN & & \\
\hline CHEMBL556526 & 573583 & 10.1079 & 9.8516 & TRN & & \\
\hline CHEMBL556135 & 573583 & 7.9101 & 9.0145 & TST & & \\
\hline CHEMBL553113 & 573583 & 10.0362 & 9.7324 & TST & & \\
\hline CHEMBL455233 & 573583 & 9.0 & 8.9293 & TRN & & \\
\hline CHEMBL502695 & 573583 & 8.7447 & 9.0113 & TRN & & \\
\hline CHEMBL554541 & 573583 & 9.4685 & 9.8063 & TRN & & \\
\hline CHEMBL553661 & 573583 & 9.3468 & 9.3518 & TRN & & \\
\hline CHEMBL506159 & 573583 & 8.9208 & 9.0508 & TRN & & \\
\hline CHEMBL551331 & 573583 & 9.28399 & 999999999 & 99 & 9.234 & TRN \\
\hline CHEMBL554560 & 573583 & 9.3565 & 9.1429 & TRN & & \\
\hline CHEMBL540690 & 573583 & 8.9431 & 9.2861 & TRN & & \\
\hline CHEMBL554540 & 573583 & 9.1675 & 9.3275 & TRN & & \\
\hline CHEMBL555697 & 573583 & 10.0362 & 9.9997 & TRN & & \\
\hline CHEMBL502942 & 573583 & 8.9586 & 9.0029 & TRN & & \\
\hline CHEMBL539890 & 573583 & 9.0915 & 9.3199 & TRN & & \\
\hline CHEMBL454522 & 573583 & 8.8539 & 8.6241 & TST & & \\
\hline CHEMBL1269102 & 859881 & 7.6882 & 7.2512 & TST & & \\
\hline CHEMBL 2163706 & 859881 & 8.1135 & 8.1518 & TRN & & \\
\hline CHEMBL 2163724 & 859881 & 8.4685 & 8.3647 & TRN & & \\
\hline CHEMBL 2163705 & 859881 & 8.5229 & 8.4626 & TRN & & \\
\hline CHEMBL 2165327 & 859881 & 6.0 & 11.8766 & TST & & \\
\hline CHEMBL 2163727 & 859881 & 7.3979 & 7.5893 & TRN & & \\
\hline CHEMBL 2165331 & 859881 & 8.1675 & 8.1183 & TRN & & \\
\hline CHEMBL 2165326 & 859881 & 8.4685 & 8.4199 & TRN & & \\
\hline CHEMBL2165339 & 859881 & 9.5229 & 9.6392 & TRN & & \\
\hline CHEMBL 2163698 & 859881 & 8.0969 & 8.0818 & TRN & & \\
\hline CHEMBL 2163718 & 859881 & 8.0044 & 7.9347 & TRN & & \\
\hline CHEMBL 2165340 & 859881 & 8.3565 & 8.2812 & TRN & & \\
\hline CHEMBL 2163688 & 859881 & 8.3665 & 7.9801 & TST & & \\
\hline CHEMBL 2165337 & 859881 & 8.7696 & 8.5269 & TST & & \\
\hline CHEMBL112624 & 859881 & 9.3979 & 8.7462 & TST & & \\
\hline CHEMBL 2163710 & 859881 & 7.1367 & 7.2159 & TRN & & \\
\hline CHEMBL 2163717 & 859881 & 8.1024 & 8.1931 & TRN & & \\
\hline CHEMBL 2165335 & 859881 & 8.6383 & 8.2567 & TST & & \\
\hline
\end{tabular}


Supplemental Table S2.txt

\begin{tabular}{|c|c|c|c|c|c|}
\hline CHEMBL 2163722 & 859881 & 6.7282 & 6.7513 & TRN & \\
\hline CHEMBL 2163704 & 859881 & 8.9586 & 8.9468 & TRN & \\
\hline CHEMBL 2163716 & 859881 & 8.7212 & 8.7272 & TRN & \\
\hline CHEMBL 2165329 & 859881 & 9.0 & 8.8596 & TRN & \\
\hline CHEMBL 2165338 & 859881 & 9.0969 & 8.61 & TST & \\
\hline CHEMBL2163699 & 859881 & 6.1314 & 6.1837 & TRN & \\
\hline CHEMBL 2163728 & 859881 & 8.1612 & 8.0194 & TRN & \\
\hline CHEMBL 2163689 & 859881 & 8.5528 & 7.28600 & 00000000005 & TST \\
\hline CHEMBL 2163720 & 859881 & 8.7696 & 8.8177 & TRN & \\
\hline CHEMBL 2163696 & 859881 & 5.3435 & 5.4637 & TRN & \\
\hline CHEMBL 2163693 & 859881 & 8.6576 & 8.1521 & TST & \\
\hline CHEMBL 2163726 & 859881 & 7.8539 & 7.8914 & TRN & \\
\hline CHEMBL 2163701 & 859881 & 8.5528 & 8.5925 & TRN & \\
\hline CHEMBL 2163714 & 859881 & 8.0269 & 8.0558 & TRN & \\
\hline CHEMBL 2163725 & 859881 & 8.8539 & 8.845 & TRN & \\
\hline CHEMBL 2163700 & 859881 & 7.7496 & 7.7418 & TRN & \\
\hline CHEMBL 2163708 & 859881 & 8.8239 & 8.8088 & TRN & \\
\hline CHEMBL 2163713 & 859881 & 7.8539 & 7.7852 & TRN & \\
\hline CHEMBL 2165336 & 859881 & 8.4437 & 8.4178 & TST & \\
\hline CHEMBL 2163691 & 859881 & 8.7212 & 8.8592 & TRN & \\
\hline CHEMBL 2165330 & 859881 & 8.8539 & 8.97299 & э999999999 & TRN \\
\hline CHEMBL 2163712 & 859881 & 6.9469 & 6.6721 & TRN & \\
\hline CHEMBL 2165334 & 859881 & 8.7959 & 9.0289 & TST & \\
\hline CHEMBL 2163715 & 859881 & 8.3665 & 8.3942 & TRN & \\
\hline CHEMBL 2163695 & 859881 & 7.5901 & 7.4578 & TRN & \\
\hline CHEMBL 2163690 & 859881 & 8.9208 & 9.161 & TST & \\
\hline CHEMBL 2163721 & 859881 & 8.1549 & 8.105 & TRN & \\
\hline CHEMBL 2163703 & 859881 & 8.4949 & 8.6095 & TRN & \\
\hline CHEMBL 2163702 & 859881 & 8.6576 & 8.6678 & TRN & \\
\hline CHEMBL 2163719 & 859881 & 8.4202 & 8.4176 & TRN & \\
\hline CHEMBL 2163711 & 859881 & 8.1739 & 8.3709 & TRN & \\
\hline CHEMBL 2165333 & 859881 & 8.8539 & 9.2547 & TST & \\
\hline CHEMBL 2163694 & 859881 & 8.9586 & 8.6598 & TST & \\
\hline CHEMBL 2163692 & 859881 & 9.3979 & 9.3089 & TRN & \\
\hline CHEMBL 2163697 & 859881 & 8.3665 & 8.3279 & TRN & \\
\hline CHEMBL2163709 & 859881 & 7.983 & 7.9261 & TRN & \\
\hline CHEMBL 2163723 & 859881 & 8.6778 & 8.6072 & TRN & \\
\hline CHEMBL 2165328 & 859881 & 8.1612 & 8.1682 & TRN & \\
\hline CHEMBL 2165332 & 859881 & 9.1549 & 8.895 & TST & \\
\hline CHEMBL 2163707 & 859881 & \multicolumn{3}{|c|}{5.321000000000001} & I \\
\hline CHEMBL3675573 & 1527654 & 7.7423 & 7.1556 & TST & \\
\hline CHEMBL 3675580 & 1527654 & 5.0 & 5.1707 & TRN & \\
\hline CHEMBL 3670691 & 1527654 & 7.0458 & 7.2539 & TRN & \\
\hline CHEMBL3670705 & 1527654 & 6.0788 & 6.7009 & TRN & \\
\hline CHEMBL 3675584 & 1527654 & 6.4763 & 6.6055 & TRN & \\
\hline CHEMBL 3675592 & 1527654 & 7.0132 & 6.8805 & TRN & \\
\hline CHEMBL 3675578 & 1527654 & 5.0 & 5.1886 & TRN & \\
\hline CHEMBL3675559 & 1527654 & 5.0 & 4.437 & TRN & \\
\hline
\end{tabular}


Supplemental Table S2.txt

\begin{tabular}{|c|c|c|c|c|}
\hline CHEMBL3675596 & 1527654 & 4.301 & 4.8067 & TRN \\
\hline CHEMBL3670717 & 1527654 & 4.301 & 4.3038 & TRN \\
\hline CHEMBL3675556 & 1527654 & 4.0 & 3.9664 & TRN \\
\hline CHEMBL 3675557 & 1527654 & 5.0 & 5.0342 & TRN \\
\hline CHEMBL3675579 & 1527654 & 6.1373 & 6.1034 & TRN \\
\hline CHEMBL3670703 & 1527654 & 7.0315 & 7.1364 & TRN \\
\hline CHEMBL3675572 & 1527654 & 7.9208 & 6.4691 & TST \\
\hline CHEMBL3670714 & 1527654 & 5.0 & 5.102 & TRN \\
\hline CHEMBL3670697 & 1527654 & 5.0 & 4.8853 & TRN \\
\hline CHEMBL3670699 & 1527654 & 5.0 & 5.3804 & TRN \\
\hline CHEMBL3675599 & 1527654 & 5.0 & 5.6751 & TRN \\
\hline CHEMBL3675583 & 1527654 & 6.6308 & 6.51200 & 00000000005 \\
\hline CHEMBL3670716 & 1527654 & 5.0 & 4.9009 & TST \\
\hline CHEMBL 3670720 & 1527654 & 6.3546 & 6.3011 & TRN \\
\hline CHEMBL3675577 & 1527654 & 6.0685 & 5.8717 & TRN \\
\hline CHEMBL3670698 & 1527654 & 6.8239 & 6.4481 & TRN \\
\hline CHEMBL3675567 & 1527654 & 7.1367 & 6.5457 & TRN \\
\hline CHEMBL 3675554 & 1527654 & 6.2628 & 7.1556 & TST \\
\hline CHEMBL 3670700 & 1527654 & 6.11799 & 99999999 & 6.1822 \\
\hline CHEMBL3675601 & 1527654 & 5.0 & 5.4899 & TRN \\
\hline CHEMBL3670719 & 1527654 & 4.301 & 4.7274 & TST \\
\hline CHEMBL3675597 & 1527654 & 5.0 & 4.8067 & TRN \\
\hline CHEMBL3670706 & 1527654 & 7.4056 & 6.7009 & TRN \\
\hline CHEMBL 3675541 & 1527654 & 6.1824 & 5.9425 & TRN \\
\hline CHEMBL 3675562 & 1527654 & 4.301 & 4.2677 & TRN \\
\hline CHEMBL3670707 & 1527654 & 5.0 & 5.8809 & TST \\
\hline CHEMBL3670721 & 1527654 & 5.0 & 4.8385 & TRN \\
\hline CHEMBL 3675587 & 1527654 & 6.4306 & 6.4698 & TRN \\
\hline CHEMBL 3675585 & 1527654 & 6.8539 & 6.9853 & TRN \\
\hline CHEMBL3675560 & 1527654 & 5.0 & 5.0845 & TRN \\
\hline CHEMBL3675566 & 1527654 & 7.2596 & 6.7036 & TRN \\
\hline CHEMBL3670704 & 1527654 & 7.284 & 6.718 & TST \\
\hline CHEMBL3670712 & 1527654 & 5.0 & 4.8276 & TST \\
\hline CHEMBL3670709 & 1527654 & 4.301 & 4.2619 & TST \\
\hline CHEMBL 3675582 & 1527654 & 6.6904 & 6.9131 & TRN \\
\hline CHEMBL3675565 & 1527654 & 6.9586 & 6.1306 & TRN \\
\hline CHEMBL3670710 & 1527654 & 5.0 & 5.6675 & TST \\
\hline CHEMBL3675595 & 1527654 & 6.0615 & 5.8779 & TRN \\
\hline CHEMBL3675553 & 1527654 & 5.0 & 6.4691 & TST \\
\hline CHEMBL3675603 & 1527654 & 6.4698 & 6.5056 & TST \\
\hline CHEMBL3675552 & 1527654 & 5.0 & 5.7298 & TRN \\
\hline CHEMBL3670701 & 1527654 & 7.0809 & 7.4653 & TST \\
\hline CHEMBL3675571 & 1527654 & 6.4789 & 5.7298 & TRN \\
\hline CHEMBL 3675548 & 1527654 & 6.1993 & 6.5457 & TRN \\
\hline CHEMBL3675575 & 1527654 & 7.4089 & 7.0696 & TRN \\
\hline CHEMBL3675589 & 1527654 & 6.5258 & 6.0024 & TRN \\
\hline CHEMBL3675545 & 1527654 & 6.3487 & 6.4377 & TRN \\
\hline CHEMBL3670695 & 1527654 & 6.9508 & 6.4941 & TST \\
\hline
\end{tabular}


Supplemental Table S2.txt

\begin{tabular}{|c|c|c|c|c|}
\hline CHEMBL 3675591 & 1527654 & 6.9355 & 7.4111 & TST \\
\hline CHEMBL 3675569 & 1527654 & 7.1675 & 6.4733 & TRN \\
\hline CHEMBL 3670702 & 1527654 & 7.1871 & 6.6859 & TST \\
\hline CHEMBL 3675550 & 1527654 & 6.0721 & 6.4733 & TRN \\
\hline CHEMBL 3675564 & 1527654 & 7.3468 & 7.0942 & TRN \\
\hline CHEMBL 3670715 & 1527654 & 5.0 & 5.046 & TRN \\
\hline CHEMBL 3675543 & 1527654 & \multicolumn{2}{|c|}{6.821000000000001} & 6.4537 \\
\hline CHEMBL 3675593 & 1527654 & 6.5544 & 6.6726 & TRN \\
\hline CHEMBL 3675594 & 1527654 & 5.0 & 5.3769 & TRN \\
\hline CHEMBL 3675576 & 1527654 & 5.0 & 5.4703 & TRN \\
\hline CHEMBL1232489 & 1527654 & 6.1215 & 5.8134 & TST \\
\hline CHEMBL 3675581 & 1527654 & 6.8477 & 7.0093 & TRN \\
\hline CHEMBL 3670708 & 1527654 & 7.1079 & 6.7612 & TST \\
\hline CHEMBL 3675558 & 1527654 & 4.301 & 4.1701 & TRN \\
\hline CHEMBL 3675600 & 1527654 & 5.0 & 4.5403 & TRN \\
\hline CHEMBL 3675607 & 1527654 & 6.4237 & 6.2149 & TRN \\
\hline CHEMBL 3670711 & 1527654 & 4.301 & 4.6712 & TST \\
\hline CHEMBL 3675561 & 1527654 & 4.301 & 4.5285 & TRN \\
\hline CHEMBL 3670718 & 1527654 & 5.0 & 4.98 & TST \\
\hline CHEMBL 3675549 & 1527654 & 5.0 & 6.1364 & TRN \\
\hline CHEMBL 3675605 & 1527654 & 6.3969 & 6.6758 & TRN \\
\hline CHEMBL 3675590 & 1527654 & 6.3152 & 6.1809 & TST \\
\hline CHEMBL 3675570 & 1527654 & 7.5086 & 6.8744 & TRN \\
\hline CHEMBL 3670696 & 1527654 & 7.041 & 6.3724 & TST \\
\hline CHEMBL 3675574 & 1527654 & 6.2668 & 6.1306 & TRN \\
\hline CHEMBL 3639695 & 1527654 & 7.0655 & 6.3747 & TST \\
\hline CHEMBL 3675555 & 1527654 & 5.0 & 4.8472 & TRN \\
\hline CHEMBL 3675542 & 1527654 & 6.6478 & 6.991006 & 00000000005 \\
\hline CHEMBL 3670713 & 1527654 & 5.0 & 5.1318 & TRN \\
\hline CHEMBL 3675588 & 1527654 & 6.8327 & 6.7753 & TRN \\
\hline CHEMBL 3675547 & 1527654 & 5.0 & 6.1306 & TRN \\
\hline CHEMBL 3675544 & 1527654 & 6.3516 & 6.4491 & TRN \\
\hline CHEMBL 3639744 & 1527654 & 6.0477 & 6.7036 & TRN \\
\hline CHEMBL 3675598 & 1527654 & 6.0645 & 5.7004 & TRN \\
\hline CHEMBL 3675604 & 1527654 & 5.0 & 5.886 & TST \\
\hline CHEMBL 3675546 & 1527654 & 6.4962 & 6.2632 & TRN \\
\hline CHEMBL 3675602 & 1527654 & 4.301 & 4.4318 & TRN \\
\hline CHEMBL 3675551 & 1527654 & 6.1024 & 6.8744 & TRN \\
\hline CHEMBL 3675586 & 1527654 & 6.4584 & 6.2491 & TRN \\
\hline CHEMBL 3675568 & 1527654 & 7.3098 & 6.1364 & TRN \\
\hline CHEMBL87810 & 158520 & 3.0 & 2.9853 & TRN \\
\hline CHEMBL 89363 & 158520 & 4.2154 & 4.1938 & TRN \\
\hline CHEMBL330321 & 158520 & 3.0 & 3.0195 & TRN \\
\hline CHEMBL328710 & 158520 & 4.7122 & 4.6757 & TRN \\
\hline CHEMBL 315546 & 158520 & 5.2924 & 5.2105 & TRN \\
\hline CHEMBL 87208 & 158520 & 5.5528 & 5.5522 & TRN \\
\hline CHEMBL 85021 & 158520 & 4.757 & 4.7402 & TRN \\
\hline CHEMBL 86837 & 158520 & 3.0 & 3.0109 & TRN \\
\hline
\end{tabular}




\begin{tabular}{|c|c|c|c|c|c|c|}
\hline & & \multicolumn{5}{|c|}{ Supplemental Table S2.txt } \\
\hline CHEMBL 86755 & 158520 & 4.9208 & 4.9705 & TRN & & \\
\hline CHEMBL316268 & 158520 & 3.0 & 2.9661 & TRN & & \\
\hline CHEMBL86480 & 158520 & 4.4802 & 4.5362 & TRN & & \\
\hline CHEMBL86944 & 158520 & 3.0 & 2.9655 & TRN & & \\
\hline CHEMBL87402 & 158520 & 3.0 & 3.0969 & TST & & \\
\hline CHEMBL 86945 & 158520 & 3.0 & 2.9812 & TRN & & \\
\hline CHEMBL 89483 & 158520 & 4.5935 & 4.5753 & TRN & & \\
\hline CHEMBL 89723 & 158520 & \multicolumn{3}{|c|}{ 4.218999999999999 } & .2324 & TRN \\
\hline CHEMBL420411 & 158520 & 3.0 & 3.0168 & TRN & & \\
\hline CHEMBL88405 & 158520 & 4.8601 & 4.8162 & TRN & & \\
\hline CHEMBL 89721 & 158520 & 3.0 & 3.0074 & TRN & & \\
\hline CHEMBL316009 & 158520 & 4.1805 & 4.2042 & TRN & & \\
\hline CHEMBL431025 & 158520 & 4.0685 & 4.0849 & TRN & & \\
\hline CHEMBL 87324 & 158520 & 4.7399 & 4.7569 & TRN & & \\
\hline CHEMBL 86326 & 158520 & 3.0 & 3.0309 & TRN & & \\
\hline CHEMBL316020 & 158520 & 3.0 & 2.9803 & TRN & & \\
\hline CHEMBL316008 & 158520 & 3.0 & 3.9019 & TST & & \\
\hline CHEMBL 313578 & 158520 & 5.0762 & 5.0704 & TRN & & \\
\hline CHEMBL48760 & 158520 & 4.6162 & 4.6486 & TRN & & \\
\hline CHEMBL 86432 & 158520 & 3.0 & 1.4397 & TST & & \\
\hline CHEMBL87325 & 158520 & 4.3799 & 4.3632 & TRN & & \\
\hline CHEMBL89505 & 158520 & 3.0 & 2.9937 & TRN & & \\
\hline CHEMBL 87746 & 158520 & 3.0 & 3.03 & TRN & & \\
\hline CHEMBL314021 & 158520 & 3.0 & 2.8463 & TST & & \\
\hline CHEMBL 89646 & 158520 & 3.0 & 2.5598 & TST & & \\
\hline CHEMBL 86943 & 158520 & 3.0 & 4.60800 & 00000000005 & & TST \\
\hline CHEMBL314146 & 158520 & 3.0 & 3.1271 & TST & & \\
\hline CHEMBL 89040 & 158520 & 4.6108 & 4.6978 & TRN & & \\
\hline CHEMBL 85403 & 158520 & 3.0 & 2.9548 & TRN & & \\
\hline CHEMBL89697 & 158520 & 3.0 & 2.9005 & TST & & \\
\hline CHEMBL 314217 & 158520 & 3.0 & 3.0249 & TRN & & \\
\hline CHEMBL 90277 & 158520 & 4.3019 & 4.2276 & TRN & & \\
\hline CHEMBL 86921 & 158520 & 3.0 & 3.8949 & TST & & \\
\hline CHEMBL421548 & 158520 & 4.0 & 3.9506 & TRN & & \\
\hline CHEMBL314798 & 158520 & 3.0 & 1.5286 & TST & & \\
\hline CHEMBL 329367 & 158520 & 4.1805 & 4.1738 & TRN & & \\
\hline CHEMBL315701 & 158520 & 3.0 & 2.9929 & TRN & & \\
\hline CHEMBL328452 & 158520 & 3.0 & 2.9668 & TST & & \\
\hline CHEMBL312826 & 158520 & 3.0 & 2.7517 & TST & & \\
\hline CHEMBL 87080 & 158520 & 4.0 & 4.0923 & TRN & & \\
\hline CHEMBL 313433 & 158520 & 4.1838 & 3.8581 & TST & & \\
\hline CHEMBL87783 & 158520 & 3.0 & 3.0078 & TRN & & \\
\hline CHEMBL 86631 & 158520 & 3.0 & 3.6501 & TST & & \\
\hline CHEMBL313259 & 158520 & 3.0 & 2.9907 & TRN & & \\
\hline CHEMBL89809 & 158520 & 3.0 & 3.0259 & TRN & & \\
\hline CHEMBL 334707 & 688210 & 2.7447 & 3.2728 & TRN & & \\
\hline CHEMBL1570820 & 688210 & 2.7447 & 3.2186 & TRN & & \\
\hline CHEMBL1581627 & 688210 & 2.7447 & 2.7797 & TRN & & \\
\hline
\end{tabular}




\begin{tabular}{|c|c|c|c|c|c|}
\hline \multicolumn{6}{|c|}{ Supplemental Table S2.txt } \\
\hline CHEMBL1347656 & 688210 & 2.7447 & 3.0566 & TST & \\
\hline CHEMBL1382191 & 688210 & 4.6169 & 3.0457 & TRN & \\
\hline CHEMBL1602947 & 688210 & 2.7447 & 2.7634 & TRN & \\
\hline CHEMBL87285 & 688210 & 2.7447 & 3.0249 & TST & \\
\hline CHEMBL3190697 & 688210 & 2.7447 & 2.7252 & TRN & \\
\hline CHEMBL1594071 & 688210 & 2.7447 & 2.71 & TRN & \\
\hline CHEMBL1979784 & 688210 & 2.7447 & 2.7517 & TRN & \\
\hline CHEMBL1380975 & 688210 & 2.7447 & 3.1263 & TRN & \\
\hline CHEMBL3190873 & 688210 & 5.5887 & 3.2941 & TRN & \\
\hline CHEMBL1362096 & 688210 & 2.7447 & 2.7209 & TRN & \\
\hline CHEMBL1502020 & 688210 & 4.4434 & 2.7367 & TRN & \\
\hline CHEMBL602363 & 688210 & 2.7447 & 3.1327 & TRN & \\
\hline CHEMBL1477033 & 688210 & 2.7447 & 2.7407 & TRN & \\
\hline CHEMBL1361307 & 688210 & 2.7447 & 2.7593 & TRN & \\
\hline CHEMBL1377705 & 688210 & 2.7447 & 2.7499 & TRN & \\
\hline CHEMBL1336535 & 688210 & 2.7447 & 2.6823 & TRN & \\
\hline CHEMBL1524956 & 688210 & 2.7447 & 2.6832 & TRN & \\
\hline CHEMBL1455523 & 688210 & 2.7447 & 3.1614 & TRN & \\
\hline CHEMBL 2000750 & 688210 & 2.7447 & 3.1475 & TRN & \\
\hline CHEMBL1447219 & 688210 & 2.7447 & 2.7458 & TRN & \\
\hline CHEMBL1452090 & 688210 & 2.7447 & 2.721 & TRN & \\
\hline CHEMBL1329129 & 688210 & 2.7447 & 2.7557 & TRN & \\
\hline CHEMBL1386774 & 688210 & 5.5123 & 3.324 & TRN & \\
\hline CHEMBL1455627 & 688210 & 2.7447 & 3.1553 & TRN & \\
\hline CHEMBL1995550 & 688210 & 2.7447 & 3.1528 & TRN & \\
\hline CHEMBL1346226 & 688210 & 2.7447 & 3.0567 & TRN & \\
\hline CHEMBL1472418 & 688210 & 2.7447 & 2.6937 & TRN & \\
\hline CHEMBL1534596 & 688210 & 2.7447 & 2.6651 & TRN & \\
\hline CHEMBL1547347 & 688210 & 2.7447 & 3.1007 & TRN & \\
\hline CHEMBL1393829 & 688210 & 2.7447 & 2.6886 & TRN & \\
\hline CHEMBL3196754 & 688210 & 2.7447 & 3.1052 & TRN & \\
\hline CHEMBL1588513 & 688210 & 2.7447 & 2.9812 & TRN & \\
\hline CHEMBL1440514 & 688210 & 2.7447 & 2.7157 & TST & \\
\hline CHEMBL3193098 & 688210 & 2.7447 & 3.1253 & TRN & \\
\hline CHEMBL1579999 & 688210 & 2.7447 & 2.7802 & TRN & \\
\hline CHEMBL1603001 & 688210 & 2.7447 & 2.72399 & 99999999998 & TST \\
\hline CHEMBL453974 & 688210 & 2.7447 & 3.0824 & TST & \\
\hline CHEMBL1483964 & 688210 & 2.7447 & 2.7173 & TRN & \\
\hline CHEMBL1310713 & 688210 & 2.7447 & 3.1192 & TRN & \\
\hline CHEMBL1303401 & 688210 & 2.7447 & 2.7184 & TRN & \\
\hline CHEMBL3192165 & 688210 & 2.7447 & 3.0665 & TRN & \\
\hline CHEMBL1500188 & 688210 & 2.7447 & 3.0293 & TRN & \\
\hline CHEMBL455284 & 688210 & 2.7447 & 2.7894 & TRN & \\
\hline CHEMBL1519902 & 688210 & 2.7447 & 2.7854 & TRN & \\
\hline CHEMBL1351542 & 688210 & 2.7447 & 3.2179 & TRN & \\
\hline CHEMBL1320281 & 688210 & 2.7447 & 2.736 & TRN & \\
\hline CHEMBL1350245 & 688210 & 2.7447 & 2.7677 & TST & \\
\hline CHEMBL585827 & 688210 & 2.7447 & 2.9978 & TRN & \\
\hline
\end{tabular}




\begin{tabular}{|c|c|c|c|c|c|}
\hline \multirow[b]{2}{*}{ CHEMBL1319004 } & & \multicolumn{4}{|c|}{ Supplemental Table s2.txt } \\
\hline & 688210 & 2.7447 & 2.7548 & TRN & \\
\hline CHEMBL1309890 & 688210 & 2.7447 & 2.9819 & TRN & \\
\hline CHEMBL1312049 & 688210 & 2.7447 & 2.7406 & TRN & \\
\hline CHEMBL1576118 & 688210 & 2.7447 & 2.7297 & TRN & \\
\hline CHEMBL 3190230 & 688210 & 2.7447 & 2.7164 & TST & \\
\hline CHEMBL3197024 & 688210 & 2.7447 & 3.0904 & TRN & \\
\hline CHEMBL1596066 & 688210 & 4.7157 & 3.0944 & TRN & \\
\hline CHEMBL1503006 & 688210 & 2.7447 & 2.6883 & TRN & \\
\hline CHEMBL1475477 & 688210 & 2.7447 & 2.7308 & TRN & \\
\hline CHEMBL547285 & 688210 & 2.7447 & 2.6647 & TRN & \\
\hline CHEMBL1504569 & 688210 & 2.7447 & 3.1371 & TRN & \\
\hline CHEMBL1499233 & 688210 & 2.7447 & 2.6693 & TRN & \\
\hline CHEMBL1539624 & 688210 & 2.7447 & 3.2004 & TRN & \\
\hline CHEMBL1405204 & 688210 & 4.3431 & 3.1675 & TRN & \\
\hline CHEMBL1576945 & 688210 & 2.7447 & 2.7495 & TST & \\
\hline CHEMBL1550442 & 688210 & 2.7447 & 2.7833 & TRN & \\
\hline CHEMBL586031 & 688210 & 2.7447 & 2.7261 & TRN & \\
\hline CHEMBL1500742 & 688210 & 2.7447 & 2.7295 & TST & \\
\hline CHEMBL1439020 & 688210 & 2.7447 & 3.074 & TRN & \\
\hline CHEMBL3145031 & 688210 & 2.7447 & 2.7347 & TST & \\
\hline CHEMBL1521297 & 688210 & $5.4220 e$ & 000000000 & 3.2889 & TRN \\
\hline CHEMBL1318943 & 688210 & 2.7447 & 2.7135 & TST & \\
\hline CHEMBL1408965 & 688210 & 2.7447 & 2.767 & TRN & \\
\hline CHEMBL1468024 & 688210 & 2.7447 & 2.6914 & TRN & \\
\hline CHEMBL1341308 & 688210 & 2.7447 & 2.7649 & TRN & \\
\hline CHEMBL1789993 & 688210 & 2.7447 & 2.7046 & TST & \\
\hline CHEMBL1389335 & 688210 & 2.7447 & 2.7025 & TRN & \\
\hline CHEMBL1543255 & 688210 & 2.7447 & 2.7076 & TRN & \\
\hline CHEMBL1437579 & 688210 & 2.7447 & 2.7557 & TRN & \\
\hline CHEMBL1406031 & 688210 & 2.7447 & 2.6846 & TRN & \\
\hline CHEMBL548615 & 688210 & 2.7447 & 3.1891 & TRN & \\
\hline CHEMBL1534035 & 688210 & 2.7447 & 2.6816 & TRN & \\
\hline CHEMBL1595820 & 688210 & 2.7447 & 2.6871 & TRN & \\
\hline CHEMBL1534520 & 688210 & 2.7447 & 2.7328 & TRN & \\
\hline CHEMBL588804 & 688210 & 2.7447 & 3.0727 & TRN & \\
\hline CHEMBL1350780 & 688210 & 2.7447 & 3.2372 & TRN & \\
\hline CHEMBL530499 & 688210 & 2.7447 & 2.6596 & TRN & \\
\hline CHEMBL1970872 & 688210 & 2.7447 & 3.112 & TRN & \\
\hline CHEMBL1545702 & 688210 & 2.7447 & 2.7861 & TST & \\
\hline CHEMBL1574132 & 688210 & 2.7447 & 3.1102 & TRN & \\
\hline CHEMBL1391737 & 688210 & 2.7447 & 3.0738 & TRN & \\
\hline CHEMBL3197761 & 688210 & 2.7447 & 3.098999 & 79999999998 & TRN \\
\hline CHEMBL1390303 & 688210 & 2.7447 & 3.0735 & TRN & \\
\hline CHEMBL1451169 & 688210 & 2.7447 & 2.7306 & TRN & \\
\hline CHEMBL3199428 & 688210 & 2.7447 & 2.7609 & TRN & \\
\hline CHEMBL1505028 & 688210 & 2.7447 & 2.6997 & TRN & \\
\hline CHEMBL1468661 & 688210 & 2.7447 & 3.1149 & TRN & \\
\hline CHEMBL1548492 & 688210 & 2.7447 & 2.655 & TRN & \\
\hline
\end{tabular}


Supplemental Table S2.txt

\begin{tabular}{|c|c|c|c|c|c|}
\hline CHEMBL1306256 & 688210 & 2.7447 & 2.7813 & TRN & \\
\hline CHEMBL1308052 & 688210 & 4.5517 & 3.3163 & TRN & \\
\hline CHEMBL1364071 & 688210 & 2.7447 & 3.0163 & TRN & \\
\hline CHEMBL1464485 & 688210 & 2.7447 & 2.6994 & TRN & \\
\hline CHEMBL1484777 & 688210 & 5.0916 & 3.3002 & TRN & \\
\hline CHEMBL1383916 & 688210 & 2.7447 & 2.7298 & TRN & \\
\hline CHEMBL1547468 & 688210 & 2.7447 & 3.0147 & TST & \\
\hline CHEMBL1537190 & 688210 & 2.7447 & 2.7823 & TRN & \\
\hline CHEMBL1328373 & 688210 & 5.4066 & 3.2924 & TRN & \\
\hline CHEMBL1524829 & 688210 & 2.7447 & 3.1714 & TRN & \\
\hline CHEMBL1448584 & 688210 & 2.7447 & 3.0771 & TRN & \\
\hline CHEMBL461579 & 688210 & 2.7447 & 3.0847 & TRN & \\
\hline CHEMBL1612118 & 688210 & 2.7447 & 2.7224 & TST & \\
\hline CHEMBL1433075 & 688210 & 2.7447 & 3.1317 & TST & \\
\hline CHEMBL1598785 & 688210 & 2.7447 & 2.72399 & 99999999998 & TRN \\
\hline CHEMBL1365988 & 688210 & 2.7447 & 2.6838 & TRN & \\
\hline CHEMBL3191808 & 688210 & 2.7447 & 2.7142 & TRN & \\
\hline CHEMBL1492378 & 688210 & 2.7447 & 2.7556 & TRN & \\
\hline CHEMBL193872 & 688210 & 2.7447 & 3.0731 & TRN & \\
\hline CHEMBL1376904 & 688210 & 2.7447 & 2.733 & TST & \\
\hline CHEMBL1556805 & 688210 & 2.7447 & 3.0652 & TRN & \\
\hline CHEMBL1588660 & 688210 & 2.7447 & 3.2444 & TRN & \\
\hline CHEMBL1595088 & 688210 & 2.7447 & 3.0787 & TRN & \\
\hline CHEMBL 3198836 & 688210 & 2.7447 & 3.0865 & TRN & \\
\hline CHEMBL1302439 & 688210 & 2.7447 & 2.9177 & TRN & \\
\hline CHEMBL1433124 & 688210 & 2.7447 & 3.0958 & TRN & \\
\hline CHEMBL1353371 & 688210 & 2.7447 & 3.1228 & TRN & \\
\hline CHEMBL1550278 & 688210 & 2.7447 & 2.7353 & TRN & \\
\hline CHEMBL1988042 & 688210 & 2.7447 & 3.1217 & TRN & \\
\hline CHEMBL1462215 & 688210 & 2.7447 & 2.7658 & TRN & \\
\hline CHEMBL1990174 & 688210 & 2.7447 & 3.157 & TRN & \\
\hline CHEMBL 3197343 & 688210 & 2.7447 & 2.8017 & TRN & \\
\hline CHEMBL1571370 & 688210 & 2.7447 & 2.7108 & TRN & \\
\hline CHEMBL1466179 & 688210 & 2.7447 & 2.7452 & TST & \\
\hline CHEMBL1352792 & 688210 & 2.7447 & 3.1001 & TRN & \\
\hline CHEMBL1404792 & 688210 & 2.7447 & 2.7221 & TRN & \\
\hline CHEMBL1352025 & 688210 & 2.7447 & 3.0569 & TST & \\
\hline CHEMBL1544423 & 688210 & 2.7447 & 3.2844 & TRN & \\
\hline CHEMBL1487639 & 688210 & 5.4062 & 3.1524 & TRN & \\
\hline CHEMBL3189966 & 688210 & 2.7447 & 2.7153 & TRN & \\
\hline CHEMBL1544114 & 688210 & 2.7447 & 3.1854 & TRN & \\
\hline CHEMBL1318693 & 688210 & 2.7447 & 3.1476 & TRN & \\
\hline CHEMBL1527022 & 688210 & 2.7447 & 2.74600 & 00000000004 & TRN \\
\hline CHEMBL1377316 & 688210 & 2.7447 & 3.0303 & TRN & \\
\hline CHEMBL1389318 & 688210 & 2.7447 & 2.7726 & TRN & \\
\hline CHEMBL1979455 & 688210 & 2.7447 & 2.8305 & TRN & \\
\hline CHEMBL1359343 & 688210 & 2.7447 & 3.0573 & TRN & \\
\hline CHEMBL1438970 & 688210 & 2.7447 & 2.6926 & TRN & \\
\hline
\end{tabular}




\begin{tabular}{|c|c|c|c|c|c|}
\hline & & \multicolumn{4}{|c|}{ Supplemental Table s2.txt } \\
\hline CHEMBL580727 & 688210 & 2.7447 & 2.6635 & TRN & \\
\hline CHEMBL1301513 & 688210 & 2.7447 & 2.6634 & TRN & \\
\hline CHEMBL1370536 & 688210 & 2.7447 & 3.0408 & TST & \\
\hline CHEMBL1994623 & 688210 & 2.7447 & 3.0875 & TRN & \\
\hline CHEMBL1545677 & 688210 & 2.7447 & 3.0351 & TRN & \\
\hline CHEMBL 1451060 & 688210 & 2.7447 & 2.7706 & TRN & \\
\hline CHEMBL1511029 & 688210 & 2.7447 & 2.7168 & TRN & \\
\hline CHEMBL 3195688 & 688210 & 2.7447 & 2.7251 & TRN & \\
\hline CHEMBL1412002 & 688210 & 2.7447 & 2.7001 & TRN & \\
\hline CHEMBL1387710 & 688210 & 2.7447 & 3.0719 & TRN & \\
\hline CHEMBL1362036 & 688210 & 2.7447 & 2.72300 & 00000000003 & TRN \\
\hline CHEMBL1311826 & 688210 & 2.7447 & 3.2823 & TRN & \\
\hline CHEMBL1587806 & 688210 & 4.05 & 2.7513 & TRN & \\
\hline CHEMBL1478797 & 688210 & 2.7447 & 2.7016 & TRN & \\
\hline CHEMBL1318350 & 688210 & 2.7447 & 3.0443 & TRN & \\
\hline CHEMBL1480836 & 688210 & 2.7447 & 2.7025 & TRN & \\
\hline CHEMBL1329507 & 688210 & 2.7447 & 3.1927 & TRN & \\
\hline CHEMBL1557243 & 688210 & 2.7447 & 2.7323 & TST & \\
\hline CHEMBL1514530 & 688210 & 4.6049 & 2.9634 & TRN & \\
\hline CHEMBL1304950 & 688210 & 2.7447 & 2.74899 & 99999999997 & TRN \\
\hline CHEMBL1348582 & 688210 & 2.7447 & 2.7909 & TRN & \\
\hline CHEMBL1568848 & 688210 & 2.7447 & 3.0224 & TST & \\
\hline CHEMBL1323512 & 688210 & 2.7447 & 2.7462 & TRN & \\
\hline CHEMBL140425 & 688210 & 2.7447 & 3.3545 & TRN & \\
\hline CHEMBL585591 & 688210 & 3.9848 & 3.0703 & TST & \\
\hline CHEMBL1468776 & 688210 & 2.7447 & 3.0899 & TRN & \\
\hline CHEMBL1533353 & 688210 & 2.7447 & 2.9219 & TRN & \\
\hline CHEMBL1310176 & 688210 & 2.7447 & 2.72899 & 99999999996 & TRN \\
\hline CHEMBL1374462 & 688210 & 2.7447 & 2.733 & TST & \\
\hline CHEMBL601768 & 688210 & 4.3431 & 2.7301 & TRN & \\
\hline CHEMBL 2005246 & 688210 & 2.7447 & 3.0193 & TRN & \\
\hline CHEMBL1491222 & 688210 & 2.7447 & 2.7475 & TRN & \\
\hline CHEMBL1469579 & 688210 & 5.2559 & 3.3134 & TRN & \\
\hline CHEMBL3195036 & 688210 & 2.7447 & 2.6791 & TRN & \\
\hline CHEMBL600862 & 688210 & 2.7447 & 2.6964 & TRN & \\
\hline CHEMBL1222385 & 688210 & 2.7447 & 3.0642 & TRN & \\
\hline CHEMBL3198729 & 688210 & 2.7447 & 3.0353 & TRN & \\
\hline CHEMBL3392051 & 688210 & 2.7447 & 2.7528 & TST & \\
\hline CHEMBL1497549 & 688210 & 2.7447 & 3.1002 & TRN & \\
\hline CHEMBL1383721 & 688210 & 2.7447 & 3.1085 & TST & \\
\hline CHEMBL1392455 & 688210 & 2.7447 & 2.8176 & TST & \\
\hline CHEMBL 225963 & 688210 & 2.7447 & 2.8207 & TST & \\
\hline CHEMBL1416601 & 688210 & 2.7447 & 3.2251 & TRN & \\
\hline CHEMBL1585127 & 688210 & 2.7447 & 2.74600 & 00000000004 & TRN \\
\hline CHEMBL1969300 & 688210 & 2.7447 & 3.111 & TRN & \\
\hline CHEMBL1487498 & 688210 & 2.7447 & 2.75399 & 99999999996 & TRN \\
\hline CHEMBL580955 & 688210 & 2.7447 & 2.6634 & TRN & \\
\hline CHEMBL1602855 & 688210 & 2.7447 & 2.7356 & TRN & \\
\hline
\end{tabular}




\begin{tabular}{|c|c|c|c|c|c|c|}
\hline \multirow[b]{2}{*}{ CHEMBL1330113 } & & \multicolumn{5}{|c|}{ Supplemental Table S2.txt } \\
\hline & 688210 & 2.7447 & 2.8199 & TST & & \\
\hline CHEMBL 3193010 & 688210 & 2.7447 & 2.7137 & TRN & & \\
\hline CHEMBL1331790 & 688210 & 2.7447 & 3.0671 & TRN & & \\
\hline CHEMBL1609315 & 688210 & 2.7447 & 2.7849 & TRN & & \\
\hline CHEMBL3189845 & 688210 & 2.7447 & 2.761 & TRN & & \\
\hline CHEMBL1491815 & 688210 & 2.7447 & 3.0837 & TRN & & \\
\hline CHEMBL600315 & 688210 & 2.7447 & 3.0372 & TST & & \\
\hline CHEMBL1420556 & 688210 & $6.0820 e$ & 00000000 & $\partial 1$ & 3.3299 & TRN \\
\hline CHEMBL1555271 & 688210 & 2.7447 & 2.6864 & TRN & & \\
\hline CHEMBL1789998 & 688210 & 2.7447 & 2.6733 & TST & & \\
\hline CHEMBL193627 & 688210 & 2.7447 & 3.043 & TRN & & \\
\hline CHEMBL1430893 & 688210 & 2.7447 & 2.7638 & TRN & & \\
\hline CHEMBL1488279 & 688210 & 2.7447 & 2.7241 & TRN & & \\
\hline CHEMBL1503033 & 688210 & 2.7447 & 2.7585 & TST & & \\
\hline CHEMBL1349480 & 688210 & 2.7447 & 3.1124 & TRN & & \\
\hline CHEMBL1610563 & 688210 & 2.7447 & 2.7524 & TRN & & \\
\hline CHEMBL3196726 & 688210 & 2.7447 & 2.6919 & TRN & & \\
\hline CHEMBL1317642 & 688210 & 2.7447 & 3.0037 & TRN & & \\
\hline CHEMBL1578127 & 688210 & 2.7447 & 3.0373 & TST & & \\
\hline CHEMBL1446034 & 688210 & 2.7447 & 2.7049 & TRN & & \\
\hline CHEMBL1422472 & 688210 & 2.7447 & 2.7373 & TRN & & \\
\hline CHEMBL1393700 & 688210 & 2.7447 & 3.0819 & TRN & & \\
\hline CHEMBL1371081 & 688210 & 2.7447 & 2.761 & TRN & & \\
\hline CHEMBL1587683 & 688210 & 2.7447 & 3.1159 & TRN & & \\
\hline CHEMBL1300080 & 688210 & 2.7447 & 3.0264 & TRN & & \\
\hline CHEMBL1449883 & 688210 & 2.7447 & 2.6575 & TRN & & \\
\hline CHEMBL1520556 & 688210 & 2.7447 & 2.7244 & TRN & & \\
\hline CHEMBL1317657 & 688210 & 2.7447 & 2.7416 & TRN & & \\
\hline CHEMBL1470382 & 688210 & 2.7447 & 3.114 & TRN & & \\
\hline CHEMBL1368410 & 688210 & 2.7447 & 2.7337 & TST & & \\
\hline CHEMBL1997747 & 688210 & 2.7447 & 2.7139 & TRN & & \\
\hline CHEMBL3195142 & 688210 & 2.7447 & 3.0557 & TRN & & \\
\hline CHEMBL1346822 & 688210 & 2.7447 & 3.0539 & TRN & & \\
\hline CHEMBL1424665 & 688210 & 2.7447 & 3.1058 & TRN & & \\
\hline CHEMBL3198503 & 688210 & 2.7447 & 2.7453 & TRN & & \\
\hline CHEMBL1392564 & 688210 & 2.7447 & 3.1048 & TRN & & \\
\hline CHEMBL1369893 & 688210 & 2.7447 & 2.9862 & TRN & & \\
\hline CHEMBL584442 & 688210 & 4.5291 & 2.992 & TRN & & \\
\hline CHEMBL1524014 & 688210 & 2.7447 & 2.6849 & TST & & \\
\hline CHEMBL1414734 & 688210 & 2.7447 & 3.0585 & TST & & \\
\hline CHEMBL1517151 & 688210 & 2.7447 & 2.7026 & TRN & & \\
\hline CHEMBL1460705 & 688210 & 2.7447 & 3.1534 & TRN & & \\
\hline CHEMBL1372734 & 688210 & 2.7447 & 2.7042 & TRN & & \\
\hline CHEMBL1340519 & 688210 & 2.7447 & 3.1609 & TRN & & \\
\hline CHEMBL1304603 & 688210 & 2.7447 & 2.9876 & TRN & & \\
\hline CHEMBL1332450 & 688210 & 2.7447 & 3.0553 & TRN & & \\
\hline CHEMBL1383706 & 688210 & 2.7447 & 2.7597 & TRN & & \\
\hline CHEMBL1519450 & 688210 & 2.7447 & 2.9802 & TRN & & \\
\hline
\end{tabular}




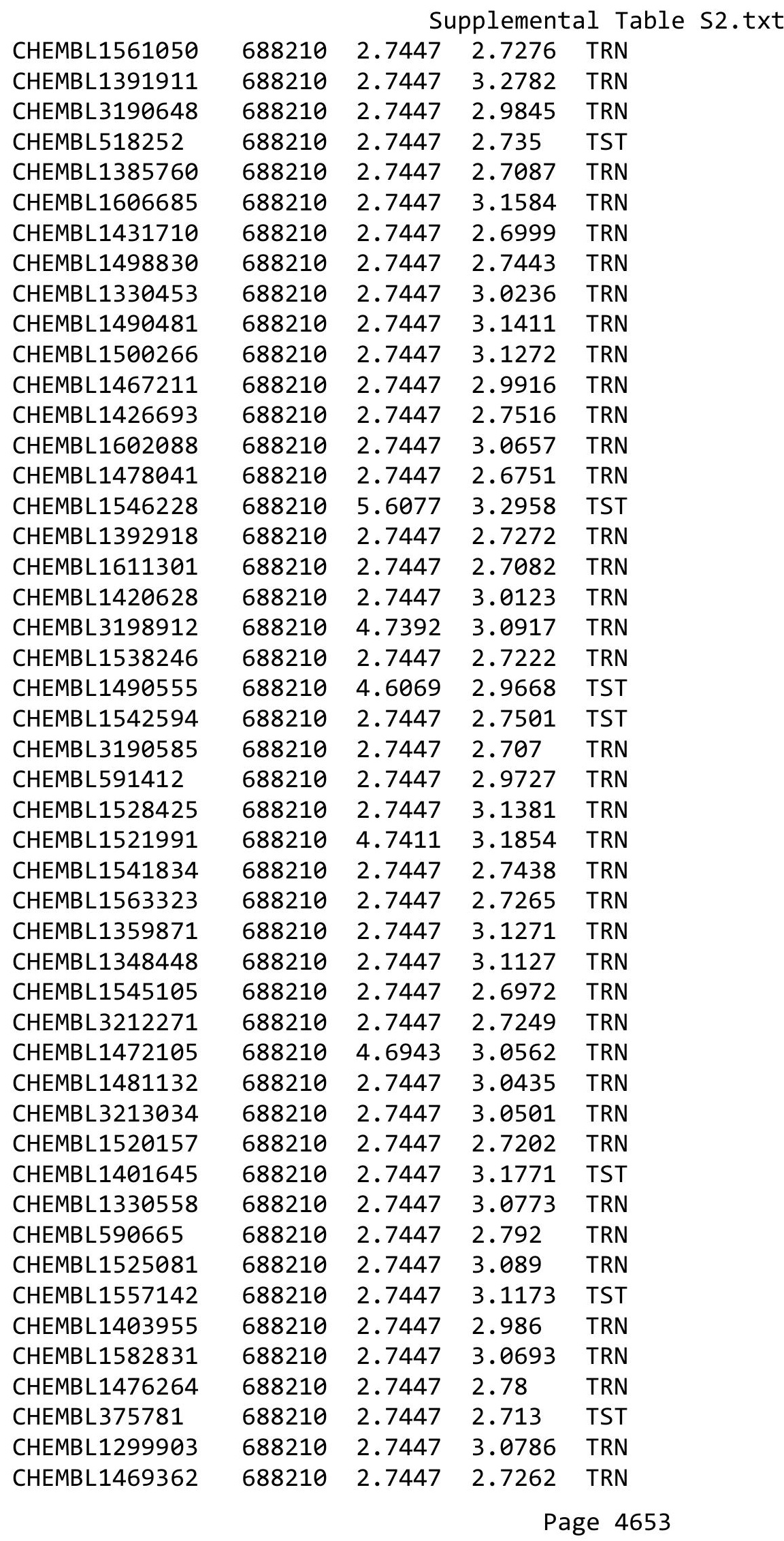


Supplemental Table S2.txt

\begin{tabular}{|c|c|c|c|c|}
\hline IE & & 7 & & \\
\hline HEMBL1426340 & 88210 & .7447 & 2.7131 & \\
\hline & & 7447 & & \\
\hline AEMBL1 & & 7447 & 5718 & \\
\hline IEMBL1342093 & & .7447 & $\partial 987$ & \\
\hline HEMBL1369425 & 88210 &. .7447 & .7241 & \\
\hline 331 & & .7447 & 7571 & \\
\hline FMRI 1 & & .7447 & 0732 & \\
\hline AEMBL13 & & 2.7447 & 725 & \\
\hline AEMBL 14 & 38210 & .7447 & 9653 & \\
\hline HEMBL13 & 10 & 2.7447 & 1857 & \\
\hline IEMBL13 & & .7447 & 839 & \\
\hline IEMBL1: & & 47 & & \\
\hline AEMBL22 & & 2.7447 & 5687 & \\
\hline AEMBL13 & & .7447 & 582 & \\
\hline AEMBL19 & 0 & 2.7447 & 3.2041 & \\
\hline AEMBL15 & & 47 & 478 & \\
\hline HEMBL32 & & 47 & 43 & \\
\hline AEMBL59 & & 2.7447 & 2.7006 & \\
\hline IEMBL13 & & 17 & & \\
\hline AEIMBL & & 2.7 & 984 & \\
\hline AEMBL: & & 7 & 882 & \\
\hline AEMBLI & & 17 & 294 & \\
\hline 452 & & & 0759 & \\
\hline IEMBL16 & & 7 & 53 & ST \\
\hline AEMBL1 & & 2.7 & 831 & \\
\hline AEMBL1 & & 7 & & \\
\hline AFMBI & & 2. & 395 & ST \\
\hline AEMBL13 & & & 926 & \\
\hline HEMBL13 & & 2.7 & 484 & ISI \\
\hline HEMBL13 & & 2.7 & 682 & \\
\hline AFMBI 1 & & 2. & 69 & ו \\
\hline 42 & & 2. & & \\
\hline JEMBL16 & & & 006 & SI \\
\hline HEMBL1483620 & & 2.7 & 3.0642 & IST \\
\hline HEMBL14 & & 2.7 & $\partial 897$ & \\
\hline 1 & & 2. & & ST \\
\hline HEMBL12 & & 2.7 & 2.9711 & ST \\
\hline HEMBL13 & & 2.7 & .7304 & TS \\
\hline IEMBL5S & & 2.7 & 2.7171 & IST \\
\hline HEMBL31 & & 2.74 & 2.6747 & \\
\hline HEMBL31 & & & 2.7511 & 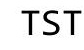 \\
\hline HEMBL 20 & & 2.74 & 3.0785 & IST \\
\hline AEMBL1363249 & & 2.7 & 2.7708 & is \\
\hline MBL1 & & 2.7 & 3.1057 & \\
\hline CHEMBL148 & & 2.7447 & 2.9763 & \\
\hline CHEMBL19 & & 4.3546 & 4.4324 & \\
\hline HEMBL 212835 & 396848 & 6.6576 & 6.925 & \\
\hline
\end{tabular}

Page 4654 


\begin{tabular}{|c|c|c|c|c|c|}
\hline & & & & & \\
\hline CHEMBL215119 & 396848 & 3.9172 & 3.8379 & TRN & \\
\hline CHEMBL386386 & 396848 & 3.8794 & 3.9888 & TRN & \\
\hline CHEMBL213206 & 396848 & 5.5817 & 6.581 & TST & \\
\hline CHEMBL52621 & 396848 & 3.4698 & 3.8596 & TST & \\
\hline CHEMBL215472 & 396848 & 3.3883 & 3.4043 & TRN & \\
\hline CHEMBL441692 & 396848 & 4.4609 & 4.5358 & TRN & \\
\hline CHEMBL213490 & 396848 & 3.8182 & 3.82899 & 99999999997 & TRN \\
\hline CHEMBL213489 & 396848 & 1.0 & 0.9039 & TRN & \\
\hline CHEMBL378256 & 396848 & 6.4685 & 6.6057 & TST & \\
\hline CHEMBL294192 & 396848 & 3.6517 & 4.6816 & TST & \\
\hline CHEMBL383962 & 396848 & 4.8386 & 4.7043 & TRN & \\
\hline CHEMBL213343 & 396848 & 4.4191 & 4.3333 & TRN & \\
\hline CHEMBL373332 & 396848 & 4.6696 & 4.6458 & TRN & \\
\hline CHEMBL212895 & 396848 & 3.5391 & 3.4085 & TRN & \\
\hline CHEMBL217805 & 396848 & 3.8894 & 3.6258 & TRN & \\
\hline CHEMBL385291 & 396848 & 4.3575 & 4.2137 & TRN & \\
\hline CHEMBL213280 & 396848 & 3.5528 & 3.3597 & TRN & \\
\hline CHEMBL215413 & 396848 & 3.5086 & 3.6629 & TRN & \\
\hline CHEMBL215490 & 396848 & 3.6271 & 3.8079 & TRN & \\
\hline CHEMBL384308 & 396848 & 4.1409 & 4.1967 & TRN & \\
\hline CHEMBL383957 & 396848 & 4.5768 & 4.6293 & TRN & \\
\hline CHEMBL436772 & 396848 & 3.9031 & 3.8461 & TRN & \\
\hline CHEMBL212842 & 396848 & 5.7055 & 6.0985 & TST & \\
\hline CHEMBL378354 & 396848 & 4.475 & 4.1831 & TRN & \\
\hline CHEMBL385542 & 396848 & 3.3851 & 3.1592 & TRN & \\
\hline CHEMBL436939 & 396848 & 3.5171 & 3.4155 & TRN & \\
\hline CHEMBL216027 & 396848 & 2.9735 & 3.2794 & TRN & \\
\hline CHEMBL212182 & 396848 & 3.2733 & 3.4683 & TST & \\
\hline CHEMBL214544 & 396848 & 3.7077 & 3.7335 & TRN & \\
\hline CHEMBL294191 & 396848 & 4.644 & 5.0985 & TST & \\
\hline CHEMBL425896 & 396848 & 3.5406 & 3.546006 & 00000000003 & TRN \\
\hline CHEMBL191634 & 396848 & 4.1002 & 4.0473 & TRN & \\
\hline CHEMBL213470 & 396848 & 3.8447 & 4.0911 & TRN & \\
\hline CHEMBL56011 & 396848 & 3.3497 & 4.0744 & TST & \\
\hline CHEMBL213059 & 396848 & 1.0 & 1.1246 & TRN & \\
\hline CHEMBL213289 & 396848 & 2.0 & 2.1863 & TST & \\
\hline CHEMBL213463 & 396848 & 3.8356 & 3.8178 & TRN & \\
\hline CHEMBL192017 & 396848 & 3.767 & 3.8369 & TRN & \\
\hline CHEMBL363434 & 396848 & 4.1599 & 4.1889 & TRN & \\
\hline CHEMBL378940 & 396848 & 3.9101 & 4.00899 & 99999999995 & TRN \\
\hline CHEMBL190258 & 396848 & 3.719 & 3.7927 & TRN & \\
\hline CHEMBL215608 & 396848 & 4.0329 & 4.019 & TRN & \\
\hline CHEMBL215664 & 396848 & 1.0 & 0.8043 & TRN & \\
\hline CHEMBL386831 & 396848 & 4.6003 & 4.61 & TRN & \\
\hline CHEMBL378858 & 396848 & 1.0 & 1.1008 & TRN & \\
\hline CHEMBL213327 & 396848 & 5.1911 & 6.3098 & TST & \\
\hline CHEMBL212792 & 396848 & 4.2321 & 5.4584 & TST & \\
\hline CHEMBL193619 & 396848 & 4.4295 & 4.3452 & TRN & \\
\hline
\end{tabular}




\begin{tabular}{|c|c|c|c|c|c|c|}
\hline & & \multicolumn{5}{|c|}{ Supplemental Table S2.txt } \\
\hline CHEMBL214851 & 396848 & 4.3372 & 5.3046 & TST & & \\
\hline CHEMBL214519 & 396848 & 1.0 & 1.0154 & TRN & & \\
\hline CHEMBL212662 & 396848 & 4.762 & 5.0183 & TRN & & \\
\hline CHEMBL377025 & 396848 & 1.0 & 1.2016 & TRN & & \\
\hline CHEMBL193356 & 396848 & 4.0083 & 3.9868 & TRN & & \\
\hline CHEMBL192043 & 396848 & 4.295 & 4.2168 & TRN & & \\
\hline CHEMBL212843 & 396848 & 4.8182 & 5.2303 & TST & & \\
\hline CHEMBL56073 & 396848 & 4.0835 & 4.3867 & TST & & \\
\hline CHEMBL386646 & 396848 & 1.0 & 1.0713 & TRN & & \\
\hline CHEMBL384162 & 396848 & 3.585 & 3.3837 & TRN & & \\
\hline CHEMBL384601 & 396848 & 4.3706 & 4.4958 & TRN & & \\
\hline CHEMBL193722 & 396848 & 4.2358 & 4.0099 & TST & & \\
\hline CHEMBL3688446 & 1528786 & 9.0 & 9.1759 & TRN & & \\
\hline CHEMBL3688435 & 1528786 & 8.1549 & 7.9853 & TRN & & \\
\hline CHEMBL3688452 & 1528786 & 6.8477 & 7.1155 & TRN & & \\
\hline CHEMBL3697259 & 1528786 & 8.0 & 9.0571 & TST & & \\
\hline CHEMBL3688500 & 1528786 & 7.4559 & 7.9452 & TRN & & \\
\hline CHEMBL3639997 & 1528786 & 7.5528 & 8.3262 & TST & & \\
\hline CHEMBL 3697167 & 1528786 & \multicolumn{3}{|c|}{6.4510000000000005} & .66 & TRN \\
\hline CHEMBL3693051 & 1528786 & 6.4012 & 6.4984 & TRN & & \\
\hline CHEMBL3700878 & 1528786 & 7.8069 & 6.9789 & TRN & & \\
\hline CHEMBL 3700854 & 1528786 & 7.3925 & 7.1733 & TRN & & \\
\hline CHEMBL3693155 & 1528786 & 7.9586 & 7.4548 & TRN & & \\
\hline CHEMBL 3688455 & 1528786 & 7.3098 & 7.3935 & TRN & & \\
\hline CHEMBL 3697234 & 1528786 & 8.301 & 8.2041 & TRN & & \\
\hline CHEMBL3693175 & 1528786 & 6.5114 & 6.85 & TRN & & \\
\hline CHEMBL3697306 & 1528786 & 5.7224 & 5.7429 & TST & & \\
\hline CHEMBL 3688532 & 1528786 & 8.5229 & 8.4252 & TRN & & \\
\hline CHEMBL 3697181 & 1528786 & 7.6021 & 7.99799 & 9999999999 & & TST \\
\hline CHEMBL3940195 & 1528786 & 6.0 & 6.0999 & TRN & & \\
\hline CHEMBL3688512 & 1528786 & 9.0 & 8.3843 & TST & & \\
\hline CHEMBL3688511 & 1528786 & 6.8761 & 7.0988 & TST & & \\
\hline CHEMBL 3697278 & 1528786 & 5.6038 & 8.1171 & TST & & \\
\hline CHEMBL3700815 & 1528786 & 4.0 & 4.4784 & TRN & & \\
\hline CHEMBL 3697281 & 1528786 & 4.0 & 6.0278 & TST & & \\
\hline CHEMBL3700818 & 1528786 & 4.0 & 4.4057 & TRN & & \\
\hline CHEMBL3693039 & 1528786 & 8.699 & 7.9536 & TRN & & \\
\hline CHEMBL3697211 & 1528786 & 7.1308 & 7.3237 & TRN & & \\
\hline CHEMBL 3697294 & 1528786 & 6.6684 & 6.7176 & TRN & & \\
\hline CHEMBL 3688524 & 1528786 & 8.0 & 7.7565 & TRN & & \\
\hline CHEMBL3700778 & 1528786 & 6.0069 & 5.6972 & TRN & & \\
\hline CHEMBL3697366 & 1528786 & 4.0 & 3.7876 & TRN & & \\
\hline CHEMBL3700869 & 1528786 & 7.3107 & 5.5387 & TST & & \\
\hline CHEMBL 3688601 & 1528786 & 7.3468 & 7.7555 & TRN & & \\
\hline CHEMBL 3700771 & 1528786 & 8.1739 & 7.2974 & TST & & \\
\hline CHEMBL3697246 & 1528786 & 6.699 & 6.8153 & TRN & & \\
\hline CHEMBL3693066 & 1528786 & 6.2967 & 7.318 & TST & & \\
\hline CHEMBL3697362 & 1528786 & 8.0757 & 7.7375 & TRN & & \\
\hline
\end{tabular}


Supplemental Table S2.txt

\begin{tabular}{|c|c|c|c|c|}
\hline - & & & & \\
\hline HEMBL3693037 & 528786 & & 6.6459 & \\
\hline & 28786 & & & \\
\hline 97377 & 28786 & 6.0 & 02 & $2 \mathrm{~N}$ \\
\hline AEMBL3688580 & 528786 & 6.0 & 4148 & \\
\hline AEMBL3688518 & 528786 & 9.0 & 0508 & \\
\hline HEMBL3688582 & 528786 & 6.67 & 6708 & \\
\hline AEMBL & 86 & 8.4 & 9236 & \\
\hline AEMBL & 528786 & 7.9208 & 9974 & \\
\hline AEMBL3697231 & 528786 & 6.3307 & .1754 & \\
\hline HEMBL3700875 & 528786 & 7.8962 & .671 & \\
\hline AEMBL3688541 & 528786 & 7.699 & 3211 & \\
\hline AEM & & & & RN \\
\hline HEMBL3 & 528 & 8.0706 & 3455 & \\
\hline AEMBL3982050 & 528786 & 6.6968 & 825 & \\
\hline AEMBL 3697347 & 528 & 6.2149 & 3689 & \\
\hline HEMBL36 & 86 & 7.9208 & 5784 & RIN \\
\hline HEMBL37 & 36 & 6.6099 & & \\
\hline 3098 & 36 & 8.301 & 1098 & \\
\hline AEMBL3693210 & 36 & 6.6021 & & \\
\hline HEMBL369, & 36 & 8.3979 & 676 & SIV \\
\hline HEMBL36 & 36 & 4 & 7504 & RN \\
\hline HEMBL36 & 36 & 8.699 & 3335 & \\
\hline 264 & 36 & 4.0 & 4857 & \\
\hline HEMBL369 & 36 & 6.0 & 465 & Riv \\
\hline AEMBL3693041 & 5287 & 8. & 2348 & RN \\
\hline AEMBL3 & 52 & 9 . & 136 & RN \\
\hline HEM & 36 & 7. & 468 & \\
\hline HEMBL3 & & 9.0 & 128 & 151 \\
\hline HEMBL37 & 52 & 8.09 & 341 & IRN \\
\hline AEMBL36 & 36 & 4 & 69 & RN \\
\hline HFMBI = & 6 & & 621 & RN \\
\hline 7 & & & & $\mathrm{R}$ \\
\hline HEMBL3688521 & & 7.5376 & 29 & TRN \\
\hline AEMBL3697368 & 6 & 6.51 & 6883 & TST \\
\hline HEMBL369 & 52 & 8 & 305 & RN \\
\hline HEMRI 2 & 6 & 4 & 54 & RN \\
\hline & 36 & 4.0 & 3037 & 「RN \\
\hline HEMBL3693208 & 528 & 6.6021 & .1062 & TRN \\
\hline AEMBL369 & 52 & 7.44 & 7.5632 & 「RN \\
\hline HEMBL3700880 & 528 & 4. & 5.3868 & RN \\
\hline HEMBL 3697232 & & & 3.5278 & RIN \\
\hline HEMBL3688397 & 528786 & 6.6635 & 5.8286 & זRN \\
\hline HEMBL3697338 & 528786 & 7.8041 & 7.7509 & $T R$ \\
\hline EMBL369 & 52 & 9 & 9.0223 & RIN \\
\hline HEMBL 3693182 & 5287 & .4647 & 5.1492 & \\
\hline HEMBL3 & 15287 & 8.1427 & 8.237 & \\
\hline CHEMBL 3693022 & 1528786 & 6.0 & 5.9792 & ГRN \\
\hline
\end{tabular}


Supplemental Table S2.txt

\begin{tabular}{|c|c|c|c|c|}
\hline CHEMBL 3688564 & 1528786 & 8.699 & 8.5536 & TRN \\
\hline CHEMBL 3700802 & 1528786 & 5.9528 & 7.7572 & TST \\
\hline CHEMBL 3693030 & 1528786 & 8.0458 & 7.8324 & TRN \\
\hline CHEMBL 3693081 & 1528786 & 5.6021 & 5.4847 & TRN \\
\hline CHEMBL3700799 & 1528786 & 5.9371 & 6.0111 & TRN \\
\hline CHEMBL 3700779 & 1528786 & 6.6198 & 5.9799 & TST \\
\hline CHEMBL 3688559 & 1528786 & 7.6778 & 7.7842 & TST \\
\hline CHEMBL3697218 & 1528786 & 7.9208 & 7.6473 & TRN \\
\hline CHEMBL 3697360 & 1528786 & 7.3054 & 7.3132 & TRN \\
\hline CHEMBL3700781 & 1528786 & 4.0 & 5.2719 & TST \\
\hline CHEMBL 3920350 & 1528786 & 6.1699 & 4.606 & TST \\
\hline CHEMBL 3688596 & 1528786 & 8.699 & 6.2929 & TST \\
\hline CHEMBL 3693119 & 1528786 & 7.4815 & 6.818 & TRN \\
\hline CHEMBL 3688515 & 1528786 & 6.0 & 6.6355 & TRN \\
\hline CHEMBL3693141 & 1528786 & 6.8013 & 7.3184 & TRN \\
\hline CHEMBL 3697280 & 1528786 & 4.0 & 5.5329 & TST \\
\hline CHEMBL3693142 & 1528786 & 7.0362 & 7.4125 & TRN \\
\hline CHEMBL 3693027 & 1528786 & 8.5229 & 8.1999 & TRN \\
\hline CHEMBL 3700853 & 1528786 & 7.5654 & 8.5226 & TST \\
\hline CHEMBL3693082 & 1528786 & 6.7011 & 6.7571 & TRN \\
\hline CHEMBL 3697168 & 1528786 & 7.1079 & 6.92 & TRN \\
\hline CHEMBL 3693073 & 1528786 & 7.9208 & 7.5215 & TRN \\
\hline CHEMBL 3688489 & 1528786 & 7.7212 & 7.8858 & TRN \\
\hline CHEMBL 3700774 & 1528786 & 4.0 & 4.5077 & TRN \\
\hline CHEMBL 3693180 & 1528786 & 9.0 & 8.6665 & TRN \\
\hline CHEMBL 3693065 & 1528786 & 6.8894 & 6.6317 & TST \\
\hline CHEMBL 3688460 & 1528786 & 8.699 & 8.0616 & TRN \\
\hline CHEMBL 3688520 & 1528786 & 8.5229 & \multicolumn{2}{|c|}{8.357000000000001} \\
\hline CHEMBL 3693219 & 1528786 & 6.45100 & 00000006 & 5.9589 \\
\hline CHEMBL 3697295 & 1528786 & 7.8356 & 8.0428 & TST \\
\hline CHEMBL 3697301 & 1528786 & 8.1079 & 7.7665 & TRN \\
\hline CHEMBL 3700856 & 1528786 & 4.0 & 6.1996 & TST \\
\hline CHEMBL 3700836 & 1528786 & 4.0 & 4.1082 & TST \\
\hline CHEMBL 3688501 & 1528786 & 7.301 & 7.6796 & TRN \\
\hline CHEMBL 3693057 & 1528786 & 6.5817 & 6.9171 & TRN \\
\hline CHEMBL 3700873 & 1528786 & 7.5436 & 7.6944 & TRN \\
\hline CHEMBL 3688488 & 1528786 & 6.0 & 6.4117 & TRN \\
\hline CHEMBL 3688592 & 1528786 & 7.2441 & 6.9756 & TRN \\
\hline CHEMBL 3700839 & 1528786 & 6.1966 & 5.539 & TRN \\
\hline CHEMBL 3697310 & 1528786 & 8.3372 & 8.5445 & TRN \\
\hline CHEMBL 3697292 & 1528786 & 6.604 & 6.8729 & TRN \\
\hline CHEMBL 3688527 & 1528786 & 9.0 & 9.1727 & TRN \\
\hline CHEMBL 3693150 & 1528786 & 6.0 & 6.6338 & TRN \\
\hline CHEMBL 3688408 & 1528786 & 8.699 & 9.1526 & TRN \\
\hline CHEMBL 3688534 & 1528786 & 8.3979 & 8.6762 & TRN \\
\hline CHEMBL 3693035 & 1528786 & 6.9872 & 6.7459 & TRN \\
\hline CHEMBL 3688401 & 1528786 & 7.4559 & 6.6719 & TRN \\
\hline CHEMBL 3688442 & 1528786 & 8.3979 & 8.7388 & TRN \\
\hline
\end{tabular}


Supplemental Table S2.txt

\begin{tabular}{|c|c|c|c|c|c|c|}
\hline CHEMBL3693158 & 1528786 & 5.9031 & 5.7839 & TRN & & \\
\hline CHEMBL3693004 & 1528786 & 8.0969 & 8.4398 & TRN & & \\
\hline CHEMBL3688485 & 1528786 & 8.699 & 9.9052 & TST & & \\
\hline CHEMBL3700846 & 1528786 & 6.5018 & 6.4876 & TRN & & \\
\hline CHEMBL3697220 & 1528786 & 7.6778 & 8.0131 & TRN & & \\
\hline CHEMBL3693216 & 1528786 & 7.7959 & 7.489 & TRN & & \\
\hline CHEMBL3688480 & 1528786 & 9.0 & 8.5169 & TRN & & \\
\hline CHEMBL 3688440 & 1528786 & 8.699 & 8.3976 & TRN & & \\
\hline CHEMBL3693109 & 1528786 & 9.0 & 9.0635 & TRN & & \\
\hline CHEMBL3693042 & 1528786 & 6.0 & 6.3201 & TRN & & \\
\hline CHEMBL3688604 & 1528786 & 7.301 & 7.7793 & TRN & & \\
\hline CHEMBL3688486 & 1528786 & 9.0 & 8.9436 & TRN & & \\
\hline CHEMBL3700797 & 1528786 & 6.2542 & 5.6611 & TRN & & \\
\hline CHEMBL3688536 & 1528786 & 8.699 & 8.8143 & TRN & & \\
\hline CHEMBL3688537 & 1528786 & 9.0 & 8.8468 & TRN & & \\
\hline CHEMBL3693167 & 1528786 & 7.2676 & 8.229 & TRN & & \\
\hline CHEMBL3688468 & 1528786 & 9.0 & 8.9302 & TRN & & \\
\hline CHEMBL3693112 & 1528786 & 7.7696 & 7.2831 & TRN & & \\
\hline CHEMBL3700883 & 1528786 & 7.0141 & 7.0714 & TRN & & \\
\hline CHEMBL3700870 & 1528786 & 6.4515 & 5.9409 & TRN & & \\
\hline CHEMBL3693046 & 1528786 & 7.8861 & 7.6676 & TRN & & \\
\hline CHEMBL3697193 & 1528786 & 6.8327 & 6.0623 & TRN & & \\
\hline CHEMBL3697187 & 1528786 & 7.8539 & 7.7761 & TRN & & \\
\hline CHEMBL3697239 & 1528786 & 6.8327 & 8.2871 & TST & & \\
\hline CHEMBL3693076 & 1528786 & 7.1871 & 7.1399 & TRN & & \\
\hline CHEMBL 3688588 & 1528786 & 6.4461 & 6.2858 & TRN & & \\
\hline CHEMBL3688538 & 1528786 & 5.8784 & 6.2912 & TRN & & \\
\hline CHEMBL3697298 & 1528786 & 8.301 & 8.1675 & TRN & & \\
\hline CHEMBL3688539 & 1528786 & 8.699 & 8.8789 & TRN & & \\
\hline CHEMBL3693104 & 1528786 & 8.301 & 7.9978 & TRN & & \\
\hline CHEMBL3700872 & 1528786 & \multicolumn{3}{|c|}{5.757000000000001} & 5.8128 TRN & \\
\hline CHEMBL3688458 & 1528786 & 9.0 & 8.4953 & TRN & & \\
\hline CHEMBL3700859 & 1528786 & 7.9872 & 7.8629 & TRN & & \\
\hline CHEMBL3693148 & 1528786 & 6.8928 & 6.8778 & TRN & & \\
\hline CHEMBL3693095 & 1528786 & 7.7696 & 7.3179 & TRN & & \\
\hline CHEMBL3693132 & 1528786 & 9.0 & 7.2108 & TST & & \\
\hline CHEMBL3967473 & 1528786 & 6.6144 & 6.0805 & TST & & \\
\hline CHEMBL 3688547 & 1528786 & \multicolumn{3}{|c|}{6.7620000000000005} & 6.7620000000000005 & TRN \\
\hline CHEMBL3693185 & 1528786 & 6.5171 & 6.3415 & TRN & & \\
\hline CHEMBL3639996 & 1528786 & 6.869 & 6.7529 & TRN & & \\
\hline CHEMBL 3688571 & 1528786 & 8.699 & 8.6203 & TRN & & \\
\hline CHEMBL3697358 & 1528786 & 4.0 & 5.9148 & TST & & \\
\hline CHEMBL3697225 & 1528786 & 7.9208 & 8.1898 & TRN & & \\
\hline CHEMBL3697311 & 1528786 & 7.7258 & 7.727 & TRN & & \\
\hline CHEMBL3693203 & 1528786 & 6.9172 & 6.7993 & TRN & & \\
\hline CHEMBL3693045 & 1528786 & 7.8861 & 7.876 & TRN & & \\
\hline CHEMBL3700886 & 1528786 & 7.4868 & 8.3182 & TST & & \\
\hline CHEMBL3693090 & 1528786 & 8.301 & 8.3752 & TRN & & \\
\hline
\end{tabular}




$$
\text { Supplemental Table S2.txt }
$$

\begin{tabular}{|c|c|c|c|c|c|c|}
\hline CHEMBL 3697354 & 1528786 & 6.1308 & 6.1959 & TRN & & \\
\hline CHEMBL 3693050 & 1528786 & 8.699 & 7.9839 & TRN & & \\
\hline CHEMBL3688491 & 1528786 & 8.0 & 7.3595 & TRN & & \\
\hline CHEMBL 3700885 & 1528786 & 7.4237 & 7.5289 & TST & & \\
\hline CHEMBL 3688409 & 1528786 & 9.0 & 9.1681 & TRN & & \\
\hline CHEMBL3693121 & 1528786 & 9.0 & 8.4531 & TRN & & \\
\hline CHEMBL 3693188 & 1528786 & 7.6576 & 7.7717 & TRN & & \\
\hline CHEMBL 3697216 & 1528786 & 8.2218 & 7.1079 & TST & & \\
\hline CHEMBL 3697363 & 1528786 & 6.6022 & 6.8254 & TRN & & \\
\hline CHEMBL 3700865 & 1528786 & 8.5376 & 8.4536 & TRN & & \\
\hline CHEMBL3697275 & 1528786 & 4.0 & 4.7037 & TRN & & \\
\hline CHEMBL 3697269 & 1528786 & 6.8761 & 8.4031 & TST & & \\
\hline CHEMBL 3693164 & 1528786 & 8.0 & 7.4254 & TST & & \\
\hline CHEMBL 3700791 & 1528786 & 5.9362 & 6.3406 & TRN & & \\
\hline CHEMBL 3693157 & 1528786 & 6.9666 & 6.9797 & TRN & & \\
\hline CHEMBL3693092 & 1528786 & 8.301 & 8.2725 & TRN & & \\
\hline CHEMBL3697274 & 1528786 & 4.0 & 4.5611 & TRN & & \\
\hline CHEMBL 3697276 & 1528786 & 5.6038 & 7.9085 & TST & & \\
\hline CHEMBL 3697198 & 1528786 & 6.8794 & 5.8805 & TRN & & \\
\hline CHEMBL 3700811 & 1528786 & 4.0 & 3.4221 & TRN & & \\
\hline CHEMBL 3688565 & 1528786 & 7.7696 & 7.8965 & TRN & & \\
\hline CHEMBL3693194 & 1528786 & 9.0 & 8.4736 & TST & & \\
\hline CHEMBL 3693125 & 1528786 & 8.3979 & 9.6378 & TST & & \\
\hline CHEMBL3700879 & 1528786 & 6.29299 & 999999999 & 99 & 6.0617 & TRN \\
\hline CHEMBL 3639920 & 1528786 & 8.301 & 8.0762 & TRN & & \\
\hline CHEMBL 3688558 & 1528786 & 7.4559 & 7.0406 & TST & & \\
\hline CHEMBL3697194 & 1528786 & 5.7124 & 5.9023 & TRN & & \\
\hline CHEMBL 3688481 & 1528786 & 6.0 & 5.7537 & TRN & & \\
\hline CHEMBL3697287 & 1528786 & 7.3344 & 6.5501 & TST & & \\
\hline CHEMBL 3693005 & 1528786 & 6.0 & 5.5064 & TRN & & \\
\hline CHEMBL 3700768 & 1528786 & 6.3153 & 6.2171 & TRN & & \\
\hline CHEMBL 3700792 & 1528786 & 7.0921 & 6.7298 & TRN & & \\
\hline CHEMBL 3697384 & 1528786 & 4.0 & 4.537 & TRN & & \\
\hline CHEMBL3697237 & 1528786 & 8.699 & 9.0826 & TRN & & \\
\hline CHEMBL 3700821 & 1528786 & 6.0 & 6.3647 & TRN & & \\
\hline CHEMBL 3697260 & 1528786 & 7.6021 & 9.0776 & TST & & \\
\hline CHEMBL3693099 & 1528786 & 7.4949 & 6.7387 & TST & & \\
\hline CHEMBL 3697314 & 1528786 & 5.87299 & 999999999 & 99 & 5.4457 & TRN \\
\hline CHEMBL 3700827 & 1528786 & 4.0 & 4.016 & TRN & & \\
\hline CHEMBL 3688422 & 1528786 & 8.3979 & 8.2511 & TRN & & \\
\hline CHEMBL 3700833 & 1528786 & 6.5896 & 5.8788 & TRN & & \\
\hline CHEMBL 3688576 & 1528786 & 6.6882 & 5.9356 & TRN & & \\
\hline CHEMBL3697372 & 1528786 & 7.0991 & 6.9568 & TRN & & \\
\hline CHEMBL 3688574 & 1528786 & 8.5229 & 8.0934 & TRN & & \\
\hline CHEMBL 3700794 & 1528786 & 6.0271 & 5.858 & TRN & & \\
\hline CHEMBL 3693093 & 1528786 & 9.0 & 8.9109 & TRN & & \\
\hline CHEMBL 3697205 & 1528786 & 8.301 & 8.6834 & TRN & & \\
\hline CHEMBL3693206 & 1528786 & 6.6021 & 6.0818 & TST & & \\
\hline
\end{tabular}




\begin{tabular}{|c|c|c|c|c|}
\hline \multicolumn{5}{|c|}{ Supplemental Table S2.txt } \\
\hline CHEMBL3700817 & 1528786 & 4.0 & 3.5214 & TRN \\
\hline CHEMBL3693091 & 1528786 & 6.0 & 6.0916 & TRN \\
\hline CHEMBL3700900 & 1528786 & 6.0 & 6.6244 & TRN \\
\hline CHEMBL 3693149 & 1528786 & 4.0 & 4.0192 & TRN \\
\hline CHEMBL3693165 & 1528786 & 8.699 & 8.3993 & TRN \\
\hline CHEMBL3697378 & 1528786 & 8.7212 & 8.5682 & TRN \\
\hline CHEMBL3697330 & 1528786 & 8.2366 & 7.2802 & TST \\
\hline CHEMBL3693129 & 1528786 & 8.699 & 7.2617 & TST \\
\hline CHEMBL3688535 & 1528786 & 9.0 & 9.0124 & TRN \\
\hline CHEMBL3700767 & 1528786 & 6.0438 & 6.0188 & TRN \\
\hline CHEMBL3700783 & 1528786 & 8.5376 & 9.1808 & TRN \\
\hline CHEMBL 3697381 & 1528786 & 8.0862 & 8.2048 & TRN \\
\hline CHEMBL 3688507 & 1528786 & 9.0 & 8.1048 & TRN \\
\hline CHEMBL 3693084 & 1528786 & 6.983 & 8.6095 & TST \\
\hline CHEMBL3693204 & 1528786 & 6.7305 & 5.9298 & TRN \\
\hline CHEMBL3639960 & 1528786 & 7.9208 & 7.4582 & TRN \\
\hline CHEMBL 3688505 & 1528786 & 8.699 & 9.1146 & TRN \\
\hline CHEMBL3693067 & 1528786 & 7.4949 & 7.1894 & TRN \\
\hline CHEMBL3688546 & 1528786 & 7.1805 & 7.0563 & TRN \\
\hline CHEMBL3688490 & 1528786 & 7.7959 & 7.6967 & TRN \\
\hline CHEMBL3700888 & 1528786 & 8.3279 & 6.3868 & TRN \\
\hline CHEMBL 3688411 & 1528786 & 8.0 & 7.7711 & TRN \\
\hline CHEMBL 3697182 & 1528786 & 7.7959 & 7.0976 & TST \\
\hline CHEMBL 3700887 & 1528786 & 6.9285 & 7.3189 & TST \\
\hline CHEMBL3688573 & 1528786 & 9.0 & 8.844 & TRN \\
\hline CHEMBL3697336 & 1528786 & 8.3979 & 8.9341 & TST \\
\hline CHEMBL 3891680 & 1528786 & 6.8508 & 7.051 & TRN \\
\hline CHEMBL3693079 & 1528786 & 8.699 & 8.8458 & TRN \\
\hline CHEMBL 3697316 & 1528786 & 7.1035 & 7.159 & TRN \\
\hline CHEMBL3688473 & 1528786 & 9.0 & 9.0269 & TRN \\
\hline CHEMBL3700807 & 1528786 & 6.0 & 6.1835 & TRN \\
\hline CHEMBL 3697318 & 1528786 & 4.0 & 4.2609 & TRN \\
\hline CHEMBL3693085 & 1528786 & 4.0 & 4.7238 & TRN \\
\hline CHEMBL 3700832 & 1528786 & 4.0 & 6.6051 & TST \\
\hline CHEMBL 3688444 & 1528786 & 8.5229 & 8.6673 & TRN \\
\hline CHEMBL3688487 & 1528786 & 8.699 & 8.2229 & TRN \\
\hline CHEMBL3693153 & 1528786 & 7.7212 & 7.7964 & TRN \\
\hline CHEMBL3697257 & 1528786 & 6.1249 & 6.6803 & TRN \\
\hline CHEMBL 3688554 & 1528786 & 8.0 & 7.8554 & TRN \\
\hline CHEMBL3697266 & 1528786 & 4.0 & 8.0582 & TST \\
\hline CHEMBL3693053 & 1528786 & 4.0 & 4.3227 & TRN \\
\hline CHEMBL 3688495 & 1528786 & 9.0 & 8.8759 & TRN \\
\hline CHEMBL3693064 & 1528786 & 6.6904 & 7.9026 & TST \\
\hline CHEMBL3697219 & 1528786 & 9.0 & 8.9747 & TRN \\
\hline CHEMBL3693131 & 1528786 & 8.699 & 8.7279 & TST \\
\hline CHEMBL3903165 & 1528786 & 7.7212 & 7.2601 & TRN \\
\hline CHEMBL 3700787 & 1528786 & 8.699 & 8.6197 & TRN \\
\hline CHEMBL 3700782 & 1528786 & 8.3372 & 8.2037 & TRN \\
\hline
\end{tabular}


Supplemental Table S2.txt

\begin{tabular}{|c|c|c|c|c|}
\hline HEMBL36 & & 36 & 79 & TST \\
\hline HFMRI 379976 & 528786 & 6.1072 & 6.1211 & \\
\hline HEMBL & 28786 & & & \\
\hline HEMBL3693055 & $528 / 86$ & 6.308 & 4227 & \\
\hline HEMBL 3697348 & 528786 & 7.2823 & 5.8967 & \\
\hline HEMBL36 & 528786 & 8.5229 & 3945 & \\
\hline AEMBL3 & & 5.9718 & & \\
\hline HEMBL3 & 786 & 4437 & & \\
\hline HEMBL3688563 & 528786 & 8.0969 & 9.3913 & \\
\hline HEMBL3700776 & 528786 & 7.4949 & 76 & \\
\hline HEMBL3C & 786 & 6.0779 & 83 & \\
\hline HEMBL3 & & 223 & & \\
\hline HEMBL3 & 786 & 6.5952 & & \\
\hline HEMBL 369 & 886 & 6.1249 & & \\
\hline HEMBL37e & 886 & 7.5272 & 87 & \\
\hline HEMBL & 36 & 4 & & \\
\hline HEMBL & & & & \\
\hline HEMBL & 886 & 8 . & & \\
\hline HEMBL3 & 86 & 8. & & \\
\hline AEMBL36 & 36 & 4. & 349 & \\
\hline AEMBL & 36 & & & \\
\hline AEMBL & & & & \\
\hline HEMBL; & 86 & 147 & & \\
\hline HEMBL3 & 36 & 9.0 & & \\
\hline AEMBL36 & 36 & 6. & 74 & IRN \\
\hline AEMBL 3 & 6 & & 39 & $R \Lambda$ \\
\hline AEME & & & & \\
\hline HEMPI & & & & \\
\hline AEMBL & & & & IRN \\
\hline HEMBL369 & 86 & 979 & 07 & $\mathrm{RN}$ \\
\hline AEMBL & 6 & 6 & & RN \\
\hline AFM & 36 & 6 & & RN \\
\hline HEMBL & & & & RN \\
\hline HEMBL36 & 36 & & & R \\
\hline HEMBL36 & 786 & 098 & 334 & 「RN \\
\hline AEMBL & 6 & & & \\
\hline & & & & ST \\
\hline HEMBL3 & & & & TRN \\
\hline HEMBL 369 & 786 & 8.699 & & $\Gamma R$ \\
\hline AEMBL3 & 86 & 6 & & IRN \\
\hline HEMBL3 & & & & \\
\hline HEMBL3 & & & & $\mathrm{RN}$ \\
\hline HEMBL3 & & 7.4486 & & RN \\
\hline HEMBL 36 & 86 & 6. & & TR \\
\hline MBL & & & & \\
\hline CHEMBL37 & & & & \\
\hline CHEMBL3688404 & .528786 & - & 7.2139 & \\
\hline CHEMBL3697233 & 1528786 & 8.699 & 8.2475 & \\
\hline
\end{tabular}

Page 4662 
Supplemental Table S2.txt

\begin{tabular}{|c|c|c|c|c|}
\hline CHEMBL 3693221 & 1528786 & 6.9208 & 6.9144 & TRN \\
\hline CHEMBL 3693060 & 1528786 & 9.0 & 8.6586 & TRN \\
\hline CHEMBL 3688405 & 1528786 & 8.5229 & 8.7049 & TRN \\
\hline CHEMBL 3697251 & 1528786 & 7.1549 & 6.9907 & TRN \\
\hline CHEMBL 3697235 & 1528786 & 7.7212 & 7.2627 & TRN \\
\hline CHEMBL 3693058 & 1528786 & 6.4012 & 6.0514 & TRN \\
\hline CHEMBL 3697179 & 1528786 & 8.3979 & 8.8004 & TRN \\
\hline CHEMBL 3697247 & 1528786 & 7.0915 & 6.8745 & TRN \\
\hline CHEMBL 3697293 & 1528786 & 7.8356 & 7.5633 & TRN \\
\hline CHEMBL 3697277 & 1528786 & 4.0 & 6.4053 & TST \\
\hline CHEMBL 3693201 & 1528786 & 8.699 & 9.0971 & TRN \\
\hline CHEMBL 3697291 & 1528786 & 7.5622 & 7.535 & TRN \\
\hline CHEMBL 3688430 & 1528786 & 8.0969 & 7.665 & TRN \\
\hline CHEMBL 3700834 & 1528786 & 4.0 & 4.3682 & TRN \\
\hline CHEMBL 3697349 & 1528786 & 6.6499 & 7.0455 & TST \\
\hline CHEMBL 3688531 & 1528786 & 7.8539 & 7.7688 & TRN \\
\hline CHEMBL 3697209 & 1528786 & 8.5229 & 8.1966 & TRN \\
\hline CHEMBL 3693191 & 1528786 & 7.0915 & 6.9506 & TRN \\
\hline CHEMBL 3693003 & 1528786 & 6.0 & 6.3875 & TRN \\
\hline CHEMBL 3697324 & 1528786 & 6.8851 & 6.87200 & 000000001 \\
\hline CHEMBL 3688600 & 1528786 & 7.5376 & 9.2233 & TST \\
\hline CHEMBL 3688607 & 1528786 & 8.301 & 8.5008 & TRN \\
\hline CHEMBL 3693113 & 1528786 & 8.699 & 8.6534 & TRN \\
\hline CHEMBL 3697321 & 1528786 & 6.51399 & 79999999 & 6.3155 \\
\hline CHEMBL 3697224 & 1528786 & 7.7959 & 8.1629 & TRN \\
\hline CHEMBL 3697229 & 1528786 & 6.8297 & 6.8371 & TRN \\
\hline CHEMBL 3688441 & 1528786 & 9.0 & 9.0521 & TRN \\
\hline CHEMBL 3688413 & 1528786 & 8.699 & 8.8577 & TRN \\
\hline CHEMBL 3697171 & 1528786 & 7.2676 & 7.4073 & TRN \\
\hline CHEMBL 3693062 & 1528786 & 6.475 & 6.3394 & TST \\
\hline CHEMBL 3693097 & 1528786 & 7.4318 & 7.2807 & TRN \\
\hline CHEMBL 3693069 & 1528786 & 7.7212 & 7.9671 & TRN \\
\hline CHEMBL 3688431 & 1528786 & 7.8539 & 7.7937 & TRN \\
\hline CHEMBL 3697210 & 1528786 & 8.0969 & 8.0229 & TRN \\
\hline CHEMBL 3700804 & 1528786 & 4.0 & 6.465 & TST \\
\hline CHEMBL 3693072 & 1528786 & 7.8239 & 7.7552 & TRN \\
\hline CHEMBL 3697228 & 1528786 & 7.5528 & 7.8069 & TRN \\
\hline CHEMBL 3688567 & 1528786 & 9.0 & 9.427 & TRN \\
\hline CHEMBL 3693146 & 1528786 & 6.8697 & 7.5118 & TST \\
\hline CHEMBL 3697286 & 1528786 & 8.7212 & 7.5969 & TST \\
\hline CHEMBL 3693047 & 1528786 & 5.6021 & 5.2794 & TRN \\
\hline CHEMBL 3700892 & 1528786 & 6.6784 & 7.0794 & TST \\
\hline CHEMBL3693196 & 1528786 & 8.5229 & 7.1669 & TST \\
\hline CHEMBL 3697176 & 1528786 & 7.8239 & 8.0225 & TRN \\
\hline CHEMBL 3688549 & 1528786 & 6.1818 & 6.6987 & TRN \\
\hline CHEMBL 3697270 & 1528786 & 4.0 & 4.2065 & TRN \\
\hline CHEMBL 3688438 & 1528786 & 9.0 & 8.6054 & TRN \\
\hline CHEMBL3700837 & 1528786 & 4.0 & 5.2725 & TST \\
\hline
\end{tabular}


Supplemental Table S2.txt

\begin{tabular}{|c|c|c|c|c|c|}
\hline CHEMBL3688496 & 1528786 & 8.5229 & 8.1062 & TRN & \\
\hline CHEMBL 3697250 & 1528786 & 5.6021 & 6.7692 & TST & \\
\hline CHEMBL3697337 & 1528786 & 7.0101 & 7.2427 & TRN & \\
\hline CHEMBL3688519 & 1528786 & 7.0915 & 7.1102 & TRN & \\
\hline CHEMBL3697297 & 1528786 & 8.7212 & 8.8223 & TRN & \\
\hline CHEMBL3693044 & 1528786 & 6.9172 & 6.7723 & TRN & \\
\hline CHEMBL3688494 & 1528786 & 6.0 & 6.3753 & TRN & \\
\hline CHEMBL3693088 & 1528786 & 7.0915 & 7.3729 & TRN & \\
\hline CHEMBL3693033 & 1528786 & 6.0 & 5.7532 & TRN & \\
\hline CHEMBL3693002 & 1528786 & 6.0 & 5.729 & TRN & \\
\hline CHEMBL3697365 & 1528786 & 8.0605 & 6.4228 & TST & \\
\hline CHEMBL3693187 & 1528786 & 8.0 & 8.1614 & TRN & \\
\hline CHEMBL3688608 & 1528786 & 6.8962 & 7.1025 & TRN & \\
\hline CHEMBL3700861 & 1528786 & 9.1549 & 8.5924 & TST & \\
\hline CHEMBL3688504 & 1528786 & 6.0 & 6.9039 & TST & \\
\hline CHEMBL3697359 & 1528786 & 7.2733 & 7.0089 & TRN & \\
\hline CHEMBL3693168 & 1528786 & 8.3979 & 8.3473 & TRN & \\
\hline CHEMBL3688508 & 1528786 & 9.0 & 8.5548 & TRN & \\
\hline CHEMBL3693183 & 1528786 & 6.7375 & 7.66100 & 00000000005 & TST \\
\hline CHEMBL3915880 & 1528786 & 6.0 & 6.6968 & TRN & \\
\hline CHEMBL3909200 & 1528786 & 4.0 & 3.6273 & TST & \\
\hline CHEMBL 3700788 & 1528786 & 7.567 & 7.5409 & TRN & \\
\hline CHEMBL3700860 & 1528786 & 6.5635 & 6.5108 & TRN & \\
\hline CHEMBL3688449 & 1528786 & 7.699 & 7.6025 & TRN & \\
\hline CHEMBL3693213 & 1528786 & 7.6778 & 7.6973 & TRN & \\
\hline CHEMBL3688513 & 1528786 & 9.0 & 9.1131 & TRN & \\
\hline CHEMBL3697212 & 1528786 & 8.301 & 8.4448 & TRN & \\
\hline CHEMBL3693021 & 1528786 & 7.4949 & 7.5515 & TRN & \\
\hline CHEMBL3693096 & 1528786 & 9.0 & 8.7421 & TRN & \\
\hline CHEMBL 3693144 & 1528786 & 6.8097 & 6.66299 & 9999999999 & TRN \\
\hline CHEMBL3693043 & 1528786 & 7.0915 & 7.1582 & TRN & \\
\hline CHEMBL3688602 & 1528786 & 6.7011 & 6.6114 & TRN & \\
\hline CHEMBL3693036 & 1528786 & 6.0269 & 5.6587 & TRN & \\
\hline CHEMBL3688412 & 1528786 & 8.2218 & 8.1112 & TRN & \\
\hline CHEMBL3688483 & 1528786 & \multicolumn{3}{|c|}{6.4510000000000005} & TRN \\
\hline CHEMBL3700770 & 1528786 & 7.1891 & 6.9853 & TRN & \\
\hline CHEMBL3693133 & 1528786 & 9.0 & 8.6049 & TST & \\
\hline CHEMBL 3697184 & 1528786 & 7.3188 & 6.8839 & TST & \\
\hline CHEMBL3700793 & 1528786 & 7.1555 & 7.4479 & TRN & \\
\hline CHEMBL3700855 & 1528786 & 8.4815 & 8.4673 & TRN & \\
\hline CHEMBL3693186 & 1528786 & 8.5229 & 8.6484 & TRN & \\
\hline CHEMBL3688575 & 1528786 & 8.301 & 8.683 & TRN & \\
\hline CHEMBL3700894 & 1528786 & 5.83 & 5.7098 & TST & \\
\hline CHEMBL3693118 & 1528786 & 8.699 & 8.2913 & TRN & \\
\hline CHEMBL3697299 & 1528786 & 7.3363 & 6.8622 & TRN & \\
\hline CHEMBL3688551 & 1528786 & 7.585 & 7.44600 & 0000000001 & TRN \\
\hline CHEMBL3688568 & 1528786 & 9.0 & 8.8995 & TRN & \\
\hline CHEMBL3697307 & 1528786 & 4.0 & 5.2362 & TST & \\
\hline
\end{tabular}


Supplemental Table S2.txt

\begin{tabular}{|c|c|c|c|c|c|}
\hline CHEMBL3693038 & 1528786 & 4.0 & 4.3109 & TRN & \\
\hline CHEMBL3700841 & 1528786 & 8.7447 & 8.7034 & TRN & \\
\hline CHEMBL3693189 & 1528786 & 7.1308 & 7.5453 & TRN & \\
\hline CHEMBL3697364 & 1528786 & 4.0 & 4.7612 & TST & \\
\hline CHEMBL3700857 & 1528786 & 6.5522 & 6.9392 & TST & \\
\hline CHEMBL3697227 & 1528786 & 6.3526 & 7.0115 & TRN & \\
\hline CHEMBL3700851 & 1528786 & 7.6615 & 7.6847 & TRN & \\
\hline CHEMBL3700828 & 1528786 & 6.5536 & 6.6149 & TRN & \\
\hline CHEMBL 3688448 & 1528786 & 8.301 & 8.2455 & TRN & \\
\hline CHEMBL3688410 & 1528786 & 8.5229 & 8.8055 & TRN & \\
\hline CHEMBL3948581 & 1528786 & 6.0 & 6.4706 & TRN & \\
\hline CHEMBL3688465 & 1528786 & 7.9208 & 7.9768 & TRN & \\
\hline CHEMBL 3688484 & 1528786 & 8.0969 & 7.3724 & TRN & \\
\hline CHEMBL3639961 & 1528786 & 7.0794 & 7.2258 & TRN & \\
\hline CHEMBL3700890 & 1528786 & 4.0 & 5.3108 & TST & \\
\hline CHEMBL3697352 & 1528786 & 6.0 & 5.9543 & TRN & \\
\hline CHEMBL3697217 & 1528786 & 8.301 & 8.2795 & TRN & \\
\hline CHEMBL3700866 & 1528786 & 6.8831 & 7.1965 & TRN & \\
\hline CHEMBL3693166 & 1528786 & 8.699 & 8.7176 & TRN & \\
\hline CHEMBL3693063 & 1528786 & 6.1618 & 5.6076 & TST & \\
\hline CHEMBL3693139 & 1528786 & 7.5528 & 8.4462 & TST & \\
\hline CHEMBL3697373 & 1528786 & 6.0 & 6.391 & TRN & \\
\hline CHEMBL3693054 & 1528786 & 6.6696 & 6.3951 & TRN & \\
\hline CHEMBL3688556 & 1528786 & 7.0809 & 7.4792 & TRN & \\
\hline CHEMBL3700838 & 1528786 & 6.9727 & 6.9124 & TRN & \\
\hline CHEMBL 3688434 & 1528786 & 8.699 & 8.6673 & TRN & \\
\hline CHEMBL3693217 & 1528786 & 6.6021 & 6.3925 & TRN & \\
\hline CHEMBL3700848 & 1528786 & 7.4698 & 7.546 & TRN & \\
\hline CHEMBL3693162 & 1528786 & 8.5229 & 8.3479 & TRN & \\
\hline CHEMBL 3688510 & 1528786 & 7.9586 & 7.7064 & TRN & \\
\hline CHEMBL3688416 & 1528786 & 8.699 & 8.9583 & TRN & \\
\hline CHEMBL3693107 & 1528786 & 8.5229 & 8.49 & TRN & \\
\hline CHEMBL3688406 & 1528786 & 8.5229 & 8.2333 & TRN & \\
\hline CHEMBL3688402 & 1528786 & 9.0 & 9.1039 & TRN & \\
\hline CHEMBL3693094 & 1528786 & 8.699 & 8.8087 & TRN & \\
\hline CHEMBL3697207 & 1528786 & 9.0 & 9.0179 & TRN & \\
\hline CHEMBL3700816 & 1528786 & $6.1370 e$ & j00000006 & 205 & 5.4209 \\
\hline CHEMBL3697319 & 1528786 & 4.0 & 5.6562 & TST & \\
\hline CHEMBL 3693145 & 1528786 & 7.0 & 7.0309 & TRN & \\
\hline CHEMBL3693048 & 1528786 & 6.2132 & 6.9039 & TRN & \\
\hline CHEMBL3693140 & 1528786 & 7.8539 & 7.5743 & TST & \\
\hline CHEMBL3693114 & 1528786 & 9.0 & 9.4543 & TRN & \\
\hline CHEMBL3697223 & 1528786 & 8.699 & 8.683 & TRN & \\
\hline CHEMBL3688479 & 1528786 & 8.2218 & 8.3211 & TRN & \\
\hline CHEMBL3697172 & 1528786 & 7.0132 & 7.1419 & TRN & \\
\hline CHEMBL3688586 & 1528786 & 5.919 & 6.3338 & TRN & \\
\hline CHEMBL3693193 & 1528786 & 7.9208 & 7.3858 & TRN & \\
\hline CHEMBL3697334 & 1528786 & 8.2218 & 8.1328 & TRN & \\
\hline
\end{tabular}


Supplemental Table S2.txt

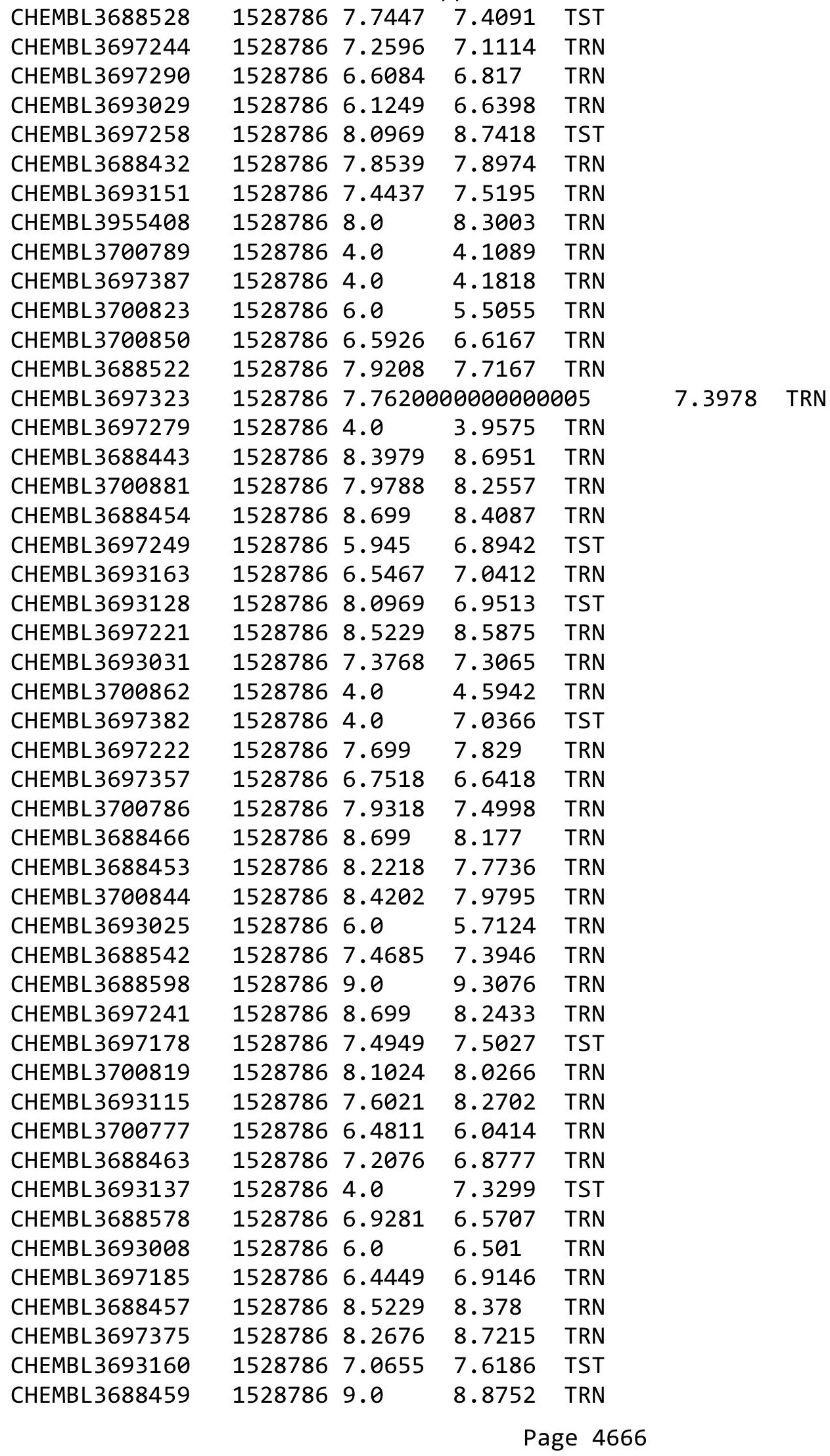


Supplemental Table S2.txt

\begin{tabular}{|c|c|c|c|c|c|}
\hline CHEMBL3697173 & 1528786 & 7.699 & 7.6805 & TRN & \\
\hline CHEMBL3700765 & 1528786 & 4.0 & 4.3713 & TRN & \\
\hline CHEMBL3697238 & 1528786 & 9.0 & 9.2984 & TRN & \\
\hline CHEMBL3697380 & 1528786 & 8.6198 & 8.1503 & TRN & \\
\hline CHEMBL 3693120 & 1528786 & 9.0 & 8.6166 & TRN & \\
\hline CHEMBL 3693116 & 1528786 & 9.0 & 9.4993 & TRN & \\
\hline CHEMBL 3697204 & 1528786 & 4.0 & 3.0416 & TRN & \\
\hline CHEMBL 3700867 & 1528786 & 5.8821 & 5.9158 & TRN & \\
\hline CHEMBL 3688550 & 1528786 & 7.2366 & 7.2101 & TRN & \\
\hline CHEMBL 3688525 & 1528786 & 9.0 & 8.7463 & TRN & \\
\hline CHEMBL 3700796 & 1528786 & 8.28399 & 999999999 & 8.2458 & TRN \\
\hline CHEMBL 3688560 & 1528786 & 7.1427 & 8.4387 & TST & \\
\hline CHEMBL 3700775 & 1528786 & 4.0 & 4.4194 & TRN & \\
\hline CHEMBL3688555 & 1528786 & 8.0 & 7.717000 & 00000000005 & TRN \\
\hline CHEMBL 3697215 & 1528786 & 8.0969 & 7.2423 & TST & \\
\hline CHEMBL 3951410 & 1528786 & 7.5376 & 7.4968 & TRN & \\
\hline CHEMBL3700812 & 1528786 & 6.6523 & 5.9976 & TRN & \\
\hline CHEMBL 3693171 & 1528786 & 8.3979 & 8.67 & TRN & \\
\hline CHEMBL3688605 & 1528786 & 7.2291 & 7.3832 & TRN & \\
\hline CHEMBL 3697226 & 1528786 & 6.9706 & 7.4384 & TRN & \\
\hline CHEMBL3688492 & 1528786 & 8.5229 & 8.7778 & TRN & \\
\hline CHEMBL 3697206 & 1528786 & 6.4584 & 7.2242 & TRN & \\
\hline CHEMBL3693018 & 1528786 & 6.0 & 5.7616 & TRN & \\
\hline CHEMBL3697177 & 1528786 & 8.1549 & 8.4493 & TRN & \\
\hline CHEMBL 3697332 & 1528786 & 8.585 & 8.4642 & TRN & \\
\hline CHEMBL3693214 & 1528786 & 6.1249 & 6.1042 & TRN & \\
\hline CHEMBL 3700858 & 1528786 & 6.716 & 6.8037 & TRN & \\
\hline CHEMBL 3697320 & 1528786 & 6.0801 & 6.4513 & TRN & \\
\hline CHEMBL3697345 & 1528786 & 4.0 & 6.0799 & TST & \\
\hline CHEMBL 3693200 & 1528786 & 7.3872 & 6.3797 & TRN & \\
\hline CHEMBL 3688570 & 1528786 & 7.9208 & 8.154 & TRN & \\
\hline CHEMBL 3697256 & 1528786 & 7.8239 & 7.7489 & TRN & \\
\hline CHEMBL 3688467 & 1528786 & 8.5229 & 8.7071 & TRN & \\
\hline CHEMBL3688451 & 1528786 & 7.9586 & 7.9217 & TRN & \\
\hline CHEMBL 3697230 & 1528786 & 7.4559 & 7.1719 & TRN & \\
\hline CHEMBL 3700845 & 1528786 & 9.2218 & 9.3053 & TRN & \\
\hline CHEMBL 3688478 & 1528786 & 8.1549 & 8.1374 & TRN & \\
\hline CHEMBL 3971208 & 1528786 & 7.1192 & 6.9658 & TRN & \\
\hline CHEMBL3985496 & 1528786 & 9.0 & 9.0447 & TRN & \\
\hline CHEMBL 3942666 & 1528786 & 7.2291 & 7.2036 & TRN & \\
\hline CHEMBL 3693179 & 1528786 & 7.5086 & 7.0693 & TST & \\
\hline CHEMBL3697371 & 1528786 & 7.061 & 7.1446 & TRN & \\
\hline CHEMBL 3688429 & 1528786 & 7.4815 & 7.684 & TRN & \\
\hline CHEMBL3697312 & 1528786 & 8.8539 & 9.0593 & TRN & \\
\hline CHEMBL 3700877 & 1528786 & 8.2757 & 8.7482 & TRN & \\
\hline CHEMBL3697315 & 1528786 & 4.0 & 4.7509 & TRN & \\
\hline CHEMBL 3700874 & 1528786 & 6.0811 & 6.473 & TRN & \\
\hline CHEMBL 3697272 & 1528786 & 5.6038 & 5.9568 & TRN & \\
\hline
\end{tabular}




\begin{tabular}{|c|c|c|c|c|}
\hline \multicolumn{5}{|c|}{ Supplemental Table S2.txt } \\
\hline CHEMBL 3700825 & 1528786 & 6.0 & 6.6869 & TRN \\
\hline CHEMBL 3697383 & 1528786 & 5.9964 & 5.8111 & TST \\
\hline CHEMBL3693110 & 1528786 & 9.0 & 9.7987 & TRN \\
\hline CHEMBL3700806 & 1528786 & 4.0 & 4.5069 & TRN \\
\hline CHEMBL 3697343 & 1528786 & 6.631 & 5.5162 & TST \\
\hline CHEMBL 3693070 & 1528786 & 8.3979 & 8.1945 & TRN \\
\hline CHEMBL 3688562 & 1528786 & 8.3979 & 8.9171 & TST \\
\hline CHEMBL3697253 & 1528786 & 8.699 & 7.4516 & TRN \\
\hline CHEMBL 3693220 & 1528786 & 5.7185 & 5.5495 & TRN \\
\hline CHEMBL3697191 & 1528786 & 4.0 & 4.708 & TRN \\
\hline CHEMBL3693197 & 1528786 & 8.3979 & 8.0937 & TRN \\
\hline CHEMBL 3697273 & 1528786 & 4.0 & 4.3006 & TRN \\
\hline CHEMBL 3697214 & 1528786 & 7.4685 & 8.9793 & TST \\
\hline CHEMBL 3697200 & 1528786 & 4.0 & 4.388 & TRN \\
\hline CHEMBL3693100 & 1528786 & 6.9431 & 10.5416 & TST \\
\hline CHEMBL 3688470 & 1528786 & 8.3979 & 8.5937 & TRN \\
\hline CHEMBL3693202 & 1528786 & 6.0079 & 6.5259 & TRN \\
\hline CHEMBL 3697302 & 1528786 & 8.2076 & 8.302 & TRN \\
\hline CHEMBL 3697350 & 1528786 & 6.2203 & 6.5484 & TRN \\
\hline CHEMBL3693181 & 1528786 & 9.0 & 8.9861 & TRN \\
\hline CHEMBL 3688428 & 1528786 & 7.5229 & 7.5054 & TRN \\
\hline CHEMBL 3697203 & 1528786 & 4.0 & 4.6274 & TRN \\
\hline CHEMBL 3688572 & 1528786 & 8.699 & 8.6433 & TRN \\
\hline CHEMBL 3697263 & 1528786 & 7.2218 & 9.0759 & TST \\
\hline CHEMBL3700852 & 1528786 & 6.3345 & 7.8979 & TST \\
\hline CHEMBL3693136 & 1528786 & 8.0969 & 6.0413 & TST \\
\hline CHEMBL3697329 & 1528786 & 5.9136 & 5.7091 & TRN \\
\hline CHEMBL3693215 & 1528786 & 7.4949 & 7.3836 & TRN \\
\hline CHEMBL 3639872 & 1528786 & 9.0 & 9.0656 & TRN \\
\hline CHEMBL3697339 & 1528786 & 7.8633 & 7.5639 & TRN \\
\hline CHEMBL 3697386 & 1528786 & 4.0 & 4.1741 & TRN \\
\hline CHEMBL 3700772 & 1528786 & 7.8327 & 6.3595 & TST \\
\hline CHEMBL 3697331 & 1528786 & 8.301 & 8.5281 & TST \\
\hline CHEMBL3688566 & 1528786 & 9.0 & 9.1133 & TRN \\
\hline CHEMBL3697328 & 1528786 & 5.6038 & 7.0047 & TRN \\
\hline CHEMBL3697252 & 1528786 & 7.4559 & 7.1334 & TRN \\
\hline CHEMBL 3688606 & 1528786 & 7.4202 & 7.2728 & TRN \\
\hline CHEMBL3700795 & 1528786 & 4.0 & 7.8318 & TST \\
\hline CHEMBL 3697341 & 1528786 & 8.6198 & 8.3801 & TRN \\
\hline CHEMBL3700876 & 1528786 & 6.8362 & 6.9957 & TRN \\
\hline CHEMBL 3697236 & 1528786 & 8.699 & 8.3718 & TRN \\
\hline CHEMBL3688552 & 1528786 & 6.1349 & 5.6426 & TRN \\
\hline CHEMBL3693080 & 1528786 & 8.3979 & 8.2611 & TRN \\
\hline CHEMBL3688472 & 1528786 & 6.0 & 6.379 & TRN \\
\hline CHEMBL3911080 & 1528786 & 9.0 & 8.6012 & TRN \\
\hline CHEMBL3693169 & 1528786 & 7.8861 & 8.0152 & TRN \\
\hline CHEMBL3693103 & 1528786 & 7.6576 & 7.4408 & TRN \\
\hline CHEMBL3693056 & 1528786 & 6.1267 & 6.6279 & TST \\
\hline
\end{tabular}


Supplemental Table S2.txt

\begin{tabular}{|c|c|c|c|c|}
\hline HEMBL & 528786 & & 8.2934 & TR \\
\hline HEMBL3697271 & 528786 & 4.0 & .8203 & \\
\hline 56 & 28786 & 7.6778 & & \\
\hline AEMBL & & 4.0 & & \\
\hline HEMBL3697170 & 528786 & 5.6021 & 4884 & \\
\hline HEMBL3697186 & 528786 & 7.0809 & 4186 & \\
\hline HEMBL 368 & 86 & 6.0 & 021 & \\
\hline AFMBL: & & 8.5229 & 117 & \\
\hline HEMBL 369 & 886 & 7.5421 & 3677 & \\
\hline HEMBL369: & 528786 & 6.2076 & 5402 & \\
\hline HEMBL 369 & 36 & 9.2218 & 2804 & \\
\hline AEMBL36 & 50 & 5.8508 & 9517 & \\
\hline AEMBL3 & & & & \\
\hline HEMBL36 & 36 & 6.5171 & 3138 & \\
\hline AEMBL369 & 36 & 469 & 2944 & \\
\hline AEMBL369 & 50 & 383 & $\$ 351$ & \\
\hline HEMBL36 & 6 & 969 & 591 & \\
\hline HEMBL36 & & 528 & & \\
\hline HEMBL36 & 5 & 8.3979 & 5505 & \\
\hline AEMBL36 & & & 305 & \\
\hline HEMBLS & 52 & 7.2596 & 802 & t. \\
\hline HEMBL: & 0 & 7 & 529 & 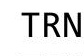 \\
\hline HEMBL; & 6 & 458 & 38 & \\
\hline HEMBL36 & & 9.0 & 493 & \\
\hline HEMBL 369 & & & & N \\
\hline HEMBL & 52 & 4 & 199 & RN \\
\hline HEMBL; & & & 333 & RN \\
\hline HFMBI : & 6 & 18 & 14 & \\
\hline HEMBL3 & & 5. & 401 & I KIV \\
\hline HEMBL 369 & & & 435 & I RIV \\
\hline HEMBL3 & & 6 & 385 & RN \\
\hline HEMBL & & 7 & 33 & RN \\
\hline HEMBL & & 6. & 03 & RN \\
\hline HEMBL369 & & 5.60 & 1929 & IRN \\
\hline HEMBL 369317 & 52 & 9.0 & 7238 & TRN \\
\hline HEMBL36 & & & 2339 & \\
\hline HFMRI & & 7. & 697 & RN \\
\hline HEMBL3 & & 4 . & 125 & TST \\
\hline HEMBL3697 & 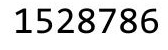 & 8.4685 & 0349 & TST \\
\hline AEMBL3 & -8 & 893 & 1117 & $\Gamma \mathrm{RN}$ \\
\hline HEMBL36 & & 6 & 889 & \\
\hline CHEMBL36 & & 7. & 589 & TRN \\
\hline HEMBL 369 & 36 & 6.7721 & 7561 & $\Gamma \mathrm{RN}$ \\
\hline HEMBL3693077 & 52 & 7.3468 & 4603 & TRN \\
\hline$M B L$ & & 0 & 632 & \\
\hline HEMBL36 & & & $\partial 141$ & \\
\hline HEMBL 36 & & 20 & 8.3535 & \\
\hline HEMBL3693023 & 152878 & 7.1871 & 7.1794 & \\
\hline
\end{tabular}

Page 4669 
Supplemental Table S2.txt

\begin{tabular}{|c|c|c|c|c|c|}
\hline CHEMBL 3688587 & 1528786 & 6.8697 & 7.2497 & TRN & \\
\hline CHEMBL3697255 & 1528786 & 6.9431 & 6.4295 & TRN & \\
\hline CHEMBL3700785 & 1528786 & 7.8097 & 7.89 & TRN & \\
\hline CHEMBL3693126 & 1528786 & 7.3768 & 5.7205 & TST & \\
\hline CHEMBL 3700780 & 1528786 & 6.4317 & 4.7958 & TST & \\
\hline CHEMBL 3693074 & 1528786 & 7.9208 & 7.4553 & TRN & \\
\hline CHEMBL3697317 & 1528786 & 6.4915 & 6.2332 & TRN & \\
\hline CHEMBL 3697284 & 1528786 & 7.5591 & 6.6862 & TRN & \\
\hline CHEMBL 3697248 & 1528786 & 4.0 & 6.569 & TST & \\
\hline CHEMBL3693138 & 1528786 & 7.4685 & 8.5371 & TST & \\
\hline CHEMBL3697242 & 1528786 & 8.301 & 8.292 & TRN & \\
\hline CHEMBL3688399 & 1528786 & 4.0 & 4.7584 & TRN & \\
\hline CHEMBL3697335 & 1528786 & 7.6383 & 7.0486 & TRN & \\
\hline CHEMBL3688506 & 1528786 & 9.0 & 9.1146 & TRN & \\
\hline CHEMBL 3688436 & 1528786 & 8.5229 & 8.0812 & TRN & \\
\hline CHEMBL3700829 & 1528786 & 7.4841 & 7.3156 & TRN & \\
\hline CHEMBL3697285 & 1528786 & 8.301 & 8.1801 & TRN & \\
\hline CHEMBL 3693101 & 1528786 & 7.2596 & 7.9058 & TST & \\
\hline CHEMBL 3697267 & 1528786 & 4.0 & 8.3274 & TST & \\
\hline CHEMBL 3693190 & 1528786 & 8.699 & 8.818999 & 9999999999 & TRN \\
\hline CHEMBL3693170 & 1528786 & 9.0 & 7.9377 & TST & \\
\hline CHEMBL3697385 & 1528786 & 4.0 & 3.5464 & TRN & \\
\hline CHEMBL3693135 & 1528786 & 8.0458 & 7.6003 & TRN & \\
\hline CHEMBL3693087 & 1528786 & 8.3979 & 8.2723 & TRN & \\
\hline CHEMBL3697245 & 1528786 & 7.699 & 7.5268 & TRN & \\
\hline CHEMBL 3688548 & 1528786 & 7.2366 & 7.1423 & TRN & \\
\hline CHEMBL 3688561 & 1528786 & 8.301 & 7.8475 & TST & \\
\hline CHEMBL 3688545 & 1528786 & 7.7212 & 7.6163 & TRN & \\
\hline CHEMBL3697268 & 1528786 & 4.0 & 10.3258 & TST & \\
\hline CHEMBL3693143 & 1528786 & 7.1549 & 7.7034 & TRN & \\
\hline CHEMBL 3688482 & 1528786 & 6.0 & 6.7254 & TRN & \\
\hline CHEMBL3639919 & 1528786 & 8.5229 & 8.7358 & TRN & \\
\hline CHEMBL 3697265 & 1528786 & 4.0 & 8.6173 & TST & \\
\hline CHEMBL3700891 & 1528786 & 7.2182 & 7.7706 & TST & \\
\hline CHEMBL3688557 & 1528786 & 7.4089 & 7.4142 & TRN & \\
\hline CHEMBL3688464 & 1528786 & 6.0 & 6.1639 & TRN & \\
\hline CHEMBL 3688433 & 1528786 & 7.9586 & 7.9169 & TRN & \\
\hline CHEMBL3700868 & 1528786 & 6.301 & 4.9776 & TST & \\
\hline CHEMBL 3688502 & 1528786 & 9.0 & 8.6769 & TST & \\
\hline CHEMBL3693032 & 1528786 & 8.5229 & 8.032 & TRN & \\
\hline CHEMBL 3693061 & 1528786 & 6.1273 & 6.3999 & TRN & \\
\hline CHEMBL 3688450 & 1528786 & 7.5528 & 7.8486 & TRN & \\
\hline CHEMBL3688445 & 1528786 & 6.0 & 7.0906 & TRN & \\
\hline CHEMBL3693130 & 1528786 & 7.8861 & \multicolumn{2}{|c|}{7.077000000000001} & TST \\
\hline CHEMBL3697189 & 1528786 & 6.0 & 5.5214 & TRN & \\
\hline CHEMBL 3693075 & 1528786 & 7.8539 & 8.0084 & TRN & \\
\hline CHEMBL3700864 & 1528786 & 8.4949 & 8.4397 & TRN & \\
\hline CHEMBL 3693211 & 1528786 & 6.8386 & 6.9095 & TRN & \\
\hline
\end{tabular}


Supplemental Table S2.txt

\begin{tabular}{|c|c|c|c|c|}
\hline CHEMBL3688597 & 1528786 & 7.8239 & 7.7298 & TST \\
\hline CHEMBL3688499 & 1528786 & 7.0809 & 6.8414 & TST \\
\hline CHEMBL 3700831 & 1528786 & 6.4076 & 6.4446 & TST \\
\hline CHEMBL3693154 & 1528786 & 7.1871 & 7.644 & TST \\
\hline CHEMBL3688398 & 1528786 & 6.5436 & 6.285 & TST \\
\hline CHEMBL 3972620 & 1528786 & 8.699 & 8.1812 & TST \\
\hline CHEMBL3688447 & 1528786 & 7.8239 & 7.3061 & TST \\
\hline CHEMBL 3897874 & 1528786 & 7.2007 & 5.8829 & TST \\
\hline CHEMBL3697346 & 1528786 & 6.8807 & 7.7132 & TST \\
\hline CHEMBL3700784 & 1528786 & 8.7959 & 8.9143 & TST \\
\hline CHEMBL3688591 & 1528786 & 7.4437 & 7.0488 & TST \\
\hline CHEMBL3688529 & 1528786 & 6.7852 & 8.8809 & TST \\
\hline CHEMBL 3688577 & 1528786 & 6.5229 & 6.865 & TST \\
\hline CHEMBL3688595 & 1528786 & 8.2218 & 6.4664 & TST \\
\hline CHEMBL 3697325 & 1528786 & 6.0 & 6.9547 & TST \\
\hline CHEMBL 3697342 & 1528786 & 9.1549 & 8.2462 & TST \\
\hline CHEMBL3697174 & 1528786 & 6.45100 & 000000000 & 7.0532 \\
\hline CHEMBL3693059 & 1528786 & 7.0506 & 7.007000 & 0000000001 \\
\hline CHEMBL3693013 & 1528786 & 7.5528 & 6.8685 & TST \\
\hline CHEMBL 3688530 & 1528786 & 7.3279 & 6.5898 & TST \\
\hline CHEMBL3983007 & 1528786 & 8.0969 & 7.3694 & TST \\
\hline CHEMBL3693184 & 1528786 & 9.0 & 8.736 & TST \\
\hline CHEMBL3697180 & 1528786 & 7.7212 & 7.6398 & TST \\
\hline CHEMBL3700893 & 1528786 & 5.9034 & 6.4062 & TST \\
\hline CHEMBL 3693147 & 1528786 & 4.0 & 6.2908 & TST \\
\hline CHEMBL3688414 & 1528786 & 8.699 & 7.5358 & TST \\
\hline CHEMBL3688400 & 1528786 & 9.0 & 8.8728 & TST \\
\hline CHEMBL3700800 & 1528786 & 4.0 & 4.8539 & TST \\
\hline CHEMBL3697369 & 1528786 & 4.0 & 6.8332 & TST \\
\hline CHEMBL 3688589 & 1528786 & 6.1959 & 6.4441 & TST \\
\hline CHEMBL3700842 & 1528786 & 8.2366 & 8.3683 & TST \\
\hline CHEMBL3697322 & 1528786 & 7.2027 & 6.7814 & TST \\
\hline CHEMBL3688497 & 1528786 & 6.0 & 7.8565 & TST \\
\hline CHEMBL3688462 & 1528786 & 6.9547 & 7.9531 & TST \\
\hline CHEMBL 3688523 & 1528786 & 6.4547 & 5.3411 & TST \\
\hline CHEMBL3688516 & 1528786 & 9.0 & 9.0186 & TST \\
\hline CHEMBL3929989 & 1528786 & 6.8719 & 7.2106 & TST \\
\hline CHEMBL3697379 & 1528786 & 8.7696 & 8.4268 & TST \\
\hline CHEMBL3688553 & 1528786 & 8.5229 & 8.4831 & TST \\
\hline CHEMBL3697303 & 1528786 & 7.3595 & 7.419 & TST \\
\hline CHEMBL3700863 & 1528786 & 6.9382 & 7.115 & TST \\
\hline CHEMBL3697175 & 1528786 & 7.8239 & 7.7352 & TST \\
\hline CHEMBL3688540 & 1528786 & 8.1549 & 7.3892 & TST \\
\hline CHEMBL3688403 & 1528786 & 8.699 & 8.492 & TST \\
\hline CHEMBL3693111 & 1528786 & 7.8861 & 8.0612 & TST \\
\hline CHEMBL3697288 & 1528786 & 6.8589 & 7.8194 & TST \\
\hline CHEMBL3688594 & 1528786 & 8.301 & 7.6953 & TST \\
\hline CHEMBL3688437 & 1528786 & 7.2441 & 6.7781 & TST \\
\hline
\end{tabular}




\begin{tabular}{|c|c|c|c|c|}
\hline & & & & \\
\hline CHEMBL 3697282 & 1528786 & 4.0 & 7.0512 & TST \\
\hline CHEMBL1964290 & 809280 & 4.3 & 4.4295 & TRN \\
\hline CHEMBL2001398 & 809280 & 6.3 & 4.713 & TRN \\
\hline CHEMBL213505 & 809280 & 6.7 & 6.563 & TRN \\
\hline CHEMBL202721 & 809280 & 5.5 & 4.1123 & TRN \\
\hline CHEMBL1987034 & 809280 & 6.9 & 7.0096 & TRN \\
\hline CHEMBL1993941 & 809280 & 6.8 & 7.4273 & TRN \\
\hline CHEMBL377383 & 809280 & 4.3 & 4.2754 & TRN \\
\hline CHEMBL 2005886 & 809280 & 7.8 & 6.7328 & TRN \\
\hline CHEMBL481491 & 809280 & 4.3 & 4.3045 & TST \\
\hline CHEMBL1682345 & 809280 & 4.3 & 4.2906 & TRN \\
\hline CHEMBL1973142 & 809280 & 4.3 & 4.337 & TST \\
\hline CHEMBL388311 & 809280 & 8.3 & 7.0814 & TRN \\
\hline CHEMBL1973145 & 809280 & 4.4 & 5.6671 & TRN \\
\hline CHEMBL1982924 & 809280 & 5.4 & 5.7848 & TRN \\
\hline CHEMBL 2005936 & 809280 & 4.3 & 4.1588 & TRN \\
\hline CHEMBL1807515 & 809280 & 4.3 & 5.2579 & TRN \\
\hline CHEMBL1964948 & 809280 & 4.4 & 4.295 & TRN \\
\hline CHEMBL1971141 & 809280 & 4.3 & 4.5705 & TRN \\
\hline CHEMBL1995813 & 809280 & 4.3 & 5.6299 & TRN \\
\hline CHEMBL1979718 & 809280 & 4.3 & 4.5884 & TRN \\
\hline CHEMBL206236 & 809280 & 4.3 & 4.3351 & TRN \\
\hline CHEMBL1989834 & 809280 & 3.9 & 3.6196 & TRN \\
\hline CHEMBL523823 & 809280 & 4.3 & 4.6024 & TST \\
\hline CHEMBL1562756 & 809280 & 4.3 & 4.7205 & TST \\
\hline CHEMBL1987430 & 809280 & 4.4 & 4.3415 & TRN \\
\hline CHEMBL 244378 & 809280 & 4.3 & 5.4967 & TRN \\
\hline CHEMBL 2001957 & 809280 & 4.3 & 4.1317 & TRN \\
\hline CHEMBL1969372 & 809280 & 4.3 & 4.4427 & TRN \\
\hline CHEMBL1993413 & 809280 & 4.4 & 4.5973 & TRN \\
\hline CHEMBL1990583 & 809280 & 5.4 & 5.7277 & TRN \\
\hline CHEMBL1986943 & 809280 & 6.4 & 5.4562 & TRN \\
\hline CHEMBL 2006263 & 809280 & 4.3 & 4.5127 & TST \\
\hline CHEMBL1993584 & 809280 & 4.3 & 4.2082 & TRN \\
\hline CHEMBL1986263 & 809280 & 4.6 & 4.5857 & TRN \\
\hline CHEMBL2000114 & 809280 & 4.3 & 4.4929 & TRN \\
\hline CHEMBL 210618 & 809280 & 4.3 & 4.3044 & TRN \\
\hline CHEMBL1986265 & 809280 & 4.4 & 4.3399 & TRN \\
\hline CHEMBL1975647 & 809280 & 4.3 & 4.455 & TRN \\
\hline CHEMBL1968380 & 809280 & 4.3 & 4.4182 & TRN \\
\hline CHEMBL1964644 & 809280 & 4.3 & 4.3431 & TRN \\
\hline CHEMBL1991734 & 809280 & 5.9 & 5.5033 & TST \\
\hline CHEMBL1981782 & 809280 & 4.3 & 4.3404 & TRN \\
\hline CHEMBL1977681 & 809280 & 4.3 & 4.5893 & TRN \\
\hline CHEMBL1970142 & 809280 & 8.0 & 7.4865 & TRN \\
\hline CHEMBL1990912 & 809280 & 4.3 & 4.1535 & TRN \\
\hline CHEMBL1991782 & 809280 & 3.1 & 3.2685 & TRN \\
\hline CHEMBL 2002105 & 809280 & 4.4 & 4.2096 & TRN \\
\hline
\end{tabular}




\begin{tabular}{|c|c|c|c|c|}
\hline & & & & al Ta \\
\hline CHEMBL1983348 & 809280 & 6.5 & 5.5199 & TRN \\
\hline CHEMBL1988163 & 809280 & 5.8 & 6.5228 & TRN \\
\hline CHEMBL1995592 & 809280 & 4.3 & 4.5671 & TST \\
\hline CHEMBL1974480 & 809280 & 5.6 & 5.1543 & TST \\
\hline CHEMBL 2006493 & 809280 & 4.3 & 4.4436 & TST \\
\hline CHEMBL1986177 & 809280 & 4.4 & 4.2951 & TRN \\
\hline CHEMBL1996923 & 809280 & 4.3 & 4.3315 & TST \\
\hline CHEMBL1983449 & 809280 & 4.3 & 4.3043 & TRN \\
\hline CHEMBL1992323 & 809280 & 4.3 & 4.272 & TST \\
\hline CHEMBL1969735 & 809280 & 4.3 & 4.0919 & TRN \\
\hline CHEMBL 2003524 & 809280 & 4.3 & 4.8343 & TST \\
\hline CHEMBL 2002649 & 809280 & 6.9 & 5.8838 & TRN \\
\hline CHEMBL1985367 & 809280 & 6.3 & 4.6894 & TST \\
\hline CHEMBL1996510 & 809280 & 4.4 & 5.5257 & TST \\
\hline CHEMBL437747 & 809280 & 4.3 & 4.5021 & TRN \\
\hline CHEMBL1995172 & 809280 & 4.4 & 4.0442 & TST \\
\hline CHEMBL 2001584 & 809280 & 4.4 & 3.8223 & TRN \\
\hline CHEMBL507936 & 809280 & 4.3 & 5.0324 & TRN \\
\hline CHEMBL104264 & 809280 & 4.3 & 4.7898 & TST \\
\hline CHEMBL1967998 & 809280 & 6.7 & 6.3603 & TRN \\
\hline CHEMBL1994321 & 809280 & 7.5 & 7.2805 & TRN \\
\hline CHEMBL1978562 & 809280 & 5.7 & 5.9783 & TST \\
\hline CHEMBL1997129 & 809280 & 4.3 & 4.1841 & TRN \\
\hline CHEMBL1984788 & 809280 & 4.3 & 4.0396 & TRN \\
\hline CHEMBL451964 & 809280 & 4.3 & 4.3316 & TRN \\
\hline CHEMBL1964307 & 809280 & 5.8 & 5.3374 & TRN \\
\hline CHEMBL1989471 & 809280 & 6.0 & 4.6846 & TST \\
\hline CHEMBL 2000508 & 809280 & 4.3 & 4.2906 & TRN \\
\hline CHEMBL1971694 & 809280 & 4.3 & 4.4066 & TST \\
\hline CHEMBL 2001547 & 809280 & 4.3 & 4.2423 & TRN \\
\hline CHEMBL 210928 & 809280 & 4.3 & 4.2784 & TRN \\
\hline CHEMBL1978195 & 809280 & 4.4 & 4.217 & TRN \\
\hline CHEMBL1994361 & 809280 & 4.3 & 4.3778 & TRN \\
\hline CHEMBL1986603 & 809280 & 4.3 & 4.5951 & TST \\
\hline CHEMBL1972840 & 809280 & 4.3 & 4.1257 & TRN \\
\hline CHEMBL1977148 & 809280 & 7.6 & 7.8598 & TRN \\
\hline CHEMBL 2003286 & 809280 & 4.3 & 4.2303 & TRN \\
\hline CHEMBL1992306 & 809280 & 6.9 & 6.4066 & TRN \\
\hline CHEMBL 2002165 & 809280 & 7.0 & 7.5432 & TRN \\
\hline CHEMBL1979318 & 809280 & 4.3 & 4.3667 & TRN \\
\hline CHEMBL 206382 & 809280 & 4.3 & 4.4021 & TRN \\
\hline CHEMBL1998585 & 809280 & 7.9 & 8.0847 & TRN \\
\hline CHEMBL127898 & 809280 & 4.3 & 4.3256 & TST \\
\hline CHEMBL519697 & 809280 & 4.3 & 4.1221 & TRN \\
\hline CHEMBL 2004934 & 809280 & 4.3 & 4.2536 & TRN \\
\hline CHEMBL1996345 & 809280 & 4.4 & 4.6102 & TRN \\
\hline CHEMBL1975128 & 809280 & 4.3 & 4.2411 & TRN \\
\hline CHEMBL 2004025 & 809280 & 5.8 & 6.0791 & TRN \\
\hline
\end{tabular}




\begin{tabular}{|c|c|c|c|c|c|}
\hline \multirow[b]{2}{*}{ CHEMBL1996048 } & \multirow[b]{2}{*}{809280} & \\
\hline & & 4.5 & 4.6141 & TST & \\
\hline CHEMBL1970369 & 809280 & 4.3 & 4.4351 & TRN & \\
\hline CHEMBL461876 & 809280 & 4.4 & 5.3371 & TRN & \\
\hline CHEMBL1965033 & 809280 & 6.9 & 6.3592 & TRN & \\
\hline CHEMBL 2001485 & 809280 & 7.1 & 6.8707 & TRN & \\
\hline CHEMBL504950 & 809280 & 4.3 & 4.5979 & TRN & \\
\hline CHEMBL1997335 & 809280 & 4.4 & 4.0746 & TRN & \\
\hline CHEMBL1966425 & 809280 & 4.3 & 4.3662 & TRN & \\
\hline CHEMBL1984363 & 809280 & 6.0 & 5.1214 & TRN & \\
\hline CHEMBL1978099 & 809280 & 6.1 & 5.9345 & TRN & \\
\hline CHEMBL1977041 & 809280 & 6.1 & 5.9622 & TRN & \\
\hline CHEMBL1968070 & 809280 & 4.3 & 5.0167 & TRN & \\
\hline CHEMBL1988608 & 809280 & 4.3 & 4.4068 & TRN & \\
\hline CHEMBL184847 & 809280 & 4.3 & 4.9206 & TRN & \\
\hline CHEMBL1994808 & 809280 & 4.1 & 4.3295 & TRN & \\
\hline CHEMBL1984367 & 809280 & 4.3 & 4.8175 & TRN & \\
\hline CHEMBL178737 & 809280 & 4.3 & 4.8337 & TST & \\
\hline CHEMBL226898 & 809280 & 4.3 & 4.0763 & TRN & \\
\hline CHEMBL1982563 & 809280 & 4.3 & 4.1473 & TRN & \\
\hline CHEMBL539474 & 809280 & 4.3 & 4.795 & TST & \\
\hline CHEMBL575824 & 809280 & 4.3 & 4.3801 & TRN & \\
\hline CHEMBL1988387 & 809280 & 7.7 & 7.4199 & TRN & \\
\hline CHEMBL1973868 & 809280 & 4.4 & 4.2722 & TRN & \\
\hline CHEMBL1972462 & 809280 & 4.4 & 4.4864 & TRN & \\
\hline CHEMBL1997759 & 809280 & 4.3 & 4.6885 & TRN & \\
\hline CHEMBL1990288 & 809280 & 4.3 & 4.268 & TRN & \\
\hline CHEMBL1974803 & 809280 & 4.3 & 4.8412 & TST & \\
\hline CHEMBL1970074 & 809280 & 6.7 & 6.6148 & TRN & \\
\hline CHEMBL1984500 & 809280 & 3.1 & 3.8578 & TRN & \\
\hline CHEMBL1986970 & 809280 & 4.3 & 4.2896 & TRN & \\
\hline CHEMBL 2005112 & 809280 & 4.3 & 5.2943 & TST & \\
\hline CHEMBL1958401 & 809280 & 4.3 & 4.32100 & 2000000001 & TRN \\
\hline CHEMBL2003456 & 809280 & 4.3 & 4.1608 & TRN & \\
\hline CHEMBL1966816 & 809280 & 4.3 & 4.2911 & TRN & \\
\hline CHEMBL1972584 & 809280 & 5.8 & 5.1524 & TRN & \\
\hline CHEMBL 2002992 & 809280 & 4.5 & 4.3706 & TRN & \\
\hline CHEMBL560813 & 809280 & 4.3 & 4.7923 & TRN & \\
\hline CHEMBL1982700 & 809280 & 4.4 & 4.2981 & TST & \\
\hline CHEMBL1968791 & 809280 & 4.3 & 4.4773 & TRN & \\
\hline CHEMBL326282 & 809280 & 4.3 & 4.4342 & TST & \\
\hline CHEMBL 2002682 & 809280 & 4.3 & 4.6642 & TST & \\
\hline CHEMBL1977634 & 809280 & 4.4 & 4.4252 & TRN & \\
\hline CHEMBL1992732 & 809280 & 4.3 & 4.543 & TST & \\
\hline CHEMBL1971186 & 809280 & 4.3 & 4.4832 & TRN & \\
\hline CHEMBL 2003482 & 809280 & 4.3 & 4.3118 & TRN & \\
\hline CHEMBL1973211 & 809280 & 6.6 & 6.5488 & TRN & \\
\hline CHEMBL1984700 & 809280 & 4.3 & 4.1576 & TRN & \\
\hline CHEMBL 2007151 & 809280 & 4.3 & 4.5019 & TRN & \\
\hline & & & & 4674 & \\
\hline
\end{tabular}




\begin{tabular}{|c|c|c|c|c|}
\hline \multicolumn{5}{|c|}{ pplemental T } \\
\hline CHEMBL1971606 & 809280 & 4.4 & 4.3122 & TRN \\
\hline CHEMBL1972125 & 809280 & 4.3 & 4.3649 & TRN \\
\hline CHEMBL1461728 & 809280 & 4.3 & 4.5011 & TRN \\
\hline CHEMBL1976134 & 809280 & 6.3 & 5.5506 & TRN \\
\hline CHEMBL1965131 & 809280 & 4.3 & 4.0265 & TST \\
\hline CHEMBL1972158 & 809280 & 4.3 & 4.3851 & TRN \\
\hline CHEMBL1981215 & 809280 & 4.4 & 4.4324 & TRN \\
\hline CHEMBL1974457 & 809280 & 4.3 & 4.2283 & TRN \\
\hline CHEMBL 2006580 & 809280 & 4.3 & 4.4626 & TRN \\
\hline CHEMBL1999414 & 809280 & 7.3 & 7.3213 & TRN \\
\hline CHEMBL1967336 & 809280 & 4.4 & 4.4117 & TRN \\
\hline CHEMBL 2006581 & 809280 & 4.3 & 4.271 & TRN \\
\hline CHEMBL1979855 & 809280 & 4.3 & 4.6611 & TRN \\
\hline CHEMBL1970340 & 809280 & 3.7 & 4.6152 & TRN \\
\hline CHEMBL1967992 & 809280 & 4.4 & 4.3188 & TRN \\
\hline CHEMBL 2005186 & 809280 & 4.3 & 4.3632 & TRN \\
\hline CHEMBL 2006450 & 809280 & 4.4 & 4.3711 & TRN \\
\hline CHEMBL1975534 & 809280 & 4.3 & 4.2804 & TRN \\
\hline CHEMBL1993424 & 809280 & 6.8 & 7.2381 & TRN \\
\hline CHEMBL1966703 & 809280 & 4.3 & 4.4301 & TST \\
\hline CHEMBL2001987 & 809280 & 4.4 & 4.3495 & TRN \\
\hline CHEMBL1969561 & 809280 & 4.3 & 4.1696 & TRN \\
\hline CHEMBL1994555 & 809280 & 4.4 & 4.9915 & TST \\
\hline CHEMBL1983640 & 809280 & 7.3 & 6.6927 & TRN \\
\hline CHEMBL1997023 & 809280 & 4.3 & 4.3303 & TST \\
\hline CHEMBL1964687 & 809280 & 6.8 & 6.4587 & TRN \\
\hline CHEMBL1971943 & 809280 & 4.6 & 4.5745 & TRN \\
\hline CHEMBL1999918 & 809280 & 4.3 & 4.3999 & TRN \\
\hline CHEMBL1974254 & 809280 & 6.9 & 7.5768 & TRN \\
\hline CHEMBL1988537 & 809280 & 4.3 & 4.7946 & TST \\
\hline CHEMBL1969049 & 809280 & 4.3 & 4.2733 & TRN \\
\hline CHEMBL 2005828 & 809280 & 4.3 & 5.2739 & TRN \\
\hline CHEMBL1998611 & 809280 & 4.3 & 4.1444 & TST \\
\hline CHEMBL485556 & 809280 & 4.3 & 4.482 & TRN \\
\hline CHEMBL1975900 & 809280 & 4.3 & 4.1717 & TRN \\
\hline CHEMBL 255822 & 809280 & 4.3 & 4.2775 & TRN \\
\hline CHEMBL1972221 & 809280 & 4.3 & 4.3367 & TRN \\
\hline CHEMBL 2006778 & 809280 & 5.5 & 5.8275 & TRN \\
\hline CHEMBL378627 & 809280 & 4.3 & 4.2317 & TRN \\
\hline CHEMBL1996979 & 809280 & 5.6 & 5.7514 & TRN \\
\hline CHEMBL1997025 & 809280 & 4.3 & 4.0263 & TRN \\
\hline CHEMBL1968406 & 809280 & 7.3 & 6.8914 & TRN \\
\hline CHEMBL1982476 & 809280 & 8.2 & 7.6712 & TRN \\
\hline CHEMBL1998545 & 809280 & 4.3 & 4.2574 & TRN \\
\hline CHEMBL1986869 & 809280 & 4.3 & 4.3022 & TRN \\
\hline CHEMBL1975923 & 809280 & 4.7 & 4.399 & TST \\
\hline CHEMBL 2005449 & 809280 & 6.5 & 5.1384 & TRN \\
\hline CHEMBL1987998 & 809280 & 4.4 & 4.2241 & TRN \\
\hline
\end{tabular}




\begin{tabular}{|c|c|c|c|c|c|}
\hline \\
\hline CHEMBL2006010 & 809280 & 4.3 & 4.4838 & TRN & \\
\hline CHEMBL1682558 & 809280 & 4.3 & 4.3161 & TRN & \\
\hline CHEMBL1989259 & 809280 & 5.7 & 4.8337 & TST & \\
\hline CHEMBL1990496 & 809280 & 4.4 & 4.3689 & TRN & \\
\hline CHEMBL2002799 & 809280 & 6.2 & 4.7271 & TST & \\
\hline CHEMBL242865 & 809280 & 4.4 & 4.982 & TRN & \\
\hline CHEMBL1997623 & 809280 & 7.4 & 6.8965 & TRN & \\
\hline CHEMBL1968460 & 809280 & 4.2 & 4.2139 & TRN & \\
\hline CHEMBL 2002479 & 809280 & 4.3 & 4.7111 & TRN & \\
\hline CHEMBL1993166 & 809280 & 4.3 & 4.3774 & TRN & \\
\hline CHEMBL1967094 & 809280 & 4.3 & 4.6105 & TRN & \\
\hline CHEMBL1966035 & 809280 & 4.3 & 4.3036 & TRN & \\
\hline CHEMBL2003341 & 809280 & 4.3 & 4.2568 & TRN & \\
\hline CHEMBL1992645 & 809280 & 4.3 & 4.6852 & TST & \\
\hline CHEMBL1982992 & 809280 & 4.3 & 4.2834 & TRN & \\
\hline CHEMBL1998110 & 809280 & 4.4 & 4.2879 & TRN & \\
\hline CHEMBL1999590 & 809280 & 4.3 & 4.3798 & TST & \\
\hline CHEMBL1981079 & 809280 & 4.3 & 4.2752 & TRN & \\
\hline CHEMBL1978166 & 809280 & 6.6 & 6.8355 & TRN & \\
\hline CHEMBL1972276 & 809280 & 4.3 & 4.5779 & TRN & \\
\hline CHEMBL1980489 & 809280 & 4.3 & 4.1352 & TRN & \\
\hline CHEMBL 2000832 & 809280 & 4.3 & 4.4554 & TRN & \\
\hline CHEMBL1967116 & 809280 & 7.9 & 8.0192 & TRN & \\
\hline CHEMBL513846 & 809280 & 4.3 & 4.478 & TRN & \\
\hline CHEMBL1970709 & 809280 & 4.3 & 4.4135 & TRN & \\
\hline CHEMBL1965660 & 809280 & 4.4 & 4.35800 & 00000000005 & TRN \\
\hline CHEMBL1992125 & 809280 & 6.1 & 5.7309 & TRN & \\
\hline CHEMBL1998112 & 809280 & 4.3 & 4.26 & TRN & \\
\hline CHEMBL1969126 & 809280 & 4.3 & 4.1814 & TRN & \\
\hline CHEMBL1980896 & 809280 & 5.9 & 4.5605 & TRN & \\
\hline CHEMBL1975208 & 809280 & 4.3 & 4.7744 & TST & \\
\hline CHEMBL1970104 & 809280 & 6.9 & 6.2559 & TRN & \\
\hline CHEMBL1991429 & 809280 & 5.5 & 5.3206 & TRN & \\
\hline CHEMBL1964777 & 809280 & 4.3 & 4.2141 & TRN & \\
\hline CHEMBL1971149 & 809280 & 4.3 & 4.3571 & TRN & \\
\hline CHEMBL1999714 & 809280 & 4.3 & 4.0757 & TRN & \\
\hline CHEMBL1987533 & 809280 & 4.3 & 4.5384 & TRN & \\
\hline CHEMBL1994040 & 809280 & 4.3 & 4.2549 & TRN & \\
\hline CHEMBL 388978 & 809280 & 9.1 & 7.2802 & TST & \\
\hline CHEMBL579246 & 809280 & 4.3 & 4.3839 & TRN & \\
\hline CHEMBL398951 & 809280 & 4.4 & 4.5514 & TST & \\
\hline CHEMBL1982506 & 809280 & 4.3 & 4.3027 & TST & \\
\hline CHEMBL 2004716 & 809280 & 8.0 & 7.6471 & TRN & \\
\hline CHEMBL1968127 & 809280 & 4.3 & 4.2775 & TRN & \\
\hline CHEMBL1975233 & 809280 & 4.3 & 4.3471 & TRN & \\
\hline CHEMBL1985406 & 809280 & 4.3 & 4.0131 & TRN & \\
\hline CHEMBL 207400 & 809280 & 4.3 & 4.7893 & TST & \\
\hline CHEMBL 2000894 & 809280 & 4.3 & 4.3205 & TST & \\
\hline
\end{tabular}




\begin{tabular}{|c|c|c|c|c|c|}
\hline & & & & & \\
\hline CHEMBL1421720 & 809280 & 4.4 & 5.2644 & TRN & \\
\hline CHEMBL1982135 & 809280 & 4.3 & 5.3021 & TRN & \\
\hline CHEMBL1976090 & 809280 & 4.3 & 4.7361 & TRN & \\
\hline CHEMBL1993243 & 809280 & 6.0 & 5.7824 & TRN & \\
\hline CHEMBL2004771 & 809280 & 4.3 & 4.3925 & TRN & \\
\hline CHEMBL1992922 & 809280 & 5.4 & 5.5415 & TRN & \\
\hline CHEMBL399021 & 809280 & 4.3 & 4.34699 & 99999999995 & TRN \\
\hline CHEMBL1997597 & 809280 & 4.3 & 4.2971 & TRN & \\
\hline CHEMBL1969537 & 809280 & 4.3 & 4.9895 & TST & \\
\hline CHEMBL1976093 & 809280 & 4.3 & 4.2709 & TRN & \\
\hline CHEMBL1996543 & 809280 & 4.3 & 4.2069 & TRN & \\
\hline CHEMBL1975256 & 809280 & 4.3 & 4.5382 & TST & \\
\hline CHEMBL508928 & 809280 & 6.8 & 6.7104 & TRN & \\
\hline CHEMBL1991356 & 809280 & 4.3 & 4.421 & TST & \\
\hline CHEMBL2004892 & 809280 & 4.3 & 4.4888 & TRN & \\
\hline CHEMBL1997503 & 809280 & 4.3 & 4.6171 & TST & \\
\hline CHEMBL116070 & 809280 & 4.3 & 4.0288 & TRN & \\
\hline CHEMBL1990821 & 809280 & 4.3 & 4.6039 & TST & \\
\hline CHEMBL1970314 & 809280 & 4.3 & 4.5668 & TRN & \\
\hline CHEMBL2004871 & 809280 & 4.3 & 4.062 & TRN & \\
\hline CHEMBL2004872 & 809280 & 4.3 & 4.3851 & TRN & \\
\hline CHEMBL1727312 & 809280 & 4.3 & 3.8534 & TRN & \\
\hline CHEMBL1990223 & 809280 & 4.4 & 4.2046 & TRN & \\
\hline CHEMBL1969879 & 809280 & 4.3 & 4.396 & TRN & \\
\hline CHEMBL1964382 & 809280 & 4.4 & 4.8131 & TST & \\
\hline CHEMBL101311 & 809280 & 5.5 & 4.658 & TRN & \\
\hline CHEMBL1981720 & 809280 & 4.3 & 4.2128 & TRN & \\
\hline CHEMBL419932 & 809280 & 4.3 & 4.3867 & TRN & \\
\hline CHEMBL262433 & 809280 & 6.1 & 5.6935 & TRN & \\
\hline CHEMBL306380 & 809280 & 6.5 & 5.4065 & TRN & \\
\hline CHEMBL1966722 & 809280 & 4.3 & 4.0723 & TST & \\
\hline CHEMBL1988581 & 809280 & 6.5 & 5.9679 & TST & \\
\hline CHEMBL2005699 & 809280 & 4.4 & 4.3094 & TRN & \\
\hline CHEMBL1975500 & 809280 & 4.3 & 4.5275 & TRN & \\
\hline CHEMBL1976328 & 809280 & 4.3 & 5.4053 & TRN & \\
\hline CHEMBL394619 & 809280 & 6.0 & 6.0154 & TRN & \\
\hline CHEMBL2006564 & 809280 & 6.4 & 5.8482 & TRN & \\
\hline CHEMBL1964399 & 809280 & 4.3 & 4.4797 & TRN & \\
\hline CHEMBL1996831 & 809280 & 4.3 & 4.1189 & TST & \\
\hline CHEMBL411903 & 809280 & 8.4 & 7.7511 & TRN & \\
\hline CHEMBL1978167 & 809280 & 4.4 & 5.1439 & TST & \\
\hline CHEMBL1965988 & 809280 & 7.1 & 6.9485 & TRN & \\
\hline CHEMBL418203 & 809280 & 4.4 & 4.7134 & TST & \\
\hline CHEMBL1989646 & 809280 & 4.3 & 4.2678 & TRN & \\
\hline CHEMBL1682357 & 809280 & 4.3 & 4.3759 & TRN & \\
\hline CHEMBL225519 & 809280 & 4.4 & 4.1778 & TRN & \\
\hline CHEMBL209534 & 809280 & 4.3 & 4.1597 & TRN & \\
\hline CHEMBL1978200 & 809280 & 4.3 & 4.5554 & TRN & \\
\hline & & & & 4677 & \\
\hline
\end{tabular}




\begin{tabular}{|c|c|c|c|c|}
\hline \multicolumn{5}{|r|}{1 Table } \\
\hline CHEMBL1970522 & 809280 & 4.3 & 4.1764 & TRN \\
\hline CHEMBL1990415 & 809280 & 4.3 & 4.3086 & TRN \\
\hline CHEMBL1966087 & 809280 & 4.3 & 4.4929 & TRN \\
\hline CHEMBL1964692 & 809280 & 7.6 & 7.2777 & TRN \\
\hline CHEMBL1996931 & 809280 & 4.3 & 4.227 & TRN \\
\hline CHEMBL1964413 & 809280 & 4.3 & 4.3975 & TRN \\
\hline CHEMBL1973483 & 809280 & 4.3 & 4.5014 & TRN \\
\hline CHEMBL1998470 & 809280 & 4.4 & 4.1754 & TRN \\
\hline CHEMBL1984432 & 809280 & 4.3 & 4.2752 & TRN \\
\hline CHEMBL1970735 & 809280 & 4.3 & 4.063 & TRN \\
\hline CHEMBL219722 & 809280 & 6.2 & 5.5515 & TRN \\
\hline CHEMBL1975903 & 809280 & 5.4 & 4.8607 & TRN \\
\hline CHEMBL1997340 & 809280 & 4.3 & 4.4258 & TRN \\
\hline CHEMBL 2004365 & 809280 & 4.3 & 4.4797 & TST \\
\hline CHEMBL1522508 & 809280 & 4.3 & 4.093 & TRN \\
\hline CHEMBL1989474 & 809280 & 4.3 & 4.3657 & TRN \\
\hline CHEMBL1090360 & 809280 & 4.3 & 4.7103 & TRN \\
\hline CHEMBL 210887 & 809280 & 4.3 & 4.6024 & TRN \\
\hline CHEMBL1988805 & 809280 & 4.4 & 4.5488 & TRN \\
\hline CHEMBL458997 & 809280 & 4.5 & 5.1068 & TRN \\
\hline CHEMBL1971021 & 809280 & 6.9 & 6.7616 & TRN \\
\hline CHEMBL227271 & 809280 & 4.3 & 4.336 & TRN \\
\hline CHEMBL583144 & 809280 & 4.3 & 4.6524 & TST \\
\hline CHEMBL1974310 & 809280 & 4.3 & 4.133 & TRN \\
\hline CHEMBL1969942 & 809280 & 4.4 & 4.6885 & TRN \\
\hline CHEMBL1978567 & 809280 & 4.4 & 4.2879 & TRN \\
\hline CHEMBL1982660 & 809280 & 4.4 & 4.5694 & TRN \\
\hline CHEMBL1994693 & 809280 & 5.7 & 5.3446 & TRN \\
\hline CHEMBL1982957 & 809280 & 5.8 & 6.1445 & TRN \\
\hline CHEMBL1725279 & 809280 & 6.1 & 5.6196 & TST \\
\hline CHEMBL1975138 & 809280 & 4.3 & 4.0317 & TST \\
\hline CHEMBL424872 & 809280 & 4.3 & 4.3128 & TRN \\
\hline CHEMBL 2006836 & 809280 & 4.3 & $5.2020 \ell$ & 0000000001 \\
\hline CHEMBL1971947 & 809280 & 8.3 & 7.5929 & TRN \\
\hline CHEMBL412142 & 809280 & 4.3 & 4.6642 & TST \\
\hline CHEMBL1980704 & 809280 & 4.3 & 4.3033 & TST \\
\hline CHEMBL 2003271 & 809280 & 4.3 & 4.0791 & TST \\
\hline CHEMBL1966808 & 809280 & 4.3 & 4.2188 & TRN \\
\hline CHEMBL 2004447 & 809280 & 4.3 & 4.4188 & TRN \\
\hline CHEMBL1983111 & 809280 & 7.5 & 6.8369 & TRN \\
\hline CHEMBL1973860 & 809280 & 4.3 & 4.2033 & TRN \\
\hline CHEMBL260135 & 809280 & 4.3 & 4.288 & TRN \\
\hline CHEMBL220241 & 809280 & 4.3 & 4.3576 & TRN \\
\hline CHEMBL 2004544 & 809280 & 4.3 & 4.1809 & TST \\
\hline CHEMBL1988141 & 809280 & 6.1 & 5.9817 & TST \\
\hline CHEMBL1982610 & 809280 & 4.3 & 4.4243 & TST \\
\hline CHEMBL1977134 & 809280 & 7.9 & 7.4763 & TRN \\
\hline CHEMBL1999496 & 809280 & 4.3 & 4.5433 & TRN \\
\hline
\end{tabular}




\begin{tabular}{|c|c|c|c|c|}
\hline \multicolumn{5}{|c|}{ Supplemental Table S2.txt } \\
\hline CHEMBL 2006933 & 809280 & 4.3 & 4.5764 & TST \\
\hline CHEMBL1985206 & 809280 & 5.8 & 4.3448 & TST \\
\hline CHEMBL1988300 & 809280 & 5.6 & 5.9448 & TRN \\
\hline CHEMBL1991078 & 809280 & 4.3 & 5.2621 & TRN \\
\hline CHEMBL1987359 & 809280 & 4.3 & 4.4206 & TST \\
\hline CHEMBL1977749 & 809280 & 4.4 & 4.9232 & TST \\
\hline CHEMBL1975212 & 809280 & 5.0 & 5.0044 & TRN \\
\hline CHEMBL 2000685 & 809280 & 4.3 & 4.2573 & TRN \\
\hline CHEMBL1997275 & 809280 & 6.6 & 6.0695 & TRN \\
\hline CHEMBL1993904 & 809280 & 5.8 & 5.8205 & TRN \\
\hline CHEMBL1967513 & 809280 & 4.4 & 4.5334 & TRN \\
\hline CHEMBL1985311 & 809280 & 5.7 & 5.6063 & TRN \\
\hline CHEMBL1989265 & 809280 & 4.3 & 4.802 & TST \\
\hline CHEMBL1982413 & 809280 & 4.4 & 5.22 & TST \\
\hline CHEMBL1969502 & 809280 & 4.3 & 5.0931 & TRN \\
\hline CHEMBL1965910 & 809280 & 4.3 & 4.5572 & TRN \\
\hline CHEMBL1682553 & 809280 & 4.3 & 4.4718 & TRN \\
\hline CHEMBL1971430 & 809280 & 4.3 & 4.3197 & TRN \\
\hline CHEMBL1983963 & 809280 & 6.8 & 6.479 & TRN \\
\hline CHEMBL1997764 & 809280 & 4.3 & 5.5972 & TRN \\
\hline CHEMBL 2000271 & 809280 & 4.3 & 3.9863 & TRN \\
\hline CHEMBL1981792 & 809280 & 4.4 & 5.1831 & TRN \\
\hline CHEMBL1987535 & 809280 & 4.4 & 4.541 & TRN \\
\hline CHEMBL1985092 & 809280 & 4.3 & 4.742 & TRN \\
\hline CHEMBL 2004692 & 809280 & 4.3 & 4.6286 & TST \\
\hline CHEMBL1981410 & 809280 & 6.0 & 6.1683 & TRN \\
\hline CHEMBL 2002586 & 809280 & 5.7 & 4.7716 & TRN \\
\hline CHEMBL1996234 & 809280 & 4.3 & 4.1949 & TRN \\
\hline CHEMBL383264 & 809280 & 4.4 & 3.9898 & TRN \\
\hline CHEMBL 2007421 & 809280 & 9.0 & 7.0603 & TST \\
\hline CHEMBL1991434 & 809280 & 4.3 & 4.6133 & TST \\
\hline CHEMBL1967544 & 809280 & 4.3 & 4.3565 & TRN \\
\hline CHEMBL1973138 & 809280 & 4.4 & 3.8876 & TRN \\
\hline CHEMBL 223367 & 809280 & 4.3 & 4.249 & TST \\
\hline CHEMBL340384 & 809280 & 4.3 & 4.7293 & TST \\
\hline CHEMBL1969151 & 809280 & 5.8 & 4.9774 & TRN \\
\hline CHEMBL1996587 & 809280 & 4.3 & 4.5459 & TRN \\
\hline CHEMBL1993335 & 809280 & 6.7 & 6.0557 & TST \\
\hline CHEMBL1988692 & 809280 & 6.9 & 4.9162 & TRN \\
\hline CHEMBL 2007574 & 809280 & 4.4 & 4.585 & TRN \\
\hline CHEMBL1964804 & 809280 & 4.3 & 4.2869 & TRN \\
\hline CHEMBL443962 & 809280 & 5.3 & 4.5683 & TST \\
\hline CHEMBL 2000354 & 809280 & 4.3 & 4.0918 & TRN \\
\hline CHEMBL1965507 & 809280 & 6.0 & 4.7444 & TRN \\
\hline CHEMBL 274064 & 809280 & 4.3 & 4.2376 & TRN \\
\hline CHEMBL1998680 & 809280 & 4.4 & 4.3719 & TRN \\
\hline CHEMBL1967564 & 809280 & 4.3 & 4.2544 & TRN \\
\hline CHEMBL592030 & 809280 & 4.4 & 4.0775 & TST \\
\hline
\end{tabular}




\begin{tabular}{|c|c|c|c|c|}
\hline & & & & al labıe \\
\hline CHEMBL 2000071 & 809280 & 4.5 & 5.0293 & TRN \\
\hline CHEMBL1979176 & 809280 & 4.3 & 4.4582 & TRN \\
\hline CHEMBL1970317 & 809280 & 7.3 & 7.3584 & TRN \\
\hline CHEMBL 2000408 & 809280 & 4.3 & 4.1499 & TRN \\
\hline CHEMBL248757 & 809280 & 4.3 & 4.0838 & TST \\
\hline CHEMBL1978014 & 809280 & 4.3 & 4.3889 & TRN \\
\hline CHEMBL1997007 & 809280 & 4.4 & 5.1733 & TRN \\
\hline CHEMBL1994538 & 809280 & 4.3 & 4.3119 & TRN \\
\hline CHEMBL1983195 & 809280 & 4.3 & 4.428 & TST \\
\hline CHEMBL1975490 & 809280 & 4.3 & 4.5578 & TRN \\
\hline CHEMBL1964444 & 809280 & 4.3 & 4.1798 & TRN \\
\hline CHEMBL2002690 & 809280 & 4.4 & 4.7967 & TRN \\
\hline CHEMBL 2006567 & 809280 & 4.3 & 4.1954 & TRN \\
\hline CHEMBL1986139 & 809280 & 4.3 & 4.2157 & TRN \\
\hline CHEMBL383527 & 809280 & 4.3 & 4.2788 & TRN \\
\hline CHEMBL1980540 & 809280 & 4.3 & 4.3162 & TRN \\
\hline CHEMBL 278041 & 809280 & 6.1 & 4.547 & TRN \\
\hline CHEMBL1979883 & 809280 & 6.9 & 6.9618 & TRN \\
\hline CHEMBL1984162 & 809280 & 7.0 & 6.6562 & TRN \\
\hline CHEMBL491758 & 809280 & 5.6 & 5.1609 & TRN \\
\hline CHEMBL1986590 & 809280 & 6.7 & 6.0984 & TRN \\
\hline CHEMBL549730 & 809280 & 4.3 & 4.2022 & TRN \\
\hline CHEMBL1682360 & 809280 & 4.3 & 4.4756 & TRN \\
\hline CHEMBL1970189 & 809280 & 4.3 & 4.2678 & TRN \\
\hline CHEMBL1870106 & 809280 & 4.4 & 4.4172 & TRN \\
\hline CHEMBL1996791 & 809280 & 4.3 & 5.5793 & TRN \\
\hline CHEMBL371206 & 809280 & 6.7 & 6.6577 & TRN \\
\hline CHEMBL1974664 & 809280 & 4.3 & 5.2201 & TST \\
\hline CHEMBL406845 & 809280 & 4.4 & 4.8024 & TRN \\
\hline CHEMBL482538 & 809280 & 4.3 & 4.4646 & TRN \\
\hline CHEMBL1974288 & 809280 & 4.3 & 4.2732 & TRN \\
\hline CHEMBL1984296 & 809280 & 4.4 & 5.165 & TST \\
\hline CHEMBL196363 & 809280 & 7.2 & 6.9742 & TRN \\
\hline CHEMBL1190711 & 809280 & 4.3 & 4.1263 & TRN \\
\hline CHEMBL1990346 & 809280 & 4.3 & 4.4583 & TRN \\
\hline CHEMBL1968705 & 809280 & 4.4 & 4.252 & TRN \\
\hline CHEMBL1964441 & 809280 & 7.0 & 7.0507 & TRN \\
\hline CHEMBL1991410 & 809280 & 4.4 & 4.6213 & TRN \\
\hline CHEMBL546797 & 809280 & 5.6 & 5.32100 & 0000000001 \\
\hline CHEMBL404367 & 809280 & 4.5 & 6.0505 & TRN \\
\hline CHEMBL1966343 & 809280 & 4.3 & 4.9651 & TRN \\
\hline CHEMBL1978271 & 809280 & 4.4 & 4.6326 & TRN \\
\hline CHEMBL1967887 & 809280 & 4.3 & 4.2304 & TRN \\
\hline CHEMBL 2007266 & 809280 & 5.9 & 5.6833 & TRN \\
\hline CHEMBL 2000568 & 809280 & 4.5 & 4.3434 & TRN \\
\hline CHEMBL1994308 & 809280 & 4.4 & 4.8819 & TRN \\
\hline CHEMBL 2000335 & 809280 & 6.7 & 6.7287 & TRN \\
\hline CHEMBL 2007097 & 809280 & 4.2 & 3.9873 & TRN \\
\hline
\end{tabular}




\begin{tabular}{|c|c|c|c|c|}
\hline \\
\hline CHEMBL1988717 & 809280 & 7.6 & 7.9167 & TRN \\
\hline CHEMBL1974328 & 809280 & 5.6 & 5.0286 & TRN \\
\hline CHEMBL509032 & 809280 & 5.3 & 5.2797 & TRN \\
\hline CHEMBL1973808 & 809280 & 4.3 & 4.336 & TRN \\
\hline CHEMBL 2000429 & 809280 & 4.3 & 4.0628 & TRN \\
\hline CHEMBL1972576 & 809280 & 4.3 & 4.5828 & TRN \\
\hline CHEMBL1992555 & 809280 & 4.3 & 5.0385 & TRN \\
\hline CHEMBL1992342 & 809280 & 4.3 & 4.4044 & TRN \\
\hline CHEMBL 2002202 & 809280 & 4.0 & 3.8321 & TRN \\
\hline CHEMBL1988173 & 809280 & 4.3 & 4.4781 & TST \\
\hline CHEMBL1973013 & 809280 & 5.6 & 4.9238 & TST \\
\hline CHEMBL1164265 & 809280 & 6.2 & 5.4673 & TST \\
\hline CHEMBL535331 & 809280 & 4.3 & 4.9115 & TRN \\
\hline CHEMBL1989805 & 809280 & 4.3 & 4.9808 & TST \\
\hline CHEMBL1982980 & 809280 & 4.3 & 4.5997 & TST \\
\hline CHEMBL1965423 & 809280 & 4.3 & 4.1759 & TRN \\
\hline CHEMBL1983025 & 809280 & 6.2 & 7.2106 & TRN \\
\hline CHEMBL1975927 & 809280 & 5.6 & 5.5753 & TRN \\
\hline CHEMBL205415 & 809280 & 4.4 & 4.329 & TRN \\
\hline CHEMBL1977135 & 809280 & 4.3 & 4.1314 & TRN \\
\hline CHEMBL 2001920 & 809280 & 4.3 & 4.3953 & TRN \\
\hline CHEMBL 2002322 & 809280 & 4.3 & 4.0855 & TRN \\
\hline CHEMBL1997119 & 809280 & 4.2 & 4.3502 & TRN \\
\hline CHEMBL1977138 & 809280 & 6.8 & 5.3459 & TST \\
\hline CHEMBL 2002323 & 809280 & 4.3 & 4.2212 & TST \\
\hline CHEMBL1241473 & 809280 & 6.9 & 6.1484 & TRN \\
\hline CHEMBL 2000879 & 809280 & 4.0 & 3.98199 & 99999999998 \\
\hline CHEMBL1978448 & 809280 & 4.4 & 4.4412 & TST \\
\hline CHEMBL1972258 & 809280 & 4.3 & 4.4428 & TRN \\
\hline CHEMBL1980329 & 809280 & 6.2 & 6.6737 & TRN \\
\hline CHEMBL 2004515 & 809280 & 5.5 & 4.6103 & TRN \\
\hline CHEMBL 2001257 & 809280 & 6.1 & 6.3858 & TRN \\
\hline CHEMBL1992042 & 809280 & 4.4 & 5.4897 & TRN \\
\hline CHEMBL 2005548 & 809280 & 4.3 & 4.5301 & TRN \\
\hline CHEMBL1987793 & 809280 & 4.3 & 4.5325 & TST \\
\hline CHEMBL1992536 & 809280 & 4.3 & 4.3175 & TRN \\
\hline CHEMBL 21156 & 809280 & 6.0 & 5.0982 & TST \\
\hline CHEMBL1992740 & 809280 & 4.3 & 4.3902 & TRN \\
\hline CHEMBL1994724 & 809280 & 4.4 & 4.2655 & TRN \\
\hline CHEMBL1989267 & 809280 & 6.0 & 5.42 & TRN \\
\hline CHEMBL 2002373 & 809280 & 4.3 & 4.1145 & TRN \\
\hline CHEMBL439340 & 809280 & 4.3 & 4.4215 & TRN \\
\hline CHEMBL1974574 & 809280 & 4.4 & 4.7271 & TST \\
\hline CHEMBL 2006188 & 809280 & 4.3 & 4.3498 & TRN \\
\hline CHEMBL1970290 & 809280 & 6.3 & 5.7653 & TRN \\
\hline CHEMBL1967531 & 809280 & 5.8 & 5.8246 & TRN \\
\hline CHEMBL1970913 & 809280 & 4.3 & 4.292 & TRN \\
\hline CHEMBL1973893 & 809280 & 4.3 & 4.3047 & TRN \\
\hline
\end{tabular}





\begin{tabular}{|c|c|c|c|c|c|}
\hline \multicolumn{6}{|c|}{ Supplemental Table S2.txt } \\
\hline CHEMBL223460 & 809280 & 4.3 & 4.2835 & TST & \\
\hline CHEMBL1998829 & 809280 & 4.3 & 5.4592 & TRN & \\
\hline CHEMBL50894 & 809280 & 4.4 & 4.2294 & TRN & \\
\hline CHEMBL1995211 & 809280 & 6.1 & 5.6072 & TRN & \\
\hline CHEMBL1988838 & 809280 & 7.0 & 6.3124 & TRN & \\
\hline CHEMBL1981725 & 809280 & 4.3 & 4.5935 & TRN & \\
\hline CHEMBL375284 & 809280 & 4.3 & 4.9261 & TRN & \\
\hline CHEMBL2006299 & 809280 & 4.4 & 4.2201 & TRN & \\
\hline CHEMBL1965169 & 809280 & 4.4 & 4.7356 & TST & \\
\hline CHEMBL1081312 & 809280 & 4.4 & 5.3109 & TRN & \\
\hline CHEMBL1965170 & 809280 & 8.0 & 7.67 & TRN & \\
\hline CHEMBL1982866 & 809280 & 4.3 & 4.3814 & TRN & \\
\hline CHEMBL 2005792 & 809280 & 4.4 & 4.0853 & TRN & \\
\hline CHEMBL1968926 & 809280 & 4.3 & 4.2142 & TRN & \\
\hline CHEMBL1984206 & 809280 & 5.4 & 4.1297 & TRN & \\
\hline CHEMBL462120 & 809280 & 4.3 & 4.6429 & TST & \\
\hline CHEMBL1991577 & 809280 & 4.3 & 4.2772 & TRN & \\
\hline CHEMBL1986503 & 809280 & 4.4 & 4.6071 & TST & \\
\hline CHEMBL1965570 & 809280 & 6.3 & 6.5851 & TRN & \\
\hline CHEMBL 2007592 & 809280 & 4.3 & 4.1786 & TRN & \\
\hline CHEMBL1972355 & 809280 & 5.5 & 5.6875 & TRN & \\
\hline CHEMBL1997892 & 809280 & 8.0 & 6.9788 & TRN & \\
\hline CHEMBL1997193 & 809280 & 5.5 & 5.7212 & TST & \\
\hline CHEMBL210963 & 809280 & 4.3 & 4.2337 & TRN & \\
\hline CHEMBL1964902 & 809280 & 4.4 & 4.3059 & TRN & \\
\hline CHEMBL1082440 & 809280 & 4.3 & 4.6508 & TST & \\
\hline CHEMBL1614705 & 809280 & 4.3 & 4.3715 & TRN & \\
\hline CHEMBL1972362 & 809280 & 4.3 & 4.2405 & TRN & \\
\hline CHEMBL1984633 & 809280 & 4.3 & 4.3655 & TRN & \\
\hline CHEMBL1965845 & 809280 & 4.3 & 4.7859 & TRN & \\
\hline CHEMBL 2007372 & 809280 & 4.3 & 4.2458 & TRN & \\
\hline CHEMBL1983715 & 809280 & 6.3 & 5.306 & TRN & \\
\hline CHEMBL1982167 & 809280 & 4.3 & 4.4712 & TRN & \\
\hline CHEMBL1971017 & 809280 & 4.3 & 4.3075 & TRN & \\
\hline CHEMBL 2006715 & 809280 & 4.3 & 5.077 & TRN & \\
\hline CHEMBL1986597 & 809280 & 4.3 & 4.33899 & 99999999995 & TRN \\
\hline CHEMBL1990482 & 809280 & 4.3 & 4.1815 & TRN & \\
\hline CHEMBL1990904 & 809280 & 4.3 & 4.2893 & TRN & \\
\hline CHEMBL 2000104 & 809280 & 4.3 & 4.376 & TRN & \\
\hline CHEMBL 2005475 & 809280 & 4.3 & 4.7011 & TRN & \\
\hline CHEMBL402846 & 809280 & 5.7 & 6.1199 & TRN & \\
\hline CHEMBL1997349 & 809280 & 4.3 & 5.3054 & TST & \\
\hline CHEMBL183844 & 809280 & 4.3 & 5.7526 & TRN & \\
\hline CHEMBL220057 & 809280 & 6.0 & 5.7573 & TRN & \\
\hline CHEMBL1682545 & 809280 & 4.3 & 4.4258 & TRN & \\
\hline CHEMBL383541 & 809280 & 4.3 & 4.2886 & TRN & \\
\hline CHEMBL 2001224 & 809280 & 4.3 & 4.3322 & TRN & \\
\hline CHEMBL10 & 809280 & 4.4 & 4.3795 & TRN & \\
\hline
\end{tabular}




\begin{tabular}{|c|c|c|c|c|}
\hline & & & nent & al Ta \\
\hline CHEMBL1976732 & 809280 & 4.3 & 4.407 & TRN \\
\hline CHEMBL1969506 & 809280 & 4.3 & 4.5205 & TRN \\
\hline CHEMBL1980763 & 809280 & 5.8 & 5.3541 & TRN \\
\hline CHEMBL1964937 & 809280 & 4.3 & 4.3963 & TRN \\
\hline CHEMBL1980163 & 809280 & 4.3 & 4.0728 & TRN \\
\hline CHEMBL590109 & 809280 & 4.3 & 3.8723 & TST \\
\hline CHEMBL1970879 & 809280 & 4.3 & 4.6709 & TRN \\
\hline CHEMBL1989856 & 809280 & 4.3 & 4.3997 & TST \\
\hline CHEMBL 2005899 & 809280 & 4.3 & 4.3715 & TRN \\
\hline CHEMBL1682552 & 809280 & 4.3 & 4.4202 & TRN \\
\hline CHEMBL 259850 & 809280 & 4.3 & 4.3013 & TRN \\
\hline CHEMBL1972568 & 809280 & 4.3 & 4.5518 & TRN \\
\hline CHEMBL 2007479 & 809280 & 4.4 & 4.2487 & TRN \\
\hline CHEMBL1996155 & 809280 & 4.3 & 4.4129 & TRN \\
\hline CHEMBL229799 & 809280 & 4.3 & 4.5445 & TRN \\
\hline CHEMBL1971223 & 809280 & 4.4 & 4.7659 & TRN \\
\hline CHEMBL105739 & 809280 & 6.3 & 6.3435 & TRN \\
\hline CHEMBL1682359 & 809280 & 4.3 & 4.2277 & TRN \\
\hline CHEMBL1972220 & 809280 & 8.4 & 8.1905 & TRN \\
\hline CHEMBL379300 & 809280 & 4.3 & 4.2935 & TRN \\
\hline CHEMBL 203673 & 809280 & 4.3 & 4.3168 & TRN \\
\hline CHEMBL1973720 & 809280 & 6.1 & 5.0269 & TRN \\
\hline CHEMBL1969523 & 809280 & 4.3 & 4.4953 & TRN \\
\hline CHEMBL1988995 & 809280 & 4.3 & 4.4553 & TRN \\
\hline CHEMBL 207995 & 809280 & 4.3 & 4.3478 & TRN \\
\hline CHEMBL 2001923 & 809280 & 4.4 & 4.3039 & TRN \\
\hline CHEMBL1986781 & 809280 & 4.3 & 4.4187 & TRN \\
\hline CHEMBL526133 & 809280 & 4.3 & 4.317 & TRN \\
\hline CHEMBL 2003514 & 809280 & 4.4 & 4.3706 & TRN \\
\hline CHEMBL1989043 & 809280 & 4.4 & 4.8716 & TRN \\
\hline CHEMBL1979057 & 809280 & 4.3 & 4.3561 & TRN \\
\hline CHEMBL1981045 & 809280 & 4.3 & 4.3676 & TRN \\
\hline CHEMBL387971 & 809280 & 5.5 & 4.6449 & TST \\
\hline CHEMBL1975418 & 809280 & 4.3 & 4.3454 & TRN \\
\hline CHEMBL1992796 & 809280 & 4.3 & 4.537 & TST \\
\hline CHEMBL1164180 & 809280 & 6.7 & 5.8046 & TST \\
\hline CHEMBL 223257 & 809280 & 4.3 & 4.2472 & TST \\
\hline CHEMBL1999428 & 809280 & 4.3 & 4.1211 & TRN \\
\hline CHEMBL1967560 & 809280 & 4.3 & 4.497 & TRN \\
\hline CHEMBL1997611 & 809280 & 4.4 & 4.3616 & TST \\
\hline CHEMBL1516890 & 809280 & 6.1 & 6.2422 & TRN \\
\hline CHEMBL 211378 & 809280 & 4.3 & 5.0087 & TRN \\
\hline CHEMBL1982465 & 809280 & 6.9 & 7.2994 & TRN \\
\hline CHEMBL 2001751 & 809280 & 6.5 & 6.6653 & TRN \\
\hline CHEMBL 2003420 & 809280 & 4.3 & 4.3746 & TRN \\
\hline CHEMBL1984586 & 809280 & 4.3 & 4.5735 & TRN \\
\hline CHEMBL1999774 & 809280 & 4.3 & 4.6007 & TST \\
\hline CHEMBL1972659 & 809280 & 5.4 & 4.4472 & TST \\
\hline
\end{tabular}




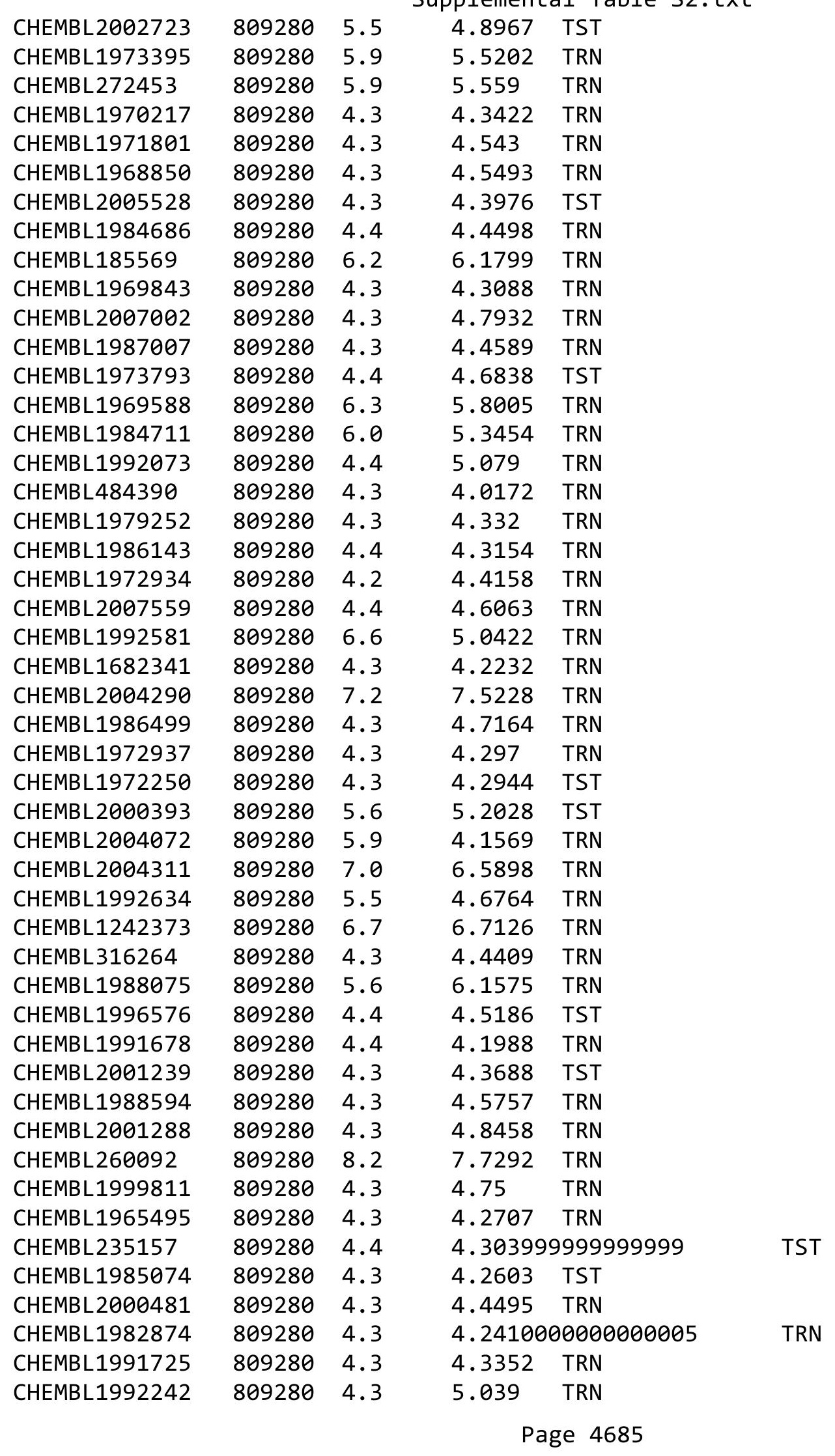




\begin{tabular}{|c|c|c|c|c|c|}
\hline \\
\hline CHEMBL2007296 & 809280 & 4.3 & 4.2704 & TRN & \\
\hline CHEMBL208637 & 809280 & 4.3 & 4.1436 & TRN & \\
\hline CHEMBL396523 & 809280 & 4.3 & 5.4839 & TRN & \\
\hline CHEMBL 2004159 & 809280 & 4.4 & 4.3008 & TRN & \\
\hline CHEMBL1978371 & 809280 & 5.5 & 5.2251 & TST & \\
\hline CHEMBL1970203 & 809280 & 4.3 & 4.6953 & TRN & \\
\hline CHEMBL1986530 & 809280 & 4.3 & 4.12 & TST & \\
\hline CHEMBL440084 & 809280 & 4.4 & 4.3548 & TRN & \\
\hline CHEMBL1999321 & 809280 & 4.3 & 4.5901 & TRN & \\
\hline CHEMBL1968590 & 809280 & 4.3 & 4.9604 & TRN & \\
\hline CHEMBL1999749 & 809280 & 4.3 & 4.3089 & TRN & \\
\hline CHEMBL 2005375 & 809280 & 4.3 & 4.3817 & TRN & \\
\hline CHEMBL1984191 & 809280 & 4.3 & 4.0953 & TRN & \\
\hline CHEMBL1983006 & 809280 & 4.3 & 4.5027 & TRN & \\
\hline CHEMBL1972183 & 809280 & 4.3 & 4.4883 & TRN & \\
\hline CHEMBL1971029 & 809280 & 6.6 & 6.5847 & TRN & \\
\hline CHEMBL394790 & 809280 & 5.7 & 5.4883 & TRN & \\
\hline CHEMBL2001451 & 809280 & 5.5 & 4.7144 & TRN & \\
\hline CHEMBL226471 & 809280 & 4.3 & 4.0274 & TRN & \\
\hline CHEMBL1974702 & 809280 & 4.3 & 4.3542 & TST & \\
\hline CHEMBL1996111 & 809280 & 4.3 & 4.107 & TRN & \\
\hline CHEMBL1966175 & 809280 & 4.4 & 4.724 & TRN & \\
\hline CHEMBL1965589 & 809280 & 4.3 & 4.3759 & TRN & \\
\hline CHEMBL 2007375 & 809280 & 4.4 & 4.3658 & TRN & \\
\hline CHEMBL1998193 & 809280 & 4.3 & 4.1329 & TRN & \\
\hline CHEMBL379975 & 809280 & 4.4 & 4.4343 & TST & \\
\hline CHEMBL474432 & 809280 & 6.1 & 4.7286 & TST & \\
\hline CHEMBL1973016 & 809280 & 4.4 & 4.4557 & TRN & \\
\hline CHEMBL1965387 & 809280 & 4.4 & 5.3236 & TRN & \\
\hline CHEMBL1988153 & 809280 & 4.3 & 4.1856 & TRN & \\
\hline CHEMBL550418 & 809280 & 4.4 & 4.4508 & TRN & \\
\hline CHEMBL1971289 & 809280 & 4.4 & 4.3122 & TRN & \\
\hline CHEMBL1999556 & 809280 & 4.3 & 4.2449 & TRN & \\
\hline CHEMBL1988437 & 809280 & 5.9 & 5.3932 & TST & \\
\hline CHEMBL1968245 & 809280 & 4.3 & 4.1429 & TRN & \\
\hline CHEMBL1979577 & 809280 & 6.8 & 7.1578 & TRN & \\
\hline CHEMBL1998121 & 809280 & 4.3 & 4.664 & TRN & \\
\hline CHEMBL1233887 & 809280 & 4.4 & 4.3953 & TST & \\
\hline CHEMBL1991800 & 809280 & 4.3 & 4.1212 & TRN & \\
\hline CHEMBL52387 & 809280 & 4.3 & 4.6781 & TST & \\
\hline CHEMBL 2003689 & 809280 & 4.4 & 4.44306 & 00000000005 & TRN \\
\hline CHEMBL379835 & 809280 & 4.3 & 4.5465 & TST & \\
\hline CHEMBL1979357 & 809280 & 4.3 & 4.3211 & TRN & \\
\hline CHEMBL1980802 & 809280 & 4.3 & 4.2769 & TST & \\
\hline CHEMBL1996649 & 809280 & 6.7 & 6.6538 & TRN & \\
\hline CHEMBL1996817 & 809280 & 4.6 & 5.5299 & TRN & \\
\hline CHEMBL1979554 & 809280 & 4.3 & 4.3567 & TRN & \\
\hline CHEMBL1986756 & 809280 & 4.4 & 4.4216 & TRN & \\
\hline & & & & 4686 & \\
\hline
\end{tabular}




\begin{tabular}{|c|c|c|c|c|c|}
\hline \multirow[b]{2}{*}{ CHEMBL3197315 } & \multirow[b]{2}{*}{809280} & \multirow[b]{2}{*}{4.3} & \\
\hline & & & 4.9051 & TST & \\
\hline CHEMBL 2004355 & 809280 & 4.3 & 4.266 & TRN & \\
\hline CHEMBL468280 & 809280 & 4.3 & 4.3252 & TST & \\
\hline CHEMBL1990884 & 809280 & 6.3 & 5.4618 & TRN & \\
\hline CHEMBL3109278 & 809280 & 6.0 & 6.4227 & TRN & \\
\hline CHEMBL256835 & 809280 & 4.3 & 4.074 & TRN & \\
\hline CHEMBL1974998 & 809280 & 4.4 & 4.6933 & TRN & \\
\hline CHEMBL1980142 & 809280 & 4.3 & 4.3295 & TRN & \\
\hline CHEMBL41783 & 809280 & 4.3 & 4.3393 & TRN & \\
\hline CHEMBL2004438 & 809280 & 6.5 & 6.228 & TRN & \\
\hline CHEMBL1940137 & 809280 & 5.5 & 4.8193 & TRN & \\
\hline CHEMBL2006276 & 809280 & 4.3 & 4.3132 & TRN & \\
\hline CHEMBL191003 & 809280 & 5.7 & 5.2998 & TRN & \\
\hline CHEMBL271381 & 809280 & 6.4 & 6.7866 & TRN & \\
\hline CHEMBL2006785 & 809280 & 5.4 & 4.3313 & TST & \\
\hline CHEMBL1982466 & 809280 & 7.6 & 7.3185 & TRN & \\
\hline CHEMBL1973359 & 809280 & 4.4 & 5.4428 & TST & \\
\hline CHEMBL1995740 & 809280 & 4.3 & 4.1937 & TRN & \\
\hline CHEMBL1996390 & 809280 & 4.3 & 4.1186 & TRN & \\
\hline CHEMBL1979690 & 809280 & 7.0 & 6.4464 & TRN & \\
\hline CHEMBL234085 & 809280 & 4.4 & 4.4846 & TRN & \\
\hline CHEMBL1998414 & 809280 & 4.3 & 4.8732 & TRN & \\
\hline CHEMBL1995832 & 809280 & 4.3 & 4.0568 & TRN & \\
\hline CHEMBL1969042 & 809280 & 4.3 & 5.1122 & TRN & \\
\hline CHEMBL2000345 & 809280 & 4.3 & 4.3251 & TRN & \\
\hline CHEMBL1999931 & 809280 & 4.3 & 4.7611 & TRN & \\
\hline CHEMBL1976376 & 809280 & 5.7 & 4.3957 & TRN & \\
\hline CHEMBL1991640 & 809280 & 4.3 & 4.4962 & TST & \\
\hline CHEMBL1983575 & 809280 & 6.5 & 5.6984 & TRN & \\
\hline CHEMBL1968868 & 809280 & 4.4 & 4.3152 & TRN & \\
\hline CHEMBL1375418 & 809280 & 4.3 & 4.2872 & TRN & \\
\hline CHEMBL2007064 & 809280 & 6.8 & 6.5113 & TRN & \\
\hline CHEMBL1981047 & 809280 & 6.4 & 6.40799 & 99999999995 & TRN \\
\hline CHEMBL229968 & 809280 & 4.3 & 4.4218 & TRN & \\
\hline CHEMBL1976196 & 809280 & 4.4 & 4.0752 & TST & \\
\hline CHEMBL1976240 & 809280 & 4.3 & 4.2466 & TRN & \\
\hline CHEMBL1997197 & 809280 & 4.4 & 4.2229 & TRN & \\
\hline CHEMBL1983630 & 809280 & 4.0 & 3.8476 & TRN & \\
\hline CHEMBL1979093 & 809280 & 6.2 & 6.15600 & 0000000001 & TRN \\
\hline CHEMBL1968151 & 809280 & 4.3 & 4.2211 & TRN & \\
\hline CHEMBL1381197 & 809280 & 4.3 & 4.1118 & TRN & \\
\hline CHEMBL1973795 & 809280 & 4.6 & 3.7599 & TRN & \\
\hline CHEMBL1987009 & 809280 & 4.3 & 4.4526 & TRN & \\
\hline CHEMBL379218 & 809280 & 4.3 & 4.027 & TRN & \\
\hline CHEMBL2003817 & 809280 & 4.3 & 4.3951 & TRN & \\
\hline CHEMBL336961 & 809280 & 4.3 & 4.1697 & TRN & \\
\hline CHEMBL1994830 & 809280 & 4.3 & 4.3757 & TRN & \\
\hline CHEMBL1987054 & 809280 & 6.8 & 6.5338 & TRN & \\
\hline & & & & 4687 & \\
\hline
\end{tabular}




\begin{tabular}{|c|c|c|c|c|}
\hline & & & pplement & al $\mathrm{Ta}$ \\
\hline CHEMBL1970083 & 809280 & 8.0 & 8.1264 & TRN \\
\hline CHEMBL226403 & 809280 & 4.3 & 4.0679 & TRN \\
\hline CHEMBL2005631 & 809280 & 8.2 & 7.8584 & TRN \\
\hline CHEMBL1994938 & 809280 & 6.4 & 6.4992 & TRN \\
\hline CHEMBL1977223 & 809280 & 4.3 & 4.2128 & TRN \\
\hline CHEMBL1995765 & 809280 & 4.0 & 4.3254 & TST \\
\hline CHEMBL1966279 & 809280 & 4.3 & 4.25 & TRN \\
\hline CHEMBL1236126 & 809280 & 4.3 & 4.5608 & TRN \\
\hline CHEMBL1997846 & 809280 & 4.3 & 4.7881 & TRN \\
\hline CHEMBL1984760 & 809280 & 5.7 & 5.1577 & TRN \\
\hline CHEMBL2004419 & 809280 & 4.3 & 4.2986 & TRN \\
\hline CHEMBL1991728 & 809280 & 4.3 & 4.2947 & TRN \\
\hline CHEMBL 360847 & 809280 & 4.4 & 4.6809 & TST \\
\hline CHEMBL1995811 & 809280 & 4.4 & 4.4645 & TRN \\
\hline CHEMBL1975787 & 809280 & 4.3 & 4.3107 & TRN \\
\hline CHEMBL 2002407 & 809280 & 4.3 & 4.5331 & TRN \\
\hline CHEMBL1972489 & 809280 & 4.3 & 4.4789 & TRN \\
\hline CHEMBL1994074 & 809280 & 4.3 & 4.1998 & TRN \\
\hline CHEMBL1992937 & 809280 & 4.4 & 4.6479 & TST \\
\hline CHEMBL1985566 & 809280 & 4.3 & 4.3864 & TRN \\
\hline CHEMBL1972119 & 809280 & 4.3 & 4.3705 & TRN \\
\hline CHEMBL1986328 & 809280 & 4.3 & 4.4128 & TST \\
\hline CHEMBL95692 & 809280 & 4.3 & 4.0573 & TRN \\
\hline CHEMBL1090356 & 809280 & 4.3 & 4.2769 & TRN \\
\hline CHEMBL 2002450 & 809280 & 4.0 & 3.9969 & TRN \\
\hline CHEMBL1976455 & 809280 & 4.3 & 4.6344 & TRN \\
\hline CHEMBL261849 & 809280 & 6.8 & 5.185 & TST \\
\hline CHEMBL1983923 & 809280 & 6.7 & 6.1873 & TRN \\
\hline CHEMBL1983534 & 809280 & 4.3 & 4.1874 & TRN \\
\hline CHEMBL1982361 & 809280 & 4.3 & 4.2917 & TRN \\
\hline CHEMBL1999112 & 809280 & 4.3 & 4.811 & TST \\
\hline CHEMBL1982122 & 809280 & 4.3 & 4.2057 & TRN \\
\hline CHEMBL 2000801 & 809280 & 4.3 & 4.9206 & TRN \\
\hline CHEMBL1682546 & 809280 & 4.3 & 4.2936 & TRN \\
\hline CHEMBL1991395 & 809280 & 4.3 & 4.0946 & TRN \\
\hline CHEMBL1971245 & 809280 & 4.3 & 4.3345 & TRN \\
\hline CHEMBL1987648 & 809280 & 4.3 & 4.0181 & TRN \\
\hline CHEMBL1996780 & 809280 & 4.3 & 4.4218 & TST \\
\hline CHEMBL1972142 & 809280 & 4.3 & 4.5112 & TRN \\
\hline CHEMBL1966514 & 809280 & 6.8 & 6.7594 & TRN \\
\hline CHEMBL 2003638 & 809280 & 4.3 & 4.8278 & TRN \\
\hline CHEMBL 296586 & 809280 & 4.3 & 4.1244 & TRN \\
\hline CHEMBL1996066 & 809280 & 4.3 & 5.0315 & TRN \\
\hline CHEMBL1983393 & 809280 & 6.1 & 5.1594 & TRN \\
\hline CHEMBL516429 & 809280 & 4.3 & 4.2182 & TRN \\
\hline CHEMBL1993722 & 809280 & 4.3 & 5.4069 & TRN \\
\hline CHEMBL1970806 & 809280 & 4.3 & 4.2543 & TRN \\
\hline CHEMBL 2006674 & 809280 & 4.4 & 4.4849 & TST \\
\hline
\end{tabular}




\begin{tabular}{|c|c|c|c|c|}
\hline & & & plement & \\
\hline CHEMBL1984236 & 809280 & 4.4 & 4.3554 & TST \\
\hline CHEMBL1992371 & 809280 & 4.4 & 5.2426 & TST \\
\hline CHEMBL1375640 & 809280 & 4.3 & 4.063 & TST \\
\hline CHEMBL1979970 & 809280 & 4.3 & 4.2994 & TST \\
\hline CHEMBL 2002599 & 809280 & 4.4 & 4.5803 & TST \\
\hline CHEMBL249282 & 809280 & 4.3 & 4.4148 & TST \\
\hline CHEMBL1967252 & 809280 & 4.1 & 4.3035 & TST \\
\hline CHEMBL 2004637 & 809280 & 6.3 & 5.1556 & TST \\
\hline CHEMBL1993374 & 809280 & 4.4 & 4.6629 & TST \\
\hline CHEMBL1969264 & 809280 & 4.3 & 4.5995 & TST \\
\hline CHEMBL1994318 & 809280 & 5.7 & 4.993 & TST \\
\hline CHEMBL1973711 & 809280 & 4.3 & 4.2683 & TST \\
\hline CHEMBL 2006237 & 809280 & 4.3 & 4.322 & TST \\
\hline CHEMBL1999506 & 809280 & 4.4 & 4.525 & TST \\
\hline CHEMBL1967720 & 809280 & 6.7 & 7.221 & TST \\
\hline CHEMBL1572266 & 809280 & 4.3 & 4.7641 & TST \\
\hline CHEMBL1991138 & 809280 & 4.3 & 4.2776 & TST \\
\hline CHEMBL1969755 & 809280 & 4.3 & 4.3064 & TST \\
\hline CHEMBL1979516 & 809280 & 4.6 & 6.6559 & TST \\
\hline CHEMBL1972820 & 809280 & 4.3 & 4.6581 & TST \\
\hline CHEMBL1605605 & 809280 & 4.4 & 4.2617 & TST \\
\hline CHEMBL1989029 & 809280 & 4.3 & 5.6848 & TST \\
\hline CHEMBL392642 & 809280 & 4.3 & 4.0377 & TST \\
\hline CHEMBL514499 & 809280 & 4.3 & 5.0308 & TST \\
\hline CHEMBL1970352 & 809280 & 4.4 & 4.7784 & TST \\
\hline CHEMBL1965631 & 809280 & 4.3 & 4.2801 & TST \\
\hline CHEMBL1980144 & 809280 & 4.3 & 4.3591 & TST \\
\hline CHEMBL1991188 & 809280 & 4.3 & 4.3321 & TST \\
\hline CHEMBL1980167 & 809280 & 4.4 & 5.9397 & TST \\
\hline CHEMBL1972849 & 809280 & 4.3 & 4.3264 & TST \\
\hline CHEMBL377408 & 809280 & 4.3 & 4.3671 & TST \\
\hline CHEMBL215152 & 809280 & 4.4 & 4.3348 & TST \\
\hline CHEMBL231209 & 809280 & 5.4 & 5.008 & TST \\
\hline CHEMBL1976220 & 809280 & 6.3 & 6.3315 & TST \\
\hline CHEMBL 2006765 & 809280 & 7.4 & 5.9581 & TST \\
\hline CHEMBL259922 & 809280 & 4.3 & 4.7634 & TST \\
\hline CHEMBL1997617 & 809280 & 5.7 & 5.2191 & TST \\
\hline CHEMBL1969301 & 809280 & 4.3 & 4.0309 & TST \\
\hline CHEMBL1982383 & 809280 & 4.3 & 3.8389 & TST \\
\hline CHEMBL17370 & 809280 & 4.3 & 4.4731 & TST \\
\hline CHEMBL1980246 & 809280 & 4.4 & 4.4648 & TST \\
\hline CHEMBL1987910 & 809280 & 5.5 & 4.4653 & TST \\
\hline CHEMBL1983932 & 809280 & 4.3 & 4.1989 & TST \\
\hline CHEMBL1983980 & 809280 & 5.6 & 5.5408 & TST \\
\hline CHEMBL1999484 & 809280 & 5.8 & 4.9041 & TST \\
\hline CHEMBL1966069 & 809280 & 4.3 & 4.3294 & TST \\
\hline CHEMBL1986899 & 809280 & 4.4 & 5.1014 & TST \\
\hline CHEMBL1991285 & 809280 & 4.3 & 4.5965 & TST \\
\hline
\end{tabular}




\begin{tabular}{|c|c|c|c|c|c|}
\hline \\
\hline CHEMBL1997822 & 809280 & 4.3 & 4.8349 & TST & \\
\hline CHEMBL243088 & 809280 & 4.3 & 5.0854 & TST & \\
\hline CHEMBL1984038 & 809280 & 4.4 & 4.3692 & TST & \\
\hline CHEMBL1968606 & 809280 & 5.8 & 4.7961 & TST & \\
\hline CHEMBL1993661 & 809280 & 7.7 & 7.4122 & TST & \\
\hline CHEMBL1974416 & 809280 & 4.3 & 5.4286 & TST & \\
\hline CHEMBL 2004615 & 809280 & 4.3 & 4.2201 & TST & \\
\hline CHEMBL1997872 & 809280 & 4.3 & 4.3314 & TST & \\
\hline CHEMBL1726168 & 737376 & 3.0 & 3.0742 & TRN & \\
\hline CHEMBL1322542 & 737376 & 5.8962 & 6.2423 & TRN & \\
\hline CHEMBL1447397 & 737376 & 5.3645 & 5.1419 & TRN & \\
\hline CHEMBL1305463 & 737376 & 3.0 & 2.9567 & TRN & \\
\hline CHEMBL1699305 & 737376 & 4.51 & 4.4506 & TRN & \\
\hline CHEMBL1711927 & 737376 & 5.0565 & 4.7305 & TRN & \\
\hline CHEMBL1714980 & 737376 & 4.2924 & 3.3128 & TRN & \\
\hline CHEMBL1597485 & 737376 & 4.5622 & 4.7826 & TRN & \\
\hline CHEMBL1720016 & 737376 & 4.1938 & 4.3866 & TRN & \\
\hline CHEMBL1470219 & 737376 & 3.0 & 3.0974 & TRN & \\
\hline CHEMBL1416769 & 737376 & 4.0605 & 3.1115 & TRN & \\
\hline CHEMBL1422255 & 737376 & 3.0 & 3.3669 & TST & \\
\hline CHEMBL1536551 & 737376 & 3.0 & 3.728 & TST & \\
\hline CHEMBL1391676 & 737376 & 3.0 & 3.2978 & TST & \\
\hline CHEMBL1477806 & 737376 & 3.0 & 3.0401 & TST & \\
\hline CHEMBL1723513 & 737376 & 4.1379 & 4.1694 & TRN & \\
\hline CHEMBL1413291 & 737376 & 3.0 & 3.36 & TRN & \\
\hline CHEMBL1408579 & 737376 & 6.3497 & 6.0157 & TRN & \\
\hline CHEMBL1411223 & 737376 & 3.0 & 2.9708 & TRN & \\
\hline CHEMBL1723290 & 737376 & 4.3036 & 4.3366 & TRN & \\
\hline CHEMBL1385949 & 737376 & 6.1791 & 5.9091 & TST & \\
\hline CHEMBL1605172 & 737376 & 6.34200 & 00000000 & 5.8418 & TST \\
\hline CHEMBL1710168 & 737376 & 4.6308 & 4.3439 & TRN & \\
\hline CHEMBL1710618 & 737376 & 3.0 & 3.1353 & TRN & \\
\hline CHEMBL1369492 & 737376 & 5.2226 & 4.5506 & TRN & \\
\hline CHEMBL1304193 & 737376 & 5.9788 & 6.0766 & TST & \\
\hline CHEMBL1461661 & 737376 & 4.2007 & 3.8487 & TRN & \\
\hline CHEMBL1532240 & 737376 & 3.0 & 3.2988 & TRN & \\
\hline CHEMBL1455260 & 737376 & 3.0 & 4.1644 & TST & \\
\hline CHEMBL1733159 & 737376 & 4.4157 & 4.40300 & 00000000005 & TRN \\
\hline CHEMBL1714887 & 737376 & 4.4067 & 4.4126 & TRN & \\
\hline CHEMBL1569076 & 737376 & 4.5544 & 5.3854 & TRN & \\
\hline CHEMBL1452827 & 737376 & 3.0 & 3.1109 & TRN & \\
\hline CHEMBL1704720 & 737376 & 4.71 & 4.7702 & TRN & \\
\hline CHEMBL1704444 & 737376 & 4.7258 & 4.7248 & TRN & \\
\hline CHEMBL1735969 & 737376 & 4.2596 & 4.1952 & TRN & \\
\hline CHEMBL1301020 & 737376 & 3.0 & 4.112 & TST & \\
\hline CHEMBL1478726 & 737376 & 3.0 & 2.8624 & TRN & \\
\hline CHEMBL1712133 & 737376 & 3.0 & 3.4863 & TRN & \\
\hline CHEMBL1457385 & 737376 & 3.0 & 2.9443 & TRN & \\
\hline
\end{tabular}




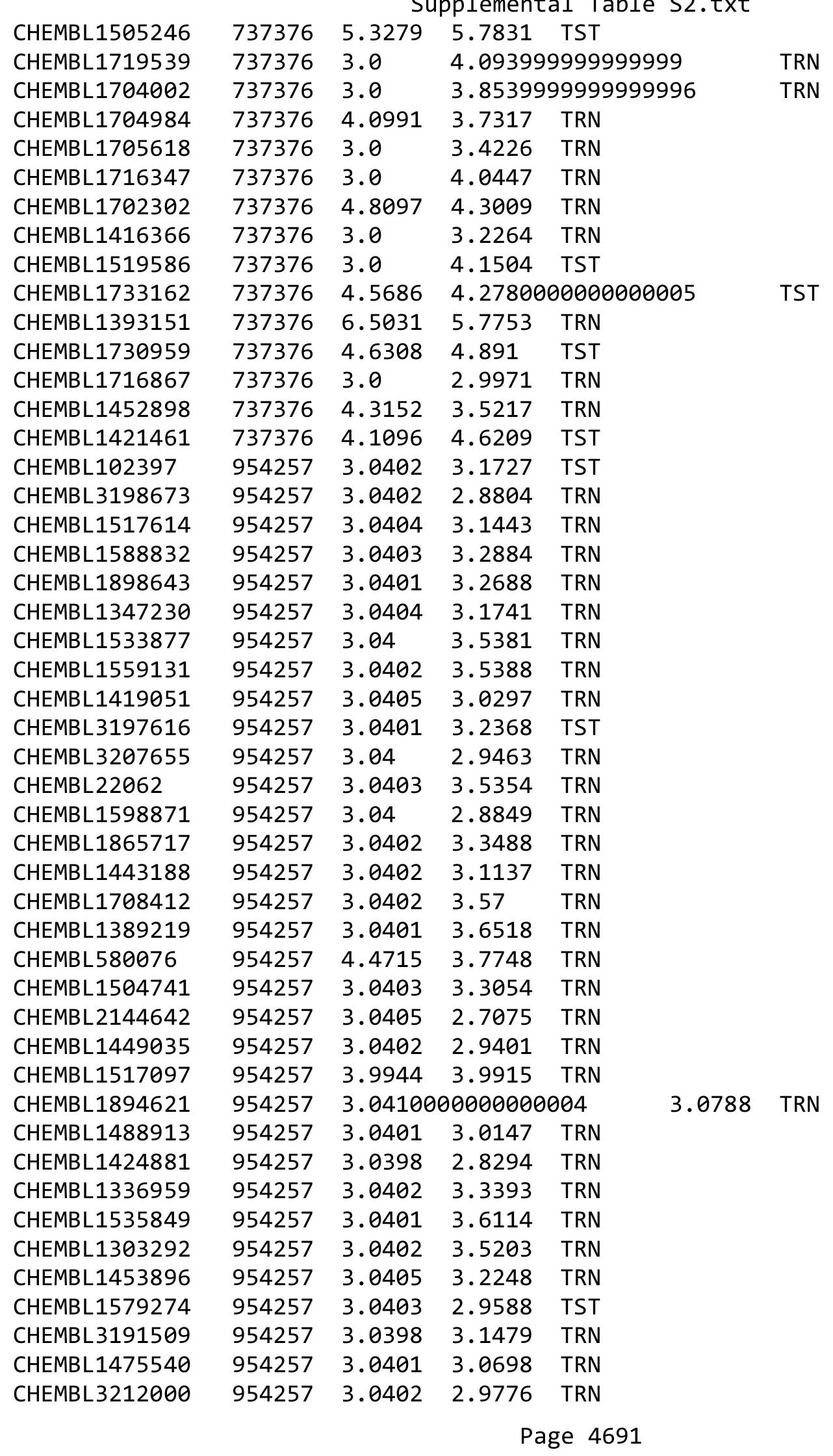




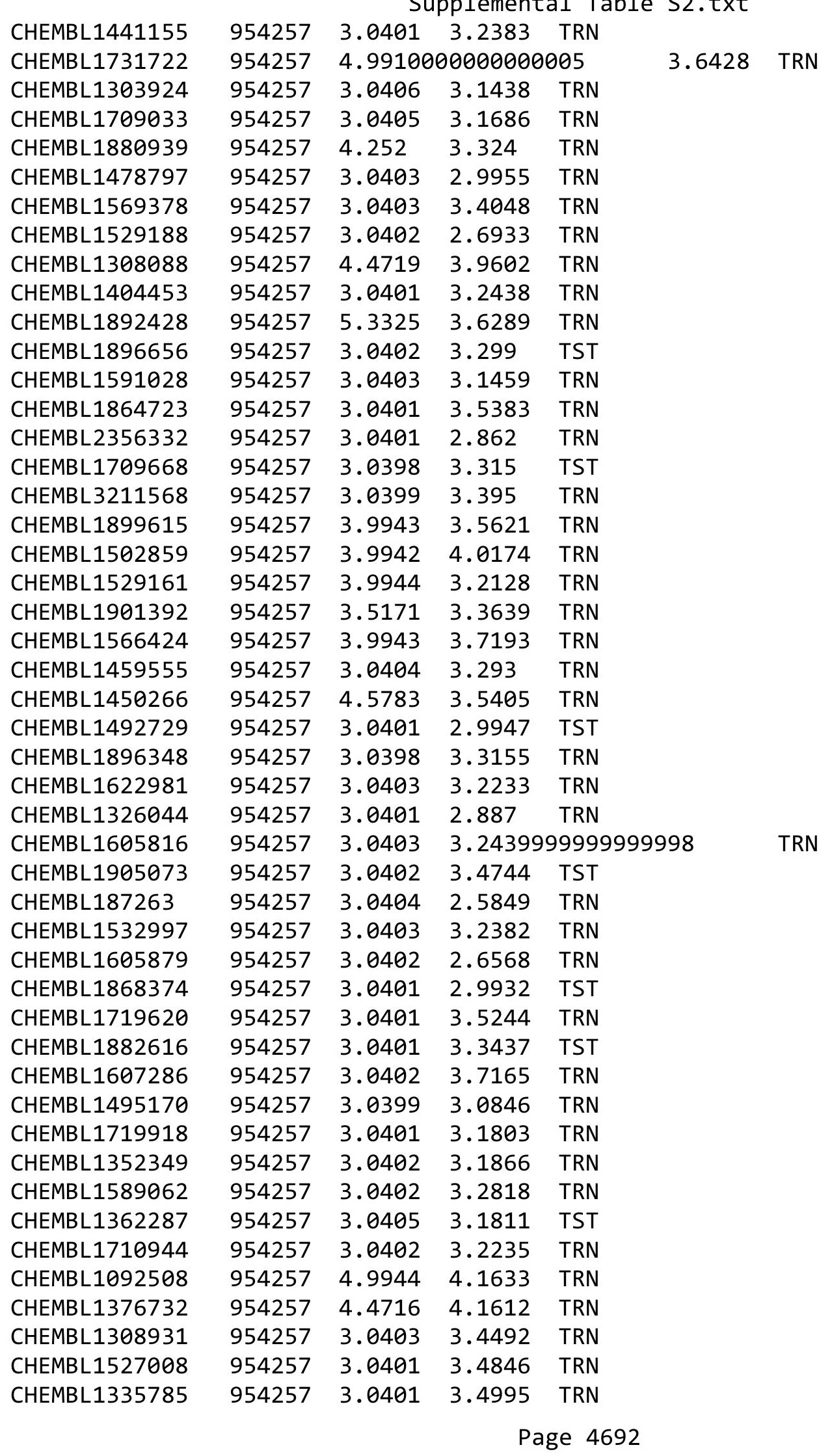




\begin{tabular}{|c|c|c|c|c|c|}
\hline & & & & & \\
\hline CHEMBL583824 & 954257 & 4.4712 & 3.4218 & TRN & \\
\hline CHEMBL1501307 & 954257 & 3.9943 & 3.7124 & TRN & \\
\hline CHEMBL3194755 & 954257 & 3.0399 & 3.3567 & TRN & \\
\hline CHEMBL1559727 & 954257 & 3.0401 & 2.8585 & TRN & \\
\hline CHEMBL1181670 & 954257 & 4.4707 & 3.7627 & TRN & \\
\hline CHEMBL1351842 & 954257 & 3.0403 & 2.85699 & 99999999998 & TRN \\
\hline CHEMBL1310196 & 954257 & 3.0403 & 2.9091 & TRN & \\
\hline CHEMBL2138653 & 954257 & 3.0405 & 2.9725 & TRN & \\
\hline CHEMBL1349151 & 954257 & 5.1221 & 4.0018 & TRN & \\
\hline CHEMBL1579644 & 954257 & 4.4715 & 4.3205 & TRN & \\
\hline CHEMBL1527814 & 954257 & 3.0402 & 2.7728 & TRN & \\
\hline CHEMBL1391082 & 954257 & 3.0404 & 3.3987 & TST & \\
\hline CHEMBL1414490 & 954257 & 3.0404 & 3.1156 & TRN & \\
\hline CHEMBL2354573 & 954257 & 3.0397 & 2.96 & TRN & \\
\hline CHEMBL1509181 & 954257 & 3.0406 & 3.3353 & TRN & \\
\hline CHEMBL1348864 & 954257 & 3.04 & 3.5635 & TRN & \\
\hline CHEMBL1493226 & 954257 & 3.0402 & 3.5718 & TRN & \\
\hline CHEMBL19954 & 954257 & 4.471 & 3.4604 & TRN & \\
\hline CHEMBL1530766 & 954257 & 3.0404 & 2.64 & TRN & \\
\hline CHEMBL1438592 & 954257 & 3.0401 & 3.3124 & TRN & \\
\hline CHEMBL1550035 & 954257 & 3.0398 & 3.5009 & TRN & \\
\hline CHEMBL1409273 & 954257 & 3.0403 & 2.7429 & TRN & \\
\hline CHEMBL1487460 & 954257 & 3.9944 & 3.675 & TRN & \\
\hline CHEMBL577752 & 954257 & 3.0402 & 2.8895 & TRN & \\
\hline CHEMBL60662 & 954257 & 3.0395 & 3.2688 & TST & \\
\hline CHEMBL1307737 & 954257 & 3.0402 & 3.1749 & TRN & \\
\hline CHEMBL1428054 & 954257 & 3.0403 & 3.326 & TRN & \\
\hline CHEMBL1418134 & 954257 & 3.99399 & 99999999 & 3.352 & TST \\
\hline CHEMBL1582817 & 954257 & 3.0399 & 2.7107 & TRN & \\
\hline CHEMBL589469 & 954257 & 3.0402 & 3.247 & TRN & \\
\hline CHEMBL1899240 & 954257 & 3.0399 & 2.7957 & TRN & \\
\hline CHEMBL1334011 & 954257 & 3.0402 & 3.3381 & TRN & \\
\hline CHEMBL3145108 & 954257 & 3.0401 & 3.3391 & TRN & \\
\hline CHEMBL1515647 & 954257 & 3.0398 & 3.0731 & TRN & \\
\hline CHEMBL1712646 & 954257 & 4.9629 & 4.2517 & TRN & \\
\hline CHEMBL1339547 & 954257 & 3.0401 & 2.7662 & TRN & \\
\hline CHEMBL1404894 & 954257 & 3.04 & 3.448 & TRN & \\
\hline CHEMBL401149 & 954257 & 3.04 & 3.2362 & TST & \\
\hline CHEMBL1310024 & 954257 & 3.0403 & 3.1968 & TRN & \\
\hline CHEMBL1405838 & 954257 & 3.0402 & 3.1069 & TRN & \\
\hline CHEMBL1466616 & 954257 & 3.0403 & 3.2862 & TRN & \\
\hline CHEMBL1324790 & 954257 & 3.0404 & 2.8808 & TRN & \\
\hline CHEMBL1371531 & 954257 & 3.0401 & 3.5546 & TRN & \\
\hline CHEMBL1896726 & 954257 & 5.2311 & 3.74399 & 99999999998 & TRN \\
\hline CHEMBL233896 & 954257 & 3.9945 & 3.9558 & TRN & \\
\hline CHEMBL1565009 & 954257 & 3.0402 & 2.9343 & TRN & \\
\hline CHEMBL1487849 & 954257 & 3.0402 & 3.2658 & TRN & \\
\hline CHEMBL600008 & 954257 & 3.0405 & 3.4784 & TRN & \\
\hline
\end{tabular}




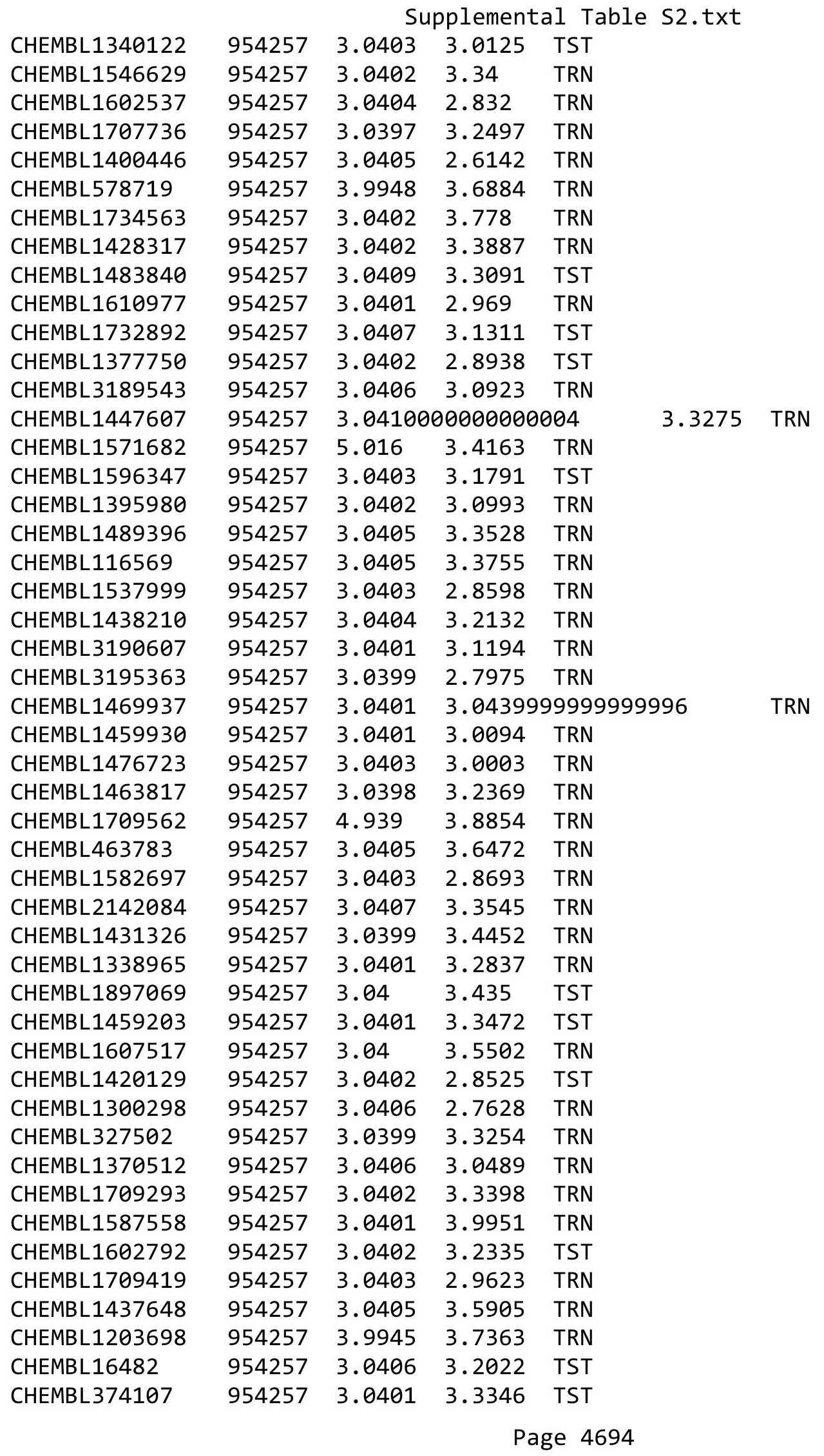




\begin{tabular}{|c|c|c|c|c|c|}
\hline & & \multicolumn{4}{|c|}{ Supplemental Table s2.txt } \\
\hline CHEMBL1508610 & 954257 & 3.0401 & 3.0715 & TRN & \\
\hline CHEMBL1329388 & 954257 & 4.4304 & 4.1415 & TRN & \\
\hline CHEMBL1730820 & 954257 & 3.0398 & 3.2537 & TST & \\
\hline CHEMBL1363844 & 954257 & 3.0402 & 3.2663 & TST & \\
\hline CHEMBL1710047 & 954257 & 3.0399 & 3.4691 & TRN & \\
\hline CHEMBL1400686 & 954257 & 3.04 & 3.2603 & TST & \\
\hline CHEMBL1301481 & 954257 & 3.0401 & 3.3077 & TRN & \\
\hline CHEMBL1562170 & 954257 & 3.0403 & 3.5147 & TRN & \\
\hline CHEMBL1733469 & 954257 & 3.0401 & 3.1697 & TRN & \\
\hline CHEMBL1901251 & 954257 & 3.0401 & 3.3821 & TST & \\
\hline CHEMBL 2362097 & 954257 & 3.0399 & 3.2747 & TRN & \\
\hline CHEMBL1417823 & 954257 & 4.5963 & 4.2947 & TRN & \\
\hline CHEMBL35228 & 954257 & 4.4715 & 3.7231 & TRN & \\
\hline CHEMBL1491894 & 954257 & 3.0402 & 3.2081 & TRN & \\
\hline CHEMBL1610676 & 954257 & 3.0398 & 2.8828 & TRN & \\
\hline CHEMBL1594753 & 954257 & 3.0402 & 3.3341 & TRN & \\
\hline CHEMBL1434250 & 954257 & 3.0403 & 2.8635 & TRN & \\
\hline CHEMBL1382621 & 954257 & 3.0402 & 3.6454 & TRN & \\
\hline CHEMBL1491617 & 954257 & 3.0402 & 3.4114 & TRN & \\
\hline CHEMBL1490332 & 954257 & 3.0402 & 3.9086 & TST & \\
\hline CHEMBL1902074 & 954257 & 3.0395 & 2.8969 & TST & \\
\hline CHEMBL1382693 & 954257 & 4.4314 & 3.7219 & TST & \\
\hline CHEMBL602400 & 954257 & 3.0401 & 3.8404 & TST & \\
\hline CHEMBL451208 & 954257 & 3.0399 & 3.2205 & TST & \\
\hline CHEMBL1399191 & 954257 & 3.0402 & 3.088 & TST & \\
\hline CHEMBL1732657 & 954257 & 4.6886 & 3.8089 & TST & \\
\hline CHEMBL1500773 & 954257 & 3.0402 & 3.8725 & TST & \\
\hline CHEMBL1320709 & 954257 & 3.0403 & 3.2629 & TST & \\
\hline CHEMBL533082 & 954257 & 4.9533 & 4.0706 & TST & \\
\hline CHEMBL592316 & 954257 & 4.9444 & 3.4869 & TST & \\
\hline CHEMBL1557957 & 954257 & 3.0401 & 2.88100 & 00000000002 & TST \\
\hline CHEMBL1573309 & 954257 & 4.4716 & 3.9176 & TST & \\
\hline CHEMBL1500013 & 954257 & 3.0401 & 3.4363 & TST & \\
\hline CHEMBL1322056 & 954257 & 3.0406 & 3.1268 & TST & \\
\hline CHEMBL1888857 & 954257 & 3.9942 & 3.5645 & TST & \\
\hline CHEMBL 2304051 & 954257 & 3.0397 & 3.1568 & TST & \\
\hline CHEMBL1556655 & 954257 & 4.4887 & 3.9918 & TST & \\
\hline CHEMBL1883840 & 954257 & 3.0402 & 2.9717 & TST & \\
\hline CHEMBL1585003 & 954257 & 3.0399 & 2.9762 & TST & \\
\hline CHEMBL129795 & 954257 & 3.0403 & 3.0271 & TST & \\
\hline CHEMBL1427555 & 954257 & 3.0403 & 3.5322 & TST & \\
\hline CHEMBL1578657 & 954257 & 4.9668 & 3.4303 & TST & \\
\hline CHEMBL3191149 & 954257 & 3.0402 & 3.5836 & TST & \\
\hline CHEMBL1710798 & 954257 & 3.0401 & 2.9312 & TST & \\
\hline CHEMBL1508072 & 954257 & 3.0401 & 3.5884 & TST & \\
\hline CHEMBL1305054 & 954257 & 3.0402 & 3.3203 & TST & \\
\hline CHEMBL1499823 & 752577 & 4.3295 & 4.1338 & TRN & \\
\hline CHEMBL535331 & 752577 & 4.3974 & 4.1998 & TRN & \\
\hline
\end{tabular}




\begin{tabular}{|c|c|c|c|c|c|c|}
\hline & & \multicolumn{5}{|c|}{ Supplemental Table S2.txt } \\
\hline CHEMBL1338720 & 752577 & 3.6714 & 3.7879 & TRN & & \\
\hline CHEMBL1383081 & 752577 & 4.4 & 3.9027 & TRN & & \\
\hline CHEMBL1375414 & 752577 & 4.2692 & 3.8879 & TRN & & \\
\hline CHEMBL1492137 & 752577 & 4.2596 & 3.7786 & TRN & & \\
\hline CHEMBL1342364 & 752577 & 4.0991 & 3.7309 & TRN & & \\
\hline CHEMBL1537846 & 752577 & 4.5009 & 4.13399 & 9999999999 & 95 & TRN \\
\hline CHEMBL1334656 & 752577 & 4.2578 & 4.0019 & TRN & & \\
\hline CHEMBL1606790 & 752577 & 3.7884 & 3.958 & TRN & & \\
\hline CHEMBL1390388 & 752577 & 4.0011 & 3.8027 & TRN & & \\
\hline CHEMBL1399377 & 752577 & 4.3422 & 4.0432 & TRN & & \\
\hline CHEMBL1716586 & 752577 & 2.4559 & 4.211 & TRN & & \\
\hline CHEMBL1343239 & 752577 & \multicolumn{3}{|c|}{3.7239999999999998} & 4.1004 & TRN \\
\hline CHEMBL1444483 & 752577 & 4.1421 & 3.8347 & TST & & \\
\hline CHEMBL1535487 & 752577 & 4.3782 & 3.8524 & TRN & & \\
\hline CHEMBL1472437 & 752577 & 4.1742 & 3.659 & TRN & & \\
\hline CHEMBL1404461 & 752577 & 4.2554 & 4.0856 & TRN & & \\
\hline CHEMBL3208540 & 752577 & 4.3302 & 4.0827 & TRN & & \\
\hline CHEMBL1495561 & 752577 & 4.2879 & 3.7843 & TRN & & \\
\hline CHEMBL1458670 & 752577 & 4.1925 & 4.2177 & TRN & & \\
\hline CHEMBL587449 & 752577 & 2.4559 & 3.6768 & TRN & & \\
\hline CHEMBL1410552 & 752577 & 4.0991 & 4.0472 & TRN & & \\
\hline CHEMBL1521754 & 752577 & 3.5217 & 3.8483 & TRN & & \\
\hline CHEMBL1484233 & 752577 & 2.4559 & 3.8918 & TRN & & \\
\hline CHEMBL 3212032 & 752577 & 4.1232 & 4.0212 & TST & & \\
\hline CHEMBL1517433 & 752577 & \multicolumn{3}{|c|}{3.8680000000000003} & 3.6894 & TRN \\
\hline CHEMBL1529019 & 752577 & 4.4354 & 4.1082 & TRN & & \\
\hline CHEMBL1598005 & 752577 & 2.4559 & 4.05399 & 9999999999 & & TRN \\
\hline CHEMBL1525953 & 752577 & 4.0085 & 4.2829 & TRN & & \\
\hline CHEMBL1355537 & 752577 & 4.4432 & 4.3131 & TRN & & \\
\hline CHEMBL1611123 & 752577 & 4.319 & 3.9007 & TRN & & \\
\hline CHEMBL1302618 & 752577 & 4.1656 & 4.0883 & TRN & & \\
\hline CHEMBL1597933 & 752577 & 4.1713 & 3.9869 & TRN & & \\
\hline CHEMBL1479595 & 752577 & 4.0096 & 4.1647 & TRN & & \\
\hline CHEMBL 3197310 & 752577 & 3.8986 & 3.8624 & TRN & & \\
\hline CHEMBL1361693 & 752577 & 4.1365 & 4.1506 & TRN & & \\
\hline CHEMBL1351022 & 752577 & 4.3618 & 4.0752 & TRN & & \\
\hline CHEMBL1601433 & 752577 & 4.2391 & 3.8593 & TRN & & \\
\hline CHEMBL1412627 & 752577 & 4.3035 & 3.6624 & TRN & & \\
\hline CHEMBL1439772 & 752577 & 4.1614 & 3.8508 & TRN & & \\
\hline CHEMBL1456251 & 752577 & 4.3317 & 4.0428 & TRN & & \\
\hline CHEMBL1610982 & 752577 & 3.9584 & 4.0653 & TRN & & \\
\hline CHEMBL1361424 & 752577 & 4.2597 & 3.858 & TRN & & \\
\hline CHEMBL3210095 & 752577 & 3.4665 & 3.9266 & TST & & \\
\hline CHEMBL1479417 & 752577 & 4.1751 & 3.7554 & TRN & & \\
\hline CHEMBL97407 & 752577 & 4.2641 & 4.1741 & TRN & & \\
\hline CHEMBL1349408 & 752577 & 4.3289 & 4.1473 & TST & & \\
\hline CHEMBL1492507 & 752577 & 3.8043 & 3.7203 & TST & & \\
\hline CHEMBL1350251 & 752577 & 2.4559 & 3.9564 & TRN & & \\
\hline
\end{tabular}




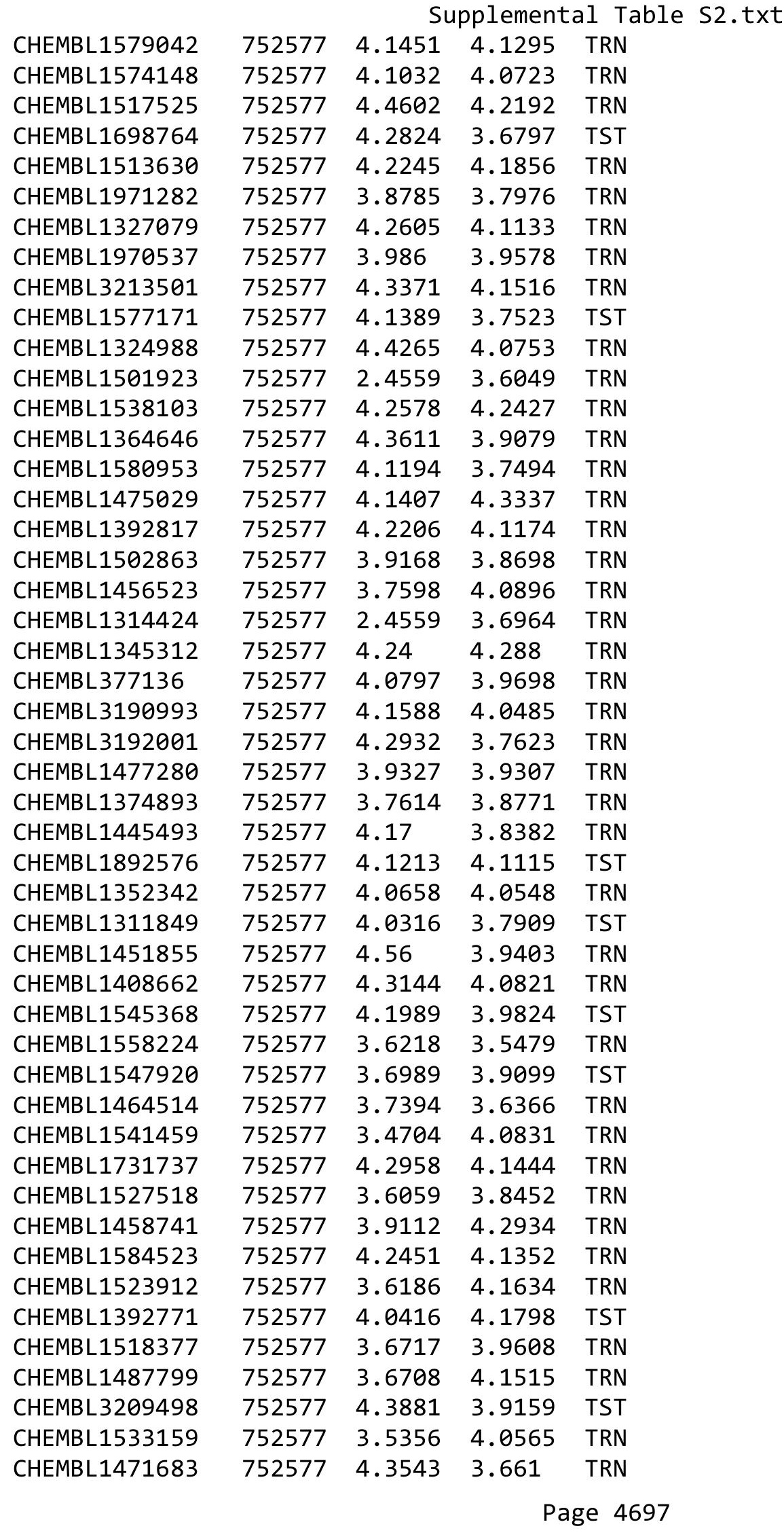


Supplemental Table S2.txt

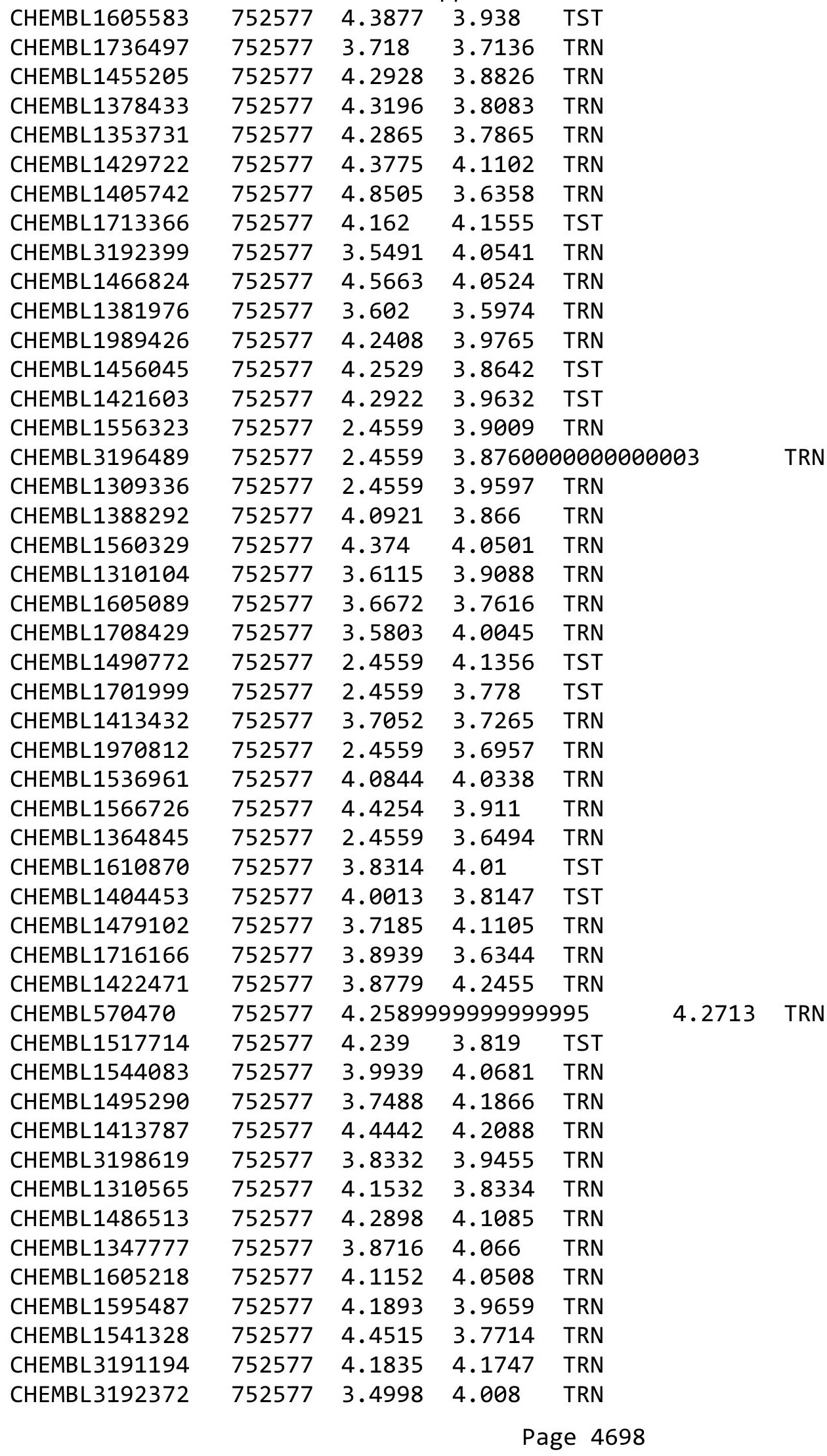


Supplemental Table S2.txt

\begin{tabular}{|c|c|c|c|c|c|}
\hline CHEMBL1307538 & 752577 & 4.3065 & 4.0735 & TRN & \\
\hline CHEMBL1404056 & 752577 & 4.2104 & 4.0318 & TRN & \\
\hline CHEMBL1538435 & 752577 & 3.8363 & 3.6613 & TST & \\
\hline CHEMBL1450953 & 752577 & 4.0764 & 3.9115 & TRN & \\
\hline CHEMBL1558046 & 752577 & 4.28 & 3.8673 & TRN & \\
\hline CHEMBL1606690 & 752577 & 4.1084 & 4.0629 & TRN & \\
\hline CHEMBL1553168 & 752577 & 2.4559 & 3.718 & TRN & \\
\hline CHEMBL1568104 & 752577 & 4.3246 & 3.7336 & TRN & \\
\hline CHEMBL1445639 & 752577 & 3.7158 & 4.075 & TRN & \\
\hline CHEMBL1376505 & 752577 & 4.2028 & 3.9336 & TRN & \\
\hline CHEMBL1734750 & 752577 & 4.5531 & 3.9121 & TRN & \\
\hline CHEMBL1543734 & 752577 & 4.4452 & 4.1413 & TST & \\
\hline CHEMBL1431742 & 752577 & 4.3642 & 3.8487 & TRN & \\
\hline CHEMBL1421615 & 752577 & 3.9833 & 3.5835 & TRN & \\
\hline CHEMBL1342873 & 752577 & 4.2091 & 3.9168 & TRN & \\
\hline CHEMBL1431995 & 752577 & 4.3758 & 3.7045 & TRN & \\
\hline CHEMBL1984639 & 752577 & 4.3868 & 3.9896 & TRN & \\
\hline CHEMBL1590338 & 752577 & 2.4559 & 3.6916 & TRN & \\
\hline CHEMBL1377820 & 752577 & 3.9397 & 3.9528 & TRN & \\
\hline CHEMBL1389445 & 752577 & 3.6214 & 3.8729 & TRN & \\
\hline CHEMBL1599674 & 752577 & 4.7278 & 4.0736 & TST & \\
\hline CHEMBL1502706 & 752577 & 4.2858 & 4.0104 & TRN & \\
\hline CHEMBL1516000 & 752577 & 4.2037 & 3.7897 & TST & \\
\hline CHEMBL3192514 & 752577 & 4.3496 & 4.1781 & TRN & \\
\hline CHEMBL1363543 & 752577 & 2.4559 & 3.8585 & TRN & \\
\hline CHEMBL577121 & 752577 & 4.3008 & 3.8472 & TRN & \\
\hline CHEMBL1409241 & 752577 & 4.3267 & 3.9587 & TRN & \\
\hline CHEMBL1472062 & 752577 & 4.3923 & 4.1947 & TRN & \\
\hline CHEMBL1313741 & 752577 & 2.4559 & 3.7076 & TRN & \\
\hline CHEMBL1588246 & 752577 & 4.1953 & 3.9467 & TST & \\
\hline CHEMBL1701289 & 752577 & 4.3707 & 4.1659 & TST & \\
\hline CHEMBL1331338 & 752577 & 4.2264 & 3.9098 & TRN & \\
\hline CHEMBL1700430 & 752577 & 4.0089 & 3.798 & TRN & \\
\hline CHEMBL1341232 & 752577 & 4.47 & 4.1823 & TRN & \\
\hline CHEMBL1566148 & 752577 & 3.5225 & 4.0432 & TST & \\
\hline CHEMBL1367394 & 752577 & 3.4929 & 3.5233 & TRN & \\
\hline CHEMBL1349795 & 752577 & 3.6649 & 3.9916 & TRN & \\
\hline CHEMBL3214164 & 752577 & 4.0864 & 3.981999 & 99999999998 & I R KN \\
\hline CHEMBL1435688 & 752577 & 4.3979 & 4.0017 & TRN & \\
\hline CHEMBL1478972 & 752577 & 2.4559 & 3.7845 & TRN & \\
\hline CHEMBL1571896 & 752577 & 3.6385 & 3.6833 & TRN & \\
\hline CHEMBL1346269 & 752577 & 4.0039 & 3.609 & TST & \\
\hline CHEMBL1322056 & 752577 & 4.1192 & 4.0075 & TST & \\
\hline CHEMBL1345313 & 752577 & 3.9885 & 3.917 & TRN & \\
\hline CHEMBL1461193 & 752577 & 4.2348 & 4.042 & TRN & \\
\hline CHEMBL1568818 & 752577 & \multicolumn{4}{|c|}{3.5980000000000003} \\
\hline CHEMBL1484821 & 752577 & 4.3185 & 4.0924 & TRN & \\
\hline CHEMBL1320798 & 752577 & 4.495 & 4.022 & TRN & \\
\hline
\end{tabular}




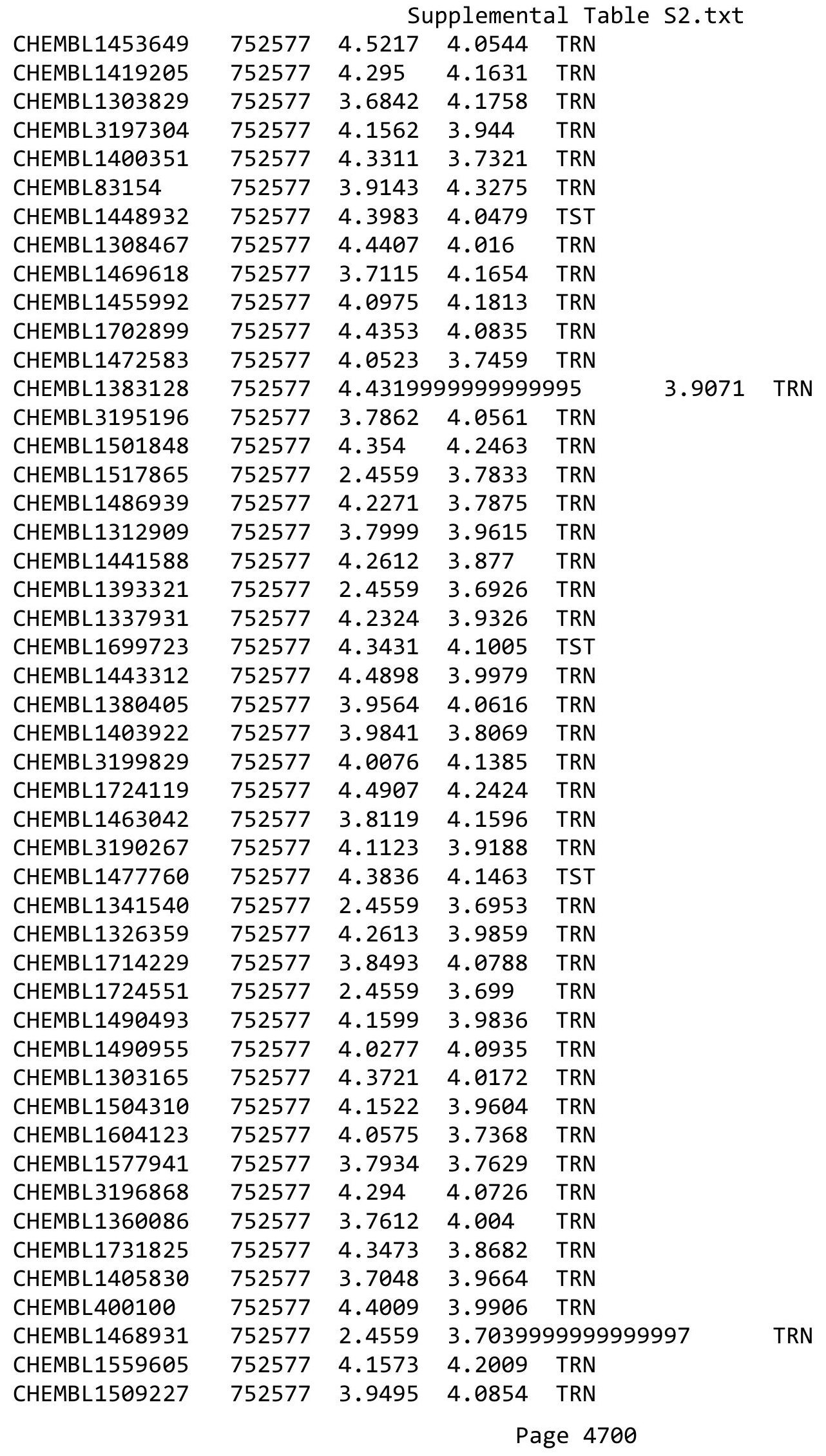




\begin{tabular}{|c|c|c|c|c|c|c|}
\hline & & \multicolumn{5}{|c|}{ Supplemental Table S2.txt } \\
\hline CHEMBL1362810 & 752577 & 3.6865 & 4.0429 & TRN & & \\
\hline CHEMBL3211514 & 752577 & 4.3833 & 3.9595 & TST & & \\
\hline CHEMBL1494477 & 752577 & 4.2695 & 3.665 & TRN & & \\
\hline CHEMBL1383801 & 752577 & 2.4559 & 3.824 & TRN & & \\
\hline CHEMBL1344291 & 752577 & 4.0714 & 3.8841 & TRN & & \\
\hline CHEMBL1511172 & 752577 & 4.1249 & 4.0549 & TRN & & \\
\hline CHEMBL1568184 & 752577 & 4.3035 & 3.8079 & TRN & & \\
\hline CHEMBL 3196840 & 752577 & 4.3802 & 3.9991 & TRN & & \\
\hline CHEMBL1488337 & 752577 & 4.0089 & 4.0928 & TRN & & \\
\hline CHEMBL292785 & 752577 & 2.4559 & 3.7539 & TRN & & \\
\hline CHEMBL1300116 & 752577 & 4.2766 & 3.8484 & TST & & \\
\hline CHEMBL1372155 & 752577 & \multicolumn{3}{|c|}{4.1339999999999995} & 3.8358 & TRN \\
\hline CHEMBL1408078 & 752577 & 3.6873 & 3.7815 & TRN & & \\
\hline CHEMBL1431091 & 752577 & 4.1369 & 3.9726 & TRN & & \\
\hline CHEMBL1303845 & 752577 & \multicolumn{3}{|c|}{3.9560000000000004} & 3.998 & TRN \\
\hline CHEMBL1362340 & 752577 & 3.9473 & 3.6835 & TRN & & \\
\hline CHEMBL1727807 & 752577 & 4.1182 & 3.7221 & TST & & \\
\hline CHEMBL1453029 & 752577 & 3.7188 & 3.9536 & TRN & & \\
\hline CHEMBL1444772 & 752577 & 4.3807 & 3.7774 & TRN & & \\
\hline CHEMBL164841 & 752577 & 4.3357 & 4.1332 & TRN & & \\
\hline CHEMBL1362662 & 752577 & 4.3525 & 3.8914 & TRN & & \\
\hline CHEMBL3195856 & 752577 & 4.0444 & 4.1535 & TRN & & \\
\hline CHEMBL1546781 & 752577 & 4.2776 & 3.7034 & TRN & & \\
\hline CHEMBL1487914 & 752577 & 3.5854 & 3.7451 & TRN & & \\
\hline CHEMBL1613216 & 752577 & 3.7915 & 3.9578 & TRN & & \\
\hline CHEMBL1571627 & 752577 & 2.4559 & 3.8398 & TRN & & \\
\hline CHEMBL1376118 & 752577 & 4.3428 & 4.1865 & TRN & & \\
\hline CHEMBL1342890 & 752577 & 4.249 & 3.995 & TRN & & \\
\hline CHEMBL1486711 & 752577 & 3.9676 & \multicolumn{3}{|c|}{4.093999999999999} & TRN \\
\hline CHEMBL1333282 & 752577 & 4.2994 & 3.5851 & TRN & & \\
\hline CHEMBL1591303 & 752577 & 4.1593 & 3.7728 & TRN & & \\
\hline CHEMBL1464734 & 752577 & 3.9539 & 3.8591 & TRN & & \\
\hline CHEMBL1527484 & 752577 & 4.4994 & 4.0731 & TST & & \\
\hline CHEMBL1493705 & 752577 & 3.8458 & 4.1788 & TRN & & \\
\hline CHEMBL1564416 & 752577 & 3.6562 & \multicolumn{3}{|c|}{3.8939999999999997} & TRN \\
\hline CHEMBL1431405 & 752577 & 4.2493 & 4.2307 & TRN & & \\
\hline CHEMBL1469986 & 752577 & 4.2948 & 3.6974 & TRN & & \\
\hline CHEMBL1472422 & 752577 & 3.6623 & 3.7622 & TRN & & \\
\hline CHEMBL1538167 & 752577 & 4.166 & 3.8084 & TRN & & \\
\hline CHEMBL1359308 & 752577 & 4.0009 & 3.7267 & TRN & & \\
\hline CHEMBL1420181 & 752577 & 4.1336 & 4.2546 & TRN & & \\
\hline CHEMBL1546895 & 752577 & 4.0108 & 3.7988 & TRN & & \\
\hline CHEMBL1520048 & 752577 & 4.0917 & 4.1227 & TRN & & \\
\hline CHEMBL1446408 & 752577 & 2.4559 & 3.8339 & TRN & & \\
\hline CHEMBL1545961 & 752577 & 3.6189 & 3.8826 & TRN & & \\
\hline CHEMBL 3190217 & 752577 & 3.7925 & 3.96100 & 00000 & 0003 & TRN \\
\hline CHEMBL1513162 & 752577 & 4.1134 & 3.9046 & TRN & & \\
\hline CHEMBL1701251 & 752577 & 4.1026 & 4.2946 & TRN & & \\
\hline
\end{tabular}




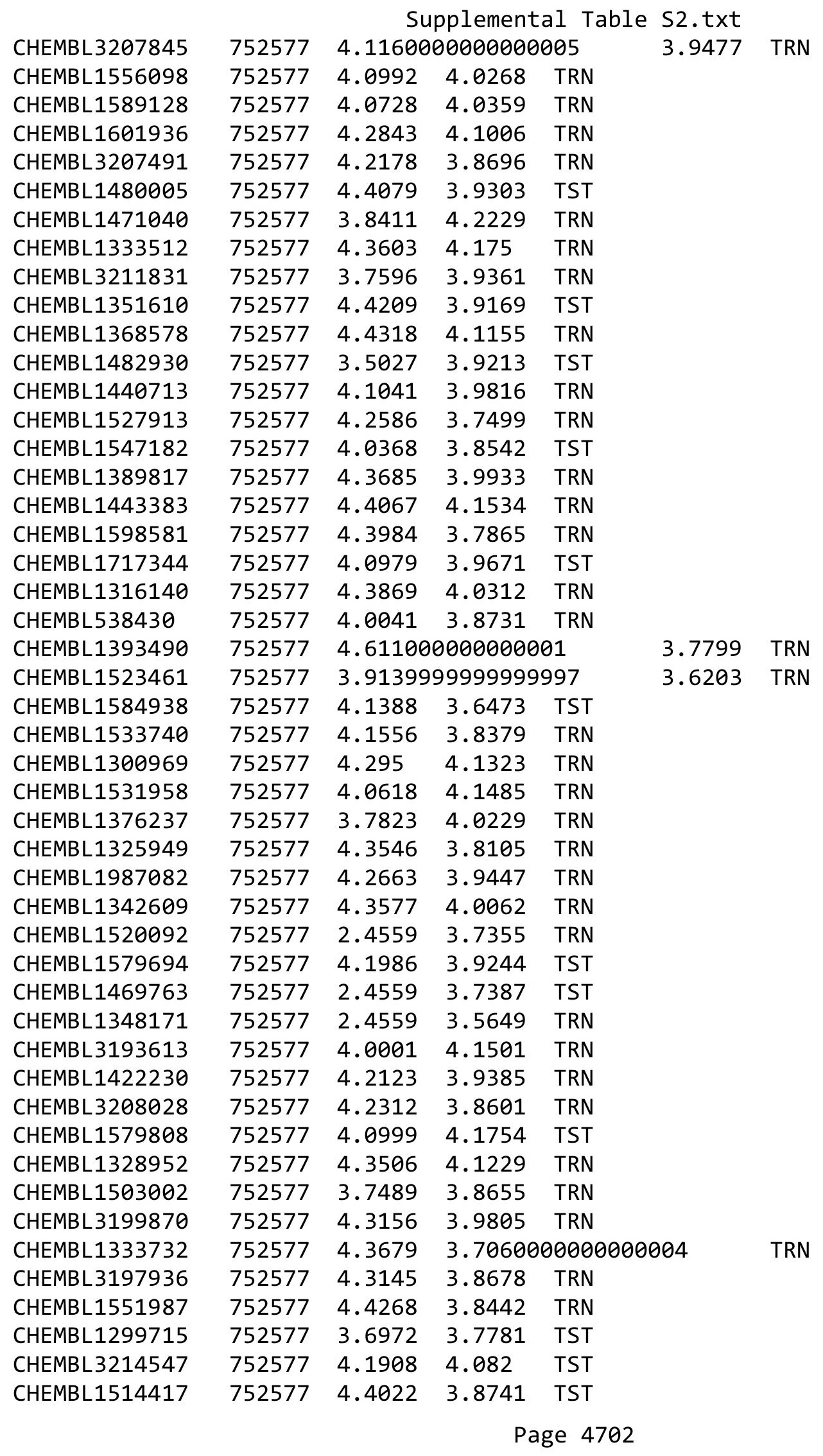


Supplemental Table S2.txt

\begin{tabular}{|c|c|c|c|c|}
\hline CHEMBL3192445 & 752577 & 3.557 & 3.9665 & TST \\
\hline CHEMBL3192231 & 752577 & 4.3901 & 4.0426 & TST \\
\hline CHEMBL1601176 & 752577 & 3.5415 & 3.975 & TST \\
\hline CHEMBL1607129 & 752577 & 2.4559 & 4.1887 & TST \\
\hline CHEMBL1391321 & 752577 & 4.3248 & 3.7772 & TST \\
\hline CHEMBL1305810 & 752577 & 4.0683 & 4.1748 & TST \\
\hline CHEMBL1445116 & 752577 & 4.2846 & 3.8045 & TST \\
\hline CHEMBL1387463 & 752577 & 4.2568 & 3.9886 & TST \\
\hline CHEMBL1321156 & 752577 & 4.1308 & 4.1357 & TST \\
\hline CHEMBL1565578 & 752577 & 2.4559 & 4.3029 & TST \\
\hline CHEMBL1469897 & 752577 & 2.4559 & 3.8642 & TST \\
\hline CHEMBL1449685 & 752577 & 3.534 & 4.1723 & TST \\
\hline CHEMBL1347188 & 752577 & 4.4282 & 4.1475 & TST \\
\hline CHEMBL1402587 & 752577 & 4.2611 & 3.755 & TST \\
\hline CHEMBL1556848 & 752577 & 4.2654 & 4.0567 & TST \\
\hline CHEMBL1389540 & 752577 & 4.2323 & 3.8704 & TST \\
\hline CHEMBL1731520 & 752577 & 4.3539 & 3.8471 & TST \\
\hline CHEMBL1482740 & 752577 & 4.4627 & 3.9458 & TST \\
\hline CHEMBL1553969 & 752577 & 4.2794 & 3.9283 & TST \\
\hline CHEMBL1612862 & 752577 & 4.4536 & 3.8877 & TST \\
\hline CHEMBL1456179 & 752577 & 3.7967 & 3.6476 & TST \\
\hline CHEMBL1484997 & 752577 & 4.1637 & 4.0004 & TST \\
\hline CHEMBL1538718 & 752577 & 3.5372 & 3.9272 & TST \\
\hline CHEMBL1361785 & 752577 & 2.4559 & 3.8216 & TST \\
\hline CHEMBL1399891 & 752577 & 2.4559 & 3.9275 & TST \\
\hline CHEMBL1425422 & 752577 & 4.2032 & 3.988 & TST \\
\hline CHEMBL1412392 & 752577 & 4.1336 & 4.047 & TST \\
\hline CHEMBL1365162 & 752577 & 3.8895 & 3.8218 & TST \\
\hline CHEMBL3196718 & 752577 & 4.2049 & 3.9877 & TST \\
\hline CHEMBL1586511 & 752577 & 4.4007 & 4.0357 & TST \\
\hline CHEMBL1565380 & 752577 & 4.1976 & 3.8932 & TST \\
\hline CHEMBL1438341 & 752577 & 4.329 & 3.9869 & TST \\
\hline CHEMBL1477988 & 752577 & 3.7416 & 3.7451 & TST \\
\hline CHEMBL1522988 & 752577 & 4.4032 & 3.72600 & 30000000004 \\
\hline CHEMBL1398616 & 752577 & 4.3298 & 4.2336 & TST \\
\hline CHEMBL1523565 & 752577 & 4.296 & 4.2081 & TST \\
\hline CHEMBL1389565 & 752577 & 2.4559 & 3.6379 & TST \\
\hline CHEMBL1525701 & 752577 & 3.597 & 4.1074 & TST \\
\hline CHEMBL1341029 & 752577 & 3.821 & 3.7815 & TST \\
\hline CHEMBL1711840 & 752577 & 4.272 & 4.1518 & TST \\
\hline CHEMBL1417719 & 752577 & 4.334 & 4.087 & TST \\
\hline CHEMBL1538117 & 752577 & 4.2772 & 3.8268 & TST \\
\hline CHEMBL3208182 & 752577 & 4.2917 & 3.9438 & TST \\
\hline CHEMBL1601470 & 752577 & 4.0141 & 3.9502 & TST \\
\hline CHEMBL604311 & 752577 & 4.3087 & 3.7076 & TST \\
\hline CHEMBL1362464 & 752577 & 3.4948 & 3.9501 & TST \\
\hline CHEMBL1346510 & 752577 & 3.7745 & 4.165 & TST \\
\hline CHEMBL 2145398 & 954358 & 4.8465 & 4.7105 & TRN \\
\hline
\end{tabular}

Page 4703 


\begin{tabular}{|c|c|c|c|c|}
\hline & & & oplement & al Ta \\
\hline CHEMBL2359127 & 954358 & 4.5098 & 4.8147 & TRN \\
\hline CHEMBL1331798 & 954358 & 4.5743 & 4.7192 & TST \\
\hline CHEMBL2357706 & 954358 & 4.7231 & 4.8343 & TRN \\
\hline CHEMBL2356101 & 954358 & 5.0182 & 5.4279 & TRN \\
\hline CHEMBL2362504 & 954358 & 3.284 & 4.426 & TRN \\
\hline CHEMBL1567775 & 954358 & 4.4451 & 4.3146 & TRN \\
\hline CHEMBL 2359180 & 954358 & 4.5206 & 4.6318 & TST \\
\hline CHEMBL1532941 & 954358 & 6.0 & 4.7374 & TST \\
\hline CHEMBL 2354445 & 954358 & 6.0 & 5.5696 & TRN \\
\hline CHEMBL2360305 & 954358 & 4.5485 & 4.8458 & TRN \\
\hline CHEMBL1891222 & 954358 & 6.0 & 5.3425 & TRN \\
\hline CHEMBL1559261 & 954358 & 3.0362 & 4.0138 & TRN \\
\hline CHEMBL2361889 & 954358 & 4.5989 & 4.4962 & TRN \\
\hline CHEMBL1470452 & 954358 & 4.8861 & 4.7296 & TST \\
\hline CHEMBL 2355944 & 954358 & 4.7778 & 4.6279 & TRN \\
\hline CHEMBL2360952 & 954358 & 4.3311 & 4.949 & TRN \\
\hline CHEMBL2356982 & 954358 & 4.5799 & 4.8265 & TRN \\
\hline CHEMBL1447827 & 954358 & 4.6096 & 4.5343 & TRN \\
\hline CHEMBL2358956 & 954358 & 4.475 & 4.4642 & TRN \\
\hline CHEMBL 2354448 & 954358 & 6.0 & 5.6269 & TRN \\
\hline CHEMBL2359995 & 954358 & 4.7298 & 4.7987 & TRN \\
\hline CHEMBL 2354566 & 954358 & 4.6536 & 4.7765 & TRN \\
\hline CHEMBL2361477 & 954358 & 4.5571 & 4.5173 & TRN \\
\hline CHEMBL 2356243 & 954358 & 4.6413 & 5.0069 & TRN \\
\hline CHEMBL1730981 & 954358 & 3.284 & 4.5209 & TST \\
\hline CHEMBL 2358284 & 954358 & 6.0 & 4.6951 & TRN \\
\hline CHEMBL 2362454 & 954358 & 4.8058 & 4.9541 & TRN \\
\hline CHEMBL 2357722 & 954358 & 4.7873 & 4.8871 & TRN \\
\hline CHEMBL2362456 & 954358 & 4.5278 & 4.6887 & TRN \\
\hline CHEMBL 2356756 & 954358 & 4.4477 & 4.2068 & TRN \\
\hline CHEMBL 2356488 & 954358 & 4.6859 & 4.9065 & TRN \\
\hline CHEMBL1315275 & 954358 & 4.6891 & 3.9263 & TST \\
\hline CHEMBL 2357894 & 954358 & 4.618 & 4.1463 & TRN \\
\hline CHEMBL2356371 & 954358 & 4.6955 & 4.5823 & TST \\
\hline CHEMBL 2357001 & 954358 & 4.6124 & 4.6486 & TRN \\
\hline CHEMBL1365054 & 954358 & 4.4955 & 4.3869 & TRN \\
\hline CHEMBL2362889 & 954358 & 4.5748 & 4.4787 & TRN \\
\hline CHEMBL2359643 & 954358 & 5.2097 & 4.765 & TRN \\
\hline CHEMBL2360959 & 954358 & 6.0 & 4.7537 & TRN \\
\hline CHEMBL2360606 & 954358 & 4.4791 & 4.5218 & TRN \\
\hline CHEMBL2356799 & 954358 & 6.0 & 4.8689 & TRN \\
\hline CHEMBL2358205 & 954358 & 3.284 & 4.6656 & TST \\
\hline CHEMBL2361240 & 954358 & 4.613 & 4.9725 & TRN \\
\hline CHEMBL 2354758 & 954358 & 5.1506 & 4.4911 & TRN \\
\hline CHEMBL1714379 & 954358 & 4.4761 & 4.2485 & TRN \\
\hline CHEMBL 2357707 & 954358 & 4.547 & 4.7145 & TRN \\
\hline CHEMBL1428940 & 954358 & 4.6975 & 4.4687 & TST \\
\hline CHEMBL2357624 & 954358 & 4.7033 & 4.3504 & TRN \\
\hline
\end{tabular}


Supplemental Table S2.txt

\begin{tabular}{|c|c|c|c|c|}
\hline CHEMBL 2359550 & 954358 & 4.6702 & 4.7626 & TRN \\
\hline CHEMBL2354923 & 954358 & 4.4186 & 4.4937 & TRN \\
\hline CHEMBL2357125 & 954358 & 5.7932 & 5.0744 & TRN \\
\hline CHEMBL1421353 & 954358 & 4.8119 & 4.6665 & TST \\
\hline CHEMBL2359733 & 954358 & 6.0 & 5.5251 & TRN \\
\hline CHEMBL2359500 & 954358 & 4.5524 & 4.4793 & TRN \\
\hline CHEMBL 2358333 & 954358 & 4.8348 & 5.5442 & TRN \\
\hline CHEMBL 2357888 & 954358 & 4.5535 & 5.0649 & TRN \\
\hline CHEMBL 2360267 & 954358 & 4.8027 & 5.5732 & TRN \\
\hline CHEMBL 2362204 & 954358 & 3.284 & 4.7409 & TRN \\
\hline CHEMBL 2358058 & 954358 & 4.8297 & 4.5486 & TRN \\
\hline CHEMBL 2360317 & 954358 & 4.2889 & 4.3099 & TRN \\
\hline CHEMBL2356395 & 954358 & 4.6061 & 4.5239 & TRN \\
\hline CHEMBL 2357805 & 954358 & 4.6688 & 4.6755 & TRN \\
\hline CHEMBL 2359510 & 954358 & 4.58 & 5.3453 & TRN \\
\hline CHEMBL2359303 & 954358 & 5.3089 & 5.3473 & TRN \\
\hline CHEMBL2354976 & 954358 & 4.6914 & 4.6025 & TRN \\
\hline CHEMBL2356428 & 954358 & 4.3949 & 4.4895 & TRN \\
\hline CHEMBL 2361873 & 954358 & 4.7036 & 4.7151 & TRN \\
\hline CHEMBL2361534 & 954358 & 4.8038 & 4.6107 & TRN \\
\hline CHEMBL 2357418 & 954358 & 4.7224 & 4.9567 & TRN \\
\hline CHEMBL 2354953 & 954358 & 3.2441 & 4.0545 & TRN \\
\hline CHEMBL 2358481 & 954358 & 3.284 & 4.225 & TRN \\
\hline CHEMBL 2359003 & 954358 & 5.0888 & 5.4574 & TRN \\
\hline CHEMBL2358581 & 954358 & 4.6623 & 4.2183 & TRN \\
\hline CHEMBL 2360390 & 954358 & 4.8468 & 4.7247 & TRN \\
\hline CHEMBL3184262 & 954358 & 5.0846 & 4.9338 & TRN \\
\hline CHEMBL 2354443 & 954358 & 4.4861 & 4.2572 & TRN \\
\hline CHEMBL1452358 & 954358 & 3.284 & 4.6271 & TST \\
\hline CHEMBL 2356202 & 954358 & 6.0 & 4.7675 & TRN \\
\hline CHEMBL 2356039 & 954358 & 5.4949 & 4.55699 & 99999999995 \\
\hline CHEMBL 2355642 & 954358 & 4.9442 & 4.7795 & TRN \\
\hline CHEMBL 2360807 & 954358 & 4.5578 & 4.6289 & TRN \\
\hline CHEMBL 2357995 & 954358 & 6.0 & 5.3548 & TRN \\
\hline CHEMBL 2355416 & 954358 & 4.4438 & 5.0234 & TRN \\
\hline CHEMBL 2358709 & 954358 & 4.5955 & 4.726 & TRN \\
\hline CHEMBL2361950 & 954358 & 4.6315 & 4.7473 & TRN \\
\hline CHEMBL 2362046 & 954358 & 3.284 & 4.1371 & TRN \\
\hline CHEMBL2359386 & 954358 & 4.4224 & 4.0938 & TRN \\
\hline CHEMBL 2361773 & 954358 & 4.7149 & 4.8405 & TST \\
\hline CHEMBL1865449 & 954358 & 3.284 & 4.492 & TST \\
\hline CHEMBL2355897 & 954358 & 5.2967 & 4.6538 & TST \\
\hline CHEMBL1389242 & 954358 & 4.4638 & 4.5393 & TST \\
\hline CHEMBL 2355749 & 954358 & 4.473 & 4.7869 & TST \\
\hline CHEMBL1505054 & 954358 & 4.2941 & 4.4423 & TST \\
\hline CHEMBL 2360064 & 954358 & 4.5776 & 4.8223 & TST \\
\hline CHEMBL2361971 & 954358 & 4.5854 & 4.5724 & TST \\
\hline CHEMBL1451017 & 954358 & 4.6291 & 4.4809 & TST \\
\hline
\end{tabular}

Page 4705 
Supplemental Table S2.txt

\begin{tabular}{|c|c|c|c|c|c|}
\hline CHEMBL 2360173 & 954358 & 4.622 & 4.2811 & TST & \\
\hline CHEMBL1382360 & 954358 & 4.9442 & 4.918 & TST & \\
\hline CHEMBL 2356340 & 954358 & 4.6645 & 4.6635 & TST & \\
\hline CHEMBL 2360919 & 954358 & 4.7503 & 5.4977 & TST & \\
\hline CHEMBL 2359950 & 954358 & 6.0 & 4.8915 & TST & \\
\hline CHEMBL 2358214 & 954358 & 6.0 & 4.6209 & TST & \\
\hline CHEMBL573771 & 587702 & 7.0742 & 6.7898 & TRN & \\
\hline CHEMBL573089 & 587702 & 6.9172 & 7.5476 & TRN & \\
\hline CHEMBL572419 & 587702 & 7.6421 & 7.2167 & TRN & \\
\hline CHEMBL576538 & 587702 & 6.8761 & 6.2983 & TRN & \\
\hline CHEMBL578008 & 587702 & 6.7328 & 6.8448 & TRN & \\
\hline CHEMBL574484 & 587702 & 6.1391 & 6.1985 & TRN & \\
\hline CHEMBL541455 & 587702 & 6.8928 & 6.8281 & TRN & \\
\hline CHEMBL573780 & 587702 & 6.9393 & 7.2831 & TST & \\
\hline CHEMBL576567 & 587702 & 6.8539 & 7.1971 & TRN & \\
\hline CHEMBL573594 & 587702 & 5.7328 & 6.0968 & TRN & \\
\hline CHEMBL575855 & 587702 & 6.5129 & 6.8386 & TST & \\
\hline CHEMBL573807 & 587702 & 6.3526 & 6.6131 & TST & \\
\hline CHEMBL572601 & 587702 & 7.5935 & 7.5105 & TRN & \\
\hline CHEMBL583960 & 587702 & 6.3872 & 6.7816 & TRN & \\
\hline CHEMBL572653 & 587702 & 6.2248 & 6.1654 & TRN & \\
\hline CHEMBL574775 & 587702 & 7.0958 & 7.231 & TST & \\
\hline CHEMBL575825 & 587702 & 6.0595 & 5.9394 & TRN & \\
\hline CHEMBL572386 & 587702 & 7.8794 & 7.3615 & TRN & \\
\hline CHEMBL574263 & 587702 & 7.317 & 7.4377 & TRN & \\
\hline CHEMBL575386 & 587702 & 6.7696 & 6.643 & TRN & \\
\hline CHEMBL578649 & 587702 & 6.1046 & 6.5716 & TRN & \\
\hline CHEMBL578224 & 587702 & 6.857 & 6.8006 & TST & \\
\hline CHEMBL576018 & 587702 & 6.4112 & 6.5693 & TRN & \\
\hline CHEMBL576351 & 587702 & 7.0742 & 7.0373 & TRN & \\
\hline CHEMBL573779 & 587702 & 6.8297 & 7.1367 & TST & \\
\hline CHEMBL335950 & 587702 & 6.1487 & 6.1912 & TRN & \\
\hline CHEMBL575197 & 587702 & 7.7328 & 7.2257 & TRN & \\
\hline CHEMBL578005 & 587702 & 7.2857 & 7.2716 & TRN & \\
\hline CHEMBL573327 & 587702 & 7.6459 & 7.5459 & TRN & \\
\hline CHEMBL575204 & 587702 & 6.7212 & 6.2735 & TRN & \\
\hline CHEMBL575198 & 587702 & 6.8125 & 7.1889 & TRN & \\
\hline CHEMBL577135 & 587702 & 6.7959 & 6.9732 & TRN & \\
\hline CHEMBL574489 & 587702 & 7.1543 & 7.4484 & TST & \\
\hline CHEMBL572906 & 587702 & 6.8894 & 7.2388 & TST & \\
\hline CHEMBL576153 & 587702 & 7.1481 & 6.9065 & TRN & \\
\hline CHEMBL577162 & 587702 & 6.0164 & 6.5658 & TST & \\
\hline CHEMBL576185 & 587702 & 7.8633 & 7.8874 & TRN & \\
\hline CHEMBL574483 & 587702 & 6.1302 & 6.1653 & TRN & \\
\hline CHEMBL574490 & 587702 & 6.0419 & 6.4422 & TST & \\
\hline CHEMBL575605 & 587702 & 6.617999 & 999999999 & 99 & 6.5176 \\
\hline CHEMBL575604 & 587702 & 6.1146 & 6.2265 & TRN & \\
\hline CHEMBL573088 & 587702 & 6.5918 & 6.5178 & TRN & \\
\hline
\end{tabular}




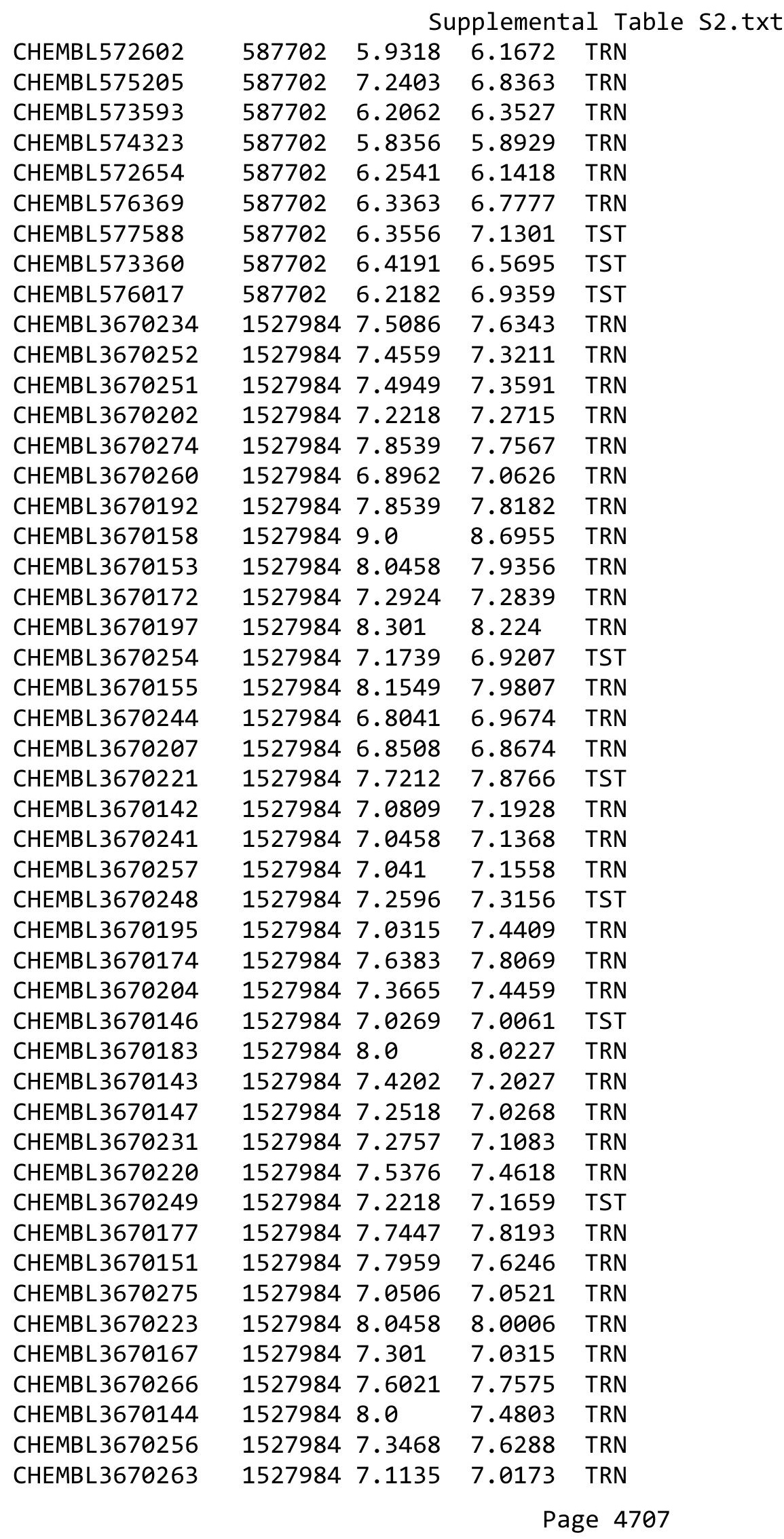


Supplemental Table S2.txt

\begin{tabular}{|c|c|c|c|c|}
\hline CHEMBL3670184 & 1527984 & 8.0 & 8.0611 & TRN \\
\hline CHEMBL3670186 & 1527984 & 7.8539 & 7.8811 & TRN \\
\hline CHEMBL3670193 & 1527984 & 7.585 & 7.6007 & TRN \\
\hline CHEMBL3670176 & 1527984 & 7.4437 & 7.2766 & TRN \\
\hline CHEMBL 3670277 & 1527984 & 7.3279 & 7.2832 & TRN \\
\hline CHEMBL 3670227 & 1527984 & 6.3401 & 6.5253 & TRN \\
\hline CHEMBL3670159 & 1527984 & 7.7959 & 6.7388 & TST \\
\hline CHEMBL3670213 & 1527984 & 7.0132 & 7.0836 & TST \\
\hline CHEMBL 3670175 & 1527984 & 8.301 & 8.3723 & TRN \\
\hline CHEMBL3670188 & 1527984 & 7.5229 & \multicolumn{2}{|c|}{7.8839999999999995} \\
\hline CHEMBL3670230 & 1527984 & 7.2291 & 6.8401 & TST \\
\hline CHEMBL3670141 & 1527984 & 7.4949 & 7.3642 & TRN \\
\hline CHEMBL 3670200 & 1527984 & 7.5528 & 7.5026 & TRN \\
\hline CHEMBL3670242 & 1527984 & 7.041 & 7.0624 & TRN \\
\hline CHEMBL3670222 & 1527984 & 7.5229 & 8.0466 & TST \\
\hline CHEMBL3670206 & 1527984 & 6.7747 & 6.7492 & TRN \\
\hline CHEMBL3670269 & 1527984 & 7.0809 & 7.4074 & TST \\
\hline CHEMBL3670165 & 1527984 & 8.0 & 8.324 & TRN \\
\hline CHEMBL3670226 & 1527984 & 6.4365 & 6.6305 & TST \\
\hline CHEMBL 3670148 & 1527984 & 7.9586 & 7.8176 & TST \\
\hline CHEMBL3670216 & 1527984 & 7.7447 & 7.6531 & TRN \\
\hline CHEMBL3670265 & 1527984 & 7.7447 & 7.7165 & TRN \\
\hline CHEMBL3670196 & 1527984 & 7.3768 & 7.3041 & TRN \\
\hline CHEMBL3670201 & 1527984 & 9.2147 & 8.9857 & TRN \\
\hline CHEMBL 3670228 & 1527984 & 6.8416 & 6.7939 & TRN \\
\hline CHEMBL 3670258 & 1527984 & 7.8239 & 7.8622 & TRN \\
\hline CHEMBL3670182 & 1527984 & 7.7959 & 8.0659 & TRN \\
\hline CHEMBL3670171 & 1527984 & 8.5229 & 8.5634 & TRN \\
\hline CHEMBL3670190 & 1527984 & 7.5528 & 7.4029 & TRN \\
\hline CHEMBL 3670210 & 1527984 & 7.5229 & 7.3836 & TRN \\
\hline CHEMBL 3670140 & 1527984 & 6.9788 & 7.6356 & TST \\
\hline CHEMBL3670198 & 1527984 & 8.2218 & 8.0052 & TRN \\
\hline CHEMBL3670157 & 1527984 & 8.301 & 8.2544 & TRN \\
\hline CHEMBL3670212 & 1527984 & 8.0 & 8.1309 & TST \\
\hline CHEMBL3670239 & 1527984 & 6.6253 & \multicolumn{2}{|c|}{6.632000000000001} \\
\hline CHEMBL3670218 & 1527984 & 8.1549 & 7.8321 & TRN \\
\hline CHEMBL 3670211 & 1527984 & 7.5229 & 7.4958 & TRN \\
\hline CHEMBL3670163 & 1527984 & 7.3372 & 6.6409 & TST \\
\hline CHEMBL3670169 & 1527984 & 8.0458 & 8.0348 & TRN \\
\hline CHEMBL3670209 & 1527984 & 7.1549 & 6.9941 & TRN \\
\hline CHEMBL3670262 & 1527984 & 7.5686 & 7.1404 & TST \\
\hline CHEMBL 3670237 & 1527984 & 7.7447 & 7.4506 & TRN \\
\hline CHEMBL3670173 & 1527984 & 8.3979 & 8.4536 & TRN \\
\hline CHEMBL3670164 & 1527984 & 7.3768 & 6.7985 & TST \\
\hline CHEMBL 3670214 & 1527984 & 8.0969 & 8.3391 & TST \\
\hline CHEMBL 3670145 & 1527984 & 7.1427 & 7.0802 & TRN \\
\hline CHEMBL3670194 & 1527984 & 7.2441 & 7.2665 & TRN \\
\hline CHEMBL 3670168 & 1527984 & 7.1739 & 7.2157 & TRN \\
\hline
\end{tabular}


Supplemental Table S2.txt

\begin{tabular}{|c|c|c|c|c|}
\hline CHEMBL 3670250 & 1527984 & 7.5229 & 7.5166 & TRN \\
\hline CHEMBL3670270 & 1527984 & 5.699 & 7.6427 & TST \\
\hline CHEMBL3670178 & 1527984 & 7.7212 & 7.7401 & TRN \\
\hline CHEMBL 3670276 & 1527984 & 7.8539 & 7.6666 & TRN \\
\hline CHEMBL3670271 & 1527984 & 7.2924 & 7.523 & TST \\
\hline CHEMBL 3670243 & 1527984 & 6.9469 & 6.9659 & TRN \\
\hline CHEMBL 3670235 & 1527984 & 7.7959 & 6.6576 & TST \\
\hline CHEMBL3670245 & 1527984 & 6.9957 & 7.0658 & TRN \\
\hline CHEMBL3670246 & 1527984 & 7.2218 & 7.2928 & TST \\
\hline CHEMBL3670161 & 1527984 & 8.3979 & 8.4926 & TRN \\
\hline CHEMBL3670191 & 1527984 & 7.9208 & 8.0746 & TRN \\
\hline CHEMBL 3670267 & 1527984 & 7.6576 & 7.5326 & TRN \\
\hline CHEMBL3670208 & 1527984 & 6.9666 & 6.7254 & TRN \\
\hline CHEMBL 3670224 & 1527984 & 7.699 & 7.7377 & TRN \\
\hline CHEMBL3670185 & 1527984 & 7.7959 & 7.7874 & TRN \\
\hline CHEMBL3670199 & 1527984 & 8.3979 & 8.1821 & TRN \\
\hline CHEMBL3670180 & 1527984 & 8.0458 & 7.90799 & 99999999995 \\
\hline CHEMBL 3670240 & 1527984 & 7.0757 & 7.3182 & TRN \\
\hline CHEMBL 3670170 & 1527984 & 7.4318 & 7.5956 & TRN \\
\hline CHEMBL3670160 & 1527984 & 7.7212 & 6.9211 & TST \\
\hline CHEMBL3670255 & 1527984 & 6.4776 & 7.1112 & TRN \\
\hline CHEMBL3670261 & 1527984 & 5.8044 & 6.1299 & TRN \\
\hline CHEMBL3670179 & 1527984 & 7.4949 & 7.5654 & TRN \\
\hline CHEMBL3670253 & 1527984 & 7.2596 & 6.9947 & TRN \\
\hline CHEMBL3670156 & 1527984 & 7.1308 & 7.2263 & TRN \\
\hline CHEMBL3670149 & 1527984 & 7.3872 & 7.6199 & TRN \\
\hline CHEMBL3670259 & 1527984 & 6.8601 & 7.6436 & TST \\
\hline CHEMBL3670187 & 1527984 & 7.5528 & 7.7845 & TRN \\
\hline CHEMBL3670189 & 1527984 & 7.3665 & 7.6032 & TRN \\
\hline CHEMBL3670232 & 1527984 & 6.5834 & 6.2704 & TST \\
\hline CHEMBL3670215 & 1527984 & 7.5086 & 7.1979 & TST \\
\hline CHEMBL3670278 & 1527984 & 6.857 & 6.849 & TRN \\
\hline CHEMBL 3670225 & 1527984 & 7.3468 & 6.7784 & TST \\
\hline CHEMBL3639690 & 1527984 & 8.0 & 7.5625 & TRN \\
\hline CHEMBL3670150 & 1527984 & 8.1549 & 8.1281 & TRN \\
\hline CHEMBL3670247 & 1527984 & 7.1938 & 6.7727 & TST \\
\hline CHEMBL3670152 & 1527984 & 7.7447 & 7.8783 & TRN \\
\hline CHEMBL3670217 & 1527984 & 7.6021 & 7.272 & TRN \\
\hline CHEMBL3670181 & 1527984 & 7.5086 & 7.7184 & TRN \\
\hline CHEMBL3670203 & 1527984 & 8.301 & 8.7362 & TRN \\
\hline CHEMBL 3670264 & 1527984 & 7.4318 & 7.5396 & TRN \\
\hline CHEMBL3670205 & 1527984 & 6.9136 & 7.0037 & TRN \\
\hline CHEMBL3670233 & 1527984 & 7.8239 & 7.5375 & TST \\
\hline CHEMBL3670272 & 1527984 & 7.4815 & 7.5749 & TRN \\
\hline CHEMBL3670219 & 1527984 & 8.301 & 8.2437 & TRN \\
\hline CHEMBL 3670273 & 1527984 & 7.3098 & 7.317 & TRN \\
\hline CHEMBL3670166 & 1527984 & 7.6383 & 7.7439 & TRN \\
\hline CHEMBL3670279 & 1527984 & 6.5884 & 7.47 & TST \\
\hline
\end{tabular}


Supplemental Table S2.txt

\begin{tabular}{|c|c|c|c|c|}
\hline CHEMBL 3670229 & 1527984 & 7.2366 & 6.9986 & TST \\
\hline CHEMBL 3670238 & 1527984 & 7.1079 & 6.3471 & TST \\
\hline CHEMBL3670236 & 1527984 & 6.3401 & 6.8167 & TST \\
\hline CHEMBL 3670268 & 1527984 & 7.1675 & 7.232 & TST \\
\hline CHEMBL 3670154 & 1527984 & 7.1938 & 7.3988 & TRN \\
\hline CHEMBL3126871 & 1294961 & 3.699 & 3.9548 & TRN \\
\hline CHEMBL3126883 & 1294961 & 3.699 & 3.8292 & TRN \\
\hline CHEMBL3126889 & 1294961 & 3.699 & 3.4068 & TRN \\
\hline CHEMBL3126895 & 1294961 & 3.699 & 3.7709 & TRN \\
\hline CHEMBL3126899 & 1294961 & 5.9245 & 5.6171 & TRN \\
\hline CHEMBL 3127060 & 1294961 & 3.699 & 3.6966 & TRN \\
\hline CHEMBL1269812 & 1294961 & 7.699 & 5.7629 & TST \\
\hline CHEMBL 3126884 & 1294961 & 3.699 & 3.7254 & TRN \\
\hline CHEMBL3126910 & 1294961 & 3.8239 & 4.0547 & TRN \\
\hline CHEMBL 3126867 & 1294961 & 3.699 & 3.8725 & TRN \\
\hline CHEMBL 3127057 & 1294961 & 6.6021 & 5.4031 & TST \\
\hline CHEMBL3126902 & 1294961 & 3.8239 & 4.2623 & TRN \\
\hline CHEMBL 3126900 & 1294961 & 5.0429 & 4.6316 & TRN \\
\hline CHEMBL3126882 & 1294961 & 3.699 & 3.6367 & TRN \\
\hline CHEMBL 3127051 & 1294961 & 5.7077 & 4.9487 & TRN \\
\hline CHEMBL3127068 & 1294961 & 5.475 & 5.3709 & TRN \\
\hline CHEMBL3127055 & 1294961 & 6.9586 & 6.3085 & TST \\
\hline CHEMBL319177 & 1294961 & 3.699 & 3.7148 & TST \\
\hline CHEMBL3126872 & 1294961 & 3.699 & 3.9627 & TST \\
\hline CHEMBL 3126885 & 1294961 & 3.699 & 3.6584 & TRN \\
\hline CHEMBL3126869 & 1294961 & 3.699 & 3.5929 & TRN \\
\hline CHEMBL3126913 & 1294961 & 3.699 & 3.9227 & TRN \\
\hline CHEMBL3126897 & 1294961 & 3.699 & 4.0643 & TST \\
\hline CHEMBL3126896 & 1294961 & 3.699 & 3.961006 & 30000000003 \\
\hline CHEMBL 3126901 & 1294961 & 3.699 & 4.0435 & TRN \\
\hline CHEMBL3127054 & 1294961 & 5.7144 & 5.0762 & TRN \\
\hline CHEMBL 3126886 & 1294961 & 3.699 & 3.4836 & TRN \\
\hline CHEMBL3126911 & 1294961 & 4.8447 & 4.65600 & 0000000001 \\
\hline CHEMBL3126877 & 1294961 & 3.699 & 3.7714 & TRN \\
\hline CHEMBL 3127044 & 1294961 & 4.8601 & 4.4187 & TST \\
\hline CHEMBL3127059 & 1294961 & 3.699 & 3.7147 & TRN \\
\hline CHEMBL 3127049 & 1294961 & 6.2676 & 6.4802 & TRN \\
\hline CHEMBL403715 & 1294961 & 3.699 & 4.4354 & TST \\
\hline CHEMBL 3127066 & 1294961 & 5.7471 & 5.4924 & TRN \\
\hline CHEMBL3126888 & 1294961 & 3.699 & 3.6006 & TRN \\
\hline CHEMBL3126906 & 1294961 & 4.9747 & 4.8505 & TST \\
\hline CHEMBL3126914 & 1294961 & 4.8327 & 5.0375 & TST \\
\hline CHEMBL3126874 & 1294961 & 4.9706 & 4.4209 & TRN \\
\hline CHEMBL3126904 & 1294961 & 3.699 & 3.9203 & TRN \\
\hline CHEMBL3127065 & 1294961 & 5.9914 & 6.0292 & TRN \\
\hline CHEMBL3126891 & 1294961 & 3.699 & 3.8788 & TRN \\
\hline CHEMBL 3126915 & 1294961 & 5.3893 & 4.5553 & TST \\
\hline CHEMBL3126881 & 1294961 & 3.699 & 3.7301 & TRN \\
\hline
\end{tabular}


Supplemental Table S2.txt

\begin{tabular}{|c|c|c|c|c|c|}
\hline CHEMBL3127052 & 1294961 & 3.699 & 4.4664 & TRN & \\
\hline CHEMBL3126908 & 1294961 & 5.8761 & 5.9003 & TRN & \\
\hline CHEMBL3126909 & 1294961 & 3.699 & 3.7648 & TRN & \\
\hline CHEMBL3126868 & 1294961 & 3.699 & 3.6331 & TRN & \\
\hline CHEMBL3126892 & 1294961 & 3.699 & 3.7135 & TRN & \\
\hline CHEMBL3126873 & 1294961 & 3.699 & 4.0933 & TRN & \\
\hline CHEMBL3126905 & 1294961 & 6.0915 & 5.6482 & TST & \\
\hline CHEMBL3127067 & 1294961 & 5.7545 & 5.7946 & TRN & \\
\hline CHEMBL 3127061 & 1294961 & 3.699 & 3.4581 & TRN & \\
\hline CHEMBL3127063 & 1294961 & 3.699 & 3.8437 & TRN & \\
\hline CHEMBL3126898 & 1294961 & 3.699 & 4.1161 & TST & \\
\hline CHEMBL3126890 & 1294961 & 3.699 & 4.0047 & TRN & \\
\hline CHEMBL3126878 & 1294961 & 3.699 & 3.6308 & TRN & \\
\hline CHEMBL 3126870 & 1294961 & 3.699 & 3.7854 & TRN & \\
\hline CHEMBL3126893 & 1294961 & 3.699 & 3.5204 & TRN & \\
\hline CHEMBL 3127064 & 1294961 & 3.699 & 4.1827 & TST & \\
\hline CHEMBL3127050 & 1294961 & 5.2684 & 5.6573 & TRN & \\
\hline CHEMBL3126912 & 1294961 & 3.699 & 3.3635 & TRN & \\
\hline CHEMBL3126865 & 1294961 & 5.3788 & 4.6899 & TST & \\
\hline CHEMBL3126880 & 1294961 & 3.699 & 4.2832 & TRN & \\
\hline CHEMBL3127046 & 1294961 & 5.0343 & 4.822 & TRN & \\
\hline CHEMBL3126876 & 1294961 & 3.699 & 3.7505 & TRN & \\
\hline CHEMBL3126894 & 1294961 & 3.699 & 3.68 & TRN & \\
\hline CHEMBL 3126887 & 1294961 & 3.699 & 3.5121 & TRN & \\
\hline CHEMBL3127047 & 1294961 & \multicolumn{2}{|c|}{5.7620000000000005} & 5.4074 & TST \\
\hline CHEMBL3127062 & 1294961 & 3.699 & 3.4765 & TRN & \\
\hline CHEMBL 3127048 & 1294961 & 4.8447 & 5.2131 & TST & \\
\hline CHEMBL 3127058 & 1294961 & 5.301 & 4.8262 & TRN & \\
\hline CHEMBL1814768 & 1294961 & 7.699 & 7.5628 & TRN & \\
\hline CHEMBL3126866 & 1294961 & 3.699 & 3.7527 & TRN & \\
\hline CHEMBL3126903 & 1294961 & 3.699 & 3.5668 & TRN & \\
\hline CHEMBL3126907 & 1294961 & 6.7212 & 6.0042 & TST & \\
\hline CHEMBL 3126875 & 1294961 & 3.699 & 3.6494 & TRN & \\
\hline CHEMBL3126879 & 1294961 & 5.2381 & 5.0064 & TRN & \\
\hline CHEMBL3127053 & 1294961 & 3.699 & 4.0724 & TRN & \\
\hline CHEMBL1814767 & 1294961 & 7.301 & 7.6618 & TRN & \\
\hline CHEMBL 3127045 & 1294961 & 3.699 & 3.9612 & TRN & \\
\hline CHEMBL3124960 & 1294961 & 3.699 & 3.8392 & TST & \\
\hline CHEMBL 3127056 & 1294961 & 4.9245 & 5.1078 & TST & \\
\hline CHEMBL2070070 & 834203 & 4.0 & 4.059 & TRN & \\
\hline CHEMBL 2070087 & 834203 & 5.2007 & 5.2764 & TRN & \\
\hline CHEMBL2070081 & 834203 & 4.0 & 3.8812 & TRN & \\
\hline CHEMBL2069953 & 834203 & 4.0 & 3.848000 & 00000000003 & $\mathrm{TR}$ \\
\hline CHEMBL 2070067 & 834203 & 6.4202 & 6.2955 & TRN & \\
\hline CHEMBL2069314 & 834203 & 4.0 & 4.1028 & TST & \\
\hline CHEMBL 2070089 & 834203 & 5.0862 & 5.5545 & TRN & \\
\hline CHEMBL2070057 & 834203 & 6.585 & 6.329 & TRN & \\
\hline CHEMBL 2070083 & 834203 & 4.0 & 4.1495 & TRN & \\
\hline
\end{tabular}




\begin{tabular}{|c|c|c|c|c|c|}
\hline & & \multicolumn{4}{|c|}{ Supplemental Table S2.txt } \\
\hline CHEMBL1242754 & 834203 & 6.699 & 6.6763 & TRN & \\
\hline CHEMBL 2070074 & 834203 & 5.301 & 5.2559 & TRN & \\
\hline CHEMBL2069936 & 834203 & 4.0 & 4.9131 & TST & \\
\hline CHEMBL 2070071 & 834203 & 4.0 & 3.7962 & TRN & \\
\hline CHEMBL2069961 & 834203 & 5.3872 & 5.5934 & TRN & \\
\hline CHEMBL 2070085 & 834203 & 5.4815 & 5.4424 & TRN & \\
\hline CHEMBL 2069940 & 834203 & 5.8861 & 6.6686 & TST & \\
\hline CHEMBL 2069946 & 834203 & 5.8239 & 6.5289 & TST & \\
\hline CHEMBL 2070084 & 834203 & 4.0 & 4.3714 & TRN & \\
\hline CHEMBL2070076 & 834203 & 5.0605 & 5.1654 & TRN & \\
\hline CHEMBL 2070065 & 834203 & 5.7447 & 5.3273 & TRN & \\
\hline CHEMBL2069958 & 834203 & 4.0 & 4.6144 & TRN & \\
\hline CHEMBL 2069949 & 834203 & 4.0 & 4.2092 & TRN & \\
\hline CHEMBL 2069960 & 834203 & 4.0 & 4.2041 & TRN & \\
\hline CHEMBL 2070052 & 834203 & 6.2596 & 6.326006 & 00000000005 & TRN \\
\hline CHEMBL 2069952 & 834203 & 5.6778 & 5.8409 & TRN & \\
\hline CHEMBL2070059 & 834203 & 4.0 & 4.2662 & TRN & \\
\hline CHEMBL1242847 & 834203 & 5.2924 & 5.4163 & TRN & \\
\hline CHEMBL 2070075 & 834203 & 5.2518 & 5.336 & TRN & \\
\hline CHEMBL2069955 & 834203 & 5.6576 & 5.65799 & 99999999995 & TST \\
\hline CHEMBL 2070063 & 834203 & 5.5086 & 5.4099 & TRN & \\
\hline CHEMBL2069951 & 834203 & 6.284 & 6.2894 & TRN & \\
\hline CHEMBL 2069944 & 834203 & 6.7447 & 6.0488 & TST & \\
\hline CHEMBL 2069315 & 834203 & 4.0 & 4.4016 & TRN & \\
\hline CHEMBL 2070047 & 834203 & 4.0 & 3.7766 & TRN & \\
\hline CHEMBL 2070072 & 834203 & 4.0 & 3.9385 & TRN & \\
\hline CHEMBL2070079 & 834203 & 5.7959 & 5.6358 & TRN & \\
\hline CHEMBL 2070044 & 834203 & 4.0 & 3.6577 & TRN & \\
\hline CHEMBL2069939 & 834203 & 4.0 & 3.8612 & TRN & \\
\hline CHEMBL 2070054 & 834203 & 6.699 & 6.4557 & TRN & \\
\hline CHEMBL1231371 & 834203 & 6.9208 & 6.553 & TRN & \\
\hline CHEMBL2070053 & 834203 & 4.0 & 4.0578 & TRN & \\
\hline CHEMBL1241489 & 834203 & 7.1871 & 6.9662 & TRN & \\
\hline CHEMBL 2069937 & 834203 & 4.0 & 3.2675 & TST & \\
\hline CHEMBL 2069943 & 834203 & 6.1871 & 6.2936 & TST & \\
\hline CHEMBL 2070058 & 834203 & 5.9586 & 5.8173 & TRN & \\
\hline CHEMBL 2070082 & 834203 & 4.0 & 3.705 & TRN & \\
\hline CHEMBL 2070080 & 834203 & 6.0915 & 5.8932 & TRN & \\
\hline CHEMBL 2070069 & 834203 & 5.7959 & 5.2899 & TRN & \\
\hline CHEMBL 2069954 & 834203 & 5.0555 & 5.9159 & TST & \\
\hline CHEMBL 2070073 & 834203 & 4.0 & 3.8469 & TRN & \\
\hline CHEMBL 2070046 & 834203 & 5.699 & 5.58299 & 9999999999 & TRN \\
\hline CHEMBL 2070050 & 834203 & 4.0 & 3.9394 & TRN & \\
\hline CHEMBL 2070060 & 834203 & 6.1079 & 5.9488 & TRN & \\
\hline CHEMBL 2070064 & 834203 & 6.5528 & 7.0811 & TRN & \\
\hline CHEMBL 2069948 & 834203 & 5.9208 & 6.4699 & TST & \\
\hline CHEMBL 2070068 & 834203 & 6.5686 & 7.0209 & TRN & \\
\hline CHEMBL 2069947 & 834203 & 4.0 & 4.0539 & TRN & \\
\hline
\end{tabular}


Supplemental Table S2.txt

\begin{tabular}{|c|c|c|c|c|c|c|}
\hline CHEMBL 2070049 & 834203 & 5.6576 & 5.2427 & TST & & \\
\hline CHEMBL 2070048 & 834203 & 6.4202 & 5.7128 & TST & & \\
\hline CHEMBL 2070086 & 834203 & 5.284 & 5.4012 & TRN & & \\
\hline CHEMBL 2069938 & 834203 & 6.8861 & 5.9051 & TST & & \\
\hline CHEMBL 2070062 & 834203 & 7.3872 & 7.4151 & TST & & \\
\hline CHEMBL1242384 & 834203 & 6.5376 & 6.6606 & TST & & \\
\hline CHEMBL 2070088 & 834203 & 5.1739 & 4.9288 & TRN & & \\
\hline CHEMBL 2070066 & 834203 & 6.5528 & 7.9928 & TST & & \\
\hline CHEMBL 2070045 & 834203 & 6.1739 & 5.9735 & TST & & \\
\hline CHEMBL2069941 & 834203 & 6.2366 & 6.3796 & TST & & \\
\hline CHEMBL 2070055 & 834203 & 6.5229 & 5.7665 & TST & & \\
\hline CHEMBL 2069945 & 834203 & 4.0 & 4.14 & TRN & & \\
\hline CHEMBL 2070051 & 834203 & 4.0 & 3.9492 & TRN & & \\
\hline CHEMBL 2070077 & 834203 & 4.0 & 4.8206 & TRN & & \\
\hline CHEMBL2070056 & 834203 & 4.0 & 3.9815 & TRN & & \\
\hline CHEMBL 2070078 & 834203 & 6.1367 & 5.5339 & TRN & & \\
\hline CHEMBL2070061 & 834203 & 4.0 & 4.0395 & TRN & & \\
\hline CHEMBL 303918 & 104542 & 6.7696 & 7.6729 & TST & & \\
\hline CHEMBL 308429 & 104542 & 8.2007 & \multicolumn{3}{|c|}{8.472000000000001} & TST \\
\hline CHEMBL68890 & 104542 & 9.2441 & 9.336 & TRN & & \\
\hline CHEMBL 74175 & 104542 & 9.0177 & 8.9555 & TRN & & \\
\hline CHEMBL68149 & 104542 & 8.5229 & 8.3418 & TRN & & \\
\hline CHEMBL 305222 & 104542 & 9.1549 & 9.1299 & TRN & & \\
\hline CHEMBL430612 & 104542 & 7.9586 & 7.9994 & TST & & \\
\hline CHEMBL302311 & 104542 & 8.7212 & 8.7262 & TRN & & \\
\hline CHEMBL 70570 & 104542 & 8.9586 & 9.0185 & TRN & & \\
\hline CHEMBL 308012 & 104542 & 8.1612 & 8.1463 & TRN & & \\
\hline CHEMBL71014 & 104542 & 7.3665 & 7.271 & TRN & & \\
\hline CHEMBL 310249 & 104542 & 9.2218 & 9.2265 & TRN & & \\
\hline CHEMBL420932 & 104542 & 9.3565 & 9.3576 & TRN & & \\
\hline CHEMBL70398 & 104542 & 9.3279 & 9.4846 & TST & & \\
\hline CHEMBL70430 & 104542 & 9.2291 & 9.3358 & TRN & & \\
\hline CHEMBL302954 & 104542 & 7.8861 & 7.9612 & TRN & & \\
\hline CHEMBL 70417 & 104542 & \multicolumn{3}{|c|}{9.283999999999999} & 9.3176 & TRN \\
\hline CHEMBL306524 & 104542 & \multicolumn{3}{|c|}{9.283999999999999} & 9.2331 & TRN \\
\hline CHEMBL152104 & 104542 & 6.0 & 5.9981 & TRN & & \\
\hline CHEMBL 308032 & 104542 & 4.1487 & 6.6805 & TST & & \\
\hline CHEMBL306224 & 104542 & 9.0555 & 9.0717 & TRN & & \\
\hline CHEMBL70315 & 104542 & 9.0 & 9.0351 & TRN & & \\
\hline CHEMBL 70965 & 104542 & 9.2676 & 9.2391 & TRN & & \\
\hline CHEMBL 302368 & 104542 & 8.699 & 8.7588 & TRN & & \\
\hline CHEMBL72337 & 104542 & 7.7447 & 7.7707 & TRN & & \\
\hline CHEMBL 305780 & 104542 & 8.3979 & 8.3774 & TRN & & \\
\hline CHEMBL 71713 & 104542 & 8.3372 & 8.3523 & TRN & & \\
\hline CHEMBL 70426 & 104542 & 8.4559 & 8.43700 & 0000000001 & & TRN \\
\hline CHEMBL 70049 & 104542 & 7.7212 & 7.7431 & TRN & & \\
\hline CHEMBL306871 & 104542 & 9.1367 & 9.24 & TRN & & \\
\hline CHEMBL 70492 & 104542 & 9.3768 & 9.2193 & TRN & & \\
\hline
\end{tabular}

Page 4713 


\begin{tabular}{|c|c|c|c|c|c|}
\hline \multicolumn{6}{|c|}{ Supplemental Table S2.txt } \\
\hline CHEMBL69072 & 104542 & 7.699 & 7.7766 & TRN & \\
\hline CHEMBL 71468 & 104542 & 7.7696 & 7.5802 & TST & \\
\hline CHEMBL422948 & 104542 & 9.1487 & 9.1943 & TRN & \\
\hline CHEMBL70639 & 104542 & 7.3768 & 7.4726 & TRN & \\
\hline CHEMBL 70354 & 104542 & 8.1739 & 8.1809 & TRN & \\
\hline CHEMBL308598 & 104542 & 7.7212 & 7.6888 & TRN & \\
\hline CHEMBL 306189 & 104542 & 9.1805 & 9.4341 & TRN & \\
\hline CHEMBL 308228 & 104542 & 8.7212 & 9.1655 & TST & \\
\hline CHEMBL 72743 & 104542 & 8.1367 & 8.1151 & TRN & \\
\hline CHEMBL 70571 & 104542 & 9.0506 & 9.5059 & TST & \\
\hline CHEMBL 307090 & 104542 & 8.8861 & 8.8525 & TRN & \\
\hline CHEMBL 71071 & 104542 & 9.1938 & 9.0437 & TRN & \\
\hline CHEMBL72788 & 104542 & 9.0362 & 9.0038 & TRN & \\
\hline CHEMBL 306470 & 104542 & 8.585 & 8.5996 & TRN & \\
\hline CHEMBL308397 & 104542 & 8.0915 & 7.9611 & TST & \\
\hline CHEMBL71618 & 104542 & 9.1549 & 8.6838 & TST & \\
\hline CHEMBL71630 & 104542 & 8.0915 & 7.7961 & TST & \\
\hline CHEMBL306912 & 104542 & 9.3565 & 9.406 & TST & \\
\hline CHEMBL303155 & 104542 & 8.8861 & 8.6825 & TST & \\
\hline CHEMBL70406 & 104542 & 7.6021 & 7.9492 & TST & \\
\hline CHEMBL71482 & 104542 & 9.6778 & 9.4341 & TRN & \\
\hline CHEMBL68049 & 104542 & 7.2596 & 7.28100 & 0000000001 & TRN \\
\hline CHEMBL 3681260 & 1528790 & 6.4559 & 7.36600 & 00000000005 & TRN \\
\hline CHEMBL 3676314 & 1528790 & 8.2518 & 7.9381 & TRN & \\
\hline CHEMBL 3681264 & 1528790 & 8.2076 & 7.63700 & 00000000005 & TST \\
\hline CHEMBL 3676315 & 1528790 & 8.4949 & 8.2818 & TRN & \\
\hline CHEMBL 3676316 & 1528790 & 8.3665 & 8.2853 & TRN & \\
\hline CHEMBL 3676313 & 1528790 & 8.2596 & 8.0826 & TRN & \\
\hline CHEMBL 3681310 & 1528790 & 7.6576 & 7.9991 & TST & \\
\hline CHEMBL 3681283 & 1528790 & 7.5376 & 7.7024 & TRN & \\
\hline CHEMBL 3676331 & 1528790 & 8.0655 & 7.7629 & TRN & \\
\hline CHEMBL 3681316 & 1528790 & 7.7447 & 7.2076 & TRN & \\
\hline CHEMBL3681271 & 1528790 & 7.9208 & 8.2878 & TRN & \\
\hline CHEMBL 3681286 & 1528790 & 6.699 & 7.2367 & TRN & \\
\hline CHEMBL 3676319 & 1528790 & 7.1938 & 6.9391 & TRN & \\
\hline CHEMBL 3681250 & 1528790 & 8.2596 & 8.1274 & TRN & \\
\hline CHEMBL 3681308 & 1528790 & 7.699 & 7.5228 & TST & \\
\hline CHEMBL3681315 & 1528790 & 7.699 & 8.2489 & TRN & \\
\hline CHEMBL 3681258 & 1528790 & 8.0 & 7.8377 & TRN & \\
\hline CHEMBL 3681242 & 1528790 & 7.6778 & 7.7018 & TRN & \\
\hline CHEMBL 3681307 & 1528790 & 8.2596 & 7.5154 & TRN & \\
\hline CHEMBL3681309 & 1528790 & 7.1079 & 7.2043 & TRN & \\
\hline CHEMBL3681292 & 1528790 & 8.3372 & 8.4536 & TRN & \\
\hline CHEMBL 3681240 & 1528790 & 7.7959 & 7.7582 & TRN & \\
\hline CHEMBL 3681244 & 1528790 & 7.585 & 7.4763 & TRN & \\
\hline CHEMBL 3681255 & 1528790 & 7.585 & 7.5542 & TRN & \\
\hline CHEMBL3681319 & 1528790 & 6.4056 & 6.4509 & TRN & \\
\hline CHEMBL3676322 & 1528790 & 7.7212 & 7.6256 & TRN & \\
\hline
\end{tabular}


Supplemental Table S2.txt

\begin{tabular}{|c|c|c|c|c|c|}
\hline CHEMBL 3681266 & 1528790 & 7.4202 & 7.8374 & TST & \\
\hline CHEMBL3676336 & 1528790 & 7.6576 & 7.477 & TRN & \\
\hline CHEMBL3681296 & 1528790 & 7.8239 & 7.6879 & TRN & \\
\hline CHEMBL 3676324 & 1528790 & 7.8239 & 8.0399 & TRN & \\
\hline CHEMBL3681268 & 1528790 & 7.4089 & 7.0779 & TRN & \\
\hline CHEMBL3681254 & 1528790 & 7.4318 & 7.2372 & TRN & \\
\hline CHEMBL 3681272 & 1528790 & 8.0706 & 8.1627 & TRN & \\
\hline CHEMBL 3681304 & 1528790 & 7.7959 & 7.727 & TRN & \\
\hline CHEMBL 3676337 & 1528790 & 7.7959 & 7.6595 & TST & \\
\hline CHEMBL3681243 & 1528790 & 7.4437 & 7.4601 & TRN & \\
\hline CHEMBL3681294 & 1528790 & 8.4437 & 7.6729 & TST & \\
\hline CHEMBL 3681285 & 1528790 & 8.041 & 8.0298 & TRN & \\
\hline CHEMBL3681238 & 1528790 & 7.6021 & 7.7752 & TRN & \\
\hline CHEMBL 3681284 & 1528790 & 8.3979 & 8.4182 & TRN & \\
\hline CHEMBL3639801 & 1528790 & 7.4202 & 7.7299 & TRN & \\
\hline CHEMBL3681245 & 1528790 & 7.6576 & 7.697 & TRN & \\
\hline CHEMBL3681236 & 1528790 & 7.9208 & 7.9241 & TRN & \\
\hline CHEMBL3681299 & 1528790 & 7.2518 & 7.1694 & TRN & \\
\hline CHEMBL3681239 & 1528790 & 6.699 & 7.1976 & TRN & \\
\hline CHEMBL3681291 & 1528790 & 8.3188 & 8.1973 & TRN & \\
\hline CHEMBL3681267 & 1528790 & 7.7696 & 7.8885 & TRN & \\
\hline CHEMBL 3681270 & 1528790 & 8.0757 & 7.9335 & TRN & \\
\hline CHEMBL 3681290 & 1528790 & 8.2007 & 8.1804 & TRN & \\
\hline CHEMBL3681261 & 1528790 & 6.2692 & 6.657 & TRN & \\
\hline CHEMBL 3676321 & 1528790 & 7.6778 & 7.6464 & TRN & \\
\hline CHEMBL3681306 & 1528790 & 8.1192 & 7.8516 & TRN & \\
\hline CHEMBL3681246 & 1528790 & 8.0 & 7.8861 & TRN & \\
\hline CHEMBL 3681241 & 1528790 & 7.5686 & 7.5281 & TRN & \\
\hline CHEMBL3681278 & 1528790 & 8.4685 & 8.5695 & TRN & \\
\hline CHEMBL 3681274 & 1528790 & 7.9208 & 8.0214 & TRN & \\
\hline CHEMBL 3681253 & 1528790 & 5.7212 & 6.2527 & TST & \\
\hline CHEMBL 3681275 & 1528790 & 6.585 & 6.7029 & TRN & \\
\hline CHEMBL 3681302 & 1528790 & 7.5376 & 7.6733 & TRN & \\
\hline CHEMBL3676326 & 1528790 & 7.6383 & 7.8358 & TST & \\
\hline CHEMBL 3681288 & 1528790 & 6.4949 & 6.7886 & TRN & \\
\hline CHEMBL 3681252 & 1528790 & 7.2441 & \multicolumn{2}{|c|}{7.617000000000001} & TRN \\
\hline CHEMBL3681259 & 1528790 & 6.6576 & 7.1845 & TST & \\
\hline CHEMBL 3681247 & 1528790 & 7.9208 & 8.1291 & TRN & \\
\hline CHEMBL3681300 & 1528790 & 6.9586 & 7.3677 & TRN & \\
\hline CHEMBL 3681281 & 1528790 & 7.7212 & 7.8757 & TRN & \\
\hline CHEMBL3676318 & 1528790 & 7.5086 & 7.7936 & TRN & \\
\hline CHEMBL3681262 & 1528790 & 7.3979 & 7.5308 & TST & \\
\hline CHEMBL3676330 & 1528790 & 7.585 & 7.4524 & TRN & \\
\hline CHEMBL3676320 & 1528790 & 8.2676 & 7.8225 & TRN & \\
\hline CHEMBL3681311 & 1528790 & 7.3979 & 7.1955 & TST & \\
\hline CHEMBL3681301 & 1528790 & 7.699 & 7.7601 & TRN & \\
\hline CHEMBL3681263 & 1528790 & 7.7447 & 7.604 & TRN & \\
\hline CHEMBL3681249 & 1528790 & 7.8539 & 7.5877 & TRN & \\
\hline
\end{tabular}

Page 4715 
Supplemental Table S2.txt

\begin{tabular}{|c|c|c|c|c|c|}
\hline CHEMBL3681280 & 1528790 & 7.9208 & 8.012 & TRN & \\
\hline CHEMBL3681248 & 1528790 & 8.0809 & 7.8622 & TRN & \\
\hline CHEMBL3681256 & 1528790 & 7.7696 & 7.6518 & TRN & \\
\hline CHEMBL 3676323 & 1528790 & 7.6383 & 7.7242 & TRN & \\
\hline CHEMBL3676332 & 1528790 & 7.6778 & 7.16 & TRN & \\
\hline CHEMBL3676317 & 1528790 & 8.0706 & 7.7576 & TRN & \\
\hline CHEMBL3676327 & 1528790 & 7.7696 & 8.0194 & TRN & \\
\hline CHEMBL3681317 & 1528790 & 7.6778 & 7.6655 & TRN & \\
\hline CHEMBL3676328 & 1528790 & 8.3665 & 8.3772 & TRN & \\
\hline CHEMBL3681279 & 1528790 & 7.585 & 7.5471 & TRN & \\
\hline CHEMBL3681298 & 1528790 & 7.8239 & 7.4885 & TRN & \\
\hline CHEMBL3676312 & 1528790 & 7.6383 & 7.6238 & TST & \\
\hline CHEMBL3676335 & 1528790 & 7.0655 & 7.0748 & TST & \\
\hline CHEMBL3681312 & 1528790 & 7.4949 & 7.011 & TST & \\
\hline CHEMBL 3676334 & 1528790 & 7.4685 & 7.2487 & TRN & \\
\hline CHEMBL3681313 & 1528790 & 6.7447 & 6.9683 & TRN & \\
\hline CHEMBL3681305 & 1528790 & 7.585 & 7.3749 & TRN & \\
\hline CHEMBL3681295 & 1528790 & 8.0 & 7.9645 & TRN & \\
\hline CHEMBL 3681287 & 1528790 & 7.1871 & 7.6113 & TRN & \\
\hline CHEMBL3681265 & 1528790 & 7.4089 & 7.6638 & TST & \\
\hline CHEMBL3681277 & 1528790 & 7.1739 & 6.8812 & TRN & \\
\hline CHEMBL3681276 & 1528790 & 6.2924 & 6.5095 & TRN & \\
\hline CHEMBL3681297 & 1528790 & 7.6778 & 7.8446 & TST & \\
\hline CHEMBL3681269 & 1528790 & 7.5086 & 7.5828 & TST & \\
\hline CHEMBL3681314 & 1528790 & 8.0269 & 8.179 & TST & \\
\hline CHEMBL3681273 & 1528790 & 6.9586 & 7.1664 & TST & \\
\hline CHEMBL3681237 & 1528790 & 7.3188 & 8.4717 & TST & \\
\hline CHEMBL3681282 & 1528790 & 8.2218 & 7.6875 & TST & \\
\hline CHEMBL 3681303 & 1528790 & 8.3979 & 8.0537 & TST & \\
\hline CHEMBL 3681293 & 1528790 & 7.5528 & 7.3135 & TST & \\
\hline CHEMBL3676333 & 1528790 & 7.3768 & 6.943 & TST & \\
\hline CHEMBL 3681251 & 1528790 & 7.8539 & 7.5637 & TST & \\
\hline CHEMBL3676325 & 1528790 & 7.9208 & 8.6166 & TST & \\
\hline CHEMBL 3681318 & 1528790 & 7.1805 & 6.8917 & TST & \\
\hline CHEMBL 3681257 & 1528790 & 7.5528 & 7.6608 & TST & \\
\hline CHEMBL1289932 & 686303 & 5.475 & 5.961 & TRN & \\
\hline CHEMBL1290585 & 686303 & 4.0 & 6.082999 & 9999999999 & TRN \\
\hline CHEMBL1290144 & 686303 & 7.1549 & 6.4951 & TRN & \\
\hline CHEMBL1290145 & 686303 & 5.556 & 5.2886 & TRN & \\
\hline CHEMBL1289500 & 686303 & 7.2147 & 7.8349 & TRN & \\
\hline CHEMBL1290584 & 686303 & 7.7447 & 6.2333 & TRN & \\
\hline CHEMBL1289933 & 686303 & 6.8861 & 6.0823 & TRN & \\
\hline CHEMBL1290480 & 686303 & 6.3354 & 6.5382 & TST & \\
\hline CHEMBL1290370 & 686303 & 6.284 & 5.865 & TRN & \\
\hline CHEMBL461658 & 686303 & 7.8239 & 6.2348 & TRN & \\
\hline CHEMBL1289264 & 686303 & 7.4318 & 7.4057 & TRN & \\
\hline CHEMBL1289934 & 686303 & 7.284 & 7.3467 & TRN & \\
\hline CHEMBL1290254 & 686303 & 5.8386 & 5.8676 & TRN & \\
\hline
\end{tabular}




\begin{tabular}{|c|c|c|c|c|c|c|}
\hline & & \multicolumn{5}{|c|}{ Supplemental Table S2.txt } \\
\hline CHEMBL1289385 & 686303 & 5.8386 & 5.7283 & TRN & & \\
\hline CHEMBL1290255 & 686303 & 7.6778 & 7.5235 & TRN & & \\
\hline CHEMBL1290372 & 686303 & 5.6091 & 5.4928 & TRN & & \\
\hline CHEMBL1289713 & 686303 & 5.5986 & 6.103 & TRN & & \\
\hline CHEMBL1290257 & 686303 & 5.3747 & 5.2874 & TST & & \\
\hline CHEMBL1289712 & 686303 & 7.7212 & 7.5711 & TRN & & \\
\hline CHEMBL1290587 & 686303 & 6.7447 & 6.8113 & TRN & & \\
\hline CHEMBL1289151 & 686303 & 7.2924 & 6.2805 & TRN & & \\
\hline CHEMBL1289152 & 686303 & 7.7447 & 7.7471 & TRN & & \\
\hline CHEMBL1290478 & 686303 & 7.0969 & 7.1449 & TRN & & \\
\hline CHEMBL1290705 & 686303 & 6.4425 & 7.5591 & TRN & & \\
\hline CHEMBL1290479 & 686303 & 4.1759 & 4.9638 & TRN & & \\
\hline CHEMBL1289817 & 686303 & 3.699 & 4.8231 & TRN & & \\
\hline CHEMBL1290036 & 686303 & 5.6326 & 5.1262 & TRN & & \\
\hline CHEMBL1290369 & 686303 & 8.0458 & 6.2351 & TRN & & \\
\hline CHEMBL1290588 & 686303 & 6.7545 & 6.2751 & TST & & \\
\hline CHEMBL1290256 & 686303 & 5.7122 & 6.2835 & TRN & & \\
\hline CHEMBL1289037 & 686303 & 6.2366 & 6.0506 & TST & & \\
\hline CHEMBL1289035 & 686303 & 7.0132 & 7.2863 & TRN & & \\
\hline CHEMBL1289036 & 686303 & 7.2518 & 7.2883 & TRN & & \\
\hline CHEMBL1289607 & 686303 & 8.2218 & 6.9152 & TRN & & \\
\hline CHEMBL1289608 & 686303 & 6.6383 & 6.8337 & TRN & & \\
\hline CHEMBL1289818 & 686303 & 7.6021 & 7.5039 & TRN & & \\
\hline CHEMBL1290034 & 686303 & 7.3665 & 7.3979 & TRN & & \\
\hline CHEMBL1290143 & 686303 & 7.4202 & 7.4724 & TRN & & \\
\hline CHEMBL1289384 & 686303 & 7.0605 & 7.6635 & TRN & & \\
\hline CHEMBL1290477 & 686303 & 3.699 & 5.9284 & TRN & & \\
\hline CHEMBL1290703 & 686303 & 5.6904 & 6.4797 & TRN & & \\
\hline CHEMBL 254778 & 686303 & 6.7959 & 6.3559 & TST & & \\
\hline CHEMBL1289150 & 686303 & 7.5086 & 6.5622 & TRN & & \\
\hline CHEMBL1289935 & 686303 & 5.2104 & 4.9857 & TRN & & \\
\hline CHEMBL1289266 & 686303 & 7.4318 & 7.7476 & TST & & \\
\hline CHEMBL1289034 & 686303 & 6.7258 & 6.0626 & TST & & \\
\hline CHEMBL1290035 & 686303 & 6.0424 & 5.7876 & TST & & \\
\hline CHEMBL1290704 & 686303 & 7.6021 & 6.0867 & TST & & \\
\hline CHEMBL1289501 & 686303 & 7.2366 & 7.2127 & TST & & \\
\hline CHEMBL1289265 & 686303 & 5.9755 & 6.3663 & TST & & \\
\hline CHEMBL1289383 & 686303 & 7.2518 & 7.1794 & TST & & \\
\hline CHEMBL1290373 & 686303 & 6.3478 & 6.2013 & TST & & \\
\hline CHEMBL1290146 & 686303 & 5.6271 & 5.3004 & TST & & \\
\hline CHEMBL102714 & 954786 & 3.2707 & 3.5588 & TRN & & \\
\hline CHEMBL483847 & 954786 & 3.8834 & 3.9609 & TRN & & \\
\hline CHEMBL 213100 & 954786 & $4.8610 €$ & 30000000 & $\partial 1$ & 5.2665 & TRN \\
\hline CHEMBL577784 & 954786 & 5.4946 & 5.5979 & TRN & & \\
\hline CHEMBL1516890 & 954786 & 3.7739 & 3.6285 & TRN & & \\
\hline CHEMBL 2137530 & 954786 & 4.6443 & 4.8399 & TRN & & \\
\hline CHEMBL1242367 & 954786 & 4.675 & 4.3372 & TRN & & \\
\hline CHEMBL 2144069 & 954786 & 5.1782 & 5.0001 & TRN & & \\
\hline
\end{tabular}




\begin{tabular}{|c|c|c|c|c|c|c|}
\hline & & \multicolumn{5}{|c|}{ Supplemental Table s2.txt } \\
\hline CHEMBL300389 & 954786 & 5.994 & 6.1799 & TRN & & \\
\hline CHEMBL1230020 & 954786 & 4.206 & 4.0511 & TRN & & \\
\hline CHEMBL3392440 & 954786 & 3.6454 & 3.8713 & TRN & & \\
\hline CHEMBL412142 & 954786 & 6.023 & 5.3673 & TRN & & \\
\hline CHEMBL1590308 & 954786 & 4.1335 & 4.1597 & TST & & \\
\hline CHEMBL585951 & 954786 & 5.3305 & 5.6114 & TRN & & \\
\hline CHEMBL 240954 & 954786 & 3.4078 & 3.6862 & TST & & \\
\hline CHEMBL1256459 & 954786 & 5.3534 & 5.6453 & TRN & & \\
\hline CHEMBL515416 & 954786 & 4.4504 & 4.2391 & TRN & & \\
\hline CHEMBL92309 & 954786 & 2.6172 & 3.1118 & TST & & \\
\hline CHEMBL 2005886 & 954786 & 4.9629 & 4.8202 & TRN & & \\
\hline CHEMBL1186585 & 954786 & 4.2646 & 4.14199 & 9999999999 & 95 & TRN \\
\hline CHEMBL209148 & 954786 & 4.1998 & 4.2457 & TRN & & \\
\hline CHEMBL512504 & 954786 & 4.1259 & 4.3163 & TRN & & \\
\hline CHEMBL379300 & 954786 & 6.0116 & 5.647 & TRN & & \\
\hline CHEMBL514499 & 954786 & 5.8686 & 5.5172 & TRN & & \\
\hline CHEMBL135561 & 954786 & 4.212 & 4.2911 & TRN & & \\
\hline CHEMBL1673039 & 954786 & \multicolumn{3}{|c|}{5.8020000000000005} & 5.4247 & TRN \\
\hline CHEMBL393929 & 954786 & 3.3813 & 3.5829 & TRN & & \\
\hline CHEMBL189584 & 954786 & 4.2924 & 4.5861 & TRN & & \\
\hline CHEMBL 202721 & 954786 & 5.099 & 5.4076 & TRN & & \\
\hline CHEMBL379975 & 954786 & 4.7651 & 4.9094 & TRN & & \\
\hline CHEMBL399530 & 954786 & 3.6018 & 3.8386 & TRN & & \\
\hline CHEMBL1643959 & 954786 & 4.1163 & 4.1434 & TRN & & \\
\hline CHEMBL220241 & 954786 & 6.2019 & 6.6997 & TRN & & \\
\hline CHEMBL1970879 & 954786 & 4.9568 & 4.7737 & TRN & & \\
\hline CHEMBL392695 & 954786 & 3.3336 & 3.6966 & TRN & & \\
\hline CHEMBL1909414 & 954786 & 3.9786 & 3.8364 & TRN & & \\
\hline CHEMBL 3349342 & 954786 & 5.2947 & 4.8394 & TRN & & \\
\hline CHEMBL1404918 & 954786 & 3.3151 & 2.8714 & TRN & & \\
\hline CHEMBL191334 & 954786 & 5.3232 & 5.2711 & TRN & & \\
\hline CHEMBL 258844 & 954786 & 3.6173 & 3.9181 & TRN & & \\
\hline CHEMBL 217354 & 954786 & 6.0288 & 5.6103 & TRN & & \\
\hline CHEMBL 210618 & 954786 & 3.1693 & 3.3585 & TRN & & \\
\hline CHEMBL180127 & 954786 & 4.6279 & 4.4321 & TRN & & \\
\hline CHEMBL 222102 & 954786 & 3.1356 & 3.7947 & TST & & \\
\hline CHEMBL573107 & 954786 & 4.7999 & 5.0606 & TST & & \\
\hline CHEMBL 373751 & 954786 & 3.4442 & 4.1262 & TST & & \\
\hline CHEMBL255342 & 954786 & 4.5009 & 3.4739 & TST & & \\
\hline CHEMBL483849 & 954786 & \multicolumn{3}{|c|}{1.8119999999999998} & 2.0656 & TST \\
\hline CHEMBL188678 & 954786 & 4.0131 & 4.3269 & TST & & \\
\hline CHEMBL9470 & 954786 & 5.7799 & 5.6263 & TST & & \\
\hline CHEMBL509032 & 954786 & 4.8338 & 5.461 & TST & & \\
\hline CHEMBL 2134202 & 954786 & 3.9173 & 3.906 & TST & & \\
\hline CHEMBL3186408 & 954786 & 4.6819 & 4.1899 & TST & & \\
\hline CHEMBL65 & 954786 & 7.403 & 7.348 & TST & & \\
\hline CHEMBL 3093224 & 1278703 & 5.1675 & 5.05399 & 9999999999 & & TRN \\
\hline CHEMBL 3093333 & 1278703 & 5.9957 & 5.1945 & TRN & & \\
\hline
\end{tabular}


Supplemental Table S2.txt

\begin{tabular}{|c|c|c|c|c|c|}
\hline CHEMBL 3091482 & 1278703 & 4.0 & 4.5191 & TRN & \\
\hline CHEMBL 3093324 & 1278703 & 5.0 & 4.81 & TRN & \\
\hline CHEMBL 3093223 & 1278703 & 5.0 & 4.8782 & TRN & \\
\hline CHEMBL 3093315 & 1278703 & 4.0 & 4.5165 & TRN & \\
\hline CHEMBL 3093314 & 1278703 & 5.0 & 4.9899 & TRN & \\
\hline CHEMBL 3093231 & 1278703 & 5.0 & 4.5043 & TST & \\
\hline CHEMBL 3091481 & 1278703 & 5.7959 & 5.3353 & TRN & \\
\hline CHEMBL 3093220 & 1278703 & 5.0 & 5.2446 & TRN & \\
\hline CHEMBL 3093235 & 1278703 & 4.0 & 3.9492 & TRN & \\
\hline CHEMBL3093322 & 1278703 & 4.0 & 4.7228 & TRN & \\
\hline CHEMBL 3093241 & 1278703 & 5.0 & 5.106 & TRN & \\
\hline CHEMBL 3093228 & 1278703 & 4.0 & 4.601 & TRN & \\
\hline CHEMBL 3093232 & 1278703 & 4.0 & 4.135 & TRN & \\
\hline CHEMBL 241617 & 1278703 & 4.0 & 3.8728 & TRN & \\
\hline CHEMBL3093312 & 1278703 & 5.0 & 5.0834 & TRN & \\
\hline CHEMBL 239230 & 1278703 & 4.0 & 3.6965 & TRN & \\
\hline CHEMBL 3093230 & 1278703 & 4.0 & 4.532 & TST & \\
\hline CHEMBL 3093217 & 1278703 & 4.0 & 4.8105 & TRN & \\
\hline CHEMBL 3093326 & 1278703 & 4.0 & 4.8607 & TST & \\
\hline CHEMBL 3093233 & 1278703 & 4.0 & 4.0397 & TRN & \\
\hline CHEMBL 3093218 & 1278703 & 5.6108 & 5.9195 & TRN & \\
\hline CHEMBL 3093310 & 1278703 & 4.0 & 4.6956 & TRN & \\
\hline CHEMBL 3093313 & 1278703 & 5.0 & 4.8412 & TRN & \\
\hline CHEMBL 3093225 & 1278703 & 5.5186 & 5.2137 & TRN & \\
\hline CHEMBL 3093319 & 1278703 & 5.0 & 4.7645 & TRN & \\
\hline CHEMBL 3093236 & 1278703 & 4.0 & 4.0744 & TRN & \\
\hline CHEMBL 3093226 & 1278703 & 5.4672 & 4.8723 & TRN & \\
\hline CHEMBL241618 & 1278703 & 4.8182 & 4.1365 & TRN & \\
\hline CHEMBL 3093330 & 1278703 & 5.0 & 5.0527 & TRN & \\
\hline CHEMBL 3093317 & 1278703 & 4.0 & 4.4424 & TRN & \\
\hline CHEMBL 3093238 & 1278703 & 4.0 & 3.9483 & TRN & \\
\hline CHEMBL 3093221 & 1278703 & 6.2668 & 5.252000 & 0000000001 & TST \\
\hline CHEMBL 3093331 & 1278703 & 4.0 & 4.65 & TRN & \\
\hline CHEMBL 3093328 & 1278703 & 4.8761 & 4.4621 & TRN & \\
\hline CHEMBL 3093321 & 1278703 & 4.0 & 4.5905 & TRN & \\
\hline CHEMBL 282038 & 1278703 & 4.0 & 3.8592 & TST & \\
\hline CHEMBL 3093234 & 1278703 & 5.0 & 4.298999 & 99999999995 & TRN \\
\hline CHEMBL 3093240 & 1278703 & 4.0 & 5.4207 & TST & \\
\hline CHEMBL 3093316 & 1278703 & 5.0 & 4.5624 & TRN & \\
\hline CHEMBL 3093237 & 1278703 & 4.0 & 3.9061 & TST & \\
\hline CHEMBL 3093239 & 1278703 & 4.0 & 3.9162 & TST & \\
\hline CHEMBL 3093222 & 1278703 & 5.0 & 5.8721 & TST & \\
\hline CHEMBL 3093311 & 1278703 & 5.3556 & 5.2446 & TRN & \\
\hline CHEMBL 3093229 & 1278703 & 4.0 & 4.713999 & 99999999995 & TRN \\
\hline CHEMBL 3093325 & 1278703 & 4.0 & 4.8285 & \multirow{4}{*}{\multicolumn{2}{|c|}{5.5764 TST }} \\
\hline CHEMBL 3093323 & 1278703 & 6.0 & 5.2246 & & \\
\hline CHEMBL 3093219 & 1278703 & 6.11799 & 999999999 & & \\
\hline CHEMBL 3093329 & 1278703 & 4.0 & 4.7737 & TRN & \\
\hline
\end{tabular}




\begin{tabular}{|c|c|c|c|c|c|}
\hline \multicolumn{6}{|c|}{ Supplemental Table S2.txt } \\
\hline CHEMBL413079 & 1278703 & 4.0 & 4.9105 & TST & \\
\hline CHEMBL 3093227 & 1278703 & 5.1993 & 4.6507 & TRN & \\
\hline CHEMBL3093320 & 1278703 & 5.0 & 4.5614 & TRN & \\
\hline CHEMBL 3093216 & 1278703 & 4.0 & 4.7322 & TST & \\
\hline CHEMBL 3093318 & 1278703 & 5.0 & 4.7087 & TRN & \\
\hline CHEMBL 3093332 & 1278703 & 5.0 & 4.8429 & TRN & \\
\hline CHEMBL 3093215 & 1278703 & 4.0 & 4.3742 & TST & \\
\hline CHEMBL 3093214 & 1278703 & 5.5229 & 4.7238 & TST & \\
\hline CHEMBL138643 & 105071 & 8.0969 & 8.5115 & TRN & \\
\hline CHEMBL141475 & 105071 & 8.0 & 8.1669 & TRN & \\
\hline CHEMBL140335 & 105071 & 6.5229 & 6.4969 & TRN & \\
\hline CHEMBL142071 & 105071 & 7.699 & 7.4726 & TRN & \\
\hline CHEMBL294167 & 105071 & 6.0 & 7.0123 & TRN & \\
\hline CHEMBL422105 & 105071 & 8.5229 & 8.3485 & TRN & \\
\hline CHEMBL141589 & 105071 & 7.3979 & 7.4381 & TRN & \\
\hline CHEMBL141560 & 105071 & 8.0 & 8.4724 & TRN & \\
\hline CHEMBL342710 & 105071 & 7.5229 & 7.7082 & TRN & \\
\hline CHEMBL424473 & 105071 & 7.699 & 6.8645 & TRN & \\
\hline CHEMBL137929 & 105071 & 6.699 & 6.5927 & TRN & \\
\hline CHEMBL 337585 & 105071 & 7.0969 & 7.54299 & & TRN \\
\hline CHEMBL343775 & 105071 & 6.2218 & 6.2734 & TRN & \\
\hline CHEMBL 344029 & 105071 & 6.699 & 6.1916 & TRN & \\
\hline CHEMBL434655 & 105071 & 6.301 & 6.5358 & TRN & \\
\hline CHEMBL343547 & 105071 & 5.699 & 5.9876 & TRN & \\
\hline CHEMBL141672 & 105071 & 6.0 & 5.6609 & TST & \\
\hline CHEMBL141004 & 105071 & 8.0 & 7.9742 & TRN & \\
\hline CHEMBL343392 & 105071 & 7.3979 & 7.9631 & TRN & \\
\hline CHEMBL 344410 & 105071 & 8.0 & 7.7555 & TRN & \\
\hline CHEMBL139542 & 105071 & 8.699 & 8.7315 & TRN & \\
\hline CHEMBL137900 & 105071 & 7.5229 & 7.1982 & TRN & \\
\hline CHEMBL140602 & 105071 & 8.699 & 7.7525 & TST & \\
\hline CHEMBL138656 & 105071 & 8.699 & 8.1781 & TRN & \\
\hline CHEMBL342889 & 105071 & 6.0969 & 6.5124 & TRN & \\
\hline CHEMBL138696 & 105071 & 7.301 & 7.7522 & TRN & \\
\hline CHEMBL 342374 & 105071 & 6.5229 & 6.2796 & TRN & \\
\hline CHEMBL138264 & 105071 & 6.2218 & 6.2747 & TST & \\
\hline CHEMBL141470 & 105071 & 7.0458 & 7.0448 & TRN & \\
\hline CHEMBL138338 & 105071 & 8.0969 & 7.6389 & TST & \\
\hline CHEMBL138535 & 105071 & 5.5229 & 5.724 & TRN & \\
\hline CHEMBL140888 & 105071 & 7.5229 & 7.5992 & TRN & \\
\hline CHEMBL 336243 & 105071 & 8.699 & 9.1328 & TRN & \\
\hline CHEMBL424106 & 105071 & 5.1549 & 5.5687 & TRN & \\
\hline CHEMBL424472 & 105071 & 7.5229 & 7.0712 & TRN & \\
\hline CHEMBL344827 & 105071 & 7.3979 & 7.6731 & TST & \\
\hline CHEMBL434446 & 105071 & 8.699 & 8.4029 & TRN & \\
\hline CHEMBL142134 & 105071 & 8.699 & 8.981 & TRN & \\
\hline CHEMBL142095 & 105071 & 7.699 & 7.5078 & TRN & \\
\hline CHEMBL57725 & 105071 & 8.5229 & 8.4396 & TST & \\
\hline
\end{tabular}




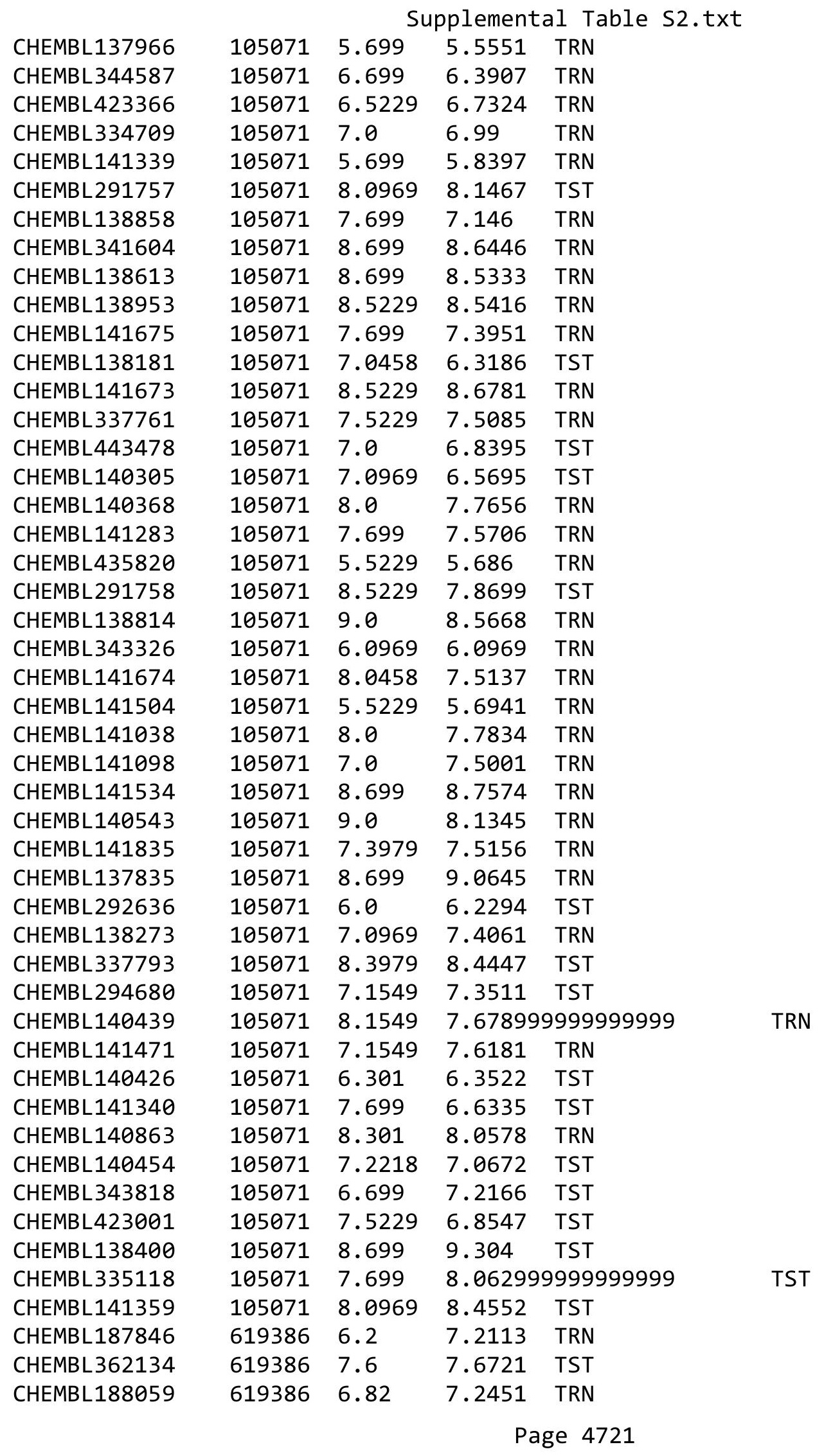




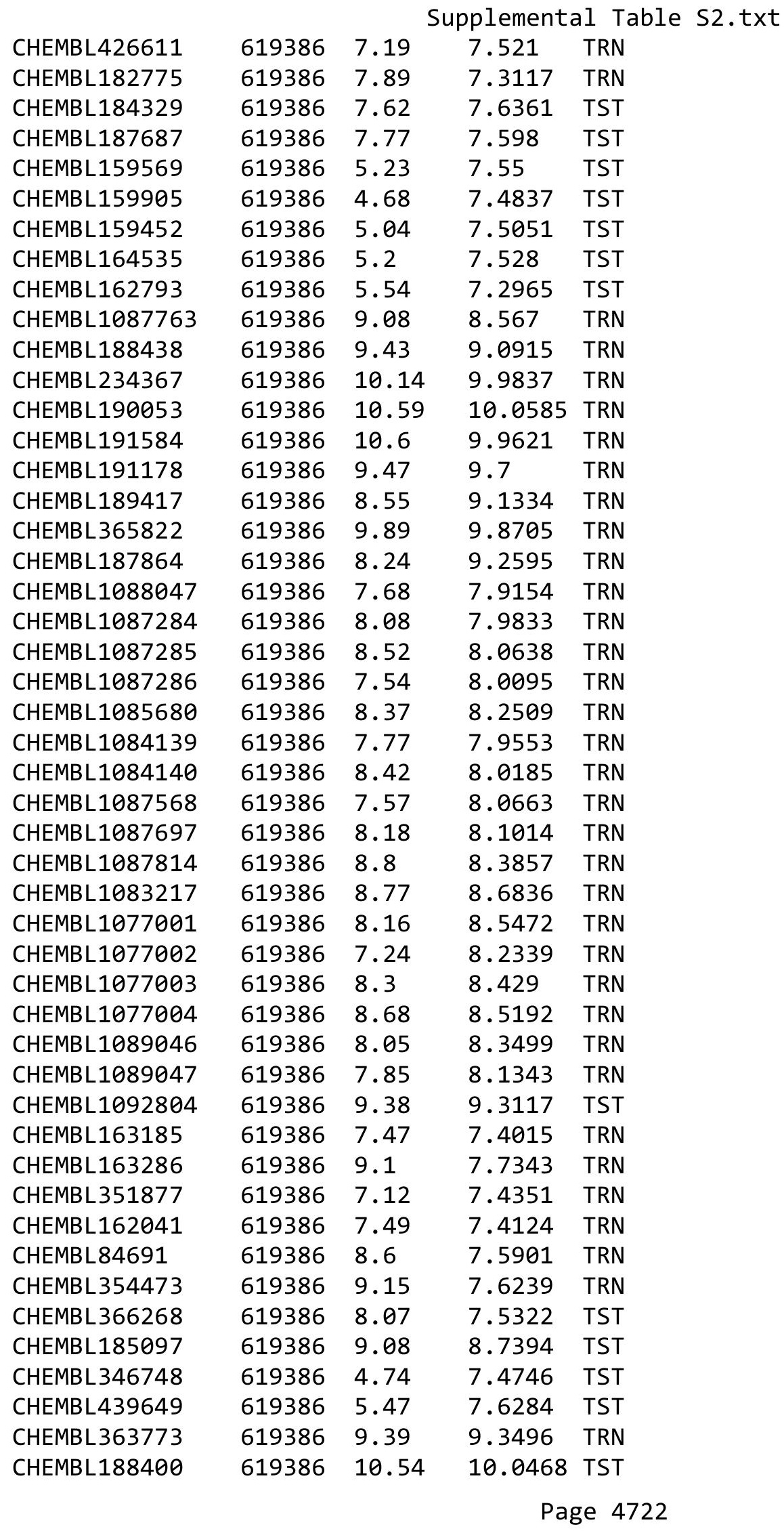




\begin{tabular}{|c|c|c|c|c|c|}
\hline \multicolumn{6}{|c|}{ Supplemental Table S2.txt } \\
\hline CHEMBL1087934 & 619386 & 9.19 & 9.6174 & TST & \\
\hline CHEMBL1087177 & 619386 & 7.19 & 8.0604 & TRN & \\
\hline CHEMBL1086659 & 619386 & 7.49 & 8.0076 & TRN & \\
\hline CHEMBL1086660 & 619386 & 8.55 & 8.5613 & TRN & \\
\hline CHEMBL1085660 & 619386 & 7.82 & 8.3184 & TRN & \\
\hline CHEMBL164373 & 619386 & 7.7 & 7.54899 & 99999999995 & TRN \\
\hline CHEMBL355138 & 619386 & 8.2 & 7.7339 & TRN & \\
\hline CHEMBL3931533 & 1637329 & 6.61 & 6.5457 & TRN & \\
\hline CHEMBL 3947740 & 1637329 & 6.43 & 6.4213 & TRN & \\
\hline CHEMBL3963816 & 1637329 & 5.64 & 5.5465 & TRN & \\
\hline CHEMBL3909951 & 1637329 & 5.67 & 5.8269 & TRN & \\
\hline CHEMBL3912630 & 1637329 & 5.54 & 5.694 & TRN & \\
\hline CHEMBL3933449 & 1637329 & 6.64 & 6.5831 & TRN & \\
\hline CHEMBL 3898908 & 1637329 & 7.09 & 6.5835 & TST & \\
\hline CHEMBL3986163 & 1637329 & 6.15 & 5.9183 & TRN & \\
\hline CHEMBL3898120 & 1637329 & 5.56 & 5.6356 & TRN & \\
\hline CHEMBL3955288 & 1637329 & 5.72 & 6.0837 & TRN & \\
\hline CHEMBL3957914 & 1637329 & 5.66 & 5.7853 & TRN & \\
\hline CHEMBL3908978 & 1637329 & 4.0 & 4.0306 & TRN & \\
\hline CHEMBL3906155 & 1637329 & 6.53 & 6.7328 & TRN & \\
\hline CHEMBL3940334 & 1637329 & 6.01 & 6.6077 & TRN & \\
\hline CHEMBL3958153 & 1637329 & 6.86 & 6.9851 & TRN & \\
\hline CHEMBL3925254 & 1637329 & 5.98 & 6.3122 & TRN & \\
\hline CHEMBL3907600 & 1637329 & 6.06 & 6.41200 & 0000000001 & TRN \\
\hline CHEMBL3954368 & 1637329 & 4.0 & 4.5779 & TRN & \\
\hline CHEMBL3951714 & 1637329 & 6.05 & 5.9074 & TRN & \\
\hline CHEMBL3965364 & 1637329 & 4.0 & 4.0874 & TRN & \\
\hline CHEMBL3969446 & 1637329 & 6.15 & 6.0018 & TRN & \\
\hline CHEMBL3951126 & 1637329 & 6.87 & 6.765 & TRN & \\
\hline CHEMBL3933015 & 1637329 & 5.09 & 4.5402 & TRN & \\
\hline CHEMBL 3898881 & 1637329 & 7.1 & 7.4515 & TRN & \\
\hline CHEMBL3901644 & 1637329 & 6.61 & 6.7923 & TRN & \\
\hline CHEMBL3944665 & 1637329 & 5.23 & 5.4187 & TST & \\
\hline CHEMBL 3947293 & 1637329 & 5.34 & 5.5612 & TRN & \\
\hline CHEMBL3947826 & 1637329 & 5.0 & 4.4072 & TST & \\
\hline CHEMBL3985692 & 1637329 & 7.0 & 6.8134 & TST & \\
\hline CHEMBL3947990 & 1637329 & 5.6 & 5.8864 & TST & \\
\hline CHEMBL3925306 & 1637329 & 6.06 & 6.0598 & TRN & \\
\hline CHEMBL3951245 & 1637329 & 6.74 & 7.0071 & TST & \\
\hline CHEMBL3948623 & 1637329 & 6.11 & 6.1041 & TRN & \\
\hline CHEMBL3892018 & 1637329 & 7.07 & 6.3638 & TRN & \\
\hline CHEMBL3987037 & 1637329 & 6.82 & 6.1971 & TRN & \\
\hline CHEMBL3921313 & 1637329 & 6.56 & 6.0432 & TRN & \\
\hline CHEMBL3927327 & 1637329 & 6.39 & 6.0098 & TRN & \\
\hline CHEMBL3976280 & 1637329 & 6.0 & 6.3239 & TRN & \\
\hline CHEMBL3973820 & 1637329 & 6.23 & 5.9253 & TRN & \\
\hline CHEMBL3918011 & 1637329 & 6.55 & 6.2032 & TRN & \\
\hline CHEMBL3915235 & 1637329 & 6.17 & 5.9048 & TRN & \\
\hline
\end{tabular}




\begin{tabular}{|c|c|c|c|c|}
\hline \multicolumn{5}{|c|}{ Supplemental Table S2.txt } \\
\hline CHEMBL3965673 & 1637329 & 4.0 & 3.8995 & TST \\
\hline CHEMBL3968094 & 1637329 & 5.75 & 6.0726 & TRN \\
\hline CHEMBL3918751 & 1637329 & 6.97 & 6.8361 & TRN \\
\hline CHEMBL3956164 & 1637329 & 5.68 & 5.5097 & TRN \\
\hline CHEMBL3908829 & 1637329 & 6.06 & 6.2797 & TRN \\
\hline CHEMBL3911573 & 1637329 & 6.15 & 5.9803 & TRN \\
\hline CHEMBL3969879 & 1637329 & 6.1 & 5.8516 & TRN \\
\hline CHEMBL3972564 & 1637329 & 5.17 & 5.1546 & TRN \\
\hline CHEMBL 3927875 & 1637329 & 6.89 & 6.5338 & TRN \\
\hline CHEMBL3930634 & 1637329 & 5.04 & 4.461 & TRN \\
\hline CHEMBL3901627 & 1637329 & 7.04 & 6.6553 & TST \\
\hline CHEMBL3904329 & 1637329 & 6.95 & 6.9204 & TRN \\
\hline CHEMBL3969408 & 1637329 & 5.11 & 4.2707 & TRN \\
\hline CHEMBL 3985853 & 1637329 & 5.91 & 6.1103 & TRN \\
\hline CHEMBL3908326 & 1637329 & 5.71 & 6.1008 & TRN \\
\hline CHEMBL3918092 & 1637329 & 8.01 & 7.8842 & TRN \\
\hline CHEMBL3964675 & 1637329 & 5.95 & 6.1857 & TRN \\
\hline CHEMBL3955706 & 1637329 & 7.0 & 7.0519 & TRN \\
\hline CHEMBL3937533 & 1637329 & 6.01 & 6.2013 & TRN \\
\hline CHEMBL3962814 & 1637329 & 5.77 & 6.0636 & TRN \\
\hline CHEMBL3931674 & 1637329 & 6.82 & 6.9223 & TRN \\
\hline CHEMBL3976219 & 1637329 & 6.11 & 5.909 & TRN \\
\hline CHEMBL3924872 & 1637329 & 5.86 & 5.9187 & TRN \\
\hline CHEMBL3908529 & 1637329 & 6.56 & 6.6863 & TRN \\
\hline CHEMBL3962805 & 1637329 & 6.09 & 5.9218 & TRN \\
\hline CHEMBL3960128 & 1637329 & 5.29 & 5.7451 & TST \\
\hline CHEMBL3909565 & 1637329 & 6.8 & 6.8825 & TRN \\
\hline CHEMBL 3948321 & 1637329 & 6.03 & 6.2801 & TRN \\
\hline CHEMBL3985750 & 1637329 & 6.07 & 6.1269 & TRN \\
\hline CHEMBL3983115 & 1637329 & 6.11 & 6.2264 & TRN \\
\hline CHEMBL3926311 & 1637329 & 6.42 & 6.2739 & TRN \\
\hline CHEMBL3926406 & 1637329 & 7.13 & 6.6193 & TRN \\
\hline CHEMBL3979490 & 1637329 & 6.89 & 6.8956 & TST \\
\hline CHEMBL 3898355 & 1637329 & 6.76 & 6.9574 & TST \\
\hline CHEMBL 3940725 & 1637329 & 6.57 & 6.2192 & TRN \\
\hline CHEMBL3973531 & 1637329 & 6.58 & 6.6068 & TRN \\
\hline CHEMBL3913757 & 1637329 & 7.17 & 7.1861 & TRN \\
\hline CHEMBL3961210 & 1637329 & 6.88 & 7.2306 & TRN \\
\hline CHEMBL3936765 & 1637329 & 4.0 & 5.0349 & TST \\
\hline CHEMBL3951156 & 1637329 & 6.12 & 6.4493 & TRN \\
\hline CHEMBL3979170 & 1637329 & 7.07 & 6.2651 & TST \\
\hline CHEMBL3921618 & 1637329 & 7.87 & 7.7752 & TRN \\
\hline CHEMBL3969815 & 1637329 & 7.22 & 7.3897 & TRN \\
\hline CHEMBL3961872 & 1637329 & 6.75 & 6.7469 & TST \\
\hline CHEMBL3985222 & 1637329 & 7.58 & 7.5659 & TRN \\
\hline CHEMBL3974664 & 1637329 & 6.92 & 7.1698 & TRN \\
\hline CHEMBL3972173 & 1637329 & 5.76 & 5.8341 & TRN \\
\hline CHEMBL3919173 & 1637329 & 7.89 & 7.7699 & TRN \\
\hline
\end{tabular}


Supplemental Table S2.txt

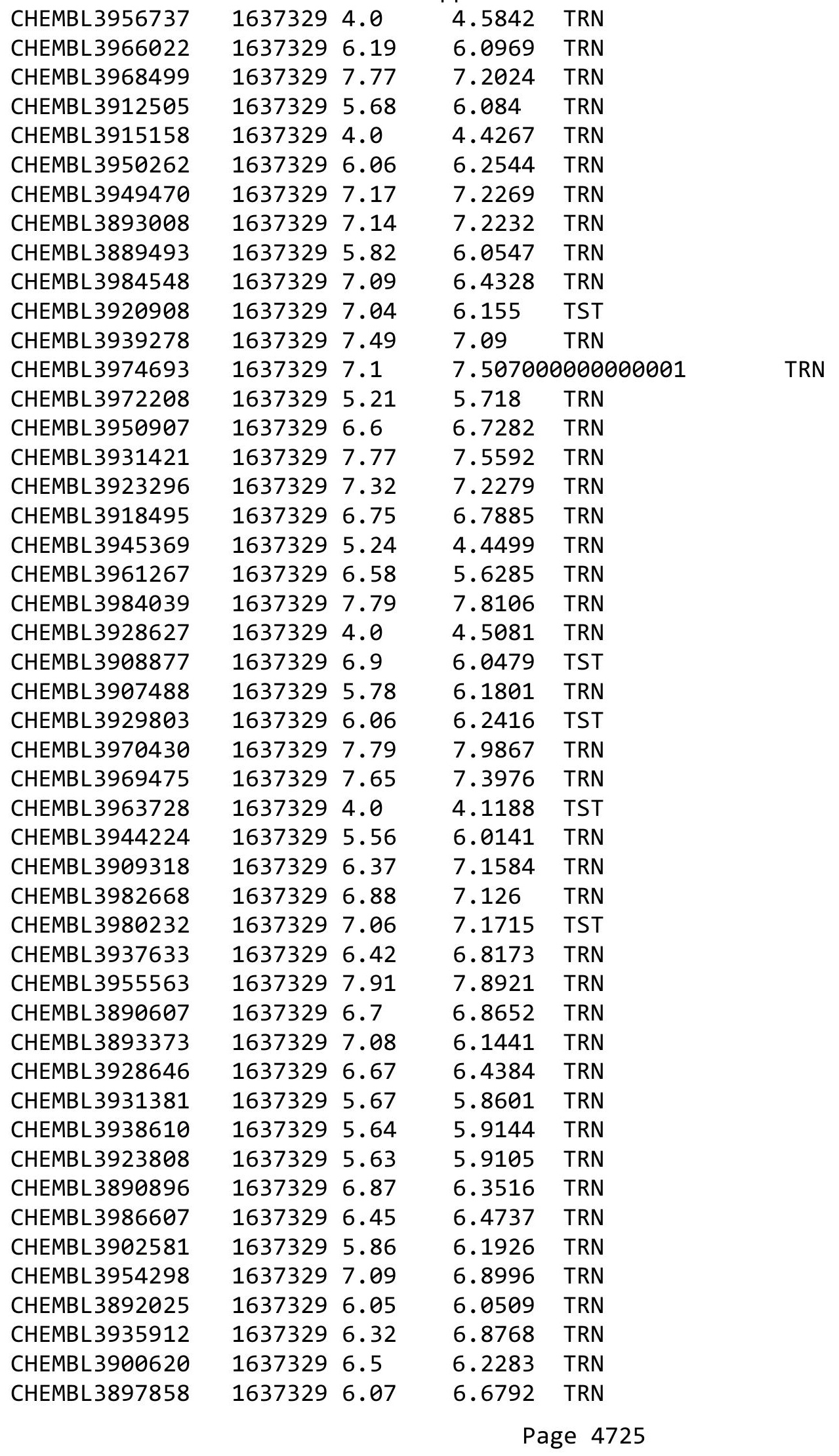


Supplemental Table S2.txt

\begin{tabular}{|c|c|c|c|c|}
\hline CHEMBL 3896104 & 1637329 & 7.53 & 7.5916 & TRN \\
\hline CHEMBL3893398 & 1637329 & 7.48 & 7.5919 & TRN \\
\hline CHEMBL3983996 & 1637329 & 6.92 & 6.7598 & TRN \\
\hline CHEMBL3935124 & 1637329 & 6.31 & 6.0817 & TRN \\
\hline CHEMBL3973645 & 1637329 & 4.0 & 4.7818 & TST \\
\hline CHEMBL 3971073 & 1637329 & 6.14 & 5.7004 & TRN \\
\hline CHEMBL3957264 & 1637329 & 7.46 & 7.386 & TRN \\
\hline CHEMBL3969096 & 1637329 & 6.26 & 6.1185 & TRN \\
\hline CHEMBL3905212 & 1637329 & 4.0 & 4.9765 & TST \\
\hline CHEMBL3897034 & 1637329 & 6.39 & 6.5232 & TRN \\
\hline CHEMBL 3979885 & 1637329 & 6.86 & 6.8277 & TRN \\
\hline CHEMBL3982334 & 1637329 & 5.0 & 4.6874 & TRN \\
\hline CHEMBL3919730 & 1637329 & 7.13 & 7.0904 & TRN \\
\hline CHEMBL3922453 & 1637329 & 6.7 & 6.903 & TRN \\
\hline CHEMBL3959345 & 1637329 & 7.57 & 7.434 & TRN \\
\hline CHEMBL 3959201 & 1637329 & 6.13 & 6.1039 & TST \\
\hline CHEMBL3915233 & 1637329 & 4.0 & 5.1394 & TRN \\
\hline CHEMBL3912569 & 1637329 & 7.6 & 7.4814 & TRN \\
\hline CHEMBL3975954 & 1637329 & 6.85 & 6.6066 & TRN \\
\hline CHEMBL3966748 & 1637329 & 7.12 & 6.6819 & TST \\
\hline CHEMBL 3929648 & 1637329 & 6.11 & 6.5346 & TRN \\
\hline CHEMBL3926964 & 1637329 & 5.37 & 4.3998 & TRN \\
\hline CHEMBL3891619 & 1637329 & 6.31 & 6.1802 & TRN \\
\hline CHEMBL3986661 & 1637329 & 7.26 & 6.4731 & TRN \\
\hline CHEMBL3943043 & 1637329 & 7.59 & 7.2888 & TRN \\
\hline CHEMBL 3904745 & 1637329 & 6.56 & 6.7176 & TRN \\
\hline CHEMBL3965614 & 1637329 & 7.22 & 7.108 & TRN \\
\hline CHEMBL3968009 & 1637329 & 7.29 & 6.7843 & TST \\
\hline CHEMBL3906122 & 1637329 & 6.32 & 5.9584 & TST \\
\hline CHEMBL3900268 & 1637329 & 5.68 & 5.4855 & TRN \\
\hline CHEMBL 3951728 & 1637329 & 6.61 & 6.4418 & TRN \\
\hline CHEMBL3962554 & 1637329 & 6.59 & 6.3447 & TRN \\
\hline CHEMBL 3913970 & 1637329 & 6.82 & 6.4198 & TST \\
\hline CHEMBL3972979 & 1637329 & 7.89 & 7.6362 & TRN \\
\hline CHEMBL3975447 & 1637329 & 7.89 & 7.4839 & TRN \\
\hline CHEMBL3911516 & 1637329 & 6.68 & 6.3555 & TRN \\
\hline CHEMBL3958756 & 1637329 & 5.55 & 5.4633 & TRN \\
\hline CHEMBL 3956120 & 1637329 & 6.56 & 6.2483 & TRN \\
\hline CHEMBL 3907551 & 1637329 & 4.0 & 3.9146 & TST \\
\hline CHEMBL3904777 & 1637329 & 5.27 & 4.7455 & TST \\
\hline CHEMBL 3975007 & 1637329 & 6.07 & 5.1325 & TST \\
\hline CHEMBL 3972517 & 1637329 & 7.38 & 7.1397 & TRN \\
\hline CHEMBL3928956 & 1637329 & 5.12 & 4.7855 & TRN \\
\hline CHEMBL 3919270 & 1637329 & 6.15 & 5.7733 & TRN \\
\hline CHEMBL 3941705 & 1637329 & 5.98 & 5.6905 & TRN \\
\hline CHEMBL 3982570 & 1637329 & 6.05 & 6.0857 & TRN \\
\hline CHEMBL3920007 & 1637329 & 7.17 & 6.9096 & TRN \\
\hline CHEMBL 3922698 & 1637329 & 6.57 & 6.3305 & TRN \\
\hline
\end{tabular}




\begin{tabular}{|c|c|c|c|c|c|}
\hline \\
\hline CHEMBL3957533 & 1637329 & 6.45 & 6.3226 & TRN & \\
\hline CHEMBL3969373 & 1637329 & 6.94 & 6.5958 & TRN & \\
\hline CHEMBL3905485 & 1637329 & 7.92 & 7.3861 & TRN & \\
\hline CHEMBL 3904674 & 1637329 & 7.63 & 7.524 & TRN & \\
\hline CHEMBL3945845 & 1637329 & 7.81 & 7.5888 & TRN & \\
\hline CHEMBL3951694 & 1637329 & 6.41 & 6.282 & TRN & \\
\hline CHEMBL3929914 & 1637329 & 6.51 & 6.1257 & TST & \\
\hline CHEMBL3971277 & 1637329 & 6.64 & 6.6356 & TRN & \\
\hline CHEMBL3891892 & 1637329 & 7.55 & 6.9428 & TRN & \\
\hline CHEMBL3985498 & 1637329 & 6.1 & 5.88299 & 9999999999 & TRN \\
\hline CHEMBL3915533 & 1637329 & 6.96 & 6.8149 & TRN & \\
\hline CHEMBL3912831 & 1637329 & 7.17 & 7.0802 & TRN & \\
\hline CHEMBL3976183 & 1637329 & 7.32 & 7.0577 & TRN & \\
\hline CHEMBL3967011 & 1637329 & 6.75 & 6.5474 & TRN & \\
\hline CHEMBL3931154 & 1637329 & 7.37 & 7.3322 & TRN & \\
\hline CHEMBL3893718 & 1637329 & 6.49 & 6.5594 & TRN & \\
\hline CHEMBL3922285 & 1637329 & 6.85 & 6.8467 & TRN & \\
\hline CHEMBL3925008 & 1637329 & 7.14 & 7.0638 & TRN & \\
\hline CHEMBL3973321 & 1637329 & 6.65 & 6.7053 & TRN & \\
\hline CHEMBL3939439 & 1637329 & 7.51 & 7.3634 & TRN & \\
\hline CHEMBL3898601 & 1637329 & 5.81 & 5.7855 & TRN & \\
\hline CHEMBL 3960327 & 1637329 & 7.06 & 6.9808 & TRN & \\
\hline CHEMBL3981706 & 1637329 & 5.79 & 6.1204 & TRN & \\
\hline CHEMBL3979314 & 1637329 & 5.57 & 5.8232 & TRN & \\
\hline CHEMBL 3985678 & 1637329 & 6.98 & 6.6802 & TRN & \\
\hline CHEMBL3969381 & 1637329 & 7.25 & 7.2973 & TRN & \\
\hline CHEMBL3968361 & 1637329 & 6.13 & 6.1356 & TST & \\
\hline CHEMBL3956571 & 1637329 & 6.05 & 6.0177 & TRN & \\
\hline CHEMBL3907314 & 1637329 & 7.88 & 7.5895 & TRN & \\
\hline CHEMBL3904561 & 1637329 & 6.74 & 6.6359 & TST & \\
\hline CHEMBL3945264 & 1637329 & 8.02 & 7.7429 & TRN & \\
\hline CHEMBL 3942594 & 1637329 & 7.07 & 6.8791 & TRN & \\
\hline CHEMBL3915268 & 1637329 & 6.54 & 6.7198 & TRN & \\
\hline CHEMBL3925081 & 1637329 & 6.87 & 6.9851 & TRN & \\
\hline CHEMBL 3959849 & 1637329 & 6.5 & 6.6851 & TST & \\
\hline CHEMBL3962549 & 1637329 & 5.93 & 6.0381 & TRN & \\
\hline CHEMBL3966626 & 1637329 & 5.79 & 5.805 & TRN & \\
\hline CHEMBL3969192 & 1637329 & 5.08 & 4.3594 & TRN & \\
\hline CHEMBL3975986 & 1637329 & 6.38 & 4.968 & TRN & \\
\hline CHEMBL3979996 & 1637329 & 4.0 & 4.4158 & TRN & \\
\hline CHEMBL3891474 & 1637329 & 6.03 & 6.5765 & TST & \\
\hline CHEMBL3892135 & 1637329 & 7.94 & 7.6763 & TRN & \\
\hline CHEMBL3969824 & 1637329 & 6.57 & 6.8404 & TRN & \\
\hline CHEMBL3932285 & 1637329 & 7.29 & 6.9098 & TRN & \\
\hline CHEMBL 3922586 & 1637329 & 7.65 & 7.2765 & TRN & \\
\hline CHEMBL3901682 & 1637329 & 5.59 & 5.9859 & TRN & \\
\hline CHEMBL 3927733 & 1637329 & 5.8 & 6.1828 & TRN & \\
\hline CHEMBL3976053 & 1637329 & 5.81 & 6.1697 & TST & \\
\hline
\end{tabular}




\begin{tabular}{|c|c|c|c|c|}
\hline \multicolumn{5}{|c|}{ Supplemental Table S2.txt } \\
\hline CHEMBL3973587 & 1637329 & 6.26 & 6.5543 & TRN \\
\hline CHEMBL 3936828 & 1637329 & 6.38 & 6.7015 & TRN \\
\hline CHEMBL3934039 & 1637329 & 6.17 & 6.3165 & TRN \\
\hline CHEMBL 3981418 & 1637329 & 7.32 & 7.4023 & TST \\
\hline CHEMBL3972694 & 1637329 & 5.63 & 5.7344 & TST \\
\hline CHEMBL3921457 & 1637329 & 7.03 & 6.4879 & TST \\
\hline CHEMBL3918739 & 1637329 & 6.63 & 7.0034 & TRN \\
\hline CHEMBL3968793 & 1637329 & 5.49 & 6.7122 & TRN \\
\hline CHEMBL3966305 & 1637329 & 6.72 & 6.8284 & TRN \\
\hline CHEMBL3891115 & 1637329 & 5.35 & 5.8269 & TST \\
\hline CHEMBL3979662 & 1637329 & 5.41 & 5.4549 & TST \\
\hline CHEMBL3983387 & 1637329 & 6.57 & 6.6372 & TST \\
\hline CHEMBL3986068 & 1637329 & 8.39 & 8.0229 & TRN \\
\hline CHEMBL3916975 & 1637329 & 7.37 & 7.2588 & TRN \\
\hline CHEMBL3919709 & 1637329 & 7.86 & 7.8103 & TRN \\
\hline CHEMBL3975791 & 1637329 & 7.85 & 7.8103 & TRN \\
\hline CHEMBL3963323 & 1637329 & 6.85 & 6.8048 & TRN \\
\hline CHEMBL3945373 & 1637329 & 7.57 & 7.1639 & TRN \\
\hline CHEMBL 3893344 & 1637329 & 6.86 & 6.6929 & TRN \\
\hline CHEMBL3896052 & 1637329 & 7.21 & 7.1687 & TRN \\
\hline CHEMBL3947361 & 1637329 & 7.94 & 7.8209 & TRN \\
\hline CHEMBL 3944739 & 1637329 & 5.76 & 5.7682 & TST \\
\hline CHEMBL3909551 & 1637329 & 7.69 & 7.8084 & TRN \\
\hline CHEMBL 3899692 & 1637329 & 7.19 & 6.9435 & TRN \\
\hline CHEMBL3961400 & 1637329 & 7.22 & 7.0312 & TRN \\
\hline CHEMBL3958708 & 1637329 & 6.6 & 6.606 & TRN \\
\hline CHEMBL3974080 & 1637329 & 5.9 & 5.8894 & TRN \\
\hline CHEMBL3921197 & 1637329 & 6.31 & 6.4013 & TST \\
\hline CHEMBL 3898568 & 1637329 & 6.81 & 6.947 & TRN \\
\hline CHEMBL3924422 & 1637329 & 6.84 & 6.6443 & TRN \\
\hline CHEMBL3959193 & 1637329 & 6.69 & 6.7538 & TRN \\
\hline CHEMBL3936087 & 1637329 & 7.34 & 7.0883 & TRN \\
\hline CHEMBL3893070 & 1637329 & 6.73 & 6.2604 & TRN \\
\hline CHEMBL 3977904 & 1637329 & 5.61 & 5.8761 & TST \\
\hline CHEMBL3904441 & 1637329 & 6.04 & 6.0752 & TRN \\
\hline CHEMBL3945159 & 1637329 & 7.83 & 7.914 & TRN \\
\hline CHEMBL3915021 & 1637329 & 6.06 & 6.2956 & TST \\
\hline CHEMBL 3892776 & 1637329 & 7.02 & 7.2426 & TRN \\
\hline CHEMBL 3981077 & 1637329 & 5.98 & 6.2416 & TST \\
\hline CHEMBL3930819 & 1637329 & 5.7 & 5.7046 & TRN \\
\hline CHEMBL3926082 & 1637329 & 8.06 & 8.2015 & TRN \\
\hline CHEMBL3970423 & 1637329 & 6.78 & 6.8837 & TRN \\
\hline CHEMBL3950089 & 1637329 & 6.45 & 6.5863 & TRN \\
\hline CHEMBL 3959573 & 1637329 & 6.82 & 6.5388 & TRN \\
\hline CHEMBL3912310 & 1637329 & 7.39 & 7.5604 & TRN \\
\hline CHEMBL3914955 & 1637329 & 6.71 & 6.6915 & TRN \\
\hline CHEMBL3973263 & 1637329 & 6.4 & 6.7708 & TRN \\
\hline CHEMBL3975714 & 1637329 & 6.5 & 6.1096 & TRN \\
\hline
\end{tabular}




\begin{tabular}{|c|c|c|c|c|c|}
\hline \multicolumn{6}{|c|}{ Supplemental Table s2.txt } \\
\hline CHEMBL3933707 & 1637329 & 7.9 & 7.5255 & TRN & \\
\hline CHEMBL3950069 & 1637329 & 7.35 & 7.5494 & TRN & \\
\hline CHEMBL3979013 & 1637329 & 7.22 & 7.2053 & TRN & \\
\hline CHEMBL3942811 & 1637329 & 6.9 & 6.9384 & TRN & \\
\hline CHEMBL3940175 & 1637329 & 7.74 & 7.4023 & TST & \\
\hline CHEMBL3968038 & 1637329 & 5.94 & 5.9602 & TRN & \\
\hline CHEMBL3965640 & 1637329 & 7.06 & 6.6151 & TRN & \\
\hline CHEMBL3928393 & 1637329 & 8.11 & 7.3088 & TST & \\
\hline CHEMBL 3918704 & 1637329 & 6.83 & 6.4231 & TRN & \\
\hline CHEMBL3947189 & 1637329 & 7.7 & 7.5868 & TRN & \\
\hline CHEMBL3944438 & 1637329 & 7.24 & 6.9943 & TRN & \\
\hline CHEMBL3964574 & 1637329 & 7.9 & 7.9238 & TRN & \\
\hline CHEMBL3942328 & 1637329 & 6.62 & 6.9656 & TRN & \\
\hline CHEMBL3951847 & 1637329 & 7.04 & 6.7688 & TRN & \\
\hline CHEMBL3930298 & 1637329 & 6.19 & 6.6324 & TST & \\
\hline CHEMBL3891464 & 1637329 & 6.76 & 6.831 & TRN & \\
\hline CHEMBL3950910 & 1637329 & 6.99 & 6.9243 & TRN & \\
\hline CHEMBL3901420 & 1637329 & 8.1 & 7.8933 & TRN & \\
\hline CHEMBL3905866 & 1637329 & 7.15 & 7.3249 & TRN & \\
\hline CHEMBL3903198 & 1637329 & 7.0 & 7.056 & TRN & \\
\hline CHEMBL3943933 & 1637329 & 6.34 & 6.5578 & TRN & \\
\hline CHEMBL3925077 & 1637329 & 7.01 & 7.1654 & TRN & \\
\hline CHEMBL3946674 & 1637329 & 7.58 & 7.3896 & TRN & \\
\hline CHEMBL3931790 & 1637329 & 7.3 & 7.5103 & TRN & \\
\hline CHEMBL3934487 & 1637329 & 7.37 & 7.1882 & TRN & \\
\hline CHEMBL3893786 & 1637329 & 8.19 & 8.2024 & TRN & \\
\hline CHEMBL3917141 & 1637329 & 7.58 & 7.5378 & TRN & \\
\hline CHEMBL3941700 & 1637329 & 7.2 & 6.9514 & TRN & \\
\hline CHEMBL3969665 & 1637329 & 6.67 & 6.4917 & TST & \\
\hline CHEMBL3981076 & 1637329 & 7.02 & 6.9206 & TRN & \\
\hline CHEMBL3983529 & 1637329 & 7.18 & 7.152 & TRN & \\
\hline CHEMBL3935457 & 1637329 & 7.51 & 7.2401 & TRN & \\
\hline CHEMBL3905048 & 1637329 & 7.34 & 7.13399 & 99999999995 & TRN \\
\hline CHEMBL3925610 & 1637329 & 7.13 & 6.5855 & TST & \\
\hline CHEMBL3928261 & 1637329 & 7.68 & 7.4809 & TRN & \\
\hline CHEMBL3985259 & 1637329 & 6.59 & 6.5922 & TST & \\
\hline CHEMBL3890205 & 1637329 & 6.09 & 6.026 & TST & \\
\hline CHEMBL3944610 & 1637329 & 7.63 & 7.2015 & TRN & \\
\hline CHEMBL3944320 & 1637329 & 7.74 & 7.4021 & TRN & \\
\hline CHEMBL3979908 & 1637329 & 5.44 & 5.765 & TRN & \\
\hline CHEMBL3934355 & 1637329 & 6.58 & 6.5935 & TRN & \\
\hline CHEMBL3919750 & 1637329 & 6.65 & 6.6598 & TRN & \\
\hline CHEMBL3969112 & 1637329 & 7.51 & 7.5648 & TRN & \\
\hline CHEMBL3966560 & 1637329 & 7.37 & 7.3252 & TRN & \\
\hline CHEMBL3910444 & 1637329 & 7.83 & 7.7678 & TRN & \\
\hline CHEMBL3907642 & 1637329 & 6.77 & 6.4712 & TRN & \\
\hline CHEMBL3973929 & 1637329 & 7.62 & 7.5823 & TRN & \\
\hline CHEMBL3972617 & 1637329 & 6.79 & 6.8535 & TRN & \\
\hline
\end{tabular}




\begin{tabular}{|c|c|c|c|c|}
\hline \multicolumn{5}{|c|}{ Supplemental Table S2.txt } \\
\hline CHEMBL 3908149 & 1637329 & 7.36 & 7.2881 & TRN \\
\hline CHEMBL 3943080 & 1637329 & 6.3 & 6.5153 & TRN \\
\hline CHEMBL3904294 & 1637329 & 7.1 & 7.1337 & TRN \\
\hline CHEMBL 3907063 & 1637329 & 7.07 & 7.2406 & TRN \\
\hline CHEMBL3896623 & 1637329 & 7.2 & 7.2841 & TRN \\
\hline CHEMBL3893950 & 1637329 & 7.07 & 7.1628 & TRN \\
\hline CHEMBL3955745 & 1637329 & 6.21 & 6.1096 & TRN \\
\hline CHEMBL3953117 & 1637329 & 6.22 & 6.388 & TST \\
\hline CHEMBL3951360 & 1637329 & 6.99 & 7.3102 & TRN \\
\hline CHEMBL3930158 & 1637329 & 6.31 & 6.5843 & TRN \\
\hline CHEMBL3911746 & 1637329 & 6.28 & 6.5192 & TST \\
\hline CHEMBL3917295 & 1637329 & 6.91 & 7.2793 & TRN \\
\hline CHEMBL3902110 & 1637329 & 6.64 & 6.6492 & TRN \\
\hline CHEMBL3904814 & 1637329 & 5.88 & 6.2052 & TST \\
\hline CHEMBL3911948 & 1637329 & 6.24 & 6.3042 & TST \\
\hline CHEMBL3928239 & 1637329 & 7.06 & 6.7476 & TRN \\
\hline CHEMBL3979028 & 1637329 & 6.05 & 6.1941 & TRN \\
\hline CHEMBL 3890378 & 1637329 & 7.01 & 7.0182 & TRN \\
\hline CHEMBL 3932363 & 1637329 & 7.81 & 7.3247 & TRN \\
\hline CHEMBL3932756 & 1637329 & 7.74 & 7.4688 & TRN \\
\hline CHEMBL3919479 & 1637329 & 8.11 & 8.0397 & TRN \\
\hline CHEMBL 3968818 & 1637329 & 7.94 & 7.6477 & TRN \\
\hline CHEMBL3966316 & 1637329 & 5.97 & 5.8947 & TRN \\
\hline CHEMBL 3940940 & 1637329 & 6.72 & 6.7493 & TST \\
\hline CHEMBL3982107 & 1637329 & 6.6 & 6.9995 & TRN \\
\hline CHEMBL3979670 & 1637329 & 7.62 & 7.7803 & TRN \\
\hline CHEMBL3911738 & 1637329 & 6.78 & 6.9086 & TRN \\
\hline CHEMBL3960571 & 1637329 & 6.93 & 6.9198 & TRN \\
\hline CHEMBL 3974206 & 1637329 & 7.17 & 7.3245 & TST \\
\hline CHEMBL3889711 & 1637329 & 6.43 & 6.4201 & TRN \\
\hline CHEMBL3927585 & 1637329 & 6.44 & 6.6137 & TRN \\
\hline CHEMBL3946103 & 1637329 & 7.11 & 6.6348 & TRN \\
\hline CHEMBL3936421 & 1637329 & 5.27 & 5.6187 & TRN \\
\hline CHEMBL 3901119 & 1637329 & 7.54 & 7.3519 & TST \\
\hline CHEMBL3919884 & 1637329 & 6.7 & 7.1035 & TST \\
\hline CHEMBL3942606 & 1637329 & 8.18 & 7.195 & TST \\
\hline CHEMBL3945277 & 1637329 & 7.54 & 7.3638 & TRN \\
\hline CHEMBL 3897523 & 1637329 & 8.27 & 7.1864 & TRN \\
\hline CHEMBL 3907327 & 1637329 & 6.61 & 6.0319 & TRN \\
\hline CHEMBL3956579 & 1637329 & 6.89 & 7.0992 & TST \\
\hline CHEMBL3959260 & 1637329 & 6.57 & 6.4816 & TRN \\
\hline CHEMBL3890852 & 1637329 & 7.22 & 6.9711 & TST \\
\hline CHEMBL3893642 & 1637329 & 6.95 & 7.5608 & TRN \\
\hline CHEMBL 3950156 & 1637329 & 6.94 & 6.5026 & TRN \\
\hline CHEMBL3952866 & 1637329 & 6.53 & 6.5026 & TST \\
\hline CHEMBL3925114 & 1637329 & 6.89 & 7.6966 & TRN \\
\hline CHEMBL3897155 & 1637329 & 6.18 & 6.4897 & TST \\
\hline CHEMBL3937972 & 1637329 & 7.52 & 7.3035 & TRN \\
\hline
\end{tabular}




\begin{tabular}{|c|c|c|c|c|}
\hline \multicolumn{5}{|c|}{ Supplemental Table S2.txt } \\
\hline CHEMBL3935177 & 1637329 & 6.58 & 6.2572 & TRN \\
\hline CHEMBL 3962492 & 1637329 & 6.79 & 6.733 & TRN \\
\hline CHEMBL3903823 & 1637329 & 6.13 & 6.2186 & TRN \\
\hline CHEMBL3964096 & 1637329 & 7.04 & 7.1763 & TST \\
\hline CHEMBL3948755 & 1637329 & 6.2 & 6.1293 & TST \\
\hline CHEMBL3892155 & 1637329 & 6.31 & 6.4492 & TRN \\
\hline CHEMBL3987162 & 1637329 & 6.08 & 6.0912 & TRN \\
\hline CHEMBL3921441 & 1637329 & 7.38 & 7.4515 & TRN \\
\hline CHEMBL 3905015 & 1637329 & 5.95 & 5.8368 & TRN \\
\hline CHEMBL3921817 & 1637329 & 6.99 & 7.4891 & TRN \\
\hline CHEMBL3927219 & 1637329 & 6.69 & 6.7122 & TRN \\
\hline CHEMBL3902434 & 1637329 & 6.81 & 7.2609 & TRN \\
\hline CHEMBL3927158 & 1637329 & 5.6 & 6.0194 & TRN \\
\hline CHEMBL3985182 & 1637329 & 7.62 & 7.221 & TRN \\
\hline CHEMBL3933442 & 1637329 & 6.57 & 7.1717 & TRN \\
\hline CHEMBL3934080 & 1637329 & 6.69 & 7.3654 & TRN \\
\hline CHEMBL 3895443 & 1637329 & 5.46 & 6.0287 & TRN \\
\hline CHEMBL3904736 & 1637329 & 4.0 & 4.6536 & TRN \\
\hline CHEMBL 3914473 & 1637329 & 4.0 & 5.0492 & TRN \\
\hline CHEMBL3898926 & 1637329 & 5.53 & 6.1091 & TRN \\
\hline CHEMBL3952277 & 1637329 & 6.99 & 7.2865 & TRN \\
\hline CHEMBL 3926245 & 1637329 & 6.46 & 6.3251 & TST \\
\hline CHEMBL3978617 & 1637329 & 6.96 & 7.4485 & TRN \\
\hline CHEMBL 3966071 & 1637329 & 6.91 & 7.4964 & TST \\
\hline CHEMBL3966200 & 1637329 & 6.81 & 7.0145 & TRN \\
\hline CHEMBL3940672 & 1637329 & 7.02 & 6.8633 & TST \\
\hline CHEMBL3979328 & 1637329 & 7.13 & 7.8203 & TRN \\
\hline CHEMBL3983918 & 1637329 & 6.99 & 7.301 & TST \\
\hline CHEMBL 3975193 & 1637329 & 7.26 & 7.3477 & TRN \\
\hline CHEMBL3924172 & 1637329 & 7.09 & 6.8952 & TRN \\
\hline CHEMBL3921469 & 1637329 & 6.98 & 7.6251 & TRN \\
\hline CHEMBL3900551 & 1637329 & 4.0 & 4.8302 & TRN \\
\hline CHEMBL3891525 & 1637329 & 6.59 & 6.7492 & TRN \\
\hline CHEMBL 3935838 & 1637329 & 6.4 & 6.6657 & TST \\
\hline CHEMBL3977010 & 1637329 & 6.45 & 6.7641 & TRN \\
\hline CHEMBL3967761 & 1637329 & 6.72 & 7.2835 & TRN \\
\hline CHEMBL3893556 & 1637329 & 7.39 & 7.2342 & TRN \\
\hline CHEMBL3896249 & 1637329 & 7.0 & 7.294 & TRN \\
\hline CHEMBL 3952789 & 1637329 & 8.04 & 7.9061 & TRN \\
\hline CHEMBL3955385 & 1637329 & 6.29 & 6.4959 & TRN \\
\hline CHEMBL3977708 & 1637329 & 7.67 & 7.651 & TRN \\
\hline CHEMBL3980069 & 1637329 & 7.65 & 8.1299 & TRN \\
\hline CHEMBL3946938 & 1637329 & 7.06 & 6.9851 & TRN \\
\hline CHEMBL 3941337 & 1637329 & 5.35 & 5.7031 & TRN \\
\hline CHEMBL3983585 & 1637329 & 6.14 & 6.3174 & TRN \\
\hline CHEMBL3918638 & 1637329 & 7.19 & 7.8103 & TRN \\
\hline CHEMBL3920637 & 1637329 & 5.88 & 6.4965 & TRN \\
\hline CHEMBL3917908 & 1637329 & 7.32 & 7.6881 & TRN \\
\hline
\end{tabular}




\begin{tabular}{|c|c|c|c|c|}
\hline & & & upplement & al $\mathrm{T}$ \\
\hline CHEMBL 3980712 & 1637329 & 5.15 & 5.2265 & TRN \\
\hline CHEMBL 3978349 & 1637329 & 6.95 & 6.77 & TST \\
\hline CHEMBL 3976721 & 1637329 & 6.28 & 6.5336 & TRN \\
\hline CHEMBL 3974273 & 1637329 & 6.34 & 6.4734 & TRN \\
\hline CHEMBL 3898255 & 1637329 & 5.92 & 5.9081 & TST \\
\hline CHEMBL3927794 & 1637329 & 5.91 & 5.8205 & TST \\
\hline CHEMBL 3953833 & 1637329 & 7.02 & 8.302 & TRN \\
\hline CHEMBL 3964043 & 1637329 & 7.51 & 7.6637 & TRN \\
\hline CHEMBL 3945658 & 1637329 & 5.99 & 6.2815 & TRN \\
\hline CHEMBL3948306 & 1637329 & 5.59 & 5.4497 & TRN \\
\hline CHEMBL 3984035 & 1637329 & 5.58 & 6.0326 & TST \\
\hline CHEMBL 3986725 & 1637329 & 6.29 & 6.3509 & TST \\
\hline CHEMBL3896142 & 1637329 & 7.75 & 7.6961 & TST \\
\hline CHEMBL 3908707 & 1637329 & 7.44 & 7.5051 & TRN \\
\hline CHEMBL 3941227 & 1637329 & 6.05 & 6.2681 & TST \\
\hline CHEMBL3943917 & 1637329 & 8.21 & 7.5731 & TRN \\
\hline CHEMBL 3979972 & 1637329 & 6.45 & 6.522 & TRN \\
\hline CHEMBL3982399 & 1637329 & 7.94 & 7.1413 & TRN \\
\hline CHEMBL 3932817 & 1637329 & 7.03 & 6.9898 & TST \\
\hline CHEMBL 3930088 & 1637329 & 5.75 & 6.0504 & TST \\
\hline CHEMBL 3972445 & 1637329 & 5.09 & 5.5017 & TRN \\
\hline CHEMBL 3969747 & 1637329 & 5.77 & 6.1125 & TST \\
\hline CHEMBL3918426 & 1637329 & 6.99 & 7.3331 & TST \\
\hline CHEMBL 3906938 & 1637329 & 7.63 & 7.2923 & TRN \\
\hline CHEMBL 3956028 & 1637329 & 4.0 & 4.7195 & TRN \\
\hline CHEMBL3964762 & 1637329 & 7.28 & 6.8628 & TRN \\
\hline CHEMBL 3948234 & 1637329 & 6.38 & 6.9574 & TST \\
\hline CHEMBL3932022 & 1637329 & 7.62 & 7.4553 & TST \\
\hline CHEMBL 3957473 & 1637329 & 7.1 & 7.5513 & TRN \\
\hline CHEMBL3950496 & 1637329 & 7.31 & 7.2572 & TRN \\
\hline CHEMBL 3902961 & 1637329 & 8.23 & 7.7054 & TRN \\
\hline CHEMBL 3905633 & 1637329 & 6.36 & 6.6216 & TST \\
\hline CHEMBL3937212 & 1637329 & 6.51 & 6.8272 & TST \\
\hline CHEMBL 3966929 & 1637329 & 6.75 & 6.7122 & TRN \\
\hline CHEMBL 3922100 & 1637329 & 6.53 & 6.7072 & TST \\
\hline CHEMBL 3906284 & 1637329 & 7.21 & 7.4515 & TRN \\
\hline CHEMBL 3921787 & 1637329 & 7.51 & 7.1808 & TRN \\
\hline CHEMBL3951171 & 1637329 & 7.44 & 7.7179 & TRN \\
\hline CHEMBL 3983694 & 1637329 & 8.03 & 7.9614 & TRN \\
\hline CHEMBL3981207 & 1637329 & 6.24 & 6.8414 & TRN \\
\hline CHEMBL 3986631 & 1637329 & 5.88 & 5.6646 & TRN \\
\hline CHEMBL3969667 & 1637329 & 8.23 & 8.3997 & TRN \\
\hline CHEMBL 3933908 & 1637329 & 7.97 & 7.7545 & TRN \\
\hline CHEMBL 3936673 & 1637329 & 7.72 & 7.4383 & TRN \\
\hline CHEMBL3980417 & 1637329 & 8.47 & 8.3114 & TRN \\
\hline CHEMBL 3921190 & 1637329 & 8.61 & 8.3746 & TRN \\
\hline CHEMBL 3920274 & 1637329 & 5.23 & 5.505 & TST \\
\hline CHEMBL3953771 & 1637329 & 8.38 & 8.2517 & TST \\
\hline
\end{tabular}




\begin{tabular}{|c|c|c|c|c|c|}
\hline \multicolumn{6}{|c|}{ Supplemental Table S2.txt } \\
\hline CHEMBL3950292 & 1637329 & 7.75 & 7.2833 & TRN & \\
\hline CHEMBL3959787 & 1637329 & 7.32 & 6.5822 & TRN & \\
\hline CHEMBL3986861 & 1637329 & 6.49 & 6.4104 & TST & \\
\hline CHEMBL3891816 & 1637329 & 6.11 & 6.2777 & TST & \\
\hline CHEMBL3927140 & 1637329 & 8.63 & 8.0518 & TRN & \\
\hline CHEMBL3929849 & 1637329 & 7.23 & 6.9497 & TRN & \\
\hline CHEMBL3966941 & 1637329 & 6.33 & 6.2798 & TST & \\
\hline CHEMBL3939018 & 1637329 & 7.12 & 6.83899 & 99999999995 & TRN \\
\hline CHEMBL3912757 & 1637329 & 6.21 & 6.2946 & TRN & \\
\hline CHEMBL3915450 & 1637329 & 6.87 & 6.7806 & TRN & \\
\hline CHEMBL3956493 & 1637329 & 6.85 & 6.9283 & TRN & \\
\hline CHEMBL3964931 & 1637329 & 6.85 & 6.8141 & TRN & \\
\hline CHEMBL3918956 & 1637329 & 5.77 & 5.9101 & TRN & \\
\hline CHEMBL 3894754 & 1637329 & 8.61 & 8.3816 & TRN & \\
\hline CHEMBL3963296 & 1637329 & 7.63 & 7.1535 & TRN & \\
\hline CHEMBL3890187 & 1637329 & 5.06 & 6.0743 & TST & \\
\hline CHEMBL3978313 & 1637329 & 7.53 & 7.41 & TRN & \\
\hline CHEMBL3889604 & 1637329 & 6.24 & 6.4376 & TRN & \\
\hline CHEMBL3939332 & 1637329 & 6.53 & 6.6334 & TRN & \\
\hline CHEMBL3912250 & 1637329 & 6.03 & 6.3202 & TRN & \\
\hline CHEMBL3901265 & 1637329 & 6.8 & 6.8938 & TRN & \\
\hline CHEMBL3903973 & 1637329 & 8.27 & 8.6778 & TRN & \\
\hline CHEMBL3957928 & 1637329 & 7.14 & 7.0891 & TRN & \\
\hline CHEMBL3960591 & 1637329 & 6.3 & 6.4759 & TST & \\
\hline CHEMBL3899721 & 1637329 & 6.93 & 6.8281 & TRN & \\
\hline CHEMBL3934772 & 1637329 & 7.49 & 7.4016 & TRN & \\
\hline CHEMBL3909752 & 1637329 & 5.62 & 6.2171 & TRN & \\
\hline CHEMBL3906945 & 1637329 & 6.17 & 6.5424 & TRN & \\
\hline CHEMBL3954396 & 1637329 & 9.0 & 8.83 & TRN & \\
\hline CHEMBL3944937 & 1637329 & 5.81 & 6.2432 & TRN & \\
\hline CHEMBL3895267 & 1637329 & 7.03 & 7.1465 & TRN & \\
\hline CHEMBL3892529 & 1637329 & 9.0 & 8.6934 & TRN & \\
\hline CHEMBL3935597 & 1637329 & 7.66 & 8.198 & TRN & \\
\hline CHEMBL3932893 & 1637329 & 5.7 & 6.0174 & TST & \\
\hline CHEMBL3952706 & 1637329 & 6.1 & 6.3897 & TST & \\
\hline CHEMBL3939860 & 1637329 & 6.81 & 6.6713 & TST & \\
\hline CHEMBL3976275 & 1637329 & 9.41 & 9.0555 & TRN & \\
\hline CHEMBL3978754 & 1637329 & 9.42 & 9.2415 & TST & \\
\hline CHEMBL3942716 & 1637329 & 7.22 & 7.2402 & TRN & \\
\hline CHEMBL3982718 & 1637329 & 8.43 & 8.1446 & TRN & \\
\hline CHEMBL3894762 & 1637329 & 7.61 & 7.289 & TST & \\
\hline CHEMBL3896514 & 1637329 & 5.34 & 6.0233 & TST & \\
\hline CHEMBL3906253 & 1637329 & 6.76 & 6.9715 & TRN & \\
\hline CHEMBL3946877 & 1637329 & 4.0 & 5.5255 & TST & \\
\hline CHEMBL3944241 & 1637329 & 5.78 & 5.7177 & TST & \\
\hline CHEMBL3947664 & 1637329 & 7.25 & 7.1148 & TST & \\
\hline CHEMBL3933492 & 1637329 & 4.0 & 3.8285 & TST & \\
\hline CHEMBL3982416 & 1637329 & 4.0 & 4.2555 & TST & \\
\hline
\end{tabular}




\begin{tabular}{|c|c|c|c|c|}
\hline & & & pplement & al $\mathrm{Ta}$ \\
\hline CHEMBL3984969 & 1637329 & 4.0 & 3.9391 & TST \\
\hline CHEMBL3953206 & 1637329 & 4.0 & 4.4922 & TST \\
\hline CHEMBL3942179 & 1637329 & 5.71 & 5.9082 & TST \\
\hline CHEMBL3930685 & 1637329 & 5.14 & 5.8504 & TST \\
\hline CHEMBL3910555 & 1637329 & 5.71 & 5.8032 & TST \\
\hline CHEMBL3918036 & 1637329 & 4.0 & 4.2488 & TST \\
\hline CHEMBL3926088 & 1637329 & 5.01 & 4.7875 & TST \\
\hline CHEMBL3972657 & 1637329 & 5.55 & 5.7313 & TST \\
\hline CHEMBL3918892 & 1637329 & 5.12 & 4.9447 & TST \\
\hline CHEMBL3966660 & 1637329 & 5.22 & 5.6092 & TST \\
\hline CHEMBL3899891 & 1637329 & 5.33 & 5.7369 & TST \\
\hline CHEMBL3890118 & 1637329 & 6.56 & 6.3193 & TST \\
\hline CHEMBL3950169 & 1637329 & 4.0 & 5.0329 & TST \\
\hline CHEMBL3952885 & 1637329 & 4.0 & 4.819 & TST \\
\hline CHEMBL3890870 & 1637329 & 6.01 & 6.0249 & TST \\
\hline CHEMBL3893659 & 1637329 & 4.0 & 4.016 & TST \\
\hline CHEMBL3928923 & 1637329 & 5.23 & 5.6919 & TST \\
\hline CHEMBL3938712 & 1637329 & 5.09 & 5.2775 & TST \\
\hline CHEMBL3975295 & 1637329 & 5.41 & 6.3979 & TST \\
\hline CHEMBL3977791 & 1637329 & 5.03 & 5.3831 & TST \\
\hline CHEMBL3916904 & 1637329 & 4.0 & 5.2686 & TST \\
\hline CHEMBL3974131 & 1637329 & 5.06 & 5.4325 & TST \\
\hline CHEMBL3925322 & 1637329 & 5.65 & 5.4594 & TST \\
\hline CHEMBL3922592 & 1637329 & 5.05 & 5.6355 & TST \\
\hline CHEMBL3985007 & 1637329 & 5.09 & 5.4325 & TST \\
\hline CHEMBL3982466 & 1637329 & 4.0 & 4.4734 & TST \\
\hline CHEMBL3910921 & 1637329 & 6.81 & 6.4827 & TST \\
\hline CHEMBL3908141 & 1637329 & 6.09 & 5.1858 & TST \\
\hline CHEMBL3971947 & 1637329 & 5.63 & 5.9755 & TST \\
\hline CHEMBL3960102 & 1637329 & 5.05 & 4.5712 & TST \\
\hline CHEMBL3952488 & 1637329 & 5.57 & 5.5583 & TST \\
\hline CHEMBL424933 & 428016 & 6.0501 & 7.0541 & TRN \\
\hline CHEMBL 220430 & 428016 & 5.9066 & 5.597 & TRN \\
\hline CHEMBL220557 & 428016 & 7.1871 & 7.0333 & TRN \\
\hline CHEMBL220325 & 428016 & 6.2596 & 6.14 & TRN \\
\hline CHEMBL219872 & 428016 & 5.4815 & 5.5871 & TRN \\
\hline CHEMBL220628 & 428016 & 5.0969 & 5.1619 & TRN \\
\hline CHEMBL223247 & 428016 & 4.0 & 5.6782 & TST \\
\hline CHEMBL219610 & 428016 & 5.301 & 5.7147 & TST \\
\hline CHEMBL220224 & 428016 & 6.5229 & 6.6013 & TRN \\
\hline CHEMBL427080 & 428016 & 6.0 & 6.984 & TRN \\
\hline CHEMBL220507 & 428016 & 6.0269 & 5.3466 & TRN \\
\hline CHEMBL373605 & 428016 & 5.9914 & 5.4368 & TRN \\
\hline CHEMBL220508 & 428016 & 6.1959 & 5.1574 & TRN \\
\hline CHEMBL220422 & 428016 & 5.2534 & 5.598 & TRN \\
\hline CHEMBL220990 & 428016 & 5.0605 & 5.7337 & TST \\
\hline CHEMBL426883 & 428016 & 7.3768 & 6.6313 & TRN \\
\hline CHEMBL221044 & 428016 & 7.3768 & 6.9079 & TST \\
\hline
\end{tabular}




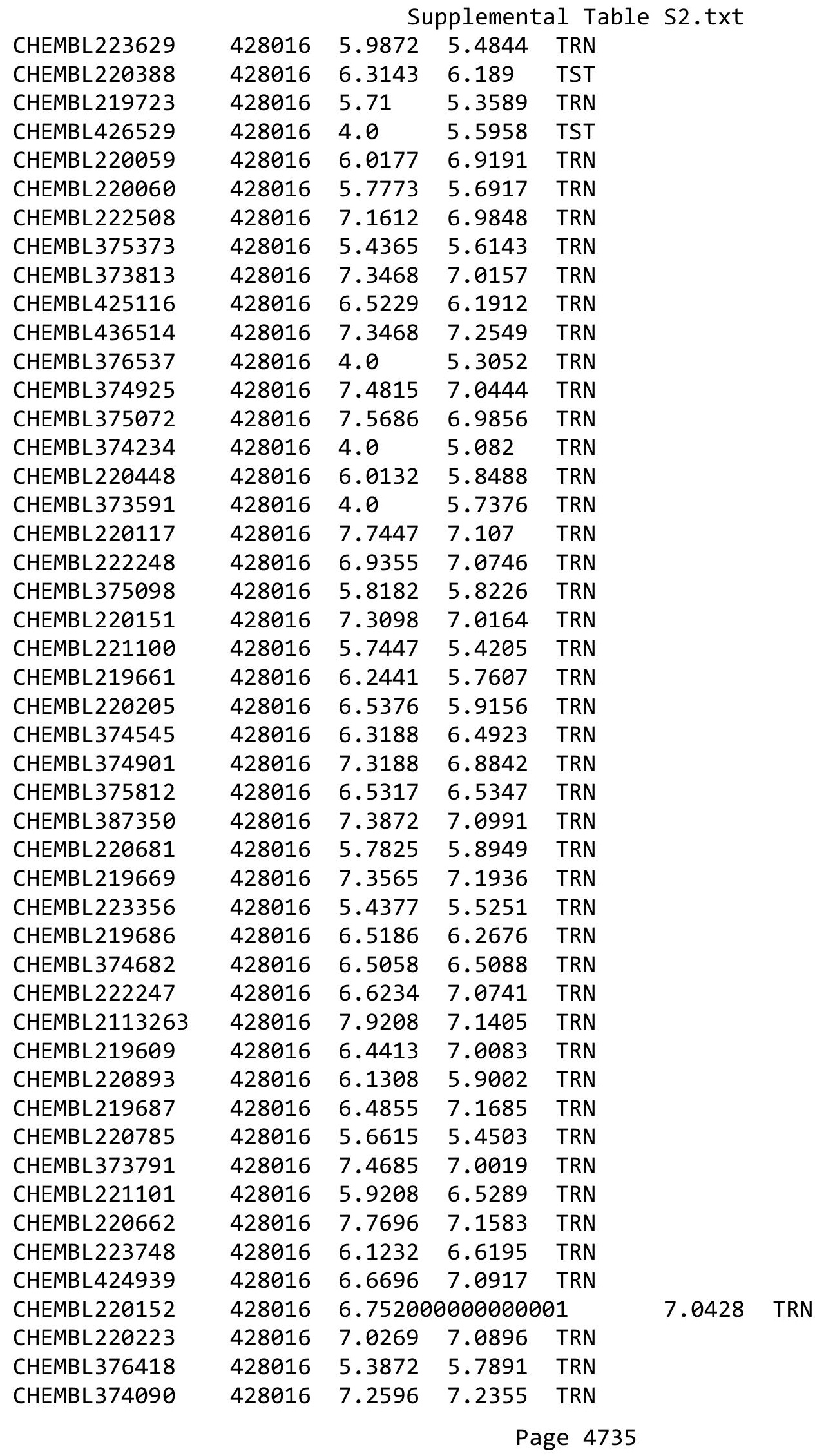




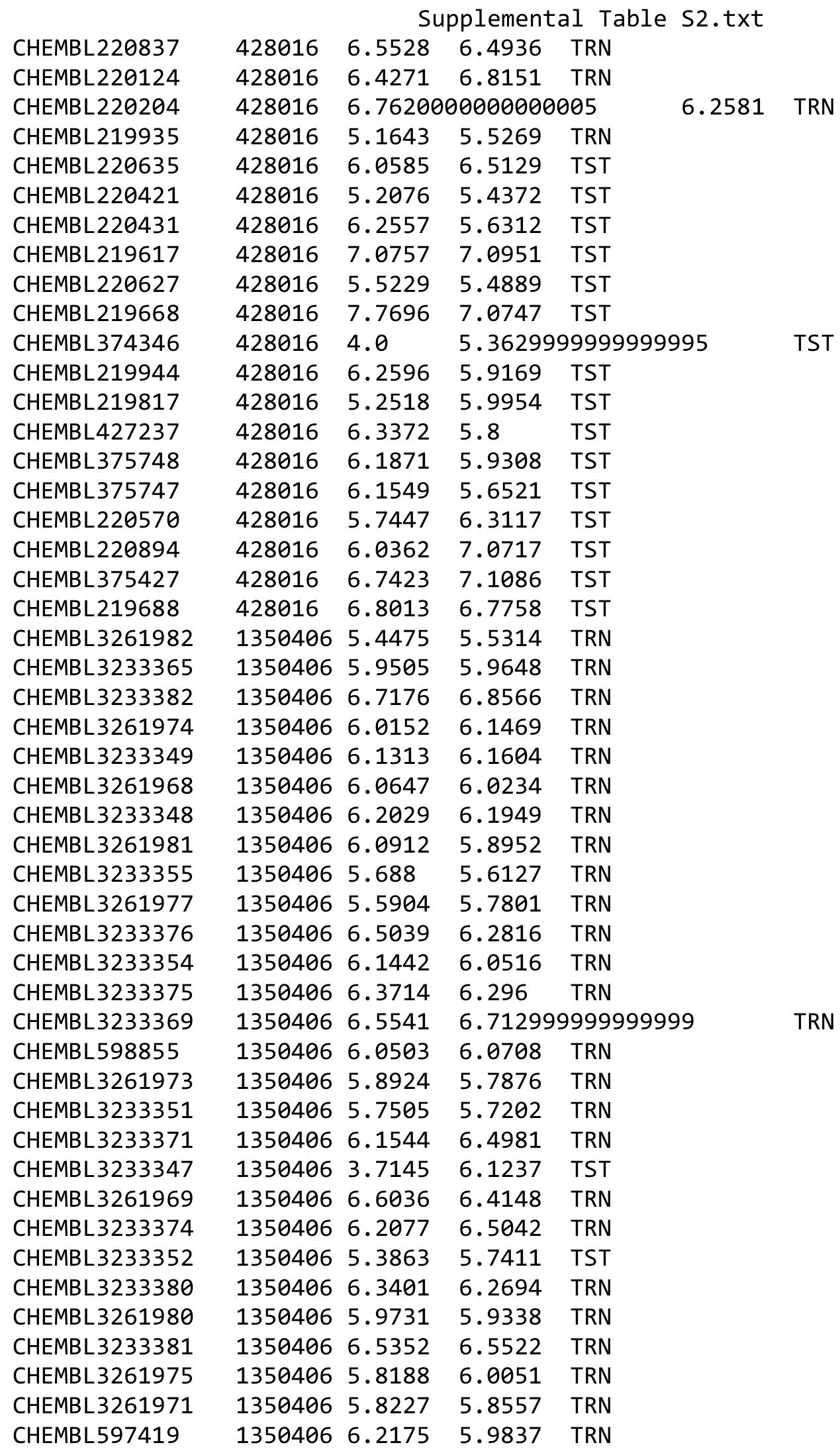

Page 4736 
Supplemental Table S2.txt

\begin{tabular}{|c|c|c|c|c|c|}
\hline CHEMBL 3233362 & 1350406 & 6.4921 & 6.3295 & TRN & \\
\hline CHEMBL 3233350 & 1350406 & 6.08799 & 79999999 & 99 & 6.1604 \\
\hline CHEMBL 3233368 & 1350406 & 4.7624 & 6.6269 & TST & \\
\hline CHEMBL 3233358 & 1350406 & 4.8178 & 6.0445 & TST & \\
\hline CHEMBL3233366 & 1350406 & 5.7171 & 5.6702 & TRN & \\
\hline CHEMBL 3261983 & 1350406 & 5.4565 & 5.3235 & TRN & \\
\hline CHEMBL 3261972 & 1350406 & 5.4408 & 5.6445 & TRN & \\
\hline CHEMBL 3261970 & 1350406 & 5.9383 & 6.0269 & TRN & \\
\hline CHEMBL 3261978 & 1350406 & 5.3867 & 5.5405 & TRN & \\
\hline CHEMBL3261976 & 1350406 & 5.3332 & 5.3568 & TRN & \\
\hline CHEMBL 3233379 & 1350406 & 6.2394 & 6.2817 & TRN & \\
\hline CHEMBL 3233385 & 1350406 & 6.9678 & 6.5948 & TRN & \\
\hline CHEMBL 3233383 & 1350406 & 6.8614 & 6.7275 & TRN & \\
\hline CHEMBL 3233370 & 1350406 & 6.5872 & 6.4994 & TST & \\
\hline CHEMBL 3233357 & 1350406 & 5.5325 & 6.2068 & TST & \\
\hline CHEMBL 3261979 & 1350406 & 5.3975 & 5.6489 & TST & \\
\hline CHEMBL3233359 & 1350406 & 6.1946 & 6.034 & TST & \\
\hline CHEMBL 3233367 & 1350406 & 5.7353 & 5.7678 & TST & \\
\hline CHEMBL603619 & 1350406 & 5.9273 & 6.1604 & TST & \\
\hline CHEMBL 3233361 & 1350406 & 6.0501 & 5.9603 & TST & \\
\hline CHEMBL596333 & 1350406 & 5.9245 & 6.654 & TST & \\
\hline CHEMBL 3233378 & 1350406 & 6.0838 & 6.4911 & TST & \\
\hline CHEMBL 2367780 & 79287 & 2.6021 & 3.536 & TST & \\
\hline CHEMBL406634 & 79287 & 5.8539 & 5.7473 & TRN & \\
\hline CHEMBL409706 & 79287 & 4.7696 & 4.7696 & TRN & \\
\hline CHEMBL407356 & 79287 & 5.0 & 4.977 & TRN & \\
\hline CHEMBL 267216 & 79287 & 4.7696 & 4.792 & TST & \\
\hline CHEMBL384064 & 79287 & 4.8239 & 4.8666 & TST & \\
\hline CHEMBL413713 & 79287 & 6.0 & 5.9801 & TRN & \\
\hline CHEMBL437840 & 79287 & 5.1549 & 5.4036 & TRN & \\
\hline CHEMBL405267 & 79287 & 6.1249 & 5.7395 & TRN & \\
\hline CHEMBL 267424 & 79287 & 4.0 & 4.0471 & TRN & \\
\hline CHEMBL 266841 & 79287 & 3.9393 & 3.6234 & TRN & \\
\hline CHEMBL406690 & 79287 & 4.6576 & 4.6525 & TRN & \\
\hline CHEMBL 2304315 & 79287 & 4.0 & 4.1498 & TRN & \\
\hline CHEMBL438554 & 79287 & 4.7696 & 4.8743 & TST & \\
\hline CHEMBL413864 & 79287 & 4.6021 & 4.9462 & TRN & \\
\hline CHEMBL 263998 & 79287 & 4.8861 & 4.8435 & TRN & \\
\hline CHEMBL412204 & 79287 & 4.7696 & 4.8521 & TRN & \\
\hline CHEMBL437476 & 79287 & 5.6021 & 5.4147 & TRN & \\
\hline CHEMBL 267368 & 79287 & 4.8861 & 4.7037 & TRN & \\
\hline CHEMBL411363 & 79287 & 5.585 & 5.5119 & TRN & \\
\hline CHEMBL 2304149 & 79287 & 4.0 & 4.4265 & TST & \\
\hline CHEMBL 267982 & 79287 & 4.6021 & 4.7469 & TST & \\
\hline CHEMBL 267410 & 79287 & 4.7696 & 4.8068 & TRN & \\
\hline CHEMBL407397 & 79287 & 5.2218 & 5.2198 & TRN & \\
\hline CHEMBL 2370219 & 79287 & 3.9393 & 4.0087 & TRN & \\
\hline CHEMBL405483 & 79287 & 4.699 & 4.6108 & TRN & \\
\hline
\end{tabular}




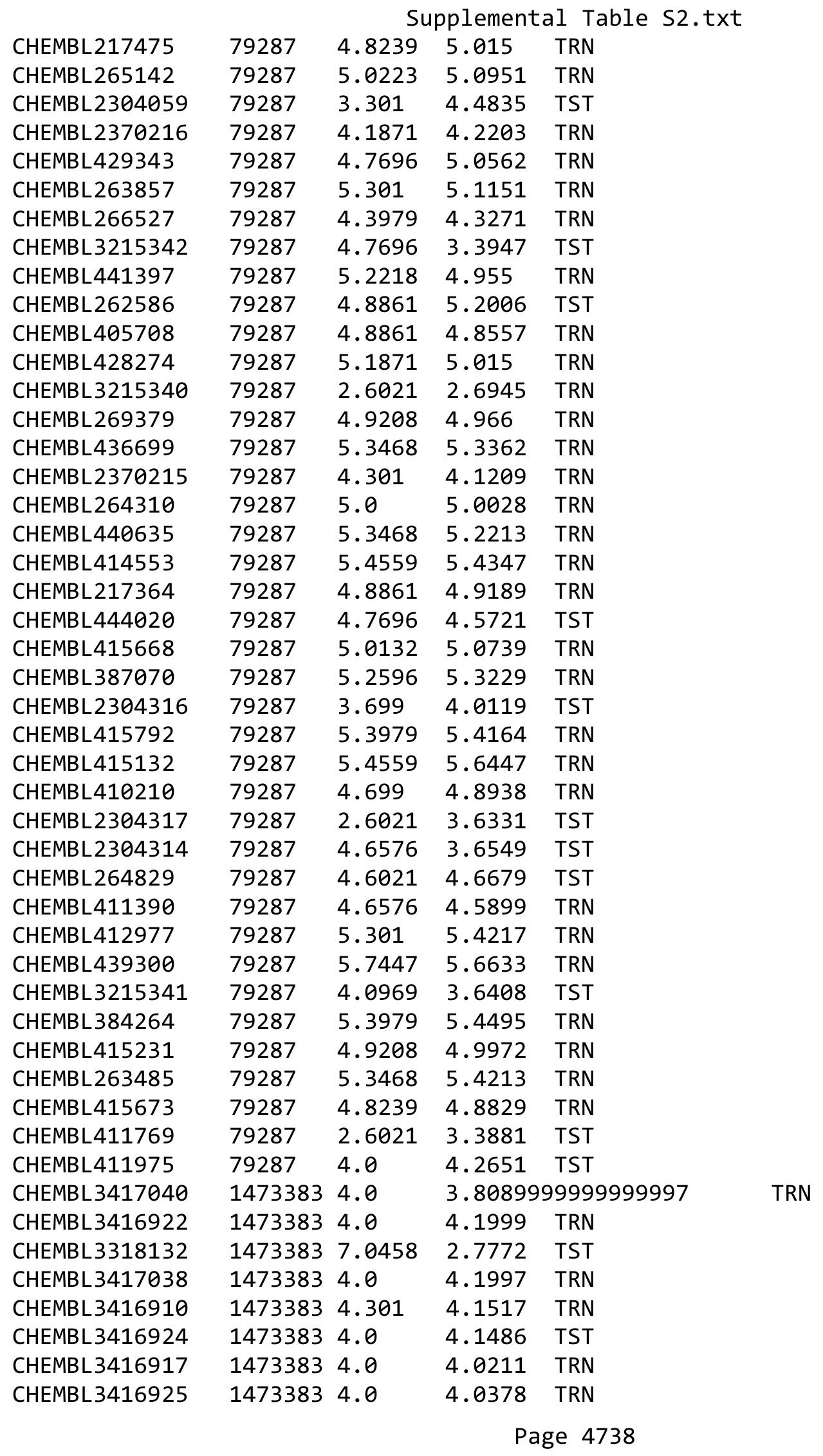


Supplemental Table S2.txt

\begin{tabular}{|c|c|c|c|c|c|}
\hline CHEMBL3416934 & 1473383 & 5.5229 & 4.6878 & TRN & \\
\hline CHEMBL3416920 & 1473383 & 4.0 & 4.218 & TRN & \\
\hline CHEMBL3416911 & 1473383 & 4.301 & 4.4315 & TST & \\
\hline CHEMBL3416905 & 1473383 & 4.301 & 4.374 & TRN & \\
\hline CHEMBL3414596 & 1473383 & 4.301 & 4.1517 & TRN & \\
\hline CHEMBL3416889 & 1473383 & 4.301 & 4.1587 & TRN & \\
\hline CHEMBL3416914 & 1473383 & 4.301 & 4.376 & TRN & \\
\hline CHEMBL3416894 & 1473383 & 4.301 & 4.3251 & TRN & \\
\hline CHEMBL3416895 & 1473383 & 4.301 & 4.1517 & TRN & \\
\hline CHEMBL3416946 & 1473383 & 5.3468 & 5.237 & TRN & \\
\hline CHEMBL3416908 & 1473383 & 4.301 & 4.7963 & TRN & \\
\hline CHEMBL3416913 & 1473383 & 4.301 & 4.4233 & TST & \\
\hline CHEMBL3416945 & 1473383 & 4.0 & 4.1228 & TRN & \\
\hline CHEMBL3416907 & 1473383 & 4.301 & 4.1517 & TRN & \\
\hline CHEMBL3417039 & 1473383 & 4.0 & 3.9652 & TRN & \\
\hline CHEMBL3416887 & 1473383 & 4.6021 & 2.6589 & TST & \\
\hline CHEMBL3416904 & 1473383 & 3.699 & 4.1517 & TRN & \\
\hline CHEMBL3416921 & 1473383 & 4.0 & 4.218 & TRN & \\
\hline CHEMBL3416886 & 1473383 & 4.0 & 4.6264 & TRN & \\
\hline CHEMBL3416888 & 1473383 & 3.6021 & 4.7748 & TST & \\
\hline CHEMBL3416937 & 1473383 & 6.3979 & 6.5052 & TRN & \\
\hline CHEMBL3416928 & 1473383 & 4.0 & 3.7685 & TRN & \\
\hline CHEMBL3416926 & 1473383 & 5.4559 & \multicolumn{2}{|c|}{5.388999999999999} & TRN \\
\hline CHEMBL3416909 & 1473383 & 4.301 & 4.2968 & TRN & \\
\hline CHEMBL3416903 & 1473383 & 4.301 & 4.1517 & TRN & \\
\hline CHEMBL3417041 & 1473383 & 4.0 & 4.1997 & TRN & \\
\hline CHEMBL3416944 & 1473383 & 6.301 & 5.237 & TRN & \\
\hline CHEMBL3416897 & 1473383 & 4.301 & 4.3159 & TRN & \\
\hline CHEMBL3416893 & 1473383 & 4.5686 & 3.9894 & TRN & \\
\hline CHEMBL3416900 & 1473383 & 4.301 & 4.1517 & TRN & \\
\hline CHEMBL3416931 & 1473383 & 5.9586 & 6.1498 & TRN & \\
\hline CHEMBL3416891 & 1473383 & 4.301 & 4.2366 & TRN & \\
\hline CHEMBL3416899 & 1473383 & 4.301 & 4.1517 & TRN & \\
\hline CHEMBL 3416892 & 1473383 & 4.301 & 4.336 & TRN & \\
\hline CHEMBL3416941 & 1473383 & 4.0 & \multicolumn{2}{|c|}{3.8089999999999997} & TRN \\
\hline CHEMBL3417035 & 1473383 & 5.0555 & 4.6264 & TRN & \\
\hline CHEMBL3416933 & 1473383 & 5.5528 & 5.4818 & TRN & \\
\hline CHEMBL3416902 & 1473383 & 3.699 & 4.1327 & TRN & \\
\hline CHEMBL3416915 & 1473383 & 4.301 & 4.2739 & TRN & \\
\hline CHEMBL3416935 & 1473383 & 4.0 & 4.6878 & TRN & \\
\hline CHEMBL3416936 & 1473383 & 5.4685 & 4.6878 & TRN & \\
\hline CHEMBL3417037 & 1473383 & 4.0 & 4.3233 & TRN & \\
\hline CHEMBL3416940 & 1473383 & 4.0 & 3.9652 & TRN & \\
\hline CHEMBL3416929 & 1473383 & 4.0 & 4.0412 & TRN & \\
\hline CHEMBL3416923 & 1473383 & 4.0 & 4.218 & TRN & \\
\hline CHEMBL3416916 & 1473383 & 4.301 & 4.2739 & TRN & \\
\hline CHEMBL3416932 & 1473383 & 4.0 & 4.6878 & TRN & \\
\hline CHEMBL3416918 & 1473383 & 4.0 & 4.0449 & TRN & \\
\hline
\end{tabular}




\begin{tabular}{|c|c|c|c|c|c|}
\hline \multirow[b]{2}{*}{ CHEMBL 3416890} & \multicolumn{5}{|c|}{ Supplemental Table S2.txt } \\
\hline & 1473383 & 4.301 & 4.46899 & 9999999999 & TRN \\
\hline CHEMBL3416930 & 1473383 & 5.6778 & 5.6915 & TRN & \\
\hline CHEMBL3416912 & 1473383 & 4.301 & 4.9345 & TST & \\
\hline CHEMBL3416919 & 1473383 & 4.0 & 5.0129 & TST & \\
\hline CHEMBL3416942 & 1473383 & 5.4437 & 5.7952 & TST & \\
\hline CHEMBL3416906 & 1473383 & 4.3279 & 4.4201 & TST & \\
\hline CHEMBL3416943 & 1473383 & 5.3372 & 5.237 & TST & \\
\hline CHEMBL3416898 & 1473383 & 4.301 & 4.1517 & TST & \\
\hline CHEMBL3416939 & 1473383 & 4.0 & 3.80899 & 99999999997 & TST \\
\hline CHEMBL3416901 & 1473383 & 3.699 & 4.2353 & TST & \\
\hline CHEMBL3416938 & 1473383 & 4.0 & 5.2633 & TST & \\
\hline CHEMBL3416927 & 1473383 & 4.0 & 3.6322 & TST & \\
\hline CHEMBL3416896 & 1473383 & 4.301 & 4.2673 & TST & \\
\hline CHEMBL 3417036 & 1473383 & 4.0 & 3.4599 & TST & \\
\hline CHEMBL549020 & 1479008 & 5.2 & 4.8044 & TRN & \\
\hline CHEMBL526199 & 1479008 & 5.3 & 5.1598 & TRN & \\
\hline CHEMBL3430919 & 1479008 & 5.9 & 6.2102 & TRN & \\
\hline CHEMBL528583 & 1479008 & 5.7 & 5.0883 & TRN & \\
\hline CHEMBL530358 & 1479008 & 5.7 & 5.251 & TRN & \\
\hline CHEMBL530275 & 1479008 & 5.5 & 5.9949 & TRN & \\
\hline CHEMBL534517 & 1479008 & 5.8 & 6.006 & TRN & \\
\hline CHEMBL 3430920 & 1479008 & 6.3 & 6.3741 & TRN & \\
\hline CHEMBL 3430921 & 1479008 & 4.9 & 4.9365 & TST & \\
\hline CHEMBL3430922 & 1479008 & 4.6 & 4.5761 & TST & \\
\hline CHEMBL 2098124 & 1479008 & 5.3 & 5.7088 & TRN & \\
\hline CHEMBL 2098408 & 1479008 & 5.5 & 5.9398 & TRN & \\
\hline CHEMBL1578482 & 1479008 & 5.7 & 5.8442 & TRN & \\
\hline CHEMBL 2098276 & 1479008 & 5.9 & 5.7535 & TRN & \\
\hline CHEMBL3430923 & 1479008 & 3.3 & 3.7641 & TST & \\
\hline CHEMBL 3430924 & 1479008 & 5.9 & 5.8715 & TRN & \\
\hline CHEMBL3430925 & 1479008 & 4.3 & 3.8182 & TST & \\
\hline CHEMBL3430926 & 1479008 & 3.3 & 3.8535 & TST & \\
\hline CHEMBL 2165401 & 1479008 & 4.8 & 5.0484 & TST & \\
\hline CHEMBL3430927 & 1479008 & 6.2 & 6.0124 & TRN & \\
\hline CHEMBL3430928 & 1479008 & 6.1 & 6.1404 & TRN & \\
\hline CHEMBL3430929 & 1479008 & 5.3 & 5.644 & TRN & \\
\hline CHEMBL3430930 & 1479008 & 3.3 & 3.7166 & TRN & \\
\hline CHEMBL 305686 & 1479008 & 3.3 & 3.8539 & TST & \\
\hline CHEMBL3430931 & 1479008 & 5.2 & 3.7066 & TST & \\
\hline CHEMBL3430932 & 1479008 & 3.3 & 3.7922 & TST & \\
\hline CHEMBL1232777 & 1479008 & 6.4 & 5.6527 & TST & \\
\hline CHEMBL 3430933 & 1479008 & 4.8 & 3.9852 & TRN & \\
\hline CHEMBL3430913 & 1479008 & 3.2 & 3.8108 & TRN & \\
\hline CHEMBL3430934 & 1479008 & 5.3 & 5.4711 & TRN & \\
\hline CHEMBL3430935 & 1479008 & 4.8 & 4.9141 & TST & \\
\hline CHEMBL3430936 & 1479008 & 3.3 & 3.6301 & TRN & \\
\hline CHEMBL 3430937 & 1479008 & 4.7 & 4.5608 & TRN & \\
\hline CHEMBL3430938 & 1479008 & 5.4 & 5.3736 & TRN & \\
\hline
\end{tabular}




\begin{tabular}{|c|c|c|c|c|c|}
\hline CHEMBL3430939 & 1479008 & 5.3 & 5.478 & TRN & \\
\hline CHEMBL 3430940 & 1479008 & 5.5 & 5.6365 & TRN & \\
\hline CHEMBL3430941 & 1479008 & 5.2 & 5.4482 & TRN & \\
\hline CHEMBL3430942 & 1479008 & 5.5 & 5.3531 & TRN & \\
\hline CHEMBL3430943 & 1479008 & 5.3 & 5.4776 & TRN & \\
\hline CHEMBL3430944 & 1479008 & 5.3 & 5.4307 & TRN & \\
\hline CHEMBL3430945 & 1479008 & 4.9 & 5.164 & TRN & \\
\hline CHEMBL3430946 & 1479008 & 5.5 & 5.4946 & TRN & \\
\hline CHEMBL3430947 & 1479008 & 5.8 & 5.5889 & TRN & \\
\hline CHEMBL3430948 & 1479008 & 5.1 & 3.60399 & 99999999996 & TRN \\
\hline CHEMBL3430949 & 1479008 & 6.8 & 6.5825 & TRN & \\
\hline CHEMBL1388922 & 1479008 & 5.4 & 5.7188 & TRN & \\
\hline CHEMBL3430950 & 1479008 & 3.3 & 3.52600 & 00000000002 & TRN \\
\hline CHEMBL3430951 & 1479008 & 5.4 & 5.2395 & TST & \\
\hline CHEMBL1321334 & 1479008 & 3.3 & 3.8642 & TRN & \\
\hline CHEMBL3430952 & 1479008 & 6.8 & 5.7672 & TRN & \\
\hline CHEMBL3430953 & 1479008 & 3.3 & 3.7627 & TRN & \\
\hline CHEMBL 3430954 & 1479008 & 4.7 & 4.082 & TRN & \\
\hline CHEMBL3430955 & 1479008 & 4.8 & 4.8755 & TST & \\
\hline CHEMBL3430956 & 1479008 & 5.3 & 5.4368 & TRN & \\
\hline CHEMBL3430957 & 1479008 & 4.8 & 4.7373 & TRN & \\
\hline CHEMBL3430958 & 1479008 & 5.0 & 5.0597 & TRN & \\
\hline CHEMBL3430959 & 1479008 & 6.4 & 6.3668 & TRN & \\
\hline CHEMBL3430960 & 1479008 & 3.3 & 3.8152 & TRN & \\
\hline CHEMBL3430961 & 1479008 & 6.3 & 5.6035 & TRN & \\
\hline CHEMBL3430962 & 1479008 & 3.3 & 4.2119 & TRN & \\
\hline CHEMBL3430963 & 1479008 & 5.4 & 5.3753 & TRN & \\
\hline CHEMBL3430964 & 1479008 & 5.6 & 5.2611 & TRN & \\
\hline CHEMBL 3430965 & 1479008 & 6.0 & 5.6987 & TRN & \\
\hline CHEMBL3430966 & 1479008 & 4.5 & 4.6182 & TRN & \\
\hline CHEMBL3430967 & 1479008 & 5.1 & 4.6327 & TRN & \\
\hline CHEMBL3430968 & 1479008 & 6.4 & 6.3551 & TRN & \\
\hline CHEMBL3430969 & 1479008 & 5.6 & 5.8753 & TRN & \\
\hline CHEMBL3430970 & 1479008 & 5.5 & 5.3742 & TRN & \\
\hline CHEMBL1482137 & 1479008 & 4.7 & 3.4973 & TRN & \\
\hline CHEMBL3430971 & 1479008 & 3.3 & 3.6407 & TRN & \\
\hline CHEMBL3430972 & 1479008 & 3.3 & 3.8322 & TRN & \\
\hline CHEMBL3430973 & 1479008 & 4.8 & 5.1603 & TRN & \\
\hline CHEMBL3430974 & 1479008 & 5.0 & 5.1076 & TRN & \\
\hline CHEMBL3430975 & 1479008 & 3.3 & 3.5321 & TRN & \\
\hline CHEMBL3430976 & 1479008 & 3.3 & 3.5217 & TRN & \\
\hline CHEMBL3430977 & 1479008 & 3.3 & 3.7721 & TST & \\
\hline CHEMBL164422 & 1479008 & 6.6 & 6.4988 & TRN & \\
\hline CHEMBL3430978 & 1479008 & 3.3 & 3.9415 & TRN & \\
\hline CHEMBL3430979 & 1479008 & 3.3 & 3.8767 & TRN & \\
\hline CHEMBL3430980 & 1479008 & 5.7 & 5.3563 & TRN & \\
\hline CHEMBL1487481 & 1479008 & 3.3 & 4.4773 & TRN & \\
\hline CHEMBL1487467 & 1479008 & 3.3 & 3.4343 & TRN & \\
\hline
\end{tabular}




\begin{tabular}{|c|c|c|c|c|}
\hline & & & & \\
\hline CHEMBL 3430981 & 1479008 & 5.4 & 5.4668 & TRN \\
\hline CHEMBL 3430982 & 1479008 & 5.6 & 5.6343 & TRN \\
\hline CHEMBL3430983 & 1479008 & 5.1 & 5.4208 & TRN \\
\hline CHEMBL592827 & 1479008 & 5.4 & 3.8189 & TRN \\
\hline CHEMBL3430984 & 1479008 & 3.3 & 3.8583 & TRN \\
\hline CHEMBL3430985 & 1479008 & 5.5 & 5.4318 & TRN \\
\hline CHEMBL1466712 & 1479008 & 5.6 & 5.8874 & TRN \\
\hline CHEMBL3430986 & 1479008 & 3.3 & 3.7691 & TRN \\
\hline CHEMBL 3430987 & 1479008 & 5.4 & 5.3547 & TST \\
\hline CHEMBL3430988 & 1479008 & 5.2 & 4.2077 & TRN \\
\hline CHEMBL3430989 & 1479008 & 3.3 & 3.6546 & TRN \\
\hline CHEMBL3430990 & 1479008 & 3.3 & 3.8003 & TRN \\
\hline CHEMBL3430991 & 1479008 & 4.4 & 3.7092 & TRN \\
\hline CHEMBL3430992 & 1479008 & 4.8 & 3.7358 & TRN \\
\hline CHEMBL3430993 & 1479008 & 3.3 & 3.6548 & TRN \\
\hline CHEMBL3430994 & 1479008 & 3.3 & 3.7806 & TRN \\
\hline CHEMBL3430995 & 1479008 & 4.8 & 4.7061 & TST \\
\hline CHEMBL3430996 & 1479008 & 3.3 & 3.6261 & TRN \\
\hline CHEMBL3430997 & 1479008 & 3.3 & 3.633 & TRN \\
\hline CHEMBL3430998 & 1479008 & 3.3 & 4.0183 & TRN \\
\hline CHEMBL3430999 & 1479008 & 5.0 & 4.6068 & TRN \\
\hline CHEMBL3431000 & 1479008 & 4.6 & 4.6981 & TRN \\
\hline CHEMBL 3431001 & 1479008 & 4.6 & 3.9761 & TRN \\
\hline CHEMBL3431002 & 1479008 & 4.5 & 4.5624 & TST \\
\hline CHEMBL3431003 & 1479008 & 6.1 & 6.3343 & TRN \\
\hline CHEMBL3431004 & 1479008 & 6.1 & 6.4032 & TRN \\
\hline CHEMBL3431005 & 1479008 & 5.3 & 5.4209 & TRN \\
\hline CHEMBL 3431006 & 1479008 & 5.8 & 5.97 & TRN \\
\hline CHEMBL 3431007 & 1479008 & 4.8 & 3.8981 & TRN \\
\hline CHEMBL3431008 & 1479008 & 5.9 & 5.8637 & TST \\
\hline CHEMBL3431009 & 1479008 & 6.0 & 5.8523 & TRN \\
\hline CHEMBL 2355685 & 1479008 & 5.4 & 5.6117 & TST \\
\hline CHEMBL 3431010 & 1479008 & 6.1 & 5.1893 & TRN \\
\hline CHEMBL 3431011 & 1479008 & 3.3 & 4.3992 & TRN \\
\hline CHEMBL3431012 & 1479008 & 3.3 & 3.6571 & TST \\
\hline CHEMBL1731664 & 1479008 & 5.3 & 5.3224 & TRN \\
\hline CHEMBL3431013 & 1479008 & 5.7 & 5.2214 & TRN \\
\hline CHEMBL3431014 & 1479008 & 4.9 & 4.867 & TRN \\
\hline CHEMBL3431015 & 1479008 & 4.6 & 4.5453 & TRN \\
\hline CHEMBL3431016 & 1479008 & 4.9 & 3.6178 & TRN \\
\hline CHEMBL3431017 & 1479008 & 3.3 & 3.9863 & TRN \\
\hline CHEMBL3431018 & 1479008 & 6.3 & 6.2317 & TRN \\
\hline CHEMBL3431019 & 1479008 & 6.3 & 5.8804 & TRN \\
\hline CHEMBL3431020 & 1479008 & 3.3 & 3.8749 & TRN \\
\hline CHEMBL 3431021 & 1479008 & 3.3 & 3.8895 & TRN \\
\hline CHEMBL3431022 & 1479008 & 6.1 & 6.28700 & 0000000001 \\
\hline CHEMBL3431023 & 1479008 & 5.0 & 4.9015 & TST \\
\hline CHEMBL3431024 & 1479008 & 3.3 & 3.5323 & TRN \\
\hline
\end{tabular}

Supplemental Table S2.txt

TRN 


\begin{tabular}{|c|c|c|c|c|}
\hline & & & & \\
\hline CHEMBL 3431025 & 1479008 & 3.3 & 4.2891 & TRN \\
\hline CHEMBL3431026 & 1479008 & 5.4 & 5.3192 & TST \\
\hline CHEMBL3431027 & 1479008 & 4.6 & 3.6096 & TRN \\
\hline CHEMBL 3431028 & 1479008 & 3.3 & 3.7537 & TRN \\
\hline CHEMBL3431029 & 1479008 & 4.4 & 3.9066 & TRN \\
\hline CHEMBL3431030 & 1479008 & 5.0 & 5.3955 & TRN \\
\hline CHEMBL3431031 & 1479008 & 4.7 & 5.0738 & TRN \\
\hline CHEMBL3431032 & 1479008 & 5.1 & 5.4284 & TRN \\
\hline CHEMBL1527364 & 1479008 & 3.3 & 3.7115 & TRN \\
\hline CHEMBL3430914 & 1479008 & 5.5 & 5.3622 & TRN \\
\hline CHEMBL3431033 & 1479008 & 6.6 & 6.2722 & TRN \\
\hline CHEMBL3431034 & 1479008 & 5.5 & 5.3383 & TRN \\
\hline CHEMBL3431035 & 1479008 & 4.9 & 4.1117 & TRN \\
\hline CHEMBL3431036 & 1479008 & 3.3 & 4.2008 & TRN \\
\hline CHEMBL3431037 & 1479008 & 5.7 & 5.9391 & TRN \\
\hline CHEMBL3431038 & 1479008 & 5.9 & 5.8229 & TRN \\
\hline CHEMBL3431039 & 1479008 & 3.3 & 3.5139 & TRN \\
\hline CHEMBL 3431040 & 1479008 & 6.0 & 5.9675 & TRN \\
\hline CHEMBL1354075 & 1479008 & 5.3 & 5.5681 & TRN \\
\hline CHEMBL3431041 & 1479008 & 4.5 & 4.4672 & TRN \\
\hline CHEMBL 3431042 & 1479008 & 4.5 & 3.8496 & TRN \\
\hline CHEMBL3431043 & 1479008 & 5.6 & 5.2457 & TST \\
\hline CHEMBL 3431044 & 1479008 & 3.3 & 3.8025 & TST \\
\hline CHEMBL3431045 & 1479008 & 4.9 & 4.5724 & TRN \\
\hline CHEMBL3431046 & 1479008 & 5.9 & 6.0102 & TRN \\
\hline CHEMBL3431047 & 1479008 & 6.2 & 6.3967 & TRN \\
\hline CHEMBL3431048 & 1479008 & 6.4 & 6.5254 & TRN \\
\hline CHEMBL3431049 & 1479008 & 6.0 & 6.2393 & TRN \\
\hline CHEMBL3431050 & 1479008 & 6.3 & 6.3914 & TRN \\
\hline CHEMBL3431051 & 1479008 & 6.1 & 6.3645 & TRN \\
\hline CHEMBL3431052 & 1479008 & 5.7 & 6.0254 & TRN \\
\hline CHEMBL3431053 & 1479008 & 6.1 & 6.3812 & TRN \\
\hline CHEMBL 2356808 & 1479008 & 3.3 & 3.3964 & TRN \\
\hline CHEMBL3431054 & 1479008 & 3.3 & 3.5802 & TRN \\
\hline CHEMBL3431055 & 1479008 & 4.5 & 3.9872 & TST \\
\hline CHEMBL3431056 & 1479008 & 3.3 & 3.7075 & TRN \\
\hline CHEMBL3431057 & 1479008 & 5.3 & 5.1973 & TST \\
\hline CHEMBL 2093320 & 1479008 & 3.3 & 4.0214 & TRN \\
\hline CHEMBL 3431058 & 1479008 & 3.3 & 3.6289 & TRN \\
\hline CHEMBL3431059 & 1479008 & 3.3 & 3.5185 & TRN \\
\hline CHEMBL3431060 & 1479008 & 3.3 & 3.6616 & TRN \\
\hline CHEMBL3431061 & 1479008 & 4.9 & 4.7336 & TRN \\
\hline CHEMBL3431062 & 1479008 & 3.3 & 3.6395 & TRN \\
\hline CHEMBL 3431063 & 1479008 & 3.3 & 3.5769 & TRN \\
\hline CHEMBL3431064 & 1479008 & 3.3 & 3.8178 & TRN \\
\hline CHEMBL3431065 & 1479008 & 4.6 & 5.0185 & TST \\
\hline CHEMBL3431066 & 1479008 & 4.8 & 4.3195 & TRN \\
\hline CHEMBL3431067 & 1479008 & 4.7 & 4.9286 & TRN \\
\hline
\end{tabular}





\begin{tabular}{|c|c|c|c|c|}
\hline & & & ient & $a \perp 1 a$ \\
\hline CHEMBL3431117 & 1479008 & 5.7 & 5.2382 & TRN \\
\hline CHEMBL3431118 & 1479008 & 4.6 & 4.6382 & TRN \\
\hline CHEMBL3431119 & 1479008 & 6.6 & 6.2533 & TRN \\
\hline CHEMBL 3431120 & 1479008 & 3.3 & 3.7126 & TRN \\
\hline CHEMBL3431121 & 1479008 & 4.4 & 3.9248 & TST \\
\hline CHEMBL3431122 & 1479008 & 4.8 & 4.0771 & TRN \\
\hline CHEMBL3431123 & 1479008 & 5.0 & 4.687 & TRN \\
\hline CHEMBL3431124 & 1479008 & 3.3 & 4.3311 & TRN \\
\hline CHEMBL3431125 & 1479008 & 3.3 & 3.9193 & TST \\
\hline CHEMBL3431126 & 1479008 & 3.3 & 3.7635 & TRN \\
\hline CHEMBL3431127 & 1479008 & 7.3 & 6.9955 & TST \\
\hline CHEMBL3431128 & 1479008 & 6.1 & 6.1183 & TST \\
\hline CHEMBL3431129 & 1479008 & 6.6 & 6.3254 & TST \\
\hline CHEMBL3431130 & 1479008 & 4.9 & 5.5934 & TST \\
\hline CHEMBL3431131 & 1479008 & 5.2 & 5.4886 & TRN \\
\hline CHEMBL3430915 & 1479008 & 3.3 & 3.8994 & TRN \\
\hline CHEMBL3431132 & 1479008 & 4.9 & 4.7809 & TRN \\
\hline CHEMBL3431133 & 1479008 & 4.7 & 4.7497 & TRN \\
\hline CHEMBL 3431134 & 1479008 & 5.7 & 5.2128 & TRN \\
\hline CHEMBL3431135 & 1479008 & 3.3 & 3.6302 & TRN \\
\hline CHEMBL3431136 & 1479008 & 6.1 & 6.022 & TRN \\
\hline CHEMBL3431137 & 1479008 & 5.4 & 5.5004 & TRN \\
\hline CHEMBL3431138 & 1479008 & 3.3 & 4.0795 & TST \\
\hline CHEMBL3431139 & 1479008 & 5.1 & 5.2327 & TST \\
\hline CHEMBL3431140 & 1479008 & 4.5 & 3.7853 & TST \\
\hline CHEMBL3431141 & 1479008 & 5.1 & 5.1188 & TRN \\
\hline CHEMBL3431142 & 1479008 & 3.3 & 4.0987 & TST \\
\hline CHEMBL3431143 & 1479008 & 6.3 & 6.1236 & TRN \\
\hline CHEMBL3431144 & 1479008 & 3.3 & 4.0253 & TRN \\
\hline CHEMBL3431145 & 1479008 & 4.9 & 5.5116 & TRN \\
\hline CHEMBL3431146 & 1479008 & 5.5 & 5.3266 & TRN \\
\hline CHEMBL3431147 & 1479008 & 4.9 & 5.006 & TST \\
\hline CHEMBL3431148 & 1479008 & 3.3 & 3.7559 & TRN \\
\hline CHEMBL3431149 & 1479008 & 5.8 & 5.5156 & TRN \\
\hline CHEMBL3431150 & 1479008 & 3.3 & 4.154 & TRN \\
\hline CHEMBL3431151 & 1479008 & 5.4 & 4.0553 & TRN \\
\hline CHEMBL3431152 & 1479008 & 4.8 & 3.548 & TRN \\
\hline CHEMBL3431153 & 1479008 & 3.3 & 3.6532 & TRN \\
\hline CHEMBL 3431154 & 1479008 & 5.5 & 5.3428 & TST \\
\hline CHEMBL3431155 & 1479008 & 6.1 & 4.0011 & TRN \\
\hline CHEMBL3431156 & 1479008 & 3.3 & 3.8975 & TRN \\
\hline CHEMBL3431157 & 1479008 & 3.3 & 4.2103 & TST \\
\hline CHEMBL3431158 & 1479008 & 6.6 & 6.0325 & TST \\
\hline CHEMBL3431159 & 1479008 & 3.3 & 4.0855 & TST \\
\hline CHEMBL1593679 & 1479008 & 3.3 & 3.9531 & TRN \\
\hline CHEMBL3431160 & 1479008 & 4.8 & 4.9067 & TRN \\
\hline CHEMBL3431161 & 1479008 & 4.7 & 5.0566 & TST \\
\hline CHEMBL3431162 & 1479008 & 4.5 & 3.9251 & TST \\
\hline
\end{tabular}




\begin{tabular}{|c|c|c|c|c|}
\hline & & & & \\
\hline CHEMBL3431163 & 1479008 & 5.0 & 4.3391 & TRN \\
\hline CHEMBL3431164 & 1479008 & 3.3 & 3.903 & TRN \\
\hline CHEMBL3431165 & 1479008 & 3.3 & 3.7361 & TST \\
\hline CHEMBL1458931 & 1479008 & 3.3 & 4.0977 & TRN \\
\hline CHEMBL3431166 & 1479008 & 3.3 & 3.6442 & TRN \\
\hline CHEMBL3431167 & 1479008 & 3.3 & 3.623 & TRN \\
\hline CHEMBL3431168 & 1479008 & 6.5 & 5.921 & TRN \\
\hline CHEMBL3431169 & 1479008 & 5.5 & 5.4431 & TRN \\
\hline CHEMBL3431170 & 1479008 & 7.1 & 6.8862 & TRN \\
\hline CHEMBL3431171 & 1479008 & 3.3 & 3.8619 & TRN \\
\hline CHEMBL3431172 & 1479008 & 5.9 & 6.2973 & TRN \\
\hline CHEMBL3431173 & 1479008 & 5.7 & 5.5728 & TRN \\
\hline CHEMBL3431174 & 1479008 & 5.6 & 5.6037 & TRN \\
\hline CHEMBL3431175 & 1479008 & 3.3 & 3.8557 & TST \\
\hline CHEMBL3431176 & 1479008 & 6.4 & 6.1046 & TRN \\
\hline CHEMBL3431177 & 1479008 & 5.8 & 5.7891 & TRN \\
\hline CHEMBL3431178 & 1479008 & 5.7 & 5.7545 & TRN \\
\hline CHEMBL3431179 & 1479008 & 5.5 & 5.4541 & TRN \\
\hline CHEMBL3431180 & 1479008 & 6.1 & 5.9697 & TRN \\
\hline CHEMBL3431181 & 1479008 & 6.2 & 5.6429 & TRN \\
\hline CHEMBL3431182 & 1479008 & 5.3 & 5.4444 & TRN \\
\hline CHEMBL3431183 & 1479008 & 4.8 & 4.0641 & TRN \\
\hline CHEMBL 3431184 & 1479008 & 5.3 & 4.9637 & TRN \\
\hline CHEMBL3431185 & 1479008 & 6.2 & 5.8376 & TRN \\
\hline CHEMBL3431186 & 1479008 & 6.2 & 6.3191 & TRN \\
\hline CHEMBL3431187 & 1479008 & 7.1 & 6.4683 & TRN \\
\hline CHEMBL3431188 & 1479008 & 7.0 & 6.7642 & TRN \\
\hline CHEMBL3431189 & 1479008 & 4.7 & 4.7568 & TST \\
\hline CHEMBL3431190 & 1479008 & 4.9 & 5.2561 & TRN \\
\hline CHEMBL3431191 & 1479008 & 4.9 & 4.6516 & TRN \\
\hline CHEMBL3431192 & 1479008 & 7.3 & 6.9793 & TRN \\
\hline CHEMBL3431193 & 1479008 & 7.1 & 7.0638 & TRN \\
\hline CHEMBL3431194 & 1479008 & 6.1 & 6.4193 & TRN \\
\hline CHEMBL3431195 & 1479008 & 6.2 & 6.5843 & TRN \\
\hline CHEMBL3431196 & 1479008 & 6.0 & 6.0262 & TRN \\
\hline CHEMBL3431197 & 1479008 & 6.1 & 6.3887 & TRN \\
\hline CHEMBL3431198 & 1479008 & 6.2 & 6.5589 & TRN \\
\hline CHEMBL3431199 & 1479008 & 4.7 & 4.8206 & TST \\
\hline CHEMBL3431200 & 1479008 & 3.3 & 3.8186 & TRN \\
\hline CHEMBL3431201 & 1479008 & 5.3 & 3.8777 & TRN \\
\hline CHEMBL3431202 & 1479008 & 3.3 & 4.0708 & TRN \\
\hline CHEMBL3431203 & 1479008 & 6.2 & 6.5301 & TRN \\
\hline CHEMBL3431204 & 1479008 & 5.3 & 5.0901 & TRN \\
\hline CHEMBL3431205 & 1479008 & 4.7 & 3.7209 & TRN \\
\hline CHEMBL 3431206 & 1479008 & 7.4 & 7.2074 & TRN \\
\hline CHEMBL 3431207 & 1479008 & 6.1 & 6.3077 & TRN \\
\hline CHEMBL 3431208 & 1479008 & 4.8 & 4.9823 & TRN \\
\hline CHEMBL3431209 & 1479008 & 6.9 & 7.0806 & TRN \\
\hline
\end{tabular}




\begin{tabular}{|c|c|c|c|c|c|}
\hline & & & & & \\
\hline CHEMBL3431210 & 1479008 & 3.3 & 3.9452 & TRN & \\
\hline CHEMBL3431211 & 1479008 & 4.8 & 5.2634 & TRN & \\
\hline CHEMBL3431212 & 1479008 & 5.9 & 5.3885 & TRN & \\
\hline CHEMBL3431213 & 1479008 & 3.3 & 4.0676 & TRN & \\
\hline CHEMBL 3431214 & 1479008 & 3.3 & 3.5982 & TRN & \\
\hline CHEMBL3431215 & 1479008 & 6.2 & 6.3029 & TRN & \\
\hline CHEMBL3431216 & 1479008 & 5.6 & 5.5171 & TRN & \\
\hline CHEMBL3431217 & 1479008 & 6.6 & 5.6719 & TRN & \\
\hline CHEMBL3431218 & 1479008 & 5.2 & 3.7101 & TRN & \\
\hline CHEMBL3431219 & 1479008 & 3.3 & 3.6241 & TRN & \\
\hline CHEMBL 3431220 & 1479008 & 5.6 & 5.649 & TRN & \\
\hline CHEMBL3431221 & 1479008 & 6.3 & 6.12299 & 9999999999 & TRN \\
\hline CHEMBL 3431222 & 1479008 & 4.8 & 3.5943 & TRN & \\
\hline CHEMBL3431223 & 1479008 & 3.3 & 3.714 & TST & \\
\hline CHEMBL 3431224 & 1479008 & 3.3 & 3.9019 & TRN & \\
\hline CHEMBL 3431225 & 1479008 & 6.2 & 6.0507 & TRN & \\
\hline CHEMBL3431226 & 1479008 & 5.9 & 5.2542 & TRN & \\
\hline CHEMBL 3431227 & 1479008 & 5.8 & 5.5979 & TRN & \\
\hline CHEMBL 3431228 & 1479008 & 4.4 & 4.088 & TRN & \\
\hline CHEMBL3431229 & 1479008 & 6.6 & 6.6559 & TRN & \\
\hline CHEMBL 3431230 & 1479008 & 6.4 & 6.6957 & TRN & \\
\hline CHEMBL 2441267 & 1479008 & 7.5 & 7.4114 & TRN & \\
\hline CHEMBL3430916 & 1479008 & 3.3 & 3.8794 & TRN & \\
\hline CHEMBL 3431231 & 1479008 & 5.8 & 6.0875 & TRN & \\
\hline CHEMBL 3431232 & 1479008 & 5.7 & 4.0866 & TRN & \\
\hline CHEMBL 3431233 & 1479008 & 6.1 & 6.2332 & TRN & \\
\hline CHEMBL3431234 & 1479008 & 5.6 & 5.8375 & TRN & \\
\hline CHEMBL 3431235 & 1479008 & 4.6 & 4.8627 & TST & \\
\hline CHEMBL3431236 & 1479008 & 4.5 & 3.7467 & TST & \\
\hline CHEMBL3431237 & 1479008 & 5.1 & 5.0342 & TRN & \\
\hline CHEMBL 3431238 & 1479008 & 4.7 & 4.1367 & TRN & \\
\hline CHEMBL3431239 & 1479008 & 3.3 & 3.64399 & 99999999997 & TRN \\
\hline CHEMBL 3431240 & 1479008 & 3.3 & 4.4166 & TST & \\
\hline CHEMBL3431241 & 1479008 & 7.7 & 4.2092 & TRN & \\
\hline CHEMBL 3431242 & 1479008 & 3.3 & 3.775 & TRN & \\
\hline CHEMBL3431243 & 1479008 & 3.3 & 3.6391 & TST & \\
\hline CHEMBL 3431244 & 1479008 & 3.3 & 3.9349 & TRN & \\
\hline CHEMBL 3431245 & 1479008 & 5.5 & 5.3794 & TRN & \\
\hline CHEMBL 3431246 & 1479008 & 5.9 & 5.6147 & TRN & \\
\hline CHEMBL 3431247 & 1479008 & 6.3 & 6.2158 & TRN & \\
\hline CHEMBL 3431248 & 1479008 & 4.5 & 3.6998 & TRN & \\
\hline CHEMBL 3431250 & 1479008 & 3.3 & 3.5886 & TRN & \\
\hline CHEMBL3431251 & 1479008 & 3.3 & 3.8418 & TRN & \\
\hline CHEMBL 3431252 & 1479008 & 3.3 & 3.7104 & TRN & \\
\hline CHEMBL 3431253 & 1479008 & 4.5 & 4.6328 & TST & \\
\hline CHEMBL 3431254 & 1479008 & 5.3 & 5.3031 & TRN & \\
\hline CHEMBL 3431255 & 1479008 & 4.5 & 4.7625 & TST & \\
\hline CHEMBL3431256 & 1479008 & 6.3 & 6.1478 & TST & \\
\hline
\end{tabular}




\begin{tabular}{|c|c|c|c|c|c|}
\hline CHEMBL3431257 & 1479008 & 3.3 & 4.0681 & TRN & \\
\hline CHEMBL3431258 & 1479008 & 5.5 & 5.2967 & TRN & \\
\hline CHEMBL3431259 & 1479008 & 3.3 & 3.6552 & TRN & \\
\hline CHEMBL 3431260 & 1479008 & 5.6 & 3.9352 & TRN & \\
\hline CHEMBL3431261 & 1479008 & 5.0 & 4.772 & TRN & \\
\hline CHEMBL2356920 & 1479008 & 4.6 & 4.8702 & TRN & \\
\hline CHEMBL 3431262 & 1479008 & 3.3 & 3.6857 & TRN & \\
\hline CHEMBL3431263 & 1479008 & 4.3 & 3.7973 & TRN & \\
\hline CHEMBL3431264 & 1479008 & 3.3 & 3.8517 & TRN & \\
\hline CHEMBL3431265 & 1479008 & 3.3 & 3.8072 & TST & \\
\hline CHEMBL3431266 & 1479008 & 5.9 & 3.8468 & TRN & \\
\hline CHEMBL 3431267 & 1479008 & 5.5 & 5.5846 & TRN & \\
\hline CHEMBL3431268 & 1479008 & 5.8 & 5.255 & TST & \\
\hline CHEMBL3431269 & 1479008 & 5.8 & 5.7601 & TRN & \\
\hline CHEMBL 3431270 & 1479008 & 4.7 & 4.9244 & TST & \\
\hline CHEMBL3431271 & 1479008 & 3.3 & 3.7009 & TRN & \\
\hline CHEMBL3431272 & 1479008 & 3.3 & 3.5732 & TRN & \\
\hline CHEMBL3431273 & 1479008 & 6.0 & 5.9393 & TRN & \\
\hline CHEMBL3431274 & 1479008 & 5.8 & 5.9325 & TRN & \\
\hline CHEMBL3431275 & 1479008 & 4.5 & 4.7634 & TRN & \\
\hline CHEMBL3431276 & 1479008 & 5.2 & 5.2005 & TST & \\
\hline CHEMBL3431277 & 1479008 & 6.0 & 5.7281 & TRN & \\
\hline CHEMBL3431278 & 1479008 & 3.3 & 3.6982 & TRN & \\
\hline CHEMBL3431279 & 1479008 & 3.3 & 4.1387 & TST & \\
\hline CHEMBL 3431280 & 1479008 & 4.6 & 4.6924 & TST & \\
\hline CHEMBL 3431281 & 1479008 & 5.1 & 5.2285 & TST & \\
\hline CHEMBL 3431282 & 1479008 & 3.3 & 3.8833 & TST & \\
\hline CHEMBL 3431283 & 1479008 & 3.3 & 3.8807 & TST & \\
\hline CHEMBL3431284 & 1479008 & 5.0 & 5.3169 & TRN & \\
\hline CHEMBL3431285 & 1479008 & 6.5 & 6.0467 & TRN & \\
\hline CHEMBL3431286 & 1479008 & 3.3 & 3.9891 & TST & \\
\hline CHEMBL 3431287 & 1479008 & 5.0 & 3.7205 & TST & \\
\hline CHEMBL3431288 & 1479008 & 5.3 & 4.2442 & TRN & \\
\hline CHEMBL3431289 & 1479008 & 3.3 & 3.85100 & 00000000004 & TST \\
\hline CHEMBL 3431290 & 1479008 & 6.1 & 4.0456 & TRN & \\
\hline CHEMBL3431291 & 1479008 & 3.3 & 3.7319 & TRN & \\
\hline CHEMBL3431292 & 1479008 & 4.8 & 3.7775 & TRN & \\
\hline CHEMBL3431293 & 1479008 & 3.3 & 3.5793 & TRN & \\
\hline CHEMBL3431294 & 1479008 & 3.3 & 3.5407 & TRN & \\
\hline CHEMBL3431295 & 1479008 & 5.7 & 5.9162 & TRN & \\
\hline CHEMBL3431296 & 1479008 & 5.3 & 5.7515 & TRN & \\
\hline CHEMBL 3431297 & 1479008 & 5.5 & 5.8482 & TRN & \\
\hline CHEMBL3431298 & 1479008 & 5.8 & 6.138 & TRN & \\
\hline CHEMBL3431299 & 1479008 & 5.6 & 5.62 & TRN & \\
\hline CHEMBL3431300 & 1479008 & 3.3 & 3.9273 & TRN & \\
\hline CHEMBL 3431301 & 1479008 & 3.3 & 3.6092 & TST & \\
\hline CHEMBL 3431302 & 1479008 & 3.3 & 4.0871 & TRN & \\
\hline CHEMBL3431303 & 1479008 & 5.5 & 3.8743 & TRN & \\
\hline
\end{tabular}




\begin{tabular}{|c|c|c|c|c|}
\hline & & & & \\
\hline CHEMBL3431304 & 1479008 & 5.5 & 5.4854 & TRN \\
\hline CHEMBL3431305 & 1479008 & 3.3 & 3.6734 & TRN \\
\hline CHEMBL3431306 & 1479008 & 5.3 & 5.5894 & TRN \\
\hline CHEMBL3431307 & 1479008 & 6.5 & 3.9365 & TRN \\
\hline CHEMBL3431308 & 1479008 & 5.2 & 5.5264 & TRN \\
\hline CHEMBL3431309 & 1479008 & 6.0 & 5.6604 & TRN \\
\hline CHEMBL3431310 & 1479008 & 5.0 & 4.7971 & TRN \\
\hline CHEMBL3431311 & 1479008 & 6.4 & 6.6447 & TRN \\
\hline CHEMBL3431312 & 1479008 & 6.1 & 6.4177 & TRN \\
\hline CHEMBL3431313 & 1479008 & 6.2 & 6.5165 & TRN \\
\hline CHEMBL3431314 & 1479008 & 6.7 & 6.5039 & TRN \\
\hline CHEMBL3431315 & 1479008 & 5.7 & 5.8278 & TRN \\
\hline CHEMBL3431316 & 1479008 & 3.3 & 4.1225 & TST \\
\hline CHEMBL3431317 & 1479008 & 5.1 & 5.553 & TRN \\
\hline CHEMBL3431318 & 1479008 & 6.2 & 3.8251 & TST \\
\hline CHEMBL3431319 & 1479008 & 5.2 & 4.7513 & TRN \\
\hline CHEMBL3431320 & 1479008 & 3.3 & 3.8023 & TST \\
\hline CHEMBL3431321 & 1479008 & 3.3 & 4.0446 & TRN \\
\hline CHEMBL3431322 & 1479008 & 3.3 & 3.8673 & TRN \\
\hline CHEMBL3431323 & 1479008 & 4.6 & 3.9366 & TRN \\
\hline CHEMBL3431324 & 1479008 & 3.3 & 4.1427 & TST \\
\hline CHEMBL3431325 & 1479008 & 4.5 & 4.4673 & TRN \\
\hline CHEMBL3431326 & 1479008 & 3.3 & 4.0453 & TRN \\
\hline CHEMBL3431327 & 1479008 & 5.9 & 5.9428 & TST \\
\hline CHEMBL3431329 & 1479008 & 5.7 & 5.6882 & TST \\
\hline CHEMBL3430917 & 1479008 & 3.3 & 3.6591 & TRN \\
\hline CHEMBL3431330 & 1479008 & 3.3 & 3.6737 & TRN \\
\hline CHEMBL3431331 & 1479008 & 5.0 & 3.6949 & TRN \\
\hline CHEMBL3431332 & 1479008 & 4.8 & 4.9049 & TRN \\
\hline CHEMBL1582997 & 1479008 & 6.0 & 6.1188 & TRN \\
\hline CHEMBL3431333 & 1479008 & 5.9 & 6.0111 & TRN \\
\hline CHEMBL3431334 & 1479008 & 4.9 & 5.0271 & TRN \\
\hline CHEMBL3431335 & 1479008 & 4.7 & 3.8072 & TRN \\
\hline CHEMBL3431336 & 1479008 & 6.4 & 6.2474 & TRN \\
\hline CHEMBL3431339 & 1479008 & 5.3 & 5.033 & TST \\
\hline CHEMBL3431340 & 1479008 & 3.3 & 3.5917 & TRN \\
\hline CHEMBL3431341 & 1479008 & 5.6 & 5.8479 & TRN \\
\hline CHEMBL3431342 & 1479008 & 5.8 & 5.8152 & TRN \\
\hline CHEMBL3431343 & 1479008 & 3.3 & 3.6902 & TRN \\
\hline CHEMBL3431344 & 1479008 & 3.3 & 3.6633 & TRN \\
\hline CHEMBL3431345 & 1479008 & 6.0 & 6.3064 & TRN \\
\hline CHEMBL 3431346 & 1479008 & 5.8 & 5.9291 & TRN \\
\hline CHEMBL1430615 & 1479008 & 5.3 & 5.3784 & TRN \\
\hline CHEMBL3431347 & 1479008 & 6.1 & 5.9461 & TRN \\
\hline CHEMBL 3431348 & 1479008 & 3.3 & 3.8736 & TRN \\
\hline CHEMBL3431349 & 1479008 & 3.3 & 3.9568 & TRN \\
\hline CHEMBL 3431350 & 1479008 & 3.3 & 4.0797 & TRN \\
\hline CHEMBL465227 & 1479008 & 3.3 & 4.1722 & TRN \\
\hline
\end{tabular}




\begin{tabular}{|c|c|c|c|c|}
\hline & & & & \\
\hline CHEMBL3431351 & 1479008 & 3.3 & 3.8885 & TRN \\
\hline CHEMBL1611993 & 1479008 & 3.3 & 3.6318 & TRN \\
\hline CHEMBL3431352 & 1479008 & 6.5 & 6.4311 & TRN \\
\hline CHEMBL3431353 & 1479008 & 6.2 & 6.3342 & TRN \\
\hline CHEMBL1393829 & 1479008 & 5.5 & 5.3306 & TST \\
\hline CHEMBL3431354 & 1479008 & 5.9 & 6.2155 & TRN \\
\hline CHEMBL3431355 & 1479008 & 5.3 & 3.6603 & TRN \\
\hline CHEMBL3431356 & 1479008 & 5.7 & 5.0648 & TRN \\
\hline CHEMBL3431357 & 1479008 & 6.0 & 5.0461 & TRN \\
\hline CHEMBL3431358 & 1479008 & 5.9 & 5.2216 & TRN \\
\hline CHEMBL3431359 & 1479008 & 3.3 & 3.9771 & TRN \\
\hline CHEMBL3431360 & 1479008 & 4.4 & 3.9698 & TRN \\
\hline CHEMBL3431361 & 1479008 & 4.5 & 4.646 & TRN \\
\hline CHEMBL1535535 & 1479008 & 3.3 & 3.5606 & TRN \\
\hline CHEMBL3431362 & 1479008 & 4.9 & 4.7914 & TRN \\
\hline CHEMBL 3431363 & 1479008 & 4.7 & 5.0879 & TRN \\
\hline CHEMBL3431364 & 1479008 & 3.3 & 3.7508 & TRN \\
\hline CHEMBL 3431365 & 1479008 & 3.3 & 3.6966 & TRN \\
\hline CHEMBL3431366 & 1479008 & 3.3 & 3.8169 & TST \\
\hline CHEMBL3431367 & 1479008 & 3.3 & 3.8674 & TST \\
\hline CHEMBL3431368 & 1479008 & 4.7 & 4.7896 & TRN \\
\hline CHEMBL3431369 & 1479008 & 3.3 & 3.93 & TRN \\
\hline CHEMBL1447267 & 1479008 & 5.5 & 5.8805 & TRN \\
\hline CHEMBL3431370 & 1479008 & 3.3 & 4.078 & TRN \\
\hline CHEMBL1325144 & 1479008 & 3.3 & 3.8055 & TRN \\
\hline CHEMBL1429841 & 1479008 & 5.1 & 5.4788 & TRN \\
\hline CHEMBL 3431371 & 1479008 & 6.1 & 4.0752 & TRN \\
\hline CHEMBL1308225 & 1479008 & 3.3 & 4.2137 & TST \\
\hline CHEMBL 2441359 & 1479008 & 5.7 & 5.8149 & TRN \\
\hline CHEMBL1517284 & 1479008 & 5.7 & 5.7601 & TRN \\
\hline CHEMBL3431372 & 1479008 & 3.3 & 3.8764 & TRN \\
\hline CHEMBL 3431373 & 1479008 & 4.8 & 4.3031 & TRN \\
\hline CHEMBL3431374 & 1479008 & 3.3 & 4.039 & TRN \\
\hline CHEMBL 3431375 & 1479008 & 4.7 & 4.1551 & TST \\
\hline CHEMBL3431376 & 1479008 & 6.1 & 6.2729 & TRN \\
\hline CHEMBL1365653 & 1479008 & 3.3 & 3.7742 & TRN \\
\hline CHEMBL 3431377 & 1479008 & 3.3 & 3.785 & TRN \\
\hline CHEMBL 3431378 & 1479008 & 6.1 & 5.6661 & TRN \\
\hline CHEMBL3431379 & 1479008 & 5.9 & 5.7573 & TRN \\
\hline CHEMBL1478826 & 1479008 & 5.9 & 6.0613 & TRN \\
\hline CHEMBL1872842 & 1479008 & 3.3 & 3.5836 & TRN \\
\hline CHEMBL 3431380 & 1479008 & 6.8 & 6.7033 & TRN \\
\hline CHEMBL3431381 & 1479008 & 5.9 & 6.1902 & TRN \\
\hline CHEMBL3431382 & 1479008 & 4.8 & 4.7674 & TRN \\
\hline CHEMBL 3431383 & 1479008 & 5.3 & 5.5406 & TRN \\
\hline CHEMBL 3431384 & 1479008 & 5.2 & 5.178 & TRN \\
\hline CHEMBL3431385 & 1479008 & 3.3 & 3.573 & TRN \\
\hline CHEMBL3431386 & 1479008 & 5.3 & 5.1584 & TRN \\
\hline
\end{tabular}




\begin{tabular}{|c|c|c|c|c|}
\hline & & & & $a \perp 1 a$ \\
\hline CHEMBL1730515 & 1479008 & 5.7 & 5.8149 & TRN \\
\hline CHEMBL3431387 & 1479008 & 3.3 & 4.1384 & TRN \\
\hline CHEMBL3431388 & 1479008 & 4.9 & 5.0401 & TRN \\
\hline CHEMBL1566898 & 1479008 & 4.4 & 4.2804 & TRN \\
\hline CHEMBL3431389 & 1479008 & 4.4 & 3.8555 & TRN \\
\hline CHEMBL3431390 & 1479008 & 4.9 & 4.9402 & TST \\
\hline CHEMBL3431391 & 1479008 & 4.6 & 3.7884 & TRN \\
\hline CHEMBL1489081 & 1479008 & 6.0 & 6.4094 & TRN \\
\hline CHEMBL3431392 & 1479008 & 4.9 & 3.9366 & TRN \\
\hline CHEMBL3431393 & 1479008 & 5.8 & 5.7549 & TRN \\
\hline CHEMBL3431394 & 1479008 & 4.5 & 3.6057 & TRN \\
\hline CHEMBL3431395 & 1479008 & 3.3 & 4.2231 & TRN \\
\hline CHEMBL3431396 & 1479008 & 3.3 & 3.9734 & TRN \\
\hline CHEMBL3431397 & 1479008 & 5.2 & 4.9197 & TRN \\
\hline CHEMBL3431398 & 1479008 & 5.7 & 5.1566 & TRN \\
\hline CHEMBL3431399 & 1479008 & 5.5 & 3.7979 & TRN \\
\hline CHEMBL3431400 & 1479008 & 5.1 & 4.1838 & TST \\
\hline CHEMBL1418463 & 1479008 & 6.4 & 6.1282 & TST \\
\hline CHEMBL3431401 & 1479008 & 3.3 & 3.6115 & TST \\
\hline CHEMBL3431402 & 1479008 & 4.5 & 4.7961 & TST \\
\hline CHEMBL3431403 & 1479008 & 4.5 & 3.7111 & TST \\
\hline CHEMBL 3431404 & 1479008 & 5.0 & 4.4593 & TST \\
\hline CHEMBL3431405 & 1479008 & 5.0 & 4.2511 & TST \\
\hline CHEMBL3431406 & 1479008 & 5.8 & 5.5355 & TST \\
\hline CHEMBL3431407 & 1479008 & 5.1 & 4.5946 & TST \\
\hline CHEMBL3431408 & 1479008 & 5.0 & 3.8801 & TST \\
\hline CHEMBL3431409 & 1479008 & 6.1 & 5.7565 & TST \\
\hline CHEMBL3431410 & 1479008 & 3.3 & 3.7703 & TST \\
\hline CHEMBL3431411 & 1479008 & 3.3 & 3.7301 & TST \\
\hline CHEMBL3431412 & 1479008 & 4.4 & 4.9752 & TST \\
\hline CHEMBL3431413 & 1479008 & 6.0 & 5.6514 & TST \\
\hline CHEMBL3431414 & 1479008 & 5.1 & 5.0669 & TST \\
\hline CHEMBL3431415 & 1479008 & 4.9 & 4.8865 & TST \\
\hline CHEMBL3431416 & 1479008 & 4.8 & 5.0744 & TST \\
\hline CHEMBL291721 & 1479008 & 4.4 & 4.8647 & TST \\
\hline CHEMBL3431417 & 1479008 & 5.0 & 4.0389 & TST \\
\hline CHEMBL3431418 & 1479008 & 3.3 & 3.6777 & TST \\
\hline CHEMBL487186 & 1479008 & 3.3 & 3.9339 & TST \\
\hline CHEMBL3431419 & 1479008 & 3.3 & 3.7678 & TST \\
\hline CHEMBL3431420 & 1479008 & 3.3 & 3.5793 & TST \\
\hline CHEMBL3431421 & 1479008 & 3.3 & 5.2045 & TST \\
\hline CHEMBL3431422 & 1479008 & 5.8 & 5.3841 & TST \\
\hline CHEMBL3431423 & 1479008 & 3.3 & 3.6772 & TST \\
\hline CHEMBL 3431424 & 1479008 & 5.9 & 3.6388 & TST \\
\hline CHEMBL 3431425 & 1479008 & 5.9 & 5.9536 & TST \\
\hline CHEMBL3431426 & 1479008 & 4.5 & 4.5528 & TST \\
\hline CHEMBL 3431427 & 1479008 & 4.6 & 3.8612 & TST \\
\hline CHEMBL3431428 & 1479008 & 4.5 & 3.7586 & TST \\
\hline
\end{tabular}




\begin{tabular}{|c|c|c|c|c|c|}
\hline & & & & & \\
\hline CHEMBL1725748 & 1479008 & 3.3 & 4.0084 & TST & \\
\hline CHEMBL3430918 & 1479008 & 4.7 & 4.61 & TST & \\
\hline CHEMBL522630 & 1479008 & 6.0 & 6.5364 & TST & \\
\hline CHEMBL3431429 & 1479008 & 6.0 & 5.9561 & TST & \\
\hline CHEMBL523468 & 1479008 & 5.6 & 6.2759 & TST & \\
\hline CHEMBL523303 & 1479008 & 6.0 & 6.443 & TST & \\
\hline CHEMBL3431430 & 1479008 & 4.7 & 3.81600 & 00000000003 & TST \\
\hline CHEMBL128672 & 1479008 & 5.1 & 3.6759 & TST & \\
\hline CHEMBL491149 & 1479008 & 5.5 & 6.1063 & TST & \\
\hline CHEMBL3431431 & 1479008 & 6.0 & 6.4765 & TST & \\
\hline CHEMBL3431432 & 1479008 & 6.0 & 6.5239 & TST & \\
\hline CHEMBL3431433 & 1479008 & 7.8 & 7.75700 & 0000000001 & TST \\
\hline CHEMBL3431434 & 1479008 & 4.9 & 4.7246 & TST & \\
\hline CHEMBL 3431435 & 1479008 & 7.9 & 7.5915 & TST & \\
\hline CHEMBL3431436 & 1479008 & 5.2 & 5.4317 & TST & \\
\hline CHEMBL3431437 & 1479008 & 3.3 & 4.044 & TST & \\
\hline CHEMBL3431438 & 1479008 & 5.6 & 5.2658 & TST & \\
\hline CHEMBL3431439 & 1479008 & 3.3 & 3.9275 & TST & \\
\hline CHEMBL3431440 & 1479008 & 4.7 & 4.5141 & TST & \\
\hline CHEMBL3431441 & 1479008 & 3.3 & 3.6341 & TST & \\
\hline CHEMBL3431442 & 1479008 & 4.6 & 4.5065 & TST & \\
\hline CHEMBL3431443 & 1479008 & 5.2 & 4.9913 & TST & \\
\hline CHEMBL3431444 & 1479008 & 5.7 & 5.635 & TST & \\
\hline CHEMBL3431445 & 1479008 & 4.6 & 3.89899 & 99999999996 & TST \\
\hline CHEMBL3126435 & 1298460 & 6.5086 & 6.5155 & TRN & \\
\hline CHEMBL3126609 & 1298460 & 5.9101 & 6.1506 & TST & \\
\hline CHEMBL3126588 & 1298460 & 8.301 & 8.4406 & TRN & \\
\hline CHEMBL3126608 & 1298460 & 7.5229 & 7.5225 & TRN & \\
\hline CHEMBL3126617 & 1298460 & 6.9031 & 6.902 & TRN & \\
\hline CHEMBL3126631 & 1298460 & 4.0 & 4.0037 & TRN & \\
\hline CHEMBL 3126622 & 1298460 & 7.6021 & 7.0354 & TST & \\
\hline CHEMBL3124957 & 1298460 & 7.3372 & 7.32600 & 00000000005 & TRN \\
\hline CHEMBL 3126602 & 1298460 & 5.9508 & 5.941 & TRN & \\
\hline CHEMBL3126589 & 1298460 & 8.6198 & 8.4187 & TRN & \\
\hline CHEMBL 3126625 & 1298460 & 6.2104 & 6.2092 & TRN & \\
\hline CHEMBL3126624 & 1298460 & 7.6198 & 7.0227 & TST & \\
\hline CHEMBL3126593 & 1298460 & 6.5129 & 6.5159 & TRN & \\
\hline CHEMBL 3126586 & 1298460 & 6.8268 & 6.77 & TRN & \\
\hline CHEMBL3126585 & 1298460 & 7.3279 & 7.5182 & TRN & \\
\hline CHEMBL 3126632 & 1298460 & 4.0 & 3.9945 & TRN & \\
\hline CHEMBL3126630 & 1298460 & 5.5376 & 5.5429 & TRN & \\
\hline CHEMBL 3126610 & 1298460 & 6.7545 & 6.4031 & TST & \\
\hline CHEMBL3126615 & 1298460 & 6.2097 & 6.7993 & TST & \\
\hline CHEMBL3126607 & 1298460 & 5.8729 & 5.8757 & TRN & \\
\hline CHEMBL 3126626 & 1298460 & 6.4949 & 6.3662 & TST & \\
\hline CHEMBL3126612 & 1298460 & 5.5114 & 6.0647 & TST & \\
\hline CHEMBL 3126621 & 1298460 & 5.58 & 5.5943 & TRN & \\
\hline CHEMBL3126584 & 1298460 & 7.6198 & 7.4984 & TRN & \\
\hline & & & & 4752 & \\
\hline
\end{tabular}


Supplemental Table S2.txt

\begin{tabular}{|c|c|c|c|c|}
\hline CHEMBL 3126436 & 1298460 & 7.4815 & 7.4888 & TRN \\
\hline CHEMBL 3126592 & 1298460 & 6.4535 & 6.4514 & TRN \\
\hline CHEMBL3126596 & 1298460 & 6.5884 & 6.5851 & TRN \\
\hline CHEMBL 3126620 & 1298460 & 6.3675 & 6.3525 & TRN \\
\hline CHEMBL3126619 & 1298460 & 6.0625 & 6.0492 & TRN \\
\hline CHEMBL 3126433 & 1298460 & 6.1331 & 6.1316 & TRN \\
\hline CHEMBL 3126597 & 1298460 & 6.3675 & 6.3773 & TRN \\
\hline CHEMBL3126613 & 1298460 & 6.9747 & 6.9823 & TRN \\
\hline CHEMBL 3126618 & 1298460 & 6.857 & 6.8567 & TRN \\
\hline CHEMBL 3126606 & 1298460 & 5.4283 & 5.4383 & TRN \\
\hline CHEMBL 3126590 & 1298460 & 7.6021 & 7.6539 & TRN \\
\hline CHEMBL 3126604 & 1298460 & 6.1549 & 6.157999 & 99999999995 \\
\hline CHEMBL 3126587 & 1298460 & 8.4437 & 8.4452 & TRN \\
\hline CHEMBL 3126629 & 1298460 & 5.75200 & 000000000 & 5.749 \\
\hline CHEMBL 3126603 & 1298460 & 5.4045 & 5.4078 & TRN \\
\hline CHEMBL 3126434 & 1298460 & 5.8147 & 5.8107 & TRN \\
\hline CHEMBL3126605 & 1298460 & 6.1209 & 6.1104 & TRN \\
\hline CHEMBL 3126598 & 1298460 & 5.2807 & 5.2748 & TRN \\
\hline CHEMBL 3126614 & 1298460 & 6.0655 & 6.074 & TRN \\
\hline CHEMBL 3126623 & 1298460 & 7.5376 & 7.5362 & TRN \\
\hline CHEMBL 3126600 & 1298460 & 4.0 & 3.5472 & TST \\
\hline CHEMBL3126599 & 1298460 & 4.0 & 4.1208 & TST \\
\hline CHEMBL 3126611 & 1298460 & 6.8125 & 7.1161 & TST \\
\hline CHEMBL 3126616 & 1298460 & 5.2248 & 5.6722 & TST \\
\hline CHEMBL 3126601 & 1298460 & 5.0022 & 4.7007 & TST \\
\hline CHEMBL3126591 & 1298460 & 6.0615 & 6.6268 & TST \\
\hline CHEMBL 3958850 & 1640595 & 8.1549 & 7.3447 & TRN \\
\hline CHEMBL 3984127 & 1640595 & 7.8861 & 7.3384 & TRN \\
\hline CHEMBL 3943717 & 1640595 & 8.1549 & 7.3079 & TRN \\
\hline CHEMBL 3971061 & 1640595 & 7.6778 & 7.6064 & TRN \\
\hline CHEMBL 3924376 & 1640595 & 8.3979 & 7.1181 & TRN \\
\hline CHEMBL 3986605 & 1640595 & 6.0159 & 6.2069 & TST \\
\hline CHEMBL3953691 & 1640595 & 6.0 & 6.6792 & TRN \\
\hline CHEMBL 3906063 & 1640595 & 7.2596 & 7.3455 & TRN \\
\hline CHEMBL 3897658 & 1640595 & 7.4318 & 7.4089 & TRN \\
\hline CHEMBL 3908879 & 1640595 & 6.2255 & 6.6725 & TST \\
\hline CHEMBL 3969451 & 1640595 & 8.3979 & 7.5532 & TRN \\
\hline CHEMBL 3974861 & 1640595 & 6.7167 & 7.3878 & TRN \\
\hline CHEMBL 3972914 & 1640595 & 6.6536 & 6.5611 & TST \\
\hline CHEMBL 3965596 & 1640595 & 8.1549 & 7.4044 & TRN \\
\hline CHEMBL 3982972 & 1640595 & 6.4547 & 7.6161 & TRN \\
\hline CHEMBL 3916161 & 1640595 & 7.7212 & 7.5655 & TRN \\
\hline CHEMBL 3986334 & 1640595 & 7.0969 & 6.6368 & TRN \\
\hline CHEMBL 3944150 & 1640595 & 6.0414 & 6.459 & TST \\
\hline CHEMBL 3932561 & 1640595 & 6.0066 & 6.6763 & TST \\
\hline CHEMBL 3956365 & 1640595 & 7.4089 & 7.3021 & TRN \\
\hline CHEMBL 3968826 & 1640595 & 7.4437 & 7.3564 & TRN \\
\hline CHEMBL 3945574 & 1640595 & 6.0419 & 6.2258 & TST \\
\hline
\end{tabular}


Supplemental Table S2.txt

\begin{tabular}{|c|c|c|c|c|c|c|}
\hline CHEMBL 3933324 & 1640595 & 7.3372 & 7.4299 & TRN & & \\
\hline CHEMBL 3980535 & 1640595 & 7.7212 & 7.4854 & TRN & & \\
\hline CHEMBL3890959 & 1640595 & 6.0209 & 6.5766 & TRN & & \\
\hline CHEMBL 3954750 & 1640595 & 6.0 & 7.3516 & TRN & & \\
\hline CHEMBL 3901654 & 1640595 & 7.3565 & 7.4489 & TRN & & \\
\hline CHEMBL3942107 & 1640595 & 6.2457 & 7.4618 & TST & & \\
\hline CHEMBL 3950974 & 1640595 & 7.3979 & 6.7891 & TRN & & \\
\hline CHEMBL 3934005 & 1640595 & 6.2557 & 6.295 & TST & & \\
\hline CHEMBL 3987089 & 1640595 & 7.4815 & 7.5817 & TRN & & \\
\hline CHEMBL3912235 & 1640595 & 6.3468 & 6.5939 & TRN & & \\
\hline CHEMBL 3900094 & 1640595 & 7.3872 & 6.6651 & TRN & & \\
\hline CHEMBL3895960 & 1640595 & 7.301 & 7.1529 & TST & & \\
\hline CHEMBL 3899982 & 1640595 & 6.2343 & 7.3204 & TRN & & \\
\hline CHEMBL 3943727 & 1640595 & 6.8297 & 6.8238 & TRN & & \\
\hline CHEMBL 3984005 & 1640595 & 7.5229 & 7.3816 & TRN & & \\
\hline CHEMBL3963700 & 1640595 & 6.5751 & 7.3872 & TRN & & \\
\hline CHEMBL 3951057 & 1640595 & 7.4685 & 6.7516 & TST & & \\
\hline CHEMBL 3954537 & 1640595 & 6.7328 & 6.5363 & TRN & & \\
\hline CHEMBL 3898263 & 1640595 & 7.9208 & 7.4651 & TRN & & \\
\hline CHEMBL3910124 & 1640595 & 7.3979 & 6.532 & TRN & & \\
\hline CHEMBL 3897320 & 1640595 & 6.104 & 6.6717 & TST & & \\
\hline CHEMBL3894513 & 1640595 & 6.8928 & 6.6261 & TRN & & \\
\hline CHEMBL 3971972 & 1640595 & 6.2487 & 6.5552 & TRN & & \\
\hline CHEMBL 3947881 & 1640595 & 6.9031 & 6.6155 & TRN & & \\
\hline CHEMBL 3929724 & 1640595 & 6.2534 & 7.2778 & TRN & & \\
\hline CHEMBL3984993 & 1640595 & 6.5031 & 7.6048 & TRN & & \\
\hline CHEMBL3904379 & 1640595 & 6.2013 & 6.2045 & TST & & \\
\hline CHEMBL 3942370 & 1640595 & 7.1308 & 6.7597 & TRN & & \\
\hline CHEMBL3939247 & 1640595 & 6.4698 & 6.5447 & TRN & & \\
\hline CHEMBL 3944080 & 1640595 & 7.7959 & 7.3469 & TRN & & \\
\hline CHEMBL 3979713 & 1640595 & 8.1549 & 7.4961 & TRN & & \\
\hline CHEMBL3966153 & 1640595 & 7.7212 & 7.5677 & TRN & & \\
\hline CHEMBL 3900563 & 1640595 & 6.8268 & 7.3098 & TRN & & \\
\hline CHEMBL 3901418 & 1640595 & 6.71899 & 999999999 & 99 & 6.7207 & TST \\
\hline CHEMBL3974099 & 1640595 & 7.1739 & 7.3099 & TRN & & \\
\hline CHEMBL 3907545 & 1640595 & 6.8297 & 6.7129 & TRN & & \\
\hline CHEMBL3972381 & 1640595 & 6.51 & 6.7247 & TST & & \\
\hline CHEMBL 3981348 & 1640595 & 7.4815 & 7.0041 & TRN & & \\
\hline CHEMBL3898555 & 1640595 & 8.0458 & 7.5443 & TRN & & \\
\hline CHEMBL 3936439 & 1640595 & 7.1805 & 7.5623 & TRN & & \\
\hline CHEMBL 3949076 & 1640595 & 6.3615 & 6.8144 & TST & & \\
\hline CHEMBL3974083 & 1640595 & 7.699 & 7.36 & TRN & & \\
\hline CHEMBL 3899888 & 1640595 & 6.8928 & 6.3634 & TST & & \\
\hline CHEMBL 3948852 & 1640595 & 7.0177 & 7.3574 & TRN & & \\
\hline CHEMBL 3970466 & 1640595 & 7.5086 & 7.1618 & TRN & & \\
\hline CHEMBL 3905457 & 1640595 & 6.0017 & 6.6101 & TST & & \\
\hline CHEMBL3920808 & 1640595 & 6.2967 & 6.3461 & TST & & \\
\hline CHEMBL 3922043 & 1640595 & 6.0066 & 7.2086 & TRN & & \\
\hline
\end{tabular}


Supplemental Table S2.txt

\begin{tabular}{|c|c|c|c|c|c|}
\hline CHEMBL3930309 & 1640595 & 8.2218 & 7.3123 & TRN & \\
\hline CHEMBL3899874 & 1640595 & 6.0 & 7.1025 & TRN & \\
\hline CHEMBL3945799 & 1640595 & 6.2434 & 7.154 & TRN & \\
\hline CHEMBL3927766 & 1640595 & 6.5544 & 6.6139 & TRN & \\
\hline CHEMBL3916568 & 1640595 & 6.8182 & 6.7949 & TRN & \\
\hline CHEMBL3945438 & 1640595 & 8.2218 & 7.3494 & TRN & \\
\hline CHEMBL3952771 & 1640595 & 6.0 & 6.9761 & TST & \\
\hline CHEMBL3940722 & 1640595 & 6.2916 & 6.7197 & TRN & \\
\hline CHEMBL3982803 & 1640595 & 7.5686 & 7.4306 & TRN & \\
\hline CHEMBL3913107 & 1640595 & 7.3979 & 7.3791 & TRN & \\
\hline CHEMBL3971702 & 1640595 & 6.0 & 6.5204 & TRN & \\
\hline CHEMBL3924107 & 1640595 & 6.5952 & 6.8166 & TST & \\
\hline CHEMBL3978482 & 1640595 & 7.3468 & 7.1993 & TRN & \\
\hline CHEMBL3924964 & 1640595 & 8.2218 & 7.5451 & TRN & \\
\hline CHEMBL3959694 & 1640595 & 7.3279 & 6.605 & TRN & \\
\hline CHEMBL3931343 & 1640595 & 6.7055 & 6.3622 & TST & \\
\hline CHEMBL3957484 & 1640595 & 7.9208 & 7.3869 & TRN & \\
\hline CHEMBL3901615 & 1640595 & 7.9208 & 7.4003 & TRN & \\
\hline CHEMBL3945714 & 1640595 & 6.4123 & 6.4376 & TST & \\
\hline CHEMBL3897564 & 1640595 & 7.3372 & 7.4434 & TRN & \\
\hline CHEMBL3939178 & 1640595 & 7.1079 & 7.4437 & TRN & \\
\hline CHEMBL3967323 & 1640595 & 8.1549 & 7.5271 & TRN & \\
\hline CHEMBL3890065 & 1640595 & 6.065 & 6.0982 & TST & \\
\hline CHEMBL3936336 & 1640595 & 6.9355 & 6.7153 & TST & \\
\hline CHEMBL3927735 & 1640595 & 6.0 & 7.3642 & TRN & \\
\hline CHEMBL3907009 & 1640595 & 7.0132 & 7.4267 & TST & \\
\hline CHEMBL3983177 & 1640595 & 6.5751 & 6.6162 & TRN & \\
\hline CHEMBL3942980 & 1640595 & 7.6198 & 7.4127 & TRN & \\
\hline CHEMBL3943870 & 1640595 & 6.1662 & 6.4677 & TST & \\
\hline CHEMBL3946453 & 1640595 & 7.4202 & 7.3483 & TRN & \\
\hline CHEMBL3961678 & 1640595 & 6.1643 & 6.358 & TRN & \\
\hline CHEMBL3905952 & 1640595 & 7.3565 & 7.3275 & TRN & \\
\hline CHEMBL3921233 & 1640595 & 7.0809 & 6.7182 & TRN & \\
\hline CHEMBL3897127 & 1640595 & 6.9318 & 6.6642 & TRN & \\
\hline CHEMBL3961985 & 1640595 & 7.8539 & 7.4166 & TRN & \\
\hline CHEMBL3968529 & 1640595 & 7.3188 & 7.2364 & TRN & \\
\hline CHEMBL3958610 & 1640595 & $6.3820 e$ & j00000006 & & 6.8304 \\
\hline CHEMBL3931300 & 1640595 & 7.3279 & 6.9234 & TRN & \\
\hline CHEMBL3955205 & 1640595 & 7.9208 & 7.5071 & TRN & \\
\hline CHEMBL3920085 & 1640595 & 7.4685 & 6.9877 & TRN & \\
\hline CHEMBL3900547 & 1640595 & 6.3536 & 6.7426 & TST & \\
\hline CHEMBL3932555 & 1640595 & 6.284 & 6.4526 & TST & \\
\hline CHEMBL3983044 & 1640595 & 7.2596 & 6.2509 & TRN & \\
\hline CHEMBL3889522 & 1640595 & 6.4737 & 7.2866 & TRN & \\
\hline CHEMBL3902026 & 1640595 & 6.0214 & 6.6067 & TRN & \\
\hline CHEMBL3969702 & 1640595 & 7.5686 & 7.3273 & TRN & \\
\hline CHEMBL3922162 & 1640595 & 6.0255 & 6.6391 & TRN & \\
\hline CHEMBL3891416 & 1640595 & 7.5686 & 7.1748 & TRN & \\
\hline
\end{tabular}


Supplemental Table S2.txt

\begin{tabular}{|c|c|c|c|c|c|}
\hline CHEMBL3956683 & 1640595 & 6.7747 & 6.9672 & TST & \\
\hline CHEMBL3973569 & 1640595 & 6.2118 & 6.9615 & TRN & \\
\hline CHEMBL3946979 & 1640595 & 7.7447 & 7.4604 & TRN & \\
\hline CHEMBL3901056 & 1640595 & 6.1221 & 6.1391 & TST & \\
\hline CHEMBL3939006 & 1640595 & 6.0 & 6.6975 & TRN & \\
\hline CHEMBL3907709 & 1640595 & 6.2083 & 6.546 & TST & \\
\hline CHEMBL3902271 & 1640595 & 6.0209 & 6.4888 & TST & \\
\hline CHEMBL3986529 & 1640595 & 6.9066 & 6.173999 & 79999999995 & TRN \\
\hline CHEMBL3896038 & 1640595 & 8.0458 & 7.4132 & TRN & \\
\hline CHEMBL3952834 & 1640595 & 6.4112 & 7.0637 & TRN & \\
\hline CHEMBL3949879 & 1640595 & 7.3872 & 7.3649 & TRN & \\
\hline CHEMBL3957828 & 1640595 & 7.9586 & 7.1889 & TRN & \\
\hline CHEMBL3896921 & 1640595 & 6.0 & 7.0995 & TRN & \\
\hline CHEMBL3934771 & 1640595 & 7.1938 & 7.2754 & TRN & \\
\hline CHEMBL3986030 & 1640595 & 8.2218 & 7.5495 & TRN & \\
\hline CHEMBL3891664 & 1640595 & 7.7696 & 7.5167 & TRN & \\
\hline CHEMBL3942180 & 1640595 & 6.5575 & 7.1778 & TRN & \\
\hline CHEMBL3913907 & 1640595 & 7.0044 & 6.3462 & TRN & \\
\hline CHEMBL3913314 & 1640595 & 7.699 & 7.2896 & TST & \\
\hline CHEMBL3899585 & 1640595 & 8.0969 & 7.4961 & TRN & \\
\hline CHEMBL3929347 & 1640595 & 7.7959 & 7.5651 & TRN & \\
\hline CHEMBL3908047 & 1640595 & 6.2741 & 6.7974 & TRN & \\
\hline CHEMBL3947688 & 1640595 & 7.2441 & 7.1161 & TRN & \\
\hline CHEMBL3934686 & 1640595 & 6.1818 & 6.7046 & TST & \\
\hline CHEMBL3922107 & 1640595 & 6.7545 & 7.2084 & TRN & \\
\hline CHEMBL3937488 & 1640595 & 7.0177 & 6.8831 & TRN & \\
\hline CHEMBL3985344 & 1640595 & 6.1475 & 6.5148 & TRN & \\
\hline CHEMBL3970025 & 1640595 & 7.0969 & 6.3895 & TST & \\
\hline CHEMBL3945693 & 1640595 & 7.1192 & 6.7357 & TRN & \\
\hline CHEMBL3951408 & 1640595 & 7.2007 & 6.6778 & TRN & \\
\hline CHEMBL3952997 & 1640595 & 7.4559 & 7.3525 & TRN & \\
\hline CHEMBL3961643 & 1640595 & 7.9586 & 7.3898 & TRN & \\
\hline CHEMBL3924775 & 1640595 & 7.7212 & 7.3503 & TRN & \\
\hline CHEMBL 3923287 & 1640595 & 7.4318 & 7.0563 & TRN & \\
\hline CHEMBL3974869 & 1640595 & 6.062 & 6.3539 & TST & \\
\hline CHEMBL3928572 & 1640595 & 6.6021 & 6.6569 & TRN & \\
\hline CHEMBL3902035 & 1640595 & 6.1688 & 6.6692 & TST & \\
\hline CHEMBL3968069 & 1640595 & 6.1085 & \multicolumn{2}{|c|}{6.712999999999999} & TRN \\
\hline CHEMBL3923335 & 1640595 & 6.4572 & 6.9761 & TST & \\
\hline CHEMBL3970038 & 1640595 & 8.0 & 7.4718 & TRN & \\
\hline CHEMBL3907849 & 1640595 & 7.2366 & 7.0311 & TST & \\
\hline CHEMBL3892808 & 1640595 & 6.5719 & 6.5732 & TRN & \\
\hline CHEMBL3912758 & 1640595 & 6.2211 & 6.5791 & TST & \\
\hline CHEMBL3937738 & 1640595 & 8.0458 & 7.5253 & TRN & \\
\hline CHEMBL3975169 & 1640595 & 7.4559 & 6.7052 & TRN & \\
\hline CHEMBL3910650 & 1640595 & 6.9031 & 6.8522 & TRN & \\
\hline CHEMBL3938409 & 1640595 & 6.5544 & 6.9717 & TST & \\
\hline CHEMBL3985699 & 1640595 & 7.5229 & 7.5381 & TRN & \\
\hline
\end{tabular}


Supplemental Table S2.txt

\begin{tabular}{|c|c|c|c|c|c|}
\hline CHEMBL3925581 & 1640595 & 6.4597 & 6.5857 & TST & \\
\hline CHEMBL3919752 & 1640595 & 6.5591 & 6.5185 & TST & \\
\hline CHEMBL3967864 & 1640595 & 8.3979 & 7.3278 & TST & \\
\hline CHEMBL3905961 & 1640595 & 8.0969 & 7.3734 & TRN & \\
\hline CHEMBL 3904871 & 1640595 & 6.9066 & 7.0225 & TRN & \\
\hline CHEMBL 3898831 & 1640595 & 6.0 & 7.1793 & TRN & \\
\hline CHEMBL3952438 & 1640595 & 8.301 & 7.5437 & TRN & \\
\hline CHEMBL3897696 & 1640595 & 6.1772 & 6.7175 & TST & \\
\hline CHEMBL3940146 & 1640595 & 7.3468 & 7.6057 & TRN & \\
\hline CHEMBL3974656 & 1640595 & 7.9586 & 7.5677 & TRN & \\
\hline CHEMBL 3896534 & 1640595 & 7.9208 & 7.5155 & TRN & \\
\hline CHEMBL3914909 & 1640595 & 7.7447 & 7.3244 & TRN & \\
\hline CHEMBL3950749 & 1640595 & 7.2757 & 7.4517 & TRN & \\
\hline CHEMBL 3908825 & 1640595 & 6.9957 & 7.0505 & TRN & \\
\hline CHEMBL3916125 & 1640595 & 6.0 & 7.3728 & TRN & \\
\hline CHEMBL 3919280 & 1640595 & 7.8239 & 6.8226 & TST & \\
\hline CHEMBL3983110 & 1640595 & 6.6383 & 6.7876 & TRN & \\
\hline CHEMBL3927168 & 1640595 & 6.8416 & 7.3885 & TRN & \\
\hline CHEMBL3943886 & 1640595 & 7.2147 & 7.4047 & TRN & \\
\hline CHEMBL3984797 & 1640595 & 7.7447 & 7.3576 & TRN & \\
\hline CHEMBL 3962767 & 1640595 & 7.1487 & 7.4752 & TRN & \\
\hline CHEMBL3980669 & 1640595 & 7.4949 & 7.5538 & TRN & \\
\hline CHEMBL3939876 & 1640595 & 6.0241 & 6.62200 & $\partial 000000001$ & TRN \\
\hline CHEMBL 3922108 & 1640595 & 6.7447 & 7.2767 & TRN & \\
\hline CHEMBL 3971244 & 1640595 & 7.3372 & 6.1438 & TRN & \\
\hline CHEMBL3956259 & 1640595 & 7.6778 & 7.5955 & TRN & \\
\hline CHEMBL3912302 & 1640595 & 7.4202 & 7.313 & TRN & \\
\hline CHEMBL3903359 & 1640595 & 6.4101 & 6.4367 & TST & \\
\hline CHEMBL3967418 & 1640595 & 6.7011 & 6.6597 & TST & \\
\hline CHEMBL3912997 & 1640595 & 6.3768 & 6.5119 & TST & \\
\hline CHEMBL3931340 & 1640595 & 8.0969 & 7.5522 & TRN & \\
\hline CHEMBL3909247 & 1640595 & 6.1858 & 6.5505 & TST & \\
\hline CHEMBL 3976871 & 1640595 & 6.3391 & 6.877006 & 3000000001 & TRN \\
\hline CHEMBL3908488 & 1640595 & 8.0969 & 7.5123 & TRN & \\
\hline CHEMBL 3949942 & 1640595 & 7.4949 & 7.5851 & TRN & \\
\hline CHEMBL3908446 & 1640595 & 8.3979 & 7.3733 & TST & \\
\hline CHEMBL3899869 & 1640595 & 6.0 & 7.3127 & TRN & \\
\hline CHEMBL 3902173 & 1640595 & 6.6364 & 6.4327 & TST & \\
\hline CHEMBL3949767 & 1640595 & 6.1656 & 6.6616 & TST & \\
\hline CHEMBL 3892701 & 1640595 & 7.0044 & 7.4335 & TRN & \\
\hline CHEMBL3976397 & 1640595 & 7.9208 & 7.3728 & TRN & \\
\hline CHEMBL3947017 & 1640595 & 7.1805 & 7.3802 & TRN & \\
\hline CHEMBL3912817 & 1640595 & 6.0 & 6.7065 & TRN & \\
\hline CHEMBL3914306 & 1640595 & 6.9469 & 7.0712 & TRN & \\
\hline CHEMBL 3950923 & 1640595 & 6.1618 & 6.3719 & TST & \\
\hline CHEMBL3960614 & 1640595 & 8.0 & 7.2738 & TRN & \\
\hline CHEMBL3981230 & 1640595 & 7.8239 & 7.4122 & TRN & \\
\hline CHEMBL3910477 & 1640595 & 6.5214 & 6.7605 & TST & \\
\hline
\end{tabular}


Supplemental Table S2.txt

\begin{tabular}{|c|c|c|c|c|c|}
\hline CHEMBL3913971 & 1640595 & 6.6757 & 6.9302 & TRN & \\
\hline CHEMBL3945216 & 1640595 & 7.4202 & 7.3491 & TRN & \\
\hline CHEMBL3952870 & 1640595 & 7.3098 & 7.5764 & TRN & \\
\hline CHEMBL3919713 & 1640595 & 8.0969 & 7.5332 & TRN & \\
\hline CHEMBL3938849 & 1640595 & 7.2757 & 7.5637 & TRN & \\
\hline CHEMBL3937780 & 1640595 & 7.1024 & 6.6609 & TRN & \\
\hline CHEMBL3916865 & 1640595 & 6.2262 & 6.6477 & TRN & \\
\hline CHEMBL3925069 & 1640595 & 6.0 & 7.0957 & TRN & \\
\hline CHEMBL3916705 & 1640595 & 6.4214 & 6.4513 & TST & \\
\hline CHEMBL3934428 & 1640595 & 7.8861 & 7.4252 & TST & \\
\hline CHEMBL3903746 & 1640595 & 6.3382 & \multicolumn{2}{|c|}{7.5520000000000005} & TRN \\
\hline CHEMBL3891433 & 1640595 & 6.7375 & 6.629 & TRN & \\
\hline CHEMBL3979793 & 1640595 & 6.3665 & 6.7102 & TST & \\
\hline CHEMBL3961702 & 1640595 & 8.1549 & 7.3787 & TRN & \\
\hline CHEMBL 3901967 & 1640595 & 7.4437 & 7.3033 & TRN & \\
\hline CHEMBL3898781 & 1640595 & 8.0 & 7.5477 & TRN & \\
\hline CHEMBL3926652 & 1640595 & 6.6091 & 6.485 & TRN & \\
\hline CHEMBL3971710 & 1640595 & 8.301 & 7.5256 & TRN & \\
\hline CHEMBL3938289 & 1640595 & 6.7645 & \multicolumn{2}{|c|}{6.8839999999999995} & TST \\
\hline CHEMBL3908936 & 1640595 & 6.6003 & 6.9923 & TRN & \\
\hline CHEMBL3962073 & 1640595 & 7.3372 & 6.8004 & TRN & \\
\hline CHEMBL3953114 & 1640595 & 7.2676 & 7.1727 & TST & \\
\hline CHEMBL3972022 & 1640595 & 7.2518 & 6.7083 & TRN & \\
\hline CHEMBL3950609 & 1640595 & 6.3497 & 6.7438 & TRN & \\
\hline CHEMBL 3898206 & 1640595 & 6.9586 & 7.1358 & TRN & \\
\hline CHEMBL3980045 & 1640595 & 7.4318 & 6.9475 & TRN & \\
\hline CHEMBL3929395 & 1640595 & 6.684 & 7.0624 & TRN & \\
\hline CHEMBL3890389 & 1640595 & 6.1107 & 7.2899 & TRN & \\
\hline CHEMBL3975842 & 1640595 & 6.567 & \multicolumn{2}{|c|}{7.218999999999999} & TRN \\
\hline CHEMBL3930565 & 1640595 & 6.0 & 7.3445 & TRN & \\
\hline CHEMBL3940381 & 1640595 & 6.2967 & 6.7308 & TST & \\
\hline CHEMBL3915768 & 1640595 & 6.9508 & 6.6115 & TST & \\
\hline CHEMBL3935918 & 1640595 & 6.0 & 7.0695 & TRN & \\
\hline CHEMBL3890391 & 1640595 & 6.7496 & 6.5197 & TRN & \\
\hline CHEMBL3960994 & 1640595 & 8.2218 & 7.374 & TRN & \\
\hline CHEMBL3976237 & 1640595 & 6.9914 & 6.8362 & TST & \\
\hline CHEMBL3917819 & 1640595 & 6.3152 & 6.2473 & TRN & \\
\hline CHEMBL3943367 & 1640595 & 7.0315 & 7.2992 & TRN & \\
\hline CHEMBL3900981 & 1640595 & 7.6021 & 7.3033 & TRN & \\
\hline CHEMBL3894787 & 1640595 & 6.9208 & 6.5207 & TST & \\
\hline CHEMBL3940500 & 1640595 & 8.1549 & 7.2865 & TRN & \\
\hline CHEMBL3975676 & 1640595 & 8.0 & 6.8863 & TST & \\
\hline CHEMBL3904831 & 1640595 & 6.8633 & 7.56 & TRN & \\
\hline CHEMBL3954969 & 1640595 & 6.0 & 6.9038 & TRN & \\
\hline CHEMBL3923313 & 1640595 & 7.8239 & 7.3329 & TRN & \\
\hline CHEMBL3926397 & 1640595 & 7.699 & 7.3592 & TRN & \\
\hline CHEMBL 3943044 & 1640595 & 7.5229 & 7.1693 & TRN & \\
\hline CHEMBL3944396 & 1640595 & 8.0 & 7.1195 & TRN & \\
\hline
\end{tabular}


Supplemental Table S2.txt

\begin{tabular}{|c|c|c|c|c|c|}
\hline CHEMBL3903322 & 1640595 & 7.6198 & 6.8894 & TRN & \\
\hline CHEMBL 3949740 & 1640595 & 7.4685 & 7.5233 & TRN & \\
\hline CHEMBL3921619 & 1640595 & 7.4437 & 7.3095 & TRN & \\
\hline CHEMBL 3928506 & 1640595 & 7.8239 & 7.5359 & TRN & \\
\hline CHEMBL 3967291 & 1640595 & 7.4685 & 7.2548 & TRN & \\
\hline CHEMBL 3933700 & 1640595 & 6.0311 & 6.3678 & TST & \\
\hline CHEMBL3959782 & 1640595 & 6.3904 & 7.4218 & TRN & \\
\hline CHEMBL3929639 & 1640595 & 6.8125 & 6.577000 & 0000000001 & TRN \\
\hline CHEMBL3921973 & 1640595 & 6.0888 & 5.8664 & TST & \\
\hline CHEMBL 3893433 & 1640595 & 6.0 & 6.6695 & TRN & \\
\hline CHEMBL 3960980 & 1640595 & 6.8633 & 7.2406 & TST & \\
\hline CHEMBL 3964005 & 1640595 & 6.8633 & 6.8283 & TRN & \\
\hline CHEMBL 3936380 & 1640595 & 7.585 & 7.342000 & 00000000005 & \\
\hline CHEMBL3982396 & 1640595 & 6.0 & 6.6445 & TRN & \\
\hline CHEMBL 3922517 & 1640595 & 6.1463 & 6.4843 & TST & \\
\hline CHEMBL 3893053 & 1640595 & 7.5686 & 6.7243 & TST & \\
\hline CHEMBL3976104 & 1640595 & 7.7959 & 7.392 & TRN & \\
\hline CHEMBL 3907238 & 1640595 & 6.0132 & 6.9999 & TST & \\
\hline CHEMBL3943527 & 1640595 & 6.4815 & 6.3042 & TST & \\
\hline CHEMBL 3940549 & 1640595 & 6.857 & 7.5333 & TRN & \\
\hline CHEMBL 3973036 & 1640595 & 7.4685 & 7.4107 & TRN & \\
\hline CHEMBL 3903287 & 1640595 & 6.4101 & 7.2138 & TRN & \\
\hline CHEMBL3890465 & 1640595 & 6.5258 & 7.3273 & TRN & \\
\hline CHEMBL 3975627 & 1640595 & 7.6383 & 7.4082 & TRN & \\
\hline CHEMBL 3919611 & 1640595 & 8.301 & 7.3648 & TRN & \\
\hline CHEMBL3891590 & 1640595 & 6.0 & 6.9364 & TRN & \\
\hline CHEMBL 3937073 & 1640595 & 7.0088 & 6.7805 & TRN & \\
\hline CHEMBL3946497 & 1640595 & 6.4001 & 6.7666 & TRN & \\
\hline CHEMBL3952839 & 1640595 & 6.0655 & 6.3413 & TST & \\
\hline CHEMBL 3961471 & 1640595 & 7.8539 & 7.1683 & TRN & \\
\hline CHEMBL 3897067 & 1640595 & 6.4473 & 6.8848 & TRN & \\
\hline CHEMBL 3930249 & 1640595 & 6.0757 & 6.2559 & TRN & \\
\hline CHEMBL3938311 & 1640595 & 7.0969 & 6.5468 & TST & \\
\hline CHEMBL3958398 & 1640595 & 7.4685 & 7.5233 & TRN & \\
\hline CHEMBL 3944479 & 1640595 & 6.983 & 7.2015 & TRN & \\
\hline CHEMBL3933150 & 1640595 & 6.8477 & 6.8346 & TST & \\
\hline CHEMBL 3954802 & 1640595 & 7.8861 & 7.4272 & TRN & \\
\hline CHEMBL 3940293 & 1640595 & 6.8761 & 7.3793 & TRN & \\
\hline CHEMBL 3929980 & 1640595 & 7.9208 & 7.3053 & TRN & \\
\hline CHEMBL 3965257 & 1640595 & 6.2013 & 7.4415 & TRN & \\
\hline CHEMBL2393253 & 963834 & 5.7226 & 5.6836 & TRN & \\
\hline CHEMBL 2393249 & 963834 & 4.0 & 4.2967 & TRN & \\
\hline CHEMBL 2393240 & 963834 & 6.6676 & 5.9373 & TRN & \\
\hline CHEMBL 2393267 & 963834 & 5.3116 & 5.3027 & TRN & \\
\hline CHEMBL2393263 & 963834 & 5.3469 & 4.7888 & TRN & \\
\hline CHEMBL 2393250 & 963834 & 4.0 & 4.1384 & TRN & \\
\hline CHEMBL2393269 & 963834 & \multicolumn{3}{|c|}{5.582000000000001} & $\mathbf{K}$ \\
\hline CHEMBL2393237 & 963834 & 4.0 & 4.1809 & TRN & \\
\hline
\end{tabular}


Supplemental Table S2.txt

\begin{tabular}{|c|c|c|c|c|c|}
\hline CHEMBL 2393243 & 963834 & 8.5702 & 5.9247 & TST & \\
\hline CHEMBL 2393241 & 963834 & 6.1649 & 6.1446 & TRN & \\
\hline CHEMBL2393248 & 963834 & 7.2411 & 5.4915 & TST & \\
\hline CHEMBL 2393242 & 963834 & 5.8959 & 5.5582 & TST & \\
\hline CHEMBL2393239 & 963834 & 4.0 & 5.7709 & TRN & \\
\hline CHEMBL2393251 & 963834 & 7.6003 & 7.0159 & TRN & \\
\hline CHEMBL2393236 & 963834 & 4.0 & 4.2813 & TST & \\
\hline CHEMBL2393402 & 963834 & 8.041 & 7.2741 & TRN & \\
\hline CHEMBL2393234 & 963834 & 4.0 & 4.2036 & TRN & \\
\hline CHEMBL2393272 & 963834 & 5.435 & 6.1589 & TRN & \\
\hline CHEMBL2393261 & 963834 & 5.182 & 4.3995 & TRN & \\
\hline CHEMBL2393262 & 963834 & 5.4358 & 5.0693 & TRN & \\
\hline CHEMBL2393256 & 963834 & 4.0 & 4.8368 & TRN & \\
\hline CHEMBL2393278 & 963834 & 5.8608 & 6.6199 & TRN & \\
\hline CHEMBL2393246 & 963834 & 7.0737 & 5.7153 & TST & \\
\hline CHEMBL 2393245 & 963834 & 8.5229 & 6.3009 & TST & \\
\hline CHEMBL2393271 & 963834 & 5.2317 & 5.7433 & TRN & \\
\hline CHEMBL2393232 & 963834 & 4.0 & 4.1167 & TRN & \\
\hline CHEMBL 2393274 & 963834 & 6.7878 & 6.7392 & TRN & \\
\hline CHEMBL2393247 & 963834 & 8.71 & 6.1268 & TST & \\
\hline CHEMBL 2393403 & 963834 & 6.4559 & 6.9268 & TRN & \\
\hline CHEMBL2393235 & 963834 & 4.0 & 4.1474 & TST & \\
\hline CHEMBL 2393257 & 963834 & 4.0 & 4.1575 & TRN & \\
\hline CHEMBL2393259 & 963834 & 4.0 & 4.1586 & TRN & \\
\hline CHEMBL2393265 & 963834 & 6.0237 & 5.0626 & TRN & \\
\hline CHEMBL 2393264 & 963834 & 5.8969 & 5.4328 & TRN & \\
\hline CHEMBL2393279 & 963834 & 5.6811 & 5.4303 & TRN & \\
\hline CHEMBL2393233 & 963834 & 4.0 & 3.9861 & TRN & \\
\hline CHEMBL 2393238 & 963834 & 5.5809 & 5.0296 & TST & \\
\hline CHEMBL2393252 & 963834 & 5.5602 & 5.2087 & TRN & \\
\hline CHEMBL 2393276 & 963834 & 7.5654 & 7.2279 & TRN & \\
\hline CHEMBL2393270 & 963834 & 5.657999 & 79999999 & 6.2526 & TRN \\
\hline CHEMBL2393266 & 963834 & 5.0114 & 4.6947 & TRN & \\
\hline CHEMBL 2393244 & 963834 & 8.308 & 6.0542 & TST & \\
\hline CHEMBL2393268 & 963834 & 5.3434 & 5.4059 & TRN & \\
\hline CHEMBL2393255 & 963834 & 5.3393 & 5.6786 & TRN & \\
\hline CHEMBL2393277 & 963834 & 7.7471 & 7.1072 & TRN & \\
\hline CHEMBL2393231 & 963834 & 4.0 & 4.3509 & TRN & \\
\hline CHEMBL2393260 & 963834 & 5.2771 & 4.103 & TRN & \\
\hline CHEMBL2393275 & 963834 & 7.2823 & 7.1315 & TRN & \\
\hline CHEMBL 2393230 & 963834 & 4.0 & 4.4848 & TST & \\
\hline CHEMBL2393258 & 963834 & 4.0 & 4.2799 & TRN & \\
\hline CHEMBL2393254 & 963834 & 7.5406 & 7.1976 & TST & \\
\hline CHEMBL2393404 & 963834 & 6.1574 & 6.792006 & 0000000001 & TST \\
\hline CHEMBL2393273 & 963834 & 7.6162 & 6.985 & TST & \\
\hline CHEMBL 2172067 & 864144 & 8.0223 & 7.9126 & TRN & \\
\hline CHEMBL 2172117 & 864144 & 7.7959 & 7.7625 & TRN & \\
\hline CHEMBL2172089 & 864144 & 7.4685 & 7.5056 & TRN & \\
\hline
\end{tabular}


Supplemental Table S2.txt

\begin{tabular}{|c|c|c|c|c|}
\hline IE & 4 & 59 & & \\
\hline HEMBL2172074 & 64144 & & & \\
\hline 9 & & & & \\
\hline AEMBL2 & 144 & 2366 & 2691 & \\
\hline AEMBL2172107 & 44 & & & \\
\hline HEMBL1566492 & 64144 & .8861 & 8113 & \\
\hline 097 & & & & \\
\hline 72082 & & & & \\
\hline AEMBL 2172080 & & & & \\
\hline HEMBL2172120 & 44 & & 5114 & \\
\hline AEMBL2172063 & .44 & & 9087 & \\
\hline 909 & & & 204 & \\
\hline AEMBL 2 & & & & \\
\hline HEMBL 2 & & & .3262 & \\
\hline AEMBL2 & 44 & & 1772 & \\
\hline AEMBL2 & 44 & 29 & 5621 & \\
\hline AEMBL 2 & & & 928 & \\
\hline HEMBL1 & & & 726 & \\
\hline 72087 & & & 0112 & \\
\hline IEMBL2 & 44 & & & \\
\hline 221 & 14 & & 57 & Niv \\
\hline IEMBL & & & 02 & \\
\hline AEMBL & & & 56 & \\
\hline 2106 & & & 991 & \\
\hline AEMBL 2 & & & & IN \\
\hline AEMBL2 & & & 561 & \\
\hline AEMBL & & & 892 & RN \\
\hline AFMBI & & & 358 & \\
\hline AEMBL 2 & & & & וכון \\
\hline HEMBL2172060 & & & & ISI \\
\hline HEMBL 2 & & & 449 & ST \\
\hline AFMBI & & & 91 & RN \\
\hline 98 & & & & RN \\
\hline AEMBL2 & & & 5977 & IRN \\
\hline HEMBL1443272 & 62 & & 3841 & TRN \\
\hline HEMBL 2 & & & 909 & ST \\
\hline HEMRI & & & 269 & RN \\
\hline & & & 704 & ГST \\
\hline HEMBL 2172062 & & & 3178 & TST \\
\hline AEMBL2 & & & 673 & IST \\
\hline HEMBL2 & & & 4669 & \\
\hline HEMBL 2172124 & & & & RN \\
\hline HEMBL2 & & & 8246 & $\mathrm{RN}$ \\
\hline AEMBL 2172115 & 14 & & 9165 & TRN \\
\hline MBL2 & & & 731 & \\
\hline CHEMBL2172105 & & & .5455 & \\
\hline HEMBL 2172071 & & & .0096 & \\
\hline HEMBL2172061 & 864144 & 6.1308 & 6.2813 & 2 \\
\hline
\end{tabular}

Page 4761 


\begin{tabular}{|c|c|c|c|c|}
\hline \multicolumn{5}{|c|}{ Supplemental Table } \\
\hline CHEMBL 2172096 & 864144 & 6.8539 & 6.0338 & TST \\
\hline CHEMBL 2172122 & 864144 & 8.2147 & 8.0543 & TRN \\
\hline CHEMBL1871992 & 864144 & 6.6576 & 6.1203 & TST \\
\hline CHEMBL 2172094 & 864144 & 6.4815 & 6.3023 & TST \\
\hline CHEMBL 2172123 & 864144 & 7.4089 & 7.5624 & TRN \\
\hline CHEMBL 2172084 & 864144 & 7.7696 & 7.6652 & TRN \\
\hline CHEMBL 2172222 & 864144 & 5.8827 & 5.9248 & TRN \\
\hline CHEMBL1493370 & 864144 & 3.5229 & 3.5652 & TRN \\
\hline CHEMBL 2172112 & 864144 & 8.0506 & 8.0867 & TRN \\
\hline CHEMBL 2172224 & 864144 & 7.6021 & 7.5366 & TRN \\
\hline CHEMBL 2172125 & 864144 & 7.4202 & 7.5383 & TRN \\
\hline CHEMBL 2172088 & 864144 & 7.8539 & 7.5538 & TRN \\
\hline CHEMBL 2172111 & 864144 & 7.2757 & 7.2839 & TRN \\
\hline CHEMBL 2172102 & 864144 & 3.5229 & 3.4397 & TRN \\
\hline CHEMBL 2172099 & 864144 & 6.2757 & 5.8493 & TST \\
\hline CHEMBL 2172070 & 864144 & 6.3468 & 6.3706 & TRN \\
\hline CHEMBL 2172090 & 864144 & 7.5376 & 7.5081 & TRN \\
\hline CHEMBL 2172220 & 864144 & 7.8861 & 7.7855 & TRN \\
\hline CHEMBL 2172108 & 864144 & 7.1675 & 3.7471 & TST \\
\hline CHEMBL 2172072 & 864144 & 7.301 & 7.4118 & TRN \\
\hline CHEMBL 2172113 & 864144 & 7.9586 & 7.9763 & TRN \\
\hline CHEMBL 2172068 & 864144 & 6.7696 & 6.8027 & TRN \\
\hline CHEMBL 2172100 & 864144 & 6.1938 & 5.2171 & TST \\
\hline CHEMBL 2172225 & 864144 & 6.6778 & 6.7212 & TRN \\
\hline CHEMBL 2172110 & 864144 & 8.0655 & 7.9467 & TRN \\
\hline CHEMBL288256 & 39493 & 4.7212 & 4.9326 & TRN \\
\hline CHEMBL44134 & 39493 & 4.6778 & 4.7403 & TRN \\
\hline CHEMBL44259 & 39493 & 6.4437 & 6.4918 & TRN \\
\hline CHEMBL42722 & 39493 & 4.9586 & 5.0405 & TST \\
\hline CHEMBL44390 & 39493 & 6.0 & 5.9506 & TRN \\
\hline CHEMBL296192 & 39493 & 5.2218 & 5.2857 & TRN \\
\hline CHEMBL296067 & 39493 & 6.4815 & 6.2422 & TST \\
\hline CHEMBL42774 & 39493 & 6.2218 & 6.1689 & TST \\
\hline CHEMBL296245 & 39493 & 4.0 & 4.831 & TST \\
\hline CHEMBL42523 & 39493 & 6.0 & 6.0131 & TRN \\
\hline CHEMBL42491 & 39493 & 6.1024 & 6.0906 & TRN \\
\hline CHEMBL295057 & 39493 & 5.1739 & 5.3889 & TST \\
\hline CHEMBL297173 & 39493 & 4.4949 & 4.4981 & TRN \\
\hline CHEMBL43706 & 39493 & 4.7447 & 4.7709 & TRN \\
\hline CHEMBL42757 & 39493 & 6.5086 & 6.4726 & TRN \\
\hline CHEMBL42046 & 39493 & 5.3979 & 5.3426 & TRN \\
\hline CHEMBL42168 & 39493 & 6.4437 & 6.8108 & TST \\
\hline CHEMBL290678 & 39493 & 5.0969 & 5.0357 & TRN \\
\hline CHEMBL44143 & 39493 & 5.8239 & 5.9795 & TRN \\
\hline CHEMBL42600 & 39493 & 6.3565 & 6.1968 & TRN \\
\hline CHEMBL295424 & 39493 & 3.6021 & 3.6685 & TRN \\
\hline CHEMBL40238 & 39493 & 5.1549 & 5.5244 & TST \\
\hline CHEMBL418072 & 39493 & 5.0969 & 6.2429 & TST \\
\hline
\end{tabular}




\begin{tabular}{|c|c|c|c|c|c|}
\hline \multicolumn{6}{|c|}{ Supplemental Table S2.txt } \\
\hline CHEMBL44188 & 39493 & 6.0 & 5.9521 & TRN & \\
\hline CHEMBL44463 & 39493 & 4.0 & 3.9783 & TRN & \\
\hline CHEMBL43988 & 39493 & 5.1549 & 5.131 & TRN & \\
\hline CHEMBL43143 & 39493 & 5.6021 & 5.6165 & TRN & \\
\hline CHEMBL42162 & 39493 & 5.8239 & 6.0082 & TRN & \\
\hline CHEMBL44472 & 39493 & 4.9586 & 4.8628 & TRN & \\
\hline CHEMBL296152 & 39493 & 5.6021 & 5.6026 & TRN & \\
\hline CHEMBL44262 & 39493 & 4.4685 & 4.5186 & TRN & \\
\hline CHEMBL42270 & 39493 & 5.6383 & 5.6038 & TRN & \\
\hline CHEMBL42044 & 39493 & 5.8861 & 5.6508 & TRN & \\
\hline CHEMBL43330 & 39493 & 4.0 & 4.0166 & TRN & \\
\hline CHEMBL417712 & 39493 & 4.4815 & 4.3907 & TRN & \\
\hline CHEMBL297761 & 39493 & 3.0 & 4.5766 & TST & \\
\hline CHEMBL297335 & 39493 & 4.4815 & 4.742 & TRN & \\
\hline CHEMBL42021 & 39493 & 4.9208 & 5.0892 & TRN & \\
\hline CHEMBL42334 & 39493 & 6.9586 & 6.7549 & TST & \\
\hline CHEMBL295405 & 39493 & 5.0458 & 4.9258 & TRN & \\
\hline CHEMBL44553 & 39493 & 4.8861 & 4.7132 & TRN & \\
\hline CHEMBL 298035 & 39493 & 6.0 & 5.9848 & TRN & \\
\hline CHEMBL42001 & 39493 & 6.3979 & 6.3742 & TRN & \\
\hline CHEMBL40468 & 39493 & 4.9586 & 5.0547 & TRN & \\
\hline CHEMBL46748 & 39493 & 5.2218 & 5.141 & TRN & \\
\hline CHEMBL41983 & 39493 & 5.5376 & 5.3667 & TST & \\
\hline CHEMBL 295560 & 39493 & 6.0 & 6.0483 & TRN & \\
\hline CHEMBL44561 & 39493 & 4.9586 & 4.84699 & 99999999995 & TRN \\
\hline CHEMBL42360 & 39493 & 4.1805 & 4.1405 & TRN & \\
\hline CHEMBL 297854 & 39493 & 5.2518 & 5.7729 & TST & \\
\hline CHEMBL42799 & 39493 & 4.5376 & 4.5061 & TRN & \\
\hline CHEMBL42060 & 39493 & 5.0 & 5.3421 & TRN & \\
\hline CHEMBL43092 & 39493 & 5.0458 & 4.9357 & TRN & \\
\hline CHEMBL44401 & 39493 & 5.4559 & 5.6423 & TRN & \\
\hline CHEMBL40771 & 39493 & 4.9586 & 5.012 & TRN & \\
\hline CHEMBL 275593 & 39493 & 5.6198 & 6.0719 & TRN & \\
\hline CHEMBL40427 & 39493 & 4.9586 & 5.0287 & TRN & \\
\hline CHEMBL42419 & 39493 & 5.8539 & 6.2241 & TST & \\
\hline CHEMBL42411 & 39493 & 4.4815 & 3.659 & TST & \\
\hline CHEMBL42226 & 39493 & 6.0315 & 6.0285 & TRN & \\
\hline CHEMBL 290845 & 39493 & 4.9586 & 5.9269 & TST & \\
\hline CHEMBL44187 & 39493 & 4.9208 & 4.9485 & TRN & \\
\hline CHEMBL289661 & 39493 & 5.1549 & 4.992 & TRN & \\
\hline CHEMBL415902 & 39493 & 5.2218 & 5.0874 & TRN & \\
\hline CHEMBL42786 & 39493 & 5.0458 & 5.9173 & TST & \\
\hline CHEMBL43758 & 39493 & 4.7447 & 5.0111 & TRN & \\
\hline CHEMBL 298230 & 39493 & 6.1612 & 5.7377 & TRN & \\
\hline CHEMBL298454 & 39493 & 6.699 & 6.5487 & TRN & \\
\hline CHEMBL43661 & 39493 & 4.4437 & 5.8017 & TST & \\
\hline CHEMBL42266 & 39493 & 6.0 & 5.9465 & TRN & \\
\hline CHEMBL 288800 & 39493 & 6.2441 & 6.1211 & TRN & \\
\hline
\end{tabular}




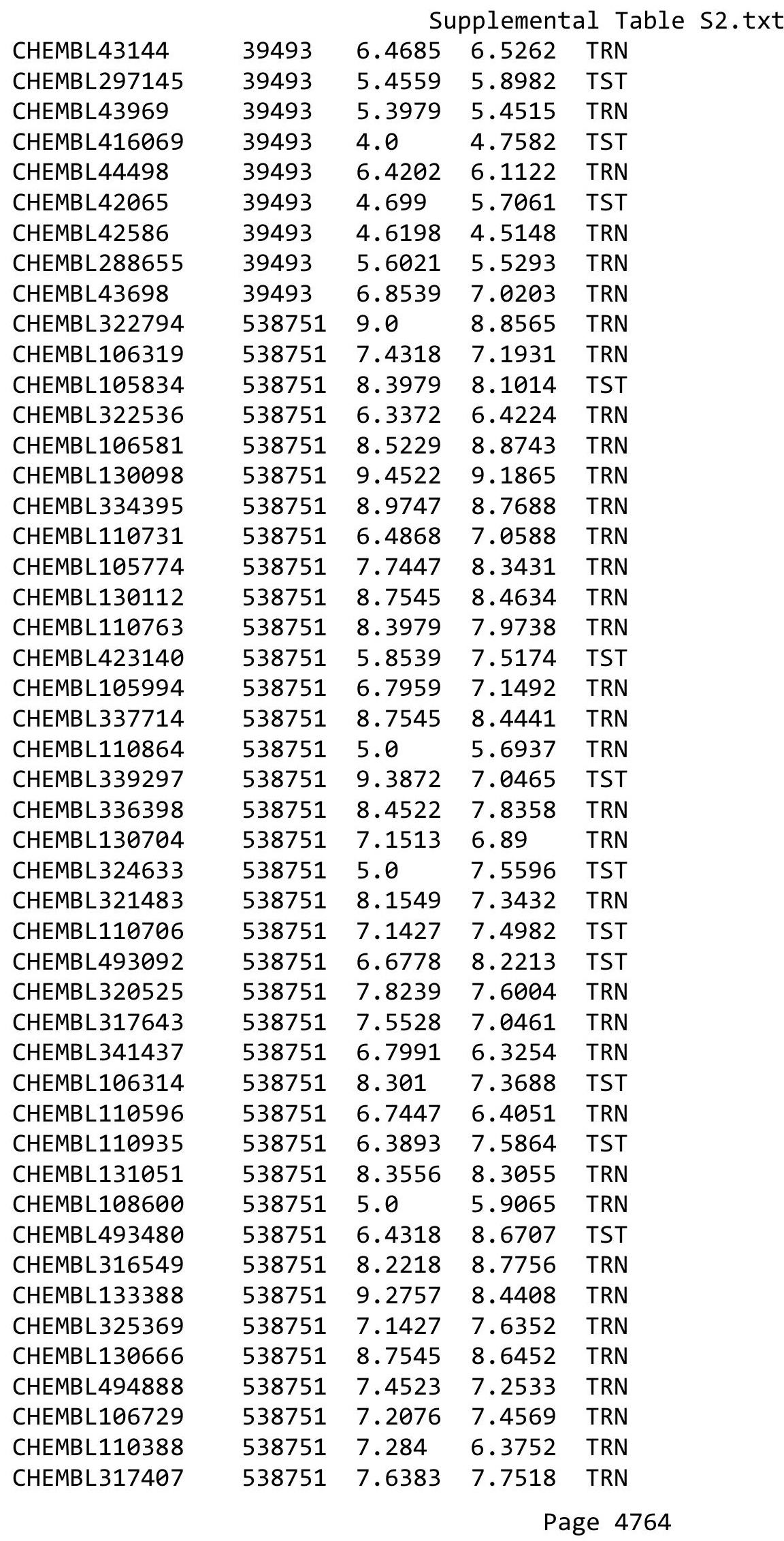




\begin{tabular}{|c|c|c|c|c|c|c|}
\hline & & & & & & \\
\hline CHEMBL130478 & 538751 & 8.7545 & 8.3364 & TRN & & \\
\hline CHEMBL 338720 & 538751 & 7.5772 & 7.8671 & TRN & & \\
\hline CHEMBL321433 & 538751 & 7.5229 & 7.49799 & 999999999 & & TRN \\
\hline CHEMBL108326 & 538751 & 7.4559 & 8.1031 & TRN & & \\
\hline CHEMBL324015 & 538751 & 5.0 & 6.1187 & TRN & & \\
\hline CHEMBL130628 & 538751 & 8.1512 & 8.2037 & TRN & & \\
\hline CHEMBL110716 & 538751 & 8.2218 & 7.6196 & TRN & & \\
\hline CHEMBL317242 & 538751 & 6.7447 & 7.5669 & TST & & \\
\hline CHEMBL110343 & 538751 & 8.3979 & 8.0425 & TRN & & \\
\hline CHEMBL323419 & 538751 & 7.9586 & 7.8781 & TRN & & \\
\hline CHEMBL105996 & 538751 & 6.6198 & 6.3853 & TST & & \\
\hline CHEMBL321903 & 538751 & 8.2218 & 7.7549 & TRN & & \\
\hline CHEMBL133897 & 538751 & $7.7120 e$ & 00000000 & 01 & 7.9666 & \\
\hline CHEMBL110166 & 538751 & 7.1739 & 6.8246 & TRN & & \\
\hline CHEMBL492678 & 538751 & 5.301 & 6.8354 & TST & & \\
\hline CHEMBL106200 & 538751 & 8.2218 & 7.7265 & TRN & & \\
\hline CHEMBL110651 & 538751 & 5.0 & 7.1824 & TST & & \\
\hline CHEMBL108523 & 538751 & 7.9208 & 7.5913 & TRN & & \\
\hline CHEMBL320708 & 538751 & 7.6198 & 7.5303 & TRN & & \\
\hline CHEMBL 322780 & 538751 & 7.8861 & 8.2558 & TRN & & \\
\hline CHEMBL107235 & 538751 & 7.7696 & 8.5176 & TST & & \\
\hline CHEMBL336276 & 538751 & 6.0544 & 6.9291 & TRN & & \\
\hline CHEMBL106892 & 538751 & 6.0458 & 7.4569 & TRN & & \\
\hline CHEMBL 320700 & 538751 & 7.0315 & 6.8372 & TRN & & \\
\hline CHEMBL107712 & 538751 & 7.8539 & 7.7864 & TRN & & \\
\hline CHEMBL131588 & 538751 & 8.5229 & 8.9173 & TRN & & \\
\hline CHEMBL322051 & 538751 & 8.0458 & 6.88200 & 0000000001 & & \\
\hline CHEMBL493268 & 538751 & 7.7696 & 7.1281 & TRN & & \\
\hline CHEMBL107365 & 538751 & 8.301 & 8.026 & TST & & \\
\hline CHEMBL106420 & 538751 & 6.9547 & 7.7749 & TST & & \\
\hline CHEMBL442883 & 538751 & 6.0544 & 7.4264 & TRN & & \\
\hline CHEMBL110653 & 538751 & 8.301 & 8.65299 & 999999999 & & \\
\hline CHEMBL108568 & 538751 & 7.1871 & 7.3208 & TRN & & \\
\hline CHEMBL324434 & 538751 & 5.0 & 6.1219 & TRN & & \\
\hline CHEMBL110322 & 538751 & 7.8539 & 7.8235 & TRN & & \\
\hline CHEMBL109182 & 538751 & 8.0 & 8.2098 & TRN & & \\
\hline CHEMBL109116 & 538751 & 8.699 & 7.4569 & TRN & & \\
\hline CHEMBL133580 & 538751 & 8.1512 & 7.7794 & TRN & & \\
\hline CHEMBL449928 & 538751 & 6.3665 & 8.1949 & TST & & \\
\hline CHEMBL107197 & 538751 & 8.699 & 7.6987 & TST & & \\
\hline CHEMBL494680 & 538751 & 5.0 & 6.7819 & TST & & \\
\hline CHEMBL106784 & 538751 & 8.0 & 8.1515 & TRN & & \\
\hline CHEMBL107352 & 538751 & 6.5031 & 6.7198 & TRN & & \\
\hline CHEMBL495495 & 538751 & 5.5258 & 8.4708 & TST & & \\
\hline CHEMBL106756 & 538751 & 8.3979 & 7.1988 & TST & & \\
\hline CHEMBL108519 & 538751 & 8.2218 & 7.6663 & TRN & & \\
\hline CHEMBL109163 & 538751 & 5.0 & 7.5088 & TST & & \\
\hline CHEMBL320813 & 538751 & 8.5229 & 8.7773 & TRN & & \\
\hline
\end{tabular}


Supplemental Table S2.txt

\begin{tabular}{|c|c|c|c|c|}
\hline CHEMBL334971 & 538751 & 8.2765 & 7.9403 & TRN \\
\hline CHEMBL336625 & 538751 & 7.9083 & 7.0574 & TRN \\
\hline CHEMBL339995 & 538751 & 6.0544 & 5.8756 & TRN \\
\hline CHEMBL131320 & 538751 & 7.9751 & 8.2439 & TRN \\
\hline CHEMBL105888 & 538751 & 5.0 & 7.6889 & TST \\
\hline CHEMBL107412 & 538751 & 6.3188 & 6.6419 & TRN \\
\hline CHEMBL110428 & 538751 & 7.2596 & 6.9203 & TRN \\
\hline CHEMBL320327 & 538751 & 6.9914 & 6.8032 & TRN \\
\hline CHEMBL110655 & 538751 & 8.2218 & 7.3379 & TRN \\
\hline CHEMBL324436 & 538751 & 8.0969 & 7.6209 & TRN \\
\hline CHEMBL493464 & 538751 & 6.2924 & 8.0183 & TST \\
\hline CHEMBL336538 & 538751 & 7.7991 & 7.792006 & 000000001 \\
\hline CHEMBL106503 & 538751 & 7.1487 & 6.9047 & TRN \\
\hline CHEMBL106927 & 538751 & 6.6021 & 6.1794 & TRN \\
\hline CHEMBL106504 & 538751 & 7.9208 & 6.9489 & TRN \\
\hline CHEMBL131536 & 538751 & 8.5498 & 9.1464 & TRN \\
\hline CHEMBL110717 & 538751 & 6.699 & 7.1201 & TRN \\
\hline CHEMBL323458 & 538751 & 7.9586 & 7.7549 & TRN \\
\hline CHEMBL106045 & 538751 & 8.301 & 8.2782 & TRN \\
\hline CHEMBL336524 & 538751 & 8.4306 & 9.1961 & TRN \\
\hline CHEMBL108207 & 538751 & 8.1549 & 8.5859 & TRN \\
\hline CHEMBL337486 & 538751 & 6.0544 & 6.1545 & TRN \\
\hline CHEMBL110597 & 538751 & 8.1549 & 7.6477 & TST \\
\hline CHEMBL321640 & 538751 & 7.2218 & 6.5833 & TST \\
\hline CHEMBL419557 & 538751 & 5.0 & 5.6528 & TRN \\
\hline CHEMBL134061 & 538751 & 6.7991 & 7.1994 & TRN \\
\hline CHEMBL108325 & 538751 & 8.2218 & 8.3152 & TRN \\
\hline CHEMBL106375 & 538751 & 7.699 & 8.3843 & TRN \\
\hline CHEMBL130645 & 538751 & 7.4523 & 7.5967 & TST \\
\hline CHEMBL320249 & 538751 & 7.9586 & 7.8359 & TRN \\
\hline CHEMBL323761 & 538751 & 6.7799 & 6.8799 & TRN \\
\hline CHEMBL335112 & 538751 & 8.9626 & 8.3418 & TST \\
\hline CHEMBL1223060 & 652133 & 6.2596 & 6.2575 & TRN \\
\hline CHEMBL1222707 & 652133 & 3.5229 & 3.5586 & TRN \\
\hline CHEMBL1222853 & 652133 & 3.5229 & 3.5585 & TRN \\
\hline CHEMBL1222564 & 652133 & 3.5229 & 3.5158 & TRN \\
\hline CHEMBL1222708 & 652133 & 3.5229 & 3.5097 & TRN \\
\hline CHEMBL1223137 & 652133 & 5.1487 & 5.1687 & TRN \\
\hline CHEMBL1223204 & 652133 & 7.1024 & 6.9122 & TST \\
\hline CHEMBL1223138 & 652133 & 3.5229 & 4.0812 & TST \\
\hline CHEMBL1222636 & 652133 & 4.8539 & 4.8313 & TRN \\
\hline CHEMBL1222787 & 652133 & 5.0506 & 5.0985 & TRN \\
\hline CHEMBL1222477 & 652133 & 5.3979 & 5.4213 & TRN \\
\hline CHEMBL1222638 & 652133 & 4.7447 & 4.7272 & TRN \\
\hline CHEMBL1223355 & 652133 & 6.9586 & 6.3923 & TST \\
\hline CHEMBL588573 & 652133 & 5.9586 & 6.0345 & TRN \\
\hline CHEMBL1222789 & 652133 & 3.5229 & \multicolumn{2}{|c|}{ 3.5389999999999997 } \\
\hline CHEMBL1222637 & 652133 & 5.2518 & 5.2349 & TRN \\
\hline
\end{tabular}


Supplemental Table S2.txt

\begin{tabular}{|c|c|c|c|c|}
\hline CHEMBL1221423 & 652133 & 5.6198 & 5.5707 & TRN \\
\hline CHEMBL1222925 & 652133 & 3.5229 & 3.5268 & TRN \\
\hline CHEMBL1222854 & 652133 & 4.5686 & 4.5432 & TRN \\
\hline CHEMBL1221431 & 652133 & 6.8539 & 6.9938 & TST \\
\hline CHEMBL1222926 & 652133 & 4.8539 & 4.8751 & TRN \\
\hline CHEMBL1223136 & 652133 & 6.2757 & 6.2158 & TRN \\
\hline CHEMBL1223289 & 652133 & 7.3279 & 7.2897 & TRN \\
\hline CHEMBL1223205 & 652133 & 6.4815 & 6.9192 & TST \\
\hline CHEMBL1222852 & 652133 & 3.5229 & 3.5157 & TRN \\
\hline CHEMBL1222929 & 652133 & 6.699 & 6.6957 & TRN \\
\hline CHEMBL1223139 & 652133 & 3.5229 & 4.8537 & TST \\
\hline CHEMBL1222993 & 652133 & 5.4318 & 5.5674 & TRN \\
\hline CHEMBL1222635 & 652133 & 5.0 & 5.0439 & TRN \\
\hline CHEMBL1222565 & 652133 & 6.4949 & 6.4924 & TRN \\
\hline CHEMBL1222928 & 652133 & 6.5686 & 6.5378 & TRN \\
\hline CHEMBL1222927 & 652133 & 5.8861 & 5.9078 & TRN \\
\hline CHEMBL1222991 & 652133 & 6.4815 & 6.4789 & TRN \\
\hline CHEMBL1223207 & 652133 & 7.1367 & 6.0069 & TST \\
\hline CHEMBL1223206 & 652133 & 6.5086 & 5.8575 & TST \\
\hline CHEMBL1222851 & 652133 & 3.5229 & 3.4278 & TRN \\
\hline CHEMBL1222474 & 652133 & 6.2291 & 6.1277 & TRN \\
\hline CHEMBL1222705 & 652133 & 3.5229 & 5.4477 & TST \\
\hline CHEMBL1222476 & 652133 & 3.5229 & 3.5068 & TRN \\
\hline CHEMBL1223062 & 652133 & 5.5229 & 5.4878 & TRN \\
\hline CHEMBL1222475 & 652133 & 5.6198 & 5.7235 & TRN \\
\hline CHEMBL1223063 & 652133 & 6.4202 & 6.4236 & TRN \\
\hline CHEMBL1222563 & 652133 & 4.9586 & 4.9439 & TRN \\
\hline CHEMBL1222992 & 652133 & 6.7212 & 6.731 & TRN \\
\hline CHEMBL1222786 & 652133 & 5.6778 & 5.6674 & TRN \\
\hline CHEMBL1223203 & 652133 & 6.699 & 7.2814 & TST \\
\hline CHEMBL1223061 & 652133 & 4.9586 & 4.931999 & э99999999995 \\
\hline CHEMBL1222706 & 652133 & 3.5229 & 3.9803 & TST \\
\hline CHEMBL1222788 & 652133 & 5.8539 & 5.9036 & TST \\
\hline CHEMBL1223564 & 652133 & 5.5528 & 5.4602 & TST \\
\hline CHEMBL3746323 & 1546247 & 5.0 & 5.2225 & TRN \\
\hline CHEMBL3746631 & 1546247 & 5.699 & 5.7465 & TRN \\
\hline CHEMBL3746772 & 1546247 & 5.0 & 5.2061 & TRN \\
\hline CHEMBL3745753 & 1546247 & 6.1249 & 6.0596 & TRN \\
\hline CHEMBL3746494 & 1546247 & 5.301 & 5.5117 & TRN \\
\hline CHEMBL 3746810 & 1546247 & 4.4559 & 4.1164 & TST \\
\hline CHEMBL3746707 & 1546247 & 5.301 & 5.5792 & TRN \\
\hline CHEMBL3745731 & 1546247 & 4.0 & 4.3186 & TST \\
\hline CHEMBL3746929 & 1546247 & 5.301 & 5.3774 & TRN \\
\hline CHEMBL3747173 & 1546247 & 5.301 & 5.516 & TRN \\
\hline CHEMBL3746270 & 1546247 & 6.301 & 6.1092 & TRN \\
\hline CHEMBL3746075 & 1546247 & 7.0 & 6.6744 & TRN \\
\hline CHEMBL3745961 & 1546247 & 5.301 & 5.7281 & TRN \\
\hline CHEMBL 3746176 & 1546247 & 5.301 & 4.8522 & TST \\
\hline
\end{tabular}


Supplemental Table S2.txt

\begin{tabular}{|c|c|c|c|c|}
\hline AEMBL3747679 & 46247 & & & \\
\hline CHEMBL 3747088 & 546247 & 5.8239 & & \\
\hline 466 & 5247 & & & \\
\hline 007 & 5247 & & & \\
\hline AEMBL 3746423 & 546247 & & 642 & \\
\hline HEMBL3747115 & 247 & 8239 & 033 & \\
\hline 145 & 247 & & & \\
\hline IEMBL & 247 & & & \\
\hline HEMBL & 247 & 249 & 818 & \\
\hline HEMBL & 247 & 229 & 145 & \\
\hline HEMBL & 247 & & & \\
\hline 735 & 247 & & 533 & \\
\hline AEMBL & & & & \\
\hline AEMBL & 247 & & 386 & \\
\hline HEMBL & 247 & & & \\
\hline AEMBL & 47 & & & \\
\hline AEMBL & & & & 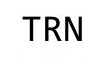 \\
\hline HEMBL & 47 & & & \\
\hline 750 & 247 & & & \\
\hline AEMBL & & & & \\
\hline AEMBL & 47 & & & RIV \\
\hline 58 & & & & NIV \\
\hline 99 & 47 & & & \\
\hline 009 & 247 & & & 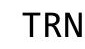 \\
\hline AEMBL & & & & 1 \\
\hline AEMBL & & & & RIN \\
\hline$T$ L & & & & RN \\
\hline 16 & 47 & & 86 & RN \\
\hline & & & & RI \\
\hline HEMBL: & & & & RN \\
\hline & & & & $\mathrm{RN}$ \\
\hline 79 & & & & RN \\
\hline 56 & 47 & & & RN \\
\hline & & & & RI \\
\hline HEMBL 374 & & & & RI \\
\hline & & & & RIV \\
\hline 6 & 47 & & & $\mathrm{RN}$ \\
\hline & & & & RN \\
\hline HEMBL 37 & 247 & & 89 & $\mathrm{RN}$ \\
\hline AEMBL. & & & & RN \\
\hline 20 & & & & RN \\
\hline CHEMBL & 247 & & 17 & RN \\
\hline CHEMBL & 247 & & & $\mathrm{RN}$ \\
\hline AEMBL: & 247 & & 076 & RI \\
\hline 967 & 5247 & & & RN \\
\hline CHEMBL & & & & RI \\
\hline CHEMBL & 546247 & 5.301 & 5.4939 & \\
\hline CHEMBL 3746450 & 546247 & 5.301 & 5.6651 & r \\
\hline
\end{tabular}

Page 4768 


\begin{tabular}{|c|c|c|c|c|c|}
\hline & & & & & \\
\hline CHEMBL3746910 & 1546247 & 6.0 & 5.4379 & TST & \\
\hline CHEMBL3745789 & 1546247 & 6.0 & 6.1821 & TST & \\
\hline CHEMBL3746527 & 1546247 & 5.301 & 5.2526 & TST & \\
\hline CHEMBL3746038 & 1546247 & 5.301 & 5.4334 & TST & \\
\hline CHEMBL3747750 & 1546247 & 6.1249 & 6.1562 & TST & \\
\hline CHEMBL3747298 & 1546247 & 5.0 & 5.165 & TST & \\
\hline CHEMBL 3746442 & 1546247 & 6.1249 & 6.0877 & TST & \\
\hline CHEMBL3746978 & 1546247 & 4.8239 & 4.4155 & TST & \\
\hline CHEMBL3621746 & 1519474 & 5.8239 & 5.7785 & TRN & \\
\hline CHEMBL3623403 & 1519474 & 5.1911 & 5.1952 & TRN & \\
\hline CHEMBL3623409 & 1519474 & 5.4584 & 5.4606 & TRN & \\
\hline CHEMBL 3621750 & 1519474 & 4.9307 & 4.9775 & TST & \\
\hline CHEMBL3623426 & 1519474 & 5.9431 & 5.7538 & TST & \\
\hline CHEMBL 3623420 & 1519474 & 5.8477 & 5.8669 & TRN & \\
\hline CHEMBL 3623431 & 1519474 & 6.0757 & 5.7415 & TST & \\
\hline CHEMBL3623411 & 1519474 & 5.2457 & 5.2695 & TRN & \\
\hline CHEMBL3623394 & 1519474 & 5.8477 & 5.4707 & TST & \\
\hline CHEMBL3623408 & 1519474 & 5.2733 & 5.2902 & TRN & \\
\hline CHEMBL3623398 & 1519474 & 5.4101 & 5.4247 & TRN & \\
\hline CHEMBL3623413 & 1519474 & 5.3197 & 5.2949 & TRN & \\
\hline CHEMBL 3623424 & 1519474 & 6.2007 & 6.1617 & TRN & \\
\hline CHEMBL 3623390 & 1519474 & 6.1675 & 6.072999 & 99999999995 & TST \\
\hline CHEMBL3623415 & 1519474 & 5.4271 & 5.4449 & TRN & \\
\hline CHEMBL3623393 & 1519474 & 5.9031 & 5.8226 & TST & \\
\hline CHEMBL 3623414 & 1519474 & 5.3851 & 5.3891 & TRN & \\
\hline CHEMBL3623407 & 1519474 & 5.6904 & 5.676 & TRN & \\
\hline CHEMBL 3623430 & 1519474 & 5.5702 & 5.5698 & TRN & \\
\hline CHEMBL 3623432 & 1519474 & 6.6576 & 6.6769 & TRN & \\
\hline CHEMBL3623419 & 1519474 & 5.9031 & 5.9276 & TRN & \\
\hline CHEMBL3623391 & 1519474 & 6.3468 & 6.0846 & TST & \\
\hline CHEMBL3623399 & 1519474 & 5.5317 & 5.5549 & TRN & \\
\hline CHEMBL 3621752 & 1519474 & 4.7535 & 4.7309 & TRN & \\
\hline CHEMBL 3621753 & 1519474 & 5.284 & 5.3568 & TST & \\
\hline CHEMBL3623396 & 1519474 & 5.3116 & 5.3032 & TRN & \\
\hline CHEMBL3623421 & 1519474 & 6.3979 & 5.9913 & TST & \\
\hline CHEMBL3623405 & 1519474 & 5.3439 & 5.3378 & TRN & \\
\hline CHEMBL 3621747 & 1519474 & 5.3028 & 5.3533 & TST & \\
\hline CHEMBL 3623404 & 1519474 & 5.2381 & 5.2364 & TRN & \\
\hline CHEMBL3623392 & 1519474 & 6.4202 & 5.862 & TST & \\
\hline CHEMBL3623401 & 1519474 & 5.3401 & 5.3372 & TRN & \\
\hline CHEMBL3623427 & 1519474 & 7.0969 & 7.0571 & TRN & \\
\hline CHEMBL 3623416 & 1519474 & 5.7399 & 5.9626 & TST & \\
\hline CHEMBL 3623400 & 1519474 & 5.5058 & 5.5087 & TRN & \\
\hline CHEMBL 3623425 & 1519474 & 6.1871 & 6.1656 & TRN & \\
\hline CHEMBL 3623410 & 1519474 & 5.17200 & 000000000 & 5.1951 & TRN \\
\hline CHEMBL 3623402 & 1519474 & 5.2351 & 5.2123 & TRN & \\
\hline CHEMBL 3621228 & 1519474 & 5.6402 & 5.6367 & TRN & \\
\hline CHEMBL3623412 & 1519474 & 5.4634 & 5.4352 & TRN & \\
\hline
\end{tabular}


Supplemental Table S2.txt

\begin{tabular}{|c|c|c|c|c|}
\hline CHEMBL3623429 & 1519474 & 6.0 & 6.0149 & TRN \\
\hline CHEMBL3623418 & 1519474 & 6.3188 & 6.3609 & TRN \\
\hline CHEMBL 3623417 & 1519474 & 6.9208 & 6.8824 & TRN \\
\hline CHEMBL 3623406 & 1519474 & 5.7235 & 5.6982 & TRN \\
\hline CHEMBL 3621751 & 1519474 & 6.1805 & 6.2059 & TRN \\
\hline CHEMBL 3621748 & 1519474 & 6.1427 & \multicolumn{2}{|c|}{6.132999999999999} \\
\hline CHEMBL3623423 & 1519474 & 6.3279 & 6.335 & TRN \\
\hline CHEMBL 3621749 & 1519474 & 5.1918 & 5.2082 & TRN \\
\hline CHEMBL3623397 & 1519474 & 5.6108 & 5.6168 & TRN \\
\hline CHEMBL 3623422 & 1519474 & 6.9586 & 7.0 & TRN \\
\hline CHEMBL3623395 & 1519474 & 5.4535 & 5.1187 & TST \\
\hline CHEMBL 3623428 & 1519474 & 5.4989 & 5.5046 & TRN \\
\hline CHEMBL 3651142 & 1535347 & 4.6234 & 4.6296 & TRN \\
\hline CHEMBL3651103 & 1535347 & 5.2218 & 5.4429 & TRN \\
\hline CHEMBL 3651109 & 1535347 & 5.2218 & 5.355 & TRN \\
\hline CHEMBL 3651097 & 1535347 & 4.5528 & 4.4134 & TRN \\
\hline CHEMBL 3651112 & 1535347 & 5.0969 & 4.8424 & TRN \\
\hline CHEMBL3929030 & 1535347 & 5.0 & 5.2333 & TRN \\
\hline CHEMBL 3651128 & 1535347 & 5.0177 & 4.3915 & TRN \\
\hline CHEMBL3651130 & 1535347 & 3.301 & 4.2372 & TRN \\
\hline CHEMBL 3651100 & 1535347 & 5.0 & 4.989 & TRN \\
\hline CHEMBL3920115 & 1535347 & 6.0 & 5.5118 & TRN \\
\hline CHEMBL3134375 & 1535347 & 4.301 & 4.3164 & TRN \\
\hline CHEMBL 3651131 & 1535347 & 3.301 & 4.2613 & TRN \\
\hline CHEMBL3651096 & 1535347 & 4.8539 & 4.9779 & TRN \\
\hline CHEMBL 3651117 & 1535347 & 4.7399 & 4.9823 & TST \\
\hline CHEMBL3651136 & 1535347 & 5.0655 & 4.9254 & TRN \\
\hline CHEMBL3651123 & 1535347 & 5.6198 & 5.443 & TST \\
\hline CHEMBL3651121 & 1535347 & 4.4647 & 4.4232 & TRN \\
\hline CHEMBL3651122 & 1535347 & 4.6198 & 4.8047 & TRN \\
\hline CHEMBL 3651137 & 1535347 & 4.8601 & 4.9908 & TRN \\
\hline CHEMBL 3651107 & 1535347 & 5.2733 & 5.1733 & TRN \\
\hline CHEMBL 3651124 & 1535347 & 5.6576 & 5.4524 & TST \\
\hline CHEMBL3651135 & 1535347 & 5.0088 & 5.0251 & TRN \\
\hline CHEMBL3651153 & 1535347 & 3.301 & 5.1439 & TST \\
\hline CHEMBL3639499 & 1535347 & 4.8861 & 4.9625 & TRN \\
\hline CHEMBL 3651110 & 1535347 & 5.5229 & 5.4562 & TRN \\
\hline CHEMBL3651114 & 1535347 & 5.4815 & 5.4071 & TRN \\
\hline CHEMBL3651152 & 1535347 & 3.301 & 3.7143 & TRN \\
\hline CHEMBL3651134 & 1535347 & 4.6655 & 4.9189 & TRN \\
\hline CHEMBL3651115 & 1535347 & 4.4498 & 5.0105 & TRN \\
\hline CHEMBL 3651147 & 1535347 & 5.6778 & 5.6665 & TRN \\
\hline CHEMBL3651113 & 1535347 & 5.7212 & 5.6711 & TRN \\
\hline CHEMBL3651105 & 1535347 & 5.6383 & 5.2748 & TRN \\
\hline CHEMBL3651151 & 1535347 & 5.1308 & 4.7566 & TST \\
\hline CHEMBL 3651104 & 1535347 & 5.0969 & 4.9772 & TRN \\
\hline CHEMBL 3651108 & 1535347 & 5.5229 & 5.4467 & TRN \\
\hline CHEMBL 3651148 & 1535347 & 5.6383 & 5.2089 & TRN \\
\hline
\end{tabular}




\begin{tabular}{|c|c|c|c|c|c|c|}
\hline \multirow[b]{2}{*}{ CHEMBL3651111 } & \multicolumn{6}{|c|}{ Supplemental Table S2.txt } \\
\hline & 1535347 & 5.2147 & 5.317 & TRN & & \\
\hline CHEMBL3651129 & 1535347 & 4.98300 & 20000000 & 005 & 5.0661 & TRN \\
\hline CHEMBL3651125 & 1535347 & 5.4559 & 5.5141 & TST & & \\
\hline CHEMBL3651120 & 1535347 & 5.0915 & 4.8723 & TRN & & \\
\hline CHEMBL3651095 & 1535347 & 4.7696 & 4.8302 & TRN & & \\
\hline CHEMBL3651119 & 1535347 & 4.8097 & 4.4272 & TRN & & \\
\hline CHEMBL3651101 & 1535347 & 5.3979 & 5.2439 & TRN & & \\
\hline CHEMBL3651138 & 1535347 & 5.0223 & 4.8809 & TST & & \\
\hline CHEMBL3651126 & 1535347 & 4.8539 & 4.77 & TRN & & \\
\hline CHEMBL3651145 & 1535347 & 5.1024 & 3.9471 & TRN & & \\
\hline CHEMBL3951323 & 1535347 & 5.1549 & 5.5595 & TRN & & \\
\hline CHEMBL3651141 & 1535347 & 4.5969 & 4.4021 & TRN & & \\
\hline CHEMBL3651146 & 1535347 & 5.0088 & 5.39 & TST & & \\
\hline CHEMBL3971292 & 1535347 & 4.7959 & 5.1464 & TRN & & \\
\hline CHEMBL3651094 & 1535347 & 4.9586 & 4.8743 & TRN & & \\
\hline CHEMBL3651102 & 1535347 & 5.699 & 5.4964 & TST & & \\
\hline CHEMBL3651132 & 1535347 & 3.301 & 4.4713 & TST & & \\
\hline CHEMBL3651118 & 1535347 & 5.2676 & 5.4956 & TST & & \\
\hline CHEMBL3651140 & 1535347 & 5.8239 & 5.1662 & TST & & \\
\hline CHEMBL3651139 & 1535347 & 5.6021 & 5.4731 & TST & & \\
\hline CHEMBL3651133 & 1535347 & 3.301 & 4.5753 & TST & & \\
\hline CHEMBL313833 & 1535347 & 6.2218 & 5.2016 & TST & & \\
\hline CHEMBL3967251 & 1640601 & 8.699 & 8.6547 & TRN & & \\
\hline CHEMBL3965025 & 1640601 & 8.0969 & 8.3939 & TRN & & \\
\hline CHEMBL3927349 & 1640601 & 7.3372 & 7.2376 & TRN & & \\
\hline CHEMBL3939766 & 1640601 & 8.5229 & 8.5101 & TRN & & \\
\hline CHEMBL3894723 & 1640601 & 9.0 & 8.7489 & TRN & & \\
\hline CHEMBL3946888 & 1640601 & 9.0 & 8.6731 & TRN & & \\
\hline CHEMBL3930630 & 1640601 & 7.9586 & 8.145 & TRN & & \\
\hline CHEMBL3951681 & 1640601 & 8.699 & 8.5984 & TRN & & \\
\hline CHEMBL3902291 & 1640601 & 7.9586 & 7.9601 & TRN & & \\
\hline CHEMBL3906541 & 1640601 & 8.3979 & 8.2901 & TRN & & \\
\hline CHEMBL3895786 & 1640601 & 8.699 & 8.4759 & TRN & & \\
\hline CHEMBL3913644 & 1640601 & 8.699 & 8.7496 & TRN & & \\
\hline CHEMBL3971859 & 1640601 & 9.0 & 9.0338 & TRN & & \\
\hline CHEMBL3926167 & 1640601 & 7.4089 & 7.0905 & TRN & & \\
\hline CHEMBL3962710 & 1640601 & 8.5229 & 8.5243 & TRN & & \\
\hline CHEMBL3940700 & 1640601 & 8.699 & 8.425 & TRN & & \\
\hline CHEMBL3924447 & 1640601 & 7.5686 & 7.4742 & TRN & & \\
\hline CHEMBL3968942 & 1640601 & 7.7696 & 7.8959 & TRN & & \\
\hline CHEMBL3963262 & 1640601 & 9.0 & 9.1148 & TRN & & \\
\hline CHEMBL3900153 & 1640601 & 8.1549 & 7.9649 & TRN & & \\
\hline CHEMBL3919273 & 1640601 & 8.3979 & 8.0768 & TRN & & \\
\hline CHEMBL3962055 & 1640601 & 7.6576 & 7.6148 & TRN & & \\
\hline CHEMBL3972749 & 1640601 & 7.4089 & 7.648 & TRN & & \\
\hline CHEMBL3909701 & 1640601 & 8.301 & 8.0953 & TRN & & \\
\hline CHEMBL3910889 & 1640601 & 7.3768 & 7.7173 & TRN & & \\
\hline CHEMBL3976034 & 1640601 & 8.2218 & 7.7538 & TRN & & \\
\hline
\end{tabular}


Supplemental Table S2.txt

\begin{tabular}{|c|c|c|c|c|c|}
\hline CHEMBL3977273 & 1640601 & 8.301 & 8.1125 & TRN & \\
\hline CHEMBL3977521 & 1640601 & 7.585 & 7.4892 & TRN & \\
\hline CHEMBL3907193 & 1640601 & 8.0969 & 7.7681 & TST & \\
\hline CHEMBL3909380 & 1640601 & 7.7212 & 7.7282 & TRN & \\
\hline CHEMBL3910447 & 1640601 & 8.2218 & 8.4999 & TST & \\
\hline CHEMBL3909195 & 1640601 & 8.699 & 8.7472 & TRN & \\
\hline CHEMBL3901849 & 1640601 & 8.0 & 7.6379 & TRN & \\
\hline CHEMBL3924060 & 1640601 & 7.7959 & 7.6329 & TRN & \\
\hline CHEMBL3937551 & 1640601 & 7.585 & 7.6925 & TRN & \\
\hline CHEMBL3931945 & 1640601 & 7.4089 & 7.4295 & TRN & \\
\hline CHEMBL3938386 & 1640601 & 7.9586 & 7.9751 & TST & \\
\hline CHEMBL3922707 & 1640601 & 8.0 & 7.8901 & TRN & \\
\hline CHEMBL3972319 & 1640601 & 7.5686 & 7.4376 & TST & \\
\hline CHEMBL3933467 & 1640601 & 6.0 & 7.7565 & TRN & \\
\hline CHEMBL3954756 & 1640601 & 8.2218 & 7.7874 & TRN & \\
\hline CHEMBL3952970 & 1640601 & 8.5229 & 8.2718 & TRN & \\
\hline CHEMBL3942007 & 1640601 & 8.1549 & 8.1835 & TRN & \\
\hline CHEMBL 3977023 & 1640601 & 9.0 & 9.2289 & TRN & \\
\hline CHEMBL3896431 & 1640601 & 7.4815 & 7.591 & TRN & \\
\hline CHEMBL3947761 & 1640601 & 9.1549 & 9.6473 & TRN & \\
\hline CHEMBL3917412 & 1640601 & 8.301 & 7.8518 & TRN & \\
\hline CHEMBL 3917550 & 1640601 & 9.301 & 9.9647 & TST & \\
\hline CHEMBL3931693 & 1640601 & 8.1549 & 8.4931 & TST & \\
\hline CHEMBL3936592 & 1640601 & 7.9208 & 7.8753 & TRN & \\
\hline CHEMBL3922678 & 1640601 & 6.0 & 7.7303 & TST & \\
\hline CHEMBL 3923760 & 1640601 & 8.5229 & 8.5656 & TRN & \\
\hline CHEMBL 3949593 & 1640601 & 8.5229 & 8.6885 & TRN & \\
\hline CHEMBL3914896 & 1640601 & 7.6778 & 7.265 & TST & \\
\hline CHEMBL3969984 & 1640601 & 7.6778 & 7.5921 & TRN & \\
\hline CHEMBL3940721 & 1640601 & 8.0 & 7.3931 & TST & \\
\hline CHEMBL3915231 & 1640601 & 8.5229 & 8.277999 & 9999999999 & TRN \\
\hline CHEMBL 3945012 & 1640601 & 9.301 & 10.2883 & TST & \\
\hline CHEMBL3931057 & 1640601 & 7.5528 & 7.5412 & TRN & \\
\hline CHEMBL3909224 & 1640601 & 8.699 & 8.8249 & TRN & \\
\hline CHEMBL3981412 & 1640601 & 8.3979 & 8.0174 & TST & \\
\hline CHEMBL 3898874 & 1640601 & 8.1549 & 8.3397 & TRN & \\
\hline CHEMBL3982996 & 1640601 & 8.5229 & 8.5479 & TRN & \\
\hline CHEMBL3940958 & 1640601 & 7.8861 & 8.0419 & TRN & \\
\hline CHEMBL3972999 & 1640601 & 7.7959 & 7.7264 & TRN & \\
\hline CHEMBL3913869 & 1640601 & 9.0 & 9.109 & TRN & \\
\hline CHEMBL3890222 & 1640601 & 7.8539 & 7.834 & TST & \\
\hline CHEMBL3981385 & 1640601 & 9.5229 & 10.3614 & TST & \\
\hline CHEMBL3901878 & 1640601 & 8.5229 & 8.3204 & TRN & \\
\hline CHEMBL3964719 & 1640601 & 7.3979 & 7.4097 & TRN & \\
\hline CHEMBL3936920 & 1640601 & 8.5229 & 8.3799 & TRN & \\
\hline CHEMBL 3944222 & 1640601 & 8.2218 & 8.0463 & TRN & \\
\hline CHEMBL3972733 & 1640601 & 7.7959 & 7.8103 & TST & \\
\hline CHEMBL3974746 & 1640601 & 7.6198 & 7.7344 & TRN & \\
\hline
\end{tabular}


Supplemental Table S2.txt

\begin{tabular}{|c|c|c|c|c|c|}
\hline CHEMBL3938822 & 1640601 & 8.5229 & 8.4561 & TRN & \\
\hline CHEMBL3943141 & 1640601 & 8.5229 & 7.8968 & TRN & \\
\hline CHEMBL3909876 & 1640601 & 8.0 & 7.6541 & TST & \\
\hline CHEMBL3964366 & 1640601 & 7.8239 & 7.4522 & TST & \\
\hline CHEMBL3946045 & 1640601 & 8.699 & 8.2547 & TRN & \\
\hline CHEMBL3949919 & 1640601 & 8.1549 & 8.4547 & TRN & \\
\hline CHEMBL3954973 & 1640601 & 7.5686 & 7.6328 & TST & \\
\hline CHEMBL3910286 & 1640601 & 7.8539 & 7.6114 & TST & \\
\hline CHEMBL3937108 & 1640601 & 8.5229 & 8.6703 & TRN & \\
\hline CHEMBL3946479 & 1640601 & 9.3979 & 9.4167 & TRN & \\
\hline CHEMBL3920320 & 1640601 & 8.2218 & 7.8522 & TRN & \\
\hline CHEMBL3965827 & 1640601 & 8.1549 & 8.3826 & TRN & \\
\hline CHEMBL3912674 & 1640601 & 8.5229 & 8.3539 & TRN & \\
\hline CHEMBL 3904128 & 1640601 & 7.3872 & 7.2827 & TRN & \\
\hline CHEMBL 3945071 & 1640601 & 7.4815 & 8.1635 & TST & \\
\hline CHEMBL3932799 & 1640601 & 7.3665 & 7.6824 & TST & \\
\hline CHEMBL3932544 & 1640601 & 7.4685 & 7.5833 & TST & \\
\hline CHEMBL3897210 & 1640601 & 8.0 & 7.9936 & TRN & \\
\hline CHEMBL3914317 & 1640601 & 7.6021 & 7.8217 & TST & \\
\hline CHEMBL3921296 & 1640601 & 8.699 & 7.797006 & 0000000001 & TST \\
\hline CHEMBL3936154 & 1640601 & 8.5229 & 8.6396 & TRN & \\
\hline CHEMBL3938872 & 1640601 & 7.9208 & 8.3547 & TRN & \\
\hline CHEMBL3916665 & 1640601 & 8.301 & 8.2412 & TRN & \\
\hline CHEMBL3968480 & 1640601 & 8.699 & 8.7298 & TRN & \\
\hline CHEMBL 3947667 & 1640601 & 7.9208 & 8.2508 & TRN & \\
\hline CHEMBL3978999 & 1640601 & 7.4318 & 7.4186 & TRN & \\
\hline CHEMBL3952666 & 1640601 & 8.3979 & 8.4205 & TRN & \\
\hline CHEMBL3910932 & 1640601 & 7.6021 & 7.5828 & TRN & \\
\hline CHEMBL3924228 & 1640601 & 6.0 & 7.709 & TST & \\
\hline CHEMBL 3895130 & 1640601 & 8.699 & 8.6549 & TST & \\
\hline CHEMBL3931654 & 1640601 & 8.699 & 8.5515 & TRN & \\
\hline CHEMBL3970504 & 1640601 & 8.5229 & 8.5888 & TRN & \\
\hline CHEMBL3946635 & 1640601 & 7.9586 & 8.0738 & TST & \\
\hline CHEMBL 3904485 & 1640601 & 8.699 & 9.2915 & TST & \\
\hline CHEMBL3962902 & 1640601 & 8.3979 & 8.2512 & TRN & \\
\hline CHEMBL3901915 & 1640601 & 7.7959 & 7.8367 & TST & \\
\hline CHEMBL3905303 & 1640601 & 9.0 & 9.316 & TST & \\
\hline CHEMBL3938981 & 1640601 & 8.5229 & 8.2561 & TRN & \\
\hline CHEMBL3967139 & 1640601 & 7.3665 & 7.5488 & TRN & \\
\hline CHEMBL3942815 & 1640601 & 8.3979 & 8.1217 & TRN & \\
\hline CHEMBL3940436 & 1640601 & 7.9586 & 7.8744 & TRN & \\
\hline CHEMBL3971116 & 1640601 & 8.5229 & 8.7945 & TST & \\
\hline CHEMBL3967125 & 1640601 & 7.9586 & 7.9639 & TRN & \\
\hline CHEMBL3905808 & 1640601 & 8.3979 & 8.9732 & TST & \\
\hline CHEMBL3929240 & 1640601 & 8.1549 & 8.3286 & TRN & \\
\hline CHEMBL3985846 & 1640601 & 8.301 & 8.4289 & TRN & \\
\hline CHEMBL3907374 & 1640601 & 9.0 & 9.1911 & TST & \\
\hline CHEMBL3936446 & 1640601 & 8.5229 & 8.158 & TST & \\
\hline
\end{tabular}




\begin{tabular}{|c|c|c|c|c|c|}
\hline \multicolumn{6}{|c|}{ Supplemental Table S2.txt } \\
\hline CHEMBL3984705 & 1640601 & 8.301 & 8.1313 & TST & \\
\hline CHEMBL3922695 & 1640601 & 7.6021 & 7.4991 & TRN & \\
\hline CHEMBL3956556 & 1640601 & 8.301 & 8.2622 & TRN & \\
\hline CHEMBL3951941 & 1640601 & 7.7959 & 7.2409 & TST & \\
\hline CHEMBL3901217 & 1640601 & 8.2218 & 8.2622 & TRN & \\
\hline CHEMBL3922611 & 1640601 & 8.699 & 8.8034 & TRN & \\
\hline CHEMBL3960556 & 1640601 & 7.3872 & 7.669 & TRN & \\
\hline CHEMBL3928551 & 1640601 & 8.0969 & 8.1604 & TRN & \\
\hline CHEMBL3950474 & 1640601 & 7.3979 & 7.4373 & TRN & \\
\hline CHEMBL3932131 & 1640601 & 8.1549 & 7.9465 & TRN & \\
\hline CHEMBL3901346 & 1640601 & 6.0 & 7.3034 & TRN & \\
\hline CHEMBL 3943170 & 1640601 & 8.5229 & 8.6771 & TRN & \\
\hline CHEMBL3954732 & 1640601 & 7.7212 & 7.6464 & TRN & \\
\hline CHEMBL3910117 & 1640601 & 9.0 & 8.7316 & TRN & \\
\hline CHEMBL3922632 & 1640601 & 7.9208 & 7.9439 & TST & \\
\hline CHEMBL3959904 & 1640601 & 9.1549 & 9.533 & TST & \\
\hline CHEMBL3947571 & 1640601 & 8.301 & 8.5564 & TRN & \\
\hline CHEMBL3939510 & 1640601 & 8.0458 & 7.763 & TRN & \\
\hline CHEMBL3932708 & 1640601 & 8.5229 & 8.4194 & TRN & \\
\hline CHEMBL3943785 & 1640601 & 7.6021 & 7.5635 & TRN & \\
\hline CHEMBL3912376 & 1640601 & 9.0 & 9.3533 & TST & \\
\hline CHEMBL3950355 & 1640601 & 7.8861 & 7.9273 & TRN & \\
\hline CHEMBL3892369 & 1640601 & 8.699 & 8.4666 & TRN & \\
\hline CHEMBL3948499 & 1640601 & 8.0969 & 8.039 & TRN & \\
\hline CHEMBL3921658 & 1640601 & 8.699 & 8.0804 & TST & \\
\hline CHEMBL3909223 & 1640601 & 8.5229 & 8.3521 & TRN & \\
\hline CHEMBL3980766 & 1640601 & 8.5229 & 8.1988 & TRN & \\
\hline CHEMBL3946474 & 1640601 & 6.0 & 7.6795 & TRN & \\
\hline CHEMBL3968722 & 1640601 & 7.3188 & 7.1209 & TRN & \\
\hline CHEMBL3959470 & 1640601 & 8.699 & 8.58 & TRN & \\
\hline CHEMBL3963023 & 1640601 & 8.301 & 8.2146 & TRN & \\
\hline CHEMBL3941635 & 1640601 & 8.5229 & 8.3515 & TST & \\
\hline CHEMBL 3914144 & 1640601 & 7.5229 & 7.5119 & TRN & \\
\hline CHEMBL3938211 & 1640601 & 7.5376 & 7.34200 & 00000000005 & TST \\
\hline CHEMBL3968141 & 1640601 & 7.9208 & 8.2292 & TRN & \\
\hline CHEMBL3901113 & 1640601 & 8.0458 & 7.715 & TRN & \\
\hline CHEMBL3930115 & 1640601 & 8.301 & 8.1437 & TRN & \\
\hline CHEMBL3934350 & 1640601 & 9.301 & 9.2844 & TRN & \\
\hline CHEMBL3946019 & 1640601 & 9.0 & 9.0308 & TRN & \\
\hline CHEMBL3974582 & 1640601 & 7.6576 & 7.5144 & TST & \\
\hline CHEMBL3906374 & 1640601 & 10.0 & 9.9376 & TRN & \\
\hline CHEMBL3916290 & 1640601 & 7.9586 & 8.0459 & TRN & \\
\hline CHEMBL3932552 & 1640601 & 7.5229 & 7.3459 & TRN & \\
\hline CHEMBL3925326 & 1640601 & 8.3979 & 8.3472 & TRN & \\
\hline CHEMBL3957752 & 1640601 & 8.5229 & 8.4847 & TRN & \\
\hline CHEMBL3957620 & 1640601 & 8.3979 & 8.0446 & TRN & \\
\hline CHEMBL3950867 & 1640601 & 7.4685 & 7.7522 & TRN & \\
\hline CHEMBL3975507 & 1640601 & 9.0 & 8.8777 & TST & \\
\hline
\end{tabular}


Supplemental Table S2.txt

\begin{tabular}{|c|c|c|c|c|c|}
\hline CHEMBL3946411 & 1640601 & 8.699 & 8.3941 & TST & \\
\hline CHEMBL3939249 & 1640601 & 7.7959 & 7.6637 & TST & \\
\hline CHEMBL 3893504 & 1640601 & 9.1549 & 8.8906 & TRN & \\
\hline CHEMBL3956147 & 1640601 & 7.4685 & 7.4014 & TST & \\
\hline CHEMBL 3978573 & 1640601 & 7.585 & 7.5662 & TRN & \\
\hline CHEMBL 3982154 & 1640601 & 8.699 & 8.4385 & TRN & \\
\hline CHEMBL3933744 & 1640601 & 7.4685 & 7.3745 & TRN & \\
\hline CHEMBL3923356 & 1640601 & 7.6778 & 8.0958 & TRN & \\
\hline CHEMBL3953726 & 1640601 & 8.301 & 8.2536 & TRN & \\
\hline CHEMBL3895759 & 1640601 & 7.7959 & 8.05 & TRN & \\
\hline CHEMBL 3941085 & 1640601 & 9.5229 & 9.3997 & TRN & \\
\hline CHEMBL 3938842 & 1640601 & 9.1549 & 9.1542 & TRN & \\
\hline CHEMBL3936519 & 1640601 & 8.2218 & 8.3262 & TRN & \\
\hline CHEMBL3972040 & 1640601 & 8.0458 & 8.9879 & TST & \\
\hline CHEMBL3933736 & 1640601 & 8.0 & 7.9656 & TRN & \\
\hline CHEMBL 3942262 & 1640601 & 8.3979 & 8.1621 & TRN & \\
\hline CHEMBL 3907310 & 1640601 & 7.8861 & 7.9605 & TST & \\
\hline CHEMBL 3904880 & 1640601 & 7.5229 & 8.0264 & TRN & \\
\hline CHEMBL 3961204 & 1640601 & 8.3979 & 8.6327 & TRN & \\
\hline CHEMBL 2324884 & 941912 & 3.0 & 3.5594 & TRN & \\
\hline CHEMBL 2324555 & 941912 & 8.6696 & 8.3911 & TRN & \\
\hline CHEMBL2324565 & 941912 & 6.4685 & 6.6023 & TRN & \\
\hline CHEMBL 2324586 & 941912 & 7.0716 & 6.5374 & TRN & \\
\hline CHEMBL 2324545 & 941912 & 6.5406 & 6.5345 & TRN & \\
\hline CHEMBL2324905 & 941912 & 6.71899 & 79999999 & 6.7711 & TRN \\
\hline CHEMBL2324564 & 941912 & 6.3536 & 7.1409 & TRN & \\
\hline CHEMBL2324575 & 941912 & 7.209 & 7.05200 & 00000000005 & TRN \\
\hline CHEMBL 2324576 & 941912 & 6.1101 & 5.9754 & TRN & \\
\hline CHEMBL 2324549 & 941912 & 7.6289 & 7.4084 & TRN & \\
\hline CHEMBL 2324544 & 941912 & 7.644 & 7.3668 & TRN & \\
\hline CHEMBL2324906 & 941912 & 8.4078 & 8.5136 & TRN & \\
\hline CHEMBL2324548 & 941912 & 6.7721 & 7.2681 & TRN & \\
\hline CHEMBL2324893 & 941912 & 6.8013 & 6.7006 & TRN & \\
\hline CHEMBL 2324880 & 941912 & 6.6038 & 6.2706 & TRN & \\
\hline CHEMBL 2324557 & 941912 & 6.983 & 7.0037 & TRN & \\
\hline CHEMBL 2324561 & 941912 & 6.7423 & 6.7918 & TRN & \\
\hline CHEMBL 2324567 & 941912 & 8.1192 & 7.6766 & TRN & \\
\hline CHEMBL2324551 & 941912 & 6.71899 & 99999999 & 5.5798 & TRN \\
\hline CHEMBL2324895 & 941912 & 6.5935 & 6.5022 & TRN & \\
\hline CHEMBL 2324902 & 941912 & 7.6861 & 7.0927 & TRN & \\
\hline CHEMBL 2324560 & 941912 & 6.9031 & 7.0895 & TRN & \\
\hline CHEMBL 2324543 & 941912 & 7.8861 & 7.8102 & TRN & \\
\hline CHEMBL 2324572 & 941912 & 6.9172 & 7.1056 & TRN & \\
\hline CHEMBL2324579 & 941912 & 5.7212 & 5.4039 & TST & \\
\hline CHEMBL2324894 & 941912 & 6.6737 & \multicolumn{2}{|c|}{6.821000000000001} & TRN \\
\hline CHEMBL2324585 & 941912 & 5.6091 & 5.5017 & TRN & \\
\hline CHEMBL2324889 & 941912 & 2.301 & 2.5828 & TST & \\
\hline CHEMBL2324571 & 941912 & 6.8794 & 6.1055 & TRN & \\
\hline
\end{tabular}




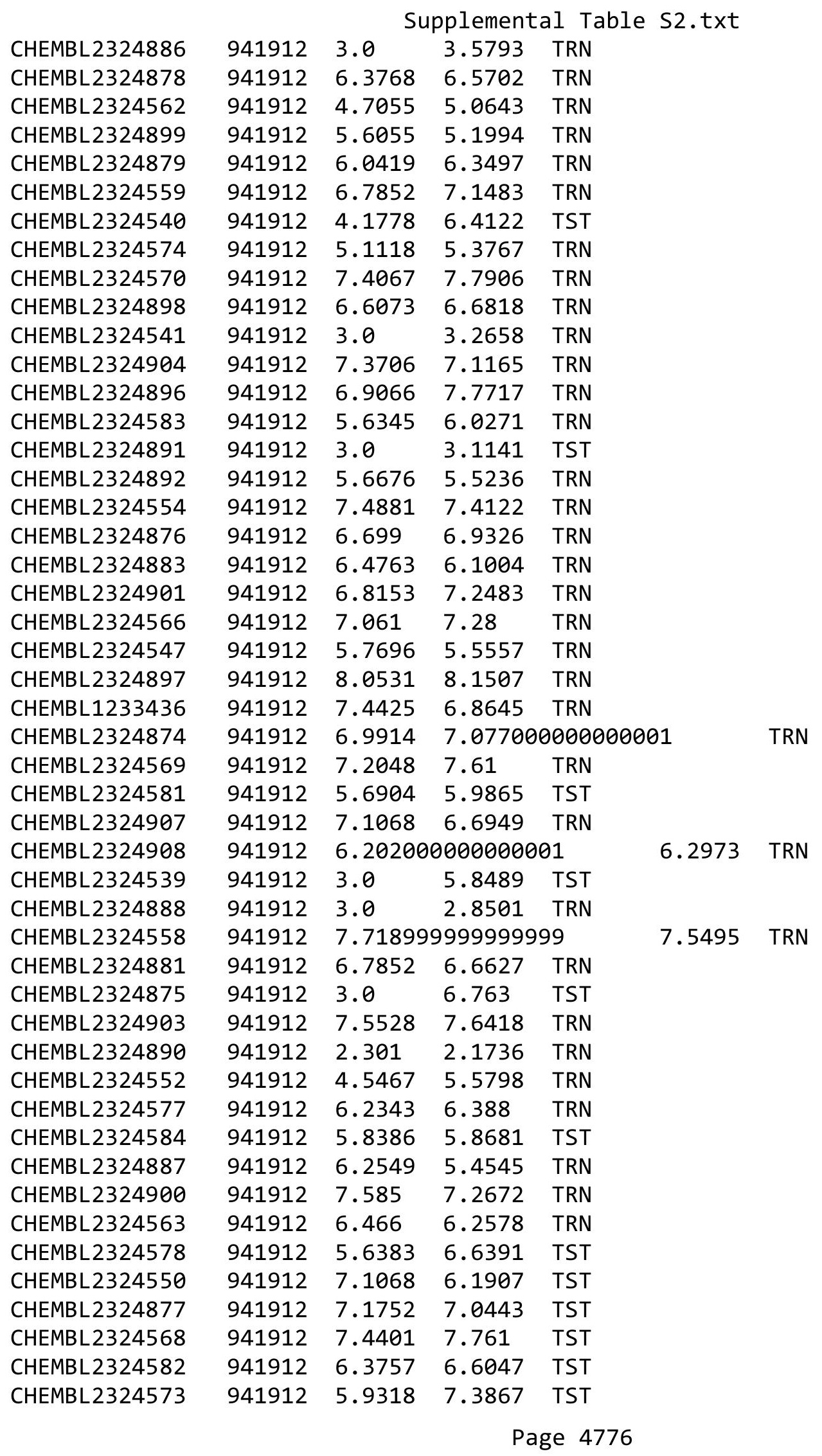




\begin{tabular}{|c|c|c|c|c|}
\hline \multicolumn{5}{|c|}{ Supplemental Table S2.txt } \\
\hline CHEMBL 2324588 & 941912 & 5.6655 & 6.2786 & TST \\
\hline CHEMBL 2324885 & 941912 & 3.0 & 3.7337 & TST \\
\hline CHEMBL 2324580 & 941912 & 6.5528 & 6.3447 & TST \\
\hline CHEMBL2324587 & 941912 & 4.2823 & 5.965 & TST \\
\hline CHEMBL 2324546 & 941912 & 6.1101 & 6.225 & TST \\
\hline CHEMBL 2324542 & 941912 & 6.1267 & 6.84 & TST \\
\hline CHEMBL 2324882 & 941912 & 6.8239 & 6.2927 & TST \\
\hline CHEMBL 2324556 & 941912 & 7.3516 & 7.5276 & TST \\
\hline CHEMBL264579 & 64034 & 6.4089 & 6.1055 & TRN \\
\hline CHEMBL269428 & 64034 & 5.0 & 5.3229 & TRN \\
\hline CHEMBL329609 & 64034 & 5.301 & 6.5331 & TRN \\
\hline CHEMBL318020 & 64034 & 5.2218 & 5.5914 & TRN \\
\hline CHEMBL431433 & 64034 & 5.3279 & 4.9196 & TRN \\
\hline CHEMBL265116 & 64034 & 7.2518 & 6.523 & TRN \\
\hline CHEMBL329170 & 64034 & 4.0 & 5.5914 & TRN \\
\hline CHEMBL 94525 & 64034 & 5.4318 & 4.9196 & TRN \\
\hline CHEMBL 2370252 & 64034 & 4.0 & 3.9119 & TRN \\
\hline CHEMBL94730 & 64034 & 4.0 & 4.8452 & TST \\
\hline CHEMBL385492 & 64034 & 7.9208 & 7.2327 & TRN \\
\hline CHEMBL97470 & 64034 & 7.284 & 7.0987 & TRN \\
\hline CHEMBL 2370246 & 64034 & 4.0 & 4.8927 & TST \\
\hline CHEMBL384052 & 64034 & 7.5229 & 5.8748 & TRN \\
\hline CHEMBL327523 & 64034 & 5.699 & 6.0125 & TST \\
\hline CHEMBL263295 & 64034 & 6.6778 & 6.5944 & TRN \\
\hline CHEMBL262993 & 64034 & 7.8239 & 7.42299 & 9999999999 \\
\hline CHEMBL439435 & 64034 & 4.0 & 5.2289 & TRN \\
\hline CHEMBL384728 & 64034 & 7.0969 & 7.0882 & TRN \\
\hline CHEMBL97431 & 64034 & 6.1367 & 6.9758 & TRN \\
\hline CHEMBL94983 & 64034 & 6.8239 & 7.0072 & TRN \\
\hline CHEMBL433349 & 64034 & 7.2218 & 6.9445 & TRN \\
\hline CHEMBL319537 & 64034 & 5.7212 & 5.8353 & TRN \\
\hline CHEMBL415238 & 64034 & 5.8861 & 5.9098 & TRN \\
\hline CHEMBL 2370253 & 64034 & 5.1675 & 4.7505 & TRN \\
\hline CHEMBL407933 & 64034 & 5.8861 & 5.9478 & TRN \\
\hline CHEMBL 2370245 & 64034 & 5.0 & 6.029 & TST \\
\hline CHEMBL330144 & 64034 & 6.1367 & 7.2325 & TRN \\
\hline CHEMBL405599 & 64034 & 8.0 & 7.9008 & TRN \\
\hline CHEMBL317099 & 64034 & 7.699 & 6.6221 & TRN \\
\hline CHEMBL319660 & 64034 & 7.2924 & 7.2325 & TRN \\
\hline CHEMBL 2370254 & 64034 & 5.2147 & 5.1373 & TRN \\
\hline CHEMBL433406 & 64034 & 6.8539 & 6.0929 & TRN \\
\hline CHEMBL94907 & 64034 & 6.4815 & 7.1285 & TRN \\
\hline CHEMBL 2370247 & 64034 & 5.7959 & 5.2636 & TST \\
\hline CHEMBL414082 & 64034 & 6.4559 & 5.8459 & TRN \\
\hline CHEMBL94689 & 64034 & 5.6198 & 6.0996 & TRN \\
\hline CHEMBL96822 & 64034 & 6.585 & 6.1674 & TRN \\
\hline CHEMBL411797 & 64034 & 6.1308 & 6.8428 & TRN \\
\hline CHEMBL413179 & 64034 & 6.2007 & 5.8795 & TST \\
\hline
\end{tabular}




\begin{tabular}{|c|c|c|c|c|c|c|}
\hline & & \multicolumn{5}{|c|}{ Supplemental Table s2.txt } \\
\hline CHEMBL319719 & 64034 & 7.7959 & 7.4316 & TRN & & \\
\hline CHEMBL405178 & 64034 & 5.2291 & 5.8521 & TRN & & \\
\hline CHEMBL2370255 & 64034 & 7.4815 & 6.0463 & TRN & & \\
\hline CHEMBL 327590 & 64034 & 4.0 & 4.7257 & TRN & & \\
\hline CHEMBL405709 & 64034 & 5.1249 & 6.523 & TST & & \\
\hline CHEMBL323331 & 64034 & 6.585 & 5.9562 & TST & & \\
\hline CHEMBL386181 & 64034 & 6.2218 & 6.1792 & TST & & \\
\hline CHEMBL262229 & 64034 & 6.3979 & 5.6297 & TST & & \\
\hline CHEMBL 265734 & 64034 & 6.7212 & 5.4902 & TST & & \\
\hline CHEMBL216082 & 64034 & 7.4815 & 6.8752 & TST & & \\
\hline CHEMBL 2046942 & 828170 & 4.2396 & 4.13899 & 9999999999 & & TRN \\
\hline CHEMBL 2046926 & 828170 & 3.9614 & 4.2787 & TRN & & \\
\hline CHEMBL2013151 & 828170 & 4.0119 & 4.0989 & TRN & & \\
\hline CHEMBL2046939 & 828170 & 3.9154 & 4.0107 & TST & & \\
\hline CHEMBL 2046934 & 828170 & 4.6737 & 4.1186 & TST & & \\
\hline CHEMBL 2003700 & 828170 & 4.1343 & 4.48 & TST & & \\
\hline CHEMBL2013146 & 828170 & 5.0862 & 4.4492 & TRN & & \\
\hline CHEMBL 2046854 & 828170 & 5.1308 & 4.4556 & TRN & & \\
\hline CHEMBL 2046943 & 828170 & 3.9974 & 3.2324 & TRN & & \\
\hline CHEMBL 2013155 & 828170 & 3.9237 & 4.2259 & TRN & & \\
\hline CHEMBL 2046938 & 828170 & 3.8139 & 4.0347 & TST & & \\
\hline CHEMBL 2046850 & 828170 & 4.0851 & 4.1181 & TRN & & \\
\hline CHEMBL 2046925 & 828170 & 3.505 & 3.8672 & TRN & & \\
\hline CHEMBL 2046848 & 828170 & 4.6364 & 4.1469 & TRN & & \\
\hline CHEMBL 2046928 & 828170 & 5.284 & 4.6678 & TRN & & \\
\hline CHEMBL 2046930 & 828170 & $3.6180 e$ & 30000000 & 003 & .9741 & TST \\
\hline CHEMBL 2013144 & 828170 & 3.7889 & 4.2928 & TRN & & \\
\hline CHEMBL 2046929 & 828170 & 3.7031 & 4.0227 & TST & & \\
\hline CHEMBL 2046855 & 828170 & 5.2518 & 4.59699 & 99999999995 & & TRN \\
\hline CHEMBL2046844 & 828170 & 2.4377 & 2.6946 & TRN & & \\
\hline CHEMBL1881695 & 828170 & 2.5003 & 2.7723 & TRN & & \\
\hline CHEMBL 2046940 & 828170 & 4.21399 & 99999999 & 995 & .324 & TST \\
\hline CHEMBL 2013149 & 828170 & 4.699 & 4.4423 & TRN & & \\
\hline CHEMBL 2046937 & 828170 & 3.7187 & 4.2334 & TST & & \\
\hline CHEMBL2005298 & 828170 & 3.7194 & 4.3013 & TRN & & \\
\hline CHEMBL2046849 & 828170 & 4.2557 & 4.1953 & TRN & & \\
\hline CHEMBL2046841 & 828170 & 2.3778 & 2.6046 & TRN & & \\
\hline CHEMBL2046936 & 828170 & 4.1979 & 4.3741 & TST & & \\
\hline CHEMBL2046845 & 828170 & 3.4944 & 3.9238 & TRN & & \\
\hline CHEMBL 2046846 & 828170 & 2.3872 & 3.8782 & TRN & & \\
\hline CHEMBL 2013140 & 828170 & 3.7744 & 4.3992 & TRN & & \\
\hline CHEMBL1969885 & 828170 & 4.0635 & 4.1565 & TRN & & \\
\hline CHEMBL2046927 & 828170 & 4.9666 & 4.6379 & TRN & & \\
\hline CHEMBL 2046847 & 828170 & 3.6741 & 3.7485 & TRN & & \\
\hline CHEMBL2046941 & 828170 & 4.0942 & 4.4094 & TRN & & \\
\hline CHEMBL 2046843 & 828170 & 4.3958 & 4.0588 & TRN & & \\
\hline CHEMBL2046924 & 828170 & 3.7165 & 3.82800 & 00000000003 & & TST \\
\hline CHEMBL 2013145 & 828170 & 3.7886 & 4.3621 & TRN & & \\
\hline
\end{tabular}


Supplemental Table S2.txt

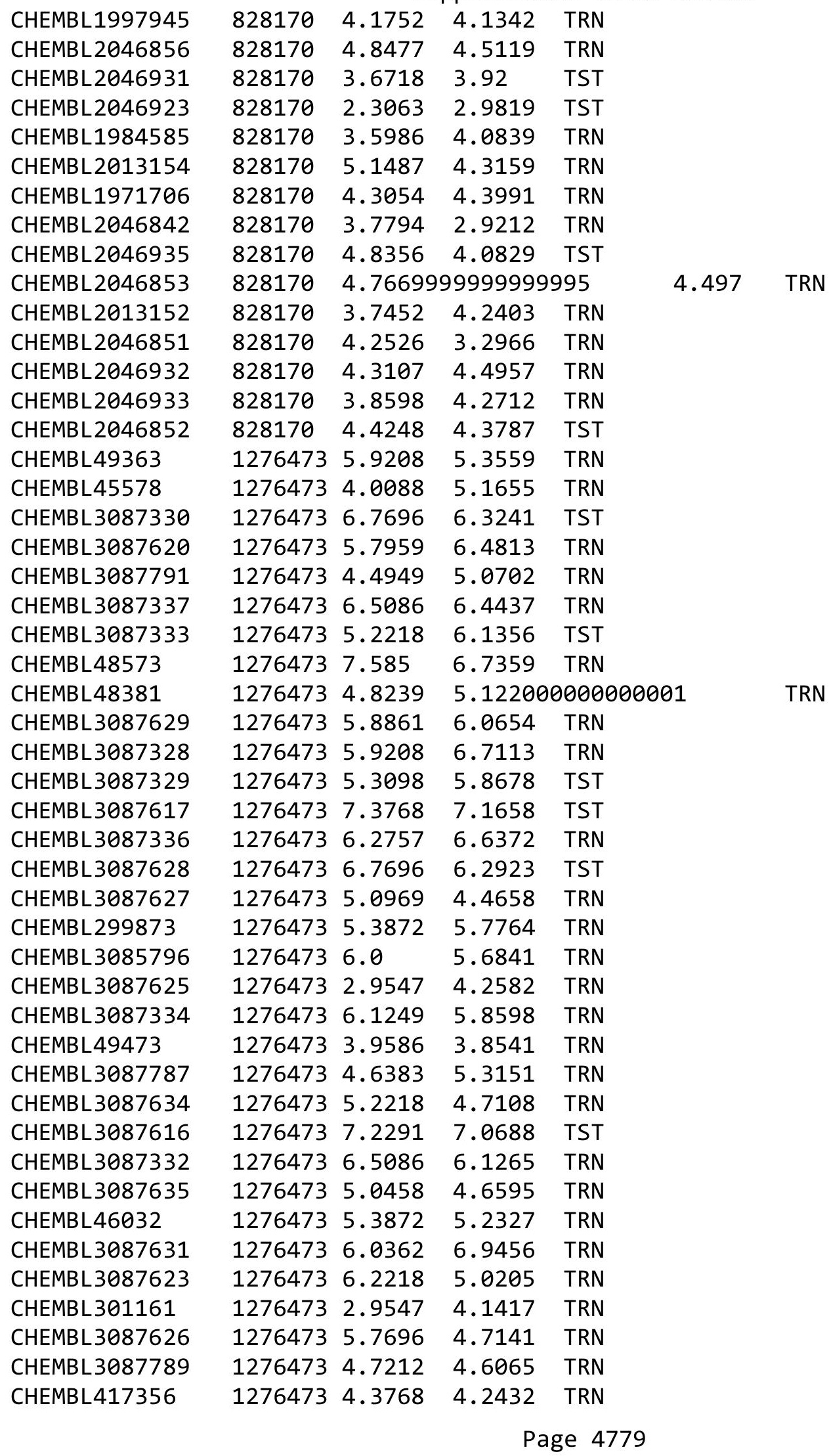


Supplemental Table S2.txt

\begin{tabular}{|c|c|c|c|c|c|c|}
\hline CHEMBL3087335 & 1276473 & 5.7696 & 5.347 & TRN & & \\
\hline CHEMBL 3087786 & 1276473 & 2.9547 & 3.7708 & TRN & & \\
\hline CHEMBL3087792 & 1276473 & 5.0969 & 4.8184 & TRN & & \\
\hline CHEMBL3087619 & 1276473 & 6.8239 & 6.9347 & TST & & \\
\hline CHEMBL3087632 & 1276473 & 6.0 & 5.5535 & TRN & & \\
\hline CHEMBL49201 & 1276473 & 7.0458 & 6.4777 & TRN & & \\
\hline CHEMBL3087618 & 1276473 & 7.284 & 7.0418 & TST & & \\
\hline CHEMBL 3087788 & 1276473 & 4.9208 & 5.4018 & TRN & & \\
\hline CHEMBL 3087785 & 1276473 & 4.8861 & 4.3957 & TRN & & \\
\hline CHEMBL3087622 & 1276473 & 5.3979 & 5.3355 & TRN & & \\
\hline CHEMBL 3087621 & 1276473 & 6.3468 & 5.5772 & TRN & & \\
\hline CHEMBL 3087630 & 1276473 & 6.0088 & 7.1221 & TST & & \\
\hline CHEMBL3087331 & 1276473 & 6.0132 & 5.9093 & TRN & & \\
\hline CHEMBL 3087338 & 1276473 & 5.7959 & 5.8624 & TRN & & \\
\hline CHEMBL 3087624 & 1276473 & 6.3098 & 5.1052 & TST & & \\
\hline CHEMBL557770 & 1276473 & 5.7212 & 6.5524 & TST & & \\
\hline CHEMBL 3087790 & 1276473 & 6.2757 & 5.5704 & TST & & \\
\hline CHEMBL 3087633 & 1276473 & 4.9586 & 5.377999 & 999999999 & TST & \\
\hline CHEMBL 227195 & 438974 & 9.283999 & 999999999 & & 9.283999999999999 & TRN \\
\hline CHEMBL 226721 & 438974 & 12.0 & 12.0 & TRN & & \\
\hline CHEMBL449703 & 438974 & 12.0 & 12.0 & TRN & & \\
\hline CHEMBL 227145 & 438974 & 8.8539 & 8.8539 & TRN & & \\
\hline CHEMBL387856 & 438974 & 10.9208 & 10.9208 & TRN & & \\
\hline CHEMBL 226931 & 438974 & 10.69900 & 000000000 & 302 & 10.699000000000002 & TRN \\
\hline CHEMBL 227222 & 438974 & 9.6778 & 9.6778 & TRN & & \\
\hline CHEMBL437546 & 438974 & 12.0 & 12.0 & TRN & & \\
\hline CHEMBL 227359 & 438974 & 10.30099 & 999999999 & 998 & 10.300999999999998 & TRN \\
\hline CHEMBL387656 & 438974 & 11.0969 & 9.9594 & TST & & \\
\hline CHEMBL450012 & 438974 & 12.0 & 12.0 & TRN & & \\
\hline CHEMBL 389210 & 438974 & 10.69900 & 300000000 & 302 & 10.2927 TST & \\
\hline CHEMBL226776 & 438974 & 11.3979 & 11.3979 & TRN & & \\
\hline CHEMBL 227146 & 438974 & 9.4949 & 9.4949 & TRN & & \\
\hline CHEMBL441880 & 438974 & 10.7212 & 10.7213 & TRN & & \\
\hline CHEMBL390055 & 438974 & 10.6576 & 10.6576 & TRN & & \\
\hline CHEMBL 226827 & 438974 & 12.0 & 10.79 & TST & & \\
\hline CHEMBL425311 & 438974 & 9.585 & 9.585 & TRN & & \\
\hline CHEMBL 226879 & 438974 & 11.30099 & 999999999 & 998 & 10.5449 TST & \\
\hline CHEMBL 227249 & 438974 & 9.1487 & 9.1487 & TRN & & \\
\hline CHEMBL 227308 & 438974 & 10.585 & 10.585 & TRN & & \\
\hline CHEMBL427421 & 438974 & 11.30099 & 999999999 & 998 & 10.5257 TST & \\
\hline CHEMBL 227196 & 438974 & 8.6576 & 8.6576 & TRN & & \\
\hline CHEMBL 227197 & 438974 & 9.6198 & 9.6198 & TRN & & \\
\hline CHEMBL 227121 & 438974 & 9.1192 & 9.2225 & TST & & \\
\hline CHEMBL 226826 & 438974 & 10.6576 & 10.5753 & TST & & \\
\hline CHEMBL 226564 & 438974 & 10.9208 & 10.9208 & TRN & & \\
\hline CHEMBL 227171 & 438974 & 9.4437 & 9.6559 & TST & & \\
\hline CHEMBL 387857 & 438974 & 11.3979 & 11.3979 & TRN & & \\
\hline CHEMBL375263 & 438974 & 9.6576 & 9.6576 & TRN & & \\
\hline
\end{tabular}


Supplemental Table S2.txt

\begin{tabular}{|c|c|c|c|c|c|}
\hline CHEMBL227248 & 438974 & 9.3979 & 9.3979 & TRN & \\
\hline CHEMBL 376790 & 438974 & 9.7447 & 9.7447 & TRN & \\
\hline CHEMBL226616 & 438974 & 10.5086 & 10.5086 & TRN & \\
\hline CHEMBL227307 & 438974 & 10.3468 & 10.3468 & TRN & \\
\hline CHEMBL226775 & 438974 & 11.3979 & 11.3979 & TRN & \\
\hline CHEMBL227221 & 438974 & 9.7959 & 9.7959 & TRN & \\
\hline CHEMBL226615 & 438974 & 9.9208 & 9.9208 & TRN & \\
\hline CHEMBL389638 & 438974 & 10.4685 & 10.4685 & TRN & \\
\hline CHEMBL449702 & 438974 & 10.6198 & 11.3161 & TST & \\
\hline CHEMBL227250 & 438974 & 9.585 & 9.585 & TRN & \\
\hline CHEMBL226825 & 438974 & 12.0 & 12.0 & TRN & \\
\hline CHEMBL390056 & 438974 & 8.6576 & 9.8803 & TST & \\
\hline CHEMBL227360 & 438974 & 10.4437 & 10.4437 & TRN & \\
\hline CHEMBL227172 & 438974 & 9.3665 & 9.3665 & TRN & \\
\hline CHEMBL427276 & 438974 & 9.9208 & 10.4203 & TST & \\
\hline CHEMBL375264 & 438974 & 8.8539 & 8.8539 & TRN & \\
\hline CHEMBL390969 & 438974 & 11.2218 & 10.3085 & TST & \\
\hline CHEMBL226722 & 438974 & 12.0 & 12.0 & TRN & \\
\hline CHEMBL173994 & 438974 & 11.1549 & 10.9298 & TST & \\
\hline CHEMBL388142 & 438974 & 9.0 & 9.0 & TRN & \\
\hline CHEMBL226668 & 438974 & 10.585 & 10.3446 & TST & \\
\hline CHEMBL226669 & 438974 & 10.2291 & 10.2291 & TRN & \\
\hline CHEMBL376791 & 438974 & 10.6198 & 10.6198 & TRN & \\
\hline CHEMBL227223 & 438974 & 9.3979 & 9.3979 & TRN & \\
\hline CHEMBL1344582 & 845108 & 5.2976 & 4.2433 & TRN & \\
\hline CHEMBL1308898 & 845108 & 5.1785 & 4.1855 & TRN & \\
\hline CHEMBL1585632 & 845108 & 4.4134 & 4.3958 & TRN & \\
\hline CHEMBL1502407 & 845108 & 4.3261 & 4.2069 & TST & \\
\hline CHEMBL1467262 & 845108 & 4.8182 & 4.6983 & TRN & \\
\hline CHEMBL1598347 & 845108 & 4.8601 & 4.1219 & TST & \\
\hline CHEMBL1731096 & 845108 & 4.4208 & 4.6157 & TRN & \\
\hline CHEMBL1549529 & 845108 & 4.6091 & 4.053999 & 7999999999 & TRN \\
\hline CHEMBL1373822 & 845108 & 4.9393 & 4.5526 & TRN & \\
\hline CHEMBL1596719 & 845108 & 4.5544 & 4.4881 & TRN & \\
\hline CHEMBL1451476 & 845108 & 4.1072 & 4.4242 & TRN & \\
\hline CHEMBL1482961 & 845108 & 4.2069 & 4.3368 & TRN & \\
\hline CHEMBL1532349 & 845108 & 4.9747 & 4.6258 & TRN & \\
\hline CHEMBL1510806 & 845108 & 4.6861 & 4.2722 & TRN & \\
\hline CHEMBL1575708 & 845108 & 4.644 & 4.4452 & TRN & \\
\hline CHEMBL1412908 & 845108 & 4.1659 & 4.0669 & TRN & \\
\hline CHEMBL1423002 & 845108 & 4.2168 & 4.335 & TRN & \\
\hline CHEMBL1470702 & 845108 & 4.0665 & 4.093 & TRN & \\
\hline CHEMBL1512359 & 845108 & 4.1397 & 4.1981 & TRN & \\
\hline CHEMBL1710533 & 845108 & 3.0 & 4.1195 & TRN & \\
\hline CHEMBL1351979 & 845108 & 4.1537 & 4.3759 & TRN & \\
\hline CHEMBL1728514 & 845108 & 3.0 & 4.1794 & TST & \\
\hline CHEMBL1543847 & 845108 & 4.4647 & 4.3947 & TRN & \\
\hline CHEMBL1582368 & 845108 & 4.7773 & 4.3698 & TRN & \\
\hline
\end{tabular}

Page 4781 


\begin{tabular}{|c|c|c|c|c|c|}
\hline & & \multicolumn{4}{|c|}{ Supplemental Table S2.txt } \\
\hline CHEMBL1717344 & 845108 & 4.2718 & 4.0206 & TST & \\
\hline CHEMBL1378710 & 845108 & 4.5607 & 4.4023 & TRN & \\
\hline CHEMBL1373913 & 845108 & 3.0 & 4.1124 & TRN & \\
\hline CHEMBL191015 & 845108 & 4.9066 & 4.5317 & TRN & \\
\hline CHEMBL1899739 & 845108 & 5.0511 & 4.9617 & TRN & \\
\hline CHEMBL1389668 & 845108 & 4.6925 & 4.2031 & TRN & \\
\hline CHEMBL1329878 & 845108 & 3.0 & 4.0404 & TRN & \\
\hline CHEMBL1546177 & 845108 & 4.3045 & 4.5704 & TRN & \\
\hline CHEMBL1403349 & 845108 & 5.2321 & 4.6341 & TRN & \\
\hline CHEMBL1472478 & 845108 & 4.1167 & 4.1411 & TRN & \\
\hline CHEMBL1565955 & 845108 & 4.6778 & 4.3434 & TRN & \\
\hline CHEMBL233302 & 845108 & 4.2493 & 4.26699 & 99999999995 & TRN \\
\hline CHEMBL1504620 & 845108 & 4.3249 & 4.3679 & TRN & \\
\hline CHEMBL1347021 & 845108 & 4.5918 & 4.4225 & TRN & \\
\hline CHEMBL1348618 & 845108 & 4.8447 & 4.2602 & TRN & \\
\hline CHEMBL1341698 & 845108 & 4.2837 & 4.0436 & TST & \\
\hline CHEMBL1531351 & 845108 & 4.1623 & 4.2069 & TRN & \\
\hline CHEMBL1407390 & 845108 & 5.5952 & 4.3975 & TRN & \\
\hline CHEMBL3193302 & 845108 & 4.3002 & 4.0859 & TRN & \\
\hline CHEMBL1417740 & 845108 & 4.71 & 4.5216 & TRN & \\
\hline CHEMBL1326967 & 845108 & 4.2874 & 4.1723 & TRN & \\
\hline CHEMBL 2133122 & 845108 & 4.2493 & 4.3443 & TRN & \\
\hline CHEMBL1311572 & 845108 & 5.5452 & 5.6275 & TRN & \\
\hline CHEMBL1608954 & 845108 & 5.5638 & 4.8057 & TRN & \\
\hline CHEMBL1604614 & 845108 & 5.1355 & 4.6613 & TRN & \\
\hline CHEMBL1517535 & 845108 & 4.1936 & 4.4173 & TRN & \\
\hline CHEMBL1519452 & 845108 & 5.1278 & 4.7183 & TRN & \\
\hline CHEMBL1409219 & 845108 & 4.9626 & 4.2051 & TST & \\
\hline CHEMBL1526471 & 845108 & 4.8794 & 4.1384 & TRN & \\
\hline CHEMBL1535826 & 845108 & 4.4711 & 4.3009 & TRN & \\
\hline CHEMBL1500042 & 845108 & 4.3413 & 4.4621 & TRN & \\
\hline CHEMBL1362398 & 845108 & 4.1765 & 4.3845 & TRN & \\
\hline CHEMBL1462011 & 845108 & 4.6596 & 4.0281 & TRN & \\
\hline CHEMBL1386766 & 845108 & 4.118 & 4.2301 & TRN & \\
\hline CHEMBL1885376 & 845108 & 4.2319 & 4.4606 & TRN & \\
\hline CHEMBL1522152 & 845108 & 3.0 & 4.1956 & TRN & \\
\hline CHEMBL417294 & 845108 & 4.5003 & 4.4602 & TRN & \\
\hline CHEMBL1528231 & 845108 & 4.0958 & 4.1079 & TRN & \\
\hline CHEMBL1300494 & 845108 & 4.1159 & 3.9869 & TST & \\
\hline CHEMBL1610255 & 845108 & 4.058 & 4.0459 & TRN & \\
\hline CHEMBL1564848 & 845108 & 4.1589 & 4.2978 & TRN & \\
\hline CHEMBL1604558 & 845108 & 4.1558 & 4.0493 & TRN & \\
\hline CHEMBL1896676 & 845108 & 4.0978 & 4.1754 & TRN & \\
\hline CHEMBL1489565 & 845108 & 4.6326 & 4.5691 & TRN & \\
\hline CHEMBL1507540 & 845108 & 4.3854 & 4.273 & TRN & \\
\hline CHEMBL1494564 & 845108 & 4.416 & 4.3822 & TRN & \\
\hline CHEMBL1588034 & 845108 & 4.3624 & 4.2662 & TRN & \\
\hline CHEMBL1702665 & 845108 & 4.3021 & 4.2439 & TST & \\
\hline
\end{tabular}




\begin{tabular}{|c|c|c|c|c|c|}
\hline \multicolumn{6}{|c|}{ Supplemental Table S2.txt } \\
\hline CHEMBL1523828 & 845108 & 4.3713 & 4.4376 & TRN & \\
\hline CHEMBL510650 & 845108 & 4.1537 & 3.9575 & TST & \\
\hline CHEMBL1502952 & 845108 & 4.0882 & 4.3151 & TRN & \\
\hline CHEMBL1452027 & 845108 & 4.1439 & 4.1468 & TRN & \\
\hline CHEMBL1443740 & 845108 & 4.1753 & 4.4069 & TRN & \\
\hline CHEMBL1422456 & 845108 & 4.249 & 4.4272 & TRN & \\
\hline CHEMBL1366918 & 845108 & 4.1435 & 4.1546 & TRN & \\
\hline CHEMBL1313891 & 845108 & 4.1516 & 4.0205 & TRN & \\
\hline CHEMBL120089 & 845108 & 3.0 & 4.3905 & TRN & \\
\hline CHEMBL1530862 & 845108 & 5.3197 & 4.6954 & TRN & \\
\hline CHEMBL1729564 & 845108 & 3.0 & 4.0476 & TST & \\
\hline CHEMBL1522851 & 845108 & 4.2373 & 4.1446 & TRN & \\
\hline CHEMBL1338476 & 845108 & 3.0 & 4.1298 & TRN & \\
\hline CHEMBL429335 & 845108 & 4.4461 & 4.07 & TRN & \\
\hline CHEMBL1608049 & 845108 & 4.4544 & 4.4934 & TRN & \\
\hline CHEMBL53738 & 845108 & 4.7167 & 4.3363 & TRN & \\
\hline CHEMBL1456197 & 845108 & 4.6925 & 4.4088 & TRN & \\
\hline CHEMBL 286593 & 845108 & 4.7375 & 4.364 & TRN & \\
\hline CHEMBL1359521 & 845108 & 4.1062 & 4.4696 & TRN & \\
\hline CHEMBL1561290 & 845108 & 4.3089 & 4.3758 & TRN & \\
\hline CHEMBL502315 & 845108 & 5.4157 & 4.1556 & TRN & \\
\hline CHEMBL1890436 & 845108 & 3.0 & 4.1405 & TRN & \\
\hline CHEMBL1490017 & 845108 & 4.7212 & 4.3046 & TRN & \\
\hline CHEMBL1491651 & 845108 & 5.1543 & 4.4092 & TRN & \\
\hline CHEMBL1410536 & 845108 & 4.175 & 4.2331 & TRN & \\
\hline CHEMBL1502047 & 845108 & 4.0869 & 4.2574 & TRN & \\
\hline CHEMBL1457561 & 845108 & 4.123 & 4.1651 & TST & \\
\hline CHEMBL1488090 & 845108 & 4.247 & 4.1901 & TRN & \\
\hline CHEMBL1717721 & 845108 & 4.184 & 4.1138 & TST & \\
\hline CHEMBL1611003 & 845108 & 4.3638 & 4.4259 & TRN & \\
\hline CHEMBL1463997 & 845108 & 4.15 & 4.3167 & TRN & \\
\hline CHEMBL1543194 & 845108 & 4.5654 & 4.6003 & TRN & \\
\hline CHEMBL1553517 & 845108 & 4.1566 & 4.2145 & TRN & \\
\hline CHEMBL112610 & 845108 & 4.2182 & 4.3174 & TRN & \\
\hline CHEMBL1505809 & 845108 & 5.041 & 4.21899 & 9999999999 & TRN \\
\hline CHEMBL1346274 & 845108 & 4.3858 & 4.5226 & TRN & \\
\hline CHEMBL1504089 & 845108 & 4.3725 & 4.4196 & TRN & \\
\hline CHEMBL1711563 & 845108 & 4.2454 & 4.1639 & TRN & \\
\hline CHEMBL1557201 & 845108 & 4.3652 & 4.1017 & TRN & \\
\hline CHEMBL1400357 & 845108 & 4.1576 & 4.2666 & TRN & \\
\hline CHEMBL1712668 & 845108 & 3.0 & 4.7178 & TRN & \\
\hline CHEMBL1407512 & 845108 & 4.2903 & 4.2762 & TRN & \\
\hline CHEMBL1498466 & 845108 & 4.085 & 4.3645 & TRN & \\
\hline CHEMBL1344419 & 845108 & 4.1676 & 4.3027 & TRN & \\
\hline CHEMBL1598424 & 845108 & 4.5143 & 4.2072 & TST & \\
\hline CHEMBL1566915 & 845108 & 4.3788 & 4.4349 & TRN & \\
\hline CHEMBL1325782 & 845108 & 4.3867 & 5.0288 & TST & \\
\hline CHEMBL1431189 & 845108 & 4.5544 & 4.2306 & TRN & \\
\hline
\end{tabular}




\begin{tabular}{|c|c|c|c|c|c|c|}
\hline & & \multicolumn{5}{|c|}{ Supplemental Table S2.txt } \\
\hline CHEMBL1346114 & 845108 & 4.6126 & 4.3377 & TRN & & \\
\hline CHEMBL1550800 & 845108 & 4.52 & 4.1765 & TRN & & \\
\hline CHEMBL1408099 & 845108 & 5.7471 & 4.1257 & TRN & & \\
\hline CHEMBL1347974 & 845108 & 5.1938 & 4.5584 & TRN & & \\
\hline CHEMBL1453510 & 845108 & 4.1113 & 4.5515 & TRN & & \\
\hline CHEMBL1462302 & 845108 & 4.0659 & 4.0866 & TRN & & \\
\hline CHEMBL1493273 & 845108 & 4.2053 & 4.3466 & TRN & & \\
\hline CHEMBL1501376 & 845108 & 3.0 & 4.0561 & TST & & \\
\hline CHEMBL1449896 & 845108 & 4.4653 & 4.5859 & TRN & & \\
\hline CHEMBL1571018 & 845108 & 4.3455 & 3.9363 & TRN & & \\
\hline CHEMBL1575926 & 845108 & 4.3304 & 4.3534 & TRN & & \\
\hline CHEMBL1410072 & 845108 & 3.0 & 4.0009 & TRN & & \\
\hline CHEMBL1359529 & 845108 & 4.5986 & 4.6572 & TRN & & \\
\hline CHEMBL1710350 & 845108 & 4.3072 & 3.9438 & TRN & & \\
\hline CHEMBL1313280 & 845108 & 3.0 & 4.0638 & TST & & \\
\hline CHEMBL1890373 & 845108 & 3.0 & 4.0541 & TRN & & \\
\hline CHEMBL 2001904 & 845108 & 4.3572 & 4.1123 & TST & & \\
\hline CHEMBL1325979 & 845108 & 4.5086 & 4.4383 & TRN & & \\
\hline CHEMBL1469808 & 845108 & 4.8928 & 4.4675 & TRN & & \\
\hline CHEMBL1340187 & 845108 & 4.3497 & 4.0036 & TRN & & \\
\hline CHEMBL1880991 & 845108 & 5.0645 & 4.9062 & TRN & & \\
\hline CHEMBL1306597 & 845108 & 3.0 & 4.2167 & TRN & & \\
\hline CHEMBL1324205 & 845108 & 4.0888 & 3.9321 & TRN & & \\
\hline CHEMBL1380585 & 845108 & 4.1109 & 4.2781 & TRN & & \\
\hline CHEMBL1522206 & 845108 & 4.9872 & 3.995 & TST & & \\
\hline CHEMBL1510128 & 845108 & 4.0576 & 4.3928 & TRN & & \\
\hline CHEMBL1481353 & 845108 & 3.0 & 4.2568 & TRN & & \\
\hline CHEMBL1713227 & 845108 & 4.71899 & 99999999 & 99 & 4.6277 & TRN \\
\hline CHEMBL1723862 & 845108 & 4.4989 & 4.3803 & TRN & & \\
\hline CHEMBL1887321 & 845108 & 4.5452 & 4.3805 & TRN & & \\
\hline CHEMBL1326897 & 845108 & 4.0832 & 4.1708 & TRN & & \\
\hline CHEMBL1583879 & 845108 & 4.4711 & 4.2118 & TRN & & \\
\hline CHEMBL1524205 & 845108 & 4.6055 & 4.5051 & TRN & & \\
\hline CHEMBL1412393 & 845108 & 4.7747 & 4.1214 & TRN & & \\
\hline CHEMBL1509778 & 845108 & 4.752 & 4.2385 & TRN & & \\
\hline CHEMBL1582785 & 845108 & 3.0 & 4.3753 & TRN & & \\
\hline CHEMBL1419839 & 845108 & 4.2996 & 4.3518 & TRN & & \\
\hline CHEMBL1483745 & 845108 & 4.1713 & 4.0844 & TRN & & \\
\hline CHEMBL1505620 & 845108 & 4.0938 & 4.0374 & TRN & & \\
\hline CHEMBL1553755 & 845108 & 4.4024 & 4.3442 & TRN & & \\
\hline CHEMBL1698134 & 845108 & 4.9031 & 4.1841 & TRN & & \\
\hline CHEMBL1427426 & 845108 & 3.0 & 4.0523 & TRN & & \\
\hline CHEMBL1440061 & 845108 & 4.7423 & 4.4567 & TRN & & \\
\hline CHEMBL3191512 & 845108 & 4.3561 & 4.2273 & TRN & & \\
\hline CHEMBL1376214 & 845108 & 4.7055 & 4.4764 & TRN & & \\
\hline CHEMBL1724217 & 845108 & 4.1022 & 4.4543 & TRN & & \\
\hline CHEMBL1557386 & 845108 & 4.0694 & 4.0516 & TRN & & \\
\hline CHEMBL1719443 & 845108 & 4.752 & 4.1966 & TRN & & \\
\hline
\end{tabular}


Supplemental Table S2.txt

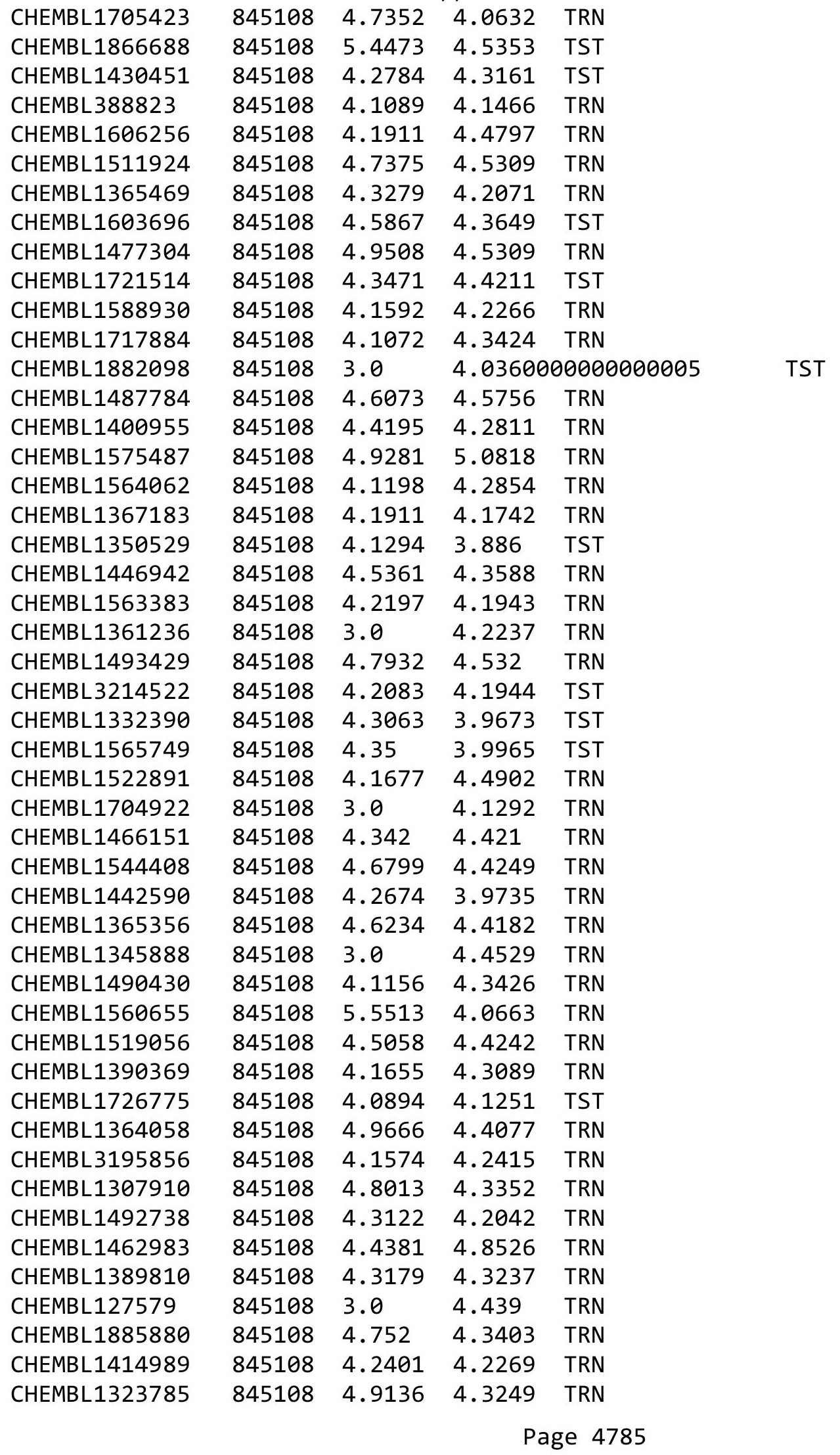


Supplemental Table S2.txt

\begin{tabular}{|c|c|c|c|c|}
\hline HEM & 108 & 5162 & 3577 & 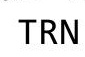 \\
\hline & 45108 & 5.0545 & & \\
\hline - & & & & \\
\hline AEMBL15851 & 108 & & & \\
\hline AEMBL1341243 & 45108 & 135 & 182 & \\
\hline HEMBL1440055 & 108 & 62 & 4.295 & \\
\hline EN & 108 & & & \\
\hline AEMBL15 & 108 & & & DN \\
\hline HEMBL1706710 & 108 & 4 & 7971 & \\
\hline HEMBL1503172 & 108 & 431 & 4546 & \\
\hline HEMBL 367376 & 108 & & & \\
\hline AEMBL1: & 08 & & & \\
\hline HEMBL14 & & & & \\
\hline HEMBL1983033 & 108 & 289 & 203 & \\
\hline HEMBL1508567 & 108 & 3 & & \\
\hline HEMBL14 & .08 & 44 & & \\
\hline HEMBL15 & & & & (1) \\
\hline HEMBL 14 & & & & \\
\hline HEMBL15 & & 17 & & \\
\hline HEMBL1380884 & & & & nIv \\
\hline HEMBL1 & & & & RN \\
\hline AEMBLI & & & & Niv \\
\hline AEMBL1 & & & & BN \\
\hline HEMBL55 & & & & \\
\hline AEMBL15 & & & & I RN \\
\hline HEMBL13 & & & & 「RN \\
\hline HEM & & & & DI \\
\hline AEMPI 1 & & 1 & & $c T$ \\
\hline AEMBL14 & & & & $\Gamma \mathrm{RN}$ \\
\hline HEMBL16004 & & 54 & 07 & TRN \\
\hline IEMBL1\& & & & & ST \\
\hline 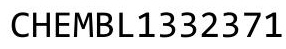 & & & & $\mathrm{RN}$ \\
\hline (1. & & & & 「RN \\
\hline HEMBL15763 & & & & 「RN \\
\hline HEMBL17330 & & & & RN \\
\hline AEMR $1:$ & & & & TRN \\
\hline 6 & & & & TRN \\
\hline HEMBL1735593 & & & & TRN \\
\hline HEMBL19053 & & & & $\Gamma R$ \\
\hline$T M$ & & & & RN \\
\hline HEMBL16 & & 5 & & 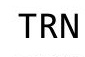 \\
\hline HEMBL14 & & 4. & 191 & 「RN \\
\hline HEMBL1523365 & & 4.7011 & 5084 & $\mathrm{TR}$ \\
\hline HEMBL13 & & 38 & & TR \\
\hline CHFMPI 15997 & & & & \\
\hline HEMBL15 & & 986 & 4571 & \\
\hline HEMBL1442918 & & 3.0 & 3.9645 & \\
\hline CHEMBL1582199 & 845108 & 4.7721 & 3.9732 & IJ \\
\hline
\end{tabular}

Page 4786 


\begin{tabular}{|c|c|c|c|c|c|}
\hline & & \multicolumn{4}{|c|}{ Supplemental Table S2.txt } \\
\hline CHEMBL1606510 & 845108 & 4.3563 & 4.0097 & TRN & \\
\hline CHEMBL1871596 & 845108 & 3.0 & 4.3025 & TRN & \\
\hline CHEMBL1307618 & 845108 & 4.4425 & 4.5304 & TRN & \\
\hline CHEMBL1605575 & 845108 & 4.1304 & 4.3843 & TRN & \\
\hline CHEMBL1420133 & 845108 & 4.5302 & 4.5189 & TRN & \\
\hline CHEMBL1461991 & 845108 & 4.2716 & 4.1287 & TRN & \\
\hline CHEMBL1380452 & 845108 & 4.1666 & 4.3892 & TRN & \\
\hline CHEMBL1442084 & 845108 & 4.5884 & 4.1012 & TRN & \\
\hline CHEMBL1887093 & 845108 & 4.105 & 4.2638 & TRN & \\
\hline CHEMBL1592023 & 845108 & 4.5834 & 4.0476 & TST & \\
\hline CHEMBL1330717 & 845108 & 4.317 & 4.3643 & TRN & \\
\hline CHEMBL1535899 & 845108 & 4.6861 & 4.3765 & TST & \\
\hline CHEMBL1467350 & 845108 & 4.1617 & 4.0221 & TRN & \\
\hline CHEMBL 3195155 & 845108 & 4.2868 & 4.1742 & TST & \\
\hline CHEMBL1604250 & 845108 & 3.0 & 4.2338 & TRN & \\
\hline CHEMBL1524020 & 845108 & 4.1129 & 4.0744 & TRN & \\
\hline CHEMBL3192253 & 845108 & 4.2518 & 4.2396 & TST & \\
\hline CHEMBL1891421 & 845108 & 4.1225 & 4.2242 & TST & \\
\hline CHEMBL1421547 & 845108 & 4.8097 & 4.4263 & TRN & \\
\hline CHEMBL 2131227 & 845108 & 4.4617 & 5.1769 & TST & \\
\hline CHEMBL1539388 & 845108 & 4.6819 & 4.044 & TRN & \\
\hline CHEMBL1462691 & 845108 & 4.6655 & 4.1705 & TRN & \\
\hline CHEMBL1466102 & 845108 & 5.6596 & 4.4662 & TRN & \\
\hline CHEMBL1455325 & 845108 & 3.0 & 3.8739 & TRN & \\
\hline CHEMBL1461506 & 845108 & 4.6234 & 4.329 & TRN & \\
\hline CHEMBL1610263 & 845108 & 4.8477 & 4.3839 & TRN & \\
\hline CHEMBL1363917 & 845108 & 4.6615 & 4.5852 & TRN & \\
\hline CHEMBL1300882 & 845108 & 4.2941 & 4.2759 & TRN & \\
\hline CHEMBL1495889 & 845108 & 4.4112 & 4.3729 & TRN & \\
\hline CHEMBL1390831 & 845108 & 4.3855 & 4.041 & TRN & \\
\hline CHEMBL1573125 & 845108 & 4.2933 & 4.41100 & 00000000005 & TRN \\
\hline CHEMBL1711673 & 845108 & 3.0 & 3.9321 & TRN & \\
\hline CHEMBL1711260 & 845108 & 4.98300 & 30000000 & 4.787 & TRN \\
\hline CHEMBL1350367 & 845108 & 4.0227 & 4.2428 & TRN & \\
\hline CHEMBL1463767 & 845108 & 4.2976 & 4.4207 & TRN & \\
\hline CHEMBL1510212 & 845108 & 4.3341 & 4.3748 & TRN & \\
\hline CHEMBL1543818 & 845108 & 4.1838 & 4.0721 & TST & \\
\hline CHEMBL1700569 & 845108 & 4.1234 & 4.2156 & TST & \\
\hline CHEMBL1454860 & 845108 & 4.303 & 4.337 & TRN & \\
\hline CHEMBL1418667 & 845108 & 4.7747 & 4.4808 & TRN & \\
\hline CHEMBL1351908 & 845108 & 3.0 & 4.0967 & TRN & \\
\hline CHEMBL3213502 & 845108 & 4.0783 & 4.1305 & TST & \\
\hline CHEMBL1563943 & 845108 & 3.0 & 4.1522 & TRN & \\
\hline CHEMBL1575201 & 845108 & 4.1165 & 4.0784 & TRN & \\
\hline CHEMBL1343697 & 845108 & 4.3602 & 4.6777 & TRN & \\
\hline CHEMBL1892476 & 845108 & 3.0 & 4.2652 & TRN & \\
\hline CHEMBL1483431 & 845108 & 4.291 & 4.1425 & TST & \\
\hline CHEMBL1417859 & 845108 & 4.0911 & 4.1624 & TRN & \\
\hline
\end{tabular}




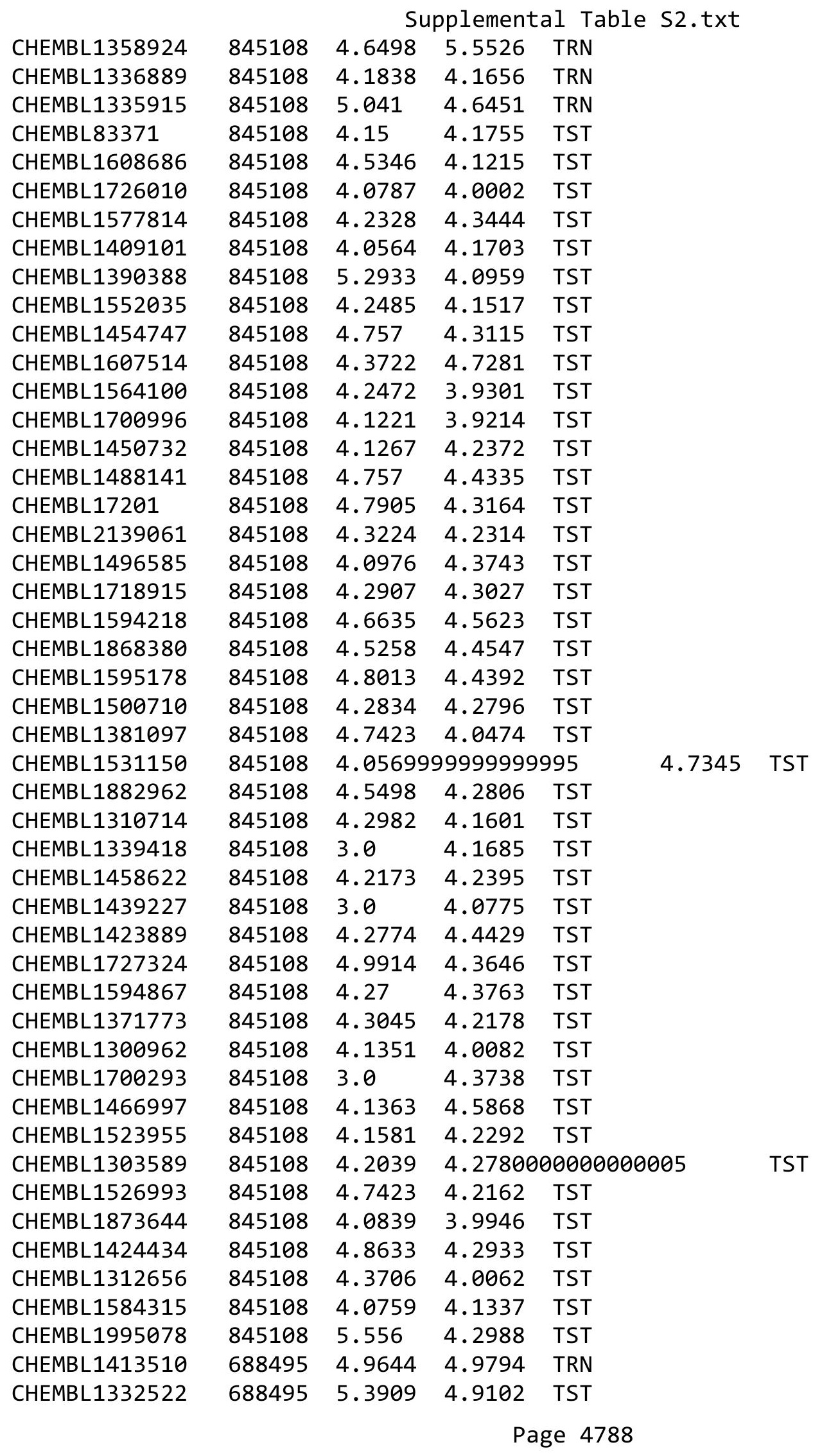




\begin{tabular}{|c|c|c|c|c|c|}
\hline & & \multicolumn{4}{|c|}{ Supplemental Table S2.txt } \\
\hline CHEMBL1724937 & 688495 & 5.8564 & 5.8599 & TRN & \\
\hline CHEMBL1597682 & 688495 & 3.2245 & 3.2079 & TRN & \\
\hline CHEMBL1527994 & 688495 & 5.0731 & 5.0225 & TRN & \\
\hline CHEMBL1510317 & 688495 & 5.0353 & 4.9862 & TRN & \\
\hline CHEMBL1607380 & 688495 & 4.2514 & 4.2745 & TRN & \\
\hline CHEMBL1500251 & 688495 & 4.5825 & 4.7608 & TRN & \\
\hline CHEMBL1439847 & 688495 & 5.0332 & 3.8245 & TST & \\
\hline CHEMBL1542877 & 688495 & 4.5935 & 4.1338 & TST & \\
\hline CHEMBL1583872 & 688495 & 5.6325 & 5.1712 & TST & \\
\hline CHEMBL1576762 & 688495 & 4.8094 & 3.984 & TRN & \\
\hline CHEMBL1362746 & 688495 & 5.6205 & 5.0783 & TST & \\
\hline CHEMBL1315955 & 688495 & 3.2245 & 3.0948 & TRN & \\
\hline CHEMBL3207378 & 688495 & 3.2245 & 3.9842 & TST & \\
\hline CHEMBL1379677 & 688495 & 5.7652 & 5.3069 & TRN & \\
\hline CHEMBL1303641 & 688495 & 5.7352 & 5.8037 & TRN & \\
\hline CHEMBL1410659 & 688495 & 4.8996 & 4.7654 & TRN & \\
\hline CHEMBL1571034 & 688495 & 5.2912 & 5.3537 & TRN & \\
\hline CHEMBL1966700 & 688495 & 3.2245 & 3.592 & TRN & \\
\hline CHEMBL1713905 & 688495 & 5.0344 & 5.3562 & TRN & \\
\hline CHEMBL1565458 & 688495 & 4.225 & 4.2947 & TRN & \\
\hline CHEMBL1373849 & 688495 & 4.3061 & 4.0845 & TRN & \\
\hline CHEMBL1310325 & 688495 & 3.2245 & 3.3054 & TRN & \\
\hline CHEMBL1966746 & 688495 & 3.2245 & 3.5579 & TST & \\
\hline CHEMBL1985601 & 688495 & 5.0269 & 5.1934 & TRN & \\
\hline CHEMBL1502551 & 688495 & 3.2245 & 3.7779 & TRN & \\
\hline CHEMBL1557243 & 688495 & 4.537 & 4.2384 & TRN & \\
\hline CHEMBL598477 & 688495 & 3.2245 & 3.3874 & TRN & \\
\hline CHEMBL1398812 & 688495 & 4.2376 & 4.00899 & 99999999995 & TRN \\
\hline CHEMBL1331195 & 688495 & 6.0485 & 5.8573 & TRN & \\
\hline CHEMBL1513792 & 688495 & 4.599 & 3.4137 & TST & \\
\hline CHEMBL1431610 & 688495 & 4.6563 & 4.5438 & TRN & \\
\hline CHEMBL1463795 & 688495 & 5.5232 & 5.1909 & TST & \\
\hline CHEMBL1446754 & 688495 & 3.2245 & 3.7116 & TST & \\
\hline CHEMBL1490312 & 688495 & 3.2245 & 4.0842 & TRN & \\
\hline CHEMBL1501987 & 688495 & 4.7753 & 4.6445 & TRN & \\
\hline CHEMBL1605743 & 688495 & 6.4269 & 6.1806 & TRN & \\
\hline CHEMBL1977499 & 688495 & 3.2245 & 3.4697 & TRN & \\
\hline CHEMBL1990694 & 688495 & 4.926 & 5.3069 & TRN & \\
\hline CHEMBL1583960 & 688495 & 4.4115 & 4.5427 & TRN & \\
\hline CHEMBL1387366 & 688495 & 5.5143 & 5.3495 & TRN & \\
\hline CHEMBL1415476 & 688495 & 4.2799 & 4.4309 & TRN & \\
\hline CHEMBL1372920 & 688495 & 4.7186 & 4.8867 & TRN & \\
\hline CHEMBL1396129 & 688495 & 4.4695 & 3.4231 & TRN & \\
\hline CHEMBL1420142 & 688495 & 4.5021 & 4.978 & TRN & \\
\hline CHEMBL1523652 & 688495 & 4.4951 & 4.3601 & TST & \\
\hline CHEMBL1985696 & 688495 & 3.2245 & 3.6072 & TRN & \\
\hline CHEMBL581251 & 688495 & 3.2245 & 3.8227 & TST & \\
\hline CHEMBL1524257 & 688495 & 4.6819 & 4.7346 & TRN & \\
\hline
\end{tabular}




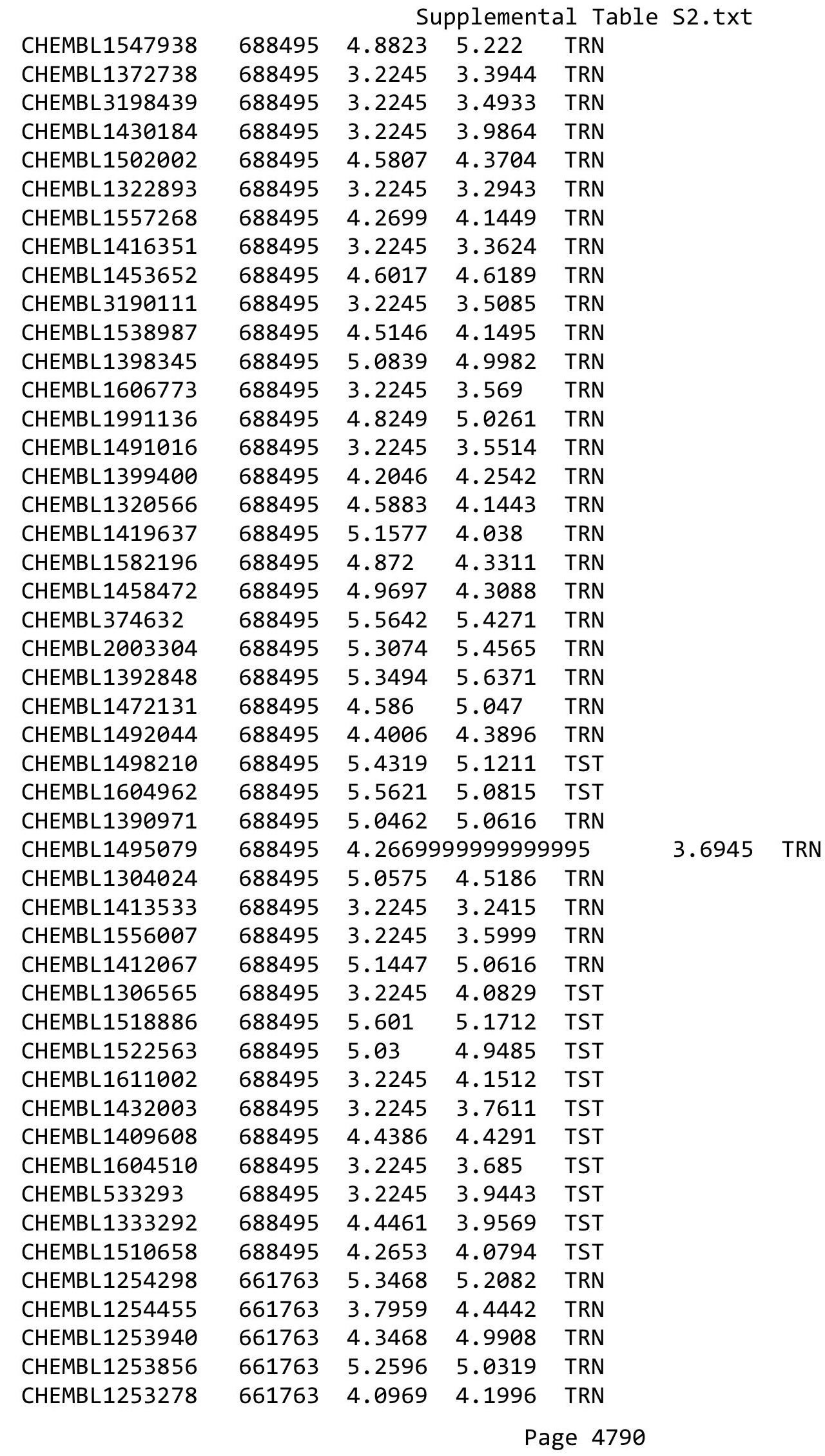




\begin{tabular}{|c|c|c|c|c|c|}
\hline & & \multicolumn{4}{|c|}{ Supplemental Table S2.txt } \\
\hline CHEMBL1254031 & 661763 & 4.3665 & 4.4963 & TRN & \\
\hline CHEMBL1254536 & 661763 & 4.3565 & 3.7806 & TRN & \\
\hline CHEMBL1254611 & 661763 & 4.3188 & 4.4374 & TRN & \\
\hline CHEMBL1254374 & 661763 & 4.6819 & 4.3079 & TRN & \\
\hline CHEMBL1254691 & 661763 & 5.1871 & 5.1557 & TRN & \\
\hline CHEMBL1254028 & 661763 & 4.3468 & 4.5521 & TRN & \\
\hline CHEMBL1253331 & 661763 & 4.5607 & 4.669 & TST & \\
\hline CHEMBL1253469 & 661763 & 4.585 & 4.2584 & TST & \\
\hline CHEMBL1253601 & 661763 & 4.2596 & 4.5652 & TRN & \\
\hline CHEMBL1253603 & 661763 & 4.0969 & 4.3292 & TRN & \\
\hline CHEMBL1254212 & 661763 & 3.3979 & 3.7106 & TRN & \\
\hline CHEMBL1254690 & 661763 & 5.0223 & 5.1664 & TRN & \\
\hline CHEMBL1253857 & 661763 & 5.2007 & 5.3701 & TRN & \\
\hline CHEMBL1253772 & 661763 & 4.9586 & 4.5957 & TRN & \\
\hline CHEMBL1254864 & 661763 & 5.3665 & 5.1339 & TRN & \\
\hline CHEMBL1253300 & 661763 & 4.9586 & 4.8911 & TRN & \\
\hline CHEMBL1253280 & 661763 & 3.7959 & 4.3951 & TRN & \\
\hline CHEMBL1253260 & 661763 & 4.8239 & 4.73 & TRN & \\
\hline CHEMBL1254122 & 661763 & 2.6383 & 4.9409 & TST & \\
\hline CHEMBL1254303 & 661763 & 4.9031 & 4.72199 & 99999999995 & TRN \\
\hline CHEMBL1253259 & 661763 & 4.757 & 4.9064 & TRN & \\
\hline CHEMBL1253332 & 661763 & 3.6021 & 4.2513 & TST & \\
\hline CHEMBL1254118 & 661763 & 4.6021 & 4.3611 & TRN & \\
\hline CHEMBL1254377 & 661763 & 4.7447 & 4.9349 & TRN & \\
\hline CHEMBL1253773 & 661763 & 4.6778 & 4.67899 & 9999999999 & TST \\
\hline CHEMBL1254211 & 661763 & 4.4559 & 4.4152 & TRN & \\
\hline CHEMBL1253299 & 661763 & 5.0706 & 4.9566 & TRN & \\
\hline CHEMBL1253714 & 661763 & 4.0339 & 4.2707 & TRN & \\
\hline CHEMBL1253682 & 661763 & 3.4559 & 4.1062 & TRN & \\
\hline CHEMBL1253202 & 661763 & 4.2596 & 4.1517 & TRN & \\
\hline CHEMBL1253195 & 661763 & 4.8239 & 5.0074 & TRN & \\
\hline CHEMBL1254026 & 661763 & 4.0555 & 3.9319 & TST & \\
\hline CHEMBL1254120 & 661763 & 4.7447 & 4.3879 & TRN & \\
\hline CHEMBL1254453 & 661763 & 4.9469 & 5.0264 & TRN & \\
\hline CHEMBL1253729 & 661763 & 4.8239 & 4.4638 & TRN & \\
\hline CHEMBL1253470 & 661763 & 4.0458 & 4.0683 & TST & \\
\hline CHEMBL1253760 & 661763 & 5.0088 & 4.3923 & TRN & \\
\hline CHEMBL1254378 & 661763 & 4.2366 & 4.0373 & TRN & \\
\hline CHEMBL1253683 & 661763 & 4.7212 & 4.4897 & TRN & \\
\hline CHEMBL1254454 & 661763 & 4.699 & 4.4333 & TRN & \\
\hline CHEMBL1254121 & 661763 & 4.6576 & 4.7129 & TRN & \\
\hline CHEMBL1254863 & 661763 & 4.8239 & 5.1683 & TRN & \\
\hline CHEMBL1253771 & 661763 & 4.757 & 5.0019 & TRN & \\
\hline CHEMBL1253203 & 661763 & 4.3188 & 4.0813 & TRN & \\
\hline CHEMBL1253938 & 661763 & 5.5686 & 5.2245 & TRN & \\
\hline CHEMBL1253200 & 661763 & 4.1487 & 4.5513 & TRN & \\
\hline CHEMBL1253761 & 661763 & 4.8239 & 4.7171 & TRN & \\
\hline CHEMBL1253201 & 661763 & 5.1549 & 4.6146 & TRN & \\
\hline
\end{tabular}


Supplemental Table S2.txt

\begin{tabular}{|c|c|c|c|c|c|}
\hline CHEMBL1253616 & 661763 & 4.757 & 4.796 & TRN & \\
\hline CHEMBL224128 & 661763 & 4.6198 & 4.9184 & TST & \\
\hline CHEMBL1253353 & 661763 & 4.585 & 4.3631 & TST & \\
\hline CHEMBL1254776 & 661763 & 4.2596 & 4.2911 & TRN & \\
\hline CHEMBL1254456 & 661763 & 2.6478 & 4.05399 & 9999999999 & TRN \\
\hline CHEMBL1254216 & 661763 & 4.1397 & 4.0683 & TST & \\
\hline CHEMBL1254949 & 661763 & 5.2218 & 4.8725 & TRN & \\
\hline CHEMBL1254029 & 661763 & 5.0706 & 4.8516 & TRN & \\
\hline CHEMBL1254214 & 661763 & 5.1249 & 4.4853 & TST & \\
\hline CHEMBL1253355 & 661763 & 3.9031 & 4.1111 & TST & \\
\hline CHEMBL1253703 & 661763 & 3.8239 & 3.9124 & TRN & \\
\hline CHEMBL1254537 & 661763 & 4.9031 & 4.2595 & TST & \\
\hline CHEMBL1253681 & 661763 & 4.9586 & 4.1232 & TRN & \\
\hline CHEMBL1253715 & 661763 & 3.1871 & 4.0002 & TRN & \\
\hline CHEMBL1253617 & 661763 & 4.5607 & 5.1421 & TRN & \\
\hline CHEMBL1253354 & 661763 & 4.426 & 4.6791 & TST & \\
\hline CHEMBL1254612 & 661763 & 4.9788 & 4.6972 & TRN & \\
\hline CHEMBL1253615 & 661763 & 4.6478 & 4.6446 & TRN & \\
\hline CHEMBL1254301 & 661763 & 4.7959 & 4.5862 & TRN & \\
\hline CHEMBL1253684 & 661763 & 4.6021 & 4.3748 & TRN & \\
\hline CHEMBL1253329 & 661763 & 4.0706 & 4.1207 & TST & \\
\hline CHEMBL1254123 & 661763 & 4.1871 & 4.261 & TST & \\
\hline CHEMBL1253258 & 661763 & 4.1675 & \multicolumn{2}{|c|}{ 3.9219999999999997 } & TRN \\
\hline CHEMBL1254610 & 661763 & 4.3468 & 4.47 & TRN & \\
\hline CHEMBL549789 & 661763 & 5.9586 & 5.063 & TST & \\
\hline CHEMBL1253602 & 661763 & 4.426 & 4.3061 & TRN & \\
\hline CHEMBL1253468 & 661763 & 4.3468 & 4.2009 & TRN & \\
\hline CHEMBL1254535 & 661763 & 4.585 & 4.7866 & TRN & \\
\hline CHEMBL2369148 & 661763 & 4.0706 & 4.1962 & TRN & \\
\hline CHEMBL1253939 & 661763 & 4.5229 & 4.5299 & TRN & \\
\hline CHEMBL1253279 & 661763 & 5.2596 & 4.8676 & TRN & \\
\hline CHEMBL1254213 & 661763 & 5.301 & 4.8698 & TRN & \\
\hline CHEMBL1253696 & 661763 & 3.2403 & 3.5611 & TRN & \\
\hline CHEMBL1253713 & 661763 & 4.9031 & 4.4834 & TRN & \\
\hline CHEMBL1253702 & 661763 & 4.0458 & 4.2858 & TRN & \\
\hline CHEMBL1254299 & 661763 & 4.2596 & 4.0129 & TRN & \\
\hline CHEMBL1254119 & 661763 & 4.6478 & 4.5685 & TRN & \\
\hline CHEMBL1255029 & 661763 & 4.3372 & 4.6432 & TRN & \\
\hline CHEMBL1254692 & 661763 & 4.5607 & 4.3467 & TRN & \\
\hline CHEMBL1254775 & 661763 & 4.9586 & 4.4375 & TRN & \\
\hline CHEMBL1254215 & 661763 & 4.8239 & 4.6284 & TRN & \\
\hline CHEMBL1253694 & 661763 & 4.6576 & 4.8839 & TRN & \\
\hline CHEMBL1253730 & 661763 & 4.699 & 4.2882 & TRN & \\
\hline CHEMBL1253855 & 661763 & 5.1675 & 5.0951 & TRN & \\
\hline CHEMBL1253728 & 661763 & 3.7959 & 3.9729 & TRN & \\
\hline CHEMBL1254774 & 661763 & 4.2041 & 4.4976 & TRN & \\
\hline CHEMBL1253467 & 661763 & 4.0223 & 4.1605 & TRN & \\
\hline CHEMBL1253352 & 661763 & 4.3188 & 4.2566 & TST & \\
\hline
\end{tabular}




\begin{tabular}{|c|c|c|c|c|c|}
\hline & & \multicolumn{4}{|c|}{ Supplemental Table S2.txt } \\
\hline CHEMBL1253701 & 661763 & 4.6478 & 4.6688 & TRN & \\
\hline CHEMBL1254534 & 661763 & 4.3979 & 5.027 & TRN & \\
\hline CHEMBL1254457 & 661763 & 5.0458 & 4.4457 & TRN & \\
\hline CHEMBL1255030 & 661763 & 4.6925 & 4.8913 & TRN & \\
\hline CHEMBL1253695 & 661763 & 3.8239 & 3.9749 & TRN & \\
\hline CHEMBL1254027 & 661763 & 4.6021 & 4.6419 & TST & \\
\hline CHEMBL1254030 & 661763 & 4.9031 & 4.4813 & TST & \\
\hline CHEMBL1254300 & 661763 & 4.2596 & 4.1558 & TST & \\
\hline CHEMBL1254865 & 661763 & 5.2218 & 4.9262 & TST & \\
\hline CHEMBL1254376 & 661763 & 3.8239 & 4.55699 & 99999999995 & TST \\
\hline CHEMBL1253500 & 661763 & 4.3468 & 4.3139 & TST & \\
\hline CHEMBL1254302 & 661763 & 4.9586 & 4.34 & TST & \\
\hline CHEMBL1253330 & 661763 & 4.301 & 4.1388 & TST & \\
\hline CHEMBL1254950 & 661763 & 4.4559 & 4.6142 & TST & \\
\hline CHEMBL1254948 & 661763 & 5.3979 & 5.3814 & TST & \\
\hline CHEMBL1253759 & 661763 & 4.1707 & 4.3308 & TST & \\
\hline CHEMBL1254375 & 661763 & 3.7959 & 4.4675 & TST & \\
\hline CHEMBL3676437 & 1528900 & 9.2218 & 8.6722 & TST & \\
\hline CHEMBL3676430 & 1528900 & 8.8861 & 9.084 & TST & \\
\hline CHEMBL3681472 & 1528900 & 7.1593 & 7.1701 & TRN & \\
\hline CHEMBL 3681520 & 1528900 & 8.585 & 8.4097 & TRN & \\
\hline CHEMBL3686277 & 1528900 & 7.3478 & 6.778 & TST & \\
\hline CHEMBL3676438 & 1528900 & 8.9208 & 8.3164 & TST & \\
\hline CHEMBL3681480 & 1528900 & 8.1308 & 7.9687 & TRN & \\
\hline CHEMBL3681583 & 1528900 & 9.301 & 8.4135 & TRN & \\
\hline CHEMBL 3681457 & 1528900 & 7.4012 & 7.4946 & TRN & \\
\hline CHEMBL3681491 & 1528900 & 7.38399 & 79999999ऽ & 8.207 & TRN \\
\hline CHEMBL 3676511 & 1528900 & 7.7352 & 5.8383 & TST & \\
\hline CHEMBL3681502 & 1528900 & 8.7959 & 8.5135 & TRN & \\
\hline CHEMBL3681634 & 1528900 & 7.7496 & 7.9124 & TRN & \\
\hline CHEMBL 3681628 & 1528900 & 8.0969 & 6.3693 & TRN & \\
\hline CHEMBL 3676524 & 1528900 & 7.5513 & 8.0688 & TST & \\
\hline CHEMBL 3681433 & 1528900 & 7.0531 & 7.0172 & TRN & \\
\hline CHEMBL3686273 & 1528900 & 7.7212 & 7.6163 & TRN & \\
\hline CHEMBL3681505 & 1528900 & 8.3979 & 8.3678 & TRN & \\
\hline CHEMBL3681514 & 1528900 & 8.3665 & 8.1326 & TST & \\
\hline CHEMBL 3676546 & 1528900 & 7.5622 & 7.8253 & TRN & \\
\hline CHEMBL 3676526 & 1528900 & 7.9318 & 8.0958 & TRN & \\
\hline CHEMBL3681428 & 1528900 & 8.2676 & 8.1715 & TRN & \\
\hline CHEMBL3681630 & 1528900 & 6.0 & 6.5462 & TRN & \\
\hline CHEMBL 3681586 & 1528900 & 9.699 & 8.34700 & 0000000001 & TST \\
\hline CHEMBL3676459 & 1528900 & 7.8477 & 7.9878 & TRN & \\
\hline CHEMBL3681543 & 1528900 & 8.9586 & 7.8563 & TST & \\
\hline CHEMBL3681464 & 1528900 & 7.5544 & 7.7546 & TRN & \\
\hline CHEMBL3676527 & 1528900 & 8.3372 & 8.3816 & TRN & \\
\hline CHEMBL 3681611 & 1528900 & 7.6737 & 7.8753 & TRN & \\
\hline CHEMBL3681473 & 1528900 & 7.7496 & 7.6244 & TRN & \\
\hline CHEMBL3681459 & 1528900 & 7.2741 & 7.2524 & TRN & \\
\hline
\end{tabular}


Supplemental Table S2.txt

\begin{tabular}{|c|c|c|c|c|c|}
\hline CHEMBL 3686274 & 1528900 & 8.0969 & 7.8839 & TRN & \\
\hline CHEMBL 3676448 & 1528900 & 9.2218 & 8.1228 & TST & \\
\hline CHEMBL3676464 & 1528900 & 8.6576 & 8.4756 & TRN & \\
\hline CHEMBL 3681620 & 1528900 & 8.2518 & 8.3052 & TRN & \\
\hline CHEMBL3681607 & 1528900 & \multicolumn{3}{|c|}{7.821000000000001} & TRN \\
\hline CHEMBL3676554 & 1528900 & 8.9208 & 8.7009 & TRN & \\
\hline CHEMBL3676533 & 1528900 & 8.3279 & 7.9334 & TRN & \\
\hline CHEMBL3681443 & 1528900 & 7.4776 & 7.5943 & TRN & \\
\hline CHEMBL 3681626 & 1528900 & 7.6402 & 7.8915 & TRN & \\
\hline CHEMBL3676507 & 1528900 & 7.4547 & 6.409 & TST & \\
\hline CHEMBL3681545 & 1528900 & 7.5513 & 7.5727 & TST & \\
\hline CHEMBL3681599 & 1528900 & \multicolumn{3}{|c|}{7.752000000000001} & TRN \\
\hline CHEMBL3681535 & 1528900 & 7.4572 & 7.3683 & TST & \\
\hline CHEMBL 3676495 & 1528900 & 7.9101 & 7.9139 & TRN & \\
\hline CHEMBL3681531 & 1528900 & 6.0 & 7.5321 & TRN & \\
\hline CHEMBL3676422 & 1528900 & 9.3979 & 9.4508 & TRN & \\
\hline CHEMBL3676498 & 1528900 & 7.8827 & 8.0597 & TRN & \\
\hline CHEMBL 3676474 & 1528900 & 8.3372 & 8.3132 & TRN & \\
\hline CHEMBL 3676493 & 1528900 & 8.0315 & 8.0286 & TRN & \\
\hline CHEMBL3681474 & 1528900 & 7.8125 & 7.6218 & TRN & \\
\hline CHEMBL3681568 & 1528900 & 8.4202 & 8.5908 & TRN & \\
\hline CHEMBL 3676427 & 1528900 & 7.8268 & 7.75799 & 9999999999 & TRN \\
\hline CHEMBL 3676431 & 1528900 & 8.9586 & 9.0063 & TST & \\
\hline CHEMBL3676503 & 1528900 & 7.2941 & 7.4991 & TRN & \\
\hline CHEMBL3681556 & 1528900 & 6.0 & 6.8268 & TRN & \\
\hline CHEMBL3681577 & 1528900 & 8.699 & 8.9025 & TRN & \\
\hline CHEMBL3681563 & 1528900 & 8.3665 & 8.32200 & 3000000001 & TRN \\
\hline CHEMBL 3681588 & 1528900 & 10.0 & 8.3496 & TST & \\
\hline CHEMBL3681453 & 1528900 & 8.1487 & 8.1041 & TRN & \\
\hline CHEMBL3681450 & 1528900 & 7.2299 & 6.9799 & TST & \\
\hline CHEMBL3681593 & 1528900 & 7.4413 & 7.5292 & TRN & \\
\hline CHEMBL3681515 & 1528900 & 8.6383 & 8.4478 & TRN & \\
\hline CHEMBL3681425 & 1528900 & 9.1549 & 8.9448 & TRN & \\
\hline CHEMBL3676436 & 1528900 & 9.5229 & 8.7416 & TST & \\
\hline CHEMBL3681488 & 1528900 & 8.6383 & $8.34100 t$ & 0000000001 & TRN \\
\hline CHEMBL3676512 & 1528900 & 7.8356 & 6.7765 & TST & \\
\hline CHEMBL3681579 & 1528900 & 8.3872 & 8.4355 & TRN & \\
\hline CHEMBL 3676520 & 1528900 & 7.2749 & 7.4997 & TRN & \\
\hline CHEMBL3681516 & 1528900 & 8.3468 & 8.1756 & TRN & \\
\hline CHEMBL3686276 & 1528900 & 7.8665 & 7.821006 & 3000000001 & TRN \\
\hline CHEMBL3681418 & 1528900 & 7.983 & 7.9648 & TRN & \\
\hline CHEMBL3676523 & 1528900 & 7.6799 & 7.7722 & TST & \\
\hline CHEMBL3681584 & 1528900 & 9.2218 & 8.2783 & TST & \\
\hline CHEMBL3681448 & 1528900 & 7.4157 & 7.629 & TRN & \\
\hline CHEMBL3676508 & 1528900 & 7.4225 & 7.3214 & TRN & \\
\hline CHEMBL3676423 & 1528900 & 9.301 & 9.3444 & TRN & \\
\hline CHEMBL3676457 & 1528900 & 7.8827 & 8.5752 & TST & \\
\hline CHEMBL 3686272 & 1528900 & 7.7235 & 7.7484 & TRN & \\
\hline
\end{tabular}


Supplemental Table S2.txt

\begin{tabular}{|c|c|c|c|c|c|}
\hline CHEMBL3676463 & 1528900 & 8.699 & 8.7381 & TRN & \\
\hline CHEMBL3676521 & 1528900 & 7.0926 & 7.2015 & TRN & \\
\hline CHEMBL3681431 & 1528900 & 8.3279 & 8.4848 & TRN & \\
\hline CHEMBL 3681518 & 1528900 & 8.699 & 8.4458 & TRN & \\
\hline CHEMBL3676480 & 1528900 & 8.5528 & 8.2915 & TRN & \\
\hline CHEMBL 3681449 & 1528900 & 7.9031 & 7.8965 & TRN & \\
\hline CHEMBL 3681560 & 1528900 & 8.6198 & 8.711 & TRN & \\
\hline CHEMBL 3676553 & 1528900 & 7.4034 & 7.1665 & TRN & \\
\hline CHEMBL 3676453 & 1528900 & 7.4377 & 7.6055 & TST & \\
\hline CHEMBL3676536 & 1528900 & 8.4437 & 8.1907 & TRN & \\
\hline CHEMBL 3681633 & 1528900 & 7.699 & 7.5258 & TRN & \\
\hline CHEMBL3681598 & 1528900 & 7.6696 & 7.8056 & TRN & \\
\hline CHEMBL3681600 & 1528900 & 8.1367 & 8.0551 & TRN & \\
\hline CHEMBL 3681591 & 1528900 & 8.2518 & 8.288 & TRN & \\
\hline CHEMBL3676425 & 1528900 & 9.5229 & 9.7983 & TRN & \\
\hline CHEMBL 3676551 & 1528900 & 7.71 & 7.626 & TRN & \\
\hline CHEMBL3681587 & 1528900 & 9.3979 & 9.2435 & TRN & \\
\hline CHEMBL3681619 & 1528900 & 7.9066 & 8.3072 & TRN & \\
\hline CHEMBL 3676467 & 1528900 & 8.28399 & 79999999 & 8.5573 & TRN \\
\hline CHEMBL3676496 & 1528900 & 7.9957 & 7.8174 & TRN & \\
\hline CHEMBL3676485 & 1528900 & 8.3098 & 8.4713 & TRN & \\
\hline CHEMBL3676513 & 1528900 & 7.9706 & 7.0548 & TST & \\
\hline CHEMBL 3681558 & 1528900 & 7.5768 & 7.7747 & TRN & \\
\hline CHEMBL 3676426 & 1528900 & 9.5229 & 9.7131 & TRN & \\
\hline CHEMBL 3681539 & 1528900 & 7.4283 & 7.7346 & TRN & \\
\hline CHEMBL 3903892 & 1528900 & 7.5346 & 7.5804 & TST & \\
\hline CHEMBL 3676518 & 1528900 & 7.7305 & 7.8047 & TST & \\
\hline CHEMBL 3676528 & 1528900 & 7.3904 & \multicolumn{2}{|c|}{ 7. 367999999999999} & TRN \\
\hline CHEMBL 3681507 & 1528900 & 7.9626 & 8.0066 & TRN & \\
\hline CHEMBL3681561 & 1528900 & 8.6383 & 8.8322 & TRN & \\
\hline CHEMBL 3676544 & 1528900 & 7.341 & 7.565 & TRN & \\
\hline CHEMBL3681547 & 1528900 & 8.5086 & 8.7151 & TRN & \\
\hline CHEMBL 3676514 & 1528900 & 7.4634 & 7.5529 & TST & \\
\hline CHEMBL 3676442 & 1528900 & 7.8508 & 8.2253 & TST & \\
\hline CHEMBL3681506 & 1528900 & 8.7447 & 8.0338 & TRN & \\
\hline CHEMBL3681526 & 1528900 & 7.4306 & 7.6077 & TRN & \\
\hline CHEMBL 3681440 & 1528900 & 7.6556 & 7.5783 & TRN & \\
\hline CHEMBL 3681483 & 1528900 & 8.1427 & 8.1032 & TRN & \\
\hline CHEMBL 3681434 & 1528900 & 7.6144 & 7.5184 & TRN & \\
\hline CHEMBL3681549 & 1528900 & 9.0 & 9.1355 & TRN & \\
\hline CHEMBL3681462 & 1528900 & 7.58 & 7.5553 & TRN & \\
\hline CHEMBL 3686275 & 1528900 & 7.7011 & 7.9078 & TRN & \\
\hline CHEMBL3681621 & 1528900 & 8.1938 & 8.5011 & TRN & \\
\hline CHEMBL 3681447 & 1528900 & 7.475 & 7.7068 & TRN & \\
\hline CHEMBL3681455 & 1528900 & 8.2518 & 8.2895 & TRN & \\
\hline CHEMBL 3676454 & 1528900 & 8.5086 & 7.6902 & TST & \\
\hline CHEMBL3681616 & 1528900 & 7.6364 & 8.264 & TST & \\
\hline CHEMBL 3681572 & 1528900 & 8.9586 & 9.0755 & TRN & \\
\hline
\end{tabular}


Supplemental Table S2.txt

\begin{tabular}{|c|c|c|c|c|}
\hline 458 & & & & \\
\hline HEMBL3676552 & 528900 & 7.7905 & 8.2012 & \\
\hline & & & & \\
\hline EMBL3681501 & 3900 & & & \\
\hline EMBL & 28900 & 356 & & \\
\hline AEMBL 3676488 & 528900 & 8.0044 & 0943 & \\
\hline IEMBL 368 & 528900 & 4921 & 3094 & \\
\hline & 28900 & 94 & & \\
\hline IEMBL & 528900 & 4989 & 7066 & \\
\hline IEMBL3676465 & 528900 & 8.585 & 8.5519 & \\
\hline AEMBL 3676479 & 528900 & 5686 & 3357 & \\
\hline IEMBL3681482 & 528900 & 269 & 546 & \\
\hline EMBL3 & 28900 & & & \\
\hline 1540 & 528900 & & & \\
\hline IEMBL3676550 & 528900 & 089 & 8.3552 & \\
\hline IEMBL3676433 & 528900 & & 0853 & \\
\hline IEMBL36 & 528900 & 861 & 584 & \\
\hline IEMBL36 & 528900 & & & \\
\hline IEMBL: & 528900 & 86 & 8.3793 & \\
\hline IEMBL36 & 528900 & & 8835 & \\
\hline EMBL3681605 & 528900 & 95 & 7.7821 & \\
\hline IEMBL36 & 528900 & & 7.8722 & \\
\hline EMBL36 & 5280 & & 7.3256 & \\
\hline 478 & 528900 & & & \\
\hline IEMBL36 & $\partial 0$ & & 64 & RI \\
\hline IEMBL3 & 528900 & & 69 & \\
\hline IEMBL3 & 528900 & 2 & 31 & \\
\hline 89 & 0 & & & \\
\hline 538 & 30 & & & \\
\hline IEMBL3 & 30 & & & SI \\
\hline IEMBL36 & 28900 & & .2085 & 5 \\
\hline 513 & 28900 & & 28 & \\
\hline 36 & 30 & & & \\
\hline EMBL3681529 & 30 & & & \\
\hline IEMBL 3676545 & 528900 & & 7.5 & RI \\
\hline EMBL36 & 28900 & 11 & 947 & \\
\hline 81 & 0 & & & DIV \\
\hline & 0 & & 7.4288 & \\
\hline AEMBL 3681573 & 528900 & & 8.6847 & $\mathrm{RN}$ \\
\hline EMBL368 & 28900 & 32 & 7.4012 & RI \\
\hline HEMBL3681582 & 528900 & 18 & 8.3466 & \\
\hline & & & & \\
\hline AEMBL3676456 & 528900 & 161 & 7.6607 & ST \\
\hline EMBL3676455 & 528900 & 5072 & 8.0224 & \\
\hline EML 36 & 5289 & & 12 & $S$ \\
\hline CHEMBL3681522 & 5289 & 862 & 8.2497 & \\
\hline CHEMBL3681629 & 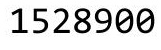 & & 8.1827 & \\
\hline CHEMBL3681467 & 152890 & 7.983 & 7.9167 & \\
\hline
\end{tabular}

Page 4796 
Supplemental Table S2.txt

\begin{tabular}{|c|c|c|c|c|c|c|}
\hline CHEMBL 3676469 & 1528900 & 8.1135 & 8.0135 & TRN & & \\
\hline CHEMBL 3681452 & 1528900 & 8.3872 & 8.16 & TRN & & \\
\hline CHEMBL 3681489 & 1528900 & 7.1343 & $7.41200 e$ & 300000006 & & TRN \\
\hline CHEMBL 3681487 & 1528900 & 8.1079 & 7.7578 & TRN & & \\
\hline CHEMBL 3676501 & 1528900 & 7.9172 & 8.0937 & TRN & & \\
\hline CHEMBL 3676421 & 1528900 & 9.5229 & 9.4526 & TRN & & \\
\hline CHEMBL 3681519 & 1528900 & 8.6576 & 8.4741 & TRN & & \\
\hline CHEMBL 3676440 & 1528900 & 8.1675 & 8.212 & TST & & \\
\hline CHEMBL 3681596 & 1528900 & 7.6946 & 7.7472 & TRN & & \\
\hline CHEMBL3676509 & 1528900 & 7.2565 & 7.3664 & TRN & & \\
\hline CHEMBL 3676543 & 1528900 & 7.3179 & 7.4189 & TRN & & \\
\hline CHEMBL 3676435 & 1528900 & 9.3979 & 8.8254 & TST & & \\
\hline CHEMBL 3681597 & 1528900 & 8.2218 & 8.4992 & TRN & & \\
\hline CHEMBL 3676439 & 1528900 & 8.0969 & 8.3718 & TST & & \\
\hline CHEMBL3681595 & 1528900 & 8.3188 & 8.5069 & TRN & & \\
\hline CHEMBL 3681601 & 1528900 & 7.9747 & 8.2633 & TST & & \\
\hline CHEMBL 3639804 & 1528900 & 9.2218 & 9.0532 & TRN & & \\
\hline CHEMBL 3681542 & 1528900 & 8.4815 & 7.4422 & TST & & \\
\hline CHEMBL 3681565 & 1528900 & 8.4815 & 8.2128 & TRN & & \\
\hline CHEMBL 3676424 & 1528900 & 9.5229 & 9.8247 & TRN & & \\
\hline CHEMBL 3676542 & 1528900 & 8.7696 & 8.436 & TRN & & \\
\hline CHEMBL 3676471 & 1528900 & 7.8827 & 7.7474 & TRN & & \\
\hline CHEMBL 3676450 & 1528900 & 7.3706 & 7.2134 & TST & & \\
\hline CHEMBL 3676482 & 1528900 & 7.8827 & 8.1672 & TRN & & \\
\hline CHEMBL 3676539 & 1528900 & 8.4949 & 8.2029 & TRN & & \\
\hline CHEMBL 3676484 & 1528900 & 8.0969 & 7.7348 & TRN & & \\
\hline CHEMBL 3676443 & 1528900 & 7.6421 & 8.1692 & TST & & \\
\hline CHEMBL 3681534 & 1528900 & 8.9586 & 8.9658 & TRN & & \\
\hline CHEMBL 3676444 & 1528900 & 7.4935 & 7.0718 & TST & & \\
\hline CHEMBL 3681441 & 1528900 & 7.2441 & 7.1842 & TRN & & \\
\hline CHEMBL 3676473 & 1528900 & 8.5528 & 8.6469 & TST & & \\
\hline CHEMBL 3676537 & 1528900 & 8.3372 & 8.2752 & TRN & & \\
\hline CHEMBL 3676516 & 1528900 & 8.8539 & 8.3678 & TRN & & \\
\hline CHEMBL 3681585 & 1528900 & 9.5229 & 8.5266 & TST & & \\
\hline CHEMBL 3681559 & 1528900 & 8.28399 & 99999999 & 99 & 7.8575 & $1 \mathrm{~K}$ \\
\hline CHEMBL 3681494 & 1528900 & 6.0 & 6.2739 & TRN & & \\
\hline CHEMBL 3681552 & 1528900 & 9.0969 & 9.373 & TRN & & \\
\hline CHEMBL3681569 & 1528900 & 8.9586 & 8.948 & TRN & & \\
\hline CHEMBL 3681622 & 1528900 & 7.9626 & 8.3513 & TST & & \\
\hline CHEMBL 3681523 & 1528900 & 7.5834 & 7.5614 & TRN & & \\
\hline CHEMBL 3676449 & 1528900 & 7.5346 & 7.4459 & TST & & \\
\hline CHEMBL 3681610 & 1528900 & 7.8827 & 7.8569 & TST & & \\
\hline CHEMBL3676492 & 1528900 & 7.8601 & 7.7179 & TRN & & \\
\hline CHEMBL 3681578 & 1528900 & 7.7167 & 7.8862 & TRN & & \\
\hline CHEMBL 3676451 & 1528900 & 8.5376 & 7.7689 & TST & & \\
\hline CHEMBL 3676549 & 1528900 & 8.1192 & 8.1662 & TRN & & \\
\hline CHEMBL 3681470 & 1528900 & 7.9747 & 7.7241 & TRN & & \\
\hline CHEMBL3681427 & 1528900 & 9.0969 & 9.0392 & TRN & & \\
\hline
\end{tabular}

Page 4797 
Supplemental Table S2.txt

\begin{tabular}{|c|c|c|c|c|c|}
\hline CHEMBL3681524 & 1528900 & 6.0 & 6.1522 & TRN & \\
\hline CHEMBL3681471 & 1528900 & 8.0555 & 7.8759 & TRN & \\
\hline CHEMBL3681574 & 1528900 & 8.7959 & 8.8069 & TRN & \\
\hline CHEMBL 3676541 & 1528900 & 7.38399 & 999999999 & 8.1797 & TRN \\
\hline CHEMBL 3676519 & 1528900 & 8.5302 & 8.2809 & TST & \\
\hline CHEMBL 3681624 & 1528900 & 7.9872 & 8.3097 & TST & \\
\hline CHEMBL 3681444 & 1528900 & 7.7825 & 7.7233 & TRN & \\
\hline CHEMBL 3681486 & 1528900 & 8.0 & 7.9847 & TRN & \\
\hline CHEMBL 3681442 & 1528900 & 7.7033 & 7.7146 & TRN & \\
\hline CHEMBL 3681533 & 1528900 & 7.4353 & 7.388999 & 9999999999 & TP \\
\hline CHEMBL 3681570 & 1528900 & 9.2218 & 8.995 & TRN & \\
\hline CHEMBL 3681422 & 1528900 & 7.6517 & 7.446000 & 0000000001 & \\
\hline CHEMBL 3681618 & 1528900 & 7.82100 & 000000000 & 8.2856 & \\
\hline CHEMBL3681490 & 1528900 & 8.1135 & 8.1856 & TRN & \\
\hline CHEMBL 3681460 & 1528900 & 7.6198 & 7.7424 & TRN & \\
\hline CHEMBL3681536 & 1528900 & 8.4437 & 8.6622 & TRN & \\
\hline CHEMBL3681602 & 1528900 & 6.0 & 6.3113 & TST & \\
\hline CHEMBL 3681517 & 1528900 & 8.0757 & 7.8776 & TRN & \\
\hline CHEMBL3681439 & 1528900 & 7.6234 & 7.3711 & TRN & \\
\hline CHEMBL 3676466 & 1528900 & 8.6021 & 8.5142 & TRN & \\
\hline CHEMBL 3681550 & 1528900 & 9.0969 & 9.0317 & TRN & \\
\hline CHEMBL3681537 & 1528900 & 7.857 & 7.552000 & 00000000005 & \\
\hline CHEMBL3681581 & 1528900 & 8.4202 & 8.3883 & TRN & \\
\hline CHEMBL3681446 & 1528900 & 7.6478 & 7.6127 & TRN & \\
\hline CHEMBL 3681477 & 1528900 & 8.2291 & 8.0069 & TRN & \\
\hline CHEMBL 3681493 & 1528900 & 8.301 & 8.1433 & TRN & \\
\hline CHEMBL 3681478 & 1528900 & 8.1192 & 7.9471 & TRN & \\
\hline CHEMBL 3676522 & 1528900 & 7.7144 & 6.564 & TST & \\
\hline CHEMBL3676515 & 1528900 & 7.6126 & 7.8406 & TRN & \\
\hline CHEMBL 3676547 & 1528900 & 8.1079 & 8.2786 & TRN & \\
\hline CHEMBL3681608 & 1528900 & 6.0 & 6.1129 & TST & \\
\hline CHEMBL 3681421 & 1528900 & 8.3468 & 8.4407 & TRN & \\
\hline CHEMBL3681485 & 1528900 & 7.9957 & 7.9112 & TRN & \\
\hline CHEMBL3676487 & 1528900 & 8.0269 & 8.0857 & TRN & \\
\hline CHEMBL 3681567 & 1528900 & 9.3979 & 9.0095 & TRN & \\
\hline CHEMBL 3676525 & 1528900 & 7.5243 & 7.4865 & TST & \\
\hline CHEMBL 3676477 & 1528900 & 7.6946 & 7.5413 & TRN & \\
\hline CHEMBL 3681592 & 1528900 & 8.0915 & 7.9938 & TRN & \\
\hline CHEMBL3681548 & 1528900 & 9.0458 & 9.1557 & TRN & \\
\hline CHEMBL3681461 & 1528900 & 7.5258 & 7.616000 & 00000000005 & 10 \\
\hline CHEMBL3676534 & 1528900 & 8.3468 & 8.2938 & TRN & \\
\hline CHEMBL 3681415 & 1528900 & 8.9586 & 8.6396 & TRN & \\
\hline CHEMBL 3681564 & 1528900 & 8.0315 & 7.9864 & TRN & \\
\hline CHEMBL3676489 & 1528900 & 8.1367 & 7.8524 & TRN & \\
\hline CHEMBL3681432 & 1528900 & 8.6198 & 8.5733 & TRN & \\
\hline CHEMBL 3676506 & 1528900 & 7.5918 & 7.7481 & TRN & \\
\hline CHEMBL 3686278 & 1528900 & 8.0315 & 6.6969 & TST & \\
\hline CHEMBL3686279 & 1528900 & 7.6696 & 6.6418 & TST & \\
\hline
\end{tabular}


Supplemental Table S2.txt

\begin{tabular}{|c|c|c|c|c|c|}
\hline CHEMBL 3676540 & 1528900 & 8.6383 & 8.3079 & TRN & \\
\hline CHEMBL 3676500 & 1528900 & 7.4202 & 8.1916 & TRN & \\
\hline CHEMBL3681562 & 1528900 & 7.5638 & 8.1629 & TRN & \\
\hline CHEMBL3681590 & 1528900 & 8.5229 & 8.4199 & TRN & \\
\hline CHEMBL3681417 & 1528900 & 7.8861 & 7.8087 & TRN & \\
\hline CHEMBL3681580 & 1528900 & 8.7959 & 9.4215 & TRN & \\
\hline CHEMBL3681495 & 1528900 & 8.6383 & 8.2075 & TRN & \\
\hline CHEMBL3676470 & 1528900 & 7.7122 & 7.7027 & TRN & \\
\hline CHEMBL3681538 & 1528900 & 7.7959 & 8.0322 & TRN & \\
\hline CHEMBL3676476 & 1528900 & 7.4559 & 7.72 & TRN & \\
\hline CHEMBL3676532 & 1528900 & 7.7747 & 7.8017 & TRN & \\
\hline CHEMBL 3676434 & 1528900 & 8.9586 & 8.3278 & TST & \\
\hline CHEMBL 3676510 & 1528900 & 7.4123 & 7.4538 & TRN & \\
\hline CHEMBL 3681468 & 1528900 & 7.4283 & 7.5444 & TST & \\
\hline CHEMBL3681575 & 1528900 & 8.1675 & 8.3097 & TRN & \\
\hline CHEMBL3676475 & 1528900 & 8.1871 & 7.5537 & TST & \\
\hline CHEMBL3676529 & 1528900 & 7.1669 & 7.1323 & TST & \\
\hline CHEMBL3681627 & 1528900 & 7.2557 & 8.1348 & TST & \\
\hline CHEMBL 3676491 & 1528900 & 8.301 & 8.1536 & TRN & \\
\hline CHEMBL3676432 & 1528900 & 8.3979 & 8.5724 & TST & \\
\hline CHEMBL3676499 & 1528900 & 7.9281 & 7.8467 & TRN & \\
\hline CHEMBL3681544 & 1528900 & $7.7520 e$ & 000000000 & 91 & 7.6514 \\
\hline CHEMBL3676483 & 1528900 & 8.6778 & 8.5117 & TRN & \\
\hline CHEMBL3686271 & 1528900 & 7.8827 & 7.8308 & TST & \\
\hline CHEMBL3681465 & 1528900 & 7.059 & 7.4425 & TST & \\
\hline CHEMBL3681625 & 1528900 & 7.399 & 7.8292 & TST & \\
\hline CHEMBL3681445 & 1528900 & 7.2381 & 7.8366 & TRN & \\
\hline CHEMBL3676531 & 1528900 & $7.8210 e$ & 000000000 & 21 & 7.9047 \\
\hline CHEMBL 3676441 & 1528900 & 7.8697 & 8.1704 & TST & \\
\hline CHEMBL3676555 & 1528900 & 8.8239 & 8.6447 & TRN & \\
\hline CHEMBL3639803 & 1528900 & 8.3468 & 8.4199 & TRN & \\
\hline CHEMBL 3676517 & 1528900 & 7.3251 & 7.1674 & TRN & \\
\hline CHEMBL3676468 & 1528900 & 8.4089 & 8.3704 & TRN & \\
\hline CHEMBL 3676452 & 1528900 & 7.9957 & 7.8387 & TST & \\
\hline CHEMBL 3681541 & 1528900 & 8.2924 & 8.4446 & TRN & \\
\hline CHEMBL3681614 & 1528900 & 8.0223 & 8.0637 & TST & \\
\hline CHEMBL3681481 & 1528900 & 8.1871 & 8.2018 & TRN & \\
\hline CHEMBL 3676556 & 1528900 & 9.1549 & 8.7539 & TRN & \\
\hline CHEMBL 3681555 & 1528900 & 8.8861 & 8.135 & TRN & \\
\hline CHEMBL 3681521 & 1528900 & 8.3872 & 8.2497 & TRN & \\
\hline CHEMBL3681484 & 1528900 & 7.7167 & 7.8142 & TRN & \\
\hline CHEMBL3681492 & 1528900 & 6.0 & 6.6734 & TRN & \\
\hline CHEMBL3676486 & 1528900 & 8.2007 & 8.2806 & TRN & \\
\hline CHEMBL 3681476 & 1528900 & 7.5867 & 7.5563 & TRN & \\
\hline CHEMBL3681623 & 1528900 & 8.1487 & 8.3493 & TST & \\
\hline CHEMBL3681566 & 1528900 & 8.1739 & 8.2217 & TRN & \\
\hline CHEMBL3686280 & 1528900 & 7.7328 & 7.1331 & TST & \\
\hline CHEMBL3676530 & 1528900 & 7.3526 & 8.0991 & TST & \\
\hline
\end{tabular}


Supplemental Table S2.txt

\begin{tabular}{|c|c|c|c|c|c|}
\hline CHEMBL 3681617 & 1528900 & 7.7122 & 8.1778 & TST & \\
\hline CHEMBL 3676462 & 1528900 & 8.3565 & 8.5223 & TRN & \\
\hline CHEMBL 3681469 & 1528900 & 8.2291 & 7.8179 & TRN & \\
\hline CHEMBL 3681456 & 1528900 & 7.0731 & 7.3119 & TRN & \\
\hline CHEMBL 3676460 & 1528900 & 8.3665 & 8.5044 & TRN & \\
\hline CHEMBL 3681451 & 1528900 & 8.2291 & 8.2735 & TRN & \\
\hline CHEMBL 3681429 & 1528900 & 8.1249 & 8.3137 & TRN & \\
\hline CHEMBL 3681525 & 1528900 & 7.3188 & 7.4006 & TRN & \\
\hline CHEMBL 3681615 & 1528900 & 7.6326 & 8.0766 & TST & \\
\hline CHEMBL 3676490 & 1528900 & 7.3615 & 7.6313 & TRN & \\
\hline CHEMBL 3681438 & 1528900 & 7.3809 & 7.456 & TRN & \\
\hline CHEMBL 3681475 & 1528900 & 7.7122 & 7.4943 & TRN & \\
\hline CHEMBL 3676447 & 1528900 & 8.9208 & 7.9176 & TST & \\
\hline CHEMBL 3676548 & 1528900 & 8.0915 & 8.169 & TRN & \\
\hline CHEMBL 3681416 & 1528900 & 9.0969 & 8.8765 & TRN & \\
\hline CHEMBL 3681546 & 1528900 & 8.4949 & 8.7142 & TRN & \\
\hline CHEMBL 3681435 & 1528900 & 7.5114 & 7.4048 & TRN & \\
\hline CHEMBL 3639754 & 1528900 & 7.7595 & 7.841 & TRN & \\
\hline CHEMBL 3676535 & 1528900 & 8.0088 & 7.9709 & TRN & \\
\hline CHEMBL 3681632 & 1528900 & 7.8827 & 8.1751 & TST & \\
\hline CHEMBL 3681466 & 1528900 & 7.5622 & 7.3754 & TRN & \\
\hline CHEMBL 3676497 & 1528900 & 8.0757 & 7.9788 & TRN & \\
\hline CHEMBL 3681454 & 1528900 & 8.3468 & 8.2258 & TRN & \\
\hline CHEMBL 3681430 & 1528900 & 8.5686 & 8.5068 & TRN & \\
\hline CHEMBL 3681423 & 1528900 & 8.6778 & 8.902999 & 9999999999 & TRN \\
\hline CHEMBL3681576 & 1528900 & 7.6517 & 7.522 & TRN & \\
\hline CHEMBL 3676504 & 1528900 & 7.7747 & 7.6034 & TRN & \\
\hline CHEMBL 3676502 & 1528900 & 7.6946 & 7.6266 & TRN & \\
\hline CHEMBL3681496 & 1528900 & 8.6778 & 8.6987 & TRN & \\
\hline CHEMBL 3661633 & 1528309 & 6.585 & 6.9456 & TRN & \\
\hline CHEMBL3666504 & 1528309 & 6.5686 & 5.5294 & TST & \\
\hline CHEMBL 3661734 & 1528309 & 6.3468 & 5.9775 & TRN & \\
\hline CHEMBL 3666551 & 1528309 & 3.301 & 3.7787 & TRN & \\
\hline CHEMBL3666636 & 1528309 & 7.301 & 7.3433 & TRN & \\
\hline CHEMBL 3661662 & 1528309 & 5.5528 & 5.7146 & TRN & \\
\hline CHEMBL3666535 & 1528309 & 7.0706 & 6.9428 & TRN & \\
\hline CHEMBL 3661748 & 1528309 & 6.585 & 6.7039 & TRN & \\
\hline CHEMBL 3661648 & 1528309 & 7.1739 & 6.8714 & TRN & \\
\hline CHEMBL 3666649 & 1528309 & 6.8861 & 6.7778 & TRN & \\
\hline CHEMBL 3661744 & 1528309 & 6.757006 & 00000000 & 6.8281 & TRN \\
\hline CHEMBL3915563 & 1528309 & 6.7696 & 5.9969 & TST & \\
\hline CHEMBL3661772 & 1528309 & 7.1549 & 6.9434 & TRN & \\
\hline CHEMBL3889727 & 1528309 & 6.6383 & 6.2546 & TST & \\
\hline CHEMBL3661746 & 1528309 & 6.4949 & 6.4306 & TRN & \\
\hline CHEMBL 3666587 & 1528309 & 3.301 & 3.8143 & TST & \\
\hline CHEMBL 3666654 & 1528309 & 7.0458 & 7.2591 & TRN & \\
\hline CHEMBL3666466 & 1528309 & 7.5229 & 7.2547 & TRN & \\
\hline CHEMBL 3661704 & 1528309 & 3.301 & 3.5013 & TRN & \\
\hline
\end{tabular}


Supplemental Table S2.txt

\begin{tabular}{|c|c|c|c|c|}
\hline CHEMBL 3661705 & 1528309 & 3.301 & 4.6367 & TST \\
\hline CHEMBL3666549 & 1528309 & 6.5229 & 5.6118 & TST \\
\hline CHEMBL3661645 & 1528309 & 5.6299 & 5.9103 & TRN \\
\hline CHEMBL 3661752 & 1528309 & 6.5229 & 6.8272 & TRN \\
\hline CHEMBL 3666639 & 1528309 & 6.0 & 6.9813 & TRN \\
\hline CHEMBL 3666473 & 1528309 & 6.2366 & 6.1925 & TRN \\
\hline CHEMBL 3661675 & 1528309 & 7.4318 & 7.4838 & TRN \\
\hline CHEMBL 3661718 & 1528309 & 6.6108 & 7.3324 & TST \\
\hline CHEMBL 3661716 & 1528309 & 5.8877 & 6.1373 & TST \\
\hline CHEMBL3661691 & 1528309 & 6.5086 & 6.6447 & TRN \\
\hline CHEMBL 3666664 & 1528309 & 5.9469 & 5.7346 & TRN \\
\hline CHEMBL 3671586 & 1528309 & 3.301 & 3.6732 & TRN \\
\hline CHEMBL 3666496 & 1528309 & 6.0 & 3.7106 & TST \\
\hline CHEMBL 3666531 & 1528309 & 6.2147 & 6.222 & TST \\
\hline CHEMBL 3666623 & 1528309 & 7.0969 & 7.3279 & TRN \\
\hline CHEMBL 3666645 & 1528309 & 7.1549 & 7.2689 & TRN \\
\hline CHEMBL 3661657 & 1528309 & 5.7696 & 6.33799 & э999999999 \\
\hline CHEMBL 2322376 & 1528309 & 6.3098 & 5.9513 & TRN \\
\hline CHEMBL 3666686 & 1528309 & 6.0 & 6.4237 & TST \\
\hline CHEMBL 3666500 & 1528309 & 3.301 & 6.9963 & TST \\
\hline CHEMBL 3666610 & 1528309 & 7.4815 & 7.5442 & TRN \\
\hline CHEMBL 3666534 & 1528309 & 6.9208 & 6.8262 & TRN \\
\hline CHEMBL 3666592 & 1528309 & 7.301 & 6.72 & TRN \\
\hline CHEMBL3666665 & 1528309 & 6.3468 & 6.1448 & TRN \\
\hline CHEMBL 3661741 & 1528309 & 5.9172 & 6.3615 & TRN \\
\hline CHEMBL 3661804 & 1528309 & 6.71 & 6.642 & TRN \\
\hline CHEMBL 3661684 & 1528309 & 7.3468 & 7.1144 & TST \\
\hline CHEMBL 3657592 & 1528309 & 6.4437 & 6.3105 & TRN \\
\hline CHEMBL 3666626 & 1528309 & 7.4559 & 7.5196 & TRN \\
\hline CHEMBL3666567 & 1528309 & 6.5086 & 5.8202 & TST \\
\hline CHEMBL3666564 & 1528309 & 6.6073 & 6.7761 & TST \\
\hline CHEMBL 3666600 & 1528309 & 7.3979 & 7.5899 & TRN \\
\hline CHEMBL 3666520 & 1528309 & 6.0 & 6.0547 & TRN \\
\hline CHEMBL 3666487 & 1528309 & 5.6299 & 5.4291 & TRN \\
\hline CHEMBL3661839 & 1528309 & 7.301 & 7.3032 & TRN \\
\hline CHEMBL3666583 & 1528309 & 3.301 & 4.215 & TST \\
\hline CHEMBL 3666515 & 1528309 & 5.0565 & 5.3685 & TRN \\
\hline CHEMBL3666589 & 1528309 & 7.1871 & 6.6686 & TRN \\
\hline CHEMBL 3666527 & 1528309 & 6.4437 & 6.3237 & TRN \\
\hline CHEMBL3666657 & 1528309 & 6.3565 & 6.5063 & TRN \\
\hline CHEMBL3661637 & 1528309 & 6.8239 & 6.7813 & TRN \\
\hline CHEMBL 3661715 & 1528309 & 6.8697 & 7.08299 & 9999999999 \\
\hline CHEMBL3666497 & 1528309 & 5.9978 & 5.481 & TST \\
\hline CHEMBL 3666663 & 1528309 & 5.6778 & 5.7913 & TRN \\
\hline CHEMBL 3661738 & 1528309 & 6.0 & 5.6982 & TRN \\
\hline CHEMBL 3666602 & 1528309 & 7.699 & 7.4315 & TRN \\
\hline CHEMBL 3661658 & 1528309 & 4.4996 & 4.599 & TRN \\
\hline CHEMBL3666566 & 1528309 & 4.4318 & 4.5667 & TST \\
\hline
\end{tabular}


Supplemental Table S2.txt

\begin{tabular}{|c|c|c|c|c|c|}
\hline CHEMBL 3666684 & 1528309 & 6.0 & 5.2556 & TST & \\
\hline CHEMBL3666635 & 1528309 & 6.9586 & 7.2459 & TRN & \\
\hline CHEMBL3661808 & 1528309 & 7.0 & 6.7955 & TRN & \\
\hline CHEMBL 3661792 & 1528309 & 6.5229 & 6.3689 & TRN & \\
\hline CHEMBL 3666554 & 1528309 & 6.0555 & 5.7291 & TST & \\
\hline CHEMBL 3897881 & 1528309 & 7.4559 & 6.2299 & TST & \\
\hline CHEMBL3661721 & 1528309 & 6.4559 & 5.8519 & TST & \\
\hline CHEMBL 3661694 & 1528309 & 6.4202 & 6.4139 & TRN & \\
\hline CHEMBL3913612 & 1528309 & 6.3768 & 5.0264 & TST & \\
\hline CHEMBL 3661779 & 1528309 & 6.2557 & 6.2703 & TRN & \\
\hline CHEMBL 3661728 & 1528309 & 3.301 & 3.2908 & TRN & \\
\hline CHEMBL 3666509 & 1528309 & 3.301 & 4.2657 & TST & \\
\hline CHEMBL 3666514 & 1528309 & 5.5607 & 5.5087 & TRN & \\
\hline CHEMBL3661786 & 1528309 & 7.0969 & 6.84 & TRN & \\
\hline CHEMBL 3661631 & 1528309 & 6.7696 & 6.7631 & TRN & \\
\hline CHEMBL 3661848 & 1528309 & 7.2218 & 7.3864 & TRN & \\
\hline CHEMBL3666516 & 1528309 & 7.6021 & 7.6385 & TRN & \\
\hline CHEMBL 3661793 & 1528309 & 6.3565 & 6.2902 & TRN & \\
\hline CHEMBL 2322358 & 1528309 & 7.4559 & 6.162006 & 0000000001 & TS \\
\hline CHEMBL 3661668 & 1528309 & 6.2924 & 6.3185 & TRN & \\
\hline CHEMBL 3661766 & 1528309 & 6.0 & 5.8648 & TRN & \\
\hline CHEMBL 3666641 & 1528309 & 6.4089 & 6.2946 & TRN & \\
\hline CHEMBL3661636 & 1528309 & 7.3468 & 6.9057 & TRN & \\
\hline CHEMBL3666479 & 1528309 & 3.301 & 4.7396 & TST & \\
\hline CHEMBL 3661654 & 1528309 & 6.7696 & 7.4698 & TRN & \\
\hline CHEMBL 3666484 & 1528309 & 5.8697 & 5.3084 & TST & \\
\hline CHEMBL3661679 & 1528309 & 6.9208 & 6.9379 & TRN & \\
\hline CHEMBL3666658 & 1528309 & 7.1871 & 6.8462 & TRN & \\
\hline CHEMBL3666552 & 1528309 & 4.4868 & 3.9622 & TRN & \\
\hline CHEMBL 3666545 & 1528309 & 6.2218 & 6.2535 & TRN & \\
\hline CHEMBL 3657586 & 1528309 & 6.6383 & 6.4747 & TRN & \\
\hline CHEMBL 3661818 & 1528309 & 6.7696 & 7.0354 & TRN & \\
\hline CHEMBL3666632 & 1528309 & 7.3979 & 7.3816 & TRN & \\
\hline CHEMBL3951617 & 1528309 & 6.3979 & 5.496 & TST & \\
\hline CHEMBL3661653 & 1528309 & 6.6383 & 6.0146 & TRN & \\
\hline CHEMBL3657589 & 1528309 & 6.8356 & 7.1015 & TRN & \\
\hline CHEMBL 3666634 & 1528309 & 7.2218 & 7.4297 & TRN & \\
\hline CHEMBL 3661750 & 1528309 & 6.7447 & 6.8577 & TRN & \\
\hline CHEMBL 3661760 & 1528309 & 7.2441 & 7.1952 & TRN & \\
\hline CHEMBL3661795 & 1528309 & 3.301 & 4.7484 & TRN & \\
\hline CHEMBL3661806 & 1528309 & 6.4949 & 6.5186 & TRN & \\
\hline CHEMBL 3661784 & 1528309 & 6.7696 & 6.5792 & TRN & \\
\hline CHEMBL 3661642 & 1528309 & 7.0969 & 6.7007 & TRN & \\
\hline CHEMBL 3666495 & 1528309 & 4.5216 & 6.1509 & TST & \\
\hline CHEMBL3894059 & 1528309 & 5.75700 & 00000000 & 6.6093 & בו \\
\hline CHEMBL 3666548 & 1528309 & 6.4815 & 6.9448 & TST & \\
\hline CHEMBL 3657594 & 1528309 & 6.9031 & 6.8355 & TRN & \\
\hline CHEMBL 3666544 & 1528309 & 7.0458 & 6.9332 & TRN & \\
\hline
\end{tabular}




\begin{tabular}{|c|c|c|c|c|c|}
\hline \multicolumn{6}{|c|}{ Supplemental Table S2.txt } \\
\hline CHEMBL 3666615 & 1528309 & 8.0 & 7.8297 & TRN & \\
\hline CHEMBL 3666524 & 1528309 & 5.9914 & 5.955 & TRN & \\
\hline CHEMBL 3661758 & 1528309 & 7.5229 & 7.3047 & TRN & \\
\hline CHEMBL 3661650 & 1528309 & 6.7447 & 6.9144 & TST & \\
\hline CHEMBL 2322659 & 1528309 & 6.0088 & 6.3094 & TRN & \\
\hline CHEMBL 3666676 & 1528309 & 7.0 & 7.1755 & TRN & \\
\hline CHEMBL 3928530 & 1528309 & 4.9038 & 5.0875 & TST & \\
\hline CHEMBL 3666560 & 1528309 & 6.0942 & 5.9063 & TST & \\
\hline CHEMBL 3661674 & 1528309 & 7.1871 & 7.1893 & TRN & \\
\hline CHEMBL3661783 & 1528309 & 6.8386 & 7.0591 & TRN & \\
\hline CHEMBL 3666572 & 1528309 & 5.4461 & 4.9304 & TST & \\
\hline CHEMBL 3666643 & 1528309 & 6.8697 & 6.3636 & TRN & \\
\hline CHEMBL3661834 & 1528309 & 3.301 & 4.9388 & TST & \\
\hline CHEMBL 3893113 & 1528309 & 7.0458 & 5.9422 & TST & \\
\hline CHEMBL 3666472 & 1528309 & 7.0458 & 5.7561 & TST & \\
\hline CHEMBL 3661764 & 1528309 & 6.9393 & 6.7022 & TRN & \\
\hline CHEMBL3666652 & 1528309 & 6.8861 & 7.1171 & TRN & \\
\hline CHEMBL 3666553 & 1528309 & 3.301 & 3.4943 & TST & \\
\hline CHEMBL 3661747 & 1528309 & 6.0862 & 5.9743 & TRN & \\
\hline CHEMBL3661652 & 1528309 & 7.301 & 7.1341 & TRN & \\
\hline CHEMBL3661753 & 1528309 & 6.3768 & 6.3779 & TRN & \\
\hline CHEMBL 3666673 & 1528309 & 6.9586 & 6.8167 & TRN & \\
\hline CHEMBL3661789 & 1528309 & 6.5686 & 6.7413 & TST & \\
\hline CHEMBL 3666593 & 1528309 & 7.3979 & 7.4639 & TRN & \\
\hline CHEMBL3666581 & 1528309 & 3.301 & 4.0882 & TST & \\
\hline CHEMBL3661693 & 1528309 & 7.5229 & 7.5498 & TRN & \\
\hline CHEMBL3666599 & 1528309 & 7.3468 & 7.6758 & TRN & \\
\hline CHEMBL3661634 & 1528309 & 6.58 & 6.6884 & TRN & \\
\hline CHEMBL 2322372 & 1528309 & 6.8861 & 6.6122 & TRN & \\
\hline CHEMBL 3666577 & 1528309 & 6.3768 & 5.4132 & TST & \\
\hline CHEMBL 3661743 & 1528309 & 3.301 & 4.5502 & TRN & \\
\hline CHEMBL3666469 & 1528309 & 7.0458 & 7.1272 & TRN & \\
\hline CHEMBL3666661 & 1528309 & 5.7423 & 5.6697 & TRN & \\
\hline CHEMBL 3666526 & 1528309 & 6.7447 & 6.5511 & TRN & \\
\hline CHEMBL 3661767 & 1528309 & 6.7959 & 6.86100 & 0000000001 & TRN \\
\hline CHEMBL 2322371 & 1528309 & 6.9706 & 7.2494 & TRN & \\
\hline CHEMBL3661711 & 1528309 & 5.8268 & 5.7552 & TRN & \\
\hline CHEMBL 3666505 & 1528309 & 5.9666 & 5.8212 & TST & \\
\hline CHEMBL3661695 & 1528309 & 5.6556 & 6.1082 & TRN & \\
\hline CHEMBL3666539 & 1528309 & 6.7825 & 5.6488 & TST & \\
\hline CHEMBL 3666475 & 1528309 & 5.4559 & 6.1479 & TST & \\
\hline CHEMBL3661655 & 1528309 & 7.3979 & 7.347 & TRN & \\
\hline CHEMBL3666613 & 1528309 & 7.699 & 7.3453 & TRN & \\
\hline CHEMBL3666543 & 1528309 & 7.0706 & 7.6364 & TST & \\
\hline CHEMBL3661635 & 1528309 & 6.7447 & 6.2779 & TRN & \\
\hline CHEMBL 3666609 & 1528309 & 7.1871 & 7.2961 & TRN & \\
\hline CHEMBL 3666570 & 1528309 & 5.1457 & 5.3214 & TST & \\
\hline CHEMBL3666675 & 1528309 & 6.6198 & 6.575 & TRN & \\
\hline
\end{tabular}




$$
\text { Supplemental Table S2.txt }
$$

\begin{tabular}{|c|c|c|c|c|c|c|}
\hline CHEMBL 2322360 & 1528309 & 7.6576 & 7.5163 & TRN & & \\
\hline CHEMBL 3661841 & 1528309 & 6.9208 & 6.8792 & TRN & & \\
\hline CHEMBL3661731 & 1528309 & 3.301 & 3.9848 & TRN & & \\
\hline CHEMBL 3666642 & 1528309 & 4.9743 & 6.5248 & TST & & \\
\hline CHEMBL3666550 & 1528309 & \multicolumn{3}{|c|}{6.3420000000000005} & 6.5465 & TRN \\
\hline CHEMBL 3661757 & 1528309 & 7.699 & 7.5747 & TRN & & \\
\hline CHEMBL3666506 & 1528309 & 5.4179 & 5.4332 & TST & & \\
\hline CHEMBL 3666614 & 1528309 & 7.301 & 7.3864 & TRN & & \\
\hline CHEMBL 3666612 & 1528309 & 7.2596 & 7.1085 & TST & & \\
\hline CHEMBL3666573 & 1528309 & 5.1965 & 4.5932 & TST & & \\
\hline CHEMBL3661706 & 1528309 & 7.0706 & 7.0623 & TRN & & \\
\hline CHEMBL3661770 & 1528309 & 7.0458 & 6.9733 & TRN & & \\
\hline CHEMBL3661659 & 1528309 & 5.7055 & 6.1969 & TRN & & \\
\hline CHEMBL3666485 & 1528309 & 5.7033 & 5.0376 & TST & & \\
\hline CHEMBL3666595 & 1528309 & 7.5229 & 7.5234 & TRN & & \\
\hline CHEMBL 2322366 & 1528309 & 6.5229 & 6.3909 & TRN & & \\
\hline CHEMBL 2322364 & 1528309 & 7.1549 & 6.7778 & TRN & & \\
\hline CHEMBL3666662 & 1528309 & 6.7696 & 6.6714 & TRN & & \\
\hline CHEMBL3666498 & 1528309 & 3.301 & 6.9395 & TST & & \\
\hline CHEMBL3666579 & 1528309 & 3.301 & 3.2689 & TST & & \\
\hline CHEMBL3666575 & 1528309 & 5.5935 & 5.5709 & TST & & \\
\hline CHEMBL3666476 & 1528309 & 4.6625 & 5.3647 & TST & & \\
\hline CHEMBL3661777 & 1528309 & 5.2226 & 6.3535 & TST & & \\
\hline CHEMBL3661798 & 1528309 & 6.1518 & 5.893 & TRN & & \\
\hline CHEMBL 3661713 & 1528309 & 6.6021 & 6.4291 & TRN & & \\
\hline CHEMBL3666625 & 1528309 & 7.2218 & 7.4504 & TRN & & \\
\hline CHEMBL3666559 & 1528309 & 6.6383 & 5.9547 & TST & & \\
\hline CHEMBL3666644 & 1528309 & 6.9788 & 6.8541 & TRN & & \\
\hline CHEMBL3666618 & 1528309 & 7.699 & 7.5109 & TRN & & \\
\hline CHEMBL 3661720 & 1528309 & 7.0458 & 7.0817 & TST & & \\
\hline CHEMBL 3661780 & 1528309 & 5.8996 & 6.1848 & TRN & & \\
\hline CHEMBL3666646 & 1528309 & 6.8861 & 7.0504 & TRN & & \\
\hline CHEMBL3661805 & 1528309 & 6.6576 & 6.4855 & TRN & & \\
\hline CHEMBL3666591 & 1528309 & 6.585 & 7.0469 & TRN & & \\
\hline CHEMBL3661733 & 1528309 & 6.6576 & 6.4606 & TRN & & \\
\hline CHEMBL3661827 & 1528309 & 7.1549 & 6.8415 & TRN & & \\
\hline CHEMBL3661651 & 1528309 & 6.8327 & 6.4886 & TRN & & \\
\hline CHEMBL3661791 & 1528309 & 6.699 & 6.3651 & TRN & & \\
\hline CHEMBL3661763 & 1528309 & 7.3979 & 7.3783 & TRN & & \\
\hline CHEMBL3661639 & 1528309 & 6.4949 & 6.7046 & TRN & & \\
\hline CHEMBL3666499 & 1528309 & 3.301 & 6.4424 & TST & & \\
\hline CHEMBL3666502 & 1528309 & 6.3279 & 5.12799 & 9999999999 & & TST \\
\hline CHEMBL3661730 & 1528309 & 5.6459 & 5.5326 & TRN & & \\
\hline CHEMBL3666608 & 1528309 & 7.4559 & 7.147 & TRN & & \\
\hline CHEMBL3661709 & 1528309 & 7.8239 & 7.3905 & TRN & & \\
\hline CHEMBL3661778 & 1528309 & 5.6757 & 5.7795 & TRN & & \\
\hline CHEMBL3666619 & 1528309 & 6.757006 & $\partial 0000000$ & & 6.3574 & TRN \\
\hline CHEMBL3661630 & 1528309 & 7.3979 & 7.2232 & TRN & & \\
\hline
\end{tabular}


Supplemental Table S2.txt

\begin{tabular}{|c|c|c|c|c|c|}
\hline CHEMBL3661756 & 1528309 & 6.9788 & 6.6937 & TRN & \\
\hline CHEMBL 3661663 & 1528309 & 7.5229 & 7.4773 & TRN & \\
\hline CHEMBL 3666594 & 1528309 & 7.4559 & 7.7471 & TRN & \\
\hline CHEMBL3666629 & 1528309 & 7.3979 & 7.5553 & TRN & \\
\hline CHEMBL 3661816 & 1528309 & 7.0458 & 7.3594 & TRN & \\
\hline CHEMBL 3661809 & 1528309 & 6.9788 & 6.7204 & TRN & \\
\hline CHEMBL 3661736 & 1528309 & 5.8761 & 5.9719 & TRN & \\
\hline CHEMBL3657588 & 1528309 & 6.2218 & 6.1686 & TRN & \\
\hline CHEMBL 3666633 & 1528309 & 7.301 & 7.2987 & TRN & \\
\hline CHEMBL 3666471 & 1528309 & 6.3872 & 6.3874 & TST & \\
\hline CHEMBL 3661846 & 1528309 & 7.301 & 7.1716 & TRN & \\
\hline CHEMBL 3661692 & 1528309 & 7.3979 & 7.3315 & TRN & \\
\hline CHEMBL 3661833 & 1528309 & 5.7878 & 6.0978 & TRN & \\
\hline CHEMBL 3661769 & 1528309 & 7.2218 & 7.1203 & TRN & \\
\hline CHEMBL 3666501 & 1528309 & 4.485 & 6.6948 & TST & \\
\hline CHEMBL 3666582 & 1528309 & 5.0522 & 4.7959 & TST & \\
\hline CHEMBL 3666568 & 1528309 & 5.9586 & 5.9799 & TST & \\
\hline CHEMBL 3661813 & 1528309 & 6.1024 & 5.23799 & 99999999995 & TRN \\
\hline CHEMBL 3661708 & 1528309 & 6.8861 & 6.8132 & TRN & \\
\hline CHEMBL 3661761 & 1528309 & 7.1549 & 6.8216 & TRN & \\
\hline CHEMBL 3666597 & 1528309 & 7.1871 & 6.9983 & TRN & \\
\hline CHEMBL 3666648 & 1528309 & 7.1135 & 7.3794 & TRN & \\
\hline CHEMBL 3661800 & 1528309 & 4.869 & 5.0863 & TRN & \\
\hline CHEMBL 3661676 & 1528309 & 7.5229 & 7.4173 & TRN & \\
\hline CHEMBL2322365 & 1528309 & 6.3188 & 6.5384 & TST & \\
\hline CHEMBL3661739 & 1528309 & 6.301 & 6.4108 & TRN & \\
\hline CHEMBL 3661714 & 1528309 & 6.5528 & 6.523 & TRN & \\
\hline CHEMBL 3666655 & 1528309 & 6.9788 & 6.8414 & TRN & \\
\hline CHEMBL 3661842 & 1528309 & 7.301 & 7.1995 & TRN & \\
\hline CHEMBL 3661817 & 1528309 & 7.0 & 7.353 & TRN & \\
\hline CHEMBL 3661702 & 1528309 & 6.0458 & 5.9906 & TRN & \\
\hline CHEMBL 3661689 & 1528309 & 5.8386 & 5.8708 & TRN & \\
\hline CHEMBL3661796 & 1528309 & 3.301 & 4.1586 & TRN & \\
\hline CHEMBL 3661664 & 1528309 & 7.6021 & 7.3903 & TRN & \\
\hline CHEMBL 3661831 & 1528309 & 6.5229 & 6.5103 & TRN & \\
\hline CHEMBL3661670 & 1528309 & 7.0458 & 7.59200 & 00000000005 & TRN \\
\hline CHEMBL3666671 & 1528309 & 6.8861 & 6.8957 & TRN & \\
\hline CHEMBL3661726 & 1528309 & 4.4831 & 4.737 & TST & \\
\hline CHEMBL 3666468 & 1528309 & 6.7447 & 6.9874 & TRN & \\
\hline CHEMBL3661682 & 1528309 & 7.0969 & 6.8878 & TRN & \\
\hline CHEMBL3666576 & 1528309 & 6.1518 & 5.7336 & TRN & \\
\hline CHEMBL3666508 & 1528309 & 7.6021 & 6.7377 & TST & \\
\hline CHEMBL3666529 & 1528309 & 6.4685 & 6.5282 & TST & \\
\hline CHEMBL 3666656 & 1528309 & 6.1079 & 5.9734 & TRN & \\
\hline CHEMBL3666536 & 1528309 & 6.0 & 6.9955 & TST & \\
\hline CHEMBL 3661681 & 1528309 & 7.4559 & 7.3628 & TRN & \\
\hline CHEMBL 3661837 & 1528309 & 7.0969 & 7.2345 & TRN & \\
\hline CHEMBL3666659 & 1528309 & 7.301 & 6.9776 & TRN & \\
\hline
\end{tabular}


Supplemental Table S2.txt

\begin{tabular}{|c|c|c|c|c|}
\hline 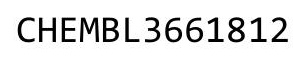 & & 5.1433 & & \\
\hline HEMBL3661755 & 528309 & 7.2596 & 7.1605 & \\
\hline 566584 & 28309 & & & \\
\hline HEMBL3914903 & 28309 & 98 & 36 & \\
\hline HEMBL2322370 & 528309 & 7.1367 & 0348 & \\
\hline AEMBL3661751 & 528309 & 6.6198 & 455 & \\
\hline HEMBL 3661824 & 528309 & 6.7959 & 2165 & \\
\hline AEMBL3666533 & 528309 & 21 & & \\
\hline AEMBL3661782 & 528309 & 6.9393 & 1584 & \\
\hline HEMBL3639606 & 528309 & 7.2596 & .1464 & \\
\hline HEMBL3661771 & 528309 & 7.0458 & .9698 & \\
\hline HEMBL3666489 & 528309 & 6.0 & .5127 & \\
\hline HEMBL3661835 & 528309 & 9 & .2962 & \\
\hline HEMBL3 & 528309 & & 6.596 & \\
\hline HEMBL3661638 & 528309 & 5.143 & 6648 & \\
\hline HEMBL3661737 & 528309 & 5.6904 & 5.853 & \\
\hline HEMBL3666603 & 528309 & 79 & 7.5264 & \\
\hline HEMBL3666653 & 528309 & 86 & 6.9687 & \\
\hline HEMBL3666493 & 528309 & 49 & 8799 & \\
\hline HEMBL3661699 & 528309 & 29 & 131 & \\
\hline HEMBL 3666542 & 528309 & 7. & 7.1119 & \\
\hline HEMBL3666622 & 528309 & 7. & 7.3321 & \\
\hline HEMBL 3666607 & 528309 & & 7.6382 & \\
\hline HEMBL3666480 & 528309 & & 4.8842 & \\
\hline HEMBL 3661765 & 09 & 6 . & 256 & \\
\hline HEMBL 3666481 & 528309 & 3 . & 174 & \\
\hline HEMBL3666604 & 528309 & 6 . & 86 & \\
\hline HEMBL3661759 & 528309 & & 329 & \\
\hline HEMBL3661814 & 309 & 4 & 5.2541 & \\
\hline HEMBL 3661849 & 528309 & 7. & 7.1394 & \\
\hline HEMBL 3666580 & 528309 & 3. & 3.3864 & \\
\hline AEMBL3661732 & 28309 & & .3448 & \\
\hline HEMBL3 & 09 & & 188 & \\
\hline HEMBL3661844 & 528309 & & 6.5356 & \\
\hline HEMBL3661788 & 528309 & 7. & 7.3182 & \\
\hline HEMBL3661725 & 528309 & & 6.2795 & \\
\hline HEMR 3 & 99 & & 696 & \\
\hline HEMBL3666470 & 09 & & 5.9128 & \\
\hline HEMBL3666628 & 1528309 & 7.1871 & 7.3324 & \\
\hline HEMBL3666596 & 528309 & 6.58 & 6. & \\
\hline CHEMBL3666482 & 1528309 & 91 & 4.9292 & \\
\hline CHEMBL3661802 & 1528309 & & 7.1227 & \\
\hline HEMBL3661641 & 1528309 & 5.1249 & 5.5912 & \\
\hline HEMBL3666677 & 1528309 & 7.1549 & 7.4902 & \\
\hline HEMBL3666571 & 1528309 & & 5.3644 & \\
\hline CHEMBL3666556 & 1528309 & & 6.1461 & \\
\hline CHEMBL3666598 & 1528309 & 7.1135 & 7.1652 & \\
\hline CHEMBL3666492 & 1528309 & 6.4815 & 6.7958 & \\
\hline
\end{tabular}

Page 4806 
Supplemental Table S2.txt

\begin{tabular}{|c|c|c|c|c|}
\hline CHEMBL3661794 & 1528309 & 6.3979 & 6.0575 & TRN \\
\hline CHEMBL3666474 & 1528309 & 5.8761 & 5.9466 & TST \\
\hline CHEMBL3666488 & 1528309 & 5.6488 & 6.0514 & TRN \\
\hline CHEMBL 3657590 & 1528309 & 6.699 & 6.8947 & TRN \\
\hline CHEMBL3661829 & 1528309 & 7.0458 & 7.1346 & TRN \\
\hline CHEMBL3661742 & 1528309 & 6.4202 & 6.49 & TRN \\
\hline CHEMBL3661656 & 1528309 & 6.284 & 5.8948 & TRN \\
\hline CHEMBL3661649 & 1528309 & 6.9586 & 7.3608 & TRN \\
\hline CHEMBL3666486 & 1528309 & 7.2218 & 7.3358 & TRN \\
\hline CHEMBL3661700 & 1528309 & 7.5229 & 7.3151 & TRN \\
\hline CHEMBL3661719 & 1528309 & 7.0458 & 7.0283 & TST \\
\hline CHEMBL3661810 & 1528309 & 6.5086 & 6.5892 & TRN \\
\hline CHEMBL3666630 & 1528309 & 6.3279 & 6.7297 & TRN \\
\hline CHEMBL3666672 & 1528309 & 6.3768 & 6.3832 & TRN \\
\hline CHEMBL 3666640 & 1528309 & 6.3098 & 5.9663 & TRN \\
\hline CHEMBL3661799 & 1528309 & 5.9747 & 5.4646 & TRN \\
\hline CHEMBL3666620 & 1528309 & 6.7825 & 6.6793 & TRN \\
\hline CHEMBL3661666 & 1528309 & 6.6383 & 6.3088 & TRN \\
\hline CHEMBL3666666 & 1528309 & 6.6383 & 6.3455 & TRN \\
\hline CHEMBL 3666585 & 1528309 & 4.7799 & 4.0785 & TST \\
\hline CHEMBL3666606 & 1528309 & 8.0 & 8.0623 & TRN \\
\hline CHEMBL 2322359 & 1528309 & 7.2366 & 7.3917 & TRN \\
\hline CHEMBL3661688 & 1528309 & 5.2741 & 5.659 & TRN \\
\hline CHEMBL3666558 & 1528309 & 3.301 & 5.807 & TST \\
\hline CHEMBL 3666483 & 1528309 & 6.4089 & 5.8482 & TST \\
\hline CHEMBL3666532 & 1528309 & 6.6576 & 6.5886 & TRN \\
\hline CHEMBL3666651 & 1528309 & 7.0969 & 7.0076 & TRN \\
\hline CHEMBL3666588 & 1528309 & 7.6021 & 7.3114 & TRN \\
\hline CHEMBL3661707 & 1528309 & 7.4559 & 7.1998 & TRN \\
\hline CHEMBL 3661660 & 1528309 & 6.5086 & 6.6867 & TRN \\
\hline CHEMBL3666523 & 1528309 & 6.0 & 7.3366 & TRN \\
\hline CHEMBL3666682 & 1528309 & 6.7447 & 6.8646 & TRN \\
\hline CHEMBL3661843 & 1528309 & 6.9208 & 6.8127 & TRN \\
\hline CHEMBL 3661749 & 1528309 & 6.6021 & 6.9189 & TRN \\
\hline CHEMBL3666667 & 1528309 & 6.9586 & 6.9745 & TRN \\
\hline CHEMBL3666562 & 1528309 & 6.5528 & 5.856 & TST \\
\hline CHEMBL3661710 & 1528309 & 6.0458 & 5.87 & TRN \\
\hline CHEMBL3666467 & 1528309 & 6.2366 & 6.4788 & TRN \\
\hline CHEMBL3666631 & 1528309 & 6.4377 & 6.6169 & TRN \\
\hline CHEMBL3661836 & 1528309 & 7.2218 & 7.4594 & TRN \\
\hline CHEMBL3661646 & 1528309 & 5.767 & 5.9925 & TRN \\
\hline CHEMBL3666611 & 1528309 & 7.3979 & 7.572 & TRN \\
\hline CHEMBL3666557 & 1528309 & 6.8539 & 6.2732 & TST \\
\hline CHEMBL 2322367 & 1528309 & 6.284 & 6.0697 & TRN \\
\hline CHEMBL3666681 & 1528309 & 7.5229 & 6.6351 & TRN \\
\hline CHEMBL3666647 & 1528309 & 7.1549 & 6.96899 & 9999999999 \\
\hline CHEMBL3666525 & 1528309 & 7.5229 & 7.4303 & TRN \\
\hline CHEMBL 3661807 & 1528309 & 6.5229 & 6.3801 & TRN \\
\hline
\end{tabular}


Supplemental Table S2.txt

\begin{tabular}{|c|c|c|c|c|}
\hline CHEMBL3661701 & 1528309 & 7.6021 & 7.4263 & TRN \\
\hline CHEMBL 2322362 & 1528309 & 7.0706 & 6.5317 & TRN \\
\hline CHEMBL 3661847 & 1528309 & 7.699 & 7.4482 & TRN \\
\hline CHEMBL3661825 & 1528309 & 6.8539 & 7.0792 & TRN \\
\hline CHEMBL3661776 & 1528309 & 6.5086 & 6.9568 & TRN \\
\hline CHEMBL3661785 & 1528309 & 7.0706 & 6.8883 & TRN \\
\hline CHEMBL3666528 & 1528309 & 5.93 & 5.6456 & TRN \\
\hline CHEMBL 3666621 & 1528309 & 7.1249 & 6.6781 & TRN \\
\hline CHEMBL3661820 & 1528309 & 7.2596 & 7.1739 & TRN \\
\hline CHEMBL3661661 & 1528309 & 7.4559 & 7.4576 & TRN \\
\hline CHEMBL3666530 & 1528309 & 5.5607 & 5.635 & TST \\
\hline CHEMBL3666478 & 1528309 & 6.6021 & 6.3876 & TST \\
\hline CHEMBL 3661680 & 1528309 & 6.8861 & 6.5027 & TRN \\
\hline CHEMBL 2322374 & 1528309 & 7.2218 & 6.8276 & TRN \\
\hline CHEMBL 3666590 & 1528309 & 6.8697 & 7.0554 & TRN \\
\hline CHEMBL3661640 & 1528309 & 6.6676 & 6.2776 & TRN \\
\hline CHEMBL3666537 & 1528309 & 6.8539 & 6.6092 & TRN \\
\hline CHEMBL 3661768 & 1528309 & 6.9031 & 7.1576 & TRN \\
\hline CHEMBL3666669 & 1528309 & 7.301 & 7.2626 & TRN \\
\hline CHEMBL 3661797 & 1528309 & 4.9545 & 5.3342 & TRN \\
\hline CHEMBL3666510 & 1528309 & 6.1675 & 6.0402 & TRN \\
\hline CHEMBL3661722 & 1528309 & 6.3372 & 6.3319 & TST \\
\hline CHEMBL3661632 & 1528309 & 6.4318 & 6.1032 & TRN \\
\hline CHEMBL3661647 & 1528309 & 7.301 & 7.4564 & TRN \\
\hline CHEMBL 3661729 & 1528309 & 6.1367 & 6.3931 & TRN \\
\hline CHEMBL3666678 & 1528309 & 6.8861 & 6.4726 & TRN \\
\hline CHEMBL3666601 & 1528309 & 8.0 & 7.603 & TRN \\
\hline CHEMBL3666512 & 1528309 & 5.5376 & 5.37700 & 000000001 \\
\hline CHEMBL3666503 & 1528309 & 6.4318 & 5.73799 & 9999999995 \\
\hline CHEMBL 3661774 & 1528309 & 6.6198 & 6.5643 & TRN \\
\hline CHEMBL3661717 & 1528309 & 6.8861 & 7.1002 & TST \\
\hline CHEMBL 3661740 & 1528309 & 6.1938 & 5.6905 & TRN \\
\hline CHEMBL3666494 & 1528309 & 4.3737 & 6.40600 & 000000001 \\
\hline CHEMBL3666670 & 1528309 & 3.301 & 2.7967 & TRN \\
\hline CHEMBL3666586 & 1528309 & 3.301 & 3.4546 & TST \\
\hline CHEMBL3666617 & 1528309 & 7.301 & 7.2013 & TRN \\
\hline CHEMBL3661686 & 1528309 & 6.699 & 6.364 & TST \\
\hline CHEMBL3661803 & 1528309 & 7.3468 & 7.4052 & TRN \\
\hline CHEMBL3661773 & 1528309 & 6.0 & 6.3162 & TRN \\
\hline CHEMBL3661822 & 1528309 & 7.1871 & 7.2705 & TRN \\
\hline CHEMBL3657587 & 1528309 & 7.1871 & 7.3744 & TRN \\
\hline CHEMBL3661828 & 1528309 & 6.9586 & 6.8871 & TRN \\
\hline CHEMBL3666563 & 1528309 & 6.4437 & 6.22 & TST \\
\hline CHEMBL3666680 & 1528309 & 6.4202 & 6.1539 & TST \\
\hline CHEMBL3639605 & 1528309 & 7.0458 & 6.968 & TRN \\
\hline CHEMBL3661790 & 1528309 & 5.2958 & 4.4429 & TRN \\
\hline CHEMBL3661830 & 1528309 & 4.5088 & 5.8767 & TST \\
\hline CHEMBL3661690 & 1528309 & 5.266 & 5.3071 & TRN \\
\hline
\end{tabular}


Supplemental Table S2.txt

\begin{tabular}{|c|c|c|c|c|}
\hline CHEMBL3661687 & 1528309 & 6.0 & 6.1379 & TRN \\
\hline CHEMBL3661840 & 1528309 & 7.301 & 7.0171 & TRN \\
\hline CHEMBL 3666517 & 1528309 & 5.7878 & 5.6685 & TRN \\
\hline CHEMBL3661815 & 1528309 & 7.0969 & 7.1076 & TRN \\
\hline CHEMBL3657593 & 1528309 & 7.301 & 7.5018 & TRN \\
\hline CHEMBL3666511 & 1528309 & 3.301 & \multicolumn{2}{|c|}{3.7460000000000004} \\
\hline CHEMBL3666547 & 1528309 & 6.0 & 5.8926 & TRN \\
\hline CHEMBL 3986403 & 1528309 & 6.8539 & 5.9293 & TST \\
\hline CHEMBL3666555 & 1528309 & 4.7328 & 6.4607 & TST \\
\hline CHEMBL3661821 & 1528309 & 6.6021 & 6.5797 & TRN \\
\hline CHEMBL 3666578 & 1528309 & 3.301 & 4.8506 & TST \\
\hline CHEMBL 2322368 & 1528309 & 6.0044 & 6.274 & TRN \\
\hline CHEMBL3661832 & 1528309 & 6.1871 & 6.1499 & TRN \\
\hline CHEMBL 3666477 & 1528309 & 5.2722 & 5.727 & TST \\
\hline CHEMBL 3666574 & 1528309 & 5.2168 & 4.9207 & TST \\
\hline CHEMBL3661673 & 1528309 & 7.0 & 7.3994 & TRN \\
\hline CHEMBL3666518 & 1528309 & 7.3279 & \multicolumn{2}{|c|}{ 7.747999999999999 } \\
\hline CHEMBL3666521 & 1528309 & 5.9318 & 5.8437 & TRN \\
\hline CHEMBL3661723 & 1528309 & 5.6383 & 5.7504 & TST \\
\hline CHEMBL 3661845 & 1528309 & 7.699 & 7.1597 & TRN \\
\hline CHEMBL3666627 & 1528309 & 7.6021 & 7.1956 & TRN \\
\hline CHEMBL3661665 & 1528309 & 7.3468 & 7.1259 & TST \\
\hline CHEMBL3661745 & 1528309 & 6.8539 & 6.8631 & TRN \\
\hline CHEMBL3661698 & 1528309 & 5.279 & 4.9981 & TRN \\
\hline CHEMBL 3661703 & 1528309 & 6.6576 & 6.6132 & TRN \\
\hline CHEMBL3666674 & 1528309 & 4.6728 & 4.5271 & TRN \\
\hline CHEMBL3666616 & 1528309 & 7.699 & 7.8769 & TRN \\
\hline CHEMBL3661724 & 1528309 & 6.0506 & 5.2787 & TST \\
\hline CHEMBL3661826 & 1528309 & 7.2596 & 7.1363 & TRN \\
\hline CHEMBL 3661667 & 1528309 & 7.0315 & \multicolumn{2}{|c|}{6.412999999999999} \\
\hline CHEMBL2322369 & 1528309 & 6.0605 & 6.1658 & TRN \\
\hline CHEMBL3661819 & 1528309 & 7.0706 & \multicolumn{2}{|c|}{7.1160000000000005} \\
\hline CHEMBL3661712 & 1528309 & 5.9788 & 6.1189 & TRN \\
\hline CHEMBL3666605 & 1528309 & 7.699 & 7.9672 & TRN \\
\hline CHEMBL3657591 & 1528309 & 7.2596 & 7.2798 & TRN \\
\hline CHEMBL3661811 & 1528309 & 6.0809 & 5.3174 & TRN \\
\hline CHEMBL3661697 & 1528309 & 6.2596 & 6.4424 & TRN \\
\hline CHEMBL3661801 & 1528309 & 4.6356 & 4.6888 & TRN \\
\hline CHEMBL3666507 & 1528309 & 5.4881 & 6.7004 & TST \\
\hline CHEMBL3661838 & 1528309 & 7.0 & 7.0226 & TRN \\
\hline CHEMBL3661781 & 1528309 & 5.0846 & 5.2893 & TRN \\
\hline CHEMBL3666513 & 1528309 & 5.2708 & 5.4508 & TRN \\
\hline CHEMBL 2322363 & 1528309 & 7.1549 & 6.9347 & TRN \\
\hline CHEMBL3661696 & 1528309 & 6.0269 & 6.3425 & TRN \\
\hline CHEMBL3666660 & 1528309 & 4.46 & 5.473 & TRN \\
\hline CHEMBL 3661727 & 1528309 & 3.301 & 5.4803 & TST \\
\hline CHEMBL 3666624 & 1528309 & 7.3979 & 7.2592 & TRN \\
\hline CHEMBL 3661643 & 1528309 & 4.6006 & 5.2534 & TRN \\
\hline
\end{tabular}


Supplemental Table S2.txt

\begin{tabular}{|c|c|c|c|c|c|}
\hline CHEMBL 3661823 & 1528309 & 7.5229 & 7.4671 & TRN & \\
\hline CHEMBL 3666561 & 1528309 & 6.9788 & 6.3454 & TST & \\
\hline CHEMBL3661787 & 1528309 & 7.1871 & 7.3204 & TRN & \\
\hline CHEMBL2151106 & 852847 & 7.4815 & 7.5672 & TRN & \\
\hline CHEMBL2151115 & 852847 & 7.4815 & 7.1603 & TRN & \\
\hline CHEMBL2151087 & 852847 & 6.5607 & 6.8534 & TRN & \\
\hline CHEMBL 2151167 & 852847 & 6.4685 & 7.0048 & TRN & \\
\hline CHEMBL2151169 & 852847 & 6.8861 & 6.535 & TRN & \\
\hline CHEMBL1208434 & 852847 & 6.0969 & 6.0749 & TST & \\
\hline CHEMBL2151173 & 852847 & 6.0757 & 6.4882 & TRN & \\
\hline CHEMBL2151073 & 852847 & 6.9586 & 6.6909 & TRN & \\
\hline CHEMBL 2151105 & 852847 & 6.6968 & 7.0247 & TRN & \\
\hline CHEMBL 2151170 & 852847 & 6.4202 & 6.7904 & TRN & \\
\hline CHEMBL 2151116 & 852847 & 7.9208 & 7.7304 & TRN & \\
\hline CHEMBL 2151228 & 852847 & 5.6488 & 6.865 & TST & \\
\hline CHEMBL 2151303 & 852847 & 5.699 & 5.961 & TRN & \\
\hline CHEMBL 2151072 & 852847 & 6.5086 & 6.3908 & TRN & \\
\hline CHEMBL 2151234 & 852847 & 7.0809 & 6.91100 & 00000000005 & TST \\
\hline CHEMBL 2151164 & 852847 & 8.2218 & 7.9908 & TRN & \\
\hline CHEMBL 2151222 & 852847 & 6.8827 & 6.7733 & TST & \\
\hline CHEMBL2151068 & 852847 & 7.0969 & 6.4749 & TRN & \\
\hline CHEMBL 2151217 & 852847 & 7.8539 & 7.5523 & TRN & \\
\hline CHEMBL392028 & 852847 & 5.1249 & 6.4012 & TST & \\
\hline CHEMBL 2151277 & 852847 & 7.0 & 7.0736 & TRN & \\
\hline CHEMBL 2151276 & 852847 & 6.6778 & 6.5188 & TRN & \\
\hline CHEMBL2151268 & 852847 & 6.3468 & 6.3733 & TRN & \\
\hline CHEMBL18797 & 852847 & 4.4685 & 6.9785 & TST & \\
\hline CHEMBL1208435 & 852847 & 6.4949 & 6.3259 & TST & \\
\hline CHEMBL 2151178 & 852847 & 6.9586 & 7.0348 & TST & \\
\hline CHEMBL 2151101 & 852847 & 7.1549 & 6.9538 & TRN & \\
\hline CHEMBL2151204 & 852847 & 7.9586 & 8.0673 & TRN & \\
\hline CHEMBL 2151113 & 852847 & 7.7447 & 7.559 & TRN & \\
\hline CHEMBL 2151308 & 852847 & 8.2218 & 7.1204 & TST & \\
\hline CHEMBL2151104 & 852847 & 6.699 & 6.6358 & TRN & \\
\hline CHEMBL593742 & 852847 & 6.1487 & 6.33 & TST & \\
\hline CHEMBL2151084 & 852847 & 6.8539 & 6.7387 & TRN & \\
\hline CHEMBL 2151199 & 852847 & 7.5086 & 7.6905 & TRN & \\
\hline CHEMBL 2151224 & 852847 & 6.1739 & 7.1953 & TST & \\
\hline CHEMBL 2151163 & 852847 & 6.1135 & 6.2147 & TRN & \\
\hline CHEMBL 2151281 & 852847 & 6.6021 & 6.4243 & TRN & \\
\hline CHEMBL593032 & 852847 & 6.6383 & 6.5333 & TST & \\
\hline CHEMBL 2151075 & 852847 & 6.4318 & 6.5555 & TRN & \\
\hline CHEMBL2151203 & 852847 & 7.6576 & 7.687 & TRN & \\
\hline CHEMBL 2151309 & 852847 & 8.3979 & 7.1665 & TST & \\
\hline CHEMBL 2151111 & 852847 & 7.7959 & 7.5991 & TRN & \\
\hline CHEMBL2151269 & 852847 & 6.1308 & 6.379 & TRN & \\
\hline CHEMBL 2151083 & 852847 & 6.6198 & 6.7913 & TRN & \\
\hline CHEMBL2151080 & 852847 & 6.6021 & 6.5892 & TRN & \\
\hline
\end{tabular}


Supplemental Table S2.txt

\begin{tabular}{|c|c|c|c|c|}
\hline 79 & & & & \\
\hline HFMBI 2151214 & 2847 & 8297 & 6.9007 & \\
\hline EMBL2151305 & 2847 & 599 & & \\
\hline IEMBL 2151275 & 2847 & 3239 & & \\
\hline AEMBL 2151225 & 52847 & .9666 & 572 & \\
\hline AEMBL 2 & 2847 & 957 & & \\
\hline 32 & 2847 & 27 & & \\
\hline AEMBL 2151211 & 52847 & 7986 & & \\
\hline AEMBL2151208 & 52847 & 5086 & 727 & \\
\hline HEMBL2151159 & 52847 & .9586 & 01 & \\
\hline IEMBL2 & 2847 & 089 & & \\
\hline EMBL2 & & & & \\
\hline AEMBL2 & 52847 & 957 & & \\
\hline IEMBL21 & 52847 & 696 & & \\
\hline AEMBL2 & 52847 & & & \\
\hline IEMBL2 & 847 & 208 & & \\
\hline IEMBL2 & & 69 & & \\
\hline HEMBL 2 & 52847 & 757 & & \\
\hline IEMBL 2 & 52847 & 576 & & \\
\hline AEMBL2 & 52847 & 021 & & \\
\hline EMBL2 & 847 & 468 & & R \\
\hline EMBL2 & & 72 & & \\
\hline EMBL & 7 & 87 & & \\
\hline EMBL2 & 7 & & & \\
\hline IEMBL2 & 847 & 827 & & \\
\hline EMBL2 & 2847 & 18 & & RI \\
\hline EMBL & & 21 & & 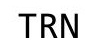 \\
\hline & & 021 & & \\
\hline EMBL2 & & & & \\
\hline EMBL2 & 52847 & 576 & & RI \\
\hline 70 & 7 & 65 & & \\
\hline 33 & & & & \\
\hline & & & & \\
\hline IEMBL2 & 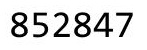 & & & \\
\hline EMBL2 & 1 & 549 & & $\mathrm{RI}$ \\
\hline 07 & 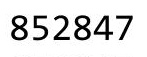 & 86 & & \\
\hline & & & & \\
\hline & & & & \\
\hline IEMBL 2 & $0<0$ & 198 & & $\Gamma R$ \\
\hline IIDL & 7 & 696 & & T \\
\hline HEMBL & 847 & 203 & & \\
\hline & & & & \\
\hline IEMBL & & & & RI \\
\hline EMBL2 & 28 & 815 & 01 & s \\
\hline 110 & & & & \\
\hline CHEMBL 21 & & 7.3565 & & \\
\hline CHEMBL 21 & 52847 & & 7.8047 & \\
\hline CHEMBL2151306 & 852847 & 8.0969 & 7.1721 & \\
\hline
\end{tabular}

Page 4811 
Supplemental Table S2.txt

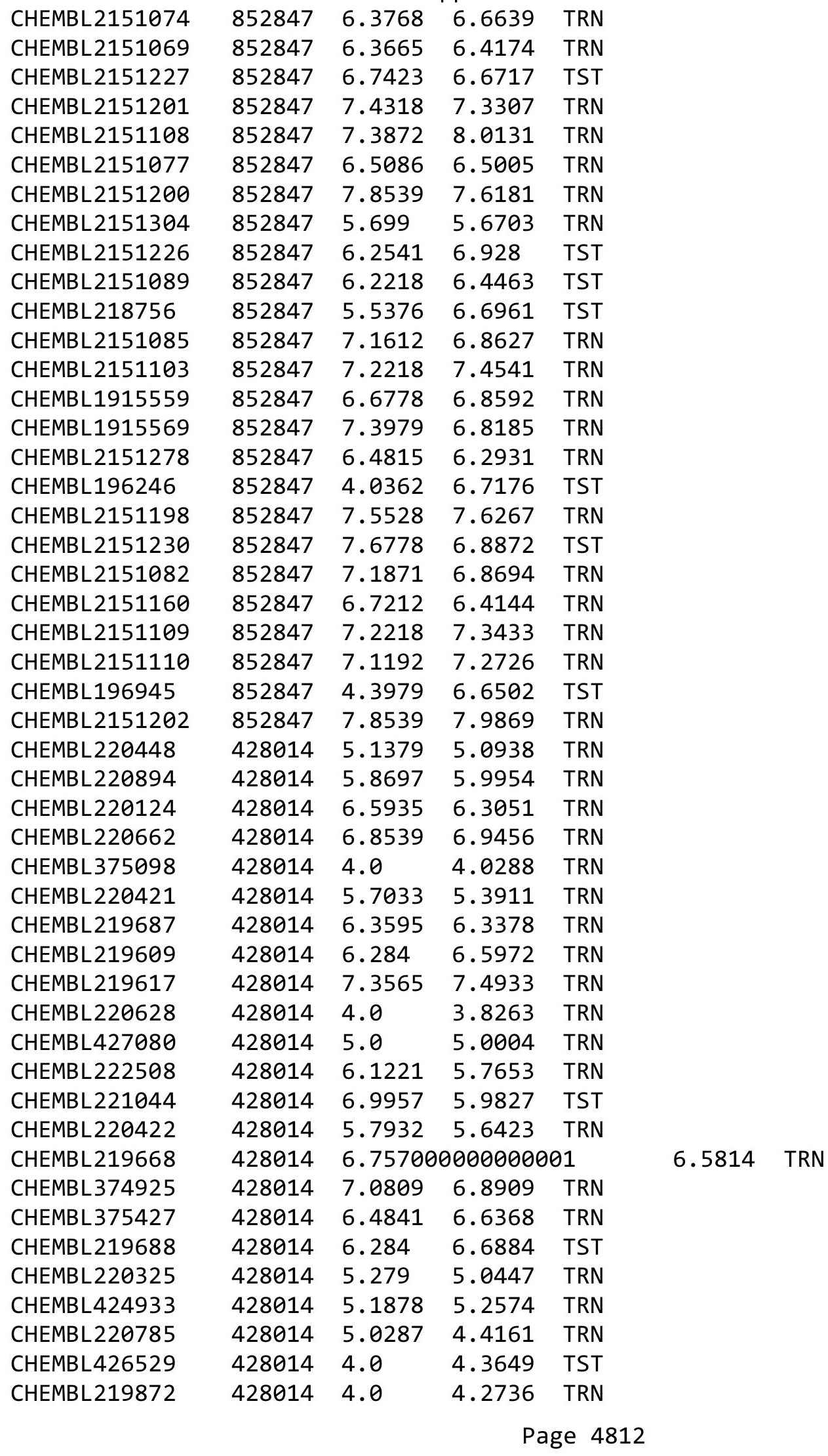




\begin{tabular}{|c|c|c|c|c|c|}
\hline \multicolumn{6}{|c|}{ supplemental } \\
\hline CHEMBL426883 & 428014 & 6.7167 & 6.1246 & TRN & \\
\hline CHEMBL220836 & 428014 & 4.0 & 4.1822 & TRN & \\
\hline CHEMBL220058 & 428014 & 4.0 & 4.1451 & TRN & \\
\hline CHEMBL219817 & 428014 & 5.0362 & 4.2485 & TST & \\
\hline CHEMBL 374545 & 428014 & 5.5969 & 5.6162 & TRN & \\
\hline CHEMBL 220508 & 428014 & 5.2441 & 5.1343 & TRN & \\
\hline CHEMBL 373791 & 428014 & 7.2147 & 7.3027 & TRN & \\
\hline CHEMBL220507 & 428014 & 4.0 & 4.4342 & TRN & \\
\hline CHEMBL219944 & 428014 & 5.7721 & 5.5407 & TRN & \\
\hline CHEMBL221100 & 428014 & 4.0 & 4.1268 & TRN & \\
\hline CHEMBL 220570 & 428014 & 5.5376 & 6.193 & TRN & \\
\hline CHEMBL2113263 & 428014 & 7.3665 & 7.9076 & TRN & \\
\hline CHEMBL 374901 & 428014 & 6.9547 & $6.86600 t$ & 00000000005 & TRN \\
\hline CHEMBL220837 & 428014 & 5.9031 & 6.2964 & TRN & \\
\hline CHEMBL436514 & 428014 & 7.3279 & 6.9659 & TRN & \\
\hline CHEMBL 220060 & 428014 & 4.0 & 4.3264 & TRN & \\
\hline CHEMBL220430 & 428014 & 4.0 & 4.4223 & TRN & \\
\hline CHEMBL220152 & 428014 & 6.8239 & 6.8753 & TRN & \\
\hline CHEMBL 219723 & 428014 & 4.0 & 4.3844 & TRN & \\
\hline CHEMBL223247 & 428014 & 4.0 & 4.2555 & TST & \\
\hline CHEMBL 219669 & 428014 & 6.7447 & 6.4516 & TRN & \\
\hline CHEMBL387350 & 428014 & 6.9788 & 6.5761 & TRN & \\
\hline CHEMBL220204 & 428014 & 4.0 & 4.4185 & TRN & \\
\hline CHEMBL 220990 & 428014 & 5.1643 & 4.1938 & TST & \\
\hline CHEMBL373591 & 428014 & 4.0 & 4.0339 & TST & \\
\hline CHEMBL 374234 & 428014 & 4.0 & 3.3984 & TRN & \\
\hline CHEMBL219661 & 428014 & 5.4034 & 5.4194 & TRN & \\
\hline CHEMBL 219610 & 428014 & 4.0 & 5.106 & TST & \\
\hline CHEMBL 376537 & 428014 & 4.0 & 3.9099 & TRN & \\
\hline CHEMBL375812 & 428014 & 6.4078 & 7.0558 & TRN & \\
\hline CHEMBL 223629 & 428014 & 5.1739 & 3.9357 & TST & \\
\hline CHEMBL219935 & 428014 & 4.0 & 3.9463 & TRN & \\
\hline CHEMBL427237 & 428014 & 4.0 & 4.4004 & TRN & \\
\hline CHEMBL 373813 & 428014 & 6.8327 & 6.6336 & TRN & \\
\hline CHEMBL 222247 & 428014 & 5.7721 & 5.6375 & TRN & \\
\hline CHEMBL424939 & 428014 & 6.279 & 6.2365 & TRN & \\
\hline CHEMBL219686 & 428014 & 5.9431 & 6.2948 & TRN & \\
\hline CHEMBL220224 & 428014 & 5.2366 & 5.3621 & TRN & \\
\hline CHEMBL 220205 & 428014 & 4.0 & 4.3585 & TRN & \\
\hline CHEMBL 376418 & 428014 & 5.4855 & 4.9372 & TRN & \\
\hline CHEMBL 373605 & 428014 & 5.1675 & 5.3575 & TRN & \\
\hline CHEMBL425116 & 428014 & 4.0 & 4.2762 & TRN & \\
\hline CHEMBL220893 & 428014 & 5.1805 & 4.8455 & TRN & \\
\hline CHEMBL 374682 & 428014 & 5.0 & 4.9343 & TRN & \\
\hline CHEMBL 222248 & 428014 & 7.2757 & 7.1735 & TRN & \\
\hline CHEMBL 220627 & 428014 & 4.0 & 3.7725 & TRN & \\
\hline CHEMBL 375747 & 428014 & 5.1249 & 5.0334 & TRN & \\
\hline CHEMBL 223748 & 428014 & 7.0 & 6.1284 & TRN & \\
\hline
\end{tabular}




\begin{tabular}{|c|c|c|c|c|}
\hline & & & 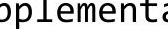 & \\
\hline CHEMBL220388 & 428014 & 4.0 & 5.3094 & TST \\
\hline CHEMBL220681 & 428014 & 6.1549 & 5.6462 & TRN \\
\hline CHEMBL220635 & 428014 & 5.8928 & 5.9517 & TRN \\
\hline CHEMBL220431 & 428014 & 4.0 & 4.7762 & TST \\
\hline CHEMBL374090 & 428014 & 6.7055 & 6.9197 & TRN \\
\hline CHEMBL375748 & 428014 & 4.0 & 4.4919 & TRN \\
\hline CHEMBL223356 & 428014 & 4.0 & 4.2826 & TST \\
\hline CHEMBL220151 & 428014 & 6.2518 & 6.0079 & TST \\
\hline CHEMBL221101 & 428014 & 6.9508 & 6.82299 & 99999999995 \\
\hline CHEMBL220173 & 428014 & 6.0953 & 6.2692 & TST \\
\hline CHEMBL220223 & 428014 & 6.4841 & 7.452006 & 0000000001 \\
\hline CHEMBL220059 & 428014 & 6.5719 & 5.9745 & TST \\
\hline CHEMBL220117 & 428014 & 7.0605 & 6.6435 & TST \\
\hline CHEMBL220557 & 428014 & 6.5952 & 6.3403 & TST \\
\hline CHEMBL374346 & 428014 & 4.0 & 3.9831 & TST \\
\hline CHEMBL375373 & 428014 & 4.0 & 4.0841 & TST \\
\hline CHEMBL375072 & 428014 & 5.6055 & 6.3481 & TST \\
\hline CHEMBL373554 & 428014 & 4.0 & 3.2639 & TST \\
\hline CHEMBL1909414 & 954702 & 3.4522 & 3.6683 & TRN \\
\hline CHEMBL191334 & 954702 & 3.1687 & 3.3056 & TRN \\
\hline CHEMBL65 & 954702 & 8.3799 & 8.5202 & TRN \\
\hline CHEMBL135561 & 954702 & 4.4112 & 4.4009 & TRN \\
\hline CHEMBL1643959 & 954702 & 4.957 & 4.9999 & TRN \\
\hline CHEMBL558642 & 954702 & 5.3855 & 5.4504 & TRN \\
\hline CHEMBL189584 & 954702 & 4.2799 & 4.466 & TRN \\
\hline CHEMBL393929 & 954702 & 3.9106 & 3.9579 & TRN \\
\hline CHEMBL 2144069 & 954702 & 4.584 & 4.6829 & TRN \\
\hline CHEMBL 9470 & 954702 & 5.8926 & 5.9701 & TST \\
\hline CHEMBL512504 & 954702 & 4.1157 & 3.9033 & TRN \\
\hline CHEMBL577784 & 954702 & 5.45 & 5.7594 & TRN \\
\hline CHEMBL1673039 & 954702 & 3.5736 & 3.8391 & TRN \\
\hline CHEMBL483847 & 954702 & 3.9596 & 4.2817 & TRN \\
\hline CHEMBL1357247 & 954702 & 3.4666 & 3.4789 & TRN \\
\hline CHEMBL221137 & 954702 & 4.9574 & 4.8837 & TST \\
\hline CHEMBL1190711 & 954702 & 5.6143 & 5.7449 & TRN \\
\hline CHEMBL192566 & 954702 & 8.8633 & 10.2327 & TST \\
\hline CHEMBL209148 & 954702 & 5.1914 & 4.9643 & TRN \\
\hline CHEMBL3186408 & 954702 & 3.3205 & 3.3678 & TST \\
\hline CHEMBL213100 & 954702 & 6.6212 & 6.8123 & TRN \\
\hline CHEMBL202721 & 954702 & 5.6046 & 5.7325 & TRN \\
\hline CHEMBL222102 & 954702 & 4.1054 & 4.065 & TRN \\
\hline CHEMBL258844 & 954702 & 4.6104 & 4.6412 & TRN \\
\hline CHEMBL180127 & 954702 & 3.9424 & 3.9012 & TRN \\
\hline CHEMBL379975 & 954702 & 4.1984 & 4.226 & TRN \\
\hline CHEMBL514499 & 954702 & 8.2299 & 8.0022 & TRN \\
\hline CHEMBL 2134202 & 954702 & 4.814 & 4.3277 & TRN \\
\hline CHEMBL220241 & 954702 & 4.9352 & 4.7783 & TRN \\
\hline CHEMBL188678 & 954702 & 4.351 & 4.3192 & TRN \\
\hline
\end{tabular}




\begin{tabular}{|c|c|c|c|c|c|}
\hline & & \multicolumn{4}{|c|}{ Supplemental Table S2.txt } \\
\hline CHEMBL373751 & 954702 & 3.2403 & 3.3244 & TRN & \\
\hline CHEMBL217354 & 954702 & 6.8885 & 6.8068 & TRN & \\
\hline CHEMBL259181 & 954702 & 5.499 & 5.6236 & TRN & \\
\hline CHEMBL1590308 & 954702 & 2.6931 & 2.943 & TST & \\
\hline CHEMBL1186585 & 954702 & 3.8863 & 4.2017 & TRN & \\
\hline CHEMBL585951 & 954702 & 6.0802 & 6.2211 & TRN & \\
\hline CHEMBL3199475 & 954702 & 4.0819 & 3.87399 & 99999999997 & TRN \\
\hline CHEMBL573107 & 954702 & 5.4959 & 5.6637 & TRN & \\
\hline CHEMBL1230020 & 954702 & 4.0248 & 3.99899 & 99999999997 & TRN \\
\hline CHEMBL255342 & 954702 & 3.3994 & 3.2827 & TRN & \\
\hline CHEMBL102714 & 954702 & 3.3853 & 3.2659 & TRN & \\
\hline CHEMBL509032 & 954702 & 6.3677 & 5.9402 & TRN & \\
\hline CHEMBL483849 & 954702 & 3.0817 & 2.3286 & TST & \\
\hline CHEMBL 2005886 & 954702 & 6.2957 & 6.0676 & TRN & \\
\hline CHEMBL 2137530 & 954702 & 4.9837 & 4.7912 & TRN & \\
\hline CHEMBL392695 & 954702 & 6.1416 & 5.9285 & TRN & \\
\hline CHEMBL1404918 & 954702 & 3.0421 & 2.8477 & TRN & \\
\hline CHEMBL1788116 & 954702 & 5.5356 & 5.3937 & TRN & \\
\hline CHEMBL 210618 & 954702 & 3.0395 & 3.1989 & TRN & \\
\hline CHEMBL1516890 & 954702 & 3.6884 & 3.5393 & TRN & \\
\hline CHEMBL3392440 & 954702 & 3.8497 & 3.9867 & TRN & \\
\hline CHEMBL300389 & 954702 & 7.6243 & 7.3255 & TRN & \\
\hline CHEMBL 2363137 & 954702 & 5.2395 & 5.2479 & TRN & \\
\hline CHEMBL1256459 & 954702 & 7.045 & 7.3877 & TRN & \\
\hline CHEMBL3349342 & 954702 & 5.9506 & 5.23799 & 99999999995 & TST \\
\hline CHEMBL1242367 & 954702 & 4.7743 & 4.5677 & TST & \\
\hline CHEMBL1970879 & 954702 & 6.6154 & 5.9272 & TST & \\
\hline CHEMBL412142 & 954702 & 4.3586 & 3.9139 & TST & \\
\hline CHEMBL472940 & 954702 & 3.3063 & 4.1237 & TST & \\
\hline CHEMBL92309 & 954702 & 2.5781 & 2.8674 & TST & \\
\hline CHEMBL379300 & 954702 & 6.8618 & 7.0923 & TST & \\
\hline CHEMBL240954 & 954702 & 3.2503 & 3.4486 & TST & \\
\hline CHEMBL515416 & 954702 & 5.7063 & 4.9543 & TST & \\
\hline CHEMBL 399530 & 954702 & 5.0542 & 4.5208 & TST & \\
\hline CHEMBL449158 & 954702 & 7.1092 & 7.2116 & TST & \\
\hline CHEMBL468220 & 513861 & 7.2757 & 7.2289 & TRN & \\
\hline CHEMBL445514 & 513861 & 7.5686 & 7.6025 & TRN & \\
\hline CHEMBL456450 & 513861 & 5.0 & 7.9135 & TST & \\
\hline CHEMBL 219880 & 513861 & 8.0969 & 8.1592 & TRN & \\
\hline CHEMBL455556 & 513861 & 6.8539 & 7.8778 & TST & \\
\hline CHEMBL468222 & 513861 & 7.6198 & 7.6633 & TRN & \\
\hline CHEMBL178071 & 513861 & 7.2596 & 7.2555 & TRN & \\
\hline CHEMBL504091 & 513861 & 8.0706 & 8.0905 & TRN & \\
\hline CHEMBL477372 & 513861 & 9.0969 & 9.1086 & TRN & \\
\hline CHEMBL469264 & 513861 & 5.0 & 7.7957 & TST & \\
\hline CHEMBL469263 & 513861 & 5.0 & 8.1324 & TST & \\
\hline CHEMBL178398 & 513861 & 9.5376 & 9.5023 & TRN & \\
\hline CHEMBL477371 & 513861 & 8.8539 & 8.8406 & TRN & \\
\hline
\end{tabular}




\begin{tabular}{|c|c|c|c|c|c|c|}
\hline \multirow[b]{2}{*}{ CHEMBL478424 } & \multicolumn{6}{|c|}{ S } \\
\hline & 513861 & 6.301 & 6.1211 & TRN & & \\
\hline CHEMBL476512 & 513861 & 7.6021 & 7.6019 & TRN & & \\
\hline CHEMBL178115 & 513861 & 8.6576 & 8.7518 & TRN & & \\
\hline CHEMBL517352 & 513861 & 8.1308 & 8.168 & TRN & & \\
\hline CHEMBL504330 & 513861 & 8.6021 & 8.5189 & TRN & & \\
\hline CHEMBL469198 & 513861 & 9.4685 & 9.4743 & TRN & & \\
\hline CHEMBL499698 & 513861 & 5.0 & 8.0588 & TST & & \\
\hline CHEMBL461163 & 513861 & 7.8539 & 7.8664 & TRN & & \\
\hline CHEMBL173992 & 513861 & 7.0969 & 7.1484 & TRN & & \\
\hline CHEMBL467140 & 513861 & 7.7959 & 7.5379 & TST & & \\
\hline CHEMBL512816 & 513861 & 5.699 & 5.6821 & TRN & & \\
\hline CHEMBL220784 & 513861 & 9.0458 & 9.0934 & TRN & & \\
\hline CHEMBL478186 & 513861 & 7.3372 & 7.31 & TRN & & \\
\hline CHEMBL467816 & 513861 & 9.0969 & 9.1191 & TRN & & \\
\hline CHEMBL476511 & 513861 & 8.1135 & 8.2147 & TRN & & \\
\hline CHEMBL177577 & 513861 & 8.3279 & 8.2631 & TRN & & \\
\hline CHEMBL469050 & 513861 & 8.1549 & 7.4034 & TST & & \\
\hline CHEMBL469051 & 513861 & 8.9586 & 9.0156 & TRN & & \\
\hline CHEMBL448922 & 513861 & 9.0 & 7.5088 & TST & & \\
\hline CHEMBL478187 & 513861 & 6.9586 & 6.9822 & TRN & & \\
\hline CHEMBL468189 & 513861 & 8.1549 & 8.164 & TRN & & \\
\hline CHEMBL477167 & 513861 & 5.0 & 5.1208 & TRN & & \\
\hline CHEMBL467796 & 513861 & 9.0 & 8.924 & TRN & & \\
\hline CHEMBL466961 & 513861 & 7.8861 & 7.8133 & TRN & & \\
\hline CHEMBL515490 & 513861 & 6.4437 & 6.4668 & TRN & & \\
\hline CHEMBL467368 & 513861 & 8.9586 & 7.7576 & TST & & \\
\hline CHEMBL426967 & 513861 & 9.2518 & 9.1776 & TRN & & \\
\hline CHEMBL469252 & 513861 & 5.8239 & 5.8246 & TRN & & \\
\hline CHEMBL512107 & 513861 & 8.1549 & 8.1409 & TRN & & \\
\hline CHEMBL511422 & 513861 & 8.0706 & 7.9881 & TST & & \\
\hline CHEMBL177356 & 513861 & 7.9208 & 7.9274 & TRN & & \\
\hline CHEMBL468188 & 513861 & 9.0 & 8.9664 & TRN & & \\
\hline CHEMBL467182 & 513861 & 6.4089 & 6.4295 & TRN & & \\
\hline CHEMBL450158 & 513861 & 9.0 & 8.9872 & TRN & & \\
\hline CHEMBL468585 & 513861 & 8.301 & 8.059 & TST & & \\
\hline CHEMBL512965 & 513861 & 8.5229 & 8.5574 & TRN & & \\
\hline CHEMBL467817 & 513861 & 8.5229 & 8.4892 & TRN & & \\
\hline CHEMBL469056 & 513861 & 7.3565 & 7.3752 & TRN & & \\
\hline CHEMBL503109 & 513861 & 7.3979 & 7.3975 & TRN & & \\
\hline CHEMBL511434 & 513861 & 3.0 & 9.0993 & TST & & \\
\hline CHEMBL468221 & 513861 & 6.0969 & 6.028 & TRN & & \\
\hline CHEMBL466954 & 513861 & 8.7959 & 8.3345 & TST & & \\
\hline CHEMBL469199 & 513861 & 9.0 & 8.5148 & TST & & \\
\hline CHEMBL1590308 & 954738 & 4.39199 & 999999999 & 995 & 3.4016 & TST \\
\hline CHEMBL393929 & 954738 & 3.2851 & 3.8371 & TRN & & \\
\hline CHEMBL412142 & 954738 & 4.3353 & 4.4147 & TRN & & \\
\hline CHEMBL 9470 & 954738 & 6.09399 & 999999999 & 99 & 5.6245 & TST \\
\hline CHEMBL192566 & 954738 & 7.2302 & 7.8629 & TST & & \\
\hline
\end{tabular}


Supplemental Table S2.txt

\begin{tabular}{|c|c|c|c|c|}
\hline 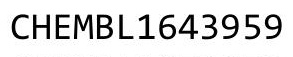 & 4738 & .2665 & 6009 & \\
\hline HEMBL1970879 & 54738 & 4.2827 & 2295 & \\
\hline HEMBL1516890 & 54738 & 2809 & 46 & \\
\hline HEM & 38 & .5906 & & \\
\hline HEMBL449158 & 738 & 2745 & 22 & \\
\hline HEMBL2363137 & 54738 & 5.1712 & .9054 & \\
\hline HEMBL 213100 & 54738 & 4.3785 & 3.81 & \\
\hline HEMBL135561 & 54738 & 4.7856 & 4.5736 & \\
\hline HEMBL 399530 & 38 & .2028 & .6384 & \\
\hline HEMBL1256459 & & 7.8554 & .7015 & \\
\hline HEMBL515416 & 54738 & 4.593 & 4.725 & \\
\hline HEMBL1190711 & 54 & 4.7126 & 4.6992 & \\
\hline HEMBL 2173 & 54 & 5.5473 & 5.9721 & \\
\hline HEMBL 202 & 38 & 96 & .3636 & \\
\hline HEMBL 213 & 38 & 543 & 16 & \\
\hline HEMBL 379300 & 38 & 6.8864 & 6.9536 & \\
\hline HEMBL1673039 & 38 & 137 & & \\
\hline HEMBL 319 & 54 & 3.9706 & 4.1576 & \\
\hline HEMBL 213 & 8 & & 4265 & \\
\hline HEMBL573 & 38 & 745 & 4.7277 & RN \\
\hline HEMBL189584 & 38 & 4.2486 & 4.2735 & RN \\
\hline AEMBL512504 & 38 & & & RIV \\
\hline HEMBL188678 & 5 & 488 & 3.8128 & RIN \\
\hline L39 & & 073 & 63 & \\
\hline HEMBL 30 & 38 & 328 & 16 & RN \\
\hline HEMBL 222102 & 38 & 271 & 3.3312 & RN \\
\hline AEMBL102714 & 8 & & & RN \\
\hline HEMBL135 & 8 & 168 & 3014 & RN \\
\hline HEMBL1S & 8 & & 3 & RN \\
\hline HEMBL190 & 38 & & 3199 & RN \\
\hline HEMBL 373751 & & & 9566 & RN \\
\hline HEMBL483847 & & & 328 & RN \\
\hline HEMBL 31 & & 847 & 56 & ST \\
\hline HEMBL17 & 8 & 32 & 33 & RN \\
\hline HEMBL 585 & 8 & $\partial 1$ & 31 & RN \\
\hline AEMBL472940 & & & 3387 & RN \\
\hline HEMBL180127 & 8 & 4.3099 & 2387 & RN \\
\hline HEMBL11 & & $\partial 2$ & & RN \\
\hline НᄃMDI 210 & 8 & 26 & 84 & ST \\
\hline HEMBL 65 & & 66 & 3399 & RN \\
\hline HEMBL 220241 & 38 & 3277 & 3544 & RN \\
\hline HEMBL 20058 & 8 & 07 & 2196 & TRN \\
\hline CHEMBL 209148 & 54 & & 3897 & \\
\hline CHEMBL558642 & 54 & & 3.9309 & TRN \\
\hline HEMBL221137 & & 5.0053 & 4.6672 & ST \\
\hline HEMBL 258 & 54 & 4.5961 & 5561 & RN \\
\hline SHEN & & & & \\
\hline CHEMBL 339244 & 954738 & & 3.9036 & \\
\hline
\end{tabular}

Page 4817 


\begin{tabular}{|c|c|c|c|c|c|}
\hline & & \multicolumn{4}{|c|}{ Supplemental Table s2.txt } \\
\hline CHEMBL210618 & 954738 & 3.3508 & 3.2805 & TRN & \\
\hline CHEMBL259181 & 954738 & 3.6752 & 4.1148 & TRN & \\
\hline CHEMBL509032 & 954738 & 5.2619 & 5.2881 & TST & \\
\hline CHEMBL3349342 & 954738 & 4.9071 & 4.5205 & TST & \\
\hline CHEMBL379975 & 954738 & 3.7191 & 4.624 & TST & \\
\hline CHEMBL 255342 & 954738 & 3.3463 & 3.1918 & TST & \\
\hline CHEMBL92309 & 954738 & 3.6829 & 2.8112 & TST & \\
\hline CHEMBL1404918 & 954738 & 2.8517 & 2.9547 & TST & \\
\hline CHEMBL1230020 & 954738 & 3.6668 & 3.8349 & TST & \\
\hline CHEMBL514499 & 954738 & 6.7497 & 7.287006 & 0000000001 & TST \\
\hline CHEMBL483849 & 954738 & 1.9979 & 2.2373 & TST & \\
\hline CHEMBL1242367 & 954738 & 4.0628 & 4.2335 & TST & \\
\hline CHEMBL 213505 & 809175 & 6.4 & 5.763 & TRN & \\
\hline CHEMBL 202721 & 809175 & 6.4 & 5.5259 & TRN & \\
\hline CHEMBL1982880 & 809175 & 4.2 & 4.8303 & TRN & \\
\hline CHEMBL1988038 & 809175 & 6.1 & 6.2674 & TRN & \\
\hline CHEMBL1987034 & 809175 & 8.8 & 7.6704 & TRN & \\
\hline CHEMBL1993941 & 809175 & 8.2 & 8.0918 & TRN & \\
\hline CHEMBL 377383 & 809175 & 4.8 & 4.4346 & TRN & \\
\hline CHEMBL578061 & 809175 & 7.0 & 5.9672 & TRN & \\
\hline CHEMBL 2005886 & 809175 & 7.1 & 6.9352 & TRN & \\
\hline CHEMBL481491 & 809175 & 4.8 & 5.5082 & TRN & \\
\hline CHEMBL1682345 & 809175 & 6.5 & 5.56 & TRN & \\
\hline CHEMBL1973142 & 809175 & 4.8 & 5.791 & TST & \\
\hline CHEMBL388311 & 809175 & 6.6 & 6.9826 & TRN & \\
\hline CHEMBL1973145 & 809175 & 4.4 & 6.0906 & TRN & \\
\hline CHEMBL1982924 & 809175 & 4.8 & 4.9549 & TRN & \\
\hline CHEMBL 2005936 & 809175 & 6.4 & 5.2535 & TRN & \\
\hline CHEMBL1964948 & 809175 & 4.8 & 4.795 & TRN & \\
\hline CHEMBL1972472 & 809175 & 7.4 & 6.4198 & TRN & \\
\hline CHEMBL1971141 & 809175 & 4.8 & 4.7956 & TRN & \\
\hline CHEMBL1968565 & 809175 & 6.3 & 5.369 & TST & \\
\hline CHEMBL1979718 & 809175 & 5.4 & 4.8927 & TRN & \\
\hline CHEMBL206236 & 809175 & 4.4 & 4.2408 & TRN & \\
\hline CHEMBL523823 & 809175 & 4.2 & 4.6933 & TST & \\
\hline CHEMBL1562756 & 809175 & 4.2 & 4.8224 & TST & \\
\hline CHEMBL1987430 & 809175 & 4.8 & 4.3999 & TRN & \\
\hline CHEMBL2001957 & 809175 & 4.8 & 4.7805 & TRN & \\
\hline CHEMBL1969372 & 809175 & 4.8 & 4.2784 & TRN & \\
\hline CHEMBL1993413 & 809175 & 4.8 & 5.0115 & TRN & \\
\hline CHEMBL1986943 & 809175 & 6.1 & 5.20799 & 9999999999 & TRN \\
\hline CHEMBL289959 & 809175 & 3.2 & 3.5689 & TRN & \\
\hline CHEMBL 2006263 & 809175 & 6.0 & 6.0227 & TST & \\
\hline CHEMBL1993584 & 809175 & 4.8 & 4.7823 & TRN & \\
\hline CHEMBL1986263 & 809175 & 7.4 & 6.7849 & TRN & \\
\hline CHEMBL 2000114 & 809175 & 5.8 & 5.79299 & 9999999999 & TRN \\
\hline CHEMBL210618 & 809175 & 4.4 & 4.3083 & TRN & \\
\hline CHEMBL1986265 & 809175 & 4.8 & 4.1548 & TRN & \\
\hline
\end{tabular}




\begin{tabular}{|c|c|c|c|c|}
\hline \multicolumn{5}{|c|}{ oplemental Table } \\
\hline CHEMBL1975647 & 809175 & 6.1 & 4.7916 & TRN \\
\hline CHEMBL1968380 & 809175 & 4.4 & 4.3744 & TRN \\
\hline CHEMBL1967211 & 809175 & 3.2 & 4.32 & TRN \\
\hline CHEMBL1964644 & 809175 & 4.8 & 4.453 & TRN \\
\hline CHEMBL1991734 & 809175 & 6.3 & 5.8972 & TST \\
\hline CHEMBL1981782 & 809175 & 5.8 & 4.8039 & TRN \\
\hline CHEMBL1977681 & 809175 & 4.8 & 5.6206 & TRN \\
\hline CHEMBL1970142 & 809175 & 8.1 & 7.5279 & TRN \\
\hline CHEMBL1990912 & 809175 & 4.8 & 4.9134 & TRN \\
\hline CHEMBL1991782 & 809175 & 3.5 & 3.5214 & TRN \\
\hline CHEMBL 2002105 & 809175 & 4.6 & 5.0352 & TRN \\
\hline CHEMBL1983348 & 809175 & 7.0 & 5.9878 & TRN \\
\hline CHEMBL1968394 & 809175 & 3.2 & 4.6772 & TRN \\
\hline CHEMBL1988163 & 809175 & 6.6 & 7.4134 & TRN \\
\hline CHEMBL1995592 & 809175 & 6.0 & 5.4718 & TST \\
\hline CHEMBL1980671 & 809175 & 3.2 & 5.1969 & TRN \\
\hline CHEMBL 2006493 & 809175 & 4.4 & 4.3822 & TST \\
\hline CHEMBL1986177 & 809175 & 4.8 & 4.9694 & TRN \\
\hline CHEMBL1982541 & 809175 & 4.2 & 4.5513 & TRN \\
\hline CHEMBL1996923 & 809175 & 4.4 & 4.4544 & TST \\
\hline CHEMBL1983449 & 809175 & 4.8 & 4.7325 & TRN \\
\hline CHEMBL1992323 & 809175 & 4.4 & 4.3544 & TST \\
\hline CHEMBL1969735 & 809175 & 4.8 & 4.4535 & TRN \\
\hline CHEMBL 2003524 & 809175 & 6.2 & 5.1583 & TST \\
\hline CHEMBL 2002649 & 809175 & 6.2 & 5.5659 & TRN \\
\hline CHEMBL1989423 & 809175 & 3.2 & 4.25 & TRN \\
\hline CHEMBL1985367 & 809175 & 4.8 & 4.5979 & TRN \\
\hline CHEMBL1996510 & 809175 & 4.8 & 5.37700 & 0000000001 \\
\hline CHEMBL437747 & 809175 & 4.2 & 5.2108 & TRN \\
\hline CHEMBL1995172 & 809175 & 3.6 & 4.6892 & TST \\
\hline CHEMBL 2001584 & 809175 & 4.8 & 4.8601 & TST \\
\hline CHEMBL507936 & 809175 & 5.7 & 5.6084 & TRN \\
\hline CHEMBL1971227 & 809175 & 6.0 & 5.404 & TST \\
\hline CHEMBL104264 & 809175 & 5.2 & 5.272 & TST \\
\hline CHEMBL1967998 & 809175 & 7.6 & 7.1388 & TRN \\
\hline CHEMBL1994321 & 809175 & 7.3 & 7.8253 & TRN \\
\hline CHEMBL1978562 & 809175 & 6.1 & 6.2509 & TST \\
\hline CHEMBL1997129 & 809175 & 6.5 & 7.5067 & TST \\
\hline CHEMBL451964 & 809175 & 4.2 & 4.2468 & TRN \\
\hline CHEMBL1974875 & 809175 & 4.5 & 4.3376 & TST \\
\hline CHEMBL1964307 & 809175 & 6.3 & 6.0192 & TRN \\
\hline CHEMBL1989471 & 809175 & 5.9 & 5.7385 & TST \\
\hline CHEMBL 2000508 & 809175 & 4.8 & 4.325 & TRN \\
\hline CHEMBL1971694 & 809175 & 4.4 & 4.5757 & TST \\
\hline CHEMBL 2001547 & 809175 & 4.8 & 4.409 & TRN \\
\hline CHEMBL210928 & 809175 & 4.4 & 4.2084 & TRN \\
\hline CHEMBL1978195 & 809175 & 4.8 & 5.0595 & TRN \\
\hline CHEMBL1994361 & 809175 & 4.2 & 4.5013 & TRN \\
\hline
\end{tabular}




\begin{tabular}{|c|c|c|c|c|c|}
\hline \multicolumn{6}{|c|}{ Supplemental Table s2.txt } \\
\hline CHEMBL1986603 & 809175 & 4.8 & 4.3914 & TST & \\
\hline CHEMBL 2005800 & 809175 & 5.7 & 6.2897 & TRN & \\
\hline CHEMBL1972840 & 809175 & 4.2 & 5.0738 & TRN & \\
\hline CHEMBL1977148 & 809175 & 4.8 & 7.2336 & TRN & \\
\hline CHEMBL 2003286 & 809175 & 4.8 & 4.4686 & TRN & \\
\hline CHEMBL1992306 & 809175 & 6.3 & 5.8541 & TRN & \\
\hline CHEMBL 2002165 & 809175 & 8.7 & 8.1951 & TRN & \\
\hline CHEMBL 206382 & 809175 & 4.4 & 4.2764 & TRN & \\
\hline CHEMBL1998585 & 809175 & 6.7 & 7.5602 & TRN & \\
\hline CHEMBL519697 & 809175 & 5.8 & 5.3778 & TST & \\
\hline CHEMBL1972851 & 809175 & 8.4 & 7.8861 & TRN & \\
\hline CHEMBL 2004934 & 809175 & 4.8 & 4.3288 & TRN & \\
\hline CHEMBL1983846 & 809175 & 7.2 & 6.5868 & TRN & \\
\hline CHEMBL1996345 & 809175 & 4.8 & 4.9075 & TST & \\
\hline CHEMBL1975128 & 809175 & 7.3 & 6.52 & TRN & \\
\hline CHEMBL 2004025 & 809175 & 6.4 & 6.1534 & TRN & \\
\hline CHEMBL1996048 & 809175 & 4.8 & 4.7498 & TST & \\
\hline CHEMBL461876 & 809175 & 4.8 & 4.5572 & TRN & \\
\hline CHEMBL1965033 & 809175 & 4.8 & 5.1572 & TRN & \\
\hline CHEMBL 2001485 & 809175 & 7.0 & 7.3229 & TRN & \\
\hline CHEMBL1971519 & 809175 & 3.4 & 5.2046 & TRN & \\
\hline CHEMBL504950 & 809175 & 5.6 & 5.3428 & TRN & \\
\hline CHEMBL1997335 & 809175 & 4.8 & 4.9828 & TRN & \\
\hline CHEMBL1984363 & 809175 & 6.0 & 5.6908 & TRN & \\
\hline CHEMBL1978099 & 809175 & 7.8 & 6.7312 & TRN & \\
\hline CHEMBL1977041 & 809175 & 7.9 & 6.7514 & TRN & \\
\hline CHEMBL1968070 & 809175 & 6.5 & 5.8637 & TRN & \\
\hline CHEMBL1988608 & 809175 & 4.8 & 5.66700 & 2000000001 & TRN \\
\hline CHEMBL184847 & 809175 & 4.8 & 6.2936 & TRN & \\
\hline CHEMBL1984367 & 809175 & 4.8 & 5.624 & TRN & \\
\hline CHEMBL178737 & 809175 & 5.9 & 4.745 & TST & \\
\hline CHEMBL 226898 & 809175 & 4.8 & 5.1044 & TRN & \\
\hline CHEMBL1982563 & 809175 & 4.8 & 4.3669 & TRN & \\
\hline CHEMBL539474 & 809175 & 7.4 & 5.2926 & TST & \\
\hline CHEMBL575824 & 809175 & 4.5 & 4.3468 & TRN & \\
\hline CHEMBL1988387 & 809175 & 7.6 & 7.5561 & TRN & \\
\hline CHEMBL1985523 & 809175 & 7.0 & 6.9227 & TRN & \\
\hline CHEMBL1973868 & 809175 & 4.8 & 4.5437 & TRN & \\
\hline CHEMBL1997759 & 809175 & 4.2 & 4.5587 & TRN & \\
\hline CHEMBL1981556 & 809175 & 4.7 & 5.7705 & TST & \\
\hline CHEMBL1990288 & 809175 & 4.8 & 4.4536 & TRN & \\
\hline CHEMBL1970074 & 809175 & 4.6 & 5.2189 & TRN & \\
\hline CHEMBL1967620 & 809175 & 4.7 & 5.5459 & TST & \\
\hline CHEMBL1986970 & 809175 & 6.5 & 5.5354 & TRN & \\
\hline CHEMBL 2003456 & 809175 & 4.8 & 5.0575 & TRN & \\
\hline CHEMBL 2002992 & 809175 & 4.7 & 5.3322 & TRN & \\
\hline CHEMBL560813 & 809175 & 4.8 & 5.066 & TRN & \\
\hline CHEMBL1982700 & 809175 & 4.8 & 4.5015 & TST & \\
\hline
\end{tabular}




\begin{tabular}{|c|c|c|c|c|c|}
\hline & & & & & \\
\hline CHEMBL1968791 & 809175 & 4.4 & 4.9899 & TRN & \\
\hline CHEMBL326282 & 809175 & 4.2 & 4.4888 & TST & \\
\hline CHEMBL1992732 & 809175 & 4.2 & 4.4532 & TST & \\
\hline CHEMBL1971186 & 809175 & 4.8 & 4.9117 & TRN & \\
\hline CHEMBL 2003482 & 809175 & 4.8 & 4.41100 & 00000000005 & TRN \\
\hline CHEMBL1976872 & 809175 & 3.2 & 3.4911 & TRN & \\
\hline CHEMBL1969156 & 809175 & 3.2 & 3.9049 & TRN & \\
\hline CHEMBL1973211 & 809175 & 7.5 & 7.4178 & TRN & \\
\hline CHEMBL1984700 & 809175 & 4.8 & 4.521 & TRN & \\
\hline CHEMBL 2007151 & 809175 & 4.2 & 4.7625 & TRN & \\
\hline CHEMBL1971606 & 809175 & 4.8 & 4.4782 & TRN & \\
\hline CHEMBL 2003604 & 809175 & 6.9 & 6.7752 & TRN & \\
\hline CHEMBL1972125 & 809175 & 4.8 & 4.3796 & TRN & \\
\hline CHEMBL1999120 & 809175 & 4.8 & 4.4587 & TST & \\
\hline CHEMBL1976134 & 809175 & 4.8 & 5.7957 & TRN & \\
\hline CHEMBL1965131 & 809175 & 4.8 & 5.7291 & TST & \\
\hline CHEMBL1995448 & 809175 & 4.2 & 5.165 & TRN & \\
\hline CHEMBL1972158 & 809175 & 6.8 & 6.1569 & TRN & \\
\hline CHEMBL1981215 & 809175 & 4.8 & 4.8276 & TRN & \\
\hline CHEMBL1974457 & 809175 & 6.1 & 5.5904 & TRN & \\
\hline CHEMBL1999414 & 809175 & 7.4 & 8.0307 & TRN & \\
\hline CHEMBL1967336 & 809175 & 4.8 & 4.6409 & TRN & \\
\hline CHEMBL 2006581 & 809175 & 4.2 & 4.4701 & TRN & \\
\hline CHEMBL1970340 & 809175 & 3.5 & 4.74100 & 00000000005 & TRN \\
\hline CHEMBL1967992 & 809175 & 4.8 & 4.5943 & TRN & \\
\hline CHEMBL 2005186 & 809175 & 4.8 & 4.9714 & TRN & \\
\hline CHEMBL 2006450 & 809175 & 4.8 & 4.9571 & TRN & \\
\hline CHEMBL1975534 & 809175 & 4.8 & 4.4092 & TRN & \\
\hline CHEMBL1993424 & 809175 & 6.9 & 6.9586 & TRN & \\
\hline CHEMBL1966703 & 809175 & 4.8 & 4.4336 & TST & \\
\hline CHEMBL 2001987 & 809175 & 4.8 & 4.2249 & TRN & \\
\hline CHEMBL 243518 & 809175 & 7.8 & 8.249 & TRN & \\
\hline CHEMBL1969561 & 809175 & 7.0 & 5.9763 & TRN & \\
\hline CHEMBL1994555 & 809175 & 6.4 & 5.226 & TST & \\
\hline CHEMBL1975121 & 809175 & 4.8 & 4.4533 & TRN & \\
\hline CHEMBL1983640 & 809175 & 6.9 & 6.6165 & TRN & \\
\hline CHEMBL1997023 & 809175 & 5.9 & 5.6273 & TST & \\
\hline CHEMBL1964687 & 809175 & 6.8 & 6.5041 & TRN & \\
\hline CHEMBL1971943 & 809175 & 4.8 & 5.263 & TRN & \\
\hline CHEMBL1999918 & 809175 & 5.6 & 5.6293 & TRN & \\
\hline CHEMBL1974254 & 809175 & 8.0 & 7.7743 & TRN & \\
\hline CHEMBL1987334 & 809175 & 7.0 & 5.8282 & TRN & \\
\hline CHEMBL1988537 & 809175 & 6.3 & 5.7936 & TST & \\
\hline CHEMBL1969049 & 809175 & 4.8 & 4.3139 & TRN & \\
\hline CHEMBL 2005828 & 809175 & 4.8 & 7.0502 & TRN & \\
\hline CHEMBL1982388 & 809175 & 4.7 & 5.6453 & TST & \\
\hline CHEMBL 231153 & 809175 & 5.9 & 5.6675 & TRN & \\
\hline CHEMBL1991143 & 809175 & 6.3 & 5.2776 & TST & \\
\hline & & & & 4821 & \\
\hline
\end{tabular}




\begin{tabular}{|c|c|c|c|c|}
\hline & & & & $a \perp 1 a$ \\
\hline CHEMBL1998611 & 809175 & 5.8 & 5.6949 & TST \\
\hline CHEMBL485556 & 809175 & 4.2 & 5.37 & TST \\
\hline CHEMBL1975900 & 809175 & 4.8 & 4.8851 & TRN \\
\hline CHEMBL 255822 & 809175 & 4.8 & 5.0375 & TRN \\
\hline CHEMBL1972221 & 809175 & 5.8 & 5.4625 & TRN \\
\hline CHEMBL 2006778 & 809175 & 6.4 & 6.7792 & TRN \\
\hline CHEMBL378627 & 809175 & 4.4 & 4.1896 & TRN \\
\hline CHEMBL1996979 & 809175 & 4.8 & 4.6599 & TRN \\
\hline CHEMBL1997025 & 809175 & 4.4 & 5.3579 & TRN \\
\hline CHEMBL1968406 & 809175 & 6.3 & 6.0422 & TRN \\
\hline CHEMBL1966411 & 809175 & 5.9 & 6.3483 & TRN \\
\hline CHEMBL1975921 & 809175 & 5.0 & 4.7667 & TRN \\
\hline CHEMBL1982476 & 809175 & 8.5 & 7.9468 & TRN \\
\hline CHEMBL1998545 & 809175 & 4.4 & 4.4379 & TRN \\
\hline CHEMBL1986869 & 809175 & 4.8 & 4.5845 & TRN \\
\hline CHEMBL1975923 & 809175 & 5.1 & 5.7128 & TST \\
\hline CHEMBL2005449 & 809175 & 6.9 & 5.8193 & TRN \\
\hline CHEMBL1987998 & 809175 & 4.8 & 4.3222 & TRN \\
\hline CHEMBL1992527 & 809175 & 6.6 & 6.7085 & TRN \\
\hline CHEMBL1682558 & 809175 & 4.8 & 4.5253 & TRN \\
\hline CHEMBL1971534 & 809175 & 4.2 & 4.5861 & TRN \\
\hline CHEMBL1990496 & 809175 & 4.5 & 4.5829 & TRN \\
\hline CHEMBL 242865 & 809175 & 7.1 & 7.4371 & TRN \\
\hline CHEMBL1997623 & 809175 & 6.3 & 5.9208 & TRN \\
\hline CHEMBL1978973 & 809175 & 7.1 & 5.5856 & TRN \\
\hline CHEMBL1993166 & 809175 & 4.2 & 5.1506 & TRN \\
\hline CHEMBL1967094 & 809175 & 7.0 & 6.1576 & TRN \\
\hline CHEMBL 2003341 & 809175 & 4.8 & 4.4626 & TRN \\
\hline CHEMBL 2000137 & 809175 & 6.6 & 6.8674 & TRN \\
\hline CHEMBL1992644 & 809175 & 5.2 & 4.5271 & TRN \\
\hline CHEMBL1992645 & 809175 & 6.7 & 5.0593 & TST \\
\hline CHEMBL 2000746 & 809175 & 5.9 & 5.1181 & TRN \\
\hline CHEMBL1982992 & 809175 & 4.8 & 4.9102 & TRN \\
\hline CHEMBL1998110 & 809175 & 4.8 & 4.5246 & TRN \\
\hline CHEMBL1999590 & 809175 & 4.8 & 4.372 & TST \\
\hline CHEMBL1978166 & 809175 & 6.7 & 7.072 & TRN \\
\hline CHEMBL1980489 & 809175 & 4.8 & 4.7538 & TRN \\
\hline CHEMBL 2000832 & 809175 & 6.0 & 5.3513 & TRN \\
\hline CHEMBL1967116 & 809175 & 8.2 & 8.1728 & TRN \\
\hline CHEMBL1972454 & 809175 & 4.2 & 4.6751 & TRN \\
\hline CHEMBL1990590 & 809175 & 4.8 & 5.0785 & TRN \\
\hline CHEMBL1977814 & 809175 & 4.4 & 4.5936 & TST \\
\hline CHEMBL1970709 & 809175 & 4.8 & 4.515 & TRN \\
\hline CHEMBL1974617 & 809175 & 4.8 & 4.4878 & TRN \\
\hline CHEMBL1965660 & 809175 & 4.8 & 5.8498 & TRN \\
\hline CHEMBL1992125 & 809175 & 5.8 & 5.9769 & TRN \\
\hline CHEMBL1998112 & 809175 & 7.4 & 6.3205 & TRN \\
\hline CHEMBL1969126 & 809175 & 4.8 & 4.843 & TRN \\
\hline
\end{tabular}




\begin{tabular}{|c|c|c|c|c|}
\hline & & & ent & al \\
\hline CHEMBL1998724 & 809175 & 6.7 & 6.4508 & TRN \\
\hline CHEMBL1980896 & 809175 & 6.3 & 6.2966 & TRN \\
\hline CHEMBL1970104 & 809175 & 6.9 & 6.5428 & TRN \\
\hline CHEMBL1991429 & 809175 & 7.2 & 6.4697 & TRN \\
\hline CHEMBL1971149 & 809175 & 4.8 & 4.4621 & TRN \\
\hline CHEMBL1999714 & 809175 & 4.8 & 4.11 & TRN \\
\hline CHEMBL1987533 & 809175 & 4.4 & 4.5002 & TRN \\
\hline CHEMBL1979749 & 809175 & 7.3 & 5.4899 & TRN \\
\hline CHEMBL1994040 & 809175 & 4.8 & 4.4848 & TRN \\
\hline CHEMBL 388978 & 809175 & 8.6 & 7.0569 & TST \\
\hline CHEMBL1969834 & 809175 & 6.7 & 6.7452 & TRN \\
\hline CHEMBL579246 & 809175 & 4.4 & 4.3495 & TRN \\
\hline CHEMBL398951 & 809175 & 4.8 & 4.7675 & TST \\
\hline CHEMBL1982506 & 809175 & 4.9 & 5.3395 & TST \\
\hline CHEMBL 2004716 & 809175 & 7.9 & 7.6647 & TRN \\
\hline CHEMBL1968127 & 809175 & 4.8 & 4.3911 & TRN \\
\hline CHEMBL1975233 & 809175 & 5.4 & 4.0486 & TRN \\
\hline CHEMBL1985406 & 809175 & 4.8 & 4.8577 & TRN \\
\hline CHEMBL 207400 & 809175 & 4.4 & 4.6687 & TST \\
\hline CHEMBL 2000894 & 809175 & 4.8 & 4.1504 & TST \\
\hline CHEMBL1421720 & 809175 & 6.4 & 5.6228 & TRN \\
\hline CHEMBL1968130 & 809175 & 4.5 & 4.7386 & TRN \\
\hline CHEMBL1982135 & 809175 & 6.4 & 6.7779 & TRN \\
\hline CHEMBL1976090 & 809175 & 6.3 & 5.796 & TRN \\
\hline CHEMBL1993243 & 809175 & 4.8 & 6.1975 & TRN \\
\hline CHEMBL1992922 & 809175 & 4.7 & 5.3522 & TRN \\
\hline CHEMBL399021 & 809175 & 5.4 & 5.5158 & TRN \\
\hline CHEMBL1997597 & 809175 & 4.8 & 5.7217 & TRN \\
\hline CHEMBL1969537 & 809175 & 4.8 & 5.1259 & TST \\
\hline CHEMBL1996539 & 809175 & 6.2 & 6.1059 & TRN \\
\hline CHEMBL1976093 & 809175 & 4.8 & 4.3912 & TRN \\
\hline CHEMBL1996543 & 809175 & 4.2 & 4.5005 & TRN \\
\hline CHEMBL1975256 & 809175 & 5.8 & 4.2609 & TST \\
\hline CHEMBL508928 & 809175 & 7.1 & 6.4853 & TRN \\
\hline CHEMBL 2004892 & 809175 & 4.8 & 5.6238 & TRN \\
\hline CHEMBL1949855 & 809175 & 5.0 & 4.4548 & TST \\
\hline CHEMBL116070 & 809175 & 4.3 & 4.3196 & TRN \\
\hline CHEMBL1970314 & 809175 & 4.8 & 5.3624 & TRN \\
\hline CHEMBL 243517 & 809175 & 8.2 & 8.25 & TRN \\
\hline CHEMBL 2004871 & 809175 & 4.8 & 4.776 & TRN \\
\hline CHEMBL1727312 & 809175 & 3.5 & 3.8786 & TRN \\
\hline CHEMBL1969879 & 809175 & 4.8 & 5.1633 & TRN \\
\hline CHEMBL244793 & 809175 & 8.6 & 7.5005 & TRN \\
\hline CHEMBL1987658 & 809175 & 6.3 & 6.3302 & TRN \\
\hline CHEMBL1964382 & 809175 & 4.8 & 5.5865 & TST \\
\hline CHEMBL101311 & 809175 & 4.8 & 5.7336 & TRN \\
\hline CHEMBL1981720 & 809175 & 4.5 & 5.4547 & TRN \\
\hline CHEMBL419932 & 809175 & 4.8 & 4.3318 & TRN \\
\hline
\end{tabular}




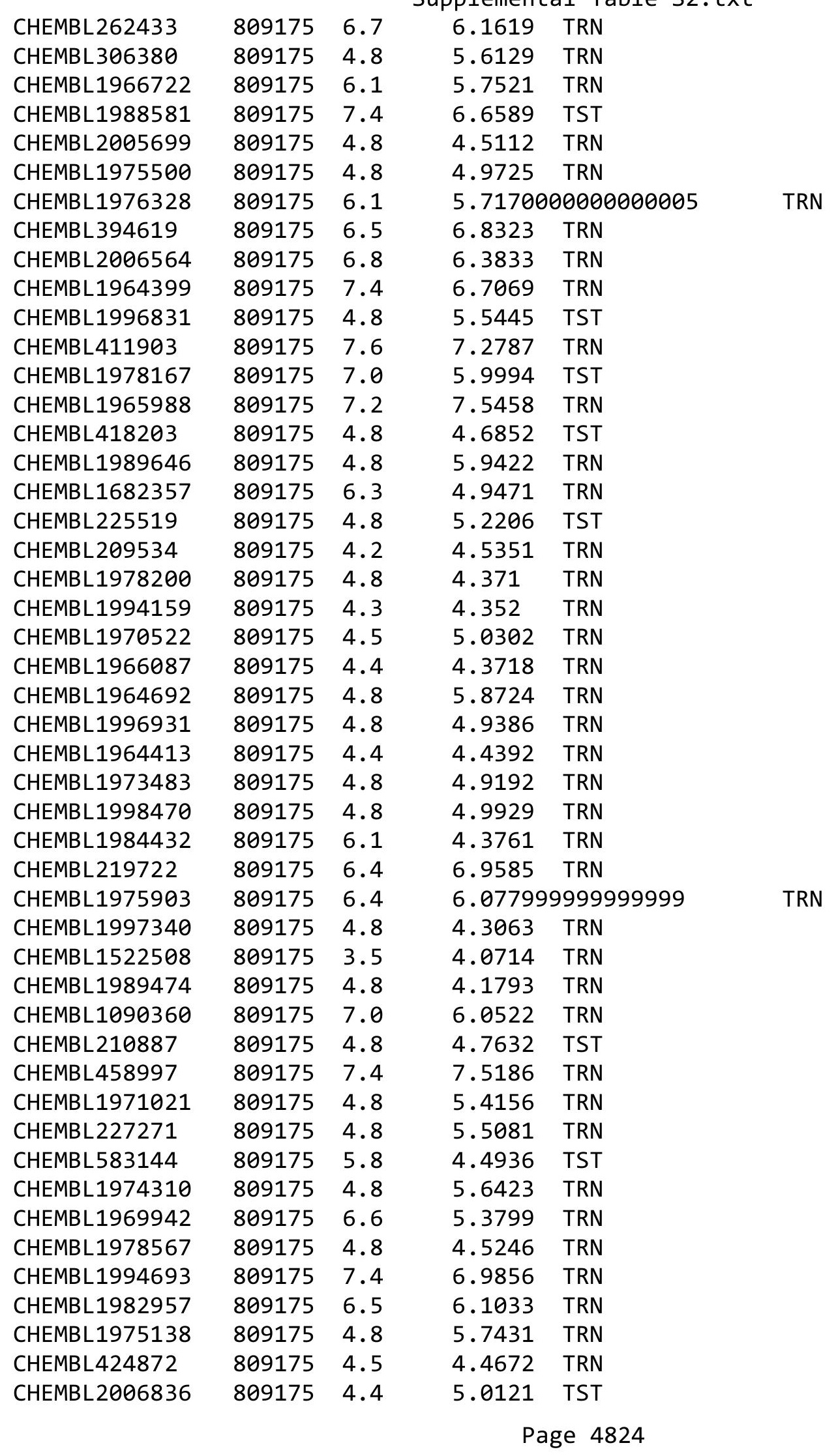




\begin{tabular}{|c|c|c|c|c|c|}
\hline & & & & & \\
\hline CHEMBL1971947 & 809175 & 6.7 & 7.1268 & TRN & \\
\hline CHEMBL412142 & 809175 & 4.5 & 4.6585 & TST & \\
\hline CHEMBL1980704 & 809175 & 4.8 & 4.8497 & TST & \\
\hline CHEMBL 2003271 & 809175 & 4.8 & 5.8539 & TST & \\
\hline CHEMBL1966808 & 809175 & 4.8 & 4.3501 & TRN & \\
\hline CHEMBL 2004447 & 809175 & 4.4 & 4.4152 & TST & \\
\hline CHEMBL1983111 & 809175 & 8.4 & 7.5495 & TRN & \\
\hline CHEMBL1973860 & 809175 & 4.8 & 4.8503 & TRN & \\
\hline CHEMBL 260135 & 809175 & 4.4 & 4.7665 & TRN & \\
\hline CHEMBL220241 & 809175 & 6.3 & 5.4298 & TRN & \\
\hline CHEMBL1988141 & 809175 & 6.8 & 6.3922 & TST & \\
\hline CHEMBL1982610 & 809175 & 4.8 & 4.2846 & TST & \\
\hline CHEMBL1977134 & 809175 & 4.8 & 5.33700 & 0000000001 & TRN \\
\hline CHEMBL496412 & 809175 & 6.9 & 5.8173 & TST & \\
\hline CHEMBL1969787 & 809175 & 4.9 & 4.9067 & TST & \\
\hline CHEMBL1999496 & 809175 & 4.8 & 4.4891 & TRN & \\
\hline CHEMBL1970873 & 809175 & 3.5 & 3.6722 & TRN & \\
\hline CHEMBL 2006933 & 809175 & 6.1 & 5.0302 & TST & \\
\hline CHEMBL1985206 & 809175 & 4.8 & 5.0181 & TST & \\
\hline CHEMBL1988300 & 809175 & 6.0 & 6.546 & TRN & \\
\hline CHEMBL1991078 & 809175 & 6.4 & 6.4592 & TRN & \\
\hline CHEMBL1974365 & 809175 & 4.7 & 4.5656 & TRN & \\
\hline CHEMBL1977749 & 809175 & 6.1 & 5.4981 & TST & \\
\hline CHEMBL1982837 & 809175 & 7.4 & 6.9161 & TRN & \\
\hline CHEMBL1975212 & 809175 & 3.3 & 5.5371 & TRN & \\
\hline CHEMBL 2000685 & 809175 & 5.9 & 6.0005 & TRN & \\
\hline CHEMBL2001613 & 809175 & 5.1 & 4.6737 & TRN & \\
\hline CHEMBL1993904 & 809175 & 4.8 & 5.7846 & TRN & \\
\hline CHEMBL1980376 & 809175 & 3.2 & 4.8573 & TRN & \\
\hline CHEMBL1967513 & 809175 & 4.8 & 4.4755 & TRN & \\
\hline CHEMBL 2000724 & 809175 & 4.8 & 5.0721 & TRN & \\
\hline CHEMBL1985311 & 809175 & 6.4 & 6.7608 & TRN & \\
\hline CHEMBL1982660 & 809175 & 4.8 & 6.0075 & TRN & \\
\hline CHEMBL1989265 & 809175 & 4.4 & 4.1657 & TST & \\
\hline CHEMBL1982413 & 809175 & 4.8 & 5.4516 & TST & \\
\hline CHEMBL1969502 & 809175 & 6.3 & 5.7038 & TRN & \\
\hline CHEMBL1965910 & 809175 & 5.5 & 5.3397 & TRN & \\
\hline CHEMBL1682553 & 809175 & 4.4 & 4.1285 & TRN & \\
\hline CHEMBL1971430 & 809175 & 4.5 & 4.372 & TRN & \\
\hline CHEMBL1983963 & 809175 & 7.3 & 7.0955 & TRN & \\
\hline CHEMBL1997764 & 809175 & 4.8 & 4.7639 & TRN & \\
\hline CHEMBL 2000271 & 809175 & 6.0 & 6.4003 & TRN & \\
\hline CHEMBL1985042 & 809175 & 4.3 & 5.3418 & TST & \\
\hline CHEMBL1981792 & 809175 & 4.8 & 4.8061 & TRN & \\
\hline CHEMBL1987535 & 809175 & 4.8 & 4.4709 & TRN & \\
\hline CHEMBL354676 & 809175 & 3.4 & 4.2717 & TRN & \\
\hline CHEMBL 1985092 & 809175 & 4.8 & 5.3651 & TRN & \\
\hline CHEMBL 2004692 & 809175 & 4.4 & 4.2633 & TST & \\
\hline & & & & e 4825 & \\
\hline
\end{tabular}




\begin{tabular}{|c|c|c|c|c|}
\hline & & & 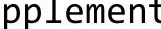 & al Ta \\
\hline CHEMBL1981410 & 809175 & 4.8 & 5.5942 & TRN \\
\hline CHEMBL 2002586 & 809175 & 4.8 & 4.7549 & TRN \\
\hline CHEMBL1987815 & 809175 & 4.2 & 3.9787 & TST \\
\hline CHEMBL1996234 & 809175 & 4.8 & 5.2747 & TRN \\
\hline CHEMBL 383264 & 809175 & 4.8 & 4.8534 & TRN \\
\hline CHEMBL 2007421 & 809175 & 6.2 & 5.7488 & TST \\
\hline CHEMBL1991434 & 809175 & 4.4 & 4.4645 & TST \\
\hline CHEMBL1967544 & 809175 & 4.8 & 4.9779 & TRN \\
\hline CHEMBL1973138 & 809175 & 4.8 & 4.7818 & TST \\
\hline CHEMBL223367 & 809175 & 4.4 & 4.4572 & TST \\
\hline CHEMBL1992673 & 809175 & 4.8 & 4.6827 & TST \\
\hline CHEMBL407391 & 809175 & 5.4 & 4.8818 & TST \\
\hline CHEMBL340384 & 809175 & 4.8 & 5.3169 & TST \\
\hline CHEMBL1969151 & 809175 & 4.8 & 5.2016 & TRN \\
\hline CHEMBL1996587 & 809175 & 4.8 & 4.2969 & TRN \\
\hline CHEMBL1981492 & 809175 & 3.2 & 4.4793 & TRN \\
\hline CHEMBL1993335 & 809175 & 7.3 & 6.4954 & TST \\
\hline CHEMBL1988692 & 809175 & 6.3 & 5.5066 & TRN \\
\hline CHEMBL 2007574 & 809175 & 4.8 & 5.0383 & TRN \\
\hline CHEMBL1964804 & 809175 & 4.8 & 5.0131 & TRN \\
\hline CHEMBL443962 & 809175 & 6.7 & 5.5817 & TST \\
\hline CHEMBL 2000354 & 809175 & 4.8 & 5.1461 & TRN \\
\hline CHEMBL 274064 & 809175 & 4.7 & 4.6081 & TRN \\
\hline CHEMBL1967564 & 809175 & 4.4 & 4.4452 & TRN \\
\hline CHEMBL592030 & 809175 & 4.8 & 5.4055 & TST \\
\hline CHEMBL 2000071 & 809175 & 6.1 & 5.7204 & TRN \\
\hline CHEMBL1979176 & 809175 & 4.8 & 4.7708 & TRN \\
\hline CHEMBL1970317 & 809175 & 8.4 & 8.3773 & TRN \\
\hline CHEMBL 2000408 & 809175 & 4.8 & 4.52 & TRN \\
\hline CHEMBL 248757 & 809175 & 4.7 & 5.5097 & TST \\
\hline CHEMBL1978014 & 809175 & 4.8 & 4.5846 & TRN \\
\hline CHEMBL1997007 & 809175 & 5.9 & 5.642 & TRN \\
\hline CHEMBL1994538 & 809175 & 4.8 & 4.5782 & TRN \\
\hline CHEMBL1990228 & 809175 & 8.1 & 8.0461 & TRN \\
\hline CHEMBL 2002690 & 809175 & 4.8 & 4.9112 & TRN \\
\hline CHEMBL1984131 & 809175 & 7.3 & 5.1904 & TRN \\
\hline CHEMBL 2006567 & 809175 & 4.2 & 4.4076 & TRN \\
\hline CHEMBL1986139 & 809175 & 4.8 & 4.7986 & TRN \\
\hline CHEMBL1975503 & 809175 & 3.2 & 4.6486 & TRN \\
\hline CHEMBL 383527 & 809175 & 4.2 & 4.5436 & TRN \\
\hline CHEMBL278041 & 809175 & 4.8 & 4.4282 & TRN \\
\hline CHEMBL1979883 & 809175 & 7.5 & 7.4774 & TRN \\
\hline CHEMBL491758 & 809175 & 7.6 & 7.1732 & TRN \\
\hline CHEMBL1618860 & 809175 & 7.1 & 5.5 & TST \\
\hline CHEMBL1986590 & 809175 & 4.8 & 5.9115 & TRN \\
\hline CHEMBL549730 & 809175 & 4.3 & 4.7206 & TRN \\
\hline CHEMBL1682360 & 809175 & 5.6 & 4.7432 & TRN \\
\hline CHEMBL1970189 & 809175 & 4.8 & 4.4771 & TST \\
\hline
\end{tabular}




\begin{tabular}{|c|c|c|c|c|}
\hline & & & pl & \\
\hline CHEMBL1870106 & 809175 & 4.8 & 4.9083 & TRN \\
\hline CHEMBL1996791 & 809175 & 4.8 & 5.5072 & TRN \\
\hline CHEMBL371206 & 809175 & 7.6 & 7.2816 & TRN \\
\hline CHEMBL1974664 & 809175 & 4.8 & 5.3873 & TST \\
\hline CHEMBL406845 & 809175 & 4.8 & 4.771 & TRN \\
\hline CHEMBL482538 & 809175 & 3.2 & 4.6588 & TRN \\
\hline CHEMBL1974288 & 809175 & 4.8 & 4.4489 & TRN \\
\hline CHEMBL1984296 & 809175 & 6.0 & 5.5666 & TST \\
\hline CHEMBL196363 & 809175 & 7.7 & 7.2334 & TRN \\
\hline CHEMBL1996837 & 809175 & 3.2 & 3.8777 & TST \\
\hline CHEMBL1190711 & 809175 & 4.8 & 5.9499 & TRN \\
\hline CHEMBL1990346 & 809175 & 6.0 & 5.6451 & TRN \\
\hline CHEMBL1964718 & 809175 & 4.5 & 4.2515 & TST \\
\hline CHEMBL1968705 & 809175 & 4.8 & 5.7856 & TRN \\
\hline CHEMBL1964441 & 809175 & 7.0 & 7.2065 & TRN \\
\hline CHEMBL1991410 & 809175 & 4.8 & 4.7628 & TRN \\
\hline CHEMBL1986684 & 809175 & 4.3 & 4.8078 & TST \\
\hline CHEMBL546797 & 809175 & 5.9 & 5.8312 & TRN \\
\hline CHEMBL404367 & 809175 & 6.0 & 5.8895 & TRN \\
\hline CHEMBL1966343 & 809175 & 4.8 & 5.7908 & TRN \\
\hline CHEMBL1978271 & 809175 & 4.8 & 4.6886 & TRN \\
\hline CHEMBL1967887 & 809175 & 4.8 & 5.0812 & TRN \\
\hline CHEMBL 2007266 & 809175 & 4.8 & 5.0889 & TRN \\
\hline CHEMBL 2000335 & 809175 & 7.4 & 7.3719 & TRN \\
\hline CHEMBL 2007097 & 809175 & 4.5 & 4.4181 & TRN \\
\hline CHEMBL1988717 & 809175 & 6.2 & 5.8084 & TRN \\
\hline CHEMBL1974328 & 809175 & 4.8 & 5.188 & TRN \\
\hline CHEMBL509032 & 809175 & 7.9 & 6.8374 & TRN \\
\hline CHEMBL143703 & 809175 & 3.2 & 3.7857 & TRN \\
\hline CHEMBL1979528 & 809175 & 6.8 & 6.5521 & TRN \\
\hline CHEMBL1973808 & 809175 & 4.8 & 4.3558 & TRN \\
\hline CHEMBL 2000429 & 809175 & 4.8 & 4.7184 & TRN \\
\hline CHEMBL1986367 & 809175 & 7.3 & 7.5041 & TRN \\
\hline CHEMBL1972576 & 809175 & 9.2 & 7.8234 & TRN \\
\hline CHEMBL1990254 & 809175 & 4.8 & 4.7802 & TRN \\
\hline CHEMBL1989069 & 809175 & 5.3 & 4.6462 & TRN \\
\hline CHEMBL1992342 & 809175 & 4.8 & 5.9143 & TRN \\
\hline CHEMBL 2001535 & 809175 & 7.4 & 7.046 & TRN \\
\hline CHEMBL1988173 & 809175 & 6.7 & 5.9899 & TRN \\
\hline CHEMBL1973013 & 809175 & 6.1 & 5.5833 & TST \\
\hline CHEMBL1965423 & 809175 & 4.4 & 4.2596 & TRN \\
\hline CHEMBL1993073 & 809175 & 6.9 & 6.0175 & TRN \\
\hline CHEMBL1983025 & 809175 & 6.8 & 7.1951 & TRN \\
\hline CHEMBL1975927 & 809175 & 6.5 & 6.2954 & TRN \\
\hline CHEMBL205415 & 809175 & 4.5 & 4.3899 & TRN \\
\hline CHEMBL1977135 & 809175 & 4.8 & 4.4244 & TRN \\
\hline CHEMBL 2001920 & 809175 & 6.3 & 5.2071 & TRN \\
\hline CHEMBL 2002322 & 809175 & 4.2 & 4.7107 & TRN \\
\hline
\end{tabular}




\begin{tabular}{|c|c|c|c|c|}
\hline \multicolumn{5}{|c|}{ Supplemental Tak } \\
\hline CHEMBL1997119 & 809175 & 4.3 & 4.2689 & TRN \\
\hline CHEMBL 2002323 & 809175 & 4.2 & 4.2992 & TST \\
\hline CHEMBL1241473 & 809175 & 5.2 & 7.8761 & TRN \\
\hline CHEMBL1978448 & 809175 & 5.1 & 5.2742 & TST \\
\hline CHEMBL1972258 & 809175 & 4.4 & 4.2774 & TRN \\
\hline CHEMBL1980329 & 809175 & 4.8 & 6.8471 & TRN \\
\hline CHEMBL 2004515 & 809175 & 5.4 & 4.7393 & TRN \\
\hline CHEMBL 2001257 & 809175 & 6.7 & 7.5654 & TRN \\
\hline CHEMBL1968271 & 809175 & 6.0 & 6.1103 & TRN \\
\hline CHEMBL1992042 & 809175 & 6.3 & 6.2184 & TST \\
\hline CHEMBL 2005548 & 809175 & 4.2 & 4.4953 & TRN \\
\hline CHEMBL1992536 & 809175 & 4.8 & 4.5263 & TRN \\
\hline CHEMBL21156 & 809175 & 4.8 & 5.2642 & TST \\
\hline CHEMBL1992740 & 809175 & 4.4 & 4.4389 & TRN \\
\hline CHEMBL1994724 & 809175 & 6.7 & 5.1719 & TRN \\
\hline CHEMBL1989267 & 809175 & 6.7 & 6.6259 & TRN \\
\hline CHEMBL1964519 & 809175 & 7.7 & 8.273 & TRN \\
\hline CHEMBL439340 & 809175 & 4.4 & 4.4079 & TRN \\
\hline CHEMBL1974574 & 809175 & 5.9 & 4.8141 & TST \\
\hline CHEMBL1970290 & 809175 & 5.8 & 5.0596 & TRN \\
\hline CHEMBL1967531 & 809175 & 8.3 & 7.1652 & TRN \\
\hline CHEMBL1970913 & 809175 & 4.4 & 4.4952 & TRN \\
\hline CHEMBL1973893 & 809175 & 6.0 & 5.5853 & TRN \\
\hline CHEMBL1993877 & 809175 & 4.8 & 5.2604 & TRN \\
\hline CHEMBL1996500 & 809175 & 4.8 & 4.3732 & TRN \\
\hline CHEMBL1985095 & 809175 & 5.9 & 5.6177 & TST \\
\hline CHEMBL1973363 & 809175 & 5.8 & 5.4648 & TRN \\
\hline CHEMBL1991180 & 809175 & 7.0 & 5.1427 & TST \\
\hline CHEMBL1682540 & 809175 & 4.8 & 4.4083 & TRN \\
\hline CHEMBL1978656 & 809175 & 4.2 & 4.4465 & TRN \\
\hline CHEMBL1976420 & 809175 & 6.1 & 5.5784 & TST \\
\hline CHEMBL413779 & 809175 & 6.3 & 4.3416 & TST \\
\hline CHEMBL1981744 & 809175 & 4.8 & 4.6004 & TRN \\
\hline CHEMBL1994864 & 809175 & 4.8 & 4.7787 & TRN \\
\hline CHEMBL 2002446 & 809175 & 4.4 & 5.0509 & TST \\
\hline CHEMBL497151 & 809175 & 6.1 & 5.5378 & TRN \\
\hline CHEMBL 2000029 & 809175 & 6.0 & 5.8335 & TRN \\
\hline CHEMBL1973961 & 809175 & 4.8 & 4.7215 & TRN \\
\hline CHEMBL 2001099 & 809175 & 6.3 & 5.9331 & TRN \\
\hline CHEMBL246970 & 809175 & 4.8 & 4.8521 & TRN \\
\hline CHEMBL340921 & 809175 & 4.3 & 4.6165 & TST \\
\hline CHEMBL1994977 & 809175 & 4.8 & 4.6192 & TRN \\
\hline CHEMBL373598 & 809175 & 4.2 & 4.3434 & TST \\
\hline CHEMBL1999718 & 809175 & 4.8 & 4.4782 & TRN \\
\hline CHEMBL 2005478 & 809175 & 7.3 & 6.2844 & TST \\
\hline CHEMBL1276446 & 809175 & 7.8 & 7.2812 & TST \\
\hline CHEMBL1996646 & 809175 & 6.2 & 6.7217 & TRN \\
\hline CHEMBL1979773 & 809175 & 4.8 & 5.0421 & TRN \\
\hline
\end{tabular}




\begin{tabular}{|c|c|c|c|c|}
\hline & & & ient & al Ta \\
\hline CHEMBL1977346 & 809175 & 6.7 & 6.0041 & TRN \\
\hline CHEMBL 2003657 & 809175 & 4.2 & 4.5943 & TRN \\
\hline CHEMBL1971649 & 809175 & 4.8 & 5.0864 & TRN \\
\hline CHEMBL1992723 & 809175 & 3.2 & 4.1906 & TRN \\
\hline CHEMBL1996702 & 809175 & 4.8 & 5.244 & TRN \\
\hline CHEMBL 2007124 & 809175 & 4.8 & 5.1994 & TRN \\
\hline CHEMBL1995068 & 809175 & 7.1 & 6.615 & TRN \\
\hline CHEMBL 2006439 & 809175 & 4.8 & 4.6336 & TRN \\
\hline CHEMBL1985681 & 809175 & 5.8 & 5.3686 & TST \\
\hline CHEMBL1969190 & 809175 & 7.3 & 6.5315 & TRN \\
\hline CHEMBL1973937 & 809175 & 6.4 & 6.3081 & TRN \\
\hline CHEMBL1982711 & 809175 & 4.8 & 5.3152 & TRN \\
\hline CHEMBL1989505 & 809175 & 7.1 & 6.8647 & TRN \\
\hline CHEMBL262623 & 809175 & 5.1 & 4.9427 & TRN \\
\hline CHEMBL1984842 & 809175 & 4.4 & 4.6116 & TRN \\
\hline CHEMBL1969102 & 809175 & 7.6 & 7.6105 & TRN \\
\hline CHEMBL 2004118 & 809175 & 6.0 & 5.4891 & TRN \\
\hline CHEMBL1682346 & 809175 & 6.6 & 5.9777 & TRN \\
\hline CHEMBL 2007044 & 809175 & 4.4 & 4.8992 & TST \\
\hline CHEMBL 2001998 & 809175 & 6.2 & 5.4367 & TST \\
\hline CHEMBL1994241 & 809175 & 4.8 & 5.4823 & TRN \\
\hline CHEMBL 223460 & 809175 & 4.4 & 4.7079 & TST \\
\hline CHEMBL1998829 & 809175 & 4.8 & 4.39 & TRN \\
\hline CHEMBL50894 & 809175 & 4.7 & 4.8182 & TRN \\
\hline CHEMBL1995211 & 809175 & 4.8 & 5.2361 & TRN \\
\hline CHEMBL1988838 & 809175 & 7.6 & 7.1456 & TRN \\
\hline CHEMBL1981725 & 809175 & 7.5 & 7.3935 & TRN \\
\hline CHEMBL375284 & 809175 & 5.9 & 5.5596 & TRN \\
\hline CHEMBL2006299 & 809175 & 4.8 & 4.4513 & TRN \\
\hline CHEMBL1965169 & 809175 & 4.8 & 5.5742 & TST \\
\hline CHEMBL1081312 & 809175 & 4.8 & 5.6037 & TRN \\
\hline CHEMBL1965170 & 809175 & 8.7 & 7.6663 & TRN \\
\hline CHEMBL1982866 & 809175 & 4.8 & 4.3128 & TRN \\
\hline CHEMBL 2005792 & 809175 & 4.4 & 4.6464 & TRN \\
\hline CHEMBL1984206 & 809175 & 4.2 & 4.5514 & TRN \\
\hline CHEMBL462120 & 809175 & 4.4 & 4.6352 & TST \\
\hline CHEMBL1991577 & 809175 & 4.2 & 4.632 & TRN \\
\hline CHEMBL1991867 & 809175 & 4.6 & 4.2148 & TST \\
\hline CHEMBL1965570 & 809175 & 8.0 & 7.4516 & TRN \\
\hline CHEMBL 2007592 & 809175 & 4.4 & 4.453 & TRN \\
\hline CHEMBL1972355 & 809175 & 6.6 & 6.0862 & TST \\
\hline CHEMBL1997892 & 809175 & 4.8 & 4.9834 & TRN \\
\hline CHEMBL2001641 & 809175 & 4.6 & 4.7825 & TRN \\
\hline CHEMBL1997193 & 809175 & 5.8 & 5.7473 & TST \\
\hline CHEMBL210963 & 809175 & 4.4 & 4.1704 & TRN \\
\hline CHEMBL1964902 & 809175 & 4.8 & 4.5424 & TRN \\
\hline CHEMBL1082440 & 809175 & 6.4 & 6.3205 & TST \\
\hline CHEMBL1614705 & 809175 & 4.4 & 4.3453 & TST \\
\hline
\end{tabular}




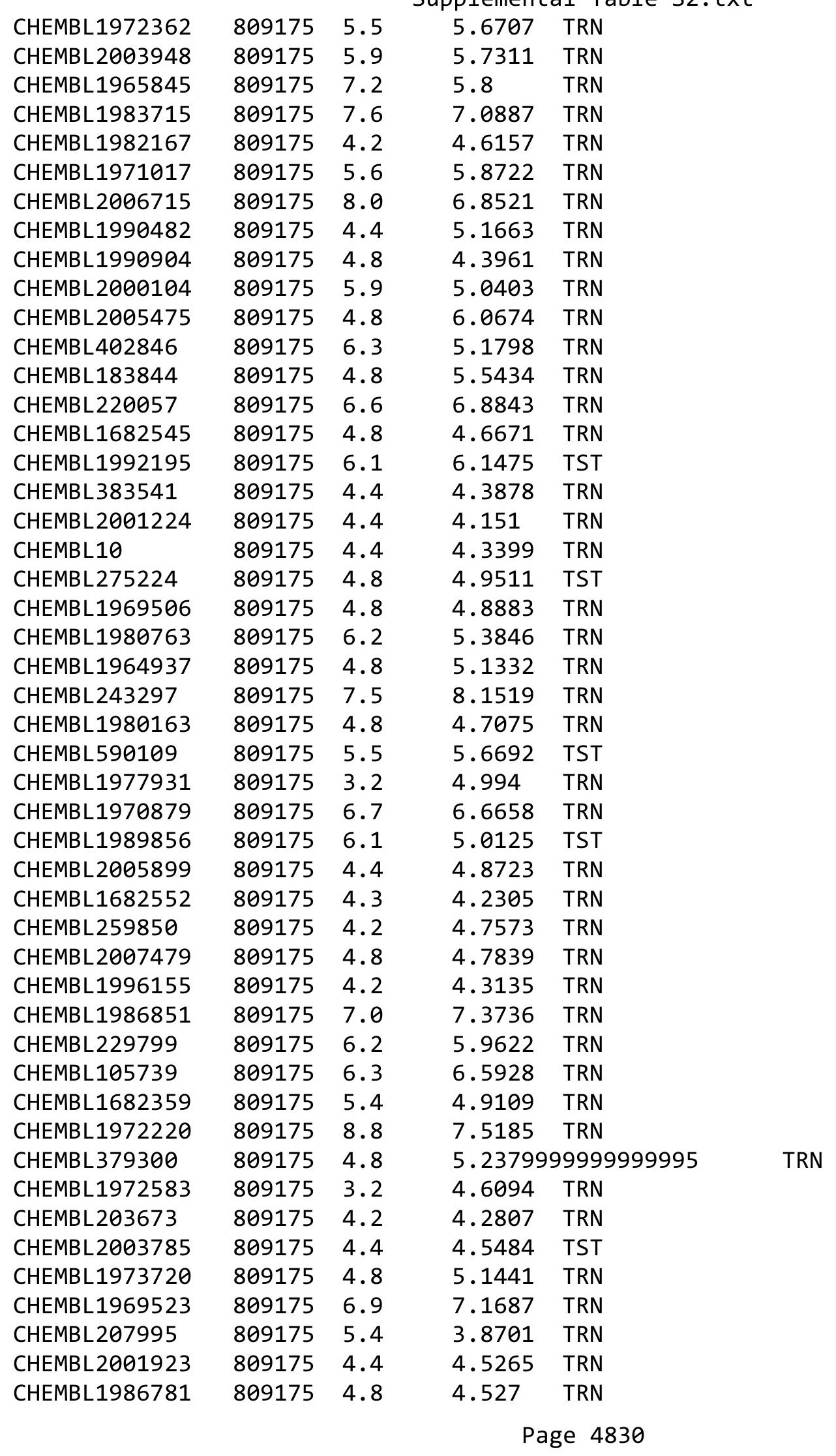




\begin{tabular}{|c|c|c|c|c|c|}
\hline \\
\hline CHEMBL1983070 & 809175 & 4.8 & 5.2409 & TRN & \\
\hline CHEMBL526133 & 809175 & 4.8 & 5.1607 & TRN & \\
\hline CHEMBL 2003514 & 809175 & 4.8 & 4.3505 & TRN & \\
\hline CHEMBL1989043 & 809175 & 4.8 & 4.7495 & TRN & \\
\hline CHEMBL1967538 & 809175 & 3.2 & 3.7658 & TST & \\
\hline CHEMBL1979057 & 809175 & 7.4 & 6.4482 & TRN & \\
\hline CHEMBL1981045 & 809175 & 4.2 & 4.6938 & TRN & \\
\hline CHEMBL387971 & 809175 & 5.6 & 5.3346 & TST & \\
\hline CHEMBL1975418 & 809175 & 7.2 & 5.8216 & TRN & \\
\hline CHEMBL1992796 & 809175 & 4.2 & 4.604 & TST & \\
\hline CHEMBL1968515 & 809175 & 3.2 & 4.7261 & TST & \\
\hline CHEMBL1164180 & 809175 & 6.0 & 5.7392 & TST & \\
\hline CHEMBL1974408 & 809175 & 7.2 & 5.6724 & TRN & \\
\hline CHEMBL223257 & 809175 & 4.2 & 4.4643 & TST & \\
\hline CHEMBL1999428 & 809175 & 4.8 & 4.6922 & TRN & \\
\hline CHEMBL1967560 & 809175 & 4.4 & 4.3096 & TRN & \\
\hline CHEMBL1516890 & 809175 & 6.6 & 6.0778 & TRN & \\
\hline CHEMBL211378 & 809175 & 5.0 & 5.6594 & TRN & \\
\hline CHEMBL1982465 & 809175 & 7.5 & 7.6245 & TRN & \\
\hline CHEMBL 2001751 & 809175 & 4.8 & 5.8747 & TRN & \\
\hline CHEMBL1984586 & 809175 & 7.2 & 6.943 & TRN & \\
\hline CHEMBL1999774 & 809175 & 4.2 & 4.3177 & TST & \\
\hline CHEMBL1972659 & 809175 & 4.4 & 4.4872 & TST & \\
\hline CHEMBL 2002723 & 809175 & 5.8 & 5.5313 & TST & \\
\hline CHEMBL1973395 & 809175 & 6.8 & 6.1581 & TRN & \\
\hline CHEMBL 272453 & 809175 & 6.0 & 6.11299 & 99999999995 & TRN \\
\hline CHEMBL1970217 & 809175 & 4.8 & 4.4746 & TRN & \\
\hline CHEMBL1971801 & 809175 & 5.7 & 5.6395 & TRN & \\
\hline CHEMBL1968850 & 809175 & 6.1 & 5.7081 & TRN & \\
\hline CHEMBL 2005528 & 809175 & 4.8 & 5.4465 & TST & \\
\hline CHEMBL185569 & 809175 & 6.9 & 6.63299 & 9999999999 & TRN \\
\hline CHEMBL1969843 & 809175 & 4.8 & 4.7146 & TRN & \\
\hline CHEMBL 2007002 & 809175 & 4.8 & 4.8736 & TRN & \\
\hline CHEMBL1987007 & 809175 & 4.8 & 5.0679 & TRN & \\
\hline CHEMBL1973793 & 809175 & 4.7 & 5.9858 & TRN & \\
\hline CHEMBL1992935 & 809175 & 4.7 & 5.6148 & TRN & \\
\hline CHEMBL1969588 & 809175 & 4.8 & 6.1235 & TRN & \\
\hline CHEMBL1984711 & 809175 & 6.2 & 6.4681 & TRN & \\
\hline CHEMBL1981183 & 809175 & 6.0 & 5.761 & TST & \\
\hline CHEMBL1992073 & 809175 & 5.9 & 5.3479 & TRN & \\
\hline CHEMBL1990212 & 809175 & 4.2 & 4.511 & TRN & \\
\hline CHEMBL484390 & 809175 & 4.8 & 5.2455 & TST & \\
\hline CHEMBL1979252 & 809175 & 4.8 & 4.9003 & TRN & \\
\hline CHEMBL1986143 & 809175 & 4.8 & 4.4788 & TRN & \\
\hline CHEMBL1972934 & 809175 & 4.7 & 4.8375 & TRN & \\
\hline CHEMBL 2007559 & 809175 & 4.8 & 4.9005 & TRN & \\
\hline CHEMBL1992581 & 809175 & 4.8 & 4.9804 & TRN & \\
\hline CHEMBL1682341 & 809175 & 5.9 & 5.3297 & TRN & \\
\hline
\end{tabular}




\begin{tabular}{|c|c|c|c|c|}
\hline & & & CII & al Ta \\
\hline CHEMBL 2004290 & 809175 & 8.2 & 7.6924 & TRN \\
\hline CHEMBL1972937 & 809175 & 4.8 & 4.5363 & TRN \\
\hline CHEMBL1972250 & 809175 & 6.1 & 5.0564 & TST \\
\hline CHEMBL 2000393 & 809175 & 8.0 & 6.2238 & TST \\
\hline CHEMBL1993510 & 809175 & 6.3 & 6.277 & TRN \\
\hline CHEMBL 2004072 & 809175 & 4.2 & 5.5755 & TRN \\
\hline CHEMBL1983573 & 809175 & 3.5 & 5.0449 & TRN \\
\hline CHEMBL 2004311 & 809175 & 6.2 & 5.9961 & TRN \\
\hline CHEMBL1992634 & 809175 & 6.5 & 5.9936 & TRN \\
\hline CHEMBL1242373 & 809175 & 7.1 & 6.5852 & TRN \\
\hline CHEMBL 2000433 & 809175 & 5.3 & 5.103 & TST \\
\hline CHEMBL1985433 & 809175 & 6.4 & 6.1589 & TRN \\
\hline CHEMBL1984847 & 809175 & 4.8 & 5.3326 & TST \\
\hline CHEMBL1984402 & 809175 & 3.2 & 4.4992 & TST \\
\hline CHEMBL316264 & 809175 & 4.8 & 4.3252 & TRN \\
\hline CHEMBL1988075 & 809175 & 7.2 & 7.7309 & TRN \\
\hline CHEMBL1996576 & 809175 & 4.8 & 4.8472 & TST \\
\hline CHEMBL1991678 & 809175 & 4.7 & 4.4868 & TRN \\
\hline CHEMBL2001239 & 809175 & 4.4 & 5.2988 & TRN \\
\hline CHEMBL 2001288 & 809175 & 4.8 & 4.7326 & TRN \\
\hline CHEMBL 260092 & 809175 & 7.7 & 7.1347 & TRN \\
\hline CHEMBL1999811 & 809175 & 4.8 & 5.4697 & TRN \\
\hline CHEMBL1965495 & 809175 & 6.6 & 6.1637 & TRN \\
\hline CHEMBL235157 & 809175 & 4.8 & 5.2843 & TST \\
\hline CHEMBL1985074 & 809175 & 4.8 & 4.9191 & TST \\
\hline CHEMBL1982874 & 809175 & 5.9 & 4.7201 & TRN \\
\hline CHEMBL1991725 & 809175 & 4.8 & 4.7986 & TRN \\
\hline CHEMBL1992242 & 809175 & 4.4 & 4.8312 & TRN \\
\hline CHEMBL208637 & 809175 & 4.4 & 4.1716 & TRN \\
\hline CHEMBL 2004159 & 809175 & 4.8 & 4.4193 & TRN \\
\hline CHEMBL 2007138 & 809175 & 4.8 & 4.9123 & TRN \\
\hline CHEMBL1978371 & 809175 & 6.5 & 5.7072 & TST \\
\hline CHEMBL1970203 & 809175 & 8.6 & 7.651 & TRN \\
\hline CHEMBL1986530 & 809175 & 4.8 & 5.1767 & TST \\
\hline CHEMBL440084 & 809175 & 4.8 & 5.3028 & TRN \\
\hline CHEMBL1968590 & 809175 & 4.8 & 6.0887 & TRN \\
\hline CHEMBL1999749 & 809175 & 4.2 & 4.3193 & TRN \\
\hline CHEMBL 2005375 & 809175 & 4.8 & 4.238 & TRN \\
\hline CHEMBL1984191 & 809175 & 4.8 & 4.3031 & TRN \\
\hline CHEMBL1983006 & 809175 & 5.5 & 4.0327 & TRN \\
\hline CHEMBL1971029 & 809175 & 7.7 & 6.8759 & TRN \\
\hline CHEMBL1995391 & 809175 & 3.8 & 5.1057 & TRN \\
\hline CHEMBL394790 & 809175 & 6.7 & 6.3792 & TRN \\
\hline CHEMBL 226471 & 809175 & 4.4 & 5.8229 & TST \\
\hline CHEMBL1974702 & 809175 & 5.8 & 5.1254 & TST \\
\hline CHEMBL1996111 & 809175 & 6.8 & 5.678 & TRN \\
\hline CHEMBL1966175 & 809175 & 4.8 & 5.1023 & TRN \\
\hline CHEMBL1965589 & 809175 & 4.8 & 4.5131 & TRN \\
\hline
\end{tabular}




\begin{tabular}{|c|c|c|c|c|c|}
\hline \\
\hline CHEMBL 2007375 & 809175 & 4.8 & 4.4719 & TRN & \\
\hline CHEMBL379975 & 809175 & 4.8 & 5.1467 & TST & \\
\hline CHEMBL474432 & 809175 & 6.1 & 6.9352 & TRN & \\
\hline CHEMBL1965387 & 809175 & 4.8 & 5.2617 & TRN & \\
\hline CHEMBL2001539 & 809175 & 4.5 & 4.1789 & TST & \\
\hline CHEMBL1997041 & 809175 & 5.0 & 5.061 & TRN & \\
\hline CHEMBL1970534 & 809175 & 6.1 & 5.6897 & TRN & \\
\hline CHEMBL1988153 & 809175 & 4.8 & 4.272 & TRN & \\
\hline CHEMBL1487428 & 809175 & 4.8 & 4.5237 & TRN & \\
\hline CHEMBL550418 & 809175 & 4.8 & 5.0168 & TRN & \\
\hline CHEMBL1972584 & 809175 & 8.1 & 7.6015 & TRN & \\
\hline CHEMBL1971289 & 809175 & 4.8 & 4.7891 & TRN & \\
\hline CHEMBL1999556 & 809175 & 5.6 & 5.7084 & TRN & \\
\hline CHEMBL1988437 & 809175 & 7.8 & 6.9022 & TRN & \\
\hline CHEMBL1968245 & 809175 & 4.2 & 4.8409 & TRN & \\
\hline CHEMBL1979577 & 809175 & 7.3 & 7.352 & TRN & \\
\hline CHEMBL1998121 & 809175 & 4.8 & 5.20299 & 9999999999 & TRN \\
\hline CHEMBL1233887 & 809175 & 4.8 & 6.1828 & TST & \\
\hline CHEMBL1991800 & 809175 & 4.4 & 4.7802 & TRN & \\
\hline CHEMBL52387 & 809175 & 4.4 & 4.3845 & TST & \\
\hline CHEMBL1985566 & 809175 & 5.4 & 4.4503 & TRN & \\
\hline CHEMBL379835 & 809175 & 4.4 & 5.2551 & TST & \\
\hline CHEMBL1969284 & 809175 & 5.8 & 6.0875 & TRN & \\
\hline CHEMBL1979357 & 809175 & 4.8 & 4.8724 & TRN & \\
\hline CHEMBL1980802 & 809175 & 4.2 & 4.5396 & TST & \\
\hline CHEMBL1996649 & 809175 & 7.7 & 7.8414 & TRN & \\
\hline CHEMBL1996817 & 809175 & 5.1 & 6.07 & TRN & \\
\hline CHEMBL1979554 & 809175 & 4.2 & 4.8832 & TRN & \\
\hline CHEMBL1986756 & 809175 & 4.8 & 4.4587 & TRN & \\
\hline CHEMBL 2004355 & 809175 & 5.2 & 4.5393 & TRN & \\
\hline CHEMBL468280 & 809175 & 4.5 & 4.4269 & TST & \\
\hline CHEMBL1990884 & 809175 & 4.8 & 5.3404 & TRN & \\
\hline CHEMBL 3109278 & 809175 & 5.2 & 6.1533 & TRN & \\
\hline CHEMBL256835 & 809175 & 4.6 & 4.2905 & TRN & \\
\hline CHEMBL1980142 & 809175 & 5.9 & 4.4016 & TRN & \\
\hline CHEMBL41783 & 809175 & 4.8 & 4.2984 & TRN & \\
\hline CHEMBL 2004438 & 809175 & 4.8 & 5.2502 & TRN & \\
\hline CHEMBL 2006276 & 809175 & 4.8 & 4.4872 & TRN & \\
\hline CHEMBL191003 & 809175 & 7.3 & 6.6998 & TRN & \\
\hline CHEMBL271381 & 809175 & 6.9 & 6.4848 & TRN & \\
\hline CHEMBL 2006785 & 809175 & 4.8 & 4.3893 & TST & \\
\hline CHEMBL1982466 & 809175 & 8.0 & 7.6387 & TRN & \\
\hline CHEMBL1973359 & 809175 & 6.9 & 5.9835 & TST & \\
\hline CHEMBL1995740 & 809175 & 4.4 & 5.0005 & TRN & \\
\hline CHEMBL1996390 & 809175 & 6.0 & 5.6877 & TRN & \\
\hline CHEMBL1979690 & 809175 & 7.7 & 7.2572 & TRN & \\
\hline CHEMBL 234085 & 809175 & 4.8 & 4.8255 & TRN & \\
\hline CHEMBL1998414 & 809175 & 6.2 & 5.4948 & TRN & \\
\hline & & & & 1833 & \\
\hline
\end{tabular}




\begin{tabular}{|c|c|c|c|c|}
\hline & & & pplement & al Ta \\
\hline CHEMBL1995832 & 809175 & 4.8 & 4.7807 & TRN \\
\hline CHEMBL1969042 & 809175 & 4.8 & 5.419 & TRN \\
\hline CHEMBL 2005714 & 809175 & 6.1 & 6.1767 & TRN \\
\hline CHEMBL 2000345 & 809175 & 4.9 & 5.5887 & TRN \\
\hline CHEMBL1999931 & 809175 & 6.8 & 6.1781 & TRN \\
\hline CHEMBL1976376 & 809175 & 4.8 & 5.3564 & TRN \\
\hline CHEMBL1991640 & 809175 & 5.4 & 4.525 & TST \\
\hline CHEMBL1988622 & 809175 & 3.2 & 4.6651 & TRN \\
\hline CHEMBL1983575 & 809175 & 7.3 & 6.5344 & TRN \\
\hline CHEMBL 2006873 & 809175 & 4.7 & 5.5553 & TRN \\
\hline CHEMBL1968868 & 809175 & 4.8 & 4.5324 & TRN \\
\hline CHEMBL 302449 & 809175 & 7.5 & 6.7168 & TST \\
\hline CHEMBL 2007064 & 809175 & 7.8 & 7.4645 & TRN \\
\hline CHEMBL1981047 & 809175 & 8.1 & 6.6013 & TRN \\
\hline CHEMBL229968 & 809175 & 6.0 & 5.6211 & TRN \\
\hline CHEMBL1976196 & 809175 & 4.8 & 5.5413 & TST \\
\hline CHEMBL1976240 & 809175 & 4.8 & 4.8117 & TRN \\
\hline CHEMBL1997197 & 809175 & 4.8 & 4.6604 & TRN \\
\hline CHEMBL1983630 & 809175 & 4.7 & 4.5897 & TRN \\
\hline CHEMBL1979093 & 809175 & 7.0 & 6.107 & TRN \\
\hline CHEMBL1968151 & 809175 & 4.8 & 4.3109 & TRN \\
\hline CHEMBL1381197 & 809175 & 4.2 & 4.4531 & TRN \\
\hline CHEMBL1973795 & 809175 & 3.2 & 4.7121 & TRN \\
\hline CHEMBL1987009 & 809175 & 7.3 & 6.5496 & TRN \\
\hline CHEMBL379218 & 809175 & 5.3 & 5.3701 & TRN \\
\hline CHEMBL 2003817 & 809175 & 4.5 & 5.4543 & TRN \\
\hline CHEMBL336961 & 809175 & 4.2 & 4.5025 & TRN \\
\hline CHEMBL1994830 & 809175 & 4.8 & 4.3315 & TRN \\
\hline CHEMBL1987054 & 809175 & 8.1 & 7.6429 & TRN \\
\hline CHEMBL1970083 & 809175 & 7.0 & 7.6668 & TRN \\
\hline CHEMBL226403 & 809175 & 5.0 & 6.0745 & TST \\
\hline CHEMBL1977652 & 809175 & 6.2 & 6.176 & TRN \\
\hline CHEMBL1976530 & 809175 & 5.9 & 5.7353 & TRN \\
\hline CHEMBL243749 & 809175 & 8.3 & 7.8346 & TRN \\
\hline CHEMBL 2005631 & 809175 & 8.2 & 7.8036 & TRN \\
\hline CHEMBL1994938 & 809175 & 4.8 & 6.272 & TRN \\
\hline CHEMBL1977223 & 809175 & 6.3 & 4.98 & TRN \\
\hline CHEMBL1995765 & 809175 & 5.1 & 4.9155 & TST \\
\hline CHEMBL1976290 & 809175 & 3.2 & 4.6992 & TRN \\
\hline CHEMBL1236126 & 809175 & 4.4 & 4.5473 & TST \\
\hline CHEMBL1997846 & 809175 & 4.8 & 5.0759 & TRN \\
\hline CHEMBL1984760 & 809175 & 5.8 & 5.4733 & TRN \\
\hline CHEMBL2004419 & 809175 & 4.8 & 4.3476 & TRN \\
\hline CHEMBL1991728 & 809175 & 5.3 & 5.3954 & TRN \\
\hline CHEMBL 360847 & 809175 & 4.8 & 4.7174 & TST \\
\hline CHEMBL1995811 & 809175 & 4.8 & 4.8186 & TRN \\
\hline CHEMBL1975787 & 809175 & 5.6 & 5.5966 & TRN \\
\hline CHEMBL1995916 & 809175 & 3.2 & 4.6678 & TRN \\
\hline
\end{tabular}




\begin{tabular}{|c|c|c|c|c|}
\hline & & & 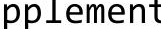 & al Ta \\
\hline CHEMBL 2002407 & 809175 & 5.4 & 5.0575 & TRN \\
\hline CHEMBL1972489 & 809175 & 4.8 & 4.3628 & TRN \\
\hline CHEMBL1994074 & 809175 & 4.8 & 5.0239 & TRN \\
\hline CHEMBL1992937 & 809175 & 4.9 & 5.3731 & TST \\
\hline CHEMBL451401 & 809175 & 4.5 & 4.6359 & TRN \\
\hline CHEMBL1972119 & 809175 & 4.8 & 4.5797 & TRN \\
\hline CHEMBL1986328 & 809175 & 4.8 & 5.5406 & TST \\
\hline CHEMBL95692 & 809175 & 4.4 & 4.2981 & TRN \\
\hline CHEMBL1090356 & 809175 & 6.2 & 5.9288 & TRN \\
\hline CHEMBL 2002450 & 809175 & 3.3 & 4.6277 & TRN \\
\hline CHEMBL1976455 & 809175 & 5.7 & 5.3515 & TRN \\
\hline CHEMBL261849 & 809175 & 4.8 & 4.9616 & TST \\
\hline CHEMBL1983923 & 809175 & 7.8 & 7.0023 & TRN \\
\hline CHEMBL1983534 & 809175 & 4.8 & 4.9403 & TRN \\
\hline CHEMBL1982361 & 809175 & 4.8 & 5.0173 & TRN \\
\hline CHEMBL1999112 & 809175 & 4.8 & 5.6313 & TST \\
\hline CHEMBL1982122 & 809175 & 4.8 & 4.9279 & TRN \\
\hline CHEMBL 2000801 & 809175 & 4.8 & 5.0782 & TRN \\
\hline CHEMBL1682546 & 809175 & 4.7 & 4.8731 & TRN \\
\hline CHEMBL1991395 & 809175 & 4.5 & 4.5302 & TRN \\
\hline CHEMBL1971245 & 809175 & 4.8 & 6.0019 & TRN \\
\hline CHEMBL1991915 & 809175 & 7.6 & 5.9471 & TST \\
\hline CHEMBL1987648 & 809175 & 4.2 & 4.5978 & TRN \\
\hline CHEMBL1996780 & 809175 & 4.2 & 4.2532 & TST \\
\hline CHEMBL1988769 & 809175 & 6.9 & 7.3114 & TRN \\
\hline CHEMBL1972142 & 809175 & 4.8 & 5.513 & TRN \\
\hline CHEMBL1966514 & 809175 & 7.3 & 7.8463 & TRN \\
\hline CHEMBL 2003638 & 809175 & 6.9 & 5.9916 & TRN \\
\hline CHEMBL 296586 & 809175 & 5.9 & 4.7957 & TRN \\
\hline CHEMBL1996066 & 809175 & 4.8 & 6.0949 & TST \\
\hline CHEMBL1983393 & 809175 & 4.8 & 4.942 & TRN \\
\hline CHEMBL516429 & 809175 & 4.2 & 5.2097 & TRN \\
\hline CHEMBL1999910 & 809175 & 4.7 & 6.3305 & TRN \\
\hline CHEMBL1993722 & 809175 & 6.5 & 6.7472 & TRN \\
\hline CHEMBL1970806 & 809175 & 4.5 & 4.3542 & TRN \\
\hline CHEMBL 2006674 & 809175 & 4.8 & 4.614 & TST \\
\hline CHEMBL1984236 & 809175 & 4.8 & 4.6328 & TST \\
\hline CHEMBL1992371 & 809175 & 4.8 & 5.0173 & TRN \\
\hline CHEMBL1375640 & 809175 & 4.8 & 5.5511 & TRN \\
\hline CHEMBL1979970 & 809175 & 4.6 & 4.355 & TRN \\
\hline CHEMBL2002599 & 809175 & 4.8 & 4.9608 & TRN \\
\hline CHEMBL 249282 & 809175 & 4.9 & 5.0471 & TST \\
\hline CHEMBL1967252 & 809175 & 4.8 & 4.7422 & TST \\
\hline CHEMBL1993966 & 809175 & 7.3 & 6.7341 & TST \\
\hline CHEMBL 2004637 & 809175 & 4.8 & 5.1146 & TST \\
\hline CHEMBL1993374 & 809175 & 4.8 & 4.9793 & TST \\
\hline CHEMBL1969264 & 809175 & 5.7 & 5.8006 & TST \\
\hline CHEMBL1973711 & 809175 & 5.6 & 4.9611 & TST \\
\hline
\end{tabular}




\begin{tabular}{|c|c|c|c|c|}
\hline & & & pplement & $d \pm$ \\
\hline CHEMBL 2006237 & 809175 & 4.4 & 4.7256 & TST \\
\hline CHEMBL1967720 & 809175 & 8.5 & 8.0024 & TST \\
\hline CHEMBL1991138 & 809175 & 4.4 & 5.0269 & TST \\
\hline CHEMBL1969755 & 809175 & 4.4 & 4.4288 & TST \\
\hline CHEMBL1979516 & 809175 & 8.7 & 7.7458 & TST \\
\hline CHEMBL1605605 & 809175 & 4.8 & 4.3501 & TST \\
\hline CHEMBL1989029 & 809175 & 6.3 & 5.49 & TST \\
\hline CHEMBL392642 & 809175 & 4.8 & 4.6787 & TST \\
\hline CHEMBL514499 & 809175 & 4.4 & 5.7721 & TST \\
\hline CHEMBL1970352 & 809175 & 6.2 & 5.1007 & TST \\
\hline CHEMBL1965631 & 809175 & 4.8 & 4.9273 & TST \\
\hline CHEMBL1980144 & 809175 & 8.2 & 7.7334 & TST \\
\hline CHEMBL1980167 & 809175 & 6.3 & 6.2252 & TST \\
\hline CHEMBL 377408 & 809175 & 4.2 & 4.2447 & TST \\
\hline CHEMBL 215152 & 809175 & 6.5 & 5.1032 & TST \\
\hline CHEMBL231209 & 809175 & 6.3 & 6.5747 & TST \\
\hline CHEMBL1976220 & 809175 & 6.9 & 6.6736 & TST \\
\hline CHEMBL2006765 & 809175 & 6.7 & 5.9959 & TST \\
\hline CHEMBL259922 & 809175 & 4.4 & 4.4206 & TST \\
\hline CHEMBL1997617 & 809175 & 4.9 & 5.9406 & TST \\
\hline CHEMBL1969301 & 809175 & 4.8 & 5.1577 & TST \\
\hline CHEMBL1982383 & 809175 & 4.8 & 4.9743 & TST \\
\hline CHEMBL17370 & 809175 & 4.8 & 4.5188 & TST \\
\hline CHEMBL1980246 & 809175 & 4.8 & 5.2397 & TST \\
\hline CHEMBL1987910 & 809175 & 4.8 & 6.6298 & TST \\
\hline CHEMBL1983932 & 809175 & 4.8 & 5.682 & TST \\
\hline CHEMBL1983980 & 809175 & 6.7 & 5.7639 & TST \\
\hline CHEMBL487402 & 809175 & 6.0 & 5.6513 & TST \\
\hline CHEMBL1999484 & 809175 & 6.9 & 6.8162 & TST \\
\hline CHEMBL1973399 & 809175 & 3.2 & 4.6209 & TST \\
\hline CHEMBL1966069 & 809175 & 5.5 & 5.3875 & TST \\
\hline CHEMBL1986899 & 809175 & 6.5 & 5.6976 & TST \\
\hline CHEMBL1991285 & 809175 & 4.6 & 4.3114 & TST \\
\hline CHEMBL1997822 & 809175 & 5.4 & 5.9238 & TST \\
\hline CHEMBL 243088 & 809175 & 7.9 & 8.4518 & TST \\
\hline CHEMBL1984038 & 809175 & 4.8 & 4.7837 & TST \\
\hline CHEMBL1993661 & 809175 & 8.3 & 7.471 & TST \\
\hline CHEMBL1974416 & 809175 & 4.8 & 4.3426 & TST \\
\hline CHEMBL1834385 & 809175 & 4.8 & 4.8772 & TST \\
\hline CHEMBL 358020 & 63369 & 7.2596 & 7.2455 & TRN \\
\hline CHEMBL347982 & 63369 & 7.7696 & 8.0103 & TRN \\
\hline CHEMBL348685 & 63369 & 7.4089 & 7.5604 & TRN \\
\hline CHEMBL421955 & 63369 & 8.301 & 7.6301 & TRN \\
\hline CHEMBL 348700 & 63369 & 7.301 & 7.3223 & TRN \\
\hline CHEMBL149391 & 63369 & 6.301 & 6.415 & TRN \\
\hline CHEMBL345551 & 63369 & 7.0969 & 7.2369 & TRN \\
\hline CHEMBL356972 & 63369 & 5.4089 & 5.8871 & TST \\
\hline CHEMBL422851 & 63369 & 8.0969 & 7.6575 & TRN \\
\hline
\end{tabular}




\begin{tabular}{|c|c|c|c|c|c|}
\hline \multicolumn{6}{|c|}{ Supplemental Table S2.txt } \\
\hline CHEMBL146904 & 63369 & 7.0 & 7.2477 & TRN & \\
\hline CHEMBL359152 & 63369 & 6.4318 & 6.269 & TRN & \\
\hline CHEMBL422496 & 63369 & 7.4815 & 6.9805 & TRN & \\
\hline CHEMBL151545 & 63369 & 5.4559 & 6.0428 & TST & \\
\hline CHEMBL149171 & 63369 & 5.8861 & 6.5846 & TRN & \\
\hline CHEMBL150697 & 63369 & 6.1549 & 5.6996 & TST & \\
\hline CHEMBL151422 & 63369 & 7.4685 & 7.92899 & 9999999999 & TRN \\
\hline CHEMBL150891 & 63369 & 7.3979 & 7.2226 & TRN & \\
\hline CHEMBL147081 & 63369 & 7.8539 & 8.058 & TRN & \\
\hline CHEMBL150273 & 63369 & 6.3979 & 6.1058 & TST & \\
\hline CHEMBL150474 & 63369 & 8.2007 & 8.047 & TRN & \\
\hline CHEMBL149152 & 63369 & 7.3768 & 6.5789 & TRN & \\
\hline CHEMBL151395 & 63369 & 6.4815 & 6.6528 & TRN & \\
\hline CHEMBL151926 & 63369 & 7.4318 & 7.5901 & TRN & \\
\hline CHEMBL149241 & 63369 & 7.2218 & 7.3882 & TRN & \\
\hline CHEMBL358545 & 63369 & 6.9586 & 7.1057 & TRN & \\
\hline CHEMBL151954 & 63369 & 5.1938 & 5.2168 & TRN & \\
\hline CHEMBL147007 & 63369 & 5.6778 & 5.6678 & TST & \\
\hline CHEMBL356220 & 63369 & 5.3565 & 5.2679 & TRN & \\
\hline CHEMBL149953 & 63369 & 7.5528 & 7.1266 & TRN & \\
\hline CHEMBL1269102 & 63369 & 7.3979 & 3.6727 & TST & \\
\hline CHEMBL151440 & 63369 & 8.699 & 8.2099 & TRN & \\
\hline CHEMBL357099 & 63369 & 6.2518 & 6.4463 & TRN & \\
\hline CHEMBL356618 & 63369 & 3.699 & 3.0409 & TRN & \\
\hline CHEMBL148853 & 63369 & 7.1308 & 7.3587 & TRN & \\
\hline CHEMBL150481 & 63369 & 5.6021 & 6.5618 & TRN & \\
\hline CHEMBL343867 & 63369 & 7.301 & 7.2622 & TRN & \\
\hline CHEMBL149060 & 63369 & 6.0132 & 6.2292 & TRN & \\
\hline CHEMBL423583 & 63369 & 7.0 & 7.6632 & TRN & \\
\hline CHEMBL149111 & 63369 & 5.8239 & 6.3663 & TRN & \\
\hline CHEMBL422128 & 63369 & 7.7959 & 7.2337 & TRN & \\
\hline CHEMBL151971 & 63369 & 7.2147 & 6.8771 & TRN & \\
\hline CHEMBL106684 & 63369 & 8.3279 & 7.9246 & TRN & \\
\hline CHEMBL 105490 & 63369 & 7.7447 & 7.3965 & TRN & \\
\hline CHEMBL78499 & 63369 & 5.3279 & 5.7851 & TRN & \\
\hline CHEMBL346853 & 63369 & 7.7696 & 7.8078 & TRN & \\
\hline CHEMBL357580 & 63369 & 6.8539 & 6.8294 & TST & \\
\hline CHEMBL358461 & 63369 & 6.2596 & 6.0372 & TRN & \\
\hline CHEMBL 347125 & 63369 & 7.4949 & 7.0065 & TRN & \\
\hline CHEMBL356591 & 63369 & 6.9508 & 6.6946 & TRN & \\
\hline CHEMBL149050 & 63369 & 6.9586 & 7.0444 & TRN & \\
\hline CHEMBL359332 & 63369 & 6.9872 & 6.5471 & TRN & \\
\hline CHEMBL151525 & 63369 & 5.1427 & 6.1254 & TRN & \\
\hline CHEMBL345542 & 63369 & 8.1938 & 8.3842 & TRN & \\
\hline CHEMBL358226 & 63369 & 6.7212 & 6.9749 & TRN & \\
\hline CHEMBL146845 & 63369 & 7.5376 & 8.0358 & TRN & \\
\hline CHEMBL148702 & 63369 & 5.2291 & 6.0738 & TRN & \\
\hline CHEMBL151160 & 63369 & 7.699 & 7.9123 & TRN & \\
\hline
\end{tabular}




\begin{tabular}{|c|c|c|c|c|}
\hline & & & pplement & a] \\
\hline CHEMBL 358254 & 63369 & 8.301 & 7.5348 & TRN \\
\hline CHEMBL150269 & 63369 & 5.5528 & 5.6979 & TRN \\
\hline CHEMBL 347958 & 63369 & 7.7959 & 6.9203 & TRN \\
\hline CHEMBL 357395 & 63369 & 7.699 & 7.4306 & TRN \\
\hline CHEMBL357823 & 63369 & 7.0506 & 7.1253 & TRN \\
\hline CHEMBL356901 & 63369 & 7.2676 & 7.3199 & TRN \\
\hline CHEMBL310427 & 63369 & 7.0458 & 6.4585 & TST \\
\hline CHEMBL149818 & 63369 & 7.3665 & 7.5735 & TST \\
\hline CHEMBL359167 & 63369 & 7.8539 & 6.6646 & TST \\
\hline CHEMBL147521 & 63369 & 6.7212 & 4.4476 & TST \\
\hline CHEMBL 343477 & 63369 & 5.2366 & 5.1105 & TST \\
\hline CHEMBL149819 & 63369 & 8.5686 & 6.7746 & TST \\
\hline CHEMBL424504 & 63369 & 7.2076 & 6.5286 & TST \\
\hline CHEMBL342498 & 63369 & 6.2218 & 6.4604 & TST \\
\hline CHEMBL 267458 & 63369 & 7.2596 & 5.9807 & TST \\
\hline CHEMBL148953 & 63369 & 5.9208 & 5.644 & TST \\
\hline CHEMBL434082 & 63369 & 7.8861 & 6.7898 & TST \\
\hline CHEMBL148757 & 63369 & 4.6198 & 5.2251 & TST \\
\hline CHEMBL1583713 & 688550 & 4.4 & 4.8218 & TRN \\
\hline CHEMBL1335730 & 688550 & 4.5 & 4.8766 & TRN \\
\hline CHEMBL1444565 & 688550 & 5.1 & 4.8813 & TRN \\
\hline CHEMBL1606993 & 688550 & 5.25 & 4.9282 & TRN \\
\hline CHEMBL1385074 & 688550 & 4.55 & 4.8311 & TRN \\
\hline CHEMBL1345816 & 688550 & 4.4 & 4.8562 & TST \\
\hline CHEMBL1420105 & 688550 & 4.5 & 4.9265 & TRN \\
\hline CHEMBL1411267 & 688550 & 4.6 & 4.9965 & TRN \\
\hline CHEMBL1365347 & 688550 & 4.85 & 4.8756 & TRN \\
\hline CHEMBL1452820 & 688550 & 4.4 & 4.8829 & TRN \\
\hline CHEMBL1344582 & 688550 & 5.1 & 4.7645 & TRN \\
\hline CHEMBL1570008 & 688550 & 5.1 & 4.7896 & TRN \\
\hline CHEMBL1588624 & 688550 & 5.15 & 5.0212 & TRN \\
\hline CHEMBL1431917 & 688550 & 4.5 & 4.912 & TRN \\
\hline CHEMBL1415407 & 688550 & 4.9 & 4.8615 & TRN \\
\hline CHEMBL469424 & 688550 & 5.4 & 4.8775 & TST \\
\hline CHEMBL1364777 & 688550 & 5.3 & 4.8967 & TST \\
\hline CHEMBL1462603 & 688550 & 5.7 & 4.7686 & TRN \\
\hline CHEMBL 2001433 & 688550 & 4.65 & 4.7972 & TRN \\
\hline CHEMBL1523263 & 688550 & 4.8 & 4.7769 & TST \\
\hline CHEMBL1478109 & 688550 & 6.9 & 4.9216 & TRN \\
\hline CHEMBL1414963 & 688550 & 4.5 & 4.8973 & TRN \\
\hline CHEMBL1366759 & 688550 & 4.4 & 4.8987 & TRN \\
\hline CHEMBL1567147 & 688550 & 4.55 & 4.985 & TRN \\
\hline CHEMBL3211672 & 688550 & 4.4 & 4.7809 & TRN \\
\hline CHEMBL1990093 & 688550 & 4.95 & 4.7561 & TRN \\
\hline CHEMBL1384014 & 688550 & 4.65 & 4.9099 & TRN \\
\hline CHEMBL3191940 & 688550 & 4.85 & 4.8691 & TST \\
\hline CHEMBL 1379686 & 688550 & 4.6 & 5.0069 & TRN \\
\hline CHEMBL1556151 & 688550 & 4.4 & 4.8906 & TRN \\
\hline
\end{tabular}




\begin{tabular}{|c|c|c|c|c|c|}
\hline \multicolumn{6}{|c|}{ Supplemental Table S2.txt } \\
\hline CHEMBL1430211 & 688550 & 4.5 & 4.9294 & TRN & \\
\hline CHEMBL1308961 & 688550 & 5.2 & 4.862 & TRN & \\
\hline CHEMBL1528095 & 688550 & 4.7 & 4.9229 & TRN & \\
\hline CHEMBL1456719 & 688550 & 4.45 & 4.8681 & TRN & \\
\hline CHEMBL1603691 & 688550 & 4.6 & 4.8457 & TRN & \\
\hline CHEMBL 1411280 & 688550 & 4.45 & 4.8496 & TRN & \\
\hline CHEMBL1439730 & 688550 & 4.8 & 4.7786 & TRN & \\
\hline CHEMBL1457597 & 688550 & 5.55 & 4.8576 & TRN & \\
\hline CHEMBL 3184468 & 688550 & 4.4 & 4.914 & TST & \\
\hline CHEMBL1299362 & 688550 & 4.4 & 4.8989 & TRN & \\
\hline CHEMBL1525076 & 688550 & 4.55 & 5.0193 & TRN & \\
\hline CHEMBL 3212373 & 688550 & 4.65 & 4.7716 & TRN & \\
\hline CHEMBL1494784 & 688550 & 4.4 & 4.9578 & TST & \\
\hline CHEMBL1423143 & 688550 & 5.3 & 5.0077 & TRN & \\
\hline CHEMBL1372330 & 688550 & 4.65 & 4.8656 & TRN & \\
\hline CHEMBL1563798 & 688550 & 4.75 & 4.9144 & TRN & \\
\hline CHEMBL1997899 & 688550 & 5.1 & 4.8114 & TRN & \\
\hline CHEMBL1529716 & 688550 & 4.65 & 4.855 & TRN & \\
\hline CHEMBL1404818 & 688550 & 4.8 & 4.9205 & TRN & \\
\hline CHEMBL1542422 & 688550 & 6.2 & 4.8971 & TRN & \\
\hline CHEMBL3212312 & 688550 & 5.0 & 4.8096 & TRN & \\
\hline CHEMBL1428462 & 688550 & 4.85 & 4.8687 & TRN & \\
\hline CHEMBL1383459 & 688550 & 4.65 & 4.8413 & TRN & \\
\hline CHEMBL1603125 & 688550 & 4.65 & 4.8694 & TRN & \\
\hline CHEMBL1585191 & 688550 & 4.65 & 4.7859 & TRN & \\
\hline CHEMBL1442224 & 688550 & 5.4 & 4.7449 & TRN & \\
\hline CHEMBL3191094 & 688550 & 4.8 & 4.7233 & TRN & \\
\hline CHEMBL1405264 & 688550 & 4.6 & 4.7484 & TRN & \\
\hline CHEMBL1562525 & 688550 & 4.85 & 4.9689 & TRN & \\
\hline CHEMBL1559930 & 688550 & 4.9 & 4.979 & TRN & \\
\hline CHEMBL1584572 & 688550 & 4.8 & 4.8552 & TRN & \\
\hline CHEMBL 1427752 & 688550 & 4.5 & 4.9471 & TST & \\
\hline CHEMBL1525300 & 688550 & 4.8 & 4.8173 & TRN & \\
\hline CHEMBL1532988 & 688550 & 4.45 & 4.9538 & TRN & \\
\hline CHEMBL1468300 & 688550 & 4.4 & 4.8479 & TRN & \\
\hline CHEMBL1417385 & 688550 & 4.4 & $4.9430 e$ & 00000000005 & TRN \\
\hline CHEMBL1340454 & 688550 & 5.9 & 4.8843 & TRN & \\
\hline CHEMBL1459594 & 688550 & 4.75 & 4.8934 & TRN & \\
\hline CHEMBL1454363 & 688550 & 4.5 & 4.8956 & TRN & \\
\hline CHEMBL1376192 & 688550 & 4.55 & 4.8613 & TRN & \\
\hline CHEMBL1404641 & 688550 & 4.4 & 4.9091 & TRN & \\
\hline CHEMBL607524 & 688550 & 4.45 & 4.9562 & TRN & \\
\hline CHEMBL1332291 & 688550 & 4.4 & 4.8318 & TRN & \\
\hline CHEMBL1338266 & 688550 & 5.7 & 4.8273 & TRN & \\
\hline CHEMBL154358 & 688550 & 4.5 & 4.9198 & TST & \\
\hline CHEMBL1474701 & 688550 & 4.75 & 4.8001 & TST & \\
\hline CHEMBL1595110 & 688550 & 4.85 & 4.8878 & TRN & \\
\hline CHEMBL1540929 & 688550 & 4.4 & 4.9125 & TRN & \\
\hline
\end{tabular}




\begin{tabular}{|c|c|c|c|c|}
\hline \multicolumn{5}{|c|}{ pplemental $\mathrm{T}$} \\
\hline CHEMBL1600668 & 688550 & 4.6 & 4.7715 & TRN \\
\hline CHEMBL1569080 & 688550 & 5.0 & 4.9954 & TRN \\
\hline CHEMBL1511141 & 688550 & 4.4 & 4.8899 & TST \\
\hline CHEMBL1344752 & 688550 & 4.6 & 5.0331 & TRN \\
\hline CHEMBL1447901 & 688550 & 4.6 & 4.8749 & TST \\
\hline CHEMBL1569222 & 688550 & 5.45 & 4.8234 & TRN \\
\hline CHEMBL1606558 & 688550 & 5.35 & 4.8246 & TRN \\
\hline CHEMBL1361919 & 688550 & 4.85 & 4.8873 & TRN \\
\hline CHEMBL1366110 & 688550 & 4.45 & 4.8784 & TST \\
\hline CHEMBL473314 & 688550 & 5.15 & 4.8282 & TRN \\
\hline CHEMBL1363706 & 688550 & 5.5 & 4.822 & TRN \\
\hline CHEMBL1504339 & 688550 & 4.55 & 4.9473 & TRN \\
\hline CHEMBL1517299 & 688550 & 4.8 & 4.8872 & TST \\
\hline CHEMBL1405082 & 688550 & 4.5 & 4.877 & TRN \\
\hline CHEMBL1604603 & 688550 & 6.8 & 4.8451 & TRN \\
\hline CHEMBL1311880 & 688550 & 5.4 & 5.0076 & TRN \\
\hline CHEMBL1331931 & 688550 & 4.85 & 4.9543 & TRN \\
\hline CHEMBL1303948 & 688550 & 4.95 & 4.8278 & TRN \\
\hline CHEMBL1311139 & 688550 & 4.55 & 4.8763 & TST \\
\hline CHEMBL1480601 & 688550 & 4.4 & 4.9686 & TRN \\
\hline CHEMBL1533351 & 688550 & 4.45 & 4.9027 & TRN \\
\hline CHEMBL3192009 & 688550 & 4.6 & 4.819 & TRN \\
\hline CHEMBL1437782 & 688550 & 5.7 & 4.8526 & TRN \\
\hline CHEMBL1540416 & 688550 & 4.4 & 4.8833 & TRN \\
\hline CHEMBL1423475 & 688550 & 4.4 & 4.8772 & TRN \\
\hline CHEMBL1532262 & 688550 & 4.45 & 4.8888 & TST \\
\hline CHEMBL1349769 & 688550 & 4.95 & 4.9025 & TRN \\
\hline CHEMBL1488194 & 688550 & 5.4 & 4.8441 & TST \\
\hline CHEMBL3195785 & 688550 & 4.95 & 4.7734 & TRN \\
\hline CHEMBL1459404 & 688550 & 5.35 & 4.9093 & TRN \\
\hline CHEMBL1533269 & 688550 & 5.3 & 4.8078 & TRN \\
\hline CHEMBL1500050 & 688550 & 4.5 & 4.913 & TST \\
\hline CHEMBL1368385 & 688550 & 5.3 & 4.9793 & TRN \\
\hline CHEMBL1449695 & 688550 & 5.35 & 5.024 & TRN \\
\hline CHEMBL1347052 & 688550 & 4.7 & 4.8951 & TRN \\
\hline CHEMBL1472108 & 688550 & 5.0 & 4.8425 & TRN \\
\hline CHEMBL1449846 & 688550 & 4.5 & 4.7836 & TRN \\
\hline CHEMBL1465995 & 688550 & 4.55 & 4.798 & TRN \\
\hline CHEMBL1507225 & 688550 & 4.7 & 4.7985 & TRN \\
\hline CHEMBL1549166 & 688550 & 4.5 & 4.9478 & TRN \\
\hline CHEMBL1400185 & 688550 & 4.4 & 4.8818 & TRN \\
\hline CHEMBL1384332 & 688550 & 4.4 & 4.851 & TRN \\
\hline CHEMBL1529307 & 688550 & 4.55 & 4.9117 & TRN \\
\hline CHEMBL1562605 & 688550 & 5.45 & 4.8061 & TRN \\
\hline CHEMBL3210746 & 688550 & 5.2 & 4.9779 & TRN \\
\hline CHEMBL1493066 & 688550 & 4.7 & 4.7781 & TRN \\
\hline CHEMBL1533950 & 688550 & 4.6 & 4.9913 & TRN \\
\hline CHEMBL1383322 & 688550 & 4.75 & 4.9162 & TRN \\
\hline
\end{tabular}




\begin{tabular}{|c|c|c|c|c|}
\hline \multicolumn{5}{|c|}{ Supplemental Table S2.txt } \\
\hline CHEMBL1492553 & 688550 & 4.5 & 4.8354 & TRN \\
\hline CHEMBL1499070 & 688550 & 4.6 & 4.8718 & TRN \\
\hline CHEMBL1599175 & 688550 & 4.45 & 4.8205 & TRN \\
\hline CHEMBL1425504 & 688550 & 4.6 & 4.8756 & TST \\
\hline CHEMBL1459938 & 688550 & 4.8 & 4.9565 & TRN \\
\hline CHEMBL1508240 & 688550 & 4.85 & 4.8159 & TRN \\
\hline CHEMBL1338606 & 688550 & 4.6 & 4.9166 & TST \\
\hline CHEMBL1518761 & 688550 & 4.45 & 4.9059 & TRN \\
\hline CHEMBL1390155 & 688550 & 4.4 & 4.7442 & TRN \\
\hline CHEMBL1561282 & 688550 & 4.4 & 4.7978 & TRN \\
\hline CHEMBL1481920 & 688550 & 4.4 & 5.0042 & TRN \\
\hline CHEMBL1399826 & 688550 & 5.45 & 4.9553 & TRN \\
\hline CHEMBL1302266 & 688550 & 4.9 & 4.8034 & TRN \\
\hline CHEMBL1333049 & 688550 & 4.75 & 4.7609 & TRN \\
\hline CHEMBL1536873 & 688550 & 5.35 & 5.0253 & TRN \\
\hline CHEMBL1431566 & 688550 & 4.75 & 4.7399 & TRN \\
\hline CHEMBL1978830 & 688550 & 4.85 & 4.8716 & TRN \\
\hline CHEMBL1536303 & 688550 & 4.9 & 4.9019 & TRN \\
\hline CHEMBL1452558 & 688550 & 6.25 & 4.9063 & TRN \\
\hline CHEMBL1339678 & 688550 & 4.8 & 4.7881 & TRN \\
\hline CHEMBL1489104 & 688550 & 4.55 & 4.8013 & TRN \\
\hline CHEMBL1345831 & 688550 & 4.45 & 4.8287 & TRN \\
\hline CHEMBL1312751 & 688550 & 4.45 & 4.8327 & TRN \\
\hline CHEMBL1443210 & 688550 & 5.65 & 4.7713 & TRN \\
\hline CHEMBL1466699 & 688550 & 4.55 & 4.8158 & TRN \\
\hline CHEMBL1427749 & 688550 & 4.75 & 4.9504 & TRN \\
\hline CHEMBL1543208 & 688550 & 4.7 & 5.0449 & TRN \\
\hline CHEMBL1426233 & 688550 & 4.95 & 4.8544 & TRN \\
\hline CHEMBL1612222 & 688550 & 4.55 & 4.9472 & TRN \\
\hline CHEMBL1430263 & 688550 & 4.85 & 4.9228 & TRN \\
\hline CHEMBL1483173 & 688550 & 4.85 & 4.838 & TRN \\
\hline CHEMBL1598011 & 688550 & 4.8 & 4.8181 & TRN \\
\hline CHEMBL1392244 & 688550 & 4.4 & 4.8177 & TRN \\
\hline CHEMBL1522734 & 688550 & 5.35 & 4.8716 & TST \\
\hline CHEMBL164103 & 688550 & 4.65 & 4.766 & TRN \\
\hline CHEMBL1509543 & 688550 & 5.0 & 4.8518 & TRN \\
\hline CHEMBL1538938 & 688550 & 4.7 & 4.8971 & TRN \\
\hline CHEMBL1588299 & 688550 & 5.45 & 4.7938 & TRN \\
\hline CHEMBL1578953 & 688550 & 5.0 & 4.7036 & TRN \\
\hline CHEMBL1446871 & 688550 & 4.4 & 4.8915 & TRN \\
\hline CHEMBL1417083 & 688550 & 4.4 & 4.7377 & TRN \\
\hline CHEMBL1241452 & 688550 & 4.4 & 4.7865 & TRN \\
\hline CHEMBL1519680 & 688550 & 6.15 & 5.0204 & TRN \\
\hline CHEMBL52347 & 688550 & 4.9 & 4.79899 & 99999999995 \\
\hline CHEMBL1509613 & 688550 & 4.4 & 4.8058 & TRN \\
\hline CHEMBL1413928 & 688550 & 4.45 & 4.9229 & TRN \\
\hline CHEMBL 3214148 & 688550 & 4.55 & 4.7651 & TRN \\
\hline CHEMBL1329531 & 688550 & 4.4 & 4.7723 & TRN \\
\hline
\end{tabular}




\begin{tabular}{|c|c|c|c|c|c|}
\hline \multicolumn{6}{|c|}{ Supplemental Table S2.txt } \\
\hline CHEMBL3209587 & 688550 & 4.4 & 4.8349 & TRN & \\
\hline CHEMBL1988883 & 688550 & 4.5 & 4.7755 & TRN & \\
\hline CHEMBL1344927 & 688550 & 4.5 & 4.8222 & TRN & \\
\hline CHEMBL1413180 & 688550 & 6.6 & 4.9151 & TST & \\
\hline CHEMBL3192436 & 688550 & 4.5 & 4.7903 & TRN & \\
\hline CHEMBL1585623 & 688550 & 4.5 & 4.8219 & TRN & \\
\hline CHEMBL1380792 & 688550 & 4.4 & 4.79899 & 99999999995 & TRN \\
\hline CHEMBL1556849 & 688550 & 4.4 & 4.8283 & TRN & \\
\hline CHEMBL1393847 & 688550 & 4.45 & 4.9096 & TRN & \\
\hline CHEMBL1491227 & 688550 & 4.5 & 4.8019 & TRN & \\
\hline CHEMBL1383991 & 688550 & 4.85 & 4.7348 & TRN & \\
\hline CHEMBL1582828 & 688550 & 4.85 & 5.0181 & TRN & \\
\hline CHEMBL1398766 & 688550 & 4.4 & 4.8787 & TRN & \\
\hline CHEMBL1451828 & 688550 & 4.9 & 5.0122 & TRN & \\
\hline CHEMBL1350157 & 688550 & 5.1 & 4.8173 & TRN & \\
\hline CHEMBL1325966 & 688550 & 4.7 & 4.8996 & TRN & \\
\hline CHEMBL1330201 & 688550 & 4.5 & 4.783 & TRN & \\
\hline CHEMBL1600919 & 688550 & 4.95 & 4.6845 & TRN & \\
\hline CHEMBL383475 & 688550 & 4.6 & 4.8371 & TRN & \\
\hline CHEMBL1417534 & 688550 & 5.2 & 4.9495 & TRN & \\
\hline CHEMBL1565440 & 688550 & 5.3 & 4.8843 & TRN & \\
\hline CHEMBL3213485 & 688550 & 4.4 & 4.8696 & TRN & \\
\hline CHEMBL 398765 & 688550 & 5.25 & 4.7994 & TRN & \\
\hline CHEMBL211969 & 688550 & 4.4 & 4.9062 & TST & \\
\hline CHEMBL1330005 & 688550 & 4.5 & 4.8046 & TRN & \\
\hline CHEMBL1466902 & 688550 & 4.5 & 4.8856 & TRN & \\
\hline CHEMBL1482361 & 688550 & 5.2 & 4.9994 & TRN & \\
\hline CHEMBL1353714 & 688550 & 4.4 & 4.7941 & TRN & \\
\hline CHEMBL1540922 & 688550 & 4.6 & 4.8604 & TRN & \\
\hline CHEMBL1578700 & 688550 & 4.95 & 4.9701 & TRN & \\
\hline CHEMBL1484883 & 688550 & 5.5 & 4.9776 & TRN & \\
\hline CHEMBL1992394 & 688550 & 4.5 & 4.8178 & TRN & \\
\hline CHEMBL1454397 & 688550 & 4.65 & 4.8621 & TRN & \\
\hline CHEMBL1313200 & 688550 & 4.7 & 4.9184 & TST & \\
\hline CHEMBL1421232 & 688550 & 5.25 & 4.7771 & TRN & \\
\hline CHEMBL1441449 & 688550 & 4.95 & 4.9172 & TST & \\
\hline CHEMBL1421887 & 688550 & 6.6 & 4.9418 & TRN & \\
\hline CHEMBL1574550 & 688550 & 4.4 & 4.8521 & TST & \\
\hline CHEMBL1594431 & 688550 & 4.4 & 4.8673 & TRN & \\
\hline CHEMBL1323735 & 688550 & 5.35 & 4.8705 & TRN & \\
\hline CHEMBL1310030 & 688550 & 4.45 & 4.8444 & TRN & \\
\hline CHEMBL1439985 & 688550 & 5.3 & 4.6972 & TRN & \\
\hline CHEMBL1457241 & 688550 & 4.5 & 4.79899 & 99999999995 & TRN \\
\hline CHEMBL1604258 & 688550 & 4.4 & 4.9123 & TRN & \\
\hline CHEMBL1446963 & 688550 & 5.75 & 4.8952 & TRN & \\
\hline CHEMBL523844 & 688550 & 4.75 & 4.803 & TRN & \\
\hline CHEMBL1529511 & 688550 & 4.6 & 4.8274 & TRN & \\
\hline CHEMBL1544921 & 688550 & 4.6 & 4.8384 & TRN & \\
\hline
\end{tabular}




\begin{tabular}{|c|c|c|c|c|c|}
\hline \multicolumn{6}{|c|}{ Supplemental Table S2.txt } \\
\hline CHEMBL1586957 & 688550 & 4.8 & 4.8974 & TST & \\
\hline CHEMBL1458288 & 688550 & 4.65 & 4.8774 & TRN & \\
\hline CHEMBL1580274 & 688550 & 5.05 & 4.8568 & TRN & \\
\hline CHEMBL1965873 & 688550 & 5.15 & 4.7678 & TRN & \\
\hline CHEMBL1584578 & 688550 & 4.75 & 4.8667 & TST & \\
\hline CHEMBL1542970 & 688550 & 5.55 & 4.977 & TRN & \\
\hline CHEMBL1557911 & 688550 & 6.1 & \multicolumn{2}{|c|}{5.0280000000000005} & TRN \\
\hline CHEMBL1435620 & 688550 & 4.5 & 5.0055 & TRN & \\
\hline CHEMBL1441142 & 688550 & 4.7 & 4.8649 & TRN & \\
\hline CHEMBL1470729 & 688550 & 4.6 & 4.8659 & TRN & \\
\hline CHEMBL1489618 & 688550 & 5.1 & 4.9076 & TRN & \\
\hline CHEMBL 2000748 & 688550 & 5.5 & 4.904 & TST & \\
\hline CHEMBL1423901 & 688550 & 4.85 & 4.934 & TRN & \\
\hline CHEMBL225951 & 688550 & 4.9 & 4.7662 & TRN & \\
\hline CHEMBL1539369 & 688550 & 5.4 & 4.9515 & TRN & \\
\hline CHEMBL1519992 & 688550 & 4.55 & 4.8275 & TRN & \\
\hline CHEMBL1378230 & 688550 & 4.4 & 4.7894 & TRN & \\
\hline CHEMBL1325946 & 688550 & 5.15 & 4.9101 & TST & \\
\hline CHEMBL1577228 & 688550 & 6.1 & 4.917 & TRN & \\
\hline CHEMBL1320043 & 688550 & 4.45 & 4.8927 & TRN & \\
\hline CHEMBL1349189 & 688550 & 4.6 & 4.8891 & TRN & \\
\hline CHEMBL1511219 & 688550 & 4.8 & 4.7486 & TRN & \\
\hline CHEMBL1418601 & 688550 & 4.8 & 4.8422 & TRN & \\
\hline CHEMBL1382616 & 688550 & 4.5 & 4.7982 & TRN & \\
\hline CHEMBL1351515 & 688550 & 4.4 & 4.7857 & TRN & \\
\hline CHEMBL1413729 & 688550 & 5.05 & 4.9836 & TRN & \\
\hline CHEMBL1457836 & 688550 & 4.6 & 4.8772 & TRN & \\
\hline CHEMBL1603187 & 688550 & 4.65 & 4.9097 & TRN & \\
\hline CHEMBL1392570 & 688550 & 5.45 & 4.7336 & TRN & \\
\hline CHEMBL1407267 & 688550 & 4.4 & 4.85 & TRN & \\
\hline CHEMBL1331050 & 688550 & 4.5 & 4.896 & TST & \\
\hline CHEMBL1454580 & 688550 & 4.5 & 4.8426 & TRN & \\
\hline CHEMBL1301001 & 688550 & 4.4 & 4.9095 & TST & \\
\hline CHEMBL1428912 & 688550 & 4.45 & 4.7742 & TRN & \\
\hline CHEMBL1353101 & 688550 & 5.2 & 4.91 & TRN & \\
\hline CHEMBL1593082 & 688550 & 4.45 & 4.9135 & TST & \\
\hline CHEMBL1495934 & 688550 & 5.05 & 4.8717 & TRN & \\
\hline CHEMBL1462302 & 688550 & 4.75 & 4.7712 & TRN & \\
\hline CHEMBL1414273 & 688550 & 4.9 & 4.83 & TRN & \\
\hline CHEMBL1456838 & 688550 & 4.4 & 5.0004 & TRN & \\
\hline CHEMBL1400830 & 688550 & 5.15 & 5.0331 & TRN & \\
\hline CHEMBL3194470 & 688550 & 4.4 & 4.7845 & TRN & \\
\hline CHEMBL1429956 & 688550 & 5.1 & 4.9267 & TRN & \\
\hline CHEMBL1538371 & 688550 & 4.4 & 4.8085 & TRN & \\
\hline CHEMBL1385366 & 688550 & 4.4 & 4.7802 & TRN & \\
\hline CHEMBL1484458 & 688550 & 4.4 & 4.9852 & TRN & \\
\hline CHEMBL1494130 & 688550 & 5.3 & 4.9035 & TST & \\
\hline \multirow[t]{2}{*}{ CHEMBL1493784 } & 688550 & 4.45 & \multicolumn{2}{|c|}{4.9110000000000005} & TST \\
\hline & & & & e 4843 & \\
\hline
\end{tabular}




\begin{tabular}{|c|c|c|c|c|c|}
\hline & & \multicolumn{4}{|c|}{ Supplemental Table S2.txt } \\
\hline CHEMBL1519501 & 688550 & 4.95 & 4.7305 & TRN & \\
\hline CHEMBL1322028 & 688550 & 4.8 & 4.9184 & TRN & \\
\hline CHEMBL1352194 & 688550 & 4.4 & 4.9257 & TST & \\
\hline CHEMBL1407312 & 688550 & 5.45 & 4.8875 & TST & \\
\hline CHEMBL1484796 & 688550 & 5.85 & 4.8577 & TST & \\
\hline CHEMBL1301481 & 688550 & 4.5 & 4.7876 & TRN & \\
\hline CHEMBL1582314 & 688550 & 4.55 & 4.8299 & TRN & \\
\hline CHEMBL1336490 & 688550 & 5.85 & 4.919 & TST & \\
\hline CHEMBL1427185 & 688550 & 4.75 & 4.9043 & TRN & \\
\hline CHEMBL1541785 & 688550 & 4.6 & 4.8772 & TRN & \\
\hline CHEMBL1324278 & 688550 & 4.55 & 4.9634 & TRN & \\
\hline CHEMBL1975516 & 688550 & 4.85 & 4.7612 & TRN & \\
\hline CHEMBL1371795 & 688550 & 5.4 & 4.8382 & TRN & \\
\hline CHEMBL1608430 & 688550 & 5.0 & 4.776 & TRN & \\
\hline CHEMBL1386301 & 688550 & 4.65 & 4.8963 & TRN & \\
\hline CHEMBL1562712 & 688550 & 4.9 & 4.8048 & TRN & \\
\hline CHEMBL1613473 & 688550 & 4.7 & 4.7666 & TRN & \\
\hline CHEMBL1376836 & 688550 & 4.4 & 4.8728 & TST & \\
\hline CHEMBL1583295 & 688550 & 4.5 & 4.7165 & TRN & \\
\hline CHEMBL1505602 & 688550 & 4.4 & 4.9289 & TST & \\
\hline CHEMBL1484182 & 688550 & 4.75 & 4.8737 & TRN & \\
\hline CHEMBL1608486 & 688550 & 4.6 & 4.7677 & TRN & \\
\hline CHEMBL1364927 & 688550 & 5.15 & 4.96899 & 9999999999 & TRN \\
\hline CHEMBL1214407 & 688550 & 4.85 & 4.7974 & TRN & \\
\hline CHEMBL1329475 & 688550 & 5.15 & 4.8299 & TRN & \\
\hline CHEMBL1360928 & 688550 & 4.65 & 4.7479 & TRN & \\
\hline CHEMBL3197268 & 688550 & 4.45 & 4.761 & TRN & \\
\hline CHEMBL1392052 & 688550 & 4.4 & 4.8077 & TRN & \\
\hline CHEMBL 1351338 & 688550 & 4.75 & 4.89 & TRN & \\
\hline CHEMBL 2000264 & 688550 & 4.5 & 4.777 & TRN & \\
\hline CHEMBL1581261 & 688550 & 5.05 & 4.7988 & TRN & \\
\hline CHEMBL1347937 & 688550 & 5.05 & 4.9017 & TRN & \\
\hline CHEMBL1467247 & 688550 & 4.55 & 4.8283 & TRN & \\
\hline CHEMBL1410096 & 688550 & 4.85 & 4.9114 & TRN & \\
\hline CHEMBL1341923 & 688550 & 6.1 & 4.9105 & TRN & \\
\hline CHEMBL1560117 & 688550 & 4.8 & 4.9001 & TRN & \\
\hline CHEMBL1467766 & 688550 & 5.85 & 4.8882 & TRN & \\
\hline CHEMBL1567247 & 688550 & 4.4 & 4.9345 & TRN & \\
\hline CHEMBL1368231 & 688550 & 5.5 & 4.9659 & TRN & \\
\hline CHEMBL1596427 & 688550 & 4.75 & 4.7888 & TRN & \\
\hline CHEMBL 307893 & 688550 & 4.95 & 4.8812 & TST & \\
\hline CHEMBL1429106 & 688550 & 4.45 & 4.7754 & TST & \\
\hline CHEMBL1516620 & 688550 & 4.4 & 4.8966 & TRN & \\
\hline CHEMBL1412068 & 688550 & 4.45 & 4.7135 & TRN & \\
\hline CHEMBL1373095 & 688550 & 4.55 & 4.8713 & TRN & \\
\hline CHEMBL1537100 & 688550 & 4.65 & 4.9019 & TRN & \\
\hline CHEMBL1333718 & 688550 & 5.55 & 4.8735 & TRN & \\
\hline CHEMBL1480310 & 688550 & 4.7 & 4.8118 & TRN & \\
\hline
\end{tabular}




\begin{tabular}{|c|c|c|c|c|c|}
\hline \multicolumn{6}{|c|}{ Supplemental Table S2.txt } \\
\hline CHEMBL1483838 & 688550 & 4.5 & 4.9092 & TRN & \\
\hline CHEMBL1599161 & 688550 & 5.0 & 4.7935 & TRN & \\
\hline CHEMBL1479362 & 688550 & 5.3 & 4.8217 & TRN & \\
\hline CHEMBL1328778 & 688550 & 5.65 & 4.9383 & TRN & \\
\hline CHEMBL1372910 & 688550 & 4.4 & 4.8613 & TRN & \\
\hline CHEMBL1522755 & 688550 & 5.35 & 4.8838 & TRN & \\
\hline CHEMBL1573181 & 688550 & 6.6 & 4.9134 & TRN & \\
\hline CHEMBL1402679 & 688550 & 5.2 & 4.8066 & TRN & \\
\hline CHEMBL1522275 & 688550 & 5.0 & 4.8981 & TST & \\
\hline CHEMBL1389829 & 688550 & 4.9 & 4.8257 & TRN & \\
\hline CHEMBL1309228 & 688550 & 4.6 & 4.8642 & TRN & \\
\hline CHEMBL1576795 & 688550 & 5.75 & 4.7735 & TRN & \\
\hline CHEMBL1558111 & 688550 & 4.9 & 5.015 & TRN & \\
\hline CHEMBL1299725 & 688550 & 4.6 & 4.8684 & TRN & \\
\hline CHEMBL1508182 & 688550 & 4.85 & 4.8471 & TST & \\
\hline CHEMBL1437959 & 688550 & 8.0506 & 4.7874 & TRN & \\
\hline CHEMBL1336339 & 688550 & 8.2007 & 4.8895 & TST & \\
\hline CHEMBL1346679 & 688550 & 4.5 & 4.8691 & TRN & \\
\hline CHEMBL1481192 & 688550 & 4.75 & 4.8462 & TRN & \\
\hline CHEMBL1559317 & 688550 & 4.6 & 4.8735 & TRN & \\
\hline CHEMBL1390185 & 688550 & 5.35 & 4.8906 & TRN & \\
\hline CHEMBL1599381 & 688550 & 4.6 & 5.0088 & TRN & \\
\hline CHEMBL3214355 & 688550 & 4.55 & 4.8293 & TRN & \\
\hline CHEMBL1326309 & 688550 & 4.8 & 4.9569 & TRN & \\
\hline CHEMBL1438903 & 688550 & 4.55 & 4.8293 & TRN & \\
\hline CHEMBL1447353 & 688550 & 5.6 & 5.0124 & TRN & \\
\hline CHEMBL1507679 & 688550 & 4.75 & 4.9009 & TST & \\
\hline CHEMBL1331554 & 688550 & 4.4 & 4.8301 & TRN & \\
\hline CHEMBL1362658 & 688550 & 4.55 & 4.8618 & TRN & \\
\hline CHEMBL1372854 & 688550 & 4.8 & 4.9245 & TST & \\
\hline CHEMBL3211445 & 688550 & 4.6 & 4.8648 & TRN & \\
\hline CHEMBL1429403 & 688550 & 4.4 & 4.8141 & TRN & \\
\hline CHEMBL1401954 & 688550 & 5.4 & 4.8691 & TRN & \\
\hline CHEMBL1331498 & 688550 & 4.6 & 4.92399 & 99999999995 & TRN \\
\hline CHEMBL1499136 & 688550 & 4.65 & 4.8908 & TRN & \\
\hline CHEMBL1542127 & 688550 & 5.2 & 4.8083 & TRN & \\
\hline CHEMBL1348456 & 688550 & 5.1 & 4.7932 & TST & \\
\hline CHEMBL1588990 & 688550 & 5.4 & 4.8588 & TRN & \\
\hline CHEMBL1507972 & 688550 & 4.95 & 4.7425 & TRN & \\
\hline CHEMBL1589244 & 688550 & 4.65 & 4.7169 & TRN & \\
\hline CHEMBL1399557 & 688550 & 4.55 & 5.0363 & TRN & \\
\hline CHEMBL1469770 & 688550 & 4.75 & 4.7881 & TST & \\
\hline CHEMBL1408965 & 688550 & 4.5 & 4.7845 & TRN & \\
\hline CHEMBL1362013 & 688550 & 4.85 & 4.7644 & TRN & \\
\hline CHEMBL3210209 & 688550 & 4.6 & 4.9535 & TST & \\
\hline CHEMBL1410716 & 688550 & 4.55 & 4.8161 & TRN & \\
\hline CHEMBL1372781 & 688550 & 5.3 & 4.9433 & TRN & \\
\hline CHEMBL1405786 & 688550 & 4.5 & 4.7709 & TRN & \\
\hline
\end{tabular}




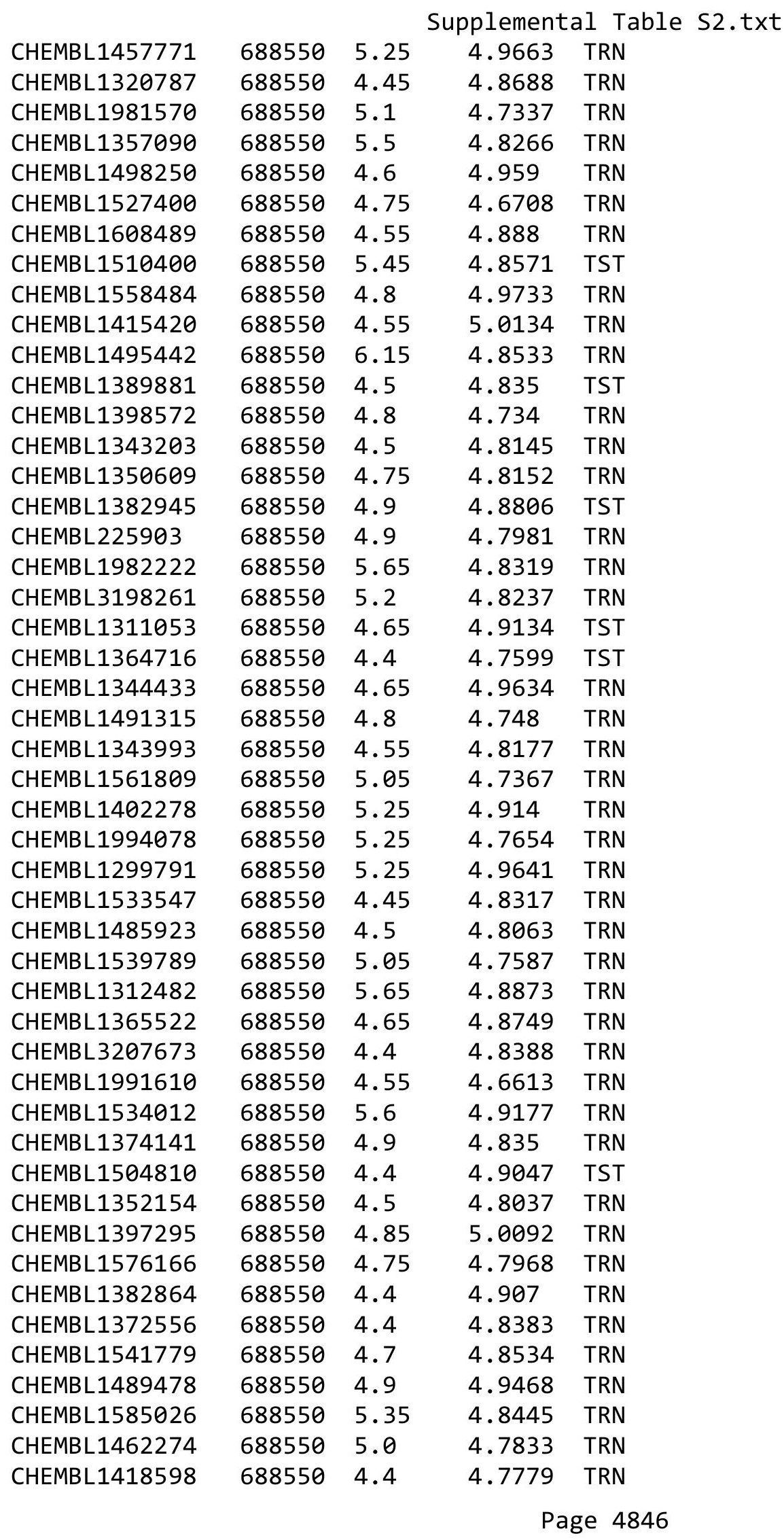




\begin{tabular}{|c|c|c|c|c|}
\hline \multicolumn{5}{|c|}{ Supplemental Table S2.txt } \\
\hline CHEMBL1585127 & 688550 & 4.5 & 4.7932 & TRN \\
\hline CHEMBL1368046 & 688550 & 4.6 & 4.9325 & TRN \\
\hline CHEMBL1586973 & 688550 & 4.6 & 4.8196 & TRN \\
\hline CHEMBL1501901 & 688550 & 6.4 & 4.9015 & TRN \\
\hline CHEMBL1550795 & 688550 & 5.15 & 4.8467 & TRN \\
\hline CHEMBL1534717 & 688550 & 4.55 & 4.8701 & TRN \\
\hline CHEMBL1480031 & 688550 & 4.55 & 4.8657 & TRN \\
\hline CHEMBL1330727 & 688550 & 5.15 & 4.8958 & TRN \\
\hline CHEMBL1353220 & 688550 & 5.6 & 4.8619 & TRN \\
\hline CHEMBL1597895 & 688550 & 4.7 & 4.8703 & TRN \\
\hline CHEMBL1497684 & 688550 & 4.5 & 4.8483 & TRN \\
\hline CHEMBL1400070 & 688550 & 4.4 & 4.8922 & TRN \\
\hline CHEMBL1566887 & 688550 & 4.6 & 4.8154 & TRN \\
\hline CHEMBL1458486 & 688550 & 4.5 & 4.7451 & TRN \\
\hline CHEMBL1573686 & 688550 & 4.6 & 4.9727 & TRN \\
\hline CHEMBL1486767 & 688550 & 4.4 & 4.8284 & TRN \\
\hline CHEMBL3214413 & 688550 & 6.0 & 4.8075 & TST \\
\hline CHEMBL1608798 & 688550 & 4.4 & 4.7912 & TRN \\
\hline CHEMBL1441778 & 688550 & 5.45 & 4.8489 & TST \\
\hline CHEMBL1372272 & 688550 & 5.0 & 4.8144 & TRN \\
\hline CHEMBL1555207 & 688550 & 4.5 & 4.9068 & TST \\
\hline CHEMBL1577121 & 688550 & 4.55 & 4.8365 & TRN \\
\hline CHEMBL1409317 & 688550 & 6.1 & 4.8333 & TST \\
\hline CHEMBL 3208023 & 688550 & 4.7 & 4.8417 & TRN \\
\hline CHEMBL1469904 & 688550 & 5.3 & 4.7319 & TRN \\
\hline CHEMBL1511238 & 688550 & 4.65 & 4.7648 & TRN \\
\hline CHEMBL1545623 & 688550 & 4.65 & 4.9875 & TRN \\
\hline CHEMBL1533166 & 688550 & 4.8 & 4.7819 & TRN \\
\hline CHEMBL1470485 & 688550 & 4.5 & 4.8278 & TRN \\
\hline CHEMBL3214202 & 688550 & 4.4 & 4.8447 & TRN \\
\hline CHEMBL1386835 & 688550 & 4.55 & 4.8868 & TRN \\
\hline CHEMBL1368202 & 688550 & 4.4 & 4.8635 & TRN \\
\hline CHEMBL1452128 & 688550 & 4.75 & 4.8107 & TRN \\
\hline CHEMBL1319028 & 688550 & 5.0 & 4.9718 & TRN \\
\hline CHEMBL1391824 & 688550 & 4.7 & 5.0622 & TRN \\
\hline CHEMBL1556156 & 688550 & 5.6 & 4.8446 & TRN \\
\hline CHEMBL1423778 & 688550 & 4.4 & 4.8866 & TRN \\
\hline CHEMBL 3197141 & 688550 & 4.55 & 4.7862 & TRN \\
\hline CHEMBL1560371 & 688550 & 4.6 & 4.8467 & TST \\
\hline CHEMBL1999046 & 688550 & 5.05 & 4.8819 & TST \\
\hline CHEMBL1443366 & 688550 & 5.15 & 4.965 & TST \\
\hline CHEMBL1557191 & 688550 & 4.9 & 4.7818 & TRN \\
\hline CHEMBL1312988 & 688550 & 4.65 & 4.8345 & TRN \\
\hline CHEMBL1336077 & 688550 & 4.55 & 4.975 & TRN \\
\hline CHEMBL1338333 & 688550 & 5.1 & 4.7722 & TST \\
\hline CHEMBL1566375 & 688550 & 6.1 & 4.8636 & TRN \\
\hline CHEMBL1469891 & 688550 & 4.75 & 4.7956 & TST \\
\hline CHEMBL1337986 & 688550 & 4.9 & 4.8568 & TRN \\
\hline
\end{tabular}




\begin{tabular}{|c|c|c|c|c|}
\hline \multicolumn{5}{|c|}{ Supplemental Table } \\
\hline CHEMBL1596536 & 688550 & 4.85 & 4.8474 & TRN \\
\hline CHEMBL1430020 & 688550 & 4.4 & 4.8982 & TRN \\
\hline CHEMBL1450977 & 688550 & 4.8 & 4.9131 & TRN \\
\hline CHEMBL1495929 & 688550 & 6.1 & 4.7629 & TRN \\
\hline CHEMBL1598034 & 688550 & 4.4 & 4.8433 & TRN \\
\hline CHEMBL3213103 & 688550 & 4.8 & 4.8742 & TST \\
\hline CHEMBL1405525 & 688550 & 4.4 & 4.8293 & TRN \\
\hline CHEMBL1321827 & 688550 & 6.1 & 4.8831 & TRN \\
\hline CHEMBL1327682 & 688550 & 4.55 & 4.8379 & TRN \\
\hline CHEMBL1443180 & 688550 & 4.5 & 4.8355 & TRN \\
\hline CHEMBL1375285 & 688550 & 6.0 & 4.8416 & TRN \\
\hline CHEMBL1300237 & 688550 & 4.8 & 4.7797 & TRN \\
\hline CHEMBL1348181 & 688550 & 5.75 & 4.7775 & TRN \\
\hline CHEMBL1377183 & 688550 & 4.4 & 4.8509 & TRN \\
\hline CHEMBL1343883 & 688550 & 4.8 & 4.9145 & TRN \\
\hline CHEMBL1524083 & 688550 & 6.1 & 4.9 & TRN \\
\hline CHEMBL1499740 & 688550 & 5.05 & 4.9095 & TRN \\
\hline CHEMBL1534039 & 688550 & 5.05 & 4.9413 & TRN \\
\hline CHEMBL1366524 & 688550 & 4.6 & 4.8812 & TRN \\
\hline CHEMBL1438064 & 688550 & 4.5 & 4.9472 & TRN \\
\hline CHEMBL1311881 & 688550 & 4.65 & 4.9172 & TST \\
\hline CHEMBL1543818 & 688550 & 4.75 & 4.7849 & TRN \\
\hline CHEMBL1566018 & 688550 & 4.4 & 4.871 & TRN \\
\hline CHEMBL1990081 & 688550 & 4.75 & 4.8295 & TRN \\
\hline CHEMBL1464547 & 688550 & 4.8 & 4.876 & TRN \\
\hline CHEMBL1511579 & 688550 & 5.35 & 5.0272 & TRN \\
\hline CHEMBL1484144 & 688550 & 5.35 & 4.8676 & TST \\
\hline CHEMBL1394517 & 688550 & 5.3 & 4.8368 & TRN \\
\hline CHEMBL1520245 & 688550 & 5.1 & 4.8623 & TRN \\
\hline CHEMBL 265686 & 688550 & 4.65 & 4.7228 & TRN \\
\hline CHEMBL1457955 & 688550 & 4.5 & 4.8365 & TRN \\
\hline CHEMBL1446015 & 688550 & 8.0 & 5.0369 & TRN \\
\hline CHEMBL1304837 & 688550 & 4.55 & 4.9535 & TRN \\
\hline CHEMBL1560714 & 688550 & 5.1 & 4.9903 & TRN \\
\hline CHEMBL1506667 & 688550 & 5.6 & 4.8838 & TRN \\
\hline CHEMBL1413356 & 688550 & 4.4 & 5.0106 & TRN \\
\hline CHEMBL1441840 & 688550 & 6.1 & 4.8917 & TRN \\
\hline CHEMBL1347073 & 688550 & 5.35 & 4.7992 & TRN \\
\hline CHEMBL448490 & 688550 & 4.4 & 4.811 & TST \\
\hline CHEMBL1536409 & 688550 & 4.4 & 4.8697 & TRN \\
\hline CHEMBL1399453 & 688550 & 4.85 & 4.8294 & TRN \\
\hline CHEMBL1446030 & 688550 & 5.05 & 4.8246 & TRN \\
\hline CHEMBL1388088 & 688550 & 4.65 & 4.8125 & TRN \\
\hline CHEMBL1378098 & 688550 & 4.6 & 4.8549 & TRN \\
\hline CHEMBL1486044 & 688550 & 4.85 & 4.9369 & TST \\
\hline CHEMBL1421390 & 688550 & 4.85 & 5.038 & TRN \\
\hline CHEMBL1521930 & 688550 & 4.55 & 4.8673 & TRN \\
\hline CHEMBL1324093 & 688550 & 4.75 & 4.8484 & TRN \\
\hline
\end{tabular}




\begin{tabular}{|c|c|c|c|c|}
\hline & & & pplement & al $\mathrm{T}$ \\
\hline CHEMBL1563328 & 688550 & 4.5 & 5.0154 & TRN \\
\hline CHEMBL1565179 & 688550 & 5.05 & 4.842 & TRN \\
\hline CHEMBL1557668 & 688550 & 4.7 & 4.902 & TRN \\
\hline CHEMBL1350152 & 688550 & 4.95 & 4.7529 & TRN \\
\hline CHEMBL1453592 & 688550 & 4.4 & 4.8716 & TRN \\
\hline CHEMBL1387716 & 688550 & 4.85 & 4.989 & TRN \\
\hline CHEMBL1497186 & 688550 & 6.1 & 4.8876 & TRN \\
\hline CHEMBL1502878 & 688550 & 5.05 & 4.9018 & TST \\
\hline CHEMBL1486262 & 688550 & 4.4 & 4.771 & TRN \\
\hline CHEMBL1502149 & 688550 & 4.4 & 4.7818 & TRN \\
\hline CHEMBL1573371 & 688550 & 4.75 & 4.9041 & TRN \\
\hline CHEMBL1493565 & 688550 & 4.85 & 4.8 & TRN \\
\hline CHEMBL1313663 & 688550 & 4.9 & 4.8382 & TRN \\
\hline CHEMBL1463212 & 688550 & 4.85 & 4.9338 & TRN \\
\hline CHEMBL1560223 & 688550 & 4.9 & 4.7573 & TRN \\
\hline CHEMBL1611655 & 688550 & 4.55 & 4.8763 & TRN \\
\hline CHEMBL3194220 & 688550 & 5.1 & 4.8252 & TST \\
\hline CHEMBL1361349 & 688550 & 4.95 & 4.8399 & TRN \\
\hline CHEMBL1451130 & 688550 & 6.45 & 4.8639 & TRN \\
\hline CHEMBL1612474 & 688550 & 5.75 & 4.7834 & TRN \\
\hline CHEMBL1348188 & 688550 & 4.4 & 5.0111 & TRN \\
\hline CHEMBL1344936 & 688550 & 5.1 & 4.8906 & TRN \\
\hline CHEMBL1595457 & 688550 & 4.85 & 4.9893 & TRN \\
\hline CHEMBL1424911 & 688550 & 5.15 & 4.8118 & TRN \\
\hline CHEMBL1465644 & 688550 & 4.8 & 4.8706 & TRN \\
\hline CHEMBL1392651 & 688550 & 5.05 & 4.9167 & TST \\
\hline CHEMBL1402596 & 688550 & 4.45 & 4.9063 & TST \\
\hline CHEMBL3214200 & 688550 & 4.4 & 4.8256 & TRN \\
\hline CHEMBL1579799 & 688550 & 4.6 & 4.7793 & TRN \\
\hline CHEMBL1303801 & 688550 & 8.4949 & 5.0359 & TRN \\
\hline CHEMBL1494296 & 688550 & 5.95 & 4.8689 & TRN \\
\hline CHEMBL1376411 & 688550 & 4.75 & 4.8256 & TRN \\
\hline CHEMBL1386652 & 688550 & 6.7001 & 4.9821 & TRN \\
\hline CHEMBL1323049 & 688550 & 4.4 & 4.8443 & TRN \\
\hline CHEMBL1379643 & 688550 & 4.5 & 4.888 & TRN \\
\hline CHEMBL1409730 & 688550 & 5.8 & 4.9281 & TRN \\
\hline CHEMBL1588818 & 688550 & 4.55 & 4.8458 & TRN \\
\hline CHEMBL1445917 & 688550 & 4.85 & 4.8873 & TRN \\
\hline CHEMBL1392776 & 688550 & 4.6 & 4.8971 & TRN \\
\hline CHEMBL1466323 & 688550 & 4.5 & 4.8768 & TRN \\
\hline CHEMBL1310318 & 688550 & 4.45 & 4.8773 & TRN \\
\hline CHEMBL1537694 & 688550 & 5.75 & 4.6994 & TRN \\
\hline CHEMBL3191942 & 688550 & 6.0 & 4.7934 & TRN \\
\hline CHEMBL1323903 & 688550 & 5.45 & 4.8867 & TRN \\
\hline CHEMBL1360905 & 688550 & 5.7 & 4.8111 & TRN \\
\hline CHEMBL1382702 & 688550 & 5.0 & 4.8574 & TRN \\
\hline CHEMBL1347477 & 688550 & 4.95 & 4.7024 & TRN \\
\hline CHEMBL1596611 & 688550 & 4.4 & 4.7956 & TRN \\
\hline
\end{tabular}




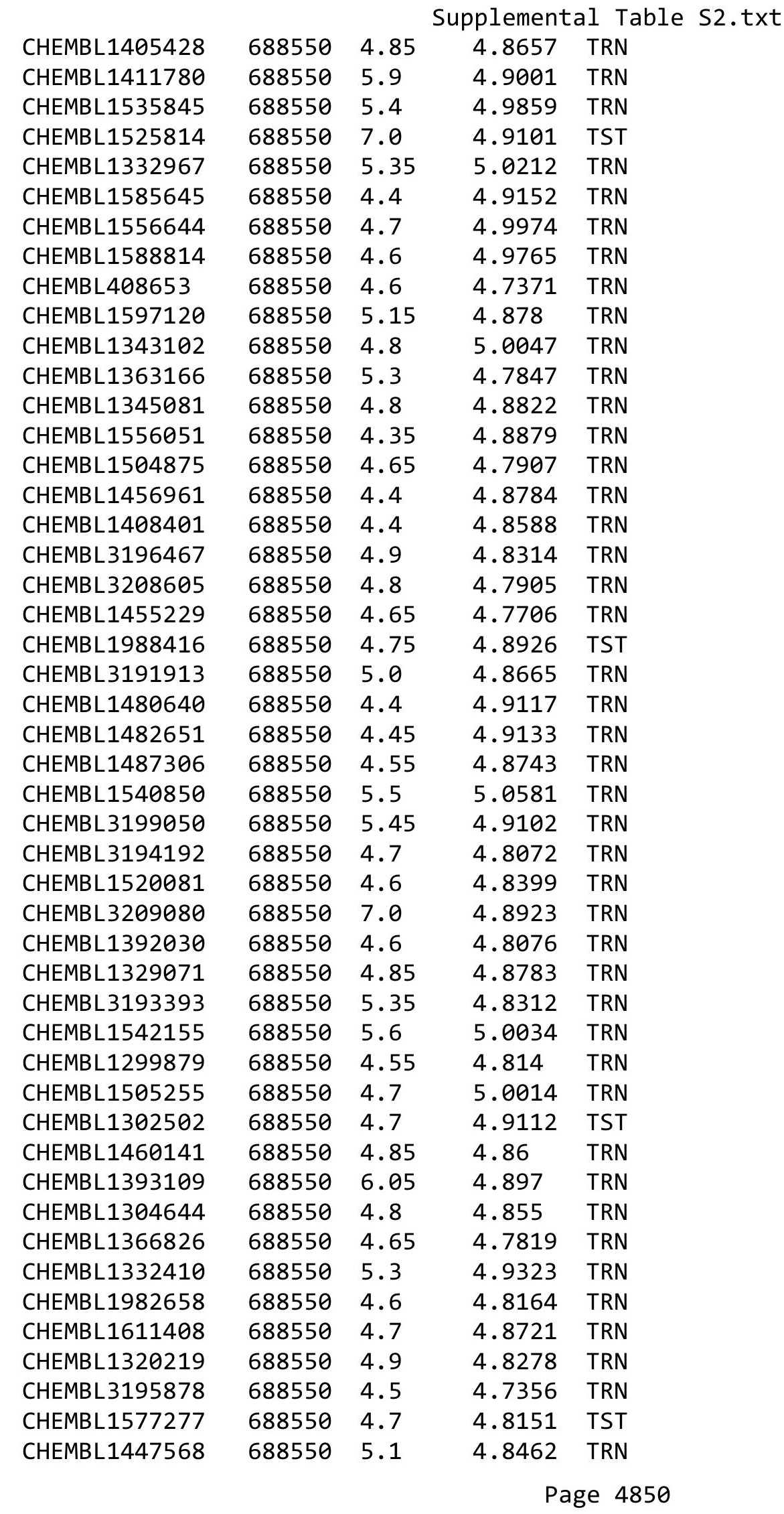




\begin{tabular}{|c|c|c|c|c|c|}
\hline \multicolumn{6}{|c|}{ Supplemental Table S2.txt } \\
\hline CHEMBL1333479 & 688550 & 4.5 & 4.9102 & TRN & \\
\hline CHEMBL1495592 & 688550 & 5.25 & 4.8323 & TST & \\
\hline CHEMBL1459239 & 688550 & 5.05 & 4.8871 & TRN & \\
\hline CHEMBL1466624 & 688550 & 4.4 & 4.8514 & TRN & \\
\hline CHEMBL1401901 & 688550 & 4.6 & 4.8191 & TRN & \\
\hline CHEMBL1501764 & 688550 & 4.4 & 4.8789 & TST & \\
\hline CHEMBL 230143 & 688550 & 6.6 & 4.9094 & TRN & \\
\hline CHEMBL1407306 & 688550 & 4.65 & 4.9051 & TRN & \\
\hline CHEMBL1506274 & 688550 & 4.5 & 4.7405 & TRN & \\
\hline CHEMBL1422578 & 688550 & 5.0 & 4.9466 & TRN & \\
\hline CHEMBL1344369 & 688550 & 5.05 & 5.0785 & TRN & \\
\hline CHEMBL1566069 & 688550 & 4.95 & 4.8446 & TRN & \\
\hline CHEMBL1321932 & 688550 & 4.45 & 4.979 & TRN & \\
\hline CHEMBL1416417 & 688550 & 4.75 & 4.9069 & TST & \\
\hline CHEMBL1410635 & 688550 & 5.6 & 4.9165 & TST & \\
\hline CHEMBL1455932 & 688550 & 4.45 & 4.8418 & TRN & \\
\hline CHEMBL1410025 & 688550 & 5.05 & 4.846 & TRN & \\
\hline CHEMBL1490044 & 688550 & 4.7 & 4.9337 & TST & \\
\hline CHEMBL1560540 & 688550 & 4.6 & 4.8771 & TST & \\
\hline CHEMBL1561801 & 688550 & 4.55 & 4.8885 & TRN & \\
\hline CHEMBL1322645 & 688550 & 4.55 & 4.8525 & TRN & \\
\hline CHEMBL1330063 & 688550 & 5.05 & 4.7234 & TRN & \\
\hline CHEMBL1610101 & 688550 & 5.3 & 4.9302 & TRN & \\
\hline CHEMBL1458268 & 688550 & 4.7 & 4.8504 & TRN & \\
\hline CHEMBL1586204 & 688550 & 4.45 & 4.8708 & TRN & \\
\hline CHEMBL1380592 & 688550 & 4.45 & 4.863 & TRN & \\
\hline CHEMBL567622 & 688550 & 5.5 & 4.8177 & TRN & \\
\hline CHEMBL1582442 & 688550 & 4.45 & 4.8252 & TRN & \\
\hline CHEMBL1342767 & 688550 & 4.4 & 4.7521 & TRN & \\
\hline CHEMBL1516388 & 688550 & 4.5 & 4.9116 & TST & \\
\hline CHEMBL1540072 & 688550 & 4.6 & 4.9189 & TRN & \\
\hline CHEMBL1388312 & 688550 & 4.6 & 4.8774 & TRN & \\
\hline CHEMBL1489771 & 688550 & 4.6 & 5.0016 & TST & \\
\hline CHEMBL1576679 & 688550 & 4.4 & 4.876 & TST & \\
\hline CHEMBL1304007 & 688550 & 4.55 & 4.9055 & TRN & \\
\hline CHEMBL1361191 & 688550 & 4.5 & 4.8019 & TRN & \\
\hline CHEMBL1300487 & 688550 & 4.4 & 4.8526 & TRN & \\
\hline CHEMBL1589404 & 688550 & 4.85 & 4.88899 & 9999999999 & TRN \\
\hline CHEMBL1528965 & 688550 & 6.95 & 4.7747 & TRN & \\
\hline CHEMBL1478187 & 688550 & 6.1 & 4.9227 & TST & \\
\hline CHEMBL1504412 & 688550 & 6.7001 & 4.8212 & TST & \\
\hline CHEMBL3198821 & 688550 & 4.75 & 4.789 & TRN & \\
\hline CHEMBL1087863 & 688550 & 4.4 & 4.7953 & TRN & \\
\hline CHEMBL3210365 & 688550 & 6.1 & 4.7538 & TRN & \\
\hline CHEMBL127757 & 688550 & 4.85 & 4.7802 & TRN & \\
\hline CHEMBL1403775 & 688550 & 4.4 & 4.8645 & TRN & \\
\hline CHEMBL3189499 & 688550 & 7.0 & 4.8143 & TRN & \\
\hline CHEMBL1323575 & 688550 & 4.55 & 4.8166 & TST & \\
\hline
\end{tabular}




\begin{tabular}{|c|c|c|c|c|c|}
\hline \multicolumn{6}{|c|}{ Supplemental Table S2.txt } \\
\hline CHEMBL1312836 & 688550 & 4.9 & 4.8599 & TRN & \\
\hline CHEMBL1384821 & 688550 & 4.45 & 4.9918 & TRN & \\
\hline CHEMBL1983323 & 688550 & 4.55 & 4.7471 & TRN & \\
\hline CHEMBL1486214 & 688550 & 4.85 & 4.7724 & TRN & \\
\hline CHEMBL379179 & 688550 & 4.9 & 4.7658 & TRN & \\
\hline CHEMBL1479488 & 688550 & 4.65 & 4.8552 & TST & \\
\hline CHEMBL1442553 & 688550 & 4.55 & 4.8507 & TRN & \\
\hline CHEMBL1573413 & 688550 & 4.9 & 4.8783 & TRN & \\
\hline CHEMBL1527727 & 688550 & 4.55 & 4.6848 & TRN & \\
\hline CHEMBL1393692 & 688550 & 4.8 & 4.9978 & TRN & \\
\hline CHEMBL1420432 & 688550 & 4.75 & 4.8337 & TRN & \\
\hline CHEMBL1497301 & 688550 & 4.5 & 4.7529 & TRN & \\
\hline CHEMBL1344077 & 688550 & 4.8 & 4.8737 & TRN & \\
\hline CHEMBL3191557 & 688550 & 4.4 & 4.7576 & TRN & \\
\hline CHEMBL1510651 & 688550 & 4.6 & 4.8555 & TRN & \\
\hline CHEMBL1613188 & 688550 & 4.65 & 4.77800 & 00000000005 & TRN \\
\hline CHEMBL1443570 & 688550 & 4.5 & 4.865 & TRN & \\
\hline CHEMBL1319476 & 688550 & 4.4 & 4.9542 & TST & \\
\hline CHEMBL1583534 & 688550 & 5.85 & 4.8586 & TST & \\
\hline CHEMBL1419929 & 688550 & 4.55 & 4.8744 & TRN & \\
\hline CHEMBL257856 & 688550 & 4.45 & 5.0139 & TRN & \\
\hline CHEMBL1507009 & 688550 & 4.6 & 4.8518 & TST & \\
\hline CHEMBL1382028 & 688550 & 4.8 & 4.8027 & TRN & \\
\hline CHEMBL1311895 & 688550 & 4.55 & 4.8793 & TRN & \\
\hline CHEMBL1482228 & 688550 & 4.8 & 4.9209 & TRN & \\
\hline CHEMBL1611799 & 688550 & 5.35 & 5.0232 & TRN & \\
\hline CHEMBL1428817 & 688550 & 4.7 & 4.9317 & TRN & \\
\hline CHEMBL 3212224 & 688550 & 5.0 & 4.8721 & TRN & \\
\hline CHEMBL 1557806 & 688550 & 4.7 & 4.9494 & TRN & \\
\hline CHEMBL1535709 & 688550 & 4.4 & 4.904 & TRN & \\
\hline CHEMBL503470 & 688550 & 4.4 & 4.7977 & TRN & \\
\hline CHEMBL 75412 & 688550 & 4.5 & 4.8124 & TST & \\
\hline CHEMBL1418029 & 688550 & 4.55 & 5.0026 & TRN & \\
\hline CHEMBL1485473 & 688550 & 4.6 & 4.8771 & TRN & \\
\hline CHEMBL1608754 & 688550 & 5.4 & 4.9124 & TRN & \\
\hline CHEMBL259784 & 688550 & 4.8 & 4.7909 & TRN & \\
\hline CHEMBL1325840 & 688550 & 4.55 & 4.8876 & TRN & \\
\hline CHEMBL1383728 & 688550 & 4.9 & 5.0066 & TRN & \\
\hline CHEMBL1423832 & 688550 & 4.8 & 4.9709 & TRN & \\
\hline CHEMBL1412162 & 688550 & 4.95 & 4.9462 & TRN & \\
\hline CHEMBL1507084 & 688550 & 4.4 & 4.9124 & TRN & \\
\hline CHEMBL1586704 & 688550 & 4.5 & 4.8909 & TRN & \\
\hline CHEMBL3212061 & 688550 & 4.5 & 4.8571 & TRN & \\
\hline CHEMBL1449644 & 688550 & 4.45 & 4.8801 & TRN & \\
\hline CHEMBL1597808 & 688550 & 6.3 & 4.7983 & TRN & \\
\hline CHEMBL1387269 & 688550 & 4.9 & 4.9678 & TRN & \\
\hline CHEMBL1380653 & 688550 & 4.4 & 4.8993 & TRN & \\
\hline CHEMBL1447108 & 688550 & 4.65 & 4.8813 & TRN & \\
\hline
\end{tabular}




\begin{tabular}{|c|c|c|c|c|c|}
\hline & & \multicolumn{4}{|c|}{ Supplemental Table S2.txt } \\
\hline CHEMBL1351526 & 688550 & 4.45 & 4.8076 & TRN & \\
\hline CHEMBL1576494 & 688550 & 4.55 & 4.8425 & TRN & \\
\hline CHEMBL1497780 & 688550 & 4.55 & 4.8297 & TRN & \\
\hline CHEMBL1404828 & 688550 & 5.45 & 4.9088 & TRN & \\
\hline CHEMBL1510344 & 688550 & 4.55 & 4.8151 & TRN & \\
\hline CHEMBL1504637 & 688550 & 4.55 & 4.975 & TRN & \\
\hline CHEMBL1466454 & 688550 & 4.8 & 4.9882 & TRN & \\
\hline CHEMBL1543801 & 688550 & 4.75 & 4.8715 & TRN & \\
\hline CHEMBL1339846 & 688550 & 4.45 & 4.9206 & TRN & \\
\hline CHEMBL1598274 & 688550 & 7.0501 & 5.0275 & TRN & \\
\hline CHEMBL556024 & 688550 & 4.85 & 4.9506 & TST & \\
\hline CHEMBL1548422 & 688550 & 4.7 & 4.8105 & TRN & \\
\hline CHEMBL1574958 & 688550 & 5.0 & 4.867 & TRN & \\
\hline CHEMBL1387097 & 688550 & 5.15 & 4.81800 & 00000000005 & TRN \\
\hline CHEMBL1587815 & 688550 & 4.6 & 4.9912 & TRN & \\
\hline CHEMBL1494908 & 688550 & 4.7 & 4.8154 & TST & \\
\hline CHEMBL1570417 & 688550 & 4.65 & 4.8292 & TRN & \\
\hline CHEMBL1381128 & 688550 & 4.6 & 4.8103 & TST & \\
\hline CHEMBL395296 & 688550 & 6.5 & 4.7636 & TST & \\
\hline CHEMBL1335541 & 688550 & 5.15 & 4.7925 & TRN & \\
\hline CHEMBL1338958 & 688550 & 4.55 & 4.9399 & TST & \\
\hline CHEMBL1596486 & 688550 & 4.55 & 4.8628 & TRN & \\
\hline CHEMBL1444240 & 688550 & 4.4 & 4.7569 & TRN & \\
\hline CHEMBL1482475 & 688550 & 4.75 & 4.8257 & TRN & \\
\hline CHEMBL1441583 & 688550 & 4.4 & 4.7269 & TRN & \\
\hline CHEMBL1565445 & 688550 & 4.5 & 4.9141 & TRN & \\
\hline CHEMBL1399243 & 688550 & 4.65 & 4.9262 & TRN & \\
\hline CHEMBL1478043 & 688550 & 5.3 & 4.8785 & TRN & \\
\hline CHEMBL1471965 & 688550 & 4.6 & 4.8136 & TRN & \\
\hline CHEMBL3189384 & 688550 & 4.85 & 4.8933 & TRN & \\
\hline CHEMBL1346393 & 688550 & 4.5 & 4.8617 & TRN & \\
\hline CHEMBL1433058 & 688550 & 4.85 & 4.9001 & TRN & \\
\hline CHEMBL1534118 & 688550 & 4.45 & 4.8584 & TRN & \\
\hline CHEMBL1580671 & 688550 & 4.95 & 4.8066 & TRN & \\
\hline CHEMBL1306740 & 688550 & 5.5 & 4.9901 & TRN & \\
\hline CHEMBL1447922 & 688550 & 4.55 & 4.944 & TRN & \\
\hline CHEMBL1400751 & 688550 & 4.6 & 4.8965 & TRN & \\
\hline CHEMBL1409288 & 688550 & 4.9 & 4.7814 & TRN & \\
\hline CHEMBL1379592 & 688550 & 4.8 & 4.8409 & TST & \\
\hline CHEMBL1530214 & 688550 & 4.8 & 4.8392 & TRN & \\
\hline CHEMBL1392753 & 688550 & 4.7 & 4.8252 & TST & \\
\hline CHEMBL1300722 & 688550 & 4.55 & 4.9807 & TRN & \\
\hline CHEMBL1538769 & 688550 & 6.35 & 4.8871 & TRN & \\
\hline CHEMBL1510655 & 688550 & 4.95 & 4.8292 & TRN & \\
\hline CHEMBL3210270 & 688550 & 4.4 & 4.8097 & TRN & \\
\hline CHEMBL1611573 & 688550 & 5.05 & 4.8098 & TRN & \\
\hline CHEMBL1578930 & 688550 & 4.4 & 4.7805 & TRN & \\
\hline CHEMBL1485571 & 688550 & 5.4 & 4.9337 & TRN & \\
\hline
\end{tabular}




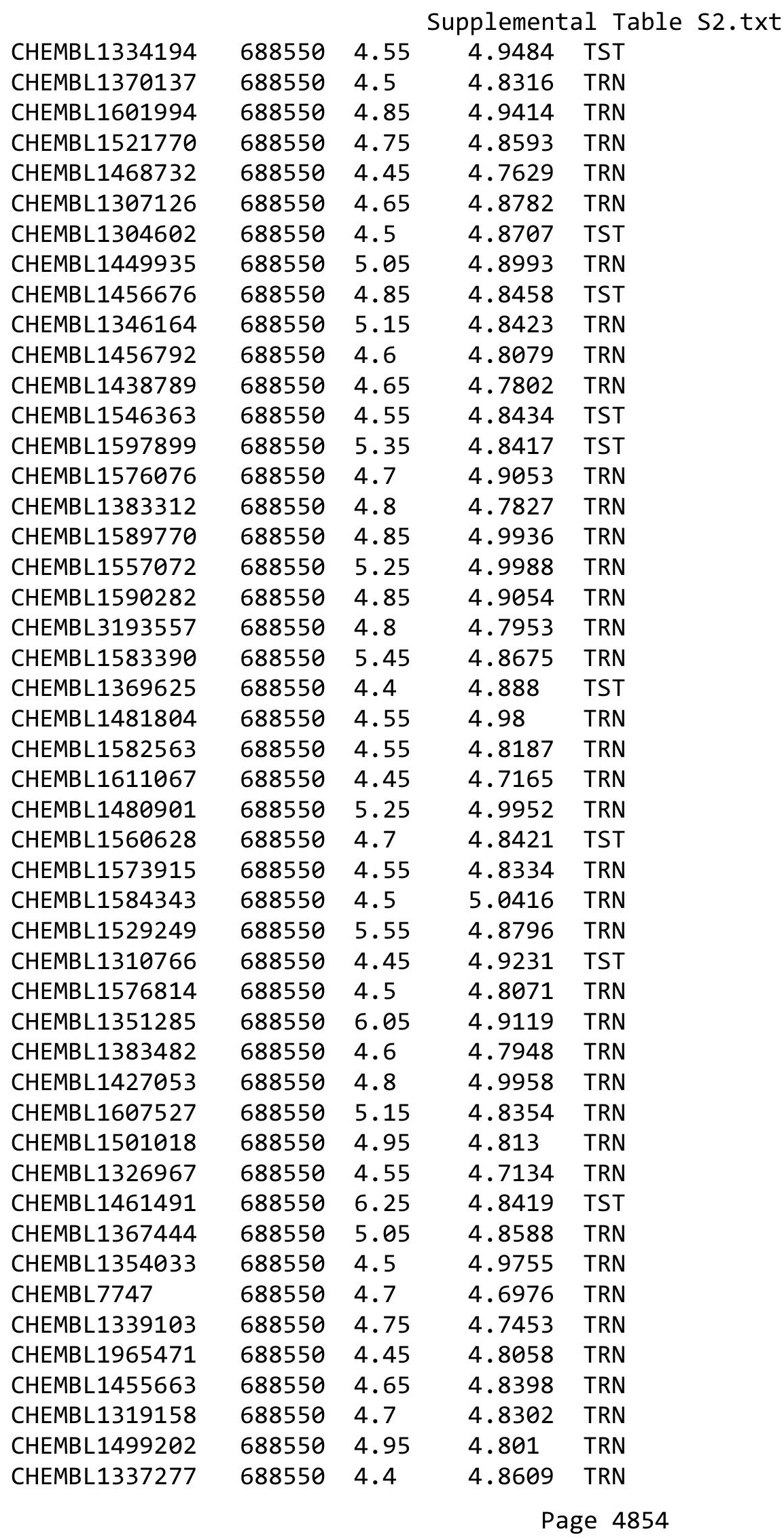




\begin{tabular}{|c|c|c|c|c|}
\hline \multicolumn{5}{|c|}{ Supplemental Table } \\
\hline CHEMBL1422908 & 688550 & 4.85 & 4.9 & TRN \\
\hline CHEMBL1496651 & 688550 & 4.7 & 4.7571 & TRN \\
\hline CHEMBL1525935 & 688550 & 5.25 & 4.954 & TRN \\
\hline CHEMBL1486834 & 688550 & 4.6 & 4.873 & TRN \\
\hline CHEMBL1589046 & 688550 & 4.55 & 4.8579 & TRN \\
\hline CHEMBL1572850 & 688550 & 4.65 & 4.8873 & TRN \\
\hline CHEMBL 259805 & 688550 & 4.6 & 4.7839 & TRN \\
\hline CHEMBL1428733 & 688550 & 4.75 & 4.8431 & TRN \\
\hline CHEMBL1527266 & 688550 & 4.95 & 4.8519 & TRN \\
\hline CHEMBL1507023 & 688550 & 4.85 & 4.7205 & TRN \\
\hline CHEMBL1581173 & 688550 & 4.8 & 4.8142 & TRN \\
\hline CHEMBL1588436 & 688550 & 4.6 & 4.8525 & TRN \\
\hline CHEMBL1546386 & 688550 & 4.45 & 4.854 & TRN \\
\hline CHEMBL1402940 & 688550 & 4.45 & 4.8343 & TRN \\
\hline CHEMBL1888240 & 688550 & 5.0 & 4.8484 & TRN \\
\hline CHEMBL3190938 & 688550 & 4.85 & 4.8568 & TRN \\
\hline CHEMBL1502229 & 688550 & 4.5 & 4.7842 & TST \\
\hline CHEMBL1406745 & 688550 & 4.4 & 4.8477 & TRN \\
\hline CHEMBL1538069 & 688550 & 4.4 & 4.8308 & TRN \\
\hline CHEMBL1539092 & 688550 & 5.1 & 4.8834 & TRN \\
\hline CHEMBL1543093 & 688550 & 6.35 & 4.8984 & TRN \\
\hline CHEMBL1381590 & 688550 & 4.45 & 4.8339 & TRN \\
\hline CHEMBL1335725 & 688550 & 5.4 & 4.8939 & TRN \\
\hline CHEMBL1414312 & 688550 & 4.55 & 5.0042 & TRN \\
\hline CHEMBL1538180 & 688550 & 4.75 & 4.9633 & TRN \\
\hline CHEMBL1549038 & 688550 & 4.55 & 4.9155 & TRN \\
\hline CHEMBL 227447 & 688550 & 5.2 & 4.9869 & TRN \\
\hline CHEMBL1467259 & 688550 & 4.6 & 4.8711 & TRN \\
\hline CHEMBL1609239 & 688550 & 4.4 & 4.795 & TRN \\
\hline CHEMBL1337876 & 688550 & 4.8 & 5.0294 & TRN \\
\hline CHEMBL1401774 & 688550 & 4.75 & 4.8154 & TRN \\
\hline CHEMBL1545209 & 688550 & 4.6 & 4.8482 & TST \\
\hline CHEMBL1967185 & 688550 & 4.85 & 4.813 & TRN \\
\hline CHEMBL1509832 & 688550 & 4.8 & 4.8592 & TST \\
\hline CHEMBL1382410 & 688550 & 4.6 & 4.762 & TRN \\
\hline CHEMBL1602085 & 688550 & 4.9 & 4.7869 & TRN \\
\hline CHEMBL572994 & 688550 & 5.3 & 4.8282 & TRN \\
\hline CHEMBL1301861 & 688550 & 4.55 & 4.8439 & TRN \\
\hline CHEMBL3198342 & 688550 & 4.8 & 4.796 & TRN \\
\hline CHEMBL3212937 & 688550 & 5.7 & 4.8226 & TRN \\
\hline CHEMBL1525529 & 688550 & 4.55 & 4.8241 & TRN \\
\hline CHEMBL3199923 & 688550 & 4.55 & 4.8456 & TRN \\
\hline CHEMBL1423828 & 688550 & 4.9 & 4.7658 & TST \\
\hline CHEMBL1499339 & 688550 & 4.9 & 4.8291 & TRN \\
\hline CHEMBL1981539 & 688550 & 6.4 & 4.9056 & TST \\
\hline CHEMBL1527186 & 688550 & 4.8 & 4.8088 & TRN \\
\hline CHEMBL3207897 & 688550 & 4.4 & 4.8303 & TRN \\
\hline CHEMBL1393636 & 688550 & 4.8 & 4.8704 & TRN \\
\hline
\end{tabular}




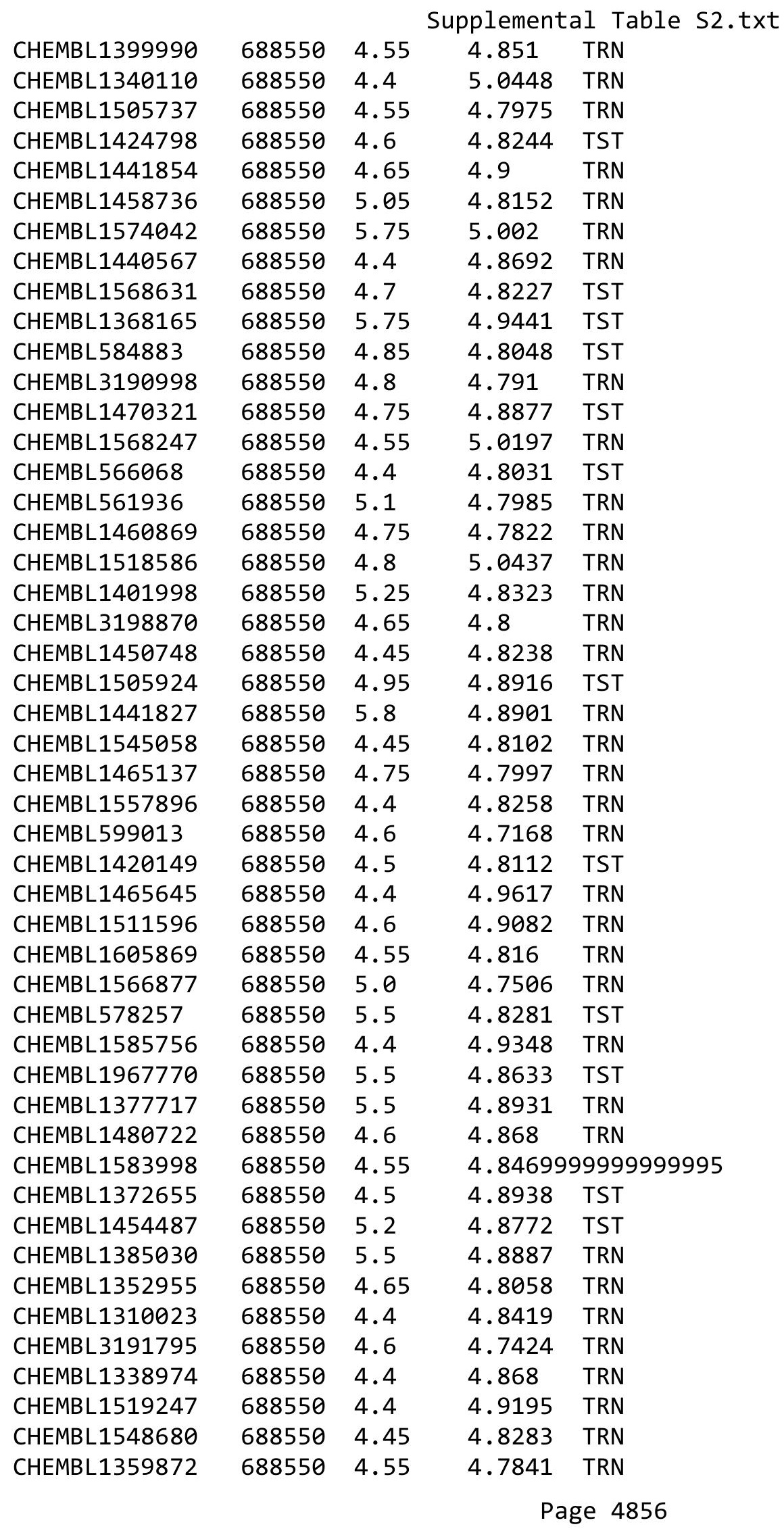




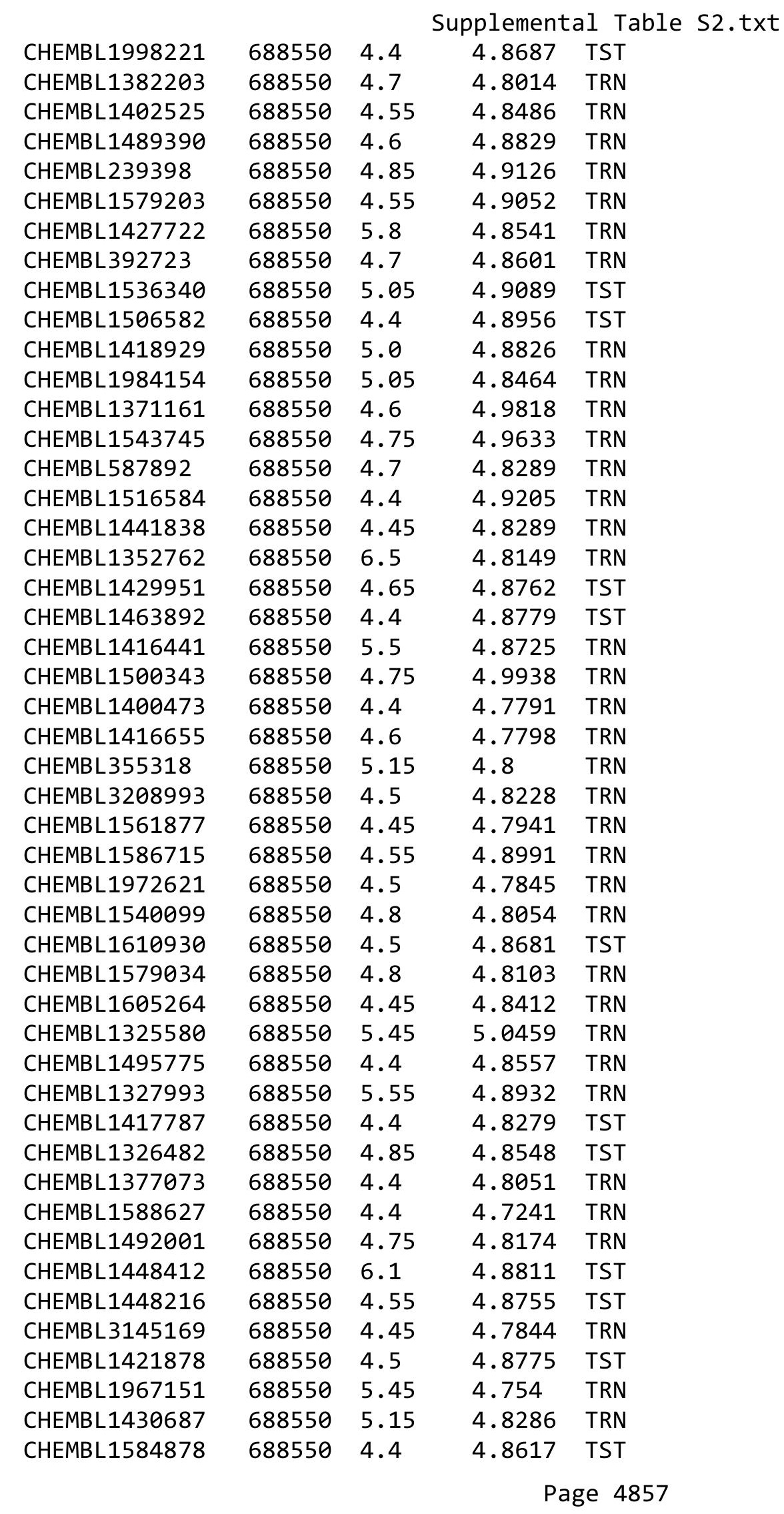




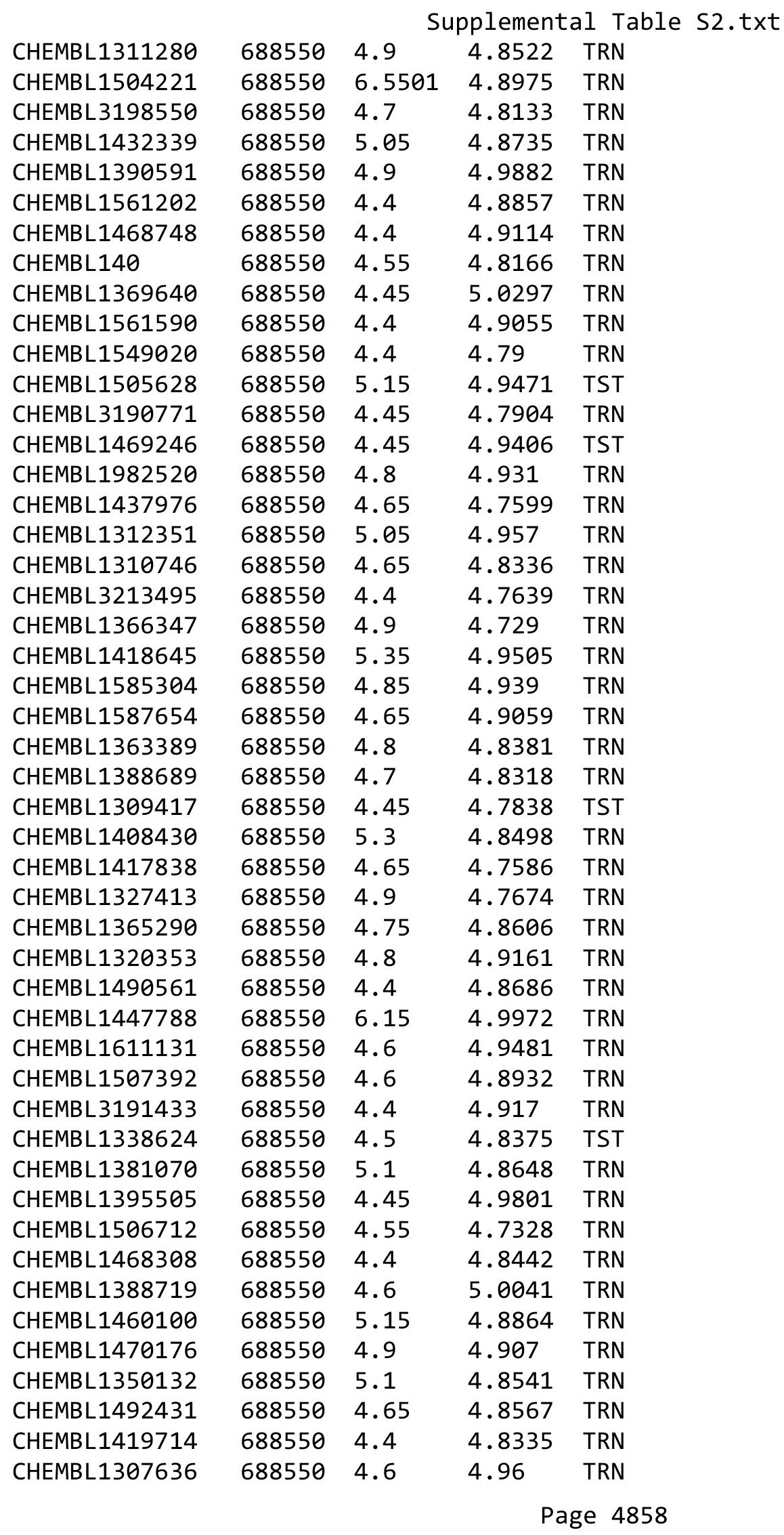




\begin{tabular}{|c|c|c|c|c|c|}
\hline \multicolumn{6}{|c|}{ Supplemental Table S2.txt } \\
\hline CHEMBL3196551 & 688550 & 5.2 & 4.7487 & TRN & \\
\hline CHEMBL1381627 & 688550 & 4.7 & 4.9107 & TST & \\
\hline CHEMBL1601432 & 688550 & 4.65 & 4.8334 & TST & \\
\hline CHEMBL1600114 & 688550 & 5.0 & 4.7947 & TST & \\
\hline CHEMBL1487538 & 688550 & 6.7501 & 4.81800 & 00000000005 & TRN \\
\hline CHEMBL1974389 & 688550 & 5.65 & 4.9385 & TRN & \\
\hline CHEMBL1311829 & 688550 & 6.5 & 4.9459 & TRN & \\
\hline CHEMBL1605369 & 688550 & 5.3 & 4.8841 & TRN & \\
\hline CHEMBL1421117 & 688550 & 4.55 & 4.8445 & TRN & \\
\hline CHEMBL1378869 & 688550 & 4.55 & 4.8879 & TRN & \\
\hline CHEMBL1536179 & 688550 & 5.0 & 4.9538 & TRN & \\
\hline CHEMBL1562132 & 688550 & 5.9 & 4.898 & TRN & \\
\hline CHEMBL1345933 & 688550 & 6.1 & 4.8715 & TRN & \\
\hline CHEMBL1445736 & 688550 & 4.45 & 4.8498 & TST & \\
\hline CHEMBL1556975 & 688550 & 4.7 & 4.8109 & TST & \\
\hline CHEMBL1567793 & 688550 & 4.55 & 4.7696 & TRN & \\
\hline CHEMBL1418951 & 688550 & 4.4 & 4.9261 & TRN & \\
\hline CHEMBL1300515 & 688550 & 4.8 & 5.0218 & TRN & \\
\hline CHEMBL 8883 & 688550 & 4.4 & 4.9061 & TRN & \\
\hline CHEMBL1319154 & 688550 & 5.0 & 4.9072 & TRN & \\
\hline CHEMBL1348026 & 688550 & 4.6 & 4.8626 & TRN & \\
\hline CHEMBL1303763 & 688550 & 4.7 & 5.0399 & TRN & \\
\hline CHEMBL1520438 & 688550 & 4.4 & 4.9174 & TST & \\
\hline CHEMBL1357580 & 688550 & 5.45 & 5.0159 & TST & \\
\hline CHEMBL1300266 & 688550 & 4.75 & 4.8328 & TRN & \\
\hline CHEMBL3208593 & 688550 & 4.9 & 4.7517 & TRN & \\
\hline CHEMBL1420365 & 688550 & 6.5 & 4.8644 & TRN & \\
\hline CHEMBL1376147 & 688550 & 4.6 & 4.8343 & TRN & \\
\hline CHEMBL1584288 & 688550 & 4.4 & 4.8433 & TRN & \\
\hline CHEMBL1367163 & 688550 & 5.8 & 4.9242 & TRN & \\
\hline CHEMBL1519004 & 688550 & 4.45 & 4.8971 & TRN & \\
\hline CHEMBL1389610 & 688550 & 4.45 & 4.8958 & TRN & \\
\hline CHEMBL1559336 & 688550 & 6.45 & 4.8629 & TST & \\
\hline CHEMBL1416093 & 688550 & 4.4 & 4.7345 & TRN & \\
\hline CHEMBL1428256 & 688550 & 4.85 & 4.8818 & TRN & \\
\hline CHEMBL3196684 & 688550 & 4.6 & 4.7968 & TRN & \\
\hline CHEMBL1325943 & 688550 & 4.9 & 4.7907 & TRN & \\
\hline CHEMBL1310508 & 688550 & 5.45 & 4.9468 & TRN & \\
\hline CHEMBL1526836 & 688550 & 4.5 & 5.0214 & TRN & \\
\hline CHEMBL1301244 & 688550 & 5.25 & 4.8832 & TRN & \\
\hline CHEMBL1425837 & 688550 & 4.95 & 4.8953 & TRN & \\
\hline CHEMBL3191527 & 688550 & 4.75 & 4.7362 & TRN & \\
\hline CHEMBL1386269 & 688550 & 4.65 & 4.9966 & TRN & \\
\hline CHEMBL1994973 & 688550 & 5.15 & 4.8061 & TRN & \\
\hline CHEMBL1558913 & 688550 & 6.05 & 4.9078 & TST & \\
\hline CHEMBL1321132 & 688550 & 4.8 & 4.9113 & TRN & \\
\hline CHEMBL1527417 & 688550 & 4.55 & 4.8659 & TRN & \\
\hline CHEMBL1346584 & 688550 & 5.7 & 4.9154 & TST & \\
\hline
\end{tabular}




\begin{tabular}{|c|c|c|c|c|c|}
\hline \multicolumn{6}{|c|}{ Supplemental Table S2.txt } \\
\hline CHEMBL1459468 & 688550 & 4.8 & 4.7292 & TRN & \\
\hline CHEMBL1543847 & 688550 & 4.6 & 4.8141 & TRN & \\
\hline CHEMBL1607759 & 688550 & 6.7501 & 4.9635 & TRN & \\
\hline CHEMBL1411307 & 688550 & 4.4 & 4.7969 & TST & \\
\hline CHEMBL1450393 & 688550 & 5.45 & 4.8935 & TST & \\
\hline CHEMBL1349597 & 688550 & 5.2 & 4.8544 & TRN & \\
\hline CHEMBL1328072 & 688550 & 4.75 & 4.8009 & TRN & \\
\hline CHEMBL1345201 & 688550 & 4.4 & 4.9092 & TRN & \\
\hline CHEMBL 3207632 & 688550 & 4.4 & 4.8242 & TRN & \\
\hline CHEMBL1485289 & 688550 & 6.3 & 4.9654 & TRN & \\
\hline CHEMBL1607882 & 688550 & 4.4 & 4.8336 & TST & \\
\hline CHEMBL1597798 & 688550 & 4.85 & 4.9508 & TRN & \\
\hline CHEMBL1570329 & 688550 & 4.65 & 4.9171 & TST & \\
\hline CHEMBL1506512 & 688550 & 4.45 & 4.8505 & TRN & \\
\hline CHEMBL1423069 & 688550 & 5.3 & 4.7743 & TRN & \\
\hline CHEMBL1461937 & 688550 & 4.65 & 4.771 & TRN & \\
\hline CHEMBL1446094 & 688550 & 4.85 & 4.8773 & TRN & \\
\hline CHEMBL1391168 & 688550 & 5.55 & 5.0743 & TRN & \\
\hline CHEMBL1483915 & 688550 & 5.05 & 4.915 & TRN & \\
\hline CHEMBL1305526 & 688550 & 5.0 & 4.8353 & TST & \\
\hline CHEMBL1480108 & 688550 & 4.8 & 4.8615 & TRN & \\
\hline CHEMBL1607313 & 688550 & 5.9 & 4.8728 & TRN & \\
\hline CHEMBL542493 & 688550 & 4.5 & 4.8551 & TST & \\
\hline CHEMBL1533195 & 688550 & 4.5 & 4.9254 & TRN & \\
\hline CHEMBL1575442 & 688550 & 5.0 & 4.8569 & TRN & \\
\hline CHEMBL1300897 & 688550 & 4.4 & 4.8502 & TRN & \\
\hline CHEMBL1416657 & 688550 & 5.3 & 4.7931 & TRN & \\
\hline CHEMBL1405197 & 688550 & 4.55 & 4.88399 & 99999999995 & TRN \\
\hline CHEMBL1340144 & 688550 & 5.3 & 4.8432 & TRN & \\
\hline CHEMBL1521673 & 688550 & 6.7001 & 5.0617 & TRN & \\
\hline CHEMBL1508694 & 688550 & 4.4 & 4.8231 & TRN & \\
\hline CHEMBL1504492 & 688550 & 4.75 & 4.8188 & TRN & \\
\hline CHEMBL1483103 & 688550 & 4.8 & 4.8644 & TRN & \\
\hline CHEMBL1368371 & 688550 & 5.7 & 4.8877 & TRN & \\
\hline CHEMBL1329322 & 688550 & 4.4 & 4.7456 & TST & \\
\hline CHEMBL1489025 & 688550 & 4.7 & 4.8758 & TST & \\
\hline CHEMBL1503512 & 688550 & 4.55 & 5.0098 & TRN & \\
\hline CHEMBL1428448 & 688550 & 4.8 & 4.9214 & TRN & \\
\hline CHEMBL3199590 & 688550 & 6.0 & 4.7376 & TRN & \\
\hline CHEMBL1994596 & 688550 & 4.75 & 4.7232 & TRN & \\
\hline CHEMBL1508076 & 688550 & 4.6 & 4.8309 & TRN & \\
\hline CHEMBL1351374 & 688550 & 5.4 & 4.8858 & TRN & \\
\hline CHEMBL1419721 & 688550 & 4.65 & 4.9248 & TRN & \\
\hline CHEMBL1386409 & 688550 & 4.4 & 4.812 & TRN & \\
\hline CHEMBL1530245 & 688550 & 4.5 & 4.8171 & TRN & \\
\hline CHEMBL1520595 & 688550 & 4.4 & 4.7704 & TRN & \\
\hline CHEMBL1539400 & 688550 & 4.6 & 4.7844 & TRN & \\
\hline CHEMBL1573636 & 688550 & 4.55 & 4.7199 & TRN & \\
\hline
\end{tabular}




\begin{tabular}{|c|c|c|c|c|}
\hline \multicolumn{5}{|c|}{ Supplemental Table } \\
\hline CHEMBL1367311 & 688550 & 8.2007 & 4.905 & TST \\
\hline CHEMBL3211771 & 688550 & 4.4 & 4.8984 & TRN \\
\hline CHEMBL1966984 & 688550 & 5.35 & 4.8403 & TRN \\
\hline CHEMBL1526308 & 688550 & 4.95 & 5.0191 & TRN \\
\hline CHEMBL1378605 & 688550 & 4.4 & 4.8802 & TRN \\
\hline CHEMBL1383531 & 688550 & 4.6 & 4.8207 & TRN \\
\hline CHEMBL1350862 & 688550 & 4.45 & 4.8096 & TRN \\
\hline CHEMBL1498908 & 688550 & 4.55 & 4.9394 & TRN \\
\hline CHEMBL1438570 & 688550 & 4.4 & 4.8553 & TRN \\
\hline CHEMBL1503357 & 688550 & 4.45 & 4.7698 & TRN \\
\hline CHEMBL1562448 & 688550 & 4.65 & 5.0245 & TRN \\
\hline CHEMBL1588958 & 688550 & 5.25 & 4.8306 & TST \\
\hline CHEMBL1438559 & 688550 & 5.85 & 4.8723 & TST \\
\hline CHEMBL1601562 & 688550 & 5.35 & 4.8047 & TRN \\
\hline CHEMBL1468195 & 688550 & 4.75 & 4.9359 & TRN \\
\hline CHEMBL1367689 & 688550 & 4.4 & 4.8098 & TRN \\
\hline CHEMBL1432734 & 688550 & 5.9 & 4.8482 & TST \\
\hline CHEMBL1386109 & 688550 & 4.45 & 4.8635 & TRN \\
\hline CHEMBL3207620 & 688550 & 4.55 & 4.7982 & TRN \\
\hline CHEMBL1313009 & 688550 & 5.45 & 4.8678 & TRN \\
\hline CHEMBL1421806 & 688550 & 4.55 & 4.832 & TRN \\
\hline CHEMBL1529066 & 688550 & 5.0 & 4.9037 & TRN \\
\hline CHEMBL1301494 & 688550 & 5.1 & 4.8373 & TST \\
\hline CHEMBL1309198 & 688550 & 4.75 & 4.8194 & TRN \\
\hline CHEMBL1529281 & 688550 & 4.6 & 4.8357 & TRN \\
\hline CHEMBL1496857 & 688550 & 4.95 & 4.8272 & TRN \\
\hline CHEMBL1358266 & 688550 & 4.6 & 4.8795 & TST \\
\hline CHEMBL1969647 & 688550 & 4.65 & 4.7358 & TRN \\
\hline CHEMBL1549297 & 688550 & 4.4 & 4.8888 & TRN \\
\hline CHEMBL1381099 & 688550 & 5.5 & 4.7447 & TRN \\
\hline CHEMBL1418809 & 688550 & 4.55 & 4.8206 & TRN \\
\hline CHEMBL1555873 & 688550 & 4.4 & 4.6748 & TRN \\
\hline CHEMBL1547184 & 688550 & 5.45 & 4.9441 & TST \\
\hline CHEMBL1377248 & 688550 & 5.2 & 4.9566 & TST \\
\hline CHEMBL1362099 & 688550 & 5.4 & 4.7933 & TRN \\
\hline CHEMBL1391815 & 688550 & 4.85 & 4.875 & TRN \\
\hline CHEMBL1559112 & 688550 & 5.05 & 4.9724 & TRN \\
\hline CHEMBL1543562 & 688550 & 7.0 & 5.0434 & TRN \\
\hline CHEMBL3208880 & 688550 & 4.6 & 4.7714 & TRN \\
\hline CHEMBL1325243 & 688550 & 4.8 & 4.7742 & TRN \\
\hline CHEMBL1420318 & 688550 & 4.45 & 4.8827 & TRN \\
\hline CHEMBL1556069 & 688550 & 4.65 & 4.9306 & TRN \\
\hline CHEMBL125044 & 688550 & 4.8 & 4.8205 & TRN \\
\hline CHEMBL1477957 & 688550 & 4.85 & 4.7611 & TRN \\
\hline CHEMBL1527095 & 688550 & 4.4 & 4.7437 & TRN \\
\hline CHEMBL3189719 & 688550 & 5.05 & 4.8236 & TST \\
\hline CHEMBL1566544 & 688550 & 4.55 & 4.9621 & TRN \\
\hline CHEMBL1379300 & 688550 & 5.6 & 4.9586 & TRN \\
\hline
\end{tabular}




\begin{tabular}{|c|c|c|c|c|c|}
\hline & & \multicolumn{4}{|c|}{ Supplemental Table s2.txt } \\
\hline CHEMBL1478351 & 688550 & 5.55 & 4.8982 & TRN & \\
\hline CHEMBL1577863 & 688550 & 4.55 & 4.876 & TRN & \\
\hline CHEMBL1404347 & 688550 & 4.4 & 4.8144 & TRN & \\
\hline CHEMBL1607646 & 688550 & 5.05 & 4.8305 & TRN & \\
\hline CHEMBL1449174 & 688550 & 4.75 & 4.9718 & TRN & \\
\hline CHEMBL1403469 & 688550 & 4.4 & 4.8427 & TRN & \\
\hline CHEMBL1592493 & 688550 & 5.05 & 4.7807 & TRN & \\
\hline CHEMBL1407254 & 688550 & 5.1 & 4.8841 & TRN & \\
\hline CHEMBL1500013 & 688550 & 4.4 & 4.8333 & TRN & \\
\hline CHEMBL1482063 & 688550 & 6.3 & 4.831 & TRN & \\
\hline CHEMBL1974613 & 688550 & 5.15 & 4.7518 & TRN & \\
\hline CHEMBL1321367 & 688550 & 4.65 & 5.0245 & TRN & \\
\hline CHEMBL1511203 & 688550 & 5.6 & 4.9222 & TRN & \\
\hline CHEMBL1560384 & 688550 & 4.7 & 5.02800 & 00000000005 & TRN \\
\hline CHEMBL1390472 & 688550 & 4.4 & 4.916 & TST & \\
\hline CHEMBL1594607 & 688550 & 5.1 & 4.8519 & TRN & \\
\hline CHEMBL1606160 & 688550 & 5.05 & 4.9059 & TRN & \\
\hline CHEMBL1494029 & 688550 & 4.75 & 4.8927 & TRN & \\
\hline CHEMBL1374167 & 688550 & 4.5 & 4.833 & TST & \\
\hline CHEMBL1372543 & 688550 & 4.6 & 4.9394 & TRN & \\
\hline CHEMBL1568871 & 688550 & 5.1 & 5.0243 & TRN & \\
\hline CHEMBL1459930 & 688550 & 4.9 & 4.7186 & TRN & \\
\hline CHEMBL1322212 & 688550 & 5.45 & 4.8419 & TRN & \\
\hline CHEMBL1454081 & 688550 & 4.6 & 4.8556 & TRN & \\
\hline CHEMBL1507028 & 688550 & 4.4 & 4.8403 & TRN & \\
\hline CHEMBL1558488 & 688550 & 5.15 & 4.9472 & TRN & \\
\hline CHEMBL1366069 & 688550 & 4.4 & 4.9174 & TRN & \\
\hline CHEMBL1381310 & 688550 & 5.25 & 4.8054 & TRN & \\
\hline CHEMBL1363037 & 688550 & 4.4 & 4.849 & TRN & \\
\hline CHEMBL1516719 & 688550 & 4.55 & 4.8368 & TRN & \\
\hline CHEMBL1324032 & 688550 & 4.85 & 4.823 & TST & \\
\hline CHEMBL1550554 & 688550 & 5.45 & 4.8607 & TRN & \\
\hline CHEMBL1504861 & 688550 & 4.8 & 4.9487 & TRN & \\
\hline CHEMBL1390419 & 688550 & 4.4 & 4.8462 & TST & \\
\hline CHEMBL1309510 & 688550 & 5.05 & 4.8177 & TRN & \\
\hline CHEMBL1471193 & 688550 & 4.75 & 4.8316 & TRN & \\
\hline CHEMBL1555930 & 688550 & 4.85 & 4.7804 & TRN & \\
\hline CHEMBL1564130 & 688550 & 4.4 & 4.9419 & TST & \\
\hline CHEMBL1567844 & 688550 & 5.2 & 4.8626 & TST & \\
\hline CHEMBL1369416 & 688550 & 4.75 & 4.7784 & TRN & \\
\hline CHEMBL1405653 & 688550 & 4.65 & 4.9788 & TRN & \\
\hline CHEMBL1586813 & 688550 & 5.25 & 4.9316 & TRN & \\
\hline CHEMBL1558563 & 688550 & 4.95 & 4.795 & TRN & \\
\hline CHEMBL1362102 & 688550 & 6.0 & 4.8177 & TST & \\
\hline CHEMBL3198521 & 688550 & 5.65 & 4.8938 & TRN & \\
\hline CHEMBL1376336 & 688550 & 5.25 & 4.8362 & TRN & \\
\hline CHEMBL1557727 & 688550 & 4.45 & 4.888 & TRN & \\
\hline CHEMBL1601571 & 688550 & 4.9 & 4.8596 & TRN & \\
\hline
\end{tabular}




\begin{tabular}{|c|c|c|c|c|}
\hline \multicolumn{5}{|c|}{ Supplemental Table S2.txt } \\
\hline CHEMBL1346930 & 688550 & 7.4001 & 4.8979 & TRN \\
\hline CHEMBL1432648 & 688550 & 4.65 & 5.0054 & TRN \\
\hline CHEMBL1411856 & 688550 & 4.6 & 4.9826 & TRN \\
\hline CHEMBL1431222 & 688550 & 5.2 & 5.0037 & TRN \\
\hline CHEMBL1572756 & 688550 & 4.75 & 4.8606 & TRN \\
\hline CHEMBL1602426 & 688550 & 5.05 & 4.9875 & TRN \\
\hline CHEMBL1303712 & 688550 & 4.35 & 4.8615 & TRN \\
\hline CHEMBL1400958 & 688550 & 4.4 & 4.8208 & TST \\
\hline CHEMBL 3194443 & 688550 & 4.4 & 4.7633 & TRN \\
\hline CHEMBL1380662 & 688550 & 4.85 & 4.7821 & TRN \\
\hline CHEMBL1312377 & 688550 & 5.5 & 4.8577 & TRN \\
\hline CHEMBL1548669 & 688550 & 4.5 & 4.9094 & TRN \\
\hline CHEMBL1424486 & 688550 & 4.65 & 4.7347 & TRN \\
\hline CHEMBL1402243 & 688550 & 4.6 & 4.9014 & TST \\
\hline CHEMBL1396181 & 688550 & 4.55 & 4.8912 & TST \\
\hline CHEMBL1560782 & 688550 & 4.6 & 4.9376 & TRN \\
\hline CHEMBL1414041 & 688550 & 5.15 & 4.8801 & TRN \\
\hline CHEMBL1517700 & 688550 & 4.45 & 4.8352 & TRN \\
\hline CHEMBL1381321 & 688550 & 4.5 & 4.9619 & TRN \\
\hline CHEMBL1346108 & 688550 & 5.2 & 4.8277 & TRN \\
\hline CHEMBL1506176 & 688550 & 4.5 & 4.9133 & TRN \\
\hline CHEMBL1320230 & 688550 & 5.35 & 4.7747 & TRN \\
\hline CHEMBL1522846 & 688550 & 4.4 & 4.8898 & TST \\
\hline CHEMBL1610435 & 688550 & 5.4 & 4.8837 & TRN \\
\hline CHEMBL1432275 & 688550 & 4.7 & 4.8413 & TRN \\
\hline CHEMBL1542792 & 688550 & 5.0 & 4.8545 & TST \\
\hline CHEMBL1980574 & 688550 & 4.7 & 4.7766 & TRN \\
\hline CHEMBL1597238 & 688550 & 6.05 & 4.9663 & TRN \\
\hline CHEMBL1457590 & 688550 & 4.8 & 4.9293 & TRN \\
\hline CHEMBL1536562 & 688550 & 4.65 & 4.8708 & TRN \\
\hline CHEMBL1561189 & 688550 & 4.4 & 4.8577 & TRN \\
\hline CHEMBL1303955 & 688550 & 4.5 & 4.8998 & TST \\
\hline CHEMBL1444916 & 688550 & 4.7 & 4.9734 & TRN \\
\hline CHEMBL1564088 & 688550 & 7.0501 & 4.865 & TRN \\
\hline CHEMBL3210689 & 688550 & 4.6 & 4.841 & TST \\
\hline CHEMBL1539023 & 688550 & 4.45 & 4.7526 & TRN \\
\hline CHEMBL1504371 & 688550 & 4.6 & 4.8869 & TRN \\
\hline CHEMBL1528386 & 688550 & 6.8 & 4.9385 & TST \\
\hline CHEMBL1319910 & 688550 & 4.7 & 4.8656 & TRN \\
\hline CHEMBL1448704 & 688550 & 4.55 & 4.8182 & TRN \\
\hline CHEMBL1388726 & 688550 & 4.7 & 4.8461 & TRN \\
\hline CHEMBL1350161 & 688550 & 5.55 & 4.9459 & TRN \\
\hline CHEMBL1613469 & 688550 & 4.65 & 4.8961 & TST \\
\hline CHEMBL1426302 & 688550 & 4.75 & 4.8503 & TRN \\
\hline CHEMBL1299579 & 688550 & 4.4 & 4.8566 & TRN \\
\hline CHEMBL1303587 & 688550 & 4.55 & 4.813 & TRN \\
\hline CHEMBL1463953 & 688550 & 4.9 & 4.8279 & TRN \\
\hline CHEMBL1543163 & 688550 & 4.45 & 4.8907 & TST \\
\hline
\end{tabular}




\begin{tabular}{|c|c|c|c|c|c|}
\hline \multicolumn{6}{|c|}{ Supplemental Table S2.txt } \\
\hline CHEMBL1407401 & 688550 & 4.65 & 4.9002 & TRN & \\
\hline CHEMBL1489534 & 688550 & 6.0 & 4.9944 & TRN & \\
\hline CHEMBL1545556 & 688550 & 4.85 & 4.8075 & TRN & \\
\hline CHEMBL1411689 & 688550 & 4.8 & 4.9032 & TRN & \\
\hline CHEMBL1375021 & 688550 & 4.95 & 5.0559 & TRN & \\
\hline CHEMBL1538822 & 688550 & 6.6 & 4.8676 & TRN & \\
\hline CHEMBL1506921 & 688550 & 4.45 & 4.8584 & TRN & \\
\hline CHEMBL1585000 & 688550 & 4.8 & 4.8817 & TRN & \\
\hline CHEMBL1607918 & 688550 & 4.8 & 4.8108 & TRN & \\
\hline CHEMBL512214 & 688550 & 4.4 & 4.8867 & TRN & \\
\hline CHEMBL1402097 & 688550 & 4.45 & 4.8626 & TRN & \\
\hline CHEMBL589101 & 688550 & 4.85 & 4.893 & TRN & \\
\hline CHEMBL1510948 & 688550 & 4.5 & 4.8953 & TRN & \\
\hline CHEMBL1382917 & 688550 & 5.3 & 4.8866 & TST & \\
\hline CHEMBL1389013 & 688550 & 4.5 & 4.9281 & TRN & \\
\hline CHEMBL1323292 & 688550 & 4.4 & 4.9942 & TRN & \\
\hline CHEMBL1421941 & 688550 & 4.65 & 4.7661 & TRN & \\
\hline CHEMBL1334170 & 688550 & 4.7 & 4.9306 & TRN & \\
\hline CHEMBL1517046 & 688550 & 5.4 & 5.0067 & TRN & \\
\hline CHEMBL1529084 & 688550 & 4.6 & 4.8952 & TRN & \\
\hline CHEMBL1549097 & 688550 & 5.45 & 4.915 & TRN & \\
\hline CHEMBL1519182 & 688550 & 5.35 & 4.868 & TRN & \\
\hline CHEMBL1586246 & 688550 & 4.55 & 4.7795 & TRN & \\
\hline CHEMBL1346905 & 688550 & 4.45 & 5.0639 & TRN & \\
\hline CHEMBL1549582 & 688550 & 4.5 & 4.8451 & TRN & \\
\hline CHEMBL1535723 & 688550 & 4.55 & 4.8789 & TRN & \\
\hline CHEMBL1555617 & 688550 & 4.65 & 4.8117 & TRN & \\
\hline CHEMBL1369930 & 688550 & 4.85 & 4.8324 & TRN & \\
\hline CHEMBL1422415 & 688550 & 4.4 & 4.8229 & TST & \\
\hline CHEMBL1561207 & 688550 & 4.55 & 4.9737 & TRN & \\
\hline CHEMBL1980658 & 688550 & 4.85 & 4.74100 & 00000000005 & TRN \\
\hline CHEMBL1453753 & 688550 & 4.95 & 4.8935 & TST & \\
\hline CHEMBL1441243 & 688550 & 5.55 & 4.901 & TRN & \\
\hline CHEMBL1347089 & 688550 & 4.4 & 4.82100 & 0000000001 & TRN \\
\hline CHEMBL1537383 & 688550 & 4.45 & 4.8607 & TRN & \\
\hline CHEMBL1393926 & 688550 & 4.9 & 4.8171 & TRN & \\
\hline CHEMBL1360026 & 688550 & 4.6 & 4.9252 & TRN & \\
\hline CHEMBL1481785 & 688550 & 4.55 & 5.0269 & TRN & \\
\hline CHEMBL1449338 & 688550 & 5.0 & 4.8725 & TRN & \\
\hline CHEMBL1479572 & 688550 & 8.1487 & 4.8728 & TRN & \\
\hline CHEMBL1336959 & 688550 & 4.4 & 4.8451 & TRN & \\
\hline CHEMBL1567007 & 688550 & 4.9 & 4.7581 & TRN & \\
\hline CHEMBL1343858 & 688550 & 5.75 & 4.8508 & TST & \\
\hline CHEMBL3199318 & 688550 & 5.15 & 4.7802 & TST & \\
\hline CHEMBL3209663 & 688550 & 5.15 & 4.8224 & TST & \\
\hline CHEMBL1588058 & 688550 & 4.6 & 4.7865 & TRN & \\
\hline CHEMBL1569585 & 688550 & 4.8 & 4.8632 & TST & \\
\hline CHEMBL1303333 & 688550 & 4.85 & 4.838 & TRN & \\
\hline
\end{tabular}




\begin{tabular}{|c|c|c|c|c|}
\hline \multicolumn{5}{|c|}{ Supplemental Table s2.txt } \\
\hline CHEMBL1323361 & 688550 & 4.4 & 4.7747 & TRN \\
\hline CHEMBL1708832 & 688550 & 4.9 & 4.8194 & TRN \\
\hline CHEMBL1423690 & 688550 & 6.45 & 5.03100 & 0000000001 \\
\hline CHEMBL1394344 & 688550 & 4.6 & 4.8777 & TRN \\
\hline CHEMBL1569153 & 688550 & 4.4 & 4.845 & TST \\
\hline CHEMBL1501676 & 688550 & 4.85 & 4.8554 & TRN \\
\hline CHEMBL3196960 & 688550 & 4.9 & 4.7278 & TRN \\
\hline CHEMBL1353674 & 688550 & 6.0 & 5.004 & TRN \\
\hline CHEMBL1364752 & 688550 & 4.5 & 4.8525 & TRN \\
\hline CHEMBL1246 & 688550 & 5.05 & 4.8557 & TRN \\
\hline CHEMBL1334447 & 688550 & 5.4 & 4.854 & TRN \\
\hline CHEMBL1370828 & 688550 & 5.35 & 4.9033 & TRN \\
\hline CHEMBL1305197 & 688550 & 5.2 & 4.8775 & TRN \\
\hline CHEMBL1340704 & 688550 & 4.55 & 4.7312 & TRN \\
\hline CHEMBL1324280 & 688550 & 4.4 & 4.8155 & TRN \\
\hline CHEMBL1520214 & 688550 & 4.9 & 4.8391 & TRN \\
\hline CHEMBL1307532 & 688550 & 4.9 & 4.8923 & TRN \\
\hline CHEMBL1400779 & 688550 & 4.4 & 4.864 & TST \\
\hline CHEMBL1565408 & 688550 & 4.6 & 4.8659 & TRN \\
\hline CHEMBL1576145 & 688550 & 6.7501 & 4.9647 & TRN \\
\hline CHEMBL 3198294 & 688550 & 4.85 & 4.7065 & TRN \\
\hline CHEMBL1418000 & 688550 & 4.85 & 4.9359 & TRN \\
\hline CHEMBL3193193 & 688550 & 4.4 & 4.8253 & TST \\
\hline CHEMBL1608259 & 688550 & 5.4 & 4.9025 & TRN \\
\hline CHEMBL1339763 & 688550 & 5.4 & 4.8667 & TRN \\
\hline CHEMBL1523699 & 688550 & 4.5 & 4.8482 & TST \\
\hline CHEMBL1612619 & 688550 & 4.6 & 4.8214 & TRN \\
\hline CHEMBL1452731 & 688550 & 4.8 & 4.948 & TRN \\
\hline CHEMBL1462296 & 688550 & 5.05 & 4.8228 & TST \\
\hline CHEMBL1450354 & 688550 & 4.6 & 4.9152 & TRN \\
\hline CHEMBL1367356 & 688550 & 4.65 & 4.8739 & TRN \\
\hline CHEMBL1333254 & 688550 & 4.65 & 4.7847 & TRN \\
\hline CHEMBL1547769 & 688550 & 4.55 & 4.7521 & TRN \\
\hline CHEMBL1583794 & 688550 & 5.3 & 4.9153 & TRN \\
\hline CHEMBL1391714 & 688550 & 4.8 & 4.9006 & TRN \\
\hline CHEMBL1377501 & 688550 & 4.8 & 4.8115 & TRN \\
\hline CHEMBL1613533 & 688550 & 5.05 & 4.8608 & TST \\
\hline CHEMBL1313735 & 688550 & 4.45 & 4.8493 & TST \\
\hline CHEMBL1403131 & 688550 & 6.9 & 5.0221 & TRN \\
\hline CHEMBL1540526 & 688550 & 4.8 & 4.8546 & TRN \\
\hline CHEMBL 3193004 & 688550 & 4.45 & 4.8025 & TRN \\
\hline CHEMBL1329605 & 688550 & 4.6 & 4.8695 & TST \\
\hline CHEMBL1310850 & 688550 & 4.5 & 4.9074 & TRN \\
\hline CHEMBL1353443 & 688550 & 4.4 & 4.8227 & TRN \\
\hline CHEMBL1547751 & 688550 & 4.6 & 4.8436 & TST \\
\hline CHEMBL1360182 & 688550 & 5.5 & 4.8403 & TRN \\
\hline CHEMBL1472283 & 688550 & 4.65 & 4.7173 & TRN \\
\hline CHEMBL1344731 & 688550 & 4.5 & 4.8301 & TRN \\
\hline
\end{tabular}




\begin{tabular}{|c|c|c|c|c|c|}
\hline \multicolumn{6}{|c|}{ Supplemental Table s2.txt } \\
\hline CHEMBL1376309 & 688550 & 4.65 & 4.8282 & TRN & \\
\hline CHEMBL47986 & 688550 & 5.0 & 4.7956 & TST & \\
\hline CHEMBL591412 & 688550 & 4.5 & 4.8248 & TRN & \\
\hline CHEMBL3190131 & 688550 & 4.8 & 4.7363 & TRN & \\
\hline CHEMBL1503962 & 688550 & 4.75 & 4.8203 & TST & \\
\hline CHEMBL1386287 & 688550 & 4.55 & 4.872 & TST & \\
\hline CHEMBL1543339 & 688550 & 4.6 & 4.8238 & TRN & \\
\hline CHEMBL1391474 & 688550 & 4.75 & 4.7632 & TRN & \\
\hline CHEMBL1360927 & 688550 & 4.5 & \multicolumn{2}{|c|}{4.8839999999999995} & TRN \\
\hline CHEMBL1563443 & 688550 & 4.5 & 4.8148 & TRN & \\
\hline CHEMBL3194093 & 688550 & 5.0 & 4.6918 & TRN & \\
\hline CHEMBL1594469 & 688550 & 4.45 & 4.9063 & TRN & \\
\hline CHEMBL1492651 & 688550 & 4.9 & 4.9716 & TRN & \\
\hline CHEMBL1996724 & 688550 & 4.4 & 4.8139 & TST & \\
\hline CHEMBL1582121 & 688550 & 4.7 & 4.8825 & TRN & \\
\hline CHEMBL1595843 & 688550 & 4.4 & 4.869 & TST & \\
\hline CHEMBL1307518 & 688550 & 4.95 & 5.0389 & TRN & \\
\hline CHEMBL1525069 & 688550 & 4.75 & 4.9662 & TRN & \\
\hline CHEMBL1487084 & 688550 & 5.6 & 4.9782 & TRN & \\
\hline CHEMBL1304507 & 688550 & 4.8 & 4.9982 & TRN & \\
\hline CHEMBL1335571 & 688550 & 4.5 & 4.7362 & TRN & \\
\hline CHEMBL1545768 & 688550 & 5.5 & 4.8585 & TRN & \\
\hline CHEMBL1395526 & 688550 & 5.15 & 4.9037 & TRN & \\
\hline CHEMBL1470656 & 688550 & 4.45 & 4.8611 & TRN & \\
\hline CHEMBL1382240 & 688550 & 4.6 & 4.9558 & TRN & \\
\hline CHEMBL1440300 & 688550 & 4.95 & 4.8163 & TRN & \\
\hline CHEMBL1508326 & 688550 & 5.55 & 4.8456 & TRN & \\
\hline CHEMBL1585547 & 688550 & 4.8 & 4.8395 & TRN & \\
\hline CHEMBL1422571 & 688550 & 4.75 & 4.9755 & TRN & \\
\hline CHEMBL1485466 & 688550 & 4.9 & 4.8927 & TRN & \\
\hline CHEMBL3191022 & 688550 & 5.5 & 4.8317 & TRN & \\
\hline CHEMBL3199171 & 688550 & 4.4 & 4.7907 & TRN & \\
\hline CHEMBL1485491 & 688550 & 6.7001 & 4.817 & TRN & \\
\hline CHEMBL1398992 & 688550 & 4.7 & 4.8415 & TRN & \\
\hline CHEMBL1361913 & 688550 & 4.55 & 4.7747 & TST & \\
\hline CHEMBL1423192 & 688550 & 4.55 & 4.7556 & TRN & \\
\hline CHEMBL1491747 & 688550 & 4.4 & 4.8331 & TST & \\
\hline CHEMBL1544926 & 688550 & 4.5 & 4.8865 & TRN & \\
\hline CHEMBL1499870 & 688550 & 4.4 & 4.8132 & TRN & \\
\hline CHEMBL1463647 & 688550 & 4.4 & 4.853 & TST & \\
\hline CHEMBL1368725 & 688550 & 4.4 & 4.8572 & TRN & \\
\hline CHEMBL1524298 & 688550 & 4.85 & 4.8194 & TST & \\
\hline CHEMBL3197427 & 688550 & 5.2 & 4.8635 & TRN & \\
\hline CHEMBL1607304 & 688550 & 4.65 & 4.8429 & TRN & \\
\hline CHEMBL156717 & 688550 & 4.6 & 4.7427 & TRN & \\
\hline CHEMBL1429805 & 688550 & 5.45 & 4.7794 & TRN & \\
\hline CHEMBL1409038 & 688550 & 4.45 & 4.8494 & TRN & \\
\hline \multirow[t]{2}{*}{ CHEMBL1567998 } & 688550 & 4.45 & \multicolumn{2}{|c|}{4.861000000000001} & TRN \\
\hline & & & & 4866 & \\
\hline
\end{tabular}




\begin{tabular}{|c|c|c|c|c|}
\hline \multicolumn{5}{|c|}{ Supplemental Table S2.txt } \\
\hline CHEMBL139935 & 688550 & 4.4 & 4.7814 & TRN \\
\hline CHEMBL1993190 & 688550 & 4.6 & 4.7489 & TRN \\
\hline CHEMBL1563504 & 688550 & 4.45 & 4.8858 & TRN \\
\hline CHEMBL1571776 & 688550 & 4.8 & 4.9302 & TRN \\
\hline CHEMBL1580141 & 688550 & 5.55 & 4.9694 & TRN \\
\hline CHEMBL1360298 & 688550 & 4.6 & 4.7604 & TRN \\
\hline CHEMBL1324726 & 688550 & 4.65 & 4.9076 & TRN \\
\hline CHEMBL1457174 & 688550 & 4.5 & 4.9299 & TST \\
\hline CHEMBL1402390 & 688550 & 4.8 & 4.7356 & TRN \\
\hline CHEMBL1581238 & 688550 & 4.5 & 4.9021 & TST \\
\hline CHEMBL1505567 & 688550 & 4.9 & 4.8793 & TRN \\
\hline CHEMBL1462847 & 688550 & 4.95 & 4.9441 & TRN \\
\hline CHEMBL1374966 & 688550 & 4.55 & 4.841 & TRN \\
\hline CHEMBL1443354 & 688550 & 4.85 & 4.9183 & TST \\
\hline CHEMBL1350832 & 688550 & 4.65 & 4.8773 & TRN \\
\hline CHEMBL1352080 & 688550 & 5.45 & 4.8753 & TRN \\
\hline CHEMBL1566498 & 688550 & 5.2 & 4.8588 & TST \\
\hline CHEMBL3212590 & 688550 & 4.45 & 4.8388 & TRN \\
\hline CHEMBL1479248 & 688550 & 4.6 & 4.8059 & TRN \\
\hline CHEMBL1410598 & 688550 & 4.7 & 4.7843 & TRN \\
\hline CHEMBL1613732 & 688550 & 5.55 & 4.9028 & TRN \\
\hline CHEMBL 222709 & 688550 & 4.8 & 4.9182 & TRN \\
\hline CHEMBL1458556 & 688550 & 5.5 & 4.8985 & TRN \\
\hline CHEMBL405110 & 688550 & 4.4 & 4.7923 & TST \\
\hline CHEMBL1577927 & 688550 & 6.05 & 4.8072 & TRN \\
\hline CHEMBL1372229 & 688550 & 4.85 & 4.7831 & TRN \\
\hline CHEMBL1469745 & 688550 & 4.4 & 4.8131 & TRN \\
\hline CHEMBL1323490 & 688550 & 4.55 & 4.7398 & TRN \\
\hline CHEMBL1997062 & 688550 & 4.4 & 4.8361 & TRN \\
\hline CHEMBL1302231 & 688550 & 4.7 & 4.8313 & TRN \\
\hline CHEMBL1576791 & 688550 & 5.6 & 4.893 & TRN \\
\hline CHEMBL1541153 & 688550 & 4.8 & 4.9042 & TRN \\
\hline CHEMBL1489268 & 688550 & 4.4 & 4.8557 & TST \\
\hline CHEMBL1311761 & 688550 & 5.45 & 4.8927 & TST \\
\hline CHEMBL1490031 & 688550 & 4.8 & 4.7947 & TST \\
\hline CHEMBL1542039 & 688550 & 4.85 & 4.8565 & TRN \\
\hline CHEMBL1483790 & 688550 & 4.8 & 4.9633 & TRN \\
\hline CHEMBL1447319 & 688550 & 5.1 & 4.9434 & TRN \\
\hline CHEMBL560919 & 688550 & 4.7 & 4.809 & TRN \\
\hline CHEMBL1311879 & 688550 & 4.6 & 4.7498 & TRN \\
\hline CHEMBL1423529 & 688550 & 4.6 & 4.7867 & TRN \\
\hline CHEMBL1505050 & 688550 & 5.35 & 4.86 & TRN \\
\hline CHEMBL1547562 & 688550 & 4.6 & 4.9096 & TRN \\
\hline CHEMBL1325035 & 688550 & 4.4 & 4.894 & TRN \\
\hline CHEMBL1489522 & 688550 & 4.6 & 4.908 & TRN \\
\hline CHEMBL1444884 & 688550 & 5.05 & 4.8216 & TRN \\
\hline CHEMBL1386252 & 688550 & 4.95 & 4.8629 & TST \\
\hline CHEMBL1507061 & 688550 & 5.2 & 4.8652 & TRN \\
\hline
\end{tabular}




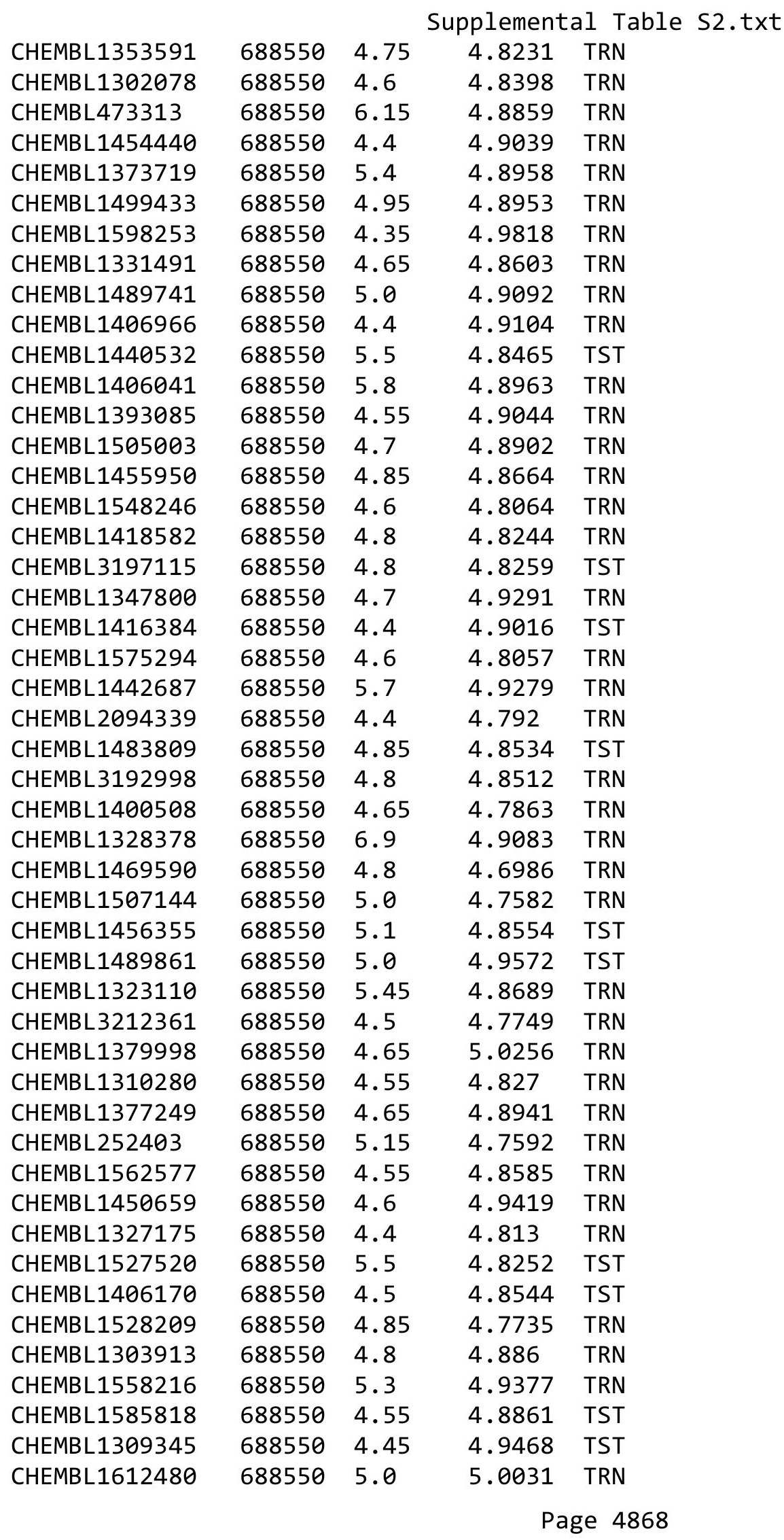




\begin{tabular}{|c|c|c|c|c|}
\hline \multicolumn{5}{|c|}{ Supplemental Table } \\
\hline CHEMBL1416049 & 688550 & 4.55 & 4.797 & TST \\
\hline CHEMBL1309122 & 688550 & 4.55 & 4.8555 & TRN \\
\hline CHEMBL1304552 & 688550 & 4.55 & 4.8093 & TRN \\
\hline CHEMBL1381407 & 688550 & 4.45 & 4.7767 & TRN \\
\hline CHEMBL1300171 & 688550 & 6.25 & 4.9779 & TRN \\
\hline CHEMBL1312800 & 688550 & 4.55 & 4.8842 & TRN \\
\hline CHEMBL1540480 & 688550 & 4.55 & 4.9555 & TRN \\
\hline CHEMBL1341192 & 688550 & 4.85 & 4.8232 & TRN \\
\hline CHEMBL1401363 & 688550 & 6.05 & 4.9854 & TRN \\
\hline CHEMBL1364876 & 688550 & 4.6 & 4.8528 & TRN \\
\hline CHEMBL1403156 & 688550 & 4.6 & 4.8298 & TRN \\
\hline CHEMBL1429070 & 688550 & 6.0 & 4.8041 & TST \\
\hline CHEMBL1412825 & 688550 & 4.7 & 4.7643 & TRN \\
\hline CHEMBL1332045 & 688550 & 4.4 & 4.9099 & TRN \\
\hline CHEMBL1588121 & 688550 & 6.0 & 4.8961 & TRN \\
\hline CHEMBL1547938 & 688550 & 4.95 & 4.8078 & TRN \\
\hline CHEMBL1347914 & 688550 & 5.45 & 4.7587 & TST \\
\hline CHEMBL1588221 & 688550 & 6.0 & 4.8412 & TRN \\
\hline CHEMBL1408050 & 688550 & 5.4 & 4.8856 & TRN \\
\hline CHEMBL1335718 & 688550 & 4.6 & 4.9826 & TRN \\
\hline CHEMBL1384492 & 688550 & 4.4 & 4.9248 & TRN \\
\hline CHEMBL1579329 & 688550 & 4.45 & 4.8507 & TST \\
\hline CHEMBL1520048 & 688550 & 4.5 & 4.8353 & TRN \\
\hline CHEMBL1542470 & 688550 & 5.45 & 4.9459 & TRN \\
\hline CHEMBL1376356 & 688550 & 5.0 & 4.8699 & TRN \\
\hline CHEMBL1336240 & 688550 & 4.4 & 4.9221 & TRN \\
\hline CHEMBL1442056 & 688550 & 4.5 & 4.8182 & TRN \\
\hline CHEMBL1518715 & 688550 & 4.55 & 4.8593 & TRN \\
\hline CHEMBL3198235 & 688550 & 5.1 & 4.8105 & TRN \\
\hline CHEMBL1398938 & 688550 & 4.6 & 4.902 & TRN \\
\hline CHEMBL1510658 & 688550 & 6.4 & 4.8477 & TST \\
\hline CHEMBL1457591 & 688550 & 4.65 & 4.851 & TRN \\
\hline CHEMBL1371936 & 688550 & 4.55 & 4.8547 & TRN \\
\hline CHEMBL1489717 & 688550 & 4.6 & 4.8847 & TRN \\
\hline CHEMBL1337752 & 688550 & 5.1 & 4.7869 & TRN \\
\hline CHEMBL1361076 & 688550 & 5.5 & 4.9225 & TRN \\
\hline CHEMBL1503366 & 688550 & 4.6 & 4.8871 & TRN \\
\hline CHEMBL1463529 & 688550 & 5.05 & 4.7205 & TRN \\
\hline CHEMBL1403065 & 688550 & 4.6 & 4.7684 & TRN \\
\hline CHEMBL1331231 & 688550 & 4.8 & 4.7859 & TRN \\
\hline CHEMBL1477218 & 688550 & 4.4 & 4.8416 & TST \\
\hline CHEMBL1491241 & 688550 & 5.15 & 4.9207 & TRN \\
\hline CHEMBL1517045 & 688550 & 4.9 & 4.7226 & TST \\
\hline CHEMBL1431993 & 688550 & 4.7 & 4.8765 & TRN \\
\hline CHEMBL3856092 & 688550 & 5.3 & 4.822 & TST \\
\hline CHEMBL1342575 & 688550 & 5.35 & 4.8852 & TRN \\
\hline CHEMBL1362264 & 688550 & 5.85 & 4.9119 & TRN \\
\hline CHEMBL1570003 & 688550 & 4.8 & 4.9303 & TRN \\
\hline
\end{tabular}




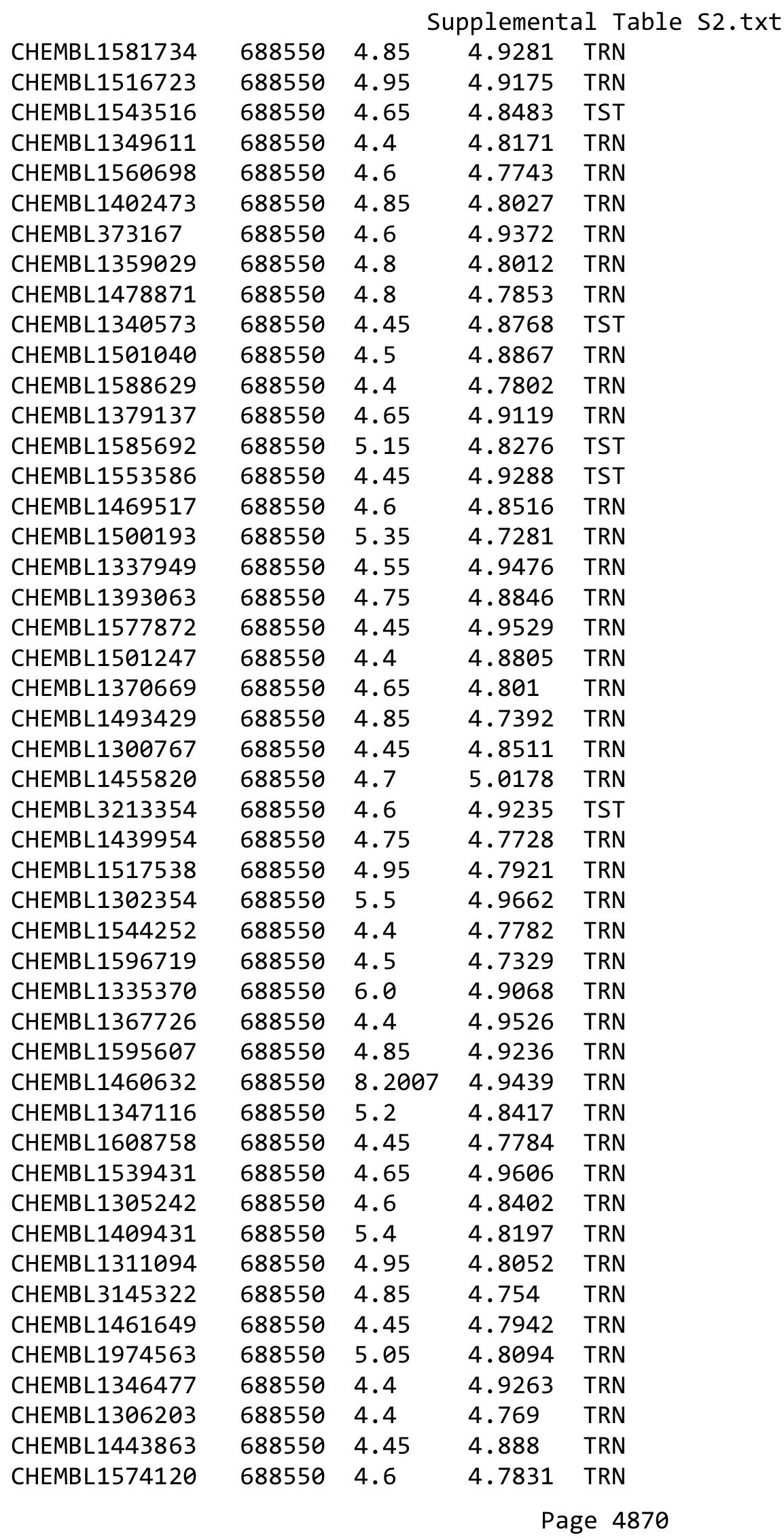




\begin{tabular}{|c|c|c|c|c|}
\hline \multicolumn{5}{|c|}{ Supplemental Table S2.txt } \\
\hline CHEMBL1332281 & 688550 & 4.9 & 4.9365 & TRN \\
\hline CHEMBL1318813 & 688550 & 4.5 & 4.8324 & TRN \\
\hline CHEMBL1427529 & 688550 & 4.6 & 4.8625 & TRN \\
\hline CHEMBL1372662 & 688550 & 4.75 & 4.9559 & TST \\
\hline CHEMBL1552575 & 688550 & 6.15 & 4.8946 & TRN \\
\hline CHEMBL3199770 & 688550 & 6.0 & 4.8523 & TRN \\
\hline CHEMBL1545279 & 688550 & 4.7 & 4.7664 & TRN \\
\hline CHEMBL1973383 & 688550 & 4.7 & 4.7871 & TST \\
\hline CHEMBL1455610 & 688550 & 4.7 & 4.9226 & TRN \\
\hline CHEMBL1579972 & 688550 & 4.4 & 4.8819 & TRN \\
\hline CHEMBL1989090 & 688550 & 4.85 & 4.7115 & TRN \\
\hline CHEMBL1530441 & 688550 & 4.55 & 4.8459 & TRN \\
\hline CHEMBL1540825 & 688550 & 6.15 & 4.9942 & TRN \\
\hline CHEMBL1376200 & 688550 & 7.0 & 4.8105 & TRN \\
\hline CHEMBL1400638 & 688550 & 4.6 & 4.9011 & TST \\
\hline CHEMBL1979849 & 688550 & 5.9 & 4.7785 & TRN \\
\hline CHEMBL1439679 & 688550 & 4.85 & 4.7793 & TRN \\
\hline CHEMBL 2000122 & 688550 & 4.8 & 4.7239 & TRN \\
\hline CHEMBL1472383 & 688550 & 6.05 & 4.9735 & TST \\
\hline CHEMBL1531320 & 688550 & 4.95 & 4.7829 & TRN \\
\hline CHEMBL1498070 & 688550 & 4.4 & 4.9115 & TRN \\
\hline CHEMBL1964843 & 688550 & 4.7 & 4.7199 & TRN \\
\hline CHEMBL1335770 & 688550 & 4.85 & 4.9187 & TRN \\
\hline CHEMBL1340058 & 688550 & 4.55 & 4.8114 & TRN \\
\hline CHEMBL1506369 & 688550 & 6.0 & 4.9021 & TRN \\
\hline CHEMBL1589085 & 688550 & 4.8 & 4.8932 & TST \\
\hline CHEMBL1301740 & 688550 & 4.45 & 4.8336 & TRN \\
\hline CHEMBL1338544 & 688550 & 4.9 & 4.806 & TST \\
\hline CHEMBL1454105 & 688550 & 4.65 & 4.9285 & TRN \\
\hline CHEMBL1403634 & 688550 & 4.65 & 4.7965 & TRN \\
\hline CHEMBL1468887 & 688550 & 4.85 & 4.9768 & TRN \\
\hline CHEMBL3191288 & 688550 & 4.4 & 4.8374 & TRN \\
\hline CHEMBL1467087 & 688550 & 6.25 & 4.9049 & TST \\
\hline CHEMBL1487360 & 688550 & 4.65 & 4.8661 & TRN \\
\hline CHEMBL1549120 & 688550 & 5.4 & 4.7639 & TRN \\
\hline CHEMBL1574363 & 688550 & 4.95 & 4.8306 & TRN \\
\hline CHEMBL1612578 & 688550 & 4.65 & 4.9284 & TRN \\
\hline CHEMBL3211820 & 688550 & 4.5 & 4.7777 & TRN \\
\hline CHEMBL1402279 & 688550 & 4.6 & 4.9427 & TRN \\
\hline CHEMBL1431345 & 688550 & 4.85 & 4.8747 & TRN \\
\hline CHEMBL1347592 & 688550 & 5.7 & 4.9849 & TRN \\
\hline CHEMBL1568810 & 688550 & 5.25 & 4.7931 & TRN \\
\hline CHEMBL 2005446 & 688550 & 5.05 & 4.8106 & TRN \\
\hline CHEMBL1428053 & 688550 & 4.55 & 4.8417 & TRN \\
\hline CHEMBL1489383 & 688550 & 4.6 & 4.8827 & TRN \\
\hline CHEMBL1319488 & 688550 & 5.75 & 4.8992 & TRN \\
\hline CHEMBL1333057 & 688550 & 5.15 & 4.9264 & TRN \\
\hline CHEMBL1579847 & 688550 & 4.5 & 4.9811 & TRN \\
\hline
\end{tabular}




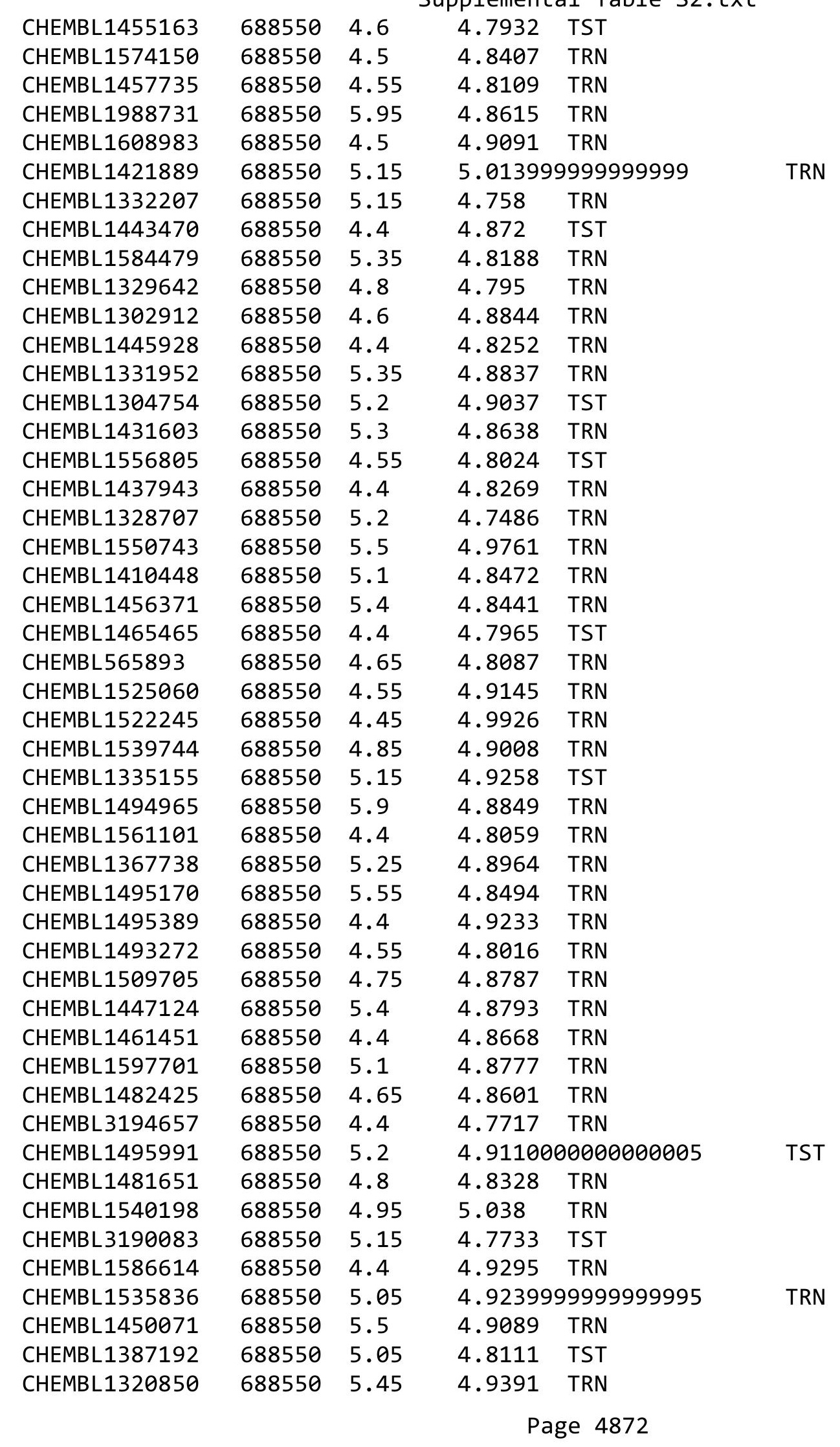




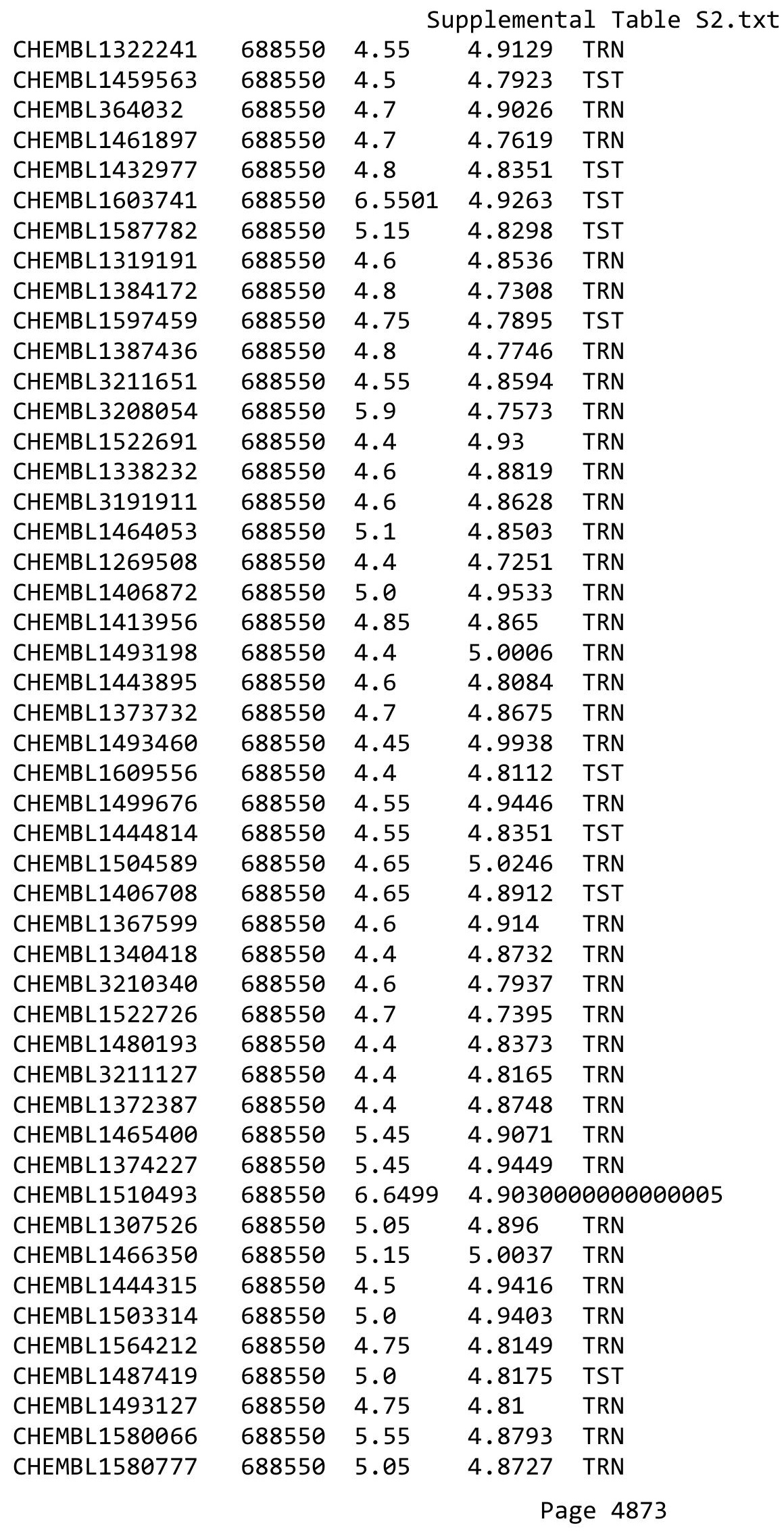




\begin{tabular}{|c|c|c|c|c|}
\hline \multicolumn{5}{|c|}{ Supplemental Table } \\
\hline CHEMBL1332177 & 688550 & 5.25 & 4.8759 & TST \\
\hline CHEMBL3193749 & 688550 & 4.4 & 4.8044 & TRN \\
\hline CHEMBL1467501 & 688550 & 4.4 & 4.8349 & TRN \\
\hline CHEMBL1333669 & 688550 & 4.45 & 4.9811 & TRN \\
\hline CHEMBL1428605 & 688550 & 5.05 & 4.9296 & TRN \\
\hline CHEMBL1393144 & 688550 & 5.3 & 4.9198 & TRN \\
\hline CHEMBL1428820 & 688550 & 4.4 & 4.8506 & TRN \\
\hline CHEMBL1565221 & 688550 & 4.5 & 4.7728 & TRN \\
\hline CHEMBL1432065 & 688550 & 4.5 & 4.9157 & TST \\
\hline CHEMBL1359521 & 688550 & 4.75 & 4.7266 & TRN \\
\hline CHEMBL1449995 & 688550 & 5.65 & 4.754 & TRN \\
\hline CHEMBL486094 & 688550 & 5.3 & 4.8511 & TRN \\
\hline CHEMBL1377675 & 688550 & 5.5 & 4.8825 & TRN \\
\hline CHEMBL1324867 & 688550 & 4.8 & 4.8119 & TST \\
\hline CHEMBL1546232 & 688550 & 4.65 & 4.7965 & TRN \\
\hline CHEMBL3209288 & 688550 & 4.4 & 4.7793 & TRN \\
\hline CHEMBL1335758 & 688550 & 4.4 & 4.84 & TST \\
\hline CHEMBL1422043 & 688550 & 6.25 & 4.9394 & TST \\
\hline CHEMBL1428889 & 688550 & 4.55 & 4.8082 & TRN \\
\hline CHEMBL1556063 & 688550 & 4.4 & 4.838 & TRN \\
\hline CHEMBL1529766 & 688550 & 4.45 & 4.8548 & TST \\
\hline CHEMBL1323805 & 688550 & 4.45 & 4.9762 & TRN \\
\hline CHEMBL 3856088 & 688550 & 5.15 & 4.8647 & TST \\
\hline CHEMBL1477073 & 688550 & 5.05 & 5.0442 & TRN \\
\hline CHEMBL1573754 & 688550 & 4.45 & 4.9059 & TST \\
\hline CHEMBL1338936 & 688550 & 4.6 & 4.8116 & TRN \\
\hline CHEMBL1537794 & 688550 & 4.45 & 4.8641 & TRN \\
\hline CHEMBL1599180 & 688550 & 4.4 & 4.8242 & TST \\
\hline CHEMBL1426411 & 688550 & 5.55 & 4.8315 & TRN \\
\hline CHEMBL1319111 & 688550 & 4.4 & 4.8639 & TRN \\
\hline CHEMBL1313597 & 688550 & 4.4 & 4.8604 & TRN \\
\hline CHEMBL1213769 & 688550 & 5.45 & 4.8008 & TRN \\
\hline CHEMBL1503147 & 688550 & 4.4 & 4.8578 & TRN \\
\hline CHEMBL1301935 & 688550 & 4.85 & 4.842 & TRN \\
\hline CHEMBL1599937 & 688550 & 4.4 & 4.9038 & TST \\
\hline CHEMBL1329846 & 688550 & 4.8 & 4.8583 & TRN \\
\hline CHEMBL1533221 & 688550 & 4.7 & 5.0128 & TRN \\
\hline CHEMBL1370700 & 688550 & 4.6 & 4.8313 & TRN \\
\hline CHEMBL1510345 & 688550 & 5.95 & 5.0358 & TRN \\
\hline CHEMBL1537146 & 688550 & 4.85 & 5.0439 & TRN \\
\hline CHEMBL1426076 & 688550 & 4.6 & 4.8507 & TST \\
\hline CHEMBL1413994 & 688550 & 5.25 & 4.8373 & TRN \\
\hline CHEMBL1319436 & 688550 & 4.45 & 4.9684 & TRN \\
\hline CHEMBL1302383 & 688550 & 5.2 & 4.8468 & TST \\
\hline CHEMBL1557112 & 688550 & 4.8 & 4.876 & TRN \\
\hline CHEMBL1571615 & 688550 & 4.55 & 4.795 & TRN \\
\hline CHEMBL1388871 & 688550 & 4.4 & 4.8392 & TST \\
\hline CHEMBL1462145 & 688550 & 4.4 & 4.8558 & TRN \\
\hline
\end{tabular}




\begin{tabular}{|c|c|c|c|c|c|}
\hline \multicolumn{6}{|c|}{ Supplemental Table S2.txt } \\
\hline CHEMBL1386322 & 688550 & 4.6 & 4.8175 & TRN & \\
\hline CHEMBL1379976 & 688550 & 4.4 & 4.8118 & TRN & \\
\hline CHEMBL1309904 & 688550 & 5.15 & 5.0194 & TRN & \\
\hline CHEMBL1386796 & 688550 & 4.5 & 4.8745 & TRN & \\
\hline CHEMBL3189703 & 688550 & 4.6 & 4.8392 & TRN & \\
\hline CHEMBL1328980 & 688550 & 4.6 & 4.8332 & TRN & \\
\hline CHEMBL1450240 & 688550 & 4.4 & 4.9757 & TRN & \\
\hline CHEMBL1440607 & 688550 & 5.05 & 4.7438 & TRN & \\
\hline CHEMBL1323648 & 688550 & 5.9 & 4.7873 & TST & \\
\hline CHEMBL1542740 & 688550 & 4.65 & 4.9059 & TRN & \\
\hline CHEMBL3189605 & 688550 & 5.5 & 4.7768 & TRN & \\
\hline CHEMBL1556737 & 688550 & 4.55 & 4.8343 & TRN & \\
\hline CHEMBL1488923 & 688550 & 4.8 & 4.8051 & TRN & \\
\hline CHEMBL1483344 & 688550 & 6.0 & 4.902 & TRN & \\
\hline CHEMBL1326120 & 688550 & 5.05 & 4.9525 & TRN & \\
\hline CHEMBL3198900 & 688550 & 5.65 & 4.7814 & TRN & \\
\hline CHEMBL1565638 & 688550 & 4.4 & 4.8414 & TRN & \\
\hline CHEMBL1543238 & 688550 & 4.85 & 4.7335 & TRN & \\
\hline CHEMBL1402056 & 688550 & 4.55 & 4.9346 & TST & \\
\hline CHEMBL1499376 & 688550 & 4.4 & 4.8524 & TRN & \\
\hline CHEMBL1394003 & 688550 & 4.4 & 4.9131 & TRN & \\
\hline CHEMBL1577618 & 688550 & 4.45 & 4.9166 & TRN & \\
\hline CHEMBL1485133 & 688550 & 4.9 & 4.9222 & TRN & \\
\hline CHEMBL1581374 & 688550 & 4.7 & 4.8526 & TRN & \\
\hline CHEMBL1504914 & 688550 & 5.5 & 4.8678 & TRN & \\
\hline CHEMBL1432944 & 688550 & 5.75 & 4.976 & TRN & \\
\hline CHEMBL3198811 & 688550 & 4.75 & 4.78600 & 00000000005 & TRN \\
\hline CHEMBL1411962 & 688550 & 4.95 & 4.7657 & TST & \\
\hline CHEMBL1510373 & 688550 & 4.55 & 4.8793 & TST & \\
\hline CHEMBL3199090 & 688550 & 4.5 & 4.7918 & TRN & \\
\hline CHEMBL1581297 & 688550 & 5.45 & 4.8209 & TRN & \\
\hline CHEMBL1338879 & 688550 & 4.6 & 4.8533 & TRN & \\
\hline CHEMBL1461913 & 688550 & 4.65 & 4.8811 & TST & \\
\hline CHEMBL1332946 & 688550 & 4.85 & 5.0273 & TRN & \\
\hline CHEMBL1320241 & 688550 & 4.6 & 5.0365 & TRN & \\
\hline CHEMBL1458057 & 688550 & 5.3 & 4.9784 & TRN & \\
\hline CHEMBL1608128 & 688550 & 5.0 & 4.9513 & TRN & \\
\hline CHEMBL1348251 & 688550 & 5.45 & 4.8836 & TRN & \\
\hline CHEMBL1541234 & 688550 & 5.1 & 5.0442 & TRN & \\
\hline CHEMBL1430356 & 688550 & 4.45 & 4.8876 & TRN & \\
\hline CHEMBL1304052 & 688550 & 4.7 & 4.8548 & TST & \\
\hline CHEMBL1559143 & 688550 & 4.65 & 4.8908 & TRN & \\
\hline CHEMBL1482208 & 688550 & 4.4 & 4.9133 & TRN & \\
\hline CHEMBL1575045 & 688550 & 4.35 & 4.9053 & TRN & \\
\hline CHEMBL1374291 & 688550 & 4.75 & 4.9237 & TRN & \\
\hline CHEMBL376426 & 688550 & 5.2 & 4.7567 & TRN & \\
\hline CHEMBL1443259 & 688550 & 5.65 & 4.8944 & TRN & \\
\hline CHEMBL1343252 & 688550 & 7.0501 & 4.8311 & TRN & \\
\hline
\end{tabular}




\begin{tabular}{|c|c|c|c|c|c|}
\hline \multicolumn{6}{|c|}{ Supplemental Table S2.txt } \\
\hline CHEMBL1568173 & 688550 & 4.4 & 4.9197 & TRN & \\
\hline CHEMBL1581987 & 688550 & 4.4 & 4.8764 & TRN & \\
\hline CHEMBL1585891 & 688550 & 4.4 & 4.8961 & TST & \\
\hline CHEMBL1482416 & 688550 & 4.8 & 4.9455 & TRN & \\
\hline CHEMBL1327614 & 688550 & 5.8 & 4.8956 & TRN & \\
\hline CHEMBL1983168 & 688550 & 4.75 & 4.8019 & TRN & \\
\hline CHEMBL1502269 & 688550 & 5.55 & 4.9335 & TST & \\
\hline CHEMBL3189792 & 688550 & 5.5 & 4.8274 & TRN & \\
\hline CHEMBL1973571 & 688550 & 4.85 & 4.7379 & TRN & \\
\hline CHEMBL1338543 & 688550 & 4.45 & 4.9811 & TRN & \\
\hline CHEMBL1529460 & 688550 & 5.7 & 4.7399 & TST & \\
\hline CHEMBL1486212 & 688550 & 4.4 & 4.79 & TRN & \\
\hline CHEMBL1978279 & 688550 & 4.55 & 4.7862 & TRN & \\
\hline CHEMBL1388194 & 688550 & 4.55 & 4.829 & TRN & \\
\hline CHEMBL1524020 & 688550 & 5.05 & 4.774 & TRN & \\
\hline CHEMBL1578083 & 688550 & 5.25 & 4.8889 & TST & \\
\hline CHEMBL3192131 & 688550 & 5.15 & 4.7211 & TRN & \\
\hline CHEMBL1599120 & 688550 & 5.1 & 4.8762 & TST & \\
\hline CHEMBL1390938 & 688550 & 4.75 & 4.9012 & TRN & \\
\hline CHEMBL1477027 & 688550 & 5.4 & 4.8583 & TST & \\
\hline CHEMBL1602624 & 688550 & 4.4 & 4.8591 & TRN & \\
\hline CHEMBL1979957 & 688550 & 4.7 & 4.7842 & TST & \\
\hline CHEMBL1547628 & 688550 & 4.4 & 4.7736 & TRN & \\
\hline CHEMBL1604546 & 688550 & 4.95 & 4.8692 & TST & \\
\hline CHEMBL1563383 & 688550 & 4.65 & 4.7451 & TRN & \\
\hline CHEMBL1446971 & 688550 & 6.9 & 4.8599 & TRN & \\
\hline CHEMBL1612912 & 688550 & 4.65 & 4.7814 & TRN & \\
\hline CHEMBL1566092 & 688550 & 5.35 & 4.82600 & 00000000005 & TRN \\
\hline CHEMBL1984804 & 688550 & 4.55 & 4.8019 & TRN & \\
\hline CHEMBL1531023 & 688550 & 4.45 & 4.9314 & TRN & \\
\hline CHEMBL1326546 & 688550 & 5.15 & 4.8111 & TRN & \\
\hline CHEMBL1311834 & 688550 & 4.65 & 4.8837 & TRN & \\
\hline CHEMBL1353231 & 688550 & 4.5 & 4.8576 & TRN & \\
\hline CHEMBL1549187 & 688550 & 5.2 & 4.9766 & TRN & \\
\hline CHEMBL1508458 & 688550 & 4.55 & 4.7638 & TRN & \\
\hline CHEMBL1333162 & 688550 & 4.9 & 4.8137 & TRN & \\
\hline CHEMBL1299210 & 688550 & 4.8 & 4.8162 & TRN & \\
\hline CHEMBL1596106 & 688550 & 4.4 & 4.9062 & TRN & \\
\hline CHEMBL1426164 & 688550 & 6.6 & 4.9676 & TRN & \\
\hline CHEMBL1378903 & 688550 & 5.1 & 4.7595 & TRN & \\
\hline CHEMBL1505764 & 688550 & 6.0 & 4.9171 & TST & \\
\hline CHEMBL1993627 & 688550 & 4.6 & 4.7706 & TRN & \\
\hline CHEMBL1452710 & 688550 & 5.45 & 4.8399 & TRN & \\
\hline CHEMBL1467378 & 688550 & 4.75 & 4.7998 & TRN & \\
\hline CHEMBL1511198 & 688550 & 4.6 & 4.8024 & TRN & \\
\hline CHEMBL1353776 & 688550 & 4.75 & 4.9049 & TRN & \\
\hline CHEMBL1538576 & 688550 & 4.85 & 4.9247 & TRN & \\
\hline CHEMBL1331416 & 688550 & 4.55 & 4.8298 & TRN & \\
\hline
\end{tabular}




\begin{tabular}{|c|c|c|c|c|c|}
\hline & & \multicolumn{4}{|c|}{ Supplemental Table S2.txt } \\
\hline CHEMBL1549883 & 688550 & 4.6 & 4.9051 & TRN & \\
\hline CHEMBL1416242 & 688550 & 4.6 & 4.876 & TRN & \\
\hline CHEMBL1377992 & 688550 & 4.7 & 4.8179 & TRN & \\
\hline CHEMBL1562684 & 688550 & 4.8 & 4.7631 & TRN & \\
\hline CHEMBL1329984 & 688550 & 5.05 & 4.955 & TRN & \\
\hline CHEMBL1403890 & 688550 & 5.05 & 4.9243 & TRN & \\
\hline CHEMBL1400998 & 688550 & 4.4 & 4.93 & TRN & \\
\hline CHEMBL1492094 & 688550 & 5.2 & 4.9135 & TRN & \\
\hline CHEMBL1503109 & 688550 & 7.0 & 4.989 & TRN & \\
\hline CHEMBL1522184 & 688550 & 6.05 & 4.8082 & TST & \\
\hline CHEMBL1510300 & 688550 & 4.55 & 4.967 & TRN & \\
\hline CHEMBL1584300 & 688550 & 4.65 & 4.8558 & TST & \\
\hline CHEMBL 3213802 & 688550 & 4.9 & 4.97199 & 99999999995 & TRN \\
\hline CHEMBL1520497 & 688550 & 4.8 & 4.8597 & TRN & \\
\hline CHEMBL1580408 & 688550 & 5.4 & 4.9081 & TRN & \\
\hline CHEMBL1392711 & 688550 & 5.45 & 4.8118 & TST & \\
\hline CHEMBL3210064 & 688550 & 4.6 & 4.8321 & TST & \\
\hline CHEMBL1443464 & 688550 & 4.5 & 4.813 & TRN & \\
\hline CHEMBL1483351 & 688550 & 4.6 & 4.9601 & TST & \\
\hline CHEMBL1449229 & 688550 & 4.85 & 4.8477 & TRN & \\
\hline CHEMBL1585677 & 688550 & 4.4 & 4.8588 & TRN & \\
\hline CHEMBL1486438 & 688550 & 4.9 & 4.8173 & TRN & \\
\hline CHEMBL1353716 & 688550 & 4.5 & 4.7659 & TRN & \\
\hline CHEMBL1472138 & 688550 & 5.25 & 4.8384 & TST & \\
\hline CHEMBL1604544 & 688550 & 6.4 & 4.9194 & TRN & \\
\hline CHEMBL1573366 & 688550 & 4.6 & 4.7769 & TRN & \\
\hline CHEMBL1325338 & 688550 & 4.4 & 4.9484 & TRN & \\
\hline CHEMBL1377333 & 688550 & 4.75 & 4.8524 & TRN & \\
\hline CHEMBL3196120 & 688550 & 4.55 & 4.8419 & TRN & \\
\hline CHEMBL1427265 & 688550 & 4.6 & 4.7595 & TRN & \\
\hline CHEMBL1504361 & 688550 & 5.05 & 4.8897 & TRN & \\
\hline CHEMBL1603542 & 688550 & 4.9 & 4.8948 & TRN & \\
\hline CHEMBL1337794 & 688550 & 4.45 & 4.824 & TRN & \\
\hline CHEMBL1413748 & 688550 & 4.4 & 4.7896 & TST & \\
\hline CHEMBL1487422 & 688550 & 4.4 & 4.8963 & TRN & \\
\hline CHEMBL1403448 & 688550 & 4.7 & 4.8452 & TRN & \\
\hline CHEMBL1574004 & 688550 & 4.5 & 4.9377 & TRN & \\
\hline CHEMBL1313485 & 688550 & 5.25 & 4.8296 & TST & \\
\hline CHEMBL1583838 & 688550 & 4.45 & 4.8032 & TRN & \\
\hline CHEMBL1608197 & 688550 & 5.45 & 4.9228 & TRN & \\
\hline CHEMBL460518 & 688550 & 4.7 & 4.6751 & TRN & \\
\hline CHEMBL1490595 & 688550 & 4.4 & 4.8074 & TRN & \\
\hline CHEMBL1529046 & 688550 & 4.55 & 4.7426 & TRN & \\
\hline CHEMBL1613205 & 688550 & 4.4 & 4.9311 & TST & \\
\hline CHEMBL1503644 & 688550 & 4.4 & 4.7895 & TRN & \\
\hline CHEMBL1538241 & 688550 & 4.75 & 4.8914 & TRN & \\
\hline CHEMBL1377036 & 688550 & 4.55 & 4.8267 & TST & \\
\hline CHEMBL1576143 & 688550 & 4.55 & 4.81 & TRN & \\
\hline
\end{tabular}




\begin{tabular}{|c|c|c|c|c|}
\hline \multicolumn{5}{|c|}{ Supplemental Table S2.txt } \\
\hline CHEMBL1459475 & 688550 & 5.05 & 4.8972 & TRN \\
\hline CHEMBL1492932 & 688550 & 4.55 & 4.8198 & TRN \\
\hline CHEMBL1480772 & 688550 & 4.45 & 4.8706 & TRN \\
\hline CHEMBL1492317 & 688550 & 5.0 & 4.9521 & TRN \\
\hline CHEMBL1416184 & 688550 & 5.4 & 4.7891 & TRN \\
\hline CHEMBL601528 & 688550 & 4.75 & 4.9011 & TRN \\
\hline CHEMBL1426649 & 688550 & 4.9 & 4.9622 & TRN \\
\hline CHEMBL1422851 & 688550 & 4.4 & 4.887 & TRN \\
\hline CHEMBL1302032 & 688550 & 4.4 & 4.8341 & TRN \\
\hline CHEMBL1389550 & 688550 & 4.8 & 5.0146 & TRN \\
\hline CHEMBL1393072 & 688550 & 7.0501 & 4.8151 & TRN \\
\hline CHEMBL1457990 & 688550 & 4.4 & 4.9171 & TST \\
\hline CHEMBL1499803 & 688550 & 4.45 & 4.7534 & TRN \\
\hline CHEMBL1426863 & 688550 & 4.4 & 4.8034 & TRN \\
\hline CHEMBL1483234 & 688550 & 4.4 & 4.8861 & TRN \\
\hline CHEMBL1321291 & 688550 & 4.6 & 4.7758 & TRN \\
\hline CHEMBL1333915 & 688550 & 4.85 & 4.8366 & TRN \\
\hline CHEMBL1433108 & 688550 & 5.55 & 4.7873 & TRN \\
\hline CHEMBL1461225 & 688550 & 4.5 & 4.9188 & TRN \\
\hline CHEMBL1470598 & 688550 & 5.9 & 4.8869 & TRN \\
\hline CHEMBL1510141 & 688550 & 4.4 & 4.8704 & TRN \\
\hline CHEMBL1309333 & 688550 & 4.4 & 4.9494 & TRN \\
\hline CHEMBL1527136 & 688550 & 5.15 & 4.9495 & TST \\
\hline CHEMBL1463780 & 688550 & 5.5 & 4.9302 & TRN \\
\hline CHEMBL1462289 & 688550 & 4.85 & 4.9056 & TRN \\
\hline CHEMBL1548591 & 688550 & 4.65 & 4.9032 & TRN \\
\hline CHEMBL1418518 & 688550 & 5.0 & 4.7952 & TRN \\
\hline CHEMBL1420886 & 688550 & 4.4 & 4.9145 & TRN \\
\hline CHEMBL1409204 & 688550 & 4.4 & 4.8027 & TRN \\
\hline CHEMBL1504074 & 688550 & 4.55 & 4.962 & TRN \\
\hline CHEMBL1426023 & 688550 & 4.55 & 4.9217 & TRN \\
\hline CHEMBL1420244 & 688550 & 5.05 & 4.9083 & TRN \\
\hline CHEMBL1504223 & 688550 & 4.7 & 5.0156 & TRN \\
\hline CHEMBL1457071 & 688550 & 4.65 & 4.9185 & TRN \\
\hline CHEMBL1588293 & 688550 & 4.7 & 4.8255 & TRN \\
\hline CHEMBL1390445 & 688550 & 4.55 & 4.8497 & TRN \\
\hline CHEMBL1483664 & 688550 & 5.45 & 4.917 & TRN \\
\hline CHEMBL1438123 & 688550 & 4.6 & 5.0327 & TRN \\
\hline CHEMBL1505082 & 688550 & 4.5 & 4.9343 & TRN \\
\hline CHEMBL1537373 & 688550 & 4.55 & 4.9496 & TST \\
\hline CHEMBL1493097 & 688550 & 4.9 & 4.9026 & TRN \\
\hline CHEMBL1307064 & 688550 & 4.4 & 4.8846 & TRN \\
\hline CHEMBL1520726 & 688550 & 4.55 & 4.8619 & TRN \\
\hline CHEMBL1373057 & 688550 & 5.05 & 4.8035 & TRN \\
\hline CHEMBL1481493 & 688550 & 4.4 & 4.8327 & TRN \\
\hline CHEMBL1407169 & 688550 & 4.5 & 4.7835 & TST \\
\hline CHEMBL1406076 & 688550 & 5.05 & 4.7639 & TRN \\
\hline CHEMBL1563888 & 688550 & 4.7 & 4.8526 & TST \\
\hline
\end{tabular}




\begin{tabular}{|c|c|c|c|c|c|}
\hline \multicolumn{6}{|c|}{ Supplemental Table S2.txt } \\
\hline CHEMBL1482567 & 688550 & 4.55 & 4.9281 & TRN & \\
\hline CHEMBL1461444 & 688550 & 4.8 & 5.0174 & TRN & \\
\hline CHEMBL1518905 & 688550 & 4.75 & 4.8493 & TST & \\
\hline CHEMBL1599401 & 688550 & 4.4 & 4.82100 & 0000000001 & TRN \\
\hline CHEMBL1361135 & 688550 & 6.4 & 5.0146 & TRN & \\
\hline CHEMBL1549079 & 688550 & 4.55 & 4.8699 & TRN & \\
\hline CHEMBL1381152 & 688550 & 5.1 & 4.8686 & TST & \\
\hline CHEMBL1333960 & 688550 & 4.5 & 4.8315 & TRN & \\
\hline CHEMBL1443459 & 688550 & 4.4 & 4.8616 & TST & \\
\hline CHEMBL1424333 & 688550 & 5.65 & 4.8422 & TRN & \\
\hline CHEMBL1384645 & 688550 & 4.4 & 4.8305 & TRN & \\
\hline CHEMBL1506801 & 688550 & 5.35 & 4.9095 & TRN & \\
\hline CHEMBL1606568 & 688550 & 4.4 & 4.7741 & TRN & \\
\hline CHEMBL1307207 & 688550 & 4.85 & 4.9118 & TRN & \\
\hline CHEMBL1538509 & 688550 & 4.45 & 4.9244 & TRN & \\
\hline CHEMBL1491543 & 688550 & 4.85 & 4.9654 & TRN & \\
\hline CHEMBL1599297 & 688550 & 5.35 & 4.8554 & TST & \\
\hline CHEMBL593944 & 688550 & 4.55 & 4.9521 & TRN & \\
\hline CHEMBL1421976 & 688550 & 4.75 & 4.8701 & TRN & \\
\hline CHEMBL1381066 & 688550 & 4.55 & 4.8415 & TST & \\
\hline CHEMBL1429002 & 688550 & 4.5 & 4.8026 & TRN & \\
\hline CHEMBL1346787 & 688550 & 4.9 & 4.995 & TRN & \\
\hline CHEMBL1332208 & 688550 & 4.45 & 4.8535 & TRN & \\
\hline CHEMBL1343458 & 688550 & 4.75 & 4.7535 & TRN & \\
\hline CHEMBL1389029 & 688550 & 4.8 & 4.8153 & TRN & \\
\hline CHEMBL1441042 & 688550 & 4.9 & 4.7187 & TRN & \\
\hline CHEMBL1540012 & 688550 & 4.4 & 4.7958 & TRN & \\
\hline CHEMBL1589490 & 688550 & 4.4 & 4.92399 & 99999999995 & TRN \\
\hline CHEMBL1364635 & 688550 & 4.4 & 4.8031 & TRN & \\
\hline CHEMBL1335330 & 688550 & 4.8 & 4.9223 & TRN & \\
\hline CHEMBL1613734 & 688550 & 4.9 & 4.8711 & TRN & \\
\hline CHEMBL3191375 & 688550 & 5.35 & 4.7005 & TRN & \\
\hline CHEMBL1382820 & 688550 & 5.05 & 4.8444 & TRN & \\
\hline CHEMBL1486369 & 688550 & 6.15 & 5.0413 & TRN & \\
\hline CHEMBL1569712 & 688550 & 4.85 & 4.8665 & TRN & \\
\hline CHEMBL1571685 & 688550 & 5.2 & 4.8462 & TRN & \\
\hline CHEMBL1571222 & 688550 & 4.65 & 4.9106 & TRN & \\
\hline CHEMBL3196877 & 688550 & 4.95 & 4.8318 & TST & \\
\hline CHEMBL1561540 & 688550 & 4.4 & 4.82 & TRN & \\
\hline CHEMBL1377584 & 688550 & 5.5 & 4.7654 & TST & \\
\hline CHEMBL1430953 & 688550 & 4.7 & 4.8871 & TST & \\
\hline CHEMBL1537835 & 688550 & 6.1 & 4.8694 & TST & \\
\hline CHEMBL1992631 & 688550 & 4.95 & 4.7955 & TRN & \\
\hline CHEMBL1340139 & 688550 & 5.45 & 4.8626 & TRN & \\
\hline CHEMBL1562056 & 688550 & 4.65 & 4.8927 & TRN & \\
\hline CHEMBL1480330 & 688550 & 5.0 & 4.8096 & TRN & \\
\hline CHEMBL1470907 & 688550 & 4.5 & 4.8731 & TRN & \\
\hline CHEMBL1613477 & 688550 & 5.2 & 4.78 & TST & \\
\hline
\end{tabular}




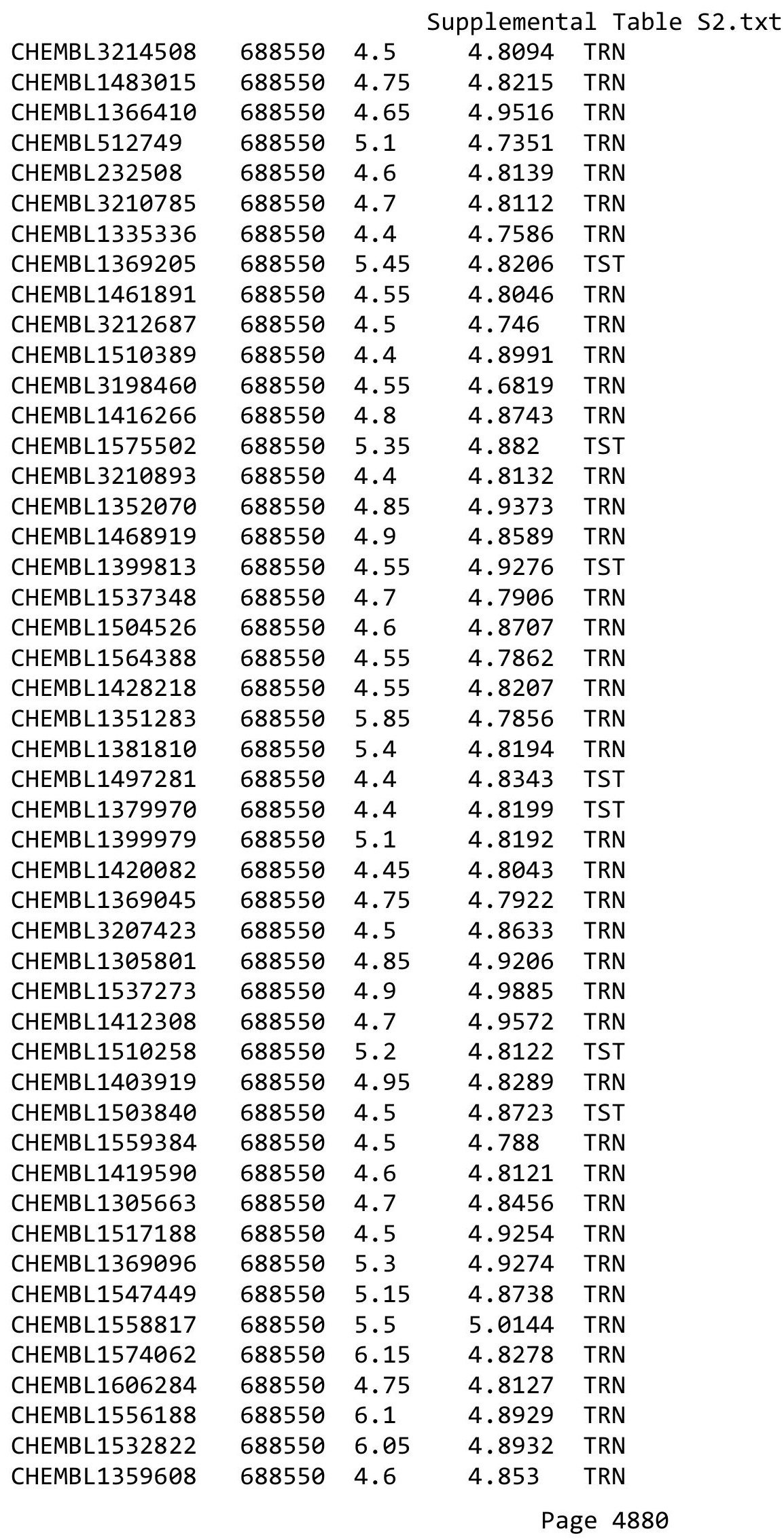




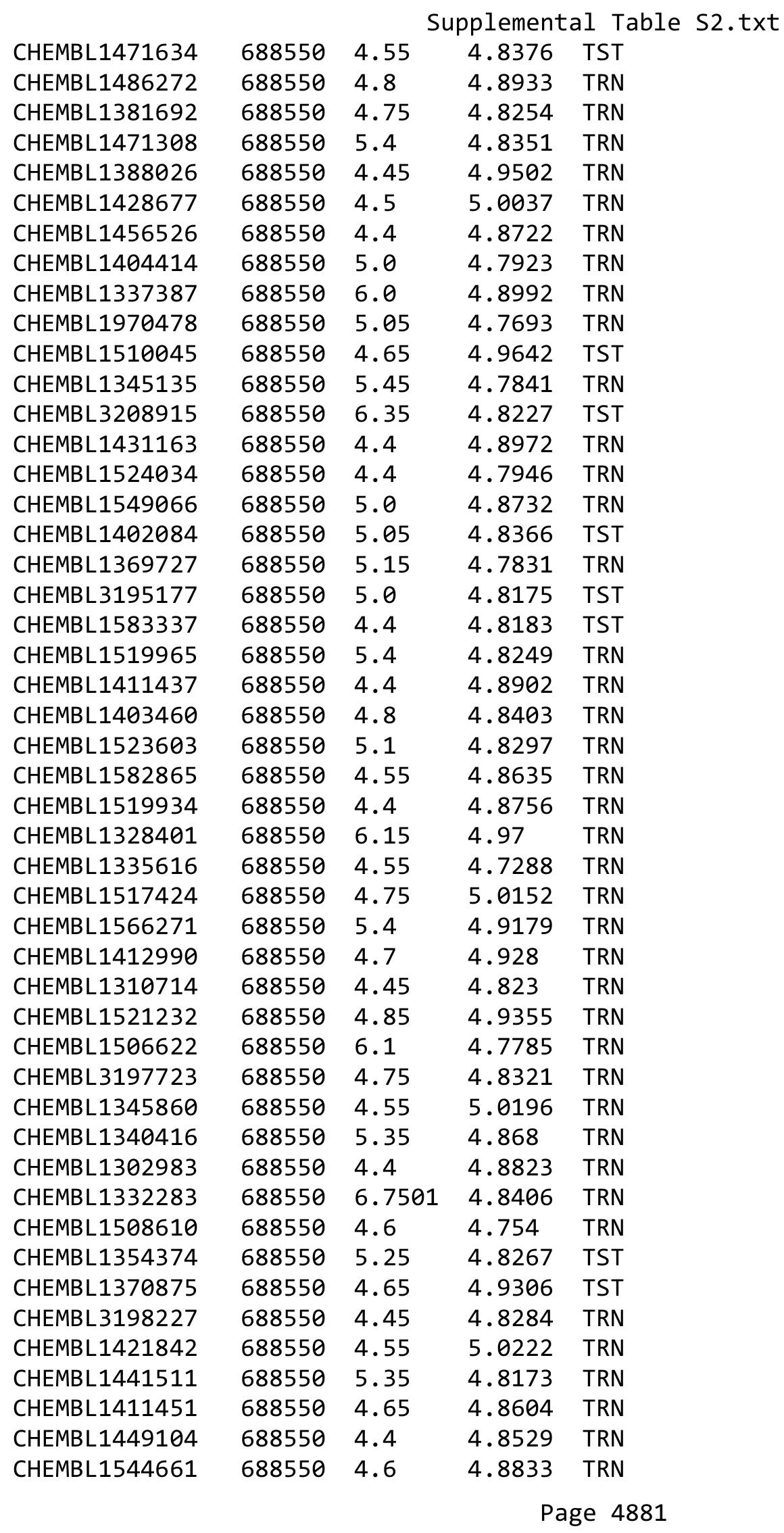




\begin{tabular}{|c|c|c|c|c|c|}
\hline \multicolumn{6}{|c|}{ Supplemental Table s2.txt } \\
\hline CHEMBL1449305 & 688550 & 5.2 & 4.864 & TRN & \\
\hline CHEMBL1560985 & 688550 & 4.5 & 4.8496 & TRN & \\
\hline CHEMBL1567159 & 688550 & 4.75 & 4.7999 & TRN & \\
\hline CHEMBL1478629 & 688550 & 4.6 & 4.8356 & TST & \\
\hline CHEMBL1356592 & 688550 & 5.3 & 4.9407 & TRN & \\
\hline CHEMBL1312579 & 688550 & 4.4 & 4.8463 & TRN & \\
\hline CHEMBL1423209 & 688550 & 4.4 & 4.8248 & TRN & \\
\hline CHEMBL1348588 & 688550 & 5.35 & 4.9029 & TRN & \\
\hline CHEMBL1423085 & 688550 & 4.85 & 4.8068 & TRN & \\
\hline CHEMBL1517628 & 688550 & 4.4 & 4.8341 & TRN & \\
\hline CHEMBL1583325 & 688550 & 4.45 & 4.8563 & TRN & \\
\hline CHEMBL1401695 & 688550 & 4.55 & 4.833 & TRN & \\
\hline CHEMBL1564201 & 688550 & 5.1 & 4.8539 & TRN & \\
\hline CHEMBL1348971 & 688550 & 4.6 & 4.8774 & TRN & \\
\hline CHEMBL1479759 & 688550 & 4.4 & 4.8937 & TST & \\
\hline CHEMBL1373869 & 688550 & 7.4001 & 4.9176 & TST & \\
\hline CHEMBL1359204 & 688550 & 7.2 & 4.8433 & TST & \\
\hline CHEMBL1483711 & 688550 & 4.55 & 4.8688 & TRN & \\
\hline CHEMBL1527937 & 688550 & 4.8 & 4.9327 & TRN & \\
\hline CHEMBL1488914 & 688550 & 4.5 & 4.9528 & TRN & \\
\hline CHEMBL1329375 & 688550 & 4.4 & 4.8398 & TRN & \\
\hline CHEMBL1463789 & 688550 & 5.1 & 4.8549 & TRN & \\
\hline CHEMBL1571518 & 688550 & 4.5 & 4.9147 & TRN & \\
\hline CHEMBL1505645 & 688550 & 4.85 & 4.7762 & TRN & \\
\hline CHEMBL1477375 & 688550 & 4.45 & 4.8223 & TRN & \\
\hline CHEMBL1577118 & 688550 & 4.45 & 4.94600 & 0000000001 & TRN \\
\hline CHEMBL3211234 & 688550 & 4.4 & 4.8095 & TST & \\
\hline CHEMBL1501488 & 688550 & 5.4 & 4.9289 & TRN & \\
\hline CHEMBL1571442 & 688550 & 4.4 & 4.8821 & TRN & \\
\hline CHEMBL1359182 & 688550 & 4.8 & 4.9051 & TRN & \\
\hline CHEMBL1542492 & 688550 & 4.85 & 4.8209 & TRN & \\
\hline CHEMBL1480398 & 688550 & 4.75 & 4.8962 & TST & \\
\hline CHEMBL1595853 & 688550 & 4.4 & 4.8835 & TRN & \\
\hline CHEMBL1333773 & 688550 & 4.45 & 4.8849 & TRN & \\
\hline CHEMBL1428832 & 688550 & 4.5 & 5.0015 & TRN & \\
\hline CHEMBL1309088 & 688550 & 5.1 & 4.8565 & TRN & \\
\hline CHEMBL1477044 & 688550 & 4.4 & 4.8323 & TRN & \\
\hline CHEMBL544115 & 688550 & 4.8 & 4.9051 & TST & \\
\hline CHEMBL1391803 & 688550 & 4.45 & 4.9044 & TST & \\
\hline CHEMBL1522230 & 688550 & 4.4 & 4.8364 & TRN & \\
\hline CHEMBL1349267 & 688550 & 4.55 & 4.9157 & TRN & \\
\hline CHEMBL3210028 & 688550 & 4.9 & 4.8721 & TRN & \\
\hline CHEMBL1326028 & 688550 & 4.85 & 4.8105 & TRN & \\
\hline CHEMBL1603358 & 688550 & 4.45 & 4.8628 & TST & \\
\hline CHEMBL3207705 & 688550 & 4.6 & 4.955 & TRN & \\
\hline CHEMBL1991779 & 688550 & 4.85 & 4.776 & TRN & \\
\hline CHEMBL1370420 & 688550 & 5.5 & 4.8045 & TRN & \\
\hline CHEMBL 2001743 & 688550 & 5.55 & 4.8273 & TRN & \\
\hline
\end{tabular}




\begin{tabular}{|c|c|c|c|c|}
\hline \multicolumn{5}{|c|}{ Supplemental Table S2.txt } \\
\hline CHEMBL1427288 & 688550 & 4.4 & 4.8996 & TRN \\
\hline CHEMBL1570845 & 688550 & 5.1 & 4.8594 & TRN \\
\hline CHEMBL1301041 & 688550 & 4.35 & 4.8273 & TRN \\
\hline CHEMBL1494495 & 688550 & 5.55 & 4.8925 & TRN \\
\hline CHEMBL1327610 & 688550 & 4.45 & 4.8386 & TRN \\
\hline CHEMBL1493646 & 688550 & 4.6 & 4.874 & TST \\
\hline CHEMBL1409348 & 688550 & 4.4 & 4.8233 & TRN \\
\hline CHEMBL1369358 & 688550 & 4.6 & 4.7681 & TRN \\
\hline CHEMBL1482787 & 688550 & 4.4 & 4.8951 & TRN \\
\hline CHEMBL1374315 & 688550 & 6.7501 & 4.9313 & TRN \\
\hline CHEMBL1401494 & 688550 & 5.1 & 4.855 & TRN \\
\hline CHEMBL1451447 & 688550 & 4.45 & 4.9195 & TRN \\
\hline CHEMBL1498309 & 688550 & 4.6 & 4.8946 & TRN \\
\hline CHEMBL1465125 & 688550 & 4.45 & 4.8738 & TRN \\
\hline CHEMBL1481616 & 688550 & 4.65 & 4.8705 & TRN \\
\hline CHEMBL388959 & 688550 & 4.85 & 4.797 & TRN \\
\hline CHEMBL1499996 & 688550 & 4.5 & 4.9796 & TRN \\
\hline CHEMBL1367860 & 688550 & 4.9 & 4.8277 & TST \\
\hline CHEMBL1334484 & 688550 & 5.25 & 4.7381 & TST \\
\hline CHEMBL1411344 & 688550 & 4.65 & 4.8118 & TRN \\
\hline CHEMBL1431572 & 688550 & 4.45 & 4.9302 & TRN \\
\hline CHEMBL1306433 & 688550 & 4.85 & 5.0291 & TRN \\
\hline CHEMBL1375544 & 688550 & 5.45 & 4.876 & TRN \\
\hline CHEMBL1401798 & 688550 & 4.55 & 4.8552 & TRN \\
\hline CHEMBL1573693 & 688550 & 4.6 & 4.9008 & TRN \\
\hline CHEMBL1542861 & 688550 & 4.7 & 4.8591 & TRN \\
\hline CHEMBL1373194 & 688550 & 4.95 & 4.763 & TRN \\
\hline CHEMBL1471095 & 688550 & 4.85 & 4.8156 & TRN \\
\hline CHEMBL1498220 & 688550 & 4.45 & 4.8761 & TRN \\
\hline CHEMBL1340713 & 688550 & 4.8 & 4.8207 & TST \\
\hline CHEMBL1407399 & 688550 & 4.55 & 4.9051 & TRN \\
\hline CHEMBL1567329 & 688550 & 4.6 & 4.9945 & TRN \\
\hline CHEMBL1505230 & 688550 & 4.75 & 4.8962 & TRN \\
\hline CHEMBL1422250 & 688550 & 4.6 & 4.8108 & TRN \\
\hline CHEMBL199194 & 688550 & 4.5 & 4.7676 & TRN \\
\hline CHEMBL1410566 & 688550 & 5.05 & 4.8117 & TST \\
\hline CHEMBL1363938 & 688550 & 4.5 & 4.8138 & TRN \\
\hline CHEMBL1336680 & 688550 & 4.45 & 4.8133 & TRN \\
\hline CHEMBL1405454 & 688550 & 4.5 & 4.8892 & TRN \\
\hline CHEMBL1455854 & 688550 & 4.55 & 4.8576 & TRN \\
\hline CHEMBL1423456 & 688550 & 4.65 & 4.8326 & TRN \\
\hline CHEMBL1470495 & 688550 & 4.85 & 4.8238 & TRN \\
\hline CHEMBL1470050 & 688550 & 4.55 & 4.9867 & TRN \\
\hline CHEMBL1350956 & 688550 & 4.45 & 4.8419 & TRN \\
\hline CHEMBL1550617 & 688550 & 4.4 & 4.8845 & TRN \\
\hline CHEMBL1570433 & 688550 & 4.5 & 4.9149 & TRN \\
\hline CHEMBL1496119 & 688550 & 4.85 & 4.8395 & TRN \\
\hline CHEMBL1982575 & 688550 & 4.9 & 4.8013 & TRN \\
\hline
\end{tabular}




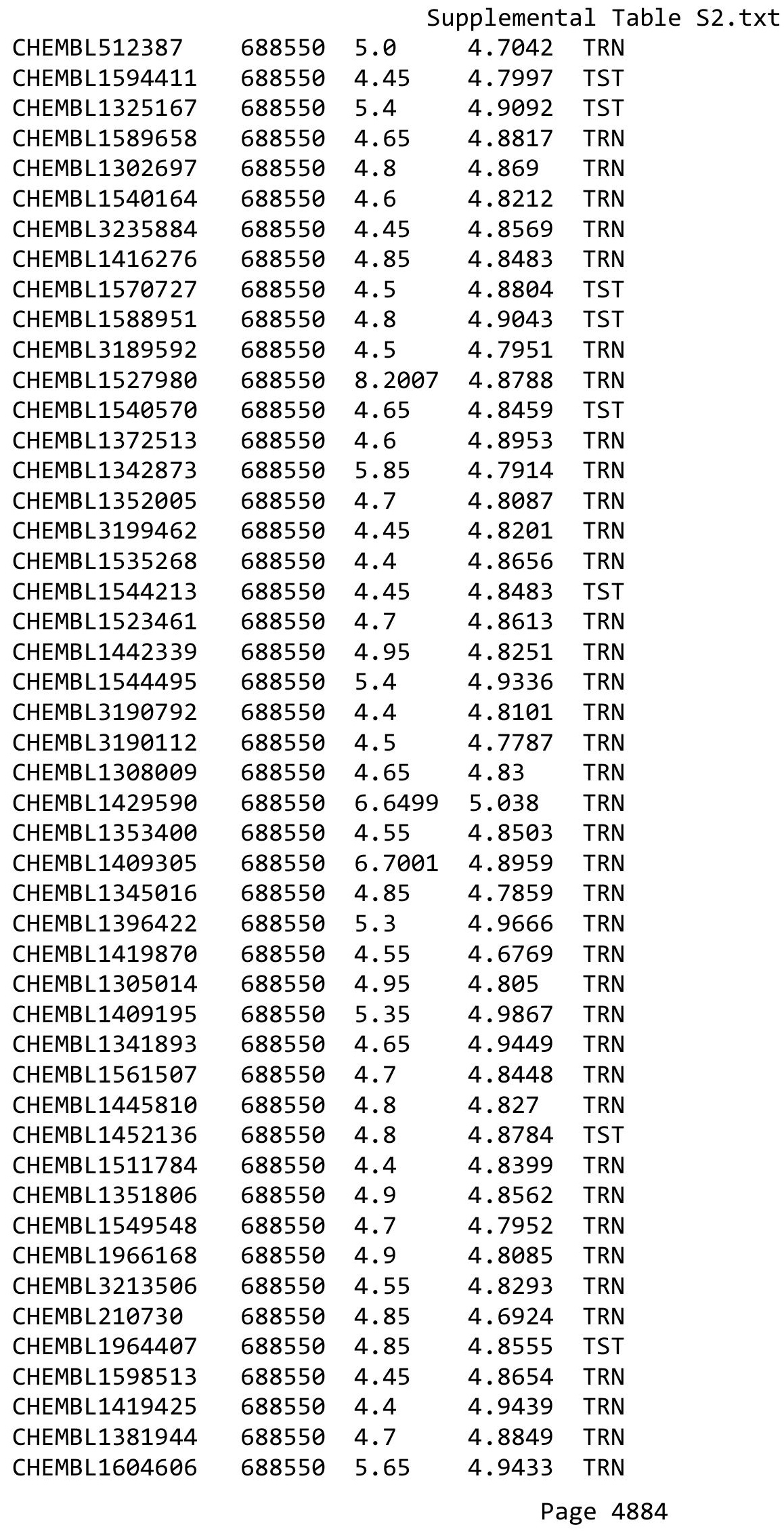




\begin{tabular}{|c|c|c|c|c|c|}
\hline & & \multicolumn{4}{|c|}{ Supplemental Table S2.txt } \\
\hline CHEMBL1530743 & 688550 & 4.45 & 4.7677 & TRN & \\
\hline CHEMBL1374875 & 688550 & 4.4 & 4.9132 & TRN & \\
\hline CHEMBL1588277 & 688550 & 5.45 & 4.9144 & TRN & \\
\hline CHEMBL1418459 & 688550 & 5.2 & 4.7533 & TRN & \\
\hline CHEMBL1422612 & 688550 & 4.6 & 4.8398 & TRN & \\
\hline CHEMBL1460681 & 688550 & 4.8 & 4.9817 & TRN & \\
\hline CHEMBL1329363 & 688550 & 6.4 & 4.9573 & TRN & \\
\hline CHEMBL1583482 & 688550 & 4.4 & 4.82600 & 00000000005 & TRN \\
\hline CHEMBL1371339 & 688550 & 4.6 & 4.7758 & TRN & \\
\hline CHEMBL1446202 & 688550 & 5.4 & 4.85 & TRN & \\
\hline CHEMBL1372889 & 688550 & 4.5 & 4.8211 & TST & \\
\hline CHEMBL1469720 & 688550 & 4.8 & 4.8758 & TRN & \\
\hline CHEMBL1983871 & 688550 & 5.0 & 4.8152 & TRN & \\
\hline CHEMBL1351853 & 688550 & 4.6 & 4.8282 & TRN & \\
\hline CHEMBL1573994 & 688550 & 4.85 & 4.8443 & TRN & \\
\hline CHEMBL1410761 & 688550 & 5.3 & 4.8449 & TRN & \\
\hline CHEMBL1467325 & 688550 & 4.8 & 4.8467 & TRN & \\
\hline CHEMBL1349445 & 688550 & 4.6 & 4.9121 & TRN & \\
\hline CHEMBL1305453 & 688550 & 4.5 & 4.8932 & TRN & \\
\hline CHEMBL1318381 & 688550 & 4.4 & 5.001 & TRN & \\
\hline CHEMBL1499414 & 688550 & 4.8 & 4.9071 & TRN & \\
\hline CHEMBL1557096 & 688550 & 4.75 & 4.8743 & TRN & \\
\hline CHEMBL1584030 & 688550 & 4.55 & 4.8014 & TRN & \\
\hline CHEMBL1365539 & 688550 & 5.45 & 5.0545 & TRN & \\
\hline CHEMBL1607586 & 688550 & 4.5 & 4.7701 & TRN & \\
\hline CHEMBL1613002 & 688550 & 4.9 & 4.8798 & TST & \\
\hline CHEMBL1484782 & 688550 & 5.15 & 4.9211 & TRN & \\
\hline CHEMBL1319098 & 688550 & 4.55 & 4.7592 & TRN & \\
\hline CHEMBL1588560 & 688550 & 4.6 & 4.8262 & TST & \\
\hline CHEMBL1548328 & 688550 & 4.65 & 4.9041 & TRN & \\
\hline CHEMBL1431841 & 688550 & 4.45 & 4.8965 & TRN & \\
\hline CHEMBL1407407 & 688550 & 4.7 & 4.8332 & TST & \\
\hline CHEMBL1536928 & 688550 & 4.4 & 4.8075 & TST & \\
\hline CHEMBL1609746 & 688550 & 4.65 & 4.8782 & TRN & \\
\hline CHEMBL1449697 & 688550 & 4.45 & 4.827 & TRN & \\
\hline CHEMBL1324416 & 688550 & 6.1 & 4.814 & TST & \\
\hline CHEMBL1441041 & 688550 & 4.4 & 4.8221 & TRN & \\
\hline CHEMBL1333395 & 688550 & 5.4 & 4.9085 & TRN & \\
\hline CHEMBL1501551 & 688550 & 4.55 & 4.8748 & TST & \\
\hline CHEMBL1573856 & 688550 & 4.5 & 4.8242 & TRN & \\
\hline CHEMBL1610124 & 688550 & 4.65 & 4.8561 & TRN & \\
\hline CHEMBL1376704 & 688550 & 5.0 & 4.809 & TRN & \\
\hline CHEMBL1526690 & 688550 & 4.9 & 4.8541 & TRN & \\
\hline CHEMBL3197242 & 688550 & 4.85 & 4.8394 & TST & \\
\hline CHEMBL1323764 & 688550 & 4.4 & 4.726 & TRN & \\
\hline CHEMBL1789996 & 688550 & 4.4 & 4.8299 & TST & \\
\hline CHEMBL1416897 & 688550 & 5.7 & 4.9852 & TRN & \\
\hline CHEMBL376896 & 688550 & 4.9 & 4.9072 & TRN & \\
\hline
\end{tabular}




\begin{tabular}{|c|c|c|c|c|}
\hline \multicolumn{5}{|c|}{ Supplemental Table S2.txt } \\
\hline CHEMBL1319748 & 688550 & 4.8 & 4.8674 & TRN \\
\hline CHEMBL1603148 & 688550 & 4.4 & 4.8986 & TRN \\
\hline CHEMBL3208841 & 688550 & 4.45 & 4.8596 & TST \\
\hline CHEMBL1540207 & 688550 & 5.25 & 4.8008 & TRN \\
\hline CHEMBL1990748 & 688550 & 5.35 & 4.8043 & TRN \\
\hline CHEMBL1367579 & 688550 & 4.4 & 4.9299 & TRN \\
\hline CHEMBL1346194 & 688550 & 4.55 & 4.8677 & TRN \\
\hline CHEMBL1377322 & 688550 & 4.65 & 4.8559 & TRN \\
\hline CHEMBL373909 & 688550 & 5.35 & 4.7574 & TRN \\
\hline CHEMBL1540359 & 688550 & 4.85 & 4.9146 & TRN \\
\hline CHEMBL1532627 & 688550 & 4.75 & 5.0267 & TRN \\
\hline CHEMBL1403570 & 688550 & 4.6 & 4.8333 & TRN \\
\hline CHEMBL1412667 & 688550 & 5.45 & 4.9042 & TRN \\
\hline CHEMBL1496425 & 688550 & 5.45 & 4.8049 & TST \\
\hline CHEMBL1410337 & 688550 & 5.95 & 4.9142 & TRN \\
\hline CHEMBL1568012 & 688550 & 5.75 & 4.8966 & TRN \\
\hline CHEMBL1578449 & 688550 & 5.0 & 4.8036 & TRN \\
\hline CHEMBL1545353 & 688550 & 4.65 & 4.8891 & TRN \\
\hline CHEMBL1498266 & 688550 & 5.1 & 4.8916 & TRN \\
\hline CHEMBL1570233 & 688550 & 4.4 & 4.7633 & TRN \\
\hline CHEMBL1539166 & 688550 & 5.6 & 4.8399 & TRN \\
\hline CHEMBL1331981 & 688550 & 6.05 & 5.0098 & TRN \\
\hline CHEMBL1346909 & 688550 & 4.45 & 4.8468 & TST \\
\hline CHEMBL3193846 & 688550 & 4.6 & 4.7817 & TRN \\
\hline CHEMBL1606718 & 688550 & 4.9 & 4.9765 & TRN \\
\hline CHEMBL1403855 & 688550 & 4.9 & 4.793 & TRN \\
\hline CHEMBL1344024 & 688550 & 4.65 & 4.8595 & TST \\
\hline CHEMBL1527183 & 688550 & 4.55 & 4.8781 & TST \\
\hline CHEMBL1480498 & 688550 & 4.55 & 4.8514 & TRN \\
\hline CHEMBL1373596 & 688550 & 4.75 & 4.8758 & TRN \\
\hline CHEMBL1594407 & 688550 & 4.75 & 4.8761 & TRN \\
\hline CHEMBL1525789 & 688550 & 4.75 & 4.789 & TRN \\
\hline CHEMBL1383710 & 688550 & 4.4 & 4.815 & TRN \\
\hline CHEMBL1421202 & 688550 & 4.5 & 4.7621 & TRN \\
\hline CHEMBL1601829 & 688550 & 5.25 & 4.8207 & TRN \\
\hline CHEMBL1510527 & 688550 & 4.55 & 4.9239 & TRN \\
\hline CHEMBL3190207 & 688550 & 4.6 & 4.7972 & TRN \\
\hline CHEMBL1562548 & 688550 & 4.75 & 4.864 & TRN \\
\hline CHEMBL1594272 & 688550 & 4.65 & 4.9437 & TRN \\
\hline CHEMBL1542219 & 688550 & 4.4 & 4.8583 & TRN \\
\hline CHEMBL1387519 & 688550 & 4.7 & 4.8766 & TRN \\
\hline CHEMBL1432901 & 688550 & 4.55 & 4.8597 & TRN \\
\hline CHEMBL1343915 & 688550 & 4.4 & 4.8732 & TRN \\
\hline CHEMBL1408743 & 688550 & 4.8 & 5.021 & TRN \\
\hline CHEMBL1573482 & 688550 & 4.6 & 4.8879 & TRN \\
\hline CHEMBL1430473 & 688550 & 6.2 & 4.8905 & TST \\
\hline CHEMBL1399492 & 688550 & 5.2 & 4.7968 & TRN \\
\hline CHEMBL290914 & 688550 & 4.75 & 4.8129 & TST \\
\hline
\end{tabular}




\begin{tabular}{|c|c|c|c|c|c|}
\hline \multicolumn{6}{|c|}{ Supplemental Table S2.txt } \\
\hline CHEMBL3191233 & 688550 & 5.4 & 4.865 & TRN & \\
\hline CHEMBL3209977 & 688550 & 5.15 & 4.9115 & TRN & \\
\hline CHEMBL1305165 & 688550 & 5.4 & 4.9797 & TRN & \\
\hline CHEMBL1577640 & 688550 & 4.8 & 4.8657 & TRN & \\
\hline CHEMBL1498834 & 688550 & 4.85 & 4.8407 & TRN & \\
\hline CHEMBL1464525 & 688550 & 4.7 & 4.8746 & TST & \\
\hline CHEMBL1308902 & 688550 & 4.4 & 4.8127 & TRN & \\
\hline CHEMBL1299987 & 688550 & 4.55 & 4.8597 & TRN & \\
\hline CHEMBL1610730 & 688550 & 5.5 & 4.9232 & TRN & \\
\hline CHEMBL1569481 & 688550 & 4.4 & 4.8829 & TRN & \\
\hline CHEMBL568739 & 688550 & 4.4 & 4.8366 & TST & \\
\hline CHEMBL1556391 & 688550 & 6.7001 & 4.8839 & TST & \\
\hline CHEMBL1964405 & 688550 & 4.5 & 4.7318 & TRN & \\
\hline CHEMBL1450203 & 688550 & 4.85 & 5.0122 & TRN & \\
\hline CHEMBL1300958 & 688550 & 4.65 & 4.8394 & TRN & \\
\hline CHEMBL1570355 & 688550 & 4.4 & 4.833 & TRN & \\
\hline CHEMBL1302616 & 688550 & 4.5 & 4.9518 & TRN & \\
\hline CHEMBL1601251 & 688550 & 5.05 & 5.0407 & TRN & \\
\hline CHEMBL1346975 & 688550 & 4.4 & 4.8498 & TRN & \\
\hline CHEMBL1346893 & 688550 & 6.7501 & 4.8462 & TRN & \\
\hline CHEMBL1560245 & 688550 & 4.45 & 4.8247 & TRN & \\
\hline CHEMBL1485940 & 688550 & 4.4 & 4.8259 & TRN & \\
\hline CHEMBL1419054 & 688550 & 4.45 & 4.7903 & TRN & \\
\hline CHEMBL1360618 & 688550 & 5.55 & 4.7573 & TST & \\
\hline CHEMBL1329390 & 688550 & 4.5 & 4.9912 & TRN & \\
\hline CHEMBL1367314 & 688550 & 5.05 & 4.8915 & TRN & \\
\hline CHEMBL1468947 & 688550 & 4.8 & 4.8784 & TRN & \\
\hline CHEMBL399121 & 688550 & 4.4 & 4.9152 & TST & \\
\hline CHEMBL1342289 & 688550 & 4.6 & 4.8077 & TRN & \\
\hline CHEMBL1509692 & 688550 & 4.6 & 4.9246 & TRN & \\
\hline CHEMBL1538515 & 688550 & 4.4 & 4.8117 & TRN & \\
\hline CHEMBL1329074 & 688550 & 5.45 & 4.9401 & TRN & \\
\hline CHEMBL1309716 & 688550 & 4.85 & 4.9297 & TRN & \\
\hline CHEMBL1335855 & 688550 & 4.95 & 4.7671 & TRN & \\
\hline CHEMBL1534723 & 688550 & 4.55 & 4.9386 & TRN & \\
\hline CHEMBL1518987 & 688550 & 5.15 & 4.8303 & TRN & \\
\hline CHEMBL1432130 & 688550 & 4.8 & 4.90600 & 2000000001 & TST \\
\hline CHEMBL1301692 & 688550 & 5.0 & 4.8896 & TRN & \\
\hline CHEMBL1347753 & 688550 & 4.6 & 4.8879 & TRN & \\
\hline CHEMBL1430467 & 688550 & 4.85 & 4.8667 & TST & \\
\hline CHEMBL1421009 & 688550 & 6.7001 & 4.8028 & TRN & \\
\hline CHEMBL1518053 & 688550 & 4.75 & 4.9369 & TST & \\
\hline CHEMBL1478755 & 688550 & 4.6 & 4.80699 & 99999999995 & TST \\
\hline CHEMBL1971376 & 688550 & 4.6 & 4.8215 & TRN & \\
\hline CHEMBL1332483 & 688550 & 4.55 & 4.7761 & TRN & \\
\hline CHEMBL1483968 & 688550 & 4.7 & 4.9474 & TRN & \\
\hline CHEMBL1318998 & 688550 & 5.55 & 4.9026 & TRN & \\
\hline CHEMBL1516134 & 688550 & 5.6 & 4.9644 & TRN & \\
\hline
\end{tabular}




\begin{tabular}{|c|c|c|c|c|}
\hline \multicolumn{5}{|c|}{ Supplemental Table S2.txt } \\
\hline CHEMBL1516092 & 688550 & 4.4 & 4.8622 & TRN \\
\hline CHEMBL1597013 & 688550 & 5.2 & 4.8515 & TRN \\
\hline CHEMBL1600851 & 688550 & 4.4 & 4.8349 & TRN \\
\hline CHEMBL1375740 & 688550 & 5.05 & 4.7196 & TRN \\
\hline CHEMBL1580372 & 688550 & 4.65 & 4.8099 & TRN \\
\hline CHEMBL3191239 & 688550 & 4.65 & 4.7784 & TRN \\
\hline CHEMBL1338317 & 688550 & 5.45 & 5.0423 & TRN \\
\hline CHEMBL1495096 & 688550 & 4.8 & 4.792 & TRN \\
\hline CHEMBL1567878 & 688550 & 4.9 & 4.8794 & TRN \\
\hline CHEMBL1411018 & 688550 & 4.4 & 4.9295 & TRN \\
\hline CHEMBL1603776 & 688550 & 5.95 & 4.8601 & TST \\
\hline CHEMBL1418183 & 688550 & 4.5 & 4.9433 & TRN \\
\hline CHEMBL1488020 & 688550 & 4.85 & 4.7995 & TRN \\
\hline CHEMBL1428165 & 688550 & 4.7 & 4.9248 & TRN \\
\hline CHEMBL1433022 & 688550 & 5.4 & 4.8873 & TRN \\
\hline CHEMBL1401692 & 688550 & 4.4 & 4.9013 & TST \\
\hline CHEMBL1328177 & 688550 & 4.5 & 4.8813 & TRN \\
\hline CHEMBL1319703 & 688550 & 4.65 & 4.8146 & TRN \\
\hline CHEMBL1404156 & 688550 & 5.45 & 5.0309 & TRN \\
\hline CHEMBL1306249 & 688550 & 5.4 & 4.8887 & TRN \\
\hline CHEMBL1480419 & 688550 & 5.15 & 4.9577 & TRN \\
\hline CHEMBL1555519 & 688550 & 4.75 & 4.88 & TRN \\
\hline CHEMBL1338774 & 688550 & 5.95 & 4.7434 & TRN \\
\hline CHEMBL1526382 & 688550 & 4.8 & 4.8309 & TST \\
\hline CHEMBL1478032 & 688550 & 4.75 & 4.7375 & TRN \\
\hline CHEMBL1429795 & 688550 & 4.85 & 4.9242 & TRN \\
\hline CHEMBL1430732 & 688550 & 4.4 & 4.9495 & TRN \\
\hline CHEMBL1369156 & 688550 & 4.4 & 4.8376 & TST \\
\hline CHEMBL1464148 & 688550 & 4.85 & 4.8701 & TRN \\
\hline CHEMBL1302232 & 688550 & 4.7 & 4.7735 & TRN \\
\hline CHEMBL1417751 & 688550 & 4.4 & 4.7375 & TRN \\
\hline CHEMBL1386684 & 688550 & 5.25 & 4.813 & TRN \\
\hline CHEMBL1481813 & 688550 & 4.4 & 4.9866 & TST \\
\hline CHEMBL1363304 & 688550 & 4.65 & 4.9362 & TRN \\
\hline CHEMBL1546956 & 688550 & 4.55 & 4.7987 & TRN \\
\hline CHEMBL1311519 & 688550 & 4.65 & 4.9244 & TRN \\
\hline CHEMBL1549232 & 688550 & 5.15 & 4.776 & TST \\
\hline CHEMBL1578473 & 688550 & 4.6 & 4.7945 & TST \\
\hline CHEMBL1504797 & 688550 & 4.6 & 5.0027 & TRN \\
\hline CHEMBL1382516 & 688550 & 4.4 & 4.928 & TRN \\
\hline CHEMBL1417271 & 688550 & 4.55 & 4.734 & TRN \\
\hline CHEMBL1561233 & 688550 & 6.05 & 4.8219 & TRN \\
\hline CHEMBL1412313 & 688550 & 4.65 & 4.9125 & TRN \\
\hline CHEMBL1341762 & 688550 & 4.9 & 4.9206 & TRN \\
\hline CHEMBL1429172 & 688550 & 4.5 & 4.9393 & TRN \\
\hline CHEMBL3197156 & 688550 & 4.6 & 4.7884 & TRN \\
\hline CHEMBL1416262 & 688550 & 4.6 & 4.9153 & TST \\
\hline CHEMBL3199842 & 688550 & 4.4 & 4.8349 & TRN \\
\hline
\end{tabular}




\begin{tabular}{|c|c|c|c|c|c|}
\hline \multicolumn{6}{|c|}{ Supplemental Table S2.txt } \\
\hline CHEMBL1324054 & 688550 & 4.75 & 4.981 & TRN & \\
\hline CHEMBL1445153 & 688550 & 4.75 & 4.9585 & TRN & \\
\hline CHEMBL1382435 & 688550 & 4.4 & 4.9789 & TST & \\
\hline CHEMBL1413985 & 688550 & 5.0 & 4.8664 & TRN & \\
\hline CHEMBL1489922 & 688550 & 4.4 & 5.0297 & TRN & \\
\hline CHEMBL1458812 & 688550 & 4.45 & 4.8681 & TST & \\
\hline CHEMBL1358604 & 688550 & 4.45 & 4.8878 & TRN & \\
\hline CHEMBL1602447 & 688550 & 4.45 & 4.8842 & TST & \\
\hline CHEMBL1308724 & 688550 & 4.8 & 4.836 & TRN & \\
\hline CHEMBL1306711 & 688550 & 4.8 & 4.8909 & TST & \\
\hline CHEMBL1535729 & 688550 & 5.15 & 4.8333 & TRN & \\
\hline CHEMBL1605029 & 688550 & 4.5 & 4.8676 & TRN & \\
\hline CHEMBL1595297 & 688550 & 4.4 & 4.8223 & TST & \\
\hline CHEMBL1491586 & 688550 & 4.85 & 4.9723 & TRN & \\
\hline CHEMBL3197464 & 688550 & 4.9 & 4.8021 & TRN & \\
\hline CHEMBL1561034 & 688550 & 4.5 & 4.8899 & TRN & \\
\hline CHEMBL1510179 & 688550 & 4.6 & 4.7694 & TRN & \\
\hline CHEMBL1500231 & 688550 & 5.85 & 4.9439 & TST & \\
\hline CHEMBL1378309 & 688550 & 4.6 & 4.8382 & TST & \\
\hline CHEMBL1539342 & 688550 & 6.15 & 4.76 & TST & \\
\hline CHEMBL1424060 & 688550 & 4.5 & 4.738 & TRN & \\
\hline CHEMBL1545891 & 688550 & 4.55 & 4.9413 & TRN & \\
\hline CHEMBL1344025 & 688550 & 4.4 & 4.9924 & TRN & \\
\hline CHEMBL179161 & 688550 & 5.3 & 4.8415 & TRN & \\
\hline CHEMBL1407450 & 688550 & 4.55 & 5.0254 & TRN & \\
\hline CHEMBL1423747 & 688550 & 5.1 & 4.8352 & TRN & \\
\hline CHEMBL1316971 & 688550 & 8.1487 & 4.931 & TRN & \\
\hline CHEMBL1494871 & 688550 & 5.2 & 4.8743 & TRN & \\
\hline CHEMBL1406362 & 688550 & 4.8 & 4.8785 & TRN & \\
\hline CHEMBL1539359 & 688550 & 4.55 & 4.7697 & TRN & \\
\hline CHEMBL1344651 & 688550 & 4.85 & 4.8693 & TRN & \\
\hline CHEMBL1500987 & 688550 & 4.75 & 4.8165 & TRN & \\
\hline CHEMBL1345944 & 688550 & 4.4 & 4.9244 & TRN & \\
\hline CHEMBL1401060 & 688550 & 4.4 & 4.7933 & TRN & \\
\hline CHEMBL1524907 & 688550 & 4.5 & 4.8566 & TRN & \\
\hline CHEMBL3197721 & 688550 & 5.2 & 4.7789 & TST & \\
\hline CHEMBL1452865 & 688550 & 4.4 & 4.8465 & TST & \\
\hline CHEMBL1484657 & 688550 & 4.95 & 4.9168 & TRN & \\
\hline CHEMBL1376737 & 688550 & 4.85 & 4.8686 & TRN & \\
\hline CHEMBL1549738 & 688550 & 5.45 & 4.9525 & TST & \\
\hline CHEMBL1556953 & 688550 & 4.4 & 4.8086 & TRN & \\
\hline CHEMBL1303693 & 688550 & 4.4 & 4.9138 & TRN & \\
\hline CHEMBL1419849 & 688550 & 5.4 & 4.8198 & TRN & \\
\hline CHEMBL1530619 & 688550 & 4.4 & 4.8546 & TRN & \\
\hline CHEMBL1321329 & 688550 & 4.85 & 4.8115 & TST & \\
\hline CHEMBL3212636 & 688550 & 5.0 & 4.79899 & 99999999995 & TRN \\
\hline CHEMBL1468756 & 688550 & 4.95 & 4.8808 & TRN & \\
\hline CHEMBL1379512 & 688550 & 4.65 & 4.8393 & TST & \\
\hline
\end{tabular}




\begin{tabular}{|c|c|c|c|c|}
\hline \multicolumn{5}{|c|}{ Supplemental Table S2.txt } \\
\hline CHEMBL1464645 & 688550 & 4.85 & 4.7472 & TRN \\
\hline CHEMBL1387670 & 688550 & 4.65 & 4.8536 & TRN \\
\hline CHEMBL1527992 & 688550 & 5.5 & 4.8062 & TST \\
\hline CHEMBL1376477 & 688550 & 5.45 & 4.9029 & TRN \\
\hline CHEMBL 3209405 & 688550 & 7.0 & 4.8232 & TST \\
\hline CHEMBL 234338 & 688550 & 4.4 & 4.812 & TST \\
\hline CHEMBL1588534 & 688550 & 4.65 & 4.8502 & TRN \\
\hline CHEMBL1447458 & 688550 & 4.7 & 4.8509 & TRN \\
\hline CHEMBL1341241 & 688550 & 4.4 & 4.9188 & TRN \\
\hline CHEMBL1350319 & 688550 & 5.2 & 4.9707 & TRN \\
\hline CHEMBL1502482 & 688550 & 4.55 & 4.9182 & TRN \\
\hline CHEMBL1300697 & 688550 & 6.0 & 4.8965 & TRN \\
\hline CHEMBL1352217 & 688550 & 4.4 & 4.8772 & TRN \\
\hline CHEMBL1612225 & 688550 & 8.2007 & 4.8748 & TRN \\
\hline CHEMBL1443637 & 688550 & 5.15 & 4.8441 & TRN \\
\hline CHEMBL1585268 & 688550 & 6.05 & 4.8862 & TST \\
\hline CHEMBL1610025 & 688550 & 5.45 & 4.8109 & TRN \\
\hline CHEMBL1454233 & 688550 & 5.0 & 4.9713 & TRN \\
\hline CHEMBL1594867 & 688550 & 4.6 & 4.7103 & TRN \\
\hline CHEMBL1383055 & 688550 & 4.65 & 4.8365 & TRN \\
\hline CHEMBL1380295 & 688550 & 4.75 & 4.8829 & TRN \\
\hline CHEMBL1582486 & 688550 & 6.25 & 4.9058 & TRN \\
\hline CHEMBL1539144 & 688550 & 4.4 & 4.9156 & TRN \\
\hline CHEMBL1594316 & 688550 & 4.85 & 4.769 & TRN \\
\hline CHEMBL1580880 & 688550 & 4.85 & 4.8464 & TRN \\
\hline CHEMBL1570876 & 688550 & 4.7 & 5.0734 & TRN \\
\hline CHEMBL1368141 & 688550 & 4.85 & 4.8981 & TRN \\
\hline CHEMBL1389916 & 688550 & 5.15 & 5.0176 & TRN \\
\hline CHEMBL1441794 & 688550 & 5.1 & 4.8818 & TRN \\
\hline CHEMBL1420775 & 688550 & 4.8 & 4.8583 & TRN \\
\hline CHEMBL1501092 & 688550 & 4.65 & 4.8944 & TRN \\
\hline CHEMBL1311453 & 688550 & 4.85 & 4.8832 & TST \\
\hline CHEMBL3189607 & 688550 & 4.7 & 4.7054 & TRN \\
\hline CHEMBL1407000 & 688550 & 4.5 & 4.8841 & TRN \\
\hline CHEMBL1366050 & 688550 & 4.85 & 4.8329 & TRN \\
\hline CHEMBL1313410 & 688550 & 4.5 & 4.8425 & TST \\
\hline CHEMBL1345956 & 688550 & 4.55 & 4.8508 & TRN \\
\hline CHEMBL1382293 & 688550 & 5.1 & 5.0528 & TRN \\
\hline CHEMBL1562273 & 688550 & 4.75 & 4.9985 & TRN \\
\hline CHEMBL1369599 & 688550 & 5.4 & 4.9978 & TRN \\
\hline CHEMBL1537703 & 688550 & 4.55 & 4.9522 & TRN \\
\hline CHEMBL1549138 & 688550 & 5.05 & 4.8954 & TST \\
\hline CHEMBL1313249 & 688550 & 5.45 & 4.8223 & TRN \\
\hline CHEMBL1340066 & 688550 & 6.1 & 4.8164 & TRN \\
\hline CHEMBL1507021 & 688550 & 4.5 & 5.0058 & TRN \\
\hline CHEMBL1373360 & 688550 & 5.35 & 4.8035 & TRN \\
\hline CHEMBL1612297 & 688550 & 6.05 & 4.8583 & TRN \\
\hline CHEMBL1241371 & 688550 & 4.45 & 4.7618 & TRN \\
\hline
\end{tabular}




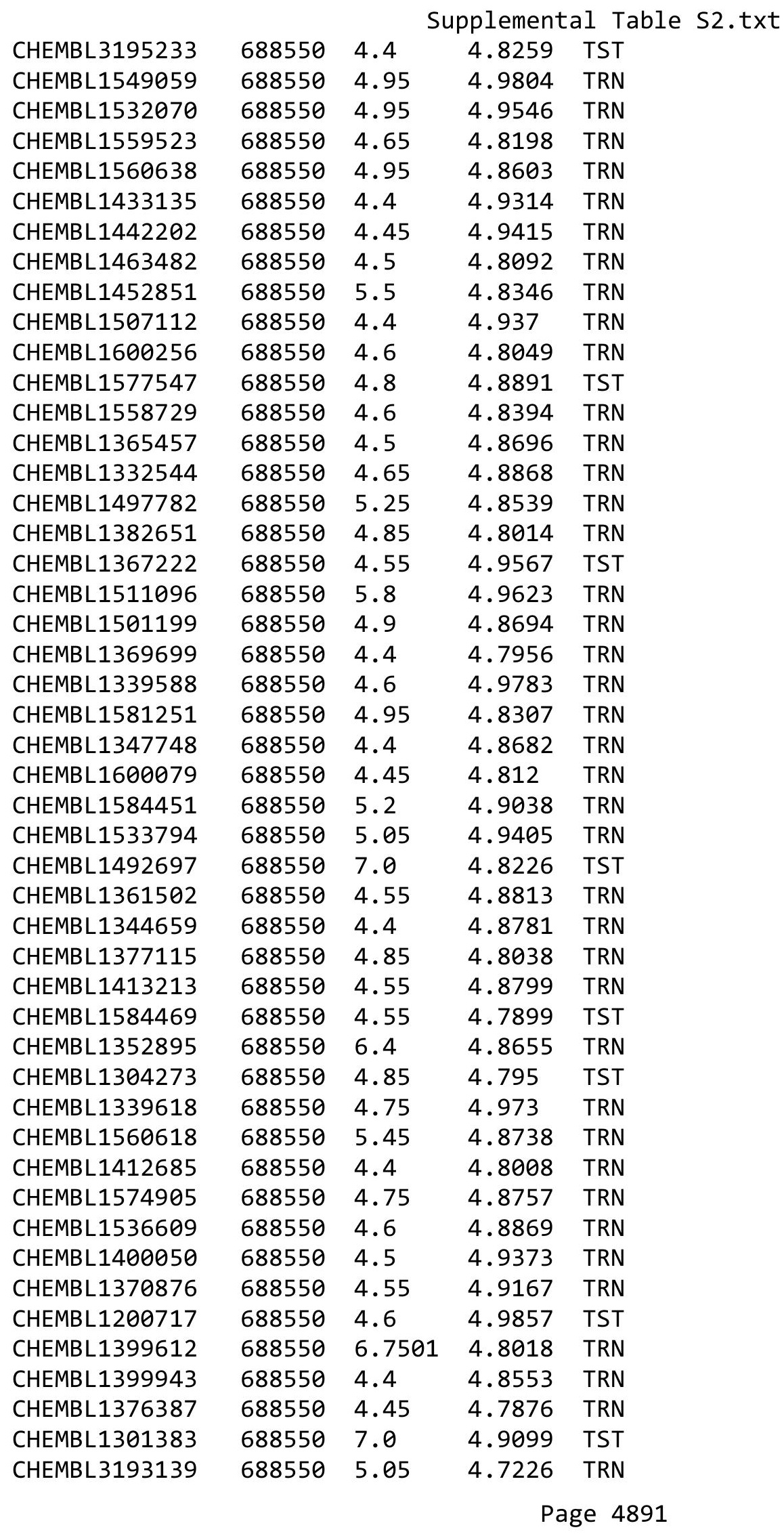




\begin{tabular}{|c|c|c|c|c|}
\hline \multicolumn{5}{|c|}{ Supplemental Table S2.txt } \\
\hline CHEMBL1539905 & 688550 & 5.5 & 4.855 & TRN \\
\hline CHEMBL1467213 & 688550 & 5.0 & 4.9347 & TRN \\
\hline CHEMBL1338767 & 688550 & 5.4 & 4.8063 & TRN \\
\hline CHEMBL1336295 & 688550 & 4.65 & 4.8489 & TRN \\
\hline CHEMBL1369296 & 688550 & 4.6 & 4.7791 & TRN \\
\hline CHEMBL1333524 & 688550 & 5.4 & 4.9823 & TRN \\
\hline CHEMBL1384621 & 688550 & 4.45 & 4.8175 & TRN \\
\hline CHEMBL1307692 & 688550 & 5.5 & 4.8086 & TRN \\
\hline CHEMBL146842 & 688550 & 5.5 & 4.8869 & TRN \\
\hline CHEMBL1525895 & 688550 & 6.9 & 4.8439 & TRN \\
\hline CHEMBL1479010 & 688550 & 4.9 & 4.7748 & TRN \\
\hline CHEMBL1549129 & 688550 & 4.4 & 4.8379 & TST \\
\hline CHEMBL1422426 & 688550 & 5.85 & 4.9747 & TRN \\
\hline CHEMBL1360260 & 688550 & 4.45 & 4.7068 & TRN \\
\hline CHEMBL1539826 & 688550 & 5.15 & 4.7279 & TRN \\
\hline CHEMBL1495878 & 688550 & 4.45 & 4.8474 & TRN \\
\hline CHEMBL1347047 & 688550 & 5.1 & 4.8869 & TST \\
\hline CHEMBL1549055 & 688550 & 6.5 & 4.9373 & TRN \\
\hline CHEMBL1332528 & 688550 & 4.6 & 4.9069 & TRN \\
\hline CHEMBL1309000 & 688550 & 4.6 & 4.8583 & TST \\
\hline CHEMBL1478419 & 688550 & 5.3 & 4.8161 & TST \\
\hline CHEMBL1540219 & 688550 & 4.5 & 4.917 & TRN \\
\hline CHEMBL1481374 & 688550 & 8.1024 & 4.9144 & TST \\
\hline CHEMBL1303506 & 688550 & 4.6 & 4.7886 & TRN \\
\hline CHEMBL1445966 & 688550 & 5.15 & 4.9052 & TST \\
\hline CHEMBL1541353 & 688550 & 4.6 & 4.8976 & TRN \\
\hline CHEMBL1599090 & 688550 & 4.9 & 4.7764 & TRN \\
\hline CHEMBL1374474 & 688550 & 4.4 & 4.8343 & TRN \\
\hline CHEMBL45152 & 688550 & 4.4 & 4.8146 & TRN \\
\hline CHEMBL1605232 & 688550 & 4.4 & 4.8306 & TRN \\
\hline CHEMBL1348802 & 688550 & 4.4 & 4.8214 & TST \\
\hline CHEMBL1542687 & 688550 & 4.4 & 4.9995 & TRN \\
\hline CHEMBL1369431 & 688550 & 4.6 & 4.8877 & TRN \\
\hline CHEMBL1548458 & 688550 & 4.4 & 4.7931 & TRN \\
\hline CHEMBL3195494 & 688550 & 5.45 & 4.8025 & TST \\
\hline CHEMBL1561273 & 688550 & 5.05 & 4.8921 & TRN \\
\hline CHEMBL1501015 & 688550 & 5.9 & 4.9469 & TRN \\
\hline CHEMBL1483315 & 688550 & 4.95 & 4.8754 & TRN \\
\hline CHEMBL3189882 & 688550 & 6.7501 & 4.8953 & TRN \\
\hline CHEMBL1341684 & 688550 & 4.7 & 4.9051 & TRN \\
\hline CHEMBL1465234 & 688550 & 4.4 & 4.8766 & TRN \\
\hline CHEMBL1388616 & 688550 & 4.75 & 4.8974 & TRN \\
\hline CHEMBL1339825 & 688550 & 4.5 & 4.9112 & TRN \\
\hline CHEMBL1302144 & 688550 & 4.55 & 4.8556 & TRN \\
\hline CHEMBL3214518 & 688550 & 5.15 & 4.7405 & TRN \\
\hline CHEMBL1577267 & 688550 & 5.05 & 4.8031 & TST \\
\hline CHEMBL1607959 & 688550 & 5.5 & 4.9486 & TRN \\
\hline CHEMBL66966 & 688550 & 6.0 & 4.8141 & TRN \\
\hline
\end{tabular}




\begin{tabular}{|c|c|c|c|c|}
\hline \multicolumn{5}{|c|}{ Supplemental Table S2.txt } \\
\hline CHEMBL1334552 & 688550 & 4.4 & 4.9136 & TRN \\
\hline CHEMBL1345994 & 688550 & 4.55 & 4.8428 & TRN \\
\hline CHEMBL1588389 & 688550 & 5.0 & 4.8287 & TRN \\
\hline CHEMBL1557499 & 688550 & 4.6 & 4.7995 & TRN \\
\hline CHEMBL1986514 & 688550 & 4.6 & 4.7904 & TRN \\
\hline CHEMBL1587401 & 688550 & 5.1 & 4.9487 & TST \\
\hline CHEMBL1548588 & 688550 & 4.6 & 4.9582 & TRN \\
\hline CHEMBL1323432 & 688550 & 5.4 & 4.8543 & TRN \\
\hline CHEMBL1342297 & 688550 & 5.5 & 4.8978 & TRN \\
\hline CHEMBL1531691 & 688550 & 4.75 & 5.0006 & TRN \\
\hline CHEMBL1308688 & 688550 & 6.0 & 5.0265 & TRN \\
\hline CHEMBL1377108 & 688550 & 4.85 & 4.7779 & TRN \\
\hline CHEMBL1335413 & 688550 & 5.6 & 4.8821 & TRN \\
\hline CHEMBL1312950 & 688550 & 4.45 & 4.8806 & TST \\
\hline CHEMBL1312092 & 688550 & 4.6 & 5.0377 & TRN \\
\hline CHEMBL1504463 & 688550 & 4.5 & 5.0113 & TRN \\
\hline CHEMBL1374117 & 688550 & 4.55 & 4.8487 & TRN \\
\hline CHEMBL1543347 & 688550 & 4.55 & 4.8266 & TRN \\
\hline CHEMBL1389633 & 688550 & 5.85 & 4.8445 & TRN \\
\hline CHEMBL3193885 & 688550 & 4.4 & 4.697 & TRN \\
\hline CHEMBL1330647 & 688550 & 4.5 & 4.8564 & TRN \\
\hline CHEMBL1504838 & 688550 & 4.8 & 4.9746 & TRN \\
\hline CHEMBL3189381 & 688550 & 4.8 & 4.7733 & TRN \\
\hline CHEMBL1493497 & 688550 & 4.6 & 4.7968 & TRN \\
\hline CHEMBL1471580 & 688550 & 4.5 & 4.8823 & TRN \\
\hline CHEMBL1324828 & 688550 & 5.0 & 5.0453 & TRN \\
\hline CHEMBL1454917 & 688550 & 4.95 & 4.8845 & TRN \\
\hline CHEMBL1588874 & 688550 & 4.65 & 4.963 & TRN \\
\hline CHEMBL1313965 & 688550 & 4.45 & 4.8349 & TRN \\
\hline CHEMBL1462765 & 688550 & 5.35 & 4.9639 & TST \\
\hline CHEMBL1345685 & 688550 & 4.45 & 4.8522 & TRN \\
\hline CHEMBL1499632 & 688550 & 4.9 & 4.7696 & TRN \\
\hline CHEMBL1984271 & 688550 & 4.7 & 4.8264 & TST \\
\hline CHEMBL1598769 & 688550 & 4.85 & 4.7846 & TRN \\
\hline CHEMBL1570504 & 688550 & 6.2 & 4.77 & TRN \\
\hline CHEMBL1461268 & 688550 & 5.95 & 4.9026 & TRN \\
\hline CHEMBL1318462 & 688550 & 5.0 & 4.8934 & TRN \\
\hline CHEMBL1594961 & 688550 & 4.8 & 4.7456 & TRN \\
\hline CHEMBL1542326 & 688550 & 4.35 & 4.789 & TRN \\
\hline CHEMBL1448663 & 688550 & 5.0 & 5.025 & TRN \\
\hline CHEMBL42178 & 688550 & 4.85 & 4.8591 & TRN \\
\hline CHEMBL1391720 & 688550 & 4.55 & 4.9245 & TST \\
\hline CHEMBL1584634 & 688550 & 4.85 & 4.7825 & TRN \\
\hline CHEMBL1393628 & 688550 & 4.5 & 4.8292 & TRN \\
\hline CHEMBL1343677 & 688550 & 5.2 & 4.8862 & TRN \\
\hline CHEMBL1385105 & 688550 & 4.95 & 4.9145 & TRN \\
\hline CHEMBL1540267 & 688550 & 4.45 & 4.8958 & TRN \\
\hline CHEMBL1380214 & 688550 & 4.85 & 4.7152 & TRN \\
\hline
\end{tabular}




\begin{tabular}{|c|c|c|c|c|}
\hline \multicolumn{5}{|c|}{ Supplemental Table S2.txt } \\
\hline CHEMBL1547448 & 688550 & 5.15 & 4.9032 & TST \\
\hline CHEMBL1380740 & 688550 & 4.55 & 4.8816 & TRN \\
\hline CHEMBL1492677 & 688550 & 4.6 & 4.8895 & TST \\
\hline CHEMBL1084720 & 688550 & 4.4 & 4.9326 & TRN \\
\hline CHEMBL1544731 & 688550 & 4.4 & 4.8061 & TRN \\
\hline CHEMBL1312622 & 688550 & 4.65 & 4.8934 & TRN \\
\hline CHEMBL1302559 & 688550 & 4.5 & 4.8328 & TST \\
\hline CHEMBL393296 & 688550 & 4.8 & 4.9403 & TRN \\
\hline CHEMBL1384800 & 688550 & 4.4 & 4.7664 & TRN \\
\hline CHEMBL1498566 & 688550 & 5.0 & 4.9558 & TRN \\
\hline CHEMBL1306132 & 688550 & 4.9 & 4.8359 & TST \\
\hline CHEMBL3196626 & 688550 & 5.15 & 4.8514 & TRN \\
\hline CHEMBL1538625 & 688550 & 4.6 & 4.8397 & TRN \\
\hline CHEMBL1559777 & 688550 & 4.4 & 4.8638 & TST \\
\hline CHEMBL1504353 & 688550 & 5.15 & 4.9397 & TRN \\
\hline CHEMBL1465175 & 688550 & 4.45 & 4.8603 & TRN \\
\hline CHEMBL1447137 & 688550 & 4.6 & 4.8923 & TRN \\
\hline CHEMBL1503964 & 688550 & 4.75 & 4.9511 & TRN \\
\hline CHEMBL1402508 & 688550 & 4.75 & 4.8912 & TRN \\
\hline CHEMBL1377737 & 688550 & 4.8 & 4.8249 & TRN \\
\hline CHEMBL1381730 & 688550 & 4.75 & 4.8525 & TRN \\
\hline CHEMBL1381479 & 688550 & 5.4 & 5.0278 & TRN \\
\hline CHEMBL1382570 & 688550 & 4.5 & 4.8721 & TRN \\
\hline CHEMBL 3194554 & 688550 & 4.45 & 4.8493 & TRN \\
\hline CHEMBL1333620 & 688550 & 4.4 & 4.8592 & TRN \\
\hline CHEMBL1329047 & 688550 & 4.4 & 4.9943 & TRN \\
\hline CHEMBL1598010 & 688550 & 4.4 & 4.813 & TST \\
\hline CHEMBL1373015 & 688550 & 4.55 & 4.7847 & TRN \\
\hline CHEMBL1349365 & 688550 & 4.45 & 4.7764 & TRN \\
\hline CHEMBL1509029 & 688550 & 4.6 & 4.9634 & TRN \\
\hline CHEMBL1596040 & 688550 & 4.85 & 4.8451 & TRN \\
\hline CHEMBL1548465 & 688550 & 5.05 & 4.864 & TRN \\
\hline CHEMBL 2000888 & 688550 & 5.05 & 4.8119 & TRN \\
\hline CHEMBL1427726 & 688550 & 4.55 & 4.8678 & TRN \\
\hline CHEMBL1375545 & 688550 & 5.1 & 4.9789 & TRN \\
\hline CHEMBL3194427 & 688550 & 5.0 & 4.742 & TRN \\
\hline CHEMBL1545527 & 688550 & 5.0 & 4.9563 & TRN \\
\hline CHEMBL1420119 & 688550 & 4.9 & 4.8011 & TRN \\
\hline CHEMBL1385209 & 688550 & 5.2 & 4.9868 & TRN \\
\hline CHEMBL1436306 & 688550 & 4.5 & 4.9564 & TRN \\
\hline CHEMBL1088762 & 688550 & 6.6499 & 5.0314 & TRN \\
\hline CHEMBL1463423 & 688550 & 4.4 & 4.8411 & TST \\
\hline CHEMBL1576312 & 688550 & 5.35 & 4.7991 & TRN \\
\hline CHEMBL1388241 & 688550 & 4.4 & 4.9244 & TRN \\
\hline CHEMBL1431524 & 688550 & 4.8 & 4.8981 & TRN \\
\hline CHEMBL1596116 & 688550 & 4.45 & 4.9858 & TRN \\
\hline CHEMBL1303178 & 688550 & 5.35 & 4.9127 & TRN \\
\hline CHEMBL1385230 & 688550 & 4.65 & 4.8207 & TRN \\
\hline
\end{tabular}




\begin{tabular}{|c|c|c|c|c|}
\hline \multicolumn{5}{|c|}{ Supplemental Table S2.txt } \\
\hline CHEMBL1539133 & 688550 & 4.4 & 4.8742 & TRN \\
\hline CHEMBL1349983 & 688550 & 5.25 & 4.8329 & TRN \\
\hline CHEMBL1506697 & 688550 & 4.5 & 4.7814 & TRN \\
\hline CHEMBL1549324 & 688550 & 5.0 & 4.8916 & TRN \\
\hline CHEMBL1571258 & 688550 & 4.7 & 4.7912 & TRN \\
\hline CHEMBL1393638 & 688550 & 5.5 & 4.8647 & TRN \\
\hline CHEMBL1384375 & 688550 & 5.4 & 4.9339 & TRN \\
\hline CHEMBL1488643 & 688550 & 5.3 & 4.8777 & TST \\
\hline CHEMBL1467905 & 688550 & 4.9 & 5.0105 & TRN \\
\hline CHEMBL1588056 & 688550 & 4.6 & 4.8511 & TRN \\
\hline CHEMBL1578178 & 688550 & 5.0 & 4.8784 & TST \\
\hline CHEMBL1372555 & 688550 & 5.85 & 4.8683 & TRN \\
\hline CHEMBL1448475 & 688550 & 4.7 & 4.7402 & TRN \\
\hline CHEMBL1538161 & 688550 & 4.7 & 4.8691 & TRN \\
\hline CHEMBL1471762 & 688550 & 4.7 & 4.7993 & TRN \\
\hline CHEMBL1340178 & 688550 & 4.4 & 4.8457 & TRN \\
\hline CHEMBL1407548 & 688550 & 4.6 & 4.8969 & TRN \\
\hline CHEMBL1389438 & 688550 & 4.7 & 4.8462 & TRN \\
\hline CHEMBL1475708 & 688550 & 4.6 & 4.9271 & TRN \\
\hline CHEMBL1467626 & 688550 & 4.8 & 4.9379 & TRN \\
\hline CHEMBL1579367 & 688550 & 4.85 & 4.8289 & TRN \\
\hline CHEMBL3196042 & 688550 & 4.7 & 4.81 & TRN \\
\hline CHEMBL1332375 & 688550 & 4.75 & 4.816 & TRN \\
\hline CHEMBL1339149 & 688550 & 5.55 & 4.9529 & TRN \\
\hline CHEMBL1362048 & 688550 & 4.55 & 4.8194 & TRN \\
\hline CHEMBL1335010 & 688550 & 5.4 & 4.7688 & TRN \\
\hline CHEMBL1364030 & 688550 & 5.25 & 4.87 & TRN \\
\hline CHEMBL1409197 & 688550 & 4.65 & 4.8384 & TRN \\
\hline CHEMBL1488320 & 688550 & 4.6 & 4.9828 & TRN \\
\hline CHEMBL1365159 & 688550 & 4.6 & 4.7327 & TRN \\
\hline CHEMBL1376724 & 688550 & 9.1549 & 4.8968 & TRN \\
\hline CHEMBL1605356 & 688550 & 5.15 & 4.9074 & TST \\
\hline CHEMBL1388201 & 688550 & 4.6 & 4.7747 & TRN \\
\hline CHEMBL1518308 & 688550 & 5.2 & 4.8259 & TST \\
\hline CHEMBL1539501 & 688550 & 4.75 & 5.0172 & TRN \\
\hline CHEMBL1323968 & 688550 & 4.6 & 4.806 & TRN \\
\hline CHEMBL3196996 & 688550 & 4.95 & 4.8903 & TST \\
\hline CHEMBL1989440 & 688550 & 4.8 & 4.7527 & TRN \\
\hline CHEMBL1561889 & 688550 & 4.35 & 4.8997 & TRN \\
\hline CHEMBL1577645 & 688550 & 5.25 & 4.8523 & TRN \\
\hline CHEMBL1520315 & 688550 & 4.6 & 5.0017 & TRN \\
\hline CHEMBL1540680 & 688550 & 4.4 & 4.8467 & TRN \\
\hline CHEMBL1574220 & 688550 & 4.4 & 4.9656 & TRN \\
\hline CHEMBL1431375 & 688550 & 4.55 & 4.852 & TRN \\
\hline CHEMBL1492732 & 688550 & 4.4 & 4.8067 & TRN \\
\hline CHEMBL1561215 & 688550 & 5.1 & 4.8349 & TST \\
\hline CHEMBL3191719 & 688550 & 4.45 & 4.8508 & TRN \\
\hline CHEMBL1533549 & 688550 & 4.65 & 4.6765 & TRN \\
\hline
\end{tabular}




\begin{tabular}{|c|c|c|c|c|c|}
\hline \multicolumn{6}{|c|}{ Supplemental Table S2.txt } \\
\hline CHEMBL1529842 & 688550 & 4.45 & 4.8418 & TRN & \\
\hline CHEMBL1442928 & 688550 & 5.0 & 4.8745 & TRN & \\
\hline CHEMBL3191554 & 688550 & 4.55 & 4.9025 & TST & \\
\hline CHEMBL1328069 & 688550 & 4.85 & 4.8283 & TRN & \\
\hline CHEMBL1431036 & 688550 & 4.65 & 4.9567 & TRN & \\
\hline CHEMBL1532981 & 688550 & 4.6 & 4.9438 & TRN & \\
\hline CHEMBL1503755 & 688550 & 4.75 & 4.8561 & TRN & \\
\hline CHEMBL1510399 & 688550 & 4.65 & 4.7784 & TRN & \\
\hline CHEMBL1303824 & 688550 & 4.5 & 4.9178 & TRN & \\
\hline CHEMBL1391916 & 688550 & 4.75 & 4.8995 & TRN & \\
\hline CHEMBL1386455 & 688550 & 4.45 & 4.7438 & TRN & \\
\hline CHEMBL1482760 & 688550 & 4.85 & 4.8332 & TRN & \\
\hline CHEMBL1544412 & 688550 & 4.6 & 4.9388 & TRN & \\
\hline CHEMBL1530741 & 688550 & 4.7 & 4.9151 & TRN & \\
\hline CHEMBL1404880 & 688550 & 4.8 & 4.8726 & TRN & \\
\hline CHEMBL1565995 & 688550 & 5.05 & 4.9243 & TRN & \\
\hline CHEMBL1447678 & 688550 & 4.65 & 4.8249 & TRN & \\
\hline CHEMBL1503937 & 688550 & 4.4 & 4.7994 & TST & \\
\hline CHEMBL1539167 & 688550 & 4.6 & 4.7728 & TST & \\
\hline CHEMBL1555664 & 688550 & 4.6 & 4.8927 & TRN & \\
\hline CHEMBL1458701 & 688550 & 4.85 & 4.8366 & TRN & \\
\hline CHEMBL1472389 & 688550 & 4.4 & 4.8891 & TST & \\
\hline CHEMBL1571842 & 688550 & 4.85 & 4.8566 & TRN & \\
\hline CHEMBL1304195 & 688550 & 4.5 & $4.9460 €$ & 0000000001 & TRN \\
\hline CHEMBL1465011 & 688550 & 4.45 & 4.8 & TRN & \\
\hline CHEMBL1440076 & 688550 & 5.45 & 4.8625 & TRN & \\
\hline CHEMBL1461962 & 688550 & 5.45 & 4.9079 & TRN & \\
\hline CHEMBL1584844 & 688550 & 5.3 & 4.88 & TST & \\
\hline CHEMBL1313964 & 688550 & 4.9 & 4.9004 & TRN & \\
\hline CHEMBL1603556 & 688550 & 4.45 & 4.8666 & TRN & \\
\hline CHEMBL1490610 & 688550 & 4.4 & 4.8043 & TRN & \\
\hline CHEMBL1500411 & 688550 & 5.15 & 4.9952 & TRN & \\
\hline CHEMBL1324556 & 688550 & 4.45 & 4.8351 & TRN & \\
\hline CHEMBL1500083 & 688550 & 4.4 & 4.8608 & TRN & \\
\hline CHEMBL1305881 & 688550 & 4.45 & 4.8538 & TRN & \\
\hline CHEMBL1521940 & 688550 & 4.75 & 4.9744 & TRN & \\
\hline CHEMBL1980889 & 688550 & 4.5 & 4.7056 & TRN & \\
\hline CHEMBL1504286 & 688550 & 5.5 & 4.9173 & TRN & \\
\hline CHEMBL1391263 & 688550 & 4.85 & 4.8972 & TRN & \\
\hline CHEMBL1366681 & 688550 & 4.85 & 4.7611 & TST & \\
\hline CHEMBL1482623 & 688550 & 4.95 & 4.9814 & TRN & \\
\hline CHEMBL1352300 & 688550 & 4.45 & 4.9555 & TRN & \\
\hline CHEMBL1494543 & 688550 & 4.75 & 4.9719 & TRN & \\
\hline CHEMBL1586326 & 688550 & 5.35 & 4.8445 & TST & \\
\hline CHEMBL1381560 & 688550 & 7.5003 & 4.919 & TRN & \\
\hline CHEMBL1507287 & 688550 & 4.55 & 4.7621 & TRN & \\
\hline CHEMBL1501537 & 688550 & 4.7 & 4.8869 & TRN & \\
\hline CHEMBL1389473 & 688550 & 4.9 & 4.8305 & TRN & \\
\hline
\end{tabular}




\begin{tabular}{|c|c|c|c|c|}
\hline \multicolumn{5}{|c|}{ Supplemental Table S2.txt } \\
\hline CHEMBL1526378 & 688550 & 4.55 & 4.948 & TRN \\
\hline CHEMBL1477308 & 688550 & 6.4 & 4.9952 & TRN \\
\hline CHEMBL1498564 & 688550 & 4.6 & 4.8042 & TRN \\
\hline CHEMBL1344071 & 688550 & 5.15 & 4.8307 & TRN \\
\hline CHEMBL1312852 & 688550 & 4.55 & 4.9649 & TRN \\
\hline CHEMBL1556089 & 688550 & 4.7 & 4.814 & TRN \\
\hline CHEMBL1346456 & 688550 & 4.95 & 4.8726 & TST \\
\hline CHEMBL1381607 & 688550 & 4.9 & 5.011 & TRN \\
\hline CHEMBL1561089 & 688550 & 4.4 & 4.8313 & TRN \\
\hline CHEMBL112597 & 688550 & 4.8 & 4.713 & TRN \\
\hline CHEMBL1464370 & 688550 & 6.05 & 4.8869 & TRN \\
\hline CHEMBL1573483 & 688550 & 6.0 & 5.0245 & TRN \\
\hline CHEMBL1982901 & 688550 & 4.65 & 4.6951 & TRN \\
\hline CHEMBL1601509 & 688550 & 5.15 & 4.8212 & TRN \\
\hline CHEMBL1368822 & 688550 & 4.4 & 4.8268 & TRN \\
\hline CHEMBL1330336 & 688550 & 4.4 & 4.8912 & TST \\
\hline CHEMBL3208220 & 688550 & 4.4 & 4.8764 & TRN \\
\hline CHEMBL1368166 & 688550 & 4.45 & 4.8991 & TRN \\
\hline CHEMBL 3190104 & 688550 & 4.6 & 4.7252 & TRN \\
\hline CHEMBL3191304 & 688550 & 4.8 & 4.841 & TRN \\
\hline CHEMBL1321639 & 688550 & 5.2 & 4.8443 & TRN \\
\hline CHEMBL1386015 & 688550 & 4.4 & 4.7963 & TRN \\
\hline CHEMBL 3196786 & 688550 & 5.05 & 4.8837 & TST \\
\hline CHEMBL1333805 & 688550 & 4.4 & 4.8623 & TRN \\
\hline CHEMBL1492443 & 688550 & 4.85 & 4.8496 & TRN \\
\hline CHEMBL1613265 & 688550 & 5.05 & 4.8968 & TST \\
\hline CHEMBL1525678 & 688550 & 4.5 & 4.7452 & TRN \\
\hline CHEMBL1462373 & 688550 & 4.85 & 4.8254 & TRN \\
\hline CHEMBL1347204 & 688550 & 4.65 & 4.7485 & TRN \\
\hline CHEMBL 3145314 & 688550 & 4.8 & 4.9109 & TRN \\
\hline CHEMBL1560185 & 688550 & 4.75 & 4.9088 & TRN \\
\hline CHEMBL1413321 & 688550 & 4.85 & 4.8493 & TRN \\
\hline CHEMBL1386949 & 688550 & 4.4 & 4.9123 & TRN \\
\hline CHEMBL1501311 & 688550 & 4.4 & 4.8566 & TST \\
\hline CHEMBL1310875 & 688550 & 4.75 & 4.954 & TRN \\
\hline CHEMBL1386067 & 688550 & 5.25 & 4.8696 & TRN \\
\hline CHEMBL1452026 & 688550 & 4.4 & 4.8599 & TRN \\
\hline CHEMBL1585075 & 688550 & 6.6499 & 4.8729 & TRN \\
\hline CHEMBL1309877 & 688550 & 4.7 & 4.8737 & TRN \\
\hline CHEMBL1502432 & 688550 & 4.4 & 4.8622 & TST \\
\hline CHEMBL1535216 & 688550 & 4.85 & 4.8837 & TRN \\
\hline CHEMBL1399975 & 688550 & 5.25 & 4.9414 & TRN \\
\hline CHEMBL1495167 & 688550 & 4.45 & 4.9001 & TRN \\
\hline CHEMBL1570853 & 688550 & 4.6 & 4.9648 & TRN \\
\hline CHEMBL1610689 & 688550 & 5.5 & 4.852 & TRN \\
\hline CHEMBL3197525 & 688550 & 5.6 & 4.8881 & TRN \\
\hline CHEMBL1459695 & 688550 & 4.45 & 4.8864 & TST \\
\hline CHEMBL1326933 & 688550 & 4.45 & 4.8731 & TRN \\
\hline
\end{tabular}




\begin{tabular}{|c|c|c|c|c|}
\hline \multicolumn{5}{|c|}{ Supplemental Table S2.txt } \\
\hline CHEMBL1557069 & 688550 & 4.5 & 4.9062 & TRN \\
\hline CHEMBL1555729 & 688550 & 4.65 & 4.8112 & TRN \\
\hline CHEMBL1540529 & 688550 & 4.8 & 4.9826 & TRN \\
\hline CHEMBL1364404 & 688550 & 4.85 & 4.811 & TRN \\
\hline CHEMBL1319307 & 688550 & 4.85 & 4.8814 & TRN \\
\hline CHEMBL1471955 & 688550 & 5.2 & 4.9986 & TRN \\
\hline CHEMBL1464133 & 688550 & 5.3 & 4.8213 & TRN \\
\hline CHEMBL1333135 & 688550 & 5.0 & 4.8548 & TRN \\
\hline CHEMBL1309987 & 688550 & 4.8 & 4.8571 & TST \\
\hline CHEMBL1600121 & 688550 & 4.4 & 4.7748 & TRN \\
\hline CHEMBL1585974 & 688550 & 4.4 & 4.7697 & TRN \\
\hline CHEMBL1549914 & 688550 & 4.5 & 4.7968 & TST \\
\hline CHEMBL19954 & 688550 & 4.45 & 4.8579 & TRN \\
\hline CHEMBL1583167 & 688550 & 4.45 & 4.9393 & TST \\
\hline CHEMBL3210177 & 688550 & 4.75 & 4.7858 & TST \\
\hline CHEMBL1967540 & 688550 & 5.3 & 4.7791 & TRN \\
\hline CHEMBL1535157 & 688550 & 4.55 & 4.8402 & TRN \\
\hline CHEMBL1489151 & 688550 & 4.85 & 4.8242 & TRN \\
\hline CHEMBL1538326 & 688550 & 4.4 & 4.8761 & TRN \\
\hline CHEMBL1574847 & 688550 & 5.95 & 4.9527 & TRN \\
\hline CHEMBL1571040 & 688550 & 4.4 & 4.8086 & TRN \\
\hline CHEMBL1492820 & 688550 & 5.1 & 5.0184 & TRN \\
\hline CHEMBL1418847 & 688550 & 4.4 & 4.8944 & TRN \\
\hline CHEMBL1525946 & 688550 & 4.4 & 4.8306 & TRN \\
\hline CHEMBL1413495 & 688550 & 4.8 & 4.8343 & TST \\
\hline CHEMBL1352039 & 688550 & 2.3 & 4.8125 & TRN \\
\hline CHEMBL1331527 & 688550 & 6.1 & 4.8188 & TST \\
\hline CHEMBL1375704 & 688550 & 6.2 & 4.9295 & TRN \\
\hline CHEMBL1305224 & 688550 & 5.05 & 5.0279 & TRN \\
\hline CHEMBL1304086 & 688550 & 4.55 & 4.9877 & TRN \\
\hline CHEMBL1482758 & 688550 & 5.0 & 4.823 & TRN \\
\hline CHEMBL1465516 & 688550 & 4.9 & 4.7971 & TRN \\
\hline CHEMBL1335489 & 688550 & 5.05 & 4.7295 & TRN \\
\hline CHEMBL1499554 & 688550 & 4.4 & 4.9547 & TRN \\
\hline CHEMBL1587813 & 688550 & 5.0 & 4.9085 & TRN \\
\hline CHEMBL1610008 & 688550 & 4.4 & 4.7986 & TRN \\
\hline CHEMBL 1405660 & 688550 & 4.7 & 4.8859 & TRN \\
\hline CHEMBL1501356 & 688550 & 4.45 & 4.773 & TRN \\
\hline CHEMBL1579526 & 688550 & 4.7 & 4.9108 & TST \\
\hline CHEMBL1485148 & 688550 & 4.6 & 4.7554 & TRN \\
\hline CHEMBL1997422 & 688550 & 4.4 & 4.8146 & TRN \\
\hline CHEMBL1459802 & 688550 & 6.95 & 4.9179 & TRN \\
\hline CHEMBL1340915 & 688550 & 4.65 & 4.7829 & TRN \\
\hline CHEMBL1345696 & 688550 & 4.6 & 4.865 & TRN \\
\hline CHEMBL1464751 & 688550 & 4.9 & 4.9513 & TRN \\
\hline CHEMBL1600924 & 688550 & 4.8 & 4.9805 & TRN \\
\hline CHEMBL1371020 & 688550 & 4.5 & 4.8084 & TST \\
\hline CHEMBL1359123 & 688550 & 4.7 & 4.8061 & TRN \\
\hline
\end{tabular}




\begin{tabular}{|c|c|c|c|c|c|}
\hline & & \multicolumn{4}{|c|}{ Supplemental Table s2.txt } \\
\hline CHEMBL1473119 & 688550 & 4.85 & 4.9564 & TST & \\
\hline CHEMBL1376115 & 688550 & 4.65 & 4.8057 & TST & \\
\hline CHEMBL1448856 & 688550 & 4.8 & 4.8301 & TRN & \\
\hline CHEMBL1584631 & 688550 & 4.8 & 4.8455 & TRN & \\
\hline CHEMBL1377884 & 688550 & 5.55 & 4.9253 & TRN & \\
\hline CHEMBL1539675 & 688550 & 4.85 & 4.7472 & TRN & \\
\hline CHEMBL1558588 & 688550 & 4.65 & 4.8577 & TRN & \\
\hline CHEMBL1344197 & 688550 & 5.15 & 4.9682 & TRN & \\
\hline CHEMBL1351070 & 688550 & 5.2 & 4.8447 & TRN & \\
\hline CHEMBL1444983 & 688550 & 4.55 & 4.999 & TRN & \\
\hline CHEMBL193872 & 688550 & 4.85 & 4.8199 & TST & \\
\hline CHEMBL1547901 & 688550 & 4.55 & 4.8116 & TRN & \\
\hline CHEMBL1425309 & 688550 & 4.45 & 4.7444 & TRN & \\
\hline CHEMBL1890899 & 688550 & 4.65 & 4.88899 & 9999999999 & TRN \\
\hline CHEMBL1543574 & 688550 & 4.4 & 4.7659 & TRN & \\
\hline CHEMBL1370260 & 688550 & 6.45 & 4.928 & TRN & \\
\hline CHEMBL1492205 & 688550 & 4.9 & 4.9422 & TST & \\
\hline CHEMBL 3207648 & 688550 & 4.85 & 4.8674 & TRN & \\
\hline CHEMBL1974425 & 688550 & 4.6 & 4.8169 & TRN & \\
\hline CHEMBL1489627 & 688550 & 4.4 & 4.7844 & TRN & \\
\hline CHEMBL1509421 & 688550 & 4.85 & 4.9217 & TRN & \\
\hline CHEMBL1467772 & 688550 & 4.95 & 4.9537 & TRN & \\
\hline CHEMBL1412664 & 688550 & 5.05 & 4.8193 & TRN & \\
\hline CHEMBL1413188 & 688550 & 5.5 & 4.831 & TRN & \\
\hline CHEMBL1562478 & 688550 & 5.5 & 4.8307 & TRN & \\
\hline CHEMBL1547533 & 688550 & 4.4 & 4.8603 & TST & \\
\hline CHEMBL1704267 & 688550 & 4.6 & 4.6955 & TRN & \\
\hline CHEMBL1342326 & 688550 & 4.4 & 4.9616 & TRN & \\
\hline CHEMBL1586970 & 688550 & 4.75 & 4.7923 & TRN & \\
\hline CHEMBL1498952 & 688550 & 4.7 & 4.8458 & TRN & \\
\hline CHEMBL1584194 & 688550 & 4.65 & 4.7998 & TRN & \\
\hline CHEMBL1347304 & 688550 & 4.9 & 5.0424 & TRN & \\
\hline CHEMBL1338776 & 688550 & 4.9 & 4.8273 & TRN & \\
\hline CHEMBL1471258 & 688550 & 5.45 & 4.931 & TRN & \\
\hline CHEMBL1493396 & 688550 & 5.4 & 4.7576 & TST & \\
\hline CHEMBL3195808 & 688550 & 5.75 & 4.8036 & TRN & \\
\hline CHEMBL1369110 & 688550 & 4.4 & 5.0641 & TRN & \\
\hline CHEMBL1366006 & 688550 & 5.6 & 4.8882 & TRN & \\
\hline CHEMBL1488864 & 688550 & 4.95 & 4.9359 & TRN & \\
\hline CHEMBL1309148 & 688550 & 4.85 & 4.9688 & TRN & \\
\hline CHEMBL1432947 & 688550 & 4.4 & 4.9491 & TRN & \\
\hline CHEMBL1498328 & 688550 & 5.4 & 4.8408 & TRN & \\
\hline CHEMBL1490429 & 688550 & 5.45 & 4.7506 & TRN & \\
\hline CHEMBL1464128 & 688550 & 4.5 & 4.8802 & TST & \\
\hline CHEMBL1395885 & 688550 & 4.4 & 4.8943 & TRN & \\
\hline CHEMBL1507307 & 688550 & 4.5 & 4.876 & TST & \\
\hline CHEMBL1384912 & 688550 & 4.6 & 4.91 & TRN & \\
\hline CHEMBL1307117 & 688550 & 4.8 & 4.808 & TRN & \\
\hline
\end{tabular}




\begin{tabular}{|c|c|c|c|c|}
\hline \multicolumn{5}{|c|}{ Supplemental Table S2.txt } \\
\hline CHEMBL1613669 & 688550 & 5.6 & 4.9971 & TRN \\
\hline CHEMBL1455138 & 688550 & 5.05 & 4.8512 & TRN \\
\hline CHEMBL1547025 & 688550 & 4.45 & 4.7717 & TRN \\
\hline CHEMBL1417745 & 688550 & 4.9 & 4.8681 & TRN \\
\hline CHEMBL1575495 & 688550 & 5.15 & 4.8664 & TRN \\
\hline CHEMBL1347863 & 688550 & 4.4 & 4.8742 & TST \\
\hline CHEMBL1457033 & 688550 & 4.55 & 4.9225 & TRN \\
\hline CHEMBL1365770 & 688550 & 4.8 & 4.9678 & TRN \\
\hline CHEMBL1514207 & 688550 & 5.15 & 4.8759 & TST \\
\hline CHEMBL1335726 & 688550 & 4.65 & 5.0078 & TRN \\
\hline CHEMBL1448792 & 688550 & 4.5 & 4.9626 & TRN \\
\hline CHEMBL1521317 & 688550 & 4.9 & 4.8211 & TRN \\
\hline CHEMBL1520078 & 688550 & 4.95 & 4.9482 & TRN \\
\hline CHEMBL1504592 & 688550 & 4.6 & 4.7709 & TRN \\
\hline CHEMBL1549752 & 688550 & 4.45 & 4.9429 & TST \\
\hline CHEMBL1393209 & 688550 & 4.55 & 4.8263 & TRN \\
\hline CHEMBL1415889 & 688550 & 4.65 & 4.8884 & TRN \\
\hline CHEMBL1462913 & 688550 & 6.15 & 4.9707 & TRN \\
\hline CHEMBL1556628 & 688550 & 6.7501 & 4.9413 & TRN \\
\hline CHEMBL1367267 & 688550 & 4.55 & 4.8939 & TRN \\
\hline CHEMBL1353518 & 688550 & 4.75 & 4.9584 & TRN \\
\hline CHEMBL3189148 & 688550 & 6.05 & 4.8312 & TST \\
\hline CHEMBL1610275 & 688550 & 4.65 & 4.989 & TRN \\
\hline CHEMBL1365977 & 688550 & 4.85 & 4.9077 & TRN \\
\hline CHEMBL1332725 & 688550 & 4.4 & 4.9225 & TRN \\
\hline CHEMBL1494938 & 688550 & 5.05 & 4.8834 & TRN \\
\hline CHEMBL1369845 & 688550 & 4.65 & 4.8111 & TRN \\
\hline CHEMBL1401302 & 688550 & 4.8 & 4.7922 & TRN \\
\hline CHEMBL1589216 & 688550 & 4.45 & 4.9652 & TRN \\
\hline CHEMBL1451245 & 688550 & 4.6 & 4.7606 & TRN \\
\hline CHEMBL1408535 & 688550 & 4.55 & 4.768 & TRN \\
\hline CHEMBL1488741 & 688550 & 5.45 & 4.9463 & TRN \\
\hline CHEMBL1464373 & 688550 & 4.85 & 4.8194 & TRN \\
\hline CHEMBL1465935 & 688550 & 4.4 & 4.9451 & TRN \\
\hline CHEMBL1424468 & 688550 & 4.4 & 4.8031 & TRN \\
\hline CHEMBL1327376 & 688550 & 4.45 & 4.9247 & TRN \\
\hline CHEMBL1586224 & 688550 & 4.8 & 4.8402 & TRN \\
\hline CHEMBL1304835 & 688550 & 4.6 & 4.9598 & TRN \\
\hline CHEMBL3191238 & 688550 & 4.75 & 4.7365 & TRN \\
\hline CHEMBL1459399 & 688550 & 4.4 & 4.8556 & TRN \\
\hline CHEMBL1572533 & 688550 & 6.0 & 4.8012 & TRN \\
\hline CHEMBL1414364 & 688550 & 4.55 & 4.9114 & TRN \\
\hline CHEMBL1587959 & 688550 & 4.55 & 4.8942 & TST \\
\hline CHEMBL3191796 & 688550 & 6.05 & 4.9209 & TST \\
\hline CHEMBL1347169 & 688550 & 4.5 & 4.7853 & TRN \\
\hline CHEMBL1380145 & 688550 & 4.5 & 4.805 & TRN \\
\hline CHEMBL1422590 & 688550 & 4.7 & 4.9075 & TRN \\
\hline CHEMBL1369433 & 688550 & 4.55 & 4.8277 & TRN \\
\hline
\end{tabular}




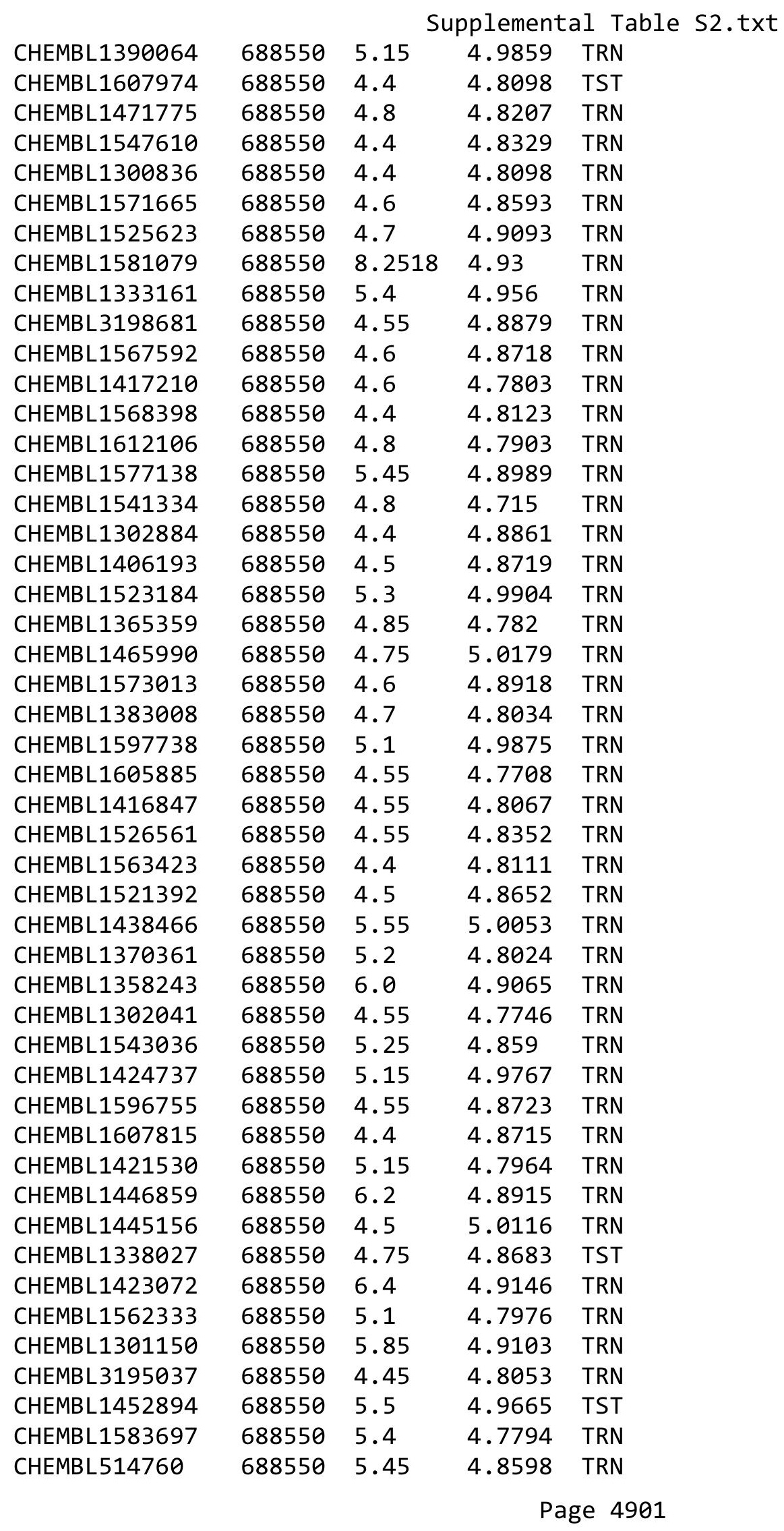




\begin{tabular}{|c|c|c|c|c|c|}
\hline \multicolumn{6}{|c|}{ Supplemental Table S2.txt } \\
\hline CHEMBL1550895 & 688550 & 4.65 & 4.7898 & TRN & \\
\hline CHEMBL1533652 & 688550 & 6.7001 & 4.9196 & TRN & \\
\hline CHEMBL1607488 & 688550 & 5.45 & 4.8891 & TRN & \\
\hline CHEMBL3192853 & 688550 & 5.4 & 4.869 & TRN & \\
\hline CHEMBL1611106 & 688550 & 4.5 & 4.795 & TRN & \\
\hline CHEMBL1306924 & 688550 & 4.45 & 5.001 & TRN & \\
\hline CHEMBL1578760 & 688550 & 4.9 & 4.7948 & TRN & \\
\hline CHEMBL1422691 & 688550 & 4.7 & 4.8891 & TRN & \\
\hline CHEMBL1520392 & 688550 & 4.7 & 4.7764 & TRN & \\
\hline CHEMBL1490306 & 688550 & 5.45 & 4.7858 & TRN & \\
\hline CHEMBL1982774 & 688550 & 4.5 & 4.7225 & TRN & \\
\hline CHEMBL1575179 & 688550 & 4.65 & 5.0205 & TRN & \\
\hline CHEMBL1339312 & 688550 & 4.5 & 4.8549 & TRN & \\
\hline CHEMBL1566719 & 688550 & 4.6 & 4.8973 & TST & \\
\hline CHEMBL1565536 & 688550 & 4.5 & 4.8406 & TRN & \\
\hline CHEMBL1530670 & 688550 & 6.1 & 4.8489 & TST & \\
\hline CHEMBL1330120 & 688550 & 4.85 & 4.8225 & TST & \\
\hline CHEMBL1500060 & 688550 & 4.65 & 4.806 & TRN & \\
\hline CHEMBL1413930 & 688550 & 4.65 & 4.9913 & TRN & \\
\hline CHEMBL1333829 & 688550 & 5.0 & 4.9685 & TRN & \\
\hline CHEMBL1531635 & 688550 & 4.45 & 4.79899 & 99999999995 & TRN \\
\hline CHEMBL1382674 & 688550 & 4.6 & 4.8758 & TST & \\
\hline CHEMBL1532186 & 688550 & 5.45 & 4.8748 & TRN & \\
\hline CHEMBL1350315 & 688550 & 4.45 & 4.9472 & TRN & \\
\hline CHEMBL1368651 & 688550 & 4.45 & 4.8448 & TRN & \\
\hline CHEMBL1455588 & 688550 & 5.85 & 4.8781 & TRN & \\
\hline CHEMBL1411125 & 688550 & 4.6 & 4.869 & TRN & \\
\hline CHEMBL1302030 & 688550 & 5.0 & 4.9667 & TRN & \\
\hline CHEMBL1612139 & 688550 & 4.55 & 4.7769 & TRN & \\
\hline CHEMBL1493103 & 688550 & 4.65 & 4.9224 & TST & \\
\hline CHEMBL1574853 & 688550 & 4.4 & 4.9595 & TST & \\
\hline CHEMBL1506025 & 688550 & 4.4 & 4.8127 & TRN & \\
\hline CHEMBL1424694 & 688550 & 4.7 & 4.8638 & TRN & \\
\hline CHEMBL1575306 & 688550 & 4.8 & 4.9146 & TST & \\
\hline CHEMBL1384436 & 688550 & 5.0 & 4.8664 & TST & \\
\hline CHEMBL1520679 & 688550 & 4.65 & 5.0286 & TRN & \\
\hline CHEMBL1310511 & 688550 & 7.6003 & 4.88 & TST & \\
\hline CHEMBL1384304 & 688550 & 5.4 & 4.8706 & TRN & \\
\hline CHEMBL1368898 & 688550 & 5.5 & 4.7365 & TRN & \\
\hline CHEMBL1550108 & 688550 & 4.6 & 4.879 & TRN & \\
\hline CHEMBL1452695 & 688550 & 4.4 & 4.8186 & TRN & \\
\hline CHEMBL1507274 & 688550 & 5.1 & 4.7164 & TRN & \\
\hline CHEMBL1335290 & 688550 & 4.5 & 4.7956 & TST & \\
\hline CHEMBL1392155 & 688550 & 5.05 & 4.8376 & TRN & \\
\hline CHEMBL1566926 & 688550 & 4.4 & 4.9312 & TRN & \\
\hline CHEMBL 260213 & 688550 & 4.5 & 4.8138 & TRN & \\
\hline CHEMBL1424743 & 688550 & 4.8 & 4.8742 & TRN & \\
\hline CHEMBL3194871 & 688550 & 4.55 & 4.7777 & TRN & \\
\hline
\end{tabular}




\begin{tabular}{|c|c|c|c|c|}
\hline \multicolumn{5}{|c|}{ Supplemental Table } \\
\hline CHEMBL1515585 & 688550 & 6.15 & 4.9146 & TRN \\
\hline CHEMBL1547034 & 688550 & 4.8 & 4.7599 & TRN \\
\hline CHEMBL1496996 & 688550 & 4.4 & 4.8636 & TST \\
\hline CHEMBL1428758 & 688550 & 4.85 & 4.8603 & TRN \\
\hline CHEMBL1575110 & 688550 & 6.05 & 4.899 & TRN \\
\hline CHEMBL1446575 & 688550 & 4.85 & 4.8412 & TRN \\
\hline CHEMBL1483695 & 688550 & 4.65 & 4.9205 & TRN \\
\hline CHEMBL1385659 & 688550 & 4.55 & 4.8565 & TST \\
\hline CHEMBL1504774 & 688550 & 4.4 & 4.8222 & TST \\
\hline CHEMBL1377067 & 688550 & 4.45 & 4.8285 & TRN \\
\hline CHEMBL1330807 & 688550 & 4.55 & 4.8497 & TRN \\
\hline CHEMBL1374665 & 688550 & 4.4 & 4.9463 & TRN \\
\hline CHEMBL1365746 & 688550 & 5.2 & 4.8679 & TRN \\
\hline CHEMBL1972090 & 688550 & 4.85 & 4.686 & TRN \\
\hline CHEMBL1511484 & 688550 & 4.4 & 4.9517 & TRN \\
\hline CHEMBL1599007 & 688550 & 4.4 & 4.952 & TST \\
\hline CHEMBL1350960 & 688550 & 4.5 & 4.8216 & TRN \\
\hline CHEMBL3195360 & 688550 & 4.85 & 4.8801 & TST \\
\hline CHEMBL1498009 & 688550 & 5.15 & 4.8774 & TST \\
\hline CHEMBL1478561 & 688550 & 5.0 & 4.873 & TRN \\
\hline CHEMBL1582887 & 688550 & 4.8 & 4.854 & TST \\
\hline CHEMBL1420785 & 688550 & 4.65 & 4.9575 & TRN \\
\hline CHEMBL1507747 & 688550 & 5.55 & 4.9393 & TRN \\
\hline CHEMBL1399802 & 688550 & 4.95 & 4.9345 & TRN \\
\hline CHEMBL1411084 & 688550 & 4.5 & 4.827 & TRN \\
\hline CHEMBL1445307 & 688550 & 4.55 & 4.8832 & TRN \\
\hline CHEMBL1483641 & 688550 & 5.15 & 4.9648 & TST \\
\hline CHEMBL1511593 & 688550 & 4.8 & 4.8756 & TRN \\
\hline CHEMBL1449108 & 688550 & 4.8 & 4.9301 & TRN \\
\hline CHEMBL1425641 & 688550 & 4.45 & 4.8963 & TST \\
\hline CHEMBL1569240 & 688550 & 4.9 & 5.0198 & TRN \\
\hline CHEMBL1595473 & 688550 & 4.9 & 4.8225 & TRN \\
\hline CHEMBL1301103 & 688550 & 4.45 & 4.7814 & TRN \\
\hline CHEMBL1346172 & 688550 & 5.35 & 4.7332 & TRN \\
\hline CHEMBL1461167 & 688550 & 4.4 & 4.8922 & TRN \\
\hline CHEMBL1493615 & 688550 & 4.5 & 4.8316 & TRN \\
\hline CHEMBL3193134 & 688550 & 5.0 & 4.8546 & TRN \\
\hline CHEMBL1318643 & 688550 & 6.0 & 4.845 & TST \\
\hline CHEMBL1587985 & 688550 & 4.55 & 4.7973 & TRN \\
\hline CHEMBL1563327 & 688550 & 4.4 & 4.8164 & TST \\
\hline CHEMBL1580357 & 688550 & 4.5 & 4.8315 & TRN \\
\hline CHEMBL1380732 & 688550 & 4.5 & 4.8829 & TRN \\
\hline CHEMBL1536418 & 688550 & 4.8 & 4.7652 & TST \\
\hline CHEMBL1568902 & 688550 & 4.4 & 4.8092 & TRN \\
\hline CHEMBL1517608 & 688550 & 4.9 & 4.7554 & TRN \\
\hline CHEMBL1487489 & 688550 & 4.6 & 4.846 & TST \\
\hline CHEMBL193627 & 688550 & 5.35 & 4.8437 & TST \\
\hline CHEMBL1305116 & 688550 & 4.4 & 4.8841 & TRN \\
\hline
\end{tabular}




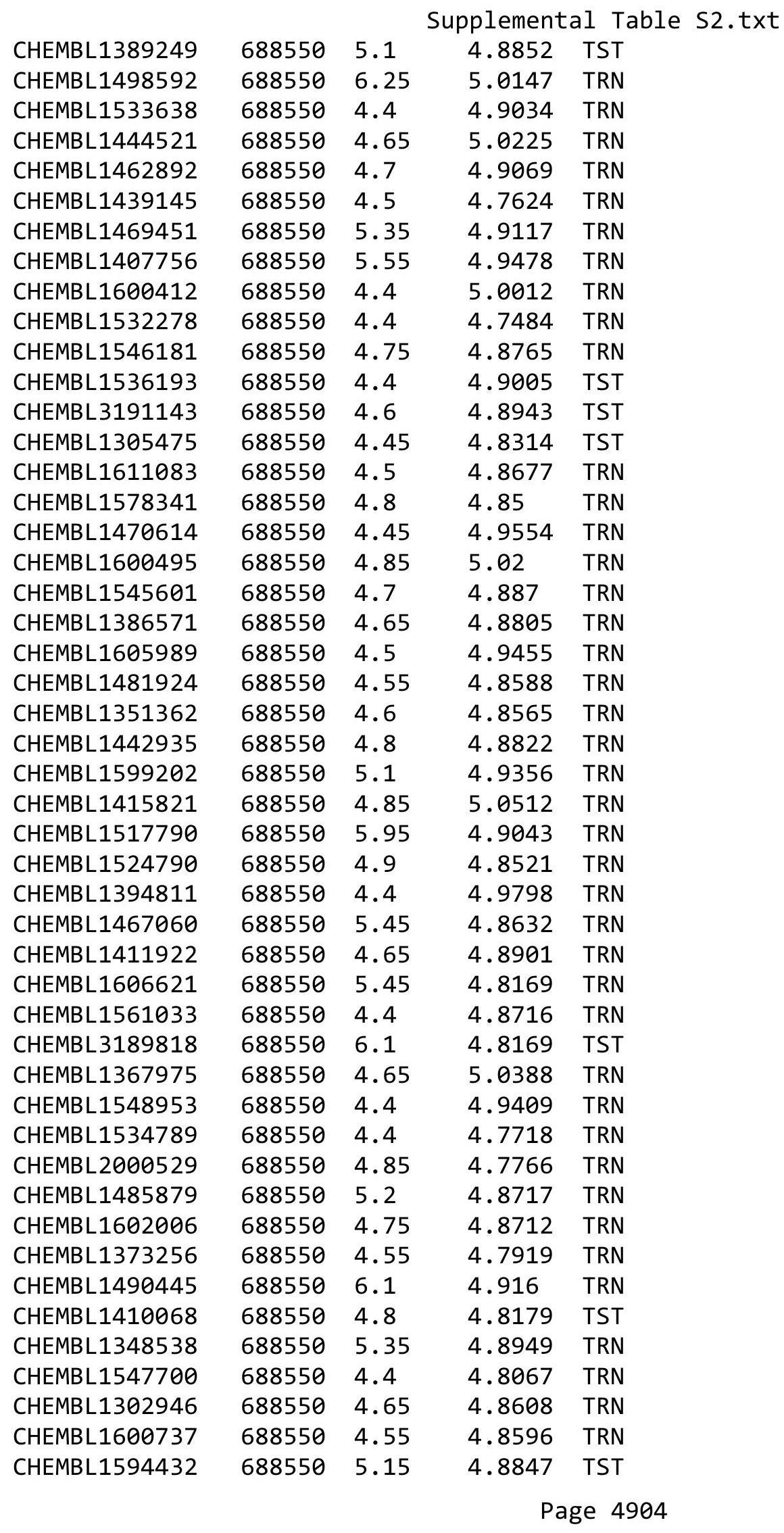




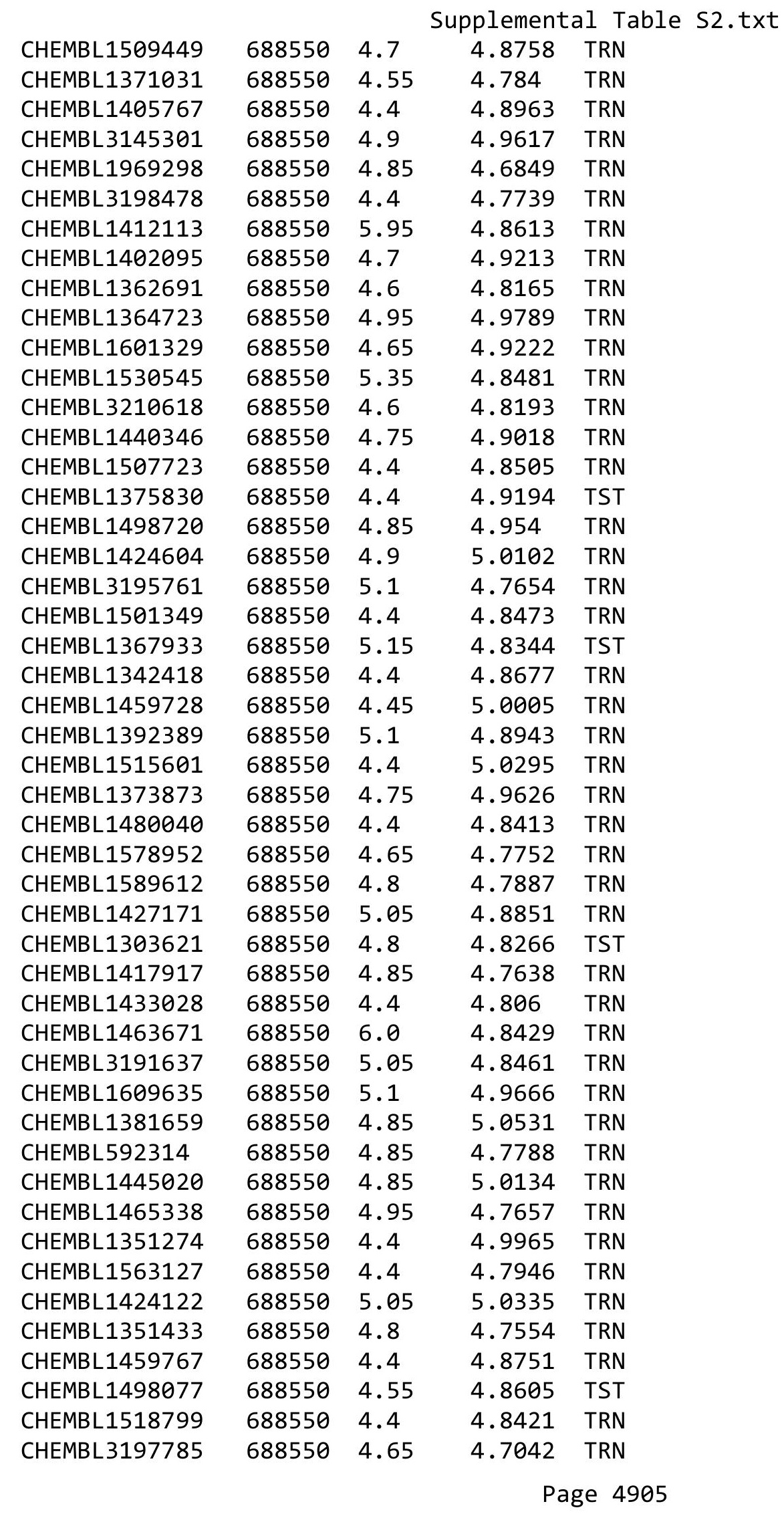




\begin{tabular}{|c|c|c|c|c|}
\hline \multicolumn{5}{|c|}{ Supplemental Table S2.txt } \\
\hline CHEMBL 2003587 & 688550 & 4.4 & 4.8367 & TRN \\
\hline CHEMBL1471306 & 688550 & 5.1 & 4.8806 & TST \\
\hline CHEMBL1341511 & 688550 & 4.55 & 4.9333 & TRN \\
\hline CHEMBL1388715 & 688550 & 4.85 & 4.8379 & TRN \\
\hline CHEMBL1502693 & 688550 & 4.6 & 4.8964 & TRN \\
\hline CHEMBL1612281 & 688550 & 4.95 & 4.8565 & TRN \\
\hline CHEMBL1569790 & 688550 & 4.45 & 4.8268 & TRN \\
\hline CHEMBL1611168 & 688550 & 4.4 & 4.8446 & TRN \\
\hline CHEMBL1411661 & 688550 & 4.4 & 4.8649 & TRN \\
\hline CHEMBL1562026 & 688550 & 4.85 & 4.9764 & TRN \\
\hline CHEMBL1458565 & 688550 & 4.75 & 4.8956 & TRN \\
\hline CHEMBL1470847 & 688550 & 4.4 & 5.0026 & TST \\
\hline CHEMBL1445900 & 688550 & 4.7 & 4.8975 & TRN \\
\hline CHEMBL1426797 & 688550 & 4.55 & 4.8008 & TRN \\
\hline CHEMBL3190023 & 688550 & 4.55 & 4.7524 & TRN \\
\hline CHEMBL1320620 & 688550 & 4.8 & 4.7856 & TST \\
\hline CHEMBL1563855 & 688550 & 7.0 & 4.8488 & TRN \\
\hline CHEMBL1496184 & 688550 & 4.85 & 4.8895 & TRN \\
\hline CHEMBL1559001 & 688550 & 5.5 & 4.8571 & TRN \\
\hline CHEMBL1613115 & 688550 & 4.45 & 4.9921 & TRN \\
\hline CHEMBL1307858 & 688550 & 6.35 & 4.8594 & TRN \\
\hline CHEMBL1471450 & 688550 & 4.75 & 4.7998 & TRN \\
\hline CHEMBL1989500 & 688550 & 4.95 & 4.7478 & TRN \\
\hline CHEMBL1305658 & 688550 & 4.65 & 4.936 & TST \\
\hline CHEMBL1418027 & 688550 & 4.6 & 4.8367 & TRN \\
\hline CHEMBL1568147 & 688550 & 4.8 & 4.7677 & TRN \\
\hline CHEMBL1469551 & 688550 & 4.95 & 4.8098 & TRN \\
\hline CHEMBL1471488 & 688550 & 4.85 & 4.9516 & TST \\
\hline CHEMBL1368206 & 688550 & 4.7 & 4.7938 & TRN \\
\hline CHEMBL1347345 & 688550 & 4.45 & 4.9714 & TRN \\
\hline CHEMBL1509369 & 688550 & 4.7 & 4.84399 & \\
\hline CHEMBL1408546 & 688550 & 5.3 & 4.9419 & TRN \\
\hline CHEMBL1566422 & 688550 & 5.3 & 4.9371 & TRN \\
\hline CHEMBL1560434 & 688550 & 4.45 & 4.7713 & TRN \\
\hline CHEMBL1338645 & 688550 & 4.85 & 4.8592 & TRN \\
\hline CHEMBL1522443 & 688550 & 5.05 & 4.8828 & TRN \\
\hline CHEMBL1309035 & 688550 & 4.95 & 4.8191 & TRN \\
\hline CHEMBL1399087 & 688550 & 4.4 & 4.831 & TRN \\
\hline CHEMBL1548229 & 688550 & 4.8 & 4.8754 & TST \\
\hline CHEMBL3199673 & 688550 & 4.85 & 4.7489 & TRN \\
\hline CHEMBL1440612 & 688550 & 4.9 & 4.8916 & TRN \\
\hline CHEMBL1324516 & 688550 & 4.85 & 4.8582 & TRN \\
\hline CHEMBL1503795 & 688550 & 4.45 & 4.8891 & TRN \\
\hline CHEMBL1541592 & 688550 & 4.6 & 4.6774 & TRN \\
\hline CHEMBL1445881 & 688550 & 5.2 & 4.7759 & TRN \\
\hline CHEMBL1580398 & 688550 & 4.8 & 4.8992 & TRN \\
\hline CHEMBL1337712 & 688550 & 4.4 & 4.817 & TRN \\
\hline CHEMBL1387360 & 688550 & 4.6 & 4.8723 & TRN \\
\hline
\end{tabular}




\begin{tabular}{|c|c|c|c|c|}
\hline \multicolumn{5}{|c|}{ Supplemental Table S2.txt } \\
\hline CHEMBL1421820 & 688550 & 4.9 & 4.8789 & TRN \\
\hline CHEMBL1555772 & 688550 & 5.55 & 5.0043 & TRN \\
\hline CHEMBL1561302 & 688550 & 4.85 & 4.9307 & TRN \\
\hline CHEMBL1529634 & 688550 & 4.4 & 4.8625 & TRN \\
\hline CHEMBL 1242180 & 688550 & 5.05 & 4.7899 & TST \\
\hline CHEMBL1545016 & 688550 & 4.85 & 4.9852 & TRN \\
\hline CHEMBL1303816 & 688550 & 4.8 & 4.7923 & TRN \\
\hline CHEMBL 3189420 & 688550 & 4.55 & 4.8256 & TRN \\
\hline CHEMBL1320370 & 688550 & 4.45 & 4.8823 & TRN \\
\hline CHEMBL1385690 & 688550 & 4.85 & 4.8976 & TRN \\
\hline CHEMBL1589462 & 688550 & 6.9 & 4.8424 & TRN \\
\hline CHEMBL3209672 & 688550 & 4.7 & 4.816 & TRN \\
\hline CHEMBL1481018 & 688550 & 4.4 & 4.8452 & TRN \\
\hline CHEMBL1566723 & 688550 & 5.2 & 4.9708 & TRN \\
\hline CHEMBL1377664 & 688550 & 5.2 & 4.793 & TRN \\
\hline CHEMBL1461530 & 688550 & 5.1 & 4.8555 & TST \\
\hline CHEMBL3193893 & 688550 & 4.7 & 4.7755 & TRN \\
\hline CHEMBL1467957 & 688550 & 4.4 & 4.8525 & TRN \\
\hline CHEMBL1579532 & 688550 & 4.7 & 4.8874 & TRN \\
\hline CHEMBL1387307 & 688550 & 5.05 & 4.7764 & TRN \\
\hline CHEMBL1484071 & 688550 & 4.55 & 4.921 & TST \\
\hline CHEMBL3194445 & 688550 & 4.75 & 4.856 & TST \\
\hline CHEMBL1522035 & 688550 & 5.0 & 4.8666 & TRN \\
\hline CHEMBL1301667 & 688550 & 4.4 & 4.8355 & TST \\
\hline CHEMBL1585426 & 688550 & 4.4 & 4.7925 & TRN \\
\hline CHEMBL3199911 & 688550 & 4.4 & 4.8954 & TRN \\
\hline CHEMBL1308908 & 688550 & 4.9 & 4.8712 & TRN \\
\hline CHEMBL1367149 & 688550 & 5.45 & 4.9181 & TRN \\
\hline CHEMBL1390497 & 688550 & 4.4 & 4.8306 & TRN \\
\hline CHEMBL3196587 & 688550 & 4.5 & 4.8514 & TST \\
\hline CHEMBL3145316 & 688550 & 5.05 & 4.8717 & TRN \\
\hline CHEMBL530609 & 688550 & 4.8 & 4.7962 & TRN \\
\hline CHEMBL1423709 & 688550 & 4.6 & 4.8559 & TRN \\
\hline CHEMBL1491626 & 688550 & 5.45 & 4.9173 & TRN \\
\hline CHEMBL1441085 & 688550 & 4.7 & 4.7977 & TRN \\
\hline CHEMBL1519037 & 688550 & 4.55 & 4.9178 & TRN \\
\hline CHEMBL1613708 & 688550 & 4.55 & 4.8312 & TRN \\
\hline CHEMBL1470568 & 688550 & 4.85 & 4.7749 & TRN \\
\hline CHEMBL1559164 & 688550 & 4.7 & 4.9913 & TRN \\
\hline CHEMBL1544857 & 688550 & 4.8 & 4.992 & TRN \\
\hline CHEMBL3194726 & 688550 & 5.05 & 4.7551 & TRN \\
\hline CHEMBL 1457543 & 688550 & 4.5 & 4.8784 & TST \\
\hline CHEMBL1527818 & 688550 & 5.1 & 4.864 & TRN \\
\hline CHEMBL1586003 & 688550 & 5.8 & 5.0388 & TRN \\
\hline CHEMBL1972405 & 688550 & 4.75 & 4.7678 & TRN \\
\hline CHEMBL1992641 & 688550 & 4.55 & 4.8293 & TST \\
\hline CHEMBL1358996 & 688550 & 4.8 & 4.9966 & TRN \\
\hline CHEMBL3213151 & 688550 & 4.8 & 4.9333 & TRN \\
\hline
\end{tabular}




\begin{tabular}{|c|c|c|c|c|}
\hline \multicolumn{5}{|c|}{ Supplemental Table s2.txt } \\
\hline CHEMBL1470182 & 688550 & 5.2 & 4.8782 & TST \\
\hline CHEMBL1579853 & 688550 & 4.85 & 4.8665 & TRN \\
\hline CHEMBL1399724 & 688550 & 5.2 & 4.8388 & TRN \\
\hline CHEMBL1084625 & 688550 & 6.95 & 4.9013 & TST \\
\hline CHEMBL219778 & 688550 & 4.85 & 4.8871 & TRN \\
\hline CHEMBL1387313 & 688550 & 4.45 & 4.8168 & TST \\
\hline CHEMBL3196976 & 688550 & 4.85 & 4.9009 & TRN \\
\hline CHEMBL1579959 & 688550 & 4.8 & 4.8454 & TRN \\
\hline CHEMBL1462286 & 688550 & 4.45 & 4.8753 & TRN \\
\hline CHEMBL1300047 & 688550 & 4.75 & 4.864 & TST \\
\hline CHEMBL1555787 & 688550 & 5.05 & 4.8566 & TST \\
\hline CHEMBL1479222 & 688550 & 4.8 & 5.0007 & TRN \\
\hline CHEMBL1345420 & 688550 & 5.1 & 4.8414 & TRN \\
\hline CHEMBL1416550 & 688550 & 5.9 & 4.9109 & TRN \\
\hline CHEMBL1370320 & 688550 & 4.8 & 4.8808 & TRN \\
\hline CHEMBL1402928 & 688550 & 4.7 & 4.8721 & TRN \\
\hline CHEMBL1531761 & 688550 & 4.5 & 4.9277 & TRN \\
\hline CHEMBL1328560 & 688550 & 4.45 & 4.8458 & TRN \\
\hline CHEMBL1330331 & 688550 & 4.65 & 4.8451 & TRN \\
\hline CHEMBL1549762 & 688550 & 4.7 & 4.9177 & TRN \\
\hline CHEMBL1351847 & 688550 & 5.1 & 4.9103 & TST \\
\hline CHEMBL1564138 & 688550 & 4.4 & 4.9686 & TRN \\
\hline CHEMBL1510030 & 688550 & 4.65 & 4.8079 & TRN \\
\hline CHEMBL1344687 & 688550 & 4.75 & 4.8657 & TST \\
\hline CHEMBL1444643 & 688550 & 4.4 & 4.8514 & TST \\
\hline CHEMBL1442810 & 688550 & 4.4 & 4.9131 & TRN \\
\hline CHEMBL1409235 & 688550 & 4.9 & 4.8595 & TRN \\
\hline CHEMBL1535345 & 688550 & 5.3 & 4.8206 & TRN \\
\hline CHEMBL1542102 & 688550 & 4.4 & 4.9376 & TRN \\
\hline CHEMBL1324717 & 688550 & 4.4 & 4.8942 & TST \\
\hline CHEMBL1444437 & 688550 & 4.4 & 4.7994 & TRN \\
\hline CHEMBL1419375 & 688550 & 4.6 & 4.8329 & TRN \\
\hline CHEMBL1311954 & 688550 & 5.55 & 4.9312 & TRN \\
\hline CHEMBL3198017 & 688550 & 5.05 & 4.8381 & TRN \\
\hline CHEMBL1471686 & 688550 & 5.15 & 4.9132 & TRN \\
\hline CHEMBL1368677 & 688550 & 4.75 & 5.0058 & TRN \\
\hline CHEMBL1371918 & 688550 & 4.65 & 4.8505 & TRN \\
\hline CHEMBL1346768 & 688550 & 4.4 & 4.8292 & TRN \\
\hline CHEMBL1598907 & 688550 & 4.4 & 4.8108 & TRN \\
\hline CHEMBL1347084 & 688550 & 5.15 & 4.8973 & TRN \\
\hline CHEMBL1392228 & 688550 & 4.7 & 4.7705 & TRN \\
\hline CHEMBL1406791 & 688550 & 6.05 & 4.8362 & TRN \\
\hline CHEMBL3191199 & 688550 & 4.4 & 4.8452 & TRN \\
\hline CHEMBL1371969 & 688550 & 5.05 & 4.9474 & TRN \\
\hline CHEMBL1469024 & 688550 & 5.15 & 4.8344 & TST \\
\hline CHEMBL1603224 & 688550 & 6.45 & 4.7698 & TRN \\
\hline CHEMBL1365849 & 688550 & 5.35 & 4.8459 & TRN \\
\hline CHEMBL1577971 & 688550 & 4.8 & 4.8836 & TRN \\
\hline
\end{tabular}




\begin{tabular}{|c|c|c|c|c|c|}
\hline & & & & & \\
\hline CHEMBL3197737 & 688550 & 4.4 & 4.7764 & TRN & \\
\hline CHEMBL1362296 & 688550 & 4.4 & 4.8014 & TST & \\
\hline CHEMBL1578299 & 688550 & 4.75 & 4.8087 & TRN & \\
\hline CHEMBL1557775 & 688550 & 4.9 & 4.8576 & TRN & \\
\hline CHEMBL1375672 & 688550 & 4.6 & 4.8199 & TRN & \\
\hline CHEMBL1584721 & 688550 & 4.6 & 4.7564 & TRN & \\
\hline CHEMBL3194740 & 688550 & 5.0 & 4.9456 & TRN & \\
\hline CHEMBL1341892 & 688550 & 5.55 & 5.0053 & TRN & \\
\hline CHEMBL1401167 & 688550 & 4.55 & 4.70100 & 30000000005 & TRN \\
\hline CHEMBL1421552 & 688550 & 4.55 & 4.8777 & TRN & \\
\hline CHEMBL1337329 & 688550 & 6.6499 & 4.7257 & TRN & \\
\hline CHEMBL1461002 & 688550 & 5.25 & 4.9082 & TRN & \\
\hline CHEMBL1345754 & 688550 & 4.6 & 4.8654 & TRN & \\
\hline CHEMBL1600753 & 688550 & 4.8 & 4.7842 & TRN & \\
\hline CHEMBL1318815 & 688550 & 4.5 & 4.907 & TRN & \\
\hline CHEMBL1575021 & 688550 & 5.35 & 4.8291 & TST & \\
\hline CHEMBL1351264 & 688550 & 4.75 & 4.9752 & TRN & \\
\hline CHEMBL1567210 & 688550 & 4.4 & 4.9358 & TRN & \\
\hline CHEMBL1333510 & 688550 & 4.45 & 4.8462 & TRN & \\
\hline CHEMBL1429799 & 688550 & 5.0 & 4.8519 & TRN & \\
\hline CHEMBL1400320 & 688550 & 6.9 & 4.9645 & TRN & \\
\hline CHEMBL1312400 & 688550 & 4.9 & 5.0223 & TRN & \\
\hline CHEMBL1447433 & 688550 & 5.3 & 4.841 & TST & \\
\hline CHEMBL1374735 & 688550 & 4.6 & 4.8557 & TRN & \\
\hline CHEMBL1488848 & 688550 & 4.4 & 4.791 & TRN & \\
\hline CHEMBL3213419 & 688550 & 4.7 & 4.7761 & TRN & \\
\hline CHEMBL1608610 & 688550 & 5.0 & 4.8313 & TRN & \\
\hline CHEMBL1546250 & 688550 & 4.6 & 4.8836 & TRN & \\
\hline CHEMBL1489368 & 688550 & 5.5 & 4.9142 & TRN & \\
\hline CHEMBL1538833 & 688550 & 4.6 & 5.0394 & TRN & \\
\hline CHEMBL3193211 & 688550 & 5.3 & 4.7801 & TRN & \\
\hline CHEMBL1490438 & 688550 & 4.4 & 4.8643 & TRN & \\
\hline CHEMBL1481603 & 688550 & 6.05 & 4.8478 & TST & \\
\hline CHEMBL1975615 & 688550 & 4.6 & 4.8582 & TRN & \\
\hline CHEMBL 3145285 & 688550 & 5.0 & 4.8369 & TRN & \\
\hline CHEMBL1363666 & 688550 & 4.6 & 4.8603 & TRN & \\
\hline CHEMBL1415522 & 688550 & 4.55 & 4.8903 & TRN & \\
\hline CHEMBL1477227 & 688550 & 4.4 & 4.9141 & TST & \\
\hline CHEMBL1612046 & 688550 & 5.15 & 4.8067 & TRN & \\
\hline CHEMBL1417732 & 688550 & 5.0 & 4.7866 & TRN & \\
\hline CHEMBL1603643 & 688550 & 5.05 & 4.7277 & TRN & \\
\hline CHEMBL1332402 & 688550 & 4.45 & 4.8506 & TRN & \\
\hline CHEMBL1359564 & 688550 & 4.45 & 4.8554 & TRN & \\
\hline CHEMBL1565168 & 688550 & 5.45 & 4.9903 & TRN & \\
\hline CHEMBL1465339 & 688550 & 4.75 & 4.854 & TST & \\
\hline CHEMBL1369983 & 688550 & 5.0 & 4.8231 & TRN & \\
\hline CHEMBL127579 & 688550 & 4.85 & 4.6992 & TRN & \\
\hline CHEMBL1456260 & 688550 & 4.8 & 4.8436 & TRN & \\
\hline
\end{tabular}




\begin{tabular}{|c|c|c|c|c|}
\hline \multicolumn{5}{|c|}{ Supplemental Table s2.txt } \\
\hline CHEMBL1462723 & 688550 & 5.4 & 4.8992 & TRN \\
\hline CHEMBL1487205 & 688550 & 5.25 & 4.8278 & TRN \\
\hline CHEMBL1393406 & 688550 & 4.5 & 4.8986 & TRN \\
\hline CHEMBL1481675 & 688550 & 4.55 & 4.7852 & TRN \\
\hline CHEMBL1423466 & 688550 & 4.85 & 4.7849 & TRN \\
\hline CHEMBL1586350 & 688550 & 4.65 & 4.8693 & TRN \\
\hline CHEMBL1363178 & 688550 & 4.95 & 4.8553 & TRN \\
\hline CHEMBL1476957 & 688550 & 4.4 & 4.9662 & TRN \\
\hline CHEMBL585804 & 688550 & 4.5 & 4.7887 & TRN \\
\hline CHEMBL1391094 & 688550 & 5.35 & 4.8865 & TRN \\
\hline CHEMBL1412489 & 688550 & 6.95 & 4.8785 & TST \\
\hline CHEMBL1974432 & 688550 & 4.55 & 4.7344 & TRN \\
\hline CHEMBL1369309 & 688550 & 5.75 & 4.9772 & TRN \\
\hline CHEMBL1349680 & 688550 & 6.7001 & 4.9168 & TRN \\
\hline CHEMBL1556394 & 688550 & 4.8 & 4.8564 & TRN \\
\hline CHEMBL1402494 & 688550 & 5.85 & 4.8791 & TRN \\
\hline CHEMBL1567664 & 688550 & 4.4 & 4.8122 & TRN \\
\hline CHEMBL1584810 & 688550 & 4.5 & 4.8915 & TRN \\
\hline CHEMBL1334823 & 688550 & 6.45 & 5.0455 & TRN \\
\hline CHEMBL1373608 & 688550 & 5.35 & 4.8563 & TRN \\
\hline CHEMBL1322905 & 688550 & 4.45 & 4.8691 & TRN \\
\hline CHEMBL1334320 & 688550 & 4.4 & 4.8651 & TRN \\
\hline CHEMBL1392192 & 688550 & 4.6 & 4.9571 & TRN \\
\hline CHEMBL3196706 & 688550 & 4.65 & 4.7777 & TRN \\
\hline CHEMBL1314157 & 688550 & 5.75 & 4.7478 & TRN \\
\hline CHEMBL1987472 & 688550 & 4.45 & 4.8093 & TRN \\
\hline CHEMBL1319113 & 688550 & 4.5 & 4.8486 & TRN \\
\hline CHEMBL3197462 & 688550 & 4.6 & 4.7865 & TRN \\
\hline CHEMBL1507433 & 688550 & 4.45 & 4.9457 & TRN \\
\hline CHEMBL1586047 & 688550 & 5.3 & 4.8615 & TRN \\
\hline CHEMBL3213264 & 688550 & 4.4 & 4.7503 & TRN \\
\hline CHEMBL1390996 & 688550 & 4.6 & 4.8911 & TRN \\
\hline CHEMBL1312319 & 688550 & 4.45 & 4.8816 & TST \\
\hline CHEMBL1360977 & 688550 & 4.85 & 4.7148 & TRN \\
\hline CHEMBL1490676 & 688550 & 6.15 & 4.8993 & TRN \\
\hline CHEMBL1502133 & 688550 & 4.75 & 4.7764 & TRN \\
\hline CHEMBL1502322 & 688550 & 5.5 & 5.0217 & TRN \\
\hline CHEMBL1484231 & 688550 & 4.85 & 4.8832 & TST \\
\hline CHEMBL1574932 & 688550 & 5.7 & 4.8255 & TST \\
\hline CHEMBL1494057 & 688550 & 4.85 & 4.90600 & 0000000001 \\
\hline CHEMBL1392095 & 688550 & 4.8 & 4.8486 & TRN \\
\hline CHEMBL1380522 & 688550 & 4.65 & 4.813 & TST \\
\hline CHEMBL1387248 & 688550 & 5.05 & 4.9232 & TST \\
\hline CHEMBL1577070 & 688550 & 4.45 & 4.8189 & TRN \\
\hline CHEMBL1377716 & 688550 & 8.2007 & 4.9629 & TRN \\
\hline CHEMBL1419634 & 688550 & 5.45 & 5.0101 & TRN \\
\hline CHEMBL1421334 & 688550 & 4.95 & 4.8351 & TRN \\
\hline CHEMBL1404137 & 688550 & 4.7 & 4.7796 & TRN \\
\hline
\end{tabular}




\begin{tabular}{|c|c|c|c|c|c|}
\hline \multicolumn{6}{|c|}{ Supplemental Table s2.txt } \\
\hline CHEMBL1422394 & 688550 & 4.4 & 4.8256 & TRN & \\
\hline CHEMBL1359931 & 688550 & 5.05 & 4.8624 & TST & \\
\hline CHEMBL1965453 & 688550 & 4.4 & 4.8164 & TRN & \\
\hline CHEMBL1333963 & 688550 & 5.0 & 4.8316 & TRN & \\
\hline CHEMBL1370549 & 688550 & 4.6 & 4.8276 & TRN & \\
\hline CHEMBL1545660 & 688550 & 4.65 & 4.7993 & TRN & \\
\hline CHEMBL1450809 & 688550 & 5.45 & 4.9 & TRN & \\
\hline CHEMBL1408737 & 688550 & 4.6 & 4.883 & TRN & \\
\hline CHEMBL1350884 & 688550 & 4.7 & 4.9686 & TRN & \\
\hline CHEMBL1533502 & 688550 & 4.9 & 4.7998 & TRN & \\
\hline CHEMBL1365612 & 688550 & 4.65 & 4.9479 & TRN & \\
\hline CHEMBL1311651 & 688550 & 4.85 & 4.8179 & TRN & \\
\hline CHEMBL1465518 & 688550 & 4.85 & 4.8403 & TRN & \\
\hline CHEMBL1576113 & 688550 & 4.55 & 4.9095 & TRN & \\
\hline CHEMBL1455935 & 688550 & 8.301 & 4.93199 & 99999999995 & TRN \\
\hline CHEMBL1427781 & 688550 & 5.35 & 4.9159 & TRN & \\
\hline CHEMBL1501360 & 688550 & 5.25 & 4.9353 & TST & \\
\hline CHEMBL1482310 & 688550 & 5.05 & 4.906006 & 0000000001 & TRN \\
\hline CHEMBL1415344 & 688550 & 4.5 & 4.7844 & TRN & \\
\hline CHEMBL1407791 & 688550 & 5.45 & 4.9072 & TRN & \\
\hline CHEMBL1567981 & 688550 & 5.4 & 4.9154 & TRN & \\
\hline CHEMBL1543735 & 688550 & 4.5 & 4.8596 & TRN & \\
\hline CHEMBL1582131 & 688550 & 5.45 & 4.8721 & TST & \\
\hline CHEMBL1501515 & 688550 & 4.9 & 4.7972 & TRN & \\
\hline CHEMBL1445957 & 688550 & 5.4 & 4.8535 & TRN & \\
\hline CHEMBL1374900 & 688550 & 4.4 & 4.83 & TRN & \\
\hline CHEMBL1441439 & 688550 & 4.4 & 4.827 & TST & \\
\hline CHEMBL140425 & 688550 & 4.45 & 4.8116 & TRN & \\
\hline CHEMBL 3198740 & 688550 & 4.4 & 4.8378 & TRN & \\
\hline CHEMBL1596226 & 688550 & 4.85 & 4.8825 & TST & \\
\hline CHEMBL3192160 & 688550 & 5.15 & 4.7829 & TRN & \\
\hline CHEMBL1349179 & 688550 & 4.85 & 4.8035 & TRN & \\
\hline CHEMBL1986348 & 688550 & 4.6 & 4.8485 & TRN & \\
\hline CHEMBL1350860 & 688550 & 5.0 & 4.8824 & TRN & \\
\hline CHEMBL1416895 & 688550 & 5.45 & 4.9598 & TRN & \\
\hline CHEMBL1527433 & 688550 & 4.8 & 4.7581 & TRN & \\
\hline CHEMBL1429669 & 688550 & 4.55 & 4.8796 & TRN & \\
\hline CHEMBL1366175 & 688550 & 4.9 & 4.7899 & TRN & \\
\hline CHEMBL1370165 & 688550 & 4.45 & 4.8499 & TRN & \\
\hline CHEMBL1469250 & 688550 & 4.45 & 4.7946 & TRN & \\
\hline CHEMBL 270472 & 688550 & 4.4 & 4.8677 & TRN & \\
\hline CHEMBL1299519 & 688550 & 5.25 & 4.809 & TRN & \\
\hline CHEMBL1330354 & 688550 & 4.75 & 4.9517 & TRN & \\
\hline CHEMBL3214502 & 688550 & 5.1 & 4.711 & TRN & \\
\hline CHEMBL1523086 & 688550 & 4.45 & 4.9497 & TST & \\
\hline CHEMBL1338432 & 688550 & 4.7 & 4.9533 & TRN & \\
\hline CHEMBL1506328 & 688550 & 4.8 & 4.9995 & TRN & \\
\hline CHEMBL1597486 & 688550 & 4.4 & 4.8296 & TST & \\
\hline
\end{tabular}




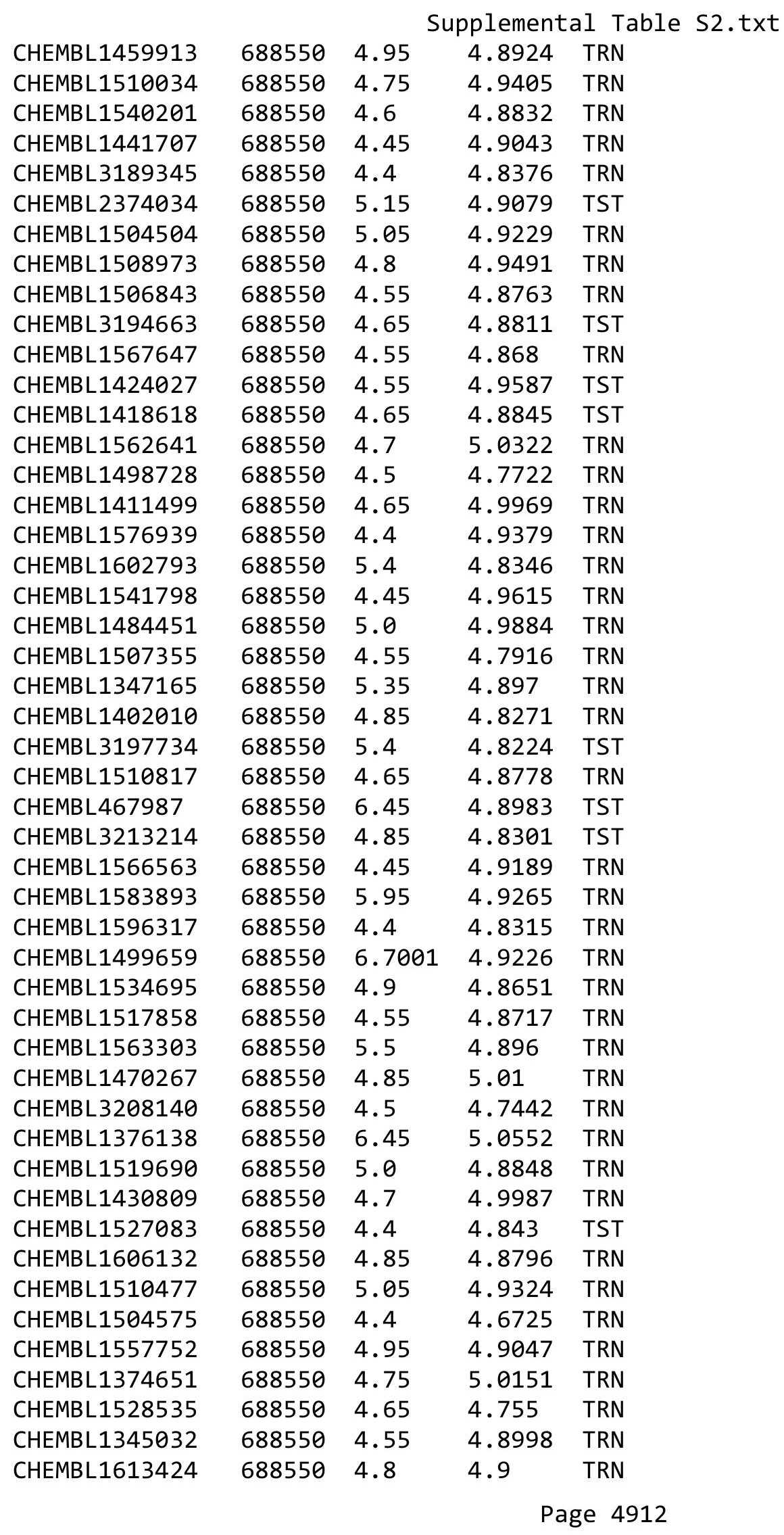




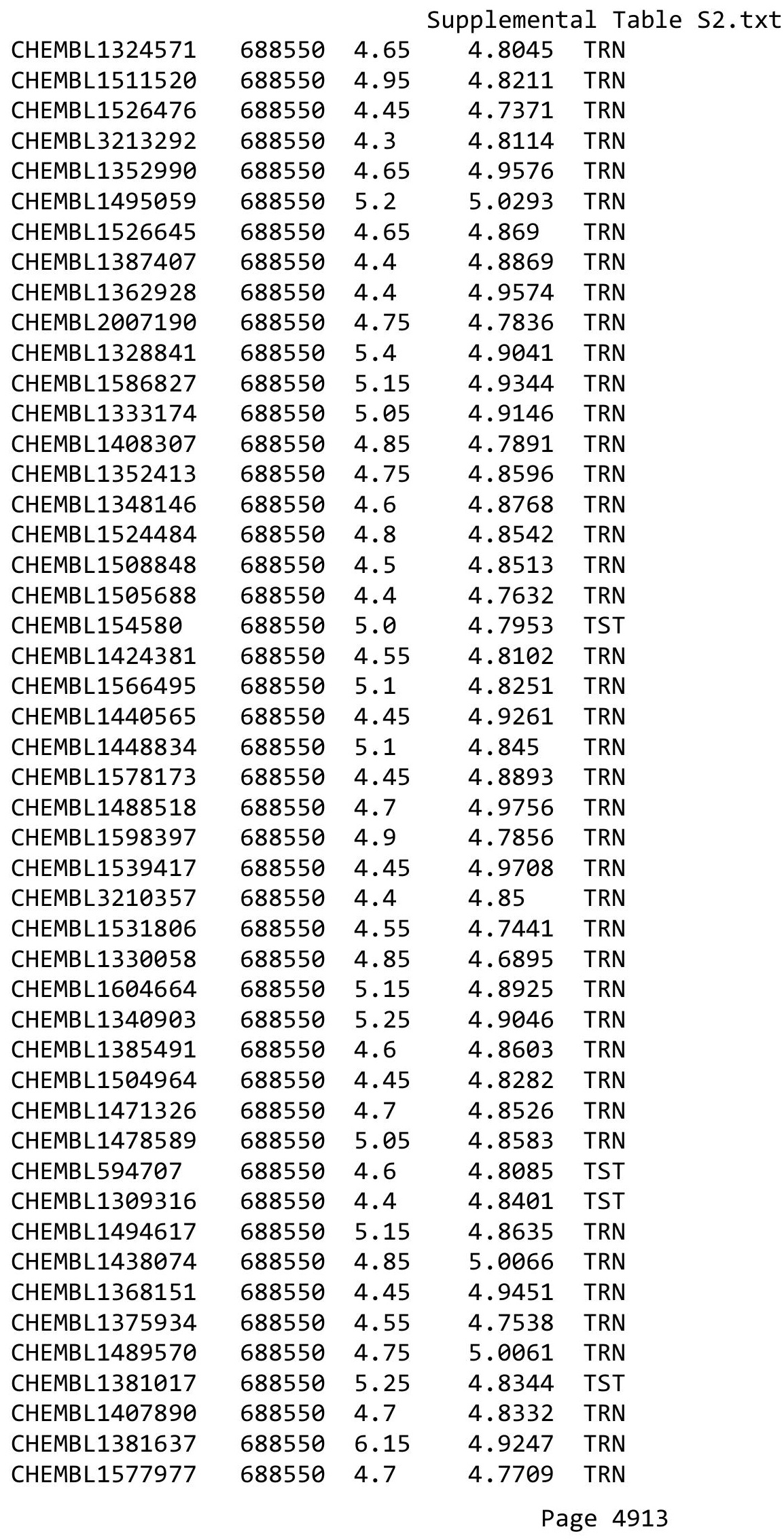




\begin{tabular}{|c|c|c|c|c|}
\hline \multicolumn{5}{|c|}{ Supplemental Table } \\
\hline CHEMBL1546760 & 688550 & 4.85 & 4.8387 & TRN \\
\hline CHEMBL1999049 & 688550 & 4.8 & 4.9103 & TST \\
\hline CHEMBL1547206 & 688550 & 4.65 & 4.8452 & TST \\
\hline CHEMBL1524713 & 688550 & 6.1 & 4.984 & TRN \\
\hline CHEMBL1498639 & 688550 & 4.8 & 4.6893 & TRN \\
\hline CHEMBL1580318 & 688550 & 4.45 & 4.7935 & TRN \\
\hline CHEMBL1490692 & 688550 & 4.9 & 4.8281 & TRN \\
\hline CHEMBL1376122 & 688550 & 4.4 & 4.8513 & TRN \\
\hline CHEMBL1470203 & 688550 & 4.4 & 4.9737 & TRN \\
\hline CHEMBL1571906 & 688550 & 4.4 & 4.76 & TST \\
\hline CHEMBL1550726 & 688550 & 4.75 & 4.8571 & TRN \\
\hline CHEMBL1976049 & 688550 & 4.55 & 4.8388 & TRN \\
\hline CHEMBL1471698 & 688550 & 4.4 & 4.8601 & TST \\
\hline CHEMBL1342372 & 688550 & 4.95 & 5.0041 & TRN \\
\hline CHEMBL1487563 & 688550 & 4.55 & 4.7711 & TRN \\
\hline CHEMBL1389485 & 688550 & 4.65 & 4.8741 & TST \\
\hline CHEMBL1378566 & 688550 & 4.6 & 4.9272 & TRN \\
\hline CHEMBL1984816 & 688550 & 4.5 & 4.8462 & TRN \\
\hline CHEMBL1481543 & 688550 & 5.1 & 4.7582 & TRN \\
\hline CHEMBL1446064 & 688550 & 4.55 & 4.8916 & TRN \\
\hline CHEMBL1445585 & 688550 & 5.35 & 4.954 & TRN \\
\hline CHEMBL1583508 & 688550 & 5.8 & 4.8797 & TRN \\
\hline CHEMBL3196993 & 688550 & 5.0 & 4.8427 & TRN \\
\hline CHEMBL 3193206 & 688550 & 4.4 & 4.9614 & TST \\
\hline CHEMBL1422477 & 688550 & 4.7 & 4.9317 & TRN \\
\hline CHEMBL3211753 & 688550 & 4.4 & 4.8645 & TRN \\
\hline CHEMBL1427842 & 688550 & 4.6 & 4.8024 & TRN \\
\hline CHEMBL1582053 & 688550 & 4.75 & 4.84 & TRN \\
\hline CHEMBL1563859 & 688550 & 4.45 & 4.8971 & TRN \\
\hline CHEMBL1557115 & 688550 & 4.6 & 4.8576 & TRN \\
\hline CHEMBL 235586 & 688550 & 5.2 & 4.7926 & TRN \\
\hline CHEMBL1324188 & 688550 & 4.9 & 4.8791 & TST \\
\hline CHEMBL1312167 & 688550 & 4.5 & 5.0226 & TRN \\
\hline CHEMBL 241721 & 688550 & 4.6 & 4.9686 & TRN \\
\hline CHEMBL1541807 & 688550 & 4.85 & 4.8639 & TRN \\
\hline CHEMBL1560670 & 688550 & 4.7 & 4.8773 & TRN \\
\hline CHEMBL1431940 & 688550 & 4.4 & 4.8834 & TRN \\
\hline CHEMBL1596938 & 688550 & 4.7 & 4.9906 & TRN \\
\hline CHEMBL3199008 & 688550 & 4.75 & 4.7842 & TRN \\
\hline CHEMBL1350435 & 688550 & 4.95 & 4.8423 & TRN \\
\hline CHEMBL1471615 & 688550 & 4.4 & 4.7855 & TRN \\
\hline CHEMBL1611865 & 688550 & 4.6 & 4.9514 & TRN \\
\hline CHEMBL1389973 & 688550 & 4.8 & 4.9453 & TRN \\
\hline CHEMBL1320254 & 688550 & 4.4 & 4.8127 & TST \\
\hline CHEMBL1388580 & 688550 & 4.6 & 4.9071 & TRN \\
\hline CHEMBL1416391 & 688550 & 6.95 & 4.8579 & TRN \\
\hline CHEMBL1611239 & 688550 & 4.45 & 4.8617 & TST \\
\hline CHEMBL1478632 & 688550 & 6.1 & 4.8675 & TST \\
\hline
\end{tabular}




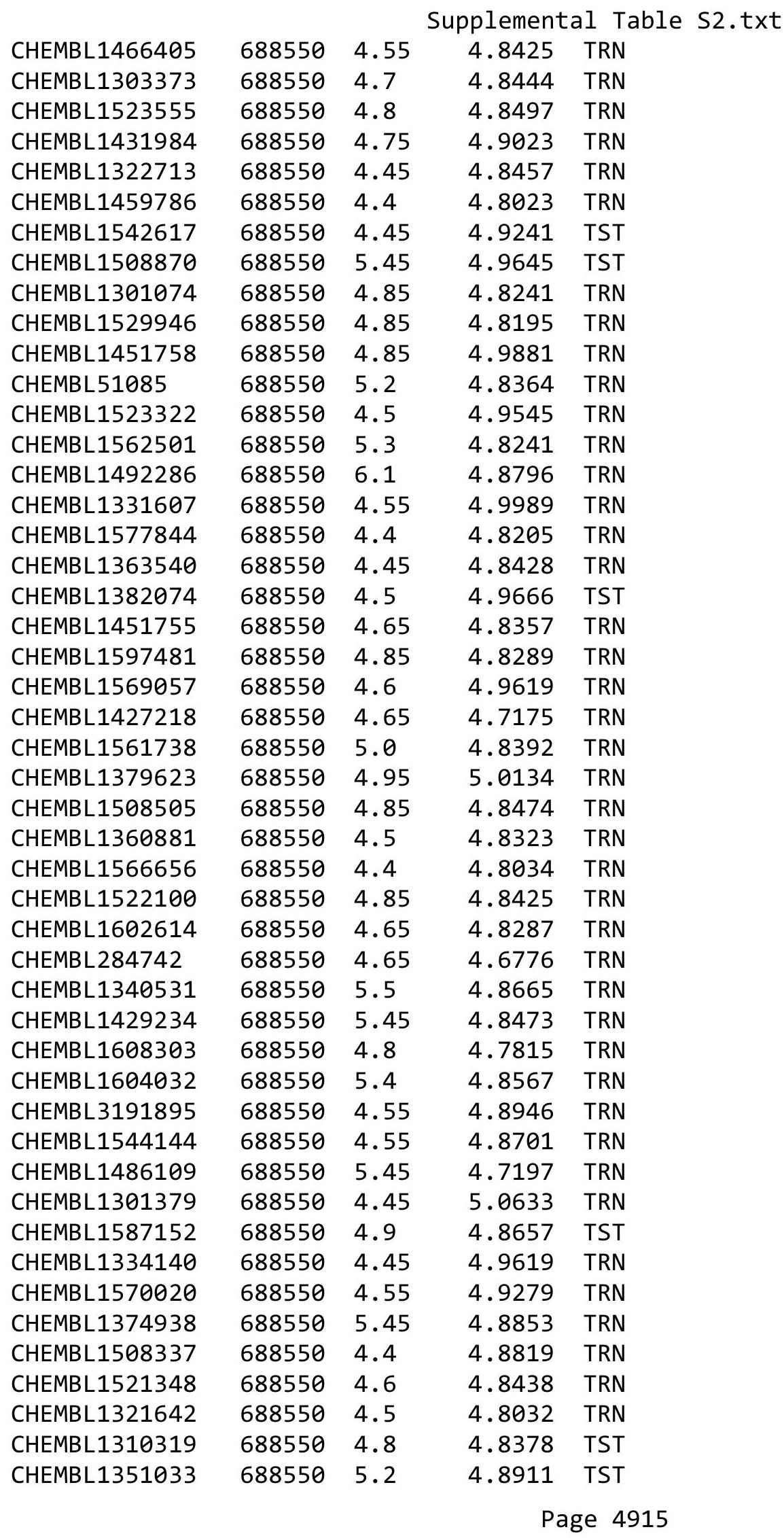




\begin{tabular}{|c|c|c|c|c|}
\hline \multicolumn{5}{|c|}{ Supplemental T } \\
\hline CHEMBL1596249 & 688550 & 4.4 & 4.8469 & TST \\
\hline CHEMBL1448596 & 688550 & 5.3 & 4.9778 & TRN \\
\hline CHEMBL1406930 & 688550 & 5.0 & 4.9586 & TRN \\
\hline CHEMBL1579691 & 688550 & 4.55 & 4.872 & TRN \\
\hline CHEMBL1312788 & 688550 & 6.0 & 4.7785 & TRN \\
\hline CHEMBL1347749 & 688550 & 4.7 & 4.8294 & TRN \\
\hline CHEMBL1442981 & 688550 & 4.5 & 4.7779 & TRN \\
\hline CHEMBL1556096 & 688550 & 4.5 & 4.9188 & TST \\
\hline CHEMBL1596329 & 688550 & 4.5 & 4.7806 & TRN \\
\hline CHEMBL1511458 & 688550 & 4.5 & 4.8367 & TRN \\
\hline CHEMBL1503961 & 688550 & 4.55 & 4.8447 & TST \\
\hline CHEMBL1544420 & 688550 & 4.6 & 4.9253 & TRN \\
\hline CHEMBL1495417 & 688550 & 4.85 & 4.8767 & TRN \\
\hline CHEMBL1465313 & 688550 & 4.4 & 4.899 & TRN \\
\hline CHEMBL3194210 & 688550 & 4.95 & 4.868 & TRN \\
\hline CHEMBL1386461 & 688550 & 4.5 & 4.8503 & TRN \\
\hline CHEMBL1403896 & 688550 & 4.8 & 4.9005 & TRN \\
\hline CHEMBL1521425 & 688550 & 4.4 & 4.8705 & TRN \\
\hline CHEMBL1337144 & 688550 & 4.4 & 4.801 & TRN \\
\hline CHEMBL1973921 & 688550 & 4.7 & 4.7592 & TRN \\
\hline CHEMBL585265 & 688550 & 5.25 & 4.8969 & TRN \\
\hline CHEMBL1500986 & 688550 & 4.4 & 4.8397 & TRN \\
\hline CHEMBL1487173 & 688550 & 4.55 & 4.8618 & TRN \\
\hline CHEMBL1343919 & 688550 & 4.65 & 4.8312 & TST \\
\hline CHEMBL 2139212 & 688550 & 4.85 & 4.9088 & TRN \\
\hline CHEMBL1449441 & 688550 & 4.4 & 4.9386 & TRN \\
\hline CHEMBL1535701 & 688550 & 5.15 & 5.0216 & TRN \\
\hline CHEMBL1550137 & 688550 & 5.05 & 4.9978 & TRN \\
\hline CHEMBL3197841 & 688550 & 4.55 & 4.8342 & TRN \\
\hline CHEMBL1335008 & 688550 & 4.6 & 4.8436 & TRN \\
\hline CHEMBL1429456 & 688550 & 5.35 & 4.8938 & TRN \\
\hline CHEMBL1465439 & 688550 & 5.1 & 5.0479 & TRN \\
\hline CHEMBL1405602 & 688550 & 6.3 & 4.7805 & TRN \\
\hline CHEMBL1510922 & 688550 & 4.55 & 4.9155 & TRN \\
\hline CHEMBL1530379 & 688550 & 4.85 & 4.7553 & TRN \\
\hline CHEMBL1547519 & 688550 & 4.4 & 4.7844 & TRN \\
\hline CHEMBL1599550 & 688550 & 4.45 & 4.9044 & TRN \\
\hline CHEMBL1334584 & 688550 & 4.45 & 4.8461 & TRN \\
\hline CHEMBL1349109 & 688550 & 6.2 & 5.0 & TRN \\
\hline CHEMBL1369716 & 688550 & 4.55 & 4.9006 & TRN \\
\hline CHEMBL1310777 & 688550 & 4.65 & 4.8545 & TRN \\
\hline CHEMBL1509096 & 688550 & 4.85 & 4.9129 & TRN \\
\hline CHEMBL1302800 & 688550 & 4.45 & 4.8703 & TRN \\
\hline CHEMBL1344976 & 688550 & 4.45 & 4.9028 & TRN \\
\hline CHEMBL1446833 & 688550 & 4.8 & 5.047 & TRN \\
\hline CHEMBL1444201 & 688550 & 4.65 & 4.8698 & TRN \\
\hline CHEMBL1333250 & 688550 & 5.6 & 4.9592 & TRN \\
\hline CHEMBL1375066 & 688550 & 4.4 & 4.8003 & TRN \\
\hline
\end{tabular}




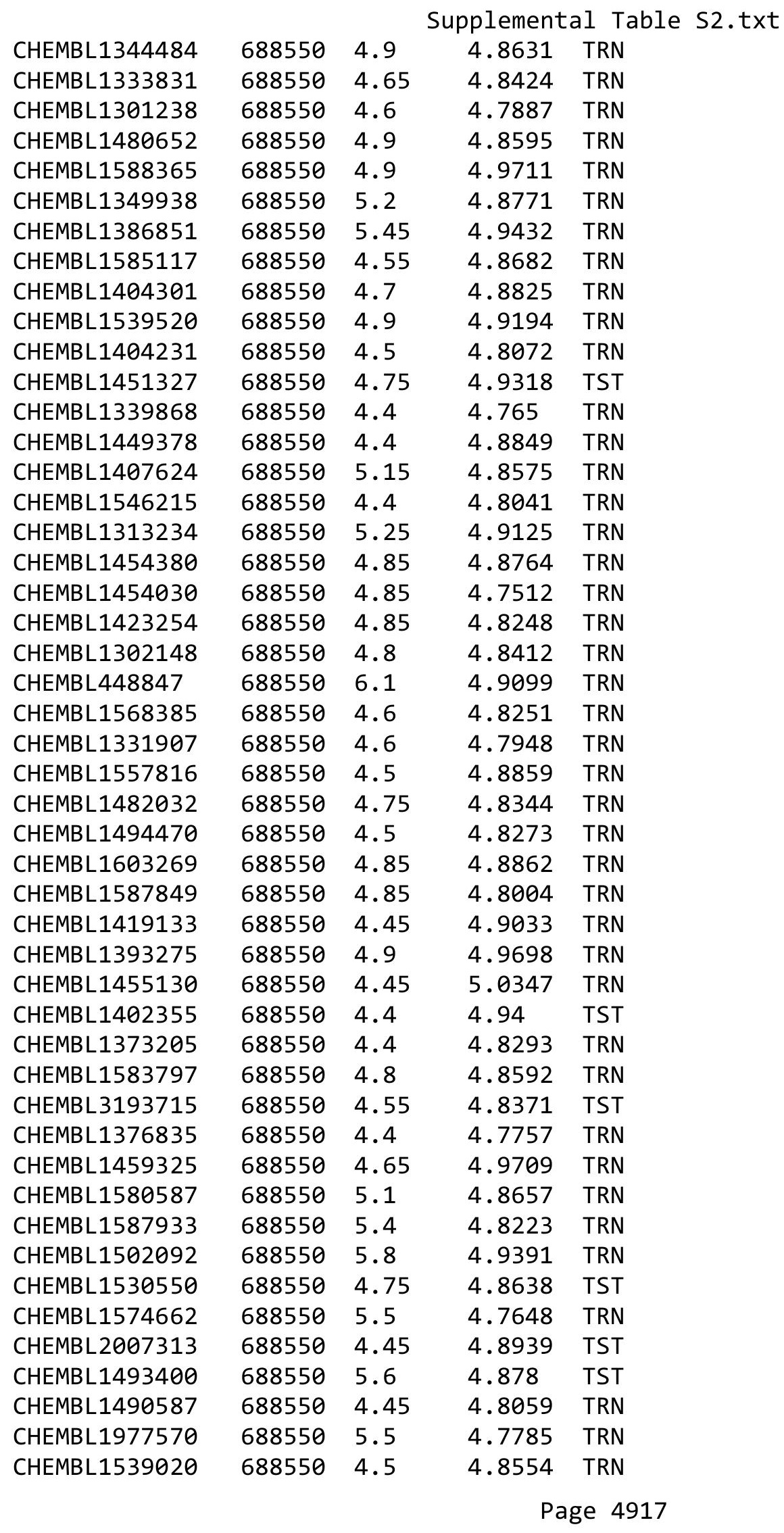




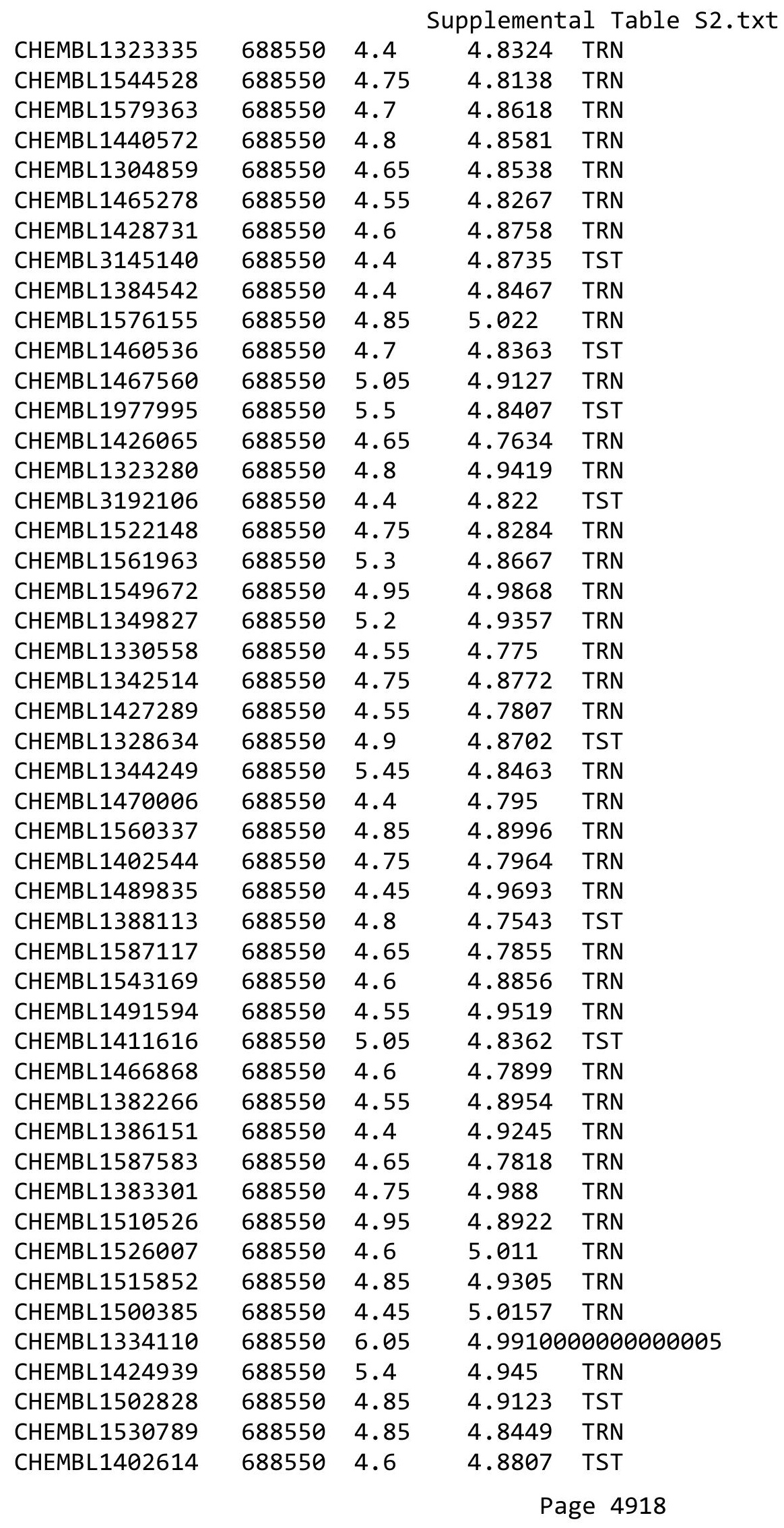

TRN 


\begin{tabular}{|c|c|c|c|c|}
\hline \multicolumn{5}{|c|}{ Supplemental Table S2.txt } \\
\hline CHEMBL1535804 & 688550 & 4.6 & 5.0187 & TRN \\
\hline CHEMBL1413662 & 688550 & 6.1 & 4.8269 & TRN \\
\hline CHEMBL1300595 & 688550 & 4.5 & 4.9101 & TRN \\
\hline CHEMBL1562961 & 688550 & 4.85 & 4.9415 & TRN \\
\hline CHEMBL1425290 & 688550 & 4.45 & 4.8084 & TRN \\
\hline CHEMBL1306204 & 688550 & 5.75 & 4.8949 & TRN \\
\hline CHEMBL1336549 & 688550 & 4.5 & 4.8505 & TRN \\
\hline CHEMBL1542706 & 688550 & 4.9 & 5.0308 & TRN \\
\hline CHEMBL1477601 & 688550 & 5.1 & 4.9136 & TRN \\
\hline CHEMBL1362955 & 688550 & 4.4 & 4.895 & TRN \\
\hline CHEMBL1451410 & 688550 & 4.5 & 5.0561 & TRN \\
\hline CHEMBL1354000 & 688550 & 6.7501 & 4.7725 & TRN \\
\hline CHEMBL1312606 & 688550 & 4.5 & 4.8268 & TRN \\
\hline CHEMBL1425215 & 688550 & 4.4 & 4.8444 & TRN \\
\hline CHEMBL1502957 & 688550 & 4.75 & 4.8813 & TRN \\
\hline CHEMBL1522139 & 688550 & 4.95 & 4.8853 & TRN \\
\hline CHEMBL1503633 & 688550 & 4.45 & 4.8359 & TRN \\
\hline CHEMBL1410119 & 688550 & 4.5 & 4.8303 & TRN \\
\hline CHEMBL1577174 & 688550 & 4.75 & 4.7854 & TRN \\
\hline CHEMBL1541915 & 688550 & 6.0 & 4.7926 & TRN \\
\hline CHEMBL1418479 & 688550 & 4.4 & 4.9986 & TRN \\
\hline CHEMBL1374460 & 688550 & 4.8 & 4.8418 & TRN \\
\hline CHEMBL1430919 & 688550 & 4.4 & 4.7486 & TRN \\
\hline CHEMBL1457157 & 688550 & 4.95 & 4.8432 & TRN \\
\hline CHEMBL1701224 & 688550 & 5.7 & 4.7595 & TST \\
\hline CHEMBL1479132 & 688550 & 4.4 & 4.7034 & TRN \\
\hline CHEMBL1383507 & 688550 & 4.5 & 4.8824 & TRN \\
\hline CHEMBL3192455 & 688550 & 5.35 & 4.9772 & TRN \\
\hline CHEMBL1379740 & 688550 & 4.85 & 4.812 & TST \\
\hline CHEMBL1309580 & 688550 & 4.85 & 4.7874 & TRN \\
\hline CHEMBL1447939 & 688550 & 4.4 & 4.958 & TRN \\
\hline CHEMBL1509287 & 688550 & 4.75 & 4.7689 & TRN \\
\hline CHEMBL1326803 & 688550 & 4.9 & 4.7943 & TRN \\
\hline CHEMBL1359384 & 688550 & 6.0 & 4.95 & TRN \\
\hline CHEMBL1547278 & 688550 & 4.8 & 4.8479 & TRN \\
\hline CHEMBL1604245 & 688550 & 4.9 & 4.7363 & TRN \\
\hline CHEMBL3196906 & 688550 & 6.0 & 4.825 & TRN \\
\hline CHEMBL1598532 & 688550 & 6.8499 & 4.7382 & TST \\
\hline CHEMBL1335132 & 688550 & 6.05 & 4.8371 & TST \\
\hline CHEMBL1371053 & 688550 & 4.55 & 4.8568 & TRN \\
\hline CHEMBL1343727 & 688550 & 6.1 & 4.9318 & TRN \\
\hline CHEMBL1540427 & 688550 & 4.85 & 4.8138 & TRN \\
\hline CHEMBL1493929 & 688550 & 4.85 & 4.8621 & TRN \\
\hline CHEMBL3211187 & 688550 & 4.55 & 4.9452 & TRN \\
\hline CHEMBL1387000 & 688550 & 4.65 & 4.9016 & TRN \\
\hline CHEMBL1464595 & 688550 & 4.6 & 4.8127 & TRN \\
\hline CHEMBL1579449 & 688550 & 4.4 & 4.962 & TRN \\
\hline CHEMBL1299632 & 688550 & 4.5 & 4.9711 & TST \\
\hline
\end{tabular}




\begin{tabular}{|c|c|c|c|c|c|}
\hline \multicolumn{6}{|c|}{ Supplemental Table S2.txt } \\
\hline CHEMBL1516704 & 688550 & 5.55 & 4.9059 & TRN & \\
\hline CHEMBL1579755 & 688550 & 4.85 & 4.8791 & TST & \\
\hline CHEMBL1530581 & 688550 & 4.85 & 4.7889 & TRN & \\
\hline CHEMBL1405054 & 688550 & 4.65 & 4.801 & TRN & \\
\hline CHEMBL1507701 & 688550 & 4.55 & 4.8965 & TRN & \\
\hline CHEMBL1491944 & 688550 & 4.4 & 4.83899 & 99999999995 & TRN \\
\hline CHEMBL1445387 & 688550 & 4.4 & 4.9278 & TST & \\
\hline CHEMBL1378417 & 688550 & 4.75 & 4.8473 & TRN & \\
\hline CHEMBL1388162 & 688550 & 5.25 & 4.9719 & TRN & \\
\hline CHEMBL1497863 & 688550 & 4.6 & 4.8317 & TRN & \\
\hline CHEMBL1335401 & 688550 & 5.1 & 4.8742 & TRN & \\
\hline CHEMBL1458531 & 688550 & 4.45 & 4.8842 & TST & \\
\hline CHEMBL1339860 & 688550 & 5.05 & 4.823 & TRN & \\
\hline CHEMBL1332143 & 688550 & 4.45 & 4.8306 & TRN & \\
\hline CHEMBL1441987 & 688550 & 5.15 & 4.8048 & TRN & \\
\hline CHEMBL1340397 & 688550 & 4.6 & 4.7726 & TST & \\
\hline CHEMBL1422616 & 688550 & 5.55 & 4.8048 & TRN & \\
\hline CHEMBL179024 & 688550 & 4.45 & 4.798 & TRN & \\
\hline CHEMBL1543789 & 688550 & 4.6 & 4.8828 & TST & \\
\hline CHEMBL1382017 & 688550 & 5.2 & 4.8446 & TRN & \\
\hline CHEMBL3199175 & 688550 & 5.5 & 4.7812 & TRN & \\
\hline CHEMBL1429218 & 688550 & 4.8 & 4.7268 & TRN & \\
\hline CHEMBL3145329 & 688550 & 4.65 & 4.842 & TRN & \\
\hline CHEMBL1323348 & 688550 & 6.05 & 4.8904 & TRN & \\
\hline CHEMBL1562713 & 688550 & 4.4 & 4.7545 & TRN & \\
\hline CHEMBL1707275 & 688550 & 4.5 & 4.7978 & TST & \\
\hline CHEMBL1402037 & 688550 & 4.9 & 4.93 & TRN & \\
\hline CHEMBL1605408 & 688550 & 4.6 & 4.7397 & TRN & \\
\hline CHEMBL1987173 & 688550 & 4.5 & 4.7895 & TRN & \\
\hline CHEMBL1305166 & 688550 & 4.65 & 4.9525 & TST & \\
\hline CHEMBL1511645 & 688550 & 4.85 & 4.8368 & TRN & \\
\hline CHEMBL1581846 & 688550 & 4.55 & 4.8966 & TRN & \\
\hline CHEMBL1540684 & 688550 & 10.05 & 4.95100 & 00000000005 & TST \\
\hline CHEMBL3189629 & 688550 & 5.1 & 4.7744 & TRN & \\
\hline CHEMBL1455821 & 688550 & 4.45 & 4.7772 & TST & \\
\hline CHEMBL1367120 & 688550 & 5.25 & 4.8872 & TRN & \\
\hline CHEMBL1421179 & 688550 & 4.6 & 4.8413 & TRN & \\
\hline CHEMBL1448774 & 688550 & 4.5 & 4.7802 & TRN & \\
\hline CHEMBL3199216 & 688550 & 4.6 & 4.7237 & TRN & \\
\hline CHEMBL1546698 & 688550 & 4.9 & 4.8448 & TRN & \\
\hline CHEMBL1412104 & 688550 & 4.85 & 4.9576 & TRN & \\
\hline CHEMBL1611507 & 688550 & 4.6 & 4.9002 & TRN & \\
\hline CHEMBL1420849 & 688550 & 4.6 & 4.8952 & TRN & \\
\hline CHEMBL602259 & 688550 & 5.1 & 4.8404 & TRN & \\
\hline CHEMBL1521960 & 688550 & 4.75 & 4.8977 & TST & \\
\hline CHEMBL1524199 & 688550 & 4.65 & 4.8246 & TRN & \\
\hline CHEMBL1379711 & 688550 & 4.75 & 4.9386 & TRN & \\
\hline CHEMBL1496609 & 688550 & 4.4 & 4.9178 & TST & \\
\hline
\end{tabular}




\begin{tabular}{|c|c|c|c|c|}
\hline \multicolumn{5}{|c|}{ Supplemental Table S2.txt } \\
\hline CHEMBL1538355 & 688550 & 4.75 & 4.8874 & TRN \\
\hline CHEMBL1493333 & 688550 & 4.95 & 4.8593 & TRN \\
\hline CHEMBL1382910 & 688550 & 4.6 & 4.9118 & TRN \\
\hline CHEMBL1339009 & 688550 & 4.85 & 4.9806 & TRN \\
\hline CHEMBL1477550 & 688550 & 4.95 & 4.7307 & TRN \\
\hline CHEMBL1351372 & 688550 & 5.4 & 4.8757 & TST \\
\hline CHEMBL 1444920 & 688550 & 4.65 & 5.0016 & TRN \\
\hline CHEMBL1411788 & 688550 & 7.3497 & 4.9297 & TST \\
\hline CHEMBL 1464352 & 688550 & 4.45 & 4.8222 & TRN \\
\hline CHEMBL 1457285 & 688550 & 4.6 & 4.9065 & TRN \\
\hline CHEMBL1364288 & 688550 & 6.0 & 4.8661 & TRN \\
\hline CHEMBL1585474 & 688550 & 4.8 & 4.827 & TRN \\
\hline CHEMBL1421754 & 688550 & 4.6 & 4.8896 & TRN \\
\hline CHEMBL1490305 & 688550 & 4.9 & 4.827 & TRN \\
\hline CHEMBL1589562 & 688550 & 6.1 & 4.8318 & TRN \\
\hline CHEMBL1613015 & 688550 & 4.7 & 4.8382 & TRN \\
\hline CHEMBL1321021 & 688550 & 4.4 & 4.7995 & TRN \\
\hline CHEMBL1310224 & 688550 & 4.8 & 4.8571 & TRN \\
\hline CHEMBL1544685 & 688550 & 4.8 & 4.7599 & TRN \\
\hline CHEMBL1526851 & 688550 & 5.5 & 4.7465 & TRN \\
\hline CHEMBL1357907 & 688550 & 4.4 & 4.8884 & TRN \\
\hline CHEMBL1526637 & 688550 & 5.15 & 4.7263 & TRN \\
\hline CHEMBL 3194561 & 688550 & 4.8 & 4.7719 & TRN \\
\hline CHEMBL1493226 & 688550 & 4.8 & 4.8574 & TRN \\
\hline CHEMBL1346300 & 688550 & 4.6 & 4.9337 & TST \\
\hline CHEMBL1440753 & 688550 & 5.0 & 4.8064 & TRN \\
\hline CHEMBL1581440 & 688550 & 4.65 & 4.8022 & TRN \\
\hline CHEMBL1471694 & 688550 & 4.45 & 4.9197 & TRN \\
\hline CHEMBL1577064 & 688550 & 5.25 & 4.8914 & TST \\
\hline CHEMBL 1470313 & 688550 & 4.5 & 4.9742 & TRN \\
\hline CHEMBL1409407 & 688550 & 5.3 & 4.8833 & TRN \\
\hline CHEMBL1303051 & 688550 & 5.8 & 5.0158 & TRN \\
\hline CHEMBL1369531 & 688550 & 4.6 & 4.9214 & TRN \\
\hline CHEMBL1978103 & 688550 & 4.6 & 4.7892 & TRN \\
\hline CHEMBL1389673 & 688550 & 4.8 & 4.8648 & TRN \\
\hline CHEMBL1510463 & 688550 & 4.65 & 4.9832 & TRN \\
\hline CHEMBL3192879 & 688550 & 4.9 & 4.8572 & TRN \\
\hline CHEMBL3195816 & 688550 & 5.4 & 4.8644 & TRN \\
\hline CHEMBL1500766 & 688550 & 4.8 & 4.8183 & TRN \\
\hline CHEMBL1429058 & 688550 & 4.4 & 4.8355 & TRN \\
\hline CHEMBL1440032 & 688550 & 5.15 & 4.91100 & 00000000005 \\
\hline CHEMBL1326084 & 688550 & 5.55 & 5.0214 & TRN \\
\hline CHEMBL1463199 & 688550 & 4.45 & 4.8725 & TST \\
\hline CHEMBL3208369 & 688550 & 4.4 & 4.7417 & TRN \\
\hline CHEMBL1528469 & 688550 & 4.65 & 4.8228 & TRN \\
\hline CHEMBL3214275 & 688550 & 8.1024 & 4.7429 & TRN \\
\hline CHEMBL1587772 & 688550 & 5.4 & 4.8342 & TRN \\
\hline CHEMBL1985649 & 688550 & 4.5 & 4.8319 & TST \\
\hline
\end{tabular}




\begin{tabular}{|c|c|c|c|c|}
\hline \multicolumn{5}{|c|}{ Supplemental Table S2.txt } \\
\hline CHEMBL1533598 & 688550 & 6.8 & 4.8772 & TRN \\
\hline CHEMBL1529233 & 688550 & 5.15 & 4.8138 & TRN \\
\hline CHEMBL1557373 & 688550 & 5.3 & 4.9112 & TRN \\
\hline CHEMBL1408233 & 688550 & 4.4 & 4.8614 & TRN \\
\hline CHEMBL1327165 & 688550 & 4.75 & 4.9117 & TRN \\
\hline CHEMBL1388713 & 688550 & 4.6 & 5.0234 & TRN \\
\hline CHEMBL1466389 & 688550 & 5.35 & 4.7998 & TRN \\
\hline CHEMBL1332712 & 688550 & 4.4 & 4.8976 & TRN \\
\hline CHEMBL1530117 & 688550 & 4.4 & 4.9239 & TST \\
\hline CHEMBL1347979 & 688550 & 4.4 & 4.8289 & TRN \\
\hline CHEMBL1428973 & 688550 & 4.4 & 4.9394 & TRN \\
\hline CHEMBL1567873 & 688550 & 6.0 & 4.8532 & TRN \\
\hline CHEMBL1340987 & 688550 & 4.4 & 4.7998 & TST \\
\hline CHEMBL1408241 & 688550 & 4.85 & 4.8697 & TRN \\
\hline CHEMBL1356213 & 688550 & 5.4 & 4.9544 & TRN \\
\hline CHEMBL1504532 & 688550 & 6.35 & 4.9256 & TRN \\
\hline CHEMBL1460199 & 688550 & 4.45 & 4.8537 & TRN \\
\hline CHEMBL1502268 & 688550 & 5.45 & 4.865 & TRN \\
\hline CHEMBL1330751 & 688550 & 4.65 & 4.8343 & TRN \\
\hline CHEMBL1468087 & 688550 & 5.35 & 4.8622 & TRN \\
\hline CHEMBL3187659 & 688550 & 4.85 & 4.7783 & TRN \\
\hline CHEMBL1582195 & 688550 & 4.65 & 4.7671 & TST \\
\hline CHEMBL1570958 & 688550 & 5.15 & 4.8945 & TRN \\
\hline CHEMBL1331809 & 688550 & 5.3 & 4.8355 & TST \\
\hline CHEMBL1432691 & 688550 & 4.4 & 4.9885 & TRN \\
\hline CHEMBL1606229 & 688550 & 4.55 & 5.0061 & TRN \\
\hline CHEMBL1508252 & 688550 & 4.85 & 4.8837 & TRN \\
\hline CHEMBL1541140 & 688550 & 4.45 & 4.8832 & TRN \\
\hline CHEMBL453291 & 688550 & 4.6 & 4.8731 & TST \\
\hline CHEMBL1533268 & 688550 & 6.05 & 4.9569 & TRN \\
\hline CHEMBL1340016 & 688550 & 4.5 & 4.8977 & TRN \\
\hline CHEMBL1448433 & 688550 & 5.95 & 4.7726 & TST \\
\hline CHEMBL1602297 & 688550 & 4.55 & 4.8222 & TRN \\
\hline CHEMBL1399009 & 688550 & 4.55 & 4.9134 & TRN \\
\hline CHEMBL1606486 & 688550 & 4.55 & 4.8139 & TRN \\
\hline CHEMBL1306725 & 688550 & 4.5 & 4.8616 & TST \\
\hline CHEMBL1461620 & 688550 & 5.35 & 5.0455 & TRN \\
\hline CHEMBL1522155 & 688550 & 4.55 & 4.8651 & TST \\
\hline CHEMBL1302238 & 688550 & 4.55 & 4.8154 & TRN \\
\hline CHEMBL1457396 & 688550 & 4.7 & 4.9168 & TRN \\
\hline CHEMBL1375816 & 688550 & 4.55 & 5.0458 & TRN \\
\hline CHEMBL1469463 & 688550 & 4.5 & 4.8427 & TRN \\
\hline CHEMBL602418 & 688550 & 5.5 & 4.8406 & TRN \\
\hline CHEMBL1485656 & 688550 & 5.0 & 4.9013 & TRN \\
\hline CHEMBL1505478 & 688550 & 5.1 & 4.867 & TRN \\
\hline CHEMBL1492719 & 688550 & 4.75 & 4.8956 & TRN \\
\hline CHEMBL1470755 & 688550 & 6.5 & 4.8254 & TRN \\
\hline CHEMBL1577952 & 688550 & 5.55 & 4.7538 & TST \\
\hline
\end{tabular}




\begin{tabular}{|c|c|c|c|c|}
\hline \multicolumn{5}{|c|}{ Supplemental Table S2.txt } \\
\hline CHEMBL1351253 & 688550 & 5.2 & 4.8365 & TRN \\
\hline CHEMBL1537869 & 688550 & 5.35 & 4.8233 & TRN \\
\hline CHEMBL1536511 & 688550 & 4.5 & 4.8634 & TST \\
\hline CHEMBL1408832 & 688550 & 5.25 & 4.8381 & TRN \\
\hline CHEMBL1496173 & 688550 & 5.0 & 4.789 & TRN \\
\hline CHEMBL3199340 & 688550 & 5.5 & 4.919 & TRN \\
\hline CHEMBL1408919 & 688550 & 4.6 & 4.7689 & TRN \\
\hline CHEMBL1310496 & 688550 & 4.55 & 4.7473 & TRN \\
\hline CHEMBL1585632 & 688550 & 4.9 & 4.731 & TRN \\
\hline CHEMBL3196729 & 688550 & 4.9 & 4.7008 & TRN \\
\hline CHEMBL1556511 & 688550 & 4.65 & 4.8123 & TRN \\
\hline CHEMBL1314094 & 688550 & 4.85 & 4.7675 & TRN \\
\hline CHEMBL1388980 & 688550 & 4.6 & 4.9798 & TRN \\
\hline CHEMBL1420642 & 688550 & 4.6 & 4.8832 & TST \\
\hline CHEMBL1542765 & 688550 & 4.7 & 4.8791 & TST \\
\hline CHEMBL1336444 & 688550 & 4.8 & 4.9504 & TRN \\
\hline CHEMBL1369784 & 688550 & 4.75 & 4.8172 & TRN \\
\hline CHEMBL1320020 & 688550 & 5.95 & 4.9386 & TST \\
\hline CHEMBL1479701 & 688550 & 4.5 & 4.841 & TRN \\
\hline CHEMBL1384592 & 688550 & 4.4 & 4.7607 & TRN \\
\hline CHEMBL1569079 & 688550 & 4.65 & 4.8819 & TRN \\
\hline CHEMBL1537049 & 688550 & 4.5 & 4.9358 & TST \\
\hline CHEMBL1434136 & 688550 & 5.15 & 4.9351 & TRN \\
\hline CHEMBL1409488 & 688550 & 4.55 & 4.7718 & TRN \\
\hline CHEMBL1447343 & 688550 & 4.7 & 4.8244 & TRN \\
\hline CHEMBL1312552 & 688550 & 5.45 & 4.9481 & TRN \\
\hline CHEMBL1450826 & 688550 & 5.0 & 4.9522 & TRN \\
\hline CHEMBL3212127 & 688550 & 4.8 & 4.765 & TRN \\
\hline CHEMBL1501396 & 688550 & 5.05 & 4.9012 & TRN \\
\hline CHEMBL1305154 & 688550 & 4.85 & 4.8411 & TRN \\
\hline CHEMBL1368547 & 688550 & 5.05 & 4.7961 & TRN \\
\hline CHEMBL209521 & 688550 & 5.45 & 4.8856 & TRN \\
\hline CHEMBL3197798 & 688550 & 5.85 & 4.8355 & TRN \\
\hline CHEMBL1378362 & 688550 & 5.2 & 4.9187 & TRN \\
\hline CHEMBL1489786 & 688550 & 4.65 & 4.7808 & TRN \\
\hline CHEMBL1531074 & 688550 & 5.65 & 5.0638 & TRN \\
\hline CHEMBL3196335 & 688550 & 4.6 & 4.7293 & TRN \\
\hline CHEMBL1973156 & 688550 & 5.85 & 4.7658 & TST \\
\hline CHEMBL1599855 & 688550 & 4.8 & 4.9807 & TRN \\
\hline CHEMBL1429429 & 688550 & 5.0 & 4.8769 & TST \\
\hline CHEMBL1545099 & 688550 & 4.75 & 4.8362 & TRN \\
\hline CHEMBL1415670 & 688550 & 4.5 & 5.0417 & TRN \\
\hline CHEMBL3194236 & 688550 & 4.6 & 4.8528 & TRN \\
\hline CHEMBL1305289 & 688550 & 4.4 & 4.8339 & TST \\
\hline CHEMBL1416853 & 688550 & 4.85 & 4.8234 & TST \\
\hline CHEMBL1536196 & 688550 & 6.3 & 4.8428 & TST \\
\hline CHEMBL1410009 & 688550 & 5.6 & 4.8713 & TRN \\
\hline CHEMBL3213864 & 688550 & 4.55 & 4.928 & TRN \\
\hline
\end{tabular}




\begin{tabular}{|c|c|c|c|c|c|}
\hline \multicolumn{6}{|c|}{ Supplemental Table S2.txt } \\
\hline CHEMBL1441314 & 688550 & 4.6 & 4.8223 & TRN & \\
\hline CHEMBL1583788 & 688550 & 4.6 & 4.842 & TRN & \\
\hline CHEMBL1372096 & 688550 & 4.65 & 4.8487 & TRN & \\
\hline CHEMBL1549373 & 688550 & 4.5 & 4.8603 & TST & \\
\hline CHEMBL1426844 & 688550 & 5.45 & 5.0436 & TRN & \\
\hline CHEMBL1575701 & 688550 & 5.1 & 4.8353 & TST & \\
\hline CHEMBL1386764 & 688550 & 4.65 & 4.9657 & TRN & \\
\hline CHEMBL1376414 & 688550 & 5.55 & 4.9095 & TRN & \\
\hline CHEMBL1383026 & 688550 & 4.4 & 4.8962 & TRN & \\
\hline CHEMBL1417251 & 688550 & 4.8 & 4.9172 & TRN & \\
\hline CHEMBL1523920 & 688550 & 5.05 & 4.7919 & TRN & \\
\hline CHEMBL1458581 & 688550 & 6.95 & 4.8325 & TST & \\
\hline CHEMBL1389160 & 688550 & 4.4 & 4.9002 & TRN & \\
\hline CHEMBL1503822 & 688550 & 4.7 & 4.8975 & TRN & \\
\hline CHEMBL1433946 & 688550 & 4.5 & 4.9375 & TRN & \\
\hline CHEMBL1485672 & 688550 & 4.4 & 4.9005 & TRN & \\
\hline CHEMBL1455335 & 688550 & 4.85 & 4.8499 & TRN & \\
\hline CHEMBL1269862 & 688550 & 4.7 & 4.893 & TRN & \\
\hline CHEMBL1381618 & 688550 & 6.15 & 4.958 & TRN & \\
\hline CHEMBL1573673 & 688550 & 4.4 & 4.8101 & TRN & \\
\hline CHEMBL1458226 & 688550 & 4.4 & 4.85 & TRN & \\
\hline CHEMBL1531315 & 688550 & 4.75 & 4.8441 & TRN & \\
\hline CHEMBL1547684 & 688550 & 5.0 & 4.8046 & TRN & \\
\hline CHEMBL1570643 & 688550 & 6.2 & 4.8861 & TRN & \\
\hline CHEMBL1589526 & 688550 & 4.75 & 4.8181 & TST & \\
\hline CHEMBL261693 & 688550 & 4.9 & 4.8149 & TRN & \\
\hline CHEMBL1573962 & 688550 & 4.65 & 4.882 & TRN & \\
\hline CHEMBL1589041 & 688550 & 4.4 & 4.8719 & TRN & \\
\hline CHEMBL1360939 & 688550 & 4.55 & 4.7892 & TRN & \\
\hline CHEMBL1380122 & 688550 & 4.6 & 4.8819 & TRN & \\
\hline CHEMBL1305439 & 688550 & 4.45 & 4.8634 & TRN & \\
\hline CHEMBL1374522 & 688550 & 5.25 & 4.7993 & TST & \\
\hline CHEMBL1084441 & 688550 & 4.55 & 4.7816 & TRN & \\
\hline CHEMBL1488712 & 688550 & 5.0 & 4.7424 & TRN & \\
\hline CHEMBL1320613 & 688550 & 5.4 & 4.8351 & TRN & \\
\hline CHEMBL1495505 & 688550 & 4.6 & 4.7042 & TRN & \\
\hline CHEMBL1304120 & 688550 & 4.55 & 4.8919 & TRN & \\
\hline CHEMBL1602160 & 688550 & 6.0 & 4.8849 & TRN & \\
\hline CHEMBL1414010 & 688550 & 4.4 & 4.8223 & TRN & \\
\hline CHEMBL1409158 & 688550 & 5.0 & 4.98600 & 0000000001 & TRN \\
\hline CHEMBL1418068 & 688550 & 4.75 & 4.8575 & TST & \\
\hline CHEMBL1416914 & 688550 & 5.0 & 4.9772 & TRN & \\
\hline CHEMBL 2000253 & 688550 & 4.65 & 4.8034 & TRN & \\
\hline CHEMBL1332073 & 688550 & 4.9 & 4.8389 & TRN & \\
\hline CHEMBL1534959 & 688550 & 4.85 & 4.7907 & TRN & \\
\hline CHEMBL1522554 & 688550 & 4.4 & 4.8336 & TRN & \\
\hline CHEMBL1405532 & 688550 & 5.5 & 5.0365 & TRN & \\
\hline CHEMBL1595879 & 688550 & 4.6 & 4.7186 & TRN & \\
\hline
\end{tabular}




\begin{tabular}{|c|c|c|c|c|}
\hline \multicolumn{5}{|c|}{ Supplemental Table S2.txt } \\
\hline CHEMBL1530932 & 688550 & 4.6 & 4.7921 & TRN \\
\hline CHEMBL3199413 & 688550 & 4.7 & 4.782 & TRN \\
\hline CHEMBL1457077 & 688550 & 4.85 & 4.8845 & TRN \\
\hline CHEMBL1371378 & 688550 & 4.65 & 4.8895 & TRN \\
\hline CHEMBL 1495778 & 688550 & 4.55 & 4.8276 & TRN \\
\hline CHEMBL1440920 & 688550 & 5.4 & 4.797 & TRN \\
\hline CHEMBL1334593 & 688550 & 8.1487 & 4.8779 & TRN \\
\hline CHEMBL1488671 & 688550 & 4.4 & 4.8402 & TRN \\
\hline CHEMBL1546667 & 688550 & 4.55 & 4.8789 & TRN \\
\hline CHEMBL1376712 & 688550 & 5.15 & 4.7674 & TST \\
\hline CHEMBL1625328 & 688550 & 5.05 & 4.9118 & TST \\
\hline CHEMBL1535553 & 688550 & 5.55 & 4.878 & TRN \\
\hline CHEMBL1477912 & 688550 & 5.1 & 4.896 & TRN \\
\hline CHEMBL1421330 & 688550 & 4.65 & 4.8374 & TST \\
\hline CHEMBL1407374 & 688550 & 4.45 & 4.9367 & TRN \\
\hline CHEMBL1561492 & 688550 & 6.15 & 4.971 & TRN \\
\hline CHEMBL1384158 & 688550 & 4.45 & 4.7502 & TST \\
\hline CHEMBL1387695 & 688550 & 4.5 & 4.9294 & TRN \\
\hline CHEMBL1412811 & 688550 & 5.15 & 4.8361 & TRN \\
\hline CHEMBL1423169 & 688550 & 4.6 & 5.0199 & TRN \\
\hline CHEMBL1577182 & 688550 & 4.4 & 4.8939 & TRN \\
\hline CHEMBL1464554 & 688550 & 4.65 & 4.8679 & TRN \\
\hline CHEMBL1443516 & 688550 & 4.85 & 4.8371 & TRN \\
\hline CHEMBL1533620 & 688550 & 5.1 & 4.8491 & TRN \\
\hline CHEMBL1601647 & 688550 & 4.6 & 4.7933 & TRN \\
\hline CHEMBL1482609 & 688550 & 6.8499 & 4.8267 & TRN \\
\hline CHEMBL1385743 & 688550 & 4.65 & 4.7902 & TRN \\
\hline CHEMBL3207833 & 688550 & 5.35 & 4.9657 & TST \\
\hline CHEMBL1410545 & 688550 & 4.45 & 4.9504 & TRN \\
\hline CHEMBL1451493 & 688550 & 4.85 & 4.9472 & TRN \\
\hline CHEMBL1378232 & 688550 & 4.65 & 4.7927 & TRN \\
\hline CHEMBL1388509 & 688550 & 4.95 & 4.8955 & TRN \\
\hline CHEMBL1567019 & 688550 & 4.85 & 4.7521 & TRN \\
\hline CHEMBL1568043 & 688550 & 5.15 & 4.8357 & TRN \\
\hline CHEMBL1393735 & 688550 & 4.65 & 4.8907 & TRN \\
\hline CHEMBL1527410 & 688550 & 4.85 & 4.8668 & TRN \\
\hline CHEMBL1431573 & 688550 & 4.5 & 4.8681 & TRN \\
\hline CHEMBL1421182 & 688550 & 4.55 & 4.8058 & TRN \\
\hline CHEMBL1507267 & 688550 & 4.4 & 4.9543 & TRN \\
\hline CHEMBL1353221 & 688550 & 4.55 & 4.872 & TST \\
\hline CHEMBL1331388 & 688550 & 5.25 & 4.9495 & TST \\
\hline CHEMBL3210268 & 688550 & 4.8 & 4.8603 & TST \\
\hline CHEMBL1582818 & 688550 & 4.4 & 4.9007 & TRN \\
\hline CHEMBL1482489 & 688550 & 4.75 & 5.0152 & TRN \\
\hline CHEMBL1301962 & 688550 & 5.65 & 4.9234 & TRN \\
\hline CHEMBL1501859 & 688550 & 4.7 & 4.8316 & TRN \\
\hline CHEMBL1335988 & 688550 & 5.5 & 4.8257 & TST \\
\hline CHEMBL1508584 & 688550 & 5.4 & 4.7241 & TRN \\
\hline
\end{tabular}




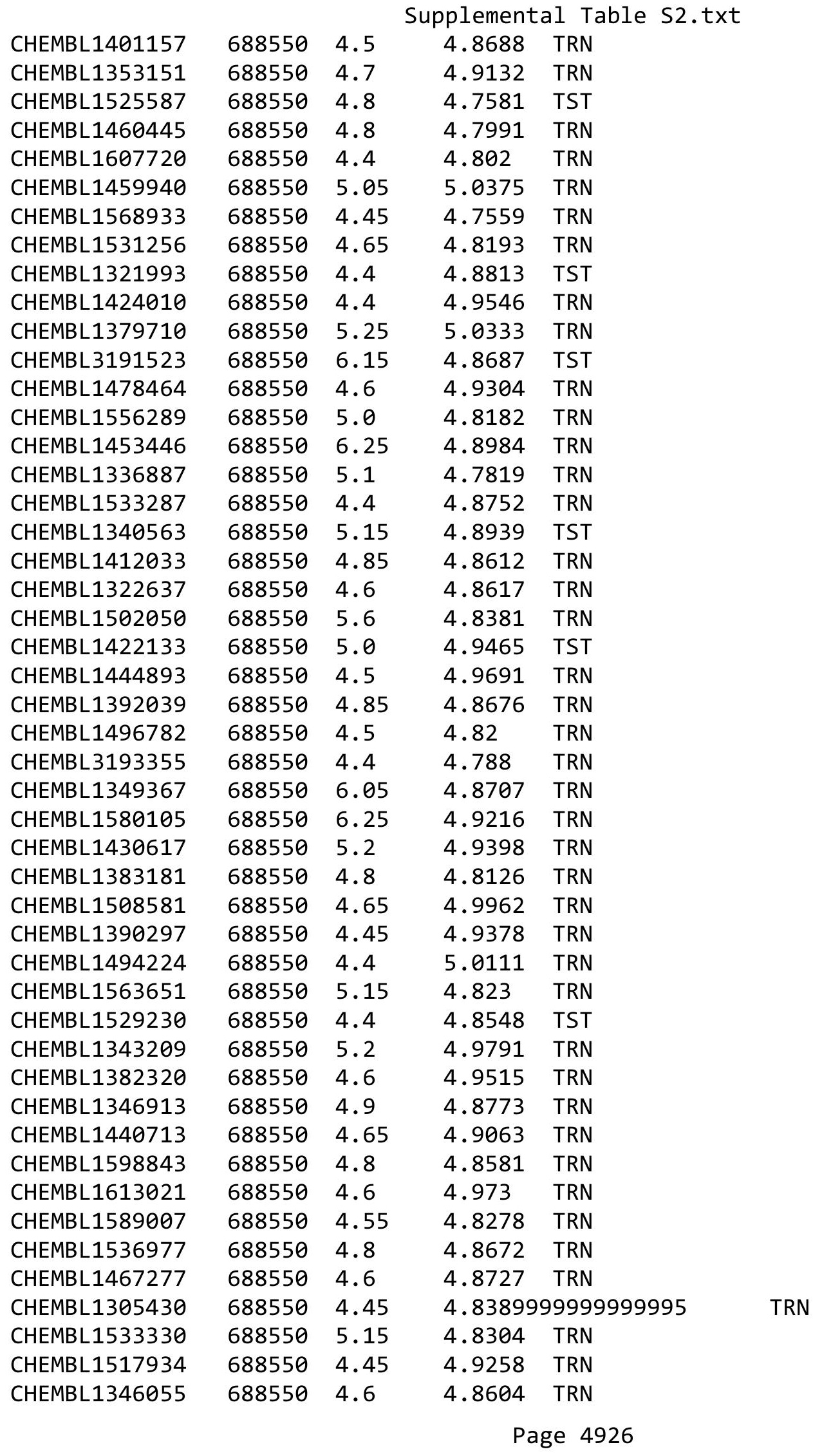




\begin{tabular}{|c|c|c|c|c|c|}
\hline \multicolumn{6}{|c|}{ Supplemental Table S2.txt } \\
\hline CHEMBL1371133 & 688550 & 4.4 & 4.8111 & TRN & \\
\hline CHEMBL1421073 & 688550 & 4.55 & 4.8706 & TRN & \\
\hline CHEMBL1474181 & 688550 & 4.9 & 4.9343 & TRN & \\
\hline CHEMBL1464122 & 688550 & 4.65 & 4.8378 & TST & \\
\hline CHEMBL1483419 & 688550 & 4.4 & 4.7715 & TRN & \\
\hline CHEMBL1388639 & 688550 & 4.55 & 4.862 & TRN & \\
\hline CHEMBL1324817 & 688550 & 5.35 & 4.7869 & TRN & \\
\hline CHEMBL1537833 & 688550 & 4.75 & 4.9068 & TRN & \\
\hline CHEMBL1359902 & 688550 & 5.1 & 4.9571 & TRN & \\
\hline CHEMBL3212363 & 688550 & 6.15 & 4.8455 & TST & \\
\hline CHEMBL1307811 & 688550 & 4.65 & 4.8744 & TRN & \\
\hline CHEMBL1339579 & 688550 & 4.4 & 4.7867 & TRN & \\
\hline CHEMBL1533940 & 688550 & 5.5 & 4.7939 & TRN & \\
\hline CHEMBL1521810 & 688550 & 5.55 & 5.0014 & TRN & \\
\hline CHEMBL1324654 & 688550 & 4.6 & 4.877 & TST & \\
\hline CHEMBL1490593 & 688550 & 4.95 & 4.92399 & 99999999995 & TRN \\
\hline CHEMBL1595606 & 688550 & 5.85 & 4.8677 & TRN & \\
\hline CHEMBL2000172 & 688550 & 4.5 & 4.6676 & TRN & \\
\hline CHEMBL1469974 & 688550 & 5.1 & 4.8821 & TRN & \\
\hline CHEMBL1544730 & 688550 & 4.6 & 4.9803 & TRN & \\
\hline CHEMBL1332471 & 688550 & 5.55 & 4.9528 & TST & \\
\hline CHEMBL1447309 & 688550 & 5.0 & 4.8314 & TRN & \\
\hline CHEMBL1578616 & 688550 & 6.2 & 4.8947 & TST & \\
\hline CHEMBL1393432 & 688550 & 5.2 & 4.935 & TRN & \\
\hline CHEMBL1452462 & 688550 & 5.85 & 4.8901 & TRN & \\
\hline CHEMBL1507072 & 688550 & 4.4 & 4.8642 & TRN & \\
\hline CHEMBL1385535 & 688550 & 4.55 & 4.8717 & TRN & \\
\hline CHEMBL1493886 & 688550 & 4.75 & 4.7448 & TRN & \\
\hline CHEMBL1558699 & 688550 & 4.4 & 4.7933 & TRN & \\
\hline CHEMBL1480163 & 688550 & 5.05 & 4.8172 & TRN & \\
\hline CHEMBL1530341 & 688550 & 4.85 & 4.7443 & TRN & \\
\hline CHEMBL1375576 & 688550 & 5.0 & 4.9013 & TST & \\
\hline CHEMBL1468505 & 688550 & 4.7 & 4.8885 & TRN & \\
\hline CHEMBL1464517 & 688550 & 4.55 & 4.9585 & TRN & \\
\hline CHEMBL1362507 & 688550 & 4.7 & 4.8481 & TRN & \\
\hline CHEMBL1388186 & 688550 & 4.85 & 4.8397 & TST & \\
\hline CHEMBL1311185 & 688550 & 4.4 & 4.746 & TRN & \\
\hline CHEMBL1509104 & 688550 & 4.55 & 4.82600 & 00000000005 & TRN \\
\hline CHEMBL1506936 & 688550 & 4.4 & 4.8326 & TRN & \\
\hline CHEMBL1550170 & 688550 & 5.2 & 4.8832 & TRN & \\
\hline CHEMBL3212751 & 688550 & 4.85 & 4.8966 & TRN & \\
\hline CHEMBL1324328 & 688550 & 4.85 & 4.7891 & TRN & \\
\hline CHEMBL1300312 & 688550 & 4.7 & 4.7649 & TRN & \\
\hline CHEMBL1303347 & 688550 & 5.5 & 4.966 & TRN & \\
\hline CHEMBL1303738 & 688550 & 4.8 & 4.8906 & TRN & \\
\hline CHEMBL1554982 & 688550 & 5.05 & 4.9212 & TST & \\
\hline CHEMBL 235541 & 688550 & 4.7 & 4.9591 & TRN & \\
\hline CHEMBL1545290 & 688550 & 4.75 & 4.8148 & TRN & \\
\hline
\end{tabular}




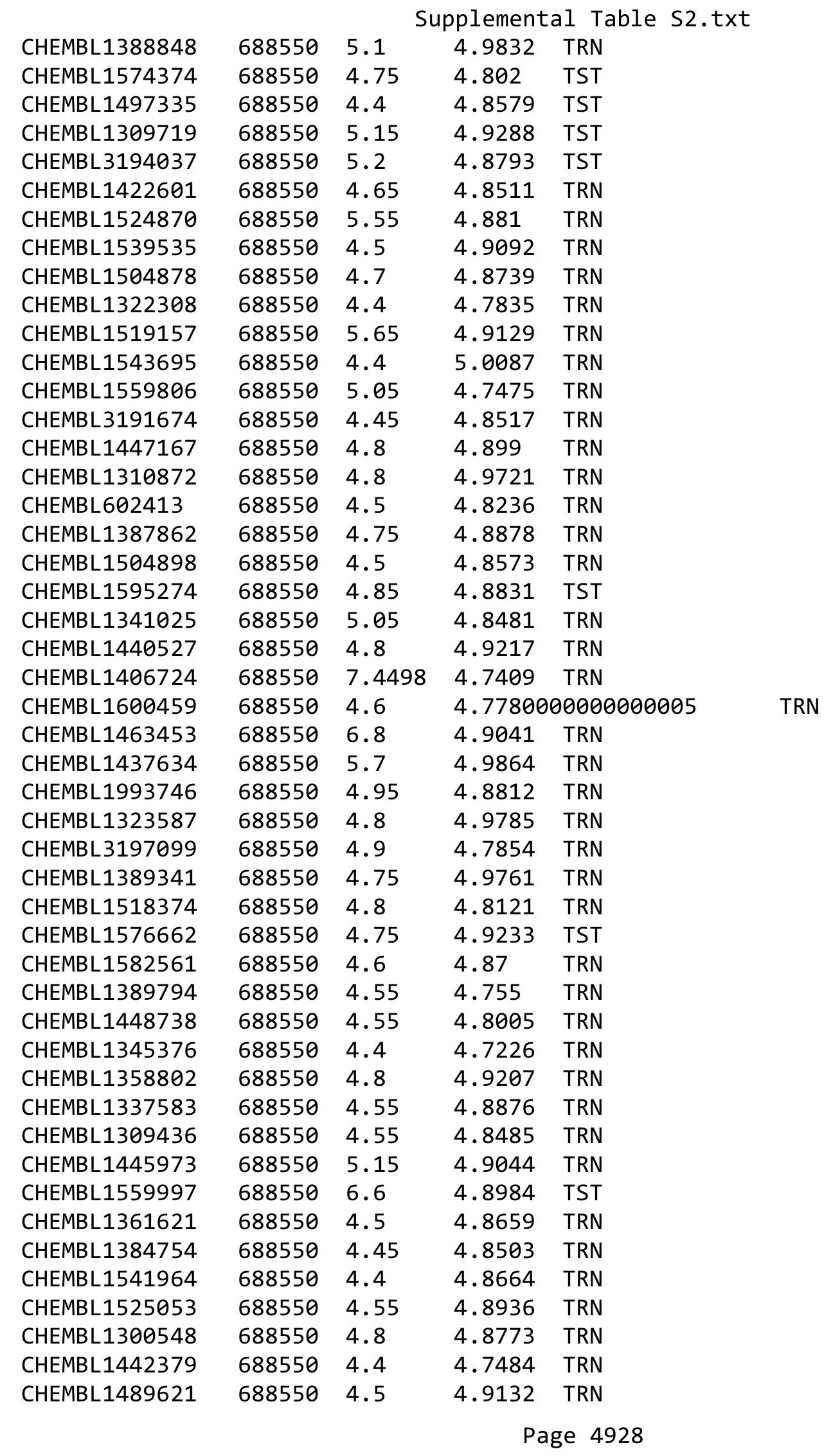




\begin{tabular}{|c|c|c|c|c|c|}
\hline \multicolumn{6}{|c|}{ Supplemental Table S2.txt } \\
\hline CHEMBL1577159 & 688550 & 4.4 & 4.8208 & TRN & \\
\hline CHEMBL1986111 & 688550 & 5.05 & 4.7186 & TRN & \\
\hline CHEMBL1410592 & 688550 & 5.7 & 4.9088 & TRN & \\
\hline CHEMBL1998940 & 688550 & 5.5 & 4.8816 & TRN & \\
\hline CHEMBL1488925 & 688550 & 4.4 & 4.7957 & TRN & \\
\hline CHEMBL1377380 & 688550 & 4.5 & 4.9498 & TRN & \\
\hline CHEMBL1598791 & 688550 & 4.45 & 4.8659 & TST & \\
\hline CHEMBL1556843 & 688550 & 5.15 & 4.8421 & TRN & \\
\hline CHEMBL1307290 & 688550 & 5.55 & 5.0095 & TRN & \\
\hline CHEMBL1313977 & 688550 & 4.7 & 4.8712 & TRN & \\
\hline CHEMBL1479729 & 688550 & 4.7 & 4.9114 & TRN & \\
\hline CHEMBL1604456 & 688550 & 4.4 & 4.771 & TRN & \\
\hline CHEMBL1471242 & 688550 & 4.6 & 5.0067 & TRN & \\
\hline CHEMBL1585699 & 688550 & 4.4 & 4.8574 & TST & \\
\hline CHEMBL1486335 & 688550 & 4.6 & 4.8246 & TRN & \\
\hline CHEMBL1359815 & 688550 & 4.85 & 5.0344 & TRN & \\
\hline CHEMBL1324792 & 688550 & 5.1 & 4.8615 & TRN & \\
\hline CHEMBL1571315 & 688550 & 4.8 & 4.7576 & TRN & \\
\hline CHEMBL1453807 & 688550 & 4.95 & 4.9846 & TRN & \\
\hline CHEMBL1300714 & 688550 & 5.15 & 4.89199 & 99999999995 & TRN \\
\hline CHEMBL1352586 & 688550 & 5.0 & 4.8426 & TRN & \\
\hline CHEMBL1390753 & 688550 & 4.4 & 4.7862 & TRN & \\
\hline CHEMBL1494595 & 688550 & 4.65 & 4.7867 & TST & \\
\hline CHEMBL1313891 & 688550 & 4.85 & 4.7388 & TRN & \\
\hline CHEMBL3210195 & 688550 & 4.75 & 4.9227 & TRN & \\
\hline CHEMBL1391042 & 688550 & 4.45 & 4.8106 & TRN & \\
\hline CHEMBL1414382 & 688550 & 5.1 & 4.9338 & TRN & \\
\hline CHEMBL1378036 & 688550 & 4.65 & 4.8485 & TRN & \\
\hline CHEMBL1518866 & 688550 & 4.7 & 4.7476 & TRN & \\
\hline CHEMBL1507455 & 688550 & 4.8 & 4.9455 & TRN & \\
\hline CHEMBL1497483 & 688550 & 4.45 & 4.8663 & TRN & \\
\hline CHEMBL1608391 & 688550 & 4.85 & 4.842 & TST & \\
\hline CHEMBL1369587 & 688550 & 4.7 & 4.8524 & TRN & \\
\hline CHEMBL1601582 & 688550 & 4.4 & 4.8346 & TRN & \\
\hline CHEMBL1330405 & 688550 & 4.55 & 4.9282 & TRN & \\
\hline CHEMBL1484517 & 688550 & 4.95 & 4.887 & TRN & \\
\hline CHEMBL1579447 & 688550 & 4.4 & 4.9398 & TRN & \\
\hline CHEMBL1462469 & 688550 & 4.5 & 4.8593 & TRN & \\
\hline CHEMBL1387797 & 688550 & 4.65 & 4.859 & TRN & \\
\hline CHEMBL512216 & 688550 & 5.85 & 4.8411 & TST & \\
\hline CHEMBL1506088 & 688550 & 4.4 & 4.849 & TRN & \\
\hline CHEMBL1610587 & 688550 & 5.3 & 4.8049 & TST & \\
\hline CHEMBL1442040 & 688550 & 4.4 & 4.9327 & TRN & \\
\hline CHEMBL1313560 & 688550 & 4.85 & 4.8335 & TST & \\
\hline CHEMBL1392315 & 688550 & 5.85 & 5.0077 & TRN & \\
\hline CHEMBL3207941 & 688550 & 4.7 & 4.8481 & TRN & \\
\hline CHEMBL1430987 & 688550 & 4.5 & 4.8807 & TRN & \\
\hline CHEMBL1986805 & 688550 & 4.9 & 4.7829 & TRN & \\
\hline
\end{tabular}




\begin{tabular}{|c|c|c|c|c|}
\hline \multicolumn{5}{|c|}{ Supplemental Table S2.txt } \\
\hline CHEMBL1539900 & 688550 & 5.35 & 4.7981 & TST \\
\hline CHEMBL1499574 & 688550 & 4.45 & 4.8287 & TRN \\
\hline CHEMBL1985333 & 688550 & 4.85 & 4.7507 & TRN \\
\hline CHEMBL1350240 & 688550 & 4.45 & 4.7389 & TRN \\
\hline CHEMBL1360155 & 688550 & 4.6 & 4.7849 & TRN \\
\hline CHEMBL1345128 & 688550 & 4.75 & 4.8277 & TRN \\
\hline CHEMBL1556777 & 688550 & 4.5 & 4.8622 & TRN \\
\hline CHEMBL1513620 & 688550 & 5.2 & 4.8522 & TST \\
\hline CHEMBL1385413 & 688550 & 4.65 & 4.8206 & TRN \\
\hline CHEMBL1390512 & 688550 & 4.85 & 4.8488 & TRN \\
\hline CHEMBL1333796 & 688550 & 4.4 & 4.894 & TST \\
\hline CHEMBL1310972 & 688550 & 4.65 & 4.7994 & TRN \\
\hline CHEMBL1373831 & 688550 & 4.4 & 4.7531 & TRN \\
\hline CHEMBL1303028 & 688550 & 5.35 & 4.8888 & TRN \\
\hline CHEMBL1302721 & 688550 & 4.55 & 4.86 & TRN \\
\hline CHEMBL1987655 & 688550 & 4.8 & 4.7134 & TRN \\
\hline CHEMBL1350800 & 688550 & 5.65 & 4.8296 & TST \\
\hline CHEMBL1404745 & 688550 & 4.4 & 4.9339 & TRN \\
\hline CHEMBL1394971 & 688550 & 6.05 & 5.0339 & TRN \\
\hline CHEMBL1500106 & 688550 & 4.6 & 4.7416 & TRN \\
\hline CHEMBL1536612 & 688550 & 4.6 & 4.985 & TST \\
\hline CHEMBL1392671 & 688550 & 4.9 & 4.9033 & TRN \\
\hline CHEMBL1492233 & 688550 & 4.5 & 4.8161 & TRN \\
\hline CHEMBL1489812 & 688550 & 4.5 & 4.8016 & TRN \\
\hline CHEMBL1503930 & 688550 & 4.8 & 4.7998 & TRN \\
\hline CHEMBL1418583 & 688550 & 6.1 & 4.9088 & TRN \\
\hline CHEMBL 72683 & 688550 & 4.8 & 4.7037 & TRN \\
\hline CHEMBL1375679 & 688550 & 4.6 & 4.8999 & TRN \\
\hline CHEMBL1420399 & 688550 & 4.6 & 4.8701 & TRN \\
\hline CHEMBL1604007 & 688550 & 4.85 & 4.8078 & TRN \\
\hline CHEMBL3213993 & 688550 & 4.65 & 4.8169 & TRN \\
\hline CHEMBL1380239 & 688550 & 4.8 & 5.0482 & TRN \\
\hline CHEMBL3190501 & 688550 & 4.9 & 4.9179 & TRN \\
\hline CHEMBL1341444 & 688550 & 4.6 & 4.8114 & TRN \\
\hline CHEMBL1307669 & 688550 & 4.45 & 4.8504 & TRN \\
\hline CHEMBL1414309 & 688550 & 4.65 & 5.0063 & TRN \\
\hline CHEMBL1448851 & 688550 & 4.7 & 4.7079 & TRN \\
\hline CHEMBL1400480 & 688550 & 4.75 & 4.9987 & TRN \\
\hline CHEMBL1363849 & 688550 & 4.45 & 4.8273 & TRN \\
\hline CHEMBL1390650 & 688550 & 4.75 & 4.7646 & TRN \\
\hline CHEMBL1349193 & 688550 & 5.45 & 4.8662 & TRN \\
\hline CHEMBL1986443 & 688550 & 4.85 & 4.7602 & TRN \\
\hline CHEMBL1413479 & 688550 & 5.3 & 4.873 & TRN \\
\hline CHEMBL1478445 & 688550 & 4.6 & 4.8609 & TRN \\
\hline CHEMBL1388304 & 688550 & 6.2 & 4.8319 & TRN \\
\hline CHEMBL1345574 & 688550 & 4.55 & 4.9124 & TST \\
\hline CHEMBL3192197 & 688550 & 5.3 & 4.7186 & TRN \\
\hline CHEMBL1336534 & 688550 & 6.45 & 4.8925 & TRN \\
\hline
\end{tabular}




\begin{tabular}{|c|c|c|c|c|c|}
\hline \multicolumn{6}{|c|}{ Supplemental Table S2.txt } \\
\hline CHEMBL1449253 & 688550 & 4.4 & 4.8309 & TRN & \\
\hline CHEMBL1418209 & 688550 & 5.1 & 4.8746 & TRN & \\
\hline CHEMBL1588910 & 688550 & 5.15 & 4.8485 & TRN & \\
\hline CHEMBL1309737 & 688550 & 5.2 & 4.9115 & TST & \\
\hline CHEMBL1554411 & 688550 & 4.8 & 4.8326 & TRN & \\
\hline CHEMBL3192083 & 688550 & 4.6 & 4.8487 & TRN & \\
\hline CHEMBL1571713 & 688550 & 4.85 & 5.0057 & TRN & \\
\hline CHEMBL1429711 & 688550 & 4.5 & 4.7522 & TRN & \\
\hline CHEMBL1548653 & 688550 & 4.5 & 4.8739 & TRN & \\
\hline CHEMBL1302934 & 688550 & 6.8 & 4.8462 & TRN & \\
\hline CHEMBL1453548 & 688550 & 6.1 & 4.8451 & TRN & \\
\hline CHEMBL1374795 & 688550 & 4.8 & 4.7826 & TRN & \\
\hline CHEMBL1367279 & 688550 & 4.7 & 4.9269 & TRN & \\
\hline CHEMBL3199264 & 688550 & 5.05 & 4.8883 & TRN & \\
\hline CHEMBL1368944 & 688550 & 5.8 & 4.9024 & TRN & \\
\hline CHEMBL3213377 & 688550 & 4.5 & 4.8415 & TRN & \\
\hline CHEMBL1387775 & 688550 & 4.5 & 4.7337 & TRN & \\
\hline CHEMBL1487967 & 688550 & 4.85 & 4.758 & TRN & \\
\hline CHEMBL1432351 & 688550 & 4.5 & 4.8644 & TRN & \\
\hline CHEMBL1609070 & 688550 & 4.55 & 4.785 & TRN & \\
\hline CHEMBL1446067 & 688550 & 6.9 & 4.8098 & TRN & \\
\hline CHEMBL1419688 & 688550 & 4.55 & 4.8448 & TRN & \\
\hline CHEMBL1574430 & 688550 & 5.0 & 4.8853 & TRN & \\
\hline CHEMBL 3214470 & 688550 & 5.4 & 4.876 & TST & \\
\hline CHEMBL3194929 & 688550 & 4.6 & 4.8425 & TRN & \\
\hline CHEMBL1419553 & 688550 & 5.2 & 4.9113 & TST & \\
\hline CHEMBL1586936 & 688550 & 5.4 & 4.8443 & TRN & \\
\hline CHEMBL1487067 & 688550 & 4.7 & 4.9212 & TST & \\
\hline CHEMBL1609076 & 688550 & 4.45 & 4.84399 & 9999999999 & TRN \\
\hline CHEMBL1588458 & 688550 & 5.3 & 4.7739 & TST & \\
\hline CHEMBL460517 & 688550 & 4.85 & 4.6885 & TRN & \\
\hline CHEMBL3209541 & 688550 & 4.75 & 4.9125 & TRN & \\
\hline CHEMBL1336437 & 688550 & 4.4 & 4.7524 & TRN & \\
\hline CHEMBL1370950 & 688550 & 5.35 & 4.9026 & TRN & \\
\hline CHEMBL1406720 & 688550 & 4.4 & 4.8262 & TRN & \\
\hline CHEMBL1594574 & 688550 & 4.55 & 4.8984 & TRN & \\
\hline CHEMBL365161 & 688550 & 5.85 & 4.86100 & 0000000001 & TST \\
\hline CHEMBL1368942 & 688550 & 4.55 & 4.947 & TST & \\
\hline CHEMBL1557110 & 688550 & 4.85 & 5.0153 & TRN & \\
\hline CHEMBL1330965 & 688550 & 4.45 & 4.8209 & TRN & \\
\hline CHEMBL1428274 & 688550 & 4.4 & 4.8976 & TRN & \\
\hline CHEMBL1388207 & 688550 & 4.6 & 4.8596 & TRN & \\
\hline CHEMBL1565308 & 688550 & 4.8 & 4.9035 & TRN & \\
\hline CHEMBL1545263 & 688550 & 4.4 & 4.9338 & TST & \\
\hline CHEMBL1385562 & 688550 & 4.45 & 4.977 & TRN & \\
\hline CHEMBL1460926 & 688550 & 4.4 & 4.9461 & TST & \\
\hline CHEMBL1502774 & 688550 & 5.35 & 4.8771 & TRN & \\
\hline CHEMBL1529411 & 688550 & 4.7 & 4.7979 & TRN & \\
\hline
\end{tabular}




\begin{tabular}{|c|c|c|c|c|}
\hline & & & pplement & al $\mathrm{Ta}$ \\
\hline CHEMBL1310283 & 688550 & 6.5 & 4.8137 & TRN \\
\hline CHEMBL1576421 & 688550 & 4.95 & 4.7839 & TST \\
\hline CHEMBL1370870 & 688550 & 4.6 & 4.8498 & TRN \\
\hline CHEMBL1556561 & 688550 & 5.4 & 4.9081 & TRN \\
\hline CHEMBL1331234 & 688550 & 4.95 & 4.8854 & TST \\
\hline CHEMBL1414289 & 688550 & 5.4 & 4.8328 & TRN \\
\hline CHEMBL1556882 & 688550 & 4.5 & 4.829 & TRN \\
\hline CHEMBL3209570 & 688550 & 4.55 & 4.8578 & TRN \\
\hline CHEMBL1352624 & 688550 & 4.8 & 4.7388 & TRN \\
\hline CHEMBL1404458 & 688550 & 4.85 & 4.8209 & TRN \\
\hline CHEMBL1511752 & 688550 & 5.15 & 4.8116 & TST \\
\hline CHEMBL1413358 & 688550 & 6.2 & 4.8355 & TRN \\
\hline CHEMBL1464182 & 688550 & 5.45 & 4.8672 & TRN \\
\hline CHEMBL421088 & 688550 & 5.05 & 4.7832 & TRN \\
\hline CHEMBL1349743 & 688550 & 4.6 & 4.8525 & TRN \\
\hline CHEMBL1430344 & 688550 & 5.05 & 4.8694 & TRN \\
\hline CHEMBL1351514 & 688550 & 6.0 & 4.8506 & TRN \\
\hline CHEMBL1507702 & 688550 & 4.85 & 4.8621 & TRN \\
\hline CHEMBL3194463 & 688550 & 4.5 & 4.9326 & TRN \\
\hline CHEMBL1978101 & 688550 & 4.65 & 4.8107 & TRN \\
\hline CHEMBL1528524 & 688550 & 6.05 & 4.9726 & TRN \\
\hline CHEMBL1374125 & 688550 & 5.0 & 4.8743 & TRN \\
\hline CHEMBL1464024 & 688550 & 4.95 & 4.9928 & TRN \\
\hline CHEMBL1362784 & 688550 & 4.45 & 4.915 & TRN \\
\hline CHEMBL1486510 & 688550 & 4.5 & 4.8516 & TRN \\
\hline CHEMBL1558284 & 688550 & 4.6 & 4.8248 & TRN \\
\hline CHEMBL1536637 & 688550 & 4.8 & 4.8393 & TRN \\
\hline CHEMBL1486092 & 688550 & 4.8 & 4.9714 & TRN \\
\hline CHEMBL3193124 & 688550 & 4.7 & 4.746 & TRN \\
\hline CHEMBL1370536 & 688550 & 5.6 & 4.9668 & TRN \\
\hline CHEMBL1350891 & 688550 & 4.4 & 4.8958 & TRN \\
\hline CHEMBL 2003887 & 688550 & 5.1 & 4.8058 & TRN \\
\hline CHEMBL3208408 & 688550 & 4.95 & 4.8036 & TRN \\
\hline CHEMBL3194911 & 688550 & 5.4 & 4.8114 & TRN \\
\hline CHEMBL1457320 & 688550 & 4.4 & 4.8921 & TRN \\
\hline CHEMBL1302635 & 688550 & 4.95 & 4.9639 & TRN \\
\hline CHEMBL1928491 & 688550 & 5.0 & 4.7632 & TRN \\
\hline CHEMBL1348638 & 688550 & 4.8 & 4.8579 & TRN \\
\hline CHEMBL3197422 & 688550 & 4.6 & 4.7965 & TRN \\
\hline CHEMBL1557846 & 688550 & 5.35 & 4.9567 & TRN \\
\hline CHEMBL1370145 & 688550 & 4.6 & 4.7704 & TRN \\
\hline CHEMBL1336523 & 688550 & 4.55 & 4.9917 & TRN \\
\hline CHEMBL1429161 & 688550 & 5.4 & 5.0122 & TRN \\
\hline CHEMBL1608398 & 688550 & 4.65 & 4.8423 & TRN \\
\hline CHEMBL1393451 & 688550 & 5.0 & 4.8773 & TRN \\
\hline CHEMBL1536321 & 688550 & 4.55 & 4.8992 & TRN \\
\hline CHEMBL1330368 & 688550 & 5.05 & 4.8904 & TRN \\
\hline CHEMBL1373347 & 688550 & 4.55 & 4.8141 & TRN \\
\hline
\end{tabular}




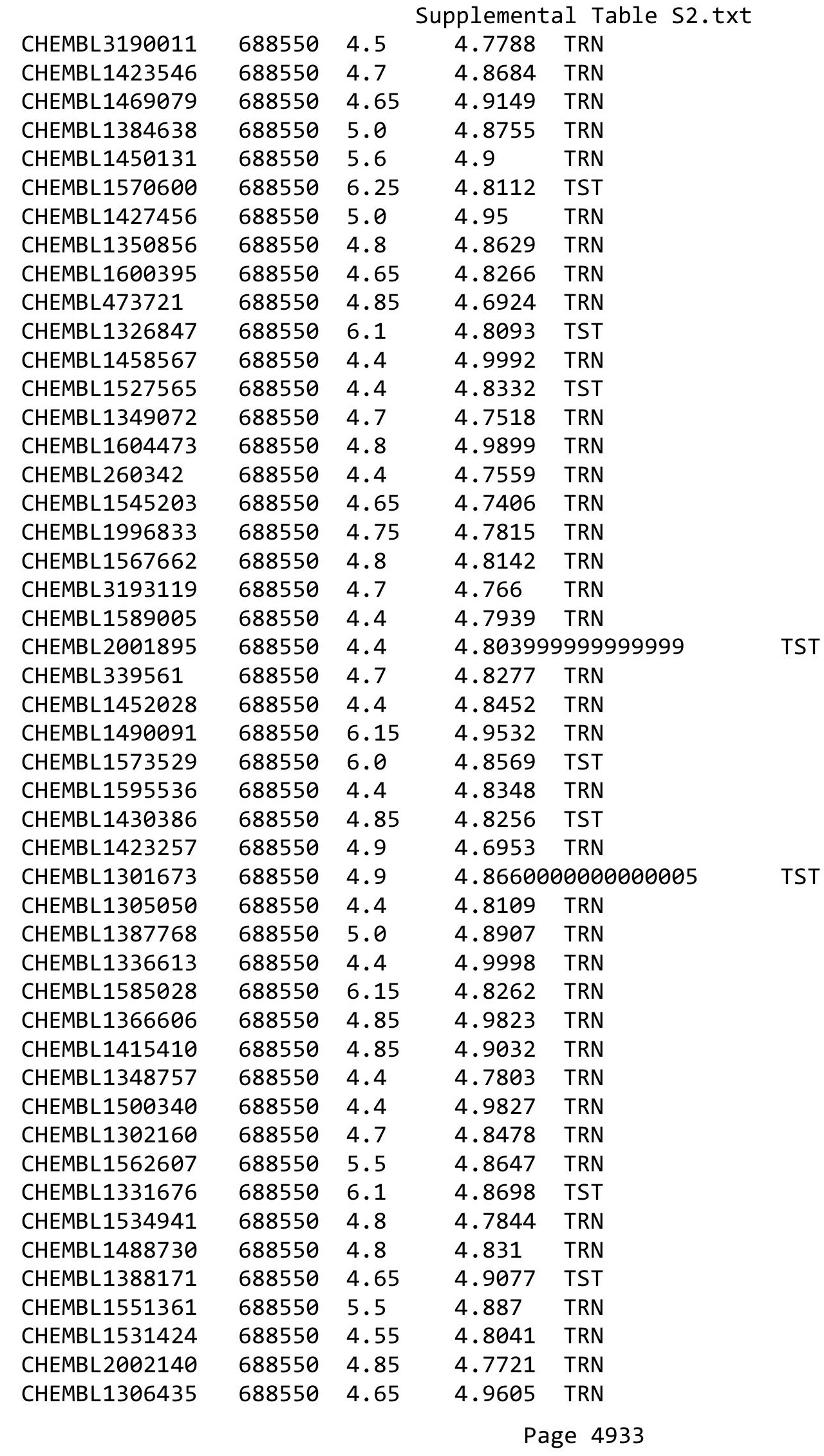




\begin{tabular}{|c|c|c|c|c|c|}
\hline \multicolumn{6}{|c|}{ Supplemental Table S2.txt } \\
\hline CHEMBL1417965 & 688550 & 5.4 & 4.8666 & TRN & \\
\hline CHEMBL1322728 & 688550 & 5.15 & 4.9348 & TRN & \\
\hline CHEMBL1516533 & 688550 & 4.5 & 4.8508 & TRN & \\
\hline CHEMBL1389600 & 688550 & 4.6 & 4.8703 & TRN & \\
\hline CHEMBL1581017 & 688550 & 8.2518 & 5.0034 & TRN & \\
\hline CHEMBL1318802 & 688550 & 5.3 & 4.77800 & 00000000005 & TST \\
\hline CHEMBL1492391 & 688550 & 4.6 & 4.8619 & TRN & \\
\hline CHEMBL1600326 & 688550 & 5.0 & 4.8797 & TST & \\
\hline CHEMBL1495025 & 688550 & 4.6 & 4.7826 & TRN & \\
\hline CHEMBL1458351 & 688550 & 4.85 & 4.8578 & TRN & \\
\hline CHEMBL1309573 & 688550 & 4.5 & 4.699 & TRN & \\
\hline CHEMBL3194966 & 688550 & 4.4 & 4.8879 & TRN & \\
\hline CHEMBL1546959 & 688550 & 5.15 & 5.0376 & TRN & \\
\hline CHEMBL1466907 & 688550 & 4.65 & 4.8943 & TRN & \\
\hline CHEMBL1541664 & 688550 & 4.85 & 4.9574 & TRN & \\
\hline CHEMBL1386849 & 688550 & 4.4 & 4.8475 & TRN & \\
\hline CHEMBL1612609 & 688550 & 4.65 & 4.8891 & TRN & \\
\hline CHEMBL1447412 & 688550 & 4.55 & 4.8101 & TRN & \\
\hline CHEMBL1478044 & 688550 & 4.4 & 4.8976 & TRN & \\
\hline CHEMBL1596248 & 688550 & 4.5 & 4.7188 & TRN & \\
\hline CHEMBL1572154 & 688550 & 6.2 & 4.8701 & TRN & \\
\hline CHEMBL1556627 & 688550 & 5.0 & 4.9344 & TRN & \\
\hline CHEMBL1537133 & 688550 & 4.7 & 4.8052 & TRN & \\
\hline CHEMBL3191921 & 688550 & 4.55 & 4.7259 & TRN & \\
\hline CHEMBL1495269 & 688550 & 5.1 & 4.9715 & TRN & \\
\hline CHEMBL1612433 & 688550 & 4.45 & 4.85800 & 00000000005 & TRN \\
\hline CHEMBL1530922 & 688550 & 5.05 & 4.7989 & TRN & \\
\hline CHEMBL1357104 & 688550 & 4.8 & 5.0017 & TRN & \\
\hline CHEMBL1359363 & 688550 & 5.15 & 5.0446 & TRN & \\
\hline CHEMBL11326 & 688550 & 4.6 & 4.8567 & TRN & \\
\hline CHEMBL1532453 & 688550 & 5.1 & 4.814 & TRN & \\
\hline CHEMBL1504113 & 688550 & 5.4 & 4.9624 & TST & \\
\hline CHEMBL1371083 & 688550 & 5.15 & 5.0425 & TRN & \\
\hline CHEMBL1308240 & 688550 & 5.35 & 4.8804 & TRN & \\
\hline CHEMBL1596047 & 688550 & 5.05 & 4.9218 & TRN & \\
\hline CHEMBL1567218 & 688550 & 4.85 & 4.9649 & TRN & \\
\hline CHEMBL1337058 & 688550 & 4.6 & 4.9416 & TRN & \\
\hline CHEMBL1989750 & 688550 & 4.4 & 4.7325 & TRN & \\
\hline CHEMBL1430306 & 688550 & 4.55 & 4.9378 & TRN & \\
\hline CHEMBL1350634 & 688550 & 4.4 & 4.8697 & TRN & \\
\hline CHEMBL1456295 & 688550 & 5.85 & 4.8641 & TRN & \\
\hline CHEMBL1569308 & 688550 & 4.55 & 4.93 & TRN & \\
\hline CHEMBL1322380 & 688550 & 5.3 & 4.9238 & TST & \\
\hline CHEMBL1372228 & 688550 & 4.85 & 4.9961 & TRN & \\
\hline CHEMBL1486877 & 688550 & 4.8 & 4.7651 & TRN & \\
\hline CHEMBL1308182 & 688550 & 6.1 & 4.9316 & TRN & \\
\hline CHEMBL1338094 & 688550 & 5.8 & 4.8886 & TRN & \\
\hline CHEMBL1346882 & 688550 & 4.4 & 4.8289 & TST & \\
\hline
\end{tabular}




\begin{tabular}{|c|c|c|c|c|c|}
\hline \multirow{3}{*}{$\begin{array}{l}\text { CHEMBL1302252 } \\
\text { CHFMBI } 1370866\end{array}$} & & \multicolumn{4}{|c|}{ Supplemental Table S2.txt } \\
\hline & & 4.5 & 4.8610 & 0000000001 & TRN \\
\hline & 688550 & 4.75 & 4.8344 & TRN & \\
\hline CHEMBL1334372 & 688550 & 4.65 & 4.9862 & TRN & \\
\hline CHEMBL1486448 & 688550 & 4.7 & 4.8737 & TRN & \\
\hline CHEMBL1491312 & 688550 & 4.4 & 4.7971 & TRN & \\
\hline CHEMBL1520121 & 688550 & 4.9 & 4.7631 & TRN & \\
\hline CHEMBL1575265 & 688550 & 6.2 & 4.8614 & TRN & \\
\hline CHEMBL1564250 & 688550 & 4.4 & 4.7861 & TST & \\
\hline CHEMBL1564756 & 688550 & 4.8 & 4.9383 & TRN & \\
\hline CHEMBL1528096 & 688550 & 4.45 & 4.9366 & TRN & \\
\hline CHEMBL1504133 & 688550 & 5.55 & 4.9697 & TRN & \\
\hline CHEMBL1408102 & 688550 & 4.8 & 4.8491 & TRN & \\
\hline CHEMBL1337744 & 688550 & 4.45 & 4.9392 & TRN & \\
\hline CHEMBL1343400 & 688550 & 4.95 & 4.9801 & TRN & \\
\hline CHEMBL1428228 & 688550 & 5.1 & 4.9346 & TRN & \\
\hline CHEMBL3192631 & 688550 & 4.65 & 4.8116 & TRN & \\
\hline CHEMBL1480628 & 688550 & 6.25 & 4.9983 & TRN & \\
\hline CHEMBL1398944 & 688550 & 4.9 & 4.8398 & TST & \\
\hline CHEMBL1372703 & 688550 & 4.4 & 4.9151 & TRN & \\
\hline CHEMBL1453880 & 688550 & 4.7 & 4.9389 & TRN & \\
\hline CHEMBL1461939 & 688550 & 4.65 & 4.8479 & TRN & \\
\hline CHEMBL1371282 & 688550 & 4.75 & 4.8378 & TRN & \\
\hline CHEMBL1523465 & 688550 & 4.6 & 4.9941 & TRN & \\
\hline CHEMBL 1400003 & 688550 & 4.75 & 4.8836 & TST & \\
\hline CHEMBL1428934 & 688550 & 5.65 & 4.934 & TRN & \\
\hline CHEMBL1416770 & 688550 & 5.35 & 4.7958 & TRN & \\
\hline CHEMBL1537287 & 688550 & 5.05 & 4.8811 & TRN & \\
\hline CHEMBL1350028 & 688550 & 4.6 & 4.7963 & TRN & \\
\hline CHEMBL1366622 & 688550 & 4.5 & 4.8949 & TST & \\
\hline CHEMBL1302931 & 688550 & 4.5 & 4.9792 & TST & \\
\hline CHEMBL1387495 & 688550 & 4.65 & 4.8389 & TST & \\
\hline CHEMBL1309568 & 688550 & 4.5 & 4.9249 & TRN & \\
\hline CHEMBL3207312 & 688550 & 4.65 & 4.8348 & TRN & \\
\hline CHEMBL 1482740 & 688550 & 5.45 & 4.8078 & TRN & \\
\hline CHEMBL1536044 & 688550 & 5.45 & 4.882 & TRN & \\
\hline CHEMBL1402510 & 688550 & 4.55 & 4.7841 & TRN & \\
\hline CHEMBL1525337 & 688550 & 4.75 & 4.9411 & TST & \\
\hline CHEMBL1359537 & 688550 & 4.65 & 4.8376 & TST & \\
\hline CHEMBL1441713 & 688550 & 4.7 & 4.9291 & TRN & \\
\hline CHEMBL1372906 & 688550 & 6.4 & 4.8831 & TST & \\
\hline CHEMBL1438038 & 688550 & 4.55 & 4.9158 & TRN & \\
\hline CHEMBL1595786 & 688550 & 4.65 & 4.7884 & TRN & \\
\hline CHEMBL1496280 & 688550 & 4.55 & 4.79 & TRN & \\
\hline CHEMBL 1417563 & 688550 & 4.45 & 4.9465 & TRN & \\
\hline CHEMBL3191888 & 688550 & 4.7 & 4.7742 & TRN & \\
\hline CHEMBL1522914 & 688550 & 4.4 & 4.8235 & TRN & \\
\hline CHEMBL1509990 & 688550 & 5.0 & 5.034 & TRN & \\
\hline CHEMBL1533819 & 688550 & 5.6 & 4.8158 & TRN & \\
\hline
\end{tabular}




\begin{tabular}{|c|c|c|c|c|c|}
\hline \multicolumn{6}{|c|}{ Supplemental Table S2.txt } \\
\hline CHEMBL1480582 & 688550 & 4.45 & 4.8215 & TRN & \\
\hline CHEMBL 2005284 & 688550 & 4.85 & 4.7702 & TRN & \\
\hline CHEMBL1588741 & 688550 & 4.75 & 4.9361 & TRN & \\
\hline CHEMBL1442910 & 688550 & 4.65 & 4.8702 & TST & \\
\hline CHEMBL1600150 & 688550 & 5.55 & 5.0051 & TRN & \\
\hline CHEMBL1393499 & 688550 & 4.5 & 4.8714 & TRN & \\
\hline CHEMBL1384916 & 688550 & 4.85 & 4.9519 & TRN & \\
\hline CHEMBL1373563 & 688550 & 5.15 & 4.872 & TRN & \\
\hline CHEMBL1338441 & 688550 & 5.55 & 4.8549 & TRN & \\
\hline CHEMBL 245962 & 688550 & 5.3 & 4.8189 & TRN & \\
\hline CHEMBL1540596 & 688550 & 4.55 & 4.8769 & TRN & \\
\hline CHEMBL1380305 & 688550 & 4.85 & 4.9933 & TRN & \\
\hline CHEMBL1539778 & 688550 & 4.6 & 4.9012 & TST & \\
\hline CHEMBL1529994 & 688550 & 4.4 & 4.7633 & TRN & \\
\hline CHEMBL3192752 & 688550 & 5.35 & 4.8481 & TRN & \\
\hline CHEMBL3210051 & 688550 & 5.2 & 4.8901 & TRN & \\
\hline CHEMBL1544221 & 688550 & 4.55 & 4.8209 & TRN & \\
\hline CHEMBL1521187 & 688550 & 5.2 & 4.7509 & TRN & \\
\hline CHEMBL1362870 & 688550 & 5.7 & 4.8289 & TRN & \\
\hline CHEMBL175266 & 688550 & 5.0 & 4.8885 & TST & \\
\hline CHEMBL1543305 & 688550 & 4.4 & 4.8848 & TRN & \\
\hline CHEMBL1458720 & 688550 & 4.95 & 4.8271 & TRN & \\
\hline CHEMBL1575124 & 688550 & 4.85 & 4.8073 & TRN & \\
\hline CHEMBL1324618 & 688550 & 4.8 & 4.7057 & TRN & \\
\hline CHEMBL1550078 & 688550 & 4.4 & 4.7119 & TRN & \\
\hline CHEMBL1504320 & 688550 & 4.6 & 4.8997 & TRN & \\
\hline CHEMBL1563581 & 688550 & 4.5 & 4.7038 & TRN & \\
\hline CHEMBL1544136 & 688550 & 5.05 & 4.9757 & TRN & \\
\hline CHEMBL1529871 & 688550 & 4.85 & 4.8717 & TST & \\
\hline CHEMBL1386636 & 688550 & 4.4 & 4.724 & TRN & \\
\hline CHEMBL1369932 & 688550 & 5.3 & 4.8619 & TST & \\
\hline CHEMBL1429164 & 688550 & 4.75 & 4.841 & TRN & \\
\hline CHEMBL1491354 & 688550 & 5.25 & 4.8415 & TRN & \\
\hline CHEMBL1574851 & 688550 & 4.9 & 4.8838 & TRN & \\
\hline CHEMBL1342147 & 688550 & 4.9 & 4.7177 & TRN & \\
\hline CHEMBL1534974 & 688550 & 4.45 & 4.8354 & TRN & \\
\hline CHEMBL1597179 & 688550 & 5.05 & 4.9876 & TRN & \\
\hline CHEMBL1564713 & 688550 & 4.65 & 4.76399 & 9999999999 & TRN \\
\hline CHEMBL1332882 & 688550 & 4.55 & 4.7496 & TRN & \\
\hline CHEMBL1603695 & 688550 & 5.55 & 4.7107 & TRN & \\
\hline CHEMBL1420782 & 688550 & 4.4 & 4.9469 & TRN & \\
\hline CHEMBL1506006 & 688550 & 4.95 & 5.00899 & 99999999995 & TRN \\
\hline CHEMBL1403024 & 688550 & 5.25 & 4.7239 & TRN & \\
\hline CHEMBL1606966 & 688550 & 5.95 & 4.9305 & TRN & \\
\hline CHEMBL1609413 & 688550 & 4.6 & 4.92399 & 99999999995 & TRN \\
\hline CHEMBL1450104 & 688550 & 5.15 & 4.8958 & TRN & \\
\hline CHEMBL1600311 & 688550 & 4.45 & 4.8218 & TRN & \\
\hline CHEMBL1308799 & 688550 & 4.55 & 4.838 & TST & \\
\hline
\end{tabular}




\begin{tabular}{|c|c|c|c|c|c|}
\hline \multicolumn{6}{|c|}{ Supplemental Table S2.txt } \\
\hline CHEMBL1318728 & 688550 & 4.85 & 4.9239 & TRN & \\
\hline CHEMBL1384630 & 688550 & 4.85 & 4.8774 & TST & \\
\hline CHEMBL1409800 & 688550 & 4.85 & 4.8913 & TRN & \\
\hline CHEMBL3194770 & 688550 & 4.8 & 4.8037 & TRN & \\
\hline CHEMBL1608377 & 688550 & 5.15 & 4.8782 & TRN & \\
\hline CHEMBL1342038 & 688550 & 5.25 & 4.75899 & 99999999995 & TRN \\
\hline CHEMBL1421468 & 688550 & 4.75 & 4.8226 & TRN & \\
\hline CHEMBL1596675 & 688550 & 5.05 & 4.8905 & TST & \\
\hline CHEMBL1347028 & 688550 & 5.35 & 4.7936 & TRN & \\
\hline CHEMBL1327488 & 688550 & 4.9 & 4.8759 & TST & \\
\hline CHEMBL1484539 & 688550 & 4.4 & 4.8463 & TST & \\
\hline CHEMBL3212666 & 688550 & 4.45 & 4.8469 & TRN & \\
\hline CHEMBL1442065 & 688550 & 5.55 & 4.8904 & TRN & \\
\hline CHEMBL1334719 & 688550 & 4.8 & 4.8816 & TST & \\
\hline CHEMBL1349067 & 688550 & 4.75 & 4.7696 & TRN & \\
\hline CHEMBL1516017 & 688550 & 6.3 & 4.99100 & 00000000005 & TRN \\
\hline CHEMBL1337405 & 688550 & 4.55 & 4.8549 & TRN & \\
\hline CHEMBL1426521 & 688550 & 5.35 & 4.9708 & TRN & \\
\hline CHEMBL1412129 & 688550 & 4.85 & 4.84 & TST & \\
\hline CHEMBL3192383 & 688550 & 4.75 & 4.8969 & TRN & \\
\hline CHEMBL1406734 & 688550 & 4.5 & 4.8132 & TRN & \\
\hline CHEMBL1526855 & 688550 & 5.45 & 4.9077 & TRN & \\
\hline CHEMBL3193861 & 688550 & 4.55 & 4.8461 & TRN & \\
\hline CHEMBL1392222 & 688550 & 4.5 & 4.8531 & TRN & \\
\hline CHEMBL1519576 & 688550 & 4.4 & 4.8413 & TRN & \\
\hline CHEMBL1571752 & 688550 & 4.4 & 4.9054 & TST & \\
\hline CHEMBL1610783 & 688550 & 4.8 & 4.7153 & TRN & \\
\hline CHEMBL1502908 & 688550 & 4.6 & 4.7646 & TRN & \\
\hline CHEMBL1301457 & 688550 & 6.1 & 4.898 & TRN & \\
\hline CHEMBL1479542 & 688550 & 5.05 & 4.8046 & TRN & \\
\hline CHEMBL1536211 & 688550 & 4.4 & 4.988 & TRN & \\
\hline CHEMBL1381708 & 688550 & 4.4 & 4.8902 & TRN & \\
\hline CHEMBL1404090 & 688550 & 4.7 & 4.8299 & TRN & \\
\hline CHEMBL1448625 & 688550 & 4.75 & 4.7993 & TRN & \\
\hline CHEMBL3193575 & 688550 & 4.55 & 4.8103 & TRN & \\
\hline CHEMBL1529359 & 688550 & 4.6 & 4.8676 & TRN & \\
\hline CHEMBL1383340 & 688550 & 4.8 & 4.8373 & TST & \\
\hline CHEMBL3209768 & 688550 & 4.7 & 4.8716 & TST & \\
\hline CHEMBL1458929 & 688550 & 4.55 & 4.8271 & TRN & \\
\hline CHEMBL1469505 & 688550 & 4.8 & 4.9003 & TRN & \\
\hline CHEMBL1457996 & 688550 & 4.4 & 4.9217 & TRN & \\
\hline CHEMBL1600669 & 688550 & 4.55 & 4.9484 & TST & \\
\hline CHEMBL1521330 & 688550 & 4.45 & 4.7473 & TRN & \\
\hline CHEMBL1305721 & 688550 & 4.85 & 4.8441 & TST & \\
\hline CHEMBL1387866 & 688550 & 5.2 & 4.8469 & TRN & \\
\hline CHEMBL1527314 & 688550 & 4.4 & 4.8316 & TST & \\
\hline CHEMBL322036 & 688550 & 4.5 & 4.8165 & TST & \\
\hline CHEMBL1540717 & 688550 & 4.6 & 4.8891 & TST & \\
\hline
\end{tabular}




\begin{tabular}{|c|c|c|c|c|}
\hline \multicolumn{5}{|c|}{ Supplemental Table S2.txt } \\
\hline CHEMBL1330930 & 688550 & 5.1 & 5.0308 & TRN \\
\hline CHEMBL1465541 & 688550 & 4.8 & 4.9153 & TRN \\
\hline CHEMBL408850 & 688550 & 4.8 & 4.7493 & TRN \\
\hline CHEMBL1509092 & 688550 & 4.6 & 4.9091 & TRN \\
\hline CHEMBL1518446 & 688550 & 4.55 & 4.8313 & TRN \\
\hline CHEMBL1605011 & 688550 & 4.4 & 4.9208 & TRN \\
\hline CHEMBL1341399 & 688550 & 4.75 & 4.856 & TRN \\
\hline CHEMBL1609703 & 688550 & 5.2 & 4.8165 & TST \\
\hline CHEMBL1343392 & 688550 & 4.4 & 4.8645 & TRN \\
\hline CHEMBL1544306 & 688550 & 4.55 & 4.8043 & TRN \\
\hline CHEMBL1467714 & 688550 & 4.5 & 4.8484 & TRN \\
\hline CHEMBL1495685 & 688550 & 5.65 & 4.8094 & TRN \\
\hline CHEMBL1440220 & 688550 & 4.4 & 4.841 & TRN \\
\hline CHEMBL1533390 & 688550 & 4.8 & 5.0142 & TRN \\
\hline CHEMBL1509858 & 688550 & 7.4001 & 4.9328 & TST \\
\hline CHEMBL1378295 & 688550 & 4.6 & 4.9056 & TRN \\
\hline CHEMBL1543309 & 688550 & 5.05 & 4.8862 & TRN \\
\hline CHEMBL3191594 & 688550 & 5.0 & 4.8455 & TRN \\
\hline CHEMBL1581007 & 688550 & 5.55 & 4.8292 & TRN \\
\hline CHEMBL1348358 & 688550 & 5.0 & 4.8747 & TRN \\
\hline CHEMBL1459185 & 688550 & 5.4 & 4.8275 & TRN \\
\hline CHEMBL1499853 & 688550 & 4.95 & 4.8758 & TRN \\
\hline CHEMBL1565157 & 688550 & 5.4 & 5.0576 & TRN \\
\hline CHEMBL1600475 & 688550 & 4.5 & 4.8558 & TRN \\
\hline CHEMBL1565838 & 688550 & 4.95 & 5.0202 & TRN \\
\hline CHEMBL1449208 & 688550 & 4.6 & 4.8589 & TRN \\
\hline CHEMBL 3192753 & 688550 & 4.8 & 4.8288 & TRN \\
\hline CHEMBL1470956 & 688550 & 4.4 & 5.0872 & TRN \\
\hline CHEMBL1321058 & 688550 & 4.55 & 4.8699 & TRN \\
\hline CHEMBL3194724 & 688550 & 4.5 & 4.8714 & TRN \\
\hline CHEMBL1539710 & 688550 & 4.6 & 4.8423 & TST \\
\hline CHEMBL1413901 & 688550 & 4.6 & 4.7352 & TRN \\
\hline CHEMBL1383533 & 688550 & 4.45 & 4.8438 & TRN \\
\hline CHEMBL1573273 & 688550 & 4.65 & 4.8206 & TRN \\
\hline CHEMBL1339591 & 688550 & 4.8 & 4.8258 & TST \\
\hline CHEMBL1325757 & 688550 & 4.55 & 4.7809 & TRN \\
\hline CHEMBL1404910 & 688550 & 4.5 & 4.822 & TRN \\
\hline CHEMBL1371578 & 688550 & 4.8 & 4.8774 & TST \\
\hline CHEMBL1507757 & 688550 & 4.65 & 4.6699 & TRN \\
\hline CHEMBL1413557 & 688550 & 4.75 & 4.771 & TRN \\
\hline CHEMBL1384851 & 688550 & 5.25 & 4.8682 & TRN \\
\hline CHEMBL1425516 & 688550 & 4.65 & 4.8322 & TRN \\
\hline CHEMBL1387816 & 688550 & 4.6 & 4.8735 & TRN \\
\hline CHEMBL1574759 & 688550 & 4.4 & 4.8539 & TRN \\
\hline CHEMBL1504800 & 688550 & 5.4 & 4.8094 & TST \\
\hline CHEMBL1371396 & 688550 & 4.4 & 4.9181 & TST \\
\hline CHEMBL1610169 & 688550 & 5.25 & 4.7816 & TST \\
\hline CHEMBL1304445 & 688550 & 4.4 & 4.8448 & TRN \\
\hline
\end{tabular}




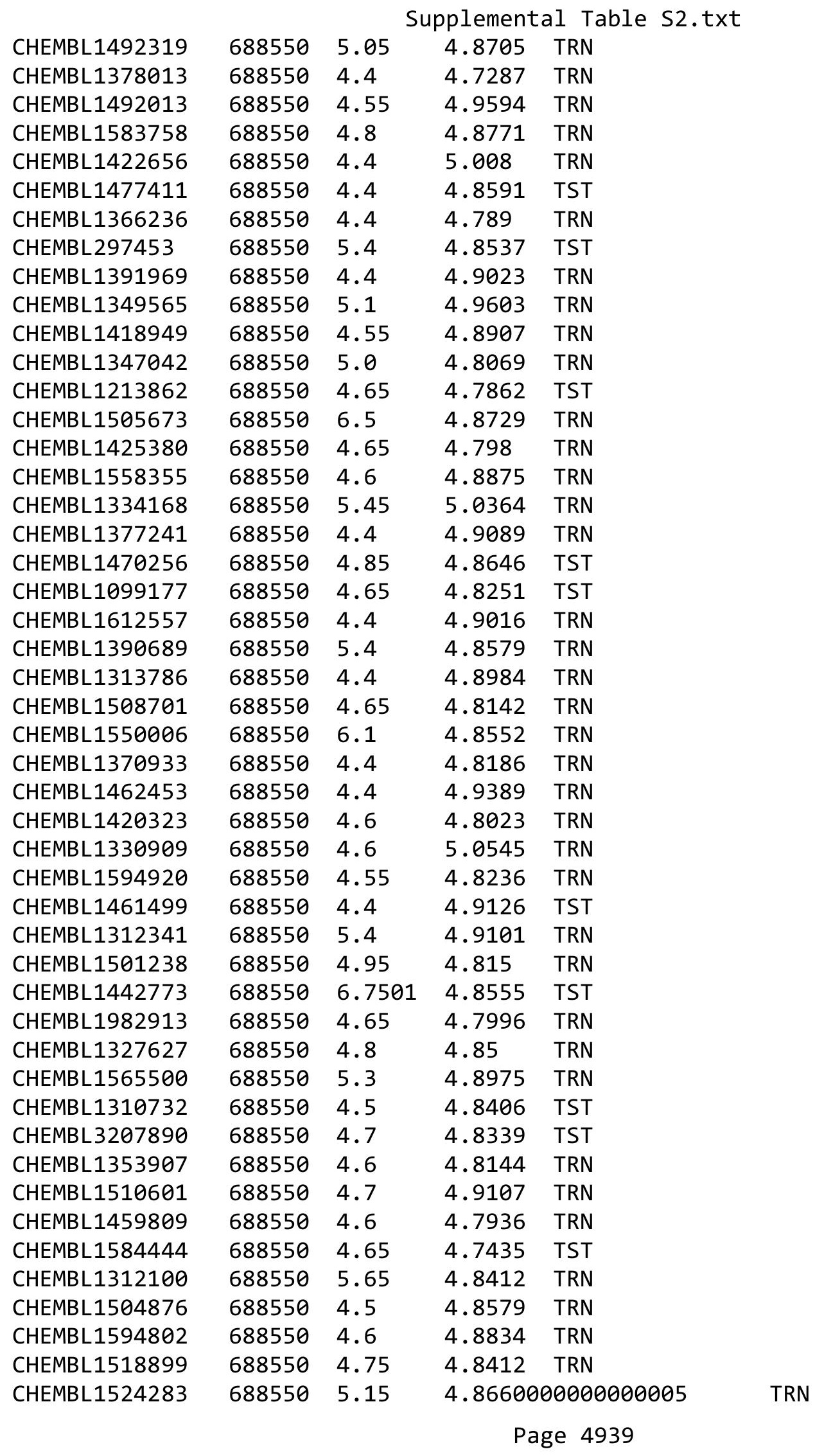




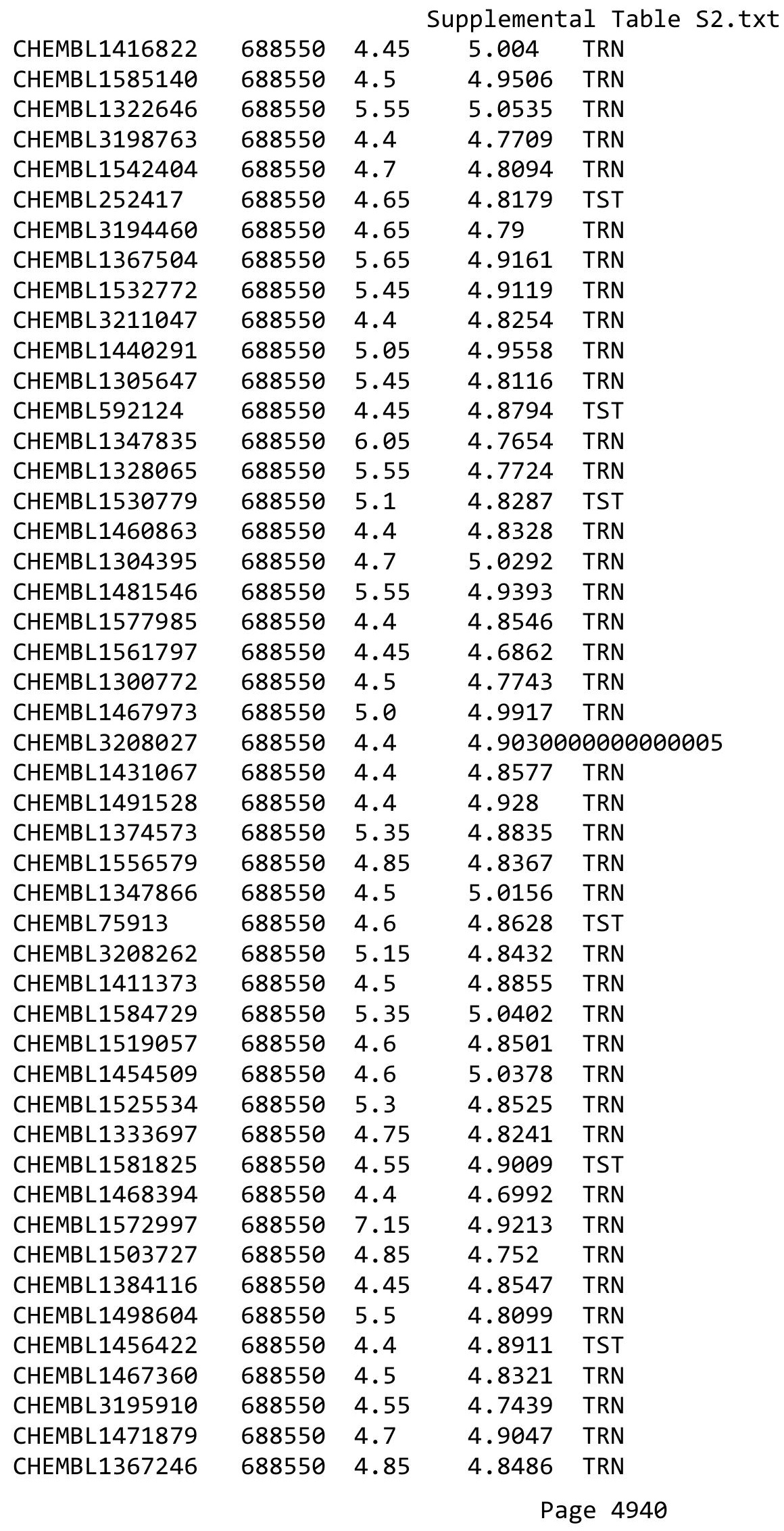




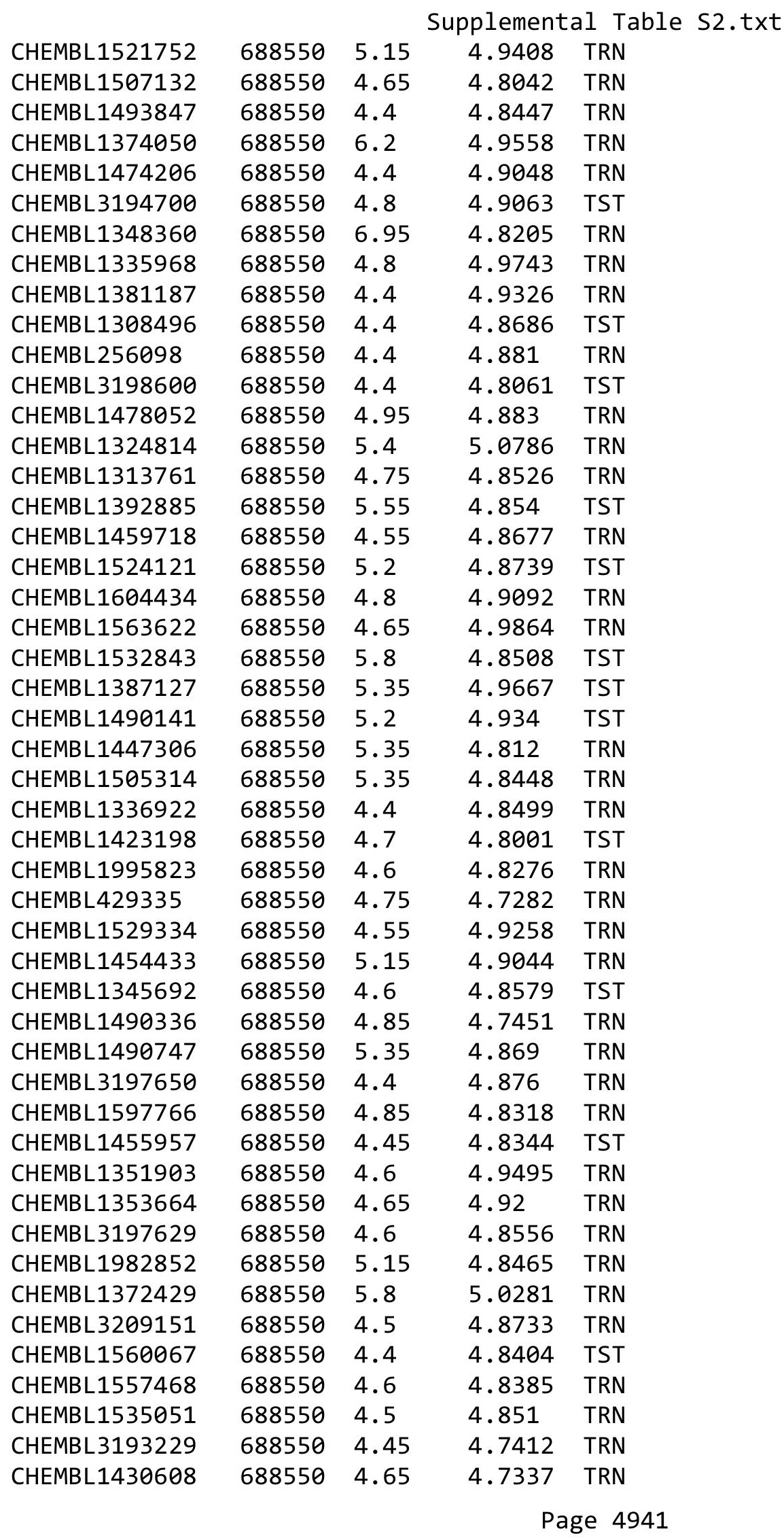




\begin{tabular}{|c|c|c|c|c|c|}
\hline \multicolumn{6}{|c|}{ Supplemental Table s2.txt } \\
\hline CHEMBL1481492 & 688550 & 5.5 & 4.8519 & TST & \\
\hline CHEMBL1448479 & 688550 & 5.2 & 4.8839 & TST & \\
\hline CHEMBL1459912 & 688550 & 4.65 & 4.8648 & TRN & \\
\hline CHEMBL1359820 & 688550 & 4.4 & 4.9588 & TRN & \\
\hline CHEMBL1531802 & 688550 & 5.35 & 4.8892 & TRN & \\
\hline CHEMBL1439777 & 688550 & 4.85 & 4.8673 & TRN & \\
\hline CHEMBL1588809 & 688550 & 4.4 & 4.9038 & TRN & \\
\hline CHEMBL1415866 & 688550 & 4.7 & 4.8634 & TRN & \\
\hline CHEMBL1301438 & 688550 & 4.8 & 4.8833 & TRN & \\
\hline CHEMBL1392842 & 688550 & 4.5 & 4.7413 & TRN & \\
\hline CHEMBL1558540 & 688550 & 4.45 & 4.7474 & TRN & \\
\hline CHEMBL1598317 & 688550 & 6.05 & 4.8571 & TRN & \\
\hline CHEMBL1346130 & 688550 & 4.65 & 5.0233 & TRN & \\
\hline CHEMBL1531728 & 688550 & 4.4 & 4.8284 & TRN & \\
\hline CHEMBL1572440 & 688550 & 4.55 & 4.8712 & TRN & \\
\hline CHEMBL1304955 & 688550 & 4.4 & 4.7345 & TRN & \\
\hline CHEMBL1538023 & 688550 & 4.45 & 4.8409 & TRN & \\
\hline CHEMBL66953 & 688550 & 4.8 & 4.8242 & TST & \\
\hline CHEMBL3193016 & 688550 & 4.75 & 4.6762 & TRN & \\
\hline CHEMBL1444465 & 688550 & 4.4 & 4.95100 & 00000000005 & TRN \\
\hline CHEMBL1572289 & 688550 & 4.75 & 4.9993 & TRN & \\
\hline CHEMBL1526761 & 688550 & 6.2 & 4.8719 & TRN & \\
\hline CHEMBL1985932 & 688550 & 4.4 & 4.8526 & TST & \\
\hline CHEMBL1404559 & 688550 & 4.9 & 4.8541 & TRN & \\
\hline CHEMBL1375217 & 688550 & 4.4 & 4.8676 & TRN & \\
\hline CHEMBL1327498 & 688550 & 4.55 & 4.8875 & TRN & \\
\hline CHEMBL3193188 & 688550 & 4.85 & 4.941 & TST & \\
\hline CHEMBL1307360 & 688550 & 4.5 & 4.8511 & TRN & \\
\hline CHEMBL1380781 & 688550 & 5.2 & 4.8129 & TRN & \\
\hline CHEMBL1581944 & 688550 & 5.25 & 4.9182 & TST & \\
\hline CHEMBL1458771 & 688550 & 5.45 & 4.8372 & TRN & \\
\hline CHEMBL1990418 & 688550 & 4.9 & 4.9312 & TST & \\
\hline CHEMBL1490970 & 688550 & 6.0 & 4.8097 & TRN & \\
\hline CHEMBL1342337 & 688550 & 5.55 & 4.9343 & TRN & \\
\hline CHEMBL3199771 & 688550 & 5.2 & 4.8664 & TRN & \\
\hline CHEMBL1549704 & 688550 & 5.3 & 5.03600 & 00000000005 & TRN \\
\hline CHEMBL1400583 & 688550 & 4.4 & 4.817 & TRN & \\
\hline CHEMBL1302917 & 688550 & 5.35 & 4.84399 & 9999999999 & TRN \\
\hline CHEMBL1342141 & 688550 & 4.5 & 4.8247 & TRN & \\
\hline CHEMBL1320234 & 688550 & 5.8 & 4.7948 & TRN & \\
\hline CHEMBL1588050 & 688550 & 4.55 & 4.8278 & TRN & \\
\hline CHEMBL1485349 & 688550 & 6.25 & 4.8833 & TRN & \\
\hline CHEMBL1305805 & 688550 & 4.55 & 4.9387 & TRN & \\
\hline CHEMBL1443467 & 688550 & 4.4 & 4.9457 & TRN & \\
\hline CHEMBL1471809 & 688550 & 5.4 & 4.8812 & TST & \\
\hline CHEMBL1491855 & 688550 & 5.3 & 4.8131 & TRN & \\
\hline CHEMBL1541866 & 688550 & 4.6 & 4.9947 & TRN & \\
\hline CHEMBL1501868 & 688550 & 4.8 & 4.8121 & TRN & \\
\hline
\end{tabular}




\begin{tabular}{|c|c|c|c|c|c|}
\hline & & \multicolumn{4}{|c|}{ Supplemental Table S2.txt } \\
\hline CHEMBL1533294 & 688550 & 4.45 & 4.8381 & TST & \\
\hline CHEMBL1379862 & 688550 & 4.85 & 4.8081 & TRN & \\
\hline CHEMBL1604679 & 688550 & 5.0 & 4.9078 & TRN & \\
\hline CHEMBL1493936 & 688550 & 5.4 & 4.8241 & TRN & \\
\hline CHEMBL1333118 & 688550 & 4.9 & 4.8709 & TRN & \\
\hline CHEMBL1454772 & 688550 & 5.15 & 4.8195 & TST & \\
\hline CHEMBL1547597 & 688550 & 4.9 & 4.8876 & TST & \\
\hline CHEMBL1516252 & 688550 & 4.75 & 4.8543 & TRN & \\
\hline CHEMBL1360844 & 688550 & 5.2 & 4.8188 & TST & \\
\hline CHEMBL1326881 & 688550 & 4.85 & 4.8005 & TRN & \\
\hline CHEMBL1391246 & 688550 & 4.4 & 4.8959 & TST & \\
\hline CHEMBL3192684 & 688550 & 4.4 & 4.856 & TRN & \\
\hline CHEMBL1381080 & 688550 & 4.8 & 4.9536 & TRN & \\
\hline CHEMBL1564712 & 688550 & 5.05 & 4.8536 & TRN & \\
\hline CHEMBL1485168 & 688550 & 4.55 & 4.84699 & 99999999995 & TRN \\
\hline CHEMBL567422 & 688550 & 5.0 & 4.8352 & TST & \\
\hline CHEMBL3191282 & 688550 & 4.55 & 4.9229 & TRN & \\
\hline CHEMBL3195377 & 688550 & 4.45 & 4.898 & TRN & \\
\hline CHEMBL1611831 & 688550 & 4.4 & 4.9162 & TRN & \\
\hline CHEMBL1348393 & 688550 & 4.55 & 4.7888 & TRN & \\
\hline CHEMBL1318061 & 688550 & 4.45 & 4.9606 & TRN & \\
\hline CHEMBL1604678 & 688550 & 4.8 & 4.8483 & TRN & \\
\hline CHEMBL3211204 & 688550 & 4.55 & 4.78600 & 00000000005 & TRN \\
\hline CHEMBL1502580 & 688550 & 4.5 & 4.8302 & TRN & \\
\hline CHEMBL2005973 & 688550 & 4.5 & 4.8265 & TST & \\
\hline CHEMBL1544407 & 688550 & 4.55 & 4.8168 & TRN & \\
\hline CHEMBL1424364 & 688550 & 5.05 & 4.7657 & TRN & \\
\hline CHEMBL1340455 & 688550 & 5.2 & 4.8509 & TRN & \\
\hline CHEMBL1570148 & 688550 & 4.55 & 4.8239 & TRN & \\
\hline CHEMBL1588105 & 688550 & 4.4 & 4.878 & TRN & \\
\hline CHEMBL1399262 & 688550 & 4.75 & 4.9199 & TRN & \\
\hline CHEMBL3213089 & 688550 & 4.45 & 4.7802 & TRN & \\
\hline CHEMBL1431126 & 688550 & 4.6 & 4.7683 & TRN & \\
\hline CHEMBL1457910 & 688550 & 4.65 & 4.8753 & TRN & \\
\hline CHEMBL1328504 & 688550 & 4.8 & 4.7824 & TRN & \\
\hline CHEMBL1417064 & 688550 & 4.4 & 4.7611 & TRN & \\
\hline CHEMBL1453201 & 688550 & 4.4 & 4.8648 & TST & \\
\hline CHEMBL1309192 & 688550 & 4.95 & 4.9734 & TRN & \\
\hline CHEMBL1313003 & 688550 & 4.4 & 4.7876 & TRN & \\
\hline CHEMBL1432279 & 688550 & 4.85 & 4.9323 & TRN & \\
\hline CHEMBL1569897 & 688550 & 4.45 & 4.934 & TRN & \\
\hline CHEMBL1412821 & 688550 & 4.5 & 4.9149 & TST & \\
\hline CHEMBL1398991 & 688550 & 4.6 & 5.0187 & TRN & \\
\hline CHEMBL1425566 & 688550 & 4.45 & 4.9985 & TRN & \\
\hline CHEMBL1508243 & 688550 & 4.4 & 4.9357 & TRN & \\
\hline CHEMBL1527840 & 688550 & 4.55 & 4.8569 & TRN & \\
\hline CHEMBL1587981 & 688550 & 4.6 & 4.9649 & TRN & \\
\hline CHEMBL1565830 & 688550 & 4.75 & 4.8238 & TRN & \\
\hline
\end{tabular}




\begin{tabular}{|c|c|c|c|c|c|}
\hline & & \multicolumn{4}{|c|}{ Supplemental Table S2.txt } \\
\hline CHEMBL1339512 & 688550 & 4.4 & 4.8729 & TRN & \\
\hline CHEMBL1328356 & 688550 & 4.85 & 4.8494 & TRN & \\
\hline CHEMBL1529827 & 688550 & 5.3 & 4.8938 & TRN & \\
\hline CHEMBL1359468 & 688550 & 4.65 & 4.8801 & TRN & \\
\hline CHEMBL1509528 & 688550 & 4.4 & 4.9074 & TRN & \\
\hline CHEMBL1536935 & 688550 & 4.45 & 4.8536 & TST & \\
\hline CHEMBL3193168 & 688550 & 5.15 & 4.8302 & TST & \\
\hline CHEMBL1613238 & 688550 & 4.7 & 4.8299 & TST & \\
\hline CHEMBL1550342 & 688550 & 4.65 & 4.9324 & TST & \\
\hline CHEMBL1986893 & 688550 & 4.45 & 4.7538 & TRN & \\
\hline CHEMBL1495687 & 688550 & 6.25 & 4.9896 & TRN & \\
\hline CHEMBL1528486 & 688550 & 5.05 & 5.0164 & TRN & \\
\hline CHEMBL1538098 & 688550 & 5.6 & 5.0353 & TRN & \\
\hline CHEMBL1419366 & 688550 & 5.0 & 4.8958 & TST & \\
\hline CHEMBL1596529 & 688550 & 4.6 & 4.9873 & TRN & \\
\hline CHEMBL1336857 & 688550 & 5.1 & 4.8135 & TRN & \\
\hline CHEMBL1300471 & 688550 & 4.65 & 4.8887 & TRN & \\
\hline CHEMBL1551004 & 688550 & 4.45 & 4.8056 & TRN & \\
\hline CHEMBL1531526 & 688550 & 4.6 & 4.8275 & TST & \\
\hline CHEMBL1580946 & 688550 & 4.85 & 4.8715 & TRN & \\
\hline CHEMBL1425986 & 688550 & 4.6 & 4.9137 & TRN & \\
\hline CHEMBL1463463 & 688550 & 5.15 & 4.9012 & TRN & \\
\hline CHEMBL602880 & 688550 & 4.75 & 4.9034 & TRN & \\
\hline CHEMBL1519554 & 688550 & 4.8 & $4.7410 e$ & 00000000005 & TRN \\
\hline CHEMBL1302845 & 688550 & 4.65 & 4.9102 & TRN & \\
\hline CHEMBL1462021 & 688550 & 4.65 & 4.9185 & TRN & \\
\hline CHEMBL1605978 & 688550 & 4.45 & 4.9004 & TST & \\
\hline CHEMBL3196816 & 688550 & 4.5 & 4.8383 & TRN & \\
\hline CHEMBL1555949 & 688550 & 4.9 & 4.8885 & TST & \\
\hline CHEMBL1371188 & 688550 & 4.55 & 4.8453 & TRN & \\
\hline CHEMBL1371592 & 688550 & 4.55 & 4.9798 & TRN & \\
\hline CHEMBL1433203 & 688550 & 4.4 & 4.7353 & TRN & \\
\hline CHEMBL1478124 & 688550 & 5.25 & 4.8961 & TRN & \\
\hline CHEMBL1381005 & 688550 & 4.55 & 4.92 & TRN & \\
\hline CHEMBL1331605 & 688550 & 4.5 & 4.8645 & TST & \\
\hline CHEMBL1542456 & 688550 & 4.65 & 5.0498 & TRN & \\
\hline CHEMBL1538753 & 688550 & 4.55 & 4.784 & TRN & \\
\hline CHEMBL1487834 & 688550 & 5.35 & 4.849 & TRN & \\
\hline CHEMBL1368535 & 688550 & 4.4 & 4.7385 & TST & \\
\hline CHEMBL1524009 & 688550 & 4.9 & 4.8535 & TRN & \\
\hline CHEMBL1486489 & 688550 & 4.4 & 4.8741 & TRN & \\
\hline CHEMBL1331249 & 688550 & 4.9 & 4.9251 & TRN & \\
\hline CHEMBL1587045 & 688550 & 5.5 & 4.8973 & TRN & \\
\hline CHEMBL1391741 & 688550 & 5.3 & 4.8461 & TRN & \\
\hline CHEMBL1361074 & 688550 & 5.5 & 4.8188 & TRN & \\
\hline CHEMBL1302981 & 688550 & 4.4 & 4.87 & TST & \\
\hline CHEMBL1340853 & 688550 & 4.45 & 4.8352 & TRN & \\
\hline CHEMBL3192508 & 688550 & 4.8 & 4.9795 & TRN & \\
\hline
\end{tabular}




\begin{tabular}{|c|c|c|c|c|}
\hline \multicolumn{5}{|c|}{ Supplemental Table S2.txt } \\
\hline CHEMBL3198100 & 688550 & 4.95 & 4.8081 & TRN \\
\hline CHEMBL1494650 & 688550 & 4.45 & 4.886 & TRN \\
\hline CHEMBL1506281 & 688550 & 4.7 & 4.9157 & TRN \\
\hline CHEMBL1587826 & 688550 & 4.65 & 4.8959 & TRN \\
\hline CHEMBL1562631 & 688550 & 4.8 & 4.8816 & TRN \\
\hline CHEMBL1502860 & 688550 & 4.6 & 4.7433 & TRN \\
\hline CHEMBL1578235 & 688550 & 4.45 & 4.8597 & TRN \\
\hline CHEMBL1384322 & 688550 & 4.8 & 4.8678 & TRN \\
\hline CHEMBL1448309 & 688550 & 4.7 & 4.8466 & TST \\
\hline CHEMBL1523079 & 688550 & 5.45 & 4.8752 & TRN \\
\hline CHEMBL1546072 & 688550 & 6.5 & 4.9048 & TRN \\
\hline CHEMBL3194340 & 688550 & 4.45 & 4.7915 & TRN \\
\hline CHEMBL1447002 & 688550 & 5.0 & 4.8421 & TRN \\
\hline CHEMBL1563111 & 688550 & 6.0 & 4.8792 & TRN \\
\hline CHEMBL1541411 & 688550 & 5.05 & 4.8618 & TRN \\
\hline CHEMBL1408955 & 688550 & 4.6 & 4.9062 & TRN \\
\hline CHEMBL1576056 & 688550 & 5.85 & 4.8506 & TRN \\
\hline CHEMBL1589342 & 688550 & 5.1 & 4.8814 & TRN \\
\hline CHEMBL1388544 & 688550 & 4.55 & 4.8179 & TRN \\
\hline CHEMBL42870 & 688550 & 4.75 & 4.8472 & TRN \\
\hline CHEMBL1603175 & 688550 & 4.8 & 4.9282 & TRN \\
\hline CHEMBL1494147 & 688550 & 5.35 & 4.8337 & TRN \\
\hline CHEMBL 260311 & 688550 & 4.7 & 4.7194 & TRN \\
\hline CHEMBL595111 & 688550 & 4.55 & 4.9902 & TRN \\
\hline CHEMBL1500580 & 688550 & 4.7 & 4.8164 & TRN \\
\hline CHEMBL1474864 & 688550 & 5.15 & 4.8689 & TST \\
\hline CHEMBL1529657 & 688550 & 6.7001 & 4.8755 & TRN \\
\hline CHEMBL1346677 & 688550 & 4.8 & 4.8299 & TRN \\
\hline CHEMBL1572006 & 688550 & 5.9 & 4.8934 & TRN \\
\hline CHEMBL1449527 & 688550 & 5.4 & 4.8589 & TRN \\
\hline CHEMBL1599932 & 688550 & 4.9 & 4.9054 & TRN \\
\hline CHEMBL3194151 & 688550 & 4.9 & 4.8648 & TRN \\
\hline CHEMBL1364833 & 688550 & 4.45 & 4.7745 & TRN \\
\hline CHEMBL1584476 & 688550 & 4.9 & 4.8861 & TRN \\
\hline CHEMBL1541244 & 688550 & 4.55 & 4.7083 & TRN \\
\hline CHEMBL1464304 & 688550 & 4.5 & 4.8483 & TRN \\
\hline CHEMBL1585236 & 688550 & 4.65 & 4.8914 & TRN \\
\hline CHEMBL1610118 & 688550 & 5.75 & 4.9175 & TRN \\
\hline CHEMBL1336716 & 688550 & 4.65 & 4.8234 & TRN \\
\hline CHEMBL1576392 & 688550 & 4.45 & 4.9331 & TRN \\
\hline CHEMBL373481 & 688550 & 6.05 & 4.8237 & TST \\
\hline CHEMBL1326709 & 688550 & 4.45 & 4.9979 & TRN \\
\hline CHEMBL1321057 & 688550 & 6.1 & 4.8561 & TRN \\
\hline CHEMBL1600826 & 688550 & 5.35 & 4.8837 & TRN \\
\hline CHEMBL3211179 & 688550 & 5.1 & 4.7949 & TRN \\
\hline CHEMBL1610697 & 688550 & 4.65 & 4.9683 & TRN \\
\hline CHEMBL1417633 & 688550 & 5.35 & 4.8848 & TST \\
\hline CHEMBL1369199 & 688550 & 4.5 & 5.0015 & TRN \\
\hline
\end{tabular}




\begin{tabular}{|c|c|c|c|c|c|}
\hline \multirow{3}{*}{$\begin{array}{l}\text { CHEMBL1604448 } \\
\text { CHEMBL1429330 }\end{array}$} & \multirow{3}{*}{$\begin{array}{l}688550 \\
688550\end{array}$} & \multicolumn{4}{|c|}{ Supplemental Table S2.txt } \\
\hline & & 4.45 & \multicolumn{2}{|c|}{4.928999999999999} & TRN \\
\hline & & 4.4 & 4.6861 & TRN & \\
\hline CHEMBL1486939 & 688550 & 4.45 & 4.7507 & TRN & \\
\hline CHEMBL1517936 & 688550 & 4.45 & 4.9234 & TRN & \\
\hline CHEMBL1301436 & 688550 & 4.4 & 4.8897 & TRN & \\
\hline CHEMBL1447031 & 688550 & 4.9 & 4.928 & TRN & \\
\hline CHEMBL1595632 & 688550 & 5.45 & 4.7823 & TRN & \\
\hline CHEMBL1541324 & 688550 & 4.6 & 4.8558 & TST & \\
\hline CHEMBL1414867 & 688550 & 4.45 & 4.872 & TRN & \\
\hline CHEMBL1498260 & 688550 & 4.65 & 4.9424 & TST & \\
\hline CHEMBL3194706 & 688550 & 4.75 & 4.8331 & TRN & \\
\hline CHEMBL1505968 & 688550 & 4.7 & 4.8254 & TRN & \\
\hline CHEMBL1441977 & 688550 & 6.1 & 5.0223 & TRN & \\
\hline CHEMBL1429510 & 688550 & 4.6 & 4.8931 & TRN & \\
\hline CHEMBL1538717 & 688550 & 5.15 & 4.8615 & TRN & \\
\hline CHEMBL1307608 & 688550 & 4.85 & 4.8968 & TRN & \\
\hline CHEMBL3210521 & 688550 & 4.45 & 4.8109 & TRN & \\
\hline CHEMBL1605917 & 688550 & 5.15 & 4.9663 & TRN & \\
\hline CHEMBL1596108 & 688550 & 4.65 & 4.9696 & TRN & \\
\hline CHEMBL1540218 & 688550 & 5.0 & 4.9671 & TRN & \\
\hline CHEMBL1450324 & 688550 & 4.4 & 4.797 & TRN & \\
\hline CHEMBL1565124 & 688550 & 4.45 & 4.8203 & TRN & \\
\hline CHEMBL1559414 & 688550 & 4.7 & 4.8051 & TRN & \\
\hline CHEMBL590660 & 688550 & 4.45 & 4.7865 & TRN & \\
\hline CHEMBL1470463 & 688550 & 5.5 & 4.8239 & TRN & \\
\hline CHEMBL1561213 & 688550 & 4.4 & 4.9025 & TRN & \\
\hline CHEMBL1385027 & 688550 & 4.8 & 4.823 & TRN & \\
\hline CHEMBL1329764 & 688550 & 4.75 & 4.7959 & TRN & \\
\hline CHEMBL1567704 & 688550 & 4.85 & 4.9158 & TRN & \\
\hline CHEMBL378679 & 688550 & 5.15 & 4.8451 & TRN & \\
\hline CHEMBL1336655 & 688550 & 5.65 & 4.9459 & TRN & \\
\hline CHEMBL1451630 & 688550 & 4.4 & 4.8359 & TRN & \\
\hline CHEMBL1360913 & 688550 & 4.6 & 4.8584 & TRN & \\
\hline CHEMBL1581132 & 688550 & 4.4 & 4.8063 & TRN & \\
\hline CHEMBL1424094 & 688550 & 4.75 & 4.8423 & TRN & \\
\hline CHEMBL1359212 & 688550 & 6.2 & 4.7775 & TRN & \\
\hline CHEMBL1587018 & 688550 & 4.8 & 4.83899 & 99999999995 & TRN \\
\hline CHEMBL1373584 & 688550 & 5.45 & 4.7856 & TRN & \\
\hline CHEMBL3194619 & 688550 & 4.8 & 4.8589 & TST & \\
\hline CHEMBL1419251 & 688550 & 4.7 & 4.8277 & TRN & \\
\hline CHEMBL1612163 & 688550 & 5.0 & 4.9389 & TRN & \\
\hline CHEMBL1387563 & 688550 & 4.55 & 4.8291 & TRN & \\
\hline CHEMBL1321179 & 688550 & 4.85 & 4.9407 & TRN & \\
\hline CHEMBL1596599 & 688550 & 4.7 & 4.8669 & TRN & \\
\hline CHEMBL1308513 & 688550 & 4.5 & 4.9313 & TST & \\
\hline CHEMBL1372929 & 688550 & 5.05 & 4.7967 & TRN & \\
\hline CHEMBL1389241 & 688550 & 4.45 & 4.8561 & TRN & \\
\hline CHEMBL1424454 & 688550 & 4.45 & 4.8704 & TRN & \\
\hline
\end{tabular}




\begin{tabular}{|c|c|c|c|c|c|}
\hline & & \multicolumn{4}{|c|}{ Supplemental Table S2.txt } \\
\hline CHEMBL1495038 & 688550 & 4.95 & 4.9647 & TRN & \\
\hline CHEMBL1544171 & 688550 & 5.1 & 5.0151 & TRN & \\
\hline CHEMBL1431326 & 688550 & 4.4 & 4.7205 & TRN & \\
\hline CHEMBL1413879 & 688550 & 6.5 & 4.872 & TST & \\
\hline CHEMBL1585250 & 688550 & 5.75 & 4.9106 & TRN & \\
\hline CHEMBL1333190 & 688550 & 4.6 & 4.8074 & TRN & \\
\hline CHEMBL1524978 & 688550 & 4.5 & 4.9314 & TRN & \\
\hline CHEMBL3210421 & 688550 & 4.45 & 4.7754 & TRN & \\
\hline CHEMBL1509919 & 688550 & 4.85 & 4.8407 & TRN & \\
\hline CHEMBL1587145 & 688550 & 4.5 & 4.8084 & TRN & \\
\hline CHEMBL1327251 & 688550 & 4.6 & 4.8935 & TST & \\
\hline CHEMBL1509755 & 688550 & 4.5 & 4.8409 & TRN & \\
\hline CHEMBL1498693 & 688550 & 5.4 & 4.9268 & TRN & \\
\hline CHEMBL1580684 & 688550 & 4.55 & 4.9086 & TRN & \\
\hline CHEMBL1519434 & 688550 & 5.1 & 4.8078 & TRN & \\
\hline CHEMBL1323985 & 688550 & 4.6 & 4.7661 & TRN & \\
\hline CHEMBL1586236 & 688550 & 5.4 & 5.0055 & TRN & \\
\hline CHEMBL3214466 & 688550 & 4.4 & 4.7369 & TST & \\
\hline CHEMBL1571426 & 688550 & 4.65 & 4.7977 & TRN & \\
\hline CHEMBL1540894 & 688550 & 4.9 & 4.8182 & TRN & \\
\hline CHEMBL1427476 & 688550 & 4.65 & 4.7986 & TRN & \\
\hline CHEMBL1479319 & 688550 & 4.75 & 4.9398 & TRN & \\
\hline CHEMBL1307806 & 688550 & 4.55 & 4.8278 & TRN & \\
\hline CHEMBL1506395 & 688550 & 6.4 & 4.9895 & TRN & \\
\hline CHEMBL1382438 & 688550 & 4.85 & 4.83899 & 99999999995 & TRN \\
\hline CHEMBL1402698 & 688550 & 4.45 & 4.7612 & TRN & \\
\hline CHEMBL1443090 & 688550 & 6.35 & 4.8769 & TST & \\
\hline CHEMBL1312303 & 688550 & 4.4 & 4.7701 & TRN & \\
\hline CHEMBL1575115 & 688550 & 4.95 & 4.9318 & TRN & \\
\hline CHEMBL3189395 & 688550 & 4.5 & 4.8348 & TRN & \\
\hline CHEMBL1328731 & 688550 & 4.85 & 5.0381 & TRN & \\
\hline CHEMBL1366431 & 688550 & 4.4 & 4.7731 & TRN & \\
\hline CHEMBL1524968 & 688550 & 4.55 & 4.966 & TRN & \\
\hline CHEMBL3190025 & 688550 & 4.45 & 4.7832 & TRN & \\
\hline CHEMBL1434324 & 688550 & 5.35 & 4.9328 & TRN & \\
\hline CHEMBL1349125 & 688550 & 4.45 & 4.8312 & TST & \\
\hline CHEMBL1463706 & 688550 & 4.75 & 4.8201 & TRN & \\
\hline CHEMBL1337367 & 688550 & 4.5 & 4.7646 & TRN & \\
\hline CHEMBL251998 & 688550 & 4.4 & 4.8925 & TRN & \\
\hline CHEMBL1543251 & 688550 & 4.55 & 4.8353 & TRN & \\
\hline CHEMBL512048 & 688550 & 4.9 & 4.7105 & TRN & \\
\hline CHEMBL1599320 & 688550 & 4.5 & 4.8389 & TRN & \\
\hline CHEMBL1564490 & 688550 & 4.65 & 4.8318 & TRN & \\
\hline CHEMBL1500066 & 688550 & 4.3 & 4.8023 & TRN & \\
\hline CHEMBL3190456 & 688550 & 4.4 & 4.7618 & TRN & \\
\hline CHEMBL1414534 & 688550 & 5.05 & 4.8071 & TRN & \\
\hline CHEMBL1359534 & 688550 & 5.2 & 4.8784 & TST & \\
\hline CHEMBL3193859 & 688550 & 4.4 & 4.777 & TRN & \\
\hline
\end{tabular}




\begin{tabular}{|c|c|c|c|c|c|}
\hline \multicolumn{6}{|c|}{ Supplemental Table S2.txt } \\
\hline CHEMBL1338926 & 688550 & 4.6 & 4.8349 & TRN & \\
\hline CHEMBL1469774 & 688550 & 5.15 & 4.8803 & TRN & \\
\hline CHEMBL1349446 & 688550 & 4.95 & 4.8243 & TRN & \\
\hline CHEMBL1352516 & 688550 & 5.35 & 4.8865 & TRN & \\
\hline CHEMBL1407667 & 688550 & 6.95 & 4.8555 & TRN & \\
\hline CHEMBL3209338 & 688550 & 6.5 & 4.86600 & 00000000005 & TRN \\
\hline CHEMBL1398981 & 688550 & 4.9 & 4.948 & TRN & \\
\hline CHEMBL1471458 & 688550 & 4.4 & 4.8666 & TRN & \\
\hline CHEMBL1527911 & 688550 & 4.7 & 5.0642 & TRN & \\
\hline CHEMBL1978120 & 688550 & 4.85 & 4.8623 & TRN & \\
\hline CHEMBL1332604 & 688550 & 5.2 & 4.9334 & TRN & \\
\hline CHEMBL229359 & 688550 & 4.4 & 4.776 & TRN & \\
\hline CHEMBL1300246 & 688550 & 4.5 & 4.8874 & TRN & \\
\hline CHEMBL1408705 & 688550 & 4.65 & 4.833 & TRN & \\
\hline CHEMBL1966921 & 688550 & 4.85 & 4.752 & TRN & \\
\hline CHEMBL1543184 & 688550 & 4.6 & 4.8827 & TRN & \\
\hline CHEMBL1326359 & 688550 & 6.05 & 4.7965 & TRN & \\
\hline CHEMBL1587263 & 688550 & 4.65 & 4.8823 & TRN & \\
\hline CHEMBL1360965 & 688550 & 4.6 & 4.8899 & TRN & \\
\hline CHEMBL1501067 & 688550 & 4.8 & 4.9964 & TRN & \\
\hline CHEMBL1527176 & 688550 & 5.15 & 4.7463 & TRN & \\
\hline CHEMBL1401431 & 688550 & 4.75 & 4.8929 & TRN & \\
\hline CHEMBL1381008 & 688550 & 4.4 & 4.8971 & TRN & \\
\hline CHEMBL1338033 & 688550 & 5.15 & 4.8706 & TRN & \\
\hline CHEMBL1381157 & 688550 & 4.8 & 4.883 & TRN & \\
\hline CHEMBL1368665 & 688550 & 4.5 & 4.8565 & TRN & \\
\hline CHEMBL1390100 & 688550 & 5.4 & 4.7951 & TST & \\
\hline CHEMBL1378876 & 688550 & 4.5 & 4.8682 & TRN & \\
\hline CHEMBL1573120 & 688550 & 4.95 & 4.789 & TRN & \\
\hline CHEMBL1468238 & 688550 & 4.45 & 4.8631 & TRN & \\
\hline CHEMBL1369177 & 688550 & 4.8 & 4.8147 & TRN & \\
\hline CHEMBL1432332 & 688550 & 4.8 & 4.9188 & TRN & \\
\hline CHEMBL1480448 & 688550 & 5.15 & 4.8913 & TRN & \\
\hline CHEMBL1462244 & 688550 & 4.5 & 4.7114 & TRN & \\
\hline CHEMBL1335690 & 688550 & 5.5 & 4.8894 & TRN & \\
\hline CHEMBL1455535 & 688550 & 4.9 & 4.8885 & TRN & \\
\hline CHEMBL1508177 & 688550 & 5.5 & 4.8612 & TRN & \\
\hline CHEMBL1412922 & 688550 & 4.4 & 4.83 & TRN & \\
\hline CHEMBL1522025 & 688550 & 4.55 & 4.8074 & TRN & \\
\hline CHEMBL1448617 & 688550 & 4.4 & 4.9617 & TRN & \\
\hline CHEMBL1995193 & 688550 & 4.55 & 4.7148 & TRN & \\
\hline CHEMBL1519022 & 688550 & 4.8 & 4.9316 & TRN & \\
\hline CHEMBL460508 & 688550 & 4.55 & 4.7217 & TRN & \\
\hline CHEMBL1459949 & 688550 & 4.8 & 4.8488 & TRN & \\
\hline CHEMBL1363581 & 688550 & 4.4 & 4.9116 & TST & \\
\hline CHEMBL1331600 & 688550 & 4.6 & 4.8511 & TRN & \\
\hline CHEMBL1329272 & 688550 & 4.9 & 4.7689 & TRN & \\
\hline CHEMBL1576906 & 688550 & 4.4 & 4.8636 & TST & \\
\hline
\end{tabular}




\begin{tabular}{|c|c|c|c|c|c|}
\hline & & \multicolumn{4}{|c|}{ Supplemental Table S2.txt } \\
\hline CHEMBL1457179 & 688550 & 4.55 & 4.8653 & TRN & \\
\hline CHEMBL1359006 & 688550 & 4.55 & 4.8441 & TRN & \\
\hline CHEMBL305978 & 688550 & 4.6 & 4.6947 & TRN & \\
\hline CHEMBL1422767 & 688550 & 4.6 & 4.9489 & TST & \\
\hline CHEMBL1388130 & 688550 & 6.0 & 4.966 & TRN & \\
\hline CHEMBL1359354 & 688550 & 5.05 & 4.8102 & TRN & \\
\hline CHEMBL1469653 & 688550 & 4.8 & 4.8977 & TRN & \\
\hline CHEMBL1528959 & 688550 & 4.6 & 4.95 & TRN & \\
\hline CHEMBL1342598 & 688550 & 4.5 & 4.7977 & TRN & \\
\hline CHEMBL1309107 & 688550 & 5.0 & 4.8302 & TST & \\
\hline CHEMBL1528450 & 688550 & 4.95 & 4.8201 & TST & \\
\hline CHEMBL1606007 & 688550 & 4.6 & 4.8654 & TST & \\
\hline CHEMBL1550085 & 688550 & 5.0 & 4.8194 & TRN & \\
\hline CHEMBL1605212 & 688550 & 4.5 & 4.9208 & TRN & \\
\hline CHEMBL29542 & 688550 & 4.7 & 4.8689 & TRN & \\
\hline CHEMBL1439220 & 688550 & 4.65 & 4.9982 & TRN & \\
\hline CHEMBL1354063 & 688550 & 5.0 & 4.8109 & TST & \\
\hline CHEMBL1516879 & 688550 & 4.7 & 4.81 & TRN & \\
\hline CHEMBL1387514 & 688550 & 4.55 & 4.8507 & TRN & \\
\hline CHEMBL1970272 & 688550 & 4.95 & 4.9127 & TST & \\
\hline CHEMBL1348419 & 688550 & 4.4 & 4.8952 & TST & \\
\hline CHEMBL1313196 & 688550 & 4.4 & 4.9387 & TST & \\
\hline CHEMBL1522413 & 688550 & 4.85 & 4.8094 & TRN & \\
\hline CHEMBL1425705 & 688550 & 4.4 & 4.7939 & TST & \\
\hline CHEMBL1440902 & 688550 & 4.55 & 4.8376 & TRN & \\
\hline CHEMBL1563161 & 688550 & 4.6 & 4.8302 & TRN & \\
\hline CHEMBL1431953 & 688550 & 5.05 & 4.883 & TST & \\
\hline CHEMBL1606600 & 688550 & 6.1 & 4.852 & TRN & \\
\hline CHEMBL1585691 & 688550 & 4.65 & 4.8148 & TRN & \\
\hline CHEMBL1543588 & 688550 & 4.6 & 4.8123 & TRN & \\
\hline CHEMBL1375360 & 688550 & 5.2 & 4.817 & TRN & \\
\hline CHEMBL1370195 & 688550 & 4.7 & 5.042 & TRN & \\
\hline CHEMBL1454092 & 688550 & 4.9 & 4.9516 & TRN & \\
\hline CHEMBL1299882 & 688550 & 5.15 & 4.8124 & TRN & \\
\hline CHEMBL1580767 & 688550 & 4.45 & 4.9361 & TRN & \\
\hline CHEMBL1366957 & 688550 & 4.6 & 4.8106 & TRN & \\
\hline CHEMBL1362291 & 688550 & 4.55 & 4.8834 & TRN & \\
\hline CHEMBL 3198440 & 688550 & 4.45 & 4.84699 & 99999999995 & TRN \\
\hline CHEMBL1411673 & 688550 & 4.85 & 4.84699 & 99999999995 & TRN \\
\hline CHEMBL 2004475 & 688550 & 4.95 & 4.8817 & TST & \\
\hline CHEMBL1985165 & 688550 & 4.55 & 4.7567 & TRN & \\
\hline CHEMBL1568612 & 688550 & 4.6 & 4.7987 & TRN & \\
\hline CHEMBL1322072 & 688550 & 5.4 & 4.8312 & TRN & \\
\hline CHEMBL 2000670 & 688550 & 4.85 & 4.7368 & TRN & \\
\hline CHEMBL1499013 & 688550 & 4.8 & 4.8456 & TST & \\
\hline CHEMBL1465944 & 688550 & 5.35 & 4.9161 & TST & \\
\hline CHEMBL3209946 & 688550 & 5.15 & 4.9449 & TRN & \\
\hline CHEMBL1971404 & 688550 & 4.4 & 4.8163 & TRN & \\
\hline
\end{tabular}




\begin{tabular}{|c|c|c|c|c|}
\hline & & & pplemen & \\
\hline CHEMBL1567444 & 688550 & 4.55 & 4.9558 & TRN \\
\hline CHEMBL1447252 & 688550 & 5.95 & 4.825 & TRN \\
\hline CHEMBL1426320 & 688550 & 4.6 & 4.9189 & TRN \\
\hline CHEMBL1440626 & 688550 & 4.65 & 4.8496 & TRN \\
\hline CHEMBL1414231 & 688550 & 4.8 & 4.883 & TRN \\
\hline CHEMBL1400641 & 688550 & 6.1 & 4.8416 & TRN \\
\hline CHEMBL1402302 & 688550 & 5.05 & 4.8798 & TST \\
\hline CHEMBL1446929 & 688550 & 4.45 & 4.8679 & TST \\
\hline CHEMBL1496495 & 688550 & 5.2 & 5.0018 & TRN \\
\hline CHEMBL3190169 & 688550 & 4.95 & 4.8372 & TRN \\
\hline CHEMBL1389177 & 688550 & 5.4 & 4.7139 & TRN \\
\hline CHEMBL1544484 & 688550 & 4.95 & 4.9374 & TST \\
\hline CHEMBL 221415 & 688550 & 4.4 & 4.7942 & TRN \\
\hline CHEMBL1522989 & 688550 & 4.65 & 4.6761 & TRN \\
\hline CHEMBL1410425 & 688550 & 4.5 & 4.8954 & TRN \\
\hline CHEMBL1373059 & 688550 & 5.2 & 4.8566 & TRN \\
\hline CHEMBL1378111 & 688550 & 4.45 & 4.8574 & TRN \\
\hline CHEMBL1341869 & 688550 & 5.55 & 5.0081 & TRN \\
\hline CHEMBL1586765 & 688550 & 5.1 & 4.9691 & TRN \\
\hline CHEMBL1541183 & 688550 & 4.7 & 4.712 & TRN \\
\hline CHEMBL1340736 & 688550 & 6.5 & 4.864 & TRN \\
\hline CHEMBL1565717 & 688550 & 6.0 & 4.8559 & TRN \\
\hline CHEMBL1420885 & 688550 & 4.4 & 4.8795 & TRN \\
\hline CHEMBL1489200 & 688550 & 4.55 & 4.79 & TST \\
\hline CHEMBL1443550 & 688550 & 4.85 & 4.9463 & TRN \\
\hline CHEMBL1313682 & 688550 & 5.45 & 4.7959 & TST \\
\hline CHEMBL 243644 & 688550 & 4.75 & 4.8352 & TRN \\
\hline CHEMBL1470471 & 688550 & 4.5 & 4.7789 & TRN \\
\hline CHEMBL3209639 & 688550 & 4.9 & 4.9504 & TST \\
\hline CHEMBL1449317 & 688550 & 5.45 & 4.9208 & TRN \\
\hline CHEMBL1331546 & 688550 & 4.65 & 4.9235 & TRN \\
\hline CHEMBL1489339 & 688550 & 5.05 & 4.9777 & TRN \\
\hline CHEMBL1583967 & 688550 & 6.0 & 4.8371 & TRN \\
\hline CHEMBL 2002162 & 688550 & 4.95 & 4.8553 & TST \\
\hline CHEMBL1312599 & 688550 & 5.4 & 4.9168 & TRN \\
\hline CHEMBL1457794 & 688550 & 4.75 & 4.9117 & TRN \\
\hline CHEMBL1561773 & 688550 & 4.5 & 4.9581 & TRN \\
\hline CHEMBL1427047 & 688550 & 4.65 & 4.7873 & TRN \\
\hline CHEMBL1300610 & 688550 & 5.4 & 4.7934 & TRN \\
\hline CHEMBL1538541 & 688550 & 4.55 & 4.7388 & TRN \\
\hline CHEMBL1500324 & 688550 & 4.4 & 4.8418 & TRN \\
\hline CHEMBL1509292 & 688550 & 4.8 & 4.9609 & TRN \\
\hline CHEMBL3212480 & 688550 & 5.5 & 4.8104 & TST \\
\hline CHEMBL1400143 & 688550 & 4.8 & 4.7804 & TRN \\
\hline CHEMBL1537058 & 688550 & 4.7 & 4.8472 & TRN \\
\hline CHEMBL1421517 & 688550 & 4.55 & 4.8916 & TRN \\
\hline CHEMBL1612932 & 688550 & 5.45 & 4.8804 & TRN \\
\hline CHEMBL3213197 & 688550 & 5.8 & 4.9663 & TRN \\
\hline
\end{tabular}




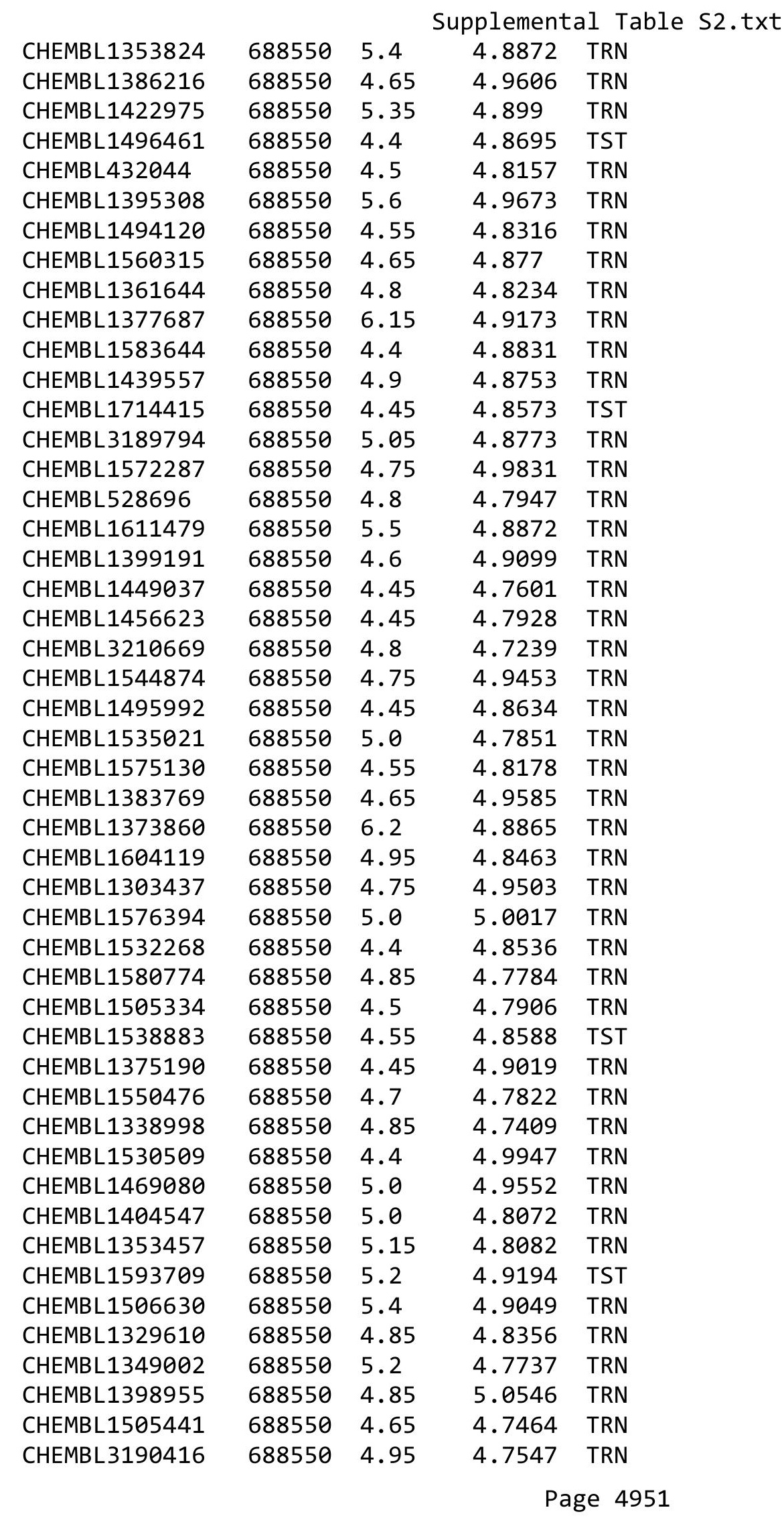




\begin{tabular}{|c|c|c|c|c|c|}
\hline & & \multicolumn{4}{|c|}{ Supplemental Table S2.txt } \\
\hline CHEMBL1569543 & 688550 & 4.45 & 4.8202 & TRN & \\
\hline CHEMBL1390280 & 688550 & 5.1 & 4.9621 & TRN & \\
\hline CHEMBL1403924 & 688550 & 4.65 & 4.95100 & 00000000005 & TRN \\
\hline CHEMBL1386691 & 688550 & 4.85 & 4.8023 & TRN & \\
\hline CHEMBL1335822 & 688550 & 4.75 & 5.005 & TRN & \\
\hline CHEMBL1568728 & 688550 & 5.55 & 4.873 & TRN & \\
\hline CHEMBL1401101 & 688550 & 4.8 & 4.7942 & TRN & \\
\hline CHEMBL1431271 & 688550 & 5.45 & 4.8916 & TST & \\
\hline CHEMBL1381289 & 688550 & 4.7 & 4.9738 & TRN & \\
\hline CHEMBL1371377 & 688550 & 4.4 & 4.797 & TRN & \\
\hline CHEMBL1460191 & 688550 & 5.0 & 4.8373 & TST & \\
\hline CHEMBL1369041 & 688550 & 4.7 & 4.9368 & TRN & \\
\hline CHEMBL1492897 & 688550 & 4.5 & 4.9565 & TRN & \\
\hline CHEMBL1420325 & 688550 & 4.85 & 4.8937 & TST & \\
\hline CHEMBL1572340 & 688550 & 4.4 & 4.9338 & TRN & \\
\hline CHEMBL1439266 & 688550 & 4.4 & 4.8672 & TRN & \\
\hline CHEMBL1389195 & 688550 & 4.75 & 4.9294 & TRN & \\
\hline CHEMBL1386036 & 688550 & 4.7 & 4.8419 & TRN & \\
\hline CHEMBL 3212167 & 688550 & 5.25 & 4.8638 & TST & \\
\hline CHEMBL1493395 & 688550 & 5.45 & 4.9711 & TRN & \\
\hline CHEMBL1547734 & 688550 & 4.55 & 4.9132 & TRN & \\
\hline CHEMBL1341050 & 688550 & 4.7 & 4.9817 & TRN & \\
\hline CHEMBL1421757 & 688550 & 4.8 & 4.8653 & TRN & \\
\hline CHEMBL1401232 & 688550 & 4.8 & 4.8915 & TST & \\
\hline CHEMBL1532794 & 688550 & 4.65 & 4.8643 & TST & \\
\hline CHEMBL1354458 & 688550 & 5.15 & 4.933 & TRN & \\
\hline CHEMBL1313428 & 688550 & 4.85 & 4.7843 & TRN & \\
\hline CHEMBL1369079 & 688550 & 6.95 & 4.8662 & TST & \\
\hline CHEMBL1301806 & 688550 & 5.1 & 4.8144 & TRN & \\
\hline CHEMBL1533055 & 688550 & 4.9 & 4.8314 & TRN & \\
\hline CHEMBL1481187 & 688550 & 5.2 & 4.9173 & TRN & \\
\hline CHEMBL1347122 & 688550 & 4.75 & 4.7495 & TRN & \\
\hline CHEMBL1364176 & 688550 & 4.4 & 4.79899 & 99999999995 & TRN \\
\hline CHEMBL1511369 & 688550 & 4.85 & 4.9387 & TRN & \\
\hline CHEMBL1336775 & 688550 & 4.4 & 4.8542 & TST & \\
\hline CHEMBL1415437 & 688550 & 4.9 & 4.9816 & TRN & \\
\hline CHEMBL3192565 & 688550 & 4.65 & 4.867 & TST & \\
\hline CHEMBL1366683 & 688550 & 4.55 & 4.8331 & TRN & \\
\hline CHEMBL1303464 & 688550 & 4.8 & 5.0472 & TRN & \\
\hline CHEMBL1376392 & 688550 & 4.95 & 4.788 & TRN & \\
\hline CHEMBL1545934 & 688550 & 4.5 & 4.8645 & TST & \\
\hline CHEMBL1567872 & 688550 & 4.6 & 4.7718 & TRN & \\
\hline CHEMBL1413450 & 688550 & 4.45 & 4.8998 & TRN & \\
\hline CHEMBL1430311 & 688550 & 4.45 & 4.8318 & TRN & \\
\hline CHEMBL1353989 & 688550 & 4.95 & 4.7848 & TRN & \\
\hline CHEMBL1409648 & 688550 & 4.85 & 4.9115 & TRN & \\
\hline CHEMBL1996490 & 688550 & 4.6 & 4.6859 & TRN & \\
\hline CHEMBL1402051 & 688550 & 4.55 & 4.7635 & TRN & \\
\hline
\end{tabular}




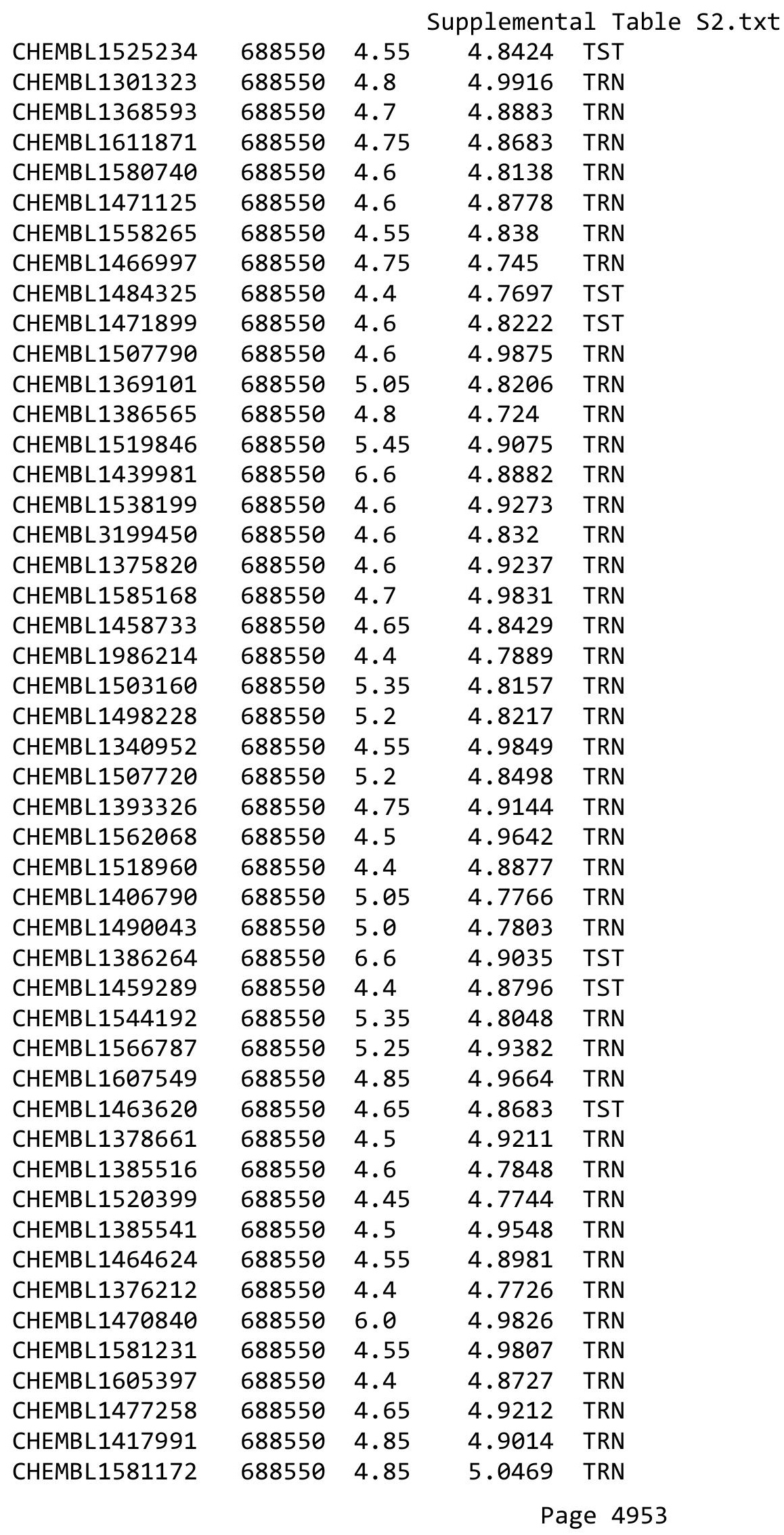




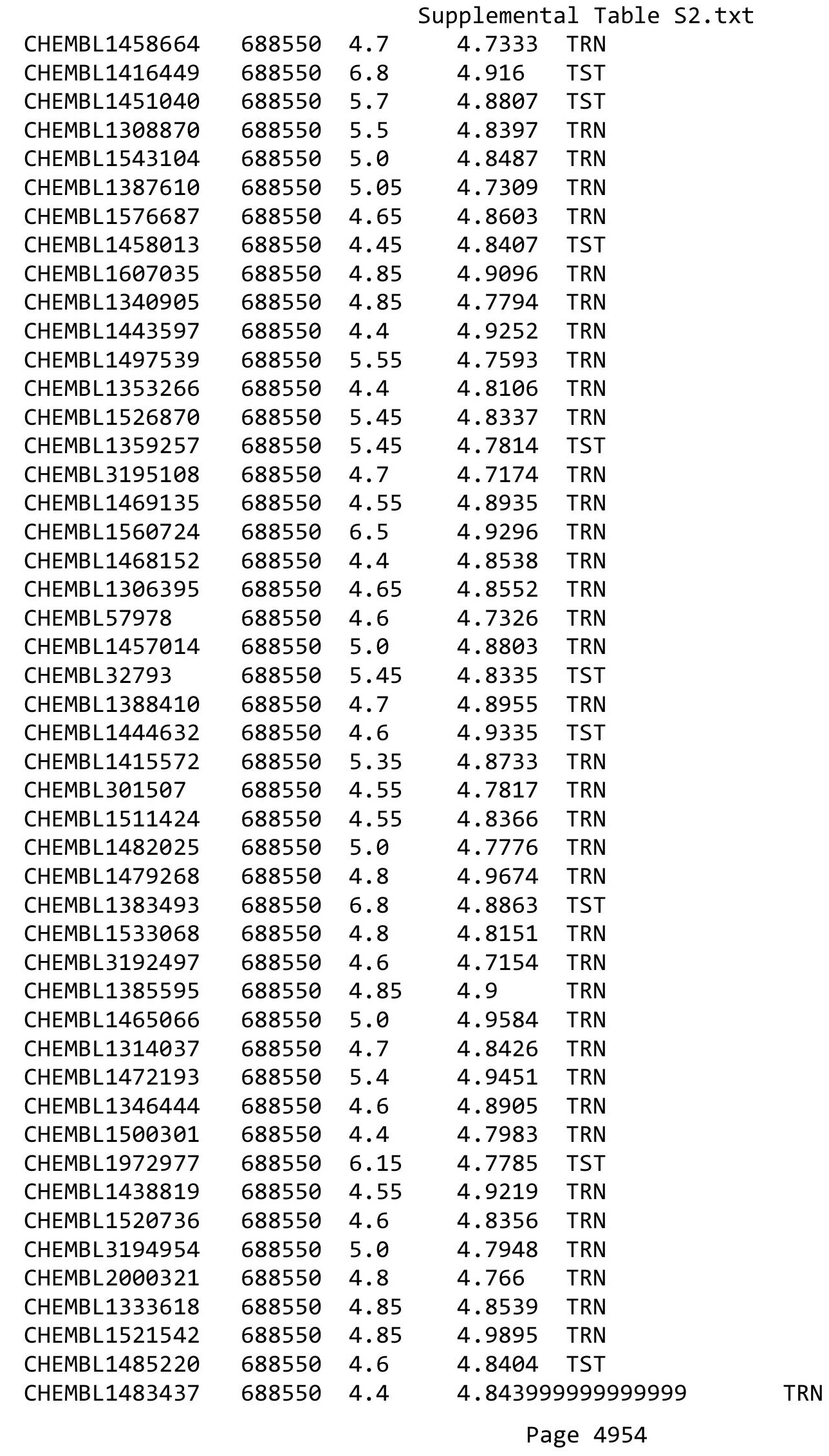




\begin{tabular}{|c|c|c|c|c|}
\hline \multicolumn{5}{|c|}{ Supplemental Table S2.txt } \\
\hline CHEMBL1574389 & 688550 & 4.4 & 4.8508 & TRN \\
\hline CHEMBL1324015 & 688550 & 5.1 & 4.8104 & TST \\
\hline CHEMBL1493791 & 688550 & 4.4 & 4.8569 & TRN \\
\hline CHEMBL1537858 & 688550 & 5.0 & 4.8308 & TRN \\
\hline CHEMBL1452409 & 688550 & 4.8 & 4.7338 & TRN \\
\hline CHEMBL1547301 & 688550 & 4.55 & 4.8618 & TRN \\
\hline CHEMBL1491047 & 688550 & 4.9 & 4.9618 & TRN \\
\hline CHEMBL1380297 & 688550 & 4.5 & 4.862 & TRN \\
\hline CHEMBL1415509 & 688550 & 4.8 & 4.9779 & TRN \\
\hline CHEMBL1477100 & 688550 & 4.85 & 4.8201 & TRN \\
\hline CHEMBL1528393 & 688550 & 4.8 & 4.9907 & TRN \\
\hline CHEMBL1510194 & 688550 & 4.6 & 5.016 & TRN \\
\hline CHEMBL1333451 & 688550 & 5.05 & 4.8373 & TST \\
\hline CHEMBL1484173 & 688550 & 4.45 & 4.813 & TRN \\
\hline CHEMBL3197055 & 688550 & 5.1 & 4.8933 & TRN \\
\hline CHEMBL1344703 & 688550 & 5.25 & 4.7715 & TST \\
\hline CHEMBL1409874 & 688550 & 4.85 & 4.9048 & TRN \\
\hline CHEMBL1448181 & 688550 & 4.8 & 4.8297 & TST \\
\hline CHEMBL1344131 & 688550 & 4.6 & 4.7615 & TST \\
\hline CHEMBL1968361 & 688550 & 4.75 & 4.7585 & TST \\
\hline CHEMBL1599057 & 688550 & 4.4 & 4.854 & TST \\
\hline CHEMBL1531759 & 688550 & 5.15 & 4.8457 & TST \\
\hline CHEMBL1494838 & 688550 & 4.45 & 4.8293 & TST \\
\hline CHEMBL1605713 & 688550 & 4.65 & 4.8527 & TST \\
\hline CHEMBL1409863 & 688550 & 4.5 & 4.8191 & TST \\
\hline CHEMBL1429437 & 688550 & 5.5 & 4.894 & TST \\
\hline CHEMBL1388408 & 688550 & 4.55 & 4.7746 & TST \\
\hline CHEMBL1972652 & 688550 & 5.5 & 4.8377 & TST \\
\hline CHEMBL1382734 & 688550 & 4.5 & 4.7931 & TST \\
\hline CHEMBL1310138 & 688550 & 4.6 & 4.8225 & TST \\
\hline CHEMBL1533962 & 688550 & 5.15 & 4.8505 & TST \\
\hline CHEMBL1419335 & 688550 & 5.55 & 4.8312 & TST \\
\hline CHEMBL1364292 & 688550 & 4.4 & 4.8461 & TST \\
\hline CHEMBL1432327 & 688550 & 4.8 & 4.8907 & TST \\
\hline CHEMBL1541005 & 688550 & 4.4 & 4.7889 & TST \\
\hline CHEMBL1339662 & 688550 & 4.85 & 4.9943 & TST \\
\hline CHEMBL1561230 & 688550 & 4.6 & 4.7781 & TST \\
\hline CHEMBL1448089 & 688550 & 5.4 & 4.8569 & TST \\
\hline CHEMBL1327648 & 688550 & 4.85 & 4.8833 & TST \\
\hline CHEMBL3210794 & 688550 & 4.55 & 4.8987 & TST \\
\hline CHEMBL1506811 & 688550 & 4.95 & 4.9504 & TST \\
\hline CHEMBL1348969 & 688550 & 5.05 & 4.8421 & TST \\
\hline CHEMBL1341981 & 688550 & 4.6 & 4.9017 & TST \\
\hline CHEMBL1333817 & 688550 & 4.6 & 4.7855 & TST \\
\hline CHEMBL1348144 & 688550 & 4.5 & 4.8398 & TST \\
\hline CHEMBL1531944 & 688550 & 4.65 & 4.8007 & TST \\
\hline CHEMBL1499494 & 688550 & 5.45 & 4.8752 & TST \\
\hline CHEMBL243651 & 688550 & 5.2 & 4.8262 & TST \\
\hline
\end{tabular}




\begin{tabular}{|c|c|c|c|c|}
\hline & & & upplement & al Table S \\
\hline CHEMBL1332728 & 688550 & 4.85 & 4.7754 & TST \\
\hline CHEMBL1595988 & 688550 & 5.35 & 4.8742 & TST \\
\hline CHEMBL1381149 & 688550 & 4.5 & 4.8652 & TST \\
\hline CHEMBL1419161 & 688550 & 4.8 & 4.8202 & TST \\
\hline CHEMBL1607263 & 688550 & 4.85 & 4.9546 & TST \\
\hline CHEMBL1332890 & 688550 & 4.65 & 4.8747 & TST \\
\hline CHEMBL1497352 & 688550 & 4.6 & 4.8892 & TST \\
\hline CHEMBL1415222 & 688550 & 4.6 & 5.0192 & TST \\
\hline CHEMBL1327333 & 688550 & 4.7 & 4.8268 & TST \\
\hline CHEMBL1299856 & 688550 & 4.45 & 4.8175 & TST \\
\hline CHEMBL1405834 & 688550 & 4.6 & 4.8106 & TST \\
\hline CHEMBL1458383 & 688550 & 5.0 & 4.8798 & TST \\
\hline CHEMBL1349433 & 688550 & 4.85 & 4.9343 & TST \\
\hline CHEMBL1549112 & 688550 & 4.8 & 4.8852 & TST \\
\hline CHEMBL1612994 & 688550 & 4.5 & 4.8955 & TST \\
\hline CHEMBL1302662 & 688550 & 5.05 & 4.947 & TST \\
\hline CHEMBL1311694 & 688550 & 4.55 & 4.8277 & TST \\
\hline CHEMBL1459140 & 688550 & 6.0 & 4.8213 & TST \\
\hline CHEMBL1393976 & 688550 & 4.7 & 4.8362 & TST \\
\hline CHEMBL1313708 & 688550 & 4.5 & 4.9134 & TST \\
\hline CHEMBL1320475 & 688550 & 4.4 & 4.9565 & TST \\
\hline CHEMBL1489449 & 688550 & 5.0 & 4.7841 & TST \\
\hline CHEMBL1478140 & 688550 & 4.55 & 4.843 & TST \\
\hline CHEMBL1598199 & 688550 & 5.0 & 5.0459 & TST \\
\hline CHEMBL1444187 & 688550 & 5.0 & 4.9487 & TST \\
\hline CHEMBL1391552 & 688550 & 4.4 & 4.791 & TST \\
\hline CHEMBL161957 & 688550 & 4.6 & 4.859 & TST \\
\hline CHEMBL1484226 & 688550 & 5.4 & 4.9559 & TST \\
\hline CHEMBL1325882 & 688550 & 4.4 & 4.8729 & TST \\
\hline CHEMBL1301917 & 688550 & 4.65 & 4.8902 & TST \\
\hline CHEMBL1461619 & 688550 & 4.6 & 4.8579 & TST \\
\hline CHEMBL1455116 & 688550 & 4.4 & 4.9637 & TST \\
\hline CHEMBL1571107 & 688550 & 4.4 & 4.8621 & TST \\
\hline CHEMBL1604547 & 688550 & 4.55 & 4.8098 & TST \\
\hline CHEMBL1329799 & 688550 & 4.4 & 4.8556 & TST \\
\hline CHEMBL1444730 & 688550 & 5.45 & 4.9214 & TST \\
\hline CHEMBL1463990 & 688550 & 4.6 & 4.8025 & TST \\
\hline CHEMBL1452082 & 688550 & 4.65 & 4.8453 & TST \\
\hline CHEMBL1469532 & 688550 & 4.4 & 4.8079 & TST \\
\hline CHEMBL1600380 & 688550 & 4.95 & 4.73600 & 0000000001 \\
\hline CHEMBL1470914 & 688550 & 4.6 & 4.8431 & TST \\
\hline CHEMBL1340470 & 688550 & 4.65 & 4.9022 & TST \\
\hline CHEMBL1342878 & 688550 & 4.35 & 4.8355 & TST \\
\hline CHEMBL1197556 & 688550 & 4.85 & 4.8487 & TST \\
\hline CHEMBL1422502 & 688550 & 4.55 & 4.9044 & TST \\
\hline CHEMBL 3194478 & 688550 & 6.1 & 4.8356 & TST \\
\hline CHEMBL3197861 & 688550 & 4.8 & 4.779 & TST \\
\hline CHEMBL1345029 & 688550 & 4.45 & 4.899 & TST \\
\hline
\end{tabular}




\begin{tabular}{|c|c|c|c|c|}
\hline & & & ipplement & al Table S2 \\
\hline CHEMBL1304259 & 688550 & 4.55 & 4.8941 & TST \\
\hline CHEMBL1393020 & 688550 & 4.4 & 4.78 & TST \\
\hline CHEMBL1350146 & 688550 & 4.55 & 4.8981 & TST \\
\hline CHEMBL1613091 & 688550 & 4.55 & 4.8421 & TST \\
\hline CHEMBL1610067 & 688550 & 5.5 & 4.9847 & TST \\
\hline CHEMBL1462443 & 688550 & 5.15 & 4.837 & TST \\
\hline CHEMBL1352152 & 688550 & 4.85 & 4.9607 & TST \\
\hline CHEMBL1403417 & 688550 & 4.4 & 4.7847 & TST \\
\hline CHEMBL1362523 & 688550 & 4.4 & 4.9372 & TST \\
\hline CHEMBL1336173 & 688550 & 4.45 & 4.8287 & TST \\
\hline CHEMBL1360295 & 688550 & 4.85 & 4.7478 & TST \\
\hline CHEMBL1549532 & 688550 & 4.45 & 4.8643 & TST \\
\hline CHEMBL1343121 & 688550 & 4.4 & 4.865 & TST \\
\hline CHEMBL1371792 & 688550 & 4.95 & 5.0274 & TST \\
\hline CHEMBL1524331 & 688550 & 4.95 & 4.8813 & TST \\
\hline CHEMBL1430777 & 688550 & 4.6 & 5.0657 & TST \\
\hline CHEMBL1387390 & 688550 & 5.3 & 4.8375 & TST \\
\hline CHEMBL1367161 & 688550 & 4.6 & 4.9124 & TST \\
\hline CHEMBL1546098 & 688550 & 4.4 & 4.8421 & TST \\
\hline CHEMBL1367634 & 688550 & 6.95 & 4.8062 & TST \\
\hline CHEMBL1430606 & 688550 & 4.5 & 4.9217 & TST \\
\hline CHEMBL1400220 & 688550 & 4.8 & 4.8224 & TST \\
\hline CHEMBL1477842 & 688550 & 5.55 & 4.928 & TST \\
\hline CHEMBL1383569 & 688550 & 4.8 & 4.84 & TST \\
\hline CHEMBL1455750 & 688550 & 4.7 & 4.7558 & TST \\
\hline CHEMBL1585654 & 688550 & 4.6 & 4.7994 & TST \\
\hline CHEMBL1531298 & 688550 & 4.5 & 4.8505 & TST \\
\hline CHEMBL1541859 & 688550 & 4.55 & 4.9584 & TST \\
\hline CHEMBL199925 & 688550 & 5.45 & 4.7435 & TST \\
\hline CHEMBL1525074 & 688550 & 4.5 & 4.9097 & TST \\
\hline CHEMBL1505608 & 688550 & 4.85 & 4.8315 & TST \\
\hline CHEMBL1386149 & 688550 & 4.65 & 4.7189 & TST \\
\hline CHEMBL1455919 & 688550 & 5.5 & 4.8746 & TST \\
\hline CHEMBL1390047 & 688550 & 4.85 & 4.8669 & TST \\
\hline CHEMBL1544309 & 688550 & 4.9 & 4.8322 & TST \\
\hline CHEMBL1307506 & 688550 & 4.75 & 4.9658 & TST \\
\hline CHEMBL1390727 & 688550 & 4.6 & 4.9379 & TST \\
\hline CHEMBL1375660 & 688550 & 5.15 & 4.8354 & TST \\
\hline CHEMBL1511872 & 688550 & 5.4 & 4.7251 & TST \\
\hline CHEMBL1326479 & 688550 & 4.4 & 4.7796 & TST \\
\hline CHEMBL1345786 & 688550 & 4.6 & 4.8638 & TST \\
\hline CHEMBL1452978 & 688550 & 4.85 & 4.7698 & TST \\
\hline CHEMBL1589334 & 688550 & 4.85 & 4.7604 & TST \\
\hline CHEMBL1503518 & 688550 & 4.45 & 4.93199 & 99999999995 \\
\hline CHEMBL1507328 & 688550 & 4.4 & 4.9146 & TST \\
\hline CHEMBL1361145 & 688550 & 4.4 & 4.879 & TST \\
\hline CHEMBL1533880 & 688550 & 4.6 & 4.8502 & TST \\
\hline CHEMBL1597705 & 688550 & 4.55 & 4.8099 & TST \\
\hline
\end{tabular}




\begin{tabular}{|c|c|c|c|c|}
\hline \multicolumn{5}{|c|}{ Supplemental Table S2.txt } \\
\hline CHEMBL1516758 & 688550 & 4.4 & 4.9468 & TST \\
\hline CHEMBL1455421 & 688550 & 4.95 & 4.7848 & TST \\
\hline CHEMBL1456317 & 688550 & 4.65 & 4.9074 & TST \\
\hline CHEMBL1569759 & 688550 & 5.2 & 4.8331 & TST \\
\hline CHEMBL1319607 & 688550 & 4.4 & 4.8003 & TST \\
\hline CHEMBL1578534 & 688550 & 4.9 & 4.9997 & TST \\
\hline CHEMBL3193108 & 688550 & 5.2 & 4.8552 & TST \\
\hline CHEMBL1595525 & 688550 & 4.5 & 4.7404 & TST \\
\hline CHEMBL1504792 & 688550 & 4.8 & 4.8947 & TST \\
\hline CHEMBL1433158 & 688550 & 5.45 & 4.8728 & TST \\
\hline CHEMBL1367305 & 688550 & 5.45 & 4.8845 & TST \\
\hline CHEMBL1360500 & 688550 & 5.2 & 4.7823 & TST \\
\hline CHEMBL1401801 & 688550 & 4.4 & 4.7291 & TST \\
\hline CHEMBL1558779 & 688550 & 4.55 & 4.7602 & TST \\
\hline CHEMBL1411321 & 688550 & 4.85 & 4.9174 & TST \\
\hline CHEMBL1540497 & 688550 & 4.95 & 4.9193 & TST \\
\hline CHEMBL1447350 & 688550 & 4.7 & 4.8533 & TST \\
\hline CHEMBL1595283 & 688550 & 4.6 & 4.777 & TST \\
\hline CHEMBL1463582 & 688550 & 4.8 & 4.8446 & TST \\
\hline CHEMBL405317 & 688550 & 4.5 & 4.6675 & TST \\
\hline CHEMBL1377406 & 688550 & 5.15 & 4.9913 & TST \\
\hline CHEMBL1367886 & 688550 & 5.0 & 4.7941 & TST \\
\hline CHEMBL1313152 & 688550 & 4.6 & 4.8369 & TST \\
\hline CHEMBL1348749 & 688550 & 4.55 & 4.8042 & TST \\
\hline CHEMBL1341526 & 688550 & 5.8 & 4.8328 & TST \\
\hline CHEMBL1410738 & 688550 & 4.55 & 4.8589 & TST \\
\hline CHEMBL1551975 & 688550 & 4.4 & 4.805 & TST \\
\hline CHEMBL1383892 & 688550 & 4.65 & 4.7587 & TST \\
\hline CHEMBL1545122 & 688550 & 5.0 & 4.8534 & TST \\
\hline CHEMBL1401915 & 688550 & 6.0 & 5.0121 & TST \\
\hline CHEMBL1543750 & 688550 & 4.4 & 4.9696 & TST \\
\hline CHEMBL1502008 & 688550 & 4.55 & 4.8795 & TST \\
\hline CHEMBL1446502 & 688550 & 4.85 & 4.8411 & TST \\
\hline CHEMBL1304177 & 688550 & 4.4 & 4.7954 & TST \\
\hline CHEMBL1523641 & 688550 & 4.45 & 4.7672 & TST \\
\hline CHEMBL1325917 & 688550 & 4.65 & 4.9139 & TST \\
\hline CHEMBL1385122 & 688550 & 4.6 & 4.8994 & TST \\
\hline CHEMBL1539824 & 688550 & 5.45 & 4.8041 & TST \\
\hline CHEMBL1462301 & 688550 & 4.9 & 4.7722 & TST \\
\hline CHEMBL1402998 & 688550 & 4.45 & 4.9102 & TST \\
\hline CHEMBL1404385 & 688550 & 4.4 & 5.0008 & TST \\
\hline CHEMBL116548 & 688550 & 4.55 & 4.8817 & TST \\
\hline CHEMBL1557926 & 688550 & 4.4 & 4.8085 & TST \\
\hline CHEMBL1577829 & 688550 & 5.0 & 4.9069 & TST \\
\hline CHEMBL145558 & 688550 & 4.75 & 4.8921 & TST \\
\hline CHEMBL1479571 & 688550 & 4.65 & 4.9044 & TST \\
\hline CHEMBL1326112 & 688550 & 5.35 & 4.8664 & TST \\
\hline CHEMBL1336116 & 688550 & 4.7 & 5.0082 & TST \\
\hline
\end{tabular}




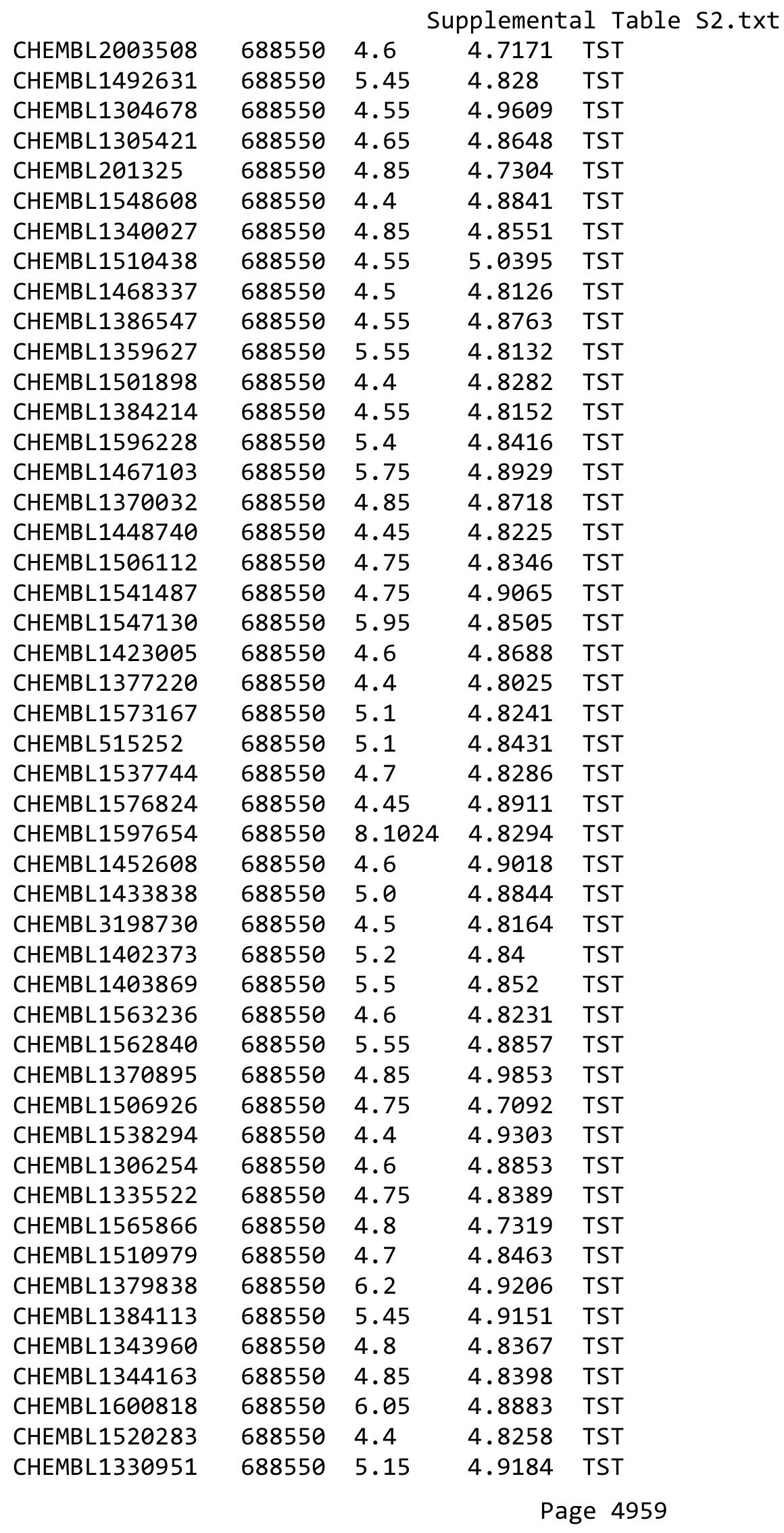




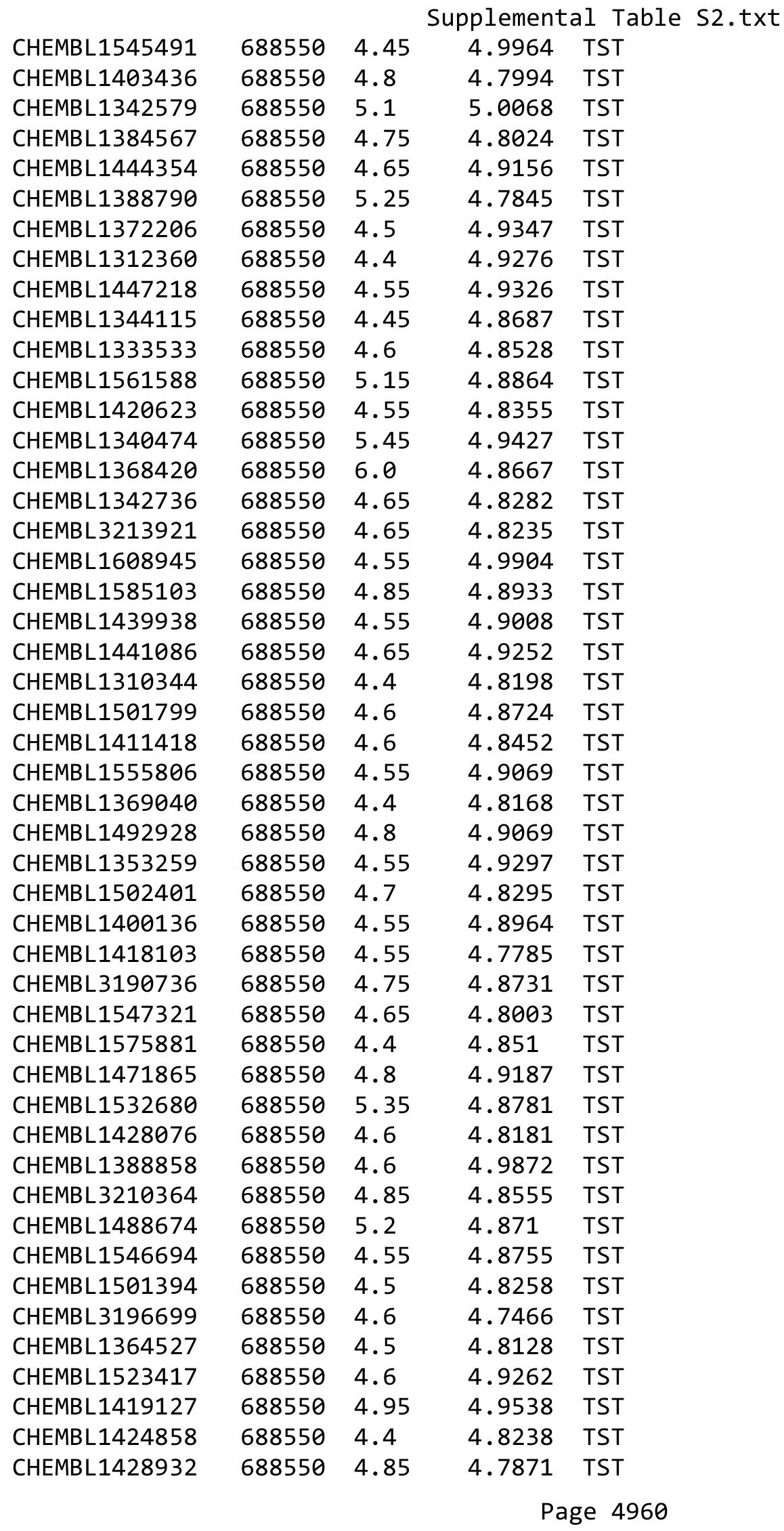




\begin{tabular}{|c|c|c|c|c|}
\hline \multicolumn{5}{|c|}{ Supplemental Table S2.txt } \\
\hline CHEMBL 3199145 & 688550 & 5.15 & 4.8857 & TST \\
\hline CHEMBL1517374 & 688550 & 5.05 & 4.8684 & TST \\
\hline CHEMBL1439929 & 688550 & 4.55 & 4.7235 & TST \\
\hline CHEMBL1410147 & 688550 & 5.0 & 4.7071 & TST \\
\hline CHEMBL1978730 & 688550 & 5.0 & 4.7777 & TST \\
\hline CHEMBL1587424 & 688550 & 4.55 & 4.9046 & TST \\
\hline CHEMBL1531120 & 688550 & 4.75 & 4.8448 & TST \\
\hline CHEMBL1610657 & 688550 & 5.15 & 4.7994 & TST \\
\hline CHEMBL1468487 & 688550 & 4.45 & 4.8075 & TST \\
\hline CHEMBL1374536 & 688550 & 4.8 & 4.8271 & TST \\
\hline CHEMBL1481478 & 688550 & 4.65 & 4.9659 & TST \\
\hline CHEMBL1346114 & 688550 & 4.55 & 4.7803 & TST \\
\hline CHEMBL1548783 & 688550 & 4.5 & 5.0105 & TST \\
\hline CHEMBL1321369 & 688550 & 4.85 & 4.9245 & TST \\
\hline CHEMBL3192033 & 688550 & 4.4 & 4.8431 & TST \\
\hline CHEMBL1330583 & 688550 & 4.75 & 4.7941 & TST \\
\hline CHEMBL1303972 & 688550 & 4.4 & 4.9363 & TST \\
\hline CHEMBL1350072 & 688550 & 5.45 & 4.8453 & TST \\
\hline CHEMBL1547455 & 688550 & 4.5 & 4.8596 & TST \\
\hline CHEMBL1409450 & 688550 & 4.6 & 4.7981 & TST \\
\hline CHEMBL1419692 & 688550 & 6.05 & 4.8915 & TST \\
\hline CHEMBL1572540 & 688550 & 4.55 & 4.9101 & TST \\
\hline CHEMBL3199938 & 688550 & 4.55 & 4.7699 & TST \\
\hline CHEMBL1470880 & 688550 & 5.2 & 4.8697 & TST \\
\hline CHEMBL1445681 & 688550 & 4.95 & 4.9092 & TST \\
\hline CHEMBL1329395 & 688550 & 5.05 & 4.8843 & TST \\
\hline CHEMBL1523936 & 688550 & 7.5498 & 4.8689 & TST \\
\hline CHEMBL1968732 & 688550 & 4.6 & 4.8702 & TST \\
\hline CHEMBL3211930 & 688550 & 4.65 & 4.7651 & TST \\
\hline CHEMBL1582163 & 688550 & 4.95 & 4.7977 & TST \\
\hline CHEMBL1469622 & 688550 & 4.6 & 4.8752 & TST \\
\hline CHEMBL1359359 & 688550 & 6.2 & 4.8449 & TST \\
\hline CHEMBL1450797 & 688550 & 5.1 & 4.7506 & TST \\
\hline CHEMBL1311408 & 688550 & 4.55 & 5.0219 & TST \\
\hline CHEMBL1335221 & 688550 & 6.25 & 4.9036 & TST \\
\hline CHEMBL1411168 & 688550 & 5.05 & 4.9236 & TST \\
\hline CHEMBL1325367 & 688550 & 4.4 & 4.8096 & TST \\
\hline CHEMBL1555941 & 688550 & 4.4 & 4.9261 & TST \\
\hline CHEMBL1314518 & 688550 & 5.1 & 4.8135 & TST \\
\hline CHEMBL1586720 & 688550 & 4.45 & 4.824 & TST \\
\hline CHEMBL1347854 & 688550 & 5.05 & 4.8306 & TST \\
\hline CHEMBL3199737 & 688550 & 4.7 & 4.7809 & TST \\
\hline CHEMBL1380684 & 688550 & 6.0 & 4.86 & TST \\
\hline CHEMBL1324343 & 688550 & 5.4 & 4.8448 & TST \\
\hline CHEMBL1381824 & 688550 & 4.8 & 4.8116 & TST \\
\hline CHEMBL1467033 & 688550 & 4.75 & 4.8279 & TST \\
\hline CHEMBL1555400 & 688550 & 5.9 & 4.8146 & TST \\
\hline CHEMBL1368302 & 688550 & 4.4 & 4.863 & TST \\
\hline
\end{tabular}




\begin{tabular}{|c|c|c|c|c|c|}
\hline & & \multicolumn{4}{|c|}{ Supplemental Table s2.txt } \\
\hline CHEMBL1486726 & 688550 & 4.85 & 4.7316 & TST & \\
\hline CHEMBL1406315 & 688550 & 4.45 & 4.9694 & TST & \\
\hline CHEMBL1524929 & 688550 & 4.5 & 4.7012 & TST & \\
\hline CHEMBL334707 & 688550 & 4.4 & 4.7931 & TST & \\
\hline CHEMBL1438081 & 688550 & 4.6 & 4.9507 & TST & \\
\hline CHEMBL3196363 & 688550 & 4.55 & 4.8472 & TST & \\
\hline CHEMBL1300864 & 688550 & 7.0 & 4.8297 & TST & \\
\hline CHEMBL1425632 & 688550 & 4.55 & 4.9208 & TST & \\
\hline CHEMBL1527768 & 688550 & 4.65 & 4.8335 & TST & \\
\hline CHEMBL1995156 & 688550 & 4.4 & 4.8097 & TST & \\
\hline CHEMBL1532377 & 688550 & 5.2 & 4.78 & TST & \\
\hline CHEMBL1501005 & 688550 & 5.65 & 4.8539 & TST & \\
\hline CHEMBL1601553 & 688550 & 4.5 & 4.8786 & TST & \\
\hline CHEMBL1536344 & 688550 & 5.3 & 4.925 & TST & \\
\hline CHEMBL1480798 & 688550 & 5.55 & 4.8149 & TST & \\
\hline CHEMBL1504431 & 688550 & 4.5 & 4.8207 & TST & \\
\hline CHEMBL1531439 & 688550 & 5.05 & 4.9453 & TST & \\
\hline CHEMBL1500147 & 688550 & 5.05 & 4.8524 & TST & \\
\hline CHEMBL1449708 & 688550 & 4.55 & 4.8666 & TST & \\
\hline CHEMBL1480254 & 688550 & 4.55 & 4.9387 & TST & \\
\hline CHEMBL1407293 & 688550 & 5.35 & 4.8216 & TST & \\
\hline CHEMBL1313352 & 688550 & 4.65 & 4.9905 & TST & \\
\hline CHEMBL1533248 & 688550 & 4.9 & 4.8395 & TST & \\
\hline CHEMBL1402717 & 688550 & 4.5 & 4.9456 & TST & \\
\hline CHEMBL1505806 & 688550 & 4.45 & 4.7159 & TST & \\
\hline CHEMBL1406687 & 688550 & 4.45 & 4.8136 & TST & \\
\hline CHEMBL1403316 & 688550 & 4.4 & 4.7977 & TST & \\
\hline CHEMBL1560045 & 688550 & 4.45 & 4.8872 & TST & \\
\hline CHEMBL1500913 & 688550 & 4.85 & 4.8564 & TST & \\
\hline CHEMBL1415568 & 688550 & 4.65 & 4.82100 & 0000000001 & TST \\
\hline CHEMBL1584013 & 688550 & 4.55 & 4.8721 & TST & \\
\hline CHEMBL1335311 & 688550 & 4.4 & 5.0364 & TST & \\
\hline CHEMBL1486454 & 688550 & 4.65 & 5.0053 & TST & \\
\hline CHEMBL1575954 & 688550 & 4.55 & 4.9744 & TST & \\
\hline CHEMBL1423715 & 688550 & 4.8 & 4.9104 & TST & \\
\hline CHEMBL1471293 & 688550 & 4.5 & 4.9118 & TST & \\
\hline CHEMBL1469265 & 688550 & 4.55 & 4.8379 & TST & \\
\hline CHEMBL1539059 & 688550 & 4.55 & 4.8836 & TST & \\
\hline CHEMBL1610680 & 688550 & 4.6 & 4.8214 & TST & \\
\hline CHEMBL3190951 & 688550 & 4.45 & 4.8484 & TST & \\
\hline CHEMBL1380546 & 688550 & 4.5 & 4.8223 & TST & \\
\hline CHEMBL1471645 & 688550 & 4.4 & 4.8361 & TST & \\
\hline CHEMBL1471249 & 688550 & 4.75 & 4.9839 & TST & \\
\hline CHEMBL1330064 & 688550 & 6.1 & 4.8002 & TST & \\
\hline CHEMBL1372760 & 688550 & 4.85 & 4.7821 & TST & \\
\hline CHEMBL1576311 & 688550 & 5.45 & 4.9758 & TST & \\
\hline CHEMBL1496638 & 688550 & 4.4 & 4.8172 & TST & \\
\hline CHEMBL1604319 & 688550 & 4.6 & 4.9545 & TST & \\
\hline
\end{tabular}




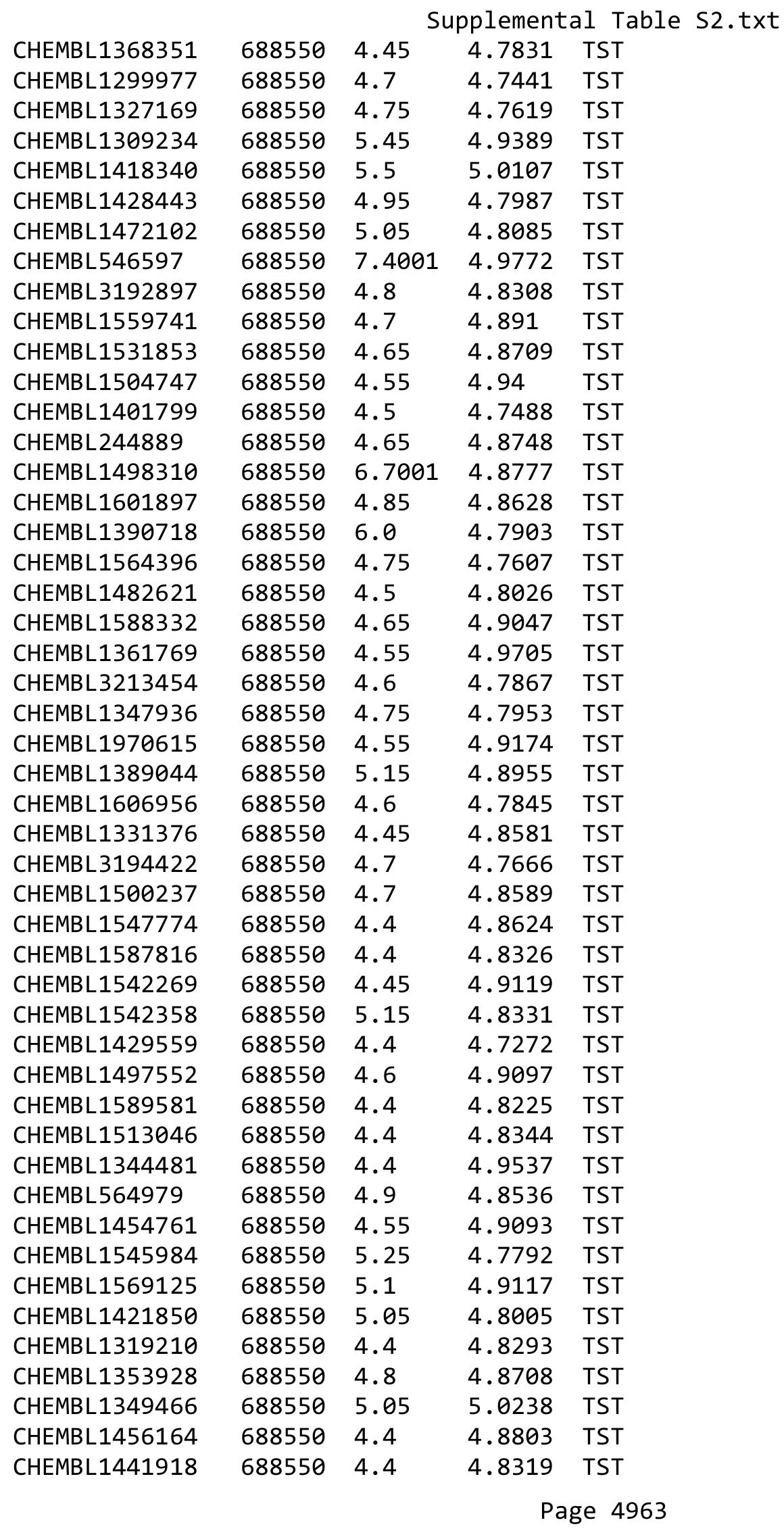




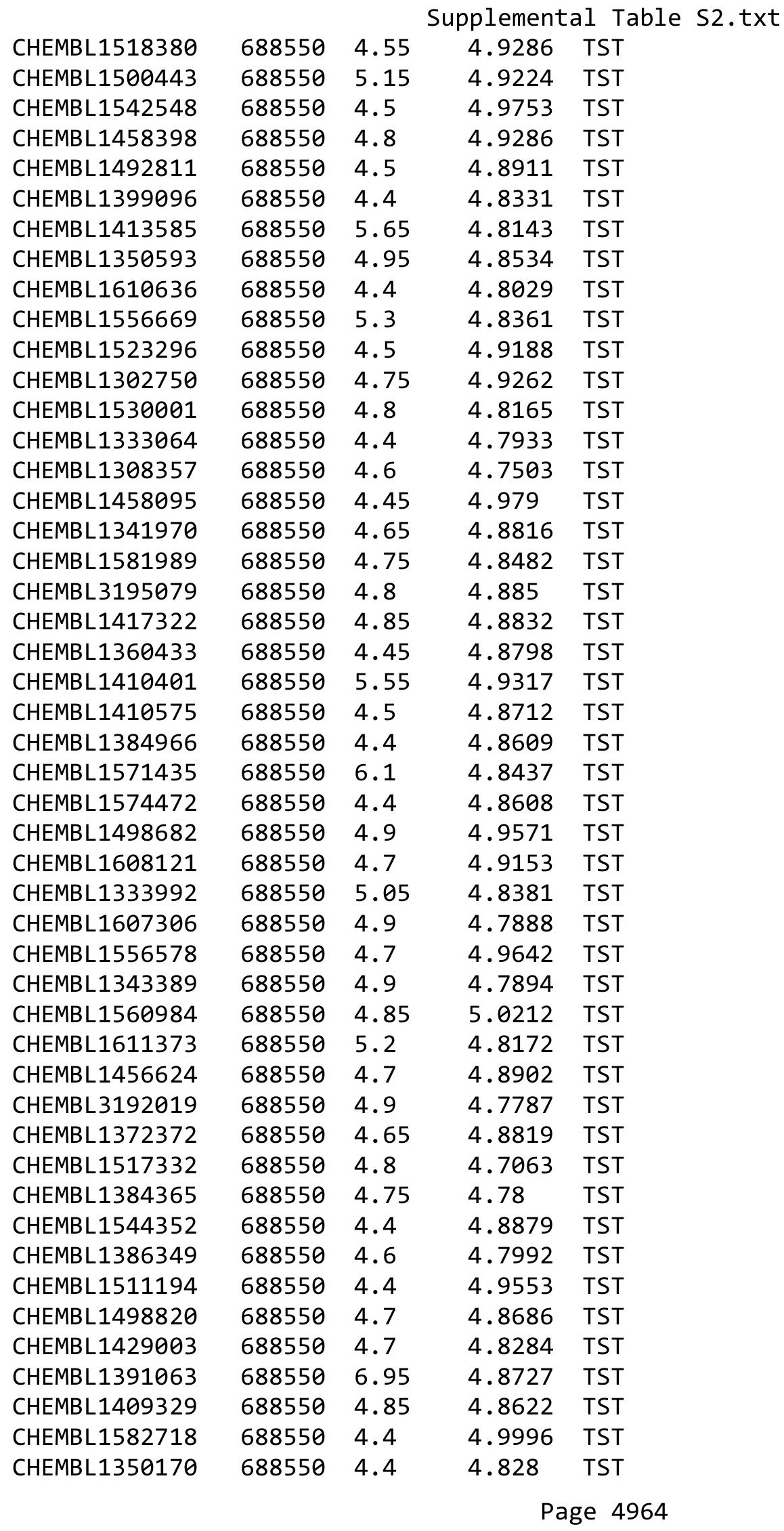




\begin{tabular}{|c|c|c|c|c|c|}
\hline \multicolumn{6}{|c|}{ Supplemental Table S2.txt } \\
\hline CHEMBL1469513 & 688550 & 4.5 & 4.8571 & TST & \\
\hline CHEMBL1469488 & 688550 & 4.75 & 5.0213 & TST & \\
\hline CHEMBL512261 & 688550 & 4.5 & 4.8314 & TST & \\
\hline CHEMBL1406688 & 688550 & 5.5 & 4.8715 & TST & \\
\hline CHEMBL1523068 & 688550 & 4.4 & 4.8189 & TST & \\
\hline CHEMBL1308449 & 688550 & 4.55 & 4.8249 & TST & \\
\hline CHEMBL 3197152 & 688550 & 4.5 & 4.7417 & TST & \\
\hline CHEMBL1321480 & 688550 & 4.55 & 4.777 & TST & \\
\hline CHEMBL1486129 & 688550 & 4.9 & 4.8435 & TST & \\
\hline CHEMBL1504712 & 688550 & 4.65 & 4.8562 & TST & \\
\hline CHEMBL1359641 & 688550 & 4.8 & 4.7959 & TST & \\
\hline CHEMBL1542511 & 688550 & 4.6 & 4.7825 & TST & \\
\hline CHEMBL3190678 & 688550 & 4.4 & 4.7652 & TST & \\
\hline CHEMBL1351391 & 688550 & 4.55 & 4.9958 & TST & \\
\hline CHEMBL1321599 & 688550 & 4.65 & 4.9698 & TST & \\
\hline CHEMBL1432395 & 688550 & 5.4 & 4.7063 & TST & \\
\hline CHEMBL1587260 & 688550 & 4.4 & 4.8996 & TST & \\
\hline CHEMBL1409366 & 688550 & 4.9 & 4.9723 & TST & \\
\hline CHEMBL1404932 & 688550 & 4.6 & 4.8589 & TST & \\
\hline CHEMBL1440986 & 688550 & 4.9 & 4.7738 & TST & \\
\hline CHEMBL1500903 & 688550 & 4.9 & 4.923 & TST & \\
\hline CHEMBL 2000877 & 688550 & 4.6 & 4.8046 & TST & \\
\hline CHEMBL1342229 & 688550 & 4.5 & 4.8862 & TST & \\
\hline CHEMBL1453291 & 688550 & 4.4 & 4.72199 & 99999999995 & TST \\
\hline CHEMBL1478008 & 688550 & 4.6 & 4.8487 & TST & \\
\hline CHEMBL1596828 & 688550 & 5.05 & 4.8298 & TST & \\
\hline CHEMBL1425723 & 688550 & 4.6 & 4.8982 & TST & \\
\hline CHEMBL1307093 & 688550 & 5.05 & 4.9304 & TST & \\
\hline CHEMBL1491228 & 688550 & 4.55 & 4.8179 & TST & \\
\hline CHEMBL1603676 & 688550 & 4.75 & 4.8861 & TST & \\
\hline CHEMBL1419913 & 688550 & 5.15 & 4.8731 & TST & \\
\hline CHEMBL1312689 & 688550 & 4.4 & 4.8449 & TST & \\
\hline CHEMBL1487498 & 688550 & 4.95 & 4.8775 & TST & \\
\hline CHEMBL1352775 & 688550 & 5.5 & 4.9982 & TST & \\
\hline CHEMBL1469921 & 688550 & 8.2518 & 4.8095 & TST & \\
\hline CHEMBL1612553 & 688550 & 4.55 & 4.9344 & TST & \\
\hline CHEMBL1444114 & 688550 & 5.4 & 4.7861 & TST & \\
\hline CHEMBL1392999 & 688550 & 4.4 & 4.8468 & TST & \\
\hline CHEMBL1438532 & 688550 & 4.8 & 4.8521 & TST & \\
\hline CHEMBL 2001904 & 688550 & 5.5 & 4.9126 & TST & \\
\hline CHEMBL1575075 & 688550 & 4.75 & 4.8458 & TST & \\
\hline CHEMBL1585841 & 688550 & 4.85 & 4.8611 & TST & \\
\hline CHEMBL1584716 & 688550 & 5.5 & 4.8963 & TST & \\
\hline CHEMBL1370557 & 688550 & 6.2 & 4.7803 & TST & \\
\hline CHEMBL1470421 & 688550 & 4.9 & 4.7785 & TST & \\
\hline CHEMBL1537403 & 688550 & 4.6 & 4.9718 & TST & \\
\hline CHEMBL1491698 & 688550 & 5.1 & 4.7965 & TST & \\
\hline CHEMBL1574562 & 688550 & 4.4 & 4.8961 & TST & \\
\hline
\end{tabular}




\begin{tabular}{|c|c|c|c|c|c|}
\hline & & & & & \\
\hline CHEMBL1567992 & 688550 & 5.3 & 4.9744 & TST & \\
\hline CHEMBL1994635 & 688550 & 4.8 & 4.7349 & TST & \\
\hline CHEMBL1544653 & 688550 & 4.65 & 4.9935 & TST & \\
\hline CHEMBL1488204 & 688550 & 4.75 & 4.7617 & TST & \\
\hline CHEMBL1507882 & 688550 & 4.5 & 4.8976 & TST & \\
\hline CHEMBL1403373 & 688550 & 4.4 & 4.8226 & TST & \\
\hline CHEMBL1554376 & 688550 & 4.4 & 4.9739 & TST & \\
\hline CHEMBL1392956 & 688550 & 4.65 & 4.937 & TST & \\
\hline CHEMBL1543984 & 688550 & 4.4 & 4.8813 & TST & \\
\hline CHEMBL1491858 & 688550 & 6.15 & 4.7855 & TST & \\
\hline CHEMBL1432352 & 688550 & 4.55 & 4.80699 & 99999999995 & TST \\
\hline CHEMBL1567815 & 688550 & 4.8 & 4.9351 & TST & \\
\hline CHEMBL1574105 & 688550 & 5.35 & 4.7925 & TST & \\
\hline CHEMBL1576135 & 688550 & 4.4 & 4.8387 & TST & \\
\hline CHEMBL1501824 & 688550 & 4.55 & 4.8679 & TST & \\
\hline CHEMBL1464803 & 688550 & 4.7 & 4.8435 & TST & \\
\hline CHEMBL3213588 & 688550 & 4.4 & 4.7804 & TST & \\
\hline CHEMBL1611199 & 688550 & 4.4 & 4.8248 & TST & \\
\hline CHEMBL1603864 & 688550 & 4.4 & 4.8881 & TST & \\
\hline CHEMBL1456349 & 688550 & 5.15 & 4.9565 & TST & \\
\hline CHEMBL1359782 & 688550 & 4.7 & 4.8518 & TST & \\
\hline CHEMBL1539103 & 688550 & 5.4 & 4.7638 & TST & \\
\hline CHEMBL1404792 & 688550 & 5.5 & 4.8935 & TST & \\
\hline CHEMBL1349506 & 688550 & 4.4 & 4.9212 & TST & \\
\hline CHEMBL1344438 & 688550 & 5.3 & 4.9485 & TST & \\
\hline CHEMBL1575708 & 688550 & 4.6 & 4.7541 & TST & \\
\hline CHEMBL1585855 & 688550 & 5.0 & 4.9221 & TST & \\
\hline CHEMBL1328547 & 688550 & 5.45 & 4.8397 & TST & \\
\hline CHEMBL608699 & 688550 & 5.65 & 4.8158 & TST & \\
\hline CHEMBL 3197831 & 688550 & 5.45 & 4.9375 & TST & \\
\hline CHEMBL1453131 & 688550 & 4.55 & 4.9794 & TST & \\
\hline CHEMBL1431002 & 688550 & 4.6 & 4.9359 & TST & \\
\hline CHEMBL1359860 & 688550 & 4.45 & 4.8379 & TST & \\
\hline CHEMBL1326999 & 688550 & 4.5 & 4.7864 & TST & \\
\hline CHEMBL1325791 & 688550 & 6.0 & 4.8296 & TST & \\
\hline CHEMBL1601475 & 688550 & 5.75 & 4.9067 & TST & \\
\hline CHEMBL1428088 & 688550 & 4.65 & 4.8821 & TST & \\
\hline CHEMBL1578479 & 688550 & 5.0 & 4.7921 & TST & \\
\hline CHEMBL1580421 & 688550 & 4.85 & 4.8906 & TST & \\
\hline CHEMBL1609697 & 688550 & 4.6 & 4.8928 & TST & \\
\hline CHEMBL1401415 & 688550 & 4.55 & 4.7563 & TST & \\
\hline CHEMBL1529764 & 688550 & 5.5 & 4.7816 & TST & \\
\hline CHEMBL1352743 & 688550 & 4.55 & 4.8861 & TST & \\
\hline CHEMBL1431490 & 688550 & 4.65 & 4.76399 & 9999999999 & TST \\
\hline CHEMBL1595161 & 688550 & 4.6 & 4.7964 & TST & \\
\hline CHEMBL1537417 & 688550 & 4.9 & 4.8604 & TST & \\
\hline CHEMBL1466466 & 688550 & 4.5 & 4.8346 & TST & \\
\hline CHEMBL1416326 & 688550 & 4.6 & 4.8754 & TST & \\
\hline
\end{tabular}




\begin{tabular}{|c|c|c|c|c|c|}
\hline \multicolumn{6}{|c|}{ plemental } \\
\hline CHEMBL1496457 & 688550 & 4.4 & 4.8467 & TST & \\
\hline CHEMBL1391383 & 688550 & 4.4 & 4.928 & TST & \\
\hline CHEMBL1478591 & 688550 & 4.45 & 4.79899 & 99999999995 & TST \\
\hline CHEMBL1511083 & 688550 & 4.5 & 4.8545 & TST & \\
\hline CHEMBL1320162 & 688550 & 4.4 & 4.9169 & TST & \\
\hline CHEMBL1393861 & 688550 & 4.4 & 4.8229 & TST & \\
\hline CHEMBL1379875 & 688550 & 5.15 & 4.8913 & TST & \\
\hline CHEMBL1562443 & 688550 & 5.05 & 4.9382 & TST & \\
\hline CHEMBL1383509 & 688550 & 4.4 & 4.9951 & TST & \\
\hline CHEMBL1449670 & 688550 & 4.5 & 4.8862 & TST & \\
\hline CHEMBL1561218 & 688550 & 4.5 & 4.8406 & TST & \\
\hline CHEMBL1354100 & 688550 & 4.8 & 4.8324 & TST & \\
\hline CHEMBL1529652 & 688550 & 4.55 & 4.8494 & TST & \\
\hline CHEMBL1431644 & 688550 & 4.6 & 4.8317 & TST & \\
\hline CHEMBL1556821 & 688550 & 4.4 & 4.8429 & TST & \\
\hline CHEMBL1453722 & 688550 & 4.55 & 4.8239 & TST & \\
\hline CHEMBL1384790 & 688550 & 4.6 & 4.9831 & TST & \\
\hline CHEMBL1393447 & 688550 & 4.4 & 4.8002 & TST & \\
\hline CHEMBL3211460 & 688550 & 4.75 & 4.7565 & TST & \\
\hline CHEMBL1384974 & 688550 & 4.45 & 4.8644 & TST & \\
\hline CHEMBL1518723 & 688550 & 4.85 & 4.8089 & TST & \\
\hline CHEMBL3211397 & 688550 & 4.5 & 4.7867 & TST & \\
\hline CHEMBL1457634 & 688550 & 5.05 & 4.7689 & TST & \\
\hline CHEMBL1430463 & 688550 & 4.75 & 4.8486 & TST & \\
\hline CHEMBL1558771 & 688550 & 4.6 & 4.9898 & TST & \\
\hline CHEMBL1350287 & 688550 & 4.4 & 4.7918 & TST & \\
\hline CHEMBL1498877 & 688550 & 4.45 & 4.9734 & TST & \\
\hline CHEMBL1370171 & 688550 & 4.7 & 5.0183 & TST & \\
\hline CHEMBL1563218 & 688550 & 4.45 & 4.78600 & 00000000005 & TST \\
\hline CHEMBL1586233 & 688550 & 4.65 & 4.8141 & TST & \\
\hline CHEMBL1343228 & 688550 & 4.9 & 5.0532 & TST & \\
\hline CHEMBL1429632 & 688550 & 4.5 & 4.8465 & TST & \\
\hline CHEMBL1607603 & 688550 & 5.7 & 4.9922 & TST & \\
\hline CHEMBL1584920 & 688550 & 4.65 & 4.9498 & TST & \\
\hline CHEMBL1456254 & 688550 & 5.35 & 4.9263 & TST & \\
\hline CHEMBL1339466 & 688550 & 4.7 & 4.7371 & TST & \\
\hline CHEMBL1310587 & 688550 & 4.4 & 4.8994 & TST & \\
\hline CHEMBL1503910 & 688550 & 6.05 & 5.0684 & TST & \\
\hline CHEMBL 2002465 & 688550 & 5.2 & 4.7721 & TST & \\
\hline CHEMBL1497097 & 688550 & 4.4 & 4.9176 & TST & \\
\hline CHEMBL1351175 & 688550 & 4.5 & 4.8728 & TST & \\
\hline CHEMBL1557772 & 688550 & 4.4 & 4.8979 & TST & \\
\hline CHEMBL1577027 & 688550 & 4.85 & 4.9024 & TST & \\
\hline CHEMBL1310529 & 688550 & 4.6 & 4.9625 & TST & \\
\hline CHEMBL1483246 & 688550 & 5.35 & 4.8725 & TST & \\
\hline CHEMBL1606465 & 688550 & 4.55 & 4.8371 & TST & \\
\hline CHEMBL1386035 & 688550 & 4.8 & 5.0087 & TST & \\
\hline CHEMBL1579763 & 688550 & 4.4 & 4.9178 & TST & \\
\hline
\end{tabular}




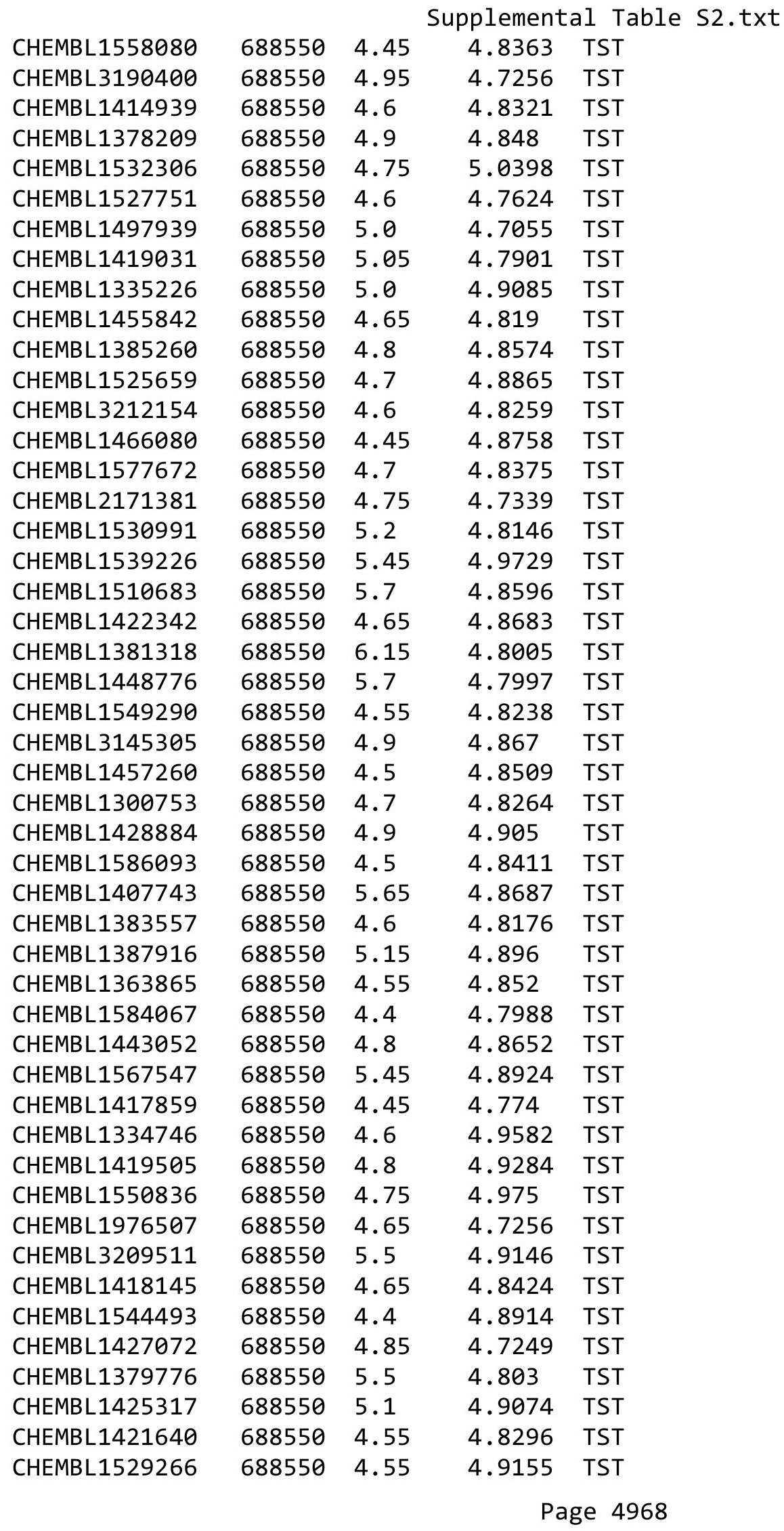




\begin{tabular}{|c|c|c|c|c|c|}
\hline \multicolumn{6}{|c|}{ Supplemental Table S2.txt } \\
\hline CHEMBL1586674 & 688550 & 4.85 & 4.8642 & TST & \\
\hline CHEMBL1348245 & 688550 & 5.4 & 4.9622 & TST & \\
\hline CHEMBL1584875 & 688550 & 4.65 & 4.7758 & TST & \\
\hline CHEMBL1548864 & 688550 & 6.0 & 4.8742 & TST & \\
\hline CHEMBL1468476 & 688550 & 5.35 & 4.9067 & TST & \\
\hline CHEMBL1600417 & 688550 & 4.4 & 4.9506 & TST & \\
\hline CHEMBL202131 & 688550 & 4.5 & 4.8186 & TST & \\
\hline CHEMBL1482783 & 688550 & 4.6 & 4.926 & TST & \\
\hline CHEMBL1562983 & 688550 & 6.15 & 4.8577 & TST & \\
\hline CHEMBL1385946 & 688550 & 6.15 & 4.9016 & TST & \\
\hline CHEMBL1404424 & 688550 & 5.15 & 4.8011 & TST & \\
\hline CHEMBL1478754 & 688550 & 4.75 & 4.8873 & TST & \\
\hline CHEMBL1509101 & 688550 & 6.1 & 5.0105 & TST & \\
\hline CHEMBL1347258 & 688550 & 4.4 & 4.8735 & TST & \\
\hline CHEMBL1300561 & 688550 & 4.45 & 4.8831 & TST & \\
\hline CHEMBL1534535 & 688550 & 5.4 & 5.035 & TST & \\
\hline CHEMBL1331531 & 688550 & 4.65 & 4.8916 & TST & \\
\hline CHEMBL1496624 & 688550 & 4.9 & 4.7955 & TST & \\
\hline CHEMBL 3210215 & 688550 & 4.4 & 4.8933 & TST & \\
\hline CHEMBL1517633 & 688550 & 4.55 & 4.8734 & TST & \\
\hline CHEMBL1529950 & 688550 & 4.95 & 4.79 & TST & \\
\hline CHEMBL421589 & 900186 & 5.2218 & 5.1276 & TRN & \\
\hline CHEMBL2235259 & 900186 & 7.3468 & 7.4849 & TRN & \\
\hline CHEMBL 2235266 & 900186 & 8.3468 & 8.1977 & TRN & \\
\hline CHEMBL 2235263 & 900186 & 8.0969 & 7.9746 & TRN & \\
\hline CHEMBL556332 & 900186 & 6.2291 & 8.2966 & TST & \\
\hline CHEMBL555906 & 900186 & 6.4949 & 7.9087 & TST & \\
\hline CHEMBL99853 & 900186 & 3.0 & 3.5845 & TRN & \\
\hline CHEMBL552058 & 900186 & 4.9119 & 6.1736 & TST & \\
\hline CHEMBL99835 & 900186 & 3.0 & 3.6826 & TRN & \\
\hline CHEMBL 2235660 & 900186 & 5.699 & 5.67299 & 9999999999 & TRN \\
\hline CHEMBL95195 & 900186 & 7.0 & 6.8465 & TRN & \\
\hline CHEMBL 2235658 & 900186 & 7.6021 & 7.9142 & TRN & \\
\hline CHEMBL 319248 & 900186 & 6.0458 & 6.0093 & TRN & \\
\hline CHEMBL 2235666 & 900186 & 6.0 & 5.8363 & TST & \\
\hline CHEMBL561118 & 900186 & 5.6198 & 5.8232 & TRN & \\
\hline CHEMBL 2235256 & 900186 & 7.0223 & 7.063 & TRN & \\
\hline CHEMBL 2235255 & 900186 & 6.8153 & 6.7423 & TRN & \\
\hline CHEMBL 321105 & 900186 & 4.3565 & 4.4876 & TRN & \\
\hline CHEMBL552465 & 900186 & 6.0757 & 5.9982 & TRN & \\
\hline CHEMBL99737 & 900186 & 3.0 & 3.1479 & TRN & \\
\hline CHEMBL 2235253 & 900186 & 7.1463 & 7.0947 & TRN & \\
\hline CHEMBL 2235251 & 900186 & 7.699 & 7.1308 & TST & \\
\hline CHEMBL557560 & 900186 & 5.699 & 5.8113 & TST & \\
\hline CHEMBL97384 & 900186 & 6.2218 & 6.3614 & TRN & \\
\hline CHEMBL 2235254 & 900186 & 6.8697 & 6.4938 & TRN & \\
\hline CHEMBL539664 & 900186 & 4.2793 & 5.9714 & TST & \\
\hline CHEMBL 2235665 & 900186 & 7.0458 & 7.4371 & TRN & \\
\hline
\end{tabular}




\begin{tabular}{|c|c|c|c|c|c|}
\hline \multicolumn{6}{|c|}{ Supplemental Table s2.txt } \\
\hline CHEMBL98346 & 900186 & 7.0 & 6.4459 & TRN & \\
\hline CHEMBL 2235260 & 900186 & 8.301 & 8.3491 & TRN & \\
\hline CHEMBL95916 & 900186 & 5.8239 & 6.4938 & TRN & \\
\hline CHEMBL95959 & 900186 & 6.301 & 6.4938 & TRN & \\
\hline CHEMBL551151 & 900186 & 5.7696 & 8.13600 & 2000000001 & TST \\
\hline CHEMBL 2235261 & 900186 & 8.0706 & 8.2295 & TRN & \\
\hline CHEMBL 2235657 & 900186 & 8.2218 & 8.0694 & TRN & \\
\hline CHEMBL96966 & 900186 & 7.0 & 6.7164 & TRN & \\
\hline CHEMBL541000 & 900186 & 5.0155 & 6.11799 & 9999999999 & TST \\
\hline CHEMBL97387 & 900186 & 6.2218 & 6.272 & TRN & \\
\hline CHEMBL419716 & 900186 & 5.6576 & 4.8867 & TRN & \\
\hline CHEMBL101167 & 900186 & 5.5528 & 4.8627 & TRN & \\
\hline CHEMBL 2235659 & 900186 & 7.4559 & 7.2355 & TRN & \\
\hline CHEMBL 2235664 & 900186 & 7.2218 & 7.407 & TRN & \\
\hline CHEMBL 2235265 & 900186 & 8.0223 & 8.0305 & TRN & \\
\hline CHEMBL 2235252 & 900186 & 6.3372 & 7.50200 & 0000000001 & TST \\
\hline CHEMBL321283 & 900186 & 5.1135 & 4.677 & TST & \\
\hline CHEMBL 2235663 & 900186 & 6.2218 & 5.9532 & TRN & \\
\hline CHEMBL 97860 & 900186 & 6.0 & 6.4179 & TRN & \\
\hline CHEMBL 2235257 & 900186 & 7.8239 & 7.1872 & TRN & \\
\hline CHEMBL538967 & 900186 & 4.301 & 7.9794 & TST & \\
\hline CHEMBL 2235262 & 900186 & 8.3979 & 8.728 & TRN & \\
\hline CHEMBL95273 & 900186 & 7.4559 & 7.671 & TRN & \\
\hline CHEMBL95850 & 900186 & 7.0 & 6.9698 & TRN & \\
\hline CHEMBL 2235661 & 900186 & 4.7696 & 4.8145 & TRN & \\
\hline CHEMBL 2235662 & 900186 & 7.0 & 6.8974 & TRN & \\
\hline CHEMBL317814 & 900186 & 6.699 & 6.6885 & TRN & \\
\hline CHEMBL100631 & 900186 & 3.0 & 3.6843 & TST & \\
\hline CHEMBL318642 & 900186 & 7.1249 & 6.7693 & TRN & \\
\hline CHEMBL 2235267 & 900186 & 6.2218 & 5.76200 & 00000000005 & TRN \\
\hline CHEMBL99810 & 900186 & 7.1871 & 6.4938 & TRN & \\
\hline CHEMBL 2235264 & 900186 & 8.699 & 8.6583 & TRN & \\
\hline CHEMBL100282 & 900186 & 5.3372 & 4.7096 & TST & \\
\hline CHEMBL 317570 & 900186 & 6.5229 & 6.9609 & TRN & \\
\hline CHEMBL95835 & 900186 & 6.3468 & 7.1872 & TRN & \\
\hline CHEMBL319375 & 900186 & 4.3979 & 4.5687 & TST & \\
\hline CHEMBL 2235258 & 900186 & 7.3468 & 7.0648 & TRN & \\
\hline CHEMBL100925 & 900186 & 3.0 & 3.6534 & TST & \\
\hline CHEMBL95849 & 900186 & 6.5229 & 6.7555 & TRN & \\
\hline CHEMBL317252 & 900186 & 3.0 & 4.5425 & TST & \\
\hline CHEMBL149606 & 900186 & 6.9872 & 7.0947 & TRN & \\
\hline CHEMBL539180 & 900186 & 4.9488 & 5.9044 & TST & \\
\hline CHEMBL1964290 & 809134 & 7.2 & 7.4324 & TRN & \\
\hline CHEMBL 2003768 & 809134 & 4.1 & 4.1897 & TRN & \\
\hline CHEMBL213505 & 809134 & 5.6 & 5.0114 & TRN & \\
\hline CHEMBL1987034 & 809134 & 6.5 & 6.2191 & TRN & \\
\hline CHEMBL1993941 & 809134 & 4.1 & 4.5802 & TRN & \\
\hline CHEMBL377383 & 809134 & 4.1 & 4.1761 & TRN & \\
\hline
\end{tabular}




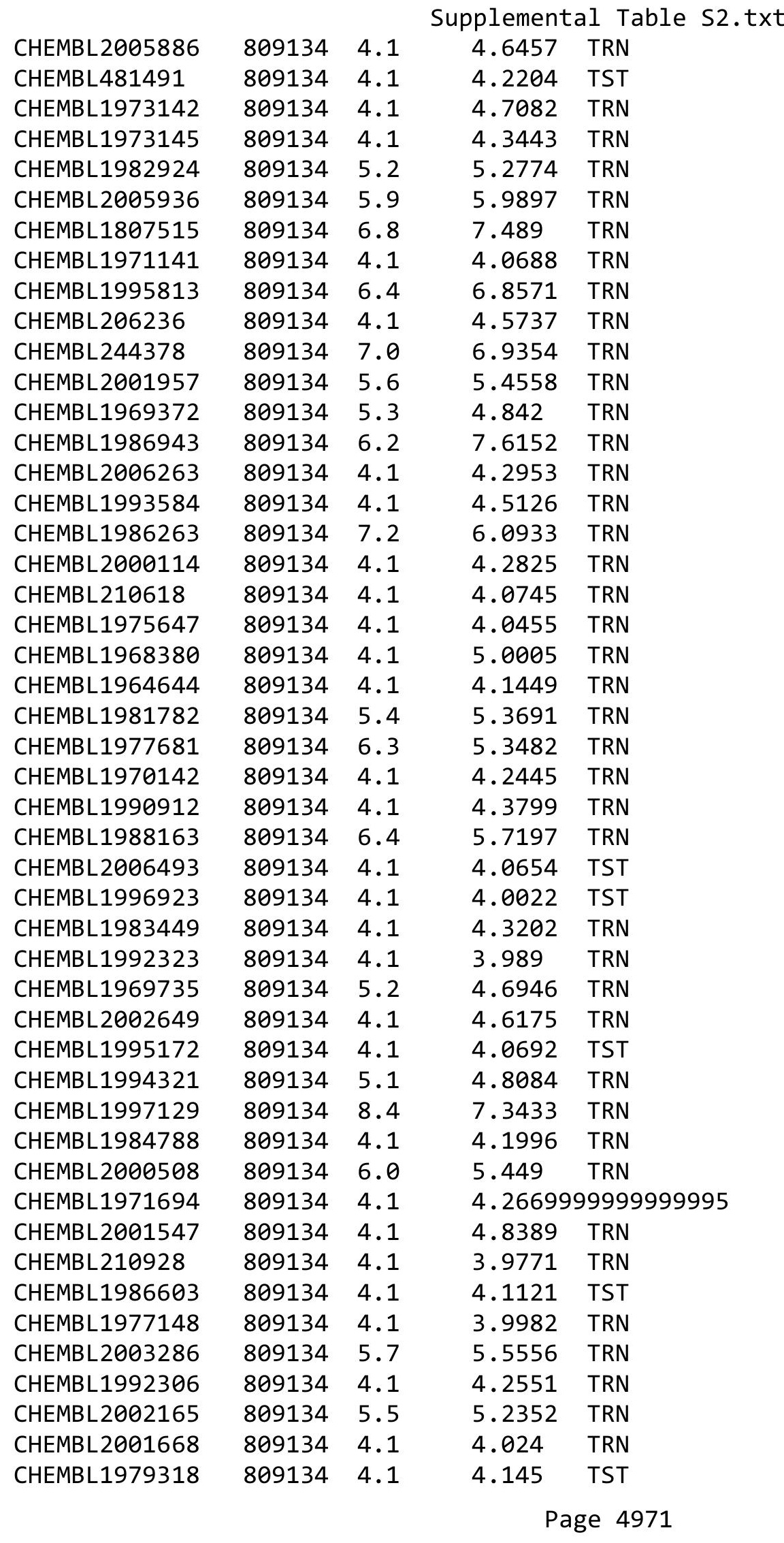




\begin{tabular}{|c|c|c|c|c|}
\hline \multicolumn{5}{|c|}{ Supplemental Table S2.txt } \\
\hline CHEMBL206382 & 809134 & 4.1 & 4.2282 & TRN \\
\hline CHEMBL1998585 & 809134 & 5.3 & 5.8968 & TRN \\
\hline CHEMBL127898 & 809134 & 4.1 & 4.3825 & TST \\
\hline CHEMBL519697 & 809134 & 5.2 & 5.3742 & TRN \\
\hline CHEMBL 2004934 & 809134 & 4.1 & 4.1665 & TRN \\
\hline CHEMBL1975128 & 809134 & 6.9 & 6.2506 & TRN \\
\hline CHEMBL1970369 & 809134 & 4.1 & 4.9 & TRN \\
\hline CHEMBL 2001485 & 809134 & 4.1 & 4.3581 & TRN \\
\hline CHEMBL1966425 & 809134 & 4.1 & 4.8939 & TRN \\
\hline CHEMBL1984363 & 809134 & 5.3 & 4.4489 & TRN \\
\hline CHEMBL1978099 & 809134 & 5.4 & 4.7943 & TRN \\
\hline CHEMBL1988608 & 809134 & 4.1 & 4.7044 & TRN \\
\hline CHEMBL184847 & 809134 & 4.1 & 4.226 & TRN \\
\hline CHEMBL1984367 & 809134 & 5.9 & 4.4771 & TRN \\
\hline CHEMBL178737 & 809134 & 4.1 & 4.3766 & TST \\
\hline CHEMBL226898 & 809134 & 6.8 & 7.0621 & TRN \\
\hline CHEMBL1982563 & 809134 & 5.7 & 5.1876 & TRN \\
\hline CHEMBL539474 & 809134 & 4.1 & 4.5704 & TST \\
\hline CHEMBL575824 & 809134 & 4.1 & 4.4873 & TRN \\
\hline CHEMBL1988387 & 809134 & 4.1 & 4.3258 & TRN \\
\hline CHEMBL1974803 & 809134 & 4.1 & 4.2894 & TRN \\
\hline CHEMBL1970074 & 809134 & 5.4 & 4.3436 & TRN \\
\hline CHEMBL1986970 & 809134 & 5.1 & 4.7039 & TRN \\
\hline CHEMBL 2005112 & 809134 & 4.1 & 4.2212 & TST \\
\hline CHEMBL1958401 & 809134 & 5.5 & 5.2957 & TRN \\
\hline CHEMBL1984044 & 809134 & 4.1 & 4.1484 & TRN \\
\hline CHEMBL 2003456 & 809134 & 5.2 & 4.4305 & TRN \\
\hline CHEMBL1966816 & 809134 & 4.1 & 3.9953 & TRN \\
\hline CHEMBL1972584 & 809134 & 4.1 & 4.7234 & TRN \\
\hline CHEMBL 2002992 & 809134 & 4.1 & 4.6329 & TRN \\
\hline CHEMBL560813 & 809134 & 5.2 & 4.232 & TRN \\
\hline CHEMBL207253 & 809134 & 4.1 & 4.1302 & TST \\
\hline CHEMBL1968791 & 809134 & 4.1 & 4.8199 & TRN \\
\hline CHEMBL 2002682 & 809134 & 4.1 & 4.7106 & TST \\
\hline CHEMBL1971186 & 809134 & 6.0 & 6.0894 & TRN \\
\hline CHEMBL 2003482 & 809134 & 4.1 & 4.3232 & TRN \\
\hline CHEMBL1973211 & 809134 & 5.9 & 5.3 & TRN \\
\hline CHEMBL1984700 & 809134 & 5.5 & 4.8617 & TRN \\
\hline CHEMBL1972125 & 809134 & 4.1 & 4.1812 & TRN \\
\hline CHEMBL1461728 & 809134 & 4.1 & 4.2106 & TRN \\
\hline CHEMBL1976134 & 809134 & 5.6 & 4.8992 & TRN \\
\hline CHEMBL1965131 & 809134 & 4.1 & 4.8187 & TRN \\
\hline CHEMBL1972158 & 809134 & 6.0 & 6.2337 & TRN \\
\hline CHEMBL 2006580 & 809134 & 4.1 & 4.5948 & TRN \\
\hline CHEMBL 2006481 & 809134 & 4.1 & 4.3233 & TRN \\
\hline CHEMBL1979855 & 809134 & 4.1 & 4.0475 & TRN \\
\hline CHEMBL1970340 & 809134 & 4.1 & 4.2127 & TRN \\
\hline CHEMBL2005186 & 809134 & 4.1 & 4.2096 & TRN \\
\hline
\end{tabular}




\begin{tabular}{|c|c|c|c|c|}
\hline & & & pमeme & \\
\hline CHEMBL1995927 & 809134 & 4.1 & 4.0191 & TST \\
\hline CHEMBL1975534 & 809134 & 5.5 & 4.8357 & TRN \\
\hline CHEMBL1993424 & 809134 & 5.6 & 5.2605 & TRN \\
\hline CHEMBL1966703 & 809134 & 4.1 & 4.19 & TST \\
\hline CHEMBL1969561 & 809134 & 4.2 & 4.6157 & TRN \\
\hline CHEMBL1975121 & 809134 & 4.1 & 4.0936 & TRN \\
\hline CHEMBL1997023 & 809134 & 4.1 & 4.2459 & TST \\
\hline CHEMBL1964687 & 809134 & 5.2 & 5.3067 & TRN \\
\hline CHEMBL1971943 & 809134 & 5.6 & 4.2679 & TST \\
\hline CHEMBL1974254 & 809134 & 4.1 & 4.2812 & TRN \\
\hline CHEMBL1988537 & 809134 & 4.1 & 4.2909 & TST \\
\hline CHEMBL1969049 & 809134 & 4.1 & 4.1946 & TRN \\
\hline CHEMBL 2005828 & 809134 & 6.1 & 6.2784 & TRN \\
\hline CHEMBL 2002240 & 809134 & 4.1 & 3.9051 & TRN \\
\hline CHEMBL1991143 & 809134 & 4.1 & 3.9502 & TST \\
\hline CHEMBL1998611 & 809134 & 4.2 & 4.4131 & TRN \\
\hline CHEMBL1975900 & 809134 & 6.6 & 5.6188 & TRN \\
\hline CHEMBL 255822 & 809134 & 6.2 & 6.2462 & TRN \\
\hline CHEMBL1972221 & 809134 & 4.1 & 5.2046 & TRN \\
\hline CHEMBL 2006778 & 809134 & 5.2 & 4.5206 & TRN \\
\hline CHEMBL 378627 & 809134 & 4.1 & 4.0759 & TRN \\
\hline CHEMBL1996979 & 809134 & 5.3 & 5.1891 & TRN \\
\hline CHEMBL1997025 & 809134 & 4.1 & 4.0567 & TRN \\
\hline CHEMBL1968406 & 809134 & 5.3 & 5.39 & TRN \\
\hline CHEMBL1984274 & 809134 & 4.1 & 4.2062 & TST \\
\hline CHEMBL1998545 & 809134 & 4.1 & 4.1961 & TRN \\
\hline CHEMBL1986869 & 809134 & 4.1 & 4.1642 & TRN \\
\hline CHEMBL 2006010 & 809134 & 4.1 & 3.9105 & TRN \\
\hline CHEMBL1682558 & 809134 & 4.1 & 4.204 & TRN \\
\hline CHEMBL1990496 & 809134 & 4.1 & 4.2948 & TRN \\
\hline CHEMBL 2002479 & 809134 & 6.5 & 5.4995 & TRN \\
\hline CHEMBL1967094 & 809134 & 5.9 & 4.9761 & TRN \\
\hline CHEMBL1966035 & 809134 & 5.3 & 4.3811 & TRN \\
\hline CHEMBL 2003341 & 809134 & 4.1 & 4.199 & TRN \\
\hline CHEMBL1982992 & 809134 & 4.1 & 4.3329 & TRN \\
\hline CHEMBL1999590 & 809134 & 4.1 & 4.1011 & TST \\
\hline CHEMBL1981079 & 809134 & 7.4 & 7.8439 & TRN \\
\hline CHEMBL1972276 & 809134 & 4.1 & 4.239 & TRN \\
\hline CHEMBL1980489 & 809134 & 6.3 & 5.3745 & TRN \\
\hline CHEMBL1967116 & 809134 & 5.3 & 5.1291 & TRN \\
\hline CHEMBL 2000832 & 809134 & 5.3 & 5.1866 & TRN \\
\hline CHEMBL513846 & 809134 & 4.1 & 4.1099 & TRN \\
\hline CHEMBL1970709 & 809134 & 4.1 & 4.256 & TRN \\
\hline CHEMBL1965660 & 809134 & 7.6 & 8.0923 & TRN \\
\hline CHEMBL1998112 & 809134 & 4.1 & 4.0932 & TRN \\
\hline CHEMBL1969126 & 809134 & 5.2 & 4.3118 & TRN \\
\hline CHEMBL1980896 & 809134 & 5.3 & 5.0311 & TRN \\
\hline CHEMBL1975208 & 809134 & 4.1 & 4.4981 & TST \\
\hline
\end{tabular}




\begin{tabular}{|c|c|c|c|c|c|}
\hline \\
\hline CHEMBL1970104 & 809134 & 6.3 & 5.4916 & TRN & \\
\hline CHEMBL1991429 & 809134 & 4.1 & 4.0942 & TRN & \\
\hline CHEMBL1964777 & 809134 & 6.0 & 5.5268 & TST & \\
\hline CHEMBL1971149 & 809134 & 4.1 & 4.6658 & TRN & \\
\hline CHEMBL1999714 & 809134 & 4.1 & 5.1677 & TRN & \\
\hline CHEMBL1987533 & 809134 & 4.1 & 4.1304 & TRN & \\
\hline CHEMBL1994040 & 809134 & 5.3 & 4.8149 & TRN & \\
\hline CHEMBL579246 & 809134 & 4.1 & 4.885 & TRN & \\
\hline CHEMBL398951 & 809134 & 4.1 & 4.228 & TRN & \\
\hline CHEMBL1982506 & 809134 & 4.1 & 4.0511 & TST & \\
\hline CHEMBL 2004716 & 809134 & 5.4 & 5.3776 & TRN & \\
\hline CHEMBL1968127 & 809134 & 5.5 & 5.1667 & TRN & \\
\hline CHEMBL1975233 & 809134 & 5.1 & 3.9395 & TRN & \\
\hline CHEMBL1985406 & 809134 & 4.1 & 4.6161 & TRN & \\
\hline CHEMBL207400 & 809134 & 4.1 & 3.9889 & TST & \\
\hline CHEMBL 2000894 & 809134 & 4.1 & 4.1395 & TST & \\
\hline CHEMBL1982135 & 809134 & 5.4 & 5.2809 & TRN & \\
\hline CHEMBL1976090 & 809134 & 5.9 & 5.7299 & TRN & \\
\hline CHEMBL1993243 & 809134 & 4.1 & 4.3802 & TRN & \\
\hline CHEMBL1992922 & 809134 & 4.1 & 4.58899 & 99999999995 & TRN \\
\hline CHEMBL2004771 & 809134 & 4.1 & 4.3315 & TRN & \\
\hline CHEMBL1997597 & 809134 & 4.1 & 4.5629 & TRN & \\
\hline CHEMBL1969537 & 809134 & 4.1 & 4.4615 & TST & \\
\hline CHEMBL1976093 & 809134 & 4.1 & 4.6387 & TRN & \\
\hline CHEMBL210032 & 809134 & 4.1 & 3.9305 & TRN & \\
\hline CHEMBL1975256 & 809134 & 4.1 & 4.0149 & TST & \\
\hline CHEMBL508928 & 809134 & 4.1 & 4.1737 & TRN & \\
\hline CHEMBL1991356 & 809134 & 4.1 & 4.2685 & TRN & \\
\hline CHEMBL1983309 & 809134 & 4.1 & 4.1123 & TRN & \\
\hline CHEMBL2004892 & 809134 & 4.1 & 4.5027 & TRN & \\
\hline CHEMBL1999126 & 809134 & 4.1 & 4.1508 & TST & \\
\hline CHEMBL1997503 & 809134 & 4.1 & 4.3611 & TST & \\
\hline CHEMBL116070 & 809134 & 6.6 & 5.5907 & TST & \\
\hline CHEMBL1990821 & 809134 & 4.1 & 4.3099 & TST & \\
\hline CHEMBL1970314 & 809134 & 4.1 & 4.2746 & TRN & \\
\hline CHEMBL2004871 & 809134 & 4.1 & 4.49 & TRN & \\
\hline CHEMBL2004872 & 809134 & 4.1 & 4.1974 & TRN & \\
\hline CHEMBL1727312 & 809134 & 4.1 & 4.0963 & TRN & \\
\hline CHEMBL1969879 & 809134 & 4.1 & 4.2529 & TRN & \\
\hline CHEMBL1981720 & 809134 & 4.1 & 4.2073 & TRN & \\
\hline CHEMBL419932 & 809134 & 4.1 & 4.8355 & TRN & \\
\hline CHEMBL 262433 & 809134 & 5.5 & 5.0346 & TRN & \\
\hline CHEMBL306380 & 809134 & 4.1 & 4.6737 & TRN & \\
\hline CHEMBL1966722 & 809134 & 5.7 & 4.4779 & TRN & \\
\hline CHEMBL1975500 & 809134 & 4.1 & 4.7059 & TRN & \\
\hline CHEMBL394619 & 809134 & 5.7 & 5.4576 & TRN & \\
\hline CHEMBL1996831 & 809134 & 5.3 & 4.7083 & TST & \\
\hline CHEMBL411903 & 809134 & 4.1 & 4.8063 & TRN & \\
\hline
\end{tabular}




\begin{tabular}{|c|c|c|c|c|}
\hline \multicolumn{5}{|c|}{ Supplemental Table s2.txt } \\
\hline CHEMBL1965988 & 809134 & 5.5 & 5.6105 & TRN \\
\hline CHEMBL418203 & 809134 & 4.1 & 4.2537 & TST \\
\hline CHEMBL1989646 & 809134 & 7.5 & 6.9328 & TRN \\
\hline CHEMBL225519 & 809134 & 7.2 & 6.6438 & TRN \\
\hline CHEMBL1978200 & 809134 & 5.6 & 4.7769 & TRN \\
\hline CHEMBL1970522 & 809134 & 6.2 & \multicolumn{2}{|c|}{5.781000000000001} \\
\hline CHEMBL402846 & 809134 & 6.2 & 5.7431 & TRN \\
\hline CHEMBL1990415 & 809134 & 4.1 & 4.19 & TRN \\
\hline CHEMBL1966087 & 809134 & 4.1 & 4.1761 & TRN \\
\hline CHEMBL1964692 & 809134 & 6.8 & 5.9746 & TRN \\
\hline CHEMBL1996931 & 809134 & 4.1 & 4.6973 & TRN \\
\hline CHEMBL1964413 & 809134 & 6.1 & 5.1786 & TRN \\
\hline CHEMBL1973483 & 809134 & 4.1 & 3.9848 & TRN \\
\hline CHEMBL1970735 & 809134 & 4.1 & 3.9242 & TRN \\
\hline CHEMBL1997340 & 809134 & 4.1 & 5.4915 & TRN \\
\hline CHEMBL 2004365 & 809134 & 5.5 & 4.7774 & TST \\
\hline CHEMBL1522508 & 809134 & 4.1 & 3.877 & TRN \\
\hline CHEMBL1989474 & 809134 & 4.1 & 4.4941 & TRN \\
\hline CHEMBL1090360 & 809134 & 4.1 & 4.0262 & TRN \\
\hline CHEMBL 210887 & 809134 & 6.6 & 5.3681 & TRN \\
\hline CHEMBL458997 & 809134 & 4.1 & 5.1015 & TRN \\
\hline CHEMBL 227271 & 809134 & 6.6 & 7.0355 & TRN \\
\hline CHEMBL1971021 & 809134 & 4.1 & 3.9652 & TRN \\
\hline CHEMBL583144 & 809134 & 4.1 & 4.2327 & TRN \\
\hline CHEMBL1974310 & 809134 & 5.9 & 5.9697 & TST \\
\hline CHEMBL1982660 & 809134 & 4.1 & 3.8753 & TRN \\
\hline CHEMBL1994693 & 809134 & 5.5 & 5.4322 & TRN \\
\hline CHEMBL1982957 & 809134 & 5.4 & 5.1356 & TRN \\
\hline CHEMBL1725279 & 809134 & 5.7 & 5.3775 & TST \\
\hline CHEMBL1975138 & 809134 & 5.3 & 4.2485 & TRN \\
\hline CHEMBL424872 & 809134 & 4.1 & 4.2787 & TRN \\
\hline CHEMBL 2006836 & 809134 & 4.1 & 4.0886 & TST \\
\hline CHEMBL412142 & 809134 & 4.1 & 4.6719 & TST \\
\hline CHEMBL1980704 & 809134 & 4.1 & 4.2068 & TST \\
\hline CHEMBL 2003271 & 809134 & 4.1 & 5.9811 & TRN \\
\hline CHEMBL1966808 & 809134 & 4.1 & 4.2541 & TST \\
\hline CHEMBL 2004447 & 809134 & 4.1 & 4.0289 & TST \\
\hline CHEMBL1983111 & 809134 & 5.9 & 5.7632 & TST \\
\hline CHEMBL1973860 & 809134 & 4.1 & 4.1392 & TRN \\
\hline CHEMBL 260135 & 809134 & 4.1 & 4.1833 & TRN \\
\hline CHEMBL220241 & 809134 & 4.1 & 4.5791 & TRN \\
\hline CHEMBL 2004544 & 809134 & 5.6 & 4.0891 & TST \\
\hline CHEMBL1982610 & 809134 & 4.1 & 4.0701 & TRN \\
\hline CHEMBL1999496 & 809134 & 4.1 & 4.1231 & TRN \\
\hline CHEMBL1988300 & 809134 & 6.4 & 5.0517 & TRN \\
\hline CHEMBL1991078 & 809134 & 8.2 & 7.6864 & TRN \\
\hline CHEMBL1987359 & 809134 & 4.1 & 4.0089 & TST \\
\hline CHEMBL1989265 & 809134 & 4.1 & 4.2079 & TST \\
\hline
\end{tabular}

TRN 


\begin{tabular}{|c|c|c|c|c|}
\hline \multicolumn{5}{|r|}{11 Table S } \\
\hline CHEMBL1969502 & 809134 & 4.1 & 4.6671 & TRN \\
\hline CHEMBL1682553 & 809134 & 5.6 & 4.6844 & TRN \\
\hline CHEMBL1971430 & 809134 & 4.1 & 4.6552 & TRN \\
\hline CHEMBL1997764 & 809134 & 4.1 & 5.3104 & TRN \\
\hline CHEMBL1983963 & 809134 & 5.8 & 5.5894 & TRN \\
\hline CHEMBL1985092 & 809134 & 5.7 & 5.1866 & TST \\
\hline CHEMBL 2004692 & 809134 & 4.1 & 3.99399 & 99999999998 \\
\hline CHEMBL1981410 & 809134 & 4.1 & 4.3472 & TRN \\
\hline CHEMBL1996234 & 809134 & 4.1 & 4.2391 & TRN \\
\hline CHEMBL1991434 & 809134 & 4.1 & 4.1399 & TRN \\
\hline CHEMBL1967544 & 809134 & 4.1 & 4.4526 & TRN \\
\hline CHEMBL223367 & 809134 & 4.1 & 4.3518 & TST \\
\hline CHEMBL340384 & 809134 & 6.5 & 5.6393 & TST \\
\hline CHEMBL1996587 & 809134 & 4.1 & 3.995 & TRN \\
\hline CHEMBL1964804 & 809134 & 4.1 & 4.3324 & TRN \\
\hline CHEMBL443962 & 809134 & 6.3 & 4.8794 & TST \\
\hline CHEMBL 2000354 & 809134 & 6.4 & 5.7299 & TRN \\
\hline CHEMBL1965507 & 809134 & 5.2 & 4.784 & TRN \\
\hline CHEMBL 274064 & 809134 & 5.5 & 5.7242 & TRN \\
\hline CHEMBL1967564 & 809134 & 4.1 & 3.9637 & TRN \\
\hline CHEMBL592030 & 809134 & 5.9 & 5.7074 & TST \\
\hline CHEMBL 2000071 & 809134 & 4.1 & 4.4411 & TRN \\
\hline CHEMBL1979176 & 809134 & 4.1 & 4.1317 & TRN \\
\hline CHEMBL 2000408 & 809134 & 5.8 & 5.3066 & TRN \\
\hline CHEMBL 248757 & 809134 & 4.1 & 4.3908 & TST \\
\hline CHEMBL1978014 & 809134 & 6.6 & 5.4793 & TRN \\
\hline CHEMBL1994538 & 809134 & 4.1 & 4.0201 & TRN \\
\hline CHEMBL1983195 & 809134 & 5.4 & 4.8181 & TST \\
\hline CHEMBL1975490 & 809134 & 5.5 & 4.8556 & TRN \\
\hline CHEMBL1964444 & 809134 & 4.1 & 3.9334 & TRN \\
\hline CHEMBL1986139 & 809134 & 4.1 & 5.5612 & TRN \\
\hline CHEMBL1980540 & 809134 & 4.1 & 3.9209 & TRN \\
\hline CHEMBL1979883 & 809134 & 5.4 & 5.2632 & TRN \\
\hline CHEMBL1984162 & 809134 & 4.1 & 4.9405 & TRN \\
\hline CHEMBL491758 & 809134 & 4.1 & 4.7386 & TRN \\
\hline CHEMBL549730 & 809134 & 6.0 & 5.4568 & TRN \\
\hline CHEMBL1970189 & 809134 & 4.1 & 4.2239 & TST \\
\hline CHEMBL1996791 & 809134 & 5.5 & 5.2384 & TRN \\
\hline CHEMBL371206 & 809134 & 5.6 & 6.5711 & TRN \\
\hline CHEMBL1974664 & 809134 & 4.1 & 4.1617 & TRN \\
\hline CHEMBL1974288 & 809134 & 4.1 & 4.234 & TRN \\
\hline CHEMBL196363 & 809134 & 5.4 & 5.4641 & TRN \\
\hline CHEMBL1190711 & 809134 & 4.1 & 4.3142 & TRN \\
\hline CHEMBL1968705 & 809134 & 4.1 & 4.2388 & TRN \\
\hline CHEMBL404367 & 809134 & 6.4 & 5.8495 & TRN \\
\hline CHEMBL1966343 & 809134 & 6.0 & 5.6128 & TRN \\
\hline CHEMBL1967887 & 809134 & 5.8 & 5.6964 & TRN \\
\hline CHEMBL 2000568 & 809134 & 5.6 & 4.3683 & TRN \\
\hline
\end{tabular}




\begin{tabular}{|c|c|c|c|c|}
\hline & & & & al Ta \\
\hline CHEMBL 2000335 & 809134 & 5.3 & 5.5093 & TRN \\
\hline CHEMBL1977604 & 809134 & 4.1 & 4.8229 & TST \\
\hline CHEMBL1988717 & 809134 & 4.1 & 4.0561 & TRN \\
\hline CHEMBL1974328 & 809134 & 6.3 & 6.0379 & TRN \\
\hline CHEMBL509032 & 809134 & 4.1 & 5.2679 & TRN \\
\hline CHEMBL1973808 & 809134 & 4.1 & 4.1358 & TRN \\
\hline CHEMBL 2000429 & 809134 & 5.7 & 5.5646 & TRN \\
\hline CHEMBL1972576 & 809134 & 5.3 & 5.2548 & TRN \\
\hline CHEMBL1992555 & 809134 & 4.1 & 4.2736 & TRN \\
\hline CHEMBL1992342 & 809134 & 4.1 & 4.7419 & TRN \\
\hline CHEMBL1988173 & 809134 & 5.7 & 5.1092 & TRN \\
\hline CHEMBL535331 & 809134 & 4.1 & 4.083 & TRN \\
\hline CHEMBL1989805 & 809134 & 5.7 & 4.7894 & TST \\
\hline CHEMBL1965423 & 809134 & 4.1 & 4.6396 & TRN \\
\hline CHEMBL1982980 & 809134 & 4.1 & 4.1844 & TST \\
\hline CHEMBL1983025 & 809134 & 5.3 & 5.2786 & TRN \\
\hline CHEMBL 205415 & 809134 & 4.1 & 4.4858 & TRN \\
\hline CHEMBL1977135 & 809134 & 4.1 & 4.1762 & TRN \\
\hline CHEMBL 2001920 & 809134 & 4.1 & 4.7026 & TRN \\
\hline CHEMBL1241473 & 809134 & 6.2 & 5.7266 & TRN \\
\hline CHEMBL1978448 & 809134 & 4.1 & 4.8268 & TST \\
\hline CHEMBL 2004513 & 809134 & 4.1 & 4.2956 & TRN \\
\hline CHEMBL1972258 & 809134 & 4.1 & 4.1667 & TRN \\
\hline CHEMBL 2001257 & 809134 & 5.5 & 5.1953 & TRN \\
\hline CHEMBL1992536 & 809134 & 4.1 & 4.1666 & TRN \\
\hline CHEMBL1987793 & 809134 & 4.1 & 4.6146 & TST \\
\hline CHEMBL1992740 & 809134 & 4.1 & 4.3028 & TRN \\
\hline CHEMBL439340 & 809134 & 4.1 & 4.1129 & TRN \\
\hline CHEMBL 2002373 & 809134 & 4.1 & 4.5438 & TRN \\
\hline CHEMBL 2006188 & 809134 & 4.1 & 4.2487 & TRN \\
\hline CHEMBL1967531 & 809134 & 6.1 & 6.4229 & TRN \\
\hline CHEMBL1973893 & 809134 & 4.1 & 5.7103 & TRN \\
\hline CHEMBL1970913 & 809134 & 4.1 & 4.0334 & TRN \\
\hline CHEMBL1995736 & 809134 & 4.1 & 4.0677 & TRN \\
\hline CHEMBL1997534 & 809134 & 4.1 & 4.513 & TRN \\
\hline CHEMBL1996500 & 809134 & 4.2 & 4.7104 & TRN \\
\hline CHEMBL1985095 & 809134 & 4.1 & 5.1108 & TST \\
\hline CHEMBL1998551 & 809134 & 4.1 & 3.9435 & TRN \\
\hline CHEMBL1977374 & 809134 & 4.1 & 3.9283 & TRN \\
\hline CHEMBL1682540 & 809134 & 6.0 & 4.3786 & TRN \\
\hline CHEMBL1976420 & 809134 & 4.1 & 4.2344 & TST \\
\hline CHEMBL1994864 & 809134 & 5.9 & 5.1873 & TRN \\
\hline CHEMBL 2002446 & 809134 & 4.1 & 4.2671 & TRN \\
\hline CHEMBL497151 & 809134 & 6.4 & 5.6414 & TST \\
\hline CHEMBL 246970 & 809134 & 4.1 & 4.9916 & TRN \\
\hline CHEMBL340921 & 809134 & 5.7 & 4.6866 & TST \\
\hline CHEMBL1999718 & 809134 & 4.1 & 4.075 & TRN \\
\hline CHEMBL 1276446 & 809134 & 5.5 & 6.1489 & TST \\
\hline
\end{tabular}




\begin{tabular}{|c|c|c|c|c|}
\hline \multicolumn{5}{|c|}{ Supplemental Table S2.txt } \\
\hline CHEMBL1977346 & 809134 & 4.1 & 4.4719 & TRN \\
\hline CHEMBL1971649 & 809134 & 5.4 & 4.582 & TRN \\
\hline CHEMBL1998435 & 809134 & 4.1 & 3.986 & TRN \\
\hline CHEMBL2006439 & 809134 & 7.4 & 7.1191 & TRN \\
\hline CHEMBL2006156 & 809134 & 4.1 & 4.6534 & TST \\
\hline CHEMBL1969190 & 809134 & 4.1 & 4.3592 & TRN \\
\hline CHEMBL1973937 & 809134 & 5.5 & 4.963 & TRN \\
\hline CHEMBL1991674 & 809134 & 5.3 & 5.5505 & TRN \\
\hline CHEMBL1982711 & 809134 & 5.5 & 4.9478 & TRN \\
\hline CHEMBL1987982 & 809134 & 4.1 & 4.5621 & TST \\
\hline CHEMBL1964623 & 809134 & 5.2 & 4.8815 & TST \\
\hline CHEMBL 2007044 & 809134 & 4.1 & 4.3364 & TRN \\
\hline CHEMBL1994241 & 809134 & 5.3 & 4.6301 & TST \\
\hline CHEMBL223460 & 809134 & 4.1 & 4.3527 & TST \\
\hline CHEMBL1998829 & 809134 & 4.1 & 4.5478 & TRN \\
\hline CHEMBL50894 & 809134 & 5.4 & 4.9584 & TRN \\
\hline CHEMBL1988838 & 809134 & 5.7 & 5.5232 & TRN \\
\hline CHEMBL1981725 & 809134 & 4.1 & 4.5844 & TRN \\
\hline CHEMBL1982866 & 809134 & 4.1 & 4.1272 & TRN \\
\hline CHEMBL1968926 & 809134 & 4.1 & 4.0438 & TRN \\
\hline CHEMBL462120 & 809134 & 4.1 & 4.2233 & TRN \\
\hline CHEMBL1965570 & 809134 & 5.5 & 5.3967 & TRN \\
\hline CHEMBL 2007592 & 809134 & 4.1 & 4.141 & TST \\
\hline CHEMBL210963 & 809134 & 4.1 & 4.016 & TRN \\
\hline CHEMBL1082440 & 809134 & 4.1 & 4.7154 & TST \\
\hline CHEMBL1614705 & 809134 & 4.1 & 4.4764 & TRN \\
\hline CHEMBL1984633 & 809134 & 4.1 & 4.7099 & TRN \\
\hline CHEMBL 2007372 & 809134 & 4.1 & 4.3966 & TRN \\
\hline CHEMBL1965845 & 809134 & 4.1 & 4.9082 & TRN \\
\hline CHEMBL 2006715 & 809134 & 4.1 & 4.3667 & TRN \\
\hline CHEMBL1986597 & 809134 & 4.1 & 4.51 & TRN \\
\hline CHEMBL1990482 & 809134 & 4.1 & 4.2946 & TRN \\
\hline CHEMBL1990904 & 809134 & 6.2 & 5.0942 & TRN \\
\hline CHEMBL2005475 & 809134 & 5.9 & 5.7426 & TRN \\
\hline CHEMBL183844 & 809134 & 4.1 & 4.1313 & TRN \\
\hline CHEMBL1997349 & 809134 & 5.2 & 4.5256 & TST \\
\hline CHEMBL220057 & 809134 & 5.4 & 4.4601 & TRN \\
\hline CHEMBL1682545 & 809134 & 4.1 & 4.4698 & TRN \\
\hline CHEMBL383541 & 809134 & 5.8 & 5.2071 & TRN \\
\hline CHEMBL 2001224 & 809134 & 4.1 & 3.9993 & TRN \\
\hline CHEMBL10 & 809134 & 4.1 & 4.7548 & TRN \\
\hline CHEMBL1976732 & 809134 & 4.1 & 4.1635 & TRN \\
\hline CHEMBL1964937 & 809134 & 4.1 & 4.8548 & TRN \\
\hline CHEMBL1969506 & 809134 & 4.1 & 4.3109 & TRN \\
\hline CHEMBL1980163 & 809134 & 4.1 & 4.2143 & TRN \\
\hline CHEMBL 2005899 & 809134 & 6.0 & 5.3862 & TRN \\
\hline CHEMBL1682552 & 809134 & 6.3 & 5.3938 & TRN \\
\hline CHEMBL1972568 & 809134 & 4.1 & 4.1569 & TRN \\
\hline
\end{tabular}




\begin{tabular}{|c|c|c|c|c|c|}
\hline \multicolumn{6}{|c|}{ Supplemental Table S2.txt } \\
\hline CHEMBL229799 & 809134 & 7.1 & 7.5637 & TRN & \\
\hline CHEMBL105739 & 809134 & 5.7 & 4.7339 & TRN & \\
\hline CHEMBL379300 & 809134 & 6.2 & 6.9212 & TRN & \\
\hline CHEMBL1969523 & 809134 & 7.2 & 5.8799 & TRN & \\
\hline CHEMBL1988995 & 809134 & 4.1 & 3.9696 & TRN & \\
\hline CHEMBL1986781 & 809134 & 6.3 & 5.8371 & TRN & \\
\hline CHEMBL526133 & 809134 & 5.7 & 5.4127 & TRN & \\
\hline CHEMBL387971 & 809134 & 4.1 & 4.1355 & TRN & \\
\hline CHEMBL1979057 & 809134 & 5.5 & 4.5257 & TRN & \\
\hline CHEMBL1999428 & 809134 & 4.1 & 4.1646 & TRN & \\
\hline CHEMBL1967560 & 809134 & 4.1 & 4.6313 & TRN & \\
\hline CHEMBL 211378 & 809134 & 5.2 & 4.4923 & TRN & \\
\hline CHEMBL1516890 & 809134 & 4.1 & 4.7444 & TRN & \\
\hline CHEMBL1982465 & 809134 & 5.3 & 5.1454 & TRN & \\
\hline CHEMBL 2001751 & 809134 & 6.1 & 6.5395 & TRN & \\
\hline CHEMBL 2003420 & 809134 & 4.1 & 4.2143 & TRN & \\
\hline CHEMBL1984586 & 809134 & 6.0 & 6.2791 & TRN & \\
\hline CHEMBL1972659 & 809134 & 4.1 & 4.0915 & TST & \\
\hline CHEMBL 272453 & 809134 & 4.1 & 4.24100 & 00000000005 & TRN \\
\hline CHEMBL1970217 & 809134 & 4.1 & 4.2408 & TRN & \\
\hline CHEMBL 2005528 & 809134 & 4.1 & 4.6518 & TST & \\
\hline CHEMBL185569 & 809134 & 4.1 & 4.1901 & TRN & \\
\hline CHEMBL1969843 & 809134 & 7.0 & 5.3809 & TRN & \\
\hline CHEMBL 2007002 & 809134 & 5.4 & 4.7168 & TRN & \\
\hline CHEMBL1987007 & 809134 & 4.1 & 4.3672 & TRN & \\
\hline CHEMBL1969588 & 809134 & 8.2 & 7.2952 & TRN & \\
\hline CHEMBL1984711 & 809134 & 4.1 & 4.6475 & TRN & \\
\hline CHEMBL484390 & 809134 & 5.4 & 5.3038 & TRN & \\
\hline CHEMBL1979252 & 809134 & 5.8 & 5.3233 & TRN & \\
\hline CHEMBL1986499 & 809134 & 5.9 & 6.2097 & TRN & \\
\hline CHEMBL 2004290 & 809134 & 4.1 & 4.1683 & TRN & \\
\hline CHEMBL1972937 & 809134 & 4.1 & 5.6162 & TRN & \\
\hline CHEMBL 2000393 & 809134 & 5.1 & 4.6595 & TST & \\
\hline CHEMBL 2004311 & 809134 & 4.1 & 4.1574 & TRN & \\
\hline CHEMBL1992634 & 809134 & 4.1 & 4.677 & TRN & \\
\hline CHEMBL1242373 & 809134 & 5.3 & 5.3766 & TRN & \\
\hline CHEMBL56543 & 809134 & 4.1 & 4.4703 & TRN & \\
\hline CHEMBL1988075 & 809134 & 6.0 & 5.1211 & TRN & \\
\hline CHEMBL316264 & 809134 & 4.1 & 4.6386 & TRN & \\
\hline CHEMBL1991678 & 809134 & 4.2 & 4.8955 & TRN & \\
\hline CHEMBL2001239 & 809134 & 5.6 & 5.3871 & TST & \\
\hline CHEMBL1988594 & 809134 & 5.5 & 4.7984 & TRN & \\
\hline CHEMBL 2001288 & 809134 & 4.1 & 4.7892 & TRN & \\
\hline CHEMBL1999811 & 809134 & 5.8 & 4.846 & TST & \\
\hline CHEMBL1985074 & 809134 & 4.1 & 4.6343 & TST & \\
\hline CHEMBL1982874 & 809134 & 4.1 & 4.2542 & TRN & \\
\hline CHEMBL 2000481 & 809134 & 4.1 & 4.453 & TRN & \\
\hline CHEMBL1991725 & 809134 & 4.1 & 4.5687 & TRN & \\
\hline
\end{tabular}




\begin{tabular}{|c|c|c|c|c|c|}
\hline \multicolumn{6}{|c|}{ Supplemental Table S2.txt } \\
\hline CHEMBL1992242 & 809134 & 4.1 & 4.0872 & TRN & \\
\hline CHEMBL 2007296 & 809134 & 4.1 & 3.9169 & TRN & \\
\hline CHEMBL396523 & 809134 & 7.3 & 6.9847 & TRN & \\
\hline CHEMBL208637 & 809134 & 4.1 & 3.9167 & TRN & \\
\hline CHEMBL1970203 & 809134 & 4.1 & 4.7905 & TRN & \\
\hline CHEMBL1986530 & 809134 & 4.1 & 4.2159 & TST & \\
\hline CHEMBL1999321 & 809134 & 4.1 & 4.2129 & TRN & \\
\hline CHEMBL1968590 & 809134 & 4.1 & 4.1625 & TRN & \\
\hline CHEMBL 2007336 & 809134 & 5.5 & 4.2649 & TRN & \\
\hline CHEMBL 2005375 & 809134 & 4.1 & 4.869 & TRN & \\
\hline CHEMBL1984191 & 809134 & 4.1 & 4.374 & TRN & \\
\hline CHEMBL1972183 & 809134 & 4.1 & 4.2342 & TST & \\
\hline CHEMBL1971029 & 809134 & 4.1 & 5.3827 & TRN & \\
\hline CHEMBL394790 & 809134 & 5.6 & 5.2634 & TRN & \\
\hline CHEMBL226471 & 809134 & 6.8 & 6.4806 & TRN & \\
\hline CHEMBL1996111 & 809134 & 5.3 & 4.7304 & TRN & \\
\hline CHEMBL1974702 & 809134 & 4.1 & 4.2112 & TRN & \\
\hline CHEMBL1965589 & 809134 & 4.2 & 4.7876 & TRN & \\
\hline CHEMBL1998193 & 809134 & 4.1 & 4.1058 & TRN & \\
\hline CHEMBL474432 & 809134 & 4.3 & 5.2146 & TST & \\
\hline CHEMBL1988153 & 809134 & 6.7 & 5.5068 & TST & \\
\hline CHEMBL1988437 & 809134 & 4.1 & 4.4966 & TST & \\
\hline CHEMBL1998121 & 809134 & 6.2 & 5.765 & TRN & \\
\hline CHEMBL1979577 & 809134 & 5.2 & 5.669 & TRN & \\
\hline CHEMBL1991800 & 809134 & 5.7 & 5.2093 & TRN & \\
\hline CHEMBL52387 & 809134 & 5.6 & 4.6978 & TST & \\
\hline CHEMBL379835 & 809134 & 4.1 & 3.9365 & TST & \\
\hline CHEMBL1979357 & 809134 & 4.1 & 4.0577 & TRN & \\
\hline CHEMBL1996817 & 809134 & 4.2 & 4.9221 & TRN & \\
\hline CHEMBL3197315 & 809134 & 4.1 & 4.1783 & TST & \\
\hline CHEMBL468280 & 809134 & 4.1 & 4.0853 & TST & \\
\hline CHEMBL1990884 & 809134 & 5.7 & 4.2064 & TRN & \\
\hline CHEMBL3109278 & 809134 & 6.2 & 5.1357 & TRN & \\
\hline CHEMBL256835 & 809134 & 4.1 & 4.7429 & TRN & \\
\hline CHEMBL1980142 & 809134 & 4.1 & 3.88199 & 99999999997 & TRN \\
\hline CHEMBL41783 & 809134 & 4.1 & 4.5728 & TRN & \\
\hline CHEMBL 2006276 & 809134 & 4.1 & 4.3244 & TRN & \\
\hline CHEMBL 271381 & 809134 & 4.1 & 4.534 & TRN & \\
\hline CHEMBL 2006785 & 809134 & 4.1 & 5.4024 & TRN & \\
\hline CHEMBL1982466 & 809134 & 4.1 & 4.2505 & TRN & \\
\hline CHEMBL1995740 & 809134 & 4.1 & 4.6419 & TRN & \\
\hline CHEMBL234085 & 809134 & 4.1 & 4.40300 & 00000000005 & TRN \\
\hline CHEMBL1995832 & 809134 & 5.8 & 5.4922 & TRN & \\
\hline CHEMBL1998414 & 809134 & 6.1 & 4.4545 & TRN & \\
\hline CHEMBL1969042 & 809134 & 4.1 & 4.5625 & TST & \\
\hline CHEMBL 2000345 & 809134 & 5.2 & 4.8969 & TST & \\
\hline CHEMBL1999931 & 809134 & 8.1 & 7.976 & TRN & \\
\hline CHEMBL1375418 & 809134 & 4.1 & 4.1398 & TRN & \\
\hline
\end{tabular}




\begin{tabular}{|c|c|c|c|c|}
\hline & & & pplement & al Ta \\
\hline CHEMBL2007064 & 809134 & 5.2 & 4.4479 & TRN \\
\hline CHEMBL1981047 & 809134 & 4.1 & 4.8627 & TST \\
\hline CHEMBL229968 & 809134 & 6.9 & 7.4593 & TRN \\
\hline CHEMBL1976240 & 809134 & 4.1 & 4.152 & TRN \\
\hline CHEMBL1979093 & 809134 & 4.1 & 4.3886 & TRN \\
\hline CHEMBL1968151 & 809134 & 4.1 & 4.0959 & TST \\
\hline CHEMBL1987009 & 809134 & 6.0 & 5.3095 & TRN \\
\hline CHEMBL379218 & 809134 & 6.5 & 6.9361 & TRN \\
\hline CHEMBL 2003817 & 809134 & 5.2 & 4.1014 & TRN \\
\hline CHEMBL1994830 & 809134 & 7.4 & 5.9277 & TST \\
\hline CHEMBL226403 & 809134 & 6.5 & 6.8615 & TRN \\
\hline CHEMBL 2005631 & 809134 & 5.4 & 5.5857 & TRN \\
\hline CHEMBL1994938 & 809134 & 4.1 & 4.4089 & TRN \\
\hline CHEMBL1977223 & 809134 & 7.7 & 6.8715 & TRN \\
\hline CHEMBL1825138 & 809134 & 4.1 & 4.566 & TST \\
\hline CHEMBL1236126 & 809134 & 4.1 & 4.9747 & TRN \\
\hline CHEMBL1966279 & 809134 & 4.1 & 4.1736 & TRN \\
\hline CHEMBL1997846 & 809134 & 5.9 & 5.4331 & TRN \\
\hline CHEMBL 2004419 & 809134 & 4.1 & 4.8724 & TRN \\
\hline CHEMBL1972489 & 809134 & 4.1 & 4.0301 & TRN \\
\hline CHEMBL1994074 & 809134 & 5.6 & 4.4942 & TRN \\
\hline CHEMBL1992937 & 809134 & 7.3 & 5.6174 & TRN \\
\hline CHEMBL1972119 & 809134 & 4.1 & 4.0281 & TRN \\
\hline CHEMBL1090356 & 809134 & 4.3 & 4.0624 & TRN \\
\hline CHEMBL95692 & 809134 & 4.1 & 4.7832 & TRN \\
\hline CHEMBL1986328 & 809134 & 5.5 & 4.6979 & TST \\
\hline CHEMBL1976455 & 809134 & 5.5 & 4.5634 & TRN \\
\hline CHEMBL1983923 & 809134 & 4.1 & 4.4734 & TST \\
\hline CHEMBL1982361 & 809134 & 4.1 & 4.6575 & TRN \\
\hline CHEMBL1983534 & 809134 & 4.1 & 4.7847 & TRN \\
\hline CHEMBL1982122 & 809134 & 5.6 & 4.9744 & TRN \\
\hline CHEMBL 2000801 & 809134 & 4.1 & 4.0952 & TRN \\
\hline CHEMBL1999112 & 809134 & 4.1 & 4.4189 & TST \\
\hline CHEMBL1682546 & 809134 & 4.1 & 4.598 & TRN \\
\hline CHEMBL1991395 & 809134 & 5.6 & 5.0648 & TRN \\
\hline CHEMBL1971245 & 809134 & 4.1 & 4.3807 & TRN \\
\hline CHEMBL1972142 & 809134 & 4.1 & 4.4211 & TST \\
\hline CHEMBL1966514 & 809134 & 6.0 & 5.7134 & TST \\
\hline CHEMBL 2003638 & 809134 & 8.4 & 7.9411 & TST \\
\hline CHEMBL1996066 & 809134 & 7.6 & 6.0435 & TST \\
\hline CHEMBL1993722 & 809134 & 5.9 & 4.4006 & TST \\
\hline CHEMBL1970806 & 809134 & 4.1 & 4.1761 & TST \\
\hline CHEMBL1375640 & 809134 & 6.3 & 5.6784 & TST \\
\hline CHEMBL1979970 & 809134 & 4.1 & 4.2558 & TST \\
\hline CHEMBL 249282 & 809134 & 4.1 & 4.194 & TST \\
\hline CHEMBL 2006237 & 809134 & 4.1 & 4.3075 & TST \\
\hline CHEMBL1967720 & 809134 & 6.1 & 5.6493 & TST \\
\hline CHEMBL1572266 & 809134 & 4.1 & 4.1606 & TST \\
\hline
\end{tabular}




\begin{tabular}{|c|c|c|c|c|}
\hline \multicolumn{5}{|c|}{ Supplemental Table S2.txt } \\
\hline CHEMBL1991138 & 809134 & 4.1 & 4.2225 & TST \\
\hline CHEMBL1969755 & 809134 & 4.1 & 4.2473 & TST \\
\hline CHEMBL1979516 & 809134 & 4.1 & 4.49 & TST \\
\hline CHEMBL1605605 & 809134 & 4.1 & 4.0707 & TST \\
\hline CHEMBL1972820 & 809134 & 4.1 & 4.1732 & TST \\
\hline CHEMBL1996208 & 809134 & 4.1 & 4.2009 & TST \\
\hline CHEMBL1989029 & 809134 & 4.1 & 4.2551 & TST \\
\hline CHEMBL392642 & 809134 & 5.7 & 5.0789 & TST \\
\hline CHEMBL514499 & 809134 & 4.1 & 4.2487 & TST \\
\hline CHEMBL1965631 & 809134 & 7.5 & 6.4011 & TST \\
\hline CHEMBL1980144 & 809134 & 4.1 & 4.6923 & TST \\
\hline CHEMBL1991188 & 809134 & 4.1 & 4.38899 & 9999999999 \\
\hline CHEMBL1972849 & 809134 & 4.1 & 4.0209 & TST \\
\hline CHEMBL 377408 & 809134 & 4.1 & 4.4615 & TST \\
\hline CHEMBL231209 & 809134 & 5.7 & 5.3417 & TST \\
\hline CHEMBL1975357 & 809134 & 4.1 & 4.3313 & TST \\
\hline CHEMBL1976220 & 809134 & 5.8 & 5.3726 & TST \\
\hline CHEMBL 259922 & 809134 & 4.1 & 4.2162 & TST \\
\hline CHEMBL1997617 & 809134 & 4.1 & 4.9605 & TST \\
\hline CHEMBL1982383 & 809134 & 6.1 & 5.6211 & TST \\
\hline CHEMBL1969301 & 809134 & 5.8 & 5.5394 & TST \\
\hline CHEMBL 17370 & 809134 & 5.3 & 4.7076 & TST \\
\hline CHEMBL1987910 & 809134 & 5.5 & 4.7211 & TST \\
\hline CHEMBL1983932 & 809134 & 4.1 & 3.8824 & TST \\
\hline CHEMBL1997822 & 809134 & 5.6 & 4.3169 & TST \\
\hline CHEMBL1991285 & 809134 & 4.1 & 4.0322 & TST \\
\hline CHEMBL1984038 & 809134 & 4.1 & 4.1195 & TST \\
\hline CHEMBL 243088 & 809134 & 7.1 & 6.7121 & TST \\
\hline CHEMBL1993661 & 809134 & 4.1 & 5.1557 & TST \\
\hline CHEMBL1974416 & 809134 & 4.1 & 4.7208 & TST \\
\hline CHEMBL 2004615 & 809134 & 4.1 & 4.2697 & TST \\
\hline CHEMBL1984039 & 809134 & 4.1 & 4.3403 & TST \\
\hline CHEMBL1997872 & 809134 & 5.2 & 4.1997 & TST \\
\hline CHEMBL1555363 & 752533 & 4.3875 & 3.889 & TRN \\
\hline CHEMBL 3145254 & 752533 & 3.1024 & 3.6945 & TST \\
\hline CHEMBL1498273 & 752533 & 3.1024 & 3.5391 & TRN \\
\hline CHEMBL1410989 & 752533 & 3.1024 & 3.5757 & TRN \\
\hline CHEMBL338314 & 752533 & 4.5049 & 4.0373 & TST \\
\hline CHEMBL1510105 & 752533 & 3.1024 & 3.7838 & TRN \\
\hline CHEMBL1588014 & 752533 & 3.1024 & 3.7873 & TST \\
\hline CHEMBL1587680 & 752533 & 4.3349 & 3.8494 & TRN \\
\hline CHEMBL1718652 & 752533 & 3.1024 & 3.83 & TRN \\
\hline CHEMBL591834 & 752533 & 3.1024 & 3.9157 & TST \\
\hline CHEMBL1731481 & 752533 & 3.1024 & 3.6809 & TRN \\
\hline CHEMBL 2006569 & 752533 & 3.1024 & 3.4962 & TRN \\
\hline CHEMBL1490367 & 752533 & 3.1024 & 3.6277 & TRN \\
\hline CHEMBL1412725 & 752533 & 3.1024 & 3.7653 & TRN \\
\hline CHEMBL1448654 & 752533 & 4.5083 & 3.4535 & TST \\
\hline
\end{tabular}


Supplemental Table S2.txt

\begin{tabular}{|c|c|c|c|c|}
\hline CHEMBL1596732 & 752533 & 3.1024 & 3.7473 & TST \\
\hline CHEMBL1607534 & 752533 & 4.6818 & 3.5997 & TRN \\
\hline CHEMBL1870332 & 752533 & 3.1024 & 3.5913 & TRN \\
\hline CHEMBL1372308 & 752533 & 3.1024 & 3.8207 & TRN \\
\hline CHEMBL250574 & 752533 & 4.473 & 3.7231 & TRN \\
\hline CHEMBL1492843 & 752533 & 3.1024 & 3.6129 & TRN \\
\hline CHEMBL1365585 & 752533 & 3.1024 & 3.7053 & TRN \\
\hline CHEMBL1427061 & 752533 & 4.3098 & 3.5901 & TST \\
\hline CHEMBL1992977 & 752533 & 3.1024 & 3.7567 & TRN \\
\hline CHEMBL1383503 & 752533 & 4.6533 & 3.5688 & TRN \\
\hline CHEMBL1309409 & 752533 & 4.7585 & 3.731999 & 9999999998 \\
\hline CHEMBL1449103 & 752533 & 3.1024 & 3.7065 & TRN \\
\hline CHEMBL1480223 & 752533 & 3.1024 & 3.4727 & TRN \\
\hline CHEMBL 2000316 & 752533 & 4.9756 & 3.5842 & TRN \\
\hline CHEMBL1984130 & 752533 & 4.3929 & 3.6356 & TRN \\
\hline CHEMBL1583576 & 752533 & 3.1024 & 3.6958 & TST \\
\hline CHEMBL1708448 & 752533 & 3.1024 & 3.648 & TRN \\
\hline CHEMBL1404897 & 752533 & 3.1024 & 3.6557 & TRN \\
\hline CHEMBL1550273 & 752533 & 3.1024 & 3.6413 & TRN \\
\hline CHEMBL1383978 & 752533 & 5.2227 & 3.7718 & TRN \\
\hline CHEMBL1365411 & 752533 & 3.1024 & 3.6188 & TRN \\
\hline CHEMBL1365331 & 752533 & 3.1024 & 3.7473 & TRN \\
\hline CHEMBL1982363 & 752533 & 3.1024 & 3.5938 & TRN \\
\hline CHEMBL1966108 & 752533 & 3.1024 & 3.637 & TRN \\
\hline CHEMBL1443198 & 752533 & 3.1024 & 3.7251 & TRN \\
\hline CHEMBL1331666 & 752533 & 3.1024 & 3.6811 & TST \\
\hline CHEMBL1986319 & 752533 & 5.1011 & 3.445 & TRN \\
\hline CHEMBL1311933 & 752533 & 3.1024 & 3.7376 & TST \\
\hline CHEMBL1321016 & 752533 & 3.1024 & 3.3895 & TRN \\
\hline CHEMBL1474877 & 752533 & 3.1024 & 3.5737 & TRN \\
\hline CHEMBL1408059 & 752533 & 4.8428 & 3.8636 & TRN \\
\hline CHEMBL1981303 & 752533 & 3.1024 & 3.7751 & TST \\
\hline CHEMBL1591509 & 752533 & 3.1024 & 3.4829 & TRN \\
\hline CHEMBL1880661 & 752533 & 3.1024 & 3.3949 & TRN \\
\hline CHEMBL1081637 & 752533 & 3.1024 & 3.7282 & TST \\
\hline CHEMBL1450838 & 752533 & 3.1024 & 3.7643 & TRN \\
\hline CHEMBL1486149 & 752533 & 3.1024 & 3.7258 & TRN \\
\hline CHEMBL1462924 & 752533 & 3.1024 & 3.6075 & TRN \\
\hline CHEMBL1982577 & 752533 & 3.1024 & 3.8958 & TST \\
\hline CHEMBL1591182 & 752533 & 4.9506 & 3.7441 & TRN \\
\hline CHEMBL1711523 & 752533 & 3.1024 & 3.6067 & TRN \\
\hline CHEMBL1445873 & 752533 & 3.1024 & 3.5384 & TRN \\
\hline CHEMBL1324820 & 752533 & 3.1024 & 3.8304 & TRN \\
\hline CHEMBL1322873 & 752533 & 3.1024 & 3.8382 & TRN \\
\hline CHEMBL1516113 & 752533 & 3.1024 & 3.7591 & TRN \\
\hline CHEMBL1312157 & 752533 & 3.1024 & 3.5317 & TRN \\
\hline CHEMBL1884334 & 752533 & 3.1024 & 3.4993 & TRN \\
\hline CHEMBL1550676 & 752533 & 3.1024 & 3.6316 & TRN \\
\hline
\end{tabular}


Supplemental Table S2.txt

\begin{tabular}{|c|c|c|c|c|c|}
\hline CHEMBL1459641 & 752533 & 3.1024 & 3.4945 & TRN & \\
\hline CHEMBL1307703 & 752533 & 3.1024 & 3.2971 & TRN & \\
\hline CHEMBL1971316 & 752533 & 4.9824 & 3.8407 & TRN & \\
\hline CHEMBL1438732 & 752533 & 3.1024 & 3.4548 & TRN & \\
\hline CHEMBL1892313 & 752533 & 3.1024 & 3.6612 & TRN & \\
\hline CHEMBL1903425 & 752533 & 3.1024 & 3.4964 & TRN & \\
\hline CHEMBL1898660 & 752533 & 3.1024 & 3.8024 & TRN & \\
\hline CHEMBL1370849 & 752533 & 3.1024 & 3.4168 & TST & \\
\hline CHEMBL1536722 & 752533 & 3.1024 & 3.5737 & TRN & \\
\hline CHEMBL1337433 & 752533 & 4.5571 & 3.7507 & TRN & \\
\hline CHEMBL1901953 & 752533 & 3.1024 & 3.4849 & TRN & \\
\hline CHEMBL1883315 & 752533 & 3.1024 & 3.756999 & 99999999997 & וכו \\
\hline CHEMBL1552521 & 752533 & 4.7907 & 3.6841 & TRN & \\
\hline CHEMBL1994456 & 752533 & 3.1024 & 3.5955 & TRN & \\
\hline CHEMBL1400525 & 752533 & 4.9558 & 3.9556 & TRN & \\
\hline CHEMBL1891615 & 752533 & 3.1024 & 3.7726 & TST & \\
\hline CHEMBL1420862 & 752533 & 3.1024 & 3.4474 & TRN & \\
\hline CHEMBL1704990 & 752533 & 4.6838 & 3.52 & TRN & \\
\hline CHEMBL1468550 & 752533 & 4.4663 & 3.6025 & TRN & \\
\hline CHEMBL1397758 & 752533 & 3.1024 & 3.7461 & TRN & \\
\hline CHEMBL1878991 & 752533 & 3.1024 & 3.5184 & TRN & \\
\hline CHEMBL1557268 & 752533 & 3.1024 & 3.8533 & TST & \\
\hline CHEMBL1360390 & 752533 & 3.1024 & 3.6762 & TRN & \\
\hline CHEMBL1557445 & 752533 & 3.1024 & 3.2862 & TRN & \\
\hline CHEMBL1476931 & 752533 & 4.5978 & 3.5056 & TRN & \\
\hline CHEMBL1372708 & 752533 & 4.5552 & 3.4004 & TRN & \\
\hline CHEMBL1334204 & 752533 & 4.9064 & 4.0528 & TRN & \\
\hline CHEMBL1594835 & 752533 & 3.1024 & 3.5517 & TRN & \\
\hline CHEMBL1307671 & 752533 & 4.9042 & 3.7199 & TRN & \\
\hline CHEMBL1595618 & 752533 & 3.1024 & 3.5719 & TRN & \\
\hline CHEMBL1970371 & 752533 & \multicolumn{4}{|c|}{5.0280000000000005} \\
\hline CHEMBL1985708 & 752533 & 4.7651 & 3.542 & TRN & \\
\hline CHEMBL1393543 & 752533 & 3.1024 & 3.4365 & TRN & \\
\hline CHEMBL1986898 & 752533 & 3.1024 & 3.6729 & TRN & \\
\hline CHEMBL1538754 & 752533 & 3.1024 & 3.8782 & TST & \\
\hline CHEMBL1456803 & 752533 & 3.1024 & 3.8582 & TRN & \\
\hline CHEMBL1314964 & 752533 & 3.1024 & 3.6316 & TRN & \\
\hline CHEMBL1368699 & 752533 & 4.6892 & 3.6726 & TRN & \\
\hline CHEMBL1584208 & 752533 & 3.1024 & 3.7326 & TRN & \\
\hline CHEMBL1405690 & 752533 & 3.1024 & 3.7698 & TRN & \\
\hline CHEMBL1328958 & 752533 & 4.4143 & 3.7425 & TRN & \\
\hline CHEMBL1711830 & 752533 & 3.1024 & 3.4516 & TRN & \\
\hline CHEMBL1455427 & 752533 & 3.1024 & 3.6877 & TRN & \\
\hline CHEMBL1420497 & 752533 & 3.1024 & 3.6004 & TRN & \\
\hline CHEMBL1972014 & 752533 & 3.1024 & 3.71100 & 30000000003 & Tw \\
\hline CHEMBL1333594 & 752533 & 4.6717 & 3.6451 & TRN & \\
\hline CHEMBL1987884 & 752533 & 3.1024 & 3.8665 & TST & \\
\hline CHEMBL2006998 & 752533 & 3.1024 & 3.7792 & TRN & \\
\hline
\end{tabular}


Supplemental Table S2.txt

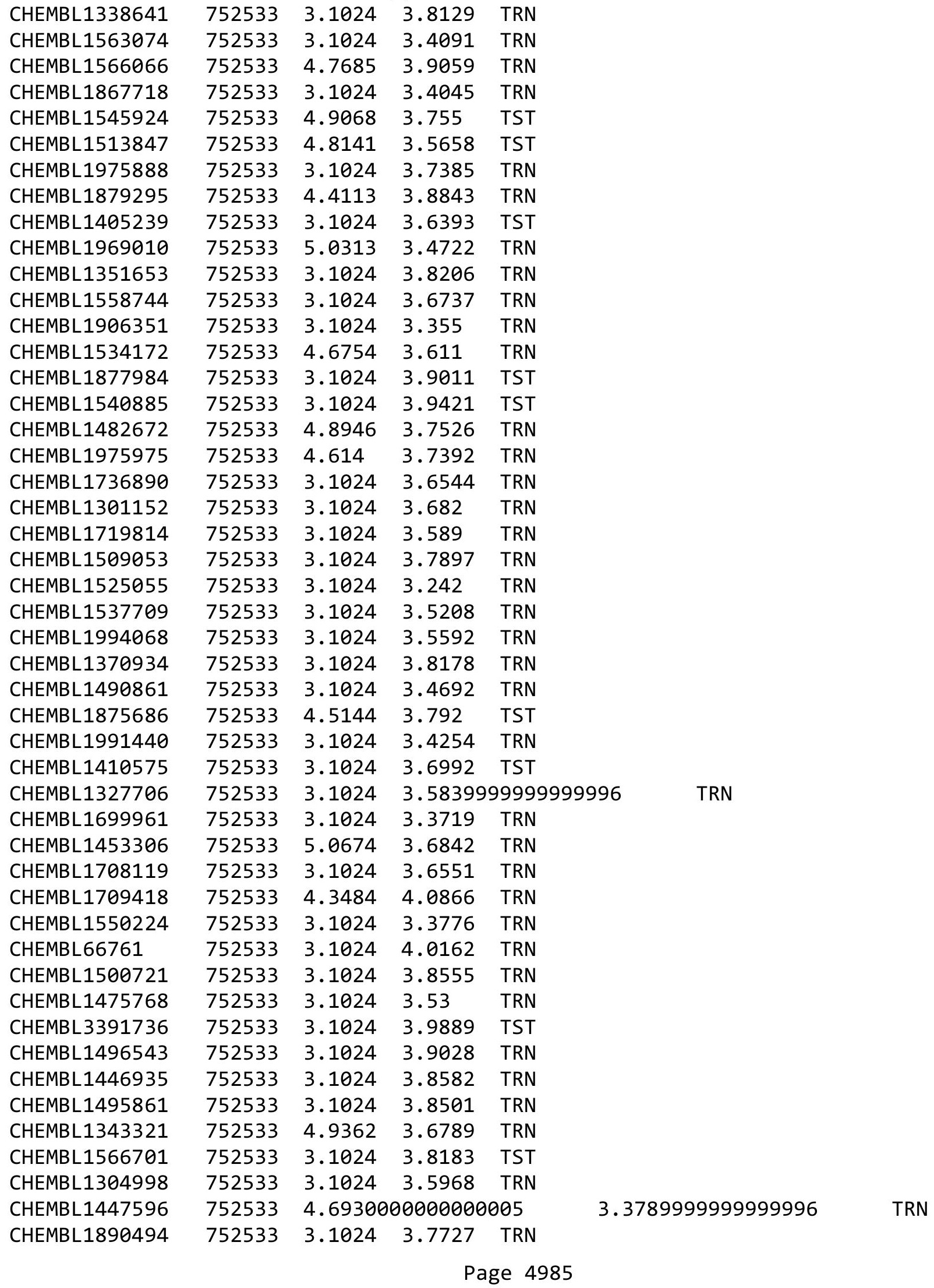


Supplemental Table S2.txt

\begin{tabular}{|c|c|c|c|c|}
\hline CHEMBL1338315 & 752533 & 4.5091 & 3.8811 & TRN \\
\hline CHEMBL1570765 & 752533 & 3.1024 & 3.7599 & TST \\
\hline CHEMBL1565006 & 752533 & 3.1024 & 3.7558 & TRN \\
\hline CHEMBL1554786 & 752533 & 3.1024 & 3.7193 & TRN \\
\hline CHEMBL1606973 & 752533 & 3.1024 & 3.8151 & TRN \\
\hline CHEMBL1440301 & 752533 & 3.1024 & 3.8002 & TST \\
\hline CHEMBL1545864 & 752533 & 3.1024 & 3.6864 & TRN \\
\hline CHEMBL 2004919 & 752533 & 4.4597 & 3.5118 & TRN \\
\hline CHEMBL1423858 & 752533 & 3.1024 & 3.4657 & TRN \\
\hline CHEMBL1497342 & 752533 & 3.1024 & 3.7224 & TRN \\
\hline CHEMBL1402530 & 752533 & 4.7594 & 3.7279 & TST \\
\hline CHEMBL1475748 & 752533 & 3.1024 & 3.6966 & TRN \\
\hline CHEMBL1503376 & 752533 & 3.1024 & 3.3754 & TRN \\
\hline CHEMBL 2003436 & 752533 & 3.1024 & 3.5995 & TRN \\
\hline CHEMBL1426855 & 752533 & 3.1024 & 3.4437 & TRN \\
\hline CHEMBL1735066 & 752533 & 5.0711 & 4.0234 & TRN \\
\hline CHEMBL1535344 & 752533 & 3.1024 & 3.4464 & TRN \\
\hline CHEMBL1899834 & 752533 & 3.1024 & 3.8006 & TRN \\
\hline CHEMBL1995870 & 752533 & 3.1024 & 3.6791 & TRN \\
\hline CHEMBL1470565 & 752533 & 4.4953 & 4.0416 & TST \\
\hline CHEMBL1993796 & 752533 & 3.1024 & 3.4546 & TRN \\
\hline CHEMBL1397381 & 752533 & 4.5939 & 3.9282 & TST \\
\hline CHEMBL1392487 & 752533 & 3.1024 & 3.813 & TRN \\
\hline CHEMBL1987709 & 752533 & 3.1024 & 3.9635 & TRN \\
\hline CHEMBL1450049 & 752533 & 3.1024 & 3.9203 & TRN \\
\hline CHEMBL1982852 & 752533 & 3.1024 & 3.6985 & TRN \\
\hline CHEMBL1699437 & 752533 & 3.1024 & 3.7366 & TRN \\
\hline CHEMBL1303540 & 752533 & 3.1024 & 3.4801 & TRN \\
\hline CHEMBL1599759 & 752533 & 3.1024 & 3.8451 & TRN \\
\hline CHEMBL1444339 & 752533 & 4.8637 & 3.8962 & TRN \\
\hline CHEMBL1477801 & 752533 & 3.1024 & 3.6447 & TRN \\
\hline CHEMBL1421246 & 752533 & 4.8072 & 3.8494 & TRN \\
\hline CHEMBL1457432 & 752533 & 4.8757 & 3.6489 & TRN \\
\hline CHEMBL1968168 & 752533 & 4.6508 & 3.8874 & TRN \\
\hline CHEMBL1484274 & 752533 & 4.8834 & 3.6382 & TRN \\
\hline CHEMBL1966961 & 752533 & 3.1024 & 3.5513 & TRN \\
\hline CHEMBL1989262 & 752533 & 4.908 & 3.6551 & TRN \\
\hline CHEMBL1305936 & 752533 & 3.1024 & 3.9108 & TRN \\
\hline CHEMBL1513328 & 752533 & 3.1024 & 3.9119 & TRN \\
\hline CHEMBL1370932 & 752533 & 4.3941 & 3.8835 & TRN \\
\hline CHEMBL1439208 & 752533 & 3.1024 & 3.52399 & 99999999996 \\
\hline CHEMBL1371305 & 752533 & 4.1296 & 3.7549 & TRN \\
\hline CHEMBL1507497 & 752533 & 3.1024 & 3.7505 & TST \\
\hline CHEMBL1971872 & 752533 & 3.1024 & 3.7035 & TRN \\
\hline CHEMBL1460101 & 752533 & 4.7155 & 3.6858 & TRN \\
\hline CHEMBL1904672 & 752533 & 4.8941 & 3.362 & TRN \\
\hline CHEMBL1352043 & 752533 & 4.4214 & 3.3983 & TRN \\
\hline CHEMBL 2000633 & 752533 & 3.1024 & 3.7383 & TRN \\
\hline
\end{tabular}


Supplemental Table S2.txt

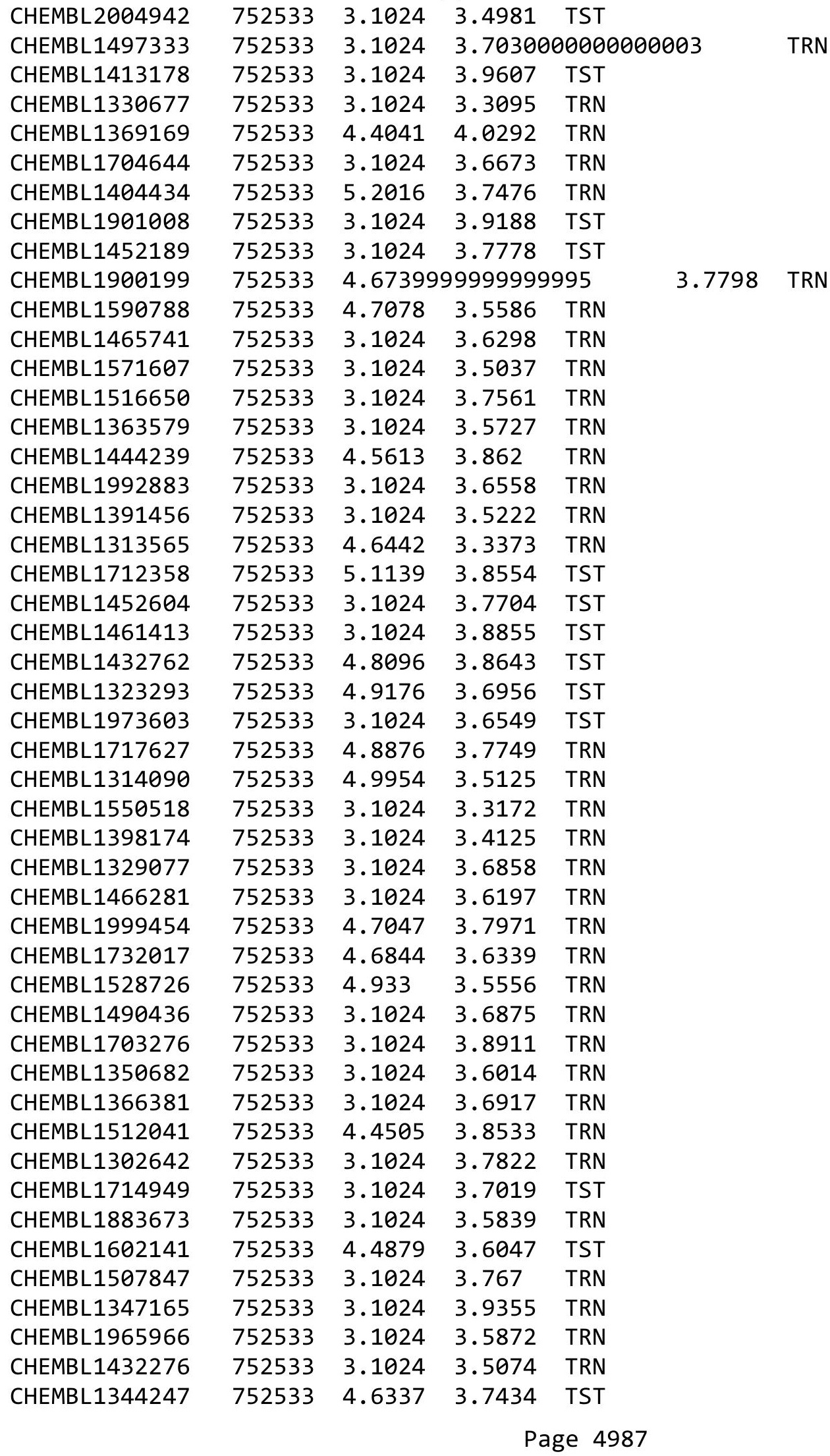


Supplemental Table S2.txt

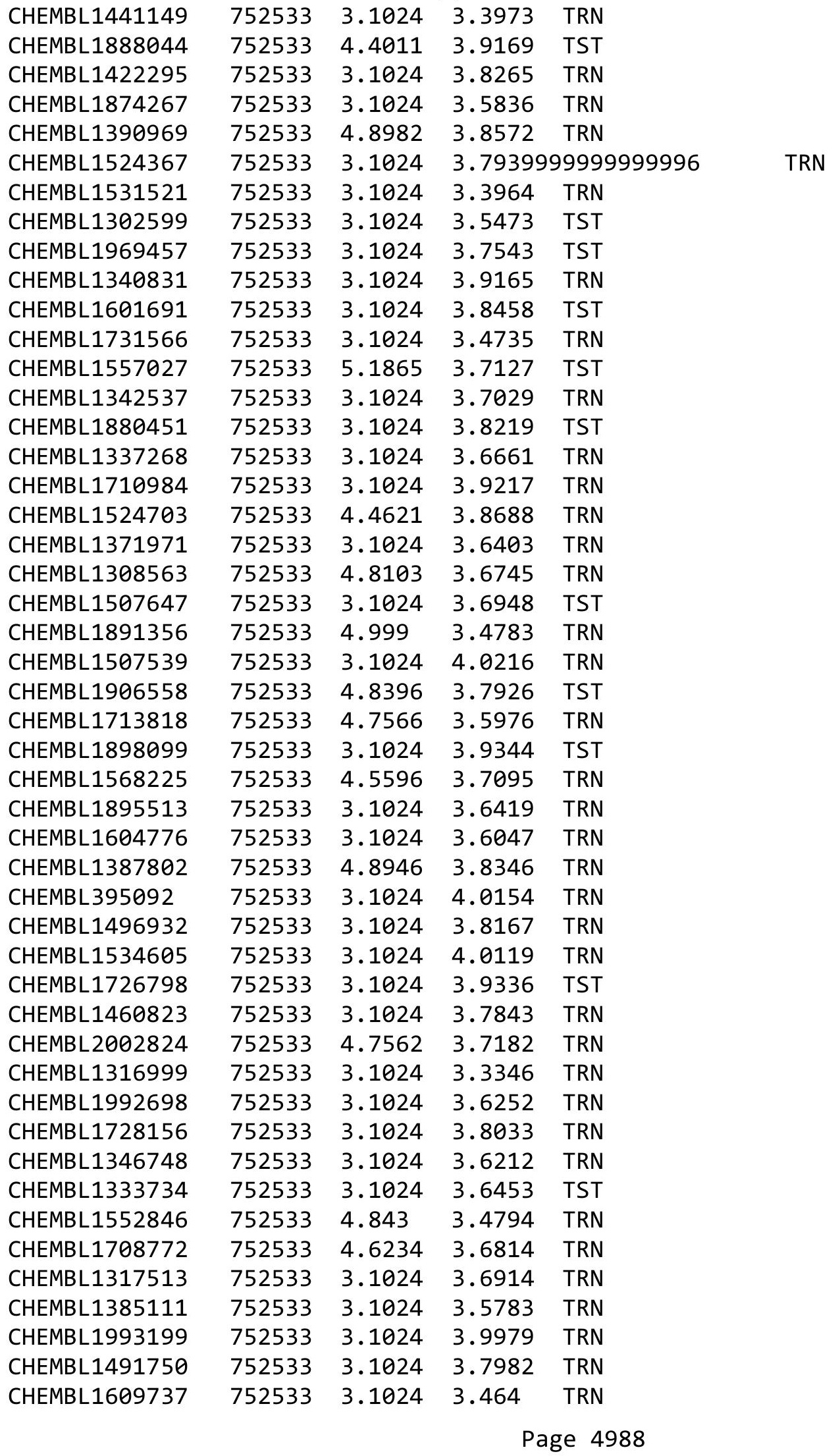




\begin{tabular}{|c|c|c|c|c|}
\hline & & & pplement & al $\mathrm{T}$ \\
\hline CHEMBL489696 & 752533 & 4.9891 & 3.4982 & TRN \\
\hline CHEMBL1591947 & 752533 & 3.1024 & 3.8122 & TRN \\
\hline CHEMBL1721460 & 752533 & 4.623 & 3.7653 & TST \\
\hline CHEMBL1734249 & 752533 & 4.4689 & 3.6911 & TRN \\
\hline CHEMBL1967640 & 752533 & 4.976 & 3.3989 & TRN \\
\hline CHEMBL1572279 & 752533 & 3.1024 & 3.7847 & TRN \\
\hline CHEMBL1419223 & 752533 & 3.1024 & 3.5452 & TRN \\
\hline CHEMBL1699667 & 752533 & 4.708 & 3.5868 & TRN \\
\hline CHEMBL1351484 & 752533 & 3.1024 & 3.699 & TRN \\
\hline CHEMBL1517909 & 752533 & 4.7821 & 3.6195 & TRN \\
\hline CHEMBL1458710 & 752533 & 3.1024 & 3.7236 & TRN \\
\hline CHEMBL1972500 & 752533 & 4.9512 & 3.8896 & TRN \\
\hline CHEMBL1412745 & 752533 & 3.1024 & 3.8575 & TRN \\
\hline CHEMBL1403619 & 752533 & 3.1024 & 3.6664 & TRN \\
\hline CHEMBL1869477 & 752533 & 3.1024 & 3.6776 & TRN \\
\hline CHEMBL1733261 & 752533 & 3.1024 & 3.7488 & TRN \\
\hline CHEMBL1597339 & 752533 & 3.1024 & 3.6486 & TRN \\
\hline CHEMBL1699258 & 752533 & 4.7651 & 3.7838 & TRN \\
\hline CHEMBL1971553 & 752533 & 3.1024 & 3.8515 & TRN \\
\hline CHEMBL1579612 & 752533 & 3.1024 & 3.6508 & TRN \\
\hline CHEMBL1880968 & 752533 & 3.1024 & 3.4815 & TRN \\
\hline CHEMBL1422847 & 752533 & 5.0023 & 3.7961 & TRN \\
\hline CHEMBL1465951 & 752533 & 3.1024 & 3.9417 & TST \\
\hline CHEMBL1490680 & 752533 & 3.1024 & 3.8967 & TRN \\
\hline CHEMBL1971117 & 752533 & 4.9058 & 3.7612 & TRN \\
\hline CHEMBL1539384 & 752533 & 3.1024 & 3.9093 & TRN \\
\hline CHEMBL1536692 & 752533 & 4.6618 & 3.653 & TRN \\
\hline CHEMBL1587526 & 752533 & 3.1024 & 3.6655 & TRN \\
\hline CHEMBL1707958 & 752533 & 3.1024 & 3.4762 & TRN \\
\hline CHEMBL1432884 & 752533 & 4.9403 & 3.6977 & TRN \\
\hline CHEMBL1579824 & 752533 & 3.1024 & 3.7496 & TRN \\
\hline CHEMBL1384484 & 752533 & 3.1024 & 3.8433 & TRN \\
\hline CHEMBL1402745 & 752533 & 4.8199 & 3.8387 & TRN \\
\hline CHEMBL1377648 & 752533 & 3.1024 & 3.8189 & TRN \\
\hline CHEMBL1352504 & 752533 & 3.1024 & 3.8878 & TRN \\
\hline CHEMBL1410544 & 752533 & 4.4912 & 3.6616 & TRN \\
\hline CHEMBL1332652 & 752533 & 4.4485 & 3.7404 & TRN \\
\hline CHEMBL1571998 & 752533 & 3.1024 & 3.5654 & TRN \\
\hline CHEMBL1481069 & 752533 & 3.1024 & 3.5697 & TRN \\
\hline CHEMBL1335751 & 752533 & 3.1024 & 3.8443 & TRN \\
\hline CHEMBL1475242 & 752533 & 3.1024 & 3.3341 & TRN \\
\hline CHEMBL1324351 & 752533 & 5.0374 & 3.862 & TRN \\
\hline CHEMBL1499592 & 752533 & 3.1024 & 3.4798 & TRN \\
\hline CHEMBL1443013 & 752533 & 3.1024 & 3.7749 & TST \\
\hline CHEMBL1553004 & 752533 & 3.1024 & 3.5727 & TRN \\
\hline CHEMBL1863958 & 752533 & 4.7882 & 3.4579 & TRN \\
\hline CHEMBL1881686 & 752533 & 4.704 & 3.7224 & TST \\
\hline CHEMBL 2001071 & 752533 & 3.1024 & 3.637 & TST \\
\hline
\end{tabular}




\begin{tabular}{|c|c|c|c|c|c|}
\hline & & \multicolumn{4}{|c|}{ Supplemental Table S2.txt } \\
\hline CHEMBL1528644 & 752533 & 4.9917 & 3.8179 & TRN & \\
\hline CHEMBL1405103 & 752533 & 4.956 & 3.5515 & TRN & \\
\hline CHEMBL1521813 & 752533 & 3.1024 & 3.8877 & TST & \\
\hline CHEMBL1500200 & 752533 & 3.1024 & 3.6214 & TRN & \\
\hline CHEMBL1863599 & 752533 & 4.7441 & 3.6753 & TST & \\
\hline CHEMBL1899974 & 752533 & 3.1024 & 3.4271 & TRN & \\
\hline CHEMBL1383421 & 752533 & 3.1024 & 3.83600 & 00000000003 & TRN \\
\hline CHEMBL1526184 & 752533 & 4.817 & 3.6977 & TST & \\
\hline CHEMBL1878680 & 752533 & 3.1024 & 3.5478 & TRN & \\
\hline CHEMBL1588886 & 752533 & 3.1024 & 3.926 & TST & \\
\hline CHEMBL1581335 & 752533 & 4.8492 & 3.5832 & TST & \\
\hline CHEMBL1505705 & 752533 & 4.467 & 3.6016 & TRN & \\
\hline CHEMBL1735332 & 752533 & 4.8799 & 3.5098 & TRN & \\
\hline CHEMBL1587670 & 752533 & 4.8252 & 3.5302 & TRN & \\
\hline CHEMBL1719240 & 752533 & 3.1024 & 3.43899 & 99999999996 & TRN \\
\hline CHEMBL1701254 & 752533 & 3.1024 & 3.6951 & TRN & \\
\hline CHEMBL1983587 & 752533 & 3.1024 & 3.8044 & TRN & \\
\hline CHEMBL1417717 & 752533 & 3.1024 & 3.4712 & TST & \\
\hline CHEMBL1416770 & 752533 & 3.1024 & 3.7571 & TRN & \\
\hline CHEMBL1878617 & 752533 & 3.1024 & 3.5237 & TRN & \\
\hline CHEMBL1463893 & 752533 & 3.1024 & 3.4668 & TRN & \\
\hline CHEMBL1456690 & 752533 & 3.1024 & 3.8309 & TRN & \\
\hline CHEMBL1723826 & 752533 & 3.1024 & 3.5008 & TRN & \\
\hline CHEMBL1423764 & 752533 & 3.1024 & 3.6919 & TRN & \\
\hline CHEMBL1376108 & 752533 & 3.1024 & 4.0013 & TRN & \\
\hline CHEMBL1548262 & 752533 & 3.1024 & 3.4381 & TRN & \\
\hline CHEMBL1400446 & 752533 & 3.1024 & 3.6311 & TRN & \\
\hline CHEMBL1576457 & 752533 & 4.8917 & 3.9239 & TRN & \\
\hline CHEMBL1431520 & 752533 & 3.1024 & 3.5239 & TRN & \\
\hline CHEMBL1982450 & 752533 & 3.1024 & 3.3768 & TRN & \\
\hline CHEMBL1380392 & 752533 & 3.1024 & 3.7408 & TST & \\
\hline CHEMBL1369130 & 752533 & 3.1024 & 3.4685 & TRN & \\
\hline CHEMBL1876301 & 752533 & 4.7284 & 3.9374 & TST & \\
\hline CHEMBL1902880 & 752533 & 3.1024 & 3.8059 & TRN & \\
\hline CHEMBL1397830 & 752533 & 3.1024 & 3.7141 & TRN & \\
\hline CHEMBL1373079 & 752533 & 3.1024 & 3.7116 & TRN & \\
\hline CHEMBL1310005 & 752533 & 3.1024 & 3.7257 & TRN & \\
\hline CHEMBL1409280 & 752533 & 3.1024 & 3.6194 & TRN & \\
\hline CHEMBL1341668 & 752533 & 3.1024 & 3.6703 & TRN & \\
\hline CHEMBL1367781 & 752533 & 3.1024 & 3.6162 & TRN & \\
\hline CHEMBL1493328 & 752533 & 5.0352 & 3.4197 & TRN & \\
\hline CHEMBL1874282 & 752533 & 4.408 & 3.5426 & TRN & \\
\hline CHEMBL1516099 & 752533 & 4.9929 & 3.8124 & TRN & \\
\hline CHEMBL1965579 & 752533 & 3.1024 & 3.6932 & TRN & \\
\hline CHEMBL1521120 & 752533 & 3.1024 & 3.6208 & TST & \\
\hline CHEMBL1375050 & 752533 & 3.1024 & 3.6571 & TRN & \\
\hline CHEMBL1365676 & 752533 & 4.6525 & 3.8161 & TRN & \\
\hline CHEMBL1368844 & 752533 & 3.1024 & 3.8809 & TRN & \\
\hline
\end{tabular}


Supplemental Table S2.txt

\begin{tabular}{|c|c|c|c|c|c|}
\hline CHEMBL1892639 & 752533 & 3.1024 & 3.4812 & TRN & \\
\hline CHEMBL492886 & 752533 & 4.6997 & 3.8271 & TRN & \\
\hline CHEMBL1605077 & 752533 & 3.1024 & 3.7055 & TST & \\
\hline CHEMBL1989527 & 752533 & 3.1024 & 3.4209 & TRN & \\
\hline CHEMBL1338135 & 752533 & 3.1024 & 3.91600 & 00000000004 & TRN \\
\hline CHEMBL 2006274 & 752533 & 3.1024 & 3.6244 & TRN & \\
\hline CHEMBL1510924 & 752533 & 3.1024 & 3.4486 & TRN & \\
\hline CHEMBL1882187 & 752533 & 3.1024 & 3.65100 & 00000000002 & TRN \\
\hline CHEMBL1362217 & 752533 & 4.8023 & 3.8329 & TRN & \\
\hline CHEMBL1699659 & 752533 & 4.3219 & 3.259 & TST & \\
\hline CHEMBL1388922 & 752533 & 3.1024 & 3.702 & TRN & \\
\hline CHEMBL1354874 & 752533 & 3.1024 & 3.5207 & TRN & \\
\hline CHEMBL1311279 & 752533 & 3.1024 & 3.4494 & TST & \\
\hline CHEMBL1729086 & 752533 & 4.967 & 3.5603 & TRN & \\
\hline CHEMBL1418287 & 752533 & 3.1024 & 3.2221 & TRN & \\
\hline CHEMBL1438811 & 752533 & 4.9025 & 4.1389 & TRN & \\
\hline CHEMBL1885453 & 752533 & 3.1024 & 3.5983 & TRN & \\
\hline CHEMBL1447305 & 752533 & 3.1024 & 3.3753 & TRN & \\
\hline CHEMBL1304801 & 752533 & 3.1024 & 3.6962 & TRN & \\
\hline CHEMBL1992858 & 752533 & 3.1024 & 3.6975 & TRN & \\
\hline CHEMBL1381625 & 752533 & 4.7276 & 3.7277 & TST & \\
\hline CHEMBL1985142 & 752533 & 3.1024 & 3.6898 & TST & \\
\hline CHEMBL1531618 & 752533 & 3.1024 & 3.6307 & TRN & \\
\hline CHEMBL1540730 & 752533 & 3.1024 & 3.6517 & TRN & \\
\hline CHEMBL1300822 & 752533 & 3.1024 & 3.2453 & TRN & \\
\hline CHEMBL578177 & 752533 & 4.4866 & 3.937 & TST & \\
\hline CHEMBL1328957 & 752533 & 3.1024 & 3.571 & TRN & \\
\hline CHEMBL1705033 & 752533 & 3.1024 & 3.7309 & TRN & \\
\hline CHEMBL1394222 & 752533 & 3.1024 & 3.5585 & TST & \\
\hline CHEMBL1584639 & 752533 & 3.1024 & 3.628 & TRN & \\
\hline CHEMBL1379578 & 752533 & 4.7889 & 3.4529 & TRN & \\
\hline CHEMBL1471101 & 752533 & 4.8933 & 3.57 & TRN & \\
\hline CHEMBL1987906 & 752533 & 4.9257 & 3.7482 & TST & \\
\hline CHEMBL1582458 & 752533 & 3.1024 & 3.6149 & TRN & \\
\hline CHEMBL1524727 & 752533 & 3.1024 & \multicolumn{2}{|c|}{ 3.7119999999999997 } & TRN \\
\hline CHEMBL1728949 & 752533 & 3.1024 & 3.5254 & TRN & \\
\hline CHEMBL1575370 & 752533 & 3.1024 & 3.8345 & TST & \\
\hline CHEMBL1534949 & 752533 & 4.9983 & 3.7183 & TRN & \\
\hline CHEMBL1313574 & 752533 & 4.9677 & 3.4012 & TRN & \\
\hline CHEMBL1578365 & 752533 & 4.9523 & 3.5594 & TRN & \\
\hline CHEMBL1343368 & 752533 & 3.1024 & 3.8691 & TRN & \\
\hline CHEMBL1510895 & 752533 & 3.1024 & 3.5256 & TRN & \\
\hline CHEMBL1475718 & 752533 & 3.1024 & 3.5686 & TRN & \\
\hline CHEMBL1530586 & 752533 & 3.1024 & 3.5872 & TRN & \\
\hline CHEMBL 255068 & 752533 & 3.1024 & 3.8066 & TRN & \\
\hline CHEMBL1472051 & 752533 & 4.9226 & 3.7557 & TRN & \\
\hline CHEMBL 2001262 & 752533 & 5.1726 & 3.7199 & TRN & \\
\hline CHEMBL1566084 & 752533 & 4.9383 & 3.787 & TRN & \\
\hline
\end{tabular}


Supplemental Table S2.txt

\begin{tabular}{|c|c|c|c|c|c|}
\hline CHEMBL1419579 & 752533 & 4.5078 & 3.4793 & TRN & \\
\hline CHEMBL1423050 & 752533 & 3.1024 & 3.3813 & TRN & \\
\hline CHEMBL1439140 & 752533 & 3.1024 & 3.5128 & TRN & \\
\hline CHEMBL1364009 & 752533 & 3.1024 & 3.8116 & TRN & \\
\hline CHEMBL1430145 & 752533 & 3.1024 & 3.7204 & TRN & \\
\hline CHEMBL1470342 & 752533 & 4.93 & 3.8747 & TRN & \\
\hline CHEMBL1364493 & 752533 & 4.5633 & 3.7544 & TRN & \\
\hline CHEMBL1449322 & 752533 & 4.4118 & 3.7971 & TRN & \\
\hline CHEMBL1726644 & 752533 & 3.1024 & 3.7158 & TRN & \\
\hline CHEMBL1512061 & 752533 & 4.3125 & 3.8372 & TRN & \\
\hline CHEMBL1408484 & 752533 & 3.1024 & 3.6632 & TRN & \\
\hline CHEMBL1467701 & 752533 & 3.1024 & 3.6129 & TRN & \\
\hline CHEMBL1729533 & 752533 & 3.1024 & 3.5082 & TRN & \\
\hline CHEMBL1421091 & 752533 & 3.1024 & 3.6226 & TRN & \\
\hline CHEMBL1427949 & 752533 & 3.1024 & 3.6824 & TST & \\
\hline CHEMBL1358434 & 752533 & 3.1024 & 3.4608 & TRN & \\
\hline CHEMBL1491564 & 752533 & 3.1024 & 3.6648 & TRN & \\
\hline CHEMBL1973705 & 752533 & 3.1024 & 3.7402 & TST & \\
\hline CHEMBL1880550 & 752533 & 3.1024 & 3.5188 & TRN & \\
\hline CHEMBL1416039 & 752533 & 5.0548 & 3.5655 & TRN & \\
\hline CHEMBL1432203 & 752533 & 3.1024 & 3.5003 & TRN & \\
\hline CHEMBL1309134 & 752533 & 3.1024 & 3.9398 & TST & \\
\hline CHEMBL1603318 & 752533 & 4.8349 & 3.7454 & TRN & \\
\hline CHEMBL1408290 & 752533 & 4.5965 & 4.0195 & TRN & \\
\hline CHEMBL1712296 & 752533 & 4.6006 & 3.6361 & TRN & \\
\hline CHEMBL1345625 & 752533 & 3.1024 & 3.7115 & TST & \\
\hline CHEMBL1881568 & 752533 & 3.1024 & 3.381999 & 99999999997 & TRN \\
\hline CHEMBL1987094 & 752533 & 3.1024 & 3.5257 & TRN & \\
\hline CHEMBL1965758 & 752533 & 3.1024 & 3.4451 & TRN & \\
\hline CHEMBL1602676 & 752533 & 3.1024 & 3.7277 & TRN & \\
\hline CHEMBL1507163 & 752533 & 4.8205 & 3.9585 & TST & \\
\hline CHEMBL1497853 & 752533 & 4.7998 & 3.4012 & TRN & \\
\hline CHEMBL1562838 & 752533 & 3.1024 & 3.589 & TRN & \\
\hline CHEMBL1494138 & 752533 & 4.8337 & 3.6329 & TRN & \\
\hline CHEMBL1563287 & 752533 & 3.1024 & 3.7373 & TST & \\
\hline CHEMBL1553364 & 752533 & 5.0607 & 3.6922 & TRN & \\
\hline CHEMBL1414819 & 752533 & 4.8592 & 3.4763 & TRN & \\
\hline CHEMBL1309516 & 752533 & 4.9986 & 3.6968 & TST & \\
\hline CHEMBL1450098 & 752533 & 3.1024 & 3.5933 & TST & \\
\hline CHEMBL1365106 & 752533 & 3.1024 & 3.6838 & TRN & \\
\hline CHEMBL1563920 & 752533 & 3.1024 & 3.2176 & TRN & \\
\hline CHEMBL1498801 & 752533 & 3.1024 & 3.5831 & TST & \\
\hline CHEMBL1344538 & 752533 & 3.1024 & 3.6225 & TRN & \\
\hline CHEMBL1329368 & 752533 & 3.1024 & 3.783 & TRN & \\
\hline CHEMBL 2002995 & 752533 & 4.8924 & 3.6009 & TRN & \\
\hline CHEMBL1611135 & 752533 & 3.1024 & 3.8584 & TRN & \\
\hline CHEMBL1456036 & 752533 & 4.51699 & 999999999 & 3.5748 & TRN \\
\hline CHEMBL1875387 & 752533 & 4.9112 & 3.9028 & TRN & \\
\hline
\end{tabular}


Supplemental Table S2.txt

\begin{tabular}{|c|c|c|c|c|c|}
\hline CHEMBL1609946 & 752533 & 3.1024 & 3.3452 & TRN & \\
\hline CHEMBL1893298 & 752533 & 3.1024 & 3.3795 & TST & \\
\hline CHEMBL1300649 & 752533 & 4.53600 & 00000000 & 305 & 3.5981 \\
\hline CHEMBL1463672 & 752533 & 3.1024 & 3.8123 & TRN & \\
\hline CHEMBL1489749 & 752533 & 3.1024 & 3.9373 & TRN & \\
\hline CHEMBL1471664 & 752533 & 3.1024 & 3.715 & TRN & \\
\hline CHEMBL1704710 & 752533 & 4.6994 & 3.4257 & TRN & \\
\hline CHEMBL1498596 & 752533 & 3.1024 & 3.8706 & TST & \\
\hline CHEMBL1883523 & 752533 & 3.1024 & 3.4606 & TRN & \\
\hline CHEMBL1355133 & 752533 & 4.7933 & 3.6691 & TRN & \\
\hline CHEMBL1974713 & 752533 & 4.6729 & 3.4858 & TRN & \\
\hline CHEMBL1992540 & 752533 & 3.1024 & 3.5199 & TRN & \\
\hline CHEMBL1905319 & 752533 & 3.1024 & 3.6116 & TRN & \\
\hline CHEMBL1993807 & 752533 & 3.1024 & 3.3941 & TRN & \\
\hline CHEMBL1707646 & 752533 & 4.7852 & 3.8914 & TRN & \\
\hline CHEMBL1577620 & 752533 & 3.1024 & 3.6962 & TRN & \\
\hline CHEMBL1452652 & 752533 & 5.0657 & 3.5959 & TRN & \\
\hline CHEMBL1531038 & 752533 & 3.1024 & 3.3306 & TRN & \\
\hline CHEMBL1977369 & 752533 & 3.1024 & 3.6029 & TRN & \\
\hline CHEMBL1429867 & 752533 & 4.5187 & 3.8576 & TRN & \\
\hline CHEMBL1570212 & 752533 & 3.1024 & 3.6074 & TRN & \\
\hline CHEMBL65892 & 752533 & 3.1024 & 3.7726 & TST & \\
\hline CHEMBL1342238 & 752533 & 4.7296 & 3.9319 & TRN & \\
\hline CHEMBL1311994 & 752533 & 4.4769 & 3.8615 & TRN & \\
\hline CHEMBL1577144 & 752533 & 3.1024 & 3.5658 & TST & \\
\hline CHEMBL1305963 & 752533 & 4.4426 & 3.6282 & TRN & \\
\hline CHEMBL1581175 & 752533 & 3.1024 & 3.7643 & TRN & \\
\hline CHEMBL1719681 & 752533 & 3.1024 & 3.4781 & TRN & \\
\hline CHEMBL1891340 & 752533 & 3.1024 & 3.5248 & TRN & \\
\hline CHEMBL1408518 & 752533 & 3.1024 & 3.8528 & TRN & \\
\hline CHEMBL1393504 & 752533 & 3.1024 & 3.5945 & TRN & \\
\hline CHEMBL1705492 & 752533 & 4.4461 & 3.8039 & TRN & \\
\hline CHEMBL1867569 & 752533 & 3.1024 & 3.4746 & TRN & \\
\hline CHEMBL1707221 & 752533 & 3.1024 & 3.635 & TST & \\
\hline CHEMBL1896933 & 752533 & 3.1024 & 3.4242 & TRN & \\
\hline CHEMBL1492744 & 752533 & 4.7855 & 3.7005 & TRN & \\
\hline CHEMBL1731097 & 752533 & 3.1024 & 3.7393 & TST & \\
\hline CHEMBL1990469 & 752533 & 4.6817 & 3.6849 & TRN & \\
\hline CHEMBL1322362 & 752533 & 3.1024 & 3.6217 & TRN & \\
\hline CHEMBL1879523 & 752533 & 5.0553 & 3.7316 & TST & \\
\hline CHEMBL1344520 & 752533 & 3.1024 & 3.6642 & TST & \\
\hline CHEMBL1520122 & 752533 & 4.6356 & 3.7321 & TRN & \\
\hline CHEMBL1984554 & 752533 & 3.1024 & 3.4682 & TRN & \\
\hline CHEMBL1307821 & 752533 & 4.8192 & 3.7824 & TRN & \\
\hline CHEMBL1364424 & 752533 & 3.1024 & 3.7659 & TST & \\
\hline CHEMBL1335734 & 752533 & 3.1024 & 3.4413 & TRN & \\
\hline CHEMBL1967814 & 752533 & 4.8686 & 3.7479 & TRN & \\
\hline CHEMBL1584490 & 752533 & 3.1024 & 3.7227 & TRN & \\
\hline
\end{tabular}


Supplemental Table S2.txt

\begin{tabular}{|c|c|c|c|c|}
\hline CHEMBL1557060 & 752533 & 5.1594 & 3.6846 & TRN \\
\hline CHEMBL1588045 & 752533 & 3.1024 & 3.8407 & TRN \\
\hline CHEMBL1547685 & 752533 & 5.0647 & 3.3391 & TRN \\
\hline CHEMBL1475057 & 752533 & 3.1024 & 3.71199 & 99999999997 \\
\hline CHEMBL1586524 & 752533 & 4.3744 & 3.9554 & TRN \\
\hline CHEMBL1312383 & 752533 & 5.2093 & 3.9354 & TRN \\
\hline CHEMBL1504419 & 752533 & 3.1024 & 3.7189 & TRN \\
\hline CHEMBL1966657 & 752533 & 3.1024 & 3.4591 & TRN \\
\hline CHEMBL1723682 & 752533 & 3.1024 & 3.7211 & TRN \\
\hline CHEMBL1484629 & 752533 & 3.1024 & 3.4884 & TRN \\
\hline CHEMBL1865969 & 752533 & 3.1024 & 4.0179 & TST \\
\hline CHEMBL1369225 & 752533 & 3.1024 & 3.7985 & TST \\
\hline CHEMBL1996299 & 752533 & 3.1024 & 3.4771 & TRN \\
\hline CHEMBL1586554 & 752533 & 3.1024 & 3.8844 & TRN \\
\hline CHEMBL1873279 & 752533 & 3.1024 & 3.6578 & TRN \\
\hline CHEMBL 2000259 & 752533 & 3.1024 & 3.6307 & TRN \\
\hline CHEMBL1343805 & 752533 & 3.1024 & 3.4843 & TRN \\
\hline CHEMBL1892438 & 752533 & 4.4467 & 3.8968 & TRN \\
\hline CHEMBL1993203 & 752533 & 3.1024 & 3.4369 & TRN \\
\hline CHEMBL1423034 & 752533 & 3.1024 & 3.7563 & TRN \\
\hline CHEMBL1558372 & 752533 & 3.1024 & 3.6354 & TRN \\
\hline CHEMBL1701835 & 752533 & 3.1024 & 3.6929 & TRN \\
\hline CHEMBL1529557 & 752533 & 4.8145 & 3.9316 & TRN \\
\hline CHEMBL1555593 & 752533 & 3.1024 & 3.3873 & TRN \\
\hline CHEMBL1705527 & 752533 & 3.1024 & 3.7742 & TST \\
\hline CHEMBL1436557 & 752533 & 3.1024 & 3.532 & TRN \\
\hline CHEMBL1518972 & 752533 & 4.1724 & 3.8368 & TST \\
\hline CHEMBL1599711 & 752533 & 3.1024 & 3.6476 & TRN \\
\hline CHEMBL1611803 & 752533 & 4.9865 & 3.7603 & TST \\
\hline CHEMBL1409324 & 752533 & 4.2191 & 3.9667 & TRN \\
\hline CHEMBL1726149 & 752533 & 4.8908 & 3.6824 & TRN \\
\hline CHEMBL1314866 & 752533 & 4.7869 & 3.6954 & TRN \\
\hline CHEMBL1531191 & 752533 & 3.1024 & 3.6517 & TRN \\
\hline CHEMBL1721561 & 752533 & 4.7521 & 3.5208 & TRN \\
\hline CHEMBL1730403 & 752533 & 5.159 & 3.5695 & TRN \\
\hline CHEMBL1527149 & 752533 & 3.1024 & 3.6521 & TRN \\
\hline CHEMBL1319627 & 752533 & 4.7117 & 3.9833 & TRN \\
\hline CHEMBL1893675 & 752533 & 3.1024 & 3.5271 & TRN \\
\hline CHEMBL1304960 & 752533 & 3.1024 & 3.8163 & TRN \\
\hline CHEMBL1530859 & 752533 & 5.0418 & 3.7772 & TRN \\
\hline CHEMBL1390527 & 752533 & 3.1024 & 3.7673 & TRN \\
\hline CHEMBL1408688 & 752533 & 4.4401 & 3.637 & TRN \\
\hline CHEMBL1604180 & 752533 & 3.1024 & 3.5523 & TRN \\
\hline CHEMBL1547457 & 752533 & 3.1024 & 3.6177 & TRN \\
\hline CHEMBL210276 & 752533 & 3.1024 & 3.8882 & TRN \\
\hline CHEMBL1476335 & 752533 & 3.1024 & 3.6816 & TRN \\
\hline CHEMBL1500702 & 752533 & 3.1024 & 3.7282 & TST \\
\hline CHEMBL1448193 & 752533 & 4.9803 & 3.9697 & TRN \\
\hline
\end{tabular}


Supplemental Table S2.txt

\begin{tabular}{|c|c|c|c|c|}
\hline & & & & \\
\hline AEMBL1\& & 2533 & 3.1024 & 6016 & \\
\hline AEMBL1464468 & 2533 & 1024 & 6641 & \\
\hline AEMBL1972651 & 52533 & 1024 & 7624 & \\
\hline 528 & 2533 & 1024 & 125 & \\
\hline AEMBL1865860 & 2533 & 1024 & 5469 & \\
\hline AEMBL1703352 & 52533 & .1024 & 2906 & \\
\hline AEMBL1345140 & 52533 & .1024 & 6877 & \\
\hline AEMBL1403274 & 52533 & .1024 & 5123 & \\
\hline IEMBL152 & 2533 & 811 & 3941 & \\
\hline AEMBL1714156 & 52533 & 938 & 7071 & \\
\hline AEMBL1534602 & 52533 & 5613 & 7577 & \\
\hline AEMBL1482332 & 52533 & 024 & 345 & \\
\hline AEMBL 148 & 33 & 3. & 325 & \\
\hline IEMBL14 & 33 & 024 & 311 & \\
\hline HEMBL 142 & & 938 & 366 & \\
\hline AEMBL1533431 & 52533 & 024 & 842 & \\
\hline HEMBL156 & 52533 & 563 & & \\
\hline IEMBL13 & 33 & 24 & 51 & \\
\hline AEMBL187 & 33 & 24 & & \\
\hline HEMBL 138 & 33 & 24 & & \\
\hline AEMBL1472228 & 52533 & 53 & & \\
\hline IEMBL1985883 & & & 65 & \\
\hline IEMBL13 & 33 & 57 & 24 & \\
\hline HEMBL17 & 33 & & & \\
\hline AFMRI 14 & 33 & 24 & 168 & \\
\hline AEMBL1496105 & 52533 & & 534 & \\
\hline AEMBL1365163 & & & & \\
\hline AEMBL15: & 52533 & 3. & 647 & \\
\hline HEMBL14 & 33 & 24 & 33 & \\
\hline 274 & 33 & 4. & 03 & \\
\hline HEMBL1964556 & 52533 & & & \\
\hline AEMBL1714606 & 52533 & & & \\
\hline AEMBL13 & 52533 & 3. & 905 & \\
\hline AFMRI 18 & 33 & 3. & 54 & \\
\hline 00 & 33 & 2 & & \\
\hline HEMBL1896831 & 52533 & 4.7212 & 361 & \\
\hline AEMBL1466799 & 52533 & & 727 & \\
\hline IEMBL156 & 33 & 24 & 392 & \\
\hline ז & 33 & 24 & 739 & \\
\hline 19 & & 3. & 92 & \\
\hline AEMBL1542157 & 52533 & 4.4954 & 3684 & RI \\
\hline HEMBL158 & 52533 & & & \\
\hline HEMBL $14 \mathrm{C}$ & & & 861 & \\
\hline HEMBL171 & & & & \\
\hline CHEMBL 1982071 & 533 & 3.1024 & 54 & \\
\hline AEMBL1970636 & 52533 & 3.1024 & 3.6465 & \\
\hline HEMBL1726305 & 52533 & 3.1024 & 3.6971 & \\
\hline
\end{tabular}

Page 4995 


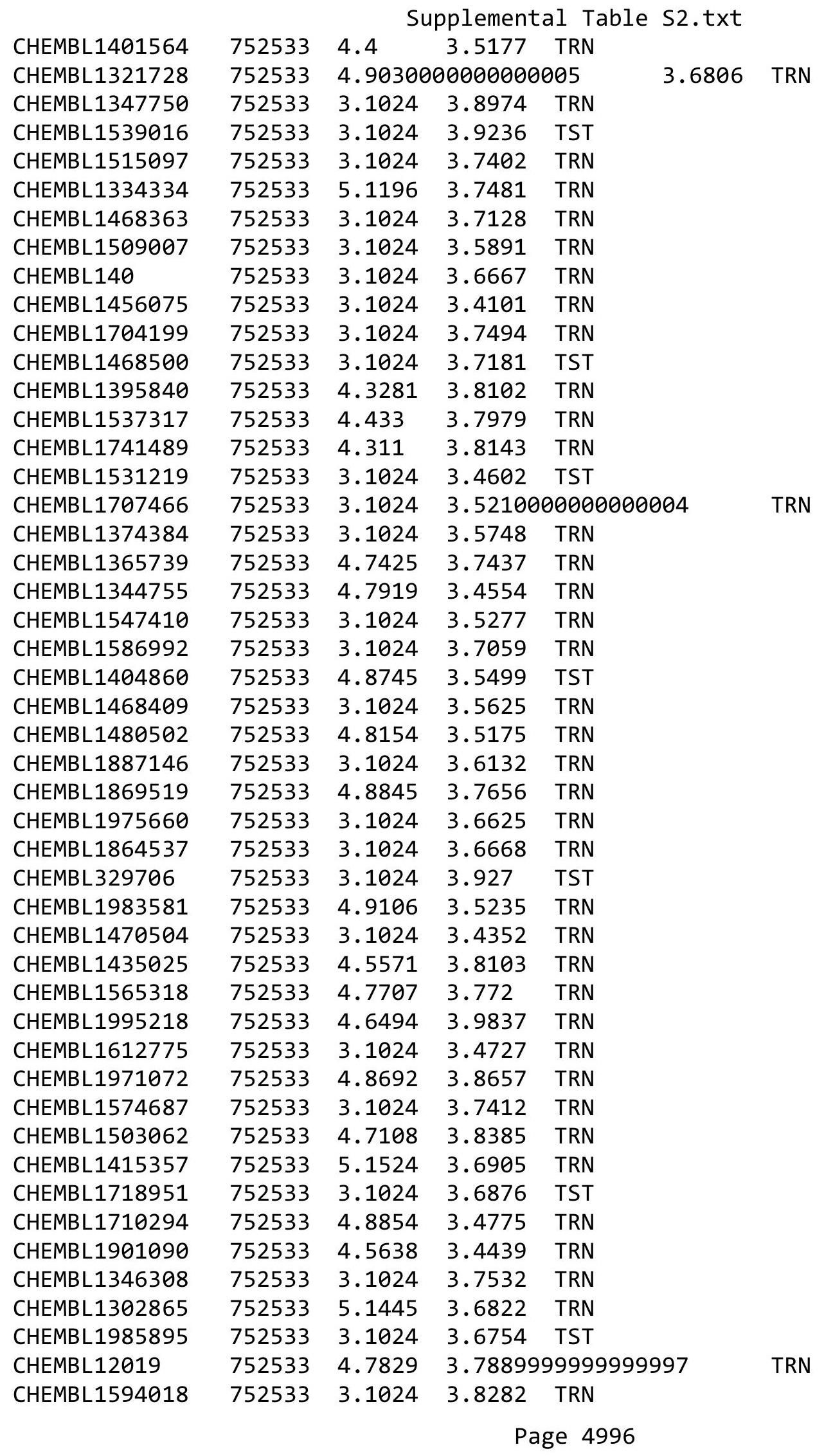


Supplemental Table S2.txt

\begin{tabular}{|c|c|c|c|c|}
\hline CHEMBL1731294 & 752533 & 3.1024 & 3.8352 & TST \\
\hline CHEMBL1356354 & 752533 & 3.1024 & 3.6023 & TRN \\
\hline CHEMBL1505748 & 752533 & 3.1024 & 3.7641 & TRN \\
\hline CHEMBL1432607 & 752533 & 3.1024 & 3.5576 & TRN \\
\hline CHEMBL1984114 & 752533 & 4.9635 & 3.7067 & TRN \\
\hline CHEMBL1538636 & 752533 & 4.56 & 3.8043 & TRN \\
\hline CHEMBL1702908 & 752533 & 4.5815 & 3.5152 & TRN \\
\hline CHEMBL1299662 & 752533 & 3.1024 & 3.8814 & TRN \\
\hline CHEMBL 2001029 & 752533 & 3.1024 & 3.733 & TRN \\
\hline CHEMBL1448982 & 752533 & 3.1024 & 3.681 & TRN \\
\hline CHEMBL1707119 & 752533 & 3.1024 & \multicolumn{2}{|c|}{3.8560000000000003} \\
\hline CHEMBL1699788 & 752533 & 4.5009 & 3.7126 & TRN \\
\hline CHEMBL1873328 & 752533 & 3.1024 & 3.4522 & TRN \\
\hline CHEMBL1586662 & 752533 & 4.8632 & 3.9499 & TRN \\
\hline CHEMBL1425112 & 752533 & 4.1243 & 3.6697 & TRN \\
\hline CHEMBL1733950 & 752533 & 3.1024 & 3.5462 & TRN \\
\hline CHEMBL1432550 & 752533 & 3.1024 & 3.372 & TRN \\
\hline CHEMBL1997195 & 752533 & 4.5811 & 3.7157 & TRN \\
\hline CHEMBL1872827 & 752533 & 3.1024 & 3.6176 & TRN \\
\hline CHEMBL1608656 & 752533 & 3.1024 & 3.7188 & TRN \\
\hline CHEMBL1497909 & 752533 & 3.1024 & 3.4696 & TRN \\
\hline CHEMBL1724709 & 752533 & 4.8872 & 3.7642 & TRN \\
\hline CHEMBL1336970 & 752533 & 3.1024 & 3.773 & TRN \\
\hline CHEMBL1460061 & 752533 & 3.1024 & 3.8022 & TRN \\
\hline CHEMBL1988660 & 752533 & 4.9162 & 3.5855 & TRN \\
\hline CHEMBL1302020 & 752533 & 4.9835 & 3.9696 & TRN \\
\hline CHEMBL1892780 & 752533 & 4.9179 & 3.6915 & TRN \\
\hline CHEMBL1893210 & 752533 & 3.1024 & 3.3535 & TRN \\
\hline CHEMBL1549839 & 752533 & 4.8683 & 3.5867 & TST \\
\hline CHEMBL1869583 & 752533 & 3.1024 & \multicolumn{2}{|c|}{3.4189999999999996} \\
\hline CHEMBL1972739 & 752533 & 3.1024 & 3.8374 & TRN \\
\hline CHEMBL1417610 & 752533 & 3.1024 & 3.8392 & TRN \\
\hline CHEMBL1500468 & 752533 & 3.1024 & 3.5842 & TRN \\
\hline CHEMBL1550407 & 752533 & 3.1024 & 3.4854 & TRN \\
\hline CHEMBL1494256 & 752533 & 3.1024 & 3.8084 & TRN \\
\hline CHEMBL1880468 & 752533 & 3.1024 & 3.3903 & TRN \\
\hline CHEMBL1479872 & 752533 & 3.1024 & 3.5592 & TRN \\
\hline CHEMBL1311027 & 752533 & 4.8104 & 3.7842 & TRN \\
\hline CHEMBL1538188 & 752533 & 3.1024 & 3.5328 & TRN \\
\hline CHEMBL 2002972 & 752533 & 3.1024 & 3.7248 & TRN \\
\hline CHEMBL1612781 & 752533 & 4.8118 & 3.5806 & TRN \\
\hline CHEMBL1864299 & 752533 & 3.1024 & 3.4424 & TRN \\
\hline CHEMBL1721546 & 752533 & 4.8575 & 3.4799 & TST \\
\hline CHEMBL1974351 & 752533 & 3.1024 & 3.7756 & TST \\
\hline CHEMBL1412113 & 752533 & 3.1024 & \multicolumn{2}{|c|}{3.7710000000000004} \\
\hline CHEMBL1887295 & 752533 & 4.4521 & 3.5851 & TRN \\
\hline CHEMBL1572906 & 752533 & 5.1262 & 3.9121 & TRN \\
\hline CHEMBL1417160 & 752533 & 3.1024 & 3.7912 & TRN \\
\hline
\end{tabular}


Supplemental Table S2.txt

\begin{tabular}{|c|c|c|c|c|c|}
\hline CHEMBL1495663 & 752533 & 3.1024 & 3.2856 & TRN & \\
\hline CHEMBL1443589 & 752533 & 3.1024 & 3.6615 & TRN & \\
\hline CHEMBL1534849 & 752533 & 3.1024 & 3.8065 & TST & \\
\hline CHEMBL1892448 & 752533 & 4.9805 & 3.641 & TRN & \\
\hline CHEMBL1870365 & 752533 & 3.1024 & 3.5932 & TRN & \\
\hline CHEMBL1315502 & 752533 & 4.6245 & 3.7358 & TRN & \\
\hline CHEMBL1589418 & 752533 & 3.1024 & 3.3924 & TRN & \\
\hline CHEMBL1506903 & 752533 & 3.1024 & 3.7284 & TRN & \\
\hline CHEMBL1698435 & 752533 & 5.1137 & 3.4391 & TRN & \\
\hline CHEMBL 2004928 & 752533 & 3.1024 & 3.5404 & TRN & \\
\hline CHEMBL1529401 & 752533 & 4.5785 & 3.7354 & TRN & \\
\hline CHEMBL1882485 & 752533 & 3.1024 & 3.2951 & TRN & \\
\hline CHEMBL1564676 & 752533 & 3.1024 & 3.9177 & TRN & \\
\hline CHEMBL1352633 & 752533 & 4.8445 & 3.9526 & TRN & \\
\hline CHEMBL1321703 & 752533 & 3.1024 & 3.1506 & TRN & \\
\hline CHEMBL1439554 & 752533 & 4.8568 & 3.6993 & TRN & \\
\hline CHEMBL1376580 & 752533 & 3.1024 & 3.3074 & TRN & \\
\hline CHEMBL1450084 & 752533 & 4.6653 & 4.0461 & TST & \\
\hline CHEMBL1599059 & 752533 & 3.1024 & 3.8795 & TST & \\
\hline CHEMBL1987417 & 752533 & 3.1024 & 3.6657 & TRN & \\
\hline CHEMBL1532449 & 752533 & 3.1024 & 3.7427 & TRN & \\
\hline CHEMBL1892123 & 752533 & 3.1024 & 3.8563 & TRN & \\
\hline CHEMBL1608653 & 752533 & 3.1024 & 3.7223 & TRN & \\
\hline CHEMBL1905593 & 752533 & 3.1024 & 3.4618 & TRN & \\
\hline CHEMBL177938 & 752533 & 3.1024 & 3.8534 & TRN & \\
\hline CHEMBL1300729 & 752533 & 3.1024 & 3.3061 & TRN & \\
\hline CHEMBL1329044 & 752533 & 3.1024 & 3.8583 & TST & \\
\hline CHEMBL1490537 & 752533 & 3.1024 & 3.6252 & TRN & \\
\hline CHEMBL1996360 & 752533 & 4.5491 & 3.6016 & TRN & \\
\hline CHEMBL1339743 & 752533 & 3.1024 & 3.5683 & TRN & \\
\hline CHEMBL1438663 & 752533 & 3.1024 & 3.9592 & TRN & \\
\hline CHEMBL1433386 & 752533 & 3.1024 & 3.4205 & TRN & \\
\hline CHEMBL1379420 & 752533 & 4.6701 & \multicolumn{2}{|c|}{3.4360000000000004} & TRN \\
\hline CHEMBL1872607 & 752533 & 4.7315 & 3.8675 & TRN & \\
\hline CHEMBL1865197 & 752533 & 3.1024 & 3.6517 & TRN & \\
\hline CHEMBL1700311 & 752533 & 3.1024 & 3.3586 & TRN & \\
\hline CHEMBL1519842 & 752533 & 4.6302 & \multicolumn{2}{|c|}{3.8160000000000003} & TRN \\
\hline CHEMBL1348996 & 752533 & 3.1024 & 3.6859 & TRN & \\
\hline CHEMBL1400198 & 752533 & 3.1024 & 3.8914 & TRN & \\
\hline CHEMBL1387165 & 752533 & 3.1024 & 3.9338 & TRN & \\
\hline CHEMBL1544440 & 752533 & 3.1024 & 3.647 & TRN & \\
\hline CHEMBL1974800 & 752533 & 3.1024 & 3.4844 & TRN & \\
\hline CHEMBL1978228 & 752533 & 4.9066 & 3.4562 & TST & \\
\hline CHEMBL1497792 & 752533 & 5.296 & 3.8557 & TST & \\
\hline CHEMBL1529254 & 752533 & 4.5018 & 4.087 & TRN & \\
\hline CHEMBL1601300 & 752533 & 3.1024 & 3.5143 & TST & \\
\hline CHEMBL1515432 & 752533 & 3.1024 & 3.5622 & TST & \\
\hline CHEMBL1370927 & 752533 & 3.1024 & 3.7952 & TRN & \\
\hline
\end{tabular}


Supplemental Table S2.txt

\begin{tabular}{|c|c|c|c|c|c|}
\hline CHEMBL1512150 & 752533 & 3.1024 & 3.7696 & TRN & \\
\hline CHEMBL1599749 & 752533 & 3.1024 & 3.76 & TST & \\
\hline CHEMBL1549006 & 752533 & 4.6948 & 3.8258 & TRN & \\
\hline CHEMBL1487042 & 752533 & 3.1024 & 3.5315 & TRN & \\
\hline CHEMBL1873030 & 752533 & 3.1024 & 3.3448 & TRN & \\
\hline CHEMBL1420733 & 752533 & 3.1024 & 3.8401 & TRN & \\
\hline CHEMBL1517184 & 752533 & 3.1024 & 3.4667 & TRN & \\
\hline CHEMBL1431668 & 752533 & 3.1024 & 3.6614 & TRN & \\
\hline CHEMBL1348954 & 752533 & 4.9991 & 3.8034 & TST & \\
\hline CHEMBL1340521 & 752533 & 3.1024 & 3.5179 & TRN & \\
\hline CHEMBL1731749 & 752533 & 3.1024 & 3.8436 & TST & \\
\hline CHEMBL1498553 & 752533 & 3.1024 & 3.6851 & TRN & \\
\hline CHEMBL1998234 & 752533 & 4.718 & 3.8474 & TRN & \\
\hline CHEMBL1380037 & 752533 & 4.8544 & 3.7164 & TRN & \\
\hline CHEMBL1328779 & 752533 & 4.6298 & 3.9994 & TRN & \\
\hline CHEMBL1605288 & 752533 & 3.1024 & 3.5712 & TRN & \\
\hline CHEMBL1557763 & 752533 & 5.062 & 3.33600 & 00000000003 & TRN \\
\hline CHEMBL1543078 & 752533 & 3.1024 & 3.5984 & TRN & \\
\hline CHEMBL1372524 & 752533 & 4.7013 & 3.7008 & TRN & \\
\hline CHEMBL1712645 & 752533 & 3.1024 & 3.5543 & TRN & \\
\hline CHEMBL1982896 & 752533 & 5.0829 & 3.4789 & TRN & \\
\hline CHEMBL1315337 & 752533 & 3.1024 & 3.5148 & TRN & \\
\hline CHEMBL1314124 & 752533 & 3.1024 & 3.4826 & TRN & \\
\hline CHEMBL1477569 & 752533 & 3.1024 & 3.9653 & TST & \\
\hline CHEMBL597888 & 752533 & 3.1024 & 3.9791 & TST & \\
\hline CHEMBL1404516 & 752533 & 4.7388 & 4.1129 & TRN & \\
\hline CHEMBL1299313 & 752533 & 4.7562 & 3.64 & TRN & \\
\hline CHEMBL1973722 & 752533 & 3.1024 & 3.6485 & TRN & \\
\hline CHEMBL1719590 & 752533 & 5.1231 & 3.6619 & TST & \\
\hline CHEMBL1478646 & 752533 & 3.1024 & 3.5105 & TRN & \\
\hline CHEMBL1526033 & 752533 & 3.1024 & 3.575 & TRN & \\
\hline CHEMBL1708251 & 752533 & 3.1024 & 3.6331 & TRN & \\
\hline CHEMBL1719740 & 752533 & 3.1024 & 3.6149 & TRN & \\
\hline CHEMBL1528882 & 752533 & 3.1024 & 3.6119 & TRN & \\
\hline CHEMBL1893196 & 752533 & 4.8387 & 3.7833 & TRN & \\
\hline CHEMBL1986459 & 752533 & 4.9124 & 3.5861 & TRN & \\
\hline CHEMBL1996203 & 752533 & 3.1024 & 3.9985 & TRN & \\
\hline CHEMBL1703524 & 752533 & 3.1024 & 3.3998 & TRN & \\
\hline CHEMBL1598158 & 752533 & 3.1024 & 3.6397 & TRN & \\
\hline CHEMBL1366561 & 752533 & 4.8522 & 3.5307 & TRN & \\
\hline CHEMBL1882724 & 752533 & 4.9605 & 3.5472 & TST & \\
\hline CHEMBL2004900 & 752533 & 5.0261 & 3.8279 & TRN & \\
\hline CHEMBL1385793 & 752533 & 3.1024 & 3.7345 & TRN & \\
\hline CHEMBL1358058 & 752533 & 3.1024 & 3.5359 & TRN & \\
\hline CHEMBL1506609 & 752533 & 3.1024 & 3.7709 & TRN & \\
\hline CHEMBL1868091 & 752533 & 4.7668 & 3.8421 & TRN & \\
\hline CHEMBL1355497 & 752533 & 3.1024 & 3.7438 & TRN & \\
\hline CHEMBL1565437 & 752533 & 3.1024 & 3.6 & TST & \\
\hline
\end{tabular}


Supplemental Table S2.txt

\begin{tabular}{|c|c|c|c|c|c|}
\hline CHEMBL1599416 & 752533 & 4.871 & 3.92 & TRN & \\
\hline CHEMBL1868168 & 752533 & 3.1024 & 3.4834 & TRN & \\
\hline CHEMBL1503607 & 752533 & 4.4917 & 3.842 & TST & \\
\hline CHEMBL1460875 & 752533 & 3.1024 & 3.7548 & TRN & \\
\hline CHEMBL1891639 & 752533 & 3.1024 & 3.4259 & TRN & \\
\hline CHEMBL1501213 & 752533 & 3.1024 & 3.6894 & TRN & \\
\hline CHEMBL 2003869 & 752533 & 4.8157 & 3.6215 & TRN & \\
\hline CHEMBL1341113 & 752533 & 4.6205 & 3.9932 & TRN & \\
\hline CHEMBL1504525 & 752533 & 3.1024 & 3.2795 & TRN & \\
\hline CHEMBL1471867 & 752533 & 3.1024 & 3.6706 & TRN & \\
\hline CHEMBL1732612 & 752533 & 3.1024 & 3.7726 & TRN & \\
\hline CHEMBL1582880 & 752533 & 4.9113 & 3.5798 & TRN & \\
\hline CHEMBL1557601 & 752533 & 3.1024 & 3.3338 & TRN & \\
\hline CHEMBL1551558 & 752533 & 3.1024 & 3.5354 & TRN & \\
\hline CHEMBL1708985 & 752533 & 3.1024 & 3.9152 & TST & \\
\hline CHEMBL1888908 & 752533 & 3.1024 & 3.4071 & TRN & \\
\hline CHEMBL1906074 & 752533 & 3.1024 & 3.6883 & TRN & \\
\hline CHEMBL1388708 & 752533 & 4.6828 & 3.8944 & TRN & \\
\hline CHEMBL1374012 & 752533 & 3.1024 & 3.6424 & TRN & \\
\hline CHEMBL1502001 & 752533 & 4.6582 & 3.6693 & TRN & \\
\hline CHEMBL1574359 & 752533 & 3.1024 & 3.8457 & TRN & \\
\hline CHEMBL1967479 & 752533 & 4.869 & 4.0098 & TRN & \\
\hline CHEMBL1387484 & 752533 & 3.1024 & 3.5148 & TST & \\
\hline CHEMBL1905395 & 752533 & 3.1024 & 3.5926 & TRN & \\
\hline CHEMBL1887390 & 752533 & 3.1024 & 3.4233 & TRN & \\
\hline CHEMBL1891270 & 752533 & 3.1024 & 3.5018 & TRN & \\
\hline CHEMBL1445287 & 752533 & 4.6715 & 3.59 & TRN & \\
\hline CHEMBL1538790 & 752533 & 3.1024 & 3.5348 & TRN & \\
\hline CHEMBL1538976 & 752533 & 4.59399 & 99999999 & 3.8808 & TR \\
\hline CHEMBL1336535 & 752533 & 3.1024 & 3.2886 & TRN & \\
\hline CHEMBL 249301 & 752533 & 5.0416 & 3.6886 & TRN & \\
\hline CHEMBL1317012 & 752533 & 3.1024 & 3.796000 & 0000000003 & TST \\
\hline CHEMBL1588387 & 752533 & 3.1024 & 3.7811 & TST & \\
\hline CHEMBL1986541 & 752533 & 3.1024 & 3.5451 & TRN & \\
\hline CHEMBL1396713 & 752533 & 3.1024 & 3.6576 & TST & \\
\hline CHEMBL1336537 & 752533 & 4.8476 & 3.5846 & TST & \\
\hline CHEMBL1460751 & 752533 & 4.8938 & 3.5522 & TST & \\
\hline CHEMBL1996181 & 752533 & 4.1451 & 3.768999 & 9999999997 & $1 \mathrm{KN}$ \\
\hline CHEMBL1470073 & 752533 & 4.9729 & 3.5694 & TST & \\
\hline CHEMBL1992394 & 752533 & 3.1024 & 3.4974 & TRN & \\
\hline CHEMBL1416156 & 752533 & 3.1024 & 3.7859 & TRN & \\
\hline CHEMBL1384547 & 752533 & 4.4162 & 3.731000 & 0000000003 & 势 \\
\hline CHEMBL1364817 & 752533 & 5.0546 & 3.7225 & TRN & \\
\hline CHEMBL1897884 & 752533 & 4.7332 & 3.7028 & TRN & \\
\hline CHEMBL1463401 & 752533 & 3.1024 & 3.6844 & TRN & \\
\hline CHEMBL1366319 & 752533 & 3.1024 & 3.6051 & TRN & \\
\hline CHEMBL1990248 & 752533 & 3.1024 & 3.9316 & TST & \\
\hline CHEMBL1329418 & 752533 & 3.1024 & 3.6234 & TST & \\
\hline
\end{tabular}


Supplemental Table S2.txt

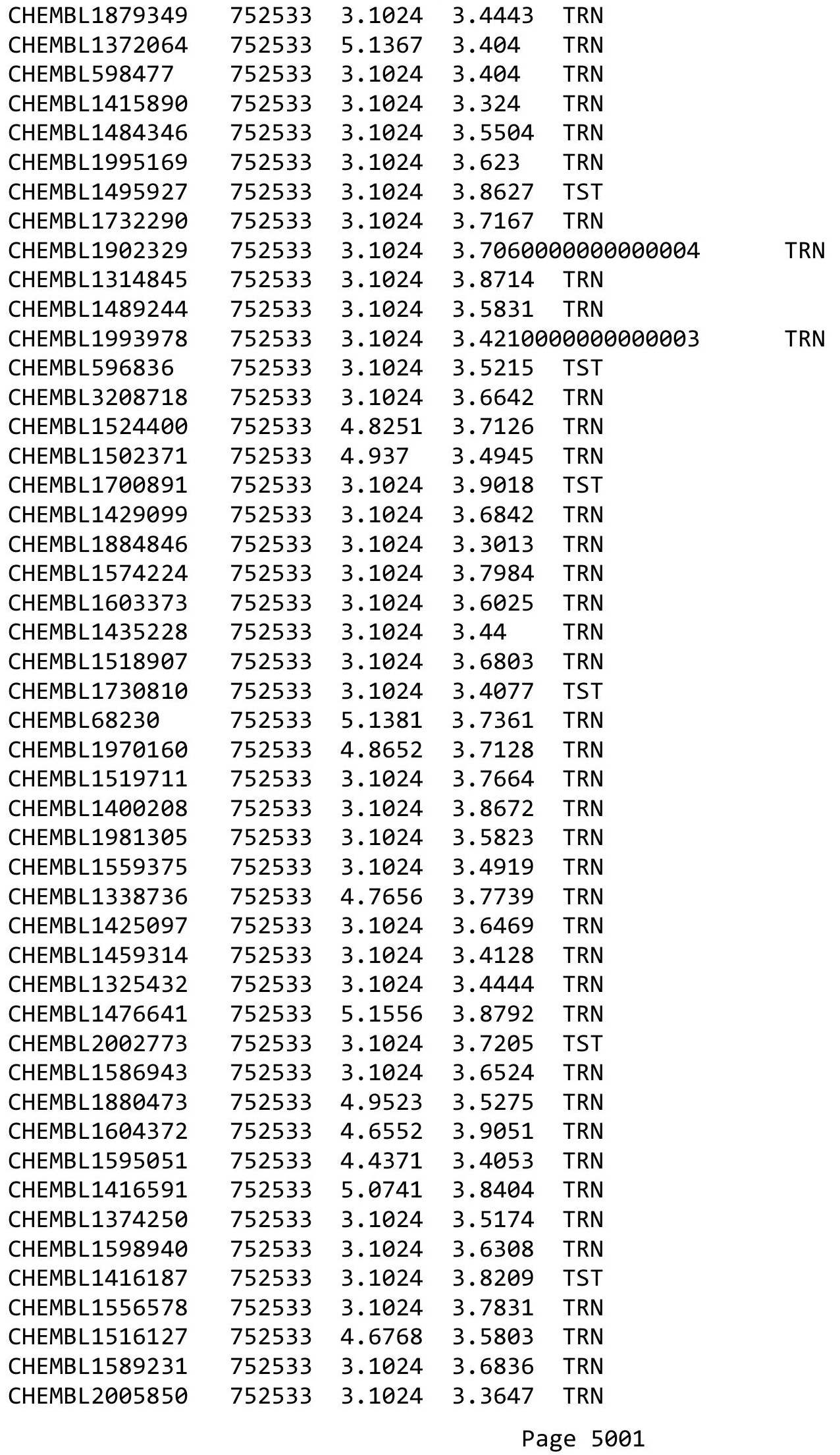


Supplemental Table S2.txt

\begin{tabular}{|c|c|c|c|c|c|c|}
\hline CHEMBL1902783 & 752533 & 4.9505 & 3.3533 & TRN & & \\
\hline CHEMBL1888730 & 752533 & 3.1024 & 3.5238 & TRN & & \\
\hline CHEMBL1871592 & 752533 & 3.1024 & 3.6789 & TRN & & \\
\hline CHEMBL1392264 & 752533 & 3.1024 & 3.91899 & 99999999996 & TRN & \\
\hline CHEMBL1368173 & 752533 & 3.1024 & 3.4482 & TRN & & \\
\hline CHEMBL1440892 & 752533 & 3.1024 & 3.6362 & TRN & & \\
\hline CHEMBL1486891 & 752533 & 3.1024 & 3.3166 & TRN & & \\
\hline CHEMBL1367230 & 752533 & 3.1024 & 3.6281 & TRN & & \\
\hline CHEMBL1879313 & 752533 & 5.30200 & 00000000 & 205 & 99999999996 & TRN \\
\hline CHEMBL1725784 & 752533 & 3.1024 & 3.6132 & TRN & & \\
\hline CHEMBL1478438 & 752533 & 3.1024 & 3.6681 & TRN & & \\
\hline CHEMBL1511370 & 752533 & 3.1024 & 3.9098 & TRN & & \\
\hline CHEMBL1734079 & 752533 & 3.1024 & 3.6196 & TRN & & \\
\hline CHEMBL1367309 & 752533 & 3.1024 & 3.7498 & TRN & & \\
\hline CHEMBL1592387 & 752533 & 4.499 & 3.7106 & TRN & & \\
\hline CHEMBL1430891 & 752533 & 3.1024 & 3.6723 & TRN & & \\
\hline CHEMBL1725294 & 752533 & 3.1024 & 3.3381 & TRN & & \\
\hline CHEMBL1373183 & 752533 & 3.1024 & 3.7737 & TRN & & \\
\hline CHEMBL1532599 & 752533 & 3.1024 & 3.4765 & TRN & & \\
\hline CHEMBL1382113 & 752533 & 4.4442 & 3.9058 & TRN & & \\
\hline CHEMBL1582714 & 752533 & 4.477 & 3.9106 & TRN & & \\
\hline CHEMBL1976625 & 752533 & 4.7426 & 3.7502 & TRN & & \\
\hline CHEMBL1728741 & 752533 & 4.937 & 3.565 & TRN & & \\
\hline CHEMBL1475866 & 752533 & 3.1024 & 3.6534 & TRN & & \\
\hline CHEMBL1474128 & 752533 & 3.1024 & 3.93300 & 00000000003 & TRN & \\
\hline CHEMBL1460775 & 752533 & 4.9734 & 3.6464 & TRN & & \\
\hline CHEMBL1584577 & 752533 & 3.1024 & 3.1669 & TRN & & \\
\hline CHEMBL 2005961 & 752533 & 3.1024 & 3.6762 & TRN & & \\
\hline CHEMBL1404985 & 752533 & 3.1024 & 4.0045 & TRN & & \\
\hline CHEMBL1397022 & 752533 & 4.7916 & 3.7752 & TRN & & \\
\hline CHEMBL1582353 & 752533 & 3.1024 & 3.4618 & TRN & & \\
\hline CHEMBL1410428 & 752533 & 3.1024 & 3.5754 & TST & & \\
\hline CHEMBL1475477 & 752533 & 3.1024 & 3.7386 & TRN & & \\
\hline CHEMBL3391749 & 752533 & 3.1024 & 4.0373 & TST & & \\
\hline CHEMBL1435138 & 752533 & 3.1024 & 3.7461 & TRN & & \\
\hline CHEMBL1904358 & 752533 & 4.5918 & 3.5609 & TRN & & \\
\hline CHEMBL1698095 & 752533 & 3.1024 & 3.6262 & TRN & & \\
\hline CHEMBL1708715 & 752533 & 3.1024 & 3.8643 & TRN & & \\
\hline CHEMBL1380024 & 752533 & 5.0498 & 3.6815 & TRN & & \\
\hline CHEMBL1571973 & 752533 & 3.1024 & 3.8134 & TST & & \\
\hline CHEMBL1457087 & 752533 & 3.1024 & 3.5269 & TRN & & \\
\hline CHEMBL1603609 & 752533 & 3.1024 & 3.8465 & TST & & \\
\hline CHEMBL1733606 & 752533 & 5.0888 & 3.6343 & TRN & & \\
\hline CHEMBL1403868 & 752533 & 3.1024 & 3.6878 & TRN & & \\
\hline CHEMBL1989592 & 752533 & 3.1024 & 3.4689 & TRN & & \\
\hline CHEMBL1512072 & 752533 & 3.1024 & 3.4601 & TRN & & \\
\hline CHEMBL1894258 & 752533 & 3.1024 & 3.7369 & TRN & & \\
\hline CHEMBL1302624 & 752533 & 3.1024 & 3.4851 & TRN & & \\
\hline
\end{tabular}


Supplemental Table S2.txt

\begin{tabular}{|c|c|c|c|c|}
\hline 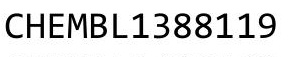 & & & & \\
\hline CHEMBL1496400 & 52533 & 3.1024 & 6984 & \\
\hline HEMBL1558069 & 2533 & 1024 & 6734 & \\
\hline HEMBL1880887 & 52533 & 1024 & 352 & \\
\hline IEMBL1598069 & 2533 & 1024 & & \\
\hline AEMBL1346278 & 52533 & .1024 & 7076 & \\
\hline AEMBL1712090 & 52533 & 3.1024 & 3429 & \\
\hline AEMBL1885362 & 52533 & .1024 & 5953 & \\
\hline IEMBL17 & 52533 & 1024 & 9447 & \\
\hline IEMBL1888498 & 52533 & .628 & & \\
\hline AEMBL1599708 & 52533 & 3.1024 & 7221 & \\
\hline AEMBL1901020 & 52533 & 3.1024 & 7912 & \\
\hline HEMBL1904959 & 33 & 4.793 & 36 & \\
\hline AEMBL1900021 & 33 & 3.1024 & & \\
\hline HEMBL1439288 & & 3.1024 & & \\
\hline AEMBL1572585 & 52533 & 4.8387 & 6753 & \\
\hline AEMBL1355706 & 52533 & .6747 & & \\
\hline AEMBL1975458 & 3 & 3.1024 & 514 & \\
\hline AEMBL1 & 33 & 759 & & \\
\hline HEMBL] & & 184 & & \\
\hline HEMBL1729028 & 33 & 3.1024 & & \\
\hline AEMBL1994259 & & 24 & & \\
\hline AEMBL1568800 & 33 & 3. & & \\
\hline JEMBL129 & 33 & 15 & & \\
\hline 22 & 33 & 3. & & \\
\hline IEMBL1 & & 3.1024 & & \\
\hline AEMBL155 & 3 & & & \\
\hline AEMBL1906483 & 3 & & & \\
\hline IFMRI & & & & \\
\hline 00 & 33 & 3. & & \\
\hline IEMBL1894129 & & & & \\
\hline AEMBL1731522 & 52533 & 28 & & \\
\hline HEMBL1411635 & 52533 & & & \\
\hline 1 & 3 & & & \\
\hline AEMBL1421022 & 33 & & & \\
\hline IEMBL1382123 & 52533 & & & \\
\hline AEMBL1727996 & 752533 & 5 . & 975 & \\
\hline IEMBL1879029 & 52533 & 3. & 99 & \\
\hline 0 & & & & \\
\hline & 52533 & & & \\
\hline IEMBL1590505 & 52533 & & 154 & \\
\hline IEMBL1457134 & 752533 & 3. & & \\
\hline HEMBL1331249 & 752533 & & & \\
\hline CHEMBL1969034 & 52533 & & $\partial 08$ & \\
\hline 83472 & 52533 & 3.1024 & 6478 & \\
\hline AEMBL1895933 & 52533 & 3.1024 & 595 & \\
\hline CHEM & & & & \\
\hline & & & & \\
\hline
\end{tabular}

Page 5003 
Supplemental Table S2.txt

\begin{tabular}{|c|c|c|c|c|c|}
\hline CHEMBL1309310 & 752533 & 3.1024 & 3.4458 & TRN & \\
\hline CHEMBL 2005653 & 752533 & 3.1024 & 3.9312 & TST & \\
\hline CHEMBL1396993 & 752533 & 3.1024 & 3.8418 & TRN & \\
\hline CHEMBL 2005247 & 752533 & 3.1024 & 3.5431 & TRN & \\
\hline CHEMBL1531414 & 752533 & 3.1024 & 3.7179 & TRN & \\
\hline CHEMBL1438487 & 752533 & 3.1024 & 3.5941 & TST & \\
\hline CHEMBL1595428 & 752533 & 4.921 & 3.3701 & TRN & \\
\hline CHEMBL1729505 & 752533 & 3.1024 & 3.4772 & TRN & \\
\hline CHEMBL1977191 & 752533 & 3.1024 & 3.516 & TRN & \\
\hline CHEMBL1890952 & 752533 & 3.1024 & 3.7495 & TRN & \\
\hline CHEMBL1319264 & 752533 & 3.1024 & 3.3904 & TRN & \\
\hline CHEMBL1504144 & 752533 & 3.1024 & 3.8563 & TRN & \\
\hline CHEMBL1498350 & 752533 & 3.1024 & 3.4837 & TRN & \\
\hline CHEMBL 2006310 & 752533 & 3.1024 & 3.5347 & TST & \\
\hline CHEMBL1339699 & 752533 & 4.9124 & 3.701 & TRN & \\
\hline CHEMBL1734642 & 752533 & 3.1024 & 3.5744 & TST & \\
\hline CHEMBL1385083 & 752533 & 3.1024 & 3.5713 & TRN & \\
\hline CHEMBL1459757 & 752533 & 3.1024 & 3.4548 & TRN & \\
\hline CHEMBL1395284 & 752533 & 4.8839 & 3.5839 & TRN & \\
\hline CHEMBL1880018 & 752533 & 3.1024 & 3.4424 & TRN & \\
\hline CHEMBL1538169 & 752533 & 4.263 & 3.6278 & TST & \\
\hline CHEMBL1606890 & 752533 & 5.05399 & 99999999 & 9 & 3.5977 \\
\hline CHEMBL1714561 & 752533 & 4.7372 & 3.8649 & TRN & \\
\hline CHEMBL1354360 & 752533 & 3.1024 & 3.5957 & TRN & \\
\hline CHEMBL1881977 & 752533 & 3.1024 & 3.6375 & TST & \\
\hline CHEMBL1736367 & 752533 & 4.8564 & 3.7543 & TRN & \\
\hline CHEMBL1525257 & 752533 & 3.1024 & 3.8009 & TRN & \\
\hline CHEMBL 2003599 & 752533 & 3.1024 & 3.7211 & TST & \\
\hline CHEMBL1479277 & 752533 & 3.1024 & 3.698 & TRN & \\
\hline CHEMBL1392137 & 752533 & 4.6075 & 3.6625 & TRN & \\
\hline CHEMBL1575293 & 752533 & 5.0514 & 3.4741 & TRN & \\
\hline CHEMBL1580989 & 752533 & 3.1024 & 3.2628 & TRN & \\
\hline CHEMBL1900518 & 752533 & 3.1024 & 3.4313 & TRN & \\
\hline CHEMBL1535237 & 752533 & 4.5905 & 4.034 & TRN & \\
\hline CHEMBL1979976 & 752533 & 3.1024 & 3.549 & TRN & \\
\hline CHEMBL1564259 & 752533 & 3.1024 & 3.7176 & TRN & \\
\hline CHEMBL1967734 & 752533 & 3.1024 & 3.5466 & TST & \\
\hline CHEMBL1724206 & 752533 & 3.1024 & 3.6871 & TRN & \\
\hline CHEMBL1335812 & 752533 & 5.2894 & 3.7874 & TRN & \\
\hline CHEMBL1873978 & 752533 & 4.1974 & 3.7562 & TRN & \\
\hline CHEMBL1893549 & 752533 & 3.1024 & 3.3568 & TST & \\
\hline CHEMBL1726868 & 752533 & 3.1024 & 3.4418 & TRN & \\
\hline CHEMBL1373819 & 752533 & 3.1024 & 3.5112 & TST & \\
\hline CHEMBL1318666 & 752533 & 3.1024 & 3.7342 & TRN & \\
\hline CHEMBL1473172 & 752533 & 3.1024 & 3.5044 & TST & \\
\hline CHEMBL1580189 & 752533 & 4.482 & 3.9421 & TRN & \\
\hline CHEMBL1368128 & 752533 & 4.2812 & 3.9013 & TRN & \\
\hline CHEMBL572180 & 752533 & 3.1024 & 4.0122 & TST & \\
\hline
\end{tabular}


Supplemental Table S2.txt

\begin{tabular}{|c|c|c|c|c|c|}
\hline CHEMBL1701946 & 752533 & 3.1024 & 3.5026 & TRN & \\
\hline CHEMBL1878613 & 752533 & 3.1024 & 3.3921 & TRN & \\
\hline CHEMBL1329148 & 752533 & 3.1024 & 3.8076 & TST & \\
\hline CHEMBL1511397 & 752533 & 3.1024 & 3.5195 & TST & \\
\hline CHEMBL1418825 & 752533 & 4.9696 & 3.8362 & TRN & \\
\hline CHEMBL1548803 & 752533 & 3.1024 & 3.6889 & TRN & \\
\hline CHEMBL1383027 & 752533 & 3.1024 & 3.6109 & TRN & \\
\hline CHEMBL1337016 & 752533 & 3.1024 & 3.4408 & TRN & \\
\hline CHEMBL1720199 & 752533 & 3.1024 & 3.5786 & TRN & \\
\hline CHEMBL1500229 & 752533 & 4.4137 & 3.6158 & TST & \\
\hline CHEMBL45245 & 752533 & 3.1024 & 4.0445 & TRN & \\
\hline CHEMBL1607222 & 752533 & 3.1024 & 3.7103 & TRN & \\
\hline CHEMBL1989704 & 752533 & 4.8597 & 3.7427 & TST & \\
\hline CHEMBL1319484 & 752533 & 3.1024 & 3.6977 & TRN & \\
\hline CHEMBL56897 & 752533 & 3.1024 & 3.88199 & 99999999997 & TST \\
\hline CHEMBL1895020 & 752533 & 3.1024 & 3.457 & TRN & \\
\hline CHEMBL1371967 & 752533 & 3.1024 & 3.7218 & TRN & \\
\hline CHEMBL1985765 & 752533 & 3.1024 & 3.6739 & TRN & \\
\hline CHEMBL1467354 & 752533 & 4.9341 & 3.8461 & TRN & \\
\hline CHEMBL1699029 & 752533 & 4.6874 & 3.9242 & TRN & \\
\hline CHEMBL1529638 & 752533 & 3.1024 & 3.7506 & TRN & \\
\hline CHEMBL1540513 & 752533 & 3.1024 & 3.478 & TRN & \\
\hline CHEMBL1339637 & 752533 & 4.5859 & 3.8616 & TRN & \\
\hline CHEMBL1896941 & 752533 & 3.1024 & 3.3985 & TRN & \\
\hline CHEMBL1990418 & 752533 & 3.1024 & 3.786 & TST & \\
\hline CHEMBL1277891 & 752533 & 3.1024 & 3.4894 & TRN & \\
\hline CHEMBL1987344 & 752533 & 3.1024 & 3.5286 & TST & \\
\hline CHEMBL1727505 & 752533 & 3.1024 & 3.5179 & TRN & \\
\hline CHEMBL1376482 & 752533 & 3.1024 & 3.5968 & TST & \\
\hline CHEMBL1468925 & 752533 & 3.1024 & 3.9153 & TST & \\
\hline CHEMBL1441918 & 752533 & 3.1024 & 3.7293 & TST & \\
\hline CHEMBL1725217 & 752533 & 3.1024 & 3.6383 & TRN & \\
\hline CHEMBL1713021 & 752533 & 3.1024 & 3.6065 & TRN & \\
\hline CHEMBL1565164 & 752533 & 4.7653 & 4.0448 & TST & \\
\hline CHEMBL1722673 & 752533 & 3.1024 & 3.7121 & TST & \\
\hline CHEMBL1716393 & 752533 & 4.8188 & 3.7801 & TRN & \\
\hline CHEMBL590457 & 752533 & 3.1024 & 3.7176 & TRN & \\
\hline CHEMBL1714180 & 752533 & 4.9171 & 3.6532 & TST & \\
\hline CHEMBL1877015 & 752533 & 3.1024 & 3.3592 & TST & \\
\hline CHEMBL1457486 & 752533 & 4.9791 & 3.9421 & TRN & \\
\hline CHEMBL1355118 & 752533 & 3.1024 & 3.5771 & TRN & \\
\hline CHEMBL1968095 & 752533 & 3.1024 & 3.4985 & TRN & \\
\hline CHEMBL1564099 & 752533 & 4.9097 & 3.5553 & TST & \\
\hline CHEMBL1305255 & 752533 & 3.1024 & 3.6547 & TRN & \\
\hline CHEMBL1301126 & 752533 & 3.1024 & 3.7901 & TST & \\
\hline CHEMBL1714012 & 752533 & 4.9438 & 3.6495 & TST & \\
\hline CHEMBL1384754 & 752533 & 4.8689 & 3.76899 & 99999999997 & TRN \\
\hline CHEMBL1329434 & 752533 & 3.1024 & 3.74300 & 00000000003 & TRN \\
\hline
\end{tabular}

Page 5005 
Supplemental Table S2.txt

\begin{tabular}{|c|c|c|c|c|}
\hline CHEMBL1611223 & 752533 & 3.1024 & 3.6074 & TRN \\
\hline CHEMBL1599015 & 752533 & 5.0568 & 3.7527 & TRN \\
\hline CHEMBL1526124 & 752533 & 3.1024 & 3.8513 & TRN \\
\hline CHEMBL1427508 & 752533 & 3.1024 & 3.7732 & TRN \\
\hline CHEMBL1610731 & 752533 & 3.1024 & 3.7135 & TRN \\
\hline CHEMBL1440686 & 752533 & 4.4994 & 3.5524 & TRN \\
\hline CHEMBL1723903 & 752533 & 4.8481 & 3.7081 & TRN \\
\hline CHEMBL1301826 & 752533 & 3.1024 & 3.5566 & TRN \\
\hline CHEMBL1463620 & 752533 & 4.6588 & 3.9254 & TRN \\
\hline CHEMBL1905929 & 752533 & 4.7405 & 3.9062 & TST \\
\hline CHEMBL1975051 & 752533 & 3.1024 & 3.5637 & TRN \\
\hline CHEMBL1324722 & 752533 & 4.9618 & 3.4382 & TRN \\
\hline CHEMBL1429513 & 752533 & 4.8445 & 3.597 & TRN \\
\hline CHEMBL1598649 & 752533 & 3.1024 & 3.6844 & TRN \\
\hline CHEMBL1386200 & 752533 & 3.1024 & 3.5207 & TRN \\
\hline CHEMBL1518924 & 752533 & 3.1024 & 3.7933 & TRN \\
\hline CHEMBL1735853 & 752533 & 3.1024 & 3.8725 & TRN \\
\hline CHEMBL1484491 & 752533 & 3.1024 & 3.7519 & TRN \\
\hline CHEMBL1999359 & 752533 & 3.1024 & 3.2999 & TRN \\
\hline CHEMBL1875031 & 752533 & 3.1024 & 3.6192 & TRN \\
\hline CHEMBL1372519 & 752533 & 3.1024 & 3.49300 & 30000000003 \\
\hline CHEMBL1332261 & 752533 & 5.0923 & 3.8645 & TRN \\
\hline CHEMBL1313961 & 752533 & 3.1024 & 3.5508 & TRN \\
\hline CHEMBL1587395 & 752533 & 3.1024 & 3.7415 & TST \\
\hline CHEMBL1895133 & 752533 & 4.7372 & 3.7627 & TST \\
\hline CHEMBL422237 & 752533 & 3.1024 & 3.6394 & TRN \\
\hline CHEMBL1567432 & 752533 & 4.4306 & 3.5883 & TRN \\
\hline CHEMBL1990091 & 752533 & 3.1024 & 3.6118 & TRN \\
\hline CHEMBL1495281 & 752533 & 3.1024 & 3.7352 & TRN \\
\hline CHEMBL1383269 & 752533 & 3.1024 & 3.90100 & 30000000002 \\
\hline CHEMBL1406133 & 752533 & 3.1024 & 3.5033 & TRN \\
\hline CHEMBL1884406 & 752533 & 3.1024 & 3.9379 & TRN \\
\hline CHEMBL1383743 & 752533 & 4.8468 & 3.6603 & TRN \\
\hline CHEMBL1867143 & 752533 & 3.1024 & 3.5785 & TRN \\
\hline CHEMBL1546779 & 752533 & 3.1024 & 3.878 & TRN \\
\hline CHEMBL3145300 & 752533 & 3.1024 & 3.7374 & TST \\
\hline CHEMBL1886490 & 752533 & 4.8246 & 3.5568 & TRN \\
\hline CHEMBL1343685 & 752533 & 3.1024 & 3.3024 & TRN \\
\hline CHEMBL1730650 & 752533 & 3.1024 & 3.4872 & TRN \\
\hline CHEMBL1868417 & 752533 & 3.1024 & 3.8279 & TRN \\
\hline CHEMBL1722488 & 752533 & 3.1024 & 3.5586 & TRN \\
\hline CHEMBL1495078 & 752533 & 3.1024 & 3.7255 & TST \\
\hline CHEMBL1574132 & 752533 & 3.1024 & 3.5974 & TRN \\
\hline CHEMBL1555186 & 752533 & 3.1024 & 3.8518 & TST \\
\hline CHEMBL 2005602 & 752533 & 4.61 & 3.7121 & TRN \\
\hline CHEMBL1363855 & 752533 & 5.0788 & 3.7697 & TRN \\
\hline CHEMBL1535801 & 752533 & 4.5789 & 3.9028 & TRN \\
\hline CHEMBL1983721 & 752533 & 3.1024 & 3.9139 & TST \\
\hline
\end{tabular}


Supplemental Table S2.txt

\begin{tabular}{|c|c|c|c|c|c|}
\hline CHEMBL1580363 & 752533 & 3.1024 & 3.9446 & TRN & \\
\hline CHEMBL1879776 & 752533 & 4.3756 & 3.4186 & TRN & \\
\hline CHEMBL1323249 & 752533 & 3.1024 & 3.3495 & TRN & \\
\hline CHEMBL1560092 & 752533 & 4.9276 & 3.6993 & TRN & \\
\hline CHEMBL1323071 & 752533 & 3.1024 & 3.1649 & TRN & \\
\hline CHEMBL1714762 & 752533 & 3.1024 & 3.6188 & TRN & \\
\hline CHEMBL1714625 & 752533 & 5.1516 & 3.706000 & 0000000004 & TRN \\
\hline CHEMBL1489418 & 752533 & 3.1024 & 3.4838 & TST & \\
\hline CHEMBL1735129 & 752533 & 3.1024 & 3.5099 & TRN & \\
\hline CHEMBL1609488 & 752533 & 3.1024 & 3.8801 & TRN & \\
\hline CHEMBL1892444 & 752533 & 3.1024 & 3.6629 & TRN & \\
\hline CHEMBL1986690 & 752533 & 3.1024 & 3.8149 & TRN & \\
\hline CHEMBL1313497 & 752533 & 4.6195 & 3.7231 & TST & \\
\hline CHEMBL1966886 & 752533 & 5.0368 & 3.4192 & TRN & \\
\hline CHEMBL1988621 & 752533 & 3.1024 & 3.4233 & TRN & \\
\hline CHEMBL1451701 & 752533 & 3.1024 & 3.9141 & TRN & \\
\hline CHEMBL1591488 & 752533 & 4.7351 & 3.6549 & TRN & \\
\hline CHEMBL1601286 & 752533 & 4.4423 & 3.759 & TRN & \\
\hline CHEMBL1604988 & 752533 & 3.1024 & 3.3933 & TRN & \\
\hline CHEMBL1577697 & 752533 & 3.1024 & 3.6149 & TRN & \\
\hline CHEMBL1404915 & 752533 & 4.5495 & 3.8008 & TST & \\
\hline CHEMBL1410280 & 752533 & 4.7591 & 3.7041 & TRN & \\
\hline CHEMBL1414448 & 752533 & 4.8309 & 3.9228 & TRN & \\
\hline CHEMBL1558819 & 752533 & 3.1024 & 3.8346 & TRN & \\
\hline CHEMBL1729491 & 752533 & 3.1024 & 3.5132 & TST & \\
\hline CHEMBL1328045 & 752533 & 3.1024 & 3.8046 & TRN & \\
\hline CHEMBL1423148 & 752533 & 5.16799 & 99999999 & 3.8312 & TRN \\
\hline CHEMBL1400996 & 752533 & 3.1024 & 3.2741 & TRN & \\
\hline CHEMBL1474285 & 752533 & 3.1024 & 3.4171 & TRN & \\
\hline CHEMBL1300874 & 752533 & 3.1024 & 3.7962 & TST & \\
\hline CHEMBL1977538 & 752533 & 4.7093 & 3.6018 & TRN & \\
\hline CHEMBL1336062 & 752533 & 3.1024 & 3.5612 & TRN & \\
\hline CHEMBL1311025 & 752533 & 3.1024 & 3.5816 & TRN & \\
\hline CHEMBL1342377 & 752533 & 4.917 & 3.8459 & TRN & \\
\hline CHEMBL1880439 & 752533 & 4.4019 & 3.9655 & TRN & \\
\hline CHEMBL1418124 & 752533 & 3.1024 & 3.7337 & TRN & \\
\hline CHEMBL1308945 & 752533 & 3.1024 & 3.8304 & TRN & \\
\hline CHEMBL1968465 & 752533 & 3.1024 & 3.7341 & TRN & \\
\hline CHEMBL1432772 & 752533 & 3.1024 & 3.1887 & TRN & \\
\hline CHEMBL1876096 & 752533 & 3.1024 & 3.4642 & TRN & \\
\hline CHEMBL1709171 & 752533 & 3.1024 & 3.6695 & TRN & \\
\hline CHEMBL1524990 & 752533 & 4.97199 & 99999999 & 3.6853 & וכ \\
\hline CHEMBL1402898 & 752533 & 3.1024 & 3.5956 & TRN & \\
\hline CHEMBL1532418 & 752533 & 3.1024 & 3.989 & TRN & \\
\hline CHEMBL1387231 & 752533 & 4.1728 & 3.6485 & TRN & \\
\hline CHEMBL1414396 & 752533 & 3.1024 & 3.7098 & TRN & \\
\hline CHEMBL1318639 & 752533 & 4.8132 & 3.5715 & TRN & \\
\hline CHEMBL1386988 & 752533 & 3.1024 & 3.5676 & TRN & \\
\hline
\end{tabular}


Supplemental Table S2.txt

\begin{tabular}{|c|c|c|c|c|}
\hline CHEMBL1432227 & 752533 & 3.1024 & 3.8858 & TRN \\
\hline CHEMBL1534665 & 752533 & 3.1024 & 3.8443 & TRN \\
\hline CHEMBL1987272 & 752533 & 4.7548 & 3.9237 & TRN \\
\hline CHEMBL1578975 & 752533 & 3.1024 & 3.7067 & TRN \\
\hline CHEMBL1479362 & 752533 & 5.0081 & 3.5078 & TRN \\
\hline CHEMBL1985660 & 752533 & 4.901 & 3.8488 & TRN \\
\hline CHEMBL1448074 & 752533 & 3.1024 & 3.5686 & TRN \\
\hline CHEMBL1374627 & 752533 & 4.6382 & 4.0252 & TRN \\
\hline CHEMBL1346584 & 752533 & 3.1024 & 3.5799 & TST \\
\hline CHEMBL1716060 & 752533 & 4.9823 & 3.7056 & TRN \\
\hline CHEMBL1966728 & 752533 & 3.1024 & 3.5937 & TRN \\
\hline CHEMBL1417515 & 752533 & 3.1024 & 4.0032 & TST \\
\hline CHEMBL1494757 & 752533 & 3.1024 & 3.7759 & TRN \\
\hline CHEMBL1555499 & 752533 & 4.9485 & 3.5374 & TRN \\
\hline CHEMBL1986047 & 752533 & 3.1024 & 3.9338 & TST \\
\hline CHEMBL1372492 & 752533 & 3.1024 & 3.7705 & TRN \\
\hline CHEMBL1422178 & 752533 & 4.3425 & 3.7541 & TST \\
\hline CHEMBL1323843 & 752533 & 4.9964 & 3.8049 & TRN \\
\hline CHEMBL1999984 & 752533 & 3.1024 & 3.457 & TRN \\
\hline CHEMBL 2006683 & 752533 & 3.1024 & 3.7013 & TRN \\
\hline CHEMBL1341814 & 752533 & 3.1024 & 3.7659 & TRN \\
\hline CHEMBL1341841 & 752533 & 4.4461 & 3.6835 & TRN \\
\hline CHEMBL1545703 & 752533 & 4.9739 & 3.7872 & TRN \\
\hline CHEMBL 2004144 & 752533 & 3.1024 & 3.6533 & TRN \\
\hline CHEMBL1470755 & 752533 & 3.1024 & 3.7294 & TRN \\
\hline CHEMBL1313763 & 752533 & 3.1024 & 4.0432 & TST \\
\hline CHEMBL1982632 & 752533 & 3.1024 & 3.7017 & TST \\
\hline CHEMBL1341199 & 752533 & 3.1024 & 3.7348 & TRN \\
\hline CHEMBL1569668 & 752533 & 4.7823 & 3.7286 & TRN \\
\hline CHEMBL1382323 & 752533 & 3.1024 & 3.4149 & TRN \\
\hline CHEMBL1583670 & 752533 & 3.1024 & 3.5668 & TRN \\
\hline CHEMBL1699386 & 752533 & 3.1024 & 3.6413 & TRN \\
\hline CHEMBL1583303 & 752533 & 3.1024 & 3.4585 & TRN \\
\hline CHEMBL1602934 & 752533 & 3.1024 & 3.4979 & TRN \\
\hline CHEMBL1393529 & 752533 & 3.1024 & 3.5119 & TRN \\
\hline CHEMBL1503702 & 752533 & 4.8762 & 3.6415 & TRN \\
\hline CHEMBL1584950 & 752533 & 3.1024 & 3.8843 & TST \\
\hline CHEMBL1563767 & 752533 & 3.1024 & 3.5517 & TRN \\
\hline CHEMBL1425624 & 752533 & 5.0374 & 3.7142 & TRN \\
\hline CHEMBL1392113 & 752533 & 3.1024 & 3.7249 & TRN \\
\hline CHEMBL1532425 & 752533 & 3.1024 & 3.4265 & TRN \\
\hline CHEMBL1507325 & 752533 & 5.3047 & 3.52100 & 0000000004 \\
\hline CHEMBL1884827 & 752533 & 3.1024 & 3.2277 & TST \\
\hline CHEMBL1882358 & 752533 & 3.1024 & 3.3741 & TRN \\
\hline CHEMBL1888464 & 752533 & 3.1024 & 3.6904 & TRN \\
\hline CHEMBL1522324 & 752533 & 4.9467 & 3.6917 & TRN \\
\hline CHEMBL1549308 & 752533 & 3.1024 & 3.9104 & TRN \\
\hline CHEMBL1416662 & 752533 & 4.98 & 3.8056 & TRN \\
\hline
\end{tabular}


Supplemental Table S2.txt

\begin{tabular}{|c|c|c|c|c|}
\hline CHEMBL1330327 & 752533 & 4.9933 & 3.5292 & TST \\
\hline CHEMBL1461430 & 752533 & 4.7598 & 3.9325 & TRN \\
\hline CHEMBL1353965 & 752533 & 3.1024 & 3.8459 & TRN \\
\hline CHEMBL1700439 & 752533 & 3.1024 & 3.6312 & TRN \\
\hline CHEMBL1467641 & 752533 & 3.1024 & 3.3987 & TRN \\
\hline CHEMBL1395025 & 752533 & 3.1024 & 3.5429 & TRN \\
\hline CHEMBL1379359 & 752533 & 3.1024 & 3.4775 & TRN \\
\hline CHEMBL1493942 & 752533 & 3.1024 & 3.8686 & TST \\
\hline CHEMBL1322215 & 752533 & 4.5092 & 3.6392 & TRN \\
\hline CHEMBL1390449 & 752533 & 4.7449 & 3.7063 & TRN \\
\hline CHEMBL1385597 & 752533 & 3.1024 & 3.5604 & TRN \\
\hline CHEMBL1723414 & 752533 & 3.1024 & 3.5184 & TRN \\
\hline CHEMBL1979539 & 752533 & 4.9741 & 3.5753 & TRN \\
\hline CHEMBL1997895 & 752533 & 3.1024 & 3.4786 & TRN \\
\hline CHEMBL1511879 & 752533 & 4.9236 & 3.7415 & TRN \\
\hline CHEMBL1397451 & 752533 & 3.1024 & 3.7688 & TRN \\
\hline CHEMBL1984056 & 752533 & 3.1024 & 3.481000 & 0000000003 \\
\hline CHEMBL1455943 & 752533 & 3.1024 & 3.5977 & TRN \\
\hline CHEMBL1376406 & 752533 & 3.1024 & 3.9567 & TRN \\
\hline CHEMBL1877908 & 752533 & 3.1024 & 3.2674 & TRN \\
\hline CHEMBL1906365 & 752533 & 3.1024 & 3.9885 & TRN \\
\hline CHEMBL1477594 & 752533 & 3.1024 & 3.8093 & TRN \\
\hline CHEMBL1870697 & 752533 & 4.9665 & 3.5716 & TRN \\
\hline CHEMBL1434073 & 752533 & 3.1024 & 3.6078 & TRN \\
\hline CHEMBL1364287 & 752533 & 3.1024 & 3.2386 & TRN \\
\hline CHEMBL1728503 & 752533 & 3.1024 & 3.5538 & TRN \\
\hline CHEMBL1506684 & 752533 & 5.0233 & 3.7599 & TRN \\
\hline CHEMBL1369562 & 752533 & 4.9415 & 3.5539 & TRN \\
\hline CHEMBL1904515 & 752533 & 3.1024 & 3.7486 & TRN \\
\hline CHEMBL1735192 & 752533 & 3.1024 & 3.5051 & TRN \\
\hline CHEMBL1324195 & 752533 & 4.5257 & 3.6095 & TRN \\
\hline CHEMBL1449136 & 752533 & 5.2789 & 3.8277 & TRN \\
\hline CHEMBL1587637 & 752533 & 4.2272 & 3.8133 & TRN \\
\hline CHEMBL1721465 & 752533 & 4.80399 & 99999999 & 3.545 \\
\hline CHEMBL1507187 & 752533 & 4.6203 & 3.5573 & TRN \\
\hline CHEMBL1374694 & 752533 & 4.4779 & 3.7139 & TST \\
\hline CHEMBL1897646 & 752533 & 3.1024 & 3.473999 & 9999999998 \\
\hline CHEMBL1974392 & 752533 & 3.1024 & 3.6754 & TRN \\
\hline CHEMBL1879283 & 752533 & 4.4983 & 3.6317 & TRN \\
\hline CHEMBL1701636 & 752533 & 3.1024 & 3.7064 & TRN \\
\hline CHEMBL1575354 & 752533 & 3.1024 & 3.4894 & TRN \\
\hline CHEMBL1480000 & 752533 & 3.1024 & 3.8615 & TRN \\
\hline CHEMBL1427466 & 752533 & 3.1024 & 3.784 & TRN \\
\hline CHEMBL1390816 & 752533 & 4.6115 & 3.6548 & TRN \\
\hline CHEMBL1705568 & 752533 & 3.1024 & 3.48 & TRN \\
\hline CHEMBL1352434 & 752533 & 3.1024 & 3.5142 & TRN \\
\hline CHEMBL1901671 & 752533 & 3.1024 & 3.4002 & TRN \\
\hline CHEMBL1972133 & 752533 & 3.1024 & 3.8167 & TRN \\
\hline
\end{tabular}


Supplemental Table S2.txt

\begin{tabular}{|c|c|c|c|c|c|}
\hline CHEMBL1877761 & 752533 & 4.5063 & 3.7806 & TRN & \\
\hline CHEMBL1980827 & 752533 & 3.1024 & 3.9303 & TRN & \\
\hline CHEMBL1442453 & 752533 & 5.1278 & 3.4967 & TRN & \\
\hline CHEMBL273807 & 752533 & 3.1024 & 3.4963 & TRN & \\
\hline CHEMBL1880985 & 752533 & 3.1024 & 3.5089 & TRN & \\
\hline CHEMBL1529402 & 752533 & 3.1024 & 3.6605 & TRN & \\
\hline CHEMBL1868131 & 752533 & 3.1024 & 3.7617 & TRN & \\
\hline CHEMBL1336927 & 752533 & 3.1024 & 3.8477 & TRN & \\
\hline CHEMBL1534716 & 752533 & 3.1024 & 3.7458 & TRN & \\
\hline CHEMBL1447281 & 752533 & 4.9068 & 3.8843 & TRN & \\
\hline CHEMBL1873948 & 752533 & 3.1024 & 3.5774 & TRN & \\
\hline CHEMBL1698139 & 752533 & 4.9228 & 3.4876 & TST & \\
\hline CHEMBL1867709 & 752533 & 3.1024 & 4.0966 & TST & \\
\hline CHEMBL1400225 & 752533 & 3.1024 & 3.8338 & TST & \\
\hline CHEMBL1384619 & 752533 & 4.8979 & \multicolumn{2}{|c|}{3.7060000000000004} & TRN \\
\hline CHEMBL1583801 & 752533 & 3.1024 & 3.82 & TRN & \\
\hline CHEMBL1570792 & 752533 & 3.1024 & 3.4242 & TRN & \\
\hline CHEMBL1894140 & 752533 & 3.1024 & 3.8105 & TRN & \\
\hline CHEMBL1968162 & 752533 & 3.1024 & 3.3972 & TRN & \\
\hline CHEMBL1897854 & 752533 & 4.8931 & 3.7125 & TST & \\
\hline CHEMBL1345381 & 752533 & 3.1024 & 3.2871 & TRN & \\
\hline CHEMBL1708696 & 752533 & 3.1024 & 3.5995 & TRN & \\
\hline CHEMBL1425581 & 752533 & 4.5455 & 3.8439 & TRN & \\
\hline CHEMBL1568409 & 752533 & 3.1024 & 3.6696 & TRN & \\
\hline CHEMBL1535190 & 752533 & 3.1024 & 3.696 & TST & \\
\hline CHEMBL1868534 & 752533 & 3.1024 & 3.7591 & TST & \\
\hline CHEMBL1375247 & 752533 & 5.1238 & 3.4309 & TRN & \\
\hline CHEMBL1443753 & 752533 & 3.1024 & 3.3373 & TST & \\
\hline CHEMBL1443499 & 752533 & 3.1024 & 3.4808 & TRN & \\
\hline CHEMBL1450744 & 752533 & 3.1024 & 3.6268 & TST & \\
\hline CHEMBL1890768 & 752533 & 3.1024 & 3.6643 & TST & \\
\hline CHEMBL1364216 & 752533 & 4.9304 & 3.7029 & TST & \\
\hline CHEMBL1485381 & 752533 & 3.1024 & 3.7797 & TST & \\
\hline CHEMBL1470112 & 752533 & 3.1024 & 3.7659 & TST & \\
\hline CHEMBL1427663 & 752533 & 3.1024 & 3.6891 & TST & \\
\hline CHEMBL1328052 & 752533 & 3.1024 & 3.6483 & TST & \\
\hline CHEMBL1414773 & 752533 & 3.1024 & 3.9364 & TST & \\
\hline CHEMBL1901063 & 752533 & 3.1024 & 3.764 & TST & \\
\hline CHEMBL1453981 & 752533 & 3.1024 & 3.6693 & TST & \\
\hline CHEMBL1999648 & 752533 & 3.1024 & \multicolumn{2}{|c|}{ 3.7939999999999996 } & TST \\
\hline CHEMBL1530972 & 752533 & 3.1024 & 3.5711 & TST & \\
\hline CHEMBL1732062 & 752533 & 3.1024 & 3.7531 & TST & \\
\hline CHEMBL1548173 & 752533 & 3.1024 & 3.7211 & TST & \\
\hline CHEMBL1372415 & 752533 & 4.9255 & 3.736 & TST & \\
\hline CHEMBL1501584 & 752533 & 3.1024 & 3.6854 & TST & \\
\hline CHEMBL1564224 & 752533 & 3.1024 & 3.5405 & TST & \\
\hline CHEMBL1487964 & 752533 & 3.1024 & 3.5018 & TST & \\
\hline CHEMBL1553358 & 752533 & 3.1024 & 3.6869 & TST & \\
\hline
\end{tabular}


Supplemental Table S2.txt

\begin{tabular}{|c|c|c|c|c|}
\hline CHEMBL1564425 & 752533 & 3.1024 & 3.8017 & TST \\
\hline CHEMBL1999513 & 752533 & 3.1024 & 3.6088 & TST \\
\hline CHEMBL1605713 & 752533 & 3.1024 & 3.9367 & TST \\
\hline CHEMBL1306971 & 752533 & 4.417 & 3.485 & TST \\
\hline CHEMBL1603166 & 752533 & 3.1024 & 3.5582 & TST \\
\hline CHEMBL1408533 & 752533 & 3.1024 & 3.7442 & TST \\
\hline CHEMBL1560069 & 752533 & 3.1024 & 3.3544 & TST \\
\hline CHEMBL1173522 & 752533 & 3.1024 & 3.7975 & TST \\
\hline CHEMBL1309416 & 752533 & 3.1024 & 3.6872 & TST \\
\hline CHEMBL601822 & 752533 & 3.1024 & 3.7087 & TST \\
\hline CHEMBL1894626 & 752533 & 3.1024 & 3.7522 & TST \\
\hline CHEMBL1496529 & 752533 & 3.1024 & 3.8526 & TST \\
\hline CHEMBL1904694 & 752533 & 4.8964 & 3.5028 & TST \\
\hline CHEMBL1463514 & 752533 & 4.1495 & 3.6731 & TST \\
\hline CHEMBL1579167 & 752533 & 3.1024 & 3.3431 & TST \\
\hline CHEMBL1359239 & 752533 & 3.1024 & 3.5668 & TST \\
\hline CHEMBL1731988 & 752533 & 3.1024 & 3.486 & TST \\
\hline CHEMBL1390768 & 752533 & 3.1024 & 3.8218 & TST \\
\hline CHEMBL1491734 & 752533 & 3.1024 & 3.7462 & TST \\
\hline CHEMBL1900738 & 752533 & 5.0391 & 3.6666 & TST \\
\hline CHEMBL1473428 & 752533 & 3.1024 & 3.7234 & TST \\
\hline CHEMBL1542574 & 752533 & 4.6482 & 3.6527 & TST \\
\hline CHEMBL2361002 & 752533 & 3.1024 & 3.6861 & TST \\
\hline CHEMBL1377309 & 752533 & 4.6423 & 3.7474 & TST \\
\hline CHEMBL1392751 & 752533 & 4.5475 & 3.4733 & TST \\
\hline CHEMBL1396056 & 752533 & 5.0219 & 3.5639 & TST \\
\hline CHEMBL1890888 & 752533 & 3.1024 & 3.6402 & TST \\
\hline CHEMBL1717744 & 752533 & 4.5845 & 3.6177 & TST \\
\hline CHEMBL1723019 & 752533 & 4.8562 & 3.6495 & TST \\
\hline CHEMBL1439268 & 752533 & 3.1024 & 3.5266 & TST \\
\hline CHEMBL1530211 & 752533 & 4.6415 & 3.4837 & TST \\
\hline CHEMBL1882042 & 752533 & 3.1024 & 3.4767 & TST \\
\hline CHEMBL1534836 & 752533 & 4.8018 & 3.5972 & TST \\
\hline CHEMBL1729751 & 752533 & 3.1024 & 3.6756 & TST \\
\hline CHEMBL1711809 & 752533 & 3.1024 & 3.4592 & TST \\
\hline CHEMBL1701510 & 752533 & 3.1024 & 3.6965 & TST \\
\hline CHEMBL1725168 & 752533 & 4.7763 & 3.5105 & TST \\
\hline CHEMBL1373868 & 752533 & 3.1024 & 3.8167 & TST \\
\hline CHEMBL1367830 & 752533 & 3.1024 & 3.7837 & TST \\
\hline CHEMBL1320932 & 752533 & 3.1024 & 3.6323 & TST \\
\hline CHEMBL1336677 & 752533 & 3.1024 & 3.5836 & TST \\
\hline CHEMBL1978995 & 752533 & 4.5932 & 3.7987 & TST \\
\hline CHEMBL1990796 & 752533 & 4.8516 & 3.7287 & TST \\
\hline CHEMBL1727940 & 752533 & 3.1024 & 3.5875 & TST \\
\hline CHEMBL1476695 & 752533 & 3.1024 & 3.7775 & TST \\
\hline CHEMBL1430507 & 752533 & 3.1024 & 3.4764 & TST \\
\hline CHEMBL1879553 & 752533 & 4.6493 & 3.5741 & TST \\
\hline \multirow[t]{2}{*}{ CHEMBL2002517 } & 752533 & 3.1024 & 3.47300 & 00000000003 \\
\hline & & \multicolumn{3}{|c|}{ Page 5011} \\
\hline
\end{tabular}


Supplemental Table S2.txt

\begin{tabular}{|c|c|c|c|c|}
\hline CHEMBL1373988 & 752533 & 3.1024 & 3.6512 & TST \\
\hline CHEMBL1894456 & 752533 & 3.1024 & 3.2599 & TST \\
\hline CHEMBL1701321 & 752533 & 3.1024 & 3.6203 & TST \\
\hline CHEMBL1532085 & 752533 & 3.1024 & 3.7952 & TST \\
\hline CHEMBL1453916 & 752533 & 5.0817 & 3.5301 & TST \\
\hline CHEMBL1502259 & 752533 & 4.6127 & 3.8661 & TST \\
\hline CHEMBL1330873 & 752533 & 3.1024 & 3.7895 & TST \\
\hline CHEMBL1966848 & 752533 & 3.1024 & 3.6329 & TST \\
\hline CHEMBL1419693 & 752533 & 4.968 & 3.6504 & TST \\
\hline CHEMBL1868465 & 752533 & 4.2897 & 3.493999 & 99999999998 \\
\hline CHEMBL1447188 & 752533 & 3.1024 & 3.2802 & TST \\
\hline CHEMBL1584903 & 752533 & 3.1024 & 3.6776 & TST \\
\hline CHEMBL1494746 & 752533 & 3.1024 & 3.6582 & TST \\
\hline CHEMBL1510326 & 752533 & 3.1024 & 3.7517 & TST \\
\hline CHEMBL1463000 & 752533 & 3.1024 & 4.0011 & TST \\
\hline CHEMBL1880327 & 752533 & 4.6596 & 3.7435 & TST \\
\hline CHEMBL1579798 & 752533 & 3.1024 & 3.5373 & TST \\
\hline CHEMBL1611912 & 752533 & 3.1024 & 3.8165 & TST \\
\hline CHEMBL1894537 & 752533 & 4.7384 & 3.6994 & TST \\
\hline CHEMBL1432015 & 752533 & 3.1024 & 3.8072 & TST \\
\hline CHEMBL1598403 & 752533 & 3.1024 & 3.4691 & TST \\
\hline CHEMBL1975487 & 752533 & 3.1024 & 3.6893 & TST \\
\hline CHEMBL1534533 & 752533 & 3.1024 & 3.6448 & TST \\
\hline CHEMBL1992359 & 752533 & 3.1024 & 3.4602 & TST \\
\hline CHEMBL2001685 & 752533 & 3.1024 & 3.5342 & TST \\
\hline CHEMBL1969761 & 752533 & 3.1024 & 3.5855 & TST \\
\hline CHEMBL1381711 & 752533 & 3.1024 & 3.3927 & TST \\
\hline CHEMBL1361392 & 752533 & 3.1024 & 3.5595 & TST \\
\hline CHEMBL1567858 & 752533 & 3.1024 & 3.7342 & TST \\
\hline CHEMBL1482960 & 752533 & 3.1024 & 3.6413 & TST \\
\hline CHEMBL1523566 & 752533 & 4.9568 & 3.5924 & TST \\
\hline CHEMBL1454154 & 752533 & 4.7678 & 3.8675 & TST \\
\hline CHEMBL1428612 & 752533 & 3.1024 & 3.3085 & TST \\
\hline CHEMBL1596782 & 752533 & 3.1024 & 3.4907 & TST \\
\hline CHEMBL1580219 & 752533 & 3.1024 & 3.4601 & TST \\
\hline CHEMBL1984924 & 752533 & 4.5021 & 3.5523 & TST \\
\hline CHEMBL1347142 & 752533 & 4.8167 & 3.7355 & TST \\
\hline CHEMBL1495295 & 752533 & 4.811 & 3.6662 & TST \\
\hline CHEMBL 2002274 & 752533 & 3.1024 & 3.7187 & TST \\
\hline CHEMBL1584010 & 752533 & 3.1024 & 3.6485 & TST \\
\hline CHEMBL1330139 & 752533 & 4.3192 & 3.7858 & TST \\
\hline CHEMBL1580005 & 752533 & 4.5198 & 3.4714 & TST \\
\hline CHEMBL1892433 & 752533 & 3.1024 & 3.534 & TST \\
\hline CHEMBL1464128 & 752533 & 3.1024 & 3.7017 & TST \\
\hline CHEMBL1513925 & 752533 & 3.1024 & 3.7725 & TST \\
\hline CHEMBL1991618 & 752533 & 3.1024 & 3.3814 & TST \\
\hline CHEMBL1494390 & 752533 & 5.1724 & 3.7923 & TST \\
\hline CHEMBL1885240 & 752533 & 3.1024 & 3.7777 & TST \\
\hline
\end{tabular}


Supplemental Table S2.txt

\begin{tabular}{|c|c|c|c|c|}
\hline & & & & \\
\hline AEMBL1547898 & 2533 & 3.1024 & 4706 & \\
\hline HEMBL1990081 & 2533 & 1024 & 6996 & \\
\hline AEMBL1302703 & 52533 & .1024 & .7975 & \\
\hline AEMBL1307075 & 2533 & 3478 & 7185 & \\
\hline AEMBL1881477 & 2533 & 3.1024 & 3658 & \\
\hline AEMBL1601471 & 52533 & 3.1024 & 3598 & \\
\hline AEMBL1340032 & 52533 & 3.1024 & .4331 & \\
\hline AEMBL1563019 & 52533 & 3.1024 & 728 & \\
\hline AEMBL1417523 & 52533 & 3.1024 & 473 & \\
\hline AEMBL1420974 & 52533 & 3.1024 & & \\
\hline AEMBL1485471 & 52533 & 4.1966 & 4507 & \\
\hline AEMBL1511158 & 52533 & 589 & 9084 & \\
\hline IEMBL1865363 & 33 & 024 & 534 & \\
\hline EMMB1581308 & 33 & 024 & 875 & \\
\hline AEMBL1878724 & 33 & 024 & 18 & \\
\hline AEMBL1390428 & 52533 & 796 & 5893 & \\
\hline AEMBL1893542 & 52533 & 24 & & \\
\hline IEMBL1512087 & 33 & 3. & 13 & \\
\hline AEMBL1723920 & 33 & & & \\
\hline AEMBL1357542 & 33 & & 83 & \\
\hline AEMBL1311198 & 52533 & 3 . & 5373 & \\
\hline AEMBL1544447 & 52533 & 45 & & \\
\hline EMBL1523 & 33 & 94 & 05 & \\
\hline HEMBL 1475 & 33 & & & \\
\hline AEMBL 2403701 & 86 & 4. & 34 & \\
\hline AEMBL 2403685 & 69986 & & & \\
\hline AEMBL 2403581 & 69986 & & & \\
\hline AEMBL 2403702 & 69986 & & & \\
\hline HEM & 986 & 4. & 59 & \\
\hline 50 & 86 & & 21 & \\
\hline AEMBL 2403657 & 69986 & & & \\
\hline AEMBL 2403586 & 69986 & & & \\
\hline AEMBL 2403688 & 69986 & & 37 & \\
\hline AFMBI 24936 & 69986 & 4. & 06 & \\
\hline 9 & 86 & & 96 & \\
\hline AEMBL 2401758 & 69986 & & 389 & RN \\
\hline AEMBL 2403664 & 69986 & & 26 & \\
\hline AEMBL 24036 & 69986 & 4. & 89 & \\
\hline ברימר וסוזו & 69986 & 7. & 05 & \\
\hline HEMBL2403647 & 86 & 4. & 962 & RN \\
\hline AEMBL 2403593 & 69986 & 4. & 972 & RN \\
\hline AEMBL 2403674 & 69986 & & 63 & \\
\hline HEMBL 2403683 & 969 & 4. & & \\
\hline CHEMBL 2403649 & 969986 & & & \\
\hline CHEMBL 2403665 & 969986 & $4 . e$ & .0758 & \\
\hline HEMBL 2403675 & 69986 & 6.18 & .8437 & \\
\hline HEMBL 2403651 & 969986 & 8.2441 & 8.2256 & \\
\hline
\end{tabular}

Page 5013 


\begin{tabular}{|c|c|c|c|c|c|}
\hline \multicolumn{6}{|c|}{ Supplemental Table S2.txt } \\
\hline CHEMBL 2403583 & 969986 & 4.0 & 3.755 & TRN & \\
\hline CHEMBL 2403589 & 969986 & 4.0 & 3.951 & TRN & \\
\hline CHEMBL2403680 & 969986 & 7.0458 & 7.2607 & TRN & \\
\hline CHEMBL 2403648 & 969986 & 4.0 & 4.0243 & TRN & \\
\hline CHEMBL2403666 & 969986 & 4.0 & 4.0366 & TRN & \\
\hline CHEMBL 2403653 & 969986 & 7.4437 & 7.1395 & TRN & \\
\hline CHEMBL 2403696 & 969986 & 4.0 & 3.8607 & TRN & \\
\hline CHEMBL2403682 & 969986 & 6.5376 & 6.2035 & TRN & \\
\hline CHEMBL 2403677 & 969986 & 6.1938 & 5.9194 & TST & \\
\hline CHEMBL2403652 & 969986 & 7.4685 & 7.5518 & TRN & \\
\hline CHEMBL 2403654 & 969986 & 6.3188 & 6.2416 & TRN & \\
\hline CHEMBL 2403695 & 969986 & 4.0 & 4.0397 & TRN & \\
\hline CHEMBL 2403689 & 969986 & 4.0 & 3.9697 & TRN & \\
\hline CHEMBL 2403692 & 969986 & 4.0 & 4.0853 & TRN & \\
\hline CHEMBL 2403684 & 969986 & 4.0 & 4.0363 & TRN & \\
\hline CHEMBL 2403656 & 969986 & 6.1079 & 6.37700 & 0000000001 & TRN \\
\hline CHEMBL 2403582 & 969986 & 4.0 & 4.1346 & TRN & \\
\hline CHEMBL 2403667 & 969986 & 4.0 & 2.5761 & TST & \\
\hline CHEMBL2403699 & 969986 & 4.0 & 4.3527 & TRN & \\
\hline CHEMBL 2403655 & 969986 & 4.0 & 3.8993 & TRN & \\
\hline CHEMBL 2403661 & 969986 & 4.0 & 4.5162 & TST & \\
\hline CHEMBL 2403668 & 969986 & 7.6383 & 4.1308 & TST & \\
\hline CHEMBL 2403659 & 969986 & 4.0 & 3.6564 & TST & \\
\hline CHEMBL 2403672 & 969986 & 7.1427 & 6.9559 & TST & \\
\hline CHEMBL 2403703 & 969986 & 4.0 & 3.8289 & TRN & \\
\hline CHEMBL 2403678 & 969986 & 6.3979 & 5.5407 & TST & \\
\hline CHEMBL 2403660 & 969986 & 4.0 & 4.0689 & TST & \\
\hline CHEMBL 2403591 & 969986 & 4.0 & 3.9617 & TRN & \\
\hline CHEMBL 2403587 & 969986 & 4.0 & 4.2474 & TRN & \\
\hline CHEMBL 2403700 & 969986 & 4.0 & 3.7359 & TRN & \\
\hline CHEMBL 2403594 & 969986 & 4.0 & 4.075 & TRN & \\
\hline CHEMBL 2403691 & 969986 & 4.0 & 4.0163 & TRN & \\
\hline CHEMBL 2403590 & 969986 & 4.0 & 4.0768 & TRN & \\
\hline CHEMBL2403658 & 969986 & 4.0 & 3.8967 & TST & \\
\hline CHEMBL2403671 & 969986 & 5.9208 & 6.9063 & TST & \\
\hline CHEMBL 2403690 & 969986 & 4.0 & 4.0389 & TRN & \\
\hline CHEMBL 2403670 & 969986 & 4.0 & 6.23600 & 0000000001 & TST \\
\hline CHEMBL 2403694 & 969986 & 4.0 & 3.9855 & TRN & \\
\hline CHEMBL 2403588 & 969986 & 4.0 & 3.9058 & TRN & \\
\hline CHEMBL 2403673 & 969986 & 4.0 & 4.6308 & TST & \\
\hline CHEMBL 2403698 & 969986 & 4.0 & 4.0725 & TRN & \\
\hline CHEMBL 2403584 & 969986 & 4.0 & 4.2501 & TRN & \\
\hline CHEMBL 2403687 & 969986 & 4.0 & 3.7776 & TRN & \\
\hline CHEMBL 2403580 & 969986 & 7.8861 & 7.8659 & TRN & \\
\hline CHEMBL 2403676 & 969986 & 6.699 & 6.3946 & TST & \\
\hline CHEMBL 2403669 & 969986 & 4.0 & 5.0699 & TST & \\
\hline CHEMBL2403693 & 969986 & 4.0 & 4.4442 & TRN & \\
\hline CHEMBL 2403662 & 969986 & 4.0 & 3.9341 & TST & \\
\hline
\end{tabular}




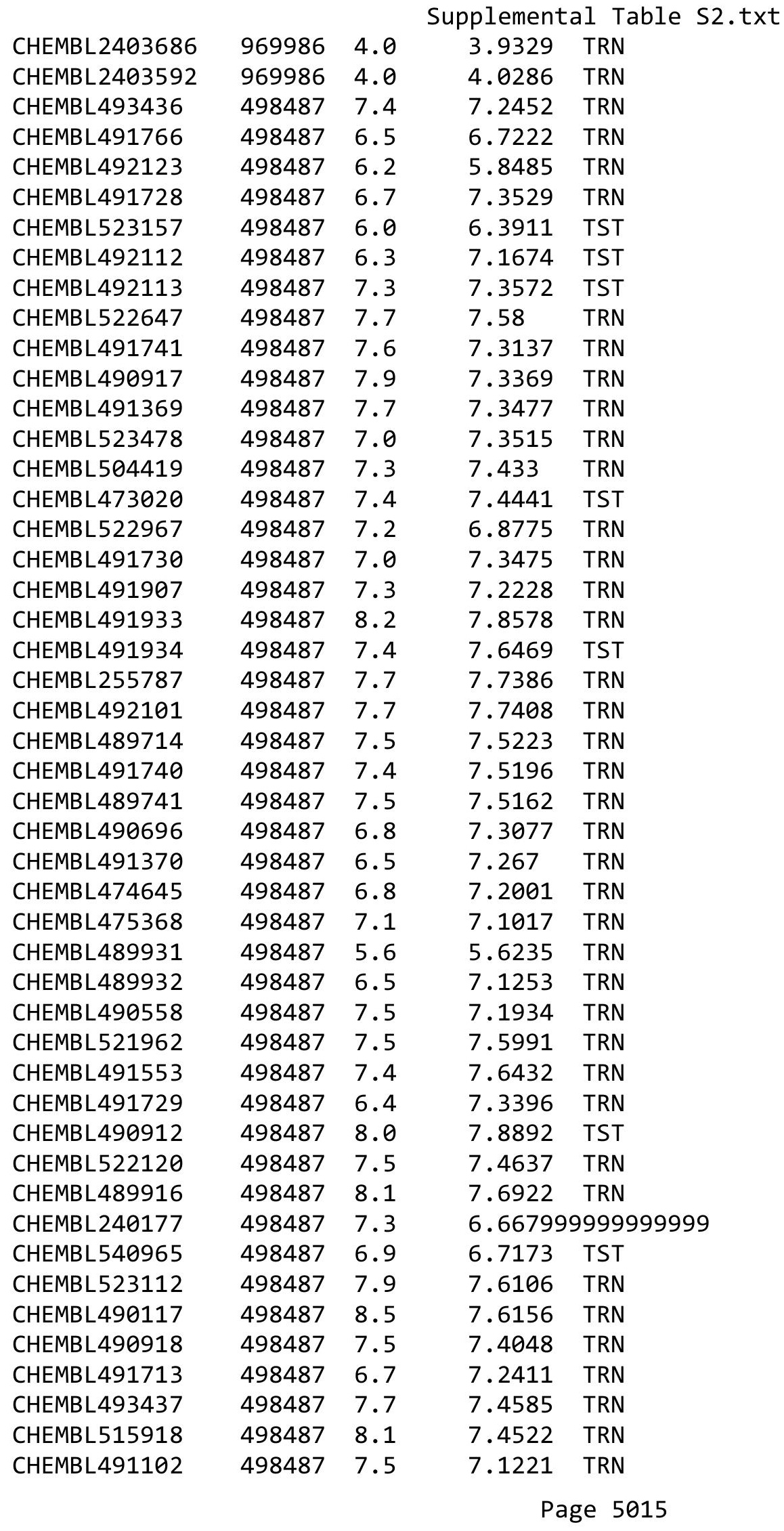




\begin{tabular}{|c|c|c|c|c|c|}
\hline \multicolumn{6}{|c|}{ opıemental } \\
\hline CHEMBL489919 & 498487 & 6.1 & 5.8627 & TRN & \\
\hline CHEMBL489939 & 498487 & 6.6 & 6.9744 & TRN & \\
\hline CHEMBL491552 & 498487 & 7.6 & 7.1484 & TRN & \\
\hline CHEMBL491916 & 498487 & 8.2 & 8.0623 & TRN & \\
\hline CHEMBL523319 & 498487 & 7.4 & 7.6161 & TRN & \\
\hline CHEMBL522955 & 498487 & 7.7 & 7.4318 & TST & \\
\hline CHEMBL490741 & 498487 & 8.1 & 7.9618 & TST & \\
\hline CHEMBL491781 & 498487 & 8.0 & 6.729 & TST & \\
\hline CHEMBL490118 & 498487 & 8.1 & 7.41200 & 0000000001 & TST \\
\hline CHEMBL524108 & 498487 & 8.0 & 7.516 & TST & \\
\hline CHEMBL489917 & 498487 & 7.7 & 6.6099 & TST & \\
\hline CHEMBL491103 & 498487 & 7.5 & 6.8717 & TST & \\
\hline CHEMBL3088106 & 1275417 & 2.699 & 2.6646 & TRN & \\
\hline CHEMBL 3088034 & 1275417 & 3.1135 & 3.5613 & TST & \\
\hline CHEMBL 3088016 & 1275417 & 2.699 & 2.9224 & TST & \\
\hline CHEMBL3088118 & 1275417 & 2.699 & 2.5521 & TRN & \\
\hline CHEMBL3088116 & 1275417 & 4.9208 & 5.1258 & TRN & \\
\hline CHEMBL 3088105 & 1275417 & 5.3429 & 5.4789 & TST & \\
\hline CHEMBL 3088040 & 1275417 & 4.6778 & 4.5391 & TST & \\
\hline CHEMBL 3085800 & 1275417 & 2.699 & 2.591 & TRN & \\
\hline CHEMBL 3088032 & 1275417 & 2.699 & 2.87899 & 99999999996 & TST \\
\hline CHEMBL 3088114 & 1275417 & 2.699 & 2.75399 & 99999999996 & TRN \\
\hline CHEMBL 3088047 & 1275417 & 4.1079 & 3.7707 & TRN & \\
\hline CHEMBL 3088112 & 1275417 & 2.699 & 2.792 & TRN & \\
\hline CHEMBL 3088033 & 1275417 & 2.699 & 2.80800 & 00000000003 & TRN \\
\hline CHEMBL 3088037 & 1275417 & 2.699 & 2.5391 & TRN & \\
\hline CHEMBL3088115 & 1275417 & 2.699 & 2.9204 & TRN & \\
\hline CHEMBL 3088050 & 1275417 & 2.699 & 2.6334 & TRN & \\
\hline CHEMBL 3088041 & 1275417 & 2.699 & 2.48599 & 99999999998 & TRN \\
\hline CHEMBL 3088046 & 1275417 & 2.699 & 2.8062 & TRN & \\
\hline CHEMBL 3088094 & 1275417 & 2.699 & 2.9522 & TRN & \\
\hline CHEMBL3088093 & 1275417 & 2.699 & 3.0004 & TRN & \\
\hline CHEMBL3088113 & 1275417 & 2.699 & 2.8191 & TRN & \\
\hline CHEMBL 3088095 & 1275417 & 2.699 & 2.8416 & TRN & \\
\hline CHEMBL 3088107 & 1275417 & 2.699 & 3.2701 & TST & \\
\hline CHEMBL3088119 & 1275417 & 2.699 & 2.66899 & 99999999996 & TRN \\
\hline CHEMBL 3088017 & 1275417 & 2.699 & 2.6052 & TRN & \\
\hline CHEMBL 3088045 & 1275417 & 2.699 & 2.687 & TRN & \\
\hline CHEMBL 3088117 & 1275417 & 3.1427 & 3.9241 & TST & \\
\hline CHEMBL 3088029 & 1275417 & 2.699 & 3.5008 & TST & \\
\hline CHEMBL 3088020 & 1275417 & 2.699 & 3.0129 & TST & \\
\hline CHEMBL 3088023 & 1275417 & 2.699 & 2.7284 & TRN & \\
\hline CHEMBL3085801 & 1275417 & 4.6073 & 4.364 & TRN & \\
\hline CHEMBL 3088042 & 1275417 & 4.1427 & 3.7691 & TST & \\
\hline CHEMBL 3088110 & 1275417 & 2.699 & 2.79399 & 99999999996 & TRN \\
\hline CHEMBL 3088018 & 1275417 & 2.699 & 2.6396 & TRN & \\
\hline CHEMBL 3088121 & 1275417 & 2.699 & 2.7672 & TRN & \\
\hline CHEMBL 3088038 & 1275417 & 2.699 & 2.6709 & TRN & \\
\hline
\end{tabular}


Supplemental Table S2.txt

\begin{tabular}{|c|c|c|c|c|c|}
\hline CHEMBL 3088043 & 1275417 & 2.699 & 2.6406 & TRN & \\
\hline CHEMBL3088030 & 1275417 & 2.699 & 2.4204 & TRN & \\
\hline CHEMBL3088035 & 1275417 & 2.699 & 2.4675 & TRN & \\
\hline CHEMBL 3088031 & 1275417 & 2.699 & 3.4754 & TRN & \\
\hline CHEMBL3088019 & 1275417 & 2.699 & 2.6638 & TRN & \\
\hline CHEMBL 3088044 & 1275417 & 2.699 & 2.739 & TRN & \\
\hline CHEMBL 3088052 & 1275417 & 5.556 & 5.4754 & TST & \\
\hline CHEMBL 3088092 & 1275417 & 2.699 & 2.685 & TRN & \\
\hline CHEMBL 3088051 & 1275417 & 4.0132 & 4.2061 & TRN & \\
\hline CHEMBL3088028 & 1275417 & 2.699 & 2.6591 & TRN & \\
\hline CHEMBL 3088026 & 1275417 & 3.7878 & 3.6947 & TRN & \\
\hline CHEMBL 3088098 & 1275417 & 2.699 & 2.6901 & TRN & \\
\hline CHEMBL 3088108 & 1275417 & 2.699 & 3.3518 & TST & \\
\hline CHEMBL 3088120 & 1275417 & 2.699 & 2.6287 & TRN & \\
\hline CHEMBL3088109 & 1275417 & 2.699 & 2.8009 & TRN & \\
\hline CHEMBL 3088024 & 1275417 & 2.699 & 2.668999 & 9999999996 & TRN \\
\hline CHEMBL3088039 & 1275417 & 2.699 & 3.4598 & TRN & \\
\hline CHEMBL 3088025 & 1275417 & 2.699 & 2.8052 & TRN & \\
\hline CHEMBL 3088053 & 1275417 & 2.699 & 2.6029 & TRN & \\
\hline CHEMBL3088104 & 1275417 & 4.8539 & 4.282 & TRN & \\
\hline CHEMBL3088099 & 1275417 & 4.3565 & 4.1995 & TST & \\
\hline CHEMBL 3088048 & 1275417 & 4.3665 & 5.1553 & TST & \\
\hline CHEMBL 3088101 & 1275417 & 2.699 & 2.7244 & TRN & \\
\hline CHEMBL 3088049 & 1275417 & 2.699 & 2.6825 & TRN & \\
\hline CHEMBL3088096 & 1275417 & 4.6308 & 4.0058 & TRN & \\
\hline CHEMBL3088103 & 1275417 & 2.699 & 2.7968 & TRN & \\
\hline CHEMBL 3088097 & 1275417 & 4.9431 & 5.5623 & TST & \\
\hline CHEMBL 3088021 & 1275417 & 4.1549 & 3.7541 & TST & \\
\hline CHEMBL 3088102 & 1275417 & 2.699 & 2.6243 & TRN & \\
\hline CHEMBL 3088100 & 1275417 & 2.699 & 2.6579 & TRN & \\
\hline CHEMBL 3088022 & 1275417 & 2.699 & 2.6849 & TRN & \\
\hline CHEMBL 3088027 & 1275417 & 4.0 & 4.7587 & TST & \\
\hline CHEMBL 3088036 & 1275417 & 2.699 & 2.627 & TRN & \\
\hline CHEMBL 3088111 & 1275417 & 2.699 & 3.1674 & TST & \\
\hline CHEMBL127036 & 104616 & 6.6904 & 6.5925 & TRN & \\
\hline CHEMBL38962 & 104616 & 4.0 & 6.0687 & TST & \\
\hline CHEMBL38520 & 104616 & 8.0809 & 7.9592 & TST & \\
\hline CHEMBL343878 & 104616 & 6.8392 & 6.7571 & TRN & \\
\hline CHEMBL 342723 & 104616 & 6.0 & 7.0182 & TRN & \\
\hline CHEMBL139873 & 104616 & 7.6198 & 6.7411 & TRN & \\
\hline CHEMBL359381 & 104616 & 5.9136 & 5.8887 & TRN & \\
\hline CHEMBL53824 & 104616 & 6.0 & 7.1763 & TRN & \\
\hline CHEMBL142343 & 104616 & 9.4225 & 8.8421 & TRN & \\
\hline CHEMBL 358401 & 104616 & 6.6676 & 6.8382 & TRN & \\
\hline CHEMBL143074 & 104616 & 8.1158 & 8.166 & TRN & \\
\hline CHEMBL538394 & 104616 & 6.247999 & 999999999 & 4.4312 & TST \\
\hline CHEMBL143524 & 104616 & 6.8894 & 6.8696 & TRN & \\
\hline CHEMBL140785 & 104616 & 6.2874 & 6.2271 & TRN & \\
\hline
\end{tabular}


Supplemental Table S2.txt

\begin{tabular}{|c|c|c|c|c|c|c|}
\hline CHEMBL358354 & 104616 & 6.3726 & 6.6342 & TRN & & \\
\hline CHEMBL359451 & 104616 & 8.7033 & 8.9262 & TRN & & \\
\hline CHEMBL343360 & 104616 & 6.5654 & 6.6059 & TRN & & \\
\hline CHEMBL143543 & 104616 & 6.2557 & 6.2302 & TRN & & \\
\hline CHEMBL141011 & 104616 & 6.8807 & 7.0939 & TRN & & \\
\hline CHEMBL41148 & 104616 & 6.3605 & 6.4498 & TST & & \\
\hline CHEMBL143547 & 104616 & 7.3497 & 7.181 & TRN & & \\
\hline CHEMBL139839 & 104616 & 5.2441 & 5.0466 & TRN & & \\
\hline CHEMBL 286615 & 104616 & 5.7943 & 5.47 & TST & & \\
\hline CHEMBL357127 & 104616 & 5.2924 & 5.2979 & TRN & & \\
\hline CHEMBL417343 & 104616 & 6.9914 & 7.8893 & TST & & \\
\hline CHEMBL289370 & 104616 & 5.3344 & 4.129 & TST & & \\
\hline CHEMBL424297 & 104616 & 7.5229 & 7.505 & TRN & & \\
\hline CHEMBL41973 & 104616 & 5.2716 & 6.3748 & TST & & \\
\hline CHEMBL358629 & 104616 & 6.7932 & 6.4405 & TRN & & \\
\hline CHEMBL143877 & 104616 & 6.3382 & 6.6352 & TRN & & \\
\hline CHEMBL141146 & 104616 & 8.6737 & 8.5685 & TRN & & \\
\hline CHEMBL127826 & 104616 & 8.8416 & 7.8273 & TRN & & \\
\hline CHEMBL290271 & 104616 & 6.2518 & 8.0632 & TST & & \\
\hline CHEMBL348238 & 104616 & 6.7277 & 6.6129 & TRN & & \\
\hline CHEMBL342849 & 104616 & 4.0 & 4.1835 & TRN & & \\
\hline CHEMBL435080 & 104616 & 7.0757 & 7.2303 & TRN & & \\
\hline CHEMBL143158 & 104616 & 4.0 & 4.3244 & TRN & & \\
\hline CHEMBL291120 & 104616 & 6.1308 & 5.4767 & TST & & \\
\hline CHEMBL287776 & 104616 & 7.3872 & 7.3331 & TST & & \\
\hline CHEMBL356536 & 104616 & $6.3270 e$ & 00000000 & $\partial 1$ & 6.2737 & TRN \\
\hline CHEMBL140728 & 104616 & 7.3958 & 7.3438 & TRN & & \\
\hline CHEMBL142631 & 104616 & 5.7721 & 5.6242 & TRN & & \\
\hline CHEMBL38720 & 104616 & 5.9747 & 6.6487 & TST & & \\
\hline CHEMBL140627 & 104616 & 5.3507 & 5.2007 & TRN & & \\
\hline CHEMBL344521 & 104616 & 6.8486 & 6.8118 & TRN & & \\
\hline CHEMBL335352 & 104616 & 7.9872 & 8.0762 & TRN & & \\
\hline CHEMBL143677 & 104616 & 7.5607 & 7.5722 & TRN & & \\
\hline CHEMBL143322 & 104616 & 5.0809 & 4.7621 & TRN & & \\
\hline CHEMBL422118 & 104616 & 4.0 & 3.8141 & TRN & & \\
\hline CHEMBL288206 & 104616 & 6.8447 & 7.4299 & TST & & \\
\hline CHEMBL41105 & 104616 & 6.6596 & 7.5714 & TST & & \\
\hline CHEMBL345090 & 104616 & 7.0862 & 6.9468 & TRN & & \\
\hline CHEMBL439619 & 104616 & 4.0 & 3.8286 & TRN & & \\
\hline CHEMBL342335 & 104616 & 6.567 & 6.949 & TRN & & \\
\hline CHEMBL141944 & 104616 & 7.6383 & 7.7491 & TRN & & \\
\hline CHEMBL142382 & 104616 & 6.6216 & 6.6834 & TRN & & \\
\hline CHEMBL139832 & 104616 & 5.9066 & 5.9619 & TRN & & \\
\hline CHEMBL346408 & 104616 & 4.0 & 4.167 & TRN & & \\
\hline CHEMBL142567 & 104616 & 7.7932 & 7.7162 & TST & & \\
\hline CHEMBL1236200 & 688630 & 4.1 & 4.1495 & TRN & & \\
\hline CHEMBL1485974 & 688630 & 4.5 & 4.6089 & TRN & & \\
\hline CHEMBL57394 & 688630 & 4.4 & 4.5054 & TRN & & \\
\hline
\end{tabular}




\begin{tabular}{|c|c|c|c|c|}
\hline \multicolumn{5}{|c|}{ plemental } \\
\hline CHEMBL1331245 & 688630 & 4.3 & 4.1989 & TRN \\
\hline CHEMBL1330518 & 688630 & 4.3 & 4.2037 & TRN \\
\hline CHEMBL172064 & 688630 & 4.3 & 4.3643 & TST \\
\hline CHEMBL 91732 & 688630 & 4.1 & 4.0272 & TRN \\
\hline CHEMBL1562104 & 688630 & 5.6 & 5.5392 & TRN \\
\hline CHEMBL1221925 & 688630 & 4.1 & 4.1896 & TRN \\
\hline CHEMBL140 & 688630 & 4.6 & 4.6177 & TRN \\
\hline CHEMBL1600998 & 688630 & 5.6 & 5.6442 & TRN \\
\hline CHEMBL1529759 & 688630 & 4.1 & 4.2145 & TST \\
\hline CHEMBL1517425 & 688630 & 4.1 & 4.1797 & TRN \\
\hline CHEMBL1450607 & 688630 & 4.9 & 4.8465 & TRN \\
\hline CHEMBL1549844 & 688630 & 5.1 & 4.6507 & TST \\
\hline CHEMBL196537 & 688630 & 4.3 & 4.3695 & TRN \\
\hline CHEMBL1531716 & 688630 & 4.1 & 4.1628 & TRN \\
\hline CHEMBL1489064 & 688630 & 4.3 & 4.279 & TRN \\
\hline CHEMBL 220845 & 688630 & 4.6 & 4.5308 & TRN \\
\hline CHEMBL224282 & 688630 & 4.4 & 4.4585 & TRN \\
\hline CHEMBL1338613 & 688630 & 4.4 & 4.1953 & TST \\
\hline CHEMBL1456906 & 688630 & 4.2 & 4.1548 & TST \\
\hline CHEMBL1418603 & 688630 & 4.3 & 4.1931 & TRN \\
\hline CHEMBL1308088 & 688630 & 4.9 & 4.8581 & TRN \\
\hline CHEMBL1585396 & 688630 & 4.4 & 4.2643 & TRN \\
\hline CHEMBL1522486 & 688630 & 4.9 & 4.8401 & TRN \\
\hline CHEMBL1430204 & 688630 & 4.6 & 4.6024 & TRN \\
\hline CHEMBL1407826 & 688630 & 4.9 & 4.7249 & TST \\
\hline CHEMBL1331312 & 688630 & 4.4 & 4.4663 & TRN \\
\hline CHEMBL1319452 & 688630 & 4.8 & 4.7888 & TRN \\
\hline CHEMBL109095 & 688630 & 4.1 & 4.2217 & TRN \\
\hline CHEMBL1425782 & 688630 & 4.2 & 4.302 & TRN \\
\hline CHEMBL1414154 & 688630 & 4.3 & 4.0999 & TRN \\
\hline CHEMBL1526319 & 688630 & 4.4 & 4.4554 & TRN \\
\hline CHEMBL1364985 & 688630 & 4.3 & 4.1912 & TRN \\
\hline CHEMBL1565705 & 688630 & 4.1 & 4.2135 & TRN \\
\hline CHEMBL1569358 & 688630 & 4.1 & 4.175 & TRN \\
\hline CHEMBL1419151 & 688630 & 4.3 & 4.3635 & TRN \\
\hline CHEMBL 28517 & 688630 & 4.3 & 4.0374 & TST \\
\hline CHEMBL443949 & 688630 & 4.3 & 4.2825 & TRN \\
\hline CHEMBL1579130 & 688630 & 6.0 & 6.0466 & TRN \\
\hline CHEMBL8320 & 688630 & 4.5 & 4.3002 & TRN \\
\hline CHEMBL468582 & 688630 & 4.1 & 4.3527 & TST \\
\hline CHEMBL8739 & 688630 & 4.4 & 4.3917 & TRN \\
\hline CHEMBL 31425 & 688630 & 4.1 & 4.0847 & TRN \\
\hline CHEMBL1366408 & 688630 & 4.4 & 4.4459 & TRN \\
\hline CHEMBL389950 & 688630 & 4.1 & 4.0641 & TST \\
\hline CHEMBL194399 & 688630 & 4.3 & 4.2831 & TRN \\
\hline CHEMBL1526721 & 688630 & 5.5 & 5.4908 & TRN \\
\hline CHEMBL242080 & 688630 & 4.5 & 4.5907 & TRN \\
\hline CHEMBL1452158 & 688630 & 4.4 & 4.3742 & TRN \\
\hline
\end{tabular}




\begin{tabular}{|c|c|c|c|c|c|}
\hline & & \\
\hline CHEMBL1569226 & 688630 & 5.6 & 5.544 & TRN & \\
\hline CHEMBL1545045 & 688630 & 4.3 & 4.3787 & TRN & \\
\hline CHEMBL230156 & 688630 & 4.4 & 4.4393 & TRN & \\
\hline CHEMBL1393325 & 688630 & 4.3 & 4.398 & TRN & \\
\hline CHEMBL1612246 & 688630 & 4.4 & 4.3565 & TRN & \\
\hline CHEMBL1518369 & 688630 & 4.5 & 4.5372 & TRN & \\
\hline CHEMBL192627 & 688630 & 5.0 & 4.9725 & TRN & \\
\hline CHEMBL1524617 & 688630 & 5.4 & 5.3129 & TST & \\
\hline CHEMBL1576086 & 688630 & 4.6 & 4.4256 & TRN & \\
\hline CHEMBL1566504 & 688630 & 4.4 & 4.4127 & TRN & \\
\hline CHEMBL1408847 & 688630 & 5.5 & 5.4799 & TRN & \\
\hline CHEMBL454173 & 688630 & 4.3 & 4.362 & TRN & \\
\hline CHEMBL105712 & 688630 & 5.1 & 5.0717 & TRN & \\
\hline CHEMBL44072 & 688630 & 4.4 & 4.3423 & TRN & \\
\hline CHEMBL167423 & 688630 & 4.4 & 4.3149 & TRN & \\
\hline CHEMBL144530 & 688630 & 4.5 & 4.4336 & TRN & \\
\hline CHEMBL509531 & 688630 & 4.9 & 4.5903 & TST & \\
\hline CHEMBL1309179 & 688630 & 5.1 & 5.0485 & TRN & \\
\hline CHEMBL 935 & 688630 & 4.4 & 4.2569 & TRN & \\
\hline CHEMBL1484480 & 688630 & 4.1 & 3.9597 & TRN & \\
\hline CHEMBL1535689 & 688630 & 4.4 & 4.28600 & 20000000005 & TRN \\
\hline CHEMBL486193 & 688630 & 4.4 & 4.4427 & TRN & \\
\hline CHEMBL1569493 & 688630 & 6.3 & 6.3217 & TRN & \\
\hline CHEMBL1409985 & 688630 & 5.7 & 5.6453 & TRN & \\
\hline CHEMBL167513 & 688630 & 3.9 & 4.1082 & TRN & \\
\hline CHEMBL1371285 & 688630 & 4.3 & 4.3952 & TRN & \\
\hline CHEMBL1530684 & 688630 & 4.5 & 4.6107 & TRN & \\
\hline CHEMBL462576 & 688630 & 4.3 & 4.2531 & TRN & \\
\hline CHEMBL1510786 & 688630 & 4.3 & 4.2677 & TST & \\
\hline CHEMBL1562553 & 688630 & 4.5 & 4.4996 & TRN & \\
\hline CHEMBL1391326 & 688630 & 4.3 & 4.2411 & TRN & \\
\hline CHEMBL36296 & 688630 & 4.3 & 4.2809 & TRN & \\
\hline CHEMBL445957 & 688630 & 4.3 & 4.4178 & TRN & \\
\hline CHEMBL1344952 & 688630 & 4.4 & 4.3199 & TRN & \\
\hline CHEMBL1303139 & 688630 & 5.6 & 5.6397 & TRN & \\
\hline CHEMBL162598 & 688630 & 4.3 & 4.1392 & TST & \\
\hline CHEMBL334255 & 688630 & 4.8 & 4.8132 & TRN & \\
\hline CHEMBL 721 & 688630 & 4.1 & 4.334 & TRN & \\
\hline CHEMBL1451833 & 688630 & 4.5 & 4.6025 & TST & \\
\hline CHEMBL440287 & 688630 & 4.4 & 4.5011 & TRN & \\
\hline CHEMBL1499545 & 688630 & 5.4 & 5.4065 & TRN & \\
\hline CHEMBL1330194 & 688630 & 4.3 & 4.3753 & TST & \\
\hline CHEMBL1559341 & 688630 & 4.4 & 4.4787 & TRN & \\
\hline CHEMBL538146 & 688630 & 4.3 & 4.3668 & TRN & \\
\hline CHEMBL1545634 & 688630 & 6.7001 & 6.6367 & TRN & \\
\hline CHEMBL1496957 & 688630 & 4.9 & 4.86 & TRN & \\
\hline CHEMBL1527567 & 688630 & 4.6 & 4.6973 & TRN & \\
\hline CHEMBL3391990 & 688630 & 4.4 & 4.2187 & TST & \\
\hline & & & & 5020 & \\
\hline
\end{tabular}




\begin{tabular}{|c|c|c|c|c|c|}
\hline \multicolumn{6}{|c|}{ Supplemental Table S2.txt } \\
\hline CHEMBL1604429 & 688630 & 4.9 & 4.735 & TRN & \\
\hline CHEMBL1462419 & 688630 & 4.3 & 4.4569 & TST & \\
\hline CHEMBL1399151 & 688630 & 4.4 & 4.3219 & TRN & \\
\hline CHEMBL1421613 & 688630 & 4.1 & 4.2532 & TST & \\
\hline CHEMBL1200471 & 688630 & 6.6 & 6.5818 & TRN & \\
\hline CHEMBL1485360 & 688630 & 5.0 & 4.5848 & TST & \\
\hline CHEMBL195953 & 688630 & 4.3 & 4.3511 & TRN & \\
\hline CHEMBL1449018 & 688630 & 4.9 & 4.7185 & TRN & \\
\hline CHEMBL1428964 & 688630 & 4.1 & 4.0347 & TRN & \\
\hline CHEMBL1471289 & 688630 & 4.5 & 4.3293 & TRN & \\
\hline CHEMBL1492884 & 688630 & 4.4 & 4.3075 & TRN & \\
\hline CHEMBL1609459 & 688630 & 5.1 & 5.135 & TRN & \\
\hline CHEMBL1333512 & 688630 & 4.1 & 4.60800 & 00000000005 & TRN \\
\hline CHEMBL1450123 & 688630 & 4.2 & 4.4195 & TST & \\
\hline CHEMBL1448387 & 688630 & 4.6 & 4.5352 & TRN & \\
\hline CHEMBL 85811 & 688630 & 4.3 & 4.2348 & TRN & \\
\hline CHEMBL1489568 & 688630 & 4.4 & 4.4801 & TRN & \\
\hline CHEMBL1519327 & 688630 & 6.4 & 6.7623 & TST & \\
\hline CHEMBL 28 & 688630 & 4.3 & 4.0551 & TST & \\
\hline CHEMBL1142 & 688630 & 4.6 & 4.6382 & TST & \\
\hline CHEMBL1447588 & 688630 & 4.9 & 4.8709 & TST & \\
\hline CHEMBL70582 & 688630 & 4.5 & 4.5483 & TST & \\
\hline CHEMBL289277 & 688630 & 4.3 & 4.3102 & TST & \\
\hline CHEMBL280998 & 688630 & 4.5 & 4.5107 & TST & \\
\hline CHEMBL402063 & 688630 & 6.0 & 5.6234 & TST & \\
\hline CHEMBL1558796 & 688630 & 4.6 & 4.6538 & TST & \\
\hline CHEMBL1304981 & 688630 & 4.4 & 3.9276 & TST & \\
\hline CHEMBL1602699 & 688630 & 5.5 & 5.3255 & TST & \\
\hline CHEMBL1492104 & 688630 & 4.9 & 4.9791 & TST & \\
\hline CHEMBL 3678292 & 1528629 & 7.1367 & 7.8415 & TST & \\
\hline CHEMBL3673479 & 1528629 & 8.5229 & 8.6175 & TRN & \\
\hline CHEMBL3673459 & 1528629 & 8.1549 & 8.1148 & TRN & \\
\hline CHEMBL3673445 & 1528629 & 6.4449 & 6.7858 & TRN & \\
\hline CHEMBL3673472 & 1528629 & 6.7932 & 7.2703 & TST & \\
\hline CHEMBL 3678301 & 1528629 & 6.8633 & 6.8225 & TRN & \\
\hline CHEMBL3673436 & 1528629 & 8.699 & 8.747 & TRN & \\
\hline CHEMBL3673488 & 1528629 & 8.301 & 8.7132 & TRN & \\
\hline CHEMBL3673446 & 1528629 & 7.5686 & 7.0815 & TRN & \\
\hline CHEMBL 3673484 & 1528629 & 7.9586 & 8.1664 & TRN & \\
\hline CHEMBL 3678284 & 1528629 & 7.7447 & 7.6997 & TRN & \\
\hline CHEMBL 3678302 & 1528629 & 7.6021 & 7.3651 & TST & \\
\hline CHEMBL3673440 & 1528629 & 9.0 & 8.5103 & TRN & \\
\hline CHEMBL3678299 & 1528629 & 7.2518 & 6.9634 & TRN & \\
\hline CHEMBL3673485 & 1528629 & 8.301 & 8.0681 & TRN & \\
\hline CHEMBL 3678291 & 1528629 & 6.1163 & 7.1748 & TST & \\
\hline CHEMBL 3673453 & 1528629 & 8.699 & 8.7294 & TRN & \\
\hline CHEMBL 3673478 & 1528629 & 8.301 & 7.9324 & TRN & \\
\hline CHEMBL3673465 & 1528629 & 7.8239 & 7.7836 & TRN & \\
\hline
\end{tabular}


Supplemental Table S2.txt

\begin{tabular}{|c|c|c|c|c|c|c|}
\hline CHEMBL 3673442 & 1528629 & 8.699 & 8.5958 & TRN & & \\
\hline CHEMBL 3673444 & 1528629 & 7.5528 & 7.4234 & TRN & & \\
\hline CHEMBL3678283 & 1528629 & 8.0969 & 8.1163 & TRN & & \\
\hline CHEMBL 3673437 & 1528629 & 8.3979 & 8.2091 & TRN & & \\
\hline CHEMBL3673476 & 1528629 & 8.5229 & 8.63 & TRN & & \\
\hline CHEMBL3673439 & 1528629 & 8.3979 & 8.4566 & TRN & & \\
\hline CHEMBL 3673471 & 1528629 & 7.8239 & 7.5148 & TST & & \\
\hline CHEMBL 3673450 & 1528629 & 7.4949 & 7.4484 & TRN & & \\
\hline CHEMBL3673469 & 1528629 & 6.4214 & 6.4671 & TRN & & \\
\hline CHEMBL3673470 & 1528629 & 6.3655 & 6.4831 & TRN & & \\
\hline CHEMBL3673438 & 1528629 & 8.699 & 8.6889 & TRN & & \\
\hline CHEMBL3673455 & 1528629 & 8.301 & 8.218 & TRN & & \\
\hline CHEMBL 3673480 & 1528629 & 8.301 & 8.5717 & TRN & & \\
\hline CHEMBL3678306 & 1528629 & 6.9914 & 6.6382 & TST & & \\
\hline CHEMBL 3678285 & 1528629 & 8.301 & 8.352 & TRN & & \\
\hline CHEMBL 3673474 & 1528629 & \multicolumn{3}{|c|}{6.821000000000001} & 7.1207 & TST \\
\hline CHEMBL 3673467 & 1528629 & 8.1549 & 8.8246 & TST & & \\
\hline CHEMBL 3673468 & 1528629 & 8.5229 & 8.5377 & TRN & & \\
\hline CHEMBL3673451 & 1528629 & 6.4815 & 6.4814 & TRN & & \\
\hline CHEMBL 3673447 & 1528629 & 7.8861 & 7.7432 & TRN & & \\
\hline CHEMBL3673489 & 1528629 & 7.5528 & 7.7647 & TRN & & \\
\hline CHEMBL 3678290 & 1528629 & 6.1002 & 6.3361 & TRN & & \\
\hline CHEMBL3678286 & 1528629 & 8.0 & 7.9853 & TRN & & \\
\hline CHEMBL 3673477 & 1528629 & 8.301 & 8.5249 & TRN & & \\
\hline CHEMBL3678296 & 1528629 & 5.3298 & 5.5227 & TRN & & \\
\hline CHEMBL3673449 & 1528629 & 7.5086 & 7.5457 & TRN & & \\
\hline CHEMBL3678287 & 1528629 & 8.1549 & 8.0395 & TRN & & \\
\hline CHEMBL3673487 & 1528629 & 8.2218 & 8.3621 & TRN & & \\
\hline CHEMBL3673466 & 1528629 & 7.8861 & 7.9963 & TRN & & \\
\hline CHEMBL3639723 & 1528629 & 7.5229 & 7.4964 & TRN & & \\
\hline CHEMBL 3678303 & 1528629 & 7.2366 & 7.2217 & TST & & \\
\hline CHEMBL 3673461 & 1528629 & 7.4949 & 7.553 & TRN & & \\
\hline CHEMBL3673456 & 1528629 & 8.0969 & 8.2598 & TRN & & \\
\hline CHEMBL3673458 & 1528629 & 7.4437 & 7.3987 & TRN & & \\
\hline CHEMBL3673448 & 1528629 & 7.9208 & 7.8287 & TRN & & \\
\hline CHEMBL3673483 & 1528629 & 8.301 & 8.5059 & TRN & & \\
\hline CHEMBL 3673464 & 1528629 & 8.1549 & 8.247 & TRN & & \\
\hline CHEMBL 3678288 & 1528629 & 6.6716 & 6.6141 & TRN & & \\
\hline CHEMBL3678289 & 1528629 & 7.8861 & 7.7186 & TRN & & \\
\hline CHEMBL 3678304 & 1528629 & 7.0862 & 6.8623 & TST & & \\
\hline CHEMBL 3673443 & 1528629 & 8.2218 & 8.2457 & TST & & \\
\hline CHEMBL 3673481 & 1528629 & 8.1549 & 8.2712 & TRN & & \\
\hline CHEMBL 3673460 & 1528629 & 7.9208 & 7.9054 & TST & & \\
\hline CHEMBL 3673475 & 1528629 & 7.2291 & 7.0027 & TRN & & \\
\hline CHEMBL3673486 & 1528629 & 8.699 & 8.797 & TRN & & \\
\hline CHEMBL 3678293 & 1528629 & 6.1637 & 6.6672 & TST & & \\
\hline CHEMBL 3673463 & 1528629 & 8.5229 & 9.0359 & TST & & \\
\hline CHEMBL 3678294 & 1528629 & 5.38399 & 99999999 & 995 & 5.7828 & TRN \\
\hline
\end{tabular}


Supplemental Table S2.txt

\begin{tabular}{|c|c|c|c|c|}
\hline 3441 & 528629 & 7.5229 & & \\
\hline & 528629 & 8.0458 & & \\
\hline & 8629 & & & \\
\hline IEMBL 3673452 & 528629 & & & \\
\hline AEMBL3673457 & 528629 & 7.7959 & & \\
\hline AEMBL3673473 & 528629 & 7.3872 & 7.2738 & \\
\hline IEMBL & 528629 & & & \\
\hline EMBL & 528629 & & & \\
\hline AEMBL3678305 & 528629 & & & \\
\hline AEMBL2420815 & 79760 & 4.4559 & & \\
\hline AEMBL 2420839 & 79760 & 39 & & \\
\hline IEMBL2 & 9760 & & 84 & \\
\hline EMBL & & & & \\
\hline AEMBL 2420822 & 79760 & 4559 & & \\
\hline IEMBL 2420848 & 79760 & 4949 & 4.5 & \\
\hline EMBL & 60 & & & \\
\hline EMBL & 60 & & 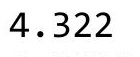 & \\
\hline EMBL & & & & \\
\hline IEMBL 2420840 & 79760 & & & \\
\hline IEMBL & 60 & & & \\
\hline IEMBL & $\theta$ & 7 & 4 & \\
\hline EMB & 30 & & & \\
\hline EMB & & & & \\
\hline 53 & 60 & & & \\
\hline IEMBL & & & & \\
\hline IEMBL & 50 & & 5 . & \\
\hline EMB & 50 & & & \\
\hline 19 & 50 & & & \\
\hline IEMBL: & & & & \\
\hline IEMBL 2420832 & 50 & 1 & & $R$ \\
\hline AEMBL & 760 & & & \\
\hline IEMBL & 50 & & & \\
\hline 5 & 50 & & & \\
\hline IEMBL & & & & \\
\hline AEMBL2420823 & 60 & 6. & & RI \\
\hline 828 & & 7. & & \\
\hline 1 & & 9 & 3 & \\
\hline & & & & \\
\hline AEMBL 2420811 & 79760 & & & \\
\hline IEMBL2 & 9760 & & 4. & \\
\hline 33 & 79760 & & 5 . & \\
\hline HEMBL2420854 & & & & \\
\hline HEMBL2420812 & 79760 & & & \\
\hline IEMBL2420826 & 9760 & 96 & 57 & \\
\hline EMBL & 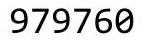 & & 24 & \\
\hline CHEMBL & & & 7.5009 & \\
\hline CHEMBL 2420835 & 79760 & & 6.0356 & \\
\hline CHEMBL 2420856 & 979760 & 5.4949 & 5.4049 & \\
\hline
\end{tabular}

Page 5023 


\begin{tabular}{|c|c|c|c|c|c|}
\hline \multirow[b]{2}{*}{ CHEMBL2420855 } & \multicolumn{5}{|c|}{ Supplemental Table S2.txt } \\
\hline & 979760 & 4.4559 & 4.70100 & 00000000005 & TRN \\
\hline CHEMBL 2420842 & 979760 & 4.4559 & 4.8724 & TRN & \\
\hline CHEMBL 2420849 & 979760 & 4.4559 & 4.3702 & TRN & \\
\hline CHEMBL 2420843 & 979760 & 4.4559 & 4.4965 & TRN & \\
\hline CHEMBL 2420818 & 979760 & 5.699 & 4.4246 & TST & \\
\hline CHEMBL1370276 & 979760 & 5.5528 & 5.8373 & TRN & \\
\hline CHEMBL 2420831 & 979760 & 7.2218 & 6.5234 & TRN & \\
\hline CHEMBL 2420851 & 979760 & 5.7696 & 5.8918 & TST & \\
\hline CHEMBL1327969 & 979760 & 5.9208 & 5.8445 & TST & \\
\hline CHEMBL 2420847 & 979760 & 4.4559 & 5.1836 & TST & \\
\hline CHEMBL 2420846 & 979760 & 4.4559 & 5.0222 & TST & \\
\hline CHEMBL 2420810 & 979760 & 4.4559 & 5.2853 & TST & \\
\hline CHEMBL 2420860 & 979760 & 4.4559 & 4.2015 & TST & \\
\hline CHEMBL 2387224 & 979760 & 7.5528 & 7.2089 & TST & \\
\hline CHEMBL 2420850 & 979760 & 5.4949 & 4.4851 & TST & \\
\hline CHEMBL3971175 & 1641907 & 6.6304 & 6.49700 & 0000000001 & TRN \\
\hline CHEMBL3923626 & 1641907 & 6.2699 & 6.388 & TRN & \\
\hline CHEMBL3930114 & 1641907 & 7.4828 & 7.5556 & TRN & \\
\hline CHEMBL3908713 & 1641907 & 8.0088 & 7.0721 & TST & \\
\hline CHEMBL3952533 & 1641907 & 3.6021 & 3.97 & TRN & \\
\hline CHEMBL3899658 & 1641907 & 3.6021 & 3.4879 & TRN & \\
\hline CHEMBL 3974891 & 1641907 & 7.2197 & 6.4859 & TRN & \\
\hline CHEMBL3910306 & 1641907 & 6.0 & 5.7021 & TST & \\
\hline CHEMBL3971361 & 1641907 & 6.1735 & 6.2318 & TRN & \\
\hline CHEMBL3671853 & 1641907 & 6.8665 & 6.2275 & TRN & \\
\hline CHEMBL3894423 & 1641907 & 5.8653 & 6.1276 & TRN & \\
\hline CHEMBL3933640 & 1641907 & 6.0 & 6.2523 & TRN & \\
\hline CHEMBL3948420 & 1641907 & 6.3571 & 6.9084 & TRN & \\
\hline CHEMBL3969387 & 1641907 & 7.1267 & 7.0872 & TRN & \\
\hline CHEMBL3943143 & 1641907 & 6.7622 & 6.7534 & TRN & \\
\hline CHEMBL3926098 & 1641907 & 6.3267 & 6.4688 & TRN & \\
\hline CHEMBL3970965 & 1641907 & 6.8908 & 6.8481 & TRN & \\
\hline CHEMBL3906817 & 1641907 & 5.1531 & 5.3343 & TRN & \\
\hline CHEMBL3963879 & 1641907 & 6.0 & 6.1932 & TRN & \\
\hline CHEMBL3914597 & 1641907 & 6.3969 & 6.4798 & TRN & \\
\hline CHEMBL3911135 & 1641907 & 6.0 & 6.1823 & TRN & \\
\hline CHEMBL3913992 & 1641907 & 6.6133 & 6.1642 & TRN & \\
\hline CHEMBL3893654 & 1641907 & 6.0 & 5.9937 & TRN & \\
\hline CHEMBL3935715 & 1641907 & 7.2967 & 7.3947 & TRN & \\
\hline CHEMBL3932404 & 1641907 & 6.806 & 6.7151 & TRN & \\
\hline CHEMBL3910652 & 1641907 & 6.7069 & 6.0576 & TST & \\
\hline CHEMBL3962224 & 1641907 & 6.0 & 6.0609 & TST & \\
\hline CHEMBL3960904 & 1641907 & 6.0 & 6.6078 & TRN & \\
\hline CHEMBL3962528 & 1641907 & 6.9136 & 6.8998 & TRN & \\
\hline CHEMBL3913616 & 1641907 & 6.6992 & 6.8778 & TRN & \\
\hline CHEMBL3945903 & 1641907 & 6.9278 & 6.756 & TRN & \\
\hline CHEMBL3906626 & 1641907 & 7.8153 & 6.5934 & TST & \\
\hline CHEMBL3923451 & 1641907 & 6.9492 & 6.4832 & TRN & \\
\hline
\end{tabular}




\begin{tabular}{|c|c|c|c|c|c|c|}
\hline \multicolumn{7}{|c|}{ Supplemental Table S2.txt } \\
\hline CHEMBL3893266 & 1641907 & 6.0 & 5.8151 & TRN & & \\
\hline CHEMBL3954601 & 1641907 & 6.9666 & 6.4245 & TRN & & \\
\hline CHEMBL3894902 & 1641907 & 7.34200 & $\partial 0000000$ & 005 & 6.4862 & TST \\
\hline CHEMBL 3671849 & 1641907 & 6.7773 & 6.2017 & TST & & \\
\hline CHEMBL3982583 & 1641907 & 7.0057 & 6.8111 & TRN & & \\
\hline CHEMBL3945132 & 1641907 & 6.6774 & 6.8507 & TRN & & \\
\hline CHEMBL3973954 & 1641907 & 6.4609 & 6.5915 & TRN & & \\
\hline CHEMBL3915856 & 1641907 & 6.0 & 5.6633 & TST & & \\
\hline CHEMBL 3896988 & 1641907 & 6.0 & 6.6297 & TST & & \\
\hline CHEMBL3924261 & 1641907 & 5.5315 & 5.843 & TRN & & \\
\hline CHEMBL3947925 & 1641907 & 7.6234 & 6.2686 & TST & & \\
\hline CHEMBL3936644 & 1641907 & 6.0343 & 5.6147 & TRN & & \\
\hline CHEMBL3945556 & 1641907 & 7.8477 & 7.5822 & TST & & \\
\hline CHEMBL 3894534 & 1641907 & 6.0 & 6.3375 & TRN & & \\
\hline CHEMBL3977449 & 1641907 & 7.4157 & 6.544 & TST & & \\
\hline CHEMBL 3898451 & 1641907 & 4.0 & 4.3996 & TRN & & \\
\hline CHEMBL3899068 & 1641907 & 6.2665 & 6.3138 & TRN & & \\
\hline CHEMBL3905687 & 1641907 & 6.0 & 6.4583 & TRN & & \\
\hline CHEMBL3947065 & 1641907 & 6.6463 & 6.7172 & TRN & & \\
\hline CHEMBL3932728 & 1641907 & 6.0 & 6.2664 & TST & & \\
\hline CHEMBL3984539 & 1641907 & 7.8097 & 6.8619 & TST & & \\
\hline CHEMBL3921168 & 1641907 & 8.1549 & 7.3746 & TST & & \\
\hline CHEMBL3915442 & 1641907 & 6.0352 & 6.0953 & TRN & & \\
\hline CHEMBL3975771 & 1641907 & 6.1493 & 6.4 & TRN & & \\
\hline CHEMBL3931726 & 1641907 & 6.0 & 6.3886 & TRN & & \\
\hline CHEMBL3899523 & 1641907 & 5.5602 & 4.9718 & TST & & \\
\hline CHEMBL3912938 & 1641907 & 6.0 & 6.4117 & TST & & \\
\hline CHEMBL3944853 & 1641907 & 6.8514 & 7.1758 & TRN & & \\
\hline CHEMBL 3908574 & 1641907 & 5.8759 & 4.4496 & TST & & \\
\hline CHEMBL3909165 & 1641907 & 6.7113 & 6.7496 & TRN & & \\
\hline CHEMBL3901246 & 1641907 & 6.4548 & 6.4007 & TRN & & \\
\hline CHEMBL3911313 & 1641907 & 7.75200 & 00000000 & & 7.296 & TRN \\
\hline CHEMBL3922262 & 1641907 & 6.2073 & 6.3065 & TRN & & \\
\hline CHEMBL 3671845 & 1641907 & 6.8827 & 6.95 & TRN & & \\
\hline CHEMBL3897286 & 1641907 & 7.2924 & 6.5423 & TRN & & \\
\hline CHEMBL3909245 & 1641907 & 6.0382 & 6.1561 & TRN & & \\
\hline CHEMBL3939806 & 1641907 & 7.062 & 7.0381 & TRN & & \\
\hline CHEMBL3895787 & 1641907 & 6.0 & 6.0943 & TRN & & \\
\hline CHEMBL3931850 & 1641907 & 6.0 & 6.0435 & TST & & \\
\hline CHEMBL3914666 & 1641907 & 6.284 & 6.0145 & TST & & \\
\hline CHEMBL3952216 & 1641907 & 7.3862 & 7.1583 & TRN & & \\
\hline CHEMBL3930289 & 1641907 & 7.2588 & 6.0472 & TST & & \\
\hline CHEMBL3903526 & 1641907 & 6.6112 & 6.7293 & TRN & & \\
\hline CHEMBL3953894 & 1641907 & 7.1101 & 6.0899 & TRN & & \\
\hline CHEMBL3984423 & 1641907 & 6.3829 & 6.2715 & TRN & & \\
\hline CHEMBL3976353 & 1641907 & 5.9682 & 6.08799 & 999999999 & & TRN \\
\hline CHEMBL3903477 & 1641907 & 4.0 & 4.4032 & TRN & & \\
\hline CHEMBL3931187 & 1641907 & 6.0635 & 5.9267 & TRN & & \\
\hline
\end{tabular}


Supplemental Table S2.txt

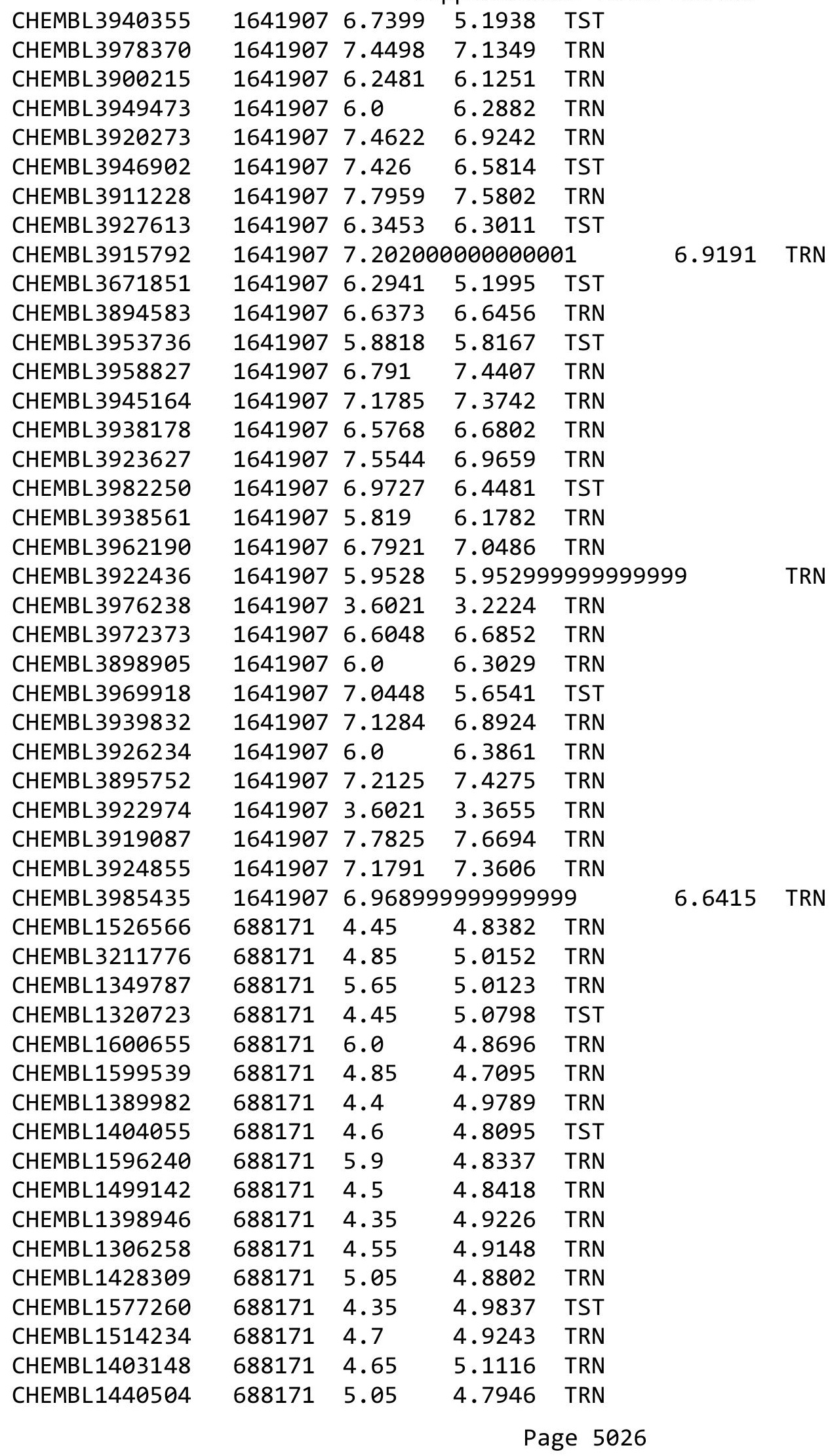




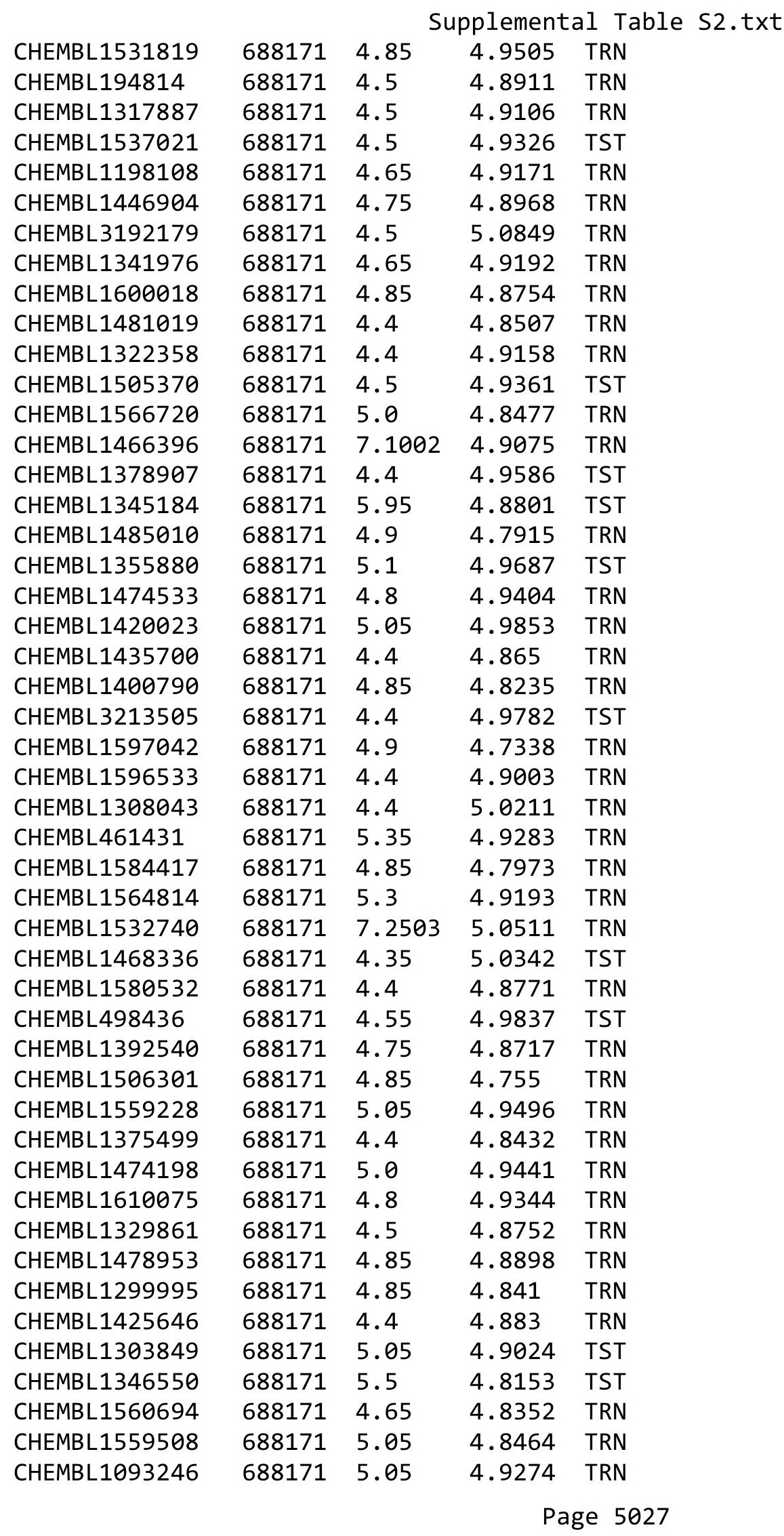




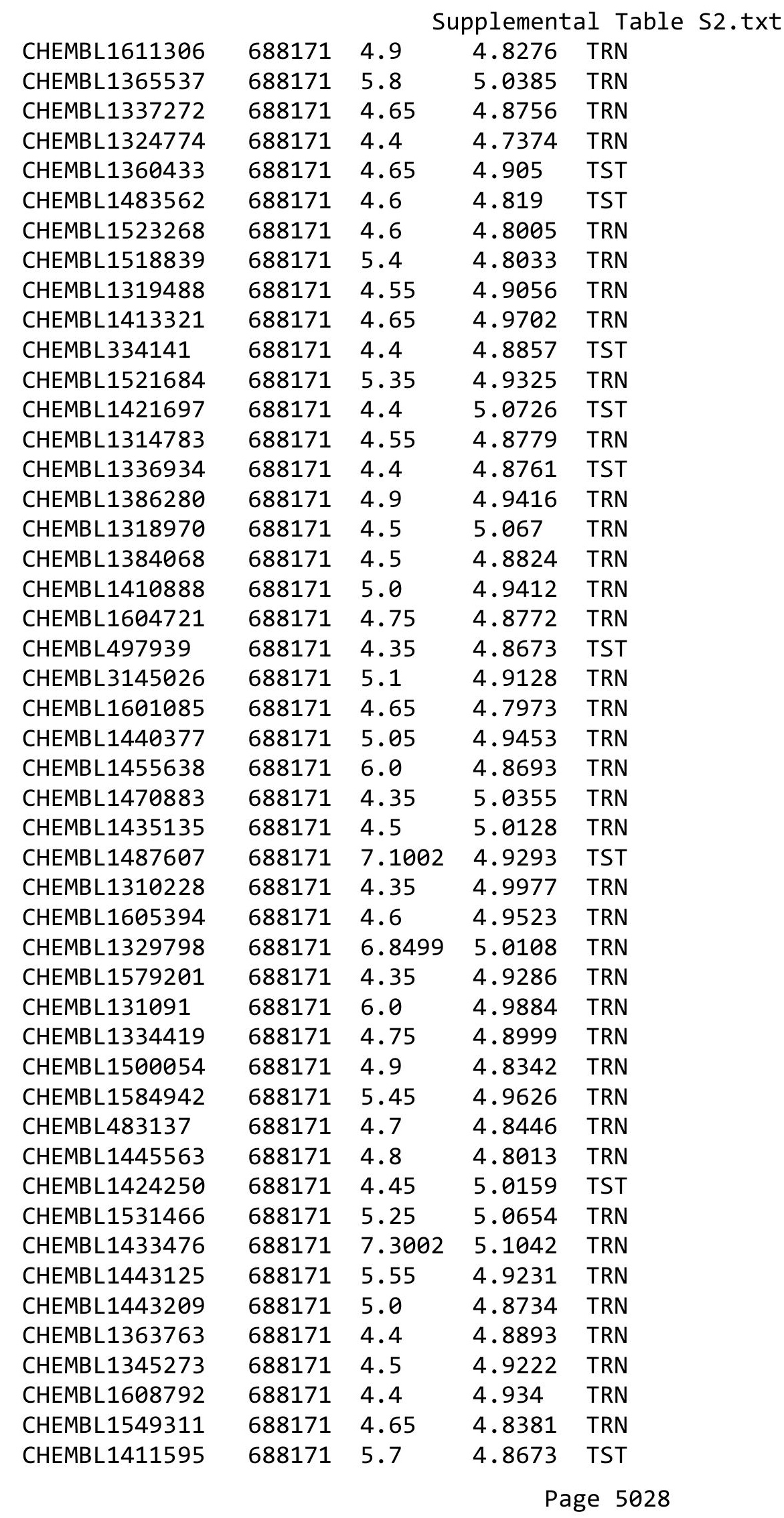




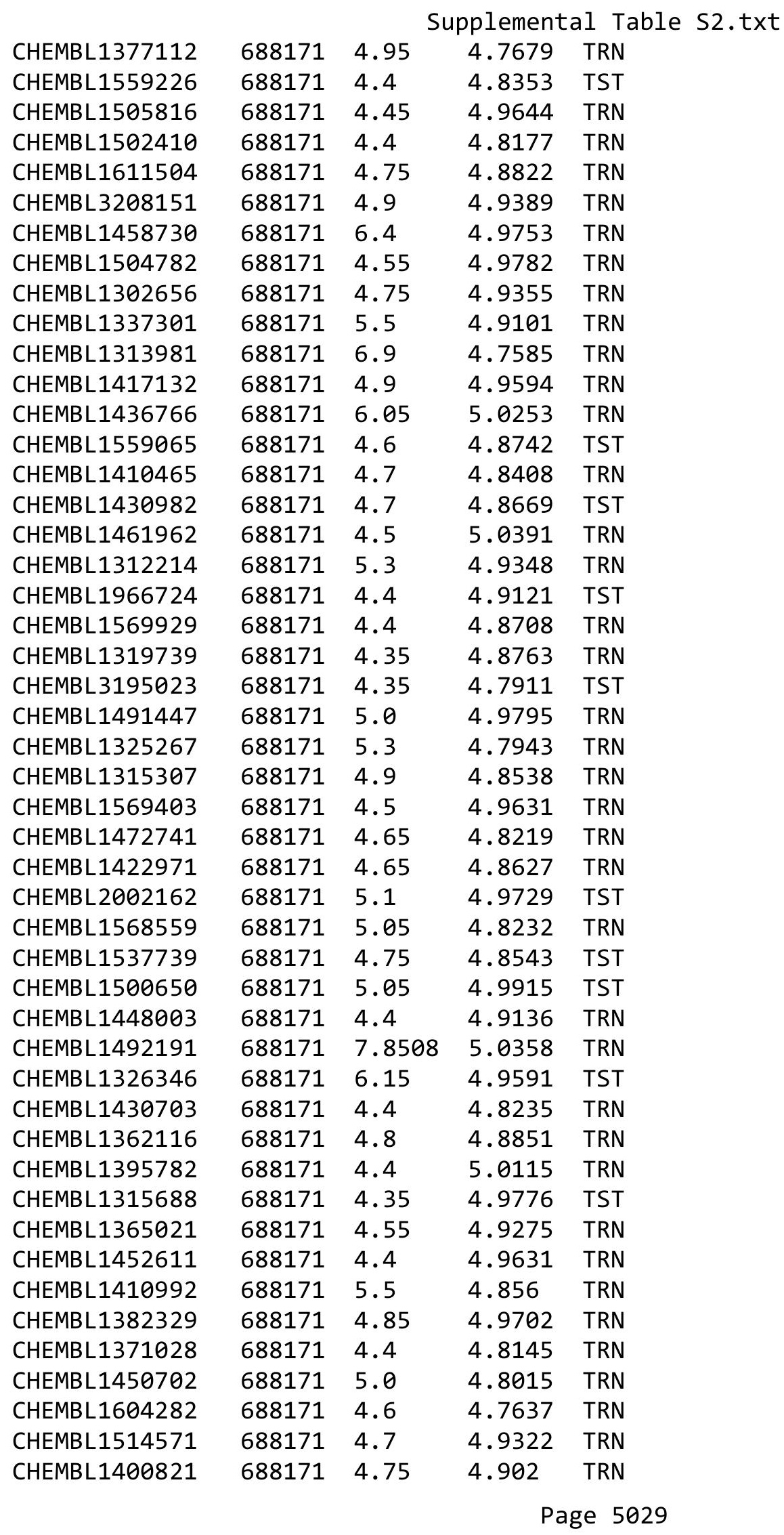




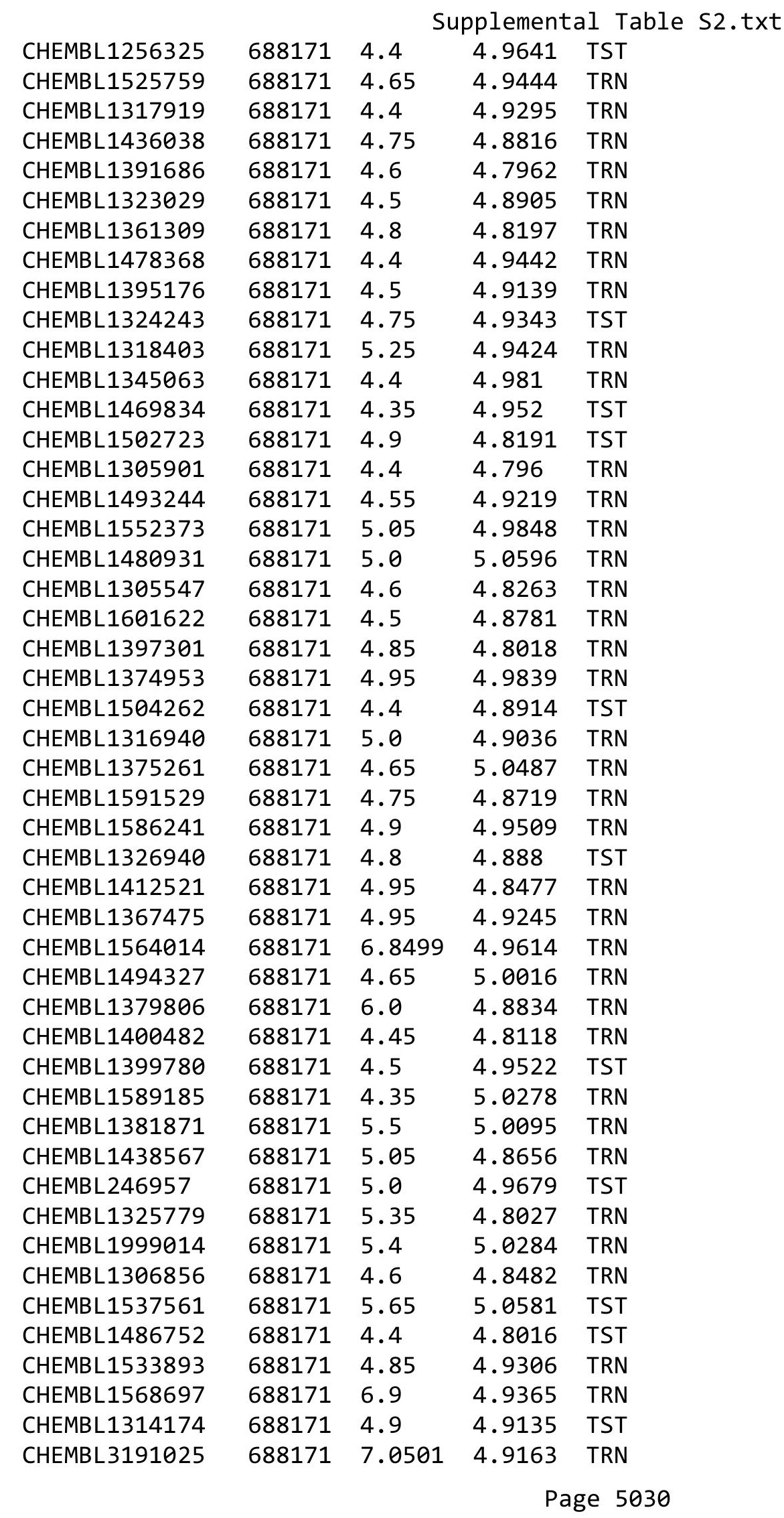




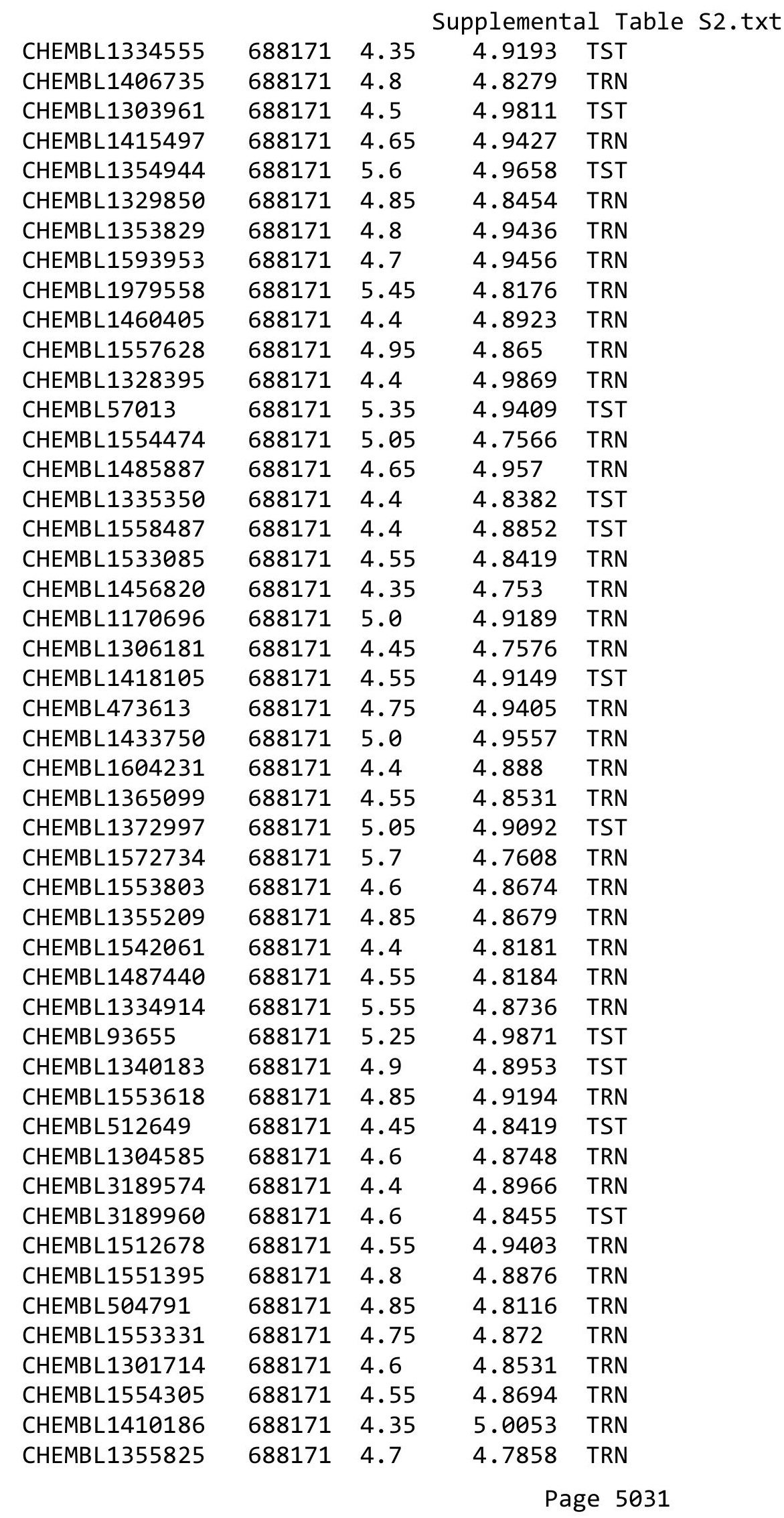




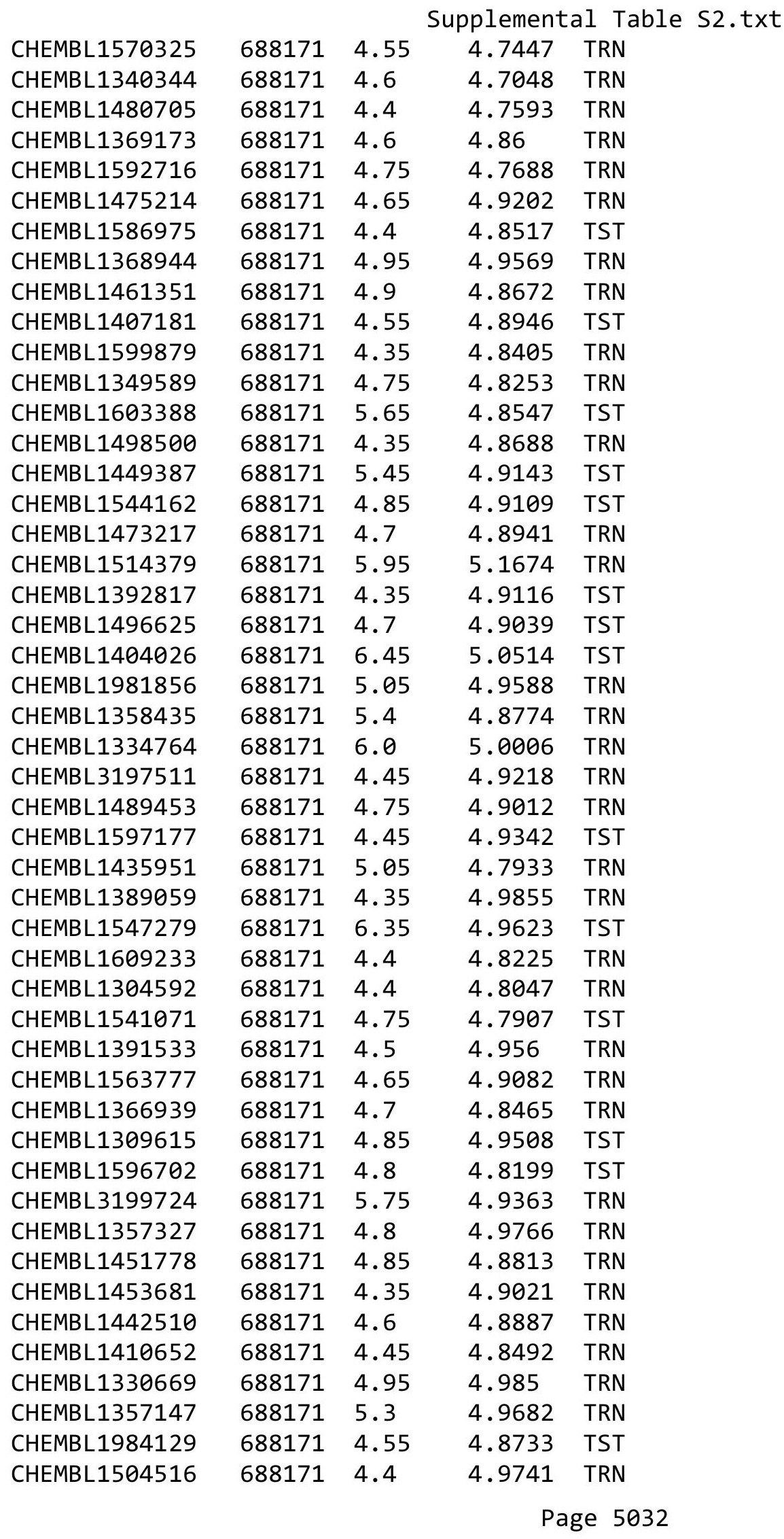




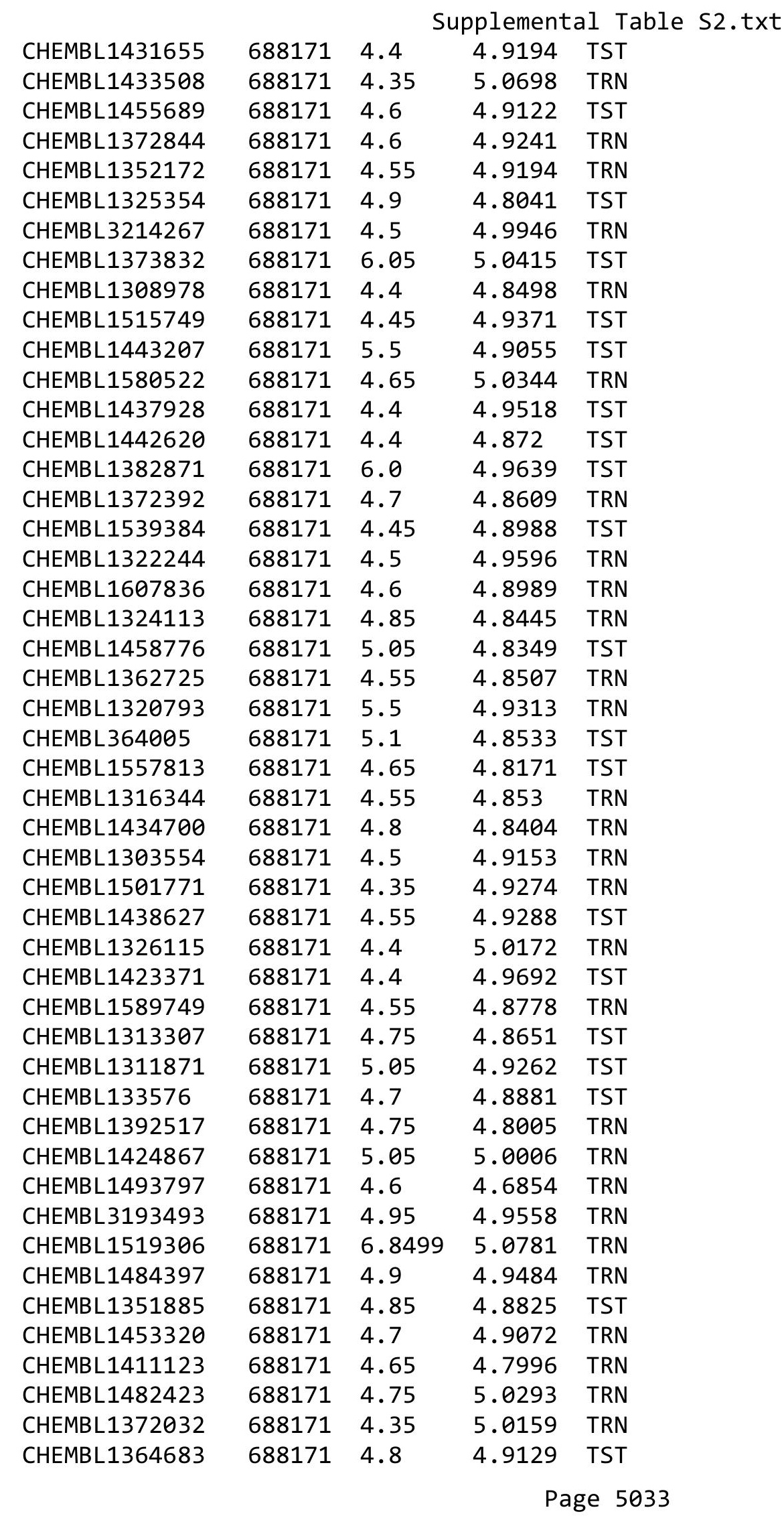




\begin{tabular}{|c|c|c|c|c|c|}
\hline \multicolumn{6}{|c|}{ Supplemental Table S2.txt } \\
\hline CHEMBL1587604 & 688171 & 4.6 & 5.0067 & TST & \\
\hline CHEMBL1554006 & 688171 & 5.3 & 4.8929 & TRN & \\
\hline CHEMBL1569165 & 688171 & 4.55 & 4.9171 & TRN & \\
\hline CHEMBL1527241 & 688171 & 4.7 & 4.9229 & TST & \\
\hline CHEMBL1556897 & 688171 & 5.1 & 4.8461 & TRN & \\
\hline CHEMBL1514933 & 688171 & 4.4 & 4.8472 & TRN & \\
\hline CHEMBL1574857 & 688171 & 5.5 & 4.8417 & TRN & \\
\hline CHEMBL1467384 & 688171 & 4.75 & 4.9106 & TRN & \\
\hline CHEMBL1575826 & 688171 & 5.5 & 4.9057 & TRN & \\
\hline CHEMBL1996068 & 688171 & 6.9 & 4.9205 & TRN & \\
\hline CHEMBL1609758 & 688171 & 4.55 & 4.7378 & TST & \\
\hline CHEMBL1577232 & 688171 & 4.45 & 4.9252 & TRN & \\
\hline CHEMBL3194423 & 688171 & 4.7 & 4.9819 & TRN & \\
\hline CHEMBL1406364 & 688171 & 5.75 & 4.9707 & TST & \\
\hline CHEMBL1473665 & 688171 & 4.5 & 5.0427 & TRN & \\
\hline CHEMBL1413426 & 688171 & 4.6 & 4.9632 & TRN & \\
\hline CHEMBL1535347 & 688171 & 4.4 & 4.9263 & TRN & \\
\hline CHEMBL1515160 & 688171 & 4.7 & 4.9414 & TRN & \\
\hline CHEMBL1320446 & 688171 & 4.4 & 4.8729 & TRN & \\
\hline CHEMBL1422699 & 688171 & 6.7001 & 4.9205 & TRN & \\
\hline CHEMBL1348415 & 688171 & 5.45 & 4.956 & TRN & \\
\hline CHEMBL1475019 & 688171 & 4.9 & 4.9994 & TRN & \\
\hline CHEMBL1513511 & 688171 & 5.0 & 4.8835 & TRN & \\
\hline CHEMBL1498652 & 688171 & 4.85 & 4.8435 & TST & \\
\hline CHEMBL1480266 & 688171 & 4.75 & 4.8488 & TRN & \\
\hline CHEMBL1362904 & 688171 & 5.4 & 4.9742 & TRN & \\
\hline CHEMBL1520968 & 688171 & 4.9 & 4.7373 & TRN & \\
\hline CHEMBL1483471 & 688171 & 4.85 & 4.8224 & TRN & \\
\hline CHEMBL1567682 & 688171 & 4.4 & 4.8664 & TRN & \\
\hline CHEMBL1466004 & 688171 & 4.7 & 4.9029 & TST & \\
\hline CHEMBL1574943 & 688171 & 4.55 & 4.9899 & TST & \\
\hline CHEMBL1598923 & 688171 & 5.9 & 4.958 & TRN & \\
\hline CHEMBL1490305 & 688171 & 4.4 & 4.9338 & TRN & \\
\hline CHEMBL1335623 & 688171 & 4.4 & 5.0144 & TRN & \\
\hline CHEMBL1606120 & 688171 & 4.8 & 4.9415 & TRN & \\
\hline CHEMBL 234180 & 688171 & 4.7 & 4.985 & TRN & \\
\hline CHEMBL1557569 & 688171 & 4.8 & 5.023 & TRN & \\
\hline CHEMBL1455256 & 688171 & 4.5 & 4.76399 & 9999999999 & TRN \\
\hline CHEMBL1497386 & 688171 & 4.8 & 4.755 & TRN & \\
\hline CHEMBL1392564 & 688171 & 4.7 & 4.8126 & TRN & \\
\hline CHEMBL1371460 & 688171 & 4.4 & 4.8704 & TRN & \\
\hline CHEMBL1337548 & 688171 & 4.65 & 4.791 & TRN & \\
\hline CHEMBL1497876 & 688171 & 4.4 & 5.1079 & TRN & \\
\hline CHEMBL3208375 & 688171 & 4.4 & 4.8714 & TST & \\
\hline CHEMBL1410739 & 688171 & 4.6 & 5.0021 & TRN & \\
\hline CHEMBL1422328 & 688171 & 4.75 & 4.9202 & TRN & \\
\hline CHEMBL1326381 & 688171 & 5.0 & 4.8589 & TRN & \\
\hline CHEMBL1509339 & 688171 & 4.85 & 4.9513 & TRN & \\
\hline
\end{tabular}




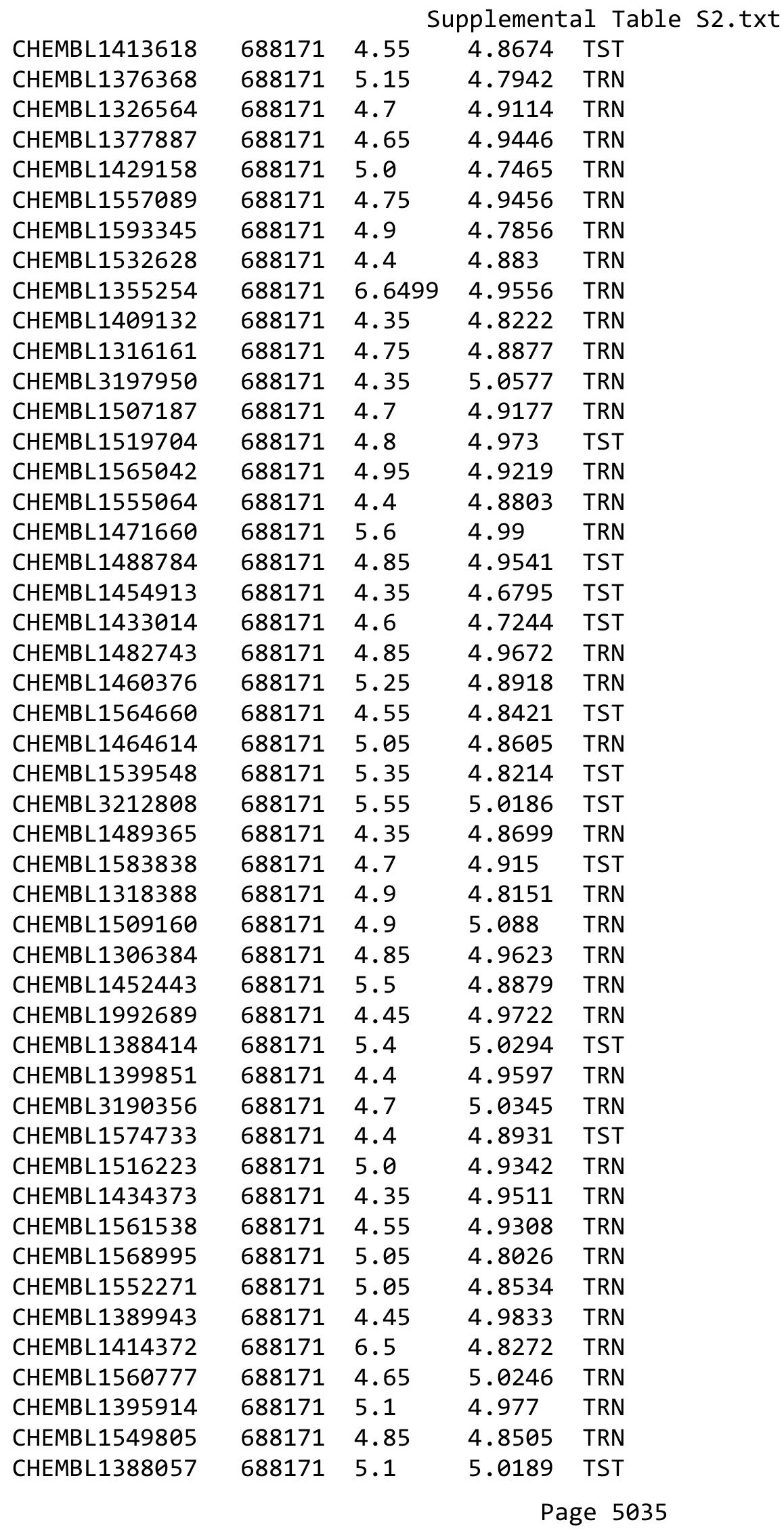




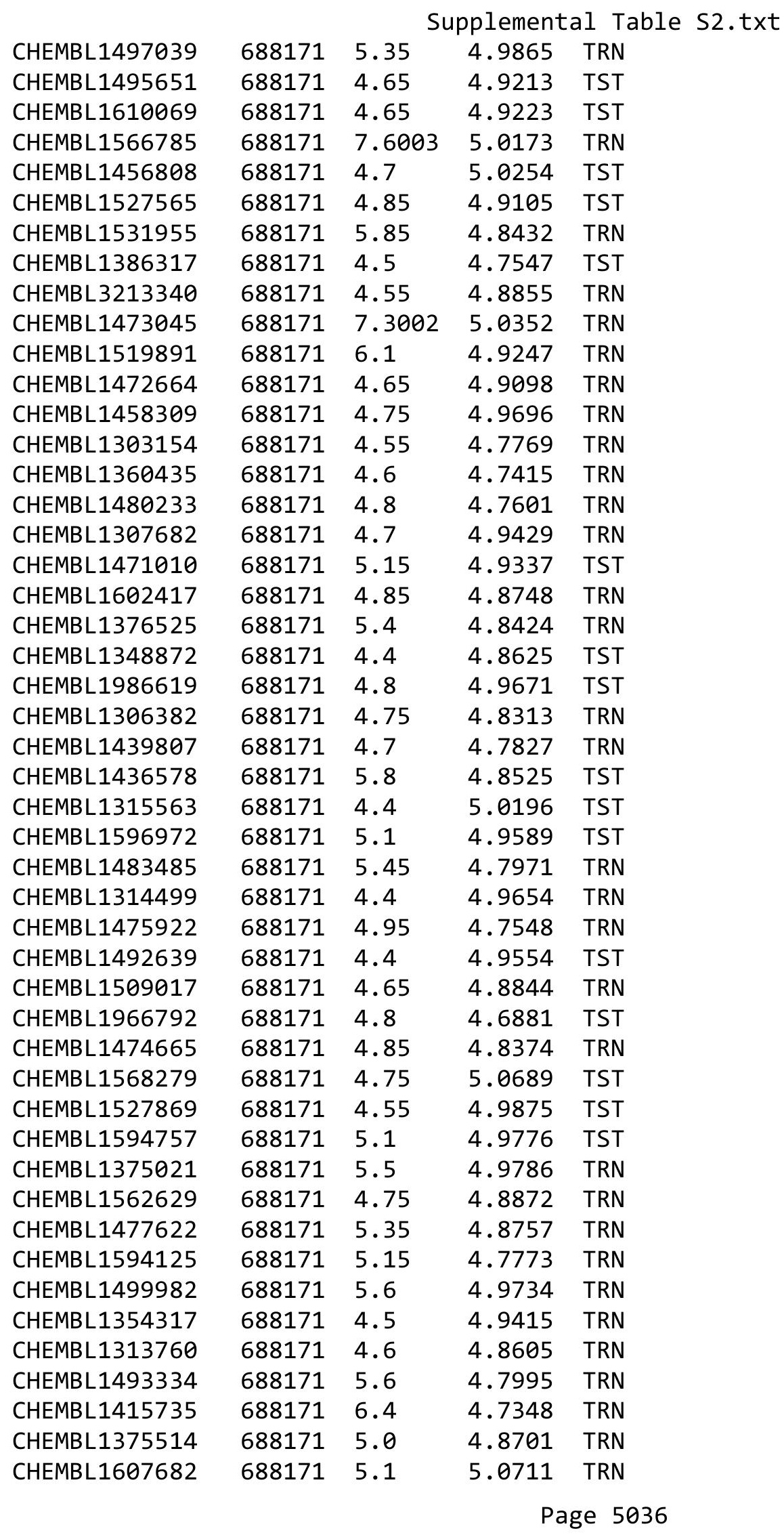




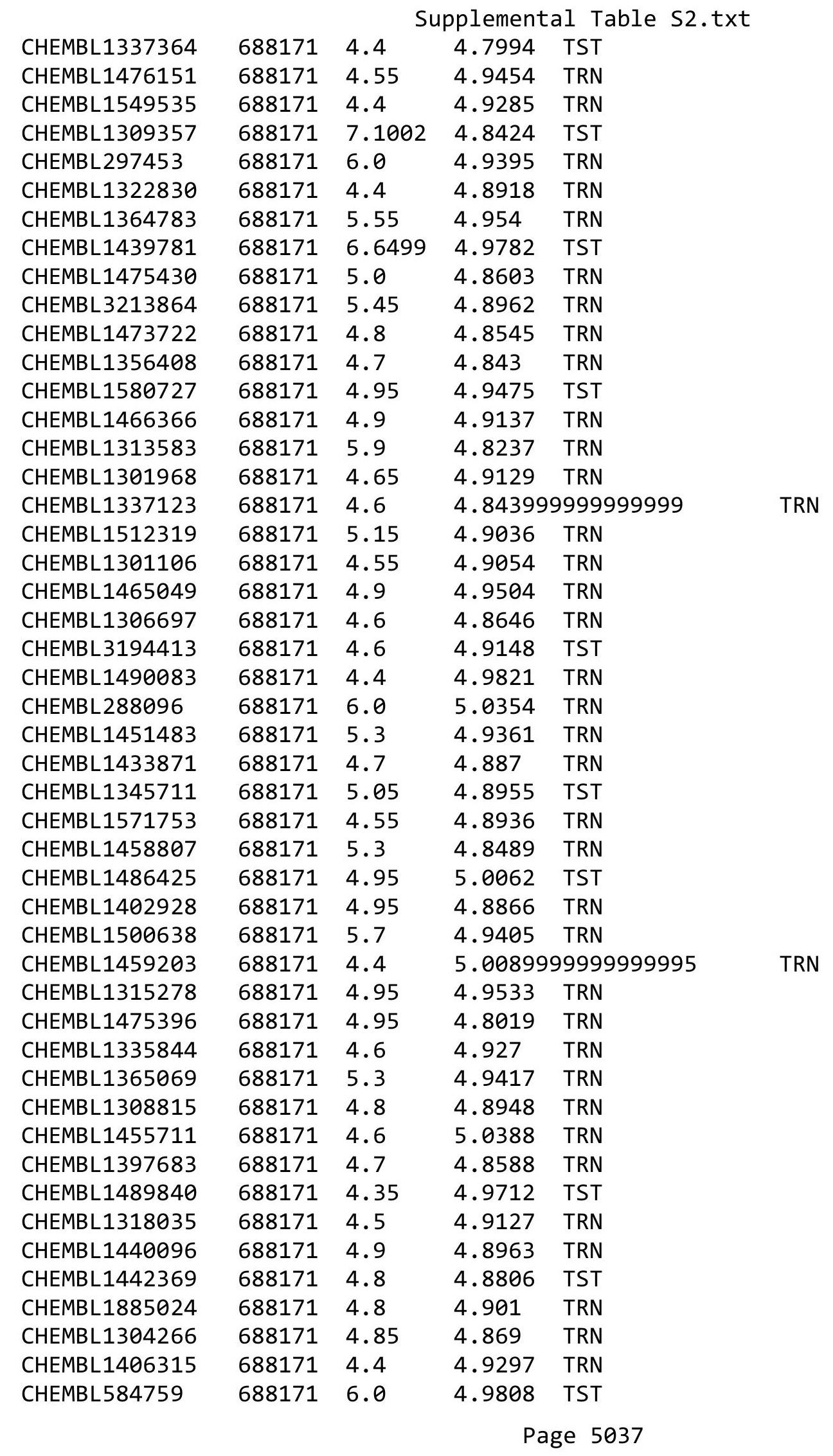




\begin{tabular}{|c|c|c|c|c|c|}
\hline \multicolumn{6}{|c|}{ Supplemental Table S2.txt } \\
\hline CHEMBL3193489 & 688171 & 4.75 & 4.9623 & TRN & \\
\hline CHEMBL1482284 & 688171 & 5.25 & 5.07 & TRN & \\
\hline CHEMBL1366565 & 688171 & 5.25 & 4.9409 & TRN & \\
\hline CHEMBL1431935 & 688171 & 5.0 & 4.7263 & TRN & \\
\hline CHEMBL1538456 & 688171 & 4.5 & 4.917 & TST & \\
\hline CHEMBL1385160 & 688171 & 4.4 & 4.857 & TRN & \\
\hline CHEMBL1505763 & 688171 & 4.9 & 4.882 & TRN & \\
\hline CHEMBL508779 & 688171 & 4.4 & 4.8395 & TST & \\
\hline CHEMBL1404218 & 688171 & 4.45 & 4.7232 & TRN & \\
\hline CHEMBL1512638 & 688171 & 4.8 & 4.8663 & TRN & \\
\hline CHEMBL1589677 & 688171 & 4.35 & 4.8426 & TRN & \\
\hline CHEMBL1533601 & 688171 & 5.3 & 4.891999 & 99999999995 & TRN \\
\hline CHEMBL1418621 & 688171 & 4.9 & 4.8428 & TRN & \\
\hline CHEMBL1340834 & 688171 & 4.4 & 4.8453 & TST & \\
\hline CHEMBL1383732 & 688171 & 4.6 & 4.9564 & TRN & \\
\hline CHEMBL1357388 & 688171 & 4.75 & 4.7737 & TRN & \\
\hline CHEMBL1568822 & 688171 & 4.55 & 4.8595 & TRN & \\
\hline CHEMBL1308759 & 688171 & 4.6 & 4.9577 & TST & \\
\hline CHEMBL1565500 & 688171 & 4.75 & 4.8707 & TRN & \\
\hline CHEMBL1319047 & 688171 & 4.6 & 4.9707 & TST & \\
\hline CHEMBL1585233 & 688171 & 4.95 & 4.9103 & TRN & \\
\hline CHEMBL1492652 & 688171 & 4.4 & 4.8018 & TRN & \\
\hline CHEMBL1549597 & 688171 & 4.35 & 4.9511 & TRN & \\
\hline CHEMBL 2369239 & 688171 & 5.4 & 4.9891 & TRN & \\
\hline CHEMBL1321860 & 688171 & 5.85 & 4.9851 & TRN & \\
\hline CHEMBL1464146 & 688171 & 5.6 & 4.8181 & TRN & \\
\hline CHEMBL1547101 & 688171 & 4.45 & 4.8991 & TST & \\
\hline CHEMBL1342702 & 688171 & 4.75 & 4.8721 & TST & \\
\hline CHEMBL1365980 & 688171 & 4.4 & 5.0728 & TST & \\
\hline CHEMBL1601077 & 688171 & 4.7 & 4.9368 & TRN & \\
\hline CHEMBL1467469 & 688171 & 4.6 & 4.9474 & TRN & \\
\hline CHEMBL1563252 & 688171 & 4.55 & 4.8135 & TST & \\
\hline CHEMBL1499029 & 688171 & 4.9 & 4.8956 & TRN & \\
\hline CHEMBL3212058 & 688171 & 4.9 & 4.931 & TRN & \\
\hline CHEMBL1353983 & 688171 & 4.8 & 5.0144 & TRN & \\
\hline CHEMBL1398481 & 688171 & 4.4 & 4.8912 & TRN & \\
\hline CHEMBL 1326522 & 688171 & 4.35 & 4.8937 & TRN & \\
\hline CHEMBL3144909 & 688171 & 5.05 & 4.8271 & TRN & \\
\hline CHEMBL1466435 & 688171 & 4.75 & 4.8207 & TRN & \\
\hline CHEMBL1361449 & 688171 & 5.85 & 4.9784 & TRN & \\
\hline CHEMBL1439938 & 688171 & 5.45 & 4.9647 & TRN & \\
\hline CHEMBL1320151 & 688171 & 4.95 & 4.6769 & TRN & \\
\hline CHEMBL1572399 & 688171 & 4.4 & 4.7544 & TRN & \\
\hline CHEMBL1312723 & 688171 & 4.7 & 4.7832 & TRN & \\
\hline CHEMBL1311556 & 688171 & 4.9 & 4.8307 & TRN & \\
\hline CHEMBL1531265 & 688171 & 4.5 & 4.8555 & TRN & \\
\hline CHEMBL1609821 & 688171 & 4.85 & 4.829 & TRN & \\
\hline CHEMBL1457682 & 688171 & 5.25 & 4.8522 & TST & \\
\hline
\end{tabular}




\begin{tabular}{|c|c|c|c|c|c|}
\hline \multicolumn{6}{|c|}{ Supplemental Table S2.txt } \\
\hline CHEMBL1537736 & 688171 & 4.35 & 4.8262 & TRN & \\
\hline CHEMBL1315088 & 688171 & 5.75 & 5.0035 & TRN & \\
\hline CHEMBL1389248 & 688171 & 7.1002 & 4.9703 & TST & \\
\hline CHEMBL1329479 & 688171 & 4.95 & 4.9051 & TRN & \\
\hline CHEMBL1555361 & 688171 & 4.4 & 4.7867 & TRN & \\
\hline CHEMBL1358196 & 688171 & 4.45 & 4.8233 & TRN & \\
\hline CHEMBL1515157 & 688171 & 4.55 & 4.9176 & TRN & \\
\hline CHEMBL1327836 & 688171 & 4.75 & 4.7999 & TRN & \\
\hline CHEMBL1506068 & 688171 & 6.45 & 4.7892 & TST & \\
\hline CHEMBL3192011 & 688171 & 7.6498 & 4.9145 & TRN & \\
\hline CHEMBL1712181 & 688171 & 5.0 & 4.8862 & TST & \\
\hline CHEMBL1553315 & 688171 & 4.8 & 4.8779 & TRN & \\
\hline CHEMBL1548459 & 688171 & 5.1 & 4.7927 & TST & \\
\hline CHEMBL580421 & 688171 & 5.0 & 4.8687 & TST & \\
\hline CHEMBL1341992 & 688171 & 4.5 & 4.8596 & TRN & \\
\hline CHEMBL3194853 & 688171 & 4.9 & 4.9276 & TRN & \\
\hline CHEMBL589507 & 688171 & 4.35 & 4.8759 & TRN & \\
\hline CHEMBL1567674 & 688171 & 4.45 & 5.0509 & TRN & \\
\hline CHEMBL1972638 & 688171 & 6.0 & 5.0133 & TST & \\
\hline CHEMBL3211289 & 688171 & 4.6 & 4.9509 & TRN & \\
\hline CHEMBL3209442 & 688171 & 4.5 & 4.9436 & TRN & \\
\hline CHEMBL1467703 & 688171 & 5.6 & 4.9253 & TST & \\
\hline CHEMBL1536790 & 688171 & 4.55 & 4.9661 & TST & \\
\hline CHEMBL1452537 & 688171 & 4.9 & 4.9639 & TRN & \\
\hline CHEMBL1339856 & 688171 & 4.75 & 4.7593 & TRN & \\
\hline CHEMBL1309521 & 688171 & 4.95 & 4.9413 & TRN & \\
\hline CHEMBL1432126 & 688171 & 5.25 & 4.9369 & TRN & \\
\hline CHEMBL1495748 & 688171 & 6.8499 & 4.9476 & TRN & \\
\hline CHEMBL1584740 & 688171 & 4.5 & 4.8107 & TRN & \\
\hline CHEMBL1428574 & 688171 & 6.4 & 5.0074 & TRN & \\
\hline CHEMBL1581913 & 688171 & 6.7001 & 4.8397 & TST & \\
\hline CHEMBL1322879 & 688171 & 4.5 & 5.004 & TRN & \\
\hline CHEMBL1435683 & 688171 & 4.75 & 5.0459 & TRN & \\
\hline CHEMBL1530823 & 688171 & 5.8 & 4.8644 & TRN & \\
\hline CHEMBL1320584 & 688171 & 4.5 & 4.9419 & TRN & \\
\hline CHEMBL1480887 & 688171 & 4.45 & 4.757 & TRN & \\
\hline CHEMBL1514677 & 688171 & 5.75 & 4.9001 & TRN & \\
\hline CHEMBL1583598 & 688171 & 4.75 & 4.8615 & TRN & \\
\hline CHEMBL1558066 & 688171 & 5.45 & 5.15799 & 99999999995 & TST \\
\hline CHEMBL1604361 & 688171 & 5.4 & 5.0219 & TRN & \\
\hline CHEMBL1401771 & 688171 & 4.4 & 4.9338 & TRN & \\
\hline CHEMBL1422138 & 688171 & 4.8 & 4.9086 & TRN & \\
\hline CHEMBL1439599 & 688171 & 4.5 & 4.9183 & TRN & \\
\hline CHEMBL1301876 & 688171 & 4.6 & 4.914 & TRN & \\
\hline CHEMBL1586274 & 688171 & 4.35 & 5.0192 & TRN & \\
\hline CHEMBL1355875 & 688171 & 4.7 & 4.9804 & TRN & \\
\hline CHEMBL1304291 & 688171 & 5.35 & 4.8454 & TRN & \\
\hline CHEMBL1365014 & 688171 & 5.0 & 4.8981 & TRN & \\
\hline
\end{tabular}




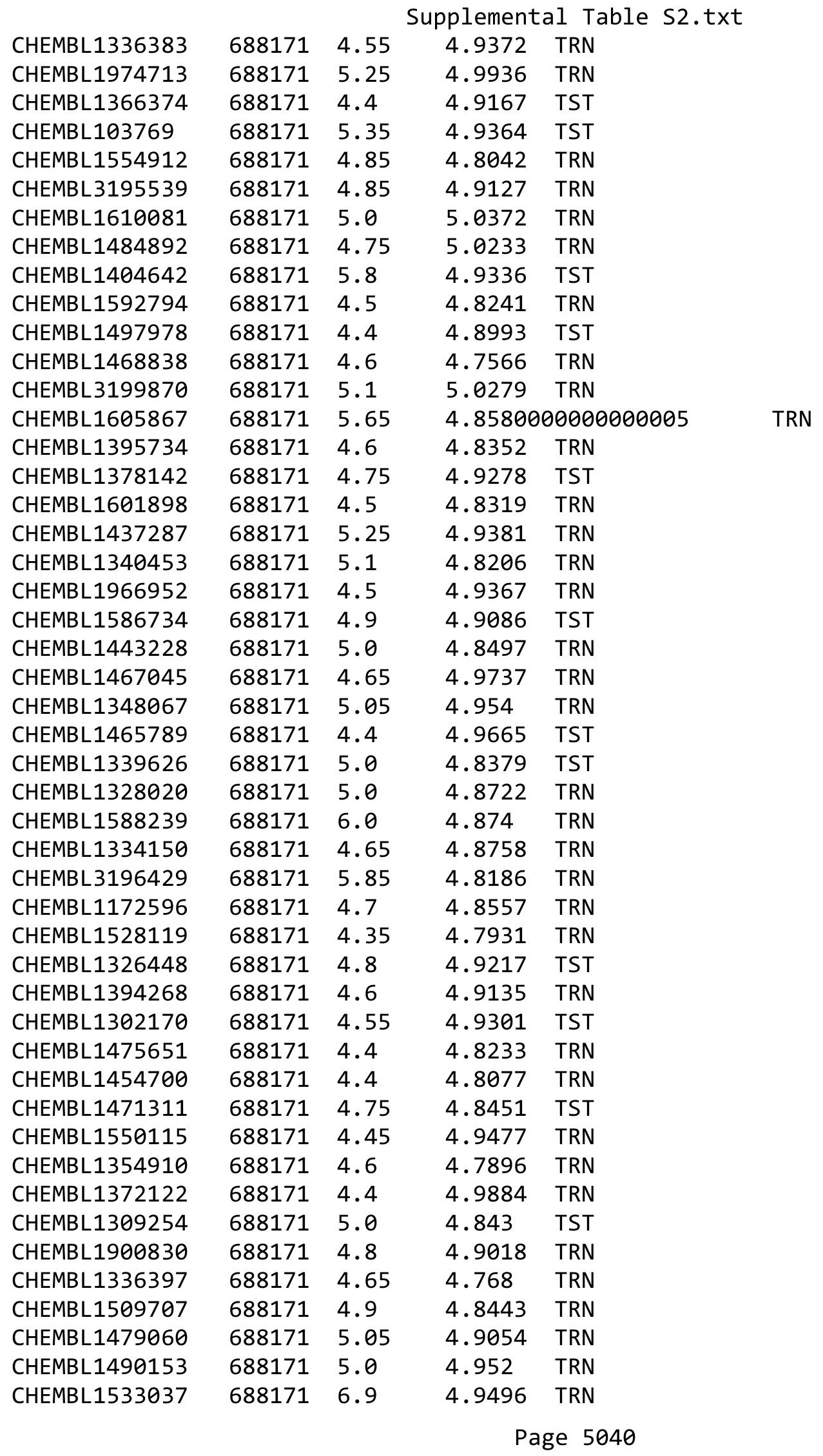




\begin{tabular}{|c|c|c|c|c|}
\hline \multicolumn{5}{|c|}{ Supplemental Table S2.txt } \\
\hline CHEMBL1513968 & 688171 & 5.0 & 4.8493 & TRN \\
\hline CHEMBL1607270 & 688171 & 5.95 & 4.7643 & TRN \\
\hline CHEMBL3209633 & 688171 & 4.55 & 4.9937 & TRN \\
\hline CHEMBL1323536 & 688171 & 4.35 & 4.9096 & TRN \\
\hline CHEMBL1310690 & 688171 & 4.7 & 4.9139 & TRN \\
\hline CHEMBL1514686 & 688171 & 4.65 & 4.953 & TRN \\
\hline CHEMBL1374570 & 688171 & 5.3 & 4.8471 & TRN \\
\hline CHEMBL1986043 & 688171 & 5.3 & 4.9494 & TRN \\
\hline CHEMBL1317821 & 688171 & 5.0 & 4.8508 & TRN \\
\hline CHEMBL1435173 & 688171 & 4.45 & 4.8963 & TST \\
\hline CHEMBL1551424 & 688171 & 4.55 & 4.8089 & TRN \\
\hline CHEMBL1592886 & 688171 & 5.0 & 4.9794 & TRN \\
\hline CHEMBL1314344 & 688171 & 4.95 & 4.7626 & TRN \\
\hline CHEMBL1579739 & 688171 & 4.35 & 4.963 & TST \\
\hline CHEMBL1489751 & 688171 & 5.05 & 4.8954 & TST \\
\hline CHEMBL1610067 & 688171 & 5.0 & 4.9881 & TST \\
\hline CHEMBL1434474 & 688171 & 5.0 & 4.9329 & TRN \\
\hline CHEMBL1524109 & 688171 & 4.6 & 4.8761 & TRN \\
\hline CHEMBL1503823 & 688171 & 5.4 & 5.1516 & TRN \\
\hline CHEMBL1484168 & 688171 & 4.75 & 4.9411 & TST \\
\hline CHEMBL1402568 & 688171 & 5.1 & 5.1272 & TRN \\
\hline CHEMBL1559242 & 688171 & 4.5 & 4.8259 & TST \\
\hline CHEMBL3191060 & 688171 & 7.6003 & 4.9086 & TST \\
\hline CHEMBL1396193 & 688171 & 4.6 & 5.0002 & TRN \\
\hline CHEMBL1335541 & 688171 & 4.85 & 4.8222 & TRN \\
\hline CHEMBL1578993 & 688171 & 4.7 & 4.9673 & TST \\
\hline CHEMBL1470952 & 688171 & 5.1 & 4.8551 & TRN \\
\hline CHEMBL1491408 & 688171 & 4.5 & 4.974 & TRN \\
\hline CHEMBL1368835 & 688171 & 5.15 & 4.9223 & TST \\
\hline CHEMBL1408886 & 688171 & 4.65 & 4.769 & TRN \\
\hline CHEMBL1336180 & 688171 & 4.35 & 4.8532 & TRN \\
\hline CHEMBL3195402 & 688171 & 4.45 & 4.9242 & TRN \\
\hline CHEMBL1481413 & 688171 & 4.6 & 4.9672 & TRN \\
\hline CHEMBL3195512 & 688171 & 4.65 & 4.9042 & TRN \\
\hline CHEMBL1409603 & 688171 & 5.05 & 4.9946 & TRN \\
\hline CHEMBL1487818 & 688171 & 4.55 & 4.9 & TRN \\
\hline CHEMBL1547033 & 688171 & 4.55 & 4.811 & TRN \\
\hline CHEMBL1486679 & 688171 & 4.4 & 4.9127 & TST \\
\hline CHEMBL1490849 & 688171 & 4.4 & 4.8658 & TRN \\
\hline CHEMBL1588602 & 688171 & 4.4 & 4.9605 & TST \\
\hline CHEMBL1454096 & 688171 & 5.45 & 4.8831 & TRN \\
\hline CHEMBL1546947 & 688171 & 4.5 & 4.7515 & TRN \\
\hline CHEMBL1354586 & 688171 & 4.4 & 4.8724 & TRN \\
\hline CHEMBL1488981 & 688171 & 4.4 & 4.9869 & TRN \\
\hline CHEMBL1580426 & 688171 & 6.7501 & 4.9313 & TST \\
\hline CHEMBL1611472 & 688171 & 4.5 & 4.9396 & TST \\
\hline CHEMBL1406438 & 688171 & 4.65 & 5.0385 & TRN \\
\hline CHEMBL1582563 & 688171 & 4.75 & 4.8268 & TRN \\
\hline
\end{tabular}




\begin{tabular}{|c|c|c|c|c|c|}
\hline \multicolumn{6}{|c|}{ Supplemental Table S2.txt } \\
\hline CHEMBL1505292 & 688171 & 4.35 & 5.0022 & TST & \\
\hline CHEMBL1337305 & 688171 & 5.45 & 4.86600 & 00000000005 & TRN \\
\hline CHEMBL1322507 & 688171 & 4.45 & 4.8222 & TRN & \\
\hline CHEMBL1302861 & 688171 & 4.45 & 4.8446 & TRN & \\
\hline CHEMBL1552300 & 688171 & 4.4 & 4.7418 & TRN & \\
\hline CHEMBL1496986 & 688171 & 4.85 & 4.8511 & TRN & \\
\hline CHEMBL1510502 & 688171 & 5.45 & 4.9957 & TST & \\
\hline CHEMBL3194218 & 688171 & 4.4 & 4.8821 & TRN & \\
\hline CHEMBL1505569 & 688171 & 5.15 & 4.8989 & TRN & \\
\hline CHEMBL1490716 & 688171 & 4.35 & 4.9404 & TRN & \\
\hline CHEMBL1346627 & 688171 & 4.65 & 4.9755 & TST & \\
\hline CHEMBL1555137 & 688171 & 5.0 & 4.9279 & TRN & \\
\hline CHEMBL1602678 & 688171 & 4.4 & 4.9163 & TST & \\
\hline CHEMBL1601544 & 688171 & 5.4 & 4.9302 & TST & \\
\hline CHEMBL 3212292 & 688171 & 5.85 & 4.9217 & TST & \\
\hline CHEMBL1387722 & 688171 & 4.35 & 4.8713 & TST & \\
\hline CHEMBL1519108 & 688171 & 4.8 & 4.8132 & TRN & \\
\hline CHEMBL1419176 & 688171 & 4.5 & 4.9975 & TST & \\
\hline CHEMBL3211142 & 688171 & 5.5 & 4.8373 & TRN & \\
\hline CHEMBL1735892 & 688171 & 5.75 & 4.9294 & TRN & \\
\hline CHEMBL1474843 & 688171 & 4.65 & 4.8448 & TRN & \\
\hline CHEMBL1432778 & 688171 & 4.4 & 4.8772 & TRN & \\
\hline CHEMBL1396264 & 688171 & 4.6 & 4.9116 & TRN & \\
\hline CHEMBL1447041 & 688171 & 7.3002 & 4.9844 & TST & \\
\hline CHEMBL1583428 & 688171 & 4.65 & 5.0074 & TRN & \\
\hline CHEMBL1426440 & 688171 & 4.6 & 4.8665 & TRN & \\
\hline CHEMBL1607879 & 688171 & 5.3 & 5.0088 & TRN & \\
\hline CHEMBL1596387 & 688171 & 4.9 & 4.7584 & TST & \\
\hline CHEMBL1402264 & 688171 & 5.0 & 4.9199 & TRN & \\
\hline CHEMBL1383018 & 688171 & 4.35 & 4.8757 & TRN & \\
\hline CHEMBL1467421 & 688171 & 4.85 & 4.9585 & TRN & \\
\hline CHEMBL1594182 & 688171 & 4.6 & 4.8653 & TRN & \\
\hline CHEMBL1450229 & 688171 & 4.75 & 4.87 & TST & \\
\hline CHEMBL1454734 & 688171 & 4.9 & 4.8916 & TRN & \\
\hline CHEMBL1518043 & 688171 & 5.1 & 5.0375 & TST & \\
\hline CHEMBL1498509 & 688171 & 6.2 & 4.8348 & TST & \\
\hline CHEMBL1598912 & 688171 & 4.9 & 4.8295 & TRN & \\
\hline CHEMBL1391912 & 688171 & 4.35 & 4.9747 & TST & \\
\hline CHEMBL1967385 & 688171 & 4.9 & 4.9458 & TST & \\
\hline CHEMBL1513778 & 688171 & 5.0 & 4.828 & TRN & \\
\hline CHEMBL1426949 & 688171 & 4.65 & 4.9436 & TRN & \\
\hline CHEMBL1505126 & 688171 & 5.15 & 4.956 & TST & \\
\hline CHEMBL270297 & 688171 & 5.5 & 5.0191 & TRN & \\
\hline CHEMBL1595070 & 688171 & 7.0 & 4.8578 & TST & \\
\hline CHEMBL3197491 & 688171 & 4.7 & 4.8067 & TRN & \\
\hline CHEMBL1405350 & 688171 & 4.45 & 4.9289 & TRN & \\
\hline CHEMBL3197903 & 688171 & 4.7 & 4.9824 & TRN & \\
\hline CHEMBL1375636 & 688171 & 4.45 & 4.8892 & TST & \\
\hline
\end{tabular}




\begin{tabular}{|c|c|c|c|c|}
\hline \multicolumn{5}{|c|}{ Supplemental Table S2.txt } \\
\hline CHEMBL1548865 & 688171 & 4.5 & 4.8354 & TRN \\
\hline CHEMBL1427138 & 688171 & 4.7 & 4.774 & TRN \\
\hline CHEMBL1408821 & 688171 & 4.5 & 4.8698 & TRN \\
\hline CHEMBL1303021 & 688171 & 4.8 & 4.85 & TRN \\
\hline CHEMBL1561742 & 688171 & 4.4 & 4.9453 & TRN \\
\hline CHEMBL1360857 & 688171 & 4.7 & 4.8469 & TST \\
\hline CHEMBL1454373 & 688171 & 4.6 & 4.9324 & TRN \\
\hline CHEMBL1555158 & 688171 & 6.6499 & 5.0157 & TRN \\
\hline CHEMBL1513888 & 688171 & 4.35 & 4.9905 & TST \\
\hline CHEMBL1515418 & 688171 & 4.4 & 4.953 & TRN \\
\hline CHEMBL1433749 & 688171 & 7.0 & 4.8894 & TRN \\
\hline CHEMBL1558765 & 688171 & 5.1 & 4.9818 & TRN \\
\hline CHEMBL1338540 & 688171 & 5.05 & 4.9784 & TRN \\
\hline CHEMBL1591038 & 688171 & 4.6 & 5.038 & TRN \\
\hline CHEMBL1516834 & 688171 & 4.6 & 4.9577 & TST \\
\hline CHEMBL1490632 & 688171 & 4.7 & 4.8561 & TRN \\
\hline CHEMBL1452917 & 688171 & 4.6 & 4.9724 & TST \\
\hline CHEMBL1981008 & 688171 & 5.0 & 4.9556 & TST \\
\hline CHEMBL1425837 & 688171 & 4.6 & 4.8268 & TRN \\
\hline CHEMBL1333338 & 688171 & 4.95 & 4.86 & TRN \\
\hline CHEMBL1336521 & 688171 & 6.2 & 5.0387 & TST \\
\hline CHEMBL1553361 & 688171 & 5.0 & 5.0268 & TRN \\
\hline CHEMBL3195710 & 688171 & 4.4 & 5.1436 & TRN \\
\hline CHEMBL1301811 & 688171 & 4.5 & 4.8565 & TST \\
\hline CHEMBL1316510 & 688171 & 4.6 & 4.9054 & TRN \\
\hline CHEMBL1870032 & 688171 & 4.95 & 4.8672 & TST \\
\hline CHEMBL1612699 & 688171 & 4.65 & 4.8588 & TST \\
\hline CHEMBL1577714 & 688171 & 4.9 & 5.0163 & TST \\
\hline CHEMBL1463600 & 688171 & 4.5 & 4.9476 & TRN \\
\hline CHEMBL1453783 & 688171 & 6.0 & 5.0114 & TRN \\
\hline CHEMBL1466685 & 688171 & 4.45 & 4.9128 & TRN \\
\hline CHEMBL1524115 & 688171 & 4.35 & 4.9123 & TRN \\
\hline CHEMBL1329417 & 688171 & 4.45 & 4.8944 & TST \\
\hline CHEMBL1599728 & 688171 & 4.75 & 4.9475 & TRN \\
\hline CHEMBL1586139 & 688171 & 5.05 & 4.7619 & TRN \\
\hline CHEMBL3194400 & 688171 & 4.55 & 4.9201 & TRN \\
\hline CHEMBL3189187 & 688171 & 5.55 & 4.9706 & TRN \\
\hline CHEMBL1396678 & 688171 & 4.5 & 4.7727 & TRN \\
\hline CHEMBL3213376 & 688171 & 4.55 & 4.8426 & TRN \\
\hline CHEMBL1315959 & 688171 & 5.6 & 4.9286 & TRN \\
\hline CHEMBL1365610 & 688171 & 4.5 & 4.8774 & TRN \\
\hline CHEMBL1517043 & 688171 & 4.85 & 4.7917 & TRN \\
\hline CHEMBL1418050 & 688171 & 4.75 & 4.9341 & TRN \\
\hline CHEMBL1435468 & 688171 & 5.75 & 4.8609 & TRN \\
\hline CHEMBL1525233 & 688171 & 5.05 & 4.994 & TRN \\
\hline CHEMBL1305419 & 688171 & 4.75 & 4.8928 & TRN \\
\hline CHEMBL1465312 & 688171 & 5.4 & 4.9253 & TST \\
\hline CHEMBL1509506 & 688171 & 4.45 & 5.1198 & TST \\
\hline
\end{tabular}




\begin{tabular}{|c|c|c|c|c|c|}
\hline \multicolumn{6}{|c|}{ Supplemental Table S2.txt } \\
\hline CHEMBL1406429 & 688171 & 4.5 & 4.9112 & TRN & \\
\hline CHEMBL1428298 & 688171 & 4.4 & 4.8835 & TRN & \\
\hline CHEMBL1554834 & 688171 & 4.6 & 4.9042 & TRN & \\
\hline CHEMBL1370884 & 688171 & 4.85 & 4.8252 & TRN & \\
\hline CHEMBL1448296 & 688171 & 4.85 & 4.8632 & TRN & \\
\hline CHEMBL1537716 & 688171 & 4.85 & 4.8583 & TRN & \\
\hline CHEMBL1452735 & 688171 & 6.0 & 4.8806 & TST & \\
\hline CHEMBL1476370 & 688171 & 4.4 & 4.8136 & TRN & \\
\hline CHEMBL1310930 & 688171 & 4.55 & 4.8344 & TRN & \\
\hline CHEMBL1546182 & 688171 & 4.7 & 4.9284 & TRN & \\
\hline CHEMBL1342953 & 688171 & 7.1002 & 4.8343 & TST & \\
\hline CHEMBL1310206 & 688171 & 5.75 & 4.9637 & TST & \\
\hline CHEMBL1525173 & 688171 & 4.9 & 4.9125 & TRN & \\
\hline CHEMBL1363986 & 688171 & 4.65 & 5.035 & TRN & \\
\hline CHEMBL1360210 & 688171 & 4.35 & 4.9609 & TRN & \\
\hline CHEMBL1423254 & 688171 & 4.65 & 4.8266 & TRN & \\
\hline CHEMBL1604447 & 688171 & 4.85 & 4.9599 & TRN & \\
\hline CHEMBL1499260 & 688171 & 4.9 & 4.9985 & TRN & \\
\hline CHEMBL1607790 & 688171 & 5.05 & 5.0227 & TRN & \\
\hline CHEMBL1549140 & 688171 & 6.05 & 4.9069 & TRN & \\
\hline CHEMBL1538398 & 688171 & 4.4 & 4.8552 & TRN & \\
\hline CHEMBL3189567 & 688171 & 4.5 & 4.9213 & TRN & \\
\hline CHEMBL1465008 & 688171 & 4.9 & 4.85 & TRN & \\
\hline CHEMBL3194782 & 688171 & 4.4 & 4.9448 & TRN & \\
\hline CHEMBL1529368 & 688171 & 5.45 & 4.7978 & TRN & \\
\hline CHEMBL1470076 & 688171 & 5.2 & 4.9815 & TST & \\
\hline CHEMBL1366134 & 688171 & 4.65 & 5.1044 & TRN & \\
\hline CHEMBL1337933 & 688171 & 4.8 & 4.9185 & TST & \\
\hline CHEMBL1401876 & 688171 & 4.4 & 4.9213 & TRN & \\
\hline CHEMBL1484595 & 688171 & 4.35 & 4.9569 & TST & \\
\hline CHEMBL1336206 & 688171 & 4.95 & 4.8921 & TRN & \\
\hline CHEMBL1372326 & 688171 & 5.1 & 4.9806 & TRN & \\
\hline CHEMBL1314090 & 688171 & 5.1 & 4.9636 & TST & \\
\hline CHEMBL1439936 & 688171 & 4.35 & 4.9659 & TST & \\
\hline CHEMBL1330174 & 688171 & 4.45 & 4.8953 & TRN & \\
\hline CHEMBL3193450 & 688171 & 5.35 & 4.9547 & TRN & \\
\hline CHEMBL3192701 & 688171 & 4.55 & 4.9608 & TRN & \\
\hline CHEMBL1551858 & 688171 & 4.4 & 4.9624 & TST & \\
\hline CHEMBL1319587 & 688171 & 4.5 & 4.9311 & TRN & \\
\hline CHEMBL1991112 & 688171 & 6.8 & 4.8561 & TRN & \\
\hline CHEMBL1600191 & 688171 & 4.55 & 4.8048 & TRN & \\
\hline CHEMBL1369200 & 688171 & 4.5 & 4.77806 & 00000000005 & TRN \\
\hline CHEMBL1434889 & 688171 & 4.7 & 4.9231 & TRN & \\
\hline CHEMBL1322689 & 688171 & 4.55 & 4.8163 & TRN & \\
\hline CHEMBL1572877 & 688171 & 5.8 & 5.091 & TST & \\
\hline CHEMBL1581800 & 688171 & 4.9 & 4.9433 & TST & \\
\hline CHEMBL1358160 & 688171 & 4.55 & 4.8318 & TRN & \\
\hline CHEMBL1472799 & 688171 & 5.05 & 4.8897 & TRN & \\
\hline
\end{tabular}




\begin{tabular}{|c|c|c|c|c|c|}
\hline \multicolumn{6}{|c|}{ Supplemental Table s2.txt } \\
\hline CHEMBL1588213 & 688171 & 4.4 & 4.8778 & TRN & \\
\hline CHEMBL1455545 & 688171 & 4.7 & 4.8481 & TRN & \\
\hline CHEMBL1433998 & 688171 & 5.0 & 4.9209 & TRN & \\
\hline CHEMBL1537481 & 688171 & 4.75 & 4.7259 & TST & \\
\hline CHEMBL1357683 & 688171 & 4.35 & 4.922 & TRN & \\
\hline CHEMBL1495223 & 688171 & 4.95 & 4.8464 & TRN & \\
\hline CHEMBL1341162 & 688171 & 4.8 & 4.9417 & TRN & \\
\hline CHEMBL1471740 & 688171 & 4.8 & 4.9207 & TRN & \\
\hline CHEMBL1584720 & 688171 & 4.5 & 4.9558 & TRN & \\
\hline CHEMBL1443065 & 688171 & 4.8 & 4.8744 & TRN & \\
\hline CHEMBL1342425 & 688171 & 4.35 & 4.8544 & TST & \\
\hline CHEMBL1299967 & 688171 & 4.4 & 5.0147 & TRN & \\
\hline CHEMBL 3193879 & 688171 & 4.75 & 4.7934 & TRN & \\
\hline CHEMBL1599425 & 688171 & 5.1 & 4.9964 & TST & \\
\hline CHEMBL1528043 & 688171 & 4.85 & 4.7964 & TRN & \\
\hline CHEMBL1523856 & 688171 & 4.8 & 4.8851 & TST & \\
\hline CHEMBL1583964 & 688171 & 4.4 & 4.9562 & TST & \\
\hline CHEMBL3209935 & 688171 & 4.9 & 4.988 & TRN & \\
\hline CHEMBL1514506 & 688171 & 4.6 & 4.8491 & TRN & \\
\hline CHEMBL 1470520 & 688171 & 5.25 & 4.9484 & TRN & \\
\hline CHEMBL75913 & 688171 & 4.6 & 4.8504 & TRN & \\
\hline CHEMBL3211856 & 688171 & 4.45 & 4.8789 & TST & \\
\hline CHEMBL1550423 & 688171 & 4.8 & 4.9292 & TST & \\
\hline CHEMBL1606599 & 688171 & 4.75 & 4.8788 & TRN & \\
\hline CHEMBL1413988 & 688171 & 4.6 & 4.9518 & TST & \\
\hline CHEMBL1490600 & 688171 & 4.35 & 4.8923 & TST & \\
\hline CHEMBL1366915 & 688171 & 4.4 & 4.973 & TRN & \\
\hline CHEMBL1574146 & 688171 & 4.65 & 4.8122 & TST & \\
\hline CHEMBL1514605 & 688171 & 4.5 & 4.9894 & TRN & \\
\hline CHEMBL1537812 & 688171 & 5.3 & 4.9866 & TST & \\
\hline CHEMBL1369376 & 688171 & 4.55 & 4.763 & TRN & \\
\hline CHEMBL1392454 & 688171 & 4.8 & 4.8811 & TST & \\
\hline CHEMBL1599895 & 688171 & 4.7 & 4.8106 & TRN & \\
\hline CHEMBL1590327 & 688171 & 5.2 & 5.0361 & TRN & \\
\hline CHEMBL1559798 & 688171 & 4.75 & 5.004 & TRN & \\
\hline CHEMBL1581740 & 688171 & 4.35 & 4.8478 & TRN & \\
\hline CHEMBL1509914 & 688171 & 7.6003 & 4.8334 & TST & \\
\hline CHEMBL105890 & 688171 & 4.4 & 5.0931 & TST & \\
\hline CHEMBL1427316 & 688171 & 5.0 & 4.8058 & TRN & \\
\hline CHEMBL1402026 & 688171 & 4.4 & 4.83899 & 99999999995 & \\
\hline CHEMBL1456379 & 688171 & 4.55 & 4.8119 & TRN & \\
\hline CHEMBL1518874 & 688171 & 4.4 & 4.8823 & TST & \\
\hline CHEMBL1319076 & 688171 & 4.75 & 4.9331 & TST & \\
\hline CHEMBL1524331 & 688171 & 4.75 & 5.0611 & TRN & \\
\hline CHEMBL1605653 & 688171 & 4.7 & 4.8423 & TRN & \\
\hline CHEMBL1593003 & 688171 & 4.95 & 4.9362 & TRN & \\
\hline CHEMBL1403903 & 688171 & 4.4 & 4.9409 & TRN & \\
\hline CHEMBL3209649 & 688171 & 5.15 & 4.6877 & TRN & \\
\hline
\end{tabular}




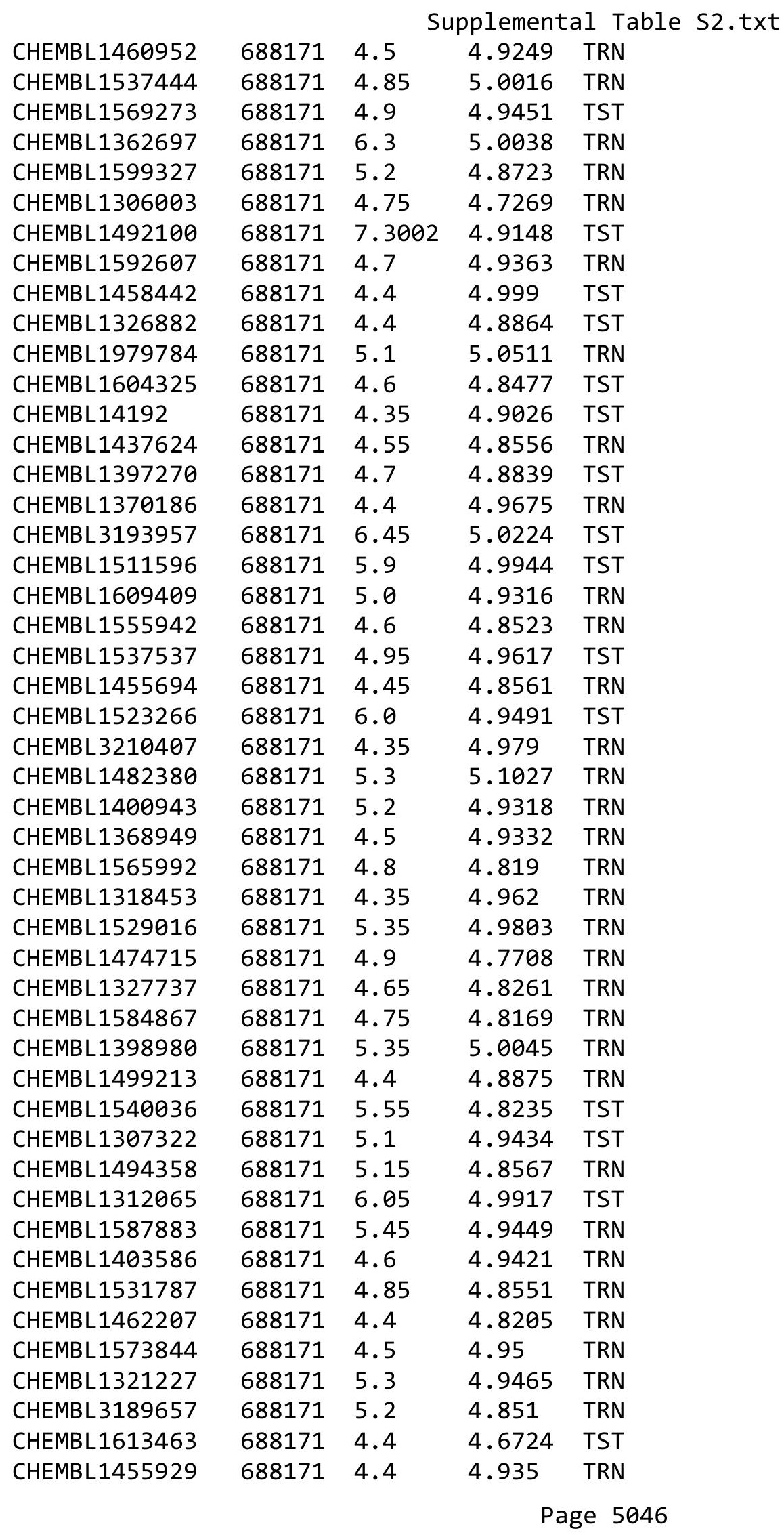




\begin{tabular}{|c|c|c|c|c|}
\hline \multicolumn{5}{|c|}{ Supplemental Table S2.txt } \\
\hline CHEMBL1310694 & 688171 & 4.9 & 4.9977 & TRN \\
\hline CHEMBL1533255 & 688171 & 4.35 & 4.9691 & TRN \\
\hline CHEMBL1318549 & 688171 & 4.65 & 4.805 & TRN \\
\hline CHEMBL1576853 & 688171 & 7.6003 & 5.0185 & TRN \\
\hline CHEMBL1558629 & 688171 & 5.55 & 4.8249 & TRN \\
\hline CHEMBL3191562 & 688171 & 4.45 & 4.8899 & TRN \\
\hline CHEMBL1550215 & 688171 & 4.4 & 4.9769 & TST \\
\hline CHEMBL1299470 & 688171 & 4.4 & 5.01 & TRN \\
\hline CHEMBL1484314 & 688171 & 4.4 & 4.8458 & TST \\
\hline CHEMBL1406102 & 688171 & 4.4 & 4.9033 & TRN \\
\hline CHEMBL 3193652 & 688171 & 4.4 & 4.9644 & TST \\
\hline CHEMBL1494335 & 688171 & 4.45 & 4.8224 & TRN \\
\hline CHEMBL1559589 & 688171 & 5.45 & 4.9618 & TRN \\
\hline CHEMBL1510129 & 688171 & 4.85 & 4.909 & TRN \\
\hline CHEMBL1460639 & 688171 & 4.4 & 4.8431 & TST \\
\hline CHEMBL1526094 & 688171 & 4.6 & 4.9342 & TRN \\
\hline CHEMBL1505608 & 688171 & 6.5 & 4.8183 & TRN \\
\hline CHEMBL1387075 & 688171 & 5.15 & 4.9287 & TRN \\
\hline CHEMBL1490845 & 688171 & 4.4 & 4.9543 & TST \\
\hline CHEMBL1467304 & 688171 & 4.9 & 4.8085 & TST \\
\hline CHEMBL1355741 & 688171 & 4.7 & 4.8729 & TRN \\
\hline CHEMBL1433894 & 688171 & 5.75 & 4.8847 & TRN \\
\hline CHEMBL1577831 & 688171 & 4.55 & 4.9251 & TRN \\
\hline CHEMBL1357848 & 688171 & 4.65 & 4.8998 & TRN \\
\hline CHEMBL1417911 & 688171 & 4.35 & 4.885 & TRN \\
\hline CHEMBL1584975 & 688171 & 5.35 & 4.9329 & TRN \\
\hline CHEMBL1333318 & 688171 & 6.4 & 4.8541 & TST \\
\hline CHEMBL523200 & 688171 & 5.0 & 4.8916 & TST \\
\hline CHEMBL1544254 & 688171 & 4.55 & 4.9061 & TRN \\
\hline CHEMBL1415271 & 688171 & 5.15 & 4.8644 & TRN \\
\hline CHEMBL1555444 & 688171 & 4.4 & 4.8922 & TRN \\
\hline CHEMBL1597207 & 688171 & 6.0 & 4.9164 & TRN \\
\hline CHEMBL1367274 & 688171 & 4.55 & 4.9285 & TST \\
\hline CHEMBL1409902 & 688171 & 4.55 & 4.9272 & TRN \\
\hline CHEMBL1554312 & 688171 & 4.4 & 4.7881 & TRN \\
\hline CHEMBL1401646 & 688171 & 5.7 & 5.0821 & TRN \\
\hline CHEMBL3196499 & 688171 & 6.05 & 5.0589 & TRN \\
\hline CHEMBL1530115 & 688171 & 4.5 & 5.0272 & TRN \\
\hline CHEMBL1590073 & 688171 & 4.75 & 5.0097 & TST \\
\hline CHEMBL1545875 & 688171 & 4.55 & 4.908 & TRN \\
\hline CHEMBL1399398 & 688171 & 5.55 & 4.9714 & TRN \\
\hline CHEMBL1564852 & 688171 & 4.95 & 4.8741 & TRN \\
\hline CHEMBL1402215 & 688171 & 4.4 & 4.9707 & TRN \\
\hline CHEMBL1502644 & 688171 & 4.65 & 4.9209 & TST \\
\hline CHEMBL1513997 & 688171 & 5.5 & 4.7624 & TRN \\
\hline CHEMBL1449533 & 688171 & 4.5 & 4.8305 & TRN \\
\hline CHEMBL1540682 & 688171 & 5.15 & 4.9054 & TRN \\
\hline CHEMBL1589916 & 688171 & 6.7001 & 4.8843 & TRN \\
\hline
\end{tabular}




\begin{tabular}{|c|c|c|c|c|c|}
\hline \multicolumn{6}{|c|}{ Supplemental Table S2.txt } \\
\hline CHEMBL1434281 & 688171 & 4.5 & 5.0797 & TRN & \\
\hline CHEMBL1357006 & 688171 & 4.95 & 4.9678 & TRN & \\
\hline CHEMBL306783 & 688171 & 4.8 & 4.9842 & TRN & \\
\hline CHEMBL1577213 & 688171 & 4.55 & 4.8704 & TRN & \\
\hline CHEMBL1439409 & 688171 & 6.0 & 4.9484 & TRN & \\
\hline CHEMBL1305537 & 688171 & 5.0 & 5.1077 & TRN & \\
\hline CHEMBL1327707 & 688171 & 6.95 & 4.88899 & 9999999999 & TST \\
\hline CHEMBL1469758 & 688171 & 4.55 & 4.9179 & TST & \\
\hline CHEMBL1309765 & 688171 & 4.45 & 4.7907 & TST & \\
\hline CHEMBL1388509 & 688171 & 4.4 & 4.8472 & TRN & \\
\hline CHEMBL1590340 & 688171 & 6.1 & 5.0434 & TRN & \\
\hline CHEMBL1534961 & 688171 & 4.75 & 4.9299 & TST & \\
\hline CHEMBL1500933 & 688171 & 4.35 & 4.8094 & TRN & \\
\hline CHEMBL1439872 & 688171 & 4.85 & 4.9176 & TRN & \\
\hline CHEMBL1458946 & 688171 & 4.85 & 4.881 & TST & \\
\hline CHEMBL1456969 & 688171 & 5.6 & 4.8834 & TRN & \\
\hline CHEMBL1316513 & 688171 & 4.8 & 4.7941 & TRN & \\
\hline CHEMBL1592160 & 688171 & 4.6 & 4.8209 & TRN & \\
\hline CHEMBL1595921 & 688171 & 5.05 & 4.8728 & TRN & \\
\hline CHEMBL1335965 & 688171 & 4.5 & 4.775 & TST & \\
\hline CHEMBL1529163 & 688171 & 4.9 & 4.8449 & TRN & \\
\hline CHEMBL3191089 & 688171 & 4.95 & 4.9332 & TRN & \\
\hline CHEMBL1537686 & 688171 & 6.0 & 4.7643 & TRN & \\
\hline CHEMBL1514884 & 688171 & 4.4 & 4.817 & TRN & \\
\hline CHEMBL1391082 & 688171 & 4.45 & 4.9887 & TST & \\
\hline CHEMBL1592500 & 688171 & 5.05 & 4.8578 & TST & \\
\hline CHEMBL1321710 & 688171 & 4.4 & 4.8018 & TST & \\
\hline CHEMBL1523219 & 688171 & 4.4 & 4.7658 & TRN & \\
\hline CHEMBL1386684 & 688171 & 4.95 & 5.0189 & TST & \\
\hline CHEMBL1326059 & 688171 & 4.85 & 4.987 & TRN & \\
\hline CHEMBL1558669 & 688171 & 5.75 & 5.0464 & TRN & \\
\hline CHEMBL1590325 & 688171 & 5.1 & 4.9194 & TRN & \\
\hline CHEMBL1388971 & 688171 & 4.35 & 4.8941 & TST & \\
\hline CHEMBL1359934 & 688171 & 5.45 & 4.9454 & TRN & \\
\hline CHEMBL1562692 & 688171 & 5.45 & 5.0368 & TST & \\
\hline CHEMBL1401880 & 688171 & 4.65 & 4.8464 & TRN & \\
\hline CHEMBL1446847 & 688171 & 5.65 & 4.9633 & TST & \\
\hline CHEMBL1567457 & 688171 & 5.1 & 5.0412 & TRN & \\
\hline CHEMBL1578269 & 688171 & 5.15 & 4.766 & TRN & \\
\hline CHEMBL1337379 & 688171 & 4.4 & 4.91100 & 00000000005 & TRN \\
\hline CHEMBL1463997 & 688171 & 6.0 & 4.7885 & TST & \\
\hline CHEMBL1341556 & 688171 & 4.95 & 4.9027 & TRN & \\
\hline CHEMBL1527405 & 688171 & 4.9 & 4.8901 & TRN & \\
\hline CHEMBL1487355 & 688171 & 4.85 & 4.9441 & TRN & \\
\hline CHEMBL1394721 & 688171 & 4.45 & 5.0105 & TST & \\
\hline CHEMBL1450692 & 688171 & 6.0 & 4.8961 & TST & \\
\hline CHEMBL1342600 & 688171 & 4.5 & 4.8143 & TRN & \\
\hline CHEMBL1320969 & 688171 & 5.05 & 4.9949 & TST & \\
\hline
\end{tabular}




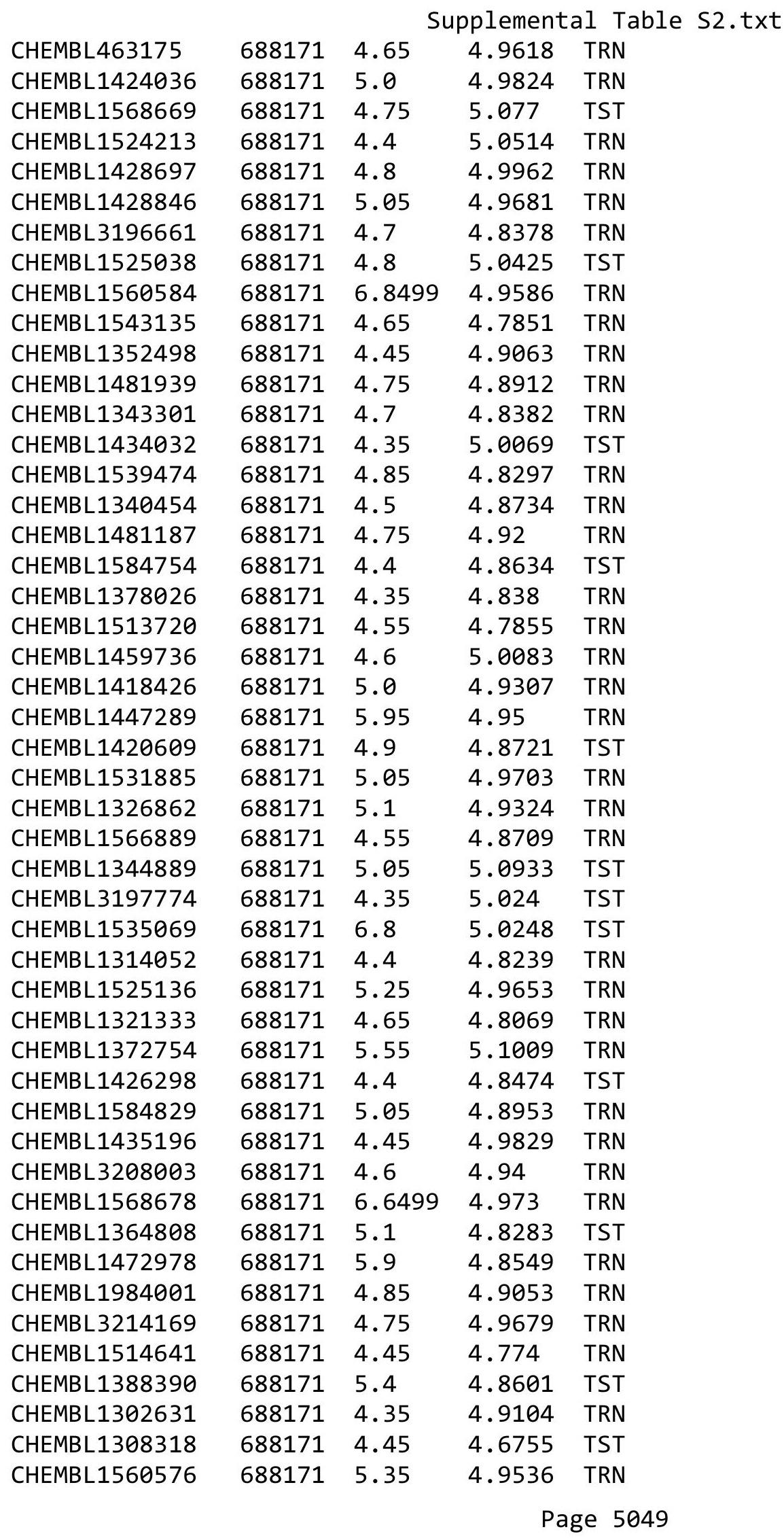




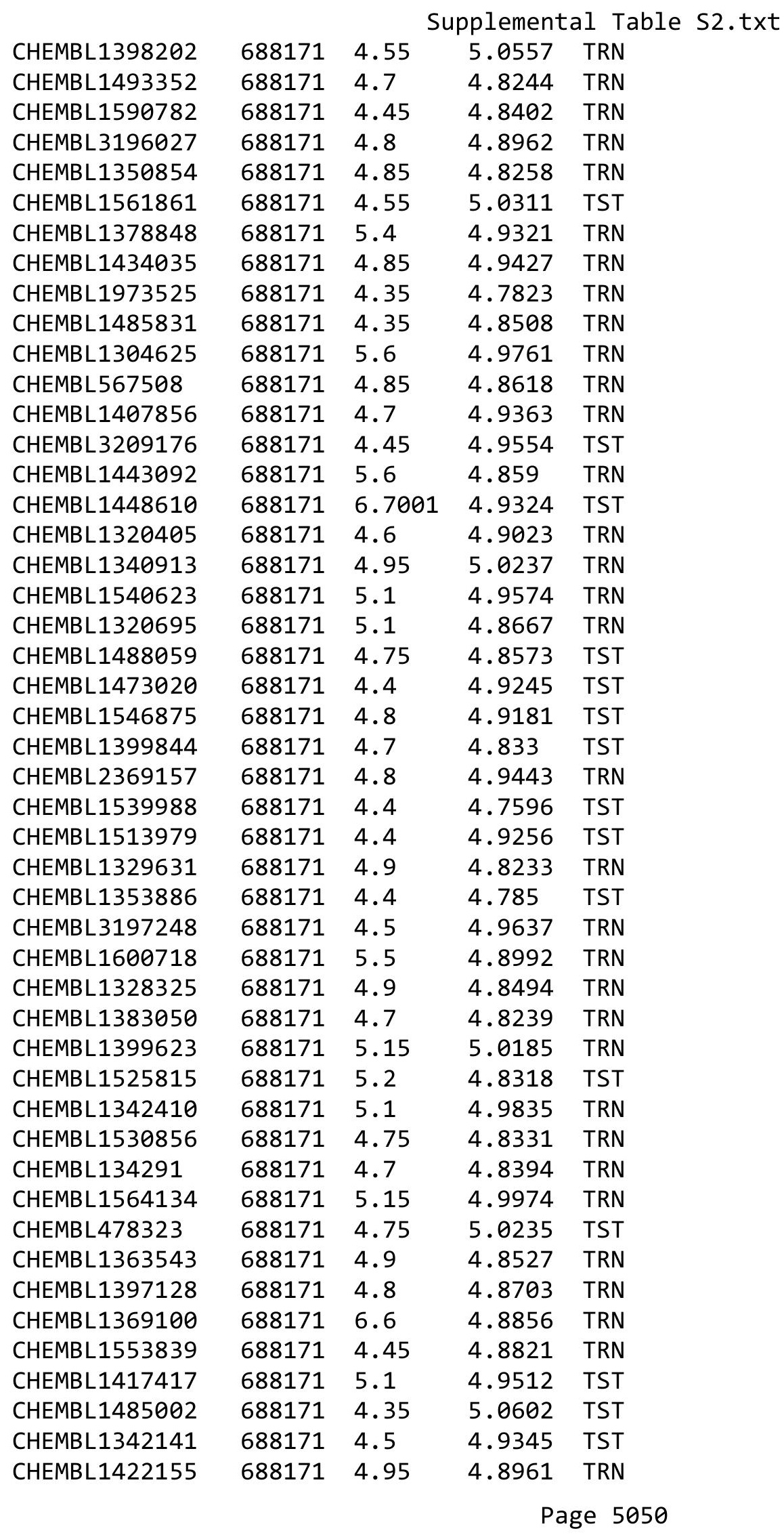




\begin{tabular}{|c|c|c|c|c|c|}
\hline \multicolumn{6}{|c|}{ Supplemental Table S2.txt } \\
\hline CHEMBL1386648 & 688171 & 5.1 & 4.8238 & TRN & \\
\hline CHEMBL1434589 & 688171 & 4.4 & 4.6413 & TRN & \\
\hline CHEMBL1334107 & 688171 & 7.6003 & 4.9527 & TRN & \\
\hline CHEMBL1438779 & 688171 & 4.75 & 4.8581 & TRN & \\
\hline CHEMBL1436784 & 688171 & 4.95 & 4.83899 & 99999999995 & TRN \\
\hline CHEMBL3392052 & 688171 & 4.35 & 4.763 & TRN & \\
\hline CHEMBL1389533 & 688171 & 5.1 & 4.8844 & TRN & \\
\hline CHEMBL1525293 & 688171 & 4.5 & 4.9139 & TRN & \\
\hline CHEMBL1356541 & 688171 & 4.95 & 4.8191 & TRN & \\
\hline CHEMBL3190603 & 688171 & 4.65 & 4.8326 & TST & \\
\hline CHEMBL1317170 & 688171 & 4.55 & 4.8426 & TRN & \\
\hline CHEMBL1380270 & 688171 & 4.6 & 4.9244 & TRN & \\
\hline CHEMBL1491079 & 688171 & 4.6 & 4.9205 & TST & \\
\hline CHEMBL1429260 & 688171 & 4.45 & 4.8161 & TST & \\
\hline CHEMBL1547342 & 688171 & 4.95 & 4.7764 & TRN & \\
\hline CHEMBL1448440 & 688171 & 4.8 & 4.8405 & TST & \\
\hline CHEMBL1505120 & 688171 & 4.95 & 4.8909 & TRN & \\
\hline CHEMBL1518925 & 688171 & 4.75 & 4.8818 & TST & \\
\hline CHEMBL1354481 & 688171 & 4.5 & 4.8047 & TRN & \\
\hline CHEMBL1429955 & 688171 & 5.5 & 4.7843 & TST & \\
\hline CHEMBL1606682 & 688171 & 4.6 & 4.9355 & TST & \\
\hline CHEMBL1368532 & 688171 & 4.8 & 4.9234 & TRN & \\
\hline CHEMBL1447052 & 688171 & 4.9 & 4.8281 & TRN & \\
\hline CHEMBL1349663 & 688171 & 5.5 & 4.8378 & TRN & \\
\hline CHEMBL1597238 & 688171 & 4.55 & 4.8411 & TRN & \\
\hline CHEMBL1971120 & 688171 & 4.4 & 4.8483 & TRN & \\
\hline CHEMBL1413268 & 688171 & 4.4 & 4.8914 & TRN & \\
\hline CHEMBL1597789 & 688171 & 4.8 & 4.8765 & TRN & \\
\hline CHEMBL1497409 & 688171 & 5.2 & 4.9547 & TRN & \\
\hline CHEMBL3197912 & 688171 & 4.65 & 5.0258 & TRN & \\
\hline CHEMBL1586235 & 688171 & 4.45 & 4.8886 & TST & \\
\hline CHEMBL1612294 & 688171 & 4.8 & 4.7912 & TRN & \\
\hline CHEMBL 3210827 & 688171 & 4.35 & 4.8373 & TST & \\
\hline CHEMBL1465522 & 688171 & 4.45 & 4.8288 & TST & \\
\hline CHEMBL1442905 & 688171 & 5.2 & 4.8232 & TST & \\
\hline CHEMBL1535449 & 688171 & 4.4 & 4.8964 & TRN & \\
\hline CHEMBL1405393 & 688171 & 4.75 & 4.6997 & TRN & \\
\hline CHEMBL1452775 & 688171 & 5.05 & 5.0594 & TST & \\
\hline CHEMBL1498952 & 688171 & 4.45 & 4.9202 & TST & \\
\hline CHEMBL1501136 & 688171 & 6.45 & 4.9832 & TRN & \\
\hline CHEMBL1319101 & 688171 & 4.8 & 4.7099 & TRN & \\
\hline CHEMBL1314911 & 688171 & 6.5 & 5.0666 & TRN & \\
\hline CHEMBL1565814 & 688171 & 4.4 & 4.956 & TST & \\
\hline CHEMBL3199451 & 688171 & 4.6 & 4.862 & TRN & \\
\hline CHEMBL1335047 & 688171 & 4.4 & 5.0073 & TST & \\
\hline CHEMBL1581410 & 688171 & 4.4 & 4.8523 & TRN & \\
\hline CHEMBL 3194174 & 688171 & 4.6 & 4.9903 & TRN & \\
\hline CHEMBL1346734 & 688171 & 4.35 & 5.0516 & TRN & \\
\hline
\end{tabular}




\begin{tabular}{|c|c|c|c|c|}
\hline \multicolumn{5}{|c|}{ Supplemental Table S2.txt } \\
\hline CHEMBL1339270 & 688171 & 5.8 & 4.8958 & TRN \\
\hline CHEMBL1551502 & 688171 & 4.8 & 4.8063 & TRN \\
\hline CHEMBL1587709 & 688171 & 4.7 & 4.9664 & TRN \\
\hline CHEMBL1593325 & 688171 & 5.05 & 4.981 & TRN \\
\hline CHEMBL1416027 & 688171 & 4.75 & 4.9085 & TST \\
\hline CHEMBL1489123 & 688171 & 5.95 & 4.8966 & TST \\
\hline CHEMBL1586593 & 688171 & 4.65 & 4.8169 & TRN \\
\hline CHEMBL1342907 & 688171 & 5.0 & 4.7993 & TRN \\
\hline CHEMBL1427233 & 688171 & 4.55 & 4.9534 & TRN \\
\hline CHEMBL1563057 & 688171 & 4.8 & 4.8972 & TRN \\
\hline CHEMBL1577001 & 688171 & 4.9 & 4.8307 & TRN \\
\hline CHEMBL1381360 & 688171 & 4.75 & 4.8889 & TST \\
\hline CHEMBL1402629 & 688171 & 4.6 & 4.8144 & TRN \\
\hline CHEMBL1454800 & 688171 & 4.55 & 4.9788 & TST \\
\hline CHEMBL1551326 & 688171 & 5.35 & 4.7698 & TRN \\
\hline CHEMBL1548676 & 688171 & 5.5 & 5.0092 & TST \\
\hline CHEMBL1541861 & 688171 & 4.45 & 4.9273 & TRN \\
\hline CHEMBL1430891 & 688171 & 5.1 & 4.9364 & TRN \\
\hline CHEMBL1334794 & 688171 & 4.4 & 5.0004 & TRN \\
\hline CHEMBL1494395 & 688171 & 6.7501 & 5.0729 & TRN \\
\hline CHEMBL1490000 & 688171 & 4.35 & 4.9783 & TST \\
\hline CHEMBL1612774 & 688171 & 4.9 & 4.9035 & TRN \\
\hline CHEMBL1430414 & 688171 & 5.65 & 4.8357 & TST \\
\hline CHEMBL1541295 & 688171 & 4.5 & 4.7683 & TRN \\
\hline CHEMBL189382 & 688171 & 7.6003 & 5.1026 & TST \\
\hline CHEMBL1595618 & 688171 & 4.75 & 4.977 & TRN \\
\hline CHEMBL1320333 & 688171 & 5.45 & 4.9349 & TRN \\
\hline CHEMBL1718398 & 688171 & 4.6 & 4.944 & TST \\
\hline CHEMBL1380099 & 688171 & 4.65 & 4.8765 & TRN \\
\hline CHEMBL261131 & 688171 & 4.95 & 4.8567 & TST \\
\hline CHEMBL1357135 & 688171 & 4.4 & 4.9742 & TRN \\
\hline CHEMBL1596058 & 688171 & 5.1 & 5.0094 & TRN \\
\hline CHEMBL3208455 & 688171 & 4.6 & 4.9478 & TRN \\
\hline CHEMBL1368778 & 688171 & 4.65 & 4.849 & TRN \\
\hline CHEMBL1536682 & 688171 & 4.4 & 4.8697 & TST \\
\hline CHEMBL1537290 & 688171 & 5.1 & 4.8857 & TRN \\
\hline CHEMBL1528925 & 688171 & 4.45 & 4.944 & TST \\
\hline CHEMBL1397240 & 688171 & 4.75 & 4.912 & TRN \\
\hline CHEMBL1445035 & 688171 & 4.55 & 4.9176 & TRN \\
\hline CHEMBL1521719 & 688171 & 5.45 & 4.8945 & TST \\
\hline CHEMBL1336911 & 688171 & 4.5 & 4.9644 & TRN \\
\hline CHEMBL1241132 & 688171 & 5.05 & 4.8742 & TST \\
\hline CHEMBL1548678 & 688171 & 4.75 & 4.7571 & TST \\
\hline CHEMBL3207674 & 688171 & 4.8 & 5.0922 & TRN \\
\hline CHEMBL1426610 & 688171 & 4.45 & 4.8871 & TRN \\
\hline CHEMBL1513564 & 688171 & 5.0 & 4.9059 & TRN \\
\hline CHEMBL1517045 & 688171 & 4.5 & 4.8666 & TST \\
\hline CHEMBL1395023 & 688171 & 5.75 & 4.8624 & TRN \\
\hline
\end{tabular}




\begin{tabular}{|c|c|c|c|c|c|}
\hline \multicolumn{6}{|c|}{ Supplemental Table S2.txt } \\
\hline CHEMBL1470532 & 688171 & 5.15 & 5.08 & TRN & \\
\hline CHEMBL1540469 & 688171 & 4.4 & 4.7363 & TRN & \\
\hline CHEMBL1401873 & 688171 & 6.15 & 5.1367 & TRN & \\
\hline CHEMBL 3209386 & 688171 & 4.4 & 4.8944 & TRN & \\
\hline CHEMBL1436849 & 688171 & 5.45 & 4.8475 & TST & \\
\hline CHEMBL1402313 & 688171 & 4.7 & 5.1317 & TST & \\
\hline CHEMBL 3208825 & 688171 & 4.85 & 4.8876 & TST & \\
\hline CHEMBL1399496 & 688171 & 4.5 & 4.8027 & TRN & \\
\hline CHEMBL1610897 & 688171 & 4.5 & 4.8403 & TRN & \\
\hline CHEMBL1317877 & 688171 & 4.4 & 4.8377 & TRN & \\
\hline CHEMBL1476489 & 688171 & 4.85 & 4.9521 & TRN & \\
\hline CHEMBL1377392 & 688171 & 4.4 & 5.1052 & TST & \\
\hline CHEMBL1299313 & 688171 & 5.3 & 4.9212 & TRN & \\
\hline CHEMBL1475844 & 688171 & 4.55 & 4.8929 & TRN & \\
\hline CHEMBL1412004 & 688171 & 5.25 & 4.8225 & TRN & \\
\hline CHEMBL 2107391 & 688171 & 5.45 & 5.0375 & TST & \\
\hline CHEMBL1504972 & 688171 & 4.55 & 4.9718 & TRN & \\
\hline CHEMBL1382785 & 688171 & 4.6 & 4.9589 & TRN & \\
\hline CHEMBL1449937 & 688171 & 4.9 & 5.0055 & TRN & \\
\hline CHEMBL1326071 & 688171 & 4.55 & 4.9008 & TRN & \\
\hline CHEMBL1386235 & 688171 & 5.45 & 5.0094 & TRN & \\
\hline CHEMBL1488344 & 688171 & 5.0 & 4.9613 & TRN & \\
\hline CHEMBL3190564 & 688171 & 5.9 & 4.8525 & TST & \\
\hline CHEMBL1312180 & 688171 & 4.4 & 4.8155 & TRN & \\
\hline CHEMBL1427169 & 688171 & 4.4 & 4.8679 & TST & \\
\hline CHEMBL3190625 & 688171 & 4.75 & 4.7856 & TRN & \\
\hline CHEMBL1436848 & 688171 & 4.35 & 4.7933 & TST & \\
\hline CHEMBL1533362 & 688171 & 4.35 & 4.939 & TRN & \\
\hline CHEMBL1589841 & 688171 & 4.7 & 4.9756 & TRN & \\
\hline CHEMBL3196836 & 688171 & 4.9 & 4.9518 & TRN & \\
\hline CHEMBL1580338 & 688171 & 4.5 & 5.0763 & TST & \\
\hline CHEMBL1593398 & 688171 & 4.85 & 5.062 & TRN & \\
\hline CHEMBL1356640 & 688171 & 5.0 & 4.91100 & 00000000005 & TRN \\
\hline CHEMBL1368363 & 688171 & 5.0 & 4.8546 & TST & \\
\hline CHEMBL1593658 & 688171 & 5.05 & 5.0326 & TRN & \\
\hline CHEMBL1302523 & 688171 & 4.65 & 4.9571 & TRN & \\
\hline CHEMBL3207351 & 688171 & 5.55 & 4.9661 & TRN & \\
\hline CHEMBL1519313 & 688171 & 5.45 & 4.9772 & TST & \\
\hline CHEMBL1447389 & 688171 & 4.6 & 4.9711 & TST & \\
\hline CHEMBL1476763 & 688171 & 4.5 & 4.8454 & TRN & \\
\hline CHEMBL1335558 & 688171 & 4.6 & 4.8071 & TRN & \\
\hline CHEMBL582715 & 688171 & 5.9 & 4.9886 & TRN & \\
\hline CHEMBL1420619 & 688171 & 4.4 & 4.9163 & TST & \\
\hline CHEMBL1361613 & 688171 & 5.05 & 4.88 & TRN & \\
\hline CHEMBL1399784 & 688171 & 4.6 & 4.9415 & TRN & \\
\hline CHEMBL1324048 & 688171 & 5.2 & 4.8185 & TST & \\
\hline CHEMBL1499346 & 688171 & 4.5 & 4.9444 & TRN & \\
\hline CHEMBL1364766 & 688171 & 4.4 & 4.8182 & TRN & \\
\hline
\end{tabular}




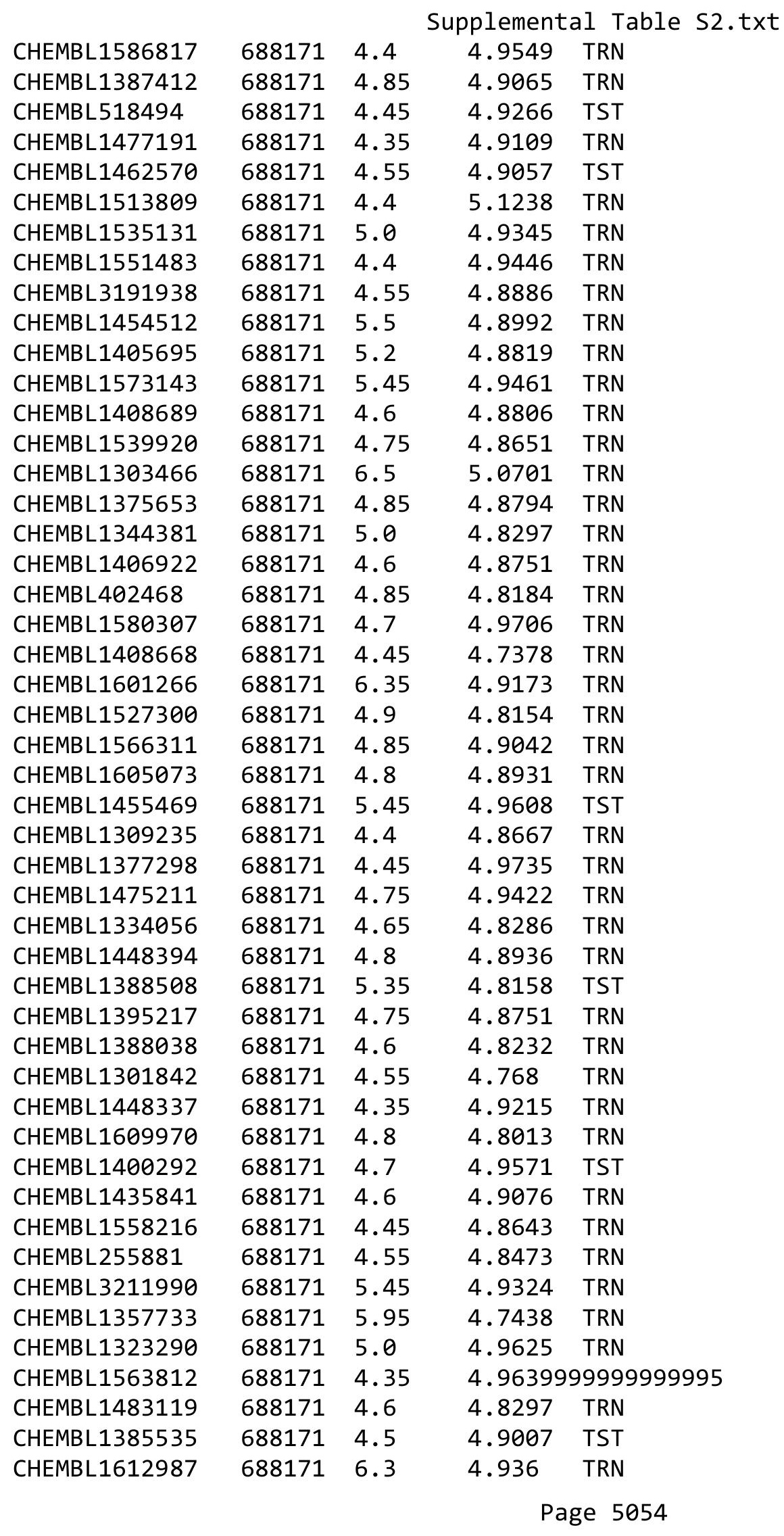




\begin{tabular}{|c|c|c|c|c|c|}
\hline \multicolumn{6}{|c|}{ Supplemental Table S2.txt } \\
\hline CHEMBL1453750 & 688171 & 4.4 & 4.8961 & TST & \\
\hline CHEMBL1356773 & 688171 & 5.0 & 4.8515 & TRN & \\
\hline CHEMBL1442022 & 688171 & 4.85 & 4.9454 & TST & \\
\hline CHEMBL1340514 & 688171 & 4.5 & 5.0174 & TRN & \\
\hline CHEMBL1548370 & 688171 & 4.55 & 4.7851 & TRN & \\
\hline CHEMBL1612155 & 688171 & 5.95 & 5.0842 & TST & \\
\hline CHEMBL1975289 & 688171 & 5.0 & 4.85 & TRN & \\
\hline CHEMBL1482883 & 688171 & 4.45 & 4.8025 & TRN & \\
\hline CHEMBL1490349 & 688171 & 4.75 & 4.7578 & TRN & \\
\hline CHEMBL1438439 & 688171 & 5.15 & 4.8691 & TRN & \\
\hline CHEMBL1519570 & 688171 & 4.6 & 4.8874 & TRN & \\
\hline CHEMBL1440119 & 688171 & 5.05 & 4.9081 & TST & \\
\hline CHEMBL1362986 & 688171 & 4.8 & 4.956 & TST & \\
\hline CHEMBL1519016 & 688171 & 4.45 & 4.9319 & TRN & \\
\hline CHEMBL1375447 & 688171 & 5.1 & 4.9758 & TRN & \\
\hline CHEMBL 3145067 & 688171 & 4.85 & 4.8713 & TST & \\
\hline CHEMBL1400828 & 688171 & 4.55 & 5.022 & TRN & \\
\hline CHEMBL1319447 & 688171 & 4.95 & 4.8006 & TRN & \\
\hline CHEMBL 3190354 & 688171 & 5.8 & 5.0098 & TRN & \\
\hline CHEMBL1391569 & 688171 & 4.4 & 4.8612 & TRN & \\
\hline CHEMBL3195953 & 688171 & 5.55 & 5.0073 & TRN & \\
\hline CHEMBL1573443 & 688171 & 4.95 & 5.0313 & TRN & \\
\hline CHEMBL1560378 & 688171 & 4.35 & 4.8286 & TRN & \\
\hline CHEMBL1559381 & 688171 & 4.4 & 4.8234 & TST & \\
\hline CHEMBL1376416 & 688171 & 5.25 & 4.8654 & TRN & \\
\hline CHEMBL1426273 & 688171 & 4.35 & 4.9336 & TRN & \\
\hline CHEMBL1608300 & 688171 & 4.4 & 4.9065 & TST & \\
\hline CHEMBL1446633 & 688171 & 4.4 & 4.9339 & TST & \\
\hline CHEMBL407734 & 688171 & 5.55 & 4.7881 & TRN & \\
\hline CHEMBL1565767 & 688171 & 5.1 & 5.0057 & TST & \\
\hline CHEMBL 3208848 & 688171 & 4.75 & 5.02 & TRN & \\
\hline CHEMBL1319612 & 688171 & 5.95 & 4.9179 & TRN & \\
\hline CHEMBL1484845 & 688171 & 4.35 & 4.85800 & 00000000005 & TRN \\
\hline CHEMBL1335369 & 688171 & 4.5 & 4.9081 & TRN & \\
\hline CHEMBL1523126 & 688171 & 4.7 & 4.9571 & TRN & \\
\hline CHEMBL1976374 & 688171 & 4.75 & 4.9678 & TST & \\
\hline CHEMBL1590488 & 688171 & 5.0 & 4.9969 & TRN & \\
\hline CHEMBL1511953 & 688171 & 4.75 & 4.8874 & TRN & \\
\hline CHEMBL1601478 & 688171 & 4.7 & 5.0084 & TRN & \\
\hline CHEMBL1595176 & 688171 & 6.6499 & 4.8674 & TRN & \\
\hline CHEMBL1405134 & 688171 & 6.6 & 4.8527 & TST & \\
\hline CHEMBL1431623 & 688171 & 6.35 & 4.9711 & TRN & \\
\hline CHEMBL1534449 & 688171 & 4.7 & 5.0072 & TRN & \\
\hline CHEMBL1493578 & 688171 & 5.3 & 4.948 & TRN & \\
\hline CHEMBL1330559 & 688171 & 4.4 & 4.729 & TST & \\
\hline CHEMBL1336951 & 688171 & 4.7 & 4.9211 & TRN & \\
\hline CHEMBL3198654 & 688171 & 4.4 & 4.9928 & TST & \\
\hline CHEMBL 3208840 & 688171 & 7.6003 & 4.8497 & TST & \\
\hline
\end{tabular}




\begin{tabular}{|c|c|c|c|c|}
\hline \multicolumn{5}{|c|}{ Supplemental Table S2.txt } \\
\hline CHEMBL1538645 & 688171 & 5.1 & 4.9736 & TRN \\
\hline CHEMBL1593858 & 688171 & 4.8 & 4.8055 & TRN \\
\hline CHEMBL1454612 & 688171 & 4.55 & 4.8843 & TRN \\
\hline CHEMBL1502794 & 688171 & 4.75 & 5.0445 & TST \\
\hline CHEMBL1593449 & 688171 & 4.55 & 4.8889 & TRN \\
\hline CHEMBL1543752 & 688171 & 4.6 & 4.9215 & TST \\
\hline CHEMBL1390706 & 688171 & 4.4 & 5.0187 & TRN \\
\hline CHEMBL1360191 & 688171 & 4.4 & 5.0818 & TRN \\
\hline CHEMBL1315148 & 688171 & 5.05 & 4.9088 & TRN \\
\hline CHEMBL1486270 & 688171 & 4.4 & 4.8851 & TRN \\
\hline CHEMBL1377239 & 688171 & 4.7 & 4.9278 & TRN \\
\hline CHEMBL1380826 & 688171 & 4.7 & 5.042 & TRN \\
\hline CHEMBL1554751 & 688171 & 4.4 & 4.8169 & TRN \\
\hline CHEMBL1527185 & 688171 & 5.0 & 4.7762 & TRN \\
\hline CHEMBL1529488 & 688171 & 5.1 & 4.8958 & TRN \\
\hline CHEMBL1543267 & 688171 & 5.2 & 4.9689 & TRN \\
\hline CHEMBL1316333 & 688171 & 4.9 & 4.9411 & TRN \\
\hline CHEMBL1490994 & 688171 & 5.25 & 5.0766 & TRN \\
\hline CHEMBL1433832 & 688171 & 4.4 & 5.0016 & TRN \\
\hline CHEMBL1500761 & 688171 & 4.5 & 4.8737 & TRN \\
\hline CHEMBL1504017 & 688171 & 4.95 & 4.8884 & TRN \\
\hline CHEMBL1460369 & 688171 & 5.95 & 4.8435 & TRN \\
\hline CHEMBL1455897 & 688171 & 4.35 & 4.8573 & TRN \\
\hline CHEMBL1398641 & 688171 & 5.35 & 4.8962 & TRN \\
\hline CHEMBL1533539 & 688171 & 5.25 & 4.9327 & TST \\
\hline CHEMBL1350978 & 688171 & 5.45 & 5.0017 & TRN \\
\hline CHEMBL3190676 & 688171 & 4.65 & 4.9567 & TRN \\
\hline CHEMBL1389246 & 688171 & 4.5 & 5.042 & TRN \\
\hline CHEMBL1383808 & 688171 & 4.4 & 4.9733 & TRN \\
\hline CHEMBL1553864 & 688171 & 4.85 & 5.0779 & TRN \\
\hline CHEMBL1373489 & 688171 & 4.75 & 4.9175 & TRN \\
\hline CHEMBL1531614 & 688171 & 4.35 & 4.7799 & TRN \\
\hline CHEMBL1590348 & 688171 & 4.5 & 4.7957 & TRN \\
\hline CHEMBL1533019 & 688171 & 5.6 & 4.917 & TRN \\
\hline CHEMBL1496468 & 688171 & 4.4 & 4.9539 & TRN \\
\hline CHEMBL1541360 & 688171 & 4.65 & 4.7671 & TRN \\
\hline CHEMBL1441804 & 688171 & 4.75 & 4.8996 & TRN \\
\hline CHEMBL1552848 & 688171 & 5.1 & 5.0256 & TRN \\
\hline CHEMBL1322500 & 688171 & 4.6 & 4.8804 & TRN \\
\hline CHEMBL1315065 & 688171 & 4.7 & 4.7893 & TRN \\
\hline CHEMBL1396152 & 688171 & 4.85 & 4.792 & TRN \\
\hline CHEMBL1491307 & 688171 & 4.75 & 4.9773 & TRN \\
\hline CHEMBL18797 & 688171 & 4.35 & 4.9039 & TST \\
\hline CHEMBL1570659 & 688171 & 5.15 & 5.0257 & TRN \\
\hline CHEMBL1319178 & 688171 & 5.05 & 4.8679 & TRN \\
\hline CHEMBL1500091 & 688171 & 4.4 & 4.8897 & TRN \\
\hline CHEMBL1371753 & 688171 & 4.9 & 4.8411 & TRN \\
\hline CHEMBL1558956 & 688171 & 5.05 & 4.9799 & TST \\
\hline
\end{tabular}




\begin{tabular}{|c|c|c|c|c|}
\hline \multicolumn{5}{|c|}{ Supplemental Table } \\
\hline CHEMBL1342925 & 688171 & 4.65 & 4.9736 & TRN \\
\hline CHEMBL1301868 & 688171 & 5.0 & 4.7281 & TRN \\
\hline CHEMBL1459288 & 688171 & 4.45 & 4.9212 & TST \\
\hline CHEMBL1379801 & 688171 & 4.4 & 4.9208 & TST \\
\hline CHEMBL1515848 & 688171 & 4.85 & 4.8952 & TRN \\
\hline CHEMBL1379578 & 688171 & 5.4 & 4.9291 & TRN \\
\hline CHEMBL1553370 & 688171 & 4.4 & 4.93 & TRN \\
\hline CHEMBL1566839 & 688171 & 5.1 & 4.9907 & TST \\
\hline CHEMBL1543793 & 688171 & 4.5 & 4.9402 & TRN \\
\hline CHEMBL3190713 & 688171 & 5.3 & 4.9284 & TRN \\
\hline CHEMBL1416837 & 688171 & 4.45 & 4.9941 & TRN \\
\hline CHEMBL1485330 & 688171 & 4.5 & 4.8278 & TRN \\
\hline CHEMBL1506738 & 688171 & 5.3 & 4.7672 & TRN \\
\hline CHEMBL1361212 & 688171 & 5.15 & 4.8762 & TST \\
\hline CHEMBL1597081 & 688171 & 4.5 & 4.8561 & TRN \\
\hline CHEMBL1394738 & 688171 & 4.5 & 5.037 & TRN \\
\hline CHEMBL3198774 & 688171 & 4.65 & 4.8952 & TRN \\
\hline CHEMBL3191942 & 688171 & 4.7 & 4.968 & TRN \\
\hline CHEMBL3210039 & 688171 & 4.45 & 4.8213 & TRN \\
\hline CHEMBL1475511 & 688171 & 6.35 & 4.9853 & TRN \\
\hline CHEMBL1340898 & 688171 & 4.75 & 4.9708 & TST \\
\hline CHEMBL1591154 & 688171 & 4.4 & 5.0229 & TRN \\
\hline CHEMBL1577994 & 688171 & 4.45 & 4.8511 & TRN \\
\hline CHEMBL1337115 & 688171 & 4.75 & 4.862 & TRN \\
\hline CHEMBL1542362 & 688171 & 4.9 & 4.9409 & TRN \\
\hline CHEMBL1522692 & 688171 & 4.35 & 4.7984 & TRN \\
\hline CHEMBL3192400 & 688171 & 5.05 & 5.0129 & TRN \\
\hline CHEMBL3197762 & 688171 & 4.4 & 4.9714 & TST \\
\hline CHEMBL3209075 & 688171 & 4.65 & 4.9939 & TRN \\
\hline CHEMBL1515257 & 688171 & 4.7 & 4.9276 & TRN \\
\hline CHEMBL505670 & 688171 & 4.8 & 4.8447 & TST \\
\hline CHEMBL1574653 & 688171 & 4.8 & 4.9392 & TRN \\
\hline CHEMBL1351959 & 688171 & 4.75 & 5.0186 & TST \\
\hline CHEMBL1366199 & 688171 & 4.55 & 4.7435 & TST \\
\hline CHEMBL3207432 & 688171 & 6.8 & 4.8755 & TRN \\
\hline CHEMBL1329917 & 688171 & 4.95 & 4.9369 & TRN \\
\hline CHEMBL1334149 & 688171 & 4.85 & 4.9404 & TRN \\
\hline CHEMBL1311929 & 688171 & 5.05 & 4.9626 & TST \\
\hline CHEMBL1480835 & 688171 & 4.7 & 4.8253 & TRN \\
\hline CHEMBL1400510 & 688171 & 4.4 & 4.8709 & TST \\
\hline CHEMBL1076722 & 688171 & 4.85 & 4.9645 & TRN \\
\hline CHEMBL1499915 & 688171 & 5.35 & 4.9429 & TST \\
\hline CHEMBL1454806 & 688171 & 4.4 & 4.7666 & TRN \\
\hline CHEMBL1158 & 688171 & 5.5 & 4.8559 & TST \\
\hline CHEMBL1505536 & 688171 & 4.65 & 4.9647 & TRN \\
\hline CHEMBL1476196 & 688171 & 4.7 & 4.9758 & TRN \\
\hline CHEMBL1509766 & 688171 & 5.7 & 4.9605 & TRN \\
\hline CHEMBL1611245 & 688171 & 4.95 & 4.9453 & TRN \\
\hline
\end{tabular}




\begin{tabular}{|c|c|c|c|c|c|}
\hline \multicolumn{6}{|c|}{ Supplemental Table s2.txt } \\
\hline CHEMBL1591397 & 688171 & 4.6 & 4.8348 & TRN & \\
\hline CHEMBL1527549 & 688171 & 4.5 & 5.0205 & TST & \\
\hline CHEMBL1460073 & 688171 & 4.65 & 4.9303 & TST & \\
\hline CHEMBL1510852 & 688171 & 5.2 & 4.8872 & TRN & \\
\hline CHEMBL1318516 & 688171 & 4.7 & 4.94600 & 0000000001 & TRN \\
\hline CHEMBL1503470 & 688171 & 4.65 & 5.0358 & TRN & \\
\hline CHEMBL1316232 & 688171 & 4.4 & 4.8588 & TRN & \\
\hline CHEMBL1469554 & 688171 & 4.5 & 4.9001 & TRN & \\
\hline CHEMBL1380591 & 688171 & 4.35 & 4.9377 & TRN & \\
\hline CHEMBL1481162 & 688171 & 5.15 & 4.9007 & TRN & \\
\hline CHEMBL1378799 & 688171 & 4.4 & 4.8741 & TRN & \\
\hline CHEMBL1526565 & 688171 & 4.9 & 4.8932 & TST & \\
\hline CHEMBL1585735 & 688171 & 4.75 & 4.9873 & TRN & \\
\hline CHEMBL1550502 & 688171 & 4.85 & 4.9393 & TRN & \\
\hline CHEMBL1388769 & 688171 & 4.4 & 4.872 & TRN & \\
\hline CHEMBL1374241 & 688171 & 4.55 & 4.849 & TRN & \\
\hline CHEMBL1404792 & 688171 & 5.8 & 4.9264 & TRN & \\
\hline CHEMBL1315288 & 688171 & 4.95 & 5.038 & TST & \\
\hline CHEMBL1315779 & 688171 & 6.7001 & 5.0052 & TRN & \\
\hline CHEMBL1300317 & 688171 & 4.4 & 5.041 & TRN & \\
\hline CHEMBL1525708 & 688171 & 4.5 & 4.7128 & TRN & \\
\hline CHEMBL1501227 & 688171 & 5.45 & 4.8761 & TST & \\
\hline CHEMBL1325466 & 688171 & 4.6 & 4.9628 & TRN & \\
\hline CHEMBL1308731 & 688171 & 4.4 & 4.8559 & TRN & \\
\hline CHEMBL1478915 & 688171 & 7.2503 & 4.9213 & TST & \\
\hline CHEMBL1435423 & 688171 & 4.55 & 4.9266 & TRN & \\
\hline CHEMBL1461573 & 688171 & 4.95 & 4.9322 & TST & \\
\hline CHEMBL1306731 & 688171 & 4.85 & 4.8384 & TST & \\
\hline CHEMBL1506956 & 688171 & 5.05 & 4.9894 & TST & \\
\hline CHEMBL1354522 & 688171 & 4.35 & 4.80699 & 99999999995 & TST \\
\hline CHEMBL1557385 & 688171 & 4.65 & 4.8966 & TST & \\
\hline CHEMBL1311174 & 688171 & 4.45 & 4.7686 & TST & \\
\hline CHEMBL1390340 & 688171 & 4.65 & 4.8466 & TST & \\
\hline CHEMBL1346771 & 688171 & 5.1 & 5.0077 & TRN & \\
\hline CHEMBL1610570 & 688171 & 4.8 & 4.923 & TRN & \\
\hline CHEMBL1396105 & 688171 & 4.75 & 5.1126 & TRN & \\
\hline CHEMBL1599273 & 688171 & 6.0 & 5.0265 & TST & \\
\hline CHEMBL1525164 & 688171 & 4.55 & 4.8609 & TST & \\
\hline CHEMBL1568790 & 688171 & 4.65 & 4.8634 & TST & \\
\hline CHEMBL1604267 & 688171 & 4.4 & 4.7683 & TRN & \\
\hline CHEMBL1490668 & 688171 & 5.3 & 4.9199 & TRN & \\
\hline CHEMBL1609326 & 688171 & 5.45 & 4.8853 & TRN & \\
\hline CHEMBL1361675 & 688171 & 4.65 & 4.9352 & TST & \\
\hline CHEMBL1492764 & 688171 & 5.0 & 5.0525 & TRN & \\
\hline CHEMBL1374844 & 688171 & 5.4 & 4.8345 & TRN & \\
\hline CHEMBL1300431 & 688171 & 5.0 & 4.9735 & TRN & \\
\hline CHEMBL1448041 & 688171 & 5.0 & 4.8785 & TRN & \\
\hline CHEMBL1398006 & 688171 & 4.4 & 4.8629 & TRN & \\
\hline
\end{tabular}




\begin{tabular}{|c|c|c|c|c|c|}
\hline \multicolumn{6}{|c|}{ Supplemental Table S2.txt } \\
\hline CHEMBL1450595 & 688171 & 5.1 & 4.9481 & TRN & \\
\hline CHEMBL1533497 & 688171 & 5.4 & 4.8105 & TST & \\
\hline CHEMBL1363295 & 688171 & 4.5 & 4.9724 & TRN & \\
\hline CHEMBL1517751 & 688171 & 4.8 & 4.8549 & TRN & \\
\hline CHEMBL54716 & 688171 & 5.15 & 4.9767 & TST & \\
\hline CHEMBL1486198 & 688171 & 6.8 & 4.9014 & TRN & \\
\hline CHEMBL1356490 & 688171 & 4.95 & 4.8635 & TRN & \\
\hline CHEMBL1383834 & 688171 & 4.4 & 4.8764 & TST & \\
\hline CHEMBL1334307 & 688171 & 4.4 & 5.0012 & TST & \\
\hline CHEMBL1424477 & 688171 & 4.9 & 4.9152 & TST & \\
\hline CHEMBL1378001 & 688171 & 5.15 & 4.9763 & TRN & \\
\hline CHEMBL1587031 & 688171 & 4.65 & 4.9076 & TST & \\
\hline CHEMBL1550090 & 688171 & 4.6 & 4.9261 & TRN & \\
\hline CHEMBL1173570 & 688171 & 4.9 & 4.9628 & TRN & \\
\hline CHEMBL1493052 & 688171 & 4.95 & 4.8256 & TRN & \\
\hline CHEMBL1300251 & 688171 & 4.55 & 4.8254 & TRN & \\
\hline CHEMBL1405721 & 688171 & 4.45 & 4.953 & TST & \\
\hline CHEMBL1313343 & 688171 & 4.45 & 4.8793 & TRN & \\
\hline CHEMBL1464338 & 688171 & 4.45 & 4.9464 & TST & \\
\hline CHEMBL1523564 & 688171 & 4.55 & 4.94600 & 0000000001 & TST \\
\hline CHEMBL446452 & 688171 & 4.35 & 4.8938 & TRN & \\
\hline CHEMBL1457036 & 688171 & 5.05 & 5.0036 & TST & \\
\hline CHEMBL1461659 & 688171 & 4.7 & 4.9219 & TRN & \\
\hline CHEMBL1889837 & 688171 & 5.05 & 4.9033 & TRN & \\
\hline CHEMBL380979 & 688171 & 5.5 & 4.9141 & TRN & \\
\hline CHEMBL1390602 & 688171 & 4.4 & 4.8644 & TRN & \\
\hline CHEMBL1472143 & 688171 & 4.4 & 5.053 & TRN & \\
\hline CHEMBL1476268 & 688171 & 4.4 & 4.88399 & 99999999995 & TST \\
\hline CHEMBL1409847 & 688171 & 4.4 & 5.0027 & TRN & \\
\hline CHEMBL1964439 & 688171 & 5.0 & 4.9789 & TST & \\
\hline CHEMBL1330813 & 688171 & 4.8 & 4.8359 & TRN & \\
\hline CHEMBL1407152 & 688171 & 4.4 & 4.9433 & TRN & \\
\hline CHEMBL1594935 & 688171 & 6.0 & 4.8677 & TST & \\
\hline CHEMBL2007180 & 688171 & 4.4 & 4.8866 & TRN & \\
\hline CHEMBL1565112 & 688171 & 4.4 & 4.7287 & TRN & \\
\hline CHEMBL3194796 & 688171 & 4.85 & 4.9799 & TRN & \\
\hline CHEMBL1436332 & 688171 & 4.35 & 4.9384 & TRN & \\
\hline CHEMBL1568332 & 688171 & 4.6 & 4.8578 & TRN & \\
\hline CHEMBL1435249 & 688171 & 4.55 & 4.895 & TRN & \\
\hline CHEMBL1358470 & 688171 & 4.4 & 4.8587 & TRN & \\
\hline CHEMBL1323909 & 688171 & 4.7 & 4.8761 & TST & \\
\hline CHEMBL1532659 & 688171 & 4.75 & 4.8469 & TRN & \\
\hline CHEMBL1561971 & 688171 & 5.05 & 5.136 & TRN & \\
\hline CHEMBL1322391 & 688171 & 5.4 & 4.9366 & TRN & \\
\hline CHEMBL3212702 & 688171 & 4.75 & 4.8838 & TST & \\
\hline CHEMBL1437856 & 688171 & 4.95 & 4.8068 & TST & \\
\hline CHEMBL1561638 & 688171 & 4.55 & 4.8592 & TRN & \\
\hline CHEMBL1448441 & 688171 & 5.05 & 4.8971 & TRN & \\
\hline
\end{tabular}




\begin{tabular}{|c|c|c|c|c|}
\hline \multicolumn{5}{|c|}{ Supplemental Table } \\
\hline CHEMBL1555322 & 688171 & 4.45 & 4.8777 & TRN \\
\hline CHEMBL1434576 & 688171 & 4.95 & 4.8718 & TRN \\
\hline CHEMBL1563851 & 688171 & 4.45 & 4.8517 & TRN \\
\hline CHEMBL1385062 & 688171 & 5.1 & 4.9026 & TST \\
\hline CHEMBL1319350 & 688171 & 5.85 & 4.805 & TRN \\
\hline CHEMBL1456931 & 688171 & 5.5 & 5.0588 & TST \\
\hline CHEMBL1398941 & 688171 & 4.4 & 4.8255 & TRN \\
\hline CHEMBL1539678 & 688171 & 4.85 & 4.7788 & TST \\
\hline CHEMBL1376784 & 688171 & 5.55 & 4.9201 & TRN \\
\hline CHEMBL1553121 & 688171 & 6.7501 & 4.9721 & TRN \\
\hline CHEMBL1605445 & 688171 & 5.0 & 4.9101 & TST \\
\hline CHEMBL1497767 & 688171 & 4.4 & 5.0071 & TST \\
\hline CHEMBL1401082 & 688171 & 4.35 & 4.8512 & TST \\
\hline CHEMBL1509231 & 688171 & 4.4 & 4.9547 & TRN \\
\hline CHEMBL1339803 & 688171 & 5.7 & 4.8355 & TST \\
\hline CHEMBL1445609 & 688171 & 4.4 & 5.0174 & TRN \\
\hline CHEMBL1560377 & 688171 & 4.4 & 4.9341 & TST \\
\hline CHEMBL463574 & 688171 & 4.4 & 4.8843 & TST \\
\hline CHEMBL1375797 & 688171 & 5.4 & 4.9787 & TRN \\
\hline CHEMBL1316682 & 688171 & 6.2 & 5.0816 & TRN \\
\hline CHEMBL1454560 & 688171 & 4.7 & 4.8904 & TRN \\
\hline CHEMBL1547678 & 688171 & 6.35 & 4.9701 & TRN \\
\hline CHEMBL1518489 & 688171 & 4.95 & 4.9194 & TRN \\
\hline CHEMBL1426027 & 688171 & 4.55 & 4.7974 & TST \\
\hline CHEMBL1471305 & 688171 & 4.65 & 4.8317 & TRN \\
\hline CHEMBL1387069 & 688171 & 4.5 & 4.8408 & TRN \\
\hline CHEMBL1535693 & 688171 & 5.0 & 4.8572 & TRN \\
\hline CHEMBL1324471 & 688171 & 5.5 & 4.8754 & TRN \\
\hline CHEMBL1418066 & 688171 & 4.9 & 4.8145 & TRN \\
\hline CHEMBL1533661 & 688171 & 4.8 & 4.9167 & TRN \\
\hline CHEMBL1437584 & 688171 & 4.9 & 4.8453 & TRN \\
\hline CHEMBL1611212 & 688171 & 5.05 & 5.0902 & TST \\
\hline CHEMBL1475110 & 688171 & 4.45 & 4.9598 & TRN \\
\hline CHEMBL1612237 & 688171 & 5.3 & 5.0232 & TST \\
\hline CHEMBL1519541 & 688171 & 4.35 & 4.8055 & TRN \\
\hline CHEMBL1467500 & 688171 & 4.4 & 4.9405 & TRN \\
\hline CHEMBL1563400 & 688171 & 5.0 & 5.0166 & TRN \\
\hline CHEMBL1412731 & 688171 & 4.55 & 4.9175 & TST \\
\hline CHEMBL1393021 & 688171 & 4.4 & 4.8157 & TST \\
\hline CHEMBL1501223 & 688171 & 4.4 & 4.843 & TRN \\
\hline CHEMBL1302619 & 688171 & 4.75 & 4.9456 & TST \\
\hline CHEMBL1378268 & 688171 & 4.7 & 5.0775 & TRN \\
\hline CHEMBL1505705 & 688171 & 4.8 & 4.8697 & TRN \\
\hline CHEMBL1300326 & 688171 & 4.8 & 4.7645 & TRN \\
\hline CHEMBL1600164 & 688171 & 4.4 & 4.913 & TST \\
\hline CHEMBL1572325 & 688171 & 5.25 & 4.893 & TST \\
\hline CHEMBL1541339 & 688171 & 5.05 & 4.8608 & TRN \\
\hline CHEMBL1516304 & 688171 & 6.15 & 4.8821 & TRN \\
\hline
\end{tabular}




\begin{tabular}{|c|c|c|c|c|c|}
\hline \multicolumn{6}{|c|}{ Supplemental Table S2.txt } \\
\hline CHEMBL1318575 & 688171 & 4.5 & 4.7716 & TRN & \\
\hline CHEMBL1525371 & 688171 & 4.9 & 4.9597 & TRN & \\
\hline CHEMBL1554092 & 688171 & 4.45 & 5.0254 & TRN & \\
\hline CHEMBL1613401 & 688171 & 5.45 & 4.9698 & TRN & \\
\hline CHEMBL1348285 & 688171 & 4.4 & 4.9927 & TRN & \\
\hline CHEMBL1507494 & 688171 & 5.0 & 4.80399 & 9999999999 & TRN \\
\hline CHEMBL1558240 & 688171 & 4.75 & 4.9325 & TST & \\
\hline CHEMBL1984247 & 688171 & 4.85 & 4.9359 & TST & \\
\hline CHEMBL1526080 & 688171 & 4.8 & 4.8845 & TST & \\
\hline CHEMBL1486124 & 688171 & 4.4 & 4.9764 & TRN & \\
\hline CHEMBL1531045 & 688171 & 4.8 & 4.9029 & TRN & \\
\hline CHEMBL468167 & 688171 & 5.75 & 4.76 & TST & \\
\hline CHEMBL305978 & 688171 & 4.4 & 4.8369 & TRN & \\
\hline CHEMBL1360641 & 688171 & 5.1 & 4.9678 & TST & \\
\hline CHEMBL1606345 & 688171 & 4.65 & 4.8687 & TRN & \\
\hline CHEMBL3213458 & 688171 & 5.25 & 5.0267 & TRN & \\
\hline CHEMBL3144939 & 688171 & 7.0501 & 4.8061 & TST & \\
\hline CHEMBL1487713 & 688171 & 5.6 & 4.9041 & TRN & \\
\hline CHEMBL1604396 & 688171 & 4.4 & 4.9392 & TST & \\
\hline CHEMBL1555040 & 688171 & 4.9 & 4.9024 & TRN & \\
\hline CHEMBL1479659 & 688171 & 4.75 & 4.9427 & TRN & \\
\hline CHEMBL1356074 & 688171 & 4.4 & 4.8806 & TRN & \\
\hline CHEMBL1541440 & 688171 & 4.85 & 4.9845 & TRN & \\
\hline CHEMBL3196392 & 688171 & 6.0 & 5.0366 & TRN & \\
\hline CHEMBL1367062 & 688171 & 6.45 & 4.7489 & TST & \\
\hline CHEMBL1563690 & 688171 & 4.6 & 4.7587 & TRN & \\
\hline CHEMBL1561896 & 688171 & 4.8 & 5.0128 & TRN & \\
\hline CHEMBL1552027 & 688171 & 4.95 & 4.6278 & TRN & \\
\hline CHEMBL1556869 & 688171 & 5.6 & 5.1196 & TRN & \\
\hline CHEMBL582005 & 688171 & 4.7 & 4.9727 & TST & \\
\hline CHEMBL1414768 & 688171 & 4.7 & 4.8602 & TRN & \\
\hline CHEMBL1339442 & 688171 & 5.0 & 4.8608 & TRN & \\
\hline CHEMBL1592769 & 688171 & 6.8 & 4.9809 & TRN & \\
\hline CHEMBL1534911 & 688171 & 4.8 & 4.834 & TRN & \\
\hline CHEMBL76144 & 688171 & 5.0 & 4.793 & TRN & \\
\hline CHEMBL1395855 & 688171 & 7.0501 & 4.9639 & TRN & \\
\hline CHEMBL1593097 & 688171 & 5.45 & 4.7625 & TRN & \\
\hline CHEMBL1362364 & 688171 & 4.7 & 4.9223 & TST & \\
\hline CHEMBL1553447 & 688171 & 4.9 & 4.8317 & TRN & \\
\hline CHEMBL1535579 & 688171 & 4.65 & 4.9633 & TRN & \\
\hline CHEMBL1299964 & 688171 & 5.05 & 4.9687 & TRN & \\
\hline CHEMBL3189667 & 688171 & 6.5501 & 4.9205 & TST & \\
\hline CHEMBL1422806 & 688171 & 4.9 & 4.8622 & TST & \\
\hline CHEMBL1336057 & 688171 & 4.4 & 4.921 & TRN & \\
\hline CHEMBL1544549 & 688171 & 5.4 & 4.8941 & TRN & \\
\hline CHEMBL3210032 & 688171 & 4.4 & 5.0698 & TRN & \\
\hline CHEMBL1590571 & 688171 & 6.15 & 4.8738 & TST & \\
\hline CHEMBL1353757 & 688171 & 5.45 & 5.0577 & TST & \\
\hline
\end{tabular}




\begin{tabular}{|c|c|c|c|c|c|}
\hline \multicolumn{6}{|c|}{ Supplemental Table S2.txt } \\
\hline CHEMBL1447936 & 688171 & 5.2 & 4.9101 & TRN & \\
\hline CHEMBL1318069 & 688171 & 4.35 & 4.9965 & TRN & \\
\hline CHEMBL1422701 & 688171 & 5.4 & 4.9493 & TRN & \\
\hline CHEMBL1528550 & 688171 & 4.9 & 4.8898 & TRN & \\
\hline CHEMBL1394600 & 688171 & 4.6 & 4.8433 & TRN & \\
\hline CHEMBL1589104 & 688171 & 4.65 & 4.92399 & 99999999995 & TST \\
\hline CHEMBL1488898 & 688171 & 4.4 & 4.9135 & TRN & \\
\hline CHEMBL1545469 & 688171 & 5.5 & 5.0341 & TST & \\
\hline CHEMBL1370610 & 688171 & 4.65 & 4.9429 & TRN & \\
\hline CHEMBL1375378 & 688171 & 4.8 & 4.8008 & TRN & \\
\hline CHEMBL1531763 & 688171 & 4.95 & 4.8627 & TST & \\
\hline CHEMBL1300405 & 688171 & 4.4 & 4.8703 & TRN & \\
\hline CHEMBL1315726 & 688171 & 4.7 & 4.8994 & TRN & \\
\hline CHEMBL1389259 & 688171 & 6.7501 & 4.9404 & TST & \\
\hline CHEMBL1606483 & 688171 & 4.6 & 4.9225 & TRN & \\
\hline CHEMBL1512240 & 688171 & 4.55 & 4.8417 & TRN & \\
\hline CHEMBL1408395 & 688171 & 4.6 & 4.9626 & TST & \\
\hline CHEMBL1343780 & 688171 & 4.8 & 4.8914 & TRN & \\
\hline CHEMBL1446105 & 688171 & 5.9 & 5.0902 & TRN & \\
\hline CHEMBL1563429 & 688171 & 4.45 & 4.7249 & TRN & \\
\hline CHEMBL1341847 & 688171 & 4.4 & 4.8875 & TST & \\
\hline CHEMBL1587715 & 688171 & 4.9 & 4.9021 & TRN & \\
\hline CHEMBL1340713 & 688171 & 5.0 & 4.9918 & TST & \\
\hline CHEMBL1356714 & 688171 & 4.85 & 4.8259 & TRN & \\
\hline CHEMBL1600669 & 688171 & 4.5 & 4.8522 & TRN & \\
\hline CHEMBL1299636 & 688171 & 5.35 & 4.9576 & TST & \\
\hline CHEMBL1473557 & 688171 & 4.55 & 4.96899 & 9999999999 & TRN \\
\hline CHEMBL1437470 & 688171 & 4.8 & 4.8758 & TRN & \\
\hline CHEMBL1393946 & 688171 & 4.95 & 4.9185 & TRN & \\
\hline CHEMBL1431976 & 688171 & 4.35 & 5.0581 & TST & \\
\hline CHEMBL1419873 & 688171 & 5.05 & 4.9742 & TRN & \\
\hline CHEMBL1489809 & 688171 & 4.85 & 4.9187 & TRN & \\
\hline CHEMBL1440323 & 688171 & 4.4 & 4.8852 & TRN & \\
\hline CHEMBL1494920 & 688171 & 4.75 & 4.9427 & TRN & \\
\hline CHEMBL1337979 & 688171 & 5.15 & 4.8869 & TRN & \\
\hline CHEMBL1568662 & 688171 & 4.9 & 4.9593 & TRN & \\
\hline CHEMBL1445867 & 688171 & 4.35 & 4.8584 & TST & \\
\hline CHEMBL1314521 & 688171 & 4.55 & 4.8603 & TRN & \\
\hline CHEMBL1610045 & 688171 & 4.95 & 4.8781 & TRN & \\
\hline CHEMBL3199764 & 688171 & 4.7 & 4.8733 & TRN & \\
\hline CHEMBL1539880 & 688171 & 4.8 & 4.8969 & TRN & \\
\hline CHEMBL1304177 & 688171 & 4.5 & 4.7389 & TST & \\
\hline CHEMBL3192018 & 688171 & 5.05 & 4.9378 & TRN & \\
\hline CHEMBL1478187 & 688171 & 4.9 & 4.9175 & TRN & \\
\hline CHEMBL1465424 & 688171 & 4.4 & 4.9022 & TST & \\
\hline CHEMBL1516391 & 688171 & 5.1 & 5.0075 & TRN & \\
\hline CHEMBL1605414 & 688171 & 4.5 & 4.7364 & TRN & \\
\hline CHEMBL1368089 & 688171 & 6.7001 & 4.9213 & TRN & \\
\hline
\end{tabular}




\begin{tabular}{|c|c|c|c|c|c|}
\hline & & & & & \\
\hline CHEMBL1475742 & 688171 & 5.5 & 4.9571 & TRN & \\
\hline CHEMBL1335158 & 688171 & 5.55 & 5.0693 & TRN & \\
\hline CHEMBL1503745 & 688171 & 4.4 & 4.7258 & TRN & \\
\hline CHEMBL1352181 & 688171 & 4.6 & 4.8554 & TST & \\
\hline CHEMBL1513154 & 688171 & 4.7 & 5.0387 & TRN & \\
\hline CHEMBL1388099 & 688171 & 4.5 & 5.0733 & TRN & \\
\hline CHEMBL1472343 & 688171 & 4.45 & 4.7601 & TRN & \\
\hline CHEMBL1445171 & 688171 & 6.9 & 4.9647 & TRN & \\
\hline CHEMBL408994 & 688171 & 4.5 & 4.9865 & TST & \\
\hline CHEMBL1435978 & 688171 & 4.35 & 5.0573 & TRN & \\
\hline CHEMBL1432031 & 688171 & 5.05 & 4.8694 & TRN & \\
\hline CHEMBL3195054 & 688171 & 4.5 & 4.8161 & TRN & \\
\hline CHEMBL1461593 & 688171 & 4.7 & 4.704 & TRN & \\
\hline CHEMBL1586105 & 688171 & 6.8499 & 4.9381 & TRN & \\
\hline CHEMBL1468259 & 688171 & 4.9 & 4.7795 & TRN & \\
\hline CHEMBL1316701 & 688171 & 4.8 & 4.8344 & TRN & \\
\hline CHEMBL1593620 & 688171 & 4.35 & 5.0629 & TST & \\
\hline CHEMBL1999480 & 688171 & 5.55 & 4.92399 & 99999999995 & TST \\
\hline CHEMBL1347892 & 688171 & 4.95 & 4.9677 & TRN & \\
\hline CHEMBL1386082 & 688171 & 5.3 & 5.0075 & TST & \\
\hline CHEMBL1429627 & 688171 & 6.05 & 5.0504 & TRN & \\
\hline CHEMBL1299463 & 688171 & 4.65 & 5.0164 & TST & \\
\hline CHEMBL1498867 & 688171 & 4.55 & 4.928 & TST & \\
\hline CHEMBL1587091 & 688171 & 5.25 & 5.01699 & 99999999995 & TST \\
\hline CHEMBL1442229 & 688171 & 4.4 & 4.9025 & TRN & \\
\hline CHEMBL3144976 & 688171 & 5.5 & 4.8343 & TRN & \\
\hline CHEMBL1593962 & 688171 & 5.15 & 4.8818 & TRN & \\
\hline CHEMBL1455934 & 688171 & 4.6 & 4.842 & TRN & \\
\hline CHEMBL1361285 & 688171 & 5.1 & 4.9372 & TRN & \\
\hline CHEMBL1564992 & 688171 & 4.75 & 5.0906 & TST & \\
\hline CHEMBL1533104 & 688171 & 5.45 & 5.0063 & TRN & \\
\hline CHEMBL1456524 & 688171 & 4.75 & 4.904 & TRN & \\
\hline CHEMBL 1456360 & 688171 & 5.0 & 4.8119 & TRN & \\
\hline CHEMBL1443893 & 688171 & 4.4 & 5.1242 & TRN & \\
\hline CHEMBL1467225 & 688171 & 5.0 & 4.9639 & TRN & \\
\hline CHEMBL1317516 & 688171 & 4.4 & 4.9599 & TRN & \\
\hline CHEMBL1554198 & 688171 & 5.05 & 4.8846 & TRN & \\
\hline CHEMBL1579805 & 688171 & 5.5 & 4.8712 & TRN & \\
\hline CHEMBL3190413 & 688171 & 4.4 & 4.9988 & TST & \\
\hline CHEMBL1401451 & 688171 & 4.45 & 5.0318 & TST & \\
\hline CHEMBL1447563 & 688171 & 4.45 & 4.9326 & TST & \\
\hline CHEMBL1563875 & 688171 & 5.0 & 4.925 & TRN & \\
\hline CHEMBL1597189 & 688171 & 4.45 & 4.8781 & TRN & \\
\hline CHEMBL1563592 & 688171 & 4.4 & 4.9578 & TRN & \\
\hline CHEMBL1516272 & 688171 & 4.6 & 4.7797 & TRN & \\
\hline CHEMBL1366978 & 688171 & 4.55 & 4.8957 & TST & \\
\hline CHEMBL1572819 & 688171 & 5.35 & 4.8315 & TRN & \\
\hline CHEMBL3197651 & 688171 & 4.8 & 4.8844 & TRN & \\
\hline
\end{tabular}




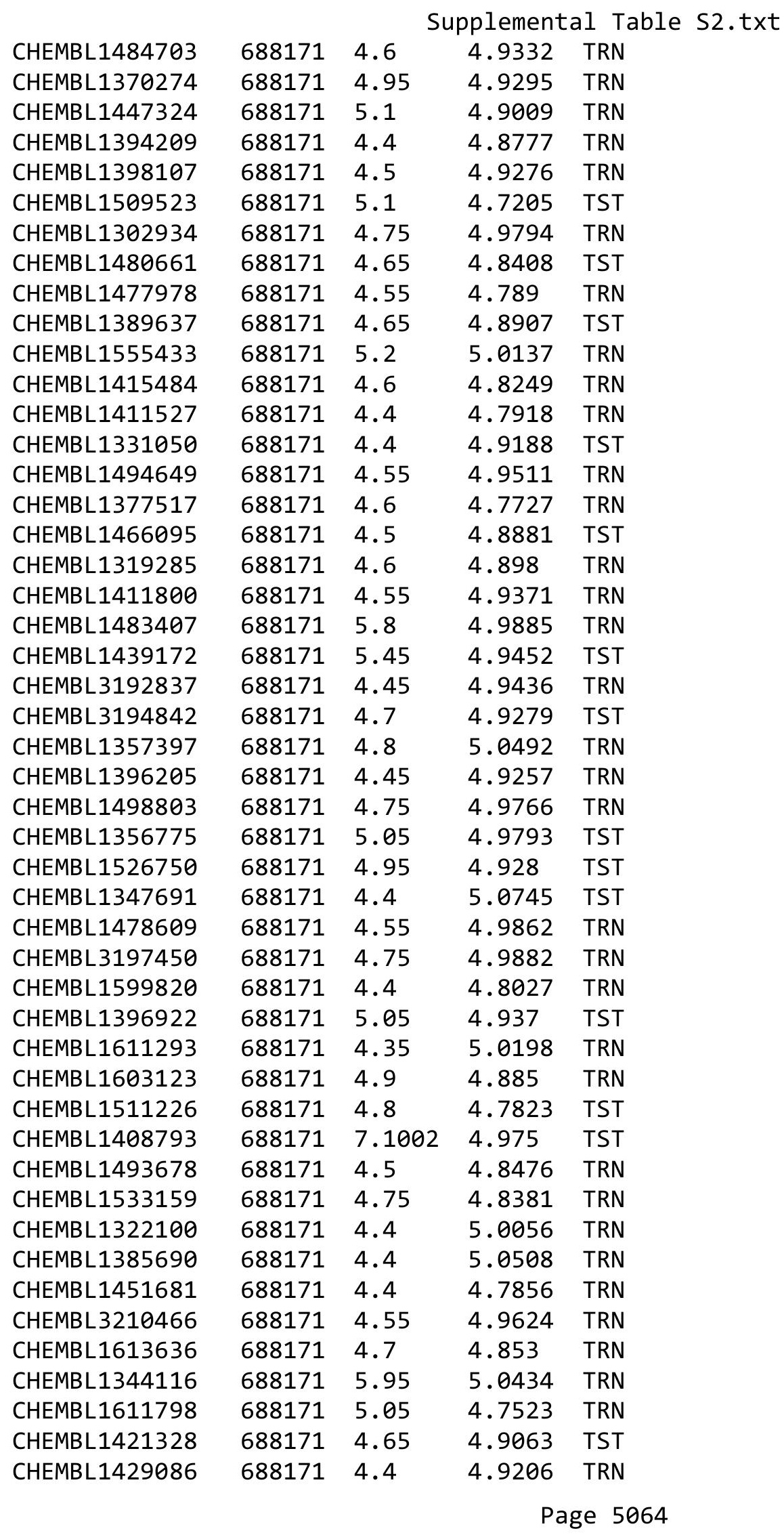




\begin{tabular}{|c|c|c|c|c|}
\hline \multicolumn{5}{|c|}{ Supplemental Table S2.txt } \\
\hline CHEMBL3193322 & 688171 & 4.4 & 5.0162 & TRN \\
\hline CHEMBL1341540 & 688171 & 5.0 & 4.8203 & TRN \\
\hline CHEMBL1436241 & 688171 & 5.95 & 4.9466 & TRN \\
\hline CHEMBL1575870 & 688171 & 5.55 & 4.8053 & TRN \\
\hline CHEMBL1303783 & 688171 & 4.7 & 4.8444 & TRN \\
\hline CHEMBL1416562 & 688171 & 4.6 & 4.8999 & TRN \\
\hline CHEMBL1299940 & 688171 & 4.9 & 4.9337 & TST \\
\hline CHEMBL1396067 & 688171 & 4.55 & 4.8364 & TRN \\
\hline CHEMBL3195177 & 688171 & 4.65 & 4.9672 & TRN \\
\hline CHEMBL1512556 & 688171 & 4.55 & 4.8949 & TRN \\
\hline CHEMBL1547684 & 688171 & 4.85 & 4.9289 & TST \\
\hline CHEMBL1513057 & 688171 & 4.7 & 4.8827 & TRN \\
\hline CHEMBL1580164 & 688171 & 5.5 & 4.8465 & TRN \\
\hline CHEMBL1453242 & 688171 & 4.95 & 4.852 & TRN \\
\hline CHEMBL1333078 & 688171 & 5.1 & 4.8791 & TRN \\
\hline CHEMBL1332309 & 688171 & 4.4 & 4.8174 & TRN \\
\hline CHEMBL1361855 & 688171 & 4.85 & 4.8148 & TST \\
\hline CHEMBL1388300 & 688171 & 4.9 & 4.92 & TRN \\
\hline CHEMBL1474099 & 688171 & 4.4 & 4.8271 & TST \\
\hline CHEMBL1490423 & 688171 & 4.4 & 4.7826 & TRN \\
\hline CHEMBL3191602 & 688171 & 5.8 & 4.9241 & TRN \\
\hline CHEMBL1313925 & 688171 & 4.75 & 4.9121 & TRN \\
\hline CHEMBL1475117 & 688171 & 4.65 & 4.8243 & TRN \\
\hline CHEMBL1416863 & 688171 & 5.05 & 4.8071 & TRN \\
\hline CHEMBL1410065 & 688171 & 5.2 & 4.8711 & TRN \\
\hline CHEMBL1499956 & 688171 & 4.5 & 4.8418 & TRN \\
\hline CHEMBL1559001 & 688171 & 4.4 & 4.8377 & TRN \\
\hline CHEMBL1462235 & 688171 & 4.4 & 5.0649 & TRN \\
\hline CHEMBL1557745 & 688171 & 4.8 & 4.8721 & TRN \\
\hline CHEMBL1527779 & 688171 & 4.65 & 4.8833 & TRN \\
\hline CHEMBL1527600 & 688171 & 4.85 & 4.9123 & TRN \\
\hline CHEMBL1613528 & 688171 & 4.55 & 4.8828 & TRN \\
\hline CHEMBL1387668 & 688171 & 4.55 & 4.7903 & TRN \\
\hline CHEMBL3198838 & 688171 & 4.5 & 4.9324 & TST \\
\hline CHEMBL1361796 & 688171 & 5.05 & 4.8585 & TRN \\
\hline CHEMBL1488937 & 688171 & 5.0 & 4.9492 & TRN \\
\hline CHEMBL1327923 & 688171 & 4.7 & 4.8724 & TRN \\
\hline CHEMBL1396919 & 688171 & 6.6499 & 4.9446 & TRN \\
\hline CHEMBL1606578 & 688171 & 5.75 & 4.8712 & TRN \\
\hline CHEMBL1512947 & 688171 & 4.4 & 4.8767 & TRN \\
\hline CHEMBL1380069 & 688171 & 4.65 & 4.8662 & TRN \\
\hline CHEMBL1533083 & 688171 & 6.25 & 4.9751 & TRN \\
\hline CHEMBL3196394 & 688171 & 6.0 & 4.954 & TRN \\
\hline CHEMBL590427 & 688171 & 6.45 & 4.9613 & TST \\
\hline CHEMBL1326637 & 688171 & 4.45 & 4.8726 & TRN \\
\hline CHEMBL1464567 & 688171 & 4.9 & 4.7909 & TST \\
\hline CHEMBL1601818 & 688171 & 4.95 & 4.8874 & TRN \\
\hline CHEMBL1491409 & 688171 & 5.65 & 4.9082 & TRN \\
\hline
\end{tabular}




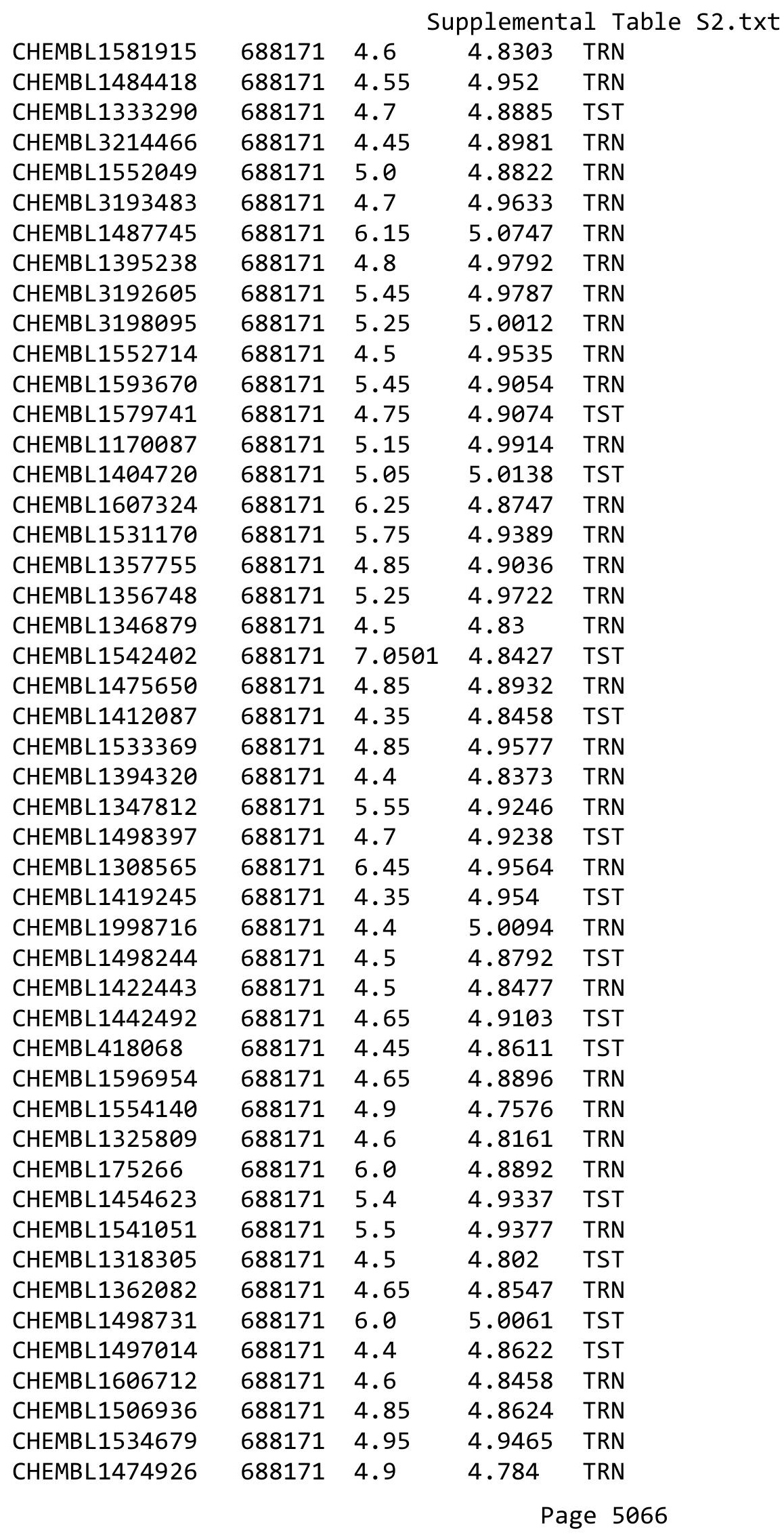




\begin{tabular}{|c|c|c|c|c|}
\hline \multicolumn{5}{|c|}{ Supplemental Table S2.txt } \\
\hline CHEMBL1544557 & 688171 & 5.4 & 5.0166 & TRN \\
\hline CHEMBL1483308 & 688171 & 4.7 & 4.8594 & TRN \\
\hline CHEMBL1435513 & 688171 & 4.6 & 5.0307 & TRN \\
\hline CHEMBL1436170 & 688171 & 4.55 & 4.8418 & TRN \\
\hline CHEMBL1312498 & 688171 & 4.6 & 4.7717 & TRN \\
\hline CHEMBL1539536 & 688171 & 4.8 & 4.8054 & TRN \\
\hline CHEMBL1396052 & 688171 & 4.35 & 4.7694 & TRN \\
\hline CHEMBL1316188 & 688171 & 4.7 & 4.8322 & TRN \\
\hline CHEMBL1538088 & 688171 & 4.4 & 4.9411 & TRN \\
\hline CHEMBL1319713 & 688171 & 4.6 & 4.8123 & TRN \\
\hline CHEMBL 2005807 & 688171 & 4.5 & 5.0231 & TST \\
\hline CHEMBL1966622 & 688171 & 4.8 & 4.8687 & TRN \\
\hline CHEMBL1333202 & 688171 & 4.7 & 4.9242 & TRN \\
\hline CHEMBL1498226 & 688171 & 6.8499 & 5.053 & TRN \\
\hline CHEMBL602213 & 688171 & 5.15 & 4.7578 & TRN \\
\hline CHEMBL1395063 & 688171 & 4.8 & 4.8937 & TRN \\
\hline CHEMBL1474627 & 688171 & 4.75 & 4.9422 & TRN \\
\hline CHEMBL1318763 & 688171 & 5.1 & 4.8655 & TRN \\
\hline CHEMBL1576499 & 688171 & 5.5 & 5.0275 & TRN \\
\hline CHEMBL1438352 & 688171 & 4.6 & 4.968 & TRN \\
\hline CHEMBL1556642 & 688171 & 5.0 & 4.9026 & TRN \\
\hline CHEMBL1494400 & 688171 & 4.85 & 4.7998 & TRN \\
\hline CHEMBL1427211 & 688171 & 4.8 & 5.0072 & TST \\
\hline CHEMBL1610341 & 688171 & 4.65 & 4.9222 & TST \\
\hline CHEMBL1451110 & 688171 & 4.7 & 4.8914 & TRN \\
\hline CHEMBL1474700 & 688171 & 5.55 & 4.9186 & TRN \\
\hline CHEMBL1302492 & 688171 & 4.6 & 4.8667 & TRN \\
\hline CHEMBL1583494 & 688171 & 5.05 & 4.9024 & TRN \\
\hline CHEMBL1600370 & 688171 & 4.55 & 4.89 & TRN \\
\hline CHEMBL1419072 & 688171 & 4.8 & 4.9314 & TRN \\
\hline CHEMBL1318955 & 688171 & 4.35 & 4.9797 & TST \\
\hline CHEMBL1542306 & 688171 & 5.0 & 4.7059 & TRN \\
\hline CHEMBL1586610 & 688171 & 4.6 & 5.0824 & TRN \\
\hline CHEMBL3192381 & 688171 & 4.4 & 4.9382 & TST \\
\hline CHEMBL1529848 & 688171 & 5.8 & 4.8887 & TST \\
\hline CHEMBL1601781 & 688171 & 4.4 & 4.9259 & TRN \\
\hline CHEMBL1544436 & 688171 & 5.9 & 4.8647 & TST \\
\hline CHEMBL1489368 & 688171 & 5.05 & 4.8427 & TRN \\
\hline CHEMBL1593526 & 688171 & 4.75 & 4.8959 & TRN \\
\hline CHEMBL1465314 & 688171 & 4.75 & 4.7855 & TRN \\
\hline CHEMBL1482203 & 688171 & 4.6 & 4.8889 & TRN \\
\hline CHEMBL1554456 & 688171 & 5.2 & 4.896 & TST \\
\hline CHEMBL570052 & 688171 & 4.95 & 4.8713 & TST \\
\hline CHEMBL1590208 & 688171 & 4.95 & 4.7846 & TRN \\
\hline CHEMBL1439874 & 688171 & 4.35 & 4.9194 & TST \\
\hline CHEMBL1502523 & 688171 & 4.55 & 4.8574 & TRN \\
\hline CHEMBL1566950 & 688171 & 4.9 & 5.1166 & TST \\
\hline CHEMBL1397474 & 688171 & 5.5 & 4.9785 & TRN \\
\hline
\end{tabular}




\begin{tabular}{|c|c|c|c|c|}
\hline \multicolumn{5}{|c|}{ Supplemental Table S2.txt } \\
\hline CHEMBL1399283 & 688171 & 5.1 & 5.0205 & TRN \\
\hline CHEMBL1566903 & 688171 & 5.0 & 4.8316 & TST \\
\hline CHEMBL1492216 & 688171 & 6.95 & 4.9904 & TST \\
\hline CHEMBL 3193221 & 688171 & 4.35 & 4.822 & TRN \\
\hline CHEMBL1565643 & 688171 & 4.4 & 4.8971 & TST \\
\hline CHEMBL1334083 & 688171 & 4.6 & 5.0544 & TRN \\
\hline CHEMBL1571317 & 688171 & 4.65 & 4.9017 & TRN \\
\hline CHEMBL1462684 & 688171 & 4.65 & 4.856 & TRN \\
\hline CHEMBL1476867 & 688171 & 5.3 & 4.9393 & TRN \\
\hline CHEMBL1334267 & 688171 & 4.6 & 4.9707 & TRN \\
\hline CHEMBL1348479 & 688171 & 4.55 & 4.9504 & TST \\
\hline CHEMBL1397280 & 688171 & 4.75 & 4.7697 & TRN \\
\hline CHEMBL1361393 & 688171 & 4.95 & 4.809 & TRN \\
\hline CHEMBL1311546 & 688171 & 4.4 & 4.8657 & TRN \\
\hline CHEMBL1316730 & 688171 & 4.55 & 4.6968 & TRN \\
\hline CHEMBL1509689 & 688171 & 5.45 & 4.9257 & TST \\
\hline CHEMBL1418060 & 688171 & 4.45 & 4.7885 & TRN \\
\hline CHEMBL1507040 & 688171 & 4.55 & 4.9466 & TRN \\
\hline CHEMBL1543174 & 688171 & 4.55 & 4.9044 & TRN \\
\hline CHEMBL1172597 & 688171 & 4.85 & 4.8666 & TRN \\
\hline CHEMBL1337116 & 688171 & 5.45 & 4.9004 & TRN \\
\hline CHEMBL1305704 & 688171 & 4.75 & 4.9436 & TRN \\
\hline CHEMBL1517898 & 688171 & 4.35 & 5.0213 & TRN \\
\hline CHEMBL1399039 & 688171 & 4.7 & 4.8525 & TRN \\
\hline CHEMBL1373918 & 688171 & 4.7 & 5.0479 & TST \\
\hline CHEMBL1345622 & 688171 & 4.85 & 4.9143 & TRN \\
\hline CHEMBL1338272 & 688171 & 5.4 & 4.97 & TST \\
\hline CHEMBL1485192 & 688171 & 4.9 & 4.9839 & TST \\
\hline CHEMBL1324864 & 688171 & 4.65 & 4.8837 & TRN \\
\hline CHEMBL1388831 & 688171 & 4.75 & 4.8705 & TRN \\
\hline CHEMBL1324181 & 688171 & 6.0 & 4.8531 & TRN \\
\hline CHEMBL1595975 & 688171 & 5.2 & 4.9468 & TST \\
\hline CHEMBL1469653 & 688171 & 6.15 & 4.8531 & TRN \\
\hline CHEMBL1560249 & 688171 & 4.4 & 4.8883 & TRN \\
\hline CHEMBL1495642 & 688171 & 4.4 & 4.7803 & TRN \\
\hline CHEMBL567331 & 688171 & 4.9 & 4.8835 & TRN \\
\hline CHEMBL1601807 & 688171 & 4.95 & 4.8784 & TST \\
\hline CHEMBL1426340 & 688171 & 4.95 & 4.9539 & TRN \\
\hline CHEMBL1440965 & 688171 & 4.6 & 4.9245 & TRN \\
\hline CHEMBL1502181 & 688171 & 4.45 & 5.0392 & TST \\
\hline CHEMBL1708334 & 688171 & 4.5 & 4.7121 & TRN \\
\hline CHEMBL1466913 & 688171 & 4.4 & 4.8557 & TST \\
\hline CHEMBL1356551 & 688171 & 5.1 & 4.8625 & TRN \\
\hline CHEMBL1375463 & 688171 & 4.65 & 4.9294 & TRN \\
\hline CHEMBL1530947 & 688171 & 5.0 & 4.8231 & TRN \\
\hline CHEMBL1610484 & 688171 & 6.05 & 4.9331 & TRN \\
\hline CHEMBL1409447 & 688171 & 4.7 & 4.7895 & TST \\
\hline CHEMBL1476314 & 688171 & 4.35 & 4.8048 & TRN \\
\hline
\end{tabular}




\begin{tabular}{|c|c|c|c|c|}
\hline & & & \multicolumn{2}{|c|}{ Supplemental Table S2.txt } \\
\hline CHEMBL582355 & 688171 & 5.45 & 5.0115 & TST \\
\hline CHEMBL1379751 & 688171 & 4.5 & 5.0211 & TST \\
\hline CHEMBL1497075 & 688171 & 4.8 & 4.9971 & TRN \\
\hline CHEMBL1387927 & 688171 & 4.9 & 4.9213 & TRN \\
\hline CHEMBL1416113 & 688171 & 4.85 & 4.8252 & TRN \\
\hline CHEMBL1386604 & 688171 & 4.4 & 4.855 & TRN \\
\hline CHEMBL1995825 & 688171 & 4.75 & 4.8149 & TRN \\
\hline CHEMBL1370704 & 688171 & 4.7 & 4.7971 & TRN \\
\hline CHEMBL1377135 & 688171 & 4.6 & 4.92 & TRN \\
\hline CHEMBL1479588 & 688171 & 4.9 & 4.9377 & TRN \\
\hline CHEMBL1576781 & 688171 & 4.75 & 4.8151 & TRN \\
\hline CHEMBL1494973 & 688171 & 5.3 & 4.8484 & TRN \\
\hline CHEMBL1325440 & 688171 & 4.4 & 4.9426 & TRN \\
\hline CHEMBL1453846 & 688171 & 4.65 & 4.819 & TRN \\
\hline CHEMBL1436815 & 688171 & 4.8 & 4.8994 & TRN \\
\hline CHEMBL1485048 & 688171 & 5.2 & 5.0249 & TRN \\
\hline CHEMBL1417875 & 688171 & 4.9 & 4.9495 & TRN \\
\hline CHEMBL1566203 & 688171 & 4.4 & 4.7769 & TRN \\
\hline CHEMBL1590510 & 688171 & 5.8 & 4.8872 & TRN \\
\hline CHEMBL1388299 & 688171 & 5.2 & 4.8098 & TRN \\
\hline CHEMBL1519929 & 688171 & 5.25 & 5.01 & TRN \\
\hline CHEMBL1384509 & 688171 & 4.55 & 4.9295 & TRN \\
\hline CHEMBL1588870 & 688171 & 4.85 & 4.8812 & TRN \\
\hline CHEMBL1340865 & 688171 & 5.1 & 4.9535 & TRN \\
\hline CHEMBL3213551 & 688171 & 4.75 & 4.8362 & TST \\
\hline CHEMBL1462487 & 688171 & 5.0 & 4.8618 & TRN \\
\hline CHEMBL565269 & 688171 & 5.3 & 4.7647 & TRN \\
\hline CHEMBL1396627 & 688171 & 5.7 & 4.9263 & TRN \\
\hline CHEMBL1368710 & 688171 & 6.9 & 5.0109 & TST \\
\hline CHEMBL1511244 & 688171 & 5.0 & 4.8025 & TRN \\
\hline CHEMBL1546048 & 688171 & 4.55 & 4.8853 & TST \\
\hline CHEMBL1603051 & 688171 & 4.55 & 4.9361 & TRN \\
\hline CHEMBL1599601 & 688171 & 4.7 & 4.8694 & TRN \\
\hline CHEMBL1377980 & 688171 & 5.1 & 4.8539 & TRN \\
\hline CHEMBL1465370 & 688171 & 4.45 & 4.935 & TRN \\
\hline CHEMBL1460955 & 688171 & 6.4 & 5.0148 & TST \\
\hline CHEMBL1334932 & 688171 & 5.0 & 5.0442 & TRN \\
\hline CHEMBL1572312 & 688171 & 4.8 & 5.0136 & TRN \\
\hline CHEMBL1575026 & 688171 & 4.6 & 4.8943 & TRN \\
\hline CHEMBL1379480 & 688171 & 4.65 & 4.7843 & TST \\
\hline CHEMBL1488001 & 688171 & 4.7 & 4.8845 & TST \\
\hline CHEMBL1355611 & 688171 & 4.55 & 4.9318 & TRN \\
\hline CHEMBL1541294 & 688171 & 5.4 & 5.0424 & TST \\
\hline CHEMBL1974538 & 688171 & 4.4 & 4.8196 & TRN \\
\hline CHEMBL1435241 & 688171 & 4.8 & 4.913 & TRN \\
\hline CHEMBL3207440 & 688171 & 5.05 & 4.8483 & TST \\
\hline CHEMBL1471949 & 688171 & 4.35 & 4.9928 & TRN \\
\hline CHEMBL1562029 & 688171 & 5.6 & 4.901 & TRN \\
\hline
\end{tabular}




\begin{tabular}{|c|c|c|c|c|c|}
\hline & & \multicolumn{4}{|c|}{ Supplemental Table S2.txt } \\
\hline CHEMBL1509087 & 688171 & 5.05 & 4.9696 & TST & \\
\hline CHEMBL1592827 & 688171 & 4.45 & 4.8562 & TRN & \\
\hline CHEMBL1551309 & 688171 & 4.7 & 4.9328 & TRN & \\
\hline CHEMBL1398387 & 688171 & 5.45 & 4.9813 & TRN & \\
\hline CHEMBL1307825 & 688171 & 6.05 & 4.8655 & TRN & \\
\hline CHEMBL1381820 & 688171 & 4.6 & 4.9792 & TST & \\
\hline CHEMBL1394459 & 688171 & 6.0 & 4.9569 & TST & \\
\hline CHEMBL1336414 & 688171 & 6.6 & 5.0107 & TRN & \\
\hline CHEMBL1554896 & 688171 & 5.0 & 4.7992 & TRN & \\
\hline CHEMBL1591952 & 688171 & 5.6 & 4.9277 & TRN & \\
\hline CHEMBL1503379 & 688171 & 5.95 & 4.9577 & TST & \\
\hline CHEMBL1368092 & 688171 & 4.7 & 5.0499 & TRN & \\
\hline CHEMBL1609941 & 688171 & 4.8 & 5.002 & TST & \\
\hline CHEMBL1340689 & 688171 & 4.55 & 4.8679 & TST & \\
\hline CHEMBL1465810 & 688171 & 6.9 & 5.0587 & TST & \\
\hline CHEMBL1395538 & 688171 & 4.5 & 4.8593 & TRN & \\
\hline CHEMBL304929 & 688171 & 4.9 & 4.8985 & TRN & \\
\hline CHEMBL1326643 & 688171 & 4.85 & 5.0042 & TST & \\
\hline CHEMBL1321082 & 688171 & 4.35 & 5.0056 & TRN & \\
\hline CHEMBL1256814 & 688171 & 4.35 & 4.9996 & TRN & \\
\hline CHEMBL1566334 & 688171 & 4.4 & 4.9008 & TRN & \\
\hline CHEMBL1427517 & 688171 & 4.9 & 4.89199 & 99999999995 & TRN \\
\hline CHEMBL3198239 & 688171 & 5.45 & 4.9494 & TRN & \\
\hline CHEMBL1320426 & 688171 & 4.4 & 4.9099 & TRN & \\
\hline CHEMBL1593799 & 688171 & 4.6 & 4.8896 & TRN & \\
\hline CHEMBL1643542 & 688171 & 5.75 & 4.848 & TST & \\
\hline CHEMBL1440303 & 688171 & 5.65 & 4.8755 & TST & \\
\hline CHEMBL1358264 & 688171 & 4.9 & 4.9385 & TRN & \\
\hline CHEMBL1593755 & 688171 & 4.8 & 4.9475 & TRN & \\
\hline CHEMBL1430227 & 688171 & 4.85 & 4.7521 & TRN & \\
\hline CHEMBL1399164 & 688171 & 5.1 & 4.9453 & TST & \\
\hline CHEMBL1609902 & 688171 & 4.5 & 4.8576 & TRN & \\
\hline CHEMBL1345530 & 688171 & 4.85 & 4.9187 & TRN & \\
\hline CHEMBL1553333 & 688171 & 4.9 & 4.9308 & TRN & \\
\hline CHEMBL1445542 & 688171 & 4.5 & 5.1044 & TRN & \\
\hline CHEMBL1497797 & 688171 & 5.3 & 4.8515 & TST & \\
\hline CHEMBL1385428 & 688171 & 5.3 & 4.9874 & TST & \\
\hline CHEMBL1316416 & 688171 & 4.95 & 4.8709 & TRN & \\
\hline CHEMBL1542246 & 688171 & 4.55 & 4.8829 & TRN & \\
\hline CHEMBL1578524 & 688171 & 5.1 & 4.9958 & TST & \\
\hline CHEMBL1350673 & 688171 & 4.4 & 5.0389 & TRN & \\
\hline CHEMBL3195746 & 688171 & 4.5 & 4.9315 & TST & \\
\hline CHEMBL1349197 & 688171 & 4.45 & 4.7572 & TRN & \\
\hline CHEMBL1333433 & 688171 & 4.9 & 4.8418 & TRN & \\
\hline CHEMBL1518896 & 688171 & 5.35 & 4.8137 & TRN & \\
\hline CHEMBL1313456 & 688171 & 4.95 & 4.9958 & TRN & \\
\hline CHEMBL1543904 & 688171 & 4.4 & 4.9606 & TST & \\
\hline CHEMBL1556640 & 688171 & 4.55 & 5.0546 & TST & \\
\hline
\end{tabular}




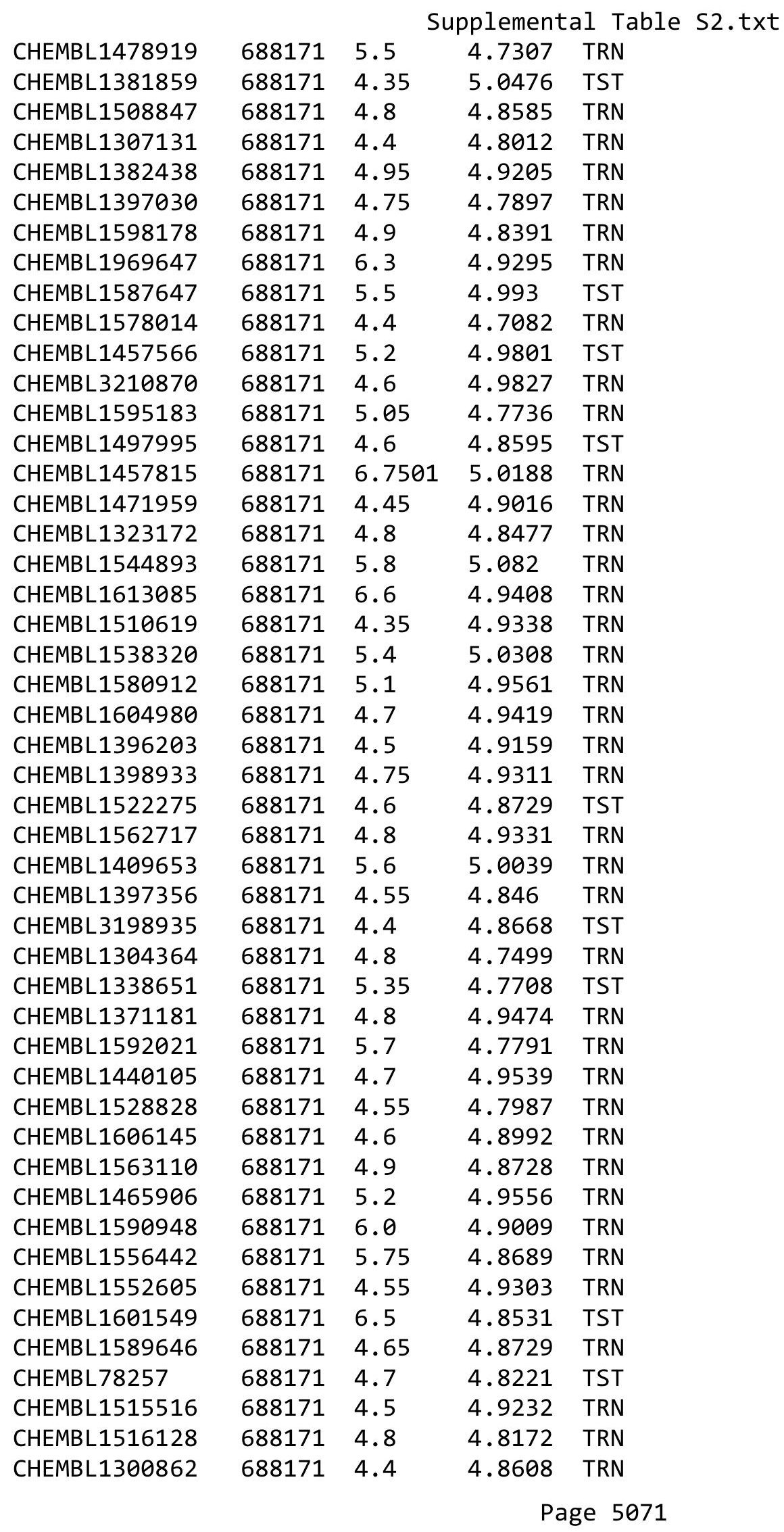




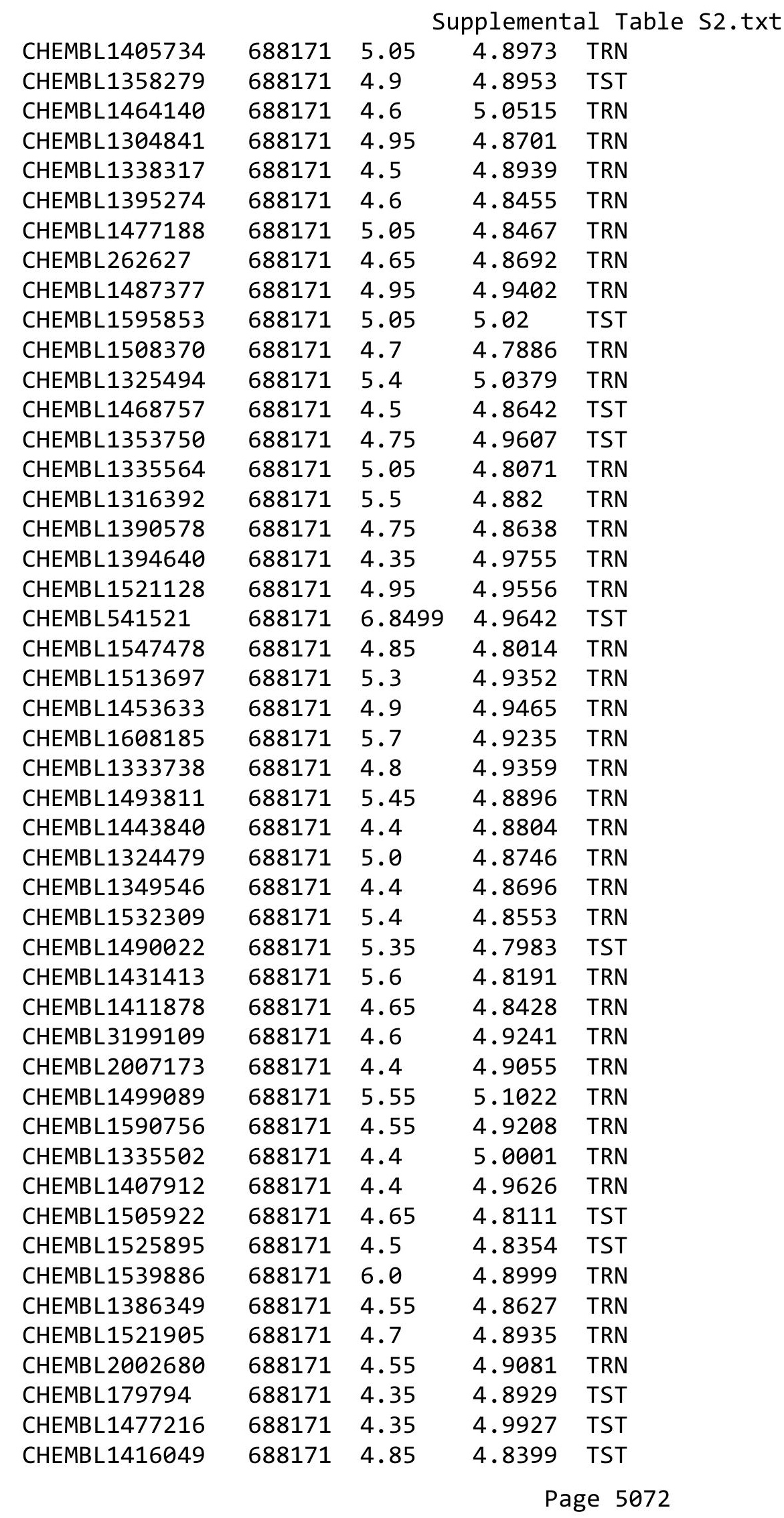




\begin{tabular}{|c|c|c|c|c|c|}
\hline \multicolumn{6}{|c|}{ Supplemental Table S2.txt } \\
\hline CHEMBL1308009 & 688171 & 4.45 & 4.7933 & TRN & \\
\hline CHEMBL1373959 & 688171 & 4.55 & 4.8081 & TRN & \\
\hline CHEMBL1566694 & 688171 & 5.5 & 5.1711 & TST & \\
\hline CHEMBL1488757 & 688171 & 4.7 & 4.8984 & TRN & \\
\hline CHEMBL1405019 & 688171 & 5.35 & 5.0242 & TRN & \\
\hline CHEMBL 3214628 & 688171 & 4.85 & 4.8681 & TRN & \\
\hline CHEMBL1442887 & 688171 & 5.45 & 4.9203 & TST & \\
\hline CHEMBL1315325 & 688171 & 5.0 & 4.8097 & TRN & \\
\hline CHEMBL1609619 & 688171 & 4.65 & 4.8549 & TRN & \\
\hline CHEMBL1522764 & 688171 & 4.4 & 4.9105 & TST & \\
\hline CHEMBL1499582 & 688171 & 4.95 & 5.0039 & TRN & \\
\hline CHEMBL1608328 & 688171 & 4.35 & 4.8977 & TRN & \\
\hline CHEMBL97858 & 688171 & 4.7 & 4.7718 & TST & \\
\hline CHEMBL1350986 & 688171 & 4.9 & 4.897 & TRN & \\
\hline CHEMBL1462667 & 688171 & 4.55 & 4.9527 & TST & \\
\hline CHEMBL1480264 & 688171 & 4.7 & 4.9452 & TRN & \\
\hline CHEMBL1532072 & 688171 & 6.0 & 4.7779 & TRN & \\
\hline CHEMBL1391325 & 688171 & 4.55 & 4.9206 & TRN & \\
\hline CHEMBL 3194432 & 688171 & 4.4 & 4.8913 & TRN & \\
\hline CHEMBL1454475 & 688171 & 4.7 & 4.9917 & TST & \\
\hline CHEMBL1323334 & 688171 & 4.9 & 4.9969 & TST & \\
\hline CHEMBL1557974 & 688171 & 4.4 & 4.9377 & TRN & \\
\hline CHEMBL1358445 & 688171 & 4.95 & 4.8924 & TRN & \\
\hline CHEMBL1371549 & 688171 & 6.7501 & 4.841 & TRN & \\
\hline CHEMBL1593584 & 688171 & 4.8 & 4.8181 & TRN & \\
\hline CHEMBL1476352 & 688171 & 4.75 & 4.8594 & TRN & \\
\hline CHEMBL580340 & 688171 & 4.4 & 4.8943 & TRN & \\
\hline CHEMBL1558968 & 688171 & 4.7 & 4.9712 & TRN & \\
\hline CHEMBL 3211553 & 688171 & 5.65 & 4.9448 & TRN & \\
\hline CHEMBL1460606 & 688171 & 5.45 & 5.12700 & 0000000001 & TRN \\
\hline CHEMBL 3209214 & 688171 & 4.5 & 5.0122 & TRN & \\
\hline CHEMBL1568301 & 688171 & 6.6 & 5.0214 & TST & \\
\hline CHEMBL1389194 & 688171 & 4.7 & 4.8222 & TRN & \\
\hline CHEMBL1455626 & 688171 & 4.95 & 4.9479 & TRN & \\
\hline CHEMBL1432679 & 688171 & 4.75 & 4.8212 & TRN & \\
\hline CHEMBL1527996 & 688171 & 4.65 & 4.8085 & TRN & \\
\hline CHEMBL1590836 & 688171 & 5.0 & 4.8373 & TRN & \\
\hline CHEMBL1345025 & 688171 & 5.6 & 4.9357 & TST & \\
\hline CHEMBL1611159 & 688171 & 4.9 & 4.748 & TRN & \\
\hline CHEMBL1407923 & 688171 & 6.0 & 5.0247 & TRN & \\
\hline CHEMBL1428063 & 688171 & 5.35 & 4.8752 & TRN & \\
\hline CHEMBL1426153 & 688171 & 4.35 & 4.7745 & TST & \\
\hline CHEMBL3209620 & 688171 & 4.6 & 4.8576 & TRN & \\
\hline CHEMBL1543375 & 688171 & 5.15 & 4.9577 & TRN & \\
\hline CHEMBL3189522 & 688171 & 4.4 & 4.9368 & TRN & \\
\hline CHEMBL1448979 & 688171 & 4.4 & 4.9004 & TST & \\
\hline CHEMBL1384077 & 688171 & 5.1 & 4.8753 & TRN & \\
\hline CHEMBL1337993 & 688171 & 5.0 & 4.8145 & TRN & \\
\hline
\end{tabular}




\begin{tabular}{|c|c|c|c|c|}
\hline \multicolumn{5}{|c|}{ Supplemental Table S2.txt } \\
\hline CHEMBL1358822 & 688171 & 4.7 & 4.8207 & TRN \\
\hline CHEMBL1311622 & 688171 & 5.05 & 4.8935 & TRN \\
\hline CHEMBL1354848 & 688171 & 4.45 & 4.8709 & TRN \\
\hline CHEMBL1313608 & 688171 & 5.0 & 4.9331 & TRN \\
\hline CHEMBL1353727 & 688171 & 4.55 & 4.8127 & TRN \\
\hline CHEMBL1560757 & 688171 & 4.45 & 4.9732 & TRN \\
\hline CHEMBL1397873 & 688171 & 5.9 & 4.9496 & TRN \\
\hline CHEMBL1535018 & 688171 & 4.5 & 4.8971 & TRN \\
\hline CHEMBL1537629 & 688171 & 6.5 & 4.9105 & TRN \\
\hline CHEMBL1589615 & 688171 & 4.35 & 4.9029 & TST \\
\hline CHEMBL351772 & 688171 & 6.5 & 4.8199 & TST \\
\hline CHEMBL1553843 & 688171 & 4.7 & 4.8563 & TRN \\
\hline CHEMBL1327029 & 688171 & 5.4 & 4.8744 & TRN \\
\hline CHEMBL1579968 & 688171 & 4.75 & 4.8703 & TRN \\
\hline CHEMBL1423229 & 688171 & 5.5 & 4.9057 & TRN \\
\hline CHEMBL1241452 & 688171 & 4.45 & 4.7732 & TRN \\
\hline CHEMBL1580214 & 688171 & 4.45 & 4.761 & TRN \\
\hline CHEMBL1434713 & 688171 & 4.55 & 4.8438 & TST \\
\hline CHEMBL3197509 & 688171 & 4.55 & 4.8754 & TRN \\
\hline CHEMBL1392537 & 688171 & 4.65 & 5.0401 & TRN \\
\hline CHEMBL1393375 & 688171 & 4.8 & 5.0093 & TST \\
\hline CHEMBL1318727 & 688171 & 4.75 & 4.8042 & TRN \\
\hline CHEMBL1376205 & 688171 & 5.8 & 4.9795 & TST \\
\hline CHEMBL1255653 & 688171 & 4.4 & 4.9202 & TST \\
\hline CHEMBL3195983 & 688171 & 4.7 & 4.9246 & TRN \\
\hline CHEMBL1577149 & 688171 & 4.4 & 4.8041 & TRN \\
\hline CHEMBL1328302 & 688171 & 4.35 & 4.834 & TRN \\
\hline CHEMBL1456626 & 688171 & 5.1 & 4.9241 & TRN \\
\hline CHEMBL1526681 & 688171 & 4.95 & 4.8025 & TRN \\
\hline CHEMBL1563583 & 688171 & 4.85 & 4.8511 & TRN \\
\hline CHEMBL3191373 & 688171 & 5.05 & 4.9999 & TRN \\
\hline CHEMBL1323722 & 688171 & 6.0 & 4.8298 & TRN \\
\hline CHEMBL1512869 & 688171 & 4.85 & 4.9163 & TRN \\
\hline CHEMBL1343925 & 688171 & 4.45 & 4.851 & TST \\
\hline CHEMBL1576343 & 688171 & 4.75 & 4.8827 & TRN \\
\hline CHEMBL1789998 & 688171 & 4.35 & 4.947 & TST \\
\hline CHEMBL1514372 & 688171 & 4.6 & 4.8008 & TRN \\
\hline CHEMBL1394031 & 688171 & 4.8 & 4.9156 & TRN \\
\hline CHEMBL1373289 & 688171 & 4.5 & 4.7262 & TST \\
\hline CHEMBL1385610 & 688171 & 4.75 & 4.9507 & TRN \\
\hline CHEMBL1478302 & 688171 & 5.2 & 4.9701 & TST \\
\hline CHEMBL1558398 & 688171 & 5.45 & 4.8128 & TRN \\
\hline CHEMBL1506624 & 688171 & 4.55 & 5.1192 & TRN \\
\hline CHEMBL1514316 & 688171 & 4.6 & 4.9529 & TRN \\
\hline CHEMBL1399607 & 688171 & 4.45 & 4.9052 & TRN \\
\hline CHEMBL1590803 & 688171 & 4.85 & 4.9588 & TRN \\
\hline CHEMBL1984894 & 688171 & 4.55 & 4.8245 & TRN \\
\hline CHEMBL1336043 & 688171 & 4.4 & 4.9446 & TRN \\
\hline
\end{tabular}




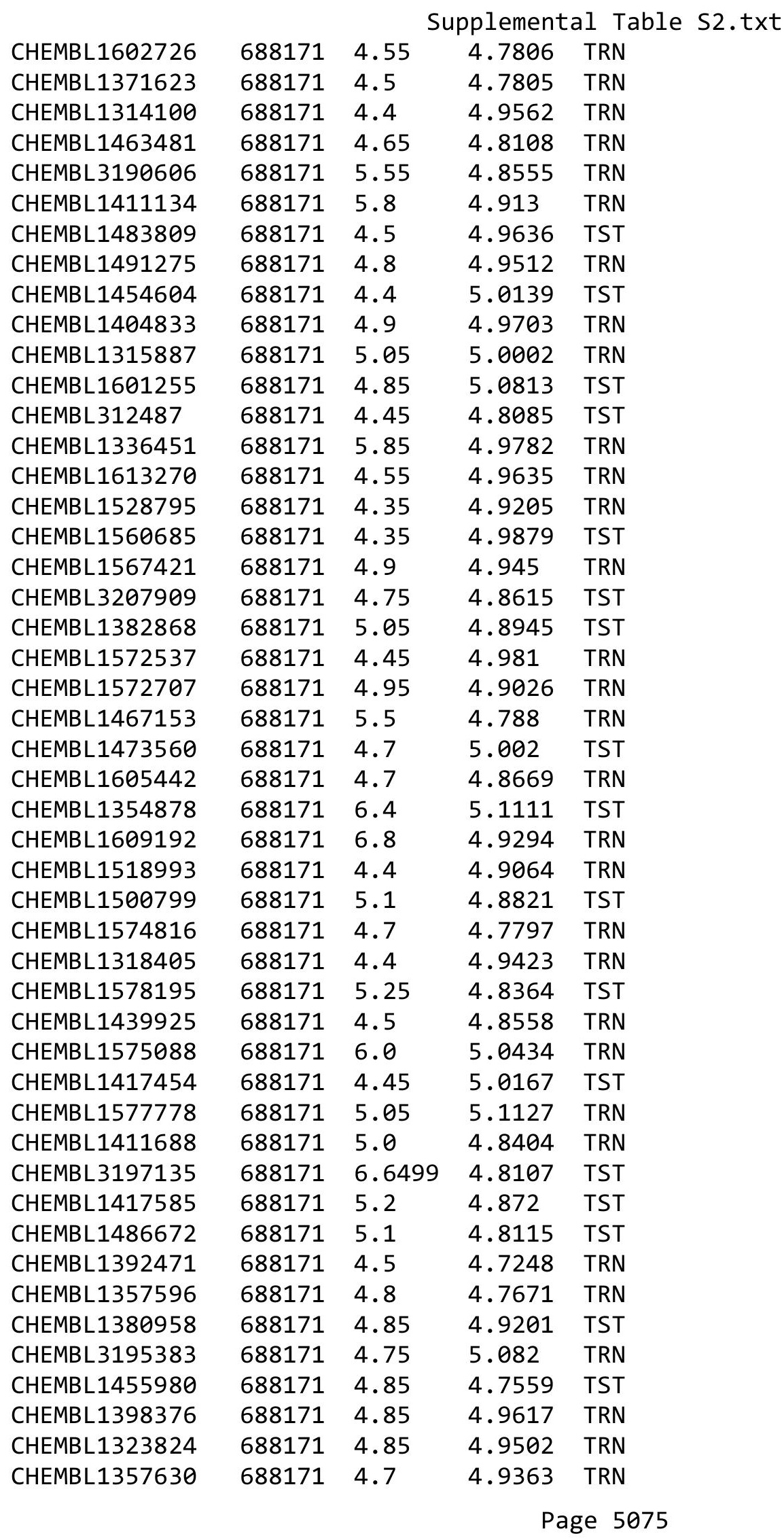




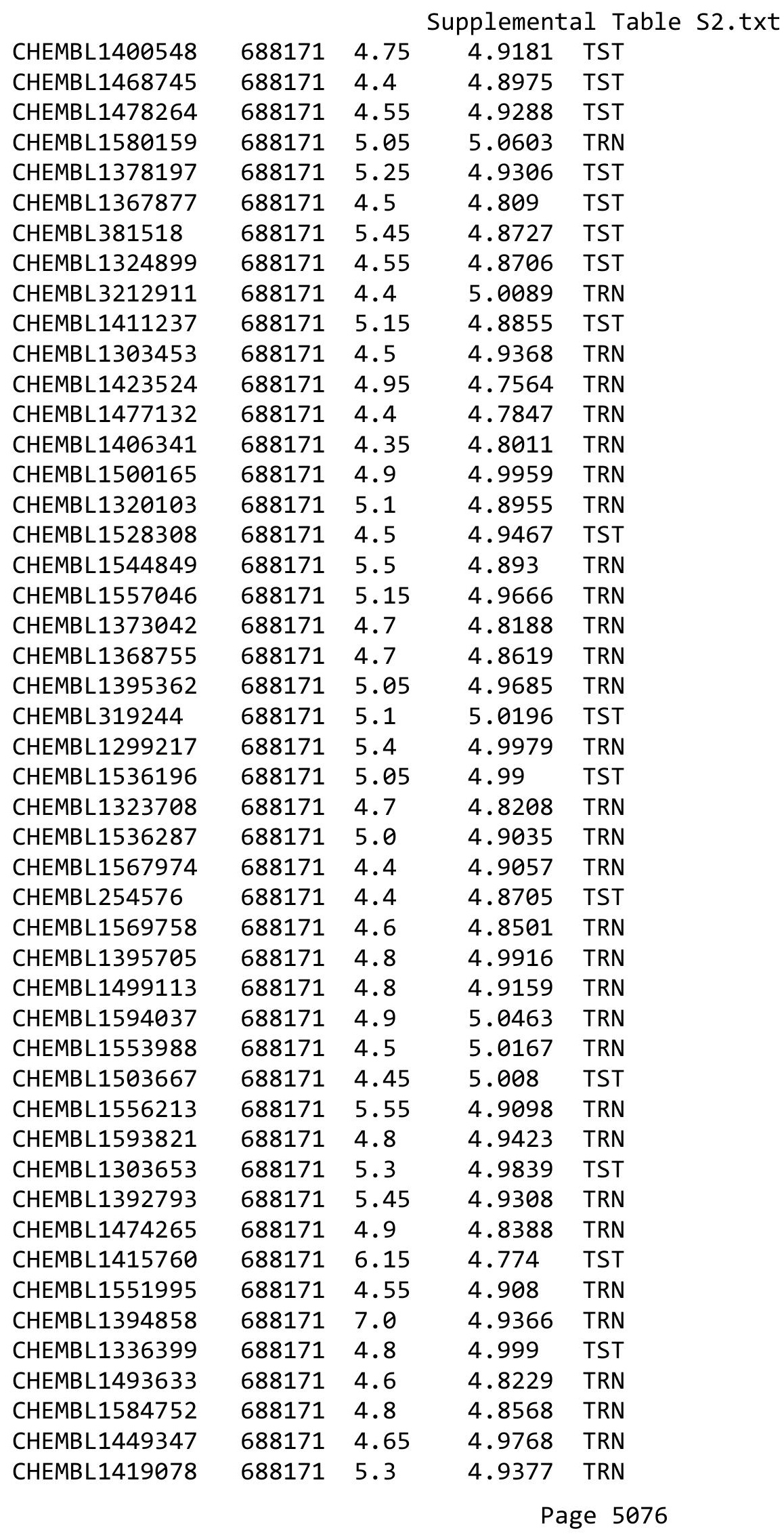




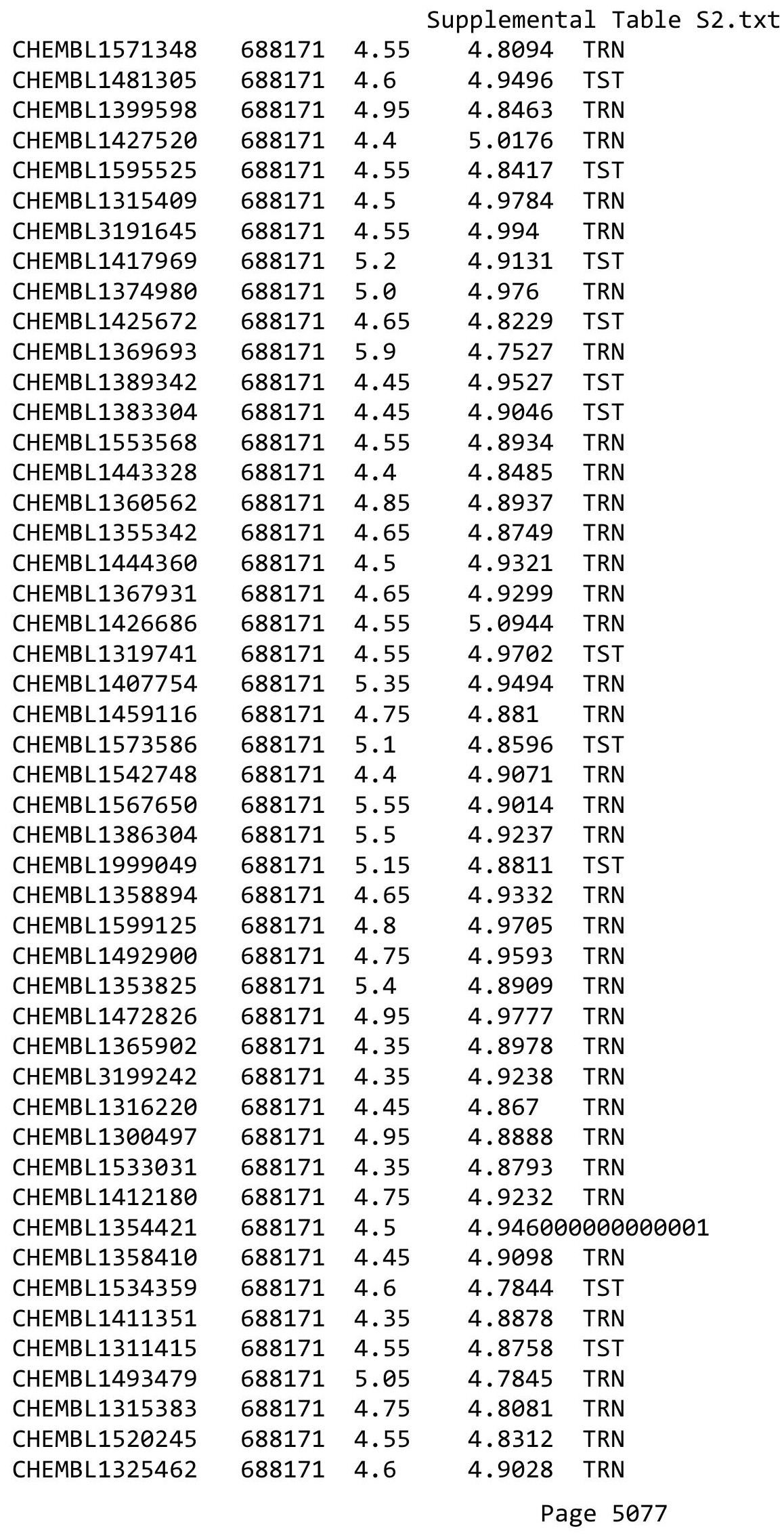




\begin{tabular}{|c|c|c|c|c|c|}
\hline \multicolumn{6}{|c|}{ Supplemental Table S2.txt } \\
\hline CHEMBL45152 & 688171 & 4.8 & 4.7902 & TRN & \\
\hline CHEMBL1514746 & 688171 & 4.55 & 4.7935 & TRN & \\
\hline CHEMBL1353574 & 688171 & 4.5 & 4.9902 & TRN & \\
\hline CHEMBL 3191770 & 688171 & 5.25 & 5.0228 & TRN & \\
\hline CHEMBL1539178 & 688171 & 4.5 & 4.9462 & TRN & \\
\hline CHEMBL1572134 & 688171 & 4.65 & 4.7719 & TRN & \\
\hline CHEMBL1564186 & 688171 & 5.05 & 4.9679 & TST & \\
\hline CHEMBL1553397 & 688171 & 4.8 & 4.7792 & TRN & \\
\hline CHEMBL59451 & 688171 & 5.2 & 4.9944 & TST & \\
\hline CHEMBL1226 & 688171 & 6.7001 & 5.0133 & TRN & \\
\hline CHEMBL1358092 & 688171 & 4.95 & 4.9564 & TRN & \\
\hline CHEMBL1518895 & 688171 & 4.8 & 4.9453 & TRN & \\
\hline CHEMBL1453229 & 688171 & 5.15 & 4.8166 & TRN & \\
\hline CHEMBL1461661 & 688171 & 4.4 & 4.9264 & TRN & \\
\hline CHEMBL1574495 & 688171 & 5.0 & 4.8812 & TRN & \\
\hline CHEMBL1373177 & 688171 & 4.4 & 5.0401 & TST & \\
\hline CHEMBL1566735 & 688171 & 6.05 & 4.871 & TST & \\
\hline CHEMBL1374476 & 688171 & 7.6003 & 4.9133 & TRN & \\
\hline CHEMBL1556551 & 688171 & 5.1 & 4.85800 & 00000000005 & TRN \\
\hline CHEMBL1425419 & 688171 & 4.65 & 4.966 & TRN & \\
\hline CHEMBL1481487 & 688171 & 5.5 & 4.9108 & TRN & \\
\hline CHEMBL3196704 & 688171 & 4.4 & 4.8376 & TRN & \\
\hline CHEMBL1341741 & 688171 & 5.05 & 4.8092 & TRN & \\
\hline CHEMBL1503826 & 688171 & 5.1 & 4.9467 & TRN & \\
\hline CHEMBL1451278 & 688171 & 4.55 & 4.9166 & TST & \\
\hline CHEMBL1420286 & 688171 & 4.4 & 5.0195 & TST & \\
\hline CHEMBL280998 & 688171 & 5.85 & 4.868 & TST & \\
\hline CHEMBL1555703 & 688171 & 4.8 & 4.9696 & TRN & \\
\hline CHEMBL 3210874 & 688171 & 5.15 & 4.9871 & TST & \\
\hline CHEMBL1314721 & 688171 & 5.0 & 5.0424 & TRN & \\
\hline CHEMBL1436109 & 688171 & 5.85 & 4.8841 & TRN & \\
\hline CHEMBL1367455 & 688171 & 5.1 & 4.9397 & TST & \\
\hline CHEMBL1610701 & 688171 & 4.35 & 4.8967 & TRN & \\
\hline CHEMBL1481042 & 688171 & 4.5 & 4.9333 & TRN & \\
\hline CHEMBL1454813 & 688171 & 4.85 & 4.7602 & TST & \\
\hline CHEMBL3145116 & 688171 & 5.7 & 5.0404 & TST & \\
\hline CHEMBL1348057 & 688171 & 4.95 & 4.9015 & TRN & \\
\hline CHEMBL1494165 & 688171 & 5.95 & 5.0539 & TST & \\
\hline CHEMBL1611655 & 688171 & 4.45 & 4.8469 & TST & \\
\hline CHEMBL187460 & 688171 & 6.0 & 4.9052 & TRN & \\
\hline CHEMBL1504329 & 688171 & 4.75 & 4.9355 & TST & \\
\hline CHEMBL1560307 & 688171 & 4.4 & 4.9559 & TST & \\
\hline CHEMBL1456924 & 688171 & 7.0 & 5.002 & TRN & \\
\hline CHEMBL1474140 & 688171 & 4.6 & 4.9499 & TST & \\
\hline CHEMBL1413017 & 688171 & 4.65 & 4.7975 & TRN & \\
\hline CHEMBL1309341 & 688171 & 4.4 & 4.8828 & TRN & \\
\hline CHEMBL1481138 & 688171 & 4.4 & 4.8682 & TRN & \\
\hline CHEMBL1607157 & 688171 & 6.45 & 5.0625 & TST & \\
\hline
\end{tabular}




\begin{tabular}{|c|c|c|c|c|c|}
\hline \multicolumn{6}{|c|}{ Supplemental Table S2.txt } \\
\hline CHEMBL1323574 & 688171 & 4.35 & 4.9345 & TRN & \\
\hline CHEMBL1495839 & 688171 & 4.95 & 5.059 & TRN & \\
\hline CHEMBL3195898 & 688171 & 4.9 & 4.8998 & TRN & \\
\hline CHEMBL1505301 & 688171 & 5.4 & 5.0536 & TRN & \\
\hline CHEMBL1451697 & 688171 & 6.35 & 5.045 & TST & \\
\hline CHEMBL1991885 & 688171 & 4.4 & 4.8671 & TRN & \\
\hline CHEMBL1472848 & 688171 & 4.9 & 4.8569 & TRN & \\
\hline CHEMBL1344032 & 688171 & 6.05 & 4.8708 & TST & \\
\hline CHEMBL1389623 & 688171 & 5.05 & 4.8561 & TRN & \\
\hline CHEMBL3191537 & 688171 & 4.45 & 4.7839 & TRN & \\
\hline CHEMBL1534950 & 688171 & 5.5 & 5.0505 & TRN & \\
\hline CHEMBL1468247 & 688171 & 4.35 & 5.0039 & TST & \\
\hline CHEMBL1363175 & 688171 & 5.05 & 5.0477 & TST & \\
\hline CHEMBL1510833 & 688171 & 4.45 & 4.9327 & TST & \\
\hline CHEMBL1592518 & 688171 & 4.45 & 5.0122 & TST & \\
\hline CHEMBL1498696 & 688171 & 5.05 & 5.0777 & TRN & \\
\hline CHEMBL1465735 & 688171 & 5.35 & 4.9482 & TST & \\
\hline CHEMBL1526580 & 688171 & 4.4 & 5.0336 & TST & \\
\hline CHEMBL1363585 & 688171 & 4.4 & 4.9936 & TST & \\
\hline CHEMBL1395234 & 688171 & 4.7 & 4.9944 & TST & \\
\hline CHEMBL1369048 & 688171 & 4.8 & 5.0248 & TRN & \\
\hline CHEMBL1555347 & 688171 & 4.95 & 4.885 & TRN & \\
\hline CHEMBL1483187 & 688171 & 4.85 & 4.9242 & TRN & \\
\hline CHEMBL1348345 & 688171 & 4.95 & 5.021 & TRN & \\
\hline CHEMBL1447418 & 688171 & 4.5 & 4.9538 & TRN & \\
\hline CHEMBL1370491 & 688171 & 4.7 & 4.8549 & TST & \\
\hline CHEMBL1520247 & 688171 & 4.75 & 4.8331 & TRN & \\
\hline CHEMBL1464742 & 688171 & 4.8 & 4.8752 & TST & \\
\hline CHEMBL1561869 & 688171 & 4.4 & 5.0563 & TRN & \\
\hline CHEMBL1575767 & 688171 & 4.9 & 4.8863 & TRN & \\
\hline CHEMBL1530893 & 688171 & 4.4 & 4.7565 & TRN & \\
\hline CHEMBL1557708 & 688171 & 4.9 & 4.885 & TRN & \\
\hline CHEMBL1401938 & 688171 & 4.55 & 4.869 & TRN & \\
\hline CHEMBL1351471 & 688171 & 4.5 & 4.9021 & TST & \\
\hline CHEMBL1523965 & 688171 & 5.05 & 4.6919 & TRN & \\
\hline CHEMBL1342941 & 688171 & 4.6 & 4.9818 & TST & \\
\hline CHEMBL1512232 & 688171 & 4.4 & 4.8104 & TRN & \\
\hline CHEMBL1422056 & 688171 & 6.0 & 4.8612 & TST & \\
\hline CHEMBL1299745 & 688171 & 4.95 & 4.7837 & TRN & \\
\hline CHEMBL1566898 & 688171 & 4.55 & 5.01699 & 99999999995 & TRN \\
\hline CHEMBL1357554 & 688171 & 5.1 & 4.7831 & TRN & \\
\hline CHEMBL1513052 & 688171 & 5.25 & 4.9046 & TRN & \\
\hline CHEMBL1337081 & 688171 & 4.95 & 5.0655 & TRN & \\
\hline CHEMBL1504514 & 688171 & 4.4 & 4.9861 & TST & \\
\hline CHEMBL1988210 & 688171 & 5.05 & 4.9757 & TRN & \\
\hline CHEMBL1377371 & 688171 & 5.5 & 4.8296 & TRN & \\
\hline CHEMBL1599441 & 688171 & 7.6003 & 4.9081 & TRN & \\
\hline CHEMBL1479057 & 688171 & 4.35 & 4.9273 & TRN & \\
\hline
\end{tabular}




\begin{tabular}{|c|c|c|c|c|}
\hline \multicolumn{5}{|c|}{ Supplemental Table S2.txt } \\
\hline CHEMBL1573388 & 688171 & 4.5 & 4.8511 & TRN \\
\hline CHEMBL1558666 & 688171 & 4.4 & 4.7294 & TRN \\
\hline CHEMBL1361361 & 688171 & 4.95 & 5.0047 & TRN \\
\hline CHEMBL1430372 & 688171 & 4.4 & 5.0673 & TST \\
\hline CHEMBL1586916 & 688171 & 4.35 & 4.85 & TST \\
\hline CHEMBL1462185 & 688171 & 4.95 & 4.872 & TRN \\
\hline CHEMBL1425992 & 688171 & 5.3 & 4.787 & TRN \\
\hline CHEMBL1377637 & 688171 & 4.5 & 4.9079 & TRN \\
\hline CHEMBL 1487135 & 688171 & 5.0 & 4.7844 & TRN \\
\hline CHEMBL1571971 & 688171 & 4.4 & 4.8493 & TRN \\
\hline CHEMBL1366598 & 688171 & 4.45 & 4.8938 & TRN \\
\hline CHEMBL1456132 & 688171 & 6.6 & 5.0341 & TST \\
\hline CHEMBL1454532 & 688171 & 5.1 & 4.7748 & TRN \\
\hline CHEMBL1602038 & 688171 & 4.4 & 4.8755 & TRN \\
\hline CHEMBL1579811 & 688171 & 4.75 & 5.0554 & TST \\
\hline CHEMBL1528722 & 688171 & 5.65 & 4.8625 & TST \\
\hline CHEMBL1504661 & 688171 & 6.1 & 4.7639 & TST \\
\hline CHEMBL1488285 & 688171 & 4.4 & 4.9261 & TRN \\
\hline CHEMBL 1453218 & 688171 & 4.8 & 4.7976 & TRN \\
\hline CHEMBL1573186 & 688171 & 4.4 & 4.7507 & TRN \\
\hline CHEMBL1590829 & 688171 & 5.35 & 4.827 & TRN \\
\hline CHEMBL1334832 & 688171 & 5.15 & 4.8651 & TRN \\
\hline CHEMBL1529228 & 688171 & 6.6499 & 4.9781 & TRN \\
\hline CHEMBL1371304 & 688171 & 4.45 & 4.9282 & TRN \\
\hline CHEMBL1455818 & 688171 & 6.7001 & 4.9037 & TRN \\
\hline CHEMBL1573680 & 688171 & 4.8 & 5.0958 & TRN \\
\hline CHEMBL1372438 & 688171 & 4.35 & 4.9256 & TST \\
\hline CHEMBL1504595 & 688171 & 4.4 & 4.7834 & TRN \\
\hline CHEMBL1324998 & 688171 & 4.95 & 4.8489 & TRN \\
\hline CHEMBL1571921 & 688171 & 4.7 & 4.9955 & TRN \\
\hline CHEMBL1699206 & 688171 & 4.6 & 5.0035 & TST \\
\hline CHEMBL1553887 & 688171 & 5.05 & 4.9718 & TRN \\
\hline CHEMBL1546282 & 688171 & 5.4 & 4.8559 & TRN \\
\hline CHEMBL1437471 & 688171 & 5.05 & 4.9364 & TRN \\
\hline CHEMBL1499657 & 688171 & 4.4 & 5.0035 & TST \\
\hline CHEMBL1537534 & 688171 & 4.65 & 4.8567 & TRN \\
\hline CHEMBL1317923 & 688171 & 5.05 & 4.984 & TRN \\
\hline CHEMBL1510495 & 688171 & 4.75 & 4.8384 & TRN \\
\hline CHEMBL1581516 & 688171 & 4.35 & 4.9053 & TRN \\
\hline CHEMBL1417470 & 688171 & 5.45 & 4.7548 & TRN \\
\hline CHEMBL1514097 & 688171 & 4.35 & 4.8251 & TRN \\
\hline CHEMBL1391681 & 688171 & 6.1 & 5.0966 & TRN \\
\hline CHEMBL1420009 & 688171 & 4.4 & 4.9572 & TST \\
\hline CHEMBL1395374 & 688171 & 4.7 & 4.7755 & TRN \\
\hline CHEMBL1468113 & 688171 & 4.7 & 4.7697 & TST \\
\hline CHEMBL1369293 & 688171 & 4.8 & 4.8231 & TST \\
\hline CHEMBL1564028 & 688171 & 5.2 & 4.7551 & TST \\
\hline CHEMBL1533336 & 688171 & 4.5 & 4.8243 & TRN \\
\hline
\end{tabular}




\begin{tabular}{|c|c|c|c|c|}
\hline \multicolumn{5}{|c|}{ Supplemental Table } \\
\hline CHEMBL3196835 & 688171 & 4.45 & 4.9235 & TST \\
\hline CHEMBL1514156 & 688171 & 5.0 & 4.9003 & TRN \\
\hline CHEMBL3190923 & 688171 & 4.75 & 4.8821 & TRN \\
\hline CHEMBL1594507 & 688171 & 4.55 & 4.8557 & TRN \\
\hline CHEMBL1411666 & 688171 & 4.85 & 4.9825 & TST \\
\hline CHEMBL455571 & 688171 & 4.4 & 4.7708 & TRN \\
\hline CHEMBL1308936 & 688171 & 5.5 & 4.8666 & TRN \\
\hline CHEMBL1428437 & 688171 & 5.5 & 4.9689 & TRN \\
\hline CHEMBL1569440 & 688171 & 5.15 & 5.0398 & TRN \\
\hline CHEMBL1316049 & 688171 & 4.5 & 4.9138 & TRN \\
\hline CHEMBL1513966 & 688171 & 6.8499 & 5.0751 & TRN \\
\hline CHEMBL1400335 & 688171 & 5.6 & 4.9241 & TST \\
\hline CHEMBL1714415 & 688171 & 4.8 & 4.856 & TRN \\
\hline CHEMBL1480679 & 688171 & 4.4 & 4.9865 & TRN \\
\hline CHEMBL1712981 & 688171 & 4.95 & 4.7094 & TST \\
\hline CHEMBL1308994 & 688171 & 4.95 & 4.8875 & TRN \\
\hline CHEMBL1500249 & 688171 & 4.75 & 4.962 & TST \\
\hline CHEMBL1332748 & 688171 & 4.6 & 4.7104 & TRN \\
\hline CHEMBL1306437 & 688171 & 4.6 & 4.8907 & TRN \\
\hline CHEMBL1444266 & 688171 & 4.4 & 5.0694 & TRN \\
\hline CHEMBL 2369170 & 688171 & 4.4 & 4.9236 & TST \\
\hline CHEMBL1466250 & 688171 & 4.6 & 4.8398 & TRN \\
\hline CHEMBL3208734 & 688171 & 6.05 & 4.9598 & TST \\
\hline CHEMBL1355594 & 688171 & 5.0 & 4.9845 & TRN \\
\hline CHEMBL1436487 & 688171 & 5.0 & 4.8843 & TRN \\
\hline CHEMBL1388358 & 688171 & 4.75 & 5.0759 & TRN \\
\hline CHEMBL1600782 & 688171 & 7.6003 & 4.9286 & TRN \\
\hline CHEMBL3190756 & 688171 & 5.0 & 4.8366 & TST \\
\hline CHEMBL1366549 & 688171 & 4.75 & 4.8942 & TRN \\
\hline CHEMBL1368252 & 688171 & 4.5 & 4.8408 & TRN \\
\hline CHEMBL1474180 & 688171 & 6.05 & 4.9316 & TST \\
\hline CHEMBL1448503 & 688171 & 4.95 & 4.9661 & TRN \\
\hline CHEMBL1558736 & 688171 & 4.4 & 4.9448 & TRN \\
\hline CHEMBL1410178 & 688171 & 4.7 & 4.8143 & TRN \\
\hline CHEMBL1411388 & 688171 & 4.8 & 4.8157 & TRN \\
\hline CHEMBL1583034 & 688171 & 4.7 & 4.7881 & TRN \\
\hline CHEMBL1583997 & 688171 & 4.65 & 4.8798 & TST \\
\hline CHEMBL1319904 & 688171 & 4.7 & 5.041 & TRN \\
\hline CHEMBL1386111 & 688171 & 5.45 & 4.7994 & TRN \\
\hline CHEMBL1400441 & 688171 & 4.35 & 4.9275 & TRN \\
\hline CHEMBL1450176 & 688171 & 6.0 & 4.9397 & TRN \\
\hline CHEMBL1543809 & 688171 & 4.5 & 4.7791 & TRN \\
\hline CHEMBL1387410 & 688171 & 4.95 & 4.9332 & TRN \\
\hline CHEMBL1530921 & 688171 & 4.7 & 5.0027 & TRN \\
\hline CHEMBL1306259 & 688171 & 5.05 & 4.854 & TRN \\
\hline CHEMBL1529823 & 688171 & 5.4 & 4.8519 & TST \\
\hline CHEMBL1429278 & 688171 & 6.25 & 5.0641 & TST \\
\hline CHEMBL1577681 & 688171 & 4.75 & 4.9174 & TST \\
\hline
\end{tabular}




\begin{tabular}{|c|c|c|c|c|c|}
\hline \multicolumn{6}{|c|}{ Supplemental Table S2.txt } \\
\hline CHEMBL1460485 & 688171 & 4.45 & 4.9668 & TRN & \\
\hline CHEMBL1521070 & 688171 & 4.4 & 4.8815 & TST & \\
\hline CHEMBL1497632 & 688171 & 4.8 & 5.0732 & TRN & \\
\hline CHEMBL1510086 & 688171 & 4.55 & 4.9147 & TRN & \\
\hline CHEMBL1563531 & 688171 & 4.5 & 4.775 & TRN & \\
\hline CHEMBL1338897 & 688171 & 5.3 & 4.7512 & TST & \\
\hline CHEMBL1602109 & 688171 & 4.5 & 4.9215 & TRN & \\
\hline CHEMBL1306671 & 688171 & 7.6003 & 4.9797 & TRN & \\
\hline CHEMBL 1357721 & 688171 & 4.75 & 4.7518 & TRN & \\
\hline CHEMBL1397571 & 688171 & 4.75 & 4.9821 & TRN & \\
\hline CHEMBL1365716 & 688171 & 5.25 & 5.0708 & TST & \\
\hline CHEMBL236685 & 688171 & 4.65 & 4.8971 & TRN & \\
\hline CHEMBL1612861 & 688171 & 4.7 & 4.9021 & TST & \\
\hline CHEMBL1501285 & 688171 & 5.5 & 4.9021 & TRN & \\
\hline CHEMBL1603994 & 688171 & 4.4 & 4.7873 & TST & \\
\hline CHEMBL1606390 & 688171 & 4.35 & 4.973 & TST & \\
\hline CHEMBL1550445 & 688171 & 5.45 & 4.762 & TRN & \\
\hline CHEMBL1300963 & 688171 & 5.65 & 4.8388 & TRN & \\
\hline CHEMBL1559434 & 688171 & 4.9 & 4.7663 & TRN & \\
\hline CHEMBL1445350 & 688171 & 5.45 & 4.7998 & TRN & \\
\hline CHEMBL1336182 & 688171 & 4.35 & 4.8852 & TST & \\
\hline CHEMBL1997970 & 688171 & 5.0 & 4.8757 & TRN & \\
\hline CHEMBL3194102 & 688171 & 4.4 & 4.966 & TRN & \\
\hline CHEMBL1343109 & 688171 & 4.4 & 5.0627 & TST & \\
\hline CHEMBL1553769 & 688171 & 4.85 & 4.88899 & 9999999999 & TRN \\
\hline CHEMBL1594191 & 688171 & 4.55 & 4.8043 & TRN & \\
\hline CHEMBL1539155 & 688171 & 4.7 & 4.8709 & TRN & \\
\hline CHEMBL1366809 & 688171 & 4.85 & 4.8459 & TRN & \\
\hline CHEMBL1359359 & 688171 & 4.5 & 5.0311 & TST & \\
\hline CHEMBL1529201 & 688171 & 5.05 & 4.8869 & TST & \\
\hline CHEMBL1512521 & 688171 & 5.15 & 4.9105 & TRN & \\
\hline CHEMBL1571941 & 688171 & 6.8 & 4.9253 & TRN & \\
\hline CHEMBL3197709 & 688171 & 4.8 & 5.0692 & TRN & \\
\hline CHEMBL1417488 & 688171 & 5.3 & 4.8504 & TRN & \\
\hline CHEMBL1388030 & 688171 & 4.35 & 4.9677 & TRN & \\
\hline CHEMBL1340694 & 688171 & 4.85 & 4.9611 & TRN & \\
\hline CHEMBL13790 & 688171 & 5.5 & 4.806 & TRN & \\
\hline CHEMBL1976940 & 688171 & 5.4 & 4.95 & TRN & \\
\hline CHEMBL1395547 & 688171 & 4.85 & 4.9113 & TRN & \\
\hline CHEMBL1457309 & 688171 & 4.75 & 4.9042 & TRN & \\
\hline CHEMBL1564294 & 688171 & 5.45 & 4.9667 & TRN & \\
\hline CHEMBL1355775 & 688171 & 4.4 & 5.0648 & TST & \\
\hline CHEMBL1450156 & 688171 & 4.6 & 4.8401 & TRN & \\
\hline CHEMBL1354652 & 688171 & 4.65 & 4.8017 & TRN & \\
\hline CHEMBL1428118 & 688171 & 5.5 & 4.9694 & TRN & \\
\hline CHEMBL1443210 & 688171 & 4.65 & 4.9258 & TRN & \\
\hline CHEMBL1313534 & 688171 & 4.6 & 4.8481 & TRN & \\
\hline CHEMBL1398506 & 688171 & 6.7501 & 4.9367 & TST & \\
\hline
\end{tabular}




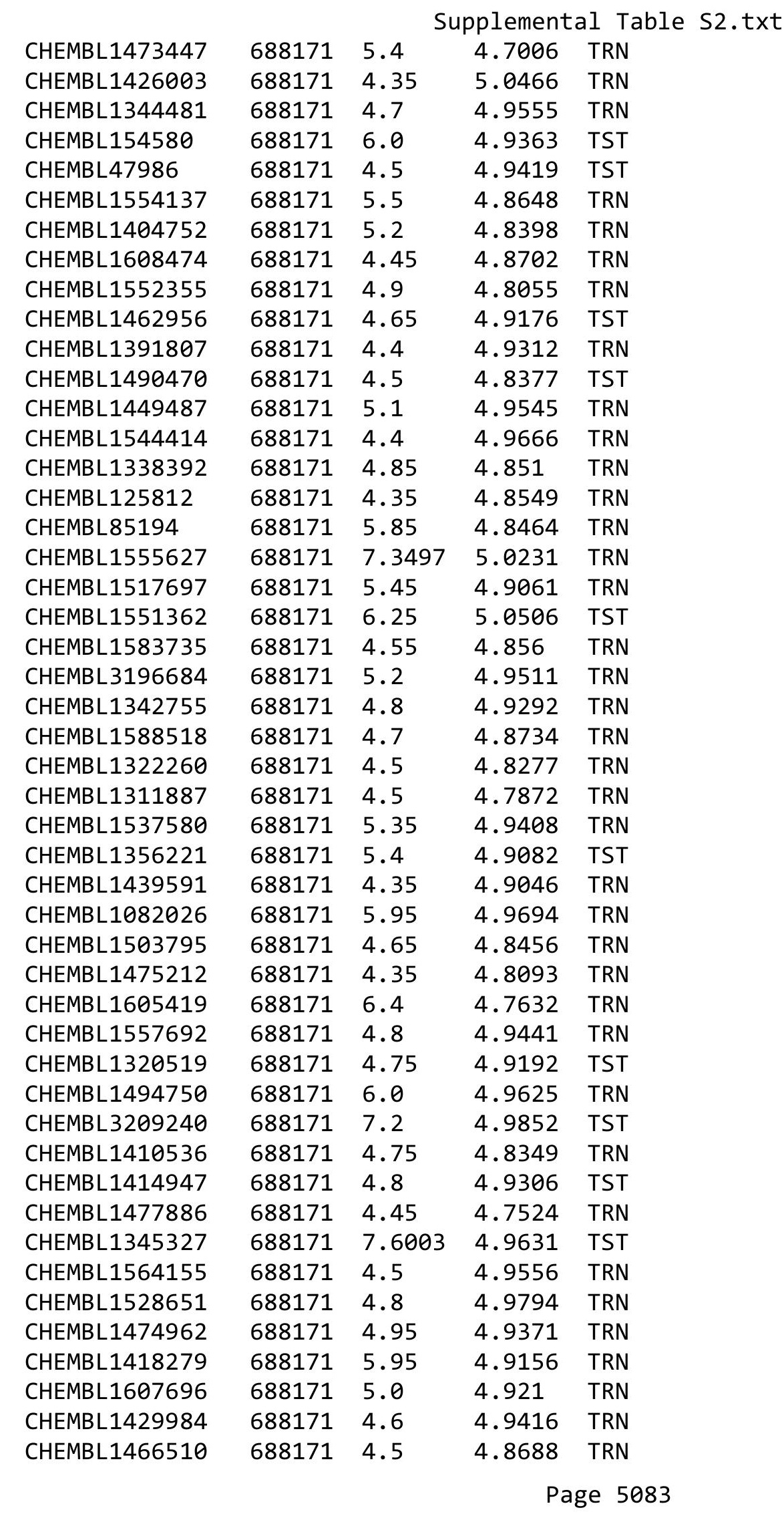




\begin{tabular}{|c|c|c|c|c|c|}
\hline \multicolumn{6}{|c|}{ Supplemental Table S2.txt } \\
\hline CHEMBL3212640 & 688171 & 4.6 & 4.7738 & TRN & \\
\hline CHEMBL1382827 & 688171 & 4.35 & 4.9899 & TST & \\
\hline CHEMBL1309349 & 688171 & 4.45 & 4.7845 & TRN & \\
\hline CHEMBL1473209 & 688171 & 4.4 & 4.77800 & 00000000005 & TRN \\
\hline CHEMBL1315611 & 688171 & 4.45 & 4.9687 & TRN & \\
\hline CHEMBL1575327 & 688171 & 7.6003 & 4.9218 & TST & \\
\hline CHEMBL1464929 & 688171 & 5.6 & 5.039 & TRN & \\
\hline CHEMBL1393142 & 688171 & 7.1002 & 4.9035 & TRN & \\
\hline CHEMBL1355115 & 688171 & 5.0 & 4.8623 & TRN & \\
\hline CHEMBL1393166 & 688171 & 5.6 & 4.9084 & TRN & \\
\hline CHEMBL1313201 & 688171 & 4.85 & 4.886 & TRN & \\
\hline CHEMBL1449700 & 688171 & 5.5 & 4.888 & TST & \\
\hline CHEMBL1525103 & 688171 & 4.9 & 4.8952 & TRN & \\
\hline CHEMBL1356781 & 688171 & 4.4 & 4.9773 & TRN & \\
\hline CHEMBL1349063 & 688171 & 4.4 & 4.9396 & TRN & \\
\hline CHEMBL1561341 & 688171 & 4.8 & 4.7993 & TRN & \\
\hline CHEMBL1530591 & 688171 & 5.95 & 4.8057 & TST & \\
\hline CHEMBL1490971 & 688171 & 4.35 & 4.9283 & TRN & \\
\hline CHEMBL1567647 & 688171 & 5.35 & 5.0162 & TRN & \\
\hline CHEMBL1510804 & 688171 & 5.75 & 4.8004 & TRN & \\
\hline CHEMBL1383244 & 688171 & 4.75 & 4.8205 & TRN & \\
\hline CHEMBL363535 & 688171 & 4.85 & 4.8179 & TRN & \\
\hline CHEMBL1517311 & 688171 & 4.75 & 4.8616 & TRN & \\
\hline CHEMBL1362291 & 688171 & 4.4 & 4.882 & TST & \\
\hline CHEMBL1366676 & 688171 & 6.45 & 4.8891 & TRN & \\
\hline CHEMBL1302706 & 688171 & 4.35 & 4.7323 & TRN & \\
\hline CHEMBL1432670 & 688171 & 5.15 & 4.9348 & TRN & \\
\hline CHEMBL 1457676 & 688171 & 4.65 & 4.9389 & TRN & \\
\hline CHEMBL1387628 & 688171 & 4.5 & 4.9101 & TST & \\
\hline CHEMBL1601566 & 688171 & 4.6 & 4.868 & TRN & \\
\hline CHEMBL1322440 & 688171 & 4.65 & 4.9302 & TRN & \\
\hline CHEMBL1533192 & 688171 & 4.7 & 4.9141 & TRN & \\
\hline CHEMBL1477227 & 688171 & 7.1002 & 4.9015 & TRN & \\
\hline CHEMBL1443826 & 688171 & 4.4 & 4.8563 & TRN & \\
\hline CHEMBL1510394 & 688171 & 4.6 & 5.0114 & TRN & \\
\hline CHEMBL1592809 & 688171 & 5.0 & 4.926 & TRN & \\
\hline CHEMBL1586973 & 688171 & 4.75 & 5.0284 & TRN & \\
\hline CHEMBL1534555 & 688171 & 4.4 & 4.82100 & 0000000001 & TRN \\
\hline CHEMBL1330179 & 688171 & 5.45 & 4.9004 & TRN & \\
\hline CHEMBL1335429 & 688171 & 4.75 & 4.9139 & TRN & \\
\hline CHEMBL1425768 & 688171 & 5.15 & 4.8909 & TRN & \\
\hline CHEMBL1581858 & 688171 & 4.55 & 4.9943 & TRN & \\
\hline CHEMBL1307483 & 688171 & 4.85 & 4.8685 & TRN & \\
\hline CHEMBL3192867 & 688171 & 4.8 & 4.9396 & TST & \\
\hline CHEMBL1612633 & 688171 & 4.95 & 4.8671 & TRN & \\
\hline CHEMBL1499550 & 688171 & 4.85 & 4.837 & TRN & \\
\hline CHEMBL1612726 & 688171 & 5.1 & 4.9418 & TST & \\
\hline CHEMBL1378634 & 688171 & 5.65 & 4.7654 & TRN & \\
\hline
\end{tabular}




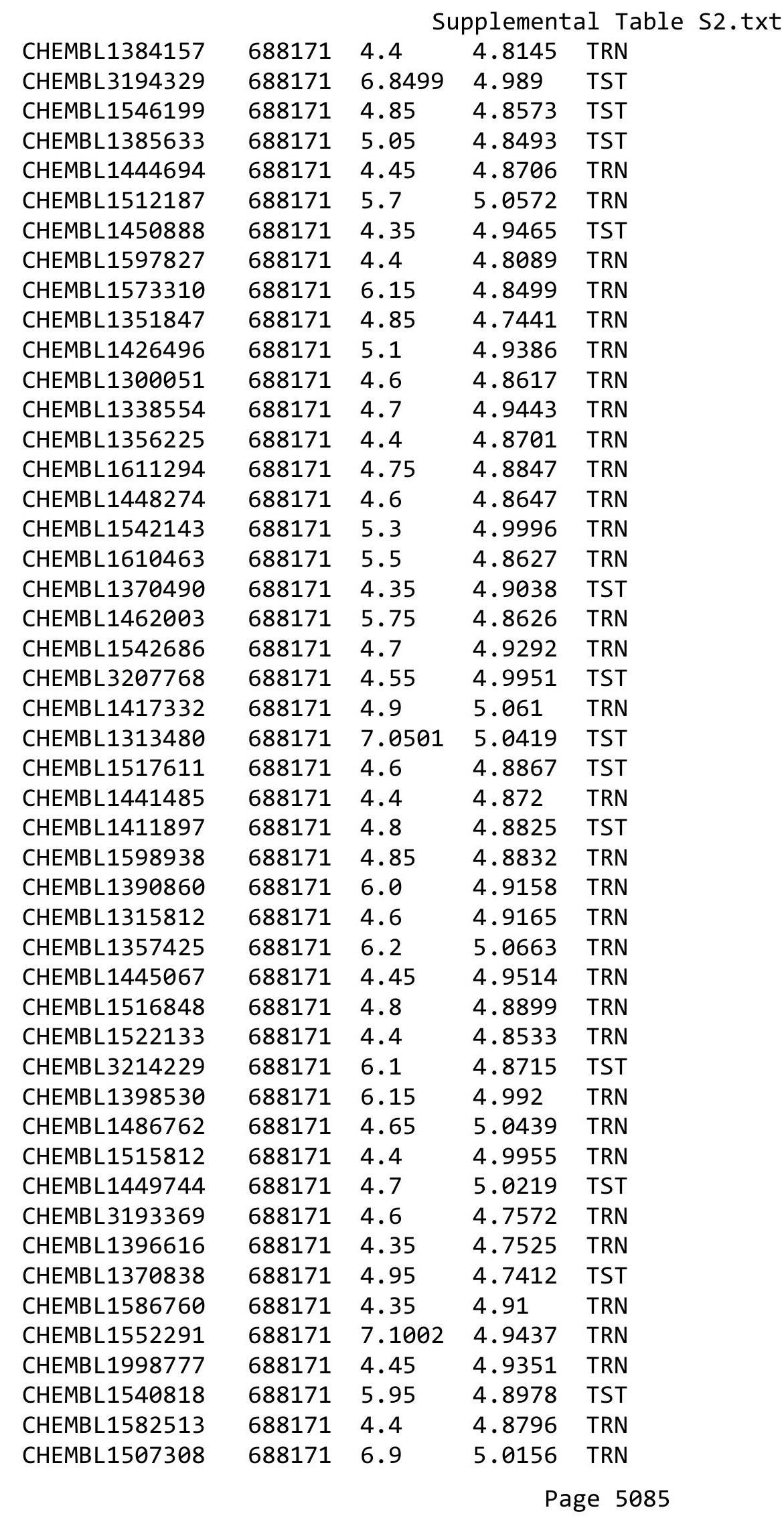




\begin{tabular}{|c|c|c|c|c|c|}
\hline \multicolumn{6}{|c|}{ Supplemental Table S2.txt } \\
\hline CHEMBL1452121 & 688171 & 4.4 & 4.9314 & TRN & \\
\hline CHEMBL3210067 & 688171 & 4.4 & 4.9452 & TST & \\
\hline CHEMBL1584497 & 688171 & 4.45 & 4.8865 & TRN & \\
\hline CHEMBL1559159 & 688171 & 4.4 & 4.8386 & TST & \\
\hline CHEMBL1455110 & 688171 & 4.4 & 4.8887 & TST & \\
\hline CHEMBL1520623 & 688171 & 5.0 & 4.9196 & TRN & \\
\hline CHEMBL1594000 & 688171 & 4.5 & 4.9419 & TRN & \\
\hline CHEMBL1255778 & 688171 & 6.0 & 4.9773 & TST & \\
\hline CHEMBL1412750 & 688171 & 6.1 & 5.0164 & TRN & \\
\hline CHEMBL1473628 & 688171 & 4.4 & 4.9119 & TRN & \\
\hline CHEMBL 74497 & 688171 & 4.4 & 4.7716 & TRN & \\
\hline CHEMBL1608989 & 688171 & 4.75 & 4.7937 & TRN & \\
\hline CHEMBL1369480 & 688171 & 4.4 & 4.9605 & TRN & \\
\hline CHEMBL531709 & 688171 & 5.15 & 4.8251 & TRN & \\
\hline CHEMBL1327965 & 688171 & 4.4 & 5.0091 & TRN & \\
\hline CHEMBL54804 & 688171 & 4.7 & 4.9654 & TST & \\
\hline CHEMBL1305571 & 688171 & 5.2 & 4.9013 & TRN & \\
\hline CHEMBL1569781 & 688171 & 4.4 & 4.9976 & TRN & \\
\hline CHEMBL1553296 & 688171 & 4.35 & 4.9728 & TST & \\
\hline CHEMBL1326847 & 688171 & 7.15 & 4.8375 & TRN & \\
\hline CHEMBL3209438 & 688171 & 4.45 & 4.9561 & TST & \\
\hline CHEMBL1463171 & 688171 & 4.85 & 4.7451 & TRN & \\
\hline CHEMBL1432099 & 688171 & 5.4 & 4.9924 & TST & \\
\hline CHEMBL1598651 & 688171 & 4.8 & 4.9227 & TRN & \\
\hline CHEMBL1540184 & 688171 & 4.4 & 4.854 & TRN & \\
\hline CHEMBL1539117 & 688171 & 7.5498 & 4.9841 & TST & \\
\hline CHEMBL1543694 & 688171 & 5.4 & 4.8269 & TRN & \\
\hline CHEMBL1359043 & 688171 & 4.85 & 4.9205 & TRN & \\
\hline CHEMBL1427471 & 688171 & 4.4 & 4.7617 & TRN & \\
\hline CHEMBL1515893 & 688171 & 5.25 & 5.0525 & TRN & \\
\hline CHEMBL1551015 & 688171 & 4.55 & 4.7589 & TRN & \\
\hline CHEMBL1407760 & 688171 & 4.35 & 4.7576 & TRN & \\
\hline CHEMBL1464249 & 688171 & 4.4 & 4.8943 & TRN & \\
\hline CHEMBL1374226 & 688171 & 4.4 & 4.8991 & TRN & \\
\hline CHEMBL3190976 & 688171 & 5.0 & 4.8487 & TRN & \\
\hline CHEMBL1491724 & 688171 & 4.6 & 4.7569 & TRN & \\
\hline CHEMBL1611468 & 688171 & 5.0 & 4.9374 & TRN & \\
\hline CHEMBL1593283 & 688171 & 4.75 & 4.8378 & TRN & \\
\hline CHEMBL1606128 & 688171 & 5.05 & 4.8673 & TRN & \\
\hline CHEMBL1307222 & 688171 & 4.6 & 5.0431 & TRN & \\
\hline CHEMBL1442586 & 688171 & 5.0 & 4.8953 & TRN & \\
\hline CHEMBL1409647 & 688171 & 4.75 & 4.8884 & TRN & \\
\hline CHEMBL1526757 & 688171 & 4.8 & 4.7456 & TRN & \\
\hline CHEMBL1475923 & 688171 & 4.75 & 4.9301 & TRN & \\
\hline CHEMBL1403003 & 688171 & 4.95 & 4.90600 & 0000000001 & TRN \\
\hline CHEMBL1463335 & 688171 & 4.45 & 4.9996 & TRN & \\
\hline CHEMBL1537553 & 688171 & 5.2 & 4.9628 & TST & \\
\hline CHEMBL1323850 & 688171 & 4.35 & 4.9235 & TRN & \\
\hline
\end{tabular}




\begin{tabular}{|c|c|c|c|c|c|}
\hline & & \multicolumn{4}{|c|}{ Supplemental Table S2.txt } \\
\hline CHEMBL1512154 & 688171 & 7.0501 & 4.9728 & TST & \\
\hline CHEMBL1500128 & 688171 & 4.8 & 4.8822 & TST & \\
\hline CHEMBL1553729 & 688171 & 4.85 & 5.0066 & TST & \\
\hline CHEMBL1569447 & 688171 & 6.8 & 4.8522 & TRN & \\
\hline CHEMBL1398212 & 688171 & 5.0 & 4.8212 & TRN & \\
\hline CHEMBL3191115 & 688171 & 4.4 & 4.7866 & TRN & \\
\hline CHEMBL3199023 & 688171 & 4.4 & 4.9235 & TRN & \\
\hline CHEMBL1325791 & 688171 & 5.8 & 4.8846 & TRN & \\
\hline CHEMBL1573261 & 688171 & 4.95 & 4.9081 & TRN & \\
\hline CHEMBL1452254 & 688171 & 4.45 & 4.7123 & TRN & \\
\hline CHEMBL1458563 & 688171 & 4.4 & 4.7505 & TRN & \\
\hline CHEMBL1391491 & 688171 & 4.4 & 4.9167 & TRN & \\
\hline CHEMBL1445709 & 688171 & 7.15 & 5.0227 & TRN & \\
\hline CHEMBL1310659 & 688171 & 5.4 & 4.8635 & TST & \\
\hline CHEMBL1570521 & 688171 & 4.75 & 4.864 & TRN & \\
\hline CHEMBL1335364 & 688171 & 5.15 & 4.9407 & TRN & \\
\hline CHEMBL1514633 & 688171 & 5.45 & 4.9622 & TRN & \\
\hline CHEMBL1480902 & 688171 & 4.65 & 4.8559 & TST & \\
\hline CHEMBL1606353 & 688171 & 5.05 & 4.8427 & TRN & \\
\hline CHEMBL3197220 & 688171 & 5.15 & 4.8592 & TRN & \\
\hline CHEMBL1317638 & 688171 & 4.95 & 4.8564 & TRN & \\
\hline CHEMBL1477435 & 688171 & 4.55 & 4.7859 & TRN & \\
\hline CHEMBL1597216 & 688171 & 4.9 & 5.0679 & TRN & \\
\hline CHEMBL1313525 & 688171 & 4.45 & 4.8612 & TRN & \\
\hline CHEMBL1552121 & 688171 & 5.1 & 4.92899 & 9999999999 & TRN \\
\hline CHEMBL1574834 & 688171 & 4.65 & 4.9328 & TST & \\
\hline CHEMBL1341758 & 688171 & 4.55 & 4.8327 & TST & \\
\hline CHEMBL1348937 & 688171 & 4.4 & 4.9687 & TRN & \\
\hline CHEMBL1404102 & 688171 & 6.15 & 4.9307 & TRN & \\
\hline CHEMBL1536418 & 688171 & 4.9 & 4.8074 & TST & \\
\hline CHEMBL1465040 & 688171 & 4.75 & 4.8185 & TRN & \\
\hline CHEMBL1998200 & 688171 & 5.35 & 4.86100 & 0000000001 & TRN \\
\hline CHEMBL1413824 & 688171 & 4.6 & 4.9839 & TST & \\
\hline CHEMBL1316413 & 688171 & 5.0 & 4.8751 & TRN & \\
\hline CHEMBL1399143 & 688171 & 4.6 & 4.8403 & TRN & \\
\hline CHEMBL1362727 & 688171 & 4.8 & 4.7688 & TRN & \\
\hline CHEMBL1611098 & 688171 & 4.4 & 4.9595 & TST & \\
\hline CHEMBL1441907 & 688171 & 4.95 & 4.947 & TRN & \\
\hline CHEMBL1395477 & 688171 & 4.65 & 4.8233 & TRN & \\
\hline CHEMBL1435432 & 688171 & 5.05 & 4.8764 & TRN & \\
\hline CHEMBL1381220 & 688171 & 7.6003 & 4.8494 & TRN & \\
\hline CHEMBL1402056 & 688171 & 4.6 & 4.8503 & TRN & \\
\hline CHEMBL1578468 & 688171 & 4.65 & 4.7581 & TRN & \\
\hline CHEMBL1271881 & 688171 & 4.6 & 4.88 & TRN & \\
\hline CHEMBL1526241 & 688171 & 5.9 & 4.9523 & TRN & \\
\hline CHEMBL3190673 & 688171 & 4.65 & 4.9149 & TRN & \\
\hline CHEMBL1365132 & 688171 & 4.4 & 5.004 & TRN & \\
\hline CHEMBL3192732 & 688171 & 4.4 & 5.0739 & TST & \\
\hline
\end{tabular}




\begin{tabular}{|c|c|c|c|c|}
\hline & & & upplement & $\mathrm{T}$ \\
\hline CHEMBL1446600 & 688171 & 4.45 & 5.0055 & TRN \\
\hline CHEMBL3196107 & 688171 & 4.4 & 4.873 & TST \\
\hline CHEMBL1493528 & 688171 & 4.5 & 5.08 & TST \\
\hline CHEMBL 3210362 & 688171 & 4.9 & 4.955 & TRN \\
\hline CHEMBL 294018 & 688171 & 5.7 & 4.9066 & TST \\
\hline CHEMBL603031 & 688171 & 4.85 & 4.7483 & TRN \\
\hline CHEMBL1441924 & 688171 & 4.7 & 4.9313 & TRN \\
\hline CHEMBL1487050 & 688171 & 4.55 & 5.0576 & TST \\
\hline CHEMBL1469200 & 688171 & 4.55 & 4.918 & TRN \\
\hline CHEMBL1608776 & 688171 & 4.35 & 4.8372 & TRN \\
\hline CHEMBL1585448 & 688171 & 5.4 & 4.9323 & TRN \\
\hline CHEMBL1375429 & 688171 & 4.4 & 5.0077 & TRN \\
\hline CHEMBL1397308 & 688171 & 4.95 & 5.012 & TRN \\
\hline CHEMBL1454269 & 688171 & 5.05 & 4.9439 & TRN \\
\hline CHEMBL1359070 & 688171 & 4.55 & 4.776 & TST \\
\hline CHEMBL3190824 & 688171 & 4.55 & 5.0222 & TRN \\
\hline CHEMBL1316174 & 688171 & 4.4 & 4.9812 & TRN \\
\hline CHEMBL1395641 & 688171 & 4.7 & 4.9369 & TST \\
\hline CHEMBL1421203 & 688171 & 4.95 & 5.0329 & TST \\
\hline CHEMBL1393172 & 688171 & 5.05 & 4.8142 & TST \\
\hline CHEMBL1500800 & 688171 & 4.85 & 4.8496 & TRN \\
\hline CHEMBL1447137 & 688171 & 4.4 & 4.7455 & TST \\
\hline CHEMBL1470207 & 688171 & 4.4 & 4.9384 & TST \\
\hline CHEMBL600008 & 688171 & 4.65 & 4.8368 & TRN \\
\hline CHEMBL1418895 & 688171 & 4.35 & 4.8837 & TRN \\
\hline CHEMBL1569494 & 688171 & 4.45 & 4.9303 & TRN \\
\hline CHEMBL1398901 & 688171 & 4.6 & 4.8267 & TRN \\
\hline CHEMBL1515152 & 688171 & 5.5 & 4.999 & TRN \\
\hline CHEMBL1480213 & 688171 & 5.8 & 5.082 & TRN \\
\hline CHEMBL1523972 & 688171 & 5.05 & 4.9227 & TRN \\
\hline CHEMBL1519844 & 688171 & 4.85 & 4.8648 & TRN \\
\hline CHEMBL1403305 & 688171 & 4.35 & 4.8365 & TRN \\
\hline CHEMBL1470896 & 688171 & 5.3 & 5.059 & TRN \\
\hline CHEMBL1399533 & 688171 & 6.45 & 4.9249 & TST \\
\hline CHEMBL1510208 & 688171 & 4.65 & 4.9378 & TRN \\
\hline CHEMBL1440977 & 688171 & 4.85 & 4.927 & TST \\
\hline CHEMBL1473324 & 688171 & 4.45 & 4.9157 & TRN \\
\hline CHEMBL1438790 & 688171 & 5.45 & 4.9009 & TST \\
\hline CHEMBL1432715 & 688171 & 4.5 & 4.9849 & TST \\
\hline CHEMBL1553690 & 688171 & 4.6 & 4.8618 & TRN \\
\hline CHEMBL1595247 & 688171 & 4.75 & 4.9503 & TST \\
\hline CHEMBL1491163 & 688171 & 4.8 & 4.9438 & TRN \\
\hline CHEMBL1516553 & 688171 & 4.7 & 4.9096 & TRN \\
\hline CHEMBL1367829 & 688171 & 4.55 & 4.835 & TST \\
\hline CHEMBL1434988 & 688171 & 4.65 & 4.8113 & TRN \\
\hline CHEMBL1566652 & 688171 & 4.9 & 4.9041 & TRN \\
\hline CHEMBL1577884 & 688171 & 4.5 & 4.9445 & TRN \\
\hline CHEMBL1433107 & 688171 & 5.55 & 4.899 & TST \\
\hline
\end{tabular}




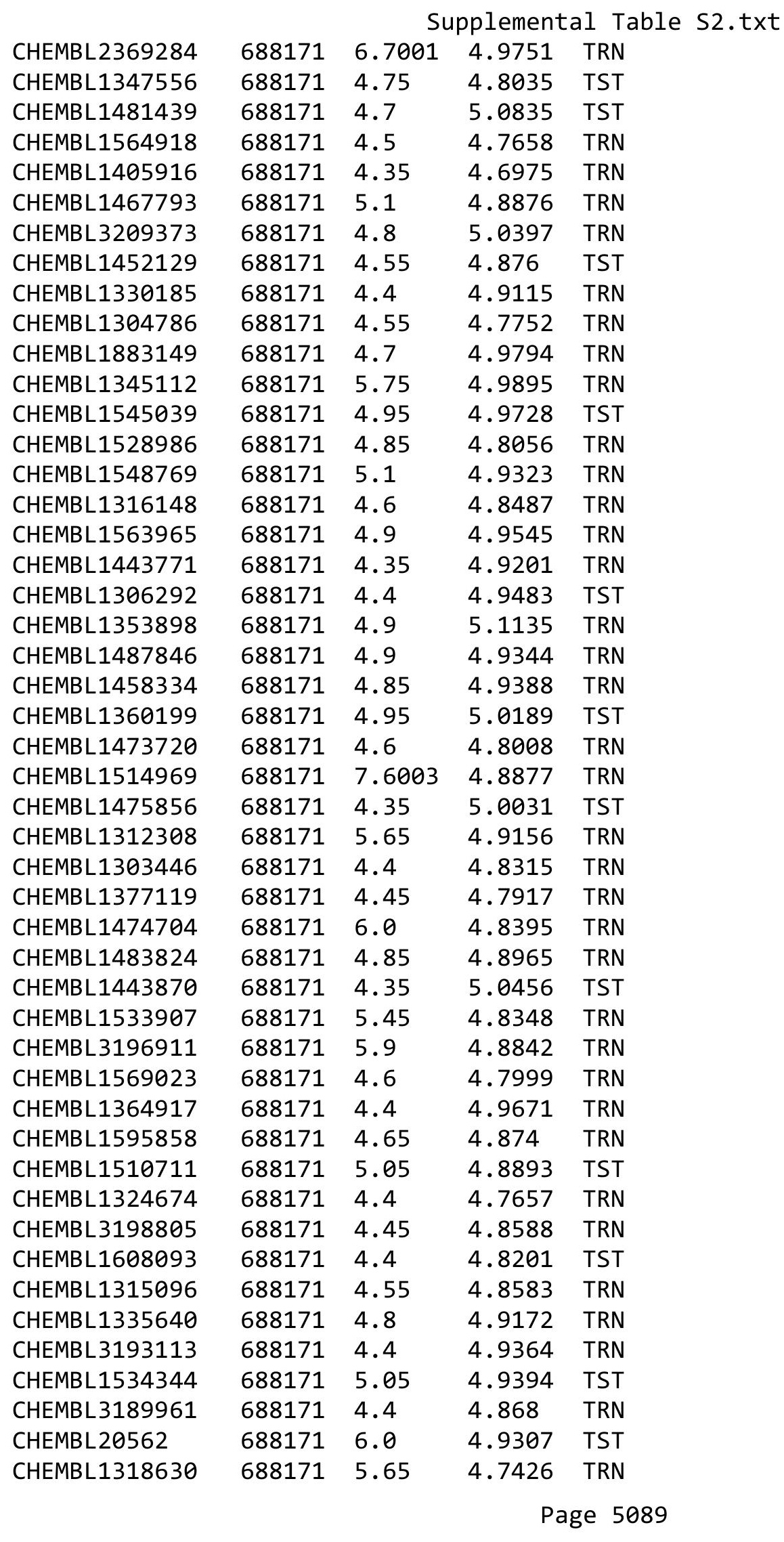




\begin{tabular}{|c|c|c|c|c|}
\hline \multicolumn{5}{|c|}{ Supplemental Table S2.txt } \\
\hline CHEMBL1404802 & 688171 & 5.6 & 4.8335 & TST \\
\hline CHEMBL1326975 & 688171 & 6.5 & 4.9952 & TST \\
\hline CHEMBL1583883 & 688171 & 4.35 & 5.0325 & TST \\
\hline CHEMBL1325265 & 688171 & 4.45 & 4.7949 & TRN \\
\hline CHEMBL1416076 & 688171 & 4.6 & 4.8538 & TRN \\
\hline CHEMBL1437189 & 688171 & 4.65 & 4.8018 & TRN \\
\hline CHEMBL1170891 & 688171 & 5.0 & 4.9173 & TRN \\
\hline CHEMBL1578467 & 688171 & 4.95 & 5.0535 & TST \\
\hline CHEMBL1572525 & 688171 & 4.45 & 4.9527 & TRN \\
\hline CHEMBL1372094 & 688171 & 7.6498 & 4.8425 & TRN \\
\hline CHEMBL1473495 & 688171 & 4.4 & 4.8435 & TRN \\
\hline CHEMBL1527348 & 688171 & 4.4 & 5.0079 & TRN \\
\hline CHEMBL1410213 & 688171 & 4.9 & 4.9508 & TST \\
\hline CHEMBL1409517 & 688171 & 4.4 & 4.9097 & TRN \\
\hline CHEMBL1322431 & 688171 & 5.4 & 4.9691 & TRN \\
\hline CHEMBL1332730 & 688171 & 4.35 & 4.7906 & TRN \\
\hline CHEMBL1563087 & 688171 & 6.25 & 4.9396 & TST \\
\hline CHEMBL1324668 & 688171 & 4.4 & 4.9049 & TRN \\
\hline CHEMBL1346279 & 688171 & 4.7 & 4.9709 & TRN \\
\hline CHEMBL1511679 & 688171 & 5.1 & 4.7766 & TRN \\
\hline CHEMBL1441291 & 688171 & 4.45 & 4.8926 & TRN \\
\hline CHEMBL1488581 & 688171 & 4.55 & 4.8647 & TRN \\
\hline CHEMBL1441577 & 688171 & 4.9 & 4.9345 & TRN \\
\hline CHEMBL1544737 & 688171 & 4.8 & 5.0116 & TRN \\
\hline CHEMBL3195569 & 688171 & 4.9 & 4.8755 & TRN \\
\hline CHEMBL1505914 & 688171 & 5.0 & 4.8967 & TRN \\
\hline CHEMBL1385373 & 688171 & 4.8 & 4.8496 & TRN \\
\hline CHEMBL1405919 & 688171 & 4.7 & 4.802 & TRN \\
\hline CHEMBL1564995 & 688171 & 5.55 & 5.0526 & TRN \\
\hline CHEMBL3192843 & 688171 & 4.95 & 4.9205 & TRN \\
\hline CHEMBL1572676 & 688171 & 4.8 & 4.8759 & TRN \\
\hline CHEMBL1452561 & 688171 & 5.5 & 4.9768 & TRN \\
\hline CHEMBL1558770 & 688171 & 4.4 & 4.9344 & TRN \\
\hline CHEMBL1560147 & 688171 & 4.65 & 4.8879 & TRN \\
\hline CHEMBL1333885 & 688171 & 4.5 & 4.8929 & TST \\
\hline CHEMBL1326812 & 688171 & 5.0 & 5.0638 & TRN \\
\hline CHEMBL1601289 & 688171 & 4.4 & 4.9167 & TRN \\
\hline CHEMBL1342292 & 688171 & 4.4 & 4.9075 & TST \\
\hline CHEMBL1987892 & 688171 & 4.4 & 4.8909 & TRN \\
\hline CHEMBL1538399 & 688171 & 4.65 & 4.9063 & TST \\
\hline CHEMBL1324454 & 688171 & 5.15 & 4.9691 & TRN \\
\hline CHEMBL1365574 & 688171 & 4.8 & 4.84 & TRN \\
\hline CHEMBL1459416 & 688171 & 4.4 & 5.0026 & TRN \\
\hline CHEMBL1500423 & 688171 & 4.35 & 4.7675 & TST \\
\hline CHEMBL1518332 & 688171 & 5.15 & 4.9486 & TRN \\
\hline CHEMBL1525614 & 688171 & 4.75 & 4.8163 & TRN \\
\hline CHEMBL1403626 & 688171 & 5.3 & 4.9476 & TST \\
\hline CHEMBL1462717 & 688171 & 4.5 & 4.9807 & TRN \\
\hline
\end{tabular}




\begin{tabular}{|c|c|c|c|c|c|}
\hline & & \multicolumn{4}{|c|}{ Supplemental Table S2.txt } \\
\hline CHEMBL1567391 & 688171 & 4.6 & 4.815 & TST & \\
\hline CHEMBL1428764 & 688171 & 4.5 & 4.9075 & TST & \\
\hline CHEMBL3212800 & 688171 & 4.7 & 4.9224 & TRN & \\
\hline CHEMBL1473942 & 688171 & 4.35 & 4.8114 & TST & \\
\hline CHEMBL1590446 & 688171 & 4.85 & 4.8019 & TRN & \\
\hline CHEMBL1600605 & 688171 & 4.35 & 4.9344 & TRN & \\
\hline CHEMBL1593522 & 688171 & 4.8 & 4.8269 & TRN & \\
\hline CHEMBL1430353 & 688171 & 4.7 & 4.9794 & TRN & \\
\hline CHEMBL1596326 & 688171 & 4.95 & 5.0379 & TRN & \\
\hline CHEMBL1342393 & 688171 & 4.85 & 4.825 & TRN & \\
\hline CHEMBL1449847 & 688171 & 4.5 & 4.8724 & TRN & \\
\hline CHEMBL1513456 & 688171 & 5.5 & 4.9866 & TRN & \\
\hline CHEMBL3197314 & 688171 & 4.4 & 5.0158 & TRN & \\
\hline CHEMBL1513863 & 688171 & 4.4 & 4.9975 & TRN & \\
\hline CHEMBL1413788 & 688171 & 4.6 & 4.9041 & TRN & \\
\hline CHEMBL1579040 & 688171 & 4.55 & 4.9709 & TRN & \\
\hline CHEMBL1468012 & 688171 & 7.2 & 5.043 & TST & \\
\hline CHEMBL1404476 & 688171 & 4.4 & 4.98300 & 00000000005 & TRN \\
\hline CHEMBL1437867 & 688171 & 4.5 & 4.916 & TST & \\
\hline CHEMBL1478801 & 688171 & 4.75 & 4.8053 & TRN & \\
\hline CHEMBL1418930 & 688171 & 5.3 & 4.8404 & TRN & \\
\hline CHEMBL1360568 & 688171 & 4.8 & 4.8583 & TRN & \\
\hline CHEMBL1500022 & 688171 & 4.8 & 4.9454 & TRN & \\
\hline CHEMBL1514841 & 688171 & 4.9 & 4.8819 & TRN & \\
\hline CHEMBL1448913 & 688171 & 4.35 & 4.967 & TRN & \\
\hline CHEMBL1483491 & 688171 & 4.95 & 4.8237 & TST & \\
\hline CHEMBL1349047 & 688171 & 4.4 & 4.915 & TST & \\
\hline CHEMBL1404648 & 688171 & 4.8 & 4.8577 & TST & \\
\hline CHEMBL1361025 & 688171 & 4.35 & 4.9402 & TRN & \\
\hline CHEMBL1369843 & 688171 & 4.5 & 5.0021 & TRN & \\
\hline CHEMBL1512882 & 688171 & 5.0 & 4.8643 & TRN & \\
\hline CHEMBL1528626 & 688171 & 4.85 & 4.909 & TRN & \\
\hline CHEMBL1369810 & 688171 & 5.1 & 4.8576 & TRN & \\
\hline CHEMBL1368954 & 688171 & 4.9 & 5.0215 & TRN & \\
\hline CHEMBL1517499 & 688171 & 4.65 & 4.7925 & TRN & \\
\hline CHEMBL1309202 & 688171 & 4.4 & 4.9182 & TRN & \\
\hline CHEMBL1318445 & 688171 & 4.85 & 4.9151 & TRN & \\
\hline CHEMBL1405678 & 688171 & 4.4 & 4.9566 & TRN & \\
\hline CHEMBL1302822 & 688171 & 5.35 & 4.9498 & TRN & \\
\hline CHEMBL1319579 & 688171 & 4.7 & 4.9483 & TRN & \\
\hline CHEMBL1336775 & 688171 & 4.4 & 4.8231 & TRN & \\
\hline CHEMBL1495273 & 688171 & 5.35 & 4.908 & TST & \\
\hline CHEMBL1598184 & 688171 & 4.55 & 4.9874 & TST & \\
\hline CHEMBL1473227 & 688171 & 4.95 & 4.9612 & TRN & \\
\hline CHEMBL1366086 & 688171 & 4.55 & 4.8246 & TRN & \\
\hline CHEMBL1408725 & 688171 & 4.5 & 4.8839 & TRN & \\
\hline CHEMBL1410562 & 688171 & 4.45 & 4.8334 & TRN & \\
\hline CHEMBL1522087 & 688171 & 5.75 & 4.842 & TST & \\
\hline
\end{tabular}




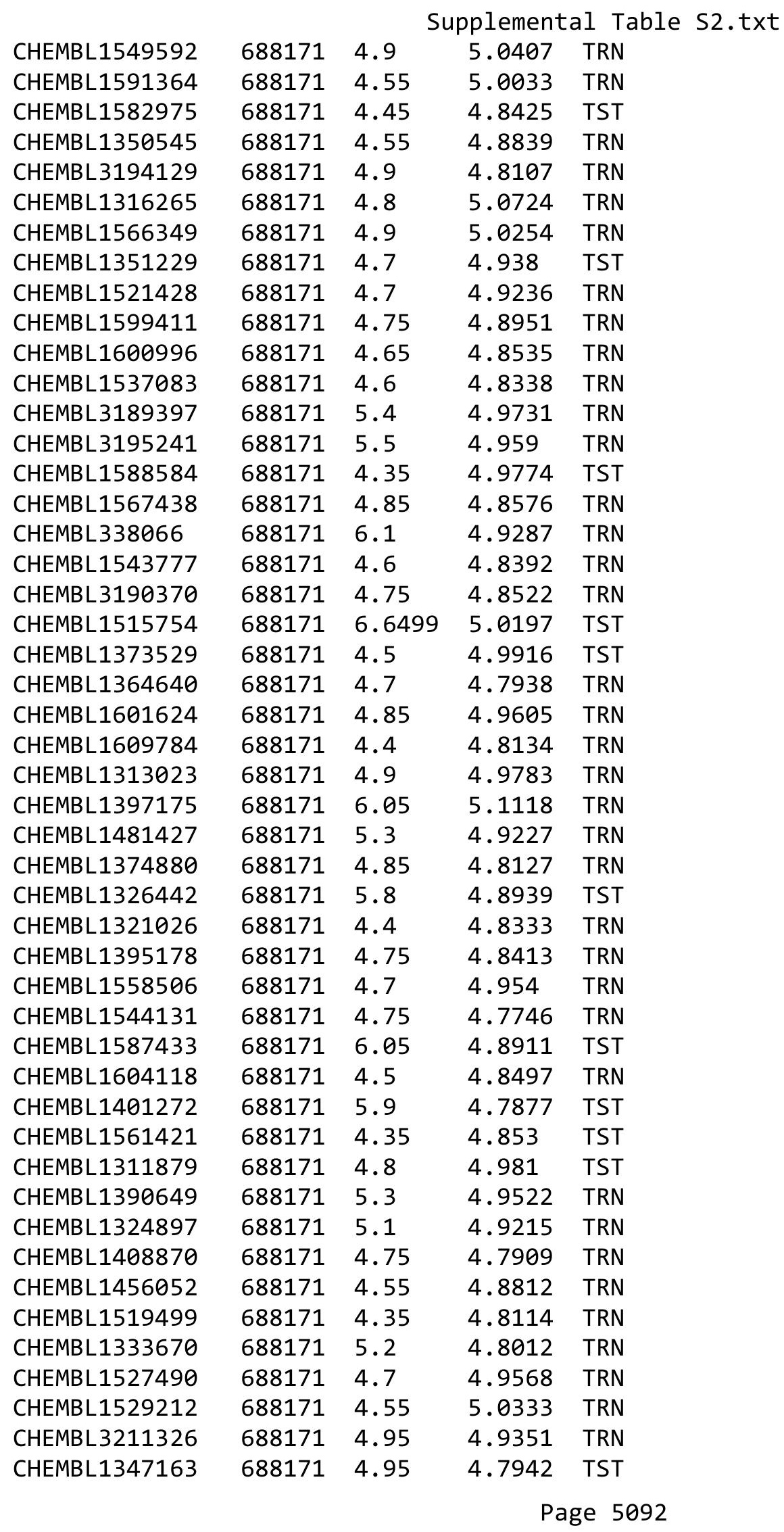




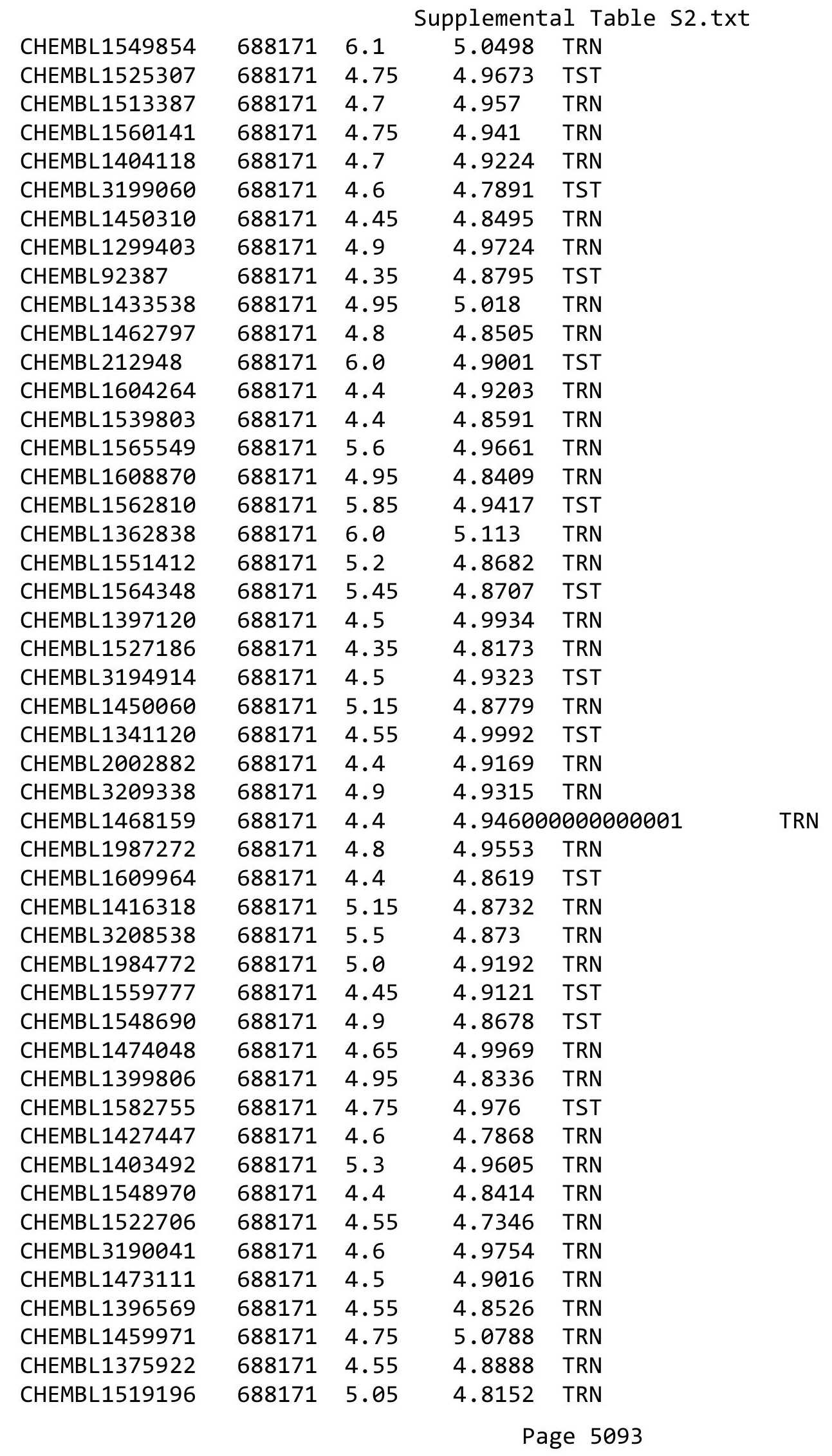




\begin{tabular}{|c|c|c|c|c|c|}
\hline \multicolumn{6}{|c|}{ Supplemental Table S2.txt } \\
\hline CHEMBL1576805 & 688171 & 5.1 & 5.0787 & TRN & \\
\hline CHEMBL1313565 & 688171 & 4.4 & 4.8329 & TRN & \\
\hline CHEMBL1528234 & 688171 & 4.4 & 4.8875 & TST & \\
\hline CHEMBL1342429 & 688171 & 4.65 & 4.8364 & TRN & \\
\hline CHEMBL1551551 & 688171 & 5.1 & 4.9042 & TRN & \\
\hline CHEMBL1597446 & 688171 & 5.1 & 4.8599 & TRN & \\
\hline CHEMBL155563 & 688171 & 5.1 & 4.7863 & TRN & \\
\hline CHEMBL1340570 & 688171 & 4.85 & 4.896 & TRN & \\
\hline CHEMBL1556634 & 688171 & 4.6 & 4.6572 & TRN & \\
\hline CHEMBL1399042 & 688171 & 5.2 & 4.9317 & TRN & \\
\hline CHEMBL1478511 & 688171 & 4.65 & 4.8205 & TRN & \\
\hline CHEMBL1556602 & 688171 & 4.55 & 4.82 & TST & \\
\hline CHEMBL1474074 & 688171 & 4.35 & 5.0069 & TST & \\
\hline CHEMBL1516372 & 688171 & 5.0 & 4.8686 & TRN & \\
\hline CHEMBL1470357 & 688171 & 4.9 & 4.9558 & TRN & \\
\hline CHEMBL1434541 & 688171 & 4.7 & 5.0668 & TRN & \\
\hline CHEMBL1974319 & 688171 & 4.7 & 4.9329 & TRN & \\
\hline CHEMBL1084478 & 688171 & 4.6 & 4.955 & TRN & \\
\hline CHEMBL1597478 & 688171 & 4.8 & 4.92399 & 99999999995 & TRN \\
\hline CHEMBL1323252 & 688171 & 4.4 & 4.9333 & TRN & \\
\hline CHEMBL1575776 & 688171 & 4.7 & 4.8512 & TST & \\
\hline CHEMBL1572123 & 688171 & 5.1 & 5.0596 & TST & \\
\hline CHEMBL1594442 & 688171 & 5.3 & 5.0638 & TRN & \\
\hline CHEMBL1458022 & 688171 & 5.8 & 4.8018 & TST & \\
\hline CHEMBL1455566 & 688171 & 6.35 & 4.9971 & TRN & \\
\hline CHEMBL 2001071 & 688171 & 5.0 & 4.8812 & TRN & \\
\hline CHEMBL1398248 & 688171 & 5.7 & 4.9465 & TRN & \\
\hline CHEMBL1591727 & 688171 & 4.4 & 4.8764 & TRN & \\
\hline CHEMBL1331164 & 688171 & 4.6 & 4.9363 & TRN & \\
\hline CHEMBL1422384 & 688171 & 4.5 & 4.9796 & TST & \\
\hline CHEMBL1437571 & 688171 & 5.9 & 4.8512 & TRN & \\
\hline CHEMBL1476509 & 688171 & 4.6 & 5.0084 & TRN & \\
\hline CHEMBL1523315 & 688171 & 5.0 & 4.9976 & TRN & \\
\hline CHEMBL1320479 & 688171 & 4.4 & 4.8815 & TRN & \\
\hline CHEMBL1409420 & 688171 & 4.95 & 4.838 & TRN & \\
\hline CHEMBL1316245 & 688171 & 4.65 & 4.9693 & TRN & \\
\hline CHEMBL1491322 & 688171 & 4.95 & 4.8538 & TRN & \\
\hline CHEMBL1308898 & 688171 & 4.55 & 4.7822 & TRN & \\
\hline CHEMBL1526567 & 688171 & 4.65 & 4.8684 & TRN & \\
\hline CHEMBL1490797 & 688171 & 4.85 & 4.7995 & TRN & \\
\hline CHEMBL3211917 & 688171 & 4.4 & 4.8823 & TRN & \\
\hline CHEMBL1494010 & 688171 & 4.35 & 4.916 & TRN & \\
\hline CHEMBL1172405 & 688171 & 4.75 & 4.9061 & TRN & \\
\hline CHEMBL 3214068 & 688171 & 4.4 & 4.9321 & TRN & \\
\hline CHEMBL1582024 & 688171 & 4.65 & 4.9124 & TRN & \\
\hline CHEMBL1447877 & 688171 & 6.0 & 4.8711 & TRN & \\
\hline CHEMBL1511959 & 688171 & 6.05 & 4.9506 & TRN & \\
\hline CHEMBL77456 & 688171 & 6.0 & 4.8752 & TRN & \\
\hline
\end{tabular}




\begin{tabular}{|c|c|c|c|c|c|}
\hline & & \multicolumn{4}{|c|}{ Supplemental Table S2.txt } \\
\hline CHEMBL 3193761 & 688171 & 4.75 & 4.9027 & TRN & \\
\hline CHEMBL1419398 & 688171 & 4.9 & \multicolumn{2}{|c|}{4.968999999999999} & TRN \\
\hline CHEMBL1358285 & 688171 & 4.35 & 4.9308 & TRN & \\
\hline CHEMBL1312940 & 688171 & 5.65 & 4.9342 & TRN & \\
\hline CHEMBL1971185 & 688171 & 5.2 & 4.9034 & TRN & \\
\hline CHEMBL1522376 & 688171 & 4.35 & 5.1209 & TRN & \\
\hline CHEMBL 3199825 & 688171 & 7.0 & 4.9236 & TST & \\
\hline CHEMBL1303474 & 688171 & 5.5 & 4.9202 & TST & \\
\hline CHEMBL1604266 & 688171 & 4.6 & 4.9329 & TRN & \\
\hline CHEMBL1577128 & 688171 & 4.6 & 5.0102 & TST & \\
\hline CHEMBL1611566 & 688171 & 4.95 & 4.7958 & TRN & \\
\hline CHEMBL1973501 & 688171 & 4.4 & 4.9158 & TRN & \\
\hline CHEMBL1513852 & 688171 & 4.6 & 4.9704 & TRN & \\
\hline CHEMBL1420359 & 688171 & 4.4 & 4.8341 & TRN & \\
\hline CHEMBL1476828 & 688171 & 4.55 & 4.8401 & TRN & \\
\hline CHEMBL1580007 & 688171 & 5.45 & 4.7551 & TRN & \\
\hline CHEMBL3190378 & 688171 & 6.0 & 4.9476 & TST & \\
\hline CHEMBL1399934 & 688171 & 4.55 & 4.8189 & TRN & \\
\hline CHEMBL1502448 & 688171 & 4.65 & 4.7638 & TRN & \\
\hline CHEMBL1360155 & 688171 & 4.9 & 4.7369 & TRN & \\
\hline CHEMBL1492712 & 688171 & 5.6 & 4.8236 & TRN & \\
\hline CHEMBL1414277 & 688171 & 5.0 & 4.896 & TRN & \\
\hline CHEMBL1514169 & 688171 & 4.65 & \multicolumn{2}{|c|}{4.7989999999999995} & TRN \\
\hline CHEMBL1338533 & 688171 & 5.05 & 4.9206 & TRN & \\
\hline CHEMBL9470 & 688171 & 4.9 & 5.0143 & TST & \\
\hline CHEMBL1538513 & 688171 & 5.05 & 4.9179 & TST & \\
\hline CHEMBL1551845 & 688171 & 5.25 & 4.9327 & TRN & \\
\hline CHEMBL1391615 & 688171 & 4.75 & 5.0145 & TST & \\
\hline CHEMBL1534542 & 688171 & 4.95 & 4.8036 & TRN & \\
\hline CHEMBL1550642 & 688171 & 4.4 & 4.8238 & TST & \\
\hline CHEMBL1396118 & 688171 & 5.0 & 4.9044 & TRN & \\
\hline CHEMBL1578828 & 688171 & 4.45 & 4.8295 & TRN & \\
\hline CHEMBL1409421 & 688171 & 4.4 & 4.8996 & TST & \\
\hline CHEMBL1365498 & 688171 & 5.0 & 4.9405 & TRN & \\
\hline CHEMBL1319230 & 688171 & 5.0 & 5.0015 & TRN & \\
\hline CHEMBL 3212935 & 688171 & 6.25 & 4.8195 & TST & \\
\hline CHEMBL1578011 & 688171 & 6.15 & 4.8177 & TRN & \\
\hline CHEMBL1497642 & 688171 & 4.85 & 4.9681 & TRN & \\
\hline CHEMBL1476073 & 688171 & 5.0 & 4.8014 & TRN & \\
\hline CHEMBL1535444 & 688171 & 6.0 & 4.9589 & TRN & \\
\hline CHEMBL1593420 & 688171 & 5.0 & 4.8351 & TST & \\
\hline CHEMBL1506501 & 688171 & 6.0 & 4.9381 & TST & \\
\hline CHEMBL1470585 & 688171 & 4.65 & 4.8454 & TRN & \\
\hline CHEMBL1305375 & 688171 & 5.25 & 4.8183 & TRN & \\
\hline CHEMBL1474422 & 688171 & 4.45 & 4.9504 & TRN & \\
\hline CHEMBL1363516 & 688171 & 6.05 & 4.9908 & TRN & \\
\hline CHEMBL177820 & 688171 & 5.25 & 4.8413 & TST & \\
\hline CHEMBL1409231 & 688171 & 4.95 & 5.0206 & TRN & \\
\hline
\end{tabular}




\begin{tabular}{|c|c|c|c|c|}
\hline \multicolumn{5}{|c|}{ Supplemental Table S2.txt } \\
\hline CHEMBL1579962 & 688171 & 5.05 & 5.0094 & TST \\
\hline CHEMBL1363326 & 688171 & 5.05 & 4.8734 & TRN \\
\hline CHEMBL1514679 & 688171 & 4.35 & 4.9588 & TRN \\
\hline CHEMBL3195289 & 688171 & 4.75 & 4.8517 & TRN \\
\hline CHEMBL1577329 & 688171 & 4.6 & 4.8527 & TRN \\
\hline CHEMBL1408839 & 688171 & 5.15 & 4.8445 & TRN \\
\hline CHEMBL1521354 & 688171 & 4.45 & 4.8226 & TST \\
\hline CHEMBL1317714 & 688171 & 5.05 & 4.9486 & TRN \\
\hline CHEMBL1337002 & 688171 & 5.3 & 4.9551 & TRN \\
\hline CHEMBL1476531 & 688171 & 4.65 & 4.9778 & TRN \\
\hline CHEMBL1394039 & 688171 & 4.75 & 4.9255 & TRN \\
\hline CHEMBL1348935 & 688171 & 4.65 & 4.927 & TRN \\
\hline CHEMBL1995948 & 688171 & 5.1 & 4.9404 & TST \\
\hline CHEMBL1510082 & 688171 & 5.05 & 4.9618 & TRN \\
\hline CHEMBL1365053 & 688171 & 5.6 & 4.9558 & TRN \\
\hline CHEMBL1991599 & 688171 & 5.0 & 5.0064 & TRN \\
\hline CHEMBL1571218 & 688171 & 5.25 & 4.993 & TRN \\
\hline CHEMBL3192006 & 688171 & 4.8 & 5.0067 & TST \\
\hline CHEMBL1520849 & 688171 & 4.5 & 4.8362 & TRN \\
\hline CHEMBL3193332 & 688171 & 4.7 & 4.8322 & TRN \\
\hline CHEMBL1552153 & 688171 & 4.7 & 4.9573 & TRN \\
\hline CHEMBL1363628 & 688171 & 5.95 & 4.7736 & TST \\
\hline CHEMBL1498790 & 688171 & 4.55 & 5.0798 & TRN \\
\hline CHEMBL1407509 & 688171 & 4.4 & 4.9861 & TRN \\
\hline CHEMBL1469057 & 688171 & 4.4 & 4.7727 & TRN \\
\hline CHEMBL1455416 & 688171 & 4.55 & 4.7926 & TRN \\
\hline CHEMBL1579050 & 688171 & 5.0 & 4.9133 & TST \\
\hline CHEMBL1573951 & 688171 & 5.3 & 4.9889 & TST \\
\hline CHEMBL1499442 & 688171 & 4.35 & 5.0057 & TRN \\
\hline CHEMBL1373233 & 688171 & 6.6 & 4.9704 & TRN \\
\hline CHEMBL1318589 & 688171 & 7.2503 & 4.9611 & TRN \\
\hline CHEMBL2003964 & 688171 & 5.25 & 4.912 & TRN \\
\hline CHEMBL3195343 & 688171 & 4.95 & 4.8634 & TST \\
\hline CHEMBL1576941 & 688171 & 5.45 & 5.1345 & TRN \\
\hline CHEMBL1344184 & 688171 & 4.6 & 4.8061 & TRN \\
\hline CHEMBL1457104 & 688171 & 4.95 & 4.8243 & TRN \\
\hline CHEMBL1593819 & 688171 & 5.1 & 4.9538 & TST \\
\hline CHEMBL1323861 & 688171 & 6.0 & 5.0735 & TRN \\
\hline CHEMBL1361237 & 688171 & 4.85 & 4.8666 & TRN \\
\hline CHEMBL1455688 & 688171 & 4.75 & 4.8511 & TRN \\
\hline CHEMBL1319039 & 688171 & 4.4 & 4.9682 & TST \\
\hline CHEMBL1381118 & 688171 & 5.05 & 4.8178 & TRN \\
\hline CHEMBL1490794 & 688171 & 6.0 & 5.0413 & TST \\
\hline CHEMBL1361322 & 688171 & 4.85 & 4.8978 & TRN \\
\hline CHEMBL1445776 & 688171 & 4.5 & 4.9369 & TRN \\
\hline CHEMBL3211210 & 688171 & 4.65 & 4.8365 & TST \\
\hline CHEMBL1303916 & 688171 & 5.35 & 4.8899 & TRN \\
\hline CHEMBL1396385 & 688171 & 4.7 & 4.8715 & TRN \\
\hline
\end{tabular}




\begin{tabular}{|c|c|c|c|c|c|}
\hline \multicolumn{6}{|c|}{ Supplemental Table S2.txt } \\
\hline CHEMBL1599185 & 688171 & 5.2 & 4.9669 & TRN & \\
\hline CHEMBL1595653 & 688171 & 6.2 & 4.9252 & TST & \\
\hline CHEMBL1398936 & 688171 & 4.5 & 4.8652 & TST & \\
\hline CHEMBL1395791 & 688171 & 4.85 & 4.8914 & TRN & \\
\hline CHEMBL1506066 & 688171 & 4.55 & 4.7828 & TRN & \\
\hline CHEMBL1486028 & 688171 & 4.45 & 4.9548 & TRN & \\
\hline CHEMBL1376305 & 688171 & 4.6 & 4.7376 & TRN & \\
\hline CHEMBL1475502 & 688171 & 4.4 & 4.9909 & TRN & \\
\hline CHEMBL1400655 & 688171 & 4.4 & 4.9068 & TRN & \\
\hline CHEMBL1965122 & 688171 & 4.55 & 5.0297 & TRN & \\
\hline CHEMBL1571199 & 688171 & 4.35 & 4.8117 & TRN & \\
\hline CHEMBL1363713 & 688171 & 4.7 & 4.7954 & TST & \\
\hline CHEMBL1590809 & 688171 & 4.85 & 4.7713 & TRN & \\
\hline CHEMBL1543548 & 688171 & 5.45 & 4.9793 & TRN & \\
\hline CHEMBL1396718 & 688171 & 4.4 & 4.8647 & TRN & \\
\hline CHEMBL1332014 & 688171 & 5.0 & 4.9289 & TRN & \\
\hline CHEMBL405110 & 688171 & 4.8 & 4.9389 & TST & \\
\hline CHEMBL1543944 & 688171 & 4.8 & 4.9328 & TRN & \\
\hline CHEMBL1440781 & 688171 & 4.4 & 4.827 & TRN & \\
\hline CHEMBL1396853 & 688171 & 4.6 & 5.0487 & TRN & \\
\hline CHEMBL1404459 & 688171 & 5.95 & 4.8523 & TRN & \\
\hline CHEMBL1329511 & 688171 & 5.4 & 4.7676 & TRN & \\
\hline CHEMBL1893861 & 688171 & 5.0 & 4.9351 & TRN & \\
\hline CHEMBL1429864 & 688171 & 6.95 & 5.0201 & TRN & \\
\hline CHEMBL1338138 & 688171 & 4.9 & 4.8199 & TRN & \\
\hline CHEMBL1585826 & 688171 & 5.0 & 4.7458 & TRN & \\
\hline CHEMBL1554447 & 688171 & 4.7 & 4.9294 & TRN & \\
\hline CHEMBL1565724 & 688171 & 5.45 & 5.1031 & TST & \\
\hline CHEMBL1440970 & 688171 & 5.2 & 4.8957 & TRN & \\
\hline CHEMBL1390840 & 688171 & 4.5 & 4.9839 & TST & \\
\hline CHEMBL1580625 & 688171 & 6.3 & 4.966 & TST & \\
\hline CHEMBL1498488 & 688171 & 4.35 & 4.8004 & TRN & \\
\hline CHEMBL1474647 & 688171 & 5.05 & $4.9110 e$ & 00000000005 & TRN \\
\hline CHEMBL1607218 & 688171 & 5.0 & 5.0305 & TRN & \\
\hline CHEMBL1489340 & 688171 & 4.35 & 4.9624 & TRN & \\
\hline CHEMBL1530160 & 688171 & 4.6 & 4.8558 & TST & \\
\hline CHEMBL1404559 & 688171 & 4.85 & 5.0023 & TRN & \\
\hline CHEMBL1344225 & 688171 & 5.35 & 4.897 & TRN & \\
\hline CHEMBL1335358 & 688171 & 5.05 & 4.8303 & TRN & \\
\hline CHEMBL1341100 & 688171 & 4.7 & 4.8413 & TST & \\
\hline CHEMBL1388405 & 688171 & 4.95 & 4.9423 & TRN & \\
\hline CHEMBL1553311 & 688171 & 4.35 & 5.0745 & TST & \\
\hline CHEMBL1470652 & 688171 & 6.9 & 4.9964 & TRN & \\
\hline CHEMBL1304646 & 688171 & 5.0 & 4.7991 & TRN & \\
\hline CHEMBL1514854 & 688171 & 4.45 & 4.8582 & TRN & \\
\hline CHEMBL1591454 & 688171 & 4.4 & 5.0097 & TRN & \\
\hline CHEMBL1571482 & 688171 & 5.1 & 4.9923 & TRN & \\
\hline CHEMBL1457490 & 688171 & 4.35 & 4.9454 & TRN & \\
\hline
\end{tabular}




\begin{tabular}{|c|c|c|c|c|c|}
\hline & & \multicolumn{4}{|c|}{ Supplemental Table S2.txt } \\
\hline CHEMBL1392313 & 688171 & 4.55 & 4.8645 & TST & \\
\hline CHEMBL1588434 & 688171 & 4.4 & 4.8523 & TST & \\
\hline CHEMBL1434172 & 688171 & 5.05 & 4.9022 & TRN & \\
\hline CHEMBL1307226 & 688171 & 5.2 & 4.9443 & TRN & \\
\hline CHEMBL1552464 & 688171 & 4.95 & 4.8506 & TRN & \\
\hline CHEMBL3199746 & 688171 & 4.4 & 5.0184 & TRN & \\
\hline CHEMBL1424887 & 688171 & 4.5 & 4.891 & TRN & \\
\hline CHEMBL1420897 & 688171 & 4.4 & 5.0638 & TST & \\
\hline CHEMBL1450807 & 688171 & 5.5 & 4.8757 & TRN & \\
\hline CHEMBL1589385 & 688171 & 4.85 & 4.8803 & TST & \\
\hline CHEMBL1367909 & 688171 & 4.45 & 4.9185 & TRN & \\
\hline CHEMBL1465170 & 688171 & 4.75 & 4.8703 & TRN & \\
\hline CHEMBL1382387 & 688171 & 4.95 & 4.9761 & TRN & \\
\hline CHEMBL1339368 & 688171 & 5.8 & 4.7787 & TST & \\
\hline CHEMBL1551154 & 688171 & 4.65 & 4.9232 & TRN & \\
\hline CHEMBL1315621 & 688171 & 4.65 & 4.94600 & 0000000001 & TRN \\
\hline CHEMBL1599086 & 688171 & 4.85 & 4.9266 & TRN & \\
\hline CHEMBL1474696 & 688171 & 4.6 & 4.7451 & TRN & \\
\hline CHEMBL1431980 & 688171 & 5.4 & 4.8382 & TST & \\
\hline CHEMBL1415438 & 688171 & 4.35 & 4.8257 & TRN & \\
\hline CHEMBL3190941 & 688171 & 4.65 & 4.8897 & TST & \\
\hline CHEMBL1971901 & 688171 & 4.9 & 4.8159 & TST & \\
\hline CHEMBL1591073 & 688171 & 4.6 & 4.9666 & TRN & \\
\hline CHEMBL1356401 & 688171 & 4.5 & 5.0036 & TRN & \\
\hline CHEMBL1302923 & 688171 & 4.35 & 4.743 & TST & \\
\hline CHEMBL1363244 & 688171 & 4.65 & 4.9813 & TRN & \\
\hline CHEMBL1596837 & 688171 & 5.6 & 5.0002 & TRN & \\
\hline CHEMBL1510842 & 688171 & 4.7 & 4.9733 & TST & \\
\hline CHEMBL1420129 & 688171 & 4.35 & 4.8762 & TRN & \\
\hline CHEMBL1413963 & 688171 & 5.0 & 4.9796 & TRN & \\
\hline CHEMBL1335462 & 688171 & 4.4 & 4.8558 & TRN & \\
\hline CHEMBL1338696 & 688171 & 4.5 & 4.9374 & TRN & \\
\hline CHEMBL1453859 & 688171 & 4.85 & 4.8662 & TRN & \\
\hline CHEMBL1448977 & 688171 & 4.4 & 4.8786 & TST & \\
\hline CHEMBL1310184 & 688171 & 4.4 & 4.842 & TRN & \\
\hline CHEMBL1544186 & 688171 & 5.1 & 4.8135 & TRN & \\
\hline CHEMBL1390771 & 688171 & 4.4 & 4.891 & TRN & \\
\hline CHEMBL1320950 & 688171 & 4.6 & 4.8394 & TRN & \\
\hline CHEMBL1363918 & 688171 & 4.9 & 4.9726 & TRN & \\
\hline CHEMBL1517117 & 688171 & 5.4 & 4.8617 & TRN & \\
\hline CHEMBL17331 & 688171 & 5.55 & 4.7235 & TRN & \\
\hline CHEMBL1509623 & 688171 & 4.6 & 4.9269 & TRN & \\
\hline CHEMBL1353378 & 688171 & 4.55 & 4.7641 & TRN & \\
\hline CHEMBL1383944 & 688171 & 4.65 & 4.8473 & TRN & \\
\hline CHEMBL1473851 & 688171 & 4.6 & 5.0107 & TRN & \\
\hline CHEMBL1534660 & 688171 & 5.45 & 4.9232 & TRN & \\
\hline CHEMBL1431850 & 688171 & 4.35 & 4.8544 & TST & \\
\hline CHEMBL3194468 & 688171 & 5.05 & 5.0156 & TRN & \\
\hline
\end{tabular}




\begin{tabular}{|c|c|c|c|c|}
\hline \multicolumn{5}{|c|}{ Supplemental Table S2.txt } \\
\hline CHEMBL1593678 & 688171 & 5.45 & 4.8452 & TRN \\
\hline CHEMBL1373840 & 688171 & 5.4 & 4.8603 & TRN \\
\hline CHEMBL1361071 & 688171 & 4.6 & 4.9589 & TST \\
\hline CHEMBL1553303 & 688171 & 4.5 & 5.0131 & TRN \\
\hline CHEMBL3211947 & 688171 & 4.95 & 4.9553 & TST \\
\hline CHEMBL1601061 & 688171 & 5.5 & 4.8694 & TRN \\
\hline CHEMBL1589388 & 688171 & 4.4 & 4.8604 & TRN \\
\hline CHEMBL1299529 & 688171 & 4.55 & 4.9771 & TRN \\
\hline CHEMBL1525788 & 688171 & 4.8 & 4.8669 & TST \\
\hline CHEMBL1355546 & 688171 & 4.9 & 4.769 & TRN \\
\hline CHEMBL1459529 & 688171 & 4.85 & 5.0007 & TST \\
\hline CHEMBL1325270 & 688171 & 4.7 & 4.8825 & TRN \\
\hline CHEMBL507900 & 688171 & 4.85 & 4.976 & TST \\
\hline CHEMBL1498460 & 688171 & 4.95 & 5.084 & TST \\
\hline CHEMBL1438434 & 688171 & 4.7 & 4.7791 & TST \\
\hline CHEMBL1395542 & 688171 & 5.35 & 4.8304 & TRN \\
\hline CHEMBL1477813 & 688171 & 4.5 & 4.8586 & TRN \\
\hline CHEMBL1535950 & 688171 & 4.35 & 5.0003 & TST \\
\hline CHEMBL1354671 & 688171 & 4.7 & 4.7818 & TRN \\
\hline CHEMBL1445327 & 688171 & 4.4 & 4.8299 & TRN \\
\hline CHEMBL1500125 & 688171 & 4.4 & 4.8183 & TST \\
\hline CHEMBL1318465 & 688171 & 4.6 & 4.9168 & TRN \\
\hline CHEMBL1427001 & 688171 & 4.6 & $4.9060 e$ & 0000000001 \\
\hline CHEMBL1364423 & 688171 & 4.5 & 4.9306 & TRN \\
\hline CHEMBL1393234 & 688171 & 4.4 & 4.8206 & TRN \\
\hline CHEMBL1405679 & 688171 & 4.4 & 4.9184 & TST \\
\hline CHEMBL1314629 & 688171 & 4.65 & 4.8605 & TRN \\
\hline CHEMBL1173431 & 688171 & 5.25 & 4.9052 & TRN \\
\hline CHEMBL1490987 & 688171 & 4.35 & 4.888 & TRN \\
\hline CHEMBL1608293 & 688171 & 4.9 & 4.8668 & TRN \\
\hline CHEMBL1563422 & 688171 & 4.55 & 4.8664 & TRN \\
\hline CHEMBL1347270 & 688171 & 4.8 & 4.8893 & TRN \\
\hline CHEMBL3196320 & 688171 & 4.4 & 4.8197 & TST \\
\hline CHEMBL1484319 & 688171 & 4.7 & 5.0024 & TRN \\
\hline CHEMBL1441020 & 688171 & 5.05 & 4.8917 & TRN \\
\hline CHEMBL1535433 & 688171 & 6.05 & 4.9526 & TRN \\
\hline CHEMBL1604163 & 688171 & 4.85 & 4.8665 & TST \\
\hline CHEMBL1591502 & 688171 & 4.95 & 4.9138 & TRN \\
\hline CHEMBL1463066 & 688171 & 4.75 & 4.7553 & TRN \\
\hline CHEMBL1505989 & 688171 & 5.45 & 4.9616 & TRN \\
\hline CHEMBL1362660 & 688171 & 4.95 & 4.9012 & TRN \\
\hline CHEMBL1569128 & 688171 & 5.3 & 4.8611 & TRN \\
\hline CHEMBL1467637 & 688171 & 5.0 & 4.9138 & TRN \\
\hline CHEMBL601140 & 688171 & 5.5 & 4.9386 & TRN \\
\hline CHEMBL1576266 & 688171 & 4.35 & 4.9771 & TRN \\
\hline CHEMBL1359251 & 688171 & 5.15 & 4.8629 & TRN \\
\hline CHEMBL1518794 & 688171 & 4.6 & 4.8272 & TRN \\
\hline CHEMBL1373413 & 688171 & 4.6 & 4.9268 & TRN \\
\hline
\end{tabular}




\begin{tabular}{|c|c|c|c|c|}
\hline \multicolumn{5}{|c|}{ Supplemental Table S2.txt } \\
\hline CHEMBL3211836 & 688171 & 5.75 & 5.0483 & TRN \\
\hline CHEMBL1609640 & 688171 & 5.55 & 4.8652 & TRN \\
\hline CHEMBL1592507 & 688171 & 5.5 & 5.0627 & TRN \\
\hline CHEMBL1423723 & 688171 & 5.4 & 4.7485 & TRN \\
\hline CHEMBL1467553 & 688171 & 4.7 & 4.8358 & TRN \\
\hline CHEMBL1597595 & 688171 & 4.9 & 4.9046 & TRN \\
\hline CHEMBL1468351 & 688171 & 4.6 & 4.9576 & TST \\
\hline CHEMBL1417556 & 688171 & 4.5 & 4.7459 & TRN \\
\hline CHEMBL1517511 & 688171 & 4.45 & 4.8393 & TST \\
\hline CHEMBL1371790 & 688171 & 5.05 & 4.9141 & TST \\
\hline CHEMBL1585920 & 688171 & 4.35 & 4.9138 & TRN \\
\hline CHEMBL1593498 & 688171 & 4.8 & 4.8487 & TRN \\
\hline CHEMBL1344800 & 688171 & 6.0 & 4.8012 & TRN \\
\hline CHEMBL1458626 & 688171 & 4.7 & 4.8121 & TRN \\
\hline CHEMBL1368428 & 688171 & 5.6 & 4.883 & TRN \\
\hline CHEMBL1416089 & 688171 & 4.35 & 4.9107 & TRN \\
\hline CHEMBL1513703 & 688171 & 5.0 & 4.8184 & TRN \\
\hline CHEMBL1486161 & 688171 & 4.4 & 4.8059 & TRN \\
\hline CHEMBL1385135 & 688171 & 4.35 & 4.9795 & TRN \\
\hline CHEMBL1515391 & 688171 & 4.4 & 4.8073 & TRN \\
\hline CHEMBL1512609 & 688171 & 5.3 & 4.9806 & TRN \\
\hline CHEMBL1351765 & 688171 & 6.95 & 5.0082 & TST \\
\hline CHEMBL1515872 & 688171 & 4.6 & 4.915 & TRN \\
\hline CHEMBL1475363 & 688171 & 4.85 & 4.8976 & TRN \\
\hline CHEMBL1324294 & 688171 & 6.9 & 4.9596 & TRN \\
\hline CHEMBL1574362 & 688171 & 5.1 & 4.994 & TRN \\
\hline CHEMBL1313096 & 688171 & 4.6 & 4.8838 & TRN \\
\hline CHEMBL1453212 & 688171 & 4.8 & 4.8411 & TST \\
\hline CHEMBL1372064 & 688171 & 4.55 & 4.8667 & TRN \\
\hline CHEMBL1380684 & 688171 & 6.0 & 4.9653 & TRN \\
\hline CHEMBL1574383 & 688171 & 5.6 & 4.8717 & TRN \\
\hline CHEMBL1372604 & 688171 & 4.6 & 4.9489 & TST \\
\hline CHEMBL1593519 & 688171 & 4.65 & 4.9365 & TRN \\
\hline CHEMBL1563190 & 688171 & 4.4 & 4.8447 & TRN \\
\hline CHEMBL1448565 & 688171 & 4.9 & 4.841 & TST \\
\hline CHEMBL1520242 & 688171 & 5.1 & 4.9267 & TST \\
\hline CHEMBL1495203 & 688171 & 6.7001 & 4.8835 & TRN \\
\hline CHEMBL1387733 & 688171 & 4.45 & 5.0819 & TRN \\
\hline CHEMBL1415730 & 688171 & 5.05 & 4.9687 & TRN \\
\hline CHEMBL1447571 & 688171 & 5.5 & 4.6996 & TRN \\
\hline CHEMBL1422039 & 688171 & 5.75 & 4.8042 & TRN \\
\hline CHEMBL1535503 & 688171 & 4.4 & 4.8936 & TRN \\
\hline CHEMBL1483422 & 688171 & 4.45 & 5.0522 & TRN \\
\hline CHEMBL1453618 & 688171 & 5.8 & 4.9645 & TST \\
\hline CHEMBL1487973 & 688171 & 4.6 & 4.9418 & TRN \\
\hline CHEMBL1355641 & 688171 & 4.65 & 4.9102 & TRN \\
\hline CHEMBL1333724 & 688171 & 4.4 & 4.8179 & TRN \\
\hline CHEMBL1428417 & 688171 & 4.85 & 4.9801 & TRN \\
\hline
\end{tabular}




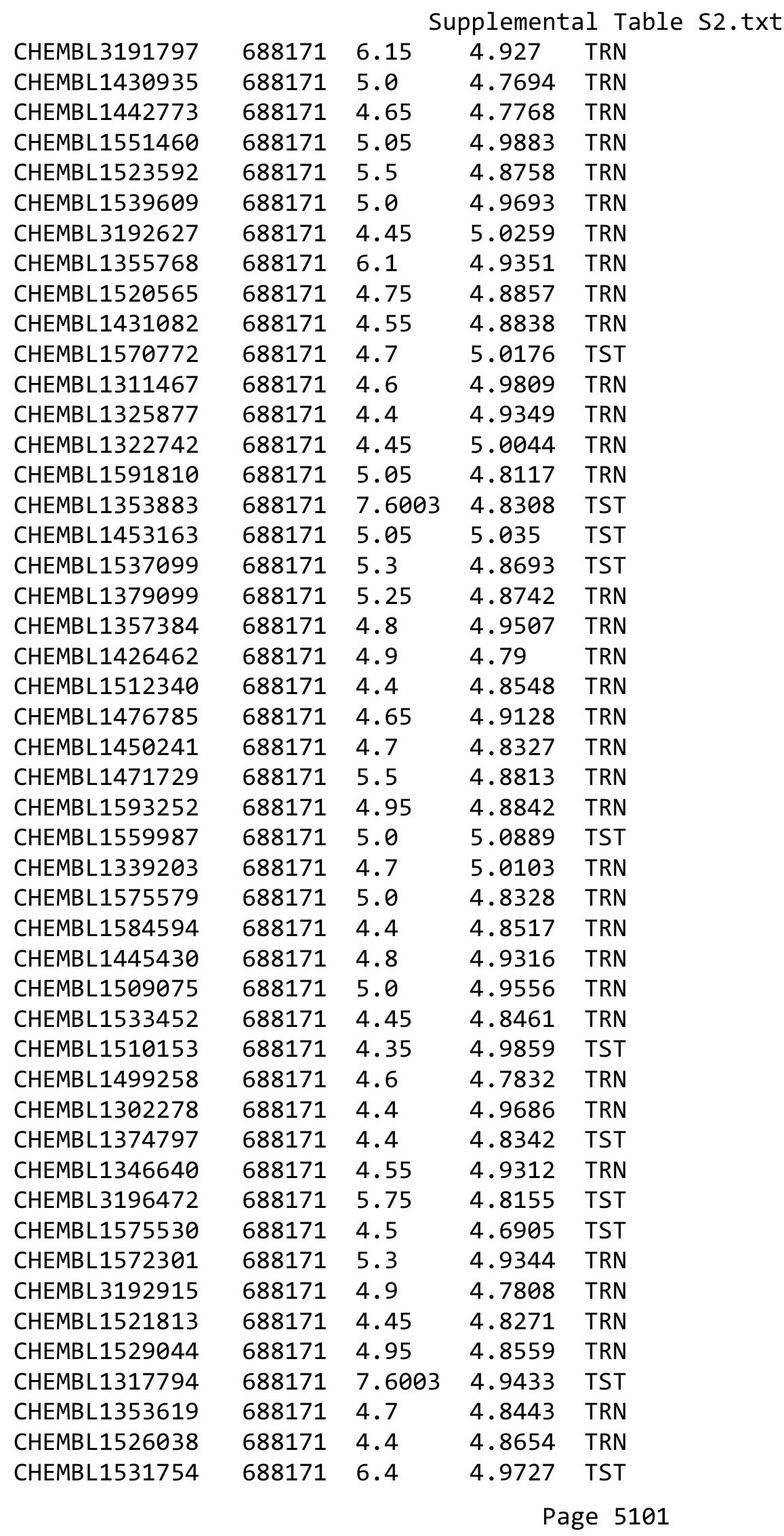




\begin{tabular}{|c|c|c|c|c|c|}
\hline & & \multicolumn{4}{|c|}{ Supplemental Table s2.txt } \\
\hline CHEMBL1478173 & 688171 & 4.4 & 4.9102 & TRN & \\
\hline CHEMBL1369125 & 688171 & 4.75 & 4.8989 & TRN & \\
\hline CHEMBL1338764 & 688171 & 4.55 & 4.9194 & TRN & \\
\hline CHEMBL1403501 & 688171 & 4.55 & 4.875 & TRN & \\
\hline CHEMBL1377333 & 688171 & 4.6 & 4.9078 & TST & \\
\hline CHEMBL1322627 & 688171 & 4.95 & 4.9181 & TST & \\
\hline CHEMBL1484321 & 688171 & 4.75 & 4.886 & TST & \\
\hline CHEMBL1363275 & 688171 & 4.4 & 4.8013 & TRN & \\
\hline CHEMBL1392991 & 688171 & 4.6 & 4.9539 & TRN & \\
\hline CHEMBL1524351 & 688171 & 4.9 & 4.9638 & TRN & \\
\hline CHEMBL1579895 & 688171 & 5.05 & 5.0759 & TST & \\
\hline CHEMBL1339221 & 688171 & 4.45 & 4.974 & TRN & \\
\hline CHEMBL1611672 & 688171 & 4.4 & 4.7759 & TRN & \\
\hline CHEMBL1465844 & 688171 & 5.4 & 4.9964 & TRN & \\
\hline CHEMBL1394692 & 688171 & 4.95 & 4.8773 & TRN & \\
\hline CHEMBL1583295 & 688171 & 4.9 & 4.8777 & TST & \\
\hline CHEMBL1377256 & 688171 & 4.65 & 4.82600 & 00000000005 & TRN \\
\hline CHEMBL1515336 & 688171 & 5.6 & 4.988 & TRN & \\
\hline CHEMBL1431651 & 688171 & 4.75 & 4.8218 & TRN & \\
\hline CHEMBL1316342 & 688171 & 5.35 & 5.0662 & TRN & \\
\hline CHEMBL1592260 & 688171 & 4.55 & 4.849 & TRN & \\
\hline CHEMBL579749 & 688171 & 5.3 & 5.0007 & TRN & \\
\hline CHEMBL1582111 & 688171 & 4.4 & 4.8367 & TST & \\
\hline CHEMBL3192217 & 688171 & 4.75 & 4.8334 & TRN & \\
\hline CHEMBL1407279 & 688171 & 6.9 & 4.9485 & TRN & \\
\hline CHEMBL1256186 & 688171 & 6.0 & 5.0663 & TST & \\
\hline CHEMBL1360892 & 688171 & 4.5 & 4.9597 & TRN & \\
\hline CHEMBL1604848 & 688171 & 4.7 & 4.7514 & TRN & \\
\hline CHEMBL1606603 & 688171 & 4.35 & 4.8285 & TRN & \\
\hline CHEMBL1301350 & 688171 & 4.55 & 5.0141 & TRN & \\
\hline CHEMBL1445603 & 688171 & 4.55 & 4.788 & TRN & \\
\hline CHEMBL1324375 & 688171 & 4.35 & 5.0138 & TRN & \\
\hline CHEMBL3190537 & 688171 & 5.15 & 4.7666 & TRN & \\
\hline CHEMBL1328943 & 688171 & 6.5 & 5.0675 & TRN & \\
\hline CHEMBL1334225 & 688171 & 4.45 & 4.8314 & TRN & \\
\hline CHEMBL1481780 & 688171 & 4.4 & 4.8423 & TST & \\
\hline CHEMBL1302756 & 688171 & 4.4 & 4.7155 & TRN & \\
\hline CHEMBL1608482 & 688171 & 4.4 & 4.8732 & TRN & \\
\hline CHEMBL1545859 & 688171 & 6.05 & 4.9263 & TRN & \\
\hline CHEMBL1398665 & 688171 & 4.35 & 4.9957 & TST & \\
\hline CHEMBL3211398 & 688171 & 4.4 & 4.9252 & TST & \\
\hline CHEMBL1351158 & 688171 & 4.95 & 5.0783 & TRN & \\
\hline CHEMBL546576 & 688171 & 4.55 & 4.7963 & TRN & \\
\hline CHEMBL1583826 & 688171 & 4.45 & 4.9475 & TRN & \\
\hline CHEMBL1456984 & 688171 & 5.15 & 4.8456 & TRN & \\
\hline CHEMBL1367279 & 688171 & 4.5 & 4.9533 & TRN & \\
\hline CHEMBL1414328 & 688171 & 5.45 & 4.9354 & TRN & \\
\hline CHEMBL1404376 & 688171 & 4.8 & 4.8302 & TST & \\
\hline
\end{tabular}




\begin{tabular}{|c|c|c|c|c|}
\hline \multicolumn{5}{|c|}{ Supplemental Table S2.txt } \\
\hline CHEMBL1436210 & 688171 & 4.55 & 4.8416 & TRN \\
\hline CHEMBL1517905 & 688171 & 5.05 & 5.0023 & TRN \\
\hline CHEMBL1452264 & 688171 & 5.0 & 4.9252 & TRN \\
\hline CHEMBL1602511 & 688171 & 5.9 & 4.8368 & TRN \\
\hline CHEMBL1499262 & 688171 & 4.4 & 4.9993 & TST \\
\hline CHEMBL1461413 & 688171 & 4.4 & 4.832 & TRN \\
\hline CHEMBL1550239 & 688171 & 4.75 & 4.787 & TST \\
\hline CHEMBL1591396 & 688171 & 5.0 & 4.9248 & TRN \\
\hline CHEMBL1427167 & 688171 & 7.6003 & 4.9471 & TRN \\
\hline CHEMBL1985495 & 688171 & 5.05 & 4.9364 & TRN \\
\hline CHEMBL1439184 & 688171 & 4.4 & 5.0178 & TRN \\
\hline CHEMBL1376268 & 688171 & 4.95 & 4.9178 & TRN \\
\hline CHEMBL1527414 & 688171 & 4.45 & 4.7847 & TST \\
\hline CHEMBL1519408 & 688171 & 4.6 & 4.8198 & TST \\
\hline CHEMBL457504 & 688171 & 4.95 & 4.7866 & TST \\
\hline CHEMBL1327695 & 688171 & 4.75 & 4.9731 & TRN \\
\hline CHEMBL1358266 & 688171 & 4.45 & 5.0291 & TST \\
\hline CHEMBL1303671 & 688171 & 5.4 & 4.9515 & TRN \\
\hline CHEMBL1338179 & 688171 & 4.4 & 4.8619 & TST \\
\hline CHEMBL1435442 & 688171 & 5.05 & 4.9123 & TRN \\
\hline CHEMBL1357745 & 688171 & 4.4 & 5.0018 & TRN \\
\hline CHEMBL1599533 & 688171 & 4.4 & 4.8733 & TRN \\
\hline CHEMBL1605693 & 688171 & 5.0 & 4.8474 & TRN \\
\hline CHEMBL1447093 & 688171 & 4.7 & 4.8176 & TRN \\
\hline CHEMBL1601610 & 688171 & 4.55 & 4.8508 & TRN \\
\hline CHEMBL1334062 & 688171 & 5.05 & 4.7377 & TRN \\
\hline CHEMBL1530758 & 688171 & 5.55 & 4.9924 & TRN \\
\hline CHEMBL1383671 & 688171 & 4.5 & 4.9238 & TST \\
\hline CHEMBL1354802 & 688171 & 4.95 & 4.8527 & TRN \\
\hline CHEMBL1374504 & 688171 & 4.4 & 4.9173 & TRN \\
\hline CHEMBL1532631 & 688171 & 5.0 & 4.9832 & TST \\
\hline CHEMBL1480583 & 688171 & 4.8 & 4.7553 & TRN \\
\hline CHEMBL1489269 & 688171 & 4.75 & 4.7166 & TRN \\
\hline CHEMBL1394591 & 688171 & 5.15 & 4.9386 & TRN \\
\hline CHEMBL1532584 & 688171 & 4.65 & 4.7604 & TST \\
\hline CHEMBL1473047 & 688171 & 5.1 & 4.8504 & TRN \\
\hline CHEMBL1447964 & 688171 & 4.6 & 4.9596 & TRN \\
\hline CHEMBL1308756 & 688171 & 4.6 & 4.7471 & TRN \\
\hline CHEMBL1311730 & 688171 & 4.45 & 4.7714 & TRN \\
\hline CHEMBL1314469 & 688171 & 4.65 & 4.8743 & TST \\
\hline CHEMBL3192017 & 688171 & 5.3 & 4.9654 & TRN \\
\hline CHEMBL1562006 & 688171 & 4.5 & 4.9165 & TST \\
\hline CHEMBL1478410 & 688171 & 5.0 & 4.8241 & TRN \\
\hline CHEMBL1394569 & 688171 & 6.15 & 4.9642 & TRN \\
\hline CHEMBL1390995 & 688171 & 4.7 & 4.8558 & TRN \\
\hline CHEMBL1492001 & 688171 & 4.6 & 4.7694 & TRN \\
\hline CHEMBL1450343 & 688171 & 4.9 & 4.8945 & TRN \\
\hline CHEMBL1395755 & 688171 & 4.65 & 4.7375 & TRN \\
\hline
\end{tabular}




\begin{tabular}{|c|c|c|c|c|}
\hline \multicolumn{5}{|c|}{ Supplemental Table S2.txt } \\
\hline CHEMBL1563213 & 688171 & 4.4 & 5.0181 & TRN \\
\hline CHEMBL1360102 & 688171 & 4.4 & 4.9794 & TRN \\
\hline CHEMBL1314652 & 688171 & 4.65 & 5.042 & TRN \\
\hline CHEMBL1489990 & 688171 & 6.2 & 4.8282 & TRN \\
\hline CHEMBL1560622 & 688171 & 4.8 & 4.7196 & TRN \\
\hline CHEMBL1572119 & 688171 & 5.4 & 4.9104 & TRN \\
\hline CHEMBL1478756 & 688171 & 4.85 & 4.8348 & TRN \\
\hline CHEMBL1368388 & 688171 & 5.5 & 4.8313 & TRN \\
\hline CHEMBL1594024 & 688171 & 5.25 & 4.9189 & TRN \\
\hline CHEMBL1559030 & 688171 & 5.1 & 5.0059 & TRN \\
\hline CHEMBL1436359 & 688171 & 4.65 & 4.9101 & TRN \\
\hline CHEMBL1601375 & 688171 & 5.8 & 4.985 & TST \\
\hline CHEMBL1406351 & 688171 & 4.35 & 5.0119 & TRN \\
\hline CHEMBL1437450 & 688171 & 4.6 & 4.8652 & TRN \\
\hline CHEMBL1357951 & 688171 & 4.6 & 4.8297 & TRN \\
\hline CHEMBL1596695 & 688171 & 4.75 & 4.9406 & TRN \\
\hline CHEMBL1327408 & 688171 & 4.35 & 4.9177 & TRN \\
\hline CHEMBL1305414 & 688171 & 7.1002 & 5.0522 & TRN \\
\hline CHEMBL1433386 & 688171 & 5.1 & 4.9099 & TRN \\
\hline CHEMBL1468708 & 688171 & 4.45 & 4.9198 & TRN \\
\hline CHEMBL1589887 & 688171 & 5.0 & 4.8518 & TRN \\
\hline CHEMBL1461459 & 688171 & 4.65 & 4.9682 & TST \\
\hline CHEMBL1452795 & 688171 & 4.35 & 4.9371 & TST \\
\hline CHEMBL1579841 & 688171 & 4.4 & 4.9014 & TRN \\
\hline CHEMBL1476272 & 688171 & 4.6 & 4.9437 & TRN \\
\hline CHEMBL1463298 & 688171 & 4.9 & 4.9345 & TRN \\
\hline CHEMBL1526979 & 688171 & 4.4 & 5.0628 & TRN \\
\hline CHEMBL1338919 & 688171 & 4.6 & 4.9071 & TRN \\
\hline CHEMBL1497849 & 688171 & 6.05 & 5.0412 & TRN \\
\hline CHEMBL1508842 & 688171 & 4.5 & 4.8354 & TST \\
\hline CHEMBL3197932 & 688171 & 5.95 & 4.7703 & TRN \\
\hline CHEMBL1310332 & 688171 & 4.4 & 4.654 & TRN \\
\hline CHEMBL1423799 & 688171 & 4.5 & 4.8472 & TRN \\
\hline CHEMBL3192328 & 688171 & 4.6 & 4.9515 & TST \\
\hline CHEMBL568092 & 688171 & 4.6 & 5.0105 & TST \\
\hline CHEMBL1966168 & 688171 & 5.95 & 4.9033 & TRN \\
\hline CHEMBL1381142 & 688171 & 4.4 & 4.9499 & TRN \\
\hline CHEMBL1497899 & 688171 & 4.35 & 5.0035 & TST \\
\hline CHEMBL1420321 & 688171 & 5.65 & 5.0093 & TRN \\
\hline CHEMBL3207856 & 688171 & 4.55 & 5.0067 & TRN \\
\hline CHEMBL1590909 & 688171 & 5.0 & 5.0061 & TRN \\
\hline CHEMBL3214598 & 688171 & 4.75 & 4.9382 & TST \\
\hline CHEMBL1356524 & 688171 & 4.6 & 4.7547 & TRN \\
\hline CHEMBL1549814 & 688171 & 4.7 & 4.9572 & TRN \\
\hline CHEMBL1368433 & 688171 & 5.05 & 5.1301 & TRN \\
\hline CHEMBL1319662 & 688171 & 4.6 & 4.8317 & TRN \\
\hline CHEMBL1446060 & 688171 & 5.0 & 4.7669 & TRN \\
\hline CHEMBL1431206 & 688171 & 4.75 & 4.9024 & TRN \\
\hline
\end{tabular}




\begin{tabular}{|c|c|c|c|c|c|}
\hline & & \multicolumn{4}{|c|}{ Supplemental Table S2.txt } \\
\hline CHEMBL1384623 & 688171 & 5.05 & 4.9752 & TRN & \\
\hline CHEMBL1548422 & 688171 & 4.6 & 4.8682 & TRN & \\
\hline CHEMBL1556866 & 688171 & 5.1 & 5.0989 & TST & \\
\hline CHEMBL1459786 & 688171 & 4.7 & 4.7636 & TRN & \\
\hline CHEMBL1306606 & 688171 & 4.6 & 4.8899 & TRN & \\
\hline CHEMBL1476917 & 688171 & 5.2 & 4.9532 & TRN & \\
\hline CHEMBL1357813 & 688171 & 4.45 & 4.9043 & TRN & \\
\hline CHEMBL1313249 & 688171 & 4.45 & \multicolumn{2}{|c|}{4.906000000000001} & TRN \\
\hline CHEMBL1359396 & 688171 & 4.5 & 4.9379 & TRN & \\
\hline CHEMBL1600192 & 688171 & 4.4 & 4.9648 & TST & \\
\hline CHEMBL3208796 & 688171 & 5.35 & 4.8797 & TST & \\
\hline CHEMBL1474270 & 688171 & 4.85 & 4.885 & TRN & \\
\hline CHEMBL1464199 & 688171 & 4.5 & 4.8609 & TRN & \\
\hline CHEMBL 236554 & 688171 & 4.4 & 4.952 & TRN & \\
\hline CHEMBL1515146 & 688171 & 4.8 & 4.8801 & TRN & \\
\hline CHEMBL1521960 & 688171 & 6.25 & 4.9017 & TST & \\
\hline CHEMBL1339797 & 688171 & 4.6 & 4.7907 & TRN & \\
\hline CHEMBL1475999 & 688171 & 6.0 & 4.8989 & TRN & \\
\hline CHEMBL 3213045 & 688171 & 4.35 & 5.016 & TST & \\
\hline CHEMBL1404178 & 688171 & 4.35 & 5.0095 & TST & \\
\hline CHEMBL1351562 & 688171 & 5.1 & 4.7474 & TRN & \\
\hline CHEMBL1401010 & 688171 & 5.4 & 4.9612 & TRN & \\
\hline CHEMBL 2004183 & 688171 & 4.5 & 4.8283 & TST & \\
\hline CHEMBL1423954 & 688171 & 6.35 & 4.9679 & TRN & \\
\hline CHEMBL1986726 & 688171 & 4.85 & 4.9285 & TRN & \\
\hline CHEMBL3196867 & 688171 & 4.45 & 4.8487 & TST & \\
\hline CHEMBL1372293 & 688171 & 4.4 & 4.8293 & TRN & \\
\hline CHEMBL1502755 & 688171 & 4.6 & 4.8469 & TST & \\
\hline CHEMBL1580643 & 688171 & 4.7 & 4.8096 & TRN & \\
\hline CHEMBL1346885 & 688171 & 4.4 & 4.8132 & TRN & \\
\hline CHEMBL1444802 & 688171 & 4.6 & 5.0639 & TRN & \\
\hline CHEMBL1371792 & 688171 & 5.45 & 4.8831 & TST & \\
\hline CHEMBL1560841 & 688171 & 4.45 & 5.1064 & TRN & \\
\hline CHEMBL1336346 & 688171 & 5.5 & 4.8921 & TRN & \\
\hline CHEMBL1507708 & 688171 & 5.35 & 4.9587 & TRN & \\
\hline CHEMBL1551623 & 688171 & 4.4 & 4.82 & TRN & \\
\hline CHEMBL1528478 & 688171 & 5.05 & 4.8674 & TST & \\
\hline CHEMBL1414317 & 688171 & 5.8 & 5.0881 & TRN & \\
\hline CHEMBL1604180 & 688171 & 4.75 & 4.92899 & 9999999999 & TRN \\
\hline CHEMBL1474701 & 688171 & 4.45 & 4.83899 & 99999999995 & TST \\
\hline CHEMBL1409785 & 688171 & 5.85 & 4.8185 & TRN & \\
\hline CHEMBL1329450 & 688171 & 4.8 & 4.9431 & TRN & \\
\hline CHEMBL1544239 & 688171 & 4.4 & 5.1566 & TST & \\
\hline CHEMBL1451059 & 688171 & 4.8 & 4.9929 & TST & \\
\hline CHEMBL1320822 & 688171 & 5.05 & 4.9783 & TST & \\
\hline CHEMBL1553531 & 688171 & 4.7 & 4.869 & TST & \\
\hline CHEMBL1547376 & 688171 & 4.55 & 4.8778 & TST & \\
\hline CHEMBL1369907 & 688171 & 4.55 & 5.0326 & TRN & \\
\hline
\end{tabular}




\begin{tabular}{|c|c|c|c|c|}
\hline \multicolumn{5}{|c|}{ Supplemental Table S2.txt } \\
\hline CHEMBL1314391 & 688171 & 4.75 & 4.9714 & TRN \\
\hline CHEMBL1552871 & 688171 & 4.85 & 4.9501 & TRN \\
\hline CHEMBL1450802 & 688171 & 4.85 & 4.9285 & TRN \\
\hline CHEMBL1215100 & 688171 & 6.9 & 4.7441 & TRN \\
\hline CHEMBL1372231 & 688171 & 4.7 & 4.8887 & TRN \\
\hline CHEMBL1569484 & 688171 & 5.5 & 5.0582 & TRN \\
\hline CHEMBL1339872 & 688171 & 6.25 & 4.9172 & TRN \\
\hline CHEMBL1504939 & 688171 & 4.7 & 4.8617 & TST \\
\hline CHEMBL1581242 & 688171 & 4.75 & 4.7765 & TST \\
\hline CHEMBL1348510 & 688171 & 5.1 & 4.9083 & TRN \\
\hline CHEMBL1382224 & 688171 & 4.4 & 4.931 & TST \\
\hline CHEMBL1599971 & 688171 & 5.35 & 4.8417 & TST \\
\hline CHEMBL1590266 & 688171 & 4.95 & 5.0716 & TST \\
\hline CHEMBL1573604 & 688171 & 5.85 & 5.0257 & TRN \\
\hline CHEMBL3198116 & 688171 & 4.95 & 4.8648 & TST \\
\hline CHEMBL1526288 & 688171 & 4.55 & 4.9292 & TRN \\
\hline CHEMBL477139 & 688171 & 4.6 & 4.9049 & TRN \\
\hline CHEMBL1501597 & 688171 & 5.4 & 4.7754 & TRN \\
\hline CHEMBL1545930 & 688171 & 5.7 & 4.8926 & TRN \\
\hline CHEMBL1310907 & 688171 & 4.95 & 4.6983 & TRN \\
\hline CHEMBL1411348 & 688171 & 4.7 & 4.8155 & TRN \\
\hline CHEMBL1358304 & 688171 & 4.35 & 4.8236 & TRN \\
\hline CHEMBL1555489 & 688171 & 4.65 & 4.8193 & TRN \\
\hline CHEMBL1538952 & 688171 & 5.05 & 4.901 & TRN \\
\hline CHEMBL1312936 & 688171 & 4.9 & 4.8893 & TRN \\
\hline CHEMBL1520554 & 688171 & 4.45 & 4.9086 & TRN \\
\hline CHEMBL39947 & 688171 & 4.7 & 4.9387 & TRN \\
\hline CHEMBL1319156 & 688171 & 4.35 & 4.9329 & TST \\
\hline CHEMBL1316660 & 688171 & 4.45 & 4.9796 & TRN \\
\hline CHEMBL1410547 & 688171 & 5.65 & 5.0008 & TRN \\
\hline CHEMBL1489150 & 688171 & 4.5 & 5.0247 & TRN \\
\hline CHEMBL1305002 & 688171 & 5.05 & 4.9014 & TRN \\
\hline CHEMBL1585097 & 688171 & 4.9 & 4.8098 & TST \\
\hline CHEMBL1319642 & 688171 & 4.6 & 4.8622 & TRN \\
\hline CHEMBL1430486 & 688171 & 4.85 & 4.85 & TRN \\
\hline CHEMBL1593338 & 688171 & 4.55 & 4.7158 & TRN \\
\hline CHEMBL1338839 & 688171 & 4.55 & 4.9953 & TRN \\
\hline CHEMBL1388967 & 688171 & 4.75 & 4.8281 & TRN \\
\hline CHEMBL1507521 & 688171 & 5.95 & 4.8666 & TRN \\
\hline CHEMBL1409492 & 688171 & 4.4 & 5.0291 & TRN \\
\hline CHEMBL1371616 & 688171 & 5.6 & 4.8321 & TRN \\
\hline CHEMBL1532924 & 688171 & 4.85 & 4.9232 & TRN \\
\hline CHEMBL1575588 & 688171 & 5.45 & 5.015 & TRN \\
\hline CHEMBL 225354 & 688171 & 5.7 & 4.8759 & TRN \\
\hline CHEMBL1373910 & 688171 & 4.65 & 4.9843 & TRN \\
\hline CHEMBL1418786 & 688171 & 5.55 & 4.9121 & TST \\
\hline CHEMBL1324515 & 688171 & 4.4 & 5.1555 & TRN \\
\hline CHEMBL1552965 & 688171 & 4.75 & 4.8735 & TRN \\
\hline
\end{tabular}




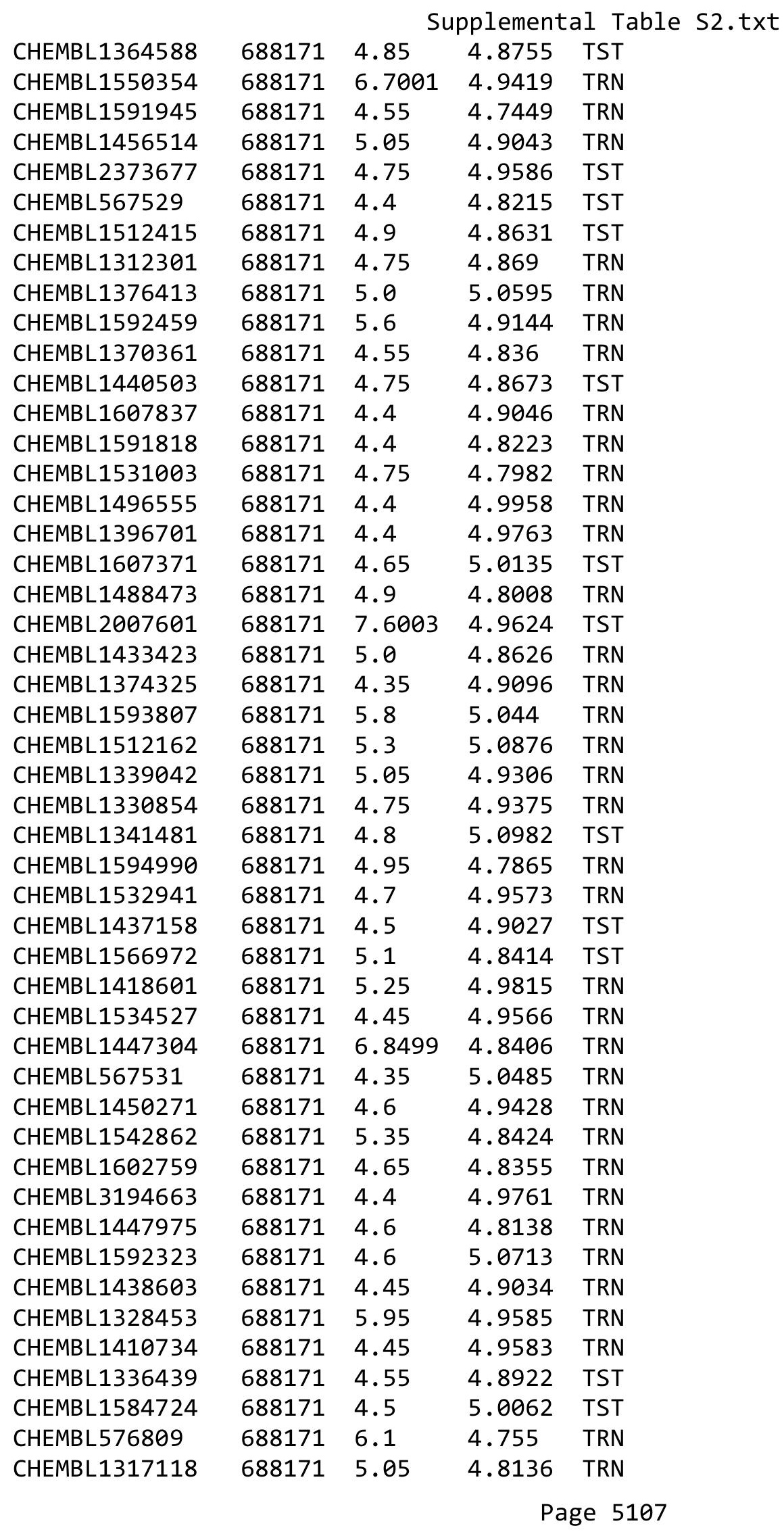




\begin{tabular}{|c|c|c|c|c|}
\hline \multicolumn{5}{|c|}{ Supplemental Table S2.txt } \\
\hline CHEMBL 3198185 & 688171 & 5.05 & 4.9144 & TRN \\
\hline CHEMBL3189916 & 688171 & 5.1 & 4.8185 & TST \\
\hline CHEMBL1491618 & 688171 & 5.05 & 4.8805 & TRN \\
\hline CHEMBL1376270 & 688171 & 4.55 & 4.7649 & TRN \\
\hline CHEMBL1708832 & 688171 & 5.05 & 4.8905 & TRN \\
\hline CHEMBL1325831 & 688171 & 5.0 & 4.7627 & TRN \\
\hline CHEMBL1448383 & 688171 & 5.65 & 4.978 & TRN \\
\hline CHEMBL1342665 & 688171 & 4.7 & 4.9465 & TRN \\
\hline CHEMBL430893 & 688171 & 5.45 & 4.9462 & TST \\
\hline CHEMBL1545093 & 688171 & 4.75 & 4.9649 & TST \\
\hline CHEMBL1524231 & 688171 & 4.4 & 5.0317 & TRN \\
\hline CHEMBL1521694 & 688171 & 4.75 & 4.8547 & TRN \\
\hline CHEMBL1477689 & 688171 & 4.9 & 4.898 & TRN \\
\hline CHEMBL1335173 & 688171 & 5.4 & 4.9779 & TRN \\
\hline CHEMBL1347205 & 688171 & 4.35 & 4.8873 & TRN \\
\hline CHEMBL1378302 & 688171 & 4.7 & 4.9098 & TRN \\
\hline CHEMBL1385252 & 688171 & 5.3 & 4.9492 & TST \\
\hline CHEMBL1488197 & 688171 & 7.6003 & 5.0004 & TRN \\
\hline CHEMBL1450025 & 688171 & 4.8 & 4.8083 & TRN \\
\hline CHEMBL1395113 & 688171 & 4.45 & 4.8254 & TRN \\
\hline CHEMBL1358851 & 688171 & 4.7 & 4.9508 & TRN \\
\hline CHEMBL1345006 & 688171 & 4.75 & 4.8364 & TRN \\
\hline CHEMBL1605897 & 688171 & 4.55 & 4.9149 & TRN \\
\hline CHEMBL1478118 & 688171 & 4.35 & 4.8952 & TRN \\
\hline CHEMBL70141 & 688171 & 5.05 & 4.8525 & TST \\
\hline CHEMBL1389726 & 688171 & 4.4 & 4.8009 & TRN \\
\hline CHEMBL1550519 & 688171 & 5.55 & 4.9226 & TRN \\
\hline CHEMBL1335186 & 688171 & 5.05 & 4.8974 & TRN \\
\hline CHEMBL1482529 & 688171 & 4.75 & 4.8451 & TRN \\
\hline CHEMBL1356718 & 688171 & 5.0 & 4.9135 & TRN \\
\hline CHEMBL1480508 & 688171 & 4.4 & 4.8921 & TST \\
\hline CHEMBL1391825 & 688171 & 4.85 & 5.0808 & TST \\
\hline CHEMBL1467665 & 688171 & 4.9 & 4.9848 & TST \\
\hline CHEMBL1583522 & 688171 & 4.4 & 4.9777 & TRN \\
\hline CHEMBL1552620 & 688171 & 4.8 & 4.9334 & TRN \\
\hline CHEMBL3199829 & 688171 & 4.7 & 4.935 & TRN \\
\hline CHEMBL1589632 & 688171 & 5.25 & 4.9552 & TRN \\
\hline CHEMBL1439902 & 688171 & 4.45 & 4.9312 & TST \\
\hline CHEMBL1438006 & 688171 & 5.35 & 5.0018 & TRN \\
\hline CHEMBL1400058 & 688171 & 5.1 & 4.7408 & TRN \\
\hline CHEMBL1978236 & 688171 & 4.6 & 4.8408 & TRN \\
\hline CHEMBL1367300 & 688171 & 4.4 & 4.8321 & TRN \\
\hline CHEMBL1414789 & 688171 & 4.55 & 4.9992 & TRN \\
\hline CHEMBL1599218 & 688171 & 4.35 & 4.9706 & TRN \\
\hline CHEMBL3193389 & 688171 & 4.95 & 4.8676 & TRN \\
\hline CHEMBL1317996 & 688171 & 7.3002 & 4.7855 & TST \\
\hline CHEMBL1490764 & 688171 & 5.15 & 4.9433 & TRN \\
\hline CHEMBL1301780 & 688171 & 4.9 & 4.9288 & TRN \\
\hline
\end{tabular}




\begin{tabular}{|c|c|c|c|c|}
\hline \multicolumn{5}{|c|}{ Supplemental Table S2.txt } \\
\hline CHEMBL1444962 & 688171 & 5.5 & 4.8853 & TRN \\
\hline CHEMBL3209775 & 688171 & 4.4 & 4.9483 & TST \\
\hline CHEMBL1376002 & 688171 & 7.0 & 5.0024 & TRN \\
\hline CHEMBL1319561 & 688171 & 4.85 & 4.7931 & TRN \\
\hline CHEMBL1396161 & 688171 & 4.55 & 4.8034 & TRN \\
\hline CHEMBL1420921 & 688171 & 4.4 & 4.8707 & TRN \\
\hline CHEMBL1570048 & 688171 & 4.4 & 4.8602 & TRN \\
\hline CHEMBL1536117 & 688171 & 5.45 & 4.9784 & TRN \\
\hline CHEMBL1556746 & 688171 & 4.4 & 4.9037 & TRN \\
\hline CHEMBL3193256 & 688171 & 5.1 & 4.9657 & TST \\
\hline CHEMBL1460413 & 688171 & 6.05 & 4.9375 & TST \\
\hline CHEMBL1391427 & 688171 & 5.8 & 4.8039 & TRN \\
\hline CHEMBL1595689 & 688171 & 4.85 & 4.9027 & TRN \\
\hline CHEMBL1480187 & 688171 & 4.65 & 4.6552 & TRN \\
\hline CHEMBL1438636 & 688171 & 4.55 & 4.8809 & TRN \\
\hline CHEMBL1356847 & 688171 & 4.4 & 5.0931 & TRN \\
\hline CHEMBL1996199 & 688171 & 5.0 & 4.9323 & TST \\
\hline CHEMBL1561032 & 688171 & 7.15 & 4.8528 & TRN \\
\hline CHEMBL1601189 & 688171 & 5.3 & 4.8795 & TST \\
\hline CHEMBL1585944 & 688171 & 6.7501 & 5.0313 & TRN \\
\hline CHEMBL1556156 & 688171 & 4.9 & 4.8461 & TRN \\
\hline CHEMBL1594081 & 688171 & 5.05 & 4.9091 & TST \\
\hline CHEMBL1551882 & 688171 & 4.65 & 4.9742 & TRN \\
\hline CHEMBL 3212224 & 688171 & 4.75 & 4.907 & TRN \\
\hline CHEMBL1515825 & 688171 & 4.45 & 4.8342 & TRN \\
\hline CHEMBL480626 & 688171 & 5.15 & 4.9174 & TST \\
\hline CHEMBL1589924 & 688171 & 5.55 & 4.9502 & TRN \\
\hline CHEMBL1324892 & 688171 & 4.4 & 4.8923 & TRN \\
\hline CHEMBL1444691 & 688171 & 4.85 & 4.8214 & TRN \\
\hline CHEMBL3199832 & 688171 & 4.35 & 4.9335 & TST \\
\hline CHEMBL446315 & 688171 & 4.6 & 5.0704 & TRN \\
\hline CHEMBL3190964 & 688171 & 4.85 & 4.9698 & TST \\
\hline CHEMBL1482953 & 688171 & 4.9 & 4.9829 & TST \\
\hline CHEMBL1555021 & 688171 & 4.75 & 4.9461 & TRN \\
\hline CHEMBL1560652 & 688171 & 4.65 & 5.0441 & TRN \\
\hline CHEMBL1364416 & 688171 & 5.45 & 4.9182 & TST \\
\hline CHEMBL1558079 & 688171 & 4.5 & 4.8429 & TRN \\
\hline CHEMBL1412077 & 688171 & 4.4 & 4.9148 & TRN \\
\hline CHEMBL1419943 & 688171 & 4.75 & 4.9199 & TRN \\
\hline CHEMBL1587951 & 688171 & 4.4 & 4.9466 & TRN \\
\hline CHEMBL1607561 & 688171 & 4.55 & 4.8692 & TRN \\
\hline CHEMBL1436391 & 688171 & 5.45 & 4.9474 & TRN \\
\hline CHEMBL1409746 & 688171 & 6.15 & 4.9348 & TRN \\
\hline CHEMBL1400321 & 688171 & 5.75 & 4.9662 & TST \\
\hline CHEMBL476668 & 688171 & 4.5 & 4.8672 & TRN \\
\hline CHEMBL1356053 & 688171 & 4.4 & 4.9557 & TRN \\
\hline CHEMBL1325820 & 688171 & 7.0 & 4.8844 & TRN \\
\hline CHEMBL1473663 & 688171 & 4.9 & 4.8021 & TRN \\
\hline
\end{tabular}




\begin{tabular}{|c|c|c|c|c|c|}
\hline \multicolumn{6}{|c|}{ Supplemental Table S2.txt } \\
\hline CHEMBL1518503 & 688171 & 4.45 & 4.7869 & TRN & \\
\hline CHEMBL1462969 & 688171 & 5.4 & 5.0015 & TRN & \\
\hline CHEMBL1319878 & 688171 & 4.55 & 4.8483 & TRN & \\
\hline CHEMBL1429953 & 688171 & 6.7001 & 5.07600 & 00000000005 & TRN \\
\hline CHEMBL1401842 & 688171 & 5.25 & 4.8741 & TRN & \\
\hline CHEMBL1518899 & 688171 & 4.9 & 4.9849 & TRN & \\
\hline CHEMBL1385483 & 688171 & 4.7 & 4.9108 & TRN & \\
\hline CHEMBL1423383 & 688171 & 4.4 & 4.9189 & TST & \\
\hline CHEMBL1333806 & 688171 & 4.35 & 4.9946 & TRN & \\
\hline CHEMBL1367795 & 688171 & 5.05 & 4.9405 & TRN & \\
\hline CHEMBL 3197414 & 688171 & 5.05 & 4.9169 & TRN & \\
\hline CHEMBL1367616 & 688171 & 4.95 & 4.8853 & TRN & \\
\hline CHEMBL3199074 & 688171 & 4.55 & 5.0133 & TRN & \\
\hline CHEMBL3196039 & 688171 & 6.95 & 4.9004 & TRN & \\
\hline CHEMBL3198729 & 688171 & 4.9 & 4.9033 & TRN & \\
\hline CHEMBL1453112 & 688171 & 4.35 & 4.8431 & TRN & \\
\hline CHEMBL1502394 & 688171 & 5.1 & 4.8626 & TST & \\
\hline CHEMBL1484646 & 688171 & 4.85 & 4.8925 & TRN & \\
\hline CHEMBL1326915 & 688171 & 4.8 & 4.8012 & TRN & \\
\hline CHEMBL601119 & 688171 & 5.25 & 4.9639 & TRN & \\
\hline CHEMBL1549883 & 688171 & 5.5 & 4.8944 & TRN & \\
\hline CHEMBL3196877 & 688171 & 4.4 & 4.8641 & TST & \\
\hline CHEMBL1591709 & 688171 & 4.7 & 4.7791 & TRN & \\
\hline CHEMBL1372400 & 688171 & 4.6 & 4.9858 & TRN & \\
\hline CHEMBL1445617 & 688171 & 5.0 & 4.8899 & TRN & \\
\hline CHEMBL1448336 & 688171 & 4.8 & 5.0232 & TRN & \\
\hline CHEMBL1341876 & 688171 & 4.65 & 4.7844 & TRN & \\
\hline CHEMBL1983700 & 688171 & 4.4 & 4.9209 & TRN & \\
\hline CHEMBL1565231 & 688171 & 4.55 & 4.9787 & TRN & \\
\hline CHEMBL1517290 & 688171 & 4.75 & 4.9292 & TST & \\
\hline CHEMBL1347192 & 688171 & 5.0 & 4.9853 & TST & \\
\hline CHEMBL1598087 & 688171 & 4.5 & 5.0085 & TST & \\
\hline CHEMBL1603373 & 688171 & 4.7 & 4.9018 & TRN & \\
\hline CHEMBL1340691 & 688171 & 4.35 & 4.9167 & TST & \\
\hline CHEMBL1548037 & 688171 & 4.4 & 4.8908 & TRN & \\
\hline CHEMBL1321528 & 688171 & 4.5 & 4.988 & TST & \\
\hline CHEMBL1469505 & 688171 & 4.55 & 4.9977 & TRN & \\
\hline CHEMBL1333689 & 688171 & 6.0 & 4.8537 & TRN & \\
\hline CHEMBL1358544 & 688171 & 5.7 & 4.9899 & TRN & \\
\hline CHEMBL1577694 & 688171 & 4.4 & 4.88 & TRN & \\
\hline CHEMBL1432011 & 688171 & 5.05 & 4.901 & TRN & \\
\hline CHEMBL1479786 & 688171 & 4.9 & 4.9476 & TRN & \\
\hline CHEMBL1434984 & 688171 & 5.0 & 4.7969 & TRN & \\
\hline CHEMBL 246446 & 688171 & 5.0 & 4.9372 & TRN & \\
\hline CHEMBL1323821 & 688171 & 4.7 & 4.9021 & TST & \\
\hline CHEMBL1602915 & 688171 & 4.4 & 4.8788 & TRN & \\
\hline CHEMBL1512579 & 688171 & 4.7 & 4.8389 & TRN & \\
\hline CHEMBL1490158 & 688171 & 4.55 & 4.9261 & TRN & \\
\hline
\end{tabular}




\begin{tabular}{|c|c|c|c|c|c|}
\hline \multicolumn{6}{|c|}{ Supplemental Table S2.txt } \\
\hline CHEMBL1554661 & 688171 & 4.9 & 4.9779 & TRN & \\
\hline CHEMBL1329977 & 688171 & 6.5501 & 4.9431 & TST & \\
\hline CHEMBL1358220 & 688171 & 4.95 & 4.9033 & TRN & \\
\hline CHEMBL1310257 & 688171 & 4.4 & 4.8461 & TRN & \\
\hline CHEMBL1974529 & 688171 & 6.0 & 4.8152 & TRN & \\
\hline CHEMBL1452028 & 688171 & 4.8 & 4.8092 & TST & \\
\hline CHEMBL1368732 & 688171 & 5.7 & 4.7547 & TRN & \\
\hline CHEMBL1990184 & 688171 & 5.65 & 4.9551 & TRN & \\
\hline CHEMBL1321550 & 688171 & 4.7 & 4.9023 & TRN & \\
\hline CHEMBL1977191 & 688171 & 4.4 & 4.981 & TRN & \\
\hline CHEMBL1507890 & 688171 & 5.3 & 4.8132 & TRN & \\
\hline CHEMBL1612230 & 688171 & 4.8 & 4.9396 & TRN & \\
\hline CHEMBL1559295 & 688171 & 4.5 & 4.8695 & TRN & \\
\hline CHEMBL1514882 & 688171 & 5.4 & 4.8469 & TST & \\
\hline CHEMBL1474327 & 688171 & 5.75 & 4.9403 & TRN & \\
\hline CHEMBL1509369 & 688171 & 4.4 & 5.0233 & TRN & \\
\hline CHEMBL1455405 & 688171 & 4.5 & 4.8569 & TRN & \\
\hline CHEMBL1592972 & 688171 & 4.85 & 4.8517 & TRN & \\
\hline CHEMBL1497323 & 688171 & 4.7 & 4.6934 & TST & \\
\hline CHEMBL56281 & 688171 & 4.65 & 4.8069 & TRN & \\
\hline CHEMBL1416046 & 688171 & 4.8 & 4.9297 & TRN & \\
\hline CHEMBL1456012 & 688171 & 5.9 & 4.9492 & TRN & \\
\hline CHEMBL1553798 & 688171 & 4.4 & 4.8476 & TRN & \\
\hline CHEMBL1538391 & 688171 & 4.4 & 4.9055 & TST & \\
\hline CHEMBL1609661 & 688171 & 4.5 & 5.1297 & TRN & \\
\hline CHEMBL1433634 & 688171 & 5.4 & 4.9029 & TRN & \\
\hline CHEMBL1386201 & 688171 & 4.6 & 4.9082 & TRN & \\
\hline CHEMBL1593912 & 688171 & 4.7 & 4.8336 & TRN & \\
\hline CHEMBL1324392 & 688171 & 4.35 & 4.8388 & TRN & \\
\hline CHEMBL1161461 & 688171 & 6.0 & 4.9829 & TRN & \\
\hline CHEMBL1498170 & 688171 & 4.35 & 4.9179 & TST & \\
\hline CHEMBL1401798 & 688171 & 4.6 & 4.7968 & TST & \\
\hline CHEMBL1546692 & 688171 & 4.65 & 4.936 & TRN & \\
\hline CHEMBL1338900 & 688171 & 4.85 & 4.9364 & TST & \\
\hline CHEMBL1451751 & 688171 & 5.45 & 4.9873 & TRN & \\
\hline CHEMBL1314968 & 688171 & 4.5 & 4.753 & TRN & \\
\hline CHEMBL1502512 & 688171 & 4.4 & 4.8067 & TST & \\
\hline CHEMBL1588765 & 688171 & 4.4 & 4.8357 & TRN & \\
\hline CHEMBL1173364 & 688171 & 4.9 & 4.8781 & TRN & \\
\hline CHEMBL3213624 & 688171 & 5.4 & 4.9486 & TST & \\
\hline CHEMBL1369198 & 688171 & 4.4 & 4.9582 & TST & \\
\hline CHEMBL1503476 & 688171 & 4.4 & 4.8793 & TRN & \\
\hline CHEMBL1317417 & 688171 & 5.2 & 4.78600 & 00000000005 & TRN \\
\hline CHEMBL1454445 & 688171 & 5.75 & 4.9748 & TRN & \\
\hline CHEMBL1389085 & 688171 & 5.15 & 4.9654 & TRN & \\
\hline CHEMBL1326191 & 688171 & 4.4 & 5.0209 & TRN & \\
\hline CHEMBL1527553 & 688171 & 4.75 & 4.8172 & TRN & \\
\hline CHEMBL1473009 & 688171 & 4.85 & 4.8654 & TRN & \\
\hline
\end{tabular}




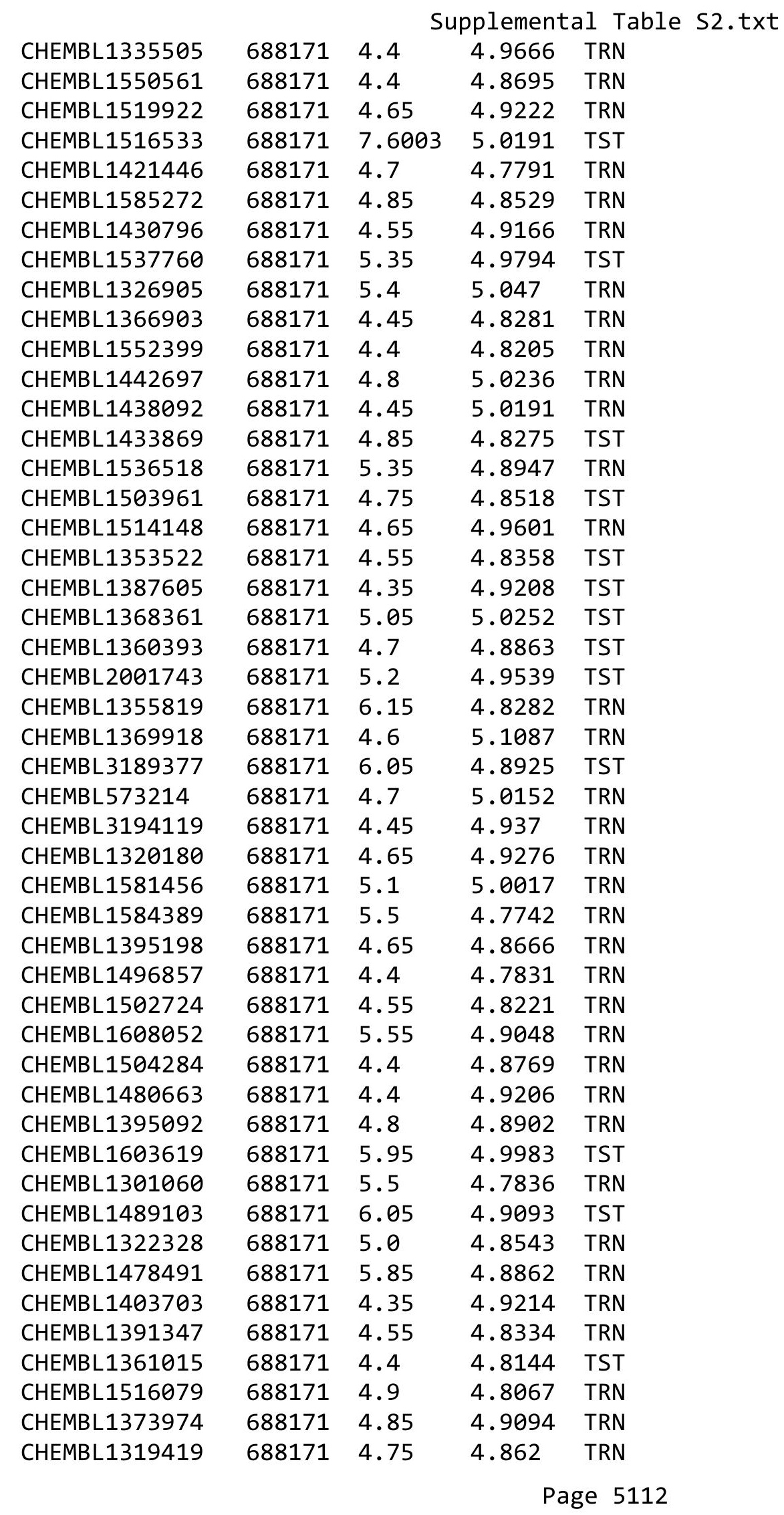




\begin{tabular}{|c|c|c|c|c|c|}
\hline & & \multicolumn{4}{|c|}{ Supplemental Table S2.txt } \\
\hline CHEMBL1481316 & 688171 & 4.75 & 4.8749 & TRN & \\
\hline CHEMBL1349908 & 688171 & 5.35 & 4.8734 & TST & \\
\hline CHEMBL1434922 & 688171 & 4.55 & 4.9237 & TRN & \\
\hline CHEMBL1373888 & 688171 & 4.95 & 4.7679 & TRN & \\
\hline CHEMBL1379292 & 688171 & 4.9 & 4.8447 & TRN & \\
\hline CHEMBL1380529 & 688171 & 7.6003 & 5.03100 & 0000000001 & TRN \\
\hline CHEMBL1501005 & 688171 & 4.4 & 4.8105 & TRN & \\
\hline CHEMBL1342705 & 688171 & 4.35 & 4.8944 & TRN & \\
\hline CHEMBL1398262 & 688171 & 5.85 & 4.9564 & TST & \\
\hline CHEMBL1534979 & 688171 & 4.75 & 4.9176 & TST & \\
\hline CHEMBL1474093 & 688171 & 7.2 & 5.0351 & TST & \\
\hline CHEMBL 1418430 & 688171 & 4.5 & 4.8853 & TST & \\
\hline CHEMBL 3190516 & 688171 & 4.4 & 4.9515 & TRN & \\
\hline CHEMBL1564711 & 688171 & 4.6 & 4.8698 & TRN & \\
\hline CHEMBL1438111 & 688171 & 4.85 & 4.9214 & TRN & \\
\hline CHEMBL1577532 & 688171 & 4.6 & 4.8131 & TST & \\
\hline CHEMBL1316957 & 688171 & 5.15 & 4.7841 & TRN & \\
\hline CHEMBL 3214506 & 688171 & 4.65 & 4.8906 & TRN & \\
\hline CHEMBL1387256 & 688171 & 6.05 & 4.9778 & TST & \\
\hline CHEMBL1602617 & 688171 & 4.7 & 4.8584 & TST & \\
\hline CHEMBL1304716 & 688171 & 4.45 & 4.7842 & TST & \\
\hline CHEMBL1538460 & 688171 & 4.65 & 4.9144 & TRN & \\
\hline CHEMBL1970824 & 688171 & 4.9 & 4.9158 & TRN & \\
\hline CHEMBL1400827 & 688171 & 4.4 & 4.9644 & TST & \\
\hline CHEMBL1403924 & 688171 & 4.75 & 4.8945 & TRN & \\
\hline CHEMBL1319431 & 688171 & 4.75 & 4.8195 & TRN & \\
\hline CHEMBL3194862 & 688171 & 4.8 & 5.041 & TRN & \\
\hline CHEMBL1495096 & 688171 & 6.8 & 4.8619 & TST & \\
\hline CHEMBL1522437 & 688171 & 5.3 & 4.9418 & TRN & \\
\hline CHEMBL1592894 & 688171 & 4.4 & 4.9334 & TRN & \\
\hline CHEMBL1393493 & 688171 & 7.6003 & 4.9091 & TST & \\
\hline CHEMBL1353918 & 688171 & 4.55 & 5.0271 & TST & \\
\hline CHEMBL1465490 & 688171 & 5.5 & 4.9031 & TRN & \\
\hline CHEMBL1538652 & 688171 & 4.5 & 4.959 & TRN & \\
\hline CHEMBL1385676 & 688171 & 6.0 & 5.0447 & TRN & \\
\hline CHEMBL1361091 & 688171 & 5.05 & 4.9976 & TRN & \\
\hline CHEMBL1401818 & 688171 & 4.75 & 4.8479 & TRN & \\
\hline CHEMBL1354430 & 688171 & 5.5 & 4.8698 & TRN & \\
\hline CHEMBL1608804 & 688171 & 7.6003 & 4.9612 & TST & \\
\hline CHEMBL1455025 & 688171 & 4.35 & 4.8031 & TRN & \\
\hline CHEMBL3198905 & 688171 & 4.6 & 4.8607 & TST & \\
\hline CHEMBL1404284 & 688171 & 5.7 & 4.9201 & TRN & \\
\hline CHEMBL1486580 & 688171 & 4.85 & 4.8028 & TRN & \\
\hline CHEMBL1592755 & 688171 & 5.25 & 4.8646 & TRN & \\
\hline CHEMBL1497950 & 688171 & 5.7 & 4.7294 & TRN & \\
\hline CHEMBL1456876 & 688171 & 4.4 & 4.8957 & TRN & \\
\hline CHEMBL1555570 & 688171 & 5.5 & 4.8218 & TRN & \\
\hline CHEMBL1987928 & 688171 & 5.15 & 4.873 & TRN & \\
\hline
\end{tabular}




\begin{tabular}{|c|c|c|c|c|}
\hline \multicolumn{5}{|c|}{ Supplemental Table s2.txt } \\
\hline CHEMBL1587635 & 688171 & 4.8 & 5.0503 & TRN \\
\hline CHEMBL1483218 & 688171 & 4.75 & 4.84 & TST \\
\hline CHEMBL1566675 & 688171 & 4.55 & 4.8036 & TRN \\
\hline CHEMBL589694 & 688171 & 4.6 & 4.9381 & TRN \\
\hline CHEMBL1318930 & 688171 & 5.6 & 4.9463 & TST \\
\hline CHEMBL1371989 & 688171 & 4.65 & 4.8767 & TRN \\
\hline CHEMBL1585309 & 688171 & 4.5 & 4.7391 & TRN \\
\hline CHEMBL1326593 & 688171 & 6.1 & 4.8944 & TRN \\
\hline CHEMBL1516419 & 688171 & 6.6499 & 4.9471 & TST \\
\hline CHEMBL1412239 & 688171 & 4.8 & 4.9265 & TRN \\
\hline CHEMBL1299989 & 688171 & 4.5 & 4.9487 & TST \\
\hline CHEMBL1483647 & 688171 & 7.3002 & 4.774 & TST \\
\hline CHEMBL1444071 & 688171 & 6.8499 & 4.9138 & TST \\
\hline CHEMBL1509809 & 688171 & 4.6 & 4.8602 & TRN \\
\hline CHEMBL1551559 & 688171 & 4.6 & 5.0097 & TRN \\
\hline CHEMBL1547106 & 688171 & 4.4 & 4.9277 & TRN \\
\hline CHEMBL1362734 & 688171 & 4.7 & 4.7749 & TRN \\
\hline CHEMBL3198502 & 688171 & 4.45 & 4.9438 & TRN \\
\hline CHEMBL1423668 & 688171 & 4.6 & 5.005 & TRN \\
\hline CHEMBL1568318 & 688171 & 4.4 & 4.9676 & TST \\
\hline CHEMBL1312355 & 688171 & 4.85 & 4.9005 & TRN \\
\hline CHEMBL1482550 & 688171 & 4.45 & 4.9318 & TRN \\
\hline CHEMBL1357017 & 688171 & 4.35 & 4.912 & TRN \\
\hline CHEMBL1334633 & 688171 & 4.4 & 4.9705 & TRN \\
\hline CHEMBL1543344 & 688171 & 5.05 & 4.9872 & TST \\
\hline CHEMBL1597427 & 688171 & 5.15 & 5.0566 & TRN \\
\hline CHEMBL1544656 & 688171 & 4.6 & 4.7815 & TRN \\
\hline CHEMBL3197599 & 688171 & 4.9 & 4.8703 & TRN \\
\hline CHEMBL1311515 & 688171 & 4.8 & 4.825 & TRN \\
\hline CHEMBL1441088 & 688171 & 4.7 & 4.8465 & TRN \\
\hline CHEMBL1396063 & 688171 & 4.7 & 4.8228 & TRN \\
\hline CHEMBL1433441 & 688171 & 4.9 & 4.9875 & TST \\
\hline CHEMBL1540523 & 688171 & 4.55 & 4.9218 & TRN \\
\hline CHEMBL3211680 & 688171 & 4.4 & 5.0783 & TST \\
\hline CHEMBL1477985 & 688171 & 4.35 & 5.0079 & TST \\
\hline CHEMBL1996253 & 688171 & 4.7 & 5.0302 & TRN \\
\hline CHEMBL1340316 & 688171 & 4.7 & 4.9184 & TRN \\
\hline CHEMBL1555350 & 688171 & 5.45 & 4.9165 & TRN \\
\hline CHEMBL1593073 & 688171 & 4.8 & 5.0991 & TRN \\
\hline CHEMBL1356320 & 688171 & 4.65 & 4.8021 & TRN \\
\hline CHEMBL1323245 & 688171 & 4.7 & 4.7365 & TST \\
\hline CHEMBL1564583 & 688171 & 5.05 & 4.9528 & TST \\
\hline CHEMBL1550023 & 688171 & 7.6003 & 5.0751 & TRN \\
\hline CHEMBL1370858 & 688171 & 5.6 & 4.9259 & TRN \\
\hline CHEMBL1612286 & 688171 & 4.4 & 4.9262 & TRN \\
\hline CHEMBL1466487 & 688171 & 4.95 & 4.8936 & TRN \\
\hline CHEMBL1509500 & 688171 & 4.85 & 4.9622 & TST \\
\hline CHEMBL1519404 & 688171 & 4.9 & 4.8416 & TST \\
\hline
\end{tabular}




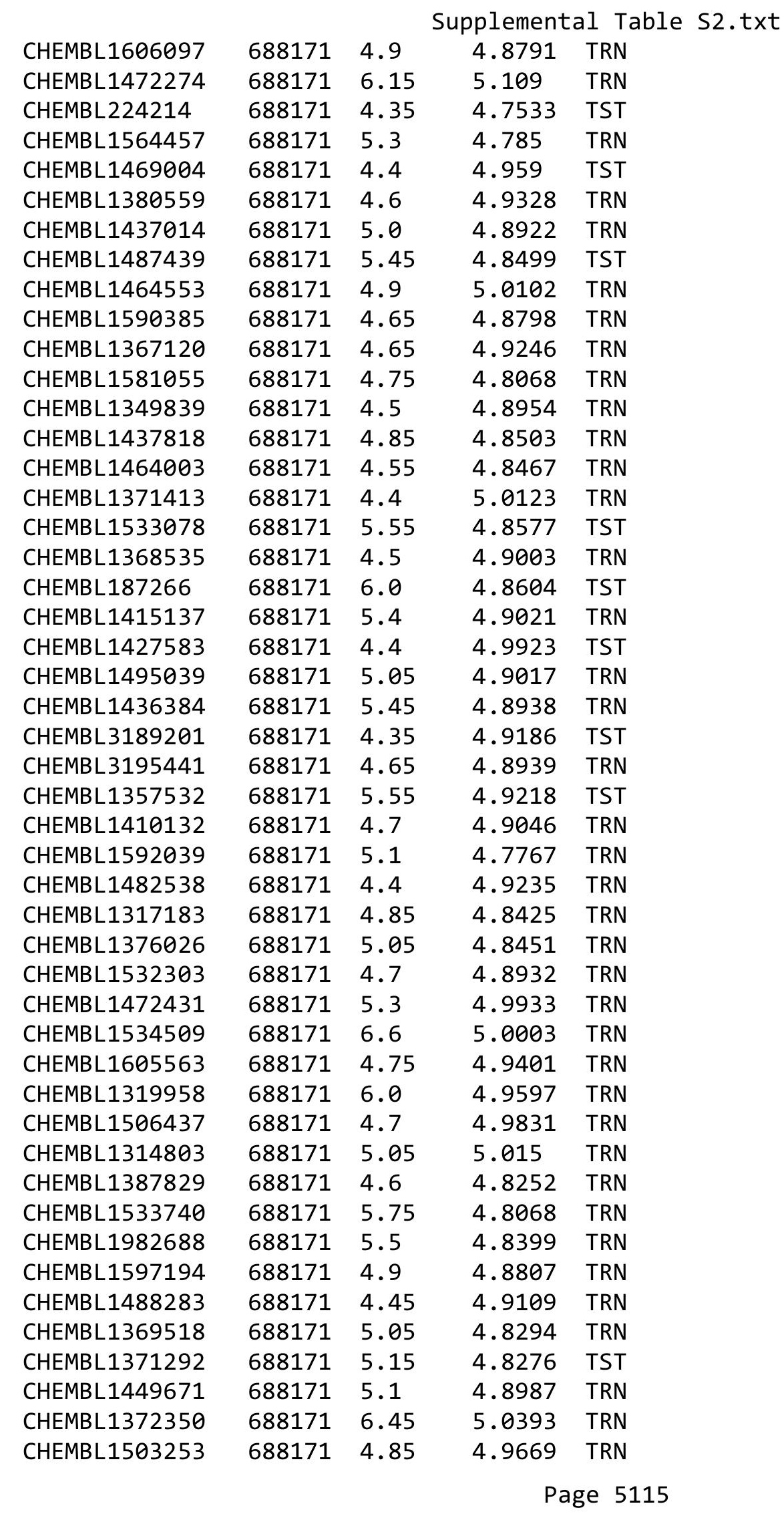




\begin{tabular}{|c|c|c|c|c|c|}
\hline \multirow[b]{2}{*}{ CHEMBL1998118 } & \multirow[b]{2}{*}{688171} & \multicolumn{4}{|c|}{ Supplemental Table S2.txt } \\
\hline & & 4.95 & 4.8893 & TRN & \\
\hline CHEMBL1332320 & 688171 & 5.05 & 5.1339 & TST & \\
\hline CHEMBL1576056 & 688171 & 4.6 & 4.8456 & TRN & \\
\hline CHEMBL1444483 & 688171 & 5.55 & 4.988 & TRN & \\
\hline CHEMBL1397880 & 688171 & 5.5 & 4.7717 & TRN & \\
\hline CHEMBL1558327 & 688171 & 4.55 & 4.8222 & TRN & \\
\hline CHEMBL1481617 & 688171 & 4.45 & 4.8554 & TRN & \\
\hline CHEMBL1580068 & 688171 & 4.55 & 4.9045 & TST & \\
\hline CHEMBL 28626 & 688171 & 6.95 & 4.9113 & TRN & \\
\hline CHEMBL1447081 & 688171 & 4.55 & 4.7982 & TST & \\
\hline CHEMBL1312641 & 688171 & 4.95 & 5.0149 & TRN & \\
\hline CHEMBL1573101 & 688171 & 4.65 & 4.8531 & TRN & \\
\hline CHEMBL1515651 & 688171 & 4.8 & 4.8292 & TRN & \\
\hline CHEMBL1334046 & 688171 & 4.85 & 4.8048 & TRN & \\
\hline CHEMBL1360758 & 688171 & 4.65 & 4.832 & TST & \\
\hline CHEMBL1570277 & 688171 & 5.0 & 4.8984 & TRN & \\
\hline CHEMBL1415678 & 688171 & 5.5 & 4.9174 & TRN & \\
\hline CHEMBL3210237 & 688171 & 4.5 & 4.955 & TRN & \\
\hline CHEMBL1436278 & 688171 & 4.85 & 4.9647 & TRN & \\
\hline CHEMBL1581106 & 688171 & 5.5 & 4.7435 & TRN & \\
\hline CHEMBL1398284 & 688171 & 5.75 & 4.9683 & TRN & \\
\hline CHEMBL66953 & 688171 & 6.0 & 4.9187 & TST & \\
\hline CHEMBL1572845 & 688171 & 4.4 & 4.8751 & TRN & \\
\hline CHEMBL1541886 & 688171 & 4.5 & 4.7807 & TRN & \\
\hline CHEMBL1572216 & 688171 & 4.9 & 4.8392 & TRN & \\
\hline CHEMBL1452175 & 688171 & 5.3 & 4.8827 & TRN & \\
\hline CHEMBL3196497 & 688171 & 5.05 & 4.8513 & TRN & \\
\hline CHEMBL1305190 & 688171 & 4.45 & 4.8562 & TRN & \\
\hline CHEMBL1558663 & 688171 & 4.9 & 4.8896 & TST & \\
\hline CHEMBL3190169 & 688171 & 4.45 & 4.8809 & TST & \\
\hline CHEMBL1583728 & 688171 & 5.85 & 4.7673 & TST & \\
\hline CHEMBL1306524 & 688171 & 4.4 & 4.9029 & TST & \\
\hline CHEMBL1418875 & 688171 & 4.5 & 4.7723 & TRN & \\
\hline CHEMBL1434587 & 688171 & 4.5 & 4.8058 & TRN & \\
\hline CHEMBL1357059 & 688171 & 4.6 & 4.8671 & TRN & \\
\hline CHEMBL1434410 & 688171 & 4.75 & 4.8185 & TRN & \\
\hline CHEMBL1339796 & 688171 & 4.65 & 4.8268 & TRN & \\
\hline CHEMBL1514865 & 688171 & 4.55 & 4.86 & TST & \\
\hline CHEMBL1437197 & 688171 & 4.4 & 5.0121 & TST & \\
\hline CHEMBL1487834 & 688171 & 4.7 & 4.90600 & 2000000001 & TRN \\
\hline CHEMBL1406332 & 688171 & 5.3 & 4.7941 & TRN & \\
\hline CHEMBL1419159 & 688171 & 4.7 & 5.006 & TRN & \\
\hline CHEMBL1430100 & 688171 & 4.4 & 4.96399 & 99999999995 & TST \\
\hline CHEMBL1970711 & 688171 & 5.15 & 4.8182 & TRN & \\
\hline CHEMBL1597636 & 688171 & 5.4 & 4.8127 & TRN & \\
\hline CHEMBL1468277 & 688171 & 4.9 & 4.8461 & TST & \\
\hline CHEMBL1543584 & 688171 & 7.0 & 5.1543 & TST & \\
\hline CHEMBL1367582 & 688171 & 4.6 & 4.9532 & TRN & \\
\hline
\end{tabular}




\begin{tabular}{|c|c|c|c|c|}
\hline \multicolumn{5}{|c|}{ Supplemental Table S2.txt } \\
\hline CHEMBL1351707 & 688171 & 4.75 & 4.7714 & TRN \\
\hline CHEMBL1610240 & 688171 & 4.55 & 4.9123 & TST \\
\hline CHEMBL1377836 & 688171 & 4.9 & 4.9062 & TRN \\
\hline CHEMBL1599118 & 688171 & 4.4 & 4.8375 & TRN \\
\hline CHEMBL1613650 & 688171 & 4.35 & 5.0263 & TST \\
\hline CHEMBL1533802 & 688171 & 4.65 & 4.8435 & TRN \\
\hline CHEMBL1588356 & 688171 & 4.4 & 4.7173 & TRN \\
\hline CHEMBL1560416 & 688171 & 4.35 & 5.0296 & TRN \\
\hline CHEMBL1310547 & 688171 & 6.8499 & 5.0088 & TRN \\
\hline CHEMBL1596927 & 688171 & 5.45 & 4.8963 & TRN \\
\hline CHEMBL1313265 & 688171 & 5.6 & 4.9883 & TRN \\
\hline CHEMBL1474297 & 688171 & 4.65 & 4.9715 & TRN \\
\hline CHEMBL1490495 & 688171 & 6.0 & 4.99 & TRN \\
\hline CHEMBL1303106 & 688171 & 4.75 & 4.928 & TST \\
\hline CHEMBL1319789 & 688171 & 6.0 & 4.9477 & TRN \\
\hline CHEMBL1506653 & 688171 & 5.05 & 4.9433 & TST \\
\hline CHEMBL1564502 & 688171 & 4.8 & 4.9103 & TRN \\
\hline CHEMBL1400355 & 688171 & 4.75 & 4.8606 & TRN \\
\hline CHEMBL1450093 & 688171 & 4.45 & 4.9864 & TST \\
\hline CHEMBL1596094 & 688171 & 5.95 & 4.9315 & TRN \\
\hline CHEMBL1366712 & 688171 & 6.0 & 4.8456 & TRN \\
\hline CHEMBL1550899 & 688171 & 5.05 & 5.0141 & TRN \\
\hline CHEMBL1607912 & 688171 & 4.7 & 4.8914 & TRN \\
\hline CHEMBL1312673 & 688171 & 4.55 & 4.857 & TRN \\
\hline CHEMBL1557430 & 688171 & 4.85 & 4.9326 & TRN \\
\hline CHEMBL1543657 & 688171 & 5.5 & 4.9471 & TRN \\
\hline CHEMBL1557432 & 688171 & 5.05 & 4.9287 & TRN \\
\hline CHEMBL1411104 & 688171 & 5.05 & 4.9367 & TRN \\
\hline CHEMBL1605968 & 688171 & 4.85 & 4.8376 & TRN \\
\hline CHEMBL3196607 & 688171 & 5.65 & 4.8558 & TRN \\
\hline CHEMBL1560326 & 688171 & 4.65 & 4.9777 & TRN \\
\hline CHEMBL1367933 & 688171 & 4.55 & 4.8907 & TST \\
\hline CHEMBL1561989 & 688171 & 4.65 & 4.8205 & TRN \\
\hline CHEMBL1347644 & 688171 & 4.4 & 4.9086 & TRN \\
\hline CHEMBL1532428 & 688171 & 5.35 & 4.834 & TST \\
\hline CHEMBL1394022 & 688171 & 4.55 & 4.8923 & TST \\
\hline CHEMBL1436704 & 688171 & 5.55 & 4.977 & TRN \\
\hline CHEMBL1436501 & 688171 & 5.0 & 4.9223 & TRN \\
\hline CHEMBL1418078 & 688171 & 4.9 & 4.8379 & TRN \\
\hline CHEMBL1311087 & 688171 & 5.9 & 4.8281 & TST \\
\hline CHEMBL3189537 & 688171 & 5.5 & 5.0496 & TRN \\
\hline CHEMBL1372127 & 688171 & 4.8 & 4.8202 & TST \\
\hline CHEMBL1521656 & 688171 & 4.65 & 4.9334 & TRN \\
\hline CHEMBL1548089 & 688171 & 7.6003 & 4.9483 & TRN \\
\hline CHEMBL1358513 & 688171 & 5.0 & 4.8972 & TRN \\
\hline CHEMBL1519608 & 688171 & 4.4 & 4.8821 & TRN \\
\hline CHEMBL1514382 & 688171 & 4.6 & 5.0229 & TRN \\
\hline CHEMBL1444648 & 688171 & 5.5 & 4.9878 & TST \\
\hline
\end{tabular}




\begin{tabular}{|c|c|c|c|c|}
\hline \multicolumn{5}{|c|}{ Supplemental Table S2.txt } \\
\hline CHEMBL1609304 & 688171 & 5.45 & 4.8718 & TST \\
\hline CHEMBL1525742 & 688171 & 5.1 & 4.918 & TRN \\
\hline CHEMBL1383733 & 688171 & 4.75 & 4.8942 & TST \\
\hline CHEMBL1357678 & 688171 & 4.4 & 4.8429 & TRN \\
\hline CHEMBL1364338 & 688171 & 4.6 & 5.0282 & TRN \\
\hline CHEMBL1408973 & 688171 & 4.35 & 4.9906 & TRN \\
\hline CHEMBL1368261 & 688171 & 5.55 & 4.8791 & TST \\
\hline CHEMBL1535077 & 688171 & 5.0 & 4.8851 & TRN \\
\hline CHEMBL1366969 & 688171 & 6.2 & 4.9411 & TRN \\
\hline CHEMBL1327683 & 688171 & 5.05 & 4.9035 & TST \\
\hline CHEMBL1559301 & 688171 & 4.6 & 4.8432 & TRN \\
\hline CHEMBL1360715 & 688171 & 4.8 & 4.8355 & TRN \\
\hline CHEMBL1396952 & 688171 & 4.65 & 5.0553 & TRN \\
\hline CHEMBL1589812 & 688171 & 4.9 & 4.7773 & TRN \\
\hline CHEMBL1394474 & 688171 & 7.5003 & 5.0101 & TRN \\
\hline CHEMBL1312377 & 688171 & 5.3 & 4.856 & TRN \\
\hline CHEMBL1495886 & 688171 & 4.85 & 4.7534 & TRN \\
\hline CHEMBL1577656 & 688171 & 4.6 & 4.9288 & TRN \\
\hline CHEMBL1406049 & 688171 & 5.1 & 4.8145 & TRN \\
\hline CHEMBL 1408320 & 688171 & 4.8 & 4.8458 & TRN \\
\hline CHEMBL1339730 & 688171 & 4.7 & 4.8104 & TRN \\
\hline CHEMBL1548712 & 688171 & 4.85 & 4.7682 & TRN \\
\hline CHEMBL1303626 & 688171 & 5.0 & 4.8781 & TST \\
\hline CHEMBL1376529 & 688171 & 5.05 & 4.9334 & TRN \\
\hline CHEMBL1410415 & 688171 & 5.85 & 4.8886 & TRN \\
\hline CHEMBL 1443448 & 688171 & 6.7001 & 4.946006 & 0000000001 \\
\hline CHEMBL1366382 & 688171 & 4.85 & 4.9466 & TRN \\
\hline CHEMBL1611234 & 688171 & 5.05 & 5.0003 & TST \\
\hline CHEMBL3198393 & 688171 & 4.85 & 4.8268 & TRN \\
\hline CHEMBL444236 & 688171 & 4.75 & 4.8473 & TST \\
\hline CHEMBL1341762 & 688171 & 4.55 & 4.9765 & TRN \\
\hline CHEMBL1454083 & 688171 & 4.9 & 4.8115 & TRN \\
\hline CHEMBL1389398 & 688171 & 4.95 & 4.842 & TRN \\
\hline CHEMBL1563258 & 688171 & 4.4 & 4.9203 & TRN \\
\hline CHEMBL1503392 & 688171 & 4.45 & 5.0806 & TRN \\
\hline CHEMBL1523620 & 688171 & 4.55 & 4.9303 & TRN \\
\hline CHEMBL1308136 & 688171 & 4.65 & 4.8311 & TRN \\
\hline CHEMBL1380140 & 688171 & 5.45 & 4.9728 & TRN \\
\hline CHEMBL1489919 & 688171 & 4.65 & 4.9069 & TST \\
\hline CHEMBL3145364 & 688171 & 5.5 & 4.7478 & TST \\
\hline CHEMBL1435774 & 688171 & 4.8 & 4.8959 & TST \\
\hline CHEMBL1401526 & 688171 & 5.3 & 4.9389 & TST \\
\hline CHEMBL1541005 & 688171 & 4.9 & 4.6443 & TRN \\
\hline CHEMBL1519673 & 688171 & 6.7501 & 5.003 & TRN \\
\hline CHEMBL1477239 & 688171 & 5.2 & 4.9313 & TRN \\
\hline CHEMBL1335571 & 688171 & 4.4 & 4.871 & TRN \\
\hline CHEMBL1457031 & 688171 & 4.55 & 4.9389 & TST \\
\hline CHEMBL1398593 & 688171 & 4.4 & 4.9434 & TRN \\
\hline
\end{tabular}




\begin{tabular}{|c|c|c|c|c|c|}
\hline \multicolumn{6}{|c|}{ Supplemental Table S2.txt } \\
\hline CHEMBL1382808 & 688171 & 4.8 & 4.979 & TST & \\
\hline CHEMBL3197231 & 688171 & 4.75 & 4.8901 & TRN & \\
\hline CHEMBL1554842 & 688171 & 5.45 & 4.9765 & TRN & \\
\hline CHEMBL1443362 & 688171 & 5.05 & 4.8114 & TST & \\
\hline CHEMBL1606670 & 688171 & 4.9 & 4.7748 & TRN & \\
\hline CHEMBL1451163 & 688171 & 4.85 & 4.8963 & TST & \\
\hline CHEMBL1394337 & 688171 & 4.65 & 4.9475 & TRN & \\
\hline CHEMBL1515384 & 688171 & 4.6 & 5.1093 & TRN & \\
\hline CHEMBL1302442 & 688171 & 4.65 & 4.8465 & TRN & \\
\hline CHEMBL1525891 & 688171 & 4.4 & 4.9196 & TRN & \\
\hline CHEMBL1305080 & 688171 & 4.4 & 4.8878 & TST & \\
\hline CHEMBL1337519 & 688171 & 4.4 & 4.7139 & TRN & \\
\hline CHEMBL1531848 & 688171 & 4.55 & 4.8211 & TRN & \\
\hline CHEMBL1490673 & 688171 & 4.4 & 4.9792 & TRN & \\
\hline CHEMBL1594650 & 688171 & 4.4 & 4.8229 & TRN & \\
\hline CHEMBL1430300 & 688171 & 4.4 & 4.8853 & TRN & \\
\hline CHEMBL1567935 & 688171 & 4.35 & 5.0585 & TRN & \\
\hline CHEMBL1551244 & 688171 & 5.1 & 4.8645 & TRN & \\
\hline CHEMBL1456553 & 688171 & 5.4 & 4.9424 & TRN & \\
\hline CHEMBL1571746 & 688171 & 4.85 & 4.9827 & TRN & \\
\hline CHEMBL1352361 & 688171 & 4.6 & 4.8883 & TRN & \\
\hline CHEMBL1313600 & 688171 & 4.35 & 5.0164 & TRN & \\
\hline CHEMBL1502293 & 688171 & 4.6 & 4.7927 & TRN & \\
\hline CHEMBL1433027 & 688171 & 4.35 & 4.8642 & TRN & \\
\hline CHEMBL1454690 & 688171 & 4.75 & 5.0345 & TST & \\
\hline CHEMBL1395042 & 688171 & 4.85 & 4.9261 & TRN & \\
\hline CHEMBL1428026 & 688171 & 4.75 & 4.7196 & TRN & \\
\hline CHEMBL1465014 & 688171 & 5.5 & 4.9535 & TRN & \\
\hline CHEMBL1232179 & 688171 & 4.8 & 4.9161 & TRN & \\
\hline CHEMBL 3192541 & 688171 & 5.15 & 4.8769 & TRN & \\
\hline CHEMBL1317764 & 688171 & 4.4 & 4.9055 & TRN & \\
\hline CHEMBL1495335 & 688171 & 4.6 & 4.7768 & TRN & \\
\hline CHEMBL1415906 & 688171 & 5.1 & 4.8701 & TRN & \\
\hline CHEMBL1451108 & 688171 & 6.05 & 4.8951 & TST & \\
\hline CHEMBL1319751 & 688171 & 4.95 & 5.0606 & TST & \\
\hline CHEMBL1410400 & 688171 & 4.5 & 4.9799 & TST & \\
\hline CHEMBL1494717 & 688171 & 4.8 & 4.8475 & TRN & \\
\hline CHEMBL1511893 & 688171 & 5.6 & 4.8647 & TRN & \\
\hline CHEMBL1597642 & 688171 & 5.0 & 4.75899 & 99999999995 & TRN \\
\hline CHEMBL1331399 & 688171 & 4.75 & 4.8945 & TST & \\
\hline CHEMBL1317159 & 688171 & 4.5 & 4.9202 & TRN & \\
\hline CHEMBL1610923 & 688171 & 4.55 & 4.8664 & TST & \\
\hline CHEMBL3193769 & 688171 & 5.5 & 4.9564 & TRN & \\
\hline CHEMBL1332010 & 688171 & 4.9 & 5.0166 & TRN & \\
\hline CHEMBL3199688 & 688171 & 5.05 & 4.835 & TST & \\
\hline CHEMBL1591162 & 688171 & 4.7 & 4.9164 & TRN & \\
\hline CHEMBL1516166 & 688171 & 6.05 & 4.8908 & TRN & \\
\hline CHEMBL3190694 & 688171 & 4.4 & 4.9074 & TRN & \\
\hline
\end{tabular}




\begin{tabular}{|c|c|c|c|c|c|}
\hline & & \multicolumn{4}{|c|}{ Supplemental Table s2.txt } \\
\hline CHEMBL1415788 & 688171 & 5.5 & 4.8955 & TRN & \\
\hline CHEMBL1593403 & 688171 & 4.5 & 4.989 & TRN & \\
\hline CHEMBL1575306 & 688171 & 4.95 & 4.9266 & TST & \\
\hline CHEMBL1563100 & 688171 & 5.1 & 4.9566 & TRN & \\
\hline CHEMBL1439852 & 688171 & 5.05 & 4.97199 & 99999999995 & TST \\
\hline CHEMBL1363614 & 688171 & 5.25 & 4.9521 & TST & \\
\hline CHEMBL1586982 & 688171 & 5.1 & 4.8141 & TRN & \\
\hline CHEMBL1408013 & 688171 & 5.5 & 5.0006 & TRN & \\
\hline CHEMBL1575556 & 688171 & 4.4 & 4.8356 & TST & \\
\hline CHEMBL1529133 & 688171 & 4.65 & 4.9197 & TRN & \\
\hline CHEMBL1411898 & 688171 & 4.55 & 4.9066 & TRN & \\
\hline CHEMBL1608111 & 688171 & 4.8 & 4.8837 & TRN & \\
\hline CHEMBL1455635 & 688171 & 5.05 & 4.8634 & TRN & \\
\hline CHEMBL1395348 & 688171 & 4.85 & 4.9571 & TRN & \\
\hline CHEMBL1459977 & 688171 & 5.8 & 5.0621 & TRN & \\
\hline CHEMBL1440334 & 688171 & 4.35 & 4.8366 & TRN & \\
\hline CHEMBL1595786 & 688171 & 4.7 & 4.9404 & TRN & \\
\hline CHEMBL3192453 & 688171 & 7.0 & 4.9749 & TST & \\
\hline CHEMBL1988416 & 688171 & 4.75 & 4.879 & TST & \\
\hline CHEMBL1397330 & 688171 & 4.55 & 4.8545 & TRN & \\
\hline CHEMBL1568007 & 688171 & 5.0 & 4.88 & TRN & \\
\hline CHEMBL1347605 & 688171 & 4.55 & 4.8835 & TRN & \\
\hline CHEMBL1300311 & 688171 & 5.6 & 4.8606 & TRN & \\
\hline CHEMBL1307954 & 688171 & 5.05 & 5.0204 & TRN & \\
\hline CHEMBL1523520 & 688171 & 4.55 & 4.8366 & TST & \\
\hline CHEMBL1404260 & 688171 & 4.8 & 4.8401 & TRN & \\
\hline CHEMBL1515038 & 688171 & 4.55 & 4.9039 & TRN & \\
\hline CHEMBL1507616 & 688171 & 4.4 & 4.8651 & TST & \\
\hline CHEMBL1440731 & 688171 & 4.95 & 4.8495 & TRN & \\
\hline CHEMBL1349709 & 688171 & 4.45 & 4.908 & TRN & \\
\hline CHEMBL1320556 & 688171 & 4.4 & 4.9811 & TRN & \\
\hline CHEMBL1414871 & 688171 & 4.95 & 4.8813 & TRN & \\
\hline CHEMBL1976208 & 688171 & 5.2 & 4.8604 & TRN & \\
\hline CHEMBL1444896 & 688171 & 4.55 & 4.9566 & TRN & \\
\hline CHEMBL1512347 & 688171 & 4.5 & 4.9577 & TRN & \\
\hline CHEMBL1529303 & 688171 & 4.85 & 4.8569 & TRN & \\
\hline CHEMBL1335220 & 688171 & 5.05 & 4.888 & TRN & \\
\hline CHEMBL1538684 & 688171 & 4.35 & 5.0445 & TST & \\
\hline CHEMBL1507368 & 688171 & 6.05 & 4.9905 & TRN & \\
\hline CHEMBL1450364 & 688171 & 4.6 & 4.8458 & TRN & \\
\hline CHEMBL1335799 & 688171 & 4.6 & 4.9802 & TRN & \\
\hline CHEMBL1392164 & 688171 & 4.5 & 4.9857 & TRN & \\
\hline CHEMBL1527520 & 688171 & 4.35 & 4.9522 & TRN & \\
\hline CHEMBL1468411 & 688171 & 5.5 & 5.0275 & TRN & \\
\hline CHEMBL1459473 & 688171 & 4.55 & 4.8954 & TRN & \\
\hline CHEMBL1401747 & 688171 & 4.65 & 4.7405 & TRN & \\
\hline CHEMBL1333427 & 688171 & 4.4 & 4.9218 & TRN & \\
\hline CHEMBL1450165 & 688171 & 4.85 & 4.8469 & TRN & \\
\hline
\end{tabular}




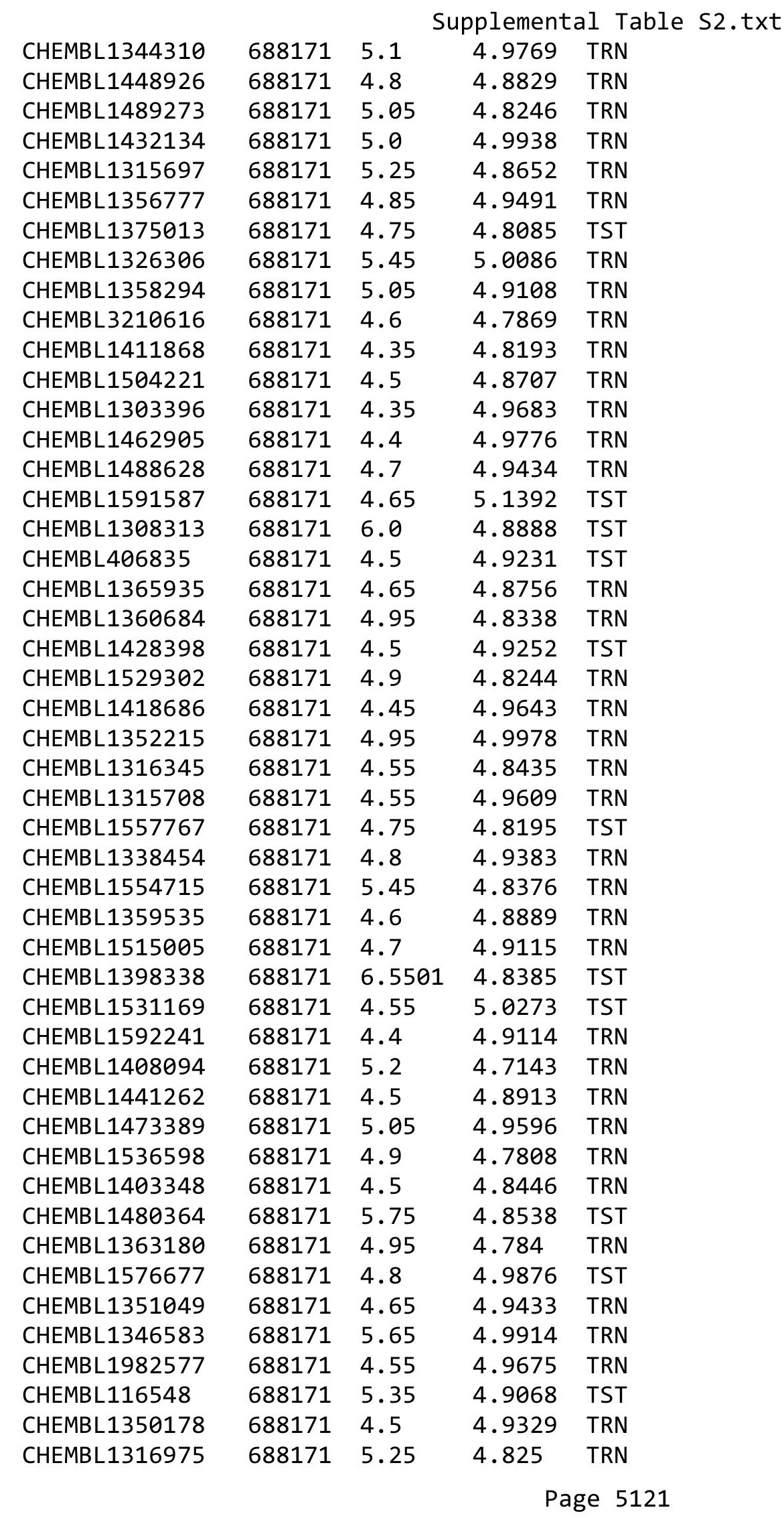




\begin{tabular}{|c|c|c|c|c|c|}
\hline \multicolumn{6}{|c|}{ Supplemental Table s2.txt } \\
\hline CHEMBL1370655 & 688171 & 5.0 & 4.9354 & TRN & \\
\hline CHEMBL1465001 & 688171 & 5.5 & 4.8688 & TRN & \\
\hline CHEMBL1433435 & 688171 & 4.55 & 4.8474 & TRN & \\
\hline CHEMBL1569602 & 688171 & 4.5 & 4.981 & TRN & \\
\hline CHEMBL1518415 & 688171 & 4.65 & 4.9615 & TRN & \\
\hline CHEMBL1463103 & 688171 & 5.1 & 5.055 & TRN & \\
\hline CHEMBL1555690 & 688171 & 5.0 & 5.0724 & TST & \\
\hline CHEMBL1407003 & 688171 & 4.45 & 4.8959 & TRN & \\
\hline CHEMBL1486528 & 688171 & 4.85 & 4.9438 & TST & \\
\hline CHEMBL1402342 & 688171 & 5.05 & 4.9539 & TRN & \\
\hline CHEMBL1549935 & 688171 & 7.0501 & 5.0016 & TRN & \\
\hline CHEMBL1598793 & 688171 & 4.65 & 4.7336 & TRN & \\
\hline CHEMBL1303044 & 688171 & 5.65 & 5.0198 & TRN & \\
\hline CHEMBL3196229 & 688171 & 5.0 & 5.0015 & TRN & \\
\hline CHEMBL1328598 & 688171 & 4.4 & 4.8282 & TRN & \\
\hline CHEMBL1473424 & 688171 & 4.5 & 4.9237 & TRN & \\
\hline CHEMBL1481867 & 688171 & 4.5 & 4.9076 & TST & \\
\hline CHEMBL1378158 & 688171 & 4.75 & 4.862 & TRN & \\
\hline CHEMBL1361690 & 688171 & 4.8 & 4.8657 & TRN & \\
\hline CHEMBL1489184 & 688171 & 4.5 & 4.8396 & TRN & \\
\hline CHEMBL1565778 & 688171 & 4.4 & 4.8501 & TRN & \\
\hline CHEMBL1309594 & 688171 & 4.4 & 5.0018 & TRN & \\
\hline CHEMBL1472255 & 688171 & 6.6499 & 5.0043 & TST & \\
\hline CHEMBL1594364 & 688171 & 4.5 & 4.9859 & TRN & \\
\hline CHEMBL 2003973 & 688171 & 4.95 & 5.0237 & TST & \\
\hline CHEMBL1384198 & 688171 & 4.4 & 4.8251 & TST & \\
\hline CHEMBL1427148 & 688171 & 4.95 & 4.9462 & TRN & \\
\hline CHEMBL1324353 & 688171 & 5.05 & 4.8878 & TST & \\
\hline CHEMBL1456199 & 688171 & 4.8 & 4.8527 & TRN & \\
\hline CHEMBL1362869 & 688171 & 4.8 & 4.9573 & TRN & \\
\hline CHEMBL1346519 & 688171 & 4.35 & 4.8263 & TRN & \\
\hline CHEMBL1486451 & 688171 & 5.0 & 4.7866 & TRN & \\
\hline CHEMBL3196436 & 688171 & 4.35 & 4.8418 & TST & \\
\hline CHEMBL1568966 & 688171 & 4.35 & 4.9698 & TRN & \\
\hline CHEMBL1543733 & 688171 & 4.9 & 4.905 & TRN & \\
\hline CHEMBL1447917 & 688171 & 4.4 & 4.9389 & TRN & \\
\hline CHEMBL1982574 & 688171 & 4.55 & 4.8818 & TST & \\
\hline CHEMBL1405997 & 688171 & 6.7501 & 4.8107 & TRN & \\
\hline CHEMBL3209604 & 688171 & 4.55 & 4.7854 & TST & \\
\hline CHEMBL1507297 & 688171 & 5.25 & 4.9897 & TRN & \\
\hline CHEMBL3190095 & 688171 & 4.8 & 4.8658 & TRN & \\
\hline CHEMBL1377467 & 688171 & 4.5 & 4.89199 & 99999999995 & TRN \\
\hline CHEMBL1592099 & 688171 & 4.65 & 4.9064 & TRN & \\
\hline CHEMBL1412489 & 688171 & 4.55 & 4.9567 & TST & \\
\hline CHEMBL1446882 & 688171 & 4.75 & 4.8934 & TRN & \\
\hline CHEMBL1410244 & 688171 & 4.5 & 4.9332 & TST & \\
\hline CHEMBL1492385 & 688171 & 4.7 & 4.9405 & TST & \\
\hline CHEMBL1559707 & 688171 & 4.6 & 4.8906 & TRN & \\
\hline
\end{tabular}




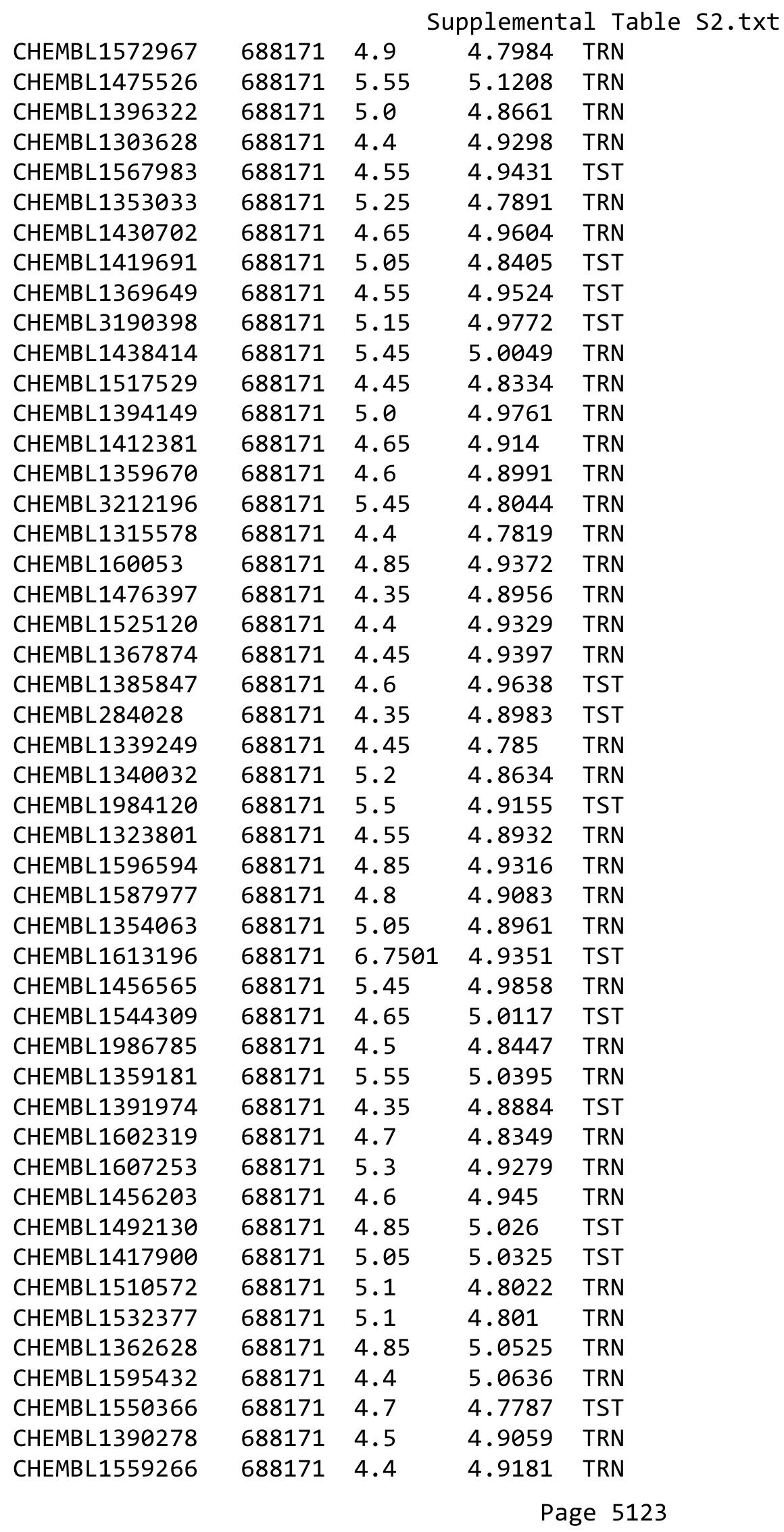




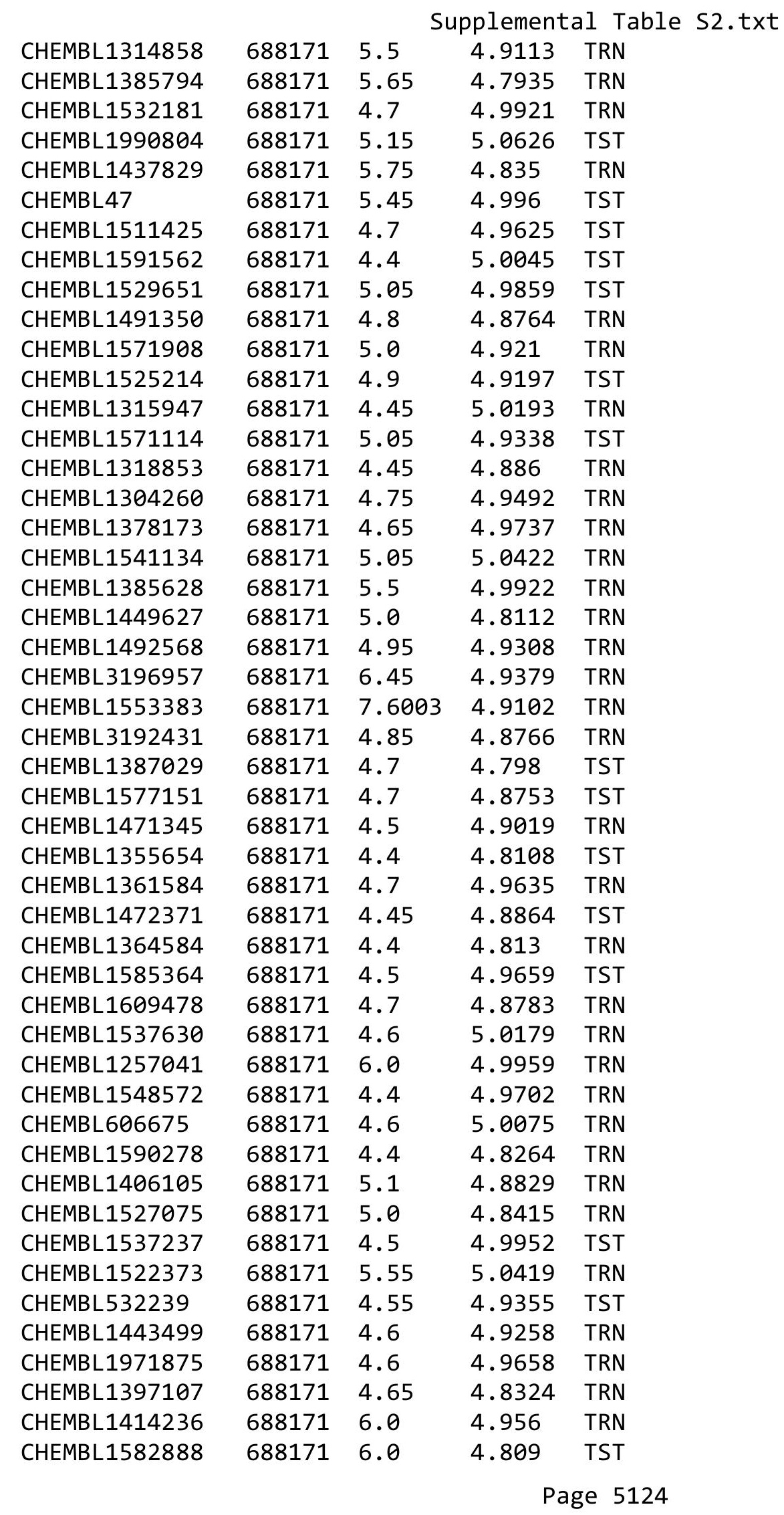




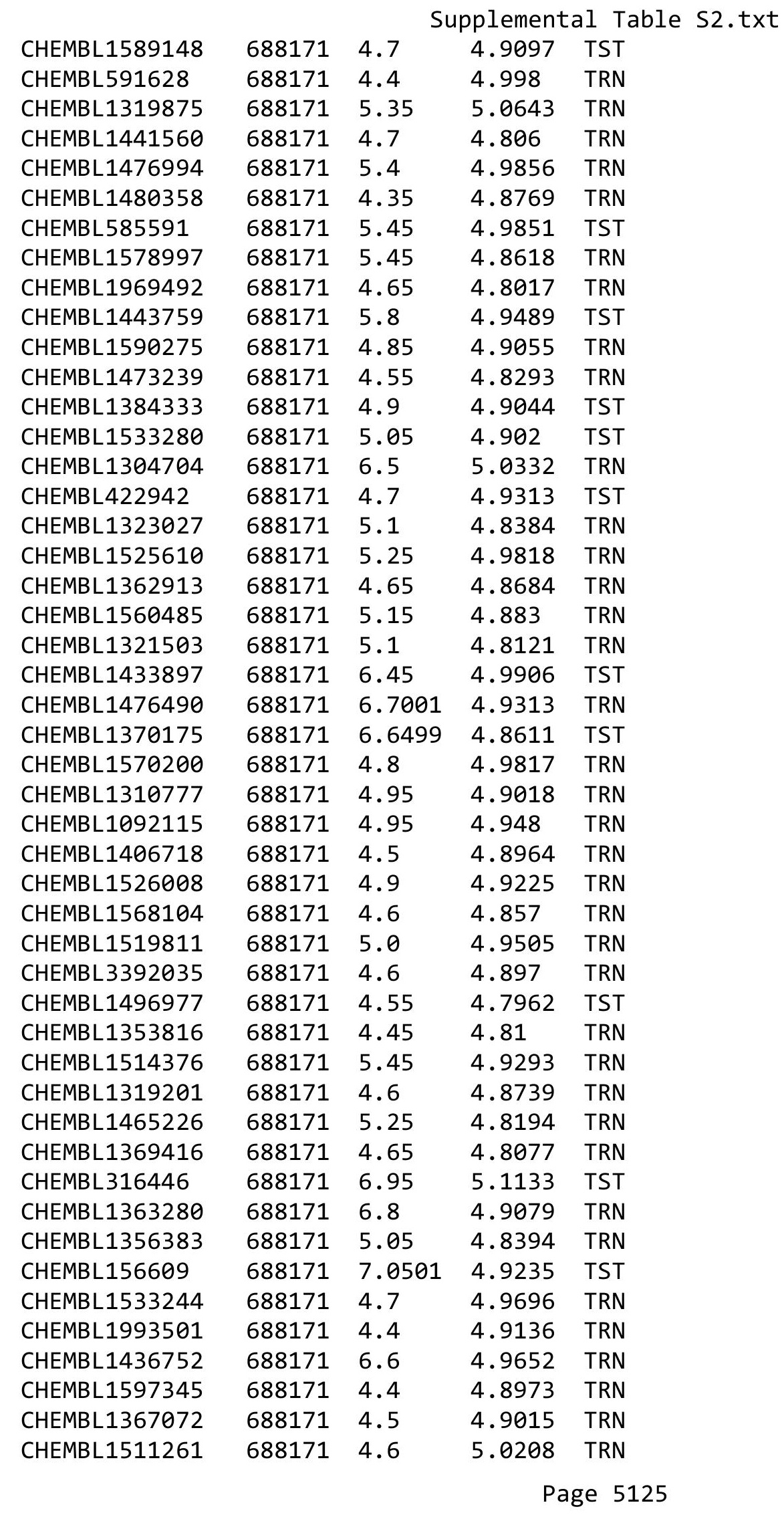




\begin{tabular}{|c|c|c|c|c|c|}
\hline \multirow{3}{*}{$\begin{array}{l}\text { CHEMBL1484248 } \\
\text { CHEMBL } 1311428\end{array}$} & \multirow{3}{*}{$\begin{array}{l}688171 \\
688171\end{array}$} & \multicolumn{4}{|c|}{ Supplemental Table s2.txt } \\
\hline & & 4.8 & 4.7810 & 0000000001 & TRN \\
\hline & & 5.05 & 4.8668 & TRN & \\
\hline CHEMBL1497170 & 688171 & 5.4 & 4.9683 & TRN & \\
\hline CHEMBL1516181 & 688171 & 4.7 & 4.8639 & TRN & \\
\hline CHEMBL1315493 & 688171 & 4.5 & 4.8798 & TRN & \\
\hline CHEMBL1497287 & 688171 & 4.35 & 4.912 & TST & \\
\hline CHEMBL1338934 & 688171 & 4.55 & 4.8533 & TRN & \\
\hline CHEMBL1520618 & 688171 & 4.65 & 4.8582 & TST & \\
\hline CHEMBL1377432 & 688171 & 4.7 & 4.8472 & TRN & \\
\hline CHEMBL3196986 & 688171 & 4.9 & 4.96 & TST & \\
\hline CHEMBL1407793 & 688171 & 4.55 & 4.8584 & TRN & \\
\hline CHEMBL1336558 & 688171 & 4.4 & 4.9686 & TRN & \\
\hline CHEMBL1316581 & 688171 & 4.8 & 4.8276 & TST & \\
\hline CHEMBL1501836 & 688171 & 4.85 & 4.8386 & TST & \\
\hline CHEMBL3195767 & 688171 & 6.2 & 4.9346 & TRN & \\
\hline CHEMBL1466465 & 688171 & 4.75 & 4.9837 & TRN & \\
\hline CHEMBL1605407 & 688171 & 4.5 & 4.802 & TST & \\
\hline CHEMBL1429919 & 688171 & 4.45 & 4.912 & TST & \\
\hline CHEMBL1595411 & 688171 & 4.95 & 4.8936 & TST & \\
\hline CHEMBL1190455 & 688171 & 5.45 & 4.7967 & TST & \\
\hline CHEMBL1353723 & 688171 & 4.75 & 4.8859 & TRN & \\
\hline CHEMBL1436113 & 688171 & 4.6 & 4.9253 & TRN & \\
\hline CHEMBL1350422 & 688171 & 4.9 & 4.8071 & TRN & \\
\hline CHEMBL3190321 & 688171 & 5.0 & 4.907 & TRN & \\
\hline CHEMBL1404340 & 688171 & 5.2 & 4.8294 & TRN & \\
\hline CHEMBL1585488 & 688171 & 4.75 & 4.8085 & TRN & \\
\hline CHEMBL1377384 & 688171 & 6.2 & 4.8662 & TST & \\
\hline CHEMBL1531926 & 688171 & 4.4 & 4.9422 & TRN & \\
\hline CHEMBL1531365 & 688171 & 4.65 & 5.1172 & TRN & \\
\hline CHEMBL1346425 & 688171 & 4.65 & 4.9486 & TRN & \\
\hline CHEMBL3207726 & 688171 & 4.8 & 4.8662 & TRN & \\
\hline CHEMBL1441418 & 688171 & 4.45 & 4.8038 & TRN & \\
\hline CHEMBL1539180 & 688171 & 4.55 & 4.8377 & TRN & \\
\hline CHEMBL1604283 & 688171 & 6.0 & 4.9996 & TST & \\
\hline CHEMBL1572807 & 688171 & 4.55 & 4.7934 & TST & \\
\hline CHEMBL1498884 & 688171 & 4.6 & 4.9276 & TRN & \\
\hline CHEMBL3193207 & 688171 & 4.95 & 4.9371 & TRN & \\
\hline CHEMBL1507504 & 688171 & 5.4 & 4.825 & TRN & \\
\hline CHEMBL1586247 & 688171 & 5.2 & 4.9635 & TRN & \\
\hline CHEMBL1364667 & 688171 & 5.05 & 4.98 & TRN & \\
\hline CHEMBL1594824 & 688171 & 5.05 & 4.7652 & TRN & \\
\hline CHEMBL1507658 & 688171 & 4.95 & 4.9238 & TRN & \\
\hline CHEMBL1566753 & 688171 & 5.35 & 4.9009 & TRN & \\
\hline CHEMBL1327247 & 688171 & 4.75 & 5.0703 & TST & \\
\hline CHEMBL1498627 & 688171 & 7.1002 & 4.887 & TRN & \\
\hline CHEMBL1371162 & 688171 & 4.7 & 4.9283 & TRN & \\
\hline CHEMBL1402285 & 688171 & 4.7 & 4.8202 & TST & \\
\hline CHEMBL1595912 & 688171 & 4.9 & 4.8687 & TRN & \\
\hline
\end{tabular}




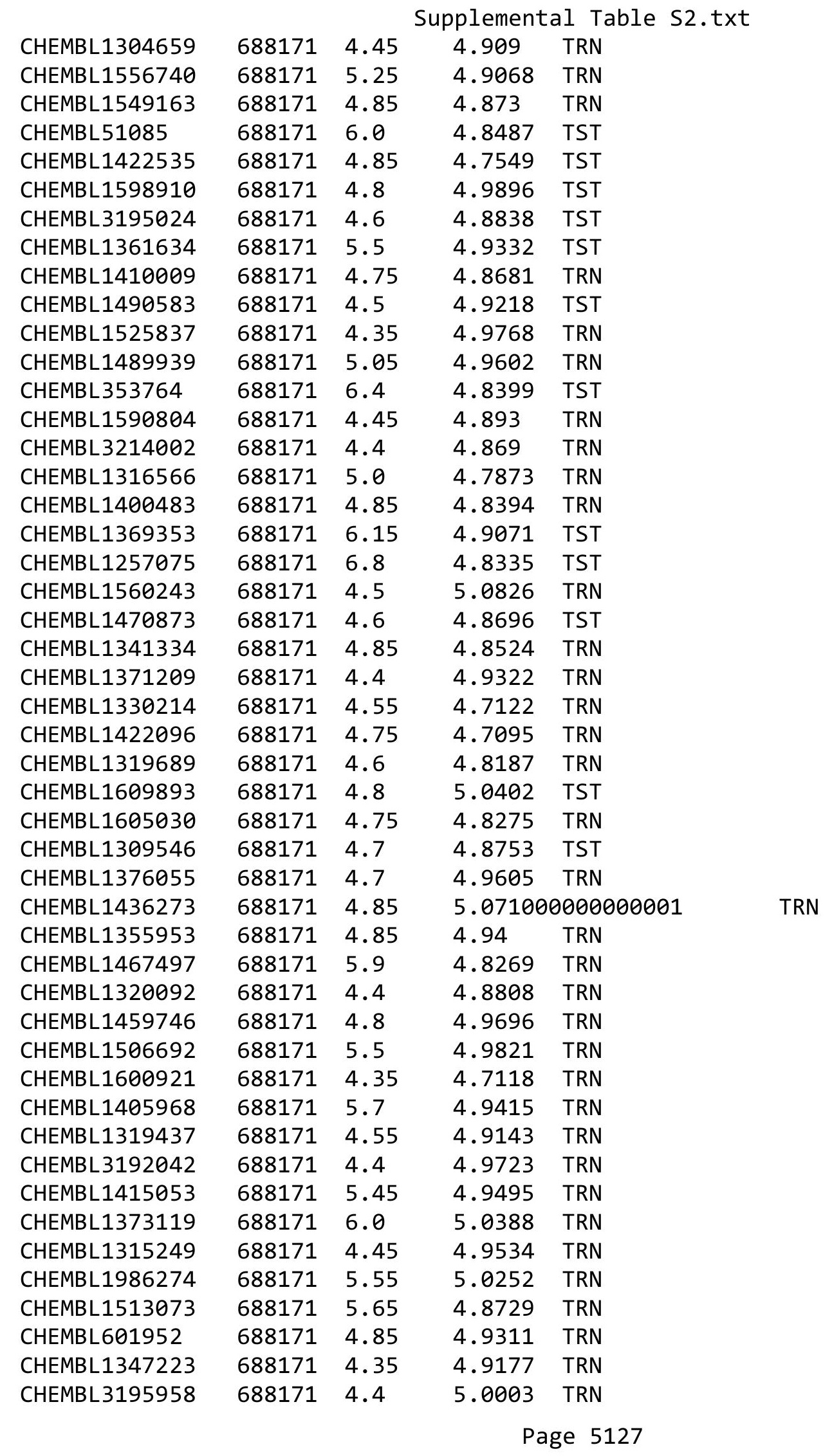




\begin{tabular}{|c|c|c|c|c|c|}
\hline \multicolumn{6}{|c|}{ Supplemental Table S2.txt } \\
\hline CHEMBL1356853 & 688171 & 5.5 & 4.7937 & TRN & \\
\hline CHEMBL1581784 & 688171 & 4.4 & 4.8469 & TRN & \\
\hline CHEMBL1483429 & 688171 & 4.6 & 4.7272 & TRN & \\
\hline CHEMBL1422125 & 688171 & 4.95 & 4.9442 & TRN & \\
\hline CHEMBL1576284 & 688171 & 4.4 & 4.8827 & TST & \\
\hline CHEMBL1444928 & 688171 & 4.35 & 4.8986 & TRN & \\
\hline CHEMBL1461171 & 688171 & 5.15 & 4.9401 & TRN & \\
\hline CHEMBL 3208653 & 688171 & 4.4 & 4.9353 & TRN & \\
\hline CHEMBL1509306 & 688171 & 5.05 & 4.8884 & TRN & \\
\hline CHEMBL1479654 & 688171 & 4.95 & 4.8837 & TRN & \\
\hline CHEMBL1410269 & 688171 & 5.2 & 4.9443 & TRN & \\
\hline CHEMBL1573031 & 688171 & 4.65 & 4.9906 & TRN & \\
\hline CHEMBL164968 & 688171 & 5.05 & 4.9178 & TRN & \\
\hline CHEMBL1379677 & 688171 & 4.7 & 4.8867 & TRN & \\
\hline CHEMBL3207675 & 688171 & 5.75 & 4.9937 & TRN & \\
\hline CHEMBL1425451 & 688171 & 5.15 & 4.9664 & TRN & \\
\hline CHEMBL1973307 & 688171 & 4.9 & 4.8577 & TRN & \\
\hline CHEMBL1472137 & 688171 & 6.7001 & 4.9494 & TST & \\
\hline CHEMBL1529125 & 688171 & 4.85 & 4.8843 & TRN & \\
\hline CHEMBL1476836 & 688171 & 4.5 & 4.9172 & TRN & \\
\hline CHEMBL 235658 & 688171 & 5.4 & 4.8389 & TST & \\
\hline CHEMBL1423747 & 688171 & 5.45 & 4.8726 & TST & \\
\hline CHEMBL1440316 & 688171 & 4.95 & 4.8146 & TRN & \\
\hline CHEMBL1410239 & 688171 & 6.6 & 4.9 & TRN & \\
\hline CHEMBL1445816 & 688171 & 6.9 & 4.9011 & TST & \\
\hline CHEMBL1528814 & 688171 & 4.5 & 4.9531 & TRN & \\
\hline CHEMBL1515356 & 688171 & 4.95 & 4.8845 & TRN & \\
\hline CHEMBL1323573 & 688171 & 5.25 & 4.9831 & TRN & \\
\hline CHEMBL1983229 & 688171 & 4.55 & 4.814 & TRN & \\
\hline CHEMBL3195977 & 688171 & 4.5 & 4.8619 & TRN & \\
\hline CHEMBL1455248 & 688171 & 4.35 & 5.0463 & TST & \\
\hline CHEMBL3208002 & 688171 & 4.5 & 4.9986 & TRN & \\
\hline CHEMBL281211 & 688171 & 4.7 & 4.9709 & TRN & \\
\hline CHEMBL1586871 & 688171 & 4.55 & 4.9783 & TRN & \\
\hline CHEMBL1542752 & 688171 & 4.7 & 4.9801 & TST & \\
\hline CHEMBL1395876 & 688171 & 4.5 & 4.9144 & TRN & \\
\hline CHEMBL1443166 & 688171 & 4.7 & 4.96399 & 99999999995 & TST \\
\hline CHEMBL1325241 & 688171 & 4.55 & 4.9381 & TST & \\
\hline CHEMBL1611725 & 688171 & 4.4 & 4.8744 & TRN & \\
\hline CHEMBL1456094 & 688171 & 4.95 & 4.8042 & TRN & \\
\hline CHEMBL1320466 & 688171 & 4.65 & 4.8733 & TRN & \\
\hline CHEMBL1411565 & 688171 & 4.75 & 4.872 & TRN & \\
\hline CHEMBL1444371 & 688171 & 5.8 & 4.9335 & TRN & \\
\hline CHEMBL1325062 & 688171 & 4.6 & 4.8666 & TST & \\
\hline CHEMBL3197304 & 688171 & 5.85 & 4.9183 & TRN & \\
\hline CHEMBL1555408 & 688171 & 4.4 & 5.05399 & 9999999999 & TRN \\
\hline CHEMBL1455756 & 688171 & 4.8 & 4.8226 & TRN & \\
\hline CHEMBL1365502 & 688171 & 4.75 & 5.0326 & TRN & \\
\hline
\end{tabular}




\begin{tabular}{|c|c|c|c|c|}
\hline \multicolumn{5}{|c|}{ Supplemental Table S2.txt } \\
\hline CHEMBL1344443 & 688171 & 4.4 & 4.9693 & TRN \\
\hline CHEMBL1570716 & 688171 & 6.1 & 5.0089 & TRN \\
\hline CHEMBL1456175 & 688171 & 4.75 & 4.8256 & TRN \\
\hline CHEMBL3193986 & 688171 & 4.4 & 4.9095 & TST \\
\hline CHEMBL 307979 & 688171 & 4.55 & 4.8783 & TST \\
\hline CHEMBL1546343 & 688171 & 4.75 & 4.9007 & TRN \\
\hline CHEMBL1431262 & 688171 & 6.5 & 4.9281 & TRN \\
\hline CHEMBL1475044 & 688171 & 5.05 & 4.8257 & TRN \\
\hline CHEMBL1340268 & 688171 & 7.2503 & 4.7545 & TRN \\
\hline CHEMBL1465634 & 688171 & 4.55 & 4.9031 & TRN \\
\hline CHEMBL1541670 & 688171 & 4.4 & 4.9197 & TRN \\
\hline CHEMBL1423892 & 688171 & 5.55 & 5.0528 & TST \\
\hline CHEMBL3191061 & 688171 & 4.45 & 4.9295 & TST \\
\hline CHEMBL1336861 & 688171 & 6.5 & 4.9118 & TRN \\
\hline CHEMBL1603493 & 688171 & 4.8 & 4.8456 & TST \\
\hline CHEMBL1387246 & 688171 & 5.15 & 4.721 & TST \\
\hline CHEMBL1485332 & 688171 & 4.5 & 4.9209 & TRN \\
\hline CHEMBL1576383 & 688171 & 4.4 & 5.0074 & TRN \\
\hline CHEMBL1317090 & 688171 & 4.85 & 4.9325 & TRN \\
\hline CHEMBL1553658 & 688171 & 4.4 & 5.0287 & TRN \\
\hline CHEMBL1542651 & 688171 & 4.45 & 4.8959 & TRN \\
\hline CHEMBL1387956 & 688171 & 5.3 & 5.0606 & TRN \\
\hline CHEMBL1463132 & 688171 & 4.55 & 4.7929 & TRN \\
\hline CHEMBL1426812 & 688171 & 4.9 & 4.8619 & TST \\
\hline CHEMBL1338990 & 688171 & 4.55 & 4.9125 & TST \\
\hline CHEMBL1536131 & 688171 & 6.5501 & 4.9092 & TST \\
\hline CHEMBL1542513 & 688171 & 5.0 & 4.8525 & TRN \\
\hline CHEMBL1393570 & 688171 & 6.0 & 4.9692 & TST \\
\hline CHEMBL1417139 & 688171 & 4.4 & 5.0234 & TRN \\
\hline CHEMBL1527120 & 688171 & 4.4 & 4.8486 & TRN \\
\hline CHEMBL 2369228 & 688171 & 4.55 & 4.9296 & TST \\
\hline CHEMBL1588034 & 688171 & 4.65 & 4.8571 & TRN \\
\hline CHEMBL1572823 & 688171 & 4.45 & 5.0289 & TRN \\
\hline CHEMBL1326050 & 688171 & 4.35 & 5.0124 & TST \\
\hline CHEMBL1448201 & 688171 & 4.8 & 4.8364 & TRN \\
\hline CHEMBL1431968 & 688171 & 6.3 & 4.9307 & TRN \\
\hline CHEMBL1310717 & 688171 & 5.05 & 4.8821 & TRN \\
\hline CHEMBL1304922 & 688171 & 6.5501 & 4.8982 & TRN \\
\hline CHEMBL1525530 & 688171 & 4.4 & 4.8887 & TRN \\
\hline CHEMBL1529281 & 688171 & 4.65 & 4.8529 & TRN \\
\hline CHEMBL1574649 & 688171 & 4.85 & 4.7779 & TRN \\
\hline CHEMBL3199380 & 688171 & 4.85 & 4.8501 & TST \\
\hline CHEMBL1590379 & 688171 & 4.85 & 4.8193 & TRN \\
\hline CHEMBL3195975 & 688171 & 4.65 & 4.8716 & TRN \\
\hline CHEMBL1320179 & 688171 & 5.6 & 4.9202 & TRN \\
\hline CHEMBL1302113 & 688171 & 4.75 & 4.8449 & TRN \\
\hline CHEMBL1416439 & 688171 & 4.8 & 4.7518 & TRN \\
\hline CHEMBL1503900 & 688171 & 5.05 & 4.8363 & TRN \\
\hline
\end{tabular}




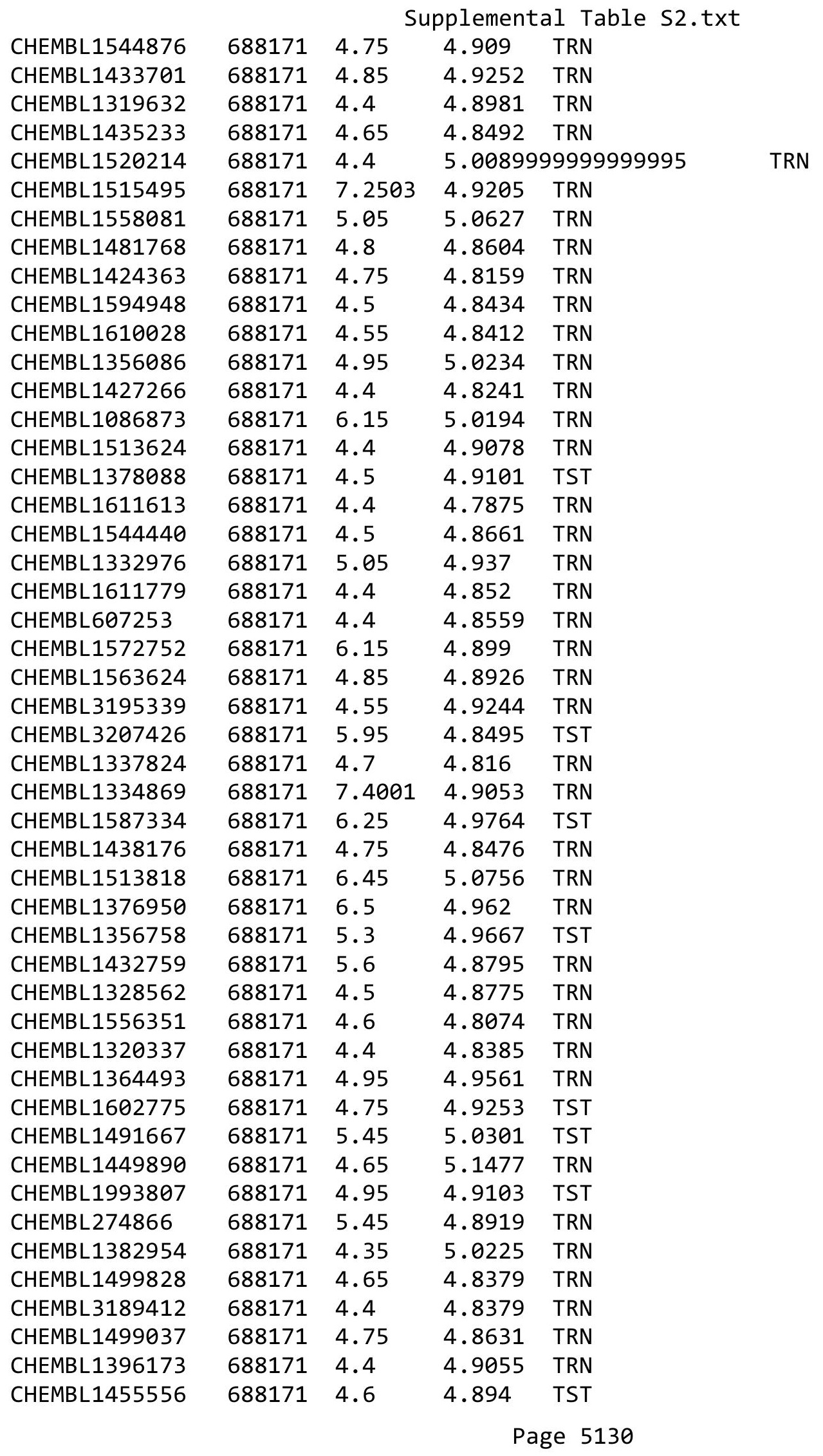




\begin{tabular}{|c|c|c|c|c|c|}
\hline \multicolumn{6}{|c|}{ Supplemental Table s2.txt } \\
\hline CHEMBL1603200 & 688171 & 4.55 & 4.9416 & TRN & \\
\hline CHEMBL1393481 & 688171 & 4.75 & 4.9023 & TRN & \\
\hline CHEMBL1517255 & 688171 & 4.75 & 4.873 & TRN & \\
\hline CHEMBL1562454 & 688171 & 5.3 & 4.7039 & TST & \\
\hline CHEMBL1548475 & 688171 & 5.05 & 4.9276 & TRN & \\
\hline CHEMBL1521056 & 688171 & 5.1 & 5.0775 & TRN & \\
\hline CHEMBL1530144 & 688171 & 4.8 & 4.9676 & TRN & \\
\hline CHEMBL1497342 & 688171 & 4.5 & 4.9767 & TRN & \\
\hline CHEMBL1532930 & 688171 & 4.45 & 5.0445 & TRN & \\
\hline CHEMBL518292 & 688171 & 5.05 & 4.9437 & TST & \\
\hline CHEMBL1440654 & 688171 & 7.1002 & 4.8662 & TRN & \\
\hline CHEMBL3192957 & 688171 & 6.0 & 4.963 & TRN & \\
\hline CHEMBL1430658 & 688171 & 4.8 & 4.7469 & TRN & \\
\hline CHEMBL202721 & 688171 & 7.6003 & 5.0469 & TST & \\
\hline CHEMBL1484743 & 688171 & 6.05 & 4.92399 & 99999999995 & TRN \\
\hline CHEMBL1593100 & 688171 & 5.0 & 4.8513 & TRN & \\
\hline CHEMBL1552084 & 688171 & 4.25 & 4.7855 & TRN & \\
\hline CHEMBL1380058 & 688171 & 4.85 & 5.0097 & TRN & \\
\hline CHEMBL546344 & 688171 & 4.4 & 4.8299 & TRN & \\
\hline CHEMBL1561737 & 688171 & 4.95 & 4.7986 & TST & \\
\hline CHEMBL1361972 & 688171 & 4.45 & 4.8348 & TRN & \\
\hline CHEMBL1605450 & 688171 & 4.7 & 4.772 & TST & \\
\hline CHEMBL1357996 & 688171 & 4.55 & 4.8602 & TRN & \\
\hline CHEMBL1518031 & 688171 & 5.05 & 4.7932 & TST & \\
\hline CHEMBL1496732 & 688171 & 5.15 & 4.939 & TRN & \\
\hline CHEMBL1507872 & 688171 & 5.1 & 4.8081 & TST & \\
\hline CHEMBL1367485 & 688171 & 6.35 & 4.9352 & TST & \\
\hline CHEMBL1603567 & 688171 & 4.75 & 4.9292 & TRN & \\
\hline CHEMBL1582898 & 688171 & 4.55 & 4.8653 & TRN & \\
\hline CHEMBL1568795 & 688171 & 4.4 & 4.9756 & TRN & \\
\hline CHEMBL1403867 & 688171 & 4.35 & 4.8122 & TST & \\
\hline CHEMBL1454204 & 688171 & 5.3 & 5.0378 & TRN & \\
\hline CHEMBL592106 & 688171 & 5.0 & 4.7687 & TRN & \\
\hline CHEMBL1565925 & 688171 & 4.7 & 4.9611 & TRN & \\
\hline CHEMBL1371581 & 688171 & 5.2 & 5.0692 & TRN & \\
\hline CHEMBL1444934 & 688171 & 4.4 & 4.9401 & TST & \\
\hline CHEMBL1415652 & 688171 & 5.0 & 4.9008 & TRN & \\
\hline CHEMBL1387133 & 688171 & 7.6003 & 4.8733 & TST & \\
\hline CHEMBL1977709 & 688171 & 4.5 & 4.8875 & TRN & \\
\hline CHEMBL1323399 & 688171 & 4.55 & 4.6809 & TRN & \\
\hline CHEMBL549216 & 688171 & 4.55 & 4.9407 & TRN & \\
\hline CHEMBL1329090 & 688171 & 5.4 & 5.0044 & TRN & \\
\hline CHEMBL1318733 & 688171 & 4.4 & 4.8346 & TRN & \\
\hline CHEMBL1437701 & 688171 & 5.85 & 4.8845 & TST & \\
\hline CHEMBL1516531 & 688171 & 4.55 & 4.7993 & TRN & \\
\hline CHEMBL1480098 & 688171 & 4.65 & 4.9156 & TRN & \\
\hline CHEMBL1591740 & 688171 & 4.8 & 4.7558 & TRN & \\
\hline CHEMBL1478686 & 688171 & 5.45 & 4.8958 & TRN & \\
\hline
\end{tabular}




\begin{tabular}{|c|c|c|c|c|c|}
\hline & & \multicolumn{4}{|c|}{ Supplemental Table S2.txt } \\
\hline CHEMBL1388157 & 688171 & 4.85 & 4.9168 & TRN & \\
\hline CHEMBL1300266 & 688171 & 4.45 & 4.8882 & TRN & \\
\hline CHEMBL1495358 & 688171 & 5.45 & 4.8322 & TRN & \\
\hline CHEMBL29197 & 688171 & 4.95 & 4.883 & TRN & \\
\hline CHEMBL3199120 & 688171 & 5.9 & 4.8853 & TRN & \\
\hline CHEMBL1582071 & 688171 & 4.8 & 4.8085 & TST & \\
\hline CHEMBL1395302 & 688171 & 5.05 & 4.8501 & TRN & \\
\hline CHEMBL1504370 & 688171 & 4.45 & 4.7394 & TRN & \\
\hline CHEMBL1572332 & 688171 & 4.55 & 4.8818 & TRN & \\
\hline CHEMBL1405257 & 688171 & 4.4 & 4.9272 & TRN & \\
\hline CHEMBL1576916 & 688171 & 4.8 & 4.8674 & TRN & \\
\hline CHEMBL1455507 & 688171 & 4.55 & 4.7916 & TRN & \\
\hline CHEMBL1432492 & 688171 & 5.55 & 5.025 & TRN & \\
\hline CHEMBL1417215 & 688171 & 4.95 & 5.0155 & TRN & \\
\hline CHEMBL1581362 & 688171 & 4.6 & 4.8826 & TRN & \\
\hline CHEMBL1407056 & 688171 & 4.55 & 4.9704 & TRN & \\
\hline CHEMBL1574918 & 688171 & 4.4 & 4.9831 & TST & \\
\hline CHEMBL1445215 & 688171 & 5.05 & 5.0505 & TRN & \\
\hline CHEMBL1569543 & 688171 & 5.1 & 4.8378 & TST & \\
\hline CHEMBL1515159 & 688171 & 4.8 & 4.961 & TRN & \\
\hline CHEMBL1438953 & 688171 & 4.55 & 5.0856 & TRN & \\
\hline CHEMBL1561190 & 688171 & 4.45 & 4.8632 & TRN & \\
\hline CHEMBL1450437 & 688171 & 4.5 & 4.873 & TRN & \\
\hline CHEMBL1583036 & 688171 & 5.35 & 5.01699 & 99999999995 & TST \\
\hline CHEMBL1464237 & 688171 & 4.35 & 4.7725 & TRN & \\
\hline CHEMBL1317561 & 688171 & 4.35 & 4.9121 & TST & \\
\hline CHEMBL1346932 & 688171 & 4.55 & 4.8918 & TST & \\
\hline CHEMBL1393450 & 688171 & 4.7 & 4.8703 & TST & \\
\hline CHEMBL1490021 & 688171 & 5.0 & 4.9075 & TRN & \\
\hline CHEMBL1374108 & 688171 & 4.9 & 5.0074 & TRN & \\
\hline CHEMBL1575221 & 688171 & 4.4 & 4.8086 & TRN & \\
\hline CHEMBL1411955 & 688171 & 4.6 & 4.9949 & TRN & \\
\hline CHEMBL1394293 & 688171 & 6.35 & 4.8492 & TST & \\
\hline CHEMBL1556733 & 688171 & 4.6 & 5.0438 & TST & \\
\hline CHEMBL1495647 & 688171 & 5.05 & 4.8657 & TRN & \\
\hline CHEMBL1338822 & 688171 & 5.35 & 4.8923 & TRN & \\
\hline CHEMBL3212293 & 688171 & 6.6 & 4.8626 & TRN & \\
\hline CHEMBL1459449 & 688171 & 4.85 & 4.9625 & TST & \\
\hline CHEMBL1558253 & 688171 & 4.6 & 4.9714 & TRN & \\
\hline CHEMBL1557273 & 688171 & 5.05 & 4.9468 & TST & \\
\hline CHEMBL1611912 & 688171 & 4.75 & 4.9459 & TRN & \\
\hline CHEMBL1424537 & 688171 & 5.5 & 4.9198 & TST & \\
\hline CHEMBL1435263 & 688171 & 4.35 & 4.9773 & TRN & \\
\hline CHEMBL1529288 & 688171 & 4.8 & 4.882 & TRN & \\
\hline CHEMBL3211651 & 688171 & 4.4 & 4.88399 & 99999999995 & TRN \\
\hline CHEMBL1424392 & 688171 & 4.6 & 4.7522 & TRN & \\
\hline CHEMBL1540929 & 688171 & 4.8 & 4.9721 & TRN & \\
\hline CHEMBL1402841 & 688171 & 4.65 & 4.7063 & TRN & \\
\hline
\end{tabular}




\begin{tabular}{|c|c|c|c|c|}
\hline \multicolumn{5}{|c|}{ Supplemental Table S2.txt } \\
\hline CHEMBL1080548 & 688171 & 4.95 & 4.888 & TRN \\
\hline CHEMBL1558020 & 688171 & 4.45 & 4.8437 & TRN \\
\hline CHEMBL3145143 & 688171 & 5.35 & 4.8317 & TST \\
\hline CHEMBL1379102 & 688171 & 4.95 & 5.0224 & TST \\
\hline CHEMBL1504286 & 688171 & 4.7 & 4.8572 & TRN \\
\hline CHEMBL1323516 & 688171 & 4.55 & 4.7028 & TRN \\
\hline CHEMBL1318345 & 688171 & 5.35 & 5.1077 & TRN \\
\hline CHEMBL1363563 & 688171 & 4.6 & 4.8623 & TRN \\
\hline CHEMBL1480812 & 688171 & 4.4 & 4.7456 & TRN \\
\hline CHEMBL1357025 & 688171 & 4.85 & 4.7683 & TRN \\
\hline CHEMBL1566076 & 688171 & 5.2 & 4.9079 & TRN \\
\hline CHEMBL1442176 & 688171 & 5.55 & 4.8501 & TRN \\
\hline CHEMBL1561438 & 688171 & 4.9 & 4.8654 & TRN \\
\hline CHEMBL1455253 & 688171 & 5.15 & 4.9717 & TST \\
\hline CHEMBL3213190 & 688171 & 5.15 & 4.9407 & TST \\
\hline CHEMBL1362572 & 688171 & 4.5 & 5.0065 & TRN \\
\hline CHEMBL1601587 & 688171 & 4.7 & 4.8853 & TRN \\
\hline CHEMBL1611476 & 688171 & 4.6 & 4.938 & TRN \\
\hline CHEMBL1434644 & 688171 & 4.35 & 4.9855 & TST \\
\hline CHEMBL1444212 & 688171 & 4.35 & 4.828 & TRN \\
\hline CHEMBL1319087 & 688171 & 5.05 & 4.9087 & TRN \\
\hline CHEMBL1448811 & 688171 & 4.4 & 4.802 & TRN \\
\hline CHEMBL 2003942 & 688171 & 4.5 & 4.8481 & TRN \\
\hline CHEMBL 1446570 & 688171 & 4.55 & 4.7782 & TRN \\
\hline CHEMBL589444 & 688171 & 5.05 & 4.8827 & TRN \\
\hline CHEMBL1347611 & 688171 & 4.5 & 4.8894 & TRN \\
\hline CHEMBL1579409 & 688171 & 4.55 & 4.9566 & TRN \\
\hline CHEMBL1348036 & 688171 & 4.6 & 4.8825 & TRN \\
\hline CHEMBL1482818 & 688171 & 4.55 & 4.8423 & TST \\
\hline CHEMBL1434908 & 688171 & 5.05 & 4.8625 & TRN \\
\hline CHEMBL1455885 & 688171 & 4.8 & 4.9792 & TRN \\
\hline CHEMBL1533288 & 688171 & 6.0 & 4.9169 & TRN \\
\hline CHEMBL1313901 & 688171 & 4.35 & 4.8552 & TRN \\
\hline CHEMBL1599161 & 688171 & 5.45 & 4.9002 & TST \\
\hline CHEMBL1460701 & 688171 & 4.4 & 4.8689 & TRN \\
\hline CHEMBL1343406 & 688171 & 5.0 & 4.7882 & TRN \\
\hline CHEMBL1352431 & 688171 & 5.15 & 4.7936 & TST \\
\hline CHEMBL3199393 & 688171 & 5.05 & 5.0196 & TRN \\
\hline CHEMBL1333741 & 688171 & 4.55 & 4.8048 & TST \\
\hline CHEMBL1497012 & 688171 & 4.6 & 4.8691 & TRN \\
\hline CHEMBL527307 & 688171 & 4.85 & 4.838 & TST \\
\hline CHEMBL1590025 & 688171 & 4.75 & 5.0185 & TRN \\
\hline CHEMBL1380907 & 688171 & 4.95 & 4.8573 & TRN \\
\hline CHEMBL1320577 & 688171 & 6.6499 & 4.9774 & TRN \\
\hline CHEMBL1458451 & 688171 & 4.95 & 4.7212 & TRN \\
\hline CHEMBL1465681 & 688171 & 5.6 & 4.7603 & TST \\
\hline CHEMBL1316662 & 688171 & 4.85 & 4.9246 & TRN \\
\hline CHEMBL1327573 & 688171 & 4.4 & 4.8568 & TRN \\
\hline
\end{tabular}




\begin{tabular}{|c|c|c|c|c|c|}
\hline \multicolumn{6}{|c|}{ Supplemental Table S2.txt } \\
\hline CHEMBL1458811 & 688171 & 5.0 & 4.9787 & TST & \\
\hline CHEMBL1602518 & 688171 & 4.9 & 4.8251 & TRN & \\
\hline CHEMBL1479113 & 688171 & 4.65 & 5.0883 & TRN & \\
\hline CHEMBL1350766 & 688171 & 4.75 & 5.0055 & TRN & \\
\hline CHEMBL1517769 & 688171 & 4.55 & 4.9372 & TRN & \\
\hline CHEMBL1585921 & 688171 & 4.3 & 4.9363 & TRN & \\
\hline CHEMBL1561150 & 688171 & 4.7 & 4.8356 & TRN & \\
\hline CHEMBL1316405 & 688171 & 4.5 & 4.9273 & TRN & \\
\hline CHEMBL1536202 & 688171 & 4.4 & 5.104 & TRN & \\
\hline CHEMBL1419684 & 688171 & 4.35 & 4.8896 & TRN & \\
\hline CHEMBL1362861 & 688171 & 6.5501 & 4.9994 & TRN & \\
\hline CHEMBL1551102 & 688171 & 4.35 & 5.0502 & TRN & \\
\hline CHEMBL1447982 & 688171 & 4.4 & 4.9537 & TRN & \\
\hline CHEMBL1500637 & 688171 & 4.85 & 4.8575 & TRN & \\
\hline CHEMBL1525841 & 688171 & 6.05 & 4.8169 & TRN & \\
\hline CHEMBL1375116 & 688171 & 4.8 & 4.9603 & TRN & \\
\hline CHEMBL1512167 & 688171 & 4.5 & 4.9868 & TRN & \\
\hline CHEMBL1322177 & 688171 & 4.6 & 4.8114 & TRN & \\
\hline CHEMBL1493191 & 688171 & 4.75 & 4.7809 & TRN & \\
\hline CHEMBL1378396 & 688171 & 4.65 & 5.082 & TRN & \\
\hline CHEMBL1424045 & 688171 & 4.75 & 4.9537 & TRN & \\
\hline CHEMBL1369299 & 688171 & 4.8 & 4.9936 & TRN & \\
\hline CHEMBL1336704 & 688171 & 5.05 & 4.8047 & TRN & \\
\hline CHEMBL1487320 & 688171 & 6.1 & 4.9748 & TST & \\
\hline CHEMBL1472394 & 688171 & 4.55 & 4.8242 & TRN & \\
\hline CHEMBL1602317 & 688171 & 4.4 & 4.8547 & TRN & \\
\hline CHEMBL3189930 & 688171 & 5.4 & 4.8799 & TRN & \\
\hline CHEMBL1469709 & 688171 & 4.6 & 4.996 & TRN & \\
\hline CHEMBL1452678 & 688171 & 4.4 & 5.0297 & TST & \\
\hline CHEMBL1552003 & 688171 & 4.4 & 4.8509 & TRN & \\
\hline CHEMBL1551038 & 688171 & 4.8 & 5.0302 & TRN & \\
\hline CHEMBL1465890 & 688171 & 4.9 & 5.0035 & TST & \\
\hline CHEMBL1599936 & 688171 & 4.55 & 5.0338 & TST & \\
\hline CHEMBL1495121 & 688171 & 5.1 & 4.8094 & TST & \\
\hline CHEMBL1339327 & 688171 & 4.7 & 4.91 & TRN & \\
\hline CHEMBL3192410 & 688171 & 5.05 & 4.83 & TRN & \\
\hline CHEMBL1354703 & 688171 & 5.4 & 5.029 & TST & \\
\hline CHEMBL1555450 & 688171 & 4.85 & 4.918 & TRN & \\
\hline CHEMBL1443062 & 688171 & 4.95 & 4.8858 & TRN & \\
\hline CHEMBL1397963 & 688171 & 4.75 & 4.8266 & TRN & \\
\hline CHEMBL1309620 & 688171 & 5.05 & 4.8905 & TRN & \\
\hline CHEMBL1435253 & 688171 & 4.7 & 4.842 & TRN & \\
\hline CHEMBL1980681 & 688171 & 4.95 & 4.9071 & TRN & \\
\hline CHEMBL 600230 & 688171 & 5.5 & 4.9066 & TST & \\
\hline CHEMBL1603803 & 688171 & 6.0 & 4.98600 & 0000000001 & TRN \\
\hline CHEMBL1536192 & 688171 & 5.5 & 5.1056 & TST & \\
\hline CHEMBL1542693 & 688171 & 4.9 & 4.9226 & TST & \\
\hline CHEMBL1320026 & 688171 & 4.4 & 4.9721 & TST & \\
\hline
\end{tabular}




\begin{tabular}{|c|c|c|c|c|c|}
\hline \multicolumn{6}{|c|}{ Supplemental Table S2.txt } \\
\hline CHEMBL1418410 & 688171 & 4.4 & 4.9188 & TRN & \\
\hline CHEMBL1344979 & 688171 & 5.5 & 5.0426 & TRN & \\
\hline CHEMBL1345594 & 688171 & 5.05 & 4.7476 & TRN & \\
\hline CHEMBL 3213235 & 688171 & 4.65 & 4.9039 & TST & \\
\hline CHEMBL1416262 & 688171 & 4.5 & 4.8953 & TRN & \\
\hline CHEMBL1542903 & 688171 & 5.35 & 4.9527 & TST & \\
\hline CHEMBL601618 & 688171 & 4.4 & 4.8469 & TST & \\
\hline CHEMBL1315142 & 688171 & 4.35 & 4.9319 & TRN & \\
\hline CHEMBL1529115 & 688171 & 4.55 & 4.8169 & TST & \\
\hline CHEMBL1551547 & 688171 & 4.85 & 4.8934 & TRN & \\
\hline CHEMBL1365437 & 688171 & 4.35 & 4.9281 & TRN & \\
\hline CHEMBL1356987 & 688171 & 6.7001 & 5.0181 & TRN & \\
\hline CHEMBL1424158 & 688171 & 4.85 & 4.9101 & TRN & \\
\hline CHEMBL1355647 & 688171 & 4.5 & 4.8734 & TRN & \\
\hline CHEMBL1402421 & 688171 & 4.5 & 4.8557 & TRN & \\
\hline CHEMBL1429228 & 688171 & 4.5 & 4.8855 & TRN & \\
\hline CHEMBL1445431 & 688171 & 4.75 & 4.7372 & TRN & \\
\hline CHEMBL1322794 & 688171 & 4.35 & 4.9075 & TRN & \\
\hline CHEMBL1325723 & 688171 & 4.55 & 4.865 & TST & \\
\hline CHEMBL1439675 & 688171 & 4.6 & 4.9828 & TRN & \\
\hline CHEMBL1453519 & 688171 & 4.55 & 4.9585 & TRN & \\
\hline CHEMBL1336285 & 688171 & 4.8 & 5.0469 & TRN & \\
\hline CHEMBL1509433 & 688171 & 5.05 & 4.917 & TST & \\
\hline CHEMBL1555387 & 688171 & 6.8 & 4.98300 & 00000000005 & TRN \\
\hline CHEMBL1573688 & 688171 & 5.25 & 4.8602 & TRN & \\
\hline CHEMBL1437262 & 688171 & 4.65 & 4.8033 & TST & \\
\hline CHEMBL1525235 & 688171 & 5.2 & 5.0154 & TRN & \\
\hline CHEMBL1554520 & 688171 & 5.45 & 5.0033 & TRN & \\
\hline CHEMBL1572771 & 688171 & 5.65 & 4.7522 & TRN & \\
\hline CHEMBL1556085 & 688171 & 4.5 & 4.9307 & TRN & \\
\hline CHEMBL1566041 & 688171 & 4.5 & 4.8745 & TST & \\
\hline CHEMBL3208276 & 688171 & 6.3 & 5.0515 & TST & \\
\hline CHEMBL1447784 & 688171 & 4.7 & 4.9208 & TRN & \\
\hline CHEMBL1479679 & 688171 & 5.6 & 4.8946 & TRN & \\
\hline CHEMBL523844 & 688171 & 4.4 & 4.7686 & TRN & \\
\hline CHEMBL1369390 & 688171 & 6.0 & 4.8757 & TST & \\
\hline CHEMBL1543386 & 688171 & 5.45 & 4.841 & TRN & \\
\hline CHEMBL1456896 & 688171 & 4.45 & 4.8613 & TRN & \\
\hline CHEMBL3207754 & 688171 & 4.4 & 4.8501 & TRN & \\
\hline CHEMBL1337616 & 688171 & 4.7 & 4.9758 & TRN & \\
\hline CHEMBL1367394 & 688171 & 5.0 & 4.8628 & TRN & \\
\hline CHEMBL1503460 & 688171 & 4.95 & 4.7012 & TRN & \\
\hline CHEMBL1375953 & 688171 & 4.4 & 5.0017 & TST & \\
\hline CHEMBL1496632 & 688171 & 4.65 & 4.8103 & TRN & \\
\hline CHEMBL1518310 & 688171 & 4.6 & 4.8363 & TST & \\
\hline CHEMBL1362809 & 688171 & 4.5 & 4.9026 & TRN & \\
\hline CHEMBL1474009 & 688171 & 4.6 & 4.9856 & TRN & \\
\hline CHEMBL1416804 & 688171 & 4.65 & 5.0659 & TRN & \\
\hline
\end{tabular}




\begin{tabular}{|c|c|c|c|c|}
\hline \multicolumn{5}{|c|}{ Supplemental Table S2.txt } \\
\hline CHEMBL1458995 & 688171 & 4.65 & 4.9203 & TRN \\
\hline CHEMBL1329382 & 688171 & 4.5 & 4.9748 & TRN \\
\hline CHEMBL1339023 & 688171 & 5.5 & 4.8132 & TRN \\
\hline CHEMBL1538025 & 688171 & 5.0 & 4.9956 & TST \\
\hline CHEMBL3198187 & 688171 & 4.35 & 4.9202 & TST \\
\hline CHEMBL1392535 & 688171 & 4.4 & 4.7267 & TRN \\
\hline CHEMBL1386444 & 688171 & 4.55 & 4.7647 & TST \\
\hline CHEMBL1575331 & 688171 & 4.4 & 4.8412 & TRN \\
\hline CHEMBL1409532 & 688171 & 4.6 & 4.8654 & TRN \\
\hline CHEMBL3196052 & 688171 & 4.8 & 4.8338 & TRN \\
\hline CHEMBL1545563 & 688171 & 4.55 & 4.8458 & TRN \\
\hline CHEMBL1564532 & 688171 & 4.4 & 4.9924 & TRN \\
\hline CHEMBL1480021 & 688171 & 4.35 & 4.8469 & TRN \\
\hline CHEMBL1965172 & 688171 & 5.45 & 4.8794 & TRN \\
\hline CHEMBL1474399 & 688171 & 4.35 & 4.7548 & TRN \\
\hline CHEMBL1373597 & 688171 & 4.55 & 4.7311 & TRN \\
\hline CHEMBL1422348 & 688171 & 5.6 & 4.8694 & TRN \\
\hline CHEMBL1546937 & 688171 & 4.45 & 4.9189 & TRN \\
\hline CHEMBL1428995 & 688171 & 4.85 & 4.7694 & TRN \\
\hline CHEMBL1409586 & 688171 & 4.8 & 4.8176 & TRN \\
\hline CHEMBL1309987 & 688171 & 4.65 & 4.8539 & TST \\
\hline CHEMBL1540990 & 688171 & 6.1 & 4.9567 & TRN \\
\hline CHEMBL1527190 & 688171 & 4.4 & 4.8413 & TST \\
\hline CHEMBL1475046 & 688171 & 4.75 & 5.0041 & TST \\
\hline CHEMBL1537535 & 688171 & 4.7 & 4.8965 & TRN \\
\hline CHEMBL1305066 & 688171 & 4.5 & 4.8456 & TRN \\
\hline CHEMBL1346628 & 688171 & 4.4 & 4.8836 & TRN \\
\hline CHEMBL1492922 & 688171 & 5.05 & 4.9079 & TST \\
\hline CHEMBL1399595 & 688171 & 5.0 & 4.9519 & TST \\
\hline CHEMBL1609046 & 688171 & 4.7 & 4.783 & TRN \\
\hline CHEMBL1407165 & 688171 & 4.7 & 4.8205 & TST \\
\hline CHEMBL1546992 & 688171 & 4.65 & 4.8856 & TRN \\
\hline CHEMBL1433635 & 688171 & 6.45 & 4.8612 & TRN \\
\hline CHEMBL1528774 & 688171 & 4.6 & 4.9147 & TRN \\
\hline CHEMBL1386913 & 688171 & 6.0 & 4.9527 & TRN \\
\hline CHEMBL1483112 & 688171 & 5.45 & 4.8815 & TST \\
\hline CHEMBL1331978 & 688171 & 4.5 & 4.8745 & TRN \\
\hline CHEMBL1593611 & 688171 & 5.2 & 4.8763 & TRN \\
\hline CHEMBL585654 & 688171 & 5.55 & 4.8804 & TRN \\
\hline CHEMBL1520708 & 688171 & 4.4 & 5.0112 & TRN \\
\hline CHEMBL1339069 & 688171 & 4.4 & 5.0535 & TRN \\
\hline CHEMBL1383094 & 688171 & 5.4 & 4.8884 & TRN \\
\hline CHEMBL1600397 & 688171 & 4.65 & 4.8629 & TRN \\
\hline CHEMBL1565923 & 688171 & 4.9 & 4.9841 & TRN \\
\hline CHEMBL1609067 & 688171 & 4.35 & 4.9385 & TRN \\
\hline CHEMBL1414452 & 688171 & 6.0 & 4.9197 & TRN \\
\hline CHEMBL1565717 & 688171 & 5.0 & 4.8185 & TRN \\
\hline CHEMBL1568841 & 688171 & 6.05 & 4.939 & TRN \\
\hline
\end{tabular}




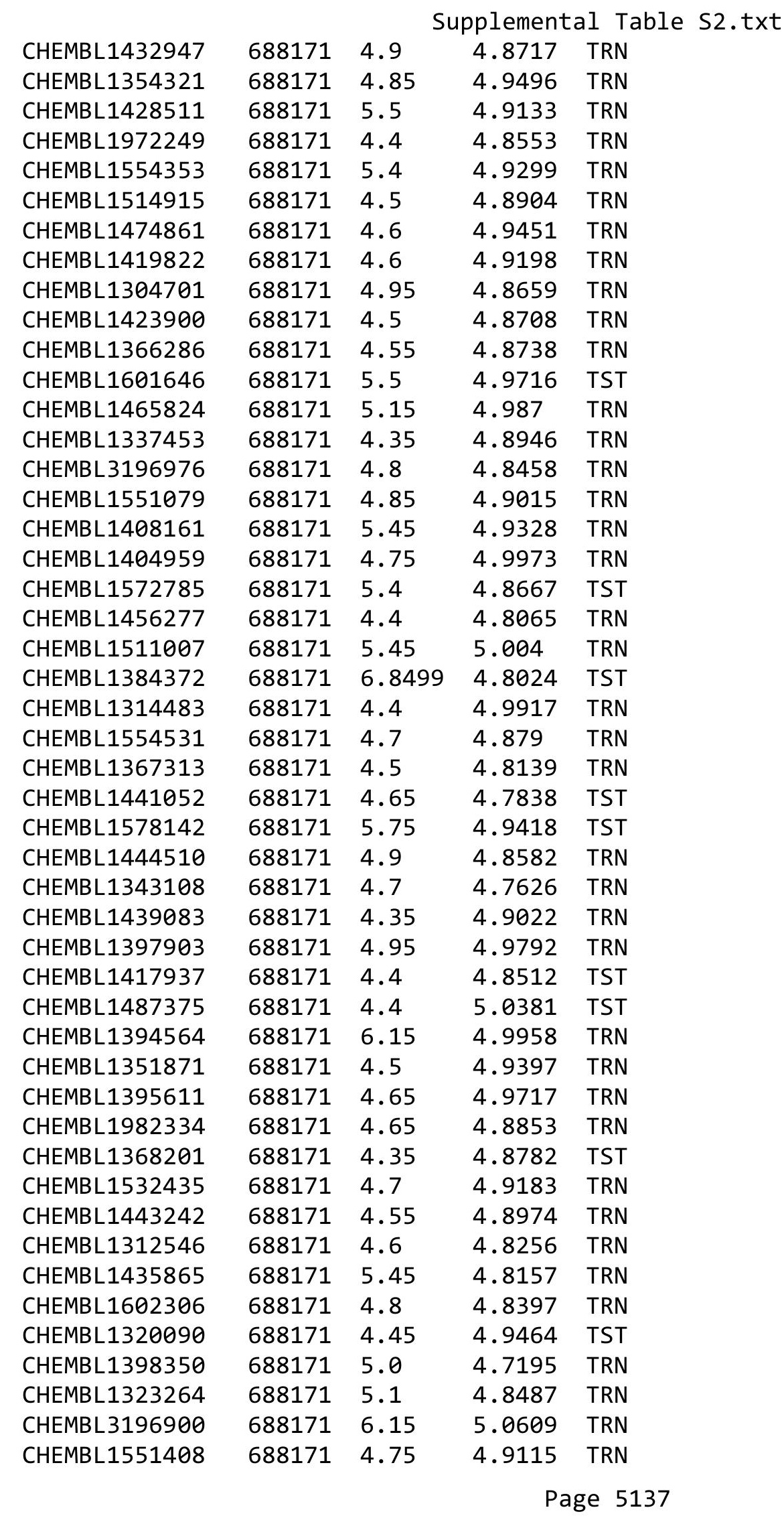




\begin{tabular}{|c|c|c|c|c|c|}
\hline & & \multicolumn{4}{|c|}{ Supplemental Table s2.txt } \\
\hline CHEMBL1599662 & 688171 & 5.4 & 4.8775 & TRN & \\
\hline CHEMBL1611025 & 688171 & 4.45 & 4.92899 & 9999999999 & TST \\
\hline CHEMBL1520798 & 688171 & 5.05 & 4.9344 & TRN & \\
\hline CHEMBL3214469 & 688171 & 4.6 & 5.0429 & TRN & \\
\hline CHEMBL3196552 & 688171 & 4.85 & 5.0145 & TRN & \\
\hline CHEMBL414890 & 688171 & 4.95 & 4.9197 & TRN & \\
\hline CHEMBL1976046 & 688171 & 4.4 & 4.8388 & TST & \\
\hline CHEMBL3194876 & 688171 & 5.7 & 4.88 & TRN & \\
\hline CHEMBL1552421 & 688171 & 5.0 & 4.8082 & TRN & \\
\hline CHEMBL3197008 & 688171 & 4.45 & 4.9378 & TRN & \\
\hline CHEMBL1474094 & 688171 & 5.8 & 4.883 & TRN & \\
\hline CHEMBL1410970 & 688171 & 5.3 & 4.9583 & TRN & \\
\hline CHEMBL1366860 & 688171 & 4.8 & 4.9209 & TRN & \\
\hline CHEMBL1310702 & 688171 & 4.4 & 4.8401 & TRN & \\
\hline CHEMBL1468143 & 688171 & 4.95 & 5.0189 & TRN & \\
\hline CHEMBL1301283 & 688171 & 4.4 & 4.945 & TRN & \\
\hline CHEMBL1448406 & 688171 & 4.55 & 4.8204 & TRN & \\
\hline CHEMBL1348219 & 688171 & 4.65 & 4.8926 & TRN & \\
\hline CHEMBL1444034 & 688171 & 5.05 & 5.0135 & TRN & \\
\hline CHEMBL1509267 & 688171 & 4.75 & 4.87 & TRN & \\
\hline CHEMBL1374970 & 688171 & 4.6 & 4.7926 & TRN & \\
\hline CHEMBL1581930 & 688171 & 4.4 & 4.8968 & TST & \\
\hline CHEMBL1402249 & 688171 & 4.4 & 4.872 & TST & \\
\hline CHEMBL1311574 & 688171 & 5.8 & 4.8696 & TRN & \\
\hline CHEMBL3192031 & 688171 & 5.8 & 4.9263 & TRN & \\
\hline CHEMBL1380396 & 688171 & 4.6 & 4.9308 & TRN & \\
\hline CHEMBL3190146 & 688171 & 4.8 & 4.9834 & TRN & \\
\hline CHEMBL1476525 & 688171 & 4.75 & 4.8091 & TRN & \\
\hline CHEMBL1452710 & 688171 & 4.9 & 4.9315 & TRN & \\
\hline CHEMBL1394497 & 688171 & 5.5 & 4.9575 & TRN & \\
\hline CHEMBL1466303 & 688171 & 5.0 & 4.8704 & TRN & \\
\hline CHEMBL1421754 & 688171 & 4.7 & 4.8146 & TRN & \\
\hline CHEMBL1489527 & 688171 & 6.95 & 5.0883 & TRN & \\
\hline CHEMBL542493 & 688171 & 6.0 & 4.9526 & TRN & \\
\hline CHEMBL1490449 & 688171 & 5.0 & 4.8859 & TRN & \\
\hline CHEMBL1605967 & 688171 & 4.95 & 4.9499 & TRN & \\
\hline CHEMBL1333470 & 688171 & 4.8 & 4.7989 & TRN & \\
\hline CHEMBL1558867 & 688171 & 4.55 & 4.9488 & TST & \\
\hline CHEMBL1511977 & 688171 & 4.65 & 4.8698 & TRN & \\
\hline CHEMBL1429822 & 688171 & 4.65 & 4.7502 & TRN & \\
\hline CHEMBL1415665 & 688171 & 4.35 & 4.8695 & TRN & \\
\hline CHEMBL1612934 & 688171 & 4.55 & 4.8399 & TRN & \\
\hline CHEMBL1424125 & 688171 & 4.65 & 4.833 & TST & \\
\hline CHEMBL1474340 & 688171 & 4.9 & 4.8685 & TRN & \\
\hline CHEMBL1402764 & 688171 & 4.65 & 4.8705 & TRN & \\
\hline CHEMBL1351385 & 688171 & 5.65 & 5.0369 & TRN & \\
\hline CHEMBL1567406 & 688171 & 4.9 & 4.9091 & TRN & \\
\hline CHEMBL1305382 & 688171 & 5.05 & 5.0344 & TST & \\
\hline
\end{tabular}




\begin{tabular}{|c|c|c|c|c|c|}
\hline \multicolumn{6}{|c|}{ Supplemental Table S2.txt } \\
\hline CHEMBL1555201 & 688171 & 4.9 & 4.7915 & TRN & \\
\hline CHEMBL1434695 & 688171 & 5.7 & 4.8109 & TRN & \\
\hline CHEMBL1481157 & 688171 & 4.35 & 4.9927 & TRN & \\
\hline CHEMBL1316423 & 688171 & 4.55 & 4.8468 & TRN & \\
\hline CHEMBL1347962 & 688171 & 4.4 & 4.9829 & TRN & \\
\hline CHEMBL1405638 & 688171 & 4.95 & 4.9277 & TRN & \\
\hline CHEMBL1581262 & 688171 & 4.4 & 4.9309 & TRN & \\
\hline CHEMBL1494534 & 688171 & 5.1 & 4.8771 & TST & \\
\hline CHEMBL1570066 & 688171 & 4.35 & 4.9903 & TRN & \\
\hline CHEMBL1448066 & 688171 & 5.7 & 4.9376 & TRN & \\
\hline CHEMBL1593384 & 688171 & 4.35 & 4.9018 & TRN & \\
\hline CHEMBL1331376 & 688171 & 4.4 & 4.8836 & TRN & \\
\hline CHEMBL1346032 & 688171 & 4.4 & 4.69600 & 2000000001 & TRN \\
\hline CHEMBL1397747 & 688171 & 4.55 & 4.864 & TRN & \\
\hline CHEMBL1436707 & 688171 & 5.05 & 4.8507 & TRN & \\
\hline CHEMBL1446548 & 688171 & 4.65 & 4.95100 & 00000000005 & TST \\
\hline CHEMBL1319502 & 688171 & 6.8499 & 4.91100 & 00000000005 & TST \\
\hline CHEMBL1536867 & 688171 & 4.4 & 4.8965 & TRN & \\
\hline CHEMBL1445710 & 688171 & 4.6 & 5.0484 & TRN & \\
\hline CHEMBL 244857 & 688171 & 7.6003 & 4.824 & TRN & \\
\hline CHEMBL1397923 & 688171 & 4.75 & 4.9772 & TRN & \\
\hline CHEMBL1588945 & 688171 & 4.4 & 4.9071 & TST & \\
\hline CHEMBL1475567 & 688171 & 4.45 & 5.15600 & 0000000001 & TRN \\
\hline CHEMBL1526465 & 688171 & 5.1 & 5.0088 & TST & \\
\hline CHEMBL1324143 & 688171 & 4.75 & 4.9446 & TRN & \\
\hline CHEMBL1419812 & 688171 & 4.8 & 4.883 & TRN & \\
\hline CHEMBL1374865 & 688171 & 5.2 & 4.9578 & TRN & \\
\hline CHEMBL455399 & 688171 & 4.35 & 4.802 & TST & \\
\hline CHEMBL1414123 & 688171 & 4.6 & 4.882 & TRN & \\
\hline CHEMBL1376184 & 688171 & 5.05 & 4.7444 & TRN & \\
\hline CHEMBL1519624 & 688171 & 4.4 & 4.9386 & TRN & \\
\hline CHEMBL1333892 & 688171 & 4.4 & 4.8032 & TRN & \\
\hline CHEMBL1492783 & 688171 & 5.5 & 4.8643 & TRN & \\
\hline CHEMBL1322140 & 688171 & 4.65 & 4.8999 & TRN & \\
\hline CHEMBL1455612 & 688171 & 5.75 & 4.88 & TRN & \\
\hline CHEMBL1476732 & 688171 & 4.9 & 4.9056 & TRN & \\
\hline CHEMBL1970265 & 688171 & 4.55 & 4.8879 & TRN & \\
\hline CHEMBL1400628 & 688171 & 4.6 & 4.8912 & TRN & \\
\hline CHEMBL1555462 & 688171 & 5.1 & 5.0721 & TRN & \\
\hline CHEMBL1377086 & 688171 & 4.9 & 4.9106 & TRN & \\
\hline CHEMBL1445273 & 688171 & 4.95 & 4.8262 & TRN & \\
\hline CHEMBL1524783 & 688171 & 4.55 & 4.7636 & TRN & \\
\hline CHEMBL1436407 & 688171 & 5.0 & 4.7567 & TRN & \\
\hline CHEMBL1362063 & 688171 & 4.55 & 4.9632 & TRN & \\
\hline CHEMBL1612157 & 688171 & 4.6 & 5.0212 & TRN & \\
\hline CHEMBL1341563 & 688171 & 6.3 & 4.9299 & TRN & \\
\hline CHEMBL1506173 & 688171 & 4.5 & 4.8947 & TRN & \\
\hline CHEMBL1998061 & 688171 & 5.0 & 4.8153 & TST & \\
\hline
\end{tabular}




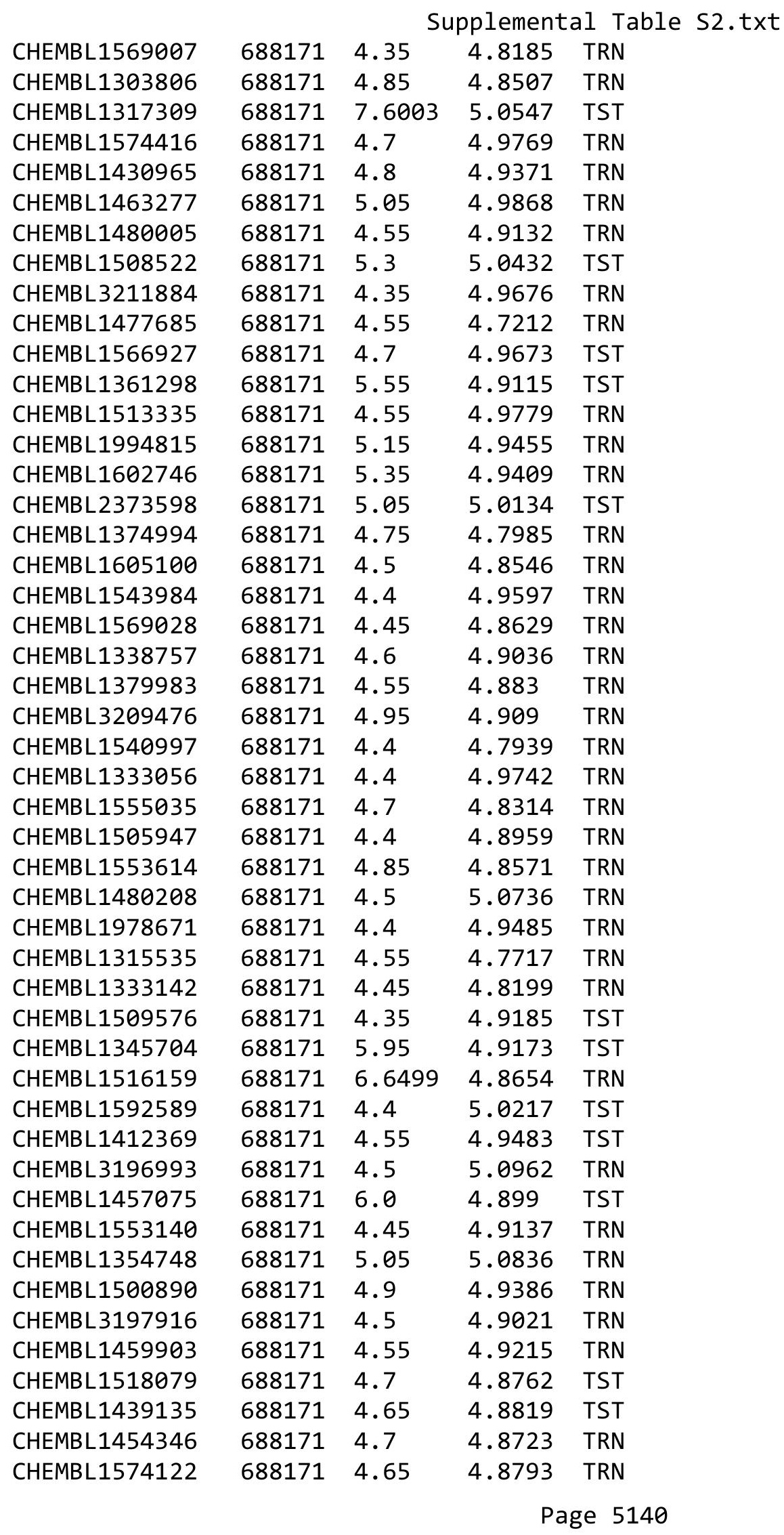




\begin{tabular}{|c|c|c|c|c|c|}
\hline \multicolumn{6}{|c|}{ Supplemental Table s2.txt } \\
\hline CHEMBL1599673 & 688171 & 4.55 & 4.8927 & TRN & \\
\hline CHEMBL1350458 & 688171 & 4.75 & 4.9096 & TRN & \\
\hline CHEMBL1363000 & 688171 & 4.4 & 4.9415 & TRN & \\
\hline CHEMBL1302838 & 688171 & 4.55 & 4.9139 & TRN & \\
\hline CHEMBL1437598 & 688171 & 4.35 & 4.8047 & TRN & \\
\hline CHEMBL1355409 & 688171 & 4.75 & 4.9382 & TRN & \\
\hline CHEMBL1416041 & 688171 & 4.4 & 4.7499 & TRN & \\
\hline CHEMBL1340120 & 688171 & 4.95 & 4.893 & TST & \\
\hline CHEMBL1594359 & 688171 & 4.65 & 4.9087 & TRN & \\
\hline CHEMBL3211445 & 688171 & 4.65 & 4.8806 & TRN & \\
\hline CHEMBL1603035 & 688171 & 4.9 & 4.8927 & TRN & \\
\hline CHEMBL3198164 & 688171 & 5.35 & 4.9638 & TRN & \\
\hline CHEMBL1420278 & 688171 & 5.4 & 4.9952 & TST & \\
\hline CHEMBL1427907 & 688171 & 5.8 & 4.8475 & TRN & \\
\hline CHEMBL1589062 & 688171 & 4.4 & 4.8765 & TRN & \\
\hline CHEMBL1433119 & 688171 & 4.8 & 4.838 & TRN & \\
\hline CHEMBL1607467 & 688171 & 4.9 & 4.8965 & TRN & \\
\hline CHEMBL1338809 & 688171 & 4.55 & 4.94300 & 00000000005 & TRN \\
\hline CHEMBL1499220 & 688171 & 5.05 & 4.8455 & TRN & \\
\hline CHEMBL1504137 & 688171 & 4.35 & 4.9681 & TRN & \\
\hline CHEMBL1479190 & 688171 & 4.75 & 4.9955 & TST & \\
\hline CHEMBL1315300 & 688171 & 4.5 & 4.8708 & TRN & \\
\hline CHEMBL1356908 & 688171 & 5.1 & 4.9347 & TRN & \\
\hline CHEMBL1566750 & 688171 & 6.6499 & 5.0545 & TRN & \\
\hline CHEMBL1384670 & 688171 & 5.0 & 4.9162 & TRN & \\
\hline CHEMBL1312427 & 688171 & 4.55 & 4.9677 & TRN & \\
\hline CHEMBL1580259 & 688171 & 5.3 & 4.7872 & TRN & \\
\hline CHEMBL1382687 & 688171 & 5.05 & 4.9923 & TST & \\
\hline CHEMBL1483967 & 688171 & 5.1 & 4.8163 & TRN & \\
\hline CHEMBL1503215 & 688171 & 4.4 & 4.9455 & TST & \\
\hline CHEMBL1445164 & 688171 & 5.5 & 5.0098 & TRN & \\
\hline CHEMBL1316887 & 688171 & 4.4 & 4.8361 & TRN & \\
\hline CHEMBL 3194486 & 688171 & 4.75 & 4.9636 & TST & \\
\hline CHEMBL1568724 & 688171 & 4.7 & 4.9758 & TRN & \\
\hline CHEMBL1527240 & 688171 & 5.4 & 5.0413 & TRN & \\
\hline CHEMBL1444830 & 688171 & 4.85 & 4.8249 & TRN & \\
\hline CHEMBL1450726 & 688171 & 5.3 & 4.9077 & TST & \\
\hline CHEMBL1472345 & 688171 & 5.75 & 4.9623 & TRN & \\
\hline CHEMBL1391593 & 688171 & 4.4 & 4.895 & TST & \\
\hline CHEMBL454280 & 688171 & 5.3 & 5.0093 & TST & \\
\hline CHEMBL1344769 & 688171 & 4.65 & 4.7816 & TST & \\
\hline CHEMBL1381978 & 688171 & 5.5 & 4.8756 & TST & \\
\hline CHEMBL1581556 & 688171 & 4.35 & 4.8093 & TRN & \\
\hline CHEMBL1380322 & 688171 & 6.95 & 5.0246 & TST & \\
\hline CHEMBL1442565 & 688171 & 4.5 & 4.9154 & TST & \\
\hline CHEMBL16687 & 688171 & 4.75 & 4.8454 & TST & \\
\hline CHEMBL1591133 & 688171 & 5.2 & 5.0151 & TRN & \\
\hline CHEMBL1562335 & 688171 & 4.5 & 4.9593 & TRN & \\
\hline
\end{tabular}




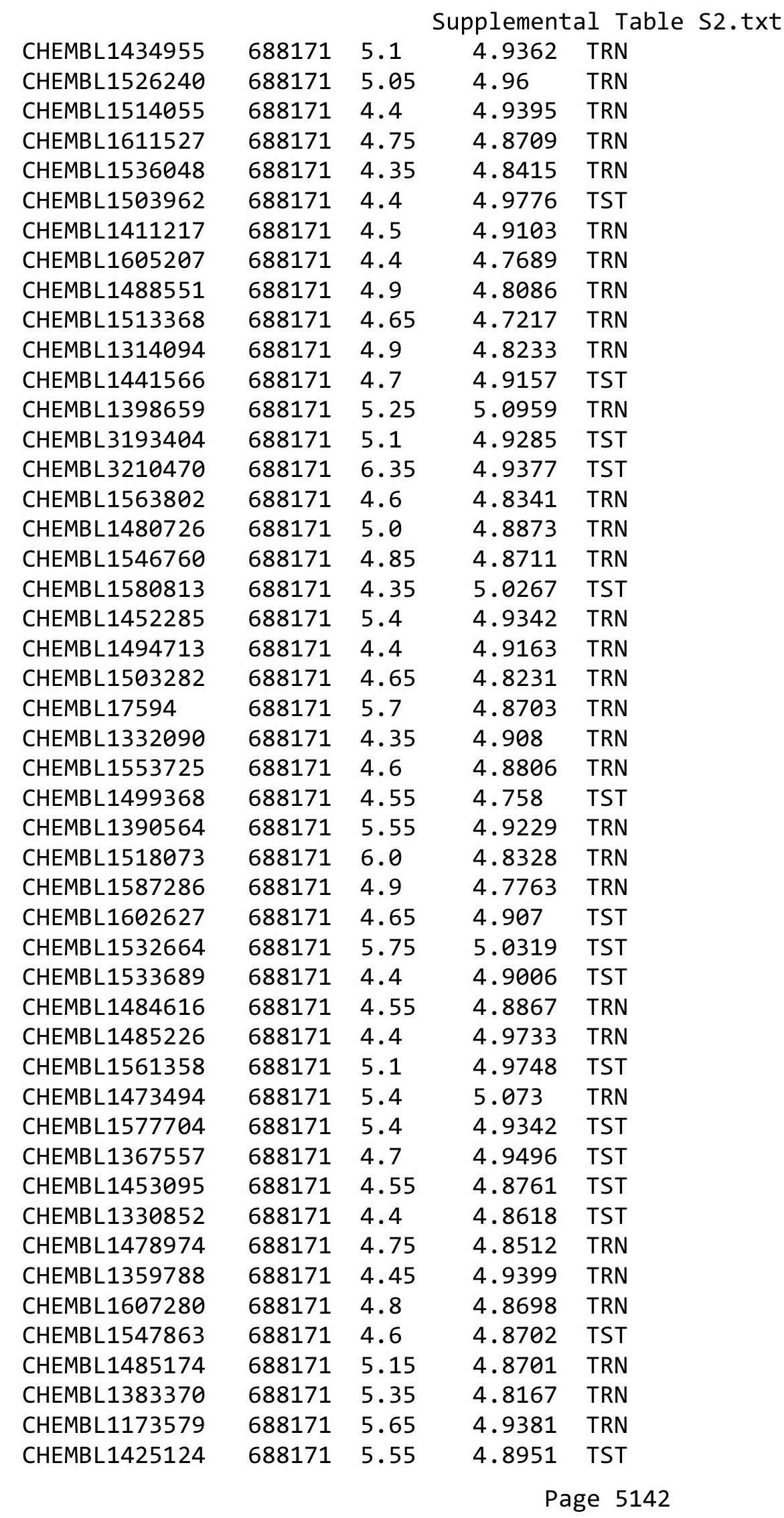




\begin{tabular}{|c|c|c|c|c|}
\hline \multicolumn{5}{|c|}{ Supplemental Table } \\
\hline CHEMBL1369618 & 688171 & 4.45 & 4.8297 & TRN \\
\hline CHEMBL1314741 & 688171 & 4.45 & 4.8505 & TRN \\
\hline CHEMBL1588103 & 688171 & 4.55 & 4.9201 & TRN \\
\hline CHEMBL1316555 & 688171 & 4.7 & 4.8893 & TRN \\
\hline CHEMBL1531927 & 688171 & 6.9 & 4.9736 & TRN \\
\hline CHEMBL1597777 & 688171 & 4.4 & 4.9194 & TRN \\
\hline CHEMBL1438946 & 688171 & 4.6 & 5.0608 & TRN \\
\hline CHEMBL1600524 & 688171 & 4.6 & 4.8867 & TST \\
\hline CHEMBL1592739 & 688171 & 4.6 & 5.0927 & TST \\
\hline CHEMBL1591499 & 688171 & 4.45 & 4.8851 & TRN \\
\hline CHEMBL1472809 & 688171 & 4.65 & 4.9274 & TRN \\
\hline CHEMBL 3207588 & 688171 & 5.1 & 4.9512 & TST \\
\hline CHEMBL1453399 & 688171 & 5.45 & 4.7804 & TRN \\
\hline CHEMBL1314044 & 688171 & 5.55 & 4.9534 & TST \\
\hline CHEMBL1422446 & 688171 & 4.35 & 4.9416 & TRN \\
\hline CHEMBL1588273 & 688171 & 7.15 & 5.0085 & TRN \\
\hline CHEMBL1485015 & 688171 & 4.45 & 4.8828 & TRN \\
\hline CHEMBL1441784 & 688171 & 6.05 & 4.9506 & TRN \\
\hline CHEMBL1432130 & 688171 & 4.4 & 4.9914 & TST \\
\hline CHEMBL3211375 & 688171 & 4.55 & 4.8196 & TRN \\
\hline CHEMBL1435312 & 688171 & 4.7 & 4.8959 & TRN \\
\hline CHEMBL1459721 & 688171 & 4.9 & 4.8266 & TRN \\
\hline CHEMBL1411681 & 688171 & 4.45 & 4.8608 & TRN \\
\hline CHEMBL1434960 & 688171 & 6.5 & 4.8749 & TRN \\
\hline CHEMBL1394323 & 688171 & 4.6 & 4.8794 & TRN \\
\hline CHEMBL1463301 & 688171 & 4.7 & 4.9153 & TRN \\
\hline CHEMBL1375570 & 688171 & 4.4 & 4.9709 & TST \\
\hline CHEMBL1507325 & 688171 & 4.35 & 4.9139 & TRN \\
\hline CHEMBL1345687 & 688171 & 5.55 & 4.8629 & TRN \\
\hline CHEMBL1474720 & 688171 & 4.7 & 4.88 & TST \\
\hline CHEMBL3196589 & 688171 & 4.4 & 4.9692 & TRN \\
\hline CHEMBL1557070 & 688171 & 4.65 & 4.8526 & TRN \\
\hline CHEMBL1452670 & 688171 & 4.65 & 4.9007 & TST \\
\hline CHEMBL1976542 & 688171 & 4.4 & 4.9294 & TST \\
\hline CHEMBL1449301 & 688171 & 4.4 & 4.9942 & TRN \\
\hline CHEMBL1473432 & 688171 & 4.85 & 4.8494 & TRN \\
\hline CHEMBL3194522 & 688171 & 4.4 & 4.9296 & TRN \\
\hline CHEMBL1404739 & 688171 & 4.45 & 4.9728 & TRN \\
\hline CHEMBL1356887 & 688171 & 4.8 & 4.8389 & TRN \\
\hline CHEMBL1878162 & 688171 & 4.55 & 4.6965 & TST \\
\hline CHEMBL1504131 & 688171 & 4.6 & 4.9225 & TRN \\
\hline CHEMBL1423165 & 688171 & 4.4 & 4.8172 & TRN \\
\hline CHEMBL1453629 & 688171 & 4.85 & 4.9151 & TST \\
\hline CHEMBL1408992 & 688171 & 4.65 & 4.9448 & TRN \\
\hline CHEMBL1463002 & 688171 & 4.4 & 4.8934 & TRN \\
\hline CHEMBL1388790 & 688171 & 4.8 & 4.8853 & TRN \\
\hline CHEMBL1514974 & 688171 & 5.0 & 4.8543 & TRN \\
\hline CHEMBL1472567 & 688171 & 5.05 & 4.9087 & TST \\
\hline
\end{tabular}




\begin{tabular}{|c|c|c|c|c|}
\hline \multicolumn{5}{|c|}{ Supplemental Table S2.txt } \\
\hline CHEMBL1532157 & 688171 & 5.5 & 4.9895 & TRN \\
\hline CHEMBL1438758 & 688171 & 4.7 & 4.8919 & TRN \\
\hline CHEMBL1401486 & 688171 & 6.0 & 5.0089 & TRN \\
\hline CHEMBL1459633 & 688171 & 4.4 & 4.9782 & TRN \\
\hline CHEMBL1336696 & 688171 & 4.55 & 4.9895 & TST \\
\hline CHEMBL1492867 & 688171 & 4.4 & 5.0176 & TRN \\
\hline CHEMBL1498227 & 688171 & 5.85 & 4.8314 & TRN \\
\hline CHEMBL1329632 & 688171 & 4.5 & 4.877 & TRN \\
\hline CHEMBL1603560 & 688171 & 6.6 & 4.9349 & TRN \\
\hline CHEMBL1445771 & 688171 & 4.35 & 5.0809 & TRN \\
\hline CHEMBL1439414 & 688171 & 4.8 & 4.7713 & TST \\
\hline CHEMBL1585849 & 688171 & 4.4 & 5.0405 & TRN \\
\hline CHEMBL3192721 & 688171 & 4.5 & 4.9598 & TRN \\
\hline CHEMBL1596141 & 688171 & 5.4 & 4.8763 & TRN \\
\hline CHEMBL1435757 & 688171 & 4.95 & 4.9311 & TRN \\
\hline CHEMBL1315964 & 688171 & 4.85 & 5.1299 & TRN \\
\hline CHEMBL1516704 & 688171 & 4.9 & 4.9229 & TRN \\
\hline CHEMBL1412415 & 688171 & 4.55 & 4.8578 & TRN \\
\hline CHEMBL1307877 & 688171 & 4.6 & 4.8367 & TRN \\
\hline CHEMBL1553610 & 688171 & 5.3 & 4.9607 & TRN \\
\hline CHEMBL3191240 & 688171 & 4.4 & 4.9753 & TRN \\
\hline CHEMBL1529448 & 688171 & 4.35 & 5.0107 & TRN \\
\hline CHEMBL1308348 & 688171 & 4.4 & 4.9006 & TRN \\
\hline CHEMBL1318320 & 688171 & 4.7 & 4.8198 & TRN \\
\hline CHEMBL1390365 & 688171 & 4.7 & 4.8107 & TST \\
\hline CHEMBL1468563 & 688171 & 4.75 & 4.9304 & TRN \\
\hline CHEMBL1516792 & 688171 & 4.85 & 4.8984 & TRN \\
\hline CHEMBL1552083 & 688171 & 4.75 & 5.0339 & TRN \\
\hline CHEMBL1340950 & 688171 & 4.9 & 4.7621 & TRN \\
\hline CHEMBL1507971 & 688171 & 4.65 & 4.859 & TRN \\
\hline CHEMBL1301355 & 688171 & 4.5 & 4.8686 & TRN \\
\hline CHEMBL1553999 & 688171 & 4.75 & 4.9308 & TRN \\
\hline CHEMBL1587128 & 688171 & 4.4 & 5.1483 & TST \\
\hline CHEMBL1522064 & 688171 & 4.9 & 4.9297 & TRN \\
\hline CHEMBL1488875 & 688171 & 4.9 & 4.8279 & TRN \\
\hline CHEMBL1431975 & 688171 & 4.4 & 4.899 & TRN \\
\hline CHEMBL 1443403 & 688171 & 4.45 & 4.9072 & TST \\
\hline CHEMBL1532794 & 688171 & 4.65 & 4.806 & TST \\
\hline CHEMBL3194435 & 688171 & 4.6 & 4.8271 & TST \\
\hline CHEMBL1315042 & 688171 & 5.15 & 4.9587 & TRN \\
\hline CHEMBL1421518 & 688171 & 4.4 & 4.9287 & TST \\
\hline CHEMBL1396189 & 688171 & 4.55 & 4.7882 & TRN \\
\hline CHEMBL1410069 & 688171 & 4.7 & 4.8232 & TRN \\
\hline CHEMBL1532780 & 688171 & 4.55 & 4.8979 & TRN \\
\hline CHEMBL1329957 & 688171 & 4.6 & 4.7723 & TST \\
\hline CHEMBL1316476 & 688171 & 4.4 & 4.8106 & TRN \\
\hline CHEMBL1400958 & 688171 & 4.45 & 4.9228 & TRN \\
\hline CHEMBL1415613 & 688171 & 4.75 & 4.8959 & TRN \\
\hline
\end{tabular}




\begin{tabular}{|c|c|c|c|c|c|}
\hline \multicolumn{6}{|c|}{ Supplemental Table S2.txt } \\
\hline CHEMBL1401479 & 688171 & 5.15 & 4.9023 & TRN & \\
\hline CHEMBL172439 & 688171 & 4.8 & 4.9391 & TRN & \\
\hline CHEMBL1527093 & 688171 & 4.85 & 4.8197 & TRN & \\
\hline CHEMBL1335206 & 688171 & 4.75 & 4.8221 & TST & \\
\hline CHEMBL1417663 & 688171 & 5.15 & 4.9811 & TRN & \\
\hline CHEMBL1427403 & 688171 & 5.4 & 5.0157 & TRN & \\
\hline CHEMBL1478967 & 688171 & 4.8 & 4.9662 & TRN & \\
\hline CHEMBL1342903 & 688171 & 4.4 & 5.0116 & TRN & \\
\hline CHEMBL1312335 & 688171 & 4.45 & 4.7714 & TRN & \\
\hline CHEMBL1552270 & 688171 & 4.5 & 4.9183 & TRN & \\
\hline CHEMBL1529295 & 688171 & 4.4 & 4.8463 & TRN & \\
\hline CHEMBL1558119 & 688171 & 5.05 & 5.0053 & TRN & \\
\hline CHEMBL1541479 & 688171 & 4.35 & 4.9154 & TST & \\
\hline CHEMBL1530147 & 688171 & 4.8 & 4.8436 & TRN & \\
\hline CHEMBL1342522 & 688171 & 4.8 & 4.9723 & TRN & \\
\hline CHEMBL1464997 & 688171 & 4.65 & 4.8982 & TRN & \\
\hline CHEMBL1376574 & 688171 & 4.4 & 4.8443 & TRN & \\
\hline CHEMBL1306960 & 688171 & 4.4 & 5.0339 & TST & \\
\hline CHEMBL1569370 & 688171 & 4.4 & 4.9916 & TST & \\
\hline CHEMBL1555323 & 688171 & 7.2503 & 5.0487 & TRN & \\
\hline CHEMBL1990619 & 688171 & 4.9 & 4.9198 & TRN & \\
\hline CHEMBL1422260 & 688171 & 5.1 & 4.9578 & TRN & \\
\hline CHEMBL 3199543 & 688171 & 4.55 & 5.0167 & TRN & \\
\hline CHEMBL 1611020 & 688171 & 4.55 & 4.876 & TRN & \\
\hline CHEMBL66966 & 688171 & 4.75 & 5.0504 & TRN & \\
\hline CHEMBL1600941 & 688171 & 5.35 & 4.8054 & TRN & \\
\hline CHEMBL1316121 & 688171 & 4.6 & 4.9779 & TST & \\
\hline CHEMBL1523317 & 688171 & 5.5 & 4.833 & TST & \\
\hline CHEMBL 1437387 & 688171 & 5.15 & 4.8695 & TRN & \\
\hline CHEMBL1452551 & 688171 & 4.5 & 4.9929 & TRN & \\
\hline CHEMBL1442896 & 688171 & 4.35 & 4.9088 & TRN & \\
\hline CHEMBL1460904 & 688171 & 4.7 & 4.9118 & TST & \\
\hline CHEMBL1534888 & 688171 & 4.55 & 4.7952 & TRN & \\
\hline CHEMBL1392052 & 688171 & 4.6 & 4.8865 & TRN & \\
\hline CHEMBL1601821 & 688171 & 4.65 & 4.8063 & TRN & \\
\hline CHEMBL1501057 & 688171 & 4.45 & 4.8597 & TRN & \\
\hline CHEMBL1370899 & 688171 & 4.65 & 4.94600 & 0000000001 & TRN \\
\hline CHEMBL1398144 & 688171 & 4.65 & 4.9513 & TRN & \\
\hline CHEMBL1554709 & 688171 & 4.55 & 5.0308 & TRN & \\
\hline CHEMBL1542998 & 688171 & 4.8 & 4.8832 & TRN & \\
\hline CHEMBL1490935 & 688171 & 4.65 & 4.9478 & TRN & \\
\hline CHEMBL1503134 & 688171 & 4.4 & 4.927 & TST & \\
\hline CHEMBL1388940 & 688171 & 4.95 & 4.856 & TRN & \\
\hline CHEMBL1309591 & 688171 & 4.4 & 4.83 & TRN & \\
\hline CHEMBL1515430 & 688171 & 5.7 & 5.0976 & TRN & \\
\hline CHEMBL1461181 & 688171 & 4.9 & 4.8429 & TRN & \\
\hline CHEMBL1552660 & 688171 & 6.3 & 4.7763 & TST & \\
\hline CHEMBL1325491 & 688171 & 4.55 & 4.9766 & TRN & \\
\hline
\end{tabular}




\begin{tabular}{|c|c|c|c|c|}
\hline \multicolumn{5}{|c|}{ Supplemental Table S2.txt } \\
\hline CHEMBL1391475 & 688171 & 5.05 & 4.9623 & TST \\
\hline CHEMBL1577124 & 688171 & 4.75 & 4.9024 & TRN \\
\hline CHEMBL1507424 & 688171 & 6.9 & 4.9285 & TST \\
\hline CHEMBL3198938 & 688171 & 4.6 & 4.897 & TRN \\
\hline CHEMBL1429415 & 688171 & 5.0 & 4.8405 & TRN \\
\hline CHEMBL1411812 & 688171 & 7.0 & 5.0921 & TRN \\
\hline CHEMBL1399076 & 688171 & 5.45 & 5.0314 & TRN \\
\hline CHEMBL1515184 & 688171 & 4.65 & 4.8888 & TRN \\
\hline CHEMBL1590107 & 688171 & 4.65 & 4.8256 & TRN \\
\hline CHEMBL1355128 & 688171 & 4.65 & 4.8625 & TRN \\
\hline CHEMBL1385495 & 688171 & 4.55 & 4.9088 & TRN \\
\hline CHEMBL1570323 & 688171 & 6.3 & 4.9878 & TST \\
\hline CHEMBL1592468 & 688171 & 5.8 & 5.0551 & TRN \\
\hline CHEMBL1450426 & 688171 & 4.4 & 4.8582 & TRN \\
\hline CHEMBL1572917 & 688171 & 5.35 & 4.9414 & TST \\
\hline CHEMBL1333653 & 688171 & 4.8 & 4.9188 & TST \\
\hline CHEMBL1300597 & 688171 & 4.85 & 5.0333 & TRN \\
\hline CHEMBL1448665 & 688171 & 4.9 & 4.7978 & TRN \\
\hline CHEMBL1555809 & 688171 & 4.45 & 4.9379 & TST \\
\hline CHEMBL1493303 & 688171 & 5.0 & 5.0221 & TST \\
\hline CHEMBL1393315 & 688171 & 5.35 & 4.9455 & TRN \\
\hline CHEMBL1574291 & 688171 & 4.55 & 4.9066 & TST \\
\hline CHEMBL1325390 & 688171 & 4.5 & 4.9564 & TRN \\
\hline CHEMBL1321988 & 688171 & 4.4 & 4.8534 & TST \\
\hline CHEMBL1495546 & 688171 & 4.5 & 4.8601 & TRN \\
\hline CHEMBL1576615 & 688171 & 5.15 & 4.9755 & TST \\
\hline CHEMBL1446477 & 688171 & 4.95 & 4.8408 & TRN \\
\hline CHEMBL1427527 & 688171 & 5.45 & 4.7971 & TST \\
\hline CHEMBL1434036 & 688171 & 4.35 & 4.9264 & TRN \\
\hline CHEMBL1598578 & 688171 & 5.2 & 4.8065 & TRN \\
\hline CHEMBL1359792 & 688171 & 4.55 & 4.9121 & TST \\
\hline CHEMBL1542266 & 688171 & 4.6 & 4.7906 & TRN \\
\hline CHEMBL1504866 & 688171 & 5.0 & 4.851 & TRN \\
\hline CHEMBL1349395 & 688171 & 4.55 & 4.8696 & TRN \\
\hline CHEMBL3197989 & 688171 & 4.35 & 5.0935 & TRN \\
\hline CHEMBL1987546 & 688171 & 4.55 & 4.8338 & TRN \\
\hline CHEMBL1538564 & 688171 & 4.45 & 4.8865 & TST \\
\hline CHEMBL3198006 & 688171 & 5.45 & 4.8125 & TRN \\
\hline CHEMBL476980 & 688171 & 4.5 & 4.8313 & TST \\
\hline CHEMBL1340221 & 688171 & 4.5 & 4.9591 & TST \\
\hline CHEMBL1476930 & 688171 & 4.85 & 4.8015 & TRN \\
\hline CHEMBL1314736 & 688171 & 5.15 & 5.0287 & TST \\
\hline CHEMBL 2002767 & 688171 & 4.4 & 4.9164 & TRN \\
\hline CHEMBL1444540 & 688171 & 4.75 & 4.8178 & TRN \\
\hline CHEMBL1372397 & 688171 & 4.8 & 4.795 & TRN \\
\hline CHEMBL1360839 & 688171 & 4.45 & 4.9281 & TRN \\
\hline CHEMBL1542879 & 688171 & 4.45 & 4.8983 & TRN \\
\hline CHEMBL1548261 & 688171 & 4.9 & 4.9565 & TST \\
\hline
\end{tabular}




\begin{tabular}{|c|c|c|c|c|c|}
\hline \multicolumn{6}{|c|}{ Supplemental Table S2.txt } \\
\hline CHEMBL3199583 & 688171 & 4.35 & 4.8782 & TRN & \\
\hline CHEMBL1612671 & 688171 & 5.15 & 4.9719 & TRN & \\
\hline CHEMBL1381613 & 688171 & 5.05 & 4.9934 & TST & \\
\hline CHEMBL1562420 & 688171 & 4.95 & 4.7246 & TST & \\
\hline CHEMBL1552471 & 688171 & 4.75 & 4.8217 & TRN & \\
\hline CHEMBL570345 & 688171 & 4.45 & 4.8205 & TRN & \\
\hline CHEMBL3192321 & 688171 & 5.25 & 5.0028 & TRN & \\
\hline CHEMBL1453436 & 688171 & 4.75 & 4.9075 & TRN & \\
\hline CHEMBL1608195 & 688171 & 7.0501 & 5.0 & TRN & \\
\hline CHEMBL1522123 & 688171 & 4.8 & 4.9059 & TRN & \\
\hline CHEMBL1544163 & 688171 & 5.45 & 4.8142 & TRN & \\
\hline CHEMBL1447402 & 688171 & 4.6 & 5.1391 & TRN & \\
\hline CHEMBL1365055 & 688171 & 4.35 & 4.9637 & TST & \\
\hline CHEMBL1972844 & 688171 & 4.6 & 4.9346 & TRN & \\
\hline CHEMBL1563138 & 688171 & 4.85 & 4.9642 & TRN & \\
\hline CHEMBL548017 & 688171 & 4.95 & 4.8515 & TRN & \\
\hline CHEMBL1486154 & 688171 & 5.1 & 4.9989 & TRN & \\
\hline CHEMBL1361252 & 688171 & 4.65 & 4.9298 & TRN & \\
\hline CHEMBL1541312 & 688171 & 5.15 & 5.0426 & TST & \\
\hline CHEMBL1345607 & 688171 & 4.8 & 4.8875 & TRN & \\
\hline CHEMBL1308233 & 688171 & 4.7 & 4.8516 & TRN & \\
\hline CHEMBL1397038 & 688171 & 4.55 & 4.8581 & TRN & \\
\hline CHEMBL1509798 & 688171 & 5.25 & 4.739 & TRN & \\
\hline CHEMBL1489729 & 688171 & 5.25 & 4.9317 & TRN & \\
\hline CHEMBL1504515 & 688171 & 4.45 & 4.79899 & 99999999995 & TRN \\
\hline CHEMBL1522709 & 688171 & 4.55 & 4.7804 & TRN & \\
\hline CHEMBL1592482 & 688171 & 4.65 & 4.9607 & TST & \\
\hline CHEMBL1524865 & 688171 & 4.6 & 4.8445 & TRN & \\
\hline CHEMBL1361996 & 688171 & 4.6 & 4.982 & TRN & \\
\hline CHEMBL1334073 & 688171 & 4.4 & 4.9529 & TRN & \\
\hline CHEMBL1408198 & 688171 & 4.95 & 4.9222 & TRN & \\
\hline CHEMBL1367704 & 688171 & 5.3 & 4.8243 & TST & \\
\hline CHEMBL3197816 & 688171 & 4.9 & 4.8407 & TRN & \\
\hline CHEMBL1399873 & 688171 & 4.7 & 4.7195 & TRN & \\
\hline CHEMBL3198793 & 688171 & 5.0 & 4.9208 & TRN & \\
\hline CHEMBL1609186 & 688171 & 4.8 & 4.8197 & TRN & \\
\hline CHEMBL1313191 & 688171 & 4.6 & 4.9313 & TST & \\
\hline CHEMBL1529384 & 688171 & 5.8 & 5.0469 & TRN & \\
\hline CHEMBL1546667 & 688171 & 4.65 & 4.9099 & TRN & \\
\hline CHEMBL1405989 & 688171 & 5.05 & 4.8937 & TST & \\
\hline CHEMBL1433045 & 688171 & 5.55 & 4.8741 & TRN & \\
\hline CHEMBL1470907 & 688171 & 6.35 & 5.0431 & TST & \\
\hline CHEMBL1500200 & 688171 & 5.55 & 5.0954 & TRN & \\
\hline CHEMBL1474105 & 688171 & 4.7 & 4.9774 & TRN & \\
\hline CHEMBL1556292 & 688171 & 4.6 & 4.7221 & TRN & \\
\hline CHEMBL1968355 & 688171 & 5.05 & 4.8141 & TRN & \\
\hline CHEMBL1309310 & 688171 & 4.95 & 4.7849 & TRN & \\
\hline CHEMBL1398259 & 688171 & 4.8 & 4.8523 & TRN & \\
\hline
\end{tabular}




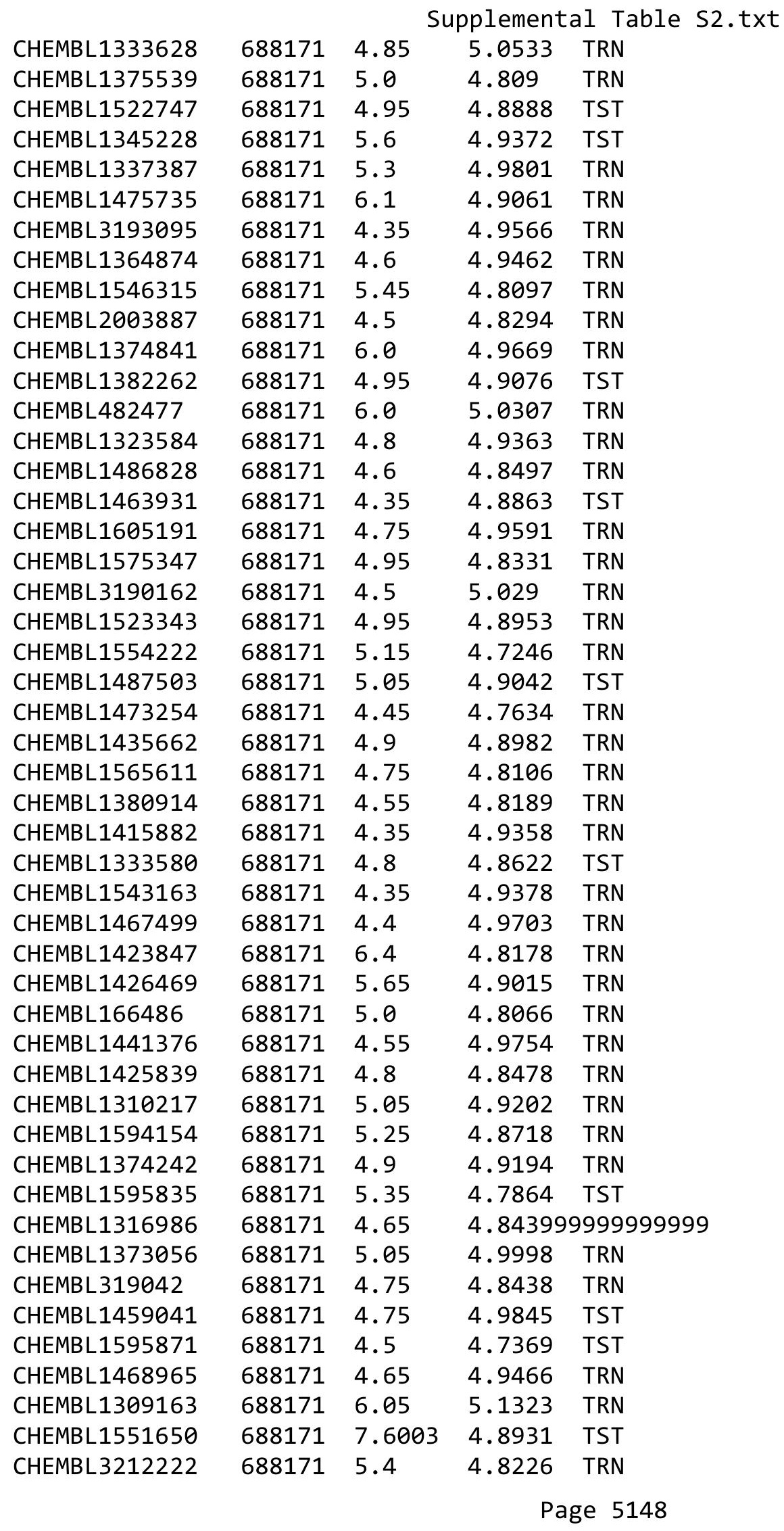




\begin{tabular}{|c|c|c|c|c|}
\hline \multicolumn{5}{|c|}{ Supplemental Table S2.txt } \\
\hline CHEMBL1497196 & 688171 & 4.65 & 4.9157 & TRN \\
\hline CHEMBL1532757 & 688171 & 5.25 & 4.9679 & TRN \\
\hline CHEMBL1577991 & 688171 & 4.55 & 4.8759 & TST \\
\hline CHEMBL1334040 & 688171 & 5.0 & 4.8282 & TRN \\
\hline CHEMBL1367121 & 688171 & 5.0 & 4.8713 & TRN \\
\hline CHEMBL1510620 & 688171 & 6.6 & 4.997 & TST \\
\hline CHEMBL1514184 & 688171 & 5.25 & 4.8189 & TST \\
\hline CHEMBL1307589 & 688171 & 4.55 & 4.9461 & TRN \\
\hline CHEMBL1337966 & 688171 & 4.4 & 4.8878 & TST \\
\hline CHEMBL1454332 & 688171 & 5.1 & 4.97 & TRN \\
\hline CHEMBL1596657 & 688171 & 4.8 & 4.8398 & TRN \\
\hline CHEMBL1510967 & 688171 & 4.4 & 4.8936 & TRN \\
\hline CHEMBL1480328 & 688171 & 4.45 & 4.9168 & TRN \\
\hline CHEMBL1475994 & 688171 & 4.65 & 4.7972 & TRN \\
\hline CHEMBL1446861 & 688171 & 4.55 & 4.7768 & TRN \\
\hline CHEMBL1303652 & 688171 & 4.35 & 4.8694 & TST \\
\hline CHEMBL1418935 & 688171 & 5.5 & 4.9898 & TST \\
\hline CHEMBL1464740 & 688171 & 4.35 & 5.1227 & TRN \\
\hline CHEMBL 3198511 & 688171 & 4.45 & 4.9667 & TRN \\
\hline CHEMBL1575701 & 688171 & 4.65 & 4.8778 & TST \\
\hline CHEMBL1534413 & 688171 & 5.95 & 4.8088 & TRN \\
\hline CHEMBL1499083 & 688171 & 4.4 & 4.823 & TRN \\
\hline CHEMBL1315793 & 688171 & 4.55 & 4.8991 & TRN \\
\hline CHEMBL1383635 & 688171 & 4.8 & 4.8442 & TRN \\
\hline CHEMBL1361413 & 688171 & 5.5 & 5.0103 & TST \\
\hline CHEMBL1437989 & 688171 & 5.25 & 4.9734 & TRN \\
\hline CHEMBL1446668 & 688171 & 4.4 & 4.9854 & TRN \\
\hline CHEMBL1430076 & 688171 & 4.35 & 4.9043 & TST \\
\hline CHEMBL1589652 & 688171 & 4.7 & 4.8415 & TST \\
\hline CHEMBL1610480 & 688171 & 4.7 & 4.8872 & TST \\
\hline CHEMBL1422709 & 688171 & 4.9 & 4.9342 & TRN \\
\hline CHEMBL1332179 & 688171 & 7.6003 & 5.0739 & TRN \\
\hline CHEMBL1551206 & 688171 & 4.35 & 4.9659 & TRN \\
\hline CHEMBL1326180 & 688171 & 4.4 & 4.9059 & TRN \\
\hline CHEMBL1346930 & 688171 & 4.6 & 4.8373 & TRN \\
\hline CHEMBL1983342 & 688171 & 6.0 & 4.949 & TRN \\
\hline CHEMBL2005139 & 688171 & 5.4 & 4.9581 & TRN \\
\hline CHEMBL3197990 & 688171 & 4.75 & 4.9195 & TRN \\
\hline CHEMBL1489346 & 688171 & 4.95 & 4.9025 & TRN \\
\hline CHEMBL1378008 & 688171 & 4.6 & 4.8695 & TRN \\
\hline CHEMBL1442056 & 688171 & 4.4 & 4.8255 & TST \\
\hline CHEMBL1170681 & 688171 & 4.9 & 4.8745 & TRN \\
\hline CHEMBL3199119 & 688171 & 4.8 & 4.9289 & TRN \\
\hline CHEMBL1595412 & 688171 & 4.85 & 4.9399 & TRN \\
\hline CHEMBL1430831 & 688171 & 4.95 & 4.874 & TRN \\
\hline CHEMBL1355564 & 688171 & 4.4 & 5.0482 & TRN \\
\hline CHEMBL3144922 & 688171 & 4.45 & 4.8825 & TST \\
\hline CHEMBL1613064 & 688171 & 4.4 & 4.9537 & TRN \\
\hline
\end{tabular}




\begin{tabular}{|c|c|c|c|c|c|}
\hline \multicolumn{6}{|c|}{ Supplemental Table S2.txt } \\
\hline CHEMBL1470208 & 688171 & 4.4 & 4.9897 & TST & \\
\hline CHEMBL1487271 & 688171 & 4.4 & 4.7801 & TRN & \\
\hline CHEMBL1375963 & 688171 & 4.4 & 4.8535 & TST & \\
\hline CHEMBL1590810 & 688171 & 6.35 & 4.9669 & TST & \\
\hline CHEMBL1413864 & 688171 & 4.9 & 4.9129 & TRN & \\
\hline CHEMBL1360439 & 688171 & 4.4 & 4.80399 & 9999999999 & TRN \\
\hline CHEMBL1563683 & 688171 & 5.2 & 4.8988 & TRN & \\
\hline CHEMBL1345808 & 688171 & 4.6 & 4.8975 & TRN & \\
\hline CHEMBL1498047 & 688171 & 4.8 & 4.8475 & TRN & \\
\hline CHEMBL1413862 & 688171 & 5.5 & 4.9363 & TRN & \\
\hline CHEMBL1326118 & 688171 & 4.9 & 4.6745 & TRN & \\
\hline CHEMBL1473410 & 688171 & 4.95 & 4.8861 & TRN & \\
\hline CHEMBL1388427 & 688171 & 4.75 & 4.8495 & TST & \\
\hline CHEMBL1512993 & 688171 & 6.1 & 4.9581 & TST & \\
\hline CHEMBL1427637 & 688171 & 5.0 & 4.9876 & TRN & \\
\hline CHEMBL3192970 & 688171 & 5.0 & 4.8898 & TRN & \\
\hline CHEMBL1316783 & 688171 & 4.7 & 5.0207 & TRN & \\
\hline CHEMBL1391527 & 688171 & 4.5 & 4.9765 & TRN & \\
\hline CHEMBL1975051 & 688171 & 4.45 & 4.9571 & TRN & \\
\hline CHEMBL1541883 & 688171 & 4.7 & 4.989 & TRN & \\
\hline CHEMBL1510019 & 688171 & 4.55 & 4.8312 & TRN & \\
\hline CHEMBL1552211 & 688171 & 5.2 & 5.0467 & TRN & \\
\hline CHEMBL1433895 & 688171 & 7.6003 & 4.7185 & TRN & \\
\hline CHEMBL2004592 & 688171 & 5.9 & 5.0209 & TST & \\
\hline CHEMBL1530937 & 688171 & 4.9 & 4.9951 & TRN & \\
\hline CHEMBL1609867 & 688171 & 4.6 & 4.9583 & TRN & \\
\hline CHEMBL1549791 & 688171 & 4.6 & 4.8535 & TRN & \\
\hline CHEMBL1603168 & 688171 & 5.25 & 4.8996 & TRN & \\
\hline CHEMBL1565673 & 688171 & 4.6 & 4.9818 & TRN & \\
\hline CHEMBL1398372 & 688171 & 4.6 & 4.8073 & TRN & \\
\hline CHEMBL1434980 & 688171 & 4.7 & 4.9209 & TRN & \\
\hline CHEMBL1405259 & 688171 & 4.75 & 4.813 & TRN & \\
\hline CHEMBL1609952 & 688171 & 6.6 & 4.8385 & TRN & \\
\hline CHEMBL1549284 & 688171 & 4.4 & 4.9209 & TRN & \\
\hline CHEMBL1456503 & 688171 & 4.6 & 4.9018 & TRN & \\
\hline CHEMBL239009 & 688171 & 4.4 & 4.8164 & TRN & \\
\hline CHEMBL1407683 & 688171 & 4.75 & 4.8784 & TRN & \\
\hline CHEMBL1408659 & 688171 & 4.75 & 4.8816 & TRN & \\
\hline CHEMBL1383878 & 688171 & 4.4 & 4.8108 & TST & \\
\hline CHEMBL1487945 & 688171 & 4.4 & 4.9427 & TRN & \\
\hline CHEMBL1520822 & 688171 & 5.1 & 4.8697 & TRN & \\
\hline CHEMBL1337210 & 688171 & 4.5 & 4.9251 & TRN & \\
\hline CHEMBL3198242 & 688171 & 5.05 & 4.9754 & TRN & \\
\hline CHEMBL1385280 & 688171 & 5.0 & 4.8909 & TRN & \\
\hline CHEMBL3198606 & 688171 & 4.8 & 4.8655 & TST & \\
\hline CHEMBL1546781 & 688171 & 4.65 & 4.8412 & TST & \\
\hline CHEMBL1580342 & 688171 & 4.75 & 4.9496 & TRN & \\
\hline CHEMBL1534871 & 688171 & 6.35 & 4.9604 & TRN & \\
\hline
\end{tabular}




\begin{tabular}{|c|c|c|c|c|c|}
\hline \multicolumn{6}{|c|}{ Supplemental Table S2.txt } \\
\hline CHEMBL1361506 & 688171 & 4.9 & 4.7742 & TRN & \\
\hline CHEMBL 295316 & 688171 & 6.0 & 4.8393 & TRN & \\
\hline CHEMBL1612234 & 688171 & 4.4 & 4.8564 & TRN & \\
\hline CHEMBL1542644 & 688171 & 6.6499 & 4.9657 & TRN & \\
\hline CHEMBL1427534 & 688171 & 4.45 & 4.8729 & TRN & \\
\hline CHEMBL1396657 & 688171 & 4.5 & 4.9511 & TRN & \\
\hline CHEMBL1587927 & 688171 & 4.6 & 4.8621 & TRN & \\
\hline CHEMBL1513869 & 688171 & 4.4 & 4.9299 & TRN & \\
\hline CHEMBL1403384 & 688171 & 5.45 & 4.9212 & TST & \\
\hline CHEMBL1610008 & 688171 & 4.55 & 4.8551 & TST & \\
\hline CHEMBL1417290 & 688171 & 4.9 & 4.9466 & TST & \\
\hline CHEMBL1568745 & 688171 & 4.5 & 4.9151 & TST & \\
\hline CHEMBL1580989 & 688171 & 4.85 & 4.8785 & TRN & \\
\hline CHEMBL1387249 & 688171 & 4.45 & 5.0305 & TRN & \\
\hline CHEMBL1336751 & 688171 & 4.5 & 4.8413 & TRN & \\
\hline CHEMBL3196913 & 688171 & 5.5 & 4.9364 & TRN & \\
\hline CHEMBL1593413 & 688171 & 5.45 & 4.9467 & TRN & \\
\hline CHEMBL1561931 & 688171 & 4.95 & 4.935 & TRN & \\
\hline CHEMBL1363509 & 688171 & 4.4 & 4.8863 & TRN & \\
\hline CHEMBL1483973 & 688171 & 4.95 & 5.0132 & TRN & \\
\hline CHEMBL117108 & 688171 & 4.65 & 4.8467 & TRN & \\
\hline CHEMBL1596675 & 688171 & 5.75 & 4.8615 & TST & \\
\hline CHEMBL1271060 & 688171 & 4.4 & 4.7042 & TRN & \\
\hline CHEMBL1303992 & 688171 & 4.6 & 4.6882 & TRN & \\
\hline CHEMBL1607918 & 688171 & 4.6 & 4.9315 & TRN & \\
\hline CHEMBL1328780 & 688171 & 5.2 & 4.8493 & TRN & \\
\hline CHEMBL3198496 & 688171 & 4.4 & 4.8828 & TRN & \\
\hline CHEMBL1501292 & 688171 & 5.0 & 4.8196 & TRN & \\
\hline CHEMBL1490258 & 688171 & 4.5 & 4.9731 & TST & \\
\hline CHEMBL1314762 & 688171 & 5.45 & 4.9775 & TRN & \\
\hline CHEMBL1349679 & 688171 & 4.7 & 4.9975 & TST & \\
\hline CHEMBL1551565 & 688171 & 5.65 & 4.8325 & TRN & \\
\hline CHEMBL1505968 & 688171 & 4.95 & 4.9126 & TRN & \\
\hline CHEMBL1525787 & 688171 & 4.7 & 4.8744 & TRN & \\
\hline CHEMBL1323809 & 688171 & 4.35 & 4.8673 & TRN & \\
\hline CHEMBL1322695 & 688171 & 5.5 & 4.8893 & TRN & \\
\hline CHEMBL1515039 & 688171 & 4.85 & 4.8747 & TRN & \\
\hline CHEMBL1611654 & 688171 & 4.8 & 5.0307 & TST & \\
\hline CHEMBL1584304 & 688171 & 5.75 & 4.88899 & 9999999999 & TRN \\
\hline CHEMBL1428006 & 688171 & 4.9 & 4.9318 & TRN & \\
\hline CHEMBL1444638 & 688171 & 5.1 & 4.8629 & TRN & \\
\hline CHEMBL1409617 & 688171 & 5.05 & 4.8615 & TST & \\
\hline CHEMBL1434367 & 688171 & 4.4 & 4.8184 & TRN & \\
\hline CHEMBL1454246 & 688171 & 5.0 & 4.8831 & TRN & \\
\hline CHEMBL1512541 & 688171 & 4.55 & 4.8211 & TRN & \\
\hline CHEMBL1366312 & 688171 & 4.35 & 5.0404 & TRN & \\
\hline CHEMBL1554484 & 688171 & 4.35 & 4.9806 & TRN & \\
\hline CHEMBL1454749 & 688171 & 4.7 & 4.9394 & TRN & \\
\hline
\end{tabular}




\begin{tabular}{|c|c|c|c|c|c|}
\hline \multicolumn{6}{|c|}{ Supplemental Table S2.txt } \\
\hline CHEMBL1574744 & 688171 & 4.35 & 5.0672 & TRN & \\
\hline CHEMBL1593229 & 688171 & 4.35 & 5.0298 & TRN & \\
\hline CHEMBL1489732 & 688171 & 6.9 & 4.9997 & TRN & \\
\hline CHEMBL 2006418 & 688171 & 5.0 & 4.988 & TRN & \\
\hline CHEMBL131921 & 688171 & 6.0 & 4.90600 & 0000000001 & TRN \\
\hline CHEMBL1423479 & 688171 & 5.05 & 4.9144 & TST & \\
\hline CHEMBL1456999 & 688171 & 4.65 & 4.8614 & TRN & \\
\hline CHEMBL1459232 & 688171 & 6.3 & 5.0157 & TST & \\
\hline CHEMBL1318541 & 688171 & 4.55 & 4.8416 & TRN & \\
\hline CHEMBL1465064 & 688171 & 5.0 & 4.8191 & TRN & \\
\hline CHEMBL1454064 & 688171 & 4.35 & 5.0458 & TRN & \\
\hline CHEMBL1533464 & 688171 & 4.4 & 4.9195 & TST & \\
\hline CHEMBL1573013 & 688171 & 4.4 & 4.9912 & TST & \\
\hline CHEMBL1308083 & 688171 & 7.0501 & 5.1524 & TST & \\
\hline CHEMBL3197592 & 688171 & 4.35 & 4.8309 & TRN & \\
\hline CHEMBL1589086 & 688171 & 5.55 & 4.7642 & TRN & \\
\hline CHEMBL1589234 & 688171 & 4.8 & 4.9157 & TST & \\
\hline CHEMBL1412545 & 688171 & 4.75 & 4.9442 & TRN & \\
\hline CHEMBL1558230 & 688171 & 4.55 & 4.8794 & TRN & \\
\hline CHEMBL1499175 & 688171 & 5.55 & 4.9619 & TST & \\
\hline CHEMBL1441745 & 688171 & 5.1 & 4.9934 & TST & \\
\hline CHEMBL1396670 & 688171 & 5.15 & 4.8683 & TST & \\
\hline CHEMBL1553108 & 688171 & 6.05 & 5.0365 & TRN & \\
\hline CHEMBL1560644 & 688171 & 4.35 & 4.9485 & TRN & \\
\hline CHEMBL1452838 & 688171 & 4.75 & 4.8744 & TRN & \\
\hline CHEMBL1552945 & 688171 & 4.4 & 4.8895 & TRN & \\
\hline CHEMBL1342220 & 688171 & 4.45 & 4.8195 & TRN & \\
\hline CHEMBL1420404 & 688171 & 4.7 & 4.9072 & TRN & \\
\hline CHEMBL1483381 & 688171 & 4.35 & 4.9313 & TST & \\
\hline CHEMBL1523512 & 688171 & 4.6 & 4.8838 & TST & \\
\hline CHEMBL1402957 & 688171 & 5.15 & 5.0226 & TRN & \\
\hline CHEMBL1351519 & 688171 & 5.0 & 4.8416 & TST & \\
\hline CHEMBL1356880 & 688171 & 4.85 & 4.9218 & TRN & \\
\hline CHEMBL1507408 & 688171 & 5.3 & 4.9866 & TRN & \\
\hline CHEMBL1429512 & 688171 & 5.5 & 4.9427 & TRN & \\
\hline CHEMBL 2000120 & 688171 & 4.55 & 4.8377 & TRN & \\
\hline CHEMBL1309010 & 688171 & 6.2 & 4.9831 & TRN & \\
\hline CHEMBL1344927 & 688171 & 4.55 & 4.6624 & TRN & \\
\hline CHEMBL1529989 & 688171 & 5.0 & 4.8034 & TRN & \\
\hline CHEMBL1502965 & 688171 & 4.5 & 4.8995 & TRN & \\
\hline CHEMBL1397045 & 688171 & 4.35 & 4.7872 & TRN & \\
\hline CHEMBL1529222 & 688171 & 4.4 & 4.8325 & TRN & \\
\hline CHEMBL1311664 & 688171 & 4.4 & 4.934 & TST & \\
\hline CHEMBL1456921 & 688171 & 4.65 & 4.9986 & TRN & \\
\hline CHEMBL1423981 & 688171 & 4.4 & 4.9439 & TRN & \\
\hline CHEMBL1514174 & 688171 & 4.35 & 4.8089 & TRN & \\
\hline CHEMBL1380978 & 688171 & 5.3 & 4.8772 & TRN & \\
\hline CHEMBL1479810 & 688171 & 4.95 & 4.8713 & TRN & \\
\hline
\end{tabular}




\begin{tabular}{|c|c|c|c|c|}
\hline \multicolumn{5}{|c|}{ Supplemental Table S2.txt } \\
\hline CHEMBL1571202 & 688171 & 4.9 & 4.9817 & TRN \\
\hline CHEMBL1370265 & 688171 & 6.0 & 4.7968 & TRN \\
\hline CHEMBL1996902 & 688171 & 4.55 & 4.9087 & TRN \\
\hline CHEMBL1535276 & 688171 & 4.45 & 4.8762 & TRN \\
\hline CHEMBL1394513 & 688171 & 4.6 & 4.9082 & TRN \\
\hline CHEMBL1414081 & 688171 & 4.5 & 4.8228 & TST \\
\hline CHEMBL1554886 & 688171 & 5.0 & 4.8761 & TRN \\
\hline CHEMBL1980678 & 688171 & 4.5 & 4.846 & TRN \\
\hline CHEMBL1357973 & 688171 & 4.35 & 4.7889 & TRN \\
\hline CHEMBL1488173 & 688171 & 5.05 & 4.8299 & TST \\
\hline CHEMBL1964383 & 688171 & 4.4 & 4.893 & TRN \\
\hline CHEMBL1304154 & 688171 & 5.4 & 4.8492 & TRN \\
\hline CHEMBL1303009 & 688171 & 4.7 & 5.0396 & TST \\
\hline CHEMBL1347107 & 688171 & 5.05 & 4.8592 & TRN \\
\hline CHEMBL1413068 & 688171 & 5.1 & 4.8766 & TRN \\
\hline CHEMBL1550006 & 688171 & 4.75 & 4.9234 & TST \\
\hline CHEMBL1373956 & 688171 & 4.4 & 4.789 & TRN \\
\hline CHEMBL1414652 & 688171 & 4.8 & 4.8881 & TST \\
\hline CHEMBL1357980 & 688171 & 6.15 & 5.0484 & TRN \\
\hline CHEMBL1473745 & 688171 & 4.5 & 4.7972 & TRN \\
\hline CHEMBL384903 & 688171 & 4.6 & 4.8435 & TST \\
\hline CHEMBL1165202 & 688171 & 4.75 & 4.9082 & TRN \\
\hline CHEMBL1411466 & 688171 & 5.1 & 4.8397 & TRN \\
\hline CHEMBL1601522 & 688171 & 5.0 & 4.9975 & TRN \\
\hline CHEMBL1533427 & 688171 & 4.8 & 4.8395 & TRN \\
\hline CHEMBL1576027 & 688171 & 4.75 & 4.8884 & TRN \\
\hline CHEMBL1550569 & 688171 & 6.1 & 4.878 & TRN \\
\hline CHEMBL1491728 & 688171 & 4.95 & 4.9146 & TRN \\
\hline CHEMBL1537300 & 688171 & 4.75 & 4.8998 & TRN \\
\hline CHEMBL1360208 & 688171 & 4.4 & 4.9754 & TST \\
\hline CHEMBL1581013 & 688171 & 4.9 & 4.9509 & TRN \\
\hline CHEMBL1387055 & 688171 & 5.7 & 4.9168 & TST \\
\hline CHEMBL1310114 & 688171 & 4.5 & 4.887 & TRN \\
\hline CHEMBL1443831 & 688171 & 4.75 & 4.8961 & TRN \\
\hline CHEMBL1408635 & 688171 & 4.55 & 4.831 & TRN \\
\hline CHEMBL1527916 & 688171 & 4.75 & 4.9137 & TRN \\
\hline CHEMBL1434782 & 688171 & 4.35 & 4.9471 & TRN \\
\hline CHEMBL1395524 & 688171 & 4.35 & 4.9086 & TRN \\
\hline CHEMBL1572404 & 688171 & 4.9 & 4.9281 & TRN \\
\hline CHEMBL1403855 & 688171 & 4.35 & 4.9036 & TRN \\
\hline CHEMBL1604813 & 688171 & 4.9 & 5.0046 & TST \\
\hline CHEMBL1433624 & 688171 & 4.7 & 4.8242 & TRN \\
\hline CHEMBL1593124 & 688171 & 6.95 & 4.9521 & TRN \\
\hline CHEMBL1527596 & 688171 & 5.35 & 4.8834 & TRN \\
\hline CHEMBL1349813 & 688171 & 4.7 & 4.8801 & TST \\
\hline CHEMBL1399284 & 688171 & 4.4 & 4.9663 & TRN \\
\hline CHEMBL1372905 & 688171 & 4.75 & 4.8276 & TST \\
\hline CHEMBL1577144 & 688171 & 5.05 & 4.854 & TST \\
\hline
\end{tabular}




\begin{tabular}{|c|c|c|c|c|c|}
\hline \multirow[b]{2}{*}{ CHEMBL1964676 } & \multicolumn{5}{|c|}{ Supplemental Table s2.txt } \\
\hline & 688171 & 4.65 & 4.7824 & TRN & \\
\hline CHEMBL1451936 & 688171 & 4.4 & 4.8863 & TRN & \\
\hline CHEMBL1447554 & 688171 & 4.45 & 4.8914 & TRN & \\
\hline CHEMBL1512098 & 688171 & 4.4 & 4.80399 & 9999999999 & TST \\
\hline CHEMBL1588264 & 688171 & 6.9 & 4.9824 & TRN & \\
\hline CHEMBL1486179 & 688171 & 4.95 & 4.8198 & TRN & \\
\hline CHEMBL1584676 & 688171 & 4.35 & 4.7748 & TST & \\
\hline CHEMBL1479708 & 688171 & 4.7 & 4.8164 & TST & \\
\hline CHEMBL1356790 & 688171 & 4.4 & 4.9991 & TRN & \\
\hline CHEMBL1535331 & 688171 & 4.35 & 5.0455 & TST & \\
\hline CHEMBL1457345 & 688171 & 4.7 & 4.9041 & TRN & \\
\hline CHEMBL1331319 & 688171 & 4.85 & 4.9533 & TRN & \\
\hline CHEMBL585038 & 688171 & 5.05 & 4.8996 & TRN & \\
\hline CHEMBL1574066 & 688171 & 4.85 & 4.8971 & TRN & \\
\hline CHEMBL1357359 & 688171 & 4.85 & 4.9313 & TRN & \\
\hline CHEMBL1406546 & 688171 & 4.35 & 4.8962 & TST & \\
\hline CHEMBL1502370 & 688171 & 4.35 & 4.716 & TRN & \\
\hline CHEMBL1381717 & 688171 & 4.35 & 5.00899 & 99999999995 & TRN \\
\hline CHEMBL1577891 & 688171 & 4.75 & 4.8553 & TRN & \\
\hline CHEMBL1516647 & 688171 & 4.55 & 4.8738 & TRN & \\
\hline CHEMBL1315783 & 688171 & 5.75 & 4.9508 & TRN & \\
\hline CHEMBL1453017 & 688171 & 4.55 & 4.9595 & TRN & \\
\hline CHEMBL1382910 & 688171 & 4.65 & 5.1337 & TRN & \\
\hline CHEMBL1506080 & 688171 & 4.45 & 4.9793 & TRN & \\
\hline CHEMBL1358598 & 688171 & 4.6 & 4.79 & TRN & \\
\hline CHEMBL1301111 & 688171 & 4.55 & 4.9213 & TRN & \\
\hline CHEMBL1307744 & 688171 & 4.95 & 4.8889 & TRN & \\
\hline CHEMBL 2000440 & 688171 & 5.05 & 4.9598 & TRN & \\
\hline CHEMBL1421558 & 688171 & 4.65 & 4.8549 & TRN & \\
\hline CHEMBL1522554 & 688171 & 5.5 & 4.897 & TRN & \\
\hline CHEMBL1569734 & 688171 & 4.65 & 5.0137 & TRN & \\
\hline CHEMBL1338466 & 688171 & 4.65 & 4.8139 & TRN & \\
\hline CHEMBL1412200 & 688171 & 4.75 & 4.8453 & TRN & \\
\hline CHEMBL1472758 & 688171 & 5.65 & 4.8527 & TRN & \\
\hline CHEMBL1404034 & 688171 & 4.45 & 4.9448 & TRN & \\
\hline CHEMBL1541771 & 688171 & 6.8499 & 4.9322 & TRN & \\
\hline CHEMBL1563285 & 688171 & 4.35 & 4.9336 & TST & \\
\hline CHEMBL1173286 & 688171 & 5.0 & 4.81800 & 00000000005 & TRN \\
\hline CHEMBL1590033 & 688171 & 4.35 & 4.9441 & TST & \\
\hline CHEMBL1464703 & 688171 & 5.0 & 4.8659 & TST & \\
\hline CHEMBL1568496 & 688171 & 4.5 & 4.8177 & TST & \\
\hline CHEMBL1326912 & 688171 & 5.1 & 4.9075 & TRN & \\
\hline CHEMBL1424257 & 688171 & 5.05 & 4.8481 & TRN & \\
\hline CHEMBL1465886 & 688171 & 4.45 & 4.8339 & TRN & \\
\hline CHEMBL1306457 & 688171 & 4.6 & 4.9522 & TRN & \\
\hline CHEMBL3192273 & 688171 & 4.95 & 4.9412 & TST & \\
\hline CHEMBL1342609 & 688171 & 4.4 & 4.7179 & TRN & \\
\hline CHEMBL1487065 & 688171 & 4.4 & 4.8381 & TRN & \\
\hline
\end{tabular}




\begin{tabular}{|c|c|c|c|c|}
\hline \multicolumn{5}{|c|}{ Supplemental Table S2.txt } \\
\hline CHEMBL1359301 & 688171 & 4.4 & 4.9392 & TRN \\
\hline CHEMBL1538268 & 688171 & 4.7 & 4.8831 & TRN \\
\hline CHEMBL1504200 & 688171 & 6.9 & 4.8943 & TRN \\
\hline CHEMBL1567103 & 688171 & 5.0 & 4.9461 & TST \\
\hline CHEMBL1418185 & 688171 & 5.2 & 4.7752 & TRN \\
\hline CHEMBL1398633 & 688171 & 5.05 & 4.9246 & TRN \\
\hline CHEMBL1583422 & 688171 & 5.1 & 4.8747 & TST \\
\hline CHEMBL1474785 & 688171 & 4.75 & 4.9231 & TRN \\
\hline CHEMBL1608709 & 688171 & 4.95 & 4.7923 & TRN \\
\hline CHEMBL1519662 & 688171 & 4.5 & 4.8734 & TRN \\
\hline CHEMBL3208972 & 688171 & 5.05 & 4.8123 & TST \\
\hline CHEMBL1455331 & 688171 & 5.45 & 4.739 & TRN \\
\hline CHEMBL1522444 & 688171 & 4.85 & 4.8974 & TRN \\
\hline CHEMBL1315183 & 688171 & 5.35 & 4.8998 & TRN \\
\hline CHEMBL1597358 & 688171 & 5.85 & 4.8953 & TRN \\
\hline CHEMBL1316053 & 688171 & 4.4 & 4.9034 & TRN \\
\hline CHEMBL1463624 & 688171 & 4.55 & 4.7972 & TRN \\
\hline CHEMBL1374510 & 688171 & 5.05 & 4.8528 & TRN \\
\hline CHEMBL1335712 & 688171 & 4.4 & 4.8605 & TRN \\
\hline CHEMBL1317145 & 688171 & 4.65 & 4.8749 & TRN \\
\hline CHEMBL1565280 & 688171 & 4.7 & 4.8132 & TRN \\
\hline CHEMBL1561756 & 688171 & 4.85 & 4.9168 & TRN \\
\hline CHEMBL1532145 & 688171 & 4.75 & 4.9638 & TRN \\
\hline CHEMBL1376540 & 688171 & 5.4 & 4.8566 & TRN \\
\hline CHEMBL1590314 & 688171 & 4.95 & 5.0945 & TRN \\
\hline CHEMBL1396976 & 688171 & 5.35 & 4.8427 & TRN \\
\hline CHEMBL1469314 & 688171 & 4.95 & 4.7954 & TRN \\
\hline CHEMBL1554533 & 688171 & 4.85 & 4.854 & TRN \\
\hline CHEMBL399491 & 688171 & 5.35 & 4.9592 & TST \\
\hline CHEMBL1322416 & 688171 & 4.55 & 4.9015 & TRN \\
\hline CHEMBL1355993 & 688171 & 6.25 & 4.8224 & TRN \\
\hline CHEMBL1492627 & 688171 & 4.4 & 4.9173 & TRN \\
\hline CHEMBL1469133 & 688171 & 4.35 & 4.795 & TST \\
\hline CHEMBL1469352 & 688171 & 5.15 & 4.9523 & TST \\
\hline CHEMBL1569192 & 688171 & 4.75 & 4.9834 & TRN \\
\hline CHEMBL527870 & 688171 & 4.4 & 4.8613 & TST \\
\hline CHEMBL1486218 & 688171 & 4.9 & 4.9005 & TRN \\
\hline CHEMBL 34990 & 688171 & 4.4 & 4.9107 & TST \\
\hline CHEMBL1473756 & 688171 & 4.4 & 4.8502 & TST \\
\hline CHEMBL1447470 & 688171 & 6.7001 & 4.7529 & TST \\
\hline CHEMBL1571300 & 688171 & 4.4 & 4.8262 & TRN \\
\hline CHEMBL1445887 & 688171 & 4.75 & 4.7845 & TRN \\
\hline CHEMBL1310746 & 688171 & 4.65 & 5.0337 & TRN \\
\hline CHEMBL1372016 & 688171 & 4.35 & 4.9202 & TRN \\
\hline CHEMBL1586823 & 688171 & 4.4 & 4.8701 & TRN \\
\hline CHEMBL1369708 & 688171 & 4.35 & 4.7179 & TST \\
\hline CHEMBL1553287 & 688171 & 4.4 & 4.945 & TRN \\
\hline CHEMBL1396021 & 688171 & 5.2 & 4.791 & TRN \\
\hline
\end{tabular}




\begin{tabular}{|c|c|c|c|c|}
\hline \multicolumn{5}{|c|}{ Supplemental Table S2.txt } \\
\hline CHEMBL1593320 & 688171 & 5.05 & 5.1505 & TRN \\
\hline CHEMBL1474075 & 688171 & 6.0 & 4.8609 & TRN \\
\hline CHEMBL1337734 & 688171 & 5.05 & 4.9295 & TRN \\
\hline CHEMBL1384436 & 688171 & 4.45 & 4.702 & TRN \\
\hline CHEMBL1483603 & 688171 & 5.35 & 4.945 & TRN \\
\hline CHEMBL 3193729 & 688171 & 5.1 & 4.9163 & TRN \\
\hline CHEMBL1530048 & 688171 & 4.75 & 5.0206 & TST \\
\hline CHEMBL1374221 & 688171 & 4.4 & 5.0356 & TST \\
\hline CHEMBL1564816 & 688171 & 5.3 & 4.931 & TST \\
\hline CHEMBL1514366 & 688171 & 5.55 & 4.7497 & TRN \\
\hline CHEMBL1565879 & 688171 & 5.05 & 4.8731 & TRN \\
\hline CHEMBL1409585 & 688171 & 4.75 & 4.9171 & TRN \\
\hline CHEMBL1431126 & 688171 & 4.85 & 4.9052 & TST \\
\hline CHEMBL1393131 & 688171 & 4.65 & 4.9335 & TRN \\
\hline CHEMBL 3208830 & 688171 & 4.85 & 4.904 & TRN \\
\hline CHEMBL1441022 & 688171 & 4.85 & 4.8078 & TRN \\
\hline CHEMBL 3212830 & 688171 & 4.4 & 4.8815 & TRN \\
\hline CHEMBL1471684 & 688171 & 4.35 & 4.751 & TRN \\
\hline CHEMBL 3190468 & 688171 & 5.1 & 4.9773 & TRN \\
\hline CHEMBL1462792 & 688171 & 4.75 & 4.8984 & TRN \\
\hline CHEMBL1453900 & 688171 & 4.85 & 4.7823 & TRN \\
\hline CHEMBL1534132 & 688171 & 4.9 & 4.8865 & TRN \\
\hline CHEMBL1430681 & 688171 & 4.65 & 4.8087 & TST \\
\hline CHEMBL1600352 & 688171 & 4.4 & 4.8276 & TRN \\
\hline CHEMBL1579414 & 688171 & 4.5 & 4.8105 & TRN \\
\hline CHEMBL 3194003 & 688171 & 5.5 & 4.9124 & TRN \\
\hline CHEMBL1476566 & 688171 & 5.0 & 4.816 & TRN \\
\hline CHEMBL1576110 & 688171 & 4.8 & 4.8831 & TRN \\
\hline CHEMBL 3213921 & 688171 & 4.5 & 4.9349 & TST \\
\hline CHEMBL1502468 & 688171 & 5.5 & 4.8565 & TST \\
\hline CHEMBL1360675 & 688171 & 5.65 & 4.91 & TRN \\
\hline CHEMBL1550584 & 688171 & 5.65 & 4.9267 & TRN \\
\hline CHEMBL1488175 & 688171 & 4.65 & 4.8385 & TRN \\
\hline CHEMBL1480749 & 688171 & 4.85 & 4.8832 & TRN \\
\hline CHEMBL 2007318 & 688171 & 4.35 & 4.9705 & TST \\
\hline CHEMBL1591905 & 688171 & 4.4 & 5.1176 & TRN \\
\hline CHEMBL1395100 & 688171 & 4.6 & 4.7446 & TRN \\
\hline CHEMBL1567229 & 688171 & 5.7 & 4.9296 & TRN \\
\hline CHEMBL1475891 & 688171 & 5.05 & 4.8732 & TRN \\
\hline CHEMBL1318582 & 688171 & 4.95 & 4.8562 & TRN \\
\hline CHEMBL1324935 & 688171 & 4.4 & 4.7385 & TRN \\
\hline CHEMBL1441959 & 688171 & 4.8 & 4.864 & TST \\
\hline CHEMBL1517930 & 688171 & 4.45 & 4.9457 & TST \\
\hline CHEMBL1436422 & 688171 & 4.4 & 4.9693 & TRN \\
\hline CHEMBL1377070 & 688171 & 4.45 & 4.7936 & TRN \\
\hline CHEMBL1426299 & 688171 & 4.95 & 4.9637 & TST \\
\hline CHEMBL1449459 & 688171 & 4.55 & 4.8123 & TRN \\
\hline CHEMBL1415425 & 688171 & 4.65 & 4.9477 & TRN \\
\hline
\end{tabular}




\begin{tabular}{|c|c|c|c|c|c|}
\hline \multicolumn{6}{|c|}{ Supplemental Table S2.txt } \\
\hline CHEMBL1399048 & 688171 & 4.5 & 4.829 & TRN & \\
\hline CHEMBL 3212370 & 688171 & 4.7 & 4.9603 & TRN & \\
\hline CHEMBL1317151 & 688171 & 4.9 & 4.955 & TRN & \\
\hline CHEMBL1464416 & 688171 & 4.95 & 4.8491 & TRN & \\
\hline CHEMBL1501390 & 688171 & 4.6 & 4.9243 & TRN & \\
\hline CHEMBL1433551 & 688171 & 5.4 & 5.0315 & TRN & \\
\hline CHEMBL1301791 & 688171 & 5.5 & 4.9234 & TST & \\
\hline CHEMBL1377103 & 688171 & 5.0 & 4.8004 & TST & \\
\hline CHEMBL1367689 & 688171 & 4.4 & 4.9513 & TRN & \\
\hline CHEMBL1431575 & 688171 & 4.4 & 4.9378 & TRN & \\
\hline CHEMBL1559375 & 688171 & 4.55 & 4.8541 & TRN & \\
\hline CHEMBL1447632 & 688171 & 5.05 & 5.07600 & 00000000005 & TRN \\
\hline CHEMBL1541441 & 688171 & 4.8 & 4.8652 & TRN & \\
\hline CHEMBL1974740 & 688171 & 6.8499 & 4.993 & TST & \\
\hline CHEMBL1412827 & 688171 & 4.9 & 4.9747 & TRN & \\
\hline CHEMBL1561408 & 688171 & 4.4 & 4.9909 & TST & \\
\hline CHEMBL1428771 & 688171 & 5.45 & 4.9455 & TRN & \\
\hline CHEMBL1555521 & 688171 & 4.65 & 4.7287 & TRN & \\
\hline CHEMBL220287 & 688171 & 4.6 & 4.9204 & TRN & \\
\hline CHEMBL1556273 & 688171 & 4.35 & 4.9678 & TST & \\
\hline CHEMBL63154 & 688171 & 5.6 & 4.8994 & TST & \\
\hline CHEMBL3199422 & 688171 & 6.7501 & 5.0904 & TST & \\
\hline CHEMBL3199590 & 688171 & 4.4 & 4.9338 & TRN & \\
\hline CHEMBL1544929 & 688171 & 4.8 & 4.7979 & TRN & \\
\hline CHEMBL1577081 & 688171 & 5.35 & 4.8563 & TRN & \\
\hline CHEMBL1344357 & 688171 & 4.4 & 4.9684 & TRN & \\
\hline CHEMBL1506746 & 688171 & 5.1 & 5.0389 & TST & \\
\hline CHEMBL1437931 & 688171 & 4.55 & 4.8666 & TRN & \\
\hline CHEMBL1393657 & 688171 & 4.7 & 4.9837 & TST & \\
\hline CHEMBL1544989 & 688171 & 4.55 & 4.8335 & TRN & \\
\hline CHEMBL1564710 & 688171 & 4.9 & 4.9876 & TST & \\
\hline CHEMBL1448721 & 688171 & 4.75 & 4.9994 & TRN & \\
\hline CHEMBL1349348 & 688171 & 7.3002 & 5.0406 & TRN & \\
\hline CHEMBL1301854 & 688171 & 4.35 & 4.9985 & TST & \\
\hline CHEMBL1580416 & 688171 & 4.55 & 4.8217 & TRN & \\
\hline CHEMBL1603584 & 688171 & 4.35 & 4.9327 & TST & \\
\hline CHEMBL1307185 & 688171 & 5.0 & 4.9469 & TRN & \\
\hline CHEMBL1515621 & 688171 & 4.6 & 4.92899 & 9999999999 & TRN \\
\hline CHEMBL1576822 & 688171 & 5.1 & 5.0245 & TST & \\
\hline CHEMBL1547042 & 688171 & 4.55 & 4.9055 & TRN & \\
\hline CHEMBL1373985 & 688171 & 5.65 & 4.9824 & TRN & \\
\hline CHEMBL1563227 & 688171 & 5.0 & 4.9508 & TRN & \\
\hline CHEMBL1976839 & 688171 & 4.75 & 4.9743 & TRN & \\
\hline CHEMBL1358323 & 688171 & 4.5 & 4.8648 & TST & \\
\hline CHEMBL1395115 & 688171 & 5.7 & 4.9947 & TRN & \\
\hline CHEMBL1598635 & 688171 & 4.85 & 4.9516 & TRN & \\
\hline CHEMBL1525243 & 688171 & 5.4 & 4.8214 & TRN & \\
\hline CHEMBL1344629 & 688171 & 4.35 & 4.779 & TRN & \\
\hline
\end{tabular}




\begin{tabular}{|c|c|c|c|c|c|}
\hline \multicolumn{6}{|c|}{ Supplemental Table S2.txt } \\
\hline CHEMBL1343714 & 688171 & 6.0 & 4.9106 & TRN & \\
\hline CHEMBL1436413 & 688171 & 4.45 & 4.9651 & TRN & \\
\hline CHEMBL1424398 & 688171 & 4.35 & 5.0612 & TRN & \\
\hline CHEMBL1406470 & 688171 & 5.95 & 4.9314 & TRN & \\
\hline CHEMBL1458891 & 688171 & 5.1 & 4.7719 & TRN & \\
\hline CHEMBL1462024 & 688171 & 5.15 & 4.7608 & TRN & \\
\hline CHEMBL1580980 & 688171 & 4.4 & 4.8975 & TST & \\
\hline CHEMBL1597976 & 688171 & 4.55 & 5.0504 & TST & \\
\hline CHEMBL1492924 & 688171 & 4.35 & 4.8771 & TRN & \\
\hline CHEMBL1467881 & 688171 & 4.5 & 4.8068 & TST & \\
\hline CHEMBL3191441 & 688171 & 5.6 & 5.0504 & TRN & \\
\hline CHEMBL528414 & 688171 & 4.9 & 4.8871 & TRN & \\
\hline CHEMBL1417526 & 688171 & 4.55 & 4.8411 & TRN & \\
\hline CHEMBL1515564 & 688171 & 4.75 & 4.9276 & TRN & \\
\hline CHEMBL1400129 & 688171 & 4.35 & 5.0074 & TRN & \\
\hline CHEMBL1512537 & 688171 & 5.6 & 5.0242 & TRN & \\
\hline CHEMBL1589093 & 688171 & 4.45 & 4.9839 & TST & \\
\hline CHEMBL1458321 & 688171 & 5.4 & 4.8112 & TRN & \\
\hline CHEMBL1361645 & 688171 & 5.25 & 4.7994 & TRN & \\
\hline CHEMBL1551327 & 688171 & 4.4 & 5.1279 & TRN & \\
\hline CHEMBL3190928 & 688171 & 4.4 & 4.7608 & TRN & \\
\hline CHEMBL3210108 & 688171 & 4.8 & 4.8072 & TRN & \\
\hline CHEMBL1472747 & 688171 & 4.45 & 4.919 & TRN & \\
\hline CHEMBL1551180 & 688171 & 4.75 & 4.8956 & TRN & \\
\hline CHEMBL1357595 & 688171 & 4.4 & 4.69600 & 0000000001 & TRN \\
\hline CHEMBL1461188 & 688171 & 4.65 & 4.8043 & TRN & \\
\hline CHEMBL1456253 & 688171 & 4.7 & 4.8512 & TRN & \\
\hline CHEMBL1348607 & 688171 & 4.55 & 4.87 & TRN & \\
\hline CHEMBL1575594 & 688171 & 5.1 & 4.9681 & TRN & \\
\hline CHEMBL1587730 & 688171 & 4.8 & 4.7849 & TRN & \\
\hline CHEMBL1553709 & 688171 & 5.7 & 4.8565 & TRN & \\
\hline CHEMBL1343711 & 688171 & 4.7 & 4.7585 & TRN & \\
\hline CHEMBL1313409 & 688171 & 4.8 & 4.8331 & TRN & \\
\hline CHEMBL3856086 & 688171 & 4.5 & 4.7994 & TRN & \\
\hline CHEMBL1458709 & 688171 & 4.8 & 4.897 & TRN & \\
\hline CHEMBL1381998 & 688171 & 4.55 & 4.8843 & TRN & \\
\hline CHEMBL1544345 & 688171 & 5.25 & 5.0221 & TRN & \\
\hline CHEMBL1394243 & 688171 & 6.5 & 4.9927 & TST & \\
\hline CHEMBL1546136 & 688171 & 4.9 & 4.9084 & TRN & \\
\hline CHEMBL1451032 & 688171 & 4.8 & 4.845 & TRN & \\
\hline CHEMBL1397080 & 688171 & 5.05 & 4.8455 & TRN & \\
\hline CHEMBL1558380 & 688171 & 4.6 & 4.9944 & TRN & \\
\hline CHEMBL1563930 & 688171 & 6.15 & 4.8308 & TRN & \\
\hline CHEMBL1320900 & 688171 & 4.6 & 4.9594 & TRN & \\
\hline CHEMBL1552649 & 688171 & 5.45 & 4.9484 & TRN & \\
\hline CHEMBL1377056 & 688171 & 6.4 & 5.0534 & TRN & \\
\hline CHEMBL1517397 & 688171 & 4.8 & 4.958 & TST & \\
\hline CHEMBL40583 & 688171 & 4.55 & 4.9589 & TST & \\
\hline
\end{tabular}




\begin{tabular}{|c|c|c|c|c|c|}
\hline & & \multicolumn{4}{|c|}{ Supplemental Table S2.txt } \\
\hline CHEMBL1556639 & 688171 & 4.55 & 4.7965 & TRN & \\
\hline CHEMBL1981464 & 688171 & 4.95 & 4.8877 & TRN & \\
\hline CHEMBL1534474 & 688171 & 4.35 & 4.9352 & TRN & \\
\hline CHEMBL 3193889 & 688171 & 5.0 & 4.9892 & TST & \\
\hline CHEMBL1977369 & 688171 & 5.15 & 4.8097 & TRN & \\
\hline CHEMBL1407610 & 688171 & 4.6 & 4.9506 & TST & \\
\hline CHEMBL1345118 & 688171 & 4.6 & 4.748 & TRN & \\
\hline CHEMBL1385058 & 688171 & 4.55 & 4.8485 & TRN & \\
\hline CHEMBL1357389 & 688171 & 4.4 & 4.7233 & TRN & \\
\hline CHEMBL1412203 & 688171 & 5.25 & 4.9176 & TRN & \\
\hline CHEMBL1378485 & 688171 & 4.75 & 4.8724 & TRN & \\
\hline CHEMBL1497696 & 688171 & 4.65 & 4.9033 & TST & \\
\hline CHEMBL1366516 & 688171 & 4.8 & 4.7932 & TST & \\
\hline CHEMBL1539362 & 688171 & 4.75 & 4.8963 & TRN & \\
\hline CHEMBL 2004241 & 688171 & 4.85 & 4.8554 & TST & \\
\hline CHEMBL1592093 & 688171 & 4.55 & 4.812 & TRN & \\
\hline CHEMBL1416957 & 688171 & 5.25 & 4.9881 & TRN & \\
\hline CHEMBL1320385 & 688171 & 4.8 & 4.8675 & TRN & \\
\hline CHEMBL1880035 & 688171 & 4.4 & 4.9768 & TST & \\
\hline CHEMBL1522802 & 688171 & 4.55 & 4.9019 & TRN & \\
\hline CHEMBL1529086 & 688171 & 4.4 & 4.725 & TRN & \\
\hline CHEMBL1571421 & 688171 & 4.9 & 4.9336 & TRN & \\
\hline CHEMBL1545676 & 688171 & 5.5 & 4.8071 & TRN & \\
\hline CHEMBL1364357 & 688171 & 4.65 & 4.8378 & TRN & \\
\hline CHEMBL1369724 & 688171 & 4.55 & 4.9672 & TRN & \\
\hline CHEMBL1490318 & 688171 & 4.4 & 4.96399 & 99999999995 & TRN \\
\hline CHEMBL1453309 & 688171 & 4.4 & 4.792 & TST & \\
\hline CHEMBL1552178 & 688171 & 5.25 & 4.8286 & TRN & \\
\hline CHEMBL1334958 & 688171 & 4.4 & 4.9195 & TRN & \\
\hline CHEMBL1508128 & 688171 & 4.4 & 4.7556 & TRN & \\
\hline CHEMBL 234338 & 688171 & 4.7 & 4.8667 & TRN & \\
\hline CHEMBL1539363 & 688171 & 4.45 & 4.9649 & TST & \\
\hline CHEMBL3189217 & 688171 & 5.0 & 4.8835 & TRN & \\
\hline CHEMBL1500987 & 688171 & 4.7 & 4.8681 & TRN & \\
\hline CHEMBL1552241 & 688171 & 4.55 & 4.881 & TRN & \\
\hline CHEMBL1541318 & 688171 & 4.6 & 5.0441 & TST & \\
\hline CHEMBL1340155 & 688171 & 4.4 & 4.8677 & TRN & \\
\hline CHEMBL1463597 & 688171 & 4.4 & 4.9742 & TST & \\
\hline CHEMBL1369612 & 688171 & 4.45 & 4.8031 & TRN & \\
\hline CHEMBL1520248 & 688171 & 4.7 & 4.9239 & TRN & \\
\hline CHEMBL1422556 & 688171 & 4.95 & 5.0292 & TRN & \\
\hline CHEMBL1572975 & 688171 & 4.45 & 4.9937 & TRN & \\
\hline CHEMBL1570184 & 688171 & 4.4 & 4.9501 & TRN & \\
\hline CHEMBL1445694 & 688171 & 5.65 & 4.82100 & 3000000001 & TRN \\
\hline CHEMBL1434902 & 688171 & 4.55 & 4.9466 & TRN & \\
\hline CHEMBL1426073 & 688171 & 4.55 & 4.9271 & TRN & \\
\hline CHEMBL1430138 & 688171 & 4.9 & 4.9641 & TST & \\
\hline CHEMBL51931 & 688171 & 5.9 & 4.8121 & TRN & \\
\hline
\end{tabular}




\begin{tabular}{|c|c|c|c|c|c|}
\hline \multicolumn{6}{|c|}{ Supplemental Table S2.txt } \\
\hline CHEMBL1490816 & 688171 & 5.75 & 5.0319 & TRN & \\
\hline CHEMBL1356814 & 688171 & 4.65 & 4.8407 & TRN & \\
\hline CHEMBL1572588 & 688171 & 4.6 & 4.8907 & TRN & \\
\hline CHEMBL1408066 & 688171 & 4.55 & 4.7644 & TRN & \\
\hline CHEMBL1301332 & 688171 & 4.4 & 4.838 & TRN & \\
\hline CHEMBL1593344 & 688171 & 5.0 & 4.7949 & TRN & \\
\hline CHEMBL1521058 & 688171 & 5.4 & 5.0101 & TST & \\
\hline CHEMBL1477369 & 688171 & 4.75 & 4.9075 & TRN & \\
\hline CHEMBL1611805 & 688171 & 4.55 & 4.8952 & TRN & \\
\hline CHEMBL1343723 & 688171 & 4.7 & 5.0284 & TRN & \\
\hline CHEMBL1416503 & 688171 & 4.65 & 4.9568 & TRN & \\
\hline CHEMBL1402651 & 688171 & 4.45 & 4.863 & TST & \\
\hline CHEMBL3208831 & 688171 & 4.6 & 4.9885 & TRN & \\
\hline CHEMBL1581326 & 688171 & 6.45 & 4.9663 & TST & \\
\hline CHEMBL1408787 & 688171 & 4.75 & 4.8521 & TRN & \\
\hline CHEMBL1452482 & 688171 & 4.7 & 4.8763 & TRN & \\
\hline CHEMBL1597039 & 688171 & 4.7 & 4.8581 & TRN & \\
\hline CHEMBL1361785 & 688171 & 4.65 & 4.8748 & TRN & \\
\hline CHEMBL1480587 & 688171 & 4.65 & 5.1025 & TRN & \\
\hline CHEMBL1549664 & 688171 & 4.85 & 4.9611 & TRN & \\
\hline CHEMBL1570334 & 688171 & 4.55 & 4.9627 & TRN & \\
\hline CHEMBL1446945 & 688171 & 4.5 & 4.8824 & TST & \\
\hline CHEMBL1515046 & 688171 & 4.6 & 4.8053 & TRN & \\
\hline CHEMBL1607313 & 688171 & 4.95 & 4.9091 & TRN & \\
\hline CHEMBL1302841 & 688171 & 5.1 & 4.9352 & TRN & \\
\hline CHEMBL1435820 & 688171 & 4.6 & 5.05399 & 9999999999 & TRN \\
\hline CHEMBL1501645 & 688171 & 4.8 & 4.7998 & TRN & \\
\hline CHEMBL1469221 & 688171 & 4.75 & 4.8642 & TRN & \\
\hline CHEMBL1585277 & 688171 & 5.5 & 4.8928 & TST & \\
\hline CHEMBL1313724 & 688171 & 4.85 & 4.9411 & TST & \\
\hline CHEMBL481577 & 688171 & 5.0 & 4.9307 & TRN & \\
\hline CHEMBL1472763 & 688171 & 4.9 & 4.8513 & TRN & \\
\hline CHEMBL1496706 & 688171 & 6.3 & 4.934 & TRN & \\
\hline CHEMBL1460616 & 688171 & 4.45 & 4.8592 & TRN & \\
\hline CHEMBL1583408 & 688171 & 4.75 & 4.8528 & TRN & \\
\hline CHEMBL1343995 & 688171 & 4.8 & 4.8565 & TST & \\
\hline CHEMBL1571656 & 688171 & 4.45 & 4.8839 & TRN & \\
\hline CHEMBL1609871 & 688171 & 4.65 & 4.8495 & TRN & \\
\hline CHEMBL1302894 & 688171 & 4.55 & 4.7028 & TRN & \\
\hline CHEMBL3192687 & 688171 & 4.35 & 4.8966 & TRN & \\
\hline CHEMBL1481868 & 688171 & 4.55 & 4.8475 & TRN & \\
\hline CHEMBL1447590 & 688171 & 4.45 & 4.7954 & TST & \\
\hline CHEMBL1612892 & 688171 & 5.1 & 4.7428 & TRN & \\
\hline CHEMBL 3209817 & 688171 & 4.35 & 4.8583 & TST & \\
\hline CHEMBL1399458 & 688171 & 5.75 & 4.6968 & TRN & \\
\hline CHEMBL1356889 & 688171 & 5.05 & 4.8017 & TRN & \\
\hline CHEMBL1387501 & 688171 & 6.1 & 4.8952 & TST & \\
\hline CHEMBL1312215 & 688171 & 4.5 & 4.8927 & TRN & \\
\hline
\end{tabular}




\begin{tabular}{|c|c|c|c|c|c|}
\hline \multicolumn{6}{|c|}{ Supplemental Table S2.txt } \\
\hline CHEMBL1544083 & 688171 & 4.75 & 4.8545 & TRN & \\
\hline CHEMBL3208393 & 688171 & 4.35 & 4.9894 & TST & \\
\hline CHEMBL1582393 & 688171 & 6.0 & 4.9162 & TRN & \\
\hline CHEMBL1364009 & 688171 & 4.5 & 5.0731 & TRN & \\
\hline CHEMBL68908 & 688171 & 6.3 & 5.0138 & TRN & \\
\hline CHEMBL1608180 & 688171 & 4.85 & 4.9226 & TRN & \\
\hline CHEMBL1541728 & 688171 & 4.8 & 4.9137 & TRN & \\
\hline CHEMBL1393379 & 688171 & 4.55 & 4.98600 & 0000000001 & TRN \\
\hline CHEMBL1300928 & 688171 & 4.5 & 4.8635 & TRN & \\
\hline CHEMBL1452668 & 688171 & 5.0 & 4.9849 & TRN & \\
\hline CHEMBL1313845 & 688171 & 4.4 & 4.8042 & TRN & \\
\hline CHEMBL1327441 & 688171 & 4.35 & 4.8987 & TRN & \\
\hline CHEMBL494255 & 688171 & 4.85 & 4.9454 & TRN & \\
\hline CHEMBL1591861 & 688171 & 4.65 & 4.8968 & TRN & \\
\hline CHEMBL1500924 & 688171 & 5.05 & 4.7503 & TRN & \\
\hline CHEMBL1981229 & 688171 & 4.4 & 4.9855 & TRN & \\
\hline CHEMBL1597924 & 688171 & 6.9 & 4.8045 & TRN & \\
\hline CHEMBL1326364 & 688171 & 5.35 & 4.8385 & TRN & \\
\hline CHEMBL1393396 & 688171 & 6.0 & 4.9498 & TRN & \\
\hline CHEMBL1516456 & 688171 & 4.6 & 4.9664 & TST & \\
\hline CHEMBL1468795 & 688171 & 4.85 & 4.9204 & TRN & \\
\hline CHEMBL1483856 & 688171 & 4.35 & 4.852 & TRN & \\
\hline CHEMBL 3211874 & 688171 & 5.7 & 4.9499 & TRN & \\
\hline CHEMBL1378891 & 688171 & 4.85 & 4.9015 & TRN & \\
\hline CHEMBL404845 & 688171 & 4.6 & 4.9517 & TRN & \\
\hline CHEMBL1326229 & 688171 & 4.4 & 4.9186 & TST & \\
\hline CHEMBL1416366 & 688171 & 4.35 & 4.8266 & TRN & \\
\hline CHEMBL 1605210 & 688171 & 5.15 & 4.7679 & TST & \\
\hline CHEMBL1402602 & 688171 & 4.95 & 4.8142 & TRN & \\
\hline CHEMBL1342568 & 688171 & 4.7 & 4.8679 & TRN & \\
\hline CHEMBL1516122 & 688171 & 5.3 & 4.9979 & TRN & \\
\hline CHEMBL3194606 & 688171 & 4.4 & 4.8871 & TRN & \\
\hline CHEMBL1408359 & 688171 & 4.45 & 4.8059 & TRN & \\
\hline CHEMBL1588461 & 688171 & 5.3 & 5.0298 & TRN & \\
\hline CHEMBL490551 & 688171 & 5.0 & 4.9471 & TRN & \\
\hline CHEMBL1437350 & 688171 & 5.55 & 4.7921 & TRN & \\
\hline CHEMBL1465069 & 688171 & 4.4 & 4.7693 & TST & \\
\hline CHEMBL1560314 & 688171 & 5.6 & 4.9018 & TRN & \\
\hline CHEMBL3195541 & 688171 & 5.65 & 4.8703 & TRN & \\
\hline CHEMBL1625031 & 688171 & 4.35 & 5.0088 & TRN & \\
\hline CHEMBL1441738 & 688171 & 4.8 & 4.802 & TST & \\
\hline CHEMBL 1375326 & 688171 & 4.95 & 5.0304 & TRN & \\
\hline CHEMBL1338819 & 688171 & 4.6 & 4.8923 & TRN & \\
\hline CHEMBL1576255 & 688171 & 4.35 & 4.9071 & TRN & \\
\hline CHEMBL1346474 & 688171 & 4.65 & 4.949 & TRN & \\
\hline CHEMBL1374385 & 688171 & 4.7 & 4.9448 & TRN & \\
\hline CHEMBL1603074 & 688171 & 5.05 & 4.7789 & TRN & \\
\hline CHEMBL1338236 & 688171 & 4.55 & 4.8359 & TRN & \\
\hline
\end{tabular}




\begin{tabular}{|c|c|c|c|c|c|}
\hline \multicolumn{6}{|c|}{ Supplemental Table S2.txt } \\
\hline CHEMBL1478423 & 688171 & 4.7 & 4.8944 & TRN & \\
\hline CHEMBL1532114 & 688171 & 4.75 & 4.8124 & TRN & \\
\hline CHEMBL1523568 & 688171 & 4.4 & 4.9332 & TRN & \\
\hline CHEMBL1413115 & 688171 & 5.1 & 4.9692 & TRN & \\
\hline CHEMBL1417631 & 688171 & 4.6 & 4.8106 & TRN & \\
\hline CHEMBL1318501 & 688171 & 7.1002 & 4.8618 & TRN & \\
\hline CHEMBL1359895 & 688171 & 4.75 & 4.9322 & TRN & \\
\hline CHEMBL1599289 & 688171 & 4.8 & 4.9107 & TRN & \\
\hline CHEMBL3196904 & 688171 & 5.0 & 4.9343 & TST & \\
\hline CHEMBL1497307 & 688171 & 5.95 & 4.7684 & TST & \\
\hline CHEMBL1500397 & 688171 & 5.0 & 4.8647 & TST & \\
\hline CHEMBL1346937 & 688171 & 6.4 & 4.9265 & TRN & \\
\hline CHEMBL1302994 & 688171 & 6.25 & 5.0501 & TST & \\
\hline CHEMBL1312986 & 688171 & 4.4 & 5.002 & TRN & \\
\hline CHEMBL1523198 & 688171 & 4.8 & 4.9818 & TRN & \\
\hline CHEMBL1521620 & 688171 & 4.75 & 4.8172 & TRN & \\
\hline CHEMBL1447308 & 688171 & 4.8 & 4.8822 & TRN & \\
\hline CHEMBL1605918 & 688171 & 7.2 & 5.0659 & TRN & \\
\hline CHEMBL1573892 & 688171 & 4.5 & 4.8578 & TRN & \\
\hline CHEMBL1561059 & 688171 & 4.6 & 5.0289 & TRN & \\
\hline CHEMBL1555310 & 688171 & 4.9 & 4.8018 & TRN & \\
\hline CHEMBL1435076 & 688171 & 4.65 & 4.9044 & TRN & \\
\hline CHEMBL1318632 & 688171 & 5.25 & 4.9153 & TRN & \\
\hline CHEMBL1300675 & 688171 & 5.25 & 4.9596 & TRN & \\
\hline CHEMBL1306270 & 688171 & 6.6 & 4.8634 & TST & \\
\hline CHEMBL1593454 & 688171 & 4.75 & 4.7944 & TRN & \\
\hline CHEMBL1487520 & 688171 & 5.05 & 4.7686 & TRN & \\
\hline CHEMBL1435584 & 688171 & 4.35 & 4.9515 & TRN & \\
\hline CHEMBL1343081 & 688171 & 4.6 & 4.8346 & TRN & \\
\hline CHEMBL1483028 & 688171 & 5.6 & 4.8943 & TST & \\
\hline CHEMBL1323854 & 688171 & 4.8 & 4.8562 & TRN & \\
\hline CHEMBL3190056 & 688171 & 4.55 & 5.0663 & TRN & \\
\hline CHEMBL3199083 & 688171 & 5.55 & 5.0619 & TRN & \\
\hline CHEMBL1357420 & 688171 & 4.35 & 4.8743 & TST & \\
\hline CHEMBL1338115 & 688171 & 4.9 & 4.8135 & TRN & \\
\hline CHEMBL 245265 & 688171 & 5.05 & 4.8446 & TRN & \\
\hline CHEMBL1374714 & 688171 & 4.5 & 4.9685 & TRN & \\
\hline CHEMBL1303553 & 688171 & 4.7 & 4.80399 & 9999999999 & TRN \\
\hline CHEMBL1344097 & 688171 & 4.4 & 4.7652 & TRN & \\
\hline CHEMBL1570371 & 688171 & 6.1 & 4.8722 & TRN & \\
\hline CHEMBL1480989 & 688171 & 7.3002 & 4.91100 & 00000000005 & TRN \\
\hline CHEMBL1582335 & 688171 & 7.6003 & 4.9091 & TRN & \\
\hline CHEMBL1427610 & 688171 & 4.9 & 4.7769 & TST & \\
\hline CHEMBL1575996 & 688171 & 6.7001 & 4.8961 & TRN & \\
\hline CHEMBL1397889 & 688171 & 4.35 & 5.0406 & TRN & \\
\hline CHEMBL3193946 & 688171 & 4.4 & 4.9163 & TST & \\
\hline CHEMBL1330485 & 688171 & 4.35 & 5.0659 & TRN & \\
\hline CHEMBL1588363 & 688171 & 4.5 & 4.8913 & TRN & \\
\hline
\end{tabular}




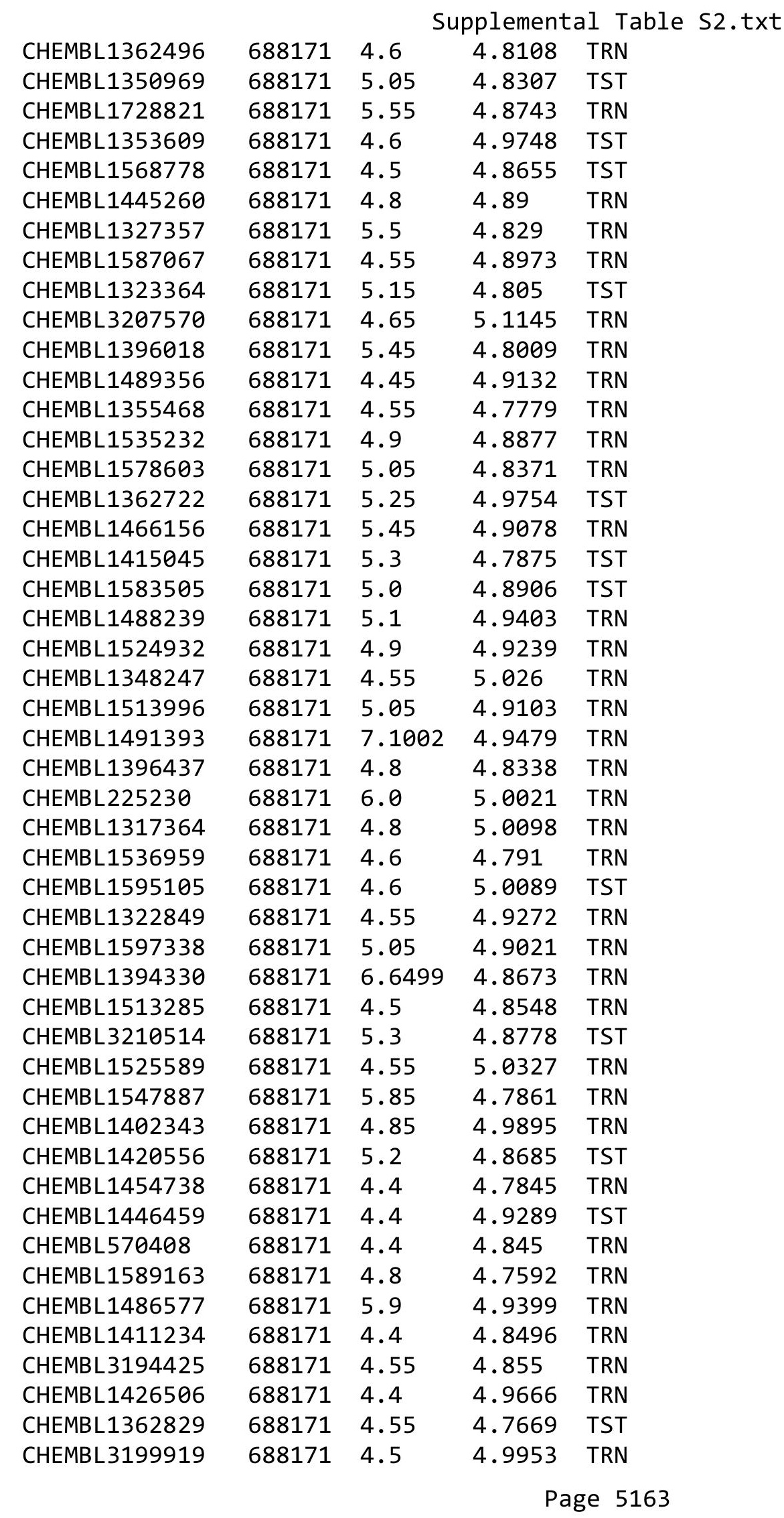




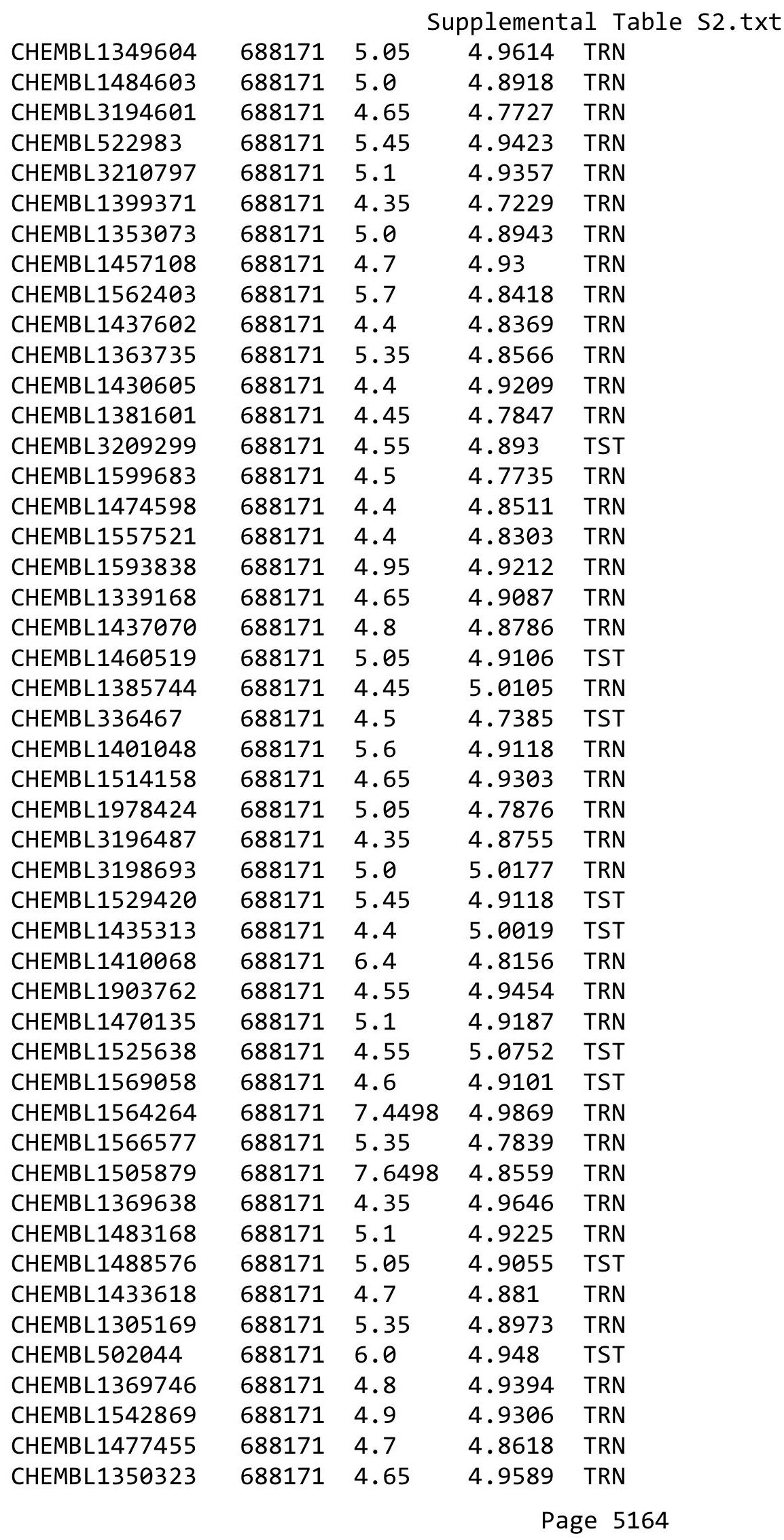




\begin{tabular}{|c|c|c|c|c|}
\hline \multicolumn{5}{|c|}{ Supplemental Table S2.txt } \\
\hline CHEMBL1490169 & 688171 & 4.5 & 4.6909 & TRN \\
\hline CHEMBL1546285 & 688171 & 4.4 & 4.8944 & TST \\
\hline CHEMBL1511501 & 688171 & 5.1 & 5.0186 & TRN \\
\hline CHEMBL1481191 & 688171 & 5.6 & 4.9865 & TRN \\
\hline CHEMBL1308600 & 688171 & 4.8 & 4.8709 & TRN \\
\hline CHEMBL600956 & 688171 & 4.35 & 4.8832 & TRN \\
\hline CHEMBL1483627 & 688171 & 4.7 & 4.8582 & TRN \\
\hline CHEMBL1602815 & 688171 & 4.95 & 4.8323 & TST \\
\hline CHEMBL1472873 & 688171 & 4.95 & 4.8644 & TRN \\
\hline CHEMBL1459531 & 688171 & 4.6 & 5.0545 & TRN \\
\hline CHEMBL1470233 & 688171 & 4.4 & 4.8383 & TRN \\
\hline CHEMBL1985090 & 688171 & 4.45 & 5.0489 & TRN \\
\hline CHEMBL1377911 & 688171 & 5.4 & 4.9897 & TST \\
\hline CHEMBL1541448 & 688171 & 5.85 & 4.7813 & TRN \\
\hline CHEMBL1339446 & 688171 & 4.7 & 4.9966 & TST \\
\hline CHEMBL1434393 & 688171 & 4.75 & 4.8656 & TRN \\
\hline CHEMBL80658 & 688171 & 4.75 & 4.7686 & TRN \\
\hline CHEMBL1487567 & 688171 & 4.75 & 5.1215 & TRN \\
\hline CHEMBL1332013 & 688171 & 5.45 & 4.9786 & TRN \\
\hline CHEMBL1479402 & 688171 & 5.3 & 4.8318 & TRN \\
\hline CHEMBL1421612 & 688171 & 4.5 & 4.8207 & TRN \\
\hline CHEMBL470181 & 688171 & 4.4 & 4.9338 & TST \\
\hline CHEMBL1401639 & 688171 & 5.4 & 4.8467 & TRN \\
\hline CHEMBL1472647 & 688171 & 4.75 & 4.9182 & TRN \\
\hline CHEMBL3211521 & 688171 & 4.65 & 4.8421 & TRN \\
\hline CHEMBL1611689 & 688171 & 4.65 & 4.9408 & TST \\
\hline CHEMBL1306138 & 688171 & 4.4 & 4.8115 & TRN \\
\hline CHEMBL1389025 & 688171 & 5.0 & 4.9084 & TRN \\
\hline CHEMBL1444726 & 688171 & 5.0 & 4.9733 & TRN \\
\hline CHEMBL1591639 & 688171 & 4.45 & 4.8772 & TRN \\
\hline CHEMBL3208293 & 688171 & 4.65 & 4.8307 & TST \\
\hline CHEMBL1361176 & 688171 & 5.1 & 4.9586 & TRN \\
\hline CHEMBL1421750 & 688171 & 4.4 & 4.8762 & TRN \\
\hline CHEMBL1551587 & 688171 & 4.55 & 4.8614 & TRN \\
\hline CHEMBL1425334 & 688171 & 5.05 & 4.9485 & TST \\
\hline CHEMBL1351950 & 688171 & 5.15 & 4.8898 & TRN \\
\hline CHEMBL1371271 & 688171 & 4.8 & 4.9264 & TRN \\
\hline CHEMBL1337283 & 688171 & 5.25 & 4.9533 & TRN \\
\hline CHEMBL1464738 & 688171 & 4.85 & 4.9967 & TRN \\
\hline CHEMBL1475990 & 688171 & 4.5 & 4.9408 & TRN \\
\hline CHEMBL1479942 & 688171 & 5.0 & 4.8587 & TRN \\
\hline CHEMBL1463663 & 688171 & 4.7 & 4.8444 & TST \\
\hline CHEMBL1337132 & 688171 & 4.4 & 4.8419 & TRN \\
\hline CHEMBL1505267 & 688171 & 4.4 & 4.8809 & TRN \\
\hline CHEMBL1553483 & 688171 & 6.7001 & 4.8087 & TRN \\
\hline CHEMBL 2007057 & 688171 & 4.55 & 4.905 & TRN \\
\hline CHEMBL1531073 & 688171 & 4.6 & 4.8352 & TRN \\
\hline CHEMBL1964556 & 688171 & 4.5 & 4.9585 & TRN \\
\hline
\end{tabular}




\begin{tabular}{|c|c|c|c|c|}
\hline & & & pplemen & \\
\hline CHEMBL1603434 & 688171 & 5.95 & 4.9429 & TRN \\
\hline CHEMBL1572432 & 688171 & 5.1 & 4.8147 & TRN \\
\hline CHEMBL1435597 & 688171 & 4.8 & 4.9749 & TRN \\
\hline CHEMBL1514449 & 688171 & 4.6 & 4.9027 & TRN \\
\hline CHEMBL1548078 & 688171 & 4.65 & 5.0779 & TRN \\
\hline CHEMBL3191278 & 688171 & 4.6 & 4.9129 & TST \\
\hline CHEMBL1371457 & 688171 & 4.9 & 4.8725 & TRN \\
\hline CHEMBL1396770 & 688171 & 5.9 & 4.9347 & TRN \\
\hline CHEMBL1539282 & 688171 & 4.75 & 4.9442 & TST \\
\hline CHEMBL1554048 & 688171 & 4.75 & 5.0982 & TRN \\
\hline CHEMBL1605698 & 688171 & 5.15 & 4.7479 & TRN \\
\hline CHEMBL1378223 & 688171 & 4.85 & 4.8932 & TST \\
\hline CHEMBL1523245 & 688171 & 5.3 & 4.8752 & TRN \\
\hline CHEMBL1324642 & 688171 & 5.5 & 5.07 & TST \\
\hline CHEMBL1318081 & 688171 & 5.1 & 5.0151 & TRN \\
\hline CHEMBL1384103 & 688171 & 4.5 & 4.8025 & TRN \\
\hline CHEMBL1411970 & 688171 & 4.85 & 4.9818 & TRN \\
\hline CHEMBL1330963 & 688171 & 4.4 & 4.8487 & TRN \\
\hline CHEMBL1339315 & 688171 & 4.6 & 4.9769 & TST \\
\hline CHEMBL1363354 & 688171 & 4.9 & 4.862 & TRN \\
\hline CHEMBL1494006 & 688171 & 6.2 & 5.0042 & TRN \\
\hline CHEMBL608555 & 688171 & 5.05 & 5.0219 & TST \\
\hline CHEMBL1422470 & 688171 & 4.6 & 4.863 & TRN \\
\hline CHEMBL3210006 & 688171 & 4.4 & 5.0076 & TRN \\
\hline CHEMBL1460748 & 688171 & 4.6 & 4.9297 & TST \\
\hline CHEMBL1351293 & 688171 & 4.75 & 4.9166 & TRN \\
\hline CHEMBL1474597 & 688171 & 5.05 & 4.8322 & TRN \\
\hline CHEMBL1562254 & 688171 & 5.05 & 5.0225 & TST \\
\hline CHEMBL 1353216 & 688171 & 4.35 & 4.7801 & TRN \\
\hline CHEMBL1486011 & 688171 & 4.85 & 4.8977 & TST \\
\hline CHEMBL1510040 & 688171 & 4.7 & 4.8373 & TRN \\
\hline CHEMBL1319191 & 688171 & 4.65 & 4.7931 & TST \\
\hline CHEMBL1371835 & 688171 & 4.8 & 4.9959 & TRN \\
\hline CHEMBL1466193 & 688171 & 4.4 & 4.8548 & TRN \\
\hline CHEMBL1408037 & 688171 & 4.5 & 4.8993 & TRN \\
\hline CHEMBL1498822 & 688171 & 4.75 & 4.8156 & TRN \\
\hline CHEMBL1449728 & 688171 & 4.35 & 4.9673 & TRN \\
\hline CHEMBL1316298 & 688171 & 4.95 & 4.9338 & TRN \\
\hline CHEMBL1343839 & 688171 & 5.5 & 5.0165 & TRN \\
\hline CHEMBL1593528 & 688171 & 4.9 & 4.8653 & TRN \\
\hline CHEMBL1384172 & 688171 & 4.95 & 4.8222 & TRN \\
\hline CHEMBL1399269 & 688171 & 5.1 & 4.8742 & TRN \\
\hline CHEMBL1442939 & 688171 & 4.7 & 4.8019 & TRN \\
\hline CHEMBL1453299 & 688171 & 4.6 & 4.7865 & TRN \\
\hline CHEMBL1432890 & 688171 & 5.8 & 5.0187 & TST \\
\hline CHEMBL1523421 & 688171 & 5.05 & 4.8926 & TRN \\
\hline CHEMBL1522129 & 688171 & 4.8 & 4.7193 & TRN \\
\hline CHEMBL1561726 & 688171 & 4.5 & 4.9054 & TRN \\
\hline
\end{tabular}




\begin{tabular}{|c|c|c|c|c|c|}
\hline \multicolumn{6}{|c|}{ Supplemental Table S2.txt } \\
\hline CHEMBL1339693 & 688171 & 6.25 & 5.0589 & TST & \\
\hline CHEMBL1452572 & 688171 & 4.85 & 4.9176 & TRN & \\
\hline CHEMBL1608578 & 688171 & 4.5 & 4.8721 & TST & \\
\hline CHEMBL1584999 & 688171 & 5.0 & 4.8794 & TRN & \\
\hline CHEMBL1387801 & 688171 & 4.4 & 4.853 & TRN & \\
\hline CHEMBL1611753 & 688171 & 4.75 & 4.8548 & TRN & \\
\hline CHEMBL1493223 & 688171 & 4.9 & 4.9587 & TRN & \\
\hline CHEMBL1393502 & 688171 & 5.25 & 4.8048 & TRN & \\
\hline CHEMBL1497670 & 688171 & 4.4 & 4.9732 & TST & \\
\hline CHEMBL1561782 & 688171 & 4.35 & 4.9217 & TST & \\
\hline CHEMBL1487717 & 688171 & 4.75 & 4.9221 & TRN & \\
\hline CHEMBL1447062 & 688171 & 5.25 & 4.9306 & TRN & \\
\hline CHEMBL1600550 & 688171 & 4.8 & 5.0096 & TRN & \\
\hline CHEMBL1531537 & 688171 & 4.8 & 4.8979 & TST & \\
\hline CHEMBL1605229 & 688171 & 5.05 & 4.9049 & TRN & \\
\hline CHEMBL1547695 & 688171 & 4.35 & 4.9062 & TRN & \\
\hline CHEMBL1364552 & 688171 & 4.9 & 4.8179 & TRN & \\
\hline CHEMBL1412080 & 688171 & 4.45 & 4.8787 & TRN & \\
\hline CHEMBL1445397 & 688171 & 5.0 & 4.9507 & TST & \\
\hline CHEMBL3191236 & 688171 & 4.7 & 4.9595 & TRN & \\
\hline CHEMBL1391176 & 688171 & 4.35 & 4.8748 & TRN & \\
\hline CHEMBL1420623 & 688171 & 5.3 & 4.7888 & TST & \\
\hline CHEMBL1492462 & 688171 & 4.5 & 4.8441 & TST & \\
\hline CHEMBL 3192112 & 688171 & 4.4 & 4.8965 & TRN & \\
\hline CHEMBL1483348 & 688171 & 4.8 & 4.8788 & TRN & \\
\hline CHEMBL1430242 & 688171 & 4.35 & 4.8732 & TST & \\
\hline CHEMBL1374658 & 688171 & 5.1 & 4.941 & TST & \\
\hline CHEMBL1396088 & 688171 & 4.9 & 4.8142 & TRN & \\
\hline CHEMBL1497250 & 688171 & 4.4 & 4.8176 & TRN & \\
\hline CHEMBL1580966 & 688171 & 4.4 & 4.7893 & TRN & \\
\hline CHEMBL1476463 & 688171 & 4.6 & 4.9416 & TRN & \\
\hline CHEMBL3207999 & 688171 & 4.9 & 4.9891 & TST & \\
\hline CHEMBL1600868 & 688171 & 4.95 & 4.90300 & 00000000005 & TRN \\
\hline CHEMBL1379136 & 688171 & 4.75 & 4.8476 & TST & \\
\hline CHEMBL1342213 & 688171 & 5.0 & 4.8457 & TRN & \\
\hline CHEMBL1590224 & 688171 & 4.9 & 4.8564 & TST & \\
\hline CHEMBL1513213 & 688171 & 4.65 & 4.9041 & TRN & \\
\hline CHEMBL3193540 & 688171 & 4.6 & 4.8586 & TRN & \\
\hline CHEMBL1556828 & 688171 & 5.8 & 5.102 & TRN & \\
\hline CHEMBL1300685 & 688171 & 4.55 & 4.8229 & TRN & \\
\hline CHEMBL1592242 & 688171 & 4.4 & 4.9148 & TRN & \\
\hline CHEMBL3214165 & 688171 & 4.45 & 5.0324 & TST & \\
\hline CHEMBL1580957 & 688171 & 6.45 & 4.9342 & TST & \\
\hline CHEMBL1602717 & 688171 & 4.5 & 4.848 & TRN & \\
\hline CHEMBL1601672 & 688171 & 4.65 & 4.8256 & TRN & \\
\hline CHEMBL1563829 & 688171 & 5.25 & 4.9671 & TST & \\
\hline CHEMBL1542074 & 688171 & 5.4 & 4.8749 & TST & \\
\hline CHEMBL1434362 & 688171 & 4.4 & 5.0265 & TRN & \\
\hline
\end{tabular}




\begin{tabular}{|c|c|c|c|c|c|}
\hline \multicolumn{6}{|c|}{ Supplemental Table S2.txt } \\
\hline CHEMBL1487273 & 688171 & 5.55 & 4.8272 & TRN & \\
\hline CHEMBL1408468 & 688171 & 4.4 & 4.7732 & TRN & \\
\hline CHEMBL1442767 & 688171 & 5.65 & 4.9149 & TRN & \\
\hline CHEMBL1370235 & 688171 & 4.65 & 4.8056 & TST & \\
\hline CHEMBL1446085 & 688171 & 4.8 & 4.9351 & TRN & \\
\hline CHEMBL1375687 & 688171 & 4.45 & 4.8684 & TRN & \\
\hline CHEMBL1609667 & 688171 & 4.75 & 4.8802 & TRN & \\
\hline CHEMBL1376783 & 688171 & 6.15 & 4.8635 & TRN & \\
\hline CHEMBL1434198 & 688171 & 5.95 & 4.9463 & TRN & \\
\hline CHEMBL1430822 & 688171 & 4.4 & 4.848 & TRN & \\
\hline CHEMBL1378070 & 688171 & 6.05 & 5.0604 & TRN & \\
\hline CHEMBL1481813 & 688171 & 4.5 & 4.7138 & TRN & \\
\hline CHEMBL1580690 & 688171 & 4.55 & 5.11600 & 00000000005 & TRN \\
\hline CHEMBL1595162 & 688171 & 5.45 & 4.8345 & TRN & \\
\hline CHEMBL1549735 & 688171 & 4.75 & 4.8019 & TRN & \\
\hline CHEMBL1394122 & 688171 & 4.4 & 4.9195 & TRN & \\
\hline CHEMBL1605324 & 688171 & 5.3 & 4.8548 & TST & \\
\hline CHEMBL1552602 & 688171 & 4.55 & 4.8181 & TST & \\
\hline CHEMBL1506241 & 688171 & 4.4 & 4.9952 & TRN & \\
\hline CHEMBL1413584 & 688171 & 4.45 & 4.8737 & TRN & \\
\hline CHEMBL1336774 & 688171 & 4.45 & 4.7971 & TRN & \\
\hline CHEMBL1529077 & 688171 & 5.55 & 4.881 & TRN & \\
\hline CHEMBL1593852 & 688171 & 4.9 & 4.975 & TST & \\
\hline CHEMBL1384801 & 688171 & 4.95 & 4.9115 & TRN & \\
\hline CHEMBL1478395 & 688171 & 7.6003 & 4.7734 & TST & \\
\hline CHEMBL1445503 & 688171 & 4.4 & 5.0298 & TRN & \\
\hline CHEMBL 2007403 & 688171 & 4.6 & 4.9686 & TRN & \\
\hline CHEMBL1466339 & 688171 & 6.95 & 4.9548 & TST & \\
\hline CHEMBL1562963 & 688171 & 4.85 & 4.7816 & TRN & \\
\hline CHEMBL1499306 & 688171 & 5.15 & 4.8652 & TRN & \\
\hline CHEMBL1300638 & 688171 & 5.6 & 4.9499 & TRN & \\
\hline CHEMBL1469000 & 688171 & 4.7 & 5.0488 & TST & \\
\hline CHEMBL1408402 & 688171 & 4.35 & 4.7751 & TRN & \\
\hline CHEMBL1580414 & 688171 & 4.7 & 4.9315 & TRN & \\
\hline CHEMBL15192 & 688171 & 6.0 & 4.815 & TST & \\
\hline CHEMBL1436980 & 688171 & 4.7 & 4.9109 & TRN & \\
\hline CHEMBL1358040 & 688171 & 5.1 & 4.7853 & TRN & \\
\hline CHEMBL1495504 & 688171 & 4.7 & 4.742 & TRN & \\
\hline CHEMBL1505467 & 688171 & 4.5 & 4.8607 & TRN & \\
\hline CHEMBL1552177 & 688171 & 4.85 & 4.7891 & TRN & \\
\hline CHEMBL1352560 & 688171 & 5.5 & 4.865 & TST & \\
\hline CHEMBL1548535 & 688171 & 5.05 & 4.9635 & TRN & \\
\hline CHEMBL1425432 & 688171 & 4.4 & 4.9407 & TRN & \\
\hline CHEMBL1516954 & 688171 & 6.15 & 5.005 & TRN & \\
\hline CHEMBL1396837 & 688171 & 4.55 & 4.9407 & TRN & \\
\hline CHEMBL1495094 & 688171 & 4.6 & 4.766 & TRN & \\
\hline CHEMBL1453822 & 688171 & 4.85 & 5.0188 & TRN & \\
\hline CHEMBL1255659 & 688171 & 4.85 & 4.8551 & TST & \\
\hline
\end{tabular}




\begin{tabular}{|c|c|c|c|c|c|}
\hline \multicolumn{6}{|c|}{ Supplemental Table s2.txt } \\
\hline CHEMBL1315001 & 688171 & 4.75 & 4.8948 & TRN & \\
\hline CHEMBL1597097 & 688171 & 5.95 & 5.0165 & TRN & \\
\hline CHEMBL1408637 & 688171 & 4.8 & 4.8198 & TRN & \\
\hline CHEMBL3209991 & 688171 & 4.8 & 4.9989 & TRN & \\
\hline CHEMBL1597368 & 688171 & 4.85 & 4.8313 & TRN & \\
\hline CHEMBL1376612 & 688171 & 4.7 & 4.7339 & TRN & \\
\hline CHEMBL1592148 & 688171 & 4.85 & 4.865 & TRN & \\
\hline CHEMBL1331573 & 688171 & 5.65 & 4.9145 & TST & \\
\hline CHEMBL1319740 & 688171 & 7.1002 & 4.9612 & TST & \\
\hline CHEMBL1512091 & 688171 & 4.8 & 4.9209 & TRN & \\
\hline CHEMBL1564354 & 688171 & 4.85 & 4.8904 & TRN & \\
\hline CHEMBL1433451 & 688171 & 5.55 & 4.9598 & TRN & \\
\hline CHEMBL1531555 & 688171 & 4.35 & 4.8234 & TRN & \\
\hline CHEMBL1355076 & 688171 & 4.85 & 4.8454 & TRN & \\
\hline CHEMBL1463595 & 688171 & 4.4 & 4.7127 & TRN & \\
\hline CHEMBL1330171 & 688171 & 4.55 & 4.8546 & TRN & \\
\hline CHEMBL1340266 & 688171 & 4.7 & 4.7586 & TRN & \\
\hline CHEMBL1308302 & 688171 & 4.35 & 4.8037 & TRN & \\
\hline CHEMBL1484378 & 688171 & 5.0 & 4.8467 & TRN & \\
\hline CHEMBL3199050 & 688171 & 4.9 & 4.8666 & TRN & \\
\hline CHEMBL1396103 & 688171 & 4.4 & 4.7234 & TRN & \\
\hline CHEMBL1525559 & 688171 & 4.7 & 4.9376 & TRN & \\
\hline CHEMBL1269202 & 688171 & 5.0 & 4.8261 & TST & \\
\hline CHEMBL1498495 & 688171 & 4.6 & 4.9442 & TRN & \\
\hline CHEMBL1414743 & 688171 & 4.65 & 4.8487 & TRN & \\
\hline CHEMBL1601509 & 688171 & 4.55 & 4.8554 & TRN & \\
\hline CHEMBL1589160 & 688171 & 4.4 & 4.77800 & 00000000005 & TST \\
\hline CHEMBL1535676 & 688171 & 4.5 & 4.8568 & TRN & \\
\hline CHEMBL1512184 & 688171 & 4.8 & 4.9511 & TRN & \\
\hline CHEMBL1567567 & 688171 & 4.75 & 4.8792 & TRN & \\
\hline CHEMBL3185655 & 688171 & 4.85 & 4.8479 & TST & \\
\hline CHEMBL3208032 & 688171 & 4.9 & 4.7977 & TRN & \\
\hline CHEMBL1357058 & 688171 & 5.05 & 4.8752 & TRN & \\
\hline CHEMBL1314318 & 688171 & 4.5 & 4.9189 & TRN & \\
\hline CHEMBL1325198 & 688171 & 4.4 & 4.9466 & TRN & \\
\hline CHEMBL1343189 & 688171 & 4.35 & 4.7673 & TST & \\
\hline CHEMBL1428558 & 688171 & 4.95 & 5.0431 & TST & \\
\hline CHEMBL3196076 & 688171 & 4.6 & 4.9305 & TRN & \\
\hline CHEMBL 3207415 & 688171 & 5.3 & 4.9432 & TRN & \\
\hline CHEMBL1372322 & 688171 & 4.7 & 4.9881 & TRN & \\
\hline CHEMBL1365553 & 688171 & 5.0 & 4.8536 & TST & \\
\hline CHEMBL1516049 & 688171 & 5.55 & 5.0335 & TST & \\
\hline CHEMBL1507683 & 688171 & 5.2 & 4.7564 & TRN & \\
\hline CHEMBL1325020 & 688171 & 4.35 & 4.8978 & TRN & \\
\hline CHEMBL3191188 & 688171 & 4.35 & 4.8361 & TRN & \\
\hline CHEMBL1422457 & 688171 & 5.7 & 4.981 & TRN & \\
\hline CHEMBL1608878 & 688171 & 4.9 & 4.9091 & TRN & \\
\hline CHEMBL1398693 & 688171 & 4.8 & 4.853 & TST & \\
\hline
\end{tabular}




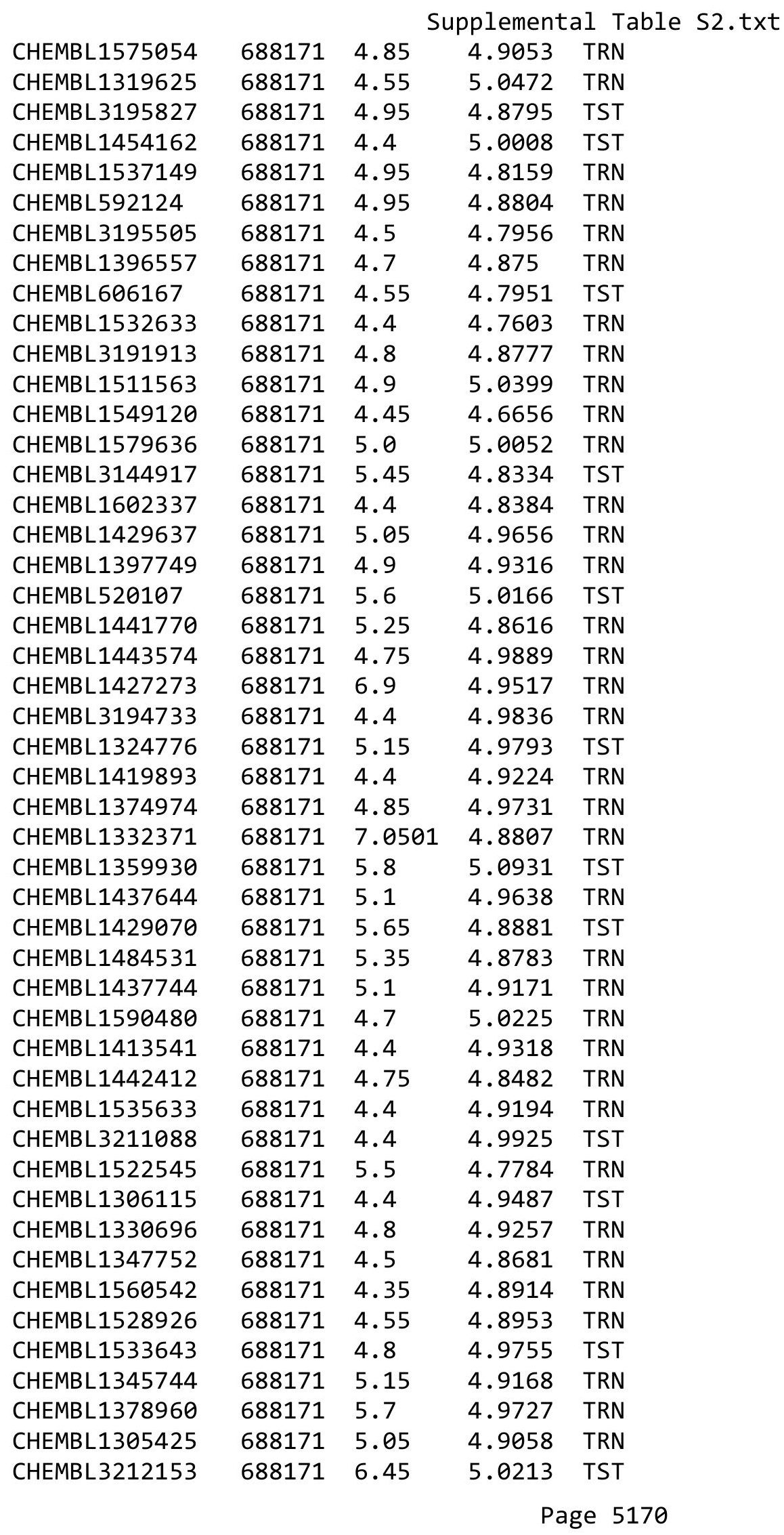




\begin{tabular}{|c|c|c|c|c|}
\hline \multicolumn{5}{|c|}{ Supplemental Table S2.txt } \\
\hline CHEMBL1256797 & 688171 & 5.1 & 5.0684 & TST \\
\hline CHEMBL1549629 & 688171 & 4.4 & 4.9388 & TRN \\
\hline CHEMBL1525947 & 688171 & 4.7 & 4.9366 & TRN \\
\hline CHEMBL1597854 & 688171 & 5.5 & 4.8234 & TRN \\
\hline CHEMBL1466492 & 688171 & 4.6 & 4.7879 & TRN \\
\hline CHEMBL1371940 & 688171 & 5.0 & 4.8949 & TST \\
\hline CHEMBL1369364 & 688171 & 5.75 & 4.9937 & TRN \\
\hline CHEMBL1353428 & 688171 & 4.5 & 4.9704 & TRN \\
\hline CHEMBL1346672 & 688171 & 4.7 & 4.8143 & TRN \\
\hline CHEMBL3199814 & 688171 & 4.6 & 4.8413 & TRN \\
\hline CHEMBL1544665 & 688171 & 5.5 & 4.9674 & TST \\
\hline CHEMBL1327893 & 688171 & 4.65 & 4.9521 & TRN \\
\hline CHEMBL1571350 & 688171 & 4.35 & 4.8899 & TRN \\
\hline CHEMBL1533127 & 688171 & 4.4 & 4.8524 & TRN \\
\hline CHEMBL1358529 & 688171 & 5.15 & 5.0696 & TRN \\
\hline CHEMBL1309568 & 688171 & 4.9 & 4.8804 & TST \\
\hline CHEMBL1352555 & 688171 & 6.0 & 4.8707 & TST \\
\hline CHEMBL1367076 & 688171 & 4.6 & 4.8565 & TRN \\
\hline CHEMBL1592542 & 688171 & 5.45 & 4.9085 & TST \\
\hline CHEMBL3210706 & 688171 & 5.05 & 5.027 & TRN \\
\hline CHEMBL1332860 & 688171 & 5.55 & 4.8362 & TRN \\
\hline CHEMBL1517493 & 688171 & 4.35 & 4.9051 & TST \\
\hline CHEMBL1432137 & 688171 & 5.45 & 4.908 & TRN \\
\hline CHEMBL1490148 & 688171 & 4.45 & 4.7368 & TRN \\
\hline CHEMBL3192901 & 688171 & 6.0 & 4.8412 & TRN \\
\hline CHEMBL1324518 & 688171 & 5.15 & 4.9418 & TRN \\
\hline CHEMBL1606751 & 688171 & 4.65 & 5.0083 & TST \\
\hline CHEMBL1381179 & 688171 & 4.8 & 4.7758 & TST \\
\hline CHEMBL1384537 & 688171 & 4.85 & 4.8654 & TRN \\
\hline CHEMBL1471575 & 688171 & 6.0 & 4.9393 & TRN \\
\hline CHEMBL1304032 & 688171 & 4.5 & 5.0069 & TRN \\
\hline CHEMBL1444046 & 688171 & 5.55 & 4.9326 & TRN \\
\hline CHEMBL1394360 & 688171 & 4.85 & 4.9047 & TRN \\
\hline CHEMBL1180496 & 688171 & 4.9 & 4.9449 & TST \\
\hline CHEMBL1470839 & 688171 & 4.8 & 4.8141 & TRN \\
\hline CHEMBL1436084 & 688171 & 4.75 & 4.9405 & TRN \\
\hline CHEMBL1512186 & 688171 & 5.6 & 4.9549 & TST \\
\hline CHEMBL1324404 & 688171 & 5.85 & 5.0368 & TRN \\
\hline CHEMBL1533415 & 688171 & 4.4 & 4.8765 & TRN \\
\hline CHEMBL1312190 & 688171 & 4.4 & 4.9162 & TST \\
\hline CHEMBL1613427 & 688171 & 5.0 & 4.8472 & TRN \\
\hline CHEMBL3192880 & 688171 & 4.35 & 4.9757 & TRN \\
\hline CHEMBL1383799 & 688171 & 5.2 & 4.9506 & TRN \\
\hline CHEMBL1325071 & 688171 & 6.95 & 4.7823 & TST \\
\hline CHEMBL1551927 & 688171 & 4.4 & 4.8115 & TRN \\
\hline CHEMBL1548815 & 688171 & 4.85 & 4.9072 & TRN \\
\hline CHEMBL1602058 & 688171 & 4.4 & 4.9731 & TRN \\
\hline CHEMBL1419590 & 688171 & 6.0 & 4.8481 & TRN \\
\hline
\end{tabular}




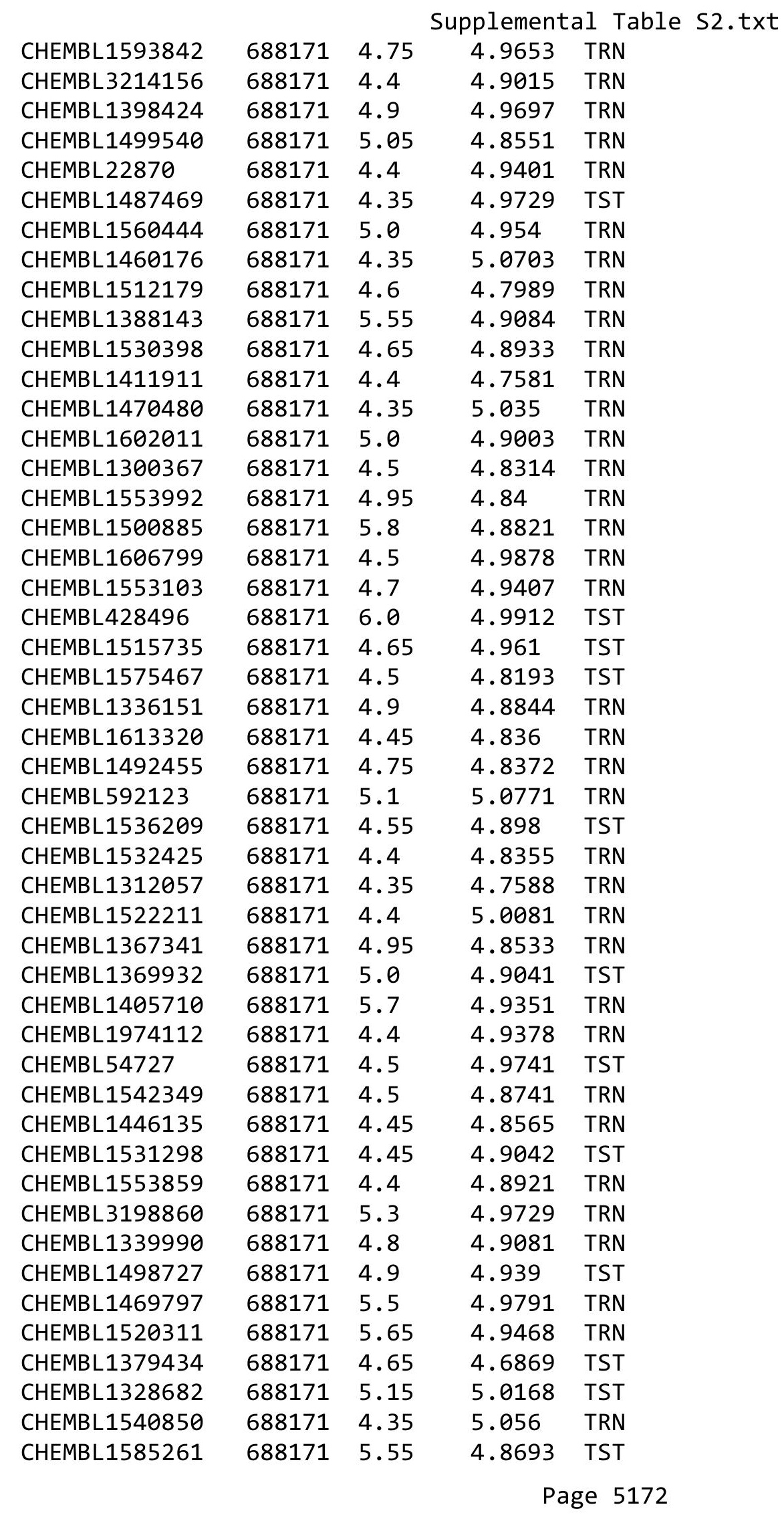




\begin{tabular}{|c|c|c|c|c|c|}
\hline \multicolumn{6}{|c|}{ Supplemental Table s2.txt } \\
\hline CHEMBL1613004 & 688171 & 4.5 & 4.8996 & TST & \\
\hline CHEMBL1504720 & 688171 & 4.5 & 4.9865 & TRN & \\
\hline CHEMBL1301797 & 688171 & 7.0 & 4.8622 & TRN & \\
\hline CHEMBL1333929 & 688171 & 6.0 & 4.7796 & TRN & \\
\hline CHEMBL1498420 & 688171 & 4.75 & 4.854 & TST & \\
\hline CHEMBL1594865 & 688171 & 5.05 & 5.0407 & TRN & \\
\hline CHEMBL1579916 & 688171 & 4.55 & 4.7699 & TRN & \\
\hline CHEMBL1556561 & 688171 & 4.6 & 4.763 & TRN & \\
\hline CHEMBL1526981 & 688171 & 4.4 & 4.8746 & TRN & \\
\hline CHEMBL1550862 & 688171 & 4.65 & 4.8683 & TRN & \\
\hline CHEMBL1309304 & 688171 & 4.4 & 5.0438 & TRN & \\
\hline CHEMBL1575732 & 688171 & 4.55 & 4.8977 & TRN & \\
\hline CHEMBL1569591 & 688171 & 7.4001 & 5.0136 & TRN & \\
\hline CHEMBL1435105 & 688171 & 4.4 & 4.96399 & 99999999995 & TRN \\
\hline CHEMBL1460334 & 688171 & 5.3 & 4.8749 & TRN & \\
\hline CHEMBL1329748 & 688171 & 4.85 & 4.9114 & TRN & \\
\hline CHEMBL1483175 & 688171 & 4.7 & 4.8041 & TST & \\
\hline CHEMBL3210922 & 688171 & 4.9 & 4.9972 & TST & \\
\hline CHEMBL165 & 688171 & 6.0 & 4.9616 & TST & \\
\hline CHEMBL3198167 & 688171 & 4.85 & 4.7991 & TRN & \\
\hline CHEMBL1506384 & 688171 & 4.85 & 4.8674 & TRN & \\
\hline CHEMBL1377282 & 688171 & 4.8 & 4.7985 & TRN & \\
\hline CHEMBL1552566 & 688171 & 5.2 & 4.8979 & TRN & \\
\hline CHEMBL1462205 & 688171 & 4.6 & 4.9558 & TST & \\
\hline CHEMBL1394535 & 688171 & 4.55 & 4.8906 & TRN & \\
\hline CHEMBL1555707 & 688171 & 4.7 & 4.8949 & TRN & \\
\hline CHEMBL1478911 & 688171 & 5.4 & 5.0293 & TST & \\
\hline CHEMBL1368134 & 688171 & 5.2 & 5.015 & TRN & \\
\hline CHEMBL1331899 & 688171 & 4.8 & 4.8025 & TRN & \\
\hline CHEMBL1587513 & 688171 & 4.4 & 4.926 & TRN & \\
\hline CHEMBL1317116 & 688171 & 4.7 & 4.8789 & TRN & \\
\hline CHEMBL1363083 & 688171 & 4.5 & 4.9645 & TRN & \\
\hline CHEMBL1329911 & 688171 & 4.8 & 4.8468 & TRN & \\
\hline CHEMBL1437374 & 688171 & 4.9 & 4.8953 & TRN & \\
\hline CHEMBL1510291 & 688171 & 4.85 & 5.03600 & 00000000005 & TST \\
\hline CHEMBL1366313 & 688171 & 4.85 & 4.8913 & TST & \\
\hline CHEMBL1392315 & 688171 & 4.85 & 4.8562 & TRN & \\
\hline CHEMBL1337149 & 688171 & 4.65 & 4.8173 & TRN & \\
\hline CHEMBL1538817 & 688171 & 4.4 & 4.8839 & TRN & \\
\hline CHEMBL1332625 & 688171 & 4.6 & 4.8508 & TRN & \\
\hline CHEMBL3210005 & 688171 & 4.4 & 4.93 & TRN & \\
\hline CHEMBL1080744 & 688171 & 4.7 & 4.9509 & TRN & \\
\hline CHEMBL1325819 & 688171 & 4.7 & 4.9458 & TST & \\
\hline CHEMBL1520850 & 688171 & 6.15 & 4.9633 & TST & \\
\hline CHEMBL1397791 & 688171 & 7.6003 & 4.9036 & TRN & \\
\hline CHEMBL1476888 & 688171 & 5.05 & 4.8596 & TRN & \\
\hline CHEMBL1326584 & 688171 & 4.85 & 4.8318 & TRN & \\
\hline CHEMBL1561066 & 688171 & 5.3 & 5.032 & TRN & \\
\hline
\end{tabular}




\begin{tabular}{|c|c|c|c|c|c|}
\hline \multicolumn{6}{|c|}{ Supplemental Table s2.txt } \\
\hline CHEMBL310798 & 688171 & 4.65 & 4.8226 & TRN & \\
\hline CHEMBL1393586 & 688171 & 4.75 & 5.1385 & TST & \\
\hline CHEMBL3187596 & 688171 & 4.95 & 4.9429 & TRN & \\
\hline CHEMBL1552887 & 688171 & 4.95 & 4.96399 & 99999999995 & TST \\
\hline CHEMBL1554021 & 688171 & 4.85 & 4.8747 & TRN & \\
\hline CHEMBL1308053 & 688171 & 4.55 & 4.9121 & TRN & \\
\hline CHEMBL1604209 & 688171 & 4.8 & 4.9545 & TRN & \\
\hline CHEMBL1342806 & 688171 & 4.5 & 4.8439 & TST & \\
\hline CHEMBL1405834 & 688171 & 4.8 & 4.7347 & TST & \\
\hline CHEMBL1490076 & 688171 & 4.8 & 4.9199 & TRN & \\
\hline CHEMBL1474052 & 688171 & 4.7 & 4.8335 & TRN & \\
\hline CHEMBL138921 & 688171 & 5.5 & 5.0939 & TRN & \\
\hline CHEMBL1527880 & 688171 & 5.0 & 4.976 & TST & \\
\hline CHEMBL1452502 & 688171 & 4.6 & 4.947 & TRN & \\
\hline CHEMBL1599570 & 688171 & 4.4 & 4.7915 & TRN & \\
\hline CHEMBL1444730 & 688171 & 4.5 & 4.8409 & TRN & \\
\hline CHEMBL1428409 & 688171 & 5.2 & 4.8571 & TST & \\
\hline CHEMBL 2003888 & 688171 & 5.3 & 4.915 & TRN & \\
\hline CHEMBL1450708 & 688171 & 5.0 & 5.0124 & TST & \\
\hline CHEMBL1513514 & 688171 & 4.4 & 4.8504 & TRN & \\
\hline CHEMBL1554128 & 688171 & 5.5 & 4.8283 & TST & \\
\hline CHEMBL1967862 & 688171 & 5.05 & 4.8193 & TRN & \\
\hline CHEMBL1987483 & 688171 & 5.2 & 4.8889 & TRN & \\
\hline CHEMBL1496449 & 688171 & 4.6 & 4.8086 & TRN & \\
\hline CHEMBL3214253 & 688171 & 4.5 & 4.8379 & TST & \\
\hline CHEMBL1302857 & 688171 & 4.8 & 4.9817 & TRN & \\
\hline CHEMBL3192506 & 688171 & 4.75 & 4.9739 & TRN & \\
\hline CHEMBL 3211544 & 688171 & 4.65 & 4.9228 & TST & \\
\hline CHEMBL1561129 & 688171 & 4.4 & 4.9837 & TRN & \\
\hline CHEMBL1464378 & 688171 & 5.0 & 4.838 & TRN & \\
\hline CHEMBL330129 & 688171 & 4.35 & 4.9796 & TST & \\
\hline CHEMBL1503499 & 688171 & 5.05 & 5.1179 & TRN & \\
\hline CHEMBL1590279 & 688171 & 5.05 & 4.8752 & TRN & \\
\hline CHEMBL1351226 & 688171 & 4.4 & 4.968 & TST & \\
\hline CHEMBL1476361 & 688171 & 4.9 & 5.004 & TRN & \\
\hline CHEMBL1326819 & 688171 & 4.95 & 4.8237 & TRN & \\
\hline CHEMBL1080898 & 688171 & 4.85 & 4.92399 & 99999999995 & TRN \\
\hline CHEMBL1428104 & 688171 & 4.85 & 4.9365 & TRN & \\
\hline CHEMBL1417406 & 688171 & 7.5498 & 4.9936 & TRN & \\
\hline CHEMBL1503190 & 688171 & 4.85 & 5.0335 & TST & \\
\hline CHEMBL1335044 & 688171 & 5.45 & 4.9448 & TRN & \\
\hline CHEMBL1443776 & 688171 & 4.5 & 4.8819 & TRN & \\
\hline CHEMBL1589969 & 688171 & 4.8 & 4.9058 & TRN & \\
\hline CHEMBL1573128 & 688171 & 5.15 & 4.9452 & TST & \\
\hline CHEMBL1338079 & 688171 & 4.65 & 5.0576 & TRN & \\
\hline CHEMBL1591045 & 688171 & 4.4 & 4.86100 & 0000000001 & TRN \\
\hline CHEMBL1386810 & 688171 & 6.05 & 4.9016 & TRN & \\
\hline CHEMBL1348169 & 688171 & 5.2 & 4.885 & TRN & \\
\hline
\end{tabular}




\begin{tabular}{|c|c|c|c|c|}
\hline \multicolumn{5}{|c|}{ Supplemental Table S2.txt } \\
\hline CHEMBL1361980 & 688171 & 4.4 & 4.8447 & TRN \\
\hline CHEMBL1481340 & 688171 & 4.4 & 4.8373 & TST \\
\hline CHEMBL1428415 & 688171 & 4.35 & 4.902 & TRN \\
\hline CHEMBL1368656 & 688171 & 4.5 & 4.9131 & TRN \\
\hline CHEMBL1608118 & 688171 & 4.4 & 4.9714 & TRN \\
\hline CHEMBL1578340 & 688171 & 7.0 & 4.9277 & TST \\
\hline CHEMBL1534666 & 688171 & 4.75 & 4.9501 & TST \\
\hline CHEMBL1511931 & 688171 & 5.25 & 4.7986 & TST \\
\hline CHEMBL126077 & 688171 & 6.0 & 4.8392 & TST \\
\hline CHEMBL1384911 & 688171 & 5.05 & 5.0147 & TRN \\
\hline CHEMBL1392116 & 688171 & 5.05 & 5.0008 & TRN \\
\hline CHEMBL1327627 & 688171 & 4.45 & 4.8674 & TRN \\
\hline CHEMBL1423428 & 688171 & 4.35 & 4.9457 & TST \\
\hline CHEMBL1554216 & 688171 & 4.75 & 4.852 & TRN \\
\hline CHEMBL3191021 & 688171 & 4.4 & 4.8904 & TRN \\
\hline CHEMBL1542237 & 688171 & 4.35 & 4.9918 & TST \\
\hline CHEMBL1447845 & 688171 & 4.65 & 4.9555 & TRN \\
\hline CHEMBL1481221 & 688171 & 4.5 & 4.9074 & TRN \\
\hline CHEMBL1341865 & 688171 & 5.0 & 5.0689 & TRN \\
\hline CHEMBL1410235 & 688171 & 4.95 & 4.915 & TRN \\
\hline CHEMBL1339433 & 688171 & 5.1 & 4.8124 & TRN \\
\hline CHEMBL1416165 & 688171 & 5.6 & 4.881 & TRN \\
\hline CHEMBL1338675 & 688171 & 5.1 & 4.7371 & TRN \\
\hline CHEMBL1603158 & 688171 & 4.75 & 4.916 & TRN \\
\hline CHEMBL1419326 & 688171 & 4.6 & 4.8089 & TRN \\
\hline CHEMBL3211866 & 688171 & 5.65 & 4.9062 & TST \\
\hline CHEMBL1322538 & 688171 & 4.4 & 4.8547 & TST \\
\hline CHEMBL1378218 & 688171 & 4.5 & 4.9686 & TRN \\
\hline CHEMBL 3210840 & 688171 & 5.45 & 4.8869 & TST \\
\hline CHEMBL1563206 & 688171 & 4.55 & 4.9471 & TRN \\
\hline CHEMBL1369292 & 688171 & 4.4 & 4.9667 & TRN \\
\hline CHEMBL1414667 & 688171 & 4.8 & 4.8889 & TRN \\
\hline CHEMBL1368678 & 688171 & 4.4 & 4.9881 & TST \\
\hline CHEMBL1440014 & 688171 & 4.4 & 5.1191 & TST \\
\hline CHEMBL1565888 & 688171 & 4.8 & 4.9341 & TRN \\
\hline CHEMBL1485132 & 688171 & 4.75 & 4.797 & TST \\
\hline CHEMBL1420932 & 688171 & 4.65 & 5.0053 & TRN \\
\hline CHEMBL1481981 & 688171 & 7.1002 & 4.8954 & TRN \\
\hline CHEMBL1572918 & 688171 & 5.1 & 4.8113 & TRN \\
\hline CHEMBL1492673 & 688171 & 6.4 & 4.9655 & TST \\
\hline CHEMBL1312357 & 688171 & 6.5 & 4.9802 & TRN \\
\hline CHEMBL1332834 & 688171 & 4.6 & 4.958 & TRN \\
\hline CHEMBL1571414 & 688171 & 4.6 & 4.7915 & TRN \\
\hline CHEMBL1305831 & 688171 & 5.3 & 4.8914 & TRN \\
\hline CHEMBL1536653 & 688171 & 4.55 & 4.8452 & TRN \\
\hline CHEMBL1355213 & 688171 & 4.45 & 4.8245 & TRN \\
\hline CHEMBL1450522 & 688171 & 7.6003 & 4.9741 & TST \\
\hline CHEMBL1357507 & 688171 & 4.7 & 4.9309 & TRN \\
\hline
\end{tabular}




\begin{tabular}{|c|c|c|c|c|}
\hline \multicolumn{5}{|c|}{ Supplemental Table S2.txt } \\
\hline CHEMBL1430377 & 688171 & 4.35 & 4.9438 & TRN \\
\hline CHEMBL1539302 & 688171 & 6.25 & 4.8713 & TRN \\
\hline CHEMBL1349417 & 688171 & 4.4 & 4.8617 & TRN \\
\hline CHEMBL1382214 & 688171 & 4.7 & 4.83 & TRN \\
\hline CHEMBL1541300 & 688171 & 4.4 & 4.9781 & TRN \\
\hline CHEMBL1322737 & 688171 & 6.45 & 4.9494 & TRN \\
\hline CHEMBL1533980 & 688171 & 5.05 & 4.793 & TRN \\
\hline CHEMBL3213690 & 688171 & 4.55 & 4.8628 & TRN \\
\hline CHEMBL1506919 & 688171 & 5.1 & 4.9786 & TST \\
\hline CHEMBL1469830 & 688171 & 4.55 & 4.8478 & TRN \\
\hline CHEMBL1435638 & 688171 & 5.45 & 4.9981 & TRN \\
\hline CHEMBL1603017 & 688171 & 5.1 & 5.0755 & TRN \\
\hline CHEMBL1582432 & 688171 & 4.85 & 4.9105 & TST \\
\hline CHEMBL3190777 & 688171 & 6.0 & 4.8964 & TST \\
\hline CHEMBL1584869 & 688171 & 4.6 & 5.0679 & TRN \\
\hline CHEMBL1448823 & 688171 & 4.7 & 5.0296 & TRN \\
\hline CHEMBL1394707 & 688171 & 5.1 & 4.8857 & TRN \\
\hline CHEMBL590670 & 688171 & 4.45 & 4.8004 & TRN \\
\hline CHEMBL1310609 & 688171 & 4.4 & 4.8611 & TRN \\
\hline CHEMBL1359410 & 688171 & 4.7 & 4.8963 & TRN \\
\hline CHEMBL1559572 & 688171 & 4.55 & 5.0571 & TRN \\
\hline CHEMBL1327820 & 688171 & 4.6 & 4.9932 & TST \\
\hline CHEMBL1369099 & 688171 & 4.4 & 4.8569 & TST \\
\hline CHEMBL1391614 & 688171 & 4.4 & 4.8841 & TRN \\
\hline CHEMBL1594063 & 688171 & 5.15 & 4.8478 & TRN \\
\hline CHEMBL1398121 & 688171 & 4.95 & 4.8746 & TRN \\
\hline CHEMBL1552812 & 688171 & 4.65 & 4.8857 & TRN \\
\hline CHEMBL1407248 & 688171 & 4.6 & 4.9019 & TRN \\
\hline CHEMBL1459198 & 688171 & 4.95 & 4.7968 & TRN \\
\hline CHEMBL3195932 & 688171 & 5.05 & 4.862 & TRN \\
\hline CHEMBL1424685 & 688171 & 4.45 & 4.8117 & TRN \\
\hline CHEMBL1444023 & 688171 & 4.7 & 4.8222 & TRN \\
\hline CHEMBL1531207 & 688171 & 4.75 & 4.9084 & TRN \\
\hline CHEMBL1366534 & 688171 & 4.35 & 4.9914 & TRN \\
\hline CHEMBL1353525 & 688171 & 4.35 & 4.944 & TRN \\
\hline CHEMBL1390373 & 688171 & 4.55 & 4.8864 & TRN \\
\hline CHEMBL1427384 & 688171 & 4.7 & 4.9296 & TST \\
\hline CHEMBL1569372 & 688171 & 4.8 & 4.7748 & TRN \\
\hline CHEMBL3209623 & 688171 & 4.5 & 4.8924 & TRN \\
\hline CHEMBL1577302 & 688171 & 4.65 & 4.8343 & TRN \\
\hline CHEMBL1317641 & 688171 & 4.8 & 4.9293 & TST \\
\hline CHEMBL1556736 & 688171 & 6.6499 & 5.002 & TST \\
\hline CHEMBL1408175 & 688171 & 6.8 & 4.8947 & TST \\
\hline CHEMBL1968789 & 688171 & 4.45 & 4.9307 & TRN \\
\hline CHEMBL1316868 & 688171 & 5.35 & 4.7963 & TRN \\
\hline CHEMBL1510251 & 688171 & 4.4 & 5.0087 & TRN \\
\hline CHEMBL1399847 & 688171 & 5.45 & 4.9668 & TST \\
\hline CHEMBL1363163 & 688171 & 4.45 & 4.8258 & TRN \\
\hline
\end{tabular}




\begin{tabular}{|c|c|c|c|c|c|}
\hline \multicolumn{6}{|c|}{ Supplemental Table S2.txt } \\
\hline CHEMBL1423878 & 688171 & 4.75 & 4.8362 & TRN & \\
\hline CHEMBL1395316 & 688171 & 5.3 & 4.9573 & TRN & \\
\hline CHEMBL1516494 & 688171 & 4.5 & 4.8427 & TRN & \\
\hline CHEMBL 3196525 & 688171 & 5.45 & 4.9616 & TRN & \\
\hline CHEMBL1496635 & 688171 & 4.8 & 4.8493 & TST & \\
\hline CHEMBL1569521 & 688171 & 4.85 & 4.9444 & TRN & \\
\hline CHEMBL1445229 & 688171 & 4.8 & 4.9655 & TST & \\
\hline CHEMBL1518159 & 688171 & 4.6 & 4.8929 & TST & \\
\hline CHEMBL1369085 & 688171 & 4.4 & 5.0199 & TST & \\
\hline CHEMBL1320327 & 688171 & 5.55 & 4.9881 & TRN & \\
\hline CHEMBL1575059 & 688171 & 4.4 & 4.9332 & TRN & \\
\hline CHEMBL1475647 & 688171 & 4.7 & 4.7979 & TRN & \\
\hline CHEMBL1389963 & 688171 & 4.8 & 4.9711 & TRN & \\
\hline CHEMBL1427191 & 688171 & 4.5 & 4.9916 & TRN & \\
\hline CHEMBL1082161 & 688171 & 4.65 & 4.9053 & TRN & \\
\hline CHEMBL1354945 & 688171 & 4.75 & 4.9681 & TST & \\
\hline CHEMBL1361221 & 688171 & 4.7 & 4.862 & TRN & \\
\hline CHEMBL1532429 & 688171 & 5.75 & 4.7225 & TRN & \\
\hline CHEMBL1081264 & 688171 & 4.75 & 4.9613 & TRN & \\
\hline CHEMBL1468472 & 688171 & 5.05 & 4.8329 & TST & \\
\hline CHEMBL1524049 & 688171 & 4.5 & 4.79 & TST & \\
\hline CHEMBL1350475 & 688171 & 4.7 & 4.8885 & TRN & \\
\hline CHEMBL1442283 & 688171 & 4.7 & 4.92899 & 9999999999 & TRN \\
\hline CHEMBL2369205 & 688171 & 4.75 & 4.8245 & TRN & \\
\hline CHEMBL1366992 & 688171 & 4.9 & 4.9319 & TST & \\
\hline CHEMBL1571959 & 688171 & 4.75 & 5.0439 & TST & \\
\hline CHEMBL1434323 & 688171 & 4.85 & 4.8691 & TRN & \\
\hline CHEMBL1468403 & 688171 & 5.05 & 5.0238 & TRN & \\
\hline CHEMBL1369754 & 688171 & 5.8 & 5.0688 & TRN & \\
\hline CHEMBL1531250 & 688171 & 4.4 & 5.0806 & TST & \\
\hline CHEMBL1987417 & 688171 & 5.05 & 4.8502 & TRN & \\
\hline CHEMBL1592370 & 688171 & 7.8013 & 4.9855 & TST & \\
\hline CHEMBL1580836 & 688171 & 4.35 & 5.0226 & TST & \\
\hline CHEMBL1425991 & 688171 & 4.7 & 4.8897 & TRN & \\
\hline CHEMBL1372270 & 688171 & 4.5 & 4.9143 & TRN & \\
\hline CHEMBL1987798 & 688171 & 6.45 & 4.9507 & TRN & \\
\hline CHEMBL1462634 & 688171 & 4.7 & 4.9511 & TRN & \\
\hline CHEMBL1300392 & 688171 & 5.0 & 4.9507 & TRN & \\
\hline CHEMBL1316388 & 688171 & 4.9 & 4.8379 & TRN & \\
\hline CHEMBL1600111 & 688171 & 4.9 & 4.8441 & TRN & \\
\hline CHEMBL1371380 & 688171 & 4.6 & 4.8647 & TRN & \\
\hline CHEMBL1315334 & 688171 & 4.95 & 4.8553 & TRN & \\
\hline CHEMBL1479829 & 688171 & 4.95 & 4.8538 & TRN & \\
\hline CHEMBL1611824 & 688171 & 4.4 & 4.8654 & TST & \\
\hline CHEMBL1336619 & 688171 & 4.55 & 4.8284 & TRN & \\
\hline CHEMBL1534729 & 688171 & 4.4 & 4.8426 & TRN & \\
\hline CHEMBL1491904 & 688171 & 5.0 & 4.8094 & TRN & \\
\hline CHEMBL1361199 & 688171 & 5.55 & 4.9036 & TRN & \\
\hline
\end{tabular}




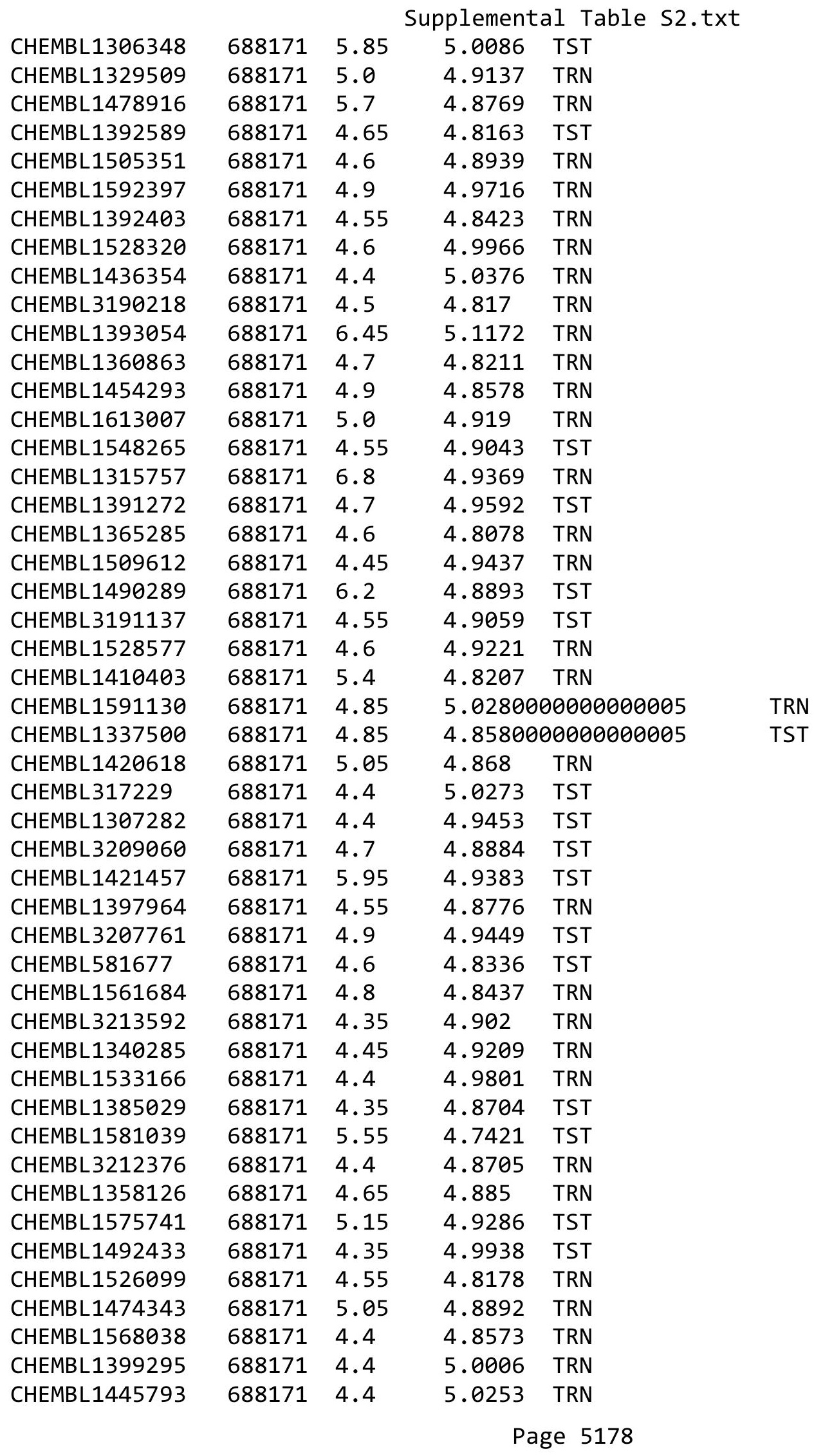




\begin{tabular}{|c|c|c|c|c|}
\hline \multicolumn{5}{|c|}{ Supplemental Table S2.txt } \\
\hline CHEMBL1356539 & 688171 & 4.85 & 4.9729 & TRN \\
\hline CHEMBL1363165 & 688171 & 5.5 & 5.0505 & TRN \\
\hline CHEMBL1486156 & 688171 & 4.65 & 4.9099 & TST \\
\hline CHEMBL1397008 & 688171 & 4.9 & 4.8588 & TRN \\
\hline CHEMBL1568996 & 688171 & 4.45 & 4.9661 & TST \\
\hline CHEMBL1456373 & 688171 & 4.6 & 4.7013 & TRN \\
\hline CHEMBL1420417 & 688171 & 4.5 & 4.8025 & TST \\
\hline CHEMBL1440461 & 688171 & 4.35 & 4.9453 & TRN \\
\hline CHEMBL1504552 & 688171 & 6.15 & 5.0712 & TRN \\
\hline CHEMBL1555147 & 688171 & 5.0 & 4.9226 & TST \\
\hline CHEMBL1472193 & 688171 & 4.7 & 4.7709 & TST \\
\hline CHEMBL3190766 & 688171 & 4.4 & 4.9062 & TST \\
\hline CHEMBL1342138 & 688171 & 6.0 & 4.8243 & TST \\
\hline CHEMBL3212065 & 688171 & 4.85 & 5.0346 & TRN \\
\hline CHEMBL 2132953 & 688171 & 4.85 & 4.9918 & TRN \\
\hline CHEMBL1301338 & 688171 & 5.15 & 5.0611 & TST \\
\hline CHEMBL1586371 & 688171 & 4.4 & 4.9257 & TRN \\
\hline CHEMBL1354500 & 688171 & 4.85 & 4.8798 & TRN \\
\hline CHEMBL1564231 & 688171 & 4.75 & 4.803 & TRN \\
\hline CHEMBL1566032 & 688171 & 6.6 & 4.8906 & TST \\
\hline CHEMBL1501799 & 688171 & 4.35 & 4.7709 & TRN \\
\hline CHEMBL1329726 & 688171 & 5.35 & 4.9736 & TST \\
\hline CHEMBL1485163 & 688171 & 6.0 & 5.0302 & TST \\
\hline CHEMBL1526181 & 688171 & 4.85 & 4.8514 & TRN \\
\hline CHEMBL1474165 & 688171 & 4.35 & 4.9332 & TRN \\
\hline CHEMBL74913 & 688171 & 4.35 & 4.9219 & TRN \\
\hline CHEMBL1389914 & 688171 & 4.4 & 4.8751 & TRN \\
\hline CHEMBL1347408 & 688171 & 4.5 & 4.9749 & TST \\
\hline CHEMBL1475395 & 688171 & 5.4 & 4.9182 & TRN \\
\hline CHEMBL1325355 & 688171 & 4.9 & 4.9669 & TRN \\
\hline CHEMBL1562504 & 688171 & 4.5 & 4.8495 & TST \\
\hline CHEMBL1527294 & 688171 & 5.05 & 4.9055 & TRN \\
\hline CHEMBL171281 & 688171 & 4.65 & 4.9599 & TRN \\
\hline CHEMBL1327620 & 688171 & 5.5 & 5.1121 & TST \\
\hline CHEMBL1387393 & 688171 & 4.35 & 4.9921 & TRN \\
\hline CHEMBL1335321 & 688171 & 4.4 & 4.9079 & TRN \\
\hline CHEMBL1552737 & 688171 & 4.55 & 4.9153 & TRN \\
\hline CHEMBL 39878 & 688171 & 5.25 & 4.9424 & TRN \\
\hline CHEMBL1303361 & 688171 & 5.0 & 4.8566 & TRN \\
\hline CHEMBL3199540 & 688171 & 4.85 & 4.9875 & TRN \\
\hline CHEMBL1398550 & 688171 & 5.0 & 4.8041 & TRN \\
\hline CHEMBL1381064 & 688171 & 4.4 & 4.8565 & TRN \\
\hline CHEMBL1420077 & 688171 & 4.55 & 4.8401 & TRN \\
\hline CHEMBL1501990 & 688171 & 5.35 & 4.8508 & TRN \\
\hline CHEMBL1533101 & 688171 & 4.7 & 4.8265 & TST \\
\hline CHEMBL 3145244 & 688171 & 5.0 & 4.772 & TST \\
\hline CHEMBL1388164 & 688171 & 4.35 & 4.9492 & TST \\
\hline CHEMBL1330917 & 688171 & 6.35 & 4.9231 & TRN \\
\hline
\end{tabular}




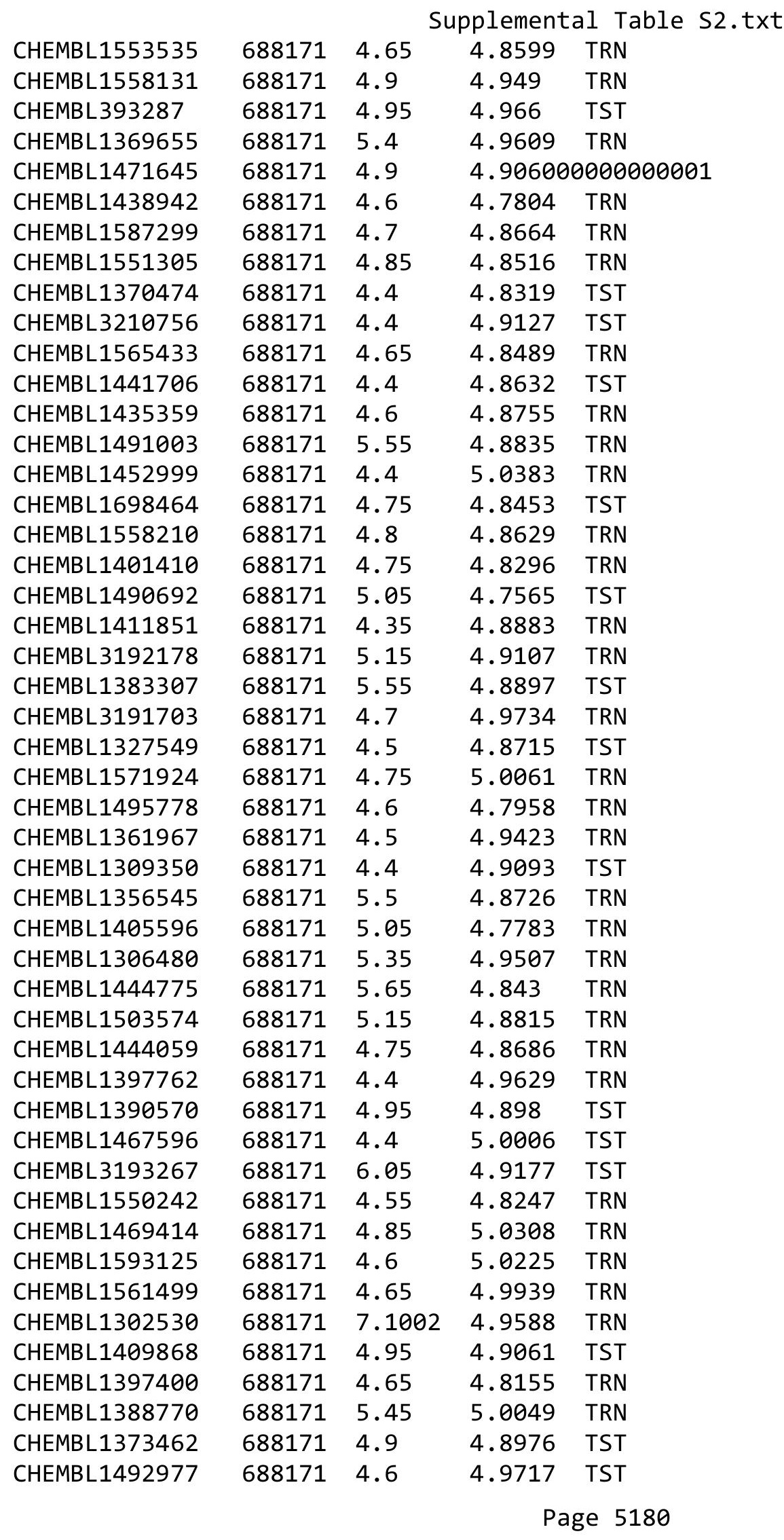




\begin{tabular}{|c|c|c|c|c|c|}
\hline & & \multicolumn{4}{|c|}{ Supplemental Table S2.txt } \\
\hline CHEMBL1594376 & 688171 & 4.55 & 4.9445 & TST & \\
\hline CHEMBL1170671 & 688171 & 4.8 & 4.9052 & TRN & \\
\hline CHEMBL1303954 & 688171 & 5.05 & 5.0122 & TRN & \\
\hline CHEMBL1443508 & 688171 & 4.6 & 4.808 & TST & \\
\hline CHEMBL1581178 & 688171 & 5.45 & 4.97199 & 99999999995 & TRN \\
\hline CHEMBL1499041 & 688171 & 4.6 & 4.9813 & TRN & \\
\hline CHEMBL1460669 & 688171 & 6.3 & 5.1155 & TRN & \\
\hline CHEMBL1329962 & 688171 & 4.45 & 4.9103 & TST & \\
\hline CHEMBL1329350 & 688171 & 4.85 & 4.9841 & TST & \\
\hline CHEMBL1363206 & 688171 & 4.4 & 4.7476 & TST & \\
\hline CHEMBL1463456 & 688171 & 4.45 & 4.8929 & TST & \\
\hline CHEMBL1417437 & 688171 & 4.65 & 5.0496 & TST & \\
\hline CHEMBL1375003 & 688171 & 7.0501 & 4.9239 & TRN & \\
\hline CHEMBL1392034 & 688171 & 4.6 & 4.9261 & TRN & \\
\hline CHEMBL1394540 & 688171 & 4.7 & 4.8767 & TRN & \\
\hline CHEMBL1406860 & 688171 & 4.65 & 4.9469 & TST & \\
\hline CHEMBL1358068 & 688171 & 4.9 & 4.933 & TRN & \\
\hline CHEMBL1535365 & 688171 & 4.55 & 4.8427 & TRN & \\
\hline CHEMBL1580956 & 688171 & 5.6 & 4.8736 & TRN & \\
\hline CHEMBL1313695 & 688171 & 4.75 & 4.8932 & TRN & \\
\hline CHEMBL1561482 & 688171 & 5.1 & 4.8193 & TRN & \\
\hline CHEMBL1489955 & 688171 & 4.65 & 4.8898 & TST & \\
\hline CHEMBL1553061 & 688171 & 4.65 & 4.7846 & TRN & \\
\hline CHEMBL1351242 & 688171 & 4.55 & 4.8144 & TRN & \\
\hline CHEMBL1430899 & 688171 & 6.05 & 4.878 & TST & \\
\hline CHEMBL1435501 & 688171 & 4.9 & 4.9626 & TRN & \\
\hline CHEMBL1468519 & 688171 & 4.4 & 4.9103 & TRN & \\
\hline CHEMBL1308037 & 688171 & 4.5 & 4.9366 & TRN & \\
\hline CHEMBL3193984 & 688171 & 4.35 & 4.89 & TRN & \\
\hline CHEMBL1299342 & 688171 & 5.0 & 4.845 & TST & \\
\hline CHEMBL1548613 & 688171 & 4.45 & 4.7595 & TST & \\
\hline CHEMBL1338985 & 688171 & 4.45 & 4.9237 & TRN & \\
\hline CHEMBL1593044 & 688171 & 4.9 & 4.8074 & TRN & \\
\hline CHEMBL1348826 & 688171 & 4.95 & 4.8299 & TRN & \\
\hline CHEMBL3189487 & 688171 & 5.0 & 4.981 & TRN & \\
\hline CHEMBL1336404 & 688171 & 4.4 & 4.8887 & TST & \\
\hline CHEMBL1476408 & 688171 & 4.9 & 4.8207 & TRN & \\
\hline CHEMBL1518688 & 688171 & 4.75 & 4.922 & TRN & \\
\hline CHEMBL1524590 & 688171 & 5.3 & 4.9436 & TRN & \\
\hline CHEMBL1452610 & 688171 & 5.45 & 5.0433 & TRN & \\
\hline CHEMBL1324337 & 688171 & 4.35 & 4.8474 & TST & \\
\hline CHEMBL1356217 & 688171 & 5.45 & 5.1358 & TST & \\
\hline CHEMBL1364265 & 688171 & 4.85 & 4.9166 & TRN & \\
\hline CHEMBL1432884 & 688171 & 4.6 & 4.8961 & TRN & \\
\hline CHEMBL1466117 & 688171 & 4.6 & 4.9045 & TRN & \\
\hline CHEMBL1335596 & 688171 & 4.35 & 4.9033 & TRN & \\
\hline CHEMBL1514118 & 688171 & 4.75 & 4.9722 & TRN & \\
\hline CHEMBL3199364 & 688171 & 4.4 & 4.9947 & TRN & \\
\hline
\end{tabular}




\begin{tabular}{|c|c|c|c|c|c|}
\hline \multicolumn{6}{|c|}{ Supplemental Table S2.txt } \\
\hline CHEMBL1327628 & 688171 & 4.6 & 4.8044 & TRN & \\
\hline CHEMBL1501132 & 688171 & 4.7 & 4.9379 & TRN & \\
\hline CHEMBL1591387 & 688171 & 4.95 & 5.0345 & TRN & \\
\hline CHEMBL1365196 & 688171 & 7.6003 & 4.9601 & TST & \\
\hline CHEMBL3191542 & 688171 & 4.65 & 4.8494 & TST & \\
\hline CHEMBL1522184 & 688171 & 4.95 & 4.9722 & TST & \\
\hline CHEMBL1550047 & 688171 & 6.3 & 4.7656 & TRN & \\
\hline CHEMBL1329602 & 688171 & 4.65 & 4.9724 & TRN & \\
\hline CHEMBL3190407 & 688171 & 4.55 & 4.9561 & TRN & \\
\hline CHEMBL1870697 & 688171 & 4.75 & 4.8345 & TRN & \\
\hline CHEMBL1991157 & 688171 & 4.6 & 4.8065 & TRN & \\
\hline CHEMBL1477360 & 688171 & 5.05 & 5.0247 & TRN & \\
\hline CHEMBL1322567 & 688171 & 4.4 & 4.7831 & TST & \\
\hline CHEMBL1536356 & 688171 & 5.35 & 4.9103 & TRN & \\
\hline CHEMBL1483638 & 688171 & 4.9 & 4.8727 & TRN & \\
\hline CHEMBL1601984 & 688171 & 5.85 & 5.023 & TRN & \\
\hline CHEMBL1499320 & 688171 & 6.0 & 5.06 & TRN & \\
\hline CHEMBL1588657 & 688171 & 4.4 & 4.9549 & TRN & \\
\hline CHEMBL1484549 & 688171 & 4.6 & 4.975 & TRN & \\
\hline CHEMBL1317326 & 688171 & 5.45 & 4.9489 & TRN & \\
\hline CHEMBL1579209 & 688171 & 4.6 & 4.8441 & TRN & \\
\hline CHEMBL1341947 & 688171 & 4.55 & 4.7091 & TRN & \\
\hline CHEMBL3214500 & 688171 & 4.4 & 4.9418 & TST & \\
\hline CHEMBL585222 & 688171 & 4.75 & 4.9671 & TRN & \\
\hline CHEMBL3211089 & 688171 & 5.4 & 4.9649 & TRN & \\
\hline CHEMBL1410482 & 688171 & 4.35 & 4.877 & TST & \\
\hline CHEMBL1388871 & 688171 & 4.35 & 4.9044 & TST & \\
\hline CHEMBL1465032 & 688171 & 4.35 & 4.9187 & TST & \\
\hline CHEMBL1327593 & 688171 & 5.05 & 4.9757 & TRN & \\
\hline CHEMBL1337811 & 688171 & 7.0 & 4.9824 & TST & \\
\hline CHEMBL1421424 & 688171 & 4.55 & 4.91100 & 00000000005 & TST \\
\hline CHEMBL1322120 & 688171 & 5.8 & 4.9109 & TRN & \\
\hline CHEMBL1996724 & 688171 & 7.6003 & 4.7645 & TRN & \\
\hline CHEMBL1482950 & 688171 & 5.3 & 4.9888 & TRN & \\
\hline CHEMBL1610996 & 688171 & 6.8499 & 4.8464 & TST & \\
\hline CHEMBL1554289 & 688171 & 5.45 & 4.9816 & TRN & \\
\hline CHEMBL495778 & 688171 & 5.9 & 4.8829 & TST & \\
\hline CHEMBL1516149 & 688171 & 4.95 & 4.8627 & TST & \\
\hline CHEMBL1316205 & 688171 & 4.35 & 4.886 & TRN & \\
\hline CHEMBL2369190 & 688171 & 5.4 & 4.8545 & TST & \\
\hline CHEMBL1577064 & 688171 & 6.5 & 4.8266 & TST & \\
\hline CHEMBL1388500 & 688171 & 6.8 & 5.0018 & TST & \\
\hline CHEMBL1537745 & 688171 & 6.0 & 4.8026 & TRN & \\
\hline CHEMBL1392875 & 688171 & 5.45 & 4.80399 & 9999999999 & TST \\
\hline CHEMBL1303654 & 688171 & 4.5 & 4.7908 & TRN & \\
\hline CHEMBL1550852 & 688171 & 4.4 & 4.9292 & TRN & \\
\hline CHEMBL1548869 & 688171 & 4.95 & 4.8297 & TRN & \\
\hline CHEMBL1352940 & 688171 & 5.4 & 4.9272 & TST & \\
\hline
\end{tabular}




\begin{tabular}{|c|c|c|c|c|c|}
\hline \multicolumn{6}{|c|}{ Supplemental Table S2.txt } \\
\hline CHEMBL1348131 & 688171 & 5.0 & 4.9597 & TST & \\
\hline CHEMBL1492328 & 688171 & 4.85 & 4.7923 & TST & \\
\hline CHEMBL1424953 & 688171 & 6.5 & 4.9405 & TRN & \\
\hline CHEMBL1410597 & 688171 & 5.05 & 4.9743 & TRN & \\
\hline CHEMBL1450782 & 688171 & 4.8 & 4.9922 & TRN & \\
\hline CHEMBL1305526 & 688171 & 5.45 & 4.9868 & TRN & \\
\hline CHEMBL1385411 & 688171 & 5.0 & 4.738 & TRN & \\
\hline CHEMBL1478399 & 688171 & 5.9 & 4.8509 & TRN & \\
\hline CHEMBL1392757 & 688171 & 4.55 & 4.9377 & TRN & \\
\hline CHEMBL1434939 & 688171 & 4.4 & 5.0777 & TRN & \\
\hline CHEMBL1532452 & 688171 & 5.55 & 4.8284 & TST & \\
\hline CHEMBL1355208 & 688171 & 4.9 & 4.9183 & TRN & \\
\hline CHEMBL1395953 & 688171 & 4.75 & 4.9617 & TRN & \\
\hline CHEMBL1345333 & 688171 & 5.85 & 4.8115 & TST & \\
\hline CHEMBL1414931 & 688171 & 5.25 & 4.915 & TST & \\
\hline CHEMBL1378938 & 688171 & 4.4 & 5.1149 & TST & \\
\hline CHEMBL1443569 & 688171 & 4.55 & 4.9551 & TRN & \\
\hline CHEMBL1381436 & 688171 & 5.4 & 4.7766 & TRN & \\
\hline CHEMBL1339164 & 688171 & 4.4 & 4.838 & TRN & \\
\hline CHEMBL1530657 & 688171 & 4.8 & 4.7636 & TRN & \\
\hline CHEMBL 2003356 & 688171 & 4.65 & 4.9915 & TRN & \\
\hline CHEMBL1598630 & 688171 & 4.65 & 5.0119 & TRN & \\
\hline CHEMBL1578151 & 688171 & 5.25 & 4.80399 & 9999999999 & TRN \\
\hline CHEMBL1393530 & 688171 & 4.6 & 4.838 & TST & \\
\hline CHEMBL3190758 & 688171 & 4.5 & 4.8997 & TRN & \\
\hline CHEMBL1396612 & 688171 & 4.85 & 4.9854 & TRN & \\
\hline CHEMBL1472076 & 688171 & 4.8 & 5.0478 & TRN & \\
\hline CHEMBL1574866 & 688171 & 4.55 & 4.8614 & TRN & \\
\hline CHEMBL1572222 & 688171 & 5.45 & 4.9475 & TRN & \\
\hline CHEMBL1568754 & 688171 & 4.85 & 4.8969 & TRN & \\
\hline CHEMBL1591721 & 688171 & 4.35 & 4.9019 & TRN & \\
\hline CHEMBL1371422 & 688171 & 5.05 & 4.8847 & TRN & \\
\hline CHEMBL1343282 & 688171 & 4.7 & 4.9031 & TRN & \\
\hline CHEMBL1582099 & 688171 & 4.75 & 4.8831 & TST & \\
\hline CHEMBL1438570 & 688171 & 4.75 & 4.8176 & TRN & \\
\hline CHEMBL1526074 & 688171 & 4.95 & 4.989 & TST & \\
\hline CHEMBL1604132 & 688171 & 4.4 & 4.8613 & TST & \\
\hline CHEMBL1359976 & 688171 & 4.45 & 4.8906 & TST & \\
\hline CHEMBL1408331 & 688171 & 4.45 & 4.8772 & TRN & \\
\hline CHEMBL1367280 & 688171 & 4.4 & 4.78600 & 00000000005 & TRN \\
\hline CHEMBL1574979 & 688171 & 7.3002 & 4.7976 & TRN & \\
\hline CHEMBL3199477 & 688171 & 4.9 & 4.9086 & TRN & \\
\hline CHEMBL1504634 & 688171 & 4.6 & 5.0193 & TRN & \\
\hline CHEMBL1546299 & 688171 & 5.05 & 4.9698 & TRN & \\
\hline CHEMBL1434871 & 688171 & 5.0 & 4.8514 & TRN & \\
\hline CHEMBL1476878 & 688171 & 4.95 & 4.8876 & TST & \\
\hline CHEMBL1391432 & 688171 & 4.6 & 4.9426 & TRN & \\
\hline CHEMBL1979495 & 688171 & 5.05 & 4.8911 & TST & \\
\hline
\end{tabular}




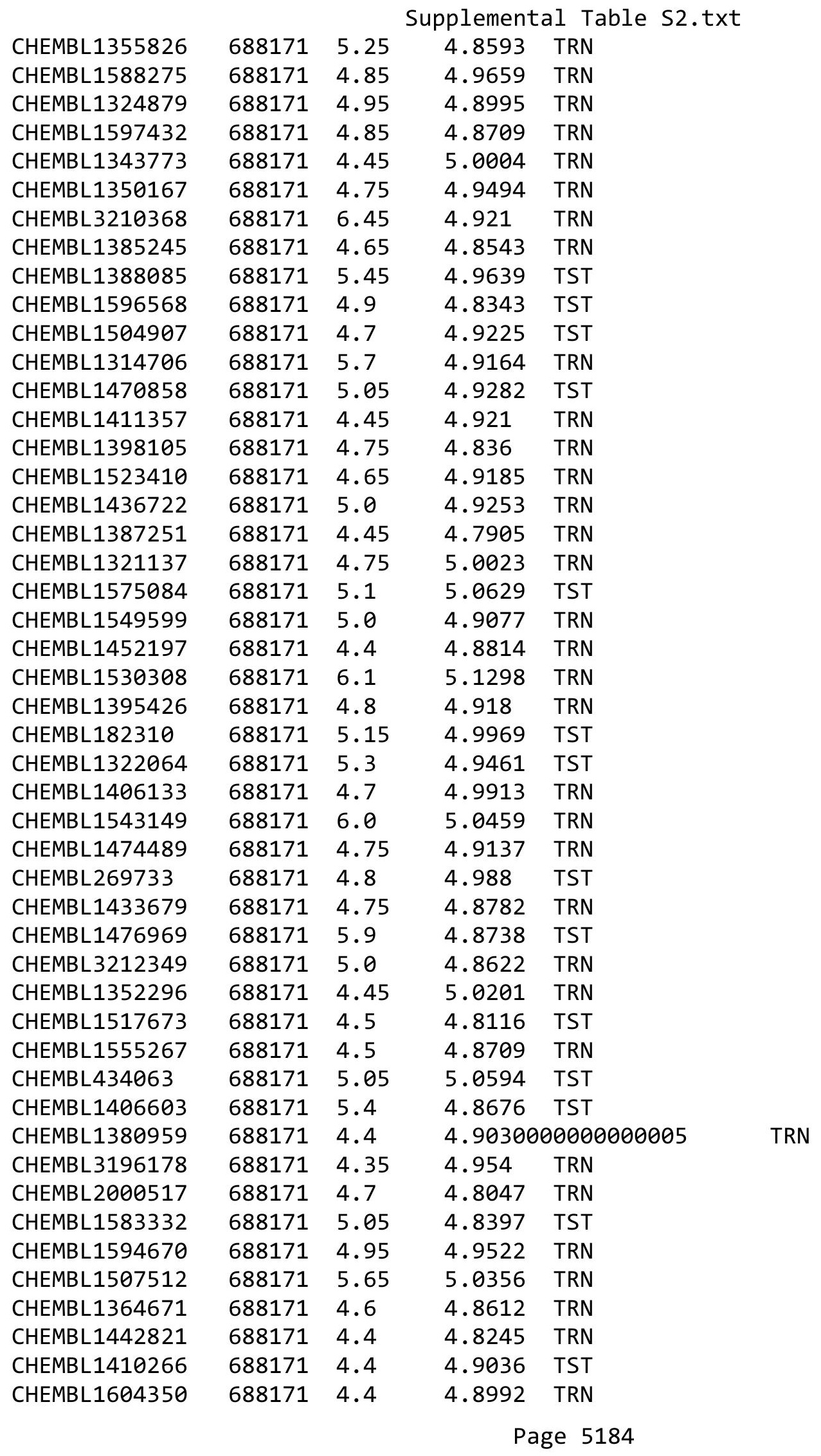




\begin{tabular}{|c|c|c|c|c|}
\hline \multicolumn{5}{|c|}{ Supplemental Table S2.txt } \\
\hline CHEMBL1512703 & 688171 & 4.4 & 4.9661 & TRN \\
\hline CHEMBL1447005 & 688171 & 4.4 & 4.8612 & TRN \\
\hline CHEMBL1343101 & 688171 & 4.4 & 4.8464 & TST \\
\hline CHEMBL1379184 & 688171 & 4.4 & 4.9149 & TRN \\
\hline CHEMBL1605247 & 688171 & 4.85 & 4.8449 & TRN \\
\hline CHEMBL1364384 & 688171 & 4.6 & 4.9812 & TRN \\
\hline CHEMBL1451118 & 688171 & 6.05 & 5.0613 & TST \\
\hline CHEMBL515998 & 688171 & 4.55 & 4.92 & TST \\
\hline CHEMBL1519715 & 688171 & 4.65 & 4.9144 & TRN \\
\hline CHEMBL1507517 & 688171 & 4.75 & 4.85 & TRN \\
\hline CHEMBL601826 & 688171 & 4.5 & 4.8434 & TRN \\
\hline CHEMBL1307468 & 688171 & 4.35 & 4.8084 & TRN \\
\hline CHEMBL1494737 & 688171 & 4.85 & 4.9119 & TST \\
\hline CHEMBL1318538 & 688171 & 4.9 & 4.8578 & TRN \\
\hline CHEMBL1354558 & 688171 & 5.1 & 4.9016 & TRN \\
\hline CHEMBL1477263 & 688171 & 4.4 & 4.8518 & TRN \\
\hline CHEMBL1568518 & 688171 & 4.65 & 4.8031 & TRN \\
\hline CHEMBL1552481 & 688171 & 4.5 & 4.8073 & TRN \\
\hline CHEMBL1524073 & 688171 & 4.55 & 4.9102 & TRN \\
\hline CHEMBL1385519 & 688171 & 5.8 & 4.7627 & TST \\
\hline CHEMBL1995715 & 688171 & 4.65 & 4.8564 & TST \\
\hline CHEMBL1491537 & 688171 & 4.45 & 4.6963 & TRN \\
\hline CHEMBL1374228 & 688171 & 6.15 & 4.8432 & TRN \\
\hline CHEMBL1522522 & 688171 & 4.6 & 4.9824 & TRN \\
\hline CHEMBL1407468 & 688171 & 4.8 & 4.895 & TRN \\
\hline CHEMBL1441739 & 688171 & 5.4 & 4.9404 & TRN \\
\hline CHEMBL1481470 & 688171 & 4.7 & 4.9315 & TRN \\
\hline CHEMBL1553403 & 688171 & 4.8 & 4.7822 & TRN \\
\hline CHEMBL1367585 & 688171 & 4.4 & 5.1771 & TRN \\
\hline CHEMBL1324794 & 688171 & 4.35 & 4.9537 & TRN \\
\hline CHEMBL1420550 & 688171 & 5.05 & 4.8767 & TRN \\
\hline CHEMBL1611111 & 688171 & 5.3 & 4.9251 & TST \\
\hline CHEMBL1592453 & 688171 & 4.4 & 4.9791 & TRN \\
\hline CHEMBL1322226 & 688171 & 4.75 & 4.9349 & TRN \\
\hline CHEMBL1592947 & 688171 & 5.05 & 4.8385 & TRN \\
\hline CHEMBL1433215 & 688171 & 7.6003 & 4.8365 & TST \\
\hline CHEMBL1309300 & 688171 & 4.45 & 4.8402 & TRN \\
\hline CHEMBL1397722 & 688171 & 4.4 & 4.8593 & TRN \\
\hline CHEMBL1584502 & 688171 & 4.45 & 4.9724 & TST \\
\hline CHEMBL 2003172 & 688171 & 5.55 & 4.8211 & TRN \\
\hline CHEMBL1407925 & 688171 & 5.3 & 4.9717 & TST \\
\hline CHEMBL1380046 & 688171 & 4.6 & 4.9459 & TST \\
\hline CHEMBL3397111 & 688171 & 4.35 & 4.7964 & TST \\
\hline CHEMBL1540240 & 688171 & 4.5 & 4.9906 & TST \\
\hline CHEMBL1306692 & 688171 & 5.05 & 4.9219 & TST \\
\hline CHEMBL1541252 & 688171 & 4.75 & 4.7849 & TRN \\
\hline CHEMBL1364579 & 688171 & 4.55 & 5.0329 & TRN \\
\hline CHEMBL1362654 & 688171 & 4.9 & 4.8716 & TRN \\
\hline
\end{tabular}




\begin{tabular}{|c|c|c|c|c|c|}
\hline \multicolumn{6}{|c|}{ Supplemental Table S2.txt } \\
\hline CHEMBL1586096 & 688171 & 4.4 & 4.9424 & TRN & \\
\hline CHEMBL1515050 & 688171 & 4.4 & 5.0281 & TRN & \\
\hline CHEMBL1435659 & 688171 & 5.55 & 5.1042 & TRN & \\
\hline CHEMBL1568193 & 688171 & 5.8 & 4.9482 & TRN & \\
\hline CHEMBL1972470 & 688171 & 5.4 & 5.021 & TRN & \\
\hline CHEMBL1474732 & 688171 & 4.75 & 4.9147 & TST & \\
\hline CHEMBL1340784 & 688171 & 5.05 & 5.0755 & TRN & \\
\hline CHEMBL1542755 & 688171 & 4.45 & 4.9793 & TRN & \\
\hline CHEMBL1419712 & 688171 & 4.9 & 4.8595 & TRN & \\
\hline CHEMBL1384345 & 688171 & 4.35 & 4.9681 & TRN & \\
\hline CHEMBL1464721 & 688171 & 4.6 & 4.8699 & TRN & \\
\hline CHEMBL1405432 & 688171 & 4.5 & 4.84399 & 9999999999 & TRN \\
\hline CHEMBL1598159 & 688171 & 4.55 & 4.9204 & TRN & \\
\hline CHEMBL1348808 & 688171 & 4.4 & 4.8624 & TRN & \\
\hline CHEMBL1417683 & 688171 & 4.5 & 4.7325 & TRN & \\
\hline CHEMBL1467578 & 688171 & 4.7 & 4.9908 & TST & \\
\hline CHEMBL1378129 & 688171 & 4.7 & 4.8483 & TRN & \\
\hline CHEMBL1398542 & 688171 & 4.85 & 4.8462 & TRN & \\
\hline CHEMBL1388033 & 688171 & 4.6 & 4.9819 & TRN & \\
\hline CHEMBL44664 & 688171 & 4.5 & 4.8416 & TRN & \\
\hline CHEMBL1584977 & 688171 & 4.9 & 4.9178 & TST & \\
\hline CHEMBL1551550 & 688171 & 4.8 & 4.82600 & 00000000005 & TRN \\
\hline CHEMBL337577 & 688171 & 4.4 & 4.9701 & TST & \\
\hline CHEMBL1382419 & 688171 & 4.4 & 5.0883 & TST & \\
\hline CHEMBL1435511 & 688171 & 5.05 & 4.9167 & TRN & \\
\hline CHEMBL1706619 & 688171 & 4.4 & 4.788 & TRN & \\
\hline CHEMBL1428935 & 688171 & 4.55 & 4.7334 & TRN & \\
\hline CHEMBL1530499 & 688171 & 4.55 & 4.8931 & TRN & \\
\hline CHEMBL1353253 & 688171 & 4.6 & 4.9299 & TST & \\
\hline CHEMBL1453322 & 688171 & 4.5 & 4.8399 & TST & \\
\hline CHEMBL1607709 & 688171 & 4.65 & 4.8478 & TRN & \\
\hline CHEMBL1428897 & 688171 & 4.45 & 4.9968 & TRN & \\
\hline CHEMBL 3084891 & 688171 & 4.35 & 4.9638 & TST & \\
\hline CHEMBL1394800 & 688171 & 4.7 & 4.8483 & TRN & \\
\hline CHEMBL1559090 & 688171 & 5.1 & 4.9821 & TRN & \\
\hline CHEMBL1309895 & 688171 & 4.75 & 4.7791 & TRN & \\
\hline CHEMBL1527451 & 688171 & 4.55 & 4.8966 & TST & \\
\hline CHEMBL1383035 & 688171 & 5.4 & 4.8443 & TRN & \\
\hline CHEMBL1590315 & 688171 & 5.0 & 4.9533 & TRN & \\
\hline CHEMBL1241420 & 688171 & 4.45 & 4.8203 & TRN & \\
\hline CHEMBL1495414 & 688171 & 4.9 & 4.7896 & TRN & \\
\hline CHEMBL1589526 & 688171 & 4.4 & 4.8108 & TRN & \\
\hline CHEMBL1502041 & 688171 & 6.7001 & 4.923 & TST & \\
\hline CHEMBL1551933 & 688171 & 4.65 & 4.9066 & TRN & \\
\hline CHEMBL1374399 & 688171 & 5.05 & 4.9461 & TRN & \\
\hline CHEMBL1990214 & 688171 & 6.25 & 4.975 & TST & \\
\hline CHEMBL3198595 & 688171 & 4.9 & 4.9485 & TST & \\
\hline CHEMBL1551648 & 688171 & 5.0 & 4.8619 & TRN & \\
\hline
\end{tabular}




\begin{tabular}{|c|c|c|c|c|}
\hline \multicolumn{5}{|c|}{ Supplemental Table S2.txt } \\
\hline CHEMBL1381992 & 688171 & 4.4 & 4.8415 & TRN \\
\hline CHEMBL1505601 & 688171 & 4.6 & 4.8675 & TRN \\
\hline CHEMBL1556345 & 688171 & 4.75 & 4.8686 & TST \\
\hline CHEMBL1969672 & 688171 & 5.0 & 4.9512 & TST \\
\hline CHEMBL1494082 & 688171 & 4.6 & 5.0034 & TRN \\
\hline CHEMBL1330586 & 688171 & 4.9 & 4.9177 & TRN \\
\hline CHEMBL1354210 & 688171 & 4.4 & 4.9391 & TRN \\
\hline CHEMBL1402258 & 688171 & 5.4 & 4.9539 & TST \\
\hline CHEMBL1567726 & 688171 & 5.1 & 4.9744 & TRN \\
\hline CHEMBL1319461 & 688171 & 5.0 & 4.9413 & TRN \\
\hline CHEMBL1363862 & 688171 & 5.05 & 4.9181 & TRN \\
\hline CHEMBL1575601 & 688171 & 4.7 & 4.947 & TST \\
\hline CHEMBL1522833 & 688171 & 4.6 & 4.904 & TRN \\
\hline CHEMBL1375818 & 688171 & 4.45 & 4.9724 & TRN \\
\hline CHEMBL494559 & 688171 & 4.95 & 4.8092 & TRN \\
\hline CHEMBL1476986 & 688171 & 4.5 & 4.8048 & TRN \\
\hline CHEMBL1349113 & 688171 & 4.75 & 5.0529 & TST \\
\hline CHEMBL1396167 & 688171 & 4.4 & 4.9763 & TRN \\
\hline CHEMBL1525149 & 688171 & 4.65 & 4.9071 & TRN \\
\hline CHEMBL1364426 & 688171 & 4.7 & 4.9879 & TRN \\
\hline CHEMBL1394538 & 688171 & 4.7 & 4.6882 & TRN \\
\hline CHEMBL1607405 & 688171 & 4.6 & 4.8761 & TST \\
\hline CHEMBL1422737 & 688171 & 5.1 & 4.8645 & TST \\
\hline CHEMBL1411580 & 688171 & 5.15 & 4.9721 & TRN \\
\hline CHEMBL1315341 & 688171 & 4.65 & 4.9523 & TRN \\
\hline CHEMBL1301137 & 688171 & 4.55 & 4.8907 & TRN \\
\hline CHEMBL1332612 & 688171 & 4.95 & 4.928 & TRN \\
\hline CHEMBL1358542 & 688171 & 4.85 & 4.9128 & TRN \\
\hline CHEMBL1470702 & 688171 & 4.75 & 4.9265 & TRN \\
\hline CHEMBL3208079 & 688171 & 5.9 & 4.921 & TRN \\
\hline CHEMBL1452305 & 688171 & 4.7 & 5.0056 & TST \\
\hline CHEMBL1330879 & 688171 & 4.8 & 4.8437 & TST \\
\hline CHEMBL1396233 & 688171 & 4.9 & 4.8495 & TRN \\
\hline CHEMBL579420 & 688171 & 4.7 & 4.7687 & TRN \\
\hline CHEMBL1328933 & 688171 & 4.4 & 4.9212 & TRN \\
\hline CHEMBL1394249 & 688171 & 4.65 & 4.7903 & TRN \\
\hline CHEMBL3194758 & 688171 & 4.65 & 4.8746 & TRN \\
\hline CHEMBL1332378 & 688171 & 5.65 & 4.9986 & TST \\
\hline CHEMBL1527256 & 688171 & 4.4 & 4.7547 & TRN \\
\hline CHEMBL1994838 & 688171 & 4.45 & 4.8725 & TRN \\
\hline CHEMBL1556586 & 688171 & 4.55 & 4.9545 & TRN \\
\hline CHEMBL3194823 & 688171 & 4.35 & 4.88 & TST \\
\hline CHEMBL1436756 & 688171 & 4.6 & 4.9673 & TRN \\
\hline CHEMBL1358755 & 688171 & 4.4 & 4.8522 & TRN \\
\hline CHEMBL1569101 & 688171 & 4.95 & 4.8599 & TRN \\
\hline CHEMBL1382784 & 688171 & 4.45 & 5.0047 & TRN \\
\hline CHEMBL1428071 & 688171 & 4.7 & 4.8295 & TRN \\
\hline CHEMBL1597994 & 688171 & 5.1 & 4.8782 & TRN \\
\hline
\end{tabular}




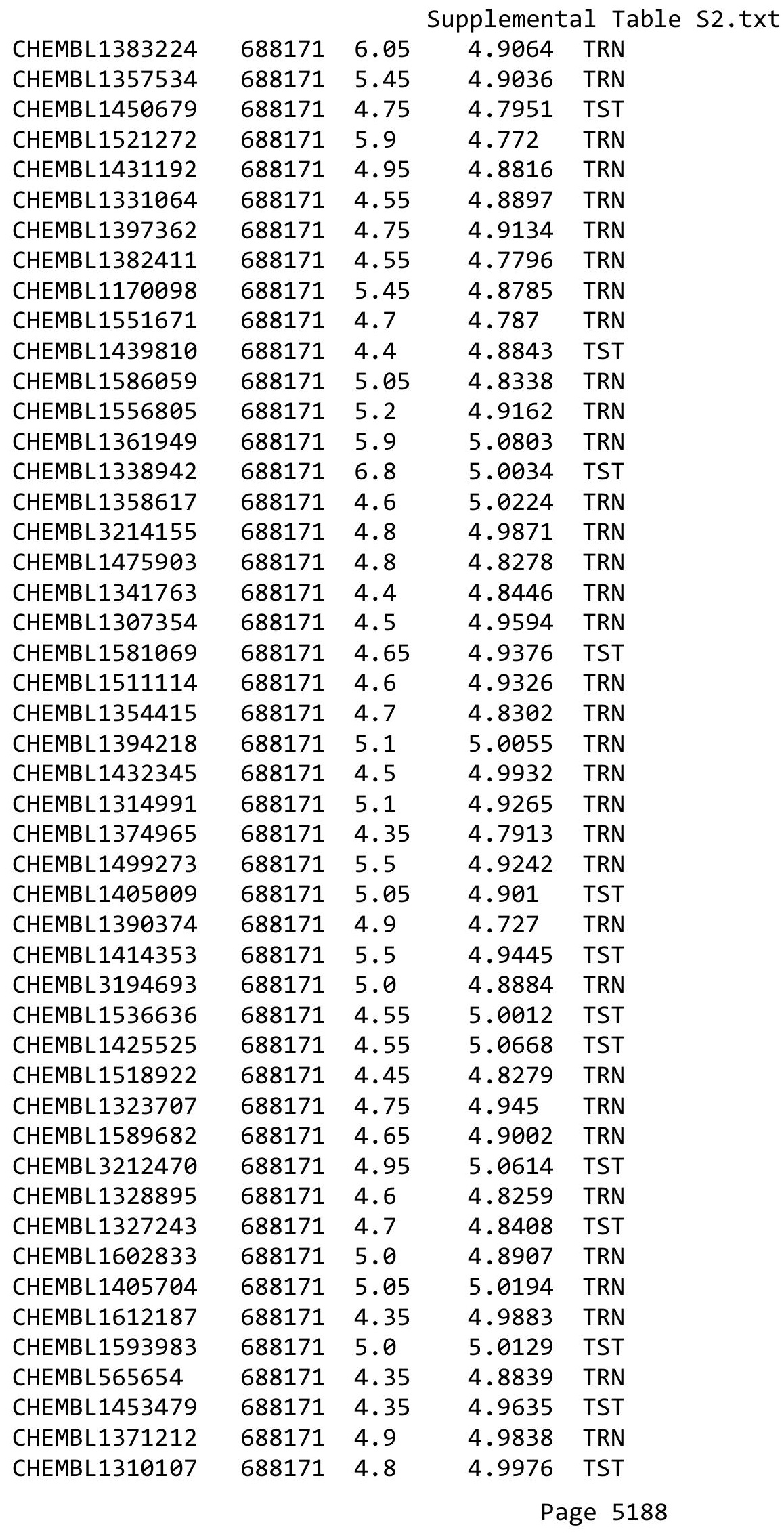




\begin{tabular}{|c|c|c|c|c|c|}
\hline & & \multicolumn{4}{|c|}{ Supplemental Table s2.txt } \\
\hline CHEMBL1370567 & 688171 & 4.4 & 4.8703 & TST & \\
\hline CHEMBL1536994 & 688171 & 4.85 & 4.9066 & TRN & \\
\hline CHEMBL1414232 & 688171 & 6.0 & 4.988 & TRN & \\
\hline CHEMBL1533110 & 688171 & 4.5 & 4.9276 & TRN & \\
\hline CHEMBL1362062 & 688171 & 4.6 & 5.0411 & TST & \\
\hline CHEMBL1581596 & 688171 & 4.5 & 4.8049 & TRN & \\
\hline CHEMBL1569585 & 688171 & 6.0 & 4.9749 & TRN & \\
\hline CHEMBL1534707 & 688171 & 5.0 & 4.9706 & TRN & \\
\hline CHEMBL1537332 & 688171 & 4.7 & 4.8207 & TRN & \\
\hline CHEMBL1476655 & 688171 & 4.95 & 4.9494 & TRN & \\
\hline CHEMBL1579846 & 688171 & 4.5 & 4.93 & TRN & \\
\hline CHEMBL1362424 & 688171 & 4.9 & 4.9572 & TRN & \\
\hline CHEMBL1379398 & 688171 & 5.05 & 4.9145 & TRN & \\
\hline CHEMBL1457047 & 688171 & 5.4 & 4.9702 & TRN & \\
\hline CHEMBL1320651 & 688171 & 4.4 & 5.0284 & TRN & \\
\hline CHEMBL1423633 & 688171 & 4.4 & 4.9267 & TRN & \\
\hline CHEMBL1489395 & 688171 & 6.05 & 5.0099 & TRN & \\
\hline CHEMBL1319675 & 688171 & 4.95 & 4.9048 & TRN & \\
\hline CHEMBL1597850 & 688171 & 4.4 & 4.9134 & TRN & \\
\hline CHEMBL 3212111 & 688171 & 5.05 & 4.9748 & TRN & \\
\hline CHEMBL1351533 & 688171 & 4.55 & 4.7337 & TRN & \\
\hline CHEMBL1590374 & 688171 & 6.0 & 4.9764 & TRN & \\
\hline CHEMBL 1585740 & 688171 & 5.35 & 4.8844 & TST & \\
\hline CHEMBL1469320 & 688171 & 4.35 & 4.8251 & TRN & \\
\hline CHEMBL1336977 & 688171 & 5.1 & 4.8285 & TRN & \\
\hline CHEMBL1394087 & 688171 & 4.6 & 4.9865 & TRN & \\
\hline CHEMBL1557654 & 688171 & 5.4 & 5.0629 & TRN & \\
\hline CHEMBL1478524 & 688171 & 6.25 & 4.9266 & TRN & \\
\hline CHEMBL1519910 & 688171 & 4.7 & 4.7882 & TRN & \\
\hline CHEMBL1485869 & 688171 & 4.6 & 4.9191 & TRN & \\
\hline CHEMBL1389210 & 688171 & 6.2 & 4.9076 & TRN & \\
\hline CHEMBL1555125 & 688171 & 5.4 & 4.959 & TRN & \\
\hline CHEMBL1304193 & 688171 & 4.5 & 4.961 & TRN & \\
\hline CHEMBL1353776 & 688171 & 4.35 & 4.8534 & TRN & \\
\hline CHEMBL1541596 & 688171 & 5.8 & 4.98 & TRN & \\
\hline CHEMBL1573017 & 688171 & 4.55 & 4.7852 & TRN & \\
\hline CHEMBL1537112 & 688171 & 6.0 & 4.8947 & TRN & \\
\hline CHEMBL 1483660 & 688171 & 4.5 & 4.891 & TRN & \\
\hline CHEMBL1468055 & 688171 & 4.55 & 4.8197 & TRN & \\
\hline CHEMBL1317307 & 688171 & 4.9 & 4.6973 & TRN & \\
\hline CHEMBL1322763 & 688171 & 5.1 & 4.7706 & TST & \\
\hline CHEMBL 3208967 & 688171 & 4.9 & 4.9366 & TST & \\
\hline CHEMBL1305077 & 688171 & 4.6 & 5.0148 & TST & \\
\hline CHEMBL1355200 & 688171 & 5.35 & 4.9559 & TRN & \\
\hline CHEMBL1345979 & 688171 & 6.25 & 4.8678 & TST & \\
\hline CHEMBL1597674 & 688171 & 5.05 & 4.9772 & TST & \\
\hline CHEMBL1502211 & 688171 & 4.4 & 4.99100 & 00000000005 & TRN \\
\hline CHEMBL1570051 & 688171 & 6.4 & 4.9502 & TRN & \\
\hline
\end{tabular}




\begin{tabular}{|c|c|c|c|c|c|}
\hline \multicolumn{6}{|c|}{ Supplemental Table S2.txt } \\
\hline CHEMBL1346796 & 688171 & 4.35 & 4.8312 & TST & \\
\hline CHEMBL483847 & 688171 & 4.55 & 4.8038 & TST & \\
\hline CHEMBL1404165 & 688171 & 4.5 & 4.9799 & TST & \\
\hline CHEMBL3197915 & 688171 & 5.0 & 4.9338 & TST & \\
\hline CHEMBL161254 & 688171 & 4.5 & 4.8528 & TST & \\
\hline CHEMBL1526044 & 688171 & 4.9 & 4.7946 & TRN & \\
\hline CHEMBL3199053 & 688171 & 5.25 & 4.9746 & TRN & \\
\hline CHEMBL1484193 & 688171 & 4.4 & 4.9666 & TST & \\
\hline CHEMBL1438956 & 688171 & 5.2 & 5.0514 & TRN & \\
\hline CHEMBL1363569 & 688171 & 4.6 & 4.8099 & TST & \\
\hline CHEMBL1404346 & 688171 & 4.85 & 4.7961 & TRN & \\
\hline CHEMBL1532239 & 688171 & 4.7 & 5.0376 & TRN & \\
\hline CHEMBL1558829 & 688171 & 4.65 & 4.852 & TRN & \\
\hline CHEMBL1481147 & 688171 & 5.1 & 4.75899 & 99999999995 & TRN \\
\hline CHEMBL1255837 & 688171 & 6.0 & 5.1044 & TST & \\
\hline CHEMBL1537100 & 688171 & 4.65 & 4.9313 & TRN & \\
\hline CHEMBL1576212 & 688171 & 6.95 & 4.9422 & TRN & \\
\hline CHEMBL3195484 & 688171 & 4.5 & 5.0197 & TST & \\
\hline CHEMBL1514619 & 688171 & 5.0 & 4.9331 & TRN & \\
\hline CHEMBL1437417 & 688171 & 4.55 & 5.0059 & TRN & \\
\hline CHEMBL1477011 & 688171 & 5.15 & 4.8919 & TRN & \\
\hline CHEMBL1377623 & 688171 & 5.4 & 5.0008 & TST & \\
\hline CHEMBL1530206 & 688171 & 4.85 & 4.8172 & TRN & \\
\hline CHEMBL1395727 & 688171 & 5.25 & 4.7902 & TRN & \\
\hline CHEMBL1530678 & 688171 & 4.45 & 4.9994 & TRN & \\
\hline CHEMBL1473509 & 688171 & 4.8 & 4.8601 & TRN & \\
\hline CHEMBL1349343 & 688171 & 4.4 & 4.7923 & TRN & \\
\hline CHEMBL1424541 & 688171 & 4.75 & 4.9174 & TRN & \\
\hline CHEMBL1473074 & 688171 & 4.9 & 4.7934 & TRN & \\
\hline CHEMBL1461435 & 688171 & 4.35 & 5.0245 & TRN & \\
\hline CHEMBL3198083 & 688171 & 4.35 & 4.9012 & TST & \\
\hline CHEMBL1571560 & 688171 & 4.4 & 4.7045 & TST & \\
\hline CHEMBL1420393 & 688171 & 4.8 & 4.9386 & TST & \\
\hline CHEMBL1408903 & 688171 & 4.85 & 4.8535 & TRN & \\
\hline CHEMBL1534385 & 688171 & 4.5 & 4.7993 & TRN & \\
\hline CHEMBL1552975 & 688171 & 5.0 & 4.8171 & TRN & \\
\hline CHEMBL 1582630 & 688171 & 4.45 & 4.8838 & TST & \\
\hline CHEMBL1541494 & 688171 & 5.7 & 5.1004 & TRN & \\
\hline CHEMBL1438653 & 688171 & 4.7 & 4.8899 & TRN & \\
\hline CHEMBL1449651 & 688171 & 4.4 & 4.9524 & TST & \\
\hline CHEMBL1377128 & 688171 & 4.5 & 4.9013 & TRN & \\
\hline CHEMBL 1353152 & 688171 & 4.65 & 4.9296 & TRN & \\
\hline CHEMBL1535972 & 688171 & 4.4 & 4.9975 & TST & \\
\hline CHEMBL1440100 & 688171 & 4.55 & 4.887 & TRN & \\
\hline CHEMBL1600086 & 688171 & 5.0 & 4.9418 & TRN & \\
\hline CHEMBL1505277 & 688171 & 5.0 & 4.8462 & TST & \\
\hline CHEMBL1981539 & 688171 & 4.4 & 4.9946 & TST & \\
\hline CHEMBL1433606 & 688171 & 5.05 & 4.8399 & TRN & \\
\hline
\end{tabular}




\begin{tabular}{|c|c|c|c|c|}
\hline \multicolumn{5}{|c|}{ Supplemental Table S2.txt } \\
\hline CHEMBL1601826 & 688171 & 4.5 & 4.9859 & TRN \\
\hline CHEMBL3191835 & 688171 & 4.4 & 4.8529 & TRN \\
\hline CHEMBL1342506 & 688171 & 6.35 & 4.9514 & TRN \\
\hline CHEMBL1445436 & 688171 & 4.7 & 4.7416 & TRN \\
\hline CHEMBL1567254 & 688171 & 4.5 & 4.9965 & TRN \\
\hline CHEMBL1450393 & 688171 & 4.55 & 5.0027 & TST \\
\hline CHEMBL1360580 & 688171 & 4.65 & 4.7753 & TRN \\
\hline CHEMBL1358689 & 688171 & 4.45 & 4.8907 & TRN \\
\hline CHEMBL1394068 & 688171 & 4.9 & 4.8896 & TRN \\
\hline CHEMBL1314885 & 688171 & 4.4 & 4.9658 & TRN \\
\hline CHEMBL3194711 & 688171 & 4.85 & 4.7737 & TST \\
\hline CHEMBL1472824 & 688171 & 4.5 & 4.9071 & TRN \\
\hline CHEMBL1436073 & 688171 & 4.95 & 4.8983 & TRN \\
\hline CHEMBL1491389 & 688171 & 4.85 & 4.8874 & TRN \\
\hline CHEMBL1381152 & 688171 & 4.55 & 4.7376 & TST \\
\hline CHEMBL1458908 & 688171 & 5.45 & 4.9155 & TRN \\
\hline CHEMBL2001105 & 688171 & 5.05 & 4.8496 & TRN \\
\hline CHEMBL1355928 & 688171 & 4.8 & 4.8299 & TRN \\
\hline CHEMBL1475615 & 688171 & 4.85 & 4.8863 & TRN \\
\hline CHEMBL1540631 & 688171 & 4.6 & 4.808 & TST \\
\hline CHEMBL1437769 & 688171 & 6.7001 & 5.0568 & TRN \\
\hline CHEMBL1608749 & 688171 & 5.0 & 4.7819 & TRN \\
\hline CHEMBL1459360 & 688171 & 4.6 & 4.7829 & TST \\
\hline CHEMBL1566417 & 688171 & 4.4 & 4.9324 & TRN \\
\hline CHEMBL1335329 & 688171 & 4.9 & 4.9122 & TST \\
\hline CHEMBL1444506 & 688171 & 5.25 & 4.8624 & TRN \\
\hline CHEMBL1537465 & 688171 & 4.65 & 4.8544 & TST \\
\hline CHEMBL1586326 & 688171 & 4.8 & 4.819 & TST \\
\hline CHEMBL1479140 & 688171 & 6.1 & 4.8395 & TRN \\
\hline CHEMBL1366289 & 688171 & 4.55 & 4.9308 & TRN \\
\hline CHEMBL1440279 & 688171 & 5.35 & 4.9614 & TRN \\
\hline CHEMBL1559336 & 688171 & 4.75 & 4.8855 & TRN \\
\hline CHEMBL1374511 & 688171 & 4.65 & 4.9673 & TRN \\
\hline CHEMBL1398346 & 688171 & 4.75 & 4.8026 & TRN \\
\hline CHEMBL1414599 & 688171 & 5.3 & 4.9047 & TRN \\
\hline CHEMBL1517129 & 688171 & 4.35 & 4.9372 & TST \\
\hline CHEMBL1538933 & 688171 & 4.35 & 5.11 & TST \\
\hline CHEMBL1485940 & 688171 & 5.4 & 5.0001 & TST \\
\hline CHEMBL1337384 & 688171 & 4.4 & 4.8015 & TRN \\
\hline CHEMBL1532195 & 688171 & 4.55 & 4.9117 & TRN \\
\hline CHEMBL 2005973 & 688171 & 4.4 & 4.9767 & TRN \\
\hline CHEMBL1479569 & 688171 & 4.75 & 4.945 & TST \\
\hline CHEMBL1979574 & 688171 & 4.35 & 5.0587 & TRN \\
\hline CHEMBL1358725 & 688171 & 4.7 & 4.8497 & TRN \\
\hline CHEMBL1560510 & 688171 & 6.9 & 4.8706 & TRN \\
\hline CHEMBL1991234 & 688171 & 5.55 & 4.9377 & TRN \\
\hline CHEMBL1603615 & 688171 & 4.95 & 4.8448 & TRN \\
\hline CHEMBL1428203 & 688171 & 4.75 & 4.9341 & TRN \\
\hline
\end{tabular}




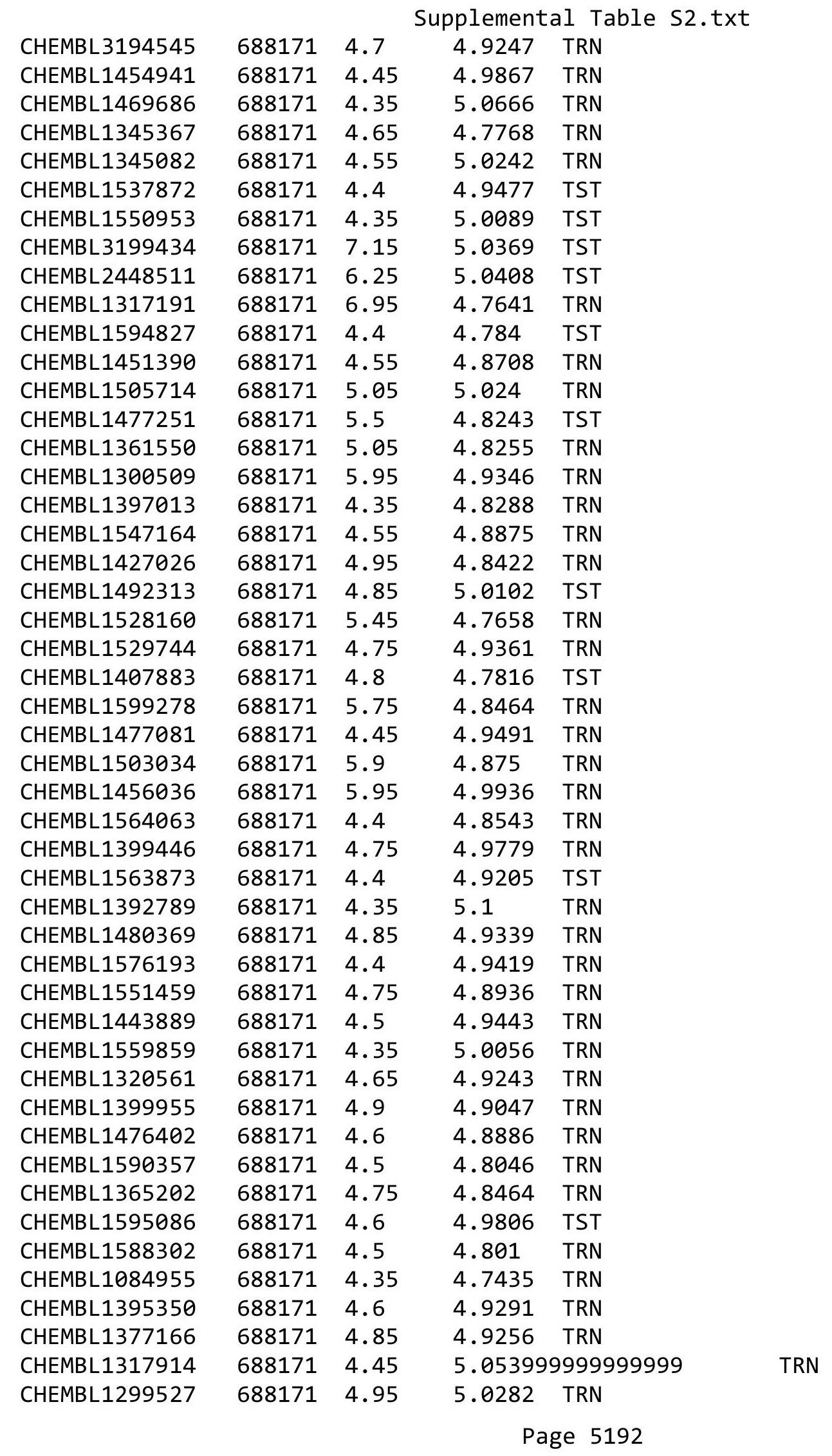




\begin{tabular}{|c|c|c|c|c|}
\hline \multicolumn{5}{|c|}{ Supplemental Table S2.txt } \\
\hline CHEMBL1384697 & 688171 & 4.55 & 5.0162 & TST \\
\hline CHEMBL1463749 & 688171 & 4.6 & 4.7478 & TST \\
\hline CHEMBL1554040 & 688171 & 4.5 & 4.7319 & TRN \\
\hline CHEMBL3199206 & 688171 & 4.5 & 4.956 & TRN \\
\hline CHEMBL1404507 & 688171 & 4.7 & 4.9426 & TRN \\
\hline CHEMBL1339007 & 688171 & 4.9 & 4.8774 & TRN \\
\hline CHEMBL585656 & 688171 & 5.05 & 4.9576 & TST \\
\hline CHEMBL1503047 & 688171 & 4.95 & 4.8658 & TRN \\
\hline CHEMBL1390559 & 688171 & 4.4 & 4.8164 & TRN \\
\hline CHEMBL1534860 & 688171 & 5.05 & 4.79 & TRN \\
\hline CHEMBL1606862 & 688171 & 4.75 & 4.8517 & TRN \\
\hline CHEMBL1500336 & 688171 & 4.4 & 4.9122 & TRN \\
\hline CHEMBL1564008 & 688171 & 4.75 & 4.8724 & TST \\
\hline CHEMBL3189493 & 688171 & 4.5 & 5.0371 & TRN \\
\hline CHEMBL1469659 & 688171 & 4.6 & 4.856 & TST \\
\hline CHEMBL1430628 & 688171 & 5.05 & 4.8118 & TST \\
\hline CHEMBL1582259 & 688171 & 4.75 & 4.9516 & TRN \\
\hline CHEMBL1300439 & 688171 & 4.4 & 4.8913 & TST \\
\hline CHEMBL1384553 & 688171 & 4.75 & 5.065 & TST \\
\hline CHEMBL1590523 & 688171 & 4.6 & 5.0544 & TRN \\
\hline CHEMBL1518435 & 688171 & 5.15 & 4.882 & TRN \\
\hline CHEMBL1386232 & 688171 & 4.5 & 4.6413 & TRN \\
\hline CHEMBL1611832 & 688171 & 5.1 & 4.96 & TRN \\
\hline CHEMBL1347493 & 688171 & 4.85 & 4.7797 & TRN \\
\hline CHEMBL1354387 & 688171 & 4.5 & 4.8793 & TRN \\
\hline CHEMBL1553995 & 688171 & 6.15 & 4.8371 & TRN \\
\hline CHEMBL1352568 & 688171 & 5.35 & 4.9704 & TRN \\
\hline CHEMBL1521754 & 688171 & 4.55 & 4.8526 & TRN \\
\hline CHEMBL1423410 & 688171 & 4.95 & 4.8377 & TRN \\
\hline CHEMBL1353357 & 688171 & 4.7 & 4.9503 & TRN \\
\hline CHEMBL1431810 & 688171 & 4.45 & 4.7993 & TRN \\
\hline CHEMBL1553829 & 688171 & 4.75 & 4.7092 & TRN \\
\hline CHEMBL1314993 & 688171 & 5.4 & 4.8282 & TRN \\
\hline CHEMBL1443824 & 688171 & 5.05 & 4.8012 & TRN \\
\hline CHEMBL1561318 & 688171 & 4.4 & 4.8259 & TST \\
\hline CHEMBL1460618 & 688171 & 4.4 & 4.7838 & TRN \\
\hline CHEMBL1423724 & 688171 & 4.6 & 4.8684 & TRN \\
\hline CHEMBL2369212 & 688171 & 6.2 & 4.9292 & TST \\
\hline CHEMBL1515121 & 688171 & 4.45 & 4.8574 & TRN \\
\hline CHEMBL1306908 & 688171 & 4.7 & 4.8123 & TRN \\
\hline CHEMBL1436167 & 688171 & 5.65 & 4.9605 & TRN \\
\hline CHEMBL1375130 & 688171 & 4.45 & 4.957 & TRN \\
\hline CHEMBL1308187 & 688171 & 4.5 & 4.9437 & TRN \\
\hline CHEMBL3198275 & 688171 & 4.75 & 4.9114 & TRN \\
\hline CHEMBL1418707 & 688171 & 4.65 & 4.8514 & TRN \\
\hline CHEMBL1319107 & 688171 & 5.0 & 4.891 & TRN \\
\hline CHEMBL1407169 & 688171 & 4.6 & 4.8755 & TST \\
\hline CHEMBL 272465 & 688171 & 4.4 & 4.8776 & TST \\
\hline
\end{tabular}




\begin{tabular}{|c|c|c|c|c|c|}
\hline \multicolumn{6}{|c|}{ Supplemental Table S2.txt } \\
\hline CHEMBL1390601 & 688171 & 4.4 & 4.95 & TST & \\
\hline CHEMBL1602489 & 688171 & 4.4 & 4.8281 & TST & \\
\hline CHEMBL1470626 & 688171 & 4.4 & 4.7917 & TRN & \\
\hline CHEMBL1321574 & 688171 & 4.85 & 4.7607 & TRN & \\
\hline CHEMBL3196124 & 688171 & 5.1 & 5.0118 & TRN & \\
\hline CHEMBL1373613 & 688171 & 5.55 & 4.9715 & TRN & \\
\hline CHEMBL1463563 & 688171 & 4.7 & 4.8021 & TRN & \\
\hline CHEMBL1529352 & 688171 & 4.85 & 4.7275 & TRN & \\
\hline CHEMBL 32363 & 688171 & 5.05 & 5.02800 & 00000000005 & TST \\
\hline CHEMBL1555356 & 688171 & 4.45 & 4.8023 & TRN & \\
\hline CHEMBL1300411 & 688171 & 4.5 & 4.9016 & TRN & \\
\hline CHEMBL1493461 & 688171 & 5.65 & 4.8673 & TST & \\
\hline CHEMBL 3193331 & 688171 & 5.1 & 4.9799 & TST & \\
\hline CHEMBL1341866 & 688171 & 4.65 & 4.8283 & TRN & \\
\hline CHEMBL1982290 & 688171 & 4.7 & 4.8779 & TRN & \\
\hline CHEMBL1331799 & 688171 & 6.0 & 4.973 & TRN & \\
\hline CHEMBL606166 & 688171 & 4.4 & 4.8708 & TRN & \\
\hline CHEMBL1612744 & 688171 & 4.65 & 4.9244 & TRN & \\
\hline CHEMBL1381215 & 688171 & 4.8 & 4.8594 & TRN & \\
\hline CHEMBL1555692 & 688171 & 5.8 & 4.9071 & TST & \\
\hline CHEMBL1488509 & 688171 & 4.4 & 5.0423 & TRN & \\
\hline CHEMBL1357278 & 688171 & 4.75 & 4.8353 & TRN & \\
\hline CHEMBL1551034 & 688171 & 5.1 & 4.8116 & TRN & \\
\hline CHEMBL1586736 & 688171 & 6.0 & 5.0144 & TRN & \\
\hline CHEMBL 206483 & 688171 & 5.15 & 4.9901 & TRN & \\
\hline CHEMBL1435904 & 688171 & 4.75 & 4.8502 & TRN & \\
\hline CHEMBL1521163 & 688171 & 4.5 & 5.0009 & TRN & \\
\hline CHEMBL1578122 & 688171 & 5.1 & 4.8513 & TRN & \\
\hline CHEMBL1384484 & 688171 & 4.75 & 4.9486 & TRN & \\
\hline CHEMBL1528118 & 688171 & 4.9 & 4.913 & TRN & \\
\hline CHEMBL1456786 & 688171 & 5.25 & 4.9663 & TST & \\
\hline CHEMBL1397538 & 688171 & 4.8 & 4.8917 & TRN & \\
\hline CHEMBL1562633 & 688171 & 5.7 & 4.9579 & TRN & \\
\hline CHEMBL1525590 & 688171 & 4.6 & 4.919 & TRN & \\
\hline CHEMBL 3196224 & 688171 & 4.7 & 4.9783 & TRN & \\
\hline CHEMBL1574668 & 688171 & 5.3 & 4.9893 & TRN & \\
\hline CHEMBL3198590 & 688171 & 4.6 & 4.9998 & TRN & \\
\hline CHEMBL1593411 & 688171 & 6.8499 & 4.9722 & TRN & \\
\hline CHEMBL1309430 & 688171 & 4.95 & 5.0239 & TRN & \\
\hline CHEMBL1365257 & 688171 & 4.7 & 4.7863 & TRN & \\
\hline CHEMBL1521393 & 688171 & 6.35 & 4.8448 & TRN & \\
\hline CHEMBL1302531 & 688171 & 4.9 & 4.8438 & TST & \\
\hline CHEMBL1451761 & 688171 & 5.5 & 4.8879 & TST & \\
\hline CHEMBL1592055 & 688171 & 5.0 & 4.9494 & TST & \\
\hline CHEMBL1318229 & 688171 & 4.95 & 4.8483 & TST & \\
\hline CHEMBL3211586 & 688171 & 6.3 & 5.07100 & 0000000001 & TST \\
\hline CHEMBL1415385 & 688171 & 4.7 & 4.8733 & TRN & \\
\hline CHEMBL3197901 & 688171 & 4.65 & 4.9123 & TRN & \\
\hline
\end{tabular}




\begin{tabular}{|c|c|c|c|c|}
\hline \multicolumn{5}{|c|}{ Supplemental Table s2.txt } \\
\hline CHEMBL1337991 & 688171 & 5.3 & 4.7989 & TST \\
\hline CHEMBL1453982 & 688171 & 5.0 & 5.2003 & TRN \\
\hline CHEMBL1413660 & 688171 & 4.75 & 4.8606 & TST \\
\hline CHEMBL1458538 & 688171 & 4.4 & 4.9772 & TRN \\
\hline CHEMBL1320676 & 688171 & 4.85 & 4.9225 & TRN \\
\hline CHEMBL1574084 & 688171 & 4.35 & 4.9546 & TRN \\
\hline CHEMBL1590559 & 688171 & 6.05 & 5.0349 & TRN \\
\hline CHEMBL1402055 & 688171 & 4.95 & 4.8711 & TST \\
\hline CHEMBL1376070 & 688171 & 4.5 & 4.8712 & TST \\
\hline CHEMBL1342527 & 688171 & 4.65 & 4.9625 & TRN \\
\hline CHEMBL1373788 & 688171 & 4.35 & 4.7641 & TRN \\
\hline CHEMBL1480047 & 688171 & 4.9 & 4.8823 & TRN \\
\hline CHEMBL1390515 & 688171 & 5.05 & 4.8737 & TRN \\
\hline CHEMBL1507156 & 688171 & 5.3 & 4.8762 & TRN \\
\hline CHEMBL1612106 & 688171 & 4.45 & 4.9044 & TRN \\
\hline CHEMBL1454432 & 688171 & 4.8 & 4.9363 & TRN \\
\hline CHEMBL1357677 & 688171 & 5.05 & 4.8559 & TRN \\
\hline CHEMBL 3210216 & 688171 & 6.1 & 4.9693 & TRN \\
\hline CHEMBL1976917 & 688171 & 6.9 & 4.8498 & TST \\
\hline CHEMBL3195018 & 688171 & 5.3 & 4.9295 & TRN \\
\hline CHEMBL 9637 & 688171 & 5.0 & 4.8641 & TRN \\
\hline CHEMBL1362894 & 688171 & 4.85 & 4.8112 & TRN \\
\hline CHEMBL1395798 & 688171 & 7.3497 & 5.0042 & TRN \\
\hline CHEMBL1304258 & 688171 & 4.7 & 4.87 & TRN \\
\hline CHEMBL1611061 & 688171 & 4.6 & 4.8586 & TRN \\
\hline CHEMBL1314932 & 688171 & 5.05 & 4.8488 & TRN \\
\hline CHEMBL1588513 & 688171 & 6.15 & 4.9522 & TRN \\
\hline CHEMBL1334919 & 688171 & 4.75 & 4.9036 & TST \\
\hline CHEMBL1412163 & 688171 & 4.7 & 5.02 & TST \\
\hline CHEMBL1481083 & 688171 & 4.4 & 4.9494 & TRN \\
\hline CHEMBL1368382 & 688171 & 5.45 & 4.88 & TRN \\
\hline CHEMBL1446120 & 688171 & 4.35 & 4.8476 & TRN \\
\hline CHEMBL1375627 & 688171 & 4.55 & 4.9167 & TRN \\
\hline CHEMBL462861 & 688171 & 4.9 & 4.8265 & TST \\
\hline CHEMBL3190721 & 688171 & 4.6 & 4.8914 & TRN \\
\hline CHEMBL1552650 & 688171 & 4.85 & 4.8442 & TRN \\
\hline CHEMBL1474989 & 688171 & 4.55 & 4.8044 & TRN \\
\hline CHEMBL1555752 & 688171 & 4.4 & 4.9619 & TST \\
\hline CHEMBL1385479 & 688171 & 4.7 & 4.9528 & TRN \\
\hline CHEMBL1525348 & 688171 & 4.5 & 4.8413 & TRN \\
\hline CHEMBL1484128 & 688171 & 4.35 & 4.8644 & TRN \\
\hline CHEMBL1999947 & 688171 & 5.95 & 4.9117 & TRN \\
\hline CHEMBL1362200 & 688171 & 4.45 & 4.9215 & TRN \\
\hline CHEMBL1491248 & 688171 & 4.55 & 4.9332 & TST \\
\hline CHEMBL1345717 & 688171 & 5.65 & 4.8588 & TRN \\
\hline CHEMBL 3197095 & 688171 & 7.0501 & 5.0274 & TST \\
\hline CHEMBL1457594 & 688171 & 4.4 & 4.9123 & TRN \\
\hline CHEMBL1372439 & 688171 & 4.95 & 4.8282 & TRN \\
\hline
\end{tabular}




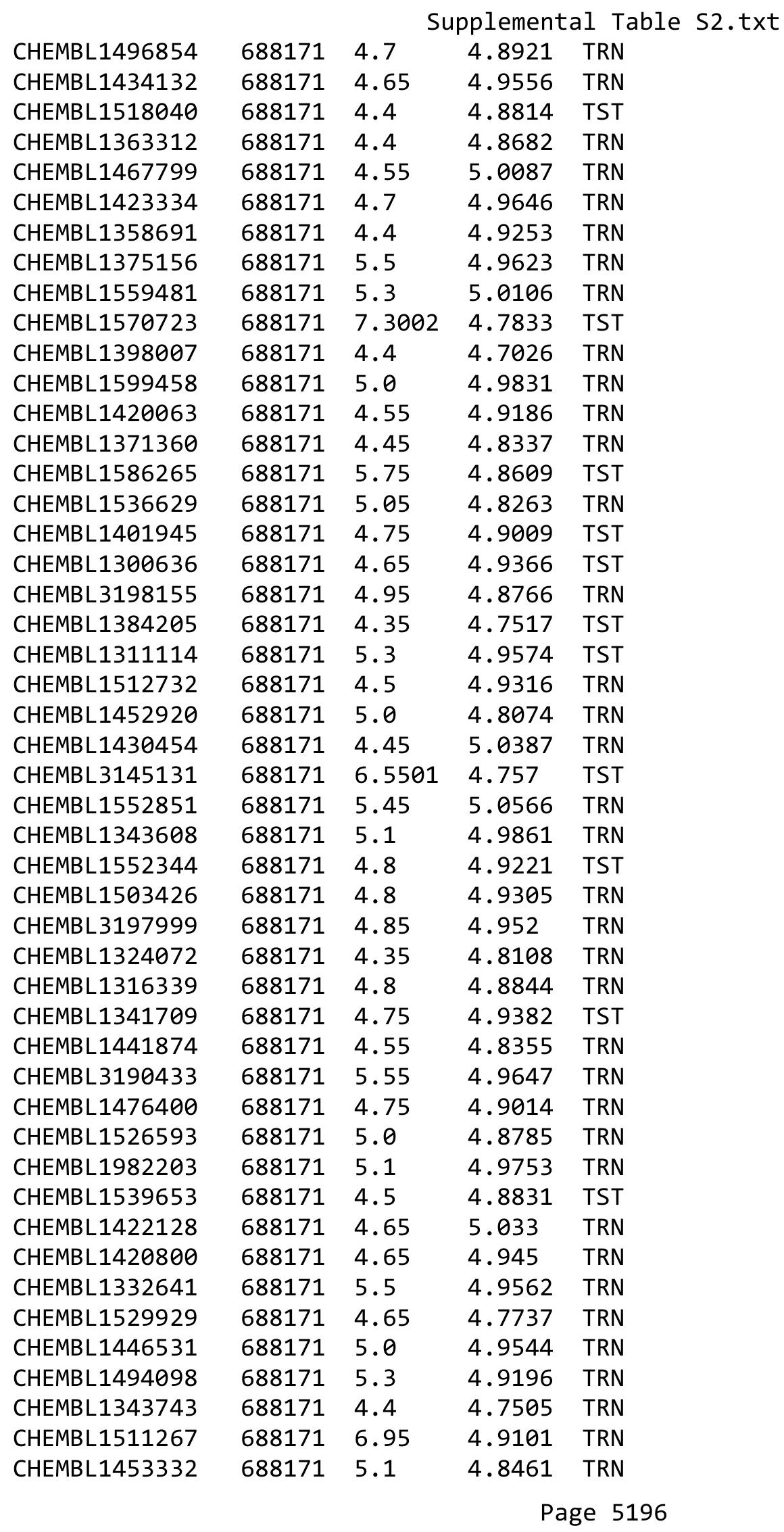




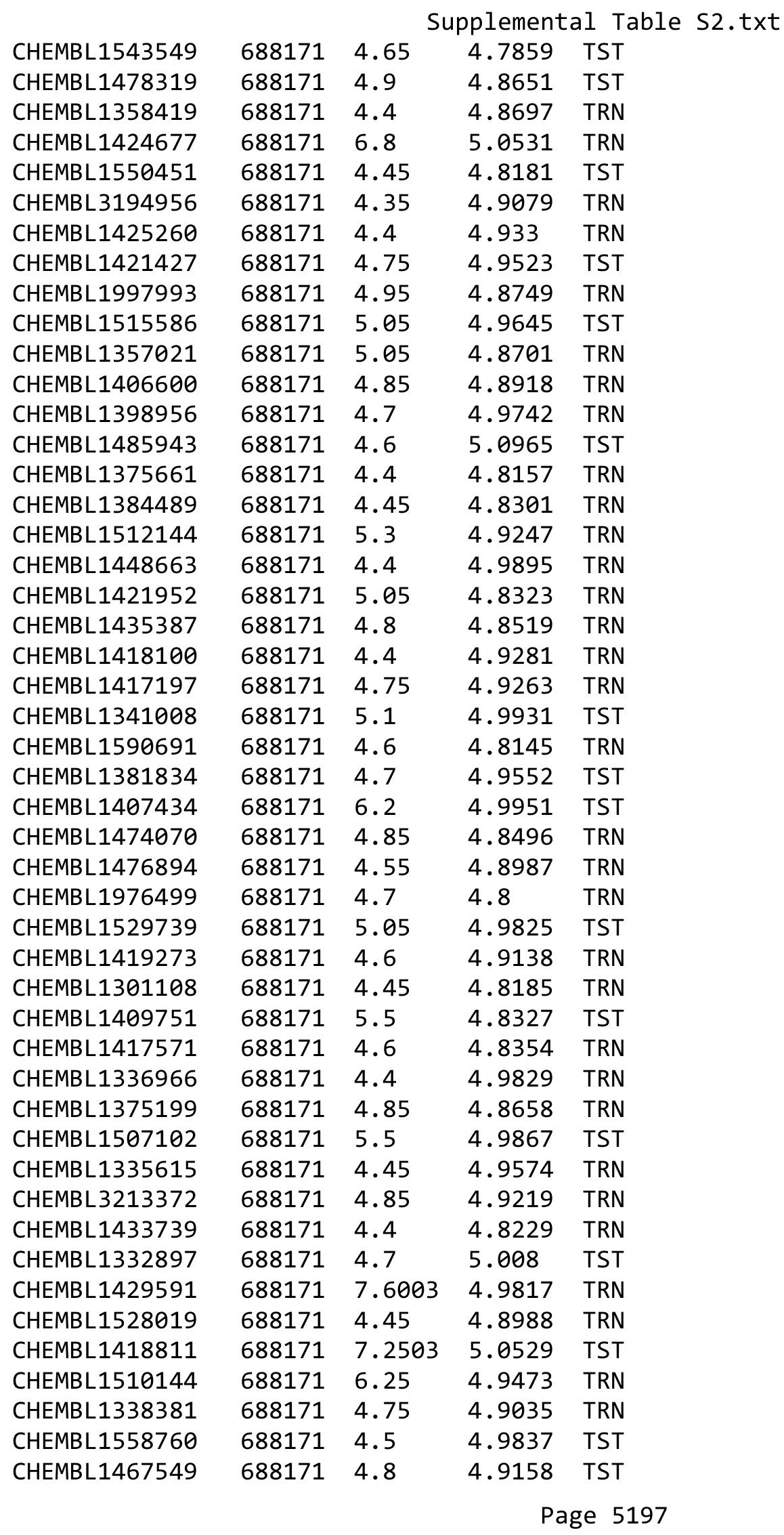




\begin{tabular}{|c|c|c|c|c|}
\hline \multicolumn{5}{|c|}{ Supplemental Table S2.txt } \\
\hline CHEMBL1480841 & 688171 & 4.4 & 4.8367 & TRN \\
\hline CHEMBL3209342 & 688171 & 4.9 & 5.0436 & TRN \\
\hline CHEMBL1388752 & 688171 & 5.2 & 4.9271 & TST \\
\hline CHEMBL1428562 & 688171 & 4.55 & 4.8369 & TST \\
\hline CHEMBL1549804 & 688171 & 4.4 & 4.8836 & TRN \\
\hline CHEMBL 3208330 & 688171 & 5.45 & 5.0181 & TRN \\
\hline CHEMBL3210953 & 688171 & 5.05 & 4.9248 & TST \\
\hline CHEMBL1320907 & 688171 & 4.4 & 4.9006 & TST \\
\hline CHEMBL1579118 & 688171 & 4.5 & 4.8322 & TRN \\
\hline CHEMBL1422001 & 688171 & 4.45 & 4.845 & TRN \\
\hline CHEMBL1611788 & 688171 & 4.75 & 5.0529 & TRN \\
\hline CHEMBL1378734 & 688171 & 4.45 & 4.7815 & TRN \\
\hline CHEMBL1612956 & 688171 & 4.9 & 4.9366 & TRN \\
\hline CHEMBL1464169 & 688171 & 5.6 & 4.891 & TST \\
\hline CHEMBL1322224 & 688171 & 5.5 & 4.7557 & TRN \\
\hline CHEMBL1399191 & 688171 & 4.55 & 4.8501 & TST \\
\hline CHEMBL1565221 & 688171 & 4.85 & 4.7973 & TRN \\
\hline CHEMBL1509857 & 688171 & 5.5 & 4.8729 & TRN \\
\hline CHEMBL1564801 & 688171 & 4.6 & 4.9181 & TST \\
\hline CHEMBL3214035 & 688171 & 4.4 & 4.8647 & TRN \\
\hline CHEMBL1533941 & 688171 & 5.05 & 4.9077 & TRN \\
\hline CHEMBL1579286 & 688171 & 6.5 & 4.9187 & TRN \\
\hline CHEMBL1551899 & 688171 & 4.8 & 5.0645 & TRN \\
\hline CHEMBL1447194 & 688171 & 4.85 & 4.9131 & TST \\
\hline CHEMBL1451937 & 688171 & 7.1002 & 5.0259 & TST \\
\hline CHEMBL1318478 & 688171 & 4.35 & 5.0642 & TST \\
\hline CHEMBL1460918 & 688171 & 5.05 & 4.7653 & TST \\
\hline CHEMBL1559748 & 688171 & 4.6 & 4.8385 & TST \\
\hline CHEMBL1346003 & 688171 & 4.5 & 4.8493 & TRN \\
\hline CHEMBL1337231 & 688171 & 4.8 & 4.788 & TRN \\
\hline CHEMBL1577215 & 688171 & 4.45 & 4.8993 & TRN \\
\hline CHEMBL1317495 & 688171 & 4.75 & 4.7852 & TRN \\
\hline CHEMBL1552250 & 688171 & 4.55 & 4.8693 & TRN \\
\hline CHEMBL1370375 & 688171 & 6.0 & 4.9525 & TRN \\
\hline CHEMBL1445971 & 688171 & 4.5 & 4.9255 & TST \\
\hline CHEMBL1575247 & 688171 & 4.4 & 4.7071 & TRN \\
\hline CHEMBL3211008 & 688171 & 4.85 & 4.9546 & TST \\
\hline CHEMBL1477918 & 688171 & 4.5 & 4.7786 & TRN \\
\hline CHEMBL1335165 & 688171 & 4.85 & 4.8036 & TST \\
\hline CHEMBL1553219 & 688171 & 4.4 & 4.792 & TRN \\
\hline CHEMBL1551963 & 688171 & 5.15 & 4.8821 & TRN \\
\hline CHEMBL1334813 & 688171 & 4.75 & 4.9463 & TRN \\
\hline CHEMBL1414491 & 688171 & 5.0 & 5.0605 & TST \\
\hline CHEMBL1356128 & 688171 & 6.05 & 4.9654 & TST \\
\hline CHEMBL1551776 & 688171 & 4.4 & 4.8606 & TRN \\
\hline CHEMBL3198995 & 688171 & 5.4 & 4.9536 & TST \\
\hline CHEMBL1563738 & 688171 & 4.35 & 4.9906 & TST \\
\hline CHEMBL1552775 & 688171 & 4.95 & 4.8916 & TRN \\
\hline
\end{tabular}




\begin{tabular}{|c|c|c|c|c|c|}
\hline & & \multicolumn{4}{|c|}{ Supplemental Table S2.txt } \\
\hline CHEMBL3194415 & 688171 & 4.5 & 4.8608 & TRN & \\
\hline CHEMBL1346558 & 688171 & 5.05 & 4.8455 & TRN & \\
\hline CHEMBL1558090 & 688171 & 5.45 & 4.8979 & TRN & \\
\hline CHEMBL1358593 & 688171 & 5.0 & 4.9141 & TRN & \\
\hline CHEMBL1317049 & 688171 & 4.55 & 4.8045 & TRN & \\
\hline CHEMBL1301948 & 688171 & 4.55 & 4.8218 & TRN & \\
\hline CHEMBL223453 & 688171 & 6.0 & 4.8591 & TRN & \\
\hline CHEMBL193627 & 688171 & 4.55 & 4.8614 & TST & \\
\hline CHEMBL1558099 & 688171 & 6.1 & 4.8865 & TRN & \\
\hline CHEMBL3191201 & 688171 & 5.15 & 4.9378 & TRN & \\
\hline CHEMBL1367547 & 688171 & 4.6 & 4.9157 & TRN & \\
\hline CHEMBL1327495 & 688171 & 4.85 & 5.0448 & TST & \\
\hline CHEMBL1551651 & 688171 & 4.65 & 4.9791 & TRN & \\
\hline CHEMBL1452286 & 688171 & 4.75 & 4.8977 & TRN & \\
\hline CHEMBL1484839 & 688171 & 4.6 & 4.8589 & TRN & \\
\hline CHEMBL1390312 & 688171 & 7.0501 & 4.9623 & TST & \\
\hline CHEMBL1441360 & 688171 & 4.9 & 4.849 & TRN & \\
\hline CHEMBL1466953 & 688171 & 4.5 & 4.9676 & TST & \\
\hline CHEMBL 1424725 & 688171 & 4.6 & 4.8378 & TRN & \\
\hline CHEMBL1595235 & 688171 & 4.35 & 4.7914 & TRN & \\
\hline CHEMBL1588140 & 688171 & 4.75 & 5.0078 & TRN & \\
\hline CHEMBL1467244 & 688171 & 4.7 & 4.9805 & TRN & \\
\hline CHEMBL1482091 & 688171 & 6.45 & 4.9142 & TRN & \\
\hline CHEMBL1526651 & 688171 & 5.0 & 4.9241 & TST & \\
\hline CHEMBL1589849 & 688171 & 5.9 & 4.7694 & TRN & \\
\hline CHEMBL1612026 & 688171 & 4.4 & 4.8066 & TST & \\
\hline CHEMBL1356313 & 688171 & 5.0 & 4.9022 & TRN & \\
\hline CHEMBL1426814 & 688171 & 5.35 & 4.9149 & TRN & \\
\hline CHEMBL1373349 & 688171 & 4.6 & 4.8333 & TRN & \\
\hline CHEMBL1500231 & 688171 & 4.75 & 4.816 & TRN & \\
\hline CHEMBL1398504 & 688171 & 4.35 & 4.9024 & TRN & \\
\hline CHEMBL1488772 & 688171 & 6.2 & 4.94600 & 2000000001 & TRN \\
\hline CHEMBL 1430872 & 688171 & 5.05 & 4.7875 & TRN & \\
\hline CHEMBL1369199 & 688171 & 5.3 & 4.9782 & TRN & \\
\hline CHEMBL1443276 & 688171 & 5.45 & 4.8596 & TST & \\
\hline CHEMBL1516340 & 688171 & 4.6 & 5.0443 & TRN & \\
\hline CHEMBL1488674 & 688171 & 4.4 & 4.9044 & TRN & \\
\hline CHEMBL1335237 & 688171 & 4.95 & 4.8344 & TRN & \\
\hline CHEMBL1320111 & 688171 & 4.75 & 4.9333 & TRN & \\
\hline CHEMBL1359484 & 688171 & 4.5 & 4.8915 & TRN & \\
\hline CHEMBL88961 & 688171 & 4.4 & 4.8964 & TST & \\
\hline CHEMBL 3211002 & 688171 & 4.95 & 4.8514 & TST & \\
\hline CHEMBL1578235 & 688171 & 6.0 & 4.8249 & TRN & \\
\hline CHEMBL1560575 & 688171 & 5.1 & 5.0127 & TST & \\
\hline CHEMBL1368039 & 688171 & 5.55 & 4.8983 & TRN & \\
\hline CHEMBL1382590 & 688171 & 4.9 & 4.875 & TRN & \\
\hline CHEMBL1447151 & 688171 & 5.05 & 4.8908 & TST & \\
\hline CHEMBL1562255 & 688171 & 4.85 & 4.9088 & TRN & \\
\hline
\end{tabular}




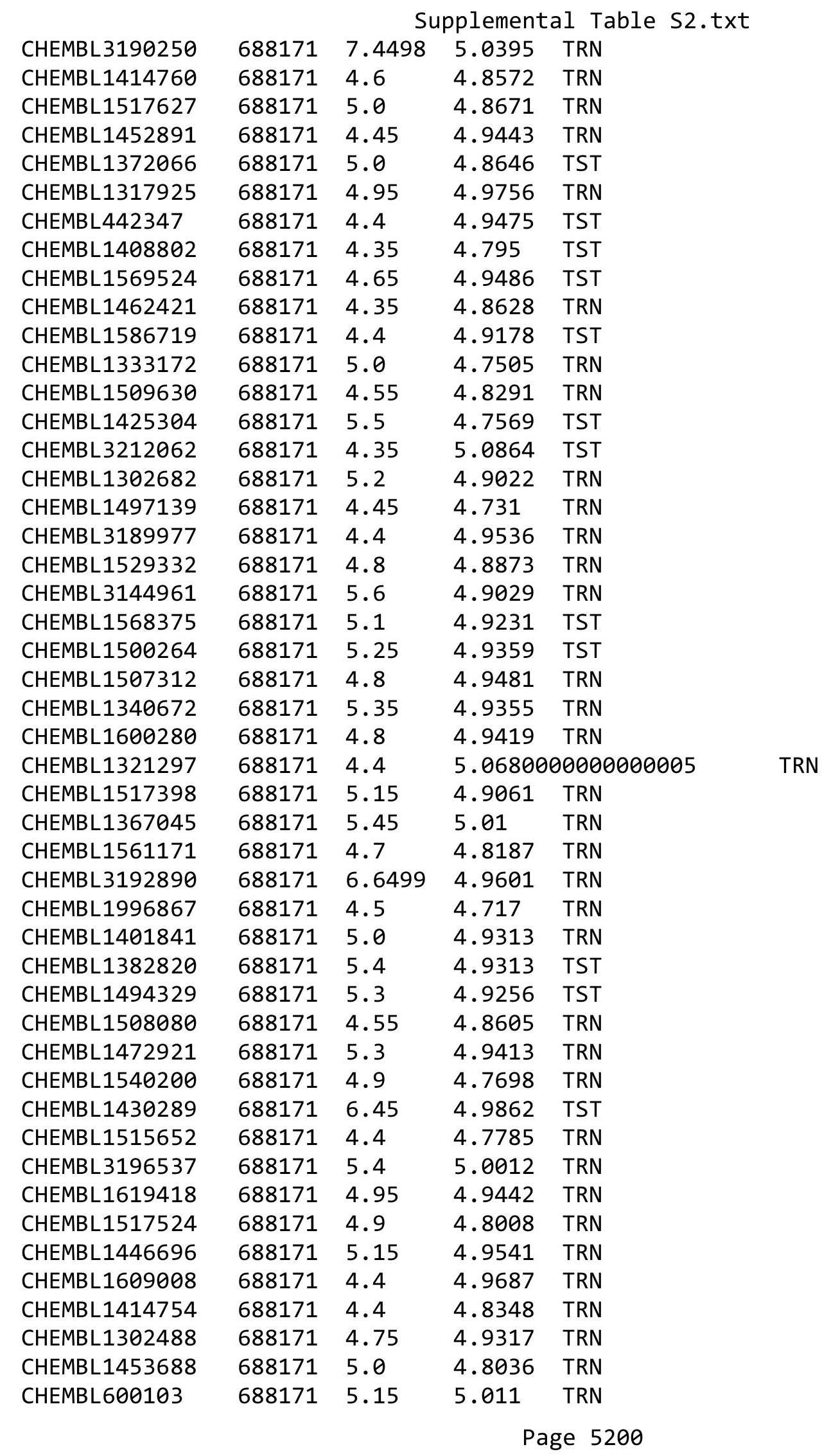




\begin{tabular}{|c|c|c|c|c|c|}
\hline \multicolumn{6}{|c|}{ Supplemental Table S2.txt } \\
\hline CHEMBL 3189145 & 688171 & 4.6 & 4.9928 & TRN & \\
\hline CHEMBL1435104 & 688171 & 4.5 & 4.8125 & TRN & \\
\hline CHEMBL1474358 & 688171 & 5.65 & 4.9861 & TRN & \\
\hline CHEMBL1353413 & 688171 & 4.35 & 4.8832 & TRN & \\
\hline CHEMBL1369628 & 688171 & 4.4 & 4.8543 & TST & \\
\hline CHEMBL1568440 & 688171 & 4.6 & 5.0962 & TRN & \\
\hline CHEMBL1537417 & 688171 & 4.4 & 4.9333 & TST & \\
\hline CHEMBL1707406 & 688171 & 4.4 & 4.86600 & 00000000005 & TRN \\
\hline CHEMBL576607 & 688171 & 6.0 & 4.9183 & TRN & \\
\hline CHEMBL1302829 & 688171 & 4.45 & 4.7412 & TRN & \\
\hline CHEMBL1516891 & 688171 & 4.75 & 4.811 & TRN & \\
\hline CHEMBL1464308 & 688171 & 5.45 & 4.8396 & TRN & \\
\hline CHEMBL1542757 & 688171 & 4.5 & 4.9222 & TST & \\
\hline CHEMBL1398537 & 688171 & 5.05 & 4.9834 & TST & \\
\hline CHEMBL1345489 & 688171 & 4.95 & 4.7379 & TRN & \\
\hline CHEMBL1329328 & 688171 & 5.3 & 4.9892 & TRN & \\
\hline CHEMBL3211731 & 688171 & 6.3 & 5.0136 & TRN & \\
\hline CHEMBL1463179 & 688171 & 4.75 & 4.893 & TST & \\
\hline CHEMBL1518631 & 688171 & 5.3 & 4.9027 & TRN & \\
\hline CHEMBL1357662 & 688171 & 4.4 & 4.7945 & TRN & \\
\hline CHEMBL1383395 & 688171 & 4.6 & 4.77 & TST & \\
\hline CHEMBL1575218 & 688171 & 5.05 & 5.0272 & TRN & \\
\hline CHEMBL1468811 & 688171 & 4.35 & 4.9895 & TST & \\
\hline CHEMBL1469246 & 688171 & 4.5 & 5.0638 & TRN & \\
\hline CHEMBL1609252 & 688171 & 4.65 & 4.8602 & TRN & \\
\hline CHEMBL1476809 & 688171 & 4.65 & 4.9465 & TRN & \\
\hline CHEMBL1441412 & 688171 & 4.6 & 4.9098 & TRN & \\
\hline CHEMBL1431459 & 688171 & 4.55 & 4.8745 & TRN & \\
\hline CHEMBL1597843 & 688171 & 4.8 & 4.8052 & TRN & \\
\hline CHEMBL1598864 & 688171 & 4.65 & 4.9009 & TRN & \\
\hline CHEMBL1581818 & 688171 & 4.7 & 4.8432 & TST & \\
\hline CHEMBL1590284 & 688171 & 5.0 & 4.7971 & TRN & \\
\hline CHEMBL1478700 & 688171 & 4.5 & 4.9085 & TRN & \\
\hline CHEMBL1406165 & 688171 & 4.35 & 4.8837 & TRN & \\
\hline CHEMBL1523750 & 688171 & 4.6 & 4.8032 & TRN & \\
\hline CHEMBL1426922 & 688171 & 4.4 & 4.9281 & TRN & \\
\hline CHEMBL527584 & 688171 & 5.25 & 5.0343 & TRN & \\
\hline CHEMBL1966224 & 688171 & 4.7 & 4.9277 & TRN & \\
\hline CHEMBL 3209820 & 688171 & 5.5 & 4.8513 & TST & \\
\hline CHEMBL1504531 & 688171 & 4.75 & 4.9231 & TST & \\
\hline CHEMBL3192084 & 688171 & 4.65 & 4.9186 & TRN & \\
\hline CHEMBL1337445 & 688171 & 4.65 & 4.9733 & TST & \\
\hline CHEMBL1349765 & 688171 & 4.35 & 4.9479 & TRN & \\
\hline CHEMBL3192206 & 688171 & 4.5 & 4.8895 & TST & \\
\hline CHEMBL1568274 & 688171 & 4.85 & 4.8905 & TRN & \\
\hline CHEMBL3196288 & 688171 & 4.4 & 4.9266 & TRN & \\
\hline CHEMBL1396646 & 688171 & 4.55 & 4.9476 & TRN & \\
\hline CHEMBL1608979 & 688171 & 5.3 & 4.8402 & TRN & \\
\hline
\end{tabular}




\begin{tabular}{|c|c|c|c|c|c|}
\hline & & \multicolumn{4}{|c|}{ Supplemental Table S2.txt } \\
\hline CHEMBL1433829 & 688171 & 4.95 & 4.9408 & TRN & \\
\hline CHEMBL1999166 & 688171 & 4.9 & 4.9362 & TRN & \\
\hline CHEMBL1403107 & 688171 & 4.85 & 4.8986 & TRN & \\
\hline CHEMBL1608383 & 688171 & 5.1 & 4.9213 & TRN & \\
\hline CHEMBL3189269 & 688171 & 4.85 & 5.0648 & TRN & \\
\hline CHEMBL3199094 & 688171 & 5.35 & 5.0358 & TRN & \\
\hline CHEMBL222556 & 688171 & 4.35 & 4.8576 & TRN & \\
\hline CHEMBL1394623 & 688171 & 4.85 & 4.9234 & TRN & \\
\hline CHEMBL1529784 & 688171 & 4.35 & \multicolumn{2}{|c|}{4.9319999999999995} & TRN \\
\hline CHEMBL1596699 & 688171 & 4.45 & 4.9163 & TRN & \\
\hline CHEMBL1497042 & 688171 & 5.4 & 4.8708 & TRN & \\
\hline CHEMBL1494334 & 688171 & 4.4 & 4.873 & TST & \\
\hline CHEMBL1613678 & 688171 & 4.9 & 4.8609 & TRN & \\
\hline CHEMBL1441808 & 688171 & 4.45 & 4.9409 & TRN & \\
\hline CHEMBL1393635 & 688171 & 4.85 & 4.9288 & TRN & \\
\hline CHEMBL1334816 & 688171 & 4.6 & 4.8194 & TRN & \\
\hline CHEMBL1501495 & 688171 & 5.0 & 4.8499 & TST & \\
\hline CHEMBL1526699 & 688171 & 4.35 & 4.9724 & TRN & \\
\hline CHEMBL1476787 & 688171 & 4.4 & 4.7944 & TRN & \\
\hline CHEMBL1500801 & 688171 & 4.5 & 4.9838 & TRN & \\
\hline CHEMBL1378879 & 688171 & 4.55 & 4.9048 & TRN & \\
\hline CHEMBL1456074 & 688171 & 4.7 & 4.7793 & TRN & \\
\hline CHEMBL1602804 & 688171 & 4.8 & 5.0476 & TRN & \\
\hline CHEMBL1477481 & 688171 & 4.65 & 4.7789 & TST & \\
\hline CHEMBL1554032 & 688171 & 4.4 & 4.8603 & TRN & \\
\hline CHEMBL1518700 & 688171 & 4.45 & 4.9239 & TST & \\
\hline CHEMBL1333957 & 688171 & 4.85 & 4.9302 & TRN & \\
\hline CHEMBL1558786 & 688171 & 6.0 & 5.0812 & TRN & \\
\hline CHEMBL1480053 & 688171 & 5.0 & 4.9064 & TRN & \\
\hline CHEMBL1385734 & 688171 & 5.65 & 5.0887 & TRN & \\
\hline CHEMBL1447147 & 688171 & 5.65 & 5.0067 & TST & \\
\hline CHEMBL1433250 & 688171 & 4.6 & 4.8647 & TRN & \\
\hline CHEMBL1502574 & 688171 & 5.1 & 4.7536 & TST & \\
\hline CHEMBL1388144 & 688171 & 5.05 & \multicolumn{2}{|c|}{4.9319999999999995} & TST \\
\hline CHEMBL1581518 & 688171 & 4.55 & 5.0513 & TRN & \\
\hline CHEMBL1309791 & 688171 & 4.45 & 4.8334 & TRN & \\
\hline CHEMBL1560327 & 688171 & 4.55 & 4.9835 & TRN & \\
\hline CHEMBL1447219 & 688171 & 5.75 & 4.8637 & TRN & \\
\hline CHEMBL1447828 & 688171 & 4.5 & 4.914 & TRN & \\
\hline CHEMBL1399455 & 688171 & 5.15 & 4.8633 & TRN & \\
\hline CHEMBL1465709 & 688171 & 4.4 & 4.8376 & TST & \\
\hline CHEMBL531401 & 688171 & 4.7 & 4.8328 & TRN & \\
\hline CHEMBL1309551 & 688171 & 4.7 & 4.9168 & TRN & \\
\hline CHEMBL1348721 & 688171 & 5.2 & 4.8103 & TRN & \\
\hline CHEMBL3214538 & 688171 & 6.2 & 4.8882 & TST & \\
\hline CHEMBL1473864 & 688171 & 5.45 & 4.8801 & TRN & \\
\hline CHEMBL1331250 & 688171 & 4.75 & \multicolumn{2}{|c|}{4.9430000000000005} & TRN \\
\hline CHEMBL1567184 & 688171 & 4.6 & 4.7737 & TRN & \\
\hline
\end{tabular}




\begin{tabular}{|c|c|c|c|c|c|}
\hline \multicolumn{6}{|c|}{ Supplemental Table S2.txt } \\
\hline CHEMBL1349795 & 688171 & 4.8 & 4.8662 & TRN & \\
\hline CHEMBL1455822 & 688171 & 4.4 & 4.9805 & TST & \\
\hline CHEMBL1394093 & 688171 & 4.5 & 4.9623 & TRN & \\
\hline CHEMBL1551247 & 688171 & 5.65 & 4.9052 & TRN & \\
\hline CHEMBL1518926 & 688171 & 5.05 & 4.8872 & TRN & \\
\hline CHEMBL3207592 & 688171 & 4.75 & 5.0537 & TRN & \\
\hline CHEMBL1389807 & 688171 & 4.75 & 4.9305 & TRN & \\
\hline CHEMBL1537145 & 688171 & 6.0 & 4.9272 & TST & \\
\hline CHEMBL1596431 & 688171 & 4.5 & 4.8767 & TRN & \\
\hline CHEMBL1509216 & 688171 & 4.55 & 4.8365 & TRN & \\
\hline CHEMBL1397893 & 688171 & 4.85 & 4.80399 & 9999999999 & TRN \\
\hline CHEMBL1433657 & 688171 & 4.5 & 4.8557 & TRN & \\
\hline CHEMBL1499017 & 688171 & 5.5 & 4.9437 & TST & \\
\hline CHEMBL1303417 & 688171 & 4.35 & 4.9483 & TST & \\
\hline CHEMBL1477923 & 688171 & 4.5 & 4.9383 & TRN & \\
\hline CHEMBL1364051 & 688171 & 4.85 & 4.8916 & TRN & \\
\hline CHEMBL1594895 & 688171 & 4.45 & 4.8759 & TST & \\
\hline CHEMBL1456488 & 688171 & 4.9 & 4.8777 & TRN & \\
\hline CHEMBL1486827 & 688171 & 4.65 & 4.9793 & TST & \\
\hline CHEMBL3191242 & 688171 & 4.45 & 4.998 & TRN & \\
\hline CHEMBL1363507 & 688171 & 4.5 & 4.8495 & TRN & \\
\hline CHEMBL1500419 & 688171 & 4.4 & 4.8787 & TST & \\
\hline CHEMBL1564821 & 688171 & 4.95 & 4.7393 & TRN & \\
\hline CHEMBL1586909 & 688171 & 5.05 & 4.8973 & TST & \\
\hline CHEMBL1382779 & 688171 & 4.4 & 4.9308 & TRN & \\
\hline CHEMBL1972217 & 688171 & 5.4 & 4.9719 & TRN & \\
\hline CHEMBL1568248 & 688171 & 4.35 & 4.9674 & TST & \\
\hline CHEMBL1513839 & 688171 & 4.55 & 4.9157 & TRN & \\
\hline CHEMBL1323755 & 688171 & 4.35 & 4.8336 & TRN & \\
\hline CHEMBL1403856 & 688171 & 7.3002 & 4.8352 & TRN & \\
\hline CHEMBL1418319 & 688171 & 4.4 & 4.8907 & TRN & \\
\hline CHEMBL1354826 & 688171 & 4.7 & 5.0855 & TST & \\
\hline CHEMBL1562658 & 688171 & 4.7 & 4.902 & TRN & \\
\hline CHEMBL1400535 & 688171 & 4.5 & 4.8908 & TRN & \\
\hline CHEMBL1364740 & 688171 & 4.9 & 4.9109 & TRN & \\
\hline CHEMBL1554690 & 688171 & 4.35 & 5.0737 & TRN & \\
\hline CHEMBL1446239 & 688171 & 5.05 & 4.9681 & TRN & \\
\hline CHEMBL1406609 & 688171 & 4.65 & 4.957 & TRN & \\
\hline CHEMBL1514941 & 688171 & 7.0 & 4.9149 & TRN & \\
\hline CHEMBL1588339 & 688171 & 4.4 & 4.8194 & TRN & \\
\hline CHEMBL1570562 & 688171 & 4.45 & 4.9004 & TRN & \\
\hline CHEMBL1498140 & 688171 & 4.8 & 4.9464 & TST & \\
\hline CHEMBL1499437 & 688171 & 4.4 & 4.8725 & TRN & \\
\hline CHEMBL1458165 & 688171 & 4.4 & 4.8743 & TRN & \\
\hline CHEMBL3195842 & 688171 & 4.55 & 4.8524 & TST & \\
\hline CHEMBL1522413 & 688171 & 4.4 & 4.724 & TRN & \\
\hline CHEMBL1354173 & 688171 & 5.4 & 4.926 & TRN & \\
\hline CHEMBL1304982 & 688171 & 4.75 & 4.7551 & TRN & \\
\hline
\end{tabular}




\begin{tabular}{|c|c|c|c|c|}
\hline \multicolumn{5}{|c|}{ Supplemental Table S2.txt } \\
\hline CHEMBL1336550 & 688171 & 6.35 & 5.0434 & TRN \\
\hline CHEMBL1518760 & 688171 & 4.9 & 4.9217 & TRN \\
\hline CHEMBL1354508 & 688171 & 4.5 & 4.8714 & TRN \\
\hline CHEMBL1426351 & 688171 & 4.65 & 5.0117 & TST \\
\hline CHEMBL1371750 & 688171 & 4.35 & 4.8851 & TRN \\
\hline CHEMBL554311 & 688171 & 5.45 & 4.9843 & TRN \\
\hline CHEMBL1312281 & 688171 & 4.6 & 4.8833 & TRN \\
\hline CHEMBL1301101 & 688171 & 4.95 & 4.8494 & TST \\
\hline CHEMBL1554560 & 688171 & 4.35 & 4.9665 & TRN \\
\hline CHEMBL1529569 & 688171 & 5.35 & 4.8102 & TRN \\
\hline CHEMBL1489749 & 688171 & 4.75 & 4.9587 & TRN \\
\hline CHEMBL1470382 & 688171 & 5.65 & 4.8802 & TRN \\
\hline CHEMBL1563911 & 688171 & 4.6 & 5.0464 & TST \\
\hline CHEMBL1600611 & 688171 & 4.4 & 5.0229 & TRN \\
\hline CHEMBL1513239 & 688171 & 4.85 & 4.8601 & TST \\
\hline CHEMBL1417285 & 688171 & 4.4 & 4.9173 & TRN \\
\hline CHEMBL1340035 & 688171 & 4.5 & 4.9237 & TST \\
\hline CHEMBL1469371 & 688171 & 4.55 & 4.837 & TRN \\
\hline CHEMBL1493953 & 688171 & 4.7 & 4.7876 & TRN \\
\hline CHEMBL587884 & 688171 & 4.55 & 4.8554 & TST \\
\hline CHEMBL1579122 & 688171 & 4.55 & 4.8239 & TST \\
\hline CHEMBL1440382 & 688171 & 6.2 & 4.9123 & TRN \\
\hline CHEMBL577546 & 688171 & 4.45 & 4.7889 & TRN \\
\hline CHEMBL1385546 & 688171 & 4.6 & 4.8721 & TRN \\
\hline CHEMBL1418483 & 688171 & 4.5 & 4.8034 & TST \\
\hline CHEMBL1530081 & 688171 & 4.5 & 5.0645 & TST \\
\hline CHEMBL1394885 & 688171 & 4.95 & 4.846 & TRN \\
\hline CHEMBL1307406 & 688171 & 4.65 & 5.05 & TRN \\
\hline CHEMBL1380041 & 688171 & 4.4 & 4.8494 & TRN \\
\hline CHEMBL1308357 & 688171 & 4.45 & 4.7869 & TRN \\
\hline CHEMBL1354701 & 688171 & 4.4 & 4.8305 & TRN \\
\hline CHEMBL1301074 & 688171 & 4.4 & 4.9615 & TRN \\
\hline CHEMBL1333356 & 688171 & 4.85 & 4.8712 & TRN \\
\hline CHEMBL1428443 & 688171 & 4.4 & 4.8443 & TRN \\
\hline CHEMBL1592791 & 688171 & 4.35 & 4.922 & TRN \\
\hline CHEMBL3196831 & 688171 & 5.65 & 4.9686 & TRN \\
\hline CHEMBL1548872 & 688171 & 4.95 & 4.9763 & TST \\
\hline CHEMBL1610017 & 688171 & 4.85 & 4.9174 & TST \\
\hline CHEMBL1378552 & 688171 & 5.05 & 5.0322 & TRN \\
\hline CHEMBL1608881 & 688171 & 4.85 & 4.7645 & TRN \\
\hline CHEMBL1379967 & 688171 & 4.55 & 4.7953 & TRN \\
\hline CHEMBL1505039 & 688171 & 4.65 & 4.749 & TST \\
\hline CHEMBL1602774 & 688171 & 5.3 & 4.8371 & TRN \\
\hline CHEMBL1350226 & 688171 & 5.5 & 4.9249 & TST \\
\hline CHEMBL1470954 & 688171 & 5.45 & 4.8911 & TRN \\
\hline CHEMBL1441876 & 688171 & 4.4 & 4.8704 & TST \\
\hline CHEMBL1983234 & 688171 & 7.1002 & 4.8928 & TRN \\
\hline CHEMBL1322857 & 688171 & 4.75 & 4.7917 & TRN \\
\hline
\end{tabular}




\begin{tabular}{|c|c|c|c|c|}
\hline \multicolumn{5}{|c|}{ Supplemental Table S2.txt } \\
\hline CHEMBL1391770 & 688171 & 4.9 & 4.9119 & TRN \\
\hline CHEMBL1387837 & 688171 & 4.4 & 5.004 & TST \\
\hline CHEMBL1361291 & 688171 & 4.45 & 4.8954 & TST \\
\hline CHEMBL1419735 & 688171 & 5.0 & 4.8099 & TST \\
\hline CHEMBL1412039 & 688171 & 5.0 & 4.7896 & TRN \\
\hline CHEMBL1473881 & 688171 & 4.7 & 4.8369 & TRN \\
\hline CHEMBL1418962 & 688171 & 4.7 & 4.8732 & TRN \\
\hline CHEMBL1458561 & 688171 & 4.4 & 4.8225 & TST \\
\hline CHEMBL1553328 & 688171 & 6.25 & 4.9535 & TST \\
\hline CHEMBL1421117 & 688171 & 6.9 & 5.0741 & TST \\
\hline CHEMBL1608809 & 688171 & 4.6 & 4.8683 & TRN \\
\hline CHEMBL1514795 & 688171 & 4.8 & 5.0164 & TST \\
\hline CHEMBL1475124 & 688171 & 4.85 & 4.8936 & TRN \\
\hline CHEMBL1467009 & 688171 & 4.35 & 4.9763 & TRN \\
\hline CHEMBL1571465 & 688171 & 5.5 & 4.9605 & TRN \\
\hline CHEMBL1306203 & 688171 & 4.4 & 4.8382 & TRN \\
\hline CHEMBL1607746 & 688171 & 6.05 & 4.9152 & TRN \\
\hline CHEMBL1379989 & 688171 & 5.0 & 4.9711 & TRN \\
\hline CHEMBL1379599 & 688171 & 4.7 & 4.9124 & TRN \\
\hline CHEMBL1439419 & 688171 & 5.05 & 5.0032 & TST \\
\hline CHEMBL1469626 & 688171 & 4.4 & 4.9094 & TRN \\
\hline CHEMBL 383200 & 688171 & 4.95 & 4.8465 & TRN \\
\hline CHEMBL1516545 & 688171 & 4.4 & 4.9655 & TRN \\
\hline CHEMBL1564556 & 688171 & 4.85 & 4.8749 & TRN \\
\hline CHEMBL1572923 & 688171 & 4.5 & 4.9135 & TRN \\
\hline CHEMBL1502229 & 688171 & 4.4 & 4.8682 & TST \\
\hline CHEMBL1396077 & 688171 & 5.3 & 4.9662 & TRN \\
\hline CHEMBL1376008 & 688171 & 4.6 & 4.9277 & TRN \\
\hline CHEMBL1436718 & 688171 & 5.45 & 4.802 & TRN \\
\hline CHEMBL1430692 & 688171 & 4.55 & 4.97 & TRN \\
\hline CHEMBL1399370 & 688171 & 4.65 & 4.9194 & TRN \\
\hline CHEMBL1402626 & 688171 & 4.6 & 4.9689 & TRN \\
\hline CHEMBL1482564 & 688171 & 5.65 & 4.8678 & TRN \\
\hline CHEMBL3207905 & 688171 & 4.55 & 5.1065 & TRN \\
\hline CHEMBL1597729 & 688171 & 4.7 & 5.0289 & TRN \\
\hline CHEMBL1458659 & 688171 & 6.05 & 4.8352 & TRN \\
\hline CHEMBL1317147 & 688171 & 5.55 & 4.9036 & TST \\
\hline CHEMBL 3208547 & 688171 & 5.05 & 4.8647 & TST \\
\hline CHEMBL1304432 & 688171 & 4.5 & 4.8503 & TRN \\
\hline CHEMBL1448415 & 688171 & 5.15 & 4.8321 & TRN \\
\hline CHEMBL566068 & 688171 & 5.6 & 4.7821 & TRN \\
\hline CHEMBL1349360 & 688171 & 4.55 & 4.8026 & TRN \\
\hline CHEMBL1324274 & 688171 & 4.8 & 4.9785 & TRN \\
\hline CHEMBL1348296 & 688171 & 4.35 & 4.9292 & TRN \\
\hline CHEMBL1335833 & 688171 & 4.5 & 4.9033 & TST \\
\hline CHEMBL1511834 & 688171 & 4.4 & 4.8338 & TST \\
\hline CHEMBL1476462 & 688171 & 6.0 & 4.8902 & TRN \\
\hline CHEMBL1448265 & 688171 & 4.85 & 4.8884 & TST \\
\hline
\end{tabular}




\begin{tabular}{|c|c|c|c|c|c|}
\hline \multicolumn{6}{|c|}{ Supplemental Table S2.txt } \\
\hline CHEMBL1580856 & 688171 & 4.55 & 5.0555 & TRN & \\
\hline CHEMBL1597772 & 688171 & 6.0 & 5.0022 & TST & \\
\hline CHEMBL1458404 & 688171 & 5.45 & 4.9093 & TRN & \\
\hline CHEMBL1522758 & 688171 & 5.3 & 4.9278 & TRN & \\
\hline CHEMBL1527611 & 688171 & 5.95 & 4.8117 & TRN & \\
\hline CHEMBL1343115 & 688171 & 5.1 & 4.8947 & TST & \\
\hline CHEMBL546865 & 688171 & 4.4 & 4.8147 & TST & \\
\hline CHEMBL1374838 & 688171 & 5.65 & 5.0212 & TRN & \\
\hline CHEMBL1596580 & 688171 & 4.45 & 4.9582 & TRN & \\
\hline CHEMBL1350983 & 688171 & 4.75 & 4.9411 & TST & \\
\hline CHEMBL1584801 & 688171 & 4.4 & 4.6945 & TRN & \\
\hline CHEMBL1504655 & 688171 & 4.55 & 4.9194 & TST & \\
\hline CHEMBL1487221 & 688171 & 4.9 & 4.94300 & 00000000005 & TST \\
\hline CHEMBL1521233 & 688171 & 4.35 & 4.9453 & TST & \\
\hline CHEMBL1531745 & 688171 & 4.8 & 4.9428 & TRN & \\
\hline CHEMBL1413884 & 688171 & 4.35 & 4.939 & TRN & \\
\hline CHEMBL334255 & 688171 & 6.6 & 4.9763 & TST & \\
\hline CHEMBL1381408 & 688171 & 4.4 & 4.8064 & TRN & \\
\hline CHEMBL1903510 & 688171 & 4.75 & 4.8601 & TST & \\
\hline CHEMBL1324024 & 688171 & 4.35 & 5.0684 & TRN & \\
\hline CHEMBL1403645 & 688171 & 4.4 & 4.8807 & TRN & \\
\hline CHEMBL1332164 & 688171 & 4.95 & 5.0829 & TRN & \\
\hline CHEMBL1452577 & 688171 & 5.75 & 4.8388 & TRN & \\
\hline CHEMBL1305770 & 688171 & 6.95 & 5.0607 & TST & \\
\hline CHEMBL1414678 & 688171 & 4.75 & 4.9168 & TRN & \\
\hline CHEMBL1337427 & 688171 & 5.25 & 4.7428 & TRN & \\
\hline CHEMBL1453508 & 688171 & 4.35 & 4.6931 & TRN & \\
\hline CHEMBL1379956 & 688171 & 4.8 & 5.0024 & TST & \\
\hline CHEMBL1329858 & 688171 & 4.4 & 4.8485 & TST & \\
\hline CHEMBL1989922 & 688171 & 6.5 & 4.8753 & TST & \\
\hline CHEMBL1513902 & 688171 & 5.0 & 4.8162 & TRN & \\
\hline CHEMBL1355525 & 688171 & 4.9 & 4.819 & TRN & \\
\hline CHEMBL1546843 & 688171 & 4.65 & 5.0213 & TRN & \\
\hline CHEMBL1974521 & 688171 & 4.35 & 4.8165 & TRN & \\
\hline CHEMBL1484512 & 688171 & 4.35 & 4.8531 & TRN & \\
\hline CHEMBL1606611 & 688171 & 4.7 & 4.7875 & TRN & \\
\hline CHEMBL 1372456 & 688171 & 4.4 & 4.8212 & TRN & \\
\hline CHEMBL1539013 & 688171 & 4.5 & 4.9395 & TST & \\
\hline CHEMBL1326606 & 688171 & 5.1 & 4.8356 & TST & \\
\hline CHEMBL1395712 & 688171 & 4.7 & 4.9752 & TRN & \\
\hline CHEMBL 2005998 & 688171 & 4.6 & 4.8477 & TST & \\
\hline CHEMBL 1453336 & 688171 & 4.4 & 5.0028 & TST & \\
\hline CHEMBL1321315 & 688171 & 4.4 & 4.8491 & TST & \\
\hline CHEMBL1335051 & 688171 & 4.9 & 4.9266 & TRN & \\
\hline CHEMBL1349720 & 688171 & 4.35 & 5.0594 & TST & \\
\hline CHEMBL1571812 & 688171 & 4.95 & 4.7789 & TST & \\
\hline CHEMBL1595482 & 688171 & 4.65 & 4.8088 & TRN & \\
\hline CHEMBL1374819 & 688171 & 4.4 & 4.8301 & TRN & \\
\hline
\end{tabular}




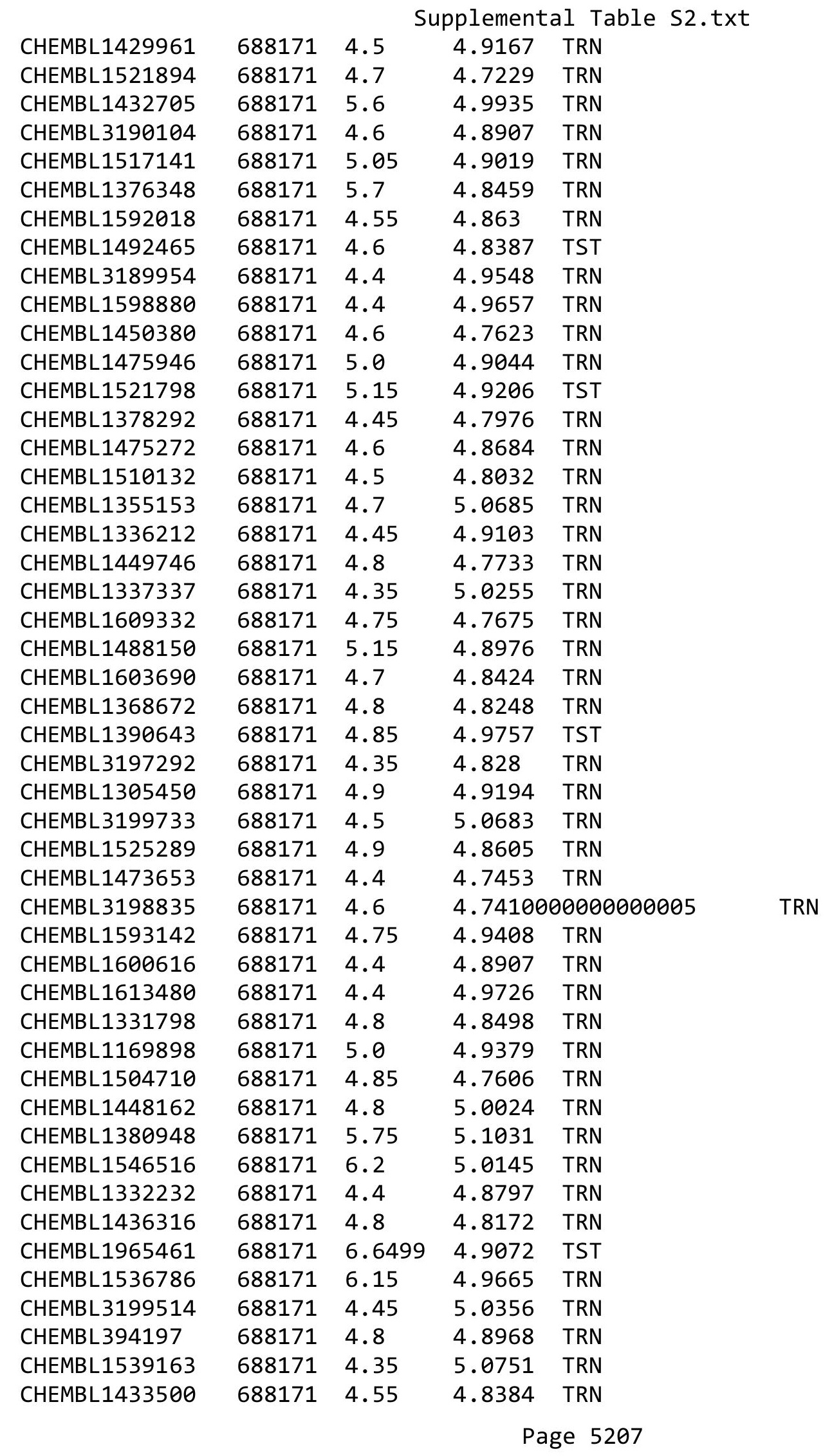




\begin{tabular}{|c|c|c|c|c|c|}
\hline \multicolumn{6}{|c|}{ Supplemental Table S2.txt } \\
\hline CHEMBL1477847 & 688171 & 4.75 & 4.9607 & TRN & \\
\hline CHEMBL1572604 & 688171 & 4.4 & 4.8172 & TRN & \\
\hline CHEMBL1417061 & 688171 & 4.7 & 4.7736 & TRN & \\
\hline CHEMBL1510878 & 688171 & 4.75 & 4.9328 & TST & \\
\hline CHEMBL1466979 & 688171 & 5.05 & 4.9064 & TST & \\
\hline CHEMBL1584472 & 688171 & 4.4 & 4.8675 & TST & \\
\hline CHEMBL1394217 & 688171 & 5.05 & 4.9488 & TRN & \\
\hline CHEMBL1553046 & 688171 & 4.5 & 4.9554 & TRN & \\
\hline CHEMBL1405551 & 688171 & 4.45 & 4.8366 & TRN & \\
\hline CHEMBL1390912 & 688171 & 4.45 & 4.9809 & TRN & \\
\hline CHEMBL1328896 & 688171 & 4.9 & 4.7633 & TST & \\
\hline CHEMBL1466446 & 688171 & 4.45 & 4.8886 & TRN & \\
\hline CHEMBL1309608 & 688171 & 4.45 & 4.9215 & TRN & \\
\hline CHEMBL1536568 & 688171 & 4.6 & 4.9096 & TRN & \\
\hline CHEMBL2001895 & 688171 & 4.55 & 4.8403 & TST & \\
\hline CHEMBL1460896 & 688171 & 5.0 & 4.7199 & TRN & \\
\hline CHEMBL1333482 & 688171 & 4.7 & 5.0019 & TRN & \\
\hline CHEMBL1330489 & 688171 & 4.45 & 5.0075 & TRN & \\
\hline CHEMBL1458441 & 688171 & 4.55 & 4.692 & TRN & \\
\hline CHEMBL1578932 & 688171 & 4.45 & 4.8757 & TRN & \\
\hline CHEMBL1329763 & 688171 & 4.7 & 5.0874 & TRN & \\
\hline CHEMBL1342888 & 688171 & 5.0 & 4.9764 & TST & \\
\hline CHEMBL1466601 & 688171 & 5.5 & 4.8294 & TST & \\
\hline CHEMBL1601741 & 688171 & 4.8 & 4.80699 & 99999999995 & TRN \\
\hline CHEMBL1452820 & 688171 & 5.35 & 4.9186 & TRN & \\
\hline CHEMBL1597646 & 688171 & 4.75 & 4.9012 & TRN & \\
\hline CHEMBL1523779 & 688171 & 4.9 & 5.0691 & TST & \\
\hline CHEMBL1381289 & 688171 & 4.5 & 4.7368 & TRN & \\
\hline CHEMBL1336899 & 688171 & 5.5 & 4.8408 & TRN & \\
\hline CHEMBL1324253 & 688171 & 4.4 & 4.9116 & TRN & \\
\hline CHEMBL1455264 & 688171 & 4.8 & 4.80699 & 99999999995 & TRN \\
\hline CHEMBL1998057 & 688171 & 4.95 & 4.9291 & TRN & \\
\hline CHEMBL1329300 & 688171 & 4.75 & 4.841 & TRN & \\
\hline CHEMBL1365691 & 688171 & 5.7 & 4.9518 & TRN & \\
\hline CHEMBL1305111 & 688171 & 5.1 & 5.0123 & TRN & \\
\hline CHEMBL1590637 & 688171 & 5.45 & 4.8854 & TRN & \\
\hline CHEMBL 1336274 & 688171 & 4.5 & 4.8462 & TRN & \\
\hline CHEMBL1349433 & 688171 & 5.1 & 4.8769 & TST & \\
\hline CHEMBL1532360 & 688171 & 4.4 & 4.8243 & TRN & \\
\hline CHEMBL1357623 & 688171 & 4.75 & 4.8692 & TRN & \\
\hline CHEMBL1591394 & 688171 & 5.45 & 4.9812 & TRN & \\
\hline CHEMBL1505774 & 688171 & 4.5 & 4.8719 & TRN & \\
\hline CHEMBL1416276 & 688171 & 4.5 & 4.8893 & TRN & \\
\hline CHEMBL1516662 & 688171 & 6.05 & 4.9242 & TRN & \\
\hline CHEMBL1321646 & 688171 & 4.7 & 4.9682 & TRN & \\
\hline CHEMBL1610780 & 688171 & 4.45 & 4.9089 & TST & \\
\hline CHEMBL1494703 & 688171 & 6.05 & 4.9342 & TRN & \\
\hline CHEMBL1569875 & 688171 & 6.0 & 4.8077 & TRN & \\
\hline
\end{tabular}




\begin{tabular}{|c|c|c|c|c|}
\hline \multicolumn{5}{|c|}{ Supplemental Table S2.txt } \\
\hline CHEMBL1486746 & 688171 & 4.4 & 4.9491 & TRN \\
\hline CHEMBL1450192 & 688171 & 4.7 & 4.8161 & TRN \\
\hline CHEMBL 3194554 & 688171 & 4.5 & 4.9177 & TRN \\
\hline CHEMBL1452364 & 688171 & 4.95 & 4.9288 & TRN \\
\hline CHEMBL1388182 & 688171 & 4.6 & 4.8089 & TST \\
\hline CHEMBL1601969 & 688171 & 4.75 & 4.9391 & TRN \\
\hline CHEMBL1613121 & 688171 & 7.6003 & 4.9326 & TST \\
\hline CHEMBL 3198344 & 688171 & 6.0 & 4.9676 & TST \\
\hline CHEMBL1612541 & 688171 & 4.8 & 4.8385 & TRN \\
\hline CHEMBL1529360 & 688171 & 4.7 & 4.9797 & TRN \\
\hline CHEMBL1592138 & 688171 & 4.5 & 4.934 & TRN \\
\hline CHEMBL277525 & 688171 & 4.6 & 4.8512 & TST \\
\hline CHEMBL 3207725 & 688171 & 4.65 & 4.9976 & TST \\
\hline CHEMBL586078 & 688171 & 4.95 & 4.8833 & TRN \\
\hline CHEMBL1354665 & 688171 & 4.8 & 4.9812 & TRN \\
\hline CHEMBL1519171 & 688171 & 5.7 & 4.936 & TRN \\
\hline CHEMBL1536060 & 688171 & 4.75 & 4.8635 & TST \\
\hline CHEMBL1468805 & 688171 & 5.5 & 4.9139 & TRN \\
\hline CHEMBL1486423 & 688171 & 4.8 & 4.8785 & TRN \\
\hline CHEMBL1318016 & 688171 & 4.85 & 4.8771 & TRN \\
\hline CHEMBL1385740 & 688171 & 4.6 & 4.7735 & TRN \\
\hline CHEMBL1380891 & 688171 & 4.8 & 4.8998 & TRN \\
\hline CHEMBL1508521 & 688171 & 4.85 & 4.8147 & TRN \\
\hline CHEMBL1392033 & 688171 & 4.35 & 5.0181 & TST \\
\hline CHEMBL1372730 & 688171 & 5.5 & 4.966 & TST \\
\hline CHEMBL1472984 & 688171 & 6.6499 & 4.9274 & TRN \\
\hline CHEMBL1426961 & 688171 & 5.6 & 4.836 & TST \\
\hline CHEMBL1308385 & 688171 & 4.55 & 5.0463 & TST \\
\hline CHEMBL1482491 & 688171 & 4.85 & 4.9804 & TRN \\
\hline CHEMBL1598092 & 688171 & 5.5 & 4.9116 & TRN \\
\hline CHEMBL1392328 & 688171 & 4.45 & 4.9455 & TST \\
\hline CHEMBL1332126 & 688171 & 5.0 & 4.9325 & TST \\
\hline CHEMBL1592891 & 688171 & 4.75 & 4.8197 & TRN \\
\hline CHEMBL1354327 & 688171 & 4.8 & 5.0144 & TRN \\
\hline CHEMBL1395764 & 688171 & 4.7 & 4.941 & TRN \\
\hline CHEMBL1589737 & 688171 & 4.4 & 4.8361 & TRN \\
\hline CHEMBL1412821 & 688171 & 4.4 & 4.9127 & TST \\
\hline CHEMBL1597464 & 688171 & 4.85 & 4.9826 & TRN \\
\hline CHEMBL1310724 & 688171 & 4.55 & 4.9815 & TRN \\
\hline CHEMBL1542674 & 688171 & 4.95 & 4.863 & TRN \\
\hline CHEMBL1467763 & 688171 & 4.6 & 5.0151 & TRN \\
\hline CHEMBL1371855 & 688171 & 5.35 & 4.9656 & TST \\
\hline CHEMBL1543892 & 688171 & 4.9 & 4.8957 & TRN \\
\hline CHEMBL1352557 & 688171 & 5.05 & 4.8101 & TST \\
\hline CHEMBL1520562 & 688171 & 5.5 & 4.8817 & TRN \\
\hline CHEMBL1589917 & 688171 & 4.75 & 4.8444 & TRN \\
\hline CHEMBL1600604 & 688171 & 5.2 & 5.0342 & TRN \\
\hline CHEMBL1580359 & 688171 & 5.4 & 4.9086 & TRN \\
\hline
\end{tabular}




\begin{tabular}{|c|c|c|c|c|c|}
\hline \multicolumn{6}{|c|}{ Supplemental Table S2.txt } \\
\hline CHEMBL1402424 & 688171 & 4.9 & 4.814 & TRN & \\
\hline CHEMBL1582927 & 688171 & 4.5 & 4.8655 & TRN & \\
\hline CHEMBL1456959 & 688171 & 4.55 & 4.757 & TRN & \\
\hline CHEMBL1409574 & 688171 & 4.7 & 4.6723 & TRN & \\
\hline CHEMBL1472347 & 688171 & 7.2503 & 4.7778 & TRN & \\
\hline CHEMBL1323052 & 688171 & 4.55 & 4.9225 & TRN & \\
\hline CHEMBL3207291 & 688171 & 5.55 & 4.9453 & TST & \\
\hline CHEMBL1529382 & 688171 & 5.5 & 5.01399 & 9999999999 & TRN \\
\hline CHEMBL1602824 & 688171 & 4.95 & 5.0632 & TRN & \\
\hline CHEMBL1421544 & 688171 & 4.9 & 4.9067 & TRN & \\
\hline CHEMBL1516239 & 688171 & 4.5 & 4.9077 & TRN & \\
\hline CHEMBL1964338 & 688171 & 5.0 & 4.9915 & TST & \\
\hline CHEMBL1379965 & 688171 & 4.5 & 4.904 & TRN & \\
\hline CHEMBL1437507 & 688171 & 4.7 & 4.8274 & TRN & \\
\hline CHEMBL1472875 & 688171 & 4.6 & 4.9156 & TRN & \\
\hline CHEMBL1520041 & 688171 & 5.35 & 4.9172 & TRN & \\
\hline CHEMBL1416692 & 688171 & 4.4 & 4.7692 & TRN & \\
\hline CHEMBL1605296 & 688171 & 4.5 & 4.7269 & TRN & \\
\hline CHEMBL1409853 & 688171 & 4.7 & 4.8359 & TRN & \\
\hline CHEMBL1526059 & 688171 & 4.9 & 4.782 & TRN & \\
\hline CHEMBL1354859 & 688171 & 5.05 & 5.0669 & TRN & \\
\hline CHEMBL1384803 & 688171 & 5.15 & 4.8899 & TST & \\
\hline CHEMBL1368312 & 688171 & 5.1 & 4.89199 & 99999999995 & TST \\
\hline CHEMBL1487962 & 688171 & 4.6 & 4.9341 & TRN & \\
\hline CHEMBL1450383 & 688171 & 7.6003 & 5.0269 & TST & \\
\hline CHEMBL3195027 & 688171 & 5.2 & 5.01 & TST & \\
\hline CHEMBL1438900 & 688171 & 4.7 & 4.8706 & TRN & \\
\hline CHEMBL1555674 & 688171 & 4.5 & 4.8736 & TST & \\
\hline CHEMBL1966025 & 688171 & 4.85 & 4.9897 & TRN & \\
\hline CHEMBL1611324 & 688171 & 4.4 & 5.0434 & TRN & \\
\hline CHEMBL1397508 & 688171 & 4.5 & 4.7995 & TRN & \\
\hline CHEMBL3193575 & 688171 & 5.1 & 5.032 & TRN & \\
\hline CHEMBL1338684 & 688171 & 4.5 & 4.9535 & TRN & \\
\hline CHEMBL1518440 & 688171 & 5.75 & 4.9573 & TST & \\
\hline CHEMBL1434581 & 688171 & 4.75 & 4.7836 & TRN & \\
\hline CHEMBL1539830 & 688171 & 5.2 & 4.9319 & TRN & \\
\hline CHEMBL1316253 & 688171 & 4.85 & 4.8489 & TRN & \\
\hline CHEMBL1323017 & 688171 & 4.5 & 4.9688 & TRN & \\
\hline CHEMBL1597701 & 688171 & 4.6 & 4.944 & TST & \\
\hline CHEMBL1489530 & 688171 & 4.6 & 4.9198 & TST & \\
\hline CHEMBL1326214 & 688171 & 4.8 & 4.9334 & TRN & \\
\hline CHEMBL1389619 & 688171 & 4.6 & 5.0503 & TRN & \\
\hline CHEMBL1363531 & 688171 & 4.75 & 4.9142 & TRN & \\
\hline CHEMBL1502002 & 688171 & 4.9 & 5.0576 & TRN & \\
\hline CHEMBL1356246 & 688171 & 5.1 & 4.8556 & TRN & \\
\hline CHEMBL1169708 & 688171 & 4.8 & 4.8855 & TRN & \\
\hline CHEMBL1589010 & 688171 & 4.55 & 4.9009 & TRN & \\
\hline CHEMBL1548886 & 688171 & 4.55 & 4.979 & TST & \\
\hline
\end{tabular}




\begin{tabular}{|c|c|c|c|c|}
\hline \multicolumn{5}{|c|}{ Supplemental Table S2.txt } \\
\hline CHEMBL1370555 & 688171 & 4.35 & 4.8975 & TRN \\
\hline CHEMBL1430811 & 688171 & 4.55 & 4.9977 & TRN \\
\hline CHEMBL1313978 & 688171 & 5.1 & 4.7936 & TRN \\
\hline CHEMBL1304388 & 688171 & 4.4 & 4.9985 & TST \\
\hline CHEMBL1996136 & 688171 & 4.4 & 4.9642 & TST \\
\hline CHEMBL1411125 & 688171 & 5.05 & 4.9676 & TRN \\
\hline CHEMBL1513466 & 688171 & 5.05 & 4.9117 & TRN \\
\hline CHEMBL1595765 & 688171 & 4.75 & 4.9184 & TRN \\
\hline CHEMBL1355512 & 688171 & 5.5 & 5.0372 & TRN \\
\hline CHEMBL1399233 & 688171 & 4.65 & 4.9472 & TRN \\
\hline CHEMBL3193164 & 688171 & 4.35 & 5.0476 & TRN \\
\hline CHEMBL1335687 & 688171 & 4.65 & 4.7554 & TRN \\
\hline CHEMBL1493973 & 688171 & 4.5 & 4.8841 & TRN \\
\hline CHEMBL1519142 & 688171 & 4.35 & 4.8768 & TRN \\
\hline CHEMBL1389922 & 688171 & 4.9 & 4.8757 & TRN \\
\hline CHEMBL1352491 & 688171 & 4.4 & 4.9992 & TRN \\
\hline CHEMBL1998566 & 688171 & 4.65 & 4.806 & TRN \\
\hline CHEMBL1352069 & 688171 & 4.4 & 4.9501 & TST \\
\hline CHEMBL1529276 & 688171 & 4.55 & 4.9122 & TRN \\
\hline CHEMBL1357269 & 688171 & 5.0 & 4.793 & TRN \\
\hline CHEMBL1392736 & 688171 & 4.9 & 5.0063 & TST \\
\hline CHEMBL1438194 & 688171 & 4.55 & 5.0317 & TRN \\
\hline CHEMBL3209052 & 688171 & 4.4 & 5.0615 & TRN \\
\hline CHEMBL1466102 & 688171 & 4.75 & 4.8226 & TRN \\
\hline CHEMBL1412970 & 688171 & 4.35 & 4.9296 & TST \\
\hline CHEMBL1472306 & 688171 & 5.35 & 4.9537 & TST \\
\hline CHEMBL1395456 & 688171 & 4.6 & 4.7614 & TRN \\
\hline CHEMBL1359306 & 688171 & 5.45 & 4.7703 & TRN \\
\hline CHEMBL3191465 & 688171 & 5.1 & 4.9711 & TRN \\
\hline CHEMBL1473635 & 688171 & 4.9 & 4.8198 & TRN \\
\hline CHEMBL1446608 & 688171 & 4.4 & 4.7965 & TST \\
\hline CHEMBL1349505 & 688171 & 5.45 & 5.0079 & TST \\
\hline CHEMBL3192889 & 688171 & 4.55 & 5.0115 & TRN \\
\hline CHEMBL1518366 & 688171 & 4.75 & 4.8417 & TRN \\
\hline CHEMBL1509659 & 688171 & 4.6 & 4.7477 & TRN \\
\hline CHEMBL1367851 & 688171 & 4.55 & 4.9089 & TRN \\
\hline CHEMBL1556725 & 688171 & 4.8 & 4.7923 & TST \\
\hline CHEMBL1416244 & 688171 & 6.05 & 5.0197 & TRN \\
\hline CHEMBL1434795 & 688171 & 4.9 & 4.936 & TRN \\
\hline CHEMBL3213911 & 688171 & 5.65 & 4.8267 & TRN \\
\hline CHEMBL1381385 & 688171 & 6.5 & 4.9545 & TRN \\
\hline CHEMBL3213047 & 688171 & 4.9 & 4.9221 & TRN \\
\hline CHEMBL1302563 & 688171 & 4.4 & 4.916 & TST \\
\hline CHEMBL1557782 & 688171 & 4.7 & 4.9485 & TRN \\
\hline CHEMBL1408786 & 688171 & 4.95 & 5.0492 & TRN \\
\hline CHEMBL1530201 & 688171 & 4.6 & 4.9103 & TRN \\
\hline CHEMBL3207331 & 688171 & 7.2 & 5.0998 & TST \\
\hline CHEMBL1538947 & 688171 & 7.2 & 4.9426 & TRN \\
\hline
\end{tabular}




\begin{tabular}{|c|c|c|c|c|c|}
\hline \multicolumn{6}{|c|}{ Supplemental Table S2.txt } \\
\hline CHEMBL1455542 & 688171 & 5.05 & 4.8416 & TRN & \\
\hline CHEMBL1435798 & 688171 & 4.4 & 4.8812 & TRN & \\
\hline CHEMBL1604466 & 688171 & 5.05 & 4.7583 & TRN & \\
\hline CHEMBL 3189924 & 688171 & 4.4 & 4.8623 & TST & \\
\hline CHEMBL1487571 & 688171 & 5.45 & 5.0074 & TRN & \\
\hline CHEMBL1593061 & 688171 & 4.6 & 4.6736 & TRN & \\
\hline CHEMBL1512757 & 688171 & 4.35 & 5.0946 & TRN & \\
\hline CHEMBL1501540 & 688171 & 5.05 & 5.0079 & TRN & \\
\hline CHEMBL345124 & 688171 & 5.2 & 4.9546 & TST & \\
\hline CHEMBL3197243 & 688171 & 4.45 & 4.9736 & TRN & \\
\hline CHEMBL1318425 & 688171 & 4.95 & 4.9828 & TRN & \\
\hline CHEMBL1574379 & 688171 & 7.15 & 4.9772 & TRN & \\
\hline CHEMBL 3192700 & 688171 & 5.6 & 4.9301 & TST & \\
\hline CHEMBL1463326 & 688171 & 4.5 & 4.9193 & TRN & \\
\hline CHEMBL1610096 & 688171 & 5.35 & 4.9584 & TRN & \\
\hline CHEMBL1571554 & 688171 & 4.6 & 5.0931 & TRN & \\
\hline CHEMBL62136 & 688171 & 6.2 & 4.9003 & TST & \\
\hline CHEMBL1556817 & 688171 & 4.9 & 4.9378 & TRN & \\
\hline CHEMBL1465221 & 688171 & 4.4 & 4.8421 & TRN & \\
\hline CHEMBL1572744 & 688171 & 4.9 & 4.9257 & TRN & \\
\hline CHEMBL1554033 & 688171 & 4.75 & 4.9009 & TST & \\
\hline CHEMBL1407184 & 688171 & 4.6 & 4.78100 & 0000000001 & TRN \\
\hline CHEMBL143360 & 688171 & 6.5 & 4.9345 & TST & \\
\hline CHEMBL1409882 & 688171 & 4.45 & 4.9705 & TST & \\
\hline CHEMBL 3193236 & 688171 & 6.8499 & 4.8046 & TRN & \\
\hline CHEMBL1311732 & 688171 & 4.65 & 4.8996 & TRN & \\
\hline CHEMBL1517556 & 688171 & 4.4 & 4.9466 & TST & \\
\hline CHEMBL1445788 & 688171 & 4.35 & 4.8006 & TRN & \\
\hline CHEMBL3195475 & 688171 & 5.05 & 4.9924 & TRN & \\
\hline CHEMBL1529376 & 688171 & 4.9 & 4.8915 & TRN & \\
\hline CHEMBL1357538 & 688171 & 4.75 & 4.8125 & TRN & \\
\hline CHEMBL1572594 & 688171 & 4.6 & 4.7872 & TRN & \\
\hline CHEMBL1315514 & 688171 & 5.05 & 4.9934 & TRN & \\
\hline CHEMBL1471866 & 688171 & 4.8 & 4.8445 & TST & \\
\hline CHEMBL429095 & 688171 & 6.0 & 4.8811 & TST & \\
\hline CHEMBL1492617 & 688171 & 4.95 & 4.7382 & TRN & \\
\hline CHEMBL1501814 & 688171 & 5.5 & 4.8917 & TST & \\
\hline CHEMBL1376484 & 688171 & 5.95 & 4.8275 & TRN & \\
\hline CHEMBL1527196 & 688171 & 4.6 & 4.9686 & TRN & \\
\hline CHEMBL1600763 & 688171 & 4.7 & 4.8558 & TST & \\
\hline CHEMBL1394143 & 688171 & 5.0 & 4.8955 & TRN & \\
\hline CHEMBL1548974 & 688171 & 6.05 & 5.0658 & TRN & \\
\hline CHEMBL1436076 & 688171 & 4.4 & 4.8684 & TRN & \\
\hline CHEMBL 1457100 & 688171 & 4.4 & 4.9459 & TST & \\
\hline CHEMBL1602608 & 688171 & 7.6498 & 4.9715 & TRN & \\
\hline CHEMBL1462794 & 688171 & 4.5 & 4.9369 & TRN & \\
\hline CHEMBL1397090 & 688171 & 4.7 & 4.9185 & TRN & \\
\hline CHEMBL1303681 & 688171 & 5.0 & 4.8422 & TST & \\
\hline
\end{tabular}


Supplemental Table S2.txt

\begin{tabular}{|c|c|c|c|c|c|}
\hline CHEMBL1567008 & 688171 & 7.1002 & 4.8159 & TRN & \\
\hline CHEMBL1553499 & 688171 & 5.0 & 4.9329 & TRN & \\
\hline CHEMBL1397480 & 688171 & 4.6 & 4.9843 & TRN & \\
\hline CHEMBL1973156 & 688171 & 4.5 & 4.7664 & TRN & \\
\hline CHEMBL1436508 & 688171 & 4.8 & 4.8008 & TRN & \\
\hline CHEMBL1364438 & 688171 & 5.0 & 4.8525 & TRN & \\
\hline CHEMBL1462131 & 688171 & 4.4 & 4.8172 & TRN & \\
\hline CHEMBL3196331 & 688171 & 4.95 & 4.9282 & TST & \\
\hline CHEMBL1314275 & 688171 & 4.95 & 5.0043 & TST & \\
\hline CHEMBL1342708 & 688171 & 4.35 & 5.105 & TRN & \\
\hline CHEMBL3198962 & 688171 & 5.45 & 4.8374 & TRN & \\
\hline CHEMBL1398505 & 688171 & 4.5 & 4.9298 & TRN & \\
\hline CHEMBL1428663 & 688171 & 4.55 & 4.7926 & TRN & \\
\hline CHEMBL1476466 & 688171 & 4.55 & 4.9156 & TRN & \\
\hline CHEMBL1402882 & 688171 & 4.4 & 4.9757 & TST & \\
\hline CHEMBL1447261 & 688171 & 4.55 & 4.8833 & TST & \\
\hline CHEMBL1301709 & 688171 & 5.3 & 4.7847 & TRN & \\
\hline CHEMBL1485745 & 688171 & 4.5 & 4.8979 & TRN & \\
\hline CHEMBL1412403 & 688171 & 4.65 & 4.8113 & TRN & \\
\hline CHEMBL1395371 & 688171 & 4.5 & 4.9059 & TRN & \\
\hline CHEMBL1474170 & 688171 & 4.9 & 4.8819 & TRN & \\
\hline CHEMBL1580155 & 688171 & 5.05 & 5.0372 & TRN & \\
\hline CHEMBL1604552 & 688171 & 4.7 & 4.8913 & TRN & \\
\hline CHEMBL1425659 & 688171 & 4.5 & 4.7974 & TRN & \\
\hline CHEMBL1592830 & 688171 & 4.65 & 4.9336 & TRN & \\
\hline CHEMBL3210458 & 688171 & 7.6003 & 5.011 & TST & \\
\hline CHEMBL1514024 & 688171 & 6.8499 & 4.7453 & TRN & \\
\hline CHEMBL1388742 & 688171 & 4.4 & 5.0075 & TST & \\
\hline CHEMBL1256716 & 688171 & 4.75 & 5.0374 & TRN & \\
\hline CHEMBL3145282 & 688171 & 4.85 & 4.7449 & TRN & \\
\hline CHEMBL1361062 & 688171 & 5.5 & 4.9097 & TST & \\
\hline CHEMBL1523961 & 688171 & 4.4 & 4.8479 & TRN & \\
\hline CHEMBL1449101 & 688171 & 4.35 & 4.8355 & TRN & \\
\hline CHEMBL3196767 & 688171 & 6.0 & 4.9393 & TRN & \\
\hline CHEMBL1533435 & 688171 & 4.55 & 4.86 & TRN & \\
\hline CHEMBL1575715 & 688171 & 4.6 & 4.8564 & TRN & \\
\hline CHEMBL1606314 & 688171 & 4.7 & 5.0577 & TRN & \\
\hline CHEMBL1487399 & 688171 & 4.85 & 4.9812 & TRN & \\
\hline CHEMBL1556455 & 688171 & 4.95 & 4.9478 & TRN & \\
\hline CHEMBL3199148 & 688171 & 5.05 & 4.9699 & TST & \\
\hline CHEMBL1526958 & 688171 & 5.7 & 4.84699 & 99999999995 & TRN \\
\hline CHEMBL1471133 & 688171 & 4.9 & 4.8187 & TRN & \\
\hline CHEMBL1389409 & 688171 & 5.15 & 4.9307 & TRN & \\
\hline CHEMBL1530741 & 688171 & 4.4 & 4.8266 & TRN & \\
\hline CHEMBL1305752 & 688171 & 4.4 & 4.8475 & TRN & \\
\hline CHEMBL1515142 & 688171 & 4.45 & 4.9409 & TRN & \\
\hline CHEMBL1331597 & 688171 & 4.9 & 4.7584 & TRN & \\
\hline CHEMBL1530087 & 688171 & 4.65 & 4.9755 & TST & \\
\hline
\end{tabular}




\begin{tabular}{|c|c|c|c|c|c|}
\hline \multicolumn{6}{|c|}{ Supplemental Table S2.txt } \\
\hline CHEMBL1613591 & 688171 & 6.35 & 4.8122 & TRN & \\
\hline CHEMBL1500735 & 688171 & 4.8 & 4.872 & TST & \\
\hline CHEMBL1357386 & 688171 & 4.6 & 4.8404 & TRN & \\
\hline CHEMBL1416540 & 688171 & 6.9 & 4.9787 & TST & \\
\hline CHEMBL1546256 & 688171 & 4.35 & 4.8144 & TST & \\
\hline CHEMBL1540065 & 688171 & 4.95 & 5.0742 & TST & \\
\hline CHEMBL1325961 & 688171 & 4.65 & 4.8365 & TRN & \\
\hline CHEMBL1392944 & 688171 & 4.45 & 4.9147 & TST & \\
\hline CHEMBL1507031 & 688171 & 4.65 & 4.888999 & 9999999999 & TST \\
\hline CHEMBL1600758 & 688171 & 4.7 & 4.9137 & TRN & \\
\hline CHEMBL1984584 & 688171 & 4.4 & 4.8531 & TRN & \\
\hline CHEMBL1459145 & 688171 & 4.45 & 4.9409 & TRN & \\
\hline CHEMBL286494 & 688171 & 6.0 & 4.8599 & TST & \\
\hline CHEMBL1560929 & 688171 & 7.6003 & 4.9091 & TST & \\
\hline CHEMBL244948 & 688171 & 4.4 & 4.8817 & TRN & \\
\hline CHEMBL1545001 & 688171 & 7.6003 & 4.9878 & TST & \\
\hline CHEMBL1465978 & 688171 & 4.6 & 4.8758 & TRN & \\
\hline CHEMBL1563656 & 688171 & 4.45 & 4.9775 & TRN & \\
\hline CHEMBL1502098 & 688171 & 6.0 & 4.7773 & TRN & \\
\hline CHEMBL1402483 & 688171 & 4.4 & 4.9798 & TRN & \\
\hline CHEMBL1335273 & 688171 & 4.8 & 4.8859 & TRN & \\
\hline CHEMBL1457496 & 688171 & 4.95 & 4.8564 & TRN & \\
\hline CHEMBL1480933 & 688171 & 4.65 & 4.922 & TRN & \\
\hline CHEMBL3189829 & 688171 & 4.4 & 5.0275 & TRN & \\
\hline CHEMBL1602451 & 688171 & 4.45 & 5.0078 & TST & \\
\hline CHEMBL3213480 & 688171 & 4.35 & 4.9737 & TRN & \\
\hline CHEMBL1514159 & 688171 & 6.05 & 4.8424 & TRN & \\
\hline CHEMBL1370718 & 688171 & 4.45 & 4.9967 & TRN & \\
\hline CHEMBL1513158 & 688171 & 4.85 & 4.891 & TRN & \\
\hline CHEMBL1382718 & 688171 & 4.65 & 4.9234 & TRN & \\
\hline CHEMBL1419079 & 688171 & 4.45 & 4.8651 & TRN & \\
\hline CHEMBL139935 & 688171 & 5.05 & 4.8832 & TST & \\
\hline CHEMBL1508555 & 688171 & 4.5 & 4.8469 & TRN & \\
\hline CHEMBL1431694 & 688171 & 5.0 & 4.9347 & TRN & \\
\hline CHEMBL3196327 & 688171 & 4.35 & 4.9805 & TST & \\
\hline CHEMBL152778 & 688171 & 4.4 & 5.0038 & TRN & \\
\hline CHEMBL1401428 & 688171 & 5.0 & 4.9724 & TRN & \\
\hline CHEMBL1584933 & 688171 & 4.55 & 4.8252 & TRN & \\
\hline CHEMBL1471369 & 688171 & 4.9 & 4.7705 & TRN & \\
\hline CHEMBL1404455 & 688171 & 5.5 & 4.8447 & TRN & \\
\hline CHEMBL3190016 & 688171 & 5.45 & 4.948 & TRN & \\
\hline CHEMBL1561240 & 688171 & 4.45 & 4.9181 & TRN & \\
\hline CHEMBL1590160 & 688171 & 4.4 & 4.9302 & TRN & \\
\hline CHEMBL1535157 & 688171 & 4.55 & 4.8752 & TRN & \\
\hline CHEMBL1438919 & 688171 & 6.8499 & 4.8586 & TST & \\
\hline CHEMBL1360144 & 688171 & 4.8 & 4.8842 & TRN & \\
\hline CHEMBL1473347 & 688171 & 4.75 & 4.9496 & TRN & \\
\hline CHEMBL1480959 & 688171 & 4.8 & 4.9428 & TRN & \\
\hline
\end{tabular}




\begin{tabular}{|c|c|c|c|c|c|}
\hline \multirow{3}{*}{$\begin{array}{l}\text { CHEMBL1505823 } \\
\text { CHEMBL1476471 }\end{array}$} & \multirow{3}{*}{$\begin{array}{l}688171 \\
688171\end{array}$} & \multicolumn{4}{|c|}{ Supplemental Table S2.txt } \\
\hline & & 4.5 & \multicolumn{2}{|c|}{5.0089999999999995} & \multirow[t]{2}{*}{ TRA } \\
\hline & & 4.35 & 5.02 & TRN & \\
\hline CHEMBL1607905 & 688171 & 5.5 & 4.8486 & TST & \\
\hline CHEMBL1587698 & 688171 & 4.4 & 4.872 & TST & \\
\hline CHEMBL1525072 & 688171 & 4.85 & 4.8383 & TRN & \\
\hline CHEMBL1421953 & 688171 & 5.85 & 4.8745 & TRN & \\
\hline CHEMBL 3192684 & 688171 & 4.45 & 4.91 & TST & \\
\hline CHEMBL1583283 & 688171 & 4.7 & 4.8658 & TRN & \\
\hline CHEMBL1375843 & 688171 & 5.45 & 4.9655 & TRN & \\
\hline CHEMBL1570465 & 688171 & 4.6 & 4.8876 & TST & \\
\hline CHEMBL1321955 & 688171 & 4.65 & 4.8549 & TRN & \\
\hline CHEMBL1360792 & 688171 & 5.5 & 4.9208 & TST & \\
\hline CHEMBL1306065 & 688171 & 5.05 & 4.7655 & TRN & \\
\hline CHEMBL542700 & 688171 & 6.0 & 4.9141 & TST & \\
\hline CHEMBL1601989 & 688171 & 4.65 & 4.8493 & TRN & \\
\hline CHEMBL1396277 & 688171 & 4.7 & 4.9782 & TRN & \\
\hline CHEMBL1316674 & 688171 & 5.1 & 4.9291 & TST & \\
\hline CHEMBL1551768 & 688171 & 4.55 & 4.8401 & TRN & \\
\hline CHEMBL1470146 & 688171 & 4.6 & 4.9631 & TRN & \\
\hline CHEMBL1348280 & 688171 & 5.35 & 5.0292 & TRN & \\
\hline CHEMBL1549128 & 688171 & 4.5 & 4.8583 & TST & \\
\hline CHEMBL1430883 & 688171 & 4.5 & 4.8987 & TRN & \\
\hline CHEMBL1593368 & 688171 & 5.3 & 4.9437 & TRN & \\
\hline CHEMBL1375778 & 688171 & 4.95 & 4.7569 & TRN & \\
\hline CHEMBL1360083 & 688171 & 4.65 & 5.0481 & TRN & \\
\hline CHEMBL1470470 & 688171 & 4.9 & 4.8703 & TRN & \\
\hline CHEMBL1355518 & 688171 & 4.75 & 4.8194 & TRN & \\
\hline CHEMBL1307031 & 688171 & 4.95 & 4.8577 & TST & \\
\hline CHEMBL1530417 & 688171 & 5.3 & 5.0499 & TST & \\
\hline CHEMBL1549573 & 688171 & 5.15 & 4.9321 & TST & \\
\hline CHEMBL1318197 & 688171 & 4.95 & 4.8785 & TRN & \\
\hline CHEMBL1303182 & 688171 & 4.9 & 4.9067 & TRN & \\
\hline CHEMBL1476037 & 688171 & 5.55 & 5.0041 & TRN & \\
\hline CHEMBL1312226 & 688171 & 5.6 & 4.8975 & TST & \\
\hline CHEMBL1490737 & 688171 & 4.75 & 4.958 & TRN & \\
\hline CHEMBL1519157 & 688171 & 4.4 & 5.1093 & TRN & \\
\hline CHEMBL1398549 & 688171 & 5.65 & 4.9787 & TRN & \\
\hline CHEMBL1376244 & 688171 & 4.35 & 5.038 & TRN & \\
\hline CHEMBL1573565 & 688171 & 5.1 & 4.9773 & TST & \\
\hline CHEMBL1318420 & 688171 & 6.0 & 5.0141 & TST & \\
\hline CHEMBL1415709 & 688171 & 4.6 & 5.0369 & TRN & \\
\hline CHEMBL1318466 & 688171 & 4.4 & $4.8610 e$ & $\partial 000000001$ & TRN \\
\hline CHEMBL1487625 & 688171 & 5.45 & 4.9167 & TRN & \\
\hline CHEMBL1591061 & 688171 & 4.4 & 4.8173 & TRN & \\
\hline CHEMBL1441119 & 688171 & 4.9 & 4.9746 & TRN & \\
\hline CHEMBL1577715 & 688171 & 4.35 & 4.912 & TRN & \\
\hline CHEMBL1509021 & 688171 & 5.1 & 5.0341 & TST & \\
\hline CHEMBL1591607 & 688171 & 5.05 & 4.9337 & TRN & \\
\hline & & & & 5215 & \\
\hline
\end{tabular}




\begin{tabular}{|c|c|c|c|c|}
\hline \multicolumn{5}{|c|}{ Supplemental Table } \\
\hline CHEMBL1331155 & 688171 & 4.95 & 5.1488 & TRN \\
\hline CHEMBL1422776 & 688171 & 4.35 & 4.936 & TRN \\
\hline CHEMBL1488035 & 688171 & 4.8 & 4.8837 & TRN \\
\hline CHEMBL1311254 & 688171 & 5.45 & 4.9274 & TST \\
\hline CHEMBL 1464775 & 688171 & 4.35 & 4.8931 & TRN \\
\hline CHEMBL1301650 & 688171 & 4.5 & 4.9502 & TRN \\
\hline CHEMBL1344508 & 688171 & 4.95 & 4.8753 & TRN \\
\hline CHEMBL1325002 & 688171 & 4.7 & 4.9249 & TRN \\
\hline CHEMBL1584864 & 688171 & 4.9 & 5.0253 & TST \\
\hline CHEMBL1535661 & 688171 & 4.55 & 4.8607 & TRN \\
\hline CHEMBL1504880 & 688171 & 5.15 & 4.8191 & TRN \\
\hline CHEMBL1396861 & 688171 & 6.6 & 4.8451 & TRN \\
\hline CHEMBL1451253 & 688171 & 5.0 & 4.8314 & TST \\
\hline CHEMBL1452292 & 688171 & 4.9 & 4.8589 & TRN \\
\hline CHEMBL1300297 & 688171 & 4.9 & 4.9825 & TRN \\
\hline CHEMBL1507927 & 688171 & 4.8 & 4.9008 & TST \\
\hline CHEMBL3189993 & 688171 & 4.4 & 5.0188 & TRN \\
\hline CHEMBL1402521 & 688171 & 5.0 & 4.9127 & TRN \\
\hline CHEMBL1585235 & 688171 & 6.8 & 5.022 & TRN \\
\hline CHEMBL1338944 & 688171 & 4.45 & 4.9801 & TRN \\
\hline CHEMBL3144984 & 688171 & 6.1 & 4.7309 & TST \\
\hline CHEMBL566933 & 688171 & 4.55 & 4.873 & TRN \\
\hline CHEMBL1535325 & 688171 & 4.6 & 5.0415 & TST \\
\hline CHEMBL60718 & 688171 & 4.4 & 4.941 & TRN \\
\hline CHEMBL1552134 & 688171 & 4.7 & 4.8097 & TRN \\
\hline CHEMBL1473446 & 688171 & 4.75 & 4.8456 & TRN \\
\hline CHEMBL3199108 & 688171 & 4.7 & 4.8945 & TRN \\
\hline CHEMBL29097 & 688171 & 4.4 & 4.9504 & TST \\
\hline CHEMBL1351212 & 688171 & 4.75 & 4.8888 & TRN \\
\hline CHEMBL1318239 & 688171 & 4.85 & 4.817 & TRN \\
\hline CHEMBL1323753 & 688171 & 4.85 & 4.9816 & TST \\
\hline CHEMBL1988660 & 688171 & 4.65 & 4.9695 & TRN \\
\hline CHEMBL1593766 & 688171 & 5.0 & 4.8989 & TST \\
\hline CHEMBL1495888 & 688171 & 4.5 & 4.8157 & TRN \\
\hline CHEMBL1418168 & 688171 & 4.7 & 4.815 & TRN \\
\hline CHEMBL1444516 & 688171 & 4.9 & 4.8465 & TRN \\
\hline CHEMBL1364482 & 688171 & 5.95 & 4.8969 & TRN \\
\hline CHEMBL1370183 & 688171 & 4.5 & 4.8688 & TRN \\
\hline CHEMBL1374958 & 688171 & 4.65 & 4.9439 & TRN \\
\hline CHEMBL1303487 & 688171 & 4.6 & 4.7839 & TRN \\
\hline CHEMBL1578183 & 688171 & 4.9 & 4.7113 & TRN \\
\hline CHEMBL1493604 & 688171 & 4.4 & 4.6971 & TRN \\
\hline CHEMBL1527580 & 688171 & 5.15 & 4.9861 & TRN \\
\hline CHEMBL1554411 & 688171 & 5.05 & 4.9928 & TRN \\
\hline CHEMBL1561494 & 688171 & 5.35 & 4.886 & TRN \\
\hline CHEMBL1549291 & 688171 & 4.4 & 4.8429 & TST \\
\hline CHEMBL1322384 & 688171 & 4.35 & 4.9577 & TRN \\
\hline CHEMBL1395446 & 688171 & 5.2 & 5.0251 & TST \\
\hline
\end{tabular}




\begin{tabular}{|c|c|c|c|c|c|}
\hline \multicolumn{6}{|c|}{ Supplemental Table S2.txt } \\
\hline CHEMBL1484863 & 688171 & 4.9 & 4.8288 & TRN & \\
\hline CHEMBL1423137 & 688171 & 5.45 & 5.0025 & TST & \\
\hline CHEMBL1375782 & 688171 & 4.4 & 4.9447 & TRN & \\
\hline CHEMBL1399024 & 688171 & 4.7 & 4.9163 & TRN & \\
\hline CHEMBL1522905 & 688171 & 4.35 & 4.887 & TRN & \\
\hline CHEMBL1341308 & 688171 & 4.9 & 4.8099 & TRN & \\
\hline CHEMBL1529072 & 688171 & 4.55 & 4.9788 & TRN & \\
\hline CHEMBL1324051 & 688171 & 4.5 & 4.9288 & TST & \\
\hline CHEMBL1324461 & 688171 & 5.45 & 5.0009 & TRN & \\
\hline CHEMBL1484590 & 688171 & 5.2 & 4.9843 & TRN & \\
\hline CHEMBL1357531 & 688171 & 5.55 & 4.9275 & TST & \\
\hline CHEMBL3189944 & 688171 & 6.15 & 4.9577 & TST & \\
\hline CHEMBL1594847 & 688171 & 4.75 & 4.9203 & TST & \\
\hline CHEMBL1567856 & 688171 & 4.4 & 4.9078 & TRN & \\
\hline CHEMBL1395192 & 688171 & 4.6 & 4.8375 & TRN & \\
\hline CHEMBL1354655 & 688171 & 5.45 & 5.1243 & TRN & \\
\hline CHEMBL1513880 & 688171 & 5.8 & 4.9038 & TRN & \\
\hline CHEMBL1317345 & 688171 & 6.1 & 4.92399 & 99999999995 & TRN \\
\hline CHEMBL1526396 & 688171 & 5.6 & 4.8821 & TRN & \\
\hline CHEMBL1401339 & 688171 & 6.35 & 4.8923 & TRN & \\
\hline CHEMBL1371763 & 688171 & 5.5 & 4.9687 & TRN & \\
\hline CHEMBL1395356 & 688171 & 5.15 & 4.7163 & TRN & \\
\hline CHEMBL1303754 & 688171 & 5.5 & 4.9906 & TRN & \\
\hline CHEMBL1407675 & 688171 & 4.35 & 4.8356 & TRN & \\
\hline CHEMBL1485561 & 688171 & 4.9 & 4.9154 & TRN & \\
\hline CHEMBL1314457 & 688171 & 4.4 & 4.8551 & TRN & \\
\hline CHEMBL1495485 & 688171 & 4.5 & 4.8726 & TRN & \\
\hline CHEMBL1321800 & 688171 & 4.4 & 4.9973 & TST & \\
\hline CHEMBL1537400 & 688171 & 4.95 & 5.0084 & TST & \\
\hline CHEMBL3198381 & 688171 & 4.6 & 4.8671 & TRN & \\
\hline CHEMBL1495177 & 688171 & 4.6 & 4.9173 & TRN & \\
\hline CHEMBL1304612 & 688171 & 4.65 & 5.0136 & TST & \\
\hline CHEMBL332686 & 688171 & 4.5 & 4.8537 & TRN & \\
\hline CHEMBL1576251 & 688171 & 4.4 & 4.935 & TST & \\
\hline CHEMBL1548221 & 688171 & 5.1 & 4.949 & TRN & \\
\hline CHEMBL1397354 & 688171 & 4.85 & 4.8671 & TRN & \\
\hline CHEMBL3209925 & 688171 & 5.05 & 4.9516 & TRN & \\
\hline CHEMBL1460982 & 688171 & 4.6 & 4.9273 & TRN & \\
\hline CHEMBL 1477874 & 688171 & 4.8 & 4.8784 & TRN & \\
\hline CHEMBL1600349 & 688171 & 4.6 & 4.9411 & TST & \\
\hline CHEMBL1299778 & 688171 & 4.4 & 4.8243 & TST & \\
\hline CHEMBL1358059 & 688171 & 6.0 & 4.9973 & TRN & \\
\hline CHEMBL1359781 & 688171 & 4.9 & 4.7772 & TRN & \\
\hline CHEMBL1373577 & 688171 & 4.6 & 4.7469 & TRN & \\
\hline CHEMBL1401660 & 688171 & 4.4 & 4.9288 & TRN & \\
\hline CHEMBL1441691 & 688171 & 4.9 & 4.9983 & TRN & \\
\hline CHEMBL1530930 & 688171 & 5.5 & 4.9468 & TST & \\
\hline CHEMBL1309756 & 688171 & 4.45 & 4.8005 & TST & \\
\hline
\end{tabular}




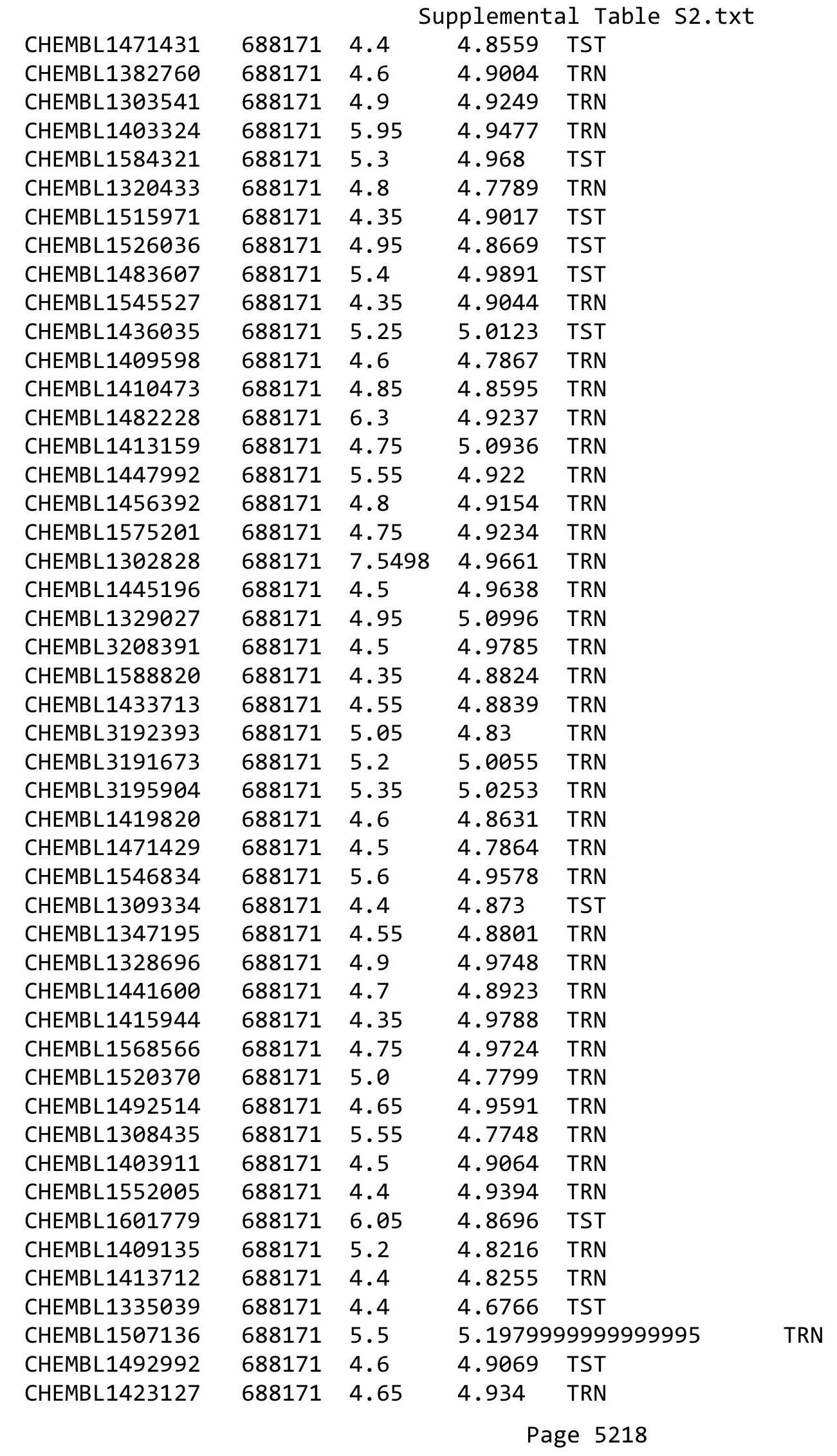




\begin{tabular}{|c|c|c|c|c|}
\hline \multicolumn{5}{|c|}{ Supplemental Table S2.txt } \\
\hline CHEMBL1368735 & 688171 & 4.35 & 4.958 & TRN \\
\hline CHEMBL1967040 & 688171 & 4.85 & 4.938 & TRN \\
\hline CHEMBL1357311 & 688171 & 4.7 & 4.9373 & TRN \\
\hline CHEMBL1558021 & 688171 & 5.95 & 4.9753 & TST \\
\hline CHEMBL1310607 & 688171 & 5.0 & 4.79 & TRN \\
\hline CHEMBL1433286 & 688171 & 4.95 & 4.8609 & TST \\
\hline CHEMBL1416904 & 688171 & 5.05 & 4.8446 & TRN \\
\hline CHEMBL1601476 & 688171 & 4.35 & 4.8674 & TRN \\
\hline CHEMBL1461232 & 688171 & 4.45 & 4.801 & TST \\
\hline CHEMBL1324290 & 688171 & 5.3 & 4.9411 & TRN \\
\hline CHEMBL1417196 & 688171 & 5.05 & 4.8181 & TRN \\
\hline CHEMBL1518054 & 688171 & 5.35 & 4.8634 & TRN \\
\hline CHEMBL1510763 & 688171 & 5.1 & 4.9083 & TST \\
\hline CHEMBL1492214 & 688171 & 4.75 & 4.9186 & TST \\
\hline CHEMBL1386983 & 688171 & 4.7 & 4.8857 & TRN \\
\hline CHEMBL1494411 & 688171 & 4.7 & 4.9405 & TRN \\
\hline CHEMBL3212008 & 688171 & 6.95 & 4.8305 & TRN \\
\hline CHEMBL1463847 & 688171 & 4.5 & 4.7974 & TRN \\
\hline CHEMBL1364979 & 688171 & 4.45 & 4.7754 & TST \\
\hline CHEMBL1518915 & 688171 & 4.4 & 4.8699 & TRN \\
\hline CHEMBL1596922 & 688171 & 5.25 & 5.0243 & TRN \\
\hline CHEMBL1320372 & 688171 & 4.4 & 4.7645 & TST \\
\hline CHEMBL1609324 & 688171 & 5.25 & 4.8355 & TRN \\
\hline CHEMBL1359573 & 688171 & 4.65 & 4.8742 & TRN \\
\hline CHEMBL1320864 & 688171 & 4.7 & 4.8667 & TRN \\
\hline CHEMBL1565758 & 688171 & 5.3 & 4.8089 & TRN \\
\hline CHEMBL1536089 & 688171 & 4.55 & 5.0169 & TRN \\
\hline CHEMBL3190362 & 688171 & 7.6003 & 4.8141 & TRN \\
\hline CHEMBL1370398 & 688171 & 5.7 & 4.8305 & TRN \\
\hline CHEMBL1307246 & 688171 & 4.8 & 4.7046 & TRN \\
\hline CHEMBL3194892 & 688171 & 4.85 & 4.9088 & TRN \\
\hline CHEMBL1387447 & 688171 & 4.45 & 4.9462 & TRN \\
\hline CHEMBL1453449 & 688171 & 6.15 & 5.0066 & TST \\
\hline CHEMBL1315329 & 688171 & 5.45 & 4.8858 & TRN \\
\hline CHEMBL1431373 & 688171 & 4.9 & 4.9456 & TRN \\
\hline CHEMBL1528450 & 688171 & 5.05 & 4.8451 & TRN \\
\hline CHEMBL1343906 & 688171 & 4.75 & 4.8899 & TRN \\
\hline CHEMBL1326472 & 688171 & 4.4 & 4.8854 & TRN \\
\hline CHEMBL1390521 & 688171 & 5.9 & 4.9534 & TRN \\
\hline CHEMBL1362565 & 688171 & 4.35 & 4.9823 & TRN \\
\hline CHEMBL1605395 & 688171 & 4.45 & 4.8266 & TRN \\
\hline CHEMBL1611070 & 688171 & 4.45 & 4.9587 & TST \\
\hline CHEMBL1491314 & 688171 & 4.6 & 4.9079 & TRN \\
\hline CHEMBL1512962 & 688171 & 4.4 & 4.7548 & TRN \\
\hline CHEMBL1973131 & 688171 & 4.6 & 4.8533 & TRN \\
\hline CHEMBL 3214024 & 688171 & 4.5 & 4.9403 & TRN \\
\hline CHEMBL1484607 & 688171 & 4.8 & 5.0903 & TRN \\
\hline CHEMBL1486289 & 688171 & 5.8 & 5.0264 & TRN \\
\hline
\end{tabular}




\begin{tabular}{|c|c|c|c|c|c|}
\hline \multicolumn{6}{|c|}{ Supplemental Table s2.txt } \\
\hline CHEMBL1593864 & 688171 & 4.4 & 4.8362 & TRN & \\
\hline CHEMBL1981992 & 688171 & 4.4 & 4.9503 & TRN & \\
\hline CHEMBL1503741 & 688171 & 5.7 & 5.0794 & TRN & \\
\hline CHEMBL1335059 & 688171 & 5.15 & 5.0063 & TRN & \\
\hline CHEMBL1366607 & 688171 & 4.95 & 5.0436 & TRN & \\
\hline CHEMBL1336846 & 688171 & 7.6003 & 4.802 & TRN & \\
\hline CHEMBL1524507 & 688171 & 5.3 & 5.0448 & TRN & \\
\hline CHEMBL1450705 & 688171 & 4.35 & 4.9141 & TRN & \\
\hline CHEMBL1389047 & 688171 & 4.85 & 4.9371 & TST & \\
\hline CHEMBL1571054 & 688171 & 4.55 & 4.8268 & TRN & \\
\hline CHEMBL1560281 & 688171 & 4.7 & 4.9829 & TRN & \\
\hline CHEMBL1540781 & 688171 & 4.4 & 5.0637 & TRN & \\
\hline CHEMBL1486569 & 688171 & 4.75 & 4.7619 & TRN & \\
\hline CHEMBL1370516 & 688171 & 5.1 & 4.8827 & TRN & \\
\hline CHEMBL1552341 & 688171 & 4.4 & 4.8847 & TRN & \\
\hline CHEMBL1381074 & 688171 & 4.5 & 4.9241 & TST & \\
\hline CHEMBL1417258 & 688171 & 4.4 & 4.763 & TRN & \\
\hline CHEMBL1485206 & 688171 & 4.6 & 4.8781 & TRN & \\
\hline CHEMBL1579217 & 688171 & 4.9 & 4.9366 & TRN & \\
\hline CHEMBL1305576 & 688171 & 5.1 & 4.8899 & TST & \\
\hline CHEMBL3189425 & 688171 & 7.0 & 4.9186 & TST & \\
\hline CHEMBL1536574 & 688171 & 6.45 & 4.8627 & TRN & \\
\hline CHEMBL1473659 & 688171 & 4.85 & 4.9303 & TRN & \\
\hline CHEMBL1471204 & 688171 & 6.9 & 5.0635 & TRN & \\
\hline CHEMBL1574285 & 688171 & 4.4 & 5.1411 & TST & \\
\hline CHEMBL1612244 & 688171 & 4.75 & 4.8838 & TRN & \\
\hline CHEMBL 2005437 & 688171 & 5.65 & 4.8913 & TRN & \\
\hline CHEMBL1323001 & 688171 & 4.7 & 4.8562 & TRN & \\
\hline CHEMBL1394055 & 688171 & 5.0 & 4.8379 & TRN & \\
\hline CHEMBL1607447 & 688171 & 5.6 & 4.935 & TST & \\
\hline CHEMBL1350045 & 688171 & 4.55 & 4.8359 & TRN & \\
\hline CHEMBL1514834 & 688171 & 4.85 & 4.871 & TRN & \\
\hline CHEMBL1522558 & 688171 & 5.75 & 4.9613 & TRN & \\
\hline CHEMBL1609476 & 688171 & 4.4 & 4.9415 & TRN & \\
\hline CHEMBL1321987 & 688171 & 4.4 & 4.9352 & TRN & \\
\hline CHEMBL1537758 & 688171 & 4.65 & 4.9694 & TRN & \\
\hline CHEMBL1307289 & 688171 & 4.45 & 4.9767 & TST & \\
\hline CHEMBL1479759 & 688171 & 4.85 & 4.9898 & TST & \\
\hline CHEMBL1407927 & 688171 & 6.1 & 4.8682 & TRN & \\
\hline CHEMBL3392067 & 688171 & 4.95 & 4.82600 & 00000000005 & TRN \\
\hline CHEMBL1303333 & 688171 & 6.35 & 4.8315 & TRN & \\
\hline CHEMBL1338278 & 688171 & 4.8 & 4.8907 & TRN & \\
\hline CHEMBL1527103 & 688171 & 4.95 & 4.953 & TRN & \\
\hline CHEMBL1390488 & 688171 & 6.6 & 4.9661 & TRN & \\
\hline CHEMBL1433850 & 688171 & 5.0 & 5.0536 & TST & \\
\hline CHEMBL1965298 & 688171 & 4.55 & 4.8794 & TRN & \\
\hline CHEMBL1600754 & 688171 & 5.6 & 4.9344 & TRN & \\
\hline CHEMBL1476630 & 688171 & 4.7 & 4.9087 & TRN & \\
\hline
\end{tabular}




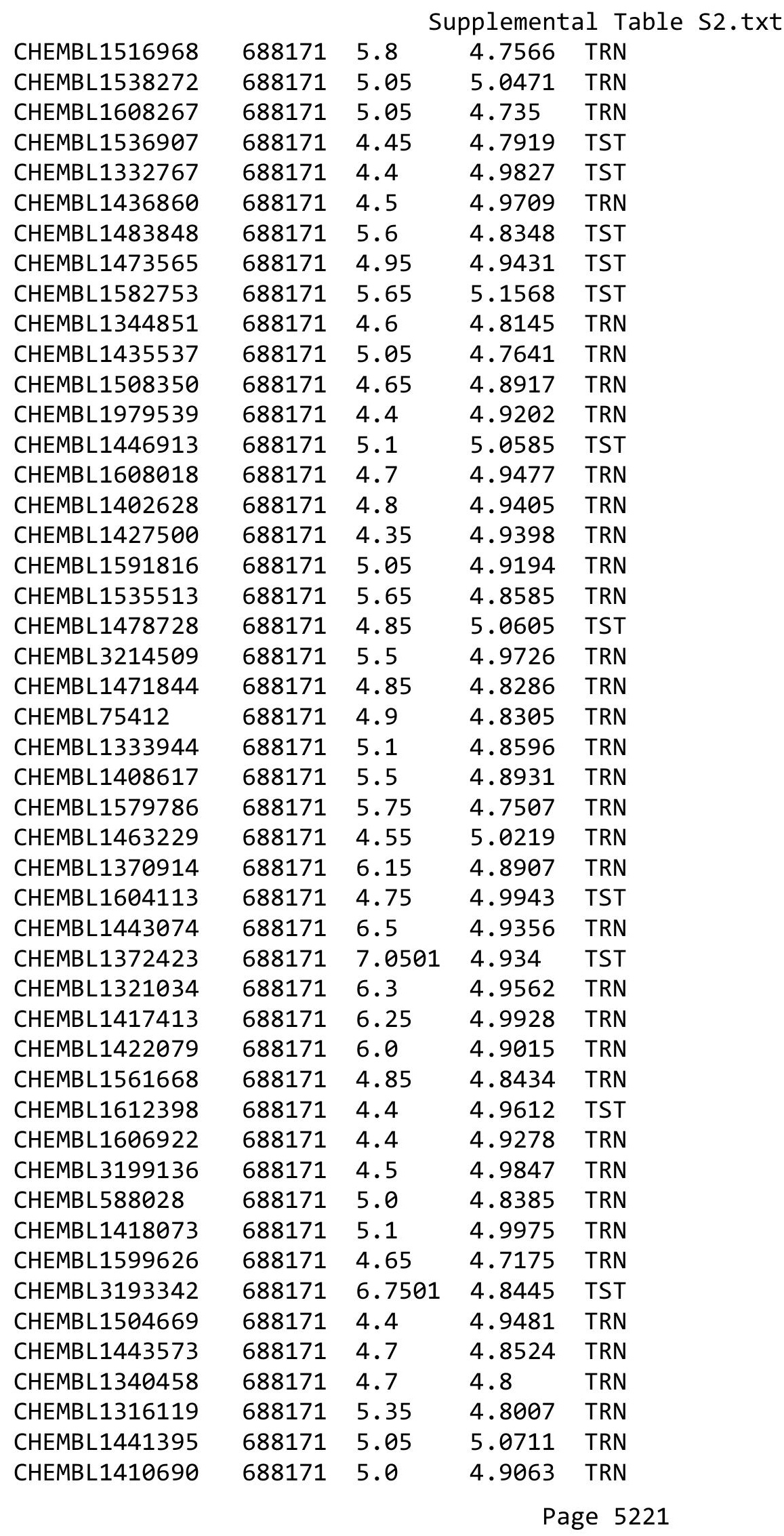




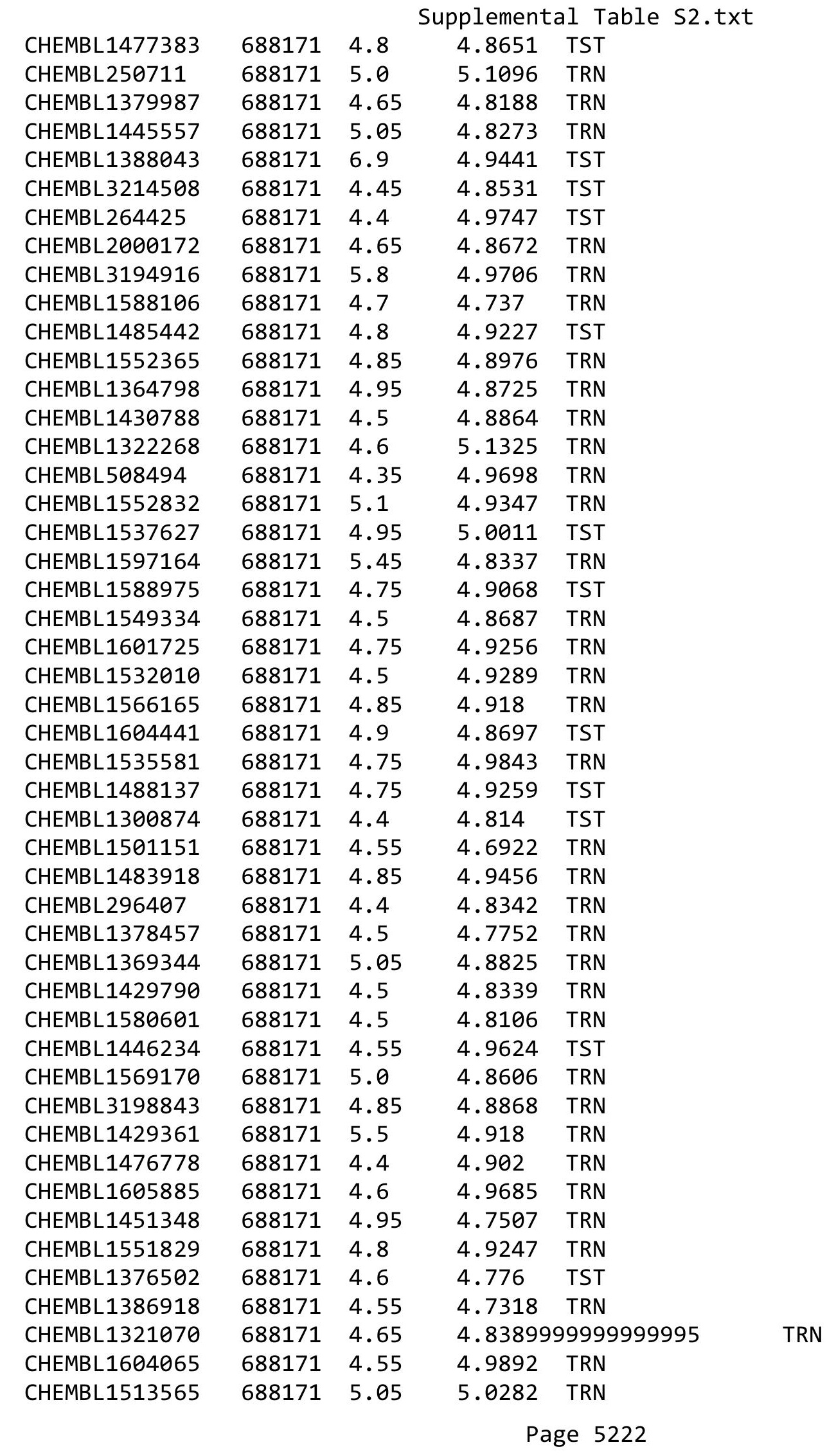




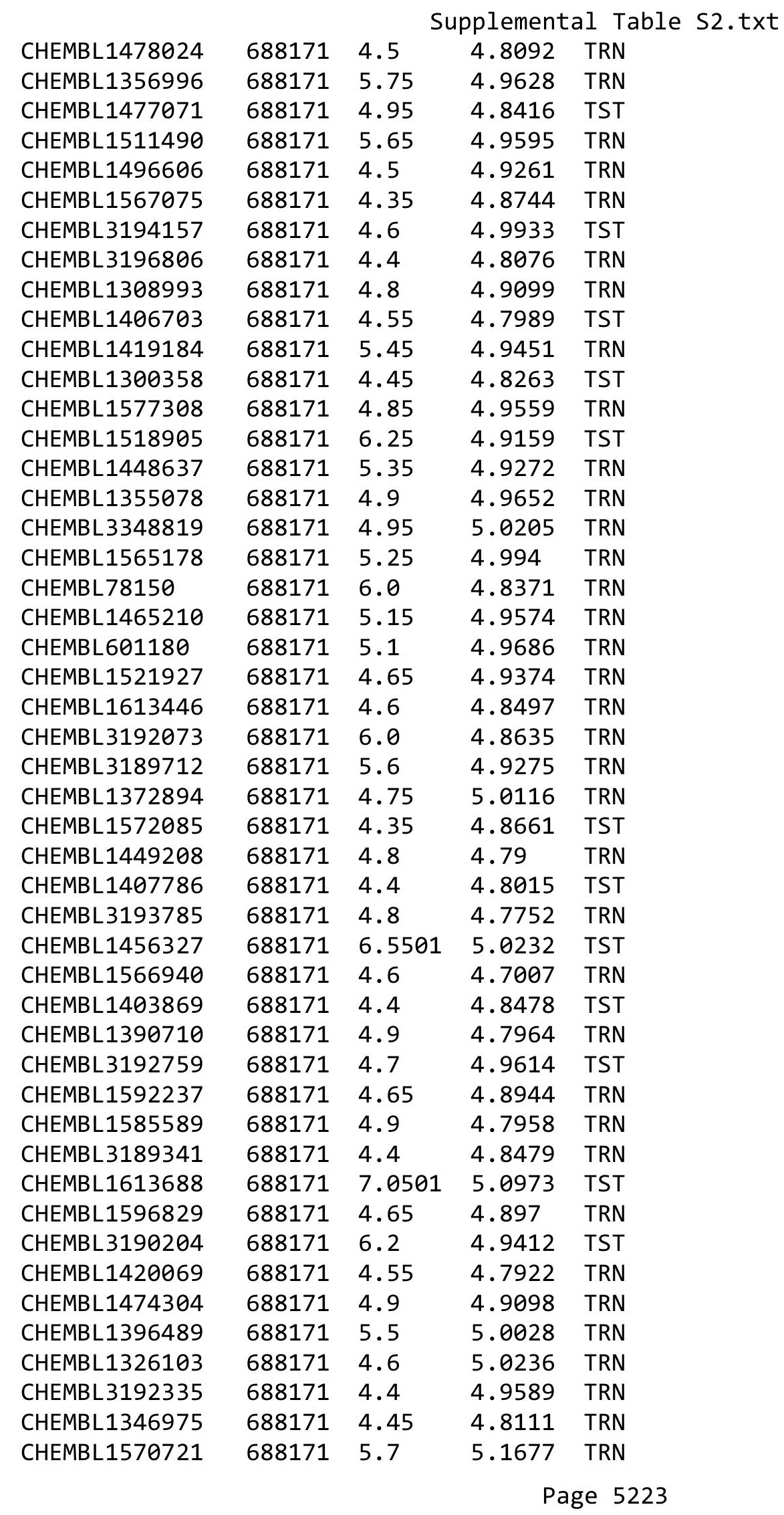




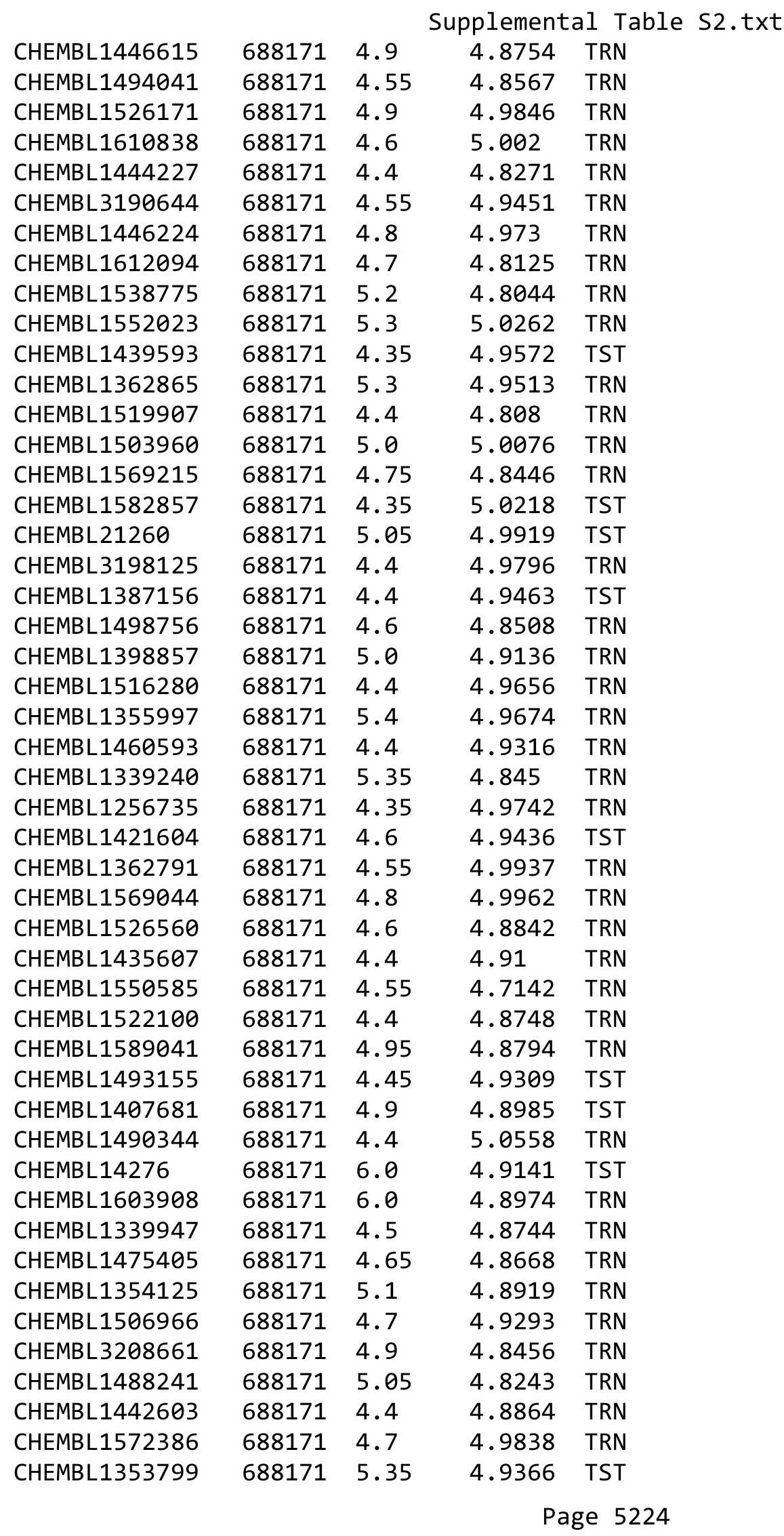




\begin{tabular}{|c|c|c|c|c|}
\hline \multicolumn{5}{|c|}{ Supplemental Table S2.txt } \\
\hline CHEMBL1578064 & 688171 & 5.75 & 4.9676 & TRN \\
\hline CHEMBL1451573 & 688171 & 7.2503 & 5.0041 & TRN \\
\hline CHEMBL1418221 & 688171 & 4.6 & 4.9022 & TRN \\
\hline CHEMBL1332037 & 688171 & 5.45 & 5.0896 & TRN \\
\hline CHEMBL1379164 & 688171 & 4.4 & 4.8662 & TST \\
\hline CHEMBL1476285 & 688171 & 4.8 & 4.8679 & TRN \\
\hline CHEMBL3212482 & 688171 & 4.5 & 4.9059 & TRN \\
\hline CHEMBL1414249 & 688171 & 5.0 & 4.8782 & TRN \\
\hline CHEMBL1575108 & 688171 & 4.75 & 4.8931 & TRN \\
\hline CHEMBL1431141 & 688171 & 5.45 & 4.9748 & TST \\
\hline CHEMBL1331257 & 688171 & 5.95 & 4.9218 & TRN \\
\hline CHEMBL1390716 & 688171 & 5.8 & 4.7506 & TST \\
\hline CHEMBL1476788 & 688171 & 4.65 & 4.7417 & TRN \\
\hline CHEMBL 1609550 & 688171 & 4.45 & 4.726 & TRN \\
\hline CHEMBL1332927 & 688171 & 6.0 & 5.0121 & TRN \\
\hline CHEMBL1407931 & 688171 & 4.45 & 4.8837 & TRN \\
\hline CHEMBL3192225 & 688171 & 4.35 & 4.959 & TST \\
\hline CHEMBL1447211 & 688171 & 4.45 & 4.841 & TRN \\
\hline CHEMBL1386314 & 688171 & 4.5 & 4.8199 & TST \\
\hline CHEMBL1561280 & 688171 & 4.75 & 4.9619 & TRN \\
\hline CHEMBL1507723 & 688171 & 4.75 & 4.9836 & TST \\
\hline CHEMBL3196703 & 688171 & 5.65 & 4.9487 & TRN \\
\hline CHEMBL3198688 & 688171 & 4.55 & 4.8527 & TRN \\
\hline CHEMBL1606082 & 688171 & 4.4 & 4.9178 & TRN \\
\hline CHEMBL1527254 & 688171 & 4.8 & 4.7869 & TRN \\
\hline CHEMBL1500704 & 688171 & 4.8 & 4.9171 & TRN \\
\hline CHEMBL1585848 & 688171 & 4.9 & 4.9057 & TRN \\
\hline CHEMBL1417707 & 688171 & 4.35 & 5.0218 & TST \\
\hline CHEMBL1527689 & 688171 & 4.8 & 4.9501 & TRN \\
\hline CHEMBL1435985 & 688171 & 4.55 & 5.0078 & TRN \\
\hline CHEMBL1545584 & 688171 & 6.0 & 5.0109 & TRN \\
\hline CHEMBL1716742 & 688171 & 4.8 & 4.8057 & TST \\
\hline CHEMBL1390586 & 688171 & 4.8 & 4.8519 & TRN \\
\hline CHEMBL1424264 & 688171 & 4.95 & 4.8571 & TRN \\
\hline CHEMBL1334189 & 688171 & 5.05 & 4.9244 & TRN \\
\hline CHEMBL1541255 & 688171 & 5.5 & 5.0517 & TRN \\
\hline CHEMBL1322413 & 688171 & 5.75 & 4.9162 & TRN \\
\hline CHEMBL3195603 & 688171 & 5.55 & 4.94 & TRN \\
\hline CHEMBL1397788 & 688171 & 5.05 & 4.8565 & TRN \\
\hline CHEMBL1304582 & 688171 & 4.9 & 5.0077 & TRN \\
\hline CHEMBL1495613 & 688171 & 4.7 & 4.9795 & TRN \\
\hline CHEMBL1404232 & 688171 & 6.7001 & 5.0323 & TST \\
\hline CHEMBL1446068 & 688171 & 4.95 & 4.9372 & TRN \\
\hline CHEMBL1334116 & 688171 & 4.55 & 4.7135 & TRN \\
\hline CHEMBL1603602 & 688171 & 5.6 & 4.8601 & TRN \\
\hline CHEMBL1476522 & 688171 & 4.55 & 4.9055 & TRN \\
\hline CHEMBL1560503 & 688171 & 4.85 & 4.9982 & TRN \\
\hline CHEMBL1319308 & 688171 & 4.4 & 5.0512 & TRN \\
\hline
\end{tabular}




\begin{tabular}{|c|c|c|c|c|c|}
\hline \multicolumn{6}{|c|}{ Supplemental Table S2.txt } \\
\hline CHEMBL1364333 & 688171 & 5.05 & 4.993 & TST & \\
\hline CHEMBL1551107 & 688171 & 4.55 & 4.7744 & TST & \\
\hline CHEMBL1324895 & 688171 & 5.85 & 4.9328 & TRN & \\
\hline CHEMBL1472111 & 688171 & 5.05 & 4.7459 & TST & \\
\hline CHEMBL 3195494 & 688171 & 4.65 & 4.9635 & TRN & \\
\hline CHEMBL1371562 & 688171 & 4.85 & 4.8889 & TRN & \\
\hline CHEMBL1315451 & 688171 & 5.15 & 4.9282 & TRN & \\
\hline CHEMBL1598819 & 688171 & 4.95 & 4.7967 & TRN & \\
\hline CHEMBL1585523 & 688171 & 5.45 & 5.0661 & TST & \\
\hline CHEMBL1610831 & 688171 & 4.65 & 4.9131 & TST & \\
\hline CHEMBL1379314 & 688171 & 4.65 & 4.9058 & TST & \\
\hline CHEMBL 3189462 & 688171 & 4.8 & 4.9848 & TST & \\
\hline CHEMBL1460100 & 688171 & 4.35 & 4.8829 & TST & \\
\hline CHEMBL1302980 & 688171 & 4.55 & 5.0095 & TRN & \\
\hline CHEMBL1407653 & 688171 & 6.7501 & 4.8217 & TRN & \\
\hline CHEMBL1531705 & 688171 & 4.4 & 4.8489 & TST & \\
\hline CHEMBL1256480 & 688171 & 5.95 & 4.9069 & TST & \\
\hline CHEMBL 2146209 & 688171 & 6.35 & 4.8883 & TST & \\
\hline CHEMBL1396220 & 688171 & 5.05 & 4.8825 & TRN & \\
\hline CHEMBL1583490 & 688171 & 4.35 & 4.9373 & TRN & \\
\hline CHEMBL1588205 & 688171 & 4.4 & 4.999 & TRN & \\
\hline CHEMBL1478072 & 688171 & 6.0 & 5.0393 & TST & \\
\hline CHEMBL1437555 & 688171 & 4.7 & 4.9556 & TRN & \\
\hline CHEMBL1314864 & 688171 & 4.65 & 4.886 & TRN & \\
\hline CHEMBL1473284 & 688171 & 4.8 & 4.9354 & TRN & \\
\hline CHEMBL1541903 & 688171 & 4.65 & 4.9263 & TST & \\
\hline CHEMBL1538707 & 688171 & 4.9 & 4.9703 & TRN & \\
\hline CHEMBL1493317 & 688171 & 6.5 & 5.1507 & TRN & \\
\hline CHEMBL1432342 & 688171 & 5.2 & 4.7793 & TRN & \\
\hline CHEMBL1338585 & 688171 & 4.5 & 4.80699 & 99999999995 & TRN \\
\hline CHEMBL1359925 & 688171 & 6.0 & 4.8001 & TRN & \\
\hline CHEMBL1339349 & 688171 & 4.5 & 4.9233 & TRN & \\
\hline CHEMBL1332036 & 688171 & 4.8 & 4.841 & TRN & \\
\hline CHEMBL1399591 & 688171 & 4.5 & 4.9723 & TRN & \\
\hline CHEMBL1401951 & 688171 & 4.7 & 4.7943 & TRN & \\
\hline CHEMBL1546789 & 688171 & 4.5 & 4.8472 & TRN & \\
\hline CHEMBL1481985 & 688171 & 4.4 & 4.9759 & TST & \\
\hline CHEMBL1336049 & 688171 & 5.05 & 4.9532 & TST & \\
\hline CHEMBL1399168 & 688171 & 4.85 & 4.7848 & TRN & \\
\hline CHEMBL1540371 & 688171 & 4.55 & 4.7997 & TST & \\
\hline CHEMBL1375049 & 688171 & 4.65 & 4.9768 & TST & \\
\hline CHEMBL1403208 & 688171 & 4.55 & 4.8346 & TRN & \\
\hline CHEMBL1438081 & 688171 & 4.7 & 4.9251 & TRN & \\
\hline CHEMBL1541849 & 688171 & 5.05 & 4.9726 & TST & \\
\hline CHEMBL1445307 & 688171 & 5.9 & 4.9549 & TST & \\
\hline CHEMBL1318678 & 688171 & 4.5 & 4.8793 & TRN & \\
\hline CHEMBL581190 & 688171 & 4.8 & 4.9072 & TRN & \\
\hline CHEMBL1444450 & 688171 & 4.95 & 4.9802 & TST & \\
\hline
\end{tabular}




\begin{tabular}{|c|c|c|c|c|c|}
\hline \multicolumn{6}{|c|}{ Supplemental Table S2.txt } \\
\hline CHEMBL1549165 & 688171 & 5.4 & 4.9396 & TRN & \\
\hline CHEMBL1437074 & 688171 & 4.5 & 4.8129 & TRN & \\
\hline CHEMBL1522635 & 688171 & 4.65 & 4.8666 & TRN & \\
\hline CHEMBL1360529 & 688171 & 4.9 & 4.9962 & TRN & \\
\hline CHEMBL1299780 & 688171 & 4.85 & 4.9798 & TRN & \\
\hline CHEMBL1494907 & 688171 & 5.0 & 4.9263 & TRN & \\
\hline CHEMBL1601632 & 688171 & 4.45 & 4.8724 & TST & \\
\hline CHEMBL1475081 & 688171 & 4.85 & 4.8849 & TRN & \\
\hline CHEMBL1316438 & 688171 & 4.4 & 4.9574 & TRN & \\
\hline CHEMBL3197890 & 688171 & 5.2 & 4.9524 & TRN & \\
\hline CHEMBL1559624 & 688171 & 4.8 & 4.77800 & 00000000005 & TRN \\
\hline CHEMBL577455 & 688171 & 6.5 & 5.0195 & TST & \\
\hline CHEMBL1463902 & 688171 & 4.6 & 4.8787 & TRN & \\
\hline CHEMBL1384716 & 688171 & 4.8 & 4.8629 & TRN & \\
\hline CHEMBL3184468 & 688171 & 4.55 & 4.893 & TST & \\
\hline CHEMBL1601195 & 688171 & 4.4 & 4.7531 & TRN & \\
\hline CHEMBL1537006 & 688171 & 5.5 & 5.0508 & TST & \\
\hline CHEMBL1337802 & 688171 & 4.45 & 4.9021 & TRN & \\
\hline CHEMBL1425652 & 688171 & 4.65 & 5.0019 & TRN & \\
\hline CHEMBL1336386 & 688171 & 4.6 & 4.9578 & TST & \\
\hline CHEMBL1513281 & 688171 & 4.95 & 4.8244 & TST & \\
\hline CHEMBL1300301 & 688171 & 6.7001 & 4.8655 & TRN & \\
\hline CHEMBL1454066 & 688171 & 5.15 & 4.9579 & TRN & \\
\hline CHEMBL1486479 & 688171 & 5.4 & 4.8948 & TRN & \\
\hline CHEMBL1507251 & 688171 & 4.5 & 4.8294 & TRN & \\
\hline CHEMBL1430325 & 688171 & 5.4 & 4.7334 & TRN & \\
\hline CHEMBL1544553 & 688171 & 4.35 & 4.8693 & TST & \\
\hline CHEMBL1531303 & 688171 & 4.95 & 4.9957 & TRN & \\
\hline CHEMBL1369937 & 688171 & 4.5 & 4.8484 & TRN & \\
\hline CHEMBL1364287 & 688171 & 4.4 & 5.0031 & TRN & \\
\hline CHEMBL1347373 & 688171 & 4.45 & 4.8347 & TST & \\
\hline CHEMBL1491743 & 688171 & 4.35 & 4.9271 & TST & \\
\hline CHEMBL1606132 & 688171 & 4.5 & 4.9698 & TST & \\
\hline CHEMBL 267373 & 688171 & 5.5 & 4.8718 & TRN & \\
\hline CHEMBL88584 & 688171 & 5.05 & 4.8955 & TST & \\
\hline CHEMBL3208417 & 688171 & 5.1 & 4.9726 & TRN & \\
\hline CHEMBL1330130 & 688171 & 4.4 & 4.7897 & TRN & \\
\hline CHEMBL1345871 & 688171 & 4.5 & 4.762 & TRN & \\
\hline CHEMBL1608914 & 688171 & 4.5 & 4.9467 & TRN & \\
\hline CHEMBL1341674 & 688171 & 4.6 & 4.8714 & TST & \\
\hline CHEMBL1411013 & 688171 & 4.85 & 4.7365 & TRN & \\
\hline CHEMBL1421903 & 688171 & 7.6003 & 5.0833 & TRN & \\
\hline CHEMBL1333171 & 688171 & 4.75 & 4.74100 & 00000000005 & TRN \\
\hline CHEMBL1436694 & 688171 & 4.9 & 4.8625 & TRN & \\
\hline CHEMBL1445444 & 688171 & 6.05 & 4.9134 & TRN & \\
\hline CHEMBL1598498 & 688171 & 4.6 & 4.9312 & TRN & \\
\hline CHEMBL1300397 & 688171 & 5.25 & 4.8019 & TRN & \\
\hline CHEMBL1436653 & 688171 & 5.0 & 4.9701 & TRN & \\
\hline
\end{tabular}




\begin{tabular}{|c|c|c|c|c|}
\hline \multicolumn{5}{|c|}{ Supplemental Table S2.txt } \\
\hline CHEMBL1327572 & 688171 & 4.4 & 4.7716 & TST \\
\hline CHEMBL1321357 & 688171 & 4.4 & 4.9828 & TRN \\
\hline CHEMBL1402054 & 688171 & 4.75 & 4.8751 & TRN \\
\hline CHEMBL1470993 & 688171 & 5.35 & 4.7886 & TRN \\
\hline CHEMBL1998940 & 688171 & 4.45 & 4.9364 & TRN \\
\hline CHEMBL1432083 & 688171 & 4.6 & 4.9434 & TRN \\
\hline CHEMBL1318772 & 688171 & 4.55 & 4.9251 & TRN \\
\hline CHEMBL3209908 & 688171 & 5.95 & 4.9443 & TRN \\
\hline CHEMBL1355543 & 688171 & 4.85 & 4.7165 & TRN \\
\hline CHEMBL1467691 & 688171 & 5.05 & 4.90600 & 0000000001 \\
\hline CHEMBL1419065 & 688171 & 4.4 & 4.8274 & TRN \\
\hline CHEMBL1546018 & 688171 & 5.5 & 4.9377 & TST \\
\hline CHEMBL1476173 & 688171 & 4.55 & 4.9098 & TRN \\
\hline CHEMBL1538457 & 688171 & 4.55 & 5.0025 & TRN \\
\hline CHEMBL1351621 & 688171 & 4.4 & 4.9808 & TRN \\
\hline CHEMBL370611 & 688171 & 5.1 & 4.8457 & TRN \\
\hline CHEMBL1477995 & 688171 & 4.35 & 5.0171 & TRN \\
\hline CHEMBL1486582 & 688171 & 4.55 & 4.754 & TRN \\
\hline CHEMBL1423448 & 688171 & 4.7 & 4.8301 & TRN \\
\hline CHEMBL1399046 & 688171 & 6.05 & 5.1218 & TRN \\
\hline CHEMBL1372717 & 688171 & 4.5 & 4.9332 & TRN \\
\hline CHEMBL3213088 & 688171 & 4.85 & 4.9932 & TRN \\
\hline CHEMBL1372470 & 688171 & 4.4 & 4.9578 & TRN \\
\hline CHEMBL1581566 & 688171 & 4.4 & 4.9426 & TRN \\
\hline CHEMBL1322389 & 688171 & 7.2503 & 4.9783 & TRN \\
\hline CHEMBL1555611 & 688171 & 5.0 & 4.9135 & TRN \\
\hline CHEMBL1554267 & 688171 & 5.0 & 4.8742 & TRN \\
\hline CHEMBL1442136 & 688171 & 4.6 & 4.9576 & TRN \\
\hline CHEMBL1552452 & 688171 & 5.9 & 5.0157 & TRN \\
\hline CHEMBL1595959 & 688171 & 4.35 & 4.8748 & TRN \\
\hline CHEMBL1465727 & 688171 & 4.45 & 4.8074 & TRN \\
\hline CHEMBL3197425 & 688171 & 4.6 & 4.9788 & TRN \\
\hline CHEMBL1581066 & 688171 & 4.7 & 4.8787 & TRN \\
\hline CHEMBL1486006 & 688171 & 4.35 & 5.0574 & TRN \\
\hline CHEMBL1577766 & 688171 & 5.4 & 4.8305 & TRN \\
\hline CHEMBL1579564 & 688171 & 4.6 & 4.7629 & TRN \\
\hline CHEMBL1455619 & 688171 & 4.5 & 4.7844 & TRN \\
\hline CHEMBL1554648 & 688171 & 4.4 & 4.834 & TRN \\
\hline CHEMBL1305771 & 688171 & 4.6 & 4.8728 & TRN \\
\hline CHEMBL1416237 & 688171 & 5.4 & 4.8122 & TRN \\
\hline CHEMBL1482671 & 688171 & 4.6 & 4.9273 & TRN \\
\hline CHEMBL1391071 & 688171 & 4.5 & 4.9716 & TRN \\
\hline CHEMBL1404086 & 688171 & 4.85 & 4.905 & TRN \\
\hline CHEMBL1327237 & 688171 & 5.0 & 4.8479 & TRN \\
\hline CHEMBL1367996 & 688171 & 4.95 & 4.8309 & TRN \\
\hline CHEMBL1349667 & 688171 & 4.4 & 4.9211 & TST \\
\hline CHEMBL1483228 & 688171 & 4.95 & 4.9321 & TRN \\
\hline CHEMBL1521305 & 688171 & 5.15 & 4.957 & TRN \\
\hline
\end{tabular}




\begin{tabular}{|c|c|c|c|c|c|}
\hline & & \multicolumn{4}{|c|}{ Supplemental Table s2.txt } \\
\hline CHEMBL1459514 & 688171 & 4.75 & 4.8991 & TST & \\
\hline CHEMBL1408951 & 688171 & 5.85 & 4.867 & TRN & \\
\hline CHEMBL1552311 & 688171 & 5.9 & 4.8273 & TRN & \\
\hline CHEMBL1414105 & 688171 & 4.55 & 4.9406 & TST & \\
\hline CHEMBL1457927 & 688171 & 5.0 & 4.8757 & TRN & \\
\hline CHEMBL1320453 & 688171 & 5.1 & 4.8018 & TRN & \\
\hline CHEMBL1434149 & 688171 & 4.85 & 4.7551 & TRN & \\
\hline CHEMBL1515570 & 688171 & 4.35 & 4.9117 & TRN & \\
\hline CHEMBL1442788 & 688171 & 4.6 & 4.7621 & TST & \\
\hline CHEMBL1430911 & 688171 & 4.6 & 4.9343 & TST & \\
\hline CHEMBL1493009 & 688171 & 4.6 & 4.9782 & TRN & \\
\hline CHEMBL1535293 & 688171 & 4.35 & 4.8974 & TRN & \\
\hline CHEMBL1357945 & 688171 & 7.15 & 4.9871 & TST & \\
\hline CHEMBL1463039 & 688171 & 4.75 & 4.9411 & TRN & \\
\hline CHEMBL1329318 & 688171 & 4.9 & 4.763 & TRN & \\
\hline CHEMBL570468 & 688171 & 7.0 & 4.8941 & TST & \\
\hline CHEMBL1533277 & 688171 & 4.4 & 4.9005 & TRN & \\
\hline CHEMBL1486317 & 688171 & 6.1 & 4.9975 & TRN & \\
\hline CHEMBL1445105 & 688171 & 5.05 & 4.9344 & TST & \\
\hline CHEMBL1575102 & 688171 & 4.95 & 4.766 & TRN & \\
\hline CHEMBL1555483 & 688171 & 4.75 & 4.9218 & TRN & \\
\hline CHEMBL1373437 & 688171 & 4.4 & 5.0197 & TRN & \\
\hline CHEMBL1336770 & 688171 & 4.45 & 4.8734 & TST & \\
\hline CHEMBL1513844 & 688171 & 4.4 & 4.8767 & TRN & \\
\hline CHEMBL1610984 & 688171 & 4.4 & 4.8898 & TST & \\
\hline CHEMBL1310268 & 688171 & 4.5 & 4.881 & TRN & \\
\hline CHEMBL1476520 & 688171 & 4.95 & 4.8732 & TRN & \\
\hline CHEMBL1336264 & 688171 & 4.65 & 4.8856 & TRN & \\
\hline CHEMBL1385840 & 688171 & 6.0 & 5.0059 & TRN & \\
\hline CHEMBL1407068 & 688171 & 5.25 & 4.96399 & 99999999995 & TRN \\
\hline CHEMBL1556767 & 688171 & 6.0 & 5.0273 & TRN & \\
\hline CHEMBL1487797 & 688171 & 5.15 & 4.8509 & TRN & \\
\hline CHEMBL1410076 & 688171 & 5.05 & 5.0366 & TRN & \\
\hline CHEMBL1485659 & 688171 & 4.6 & 4.8871 & TRN & \\
\hline CHEMBL1377144 & 688171 & 5.5 & 4.9457 & TRN & \\
\hline CHEMBL1509368 & 688171 & 4.35 & 4.773 & TRN & \\
\hline CHEMBL3209927 & 688171 & 4.4 & 5.0404 & TST & \\
\hline CHEMBL1328804 & 688171 & 5.45 & 4.8359 & TST & \\
\hline CHEMBL1404528 & 688171 & 4.55 & 4.8183 & TRN & \\
\hline CHEMBL3208420 & 688171 & 4.7 & 4.9047 & TRN & \\
\hline CHEMBL1552175 & 688171 & 4.35 & 4.9841 & TRN & \\
\hline CHEMBL1553591 & 688171 & 4.55 & 4.8173 & TRN & \\
\hline CHEMBL1531654 & 688171 & 4.75 & 4.8854 & TRN & \\
\hline CHEMBL1313891 & 688171 & 4.6 & 4.8789 & TRN & \\
\hline CHEMBL1513686 & 688171 & 4.35 & 4.999 & TST & \\
\hline CHEMBL1976044 & 688171 & 5.25 & 4.9482 & TRN & \\
\hline CHEMBL1342069 & 688171 & 5.4 & 5.0379 & TST & \\
\hline CHEMBL1356229 & 688171 & 4.55 & 4.8386 & TRN & \\
\hline
\end{tabular}




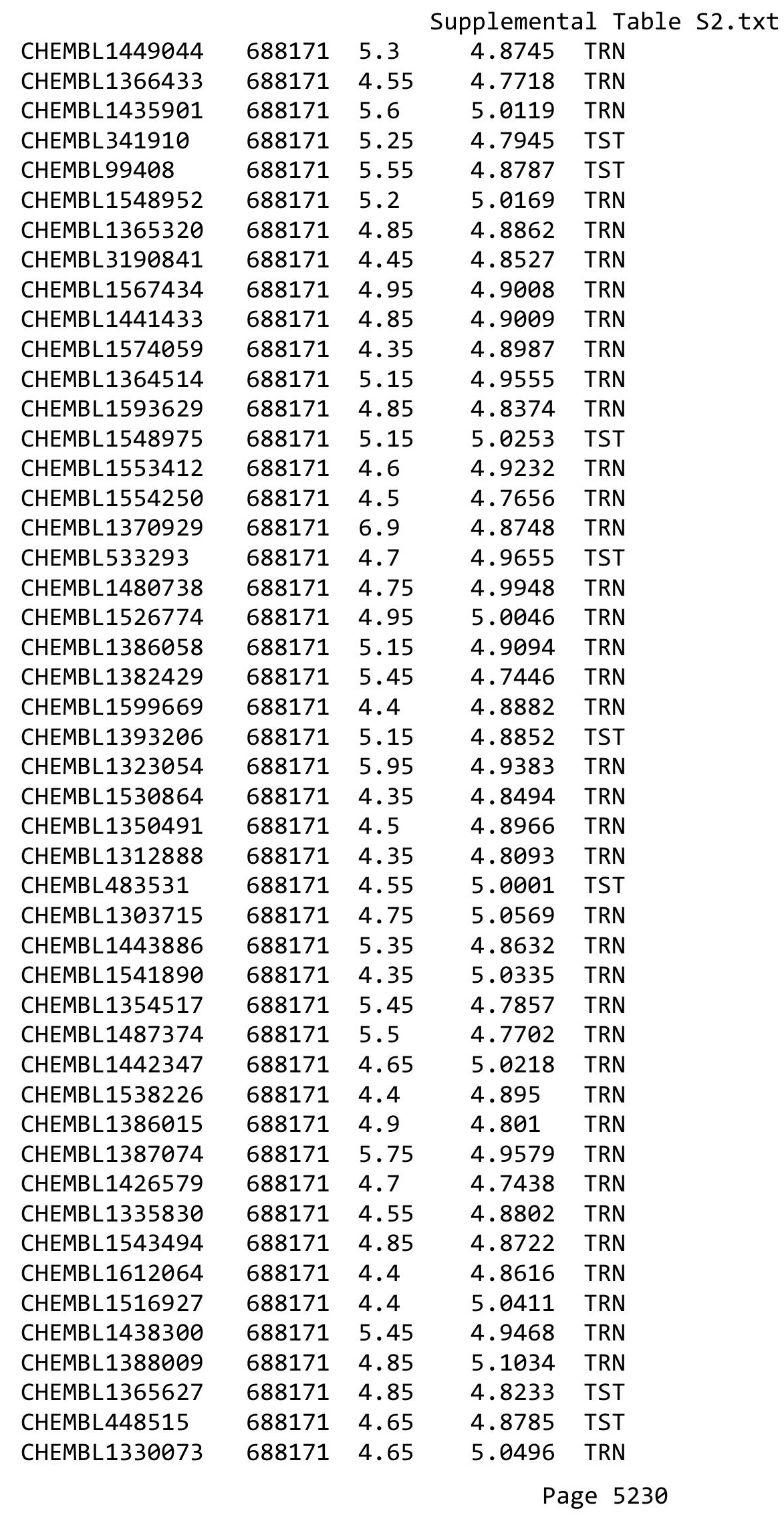




\begin{tabular}{|c|c|c|c|c|}
\hline \multicolumn{5}{|c|}{ Supplemental Table S2.txt } \\
\hline CHEMBL1591080 & 688171 & 4.35 & 4.9027 & TRN \\
\hline CHEMBL1467712 & 688171 & 5.0 & 4.8795 & TST \\
\hline CHEMBL1331801 & 688171 & 5.0 & 4.9191 & TST \\
\hline CHEMBL1514300 & 688171 & 5.6 & 4.8891 & TRN \\
\hline CHEMBL1593002 & 688171 & 4.75 & 4.9206 & TRN \\
\hline CHEMBL1339257 & 688171 & 5.1 & 4.8926 & TST \\
\hline CHEMBL1385806 & 688171 & 4.35 & 5.0004 & TRN \\
\hline CHEMBL1551728 & 688171 & 4.4 & 4.9236 & TRN \\
\hline CHEMBL1352016 & 688171 & 4.55 & 4.86600 & 20000000005 \\
\hline CHEMBL3209776 & 688171 & 4.4 & 4.9624 & TRN \\
\hline CHEMBL1590799 & 688171 & 4.35 & 4.8725 & TRN \\
\hline CHEMBL1596161 & 688171 & 4.4 & 4.8173 & TRN \\
\hline CHEMBL1474015 & 688171 & 4.5 & 4.9274 & TRN \\
\hline CHEMBL1547145 & 688171 & 4.4 & 5.0005 & TRN \\
\hline CHEMBL1585205 & 688171 & 5.7 & 4.9074 & TRN \\
\hline CHEMBL1433698 & 688171 & 5.55 & 4.9195 & TRN \\
\hline CHEMBL1358319 & 688171 & 4.9 & 4.8422 & TST \\
\hline CHEMBL1433439 & 688171 & 5.15 & 4.9265 & TRN \\
\hline CHEMBL1339157 & 688171 & 4.9 & 4.853 & TRN \\
\hline CHEMBL486706 & 688171 & 4.4 & 5.0303 & TST \\
\hline CHEMBL1409304 & 688171 & 4.45 & 4.9221 & TRN \\
\hline CHEMBL1434498 & 688171 & 4.7 & 4.8384 & TRN \\
\hline CHEMBL1436248 & 688171 & 5.9 & 5.0161 & TRN \\
\hline CHEMBL1483740 & 688171 & 4.4 & 4.8764 & TST \\
\hline CHEMBL1389510 & 688171 & 4.55 & 4.7323 & TRN \\
\hline CHEMBL1360203 & 688171 & 4.75 & 4.9865 & TRN \\
\hline CHEMBL1325133 & 688171 & 4.5 & 4.9982 & TST \\
\hline CHEMBL1372911 & 688171 & 6.0 & 4.868 & TRN \\
\hline CHEMBL1611828 & 688171 & 4.35 & 4.8903 & TRN \\
\hline CHEMBL3199512 & 688171 & 5.35 & 4.9421 & TRN \\
\hline CHEMBL1608298 & 688171 & 5.55 & 5.0227 & TST \\
\hline CHEMBL1528842 & 688171 & 4.95 & 5.0309 & TRN \\
\hline CHEMBL1308894 & 688171 & 4.9 & 4.8594 & TRN \\
\hline CHEMBL1414957 & 688171 & 5.75 & 4.803 & TRN \\
\hline CHEMBL3190318 & 688171 & 6.1 & 4.8535 & TRN \\
\hline CHEMBL1543995 & 688171 & 4.4 & 4.8632 & TRN \\
\hline CHEMBL3190629 & 688171 & 4.55 & 4.9799 & TRN \\
\hline CHEMBL3194519 & 688171 & 4.4 & 4.9304 & TST \\
\hline CHEMBL1374356 & 688171 & 5.5 & 4.8607 & TST \\
\hline CHEMBL1356260 & 688171 & 5.0 & 4.9137 & TRN \\
\hline CHEMBL1549812 & 688171 & 6.45 & 4.7302 & TRN \\
\hline CHEMBL1355251 & 688171 & 5.45 & 4.9339 & TRN \\
\hline CHEMBL1314801 & 688171 & 5.55 & 4.9284 & TRN \\
\hline CHEMBL1334403 & 688171 & 4.85 & 4.9574 & TST \\
\hline CHEMBL1351576 & 688171 & 5.35 & 4.8825 & TST \\
\hline CHEMBL1342911 & 688171 & 6.0 & 5.1087 & TRN \\
\hline CHEMBL402053 & 688171 & 4.4 & 4.8107 & TRN \\
\hline CHEMBL3193194 & 688171 & 7.3002 & 4.9333 & TRN \\
\hline
\end{tabular}




\begin{tabular}{|c|c|c|c|c|}
\hline \multicolumn{5}{|c|}{ Supplemental Table S2.txt } \\
\hline CHEMBL1471088 & 688171 & 4.5 & 4.7455 & TRN \\
\hline CHEMBL1346822 & 688171 & 4.6 & 4.7894 & TRN \\
\hline CHEMBL1336949 & 688171 & 4.55 & 4.987 & TST \\
\hline CHEMBL 3209535 & 688171 & 4.35 & 4.9534 & TRN \\
\hline CHEMBL3210589 & 688171 & 6.7501 & 4.8823 & TST \\
\hline CHEMBL1474895 & 688171 & 4.5 & 4.8299 & TRN \\
\hline CHEMBL1342350 & 688171 & 4.75 & 4.872 & TRN \\
\hline CHEMBL1343952 & 688171 & 4.8 & 4.9013 & TRN \\
\hline CHEMBL 3190943 & 688171 & 5.15 & 4.9492 & TST \\
\hline CHEMBL1391165 & 688171 & 4.95 & 4.9825 & TST \\
\hline CHEMBL1605633 & 688171 & 4.65 & 4.8704 & TRN \\
\hline CHEMBL1480283 & 688171 & 4.5 & 4.8264 & TRN \\
\hline CHEMBL1528759 & 688171 & 5.0 & 4.9591 & TRN \\
\hline CHEMBL1398383 & 688171 & 4.4 & 4.9501 & TRN \\
\hline CHEMBL1401661 & 688171 & 5.55 & 4.8916 & TRN \\
\hline CHEMBL1322419 & 688171 & 7.6003 & 4.8629 & TST \\
\hline CHEMBL3189872 & 688171 & 6.1 & 5.0139 & TRN \\
\hline CHEMBL1328210 & 688171 & 4.4 & 5.0713 & TST \\
\hline CHEMBL1568876 & 688171 & 4.55 & 4.8645 & TRN \\
\hline CHEMBL1389713 & 688171 & 4.85 & 4.8032 & TRN \\
\hline CHEMBL1362951 & 688171 & 6.1 & 4.7991 & TRN \\
\hline CHEMBL1541578 & 688171 & 5.1 & 4.8682 & TST \\
\hline CHEMBL1449923 & 688171 & 5.0 & 4.9999 & TRN \\
\hline CHEMBL1472007 & 688171 & 5.5 & 5.1063 & TRN \\
\hline CHEMBL323356 & 688171 & 5.9 & 4.8343 & TRN \\
\hline CHEMBL1419186 & 688171 & 4.4 & 4.8159 & TRN \\
\hline CHEMBL1379834 & 688171 & 4.75 & 4.8929 & TRN \\
\hline CHEMBL460366 & 688171 & 5.05 & 4.9696 & TRN \\
\hline CHEMBL1462507 & 688171 & 5.6 & 4.8143 & TST \\
\hline CHEMBL1485236 & 688171 & 5.5 & 5.0691 & TRN \\
\hline CHEMBL1365769 & 688171 & 5.0 & 5.0479 & TRN \\
\hline CHEMBL1581746 & 688171 & 4.4 & 4.9095 & TST \\
\hline CHEMBL1317543 & 688171 & 4.35 & 4.772 & TRN \\
\hline CHEMBL1505663 & 688171 & 4.6 & 5.019 & TRN \\
\hline CHEMBL1392885 & 688171 & 5.0 & 4.9184 & TST \\
\hline CHEMBL1535221 & 688171 & 4.45 & 4.9398 & TRN \\
\hline CHEMBL3392467 & 688171 & 5.3 & 4.9563 & TST \\
\hline CHEMBL3192922 & 688171 & 4.65 & 4.8058 & TST \\
\hline CHEMBL1551226 & 688171 & 4.9 & 4.9008 & TRN \\
\hline CHEMBL1256668 & 688171 & 4.6 & 4.9527 & TST \\
\hline CHEMBL1427903 & 688171 & 4.4 & 4.9154 & TRN \\
\hline CHEMBL1374156 & 688171 & 5.1 & 4.7187 & TRN \\
\hline CHEMBL1425556 & 688171 & 6.0 & 5.0168 & TRN \\
\hline CHEMBL1442958 & 688171 & 4.7 & 4.7906 & TST \\
\hline CHEMBL264684 & 688171 & 4.6 & 4.8683 & TST \\
\hline CHEMBL1610549 & 688171 & 4.5 & 4.9208 & TRN \\
\hline CHEMBL1530973 & 688171 & 5.1 & 4.9551 & TRN \\
\hline CHEMBL1343485 & 688171 & 5.3 & 5.0275 & TRN \\
\hline
\end{tabular}




\begin{tabular}{|c|c|c|c|c|}
\hline \multicolumn{5}{|c|}{ Supplemental Table S2.txt } \\
\hline CHEMBL1608397 & 688171 & 5.2 & 4.9238 & TRN \\
\hline CHEMBL3195082 & 688171 & 5.75 & 5.0495 & TRN \\
\hline CHEMBL1333854 & 688171 & 4.4 & 4.8848 & TRN \\
\hline CHEMBL1451091 & 688171 & 4.9 & 4.9477 & TRN \\
\hline CHEMBL1517201 & 688171 & 4.85 & 4.9162 & TRN \\
\hline CHEMBL1306041 & 688171 & 5.45 & 4.9357 & TRN \\
\hline CHEMBL1332893 & 688171 & 5.2 & 4.8893 & TRN \\
\hline CHEMBL1406814 & 688171 & 4.8 & 4.9997 & TRN \\
\hline CHEMBL1529675 & 688171 & 4.85 & 5.0215 & TRN \\
\hline CHEMBL1552310 & 688171 & 5.1 & 4.9371 & TRN \\
\hline CHEMBL1487918 & 688171 & 4.95 & 4.7594 & TRN \\
\hline CHEMBL1587491 & 688171 & 5.5 & 5.0386 & TRN \\
\hline CHEMBL1404601 & 688171 & 4.9 & 4.8974 & TRN \\
\hline CHEMBL1330972 & 688171 & 4.75 & 4.9737 & TRN \\
\hline CHEMBL1341198 & 688171 & 5.4 & 4.7616 & TST \\
\hline CHEMBL1467316 & 688171 & 4.75 & 4.8906 & TRN \\
\hline CHEMBL1320218 & 688171 & 4.8 & 4.8175 & TRN \\
\hline CHEMBL3195236 & 688171 & 5.45 & 5.0269 & TRN \\
\hline CHEMBL1303074 & 688171 & 5.45 & 5.0189 & TST \\
\hline CHEMBL1496489 & 688171 & 4.65 & 4.8859 & TRN \\
\hline CHEMBL1536765 & 688171 & 4.55 & 4.8651 & TRN \\
\hline CHEMBL1476950 & 688171 & 4.6 & 4.9746 & TRN \\
\hline CHEMBL1543572 & 688171 & 4.55 & 4.877 & TRN \\
\hline CHEMBL1468682 & 688171 & 5.4 & 4.9893 & TRN \\
\hline CHEMBL1403436 & 688171 & 5.1 & 4.9219 & TRN \\
\hline CHEMBL465843 & 688171 & 5.0 & 5.0358 & TRN \\
\hline CHEMBL1572853 & 688171 & 4.45 & 4.8944 & TST \\
\hline CHEMBL3189598 & 688171 & 4.7 & 4.8702 & TST \\
\hline CHEMBL1488812 & 688171 & 5.45 & 4.8631 & TST \\
\hline CHEMBL1456204 & 688171 & 5.7 & 4.9629 & TRN \\
\hline CHEMBL1446073 & 688171 & 5.55 & 4.8881 & TRN \\
\hline CHEMBL1394848 & 688171 & 4.4 & 4.9134 & TRN \\
\hline CHEMBL1495184 & 688171 & 4.55 & 4.8159 & TRN \\
\hline CHEMBL1608110 & 688171 & 6.6 & 4.9253 & TST \\
\hline CHEMBL1411089 & 688171 & 4.55 & 4.7935 & TRN \\
\hline CHEMBL1428112 & 688171 & 5.4 & 4.9094 & TRN \\
\hline CHEMBL1352808 & 688171 & 4.75 & 4.8009 & TRN \\
\hline CHEMBL1347832 & 688171 & 4.85 & 4.9093 & TST \\
\hline CHEMBL1521218 & 688171 & 4.4 & 4.9383 & TRN \\
\hline CHEMBL1612455 & 688171 & 4.35 & 4.8868 & TRN \\
\hline CHEMBL1596462 & 688171 & 5.95 & 4.9593 & TRN \\
\hline CHEMBL1553159 & 688171 & 5.15 & 4.8711 & TRN \\
\hline CHEMBL1366112 & 688171 & 4.55 & 4.9537 & TRN \\
\hline CHEMBL1433425 & 688171 & 5.5 & 4.8816 & TRN \\
\hline CHEMBL1353526 & 688171 & 4.6 & 4.6899 & TRN \\
\hline CHEMBL1516658 & 688171 & 6.7001 & 4.8298 & TRN \\
\hline CHEMBL1878966 & 688171 & 5.1 & 4.8297 & TST \\
\hline CHEMBL 3214440 & 688171 & 5.55 & 4.9471 & TST \\
\hline
\end{tabular}




\begin{tabular}{|c|c|c|c|c|c|}
\hline & & \multicolumn{4}{|c|}{ Supplemental Table S2.txt } \\
\hline CHEMBL1332776 & 688171 & 4.35 & 4.8445 & TST & \\
\hline CHEMBL1323187 & 688171 & 5.05 & 4.8984 & TST & \\
\hline CHEMBL1577238 & 688171 & 4.9 & 4.8822 & TST & \\
\hline CHEMBL1256020 & 688171 & 6.9 & 4.9384 & TST & \\
\hline CHEMBL1313721 & 688171 & 4.65 & 4.9701 & TRN & \\
\hline CHEMBL1328774 & 688171 & 4.9 & 4.881 & TRN & \\
\hline CHEMBL1496182 & 688171 & 4.45 & 4.8716 & TRN & \\
\hline CHEMBL2005364 & 688171 & 6.15 & 4.8984 & TRN & \\
\hline CHEMBL1303001 & 688171 & 4.45 & 4.9062 & TRN & \\
\hline CHEMBL1612982 & 688171 & 5.45 & 4.959 & TST & \\
\hline CHEMBL1499310 & 688171 & 4.35 & 5.0143 & TST & \\
\hline CHEMBL1513776 & 688171 & 4.5 & 4.8785 & TRN & \\
\hline CHEMBL1514036 & 688171 & 4.5 & 4.7422 & TRN & \\
\hline CHEMBL1447649 & 688171 & 4.8 & 4.8817 & TRN & \\
\hline CHEMBL1487681 & 688171 & 6.7501 & 4.8316 & TST & \\
\hline CHEMBL 29898 & 688171 & 4.9 & 4.874 & TRN & \\
\hline CHEMBL3193899 & 688171 & 4.9 & 4.8131 & TRN & \\
\hline CHEMBL1389352 & 688171 & 5.1 & 4.92899 & 9999999999 & TST \\
\hline CHEMBL1400425 & 688171 & 5.0 & 4.9128 & TRN & \\
\hline CHEMBL1400458 & 688171 & 4.9 & 4.8113 & TRN & \\
\hline CHEMBL1317081 & 688171 & 4.8 & 4.8749 & TRN & \\
\hline CHEMBL15594 & 688171 & 6.0 & 5.024 & TRN & \\
\hline CHEMBL1332159 & 688171 & 4.85 & 4.8756 & TRN & \\
\hline CHEMBL1419157 & 688171 & 4.85 & 4.907 & TRN & \\
\hline CHEMBL1466399 & 688171 & 4.85 & 4.8505 & TRN & \\
\hline CHEMBL1312638 & 688171 & 4.4 & 4.9359 & TST & \\
\hline CHEMBL1320354 & 688171 & 4.95 & 4.7207 & TRN & \\
\hline CHEMBL1343545 & 688171 & 5.6 & 4.8964 & TRN & \\
\hline CHEMBL1511507 & 688171 & 4.7 & 4.7693 & TRN & \\
\hline CHEMBL1415962 & 688171 & 4.55 & 4.8397 & TRN & \\
\hline CHEMBL1543856 & 688171 & 4.7 & 4.9276 & TRN & \\
\hline CHEMBL1516492 & 688171 & 4.55 & 4.7861 & TRN & \\
\hline CHEMBL1454411 & 688171 & 5.1 & 5.0232 & TST & \\
\hline CHEMBL1470528 & 688171 & 4.95 & 4.9008 & TST & \\
\hline CHEMBL1368555 & 688171 & 4.7 & 4.8975 & TST & \\
\hline CHEMBL1590416 & 688171 & 5.45 & 4.7811 & TRN & \\
\hline CHEMBL1485134 & 688171 & 4.5 & 4.862 & TRN & \\
\hline CHEMBL1494209 & 688171 & 5.75 & 4.8996 & TRN & \\
\hline CHEMBL1528263 & 688171 & 4.45 & 5.0469 & TRN & \\
\hline CHEMBL1369154 & 688171 & 4.65 & 4.7184 & TRN & \\
\hline CHEMBL1414406 & 688171 & 4.7 & 4.8345 & TST & \\
\hline CHEMBL1437029 & 688171 & 5.45 & 4.9784 & TRN & \\
\hline CHEMBL1504602 & 688171 & 4.6 & 4.9128 & TRN & \\
\hline CHEMBL1335287 & 688171 & 5.05 & 4.9745 & TST & \\
\hline CHEMBL1562324 & 688171 & 5.5 & 4.7808 & TRN & \\
\hline CHEMBL1434886 & 688171 & 4.35 & 5.0045 & TRN & \\
\hline CHEMBL1537864 & 688171 & 4.65 & 4.8417 & TRN & \\
\hline CHEMBL1453921 & 688171 & 4.7 & 4.8504 & TRN & \\
\hline
\end{tabular}




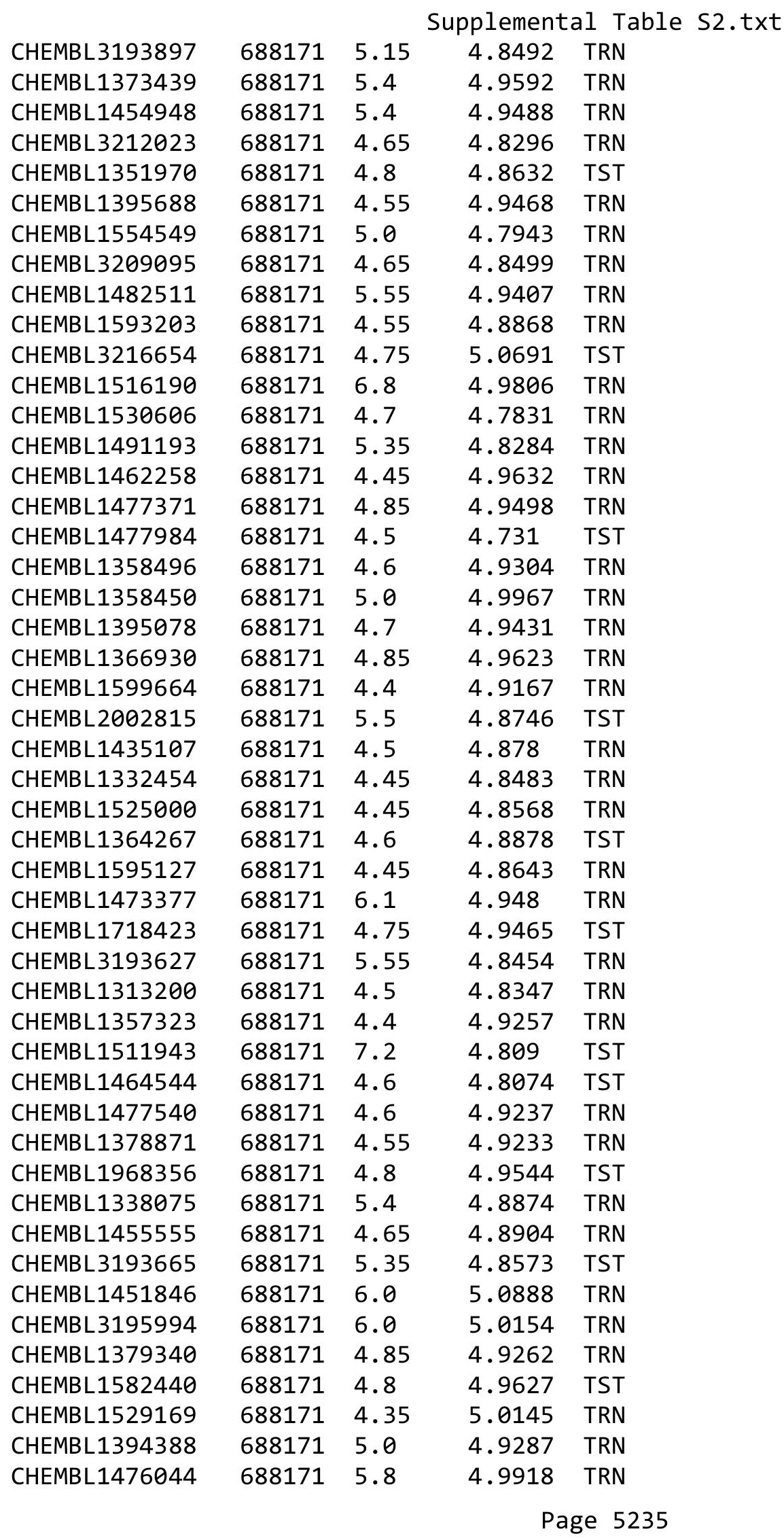




\begin{tabular}{|c|c|c|c|c|c|}
\hline \multirow[b]{2}{*}{ CHEMBL1609013 } & \multicolumn{5}{|c|}{ Supplemental Table S2.txt } \\
\hline & 688171 & 4.85 & 4.9233 & TRN & \\
\hline CHEMBL1330161 & 688171 & 4.55 & 4.751 & TRN & \\
\hline CHEMBL1522349 & 688171 & 4.75 & 4.90300 & 00000000005 & TRN \\
\hline CHEMBL1317375 & 688171 & 4.7 & 4.8081 & TRN & \\
\hline CHEMBL1533328 & 688171 & 5.2 & 4.8605 & TRN & \\
\hline CHEMBL1523598 & 688171 & 5.8 & 5.0896 & TRN & \\
\hline CHEMBL1489818 & 688171 & 5.05 & 4.9992 & TRN & \\
\hline CHEMBL1401426 & 688171 & 4.4 & 4.9714 & TRN & \\
\hline CHEMBL1469594 & 688171 & 5.05 & 4.8447 & TRN & \\
\hline CHEMBL1477414 & 688171 & 4.65 & 4.9639 & TRN & \\
\hline CHEMBL1612159 & 688171 & 4.55 & 4.9769 & TST & \\
\hline CHEMBL314639 & 688171 & 6.0 & 4.9463 & TRN & \\
\hline CHEMBL1525416 & 688171 & 4.35 & 5.0058 & TRN & \\
\hline CHEMBL1393615 & 688171 & 6.15 & 4.9951 & TRN & \\
\hline CHEMBL1471352 & 688171 & 4.45 & 4.9825 & TRN & \\
\hline CHEMBL1589240 & 688171 & 5.8 & 5.0534 & TRN & \\
\hline CHEMBL1444103 & 688171 & 5.3 & 4.867 & TRN & \\
\hline CHEMBL180920 & 688171 & 6.25 & 4.9536 & TST & \\
\hline CHEMBL1408804 & 688171 & 5.0 & 5.0243 & TRN & \\
\hline CHEMBL1362142 & 688171 & 6.05 & 4.9311 & TRN & \\
\hline CHEMBL425065 & 688171 & 4.7 & 4.7186 & TRN & \\
\hline CHEMBL1596452 & 688171 & 4.35 & 4.872 & TRN & \\
\hline CHEMBL1347694 & 688171 & 4.4 & 4.9905 & TST & \\
\hline CHEMBL1481906 & 688171 & 5.35 & 4.9161 & TRN & \\
\hline CHEMBL1978755 & 688171 & 6.3 & 4.9824 & TRN & \\
\hline CHEMBL1310544 & 688171 & 4.4 & 4.9249 & TRN & \\
\hline CHEMBL1599540 & 688171 & 4.85 & 4.8686 & TRN & \\
\hline CHEMBL1554865 & 688171 & 4.85 & 4.9408 & TRN & \\
\hline CHEMBL 3197343 & 688171 & 5.05 & 4.9257 & TST & \\
\hline CHEMBL1455485 & 688171 & 7.0 & 4.9315 & TST & \\
\hline CHEMBL1385355 & 688171 & 4.85 & 4.9017 & TRN & \\
\hline CHEMBL1535538 & 688171 & 5.0 & 4.9921 & TRN & \\
\hline CHEMBL1572376 & 688171 & 6.6499 & 4.9155 & TST & \\
\hline CHEMBL1397004 & 688171 & 6.25 & 4.8717 & TST & \\
\hline CHEMBL1358485 & 688171 & 4.4 & 5.0192 & TST & \\
\hline CHEMBL1589091 & 688171 & 5.4 & 5.044 & TRN & \\
\hline CHEMBL1319124 & 688171 & 4.6 & 4.9748 & TRN & \\
\hline CHEMBL1348617 & 688171 & 5.65 & 4.9771 & TRN & \\
\hline CHEMBL1418465 & 688171 & 4.5 & 4.9378 & TRN & \\
\hline CHEMBL1332566 & 688171 & 4.7 & 4.8751 & TST & \\
\hline CHEMBL1490605 & 688171 & 5.0 & 4.9244 & TRN & \\
\hline CHEMBL1555313 & 688171 & 4.45 & 5.0215 & TRN & \\
\hline CHEMBL1443088 & 688171 & 4.6 & 4.7534 & TRN & \\
\hline CHEMBL1571224 & 688171 & 4.45 & 4.9798 & TST & \\
\hline CHEMBL1578711 & 688171 & 4.7 & 4.9742 & TST & \\
\hline CHEMBL1595405 & 688171 & 5.7 & 4.9131 & TRN & \\
\hline CHEMBL1580920 & 688171 & 4.4 & 4.9893 & TRN & \\
\hline CHEMBL1508720 & 688171 & 5.85 & 4.9211 & TRN & \\
\hline
\end{tabular}




\begin{tabular}{|c|c|c|c|c|c|}
\hline & & \multicolumn{4}{|c|}{ Supplemental Table s2.txt } \\
\hline CHEMBL1313662 & 688171 & 5.75 & 4.954 & TRN & \\
\hline CHEMBL1514288 & 688171 & 5.6 & 4.8801 & TRN & \\
\hline CHEMBL1306583 & 688171 & 4.4 & 4.8919 & TRN & \\
\hline CHEMBL 3198078 & 688171 & 4.5 & 4.9094 & TRN & \\
\hline CHEMBL1413276 & 688171 & 4.4 & 4.9982 & TST & \\
\hline CHEMBL 1459750 & 688171 & 4.35 & 4.9384 & TST & \\
\hline CHEMBL1300834 & 688171 & 4.9 & 4.8082 & TRN & \\
\hline CHEMBL1473897 & 688171 & 4.9 & 4.8676 & TRN & \\
\hline CHEMBL600121 & 688171 & 5.6 & 4.9335 & TST & \\
\hline CHEMBL1531255 & 688171 & 4.9 & 4.7998 & TST & \\
\hline CHEMBL1451035 & 688171 & 5.4 & 5.0234 & TRN & \\
\hline CHEMBL1494637 & 688171 & 4.6 & 5.0025 & TRN & \\
\hline CHEMBL1514470 & 688171 & 4.9 & 4.83899 & 99999999995 & TRN \\
\hline CHEMBL1535252 & 688171 & 4.8 & 4.8134 & TRN & \\
\hline CHEMBL1591695 & 688171 & 5.1 & 4.8832 & TRN & \\
\hline CHEMBL1366448 & 688171 & 5.0 & 4.6525 & TRN & \\
\hline CHEMBL1301734 & 688171 & 4.45 & 4.899 & TRN & \\
\hline CHEMBL1613571 & 688171 & 4.65 & 4.8403 & TST & \\
\hline CHEMBL1528757 & 688171 & 4.9 & 4.8631 & TST & \\
\hline CHEMBL462880 & 688171 & 4.6 & 5.0099 & TRN & \\
\hline CHEMBL1486995 & 688171 & 4.4 & 4.8539 & TRN & \\
\hline CHEMBL1379579 & 688171 & 4.5 & 4.9185 & TRN & \\
\hline CHEMBL1590583 & 688171 & 4.6 & 4.8575 & TRN & \\
\hline CHEMBL193872 & 688171 & 4.4 & 4.9284 & TST & \\
\hline CHEMBL1376239 & 688171 & 5.3 & 4.8663 & TRN & \\
\hline CHEMBL1541177 & 688171 & 4.4 & 4.7671 & TRN & \\
\hline CHEMBL1514074 & 688171 & 4.6 & 5.0446 & TRN & \\
\hline CHEMBL1335863 & 688171 & 4.85 & 4.8165 & TRN & \\
\hline CHEMBL1361358 & 688171 & 4.55 & 4.8491 & TRN & \\
\hline CHEMBL1998648 & 688171 & 4.7 & 4.91100 & 00000000005 & TRN \\
\hline CHEMBL117966 & 688171 & 5.0 & 4.8093 & TRN & \\
\hline CHEMBL1986425 & 688171 & 5.0 & 4.9975 & TST & \\
\hline CHEMBL1410978 & 688171 & 4.8 & 4.7456 & TRN & \\
\hline CHEMBL1996802 & 688171 & 4.5 & 4.9333 & TRN & \\
\hline CHEMBL1455472 & 688171 & 5.75 & 4.9855 & TRN & \\
\hline CHEMBL1331601 & 688171 & 5.95 & 4.8954 & TST & \\
\hline CHEMBL1551956 & 688171 & 4.8 & 4.8867 & TRN & \\
\hline CHEMBL1414218 & 688171 & 4.9 & 5.1227 & TST & \\
\hline CHEMBL1586339 & 688171 & 4.6 & 4.9359 & TRN & \\
\hline CHEMBL1364230 & 688171 & 4.95 & 4.9634 & TST & \\
\hline CHEMBL1588037 & 688171 & 6.5501 & 5.1518 & TST & \\
\hline CHEMBL1530638 & 688171 & 5.0 & 4.9281 & TRN & \\
\hline CHEMBL1475643 & 688171 & 4.95 & 4.8097 & TRN & \\
\hline CHEMBL548399 & 688171 & 4.35 & 4.8318 & TRN & \\
\hline CHEMBL1548858 & 688171 & 5.5 & 5.0976 & TST & \\
\hline CHEMBL1393254 & 688171 & 5.05 & 5.1153 & TRN & \\
\hline CHEMBL1594811 & 688171 & 4.95 & 5.0729 & TST & \\
\hline CHEMBL1300686 & 688171 & 4.6 & 4.9625 & TST & \\
\hline
\end{tabular}




\begin{tabular}{|c|c|c|c|c|c|}
\hline \multicolumn{6}{|c|}{ Supplemental Table S2.txt } \\
\hline CHEMBL1481025 & 688171 & 4.4 & 4.9445 & TRN & \\
\hline CHEMBL1444900 & 688171 & 5.3 & 4.8049 & TRN & \\
\hline CHEMBL586061 & 688171 & 4.85 & 4.7877 & TRN & \\
\hline CHEMBL1321473 & 688171 & 4.65 & 4.8877 & TRN & \\
\hline CHEMBL3190739 & 688171 & 5.1 & 4.8709 & TRN & \\
\hline CHEMBL1548951 & 688171 & 4.75 & 4.8794 & TRN & \\
\hline CHEMBL1556258 & 688171 & 6.0 & 4.9 & TRN & \\
\hline CHEMBL1441415 & 688171 & 4.4 & 4.8394 & TRN & \\
\hline CHEMBL1393567 & 688171 & 4.8 & 4.926 & TRN & \\
\hline CHEMBL1417703 & 688171 & 4.4 & 4.8998 & TRN & \\
\hline CHEMBL1375098 & 688171 & 5.15 & 4.8447 & TST & \\
\hline CHEMBL1329393 & 688171 & 6.0 & 5.0099 & TRN & \\
\hline CHEMBL1404758 & 688171 & 4.65 & 4.8602 & TRN & \\
\hline CHEMBL1432809 & 688171 & 6.5 & 4.7418 & TRN & \\
\hline CHEMBL3189802 & 688171 & 4.4 & 4.988 & TST & \\
\hline CHEMBL1473873 & 688171 & 4.4 & 4.9321 & TST & \\
\hline CHEMBL1449209 & 688171 & 4.6 & 4.9475 & TRN & \\
\hline CHEMBL1589251 & 688171 & 7.3002 & 4.8635 & TST & \\
\hline CHEMBL1502654 & 688171 & 4.5 & 4.9438 & TST & \\
\hline CHEMBL9666 & 688171 & 5.55 & 4.9642 & TRN & \\
\hline CHEMBL1602441 & 688171 & 4.4 & 4.90300 & 00000000005 & TRN \\
\hline CHEMBL1493622 & 688171 & 4.85 & 4.8138 & TRN & \\
\hline CHEMBL1411367 & 688171 & 4.4 & 4.8692 & TST & \\
\hline CHEMBL1422414 & 688171 & 4.8 & 4.8073 & TRN & \\
\hline CHEMBL1300408 & 688171 & 5.05 & 5.0392 & TRN & \\
\hline CHEMBL498373 & 688171 & 4.5 & 4.9449 & TRN & \\
\hline CHEMBL1430548 & 688171 & 5.1 & 4.8787 & TST & \\
\hline CHEMBL1358133 & 688171 & 4.4 & 4.9093 & TRN & \\
\hline CHEMBL1542990 & 688171 & 4.35 & 4.9549 & TRN & \\
\hline CHEMBL1512117 & 688171 & 4.45 & 4.9033 & TST & \\
\hline CHEMBL1321817 & 688171 & 5.6 & 4.9209 & TRN & \\
\hline CHEMBL1524798 & 688171 & 4.6 & 4.9658 & TRN & \\
\hline CHEMBL1397978 & 688171 & 4.5 & 4.8357 & TRN & \\
\hline CHEMBL1613238 & 688171 & 4.95 & 4.9703 & TRN & \\
\hline CHEMBL1513118 & 688171 & 5.45 & 4.9503 & TRN & \\
\hline CHEMBL1398023 & 688171 & 4.6 & 4.8965 & TRN & \\
\hline CHEMBL1524324 & 688171 & 4.6 & 4.8692 & TRN & \\
\hline CHEMBL1609104 & 688171 & 4.4 & 4.925 & TST & \\
\hline CHEMBL1375561 & 688171 & 5.1 & 4.8004 & TRN & \\
\hline CHEMBL1324256 & 688171 & 4.5 & 4.7828 & TRN & \\
\hline CHEMBL1385857 & 688171 & 4.65 & 4.8464 & TRN & \\
\hline CHEMBL1517836 & 688171 & 4.75 & 4.993 & TRN & \\
\hline CHEMBL1343661 & 688171 & 4.5 & 4.8002 & TRN & \\
\hline CHEMBL1488000 & 688171 & 4.65 & 4.84699 & 99999999995 & TRN \\
\hline CHEMBL1533067 & 688171 & 4.8 & 4.8208 & TST & \\
\hline CHEMBL1559596 & 688171 & 4.35 & 4.9792 & TRN & \\
\hline CHEMBL1493987 & 688171 & 5.1 & 4.7655 & TST & \\
\hline CHEMBL1328686 & 688171 & 4.5 & 4.8171 & TST & \\
\hline
\end{tabular}




\begin{tabular}{|c|c|c|c|c|c|}
\hline & & \multicolumn{4}{|c|}{ Supplemental Table s2.txt } \\
\hline CHEMBL1329402 & 688171 & 4.85 & 4.9135 & TRN & \\
\hline CHEMBL1557519 & 688171 & 5.75 & 4.9529 & TST & \\
\hline CHEMBL1555362 & 688171 & 4.5 & 4.8668 & TRN & \\
\hline CHEMBL1518558 & 688171 & 4.55 & 4.8714 & TRN & \\
\hline CHEMBL1964614 & 688171 & 4.6 & 4.9004 & TRN & \\
\hline CHEMBL3191026 & 688171 & 4.35 & 4.9262 & TRN & \\
\hline CHEMBL 3208658 & 688171 & 4.7 & 4.8861 & TRN & \\
\hline CHEMBL1512812 & 688171 & 4.5 & 5.0274 & TRN & \\
\hline CHEMBL1329878 & 688171 & 5.45 & 4.8491 & TST & \\
\hline CHEMBL1362718 & 688171 & 4.4 & 4.9444 & TRN & \\
\hline CHEMBL1327794 & 688171 & 4.8 & 4.8058 & TRN & \\
\hline CHEMBL1236872 & 688171 & 4.6 & 4.9541 & TRN & \\
\hline CHEMBL1339149 & 688171 & 5.35 & 4.8037 & TRN & \\
\hline CHEMBL1612841 & 688171 & 6.95 & 4.9453 & TRN & \\
\hline CHEMBL1390756 & 688171 & 4.55 & 4.8615 & TRN & \\
\hline CHEMBL3208916 & 688171 & 5.4 & 4.849 & TRN & \\
\hline CHEMBL1399486 & 688171 & 4.55 & 4.79 & TRN & \\
\hline CHEMBL1592254 & 688171 & 4.5 & 4.8547 & TRN & \\
\hline CHEMBL1516601 & 688171 & 4.55 & 4.9754 & TRN & \\
\hline CHEMBL1548327 & 688171 & 4.9 & 4.92399 & 99999999995 & TST \\
\hline CHEMBL1604143 & 688171 & 4.75 & 5.0139 & TST & \\
\hline CHEMBL1612277 & 688171 & 4.55 & 4.8548 & TRN & \\
\hline CHEMBL3212694 & 688171 & 4.4 & 4.8197 & TST & \\
\hline CHEMBL1446452 & 688171 & 4.7 & 4.9076 & TRN & \\
\hline CHEMBL1376213 & 688171 & 5.0 & 4.8855 & TRN & \\
\hline CHEMBL1363237 & 688171 & 4.95 & 4.8934 & TRN & \\
\hline CHEMBL1964407 & 688171 & 5.35 & 4.9642 & TST & \\
\hline CHEMBL3198716 & 688171 & 4.5 & 4.8145 & TRN & \\
\hline CHEMBL1556467 & 688171 & 5.1 & 4.9445 & TST & \\
\hline CHEMBL1553932 & 688171 & 4.85 & 4.7973 & TRN & \\
\hline CHEMBL1548514 & 688171 & 4.55 & 4.8058 & TRN & \\
\hline CHEMBL1305532 & 688171 & 6.95 & 5.0089 & TST & \\
\hline CHEMBL1789996 & 688171 & 4.4 & 4.9291 & TST & \\
\hline CHEMBL1387746 & 688171 & 4.35 & 4.8651 & TRN & \\
\hline CHEMBL1430337 & 688171 & 4.85 & 4.9695 & TRN & \\
\hline CHEMBL1076555 & 688171 & 5.7 & 4.774 & TRN & \\
\hline CHEMBL1433141 & 688171 & 4.4 & 4.815 & TRN & \\
\hline CHEMBL1470908 & 688171 & 5.3 & 5.001 & TRN & \\
\hline CHEMBL1337735 & 688171 & 4.65 & 4.9791 & TST & \\
\hline CHEMBL1611639 & 688171 & 4.75 & 4.877 & TRN & \\
\hline CHEMBL1445183 & 688171 & 5.15 & 4.9613 & TST & \\
\hline CHEMBL1364055 & 688171 & 4.75 & 4.7949 & TST & \\
\hline CHEMBL1975853 & 688171 & 7.15 & 5.0623 & TRN & \\
\hline CHEMBL1375588 & 688171 & 4.5 & 4.7813 & TRN & \\
\hline CHEMBL1434408 & 688171 & 4.95 & 4.9632 & TRN & \\
\hline CHEMBL1495874 & 688171 & 6.15 & 4.8795 & TRN & \\
\hline CHEMBL1604938 & 688171 & 4.9 & 4.9923 & TRN & \\
\hline CHEMBL1506864 & 688171 & 4.4 & 4.7802 & TRN & \\
\hline
\end{tabular}




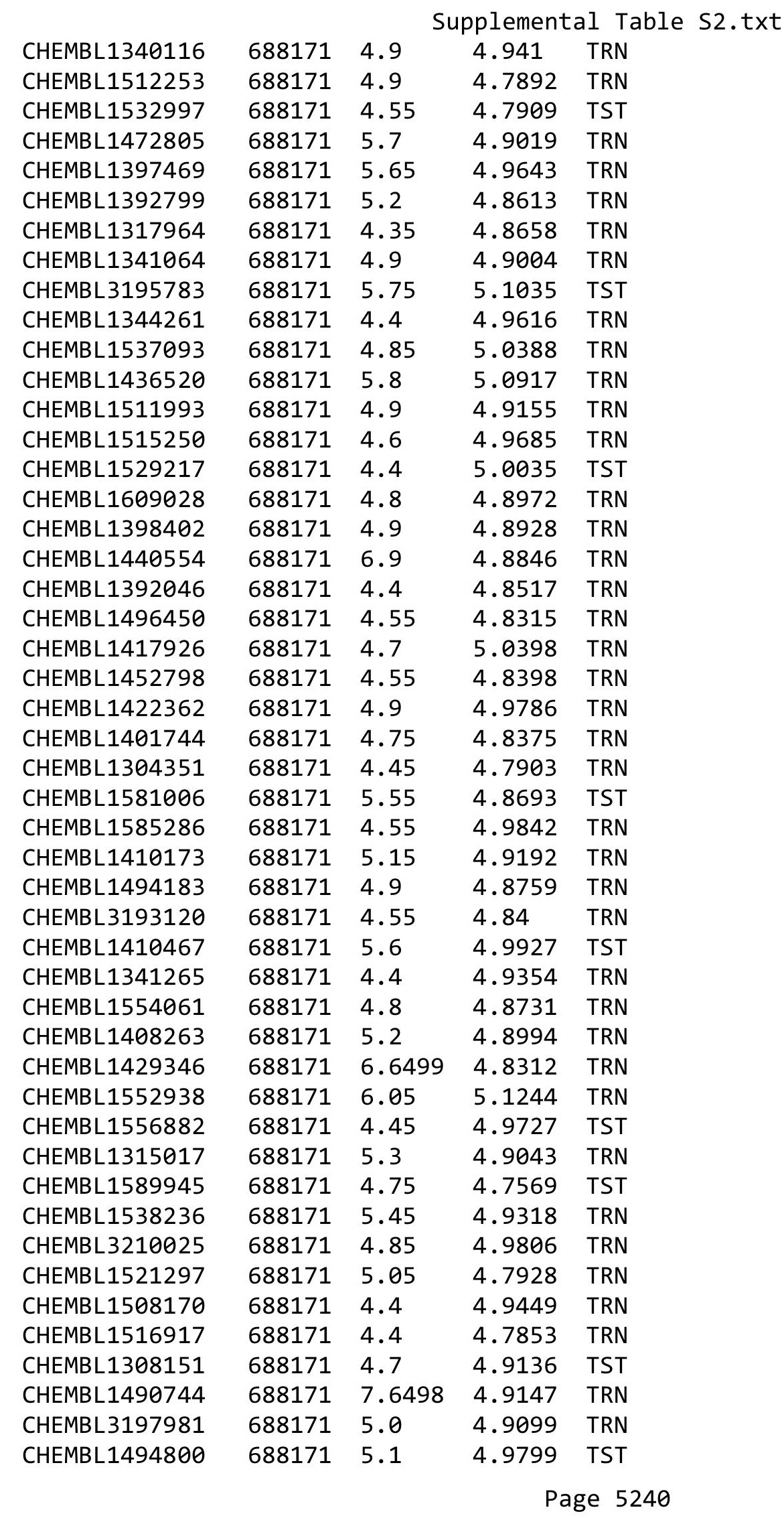




\begin{tabular}{|c|c|c|c|c|c|}
\hline \multicolumn{6}{|c|}{ Supplemental Table S2.txt } \\
\hline CHEMBL131199 & 688171 & 4.6 & 4.8471 & TST & \\
\hline CHEMBL1556975 & 688171 & 4.35 & 4.8296 & TST & \\
\hline CHEMBL1582549 & 688171 & 5.15 & 4.8684 & TRN & \\
\hline CHEMBL278295 & 688171 & 4.4 & 4.8618 & TRN & \\
\hline CHEMBL1609099 & 688171 & 4.95 & 4.8986 & TRN & \\
\hline CHEMBL1468866 & 688171 & 4.4 & 4.8234 & TRN & \\
\hline CHEMBL1304359 & 688171 & 4.55 & 4.8736 & TRN & \\
\hline CHEMBL1973886 & 688171 & 5.5 & 4.8859 & TST & \\
\hline CHEMBL1313761 & 688171 & 4.55 & 4.831 & TST & \\
\hline CHEMBL 1485246 & 688171 & 4.6 & 4.8256 & TRN & \\
\hline CHEMBL1444228 & 688171 & 6.05 & 5.0562 & TRN & \\
\hline CHEMBL3191344 & 688171 & 4.45 & 4.98600 & 0000000001 & TRN \\
\hline CHEMBL1531633 & 688171 & 4.4 & 4.8954 & TRN & \\
\hline CHEMBL1345709 & 688171 & 4.55 & 4.8899 & TRN & \\
\hline CHEMBL1363987 & 688171 & 4.9 & 4.7692 & TST & \\
\hline CHEMBL1595988 & 688171 & 4.35 & 4.9293 & TST & \\
\hline CHEMBL1537801 & 688171 & 4.7 & 4.8974 & TST & \\
\hline CHEMBL1604516 & 688171 & 4.35 & 4.8599 & TST & \\
\hline CHEMBL1566485 & 688171 & 4.4 & 4.9564 & TRN & \\
\hline CHEMBL1992880 & 688171 & 4.95 & 4.7556 & TRN & \\
\hline CHEMBL1437378 & 688171 & 6.45 & 4.9652 & TRN & \\
\hline CHEMBL1373941 & 688171 & 4.55 & 5.0388 & TRN & \\
\hline CHEMBL486193 & 688171 & 4.9 & 4.9885 & TRN & \\
\hline CHEMBL1450872 & 688171 & 4.6 & 4.6999 & TRN & \\
\hline CHEMBL1596415 & 688171 & 4.5 & 4.9913 & TRN & \\
\hline CHEMBL1608789 & 688171 & 4.45 & 4.9197 & TST & \\
\hline CHEMBL1569964 & 688171 & 5.05 & 4.8738 & TST & \\
\hline CHEMBL1546205 & 688171 & 4.4 & 4.7592 & TST & \\
\hline CHEMBL1533065 & 688171 & 5.0 & 4.9616 & TRN & \\
\hline CHEMBL1517304 & 688171 & 4.55 & 4.8454 & TRN & \\
\hline CHEMBL1582210 & 688171 & 4.4 & 4.9623 & TRN & \\
\hline CHEMBL1602311 & 688171 & 7.3497 & 4.9584 & TRN & \\
\hline CHEMBL1324266 & 688171 & 5.55 & 4.8437 & TRN & \\
\hline CHEMBL1596031 & 688171 & 4.45 & 4.9486 & TRN & \\
\hline CHEMBL1327584 & 688171 & 5.5 & 4.7857 & TRN & \\
\hline CHEMBL1391110 & 688171 & 4.4 & 5.0674 & TRN & \\
\hline CHEMBL 1512272 & 688171 & 5.4 & 4.9968 & TRN & \\
\hline CHEMBL1540102 & 688171 & 5.1 & 5.0176 & TST & \\
\hline CHEMBL1595230 & 688171 & 4.65 & 4.9446 & TST & \\
\hline CHEMBL1561935 & 688171 & 4.7 & 4.8659 & TRN & \\
\hline CHEMBL119870 & 688171 & 4.35 & 4.8618 & TRN & \\
\hline CHEMBL1333698 & 688171 & 4.6 & 4.9003 & TST & \\
\hline CHEMBL1545803 & 688171 & 4.35 & 4.9207 & TRN & \\
\hline CHEMBL1484180 & 688171 & 4.6 & 4.8901 & TST & \\
\hline CHEMBL1590057 & 688171 & 7.6003 & 4.9086 & TRN & \\
\hline CHEMBL1485388 & 688171 & 5.1 & 4.8867 & TRN & \\
\hline CHEMBL1561982 & 688171 & 4.45 & 4.9397 & TRN & \\
\hline CHEMBL3194054 & 688171 & 4.5 & 5.0235 & TRN & \\
\hline
\end{tabular}




\begin{tabular}{|c|c|c|c|c|c|}
\hline \multicolumn{6}{|c|}{ Supplemental Table s2.txt } \\
\hline CHEMBL1525897 & 688171 & 4.4 & 4.7398 & TRN & \\
\hline CHEMBL1335461 & 688171 & 5.05 & 4.7593 & TST & \\
\hline CHEMBL596633 & 688171 & 5.3 & 4.9426 & TRN & \\
\hline CHEMBL1606752 & 688171 & 4.75 & 4.8222 & TRN & \\
\hline CHEMBL1515021 & 688171 & 4.75 & 4.9845 & TRN & \\
\hline CHEMBL1488106 & 688171 & 4.95 & 4.832 & TST & \\
\hline CHEMBL1421436 & 688171 & 4.35 & 4.7982 & TST & \\
\hline CHEMBL1611326 & 688171 & 4.45 & \multicolumn{2}{|c|}{4.9030000000000005} & TRN \\
\hline CHEMBL1526878 & 688171 & 4.5 & 4.8405 & TRN & \\
\hline CHEMBL1416670 & 688171 & 5.5 & 5.0429 & TRN & \\
\hline CHEMBL1487332 & 688171 & 5.45 & 4.9471 & TRN & \\
\hline CHEMBL1384728 & 688171 & 5.0 & 4.9492 & TRN & \\
\hline CHEMBL1352170 & 688171 & 4.6 & 4.7964 & TRN & \\
\hline CHEMBL1588753 & 688171 & 4.95 & 4.905 & TRN & \\
\hline CHEMBL 222840 & 688171 & 4.35 & 4.8988 & TST & \\
\hline CHEMBL1576749 & 688171 & 4.4 & 4.7086 & TRN & \\
\hline CHEMBL1422405 & 688171 & 5.75 & 4.8401 & TRN & \\
\hline CHEMBL1993627 & 688171 & 5.05 & 4.9405 & TRN & \\
\hline CHEMBL3192542 & 688171 & 4.75 & 4.8325 & TST & \\
\hline CHEMBL1444275 & 688171 & 4.45 & 5.0055 & TRN & \\
\hline CHEMBL1434997 & 688171 & 4.6 & 4.8258 & TRN & \\
\hline CHEMBL1437110 & 688171 & 4.95 & 5.0775 & TRN & \\
\hline CHEMBL1466046 & 688171 & 4.45 & 4.9374 & TRN & \\
\hline CHEMBL1354855 & 688171 & 4.45 & 4.9568 & TRN & \\
\hline CHEMBL1316478 & 688171 & 4.4 & 4.8716 & TRN & \\
\hline CHEMBL1505543 & 688171 & 5.65 & 5.0088 & TST & \\
\hline CHEMBL1302906 & 688171 & 4.4 & 4.9589 & TRN & \\
\hline CHEMBL1587842 & 688171 & 5.05 & 4.8352 & TRN & \\
\hline CHEMBL1314959 & 688171 & 5.6 & 5.0084 & TRN & \\
\hline CHEMBL1479667 & 688171 & 4.9 & 4.9455 & TRN & \\
\hline CHEMBL1499662 & 688171 & 5.1 & 4.7519 & TST & \\
\hline CHEMBL1345701 & 688171 & 4.5 & 4.9442 & TRN & \\
\hline CHEMBL3208402 & 688171 & 5.2 & 5.0844 & TRN & \\
\hline CHEMBL1413680 & 688171 & 4.8 & \multicolumn{2}{|c|}{4.821000000000001} & TST \\
\hline CHEMBL1400165 & 688171 & 5.1 & 4.8759 & TST & \\
\hline CHEMBL1378316 & 688171 & 4.55 & 4.8677 & TST & \\
\hline CHEMBL1569241 & 688171 & 4.4 & 4.683 & TRN & \\
\hline CHEMBL1313495 & 688171 & 4.65 & 4.8493 & TRN & \\
\hline CHEMBL1495650 & 688171 & 4.35 & 4.8853 & TRN & \\
\hline CHEMBL1319631 & 688171 & 4.4 & 4.882 & TRN & \\
\hline CHEMBL1574671 & 688171 & 4.55 & 4.8923 & TST & \\
\hline CHEMBL1492963 & 688171 & 4.35 & 4.9979 & TRN & \\
\hline CHEMBL1604775 & 688171 & 4.35 & 4.9521 & TRN & \\
\hline CHEMBL1568769 & 688171 & 6.25 & 4.8576 & TST & \\
\hline CHEMBL2373596 & 688171 & 6.0 & 4.9541 & TRN & \\
\hline CHEMBL 365423 & 688171 & 5.1 & 4.9435 & TST & \\
\hline CHEMBL1554576 & 688171 & 4.9 & 4.9661 & TRN & \\
\hline CHEMBL1428629 & 688171 & 5.45 & 4.8447 & TRN & \\
\hline
\end{tabular}




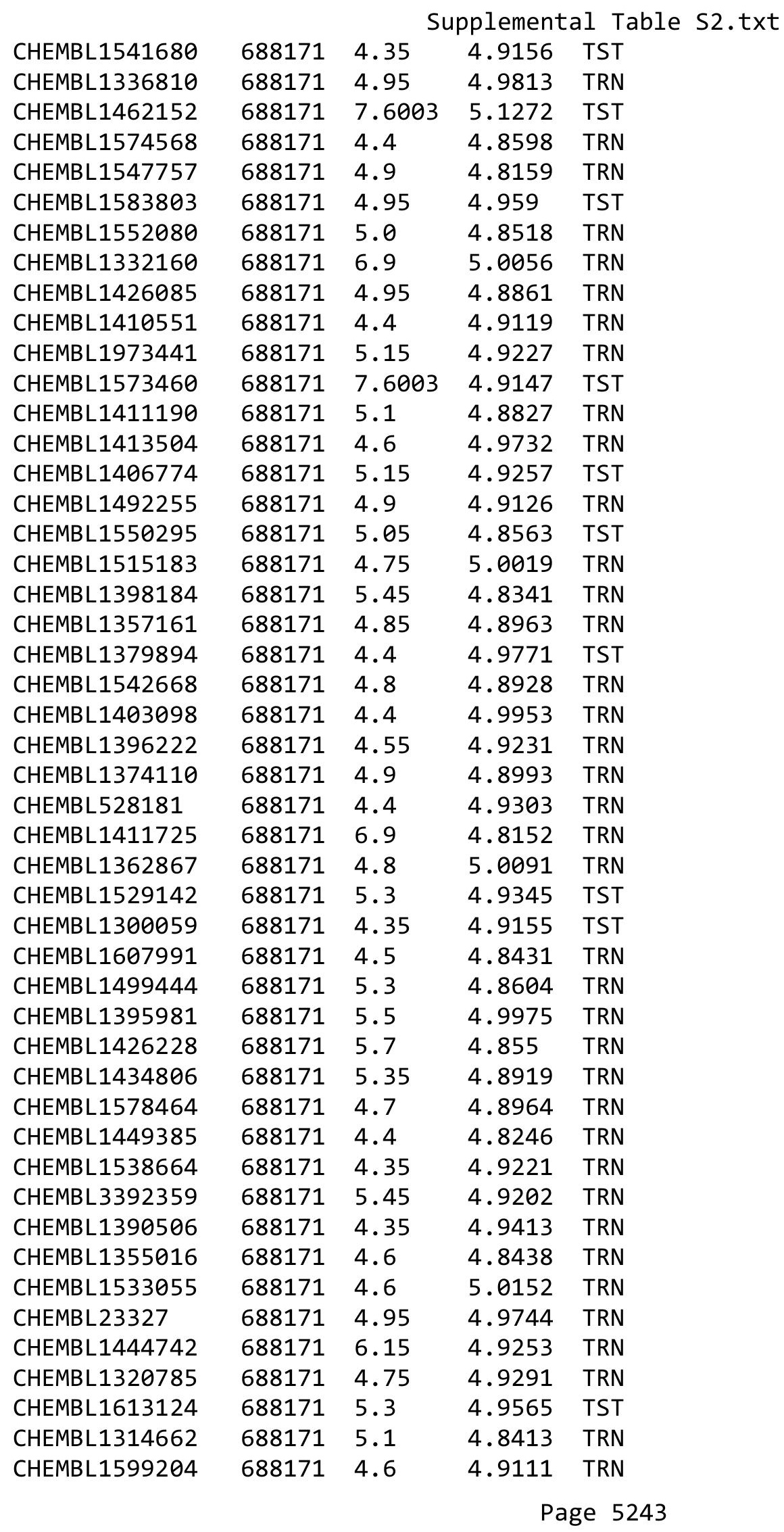




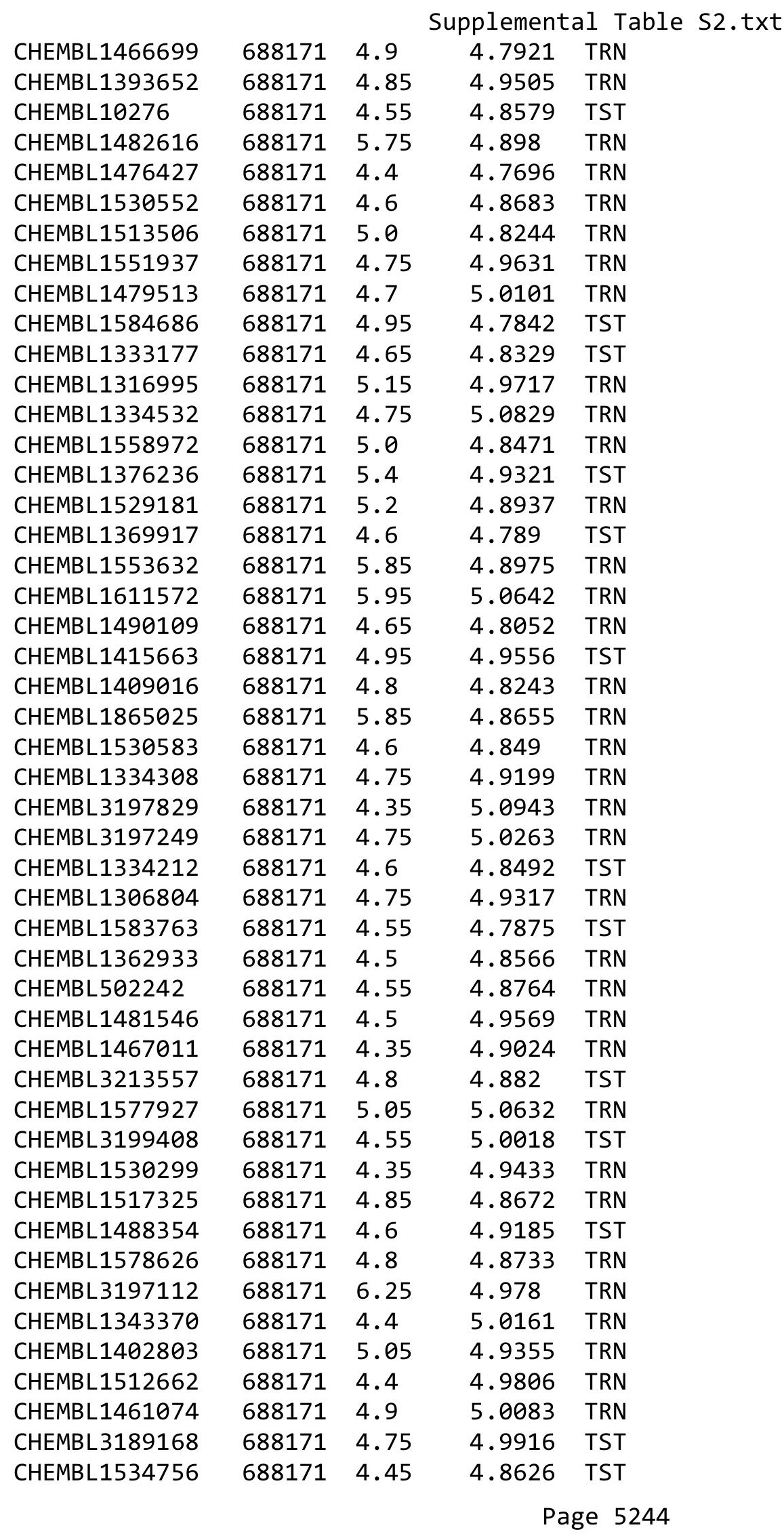




\begin{tabular}{|c|c|c|c|c|}
\hline \multicolumn{5}{|c|}{ Supplemental Table S2.txt } \\
\hline CHEMBL1425890 & 688171 & 4.4 & 4.8671 & TRN \\
\hline CHEMBL1348374 & 688171 & 4.7 & 4.9774 & TRN \\
\hline CHEMBL1556968 & 688171 & 4.35 & 4.8236 & TRN \\
\hline CHEMBL1528248 & 688171 & 5.1 & 4.9963 & TRN \\
\hline CHEMBL1515757 & 688171 & 4.4 & 4.9106 & TRN \\
\hline CHEMBL1389389 & 688171 & 5.4 & 4.9411 & TRN \\
\hline CHEMBL1379404 & 688171 & 5.05 & 5.0282 & TST \\
\hline CHEMBL79793 & 688171 & 5.55 & 4.9414 & TRN \\
\hline CHEMBL1470008 & 688171 & 5.5 & 4.9212 & TRN \\
\hline CHEMBL1555495 & 688171 & 4.7 & 4.8381 & TRN \\
\hline CHEMBL 3144987 & 688171 & 4.4 & 4.8375 & TRN \\
\hline CHEMBL1597293 & 688171 & 6.5 & 4.9799 & TRN \\
\hline CHEMBL1491801 & 688171 & 5.05 & 4.8782 & TRN \\
\hline CHEMBL1525659 & 688171 & 4.35 & 4.8962 & TRN \\
\hline CHEMBL1401802 & 688171 & 4.75 & 4.8337 & TST \\
\hline CHEMBL454761 & 688171 & 4.6 & 4.8944 & TST \\
\hline CHEMBL1493204 & 688171 & 4.35 & 4.7978 & TRN \\
\hline CHEMBL1598101 & 688171 & 4.75 & 4.8559 & TRN \\
\hline CHEMBL1400287 & 688171 & 6.2 & 4.8613 & TRN \\
\hline CHEMBL1524484 & 688171 & 4.8 & 4.9232 & TST \\
\hline CHEMBL1468721 & 688171 & 4.5 & 4.7683 & TST \\
\hline CHEMBL1482020 & 688171 & 4.55 & 4.7587 & TRN \\
\hline CHEMBL1334315 & 688171 & 5.1 & 4.8071 & TRN \\
\hline CHEMBL1340442 & 688171 & 4.6 & 4.9882 & TRN \\
\hline CHEMBL1427433 & 688171 & 4.45 & 4.8083 & TRN \\
\hline CHEMBL1545560 & 688171 & 4.85 & 4.9411 & TRN \\
\hline CHEMBL1364154 & 688171 & 4.7 & 4.9517 & TRN \\
\hline CHEMBL1981797 & 688171 & 5.0 & 4.8902 & TRN \\
\hline CHEMBL1556256 & 688171 & 5.05 & 4.8586 & TRN \\
\hline CHEMBL1351715 & 688171 & 4.7 & 4.9925 & TRN \\
\hline CHEMBL1452835 & 688171 & 5.15 & 4.85 & TRN \\
\hline CHEMBL1530883 & 688171 & 5.0 & 4.8743 & TRN \\
\hline CHEMBL1460675 & 688171 & 5.05 & 5.0343 & TST \\
\hline CHEMBL1585484 & 688171 & 4.65 & 4.9427 & TRN \\
\hline CHEMBL1544703 & 688171 & 4.85 & 4.8532 & TRN \\
\hline CHEMBL1316605 & 688171 & 4.85 & 4.9945 & TRN \\
\hline CHEMBL1303188 & 688171 & 4.4 & 4.8671 & TRN \\
\hline CHEMBL1345140 & 688171 & 4.85 & 4.9351 & TRN \\
\hline CHEMBL1301692 & 688171 & 4.85 & 4.8806 & TST \\
\hline CHEMBL1573361 & 688171 & 4.6 & 4.8714 & TRN \\
\hline CHEMBL1434357 & 688171 & 4.7 & 4.9235 & TRN \\
\hline CHEMBL141110 & 688171 & 4.7 & 4.8386 & TRN \\
\hline CHEMBL3196335 & 688171 & 4.75 & 4.8303 & TRN \\
\hline CHEMBL1471698 & 688171 & 4.7 & 4.9225 & TST \\
\hline CHEMBL1571034 & 688171 & 4.95 & 4.9396 & TRN \\
\hline CHEMBL1528209 & 688171 & 4.65 & 4.9044 & TRN \\
\hline CHEMBL1486894 & 688171 & 4.4 & 4.8738 & TST \\
\hline CHEMBL3207773 & 688171 & 4.6 & 5.0113 & TRN \\
\hline
\end{tabular}




\begin{tabular}{|c|c|c|c|c|}
\hline \multicolumn{5}{|c|}{ Supplemental Table S2.txt } \\
\hline CHEMBL1423158 & 688171 & 4.7 & 4.8657 & TST \\
\hline CHEMBL1492011 & 688171 & 5.55 & 5.0192 & TRN \\
\hline CHEMBL1502151 & 688171 & 4.4 & 5.0064 & TRN \\
\hline CHEMBL1611863 & 688171 & 4.95 & 4.7662 & TRN \\
\hline CHEMBL1533810 & 688171 & 4.55 & 4.7662 & TRN \\
\hline CHEMBL1968220 & 688171 & 4.85 & 4.9311 & TRN \\
\hline CHEMBL1589248 & 688171 & 4.5 & 4.8481 & TRN \\
\hline CHEMBL1421164 & 688171 & 5.3 & 4.9166 & TRN \\
\hline CHEMBL297548 & 688171 & 4.4 & 4.9006 & TRN \\
\hline CHEMBL1463156 & 688171 & 4.35 & 4.9491 & TST \\
\hline CHEMBL1404887 & 688171 & 4.6 & 4.8559 & TRN \\
\hline CHEMBL1549607 & 688171 & 4.8 & 4.6766 & TRN \\
\hline CHEMBL1548628 & 688171 & 4.6 & 5.0415 & TRN \\
\hline CHEMBL1434315 & 688171 & 4.6 & 4.8343 & TRN \\
\hline CHEMBL1591649 & 688171 & 4.35 & 5.0583 & TRN \\
\hline CHEMBL1517804 & 688171 & 5.05 & 4.9569 & TRN \\
\hline CHEMBL1507701 & 688171 & 4.4 & 4.9462 & TRN \\
\hline CHEMBL1363477 & 688171 & 4.9 & 5.0153 & TRN \\
\hline CHEMBL1404330 & 688171 & 4.75 & 4.9935 & TRN \\
\hline CHEMBL 3145293 & 688171 & 5.0 & 4.7336 & TRN \\
\hline CHEMBL1525860 & 688171 & 4.65 & 4.9371 & TST \\
\hline CHEMBL1475342 & 688171 & 5.9 & 4.9294 & TRN \\
\hline CHEMBL1330665 & 688171 & 4.8 & 4.8879 & TRN \\
\hline CHEMBL1573910 & 688171 & 4.7 & 5.0223 & TST \\
\hline CHEMBL1437394 & 688171 & 5.7 & 4.8398 & TRN \\
\hline CHEMBL1390827 & 688171 & 5.4 & 4.9675 & TRN \\
\hline CHEMBL1452716 & 688171 & 4.4 & 5.0273 & TST \\
\hline CHEMBL1471649 & 688171 & 4.95 & 5.0522 & TST \\
\hline CHEMBL63354 & 688171 & 4.4 & 4.8643 & TRN \\
\hline CHEMBL3190325 & 688171 & 5.0 & 4.9584 & TST \\
\hline CHEMBL1325880 & 688171 & 4.55 & 4.8316 & TRN \\
\hline CHEMBL3207423 & 688171 & 5.15 & 4.9784 & TST \\
\hline CHEMBL1326336 & 688171 & 4.65 & 4.8487 & TRN \\
\hline CHEMBL1590665 & 688171 & 4.6 & 4.7406 & TRN \\
\hline CHEMBL1344296 & 688171 & 4.4 & 4.9262 & TRN \\
\hline CHEMBL1593872 & 688171 & 6.0 & 4.9435 & TRN \\
\hline CHEMBL1440756 & 688171 & 4.75 & 4.9381 & TST \\
\hline CHEMBL1428969 & 688171 & 4.7 & 5.1617 & TRN \\
\hline CHEMBL1330109 & 688171 & 4.65 & 4.8257 & TRN \\
\hline CHEMBL1370077 & 688171 & 4.9 & 5.0022 & TRN \\
\hline CHEMBL1482664 & 688171 & 4.95 & 4.7613 & TRN \\
\hline CHEMBL1435995 & 688171 & 4.4 & 4.9072 & TRN \\
\hline CHEMBL1335123 & 688171 & 4.8 & 4.9002 & TRN \\
\hline CHEMBL1525989 & 688171 & 6.0 & 4.94600 & 0000000001 \\
\hline CHEMBL1601025 & 688171 & 4.65 & 4.9427 & TRN \\
\hline CHEMBL1542575 & 688171 & 4.6 & 4.9148 & TST \\
\hline CHEMBL1426649 & 688171 & 4.5 & 4.8105 & TST \\
\hline CHEMBL1370606 & 688171 & 6.6499 & 4.8268 & TST \\
\hline
\end{tabular}




\begin{tabular}{|c|c|c|c|c|c|}
\hline \multicolumn{6}{|c|}{ Supplemental Table S2.txt } \\
\hline CHEMBL1450640 & 688171 & 4.65 & 4.7519 & TRN & \\
\hline CHEMBL1555219 & 688171 & 4.8 & 4.7649 & TRN & \\
\hline CHEMBL492610 & 688171 & 5.6 & 4.9681 & TRN & \\
\hline CHEMBL1385164 & 688171 & 5.75 & 4.8086 & TRN & \\
\hline CHEMBL338479 & 688171 & 4.35 & 4.9117 & TRN & \\
\hline CHEMBL1324033 & 688171 & 4.75 & 4.9443 & TRN & \\
\hline CHEMBL2000888 & 688171 & 4.4 & 4.8685 & TST & \\
\hline CHEMBL1362690 & 688171 & 5.65 & 5.0056 & TST & \\
\hline CHEMBL1562875 & 688171 & 4.4 & 4.9275 & TST & \\
\hline CHEMBL3192108 & 688171 & 5.4 & 4.9623 & TRN & \\
\hline CHEMBL1314562 & 688171 & 5.3 & 4.8855 & TRN & \\
\hline CHEMBL1402525 & 688171 & 4.4 & 4.76399 & 9999999999 & TRN \\
\hline CHEMBL1585886 & 688171 & 4.6 & 4.8845 & TRN & \\
\hline CHEMBL1315595 & 688171 & 5.5 & 4.935 & TRN & \\
\hline CHEMBL1582246 & 688171 & 4.5 & 4.917 & TRN & \\
\hline CHEMBL1355931 & 688171 & 4.7 & 4.8119 & TRN & \\
\hline CHEMBL1322872 & 688171 & 4.35 & 4.9687 & TRN & \\
\hline CHEMBL1370430 & 688171 & 4.75 & 4.9425 & TRN & \\
\hline CHEMBL1606409 & 688171 & 4.4 & 4.9432 & TRN & \\
\hline CHEMBL1440116 & 688171 & 5.1 & 4.8675 & TST & \\
\hline CHEMBL1334541 & 688171 & 4.45 & 5.0399 & TRN & \\
\hline CHEMBL1524690 & 688171 & 5.05 & 5.0504 & TRN & \\
\hline CHEMBL1573548 & 688171 & 5.0 & 4.9914 & TST & \\
\hline CHEMBL3196225 & 688171 & 6.1 & 4.907 & TRN & \\
\hline CHEMBL1403248 & 688171 & 4.6 & 4.9464 & TRN & \\
\hline CHEMBL1366942 & 688171 & 4.4 & 4.9689 & TST & \\
\hline CHEMBL3211148 & 688171 & 4.8 & 5.0161 & TST & \\
\hline CHEMBL1583802 & 688171 & 4.9 & 4.9987 & TRN & \\
\hline CHEMBL1399275 & 688171 & 4.65 & 4.94600 & 0000000001 & TRN \\
\hline CHEMBL1404188 & 688171 & 4.5 & 5.138 & TRN & \\
\hline CHEMBL1567104 & 688171 & 4.6 & 4.8908 & TRN & \\
\hline CHEMBL1476248 & 688171 & 4.5 & 4.881 & TRN & \\
\hline CHEMBL1578717 & 688171 & 4.35 & 4.7864 & TRN & \\
\hline CHEMBL1362651 & 688171 & 4.55 & 4.9286 & TRN & \\
\hline CHEMBL1531454 & 688171 & 4.75 & 4.7627 & TRN & \\
\hline CHEMBL1422448 & 688171 & 4.35 & 4.8823 & TRN & \\
\hline CHEMBL1518175 & 688171 & 4.5 & 4.9365 & TRN & \\
\hline CHEMBL1603117 & 688171 & 4.5 & 4.956 & TRN & \\
\hline CHEMBL1576812 & 688171 & 5.05 & 4.9861 & TST & \\
\hline CHEMBL1343720 & 688171 & 4.95 & 4.8876 & TRN & \\
\hline CHEMBL1483579 & 688171 & 5.65 & 4.8282 & TRN & \\
\hline CHEMBL1611765 & 688171 & 4.8 & 4.7642 & TRN & \\
\hline CHEMBL1490061 & 688171 & 5.1 & 4.977 & TST & \\
\hline CHEMBL1443180 & 688171 & 4.6 & 4.8121 & TRN & \\
\hline CHEMBL1556956 & 688171 & 4.55 & 4.71899 & 9999999999 & TRN \\
\hline CHEMBL1552527 & 688171 & 4.45 & 4.9025 & TRN & \\
\hline CHEMBL1316632 & 688171 & 6.05 & 4.9169 & TRN & \\
\hline CHEMBL1339487 & 688171 & 4.5 & 4.9127 & TRN & \\
\hline
\end{tabular}




\begin{tabular}{|c|c|c|c|c|}
\hline \multicolumn{5}{|c|}{ Supplemental Table S2.txt } \\
\hline CHEMBL1502185 & 688171 & 4.8 & 4.8721 & TRN \\
\hline CHEMBL1567755 & 688171 & 4.7 & 4.6946 & TRN \\
\hline CHEMBL1441313 & 688171 & 4.85 & 5.0193 & TRN \\
\hline CHEMBL 3145314 & 688171 & 4.7 & 4.8401 & TST \\
\hline CHEMBL1382534 & 688171 & 4.9 & 4.8755 & TRN \\
\hline CHEMBL 3212677 & 688171 & 4.35 & 4.8924 & TST \\
\hline CHEMBL1417543 & 688171 & 4.55 & 4.9244 & TST \\
\hline CHEMBL1452367 & 688171 & 4.9 & 5.0063 & TRN \\
\hline CHEMBL1313887 & 688171 & 5.05 & 4.8293 & TRN \\
\hline CHEMBL1567225 & 688171 & 4.4 & 4.9346 & TRN \\
\hline CHEMBL1544825 & 688171 & 5.4 & 5.063 & TST \\
\hline CHEMBL1572603 & 688171 & 4.65 & 4.8798 & TRN \\
\hline CHEMBL1475549 & 688171 & 5.05 & 4.8579 & TRN \\
\hline CHEMBL1303212 & 688171 & 4.75 & 4.9155 & TST \\
\hline CHEMBL1424655 & 688171 & 4.6 & 4.7232 & TRN \\
\hline CHEMBL1506698 & 688171 & 4.4 & 4.8146 & TRN \\
\hline CHEMBL1477526 & 688171 & 4.9 & 4.8714 & TRN \\
\hline CHEMBL1487897 & 688171 & 4.75 & 4.8682 & TRN \\
\hline CHEMBL1562758 & 688171 & 4.75 & 4.7561 & TRN \\
\hline CHEMBL1411426 & 688171 & 4.6 & 5.0799 & TRN \\
\hline CHEMBL1482831 & 688171 & 5.3 & 4.9283 & TST \\
\hline CHEMBL1553516 & 688171 & 4.55 & 5.0438 & TRN \\
\hline CHEMBL1482740 & 688171 & 4.9 & 4.9476 & TRN \\
\hline CHEMBL1975419 & 688171 & 4.45 & 4.8525 & TRN \\
\hline CHEMBL1394146 & 688171 & 5.15 & 4.8883 & TRN \\
\hline CHEMBL1553572 & 688171 & 4.4 & 4.8953 & TRN \\
\hline CHEMBL1363658 & 688171 & 4.4 & 4.7068 & TRN \\
\hline CHEMBL1406276 & 688171 & 5.0 & 4.9544 & TRN \\
\hline CHEMBL1496343 & 688171 & 5.0 & 4.9061 & TRN \\
\hline CHEMBL1301218 & 688171 & 4.9 & 4.9455 & TRN \\
\hline CHEMBL1418302 & 688171 & 5.05 & 4.8588 & TRN \\
\hline CHEMBL1583504 & 688171 & 5.3 & 4.9872 & TST \\
\hline CHEMBL1558204 & 688171 & 4.8 & 4.8103 & TST \\
\hline CHEMBL460515 & 688171 & 5.65 & 4.9201 & TRN \\
\hline CHEMBL1344663 & 688171 & 4.45 & 4.7223 & TST \\
\hline CHEMBL1438098 & 688171 & 4.4 & 4.8967 & TRN \\
\hline CHEMBL1552407 & 688171 & 4.95 & 4.9197 & TRN \\
\hline CHEMBL1510937 & 688171 & 5.55 & 4.7692 & TRN \\
\hline CHEMBL1566539 & 688171 & 4.6 & 4.9048 & TRN \\
\hline CHEMBL1317581 & 688171 & 4.75 & 4.8985 & TST \\
\hline CHEMBL1610849 & 688171 & 4.85 & 4.9209 & TRN \\
\hline CHEMBL3196811 & 688171 & 4.75 & 4.9889 & TRN \\
\hline CHEMBL1365100 & 688171 & 4.4 & 4.9229 & TRN \\
\hline CHEMBL1612457 & 688171 & 6.45 & 4.9044 & TRN \\
\hline CHEMBL1560133 & 688171 & 4.4 & 4.7544 & TST \\
\hline CHEMBL3211667 & 688171 & 6.5501 & 4.8462 & TRN \\
\hline CHEMBL1444165 & 688171 & 5.05 & 4.8205 & TST \\
\hline CHEMBL1357575 & 688171 & 4.7 & 5.0183 & TRN \\
\hline
\end{tabular}




\begin{tabular}{|c|c|c|c|c|c|}
\hline \multicolumn{6}{|c|}{ Supplemental Table S2.txt } \\
\hline CHEMBL1594490 & 688171 & 6.35 & 4.8578 & TST & \\
\hline CHEMBL1472920 & 688171 & 5.3 & 4.9661 & TRN & \\
\hline CHEMBL3196098 & 688171 & 4.55 & 4.8489 & TST & \\
\hline CHEMBL1303576 & 688171 & 4.4 & 5.0078 & TST & \\
\hline CHEMBL1488991 & 688171 & 4.4 & 4.9296 & TRN & \\
\hline CHEMBL577365 & 688171 & 4.65 & 4.9537 & TST & \\
\hline CHEMBL1474574 & 688171 & 4.85 & 4.905 & TRN & \\
\hline CHEMBL1082515 & 688171 & 4.45 & 4.9929 & TRN & \\
\hline CHEMBL1468561 & 688171 & 5.05 & 4.9597 & TST & \\
\hline CHEMBL1401187 & 688171 & 4.75 & 4.8903 & TRN & \\
\hline CHEMBL1442478 & 688171 & 4.7 & 4.881 & TRN & \\
\hline CHEMBL1521702 & 688171 & 6.0 & 4.79899 & 99999999995 & TRN \\
\hline CHEMBL1464101 & 688171 & 4.6 & 4.8709 & TST & \\
\hline CHEMBL1386914 & 688171 & 4.4 & 4.836 & TRN & \\
\hline CHEMBL1440785 & 688171 & 4.5 & 4.7422 & TRN & \\
\hline CHEMBL1592615 & 688171 & 4.75 & 4.84699 & 99999999995 & TRN \\
\hline CHEMBL1482751 & 688171 & 4.5 & 4.8709 & TRN & \\
\hline CHEMBL1324484 & 688171 & 4.45 & 4.8595 & TRN & \\
\hline CHEMBL3212368 & 688171 & 4.4 & 4.9823 & TRN & \\
\hline CHEMBL1537253 & 688171 & 5.15 & 4.8669 & TST & \\
\hline CHEMBL1480251 & 688171 & 4.6 & 4.9359 & TRN & \\
\hline CHEMBL1578054 & 688171 & 4.4 & 4.9954 & TRN & \\
\hline CHEMBL1584170 & 688171 & 5.35 & 4.8467 & TST & \\
\hline CHEMBL1575417 & 688171 & 6.8499 & 5.0276 & TST & \\
\hline CHEMBL1596414 & 688171 & 4.6 & 4.8507 & TRN & \\
\hline CHEMBL1470051 & 688171 & 4.35 & 4.8455 & TRN & \\
\hline CHEMBL1407932 & 688171 & 4.75 & 4.9494 & TRN & \\
\hline CHEMBL1514020 & 688171 & 5.05 & 4.9875 & TRN & \\
\hline CHEMBL1985350 & 688171 & 4.9 & 4.9028 & TRN & \\
\hline CHEMBL1610184 & 688171 & 4.75 & 4.6877 & TRN & \\
\hline CHEMBL1505243 & 688171 & 4.65 & 4.7352 & TST & \\
\hline CHEMBL572994 & 688171 & 4.85 & 4.8624 & TST & \\
\hline CHEMBL1372580 & 688171 & 4.4 & 4.7683 & TRN & \\
\hline CHEMBL1528838 & 688171 & 4.75 & 5.0721 & TRN & \\
\hline CHEMBL1374563 & 688171 & 4.65 & 4.9944 & TRN & \\
\hline CHEMBL1988042 & 688171 & 4.55 & 4.9102 & TRN & \\
\hline CHEMBL1328553 & 688171 & 6.0 & 4.891 & TRN & \\
\hline CHEMBL1318780 & 688171 & 4.9 & 4.9531 & TRN & \\
\hline CHEMBL1313030 & 688171 & 4.8 & 4.8497 & TRN & \\
\hline CHEMBL1335304 & 688171 & 5.6 & 4.9984 & TST & \\
\hline CHEMBL1387843 & 688171 & 5.0 & 4.8006 & TST & \\
\hline CHEMBL1594527 & 688171 & 4.85 & 4.8931 & TST & \\
\hline CHEMBL1562359 & 688171 & 4.5 & 4.7956 & TRN & \\
\hline CHEMBL1581932 & 688171 & 4.9 & 4.8998 & TST & \\
\hline CHEMBL1356972 & 688171 & 4.85 & 4.7779 & TRN & \\
\hline CHEMBL1607306 & 688171 & 4.4 & 4.9067 & TRN & \\
\hline CHEMBL1520105 & 688171 & 4.35 & 4.8816 & TRN & \\
\hline CHEMBL1363565 & 688171 & 4.6 & 4.8993 & TRN & \\
\hline
\end{tabular}




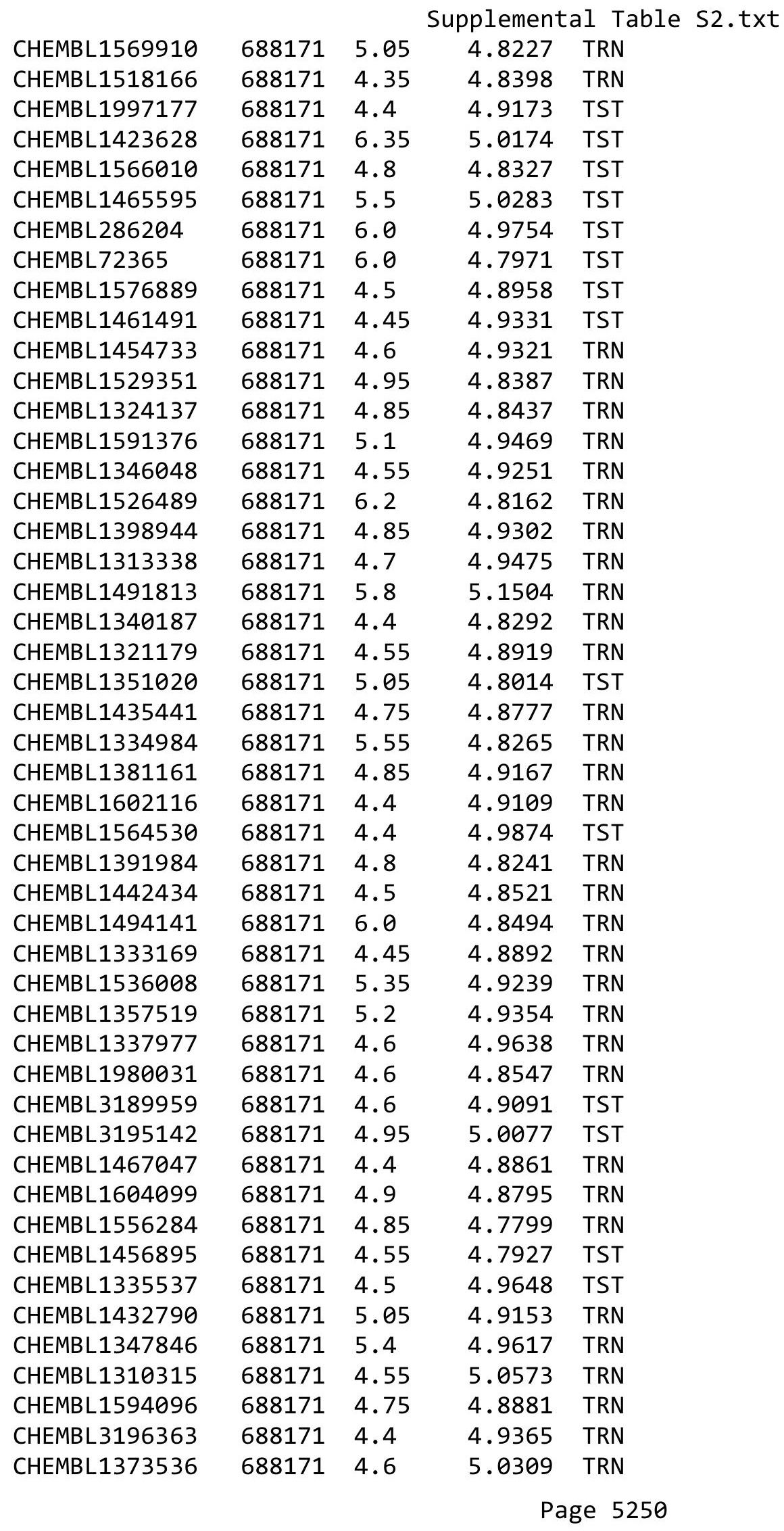




\begin{tabular}{|c|c|c|c|c|}
\hline \multicolumn{5}{|c|}{ Supplemental Table S2.txt } \\
\hline CHEMBL1576451 & 688171 & 4.95 & 4.8266 & TRN \\
\hline CHEMBL1528990 & 688171 & 5.75 & 5.019 & TST \\
\hline CHEMBL1491697 & 688171 & 4.75 & 4.8645 & TRN \\
\hline CHEMBL1408295 & 688171 & 4.55 & 4.8497 & TRN \\
\hline CHEMBL2002945 & 688171 & 4.75 & 4.9305 & TRN \\
\hline CHEMBL1472353 & 688171 & 4.85 & 4.9078 & TRN \\
\hline CHEMBL1526433 & 688171 & 4.4 & 4.8496 & TST \\
\hline CHEMBL1373072 & 688171 & 4.9 & 4.7775 & TRN \\
\hline CHEMBL1967664 & 688171 & 4.4 & 4.9658 & TRN \\
\hline CHEMBL1527971 & 688171 & 4.35 & 4.8353 & TRN \\
\hline CHEMBL3199015 & 688171 & 5.3 & 4.9201 & TRN \\
\hline CHEMBL1407983 & 688171 & 4.5 & 4.9019 & TRN \\
\hline CHEMBL1378460 & 688171 & 4.75 & 4.8548 & TRN \\
\hline CHEMBL1577337 & 688171 & 4.5 & 4.9616 & TST \\
\hline CHEMBL1388012 & 688171 & 4.35 & 4.9496 & TRN \\
\hline CHEMBL1449946 & 688171 & 5.0 & 4.8332 & TRN \\
\hline CHEMBL1344422 & 688171 & 4.75 & 4.7464 & TST \\
\hline CHEMBL1575653 & 688171 & 4.35 & 4.8907 & TST \\
\hline CHEMBL1510664 & 688171 & 4.5 & 4.8452 & TRN \\
\hline CHEMBL1527722 & 688171 & 6.0 & 5.0536 & TST \\
\hline CHEMBL1391481 & 688171 & 5.85 & 4.9056 & TST \\
\hline CHEMBL1441596 & 688171 & 4.75 & 4.9354 & TRN \\
\hline CHEMBL1544094 & 688171 & 4.75 & 4.7956 & TRN \\
\hline CHEMBL1312363 & 688171 & 5.05 & 4.8574 & TRN \\
\hline CHEMBL1388315 & 688171 & 4.7 & 4.784 & TST \\
\hline CHEMBL1437681 & 688171 & 5.9 & 5.0073 & TRN \\
\hline CHEMBL1370142 & 688171 & 4.5 & 4.8079 & TRN \\
\hline CHEMBL1323736 & 688171 & 4.4 & 4.7122 & TRN \\
\hline CHEMBL 3210215 & 688171 & 4.7 & 5.0501 & TRN \\
\hline CHEMBL1427629 & 688171 & 4.55 & 4.8958 & TRN \\
\hline CHEMBL416615 & 688171 & 4.9 & 4.9631 & TST \\
\hline CHEMBL1350968 & 688171 & 5.05 & 5.0028 & TST \\
\hline CHEMBL1532485 & 688171 & 4.4 & 4.9347 & TRN \\
\hline CHEMBL1476362 & 688171 & 4.7 & 4.993 & TST \\
\hline CHEMBL1435717 & 688171 & 4.8 & 4.8615 & TRN \\
\hline CHEMBL1566497 & 688171 & 5.05 & 5.0085 & TST \\
\hline CHEMBL1404721 & 688171 & 6.15 & 4.9172 & TRN \\
\hline CHEMBL1356215 & 688171 & 4.5 & 4.9625 & TRN \\
\hline CHEMBL1404526 & 688171 & 6.1 & 4.9474 & TRN \\
\hline CHEMBL1446764 & 688171 & 4.7 & 4.9188 & TST \\
\hline CHEMBL1521907 & 688171 & 4.4 & 4.79 & TST \\
\hline CHEMBL1301620 & 688171 & 4.4 & 4.9435 & TRN \\
\hline CHEMBL1597651 & 688171 & 5.1 & 4.9962 & TST \\
\hline CHEMBL1505207 & 688171 & 5.45 & 4.7906 & TST \\
\hline CHEMBL1409990 & 688171 & 5.0 & 4.8621 & TST \\
\hline CHEMBL1543318 & 688171 & 6.7001 & 5.0041 & TST \\
\hline CHEMBL1572850 & 688171 & 4.65 & 4.9207 & TRN \\
\hline CHEMBL1436548 & 688171 & 4.5 & 4.9842 & TRN \\
\hline
\end{tabular}




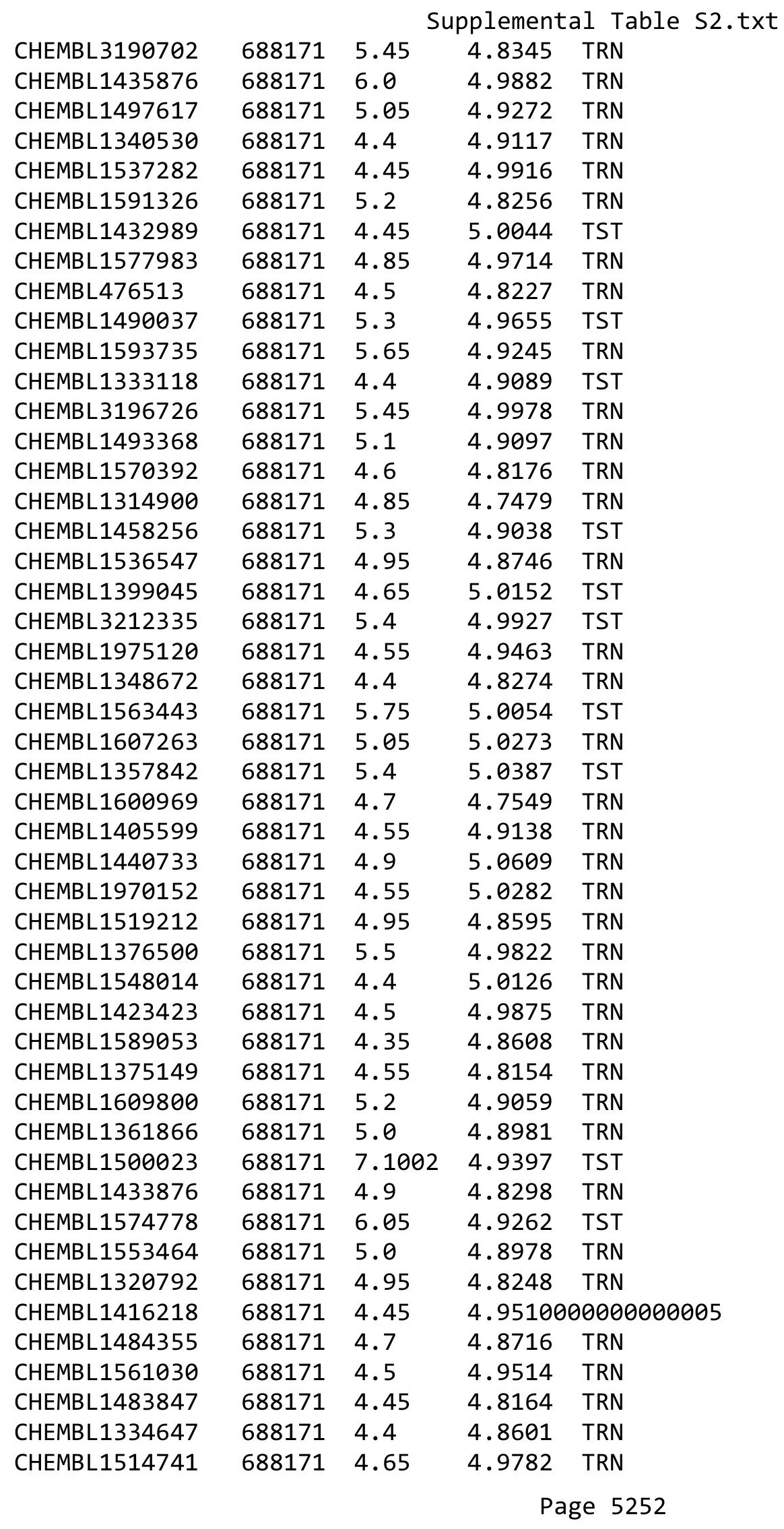

TRN 


\begin{tabular}{|c|c|c|c|c|c|}
\hline \multicolumn{6}{|c|}{ Supplemental Table s2.txt } \\
\hline CHEMBL1572716 & 688171 & 4.7 & 4.7965 & TRN & \\
\hline CHEMBL1416769 & 688171 & 5.1 & 4.8728 & TRN & \\
\hline CHEMBL1540605 & 688171 & 4.45 & 4.9138 & TRN & \\
\hline CHEMBL3190637 & 688171 & 4.9 & 4.9082 & TRN & \\
\hline CHEMBL1350078 & 688171 & 5.45 & 4.9138 & TRN & \\
\hline CHEMBL 2373654 & 688171 & 5.65 & 4.9487 & TRN & \\
\hline CHEMBL1443260 & 688171 & 4.7 & 4.8229 & TRN & \\
\hline CHEMBL1324567 & 688171 & 4.7 & 4.8826 & TRN & \\
\hline CHEMBL1605969 & 688171 & 6.25 & 4.8944 & TRN & \\
\hline CHEMBL1499548 & 688171 & 4.5 & 4.9177 & TRN & \\
\hline CHEMBL1412975 & 688171 & 4.45 & 4.8116 & TRN & \\
\hline CHEMBL1542510 & 688171 & 4.45 & 4.8052 & TRN & \\
\hline CHEMBL1400487 & 688171 & 5.75 & 4.9202 & TRN & \\
\hline CHEMBL1417077 & 688171 & 5.7 & 4.95 & TRN & \\
\hline CHEMBL1355927 & 688171 & 4.95 & 4.9436 & TRN & \\
\hline CHEMBL3208680 & 688171 & 4.45 & 5.0104 & TST & \\
\hline CHEMBL1307861 & 688171 & 4.85 & 4.8841 & TST & \\
\hline CHEMBL1406787 & 688171 & 4.45 & 5.0 & TRN & \\
\hline CHEMBL1458719 & 688171 & 4.35 & 4.7446 & TST & \\
\hline CHEMBL1535168 & 688171 & 4.7 & 4.9494 & TST & \\
\hline CHEMBL1576666 & 688171 & 4.5 & 4.7114 & TRN & \\
\hline CHEMBL1594883 & 688171 & 5.2 & 4.92399 & 99999999995 & TRN \\
\hline CHEMBL1555135 & 688171 & 5.0 & 5.0094 & TRN & \\
\hline CHEMBL1312079 & 688171 & 5.4 & 4.94600 & 0000000001 & TRN \\
\hline CHEMBL1587071 & 688171 & 5.5 & 5.1334 & TST & \\
\hline CHEMBL587433 & 688171 & 4.6 & 4.7022 & TST & \\
\hline CHEMBL1414562 & 688171 & 4.5 & 4.9562 & TST & \\
\hline CHEMBL1557622 & 688171 & 4.4 & 4.9356 & TRN & \\
\hline CHEMBL1575610 & 688171 & 4.6 & 4.8582 & TRN & \\
\hline CHEMBL1522180 & 688171 & 5.35 & 4.7975 & TST & \\
\hline CHEMBL1436816 & 688171 & 6.15 & 5.0029 & TST & \\
\hline CHEMBL1307671 & 688171 & 4.35 & 5.0233 & TRN & \\
\hline CHEMBL1534981 & 688171 & 4.75 & 4.7343 & TRN & \\
\hline CHEMBL1436105 & 688171 & 5.45 & 4.9599 & TRN & \\
\hline CHEMBL1303810 & 688171 & 5.4 & 4.856 & TRN & \\
\hline CHEMBL1415971 & 688171 & 4.6 & 4.961 & TRN & \\
\hline CHEMBL1371315 & 688171 & 5.4 & 4.8691 & TST & \\
\hline CHEMBL3192533 & 688171 & 4.4 & 4.8158 & TRN & \\
\hline CHEMBL3191078 & 688171 & 4.55 & 4.9546 & TST & \\
\hline CHEMBL1347985 & 688171 & 4.65 & 4.8158 & TRN & \\
\hline CHEMBL1339514 & 688171 & 4.4 & 4.88 & TRN & \\
\hline CHEMBL1393295 & 688171 & 4.8 & 4.9337 & TST & \\
\hline CHEMBL1459914 & 688171 & 4.7 & 4.6208 & TRN & \\
\hline CHEMBL1365533 & 688171 & 4.9 & 4.8419 & TRN & \\
\hline CHEMBL1994510 & 688171 & 5.65 & 5.0657 & TRN & \\
\hline CHEMBL1450435 & 688171 & 5.65 & 5.0841 & TRN & \\
\hline CHEMBL1462148 & 688171 & 4.4 & 5.0272 & TST & \\
\hline CHEMBL1370036 & 688171 & 4.7 & 5.0073 & TRN & \\
\hline & & & & 5253 & \\
\hline
\end{tabular}




\begin{tabular}{|c|c|c|c|c|c|}
\hline \multicolumn{6}{|c|}{ Supplemental Table S2.txt } \\
\hline CHEMBL1551764 & 688171 & 5.15 & 4.9348 & TRN & \\
\hline CHEMBL1586018 & 688171 & 4.75 & 4.7492 & TRN & \\
\hline CHEMBL1550635 & 688171 & 5.4 & 5.0146 & TST & \\
\hline CHEMBL1598118 & 688171 & 4.85 & 4.8657 & TRN & \\
\hline CHEMBL1533112 & 688171 & 4.35 & 4.8655 & TRN & \\
\hline CHEMBL1308312 & 688171 & 4.4 & 4.8016 & TST & \\
\hline CHEMBL494252 & 688171 & 4.85 & 4.8576 & TRN & \\
\hline CHEMBL1511515 & 688171 & 4.4 & 4.9077 & TRN & \\
\hline CHEMBL1420826 & 688171 & 4.85 & 4.9398 & TRN & \\
\hline CHEMBL1452747 & 688171 & 4.45 & 5.0072 & TST & \\
\hline CHEMBL1391214 & 688171 & 4.35 & 4.9555 & TRN & \\
\hline CHEMBL1603390 & 688171 & 5.05 & 4.7922 & TRN & \\
\hline CHEMBL1315110 & 688171 & 4.65 & 4.8454 & TRN & \\
\hline CHEMBL1544762 & 688171 & 4.4 & 4.7921 & TRN & \\
\hline CHEMBL1496973 & 688171 & 5.05 & 5.0082 & TRN & \\
\hline CHEMBL1546606 & 688171 & 4.75 & 5.074 & TRN & \\
\hline CHEMBL1604498 & 688171 & 5.0 & 4.78100 & 0000000001 & TRN \\
\hline CHEMBL1343892 & 688171 & 4.4 & 4.8864 & TRN & \\
\hline CHEMBL1517434 & 688171 & 5.05 & 5.0071 & TRN & \\
\hline CHEMBL1427282 & 688171 & 4.6 & 4.9491 & TRN & \\
\hline CHEMBL286721 & 688171 & 5.0 & 4.9892 & TRN & \\
\hline CHEMBL1367309 & 688171 & 4.4 & 5.0555 & TRN & \\
\hline CHEMBL1608823 & 688171 & 4.6 & 4.7898 & TST & \\
\hline CHEMBL1337052 & 688171 & 4.4 & 4.9565 & TST & \\
\hline CHEMBL3199374 & 688171 & 4.45 & 4.967 & TST & \\
\hline CHEMBL1464879 & 688171 & 4.65 & 4.9282 & TRN & \\
\hline CHEMBL1543510 & 688171 & 4.55 & 4.8533 & TRN & \\
\hline CHEMBL1569472 & 688171 & 4.4 & 4.8718 & TST & \\
\hline CHEMBL 1377825 & 688171 & 4.55 & 4.92 & TRN & \\
\hline CHEMBL1608931 & 688171 & 4.7 & 4.9749 & TRN & \\
\hline CHEMBL1551847 & 688171 & 4.35 & 4.9523 & TST & \\
\hline CHEMBL1440300 & 688171 & 5.35 & 4.8962 & TST & \\
\hline CHEMBL1486105 & 688171 & 5.45 & 4.8485 & TRN & \\
\hline CHEMBL1554056 & 688171 & 5.4 & 4.9346 & TRN & \\
\hline CHEMBL1367639 & 688171 & 4.8 & 4.8634 & TRN & \\
\hline CHEMBL3210154 & 688171 & 5.55 & 4.9325 & TRN & \\
\hline CHEMBL1452070 & 688171 & 4.45 & 5.0242 & TRN & \\
\hline CHEMBL1456933 & 688171 & 4.85 & 4.8872 & TRN & \\
\hline CHEMBL1320398 & 688171 & 4.6 & 4.9063 & TST & \\
\hline CHEMBL1598921 & 688171 & 4.4 & 4.7989 & TST & \\
\hline CHEMBL1409965 & 688171 & 4.75 & 4.8332 & TRN & \\
\hline CHEMBL1392681 & 688171 & 4.45 & 4.8233 & TRN & \\
\hline CHEMBL1598659 & 688171 & 4.75 & 4.8029 & TRN & \\
\hline CHEMBL3210191 & 688171 & 4.45 & 4.8665 & TRN & \\
\hline CHEMBL1395255 & 688171 & 6.5501 & 4.9978 & TRN & \\
\hline CHEMBL1591833 & 688171 & 4.55 & 4.8197 & TRN & \\
\hline CHEMBL1463925 & 688171 & 5.5 & 4.9435 & TRN & \\
\hline CHEMBL1575074 & 688171 & 4.6 & 4.9897 & TST & \\
\hline
\end{tabular}




\begin{tabular}{|c|c|c|c|c|}
\hline \multicolumn{5}{|c|}{ Supplemental Table s2.txt } \\
\hline CHEMBL1585661 & 688171 & 4.6 & 4.8502 & TST \\
\hline CHEMBL1565932 & 688171 & 4.95 & 4.7651 & TRN \\
\hline CHEMBL1569018 & 688171 & 5.0 & 4.8617 & TST \\
\hline CHEMBL478960 & 688171 & 4.5 & 4.8852 & TST \\
\hline CHEMBL1407175 & 688171 & 4.5 & 4.9914 & TRN \\
\hline CHEMBL1362234 & 688171 & 6.4 & 4.9578 & TRN \\
\hline CHEMBL1499288 & 688171 & 4.5 & 4.9334 & TRN \\
\hline CHEMBL1340487 & 688171 & 4.55 & 4.9449 & TRN \\
\hline CHEMBL1515740 & 688171 & 7.15 & 4.9105 & TST \\
\hline CHEMBL1600901 & 688171 & 5.0 & 4.8995 & TRN \\
\hline CHEMBL 3213879 & 688171 & 4.55 & 4.9693 & TRN \\
\hline CHEMBL1506732 & 688171 & 4.85 & 4.9214 & TRN \\
\hline CHEMBL1580066 & 688171 & 4.85 & 4.8702 & TRN \\
\hline CHEMBL1364596 & 688171 & 4.8 & 4.8785 & TRN \\
\hline CHEMBL1432399 & 688171 & 4.4 & 4.9016 & TRN \\
\hline CHEMBL1437653 & 688171 & 6.0 & 4.9124 & TRN \\
\hline CHEMBL1301139 & 688171 & 4.4 & 4.9724 & TST \\
\hline CHEMBL1354852 & 688171 & 4.9 & 4.9476 & TRN \\
\hline CHEMBL1520341 & 688171 & 4.6 & 4.9033 & TRN \\
\hline CHEMBL1392651 & 688171 & 4.8 & 4.7563 & TST \\
\hline CHEMBL1458735 & 688171 & 4.4 & 4.8982 & TRN \\
\hline CHEMBL1475997 & 688171 & 4.7 & 4.9342 & TRN \\
\hline CHEMBL1565672 & 688171 & 4.9 & 4.9509 & TST \\
\hline CHEMBL1361225 & 688171 & 6.6499 & 5.0378 & TST \\
\hline CHEMBL1559357 & 688171 & 4.4 & 4.9341 & TST \\
\hline CHEMBL1484501 & 688171 & 4.75 & 4.8522 & TRN \\
\hline CHEMBL1613054 & 688171 & 4.75 & 4.8484 & TRN \\
\hline CHEMBL1404109 & 688171 & 4.5 & 4.7655 & TST \\
\hline CHEMBL1407654 & 688171 & 4.35 & 4.8952 & TRN \\
\hline CHEMBL1592349 & 688171 & 5.6 & 4.8924 & TST \\
\hline CHEMBL1448343 & 688171 & 4.6 & 4.9349 & TST \\
\hline CHEMBL1483230 & 688171 & 4.35 & 5.0323 & TRN \\
\hline CHEMBL1451345 & 688171 & 4.65 & 4.8848 & TRN \\
\hline CHEMBL1435043 & 688171 & 4.4 & 4.837 & TRN \\
\hline CHEMBL1384228 & 688171 & 4.5 & 4.9156 & TRN \\
\hline CHEMBL1580044 & 688171 & 4.95 & 4.913 & TST \\
\hline CHEMBL1453366 & 688171 & 4.95 & 4.9438 & TST \\
\hline CHEMBL3212279 & 688171 & 4.4 & 4.9179 & TST \\
\hline CHEMBL1565903 & 688171 & 5.1 & 5.0853 & TRN \\
\hline CHEMBL1575710 & 688171 & 5.05 & 4.973 & TRN \\
\hline CHEMBL1582866 & 688171 & 4.55 & 5.0006 & TRN \\
\hline CHEMBL1353259 & 688171 & 4.75 & 4.9381 & TRN \\
\hline CHEMBL1581251 & 688171 & 4.5 & 4.9179 & TRN \\
\hline CHEMBL1451472 & 688171 & 5.25 & 4.9509 & TRN \\
\hline CHEMBL1436610 & 688171 & 4.75 & 4.9216 & TRN \\
\hline CHEMBL1445582 & 688171 & 4.35 & 4.7997 & TRN \\
\hline CHEMBL1476573 & 688171 & 4.8 & 4.9842 & TRN \\
\hline CHEMBL1317224 & 688171 & 4.55 & 4.8513 & TRN \\
\hline
\end{tabular}




\begin{tabular}{|c|c|c|c|c|}
\hline \multicolumn{5}{|c|}{ Supplemental Table S2.txt } \\
\hline CHEMBL1451206 & 688171 & 4.8 & 4.8289 & TRN \\
\hline CHEMBL1600795 & 688171 & 4.5 & 4.8507 & TRN \\
\hline CHEMBL1319959 & 688171 & 4.8 & 4.9178 & TRN \\
\hline CHEMBL1551323 & 688171 & 4.65 & 4.8418 & TRN \\
\hline CHEMBL1543224 & 688171 & 4.75 & 4.9323 & TRN \\
\hline CHEMBL527620 & 688171 & 6.0 & 5.0176 & TRN \\
\hline CHEMBL1349918 & 688171 & 5.55 & 4.9359 & TST \\
\hline CHEMBL1415066 & 688171 & 5.15 & 4.987 & TST \\
\hline CHEMBL1461356 & 688171 & 6.15 & 4.8664 & TST \\
\hline CHEMBL1366564 & 688171 & 4.5 & 4.8635 & TRN \\
\hline CHEMBL1411383 & 688171 & 6.0 & 4.86 & TST \\
\hline CHEMBL1551484 & 688171 & 4.55 & 4.9946 & TRN \\
\hline CHEMBL1358549 & 688171 & 4.65 & 4.8577 & TRN \\
\hline CHEMBL1543421 & 688171 & 4.95 & 4.837 & TRN \\
\hline CHEMBL1388796 & 688171 & 5.45 & 4.8305 & TRN \\
\hline CHEMBL1561936 & 688171 & 4.35 & 4.8852 & TRN \\
\hline CHEMBL1511331 & 688171 & 5.1 & 5.0865 & TRN \\
\hline CHEMBL1456780 & 688171 & 4.65 & 5.0284 & TRN \\
\hline CHEMBL1490036 & 688171 & 5.35 & 5.0119 & TRN \\
\hline CHEMBL1332446 & 688171 & 4.4 & 4.7882 & TRN \\
\hline CHEMBL1447028 & 688171 & 4.65 & 4.8078 & TRN \\
\hline CHEMBL1363146 & 688171 & 4.4 & 4.8316 & TRN \\
\hline CHEMBL1347385 & 688171 & 4.7 & 4.837 & TRN \\
\hline CHEMBL3213907 & 688171 & 5.25 & 4.9881 & TST \\
\hline CHEMBL1402956 & 688171 & 4.4 & 4.7751 & TRN \\
\hline CHEMBL1448911 & 688171 & 5.5 & 4.9123 & TST \\
\hline CHEMBL1403153 & 688171 & 6.5501 & 4.9594 & TRN \\
\hline CHEMBL1455727 & 688171 & 4.8 & 5.0579 & TRN \\
\hline CHEMBL1439492 & 688171 & 4.4 & 5.0393 & TRN \\
\hline CHEMBL3193136 & 688171 & 5.05 & 4.9845 & TRN \\
\hline CHEMBL1338812 & 688171 & 4.6 & 5.0219 & TRN \\
\hline CHEMBL1387750 & 688171 & 4.5 & 4.9013 & TRN \\
\hline CHEMBL1461558 & 688171 & 7.6498 & 4.9953 & TST \\
\hline CHEMBL1603991 & 688171 & 4.4 & 4.7842 & TRN \\
\hline CHEMBL1449537 & 688171 & 4.65 & 4.9041 & TRN \\
\hline CHEMBL1372295 & 688171 & 4.65 & 4.8885 & TRN \\
\hline CHEMBL1520268 & 688171 & 4.5 & 4.8341 & TRN \\
\hline CHEMBL3197969 & 688171 & 4.8 & 4.8385 & TRN \\
\hline CHEMBL1542268 & 688171 & 4.6 & 5.0384 & TST \\
\hline CHEMBL1464762 & 688171 & 5.55 & 5.0884 & TRN \\
\hline CHEMBL1434478 & 688171 & 4.7 & 4.9371 & TRN \\
\hline CHEMBL1341830 & 688171 & 6.4 & 4.8707 & TRN \\
\hline CHEMBL1603660 & 688171 & 4.4 & 4.8096 & TST \\
\hline CHEMBL1397602 & 688171 & 5.45 & 4.8313 & TRN \\
\hline CHEMBL1579925 & 688171 & 5.3 & 4.8478 & TRN \\
\hline CHEMBL1416808 & 688171 & 5.5 & 4.873 & TST \\
\hline CHEMBL1382476 & 688171 & 4.6 & 4.7795 & TRN \\
\hline CHEMBL1562459 & 688171 & 4.4 & 4.9633 & TRN \\
\hline
\end{tabular}




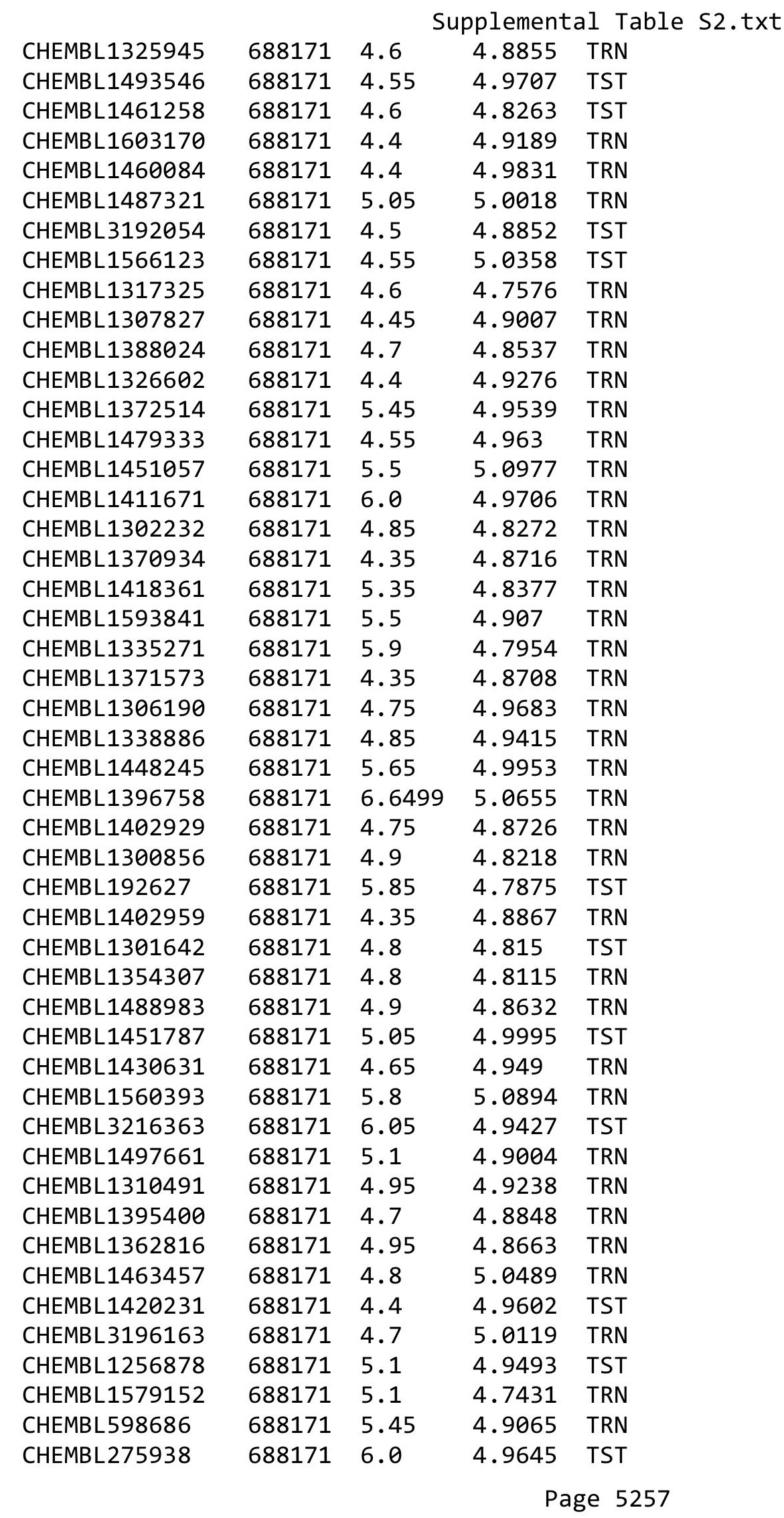




\begin{tabular}{|c|c|c|c|c|}
\hline \multicolumn{5}{|c|}{ Supplemental Table } \\
\hline CHEMBL1333527 & 688171 & 4.35 & 4.9684 & TST \\
\hline CHEMBL1610742 & 688171 & 4.55 & 4.8978 & TRN \\
\hline CHEMBL1453903 & 688171 & 4.55 & 4.8305 & TRN \\
\hline CHEMBL1439285 & 688171 & 4.65 & 4.8787 & TRN \\
\hline CHEMBL 1448182 & 688171 & 5.0 & 4.8379 & TRN \\
\hline CHEMBL1481188 & 688171 & 4.5 & 4.9742 & TST \\
\hline CHEMBL1470281 & 688171 & 4.9 & 4.9618 & TST \\
\hline CHEMBL1463302 & 688171 & 4.55 & 4.9281 & TRN \\
\hline CHEMBL1557752 & 688171 & 4.35 & 4.9632 & TRN \\
\hline CHEMBL1526217 & 688171 & 4.85 & 4.7645 & TRN \\
\hline CHEMBL1430016 & 688171 & 4.35 & 4.8633 & TRN \\
\hline CHEMBL1405477 & 688171 & 4.75 & 4.8776 & TRN \\
\hline CHEMBL3189322 & 688171 & 5.75 & 5.0249 & TRN \\
\hline CHEMBL1551782 & 688171 & 4.75 & 4.871 & TRN \\
\hline CHEMBL1607408 & 688171 & 4.45 & 4.9373 & TST \\
\hline CHEMBL3191953 & 688171 & 4.45 & 4.8016 & TRN \\
\hline CHEMBL1591337 & 688171 & 4.55 & 4.916 & TRN \\
\hline CHEMBL1405458 & 688171 & 4.4 & 4.646 & TRN \\
\hline CHEMBL1310679 & 688171 & 5.55 & 4.9586 & TST \\
\hline CHEMBL1492505 & 688171 & 4.45 & 4.8426 & TRN \\
\hline CHEMBL1434513 & 688171 & 6.0 & 4.9806 & TRN \\
\hline CHEMBL1591653 & 688171 & 4.45 & 5.0545 & TRN \\
\hline CHEMBL1433140 & 688171 & 4.35 & 4.8585 & TST \\
\hline CHEMBL1406971 & 688171 & 4.6 & 5.044 & TST \\
\hline CHEMBL1376110 & 688171 & 4.75 & 4.7592 & TRN \\
\hline CHEMBL1325908 & 688171 & 6.0 & 4.9881 & TRN \\
\hline CHEMBL1610336 & 688171 & 4.75 & 4.9091 & TRN \\
\hline CHEMBL1325217 & 688171 & 4.6 & 4.7135 & TRN \\
\hline CHEMBL1408949 & 688171 & 5.45 & 4.9396 & TST \\
\hline CHEMBL3191689 & 688171 & 5.05 & 4.8751 & TST \\
\hline CHEMBL1412585 & 688171 & 5.15 & 4.8755 & TRN \\
\hline CHEMBL1595935 & 688171 & 4.65 & 4.9365 & TST \\
\hline CHEMBL1563184 & 688171 & 4.35 & 4.9602 & TRN \\
\hline CHEMBL1992631 & 688171 & 4.65 & 4.9281 & TRN \\
\hline CHEMBL1454159 & 688171 & 4.65 & 4.9914 & TRN \\
\hline CHEMBL1478087 & 688171 & 5.05 & 5.0535 & TRN \\
\hline CHEMBL1611302 & 688171 & 5.95 & 4.9671 & TST \\
\hline CHEMBL1485355 & 688171 & 5.8 & 4.8862 & TRN \\
\hline CHEMBL1598558 & 688171 & 6.6 & 4.8962 & TRN \\
\hline CHEMBL1349942 & 688171 & 4.7 & 5.1475 & TRN \\
\hline CHEMBL1319546 & 688171 & 5.1 & 4.7591 & TRN \\
\hline CHEMBL3195540 & 688171 & 4.45 & 4.8473 & TRN \\
\hline CHEMBL1403497 & 688171 & 4.55 & 4.7943 & TRN \\
\hline CHEMBL1423473 & 688171 & 5.8 & 5.0274 & TST \\
\hline CHEMBL1463930 & 688171 & 5.3 & 4.893 & TRN \\
\hline CHEMBL1560156 & 688171 & 4.5 & 4.9042 & TRN \\
\hline CHEMBL1355967 & 688171 & 6.3 & 4.9681 & TRN \\
\hline CHEMBL1461530 & 688171 & 5.6 & 4.8755 & TRN \\
\hline
\end{tabular}




\begin{tabular}{|c|c|c|c|c|c|}
\hline \multicolumn{6}{|c|}{ Supplemental Table S2.txt } \\
\hline CHEMBL1994402 & 688171 & 4.7 & 4.9475 & TRN & \\
\hline CHEMBL1515305 & 688171 & 5.5 & 4.8525 & TST & \\
\hline CHEMBL1306232 & 688171 & 4.85 & 4.9064 & TRN & \\
\hline CHEMBL1409163 & 688171 & 4.6 & 4.7537 & TRN & \\
\hline CHEMBL1474447 & 688171 & 4.45 & 4.84399 & 9999999999 & TRN \\
\hline CHEMBL1494981 & 688171 & 5.0 & 4.9899 & TRN & \\
\hline CHEMBL1499927 & 688171 & 4.65 & 4.9957 & TST & \\
\hline CHEMBL1301125 & 688171 & 5.1 & 4.8666 & TRN & \\
\hline CHEMBL507026 & 688171 & 4.75 & 4.878 & TST & \\
\hline CHEMBL3195599 & 688171 & 4.65 & 4.9249 & TST & \\
\hline CHEMBL1495449 & 688171 & 5.25 & 4.8824 & TRN & \\
\hline CHEMBL1604119 & 688171 & 4.6 & 4.852 & TRN & \\
\hline CHEMBL1555177 & 688171 & 4.8 & 4.7683 & TRN & \\
\hline CHEMBL1607586 & 688171 & 4.6 & 4.9813 & TRN & \\
\hline CHEMBL586000 & 688171 & 4.6 & 4.8052 & TST & \\
\hline CHEMBL1451398 & 688171 & 6.05 & 4.9126 & TRN & \\
\hline CHEMBL1436099 & 688171 & 5.05 & 4.9219 & TRN & \\
\hline CHEMBL1339706 & 688171 & 5.7 & 4.9305 & TRN & \\
\hline CHEMBL3199734 & 688171 & 5.55 & 4.9075 & TST & \\
\hline CHEMBL1589922 & 688171 & 4.4 & 4.9997 & TST & \\
\hline CHEMBL3195736 & 688171 & 4.45 & 4.8853 & TRN & \\
\hline CHEMBL1430005 & 688171 & 4.8 & 4.8814 & TST & \\
\hline CHEMBL1529335 & 688171 & 4.55 & 4.8355 & TRN & \\
\hline CHEMBL1999723 & 688171 & 4.35 & 4.8747 & TRN & \\
\hline CHEMBL1409908 & 688171 & 5.05 & 4.8469 & TST & \\
\hline CHEMBL1442378 & 688171 & 4.7 & 4.9911 & TRN & \\
\hline CHEMBL1357805 & 688171 & 6.15 & 4.9209 & TRN & \\
\hline CHEMBL1370071 & 688171 & 4.7 & 4.8903 & TRN & \\
\hline CHEMBL1511276 & 688171 & 6.0 & 4.8102 & TRN & \\
\hline CHEMBL1600273 & 688171 & 4.5 & 5.0455 & TRN & \\
\hline CHEMBL1445034 & 688171 & 4.85 & 4.875 & TRN & \\
\hline CHEMBL1344272 & 688171 & 4.8 & 4.9081 & TRN & \\
\hline CHEMBL1455044 & 688171 & 4.95 & 4.9086 & TRN & \\
\hline CHEMBL1316013 & 688171 & 4.8 & 4.9656 & TST & \\
\hline CHEMBL3193116 & 688171 & 5.05 & 4.9704 & TRN & \\
\hline CHEMBL1606063 & 688171 & 4.4 & 4.9107 & TRN & \\
\hline CHEMBL1398552 & 688171 & 5.0 & 4.979 & TRN & \\
\hline CHEMBL1468306 & 688171 & 5.15 & 5.0639 & TRN & \\
\hline CHEMBL1370841 & 688171 & 4.75 & 5.0244 & TRN & \\
\hline CHEMBL1388273 & 688171 & 5.45 & 4.9318 & TRN & \\
\hline CHEMBL1363058 & 688171 & 5.25 & 4.9557 & TRN & \\
\hline CHEMBL1556923 & 688171 & 4.65 & 4.8364 & TRN & \\
\hline CHEMBL1425312 & 688171 & 5.35 & 4.9682 & TST & \\
\hline CHEMBL1308917 & 688171 & 4.85 & 4.7668 & TRN & \\
\hline CHEMBL1499805 & 688171 & 4.6 & 4.9028 & TRN & \\
\hline CHEMBL1356141 & 688171 & 5.25 & 4.8578 & TRN & \\
\hline CHEMBL1301696 & 688171 & 4.75 & 4.9385 & TRN & \\
\hline CHEMBL1564879 & 688171 & 4.5 & 4.9475 & TRN & \\
\hline
\end{tabular}




\begin{tabular}{|c|c|c|c|c|}
\hline \multicolumn{5}{|c|}{ Supplemental Table S2.txt } \\
\hline CHEMBL1417485 & 688171 & 5.15 & 4.915 & TRN \\
\hline CHEMBL1476680 & 688171 & 5.1 & 4.9268 & TRN \\
\hline CHEMBL1510525 & 688171 & 6.0 & 5.0543 & TRN \\
\hline CHEMBL3192616 & 688171 & 5.55 & 5.039 & TRN \\
\hline CHEMBL1368130 & 688171 & 4.4 & 4.8455 & TRN \\
\hline CHEMBL1590196 & 688171 & 5.15 & 4.795 & TRN \\
\hline CHEMBL1545157 & 688171 & 4.85 & 4.8222 & TST \\
\hline CHEMBL1562593 & 688171 & 5.45 & 4.897 & TRN \\
\hline CHEMBL3195996 & 688171 & 6.5501 & 4.9929 & TRN \\
\hline CHEMBL1350622 & 688171 & 5.05 & 4.7683 & TRN \\
\hline CHEMBL118009 & 688171 & 4.45 & 4.7955 & TRN \\
\hline CHEMBL1396806 & 688171 & 4.65 & 4.8824 & TRN \\
\hline CHEMBL1524037 & 688171 & 6.5 & 5.0809 & TRN \\
\hline CHEMBL1448982 & 688171 & 5.2 & 4.914 & TRN \\
\hline CHEMBL1522394 & 688171 & 4.9 & 4.9516 & TRN \\
\hline CHEMBL1994837 & 688171 & 5.1 & 4.8492 & TRN \\
\hline CHEMBL1451017 & 688171 & 4.7 & 4.7959 & TRN \\
\hline CHEMBL1376896 & 688171 & 4.4 & 4.9811 & TST \\
\hline CHEMBL1528983 & 688171 & 4.6 & 4.8874 & TRN \\
\hline CHEMBL1595923 & 688171 & 4.8 & 4.9988 & TRN \\
\hline CHEMBL 260799 & 688171 & 5.3 & 4.9325 & TST \\
\hline CHEMBL1462815 & 688171 & 6.7501 & 4.9497 & TRN \\
\hline CHEMBL1458133 & 688171 & 5.7 & 4.834 & TRN \\
\hline CHEMBL 221137 & 688171 & 6.0 & 4.9871 & TST \\
\hline CHEMBL1580845 & 688171 & 6.0 & 4.753 & TRN \\
\hline CHEMBL1328522 & 688171 & 6.0 & 4.7663 & TRN \\
\hline CHEMBL1414049 & 688171 & 4.65 & 4.7322 & TRN \\
\hline CHEMBL1400050 & 688171 & 5.6 & 5.0577 & TRN \\
\hline CHEMBL1317215 & 688171 & 4.95 & 4.8313 & TRN \\
\hline CHEMBL 365558 & 688171 & 4.65 & 4.8588 & TRN \\
\hline CHEMBL1566506 & 688171 & 4.8 & 4.8574 & TST \\
\hline CHEMBL1494527 & 688171 & 4.4 & 4.9652 & TST \\
\hline CHEMBL1400891 & 688171 & 4.7 & 4.9311 & TST \\
\hline CHEMBL1404336 & 688171 & 4.5 & 5.0587 & TRN \\
\hline CHEMBL1350761 & 688171 & 4.5 & 5.0514 & TRN \\
\hline CHEMBL1435482 & 688171 & 5.0 & 4.8463 & TRN \\
\hline CHEMBL1604825 & 688171 & 4.7 & 4.8986 & TRN \\
\hline CHEMBL1389734 & 688171 & 4.55 & 4.8921 & TRN \\
\hline CHEMBL1411401 & 688171 & 5.45 & 4.8911 & TST \\
\hline CHEMBL1455662 & 688171 & 4.65 & 4.9332 & TST \\
\hline CHEMBL1371923 & 688171 & 4.6 & 4.8253 & TRN \\
\hline CHEMBL1330326 & 688171 & 4.65 & 4.7763 & TRN \\
\hline CHEMBL1426637 & 688171 & 4.85 & 4.872 & TRN \\
\hline CHEMBL1422564 & 688171 & 4.4 & 4.9773 & TRN \\
\hline CHEMBL1329618 & 688171 & 5.0 & 5.0163 & TRN \\
\hline CHEMBL1399022 & 688171 & 5.6 & 4.9605 & TRN \\
\hline CHEMBL1589760 & 688171 & 4.65 & 4.9042 & TRN \\
\hline CHEMBL1592800 & 688171 & 4.5 & 4.7398 & TRN \\
\hline
\end{tabular}




\begin{tabular}{|c|c|c|c|c|c|}
\hline \multicolumn{6}{|c|}{ Supplemental Table S2.txt } \\
\hline CHEMBL1519040 & 688171 & 4.7 & 4.9173 & TRN & \\
\hline CHEMBL1534384 & 688171 & 4.9 & 4.8823 & TRN & \\
\hline CHEMBL1341453 & 688171 & 4.7 & 4.8454 & TRN & \\
\hline CHEMBL1603982 & 688171 & 4.75 & 4.9911 & TRN & \\
\hline CHEMBL1359287 & 688171 & 5.15 & 4.9805 & TRN & \\
\hline CHEMBL 2005484 & 688171 & 5.1 & 4.9221 & TST & \\
\hline CHEMBL1552191 & 688171 & 4.85 & 4.8987 & TRN & \\
\hline CHEMBL1299330 & 688171 & 4.55 & 4.9291 & TST & \\
\hline CHEMBL1410385 & 688171 & 4.45 & 4.8843 & TRN & \\
\hline CHEMBL1380226 & 688171 & 4.4 & 5.0119 & TRN & \\
\hline CHEMBL1373950 & 688171 & 4.8 & 4.8102 & TST & \\
\hline CHEMBL1525884 & 688171 & 6.5 & 4.8865 & TST & \\
\hline CHEMBL1527679 & 688171 & 4.4 & 4.8079 & TRN & \\
\hline CHEMBL1483944 & 688171 & 4.55 & 4.9519 & TRN & \\
\hline CHEMBL1426792 & 688171 & 4.85 & 4.8431 & TRN & \\
\hline CHEMBL1494979 & 688171 & 5.25 & 4.8761 & TST & \\
\hline CHEMBL1355195 & 688171 & 4.75 & 4.8588 & TRN & \\
\hline CHEMBL3190124 & 688171 & 4.85 & 4.8963 & TRN & \\
\hline CHEMBL1368005 & 688171 & 4.4 & 5.0634 & TRN & \\
\hline CHEMBL1585221 & 688171 & 5.1 & 4.789 & TST & \\
\hline CHEMBL1609077 & 688171 & 4.45 & 4.8738 & TRN & \\
\hline CHEMBL67378 & 688171 & 5.1 & 5.0626 & TST & \\
\hline CHEMBL1465891 & 688171 & 4.4 & 4.8259 & TRN & \\
\hline CHEMBL1503950 & 688171 & 4.7 & 4.8767 & TRN & \\
\hline CHEMBL1405448 & 688171 & 5.45 & 4.8347 & TRN & \\
\hline CHEMBL1524613 & 688171 & 4.35 & 4.9316 & TRN & \\
\hline CHEMBL1341017 & 688171 & 4.7 & 4.8694 & TRN & \\
\hline CHEMBL1609343 & 688171 & 5.1 & 5.01399 & 9999999999 & TRN \\
\hline CHEMBL1572640 & 688171 & 4.55 & 4.8539 & TRN & \\
\hline CHEMBL1447044 & 688171 & 5.2 & 5.0439 & TRN & \\
\hline CHEMBL1524483 & 688171 & 4.35 & 5.1738 & TRN & \\
\hline CHEMBL1369620 & 688171 & 4.55 & 4.9657 & TST & \\
\hline CHEMBL1510479 & 688171 & 4.75 & 4.9807 & TST & \\
\hline CHEMBL1569066 & 688171 & 4.35 & 4.7634 & TRN & \\
\hline CHEMBL1577430 & 688171 & 4.4 & 4.9685 & TRN & \\
\hline CHEMBL1455042 & 688171 & 5.5 & 4.9113 & TST & \\
\hline CHEMBL1524576 & 688171 & 5.0 & 4.8343 & TST & \\
\hline CHEMBL1577583 & 688171 & 4.6 & 4.8489 & TRN & \\
\hline CHEMBL1521675 & 688171 & 4.85 & 4.7655 & TST & \\
\hline CHEMBL1550190 & 688171 & 5.1 & 4.9136 & TRN & \\
\hline CHEMBL1551463 & 688171 & 5.25 & 4.8188 & TRN & \\
\hline CHEMBL1545571 & 688171 & 4.9 & 4.9633 & TRN & \\
\hline CHEMBL1556914 & 688171 & 5.1 & 4.9696 & TST & \\
\hline CHEMBL1332353 & 688171 & 4.55 & 4.8316 & TRN & \\
\hline CHEMBL1517374 & 688171 & 4.6 & 4.9396 & TRN & \\
\hline CHEMBL1320912 & 688171 & 4.75 & 5.008 & TRN & \\
\hline CHEMBL 3190840 & 688171 & 7.6003 & 4.9685 & TST & \\
\hline CHEMBL1422933 & 688171 & 4.4 & 4.9417 & TRN & \\
\hline
\end{tabular}




\begin{tabular}{|c|c|c|c|c|c|}
\hline & & \multicolumn{4}{|c|}{ Supplemental Table S2.txt } \\
\hline CHEMBL1582212 & 688171 & 4.7 & 4.8254 & TRN & \\
\hline CHEMBL1312356 & 688171 & 4.45 & 4.8606 & TST & \\
\hline CHEMBL1345021 & 688171 & 6.4 & 4.9391 & TST & \\
\hline CHEMBL1561654 & 688171 & 4.75 & 4.8383 & TST & \\
\hline CHEMBL1420146 & 688171 & 5.05 & 4.8541 & TRN & \\
\hline CHEMBL1329674 & 688171 & 5.05 & 4.8522 & TRN & \\
\hline CHEMBL1395664 & 688171 & 5.05 & 4.8093 & TRN & \\
\hline CHEMBL1410640 & 688171 & 5.45 & 4.945 & TRN & \\
\hline CHEMBL1301436 & 688171 & 4.8 & 4.8863 & TRN & \\
\hline CHEMBL1313339 & 688171 & 4.65 & 4.8106 & TRN & \\
\hline CHEMBL1309268 & 688171 & 4.55 & 4.7022 & TST & \\
\hline CHEMBL1443973 & 688171 & 4.6 & 4.9932 & TST & \\
\hline CHEMBL3207349 & 688171 & 4.8 & 4.9579 & TST & \\
\hline CHEMBL147514 & 688171 & 4.55 & 4.9645 & TST & \\
\hline CHEMBL208484 & 688171 & 5.05 & 4.8697 & TST & \\
\hline CHEMBL1524603 & 688171 & 4.95 & 4.8745 & TRN & \\
\hline CHEMBL1395548 & 688171 & 5.4 & 4.9405 & TST & \\
\hline CHEMBL1474047 & 688171 & 4.95 & 4.8769 & TRN & \\
\hline CHEMBL1304131 & 688171 & 4.4 & 4.9351 & TRN & \\
\hline CHEMBL1326217 & 688171 & 4.7 & 4.8494 & TRN & \\
\hline CHEMBL1344714 & 688171 & 4.4 & 5.0103 & TRN & \\
\hline CHEMBL1514532 & 688171 & 5.3 & 4.9901 & TRN & \\
\hline CHEMBL 3208487 & 688171 & 4.35 & 4.8566 & TST & \\
\hline CHEMBL1422600 & 688171 & 4.4 & 4.8431 & TRN & \\
\hline CHEMBL1395731 & 688171 & 4.65 & 4.8481 & TRN & \\
\hline CHEMBL1485028 & 688171 & 4.6 & 4.8706 & TRN & \\
\hline CHEMBL1452480 & 688171 & 5.55 & 4.8351 & TST & \\
\hline CHEMBL1487646 & 688171 & 6.8 & 4.7146 & TRN & \\
\hline CHEMBL1519278 & 688171 & 4.4 & 5.0354 & TST & \\
\hline CHEMBL1565356 & 688171 & 5.2 & 4.88399 & 99999999995 & TRN \\
\hline CHEMBL77387 & 688171 & 6.0 & 4.8308 & TRN & \\
\hline CHEMBL1433196 & 688171 & 5.3 & 5.034 & TST & \\
\hline CHEMBL1323858 & 688171 & 5.3 & 4.8649 & TRN & \\
\hline CHEMBL579742 & 688171 & 5.1 & 5.0567 & TRN & \\
\hline CHEMBL1504229 & 688171 & 4.65 & 4.7958 & TST & \\
\hline CHEMBL1387534 & 688171 & 4.45 & 4.8694 & TRN & \\
\hline CHEMBL1370871 & 688171 & 4.65 & 4.8812 & TST & \\
\hline CHEMBL1336441 & 688171 & 4.4 & 4.9357 & TRN & \\
\hline CHEMBL1314834 & 688171 & 4.8 & 4.9572 & TRN & \\
\hline CHEMBL365161 & 688171 & 4.45 & 4.7998 & TST & \\
\hline CHEMBL3191806 & 688171 & 4.95 & 4.8499 & TRN & \\
\hline CHEMBL1604351 & 688171 & 6.8 & 4.8285 & TST & \\
\hline CHEMBL1480340 & 688171 & 5.75 & 4.9263 & TRN & \\
\hline CHEMBL1551538 & 688171 & 4.6 & 4.8191 & TRN & \\
\hline CHEMBL1443982 & 688171 & 4.8 & 4.9226 & TRN & \\
\hline CHEMBL1397214 & 688171 & 4.85 & 4.8647 & TRN & \\
\hline CHEMBL3192259 & 688171 & 5.05 & 4.9454 & TRN & \\
\hline CHEMBL209793 & 688171 & 4.8 & 4.7519 & TRN & \\
\hline
\end{tabular}




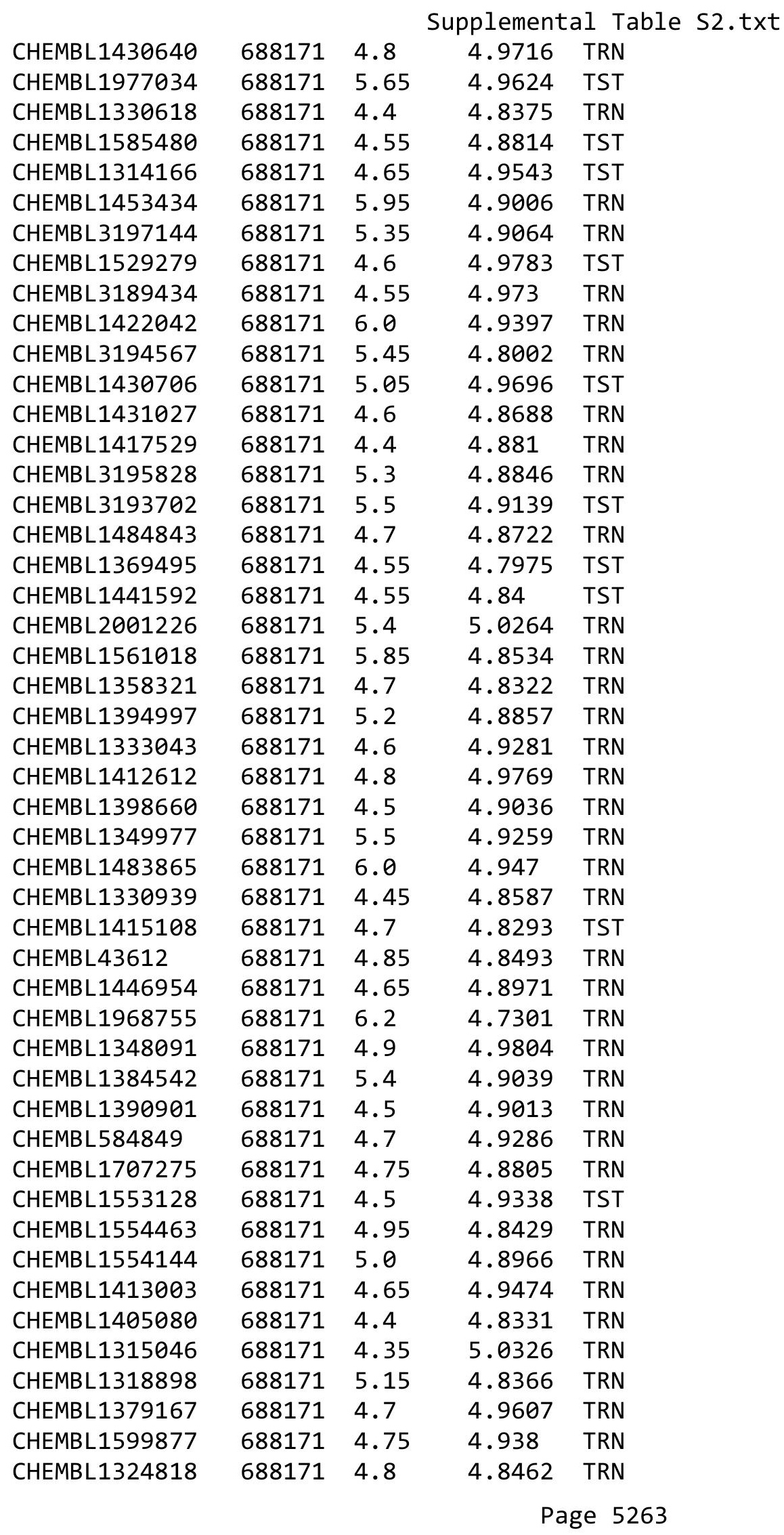




\begin{tabular}{|c|c|c|c|c|c|}
\hline & & \multicolumn{4}{|c|}{ Supplemental Table S2.txt } \\
\hline CHEMBL1416173 & 688171 & 7.5498 & 4.912 & TRN & \\
\hline CHEMBL1471841 & 688171 & 4.6 & 5.0249 & TRN & \\
\hline CHEMBL1513791 & 688171 & 4.9 & 4.8333 & TRN & \\
\hline CHEMBL1590950 & 688171 & 4.9 & 4.944 & TRN & \\
\hline CHEMBL1554909 & 688171 & 4.55 & 4.9132 & TRN & \\
\hline CHEMBL1585645 & 688171 & 4.4 & 4.841 & TST & \\
\hline CHEMBL173530 & 688171 & 6.0 & 4.9223 & TRN & \\
\hline CHEMBL1590893 & 688171 & 5.0 & 4.9574 & TRN & \\
\hline CHEMBL1525944 & 688171 & 4.35 & 5.1766 & TRN & \\
\hline CHEMBL1423842 & 688171 & 4.55 & 4.8232 & TST & \\
\hline CHEMBL1459681 & 688171 & 4.4 & 4.96899 & 9999999999 & TRN \\
\hline CHEMBL1416996 & 688171 & 4.9 & 4.7929 & TRN & \\
\hline CHEMBL1578335 & 688171 & 6.9 & 4.9866 & TRN & \\
\hline CHEMBL1362863 & 688171 & 5.0 & 4.9615 & TRN & \\
\hline CHEMBL1365416 & 688171 & 4.65 & 4.7982 & TRN & \\
\hline CHEMBL1370700 & 688171 & 7.6003 & 5.0482 & TRN & \\
\hline CHEMBL1465059 & 688171 & 4.5 & 4.9369 & TRN & \\
\hline CHEMBL1495948 & 688171 & 4.55 & 4.8592 & TST & \\
\hline CHEMBL1467791 & 688171 & 4.75 & 4.7705 & TRN & \\
\hline CHEMBL1362675 & 688171 & 5.05 & 4.9427 & TRN & \\
\hline CHEMBL1597733 & 688171 & 4.55 & 4.856 & TRN & \\
\hline CHEMBL1438240 & 688171 & 5.1 & 5.0495 & TRN & \\
\hline CHEMBL1567248 & 688171 & 4.4 & 4.9055 & TRN & \\
\hline CHEMBL1322076 & 688171 & 5.05 & 4.9386 & TRN & \\
\hline CHEMBL1528294 & 688171 & 4.45 & 4.8338 & TRN & \\
\hline CHEMBL1520853 & 688171 & 4.4 & 4.9365 & TRN & \\
\hline CHEMBL1970780 & 688171 & 4.7 & 5.0069 & TRN & \\
\hline CHEMBL1352616 & 688171 & 4.4 & 4.8634 & TRN & \\
\hline CHEMBL1459330 & 688171 & 4.55 & 4.8413 & TST & \\
\hline CHEMBL1571331 & 688171 & 4.7 & 5.0962 & TRN & \\
\hline CHEMBL1576094 & 688171 & 4.55 & 4.7034 & TRN & \\
\hline CHEMBL1461246 & 688171 & 4.8 & 4.875 & TRN & \\
\hline CHEMBL1397028 & 688171 & 4.85 & 4.9375 & TRN & \\
\hline CHEMBL1521098 & 688171 & 4.7 & 4.9465 & TST & \\
\hline CHEMBL1548174 & 688171 & 4.6 & 4.9934 & TRN & \\
\hline CHEMBL1409697 & 688171 & 5.1 & 4.9568 & TRN & \\
\hline CHEMBL1581553 & 688171 & 4.35 & 4.9056 & TRN & \\
\hline CHEMBL1437953 & 688171 & 5.35 & 4.7313 & TRN & \\
\hline CHEMBL1326061 & 688171 & 4.95 & 4.8548 & TRN & \\
\hline CHEMBL3193859 & 688171 & 4.4 & 4.922 & TST & \\
\hline CHEMBL1493778 & 688171 & 4.4 & 4.8492 & TRN & \\
\hline CHEMBL1401957 & 688171 & 4.6 & 4.9633 & TRN & \\
\hline CHEMBL1612358 & 688171 & 4.7 & 4.94 & TRN & \\
\hline CHEMBL1422159 & 688171 & 4.4 & 4.9154 & TST & \\
\hline CHEMBL1542296 & 688171 & 4.95 & 4.9855 & TRN & \\
\hline CHEMBL1465006 & 688171 & 4.45 & 4.8863 & TST & \\
\hline CHEMBL3193468 & 688171 & 5.7 & 4.9999 & TRN & \\
\hline CHEMBL1451720 & 688171 & 4.55 & 4.8943 & TRN & \\
\hline
\end{tabular}




\begin{tabular}{|c|c|c|c|c|c|}
\hline \multicolumn{6}{|c|}{ Supplemental Table S2.txt } \\
\hline CHEMBL1453180 & 688171 & 4.5 & 4.8512 & TRN & \\
\hline CHEMBL 2003621 & 688171 & 7.2503 & 4.9225 & TST & \\
\hline CHEMBL1431198 & 688171 & 4.55 & 4.8278 & TRN & \\
\hline CHEMBL1610332 & 688171 & 4.9 & 4.773 & TRN & \\
\hline CHEMBL1358308 & 688171 & 4.85 & 4.7854 & TRN & \\
\hline CHEMBL1540209 & 688171 & 4.75 & 4.9032 & TRN & \\
\hline CHEMBL1475043 & 688171 & 4.8 & 4.9686 & TRN & \\
\hline CHEMBL566707 & 688171 & 5.9 & 4.9803 & TST & \\
\hline CHEMBL1377243 & 688171 & 5.05 & 4.9263 & TRN & \\
\hline CHEMBL1395692 & 688171 & 6.0 & 4.973 & TRN & \\
\hline CHEMBL1354606 & 688171 & 5.5 & 4.9351 & TRN & \\
\hline CHEMBL3197332 & 688171 & 4.4 & 4.9622 & TRN & \\
\hline CHEMBL1323431 & 688171 & 4.5 & 4.9304 & TST & \\
\hline CHEMBL1486073 & 688171 & 4.95 & 5.0463 & TRN & \\
\hline CHEMBL1373352 & 688171 & 4.6 & 4.7812 & TRN & \\
\hline CHEMBL1593798 & 688171 & 4.55 & 4.8991 & TRN & \\
\hline CHEMBL1608035 & 688171 & 4.5 & 4.7641 & TRN & \\
\hline CHEMBL1549926 & 688171 & 4.4 & 4.8505 & TRN & \\
\hline CHEMBL1599593 & 688171 & 4.8 & 4.7988 & TRN & \\
\hline CHEMBL1604510 & 688171 & 6.0 & 4.7839 & TRN & \\
\hline CHEMBL1576416 & 688171 & 4.95 & 5.0284 & TST & \\
\hline CHEMBL1309745 & 688171 & 4.35 & 4.9606 & TST & \\
\hline CHEMBL1440844 & 688171 & 6.0 & 4.9742 & TST & \\
\hline CHEMBL1592229 & 688171 & 5.05 & 5.0113 & TST & \\
\hline CHEMBL3198227 & 688171 & 5.25 & 5.0082 & TRN & \\
\hline CHEMBL313737 & 688171 & 4.9 & 4.8697 & TST & \\
\hline CHEMBL1526471 & 688171 & 4.4 & 4.8091 & TRN & \\
\hline CHEMBL1388565 & 688171 & 4.55 & 4.857 & TRN & \\
\hline CHEMBL1426860 & 688171 & 4.8 & 4.9318 & TST & \\
\hline CHEMBL1557655 & 688171 & 4.55 & 4.9354 & TRN & \\
\hline CHEMBL1579367 & 688171 & 4.7 & 4.872 & TST & \\
\hline CHEMBL1334548 & 688171 & 7.1002 & 4.8516 & TRN & \\
\hline CHEMBL1513412 & 688171 & 6.05 & 4.7983 & TRN & \\
\hline CHEMBL1330788 & 688171 & 4.6 & 4.9322 & TRN & \\
\hline CHEMBL1367908 & 688171 & 4.55 & 4.8156 & TRN & \\
\hline CHEMBL1474513 & 688171 & 4.55 & 4.9477 & TRN & \\
\hline CHEMBL1312608 & 688171 & 4.95 & 5.0083 & TRN & \\
\hline CHEMBL355832 & 688171 & 4.75 & 4.76699 & 99999999995 & TRN \\
\hline CHEMBL1579292 & 688171 & 4.4 & 4.9103 & TRN & \\
\hline CHEMBL1412914 & 688171 & 4.8 & 4.8713 & TRN & \\
\hline CHEMBL1436919 & 688171 & 4.95 & 4.927 & TRN & \\
\hline CHEMBL1459983 & 688171 & 7.6003 & 4.9695 & TRN & \\
\hline CHEMBL1433882 & 688171 & 4.6 & 4.8787 & TRN & \\
\hline CHEMBL1399721 & 688171 & 4.4 & 4.8924 & TST & \\
\hline CHEMBL1458731 & 688171 & 4.8 & 4.9875 & TRN & \\
\hline CHEMBL1316323 & 688171 & 4.8 & 4.9188 & TRN & \\
\hline CHEMBL1591996 & 688171 & 4.45 & 4.7932 & TRN & \\
\hline CHEMBL1568611 & 688171 & 5.1 & 4.8867 & TRN & \\
\hline
\end{tabular}




\begin{tabular}{|c|c|c|c|c|c|}
\hline \multicolumn{6}{|c|}{ Supplemental Table S2.txt } \\
\hline CHEMBL1443237 & 688171 & 5.05 & 4.9009 & TST & \\
\hline CHEMBL1302293 & 688171 & 4.85 & 4.8731 & TRN & \\
\hline CHEMBL1477041 & 688171 & 5.05 & 4.8967 & TST & \\
\hline CHEMBL1377522 & 688171 & 4.75 & 4.8599 & TST & \\
\hline CHEMBL3208378 & 688171 & 5.7 & 4.9966 & TRN & \\
\hline CHEMBL1331834 & 688171 & 4.7 & 4.8431 & TRN & \\
\hline CHEMBL95606 & 688171 & 5.7 & 4.9239 & TRN & \\
\hline CHEMBL1555298 & 688171 & 4.9 & 4.8789 & TRN & \\
\hline CHEMBL1982441 & 688171 & 5.25 & 4.9052 & TRN & \\
\hline CHEMBL1437500 & 688171 & 5.6 & 4.8734 & TRN & \\
\hline CHEMBL1448251 & 688171 & 4.55 & 4.82600 & 00000000005 & TRN \\
\hline CHEMBL1312707 & 688171 & 4.45 & 4.9974 & TRN & \\
\hline CHEMBL1562928 & 688171 & 7.2503 & 4.8939 & TST & \\
\hline CHEMBL1442826 & 688171 & 5.75 & 4.865 & TRN & \\
\hline CHEMBL1597702 & 688171 & 6.2 & 5.0615 & TST & \\
\hline CHEMBL1434332 & 688171 & 4.4 & 4.9076 & TRN & \\
\hline CHEMBL1354733 & 688171 & 4.4 & 4.9413 & TRN & \\
\hline CHEMBL1523233 & 688171 & 6.0 & 4.8022 & TST & \\
\hline CHEMBL3191818 & 688171 & 4.7 & 4.7397 & TRN & \\
\hline CHEMBL1304697 & 688171 & 4.5 & 4.7937 & TRN & \\
\hline CHEMBL271023 & 688171 & 5.35 & 4.8391 & TST & \\
\hline CHEMBL3189801 & 688171 & 4.95 & 5.0433 & TRN & \\
\hline CHEMBL1306490 & 688171 & 6.05 & 4.8422 & TST & \\
\hline CHEMBL1592611 & 688171 & 4.4 & 4.8355 & TRN & \\
\hline CHEMBL1376311 & 688171 & 4.4 & 4.7905 & TRN & \\
\hline CHEMBL1391041 & 688171 & 4.75 & 4.7463 & TRN & \\
\hline CHEMBL1543543 & 688171 & 5.5 & 4.8375 & TRN & \\
\hline CHEMBL3213019 & 688171 & 5.65 & 5.0721 & TRN & \\
\hline CHEMBL1556930 & 688171 & 6.1 & 4.9832 & TRN & \\
\hline CHEMBL1552215 & 688171 & 4.5 & 4.8542 & TRN & \\
\hline CHEMBL1554963 & 688171 & 4.85 & 5.1094 & TRN & \\
\hline CHEMBL1440021 & 688171 & 5.5 & 5.0775 & TRN & \\
\hline CHEMBL1543210 & 688171 & 4.35 & 4.8005 & TRN & \\
\hline CHEMBL1601756 & 688171 & 5.45 & 4.9882 & TRN & \\
\hline CHEMBL1482613 & 688171 & 4.75 & 5.0113 & TRN & \\
\hline CHEMBL1580757 & 688171 & 5.1 & 4.7991 & TRN & \\
\hline CHEMBL1553009 & 688171 & 4.65 & 4.7774 & TRN & \\
\hline CHEMBL1552404 & 688171 & 4.75 & 4.8083 & TRN & \\
\hline CHEMBL1435945 & 688171 & 4.7 & 4.92899 & 9999999999 & TRN \\
\hline CHEMBL1445333 & 688171 & 4.75 & 5.0609 & TRN & \\
\hline CHEMBL3210019 & 688171 & 4.35 & 4.8757 & TST & \\
\hline CHEMBL1593393 & 688171 & 6.35 & 4.9484 & TRN & \\
\hline CHEMBL1496955 & 688171 & 4.55 & 5.0729 & TRN & \\
\hline CHEMBL1414867 & 688171 & 4.95 & 4.8671 & TRN & \\
\hline CHEMBL1552198 & 688171 & 7.15 & 4.9219 & TRN & \\
\hline CHEMBL1513190 & 688171 & 4.55 & 4.9016 & TRN & \\
\hline CHEMBL1473400 & 688171 & 4.4 & 4.8089 & TRN & \\
\hline CHEMBL1604638 & 688171 & 4.4 & 4.8293 & TRN & \\
\hline
\end{tabular}




\begin{tabular}{|c|c|c|c|c|c|}
\hline & & \multicolumn{4}{|c|}{ Supplemental Table S2.txt } \\
\hline CHEMBL1994803 & 688171 & 5.25 & 4.9227 & TRN & \\
\hline CHEMBL1368867 & 688171 & 5.0 & 4.9831 & TRN & \\
\hline CHEMBL1381644 & 688171 & 4.35 & 4.8354 & TST & \\
\hline CHEMBL1365090 & 688171 & 4.35 & 4.9133 & TRN & \\
\hline CHEMBL1424134 & 688171 & 4.8 & 4.9661 & TRN & \\
\hline CHEMBL1417268 & 688171 & 5.4 & 5.0185 & TST & \\
\hline CHEMBL1444606 & 688171 & 4.6 & 4.9319 & TRN & \\
\hline CHEMBL1337280 & 688171 & 5.05 & 4.8847 & TRN & \\
\hline CHEMBL3196071 & 688171 & 4.45 & 4.9412 & TRN & \\
\hline CHEMBL1316988 & 688171 & 4.85 & 4.898 & TRN & \\
\hline CHEMBL1530872 & 688171 & 4.55 & 4.8832 & TRN & \\
\hline CHEMBL1439913 & 688171 & 4.35 & 4.9537 & TRN & \\
\hline CHEMBL1438775 & 688171 & 5.1 & 4.8281 & TST & \\
\hline CHEMBL3190793 & 688171 & 5.45 & 4.9897 & TST & \\
\hline CHEMBL1363505 & 688171 & 6.45 & 4.8928 & TRN & \\
\hline CHEMBL3208974 & 688171 & 5.2 & 4.9868 & TRN & \\
\hline CHEMBL1602811 & 688171 & 4.8 & 4.8894 & TRN & \\
\hline CHEMBL1313945 & 688171 & 4.55 & 4.813 & TST & \\
\hline CHEMBL1512043 & 688171 & 4.85 & 4.8527 & TRN & \\
\hline CHEMBL1331380 & 688171 & 4.8 & 4.9373 & TRN & \\
\hline CHEMBL1595433 & 688171 & 4.4 & 4.9009 & TRN & \\
\hline CHEMBL1495586 & 688171 & 5.05 & 4.9559 & TRN & \\
\hline CHEMBL1321564 & 688171 & 4.6 & 4.7876 & TRN & \\
\hline CHEMBL1358374 & 688171 & 4.9 & 4.7042 & TRN & \\
\hline CHEMBL1502381 & 688171 & 4.95 & 4.9396 & TST & \\
\hline CHEMBL1402358 & 688171 & 5.45 & 4.9227 & TST & \\
\hline CHEMBL1597710 & 688171 & 5.5 & 4.9525 & TST & \\
\hline CHEMBL1480610 & 688171 & 6.45 & 4.9886 & TRN & \\
\hline CHEMBL1589992 & 688171 & 6.15 & 5.0473 & TRN & \\
\hline CHEMBL3214061 & 688171 & 4.75 & 5.0163 & TRN & \\
\hline CHEMBL1572968 & 688171 & 5.75 & 4.88899 & 9999999999 & TRN \\
\hline CHEMBL1375452 & 688171 & 4.9 & 4.9856 & TST & \\
\hline CHEMBL1515224 & 688171 & 5.2 & 4.8152 & TRN & \\
\hline CHEMBL1322082 & 688171 & 4.6 & 4.7836 & TRN & \\
\hline CHEMBL1403779 & 688171 & 5.3 & 4.9249 & TRN & \\
\hline CHEMBL1460380 & 688171 & 5.55 & 5.0551 & TST & \\
\hline CHEMBL1401406 & 688171 & 5.0 & 4.9318 & TRN & \\
\hline CHEMBL1551442 & 688171 & 4.65 & 4.8293 & TRN & \\
\hline CHEMBL1398752 & 688171 & 4.55 & 4.7877 & TRN & \\
\hline CHEMBL1516339 & 688171 & 5.15 & 4.9053 & TRN & \\
\hline CHEMBL17551 & 688171 & 5.0 & 4.8722 & TST & \\
\hline CHEMBL1173283 & 688171 & 4.95 & 4.8887 & TRN & \\
\hline CHEMBL1409444 & 688171 & 4.4 & 4.8612 & TRN & \\
\hline CHEMBL1497208 & 688171 & 4.55 & 4.9069 & TRN & \\
\hline CHEMBL1477024 & 688171 & 5.25 & 5.0577 & TRN & \\
\hline CHEMBL1470542 & 688171 & 5.45 & 4.8385 & TRN & \\
\hline CHEMBL1433518 & 688171 & 5.0 & 4.8783 & TRN & \\
\hline CHEMBL1406498 & 688171 & 5.05 & 4.8949 & TRN & \\
\hline
\end{tabular}




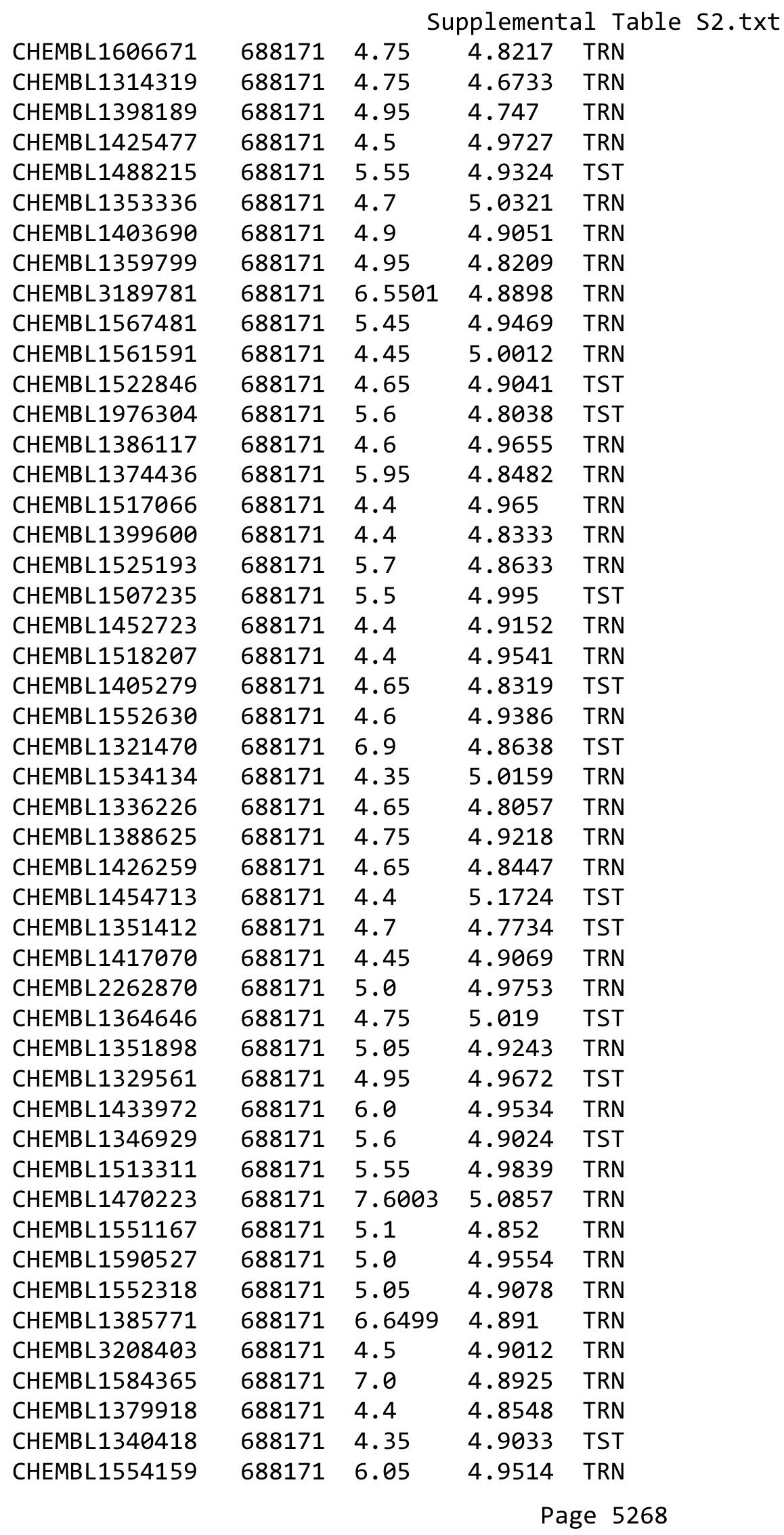




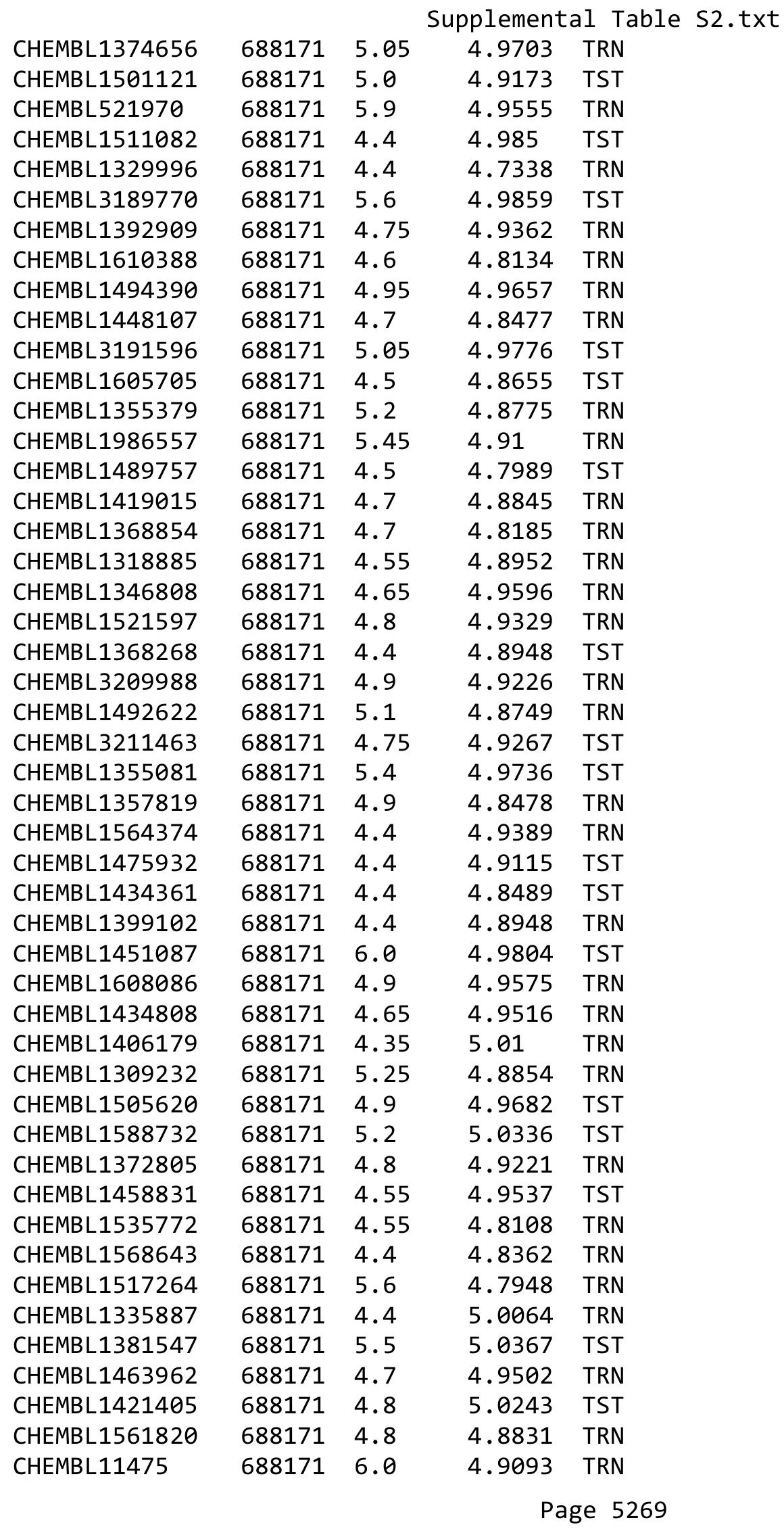




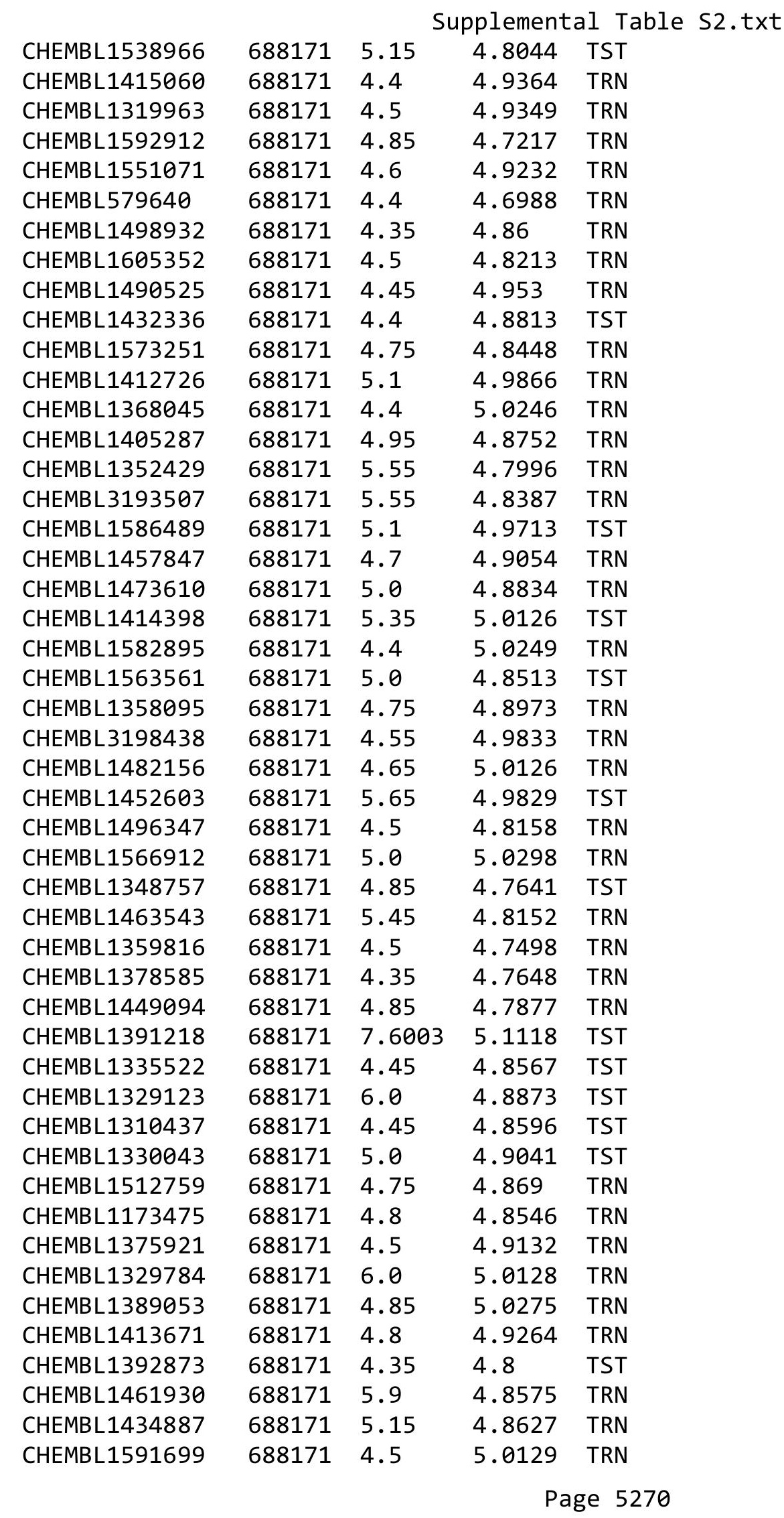




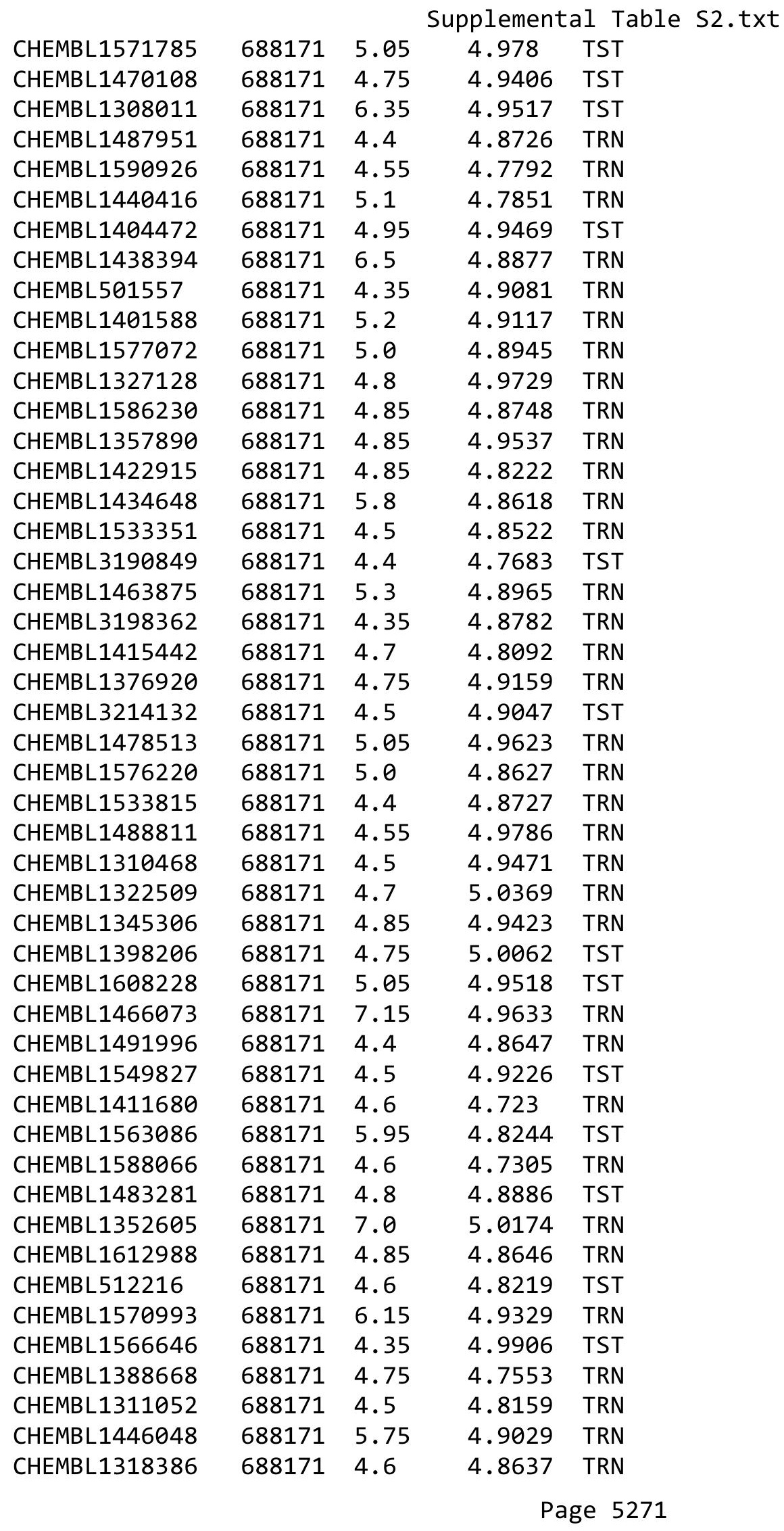




\begin{tabular}{|c|c|c|c|c|}
\hline \multicolumn{5}{|c|}{ Supplemental Table s2.txt } \\
\hline CHEMBL1499324 & 688171 & 5.3 & 4.9271 & TST \\
\hline CHEMBL1514594 & 688171 & 5.45 & 4.9575 & TRN \\
\hline CHEMBL1523971 & 688171 & 5.5 & 4.9923 & TRN \\
\hline CHEMBL1397352 & 688171 & 4.75 & 4.8436 & TRN \\
\hline CHEMBL1353623 & 688171 & 5.05 & 4.7585 & TRN \\
\hline CHEMBL1366145 & 688171 & 4.95 & 4.8229 & TRN \\
\hline CHEMBL1300338 & 688171 & 4.75 & 5.0056 & TRN \\
\hline CHEMBL1422557 & 688171 & 6.8 & 5.0352 & TST \\
\hline CHEMBL1568434 & 688171 & 5.65 & 4.9904 & TST \\
\hline CHEMBL1529232 & 688171 & 5.0 & 4.9681 & TRN \\
\hline CHEMBL1587838 & 688171 & 4.9 & 4.9922 & TST \\
\hline CHEMBL1597567 & 688171 & 4.6 & 4.9524 & TRN \\
\hline CHEMBL1555536 & 688171 & 5.55 & 4.9345 & TRN \\
\hline CHEMBL1304866 & 688171 & 5.5 & 4.9203 & TST \\
\hline CHEMBL1383456 & 688171 & 6.15 & 5.1121 & TRN \\
\hline CHEMBL1453763 & 688171 & 4.4 & 4.8745 & TRN \\
\hline CHEMBL1543881 & 688171 & 5.1 & 4.9039 & TRN \\
\hline CHEMBL1301722 & 688171 & 6.0 & 4.7345 & TST \\
\hline CHEMBL1373927 & 688171 & 4.5 & 4.9726 & TST \\
\hline CHEMBL1411419 & 688171 & 4.45 & 4.9973 & TRN \\
\hline CHEMBL1331802 & 688171 & 4.7 & 4.8561 & TST \\
\hline CHEMBL1370286 & 688171 & 4.4 & 4.9496 & TRN \\
\hline CHEMBL1541035 & 688171 & 4.9 & 4.9202 & TST \\
\hline CHEMBL1317110 & 688171 & 4.95 & 4.8423 & TRN \\
\hline CHEMBL1432427 & 688171 & 4.35 & 5.0168 & TRN \\
\hline CHEMBL1480943 & 688171 & 4.35 & 4.8482 & TST \\
\hline CHEMBL1318718 & 688171 & 4.75 & 4.8507 & TST \\
\hline CHEMBL1593769 & 688171 & 6.05 & 5.0297 & TST \\
\hline CHEMBL1394694 & 688171 & 4.85 & 4.8437 & TRN \\
\hline CHEMBL1369072 & 688171 & 4.75 & 4.8892 & TRN \\
\hline CHEMBL1566729 & 688171 & 4.85 & 4.8157 & TRN \\
\hline CHEMBL1551050 & 688171 & 4.6 & 4.8682 & TRN \\
\hline CHEMBL1398222 & 688171 & 4.45 & 4.8675 & TRN \\
\hline CHEMBL1561439 & 688171 & 4.95 & 5.0149 & TRN \\
\hline CHEMBL1450084 & 688171 & 4.8 & 4.8763 & TST \\
\hline CHEMBL1523125 & 688171 & 4.9 & 5.0259 & TRN \\
\hline CHEMBL1400392 & 688171 & 4.75 & 4.8901 & TRN \\
\hline CHEMBL 3213622 & 688171 & 4.7 & 4.8372 & TRN \\
\hline CHEMBL1437367 & 688171 & 4.4 & 4.901 & TRN \\
\hline CHEMBL1484152 & 688171 & 4.4 & 4.8936 & TRN \\
\hline CHEMBL1326779 & 688171 & 4.65 & 4.9218 & TST \\
\hline CHEMBL17201 & 688171 & 5.1 & 4.8968 & TRN \\
\hline CHEMBL1316696 & 688171 & 4.55 & 4.9034 & TRN \\
\hline CHEMBL1448646 & 688171 & 4.8 & 4.862 & TRN \\
\hline CHEMBL1604276 & 688171 & 4.5 & 4.7928 & TRN \\
\hline CHEMBL1502416 & 688171 & 5.5 & 4.8667 & TRN \\
\hline CHEMBL1354894 & 688171 & 4.65 & 4.9328 & TRN \\
\hline CHEMBL876 & 688171 & 4.4 & 4.9356 & TST \\
\hline
\end{tabular}




\begin{tabular}{|c|c|c|c|c|c|}
\hline \multicolumn{6}{|c|}{ Supplemental Table S2.txt } \\
\hline CHEMBL1413133 & 688171 & 4.95 & 4.9788 & TST & \\
\hline CHEMBL1475102 & 688171 & 5.05 & 4.9771 & TST & \\
\hline CHEMBL1435858 & 688171 & 4.9 & 4.7362 & TRN & \\
\hline CHEMBL1354428 & 688171 & 4.4 & 4.9632 & TRN & \\
\hline CHEMBL1584567 & 688171 & 4.4 & 4.8368 & TRN & \\
\hline CHEMBL1498096 & 688171 & 4.4 & 4.7547 & TRN & \\
\hline CHEMBL1359064 & 688171 & 5.9 & 5.0959 & TRN & \\
\hline CHEMBL1585938 & 688171 & 4.4 & 4.9354 & TST & \\
\hline CHEMBL1546139 & 688171 & 5.0 & 4.9141 & TST & \\
\hline CHEMBL1373182 & 688171 & 4.4 & 5.0362 & TST & \\
\hline CHEMBL1328882 & 688171 & 5.55 & 5.0394 & TRN & \\
\hline CHEMBL1481012 & 688171 & 5.5 & 4.9235 & TRN & \\
\hline CHEMBL1440145 & 688171 & 8.301 & 5.0693 & TRN & \\
\hline CHEMBL1436583 & 688171 & 4.35 & 4.9975 & TST & \\
\hline CHEMBL1722566 & 688171 & 4.7 & 4.8783 & TST & \\
\hline CHEMBL3208718 & 688171 & 4.9 & 4.8991 & TST & \\
\hline CHEMBL3191846 & 688171 & 5.05 & 5.03100 & 0000000001 & TRN \\
\hline CHEMBL1580736 & 688171 & 4.5 & 4.7383 & TST & \\
\hline CHEMBL1975191 & 688171 & 5.4 & 4.9123 & TRN & \\
\hline CHEMBL1361800 & 688171 & 4.6 & 4.9282 & TRN & \\
\hline CHEMBL1498693 & 688171 & 4.9 & 4.8639 & TRN & \\
\hline CHEMBL1476197 & 688171 & 6.3 & 4.8805 & TRN & \\
\hline CHEMBL3189663 & 688171 & 4.45 & 4.9266 & TRN & \\
\hline CHEMBL1376723 & 688171 & 4.75 & 4.8016 & TST & \\
\hline CHEMBL1330184 & 688171 & 4.5 & 4.9282 & TRN & \\
\hline CHEMBL1579958 & 688171 & 5.75 & 4.965 & TRN & \\
\hline CHEMBL1555294 & 688171 & 4.85 & 4.8251 & TRN & \\
\hline CHEMBL1478547 & 688171 & 4.5 & 4.7847 & TRN & \\
\hline CHEMBL1429094 & 688171 & 4.65 & 4.7856 & TRN & \\
\hline CHEMBL1389895 & 688171 & 5.45 & 4.8553 & TST & \\
\hline CHEMBL1609386 & 688171 & 5.35 & 4.8962 & TRN & \\
\hline CHEMBL1997837 & 688171 & 5.9 & 4.8778 & TRN & \\
\hline CHEMBL1588730 & 688171 & 4.75 & 4.9061 & TRN & \\
\hline CHEMBL1476387 & 688171 & 4.75 & 4.953 & TRN & \\
\hline CHEMBL1599288 & 688171 & 6.6499 & 4.9591 & TRN & \\
\hline CHEMBL1525533 & 688171 & 4.4 & 4.7532 & TRN & \\
\hline CHEMBL1384304 & 688171 & 4.45 & 4.9702 & TRN & \\
\hline CHEMBL1439000 & 688171 & 4.4 & 4.8342 & TRN & \\
\hline CHEMBL1355803 & 688171 & 6.7501 & 4.9764 & TRN & \\
\hline CHEMBL1550028 & 688171 & 5.5 & 4.7296 & TST & \\
\hline CHEMBL1505916 & 688171 & 4.4 & 4.9902 & TRN & \\
\hline CHEMBL1589145 & 688171 & 6.05 & 4.9283 & TRN & \\
\hline CHEMBL1524152 & 688171 & 4.65 & 4.813 & TRN & \\
\hline CHEMBL1968732 & 688171 & 4.85 & 4.7794 & TRN & \\
\hline CHEMBL1598826 & 688171 & 4.75 & 4.9671 & TRN & \\
\hline CHEMBL15134 & 688171 & 4.4 & 4.9802 & TST & \\
\hline CHEMBL1325375 & 688171 & 4.85 & 4.9039 & TRN & \\
\hline CHEMBL1318778 & 688171 & 4.5 & 4.8486 & TRN & \\
\hline
\end{tabular}




\begin{tabular}{|c|c|c|c|c|}
\hline \multicolumn{5}{|c|}{ Supplemental Table } \\
\hline CHEMBL1306132 & 688171 & 4.65 & 4.9352 & TST \\
\hline CHEMBL1606940 & 688171 & 4.4 & 4.9026 & TRN \\
\hline CHEMBL1388553 & 688171 & 4.4 & 5.0213 & TST \\
\hline CHEMBL495991 & 688171 & 4.4 & 4.8855 & TRN \\
\hline CHEMBL1415241 & 688171 & 5.0 & 4.9219 & TRN \\
\hline CHEMBL1327365 & 688171 & 5.35 & 5.003 & TST \\
\hline CHEMBL1608078 & 688171 & 4.65 & 4.8606 & TRN \\
\hline CHEMBL1503241 & 688171 & 4.6 & 4.8937 & TST \\
\hline CHEMBL1363901 & 688171 & 4.65 & 4.925 & TRN \\
\hline CHEMBL1592826 & 688171 & 4.4 & 4.7768 & TST \\
\hline CHEMBL1421081 & 688171 & 7.2 & 4.8299 & TRN \\
\hline CHEMBL1436730 & 688171 & 5.75 & 4.8225 & TRN \\
\hline CHEMBL1436433 & 688171 & 5.0 & 4.8468 & TRN \\
\hline CHEMBL1493896 & 688171 & 4.65 & 4.8857 & TRN \\
\hline CHEMBL1468934 & 688171 & 4.75 & 4.9966 & TST \\
\hline CHEMBL1358941 & 688171 & 5.4 & 4.8659 & TRN \\
\hline CHEMBL1300823 & 688171 & 4.4 & 5.0233 & TRN \\
\hline CHEMBL1503743 & 688171 & 5.05 & 4.9411 & TRN \\
\hline CHEMBL1479685 & 688171 & 4.45 & 4.92 & TRN \\
\hline CHEMBL1469737 & 688171 & 4.9 & 4.9379 & TST \\
\hline CHEMBL1406905 & 688171 & 4.45 & 4.8958 & TRN \\
\hline CHEMBL1356623 & 688171 & 6.2 & 5.0589 & TST \\
\hline CHEMBL1299889 & 688171 & 4.6 & 4.9833 & TRN \\
\hline CHEMBL1535321 & 688171 & 4.35 & 4.9421 & TRN \\
\hline CHEMBL1373659 & 688171 & 4.85 & 4.9201 & TRN \\
\hline CHEMBL1439020 & 688171 & 4.75 & 4.8025 & TRN \\
\hline CHEMBL1588291 & 688171 & 4.85 & 4.8615 & TRN \\
\hline CHEMBL1348576 & 688171 & 5.4 & 4.9138 & TRN \\
\hline CHEMBL1541367 & 688171 & 5.5 & 5.0366 & TST \\
\hline CHEMBL1343758 & 688171 & 5.15 & 4.9379 & TRN \\
\hline CHEMBL 2374054 & 688171 & 4.4 & 5.0172 & TST \\
\hline CHEMBL1355835 & 688171 & 4.4 & 4.9351 & TRN \\
\hline CHEMBL1461427 & 688171 & 4.4 & 4.8031 & TRN \\
\hline CHEMBL1317292 & 688171 & 5.4 & 4.9833 & TRN \\
\hline CHEMBL1317612 & 688171 & 4.4 & 4.8295 & TRN \\
\hline CHEMBL1472746 & 688171 & 4.6 & 5.0244 & TST \\
\hline CHEMBL1474833 & 688171 & 4.4 & 4.9487 & TRN \\
\hline CHEMBL1363799 & 688171 & 4.4 & 4.9938 & TRN \\
\hline CHEMBL3195481 & 688171 & 6.5 & 5.0318 & TST \\
\hline CHEMBL1386048 & 688171 & 5.55 & 4.8688 & TRN \\
\hline CHEMBL1431677 & 688171 & 4.55 & 4.7624 & TRN \\
\hline CHEMBL1476221 & 688171 & 4.6 & 4.8184 & TRN \\
\hline CHEMBL1520993 & 688171 & 4.5 & 4.8916 & TRN \\
\hline CHEMBL1493147 & 688171 & 4.5 & 4.8085 & TST \\
\hline CHEMBL1470193 & 688171 & 4.55 & 5.0624 & TRN \\
\hline CHEMBL1316068 & 688171 & 4.95 & 4.913 & TRN \\
\hline CHEMBL3189615 & 688171 & 4.75 & 5.029 & TRN \\
\hline CHEMBL1535895 & 688171 & 4.8 & 4.8546 & TRN \\
\hline
\end{tabular}




\begin{tabular}{|c|c|c|c|c|}
\hline \multicolumn{5}{|c|}{ Supplemental Table S2.txt } \\
\hline CHEMBL1358179 & 688171 & 4.8 & 4.8812 & TRN \\
\hline CHEMBL1522961 & 688171 & 4.4 & 5.0472 & TRN \\
\hline CHEMBL1992801 & 688171 & 4.45 & 4.8836 & TST \\
\hline CHEMBL1421555 & 688171 & 5.05 & 4.8539 & TRN \\
\hline CHEMBL371523 & 688171 & 5.05 & 4.9488 & TRN \\
\hline CHEMBL1318065 & 688171 & 4.9 & 4.981 & TRN \\
\hline CHEMBL1532234 & 688171 & 4.6 & 4.8359 & TST \\
\hline CHEMBL1362448 & 688171 & 5.05 & 4.8647 & TST \\
\hline CHEMBL1553770 & 688171 & 4.9 & 4.9929 & TRN \\
\hline CHEMBL1452741 & 688171 & 4.75 & 4.8967 & TRN \\
\hline CHEMBL1347084 & 688171 & 5.05 & 4.9053 & TRN \\
\hline CHEMBL1612712 & 688171 & 4.5 & 4.83 & TRN \\
\hline CHEMBL1499092 & 688171 & 4.95 & 4.9207 & TRN \\
\hline CHEMBL1725983 & 688171 & 6.45 & 4.8709 & TRN \\
\hline CHEMBL1543384 & 688171 & 4.65 & 4.9033 & TST \\
\hline CHEMBL1426660 & 688171 & 4.5 & 4.9341 & TRN \\
\hline CHEMBL1526891 & 688171 & 5.4 & 4.8408 & TRN \\
\hline CHEMBL1407617 & 688171 & 4.65 & 4.8903 & TRN \\
\hline CHEMBL1447744 & 688171 & 5.1 & 4.9069 & TST \\
\hline CHEMBL1404512 & 688171 & 4.9 & 5.0254 & TRN \\
\hline CHEMBL1459310 & 688171 & 4.5 & 4.8617 & TRN \\
\hline CHEMBL1475552 & 688171 & 4.35 & 4.8938 & TRN \\
\hline CHEMBL1453831 & 688171 & 5.05 & 4.9127 & TST \\
\hline CHEMBL1971316 & 688171 & 4.6 & 4.8276 & TST \\
\hline CHEMBL1444601 & 688171 & 4.6 & 4.8074 & TST \\
\hline CHEMBL1393251 & 688171 & 4.4 & 4.8731 & TRN \\
\hline CHEMBL1350104 & 688171 & 4.35 & 4.8167 & TRN \\
\hline CHEMBL1534173 & 688171 & 4.8 & 4.8803 & TRN \\
\hline CHEMBL1523469 & 688171 & 4.35 & 4.948 & TST \\
\hline CHEMBL1448747 & 688171 & 5.85 & 4.9121 & TRN \\
\hline CHEMBL1451650 & 688171 & 5.1 & 4.9758 & TRN \\
\hline CHEMBL1256746 & 688171 & 5.15 & 4.9449 & TST \\
\hline CHEMBL1599825 & 688171 & 4.75 & 4.8647 & TRN \\
\hline CHEMBL1498114 & 688171 & 4.5 & 4.7444 & TRN \\
\hline CHEMBL1434370 & 688171 & 5.6 & 4.9251 & TRN \\
\hline CHEMBL1386932 & 688171 & 6.25 & 4.9758 & TST \\
\hline CHEMBL1606962 & 688171 & 4.65 & 4.7745 & TRN \\
\hline CHEMBL1376183 & 688171 & 5.5 & 4.8025 & TRN \\
\hline CHEMBL1444050 & 688171 & 5.5 & 4.9493 & TRN \\
\hline CHEMBL1368887 & 688171 & 5.45 & 4.9783 & TRN \\
\hline CHEMBL1338027 & 688171 & 4.8 & 4.8695 & TRN \\
\hline CHEMBL1408737 & 688171 & 4.8 & 4.8136 & TST \\
\hline CHEMBL115121 & 688171 & 4.35 & 4.8477 & TST \\
\hline CHEMBL1454540 & 688171 & 4.4 & 4.8492 & TST \\
\hline CHEMBL1528266 & 688171 & 5.0 & 4.8457 & TRN \\
\hline CHEMBL1532827 & 688171 & 4.75 & 4.8524 & TRN \\
\hline CHEMBL1474932 & 688171 & 4.35 & 5.0009 & TRN \\
\hline CHEMBL1455660 & 688171 & 5.05 & 4.8591 & TST \\
\hline
\end{tabular}




\begin{tabular}{|c|c|c|c|c|c|}
\hline & & \multicolumn{4}{|c|}{ Supplemental Table S2.txt } \\
\hline CHEMBL1511784 & 688171 & 4.55 & 4.935 & TRN & \\
\hline CHEMBL1348579 & 688171 & 4.4 & 4.9459 & TRN & \\
\hline CHEMBL1398120 & 688171 & 4.95 & 4.8766 & TRN & \\
\hline CHEMBL1304471 & 688171 & 4.45 & 4.9065 & TRN & \\
\hline CHEMBL1433748 & 688171 & 4.5 & 4.8811 & TRN & \\
\hline CHEMBL1486520 & 688171 & 4.75 & 4.8515 & TRN & \\
\hline CHEMBL1465704 & 688171 & 4.75 & 4.8702 & TRN & \\
\hline CHEMBL1374291 & 688171 & 5.1 & 4.8168 & TRN & \\
\hline CHEMBL1536769 & 688171 & 4.35 & 4.9909 & TST & \\
\hline CHEMBL1492763 & 688171 & 4.65 & 4.8451 & TRN & \\
\hline CHEMBL1473613 & 688171 & 5.95 & 5.1277 & TRN & \\
\hline CHEMBL1408170 & 688171 & 4.7 & 5.024 & TRN & \\
\hline CHEMBL578905 & 688171 & 4.65 & 4.8983 & TRN & \\
\hline CHEMBL102714 & 688171 & 6.0 & 4.713 & TST & \\
\hline CHEMBL1323631 & 688171 & 5.1 & 4.9648 & TRN & \\
\hline CHEMBL1507687 & 688171 & 4.35 & 4.7376 & TRN & \\
\hline CHEMBL1493490 & 688171 & 5.1 & 4.9874 & TST & \\
\hline CHEMBL1357342 & 688171 & 4.75 & 4.8569 & TRN & \\
\hline CHEMBL605077 & 688171 & 5.0 & 4.8213 & TRN & \\
\hline CHEMBL1412105 & 688171 & 5.05 & 4.8488 & TST & \\
\hline CHEMBL1567929 & 688171 & 6.0 & 4.9216 & TRN & \\
\hline CHEMBL1712082 & 688171 & 4.4 & 4.9515 & TST & \\
\hline CHEMBL1531620 & 688171 & 4.4 & 4.9507 & TST & \\
\hline CHEMBL1339765 & 688171 & 5.45 & 4.9476 & TST & \\
\hline CHEMBL1605555 & 688171 & 4.7 & 4.8971 & TRN & \\
\hline CHEMBL1497724 & 688171 & 5.0 & 4.9156 & TST & \\
\hline CHEMBL1521838 & 688171 & 7.2 & 4.7676 & TRN & \\
\hline CHEMBL1397726 & 688171 & 4.75 & 4.9079 & TRN & \\
\hline CHEMBL1392104 & 688171 & 5.0 & 4.9699 & TRN & \\
\hline CHEMBL1317911 & 688171 & 4.8 & 4.966 & TST & \\
\hline CHEMBL1356287 & 688171 & 4.95 & 4.8871 & TRN & \\
\hline CHEMBL 3213813 & 688171 & 4.65 & 4.9761 & TST & \\
\hline CHEMBL1409748 & 688171 & 5.1 & 4.9701 & TRN & \\
\hline CHEMBL1606461 & 688171 & 5.15 & 4.8956 & TRN & \\
\hline CHEMBL1437485 & 688171 & 4.75 & 4.9559 & TRN & \\
\hline CHEMBL1421428 & 688171 & 4.65 & 4.8666 & TRN & \\
\hline CHEMBL1599154 & 688171 & 5.35 & 4.95100 & 00000000005 & TRN \\
\hline CHEMBL1380282 & 688171 & 4.75 & 4.9332 & TST & \\
\hline CHEMBL 1568010 & 688171 & 4.5 & 4.9663 & TRN & \\
\hline CHEMBL1499996 & 688171 & 4.8 & 5.0663 & TRN & \\
\hline CHEMBL1479983 & 688171 & 4.35 & 4.8284 & TRN & \\
\hline CHEMBL1358724 & 688171 & 4.55 & 4.8827 & TRN & \\
\hline CHEMBL1421400 & 688171 & 4.5 & 4.7792 & TST & \\
\hline CHEMBL1344968 & 688171 & 4.75 & 4.9619 & TRN & \\
\hline CHEMBL1370357 & 688171 & 5.45 & 4.9985 & TRN & \\
\hline CHEMBL1526692 & 688171 & 4.85 & 4.8963 & TRN & \\
\hline CHEMBL1555342 & 688171 & 4.75 & 4.8622 & TRN & \\
\hline CHEMBL1561322 & 688171 & 4.4 & 4.9175 & TRN & \\
\hline
\end{tabular}




\begin{tabular}{|c|c|c|c|c|}
\hline \multicolumn{5}{|c|}{ Supplemental Table S2.txt } \\
\hline CHEMBL1379493 & 688171 & 4.5 & 4.8574 & TRN \\
\hline CHEMBL1531103 & 688171 & 4.7 & 4.7444 & TRN \\
\hline CHEMBL1482965 & 688171 & 4.4 & 4.8048 & TRN \\
\hline CHEMBL1395942 & 688171 & 5.2 & 4.877 & TRN \\
\hline CHEMBL1607091 & 688171 & 4.4 & 4.9066 & TRN \\
\hline CHEMBL1593115 & 688171 & 4.7 & 4.8983 & TRN \\
\hline CHEMBL1356958 & 688171 & 5.4 & 4.9733 & TRN \\
\hline CHEMBL1474904 & 688171 & 5.0 & 4.8937 & TRN \\
\hline CHEMBL 3208652 & 688171 & 4.35 & 5.007 & TRN \\
\hline CHEMBL1511274 & 688171 & 5.0 & 4.8894 & TRN \\
\hline CHEMBL1392558 & 688171 & 5.35 & 4.9951 & TRN \\
\hline CHEMBL1378502 & 688171 & 5.3 & 4.8303 & TRN \\
\hline CHEMBL1299954 & 688171 & 4.4 & 4.8556 & TST \\
\hline CHEMBL1314699 & 688171 & 4.35 & 4.8395 & TRN \\
\hline CHEMBL1547664 & 688171 & 5.05 & 4.9798 & TST \\
\hline CHEMBL1466896 & 688171 & 4.7 & 4.9783 & TRN \\
\hline CHEMBL1463626 & 688171 & 5.1 & 4.8958 & TRN \\
\hline CHEMBL1491308 & 688171 & 4.4 & 4.8927 & TRN \\
\hline CHEMBL1334484 & 688171 & 4.5 & 4.8008 & TST \\
\hline CHEMBL1366270 & 688171 & 4.85 & 4.7668 & TRN \\
\hline CHEMBL1558699 & 688171 & 5.75 & 4.8911 & TST \\
\hline CHEMBL1562538 & 688171 & 7.6003 & 4.9328 & TRN \\
\hline CHEMBL1489041 & 688171 & 4.6 & 4.8054 & TRN \\
\hline CHEMBL3197060 & 688171 & 4.55 & 4.8537 & TRN \\
\hline CHEMBL1395377 & 688171 & 4.7 & 5.0341 & TRN \\
\hline CHEMBL1445219 & 688171 & 4.4 & 5.0257 & TST \\
\hline CHEMBL1492105 & 688171 & 4.55 & 4.9891 & TRN \\
\hline CHEMBL1447216 & 688171 & 4.75 & 4.8497 & TST \\
\hline CHEMBL1389272 & 688171 & 4.55 & 4.9042 & TRN \\
\hline CHEMBL 3198721 & 688171 & 4.55 & 4.9256 & TRN \\
\hline CHEMBL1504676 & 688171 & 4.55 & 4.8833 & TRN \\
\hline CHEMBL1517487 & 688171 & 7.15 & 4.9459 & TST \\
\hline CHEMBL1601101 & 688171 & 4.6 & 4.8186 & TRN \\
\hline CHEMBL1307205 & 688171 & 4.95 & 4.9921 & TRN \\
\hline CHEMBL1577245 & 688171 & 5.1 & 4.9516 & TST \\
\hline CHEMBL1594222 & 688171 & 4.65 & 4.8919 & TRN \\
\hline CHEMBL1368731 & 688171 & 5.4 & 4.872 & TRN \\
\hline CHEMBL1453108 & 688171 & 6.0 & 5.0239 & TST \\
\hline CHEMBL1328768 & 688171 & 4.4 & 5.0408 & TST \\
\hline CHEMBL1610231 & 688171 & 4.4 & 4.9042 & TRN \\
\hline CHEMBL1521317 & 688171 & 4.4 & 4.8047 & TRN \\
\hline CHEMBL1477997 & 688171 & 5.05 & 4.7745 & TRN \\
\hline CHEMBL1395213 & 688171 & 4.55 & 4.8504 & TRN \\
\hline CHEMBL1544415 & 688171 & 4.4 & 4.8715 & TST \\
\hline CHEMBL1322900 & 688171 & 4.35 & 4.8247 & TST \\
\hline CHEMBL1408190 & 688171 & 4.55 & 5.0028 & TST \\
\hline CHEMBL1413733 & 688171 & 6.95 & 5.0494 & TRN \\
\hline CHEMBL1395208 & 688171 & 4.35 & 4.926 & TRN \\
\hline
\end{tabular}




\begin{tabular}{|c|c|c|c|c|c|}
\hline & & \multicolumn{4}{|c|}{ Supplemental Table s2.txt } \\
\hline CHEMBL1475136 & 688171 & 4.95 & 4.8672 & TRN & \\
\hline CHEMBL1604575 & 688171 & 5.7 & 5.0035 & TRN & \\
\hline CHEMBL1470515 & 688171 & 4.95 & 4.9887 & TRN & \\
\hline CHEMBL1313786 & 688171 & 5.05 & 4.9469 & TST & \\
\hline CHEMBL1474157 & 688171 & 4.7 & 4.7714 & TRN & \\
\hline CHEMBL1605622 & 688171 & 5.3 & 4.933 & TST & \\
\hline CHEMBL3194167 & 688171 & 4.55 & 4.9613 & TRN & \\
\hline CHEMBL 3197546 & 688171 & 4.6 & 4.9021 & TST & \\
\hline CHEMBL1580148 & 688171 & 5.75 & 4.9787 & TRN & \\
\hline CHEMBL1415167 & 688171 & 5.05 & 4.9121 & TRN & \\
\hline CHEMBL1552601 & 688171 & 4.5 & 4.7818 & TRN & \\
\hline CHEMBL1365142 & 688171 & 4.4 & 4.9375 & TRN & \\
\hline CHEMBL1402732 & 688171 & 5.25 & 4.8976 & TRN & \\
\hline CHEMBL1373396 & 688171 & 4.35 & 4.9785 & TST & \\
\hline CHEMBL1606122 & 688171 & 4.55 & 4.9087 & TRN & \\
\hline CHEMBL1520890 & 688171 & 4.65 & 4.9101 & TRN & \\
\hline CHEMBL1554246 & 688171 & 4.8 & 5.0224 & TST & \\
\hline CHEMBL1351426 & 688171 & 4.55 & 4.9533 & TRN & \\
\hline CHEMBL1486592 & 688171 & 4.4 & 4.8761 & TRN & \\
\hline CHEMBL1415965 & 688171 & 4.55 & 4.7971 & TRN & \\
\hline CHEMBL1491431 & 688171 & 4.6 & 4.9107 & TRN & \\
\hline CHEMBL3192212 & 688171 & 4.75 & 4.9271 & TST & \\
\hline CHEMBL1589723 & 688171 & 5.55 & 4.9479 & TRN & \\
\hline CHEMBL1320221 & 688171 & 5.3 & 4.9325 & TRN & \\
\hline CHEMBL1591634 & 688171 & 4.55 & 4.7428 & TRN & \\
\hline CHEMBL1398645 & 688171 & 4.4 & 4.8879 & TRN & \\
\hline CHEMBL1460779 & 688171 & 5.05 & 4.9353 & TRN & \\
\hline CHEMBL1407679 & 688171 & 4.55 & 4.9023 & TRN & \\
\hline CHEMBL1326207 & 688171 & 4.35 & 4.9412 & TRN & \\
\hline CHEMBL1389761 & 688171 & 4.4 & 4.9086 & TST & \\
\hline CHEMBL1515322 & 688171 & 5.5 & 4.98300 & 00000000005 & TRN \\
\hline CHEMBL1464485 & 688171 & 4.6 & 4.8277 & TRN & \\
\hline CHEMBL1477573 & 688171 & 4.4 & 4.8571 & TRN & \\
\hline CHEMBL1326679 & 688171 & 4.45 & 4.8714 & TRN & \\
\hline CHEMBL1513122 & 688171 & 4.75 & 4.8574 & TRN & \\
\hline CHEMBL1414251 & 688171 & 4.35 & 4.926 & TRN & \\
\hline CHEMBL1603040 & 688171 & 5.6 & 5.034 & TRN & \\
\hline CHEMBL1447188 & 688171 & 5.0 & 4.86100 & 0000000001 & TRN \\
\hline CHEMBL1609395 & 688171 & 4.35 & 5.0169 & TRN & \\
\hline CHEMBL1469005 & 688171 & 5.3 & 5.13 & TRN & \\
\hline CHEMBL1528413 & 688171 & 5.95 & 4.8626 & TST & \\
\hline CHEMBL1438426 & 688171 & 5.65 & 4.9367 & TRN & \\
\hline CHEMBL1329332 & 688171 & 6.05 & 4.9844 & TST & \\
\hline CHEMBL1591018 & 688171 & 6.35 & 4.8582 & TRN & \\
\hline CHEMBL1473040 & 688171 & 4.9 & 4.7996 & TRN & \\
\hline CHEMBL1476246 & 688171 & 6.45 & 4.9147 & TST & \\
\hline CHEMBL1529705 & 688171 & 4.45 & 4.8106 & TRN & \\
\hline CHEMBL1584778 & 688171 & 4.6 & 4.8558 & TRN & \\
\hline
\end{tabular}




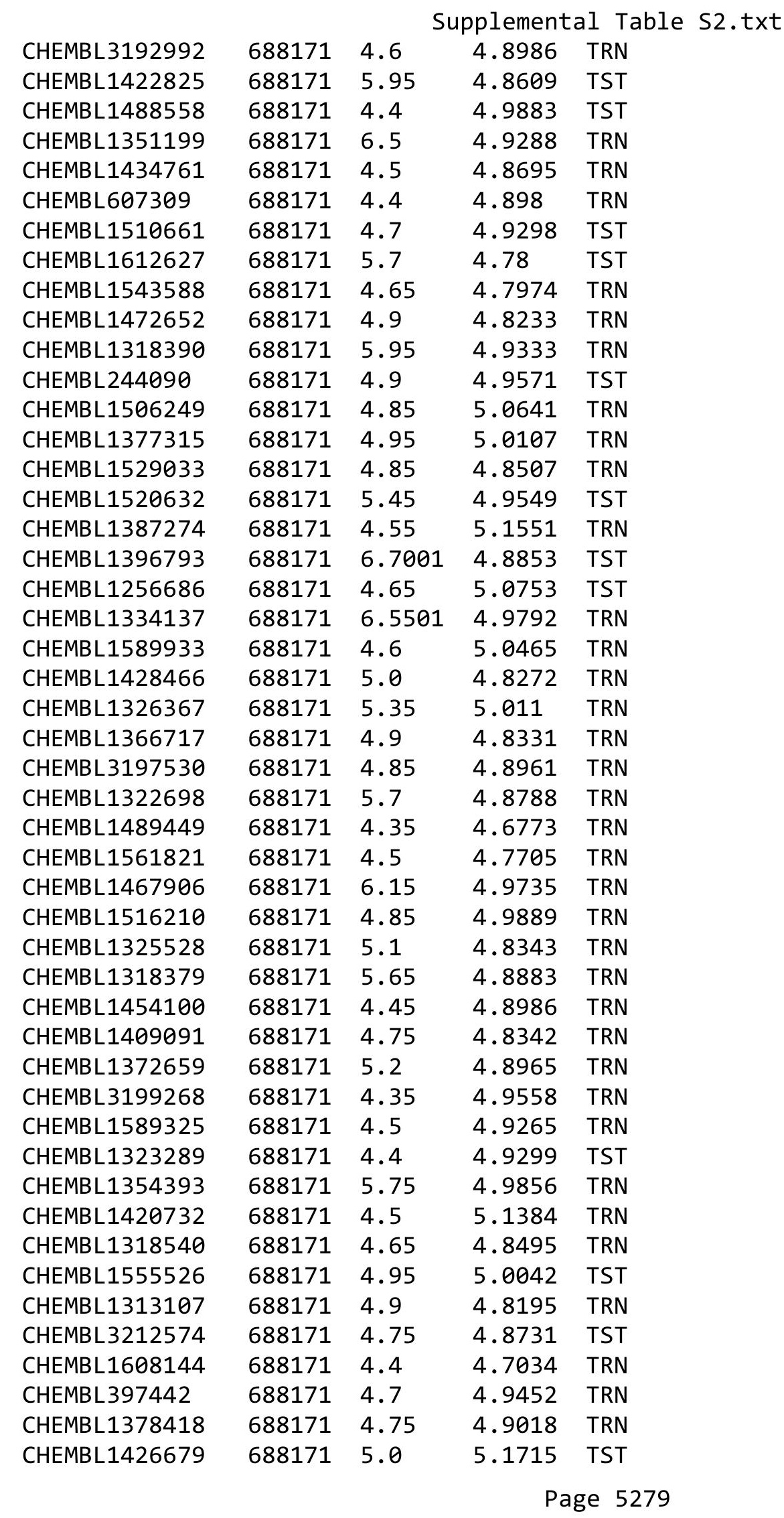




\begin{tabular}{|c|c|c|c|c|c|}
\hline \multicolumn{6}{|c|}{ Supplemental Table S2.txt } \\
\hline CHEMBL1507613 & 688171 & 6.3 & 5.04 & TRN & \\
\hline CHEMBL1333867 & 688171 & 5.0 & 4.9357 & TRN & \\
\hline CHEMBL1368987 & 688171 & 4.6 & 4.9214 & TRN & \\
\hline CHEMBL1546095 & 688171 & 4.55 & 5.0126 & TRN & \\
\hline CHEMBL1348660 & 688171 & 4.7 & 4.9412 & TRN & \\
\hline CHEMBL1453461 & 688171 & 5.05 & 4.9343 & TRN & \\
\hline CHEMBL1578336 & 688171 & 5.0 & 5.0301 & TRN & \\
\hline CHEMBL1541324 & 688171 & 4.75 & 4.9753 & TRN & \\
\hline CHEMBL1551113 & 688171 & 4.4 & 5.0139 & TRN & \\
\hline CHEMBL1326227 & 688171 & 4.55 & 4.9359 & TRN & \\
\hline CHEMBL1552091 & 688171 & 5.55 & 5.0364 & TRN & \\
\hline CHEMBL1421150 & 688171 & 5.3 & 4.8471 & TRN & \\
\hline CHEMBL1607489 & 688171 & 4.6 & 4.9421 & TRN & \\
\hline CHEMBL 1476852 & 688171 & 7.6003 & 4.8239 & TRN & \\
\hline CHEMBL1371586 & 688171 & 5.4 & 4.8885 & TRN & \\
\hline CHEMBL1995336 & 688171 & 5.0 & 4.8786 & TST & \\
\hline CHEMBL1363470 & 688171 & 4.85 & 4.9769 & TRN & \\
\hline CHEMBL1317083 & 688171 & 4.9 & 5.0348 & TRN & \\
\hline CHEMBL1509778 & 688171 & 4.35 & 4.8813 & TRN & \\
\hline CHEMBL1449836 & 688171 & 4.9 & 4.9173 & TRN & \\
\hline CHEMBL1435350 & 688171 & 5.05 & 4.8489 & TRN & \\
\hline CHEMBL1451327 & 688171 & 4.6 & 4.9371 & TST & \\
\hline CHEMBL1967583 & 688171 & 5.4 & 4.9778 & TRN & \\
\hline CHEMBL1591882 & 688171 & 5.15 & 5.0014 & TST & \\
\hline CHEMBL1476934 & 688171 & 4.6 & 4.9537 & TRN & \\
\hline CHEMBL1405548 & 688171 & 4.9 & 4.8149 & TRN & \\
\hline CHEMBL3192314 & 688171 & 5.05 & 4.8902 & TST & \\
\hline CHEMBL1353904 & 688171 & 7.3002 & 4.9562 & TRN & \\
\hline CHEMBL1551183 & 688171 & 4.35 & 4.9176 & TRN & \\
\hline CHEMBL1484156 & 688171 & 4.7 & 4.9663 & TST & \\
\hline CHEMBL1476937 & 688171 & 4.65 & 4.9858 & TRN & \\
\hline CHEMBL 3213451 & 688171 & 5.05 & 5.0324 & TRN & \\
\hline CHEMBL3391864 & 688171 & 4.75 & 4.8327 & TRN & \\
\hline CHEMBL1396070 & 688171 & 4.4 & 4.8678 & TRN & \\
\hline CHEMBL590186 & 688171 & 4.35 & 4.8548 & TRN & \\
\hline CHEMBL1561527 & 688171 & 5.65 & 4.9602 & TRN & \\
\hline CHEMBL1322585 & 688171 & 4.8 & 4.9083 & TRN & \\
\hline CHEMBL1393066 & 688171 & 6.45 & 4.9488 & TRN & \\
\hline CHEMBL1391248 & 688171 & 4.6 & 4.8803 & TRN & \\
\hline CHEMBL1364989 & 688171 & 4.6 & 4.9483 & TRN & \\
\hline CHEMBL1457219 & 688171 & 4.7 & 4.9113 & TRN & \\
\hline CHEMBL1339702 & 688171 & 5.8 & 4.8237 & TRN & \\
\hline CHEMBL1324811 & 688171 & 4.4 & 5.0161 & TRN & \\
\hline CHEMBL1386104 & 688171 & 4.6 & 4.9571 & TRN & \\
\hline CHEMBL1396985 & 688171 & 5.05 & 4.9898 & TRN & \\
\hline CHEMBL1536981 & 688171 & 4.5 & 4.793 & TRN & \\
\hline CHEMBL1346883 & 688171 & 4.4 & 4.86100 & 0000000001 & TRN \\
\hline CHEMBL3197230 & 688171 & 4.5 & 4.8301 & TRN & \\
\hline
\end{tabular}




\begin{tabular}{|c|c|c|c|c|}
\hline \multicolumn{5}{|c|}{ Supplemental Table S2.txt } \\
\hline CHEMBL1557815 & 688171 & 6.0 & 4.8486 & TRN \\
\hline CHEMBL1490348 & 688171 & 4.4 & 4.9684 & TRN \\
\hline CHEMBL1539414 & 688171 & 4.7 & 4.8298 & TRN \\
\hline CHEMBL1538919 & 688171 & 4.5 & 4.9878 & TST \\
\hline CHEMBL1582332 & 688171 & 5.65 & 5.0132 & TRN \\
\hline CHEMBL1377024 & 688171 & 4.45 & 4.8338 & TRN \\
\hline CHEMBL1593969 & 688171 & 4.35 & 4.9333 & TRN \\
\hline CHEMBL1355461 & 688171 & 5.15 & 4.7971 & TRN \\
\hline CHEMBL1600980 & 688171 & 5.1 & 4.9261 & TST \\
\hline CHEMBL1388653 & 688171 & 4.65 & 5.0488 & TRN \\
\hline CHEMBL1396165 & 688171 & 4.7 & 4.9544 & TST \\
\hline CHEMBL1572585 & 688171 & 4.65 & 5.0036 & TRN \\
\hline CHEMBL1373768 & 688171 & 5.2 & 4.9875 & TRN \\
\hline CHEMBL1471406 & 688171 & 6.8499 & 4.9418 & TST \\
\hline CHEMBL1508226 & 688171 & 4.7 & 4.9396 & TST \\
\hline CHEMBL1499923 & 688171 & 4.5 & 4.9507 & TRN \\
\hline CHEMBL1552248 & 688171 & 6.7501 & 4.9913 & TRN \\
\hline CHEMBL1364285 & 688171 & 4.6 & 4.8486 & TRN \\
\hline CHEMBL1523510 & 688171 & 4.7 & 4.9581 & TRN \\
\hline CHEMBL1397589 & 688171 & 5.35 & 4.9678 & TRN \\
\hline CHEMBL1582342 & 688171 & 4.95 & 4.8498 & TRN \\
\hline CHEMBL1414383 & 688171 & 5.05 & 4.8141 & TST \\
\hline CHEMBL3190369 & 688171 & 4.5 & 5.0289 & TST \\
\hline CHEMBL1373971 & 688171 & 4.7 & 5.022 & TRN \\
\hline CHEMBL1445080 & 688171 & 4.4 & 4.8858 & TST \\
\hline CHEMBL1339239 & 688171 & 4.4 & 4.797 & TRN \\
\hline CHEMBL1359955 & 688171 & 4.8 & 4.7893 & TRN \\
\hline CHEMBL1607969 & 688171 & 4.4 & 4.8536 & TRN \\
\hline CHEMBL3213185 & 688171 & 4.5 & 4.9419 & TST \\
\hline CHEMBL1407538 & 688171 & 4.35 & 4.9455 & TST \\
\hline CHEMBL1388744 & 688171 & 4.35 & 4.8546 & TRN \\
\hline CHEMBL1600447 & 688171 & 4.6 & 4.9298 & TST \\
\hline CHEMBL1527703 & 688171 & 6.0 & 4.9887 & TST \\
\hline CHEMBL1410720 & 688171 & 4.45 & 4.9738 & TST \\
\hline CHEMBL1478909 & 688171 & 4.8 & 4.9301 & TRN \\
\hline CHEMBL1608254 & 688171 & 6.05 & 4.8572 & TRN \\
\hline CHEMBL1367068 & 688171 & 4.4 & 4.8538 & TRN \\
\hline CHEMBL1315395 & 688171 & 5.45 & 4.8586 & TRN \\
\hline CHEMBL1586460 & 688171 & 4.8 & 4.9721 & TST \\
\hline CHEMBL1572054 & 688171 & 4.9 & 5.0045 & TRN \\
\hline CHEMBL1524927 & 688171 & 4.5 & 4.9569 & TRN \\
\hline CHEMBL3212616 & 688171 & 4.7 & 4.8816 & TST \\
\hline CHEMBL1319677 & 688171 & 4.35 & 4.8909 & TRN \\
\hline CHEMBL1476483 & 688171 & 5.65 & 4.9305 & TRN \\
\hline CHEMBL1566510 & 688171 & 5.55 & 4.9192 & TRN \\
\hline CHEMBL1565306 & 688171 & 4.95 & 5.0028 & TRN \\
\hline CHEMBL3196754 & 688171 & 5.35 & 4.9148 & TRN \\
\hline CHEMBL1584694 & 688171 & 5.8 & 4.8822 & TST \\
\hline
\end{tabular}




\begin{tabular}{|c|c|c|c|c|c|}
\hline \multicolumn{6}{|c|}{ Supplemental Table S2.txt } \\
\hline CHEMBL1547809 & 688171 & 5.25 & 5.0295 & TRN & \\
\hline CHEMBL1417266 & 688171 & 6.05 & 4.8811 & TRN & \\
\hline CHEMBL1542825 & 688171 & 4.75 & 4.9472 & TST & \\
\hline CHEMBL1570102 & 688171 & 4.4 & 4.8479 & TRN & \\
\hline CHEMBL1400414 & 688171 & 5.15 & 5.0073 & TRN & \\
\hline CHEMBL 3192022 & 688171 & 4.95 & 4.8958 & TRN & \\
\hline CHEMBL1606677 & 688171 & 4.95 & 4.8303 & TRN & \\
\hline CHEMBL1549112 & 688171 & 4.7 & 4.8324 & TST & \\
\hline CHEMBL 3190909 & 688171 & 6.6499 & 4.9585 & TRN & \\
\hline CHEMBL1473371 & 688171 & 5.0 & 5.0537 & TRN & \\
\hline CHEMBL1446202 & 688171 & 4.35 & 5.0075 & TRN & \\
\hline CHEMBL1506687 & 688171 & 4.8 & 5.015 & TST & \\
\hline CHEMBL1547343 & 688171 & 4.6 & 4.8902 & TRN & \\
\hline CHEMBL1375469 & 688171 & 7.5498 & 4.9898 & TST & \\
\hline CHEMBL1542987 & 688171 & 4.4 & 4.8966 & TST & \\
\hline CHEMBL3194929 & 688171 & 4.4 & 4.8607 & TRN & \\
\hline CHEMBL1368936 & 688171 & 4.4 & 4.9563 & TRN & \\
\hline CHEMBL1378654 & 688171 & 4.75 & 4.7638 & TRN & \\
\hline CHEMBL1488338 & 688171 & 4.55 & 4.8527 & TRN & \\
\hline CHEMBL485012 & 688171 & 4.4 & 4.9433 & TRN & \\
\hline CHEMBL1593560 & 688171 & 5.0 & 4.8338 & TRN & \\
\hline CHEMBL1569305 & 688171 & 4.7 & 4.823 & TRN & \\
\hline CHEMBL1303709 & 688171 & 4.8 & 4.8457 & TRN & \\
\hline CHEMBL1530420 & 688171 & 4.85 & 4.886 & TRN & \\
\hline CHEMBL1369629 & 688171 & 4.45 & 4.8901 & TST & \\
\hline CHEMBL1405603 & 688171 & 4.95 & 4.8304 & TRN & \\
\hline CHEMBL1313561 & 688171 & 4.65 & 4.868 & TRN & \\
\hline CHEMBL1350860 & 688171 & 4.4 & 5.0167 & TRN & \\
\hline CHEMBL1399390 & 688171 & 5.05 & 4.952 & TRN & \\
\hline CHEMBL1422467 & 688171 & 4.45 & 4.8673 & TRN & \\
\hline CHEMBL1711538 & 688171 & 5.1 & 4.9462 & TRN & \\
\hline CHEMBL1490029 & 688171 & 4.85 & 4.86600 & 00000000005 & TRN \\
\hline CHEMBL3192401 & 688171 & 4.35 & 4.8097 & TRN & \\
\hline CHEMBL1538246 & 688171 & 4.8 & 4.9636 & TRN & \\
\hline CHEMBL1567642 & 688171 & 4.35 & 4.6877 & TRN & \\
\hline CHEMBL1452111 & 688171 & 4.7 & 5.0171 & TRN & \\
\hline CHEMBL1561040 & 688171 & 5.5 & 4.9534 & TST & \\
\hline CHEMBL1450360 & 688171 & 5.05 & 4.803 & TRN & \\
\hline CHEMBL1554951 & 688171 & 4.8 & 4.9193 & TRN & \\
\hline CHEMBL1593390 & 688171 & 4.75 & 4.8932 & TRN & \\
\hline CHEMBL1324607 & 688171 & 4.6 & 4.7728 & TRN & \\
\hline CHEMBL1490656 & 688171 & 4.55 & 4.8891 & TRN & \\
\hline CHEMBL1375050 & 688171 & 6.0 & 4.9669 & TRN & \\
\hline CHEMBL1442639 & 688171 & 4.4 & 4.994 & TST & \\
\hline CHEMBL1586391 & 688171 & 5.0 & 4.7884 & TRN & \\
\hline CHEMBL1420903 & 688171 & 5.1 & 4.8552 & TRN & \\
\hline CHEMBL1367063 & 688171 & 4.65 & 4.917 & TRN & \\
\hline CHEMBL1331634 & 688171 & 4.5 & 5.1063 & TRN & \\
\hline
\end{tabular}




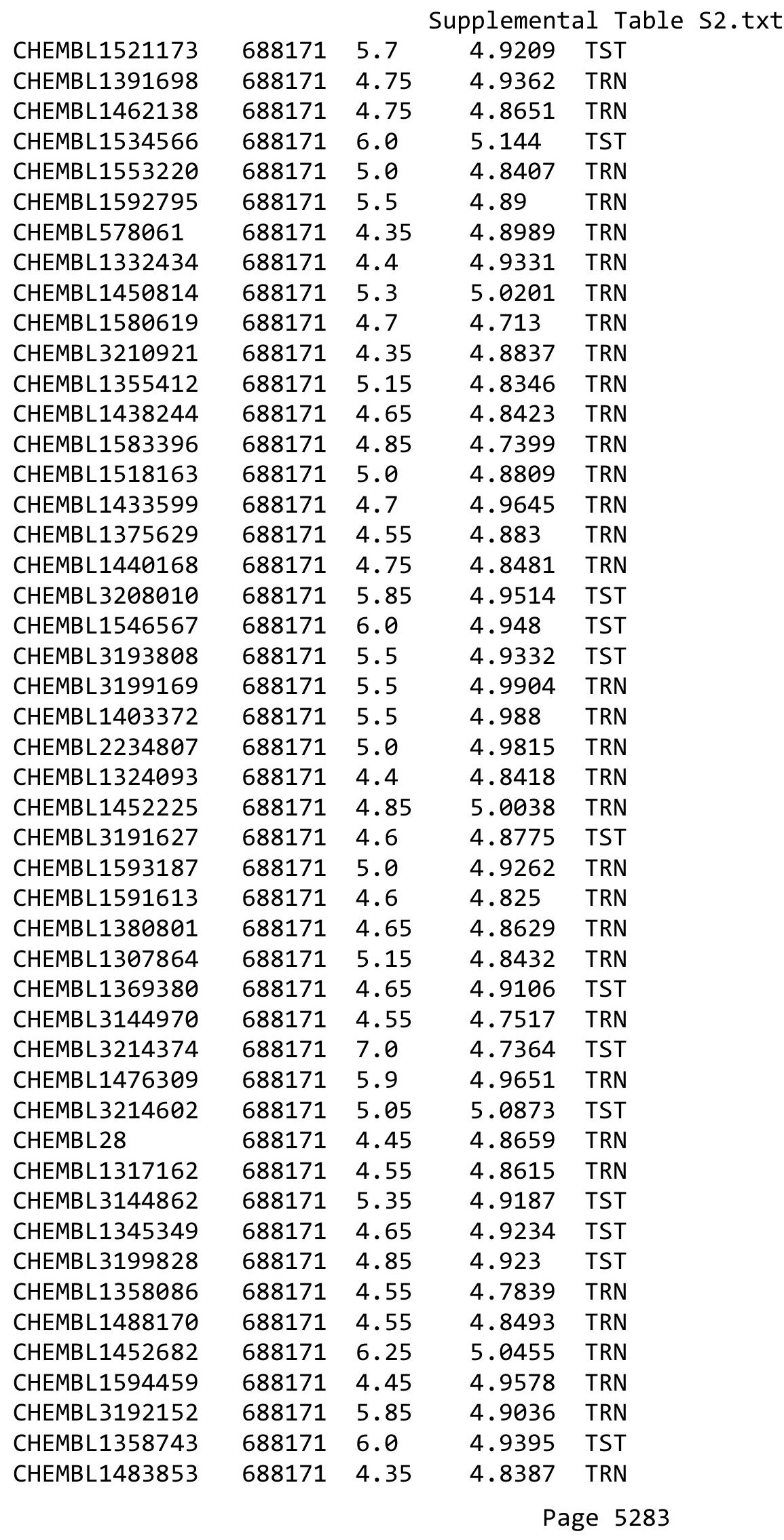




\begin{tabular}{|c|c|c|c|c|}
\hline \multicolumn{5}{|c|}{ Supplemental Table S2.txt } \\
\hline CHEMBL1394349 & 688171 & 4.7 & 4.8478 & TRN \\
\hline CHEMBL1331102 & 688171 & 5.05 & 4.7625 & TST \\
\hline CHEMBL1558896 & 688171 & 4.5 & 4.8966 & TRN \\
\hline CHEMBL1340400 & 688171 & 4.4 & 4.868 & TRN \\
\hline CHEMBL233896 & 688171 & 4.4 & 4.9784 & TRN \\
\hline CHEMBL1590860 & 688171 & 5.3 & 4.8579 & TRN \\
\hline CHEMBL1505880 & 688171 & 4.85 & 4.9038 & TRN \\
\hline CHEMBL1533982 & 688171 & 4.4 & 4.9768 & TRN \\
\hline CHEMBL1548582 & 688171 & 4.5 & 4.8543 & TST \\
\hline CHEMBL1612596 & 688171 & 6.0 & 4.8259 & TST \\
\hline CHEMBL1507888 & 688171 & 4.7 & 4.785 & TST \\
\hline CHEMBL1300905 & 688171 & 4.4 & 4.9718 & TRN \\
\hline CHEMBL1479316 & 688171 & 4.75 & 4.915 & TRN \\
\hline CHEMBL1577622 & 688171 & 4.75 & 4.8156 & TST \\
\hline CHEMBL1597025 & 688171 & 4.7 & 5.0295 & TST \\
\hline CHEMBL1464756 & 688171 & 5.7 & 4.9743 & TRN \\
\hline CHEMBL1488761 & 688171 & 4.6 & 4.8759 & TRN \\
\hline CHEMBL1374933 & 688171 & 4.85 & 4.8325 & TRN \\
\hline CHEMBL1429682 & 688171 & 5.3 & 4.8467 & TRN \\
\hline CHEMBL1561867 & 688171 & 4.7 & 4.8218 & TRN \\
\hline CHEMBL1362119 & 688171 & 4.35 & 4.9005 & TRN \\
\hline CHEMBL1309718 & 688171 & 4.4 & 5.0146 & TRN \\
\hline CHEMBL1973904 & 688171 & 4.4 & 4.8963 & TRN \\
\hline CHEMBL1498487 & 688171 & 4.65 & 5.0424 & TRN \\
\hline CHEMBL1303221 & 688171 & 4.5 & 4.9245 & TRN \\
\hline CHEMBL1586886 & 688171 & 4.8 & 4.7996 & TST \\
\hline CHEMBL1316061 & 688171 & 4.35 & 4.8939 & TST \\
\hline CHEMBL1590587 & 688171 & 6.05 & 4.8721 & TRN \\
\hline CHEMBL1367971 & 688171 & 4.85 & 5.0175 & TRN \\
\hline CHEMBL1491262 & 688171 & 4.7 & 4.8534 & TRN \\
\hline CHEMBL1598595 & 688171 & 4.9 & 4.8446 & TRN \\
\hline CHEMBL3193321 & 688171 & 4.35 & 4.8378 & TST \\
\hline CHEMBL1587231 & 688171 & 4.5 & 4.8405 & TRN \\
\hline CHEMBL1439732 & 688171 & 4.65 & 4.9339 & TRN \\
\hline CHEMBL1317477 & 688171 & 6.35 & 4.9123 & TRN \\
\hline CHEMBL1361821 & 688171 & 4.75 & 4.9564 & TST \\
\hline CHEMBL1377839 & 688171 & 4.4 & 4.8884 & TRN \\
\hline CHEMBL1387088 & 688171 & 4.6 & 4.9839 & TRN \\
\hline CHEMBL2369280 & 688171 & 5.95 & 4.7988 & TRN \\
\hline CHEMBL1438410 & 688171 & 4.85 & 4.8343 & TST \\
\hline CHEMBL1365260 & 688171 & 4.7 & 4.8182 & TRN \\
\hline CHEMBL3209792 & 688171 & 5.7 & 4.9642 & TRN \\
\hline CHEMBL1319744 & 688171 & 4.35 & 4.9506 & TRN \\
\hline CHEMBL1459258 & 688171 & 4.45 & 4.7317 & TRN \\
\hline CHEMBL1531805 & 688171 & 4.35 & 4.9251 & TRN \\
\hline CHEMBL1374669 & 688171 & 4.65 & 4.9423 & TRN \\
\hline CHEMBL1453810 & 688171 & 4.75 & 4.9453 & TRN \\
\hline CHEMBL1576346 & 688171 & 5.55 & 4.8186 & TRN \\
\hline
\end{tabular}




\begin{tabular}{|c|c|c|c|c|}
\hline \multicolumn{5}{|c|}{ Supplemental Table S2.txt } \\
\hline CHEMBL1461829 & 688171 & 4.7 & 5.0587 & TRN \\
\hline CHEMBL1566565 & 688171 & 4.8 & 5.042 & TST \\
\hline CHEMBL1566943 & 688171 & 5.25 & 4.8422 & TST \\
\hline CHEMBL1563709 & 688171 & 4.4 & 4.973 & TRN \\
\hline CHEMBL1537204 & 688171 & 4.7 & 4.9466 & TRN \\
\hline CHEMBL1573529 & 688171 & 6.0 & 4.9949 & TRN \\
\hline CHEMBL510515 & 688171 & 4.7 & 4.8802 & TRN \\
\hline CHEMBL1467359 & 688171 & 4.6 & 4.8813 & TRN \\
\hline CHEMBL1458512 & 688171 & 7.2 & 5.0567 & TST \\
\hline CHEMBL1322586 & 688171 & 5.1 & 4.9295 & TRN \\
\hline CHEMBL1610146 & 688171 & 4.85 & 4.6662 & TRN \\
\hline CHEMBL1965223 & 688171 & 4.85 & 4.9209 & TRN \\
\hline CHEMBL1364937 & 688171 & 5.65 & 4.8018 & TRN \\
\hline CHEMBL1532878 & 688171 & 4.6 & 4.8091 & TRN \\
\hline CHEMBL1478817 & 688171 & 4.65 & 4.8087 & TRN \\
\hline CHEMBL1488331 & 688171 & 4.45 & 4.8764 & TRN \\
\hline CHEMBL1604952 & 688171 & 4.35 & 4.9385 & TST \\
\hline CHEMBL1505168 & 688171 & 6.5501 & 5.022 & TST \\
\hline CHEMBL1507239 & 688171 & 4.35 & 4.7444 & TST \\
\hline CHEMBL3209364 & 688171 & 4.7 & 4.9091 & TRN \\
\hline CHEMBL1313653 & 688171 & 4.65 & 4.9196 & TRN \\
\hline CHEMBL1532823 & 688171 & 5.7 & 4.8801 & TST \\
\hline CHEMBL1426886 & 688171 & 5.6 & 4.9062 & TST \\
\hline CHEMBL1390633 & 688171 & 5.3 & 4.9008 & TST \\
\hline CHEMBL1332222 & 688171 & 5.3 & 4.9162 & TRN \\
\hline CHEMBL1484417 & 688171 & 4.45 & 5.0821 & TST \\
\hline CHEMBL3195217 & 688171 & 5.95 & 4.9381 & TST \\
\hline CHEMBL1418335 & 688171 & 4.45 & 4.9751 & TST \\
\hline CHEMBL1408480 & 688171 & 4.6 & 4.8644 & TRN \\
\hline CHEMBL1472513 & 688171 & 4.9 & 5.0626 & TRN \\
\hline CHEMBL1526835 & 688171 & 4.5 & 4.7905 & TRN \\
\hline CHEMBL1387839 & 688171 & 7.6498 & 4.9729 & TST \\
\hline CHEMBL1304052 & 688171 & 4.5 & 4.8628 & TST \\
\hline CHEMBL1579933 & 688171 & 4.4 & 4.785 & TRN \\
\hline CHEMBL1388691 & 688171 & 4.9 & 4.8853 & TST \\
\hline CHEMBL1329430 & 688171 & 4.95 & 4.999 & TRN \\
\hline CHEMBL1413918 & 688171 & 4.95 & 4.8993 & TST \\
\hline CHEMBL1486117 & 688171 & 4.45 & 4.8184 & TST \\
\hline CHEMBL1595322 & 688171 & 5.3 & 5.0047 & TST \\
\hline CHEMBL1498887 & 688171 & 6.3 & 4.8168 & TRN \\
\hline CHEMBL1540996 & 688171 & 6.45 & 4.9304 & TST \\
\hline CHEMBL1366644 & 688171 & 4.55 & 4.95 & TRN \\
\hline CHEMBL1437329 & 688171 & 5.5 & 4.9286 & TRN \\
\hline CHEMBL1390177 & 688171 & 5.5 & 4.9392 & TST \\
\hline CHEMBL 3191663 & 688171 & 4.9 & 5.0727 & TST \\
\hline CHEMBL1596376 & 688171 & 4.4 & 4.8927 & TRN \\
\hline CHEMBL351042 & 688171 & 6.0 & 5.012 & TRN \\
\hline CHEMBL1580543 & 688171 & 4.75 & 4.8846 & TST \\
\hline
\end{tabular}




\begin{tabular}{|c|c|c|c|c|c|}
\hline \multicolumn{6}{|c|}{ Supplemental Table S2.txt } \\
\hline CHEMBL1487419 & 688171 & 4.95 & 4.8532 & TRN & \\
\hline CHEMBL1440557 & 688171 & 7.4001 & 4.9144 & TST & \\
\hline CHEMBL253570 & 688171 & 5.1 & 4.8234 & TRN & \\
\hline CHEMBL1414617 & 688171 & 4.4 & 4.9355 & TRN & \\
\hline CHEMBL1360282 & 688171 & 4.4 & 4.9199 & TRN & \\
\hline CHEMBL1591137 & 688171 & 5.7 & 4.9224 & TRN & \\
\hline CHEMBL1344148 & 688171 & 4.6 & 4.9947 & TRN & \\
\hline CHEMBL1547446 & 688171 & 4.45 & 4.7052 & TRN & \\
\hline CHEMBL1487954 & 688171 & 5.45 & 5.0134 & TRN & \\
\hline CHEMBL1340216 & 688171 & 4.55 & 4.8971 & TST & \\
\hline CHEMBL1379572 & 688171 & 4.85 & 4.80399 & 9999999999 & TST \\
\hline CHEMBL1438545 & 688171 & 7.6003 & 4.9223 & TST & \\
\hline CHEMBL1528707 & 688171 & 5.25 & 5.0096 & TST & \\
\hline CHEMBL1326485 & 688171 & 4.4 & 4.7674 & TRN & \\
\hline CHEMBL1372401 & 688171 & 5.5 & 4.9765 & TRN & \\
\hline CHEMBL1378441 & 688171 & 6.2 & 5.1039 & TRN & \\
\hline CHEMBL1611097 & 688171 & 4.85 & 4.7297 & TRN & \\
\hline CHEMBL1503050 & 688171 & 4.65 & 4.9501 & TST & \\
\hline CHEMBL1533544 & 688171 & 4.65 & 4.9175 & TRN & \\
\hline CHEMBL3195713 & 688171 & 5.15 & 4.8794 & TRN & \\
\hline CHEMBL1608727 & 688171 & 4.75 & 4.9856 & TST & \\
\hline CHEMBL1574879 & 688171 & 5.6 & 4.9673 & TRN & \\
\hline CHEMBL1342240 & 688171 & 4.35 & 4.921 & TST & \\
\hline CHEMBL1586354 & 688171 & 4.4 & 4.8758 & TRN & \\
\hline CHEMBL1404402 & 688171 & 4.35 & 4.7942 & TST & \\
\hline CHEMBL1312448 & 688171 & 4.4 & 4.7808 & TRN & \\
\hline CHEMBL1457755 & 688171 & 4.55 & 4.7912 & TRN & \\
\hline CHEMBL1309030 & 688171 & 4.45 & 4.8664 & TRN & \\
\hline CHEMBL1538266 & 688171 & 4.65 & 4.8205 & TRN & \\
\hline CHEMBL1497526 & 688171 & 6.4 & 4.9615 & TRN & \\
\hline CHEMBL1382939 & 688171 & 4.55 & 4.8449 & TRN & \\
\hline CHEMBL1414044 & 688171 & 4.85 & 4.898 & TRN & \\
\hline CHEMBL1522710 & 688171 & 4.45 & 5.0475 & TST & \\
\hline CHEMBL1400491 & 688171 & 4.35 & 4.9922 & TRN & \\
\hline CHEMBL1479090 & 688171 & 4.95 & 5.0042 & TRN & \\
\hline CHEMBL1530440 & 688171 & 4.4 & 5.0099 & TRN & \\
\hline CHEMBL1567612 & 688171 & 4.7 & 4.9453 & TRN & \\
\hline CHEMBL1451772 & 688171 & 4.85 & 4.8197 & TRN & \\
\hline CHEMBL1503167 & 688171 & 6.7001 & 4.8983 & TRN & \\
\hline CHEMBL1610235 & 688171 & 4.8 & 4.8335 & TRN & \\
\hline CHEMBL1351361 & 688171 & 5.0 & 4.7821 & TST & \\
\hline CHEMBL3196832 & 688171 & 5.35 & 4.9959 & TRN & \\
\hline CHEMBL1499111 & 688171 & 4.6 & 4.7919 & TRN & \\
\hline CHEMBL1521755 & 688171 & 4.8 & 4.7572 & TRN & \\
\hline CHEMBL 3197876 & 688171 & 5.1 & 5.0026 & TRN & \\
\hline CHEMBL1437570 & 688171 & 4.45 & 4.9265 & TRN & \\
\hline CHEMBL1421142 & 688171 & 4.4 & 4.9099 & TRN & \\
\hline CHEMBL1478815 & 688171 & 5.05 & 4.9295 & TRN & \\
\hline
\end{tabular}




\begin{tabular}{|c|c|c|c|c|c|}
\hline \multicolumn{6}{|c|}{ Supplemental Table S2.txt } \\
\hline CHEMBL1447419 & 688171 & 4.35 & 4.878 & TRN & \\
\hline CHEMBL1430037 & 688171 & 5.1 & 5.0429 & TRN & \\
\hline CHEMBL1356436 & 688171 & 4.4 & 4.8762 & TRN & \\
\hline CHEMBL1354745 & 688171 & 4.75 & 4.9859 & TRN & \\
\hline CHEMBL1453722 & 688171 & 5.05 & 4.881 & TRN & \\
\hline CHEMBL1399709 & 688171 & 4.55 & 4.9134 & TRN & \\
\hline CHEMBL1417176 & 688171 & 4.35 & 4.9055 & TRN & \\
\hline CHEMBL1356037 & 688171 & 5.15 & 4.9526 & TRN & \\
\hline CHEMBL1311279 & 688171 & 5.5 & 4.9225 & TST & \\
\hline CHEMBL3210556 & 688171 & 4.45 & 4.8886 & TST & \\
\hline CHEMBL1365430 & 688171 & 4.9 & 4.8942 & TRN & \\
\hline CHEMBL1998188 & 688171 & 4.4 & 5.0378 & TRN & \\
\hline CHEMBL1355230 & 688171 & 5.1 & 4.7715 & TRN & \\
\hline CHEMBL1504979 & 688171 & 4.6 & 4.8558 & TRN & \\
\hline CHEMBL1438521 & 688171 & 4.4 & 4.9923 & TRN & \\
\hline CHEMBL1591715 & 688171 & 4.5 & 4.798 & TRN & \\
\hline CHEMBL1450079 & 688171 & 4.4 & 4.96899 & & TST \\
\hline CHEMBL1377396 & 688171 & 6.6 & 4.8855 & TRN & \\
\hline CHEMBL3198706 & 688171 & 4.65 & 4.9252 & TST & \\
\hline CHEMBL1514428 & 688171 & 5.45 & 4.9703 & TRN & \\
\hline CHEMBL1309376 & 688171 & 4.7 & 4.9516 & TRN & \\
\hline CHEMBL1461928 & 688171 & 4.4 & 4.9333 & TST & \\
\hline CHEMBL1447382 & 688171 & 4.8 & 4.9047 & TRN & \\
\hline CHEMBL1900055 & 688171 & 4.55 & 4.7136 & TRN & \\
\hline CHEMBL1970554 & 688171 & 4.4 & 4.8552 & TRN & \\
\hline CHEMBL1591284 & 688171 & 4.65 & 4.9297 & TRN & \\
\hline CHEMBL1386853 & 688171 & 6.6499 & 4.9524 & TST & \\
\hline CHEMBL357170 & 688171 & 5.0 & 4.8746 & TRN & \\
\hline CHEMBL 1415573 & 688171 & 4.65 & 4.9051 & TST & \\
\hline CHEMBL1580023 & 688171 & 5.45 & 4.9503 & TST & \\
\hline CHEMBL1368982 & 688171 & 7.6003 & 4.827 & TRN & \\
\hline CHEMBL1355488 & 688171 & 4.75 & 4.9056 & TRN & \\
\hline CHEMBL1417163 & 688171 & 4.75 & 4.875 & TRN & \\
\hline CHEMBL1537738 & 688171 & 4.6 & 4.9411 & TST & \\
\hline CHEMBL1422092 & 688171 & 5.15 & 5.0088 & TST & \\
\hline CHEMBL1356873 & 688171 & 4.8 & 4.8872 & TRN & \\
\hline CHEMBL1965975 & 688171 & 4.85 & 5.0526 & TRN & \\
\hline CHEMBL1491869 & 688171 & 4.6 & 4.7516 & TRN & \\
\hline CHEMBL 1374770 & 688171 & 4.5 & 4.8128 & TRN & \\
\hline CHEMBL1362825 & 688171 & 4.9 & 4.8229 & TRN & \\
\hline CHEMBL1445074 & 688171 & 5.2 & 4.7968 & TRN & \\
\hline CHEMBL1577282 & 688171 & 4.45 & 4.9791 & TST & \\
\hline CHEMBL1429428 & 688171 & 4.55 & 5.0752 & TRN & \\
\hline CHEMBL1556333 & 688171 & 4.9 & 4.9183 & TRN & \\
\hline CHEMBL1343934 & 688171 & 4.6 & 4.8078 & TRN & \\
\hline CHEMBL1335138 & 688171 & 4.8 & 5.0183 & TRN & \\
\hline CHEMBL1322437 & 688171 & 4.5 & 4.9219 & TRN & \\
\hline CHEMBL1548449 & 688171 & 4.75 & 4.7989 & TRN & \\
\hline
\end{tabular}




\begin{tabular}{|c|c|c|c|c|c|}
\hline \multicolumn{6}{|c|}{ Supplemental Table S2.txt } \\
\hline CHEMBL1968316 & 688171 & 4.95 & 4.9226 & TRN & \\
\hline CHEMBL1469728 & 688171 & 5.5 & 4.9704 & TRN & \\
\hline CHEMBL1305142 & 688171 & 5.5 & 4.9221 & TST & \\
\hline CHEMBL1352256 & 688171 & 5.4 & 4.8362 & TST & \\
\hline CHEMBL 3214323 & 688171 & 4.8 & 4.9032 & TRN & \\
\hline CHEMBL1554720 & 688171 & 5.6 & 4.9803 & TRN & \\
\hline CHEMBL1536878 & 688171 & 4.4 & 4.9056 & TRN & \\
\hline CHEMBL1374833 & 688171 & 4.35 & 4.9672 & TRN & \\
\hline CHEMBL1381997 & 688171 & 6.0 & 4.9083 & TST & \\
\hline CHEMBL1596985 & 688171 & 4.65 & 4.745 & TRN & \\
\hline CHEMBL1568317 & 688171 & 7.6003 & 4.8707 & TRN & \\
\hline CHEMBL1301372 & 688171 & 4.4 & 4.7943 & TST & \\
\hline CHEMBL1479181 & 688171 & 4.45 & 4.8325 & TST & \\
\hline CHEMBL 2007425 & 688171 & 4.8 & 4.9585 & TRN & \\
\hline CHEMBL1459023 & 688171 & 4.4 & 4.9016 & TRN & \\
\hline CHEMBL1588498 & 688171 & 4.35 & 5.0299 & TRN & \\
\hline CHEMBL1492389 & 688171 & 4.5 & 4.9139 & TST & \\
\hline CHEMBL1574218 & 688171 & 4.55 & 4.9708 & TRN & \\
\hline CHEMBL1573365 & 688171 & 4.45 & 4.93 & TST & \\
\hline CHEMBL1523150 & 688171 & 4.55 & 4.7675 & TRN & \\
\hline CHEMBL1325016 & 688171 & 5.65 & 5.0548 & TST & \\
\hline CHEMBL1325515 & 688171 & 6.45 & 5.0335 & TRN & \\
\hline CHEMBL1572211 & 688171 & 5.1 & 4.9879 & TST & \\
\hline CHEMBL1348324 & 688171 & 4.4 & 4.8266 & TRN & \\
\hline CHEMBL1417860 & 688171 & 5.1 & 4.9407 & TST & \\
\hline CHEMBL1335945 & 688171 & 4.45 & 4.8244 & TST & \\
\hline CHEMBL1583690 & 688171 & 5.25 & 4.9545 & TRN & \\
\hline CHEMBL1568810 & 688171 & 4.45 & 4.8423 & TRN & \\
\hline CHEMBL1333797 & 688171 & 4.45 & 4.9599 & TRN & \\
\hline CHEMBL1327040 & 688171 & 5.65 & 4.88899 & 9999999999 & TST \\
\hline CHEMBL1414364 & 688171 & 4.85 & 5.0638 & TRN & \\
\hline CHEMBL1350200 & 688171 & 4.6 & 4.956 & TRN & \\
\hline CHEMBL1411278 & 688171 & 4.4 & 4.7864 & TRN & \\
\hline CHEMBL1450860 & 688171 & 4.55 & 4.7583 & TRN & \\
\hline CHEMBL1529809 & 688171 & 4.5 & 4.7375 & TRN & \\
\hline CHEMBL1460661 & 688171 & 5.5 & 4.9669 & TRN & \\
\hline CHEMBL1366453 & 688171 & 5.0 & 4.8898 & TRN & \\
\hline CHEMBL1370438 & 688171 & 4.65 & 4.8542 & TRN & \\
\hline CHEMBL1556375 & 688171 & 6.5 & 4.7046 & TRN & \\
\hline CHEMBL1571188 & 688171 & 5.4 & 5.0195 & TST & \\
\hline CHEMBL1485718 & 688171 & 4.8 & 4.83899 & 99999999995 & TRN \\
\hline CHEMBL1564158 & 688171 & 4.5 & 4.8083 & TRN & \\
\hline CHEMBL1527322 & 688171 & 4.5 & 4.9138 & TRN & \\
\hline CHEMBL1605304 & 688171 & 4.95 & 4.9438 & TST & \\
\hline CHEMBL1522150 & 688171 & 6.3 & 5.0719 & TST & \\
\hline CHEMBL1436876 & 688171 & 6.45 & 4.8651 & TRN & \\
\hline CHEMBL1316470 & 688171 & 4.65 & 5.0125 & TRN & \\
\hline CHEMBL1300843 & 688171 & 4.9 & 4.8236 & TRN & \\
\hline
\end{tabular}




\begin{tabular}{|c|c|c|c|c|}
\hline \multicolumn{5}{|c|}{ Supplemental Table S2.txt } \\
\hline CHEMBL1555460 & 688171 & 5.65 & 4.9424 & TRN \\
\hline CHEMBL1306328 & 688171 & 4.55 & 4.9424 & TRN \\
\hline CHEMBL1416079 & 688171 & 4.7 & 4.8372 & TRN \\
\hline CHEMBL180127 & 688171 & 4.4 & 4.9123 & TRN \\
\hline CHEMBL582471 & 688171 & 5.2 & 4.8799 & TRN \\
\hline CHEMBL1584068 & 688171 & 5.35 & 4.8942 & TRN \\
\hline CHEMBL1404089 & 688171 & 4.6 & 4.9167 & TRN \\
\hline CHEMBL1312221 & 688171 & 4.4 & 4.9051 & TRN \\
\hline CHEMBL1612526 & 688171 & 4.4 & 4.8754 & TRN \\
\hline CHEMBL1403835 & 688171 & 4.35 & 4.8224 & TRN \\
\hline CHEMBL15193 & 688171 & 4.75 & 4.8857 & TST \\
\hline CHEMBL1327766 & 688171 & 6.8499 & 5.0373 & TRN \\
\hline CHEMBL1402603 & 688171 & 5.0 & 4.9162 & TST \\
\hline CHEMBL1564346 & 688171 & 4.4 & 4.8835 & TST \\
\hline CHEMBL1425489 & 688171 & 4.4 & 4.7903 & TST \\
\hline CHEMBL3145281 & 688171 & 4.6 & 4.7661 & TRN \\
\hline CHEMBL1535055 & 688171 & 4.75 & 4.8677 & TRN \\
\hline CHEMBL1595906 & 688171 & 4.85 & 4.8359 & TRN \\
\hline CHEMBL1419952 & 688171 & 6.0 & 5.0528 & TRN \\
\hline CHEMBL1357736 & 688171 & 4.9 & 4.8737 & TRN \\
\hline CHEMBL1439426 & 688171 & 4.7 & 4.888 & TRN \\
\hline CHEMBL1372381 & 688171 & 5.9 & 5.0011 & TRN \\
\hline CHEMBL1515775 & 688171 & 4.6 & 4.9308 & TRN \\
\hline CHEMBL1501711 & 688171 & 4.4 & 4.8967 & TRN \\
\hline CHEMBL530115 & 688171 & 4.5 & 4.9022 & TST \\
\hline CHEMBL1393822 & 688171 & 4.35 & 4.8212 & TST \\
\hline CHEMBL1374600 & 688171 & 4.6 & 4.7911 & TRN \\
\hline CHEMBL1446328 & 688171 & 4.55 & 4.872 & TRN \\
\hline CHEMBL1332908 & 688171 & 4.55 & 4.8874 & TRN \\
\hline CHEMBL1374879 & 688171 & 5.7 & 4.8225 & TRN \\
\hline CHEMBL1346972 & 688171 & 5.15 & 4.9002 & TRN \\
\hline CHEMBL1423318 & 688171 & 4.4 & 4.922 & TRN \\
\hline CHEMBL1526731 & 688171 & 5.25 & 4.9032 & TRN \\
\hline CHEMBL1401524 & 688171 & 4.4 & 4.9011 & TRN \\
\hline CHEMBL1319704 & 688171 & 4.35 & 5.0357 & TRN \\
\hline CHEMBL1487894 & 688171 & 4.8 & 4.7577 & TRN \\
\hline CHEMBL1998461 & 688171 & 4.55 & 4.8664 & TST \\
\hline CHEMBL1463897 & 688171 & 5.5 & 5.0045 & TST \\
\hline CHEMBL1351826 & 688171 & 5.0 & 4.9492 & TRN \\
\hline CHEMBL1440795 & 688171 & 4.55 & 4.8504 & TST \\
\hline CHEMBL3191687 & 688171 & 5.0 & 5.0041 & TRN \\
\hline CHEMBL1321790 & 688171 & 4.6 & 4.8366 & TRN \\
\hline CHEMBL1574818 & 688171 & 4.6 & 4.9337 & TRN \\
\hline CHEMBL1542157 & 688171 & 4.45 & 4.9027 & TRN \\
\hline CHEMBL1433576 & 688171 & 5.25 & 5.0039 & TST \\
\hline CHEMBL1583262 & 688171 & 4.65 & 4.7949 & TRN \\
\hline CHEMBL1530032 & 688171 & 4.35 & 4.9726 & TST \\
\hline CHEMBL1554106 & 688171 & 4.4 & 4.933 & TRN \\
\hline
\end{tabular}




\begin{tabular}{|c|c|c|c|c|}
\hline \multicolumn{5}{|c|}{ Supplemental Table S2.txt } \\
\hline CHEMBL1337150 & 688171 & 4.4 & 4.95 & TRN \\
\hline CHEMBL1306477 & 688171 & 5.3 & 5.0152 & TST \\
\hline CHEMBL1444113 & 688171 & 5.9 & 4.9406 & TRN \\
\hline CHEMBL1495686 & 688171 & 4.45 & 4.857 & TRN \\
\hline CHEMBL1314624 & 688171 & 4.75 & 4.7045 & TRN \\
\hline CHEMBL1402234 & 688171 & 5.25 & 4.857 & TRN \\
\hline CHEMBL1399633 & 688171 & 4.6 & 4.8588 & TRN \\
\hline CHEMBL1348681 & 688171 & 5.9 & 4.7567 & TST \\
\hline CHEMBL233895 & 688171 & 4.35 & 4.9723 & TRN \\
\hline CHEMBL1385413 & 688171 & 6.0 & 4.7038 & TRN \\
\hline CHEMBL1554825 & 688171 & 4.9 & 4.9078 & TRN \\
\hline CHEMBL465227 & 688171 & 4.85 & 4.8142 & TRN \\
\hline CHEMBL1580618 & 688171 & 6.7001 & 4.9202 & TRN \\
\hline CHEMBL1463448 & 688171 & 5.0 & 4.8252 & TST \\
\hline CHEMBL1307971 & 688171 & 4.35 & 4.9618 & TST \\
\hline CHEMBL1323991 & 688171 & 5.25 & 5.0133 & TRN \\
\hline CHEMBL1478147 & 688171 & 4.7 & 4.9339 & TRN \\
\hline CHEMBL1596965 & 688171 & 4.75 & 4.8287 & TRN \\
\hline CHEMBL1515385 & 688171 & 5.3 & 4.9842 & TRN \\
\hline CHEMBL1591685 & 688171 & 4.8 & 5.0676 & TRN \\
\hline CHEMBL1411750 & 688171 & 6.0 & 4.9625 & TRN \\
\hline CHEMBL1456948 & 688171 & 4.4 & 5.0213 & TRN \\
\hline CHEMBL1541457 & 688171 & 4.7 & 4.9626 & TRN \\
\hline CHEMBL1457624 & 688171 & 5.2 & 5.0262 & TRN \\
\hline CHEMBL535265 & 688171 & 4.35 & 4.9502 & TST \\
\hline CHEMBL533959 & 688171 & 5.25 & 5.0653 & TRN \\
\hline CHEMBL1354832 & 688171 & 4.4 & 4.8876 & TRN \\
\hline CHEMBL1530108 & 688171 & 4.55 & 4.8427 & TRN \\
\hline CHEMBL 3144978 & 688171 & 4.45 & 4.75 & TST \\
\hline CHEMBL1360938 & 688171 & 6.9 & 4.9432 & TST \\
\hline CHEMBL1464948 & 688171 & 4.75 & 4.825 & TST \\
\hline CHEMBL1364849 & 688171 & 4.95 & 4.9803 & TRN \\
\hline CHEMBL3211005 & 688171 & 4.5 & 4.7955 & TRN \\
\hline CHEMBL1521830 & 688171 & 4.7 & 4.9298 & TRN \\
\hline CHEMBL86464 & 688171 & 7.6003 & 4.8856 & TRN \\
\hline CHEMBL1403284 & 688171 & 4.85 & 4.9296 & TRN \\
\hline CHEMBL1534782 & 688171 & 4.9 & 4.9279 & TRN \\
\hline CHEMBL1562856 & 688171 & 4.4 & 4.8827 & TRN \\
\hline CHEMBL1602361 & 688171 & 4.75 & 4.7953 & TST \\
\hline CHEMBL1565309 & 688171 & 4.85 & 4.7901 & TRN \\
\hline CHEMBL1423039 & 688171 & 4.9 & 5.1293 & TST \\
\hline CHEMBL1482873 & 688171 & 5.15 & 4.8921 & TRN \\
\hline CHEMBL1484714 & 688171 & 4.8 & 4.8228 & TRN \\
\hline CHEMBL1543201 & 688171 & 4.4 & 5.0121 & TRN \\
\hline CHEMBL1493884 & 688171 & 4.55 & 4.8615 & TRN \\
\hline CHEMBL1324089 & 688171 & 4.85 & 4.8768 & TRN \\
\hline CHEMBL1363436 & 688171 & 5.05 & 4.8489 & TRN \\
\hline CHEMBL222838 & 688171 & 5.35 & 4.9228 & TST \\
\hline
\end{tabular}




\begin{tabular}{|c|c|c|c|c|}
\hline \multicolumn{5}{|c|}{ Supplemental Table s2.txt } \\
\hline CHEMBL1552483 & 688171 & 4.7 & 4.9397 & TRN \\
\hline CHEMBL1575325 & 688171 & 4.65 & 4.989 & TST \\
\hline CHEMBL1577793 & 688171 & 4.5 & 4.8314 & TST \\
\hline CHEMBL1514518 & 688171 & 4.65 & 4.8058 & TRN \\
\hline CHEMBL1570936 & 688171 & 4.35 & 4.9606 & TRN \\
\hline CHEMBL3209307 & 688171 & 4.5 & 5.0179 & TRN \\
\hline CHEMBL1539492 & 688171 & 6.0 & 4.8313 & TST \\
\hline CHEMBL1605337 & 688171 & 4.45 & 4.9252 & TRN \\
\hline CHEMBL1513650 & 688171 & 4.85 & 4.9912 & TRN \\
\hline CHEMBL1551635 & 688171 & 4.65 & 4.9956 & TRN \\
\hline CHEMBL1475436 & 688171 & 4.4 & 4.9255 & TRN \\
\hline CHEMBL1607625 & 688171 & 4.65 & 4.9161 & TRN \\
\hline CHEMBL1423454 & 688171 & 4.55 & 4.7996 & TRN \\
\hline CHEMBL1362121 & 688171 & 5.3 & 4.9688 & TST \\
\hline CHEMBL1425497 & 688171 & 4.5 & 4.8128 & TRN \\
\hline CHEMBL1312263 & 688171 & 4.7 & 5.0413 & TRN \\
\hline CHEMBL1422472 & 688171 & 5.35 & 4.9845 & TRN \\
\hline CHEMBL1470586 & 688171 & 7.6498 & 4.9467 & TRN \\
\hline CHEMBL1523305 & 688171 & 4.55 & 4.8534 & TRN \\
\hline CHEMBL1408105 & 688171 & 4.5 & 4.8136 & TRN \\
\hline CHEMBL 3197478 & 688171 & 4.9 & 4.8993 & TRN \\
\hline CHEMBL1541723 & 688171 & 4.8 & 4.8787 & TRN \\
\hline CHEMBL1402990 & 688171 & 4.65 & 4.8511 & TST \\
\hline CHEMBL1519539 & 688171 & 5.75 & 4.95 & TRN \\
\hline CHEMBL1402357 & 688171 & 4.4 & 4.922 & TRN \\
\hline CHEMBL1433718 & 688171 & 4.4 & 4.8944 & TRN \\
\hline CHEMBL3193579 & 688171 & 4.55 & 4.9569 & TRN \\
\hline CHEMBL1515629 & 688171 & 4.9 & 4.8354 & TRN \\
\hline CHEMBL1478012 & 688171 & 4.85 & 4.8953 & TRN \\
\hline CHEMBL1373189 & 688171 & 4.4 & 4.8013 & TRN \\
\hline CHEMBL 2004449 & 688171 & 6.1 & 4.9105 & TRN \\
\hline CHEMBL1375971 & 688171 & 4.55 & 4.9123 & TRN \\
\hline CHEMBL1384167 & 688171 & 5.2 & 4.8561 & TST \\
\hline CHEMBL12998 & 688171 & 4.75 & 5.0247 & TST \\
\hline CHEMBL1447467 & 688171 & 4.85 & 4.9246 & TST \\
\hline CHEMBL3192945 & 688171 & 5.05 & 4.8784 & TST \\
\hline CHEMBL595700 & 688171 & 4.4 & 4.9685 & TRN \\
\hline CHEMBL1305693 & 688171 & 4.6 & 4.87 & TRN \\
\hline CHEMBL1523584 & 688171 & 4.75 & 4.8241 & TRN \\
\hline CHEMBL1305490 & 688171 & 4.85 & 5.0198 & TRN \\
\hline CHEMBL1515103 & 688171 & 4.4 & 4.7874 & TRN \\
\hline CHEMBL1365424 & 688171 & 5.05 & 4.9683 & TRN \\
\hline CHEMBL1561140 & 688171 & 4.85 & 4.9329 & TRN \\
\hline CHEMBL1469428 & 688171 & 4.85 & 4.8945 & TRN \\
\hline CHEMBL1371567 & 688171 & 4.9 & 5.0498 & TRN \\
\hline CHEMBL1311453 & 688171 & 4.9 & 4.8978 & TRN \\
\hline CHEMBL1307830 & 688171 & 7.2 & 4.9238 & TRN \\
\hline CHEMBL1312761 & 688171 & 4.75 & 4.8541 & TRN \\
\hline
\end{tabular}




\begin{tabular}{|c|c|c|c|c|}
\hline \multicolumn{5}{|c|}{ Supplemental Table S2.txt } \\
\hline CHEMBL1605231 & 688171 & 4.5 & 4.8487 & TRN \\
\hline CHEMBL1605299 & 688171 & 4.8 & 4.8312 & TRN \\
\hline CHEMBL1527966 & 688171 & 5.0 & 4.9326 & TRN \\
\hline CHEMBL1355612 & 688171 & 4.4 & 4.7766 & TRN \\
\hline CHEMBL1381472 & 688171 & 4.6 & 4.9532 & TRN \\
\hline CHEMBL1492213 & 688171 & 4.4 & 4.9478 & TRN \\
\hline CHEMBL1551691 & 688171 & 5.3 & 4.8224 & TRN \\
\hline CHEMBL1339195 & 688171 & 5.05 & 4.9177 & TRN \\
\hline CHEMBL1357344 & 688171 & 7.2 & 4.9665 & TRN \\
\hline CHEMBL1382459 & 688171 & 4.6 & 4.956 & TRN \\
\hline CHEMBL1527056 & 688171 & 4.8 & 5.0141 & TRN \\
\hline CHEMBL1541427 & 688171 & 4.7 & 4.9436 & TRN \\
\hline CHEMBL1394631 & 688171 & 5.1 & 4.8198 & TRN \\
\hline CHEMBL1517112 & 688171 & 4.45 & 4.9492 & TRN \\
\hline CHEMBL 338474 & 688171 & 6.0 & 4.9779 & TRN \\
\hline CHEMBL3198819 & 688171 & 4.45 & 4.8252 & TRN \\
\hline CHEMBL1480688 & 688171 & 5.0 & 4.9471 & TRN \\
\hline CHEMBL1305938 & 688171 & 4.35 & 5.0121 & TST \\
\hline CHEMBL1579435 & 688171 & 4.45 & 4.9251 & TST \\
\hline CHEMBL1424016 & 688171 & 4.4 & 4.97 & TRN \\
\hline CHEMBL1513637 & 688171 & 7.3002 & 4.9902 & TRN \\
\hline CHEMBL1534492 & 688171 & 4.9 & 4.7691 & TRN \\
\hline CHEMBL1331600 & 688171 & 4.85 & 4.9351 & TRN \\
\hline CHEMBL1415834 & 688171 & 4.45 & 5.003 & TRN \\
\hline CHEMBL1505062 & 688171 & 4.75 & 4.9165 & TRN \\
\hline CHEMBL211481 & 688171 & 4.55 & 4.8029 & TRN \\
\hline CHEMBL1457010 & 688171 & 4.5 & 4.8319 & TRN \\
\hline CHEMBL1563103 & 688171 & 4.4 & 4.8931 & TRN \\
\hline CHEMBL1461123 & 688171 & 4.5 & 4.891 & TRN \\
\hline CHEMBL1417632 & 688171 & 4.6 & 4.886 & TRN \\
\hline CHEMBL1413530 & 688171 & 5.45 & 4.8589 & TRN \\
\hline CHEMBL1330211 & 688171 & 4.55 & 4.9938 & TRN \\
\hline CHEMBL1360283 & 688171 & 5.05 & 4.967 & TRN \\
\hline CHEMBL1462724 & 688171 & 4.6 & 4.9458 & TRN \\
\hline CHEMBL1379103 & 688171 & 4.4 & 4.8541 & TRN \\
\hline CHEMBL1464687 & 688171 & 4.6 & 4.8615 & TRN \\
\hline CHEMBL1565991 & 688171 & 4.45 & 4.9208 & TRN \\
\hline CHEMBL1338064 & 688171 & 5.5 & 4.8335 & TRN \\
\hline CHEMBL1449470 & 688171 & 4.95 & 5.0444 & TRN \\
\hline CHEMBL1356568 & 688171 & 4.4 & 4.864 & TRN \\
\hline CHEMBL1375904 & 688171 & 5.0 & 4.8872 & TRN \\
\hline CHEMBL1525017 & 688171 & 4.55 & 4.9951 & TRN \\
\hline CHEMBL1379139 & 688171 & 4.7 & 5.0959 & TRN \\
\hline CHEMBL1570002 & 688171 & 5.25 & 4.9554 & TST \\
\hline CHEMBL1598747 & 688171 & 4.35 & 4.9563 & TST \\
\hline CHEMBL1519826 & 688171 & 4.55 & 4.8629 & TRN \\
\hline CHEMBL1326131 & 688171 & 7.1002 & 5.084 & TST \\
\hline CHEMBL1539579 & 688171 & 4.45 & 4.8941 & TST \\
\hline
\end{tabular}




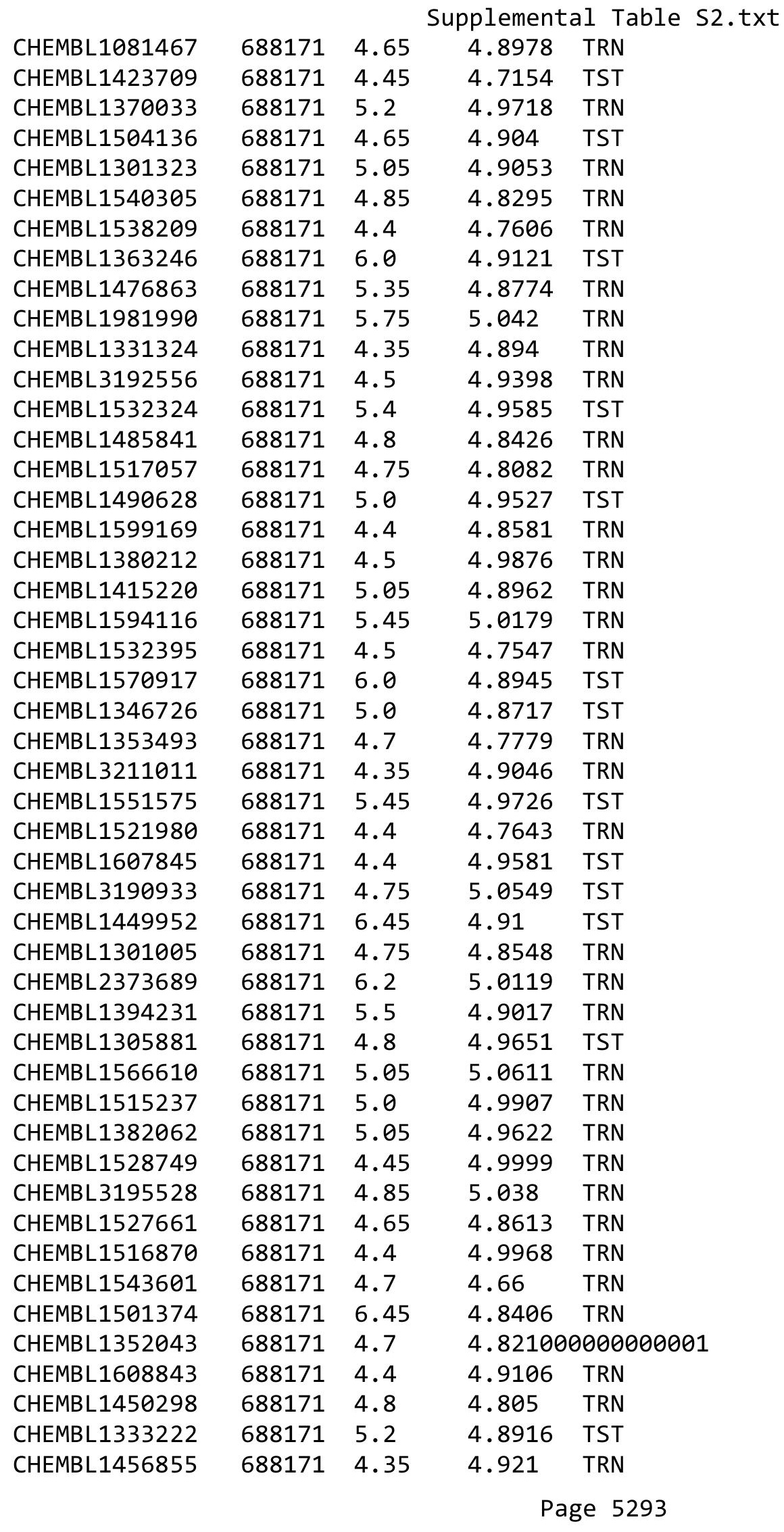

TRN 


\begin{tabular}{|c|c|c|c|c|c|}
\hline \multicolumn{6}{|c|}{ Supplemental Table S2.txt } \\
\hline CHEMBL1554525 & 688171 & 6.1 & 4.9473 & TRN & \\
\hline CHEMBL1468096 & 688171 & 4.8 & 4.8786 & TRN & \\
\hline CHEMBL1318000 & 688171 & 4.4 & 4.8953 & TRN & \\
\hline CHEMBL1481727 & 688171 & 5.05 & 5.0169 & TRN & \\
\hline CHEMBL1401843 & 688171 & 4.65 & 4.9214 & TRN & \\
\hline CHEMBL1389483 & 688171 & 4.35 & 4.8315 & TRN & \\
\hline CHEMBL1488016 & 688171 & 4.6 & 4.76699 & 99999999995 & TRN \\
\hline CHEMBL1580240 & 688171 & 4.95 & 4.9465 & TST & \\
\hline CHEMBL1390617 & 688171 & 4.8 & 5.0451 & TRN & \\
\hline CHEMBL226664 & 688171 & 4.7 & 4.8689 & TRN & \\
\hline CHEMBL3197177 & 688171 & 4.8 & 5.0274 & TRN & \\
\hline CHEMBL1524392 & 688171 & 4.85 & 4.7224 & TRN & \\
\hline CHEMBL1493251 & 688171 & 4.5 & 4.9211 & TST & \\
\hline CHEMBL3189614 & 688171 & 6.25 & 4.941 & TRN & \\
\hline CHEMBL1573534 & 688171 & 5.25 & 4.9505 & TRN & \\
\hline CHEMBL1384514 & 688171 & 5.5 & 5.0492 & TRN & \\
\hline CHEMBL1449789 & 688171 & 4.85 & 4.9132 & TRN & \\
\hline CHEMBL1307046 & 688171 & 4.65 & 4.9362 & TRN & \\
\hline CHEMBL1560775 & 688171 & 4.4 & 4.7817 & TRN & \\
\hline CHEMBL1552648 & 688171 & 4.4 & 4.7916 & TRN & \\
\hline CHEMBL3196447 & 688171 & 4.9 & 4.8141 & TRN & \\
\hline CHEMBL1380326 & 688171 & 5.05 & 4.9815 & TRN & \\
\hline CHEMBL1431191 & 688171 & 4.4 & 4.9138 & TST & \\
\hline CHEMBL1994635 & 688171 & 5.5 & 4.8761 & TRN & \\
\hline CHEMBL1499719 & 688171 & 4.7 & 4.8874 & TRN & \\
\hline CHEMBL1573317 & 688171 & 5.05 & 4.9815 & TST & \\
\hline CHEMBL1437782 & 688171 & 4.5 & 4.998 & TST & \\
\hline CHEMBL1513135 & 688171 & 5.3 & 4.8875 & TRN & \\
\hline CHEMBL1425725 & 688171 & 4.5 & 4.7816 & TRN & \\
\hline CHEMBL1381243 & 688171 & 4.9 & 5.0074 & TRN & \\
\hline CHEMBL2373676 & 688171 & 6.8 & 4.9894 & TST & \\
\hline CHEMBL1369594 & 688171 & 5.0 & 4.81800 & 00000000005 & TRN \\
\hline CHEMBL1503704 & 688171 & 5.05 & 4.8771 & TRN & \\
\hline CHEMBL1436290 & 688171 & 4.9 & 4.886 & TRN & \\
\hline CHEMBL1314668 & 688171 & 4.55 & 4.9604 & TRN & \\
\hline CHEMBL3191177 & 688171 & 5.35 & 4.9101 & TRN & \\
\hline CHEMBL3196768 & 688171 & 4.75 & 4.9815 & TRN & \\
\hline CHEMBL1417384 & 688171 & 5.65 & 4.822 & TRN & \\
\hline CHEMBL1478961 & 688171 & 4.4 & 5.0047 & TRN & \\
\hline CHEMBL1354873 & 688171 & 4.75 & 4.9832 & TRN & \\
\hline CHEMBL1379362 & 688171 & 4.4 & 5.0167 & TRN & \\
\hline CHEMBL1492116 & 688171 & 4.95 & 4.996 & TRN & \\
\hline CHEMBL1586729 & 688171 & 6.1 & 4.9279 & TRN & \\
\hline CHEMBL1461030 & 688171 & 4.4 & 4.9404 & TRN & \\
\hline CHEMBL1592554 & 688171 & 4.9 & 4.974 & TRN & \\
\hline CHEMBL1317153 & 688171 & 6.5 & 4.8551 & TRN & \\
\hline CHEMBL1551108 & 688171 & 4.55 & 4.8574 & TRN & \\
\hline CHEMBL1431123 & 688171 & 4.45 & 4.7659 & TRN & \\
\hline
\end{tabular}




\begin{tabular}{|c|c|c|c|c|}
\hline \multicolumn{5}{|c|}{ Supplemental Table S2.txt } \\
\hline CHEMBL1325371 & 688171 & 4.55 & 4.88 & TRN \\
\hline CHEMBL3195717 & 688171 & 4.7 & 4.6998 & TRN \\
\hline CHEMBL3193983 & 688171 & 4.45 & 4.8237 & TRN \\
\hline CHEMBL1555049 & 688171 & 5.5 & 4.9893 & TRN \\
\hline CHEMBL1314421 & 688171 & 5.0 & 4.9459 & TRN \\
\hline CHEMBL1358006 & 688171 & 4.55 & 4.9184 & TRN \\
\hline CHEMBL1534883 & 688171 & 5.4 & 4.9 & TRN \\
\hline CHEMBL1308294 & 688171 & 4.6 & 4.7396 & TST \\
\hline CHEMBL1565988 & 688171 & 5.3 & 4.9793 & TRN \\
\hline CHEMBL1546183 & 688171 & 4.45 & 4.9493 & TRN \\
\hline CHEMBL1575367 & 688171 & 5.1 & 4.8459 & TRN \\
\hline CHEMBL1600254 & 688171 & 5.0 & 4.9461 & TST \\
\hline CHEMBL1454942 & 688171 & 6.05 & 4.954 & TST \\
\hline CHEMBL1365599 & 688171 & 6.0 & 4.8687 & TRN \\
\hline CHEMBL1441922 & 688171 & 7.6003 & 5.103 & TST \\
\hline CHEMBL1557142 & 688171 & 4.4 & 4.9235 & TST \\
\hline CHEMBL1584295 & 688171 & 4.7 & 5.0284 & TRN \\
\hline CHEMBL1452943 & 688171 & 4.55 & 4.8252 & TST \\
\hline CHEMBL1300050 & 688171 & 4.35 & 4.9377 & TST \\
\hline CHEMBL1366537 & 688171 & 5.0 & 4.9084 & TRN \\
\hline CHEMBL1323279 & 688171 & 5.75 & 4.8552 & TRN \\
\hline CHEMBL1322303 & 688171 & 4.35 & 4.8542 & TRN \\
\hline CHEMBL1521335 & 688171 & 4.7 & 4.8926 & TRN \\
\hline CHEMBL1439395 & 688171 & 4.95 & 4.8375 & TRN \\
\hline CHEMBL1300015 & 688171 & 5.2 & 4.9176 & TRN \\
\hline CHEMBL1340962 & 688171 & 4.45 & 4.9937 & TRN \\
\hline CHEMBL1578440 & 688171 & 5.4 & 4.8817 & TRN \\
\hline CHEMBL473315 & 688171 & 7.6003 & 4.9153 & TRN \\
\hline CHEMBL1380093 & 688171 & 4.45 & 4.81800 & 00000000005 \\
\hline CHEMBL1482479 & 688171 & 4.95 & 5.0659 & TRN \\
\hline CHEMBL1376155 & 688171 & 4.35 & 4.938 & TRN \\
\hline CHEMBL1379381 & 688171 & 5.15 & 4.8919 & TST \\
\hline CHEMBL1562634 & 688171 & 4.75 & 4.8578 & TRN \\
\hline CHEMBL1420854 & 688171 & 4.4 & 4.8688 & TRN \\
\hline CHEMBL1319441 & 688171 & 4.4 & 4.9497 & TRN \\
\hline CHEMBL1612235 & 688171 & 4.45 & 4.9789 & TRN \\
\hline CHEMBL1606489 & 688171 & 4.35 & 4.9427 & TRN \\
\hline CHEMBL1564888 & 688171 & 5.05 & 4.8411 & TRN \\
\hline CHEMBL1486320 & 688171 & 4.75 & 4.8953 & TRN \\
\hline CHEMBL1592851 & 688171 & 4.7 & 4.7718 & TRN \\
\hline CHEMBL1328193 & 688171 & 6.15 & 4.9314 & TST \\
\hline CHEMBL1439619 & 688171 & 4.85 & 4.8791 & TRN \\
\hline CHEMBL1529890 & 688171 & 4.4 & 4.8439 & TRN \\
\hline CHEMBL 3189278 & 688171 & 4.8 & 4.9206 & TST \\
\hline CHEMBL1326519 & 688171 & 4.6 & 4.9263 & TRN \\
\hline CHEMBL1463789 & 688171 & 4.65 & 4.9477 & TRN \\
\hline CHEMBL1569229 & 688171 & 5.5 & 4.9667 & TRN \\
\hline CHEMBL1516297 & 688171 & 4.5 & 4.8566 & TRN \\
\hline
\end{tabular}




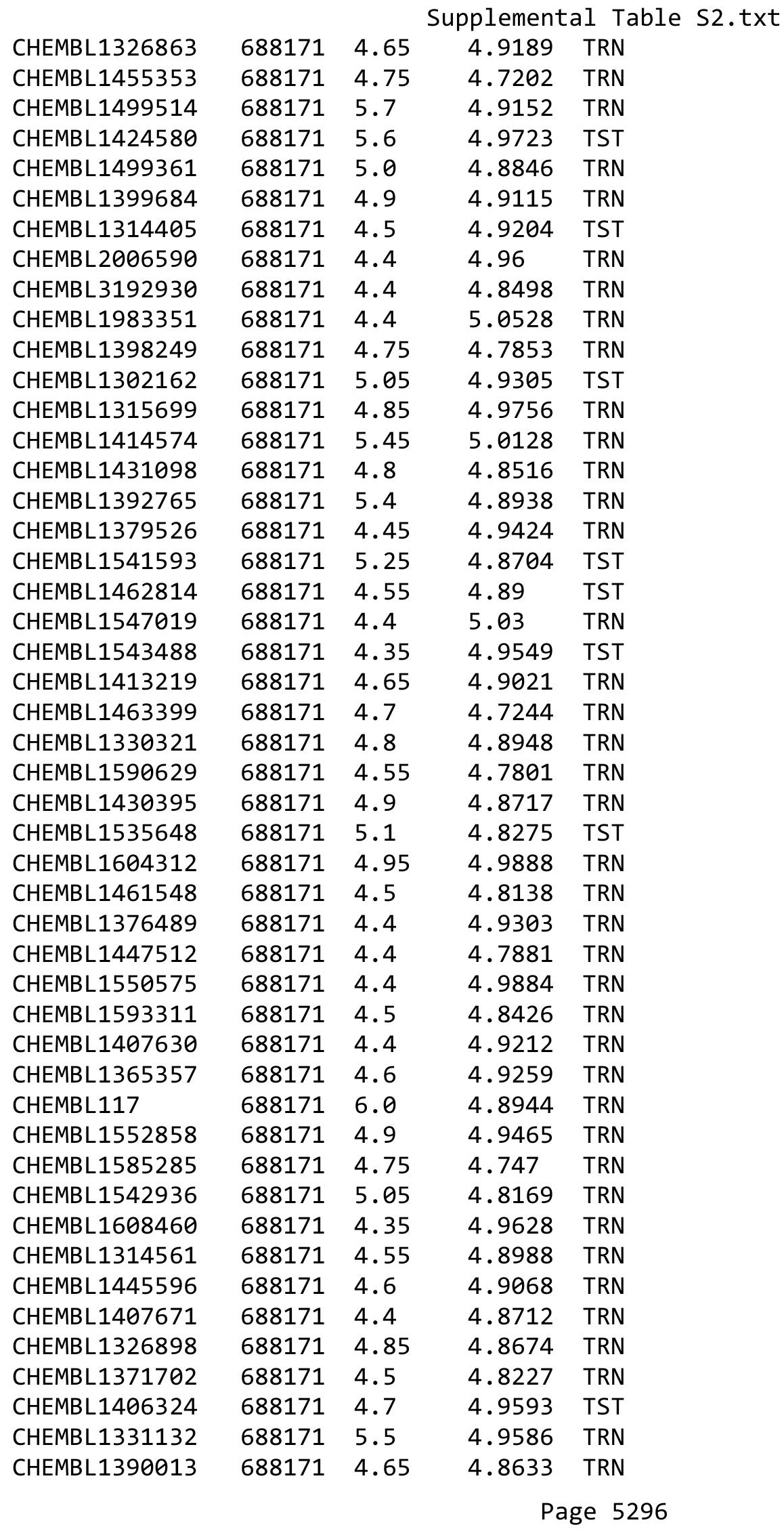




\begin{tabular}{|c|c|c|c|c|c|}
\hline \multicolumn{6}{|c|}{ Supplemental Table S2.txt } \\
\hline CHEMBL1505196 & 688171 & 4.7 & 4.8918 & TRN & \\
\hline CHEMBL 3189464 & 688171 & 7.3002 & 4.9414 & TRN & \\
\hline CHEMBL1515595 & 688171 & 4.95 & 4.9984 & TRN & \\
\hline CHEMBL1528690 & 688171 & 5.35 & 4.8775 & TRN & \\
\hline CHEMBL1553313 & 688171 & 4.95 & 4.9212 & TRN & \\
\hline CHEMBL1397097 & 688171 & 4.9 & 4.9141 & TRN & \\
\hline CHEMBL1573114 & 688171 & 5.05 & 4.9593 & TRN & \\
\hline CHEMBL1466455 & 688171 & 4.4 & 4.9669 & TRN & \\
\hline CHEMBL1514493 & 688171 & 4.6 & 4.7763 & TST & \\
\hline CHEMBL1534393 & 688171 & 4.95 & 4.9749 & TRN & \\
\hline CHEMBL1518858 & 688171 & 5.05 & 4.8913 & TRN & \\
\hline CHEMBL1502716 & 688171 & 4.5 & 4.9107 & TRN & \\
\hline CHEMBL1609673 & 688171 & 6.25 & \multicolumn{2}{|c|}{4.928999999999999} & TRN \\
\hline CHEMBL1407508 & 688171 & 4.4 & 4.9231 & TRN & \\
\hline CHEMBL1421871 & 688171 & 4.7 & 4.7727 & TST & \\
\hline CHEMBL1307333 & 688171 & 4.35 & 5.0759 & TRN & \\
\hline CHEMBL1452645 & 688171 & 5.3 & 4.9474 & TST & \\
\hline CHEMBL1494018 & 688171 & 5.35 & 5.0561 & TRN & \\
\hline CHEMBL1457218 & 688171 & 5.1 & 4.876 & TRN & \\
\hline CHEMBL1365570 & 688171 & 4.9 & 4.7535 & TRN & \\
\hline CHEMBL118175 & 688171 & 4.75 & 4.9921 & TRN & \\
\hline CHEMBL1397505 & 688171 & 4.55 & 4.9535 & TRN & \\
\hline CHEMBL1558987 & 688171 & 4.7 & 4.915 & TRN & \\
\hline CHEMBL1473589 & 688171 & 4.4 & 4.8902 & TRN & \\
\hline CHEMBL1360536 & 688171 & 5.0 & 4.8985 & TRN & \\
\hline CHEMBL1467016 & 688171 & 5.0 & 4.8814 & TRN & \\
\hline CHEMBL1351091 & 688171 & 4.6 & 4.953 & TRN & \\
\hline CHEMBL 3195627 & 688171 & 5.15 & 4.8044 & TRN & \\
\hline CHEMBL1525603 & 688171 & 4.35 & 4.977 & TRN & \\
\hline CHEMBL1437320 & 688171 & 4.4 & 4.8587 & TRN & \\
\hline CHEMBL1429951 & 688171 & 4.55 & 4.8745 & TST & \\
\hline CHEMBL605629 & 688171 & 4.4 & 4.8034 & TRN & \\
\hline CHEMBL1590036 & 688171 & 4.35 & 4.8685 & TRN & \\
\hline CHEMBL1573956 & 688171 & 4.6 & 4.8897 & TRN & \\
\hline CHEMBL1424900 & 688171 & 5.55 & 4.9749 & TRN & \\
\hline CHEMBL1410405 & 688171 & 5.8 & 5.0299 & TRN & \\
\hline CHEMBL1306448 & 688171 & 4.8 & 4.9032 & TRN & \\
\hline CHEMBL1361920 & 688171 & 7.5498 & 4.915 & TRN & \\
\hline CHEMBL1345620 & 688171 & 4.55 & 4.7982 & TRN & \\
\hline CHEMBL1536567 & 688171 & 4.5 & 4.9489 & TST & \\
\hline CHEMBL1409874 & 688171 & 4.65 & 5.0173 & TRN & \\
\hline CHEMBL1478139 & 688171 & 4.4 & 4.7436 & TST & \\
\hline CHEMBL1453970 & 688171 & 4.55 & 4.9595 & TST & \\
\hline CHEMBL1302188 & 688171 & 5.9 & 4.8792 & TRN & \\
\hline CHEMBL1462721 & 688171 & 4.55 & 4.9369 & TRN & \\
\hline CHEMBL1602067 & 688171 & 4.4 & 4.9105 & TST & \\
\hline CHEMBL1443651 & 688171 & 4.6 & 4.8392 & TRN & \\
\hline \multirow[t]{2}{*}{ CHEMBL1513472 } & 688171 & 4.7 & 4.92899 & 9999999999 & TRN \\
\hline & & \multicolumn{4}{|c|}{ Page 5297} \\
\hline
\end{tabular}




\begin{tabular}{|c|c|c|c|c|}
\hline \multicolumn{5}{|c|}{ Supplemental Table S2.txt } \\
\hline CHEMBL1547658 & 688171 & 4.35 & 4.8883 & TST \\
\hline CHEMBL1091723 & 688171 & 5.05 & 4.9663 & TST \\
\hline CHEMBL1607246 & 688171 & 5.65 & 5.1447 & TRN \\
\hline CHEMBL1479313 & 688171 & 5.5 & 4.9089 & TRN \\
\hline CHEMBL1443199 & 688171 & 5.1 & 4.8883 & TRN \\
\hline CHEMBL1579883 & 688171 & 4.4 & 4.8793 & TRN \\
\hline CHEMBL1455279 & 688171 & 4.65 & 4.8467 & TST \\
\hline CHEMBL1494264 & 688171 & 5.2 & 4.8222 & TRN \\
\hline CHEMBL1474575 & 688171 & 5.6 & 4.8747 & TRN \\
\hline CHEMBL1394615 & 688171 & 5.3 & 5.0584 & TRN \\
\hline CHEMBL1607656 & 688171 & 4.4 & 4.7803 & TRN \\
\hline CHEMBL1309219 & 688171 & 5.9 & 4.9251 & TRN \\
\hline CHEMBL1319209 & 688171 & 4.45 & 4.7864 & TRN \\
\hline CHEMBL1312449 & 688171 & 5.35 & 5.0475 & TRN \\
\hline CHEMBL3197099 & 688171 & 5.4 & 4.9637 & TRN \\
\hline CHEMBL1455016 & 688171 & 4.85 & 4.8611 & TRN \\
\hline CHEMBL1498043 & 688171 & 4.85 & 4.9614 & TRN \\
\hline CHEMBL1364745 & 688171 & 4.35 & 5.02 & TST \\
\hline CHEMBL1449880 & 688171 & 4.5 & 4.8777 & TRN \\
\hline CHEMBL1456821 & 688171 & 4.9 & 4.7674 & TRN \\
\hline CHEMBL1462352 & 688171 & 6.8499 & 4.8102 & TST \\
\hline CHEMBL1602369 & 688171 & 4.6 & 4.7764 & TRN \\
\hline CHEMBL1570727 & 688171 & 4.8 & 4.9797 & TRN \\
\hline CHEMBL1564048 & 688171 & 5.55 & 4.8791 & TRN \\
\hline CHEMBL1302628 & 688171 & 4.45 & 4.8158 & TRN \\
\hline CHEMBL1589313 & 688171 & 5.05 & 4.9379 & TRN \\
\hline CHEMBL1410979 & 688171 & 4.8 & 4.9165 & TRN \\
\hline CHEMBL1993194 & 688171 & 5.9 & 5.0125 & TRN \\
\hline CHEMBL1585979 & 688171 & 4.4 & 5.0002 & TST \\
\hline CHEMBL1594243 & 688171 & 5.0 & 4.9306 & TRN \\
\hline CHEMBL1364050 & 688171 & 4.7 & 4.9098 & TRN \\
\hline CHEMBL1532008 & 688171 & 4.55 & 4.8152 & TRN \\
\hline CHEMBL1446915 & 688171 & 6.25 & 4.9615 & TRN \\
\hline CHEMBL3189951 & 688171 & 4.5 & 4.8906 & TRN \\
\hline CHEMBL1562869 & 688171 & 4.75 & 4.8642 & TRN \\
\hline CHEMBL1546123 & 688171 & 4.5 & 4.9746 & TRN \\
\hline CHEMBL 1407002 & 688171 & 4.5 & 4.8719 & TST \\
\hline CHEMBL1588407 & 688171 & 6.1 & 4.8484 & TRN \\
\hline CHEMBL1419764 & 688171 & 4.4 & 4.8664 & TRN \\
\hline CHEMBL1366395 & 688171 & 4.7 & 4.7676 & TST \\
\hline CHEMBL1556067 & 688171 & 4.5 & 4.9751 & TST \\
\hline CHEMBL1560379 & 688171 & 4.75 & 4.8131 & TRN \\
\hline CHEMBL1572430 & 688171 & 4.65 & 4.9135 & TST \\
\hline CHEMBL1513580 & 688171 & 4.6 & 4.7893 & TRN \\
\hline CHEMBL1332059 & 688171 & 4.6 & 4.8171 & TRN \\
\hline CHEMBL1458632 & 688171 & 4.75 & 4.9618 & TRN \\
\hline CHEMBL1449223 & 688171 & 4.35 & 5.1641 & TRN \\
\hline CHEMBL1519341 & 688171 & 4.6 & 4.8464 & TRN \\
\hline
\end{tabular}




\begin{tabular}{|c|c|c|c|c|}
\hline \multicolumn{5}{|c|}{ Supplemental Table S2.txt } \\
\hline CHEMBL1502358 & 688171 & 4.8 & 4.8793 & TST \\
\hline CHEMBL1415522 & 688171 & 4.5 & 5.0132 & TRN \\
\hline CHEMBL1507534 & 688171 & 4.65 & 4.9046 & TRN \\
\hline CHEMBL1355269 & 688171 & 6.9 & 5.0178 & TST \\
\hline CHEMBL1548957 & 688171 & 4.5 & 4.9589 & TRN \\
\hline CHEMBL1302705 & 688171 & 5.0 & 4.9842 & TRN \\
\hline CHEMBL1565652 & 688171 & 5.75 & 4.9585 & TRN \\
\hline CHEMBL1357396 & 688171 & 4.9 & 4.8142 & TRN \\
\hline CHEMBL1595769 & 688171 & 5.05 & 5.0273 & TRN \\
\hline CHEMBL1501964 & 688171 & 5.65 & 4.7994 & TRN \\
\hline CHEMBL1586704 & 688171 & 4.75 & 4.8112 & TRN \\
\hline CHEMBL1314375 & 688171 & 4.4 & 4.9882 & TRN \\
\hline CHEMBL1590256 & 688171 & 5.3 & 4.8591 & TRN \\
\hline CHEMBL1466926 & 688171 & 4.5 & 5.0053 & TST \\
\hline CHEMBL1435752 & 688171 & 5.1 & 4.9096 & TRN \\
\hline CHEMBL1367456 & 688171 & 4.35 & 4.9608 & TRN \\
\hline CHEMBL1508069 & 688171 & 4.95 & 4.874 & TRN \\
\hline CHEMBL1531476 & 688171 & 4.6 & 4.922 & TRN \\
\hline CHEMBL1439794 & 688171 & 4.8 & 4.8052 & TRN \\
\hline CHEMBL1390930 & 688171 & 4.7 & 4.8801 & TRN \\
\hline CHEMBL1314740 & 688171 & 4.5 & 4.9383 & TRN \\
\hline CHEMBL1344289 & 688171 & 4.7 & 5.0103 & TRN \\
\hline CHEMBL1350220 & 688171 & 4.75 & 5.004 & TRN \\
\hline CHEMBL1304531 & 688171 & 4.9 & 4.8895 & TRN \\
\hline CHEMBL1603335 & 688171 & 4.75 & 4.9991 & TRN \\
\hline CHEMBL3196191 & 688171 & 4.55 & 4.8933 & TRN \\
\hline CHEMBL1328902 & 688171 & 4.6 & 4.7058 & TRN \\
\hline CHEMBL1592103 & 688171 & 4.7 & 4.8457 & TRN \\
\hline CHEMBL18879 & 688171 & 4.4 & 4.9368 & TST \\
\hline CHEMBL1433880 & 688171 & 5.5 & 4.8867 & TRN \\
\hline CHEMBL1606601 & 688171 & 4.35 & 5.0523 & TRN \\
\hline CHEMBL1348483 & 688171 & 5.45 & 4.7811 & TRN \\
\hline CHEMBL1604199 & 688171 & 4.9 & 4.9348 & TRN \\
\hline CHEMBL1474774 & 688171 & 4.75 & 4.9413 & TRN \\
\hline CHEMBL1548966 & 688171 & 4.5 & 4.8141 & TRN \\
\hline CHEMBL1488689 & 688171 & 5.05 & 4.7863 & TRN \\
\hline CHEMBL3210043 & 688171 & 4.7 & 5.0106 & TST \\
\hline CHEMBL1473137 & 688171 & 4.95 & 4.9116 & TRN \\
\hline CHEMBL1304669 & 688171 & 5.4 & 4.952 & TST \\
\hline CHEMBL1515179 & 688171 & 4.35 & 4.7967 & TRN \\
\hline CHEMBL1358811 & 688171 & 4.65 & 5.0028 & TRN \\
\hline CHEMBL1360011 & 688171 & 4.75 & 4.8065 & TST \\
\hline CHEMBL1573667 & 688171 & 4.4 & 5.0131 & TST \\
\hline CHEMBL1607748 & 688171 & 5.45 & 4.9209 & TRN \\
\hline CHEMBL1393175 & 688171 & 4.45 & 4.8278 & TRN \\
\hline CHEMBL3209376 & 688171 & 4.35 & 5.0037 & TRN \\
\hline CHEMBL1591053 & 688171 & 4.95 & 4.7351 & TRN \\
\hline CHEMBL1480556 & 688171 & 4.65 & 4.8842 & TRN \\
\hline
\end{tabular}




\begin{tabular}{|c|c|c|c|c|c|}
\hline & & \multicolumn{4}{|c|}{ Supplemental Table S2.txt } \\
\hline CHEMBL1506363 & 688171 & 5.45 & 4.8791 & TST & \\
\hline CHEMBL1478476 & 688171 & 6.05 & 4.9876 & TST & \\
\hline CHEMBL1490635 & 688171 & 4.75 & 4.8115 & TST & \\
\hline CHEMBL1498289 & 688171 & 4.55 & 5.0385 & TST & \\
\hline CHEMBL1351458 & 688171 & 4.55 & 4.77 & TRN & \\
\hline CHEMBL1500333 & 688171 & 4.8 & 4.8846 & TST & \\
\hline CHEMBL1496738 & 688171 & 4.55 & 4.937 & TST & \\
\hline CHEMBL1363910 & 688171 & 4.9 & 4.8965 & TRN & \\
\hline CHEMBL 213432 & 688171 & 4.4 & 4.9578 & TRN & \\
\hline CHEMBL1560942 & 688171 & 4.45 & 4.8852 & TRN & \\
\hline CHEMBL1316587 & 688171 & 4.5 & 4.8386 & TRN & \\
\hline CHEMBL1382384 & 688171 & 5.05 & 5.0758 & TST & \\
\hline CHEMBL1316326 & 688171 & 4.85 & 4.8591 & TRN & \\
\hline CHEMBL1562700 & 688171 & 5.2 & 4.9235 & TRN & \\
\hline CHEMBL1522506 & 688171 & 4.4 & 4.8851 & TRN & \\
\hline CHEMBL1494120 & 688171 & 5.55 & 4.9197 & TRN & \\
\hline CHEMBL1403021 & 688171 & 4.4 & 4.944 & TRN & \\
\hline CHEMBL1340249 & 688171 & 4.4 & 4.8761 & TRN & \\
\hline CHEMBL1455710 & 688171 & 4.55 & 5.078 & TRN & \\
\hline CHEMBL1536795 & 688171 & 4.9 & 5.0039 & TST & \\
\hline CHEMBL1482714 & 688171 & 4.45 & 4.9509 & TRN & \\
\hline CHEMBL184074 & 688171 & 5.3 & 5.0085 & TST & \\
\hline CHEMBL1568361 & 688171 & 5.5 & 4.9183 & TRN & \\
\hline CHEMBL1433460 & 688171 & 4.55 & 4.9702 & TRN & \\
\hline CHEMBL3210656 & 688171 & 4.5 & 4.9716 & TRN & \\
\hline CHEMBL1368569 & 688171 & 4.8 & 4.9314 & TRN & \\
\hline CHEMBL1600513 & 688171 & 4.5 & 4.7008 & TRN & \\
\hline CHEMBL1396341 & 688171 & 5.4 & 4.6796 & TRN & \\
\hline CHEMBL1457796 & 688171 & 5.15 & 4.76699 & 99999999995 & TST \\
\hline CHEMBL1434744 & 688171 & 4.8 & 5.103 & TRN & \\
\hline CHEMBL1403890 & 688171 & 4.8 & 4.9586 & TST & \\
\hline CHEMBL1302320 & 688171 & 4.8 & 4.8969 & TRN & \\
\hline CHEMBL1574312 & 688171 & 4.35 & 4.888 & TST & \\
\hline CHEMBL1541190 & 688171 & 5.55 & 4.8856 & TRN & \\
\hline CHEMBL1596893 & 688171 & 4.55 & 4.9333 & TST & \\
\hline CHEMBL1526219 & 688171 & 4.55 & 4.6922 & TRN & \\
\hline CHEMBL578515 & 688171 & 4.45 & 4.9308 & TRN & \\
\hline CHEMBL1419709 & 688171 & 4.7 & 4.7889 & TRN & \\
\hline CHEMBL1346240 & 688171 & 4.9 & 4.9475 & TRN & \\
\hline CHEMBL1491632 & 688171 & 4.65 & 4.8566 & TRN & \\
\hline CHEMBL1458255 & 688171 & 5.8 & 4.939 & TRN & \\
\hline CHEMBL1574667 & 688171 & 5.65 & 4.9256 & TRN & \\
\hline CHEMBL1495404 & 688171 & 5.3 & 4.8132 & TST & \\
\hline CHEMBL1476218 & 688171 & 4.5 & 4.9304 & TRN & \\
\hline CHEMBL1584059 & 688171 & 4.45 & 4.7856 & TRN & \\
\hline CHEMBL1600294 & 688171 & 5.5 & 4.8158 & TRN & \\
\hline CHEMBL1323513 & 688171 & 4.35 & 4.9198 & TRN & \\
\hline CHEMBL1383312 & 688171 & 4.9 & 4.9402 & TST & \\
\hline
\end{tabular}




\begin{tabular}{|c|c|c|c|c|}
\hline \multicolumn{5}{|c|}{ Supplemental Table S2.txt } \\
\hline CHEMBL1491536 & 688171 & 4.4 & 5.023 & TRN \\
\hline CHEMBL1370456 & 688171 & 4.4 & 5.0 & TST \\
\hline CHEMBL1350240 & 688171 & 4.65 & 4.8522 & TRN \\
\hline CHEMBL1348468 & 688171 & 5.1 & 4.8876 & TRN \\
\hline CHEMBL1545225 & 688171 & 4.4 & 4.7584 & TRN \\
\hline CHEMBL1539436 & 688171 & 4.55 & 4.8987 & TRN \\
\hline CHEMBL1570667 & 688171 & 5.15 & 4.8916 & TST \\
\hline CHEMBL1553135 & 688171 & 4.8 & 5.0208 & TRN \\
\hline CHEMBL1367801 & 688171 & 4.4 & 4.8554 & TRN \\
\hline CHEMBL1436252 & 688171 & 4.65 & 5.064 & TRN \\
\hline CHEMBL1362777 & 688171 & 4.85 & 4.9124 & TRN \\
\hline CHEMBL1386421 & 688171 & 4.4 & 4.8791 & TST \\
\hline CHEMBL1317677 & 688171 & 4.85 & 4.9173 & TRN \\
\hline CHEMBL42210 & 688171 & 5.8 & 4.9685 & TRN \\
\hline CHEMBL1434722 & 688171 & 6.3 & 4.8365 & TRN \\
\hline CHEMBL1500940 & 688171 & 5.5 & 4.8319 & TRN \\
\hline CHEMBL1501256 & 688171 & 4.4 & 4.8113 & TRN \\
\hline CHEMBL1488418 & 688171 & 7.0 & 4.8786 & TRN \\
\hline CHEMBL1467994 & 688171 & 4.4 & 4.8599 & TRN \\
\hline CHEMBL1378064 & 688171 & 4.65 & 4.842 & TRN \\
\hline CHEMBL1339846 & 688171 & 4.7 & 4.9575 & TRN \\
\hline CHEMBL1464041 & 688171 & 4.4 & 4.9032 & TST \\
\hline CHEMBL1536783 & 688171 & 4.4 & 4.7221 & TRN \\
\hline CHEMBL1317179 & 688171 & 4.7 & 4.9072 & TRN \\
\hline CHEMBL1432723 & 688171 & 4.35 & 4.9057 & TST \\
\hline CHEMBL1502165 & 688171 & 4.65 & 4.9636 & TRN \\
\hline CHEMBL1538570 & 688171 & 4.4 & 4.8842 & TST \\
\hline CHEMBL1600150 & 688171 & 5.0 & 4.8339 & TRN \\
\hline CHEMBL1415878 & 688171 & 5.0 & 4.8529 & TRN \\
\hline CHEMBL1412653 & 688171 & 4.45 & 4.8815 & TRN \\
\hline CHEMBL586005 & 688171 & 4.35 & 4.8595 & TRN \\
\hline CHEMBL1424202 & 688171 & 4.6 & 5.0257 & TST \\
\hline CHEMBL1501423 & 688171 & 4.4 & 4.9098 & TST \\
\hline CHEMBL1303889 & 688171 & 4.75 & 4.9106 & TRN \\
\hline CHEMBL1526847 & 688171 & 6.6 & 4.9458 & TRN \\
\hline CHEMBL1486618 & 688171 & 4.8 & 4.8485 & TRN \\
\hline CHEMBL1451853 & 688171 & 4.4 & 5.1074 & TRN \\
\hline CHEMBL1591588 & 688171 & 4.55 & 4.7369 & TRN \\
\hline CHEMBL1475573 & 688171 & 6.7501 & 4.9904 & TST \\
\hline CHEMBL1304071 & 688171 & 4.35 & 4.9906 & TRN \\
\hline CHEMBL1439403 & 688171 & 4.95 & 4.952 & TRN \\
\hline CHEMBL1518540 & 688171 & 5.05 & 4.8805 & TRN \\
\hline CHEMBL1507740 & 688171 & 5.3 & 5.0026 & TST \\
\hline CHEMBL1585304 & 688171 & 5.15 & 4.8702 & TST \\
\hline CHEMBL1341659 & 688171 & 4.9 & 4.9534 & TRN \\
\hline CHEMBL1989527 & 688171 & 4.6 & 4.9348 & TRN \\
\hline CHEMBL1469855 & 688171 & 5.0 & 4.9032 & TST \\
\hline CHEMBL1436807 & 688171 & 4.95 & 4.8699 & TRN \\
\hline
\end{tabular}




\begin{tabular}{|c|c|c|c|c|c|}
\hline \multicolumn{6}{|c|}{ Supplemental Table S2.txt } \\
\hline CHEMBL1485551 & 688171 & 4.8 & 5.0208 & TRN & \\
\hline CHEMBL1571750 & 688171 & 7.0501 & 4.8784 & TRN & \\
\hline CHEMBL1345901 & 688171 & 4.6 & 4.811 & TST & \\
\hline CHEMBL1467995 & 688171 & 4.95 & 4.9173 & TRN & \\
\hline CHEMBL1598911 & 688171 & 5.5 & 4.9058 & TRN & \\
\hline CHEMBL 3212725 & 688171 & 4.5 & 4.8631 & TRN & \\
\hline CHEMBL1308751 & 688171 & 4.45 & 4.7689 & TST & \\
\hline CHEMBL1345166 & 688171 & 5.2 & 4.9732 & TST & \\
\hline CHEMBL1306806 & 688171 & 5.05 & 4.9931 & TRN & \\
\hline CHEMBL1378655 & 688171 & 4.6 & 4.9832 & TRN & \\
\hline CHEMBL1373654 & 688171 & 4.55 & 5.0058 & TST & \\
\hline CHEMBL1385743 & 688171 & 4.45 & 4.8163 & TRN & \\
\hline CHEMBL1466186 & 688171 & 4.7 & 4.7735 & TRN & \\
\hline CHEMBL1604520 & 688171 & 4.35 & 4.8741 & TRN & \\
\hline CHEMBL3190021 & 688171 & 4.85 & 4.9252 & TRN & \\
\hline CHEMBL1400557 & 688171 & 5.1 & 4.8955 & TRN & \\
\hline CHEMBL1474225 & 688171 & 4.4 & 4.8715 & TRN & \\
\hline CHEMBL1420114 & 688171 & 4.6 & 4.8566 & TRN & \\
\hline CHEMBL1343068 & 688171 & 4.6 & 4.9392 & TRN & \\
\hline CHEMBL1336755 & 688171 & 6.7501 & 5.1083 & TRN & \\
\hline CHEMBL1520919 & 688171 & 4.4 & 4.86100 & 0000000001 & TRN \\
\hline CHEMBL1442507 & 688171 & 4.45 & 4.97199 & 99999999995 & TRN \\
\hline CHEMBL1170069 & 688171 & 4.85 & 4.91100 & 00000000005 & TRN \\
\hline CHEMBL1580563 & 688171 & 4.4 & 4.9466 & TRN & \\
\hline CHEMBL1564220 & 688171 & 4.75 & 4.9056 & TRN & \\
\hline CHEMBL1356896 & 688171 & 4.6 & 4.9218 & TRN & \\
\hline CHEMBL1334214 & 688171 & 5.1 & 5.0949 & TRN & \\
\hline CHEMBL1613601 & 688171 & 4.65 & 4.9018 & TRN & \\
\hline CHEMBL1412040 & 688171 & 5.8 & 4.90300 & 00000000005 & TRN \\
\hline CHEMBL1315004 & 688171 & 4.35 & 4.8826 & TRN & \\
\hline CHEMBL 3192656 & 688171 & 5.65 & 4.9989 & TRN & \\
\hline CHEMBL1471016 & 688171 & 4.75 & 4.773 & TRN & \\
\hline CHEMBL1317457 & 688171 & 4.4 & 4.9319 & TRN & \\
\hline CHEMBL1331734 & 688171 & 5.1 & 4.8411 & TST & \\
\hline CHEMBL1554359 & 688171 & 5.85 & 4.8349 & TRN & \\
\hline CHEMBL1594736 & 688171 & 4.8 & 4.9903 & TRN & \\
\hline CHEMBL1349474 & 688171 & 4.45 & 4.9431 & TRN & \\
\hline CHEMBL1596602 & 688171 & 4.6 & 4.9877 & TRN & \\
\hline CHEMBL3194086 & 688171 & 4.65 & 4.9354 & TRN & \\
\hline CHEMBL1554461 & 688171 & 4.6 & 5.0337 & TRN & \\
\hline CHEMBL1330951 & 688171 & 4.65 & 5.0848 & TST & \\
\hline CHEMBL1556675 & 688171 & 4.4 & 4.9741 & TRN & \\
\hline CHEMBL1517947 & 688171 & 5.15 & 4.9886 & TRN & \\
\hline CHEMBL1432794 & 688171 & 4.9 & 4.8121 & TRN & \\
\hline CHEMBL1445146 & 688171 & 5.25 & 5.00899 & 99999999995 & TRN \\
\hline CHEMBL1423670 & 688171 & 4.85 & 4.8025 & TRN & \\
\hline CHEMBL1442740 & 688171 & 4.7 & 4.8757 & TRN & \\
\hline CHEMBL1335516 & 688171 & 4.4 & 5.0223 & TRN & \\
\hline
\end{tabular}




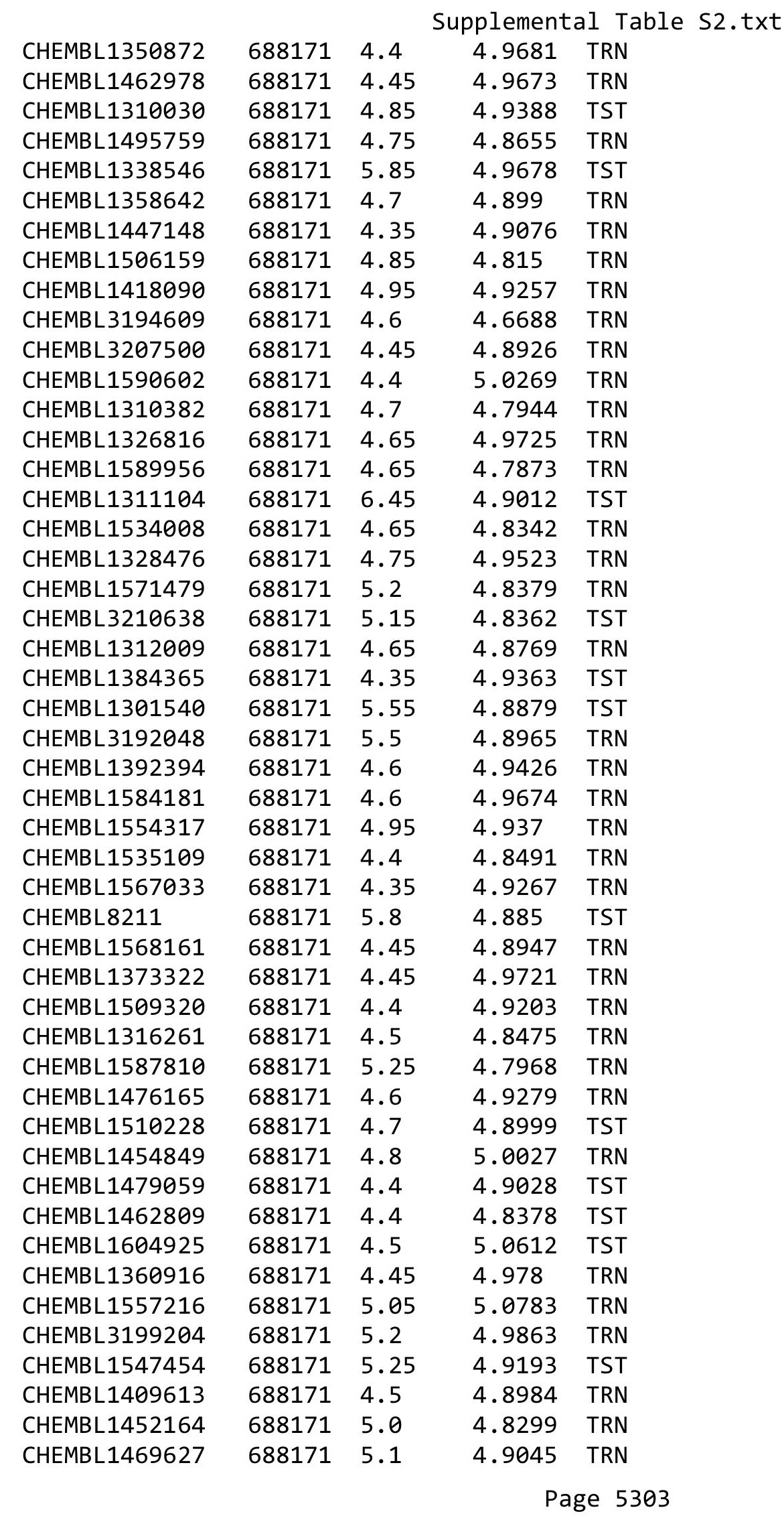




\begin{tabular}{|c|c|c|c|c|c|}
\hline \multicolumn{6}{|c|}{ Supplemental Table S2.txt } \\
\hline CHEMBL1430386 & 688171 & 4.7 & 4.8017 & TRN & \\
\hline CHEMBL1504519 & 688171 & 4.45 & 4.8874 & TRN & \\
\hline CHEMBL1445445 & 688171 & 6.7501 & 4.9965 & TRN & \\
\hline CHEMBL1322547 & 688171 & 4.75 & 4.9554 & TST & \\
\hline CHEMBL1380664 & 688171 & 5.05 & 4.8861 & TST & \\
\hline CHEMBL1528411 & 688171 & 4.65 & 4.8922 & TRN & \\
\hline CHEMBL1446802 & 688171 & 4.55 & 4.8987 & TRN & \\
\hline CHEMBL1323586 & 688171 & 6.0 & 4.7838 & TRN & \\
\hline CHEMBL1520259 & 688171 & 5.05 & 4.9353 & TRN & \\
\hline CHEMBL1513026 & 688171 & 4.35 & 4.9842 & TRN & \\
\hline CHEMBL1530219 & 688171 & 4.6 & 4.8643 & TST & \\
\hline CHEMBL1431962 & 688171 & 4.4 & 4.7936 & TST & \\
\hline CHEMBL1997413 & 688171 & 5.55 & 4.9176 & TST & \\
\hline CHEMBL1362923 & 688171 & 4.9 & 4.8256 & TRN & \\
\hline CHEMBL1314626 & 688171 & 5.5 & 4.8375 & TRN & \\
\hline CHEMBL1479945 & 688171 & 4.5 & 4.7679 & TRN & \\
\hline CHEMBL1544919 & 688171 & 4.4 & 4.9204 & TRN & \\
\hline CHEMBL 3208120 & 688171 & 4.6 & 4.8569 & TST & \\
\hline CHEMBL1314556 & 688171 & 4.6 & 4.9211 & TRN & \\
\hline CHEMBL1429957 & 688171 & 5.5 & 4.8136 & TST & \\
\hline CHEMBL1414400 & 688171 & 4.9 & 4.9267 & TRN & \\
\hline CHEMBL3192095 & 688171 & 4.5 & 4.9438 & TRN & \\
\hline CHEMBL1590542 & 688171 & 5.15 & 4.8004 & TRN & \\
\hline CHEMBL1509566 & 688171 & 6.9 & 4.96399 & 99999999995 & TRN \\
\hline CHEMBL1509064 & 688171 & 4.35 & 4.9124 & TST & \\
\hline CHEMBL1976526 & 688171 & 4.55 & 4.9836 & TRN & \\
\hline CHEMBL1435450 & 688171 & 4.85 & 4.9039 & TRN & \\
\hline CHEMBL1447728 & 688171 & 4.35 & 5.0013 & TST & \\
\hline CHEMBL1482667 & 688171 & 4.9 & 4.8522 & TRN & \\
\hline CHEMBL1579998 & 688171 & 5.45 & 4.8082 & TRN & \\
\hline CHEMBL1563375 & 688171 & 4.55 & 5.0379 & TRN & \\
\hline CHEMBL1361077 & 688171 & 4.4 & 4.8571 & TRN & \\
\hline CHEMBL1422285 & 688171 & 5.8 & 4.9395 & TRN & \\
\hline CHEMBL3199267 & 688171 & 5.1 & 4.9559 & TRN & \\
\hline CHEMBL1437160 & 688171 & 4.35 & 4.9149 & TRN & \\
\hline CHEMBL1330640 & 688171 & 4.5 & 4.9645 & TRN & \\
\hline CHEMBL1533628 & 688171 & 6.7001 & 5.0174 & TRN & \\
\hline CHEMBL1398457 & 688171 & 5.0 & 4.9596 & TRN & \\
\hline CHEMBL3195262 & 688171 & 4.7 & 4.91100 & 00000000005 & TRN \\
\hline CHEMBL1450822 & 688171 & 4.65 & 4.8163 & TST & \\
\hline CHEMBL1475793 & 688171 & 4.7 & 4.9559 & TRN & \\
\hline CHEMBL1391923 & 688171 & 6.6499 & 4.8697 & TRN & \\
\hline CHEMBL1566197 & 688171 & 4.55 & 4.751 & TST & \\
\hline CHEMBL1400450 & 688171 & 4.55 & 4.9248 & TRN & \\
\hline CHEMBL1433227 & 688171 & 5.5 & 4.8867 & TRN & \\
\hline CHEMBL1377186 & 688171 & 4.65 & 4.8761 & TRN & \\
\hline CHEMBL1337845 & 688171 & 5.6 & 4.9878 & TRN & \\
\hline CHEMBL1539556 & 688171 & 5.1 & 4.7792 & TST & \\
\hline
\end{tabular}




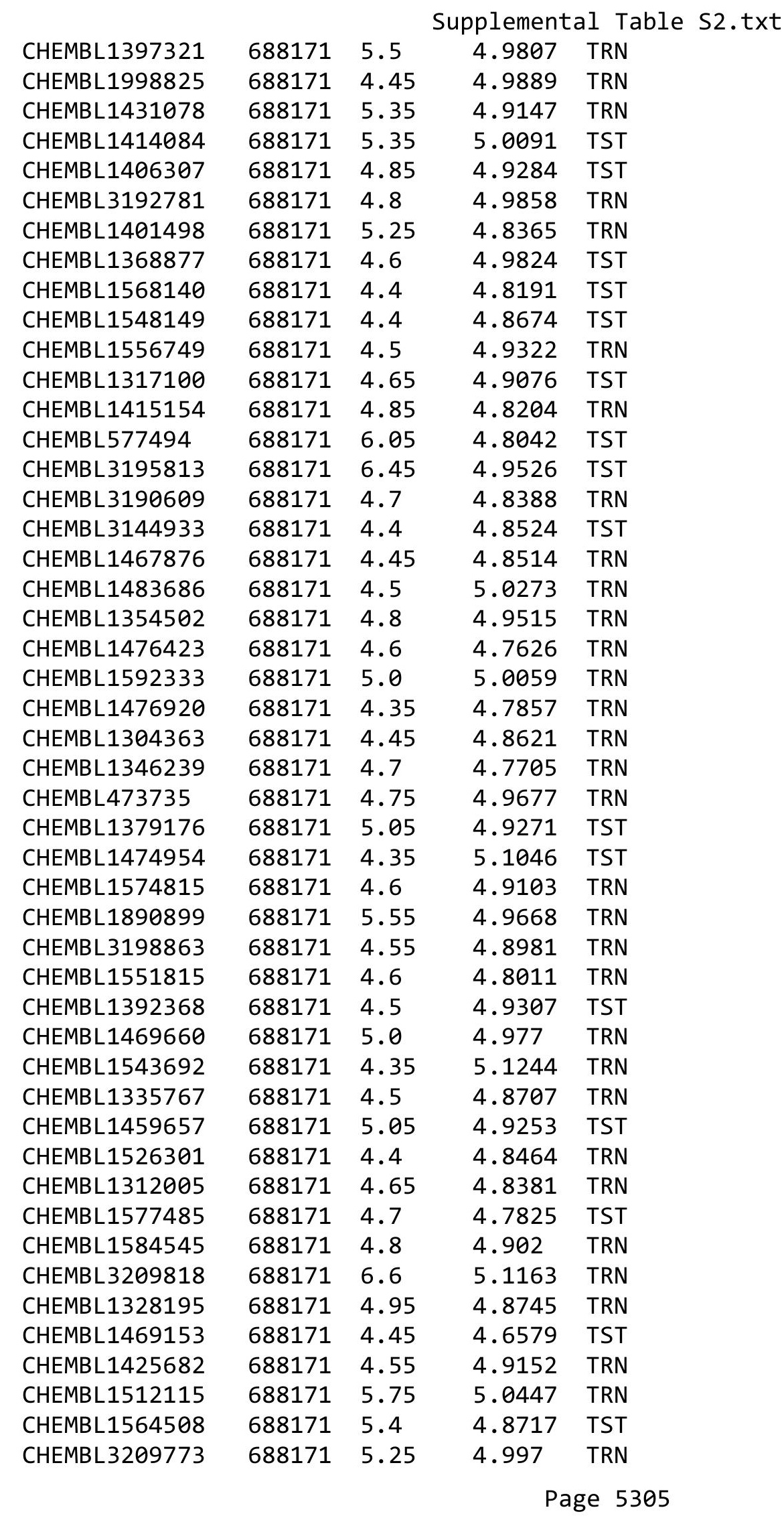




\begin{tabular}{|c|c|c|c|c|c|}
\hline \multicolumn{6}{|c|}{ Supplemental Table S2.txt } \\
\hline CHEMBL1345769 & 688171 & 4.55 & 4.7996 & TRN & \\
\hline CHEMBL24983 & 688171 & 6.0 & 4.8239 & TST & \\
\hline CHEMBL1305818 & 688171 & 5.25 & 4.7579 & TRN & \\
\hline CHEMBL 3194374 & 688171 & 4.55 & 4.9806 & TRN & \\
\hline CHEMBL 3197080 & 688171 & 4.55 & 4.9327 & TRN & \\
\hline CHEMBL1509902 & 688171 & 4.8 & 4.9256 & TRN & \\
\hline CHEMBL282489 & 688171 & 4.4 & 5.0163 & TST & \\
\hline CHEMBL1347788 & 688171 & 4.45 & 4.7701 & TRN & \\
\hline CHEMBL1511041 & 688171 & 4.8 & 4.8853 & TRN & \\
\hline CHEMBL1492107 & 688171 & 4.55 & 4.8672 & TRN & \\
\hline CHEMBL1469584 & 688171 & 4.6 & 4.8406 & TRN & \\
\hline CHEMBL1407282 & 688171 & 4.95 & 4.7717 & TRN & \\
\hline CHEMBL1517686 & 688171 & 6.0 & 4.812 & TRN & \\
\hline CHEMBL 1384840 & 688171 & 4.55 & 4.898 & TRN & \\
\hline CHEMBL1526266 & 688171 & 4.75 & 4.84699 & 99999999995 & TRN \\
\hline CHEMBL1521985 & 688171 & 4.75 & 4.8747 & TST & \\
\hline CHEMBL1360856 & 688171 & 4.4 & 4.9071 & TST & \\
\hline CHEMBL1509676 & 688171 & 4.4 & 4.8964 & TRN & \\
\hline CHEMBL1564253 & 688171 & 4.35 & 4.8856 & TST & \\
\hline CHEMBL1395770 & 688171 & 5.65 & 4.98300 & 00000000005 & TRN \\
\hline CHEMBL1573665 & 688171 & 6.5501 & 4.9333 & TRN & \\
\hline CHEMBL 275820 & 688171 & 4.9 & 4.9156 & TST & \\
\hline CHEMBL1496666 & 688171 & 4.75 & 4.8144 & TRN & \\
\hline CHEMBL1410609 & 688171 & 5.55 & 4.836 & TRN & \\
\hline CHEMBL1441970 & 688171 & 5.05 & 5.0028 & TST & \\
\hline CHEMBL1613687 & 688171 & 5.4 & 4.9128 & TST & \\
\hline CHEMBL1544600 & 688171 & 4.35 & 5.0683 & TST & \\
\hline CHEMBL3198813 & 688171 & 4.85 & 4.9149 & TRN & \\
\hline CHEMBL59030 & 688171 & 4.65 & 5.046 & TST & \\
\hline CHEMBL1476603 & 688171 & 5.0 & 4.8033 & TRN & \\
\hline CHEMBL1578237 & 688171 & 4.4 & 4.8915 & TRN & \\
\hline CHEMBL1376200 & 688171 & 4.75 & 4.9043 & TRN & \\
\hline CHEMBL1523804 & 688171 & 5.1 & 4.9919 & TST & \\
\hline CHEMBL1425286 & 688171 & 4.4 & 4.8931 & TRN & \\
\hline CHEMBL1388086 & 688171 & 5.0 & 4.9672 & TST & \\
\hline CHEMBL1482348 & 688171 & 5.95 & 4.8626 & TRN & \\
\hline CHEMBL1558138 & 688171 & 4.75 & 4.8289 & TRN & \\
\hline CHEMBL1608043 & 688171 & 5.4 & 4.9104 & TRN & \\
\hline CHEMBL1405129 & 688171 & 4.65 & 4.9447 & TRN & \\
\hline CHEMBL3197778 & 688171 & 4.9 & 4.9568 & TRN & \\
\hline CHEMBL1603238 & 688171 & 4.75 & 4.7784 & TRN & \\
\hline CHEMBL3211998 & 688171 & 5.0 & 4.9578 & TRN & \\
\hline CHEMBL1551474 & 688171 & 4.65 & 4.9059 & TRN & \\
\hline CHEMBL1587212 & 688171 & 4.55 & 4.9308 & TRN & \\
\hline CHEMBL1408535 & 688171 & 4.4 & 4.9817 & TRN & \\
\hline CHEMBL1401833 & 688171 & 4.55 & 4.8373 & TRN & \\
\hline CHEMBL1553975 & 688171 & 5.8 & 4.9779 & TRN & \\
\hline CHEMBL1414563 & 688171 & 4.6 & 4.7539 & TRN & \\
\hline
\end{tabular}




\begin{tabular}{|c|c|c|c|c|}
\hline \multicolumn{5}{|c|}{ Supplemental Table S2.txt } \\
\hline CHEMBL1491228 & 688171 & 5.75 & 4.8623 & TRN \\
\hline CHEMBL1528104 & 688171 & 4.85 & 4.8624 & TRN \\
\hline CHEMBL1328033 & 688171 & 4.4 & 4.899 & TRN \\
\hline CHEMBL1335852 & 688171 & 4.4 & 4.9687 & TST \\
\hline CHEMBL1553512 & 688171 & 4.65 & 4.9642 & TST \\
\hline CHEMBL1356579 & 688171 & 4.45 & 4.8062 & TRN \\
\hline CHEMBL1423797 & 688171 & 4.35 & 4.8973 & TST \\
\hline CHEMBL1600711 & 688171 & 5.05 & 4.8511 & TRN \\
\hline CHEMBL1500934 & 688171 & 4.4 & 4.795 & TRN \\
\hline CHEMBL1433530 & 688171 & 4.35 & 5.0005 & TRN \\
\hline CHEMBL1485060 & 688171 & 5.05 & 4.9077 & TST \\
\hline CHEMBL1544097 & 688171 & 4.4 & 4.8519 & TRN \\
\hline CHEMBL1551220 & 688171 & 5.15 & 4.9325 & TST \\
\hline CHEMBL1414463 & 688171 & 5.2 & 4.8808 & TRN \\
\hline CHEMBL1317037 & 688171 & 4.75 & 4.9148 & TRN \\
\hline CHEMBL1527610 & 688171 & 4.85 & 4.9225 & TST \\
\hline CHEMBL3210349 & 688171 & 4.35 & 4.9268 & TRN \\
\hline CHEMBL1306672 & 688171 & 4.6 & 4.9629 & TRN \\
\hline CHEMBL1519613 & 688171 & 4.75 & 4.8917 & TRN \\
\hline CHEMBL1503634 & 688171 & 5.0 & 4.9598 & TRN \\
\hline CHEMBL1513082 & 688171 & 4.6 & 5.0116 & TRN \\
\hline CHEMBL1607229 & 688171 & 4.6 & 4.9465 & TRN \\
\hline CHEMBL1518929 & 688171 & 5.05 & 4.8795 & TRN \\
\hline CHEMBL1556191 & 688171 & 4.6 & 4.8126 & TRN \\
\hline CHEMBL1456042 & 688171 & 6.4 & 4.944 & TST \\
\hline CHEMBL1481309 & 688171 & 4.45 & 4.9063 & TST \\
\hline CHEMBL1540803 & 688171 & 4.55 & 5.055 & TRN \\
\hline CHEMBL3192690 & 688171 & 5.05 & 4.965 & TRN \\
\hline CHEMBL1436783 & 688171 & 4.6 & 4.8677 & TRN \\
\hline CHEMBL1394544 & 688171 & 4.4 & 4.9068 & TRN \\
\hline CHEMBL1972037 & 688171 & 5.3 & 4.9241 & TST \\
\hline CHEMBL1490958 & 688171 & 5.8 & 4.9518 & TST \\
\hline CHEMBL1313081 & 688171 & 4.8 & 4.8856 & TST \\
\hline CHEMBL1966872 & 688171 & 5.05 & 4.8596 & TST \\
\hline CHEMBL3191251 & 688171 & 4.45 & 4.9333 & TST \\
\hline CHEMBL1501658 & 688171 & 5.05 & 4.8378 & TRN \\
\hline CHEMBL1514891 & 688171 & 4.4 & 4.8364 & TRN \\
\hline CHEMBL1519434 & 688171 & 4.9 & 4.8149 & TRN \\
\hline CHEMBL1436107 & 688171 & 4.9 & 4.9467 & TRN \\
\hline CHEMBL1596601 & 688171 & 4.45 & 4.8943 & TRN \\
\hline CHEMBL1435011 & 688171 & 4.75 & 4.856 & TRN \\
\hline CHEMBL1569838 & 688171 & 4.9 & 4.9175 & TST \\
\hline CHEMBL1469216 & 688171 & 5.5 & 4.9348 & TRN \\
\hline CHEMBL1364461 & 688171 & 4.35 & 4.9432 & TST \\
\hline CHEMBL1404301 & 688171 & 5.9 & 4.9215 & TST \\
\hline CHEMBL1538976 & 688171 & 4.5 & 5.0956 & TRN \\
\hline CHEMBL1479480 & 688171 & 4.5 & 4.882 & TST \\
\hline CHEMBL1383298 & 688171 & 4.4 & 5.0643 & TRN \\
\hline
\end{tabular}




\begin{tabular}{|c|c|c|c|c|c|}
\hline \multicolumn{6}{|c|}{ Supplemental Table S2.txt } \\
\hline CHEMBL1400040 & 688171 & 4.9 & 4.9865 & TRN & \\
\hline CHEMBL3192675 & 688171 & 4.55 & 4.9885 & TRN & \\
\hline CHEMBL3194707 & 688171 & 4.4 & 4.9679 & TRN & \\
\hline CHEMBL1509272 & 688171 & 7.1002 & 4.8273 & TST & \\
\hline CHEMBL1403520 & 688171 & 5.05 & 4.8691 & TRN & \\
\hline CHEMBL1508109 & 688171 & 4.6 & 4.7337 & TRN & \\
\hline CHEMBL1330284 & 688171 & 4.7 & 4.9315 & TRN & \\
\hline CHEMBL1474541 & 688171 & 4.5 & 4.8333 & TRN & \\
\hline CHEMBL1309683 & 688171 & 4.65 & 4.763 & TRN & \\
\hline CHEMBL1448985 & 688171 & 4.7 & 5.01 & TRN & \\
\hline CHEMBL1336209 & 688171 & 4.85 & 4.8866 & TRN & \\
\hline CHEMBL1484911 & 688171 & 4.45 & 4.8532 & TRN & \\
\hline CHEMBL3199135 & 688171 & 5.4 & 5.0094 & TST & \\
\hline CHEMBL 1415850 & 688171 & 4.8 & 4.9545 & TRN & \\
\hline CHEMBL1458786 & 688171 & 5.05 & 4.7989 & TST & \\
\hline CHEMBL1410552 & 688171 & 5.0 & 4.8347 & TRN & \\
\hline CHEMBL1425761 & 688171 & 4.8 & 4.8592 & TRN & \\
\hline CHEMBL1388594 & 688171 & 5.5 & 5.0406 & TST & \\
\hline CHEMBL1599925 & 688171 & 4.4 & 4.8134 & TST & \\
\hline CHEMBL1508293 & 688171 & 4.85 & 4.945 & TRN & \\
\hline CHEMBL1501022 & 688171 & 4.45 & 4.8055 & TRN & \\
\hline CHEMBL1531196 & 688171 & 4.5 & 4.8339 & TRN & \\
\hline CHEMBL1308010 & 688171 & 4.9 & 4.8912 & TRN & \\
\hline CHEMBL1483696 & 688171 & 5.0 & 4.7981 & TRN & \\
\hline CHEMBL1347040 & 688171 & 4.95 & 4.9845 & TST & \\
\hline CHEMBL1345381 & 688171 & 4.65 & 4.8136 & TRN & \\
\hline CHEMBL1550909 & 688171 & 4.4 & 4.84399 & 9999999999 & TRN \\
\hline CHEMBL1594735 & 688171 & 4.4 & 4.9989 & TST & \\
\hline CHEMBL1372901 & 688171 & 4.6 & 4.9013 & TRN & \\
\hline CHEMBL3212969 & 688171 & 4.9 & 4.9425 & TST & \\
\hline CHEMBL1610854 & 688171 & 4.4 & 4.9852 & TRN & \\
\hline CHEMBL1484629 & 688171 & 5.0 & 4.8238 & TRN & \\
\hline CHEMBL1451522 & 688171 & 5.7 & 4.8555 & TRN & \\
\hline CHEMBL1447441 & 688171 & 4.95 & 4.8409 & TRN & \\
\hline CHEMBL1318957 & 688171 & 6.2 & 4.8745 & TRN & \\
\hline CHEMBL1375364 & 688171 & 4.75 & 4.9357 & TRN & \\
\hline CHEMBL1484221 & 688171 & 4.45 & 4.9398 & TRN & \\
\hline CHEMBL1525119 & 688171 & 4.4 & 5.0381 & TST & \\
\hline CHEMBL1401385 & 688171 & 5.35 & 5.0505 & TRN & \\
\hline CHEMBL1517746 & 688171 & 4.4 & 4.9875 & TRN & \\
\hline CHEMBL1505044 & 688171 & 4.35 & 4.8051 & TST & \\
\hline CHEMBL1410368 & 688171 & 5.45 & 5.1208 & TRN & \\
\hline CHEMBL1409799 & 688171 & 5.9 & 5.0982 & TST & \\
\hline CHEMBL1450430 & 688171 & 4.45 & 4.7863 & TRN & \\
\hline CHEMBL1315543 & 688171 & 4.7 & 4.7518 & TRN & \\
\hline CHEMBL1568644 & 688171 & 4.5 & 4.8903 & TST & \\
\hline CHEMBL1473733 & 688171 & 4.95 & 4.8627 & TRN & \\
\hline CHEMBL3191116 & 688171 & 4.35 & 4.8988 & TRN & \\
\hline
\end{tabular}





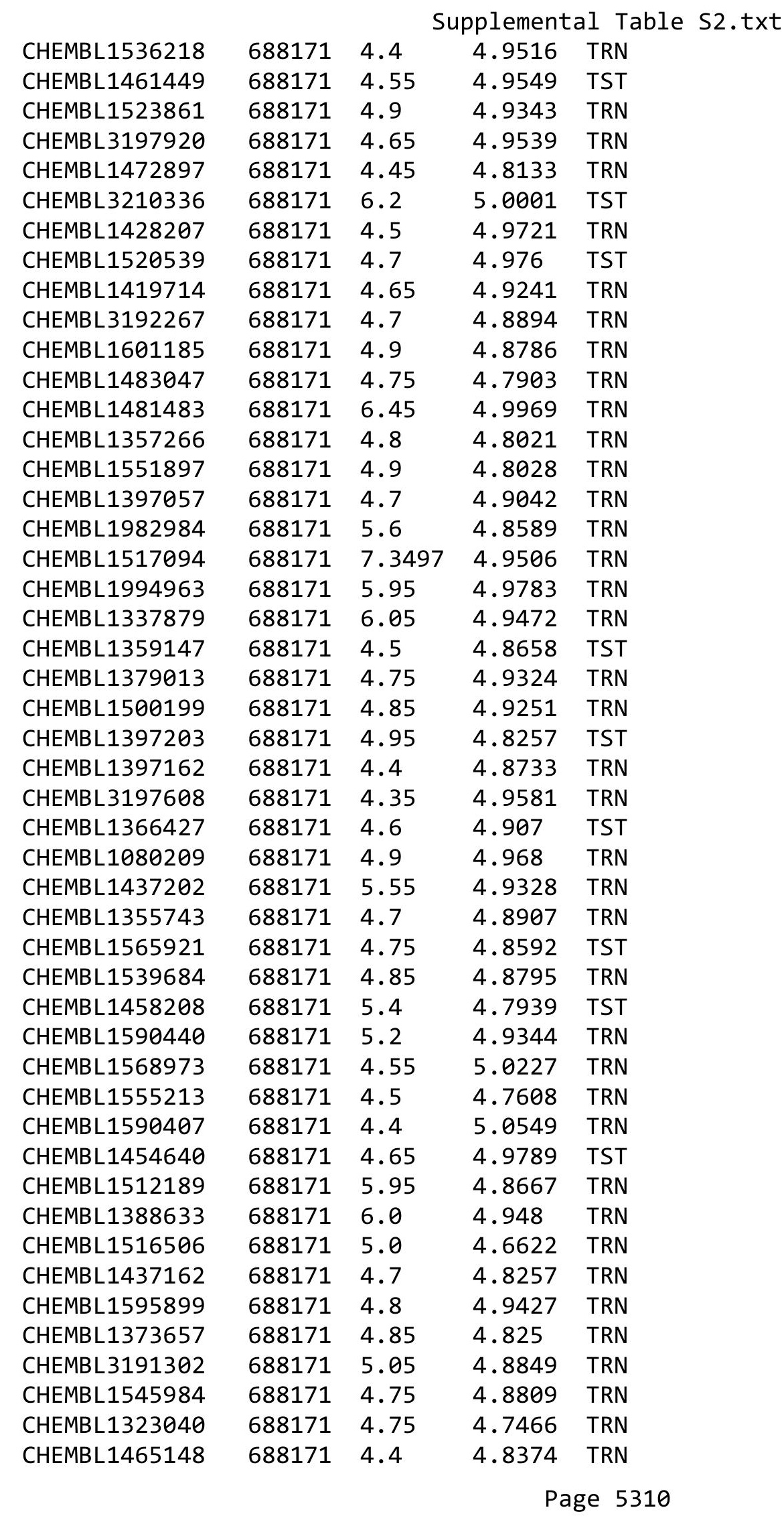




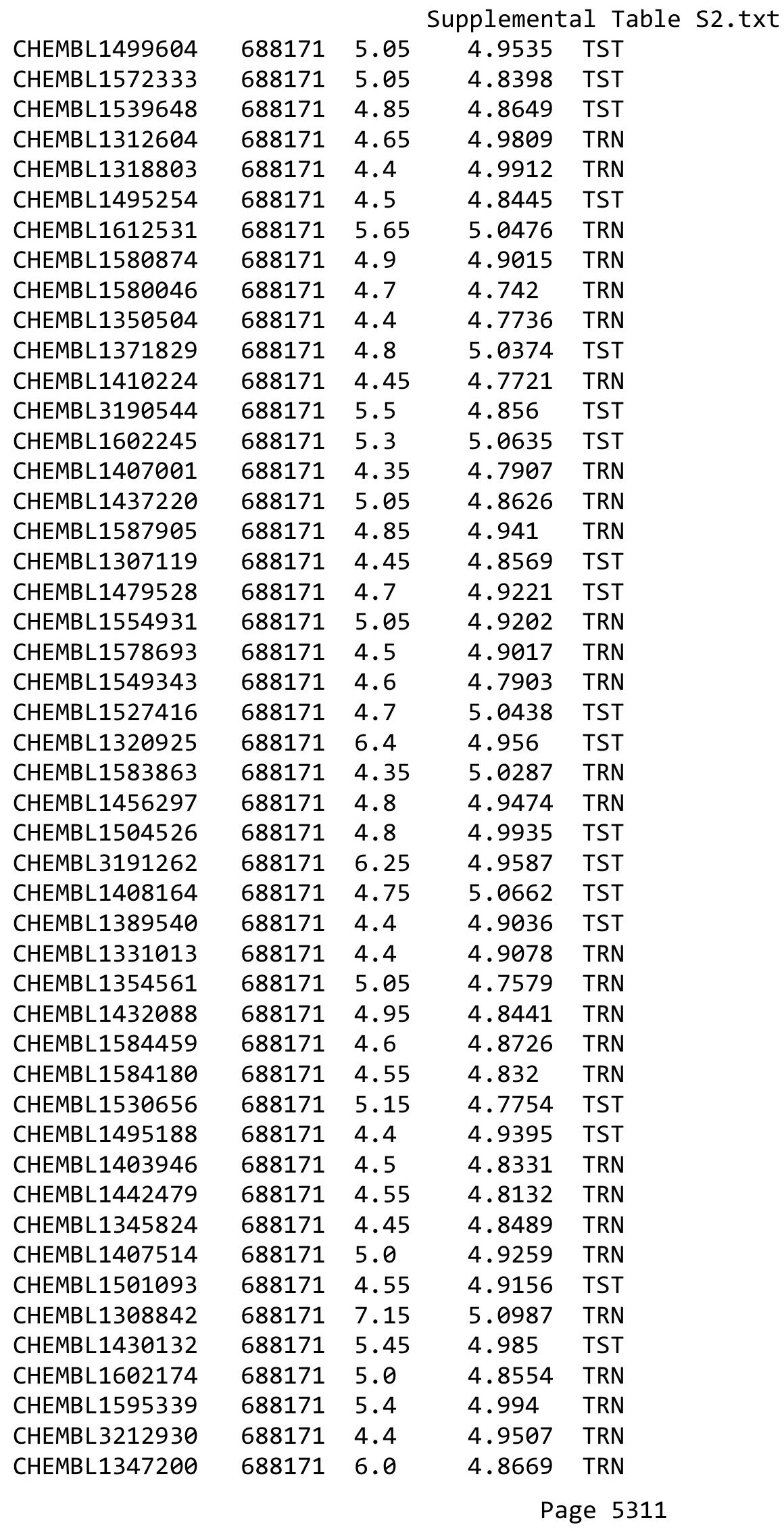




\begin{tabular}{|c|c|c|c|c|c|}
\hline \multicolumn{6}{|c|}{ Supplemental Table S2.txt } \\
\hline CHEMBL1375235 & 688171 & 5.05 & 4.7588 & TST & \\
\hline CHEMBL1538688 & 688171 & 5.5 & 4.9026 & TST & \\
\hline CHEMBL1600346 & 688171 & 6.3 & 4.8934 & TRN & \\
\hline CHEMBL1508432 & 688171 & 4.35 & 4.9012 & TRN & \\
\hline CHEMBL1364176 & 688171 & 5.75 & 4.9058 & TRN & \\
\hline CHEMBL1316577 & 688171 & 5.15 & 4.8459 & TRN & \\
\hline CHEMBL434778 & 688171 & 4.55 & 5.0453 & TRN & \\
\hline CHEMBL1460342 & 688171 & 5.05 & 4.8934 & TST & \\
\hline CHEMBL1329311 & 688171 & 4.4 & 4.7445 & TRN & \\
\hline CHEMBL1420038 & 688171 & 4.4 & 4.9033 & TRN & \\
\hline CHEMBL1366636 & 688171 & 6.7501 & 4.8351 & TRN & \\
\hline CHEMBL1358734 & 688171 & 4.95 & 4.953 & TRN & \\
\hline CHEMBL1437086 & 688171 & 4.5 & 4.8102 & TRN & \\
\hline CHEMBL1441663 & 688171 & 6.05 & 4.9741 & TRN & \\
\hline CHEMBL1437365 & 688171 & 4.4 & 5.0422 & TRN & \\
\hline CHEMBL582278 & 688171 & 5.0 & 5.0392 & TRN & \\
\hline CHEMBL1424355 & 688171 & 4.6 & 4.8912 & TRN & \\
\hline CHEMBL1442909 & 688171 & 4.95 & 4.9879 & TRN & \\
\hline CHEMBL1456785 & 688171 & 6.0 & 4.9588 & TRN & \\
\hline CHEMBL1336233 & 688171 & 4.5 & 4.9354 & TST & \\
\hline CHEMBL1316536 & 688171 & 5.45 & 4.8298 & TRN & \\
\hline CHEMBL1376107 & 688171 & 5.65 & 5.0973 & TST & \\
\hline CHEMBL1376988 & 688171 & 4.4 & 4.8663 & TRN & \\
\hline CHEMBL1556826 & 688171 & 5.4 & 5.0053 & TRN & \\
\hline CHEMBL1458848 & 688171 & 4.7 & 4.76399 & 9999999999 & TRN \\
\hline CHEMBL1569094 & 688171 & 4.65 & 4.88 & TRN & \\
\hline CHEMBL1397746 & 688171 & 4.7 & 4.9698 & TST & \\
\hline CHEMBL1311198 & 688171 & 5.6 & 4.93199 & 99999999995 & TRN \\
\hline CHEMBL1350195 & 688171 & 5.05 & 4.9845 & TST & \\
\hline CHEMBL3191943 & 688171 & 4.95 & 5.0096 & TRN & \\
\hline CHEMBL1304105 & 688171 & 4.35 & 5.0512 & TRN & \\
\hline CHEMBL1430058 & 688171 & 4.8 & 4.9895 & TRN & \\
\hline CHEMBL1434051 & 688171 & 4.45 & 4.9065 & TRN & \\
\hline CHEMBL1570908 & 688171 & 5.05 & 4.6783 & TST & \\
\hline CHEMBL1408656 & 688171 & 4.4 & 4.9492 & TRN & \\
\hline CHEMBL1426134 & 688171 & 4.55 & 5.0377 & TRN & \\
\hline CHEMBL1500639 & 688171 & 5.15 & 5.021 & TST & \\
\hline CHEMBL1333091 & 688171 & 4.4 & 4.8768 & TRN & \\
\hline CHEMBL1515976 & 688171 & 4.75 & 4.8555 & TRN & \\
\hline CHEMBL3145109 & 688171 & 4.5 & 4.8422 & TRN & \\
\hline CHEMBL1509269 & 688171 & 5.05 & 4.9598 & TST & \\
\hline CHEMBL1336173 & 688171 & 4.35 & 4.9898 & TST & \\
\hline CHEMBL1478710 & 688171 & 4.75 & 4.78 & TRN & \\
\hline CHEMBL1463249 & 688171 & 4.4 & 4.8861 & TST & \\
\hline CHEMBL1310039 & 688171 & 4.35 & 4.9572 & TRN & \\
\hline CHEMBL1347600 & 688171 & 4.95 & 4.8519 & TRN & \\
\hline CHEMBL1553078 & 688171 & 4.4 & 4.8802 & TRN & \\
\hline CHEMBL1581000 & 688171 & 4.7 & 4.7833 & TRN & \\
\hline
\end{tabular}




\begin{tabular}{|c|c|c|c|c|}
\hline \multicolumn{5}{|c|}{ Supplemental Table S2.txt } \\
\hline CHEMBL1441707 & 688171 & 4.4 & 5.0031 & TRN \\
\hline CHEMBL1442893 & 688171 & 4.65 & 4.8152 & TRN \\
\hline CHEMBL1394608 & 688171 & 4.55 & 4.8155 & TRN \\
\hline CHEMBL1334945 & 688171 & 4.5 & 4.7559 & TRN \\
\hline CHEMBL1353324 & 688171 & 4.7 & 4.9519 & TRN \\
\hline CHEMBL1543886 & 688171 & 4.9 & 4.937 & TST \\
\hline CHEMBL1309220 & 688171 & 6.1 & 5.0188 & TST \\
\hline CHEMBL1393699 & 688171 & 4.75 & 4.827 & TRN \\
\hline CHEMBL1574639 & 688171 & 5.3 & 4.8992 & TST \\
\hline CHEMBL1397003 & 688171 & 5.1 & 4.912 & TRN \\
\hline CHEMBL 3211134 & 688171 & 4.75 & 5.008 & TRN \\
\hline CHEMBL1602130 & 688171 & 4.6 & 4.7997 & TRN \\
\hline CHEMBL1380683 & 688171 & 4.35 & 4.9195 & TRN \\
\hline CHEMBL1554471 & 688171 & 5.4 & 4.7879 & TRN \\
\hline CHEMBL601605 & 688171 & 4.75 & 4.7984 & TRN \\
\hline CHEMBL1448627 & 688171 & 5.4 & 5.0596 & TST \\
\hline CHEMBL1381323 & 688171 & 4.55 & 4.8377 & TRN \\
\hline CHEMBL1509672 & 688171 & 4.75 & 5.0305 & TST \\
\hline CHEMBL1509596 & 688171 & 5.35 & 4.9675 & TRN \\
\hline CHEMBL1304671 & 688171 & 4.35 & 4.9283 & TRN \\
\hline CHEMBL1479065 & 688171 & 4.7 & 4.9301 & TRN \\
\hline CHEMBL1339800 & 688171 & 5.0 & 4.9739 & TRN \\
\hline CHEMBL1489590 & 688171 & 4.6 & 4.904 & TRN \\
\hline CHEMBL1545333 & 688171 & 6.9 & 5.001 & TST \\
\hline CHEMBL1467216 & 688171 & 5.05 & 4.9293 & TST \\
\hline CHEMBL1469327 & 688171 & 4.65 & 4.7635 & TRN \\
\hline CHEMBL1339741 & 688171 & 4.8 & 4.8825 & TRN \\
\hline CHEMBL1592925 & 688171 & 4.5 & 4.8655 & TRN \\
\hline CHEMBL1595244 & 688171 & 5.6 & 4.86 & TRN \\
\hline CHEMBL1474920 & 688171 & 5.1 & 4.8128 & TRN \\
\hline CHEMBL1425438 & 688171 & 4.9 & 5.0511 & TST \\
\hline CHEMBL1355304 & 688171 & 4.8 & 4.8958 & TRN \\
\hline CHEMBL1365861 & 688171 & 4.55 & 5.0025 & TRN \\
\hline CHEMBL1465144 & 688171 & 4.6 & 4.9292 & TST \\
\hline CHEMBL1308724 & 688171 & 4.85 & 4.796 & TST \\
\hline CHEMBL1558401 & 688171 & 5.0 & 4.7882 & TRN \\
\hline CHEMBL1990825 & 688171 & 4.7 & 4.8787 & TRN \\
\hline CHEMBL1543532 & 688171 & 5.35 & 4.9393 & TST \\
\hline CHEMBL1358317 & 688171 & 4.8 & 4.9685 & TRN \\
\hline CHEMBL1527089 & 688171 & 4.35 & 4.9482 & TRN \\
\hline CHEMBL1358511 & 688171 & 5.9 & 4.9117 & TRN \\
\hline CHEMBL1336968 & 688171 & 5.45 & 4.8634 & TRN \\
\hline CHEMBL1508365 & 688171 & 5.3 & 4.9527 & TST \\
\hline CHEMBL1436510 & 688171 & 5.2 & 4.9926 & TST \\
\hline CHEMBL1407602 & 688171 & 4.35 & 5.002 & TRN \\
\hline CHEMBL1521036 & 688171 & 6.95 & 4.9989 & TRN \\
\hline CHEMBL1454061 & 688171 & 4.75 & 4.8954 & TRN \\
\hline CHEMBL1518985 & 688171 & 5.0 & 4.9541 & TRN \\
\hline
\end{tabular}




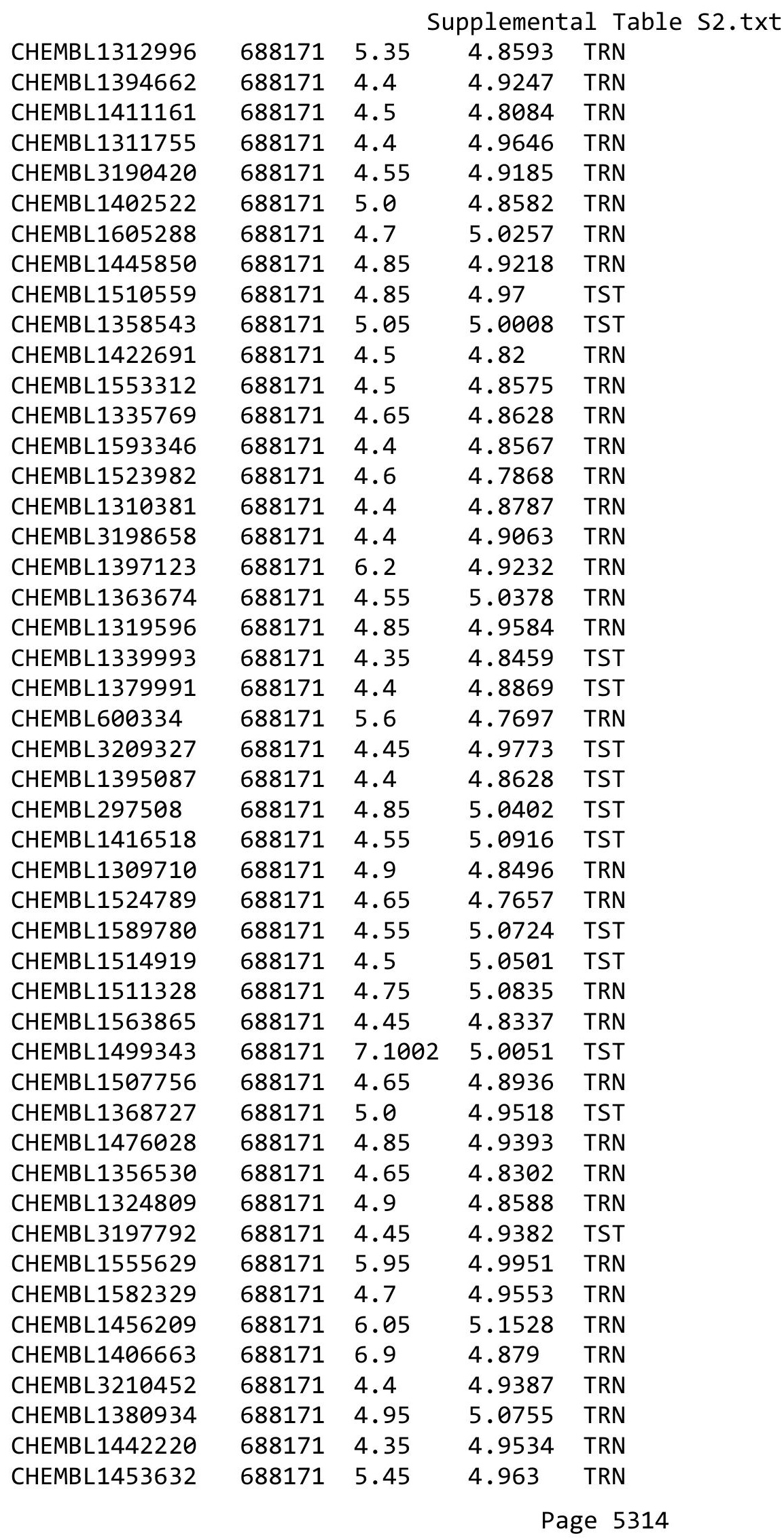




\begin{tabular}{|c|c|c|c|c|c|}
\hline \multicolumn{6}{|c|}{ Supplemental Table S2.txt } \\
\hline CHEMBL1607035 & 688171 & 4.5 & 4.9045 & TRN & \\
\hline CHEMBL1514575 & 688171 & 4.75 & 4.9048 & TRN & \\
\hline CHEMBL1567097 & 688171 & 4.5 & 4.8773 & TRN & \\
\hline CHEMBL1571643 & 688171 & 4.4 & 4.8226 & TRN & \\
\hline CHEMBL1532839 & 688171 & 5.35 & 4.9117 & TRN & \\
\hline CHEMBL1355395 & 688171 & 5.05 & 4.9406 & TRN & \\
\hline CHEMBL1359240 & 688171 & 5.05 & 4.9314 & TST & \\
\hline CHEMBL1433013 & 688171 & 5.95 & 4.8693 & TRN & \\
\hline CHEMBL 2003436 & 688171 & 5.0 & 4.9274 & TRN & \\
\hline CHEMBL1520429 & 688171 & 5.05 & 4.9054 & TST & \\
\hline CHEMBL1592559 & 688171 & 4.4 & 4.7723 & TRN & \\
\hline CHEMBL1469134 & 688171 & 4.55 & 4.9107 & TRN & \\
\hline CHEMBL1332310 & 688171 & 4.6 & 5.0056 & TRN & \\
\hline CHEMBL 240332 & 688171 & 4.4 & 4.8646 & TST & \\
\hline CHEMBL1577609 & 688171 & 4.6 & 5.0041 & TST & \\
\hline CHEMBL1977808 & 688171 & 4.8 & $4.9910 e$ & 00000000005 & TRN \\
\hline CHEMBL1443791 & 688171 & 6.25 & 5.008 & TRN & \\
\hline CHEMBL1536380 & 688171 & 4.5 & 4.8708 & TRN & \\
\hline CHEMBL1974856 & 688171 & 4.95 & 4.956 & TST & \\
\hline CHEMBL1975583 & 688171 & 4.55 & 4.9618 & TRN & \\
\hline CHEMBL1994257 & 688171 & 4.45 & 4.9325 & TRN & \\
\hline CHEMBL1604011 & 688171 & 5.15 & 4.772 & TRN & \\
\hline CHEMBL1569349 & 688171 & 4.4 & 4.8339 & TRN & \\
\hline CHEMBL1402582 & 688171 & 4.95 & 4.907 & TRN & \\
\hline CHEMBL1421559 & 688171 & 5.45 & 4.8468 & TRN & \\
\hline CHEMBL1496289 & 688171 & 5.3 & 4.9726 & TRN & \\
\hline CHEMBL1530890 & 688171 & 4.4 & 5.0144 & TRN & \\
\hline CHEMBL1429835 & 688171 & 4.4 & 4.9056 & TRN & \\
\hline CHEMBL1568826 & 688171 & 4.65 & 4.9058 & TRN & \\
\hline CHEMBL1538196 & 688171 & 4.35 & 4.8665 & TST & \\
\hline CHEMBL1510791 & 688171 & 4.75 & 4.9844 & TST & \\
\hline CHEMBL1468139 & 688171 & 4.4 & 4.9925 & TRN & \\
\hline CHEMBL1363069 & 688171 & 4.65 & 5.0807 & TST & \\
\hline CHEMBL1552400 & 688171 & 4.95 & 4.8222 & TRN & \\
\hline CHEMBL1330802 & 688171 & 4.5 & 4.9599 & TST & \\
\hline CHEMBL3196950 & 688171 & 4.45 & 4.9645 & TRN & \\
\hline CHEMBL1594333 & 688171 & 5.95 & 4.7936 & TST & \\
\hline CHEMBL1505156 & 688171 & 4.7 & 4.9814 & TRN & \\
\hline CHEMBL1493365 & 688171 & 5.95 & 4.8069 & TRN & \\
\hline CHEMBL1352237 & 688171 & 4.4 & 4.9174 & TRN & \\
\hline CHEMBL1567841 & 688171 & 4.7 & 4.9321 & TST & \\
\hline CHEMBL1389066 & 688171 & 4.5 & 4.8506 & TRN & \\
\hline CHEMBL1588008 & 688171 & 4.35 & 4.9986 & TST & \\
\hline CHEMBL1567275 & 688171 & 5.05 & 5.0494 & TRN & \\
\hline CHEMBL1549391 & 688171 & 4.5 & 4.8093 & TRN & \\
\hline CHEMBL3195765 & 688171 & 4.55 & 4.7971 & TRN & \\
\hline CHEMBL1402821 & 688171 & 4.65 & 4.9717 & TRN & \\
\hline CHEMBL1533854 & 688171 & 4.45 & 5.0408 & TRN & \\
\hline
\end{tabular}




\begin{tabular}{|c|c|c|c|c|c|}
\hline & & \multicolumn{4}{|c|}{ Supplemental Table s2.txt } \\
\hline CHEMBL1518293 & 688171 & 6.15 & 4.7527 & TRN & \\
\hline CHEMBL1518144 & 688171 & 4.45 & 4.8889 & TRN & \\
\hline CHEMBL1399826 & 688171 & 4.4 & 4.8929 & TRN & \\
\hline CHEMBL1527364 & 688171 & 4.8 & 5.0376 & TRN & \\
\hline CHEMBL3193044 & 688171 & 5.55 & 5.0266 & TRN & \\
\hline CHEMBL1561420 & 688171 & 4.6 & 4.8749 & TRN & \\
\hline CHEMBL1335843 & 688171 & 4.85 & 4.8842 & TRN & \\
\hline CHEMBL1478213 & 688171 & 4.4 & 4.8428 & TRN & \\
\hline CHEMBL1990786 & 688171 & 4.85 & 4.9725 & TRN & \\
\hline CHEMBL1529058 & 688171 & 6.05 & 4.8269 & TRN & \\
\hline CHEMBL1580863 & 688171 & 5.0 & 4.8154 & TST & \\
\hline CHEMBL1569846 & 688171 & 4.4 & 4.9451 & TRN & \\
\hline CHEMBL1330348 & 688171 & 6.0 & 4.8208 & TRN & \\
\hline CHEMBL1472546 & 688171 & 4.8 & 4.9076 & TRN & \\
\hline CHEMBL1588104 & 688171 & 4.55 & 4.883 & TST & \\
\hline CHEMBL1328778 & 688171 & 4.5 & 4.963 & TST & \\
\hline CHEMBL1606431 & 688171 & 4.55 & 5.0306 & TST & \\
\hline CHEMBL1320696 & 688171 & 4.7 & 4.9212 & TST & \\
\hline CHEMBL1315178 & 688171 & 4.4 & 4.9262 & TRN & \\
\hline CHEMBL1420406 & 688171 & 4.4 & 4.7095 & TRN & \\
\hline CHEMBL1437846 & 688171 & 6.4 & 5.065 & TST & \\
\hline CHEMBL1512136 & 688171 & 4.45 & 4.9151 & TRN & \\
\hline CHEMBL1372086 & 688171 & 4.55 & 4.7863 & TRN & \\
\hline CHEMBL1310221 & 688171 & 4.35 & 4.9193 & TRN & \\
\hline CHEMBL1570748 & 688171 & 5.35 & 4.931 & TRN & \\
\hline CHEMBL1973050 & 688171 & 4.6 & 4.8989 & TRN & \\
\hline CHEMBL1370062 & 688171 & 5.35 & 5.0726 & TRN & \\
\hline CHEMBL1314431 & 688171 & 4.45 & 4.8142 & TRN & \\
\hline CHEMBL1377705 & 688171 & 4.95 & 4.7898 & TRN & \\
\hline CHEMBL1508844 & 688171 & 4.5 & 4.8665 & TRN & \\
\hline CHEMBL1320832 & 688171 & 4.8 & 4.8143 & TRN & \\
\hline CHEMBL1315470 & 688171 & 4.85 & 5.01399 & 9999999999 & TRN \\
\hline CHEMBL1335612 & 688171 & 4.35 & 4.9681 & TRN & \\
\hline CHEMBL270299 & 688171 & 4.4 & 4.7693 & TST & \\
\hline CHEMBL1579210 & 688171 & 4.4 & 4.98600 & 0000000001 & TST \\
\hline CHEMBL1471980 & 688171 & 4.7 & 5.0105 & TRN & \\
\hline CHEMBL1524741 & 688171 & 4.65 & 4.9004 & TRN & \\
\hline CHEMBL1436060 & 688171 & 4.75 & 4.9511 & TRN & \\
\hline CHEMBL1395594 & 688171 & 4.45 & 4.987 & TST & \\
\hline CHEMBL1537583 & 688171 & 4.5 & 4.8754 & TRN & \\
\hline CHEMBL1518155 & 688171 & 4.4 & 4.9649 & TST & \\
\hline CHEMBL1498710 & 688171 & 4.65 & 4.7279 & TRN & \\
\hline CHEMBL3144900 & 688171 & 4.8 & 4.7962 & TST & \\
\hline CHEMBL1436102 & 688171 & 4.8 & 4.9309 & TRN & \\
\hline CHEMBL1337982 & 688171 & 4.65 & 4.9898 & TRN & \\
\hline CHEMBL1546422 & 688171 & 4.4 & 5.0236 & TST & \\
\hline CHEMBL1305503 & 688171 & 6.8 & 4.9826 & TRN & \\
\hline CHEMBL1534348 & 688171 & 4.8 & 4.8653 & TST & \\
\hline
\end{tabular}




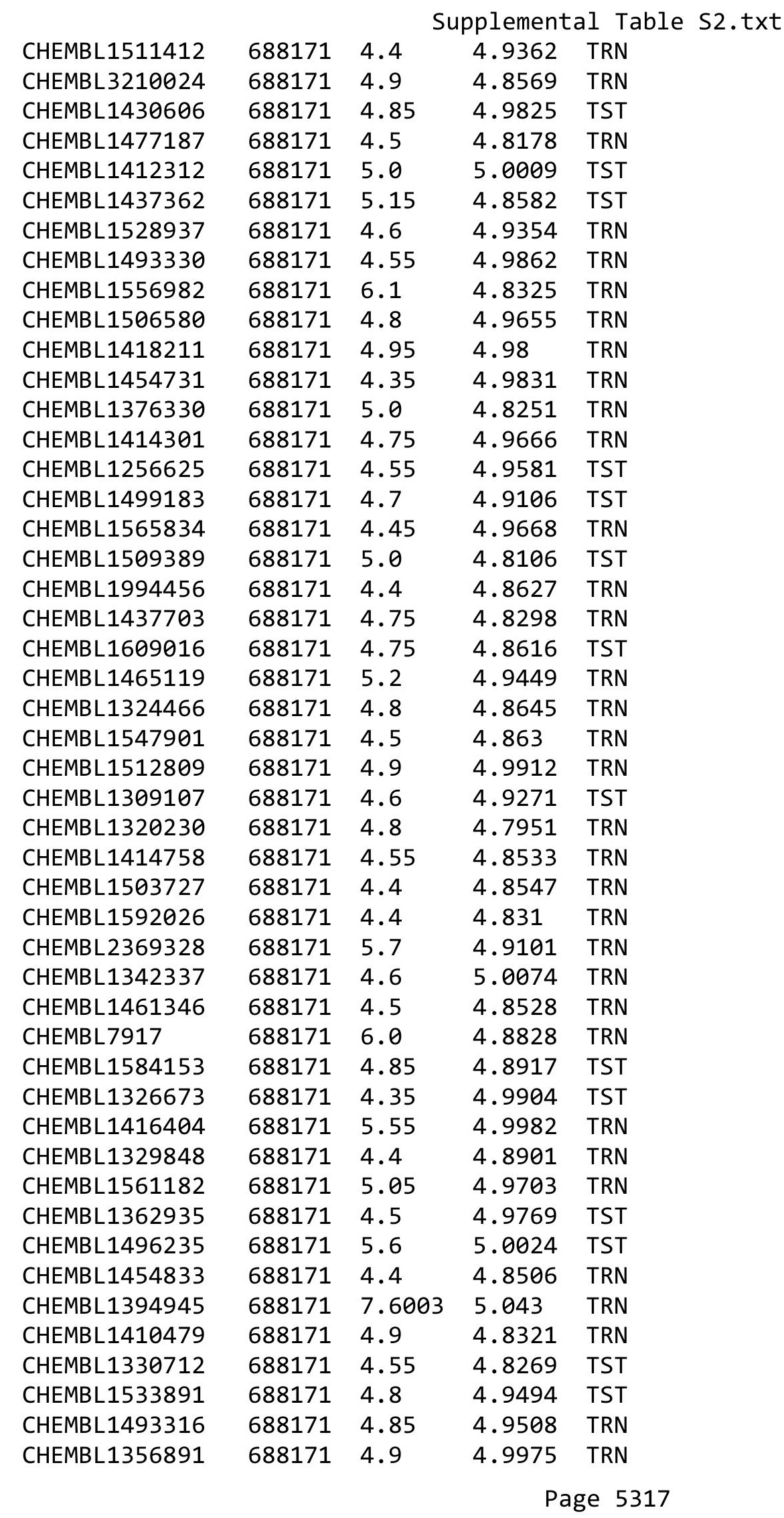




\begin{tabular}{|c|c|c|c|c|c|}
\hline & & \multicolumn{4}{|c|}{ Supplemental Table S2.txt } \\
\hline CHEMBL3189782 & 688171 & 4.95 & 4.9173 & TRN & \\
\hline CHEMBL1538642 & 688171 & 4.55 & 5.0335 & TST & \\
\hline CHEMBL3193692 & 688171 & 5.2 & 4.9964 & TRN & \\
\hline CHEMBL1599796 & 688171 & 4.8 & 4.9288 & TRN & \\
\hline CHEMBL1364411 & 688171 & 4.9 & 5.0019 & TRN & \\
\hline CHEMBL1524383 & 688171 & 4.9 & 4.9534 & TRN & \\
\hline CHEMBL1533888 & 688171 & 4.95 & 4.8297 & TST & \\
\hline CHEMBL1418080 & 688171 & 4.7 & 4.9199 & TRN & \\
\hline CHEMBL1416974 & 688171 & 4.65 & 4.8326 & TRN & \\
\hline CHEMBL1401240 & 688171 & 4.6 & 4.9203 & TST & \\
\hline CHEMBL1306989 & 688171 & 4.75 & 4.9232 & TRN & \\
\hline CHEMBL1354093 & 688171 & 4.75 & 4.98 & TRN & \\
\hline CHEMBL1502732 & 688171 & 4.7 & 4.9212 & TST & \\
\hline CHEMBL1420467 & 688171 & 4.55 & 4.782 & TST & \\
\hline CHEMBL1357688 & 688171 & 4.9 & 4.7988 & TRN & \\
\hline CHEMBL1328224 & 688171 & 4.7 & 4.8632 & TST & \\
\hline CHEMBL1301630 & 688171 & 4.75 & 4.7978 & TRN & \\
\hline CHEMBL1450897 & 688171 & 5.35 & 4.8499 & TRN & \\
\hline CHEMBL1463829 & 688171 & 4.8 & 4.9641 & TRN & \\
\hline CHEMBL1493336 & 688171 & 4.8 & 4.8261 & TRN & \\
\hline CHEMBL1389445 & 688171 & 4.95 & 4.9882 & TRN & \\
\hline CHEMBL1481954 & 688171 & 4.95 & 4.9876 & TRN & \\
\hline CHEMBL1330907 & 688171 & 4.55 & 5.0085 & TRN & \\
\hline CHEMBL1422628 & 688171 & 4.4 & 4.9556 & TST & \\
\hline CHEMBL1604834 & 688171 & 4.4 & 4.9612 & TRN & \\
\hline CHEMBL1316778 & 688171 & 4.35 & 4.8786 & TRN & \\
\hline CHEMBL1365189 & 688171 & 4.4 & 4.8492 & TST & \\
\hline CHEMBL1565187 & 688171 & 5.4 & 4.8362 & TRN & \\
\hline CHEMBL 1557022 & 688171 & 4.7 & 4.9355 & TRN & \\
\hline CHEMBL1416341 & 688171 & 4.65 & 4.7484 & TRN & \\
\hline CHEMBL1351843 & 688171 & 5.4 & 4.9057 & TST & \\
\hline CHEMBL1363093 & 688171 & 4.65 & 4.8797 & TRN & \\
\hline CHEMBL1493722 & 688171 & 4.65 & 4.9285 & TRN & \\
\hline CHEMBL1477916 & 688171 & 5.05 & 4.8849 & TRN & \\
\hline CHEMBL1482708 & 688171 & 4.75 & 4.9952 & TRN & \\
\hline CHEMBL1454504 & 688171 & 4.4 & 4.8402 & TRN & \\
\hline CHEMBL1427906 & 688171 & 4.9 & 4.80699 & 99999999995 & TRN \\
\hline CHEMBL1588557 & 688171 & 4.4 & 4.9629 & TRN & \\
\hline CHEMBL1331865 & 688171 & 4.6 & 4.793 & TRN & \\
\hline CHEMBL1457577 & 688171 & 4.65 & 4.8397 & TRN & \\
\hline CHEMBL1255656 & 688171 & 5.45 & 4.9741 & TST & \\
\hline CHEMBL1488976 & 688171 & 4.95 & 4.9883 & TRN & \\
\hline CHEMBL1325215 & 688171 & 5.05 & 4.9882 & TST & \\
\hline CHEMBL1314529 & 688171 & 4.7 & 4.7491 & TST & \\
\hline CHEMBL1477698 & 688171 & 4.35 & 4.9615 & TST & \\
\hline CHEMBL1337235 & 688171 & 5.7 & 4.9546 & TRN & \\
\hline CHEMBL1373987 & 688171 & 4.4 & 4.8668 & TRN & \\
\hline CHEMBL1411229 & 688171 & 4.4 & 4.9099 & TST & \\
\hline
\end{tabular}




\begin{tabular}{|c|c|c|c|c|}
\hline \multicolumn{5}{|c|}{ Supplemental Table S2.txt } \\
\hline CHEMBL1362585 & 688171 & 4.6 & 5.0153 & TRN \\
\hline CHEMBL1476964 & 688171 & 4.55 & 4.9667 & TRN \\
\hline CHEMBL1358457 & 688171 & 4.9 & 4.8501 & TRN \\
\hline CHEMBL1582204 & 688171 & 5.0 & 4.9396 & TST \\
\hline CHEMBL1308610 & 688171 & 4.6 & 4.7634 & TST \\
\hline CHEMBL1389870 & 688171 & 4.5 & 4.8365 & TST \\
\hline CHEMBL1553986 & 688171 & 4.4 & 4.7993 & TRN \\
\hline CHEMBL1441256 & 688171 & 4.4 & 4.8515 & TRN \\
\hline CHEMBL1452361 & 688171 & 5.8 & 4.9046 & TST \\
\hline CHEMBL1551416 & 688171 & 4.8 & 5.0128 & TRN \\
\hline CHEMBL1457975 & 688171 & 5.0 & 4.8178 & TRN \\
\hline CHEMBL1327069 & 688171 & 5.1 & 4.9401 & TRN \\
\hline CHEMBL1528473 & 688171 & 4.4 & 4.8912 & TRN \\
\hline CHEMBL1570397 & 688171 & 4.4 & 4.8094 & TST \\
\hline CHEMBL1467209 & 688171 & 6.7501 & 4.9353 & TRN \\
\hline CHEMBL1531267 & 688171 & 4.65 & 4.914 & TRN \\
\hline CHEMBL1447095 & 688171 & 5.7 & 4.9674 & TST \\
\hline CHEMBL1534313 & 688171 & 4.8 & 4.8692 & TST \\
\hline CHEMBL1369967 & 688171 & 4.5 & 4.9178 & TST \\
\hline CHEMBL1564004 & 688171 & 4.75 & 4.9435 & TST \\
\hline CHEMBL1350917 & 688171 & 4.4 & 4.8985 & TST \\
\hline CHEMBL1501843 & 688171 & 4.4 & 4.9019 & TST \\
\hline CHEMBL1513186 & 688171 & 4.55 & 4.8207 & TRN \\
\hline CHEMBL1418579 & 688171 & 5.0 & 4.9012 & TRN \\
\hline CHEMBL1410283 & 688171 & 4.4 & 4.9003 & TRN \\
\hline CHEMBL1476941 & 688171 & 4.85 & 4.9321 & TRN \\
\hline CHEMBL1591197 & 688171 & 4.4 & 4.8474 & TRN \\
\hline CHEMBL1394226 & 688171 & 5.05 & 4.8158 & TRN \\
\hline CHEMBL1981638 & 688171 & 4.45 & 4.8945 & TRN \\
\hline CHEMBL1590511 & 688171 & 4.95 & 4.7754 & TRN \\
\hline CHEMBL2003998 & 688171 & 4.6 & 5.0144 & TRN \\
\hline CHEMBL1475971 & 688171 & 4.4 & 4.8018 & TRN \\
\hline CHEMBL1486682 & 688171 & 4.45 & 4.9172 & TRN \\
\hline CHEMBL1590371 & 688171 & 4.85 & 4.9263 & TST \\
\hline CHEMBL1372971 & 688171 & 4.55 & 5.0017 & TRN \\
\hline CHEMBL1385562 & 688171 & 4.4 & 4.8998 & TRN \\
\hline CHEMBL84472 & 688171 & 7.6498 & 4.8203 & TST \\
\hline CHEMBL1325199 & 688171 & 4.5 & 4.9733 & TRN \\
\hline CHEMBL1531933 & 688171 & 4.45 & 4.8239 & TRN \\
\hline CHEMBL1492395 & 688171 & 4.4 & 4.8779 & TRN \\
\hline CHEMBL1460190 & 688171 & 4.55 & 4.8365 & TRN \\
\hline CHEMBL1539706 & 688171 & 4.4 & 4.9738 & TST \\
\hline CHEMBL1397230 & 688171 & 4.7 & 4.9672 & TST \\
\hline CHEMBL1511647 & 688171 & 4.45 & 4.9476 & TRN \\
\hline CHEMBL 301507 & 688171 & 5.2 & 4.7642 & TRN \\
\hline CHEMBL1524371 & 688171 & 4.6 & 4.8617 & TRN \\
\hline CHEMBL1397433 & 688171 & 4.7 & 4.8646 & TRN \\
\hline CHEMBL1440341 & 688171 & 4.7 & 4.8529 & TST \\
\hline
\end{tabular}




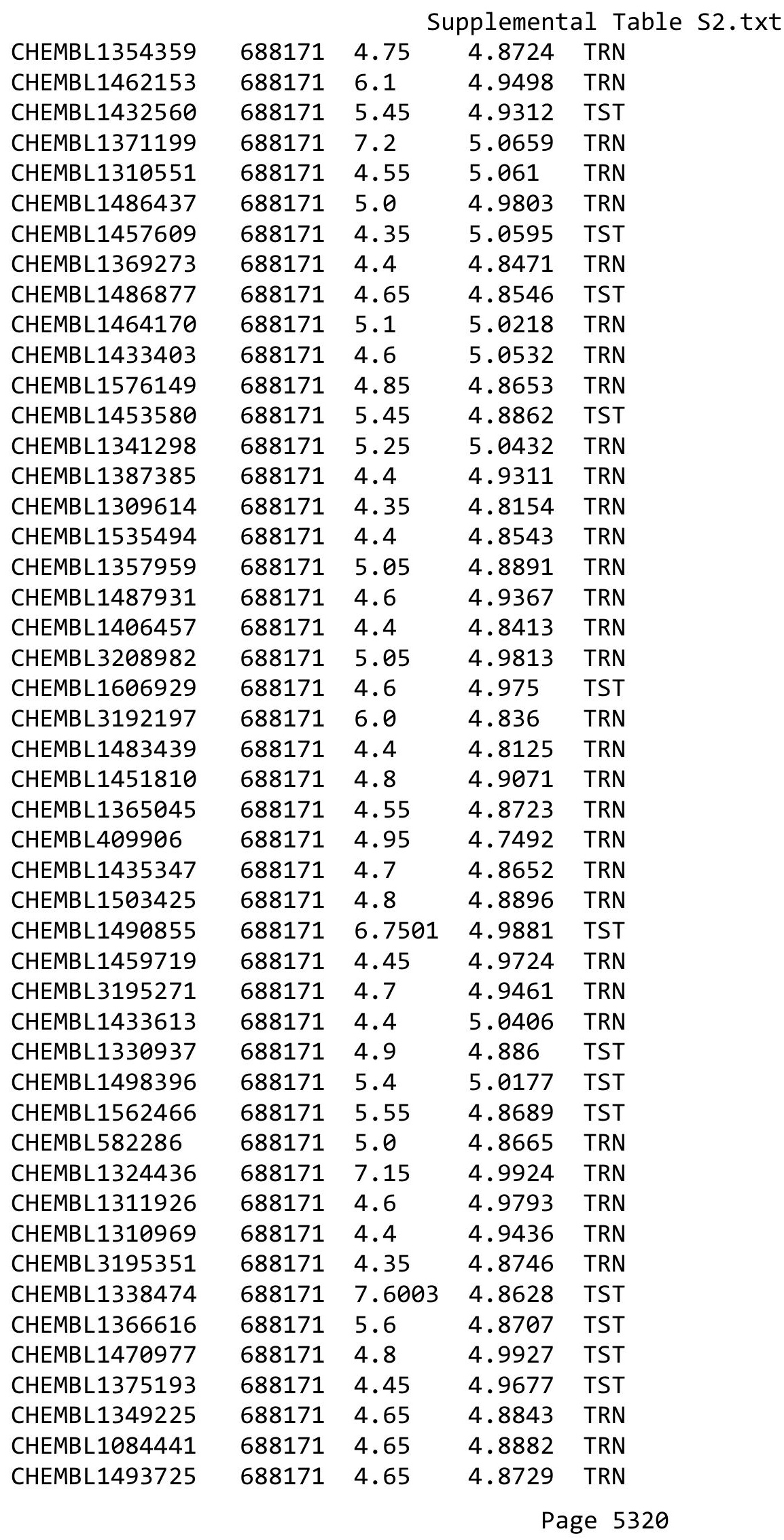




\begin{tabular}{|c|c|c|c|c|}
\hline \multicolumn{5}{|c|}{ Supplemental Table S2.txt } \\
\hline CHEMBL1589863 & 688171 & 4.85 & 5.0006 & TRN \\
\hline CHEMBL1451836 & 688171 & 5.15 & 4.9747 & TST \\
\hline CHEMBL1348980 & 688171 & 5.15 & 4.8691 & TST \\
\hline CHEMBL1965698 & 688171 & 4.35 & 4.9789 & TST \\
\hline CHEMBL1459412 & 688171 & 4.95 & 4.8954 & TST \\
\hline CHEMBL1374032 & 688171 & 5.1 & 4.8502 & TRN \\
\hline CHEMBL1495439 & 688171 & 4.8 & 4.9268 & TRN \\
\hline CHEMBL 2006757 & 688171 & 5.05 & 4.887 & TST \\
\hline CHEMBL1587831 & 688171 & 5.2 & 4.8512 & TST \\
\hline CHEMBL1540565 & 688171 & 6.7501 & 5.1371 & TST \\
\hline CHEMBL1392828 & 688171 & 5.0 & 4.7059 & TRN \\
\hline CHEMBL1441193 & 688171 & 4.55 & 4.8886 & TRN \\
\hline CHEMBL1208903 & 688171 & 4.75 & 4.9228 & TRN \\
\hline CHEMBL1590987 & 688171 & 4.95 & 4.9591 & TRN \\
\hline CHEMBL1517393 & 688171 & 4.6 & 4.8977 & TST \\
\hline CHEMBL1590981 & 688171 & 4.85 & 4.8068 & TRN \\
\hline CHEMBL1445620 & 688171 & 4.55 & 4.9045 & TRN \\
\hline CHEMBL1558711 & 688171 & 5.5 & 5.0221 & TRN \\
\hline CHEMBL1458009 & 688171 & 4.95 & 4.96 & TST \\
\hline CHEMBL1603205 & 688171 & 4.9 & 4.8958 & TST \\
\hline CHEMBL1462078 & 688171 & 4.85 & 4.9383 & TST \\
\hline CHEMBL1409359 & 688171 & 5.75 & 4.9875 & TRN \\
\hline CHEMBL1306749 & 688171 & 4.35 & 4.9073 & TRN \\
\hline CHEMBL1579102 & 688171 & 5.6 & 4.834 & TRN \\
\hline CHEMBL1567335 & 688171 & 4.4 & 5.0064 & TRN \\
\hline CHEMBL1326710 & 688171 & 4.35 & 4.888 & TST \\
\hline CHEMBL1428988 & 688171 & 5.45 & 4.8108 & TST \\
\hline CHEMBL1335376 & 688171 & 5.35 & 4.9711 & TST \\
\hline CHEMBL1481327 & 688171 & 5.0 & 4.8342 & TRN \\
\hline CHEMBL1482360 & 688171 & 4.8 & 4.9335 & TRN \\
\hline CHEMBL1504869 & 688171 & 4.55 & 4.9107 & TST \\
\hline CHEMBL1397277 & 688171 & 4.75 & 4.8468 & TRN \\
\hline CHEMBL1537386 & 688171 & 4.85 & 4.7862 & TRN \\
\hline CHEMBL1491137 & 688171 & 6.1 & 5.0123 & TRN \\
\hline CHEMBL1556707 & 688171 & 4.4 & 4.8467 & TRN \\
\hline CHEMBL1365962 & 688171 & 4.75 & 5.0386 & TRN \\
\hline CHEMBL1350793 & 688171 & 4.65 & 4.7564 & TRN \\
\hline CHEMBL1557675 & 688171 & 5.6 & 4.9612 & TRN \\
\hline CHEMBL1492068 & 688171 & 4.5 & 4.9461 & TRN \\
\hline CHEMBL1523473 & 688171 & 4.6 & 5.0042 & TRN \\
\hline CHEMBL1475345 & 688171 & 4.4 & 4.8534 & TRN \\
\hline CHEMBL1338428 & 688171 & 4.4 & 5.0162 & TRN \\
\hline CHEMBL1513725 & 688171 & 4.5 & 4.8051 & TRN \\
\hline CHEMBL1467492 & 688171 & 4.85 & 4.9349 & TRN \\
\hline CHEMBL1507284 & 688171 & 4.65 & 5.1332 & TRN \\
\hline CHEMBL1422133 & 688171 & 5.0 & 5.0032 & TST \\
\hline CHEMBL1463979 & 688171 & 4.4 & 4.8072 & TST \\
\hline CHEMBL1386874 & 688171 & 4.8 & 5.0416 & TST \\
\hline
\end{tabular}




\begin{tabular}{|c|c|c|c|c|c|}
\hline & & \multicolumn{4}{|c|}{ Supplemental Table S2.txt } \\
\hline CHEMBL1610213 & 688171 & 5.45 & 4.8612 & TRN & \\
\hline CHEMBL1506600 & 688171 & 4.45 & 4.7918 & TRN & \\
\hline CHEMBL1610397 & 688171 & 4.95 & 4.90600 & 0000000001 & TRN \\
\hline CHEMBL1461753 & 688171 & 5.25 & 4.8621 & TRN & \\
\hline CHEMBL1444980 & 688171 & 5.5 & 4.886 & TRN & \\
\hline CHEMBL1513465 & 688171 & 4.55 & 4.9027 & TRN & \\
\hline CHEMBL1489603 & 688171 & 4.5 & 4.8824 & TST & \\
\hline CHEMBL1541309 & 688171 & 5.0 & 4.9608 & TRN & \\
\hline CHEMBL1516793 & 688171 & 4.9 & 4.9226 & TST & \\
\hline CHEMBL1601327 & 688171 & 4.7 & 4.9636 & TRN & \\
\hline CHEMBL1372250 & 688171 & 4.65 & 4.8907 & TRN & \\
\hline CHEMBL1503058 & 688171 & 4.4 & 4.8613 & TRN & \\
\hline CHEMBL1339766 & 688171 & 4.35 & 5.0446 & TST & \\
\hline CHEMBL1559671 & 688171 & 5.4 & 4.7057 & TST & \\
\hline CHEMBL1441957 & 688171 & 5.2 & 5.0061 & TRN & \\
\hline CHEMBL1588525 & 688171 & 4.55 & 4.9607 & TRN & \\
\hline CHEMBL1565164 & 688171 & 4.55 & 4.8377 & TST & \\
\hline CHEMBL1399004 & 688171 & 4.9 & 5.0038 & TST & \\
\hline CHEMBL1445545 & 688171 & 4.4 & 4.7404 & TRN & \\
\hline CHEMBL3189816 & 688171 & 6.25 & 4.8558 & TST & \\
\hline CHEMBL1311176 & 688171 & 5.0 & 4.9929 & TRN & \\
\hline CHEMBL1606015 & 688171 & 4.35 & 4.8746 & TRN & \\
\hline CHEMBL1414539 & 688171 & 5.05 & 4.9343 & TRN & \\
\hline CHEMBL1516334 & 688171 & 5.2 & 4.8928 & TRN & \\
\hline CHEMBL1587272 & 688171 & 4.6 & 4.9641 & TRN & \\
\hline CHEMBL1584812 & 688171 & 4.95 & 4.9648 & TRN & \\
\hline CHEMBL1537917 & 688171 & 5.05 & 4.8734 & TST & \\
\hline CHEMBL3197065 & 688171 & 4.9 & 4.9356 & TRN & \\
\hline CHEMBL1341687 & 688171 & 5.95 & 4.7942 & TST & \\
\hline CHEMBL1498113 & 688171 & 4.4 & 4.8954 & TST & \\
\hline CHEMBL1375659 & 688171 & 5.55 & 4.81800 & 00000000005 & TST \\
\hline CHEMBL1556234 & 688171 & 4.5 & 4.8485 & TRN & \\
\hline CHEMBL1576355 & 688171 & 4.8 & 4.9825 & TRN & \\
\hline CHEMBL1451502 & 688171 & 4.35 & 4.8199 & TRN & \\
\hline CHEMBL1468369 & 688171 & 5.2 & 4.838 & TST & \\
\hline CHEMBL1548587 & 688171 & 4.5 & 4.9776 & TRN & \\
\hline CHEMBL1482029 & 688171 & 4.5 & 4.8915 & TRN & \\
\hline CHEMBL3213021 & 688171 & 4.6 & 4.7954 & TST & \\
\hline CHEMBL1377320 & 688171 & 5.5 & 4.9479 & TRN & \\
\hline CHEMBL1386090 & 688171 & 5.4 & 4.7925 & TRN & \\
\hline CHEMBL1579345 & 688171 & 4.8 & 4.8092 & TRN & \\
\hline CHEMBL3189458 & 688171 & 5.35 & 4.9555 & TRN & \\
\hline CHEMBL1610070 & 688171 & 4.75 & 4.9084 & TST & \\
\hline CHEMBL1326422 & 688171 & 4.75 & 4.913 & TRN & \\
\hline CHEMBL1348943 & 688171 & 5.05 & 4.9137 & TRN & \\
\hline CHEMBL406375 & 688171 & 4.55 & 4.8099 & TST & \\
\hline CHEMBL1335708 & 688171 & 4.9 & 4.9132 & TRN & \\
\hline CHEMBL1327714 & 688171 & 4.9 & 4.8714 & TRN & \\
\hline
\end{tabular}




\begin{tabular}{|c|c|c|c|c|c|}
\hline \multicolumn{6}{|c|}{ Supplemental Table s2.txt } \\
\hline CHEMBL1610056 & 688171 & 4.6 & 4.9271 & TST & \\
\hline CHEMBL1420370 & 688171 & 5.15 & 4.9121 & TRN & \\
\hline CHEMBL1435153 & 688171 & 5.75 & 5.0052 & TRN & \\
\hline CHEMBL1412504 & 688171 & 4.7 & 5.0134 & TRN & \\
\hline CHEMBL1367765 & 688171 & 5.0 & 4.8938 & TRN & \\
\hline CHEMBL1383668 & 688171 & 4.95 & 4.9322 & TST & \\
\hline CHEMBL1481034 & 688171 & 5.15 & 4.9685 & TRN & \\
\hline CHEMBL1543947 & 688171 & 5.0 & 5.0655 & TRN & \\
\hline CHEMBL1348383 & 688171 & 4.35 & 4.7753 & TRN & \\
\hline CHEMBL1474983 & 688171 & 4.55 & 4.9141 & TRN & \\
\hline CHEMBL1563679 & 688171 & 4.65 & 4.7782 & TRN & \\
\hline CHEMBL1492539 & 688171 & 6.0 & 4.8287 & TRN & \\
\hline CHEMBL1529285 & 688171 & 4.45 & 4.8909 & TRN & \\
\hline CHEMBL1516428 & 688171 & 4.6 & 4.9374 & TST & \\
\hline CHEMBL1425921 & 688171 & 7.1002 & 4.8467 & TST & \\
\hline CHEMBL1373583 & 688171 & 4.45 & 4.895 & TST & \\
\hline CHEMBL1447034 & 688171 & 4.9 & 4.95100 & 00000000005 & TRN \\
\hline CHEMBL1347345 & 688171 & 6.45 & 4.8727 & TST & \\
\hline CHEMBL1533860 & 688171 & 5.7 & 4.9695 & TRN & \\
\hline CHEMBL1502000 & 688171 & 4.8 & 4.7823 & TRN & \\
\hline CHEMBL1353692 & 688171 & 5.05 & 4.8428 & TRN & \\
\hline CHEMBL1990275 & 688171 & 4.4 & 4.9842 & TRN & \\
\hline CHEMBL1404244 & 688171 & 4.85 & 4.8628 & TRN & \\
\hline CHEMBL1433257 & 688171 & 4.7 & 4.88399 & 99999999995 & TST \\
\hline CHEMBL1469698 & 688171 & 5.1 & 4.9024 & TRN & \\
\hline CHEMBL1518670 & 688171 & 5.2 & 4.7979 & TRN & \\
\hline CHEMBL1377330 & 688171 & 6.7001 & 4.966 & TRN & \\
\hline CHEMBL1379951 & 688171 & 5.15 & 4.7931 & TRN & \\
\hline CHEMBL3213576 & 688171 & 4.7 & 4.9665 & TST & \\
\hline CHEMBL1606007 & 688171 & 4.65 & 4.8132 & TST & \\
\hline CHEMBL1503017 & 688171 & 4.8 & 4.8234 & TRN & \\
\hline CHEMBL1080915 & 688171 & 4.6 & 4.9542 & TRN & \\
\hline CHEMBL3198499 & 688171 & 4.9 & 4.8592 & TRN & \\
\hline CHEMBL1325989 & 688171 & 5.2 & 4.9268 & TRN & \\
\hline CHEMBL1538855 & 688171 & 5.35 & 4.9106 & TST & \\
\hline CHEMBL1524774 & 688171 & 4.45 & 4.9273 & TRN & \\
\hline CHEMBL1498829 & 688171 & 4.75 & 4.8766 & TRN & \\
\hline CHEMBL1342047 & 688171 & 4.4 & 5.0718 & TST & \\
\hline CHEMBL1516048 & 688171 & 4.7 & 4.8529 & TRN & \\
\hline CHEMBL1512980 & 688171 & 4.65 & 4.8235 & TRN & \\
\hline CHEMBL1392169 & 688171 & 4.65 & 4.881 & TRN & \\
\hline CHEMBL1549529 & 688171 & 4.7 & 4.8353 & TRN & \\
\hline CHEMBL1471798 & 688171 & 4.9 & 5.1084 & TRN & \\
\hline CHEMBL1579506 & 688171 & 4.5 & 4.9102 & TRN & \\
\hline CHEMBL1494197 & 688171 & 4.4 & 4.7734 & TRN & \\
\hline CHEMBL1470476 & 688171 & 4.4 & 4.92399 & 99999999995 & TST \\
\hline CHEMBL1383137 & 688171 & 4.85 & 4.8443 & TRN & \\
\hline CHEMBL294264 & 688171 & 6.0 & 4.886 & TRN & \\
\hline
\end{tabular}




\begin{tabular}{|c|c|c|c|c|}
\hline \multicolumn{5}{|c|}{ Supplemental Table S2.txt } \\
\hline CHEMBL1326976 & 688171 & 4.5 & 5.0628 & TST \\
\hline CHEMBL1373541 & 688171 & 5.45 & 4.79 & TRN \\
\hline CHEMBL1403854 & 688171 & 4.9 & 4.8399 & TRN \\
\hline CHEMBL1418040 & 688171 & 4.6 & 4.9195 & TRN \\
\hline CHEMBL1317792 & 688171 & 4.65 & 4.9875 & TRN \\
\hline CHEMBL1351105 & 688171 & 4.9 & 4.8861 & TRN \\
\hline CHEMBL1389650 & 688171 & 5.2 & 5.0625 & TRN \\
\hline CHEMBL1448195 & 688171 & 4.85 & 4.9518 & TRN \\
\hline CHEMBL3214529 & 688171 & 5.05 & 5.0472 & TRN \\
\hline CHEMBL1505167 & 688171 & 6.0 & 4.965 & TRN \\
\hline CHEMBL1473210 & 688171 & 5.35 & 5.0576 & TRN \\
\hline CHEMBL1509585 & 688171 & 4.65 & 4.731 & TRN \\
\hline CHEMBL1335056 & 688171 & 4.55 & 5.0093 & TRN \\
\hline CHEMBL1313254 & 688171 & 4.4 & 4.832 & TRN \\
\hline CHEMBL1512122 & 688171 & 5.3 & 4.9582 & TRN \\
\hline CHEMBL1420007 & 688171 & 4.4 & 4.7346 & TRN \\
\hline CHEMBL1562712 & 688171 & 4.8 & 5.063 & TRN \\
\hline CHEMBL1584192 & 688171 & 5.55 & 4.8965 & TRN \\
\hline CHEMBL3212630 & 688171 & 4.95 & 4.9748 & TST \\
\hline CHEMBL1437734 & 688171 & 5.65 & 5.1198 & TRN \\
\hline CHEMBL1588446 & 688171 & 6.05 & 5.032 & TRN \\
\hline CHEMBL1598852 & 688171 & 5.5 & 4.864 & TRN \\
\hline CHEMBL1594404 & 688171 & 4.4 & 4.7822 & TRN \\
\hline CHEMBL1460672 & 688171 & 5.35 & 4.9017 & TST \\
\hline CHEMBL1309841 & 688171 & 4.4 & 4.9642 & TRN \\
\hline CHEMBL1477778 & 688171 & 4.8 & 4.9522 & TRN \\
\hline CHEMBL1303155 & 688171 & 4.6 & 4.8618 & TRN \\
\hline CHEMBL1612186 & 688171 & 4.4 & 5.0511 & TST \\
\hline CHEMBL228281 & 688171 & 5.1 & 4.9126 & TRN \\
\hline CHEMBL1591813 & 688171 & 4.95 & 4.9917 & TST \\
\hline CHEMBL1337661 & 688171 & 4.5 & 4.8934 & TRN \\
\hline CHEMBL1427117 & 688171 & 5.0 & 5.0225 & TST \\
\hline CHEMBL 78573 & 688171 & 4.65 & 4.9378 & TRN \\
\hline CHEMBL1323919 & 688171 & 5.35 & 4.9479 & TST \\
\hline CHEMBL1475713 & 688171 & 4.5 & 4.9203 & TRN \\
\hline CHEMBL1320157 & 688171 & 4.6 & 4.9101 & TRN \\
\hline CHEMBL 1427752 & 688171 & 4.65 & 4.819 & TRN \\
\hline CHEMBL1315849 & 688171 & 5.0 & 4.891 & TRN \\
\hline CHEMBL1362576 & 688171 & 5.05 & 4.8141 & TRN \\
\hline CHEMBL1344966 & 688171 & 4.95 & 4.9541 & TRN \\
\hline CHEMBL1425975 & 688171 & 4.6 & 5.0133 & TRN \\
\hline CHEMBL3189169 & 688171 & 5.7 & 4.9806 & TRN \\
\hline CHEMBL1590785 & 688171 & 4.85 & 4.9681 & TRN \\
\hline CHEMBL1446868 & 688171 & 4.95 & 5.1001 & TST \\
\hline CHEMBL1431174 & 688171 & 4.5 & 4.7578 & TRN \\
\hline CHEMBL1314207 & 688171 & 4.35 & 4.9514 & TRN \\
\hline CHEMBL1542198 & 688171 & 5.3 & 4.7996 & TST \\
\hline CHEMBL1396767 & 688171 & 4.75 & 4.8953 & TRN \\
\hline
\end{tabular}




\begin{tabular}{|c|c|c|c|c|}
\hline \multicolumn{5}{|c|}{ Supplemental Table S2.txt } \\
\hline CHEMBL1447166 & 688171 & 5.45 & 4.8485 & TRN \\
\hline CHEMBL1302406 & 688171 & 4.5 & 4.8448 & TRN \\
\hline CHEMBL1371353 & 688171 & 6.0 & 4.9965 & TST \\
\hline CHEMBL1377656 & 688171 & 4.9 & 4.7638 & TRN \\
\hline CHEMBL 8260 & 688171 & 6.0 & 4.8851 & TRN \\
\hline CHEMBL1371415 & 688171 & 4.35 & 4.8209 & TRN \\
\hline CHEMBL1354245 & 688171 & 4.45 & 4.8663 & TRN \\
\hline CHEMBL1560068 & 688171 & 4.45 & 4.8824 & TRN \\
\hline CHEMBL1336344 & 688171 & 5.45 & 4.8415 & TST \\
\hline CHEMBL1486378 & 688171 & 4.35 & 4.881 & TRN \\
\hline CHEMBL1969037 & 688171 & 4.7 & 4.8273 & TRN \\
\hline CHEMBL6291 & 688171 & 6.0 & 4.8372 & TST \\
\hline CHEMBL1406374 & 688171 & 5.05 & 4.9153 & TRN \\
\hline CHEMBL3198994 & 688171 & 5.0 & 4.9231 & TST \\
\hline CHEMBL1550387 & 688171 & 5.5 & 4.9 & TRN \\
\hline CHEMBL1534537 & 688171 & 6.3 & 4.8925 & TST \\
\hline CHEMBL1586439 & 688171 & 7.3497 & 4.8169 & TST \\
\hline CHEMBL1386065 & 688171 & 4.95 & 4.9031 & TST \\
\hline CHEMBL3212203 & 688171 & 6.1 & 4.9592 & TRN \\
\hline CHEMBL1506433 & 688171 & 4.4 & 4.8324 & TRN \\
\hline CHEMBL3208299 & 688171 & 5.95 & 4.96899 & 9999999999 \\
\hline CHEMBL1367674 & 688171 & 4.55 & 4.8441 & TRN \\
\hline CHEMBL1474584 & 688171 & 4.8 & 4.7949 & TRN \\
\hline CHEMBL1428731 & 688171 & 4.75 & 4.8055 & TRN \\
\hline CHEMBL1350350 & 688171 & 5.0 & 4.8107 & TRN \\
\hline CHEMBL1549250 & 688171 & 5.55 & 4.8528 & TST \\
\hline CHEMBL1513238 & 688171 & 5.5 & 4.8788 & TRN \\
\hline CHEMBL1587319 & 688171 & 4.7 & 5.0094 & TST \\
\hline CHEMBL1492642 & 688171 & 4.85 & 4.7691 & TRN \\
\hline CHEMBL1416932 & 688171 & 4.95 & 4.7722 & TRN \\
\hline CHEMBL1500808 & 688171 & 4.4 & 4.9292 & TST \\
\hline CHEMBL1419805 & 688171 & 4.5 & 4.7987 & TST \\
\hline CHEMBL1459865 & 688171 & 5.2 & 4.9091 & TRN \\
\hline CHEMBL1509783 & 688171 & 4.45 & 4.9218 & TST \\
\hline CHEMBL1314445 & 688171 & 7.6003 & 4.9754 & TST \\
\hline CHEMBL1460012 & 688171 & 4.75 & 4.8405 & TRN \\
\hline CHEMBL1515329 & 688171 & 5.15 & 5.0102 & TST \\
\hline CHEMBL1354304 & 688171 & 5.0 & 4.9815 & TRN \\
\hline CHEMBL1410554 & 688171 & 5.25 & 4.8857 & TRN \\
\hline CHEMBL1352757 & 688171 & 4.6 & 4.8456 & TST \\
\hline CHEMBL1476260 & 688171 & 5.0 & 4.8544 & TRN \\
\hline CHEMBL151946 & 688171 & 4.55 & 4.8185 & TRN \\
\hline CHEMBL3198191 & 688171 & 5.5 & 4.966 & TST \\
\hline CHEMBL1364761 & 688171 & 5.3 & 5.0349 & TST \\
\hline CHEMBL1416498 & 688171 & 4.5 & 4.9989 & TST \\
\hline CHEMBL1554823 & 688171 & 5.45 & 4.9218 & TRN \\
\hline CHEMBL1319792 & 688171 & 5.5 & 4.8237 & TST \\
\hline CHEMBL1429437 & 688171 & 4.55 & 4.8664 & TRN \\
\hline
\end{tabular}




\begin{tabular}{|c|c|c|c|c|}
\hline \multicolumn{5}{|c|}{ Supplemental Table S2.txt } \\
\hline CHEMBL1347758 & 688171 & 5.75 & 4.9106 & TRN \\
\hline CHEMBL1362850 & 688171 & 4.9 & 4.9392 & TRN \\
\hline CHEMBL1440191 & 688171 & 6.2 & 4.8453 & TRN \\
\hline CHEMBL1173672 & 688171 & 4.6 & 4.8837 & TRN \\
\hline CHEMBL1552749 & 688171 & 4.45 & 4.9459 & TRN \\
\hline CHEMBL1469840 & 688171 & 4.35 & 4.8065 & TST \\
\hline CHEMBL1386627 & 688171 & 4.5 & 4.9876 & TRN \\
\hline CHEMBL1444471 & 688171 & 4.95 & 4.824 & TRN \\
\hline CHEMBL1436299 & 688171 & 4.5 & 4.8452 & TST \\
\hline CHEMBL1382536 & 688171 & 4.35 & 4.8672 & TRN \\
\hline CHEMBL1443059 & 688171 & 4.5 & 4.6956 & TRN \\
\hline CHEMBL1465375 & 688171 & 5.3 & 4.9825 & TST \\
\hline CHEMBL1590360 & 688171 & 4.5 & 4.9525 & TRN \\
\hline CHEMBL1590659 & 688171 & 5.0 & 4.8228 & TRN \\
\hline CHEMBL1427381 & 688171 & 4.6 & 4.8814 & TRN \\
\hline CHEMBL 3196732 & 688171 & 4.4 & 5.0876 & TRN \\
\hline CHEMBL1473750 & 688171 & 4.8 & 4.9469 & TRN \\
\hline CHEMBL1386049 & 688171 & 4.8 & 4.9313 & TRN \\
\hline CHEMBL1599721 & 688171 & 4.5 & 4.8099 & TST \\
\hline CHEMBL1467614 & 688171 & 6.15 & 4.9979 & TST \\
\hline CHEMBL1372577 & 688171 & 4.9 & 4.8968 & TRN \\
\hline CHEMBL1358344 & 688171 & 5.05 & 4.8425 & TRN \\
\hline CHEMBL1355854 & 688171 & 4.4 & 4.8397 & TRN \\
\hline CHEMBL1549801 & 688171 & 4.4 & 4.8968 & TST \\
\hline CHEMBL1345582 & 688171 & 7.5498 & 4.8938 & TST \\
\hline CHEMBL1466307 & 688171 & 4.8 & 4.9095 & TRN \\
\hline CHEMBL1355977 & 688171 & 5.0 & 4.8635 & TRN \\
\hline CHEMBL1410286 & 688171 & 4.6 & 4.9265 & TRN \\
\hline CHEMBL1478122 & 688171 & 4.9 & 5.0203 & TRN \\
\hline CHEMBL1557000 & 688171 & 5.0 & 5.0709 & TRN \\
\hline CHEMBL1340574 & 688171 & 6.45 & 4.7097 & TRN \\
\hline CHEMBL1336287 & 688171 & 4.55 & 4.992 & TST \\
\hline CHEMBL1539334 & 688171 & 4.35 & 4.8396 & TRN \\
\hline CHEMBL1535003 & 688171 & 6.1 & 4.8836 & TRN \\
\hline CHEMBL1483843 & 688171 & 5.55 & 4.9959 & TRN \\
\hline CHEMBL193747 & 688171 & 4.55 & 4.8596 & TST \\
\hline CHEMBL1536828 & 688171 & 6.8499 & 5.1154 & TRN \\
\hline CHEMBL1373612 & 688171 & 5.9 & 4.8659 & TRN \\
\hline CHEMBL1590624 & 688171 & 4.65 & 4.8273 & TRN \\
\hline CHEMBL3211401 & 688171 & 4.4 & 4.8824 & TST \\
\hline CHEMBL1482724 & 688171 & 5.45 & 4.9929 & TRN \\
\hline CHEMBL1457703 & 688171 & 5.15 & 4.9762 & TRN \\
\hline CHEMBL1592439 & 688171 & 4.75 & 4.8695 & TRN \\
\hline CHEMBL1383409 & 688171 & 5.35 & 4.8014 & TRN \\
\hline CHEMBL1395787 & 688171 & 5.95 & 4.8931 & TST \\
\hline CHEMBL1483138 & 688171 & 4.55 & 4.8616 & TST \\
\hline CHEMBL1494107 & 688171 & 4.35 & 4.8435 & TRN \\
\hline CHEMBL1503375 & 688171 & 5.5 & 4.9304 & TRN \\
\hline
\end{tabular}




\begin{tabular}{|c|c|c|c|c|}
\hline \multicolumn{5}{|c|}{ Supplemental Table S2.txt } \\
\hline CHEMBL1395245 & 688171 & 5.25 & 4.8263 & TRN \\
\hline CHEMBL1440004 & 688171 & 4.35 & 4.9162 & TRN \\
\hline CHEMBL1337492 & 688171 & 4.9 & 4.8369 & TRN \\
\hline CHEMBL1591057 & 688171 & 4.45 & 4.6199 & TRN \\
\hline CHEMBL412010 & 688171 & 5.05 & 4.9269 & TRN \\
\hline CHEMBL1397350 & 688171 & 4.85 & 4.9903 & TRN \\
\hline CHEMBL1551150 & 688171 & 4.45 & 4.9492 & TRN \\
\hline CHEMBL1325737 & 688171 & 4.5 & 4.7773 & TRN \\
\hline CHEMBL1398910 & 688171 & 5.0 & 4.9909 & TRN \\
\hline CHEMBL1325647 & 688171 & 4.7 & 4.8171 & TRN \\
\hline CHEMBL1532766 & 688171 & 4.45 & 4.9242 & TST \\
\hline CHEMBL1557932 & 688171 & 4.4 & 4.8767 & TRN \\
\hline CHEMBL1302310 & 688171 & 5.1 & 4.9398 & TRN \\
\hline CHEMBL1585731 & 688171 & 4.75 & 4.8451 & TRN \\
\hline CHEMBL1319282 & 688171 & 4.75 & 4.8795 & TRN \\
\hline CHEMBL1397115 & 688171 & 4.85 & 4.8222 & TRN \\
\hline CHEMBL3191525 & 688171 & 4.7 & 4.9751 & TST \\
\hline CHEMBL1405155 & 688171 & 4.95 & 4.8958 & TRN \\
\hline CHEMBL1356582 & 688171 & 4.5 & 4.9772 & TRN \\
\hline CHEMBL1321432 & 688171 & 5.05 & 4.8803 & TST \\
\hline CHEMBL1321480 & 688171 & 6.8 & 4.9476 & TRN \\
\hline CHEMBL1455684 & 688171 & 5.05 & 4.9671 & TRN \\
\hline CHEMBL1395630 & 688171 & 4.55 & 4.792 & TRN \\
\hline CHEMBL1592291 & 688171 & 5.7 & 5.0993 & TRN \\
\hline CHEMBL1457608 & 688171 & 4.55 & 4.9473 & TST \\
\hline CHEMBL1514910 & 688171 & 4.5 & 4.8761 & TRN \\
\hline CHEMBL1456747 & 688171 & 4.95 & 4.9468 & TST \\
\hline CHEMBL1597661 & 688171 & 4.85 & 4.8718 & TST \\
\hline CHEMBL1386372 & 688171 & 4.4 & 4.9579 & TST \\
\hline CHEMBL 1409104 & 688171 & 5.95 & 4.857 & TST \\
\hline CHEMBL1590761 & 688171 & 4.7 & 4.8536 & TRN \\
\hline CHEMBL1560628 & 688171 & 5.05 & 4.9507 & TRN \\
\hline CHEMBL1565094 & 688171 & 4.7 & 4.8987 & TRN \\
\hline CHEMBL1504276 & 688171 & 5.05 & 4.9491 & TRN \\
\hline CHEMBL1979536 & 688171 & 4.85 & 5.022 & TRN \\
\hline CHEMBL1423708 & 688171 & 6.6 & 4.9073 & TST \\
\hline CHEMBL105310 & 688171 & 4.35 & 4.9653 & TRN \\
\hline CHEMBL1570072 & 688171 & 5.75 & 4.9384 & TST \\
\hline CHEMBL1469557 & 688171 & 4.5 & 4.9042 & TRN \\
\hline CHEMBL1560526 & 688171 & 4.35 & 4.948 & TST \\
\hline CHEMBL1589980 & 688171 & 4.5 & 4.897 & TRN \\
\hline CHEMBL1306885 & 688171 & 4.7 & 4.9254 & TRN \\
\hline CHEMBL3189307 & 688171 & 4.45 & 4.9643 & TST \\
\hline CHEMBL1455368 & 688171 & 4.7 & 4.9922 & TST \\
\hline CHEMBL1508434 & 688171 & 4.55 & 4.8519 & TRN \\
\hline CHEMBL1540947 & 688171 & 4.4 & 4.9602 & TRN \\
\hline CHEMBL1423858 & 688171 & 5.3 & 4.9211 & TRN \\
\hline CHEMBL1477758 & 688171 & 4.6 & 4.824 & TRN \\
\hline
\end{tabular}




\begin{tabular}{|c|c|c|c|c|c|}
\hline \multirow[b]{2}{*}{ CHEMBL1602141 } & \multicolumn{5}{|c|}{ Supplemental Table S2.txt } \\
\hline & 688171 & 4.4 & 4.9484 & TST & \\
\hline CHEMBL1397745 & 688171 & 7.0501 & 5.1292 & TRN & \\
\hline CHEMBL1527501 & 688171 & 4.95 & 4.9786 & TST & \\
\hline CHEMBL1511813 & 688171 & 4.55 & \multicolumn{2}{|c|}{4.8919999999999995} & TST \\
\hline CHEMBL1406180 & 688171 & 4.7 & 4.9231 & TST & \\
\hline CHEMBL1319307 & 688171 & 4.7 & 4.8275 & TST & \\
\hline CHEMBL1590209 & 688171 & 5.6 & 4.8824 & TRN & \\
\hline CHEMBL1492629 & 688171 & 4.55 & 4.7622 & TRN & \\
\hline CHEMBL1511796 & 688171 & 4.4 & 4.8303 & TRN & \\
\hline CHEMBL1312153 & 688171 & 5.5 & 4.9915 & TRN & \\
\hline CHEMBL1527154 & 688171 & 7.1002 & 4.9984 & TRN & \\
\hline CHEMBL1387104 & 688171 & 4.6 & 5.0013 & TRN & \\
\hline CHEMBL3210009 & 688171 & 4.7 & 4.7808 & TRN & \\
\hline CHEMBL1418796 & 688171 & 4.55 & 4.8378 & TST & \\
\hline CHEMBL1474245 & 688171 & 4.6 & 4.9042 & TRN & \\
\hline CHEMBL1552299 & 688171 & 4.8 & 4.9164 & TRN & \\
\hline CHEMBL1372464 & 688171 & 5.35 & 4.7579 & TRN & \\
\hline CHEMBL1423690 & 688171 & 4.5 & 4.8768 & TRN & \\
\hline CHEMBL1443600 & 688171 & 4.7 & 4.8611 & TRN & \\
\hline CHEMBL1497923 & 688171 & 4.85 & 5.0608 & TRN & \\
\hline CHEMBL1607036 & 688171 & 4.45 & \multicolumn{2}{|c|}{4.9110000000000005} & TRN \\
\hline CHEMBL1985591 & 688171 & 4.9 & 4.9422 & TRN & \\
\hline CHEMBL1382777 & 688171 & 4.35 & 5.0456 & TST & \\
\hline CHEMBL1373260 & 688171 & 4.65 & 4.7677 & TRN & \\
\hline CHEMBL1891759 & 688171 & 4.7 & 4.9732 & TST & \\
\hline CHEMBL1503689 & 688171 & 4.7 & 4.8986 & TRN & \\
\hline CHEMBL1320520 & 688171 & 5.05 & 4.9223 & TRN & \\
\hline CHEMBL1466506 & 688171 & 4.5 & 4.9938 & TST & \\
\hline CHEMBL1438484 & 688171 & 4.7 & 4.9146 & TRN & \\
\hline CHEMBL 268490 & 688171 & 7.1002 & 4.9332 & TST & \\
\hline CHEMBL1365913 & 688171 & 6.7501 & 4.9503 & TST & \\
\hline CHEMBL1612483 & 688171 & 5.5 & 4.9296 & TRN & \\
\hline CHEMBL1584074 & 688171 & 4.35 & 5.0386 & TRN & \\
\hline CHEMBL1432218 & 688171 & 4.7 & 4.8345 & TRN & \\
\hline CHEMBL1347797 & 688171 & 4.75 & 5.0509 & TRN & \\
\hline CHEMBL1384383 & 688171 & 5.5 & 4.8441 & TRN & \\
\hline CHEMBL1396413 & 688171 & 5.05 & 4.9198 & TRN & \\
\hline CHEMBL1485472 & 688171 & 4.9 & 5.0632 & TRN & \\
\hline CHEMBL1449119 & 688171 & 4.45 & \multicolumn{2}{|c|}{4.8260000000000005} & TRN \\
\hline CHEMBL1341913 & 688171 & 6.0 & 5.0075 & TST & \\
\hline CHEMBL1393628 & 688171 & 4.4 & 4.9364 & TRN & \\
\hline CHEMBL1493185 & 688171 & 5.3 & 4.9575 & TST & \\
\hline CHEMBL1347480 & 688171 & 4.85 & 4.9489 & TRN & \\
\hline CHEMBL1468549 & 688171 & 4.6 & 4.9434 & TRN & \\
\hline CHEMBL1345915 & 688171 & 4.35 & 4.9866 & TRN & \\
\hline CHEMBL3199411 & 688171 & 4.8 & 4.9746 & TST & \\
\hline CHEMBL1419293 & 688171 & 4.4 & 4.9232 & TRN & \\
\hline \multirow[t]{2}{*}{ CHEMBL1319043 } & 688171 & 6.25 & 4.9862 & TRN & \\
\hline & & \multicolumn{4}{|c|}{ Page 5328} \\
\hline
\end{tabular}




\begin{tabular}{|c|c|c|c|c|}
\hline \multicolumn{5}{|c|}{ Supplemental Table S2.txt } \\
\hline CHEMBL1417483 & 688171 & 5.3 & 4.863 & TRN \\
\hline CHEMBL1491585 & 688171 & 5.15 & 5.0334 & TST \\
\hline CHEMBL3194626 & 688171 & 4.5 & 4.7694 & TST \\
\hline CHEMBL1425732 & 688171 & 4.65 & 4.8699 & TST \\
\hline CHEMBL1407234 & 688171 & 4.6 & 4.8248 & TST \\
\hline CHEMBL1765369 & 688171 & 4.7 & 5.0615 & TST \\
\hline CHEMBL1525055 & 688171 & 6.0 & 5.0014 & TRN \\
\hline CHEMBL1416696 & 688171 & 5.9 & 4.9506 & TST \\
\hline CHEMBL3199766 & 688171 & 6.2 & 5.0433 & TRN \\
\hline CHEMBL1359982 & 688171 & 4.55 & 5.0134 & TRN \\
\hline CHEMBL1596145 & 688171 & 4.95 & 5.0052 & TRN \\
\hline CHEMBL1494806 & 688171 & 4.95 & 4.8916 & TRN \\
\hline CHEMBL1512991 & 688171 & 4.55 & 5.0389 & TRN \\
\hline CHEMBL1977514 & 688171 & 4.8 & 4.9 & TRN \\
\hline CHEMBL1452794 & 688171 & 4.4 & 5.0278 & TST \\
\hline CHEMBL3195526 & 688171 & 6.6 & 4.8954 & TRN \\
\hline CHEMBL1365331 & 688171 & 4.5 & 4.9045 & TRN \\
\hline CHEMBL1358659 & 688171 & 4.75 & 4.8922 & TST \\
\hline CHEMBL1450260 & 688171 & 4.85 & 4.7409 & TRN \\
\hline CHEMBL1571015 & 688171 & 4.65 & 4.9005 & TRN \\
\hline CHEMBL1393162 & 688171 & 4.55 & 4.8698 & TRN \\
\hline CHEMBL1552096 & 688171 & 4.55 & 4.8965 & TRN \\
\hline CHEMBL1566676 & 688171 & 4.35 & 4.9354 & TRN \\
\hline CHEMBL1480042 & 688171 & 4.4 & 4.8207 & TRN \\
\hline CHEMBL1417170 & 688171 & 4.6 & 4.8397 & TRN \\
\hline CHEMBL1509005 & 688171 & 5.1 & 4.9925 & TST \\
\hline CHEMBL1357019 & 688171 & 4.7 & 4.8751 & TRN \\
\hline CHEMBL1581950 & 688171 & 5.55 & 4.8482 & TRN \\
\hline CHEMBL1392359 & 688171 & 4.65 & 4.8495 & TST \\
\hline CHEMBL1524390 & 688171 & 4.85 & 4.8598 & TRN \\
\hline CHEMBL3193738 & 688171 & 5.05 & 4.8469 & TST \\
\hline CHEMBL1461203 & 688171 & 4.6 & 4.8298 & TRN \\
\hline CHEMBL1307271 & 688171 & 4.35 & 4.9248 & TRN \\
\hline CHEMBL1470039 & 688171 & 4.75 & 4.9635 & TRN \\
\hline CHEMBL1527833 & 688171 & 4.7 & 4.788 & TRN \\
\hline CHEMBL1602938 & 688171 & 5.0 & 4.9057 & TRN \\
\hline CHEMBL1434937 & 688171 & 4.4 & 4.9057 & TRN \\
\hline CHEMBL1432963 & 688171 & 4.9 & 4.9332 & TRN \\
\hline CHEMBL1590850 & 688171 & 4.45 & 5.0588 & TRN \\
\hline CHEMBL1532600 & 688171 & 4.65 & 4.8632 & TRN \\
\hline CHEMBL1591666 & 688171 & 4.55 & 4.8192 & TRN \\
\hline CHEMBL1372680 & 688171 & 4.5 & 4.8916 & TRN \\
\hline CHEMBL1329408 & 688171 & 4.45 & 4.8583 & TST \\
\hline CHEMBL1475425 & 688171 & 4.5 & 4.8992 & TRN \\
\hline CHEMBL1985636 & 688171 & 4.95 & 5.0725 & TRN \\
\hline CHEMBL1316084 & 688171 & 4.95 & 4.9307 & TRN \\
\hline CHEMBL1443632 & 688171 & 4.4 & 4.9248 & TST \\
\hline CHEMBL1419342 & 688171 & 6.35 & 5.0155 & TRN \\
\hline
\end{tabular}




\begin{tabular}{|c|c|c|c|c|c|}
\hline & & \multicolumn{4}{|c|}{ Supplemental Table s2.txt } \\
\hline CHEMBL1484181 & 688171 & 4.35 & 4.9637 & TRN & \\
\hline CHEMBL1331008 & 688171 & 4.4 & 4.9636 & TRN & \\
\hline CHEMBL1498902 & 688171 & 4.75 & 4.9502 & TST & \\
\hline CHEMBL1363633 & 688171 & 5.0 & 4.8122 & TRN & \\
\hline CHEMBL1561128 & 688171 & 5.0 & 4.97199 & 99999999995 & TRN \\
\hline CHEMBL3194416 & 688171 & 4.85 & 4.8377 & TRN & \\
\hline CHEMBL1379268 & 688171 & 5.05 & 5.0465 & TRN & \\
\hline CHEMBL1373061 & 688171 & 4.55 & 4.8425 & TRN & \\
\hline CHEMBL1490747 & 688171 & 4.45 & 4.8427 & TRN & \\
\hline CHEMBL1321102 & 688171 & 5.2 & 4.9224 & TRN & \\
\hline CHEMBL 2005533 & 688171 & 4.95 & 4.9644 & TRN & \\
\hline CHEMBL1417064 & 688171 & 4.4 & 4.8427 & TRN & \\
\hline CHEMBL1468320 & 688171 & 5.9 & 4.9985 & TST & \\
\hline CHEMBL1382113 & 688171 & 5.5 & 4.9427 & TST & \\
\hline CHEMBL1515639 & 688171 & 4.75 & 4.95 & TRN & \\
\hline CHEMBL1355458 & 688171 & 5.6 & 4.8883 & TRN & \\
\hline CHEMBL1391099 & 688171 & 4.95 & 4.8457 & TRN & \\
\hline CHEMBL1502014 & 688171 & 4.4 & 4.9032 & TST & \\
\hline CHEMBL1413384 & 688171 & 4.4 & 4.9092 & TRN & \\
\hline CHEMBL1375889 & 688171 & 5.5 & 4.9854 & TRN & \\
\hline CHEMBL1355451 & 688171 & 4.45 & 4.754 & TRN & \\
\hline CHEMBL3193284 & 688171 & 4.7 & 4.9678 & TST & \\
\hline CHEMBL1986381 & 688171 & 5.4 & 4.939 & TST & \\
\hline CHEMBL1508711 & 688171 & 4.5 & 4.8619 & TRN & \\
\hline CHEMBL1478457 & 688171 & 4.9 & 4.8965 & TRN & \\
\hline CHEMBL1427987 & 688171 & 4.45 & 5.0334 & TST & \\
\hline CHEMBL1584990 & 688171 & 4.8 & 4.9678 & TRN & \\
\hline CHEMBL1468765 & 688171 & 5.5 & 4.9281 & TRN & \\
\hline CHEMBL1420663 & 688171 & 4.4 & 4.7937 & TST & \\
\hline CHEMBL1327667 & 688171 & 6.25 & 4.971 & TST & \\
\hline CHEMBL1451216 & 688171 & 4.9 & 4.8939 & TST & \\
\hline CHEMBL1604921 & 688171 & 4.95 & 4.9358 & TRN & \\
\hline CHEMBL1476990 & 688171 & 5.0 & 4.8349 & TST & \\
\hline CHEMBL1360080 & 688171 & 4.5 & 4.9371 & TRN & \\
\hline CHEMBL1554378 & 688171 & 4.5 & 4.9738 & TRN & \\
\hline CHEMBL1484830 & 688171 & 4.6 & 4.9512 & TST & \\
\hline CHEMBL1589384 & 688171 & 5.85 & 4.8931 & TRN & \\
\hline CHEMBL1381829 & 688171 & 4.7 & 4.7342 & TST & \\
\hline CHEMBL1476825 & 688171 & 5.1 & 4.8609 & TRN & \\
\hline CHEMBL1402021 & 688171 & 4.35 & 4.9425 & TST & \\
\hline CHEMBL1395344 & 688171 & 4.4 & 4.8844 & TST & \\
\hline CHEMBL1430635 & 688171 & 4.95 & 4.9382 & TRN & \\
\hline CHEMBL1476773 & 688171 & 4.75 & 4.9493 & TRN & \\
\hline CHEMBL1450576 & 688171 & 4.7 & 5.0289 & TRN & \\
\hline CHEMBL1514067 & 688171 & 4.85 & 5.0171 & TRN & \\
\hline CHEMBL1525390 & 688171 & 4.4 & 4.8673 & TRN & \\
\hline CHEMBL1392405 & 688171 & 5.55 & 4.9761 & TRN & \\
\hline CHEMBL1365973 & 688171 & 5.0 & 4.8181 & TRN & \\
\hline
\end{tabular}




\begin{tabular}{|c|c|c|c|c|}
\hline \multicolumn{5}{|c|}{ Supplemental Table S2.txt } \\
\hline CHEMBL1435351 & 688171 & 4.4 & 4.8839 & TRN \\
\hline CHEMBL1591258 & 688171 & 6.0 & 4.8742 & TRN \\
\hline CHEMBL1402583 & 688171 & 4.7 & 4.9366 & TRN \\
\hline CHEMBL1467133 & 688171 & 4.85 & 4.831 & TST \\
\hline CHEMBL1383060 & 688171 & 4.4 & 4.9549 & TRN \\
\hline CHEMBL1433620 & 688171 & 4.4 & 4.7859 & TRN \\
\hline CHEMBL1419477 & 688171 & 4.6 & 5.0161 & TRN \\
\hline CHEMBL1452092 & 688171 & 4.4 & 4.8788 & TRN \\
\hline CHEMBL1378397 & 688171 & 4.9 & 4.8951 & TRN \\
\hline CHEMBL109037 & 688171 & 4.75 & 5.012 & TRN \\
\hline CHEMBL1496663 & 688171 & 4.6 & 4.904 & TRN \\
\hline CHEMBL1318779 & 688171 & 5.05 & 5.0343 & TRN \\
\hline CHEMBL1536405 & 688171 & 5.35 & 4.8197 & TRN \\
\hline CHEMBL1507174 & 688171 & 4.6 & 4.8313 & TRN \\
\hline CHEMBL1599744 & 688171 & 4.45 & 4.8523 & TRN \\
\hline CHEMBL1437138 & 688171 & 6.25 & 5.0011 & TRN \\
\hline CHEMBL1310031 & 688171 & 7.6003 & 4.9117 & TST \\
\hline CHEMBL1547559 & 688171 & 4.45 & 4.9576 & TST \\
\hline CHEMBL1308058 & 688171 & 4.5 & 4.8743 & TRN \\
\hline CHEMBL1096009 & 688171 & 5.55 & 4.7779 & TST \\
\hline CHEMBL1418907 & 688171 & 4.4 & 4.8991 & TRN \\
\hline CHEMBL1520506 & 688171 & 6.45 & 4.8185 & TRN \\
\hline CHEMBL1451407 & 688171 & 5.3 & 5.0741 & TST \\
\hline CHEMBL1323698 & 688171 & 4.5 & 4.9502 & TRN \\
\hline CHEMBL1976049 & 688171 & 4.85 & 4.8437 & TRN \\
\hline CHEMBL1555056 & 688171 & 4.65 & 4.7471 & TRN \\
\hline CHEMBL1609508 & 688171 & 4.9 & 4.985 & TRN \\
\hline CHEMBL1503700 & 688171 & 4.85 & 5.0 & TRN \\
\hline CHEMBL 203108 & 688171 & 4.45 & 4.967 & TST \\
\hline CHEMBL1455731 & 688171 & 4.6 & 5.0306 & TST \\
\hline CHEMBL3190116 & 688171 & 5.35 & 4.8665 & TRN \\
\hline CHEMBL1882125 & 688171 & 4.4 & 4.97 & TRN \\
\hline CHEMBL1529844 & 688171 & 4.4 & 4.8887 & TRN \\
\hline CHEMBL1315549 & 688171 & 4.8 & 4.8927 & TRN \\
\hline CHEMBL1349784 & 688171 & 4.35 & 4.9888 & TRN \\
\hline CHEMBL1386330 & 688171 & 4.6 & 4.9317 & TRN \\
\hline CHEMBL1419640 & 688171 & 4.65 & 4.7759 & TRN \\
\hline CHEMBL1329319 & 688171 & 5.15 & 5.1104 & TRN \\
\hline CHEMBL3210021 & 688171 & 4.35 & 4.8773 & TRN \\
\hline CHEMBL1331665 & 688171 & 4.85 & 4.8154 & TRN \\
\hline CHEMBL1399317 & 688171 & 4.5 & 5.0275 & TST \\
\hline CHEMBL1551780 & 688171 & 4.6 & 4.7916 & TRN \\
\hline CHEMBL1306455 & 688171 & 5.05 & 4.92 & TRN \\
\hline CHEMBL1451023 & 688171 & 5.9 & 4.832 & TST \\
\hline CHEMBL1586681 & 688171 & 5.1 & 4.8475 & TRN \\
\hline CHEMBL1514286 & 688171 & 4.75 & 4.9354 & TRN \\
\hline CHEMBL1489300 & 688171 & 4.9 & 4.8308 & TRN \\
\hline CHEMBL1598729 & 688171 & 4.35 & 5.0009 & TST \\
\hline
\end{tabular}




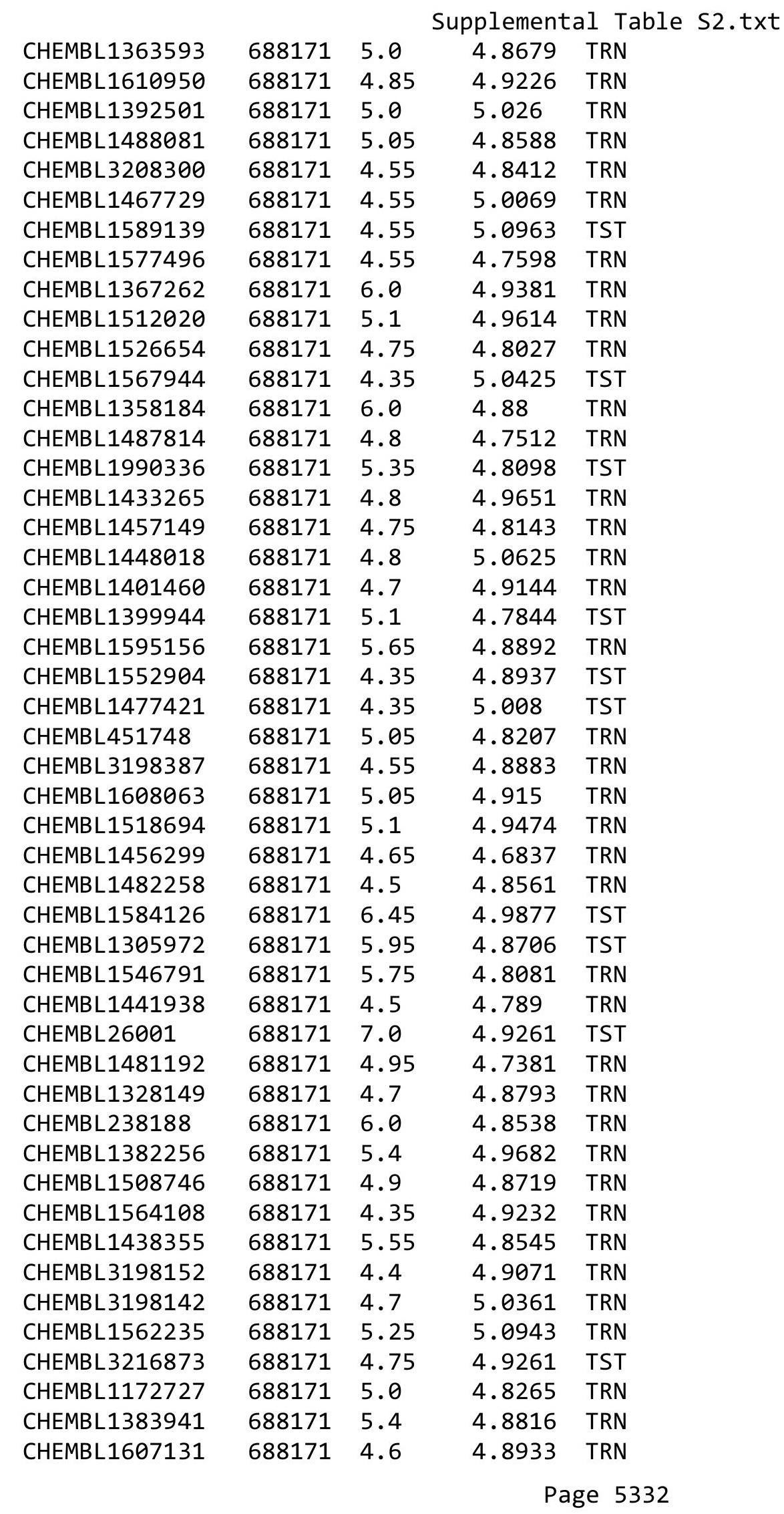




\begin{tabular}{|c|c|c|c|c|c|}
\hline \multicolumn{6}{|c|}{ Supplemental Table s2.txt } \\
\hline CHEMBL1394434 & 688171 & 5.95 & 4.9361 & TRN & \\
\hline CHEMBL1531354 & 688171 & 4.55 & 4.8087 & TRN & \\
\hline CHEMBL1542501 & 688171 & 6.05 & 4.9416 & TRN & \\
\hline CHEMBL1412213 & 688171 & 4.6 & 4.9313 & TRN & \\
\hline CHEMBL1524950 & 688171 & 4.95 & 5.0178 & TRN & \\
\hline CHEMBL1368657 & 688171 & 4.7 & 4.9056 & TRN & \\
\hline CHEMBL1972491 & 688171 & 4.95 & 4.9184 & TRN & \\
\hline CHEMBL1368214 & 688171 & 4.45 & 4.7297 & TST & \\
\hline CHEMBL1552376 & 688171 & 5.05 & 4.9205 & TRN & \\
\hline CHEMBL1478721 & 688171 & 5.45 & 4.9944 & TRN & \\
\hline CHEMBL1397415 & 688171 & 5.5 & 4.988 & TRN & \\
\hline CHEMBL1587790 & 688171 & 4.45 & 4.9577 & TRN & \\
\hline CHEMBL1353679 & 688171 & 5.05 & 4.9898 & TST & \\
\hline CHEMBL1334390 & 688171 & 4.85 & 4.9931 & TRN & \\
\hline CHEMBL1534873 & 688171 & 4.65 & 4.998 & TST & \\
\hline CHEMBL1523118 & 688171 & 4.9 & 4.8503 & TRN & \\
\hline CHEMBL1390896 & 688171 & 5.05 & 5.0118 & TRN & \\
\hline CHEMBL1509938 & 688171 & 4.65 & 5.0249 & TST & \\
\hline CHEMBL1577341 & 688171 & 4.65 & 4.854 & TRN & \\
\hline CHEMBL1391552 & 688171 & 4.75 & 4.7522 & TRN & \\
\hline CHEMBL1434475 & 688171 & 4.4 & 4.8558 & TST & \\
\hline CHEMBL1380232 & 688171 & 4.5 & 5.0466 & TRN & \\
\hline CHEMBL 3212772 & 688171 & 4.65 & 4.9169 & TRN & \\
\hline CHEMBL1393759 & 688171 & 7.6003 & 5.0358 & TRN & \\
\hline CHEMBL1396704 & 688171 & 5.6 & 4.9507 & TST & \\
\hline CHEMBL1374090 & 688171 & 4.85 & 4.7575 & TRN & \\
\hline CHEMBL1532917 & 688171 & 5.05 & 4.9558 & TST & \\
\hline CHEMBL1543395 & 688171 & 4.55 & 4.9382 & TRN & \\
\hline CHEMBL1381340 & 688171 & 5.35 & 4.8247 & TRN & \\
\hline CHEMBL1402153 & 688171 & 5.9 & 4.7997 & TRN & \\
\hline CHEMBL1335011 & 688171 & 6.9 & 4.6988 & TRN & \\
\hline CHEMBL1446166 & 688171 & 5.0 & 4.7749 & TRN & \\
\hline CHEMBL1474663 & 688171 & 4.7 & 5.0096 & TRN & \\
\hline CHEMBL1413171 & 688171 & 4.95 & 4.8903 & TRN & \\
\hline CHEMBL1540389 & 688171 & 4.7 & 4.9107 & TRN & \\
\hline CHEMBL1464863 & 688171 & 4.55 & 4.91100 & 00000000005 & TRN \\
\hline CHEMBL1489554 & 688171 & 4.6 & 4.9438 & TRN & \\
\hline CHEMBL3191771 & 688171 & 4.35 & 4.8671 & TST & \\
\hline CHEMBL1555161 & 688171 & 4.65 & 4.9262 & TRN & \\
\hline CHEMBL1350924 & 688171 & 5.05 & 4.8122 & TRN & \\
\hline CHEMBL1307124 & 688171 & 4.75 & 4.8443 & TRN & \\
\hline CHEMBL1400503 & 688171 & 4.5 & 4.9288 & TRN & \\
\hline CHEMBL1375247 & 688171 & 4.85 & 4.9832 & TRN & \\
\hline CHEMBL1467007 & 688171 & 4.7 & 4.8862 & TST & \\
\hline CHEMBL1600520 & 688171 & 4.35 & 4.937 & TRN & \\
\hline CHEMBL332898 & 688171 & 6.0 & 4.7976 & TRN & \\
\hline CHEMBL3195636 & 688171 & 4.4 & 4.9795 & TST & \\
\hline CHEMBL1322151 & 688171 & 5.0 & 4.7882 & TRN & \\
\hline
\end{tabular}




\begin{tabular}{|c|c|c|c|c|c|}
\hline \multicolumn{6}{|c|}{ Supplemental Table S2.txt } \\
\hline CHEMBL1459307 & 688171 & 5.35 & 4.9424 & TST & \\
\hline CHEMBL1505305 & 688171 & 6.05 & 4.8641 & TST & \\
\hline CHEMBL1455909 & 688171 & 5.05 & 4.7868 & TRN & \\
\hline CHEMBL1492961 & 688171 & 4.4 & 4.773 & TST & \\
\hline CHEMBL1402859 & 688171 & 4.65 & 4.9192 & TRN & \\
\hline CHEMBL1391160 & 688171 & 5.3 & 4.9223 & TRN & \\
\hline CHEMBL1427446 & 688171 & 4.4 & 4.8662 & TRN & \\
\hline CHEMBL1338467 & 688171 & 4.35 & 4.7672 & TST & \\
\hline CHEMBL1593712 & 688171 & 4.75 & 4.8527 & TRN & \\
\hline CHEMBL1271059 & 688171 & 4.35 & 4.8313 & TRN & \\
\hline CHEMBL1608452 & 688171 & 4.4 & 4.942 & TRN & \\
\hline CHEMBL1371936 & 688171 & 6.2 & 4.8523 & TRN & \\
\hline CHEMBL1568835 & 688171 & 5.35 & 4.912 & TRN & \\
\hline CHEMBL1597945 & 688171 & 5.5 & 4.8967 & TRN & \\
\hline CHEMBL1552733 & 688171 & 4.95 & 4.8984 & TRN & \\
\hline CHEMBL1578953 & 688171 & 4.45 & 4.7668 & TRN & \\
\hline CHEMBL1601584 & 688171 & 5.0 & 4.8835 & TRN & \\
\hline CHEMBL1583327 & 688171 & 4.6 & 4.8223 & TRN & \\
\hline CHEMBL119171 & 688171 & 4.85 & 4.9923 & TRN & \\
\hline CHEMBL1314460 & 688171 & 4.55 & 4.9642 & TRN & \\
\hline CHEMBL1470450 & 688171 & 4.75 & 4.69600 & 0000000001 & TRN \\
\hline CHEMBL1388802 & 688171 & 4.5 & 4.8535 & TST & \\
\hline CHEMBL1409774 & 688171 & 4.95 & 4.8488 & TRN & \\
\hline CHEMBL1393579 & 688171 & 4.8 & 4.7917 & TRN & \\
\hline CHEMBL1449324 & 688171 & 4.35 & 4.9104 & TRN & \\
\hline CHEMBL1429648 & 688171 & 4.7 & 4.8974 & TST & \\
\hline CHEMBL1527532 & 688171 & 4.4 & 4.9576 & TST & \\
\hline CHEMBL1354267 & 688171 & 4.6 & 4.9189 & TRN & \\
\hline CHEMBL1592161 & 688171 & 4.4 & 4.9626 & TRN & \\
\hline CHEMBL1449069 & 688171 & 4.4 & 4.7766 & TRN & \\
\hline CHEMBL342173 & 688171 & 4.7 & 4.8821 & TST & \\
\hline CHEMBL1312843 & 688171 & 5.1 & 4.9899 & TRN & \\
\hline CHEMBL1354928 & 688171 & 5.05 & 4.8675 & TRN & \\
\hline CHEMBL1465856 & 688171 & 6.35 & 4.9044 & TRN & \\
\hline CHEMBL1339127 & 688171 & 5.05 & 4.9193 & TRN & \\
\hline CHEMBL1565861 & 688171 & 4.45 & 4.9426 & TRN & \\
\hline CHEMBL1339933 & 688171 & 4.65 & 4.9817 & TRN & \\
\hline CHEMBL1539141 & 688171 & 4.55 & 4.9006 & TRN & \\
\hline CHEMBL1552168 & 688171 & 4.75 & 4.8027 & TRN & \\
\hline CHEMBL1317872 & 688171 & 4.35 & 5.0022 & TRN & \\
\hline CHEMBL1339527 & 688171 & 4.35 & 4.8622 & TST & \\
\hline CHEMBL1507301 & 688171 & 7.6003 & 4.8481 & TST & \\
\hline CHEMBL1564590 & 688171 & 4.95 & 4.9251 & TRN & \\
\hline CHEMBL1504786 & 688171 & 4.4 & 4.7928 & TST & \\
\hline CHEMBL1538698 & 688171 & 5.3 & 4.8857 & TRN & \\
\hline CHEMBL594707 & 688171 & 5.55 & 4.8751 & TST & \\
\hline CHEMBL 1570896 & 688171 & 4.55 & 4.7903 & TST & \\
\hline CHEMBL3145185 & 688171 & 4.85 & 4.7682 & TRN & \\
\hline
\end{tabular}




\begin{tabular}{|c|c|c|c|c|c|}
\hline & & \multicolumn{4}{|c|}{ Supplemental Table S2.txt } \\
\hline CHEMBL1512284 & 688171 & 5.15 & 4.79 & TRN & \\
\hline CHEMBL1301561 & 688171 & 6.15 & 4.882 & TRN & \\
\hline CHEMBL1939691 & 688171 & 5.4 & 4.9138 & TRN & \\
\hline CHEMBL1515603 & 688171 & 4.75 & 4.9341 & TRN & \\
\hline CHEMBL1398576 & 688171 & 6.9 & 5.0246 & TRN & \\
\hline CHEMBL1364011 & 688171 & 4.65 & 5.0155 & TRN & \\
\hline CHEMBL 2002332 & 688171 & 4.8 & 4.8831 & TRN & \\
\hline CHEMBL1563529 & 688171 & 4.4 & 4.9209 & TRN & \\
\hline CHEMBL1515399 & 688171 & 5.5 & 4.9079 & TRN & \\
\hline CHEMBL1310819 & 688171 & 4.65 & 4.8498 & TRN & \\
\hline CHEMBL1439063 & 688171 & 4.75 & 4.8356 & TRN & \\
\hline CHEMBL1479369 & 688171 & 4.4 & 5.0191 & TRN & \\
\hline CHEMBL1581166 & 688171 & 4.85 & 4.79899 & 99999999995 & TST \\
\hline CHEMBL1550557 & 688171 & 5.7 & 4.8091 & TRN & \\
\hline CHEMBL1491331 & 688171 & 5.5 & 4.9557 & TRN & \\
\hline CHEMBL1413510 & 688171 & 4.35 & 4.7548 & TST & \\
\hline CHEMBL1349582 & 688171 & 4.95 & 4.9981 & TRN & \\
\hline CHEMBL1407622 & 688171 & 4.4 & 4.9449 & TST & \\
\hline CHEMBL1351310 & 688171 & 4.75 & 4.9173 & TRN & \\
\hline CHEMBL1568926 & 688171 & 4.8 & 4.8077 & TRN & \\
\hline CHEMBL1588679 & 688171 & 5.9 & 4.7657 & TST & \\
\hline CHEMBL1335288 & 688171 & 4.7 & 4.96899 & 9999999999 & TRN \\
\hline CHEMBL1318071 & 688171 & 5.05 & 4.9211 & TRN & \\
\hline CHEMBL1377606 & 688171 & 4.55 & 4.9953 & TRN & \\
\hline CHEMBL1488526 & 688171 & 4.85 & 4.9025 & TRN & \\
\hline CHEMBL1451920 & 688171 & 4.6 & 4.8423 & TRN & \\
\hline CHEMBL1988798 & 688171 & 4.95 & 4.9341 & TRN & \\
\hline CHEMBL1544904 & 688171 & 5.65 & 4.9595 & TRN & \\
\hline CHEMBL1503938 & 688171 & 4.35 & 4.8828 & TST & \\
\hline CHEMBL1419292 & 688171 & 4.65 & 4.9141 & TST & \\
\hline CHEMBL3209581 & 688171 & 4.7 & 4.8964 & TST & \\
\hline CHEMBL1338276 & 688171 & 4.9 & 4.7315 & TST & \\
\hline CHEMBL1389421 & 688171 & 4.6 & 4.8367 & TST & \\
\hline CHEMBL1299757 & 688171 & 4.35 & 4.8809 & TST & \\
\hline CHEMBL1412271 & 688171 & 4.6 & 4.9014 & TST & \\
\hline CHEMBL1553851 & 688171 & 5.0 & 4.9242 & TST & \\
\hline CHEMBL1599188 & 688171 & 7.1002 & 4.9141 & TST & \\
\hline CHEMBL1456751 & 688171 & 5.55 & 4.9521 & TST & \\
\hline CHEMBL1605903 & 688171 & 4.75 & 4.9031 & TST & \\
\hline CHEMBL1597336 & 688171 & 5.0 & 4.939 & TRN & \\
\hline CHEMBL1409005 & 688171 & 4.4 & 4.9162 & TST & \\
\hline CHEMBL1370523 & 688171 & 4.45 & 4.7727 & TRN & \\
\hline CHEMBL1354560 & 688171 & 5.65 & 4.9236 & TRN & \\
\hline CHEMBL1578699 & 688171 & 6.2 & 4.8268 & TST & \\
\hline CHEMBL1537397 & 688171 & 6.9 & 4.9856 & TRN & \\
\hline CHEMBL1558607 & 688171 & 4.65 & 4.8268 & TRN & \\
\hline CHEMBL576656 & 688171 & 4.35 & 4.8815 & TRN & \\
\hline CHEMBL1446877 & 688171 & 4.8 & 4.8736 & TRN & \\
\hline
\end{tabular}




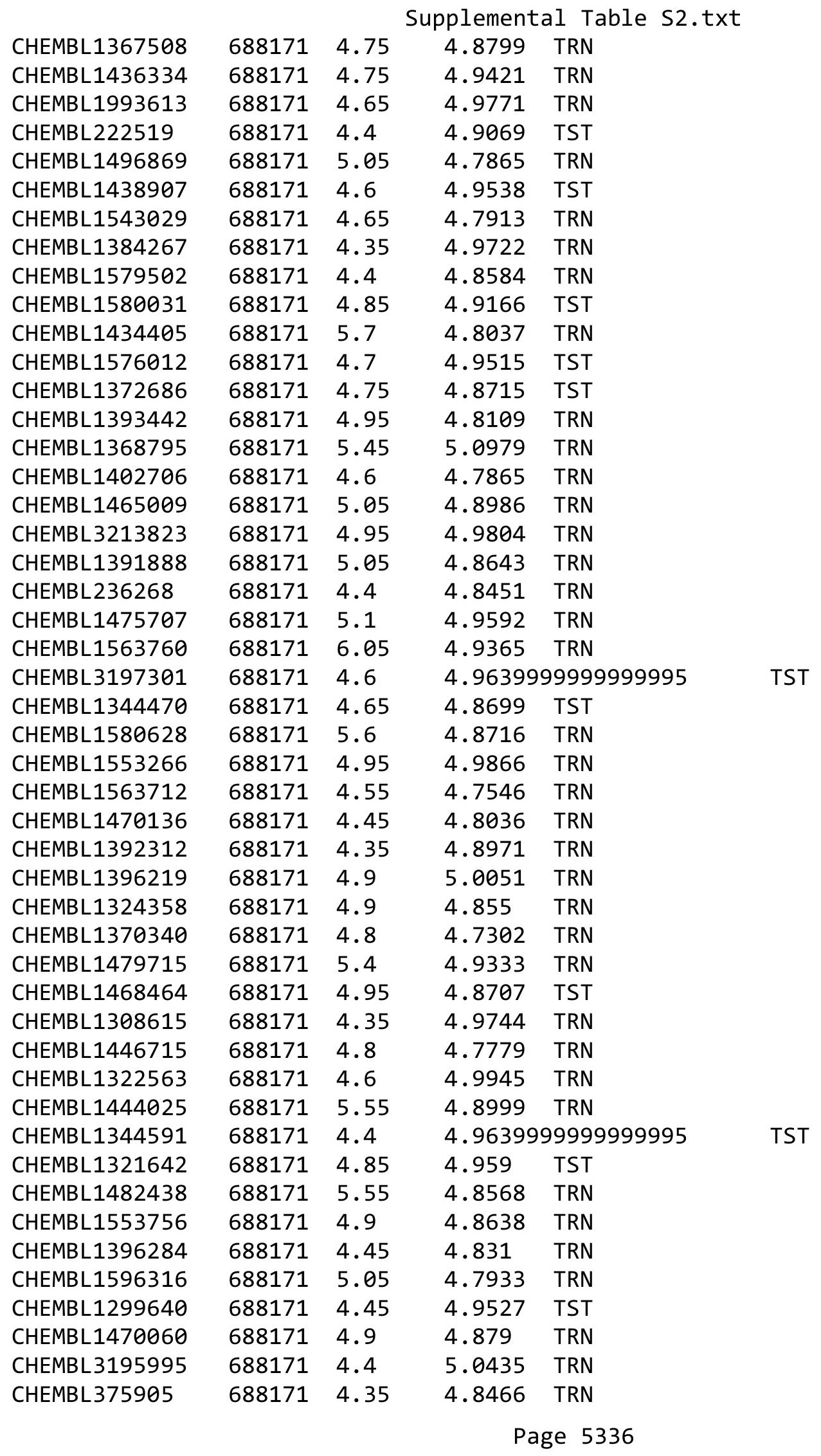




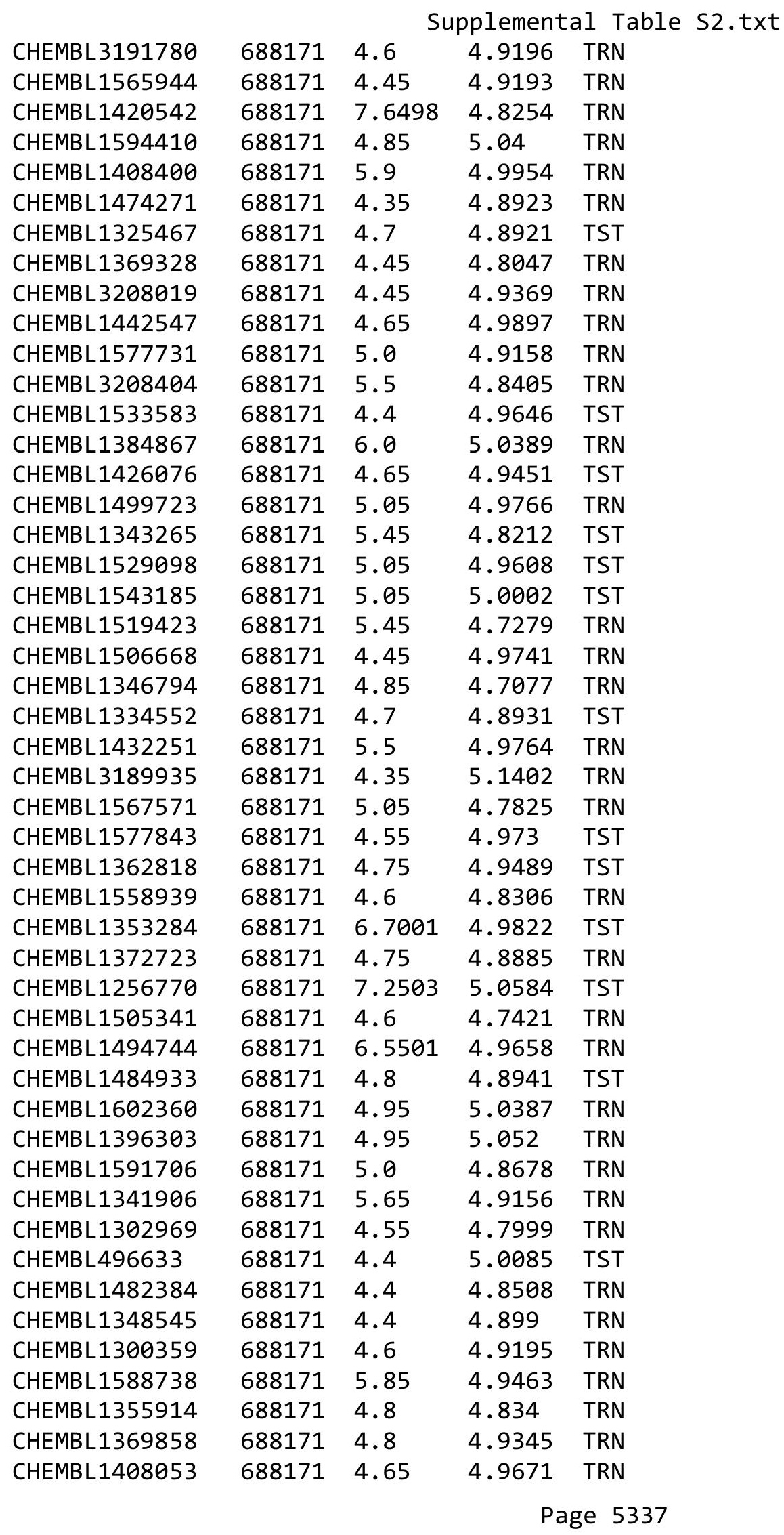




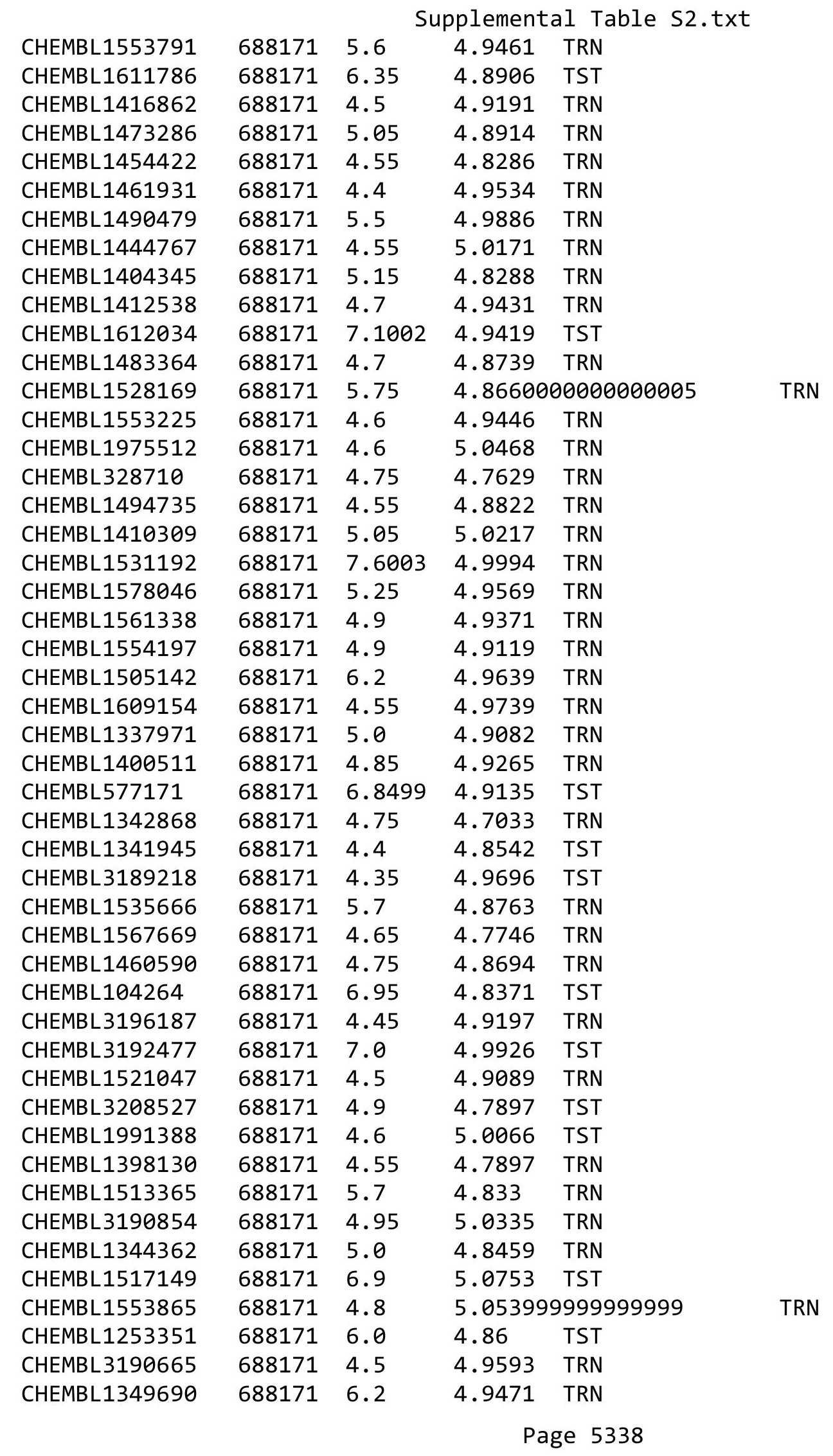




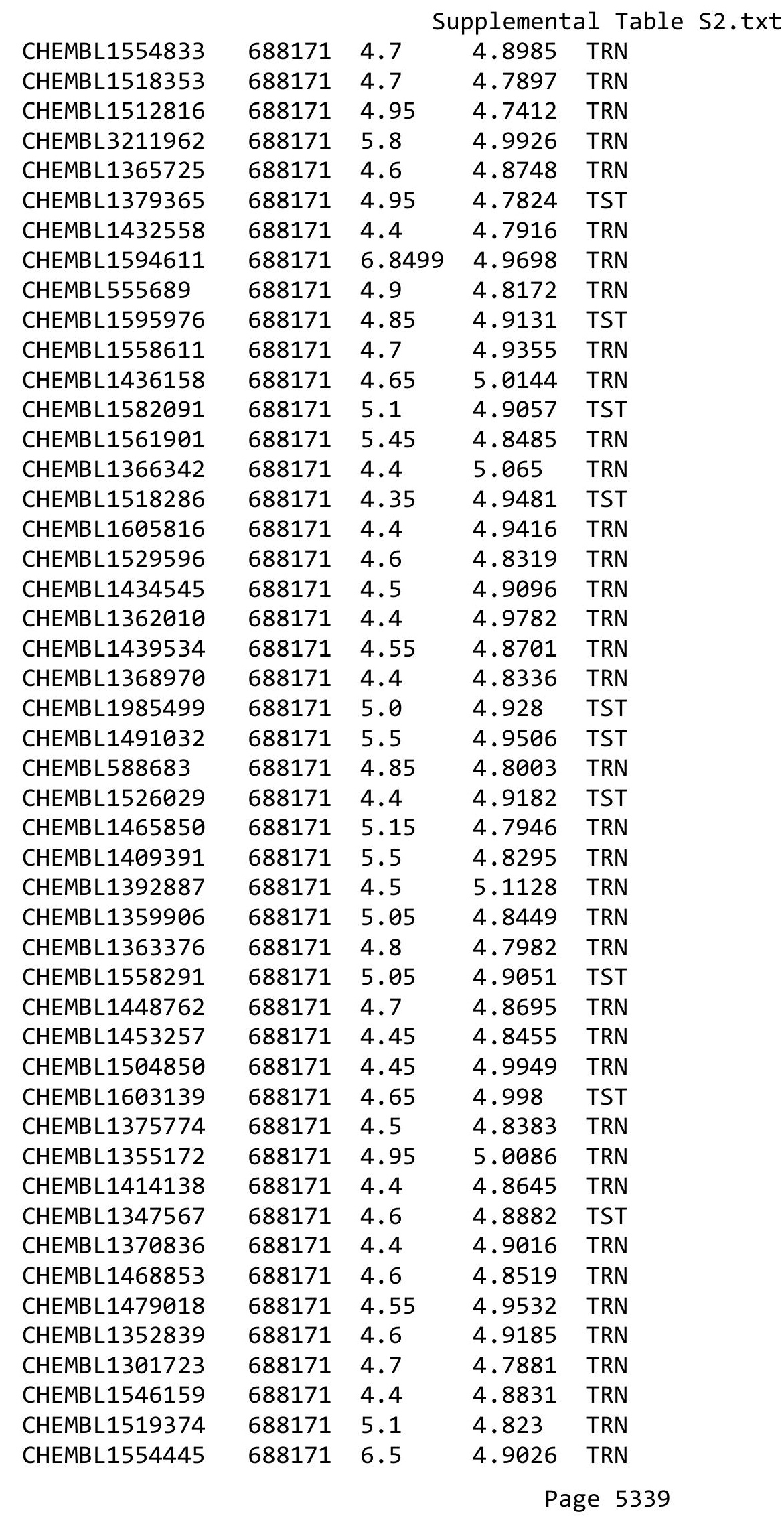




\begin{tabular}{|c|c|c|c|c|c|}
\hline & & \multicolumn{4}{|c|}{ Supplemental Table S2.txt } \\
\hline CHEMBL1345467 & 688171 & 4.4 & 4.794 & TRN & \\
\hline CHEMBL1432418 & 688171 & 4.8 & 4.9887 & TST & \\
\hline CHEMBL1325584 & 688171 & 5.05 & 5.0844 & TST & \\
\hline CHEMBL1323846 & 688171 & 4.55 & 4.8427 & TST & \\
\hline CHEMBL1513261 & 688171 & 4.5 & 4.9598 & TRN & \\
\hline CHEMBL1376308 & 688171 & 5.2 & 4.7883 & TRN & \\
\hline CHEMBL 3192113 & 688171 & 5.95 & 4.9577 & TST & \\
\hline CHEMBL1549392 & 688171 & 4.45 & 4.8419 & TST & \\
\hline CHEMBL1564170 & 688171 & 4.4 & 5.0845 & TRN & \\
\hline CHEMBL45627 & 688171 & 4.75 & 4.9663 & TST & \\
\hline CHEMBL1489771 & 688171 & 4.5 & 4.7453 & TRN & \\
\hline CHEMBL1562457 & 688171 & 4.4 & 4.8404 & TRN & \\
\hline CHEMBL1591942 & 688171 & 4.85 & 4.8245 & TRN & \\
\hline CHEMBL1485736 & 688171 & 4.5 & 4.9443 & TRN & \\
\hline CHEMBL1309864 & 688171 & 4.4 & 4.9188 & TST & \\
\hline CHEMBL1503744 & 688171 & 4.7 & 4.99 & TST & \\
\hline CHEMBL1445291 & 688171 & 4.65 & 5.0327 & TRN & \\
\hline CHEMBL1330042 & 688171 & 4.4 & 4.9713 & TRN & \\
\hline CHEMBL1546898 & 688171 & 5.2 & 4.8138 & TRN & \\
\hline CHEMBL1433891 & 688171 & 5.55 & 5.1126 & TRN & \\
\hline CHEMBL1470158 & 688171 & 5.35 & 4.9032 & TST & \\
\hline CHEMBL1451599 & 688171 & 5.55 & 5.0001 & TRN & \\
\hline CHEMBL1465396 & 688171 & 4.85 & 4.776 & TRN & \\
\hline CHEMBL1316523 & 688171 & 4.9 & 4.8052 & TRN & \\
\hline CHEMBL1499286 & 688171 & 4.4 & 4.7046 & TRN & \\
\hline CHEMBL3195508 & 688171 & 4.7 & 4.9899 & TRN & \\
\hline CHEMBL1372809 & 688171 & 4.4 & 5.0032 & TST & \\
\hline CHEMBL1457174 & 688171 & 4.5 & 4.7125 & TRN & \\
\hline CHEMBL1610148 & 688171 & 4.65 & 4.8645 & TST & \\
\hline CHEMBL 1557728 & 688171 & 5.6 & 4.8907 & TRN & \\
\hline CHEMBL1562092 & 688171 & 5.3 & 4.7218 & TRN & \\
\hline CHEMBL1471054 & 688171 & 4.7 & 5.0823 & TRN & \\
\hline CHEMBL 216504 & 688171 & 4.65 & 4.8063 & TST & \\
\hline CHEMBL1417831 & 688171 & 4.85 & 4.81800 & 00000000005 & TRN \\
\hline CHEMBL1487283 & 688171 & 4.85 & 5.0643 & TRN & \\
\hline CHEMBL3211991 & 688171 & 4.75 & 4.8942 & TRN & \\
\hline CHEMBL1340716 & 688171 & 4.7 & 4.9181 & TRN & \\
\hline CHEMBL3195172 & 688171 & 4.85 & 5.0033 & TRN & \\
\hline CHEMBL91722 & 688171 & 4.75 & 5.0221 & TST & \\
\hline CHEMBL1492010 & 688171 & 6.4 & 4.7753 & TRN & \\
\hline CHEMBL1412157 & 688171 & 4.4 & 5.0256 & TST & \\
\hline CHEMBL1593436 & 688171 & 4.65 & 4.992 & TRN & \\
\hline CHEMBL1455522 & 688171 & 4.95 & 4.8421 & TRN & \\
\hline CHEMBL1333545 & 688171 & 4.8 & 4.8186 & TRN & \\
\hline CHEMBL1328826 & 688171 & 4.95 & 4.894 & TRN & \\
\hline CHEMBL1366115 & 688171 & 4.85 & 5.0147 & TST & \\
\hline CHEMBL1347975 & 688171 & 4.95 & 5.0011 & TRN & \\
\hline CHEMBL584269 & 688171 & 5.8 & 4.8524 & TRN & \\
\hline
\end{tabular}




\begin{tabular}{|c|c|c|c|c|c|}
\hline \multicolumn{6}{|c|}{ Supplemental Table S2.txt } \\
\hline CHEMBL1320701 & 688171 & 4.4 & 4.8094 & TST & \\
\hline CHEMBL1496293 & 688171 & 4.7 & 5.0214 & TRN & \\
\hline CHEMBL1550586 & 688171 & 4.75 & 4.9715 & TRN & \\
\hline CHEMBL1381345 & 688171 & 4.6 & 4.8686 & TRN & \\
\hline CHEMBL 3189165 & 688171 & 4.55 & 4.8245 & TST & \\
\hline CHEMBL1493733 & 688171 & 7.2503 & 5.0273 & TRN & \\
\hline CHEMBL1311206 & 688171 & 6.05 & 4.8011 & TRN & \\
\hline CHEMBL1343059 & 688171 & 4.7 & 4.8983 & TST & \\
\hline CHEMBL1364395 & 688171 & 4.8 & 4.8209 & TRN & \\
\hline CHEMBL1594300 & 688171 & 5.05 & 4.9886 & TRN & \\
\hline CHEMBL1522403 & 688171 & 4.5 & 4.8942 & TST & \\
\hline CHEMBL1491866 & 688171 & 4.8 & 5.0154 & TST & \\
\hline CHEMBL1528605 & 688171 & 4.45 & 4.9303 & TST & \\
\hline CHEMBL1576392 & 688171 & 4.8 & 4.8514 & TRN & \\
\hline CHEMBL1604162 & 688171 & 4.7 & 4.9366 & TST & \\
\hline CHEMBL1396190 & 688171 & 5.5 & 4.9401 & TRN & \\
\hline CHEMBL1310353 & 688171 & 6.0 & 4.7963 & TRN & \\
\hline CHEMBL1332928 & 688171 & 4.8 & 4.8294 & TRN & \\
\hline CHEMBL1516886 & 688171 & 4.85 & 4.9279 & TRN & \\
\hline CHEMBL1311185 & 688171 & 4.65 & 4.8456 & TST & \\
\hline CHEMBL1430255 & 688171 & 4.85 & 4.8922 & TST & \\
\hline CHEMBL1432243 & 688171 & 5.0 & 5.0683 & TRN & \\
\hline CHEMBL1609090 & 688171 & 4.4 & 4.8192 & TST & \\
\hline CHEMBL1414263 & 688171 & 4.6 & 4.716 & TRN & \\
\hline CHEMBL1407744 & 688171 & 5.05 & 4.8276 & TRN & \\
\hline CHEMBL1512001 & 688171 & 4.9 & 4.9261 & TRN & \\
\hline CHEMBL491771 & 688171 & 4.75 & 4.8492 & TRN & \\
\hline CHEMBL1476607 & 688171 & 5.4 & 4.9668 & TRN & \\
\hline CHEMBL1516548 & 688171 & 4.8 & 4.9401 & TST & \\
\hline CHEMBL 1427047 & 688171 & 5.05 & 4.8413 & TRN & \\
\hline CHEMBL1322677 & 688171 & 4.35 & 5.1008 & TRN & \\
\hline CHEMBL1328169 & 688171 & 4.5 & 4.9734 & TST & \\
\hline CHEMBL1491026 & 688171 & 5.35 & 4.8243 & TRN & \\
\hline CHEMBL1590285 & 688171 & 5.5 & 4.9259 & TRN & \\
\hline CHEMBL1523835 & 688171 & 4.5 & 4.9624 & TRN & \\
\hline CHEMBL1368764 & 688171 & 4.55 & 4.894 & TRN & \\
\hline CHEMBL1416427 & 688171 & 5.2 & 4.8381 & TRN & \\
\hline CHEMBL1560925 & 688171 & 4.65 & 4.9912 & TST & \\
\hline CHEMBL1460595 & 688171 & 5.7 & 4.9056 & TST & \\
\hline CHEMBL 1423125 & 688171 & 4.85 & 4.7832 & TRN & \\
\hline CHEMBL1533114 & 688171 & 5.45 & 4.9199 & TRN & \\
\hline CHEMBL1590378 & 688171 & 6.0 & 5.0225 & TST & \\
\hline CHEMBL1558621 & 688171 & 6.0 & 4.9637 & TST & \\
\hline CHEMBL1334906 & 688171 & 5.45 & 4.9063 & TRN & \\
\hline CHEMBL1553971 & 688171 & 5.0 & 4.9643 & TRN & \\
\hline CHEMBL 1582707 & 688171 & 5.05 & 4.84399 & 9999999999 & TRN \\
\hline CHEMBL572203 & 688171 & 4.55 & 4.813 & TRN & \\
\hline CHEMBL1327451 & 688171 & 4.8 & 4.9091 & TRN & \\
\hline & & & & e 5341 & \\
\hline
\end{tabular}




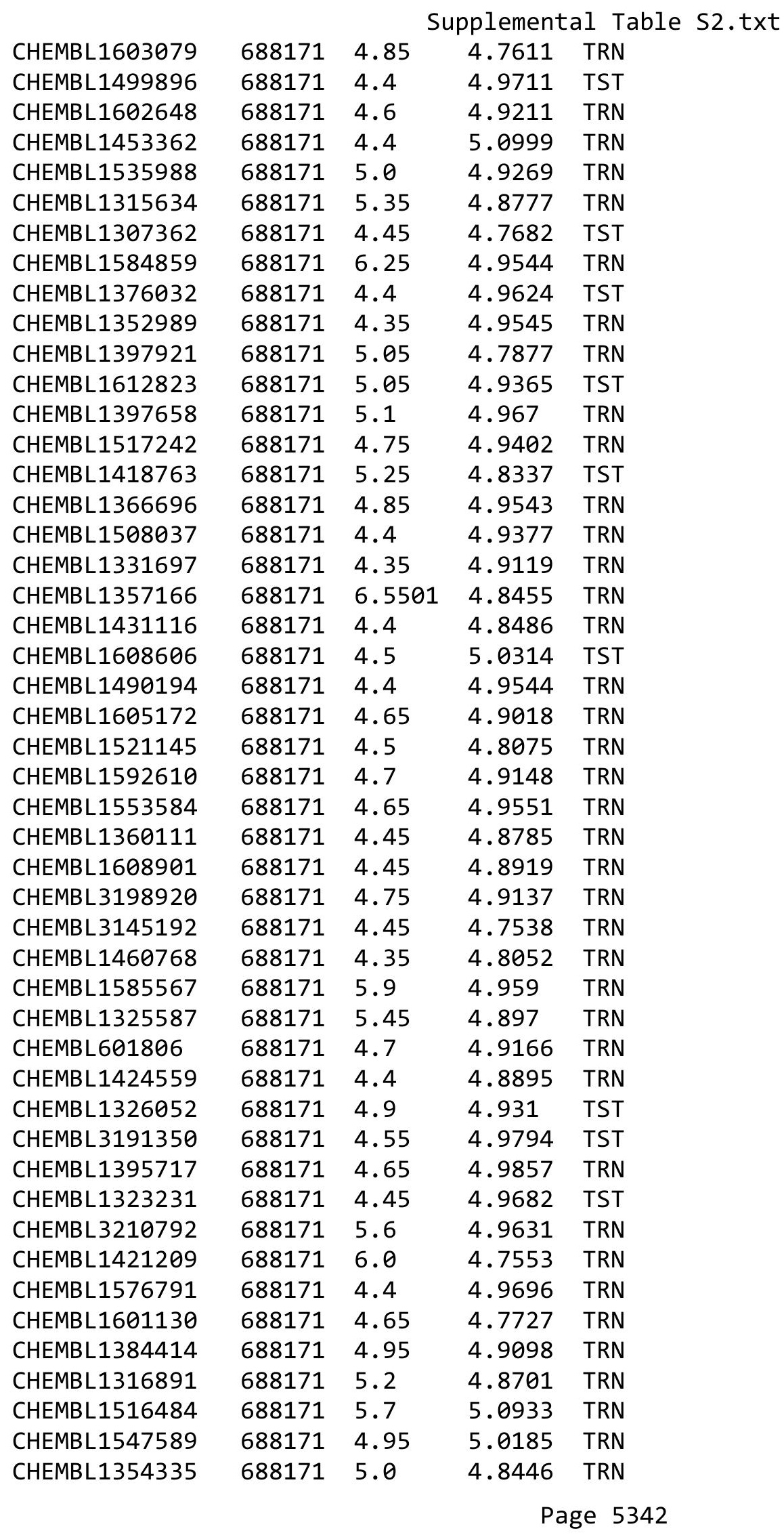




\begin{tabular}{|c|c|c|c|c|}
\hline \multicolumn{5}{|c|}{ Supplemental Table S2.txt } \\
\hline CHEMBL412355 & 688171 & 5.55 & 4.9208 & TST \\
\hline CHEMBL66105 & 688171 & 5.1 & 4.9612 & TST \\
\hline CHEMBL1545438 & 688171 & 7.6003 & 4.7783 & TST \\
\hline CHEMBL1494118 & 688171 & 4.85 & 4.9818 & TRN \\
\hline CHEMBL1421671 & 688171 & 5.05 & 5.0151 & TRN \\
\hline CHEMBL1323793 & 688171 & 4.35 & 5.0506 & TST \\
\hline CHEMBL1451385 & 688171 & 4.75 & 5.0053 & TRN \\
\hline CHEMBL1488610 & 688171 & 6.5 & 4.9061 & TRN \\
\hline CHEMBL1411429 & 688171 & 5.4 & 4.8887 & TRN \\
\hline CHEMBL1464503 & 688171 & 4.95 & 4.9043 & TST \\
\hline CHEMBL1562576 & 688171 & 4.55 & 4.9349 & TRN \\
\hline CHEMBL3210083 & 688171 & 4.4 & 4.8028 & TRN \\
\hline CHEMBL1394539 & 688171 & 5.3 & 4.8916 & TRN \\
\hline CHEMBL1560001 & 688171 & 4.35 & 4.9246 & TRN \\
\hline CHEMBL1567486 & 688171 & 5.05 & 4.8762 & TRN \\
\hline CHEMBL1503945 & 688171 & 5.05 & 5.021 & TRN \\
\hline CHEMBL1475092 & 688171 & 4.5 & 4.8344 & TRN \\
\hline CHEMBL1549606 & 688171 & 4.85 & 4.9864 & TRN \\
\hline CHEMBL1495765 & 688171 & 5.5 & 4.901 & TST \\
\hline CHEMBL1415791 & 688171 & 4.5 & 4.9134 & TRN \\
\hline CHEMBL1590551 & 688171 & 4.7 & 4.8101 & TRN \\
\hline CHEMBL1389856 & 688171 & 4.85 & 4.8997 & TRN \\
\hline CHEMBL1533602 & 688171 & 4.35 & 4.827 & TRN \\
\hline CHEMBL1368641 & 688171 & 4.4 & 4.8266 & TRN \\
\hline CHEMBL1468718 & 688171 & 5.35 & 4.9809 & TRN \\
\hline CHEMBL1475727 & 688171 & 4.7 & 4.8191 & TRN \\
\hline CHEMBL1323719 & 688171 & 4.45 & 4.7241 & TRN \\
\hline CHEMBL1411444 & 688171 & 4.4 & 4.8315 & TRN \\
\hline CHEMBL1411379 & 688171 & 4.35 & 4.8325 & TRN \\
\hline CHEMBL1579208 & 688171 & 4.35 & 4.8061 & TST \\
\hline CHEMBL3191474 & 688171 & 4.7 & 4.8443 & TRN \\
\hline CHEMBL1575603 & 688171 & 4.9 & 4.8404 & TST \\
\hline CHEMBL1452157 & 688171 & 6.6 & 4.98 & TRN \\
\hline CHEMBL1569834 & 688171 & 4.45 & 4.8896 & TRN \\
\hline CHEMBL1433703 & 688171 & 5.05 & 4.8888 & TRN \\
\hline CHEMBL1606943 & 688171 & 4.5 & 4.988 & TST \\
\hline CHEMBL1333841 & 688171 & 5.0 & 4.8214 & TRN \\
\hline CHEMBL1376424 & 688171 & 4.45 & 4.9065 & TRN \\
\hline CHEMBL1407417 & 688171 & 5.2 & 4.8733 & TST \\
\hline CHEMBL1567034 & 688171 & 4.9 & 4.8538 & TRN \\
\hline CHEMBL1593715 & 688171 & 4.4 & 4.8749 & TRN \\
\hline CHEMBL1407614 & 688171 & 6.0 & 4.9551 & TRN \\
\hline CHEMBL1458926 & 688171 & 4.35 & 4.8718 & TRN \\
\hline CHEMBL1555890 & 688171 & 5.2 & 4.9585 & TRN \\
\hline CHEMBL1581123 & 688171 & 5.0 & 4.93 & TST \\
\hline CHEMBL1486910 & 688171 & 4.5 & 4.8882 & TRN \\
\hline CHEMBL1546974 & 688171 & 4.8 & 4.9619 & TRN \\
\hline CHEMBL1511193 & 688171 & 5.05 & 4.9277 & TRN \\
\hline
\end{tabular}




\begin{tabular}{|c|c|c|c|c|}
\hline \multicolumn{5}{|c|}{ Supplemental Table S2.txt } \\
\hline CHEMBL1476900 & 688171 & 4.8 & 4.9444 & TRN \\
\hline CHEMBL1487851 & 688171 & 6.3 & 4.9333 & TST \\
\hline CHEMBL1363030 & 688171 & 5.95 & 4.8412 & TST \\
\hline CHEMBL3213431 & 688171 & 5.05 & 4.8715 & TRN \\
\hline CHEMBL1534904 & 688171 & 6.45 & 4.9783 & TRN \\
\hline CHEMBL1341951 & 688171 & 4.65 & 4.803 & TRN \\
\hline CHEMBL1309979 & 688171 & 6.0 & 4.8028 & TRN \\
\hline CHEMBL1394715 & 688171 & 4.5 & 5.0313 & TRN \\
\hline CHEMBL1386858 & 688171 & 4.4 & 4.7097 & TRN \\
\hline CHEMBL 1317580 & 688171 & 4.85 & 4.9144 & TRN \\
\hline CHEMBL1498285 & 688171 & 4.55 & 4.8031 & TRN \\
\hline CHEMBL1451528 & 688171 & 4.65 & 4.8541 & TST \\
\hline CHEMBL1361680 & 688171 & 6.0 & 4.797 & TST \\
\hline CHEMBL1351081 & 688171 & 4.75 & 4.9264 & TRN \\
\hline CHEMBL1354256 & 688171 & 4.35 & 4.9009 & TRN \\
\hline CHEMBL1384238 & 688171 & 4.45 & 4.7962 & TRN \\
\hline CHEMBL1505221 & 688171 & 4.9 & 4.8365 & TST \\
\hline CHEMBL3211584 & 688171 & 5.9 & 4.9635 & TRN \\
\hline CHEMBL1345335 & 688171 & 4.35 & 4.8215 & TRN \\
\hline CHEMBL1304553 & 688171 & 5.05 & 4.8752 & TRN \\
\hline CHEMBL1422741 & 688171 & 4.45 & 4.8809 & TST \\
\hline CHEMBL1576968 & 688171 & 5.05 & 4.9345 & TST \\
\hline CHEMBL1485826 & 688171 & 5.1 & 4.9398 & TRN \\
\hline CHEMBL1312414 & 688171 & 4.35 & 4.9387 & TST \\
\hline CHEMBL1491855 & 688171 & 4.4 & 4.8899 & TRN \\
\hline CHEMBL3197134 & 688171 & 4.9 & 4.9068 & TRN \\
\hline CHEMBL1479407 & 688171 & 4.75 & 4.8709 & TST \\
\hline CHEMBL1458944 & 688171 & 5.1 & 4.8045 & TRN \\
\hline CHEMBL1502420 & 688171 & 4.65 & 4.7085 & TST \\
\hline CHEMBL3193992 & 688171 & 4.85 & 4.8894 & TRN \\
\hline CHEMBL1356240 & 688171 & 4.35 & 4.9992 & TRN \\
\hline CHEMBL1461266 & 688171 & 4.5 & 5.0451 & TRN \\
\hline CHEMBL1339926 & 688171 & 4.5 & 4.9197 & TRN \\
\hline CHEMBL1549641 & 688171 & 5.4 & 4.8475 & TST \\
\hline CHEMBL1315971 & 688171 & 4.7 & 4.9906 & TRN \\
\hline CHEMBL3195428 & 688171 & 4.55 & 4.9285 & TRN \\
\hline CHEMBL3192402 & 688171 & 4.75 & 4.9372 & TRN \\
\hline CHEMBL1390226 & 688171 & 4.7 & 5.0889 & TRN \\
\hline CHEMBL1378659 & 688171 & 4.8 & 4.9404 & TRN \\
\hline CHEMBL1320493 & 688171 & 4.6 & 4.8163 & TRN \\
\hline CHEMBL1512892 & 688171 & 4.7 & 4.9715 & TRN \\
\hline CHEMBL1495133 & 688171 & 4.65 & 4.8698 & TRN \\
\hline CHEMBL1606981 & 688171 & 6.7001 & 4.8976 & TRN \\
\hline CHEMBL1350336 & 688171 & 4.7 & 4.9881 & TRN \\
\hline CHEMBL1513200 & 688171 & 5.05 & 4.9178 & TRN \\
\hline CHEMBL1896972 & 688171 & 4.4 & 5.0663 & TRN \\
\hline CHEMBL122355 & 688171 & 5.0 & 4.8174 & TST \\
\hline CHEMBL1304654 & 688171 & 4.85 & 4.8583 & TRN \\
\hline
\end{tabular}




\begin{tabular}{|c|c|c|c|c|c|}
\hline \multicolumn{6}{|c|}{ Supplemental Table S2.txt } \\
\hline CHEMBL1546703 & 688171 & 5.7 & 4.7844 & TRN & \\
\hline CHEMBL1609124 & 688171 & 5.85 & 4.9564 & TRN & \\
\hline CHEMBL1417224 & 688171 & 4.45 & 4.85800 & 00000000005 & TRN \\
\hline CHEMBL1546305 & 688171 & 4.45 & 4.8965 & TRN & \\
\hline CHEMBL1436349 & 688171 & 4.55 & 4.9996 & TRN & \\
\hline CHEMBL1366713 & 688171 & 4.65 & 4.8975 & TRN & \\
\hline CHEMBL1400630 & 688171 & 4.75 & 4.941 & TRN & \\
\hline CHEMBL1496534 & 688171 & 5.05 & 4.9143 & TST & \\
\hline CHEMBL1518422 & 688171 & 4.4 & 4.8136 & TST & \\
\hline CHEMBL1594298 & 688171 & 4.4 & 4.9207 & TRN & \\
\hline CHEMBL1336283 & 688171 & 4.4 & 4.945 & TRN & \\
\hline CHEMBL3195647 & 688171 & 5.9 & 4.8693 & TRN & \\
\hline CHEMBL1514999 & 688171 & 4.8 & 4.8705 & TRN & \\
\hline CHEMBL1347575 & 688171 & 4.6 & 4.954 & TST & \\
\hline CHEMBL1376804 & 688171 & 4.9 & 4.8878 & TRN & \\
\hline CHEMBL1388656 & 688171 & 5.4 & 4.763 & TRN & \\
\hline CHEMBL1380403 & 688171 & 4.4 & 4.894 & TRN & \\
\hline CHEMBL1501279 & 688171 & 7.6003 & 4.9429 & TST & \\
\hline CHEMBL1368562 & 688171 & 4.5 & 4.7749 & TRN & \\
\hline CHEMBL1493907 & 688171 & 4.95 & 5.0016 & TST & \\
\hline CHEMBL1578178 & 688171 & 6.05 & 5.0275 & TRN & \\
\hline CHEMBL1520340 & 688171 & 4.8 & 4.827 & TRN & \\
\hline CHEMBL1340890 & 688171 & 5.2 & 4.8303 & TST & \\
\hline CHEMBL1415492 & 688171 & 4.9 & 4.9837 & TRN & \\
\hline CHEMBL1546396 & 688171 & 4.4 & 4.8861 & TST & \\
\hline CHEMBL1434097 & 688171 & 4.55 & 4.813 & TRN & \\
\hline CHEMBL1462270 & 688171 & 6.6499 & 4.8273 & TRN & \\
\hline CHEMBL1612516 & 688171 & 5.5 & 4.9501 & TRN & \\
\hline CHEMBL1367879 & 688171 & 4.5 & 4.8218 & TRN & \\
\hline CHEMBL1489881 & 688171 & 4.95 & 4.9476 & TRN & \\
\hline CHEMBL1345800 & 688171 & 5.65 & 4.8889 & TST & \\
\hline CHEMBL1383603 & 688171 & 5.0 & 4.7988 & TRN & \\
\hline CHEMBL1328850 & 688171 & 4.6 & 4.8451 & TST & \\
\hline CHEMBL1383554 & 688171 & 4.4 & 4.9068 & TRN & \\
\hline CHEMBL1459126 & 688171 & 4.7 & 4.7763 & TRN & \\
\hline CHEMBL1352812 & 688171 & 4.55 & 4.9444 & TRN & \\
\hline CHEMBL1421889 & 688171 & 4.8 & 4.9613 & TRN & \\
\hline CHEMBL1396506 & 688171 & 5.0 & 4.8031 & TRN & \\
\hline CHEMBL1516200 & 688171 & 6.5 & 5.081 & TRN & \\
\hline CHEMBL1443936 & 688171 & 4.9 & 4.9252 & TST & \\
\hline CHEMBL1316898 & 688171 & 4.4 & 4.9589 & TRN & \\
\hline CHEMBL 2369294 & 688171 & 4.8 & 4.927 & TRN & \\
\hline CHEMBL1511456 & 688171 & 4.65 & 4.8018 & TRN & \\
\hline CHEMBL1552230 & 688171 & 4.7 & 4.905 & TRN & \\
\hline CHEMBL3209873 & 688171 & 4.65 & 5.0227 & TST & \\
\hline CHEMBL1435594 & 688171 & 4.8 & 4.8153 & TRN & \\
\hline CHEMBL1376635 & 688171 & 4.4 & 4.815 & TRN & \\
\hline CHEMBL1531901 & 688171 & 4.75 & 4.9527 & TRN & \\
\hline
\end{tabular}




\begin{tabular}{|c|c|c|c|c|}
\hline \multicolumn{5}{|c|}{ Supplemental Table S2.txt } \\
\hline CHEMBL1528567 & 688171 & 5.15 & 5.0117 & TRN \\
\hline CHEMBL1357481 & 688171 & 5.15 & 4.7798 & TRN \\
\hline CHEMBL1472998 & 688171 & 5.3 & 4.7831 & TST \\
\hline CHEMBL1527216 & 688171 & 4.75 & 4.9643 & TRN \\
\hline CHEMBL 1479340 & 688171 & 4.4 & 5.0277 & TST \\
\hline CHEMBL3195623 & 688171 & 4.4 & 5.0628 & TRN \\
\hline CHEMBL1332979 & 688171 & 5.0 & 4.8636 & TRN \\
\hline CHEMBL1611804 & 688171 & 4.95 & 4.8393 & TRN \\
\hline CHEMBL1472135 & 688171 & 5.6 & 4.8346 & TRN \\
\hline CHEMBL1348563 & 688171 & 7.6498 & 4.9938 & TST \\
\hline CHEMBL1474713 & 688171 & 5.4 & 4.9224 & TRN \\
\hline CHEMBL374236 & 688171 & 5.35 & 4.8074 & TRN \\
\hline CHEMBL1551748 & 688171 & 5.9 & 4.8472 & TRN \\
\hline CHEMBL1302191 & 688171 & 4.4 & 4.8904 & TRN \\
\hline CHEMBL1437645 & 688171 & 7.3497 & 4.9329 & TRN \\
\hline CHEMBL1511149 & 688171 & 4.85 & 4.8633 & TRN \\
\hline CHEMBL1561949 & 688171 & 4.65 & 4.8714 & TST \\
\hline CHEMBL1432618 & 688171 & 5.0 & 4.9947 & TRN \\
\hline CHEMBL393136 & 688171 & 4.6 & 4.8637 & TRN \\
\hline CHEMBL1317405 & 688171 & 4.45 & 4.8251 & TRN \\
\hline CHEMBL1448150 & 688171 & 4.4 & 4.837 & TST \\
\hline CHEMBL1439686 & 688171 & 4.85 & 4.9754 & TRN \\
\hline CHEMBL1593873 & 688171 & 4.85 & 4.9417 & TRN \\
\hline CHEMBL192566 & 688171 & 6.9 & 5.2733 & TST \\
\hline CHEMBL1080687 & 688171 & 4.75 & 4.9788 & TRN \\
\hline CHEMBL1399210 & 688171 & 4.4 & 5.0209 & TST \\
\hline CHEMBL1408948 & 688171 & 4.4 & 5.0193 & TRN \\
\hline CHEMBL80799 & 688171 & 4.85 & 4.7373 & TRN \\
\hline CHEMBL1438078 & 688171 & 4.6 & 4.8054 & TRN \\
\hline CHEMBL1433954 & 688171 & 4.6 & 4.8826 & TRN \\
\hline CHEMBL1413592 & 688171 & 5.0 & 4.935 & TRN \\
\hline CHEMBL582491 & 688171 & 4.6 & 4.9257 & TRN \\
\hline CHEMBL1431350 & 688171 & 4.35 & 4.9311 & TRN \\
\hline CHEMBL1484565 & 688171 & 4.4 & 4.9686 & TRN \\
\hline CHEMBL1320940 & 688171 & 4.5 & 4.8357 & TRN \\
\hline CHEMBL1425741 & 688171 & 4.8 & 4.8908 & TST \\
\hline CHEMBL1602709 & 688171 & 4.7 & 4.9531 & TRN \\
\hline CHEMBL1356499 & 688171 & 4.55 & 4.9602 & TST \\
\hline CHEMBL1309691 & 688171 & 5.45 & 4.8399 & TRN \\
\hline CHEMBL1409124 & 688171 & 5.05 & 4.8318 & TRN \\
\hline CHEMBL1360665 & 688171 & 6.0 & 5.0352 & TRN \\
\hline CHEMBL1396990 & 688171 & 5.0 & 4.8371 & TRN \\
\hline CHEMBL1333220 & 688171 & 5.6 & 4.795 & TRN \\
\hline CHEMBL1434785 & 688171 & 5.2 & 4.9676 & TRN \\
\hline CHEMBL1463801 & 688171 & 4.9 & 4.8278 & TRN \\
\hline CHEMBL1532162 & 688171 & 4.4 & 4.8401 & TST \\
\hline CHEMBL1533958 & 688171 & 4.5 & 4.8517 & TRN \\
\hline CHEMBL1712384 & 688171 & 4.75 & 4.7268 & TRN \\
\hline
\end{tabular}




\begin{tabular}{|c|c|c|c|c|c|}
\hline \multicolumn{6}{|c|}{ Supplemental Table S2.txt } \\
\hline CHEMBL1406005 & 688171 & 5.5 & 4.9703 & TST & \\
\hline CHEMBL1412810 & 688171 & 5.45 & 4.9311 & TRN & \\
\hline CHEMBL1535746 & 688171 & 4.6 & 5.0409 & TRN & \\
\hline CHEMBL1612796 & 688171 & 4.6 & 4.8151 & TST & \\
\hline CHEMBL1516125 & 688171 & 5.1 & 4.8627 & TRN & \\
\hline CHEMBL1333691 & 688171 & 4.95 & 4.9509 & TRN & \\
\hline CHEMBL1536725 & 688171 & 5.3 & 4.9261 & TST & \\
\hline CHEMBL1408222 & 688171 & 5.25 & 4.9184 & TST & \\
\hline CHEMBL1527290 & 688171 & 4.4 & 4.7955 & TRN & \\
\hline CHEMBL1572447 & 688171 & 5.5 & 4.8585 & TRN & \\
\hline CHEMBL1426896 & 688171 & 4.55 & 4.9481 & TST & \\
\hline CHEMBL1476323 & 688171 & 4.7 & 4.7571 & TRN & \\
\hline CHEMBL1574555 & 688171 & 4.4 & 4.8747 & TRN & \\
\hline CHEMBL1457745 & 688171 & 4.9 & 4.9065 & TRN & \\
\hline CHEMBL1534959 & 688171 & 6.0 & 4.7867 & TRN & \\
\hline CHEMBL1394642 & 688171 & 4.35 & 5.044 & TRN & \\
\hline CHEMBL1476856 & 688171 & 4.85 & 4.8156 & TRN & \\
\hline CHEMBL1503455 & 688171 & 4.35 & 4.982 & TRN & \\
\hline CHEMBL1596391 & 688171 & 4.4 & 4.885 & TRN & \\
\hline CHEMBL1372592 & 688171 & 4.65 & 4.8379 & TRN & \\
\hline CHEMBL1526806 & 688171 & 4.65 & 4.9392 & TRN & \\
\hline CHEMBL1449316 & 688171 & 4.55 & 4.931 & TRN & \\
\hline CHEMBL1433622 & 688171 & 4.7 & 4.7907 & TRN & \\
\hline CHEMBL1534880 & 688171 & 5.3 & 4.83899 & 99999999995 & TRN \\
\hline CHEMBL1440137 & 688171 & 4.4 & 4.8576 & TRN & \\
\hline CHEMBL1558904 & 688171 & 4.9 & 4.7705 & TRN & \\
\hline CHEMBL1533834 & 688171 & 4.55 & 4.9198 & TRN & \\
\hline CHEMBL1598008 & 688171 & 5.5 & 4.8352 & TRN & \\
\hline CHEMBL1327899 & 688171 & 5.15 & 4.9972 & TRN & \\
\hline CHEMBL1377737 & 688171 & 5.45 & 4.9865 & TRN & \\
\hline CHEMBL1410793 & 688171 & 7.5498 & 4.9182 & TST & \\
\hline CHEMBL1339937 & 688171 & 4.8 & 5.0343 & TRN & \\
\hline CHEMBL1572638 & 688171 & 4.8 & 4.9335 & TRN & \\
\hline CHEMBL1456448 & 688171 & 5.8 & 4.7998 & TRN & \\
\hline CHEMBL1475068 & 688171 & 5.05 & 4.8665 & TRN & \\
\hline CHEMBL1316719 & 688171 & 4.55 & 4.8056 & TRN & \\
\hline CHEMBL1406780 & 688171 & 4.55 & 5.146 & TST & \\
\hline CHEMBL1324731 & 688171 & 4.4 & 4.8427 & TRN & \\
\hline CHEMBL1256360 & 688171 & 6.0 & 5.0628 & TRN & \\
\hline CHEMBL1593822 & 688171 & 4.8 & 4.926 & TRN & \\
\hline CHEMBL1569446 & 688171 & 4.75 & 4.8392 & TST & \\
\hline CHEMBL1555494 & 688171 & 4.6 & 4.9734 & TST & \\
\hline CHEMBL1339695 & 688171 & 5.1 & 4.8697 & TRN & \\
\hline CHEMBL1603424 & 688171 & 4.35 & 4.9037 & TRN & \\
\hline CHEMBL1572989 & 688171 & 5.05 & 4.8687 & TRN & \\
\hline CHEMBL1432368 & 688171 & 4.5 & 4.9561 & TRN & \\
\hline CHEMBL1489370 & 688171 & 4.75 & 4.8206 & TRN & \\
\hline CHEMBL1613136 & 688171 & 5.1 & 4.8601 & TRN & \\
\hline
\end{tabular}




\begin{tabular}{|c|c|c|c|c|}
\hline \multicolumn{5}{|c|}{ Supplemental Table S2.txt } \\
\hline CHEMBL1476539 & 688171 & 4.4 & 4.9367 & TRN \\
\hline CHEMBL1435535 & 688171 & 4.45 & 4.9905 & TRN \\
\hline CHEMBL1315545 & 688171 & 4.45 & 4.7586 & TRN \\
\hline CHEMBL1469700 & 688171 & 5.8 & 4.9273 & TRN \\
\hline CHEMBL3190844 & 688171 & 5.5 & 4.9658 & TRN \\
\hline CHEMBL1572856 & 688171 & 4.45 & 4.9639 & TST \\
\hline CHEMBL1483443 & 688171 & 4.75 & 4.7706 & TRN \\
\hline CHEMBL1531600 & 688171 & 4.8 & 4.8865 & TRN \\
\hline CHEMBL1459918 & 688171 & 4.75 & 4.9114 & TRN \\
\hline CHEMBL1508072 & 688171 & 5.25 & 4.7956 & TST \\
\hline CHEMBL1561791 & 688171 & 4.55 & 4.8782 & TRN \\
\hline CHEMBL1557778 & 688171 & 4.4 & 4.7582 & TRN \\
\hline CHEMBL1549512 & 688171 & 5.05 & 5.0723 & TST \\
\hline CHEMBL1327989 & 688171 & 4.7 & 5.1044 & TRN \\
\hline CHEMBL1513969 & 688171 & 4.85 & 4.9298 & TRN \\
\hline CHEMBL1361190 & 688171 & 5.05 & 4.8801 & TRN \\
\hline CHEMBL1571775 & 688171 & 4.5 & 4.9073 & TRN \\
\hline CHEMBL1445099 & 688171 & 6.1 & 4.9423 & TRN \\
\hline CHEMBL1519558 & 688171 & 5.35 & 4.9207 & TST \\
\hline CHEMBL1400571 & 688171 & 5.15 & 4.8673 & TST \\
\hline CHEMBL1439256 & 688171 & 4.45 & 4.6792 & TRN \\
\hline CHEMBL1407422 & 688171 & 5.5 & 4.9097 & TRN \\
\hline CHEMBL1440484 & 688171 & 4.4 & 4.8852 & TST \\
\hline CHEMBL1510954 & 688171 & 4.4 & 4.761 & TRN \\
\hline CHEMBL1542614 & 688171 & 4.5 & 4.9219 & TRN \\
\hline CHEMBL1322878 & 688171 & 4.9 & 4.9965 & TRN \\
\hline CHEMBL1548687 & 688171 & 4.95 & 4.993 & TST \\
\hline CHEMBL 3193792 & 688171 & 4.75 & 4.9547 & TRN \\
\hline CHEMBL1436112 & 688171 & 5.0 & 4.8724 & TRN \\
\hline CHEMBL1395043 & 688171 & 6.3 & 4.9836 & TST \\
\hline CHEMBL 3209332 & 688171 & 4.4 & 5.0557 & TRN \\
\hline CHEMBL1317206 & 688171 & 4.55 & 4.8738 & TRN \\
\hline CHEMBL1313356 & 688171 & 4.85 & 4.8373 & TRN \\
\hline CHEMBL1901606 & 688171 & 4.9 & 4.9678 & TRN \\
\hline CHEMBL1300388 & 688171 & 4.8 & 4.8891 & TRN \\
\hline CHEMBL1436532 & 688171 & 7.4498 & 4.9734 & TRN \\
\hline CHEMBL1407682 & 688171 & 5.3 & 5.0249 & TRN \\
\hline CHEMBL1369899 & 688171 & 4.4 & 4.9358 & TRN \\
\hline CHEMBL1473728 & 688171 & 4.85 & 4.8766 & TRN \\
\hline CHEMBL1510455 & 688171 & 6.0 & 4.8334 & TRN \\
\hline CHEMBL3189163 & 688171 & 5.4 & 4.9748 & TST \\
\hline CHEMBL1342142 & 688171 & 4.7 & 4.9669 & TST \\
\hline CHEMBL1606631 & 688171 & 5.1 & 4.7939 & TRN \\
\hline CHEMBL1331613 & 688171 & 4.4 & 5.0432 & TST \\
\hline CHEMBL1994599 & 688171 & 4.75 & 5.0257 & TRN \\
\hline CHEMBL1352402 & 688171 & 4.4 & 4.8747 & TRN \\
\hline CHEMBL1609666 & 688171 & 4.85 & 4.904 & TRN \\
\hline CHEMBL1366820 & 688171 & 5.0 & 4.8117 & TRN \\
\hline
\end{tabular}




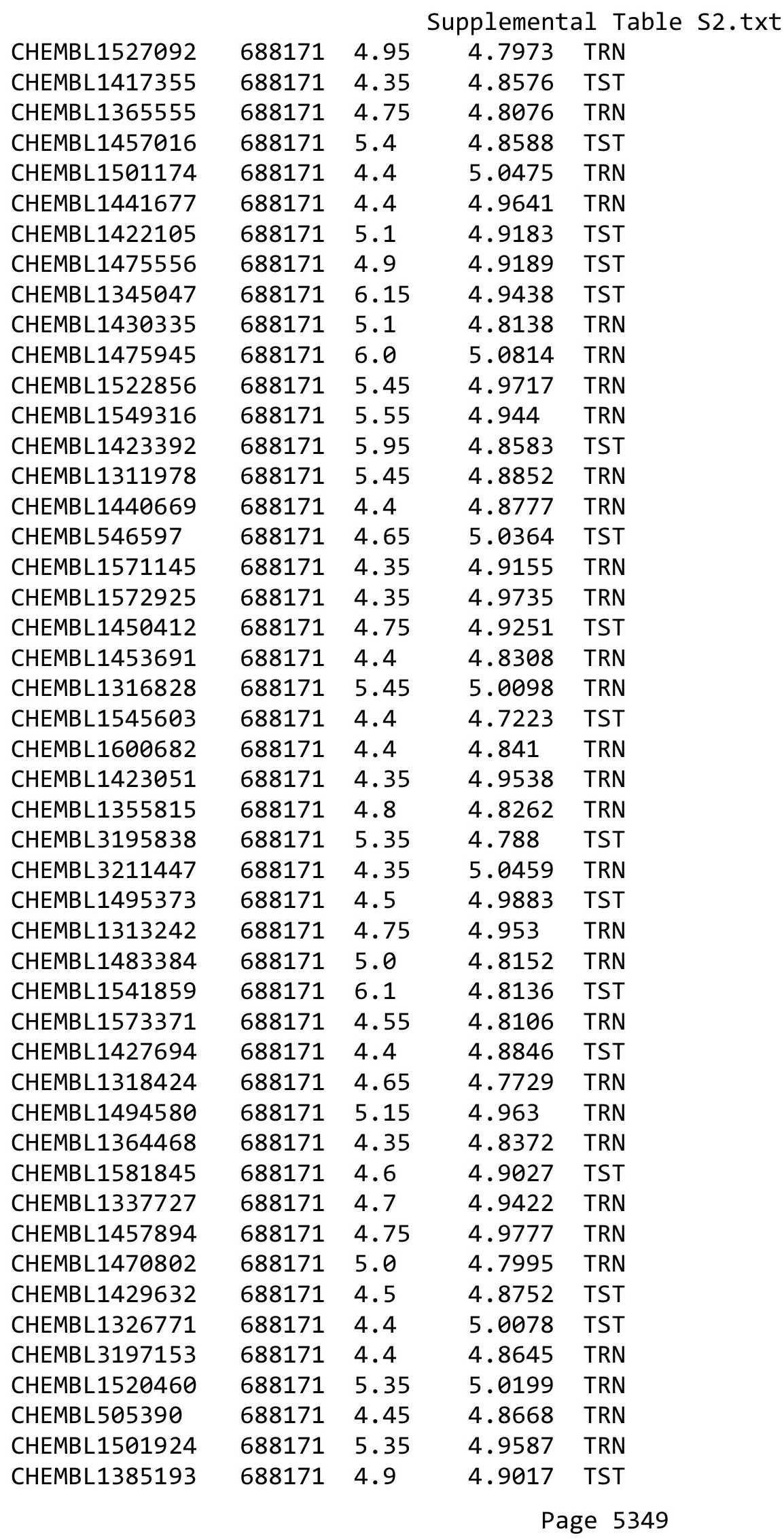




\begin{tabular}{|c|c|c|c|c|}
\hline \multicolumn{5}{|c|}{ Supplemental Table S2.txt } \\
\hline CHEMBL1475028 & 688171 & 6.05 & 5.0198 & TRN \\
\hline CHEMBL1496083 & 688171 & 4.7 & 5.0913 & TRN \\
\hline CHEMBL1470744 & 688171 & 4.4 & 4.8598 & TRN \\
\hline CHEMBL3198109 & 688171 & 5.55 & 4.8843 & TRN \\
\hline CHEMBL3212453 & 688171 & 4.35 & 5.0191 & TST \\
\hline CHEMBL1462265 & 688171 & 4.45 & 4.981 & TRN \\
\hline CHEMBL1329061 & 688171 & 4.6 & 4.8424 & TRN \\
\hline CHEMBL1423626 & 688171 & 4.4 & 4.9032 & TST \\
\hline CHEMBL1582565 & 688171 & 5.55 & 4.9414 & TRN \\
\hline CHEMBL1506520 & 688171 & 4.5 & 4.927 & TRN \\
\hline CHEMBL1502019 & 688171 & 4.4 & 5.0505 & TRN \\
\hline CHEMBL1414508 & 688171 & 5.1 & 4.9259 & TRN \\
\hline CHEMBL1590105 & 688171 & 5.55 & 5.0038 & TRN \\
\hline CHEMBL1341969 & 688171 & 5.6 & 4.8714 & TST \\
\hline CHEMBL1324556 & 688171 & 7.0501 & 4.9632 & TRN \\
\hline CHEMBL1326845 & 688171 & 4.4 & 4.886 & TST \\
\hline CHEMBL1555045 & 688171 & 5.0 & 4.9079 & TRN \\
\hline CHEMBL1551194 & 688171 & 5.0 & 4.8777 & TRN \\
\hline CHEMBL1563002 & 688171 & 4.9 & 4.8702 & TRN \\
\hline CHEMBL1334053 & 688171 & 4.4 & 4.9187 & TRN \\
\hline CHEMBL1421133 & 688171 & 5.6 & 4.9575 & TRN \\
\hline CHEMBL1461833 & 688171 & 4.55 & 4.8134 & TRN \\
\hline CHEMBL1576851 & 688171 & 5.55 & 4.9211 & TRN \\
\hline CHEMBL1497503 & 688171 & 4.95 & 4.7772 & TRN \\
\hline CHEMBL1513749 & 688171 & 4.8 & 4.8454 & TRN \\
\hline CHEMBL1180 & 688171 & 4.4 & 4.9364 & TST \\
\hline CHEMBL1357876 & 688171 & 4.55 & 5.0616 & TRN \\
\hline CHEMBL1352301 & 688171 & 4.4 & 4.8878 & TST \\
\hline CHEMBL3210456 & 688171 & 4.55 & 4.9713 & TRN \\
\hline CHEMBL1427655 & 688171 & 5.05 & 5.0125 & TST \\
\hline CHEMBL1397702 & 688171 & 4.7 & 5.0929 & TST \\
\hline CHEMBL1604365 & 688171 & 4.9 & 4.9472 & TRN \\
\hline CHEMBL1394165 & 688171 & 4.8 & 4.7751 & TRN \\
\hline CHEMBL1492186 & 688171 & 4.4 & 4.8716 & TRN \\
\hline CHEMBL1522922 & 688171 & 4.85 & 5.029 & TRN \\
\hline CHEMBL1593249 & 688171 & 6.95 & 4.9312 & TRN \\
\hline CHEMBL1612948 & 688171 & 4.65 & 4.8925 & TRN \\
\hline CHEMBL18701 & 688171 & 4.35 & 5.0433 & TST \\
\hline CHEMBL1592132 & 688171 & 4.35 & 4.8715 & TRN \\
\hline CHEMBL1402526 & 688171 & 4.7 & 4.7458 & TRN \\
\hline CHEMBL1356805 & 688171 & 5.1 & 4.9248 & TRN \\
\hline CHEMBL1316181 & 688171 & 4.55 & 4.9067 & TRN \\
\hline CHEMBL316034 & 688171 & 5.05 & 4.9644 & TST \\
\hline CHEMBL1413605 & 688171 & 6.0 & 4.9511 & TRN \\
\hline CHEMBL1423607 & 688171 & 4.55 & 4.8733 & TRN \\
\hline CHEMBL1543663 & 688171 & 4.5 & 5.1127 & TST \\
\hline CHEMBL1451349 & 688171 & 4.6 & 4.8381 & TRN \\
\hline CHEMBL1484471 & 688171 & 5.0 & 4.8697 & TRN \\
\hline
\end{tabular}




\begin{tabular}{|c|c|c|c|c|c|}
\hline \multicolumn{6}{|c|}{ Supplemental Table S2.txt } \\
\hline CHEMBL1379324 & 688171 & 4.35 & 4.8105 & TRN & \\
\hline CHEMBL1331033 & 688171 & 7.0501 & 4.9602 & TRN & \\
\hline CHEMBL1434674 & 688171 & 4.75 & 4.9204 & TRN & \\
\hline CHEMBL1488688 & 688171 & 6.25 & 4.9905 & TRN & \\
\hline CHEMBL1346630 & 688171 & 4.4 & 4.8737 & TRN & \\
\hline CHEMBL1547847 & 688171 & 4.65 & 4.7919 & TRN & \\
\hline CHEMBL1569303 & 688171 & 4.6 & 4.9685 & TRN & \\
\hline CHEMBL1303469 & 688171 & 4.6 & 4.7277 & TRN & \\
\hline CHEMBL1596407 & 688171 & 4.6 & 4.9768 & TRN & \\
\hline CHEMBL1424333 & 688171 & 4.75 & 4.9034 & TRN & \\
\hline CHEMBL1568548 & 688171 & 4.8 & 4.9572 & TRN & \\
\hline CHEMBL1516388 & 688171 & 6.0 & 4.98300 & 00000000005 & TST \\
\hline CHEMBL1395693 & 688171 & 4.4 & 4.8408 & TRN & \\
\hline CHEMBL1513019 & 688171 & 4.6 & 4.8556 & TRN & \\
\hline CHEMBL1601233 & 688171 & 4.75 & 4.8122 & TRN & \\
\hline CHEMBL1501841 & 688171 & 4.55 & 4.7652 & TRN & \\
\hline CHEMBL1376870 & 688171 & 4.45 & 4.9293 & TRN & \\
\hline CHEMBL1314659 & 688171 & 4.4 & 4.8222 & TRN & \\
\hline CHEMBL1399757 & 688171 & 5.9 & 4.8848 & TST & \\
\hline CHEMBL1596619 & 688171 & 4.4 & 4.7812 & TRN & \\
\hline CHEMBL1370296 & 688171 & 4.95 & 4.894 & TRN & \\
\hline CHEMBL1543260 & 688171 & 4.4 & 4.9777 & TST & \\
\hline CHEMBL1546783 & 688171 & 4.4 & 5.0413 & TRN & \\
\hline CHEMBL1582640 & 688171 & 4.4 & 4.845 & TST & \\
\hline CHEMBL1452907 & 688171 & 5.0 & 4.9557 & TRN & \\
\hline CHEMBL1612135 & 688171 & 4.8 & 5.0227 & TST & \\
\hline CHEMBL1346320 & 688171 & 6.7501 & 4.9111 & TRN & \\
\hline CHEMBL3198166 & 688171 & 6.5 & 5.0296 & TST & \\
\hline CHEMBL1549087 & 688171 & 4.35 & 4.9727 & TRN & \\
\hline CHEMBL 1378280 & 688171 & 4.65 & 4.9817 & TST & \\
\hline CHEMBL1383835 & 688171 & 4.4 & 4.963 & TRN & \\
\hline CHEMBL1426842 & 688171 & 4.6 & 4.982 & TRN & \\
\hline CHEMBL1592828 & 688171 & 5.4 & 4.9491 & TRN & \\
\hline CHEMBL 8867 & 688171 & 6.0 & 4.9413 & TRN & \\
\hline CHEMBL3192170 & 688171 & 4.5 & 4.998 & TST & \\
\hline CHEMBL1513306 & 688171 & 4.65 & 4.873 & TRN & \\
\hline CHEMBL1526726 & 688171 & 4.4 & 4.9652 & TRN & \\
\hline CHEMBL1533676 & 688171 & 4.65 & 4.9359 & TRN & \\
\hline CHEMBL244707 & 688171 & 4.9 & 4.8784 & TRN & \\
\hline CHEMBL1436382 & 688171 & 4.35 & 4.9756 & TRN & \\
\hline CHEMBL3392041 & 688171 & 5.8 & 4.8162 & TRN & \\
\hline CHEMBL1429643 & 688171 & 4.5 & 4.8997 & TST & \\
\hline CHEMBL1562040 & 688171 & 5.0 & 4.961 & TRN & \\
\hline CHEMBL1304263 & 688171 & 5.45 & 4.9641 & TST & \\
\hline CHEMBL1435181 & 688171 & 4.7 & 4.7707 & TRN & \\
\hline CHEMBL1316795 & 688171 & 5.35 & 4.8827 & TRN & \\
\hline CHEMBL1534865 & 688171 & 5.05 & 5.0231 & TRN & \\
\hline CHEMBL1320633 & 688171 & 4.9 & 4.9651 & TRN & \\
\hline
\end{tabular}




\begin{tabular}{|c|c|c|c|c|c|}
\hline \multicolumn{6}{|c|}{ Supplemental Table S2.txt } \\
\hline CHEMBL1605346 & 688171 & 5.5 & 4.9215 & TRN & \\
\hline CHEMBL3212537 & 688171 & 4.45 & 4.9023 & TRN & \\
\hline CHEMBL1478257 & 688171 & 4.5 & 5.0419 & TRN & \\
\hline CHEMBL1318107 & 688171 & 5.25 & 5.1183 & TRN & \\
\hline CHEMBL1325481 & 688171 & 4.9 & 4.9079 & TRN & \\
\hline CHEMBL3210389 & 688171 & 4.35 & 4.9933 & TRN & \\
\hline CHEMBL1351406 & 688171 & 4.85 & 5.034 & TRN & \\
\hline CHEMBL1446142 & 688171 & 4.65 & 4.8779 & TRN & \\
\hline CHEMBL1532295 & 688171 & 4.5 & 4.7601 & TRN & \\
\hline CHEMBL54909 & 688171 & 4.7 & 4.9476 & TRN & \\
\hline CHEMBL1390254 & 688171 & 5.35 & 4.7795 & TRN & \\
\hline CHEMBL1423121 & 688171 & 4.8 & 5.0081 & TST & \\
\hline CHEMBL1537392 & 688171 & 4.6 & 4.9302 & TRN & \\
\hline CHEMBL1395736 & 688171 & 4.85 & 4.846 & TRN & \\
\hline CHEMBL1572201 & 688171 & 5.0 & 5.0791 & TRN & \\
\hline CHEMBL1388490 & 688171 & 5.4 & 4.9871 & TRN & \\
\hline CHEMBL1590999 & 688171 & 4.55 & 4.9196 & TST & \\
\hline CHEMBL1384631 & 688171 & 5.15 & 4.9965 & TRN & \\
\hline CHEMBL1415640 & 688171 & 4.45 & 4.891 & TRN & \\
\hline CHEMBL1344571 & 688171 & 5.0 & 4.8803 & TRN & \\
\hline CHEMBL1569672 & 688171 & 4.9 & 4.9147 & TRN & \\
\hline CHEMBL1526352 & 688171 & 4.95 & 4.94600 & 0000000001 & TRN \\
\hline CHEMBL1382763 & 688171 & 4.5 & 4.78100 & 0000000001 & TRN \\
\hline CHEMBL3191052 & 688171 & 4.4 & 4.9569 & TRN & \\
\hline CHEMBL1383997 & 688171 & 5.3 & 4.9686 & TST & \\
\hline CHEMBL1365585 & 688171 & 4.7 & 4.9325 & TRN & \\
\hline CHEMBL1467612 & 688171 & 4.7 & 4.6938 & TRN & \\
\hline CHEMBL1566068 & 688171 & 4.85 & 5.0544 & TRN & \\
\hline CHEMBL1396098 & 688171 & 4.85 & 4.9179 & TRN & \\
\hline CHEMBL1509327 & 688171 & 4.8 & 4.8133 & TRN & \\
\hline CHEMBL1989853 & 688171 & 4.55 & 4.9373 & TST & \\
\hline CHEMBL1521846 & 688171 & 4.75 & 4.8193 & TST & \\
\hline CHEMBL1368549 & 688171 & 4.85 & 5.0381 & TST & \\
\hline CHEMBL1424105 & 688171 & 4.6 & 4.8727 & TRN & \\
\hline CHEMBL1360720 & 688171 & 4.35 & 4.9492 & TRN & \\
\hline CHEMBL1493662 & 688171 & 5.1 & 4.9349 & TRN & \\
\hline CHEMBL1548194 & 688171 & 7.3002 & 4.9382 & TRN & \\
\hline CHEMBL1564066 & 688171 & 4.7 & 4.9762 & TRN & \\
\hline CHEMBL1980384 & 688171 & 6.5501 & 4.9912 & TRN & \\
\hline CHEMBL1409295 & 688171 & 4.45 & 4.9038 & TRN & \\
\hline CHEMBL1356651 & 688171 & 4.8 & 4.9409 & TRN & \\
\hline CHEMBL1582527 & 688171 & 6.2 & 4.926 & TRN & \\
\hline CHEMBL1312178 & 688171 & 4.95 & 4.9768 & TRN & \\
\hline CHEMBL1530031 & 688171 & 6.0 & 4.896 & TRN & \\
\hline CHEMBL1449682 & 688171 & 5.05 & 4.9088 & TRN & \\
\hline CHEMBL536950 & 688171 & 4.45 & 4.8513 & TST & \\
\hline CHEMBL1377481 & 688171 & 4.65 & 4.79899 & 99999999995 & TRN \\
\hline CHEMBL1388263 & 688171 & 4.65 & 4.9863 & TRN & \\
\hline
\end{tabular}




\begin{tabular}{|c|c|c|c|c|}
\hline \multicolumn{5}{|c|}{ Supplemental Table S2.txt } \\
\hline CHEMBL1525711 & 688171 & 4.75 & 4.9216 & TRN \\
\hline CHEMBL1396075 & 688171 & 5.3 & 4.8419 & TRN \\
\hline CHEMBL1323410 & 688171 & 5.0 & 4.8688 & TRN \\
\hline CHEMBL1571707 & 688171 & 4.75 & 4.9782 & TST \\
\hline CHEMBL 3189778 & 688171 & 4.6 & 4.8407 & TRN \\
\hline CHEMBL1495939 & 688171 & 4.85 & 4.9749 & TST \\
\hline CHEMBL1515435 & 688171 & 5.15 & 4.9964 & TRN \\
\hline CHEMBL1316433 & 688171 & 4.4 & 4.9329 & TRN \\
\hline CHEMBL1309580 & 688171 & 5.15 & 4.8903 & TST \\
\hline CHEMBL1512065 & 688171 & 5.05 & 4.8755 & TST \\
\hline CHEMBL1326903 & 688171 & 4.4 & 4.8816 & TST \\
\hline CHEMBL1608015 & 688171 & 5.1 & 4.9046 & TRN \\
\hline CHEMBL1425166 & 688171 & 4.4 & 4.7943 & TST \\
\hline CHEMBL1475354 & 688171 & 4.95 & 4.7961 & TRN \\
\hline CHEMBL1416627 & 688171 & 4.9 & 4.8555 & TRN \\
\hline CHEMBL1483526 & 688171 & 5.05 & 4.8884 & TRN \\
\hline CHEMBL599950 & 688171 & 6.25 & 4.8754 & TRN \\
\hline CHEMBL1608862 & 688171 & 4.65 & 4.9065 & TST \\
\hline CHEMBL1570774 & 688171 & 4.9 & 4.7733 & TRN \\
\hline CHEMBL1610702 & 688171 & 5.0 & 4.8468 & TRN \\
\hline CHEMBL1345029 & 688171 & 4.85 & 4.8293 & TST \\
\hline CHEMBL1399555 & 688171 & 4.35 & 4.997 & TRN \\
\hline CHEMBL3192738 & 688171 & 4.7 & 4.9463 & TST \\
\hline CHEMBL1507162 & 688171 & 4.55 & 4.9503 & TRN \\
\hline CHEMBL1457066 & 688171 & 4.95 & 4.9544 & TRN \\
\hline CHEMBL1439562 & 688171 & 4.4 & 4.8383 & TRN \\
\hline CHEMBL1586445 & 688171 & 6.35 & 4.7979 & TRN \\
\hline CHEMBL1511045 & 688171 & 5.05 & 4.848 & TRN \\
\hline CHEMBL1549018 & 688171 & 7.6498 & 4.8998 & TRN \\
\hline CHEMBL1359756 & 688171 & 5.45 & 4.8811 & TRN \\
\hline CHEMBL1301302 & 688171 & 5.5 & 4.93 & TRN \\
\hline CHEMBL3191590 & 688171 & 4.85 & 4.8233 & TRN \\
\hline CHEMBL1384986 & 688171 & 4.75 & 4.9708 & TRN \\
\hline CHEMBL3211607 & 688171 & 4.9 & 4.9174 & TST \\
\hline CHEMBL1538493 & 688171 & 4.6 & 5.0681 & TST \\
\hline CHEMBL1406440 & 688171 & 4.85 & 5.0177 & TST \\
\hline CHEMBL1460463 & 688171 & 5.5 & 4.8709 & TRN \\
\hline CHEMBL3213936 & 688171 & 4.45 & 4.9296 & TRN \\
\hline CHEMBL1439235 & 688171 & 4.9 & 4.6926 & TRN \\
\hline CHEMBL1436762 & 688171 & 4.6 & 4.8249 & TRN \\
\hline CHEMBL1417220 & 688171 & 5.0 & 4.9996 & TST \\
\hline CHEMBL1609540 & 688171 & 5.1 & 4.9349 & TRN \\
\hline CHEMBL1377441 & 688171 & 5.45 & 4.8762 & TRN \\
\hline CHEMBL3189642 & 688171 & 4.9 & 4.8837 & TRN \\
\hline CHEMBL3208807 & 688171 & 5.15 & 4.9879 & TRN \\
\hline CHEMBL1372533 & 688171 & 7.2503 & 4.9246 & TRN \\
\hline CHEMBL1560014 & 688171 & 4.6 & 4.8586 & TRN \\
\hline CHEMBL1559218 & 688171 & 4.85 & 4.9847 & TST \\
\hline
\end{tabular}




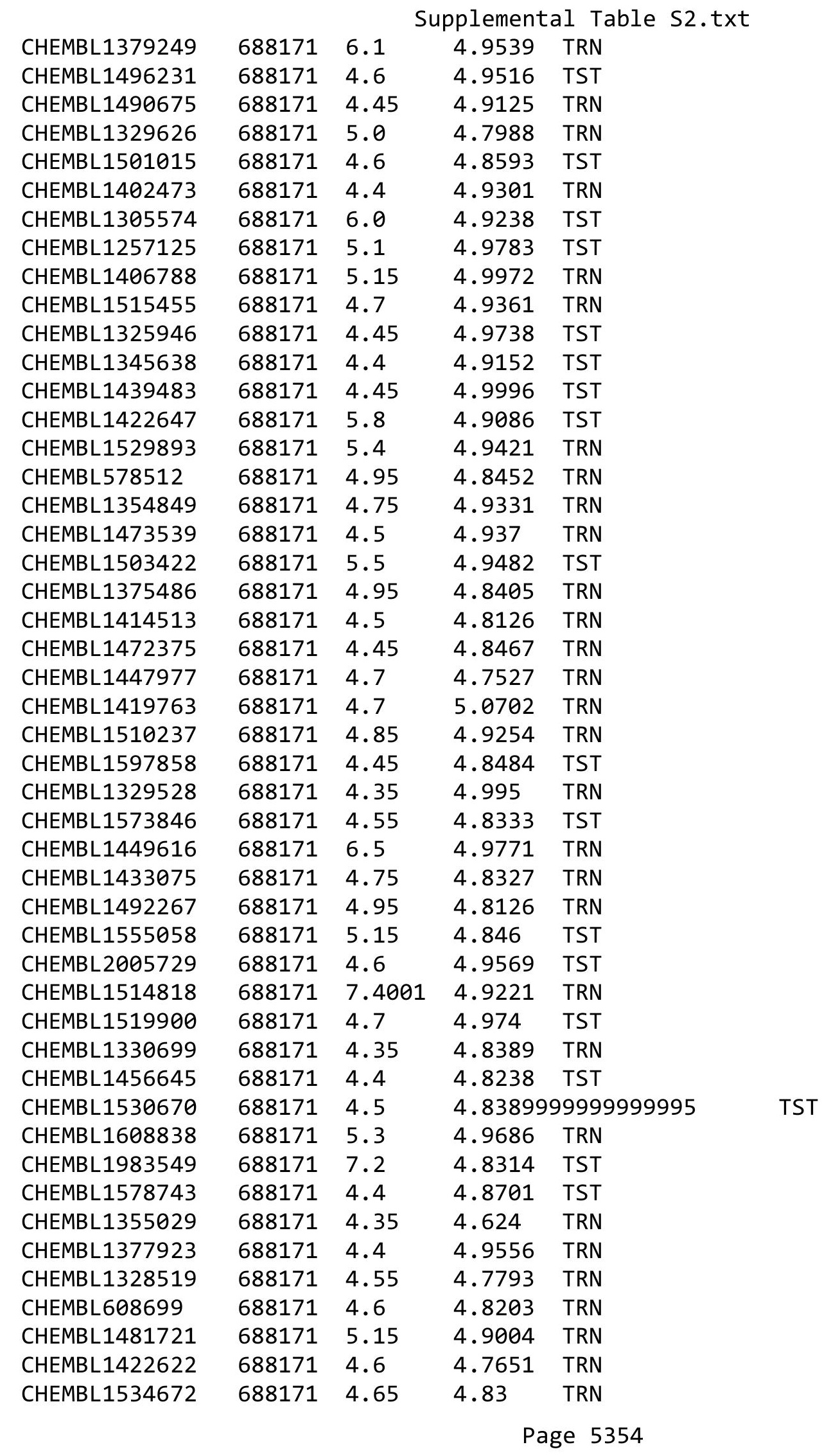




\begin{tabular}{|c|c|c|c|c|}
\hline \multicolumn{5}{|c|}{ Supplemental Table S2.txt } \\
\hline CHEMBL1513896 & 688171 & 4.4 & 5.1189 & TRN \\
\hline CHEMBL1512943 & 688171 & 4.4 & 4.9849 & TRN \\
\hline CHEMBL1486702 & 688171 & 4.55 & 4.8518 & TRN \\
\hline CHEMBL1554924 & 688171 & 4.4 & 5.0131 & TRN \\
\hline CHEMBL1433028 & 688171 & 4.85 & 4.9124 & TRN \\
\hline CHEMBL1386650 & 688171 & 4.65 & 4.8671 & TRN \\
\hline CHEMBL1333236 & 688171 & 5.0 & 5.0495 & TST \\
\hline CHEMBL1525024 & 688171 & 6.3 & 4.8329 & TRN \\
\hline CHEMBL1471154 & 688171 & 5.55 & 4.8936 & TRN \\
\hline CHEMBL1403884 & 688171 & 4.35 & 4.9214 & TRN \\
\hline CHEMBL77030 & 688171 & 6.0 & 4.8147 & TRN \\
\hline CHEMBL33103 & 688171 & 4.5 & 5.0618 & TRN \\
\hline CHEMBL1324519 & 688171 & 4.6 & 4.8117 & TRN \\
\hline CHEMBL1359154 & 688171 & 4.4 & 4.9358 & TST \\
\hline CHEMBL3214472 & 688171 & 5.5 & 4.9146 & TRN \\
\hline CHEMBL3195891 & 688171 & 4.8 & 4.8424 & TRN \\
\hline CHEMBL1459856 & 688171 & 4.7 & 4.9885 & TRN \\
\hline CHEMBL 2374044 & 688171 & 6.0 & 5.0339 & TST \\
\hline CHEMBL1553367 & 688171 & 4.65 & 4.8681 & TRN \\
\hline CHEMBL1436821 & 688171 & 5.1 & 5.0075 & TST \\
\hline CHEMBL1477603 & 688171 & 5.1 & 4.9971 & TRN \\
\hline CHEMBL1322708 & 688171 & 5.15 & 4.819 & TST \\
\hline CHEMBL1557372 & 688171 & 5.3 & 4.8938 & TRN \\
\hline CHEMBL1450973 & 688171 & 4.7 & 4.9847 & TRN \\
\hline CHEMBL602225 & 688171 & 5.0 & 4.9863 & TST \\
\hline CHEMBL1517464 & 688171 & 4.4 & 4.9765 & TRN \\
\hline CHEMBL1328853 & 688171 & 4.75 & 4.9493 & TRN \\
\hline CHEMBL1446934 & 688171 & 4.9 & 4.7915 & TRN \\
\hline CHEMBL1574618 & 688171 & 4.5 & 4.8634 & TST \\
\hline CHEMBL1536722 & 688171 & 4.7 & 4.8659 & TRN \\
\hline CHEMBL1489906 & 688171 & 4.5 & 4.9604 & TRN \\
\hline CHEMBL1483411 & 688171 & 5.0 & 4.8241 & TRN \\
\hline CHEMBL1371949 & 688171 & 5.05 & 4.8375 & TRN \\
\hline CHEMBL1336307 & 688171 & 4.8 & 4.9698 & TST \\
\hline CHEMBL1420454 & 688171 & 4.85 & 4.7788 & TRN \\
\hline CHEMBL1469597 & 688171 & 4.4 & 4.9602 & TRN \\
\hline CHEMBL3193771 & 688171 & 4.45 & 4.747 & TRN \\
\hline CHEMBL1311742 & 688171 & 5.05 & 4.8337 & TST \\
\hline CHEMBL1404031 & 688171 & 4.4 & 4.7945 & TST \\
\hline CHEMBL1362006 & 688171 & 5.2 & 4.7516 & TRN \\
\hline CHEMBL3193180 & 688171 & 4.45 & 4.9593 & TST \\
\hline CHEMBL1575169 & 688171 & 4.6 & 5.0253 & TRN \\
\hline CHEMBL1465409 & 688171 & 4.35 & 4.8192 & TRN \\
\hline CHEMBL1388972 & 688171 & 4.7 & 4.8626 & TRN \\
\hline CHEMBL1555810 & 688171 & 5.1 & 5.0219 & TRN \\
\hline CHEMBL1395028 & 688171 & 4.5 & 4.9629 & TRN \\
\hline CHEMBL1435127 & 688171 & 4.4 & 4.8284 & TRN \\
\hline CHEMBL1315854 & 688171 & 4.6 & 4.7962 & TRN \\
\hline
\end{tabular}




\begin{tabular}{|c|c|c|c|c|}
\hline \multicolumn{5}{|c|}{ Supplemental Table S2.txt } \\
\hline CHEMBL1613119 & 688171 & 4.85 & 4.8722 & TRN \\
\hline CHEMBL1581308 & 688171 & 4.75 & 4.8361 & TST \\
\hline CHEMBL1459569 & 688171 & 4.4 & 5.003 & TST \\
\hline CHEMBL1418821 & 688171 & 4.85 & 4.9991 & TST \\
\hline CHEMBL1964535 & 688171 & 4.75 & 4.819 & TST \\
\hline CHEMBL1373534 & 688171 & 5.0 & 4.9506 & TRN \\
\hline CHEMBL1472737 & 688171 & 4.35 & 4.9129 & TRN \\
\hline CHEMBL1480130 & 688171 & 4.6 & 4.9907 & TRN \\
\hline CHEMBL1486565 & 688171 & 4.55 & 4.8033 & TRN \\
\hline CHEMBL1478002 & 688171 & 4.8 & 4.8795 & TRN \\
\hline CHEMBL1473394 & 688171 & 4.95 & 4.9099 & TRN \\
\hline CHEMBL1385957 & 688171 & 4.7 & 4.9481 & TRN \\
\hline CHEMBL1505295 & 688171 & 4.95 & 4.9103 & TRN \\
\hline CHEMBL1367878 & 688171 & 4.8 & 4.9059 & TRN \\
\hline CHEMBL1567963 & 688171 & 4.4 & 4.8328 & TST \\
\hline CHEMBL1302331 & 688171 & 4.6 & 4.8197 & TRN \\
\hline CHEMBL1338210 & 688171 & 4.4 & 4.8105 & TRN \\
\hline CHEMBL1315385 & 688171 & 4.95 & 4.8285 & TRN \\
\hline CHEMBL1377117 & 688171 & 4.8 & 4.8565 & TRN \\
\hline CHEMBL1486842 & 688171 & 4.55 & 4.7863 & TRN \\
\hline CHEMBL600738 & 688171 & 4.95 & 4.9043 & TST \\
\hline CHEMBL1530560 & 688171 & 5.7 & 4.9257 & TRN \\
\hline CHEMBL3214121 & 688171 & 6.2 & 4.8218 & TST \\
\hline CHEMBL1349665 & 688171 & 4.45 & 4.9921 & TST \\
\hline CHEMBL1545738 & 688171 & 4.65 & 4.873 & TRN \\
\hline CHEMBL1390874 & 688171 & 4.8 & 4.8075 & TRN \\
\hline CHEMBL1444005 & 688171 & 4.55 & 5.0387 & TST \\
\hline CHEMBL1331134 & 688171 & 4.4 & 4.788 & TRN \\
\hline CHEMBL1441765 & 688171 & 4.55 & 4.8987 & TRN \\
\hline CHEMBL1425265 & 688171 & 5.0 & 4.7976 & TRN \\
\hline CHEMBL1498579 & 688171 & 6.05 & 4.9283 & TRN \\
\hline CHEMBL 2374066 & 688171 & 4.95 & 4.9857 & TST \\
\hline CHEMBL1423885 & 688171 & 7.2503 & 5.0203 & TRN \\
\hline CHEMBL1974389 & 688171 & 4.8 & 4.776 & TRN \\
\hline CHEMBL 3194087 & 688171 & 5.7 & 5.0368 & TRN \\
\hline CHEMBL1342645 & 688171 & 4.4 & 4.9343 & TST \\
\hline CHEMBL1423951 & 688171 & 4.55 & 4.862 & TST \\
\hline CHEMBL1522270 & 688171 & 4.9 & 4.9569 & TRN \\
\hline CHEMBL1577840 & 688171 & 4.75 & 4.762 & TST \\
\hline CHEMBL1393341 & 688171 & 4.9 & 4.8885 & TRN \\
\hline CHEMBL1588241 & 688171 & 7.6003 & 4.9144 & TRN \\
\hline CHEMBL1339398 & 688171 & 4.9 & 4.6725 & TST \\
\hline CHEMBL590691 & 688171 & 4.6 & 4.973 & TST \\
\hline CHEMBL1383078 & 688171 & 4.35 & 5.0346 & TRN \\
\hline CHEMBL1571595 & 688171 & 4.9 & 4.9387 & TRN \\
\hline CHEMBL1465506 & 688171 & 4.6 & 4.9925 & TRN \\
\hline CHEMBL 1420430 & 688171 & 4.95 & 4.851 & TRN \\
\hline CHEMBL1512857 & 688171 & 4.55 & 4.8417 & TRN \\
\hline
\end{tabular}




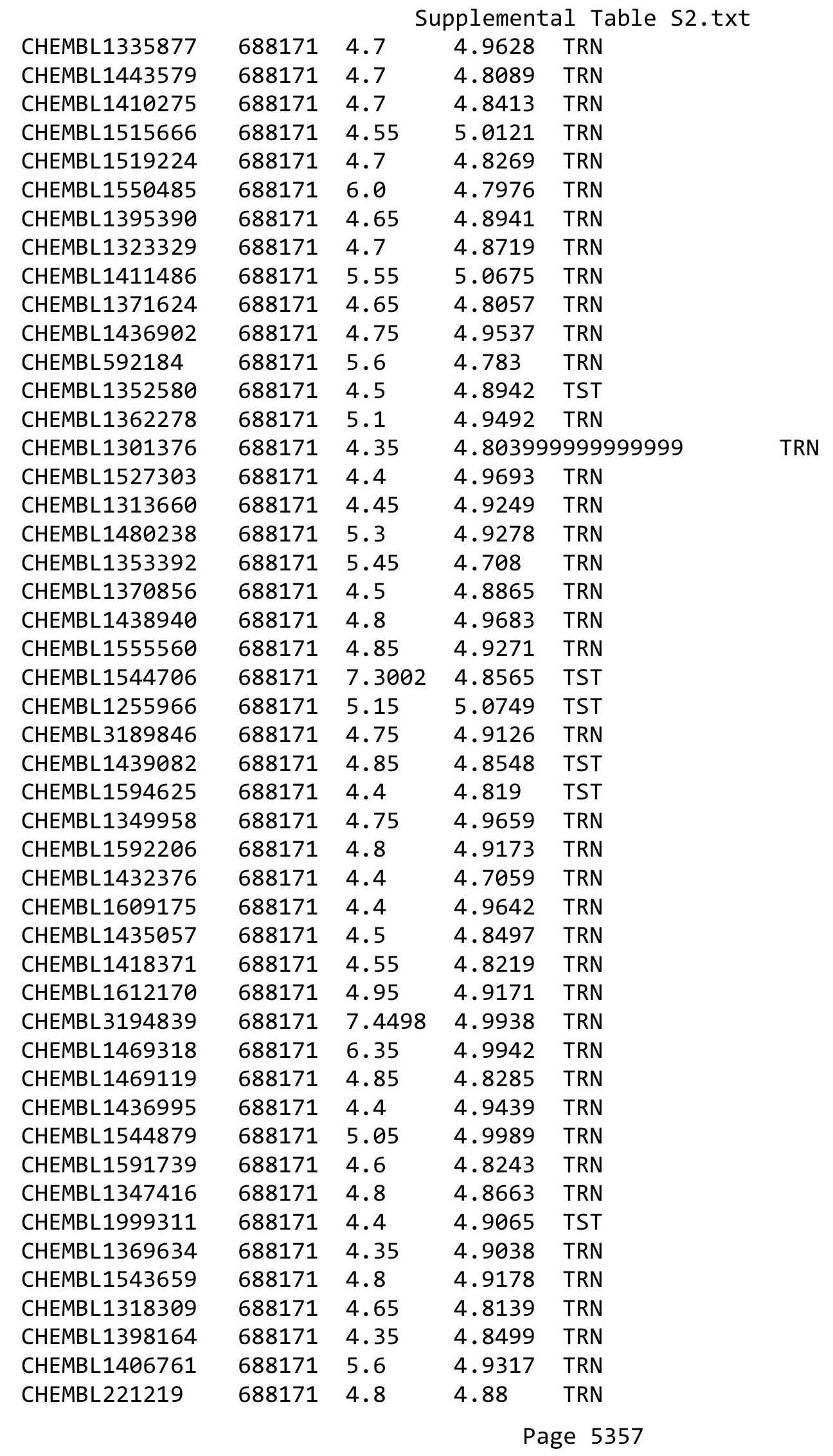




\begin{tabular}{|c|c|c|c|c|}
\hline \multicolumn{5}{|c|}{ Supplemental Table S2.txt } \\
\hline CHEMBL1352455 & 688171 & 5.6 & 4.8738 & TRN \\
\hline CHEMBL1457990 & 688171 & 4.7 & 4.8566 & TST \\
\hline CHEMBL1406404 & 688171 & 4.85 & 4.8796 & TST \\
\hline CHEMBL1411571 & 688171 & 4.85 & 5.0255 & TRN \\
\hline CHEMBL1324015 & 688171 & 4.4 & 4.829 & TST \\
\hline CHEMBL1412061 & 688171 & 4.35 & 4.9382 & TRN \\
\hline CHEMBL1452461 & 688171 & 5.15 & 5.0245 & TRN \\
\hline CHEMBL1383639 & 688171 & 4.6 & 4.9067 & TRN \\
\hline CHEMBL1555312 & 688171 & 4.4 & 4.9242 & TRN \\
\hline CHEMBL1401200 & 688171 & 4.7 & 4.9037 & TRN \\
\hline CHEMBL1613477 & 688171 & 6.0 & 4.8606 & TRN \\
\hline CHEMBL1425097 & 688171 & 6.2 & 4.9755 & TRN \\
\hline CHEMBL1326833 & 688171 & 4.8 & 4.9671 & TRN \\
\hline CHEMBL343732 & 688171 & 4.65 & 4.9806 & TRN \\
\hline CHEMBL3195985 & 688171 & 4.75 & 4.9127 & TRN \\
\hline CHEMBL1443431 & 688171 & 4.45 & 4.9078 & TRN \\
\hline CHEMBL1570010 & 688171 & 4.65 & 4.9747 & TRN \\
\hline CHEMBL600070 & 688171 & 5.5 & 4.9632 & TRN \\
\hline CHEMBL1610253 & 688171 & 4.4 & 4.9435 & TRN \\
\hline CHEMBL1449334 & 688171 & 4.8 & 4.8331 & TRN \\
\hline CHEMBL1402918 & 688171 & 4.85 & 4.8607 & TRN \\
\hline CHEMBL1420727 & 688171 & 4.7 & 4.9255 & TST \\
\hline CHEMBL1482215 & 688171 & 6.4 & 4.7197 & TST \\
\hline CHEMBL1589858 & 688171 & 4.65 & 4.8041 & TRN \\
\hline CHEMBL1484587 & 688171 & 5.45 & 4.9288 & TRN \\
\hline CHEMBL1424229 & 688171 & 4.85 & 4.7781 & TST \\
\hline CHEMBL1522486 & 688171 & 6.0 & 4.8956 & TRN \\
\hline CHEMBL1307689 & 688171 & 4.75 & 4.9083 & TRN \\
\hline CHEMBL1526996 & 688171 & 6.0 & 4.941 & TST \\
\hline CHEMBL1328209 & 688171 & 4.65 & 5.1006 & TRN \\
\hline CHEMBL1521184 & 688171 & 4.4 & 4.9784 & TRN \\
\hline CHEMBL1329140 & 688171 & 4.4 & 4.8313 & TRN \\
\hline CHEMBL1512157 & 688171 & 4.85 & 4.9375 & TRN \\
\hline CHEMBL595111 & 688171 & 4.5 & 5.0822 & TST \\
\hline CHEMBL1474809 & 688171 & 4.35 & 5.0586 & TST \\
\hline CHEMBL1384974 & 688171 & 4.85 & 4.8495 & TST \\
\hline CHEMBL1316151 & 688171 & 4.85 & 4.9516 & TRN \\
\hline CHEMBL1372613 & 688171 & 6.0 & 4.9637 & TRN \\
\hline CHEMBL1476182 & 688171 & 4.75 & 4.8043 & TRN \\
\hline CHEMBL1595804 & 688171 & 4.75 & 4.7813 & TRN \\
\hline CHEMBL1484297 & 688171 & 4.65 & 4.7771 & TRN \\
\hline CHEMBL1416515 & 688171 & 4.9 & 4.9317 & TRN \\
\hline CHEMBL1324957 & 688171 & 4.8 & 4.9498 & TRN \\
\hline CHEMBL1310329 & 688171 & 5.85 & 4.8845 & TRN \\
\hline CHEMBL1595074 & 688171 & 4.35 & 4.8496 & TRN \\
\hline CHEMBL1371598 & 688171 & 4.4 & 5.0369 & TRN \\
\hline CHEMBL1392030 & 688171 & 4.8 & 4.9046 & TRN \\
\hline CHEMBL1550243 & 688171 & 4.35 & 4.9651 & TRN \\
\hline
\end{tabular}




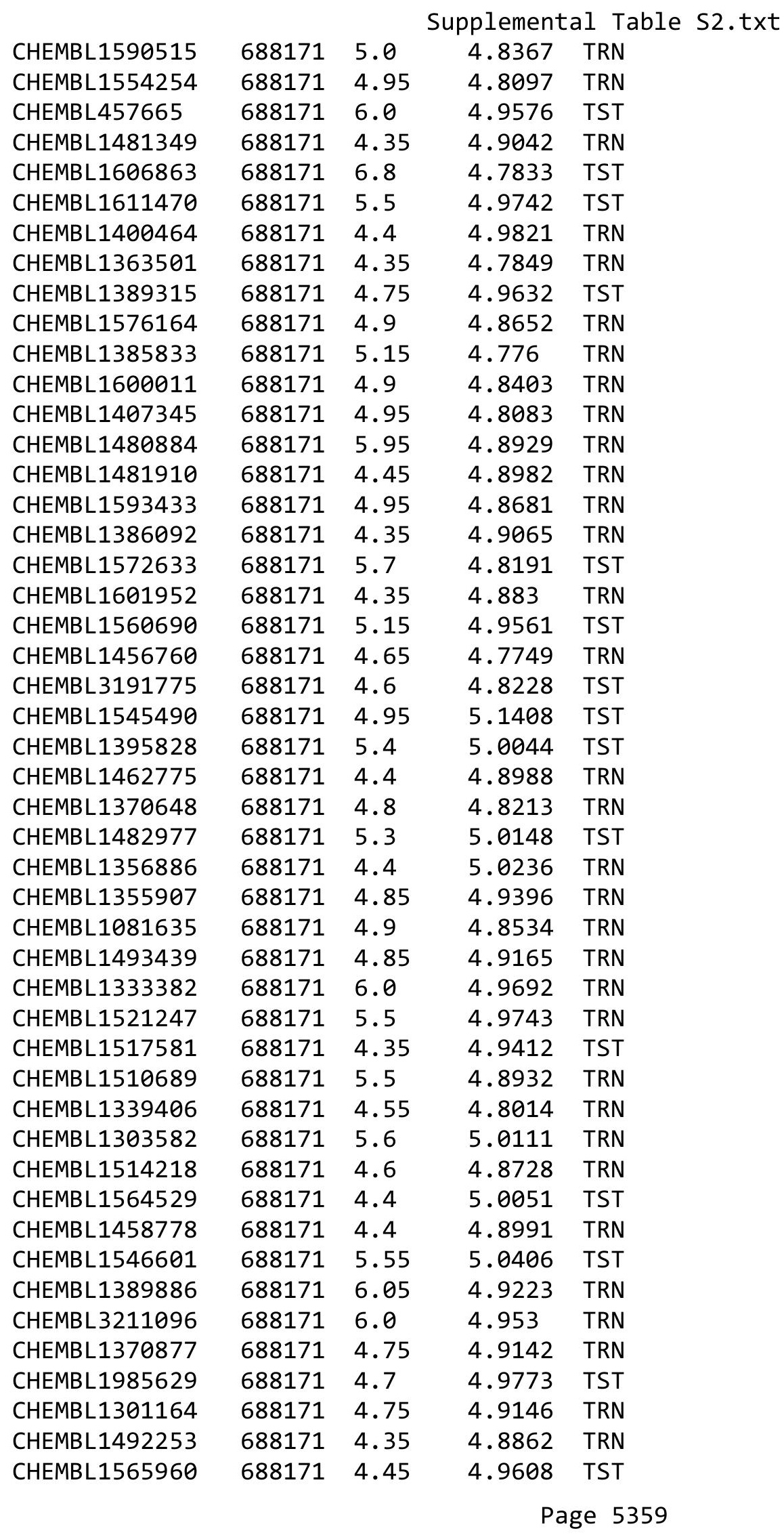




\begin{tabular}{|c|c|c|c|c|c|}
\hline \multicolumn{6}{|c|}{ Supplemental Table S2.txt } \\
\hline CHEMBL1480189 & 688171 & 4.9 & 5.011 & TRN & \\
\hline CHEMBL1496271 & 688171 & 4.45 & 4.9789 & TST & \\
\hline CHEMBL195789 & 688171 & 4.4 & 4.9035 & TRN & \\
\hline CHEMBL1395000 & 688171 & 4.9 & 4.9429 & TRN & \\
\hline CHEMBL1359993 & 688171 & 4.95 & 4.8619 & TST & \\
\hline CHEMBL337821 & 688171 & 6.1 & 4.977 & TRN & \\
\hline CHEMBL1392919 & 688171 & 4.65 & 4.9026 & TST & \\
\hline CHEMBL1535874 & 688171 & 4.95 & 4.8453 & TRN & \\
\hline CHEMBL582699 & 688171 & 4.4 & 4.8256 & TRN & \\
\hline CHEMBL1452154 & 688171 & 4.85 & 4.8685 & TRN & \\
\hline CHEMBL 3198295 & 688171 & 4.4 & 4.9674 & TRN & \\
\hline CHEMBL1341444 & 688171 & 4.35 & 4.8132 & TRN & \\
\hline CHEMBL1472387 & 688171 & 5.3 & 4.9642 & TST & \\
\hline CHEMBL1437230 & 688171 & 4.4 & 4.8285 & TRN & \\
\hline CHEMBL1487895 & 688171 & 4.65 & 4.9883 & TRN & \\
\hline CHEMBL1542473 & 688171 & 4.65 & 4.8837 & TRN & \\
\hline CHEMBL1480871 & 688171 & 4.5 & 4.8162 & TRN & \\
\hline CHEMBL1500422 & 688171 & 4.75 & 4.9183 & TRN & \\
\hline CHEMBL1394119 & 688171 & 4.75 & 4.8034 & TRN & \\
\hline CHEMBL1475037 & 688171 & 4.75 & 4.8409 & TRN & \\
\hline CHEMBL1423198 & 688171 & 4.95 & 4.8762 & TRN & \\
\hline CHEMBL1513560 & 688171 & 6.6 & 4.9259 & TRN & \\
\hline CHEMBL1450145 & 688171 & 4.85 & 4.8656 & TRN & \\
\hline CHEMBL3194994 & 688171 & 7.0 & 4.8646 & TST & \\
\hline CHEMBL1414729 & 688171 & 4.85 & 4.8548 & TST & \\
\hline CHEMBL1589300 & 688171 & 4.6 & 4.8334 & TRN & \\
\hline CHEMBL1729277 & 688171 & 4.35 & 4.9468 & TST & \\
\hline CHEMBL1455953 & 688171 & 4.4 & 4.8139 & TRN & \\
\hline CHEMBL1575502 & 688171 & 4.55 & 4.9175 & TRN & \\
\hline CHEMBL1483862 & 688171 & 6.45 & 4.9508 & TST & \\
\hline CHEMBL1345839 & 688171 & 6.35 & 4.988 & TST & \\
\hline CHEMBL1549267 & 688171 & 5.2 & 4.838 & TRN & \\
\hline CHEMBL1534425 & 688171 & 4.55 & 4.8045 & TRN & \\
\hline CHEMBL1492623 & 688171 & 4.55 & 4.8052 & TRN & \\
\hline CHEMBL1399653 & 688171 & 4.95 & 4.90300 & 00000000005 & TRN \\
\hline CHEMBL1456433 & 688171 & 4.9 & 4.9415 & TRN & \\
\hline CHEMBL1418610 & 688171 & 5.0 & 4.8711 & TST & \\
\hline CHEMBL1394057 & 688171 & 7.3002 & 5.063 & TRN & \\
\hline CHEMBL1514702 & 688171 & 4.95 & 5.0008 & TRN & \\
\hline CHEMBL1595518 & 688171 & 4.4 & 4.7806 & TRN & \\
\hline CHEMBL1576973 & 688171 & 4.4 & 5.0297 & TRN & \\
\hline CHEMBL403741 & 688171 & 4.8 & 4.8122 & TST & \\
\hline CHEMBL1482103 & 688171 & 4.35 & 5.052 & TRN & \\
\hline CHEMBL1400963 & 688171 & 5.0 & 4.9138 & TRN & \\
\hline CHEMBL1411343 & 688171 & 5.05 & 4.8379 & TST & \\
\hline CHEMBL1343568 & 688171 & 4.7 & 4.8699 & TRN & \\
\hline CHEMBL1579020 & 688171 & 5.15 & 4.8819 & TST & \\
\hline CHEMBL1343419 & 688171 & 4.85 & 4.9618 & TRN & \\
\hline
\end{tabular}




\begin{tabular}{|c|c|c|c|c|c|}
\hline \multicolumn{6}{|c|}{ Supplemental Table S2.txt } \\
\hline CHEMBL1524639 & 688171 & 4.4 & 4.803 & TRN & \\
\hline CHEMBL1520328 & 688171 & 5.0 & 4.882 & TRN & \\
\hline CHEMBL1482199 & 688171 & 4.4 & 4.9988 & TRN & \\
\hline CHEMBL3211413 & 688171 & 5.25 & 4.9625 & TRN & \\
\hline CHEMBL3213366 & 688171 & 4.7 & 4.8759 & TST & \\
\hline CHEMBL1482469 & 688171 & 4.8 & 5.0634 & TRN & \\
\hline CHEMBL1501140 & 688171 & 5.6 & 4.7607 & TRN & \\
\hline CHEMBL1473044 & 688171 & 4.55 & 4.84399 & 9999999999 & TRN \\
\hline CHEMBL1308950 & 688171 & 4.4 & 4.9401 & TRN & \\
\hline CHEMBL490106 & 688171 & 4.9 & 4.9052 & TRN & \\
\hline CHEMBL1552585 & 688171 & 5.8 & 4.8921 & TRN & \\
\hline CHEMBL1529547 & 688171 & 4.35 & 4.9369 & TRN & \\
\hline CHEMBL1320214 & 688171 & 4.95 & 4.8906 & TRN & \\
\hline CHEMBL1349952 & 688171 & 5.0 & 4.9899 & TRN & \\
\hline CHEMBL1529873 & 688171 & 4.75 & 4.8628 & TRN & \\
\hline CHEMBL1314139 & 688171 & 4.85 & 4.9295 & TRN & \\
\hline CHEMBL1392256 & 688171 & 4.35 & 4.8366 & TRN & \\
\hline CHEMBL3199198 & 688171 & 4.7 & 4.857 & TRN & \\
\hline CHEMBL1515852 & 688171 & 6.0 & 4.9084 & TRN & \\
\hline CHEMBL1363654 & 688171 & 5.55 & 4.9385 & TRN & \\
\hline CHEMBL1439666 & 688171 & 5.45 & 4.9045 & TRN & \\
\hline CHEMBL1506579 & 688171 & 4.45 & 5.0138 & TST & \\
\hline CHEMBL1454661 & 688171 & 4.4 & 4.9281 & TRN & \\
\hline CHEMBL1333507 & 688171 & 5.9 & 4.8772 & TST & \\
\hline CHEMBL1299291 & 688171 & 4.75 & 4.9759 & TST & \\
\hline CHEMBL1585333 & 688171 & 4.6 & 5.0167 & TRN & \\
\hline CHEMBL1549770 & 688171 & 4.4 & 4.9436 & TRN & \\
\hline CHEMBL1494630 & 688171 & 4.85 & 4.9141 & TST & \\
\hline CHEMBL1511797 & 688171 & 4.6 & 4.8882 & TRN & \\
\hline CHEMBL1592358 & 688171 & 4.6 & 4.9714 & TRN & \\
\hline CHEMBL1398180 & 688171 & 4.7 & 4.9365 & TRN & \\
\hline CHEMBL1481578 & 688171 & 5.0 & 4.8676 & TST & \\
\hline CHEMBL1170688 & 688171 & 5.0 & 4.8719 & TRN & \\
\hline CHEMBL1305350 & 688171 & 4.5 & 4.8036 & TRN & \\
\hline CHEMBL1323621 & 688171 & 4.45 & 4.9466 & TRN & \\
\hline CHEMBL1520336 & 688171 & 4.65 & 5.0538 & TRN & \\
\hline CHEMBL1404658 & 688171 & 4.75 & 4.8209 & TRN & \\
\hline CHEMBL1524195 & 688171 & 5.05 & 4.9487 & TST & \\
\hline CHEMBL3199884 & 688171 & 4.7 & 4.94600 & 2000000001 & TRN \\
\hline CHEMBL1358953 & 688171 & 4.9 & 4.7294 & TRN & \\
\hline CHEMBL1568565 & 688171 & 5.7 & 4.9328 & TRN & \\
\hline CHEMBL1496838 & 688171 & 4.55 & 4.8202 & TRN & \\
\hline CHEMBL1504009 & 688171 & 4.5 & 4.7632 & TRN & \\
\hline CHEMBL1315806 & 688171 & 5.45 & 4.9227 & TRN & \\
\hline CHEMBL53898 & 688171 & 4.8 & 4.9821 & TRN & \\
\hline CHEMBL1397947 & 688171 & 4.95 & 4.995 & TRN & \\
\hline CHEMBL1497072 & 688171 & 6.0 & 4.8822 & TRN & \\
\hline CHEMBL1352281 & 688171 & 5.35 & 4.9027 & TRN & \\
\hline
\end{tabular}




\begin{tabular}{|c|c|c|c|c|}
\hline \multicolumn{5}{|c|}{ Supplemental Table S2.txt } \\
\hline CHEMBL1416129 & 688171 & 4.55 & 4.8604 & TRN \\
\hline CHEMBL1536942 & 688171 & 4.65 & 4.8675 & TRN \\
\hline CHEMBL1437049 & 688171 & 4.85 & 4.8296 & TRN \\
\hline CHEMBL3199737 & 688171 & 4.55 & 4.8797 & TST \\
\hline CHEMBL1395131 & 688171 & 4.4 & 4.7996 & TRN \\
\hline CHEMBL1332997 & 688171 & 4.35 & 5.0629 & TRN \\
\hline CHEMBL1613100 & 688171 & 5.25 & 4.8954 & TRN \\
\hline CHEMBL1465682 & 688171 & 4.4 & 5.0267 & TRN \\
\hline CHEMBL 1448272 & 688171 & 5.95 & 5.1086 & TRN \\
\hline CHEMBL1304631 & 688171 & 4.45 & 4.8527 & TRN \\
\hline CHEMBL1393047 & 688171 & 4.75 & 4.8646 & TRN \\
\hline CHEMBL1462168 & 688171 & 4.85 & 4.8794 & TRN \\
\hline CHEMBL1409898 & 688171 & 5.35 & 5.0405 & TST \\
\hline CHEMBL1604919 & 688171 & 4.4 & 4.8201 & TRN \\
\hline CHEMBL1591770 & 688171 & 5.05 & 5.0831 & TST \\
\hline CHEMBL1416781 & 688171 & 4.5 & 4.9077 & TRN \\
\hline CHEMBL1486700 & 688171 & 7.6498 & 4.9698 & TRN \\
\hline CHEMBL1342894 & 688171 & 4.95 & 4.848 & TRN \\
\hline CHEMBL1344611 & 688171 & 4.45 & 4.8681 & TRN \\
\hline CHEMBL1610654 & 688171 & 5.75 & 4.9289 & TST \\
\hline CHEMBL1416242 & 688171 & 4.4 & 4.7791 & TRN \\
\hline CHEMBL1380059 & 688171 & 4.85 & 4.869 & TST \\
\hline CHEMBL1378157 & 688171 & 5.4 & 4.8889 & TST \\
\hline CHEMBL1305758 & 688171 & 5.15 & 4.919 & TST \\
\hline CHEMBL531990 & 688171 & 5.35 & 5.0973 & TST \\
\hline CHEMBL1552449 & 688171 & 4.7 & 4.8905 & TRN \\
\hline CHEMBL1347368 & 688171 & 5.95 & 4.8568 & TST \\
\hline CHEMBL1370891 & 688171 & 5.1 & 5.0428 & TRN \\
\hline CHEMBL1593009 & 688171 & 4.85 & 4.9303 & TRN \\
\hline CHEMBL1495890 & 688171 & 4.4 & 5.0088 & TST \\
\hline CHEMBL1566685 & 688171 & 4.85 & 4.9147 & TRN \\
\hline CHEMBL1345268 & 688171 & 4.75 & 4.8831 & TST \\
\hline CHEMBL1317320 & 688171 & 4.4 & 4.8909 & TRN \\
\hline CHEMBL1334452 & 688171 & 4.55 & 4.9677 & TRN \\
\hline CHEMBL1516198 & 688171 & 4.5 & 4.8888 & TRN \\
\hline CHEMBL1477306 & 688171 & 5.85 & 4.8923 & TRN \\
\hline CHEMBL1337969 & 688171 & 4.75 & 4.8674 & TRN \\
\hline CHEMBL1598269 & 688171 & 7.6003 & 4.9254 & TRN \\
\hline CHEMBL1584646 & 688171 & 4.7 & 4.7588 & TST \\
\hline CHEMBL1462615 & 688171 & 4.55 & 4.8542 & TST \\
\hline CHEMBL1520512 & 688171 & 5.25 & 5.0042 & TST \\
\hline CHEMBL1378504 & 688171 & 5.0 & 5.0158 & TST \\
\hline CHEMBL1355069 & 688171 & 4.85 & 4.9781 & TRN \\
\hline CHEMBL3209806 & 688171 & 6.5 & 4.9064 & TRN \\
\hline CHEMBL1354555 & 688171 & 4.55 & 5.0237 & TRN \\
\hline CHEMBL1577745 & 688171 & 4.75 & 4.8664 & TRN \\
\hline CHEMBL1305152 & 688171 & 4.5 & 4.9589 & TST \\
\hline CHEMBL1446749 & 688171 & 4.45 & 4.863 & TRN \\
\hline
\end{tabular}




\begin{tabular}{|c|c|c|c|c|c|}
\hline \multicolumn{6}{|c|}{ Supplemental Table S2.txt } \\
\hline CHEMBL3199433 & 688171 & 4.95 & 4.9096 & TST & \\
\hline CHEMBL1501086 & 688171 & 4.75 & 4.8969 & TST & \\
\hline CHEMBL1600105 & 688171 & 4.4 & 4.8513 & TST & \\
\hline CHEMBL1345838 & 688171 & 4.4 & 4.8315 & TRN & \\
\hline CHEMBL1470331 & 688171 & 4.75 & 4.9324 & TRN & \\
\hline CHEMBL1395651 & 688171 & 5.35 & 4.859 & TRN & \\
\hline CHEMBL1365118 & 688171 & 4.55 & 4.8982 & TRN & \\
\hline CHEMBL1508833 & 688171 & 4.35 & 4.9968 & TRN & \\
\hline CHEMBL1302848 & 688171 & 4.55 & 5.0197 & TRN & \\
\hline CHEMBL1457617 & 688171 & 5.15 & 4.9083 & TRN & \\
\hline CHEMBL1530526 & 688171 & 4.35 & 4.872 & TST & \\
\hline CHEMBL1461725 & 688171 & 4.9 & 4.956 & TRN & \\
\hline CHEMBL1499123 & 688171 & 4.55 & 5.08 & TRN & \\
\hline CHEMBL1597490 & 688171 & 4.6 & 4.9948 & TRN & \\
\hline CHEMBL1350539 & 688171 & 5.45 & 4.9795 & TST & \\
\hline CHEMBL1332442 & 688171 & 4.65 & 4.9095 & TRN & \\
\hline CHEMBL1613195 & 688171 & 5.05 & 4.8376 & TRN & \\
\hline CHEMBL1466810 & 688171 & 4.4 & 4.9616 & TRN & \\
\hline CHEMBL1594061 & 688171 & 4.55 & 4.9207 & TRN & \\
\hline CHEMBL1435969 & 688171 & 4.75 & 4.8703 & TRN & \\
\hline CHEMBL1522555 & 688171 & 4.65 & 4.8804 & TRN & \\
\hline CHEMBL1547674 & 688171 & 5.1 & 4.9593 & TRN & \\
\hline CHEMBL1575038 & 688171 & 4.55 & 4.8359 & TRN & \\
\hline CHEMBL1610593 & 688171 & 4.65 & 4.9453 & TRN & \\
\hline CHEMBL 3199796 & 688171 & 4.4 & 4.9407 & TRN & \\
\hline CHEMBL1565540 & 688171 & 4.6 & 4.7659 & TRN & \\
\hline CHEMBL1416874 & 688171 & 4.7 & 4.9533 & TRN & \\
\hline CHEMBL1428977 & 688171 & 4.6 & 4.7684 & TRN & \\
\hline CHEMBL1414096 & 688171 & 4.65 & 4.9879 & TRN & \\
\hline CHEMBL1612837 & 688171 & 4.4 & 4.8793 & TST & \\
\hline CHEMBL1480577 & 688171 & 4.35 & 4.8369 & TST & \\
\hline CHEMBL 3196856 & 688171 & 4.4 & 4.8653 & TRN & \\
\hline CHEMBL 3192223 & 688171 & 5.7 & 5.035 & TRN & \\
\hline CHEMBL1606239 & 688171 & 4.5 & 4.8504 & TST & \\
\hline CHEMBL1437321 & 688171 & 4.75 & 4.9907 & TRN & \\
\hline CHEMBL1505246 & 688171 & 5.0 & 4.9253 & TRN & \\
\hline CHEMBL1326235 & 688171 & 4.5 & 4.996 & TRN & \\
\hline CHEMBL1541930 & 688171 & 4.35 & 4.88399 & 99999999995 & TRN \\
\hline CHEMBL1445809 & 688171 & 4.4 & 5.0011 & TRN & \\
\hline CHEMBL3392069 & 688171 & 4.6 & 4.7789 & TST & \\
\hline CHEMBL1506548 & 688171 & 4.45 & 4.8092 & TRN & \\
\hline CHEMBL1995692 & 688171 & 4.65 & 4.8948 & TRN & \\
\hline CHEMBL1534709 & 688171 & 4.75 & 4.80399 & 9999999999 & TRN \\
\hline CHEMBL 1556395 & 688171 & 4.4 & 4.9552 & TRN & \\
\hline CHEMBL1442511 & 688171 & 4.75 & 4.9252 & TRN & \\
\hline CHEMBL1485379 & 688171 & 5.0 & 4.8927 & TRN & \\
\hline CHEMBL1495680 & 688171 & 4.6 & 4.8401 & TRN & \\
\hline CHEMBL1398717 & 688171 & 5.0 & 4.9344 & TRN & \\
\hline
\end{tabular}




\begin{tabular}{|c|c|c|c|c|c|}
\hline \multicolumn{6}{|c|}{ Supplemental Table S2.txt } \\
\hline CHEMBL1578346 & 688171 & 4.75 & 5.0309 & TRN & \\
\hline CHEMBL1583379 & 688171 & 5.1 & 4.9557 & TRN & \\
\hline CHEMBL1310710 & 688171 & 4.55 & 4.8298 & TRN & \\
\hline CHEMBL1601073 & 688171 & 4.55 & 4.7585 & TRN & \\
\hline CHEMBL1384289 & 688171 & 4.75 & 4.8948 & TRN & \\
\hline CHEMBL1465815 & 688171 & 4.4 & 4.82 & TRN & \\
\hline CHEMBL1359995 & 688171 & 4.7 & 4.8782 & TRN & \\
\hline CHEMBL1451478 & 688171 & 5.05 & 4.9261 & TST & \\
\hline CHEMBL1431920 & 688171 & 6.5 & 4.96399 & 99999999995 & TRN \\
\hline CHEMBL1413229 & 688171 & 4.4 & 4.9804 & TRN & \\
\hline CHEMBL486541 & 688171 & 4.45 & 4.9323 & TRN & \\
\hline CHEMBL1552155 & 688171 & 4.95 & 4.9404 & TRN & \\
\hline CHEMBL1584540 & 688171 & 5.05 & 4.9061 & TRN & \\
\hline CHEMBL1409460 & 688171 & 4.45 & 4.82 & TST & \\
\hline CHEMBL 1577090 & 688171 & 5.0 & 4.8983 & TRN & \\
\hline CHEMBL1209962 & 688171 & 4.4 & 4.9516 & TRN & \\
\hline CHEMBL1528373 & 688171 & 5.05 & 4.8827 & TRN & \\
\hline CHEMBL3189392 & 688171 & 4.35 & 4.8756 & TRN & \\
\hline CHEMBL1397735 & 688171 & 5.55 & 4.8139 & TRN & \\
\hline CHEMBL3192160 & 688171 & 4.4 & 4.9384 & TRN & \\
\hline CHEMBL1345942 & 688171 & 6.8 & 4.9478 & TST & \\
\hline CHEMBL1563920 & 688171 & 6.0 & 4.98300 & 00000000005 & TRN \\
\hline CHEMBL1499585 & 688171 & 5.3 & 4.8078 & TRN & \\
\hline CHEMBL1401767 & 688171 & 4.55 & 4.9386 & TRN & \\
\hline CHEMBL1339764 & 688171 & 4.65 & 4.9223 & TST & \\
\hline CHEMBL1546651 & 688171 & 4.7 & 4.8178 & TRN & \\
\hline CHEMBL3209683 & 688171 & 5.4 & 4.8516 & TRN & \\
\hline CHEMBL1479605 & 688171 & 5.35 & 4.9824 & TRN & \\
\hline CHEMBL1516537 & 688171 & 4.55 & 4.7855 & TRN & \\
\hline CHEMBL1445972 & 688171 & 4.4 & 4.8717 & TRN & \\
\hline CHEMBL1331751 & 688171 & 6.0 & 4.8942 & TRN & \\
\hline CHEMBL1979800 & 688171 & 5.35 & 5.0893 & TRN & \\
\hline CHEMBL1359429 & 688171 & 5.05 & 4.8972 & TST & \\
\hline CHEMBL1530929 & 688171 & 4.85 & 4.782 & TRN & \\
\hline CHEMBL1331880 & 688171 & 4.85 & 4.82 & TRN & \\
\hline CHEMBL1558863 & 688171 & 5.35 & 4.8622 & TRN & \\
\hline CHEMBL1555535 & 688171 & 4.7 & 4.9149 & TST & \\
\hline CHEMBL1411002 & 688171 & 5.45 & 4.9159 & TRN & \\
\hline CHEMBL1531208 & 688171 & 4.65 & 4.9127 & TRN & \\
\hline CHEMBL1573719 & 688171 & 5.0 & 4.7166 & TST & \\
\hline CHEMBL1584268 & 688171 & 4.5 & 4.7998 & TRN & \\
\hline CHEMBL1409862 & 688171 & 4.75 & 4.8333 & TRN & \\
\hline CHEMBL3195471 & 688171 & 5.1 & 4.8361 & TRN & \\
\hline CHEMBL1386784 & 688171 & 4.55 & 4.9396 & TST & \\
\hline CHEMBL1526157 & 688171 & 4.4 & 4.9609 & TRN & \\
\hline CHEMBL1410451 & 688171 & 4.55 & 4.8523 & TRN & \\
\hline CHEMBL1593564 & 688171 & 7.1002 & 5.0017 & TRN & \\
\hline CHEMBL1428649 & 688171 & 4.75 & 4.9563 & TST & \\
\hline
\end{tabular}




\begin{tabular}{|c|c|c|c|c|c|}
\hline \multicolumn{6}{|c|}{ Supplemental Table s2.txt } \\
\hline CHEMBL1589902 & 688171 & 4.4 & 4.8319 & TRN & \\
\hline CHEMBL1474061 & 688171 & 5.65 & 4.8932 & TRN & \\
\hline CHEMBL1443174 & 688171 & 5.4 & 4.8976 & TRN & \\
\hline CHEMBL1404788 & 688171 & 5.4 & 4.8712 & TRN & \\
\hline CHEMBL1430473 & 688171 & 4.85 & 4.9583 & TST & \\
\hline CHEMBL1299500 & 688171 & 4.9 & 4.8225 & TRN & \\
\hline CHEMBL1308654 & 688171 & 4.4 & 4.9889 & TST & \\
\hline CHEMBL410063 & 688171 & 6.0 & 4.898 & TST & \\
\hline CHEMBL1395381 & 688171 & 4.4 & 4.8835 & TST & \\
\hline CHEMBL1593515 & 688171 & 4.65 & 4.9932 & TRN & \\
\hline CHEMBL1543193 & 688171 & 4.65 & 4.9756 & TRN & \\
\hline CHEMBL1364577 & 688171 & 4.4 & 4.80699 & 99999999995 & TRN \\
\hline CHEMBL1577147 & 688171 & 5.15 & 4.9889 & TRN & \\
\hline CHEMBL1323181 & 688171 & 4.35 & 5.0391 & TST & \\
\hline CHEMBL1312903 & 688171 & 4.4 & 5.1049 & TRN & \\
\hline CHEMBL1572827 & 688171 & 4.8 & 4.9559 & TST & \\
\hline CHEMBL1498173 & 688171 & 5.5 & 5.0625 & TST & \\
\hline CHEMBL1557407 & 688171 & 4.45 & 4.84699 & 99999999995 & TRN \\
\hline CHEMBL1600781 & 688171 & 4.65 & 4.6978 & TRN & \\
\hline CHEMBL1445879 & 688171 & 4.9 & 4.9026 & TRN & \\
\hline CHEMBL1419964 & 688171 & 4.65 & 5.0085 & TRN & \\
\hline CHEMBL1320868 & 688171 & 4.95 & 4.9434 & TRN & \\
\hline CHEMBL3209251 & 688171 & 6.5 & 4.8685 & TRN & \\
\hline CHEMBL1557300 & 688171 & 4.35 & 4.9411 & TRN & \\
\hline CHEMBL1436338 & 688171 & 4.9 & 4.882 & TRN & \\
\hline CHEMBL1459406 & 688171 & 5.4 & 4.9064 & TRN & \\
\hline CHEMBL1397552 & 688171 & 5.7 & 5.0741 & TRN & \\
\hline CHEMBL1414723 & 688171 & 5.0 & 4.8618 & TRN & \\
\hline CHEMBL1388457 & 688171 & 4.55 & 4.886 & TST & \\
\hline CHEMBL3209703 & 688171 & 4.8 & 4.9652 & TRN & \\
\hline CHEMBL1519463 & 688171 & 4.35 & 4.9056 & TST & \\
\hline CHEMBL1536570 & 688171 & 6.5 & 4.9571 & TST & \\
\hline CHEMBL3189339 & 688171 & 4.9 & 4.9332 & TRN & \\
\hline CHEMBL3198636 & 688171 & 4.35 & 4.9988 & TST & \\
\hline CHEMBL1535202 & 688171 & 4.7 & 5.0104 & TST & \\
\hline CHEMBL1394967 & 688171 & 5.0 & 4.9672 & TRN & \\
\hline CHEMBL1491849 & 688171 & 4.5 & 4.8634 & TRN & \\
\hline CHEMBL1339825 & 688171 & 5.05 & 4.9036 & TST & \\
\hline CHEMBL1467324 & 688171 & 5.05 & 4.9248 & TRN & \\
\hline CHEMBL1434909 & 688171 & 5.0 & 4.8408 & TRN & \\
\hline CHEMBL1333268 & 688171 & 4.65 & 4.8799 & TRN & \\
\hline CHEMBL1513005 & 688171 & 4.5 & 4.9406 & TST & \\
\hline CHEMBL1493743 & 688171 & 4.5 & 4.8431 & TRN & \\
\hline CHEMBL1457427 & 688171 & 4.8 & 4.828 & TRN & \\
\hline CHEMBL1494644 & 688171 & 4.85 & 4.9317 & TST & \\
\hline CHEMBL1353819 & 688171 & 4.4 & 4.813 & TRN & \\
\hline CHEMBL1350293 & 688171 & 4.35 & 4.9284 & TRN & \\
\hline CHEMBL1443184 & 688171 & 4.95 & 4.8581 & TRN & \\
\hline
\end{tabular}




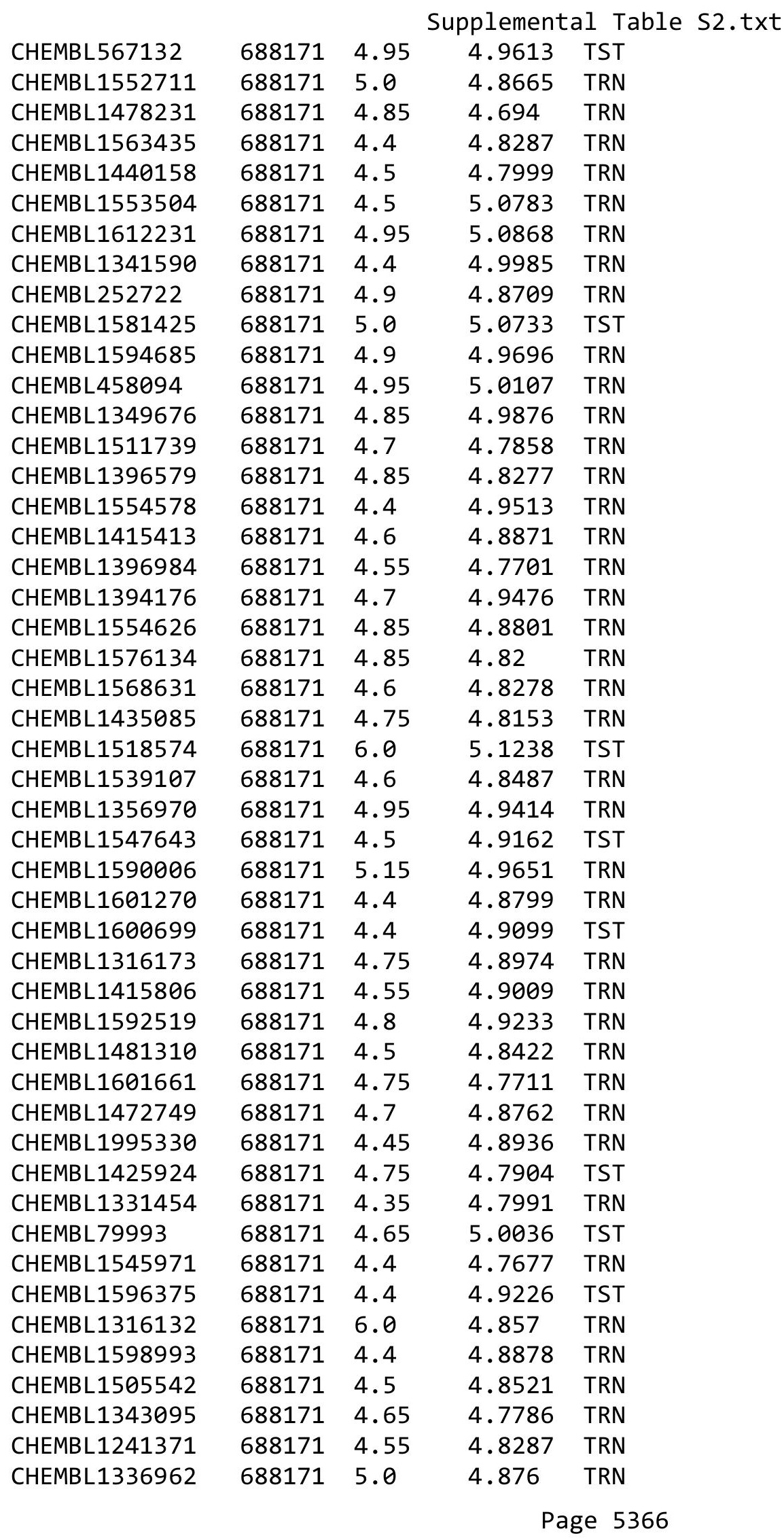




\begin{tabular}{|c|c|c|c|c|c|}
\hline \multicolumn{6}{|c|}{ Supplemental Table S2.txt } \\
\hline CHEMBL1434827 & 688171 & 4.7 & 4.982 & TST & \\
\hline CHEMBL1373783 & 688171 & 5.0 & 4.788 & TRN & \\
\hline CHEMBL1381206 & 688171 & 4.85 & 4.9955 & TST & \\
\hline CHEMBL1355898 & 688171 & 6.5501 & 4.8983 & TRN & \\
\hline CHEMBL1317480 & 688171 & 4.65 & 4.9458 & TRN & \\
\hline CHEMBL1417305 & 688171 & 4.55 & 4.8358 & TRN & \\
\hline CHEMBL1386096 & 688171 & 4.6 & 4.8335 & TRN & \\
\hline CHEMBL3189546 & 688171 & 4.7 & 4.8591 & TST & \\
\hline CHEMBL1509668 & 688171 & 4.7 & 4.945 & TRN & \\
\hline CHEMBL1521127 & 688171 & 4.35 & 4.8345 & TRN & \\
\hline CHEMBL1424565 & 688171 & 4.7 & 5.0667 & TST & \\
\hline CHEMBL2369184 & 688171 & 4.4 & 4.9012 & TST & \\
\hline CHEMBL1514423 & 688171 & 4.5 & 4.7994 & TRN & \\
\hline CHEMBL 3212049 & 688171 & 4.5 & 4.9796 & TRN & \\
\hline CHEMBL1552434 & 688171 & 4.8 & 4.8228 & TRN & \\
\hline CHEMBL1430741 & 688171 & 4.75 & 4.9554 & TST & \\
\hline CHEMBL1559255 & 688171 & 4.35 & 4.9022 & TRN & \\
\hline CHEMBL1541655 & 688171 & 4.9 & 4.9177 & TRN & \\
\hline CHEMBL1430684 & 688171 & 5.4 & 4.8676 & TRN & \\
\hline CHEMBL1531253 & 688171 & 4.4 & 4.9865 & TST & \\
\hline CHEMBL1510898 & 688171 & 6.2 & 4.8959 & TST & \\
\hline CHEMBL1442234 & 688171 & 4.5 & 4.8866 & TRN & \\
\hline CHEMBL1357748 & 688171 & 4.65 & 4.89199 & 99999999995 & TRN \\
\hline CHEMBL1597991 & 688171 & 4.95 & 4.8526 & TST & \\
\hline CHEMBL1308548 & 688171 & 5.4 & 4.9679 & TRN & \\
\hline CHEMBL1310036 & 688171 & 4.85 & 4.8136 & TRN & \\
\hline CHEMBL1453623 & 688171 & 5.55 & 4.7 & TRN & \\
\hline CHEMBL1436230 & 688171 & 5.1 & 4.9398 & TRN & \\
\hline CHEMBL1562993 & 688171 & 5.0 & 4.8917 & TST & \\
\hline CHEMBL600968 & 688171 & 4.95 & 4.8109 & TRN & \\
\hline CHEMBL1325376 & 688171 & 4.7 & 4.9093 & TRN & \\
\hline CHEMBL1454433 & 688171 & 5.05 & 4.9792 & TST & \\
\hline CHEMBL3198339 & 688171 & 4.7 & 4.9724 & TRN & \\
\hline CHEMBL1986582 & 688171 & 5.25 & 4.9395 & TRN & \\
\hline CHEMBL1592953 & 688171 & 4.4 & 4.8759 & TRN & \\
\hline CHEMBL1329679 & 688171 & 4.65 & 4.8961 & TRN & \\
\hline CHEMBL1550511 & 688171 & 4.9 & 4.8786 & TRN & \\
\hline CHEMBL1593945 & 688171 & 4.7 & 4.9372 & TRN & \\
\hline CHEMBL1433471 & 688171 & 4.9 & 4.7707 & TRN & \\
\hline CHEMBL1480588 & 688171 & 5.25 & 4.771 & TRN & \\
\hline CHEMBL1326930 & 688171 & 5.85 & 4.9607 & TST & \\
\hline CHEMBL1463187 & 688171 & 5.7 & 4.9117 & TRN & \\
\hline CHEMBL140979 & 688171 & 5.5 & 5.0077 & TST & \\
\hline CHEMBL1483129 & 688171 & 5.1 & 4.8726 & TST & \\
\hline CHEMBL1382774 & 688171 & 4.4 & 4.9175 & TST & \\
\hline CHEMBL1516259 & 688171 & 4.45 & 4.98600 & 0000000001 & TRN \\
\hline CHEMBL1430882 & 688171 & 4.4 & 4.853 & TST & \\
\hline CHEMBL428789 & 688171 & 5.25 & 4.9393 & TRN & \\
\hline
\end{tabular}




\begin{tabular}{|c|c|c|c|c|c|}
\hline \multicolumn{6}{|c|}{ Supplemental Table S2.txt } \\
\hline CHEMBL1578345 & 688171 & 5.0 & 4.8597 & TRN & \\
\hline CHEMBL3196878 & 688171 & 5.4 & 4.8506 & TST & \\
\hline CHEMBL1348701 & 688171 & 5.0 & 4.9517 & TST & \\
\hline CHEMBL1514255 & 688171 & 5.35 & 4.8381 & TRN & \\
\hline CHEMBL1401679 & 688171 & 5.9 & 5.03 & TRN & \\
\hline CHEMBL1300999 & 688171 & 4.7 & 4.854 & TRN & \\
\hline CHEMBL1444918 & 688171 & 4.6 & 4.8808 & TST & \\
\hline CHEMBL1587098 & 688171 & 5.8 & 4.8687 & TRN & \\
\hline CHEMBL1403891 & 688171 & 6.45 & 5.0119 & TRN & \\
\hline CHEMBL1534327 & 688171 & 5.5 & 4.8554 & TRN & \\
\hline CHEMBL1477979 & 688171 & 5.35 & 4.9701 & TST & \\
\hline CHEMBL1371814 & 688171 & 4.5 & 4.7746 & TRN & \\
\hline CHEMBL1391445 & 688171 & 5.75 & 4.8682 & TST & \\
\hline CHEMBL1360691 & 688171 & 4.75 & 4.8764 & TRN & \\
\hline CHEMBL1571424 & 688171 & 4.75 & 4.9023 & TRN & \\
\hline CHEMBL1332395 & 688171 & 4.35 & 4.9147 & TRN & \\
\hline CHEMBL1516909 & 688171 & 4.75 & 4.8939 & TST & \\
\hline CHEMBL1332127 & 688171 & 5.3 & 4.98300 & 00000000005 & TRN \\
\hline CHEMBL1515542 & 688171 & 4.6 & 4.8625 & TRN & \\
\hline CHEMBL3214307 & 688171 & 4.8 & 4.8654 & TST & \\
\hline CHEMBL1351479 & 688171 & 6.45 & 4.9552 & TRN & \\
\hline CHEMBL1301522 & 688171 & 4.4 & 4.7996 & TRN & \\
\hline CHEMBL1606740 & 688171 & 4.85 & 4.9657 & TRN & \\
\hline CHEMBL1440539 & 688171 & 5.25 & 4.9189 & TST & \\
\hline CHEMBL1407388 & 688171 & 6.0 & 4.99 & TRN & \\
\hline CHEMBL1551730 & 688171 & 4.35 & 4.9643 & TRN & \\
\hline CHEMBL1335003 & 688171 & 5.05 & 4.9921 & TRN & \\
\hline CHEMBL1587463 & 688171 & 5.05 & 4.9416 & TRN & \\
\hline CHEMBL1545639 & 688171 & 4.4 & 4.8279 & TRN & \\
\hline CHEMBL1510647 & 688171 & 4.65 & 4.9457 & TRN & \\
\hline CHEMBL3208024 & 688171 & 4.35 & 4.9635 & TRN & \\
\hline CHEMBL3210911 & 688171 & 4.55 & 4.794 & TST & \\
\hline CHEMBL1495727 & 688171 & 4.5 & 4.9161 & TRN & \\
\hline CHEMBL1324368 & 688171 & 4.45 & 4.9082 & TST & \\
\hline CHEMBL1351520 & 688171 & 4.55 & 4.9335 & TRN & \\
\hline CHEMBL1311182 & 688171 & 5.65 & 5.0731 & TRN & \\
\hline CHEMBL1510925 & 688171 & 4.35 & 4.9272 & TRN & \\
\hline CHEMBL1468126 & 688171 & 4.4 & 4.9227 & TRN & \\
\hline CHEMBL1493199 & 688171 & 4.9 & 4.7786 & TRN & \\
\hline CHEMBL1506031 & 688171 & 4.9 & 4.9241 & TRN & \\
\hline CHEMBL1446187 & 688171 & 5.0 & 4.8084 & TST & \\
\hline CHEMBL1374313 & 688171 & 4.6 & 4.7546 & TRN & \\
\hline CHEMBL1401303 & 688171 & 5.1 & 4.8453 & TST & \\
\hline CHEMBL1968978 & 688171 & 4.4 & 4.9341 & TRN & \\
\hline CHEMBL1360975 & 688171 & 4.85 & 4.9144 & TRN & \\
\hline CHEMBL1557706 & 688171 & 4.7 & 4.9405 & TST & \\
\hline CHEMBL 1400820 & 688171 & 4.7 & 4.7711 & TRN & \\
\hline CHEMBL1551783 & 688171 & 5.4 & 4.9965 & TRN & \\
\hline
\end{tabular}




\begin{tabular}{|c|c|c|c|c|}
\hline \multicolumn{5}{|c|}{ Supplemental Table S2.txt } \\
\hline CHEMBL1304750 & 688171 & 4.4 & 4.933 & TRN \\
\hline CHEMBL1343371 & 688171 & 4.4 & 5.0421 & TRN \\
\hline CHEMBL1587139 & 688171 & 4.65 & 4.8366 & TST \\
\hline CHEMBL1478776 & 688171 & 4.4 & 4.8661 & TRN \\
\hline CHEMBL1331766 & 688171 & 5.0 & 4.8815 & TRN \\
\hline CHEMBL1556879 & 688171 & 5.25 & 4.8538 & TRN \\
\hline CHEMBL1593990 & 688171 & 4.8 & 4.7905 & TRN \\
\hline CHEMBL1427617 & 688171 & 4.5 & 4.8389 & TRN \\
\hline CHEMBL1488393 & 688171 & 4.5 & 4.8674 & TRN \\
\hline CHEMBL1383610 & 688171 & 4.55 & 4.9266 & TRN \\
\hline CHEMBL1525726 & 688171 & 4.55 & 4.8181 & TRN \\
\hline CHEMBL1493793 & 688171 & 5.05 & 4.9271 & TRN \\
\hline CHEMBL1376163 & 688171 & 5.1 & 4.9093 & TST \\
\hline CHEMBL1432398 & 688171 & 5.5 & 4.7933 & TRN \\
\hline CHEMBL1470077 & 688171 & 4.75 & 4.8413 & TRN \\
\hline CHEMBL1557976 & 688171 & 5.45 & 4.8222 & TRN \\
\hline CHEMBL1360752 & 688171 & 5.25 & 4.9354 & TRN \\
\hline CHEMBL1592833 & 688171 & 5.0 & 4.8982 & TRN \\
\hline CHEMBL1528653 & 688171 & 5.05 & 4.926 & TST \\
\hline CHEMBL1563596 & 688171 & 6.45 & 5.0227 & TRN \\
\hline CHEMBL1357550 & 688171 & 6.0 & 4.9106 & TRN \\
\hline CHEMBL1446929 & 688171 & 5.45 & 4.8999 & TST \\
\hline CHEMBL1369025 & 688171 & 4.75 & 4.9512 & TRN \\
\hline CHEMBL1489013 & 688171 & 4.5 & 4.9469 & TRN \\
\hline CHEMBL1482306 & 688171 & 4.7 & 4.8492 & TST \\
\hline CHEMBL1607760 & 688171 & 4.55 & 4.9907 & TRN \\
\hline CHEMBL1392266 & 688171 & 5.1 & 4.9353 & TRN \\
\hline CHEMBL1609778 & 688171 & 4.5 & 4.7991 & TRN \\
\hline CHEMBL1532219 & 688171 & 4.35 & 4.8405 & TRN \\
\hline CHEMBL1515796 & 688171 & 4.4 & 4.9004 & TST \\
\hline CHEMBL1432717 & 688171 & 4.7 & 4.8438 & TRN \\
\hline CHEMBL1437002 & 688171 & 4.75 & 4.9267 & TST \\
\hline CHEMBL1606319 & 688171 & 4.5 & 4.7306 & TRN \\
\hline CHEMBL1502881 & 688171 & 4.6 & 4.8581 & TRN \\
\hline CHEMBL1533120 & 688171 & 4.4 & 4.9131 & TRN \\
\hline CHEMBL1338442 & 688171 & 4.4 & 4.8651 & TRN \\
\hline CHEMBL1476304 & 688171 & 4.6 & 4.8183 & TRN \\
\hline CHEMBL1405931 & 688171 & 4.5 & 4.9592 & TST \\
\hline CHEMBL1327816 & 688171 & 5.1 & 4.8614 & TRN \\
\hline CHEMBL1369553 & 688171 & 4.35 & 4.7461 & TRN \\
\hline CHEMBL1453871 & 688171 & 6.05 & 4.9291 & TRN \\
\hline CHEMBL1584557 & 688171 & 6.4 & 4.8904 & TRN \\
\hline CHEMBL1603037 & 688171 & 6.05 & 5.0704 & TST \\
\hline CHEMBL3189853 & 688171 & 5.6 & 4.926 & TRN \\
\hline CHEMBL1531635 & 688171 & 4.6 & 4.9222 & TRN \\
\hline CHEMBL1592309 & 688171 & 4.45 & 5.1159 & TRN \\
\hline CHEMBL1364941 & 688171 & 4.45 & 5.0346 & TRN \\
\hline CHEMBL1585641 & 688171 & 4.35 & 4.9182 & TRN \\
\hline
\end{tabular}




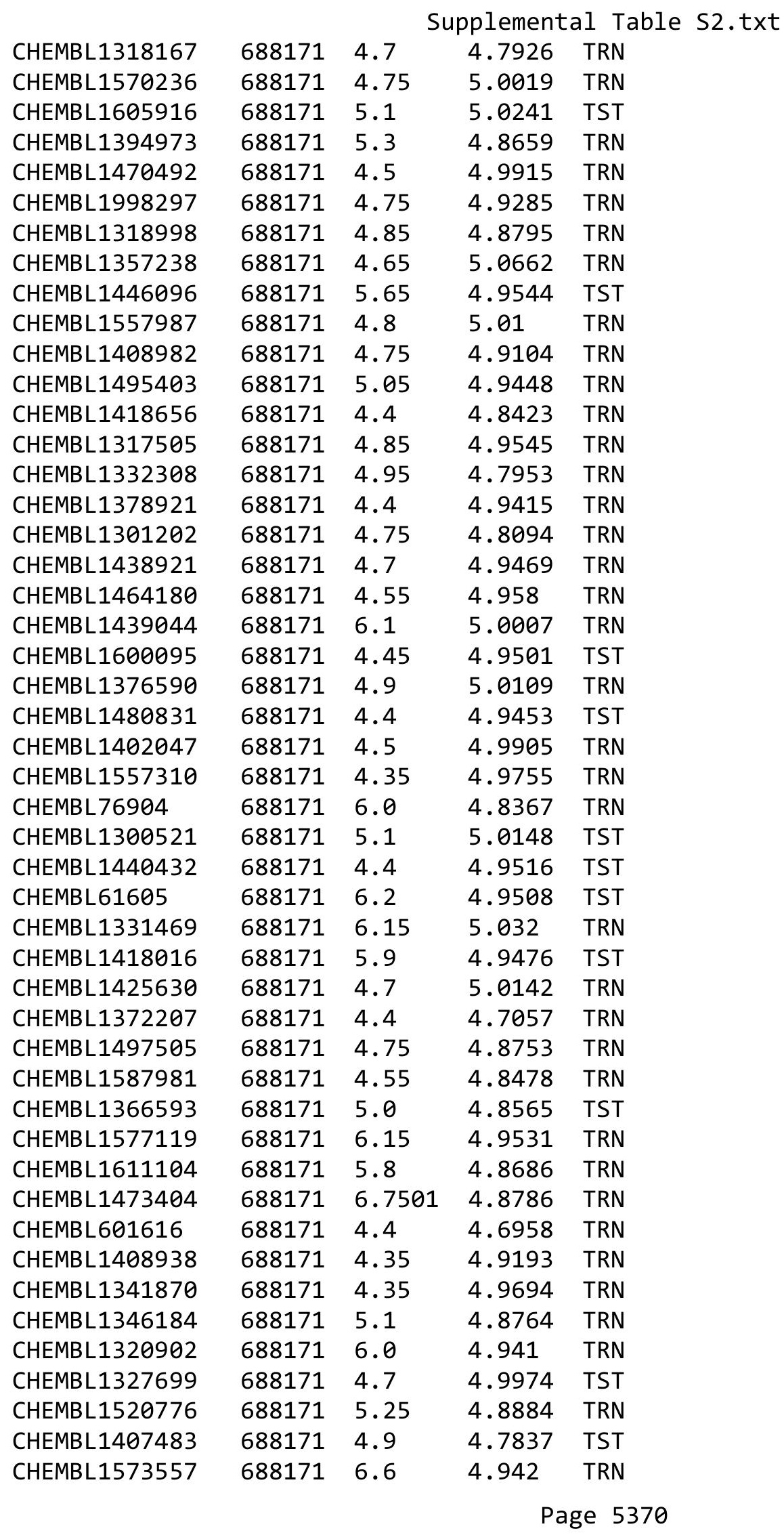




\begin{tabular}{|c|c|c|c|c|c|}
\hline \multirow[b]{2}{*}{ CHEMBL1312016 } & & \multicolumn{4}{|c|}{ Supplemental Table S2.txt } \\
\hline & 688171 & 4.85 & 4.9242 & TRN & \\
\hline CHEMBL1554829 & 688171 & 5.0 & 4.88399 & 99999999995 & TST \\
\hline CHEMBL1488131 & 688171 & 4.55 & 4.8217 & TST & \\
\hline CHEMBL1473360 & 688171 & 4.8 & 5.001 & TRN & \\
\hline CHEMBL1454145 & 688171 & 4.4 & 4.9516 & TRN & \\
\hline CHEMBL1323347 & 688171 & 5.45 & 4.8968 & TST & \\
\hline CHEMBL1347760 & 688171 & 4.35 & 4.7534 & TST & \\
\hline CHEMBL1441629 & 688171 & 5.55 & 4.9342 & TRN & \\
\hline CHEMBL1391072 & 688171 & 5.05 & 4.7644 & TRN & \\
\hline CHEMBL538104 & 688171 & 6.0 & 4.9374 & TST & \\
\hline CHEMBL1395943 & 688171 & 4.4 & 5.0699 & TRN & \\
\hline CHEMBL1604778 & 688171 & 4.55 & 4.9038 & TRN & \\
\hline CHEMBL1397661 & 688171 & 4.35 & 4.8771 & TRN & \\
\hline CHEMBL1588912 & 688171 & 5.0 & 4.8882 & TST & \\
\hline CHEMBL1378205 & 688171 & 4.65 & 4.9174 & TRN & \\
\hline CHEMBL1375094 & 688171 & 5.35 & 4.8612 & TRN & \\
\hline CHEMBL1342187 & 688171 & 4.35 & 4.9427 & TRN & \\
\hline CHEMBL1392868 & 688171 & 4.55 & 4.939 & TRN & \\
\hline CHEMBL1375366 & 688171 & 4.6 & 4.8859 & TRN & \\
\hline CHEMBL1314580 & 688171 & 4.8 & 4.9762 & TRN & \\
\hline CHEMBL1606323 & 688171 & 6.15 & 4.9001 & TRN & \\
\hline CHEMBL1475630 & 688171 & 5.5 & 4.9035 & TRN & \\
\hline CHEMBL1589423 & 688171 & 4.4 & 4.9536 & TRN & \\
\hline CHEMBL1486335 & 688171 & 6.05 & 4.9626 & TRN & \\
\hline CHEMBL1335838 & 688171 & 5.1 & 4.8711 & TRN & \\
\hline CHEMBL1329999 & 688171 & 4.6 & 4.9706 & TST & \\
\hline CHEMBL1569711 & 688171 & 5.15 & 4.9325 & TRN & \\
\hline CHEMBL3191114 & 688171 & 4.8 & 4.8403 & TRN & \\
\hline CHEMBL1482669 & 688171 & 5.1 & 4.9192 & TRN & \\
\hline CHEMBL1532699 & 688171 & 4.7 & 5.0543 & TRN & \\
\hline CHEMBL1402237 & 688171 & 4.9 & 4.8675 & TRN & \\
\hline CHEMBL1582009 & 688171 & 4.4 & 4.9152 & TRN & \\
\hline CHEMBL1531919 & 688171 & 4.65 & 4.9299 & TRN & \\
\hline CHEMBL1304934 & 688171 & 4.95 & 4.7933 & TRN & \\
\hline CHEMBL1525780 & 688171 & 5.1 & 5.0038 & TRN & \\
\hline CHEMBL 2007357 & 688171 & 6.5 & 4.9537 & TRN & \\
\hline CHEMBL1487660 & 688171 & 5.05 & 4.9146 & TRN & \\
\hline CHEMBL1350836 & 688171 & 4.4 & 4.8104 & TST & \\
\hline CHEMBL3199132 & 688171 & 6.35 & 4.8892 & TRN & \\
\hline CHEMBL1534749 & 688171 & 4.55 & 4.8245 & TRN & \\
\hline CHEMBL1602041 & 688171 & 4.8 & 4.9907 & TST & \\
\hline CHEMBL1590855 & 688171 & 5.4 & 4.9067 & TRN & \\
\hline CHEMBL466930 & 688171 & 4.4 & 4.8492 & TRN & \\
\hline CHEMBL1080326 & 688171 & 4.85 & 4.8819 & TRN & \\
\hline CHEMBL1470063 & 688171 & 4.45 & 4.8605 & TRN & \\
\hline CHEMBL1418203 & 688171 & 4.9 & 4.8313 & TRN & \\
\hline CHEMBL1355142 & 688171 & 4.45 & 5.1598 & TRN & \\
\hline CHEMBL3192653 & 688171 & 4.7 & 4.8586 & TRN & \\
\hline
\end{tabular}




\begin{tabular}{|c|c|c|c|c|c|}
\hline \multirow[b]{2}{*}{ CHEMBL1438583 } & \multirow[b]{2}{*}{688171} & \multicolumn{4}{|c|}{ Supplemental Table S2.txt } \\
\hline & & \multicolumn{2}{|c|}{$\begin{array}{ll}4.65 & 4.9161\end{array}$} & \multicolumn{2}{|c|}{ TRN } \\
\hline CHEMBL1505720 & 688171 & 4.8 & 4.9578 & TRN & \\
\hline CHEMBL1522120 & 688171 & 5.0 & \multicolumn{2}{|c|}{ 4.968999999999999 } & TRN \\
\hline CHEMBL1314315 & 688171 & 4.4 & 5.0478 & TRN & \\
\hline CHEMBL1602362 & 688171 & 5.0 & 4.9975 & TRN & \\
\hline CHEMBL1504970 & 688171 & 5.15 & 4.897 & TRN & \\
\hline CHEMBL1449749 & 688171 & 4.7 & 4.9494 & TRN & \\
\hline CHEMBL1490458 & 688171 & 4.5 & 4.9011 & TRN & \\
\hline CHEMBL1556282 & 688171 & 4.7 & 4.8524 & TRN & \\
\hline CHEMBL1386597 & 688171 & 4.6 & 4.8488 & TST & \\
\hline CHEMBL1317647 & 688171 & 5.5 & 4.9759 & TRN & \\
\hline CHEMBL1379740 & 688171 & 4.45 & 4.9094 & TRN & \\
\hline CHEMBL1586646 & 688171 & 4.6 & 4.8217 & TRN & \\
\hline CHEMBL1472846 & 688171 & 4.9 & 4.9919 & TST & \\
\hline CHEMBL1586985 & 688171 & 5.0 & 4.8589 & TRN & \\
\hline CHEMBL1321566 & 688171 & 5.05 & 4.9636 & TRN & \\
\hline CHEMBL1356104 & 688171 & 4.4 & 4.9489 & TRN & \\
\hline CHEMBL1402607 & 688171 & 4.7 & 4.9565 & TST & \\
\hline CHEMBL1457778 & 688171 & 4.65 & 4.9397 & TRN & \\
\hline CHEMBL1586335 & 688171 & 4.4 & \multicolumn{2}{|c|}{4.9239999999999995} & TRN \\
\hline CHEMBL1399717 & 688171 & 5.8 & 4.8311 & TST & \\
\hline CHEMBL1426432 & 688171 & 4.4 & 5.081 & TRN & \\
\hline CHEMBL1529832 & 688171 & 4.55 & 4.8038 & TRN & \\
\hline CHEMBL1435051 & 688171 & 4.7 & 5.0125 & TRN & \\
\hline CHEMBL1540629 & 688171 & 5.75 & 4.9264 & TRN & \\
\hline CHEMBL1611008 & 688171 & 4.65 & 4.9609 & TRN & \\
\hline CHEMBL 2001408 & 688171 & 4.5 & 4.8992 & TRN & \\
\hline CHEMBL3189803 & 688171 & 5.5 & 4.9374 & TRN & \\
\hline CHEMBL1985826 & 688171 & 4.55 & 4.9503 & TRN & \\
\hline CHEMBL1347745 & 688171 & 5.0 & 4.9561 & TRN & \\
\hline CHEMBL1446863 & 688171 & 4.55 & 4.7613 & TRN & \\
\hline CHEMBL1452714 & 688171 & 4.7 & 4.8851 & TST & \\
\hline CHEMBL1359902 & 688171 & 5.55 & 5.1484 & TST & \\
\hline CHEMBL1312889 & 688171 & 4.4 & 4.9669 & TRN & \\
\hline CHEMBL1304179 & 688171 & 6.6499 & 4.9242 & TRN & \\
\hline CHEMBL1539807 & 688171 & 4.55 & 4.8144 & TRN & \\
\hline CHEMBL1485473 & 688171 & 4.5 & 4.8493 & TRN & \\
\hline CHEMBL1596722 & 688171 & 5.15 & 4.851 & TRN & \\
\hline CHEMBL1487379 & 688171 & 7.6003 & 5.1348 & TST & \\
\hline CHEMBL1442742 & 688171 & 4.5 & 4.8392 & TRN & \\
\hline CHEMBL1446329 & 688171 & 4.4 & 4.8882 & TST & \\
\hline CHEMBL1531151 & 688171 & 4.75 & 4.8369 & TRN & \\
\hline CHEMBL1339208 & 688171 & 5.45 & 4.8861 & TRN & \\
\hline CHEMBL1455187 & 688171 & 4.5 & 4.8047 & TRN & \\
\hline CHEMBL1609529 & 688171 & 4.4 & 4.98300 & 00000000005 & TRN \\
\hline CHEMBL1549135 & 688171 & 5.6 & 4.9177 & TRN & \\
\hline CHEMBL1415577 & 688171 & 4.65 & 4.7536 & TRN & \\
\hline \multirow[t]{2}{*}{ CHEMBL1554111 } & 688171 & 4.85 & 4.9195 & TRN & \\
\hline & & \multicolumn{4}{|c|}{ Page 5372} \\
\hline
\end{tabular}




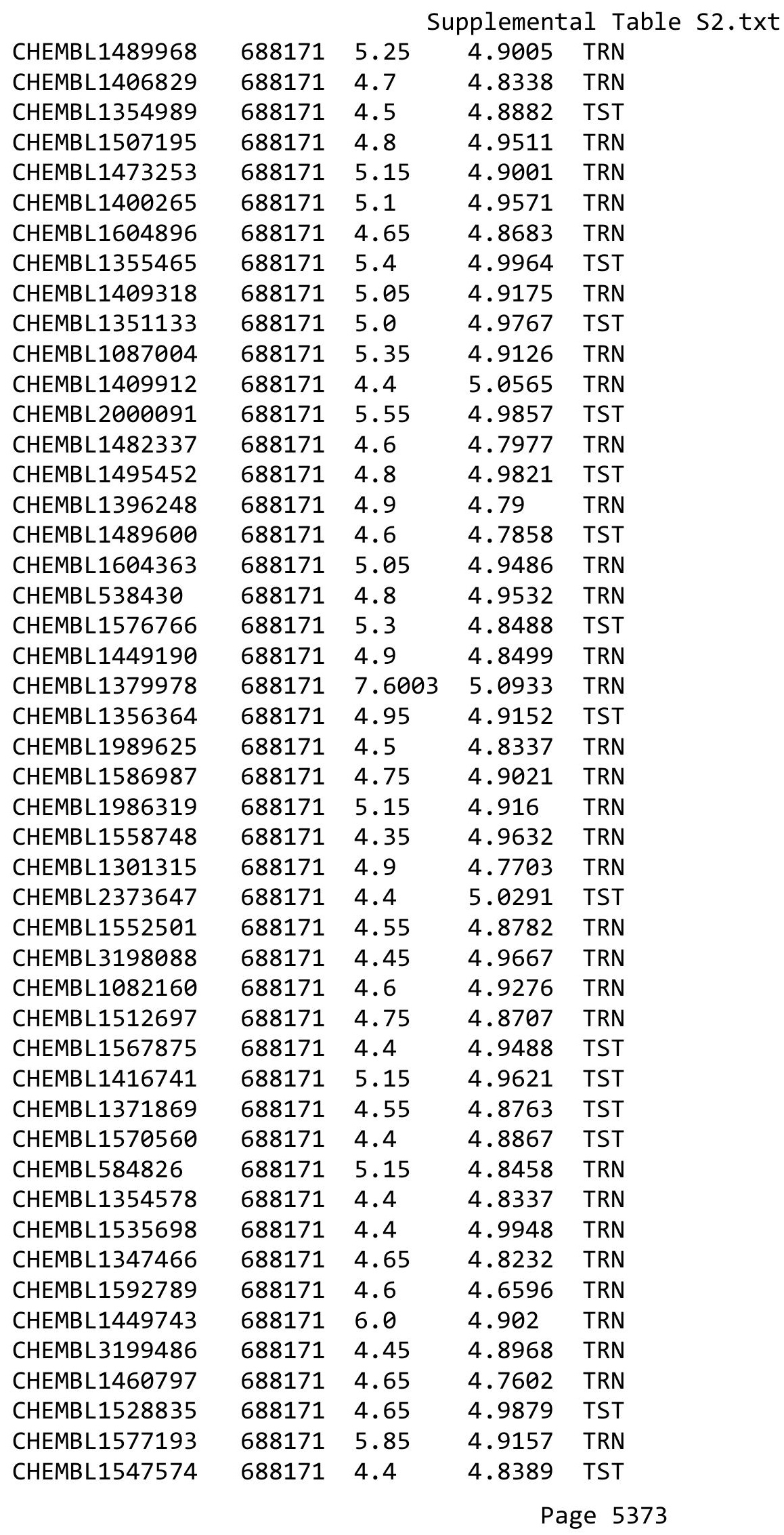




\begin{tabular}{|c|c|c|c|c|c|}
\hline \multirow{3}{*}{$\begin{array}{l}\text { CHEMBL1434019 } \\
\text { CHEMBL1513437 }\end{array}$} & \multirow{3}{*}{$\begin{array}{l}688171 \\
688171\end{array}$} & \multicolumn{4}{|c|}{ Supplemental Table s2.txt } \\
\hline & & 5.25 & 4.93199 & 99999999995 & TRN \\
\hline & & 4.55 & 4.7312 & TRN & \\
\hline CHEMBL3199064 & 688171 & 4.9 & 4.8478 & TRN & \\
\hline CHEMBL1396308 & 688171 & 4.8 & 4.7939 & TRN & \\
\hline CHEMBL 1459880 & 688171 & 4.6 & 4.7994 & TRN & \\
\hline CHEMBL1518142 & 688171 & 4.5 & 4.8486 & TRN & \\
\hline CHEMBL 2001582 & 688171 & 5.2 & 4.8853 & TRN & \\
\hline CHEMBL1558106 & 688171 & 4.5 & 4.8579 & TRN & \\
\hline CHEMBL1576815 & 688171 & 4.95 & 4.8385 & TST & \\
\hline CHEMBL1355668 & 688171 & 4.4 & 4.8425 & TRN & \\
\hline CHEMBL1455890 & 688171 & 4.85 & 4.9068 & TRN & \\
\hline CHEMBL3392386 & 688171 & 4.6 & 4.8932 & TRN & \\
\hline CHEMBL1531574 & 688171 & 4.4 & 4.9632 & TRN & \\
\hline CHEMBL1588930 & 688171 & 4.4 & 4.9505 & TRN & \\
\hline CHEMBL1514025 & 688171 & 4.4 & 4.9786 & TRN & \\
\hline CHEMBL1453603 & 688171 & 5.9 & 4.8089 & TST & \\
\hline CHEMBL585071 & 688171 & 5.1 & 4.8701 & TRN & \\
\hline CHEMBL1604174 & 688171 & 5.05 & 4.8747 & TRN & \\
\hline CHEMBL1322597 & 688171 & 4.7 & 5.0168 & TRN & \\
\hline CHEMBL1541206 & 688171 & 4.9 & 4.873 & TRN & \\
\hline CHEMBL1577601 & 688171 & 4.35 & 4.8891 & TRN & \\
\hline CHEMBL1313236 & 688171 & 4.6 & 4.8343 & TST & \\
\hline CHEMBL1601820 & 688171 & 5.0 & 4.8857 & TRN & \\
\hline CHEMBL1361854 & 688171 & 4.65 & 4.7158 & TRN & \\
\hline CHEMBL1547580 & 688171 & 4.35 & 4.8366 & TRN & \\
\hline CHEMBL1369768 & 688171 & 4.35 & 4.9326 & TRN & \\
\hline CHEMBL1548506 & 688171 & 4.5 & 4.8405 & TRN & \\
\hline CHEMBL1492309 & 688171 & 6.0 & 4.988 & TRN & \\
\hline CHEMBL1453937 & 688171 & 4.6 & 4.9164 & TRN & \\
\hline CHEMBL1474763 & 688171 & 4.65 & 4.9488 & TRN & \\
\hline CHEMBL1406639 & 688171 & 4.4 & 4.9813 & TST & \\
\hline CHEMBL1440916 & 688171 & 4.4 & 5.0547 & TRN & \\
\hline CHEMBL1542598 & 688171 & 4.55 & 4.7543 & TRN & \\
\hline CHEMBL1555637 & 688171 & 4.55 & 4.7899 & TRN & \\
\hline CHEMBL1452314 & 688171 & 4.45 & 4.9132 & TST & \\
\hline CHEMBL1356942 & 688171 & 4.95 & 4.9934 & TRN & \\
\hline CHEMBL 1326636 & 688171 & 5.75 & 5.0085 & TRN & \\
\hline CHEMBL1354498 & 688171 & 4.5 & 4.8135 & TST & \\
\hline CHEMBL1533227 & 688171 & 4.4 & 4.9829 & TRN & \\
\hline CHEMBL1477059 & 688171 & 4.7 & 4.9037 & TRN & \\
\hline CHEMBL1413495 & 688171 & 4.7 & 4.8156 & TRN & \\
\hline CHEMBL1488126 & 688171 & 6.4 & 5.0973 & TRN & \\
\hline CHEMBL1514103 & 688171 & 4.75 & 4.878 & TRN & \\
\hline CHEMBL1594720 & 688171 & 6.45 & 5.0319 & TRN & \\
\hline CHEMBL1573221 & 688171 & 6.0 & 4.9045 & TRN & \\
\hline CHEMBL1421412 & 688171 & 5.4 & 4.9405 & TST & \\
\hline CHEMBL1339455 & 688171 & 4.8 & 4.7863 & TRN & \\
\hline CHEMBL1470342 & 688171 & 4.5 & 4.936 & TST & \\
\hline
\end{tabular}




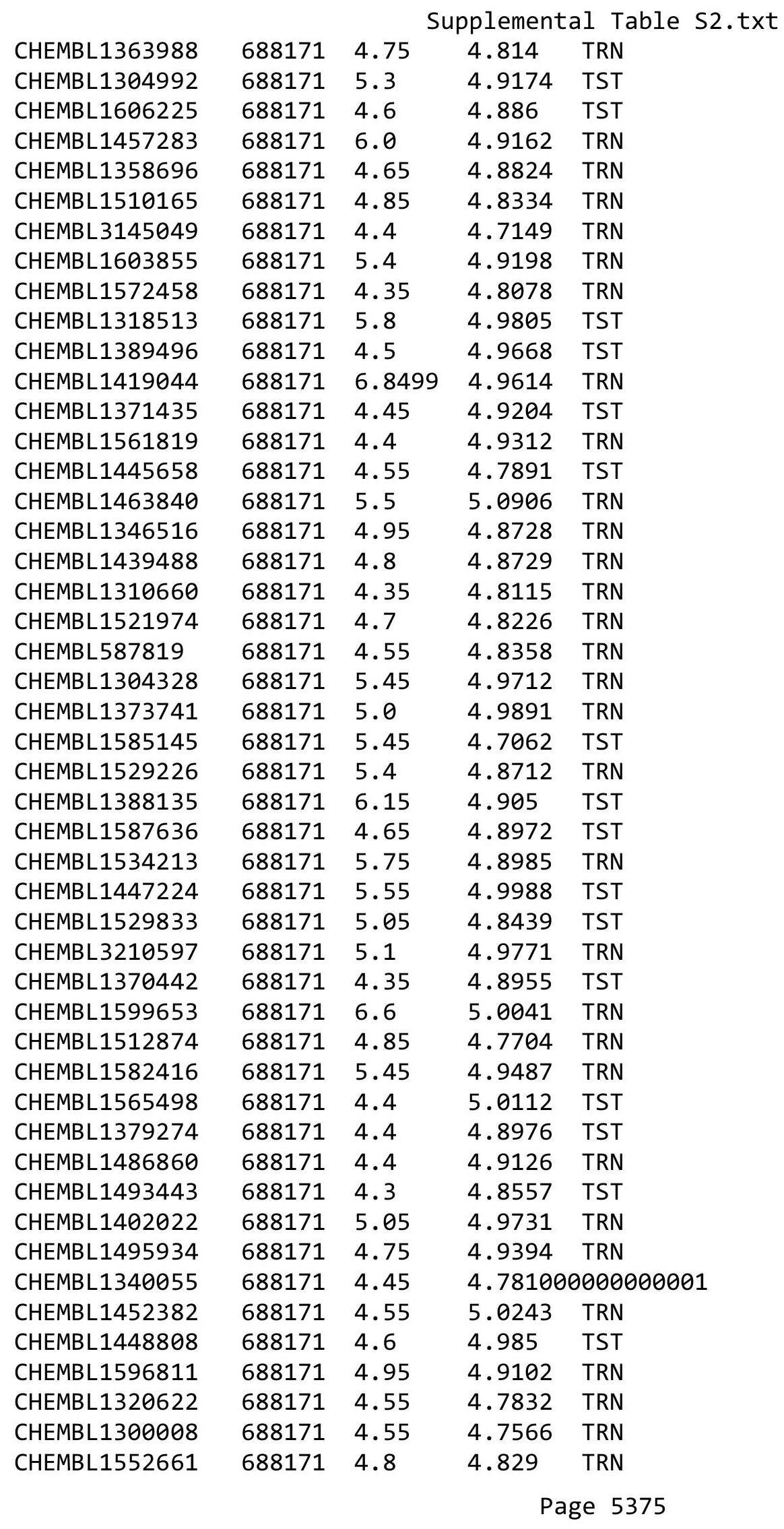

TRN 


\begin{tabular}{|c|c|c|c|c|c|}
\hline \multicolumn{6}{|c|}{ Supplemental Table S2.txt } \\
\hline CHEMBL1579110 & 688171 & 4.75 & 4.8575 & TRN & \\
\hline CHEMBL1501531 & 688171 & 7.6003 & 4.8969 & TST & \\
\hline CHEMBL1982450 & 688171 & 4.7 & 4.9938 & TRN & \\
\hline CHEMBL1347593 & 688171 & 5.65 & 5.0131 & TRN & \\
\hline CHEMBL1527742 & 688171 & 4.55 & 4.9051 & TST & \\
\hline CHEMBL1500382 & 688171 & 4.45 & 4.9019 & TRN & \\
\hline CHEMBL1320105 & 688171 & 5.25 & 4.8481 & TRN & \\
\hline CHEMBL1595038 & 688171 & 4.8 & 4.8163 & TRN & \\
\hline CHEMBL1592697 & 688171 & 4.75 & 4.7779 & TRN & \\
\hline CHEMBL1350598 & 688171 & 4.7 & 4.9099 & TRN & \\
\hline CHEMBL1483104 & 688171 & 4.45 & 4.9313 & TRN & \\
\hline CHEMBL1398849 & 688171 & 5.05 & 4.8768 & TRN & \\
\hline CHEMBL1569502 & 688171 & 7.0 & 5.0313 & TST & \\
\hline CHEMBL3212972 & 688171 & 4.55 & 4.8117 & TRN & \\
\hline CHEMBL1569501 & 688171 & 4.8 & 4.9219 & TRN & \\
\hline CHEMBL1414013 & 688171 & 6.35 & 4.7944 & TRN & \\
\hline CHEMBL1519361 & 688171 & 4.85 & 4.9498 & TRN & \\
\hline CHEMBL1317728 & 688171 & 4.9 & 4.7797 & TRN & \\
\hline CHEMBL3209497 & 688171 & 4.85 & 4.7907 & TRN & \\
\hline CHEMBL1322521 & 688171 & 4.55 & 4.7919 & TRN & \\
\hline CHEMBL1479204 & 688171 & 5.5 & 4.9103 & TST & \\
\hline CHEMBL1468800 & 688171 & 5.0 & 4.9864 & TRN & \\
\hline CHEMBL1330759 & 688171 & 4.55 & 4.9368 & TRN & \\
\hline CHEMBL1595702 & 688171 & 4.4 & 4.8108 & TRN & \\
\hline CHEMBL1510238 & 688171 & 4.4 & 4.8741 & TST & \\
\hline CHEMBL1554507 & 688171 & 4.4 & 4.9688 & TRN & \\
\hline CHEMBL1288936 & 688171 & 4.85 & 4.9173 & TST & \\
\hline CHEMBL 267548 & 688171 & 6.0 & 5.0051 & TST & \\
\hline CHEMBL1513116 & 688171 & 4.6 & 4.8897 & TRN & \\
\hline CHEMBL1410688 & 688171 & 5.5 & 4.9298 & TRN & \\
\hline CHEMBL274921 & 688171 & 6.05 & 4.86600 & 00000000005 & TRN \\
\hline CHEMBL1501383 & 688171 & 4.85 & 4.8077 & TRN & \\
\hline CHEMBL1545549 & 688171 & 4.7 & 4.8679 & TRN & \\
\hline CHEMBL1359842 & 688171 & 4.4 & 4.8779 & TRN & \\
\hline CHEMBL1334096 & 688171 & 4.85 & 4.7503 & TRN & \\
\hline CHEMBL1601382 & 688171 & 4.7 & 4.8746 & TRN & \\
\hline CHEMBL1528875 & 688171 & 4.9 & 4.9044 & TST & \\
\hline CHEMBL1411896 & 688171 & 4.6 & 4.6922 & TRN & \\
\hline CHEMBL1581949 & 688171 & 5.4 & 4.8214 & TRN & \\
\hline CHEMBL1300154 & 688171 & 4.55 & 4.9343 & TRN & \\
\hline CHEMBL1444641 & 688171 & 5.0 & 4.8841 & TRN & \\
\hline CHEMBL1483238 & 688171 & 4.8 & 4.8118 & TST & \\
\hline CHEMBL1605460 & 688171 & 5.2 & 4.9137 & TRN & \\
\hline CHEMBL3197154 & 688171 & 4.35 & 4.9691 & TRN & \\
\hline CHEMBL1984324 & 688171 & 4.5 & 4.8219 & TRN & \\
\hline CHEMBL1498152 & 688171 & 4.4 & 4.782 & TRN & \\
\hline CHEMBL1300859 & 688171 & 4.75 & 4.8741 & TRN & \\
\hline CHEMBL1592395 & 688171 & 4.4 & 4.836 & TRN & \\
\hline
\end{tabular}




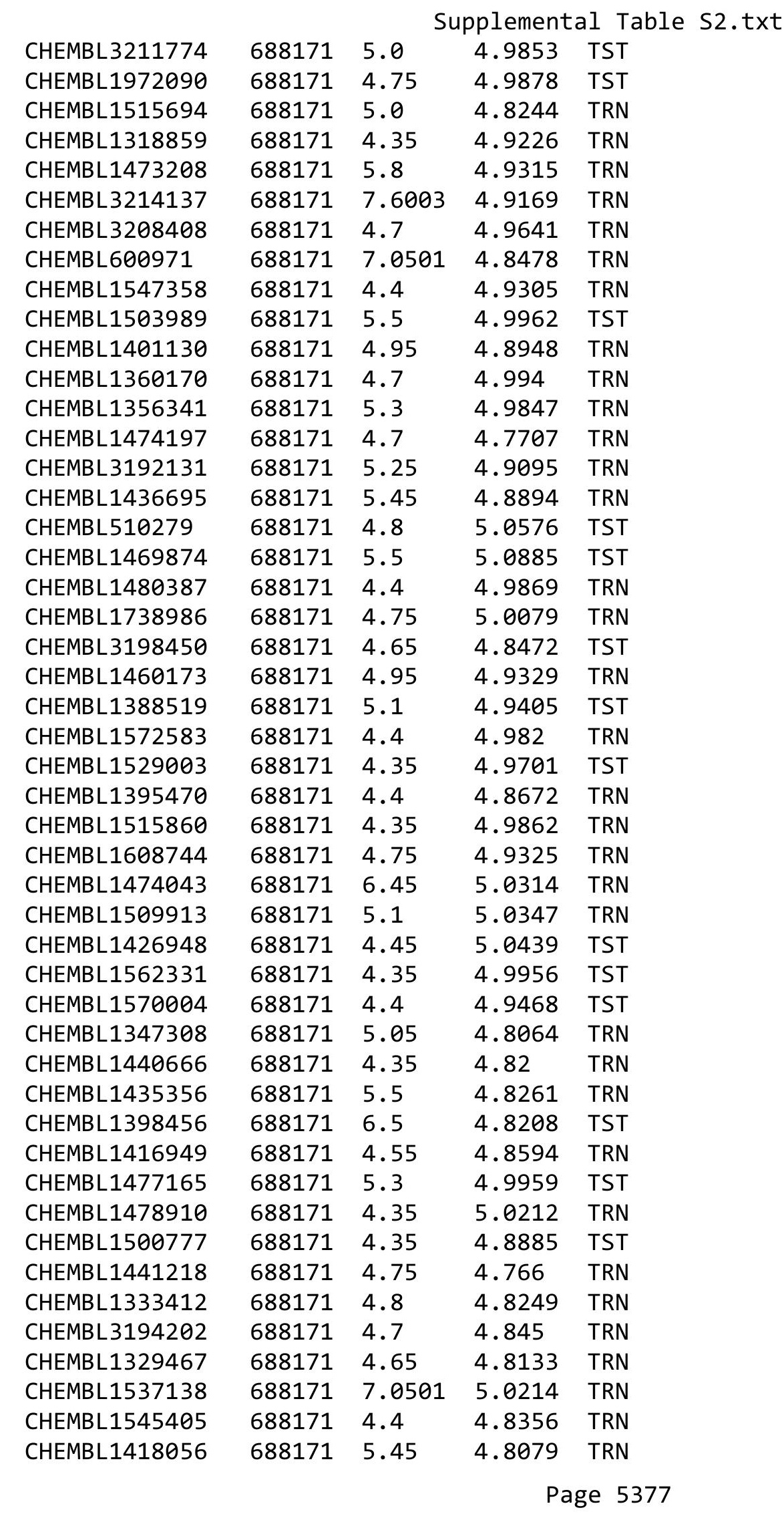




\begin{tabular}{|c|c|c|c|c|c|}
\hline \multicolumn{6}{|c|}{ Supplemental Table S2.txt } \\
\hline CHEMBL1598791 & 688171 & 4.6 & 4.802 & TST & \\
\hline CHEMBL1487905 & 688171 & 6.25 & 5.0046 & TRN & \\
\hline CHEMBL1516515 & 688171 & 5.5 & 4.89199 & 99999999995 & TST \\
\hline CHEMBL1607916 & 688171 & 4.45 & 4.8914 & TRN & \\
\hline CHEMBL1556661 & 688171 & 4.5 & 4.8187 & TST & \\
\hline CHEMBL1591432 & 688171 & 4.55 & 4.9681 & TRN & \\
\hline CHEMBL1554389 & 688171 & 4.75 & 4.7899 & TRN & \\
\hline CHEMBL1476430 & 688171 & 4.55 & 4.8673 & TRN & \\
\hline CHEMBL602807 & 688171 & 4.6 & 4.7842 & TRN & \\
\hline CHEMBL1458249 & 688171 & 4.4 & 4.8473 & TST & \\
\hline CHEMBL1562008 & 688171 & 5.0 & 4.8466 & TRN & \\
\hline CHEMBL1374246 & 688171 & 5.35 & 4.9343 & TRN & \\
\hline CHEMBL1561605 & 688171 & 4.75 & 5.0334 & TRN & \\
\hline CHEMBL597244 & 688171 & 4.85 & 4.8838 & TRN & \\
\hline CHEMBL1351314 & 688171 & 4.55 & 4.9081 & TRN & \\
\hline CHEMBL1531660 & 688171 & 6.7501 & 5.0343 & TRN & \\
\hline CHEMBL1337347 & 688171 & 5.45 & 5.0513 & TRN & \\
\hline CHEMBL1579439 & 688171 & 5.8 & 4.9 & TRN & \\
\hline CHEMBL1523452 & 688171 & 4.4 & 4.9514 & TRN & \\
\hline CHEMBL1376390 & 688171 & 5.2 & 4.9898 & TST & \\
\hline CHEMBL1350784 & 688171 & 7.2503 & 4.8509 & TST & \\
\hline CHEMBL1523853 & 688171 & 5.15 & 4.96 & TRN & \\
\hline CHEMBL1492846 & 688171 & 4.95 & 4.9621 & TST & \\
\hline CHEMBL1582581 & 688171 & 4.75 & 4.76399 & 9999999999 & TRN \\
\hline CHEMBL1609572 & 688171 & 5.5 & 4.9526 & TST & \\
\hline CHEMBL1594286 & 688171 & 4.55 & 4.9149 & TST & \\
\hline CHEMBL3197634 & 688171 & 4.35 & 4.9899 & TRN & \\
\hline CHEMBL1586726 & 688171 & 4.9 & 4.8763 & TST & \\
\hline CHEMBL1404083 & 688171 & 4.9 & 4.8353 & TST & \\
\hline CHEMBL3199580 & 688171 & 4.55 & 4.8715 & TST & \\
\hline CHEMBL1354437 & 688171 & 4.8 & 4.914 & TRN & \\
\hline CHEMBL1606412 & 688171 & 4.4 & 4.8463 & TRN & \\
\hline CHEMBL3196561 & 688171 & 4.35 & 4.8612 & TRN & \\
\hline CHEMBL1527581 & 688171 & 4.65 & 5.0292 & TRN & \\
\hline CHEMBL1204336 & 688171 & 4.8 & 4.9122 & TST & \\
\hline CHEMBL3199864 & 688171 & 5.6 & 4.965 & TRN & \\
\hline CHEMBL1470348 & 688171 & 4.55 & 4.9123 & TRN & \\
\hline CHEMBL1395582 & 688171 & 4.7 & 4.9231 & TRN & \\
\hline CHEMBL1583743 & 688171 & 4.55 & 4.7058 & TRN & \\
\hline CHEMBL1453219 & 688171 & 4.4 & 4.9187 & TRN & \\
\hline CHEMBL1451887 & 688171 & 4.45 & 4.9584 & TRN & \\
\hline CHEMBL1613545 & 688171 & 4.35 & 5.026 & TST & \\
\hline CHEMBL1474455 & 688171 & 4.75 & 4.9589 & TST & \\
\hline CHEMBL1467442 & 688171 & 4.55 & 5.0374 & TRN & \\
\hline CHEMBL1300969 & 688171 & 6.6 & 4.9508 & TRN & \\
\hline CHEMBL1515440 & 688171 & 4.45 & 5.0597 & TRN & \\
\hline CHEMBL1485515 & 688171 & 4.65 & 4.93199 & 99999999995 & TRN \\
\hline CHEMBL1414172 & 688171 & 4.4 & 4.8779 & TST & \\
\hline
\end{tabular}




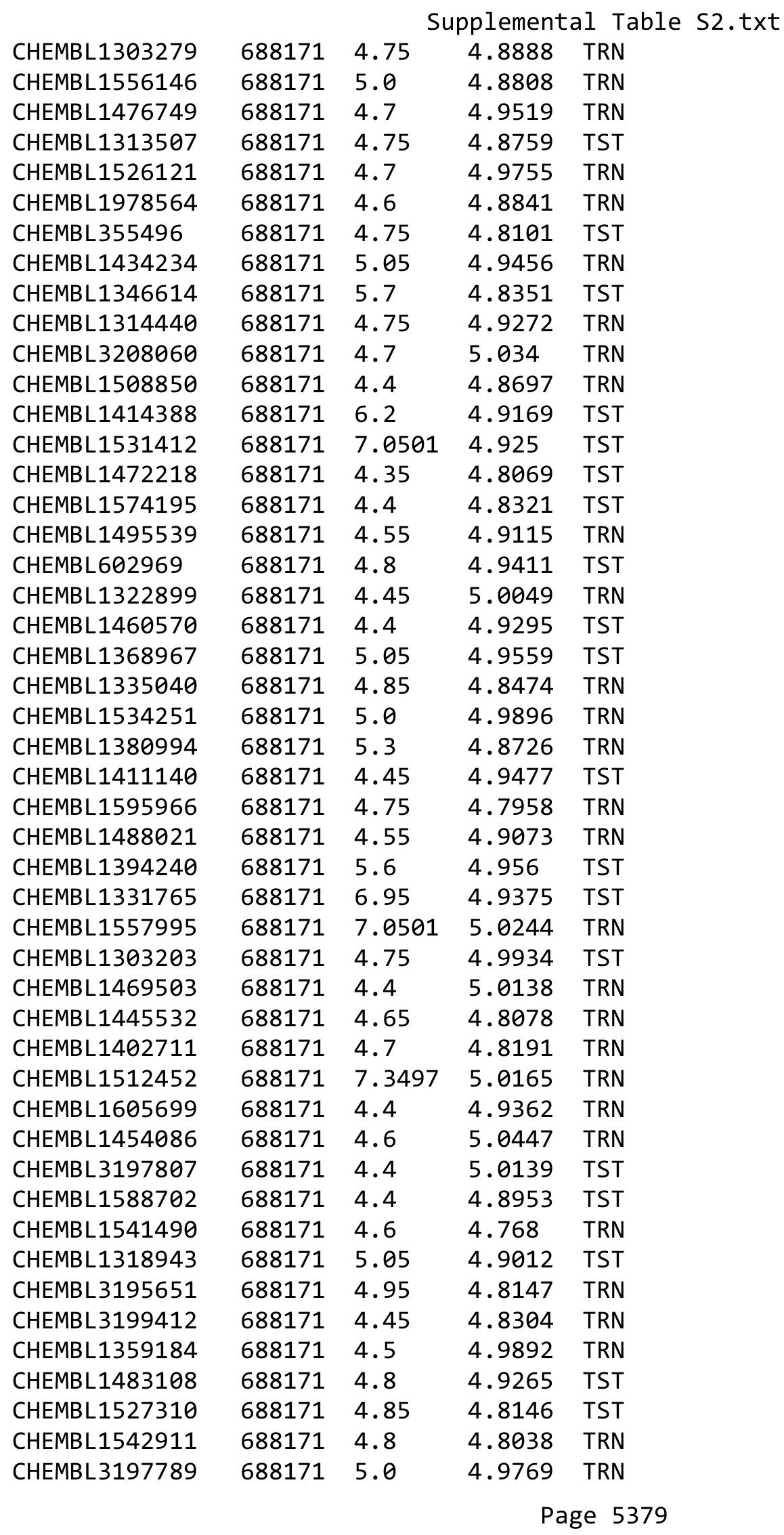




\begin{tabular}{|c|c|c|c|c|c|}
\hline \multicolumn{6}{|c|}{ Supplemental Table s2.txt } \\
\hline CHEMBL1360172 & 688171 & 5.35 & 4.8487 & TRN & \\
\hline CHEMBL1475980 & 688171 & 4.4 & 4.8691 & TST & \\
\hline CHEMBL1504392 & 688171 & 4.4 & 4.9232 & TRN & \\
\hline CHEMBL3190746 & 688171 & 4.45 & 5.0615 & TST & \\
\hline CHEMBL1429469 & 688171 & 4.55 & 4.8386 & TRN & \\
\hline CHEMBL3196455 & 688171 & 4.7 & 4.9353 & TRN & \\
\hline CHEMBL1454345 & 688171 & 4.85 & 4.8046 & TST & \\
\hline CHEMBL1308672 & 688171 & 7.6003 & 5.0348 & TST & \\
\hline CHEMBL1407995 & 688171 & 4.8 & 4.8039 & TRN & \\
\hline CHEMBL3191870 & 688171 & 4.4 & 4.8952 & TST & \\
\hline CHEMBL1392532 & 688171 & 4.7 & 4.8578 & TRN & \\
\hline CHEMBL1478472 & 688171 & 4.55 & 4.8927 & TRN & \\
\hline CHEMBL1324186 & 688171 & 4.75 & 4.8792 & TRN & \\
\hline CHEMBL3212393 & 688171 & 4.85 & 4.9594 & TRN & \\
\hline CHEMBL1565429 & 688171 & 4.7 & 4.9852 & TRN & \\
\hline CHEMBL1324409 & 688171 & 5.45 & 4.9064 & TRN & \\
\hline CHEMBL1496093 & 688171 & 4.65 & 4.8541 & TRN & \\
\hline CHEMBL1526545 & 688171 & 4.5 & 4.9295 & TST & \\
\hline CHEMBL1353015 & 688171 & 5.95 & 4.9986 & TRN & \\
\hline CHEMBL1571760 & 688171 & 4.75 & 4.9589 & TRN & \\
\hline CHEMBL1395056 & 688171 & 5.45 & 5.0821 & TRN & \\
\hline CHEMBL1473465 & 688171 & 4.75 & 4.8206 & TRN & \\
\hline CHEMBL1337533 & 688171 & 4.55 & 4.9159 & TRN & \\
\hline CHEMBL1599863 & 688171 & 4.55 & 4.9741 & TRN & \\
\hline CHEMBL1356562 & 688171 & 4.55 & 4.9082 & TRN & \\
\hline CHEMBL1416417 & 688171 & 4.75 & 4.92399 & 99999999995 & TST \\
\hline CHEMBL1299346 & 688171 & 4.6 & 4.7445 & TRN & \\
\hline CHEMBL1609353 & 688171 & 4.8 & 4.8475 & TRN & \\
\hline CHEMBL1467623 & 688171 & 4.4 & 5.0454 & TRN & \\
\hline CHEMBL1506670 & 688171 & 4.4 & 4.8656 & TRN & \\
\hline CHEMBL1555365 & 688171 & 4.4 & 4.7631 & TRN & \\
\hline CHEMBL1377926 & 688171 & 5.85 & 4.9922 & TST & \\
\hline CHEMBL1460559 & 688171 & 5.05 & 4.913 & TST & \\
\hline CHEMBL1437208 & 688171 & 4.7 & 4.80699 & 99999999995 & TRN \\
\hline CHEMBL1390197 & 688171 & 4.35 & 5.1067 & TRN & \\
\hline CHEMBL3196373 & 688171 & 4.45 & 4.9219 & TRN & \\
\hline CHEMBL1513793 & 688171 & 5.6 & 5.1061 & TRN & \\
\hline CHEMBL1543340 & 688171 & 4.55 & 4.9448 & TST & \\
\hline CHEMBL1475867 & 688171 & 4.6 & 4.9797 & TRN & \\
\hline CHEMBL1569945 & 688171 & 4.95 & 4.9068 & TRN & \\
\hline CHEMBL1479393 & 688171 & 4.75 & 4.8814 & TRN & \\
\hline CHEMBL1492316 & 688171 & 4.4 & 4.8771 & TST & \\
\hline CHEMBL1479173 & 688171 & 5.4 & 4.8654 & TRN & \\
\hline CHEMBL1490499 & 688171 & 4.85 & 4.8474 & TRN & \\
\hline CHEMBL1346226 & 688171 & 4.4 & 4.7855 & TRN & \\
\hline CHEMBL1383954 & 688171 & 4.4 & 4.9194 & TST & \\
\hline CHEMBL1606624 & 688171 & 4.6 & 4.9431 & TRN & \\
\hline CHEMBL1420642 & 688171 & 5.05 & 4.865 & TST & \\
\hline
\end{tabular}




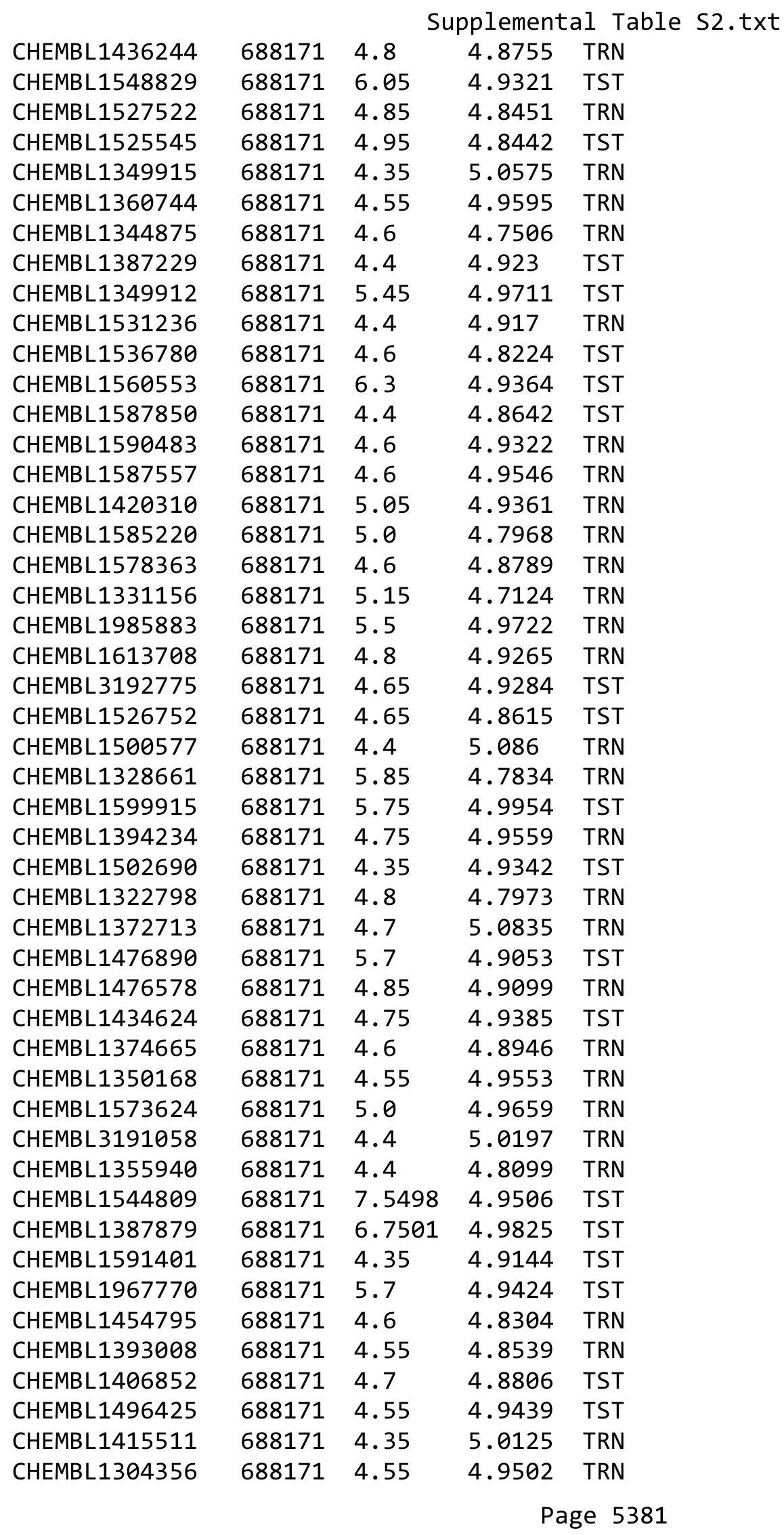




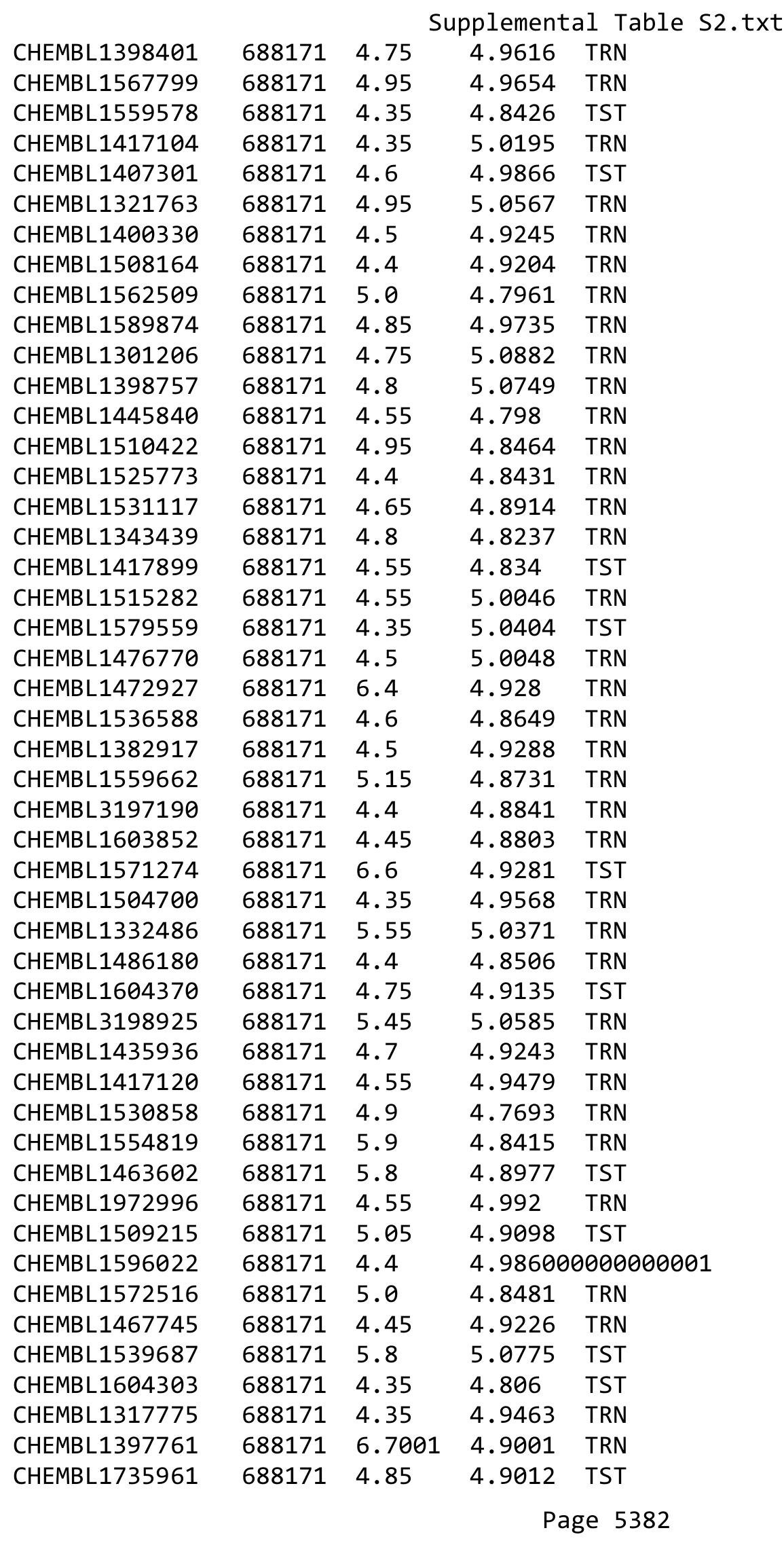




\begin{tabular}{|c|c|c|c|c|c|}
\hline \multicolumn{6}{|c|}{ Supplemental Table S2.txt } \\
\hline CHEMBL1324999 & 688171 & 5.45 & 4.8531 & TRN & \\
\hline CHEMBL1417057 & 688171 & 4.35 & 4.8981 & TRN & \\
\hline CHEMBL1967185 & 688171 & 4.4 & 4.9848 & TRN & \\
\hline CHEMBL1434536 & 688171 & 4.4 & 4.922 & TRN & \\
\hline CHEMBL1603002 & 688171 & 4.7 & 4.8063 & TST & \\
\hline CHEMBL1543481 & 688171 & 6.2 & 4.8648 & TRN & \\
\hline CHEMBL1347334 & 688171 & 4.95 & 4.9285 & TRN & \\
\hline CHEMBL1597697 & 688171 & 4.75 & 4.8551 & TRN & \\
\hline CHEMBL1426275 & 688171 & 4.6 & 4.9769 & TST & \\
\hline CHEMBL1378798 & 688171 & 5.4 & 4.9142 & TRN & \\
\hline CHEMBL1397002 & 688171 & 4.4 & 4.9696 & TRN & \\
\hline CHEMBL1507902 & 688171 & 5.05 & 4.8011 & TRN & \\
\hline CHEMBL1388543 & 688171 & 4.4 & 4.9476 & TRN & \\
\hline CHEMBL1314456 & 688171 & 4.9 & 4.9898 & TRN & \\
\hline CHEMBL1359037 & 688171 & 5.5 & 4.9438 & TRN & \\
\hline CHEMBL1964878 & 688171 & 4.45 & 4.8264 & TRN & \\
\hline CHEMBL1404805 & 688171 & 5.0 & 5.0065 & TRN & \\
\hline CHEMBL1522988 & 688171 & 4.85 & 4.8749 & TRN & \\
\hline CHEMBL1414119 & 688171 & 4.35 & 5.0049 & TRN & \\
\hline CHEMBL1602858 & 688171 & 4.65 & 4.8498 & TST & \\
\hline CHEMBL1441135 & 688171 & 5.05 & 4.9783 & TRN & \\
\hline CHEMBL1425406 & 688171 & 4.35 & 4.8062 & TRN & \\
\hline CHEMBL1574053 & 688171 & 5.05 & 4.8545 & TRN & \\
\hline CHEMBL1515362 & 688171 & 4.75 & 4.9844 & TRN & \\
\hline CHEMBL1526690 & 688171 & 4.55 & 4.9351 & TRN & \\
\hline CHEMBL1589971 & 688171 & 4.4 & 4.8543 & TRN & \\
\hline CHEMBL1432519 & 688171 & 4.85 & 4.7891 & TRN & \\
\hline CHEMBL1350506 & 688171 & 4.7 & 4.8206 & TRN & \\
\hline CHEMBL1320706 & 688171 & 4.7 & 4.8764 & TRN & \\
\hline CHEMBL1452069 & 688171 & 5.45 & 4.9494 & TRN & \\
\hline CHEMBL1454637 & 688171 & 4.45 & 4.9034 & TRN & \\
\hline CHEMBL1542301 & 688171 & 4.6 & 4.78600 & 00000000005 & TST \\
\hline CHEMBL1594474 & 688171 & 4.4 & 4.8737 & TST & \\
\hline CHEMBL1306199 & 688171 & 4.65 & 4.873 & TRN & \\
\hline CHEMBL1483036 & 688171 & 7.0501 & 5.074 & TRN & \\
\hline CHEMBL1539148 & 688171 & 6.1 & 5.0381 & TST & \\
\hline CHEMBL1393874 & 688171 & 4.8 & 4.9599 & TRN & \\
\hline CHEMBL3194333 & 688171 & 4.75 & 4.9443 & TRN & \\
\hline CHEMBL1561266 & 688171 & 4.75 & 4.7746 & TRN & \\
\hline CHEMBL1513881 & 688171 & 4.65 & 4.9196 & TRN & \\
\hline CHEMBL1479378 & 688171 & 4.5 & 4.8579 & TRN & \\
\hline CHEMBL1421442 & 688171 & 5.9 & 5.0173 & TRN & \\
\hline CHEMBL1380638 & 688171 & 5.0 & 4.9837 & TRN & \\
\hline CHEMBL1566645 & 688171 & 4.5 & 4.9049 & TST & \\
\hline CHEMBL1383439 & 688171 & 4.65 & 4.9331 & TRN & \\
\hline CHEMBL1501323 & 688171 & 4.65 & 4.8165 & TST & \\
\hline CHEMBL1354537 & 688171 & 4.75 & 4.8391 & TRN & \\
\hline CHEMBL1572255 & 688171 & 4.5 & 4.9201 & TRN & \\
\hline
\end{tabular}




\begin{tabular}{|c|c|c|c|c|}
\hline \multicolumn{5}{|c|}{ Supplemental Table s2.txt } \\
\hline CHEMBL1394364 & 688171 & 4.7 & 4.8272 & TRN \\
\hline CHEMBL1312441 & 688171 & 4.4 & 4.8266 & TST \\
\hline CHEMBL1604801 & 688171 & 6.4 & 4.9326 & TRN \\
\hline CHEMBL1322375 & 688171 & 5.3 & 4.9392 & TRN \\
\hline CHEMBL1487706 & 688171 & 4.5 & 4.8595 & TRN \\
\hline CHEMBL1329974 & 688171 & 5.4 & 4.9867 & TRN \\
\hline CHEMBL260774 & 688171 & 5.25 & 5.0341 & TRN \\
\hline CHEMBL3196297 & 688171 & 6.7501 & 4.8726 & TRN \\
\hline CHEMBL1559008 & 688171 & 4.6 & 4.8186 & TST \\
\hline CHEMBL1552874 & 688171 & 5.95 & 4.9449 & TRN \\
\hline CHEMBL1363758 & 688171 & 4.65 & 4.9199 & TRN \\
\hline CHEMBL1513291 & 688171 & 4.85 & 4.8291 & TRN \\
\hline CHEMBL1504294 & 688171 & 4.6 & 4.8003 & TST \\
\hline CHEMBL1556955 & 688171 & 6.0 & 4.8794 & TRN \\
\hline CHEMBL1564400 & 688171 & 5.0 & 4.9277 & TRN \\
\hline CHEMBL1476167 & 688171 & 5.5 & 4.8539 & TRN \\
\hline CHEMBL1558840 & 688171 & 4.5 & 4.8649 & TST \\
\hline CHEMBL1517174 & 688171 & 4.85 & 5.0133 & TRN \\
\hline CHEMBL1275655 & 688171 & 6.0 & 5.0378 & TST \\
\hline CHEMBL1504073 & 688171 & 5.35 & 4.8134 & TST \\
\hline CHEMBL1486969 & 688171 & 6.8499 & 4.8529 & TST \\
\hline CHEMBL1611145 & 688171 & 6.15 & 5.0052 & TRN \\
\hline CHEMBL1502040 & 688171 & 4.4 & 5.0002 & TST \\
\hline CHEMBL1399755 & 688171 & 4.65 & 4.8583 & TRN \\
\hline CHEMBL579503 & 688171 & 5.85 & 5.0113 & TRN \\
\hline CHEMBL1495588 & 688171 & 4.9 & 4.9906 & TRN \\
\hline CHEMBL 3192451 & 688171 & 4.5 & 4.9723 & TST \\
\hline CHEMBL1437487 & 688171 & 4.85 & 4.8621 & TRN \\
\hline CHEMBL1369997 & 688171 & 4.8 & 4.9224 & TST \\
\hline CHEMBL1604990 & 688171 & 4.55 & 4.8516 & TRN \\
\hline CHEMBL1428885 & 688171 & 6.95 & 4.8363 & TRN \\
\hline CHEMBL1515278 & 688171 & 4.65 & 4.9553 & TST \\
\hline CHEMBL 258893 & 688171 & 6.3 & 5.0154 & TST \\
\hline CHEMBL1479699 & 688171 & 4.9 & 4.8643 & TRN \\
\hline CHEMBL1435964 & 688171 & 5.0 & 4.8211 & TRN \\
\hline CHEMBL1357230 & 688171 & 4.9 & 4.8328 & TRN \\
\hline CHEMBL141159 & 688171 & 7.6003 & 4.8547 & TRN \\
\hline CHEMBL1333847 & 688171 & 4.4 & 4.8122 & TST \\
\hline CHEMBL1605792 & 688171 & 5.05 & 4.9033 & TRN \\
\hline CHEMBL1585777 & 688171 & 4.45 & 4.9226 & TRN \\
\hline CHEMBL1448226 & 688171 & 4.85 & 4.8163 & TRN \\
\hline CHEMBL1445366 & 688171 & 4.45 & 4.7748 & TRN \\
\hline CHEMBL1495010 & 688171 & 6.2 & 4.9975 & TST \\
\hline CHEMBL3208651 & 688171 & 4.5 & 4.8533 & TRN \\
\hline CHEMBL1496337 & 688171 & 4.95 & 4.8424 & TRN \\
\hline CHEMBL1316568 & 688171 & 4.65 & 4.8933 & TRN \\
\hline CHEMBL1566722 & 688171 & 5.45 & 4.8329 & TRN \\
\hline CHEMBL1478693 & 688171 & 4.85 & 4.7699 & TRN \\
\hline
\end{tabular}




\begin{tabular}{|c|c|c|c|c|c|}
\hline \multicolumn{6}{|c|}{ Supplemental Table S2.txt } \\
\hline CHEMBL3194684 & 688171 & 4.6 & 4.813 & TRN & \\
\hline CHEMBL1987145 & 688171 & 5.85 & 4.8876 & TRN & \\
\hline CHEMBL1426157 & 688171 & 4.9 & 4.9681 & TST & \\
\hline CHEMBL1562974 & 688171 & 4.4 & 4.89199 & 99999999995 & TRN \\
\hline CHEMBL1351201 & 688171 & 5.15 & 4.8572 & TRN & \\
\hline CHEMBL1393803 & 688171 & 4.45 & 4.895 & TRN & \\
\hline CHEMBL1324193 & 688171 & 4.75 & 4.9566 & TRN & \\
\hline CHEMBL1347208 & 688171 & 4.4 & 4.7797 & TRN & \\
\hline CHEMBL1532186 & 688171 & 4.85 & 4.9356 & TRN & \\
\hline CHEMBL1592085 & 688171 & 5.05 & 4.9185 & TRN & \\
\hline CHEMBL1446626 & 688171 & 4.4 & 4.8161 & TRN & \\
\hline CHEMBL1517299 & 688171 & 5.4 & 5.0411 & TST & \\
\hline CHEMBL1588660 & 688171 & 4.8 & 4.8539 & TRN & \\
\hline CHEMBL1348406 & 688171 & 4.55 & 4.9279 & TRN & \\
\hline CHEMBL3214632 & 688171 & 4.55 & 5.0118 & TRN & \\
\hline CHEMBL1449590 & 688171 & 5.55 & 4.87 & TST & \\
\hline CHEMBL1467288 & 688171 & 4.65 & 4.7666 & TRN & \\
\hline CHEMBL3189203 & 688171 & 5.1 & 5.0377 & TRN & \\
\hline CHEMBL1407966 & 688171 & 5.3 & 5.0277 & TST & \\
\hline CHEMBL1555813 & 688171 & 5.75 & 5.0003 & TRN & \\
\hline CHEMBL1594510 & 688171 & 4.55 & 5.0459 & TRN & \\
\hline CHEMBL1317150 & 688171 & 4.6 & 5.023 & TRN & \\
\hline CHEMBL1369180 & 688171 & 5.05 & 4.8255 & TRN & \\
\hline CHEMBL1365217 & 688171 & 4.4 & 4.8231 & TRN & \\
\hline CHEMBL1334337 & 688171 & 4.85 & 4.7498 & TRN & \\
\hline CHEMBL1364573 & 688171 & 4.5 & 4.938 & TST & \\
\hline CHEMBL1545902 & 688171 & 4.85 & 4.9322 & TST & \\
\hline CHEMBL1392244 & 688171 & 4.35 & 4.9443 & TRN & \\
\hline CHEMBL3192055 & 688171 & 4.75 & 4.7879 & TRN & \\
\hline CHEMBL1456532 & 688171 & 4.45 & 4.9485 & TST & \\
\hline CHEMBL1449881 & 688171 & 5.05 & 4.9612 & TRN & \\
\hline CHEMBL141690 & 688171 & 6.9 & 4.9186 & TST & \\
\hline CHEMBL1312054 & 688171 & 4.55 & 4.9104 & TRN & \\
\hline CHEMBL1370750 & 688171 & 4.4 & 4.8157 & TRN & \\
\hline CHEMBL3213810 & 688171 & 4.75 & 5.0291 & TRN & \\
\hline CHEMBL1430161 & 688171 & 5.05 & 4.9318 & TST & \\
\hline CHEMBL1430737 & 688171 & 4.85 & 4.7719 & TRN & \\
\hline CHEMBL1342679 & 688171 & 4.7 & 4.7409 & TRN & \\
\hline CHEMBL1314838 & 688171 & 4.75 & 4.7842 & TRN & \\
\hline CHEMBL1590199 & 688171 & 4.75 & 4.7472 & TRN & \\
\hline CHEMBL1452880 & 688171 & 4.6 & 4.8275 & TRN & \\
\hline CHEMBL1407342 & 688171 & 4.75 & 4.9302 & TRN & \\
\hline CHEMBL1485474 & 688171 & 7.6003 & 4.8912 & TRN & \\
\hline CHEMBL1476135 & 688171 & 4.8 & 4.9341 & TRN & \\
\hline CHEMBL1447043 & 688171 & 5.0 & 5.0131 & TRN & \\
\hline CHEMBL1542865 & 688171 & 5.05 & 4.9806 & TRN & \\
\hline CHEMBL570399 & 688171 & 5.95 & 4.8378 & TRN & \\
\hline CHEMBL1610563 & 688171 & 4.85 & 4.8126 & TST & \\
\hline
\end{tabular}




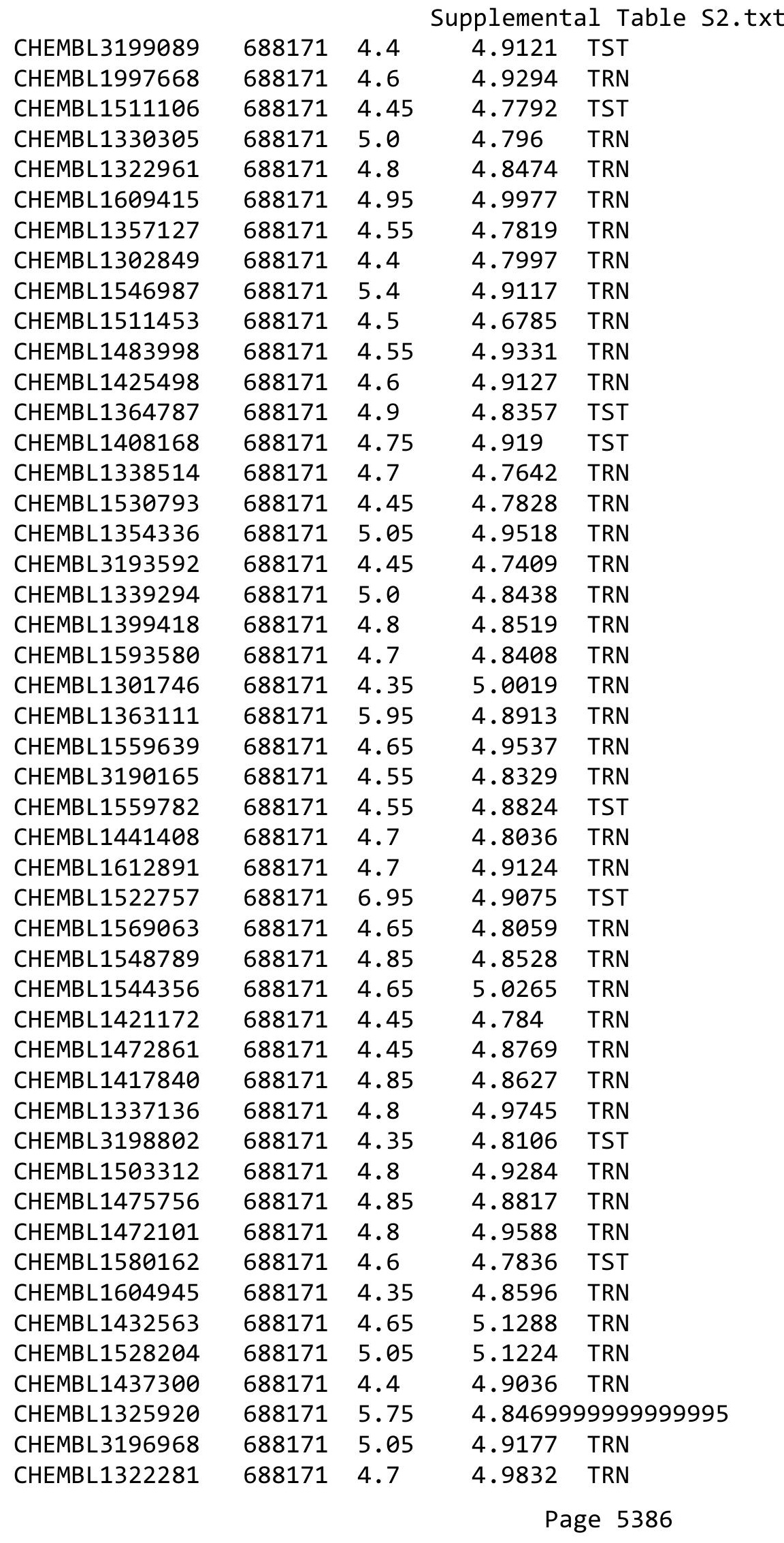




\begin{tabular}{|c|c|c|c|c|}
\hline \multicolumn{5}{|c|}{ Supplemental Table S2.txt } \\
\hline CHEMBL1440546 & 688171 & 4.4 & 4.907 & TRN \\
\hline CHEMBL1595756 & 688171 & 4.5 & 4.9513 & TRN \\
\hline CHEMBL1499695 & 688171 & 4.65 & 5.0791 & TRN \\
\hline CHEMBL1384148 & 688171 & 4.75 & 4.8841 & TRN \\
\hline CHEMBL1357013 & 688171 & 4.5 & 4.8535 & TRN \\
\hline CHEMBL1572692 & 688171 & 4.85 & 4.9198 & TRN \\
\hline CHEMBL1473185 & 688171 & 4.9 & 4.9769 & TRN \\
\hline CHEMBL1604937 & 688171 & 5.05 & 4.9248 & TRN \\
\hline CHEMBL1315299 & 688171 & 5.9 & 5.0542 & TST \\
\hline CHEMBL1514822 & 688171 & 4.4 & 4.8723 & TST \\
\hline CHEMBL1423338 & 688171 & 4.7 & 4.9798 & TRN \\
\hline CHEMBL1992432 & 688171 & 4.6 & 4.8597 & TRN \\
\hline CHEMBL1361268 & 688171 & 4.7 & 4.809 & TRN \\
\hline CHEMBL1432615 & 688171 & 4.7 & 4.8885 & TRN \\
\hline CHEMBL1594652 & 688171 & 4.4 & 4.9768 & TRN \\
\hline CHEMBL1404286 & 688171 & 5.95 & 4.9927 & TRN \\
\hline CHEMBL1419730 & 688171 & 5.05 & 4.8868 & TRN \\
\hline CHEMBL1357859 & 688171 & 5.0 & 4.8979 & TRN \\
\hline CHEMBL1513723 & 688171 & 4.35 & 4.8566 & TRN \\
\hline CHEMBL1301505 & 688171 & 5.0 & 5.0102 & TST \\
\hline CHEMBL3189828 & 688171 & 4.65 & 4.905 & TST \\
\hline CHEMBL1437508 & 688171 & 4.85 & 4.8284 & TRN \\
\hline CHEMBL1606488 & 688171 & 4.6 & 4.9334 & TST \\
\hline CHEMBL1531579 & 688171 & 5.25 & 4.8581 & TST \\
\hline CHEMBL1613644 & 688171 & 5.05 & 4.7795 & TRN \\
\hline CHEMBL1306742 & 688171 & 4.8 & 4.7585 & TRN \\
\hline CHEMBL1384055 & 688171 & 5.4 & 4.9933 & TRN \\
\hline CHEMBL1434890 & 688171 & 4.6 & 4.8575 & TRN \\
\hline CHEMBL1361765 & 688171 & 4.4 & 4.8608 & TRN \\
\hline CHEMBL3208362 & 688171 & 4.6 & 5.0809 & TRN \\
\hline CHEMBL3192255 & 688171 & 4.4 & 4.8683 & TRN \\
\hline CHEMBL1379344 & 688171 & 5.05 & 4.9949 & TRN \\
\hline CHEMBL1332920 & 688171 & 5.7 & 5.0975 & TST \\
\hline CHEMBL1591924 & 688171 & 4.35 & 4.9763 & TRN \\
\hline CHEMBL1393604 & 688171 & 4.4 & 4.8927 & TRN \\
\hline CHEMBL1593297 & 688171 & 4.85 & 4.852 & TRN \\
\hline CHEMBL566064 & 688171 & 4.7 & 4.8282 & TRN \\
\hline CHEMBL3190876 & 688171 & 4.8 & 4.9097 & TRN \\
\hline CHEMBL1374784 & 688171 & 5.85 & 5.0795 & TRN \\
\hline CHEMBL1343873 & 688171 & 5.35 & 4.8809 & TST \\
\hline CHEMBL1305399 & 688171 & 4.4 & 4.9912 & TRN \\
\hline CHEMBL1514141 & 688171 & 4.55 & 4.9066 & TRN \\
\hline CHEMBL1305025 & 688171 & 4.85 & 4.8785 & TRN \\
\hline CHEMBL1345487 & 688171 & 4.4 & 4.672 & TRN \\
\hline CHEMBL1432452 & 688171 & 6.2 & 5.016 & TRN \\
\hline CHEMBL3191616 & 688171 & 4.65 & 5.0495 & TRN \\
\hline CHEMBL1447284 & 688171 & 5.85 & 4.9958 & TRN \\
\hline CHEMBL1301374 & 688171 & 7.2503 & 4.9396 & TRN \\
\hline
\end{tabular}




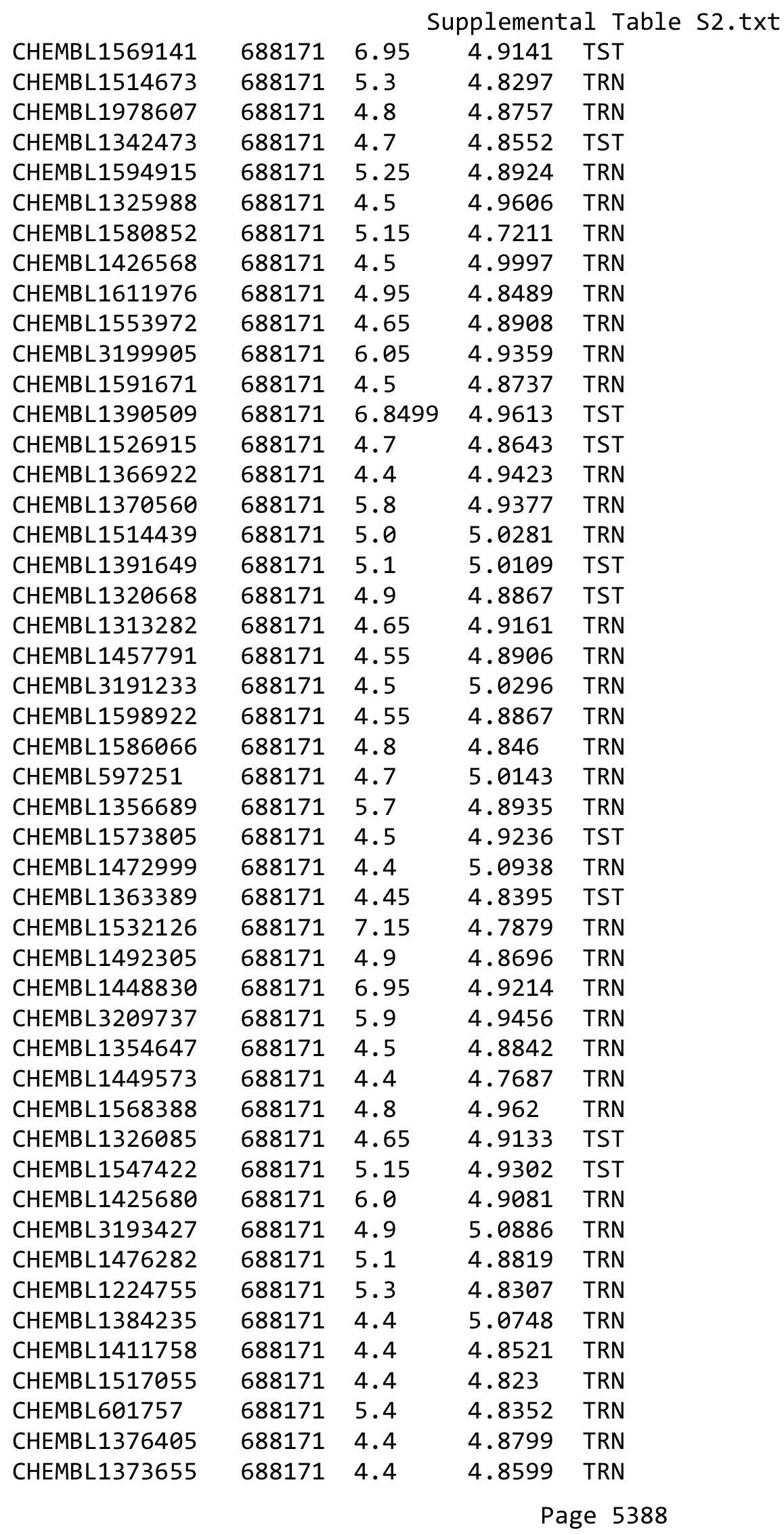




\begin{tabular}{|c|c|c|c|c|c|}
\hline \multicolumn{6}{|c|}{ Supplemental Table S2.txt } \\
\hline CHEMBL87277 & 688171 & 4.45 & 4.7803 & TRN & \\
\hline CHEMBL1372839 & 688171 & 5.4 & 5.0095 & TRN & \\
\hline CHEMBL1548826 & 688171 & 5.4 & 4.982 & TRN & \\
\hline CHEMBL1425137 & 688171 & 5.1 & 4.8404 & TRN & \\
\hline CHEMBL1613237 & 688171 & 4.7 & 4.9013 & TRN & \\
\hline CHEMBL1509603 & 688171 & 5.85 & 4.8112 & TRN & \\
\hline CHEMBL1484114 & 688171 & 4.4 & 4.9259 & TRN & \\
\hline CHEMBL1489871 & 688171 & 4.8 & 4.9538 & TRN & \\
\hline CHEMBL1577637 & 688171 & 4.4 & 4.8659 & TST & \\
\hline CHEMBL1363637 & 688171 & 4.4 & 4.9714 & TRN & \\
\hline CHEMBL3190558 & 688171 & 4.4 & 4.8319 & TST & \\
\hline CHEMBL1319364 & 688171 & 4.95 & 4.8416 & TRN & \\
\hline CHEMBL1435379 & 688171 & 4.75 & 4.9426 & TRN & \\
\hline CHEMBL1470905 & 688171 & 4.85 & 4.7681 & TRN & \\
\hline CHEMBL164 & 688171 & 6.0 & 4.8811 & TRN & \\
\hline CHEMBL1471350 & 688171 & 4.6 & 4.8981 & TRN & \\
\hline CHEMBL1333455 & 688171 & 4.4 & 5.0298 & TRN & \\
\hline CHEMBL1549287 & 688171 & 4.85 & 4.8151 & TST & \\
\hline CHEMBL1373937 & 688171 & 4.4 & 4.9846 & TST & \\
\hline CHEMBL1964389 & 688171 & 4.7 & 5.0799 & TRN & \\
\hline CHEMBL487894 & 688171 & 4.65 & 4.9067 & TST & \\
\hline CHEMBL1433969 & 688171 & 4.55 & 4.7457 & TRN & \\
\hline CHEMBL1407532 & 688171 & 4.4 & 5.0696 & TST & \\
\hline CHEMBL1396228 & 688171 & 4.4 & 4.9151 & TRN & \\
\hline CHEMBL1521111 & 688171 & 4.35 & 4.9833 & TRN & \\
\hline CHEMBL1318696 & 688171 & 4.35 & 4.84699 & 99999999995 & TRN \\
\hline CHEMBL1496300 & 688171 & 4.5 & 4.92899 & 9999999999 & TST \\
\hline CHEMBL1608593 & 688171 & 4.7 & 4.8745 & TRN & \\
\hline CHEMBL1367742 & 688171 & 4.8 & 4.9001 & TRN & \\
\hline CHEMBL1323312 & 688171 & 5.05 & 4.8587 & TRN & \\
\hline CHEMBL1554146 & 688171 & 4.85 & 4.89199 & 99999999995 & TRN \\
\hline CHEMBL1360250 & 688171 & 5.1 & 4.9717 & TRN & \\
\hline CHEMBL1356170 & 688171 & 4.75 & 4.899 & TRN & \\
\hline CHEMBL1395273 & 688171 & 4.9 & 4.8919 & TRN & \\
\hline CHEMBL1388039 & 688171 & 4.85 & 5.0136 & TRN & \\
\hline CHEMBL1338323 & 688171 & 4.6 & 4.8501 & TRN & \\
\hline CHEMBL1406350 & 688171 & 4.85 & 4.8616 & TRN & \\
\hline CHEMBL1485818 & 688171 & 5.1 & 5.0223 & TRN & \\
\hline CHEMBL1591728 & 688171 & 4.45 & 4.7852 & TRN & \\
\hline CHEMBL1463659 & 688171 & 5.3 & 4.848 & TRN & \\
\hline CHEMBL1373872 & 688171 & 4.6 & 4.9318 & TRN & \\
\hline CHEMBL1357254 & 688171 & 5.95 & 5.0646 & TST & \\
\hline CHEMBL1365614 & 688171 & 4.55 & 4.8777 & TRN & \\
\hline CHEMBL1403011 & 688171 & 4.5 & 4.936 & TRN & \\
\hline CHEMBL1570140 & 688171 & 4.4 & 4.9034 & TRN & \\
\hline CHEMBL1374495 & 688171 & 4.75 & 4.9163 & TRN & \\
\hline CHEMBL1351450 & 688171 & 4.45 & 4.8562 & TRN & \\
\hline CHEMBL1332275 & 688171 & 4.75 & 4.9132 & TRN & \\
\hline
\end{tabular}




\begin{tabular}{|c|c|c|c|c|}
\hline \multicolumn{5}{|c|}{ Supplemental Table S2.txt } \\
\hline CHEMBL1468327 & 688171 & 4.35 & 4.8588 & TRN \\
\hline CHEMBL1335365 & 688171 & 4.75 & 4.8422 & TRN \\
\hline CHEMBL1496273 & 688171 & 5.05 & 4.9331 & TRN \\
\hline CHEMBL1419949 & 688171 & 4.35 & 4.9113 & TRN \\
\hline CHEMBL1573972 & 688171 & 4.4 & 4.8845 & TRN \\
\hline CHEMBL2095095 & 688171 & 4.4 & 4.7664 & TRN \\
\hline CHEMBL1397993 & 688171 & 5.0 & 4.8208 & TRN \\
\hline CHEMBL1487098 & 688171 & 4.5 & 5.0424 & TRN \\
\hline CHEMBL1567378 & 688171 & 4.65 & 4.9591 & TRN \\
\hline CHEMBL1412169 & 688171 & 4.8 & 5.0004 & TST \\
\hline CHEMBL1330233 & 688171 & 5.05 & 4.8108 & TRN \\
\hline CHEMBL1355250 & 688171 & 4.85 & 4.9202 & TRN \\
\hline CHEMBL1598097 & 688171 & 5.45 & 4.8013 & TRN \\
\hline CHEMBL1471773 & 688171 & 4.4 & 5.0441 & TST \\
\hline CHEMBL1523526 & 688171 & 4.5 & 5.0426 & TRN \\
\hline CHEMBL1555424 & 688171 & 6.8 & 4.8612 & TST \\
\hline CHEMBL1534941 & 688171 & 4.4 & 4.8674 & TRN \\
\hline CHEMBL3214160 & 688171 & 5.95 & 4.9479 & TRN \\
\hline CHEMBL1448377 & 688171 & 4.55 & 4.8301 & TRN \\
\hline CHEMBL1541699 & 688171 & 4.95 & 4.8636 & TRN \\
\hline CHEMBL1437306 & 688171 & 4.85 & 4.6995 & TRN \\
\hline CHEMBL1404840 & 688171 & 5.5 & 4.9159 & TRN \\
\hline CHEMBL1311795 & 688171 & 4.4 & 4.908 & TRN \\
\hline CHEMBL 3213555 & 688171 & 4.35 & 4.7955 & TST \\
\hline CHEMBL1367940 & 688171 & 4.9 & 4.7643 & TRN \\
\hline CHEMBL1444301 & 688171 & 5.5 & 5.0705 & TRN \\
\hline CHEMBL1533235 & 688171 & 4.95 & 4.9682 & TRN \\
\hline CHEMBL1342468 & 688171 & 5.35 & 4.9158 & TRN \\
\hline CHEMBL1598169 & 688171 & 4.75 & 4.9051 & TST \\
\hline CHEMBL1360800 & 688171 & 4.55 & 4.9181 & TST \\
\hline CHEMBL1400192 & 688171 & 4.6 & 4.8575 & TRN \\
\hline CHEMBL3195929 & 688171 & 7.3002 & 5.0032 & TRN \\
\hline CHEMBL1419148 & 688171 & 4.45 & 4.7304 & TRN \\
\hline CHEMBL1356745 & 688171 & 4.55 & 4.9661 & TRN \\
\hline CHEMBL1593915 & 688171 & 4.55 & 4.8588 & TRN \\
\hline CHEMBL1466423 & 688171 & 4.85 & 4.8435 & TST \\
\hline CHEMBL3210087 & 688171 & 4.75 & 5.0219 & TRN \\
\hline CHEMBL1451931 & 688171 & 4.85 & 4.8922 & TRN \\
\hline CHEMBL 3212492 & 688171 & 5.25 & 4.9126 & TST \\
\hline CHEMBL1443226 & 688171 & 4.55 & 5.0236 & TRN \\
\hline CHEMBL1542287 & 688171 & 7.0501 & 4.9782 & TST \\
\hline CHEMBL1584169 & 688171 & 4.7 & 4.9397 & TRN \\
\hline CHEMBL1403738 & 688171 & 4.8 & 4.9012 & TST \\
\hline CHEMBL1447192 & 688171 & 5.15 & 4.8449 & TRN \\
\hline CHEMBL1335652 & 688171 & 4.35 & 4.8782 & TRN \\
\hline CHEMBL1371821 & 688171 & 4.45 & 4.8486 & TRN \\
\hline CHEMBL1609310 & 688171 & 4.4 & 4.8655 & TST \\
\hline CHEMBL1574200 & 688171 & 4.8 & 4.8361 & TRN \\
\hline
\end{tabular}




\begin{tabular}{|c|c|c|c|c|c|}
\hline \multicolumn{6}{|c|}{ Supplemental Table S2.txt } \\
\hline CHEMBL1448364 & 688171 & 4.55 & 4.9408 & TRN & \\
\hline CHEMBL1351514 & 688171 & 4.55 & 4.8525 & TRN & \\
\hline CHEMBL1317204 & 688171 & 7.6003 & 4.9439 & TRN & \\
\hline CHEMBL1430584 & 688171 & 5.05 & 4.6837 & TRN & \\
\hline CHEMBL1573451 & 688171 & 4.5 & 4.8197 & TRN & \\
\hline CHEMBL1561637 & 688171 & 4.45 & 4.7869 & TRN & \\
\hline CHEMBL3192830 & 688171 & 5.05 & 4.9504 & TRN & \\
\hline CHEMBL1339946 & 688171 & 5.55 & 4.775 & TRN & \\
\hline CHEMBL1570660 & 688171 & 4.55 & 4.81800 & 30000000005 & TRN \\
\hline CHEMBL1324790 & 688171 & 4.4 & 5.0062 & TRN & \\
\hline CHEMBL1535989 & 688171 & 4.75 & 4.832 & TST & \\
\hline CHEMBL1350469 & 688171 & 5.05 & 4.8506 & TST & \\
\hline CHEMBL1550819 & 688171 & 4.4 & 4.93 & TRN & \\
\hline CHEMBL3190845 & 688171 & 5.6 & 4.8685 & TRN & \\
\hline CHEMBL1484407 & 688171 & 4.65 & 5.027 & TRN & \\
\hline CHEMBL 2359072 & 688171 & 4.7 & 4.9803 & TRN & \\
\hline CHEMBL3193805 & 688171 & 4.65 & 4.9473 & TST & \\
\hline CHEMBL 366861 & 688171 & 5.45 & 5.0206 & TRN & \\
\hline CHEMBL1524159 & 688171 & 5.05 & 4.8172 & TRN & \\
\hline CHEMBL1498608 & 688171 & 5.15 & 4.8129 & TRN & \\
\hline CHEMBL3210082 & 688171 & 5.85 & 4.8715 & TRN & \\
\hline CHEMBL1445804 & 688171 & 4.85 & 4.9589 & TRN & \\
\hline CHEMBL1604522 & 688171 & 6.95 & 5.0325 & TRN & \\
\hline CHEMBL1317384 & 688171 & 4.35 & 4.8931 & TRN & \\
\hline CHEMBL1392445 & 688171 & 4.5 & 4.8577 & TST & \\
\hline CHEMBL3195845 & 688171 & 4.75 & 4.8319 & TRN & \\
\hline CHEMBL1600450 & 688171 & 5.2 & 4.8696 & TRN & \\
\hline CHEMBL1524983 & 688171 & 4.6 & 4.9089 & TRN & \\
\hline CHEMBL3397122 & 688171 & 4.8 & 4.754 & TST & \\
\hline CHEMBL1600187 & 688171 & 5.1 & 4.96399 & 99999999995 & TRN \\
\hline CHEMBL1582121 & 688171 & 4.5 & 4.8427 & TRN & \\
\hline CHEMBL1463164 & 688171 & 4.45 & 4.9567 & TRN & \\
\hline CHEMBL1518081 & 688171 & 4.4 & 4.867 & TRN & \\
\hline CHEMBL1580804 & 688171 & 4.65 & 4.9141 & TRN & \\
\hline CHEMBL1984240 & 688171 & 4.6 & 4.9494 & TRN & \\
\hline CHEMBL1557476 & 688171 & 4.8 & 4.9704 & TRN & \\
\hline CHEMBL1493501 & 688171 & 4.65 & 4.8314 & TRN & \\
\hline CHEMBL1315678 & 688171 & 4.9 & 4.9176 & TRN & \\
\hline CHEMBL1545801 & 688171 & 4.45 & 4.9497 & TRN & \\
\hline CHEMBL1566280 & 688171 & 6.7001 & 4.6899 & TST & \\
\hline CHEMBL1460624 & 688171 & 5.4 & 4.8683 & TRN & \\
\hline CHEMBL323197 & 688171 & 6.0 & 4.9953 & TST & \\
\hline CHEMBL1392551 & 688171 & 5.95 & 4.7659 & TST & \\
\hline CHEMBL1357474 & 688171 & 4.95 & 4.9082 & TRN & \\
\hline CHEMBL1558624 & 688171 & 4.6 & 4.9516 & TRN & \\
\hline CHEMBL1399189 & 688171 & 4.85 & 4.9903 & TRN & \\
\hline CHEMBL1321699 & 688171 & 4.65 & 4.8443 & TRN & \\
\hline CHEMBL1495735 & 688171 & 4.8 & 4.8476 & TRN & \\
\hline
\end{tabular}




\begin{tabular}{|c|c|c|c|c|c|}
\hline \multirow[b]{2}{*}{ CHEMBL1538640 } & \multirow[b]{2}{*}{688171} & \multicolumn{4}{|c|}{ Supplemental Table S2.txt } \\
\hline & & 7.6003 & 4.8728 & TST & \\
\hline CHEMBL1522274 & 688171 & 4.5 & 4.8894 & TRN & \\
\hline CHEMBL1389730 & 688171 & 4.4 & 4.9288 & TRN & \\
\hline CHEMBL1570202 & 688171 & 4.95 & 4.9909 & TRN & \\
\hline CHEMBL1546437 & 688171 & 4.7 & 4.8173 & TRN & \\
\hline CHEMBL1990571 & 688171 & 4.4 & 4.9168 & TST & \\
\hline CHEMBL1426021 & 688171 & 4.4 & 4.8718 & TST & \\
\hline CHEMBL1394586 & 688171 & 4.35 & 4.9772 & TRN & \\
\hline CHEMBL1579333 & 688171 & 4.6 & \multicolumn{2}{|c|}{4.803999999999999} & TRN \\
\hline CHEMBL3192802 & 688171 & 4.4 & 4.9899 & TRN & \\
\hline CHEMBL3195761 & 688171 & 6.1 & 4.9205 & TST & \\
\hline CHEMBL1539376 & 688171 & 4.6 & \multicolumn{2}{|c|}{4.8260000000000005} & TST \\
\hline CHEMBL1486170 & 688171 & 5.55 & 4.8443 & TST & \\
\hline CHEMBL1347469 & 688171 & 4.6 & 4.9333 & TRN & \\
\hline CHEMBL1397753 & 688171 & 6.5501 & 4.8637 & TRN & \\
\hline CHEMBL1554337 & 688171 & 4.4 & 4.9701 & TRN & \\
\hline CHEMBL1568768 & 688171 & 5.5 & 4.9307 & TRN & \\
\hline CHEMBL1569267 & 688171 & 4.4 & 5.001 & TST & \\
\hline CHEMBL1305289 & 688171 & 4.4 & \multicolumn{2}{|c|}{4.9830000000000005} & TST \\
\hline CHEMBL1560449 & 688171 & 5.25 & 4.8943 & TRN & \\
\hline CHEMBL1493181 & 688171 & 4.85 & 4.8265 & TRN & \\
\hline CHEMBL1403632 & 688171 & 4.55 & 4.8638 & TRN & \\
\hline CHEMBL1429320 & 688171 & 4.35 & 4.8009 & TRN & \\
\hline CHEMBL1453195 & 688171 & 6.0 & 4.9525 & TST & \\
\hline CHEMBL1402319 & 688171 & 4.6 & 4.9985 & TST & \\
\hline CHEMBL1554976 & 688171 & 4.6 & 4.8297 & TRN & \\
\hline CHEMBL1308104 & 688171 & 5.1 & 4.7544 & TST & \\
\hline CHEMBL1510555 & 688171 & 5.2 & 4.8104 & TRN & \\
\hline CHEMBL1608853 & 688171 & 4.8 & 4.8903 & TRN & \\
\hline CHEMBL1435197 & 688171 & 4.85 & 5.0029 & TRN & \\
\hline CHEMBL1471372 & 688171 & 5.8 & 5.1119 & TRN & \\
\hline CHEMBL3189551 & 688171 & 4.5 & 4.9274 & TST & \\
\hline CHEMBL1475208 & 688171 & 4.4 & 4.8264 & TRN & \\
\hline CHEMBL1343876 & 688171 & 4.5 & 4.9934 & TRN & \\
\hline CHEMBL1594662 & 688171 & 6.3 & 5.0364 & TRN & \\
\hline CHEMBL1607403 & 688171 & 4.35 & 4.8967 & TRN & \\
\hline CHEMBL3198571 & 688171 & 4.4 & 4.9247 & TST & \\
\hline CHEMBL1303332 & 688171 & 4.5 & 4.9229 & TST & \\
\hline CHEMBL1467824 & 688171 & 5.45 & 4.974 & TST & \\
\hline CHEMBL1551999 & 688171 & 4.4 & 4.9471 & TRN & \\
\hline CHEMBL3190044 & 688171 & 4.4 & 4.9336 & TST & \\
\hline CHEMBL1601309 & 688171 & 4.95 & 4.9811 & TRN & \\
\hline CHEMBL1428407 & 688171 & 5.0 & 4.8457 & TRN & \\
\hline CHEMBL1302195 & 688171 & 6.6499 & 4.9633 & TRN & \\
\hline CHEMBL1599298 & 688171 & 5.55 & 4.89199 & 99999999995 & TRN \\
\hline CHEMBL1399917 & 688171 & 4.65 & 4.8322 & TRN & \\
\hline CHEMBL3196994 & 688171 & 4.6 & 4.8521 & TRN & \\
\hline \multirow[t]{2}{*}{ CHEMBL1438156 } & 688171 & 6.9 & 4.81 & TRN & \\
\hline & & \multicolumn{4}{|c|}{ Page 5392} \\
\hline
\end{tabular}




\begin{tabular}{|c|c|c|c|c|c|}
\hline & & \multicolumn{4}{|c|}{ Supplemental Table S2.txt } \\
\hline CHEMBL1566220 & 688171 & 4.8 & 4.8671 & TRN & \\
\hline CHEMBL1519652 & 688171 & 4.6 & 4.7609 & TRN & \\
\hline CHEMBL1410892 & 688171 & 4.6 & 4.9261 & TRN & \\
\hline CHEMBL1492000 & 688171 & 4.4 & 4.8409 & TRN & \\
\hline CHEMBL1358207 & 688171 & 4.85 & 4.8235 & TRN & \\
\hline CHEMBL1346981 & 688171 & 4.65 & 4.9797 & TST & \\
\hline CHEMBL1332764 & 688171 & 4.95 & 4.9153 & TRN & \\
\hline CHEMBL1433921 & 688171 & 4.4 & 4.8266 & TRN & \\
\hline CHEMBL1408181 & 688171 & 4.35 & 5.0145 & TRN & \\
\hline CHEMBL1401629 & 688171 & 5.0 & 4.8783 & TRN & \\
\hline CHEMBL3197474 & 688171 & 4.85 & 4.8931 & TRN & \\
\hline CHEMBL1515952 & 688171 & 4.45 & 4.8627 & TRN & \\
\hline CHEMBL1347784 & 688171 & 4.5 & 4.8938 & TRN & \\
\hline CHEMBL1603333 & 688171 & 4.75 & 4.7263 & TST & \\
\hline CHEMBL1442437 & 688171 & 5.25 & 5.0086 & TRN & \\
\hline CHEMBL1500026 & 688171 & 5.0 & 4.8362 & TRN & \\
\hline CHEMBL1512956 & 688171 & 4.8 & 4.8624 & TST & \\
\hline CHEMBL1452785 & 688171 & 4.4 & 4.9938 & TRN & \\
\hline CHEMBL1487990 & 688171 & 4.6 & 5.0223 & TRN & \\
\hline CHEMBL1436786 & 688171 & 4.4 & 4.8467 & TRN & \\
\hline CHEMBL1470838 & 688171 & 4.9 & 4.8773 & TRN & \\
\hline CHEMBL1444302 & 688171 & 4.5 & 4.9277 & TRN & \\
\hline CHEMBL1406479 & 688171 & 4.6 & 4.8346 & TRN & \\
\hline CHEMBL1480353 & 688171 & 4.7 & 4.8223 & TRN & \\
\hline CHEMBL380370 & 688171 & 4.7 & 4.8545 & TRN & \\
\hline CHEMBL1469991 & 688171 & 4.9 & 4.9745 & TRN & \\
\hline CHEMBL3196691 & 688171 & 4.4 & 4.8677 & TRN & \\
\hline CHEMBL1365741 & 688171 & 4.4 & 4.7764 & TRN & \\
\hline CHEMBL1424005 & 688171 & 5.5 & 4.9456 & TRN & \\
\hline CHEMBL1551433 & 688171 & 5.4 & 5.0066 & TRN & \\
\hline CHEMBL1368747 & 688171 & 4.5 & 5.0323 & TRN & \\
\hline CHEMBL1554634 & 688171 & 4.65 & 4.7984 & TRN & \\
\hline CHEMBL1544525 & 688171 & 4.4 & 5.0755 & TST & \\
\hline CHEMBL1522393 & 688171 & 4.5 & 4.7918 & TRN & \\
\hline CHEMBL1413752 & 688171 & 4.8 & 4.8439 & TRN & \\
\hline CHEMBL1360718 & 688171 & 4.4 & 4.7849 & TRN & \\
\hline CHEMBL1336456 & 688171 & 5.5 & 4.9129 & TRN & \\
\hline CHEMBL1402588 & 688171 & 4.55 & 4.917 & TRN & \\
\hline CHEMBL1415301 & 688171 & 4.5 & 4.9144 & TRN & \\
\hline CHEMBL1564822 & 688171 & 4.6 & 4.8968 & TRN & \\
\hline CHEMBL1384702 & 688171 & 6.6 & 4.8745 & TST & \\
\hline CHEMBL3189409 & 688171 & 4.85 & 4.8889 & TRN & \\
\hline CHEMBL1551732 & 688171 & 6.8 & 5.05399 & 9999999999 & TRN \\
\hline CHEMBL1567646 & 688171 & 4.45 & 4.9732 & TRN & \\
\hline CHEMBL1309266 & 688171 & 6.95 & 4.9258 & TST & \\
\hline CHEMBL1529663 & 688171 & 4.5 & 5.0151 & TST & \\
\hline CHEMBL1563141 & 688171 & 5.3 & 4.8707 & TST & \\
\hline CHEMBL1481796 & 688171 & 6.95 & 4.8975 & TRN & \\
\hline
\end{tabular}




\begin{tabular}{|c|c|c|c|c|c|}
\hline \multicolumn{6}{|c|}{ Supplemental Table s2.txt } \\
\hline CHEMBL 1434057 & 688171 & 5.0 & 4.9242 & TST & \\
\hline CHEMBL1477826 & 688171 & 4.5 & 4.8593 & TRN & \\
\hline CHEMBL1517075 & 688171 & 6.3 & 4.9503 & TST & \\
\hline CHEMBL1446440 & 688171 & 5.1 & 5.0355 & TRN & \\
\hline CHEMBL1497331 & 688171 & 4.4 & 4.831 & TRN & \\
\hline CHEMBL1569764 & 688171 & 6.1 & 4.8795 & TRN & \\
\hline CHEMBL1564573 & 688171 & 5.5 & 4.9165 & TRN & \\
\hline CHEMBL1308284 & 688171 & 4.75 & 5.0287 & TRN & \\
\hline CHEMBL1597626 & 688171 & 4.5 & 5.0236 & TRN & \\
\hline CHEMBL3189212 & 688171 & 5.5 & 4.9343 & TST & \\
\hline CHEMBL1331538 & 688171 & 5.9 & 4.9674 & TRN & \\
\hline CHEMBL1589889 & 688171 & 4.85 & 4.8748 & TRN & \\
\hline CHEMBL1347563 & 688171 & 4.55 & 4.8145 & TRN & \\
\hline CHEMBL1381904 & 688171 & 4.55 & 4.9663 & TRN & \\
\hline CHEMBL1463068 & 688171 & 4.4 & 4.9777 & TRN & \\
\hline CHEMBL3195461 & 688171 & 5.05 & 4.8505 & TRN & \\
\hline CHEMBL1415104 & 688171 & 4.65 & 4.9276 & TRN & \\
\hline CHEMBL1479820 & 688171 & 5.3 & 5.1188 & TST & \\
\hline CHEMBL1992486 & 688171 & 4.9 & 4.9759 & TST & \\
\hline CHEMBL1382573 & 688171 & 4.55 & 5.102 & TRN & \\
\hline CHEMBL1407580 & 688171 & 4.45 & 4.8213 & TRN & \\
\hline CHEMBL1567341 & 688171 & 4.4 & 5.0055 & TRN & \\
\hline CHEMBL1468195 & 688171 & 4.45 & 4.7844 & TRN & \\
\hline CHEMBL1591239 & 688171 & 4.4 & 4.9284 & TRN & \\
\hline CHEMBL1532318 & 688171 & 4.75 & 4.9319 & TRN & \\
\hline CHEMBL1435309 & 688171 & 5.75 & 5.0358 & TST & \\
\hline CHEMBL1342842 & 688171 & 5.1 & 4.8492 & TRN & \\
\hline CHEMBL1433058 & 688171 & 4.35 & 4.7641 & TST & \\
\hline CHEMBL1529557 & 688171 & 4.75 & 4.8791 & TST & \\
\hline CHEMBL1453439 & 688171 & 4.9 & 4.9769 & TRN & \\
\hline CHEMBL1319095 & 688171 & 4.85 & 4.8462 & TRN & \\
\hline CHEMBL1515830 & 688171 & 4.8 & 4.827 & TRN & \\
\hline CHEMBL1360722 & 688171 & 4.75 & 4.8778 & TRN & \\
\hline CHEMBL 90146 & 688171 & 4.7 & 4.8442 & TRN & \\
\hline CHEMBL1381473 & 688171 & 5.0 & 4.6961 & TRN & \\
\hline CHEMBL1529749 & 688171 & 4.35 & 4.7745 & TRN & \\
\hline CHEMBL1520800 & 688171 & 4.9 & 4.90300 & 00000000005 & TRN \\
\hline CHEMBL1492052 & 688171 & 5.1 & 4.852 & TRN & \\
\hline CHEMBL1557744 & 688171 & 4.4 & 4.956 & TRN & \\
\hline CHEMBL1399837 & 688171 & 4.45 & 4.7377 & TRN & \\
\hline CHEMBL1536824 & 688171 & 4.45 & 4.7703 & TRN & \\
\hline CHEMBL1335454 & 688171 & 6.8 & 4.9517 & TST & \\
\hline CHEMBL1610651 & 688171 & 5.0 & 4.8703 & TRN & \\
\hline CHEMBL1577605 & 688171 & 6.6 & 4.9463 & TST & \\
\hline CHEMBL1570709 & 688171 & 4.7 & 4.8438 & TRN & \\
\hline CHEMBL1583510 & 688171 & 4.75 & 5.0378 & TRN & \\
\hline CHEMBL1512659 & 688171 & 4.8 & 4.8779 & TRN & \\
\hline CHEMBL1545300 & 688171 & 5.55 & 4.9391 & TST & \\
\hline
\end{tabular}




\begin{tabular}{|c|c|c|c|c|}
\hline \multicolumn{5}{|c|}{ Supplemental Table S2.txt } \\
\hline CHEMBL1445359 & 688171 & 4.4 & 4.923 & TST \\
\hline CHEMBL1516913 & 688171 & 4.5 & 4.8362 & TRN \\
\hline CHEMBL1309759 & 688171 & 4.5 & 4.7785 & TRN \\
\hline CHEMBL1496393 & 688171 & 4.7 & 4.8 & TRN \\
\hline CHEMBL1331563 & 688171 & 4.65 & 4.862 & TRN \\
\hline CHEMBL1612031 & 688171 & 5.0 & 4.8499 & TST \\
\hline CHEMBL1521868 & 688171 & 5.4 & 5.0588 & TRN \\
\hline CHEMBL1452968 & 688171 & 5.6 & 5.0601 & TST \\
\hline CHEMBL1411676 & 688171 & 4.95 & 4.7672 & TST \\
\hline CHEMBL1422670 & 688171 & 4.65 & 4.8209 & TST \\
\hline CHEMBL1397637 & 688171 & 4.55 & 5.0058 & TRN \\
\hline CHEMBL1321079 & 688171 & 4.55 & 4.7809 & TRN \\
\hline CHEMBL1609117 & 688171 & 4.85 & 4.7463 & TRN \\
\hline CHEMBL1400590 & 688171 & 4.95 & 5.0123 & TRN \\
\hline CHEMBL1475553 & 688171 & 5.2 & 4.9912 & TRN \\
\hline CHEMBL137743 & 688171 & 4.85 & 5.0374 & TRN \\
\hline CHEMBL1534183 & 688171 & 4.45 & 4.8187 & TRN \\
\hline CHEMBL1303281 & 688171 & 4.5 & 4.8457 & TRN \\
\hline CHEMBL1599063 & 688171 & 4.75 & 4.8683 & TRN \\
\hline CHEMBL1355618 & 688171 & 4.55 & 4.8188 & TRN \\
\hline CHEMBL1172404 & 688171 & 5.05 & 4.9186 & TRN \\
\hline CHEMBL1479700 & 688171 & 4.8 & 4.9232 & TRN \\
\hline CHEMBL1343502 & 688171 & 4.4 & 4.8697 & TRN \\
\hline CHEMBL1546161 & 688171 & 5.75 & 4.8208 & TRN \\
\hline CHEMBL1500321 & 688171 & 4.95 & 5.023 & TST \\
\hline CHEMBL1541565 & 688171 & 5.8 & 4.8588 & TST \\
\hline CHEMBL1548350 & 688171 & 4.95 & 4.8403 & TRN \\
\hline CHEMBL1526788 & 688171 & 5.05 & 4.9722 & TST \\
\hline CHEMBL1424052 & 688171 & 4.4 & 5.0144 & TRN \\
\hline CHEMBL1359469 & 688171 & 6.15 & 4.9142 & TST \\
\hline CHEMBL1502697 & 688171 & 4.4 & 4.9042 & TST \\
\hline CHEMBL1993301 & 688171 & 4.95 & 4.9444 & TST \\
\hline CHEMBL1402276 & 688171 & 4.4 & 4.8264 & TRN \\
\hline CHEMBL1320050 & 688171 & 4.75 & 4.9115 & TST \\
\hline CHEMBL1317687 & 688171 & 4.65 & 5.0419 & TRN \\
\hline CHEMBL1326990 & 688171 & 4.4 & 4.9646 & TRN \\
\hline CHEMBL1485096 & 688171 & 5.05 & 5.0197 & TST \\
\hline CHEMBL1512858 & 688171 & 4.55 & 4.8882 & TRN \\
\hline CHEMBL1552640 & 688171 & 5.05 & 4.8675 & TST \\
\hline CHEMBL1358905 & 688171 & 4.6 & 4.9571 & TRN \\
\hline CHEMBL1364119 & 688171 & 4.75 & 5.0718 & TRN \\
\hline CHEMBL1420630 & 688171 & 4.9 & 4.9133 & TRN \\
\hline CHEMBL1590870 & 688171 & 4.55 & 4.8333 & TRN \\
\hline CHEMBL1545782 & 688171 & 4.4 & 4.9669 & TRN \\
\hline CHEMBL1977974 & 688171 & 4.4 & 4.9596 & TRN \\
\hline CHEMBL1502515 & 688171 & 6.45 & 5.0777 & TST \\
\hline CHEMBL1414469 & 688171 & 4.4 & 4.9072 & TRN \\
\hline CHEMBL1515465 & 688171 & 4.4 & 4.9211 & TRN \\
\hline
\end{tabular}




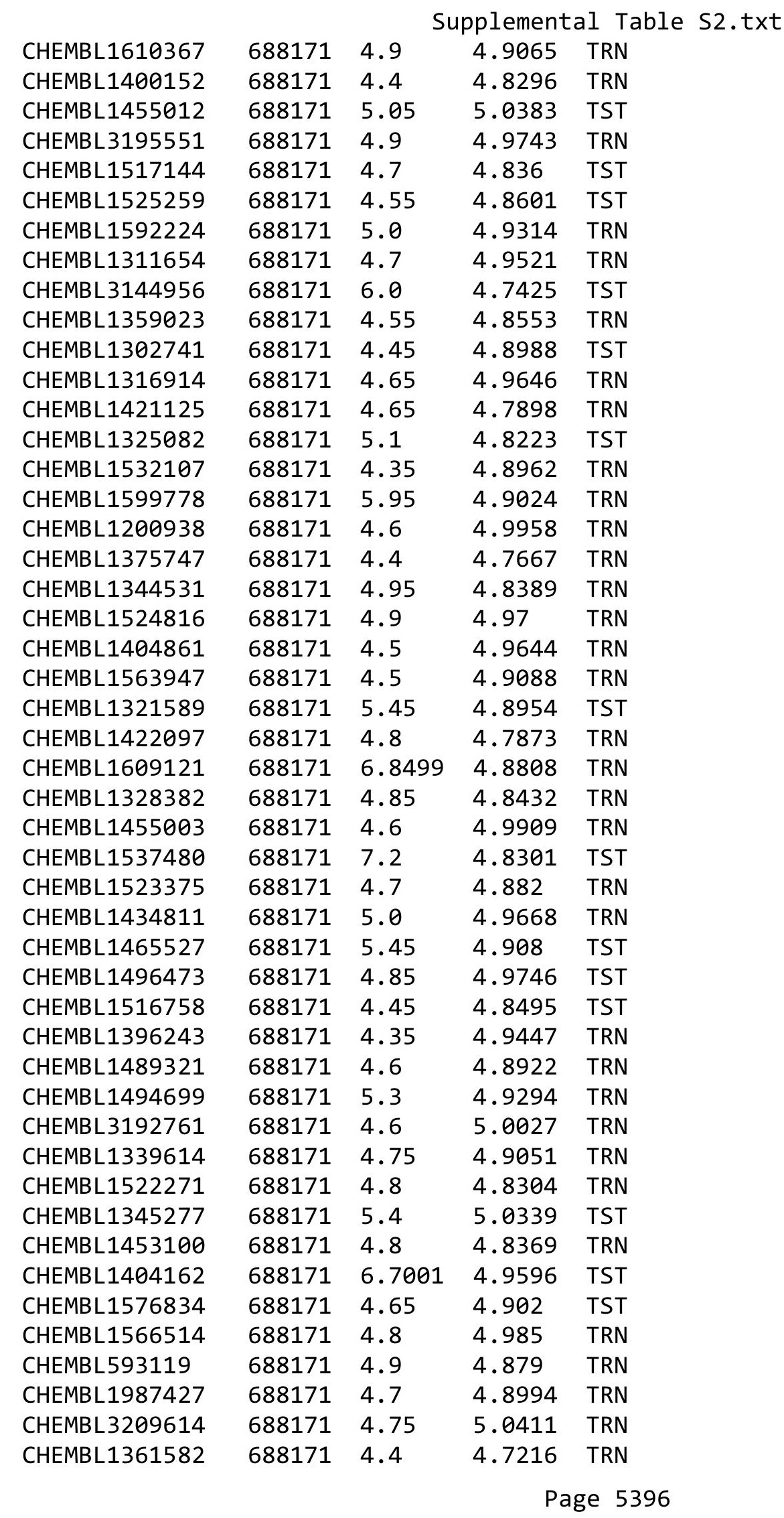




\begin{tabular}{|c|c|c|c|c|c|}
\hline \multicolumn{6}{|c|}{ Supplemental Table S2.txt } \\
\hline CHEMBL1422270 & 688171 & 4.85 & 4.7993 & TRN & \\
\hline CHEMBL1301885 & 688171 & 6.0 & 5.0958 & TRN & \\
\hline CHEMBL1477419 & 688171 & 4.7 & 4.7979 & TRN & \\
\hline CHEMBL1553576 & 688171 & 4.35 & 4.8786 & TRN & \\
\hline CHEMBL1568460 & 688171 & 5.0 & 4.9177 & TRN & \\
\hline CHEMBL1343118 & 688171 & 4.7 & 4.9119 & TRN & \\
\hline CHEMBL1600933 & 688171 & 6.5501 & 4.9427 & TST & \\
\hline CHEMBL1346172 & 688171 & 4.65 & 4.953 & TRN & \\
\hline CHEMBL1379875 & 688171 & 4.75 & 4.8078 & TRN & \\
\hline CHEMBL1423924 & 688171 & 6.05 & 4.9302 & TRN & \\
\hline CHEMBL1532407 & 688171 & 4.4 & 4.7907 & TST & \\
\hline CHEMBL1467337 & 688171 & 4.7 & 4.8982 & TST & \\
\hline CHEMBL1569567 & 688171 & 4.4 & 4.9021 & TRN & \\
\hline CHEMBL1433587 & 688171 & 5.05 & 4.9937 & TRN & \\
\hline CHEMBL3199315 & 688171 & 4.55 & 4.8884 & TRN & \\
\hline CHEMBL1602273 & 688171 & 4.4 & 4.9135 & TST & \\
\hline CHEMBL1570349 & 688171 & 5.0 & 4.8587 & TRN & \\
\hline CHEMBL1542070 & 688171 & 4.4 & 5.0256 & TST & \\
\hline CHEMBL1404741 & 688171 & 6.25 & 4.9173 & TST & \\
\hline CHEMBL1576287 & 688171 & 5.0 & 4.9416 & TRN & \\
\hline CHEMBL1436198 & 688171 & 5.0 & 4.8928 & TRN & \\
\hline CHEMBL1355839 & 688171 & 4.8 & 4.9053 & TRN & \\
\hline CHEMBL1407238 & 688171 & 5.05 & 4.9411 & TRN & \\
\hline CHEMBL1600154 & 688171 & 4.7 & 4.85800 & 00000000005 & TRN \\
\hline CHEMBL1584661 & 688171 & 4.4 & 4.8097 & TST & \\
\hline CHEMBL1394883 & 688171 & 4.65 & 4.916 & TRN & \\
\hline CHEMBL3197109 & 688171 & 5.0 & 4.9225 & TRN & \\
\hline CHEMBL1521331 & 688171 & 4.35 & 4.8049 & TRN & \\
\hline CHEMBL1584849 & 688171 & 4.85 & 4.8058 & TRN & \\
\hline CHEMBL1512973 & 688171 & 4.4 & 4.8561 & TRN & \\
\hline CHEMBL1492997 & 688171 & 4.8 & 4.8386 & TRN & \\
\hline CHEMBL1342859 & 688171 & 4.85 & 4.7954 & TRN & \\
\hline CHEMBL1498598 & 688171 & 4.9 & 4.7935 & TST & \\
\hline CHEMBL 3191560 & 688171 & 4.5 & 4.8946 & TST & \\
\hline CHEMBL1995377 & 688171 & 4.4 & 4.8232 & TRN & \\
\hline CHEMBL1405206 & 688171 & 5.0 & 4.8367 & TRN & \\
\hline CHEMBL1379048 & 688171 & 5.0 & 4.8929 & TRN & \\
\hline CHEMBL1517221 & 688171 & 4.6 & 5.0672 & TRN & \\
\hline CHEMBL1522550 & 688171 & 6.4 & 4.8798 & TRN & \\
\hline CHEMBL1421438 & 688171 & 6.6 & 4.8948 & TST & \\
\hline CHEMBL1377465 & 688171 & 4.4 & 5.055 & TST & \\
\hline CHEMBL1571001 & 688171 & 6.2 & 4.9733 & TST & \\
\hline CHEMBL1417327 & 688171 & 4.75 & 4.8189 & TRN & \\
\hline CHEMBL 3192154 & 688171 & 4.9 & 4.8429 & TST & \\
\hline CHEMBL1354904 & 688171 & 4.55 & 4.9 & TRN & \\
\hline CHEMBL1551754 & 688171 & 4.55 & 4.8163 & TRN & \\
\hline CHEMBL1333181 & 688171 & 4.8 & 4.817 & TRN & \\
\hline CHEMBL3192247 & 688171 & 4.45 & 4.9682 & TRN & \\
\hline
\end{tabular}




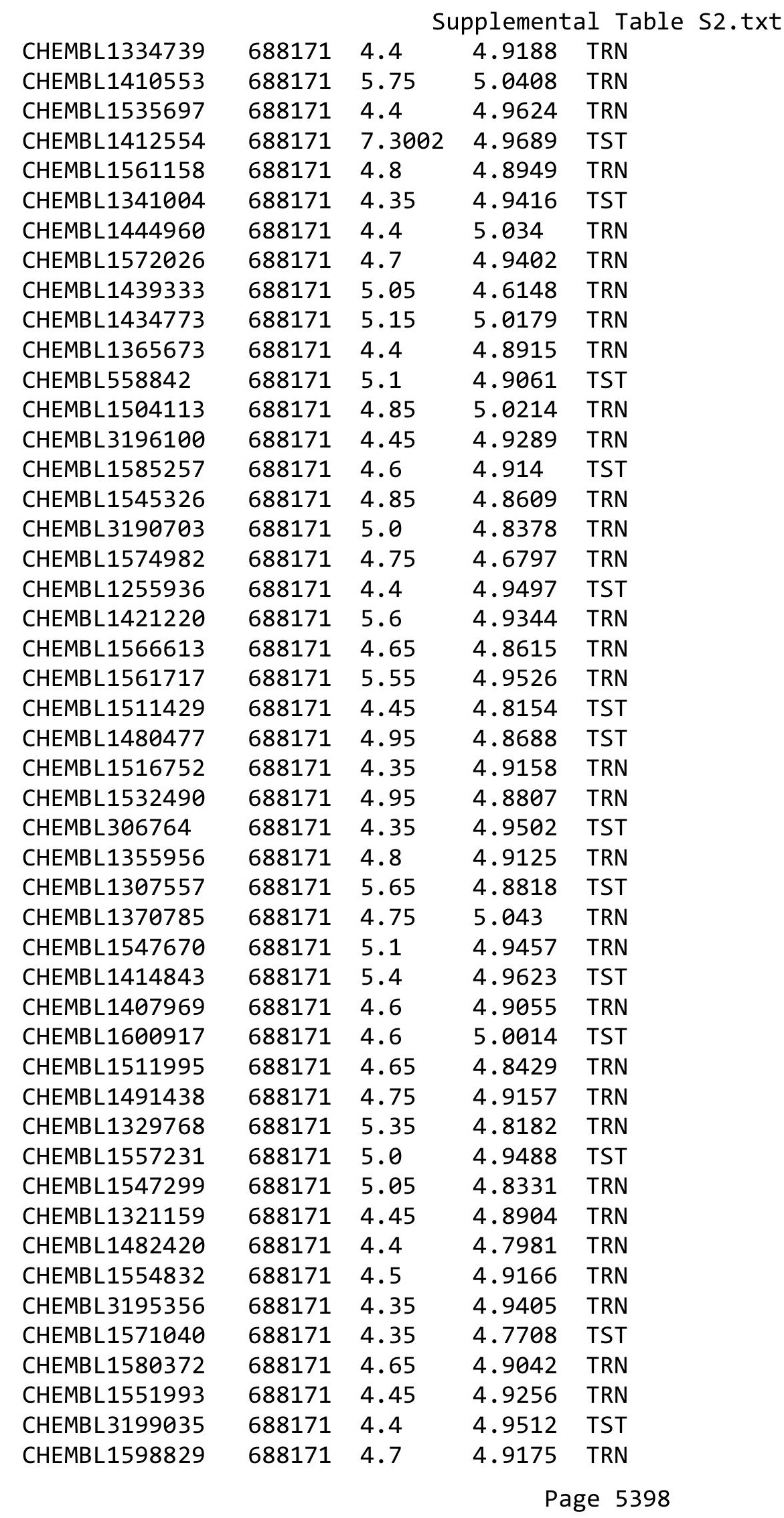




\begin{tabular}{|c|c|c|c|c|}
\hline \multicolumn{5}{|c|}{ Supplemental Table S2.txt } \\
\hline CHEMBL1536362 & 688171 & 4.4 & 4.7558 & TRN \\
\hline CHEMBL1591801 & 688171 & 4.7 & 4.8836 & TRN \\
\hline CHEMBL1340587 & 688171 & 4.95 & 4.8464 & TRN \\
\hline CHEMBL1369032 & 688171 & 4.6 & 4.9546 & TRN \\
\hline CHEMBL1336498 & 688171 & 4.65 & 4.9377 & TRN \\
\hline CHEMBL1531346 & 688171 & 5.05 & 4.9025 & TRN \\
\hline CHEMBL1448387 & 688171 & 6.0 & 4.9661 & TST \\
\hline CHEMBL1404694 & 688171 & 6.8 & 5.0624 & TRN \\
\hline CHEMBL1464853 & 688171 & 4.65 & 4.8846 & TST \\
\hline CHEMBL1438488 & 688171 & 4.7 & 4.9216 & TST \\
\hline CHEMBL1388094 & 688171 & 4.7 & 4.8597 & TST \\
\hline CHEMBL1316283 & 688171 & 4.55 & 4.9191 & TRN \\
\hline CHEMBL1364150 & 688171 & 4.6 & 5.0155 & TRN \\
\hline CHEMBL1384597 & 688171 & 5.15 & 4.9495 & TRN \\
\hline CHEMBL1402062 & 688171 & 5.5 & 5.0292 & TST \\
\hline CHEMBL1598057 & 688171 & 4.65 & 4.8971 & TRN \\
\hline CHEMBL1556941 & 688171 & 5.05 & 4.9934 & TST \\
\hline CHEMBL1358001 & 688171 & 4.85 & 4.8155 & TRN \\
\hline CHEMBL1318407 & 688171 & 4.75 & 4.8325 & TRN \\
\hline CHEMBL1389990 & 688171 & 4.65 & 4.8052 & TRN \\
\hline CHEMBL1598041 & 688171 & 6.5 & 4.9627 & TST \\
\hline CHEMBL1590514 & 688171 & 5.5 & 4.9309 & TST \\
\hline CHEMBL1436346 & 688171 & 5.4 & 5.0266 & TST \\
\hline CHEMBL1360161 & 688171 & 5.05 & 5.0847 & TRN \\
\hline CHEMBL1473563 & 688171 & 5.9 & 4.9106 & TRN \\
\hline CHEMBL1539086 & 688171 & 4.7 & 4.9912 & TRN \\
\hline CHEMBL1471678 & 688171 & 5.05 & 5.0281 & TST \\
\hline CHEMBL1532670 & 688171 & 6.0 & 5.0841 & TRN \\
\hline CHEMBL3196467 & 688171 & 4.7 & 4.8813 & TRN \\
\hline CHEMBL1364015 & 688171 & 4.75 & 4.9182 & TRN \\
\hline CHEMBL1310798 & 688171 & 5.0 & 4.872 & TRN \\
\hline CHEMBL1605226 & 688171 & 4.65 & 4.8118 & TRN \\
\hline CHEMBL 2003873 & 688171 & 4.9 & 4.8414 & TRN \\
\hline CHEMBL3213584 & 688171 & 4.4 & 4.7675 & TRN \\
\hline CHEMBL1360544 & 688171 & 4.45 & 4.7469 & TRN \\
\hline CHEMBL1528002 & 688171 & 4.4 & 5.0245 & TRN \\
\hline CHEMBL 1363050 & 688171 & 4.4 & 4.9278 & TRN \\
\hline CHEMBL1319618 & 688171 & 4.4 & 4.7701 & TST \\
\hline CHEMBL1311810 & 688171 & 4.5 & 4.8512 & TST \\
\hline CHEMBL1554697 & 688171 & 4.4 & 4.8643 & TRN \\
\hline CHEMBL1415669 & 688171 & 5.3 & 4.9269 & TST \\
\hline CHEMBL1476895 & 688171 & 4.4 & 5.0391 & TST \\
\hline CHEMBL1317955 & 688171 & 4.6 & 4.8116 & TRN \\
\hline CHEMBL2003935 & 688171 & 4.6 & 4.9228 & TST \\
\hline CHEMBL1589743 & 688171 & 4.35 & 4.914 & TRN \\
\hline CHEMBL1467870 & 688171 & 4.5 & 4.9867 & TST \\
\hline CHEMBL1543956 & 688171 & 5.85 & 4.9578 & TST \\
\hline CHEMBL1581498 & 688171 & 4.55 & 5.0032 & TST \\
\hline
\end{tabular}




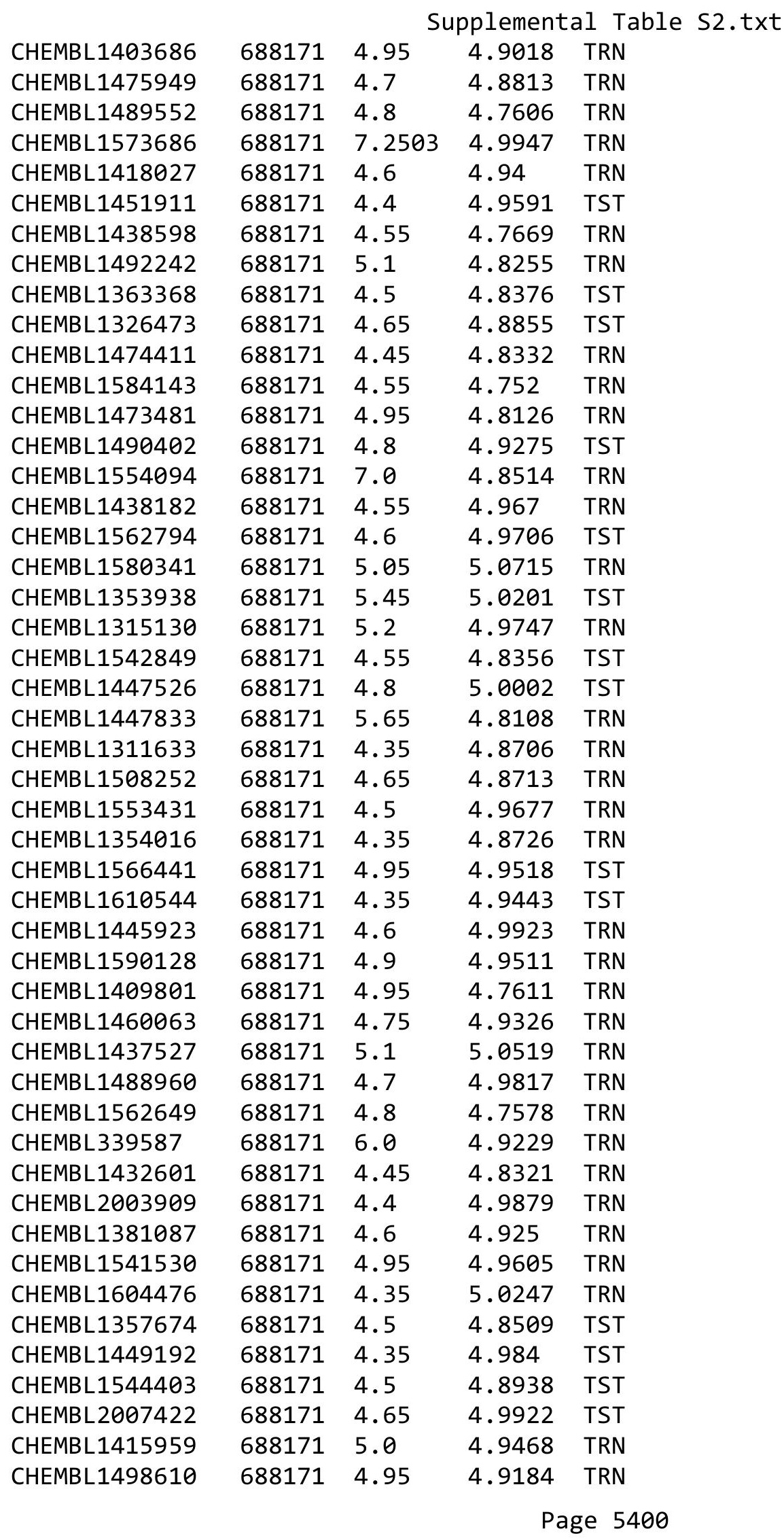




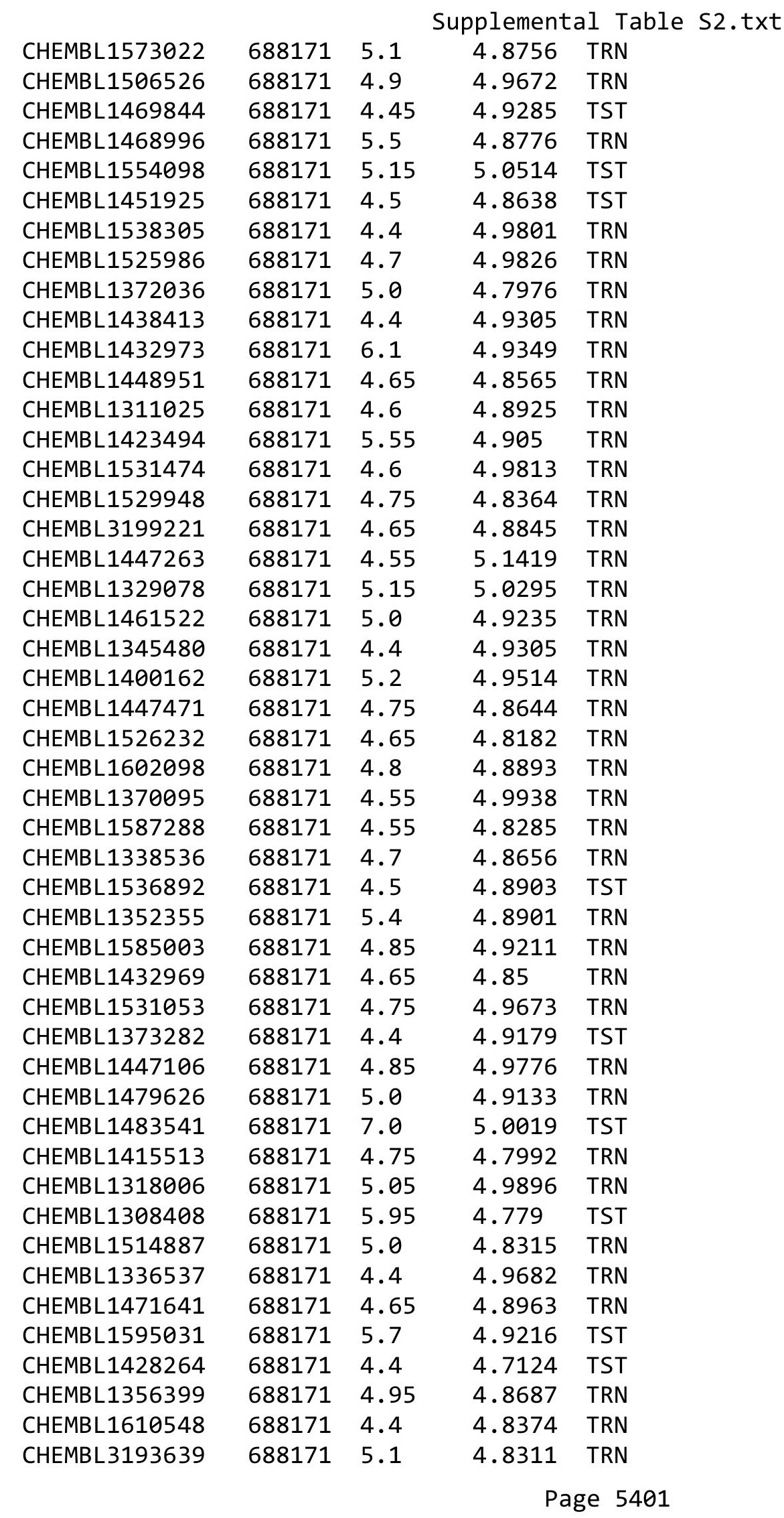




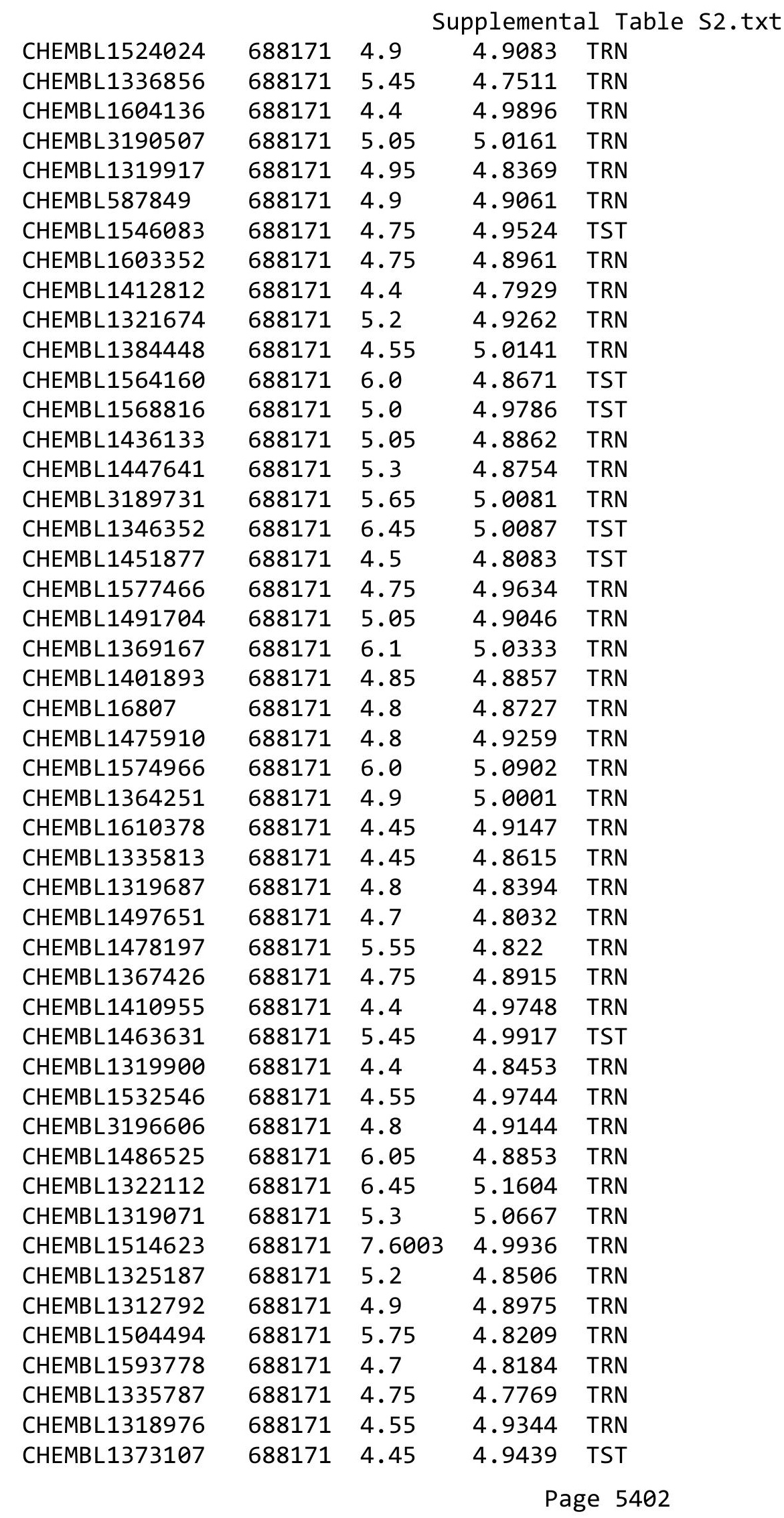




\begin{tabular}{|c|c|c|c|c|}
\hline \multicolumn{5}{|c|}{ Supplemental Table S2.txt } \\
\hline CHEMBL1587704 & 688171 & 4.35 & 4.9264 & TST \\
\hline CHEMBL1561072 & 688171 & 5.05 & 5.0315 & TRN \\
\hline CHEMBL1540477 & 688171 & 4.5 & 4.989 & TRN \\
\hline CHEMBL1332421 & 688171 & 4.65 & 4.9511 & TST \\
\hline CHEMBL3197979 & 688171 & 5.25 & 4.8591 & TST \\
\hline CHEMBL1326813 & 688171 & 4.75 & 4.8784 & TST \\
\hline CHEMBL1444077 & 688171 & 6.8 & 4.8073 & TST \\
\hline CHEMBL1581638 & 688171 & 4.75 & 4.7612 & TRN \\
\hline CHEMBL1278182 & 688171 & 4.65 & 4.8181 & TRN \\
\hline CHEMBL1478054 & 688171 & 4.4 & 4.8847 & TRN \\
\hline CHEMBL1347895 & 688171 & 6.4 & 5.0652 & TRN \\
\hline CHEMBL1569767 & 688171 & 4.35 & 4.9296 & TRN \\
\hline CHEMBL1591853 & 688171 & 4.45 & 4.8916 & TRN \\
\hline CHEMBL1523751 & 688171 & 4.4 & 5.0819 & TRN \\
\hline CHEMBL1374674 & 688171 & 4.85 & 5.0709 & TRN \\
\hline CHEMBL3210051 & 688171 & 4.7 & 4.8839 & TRN \\
\hline CHEMBL1593306 & 688171 & 5.2 & 4.8667 & TRN \\
\hline CHEMBL1561328 & 688171 & 5.5 & 5.0488 & TRN \\
\hline CHEMBL1579881 & 688171 & 4.65 & 4.6958 & TRN \\
\hline CHEMBL1317205 & 688171 & 4.7 & 4.9294 & TRN \\
\hline CHEMBL1313726 & 688171 & 5.3 & 4.9346 & TRN \\
\hline CHEMBL1590286 & 688171 & 4.75 & 4.862 & TRN \\
\hline CHEMBL1360920 & 688171 & 4.35 & 4.8297 & TRN \\
\hline CHEMBL596836 & 688171 & 5.2 & 4.8782 & TRN \\
\hline CHEMBL1330264 & 688171 & 4.8 & 4.8989 & TST \\
\hline CHEMBL1475069 & 688171 & 5.0 & 4.9703 & TRN \\
\hline CHEMBL1508223 & 688171 & 4.95 & 4.867 & TST \\
\hline CHEMBL1079456 & 688171 & 4.5 & 5.0009 & TRN \\
\hline CHEMBL1335734 & 688171 & 4.4 & 4.8601 & TRN \\
\hline CHEMBL1330735 & 688171 & 6.15 & 5.0819 & TRN \\
\hline CHEMBL1569827 & 688171 & 4.75 & 4.8992 & TRN \\
\hline CHEMBL1582805 & 688171 & 4.35 & 5.0759 & TST \\
\hline CHEMBL1347310 & 688171 & 6.4 & 5.0454 & TST \\
\hline CHEMBL1447146 & 688171 & 4.4 & 4.8737 & TRN \\
\hline CHEMBL1358358 & 688171 & 4.45 & 4.7594 & TRN \\
\hline CHEMBL1354898 & 688171 & 4.35 & 4.9734 & TRN \\
\hline CHEMBL1410534 & 688171 & 4.5 & 4.9286 & TRN \\
\hline CHEMBL1524150 & 688171 & 5.5 & 4.8931 & TRN \\
\hline CHEMBL1395789 & 688171 & 6.1 & 4.9902 & TRN \\
\hline CHEMBL1393050 & 688171 & 4.4 & 4.769 & TRN \\
\hline CHEMBL3197034 & 688171 & 4.7 & 4.9504 & TRN \\
\hline CHEMBL1489507 & 688171 & 4.9 & 4.9351 & TRN \\
\hline CHEMBL1357758 & 688171 & 4.8 & 4.8403 & TRN \\
\hline CHEMBL1449593 & 688171 & 4.4 & 4.8644 & TRN \\
\hline CHEMBL1362412 & 688171 & 5.5 & 4.9256 & TRN \\
\hline CHEMBL1546239 & 688171 & 4.55 & 4.777 & TRN \\
\hline CHEMBL3193959 & 688171 & 5.8 & 4.8739 & TST \\
\hline CHEMBL1535610 & 688171 & 5.95 & 4.8614 & TRN \\
\hline
\end{tabular}




\begin{tabular}{|c|c|c|c|c|c|}
\hline \multicolumn{6}{|c|}{ Supplemental Table S2.txt } \\
\hline CHEMBL1321173 & 688171 & 4.95 & 5.0407 & TRN & \\
\hline CHEMBL1342605 & 688171 & 6.1 & 4.8606 & TRN & \\
\hline CHEMBL1567585 & 688171 & 4.6 & 4.8235 & TRN & \\
\hline CHEMBL1420257 & 688171 & 4.55 & 4.9187 & TST & \\
\hline CHEMBL1572300 & 688171 & 4.4 & 4.9683 & TRN & \\
\hline CHEMBL 3190337 & 688171 & 4.75 & 4.9533 & TRN & \\
\hline CHEMBL1602030 & 688171 & 4.5 & 4.9177 & TRN & \\
\hline CHEMBL1399966 & 688171 & 4.4 & 4.7515 & TRN & \\
\hline CHEMBL1613334 & 688171 & 5.45 & 4.9232 & TRN & \\
\hline CHEMBL1370985 & 688171 & 4.35 & 4.8034 & TRN & \\
\hline CHEMBL1387028 & 688171 & 4.85 & 4.7637 & TST & \\
\hline CHEMBL1526484 & 688171 & 4.8 & 4.8389 & TRN & \\
\hline CHEMBL1587205 & 688171 & 4.6 & 4.8729 & TRN & \\
\hline CHEMBL1453781 & 688171 & 4.4 & 5.0035 & TRN & \\
\hline CHEMBL297304 & 688171 & 4.6 & 4.8108 & TST & \\
\hline CHEMBL1427119 & 688171 & 6.4 & 4.9087 & TRN & \\
\hline CHEMBL1499658 & 688171 & 7.2 & 5.0228 & TRN & \\
\hline CHEMBL1590456 & 688171 & 4.7 & 4.7822 & TRN & \\
\hline CHEMBL1200355 & 688171 & 4.4 & 4.9091 & TST & \\
\hline CHEMBL1305815 & 688171 & 7.1002 & 4.8016 & TST & \\
\hline CHEMBL1513100 & 688171 & 4.95 & 5.0399 & TRN & \\
\hline CHEMBL1437352 & 688171 & 4.85 & 4.7938 & TRN & \\
\hline CHEMBL1390621 & 688171 & 4.6 & 4.8536 & TST & \\
\hline CHEMBL3197554 & 688171 & 4.5 & 5.0758 & TRN & \\
\hline CHEMBL1383130 & 688171 & 4.35 & 5.1109 & TST & \\
\hline CHEMBL1413805 & 688171 & 4.4 & 4.8214 & TRN & \\
\hline CHEMBL 3207991 & 688171 & 4.4 & 5.0496 & TRN & \\
\hline CHEMBL1486341 & 688171 & 5.55 & 4.9339 & TST & \\
\hline CHEMBL1474697 & 688171 & 4.4 & 4.9689 & TRN & \\
\hline CHEMBL326958 & 688171 & 6.5 & 5.0004 & TRN & \\
\hline CHEMBL1414546 & 688171 & 4.4 & 4.9929 & TRN & \\
\hline CHEMBL1395090 & 688171 & 4.8 & 4.9739 & TRN & \\
\hline CHEMBL1359567 & 688171 & 4.4 & 4.958 & TST & \\
\hline CHEMBL1315204 & 688171 & 4.6 & 4.8323 & TRN & \\
\hline CHEMBL1609513 & 688171 & 4.8 & 4.8039 & TST & \\
\hline CHEMBL 3392033 & 688171 & 4.7 & 4.7376 & TRN & \\
\hline CHEMBL1473134 & 688171 & 4.85 & 4.9293 & TRN & \\
\hline CHEMBL1559330 & 688171 & 4.4 & 4.71899 & 9999999999 & TRN \\
\hline CHEMBL1599007 & 688171 & 4.4 & 5.0581 & TST & \\
\hline CHEMBL1348069 & 688171 & 4.4 & 5.0034 & TST & \\
\hline CHEMBL1374288 & 688171 & 4.7 & 4.9915 & TRN & \\
\hline CHEMBL1394420 & 688171 & 4.55 & 4.8966 & TRN & \\
\hline CHEMBL3199328 & 688171 & 4.4 & 4.9397 & TRN & \\
\hline CHEMBL 243664 & 688171 & 4.4 & 4.9252 & TRN & \\
\hline CHEMBL1603374 & 688171 & 4.8 & 4.9407 & TRN & \\
\hline CHEMBL 3211720 & 688171 & 4.55 & 5.0074 & TRN & \\
\hline CHEMBL257359 & 688171 & 4.6 & 4.8361 & TRN & \\
\hline CHEMBL1395994 & 688171 & 4.8 & 4.8707 & TRN & \\
\hline
\end{tabular}




\begin{tabular}{|c|c|c|c|c|}
\hline \multicolumn{5}{|c|}{ Supplemental Table S2.txt } \\
\hline CHEMBL1357962 & 688171 & 5.35 & 4.838 & TRN \\
\hline CHEMBL1412581 & 688171 & 4.35 & 4.905 & TRN \\
\hline CHEMBL1489353 & 688171 & 4.45 & 4.8687 & TST \\
\hline CHEMBL1492691 & 688171 & 7.0 & 4.9415 & TST \\
\hline CHEMBL1344269 & 688171 & 4.5 & 4.8428 & TST \\
\hline CHEMBL1432446 & 688171 & 4.9 & 5.0127 & TRN \\
\hline CHEMBL8739 & 688171 & 6.0 & 5.0247 & TRN \\
\hline CHEMBL1326652 & 688171 & 4.9 & 4.7887 & TRN \\
\hline CHEMBL1340243 & 688171 & 5.2 & 4.9592 & TRN \\
\hline CHEMBL1573958 & 688171 & 4.75 & 4.8009 & TST \\
\hline CHEMBL1462318 & 688171 & 4.95 & 4.9364 & TRN \\
\hline CHEMBL1304640 & 688171 & 4.75 & 4.9852 & TRN \\
\hline CHEMBL1462290 & 688171 & 4.75 & 4.8721 & TRN \\
\hline CHEMBL2373552 & 688171 & 6.2 & 4.8966 & TST \\
\hline CHEMBL1565863 & 688171 & 5.65 & 4.8476 & TST \\
\hline CHEMBL1500223 & 688171 & 4.6 & 4.923 & TRN \\
\hline CHEMBL3209892 & 688171 & 4.95 & 4.8865 & TRN \\
\hline CHEMBL580819 & 688171 & 4.5 & 4.8112 & TRN \\
\hline CHEMBL34241 & 688171 & 6.0 & 4.9627 & TST \\
\hline CHEMBL1490366 & 688171 & 4.9 & 4.9084 & TRN \\
\hline CHEMBL1449730 & 688171 & 7.2503 & 4.7039 & TRN \\
\hline CHEMBL1315022 & 688171 & 4.9 & 4.7611 & TRN \\
\hline CHEMBL1425263 & 688171 & 4.35 & 4.9942 & TST \\
\hline CHEMBL1422070 & 688171 & 5.7 & 4.8228 & TST \\
\hline CHEMBL1332296 & 688171 & 4.5 & 4.8531 & TRN \\
\hline CHEMBL1606251 & 688171 & 4.65 & 4.9688 & TST \\
\hline CHEMBL3208983 & 688171 & 4.9 & 4.8866 & TST \\
\hline CHEMBL1558547 & 688171 & 4.4 & 4.9172 & TST \\
\hline CHEMBL1319476 & 688171 & 5.0 & 4.8288 & TRN \\
\hline CHEMBL1326410 & 688171 & 4.45 & 5.0132 & TRN \\
\hline CHEMBL1460266 & 688171 & 4.5 & 4.9396 & TRN \\
\hline CHEMBL1456904 & 688171 & 4.4 & 4.9417 & TRN \\
\hline CHEMBL1402185 & 688171 & 5.65 & 4.8577 & TRN \\
\hline CHEMBL1441502 & 688171 & 6.35 & 4.8354 & TST \\
\hline CHEMBL1508618 & 688171 & 4.75 & 4.9841 & TRN \\
\hline CHEMBL1362608 & 688171 & 5.05 & 4.9106 & TRN \\
\hline CHEMBL1391624 & 688171 & 4.6 & 4.893 & TRN \\
\hline CHEMBL1378203 & 688171 & 5.25 & 4.7537 & TRN \\
\hline CHEMBL1348052 & 688171 & 4.6 & 4.8367 & TRN \\
\hline CHEMBL1606083 & 688171 & 4.85 & 4.8606 & TRN \\
\hline CHEMBL1581185 & 688171 & 7.0 & 5.1164 & TST \\
\hline CHEMBL1342116 & 688171 & 4.75 & 4.9233 & TRN \\
\hline CHEMBL1395382 & 688171 & 5.1 & 4.9171 & TRN \\
\hline CHEMBL162783 & 688171 & 4.6 & 4.9364 & TRN \\
\hline CHEMBL1449638 & 688171 & 5.05 & 4.9766 & TST \\
\hline CHEMBL1383746 & 688171 & 4.7 & 4.9405 & TRN \\
\hline CHEMBL1460350 & 688171 & 5.0 & 4.8054 & TRN \\
\hline CHEMBL1489989 & 688171 & 7.6003 & 4.9548 & TRN \\
\hline
\end{tabular}




\begin{tabular}{|c|c|c|c|c|}
\hline \multicolumn{5}{|c|}{ Supplemental Table } \\
\hline CHEMBL1452446 & 688171 & 4.95 & 4.8926 & TST \\
\hline CHEMBL1341118 & 688171 & 4.35 & 4.8646 & TST \\
\hline CHEMBL1362221 & 688171 & 4.8 & 4.7904 & TRN \\
\hline CHEMBL1374986 & 688171 & 4.6 & 4.944 & TST \\
\hline CHEMBL1460155 & 688171 & 4.4 & 5.0133 & TST \\
\hline CHEMBL3196046 & 688171 & 5.25 & 4.981 & TRN \\
\hline CHEMBL1515308 & 688171 & 4.4 & 5.0813 & TRN \\
\hline CHEMBL1556680 & 688171 & 4.4 & 4.8234 & TRN \\
\hline CHEMBL1472381 & 688171 & 4.45 & 5.0726 & TRN \\
\hline CHEMBL1477970 & 688171 & 4.35 & 5.0627 & TST \\
\hline CHEMBL1331206 & 688171 & 4.85 & 4.9173 & TRN \\
\hline CHEMBL1321703 & 688171 & 4.4 & 4.7646 & TRN \\
\hline CHEMBL3209932 & 688171 & 4.5 & 4.7938 & TRN \\
\hline CHEMBL1359322 & 688171 & 6.0 & 4.8124 & TST \\
\hline CHEMBL1339461 & 688171 & 4.4 & 4.8651 & TRN \\
\hline CHEMBL1416898 & 688171 & 4.4 & 4.8793 & TRN \\
\hline CHEMBL1600445 & 688171 & 4.85 & 4.8486 & TRN \\
\hline CHEMBL1465290 & 688171 & 4.4 & 4.8038 & TRN \\
\hline CHEMBL1393727 & 688171 & 4.85 & 4.9744 & TRN \\
\hline CHEMBL1439362 & 688171 & 5.0 & 4.9705 & TRN \\
\hline CHEMBL501680 & 688171 & 4.5 & 4.9295 & TST \\
\hline CHEMBL1403373 & 688171 & 6.6 & 4.8507 & TST \\
\hline CHEMBL1406184 & 688171 & 4.95 & 4.8648 & TRN \\
\hline CHEMBL1577486 & 688171 & 5.45 & 4.8914 & TRN \\
\hline CHEMBL1471276 & 688171 & 4.8 & 4.9518 & TST \\
\hline CHEMBL1460692 & 688171 & 4.75 & 4.9113 & TRN \\
\hline CHEMBL3198157 & 688171 & 4.4 & 4.9987 & TRN \\
\hline CHEMBL1554902 & 688171 & 4.85 & 4.855 & TST \\
\hline CHEMBL1432697 & 688171 & 4.35 & 4.9689 & TRN \\
\hline CHEMBL1361153 & 688171 & 5.8 & 4.9532 & TRN \\
\hline CHEMBL1355106 & 688171 & 4.4 & 4.8103 & TRN \\
\hline CHEMBL1576458 & 688171 & 4.5 & 4.9248 & TRN \\
\hline CHEMBL1389718 & 688171 & 4.4 & 4.8727 & TRN \\
\hline CHEMBL1442255 & 688171 & 4.4 & 4.9349 & TRN \\
\hline CHEMBL2005317 & 688171 & 4.55 & 4.9081 & TRN \\
\hline CHEMBL1347649 & 688171 & 4.4 & 4.8913 & TST \\
\hline CHEMBL1531978 & 688171 & 4.8 & 4.9111 & TRN \\
\hline CHEMBL1549729 & 688171 & 4.4 & 4.9383 & TRN \\
\hline CHEMBL1485684 & 688171 & 4.4 & 4.9423 & TRN \\
\hline CHEMBL1598430 & 688171 & 5.7 & 4.9989 & TRN \\
\hline CHEMBL1602585 & 688171 & 4.85 & 4.9443 & TRN \\
\hline CHEMBL1391264 & 688171 & 5.15 & 4.9585 & TRN \\
\hline CHEMBL1430435 & 688171 & 5.5 & 4.9542 & TRN \\
\hline CHEMBL1529080 & 688171 & 4.55 & 4.9304 & TST \\
\hline CHEMBL1444397 & 688171 & 5.45 & 4.9265 & TRN \\
\hline CHEMBL1565402 & 688171 & 4.7 & 4.922 & TST \\
\hline CHEMBL1557577 & 688171 & 5.2 & 4.9203 & TRN \\
\hline CHEMBL1579378 & 688171 & 4.35 & 4.9137 & TST \\
\hline
\end{tabular}




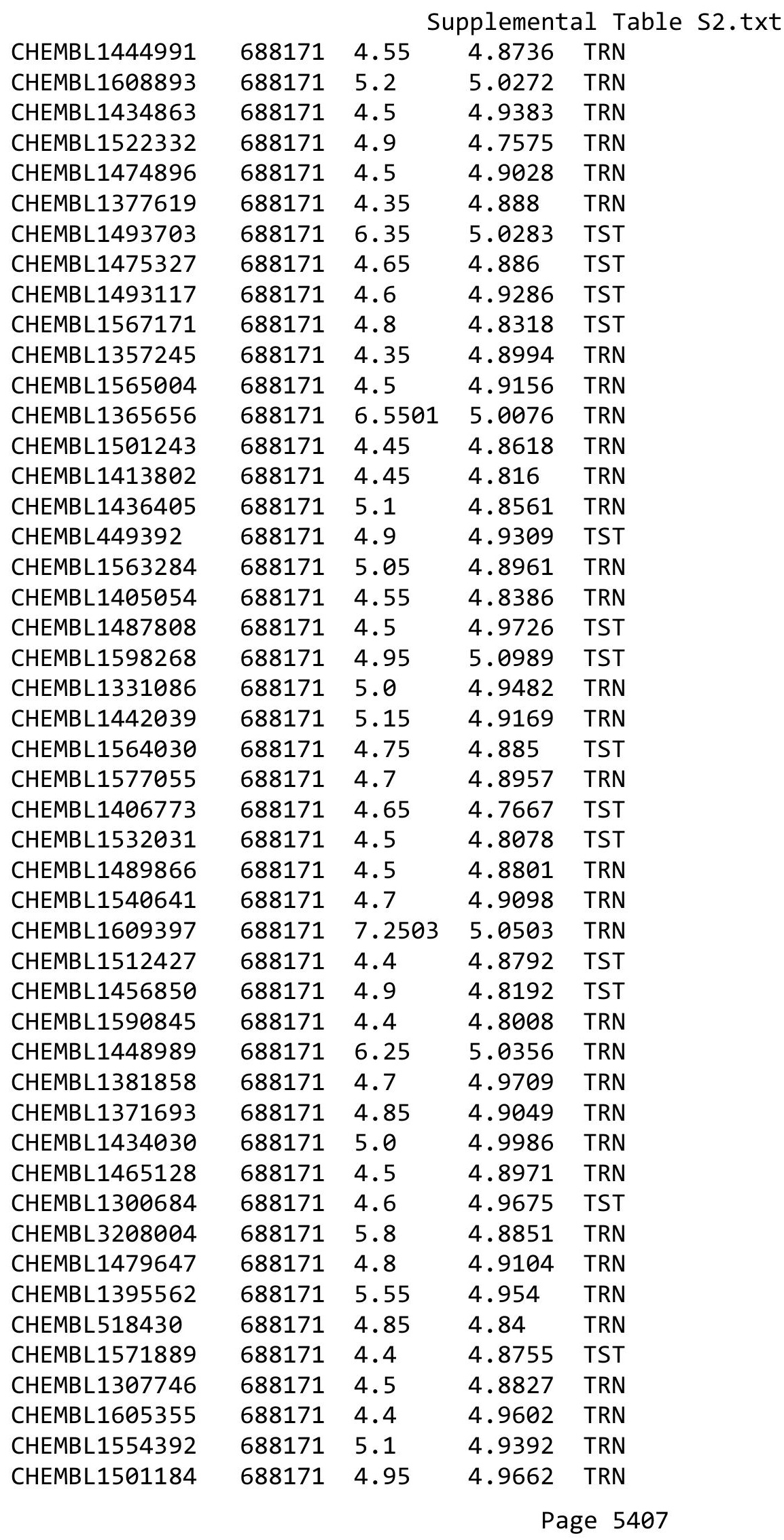




\begin{tabular}{|c|c|c|c|c|c|}
\hline \multicolumn{6}{|c|}{ Supplemental Table S2.txt } \\
\hline CHEMBL1537405 & 688171 & 4.4 & 4.8374 & TST & \\
\hline CHEMBL1341849 & 688171 & 4.35 & 4.7937 & TRN & \\
\hline CHEMBL1323962 & 688171 & 4.55 & 4.8183 & TST & \\
\hline CHEMBL1525522 & 688171 & 4.85 & 4.954 & TRN & \\
\hline CHEMBL1524939 & 688171 & 4.7 & 4.7995 & TRN & \\
\hline CHEMBL1560000 & 688171 & 4.55 & 4.9663 & TRN & \\
\hline CHEMBL1417785 & 688171 & 4.65 & 4.9366 & TRN & \\
\hline CHEMBL1325061 & 688171 & 4.85 & 5.0982 & TRN & \\
\hline CHEMBL1300890 & 688171 & 4.65 & 4.7366 & TRN & \\
\hline CHEMBL1551410 & 688171 & 5.35 & 4.9201 & TRN & \\
\hline CHEMBL1484660 & 688171 & 4.6 & 4.9343 & TRN & \\
\hline CHEMBL1325272 & 688171 & 4.6 & 4.967 & TRN & \\
\hline CHEMBL1465510 & 688171 & 4.4 & 4.9255 & TST & \\
\hline CHEMBL1461417 & 688171 & 4.35 & 4.9183 & TRN & \\
\hline CHEMBL1336187 & 688171 & 4.4 & 4.7771 & TST & \\
\hline CHEMBL1348235 & 688171 & 4.8 & 4.7108 & TST & \\
\hline CHEMBL1545841 & 688171 & 4.8 & 4.9626 & TRN & \\
\hline CHEMBL2094422 & 688171 & 6.0 & 4.987 & TRN & \\
\hline CHEMBL1347100 & 688171 & 5.0 & 4.76399 & 9999999999 & TST \\
\hline CHEMBL1524141 & 688171 & 4.35 & 4.8503 & TRN & \\
\hline CHEMBL1518206 & 688171 & 4.4 & 4.9222 & TRN & \\
\hline CHEMBL1334130 & 688171 & 4.8 & 4.8293 & TST & \\
\hline CHEMBL1461976 & 688171 & 4.6 & 4.9395 & TRN & \\
\hline CHEMBL1360343 & 688171 & 4.4 & 4.813 & TST & \\
\hline CHEMBL1506508 & 688171 & 4.35 & 4.8414 & TST & \\
\hline CHEMBL1415593 & 688171 & 4.8 & 4.9992 & TRN & \\
\hline CHEMBL1590742 & 688171 & 4.35 & 4.8917 & TRN & \\
\hline CHEMBL1513379 & 688171 & 4.75 & 4.907 & TRN & \\
\hline CHEMBL1602639 & 688171 & 4.55 & 4.7785 & TRN & \\
\hline CHEMBL1458579 & 688171 & 5.0 & 4.7904 & TRN & \\
\hline CHEMBL1403077 & 688171 & 4.75 & 4.9194 & TRN & \\
\hline CHEMBL1564936 & 688171 & 4.65 & 4.9249 & TRN & \\
\hline CHEMBL1601340 & 688171 & 4.35 & 4.9565 & TRN & \\
\hline CHEMBL1455974 & 688171 & 4.65 & 4.8563 & TRN & \\
\hline CHEMBL1396695 & 688171 & 4.4 & 4.9416 & TST & \\
\hline CHEMBL1394046 & 688171 & 5.5 & 4.7639 & TRN & \\
\hline CHEMBL1403822 & 688171 & 5.0 & 4.8619 & TRN & \\
\hline CHEMBL1415997 & 688171 & 4.65 & 4.9797 & TRN & \\
\hline CHEMBL1354368 & 688171 & 4.85 & 4.8829 & TRN & \\
\hline CHEMBL1469615 & 688171 & 6.25 & 5.063 & TST & \\
\hline CHEMBL1391622 & 688171 & 4.45 & 4.76399 & 9999999999 & TRN \\
\hline CHEMBL1331509 & 688171 & 4.45 & 4.8521 & TRN & \\
\hline CHEMBL3192554 & 688171 & 4.75 & 4.98600 & 2000000001 & TRN \\
\hline CHEMBL1356487 & 688171 & 4.75 & 4.9868 & TRN & \\
\hline CHEMBL1606964 & 688171 & 4.85 & 4.7933 & TRN & \\
\hline CHEMBL1391055 & 688171 & 4.7 & 4.7725 & TRN & \\
\hline CHEMBL1586616 & 688171 & 4.95 & 4.8675 & TST & \\
\hline CHEMBL1578487 & 688171 & 4.95 & 4.9898 & TRN & \\
\hline
\end{tabular}




\begin{tabular}{|c|c|c|c|c|c|}
\hline \multicolumn{6}{|c|}{ Supplemental Table S2.txt } \\
\hline CHEMBL1604686 & 688171 & 4.7 & 4.8873 & TST & \\
\hline CHEMBL1503814 & 688171 & 4.65 & 4.8852 & TRN & \\
\hline CHEMBL1609696 & 688171 & 4.95 & 4.9565 & TRN & \\
\hline CHEMBL1316634 & 688171 & 5.05 & 4.9099 & TRN & \\
\hline CHEMBL1547325 & 688171 & 4.5 & 4.7547 & TRN & \\
\hline CHEMBL3190974 & 688171 & 4.9 & 5.0225 & TRN & \\
\hline CHEMBL1332549 & 688171 & 4.95 & 4.8661 & TST & \\
\hline CHEMBL1452821 & 688171 & 4.6 & 4.8255 & TST & \\
\hline CHEMBL1355148 & 688171 & 4.95 & 4.8668 & TRN & \\
\hline CHEMBL1476824 & 688171 & 4.6 & 4.961 & TRN & \\
\hline CHEMBL1423824 & 688171 & 4.7 & 4.8563 & TST & \\
\hline CHEMBL1491004 & 688171 & 4.8 & 4.8073 & TRN & \\
\hline CHEMBL1589962 & 688171 & 4.75 & 4.9642 & TRN & \\
\hline CHEMBL1553585 & 688171 & 4.8 & 4.9471 & TRN & \\
\hline CHEMBL1435881 & 688171 & 4.35 & 4.8783 & TRN & \\
\hline CHEMBL1409730 & 688171 & 4.65 & 5.0364 & TRN & \\
\hline CHEMBL1377321 & 688171 & 4.9 & 4.7811 & TRN & \\
\hline CHEMBL1336166 & 688171 & 4.75 & 4.8725 & TRN & \\
\hline CHEMBL1456987 & 688171 & 4.35 & 4.9686 & TRN & \\
\hline CHEMBL1421166 & 688171 & 5.55 & 4.86100 & 0000000001 & TST \\
\hline CHEMBL1525394 & 688171 & 4.4 & 4.8751 & TST & \\
\hline CHEMBL1540208 & 688171 & 4.4 & 4.8271 & TST & \\
\hline CHEMBL3198659 & 688171 & 4.85 & 4.9078 & TST & \\
\hline CHEMBL1347633 & 688171 & 4.6 & 5.0041 & TST & \\
\hline CHEMBL1409229 & 688171 & 4.4 & 4.9029 & TRN & \\
\hline CHEMBL1446706 & 688171 & 4.4 & 4.8463 & TST & \\
\hline CHEMBL1368994 & 688171 & 7.2 & 5.0251 & TRN & \\
\hline CHEMBL1412774 & 688171 & 5.05 & 4.9912 & TRN & \\
\hline CHEMBL1471055 & 688171 & 4.4 & 4.8611 & TRN & \\
\hline CHEMBL1578640 & 688171 & 4.45 & 4.8048 & TRN & \\
\hline CHEMBL1544622 & 688171 & 4.5 & 4.8642 & TRN & \\
\hline CHEMBL1409383 & 688171 & 4.85 & 4.9165 & TRN & \\
\hline CHEMBL1408060 & 688171 & 4.65 & 4.8987 & TRN & \\
\hline CHEMBL1529961 & 688171 & 5.15 & 4.8355 & TRN & \\
\hline CHEMBL1305540 & 688171 & 4.4 & 4.8885 & TRN & \\
\hline CHEMBL1593212 & 688171 & 4.4 & 4.9543 & TRN & \\
\hline CHEMBL1607640 & 688171 & 4.95 & 4.9343 & TRN & \\
\hline CHEMBL1998868 & 688171 & 6.2 & 4.8125 & TRN & \\
\hline CHEMBL1465097 & 688171 & 5.45 & 4.808 & TRN & \\
\hline CHEMBL1331483 & 688171 & 6.8499 & 4.8969 & TRN & \\
\hline CHEMBL1412673 & 688171 & 5.7 & 4.9155 & TRN & \\
\hline CHEMBL1385447 & 688171 & 6.6 & 5.0661 & TST & \\
\hline CHEMBL1412478 & 688171 & 6.05 & 4.8754 & TRN & \\
\hline CHEMBL3208533 & 688171 & 4.9 & 4.888 & TST & \\
\hline CHEMBL1475725 & 688171 & 4.55 & 4.9545 & TRN & \\
\hline CHEMBL1539849 & 688171 & 4.45 & 4.8201 & TRN & \\
\hline CHEMBL1548882 & 688171 & 4.6 & 4.8281 & TRN & \\
\hline CHEMBL1521174 & 688171 & 4.45 & 4.968 & TST & \\
\hline
\end{tabular}




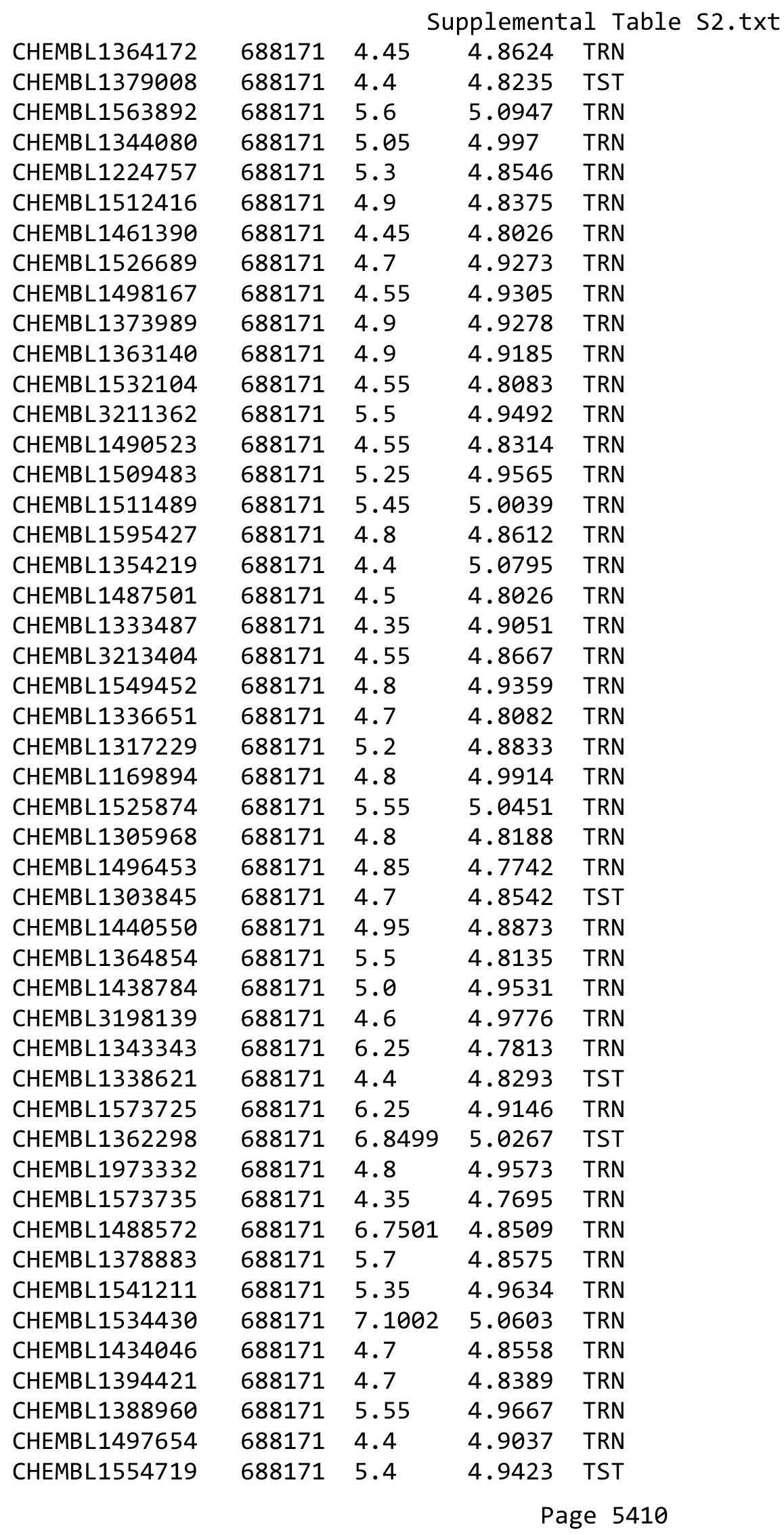




\begin{tabular}{|c|c|c|c|c|}
\hline \multicolumn{5}{|c|}{ Supplemental Table S2.txt } \\
\hline CHEMBL1365148 & 688171 & 4.55 & 4.9526 & TST \\
\hline CHEMBL1540413 & 688171 & 4.4 & 4.9253 & TST \\
\hline CHEMBL1501133 & 688171 & 4.85 & 4.9216 & TRN \\
\hline CHEMBL1485604 & 688171 & 4.9 & 4.7528 & TRN \\
\hline CHEMBL1400130 & 688171 & 4.9 & 4.8859 & TRN \\
\hline CHEMBL1391045 & 688171 & 4.35 & 4.8882 & TRN \\
\hline CHEMBL3189793 & 688171 & 4.85 & 5.0844 & TRN \\
\hline CHEMBL1373880 & 688171 & 4.55 & 4.8595 & TST \\
\hline CHEMBL1609070 & 688171 & 4.4 & 4.9069 & TRN \\
\hline CHEMBL1591003 & 688171 & 4.4 & 4.8043 & TRN \\
\hline CHEMBL1588705 & 688171 & 4.5 & 4.8034 & TST \\
\hline CHEMBL1602035 & 688171 & 6.6499 & 5.0115 & TST \\
\hline CHEMBL1501526 & 688171 & 4.5 & 4.853 & TRN \\
\hline CHEMBL1502929 & 688171 & 5.95 & 4.8807 & TST \\
\hline CHEMBL1490535 & 688171 & 4.55 & 4.845 & TRN \\
\hline CHEMBL1569232 & 688171 & 4.6 & 4.8372 & TRN \\
\hline CHEMBL1408174 & 688171 & 4.95 & 4.7983 & TST \\
\hline CHEMBL1428199 & 688171 & 4.4 & 5.0179 & TST \\
\hline CHEMBL1320977 & 688171 & 4.95 & 4.8834 & TRN \\
\hline CHEMBL1610234 & 688171 & 5.65 & 4.9302 & TRN \\
\hline CHEMBL1590871 & 688171 & 4.6 & 4.9764 & TRN \\
\hline CHEMBL1512223 & 688171 & 5.15 & 4.8326 & TRN \\
\hline CHEMBL1444940 & 688171 & 4.55 & 4.8423 & TRN \\
\hline CHEMBL1463283 & 688171 & 5.0 & 4.856 & TRN \\
\hline CHEMBL1520517 & 688171 & 4.65 & 5.043 & TST \\
\hline CHEMBL1425090 & 688171 & 4.7 & 4.7184 & TRN \\
\hline CHEMBL1518626 & 688171 & 4.45 & 4.7636 & TST \\
\hline CHEMBL1301573 & 688171 & 4.6 & 4.7585 & TST \\
\hline CHEMBL1307850 & 688171 & 5.0 & 5.0658 & TRN \\
\hline CHEMBL1303426 & 688171 & 4.8 & 4.8896 & TRN \\
\hline CHEMBL1607630 & 688171 & 5.0 & 4.8463 & TRN \\
\hline CHEMBL1323723 & 688171 & 4.75 & 4.8809 & TRN \\
\hline CHEMBL1346635 & 688171 & 4.35 & 4.8658 & TRN \\
\hline CHEMBL1374860 & 688171 & 4.8 & 4.8576 & TRN \\
\hline CHEMBL1361461 & 688171 & 5.45 & 4.9685 & TST \\
\hline CHEMBL1437737 & 688171 & 5.15 & 4.9288 & TRN \\
\hline CHEMBL1582178 & 688171 & 4.4 & 4.9017 & TST \\
\hline CHEMBL1474418 & 688171 & 5.85 & 5.007 & TRN \\
\hline CHEMBL1524403 & 688171 & 5.7 & 4.8265 & TST \\
\hline CHEMBL1472409 & 688171 & 5.0 & 4.9281 & TRN \\
\hline CHEMBL3207791 & 688171 & 4.8 & 4.815 & TRN \\
\hline CHEMBL1522657 & 688171 & 4.8 & 4.9572 & TRN \\
\hline CHEMBL1594369 & 688171 & 4.4 & 4.9498 & TST \\
\hline CHEMBL1593749 & 688171 & 4.4 & 4.8813 & TRN \\
\hline CHEMBL3191852 & 688171 & 6.5501 & 5.0945 & TRN \\
\hline CHEMBL1501635 & 688171 & 4.45 & 4.8707 & TST \\
\hline CHEMBL3194717 & 688171 & 5.65 & 5.0303 & TRN \\
\hline CHEMBL1492428 & 688171 & 4.7 & 4.8784 & TRN \\
\hline
\end{tabular}




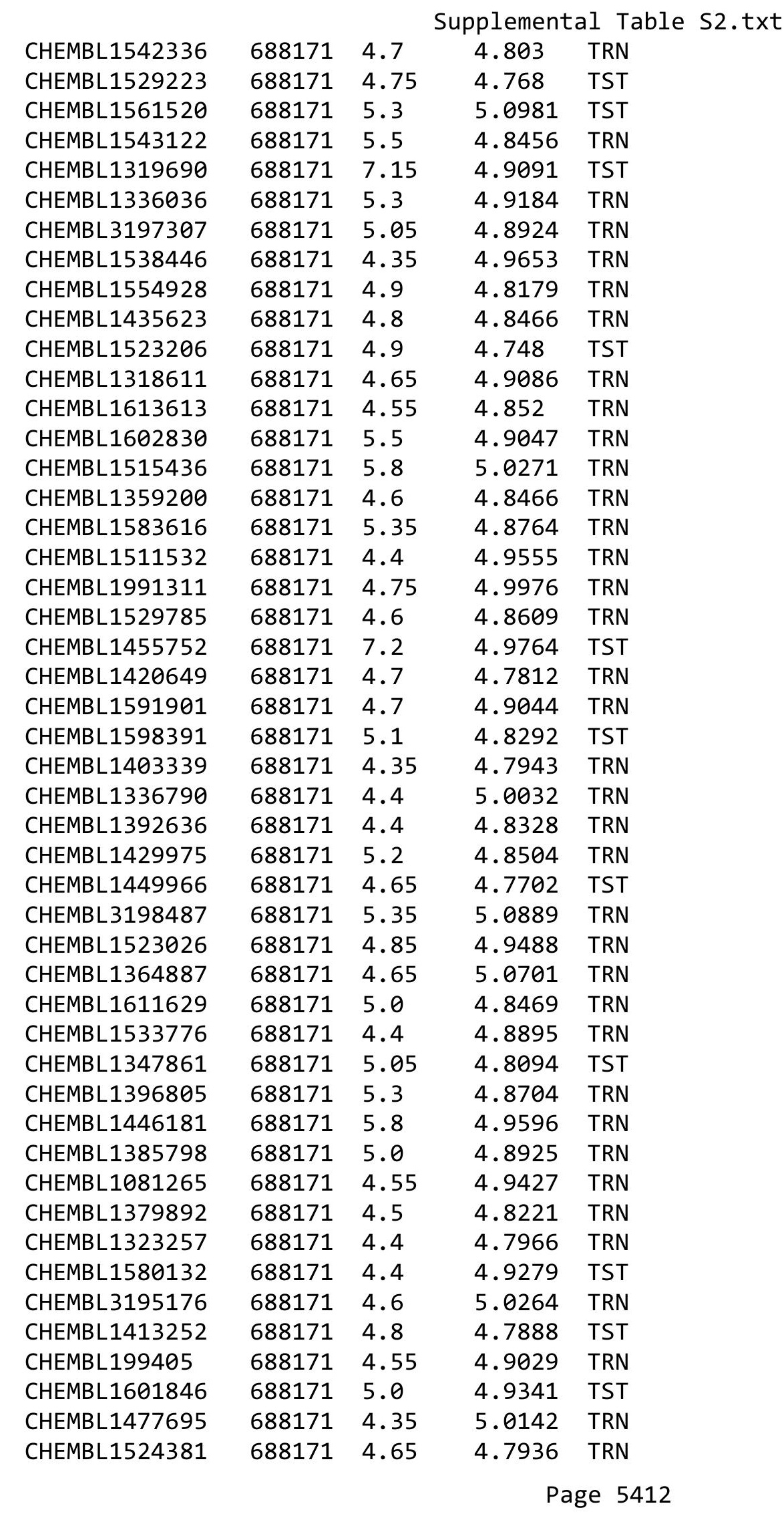




\begin{tabular}{|c|c|c|c|c|}
\hline \multicolumn{5}{|c|}{ Supplemental Table S2.txt } \\
\hline CHEMBL1414968 & 688171 & 4.75 & 4.8754 & TRN \\
\hline CHEMBL 3199237 & 688171 & 4.35 & 4.968 & TST \\
\hline CHEMBL1490579 & 688171 & 4.7 & 4.9789 & TRN \\
\hline CHEMBL1465615 & 688171 & 4.55 & 4.9952 & TST \\
\hline CHEMBL1328490 & 688171 & 7.1002 & 5.0411 & TST \\
\hline CHEMBL3198970 & 688171 & 4.5 & 4.8869 & TRN \\
\hline CHEMBL1356131 & 688171 & 4.55 & 4.8881 & TRN \\
\hline CHEMBL595227 & 688171 & 4.85 & 4.84399 & 9999999999 \\
\hline CHEMBL1404646 & 688171 & 4.55 & 4.9657 & TRN \\
\hline CHEMBL1365898 & 688171 & 4.8 & 4.7368 & TRN \\
\hline CHEMBL1512680 & 688171 & 4.8 & 4.8399 & TRN \\
\hline CHEMBL1303881 & 688171 & 5.1 & 4.8826 & TRN \\
\hline CHEMBL1418745 & 688171 & 5.15 & 4.9506 & TRN \\
\hline CHEMBL1333980 & 688171 & 4.45 & 5.0355 & TRN \\
\hline CHEMBL1337560 & 688171 & 4.4 & 4.9403 & TRN \\
\hline CHEMBL1352712 & 688171 & 4.6 & 4.7838 & TRN \\
\hline CHEMBL1501582 & 688171 & 4.55 & 4.6456 & TRN \\
\hline CHEMBL1570786 & 688171 & 4.45 & 4.9324 & TST \\
\hline CHEMBL515252 & 688171 & 5.15 & 4.8483 & TRN \\
\hline CHEMBL1514313 & 688171 & 5.25 & 4.9271 & TRN \\
\hline CHEMBL1996163 & 688171 & 5.05 & 4.9115 & TRN \\
\hline CHEMBL1394460 & 688171 & 4.65 & 5.0006 & TRN \\
\hline CHEMBL1555162 & 688171 & 4.95 & 4.8199 & TRN \\
\hline CHEMBL1420871 & 688171 & 4.8 & 4.9172 & TRN \\
\hline CHEMBL1467896 & 688171 & 4.6 & 4.8636 & TRN \\
\hline CHEMBL1381378 & 688171 & 4.4 & 4.8416 & TRN \\
\hline CHEMBL1458409 & 688171 & 4.35 & 4.8404 & TST \\
\hline CHEMBL1383337 & 688171 & 4.6 & 4.9087 & TRN \\
\hline CHEMBL1594370 & 688171 & 5.65 & 4.8838 & TRN \\
\hline CHEMBL1486838 & 688171 & 4.4 & 4.8804 & TRN \\
\hline CHEMBL1563444 & 688171 & 5.0 & 4.8793 & TRN \\
\hline CHEMBL1546124 & 688171 & 5.25 & 4.9867 & TRN \\
\hline CHEMBL1541405 & 688171 & 5.3 & 4.8021 & TRN \\
\hline CHEMBL1512220 & 688171 & 4.8 & 4.9174 & TRN \\
\hline CHEMBL1575394 & 688171 & 4.75 & 4.8511 & TRN \\
\hline CHEMBL1555907 & 688171 & 4.75 & 4.952 & TRN \\
\hline CHEMBL1378212 & 688171 & 4.35 & 4.8336 & TRN \\
\hline CHEMBL1486976 & 688171 & 4.55 & 4.8717 & TRN \\
\hline CHEMBL1390323 & 688171 & 4.45 & 4.9079 & TRN \\
\hline CHEMBL1382604 & 688171 & 4.4 & 4.909 & TST \\
\hline CHEMBL1521153 & 688171 & 5.25 & 4.9635 & TRN \\
\hline CHEMBL1461679 & 688171 & 4.6 & 4.9333 & TST \\
\hline CHEMBL388978 & 688171 & 6.0 & 4.9897 & TST \\
\hline CHEMBL1411075 & 688171 & 4.55 & 5.0607 & TRN \\
\hline CHEMBL1426818 & 688171 & 5.1 & 4.9453 & TST \\
\hline CHEMBL1501251 & 688171 & 4.4 & 4.8795 & TST \\
\hline CHEMBL1560291 & 688171 & 4.6 & 4.9268 & TST \\
\hline CHEMBL1529337 & 688171 & 5.05 & 4.9926 & TRN \\
\hline
\end{tabular}




\begin{tabular}{|c|c|c|c|c|c|}
\hline \multicolumn{6}{|c|}{ Supplemental Table S2.txt } \\
\hline CHEMBL567422 & 688171 & 4.6 & 4.9109 & TST & \\
\hline CHEMBL1343800 & 688171 & 4.65 & 4.8574 & TRN & \\
\hline CHEMBL1607163 & 688171 & 5.0 & 4.8714 & TRN & \\
\hline CHEMBL1403940 & 688171 & 4.4 & 4.9271 & TST & \\
\hline CHEMBL1320193 & 688171 & 4.55 & 4.8069 & TRN & \\
\hline CHEMBL1422794 & 688171 & 5.25 & 4.9772 & TRN & \\
\hline CHEMBL1370746 & 688171 & 4.95 & 4.8162 & TRN & \\
\hline CHEMBL1510715 & 688171 & 4.85 & 5.0653 & TRN & \\
\hline CHEMBL1395098 & 688171 & 4.4 & 4.8949 & TRN & \\
\hline CHEMBL1396022 & 688171 & 5.2 & 4.9265 & TRN & \\
\hline CHEMBL 322970 & 688171 & 5.1 & 4.8075 & TST & \\
\hline CHEMBL344344 & 688171 & 4.4 & 4.9265 & TRN & \\
\hline CHEMBL1584508 & 688171 & 5.35 & 4.9723 & TRN & \\
\hline CHEMBL1591831 & 688171 & 4.8 & 4.9111 & TRN & \\
\hline CHEMBL1434967 & 688171 & 5.0 & 4.7687 & TRN & \\
\hline CHEMBL1593226 & 688171 & 4.75 & 4.8568 & TRN & \\
\hline CHEMBL1608569 & 688171 & 4.9 & 4.763 & TRN & \\
\hline CHEMBL1446089 & 688171 & 4.55 & 4.9819 & TRN & \\
\hline CHEMBL1358106 & 688171 & 5.05 & 4.9602 & TRN & \\
\hline CHEMBL1398832 & 688171 & 5.55 & 4.9691 & TRN & \\
\hline CHEMBL1304004 & 688171 & 4.7 & 4.7694 & TRN & \\
\hline CHEMBL1386455 & 688171 & 4.5 & 4.8846 & TST & \\
\hline CHEMBL1552579 & 688171 & 5.05 & 4.9232 & TRN & \\
\hline CHEMBL1381722 & 688171 & 4.55 & 4.8745 & TRN & \\
\hline CHEMBL1450979 & 688171 & 4.55 & 4.8674 & TST & \\
\hline CHEMBL1547504 & 688171 & 5.05 & 4.876 & TRN & \\
\hline CHEMBL1428817 & 688171 & 5.3 & 4.9238 & TRN & \\
\hline CHEMBL1607553 & 688171 & 5.35 & 4.78 & TRN & \\
\hline CHEMBL1333985 & 688171 & 5.15 & 4.8903 & TST & \\
\hline CHEMBL1508414 & 688171 & 4.6 & 4.8118 & TRN & \\
\hline CHEMBL1498566 & 688171 & 4.4 & 4.9577 & TRN & \\
\hline CHEMBL1505063 & 688171 & 5.2 & 4.8396 & TRN & \\
\hline CHEMBL1503377 & 688171 & 4.95 & 4.7848 & TST & \\
\hline CHEMBL1335016 & 688171 & 4.75 & 4.8568 & TRN & \\
\hline CHEMBL1314376 & 688171 & 4.45 & 4.8991 & TST & \\
\hline CHEMBL1339699 & 688171 & 5.6 & 4.9985 & TRN & \\
\hline CHEMBL1475597 & 688171 & 4.75 & 4.9118 & TRN & \\
\hline CHEMBL1322000 & 688171 & 4.4 & 4.9643 & TRN & \\
\hline CHEMBL1578616 & 688171 & 4.35 & 5.06800 & 00000000005 & TST \\
\hline CHEMBL1477782 & 688171 & 4.65 & 4.9019 & TRN & \\
\hline CHEMBL1601285 & 688171 & 4.8 & 4.7917 & TRN & \\
\hline CHEMBL3209304 & 688171 & 4.7 & 4.8708 & TST & \\
\hline CHEMBL1492925 & 688171 & 4.85 & 4.9204 & TRN & \\
\hline CHEMBL1593137 & 688171 & 4.4 & 4.8825 & TRN & \\
\hline CHEMBL1495033 & 688171 & 4.8 & 4.9894 & TRN & \\
\hline CHEMBL1322381 & 688171 & 4.95 & 4.9011 & TRN & \\
\hline CHEMBL1607909 & 688171 & 4.7 & 4.9575 & TST & \\
\hline CHEMBL1399588 & 688171 & 4.7 & 4.9233 & TRN & \\
\hline
\end{tabular}




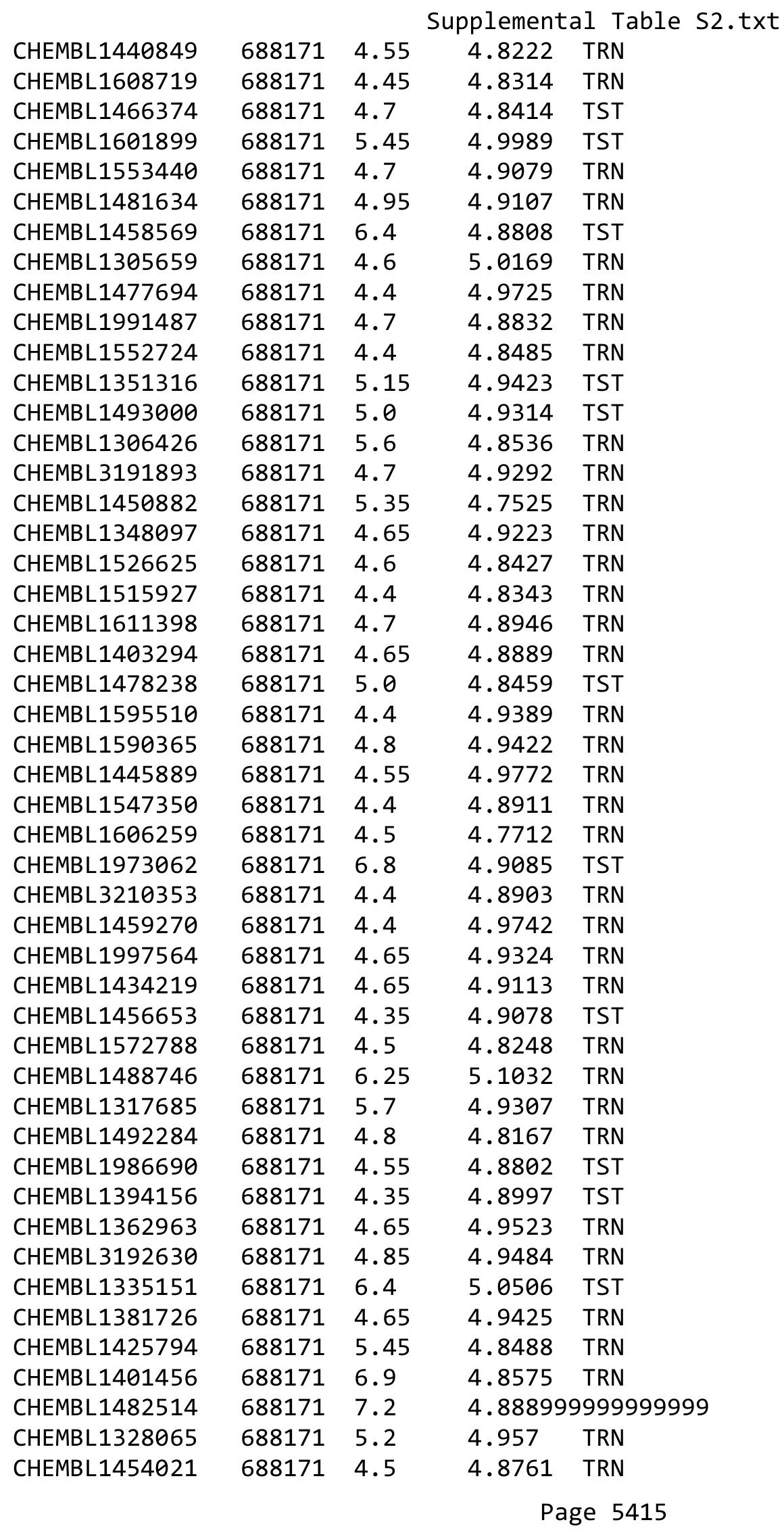




\begin{tabular}{|c|c|c|c|c|}
\hline \multicolumn{5}{|c|}{ Supplemental Table S2.txt } \\
\hline CHEMBL1336828 & 688171 & 5.35 & 4.9495 & TRN \\
\hline CHEMBL1476666 & 688171 & 5.75 & 4.7591 & TRN \\
\hline CHEMBL1379684 & 688171 & 4.4 & 4.8975 & TRN \\
\hline CHEMBL1333571 & 688171 & 4.35 & 4.9283 & TRN \\
\hline CHEMBL1310302 & 688171 & 4.7 & 4.9336 & TRN \\
\hline CHEMBL1404464 & 688171 & 4.35 & 4.9045 & TRN \\
\hline CHEMBL1588727 & 688171 & 4.35 & 4.855 & TRN \\
\hline CHEMBL1705092 & 688171 & 5.9 & 4.9656 & TST \\
\hline CHEMBL1548581 & 688171 & 4.4 & 4.8971 & TRN \\
\hline CHEMBL1554380 & 688171 & 4.6 & 4.8908 & TRN \\
\hline CHEMBL1412560 & 688171 & 4.55 & 4.8602 & TRN \\
\hline CHEMBL1486803 & 688171 & 4.6 & 4.9765 & TST \\
\hline CHEMBL1534248 & 688171 & 4.75 & 4.9075 & TST \\
\hline CHEMBL1598989 & 688171 & 4.4 & 4.7637 & TRN \\
\hline CHEMBL1590150 & 688171 & 5.0 & 4.9707 & TRN \\
\hline CHEMBL1554024 & 688171 & 4.8 & 4.7993 & TRN \\
\hline CHEMBL1530520 & 688171 & 4.95 & 4.8768 & TRN \\
\hline CHEMBL1502024 & 688171 & 5.3 & 4.8828 & TRN \\
\hline CHEMBL1435887 & 688171 & 4.4 & 4.849 & TRN \\
\hline CHEMBL1607002 & 688171 & 5.75 & 4.9343 & TST \\
\hline CHEMBL1497702 & 688171 & 4.35 & 4.9005 & TST \\
\hline CHEMBL1558425 & 688171 & 4.55 & 4.8653 & TRN \\
\hline CHEMBL1496532 & 688171 & 4.65 & 4.9116 & TRN \\
\hline CHEMBL1508457 & 688171 & 4.4 & 4.9166 & TRN \\
\hline CHEMBL1481914 & 688171 & 4.65 & 4.9334 & TRN \\
\hline CHEMBL1578206 & 688171 & 6.15 & 4.9892 & TRN \\
\hline CHEMBL1503627 & 688171 & 4.35 & 5.0121 & TST \\
\hline CHEMBL3192398 & 688171 & 4.85 & 4.8116 & TRN \\
\hline CHEMBL1512398 & 688171 & 4.45 & 4.8463 & TRN \\
\hline CHEMBL1448256 & 688171 & 7.6003 & 4.9334 & TRN \\
\hline CHEMBL1339999 & 688171 & 4.75 & 4.9533 & TST \\
\hline CHEMBL1356760 & 688171 & 4.95 & 4.8107 & TRN \\
\hline CHEMBL1453042 & 688171 & 6.0 & 4.8588 & TRN \\
\hline CHEMBL3190368 & 688171 & 4.4 & 4.9821 & TRN \\
\hline CHEMBL1464070 & 688171 & 4.4 & 4.9291 & TRN \\
\hline CHEMBL1389646 & 688171 & 4.85 & 4.8201 & TRN \\
\hline CHEMBL1395958 & 688171 & 5.1 & 4.7686 & TRN \\
\hline CHEMBL1367316 & 688171 & 4.55 & 4.8755 & TRN \\
\hline CHEMBL1977568 & 688171 & 5.0 & 4.93 & TRN \\
\hline CHEMBL1424443 & 688171 & 4.7 & 4.7092 & TST \\
\hline CHEMBL1415163 & 688171 & 4.7 & 4.9055 & TRN \\
\hline CHEMBL1326567 & 688171 & 4.4 & 4.9701 & TRN \\
\hline CHEMBL1583382 & 688171 & 4.85 & 4.8934 & TRN \\
\hline CHEMBL1568329 & 688171 & 4.85 & 4.9113 & TRN \\
\hline CHEMBL 2000340 & 688171 & 4.95 & 4.8665 & TRN \\
\hline CHEMBL1443963 & 688171 & 5.05 & 4.9978 & TST \\
\hline CHEMBL1301631 & 688171 & 6.7001 & 5.1037 & TRN \\
\hline CHEMBL1451448 & 688171 & 4.65 & 5.0128 & TRN \\
\hline
\end{tabular}




\begin{tabular}{|c|c|c|c|c|}
\hline & & & pplement & al $\mathrm{Ta}$ \\
\hline CHEMBL1515640 & 688171 & 4.7 & 4.8779 & TRN \\
\hline CHEMBL1988657 & 688171 & 5.6 & 5.0406 & TRN \\
\hline CHEMBL1330520 & 688171 & 4.8 & 4.7827 & TRN \\
\hline CHEMBL1440887 & 688171 & 5.4 & 4.8866 & TST \\
\hline CHEMBL1501828 & 688171 & 4.5 & 4.9331 & TRN \\
\hline CHEMBL1421575 & 688171 & 4.45 & 5.0195 & TRN \\
\hline CHEMBL1382026 & 688171 & 5.25 & 4.9751 & TRN \\
\hline CHEMBL1451580 & 688171 & 4.4 & 4.8818 & TRN \\
\hline CHEMBL1301257 & 688171 & 4.8 & 4.9936 & TST \\
\hline CHEMBL1986444 & 688171 & 4.4 & 4.9722 & TRN \\
\hline CHEMBL1349475 & 688171 & 4.9 & 4.9319 & TST \\
\hline CHEMBL1481591 & 688171 & 4.8 & 4.8851 & TRN \\
\hline CHEMBL1356013 & 688171 & 4.4 & 4.8066 & TRN \\
\hline CHEMBL1440659 & 688171 & 5.55 & 5.0087 & TRN \\
\hline CHEMBL1303870 & 688171 & 4.95 & 4.9271 & TRN \\
\hline CHEMBL1508904 & 688171 & 6.1 & 4.9612 & TRN \\
\hline CHEMBL1554153 & 688171 & 5.05 & 5.0263 & TRN \\
\hline CHEMBL1429108 & 688171 & 4.6 & 4.8189 & TRN \\
\hline CHEMBL1410434 & 688171 & 4.7 & 5.0424 & TST \\
\hline CHEMBL610056 & 688171 & 4.5 & 4.9713 & TST \\
\hline CHEMBL3195673 & 688171 & 4.35 & 4.7797 & TST \\
\hline CHEMBL1967105 & 688171 & 5.45 & 4.9792 & TRN \\
\hline CHEMBL1326881 & 688171 & 4.35 & 4.9428 & TRN \\
\hline CHEMBL1524502 & 688171 & 5.1 & 4.9129 & TRN \\
\hline CHEMBL1457476 & 688171 & 4.85 & 4.8959 & TRN \\
\hline CHEMBL3191340 & 688171 & 4.8 & 4.9618 & TST \\
\hline CHEMBL1558294 & 688171 & 5.55 & 4.9906 & TST \\
\hline CHEMBL1392460 & 688171 & 4.9 & 4.7472 & TST \\
\hline CHEMBL1507021 & 688171 & 4.4 & 4.8177 & TRN \\
\hline CHEMBL1476118 & 688171 & 4.75 & 4.9046 & TRN \\
\hline CHEMBL1526174 & 688171 & 4.5 & 4.8712 & TST \\
\hline CHEMBL1523894 & 688171 & 5.3 & 4.9104 & TST \\
\hline CHEMBL1526441 & 688171 & 4.7 & 4.8212 & TRN \\
\hline CHEMBL1575966 & 688171 & 5.05 & 4.8141 & TRN \\
\hline CHEMBL1543921 & 688171 & 4.75 & 4.9665 & TST \\
\hline CHEMBL374074 & 688171 & 6.8 & 4.9702 & TST \\
\hline CHEMBL3193406 & 688171 & 5.15 & 5.0684 & TRN \\
\hline CHEMBL1508508 & 688171 & 4.7 & 4.9028 & TRN \\
\hline CHEMBL3211464 & 688171 & 4.4 & 4.9839 & TRN \\
\hline CHEMBL1362937 & 688171 & 6.2 & 4.8018 & TRN \\
\hline CHEMBL1425003 & 688171 & 5.35 & 4.6844 & TRN \\
\hline CHEMBL1466582 & 688171 & 4.5 & 4.7758 & TRN \\
\hline CHEMBL1300120 & 688171 & 6.2 & 5.0783 & TST \\
\hline CHEMBL1493335 & 688171 & 5.05 & 4.8517 & TRN \\
\hline CHEMBL1520809 & 688171 & 4.9 & 4.8236 & TRN \\
\hline CHEMBL1313485 & 688171 & 4.65 & 4.9736 & TRN \\
\hline CHEMBL1459787 & 688171 & 4.4 & 4.9328 & TST \\
\hline CHEMBL1600383 & 688171 & 4.95 & 4.8339 & TRN \\
\hline
\end{tabular}




\begin{tabular}{|c|c|c|c|c|}
\hline & & & pplement & \\
\hline CHEMBL 3210880 & 688171 & 4.7 & 5.0527 & TRN \\
\hline CHEMBL3195981 & 688171 & 4.4 & 4.9594 & TRN \\
\hline CHEMBL1313003 & 688171 & 4.5 & 4.746 & TRN \\
\hline CHEMBL1604939 & 688171 & 4.7 & 4.7657 & TRN \\
\hline CHEMBL1523943 & 688171 & 6.45 & 5.0564 & TST \\
\hline CHEMBL39 & 688171 & 4.4 & 4.9806 & TRN \\
\hline CHEMBL1479389 & 688171 & 4.45 & 5.0396 & TRN \\
\hline CHEMBL1567258 & 688171 & 4.6 & 4.8491 & TST \\
\hline CHEMBL1307720 & 688171 & 4.55 & 4.9295 & TRN \\
\hline CHEMBL1310988 & 688171 & 4.4 & 4.8895 & TRN \\
\hline CHEMBL3199470 & 688171 & 4.85 & 4.9127 & TRN \\
\hline CHEMBL1998302 & 688171 & 4.4 & 4.8716 & TRN \\
\hline CHEMBL1416512 & 688171 & 4.95 & 4.8263 & TRN \\
\hline CHEMBL1437735 & 688171 & 5.95 & 5.0219 & TRN \\
\hline CHEMBL1454585 & 688171 & 4.95 & 4.8152 & TRN \\
\hline CHEMBL1598460 & 688171 & 5.0 & 4.9338 & TRN \\
\hline CHEMBL1548809 & 688171 & 4.7 & 4.936 & TRN \\
\hline CHEMBL1416876 & 688171 & 5.1 & 5.0723 & TRN \\
\hline CHEMBL1598105 & 688171 & 4.4 & 4.8465 & TRN \\
\hline CHEMBL1376006 & 688171 & 4.5 & 4.8996 & TRN \\
\hline CHEMBL1456408 & 688171 & 4.35 & 5.0057 & TRN \\
\hline CHEMBL1444351 & 688171 & 4.45 & 4.79 & TST \\
\hline CHEMBL1339565 & 688171 & 4.65 & 4.7733 & TRN \\
\hline CHEMBL19439 & 688171 & 4.8 & 4.9206 & TST \\
\hline CHEMBL1594135 & 688171 & 4.35 & 4.8838 & TRN \\
\hline CHEMBL1373340 & 688171 & 5.1 & 4.8859 & TRN \\
\hline CHEMBL1318790 & 688171 & 4.95 & 4.9475 & TRN \\
\hline CHEMBL1434565 & 688171 & 4.85 & 4.9019 & TRN \\
\hline CHEMBL1416382 & 688171 & 5.05 & 4.8674 & TRN \\
\hline CHEMBL1480847 & 688171 & 5.55 & 4.8891 & TST \\
\hline CHEMBL1370979 & 688171 & 4.35 & 4.9964 & TST \\
\hline CHEMBL1402426 & 688171 & 5.45 & 4.9233 & TRN \\
\hline CHEMBL1435037 & 688171 & 4.8 & 4.7648 & TRN \\
\hline CHEMBL1342224 & 688171 & 6.9 & 4.9216 & TST \\
\hline CHEMBL1328777 & 688171 & 5.15 & 4.8961 & TRN \\
\hline CHEMBL1357767 & 688171 & 5.45 & 4.9056 & TRN \\
\hline CHEMBL1463866 & 688171 & 6.2 & 4.8662 & TRN \\
\hline CHEMBL1435472 & 688171 & 4.55 & 4.9033 & TRN \\
\hline CHEMBL1322591 & 688171 & 6.0 & 4.9352 & TRN \\
\hline CHEMBL1574096 & 688171 & 5.45 & 4.7546 & TRN \\
\hline CHEMBL1354019 & 688171 & 4.4 & 4.9669 & TRN \\
\hline CHEMBL1483698 & 688171 & 4.7 & 4.9416 & TRN \\
\hline CHEMBL1380478 & 688171 & 5.0 & 4.8956 & TST \\
\hline CHEMBL1529023 & 688171 & 5.4 & 4.9802 & TRN \\
\hline CHEMBL1444537 & 688171 & 4.4 & 4.9266 & TRN \\
\hline CHEMBL1513406 & 688171 & 5.05 & 4.8223 & TRN \\
\hline CHEMBL1454494 & 688171 & 5.05 & 5.047 & TST \\
\hline CHEMBL1459626 & 688171 & 4.45 & 4.9516 & TRN \\
\hline
\end{tabular}




\begin{tabular}{|c|c|c|c|c|}
\hline \multicolumn{5}{|c|}{ Supplemental Table S2.txt } \\
\hline CHEMBL1592187 & 688171 & 4.9 & 4.8944 & TRN \\
\hline CHEMBL1418337 & 688171 & 4.8 & 4.9271 & TRN \\
\hline CHEMBL186366 & 688171 & 4.55 & 4.9899 & TST \\
\hline CHEMBL1594896 & 688171 & 6.35 & 4.8895 & TST \\
\hline CHEMBL1611658 & 688171 & 4.55 & 4.966 & TRN \\
\hline CHEMBL1504966 & 688171 & 6.05 & 5.1175 & TST \\
\hline CHEMBL1317482 & 688171 & 4.75 & 4.8903 & TRN \\
\hline CHEMBL1330166 & 688171 & 4.35 & 4.7454 & TRN \\
\hline CHEMBL1600944 & 688171 & 5.95 & 4.8142 & TRN \\
\hline CHEMBL1429570 & 688171 & 4.65 & 4.8772 & TRN \\
\hline CHEMBL1592443 & 688171 & 4.55 & 4.8956 & TRN \\
\hline CHEMBL3207339 & 688171 & 4.6 & 4.8574 & TRN \\
\hline CHEMBL3195900 & 688171 & 4.4 & 5.0087 & TRN \\
\hline CHEMBL1494113 & 688171 & 4.45 & 4.9074 & TRN \\
\hline CHEMBL1374742 & 688171 & 4.7 & 5.0762 & TRN \\
\hline CHEMBL1395568 & 688171 & 5.85 & 4.9008 & TRN \\
\hline CHEMBL3213548 & 688171 & 4.95 & 4.9013 & TRN \\
\hline CHEMBL1577887 & 688171 & 4.45 & 4.8829 & TRN \\
\hline CHEMBL1529176 & 688171 & 5.6 & 5.0257 & TST \\
\hline CHEMBL1316937 & 688171 & 5.05 & 4.8023 & TRN \\
\hline CHEMBL1308597 & 688171 & 4.45 & 4.9125 & TRN \\
\hline CHEMBL1368235 & 688171 & 4.55 & 4.8147 & TRN \\
\hline CHEMBL1601664 & 688171 & 5.75 & 5.0012 & TRN \\
\hline CHEMBL1545112 & 688171 & 4.75 & 4.7378 & TST \\
\hline CHEMBL1420316 & 688171 & 4.6 & 4.9235 & TRN \\
\hline CHEMBL1967772 & 688171 & 4.55 & 4.8943 & TRN \\
\hline CHEMBL1391994 & 688171 & 5.9 & 4.8798 & TRN \\
\hline CHEMBL1553556 & 688171 & 5.6 & 4.9092 & TRN \\
\hline CHEMBL1540150 & 688171 & 4.5 & 4.9582 & TRN \\
\hline CHEMBL1487674 & 688171 & 5.15 & 4.9592 & TRN \\
\hline CHEMBL1402951 & 688171 & 5.3 & 4.9279 & TRN \\
\hline CHEMBL3199700 & 688171 & 4.55 & 4.9931 & TRN \\
\hline CHEMBL1572475 & 688171 & 4.75 & 5.0246 & TRN \\
\hline CHEMBL1570435 & 688171 & 4.35 & 5.1144 & TRN \\
\hline CHEMBL1317341 & 688171 & 4.65 & 4.8053 & TRN \\
\hline CHEMBL1455465 & 688171 & 6.1 & 4.8385 & TRN \\
\hline CHEMBL 1344060 & 688171 & 5.4 & 5.0226 & TRN \\
\hline CHEMBL1350452 & 688171 & 4.4 & 4.8875 & TRN \\
\hline CHEMBL1529796 & 688171 & 4.7 & 4.7287 & TRN \\
\hline CHEMBL1599287 & 688171 & 4.35 & 4.958 & TST \\
\hline CHEMBL1571491 & 688171 & 7.2503 & 4.9906 & TRN \\
\hline CHEMBL1436183 & 688171 & 5.0 & 4.9053 & TRN \\
\hline CHEMBL1535640 & 688171 & 4.9 & 4.9649 & TRN \\
\hline CHEMBL1364367 & 688171 & 5.5 & 4.9364 & TRN \\
\hline CHEMBL1395823 & 688171 & 4.95 & 4.9137 & TST \\
\hline CHEMBL1333497 & 688171 & 5.0 & 4.8396 & TRN \\
\hline CHEMBL1322625 & 688171 & 4.4 & 4.8762 & TST \\
\hline CHEMBL1474449 & 688171 & 4.95 & 4.8584 & TRN \\
\hline
\end{tabular}




\begin{tabular}{|c|c|c|c|c|}
\hline \multicolumn{5}{|c|}{ Supplemental Table S2.txt } \\
\hline CHEMBL1451927 & 688171 & 4.5 & 4.9776 & TST \\
\hline CHEMBL1436862 & 688171 & 4.65 & 4.867 & TRN \\
\hline CHEMBL1517139 & 688171 & 4.5 & 5.0053 & TRN \\
\hline CHEMBL1567405 & 688171 & 4.55 & 4.8014 & TRN \\
\hline CHEMBL1430445 & 688171 & 4.75 & 4.9376 & TRN \\
\hline CHEMBL1473133 & 688171 & 4.45 & 4.8213 & TRN \\
\hline CHEMBL1337779 & 688171 & 5.5 & 4.8899 & TRN \\
\hline CHEMBL1556259 & 688171 & 5.95 & 4.9775 & TRN \\
\hline CHEMBL1589322 & 688171 & 4.85 & 4.8695 & TRN \\
\hline CHEMBL1389565 & 688171 & 4.75 & 4.7976 & TRN \\
\hline CHEMBL1344228 & 688171 & 5.5 & 4.8922 & TRN \\
\hline CHEMBL1425486 & 688171 & 4.7 & 5.0748 & TRN \\
\hline CHEMBL3196087 & 688171 & 5.1 & 4.9501 & TRN \\
\hline CHEMBL1503265 & 688171 & 4.75 & 4.9843 & TST \\
\hline CHEMBL1585673 & 688171 & 4.35 & 4.9865 & TST \\
\hline CHEMBL1513123 & 688171 & 5.05 & 4.9396 & TRN \\
\hline CHEMBL1349898 & 688171 & 6.45 & 4.9538 & TRN \\
\hline CHEMBL492267 & 688171 & 4.5 & 4.8921 & TRN \\
\hline CHEMBL1490541 & 688171 & 7.6003 & 4.8248 & TRN \\
\hline CHEMBL1336575 & 688171 & 5.0 & 4.8432 & TRN \\
\hline CHEMBL1499176 & 688171 & 5.05 & 5.0579 & TRN \\
\hline CHEMBL1452300 & 688171 & 4.4 & 4.9609 & TST \\
\hline CHEMBL 2373648 & 688171 & 5.45 & 4.9481 & TST \\
\hline CHEMBL1551915 & 688171 & 4.5 & 4.902 & TRN \\
\hline CHEMBL1350778 & 688171 & 4.55 & 4.7726 & TRN \\
\hline CHEMBL1331108 & 688171 & 5.15 & 4.8612 & TST \\
\hline CHEMBL1306940 & 688171 & 4.65 & 4.9654 & TST \\
\hline CHEMBL1473886 & 688171 & 4.5 & 5.0074 & TST \\
\hline CHEMBL1394111 & 688171 & 4.6 & 4.8858 & TRN \\
\hline CHEMBL1513732 & 688171 & 4.95 & 4.8844 & TRN \\
\hline CHEMBL1439122 & 688171 & 4.65 & 4.8061 & TRN \\
\hline CHEMBL1467543 & 688171 & 4.4 & 4.9466 & TST \\
\hline CHEMBL1534753 & 688171 & 4.4 & 4.8176 & TST \\
\hline CHEMBL1420189 & 688171 & 4.5 & 4.9218 & TRN \\
\hline CHEMBL1299329 & 688171 & 4.85 & 4.9482 & TRN \\
\hline CHEMBL1348609 & 688171 & 5.0 & 4.843 & TRN \\
\hline CHEMBL1518871 & 688171 & 4.4 & 4.7034 & TRN \\
\hline CHEMBL1612378 & 688171 & 5.0 & 4.9386 & TRN \\
\hline CHEMBL1437117 & 688171 & 4.4 & 4.834 & TRN \\
\hline CHEMBL1598479 & 688171 & 4.7 & 4.8902 & TRN \\
\hline CHEMBL1333767 & 688171 & 5.2 & 4.828 & TRN \\
\hline CHEMBL1350179 & 688171 & 5.0 & 4.7766 & TRN \\
\hline CHEMBL1365290 & 688171 & 4.85 & 4.7828 & TRN \\
\hline CHEMBL1591514 & 688171 & 4.65 & 4.8594 & TRN \\
\hline CHEMBL3190693 & 688171 & 4.7 & 4.9986 & TRN \\
\hline CHEMBL1555142 & 688171 & 5.95 & 4.7827 & TRN \\
\hline CHEMBL1557240 & 688171 & 4.35 & 4.9864 & TRN \\
\hline CHEMBL1554091 & 688171 & 4.35 & 4.8102 & TRN \\
\hline
\end{tabular}




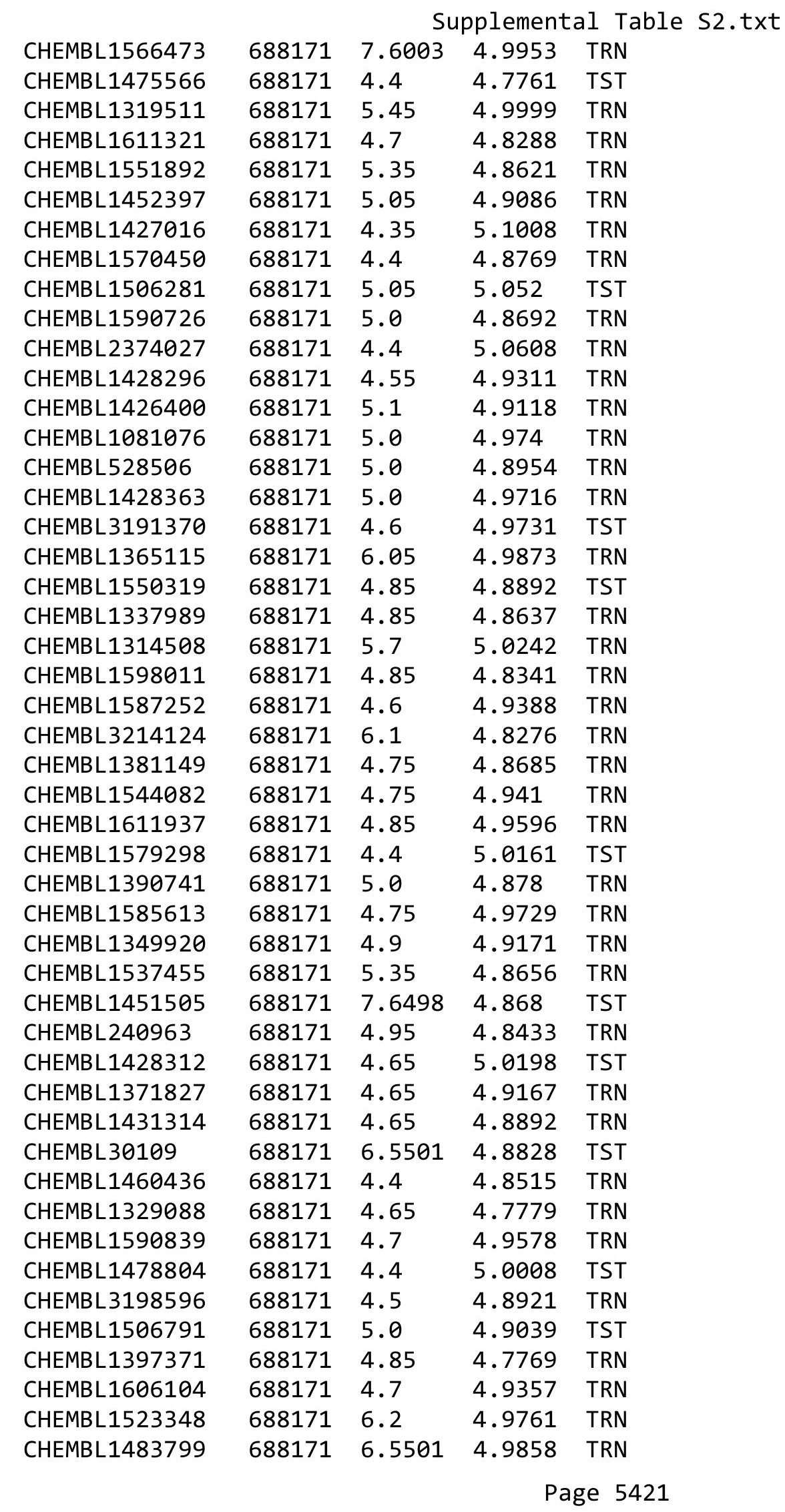




\begin{tabular}{|c|c|c|c|c|}
\hline \multicolumn{5}{|c|}{ Supplemental Table S2.txt } \\
\hline CHEMBL1441823 & 688171 & 4.65 & 4.9711 & TRN \\
\hline CHEMBL1449204 & 688171 & 5.55 & 4.9428 & TRN \\
\hline CHEMBL1326683 & 688171 & 6.0 & 4.7945 & TST \\
\hline CHEMBL1425743 & 688171 & 6.0 & 4.8544 & TST \\
\hline CHEMBL1341735 & 688171 & 4.75 & 4.9489 & TRN \\
\hline CHEMBL1435980 & 688171 & 4.6 & 4.8248 & TRN \\
\hline CHEMBL1313640 & 688171 & 6.4 & 4.9434 & TST \\
\hline CHEMBL1333793 & 688171 & 5.8 & 4.9441 & TRN \\
\hline CHEMBL1502086 & 688171 & 4.95 & 4.9282 & TRN \\
\hline CHEMBL1514857 & 688171 & 4.95 & 4.8152 & TRN \\
\hline CHEMBL1284 & 688171 & 4.6 & 4.9884 & TRN \\
\hline CHEMBL1534029 & 688171 & 4.5 & 4.7369 & TRN \\
\hline CHEMBL1513587 & 688171 & 4.5 & 5.0176 & TST \\
\hline CHEMBL1359917 & 688171 & 4.4 & 5.003 & TRN \\
\hline CHEMBL1378760 & 688171 & 4.6 & 4.9334 & TRN \\
\hline CHEMBL1608073 & 688171 & 4.95 & 4.7681 & TRN \\
\hline CHEMBL1440898 & 688171 & 4.75 & 4.9625 & TST \\
\hline CHEMBL3192014 & 688171 & 4.4 & 4.9035 & TRN \\
\hline CHEMBL1588733 & 688171 & 4.4 & 4.8098 & TST \\
\hline CHEMBL1333603 & 688171 & 5.4 & 4.8699 & TRN \\
\hline CHEMBL1312212 & 688171 & 4.55 & 4.9354 & TRN \\
\hline CHEMBL1600408 & 688171 & 7.8996 & 5.0184 & TRN \\
\hline CHEMBL1592391 & 688171 & 5.05 & 4.8083 & TRN \\
\hline CHEMBL1303933 & 688171 & 5.35 & 4.9888 & TRN \\
\hline CHEMBL1349774 & 688171 & 4.4 & 4.912 & TRN \\
\hline CHEMBL1345764 & 688171 & 4.4 & 4.8434 & TRN \\
\hline CHEMBL1464598 & 688171 & 5.25 & 5.0046 & TRN \\
\hline CHEMBL1576545 & 688171 & 4.65 & 4.7865 & TRN \\
\hline CHEMBL1449704 & 688171 & 5.35 & 5.0667 & TRN \\
\hline CHEMBL1379056 & 688171 & 6.0 & 4.8721 & TST \\
\hline CHEMBL1560530 & 688171 & 4.65 & 4.8701 & TST \\
\hline CHEMBL 260148 & 688171 & 4.35 & 4.9346 & TST \\
\hline CHEMBL226876 & 688171 & 5.6 & 4.9976 & TRN \\
\hline CHEMBL1460715 & 688171 & 4.4 & 4.9135 & TRN \\
\hline CHEMBL491991 & 688171 & 4.5 & 4.8942 & TRN \\
\hline CHEMBL1397148 & 688171 & 5.3 & 4.9468 & TRN \\
\hline CHEMBL1501194 & 688171 & 4.4 & 4.9378 & TRN \\
\hline CHEMBL1594278 & 688171 & 4.35 & 4.8298 & TRN \\
\hline CHEMBL1489101 & 688171 & 4.6 & 4.9973 & TRN \\
\hline CHEMBL1473632 & 688171 & 4.9 & 5.0671 & TST \\
\hline CHEMBL1972235 & 688171 & 5.6 & 5.0046 & TRN \\
\hline CHEMBL1382733 & 688171 & 4.45 & 4.8855 & TST \\
\hline CHEMBL1449526 & 688171 & 5.05 & 4.9683 & TRN \\
\hline CHEMBL1501452 & 688171 & 4.75 & 4.8902 & TST \\
\hline CHEMBL1394170 & 688171 & 4.55 & 4.8629 & TRN \\
\hline CHEMBL1331912 & 688171 & 5.95 & 4.8824 & TRN \\
\hline CHEMBL1469603 & 688171 & 4.55 & 4.8653 & TRN \\
\hline CHEMBL3191309 & 688171 & 4.8 & 4.931 & TRN \\
\hline
\end{tabular}




\begin{tabular}{|c|c|c|c|c|c|}
\hline \multicolumn{6}{|c|}{ Supplemental Table S2.txt } \\
\hline CHEMBL1326284 & 688171 & 4.35 & 4.8181 & TST & \\
\hline CHEMBL1592569 & 688171 & 4.4 & 4.9719 & TST & \\
\hline CHEMBL1589824 & 688171 & 5.1 & 5.0343 & TRN & \\
\hline CHEMBL1437265 & 688171 & 5.15 & 5.0217 & TRN & \\
\hline CHEMBL 3196022 & 688171 & 4.4 & 4.8291 & TRN & \\
\hline CHEMBL1373039 & 688171 & 5.4 & 4.8719 & TRN & \\
\hline CHEMBL1528149 & 688171 & 5.0 & 4.8304 & TRN & \\
\hline CHEMBL1546639 & 688171 & 4.7 & 4.9713 & TRN & \\
\hline CHEMBL1384761 & 688171 & 4.85 & 5.05699 & 99999999995 & TST \\
\hline CHEMBL1458488 & 688171 & 4.35 & 4.6907 & TST & \\
\hline CHEMBL 3195400 & 688171 & 4.45 & 4.9071 & TRN & \\
\hline CHEMBL1330619 & 688171 & 4.4 & 5.0246 & TRN & \\
\hline CHEMBL1313474 & 688171 & 5.05 & 4.8045 & TST & \\
\hline CHEMBL1554121 & 688171 & 5.5 & 4.9134 & TRN & \\
\hline CHEMBL1981243 & 688171 & 4.6 & 4.7661 & TRN & \\
\hline CHEMBL1507036 & 688171 & 4.6 & 4.79899 & 99999999995 & TST \\
\hline CHEMBL1300259 & 688171 & 4.4 & 4.8281 & TRN & \\
\hline CHEMBL1506482 & 688171 & 6.0 & 5.0178 & TRN & \\
\hline CHEMBL1577087 & 688171 & 4.75 & 4.8167 & TST & \\
\hline CHEMBL1346904 & 688171 & 4.65 & 4.9567 & TST & \\
\hline CHEMBL1371777 & 688171 & 4.45 & 4.8656 & TRN & \\
\hline CHEMBL1360091 & 688171 & 6.7001 & 4.9825 & TST & \\
\hline CHEMBL 3192184 & 688171 & 4.9 & 4.8998 & TRN & \\
\hline CHEMBL1602474 & 688171 & 5.9 & 4.846 & TST & \\
\hline CHEMBL1418175 & 688171 & 5.55 & 4.9413 & TRN & \\
\hline CHEMBL1438396 & 688171 & 4.5 & 4.9088 & TRN & \\
\hline CHEMBL1504360 & 688171 & 4.75 & 4.8565 & TRN & \\
\hline CHEMBL1558631 & 688171 & 4.9 & 4.973 & TRN & \\
\hline CHEMBL1563792 & 688171 & 6.3 & 4.9365 & TRN & \\
\hline CHEMBL1993612 & 688171 & 4.8 & 4.9917 & TRN & \\
\hline CHEMBL 381033 & 688171 & 4.9 & 4.8126 & TRN & \\
\hline CHEMBL1497673 & 688171 & 5.0 & 4.9046 & TST & \\
\hline CHEMBL1310886 & 688171 & 4.55 & 4.9031 & TRN & \\
\hline CHEMBL1544218 & 688171 & 4.6 & 4.8703 & TST & \\
\hline CHEMBL1591515 & 688171 & 4.55 & 4.912 & TRN & \\
\hline CHEMBL1402804 & 688171 & 4.75 & 4.7299 & TRN & \\
\hline CHEMBL1428894 & 688171 & 4.45 & 4.7866 & TST & \\
\hline CHEMBL1414053 & 688171 & 5.0 & 4.8772 & TST & \\
\hline CHEMBL3196834 & 688171 & 4.75 & 4.9424 & TST & \\
\hline CHEMBL1308854 & 688171 & 4.4 & 4.8653 & TRN & \\
\hline CHEMBL1460841 & 688171 & 4.6 & 4.8604 & TRN & \\
\hline CHEMBL1312984 & 688171 & 4.35 & 4.9248 & TST & \\
\hline CHEMBL1490261 & 688171 & 7.1002 & 5.0751 & TRN & \\
\hline CHEMBL1581012 & 688171 & 6.2 & 5.0226 & TST & \\
\hline CHEMBL1514227 & 688171 & 4.8 & 4.9095 & TST & \\
\hline CHEMBL 2004624 & 688171 & 7.6003 & 4.9856 & TRN & \\
\hline CHEMBL1611263 & 688171 & 4.65 & 5.001 & TRN & \\
\hline CHEMBL1365177 & 688171 & 4.5 & 4.8793 & TST & \\
\hline
\end{tabular}




\begin{tabular}{|c|c|c|c|c|c|}
\hline \multicolumn{6}{|c|}{ Supplemental Table S2.txt } \\
\hline CHEMBL1307512 & 688171 & 5.05 & 5.0425 & TRN & \\
\hline CHEMBL1504800 & 688171 & 5.45 & 4.8711 & TST & \\
\hline CHEMBL1550792 & 688171 & 4.35 & 4.9899 & TRN & \\
\hline CHEMBL1447008 & 688171 & 4.75 & 5.0029 & TRN & \\
\hline CHEMBL1354499 & 688171 & 4.55 & 4.8287 & TRN & \\
\hline CHEMBL1730100 & 688171 & 6.0 & 4.9372 & TST & \\
\hline CHEMBL1550954 & 688171 & 4.6 & 4.947 & TST & \\
\hline CHEMBL 2006519 & 688171 & 4.35 & 4.8103 & TRN & \\
\hline CHEMBL1351823 & 688171 & 4.45 & 4.89199 & 99999999995 & TRN \\
\hline CHEMBL1304584 & 688171 & 4.75 & 4.8977 & TST & \\
\hline CHEMBL1590306 & 688171 & 4.8 & 4.9017 & TRN & \\
\hline CHEMBL1513034 & 688171 & 4.4 & 4.882 & TST & \\
\hline CHEMBL1404008 & 688171 & 4.75 & 4.9006 & TST & \\
\hline CHEMBL1445250 & 688171 & 5.05 & 4.9082 & TRN & \\
\hline CHEMBL1328721 & 688171 & 5.05 & 4.8078 & TST & \\
\hline CHEMBL1396827 & 688171 & 4.4 & 4.9341 & TST & \\
\hline CHEMBL3194945 & 688171 & 4.55 & 4.8723 & TST & \\
\hline CHEMBL1544252 & 688171 & 4.4 & 4.8913 & TRN & \\
\hline CHEMBL1390346 & 688171 & 4.7 & 4.9102 & TRN & \\
\hline CHEMBL1409087 & 688171 & 4.35 & 4.9077 & TRN & \\
\hline CHEMBL1426054 & 688171 & 4.4 & 5.0379 & TRN & \\
\hline CHEMBL536375 & 688171 & 5.0 & 4.8765 & TRN & \\
\hline CHEMBL3189696 & 688171 & 6.05 & 4.945 & TRN & \\
\hline CHEMBL1359009 & 688171 & 4.6 & 4.8279 & TRN & \\
\hline CHEMBL1602144 & 688171 & 4.7 & 4.9337 & TRN & \\
\hline CHEMBL1472327 & 688171 & 4.9 & 4.8082 & TST & \\
\hline CHEMBL1514426 & 688171 & 4.75 & 4.9515 & TRN & \\
\hline CHEMBL1611452 & 688171 & 4.4 & 4.8356 & TRN & \\
\hline CHEMBL1583966 & 688171 & 4.85 & 5.0138 & TST & \\
\hline CHEMBL1613047 & 688171 & 4.85 & 4.879 & TRN & \\
\hline CHEMBL1370761 & 688171 & 5.8 & 4.8607 & TST & \\
\hline CHEMBL1482407 & 688171 & 4.95 & 5.0064 & TRN & \\
\hline CHEMBL1597836 & 688171 & 6.7501 & 4.9674 & TRN & \\
\hline CHEMBL1317466 & 688171 & 4.95 & 4.8381 & TRN & \\
\hline CHEMBL1486137 & 688171 & 4.4 & 4.81 & TRN & \\
\hline CHEMBL1312087 & 688171 & 4.85 & 4.9977 & TRN & \\
\hline CHEMBL1350643 & 688171 & 6.6499 & 4.9298 & TST & \\
\hline CHEMBL1449331 & 688171 & 4.45 & 4.8855 & TRN & \\
\hline CHEMBL1435396 & 688171 & 4.95 & 5.0727 & TRN & \\
\hline CHEMBL1386412 & 688171 & 4.4 & 4.9384 & TRN & \\
\hline CHEMBL1347687 & 688171 & 4.55 & 4.8858 & TRN & \\
\hline CHEMBL1382291 & 688171 & 4.5 & 4.8391 & TST & \\
\hline CHEMBL504598 & 688171 & 4.4 & 4.8904 & TRN & \\
\hline CHEMBL1313569 & 688171 & 4.4 & 4.7312 & TST & \\
\hline CHEMBL1495019 & 688171 & 5.35 & 4.8524 & TRN & \\
\hline CHEMBL1472047 & 688171 & 4.9 & 4.9518 & TRN & \\
\hline CHEMBL 1437728 & 688171 & 4.6 & 4.9379 & TRN & \\
\hline CHEMBL1317127 & 688171 & 4.35 & 4.9543 & TRN & \\
\hline
\end{tabular}




\begin{tabular}{|c|c|c|c|c|c|}
\hline & & \multicolumn{4}{|c|}{ Supplemental Table S2.txt } \\
\hline CHEMBL1303703 & 688171 & 4.45 & 4.8598 & TRN & \\
\hline CHEMBL1306168 & 688171 & 5.7 & 5.0463 & TRN & \\
\hline CHEMBL1383857 & 688171 & 4.5 & 4.8855 & TRN & \\
\hline CHEMBL1454183 & 688171 & 5.45 & 4.8867 & TST & \\
\hline CHEMBL1586983 & 688171 & 4.4 & 4.9165 & TRN & \\
\hline CHEMBL1602514 & 688171 & 4.7 & 4.9415 & TRN & \\
\hline CHEMBL1602799 & 688171 & 4.65 & 4.8872 & TRN & \\
\hline CHEMBL1385108 & 688171 & 4.9 & 4.9419 & TST & \\
\hline CHEMBL1606934 & 688171 & 4.5 & 4.975 & TRN & \\
\hline CHEMBL1548822 & 688171 & 4.55 & 4.7297 & TRN & \\
\hline CHEMBL1480191 & 688171 & 4.5 & 4.8907 & TRN & \\
\hline CHEMBL1590841 & 688171 & 5.0 & 4.9311 & TRN & \\
\hline CHEMBL1419941 & 688171 & 6.2 & 5.0321 & TRN & \\
\hline CHEMBL1600312 & 688171 & 4.4 & 4.9604 & TRN & \\
\hline CHEMBL1354352 & 688171 & 4.9 & 4.8873 & TRN & \\
\hline CHEMBL1789976 & 688171 & 4.95 & 4.952 & TST & \\
\hline CHEMBL1370760 & 688171 & 4.35 & 4.8868 & TST & \\
\hline CHEMBL1335176 & 688171 & 4.6 & 4.9848 & TST & \\
\hline CHEMBL 1607384 & 688171 & 4.4 & 4.98 & TST & \\
\hline CHEMBL1578506 & 688171 & 4.4 & 5.1002 & TST & \\
\hline CHEMBL1510704 & 688171 & 4.6 & 4.8948 & TRN & \\
\hline CHEMBL1361596 & 688171 & 6.0 & 5.0407 & TRN & \\
\hline CHEMBL1485373 & 688171 & 4.7 & 4.853 & TRN & \\
\hline CHEMBL1496055 & 688171 & 4.7 & 4.9158 & TRN & \\
\hline CHEMBL1600326 & 688171 & 4.4 & 4.8924 & TST & \\
\hline CHEMBL1422046 & 688171 & 4.55 & 4.84699 & 99999999995 & TRN \\
\hline CHEMBL1607437 & 688171 & 4.6 & 5.0042 & TRN & \\
\hline CHEMBL1301325 & 688171 & 4.7 & 4.8543 & TRN & \\
\hline CHEMBL1493406 & 688171 & 4.4 & 5.0368 & TRN & \\
\hline CHEMBL1613279 & 688171 & 5.05 & 4.9535 & TRN & \\
\hline CHEMBL1526844 & 688171 & 4.85 & 4.8998 & TST & \\
\hline CHEMBL1461738 & 688171 & 4.55 & 4.8538 & TRN & \\
\hline CHEMBL1514000 & 688171 & 4.5 & 4.897 & TST & \\
\hline CHEMBL1518393 & 688171 & 4.6 & 4.9708 & TRN & \\
\hline CHEMBL1607290 & 688171 & 4.85 & 4.8071 & TRN & \\
\hline CHEMBL1402727 & 688171 & 6.95 & 4.933 & TRN & \\
\hline CHEMBL3195117 & 688171 & 5.45 & 4.9373 & TRN & \\
\hline CHEMBL1440641 & 688171 & 4.5 & 4.6818 & TRN & \\
\hline CHEMBL1494852 & 688171 & 4.4 & 4.8932 & TRN & \\
\hline CHEMBL1557342 & 688171 & 4.65 & 4.9664 & TRN & \\
\hline CHEMBL1973435 & 688171 & 5.35 & 4.8042 & TST & \\
\hline CHEMBL1320196 & 688171 & 4.9 & 4.8922 & TRN & \\
\hline CHEMBL1367163 & 688171 & 4.95 & 5.046 & TRN & \\
\hline CHEMBL1354529 & 688171 & 6.0 & 5.0238 & TST & \\
\hline CHEMBL1465338 & 688171 & 4.9 & 4.7821 & TRN & \\
\hline CHEMBL1328799 & 688171 & 4.4 & 4.8826 & TST & \\
\hline CHEMBL1412709 & 688171 & 4.8 & 4.8819 & TST & \\
\hline CHEMBL3192613 & 688171 & 4.5 & 4.9453 & TRN & \\
\hline
\end{tabular}




\begin{tabular}{|c|c|c|c|c|c|}
\hline \multicolumn{6}{|c|}{ Supplemental Table S2.txt } \\
\hline CHEMBL1503819 & 688171 & 5.05 & 5.0289 & TRN & \\
\hline CHEMBL3191482 & 688171 & 4.4 & 4.9003 & TRN & \\
\hline CHEMBL1577165 & 688171 & 4.65 & 4.9085 & TRN & \\
\hline CHEMBL1482242 & 688171 & 4.6 & 4.7524 & TRN & \\
\hline CHEMBL1560582 & 688171 & 4.95 & 4.7825 & TRN & \\
\hline CHEMBL586031 & 688171 & 5.0 & 4.9523 & TRN & \\
\hline CHEMBL1574968 & 688171 & 4.85 & 4.7711 & TRN & \\
\hline CHEMBL1317387 & 688171 & 4.45 & 5.0008 & TST & \\
\hline CHEMBL3211765 & 688171 & 4.95 & 4.9302 & TRN & \\
\hline CHEMBL1366624 & 688171 & 4.7 & 4.9197 & TRN & \\
\hline CHEMBL1319911 & 688171 & 4.85 & 4.9576 & TST & \\
\hline CHEMBL1612213 & 688171 & 4.85 & 4.82600 & 00000000005 & TRN \\
\hline CHEMBL1564423 & 688171 & 4.75 & 5.0464 & TRN & \\
\hline CHEMBL1549186 & 688171 & 5.0 & 4.9853 & TRN & \\
\hline CHEMBL1371339 & 688171 & 4.4 & 4.8202 & TRN & \\
\hline CHEMBL1509152 & 688171 & 4.95 & 4.9866 & TRN & \\
\hline CHEMBL1591066 & 688171 & 4.4 & 4.9492 & TRN & \\
\hline CHEMBL1431905 & 688171 & 4.8 & 5.0092 & TRN & \\
\hline CHEMBL1555519 & 688171 & 4.9 & 5.0131 & TRN & \\
\hline CHEMBL1332799 & 688171 & 4.35 & 4.9456 & TST & \\
\hline CHEMBL1431949 & 688171 & 4.95 & 4.9931 & TRN & \\
\hline CHEMBL1397626 & 688171 & 5.0 & 4.8374 & TRN & \\
\hline CHEMBL1317945 & 688171 & 4.9 & 4.93 & TRN & \\
\hline CHEMBL1335890 & 688171 & 4.6 & 5.0366 & TRN & \\
\hline CHEMBL1604819 & 688171 & 4.75 & 4.9771 & TRN & \\
\hline CHEMBL1552176 & 688171 & 4.55 & 4.8389 & TRN & \\
\hline CHEMBL1558942 & 688171 & 4.9 & 4.7886 & TRN & \\
\hline CHEMBL1454481 & 688171 & 4.45 & 5.0138 & TRN & \\
\hline CHEMBL1482307 & 688171 & 4.5 & 4.9894 & TST & \\
\hline CHEMBL1428066 & 688171 & 4.65 & 4.8762 & TRN & \\
\hline CHEMBL1449037 & 688171 & 4.9 & 4.8959 & TRN & \\
\hline CHEMBL1592203 & 688171 & 4.55 & 4.9007 & TRN & \\
\hline CHEMBL1552333 & 688171 & 5.05 & 5.0504 & TRN & \\
\hline CHEMBL337173 & 688171 & 4.8 & 4.9528 & TST & \\
\hline CHEMBL1502479 & 688171 & 7.6003 & 4.8888 & TRN & \\
\hline CHEMBL1503067 & 688171 & 4.4 & 4.8605 & TST & \\
\hline CHEMBL1322453 & 688171 & 4.65 & 4.8619 & TRN & \\
\hline CHEMBL1299760 & 688171 & 5.15 & 4.965 & TRN & \\
\hline CHEMBL1400950 & 688171 & 4.5 & 4.8796 & TRN & \\
\hline CHEMBL1472131 & 688171 & 5.0 & 4.9129 & TST & \\
\hline CHEMBL1502626 & 688171 & 4.9 & 4.9192 & TRN & \\
\hline CHEMBL1325458 & 688171 & 4.4 & 4.7668 & TRN & \\
\hline CHEMBL3213483 & 688171 & 5.2 & 5.0399 & TRN & \\
\hline CHEMBL1342066 & 688171 & 5.4 & 4.9037 & TRN & \\
\hline CHEMBL1582710 & 688171 & 4.4 & 4.8698 & TST & \\
\hline CHEMBL1437060 & 688171 & 4.55 & 4.8377 & TRN & \\
\hline CHEMBL1362489 & 688171 & 4.65 & 4.9662 & TRN & \\
\hline CHEMBL1399803 & 688171 & 4.9 & 4.9033 & TRN & \\
\hline
\end{tabular}




\begin{tabular}{|c|c|c|c|c|c|}
\hline \multicolumn{6}{|c|}{ Supplemental Table S2.txt } \\
\hline CHEMBL1548870 & 688171 & 4.55 & 4.8382 & TRN & \\
\hline CHEMBL1552320 & 688171 & 4.8 & 4.93 & TRN & \\
\hline CHEMBL3193204 & 688171 & 4.4 & 4.8817 & TST & \\
\hline CHEMBL 2028176 & 688171 & 4.4 & 4.9814 & TST & \\
\hline CHEMBL1316026 & 688171 & 5.7 & 4.8411 & TRN & \\
\hline CHEMBL1305052 & 688171 & 5.05 & 4.8966 & TRN & \\
\hline CHEMBL1591464 & 688171 & 4.55 & 4.9114 & TRN & \\
\hline CHEMBL1435372 & 688171 & 4.55 & 5.0236 & TST & \\
\hline CHEMBL1304591 & 688171 & 4.75 & 4.8701 & TST & \\
\hline CHEMBL1424764 & 688171 & 5.6 & 5.0726 & TRN & \\
\hline CHEMBL1398455 & 688171 & 4.85 & 4.7724 & TRN & \\
\hline CHEMBL1518952 & 688171 & 4.55 & 4.8957 & TRN & \\
\hline CHEMBL1323248 & 688171 & 4.65 & 4.7608 & TRN & \\
\hline CHEMBL1317291 & 688171 & 4.9 & 4.89199 & 99999999995 & TRN \\
\hline CHEMBL1304320 & 688171 & 4.8 & 4.7588 & TRN & \\
\hline CHEMBL1418597 & 688171 & 5.45 & 4.9271 & TRN & \\
\hline CHEMBL3213515 & 688171 & 4.85 & 5.0421 & TST & \\
\hline CHEMBL1596245 & 688171 & 4.8 & 4.8756 & TST & \\
\hline CHEMBL1538165 & 688171 & 4.6 & 5.0009 & TRN & \\
\hline CHEMBL1416036 & 688171 & 4.9 & 5.0815 & TST & \\
\hline CHEMBL1369965 & 688171 & 4.95 & 4.9578 & TRN & \\
\hline CHEMBL1373268 & 688171 & 6.25 & 4.9467 & TRN & \\
\hline CHEMBL52347 & 688171 & 5.35 & 4.7602 & TST & \\
\hline CHEMBL1562383 & 688171 & 4.85 & 4.9573 & TRN & \\
\hline CHEMBL1499484 & 688171 & 6.8499 & 4.7915 & TRN & \\
\hline CHEMBL1519686 & 688171 & 4.4 & 5.0098 & TST & \\
\hline CHEMBL1504790 & 688171 & 4.55 & 4.8804 & TST & \\
\hline CHEMBL1513866 & 688171 & 7.1002 & 5.0728 & TRN & \\
\hline CHEMBL1358749 & 688171 & 5.0 & 4.9418 & TRN & \\
\hline CHEMBL1373984 & 688171 & 4.65 & 4.7702 & TRN & \\
\hline CHEMBL1422318 & 688171 & 7.15 & 4.8822 & TRN & \\
\hline CHEMBL1434307 & 688171 & 5.1 & 4.9792 & TRN & \\
\hline CHEMBL1309057 & 688171 & 4.95 & 4.8598 & TRN & \\
\hline CHEMBL1581855 & 688171 & 5.75 & 4.93 & TRN & \\
\hline CHEMBL1416000 & 688171 & 4.45 & 5.0236 & TST & \\
\hline CHEMBL1381318 & 688171 & 4.85 & 4.8216 & TRN & \\
\hline CHEMBL1172934 & 688171 & 5.3 & 4.8829 & TRN & \\
\hline CHEMBL1583619 & 688171 & 4.7 & 4.9437 & TRN & \\
\hline CHEMBL1352079 & 688171 & 4.4 & 5.0478 & TRN & \\
\hline CHEMBL146710 & 688171 & 4.95 & 4.8386 & TST & \\
\hline CHEMBL1399459 & 688171 & 5.5 & 4.9822 & TRN & \\
\hline CHEMBL1330090 & 688171 & 5.0 & 4.8738 & TRN & \\
\hline CHEMBL1460721 & 688171 & 4.4 & 4.9069 & TRN & \\
\hline CHEMBL1547457 & 688171 & 4.4 & 4.9743 & TRN & \\
\hline CHEMBL1411875 & 688171 & 5.05 & 4.992 & TRN & \\
\hline CHEMBL1357249 & 688171 & 5.05 & 4.8867 & TST & \\
\hline CHEMBL1469253 & 688171 & 4.35 & 5.0362 & TRN & \\
\hline CHEMBL1514761 & 688171 & 7.6003 & 4.8622 & TRN & \\
\hline
\end{tabular}




\begin{tabular}{|c|c|c|c|c|c|}
\hline \multicolumn{6}{|c|}{ Supplemental Table S2.txt } \\
\hline CHEMBL1453868 & 688171 & 4.65 & 4.9209 & TRN & \\
\hline CHEMBL1396719 & 688171 & 4.85 & 4.8977 & TRN & \\
\hline CHEMBL1322536 & 688171 & 6.25 & 4.8696 & TRN & \\
\hline CHEMBL1554285 & 688171 & 4.85 & 4.7817 & TRN & \\
\hline CHEMBL3193828 & 688171 & 6.95 & 4.8516 & TST & \\
\hline CHEMBL1603456 & 688171 & 4.4 & 4.8548 & TRN & \\
\hline CHEMBL1470792 & 688171 & 7.6003 & 5.0418 & TRN & \\
\hline CHEMBL3191091 & 688171 & 4.55 & 4.86100 & 0000000001 & TRN \\
\hline CHEMBL1531364 & 688171 & 4.55 & 4.9125 & TRN & \\
\hline CHEMBL1492430 & 688171 & 6.95 & 4.8554 & TRN & \\
\hline CHEMBL1559111 & 688171 & 4.6 & 4.8136 & TRN & \\
\hline CHEMBL1304487 & 688171 & 4.85 & 4.9261 & TRN & \\
\hline CHEMBL1484657 & 688171 & 4.35 & 4.935 & TRN & \\
\hline CHEMBL1567428 & 688171 & 5.9 & 4.9771 & TRN & \\
\hline CHEMBL3199694 & 688171 & 4.5 & 4.7837 & TRN & \\
\hline CHEMBL1538731 & 688171 & 6.0 & 5.0609 & TRN & \\
\hline CHEMBL1523712 & 688171 & 6.2 & 4.8857 & TRN & \\
\hline CHEMBL1457411 & 688171 & 4.45 & 4.8959 & TRN & \\
\hline CHEMBL1338217 & 688171 & 4.6 & 4.8549 & TRN & \\
\hline CHEMBL1444446 & 688171 & 4.6 & 4.9408 & TRN & \\
\hline CHEMBL1488710 & 688171 & 4.4 & 4.7432 & TRN & \\
\hline CHEMBL1331369 & 688171 & 4.4 & 4.9519 & TRN & \\
\hline CHEMBL1464021 & 688171 & 7.2503 & 4.9839 & TST & \\
\hline CHEMBL1582275 & 688171 & 4.95 & 5.0109 & TRN & \\
\hline CHEMBL1316705 & 688171 & 4.75 & 4.8528 & TRN & \\
\hline CHEMBL1570127 & 688171 & 5.05 & 4.8143 & TRN & \\
\hline CHEMBL1348074 & 688171 & 4.5 & 4.8944 & TST & \\
\hline CHEMBL1346909 & 688171 & 4.85 & 4.8911 & TST & \\
\hline CHEMBL1528210 & 688171 & 4.4 & 5.0357 & TRN & \\
\hline CHEMBL1547321 & 688171 & 4.55 & 4.8682 & TST & \\
\hline CHEMBL1478306 & 688171 & 4.4 & 5.0194 & TRN & \\
\hline CHEMBL1447077 & 688171 & 5.15 & 5.0262 & TRN & \\
\hline CHEMBL1541391 & 688171 & 4.4 & 4.9761 & TRN & \\
\hline CHEMBL1541813 & 688171 & 4.5 & 4.9035 & TRN & \\
\hline CHEMBL1339864 & 688171 & 4.55 & 4.9975 & TST & \\
\hline CHEMBL1405260 & 688171 & 4.4 & 5.1117 & TRN & \\
\hline CHEMBL1392389 & 688171 & 4.6 & 5.0444 & TST & \\
\hline CHEMBL1552343 & 688171 & 4.85 & 4.8659 & TRN & \\
\hline CHEMBL1377941 & 688171 & 4.8 & 4.8346 & TRN & \\
\hline CHEMBL1332518 & 688171 & 5.2 & 4.9171 & TST & \\
\hline CHEMBL1387831 & 688171 & 4.35 & 5.0182 & TST & \\
\hline CHEMBL1346688 & 688171 & 5.45 & 4.9973 & TST & \\
\hline CHEMBL1474476 & 688171 & 4.4 & 4.8462 & TRN & \\
\hline CHEMBL1549832 & 688171 & 4.55 & 4.86600 & 00000000005 & TST \\
\hline CHEMBL1513024 & 688171 & 4.4 & 4.9485 & TRN & \\
\hline CHEMBL1338476 & 688171 & 4.65 & 4.7811 & TRN & \\
\hline CHEMBL1422465 & 688171 & 4.45 & 4.7449 & TST & \\
\hline CHEMBL1572828 & 688171 & 4.5 & 4.8857 & TRN & \\
\hline
\end{tabular}




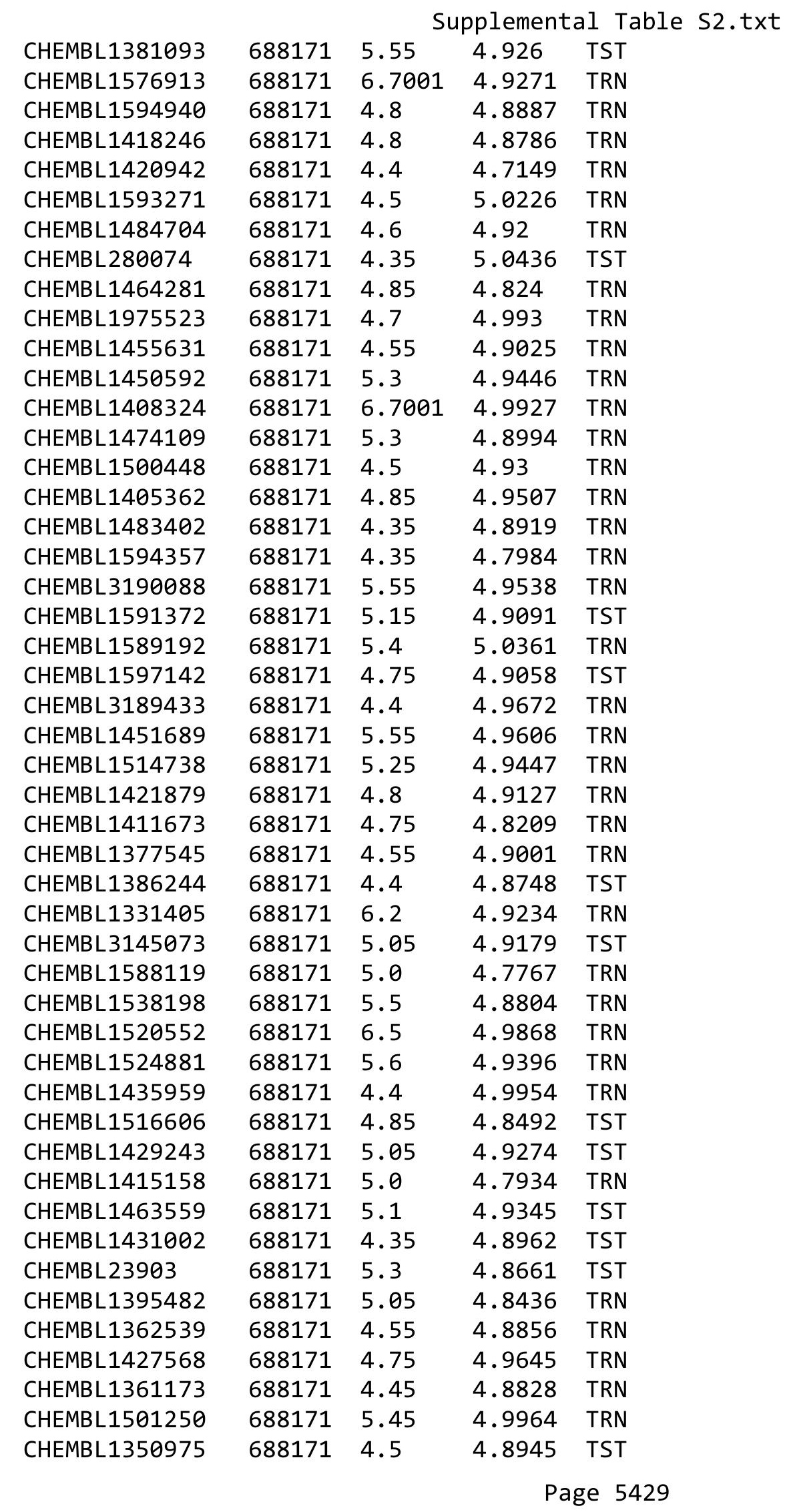




\begin{tabular}{|c|c|c|c|c|c|}
\hline \multicolumn{6}{|c|}{ Supplemental Table S2.txt } \\
\hline CHEMBL1503219 & 688171 & 4.75 & 4.8581 & TRN & \\
\hline CHEMBL1493396 & 688171 & 4.8 & 4.9359 & TST & \\
\hline CHEMBL1481123 & 688171 & 4.45 & 4.8549 & TST & \\
\hline CHEMBL1436497 & 688171 & 4.6 & 4.8963 & TRN & \\
\hline CHEMBL1520117 & 688171 & 4.7 & 4.9441 & TST & \\
\hline CHEMBL1502201 & 688171 & 4.55 & 4.9717 & TRN & \\
\hline CHEMBL1486836 & 688171 & 4.85 & 4.8349 & TRN & \\
\hline CHEMBL1460449 & 688171 & 4.4 & 5.0015 & TST & \\
\hline CHEMBL1512522 & 688171 & 4.45 & 4.9592 & TRN & \\
\hline CHEMBL1494662 & 688171 & 4.65 & 4.9941 & TRN & \\
\hline CHEMBL 3198782 & 688171 & 4.75 & 4.9211 & TST & \\
\hline CHEMBL1311422 & 688171 & 5.55 & 4.9099 & TST & \\
\hline CHEMBL1325049 & 688171 & 4.85 & 5.0594 & TRN & \\
\hline CHEMBL1978327 & 688171 & 4.4 & 4.852 & TRN & \\
\hline CHEMBL1355038 & 688171 & 4.6 & 4.8477 & TRN & \\
\hline CHEMBL1359244 & 688171 & 4.4 & 5.0229 & TST & \\
\hline CHEMBL1451988 & 688171 & 4.9 & 5.0641 & TRN & \\
\hline CHEMBL1512564 & 688171 & 4.85 & 4.8566 & TRN & \\
\hline CHEMBL1564538 & 688171 & 4.9 & 4.9008 & TRN & \\
\hline CHEMBL1611517 & 688171 & 5.4 & 5.0541 & TRN & \\
\hline CHEMBL1463860 & 688171 & 4.55 & 4.8997 & TRN & \\
\hline CHEMBL1380757 & 688171 & 4.45 & 4.973 & TRN & \\
\hline CHEMBL1345305 & 688171 & 4.5 & 4.9646 & TRN & \\
\hline CHEMBL1348917 & 688171 & 4.65 & 4.8626 & TRN & \\
\hline CHEMBL1314604 & 688171 & 5.7 & 5.0714 & TST & \\
\hline CHEMBL 3210008 & 688171 & 4.55 & 4.7323 & TST & \\
\hline CHEMBL1410861 & 688171 & 5.0 & 4.9709 & TRN & \\
\hline CHEMBL1307467 & 688171 & 4.55 & 4.8153 & TRN & \\
\hline CHEMBL1566057 & 688171 & 4.8 & 4.7764 & TRN & \\
\hline CHEMBL1434157 & 688171 & 4.65 & 4.9351 & TRN & \\
\hline CHEMBL1562693 & 688171 & 5.75 & 4.8754 & TRN & \\
\hline CHEMBL1377688 & 688171 & 4.65 & 4.8907 & TST & \\
\hline CHEMBL1343799 & 688171 & 5.1 & 4.82600 & 00000000005 & TST \\
\hline CHEMBL1501714 & 688171 & 4.4 & 4.8281 & TRN & \\
\hline CHEMBL 3214071 & 688171 & 5.0 & 4.9517 & TRN & \\
\hline CHEMBL1524103 & 688171 & 4.4 & 4.9113 & TST & \\
\hline CHEMBL1582404 & 688171 & 6.2 & 4.9123 & TRN & \\
\hline CHEMBL1467952 & 688171 & 4.45 & 4.8737 & TRN & \\
\hline CHEMBL1508567 & 688171 & 4.5 & 4.9442 & TRN & \\
\hline CHEMBL1573167 & 688171 & 4.4 & 4.8121 & TRN & \\
\hline CHEMBL1303173 & 688171 & 4.55 & 4.9364 & TRN & \\
\hline CHEMBL1379647 & 688171 & 4.6 & 4.7818 & TRN & \\
\hline CHEMBL1332241 & 688171 & 4.5 & 4.8139 & TST & \\
\hline CHEMBL1480267 & 688171 & 4.85 & 5.0032 & TRN & \\
\hline CHEMBL1583534 & 688171 & 4.6 & 4.8802 & TRN & \\
\hline CHEMBL1527964 & 688171 & 4.4 & 4.8357 & TRN & \\
\hline CHEMBL1586468 & 688171 & 4.4 & 4.9313 & TRN & \\
\hline CHEMBL1533597 & 688171 & 4.4 & 4.87 & TST & \\
\hline
\end{tabular}




\begin{tabular}{|c|c|c|c|c|c|}
\hline \multicolumn{6}{|c|}{ Supplemental Table S2.txt } \\
\hline CHEMBL1355145 & 688171 & 4.85 & 4.8135 & TRN & \\
\hline CHEMBL1482466 & 688171 & 4.4 & 4.8123 & TRN & \\
\hline CHEMBL1347447 & 688171 & 4.35 & 5.0016 & TST & \\
\hline CHEMBL1500302 & 688171 & 4.75 & 4.8788 & TST & \\
\hline CHEMBL1343643 & 688171 & 5.5 & 4.7684 & TST & \\
\hline CHEMBL1451189 & 688171 & 5.55 & 4.9125 & TRN & \\
\hline CHEMBL1513579 & 688171 & 6.7001 & 4.9992 & TST & \\
\hline CHEMBL1398008 & 688171 & 4.9 & 4.8573 & TRN & \\
\hline CHEMBL1478258 & 688171 & 4.4 & 5.0118 & TRN & \\
\hline CHEMBL1576369 & 688171 & 4.4 & 4.8755 & TRN & \\
\hline CHEMBL602922 & 688171 & 4.6 & 5.0196 & TRN & \\
\hline CHEMBL1320313 & 688171 & 4.5 & 4.8818 & TRN & \\
\hline CHEMBL1456440 & 688171 & 5.6 & 4.9016 & TRN & \\
\hline CHEMBL1570189 & 688171 & 4.9 & 4.8685 & TRN & \\
\hline CHEMBL1528872 & 688171 & 6.15 & 5.0067 & TRN & \\
\hline CHEMBL1501913 & 688171 & 4.6 & 4.8568 & TRN & \\
\hline CHEMBL1479636 & 688171 & 5.2 & 4.8394 & TRN & \\
\hline CHEMBL1566804 & 688171 & 4.45 & 4.8934 & TRN & \\
\hline CHEMBL1463016 & 688171 & 4.4 & 4.9856 & TRN & \\
\hline CHEMBL1088010 & 688171 & 4.75 & 4.8855 & TRN & \\
\hline CHEMBL1566838 & 688171 & 4.45 & 4.9877 & TST & \\
\hline CHEMBL1380131 & 688171 & 4.9 & 4.9517 & TST & \\
\hline CHEMBL1396681 & 688171 & 5.45 & 4.8445 & TRN & \\
\hline CHEMBL1490178 & 688171 & 5.15 & 4.9457 & TRN & \\
\hline CHEMBL1081075 & 688171 & 4.8 & 4.9439 & TRN & \\
\hline CHEMBL1425576 & 688171 & 6.05 & 4.9072 & TRN & \\
\hline CHEMBL1591481 & 688171 & 4.45 & 4.9098 & TRN & \\
\hline CHEMBL1553032 & 688171 & 4.75 & 4.8535 & TRN & \\
\hline CHEMBL1503118 & 688171 & 4.55 & 5.0397 & TST & \\
\hline CHEMBL1452348 & 688171 & 4.8 & 4.8005 & TRN & \\
\hline CHEMBL1999034 & 688171 & 5.4 & 4.8307 & TST & \\
\hline CHEMBL1447682 & 688171 & 4.85 & 4.9514 & TRN & \\
\hline CHEMBL1552097 & 688171 & 4.5 & 4.8977 & TRN & \\
\hline CHEMBL2373651 & 688171 & 6.0 & 4.88399 & 99999999995 & TST \\
\hline CHEMBL1543190 & 688171 & 4.45 & 4.8395 & TST & \\
\hline CHEMBL1432711 & 688171 & 5.8 & 5.0426 & TRN & \\
\hline CHEMBL1335560 & 688171 & 4.85 & 4.9652 & TRN & \\
\hline CHEMBL1489100 & 688171 & 4.65 & 4.90600 & $\partial 000000001$ & TRN \\
\hline CHEMBL1365262 & 688171 & 4.65 & 4.8188 & TRN & \\
\hline CHEMBL1317173 & 688171 & 5.45 & 4.9784 & TST & \\
\hline CHEMBL1492002 & 688171 & 4.55 & 4.918 & TRN & \\
\hline CHEMBL1534435 & 688171 & 4.8 & 5.0539 & TRN & \\
\hline CHEMBL195953 & 688171 & 4.9 & 4.8754 & TST & \\
\hline CHEMBL1484027 & 688171 & 4.6 & 4.9415 & TRN & \\
\hline CHEMBL1323213 & 688171 & 4.75 & 4.8175 & TST & \\
\hline CHEMBL1336959 & 688171 & 4.55 & 4.7412 & TRN & \\
\hline CHEMBL1483427 & 688171 & 4.8 & 4.8552 & TRN & \\
\hline CHEMBL1520976 & 688171 & 4.5 & 4.9064 & TST & \\
\hline
\end{tabular}




\begin{tabular}{|c|c|c|c|c|c|}
\hline \multicolumn{6}{|c|}{ Supplemental Table s2.txt } \\
\hline CHEMBL16223 & 688171 & 6.35 & 4.9275 & TRN & \\
\hline CHEMBL1582279 & 688171 & 5.25 & 4.9829 & TRN & \\
\hline CHEMBL1560981 & 688171 & 4.7 & 4.902 & TRN & \\
\hline CHEMBL1402098 & 688171 & 4.6 & 4.8648 & TRN & \\
\hline CHEMBL1600900 & 688171 & 6.0 & 4.9967 & TST & \\
\hline CHEMBL1484163 & 688171 & 4.9 & 4.9612 & TRN & \\
\hline CHEMBL3212953 & 688171 & 4.9 & 4.9381 & TRN & \\
\hline CHEMBL1389174 & 688171 & 4.8 & 4.8042 & TRN & \\
\hline CHEMBL1534994 & 688171 & 4.75 & 4.7959 & TRN & \\
\hline CHEMBL1459117 & 688171 & 5.0 & 5.0006 & TRN & \\
\hline CHEMBL 2007021 & 688171 & 5.55 & 5.0381 & TRN & \\
\hline CHEMBL1387517 & 688171 & 4.55 & 4.8252 & TST & \\
\hline CHEMBL1597356 & 688171 & 4.65 & 4.9091 & TRN & \\
\hline CHEMBL1347158 & 688171 & 5.0 & 5.1348 & TRN & \\
\hline CHEMBL1560889 & 688171 & 4.6 & 4.7193 & TRN & \\
\hline CHEMBL1513453 & 688171 & 4.35 & 4.9135 & TRN & \\
\hline CHEMBL1317719 & 688171 & 4.35 & 4.8229 & TRN & \\
\hline CHEMBL1326664 & 688171 & 5.65 & 4.8995 & TRN & \\
\hline CHEMBL1607509 & 688171 & 4.55 & 4.8664 & TRN & \\
\hline CHEMBL1596115 & 688171 & 4.9 & 4.9203 & TRN & \\
\hline CHEMBL1412388 & 688171 & 4.4 & 4.9129 & TRN & \\
\hline CHEMBL1532635 & 688171 & 4.35 & 4.9226 & TRN & \\
\hline CHEMBL1553794 & 688171 & 5.05 & 4.9098 & TRN & \\
\hline CHEMBL1525277 & 688171 & 4.4 & 5.0079 & TRN & \\
\hline CHEMBL1458180 & 688171 & 5.6 & 4.9395 & TRN & \\
\hline CHEMBL3192053 & 688171 & 5.3 & 4.8569 & TRN & \\
\hline CHEMBL1324296 & 688171 & 5.0 & 4.9171 & TST & \\
\hline CHEMBL1523353 & 688171 & 5.15 & 4.9226 & TRN & \\
\hline CHEMBL1469280 & 688171 & 5.05 & 4.9641 & TST & \\
\hline CHEMBL1411488 & 688171 & 7.6003 & 5.1047 & TRN & \\
\hline CHEMBL1553792 & 688171 & 4.5 & 4.9643 & TRN & \\
\hline CHEMBL1382238 & 688171 & 5.05 & 4.7961 & TRN & \\
\hline CHEMBL1476144 & 688171 & 4.4 & 4.8333 & TRN & \\
\hline CHEMBL1504768 & 688171 & 4.45 & 4.9486 & TST & \\
\hline CHEMBL1603009 & 688171 & 4.85 & 4.95 & TRN & \\
\hline CHEMBL1495234 & 688171 & 4.65 & 4.9131 & TRN & \\
\hline CHEMBL1597751 & 688171 & 4.7 & 4.8866 & TRN & \\
\hline CHEMBL1422038 & 688171 & 4.5 & 4.888 & TRN & \\
\hline CHEMBL608105 & 688171 & 4.45 & 4.9351 & TRN & \\
\hline CHEMBL1510557 & 688171 & 5.15 & 4.9443 & TRN & \\
\hline CHEMBL1342093 & 688171 & 4.5 & 4.8087 & TRN & \\
\hline CHEMBL1552228 & 688171 & 4.85 & 4.9058 & TRN & \\
\hline CHEMBL1606315 & 688171 & 4.9 & 4.7996 & TRN & \\
\hline CHEMBL1513617 & 688171 & 4.9 & 4.9378 & TRN & \\
\hline CHEMBL34704 & 688171 & 4.4 & 4.7764 & TST & \\
\hline CHEMBL1410192 & 688171 & 6.45 & 4.88899 & 9999999999 & TRN \\
\hline CHEMBL3198303 & 688171 & 4.35 & 4.7866 & TST & \\
\hline CHEMBL1468886 & 688171 & 5.0 & 5.0369 & TRN & \\
\hline
\end{tabular}




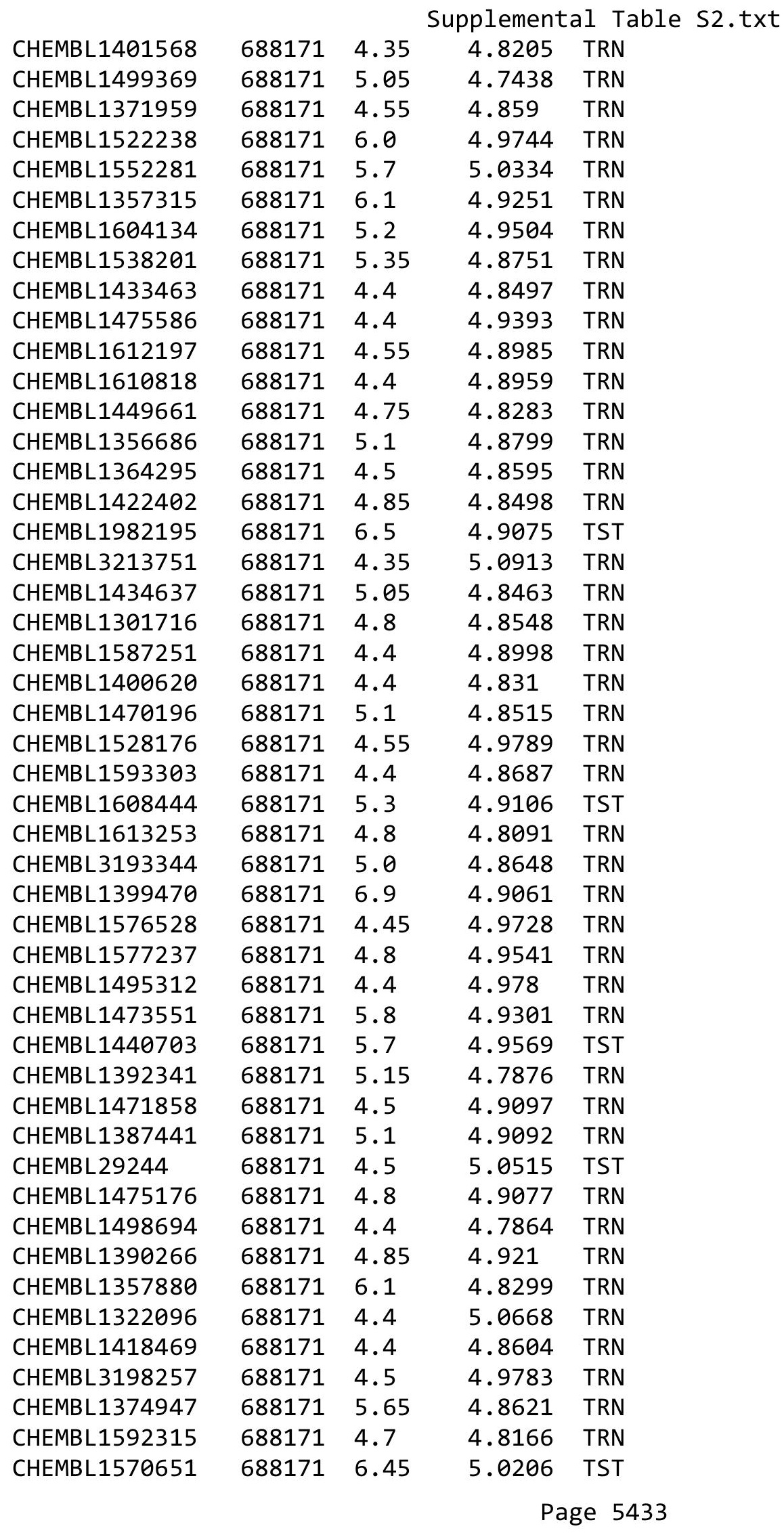




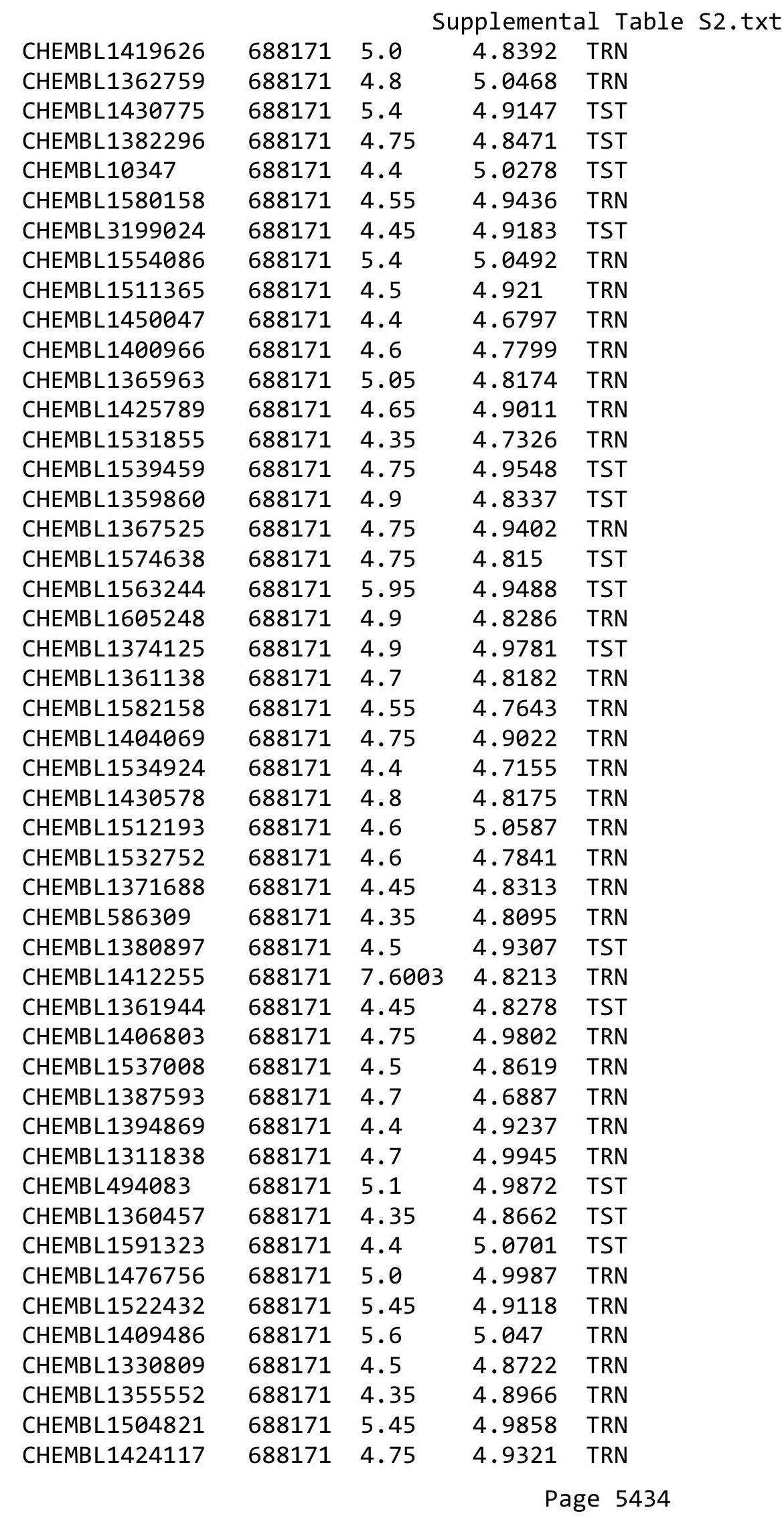




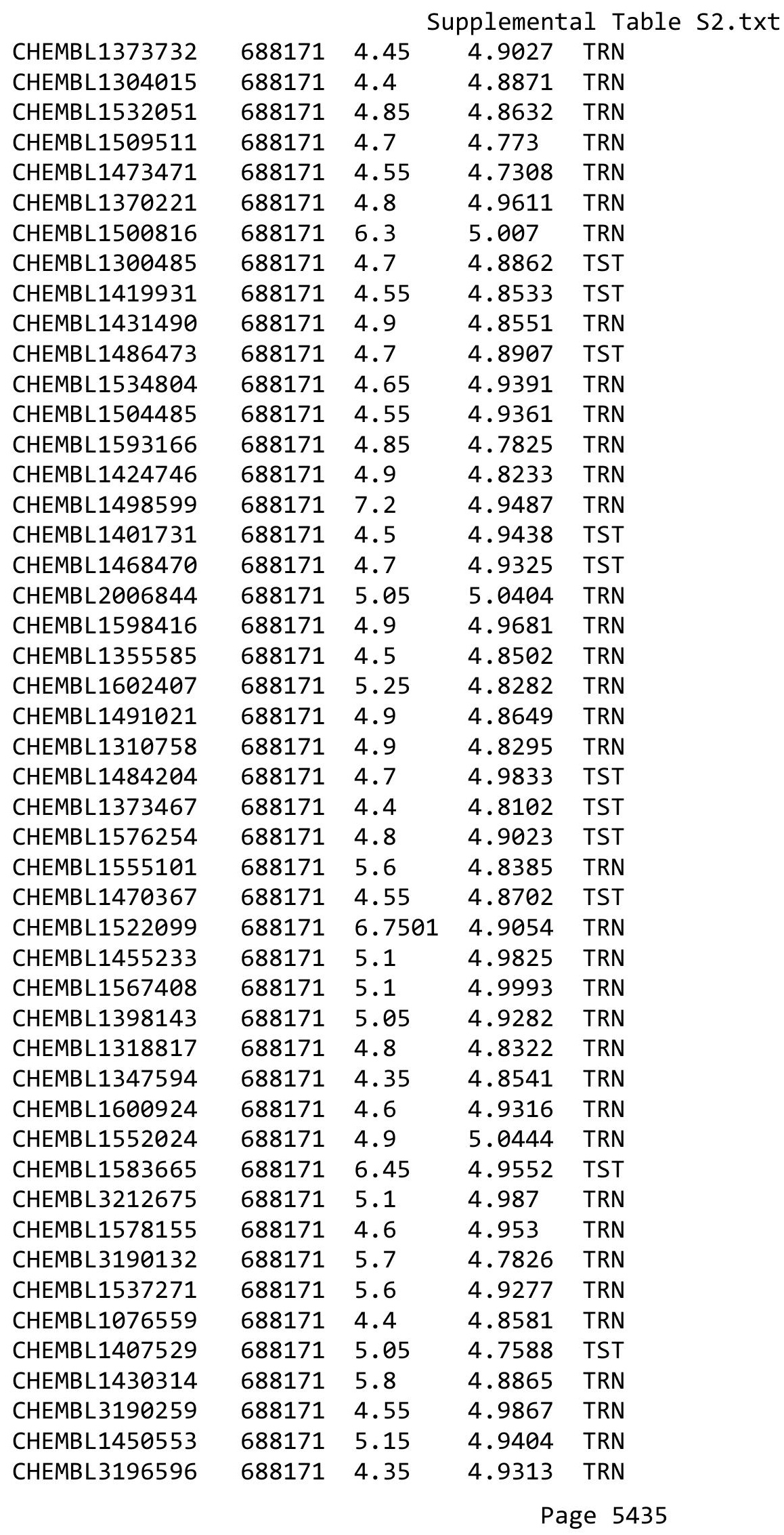




\begin{tabular}{|c|c|c|c|c|c|}
\hline \multirow[b]{2}{*}{ CHEMBL1498436 } & \multicolumn{5}{|c|}{ Supplemental Table S2.txt } \\
\hline & 688171 & 5.9 & 4.8887 & TRN & \\
\hline CHEMBL1607970 & 688171 & 4.4 & 4.92399 & 99999999995 & TRN \\
\hline CHEMBL1353512 & 688171 & 4.4 & 4.8726 & TRN & \\
\hline CHEMBL1517986 & 688171 & 4.55 & 5.0084 & TRN & \\
\hline CHEMBL1548022 & 688171 & 4.5 & 4.8637 & TST & \\
\hline CHEMBL1491957 & 688171 & 5.5 & 4.7767 & TRN & \\
\hline CHEMBL1501262 & 688171 & 4.8 & 4.8358 & TST & \\
\hline CHEMBL1358029 & 688171 & 5.35 & 4.9513 & TST & \\
\hline CHEMBL1448381 & 688171 & 4.75 & 4.7882 & TRN & \\
\hline CHEMBL1491530 & 688171 & 4.75 & 4.9142 & TST & \\
\hline CHEMBL1450645 & 688171 & 4.65 & 4.9496 & TRN & \\
\hline CHEMBL1302720 & 688171 & 4.95 & 4.9788 & TRN & \\
\hline CHEMBL1552219 & 688171 & 4.45 & 4.9534 & TRN & \\
\hline CHEMBL426862 & 688171 & 4.7 & 4.9644 & TRN & \\
\hline CHEMBL1484995 & 688171 & 4.8 & 4.9754 & TST & \\
\hline CHEMBL1483611 & 688171 & 4.4 & 5.0794 & TRN & \\
\hline CHEMBL1510843 & 688171 & 4.4 & 4.925 & TST & \\
\hline CHEMBL1509082 & 688171 & 4.85 & 4.7896 & TRN & \\
\hline CHEMBL1429197 & 688171 & 4.8 & 4.9612 & TST & \\
\hline CHEMBL1386204 & 688171 & 5.2 & 4.919 & TRN & \\
\hline CHEMBL1965654 & 688171 & 4.75 & 4.8755 & TST & \\
\hline CHEMBL1364967 & 688171 & 4.6 & 4.9067 & TRN & \\
\hline CHEMBL1533300 & 688171 & 4.4 & 4.9227 & TRN & \\
\hline CHEMBL1300915 & 688171 & 4.95 & 4.8929 & TST & \\
\hline CHEMBL1433927 & 688171 & 5.4 & 4.9342 & TRN & \\
\hline CHEMBL1428049 & 688171 & 4.4 & 4.9291 & TRN & \\
\hline CHEMBL1456741 & 688171 & 5.1 & 4.9243 & TST & \\
\hline CHEMBL1516152 & 688171 & 4.4 & 4.9368 & TRN & \\
\hline CHEMBL1373090 & 688171 & 5.0 & 5.0859 & TRN & \\
\hline CHEMBL1407895 & 688171 & 4.4 & 4.8726 & TRN & \\
\hline CHEMBL1323236 & 688171 & 5.0 & 5.0133 & TRN & \\
\hline CHEMBL1608075 & 688171 & 4.4 & 5.0738 & TRN & \\
\hline CHEMBL1323389 & 688171 & 4.7 & 5.0844 & TST & \\
\hline CHEMBL1607182 & 688171 & 5.0 & 4.975 & TRN & \\
\hline CHEMBL1572155 & 688171 & 5.35 & 4.7726 & TRN & \\
\hline CHEMBL1991187 & 688171 & 4.85 & 4.908 & TRN & \\
\hline CHEMBL1451538 & 688171 & 4.9 & 4.9545 & TRN & \\
\hline CHEMBL1415218 & 688171 & 4.95 & 4.9082 & TRN & \\
\hline CHEMBL1599965 & 688171 & 4.95 & 4.9374 & TRN & \\
\hline CHEMBL1415768 & 688171 & 4.6 & 4.9169 & TRN & \\
\hline CHEMBL1509939 & 688171 & 4.35 & 4.7543 & TST & \\
\hline CHEMBL1411529 & 688171 & 4.9 & 4.8417 & TRN & \\
\hline CHEMBL1440877 & 688171 & 4.95 & 4.7976 & TST & \\
\hline CHEMBL1565093 & 688171 & 5.2 & 4.8788 & TRN & \\
\hline CHEMBL1325084 & 688171 & 7.2503 & 4.9402 & TRN & \\
\hline CHEMBL1369867 & 688171 & 5.25 & 4.78600 & 00000000005 & TRN \\
\hline CHEMBL1431915 & 688171 & 5.2 & 4.9066 & TRN & \\
\hline CHEMBL341473 & 688171 & 4.65 & 4.9623 & TRN & \\
\hline
\end{tabular}




\begin{tabular}{|c|c|c|c|c|}
\hline \multicolumn{5}{|c|}{ Supplemental Table S2.txt } \\
\hline CHEMBL1592078 & 688171 & 5.5 & 4.97 & TRN \\
\hline CHEMBL1482470 & 688171 & 5.45 & 4.977 & TRN \\
\hline CHEMBL1608411 & 688171 & 6.25 & 4.9459 & TRN \\
\hline CHEMBL1555311 & 688171 & 4.5 & 4.859 & TRN \\
\hline CHEMBL1718499 & 688171 & 4.55 & 4.7532 & TRN \\
\hline CHEMBL1555010 & 688171 & 4.95 & 4.8081 & TRN \\
\hline CHEMBL1505704 & 688171 & 4.85 & 4.8848 & TRN \\
\hline CHEMBL1302333 & 688171 & 5.5 & 4.9022 & TST \\
\hline CHEMBL1512440 & 688171 & 6.0 & 4.9387 & TST \\
\hline CHEMBL1571152 & 688171 & 4.4 & 4.9547 & TST \\
\hline CHEMBL1476013 & 688171 & 4.55 & 4.8571 & TRN \\
\hline CHEMBL1397847 & 688171 & 4.65 & 4.9249 & TRN \\
\hline CHEMBL1396003 & 688171 & 5.45 & 4.9877 & TRN \\
\hline CHEMBL1425738 & 688171 & 4.85 & 4.9909 & TRN \\
\hline CHEMBL1370368 & 688171 & 4.85 & 4.9307 & TRN \\
\hline CHEMBL1494433 & 688171 & 4.9 & 4.9046 & TRN \\
\hline CHEMBL1610391 & 688171 & 4.35 & 4.9992 & TRN \\
\hline CHEMBL1576824 & 688171 & 4.35 & 4.8975 & TST \\
\hline CHEMBL1324111 & 688171 & 4.65 & 4.832 & TST \\
\hline CHEMBL1539778 & 688171 & 5.05 & 5.0052 & TST \\
\hline CHEMBL1556044 & 688171 & 5.45 & 4.9307 & TST \\
\hline CHEMBL1356741 & 688171 & 4.4 & 4.8145 & TRN \\
\hline CHEMBL1490919 & 688171 & 4.65 & 5.0042 & TRN \\
\hline CHEMBL1403512 & 688171 & 7.1002 & 4.8658 & TRN \\
\hline CHEMBL1417376 & 688171 & 4.7 & 4.6024 & TRN \\
\hline CHEMBL579105 & 688171 & 4.45 & 4.9303 & TRN \\
\hline CHEMBL1548704 & 688171 & 4.7 & 4.9421 & TST \\
\hline CHEMBL1728993 & 688171 & 4.55 & 4.7145 & TRN \\
\hline CHEMBL1539454 & 688171 & 4.9 & 4.8557 & TRN \\
\hline CHEMBL80941 & 688171 & 4.85 & 4.956 & TRN \\
\hline CHEMBL1313592 & 688171 & 4.65 & 4.9957 & TRN \\
\hline CHEMBL1486125 & 688171 & 7.1002 & 5.0595 & TRN \\
\hline CHEMBL1327783 & 688171 & 4.85 & 4.9424 & TST \\
\hline CHEMBL1441612 & 688171 & 4.55 & 4.7734 & TST \\
\hline CHEMBL1595395 & 688171 & 4.35 & 4.8844 & TRN \\
\hline CHEMBL1355223 & 688171 & 4.4 & 4.8761 & TRN \\
\hline CHEMBL1353894 & 688171 & 4.55 & 4.7707 & TST \\
\hline CHEMBL1573243 & 688171 & 4.4 & 5.0396 & TRN \\
\hline CHEMBL1439001 & 688171 & 5.95 & 4.9794 & TRN \\
\hline CHEMBL1412621 & 688171 & 5.45 & 4.9475 & TRN \\
\hline CHEMBL1507774 & 688171 & 4.65 & 4.9334 & TRN \\
\hline CHEMBL1338994 & 688171 & 4.95 & 4.9879 & TRN \\
\hline CHEMBL1490970 & 688171 & 4.4 & 4.9808 & TRN \\
\hline CHEMBL1302504 & 688171 & 4.6 & 4.977 & TST \\
\hline CHEMBL1563483 & 688171 & 5.35 & 4.927 & TST \\
\hline CHEMBL1434618 & 688171 & 7.3497 & 4.9951 & TRN \\
\hline CHEMBL1604915 & 688171 & 5.3 & 5.01 & TRN \\
\hline CHEMBL1573821 & 688171 & 4.5 & 5.0525 & TST \\
\hline
\end{tabular}




\begin{tabular}{|c|c|c|c|c|c|}
\hline \multicolumn{6}{|c|}{ Supplemental Table S2.txt } \\
\hline CHEMBL1536396 & 688171 & 5.45 & 4.8792 & TST & \\
\hline CHEMBL1441906 & 688171 & 4.35 & 4.8586 & TST & \\
\hline CHEMBL1558014 & 688171 & 4.8 & 4.8749 & TRN & \\
\hline CHEMBL1337742 & 688171 & 4.55 & 4.9049 & TST & \\
\hline CHEMBL1362714 & 688171 & 4.85 & 4.8513 & TST & \\
\hline CHEMBL1578252 & 688171 & 4.35 & 4.9001 & TRN & \\
\hline CHEMBL1971634 & 688171 & 5.1 & 4.8865 & TRN & \\
\hline CHEMBL1535788 & 688171 & 4.85 & 4.8166 & TRN & \\
\hline CHEMBL1581246 & 688171 & 4.5 & 4.9015 & TRN & \\
\hline CHEMBL1505572 & 688171 & 4.55 & 4.9611 & TRN & \\
\hline CHEMBL1342726 & 688171 & 5.4 & 4.9346 & TST & \\
\hline CHEMBL1463161 & 688171 & 4.7 & 4.9393 & TST & \\
\hline CHEMBL1446337 & 688171 & 6.0 & 4.9415 & TST & \\
\hline CHEMBL1365823 & 688171 & 4.65 & 4.9475 & TST & \\
\hline CHEMBL1534541 & 688171 & 5.85 & 4.9573 & TRN & \\
\hline CHEMBL1340089 & 688171 & 5.45 & 4.8078 & TRN & \\
\hline CHEMBL1484901 & 688171 & 5.0 & 4.8787 & TRN & \\
\hline CHEMBL 3212647 & 688171 & 7.6498 & 4.9512 & TST & \\
\hline CHEMBL1990774 & 688171 & 5.55 & 4.857 & TRN & \\
\hline CHEMBL1448020 & 688171 & 4.5 & 4.89199 & 99999999995 & TRN \\
\hline CHEMBL1571983 & 688171 & 4.35 & 4.8903 & TRN & \\
\hline CHEMBL1414360 & 688171 & 4.45 & 4.9381 & TRN & \\
\hline CHEMBL1432535 & 688171 & 4.65 & 4.9324 & TRN & \\
\hline CHEMBL1419563 & 688171 & 4.4 & 4.7682 & TRN & \\
\hline CHEMBL1472813 & 688171 & 5.05 & 4.886 & TRN & \\
\hline CHEMBL1407756 & 688171 & 4.8 & 4.9471 & TRN & \\
\hline CHEMBL1514801 & 688171 & 4.4 & 4.9239 & TRN & \\
\hline CHEMBL1970909 & 688171 & 4.35 & 4.9399 & TRN & \\
\hline CHEMBL1482750 & 688171 & 4.4 & 5.038 & TST & \\
\hline CHEMBL592109 & 688171 & 4.35 & 4.8461 & TRN & \\
\hline CHEMBL1334170 & 688171 & 4.9 & 5.1072 & TRN & \\
\hline CHEMBL1579548 & 688171 & 4.85 & 4.7563 & TRN & \\
\hline CHEMBL1388599 & 688171 & 4.7 & 4.9864 & TRN & \\
\hline CHEMBL1302291 & 688171 & 5.65 & 4.9865 & TRN & \\
\hline CHEMBL1502317 & 688171 & 4.9 & 4.9016 & TRN & \\
\hline CHEMBL1340299 & 688171 & 4.55 & 4.9707 & TST & \\
\hline CHEMBL1543354 & 688171 & 4.9 & 4.9038 & TRN & \\
\hline CHEMBL1602279 & 688171 & 5.35 & 4.8852 & TRN & \\
\hline CHEMBL1503082 & 688171 & 4.65 & 4.8594 & TRN & \\
\hline CHEMBL1466256 & 688171 & 4.4 & 5.0022 & TRN & \\
\hline CHEMBL1526304 & 688171 & 4.4 & 4.8995 & TRN & \\
\hline CHEMBL1545736 & 688171 & 4.4 & 4.9073 & TRN & \\
\hline CHEMBL3190482 & 688171 & 4.4 & 4.9972 & TST & \\
\hline CHEMBL1396436 & 688171 & 4.7 & 5.1173 & TRN & \\
\hline CHEMBL1459140 & 688171 & 5.45 & 4.9119 & TST & \\
\hline CHEMBL1474252 & 688171 & 4.45 & 4.7076 & TRN & \\
\hline CHEMBL1445004 & 688171 & 4.85 & 5.0813 & TRN & \\
\hline CHEMBL1355194 & 688171 & 5.45 & 5.0313 & TRN & \\
\hline
\end{tabular}




\begin{tabular}{|c|c|c|c|c|}
\hline \multicolumn{5}{|c|}{ Supplemental Table S2.txt } \\
\hline CHEMBL1584657 & 688171 & 4.4 & 4.9085 & TST \\
\hline CHEMBL1613209 & 688171 & 4.85 & 4.9745 & TST \\
\hline CHEMBL1507425 & 688171 & 4.85 & 4.8645 & TST \\
\hline CHEMBL1479728 & 688171 & 5.05 & 4.8918 & TRN \\
\hline CHEMBL1381088 & 688171 & 4.6 & 4.79 & TRN \\
\hline CHEMBL1554390 & 688171 & 4.75 & 4.8447 & TRN \\
\hline CHEMBL1527982 & 688171 & 4.35 & 4.9415 & TRN \\
\hline CHEMBL 3189326 & 688171 & 4.95 & 4.9674 & TST \\
\hline CHEMBL1554873 & 688171 & 4.45 & 4.8239 & TRN \\
\hline CHEMBL1482119 & 688171 & 4.4 & 4.8595 & TRN \\
\hline CHEMBL1556877 & 688171 & 4.6 & 4.9192 & TRN \\
\hline CHEMBL1503076 & 688171 & 7.6003 & 4.8482 & TRN \\
\hline CHEMBL1497479 & 688171 & 4.4 & 4.9287 & TRN \\
\hline CHEMBL1580642 & 688171 & 4.8 & 4.9298 & TRN \\
\hline CHEMBL1553815 & 688171 & 4.45 & 4.8603 & TRN \\
\hline CHEMBL1496940 & 688171 & 4.85 & 4.8093 & TRN \\
\hline CHEMBL1586807 & 688171 & 4.55 & 4.8773 & TRN \\
\hline CHEMBL1351074 & 688171 & 4.5 & 4.8087 & TST \\
\hline CHEMBL1503123 & 688171 & 4.5 & 4.9929 & TRN \\
\hline CHEMBL1474085 & 688171 & 4.55 & 4.8412 & TRN \\
\hline CHEMBL1560740 & 688171 & 4.35 & 4.996 & TRN \\
\hline CHEMBL1563245 & 688171 & 4.4 & 4.7876 & TST \\
\hline CHEMBL1565242 & 688171 & 4.55 & 4.8174 & TRN \\
\hline CHEMBL2004928 & 688171 & 4.5 & 4.9076 & TRN \\
\hline CHEMBL1450988 & 688171 & 4.35 & 5.0678 & TST \\
\hline CHEMBL3191688 & 688171 & 4.4 & 4.7843 & TRN \\
\hline CHEMBL1587655 & 688171 & 4.65 & 4.8844 & TRN \\
\hline CHEMBL1990598 & 688171 & 5.35 & 4.9105 & TRN \\
\hline CHEMBL1504743 & 688171 & 5.0 & 5.0078 & TRN \\
\hline CHEMBL1426131 & 688171 & 4.5 & 4.95 & TRN \\
\hline CHEMBL1446940 & 688171 & 4.7 & 4.9126 & TRN \\
\hline CHEMBL1412333 & 688171 & 4.5 & 4.913 & TRN \\
\hline CHEMBL1483245 & 688171 & 4.45 & 4.8358 & TST \\
\hline CHEMBL1386848 & 688171 & 4.55 & 4.8588 & TRN \\
\hline CHEMBL131037 & 688171 & 4.75 & 4.8263 & TST \\
\hline CHEMBL1486503 & 688171 & 4.6 & 4.8156 & TRN \\
\hline CHEMBL1508839 & 688171 & 5.15 & 4.9014 & TRN \\
\hline CHEMBL1452256 & 688171 & 4.7 & 4.7595 & TRN \\
\hline CHEMBL 2007274 & 688171 & 4.35 & 4.8399 & TRN \\
\hline CHEMBL1474948 & 688171 & 4.5 & 4.8571 & TRN \\
\hline CHEMBL1527752 & 688171 & 5.15 & 4.7721 & TRN \\
\hline CHEMBL3192357 & 688171 & 4.95 & 4.9465 & TRN \\
\hline CHEMBL1451861 & 688171 & 4.9 & 4.9396 & TRN \\
\hline CHEMBL1271764 & 688171 & 4.95 & 4.9069 & TRN \\
\hline CHEMBL1538934 & 688171 & 4.9 & 4.9346 & TRN \\
\hline CHEMBL1302139 & 688171 & 4.8 & 5.0111 & TRN \\
\hline CHEMBL1318002 & 688171 & 5.1 & 4.8586 & TRN \\
\hline CHEMBL1321938 & 688171 & 6.0 & 4.8686 & TRN \\
\hline
\end{tabular}




\begin{tabular}{|c|c|c|c|c|}
\hline \multicolumn{5}{|c|}{ Supplemental Table S2.txt } \\
\hline CHEMBL1543115 & 688171 & 4.55 & 4.93 & TST \\
\hline CHEMBL3145321 & 688171 & 4.55 & 4.7985 & TRN \\
\hline CHEMBL1606342 & 688171 & 4.45 & 5.085 & TRN \\
\hline CHEMBL1423758 & 688171 & 4.7 & 4.816 & TRN \\
\hline CHEMBL1430116 & 688171 & 4.8 & 4.8207 & TRN \\
\hline CHEMBL1406295 & 688171 & 5.5 & 4.9261 & TST \\
\hline CHEMBL1363656 & 688171 & 4.9 & 4.9488 & TST \\
\hline CHEMBL1418885 & 688171 & 4.6 & 4.8756 & TRN \\
\hline CHEMBL1469035 & 688171 & 4.75 & 4.8784 & TRN \\
\hline CHEMBL1305875 & 688171 & 5.05 & 4.82 & TRN \\
\hline CHEMBL1591490 & 688171 & 4.8 & 4.7967 & TRN \\
\hline CHEMBL1419371 & 688171 & 4.45 & 5.015 & TRN \\
\hline CHEMBL1451381 & 688171 & 4.75 & 4.9412 & TST \\
\hline CHEMBL1490953 & 688171 & 4.4 & 4.9474 & TRN \\
\hline CHEMBL1305406 & 688171 & 4.4 & 4.6741 & TRN \\
\hline CHEMBL1493516 & 688171 & 4.9 & 4.9275 & TRN \\
\hline CHEMBL1601480 & 688171 & 5.4 & 4.9903 & TST \\
\hline CHEMBL1592575 & 688171 & 4.6 & 4.8045 & TRN \\
\hline CHEMBL1598183 & 688171 & 5.5 & 4.8176 & TST \\
\hline CHEMBL1986418 & 688171 & 5.4 & 4.9769 & TST \\
\hline CHEMBL1537652 & 688171 & 5.05 & 4.9595 & TST \\
\hline CHEMBL1415435 & 688171 & 4.4 & 4.7547 & TRN \\
\hline CHEMBL1479319 & 688171 & 4.65 & 5.0939 & TRN \\
\hline CHEMBL1580535 & 688171 & 4.55 & 5.0022 & TST \\
\hline CHEMBL1453687 & 688171 & 4.45 & 5.0737 & TRN \\
\hline CHEMBL1394347 & 688171 & 4.4 & 4.9599 & TRN \\
\hline CHEMBL1479310 & 688171 & 4.6 & 4.9368 & TRN \\
\hline CHEMBL1351683 & 688171 & 5.05 & 4.9303 & TRN \\
\hline CHEMBL1337155 & 688171 & 4.65 & 4.7988 & TRN \\
\hline CHEMBL1460731 & 688171 & 4.4 & 4.9222 & TRN \\
\hline CHEMBL1543875 & 688171 & 5.0 & 4.8045 & TRN \\
\hline CHEMBL1502372 & 688171 & 4.55 & 4.9223 & TRN \\
\hline CHEMBL1609404 & 688171 & 4.75 & 4.8693 & TRN \\
\hline CHEMBL1411559 & 688171 & 4.85 & 5.0126 & TRN \\
\hline CHEMBL1338888 & 688171 & 4.45 & 4.9662 & TRN \\
\hline CHEMBL1417985 & 688171 & 4.45 & 4.8989 & TRN \\
\hline CHEMBL1539024 & 688171 & 5.0 & 4.9911 & TST \\
\hline CHEMBL1371537 & 688171 & 4.9 & 4.862 & TRN \\
\hline CHEMBL12014 & 688171 & 6.25 & 4.8543 & TST \\
\hline CHEMBL1429849 & 688171 & 4.7 & 4.9102 & TST \\
\hline CHEMBL1426151 & 688171 & 4.35 & 5.0477 & TRN \\
\hline CHEMBL1986259 & 688171 & 4.8 & 4.8564 & TRN \\
\hline CHEMBL1495590 & 688171 & 4.75 & 4.954 & TRN \\
\hline CHEMBL3192863 & 688171 & 4.4 & 4.9086 & TRN \\
\hline CHEMBL1486296 & 688171 & 4.9 & 4.9149 & TRN \\
\hline CHEMBL1172726 & 688171 & 4.5 & 4.8798 & TRN \\
\hline CHEMBL 242946 & 688171 & 4.4 & 4.9354 & TRN \\
\hline CHEMBL1306283 & 688171 & 5.0 & 4.9653 & TRN \\
\hline
\end{tabular}




\begin{tabular}{|c|c|c|c|c|c|}
\hline & & \multicolumn{4}{|c|}{ Supplemental Table S2.txt } \\
\hline CHEMBL1429817 & 688171 & 5.6 & 4.9612 & TRN & \\
\hline CHEMBL1332646 & 688171 & 4.4 & 4.9708 & TST & \\
\hline CHEMBL1476141 & 688171 & 4.45 & 5.0108 & TRN & \\
\hline CHEMBL1346136 & 688171 & 4.45 & 4.9321 & TST & \\
\hline CHEMBL1336015 & 688171 & 4.65 & 4.9424 & TRN & \\
\hline CHEMBL1359407 & 688171 & 4.85 & 4.7998 & TRN & \\
\hline CHEMBL1539294 & 688171 & 4.75 & 4.8624 & TRN & \\
\hline CHEMBL1329129 & 688171 & 5.05 & 4.82100 & 0000000001 & TRN \\
\hline CHEMBL1575022 & 688171 & 4.5 & 4.9682 & TRN & \\
\hline CHEMBL3189408 & 688171 & 5.6 & 4.9797 & TRN & \\
\hline CHEMBL1432846 & 688171 & 5.4 & 4.9336 & TRN & \\
\hline CHEMBL1370608 & 688171 & 4.65 & 4.791 & TRN & \\
\hline CHEMBL1484282 & 688171 & 4.95 & 4.9178 & TRN & \\
\hline CHEMBL1603324 & 688171 & 5.05 & 4.9663 & TRN & \\
\hline CHEMBL1461179 & 688171 & 4.4 & 5.0161 & TST & \\
\hline CHEMBL1484792 & 688171 & 4.5 & 4.843 & TRN & \\
\hline CHEMBL3191022 & 688171 & 5.1 & 5.0285 & TST & \\
\hline CHEMBL1375316 & 688171 & 4.75 & 4.9372 & TRN & \\
\hline CHEMBL1348604 & 688171 & 4.75 & 4.8725 & TRN & \\
\hline CHEMBL1357694 & 688171 & 4.65 & 4.9425 & TRN & \\
\hline CHEMBL1472812 & 688171 & 4.35 & 4.9429 & TRN & \\
\hline CHEMBL1304496 & 688171 & 4.65 & 4.9208 & TST & \\
\hline CHEMBL1357081 & 688171 & 4.75 & 4.9905 & TRN & \\
\hline CHEMBL1552684 & 688171 & 4.65 & 4.9353 & TRN & \\
\hline CHEMBL1585798 & 688171 & 6.05 & 4.8132 & TST & \\
\hline CHEMBL1559325 & 688171 & 4.7 & 5.0411 & TRN & \\
\hline CHEMBL1312177 & 688171 & 4.55 & 4.8066 & TRN & \\
\hline CHEMBL1581813 & 688171 & 4.9 & 4.8793 & TST & \\
\hline CHEMBL3210806 & 688171 & 4.35 & 4.9606 & TRN & \\
\hline CHEMBL3207406 & 688171 & 4.7 & 4.9892 & TST & \\
\hline CHEMBL1544428 & 688171 & 4.4 & 4.7526 & TRN & \\
\hline CHEMBL1474210 & 688171 & 4.5 & 4.7368 & TRN & \\
\hline CHEMBL 3190220 & 688171 & 5.1 & 4.8814 & TRN & \\
\hline CHEMBL1373576 & 688171 & 4.7 & 4.8235 & TRN & \\
\hline CHEMBL1541889 & 688171 & 4.65 & 4.8258 & TRN & \\
\hline CHEMBL1403807 & 688171 & 5.1 & 4.9793 & TST & \\
\hline CHEMBL1532063 & 688171 & 5.35 & 4.8707 & TRN & \\
\hline CHEMBL1418061 & 688171 & 5.0 & 4.8633 & TST & \\
\hline CHEMBL1594237 & 688171 & 4.4 & 4.952 & TRN & \\
\hline CHEMBL1459271 & 688171 & 4.55 & 4.8325 & TRN & \\
\hline CHEMBL3213981 & 688171 & 5.05 & 4.9829 & TST & \\
\hline CHEMBL1529668 & 688171 & 5.4 & 5.0847 & TRN & \\
\hline CHEMBL1612042 & 688171 & 4.4 & 4.8919 & TRN & \\
\hline CHEMBL1970965 & 688171 & 5.6 & 4.9986 & TRN & \\
\hline CHEMBL1578921 & 688171 & 5.55 & 4.9852 & TST & \\
\hline CHEMBL1355071 & 688171 & 4.5 & 4.8167 & TRN & \\
\hline CHEMBL1385853 & 688171 & 4.4 & 4.9934 & TRN & \\
\hline CHEMBL1386461 & 688171 & 4.4 & 4.9812 & TRN & \\
\hline
\end{tabular}




\begin{tabular}{|c|c|c|c|c|c|}
\hline & & \multicolumn{4}{|c|}{ Supplemental Table S2.txt } \\
\hline CHEMBL1496759 & 688171 & 4.85 & 4.7986 & TRN & \\
\hline CHEMBL1432814 & 688171 & 4.9 & 4.8311 & TRN & \\
\hline CHEMBL1985649 & 688171 & 4.55 & 4.8111 & TST & \\
\hline CHEMBL1453036 & 688171 & 4.6 & 4.8854 & TRN & \\
\hline CHEMBL1374664 & 688171 & 5.7 & 4.8649 & TRN & \\
\hline CHEMBL1368561 & 688171 & 5.85 & 4.8921 & TRN & \\
\hline CHEMBL1396815 & 688171 & 4.65 & 4.8333 & TRN & \\
\hline CHEMBL1517195 & 688171 & 6.0 & 5.0505 & TRN & \\
\hline CHEMBL1600893 & 688171 & 5.0 & 4.9019 & TRN & \\
\hline CHEMBL1321484 & 688171 & 5.0 & 4.8886 & TRN & \\
\hline CHEMBL1522155 & 688171 & 4.9 & 4.9013 & TST & \\
\hline CHEMBL1484833 & 688171 & 4.95 & 4.8883 & TRN & \\
\hline CHEMBL1538001 & 688171 & 5.1 & 5.0651 & TRN & \\
\hline CHEMBL1415724 & 688171 & 6.15 & 4.8418 & TST & \\
\hline CHEMBL1364872 & 688171 & 4.8 & 4.7531 & TRN & \\
\hline CHEMBL1330519 & 688171 & 5.45 & 4.9693 & TST & \\
\hline CHEMBL1468577 & 688171 & 4.4 & 4.8238 & TRN & \\
\hline CHEMBL1591021 & 688171 & 5.05 & 4.977 & TRN & \\
\hline CHEMBL1521106 & 688171 & 4.8 & 4.9489 & TRN & \\
\hline CHEMBL1412368 & 688171 & 4.7 & 4.9244 & TRN & \\
\hline CHEMBL1978364 & 688171 & 4.4 & 4.8415 & TRN & \\
\hline CHEMBL1492003 & 688171 & 4.6 & 4.8795 & TRN & \\
\hline CHEMBL1333966 & 688171 & 5.45 & 4.9369 & TRN & \\
\hline CHEMBL1309472 & 688171 & 4.4 & 4.8959 & TRN & \\
\hline CHEMBL1432046 & 688171 & 4.6 & 4.816 & TRN & \\
\hline CHEMBL1600657 & 688171 & 4.6 & 4.9013 & TRN & \\
\hline CHEMBL1494375 & 688171 & 4.8 & 4.8631 & TRN & \\
\hline CHEMBL1315206 & 688171 & 4.35 & 4.8014 & TRN & \\
\hline CHEMBL3191145 & 688171 & 4.8 & 4.8206 & TRN & \\
\hline CHEMBL1556860 & 688171 & 4.75 & 4.9759 & TRN & \\
\hline CHEMBL1321660 & 688171 & 4.35 & 4.9782 & TRN & \\
\hline CHEMBL1484690 & 688171 & 4.6 & 4.9521 & TRN & \\
\hline CHEMBL1400761 & 688171 & 4.55 & 4.9211 & TST & \\
\hline CHEMBL1523673 & 688171 & 7.0 & 4.9415 & TST & \\
\hline CHEMBL1591417 & 688171 & 4.8 & 4.849 & TRN & \\
\hline CHEMBL1548836 & 688171 & 4.65 & 4.9199 & TRN & \\
\hline CHEMBL1488076 & 688171 & 4.75 & 5.0262 & TRN & \\
\hline CHEMBL1360459 & 688171 & 5.85 & 4.9423 & TST & \\
\hline CHEMBL1497129 & 688171 & 4.7 & 4.8607 & TST & \\
\hline CHEMBL1390068 & 688171 & 4.4 & 4.9514 & TRN & \\
\hline CHEMBL3193765 & 688171 & 6.25 & 4.8975 & TRN & \\
\hline CHEMBL1455024 & 688171 & 4.85 & 4.92399 & 99999999995 & TRN \\
\hline CHEMBL1467785 & 688171 & 5.05 & 4.9152 & TRN & \\
\hline CHEMBL1973603 & 688171 & 4.8 & 4.9617 & TRN & \\
\hline CHEMBL1396939 & 688171 & 4.55 & 5.0259 & TRN & \\
\hline CHEMBL1520243 & 688171 & 4.75 & 4.823 & TRN & \\
\hline CHEMBL1359162 & 688171 & 5.5 & 4.9672 & TRN & \\
\hline CHEMBL1305536 & 688171 & 4.8 & 4.8547 & TRN & \\
\hline
\end{tabular}




\begin{tabular}{|c|c|c|c|c|c|}
\hline \multicolumn{6}{|c|}{ Supplemental Table S2.txt } \\
\hline CHEMBL1613404 & 688171 & 4.45 & 5.0691 & TRN & \\
\hline CHEMBL1538010 & 688171 & 4.45 & 4.9926 & TRN & \\
\hline CHEMBL1348543 & 688171 & 5.85 & 4.9461 & TRN & \\
\hline CHEMBL1411702 & 688171 & 5.15 & 4.9367 & TRN & \\
\hline CHEMBL 1415476 & 688171 & 4.4 & 4.9497 & TRN & \\
\hline CHEMBL1314328 & 688171 & 5.5 & 4.9181 & TRN & \\
\hline CHEMBL1350211 & 688171 & 4.45 & 4.9379 & TRN & \\
\hline CHEMBL1970542 & 688171 & 5.0 & 4.945 & TRN & \\
\hline CHEMBL1599177 & 688171 & 4.35 & 5.0815 & TST & \\
\hline CHEMBL1321614 & 688171 & 6.9 & 5.008 & TRN & \\
\hline CHEMBL1328167 & 688171 & 4.55 & 4.8927 & TRN & \\
\hline CHEMBL1463964 & 688171 & 4.4 & 4.8036 & TRN & \\
\hline CHEMBL1593085 & 688171 & 4.4 & 5.0825 & TRN & \\
\hline CHEMBL3207407 & 688171 & 5.1 & 5.0098 & TRN & \\
\hline CHEMBL1531906 & 688171 & 4.65 & 4.97199 & 99999999995 & TRN \\
\hline CHEMBL1381673 & 688171 & 4.85 & 4.8907 & TRN & \\
\hline CHEMBL1459191 & 688171 & 4.55 & 4.85 & TRN & \\
\hline CHEMBL1406973 & 688171 & 4.35 & 4.9954 & TRN & \\
\hline CHEMBL1571676 & 688171 & 5.2 & 4.8502 & TST & \\
\hline CHEMBL1314005 & 688171 & 7.2 & 4.7355 & TRN & \\
\hline CHEMBL1459969 & 688171 & 4.4 & 4.9059 & TST & \\
\hline CHEMBL1470496 & 688171 & 7.2 & 4.9144 & TST & \\
\hline CHEMBL1299201 & 688171 & 5.6 & 4.9846 & TST & \\
\hline CHEMBL1423802 & 688171 & 4.85 & 4.7769 & TRN & \\
\hline CHEMBL1337307 & 688171 & 4.55 & 4.9909 & TRN & \\
\hline CHEMBL1388080 & 688171 & 4.6 & 4.8556 & TST & \\
\hline CHEMBL1455813 & 688171 & 4.5 & 4.9652 & TRN & \\
\hline CHEMBL1319648 & 688171 & 4.55 & 5.0308 & TST & \\
\hline CHEMBL1472788 & 688171 & 4.55 & 4.9247 & TRN & \\
\hline CHEMBL1442109 & 688171 & 5.0 & 4.8589 & TRN & \\
\hline CHEMBL1395667 & 688171 & 4.85 & 4.9108 & TRN & \\
\hline CHEMBL1447636 & 688171 & 5.3 & 4.9114 & TST & \\
\hline CHEMBL1382317 & 688171 & 4.8 & 4.7803 & TRN & \\
\hline CHEMBL1509338 & 688171 & 5.0 & 4.9246 & TRN & \\
\hline CHEMBL1354072 & 688171 & 4.7 & 4.8575 & TRN & \\
\hline CHEMBL1321966 & 688171 & 4.65 & 4.9841 & TRN & \\
\hline CHEMBL1299549 & 688171 & 4.75 & 4.8934 & TRN & \\
\hline CHEMBL1512185 & 688171 & 4.35 & 5.0504 & TRN & \\
\hline CHEMBL1440953 & 688171 & 5.1 & 4.7878 & TST & \\
\hline CHEMBL1531413 & 688171 & 4.35 & 4.8954 & TRN & \\
\hline CHEMBL1404493 & 688171 & 4.4 & 4.9483 & TRN & \\
\hline CHEMBL1399615 & 688171 & 4.75 & 4.94 & TST & \\
\hline CHEMBL1531578 & 688171 & 4.55 & 4.9113 & TRN & \\
\hline CHEMBL1603687 & 688171 & 4.5 & 4.8791 & TRN & \\
\hline CHEMBL1366030 & 688171 & 7.1002 & 4.8475 & TRN & \\
\hline CHEMBL1472578 & 688171 & 4.55 & 4.8959 & TRN & \\
\hline CHEMBL 1485540 & 688171 & 6.45 & 4.9272 & TRN & \\
\hline CHEMBL1323939 & 688171 & 4.65 & 4.9116 & TRN & \\
\hline
\end{tabular}




\begin{tabular}{|c|c|c|c|c|c|}
\hline \multicolumn{6}{|c|}{ Supplemental Table s2.txt } \\
\hline CHEMBL3199077 & 688171 & 5.35 & 4.9709 & TRN & \\
\hline CHEMBL1314211 & 688171 & 5.55 & 4.9494 & TRN & \\
\hline CHEMBL1340148 & 688171 & 4.85 & 4.9094 & TST & \\
\hline CHEMBL581044 & 688171 & 4.5 & 4.8735 & TRN & \\
\hline CHEMBL1312088 & 688171 & 5.6 & 4.8596 & TST & \\
\hline CHEMBL1471750 & 688171 & 4.4 & 4.9234 & TRN & \\
\hline CHEMBL1505832 & 688171 & 4.7 & 4.9108 & TRN & \\
\hline CHEMBL1314912 & 688171 & 5.9 & 4.8027 & TRN & \\
\hline CHEMBL1435113 & 688171 & 4.45 & 4.9047 & TRN & \\
\hline CHEMBL1473713 & 688171 & 4.45 & 4.868 & TST & \\
\hline CHEMBL1566436 & 688171 & 4.6 & 4.8288 & TRN & \\
\hline CHEMBL1417099 & 688171 & 4.4 & 4.8224 & TRN & \\
\hline CHEMBL1313122 & 688171 & 5.05 & 4.9266 & TST & \\
\hline CHEMBL1340792 & 688171 & 4.75 & 4.9249 & TST & \\
\hline CHEMBL1494324 & 688171 & 4.35 & 4.9944 & TRN & \\
\hline CHEMBL1423073 & 688171 & 7.6003 & 4.9923 & TST & \\
\hline CHEMBL1363608 & 688171 & 4.75 & 4.8568 & TST & \\
\hline CHEMBL1441729 & 688171 & 5.4 & 4.9267 & TRN & \\
\hline CHEMBL1522769 & 688171 & 4.45 & 4.9316 & TRN & \\
\hline CHEMBL1355295 & 688171 & 5.4 & 4.8208 & TRN & \\
\hline CHEMBL1336039 & 688171 & 4.85 & 4.9651 & TRN & \\
\hline CHEMBL1589501 & 688171 & 4.55 & 4.9344 & TRN & \\
\hline CHEMBL1573134 & 688171 & 4.4 & 4.753 & TRN & \\
\hline CHEMBL1371013 & 688171 & 4.35 & 4.9346 & TRN & \\
\hline CHEMBL1444028 & 688171 & 5.8 & 4.9283 & TRN & \\
\hline CHEMBL1302238 & 688171 & 5.6 & 4.8735 & TRN & \\
\hline CHEMBL1395146 & 688171 & 4.9 & 4.8536 & TRN & \\
\hline CHEMBL1468543 & 688171 & 4.95 & 4.8564 & TRN & \\
\hline CHEMBL1372848 & 688171 & 4.85 & 5.0378 & TRN & \\
\hline CHEMBL1593295 & 688171 & 5.5 & 4.8631 & TRN & \\
\hline CHEMBL1565386 & 688171 & 6.5501 & 4.90600 & 0000000001 & TRN \\
\hline CHEMBL1427241 & 688171 & 4.7 & 4.9837 & TRN & \\
\hline CHEMBL1468594 & 688171 & 4.35 & 4.862 & TRN & \\
\hline CHEMBL1310318 & 688171 & 4.6 & 4.7623 & TST & \\
\hline CHEMBL1505089 & 688171 & 4.6 & 4.7624 & TRN & \\
\hline CHEMBL1396879 & 688171 & 4.75 & 4.801 & TRN & \\
\hline CHEMBL1557013 & 688171 & 4.5 & 5.0286 & TRN & \\
\hline CHEMBL1556598 & 688171 & 4.5 & 4.9631 & TRN & \\
\hline CHEMBL1448743 & 688171 & 5.15 & 4.9176 & TRN & \\
\hline CHEMBL1438359 & 688171 & 4.75 & 4.8656 & TST & \\
\hline CHEMBL1391066 & 688171 & 4.65 & 4.836 & TRN & \\
\hline CHEMBL1468147 & 688171 & 5.1 & 4.9316 & TRN & \\
\hline CHEMBL 2000670 & 688171 & 4.9 & 5.004 & TRN & \\
\hline CHEMBL1342282 & 688171 & 4.45 & 4.9277 & TRN & \\
\hline CHEMBL1400928 & 688171 & 4.75 & 4.8725 & TRN & \\
\hline CHEMBL1438931 & 688171 & 5.0 & 4.7044 & TRN & \\
\hline CHEMBL1549055 & 688171 & 4.6 & 4.9676 & TRN & \\
\hline CHEMBL1352221 & 688171 & 4.65 & 4.8491 & TRN & \\
\hline
\end{tabular}




\begin{tabular}{|c|c|c|c|c|c|}
\hline \multicolumn{6}{|c|}{ Supplemental Table S2.txt } \\
\hline CHEMBL1355532 & 688171 & 5.85 & 4.9939 & TRN & \\
\hline CHEMBL1301595 & 688171 & 4.65 & 4.9594 & TRN & \\
\hline CHEMBL1594149 & 688171 & 5.45 & 4.9632 & TST & \\
\hline CHEMBL1406045 & 688171 & 4.7 & 4.9796 & TRN & \\
\hline CHEMBL1346486 & 688171 & 4.6 & 4.9183 & TRN & \\
\hline CHEMBL1542813 & 688171 & 4.4 & 4.7837 & TRN & \\
\hline CHEMBL1518126 & 688171 & 4.45 & 4.8241 & TRN & \\
\hline CHEMBL1513557 & 688171 & 5.2 & 4.9036 & TRN & \\
\hline CHEMBL1391048 & 688171 & 5.0 & 4.9606 & TRN & \\
\hline CHEMBL1435493 & 688171 & 5.0 & 4.8798 & TRN & \\
\hline CHEMBL1326268 & 688171 & 4.6 & 4.8776 & TST & \\
\hline CHEMBL1526349 & 688171 & 4.7 & 4.9029 & TRN & \\
\hline CHEMBL1440047 & 688171 & 4.9 & 4.9411 & TST & \\
\hline CHEMBL1445066 & 688171 & 4.6 & 4.9321 & TRN & \\
\hline CHEMBL1308127 & 688171 & 5.1 & 4.94300 & 00000000005 & TRN \\
\hline CHEMBL1563170 & 688171 & 4.75 & 4.8211 & TRN & \\
\hline CHEMBL1172995 & 688171 & 6.0 & 4.8843 & TRN & \\
\hline CHEMBL1604877 & 688171 & 4.4 & 5.027 & TST & \\
\hline CHEMBL1537920 & 688171 & 4.4 & 4.9165 & TRN & \\
\hline CHEMBL1565404 & 688171 & 4.4 & 4.9194 & TRN & \\
\hline CHEMBL1550140 & 688171 & 6.6 & 4.9911 & TST & \\
\hline CHEMBL1591979 & 688171 & 4.85 & 4.9269 & TRN & \\
\hline CHEMBL1354513 & 688171 & 4.6 & 4.9541 & TRN & \\
\hline CHEMBL1587544 & 688171 & 4.7 & 4.8848 & TRN & \\
\hline CHEMBL1517543 & 688171 & 4.4 & 5.0055 & TST & \\
\hline CHEMBL1567860 & 688171 & 7.1002 & 4.8862 & TRN & \\
\hline CHEMBL1329282 & 688171 & 4.45 & 4.9978 & TRN & \\
\hline CHEMBL1529469 & 688171 & 6.7501 & 4.9688 & TRN & \\
\hline CHEMBL1515781 & 688171 & 4.95 & 4.8488 & TRN & \\
\hline CHEMBL1543374 & 688171 & 5.0 & 4.9739 & TRN & \\
\hline CHEMBL1611095 & 688171 & 4.65 & 5.0118 & TRN & \\
\hline CHEMBL1308784 & 688171 & 4.4 & 4.9094 & TRN & \\
\hline CHEMBL1561877 & 688171 & 4.65 & 4.7298 & TRN & \\
\hline CHEMBL1540435 & 688171 & 4.45 & 4.8345 & TRN & \\
\hline CHEMBL1496429 & 688171 & 4.35 & 4.907 & TRN & \\
\hline CHEMBL3213656 & 688171 & 4.65 & 4.8987 & TST & \\
\hline CHEMBL1492692 & 688171 & 4.75 & 5.0928 & TST & \\
\hline CHEMBL1387309 & 688171 & 5.5 & 4.8507 & TST & \\
\hline CHEMBL1366846 & 688171 & 4.75 & 4.8936 & TRN & \\
\hline CHEMBL3208970 & 688171 & 4.9 & 4.9505 & TRN & \\
\hline CHEMBL1552451 & 688171 & 4.55 & 4.8781 & TRN & \\
\hline CHEMBL1477928 & 688171 & 4.75 & 4.8124 & TRN & \\
\hline CHEMBL1538726 & 688171 & 4.5 & 4.8482 & TRN & \\
\hline CHEMBL1372547 & 688171 & 6.0 & 5.0407 & TRN & \\
\hline CHEMBL1381808 & 688171 & 4.4 & 5.0437 & TST & \\
\hline CHEMBL1384619 & 688171 & 5.7 & 5.0262 & TST & \\
\hline CHEMBL1400236 & 688171 & 4.4 & 4.913 & TRN & \\
\hline CHEMBL1378801 & 688171 & 4.85 & 4.8355 & TRN & \\
\hline
\end{tabular}




\begin{tabular}{|c|c|c|c|c|c|c|}
\hline & & \multicolumn{5}{|c|}{ Supplemental Table s2.txt } \\
\hline CHEMBL1331190 & 688171 & 4.35 & 4.8985 & TST & & \\
\hline CHEMBL1608286 & 688171 & 4.75 & 4.8269 & TRN & & \\
\hline CHEMBL1401080 & 688171 & 4.35 & 5.0536 & TRN & & \\
\hline CHEMBL1510835 & 688171 & 5.9 & 5.1126 & TST & & \\
\hline CHEMBL1517604 & 688171 & 4.55 & 4.6513 & TRN & & \\
\hline CHEMBL1389224 & 688171 & 5.05 & 5.0307 & TRN & & \\
\hline CHEMBL3199345 & 688171 & 4.6 & 5.0157 & TRN & & \\
\hline CHEMBL1366741 & 688171 & 5.15 & 5.0946 & TRN & & \\
\hline CHEMBL1479088 & 688171 & 4.95 & 5.0021 & TST & & \\
\hline CHEMBL1378644 & 688171 & 4.4 & 4.8586 & TRN & & \\
\hline CHEMBL1306821 & 688171 & 4.9 & 4.9349 & TRN & & \\
\hline CHEMBL1576942 & 688171 & 5.4 & 4.857 & TRN & & \\
\hline CHEMBL1408392 & 688171 & 4.45 & 4.7716 & TRN & & \\
\hline CHEMBL1588052 & 737058 & 3.0 & 3.5912 & TRN & & \\
\hline CHEMBL3198600 & 737058 & 3.0 & 4.5384 & TST & & \\
\hline CHEMBL1567396 & 737058 & 4.1051 & 3.397 & TST & & \\
\hline CHEMBL1451040 & 737058 & 3.0 & 3.6005 & TRN & & \\
\hline CHEMBL1602709 & 737058 & 4.0964 & 3.93 & TRN & & \\
\hline CHEMBL1441918 & 737058 & 3.0 & 3.125 & TRN & & \\
\hline CHEMBL3189823 & 737058 & 3.0 & 3.0928 & TRN & & \\
\hline CHEMBL1566994 & 737058 & 4.3382 & 3.8154 & TRN & & \\
\hline CHEMBL1392573 & 737058 & 4.6536 & 3.3634 & TRN & & \\
\hline CHEMBL1447139 & 737058 & 4.9281 & 4.8763 & TRN & & \\
\hline CHEMBL600956 & 737058 & 4.1986 & 3.7503 & TRN & & \\
\hline CHEMBL1370260 & 737058 & 4.9281 & 4.3392 & TRN & & \\
\hline CHEMBL1208858 & 737058 & 3.0 & 3.8868 & TST & & \\
\hline CHEMBL1311580 & 737058 & 3.0 & 4.3633 & TST & & \\
\hline CHEMBL 255881 & 737058 & 3.0 & 3.3048 & TRN & & \\
\hline CHEMBL 3194421 & 737058 & \multicolumn{3}{|c|}{4.821000000000001} & 5.2793 & TRN \\
\hline CHEMBL3193527 & 737058 & 3.0 & 3.5587 & TRN & & \\
\hline CHEMBL1518080 & 737058 & 3.0 & 4.0542 & TST & & \\
\hline CHEMBL1600440 & 737058 & 4.3468 & 3.8584 & TRN & & \\
\hline CHEMBL1488474 & 737058 & 4.4609 & 4.4248 & TRN & & \\
\hline CHEMBL1503852 & 737058 & \multicolumn{3}{|c|}{4.821000000000001} & 3.9853 & TRN \\
\hline CHEMBL1562260 & 737058 & 5.0531 & 4.7668 & TRN & & \\
\hline CHEMBL1322977 & 737058 & 4.6459 & 4.1731 & TRN & & \\
\hline CHEMBL164 & 737058 & 4.4789 & 4.1287 & TST & & \\
\hline CHEMBL1493010 & 737058 & 3.0 & 4.4198 & TST & & \\
\hline CHEMBL1505816 & 737058 & 3.0 & 3.8503 & TRN & & \\
\hline CHEMBL1367272 & 737058 & 4.4377 & 4.1498 & TRN & & \\
\hline CHEMBL1585758 & 737058 & 4.5376 & 4.3156 & TRN & & \\
\hline CHEMBL1439675 & 737058 & 4.9136 & 3.3575 & TRN & & \\
\hline CHEMBL1342091 & 737058 & 4.9281 & 4.7045 & TRN & & \\
\hline CHEMBL1500102 & 737058 & 4.8894 & 4.7774 & TRN & & \\
\hline CHEMBL1556531 & 737058 & 3.0 & 3.6642 & TRN & & \\
\hline CHEMBL1383312 & 737058 & 4.433 & 3.7172 & TST & & \\
\hline CHEMBL1532996 & 737058 & 4.0904 & 3.5224 & TRN & & \\
\hline CHEMBL1418124 & 737058 & 4.0141 & 3.483 & TRN & & \\
\hline
\end{tabular}




\begin{tabular}{|c|c|c|c|c|c|c|}
\hline & & \multicolumn{5}{|c|}{ Supplemental Table S2.txt } \\
\hline CHEMBL1421399 & 737058 & 4.4921 & 4.0649 & TRN & & \\
\hline CHEMBL1486697 & 737058 & 3.0 & 4.0597 & TRN & & \\
\hline CHEMBL1390605 & 737058 & 3.0 & 3.7014 & TST & & \\
\hline CHEMBL1985299 & 737058 & 4.1129 & 3.8699 & TRN & & \\
\hline CHEMBL1397359 & 737058 & 4.6253 & 4.6148 & TRN & & \\
\hline CHEMBL3190558 & 737058 & 3.0 & 3.7784 & TRN & & \\
\hline CHEMBL1402586 & 737058 & 3.0 & 3.7381 & TRN & & \\
\hline CHEMBL1334863 & 737058 & \multicolumn{3}{|c|}{ 4. 218999999999999} & 3.4125 & TST \\
\hline CHEMBL76904 & 737058 & 5.0013 & 3.6784 & TRN & & \\
\hline CHEMBL1733511 & 737058 & 4.8069 & 4.842 & TST & & \\
\hline CHEMBL1525897 & 737058 & 3.0 & 3.8612 & TRN & & \\
\hline CHEMBL1406077 & 737058 & 3.0 & 3.3647 & TRN & & \\
\hline CHEMBL1712676 & 737058 & 4.644 & 4.2778 & TRN & & \\
\hline CHEMBL1371869 & 737058 & 4.4989 & 3.6869 & TRN & & \\
\hline CHEMBL1356184 & 737058 & 3.0 & 3.5612 & TRN & & \\
\hline CHEMBL1872457 & 737058 & 3.0 & 4.244 & TRN & & \\
\hline CHEMBL1974737 & 737058 & 4.5638 & 5.0237 & TST & & \\
\hline CHEMBL1424867 & 737058 & 4.6216 & 4.1833 & TRN & & \\
\hline CHEMBL1284 & 737058 & 3.0 & 3.3635 & TRN & & \\
\hline CHEMBL1417159 & 737058 & 3.0 & 2.7841 & TST & & \\
\hline CHEMBL1353033 & 737058 & 3.0 & 4.0923 & TRN & & \\
\hline CHEMBL1363730 & 737058 & 4.342 & 4.2822 & TRN & & \\
\hline CHEMBL1578652 & 737058 & 3.0 & 4.5583 & TRN & & \\
\hline CHEMBL1498044 & 737058 & 4.2269 & 4.1779 & TRN & & \\
\hline CHEMBL1417168 & 737058 & 4.699 & 3.5334 & TRN & & \\
\hline CHEMBL1472524 & 737058 & 3.0 & 3.5823 & TST & & \\
\hline CHEMBL1313502 & 737058 & 4.4935 & 4.7116 & TRN & & \\
\hline CHEMBL1310309 & 737058 & 3.0 & 3.1494 & TRN & & \\
\hline CHEMBL81782 & 737058 & 4.1261 & 3.9288 & TST & & \\
\hline CHEMBL1722786 & 737058 & 3.0 & 4.0203 & TRN & & \\
\hline CHEMBL1549540 & 737058 & 5.2644 & 4.8013 & TRN & & \\
\hline CHEMBL1497487 & 737058 & 3.0 & 3.9305 & TRN & & \\
\hline CHEMBL490355 & 737058 & 4.2765 & 4.1262 & TRN & & \\
\hline CHEMBL1473059 & 737058 & 5.9747 & 5.7329 & TRN & & \\
\hline CHEMBL179512 & 737058 & 3.0 & 2.9669 & TRN & & \\
\hline CHEMBL1536250 & 737058 & 4.6308 & 4.8927 & TRN & & \\
\hline CHEMBL56393 & 737058 & 3.0 & 3.5699 & TRN & & \\
\hline CHEMBL1413866 & 737058 & 3.0 & 4.2135 & TST & & \\
\hline CHEMBL1320230 & 737058 & 4.5867 & 3.7183 & TRN & & \\
\hline CHEMBL1736894 & 737058 & 4.76699 & 79999999 & 995 & 4.6927 & $10 \mathrm{~T}$ \\
\hline CHEMBL1340344 & 737058 & 3.0 & 4.2578 & TRN & & \\
\hline CHEMBL1499828 & 737058 & 4.3862 & 3.8543 & TRN & & \\
\hline CHEMBL522990 & 737058 & 3.0 & 3.1158 & TRN & & \\
\hline CHEMBL1702104 & 737058 & 4.5086 & 4.0679 & TST & & \\
\hline CHEMBL1532097 & 737058 & 4.7055 & 4.5332 & TRN & & \\
\hline CHEMBL1496952 & 737058 & 5.2336 & 4.9028 & TRN & & \\
\hline CHEMBL1727453 & 737058 & 4.1993 & 3.8521 & TRN & & \\
\hline CHEMBL1325366 & 737058 & 4.9666 & 4.624 & TST & & \\
\hline
\end{tabular}




\begin{tabular}{|c|c|c|c|c|c|}
\hline \multicolumn{6}{|c|}{ Supplemental Table S2.txt } \\
\hline CHEMBL1608149 & 737058 & 3.0 & 3.7214 & TRN & \\
\hline CHEMBL1314787 & 737058 & 4.7077 & 3.6011 & TRN & \\
\hline CHEMBL3192085 & 737058 & 4.6737 & 4.3476 & TST & \\
\hline CHEMBL1323900 & 737058 & 3.0 & 4.0111 & TRN & \\
\hline CHEMBL1350188 & 737058 & 3.0 & 3.2105 & TRN & \\
\hline CHEMBL1534899 & 737058 & 4.7496 & 4.2705 & TRN & \\
\hline CHEMBL1454890 & 737058 & 3.0 & 3.4541 & TRN & \\
\hline CHEMBL1981446 & 737058 & 3.0 & 3.7321 & TRN & \\
\hline CHEMBL1560432 & 737058 & 4.6038 & 4.7916 & TRN & \\
\hline CHEMBL1436898 & 737058 & 4.4522 & 3.8938 & TRN & \\
\hline CHEMBL1333737 & 737058 & 3.0 & 3.3268 & TRN & \\
\hline CHEMBL1471932 & 737058 & 5.8794 & 4.0951 & TRN & \\
\hline CHEMBL1589514 & 737058 & 4.4895 & 3.6385 & TRN & \\
\hline CHEMBL1563861 & 737058 & 3.0 & 4.0765 & TRN & \\
\hline CHEMBL1446839 & 737058 & 4.1296 & 4.2832 & TRN & \\
\hline CHEMBL1987928 & 737058 & 4.2328 & 3.99399 & 99999999998 & TRN \\
\hline CHEMBL1398188 & 737058 & 3.0 & 3.7109 & TRN & \\
\hline CHEMBL1529306 & 737058 & 3.0 & 3.283 & TRN & \\
\hline CHEMBL1609295 & 737058 & 5.1838 & 4.3082 & TRN & \\
\hline CHEMBL1305055 & 737058 & 3.0 & 3.8616 & TRN & \\
\hline CHEMBL156383 & 737058 & 4.9957 & 4.2829 & TRN & \\
\hline CHEMBL1375199 & 737058 & 4.6402 & 4.2162 & TRN & \\
\hline CHEMBL1098175 & 737058 & 4.0685 & 3.3548 & TRN & \\
\hline CHEMBL1490685 & 737058 & 3.0 & 4.1387 & TST & \\
\hline CHEMBL1470091 & 737058 & 4.5607 & 3.8782 & TRN & \\
\hline CHEMBL1980281 & 737058 & 3.0 & 4.8611 & TST & \\
\hline CHEMBL1425487 & 737058 & 3.0 & 3.6163 & TST & \\
\hline CHEMBL210208 & 737058 & 4.618 & 3.9138 & TRN & \\
\hline CHEMBL1980197 & 737058 & 4.5719 & 3.5095 & TRN & \\
\hline CHEMBL1330039 & 737058 & 4.1302 & 4.3653 & TRN & \\
\hline CHEMBL1470268 & 737058 & 3.0 & 3.8937 & TST & \\
\hline CHEMBL1970597 & 737058 & 3.0 & 3.92100 & 00000000003 & TRN \\
\hline CHEMBL116438 & 737058 & 3.0 & 3.1437 & TRN & \\
\hline CHEMBL1547446 & 737058 & 4.6289 & 4.0582 & TRN & \\
\hline CHEMBL1350787 & 737058 & 4.3872 & 5.0288 & TRN & \\
\hline CHEMBL1705776 & 737058 & 4.2604 & 3.9787 & TST & \\
\hline CHEMBL 2006611 & 737058 & 4.7747 & 4.0889 & TRN & \\
\hline CHEMBL3191063 & 737058 & 5.8153 & 4.7103 & TRN & \\
\hline CHEMBL 2003964 & 737058 & 4.5272 & 4.3213 & TRN & \\
\hline CHEMBL 2028179 & 737058 & 3.0 & 4.3088 & TRN & \\
\hline CHEMBL1375627 & 737058 & 3.0 & 3.3008 & TRN & \\
\hline CHEMBL1979849 & 737058 & 3.0 & 3.471 & TRN & \\
\hline CHEMBL1417524 & 737058 & 3.0 & 3.4322 & TRN & \\
\hline CHEMBL1307435 & 737058 & 4.2757 & 4.9104 & TRN & \\
\hline CHEMBL1574857 & 737058 & 4.4078 & 3.7799 & TRN & \\
\hline CHEMBL1342821 & 737058 & 4.1079 & 4.4217 & TRN & \\
\hline CHEMBL1487973 & 737058 & 4.0329 & 3.4666 & TRN & \\
\hline CHEMBL1303188 & 737058 & 3.0 & 2.906 & TRN & \\
\hline
\end{tabular}




\begin{tabular}{|c|c|c|c|c|c|}
\hline & & \multicolumn{4}{|c|}{ Supplemental Table S2.txt } \\
\hline CHEMBL3190268 & 737058 & 4.4191 & 4.3451 & TRN & \\
\hline CHEMBL1497387 & 737058 & 4.0395 & 4.051 & TRN & \\
\hline CHEMBL1529932 & 737058 & 4.5884 & 4.0239 & TRN & \\
\hline CHEMBL 140 & 737058 & 3.0 & 2.9497 & TRN & \\
\hline CHEMBL1257003 & 737058 & 3.0 & 3.1569 & TRN & \\
\hline CHEMBL40275 & 737058 & 3.0 & 3.5167 & TRN & \\
\hline CHEMBL1446234 & 737058 & 3.0 & 3.6382 & TRN & \\
\hline CHEMBL1401747 & 737058 & 3.0 & 3.7147 & TRN & \\
\hline CHEMBL1574218 & 737058 & 3.0 & 3.3338 & TST & \\
\hline CHEMBL3199065 & 737058 & 4.6861 & 4.4232 & TRN & \\
\hline CHEMBL1714903 & 737058 & 5.104 & 4.3453 & TRN & \\
\hline CHEMBL1481632 & 737058 & 5.3261 & 5.0197 & TRN & \\
\hline CHEMBL1340338 & 737058 & 6.6757 & 4.0382 & TST & \\
\hline CHEMBL1503175 & 737058 & 4.1186 & 3.7402 & TRN & \\
\hline CHEMBL1314122 & 737058 & 4.4895 & 4.8152 & TRN & \\
\hline CHEMBL 1315784 & 737058 & 4.4101 & 3.9121 & TRN & \\
\hline CHEMBL1438081 & 737058 & 3.0 & 4.0674 & TRN & \\
\hline CHEMBL1333659 & 737058 & 5.9508 & 4.9263 & TRN & \\
\hline CHEMBL250450 & 737058 & 4.8539 & 4.6155 & TST & \\
\hline CHEMBL1340656 & 737058 & 4.9281 & 4.7435 & TRN & \\
\hline CHEMBL1980661 & 737058 & 4.02 & 5.04899 & 99999999995 & TST \\
\hline CHEMBL1535695 & 737058 & 3.0 & 3.8078 & TST & \\
\hline CHEMBL1496986 & 737058 & 3.0 & 3.5547 & TRN & \\
\hline CHEMBL1345195 & 737058 & 3.0 & 3.4851 & TRN & \\
\hline CHEMBL1416189 & 737058 & 4.9547 & 5.1377 & TRN & \\
\hline CHEMBL1984581 & 737058 & 4.4908 & 4.9124 & TST & \\
\hline CHEMBL1508847 & 737058 & 4.0372 & 3.5016 & TRN & \\
\hline CHEMBL1310972 & 737058 & 3.0 & 4.3061 & TRN & \\
\hline CHEMBL1343895 & 737058 & 4.0575 & 4.2141 & TST & \\
\hline CHEMBL1989158 & 737058 & 4.2314 & 5.0546 & TST & \\
\hline CHEMBL1353324 & 737058 & 3.0 & 3.5676 & TST & \\
\hline CHEMBL3196075 & 737058 & 3.0 & 4.1866 & TST & \\
\hline CHEMBL1698793 & 737058 & 4.0334 & 3.9812 & TST & \\
\hline CHEMBL1716336 & 737058 & 3.0 & 3.9245 & TST & \\
\hline CHEMBL1546048 & 737058 & 4.6144 & 3.9955 & TST & \\
\hline CHEMBL1709713 & 737058 & 4.7496 & 4.5446 & TST & \\
\hline CHEMBL 224916 & 737058 & 3.0 & 3.5391 & TST & \\
\hline CHEMBL1378661 & 737058 & 5.2628 & 4.3275 & TST & \\
\hline CHEMBL1309252 & 737058 & 3.0 & 4.4094 & TST & \\
\hline CHEMBL1508055 & 737058 & 4.3188 & 3.9411 & TST & \\
\hline CHEMBL1594374 & 737058 & 3.0 & 3.7746 & TST & \\
\hline CHEMBL1788116 & 954453 & 5.2196 & 5.1427 & TRN & \\
\hline CHEMBL 202721 & 954453 & 5.6917 & 5.4701 & TRN & \\
\hline CHEMBL240954 & 954453 & 3.3457 & 3.6584 & TST & \\
\hline CHEMBL472940 & 954453 & 3.4126 & 3.4694 & TRN & \\
\hline CHEMBL 1256459 & 954453 & 7.6326 & 7.5557 & TRN & \\
\hline CHEMBL393929 & 954453 & 4.4561 & 4.2981 & TRN & \\
\hline CHEMBL 2363137 & 954453 & 5.1259 & 5.1452 & TRN & \\
\hline
\end{tabular}




\begin{tabular}{|c|c|c|c|c|c|c|}
\hline & & \multicolumn{5}{|c|}{ Supplemental Table S2.txt } \\
\hline CHEMBL 300389 & 954453 & 7.3251 & 7.3728 & TRN & & \\
\hline CHEMBL 379300 & 954453 & 7.0833 & 7.1339 & TRN & & \\
\hline CHEMBL92309 & 954453 & 2.2445 & 2.5398 & TST & & \\
\hline CHEMBL573107 & 954453 & 5.0945 & 4.9743 & TRN & & \\
\hline CHEMBL392695 & 954453 & 5.255 & 5.2425 & TRN & & \\
\hline CHEMBL189584 & 954453 & 3.7112 & 3.79699 & 99999999 & 997 & TRN \\
\hline CHEMBL1673039 & 954453 & 4.6944 & 4.7776 & TRN & & \\
\hline CHEMBL 2144069 & 954453 & 6.2955 & 6.2596 & TRN & & \\
\hline CHEMBL412142 & 954453 & 4.3212 & 4.3304 & TRN & & \\
\hline CHEMBL220241 & 954453 & 3.9231 & 3.6773 & TRN & & \\
\hline CHEMBL1516890 & 954453 & 3.7274 & 4.0523 & TRN & & \\
\hline CHEMBL135561 & 954453 & 4.523 & 4.6114 & TRN & & \\
\hline CHEMBL577784 & 954453 & 4.5178 & 4.8331 & TRN & & \\
\hline CHEMBL 210618 & 954453 & 2.9769 & 2.9717 & TRN & & \\
\hline CHEMBL483849 & 954453 & 2.7833 & 2.0919 & TST & & \\
\hline CHEMBL188678 & 954453 & 3.803 & 3.7513 & TRN & & \\
\hline CHEMBL259181 & 954453 & 3.778 & 3.9487 & TRN & & \\
\hline CHEMBL1190711 & 954453 & 5.0018 & 5.0643 & TRN & & \\
\hline CHEMBL191334 & 954453 & 4.6433 & 4.5285 & TRN & & \\
\hline CHEMBL221137 & 954453 & 4.8456 & 4.7057 & TST & & \\
\hline CHEMBL1230020 & 954453 & 3.0148 & 3.1183 & TRN & & \\
\hline CHEMBL2005886 & 954453 & 6.1672 & 6.2174 & TRN & & \\
\hline CHEMBL180127 & 954453 & 3.3215 & 3.4157 & TRN & & \\
\hline CHEMBL1909414 & 954453 & 3.9123 & 3.759 & TRN & & \\
\hline CHEMBL3349342 & 954453 & 6.1825 & 6.1873 & TRN & & \\
\hline CHEMBL9470 & 954453 & 6.3552 & 6.0107 & TST & & \\
\hline CHEMBL512504 & 954453 & 4.3633 & 4.3969 & TRN & & \\
\hline CHEMBL102714 & 954453 & 4.0132 & 3.9558 & TRN & & \\
\hline CHEMBL585951 & 954453 & 5.9791 & 6.0646 & TRN & & \\
\hline CHEMBL399530 & 954453 & 4.3893 & 4.4369 & TRN & & \\
\hline CHEMBL 222102 & 954453 & 3.1785 & 3.1431 & TRN & & \\
\hline CHEMBL192566 & 954453 & 6.999 & 8.6343 & TST & & \\
\hline CHEMBL1590308 & 954453 & 2.9796 & 3.3657 & TST & & \\
\hline CHEMBL3186408 & 954453 & 4.3673 & 3.806 & TST & & \\
\hline CHEMBL 2134202 & 954453 & 3.9299 & 4.154 & TRN & & \\
\hline CHEMBL449158 & 954453 & 6.5259 & 7.0951 & TST & & \\
\hline CHEMBL 258844 & 954453 & 5.1176 & 5.1896 & TRN & & \\
\hline CHEMBL1643959 & 954453 & 4.3932 & 4.4703 & TRN & & \\
\hline CHEMBL515416 & 954453 & 5.1768 & 5.0659 & TRN & & \\
\hline CHEMBL1970879 & 954453 & 5.5436 & 5.7236 & TRN & & \\
\hline CHEMBL 255342 & 954453 & 3.4451 & 3.2912 & TRN & & \\
\hline CHEMBL509032 & 954453 & 6.30200 & 300000006 & 005 & 6.4244 & TRN \\
\hline CHEMBL 2137530 & 954453 & 4.7517 & 4.9671 & TRN & & \\
\hline CHEMBL3392440 & 954453 & 3.7876 & 3.7803 & TRN & & \\
\hline CHEMBL514499 & 954453 & 7.1154 & 6.932 & TRN & & \\
\hline CHEMBL 213100 & 954453 & 5.24100 & 0000000 & 005 & 4.881 & TRN \\
\hline CHEMBL1242367 & 954453 & 4.9685 & 4.7511 & TRN & & \\
\hline CHEMBL373751 & 954453 & 3.7415 & 3.7362 & TRN & & \\
\hline
\end{tabular}




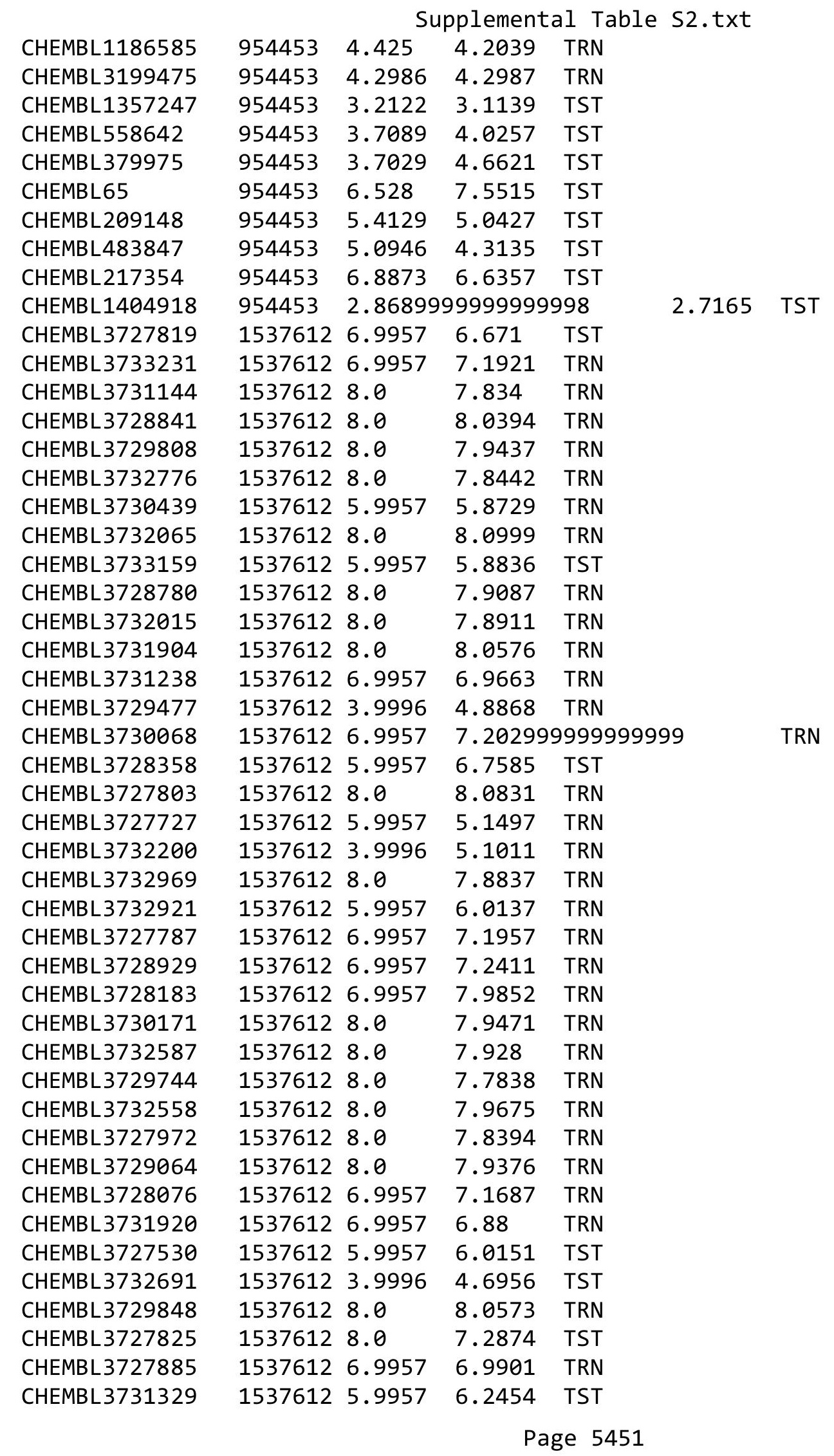




\begin{tabular}{|c|c|c|c|c|}
\hline \multicolumn{5}{|c|}{ Supplemental Table S2.txt } \\
\hline CHEMBL 3733174 & 1537612 & 8.0 & 7.8478 & TRN \\
\hline CHEMBL3730795 & 1537612 & 8.0 & 7.9809 & TRN \\
\hline CHEMBL 3727837 & 1537612 & 8.0 & 8.0955 & TRN \\
\hline CHEMBL3730733 & 1537612 & 5.9957 & 6.4802 & TRN \\
\hline CHEMBL 3730256 & 1537612 & 5.9957 & 5.8625 & TST \\
\hline CHEMBL3729037 & 1537612 & 8.0 & 8.0137 & TRN \\
\hline CHEMBL3730613 & 1537612 & 8.0 & 7.7145 & TRN \\
\hline CHEMBL3729915 & 1537612 & 3.9996 & 5.0985 & TST \\
\hline CHEMBL3727416 & 1537612 & 6.9957 & 7.1844 & TRN \\
\hline CHEMBL3732435 & 1537612 & 8.0 & 7.9464 & TRN \\
\hline CHEMBL3729723 & 1537612 & 8.0 & 7.9548 & TRN \\
\hline CHEMBL3729395 & 1537612 & 6.9957 & 7.7917 & TRN \\
\hline CHEMBL3730830 & 1537612 & 6.9957 & 7.2232 & TRN \\
\hline CHEMBL 3731747 & 1537612 & 8.0 & 8.0506 & TRN \\
\hline CHEMBL3730617 & 1537612 & 6.9957 & 7.0227 & TRN \\
\hline CHEMBL3727799 & 1537612 & 5.9957 & 5.9549 & TRN \\
\hline CHEMBL3728251 & 1537612 & 8.0 & 7.2023 & TRN \\
\hline CHEMBL 3731224 & 1537612 & 8.0 & 8.0736 & TRN \\
\hline CHEMBL3729994 & 1537612 & 8.0 & 7.6374 & TRN \\
\hline CHEMBL3731459 & 1537612 & 5.9957 & 5.9875 & TRN \\
\hline CHEMBL3732704 & 1537612 & 6.9957 & 7.1419 & TRN \\
\hline CHEMBL 3728225 & 1537612 & 8.0 & 7.331 & TST \\
\hline CHEMBL3730546 & 1537612 & 8.0 & 7.9248 & TRN \\
\hline CHEMBL 3728609 & 1537612 & 8.0 & 7.9296 & TRN \\
\hline CHEMBL3731502 & 1537612 & 8.0 & 7.9396 & TRN \\
\hline CHEMBL3732174 & 1537612 & 6.9957 & 7.8097 & TRN \\
\hline CHEMBL3728399 & 1537612 & 8.0 & 7.0081 & TST \\
\hline CHEMBL3732526 & 1537612 & 8.0 & 7.9597 & TRN \\
\hline CHEMBL 3730753 & 1537612 & 5.9957 & 5.7521 & TRN \\
\hline CHEMBL3730681 & 1537612 & 6.9957 & 7.0203 & TRN \\
\hline CHEMBL 3730320 & 1537612 & 8.0 & 7.1719 & TST \\
\hline CHEMBL 3729784 & 1537612 & 6.9957 & 5.7962 & TST \\
\hline CHEMBL3730962 & 1537612 & 8.0 & 7.6797 & TRN \\
\hline CHEMBL 3730284 & 1537612 & 8.0 & 8.1067 & TRN \\
\hline CHEMBL 3729180 & 1537612 & 6.9957 & 6.9772 & TST \\
\hline CHEMBL3728355 & 1537612 & 8.0 & 8.0695 & TRN \\
\hline CHEMBL3731497 & 1537612 & 8.0 & 7.3319 & TRN \\
\hline CHEMBL3728941 & 1537612 & 6.9957 & 7.2004 & TRN \\
\hline CHEMBL 3729074 & 1537612 & 6.9957 & 6.8893 & TST \\
\hline CHEMBL3732269 & 1537612 & 8.0 & 7.8876 & TRN \\
\hline CHEMBL3727855 & 1537612 & 8.0 & 7.8738 & TRN \\
\hline CHEMBL3731243 & 1537612 & 8.0 & 7.815 & TRN \\
\hline CHEMBL3732816 & 1537612 & 3.9996 & 4.7098 & TST \\
\hline CHEMBL3730361 & 1537612 & 5.9957 & 5.943 & TST \\
\hline CHEMBL3727939 & 1537612 & 5.9957 & 6.7708 & TRN \\
\hline CHEMBL3732459 & 1537612 & 8.0 & 8.0753 & TRN \\
\hline CHEMBL3729452 & 1537612 & 6.9957 & 6.9956 & TRN \\
\hline CHEMBL3731974 & 1537612 & 8.0 & 8.0606 & TRN \\
\hline
\end{tabular}




\begin{tabular}{|c|c|c|c|c|}
\hline \multicolumn{5}{|c|}{ Supplemental Table S2.txt } \\
\hline CHEMBL3728052 & 1537612 & 8.0 & 8.095 & TRN \\
\hline CHEMBL3730374 & 1537612 & 6.9957 & 6.7501 & TRN \\
\hline CHEMBL3732582 & 1537612 & 5.9957 & 6.053 & TRN \\
\hline CHEMBL3732299 & 1537612 & 8.0 & 8.0988 & TRN \\
\hline CHEMBL3729620 & 1537612 & 6.9957 & 7.1422 & TST \\
\hline CHEMBL3730831 & 1537612 & 3.9996 & 4.4183 & TST \\
\hline CHEMBL3730708 & 1537612 & 8.0 & 7.9355 & TRN \\
\hline CHEMBL3728608 & 1537612 & 8.0 & 7.989 & TRN \\
\hline CHEMBL 3730678 & 1537612 & 8.0 & 7.6078 & TRN \\
\hline CHEMBL3732535 & 1537612 & 3.9996 & 6.2421 & TST \\
\hline CHEMBL3732905 & 1537612 & 6.9957 & 7.2843 & TRN \\
\hline CHEMBL3731675 & 1537612 & 8.0 & 8.115 & TRN \\
\hline CHEMBL3730083 & 1537612 & 8.0 & 8.0579 & TRN \\
\hline CHEMBL 3728514 & 1537612 & 8.0 & 7.7875 & TRN \\
\hline CHEMBL3729954 & 1537612 & 6.9957 & 7.0299 & TRN \\
\hline CHEMBL3731350 & 1537612 & 5.9957 & 4.8907 & TRN \\
\hline CHEMBL3729188 & 1537612 & 6.9957 & 7.2038 & TRN \\
\hline CHEMBL3730101 & 1537612 & 8.0 & 7.8256 & TRN \\
\hline CHEMBL3731188 & 1537612 & 8.0 & 8.0771 & TRN \\
\hline CHEMBL3731923 & 1537612 & 8.0 & 8.0053 & TRN \\
\hline CHEMBL3730038 & 1537612 & 8.0 & 7.1219 & TRN \\
\hline CHEMBL3731565 & 1537612 & 8.0 & 8.0449 & TRN \\
\hline CHEMBL3732980 & 1537612 & 8.0 & 8.0052 & TRN \\
\hline CHEMBL3733027 & 1537612 & 8.0 & 8.0023 & TRN \\
\hline CHEMBL3728331 & 1537612 & 8.0 & 7.4901 & TST \\
\hline CHEMBL 3730448 & 1537612 & 5.9957 & 5.6917 & TRN \\
\hline CHEMBL3729689 & 1537612 & 8.0 & 7.9726 & TRN \\
\hline CHEMBL3731819 & 1537612 & 6.9957 & 7.2409 & TRN \\
\hline CHEMBL3732495 & 1537612 & 8.0 & 7.9419 & TRN \\
\hline CHEMBL3732693 & 1537612 & 8.0 & 7.9651 & TRN \\
\hline CHEMBL 3727441 & 1537612 & 6.9957 & 7.1036 & TRN \\
\hline CHEMBL3731762 & 1537612 & 6.9957 & 7.0703 & TST \\
\hline CHEMBL3728532 & 1537612 & 8.0 & 7.9501 & TRN \\
\hline CHEMBL3729782 & 1537612 & 5.9957 & 6.2144 & TRN \\
\hline CHEMBL3733227 & 1537612 & 8.0 & 7.6357 & TRN \\
\hline CHEMBL3728648 & 1537612 & 8.0 & 7.9236 & TRN \\
\hline CHEMBL3728339 & 1537612 & 8.0 & 7.8871 & TRN \\
\hline CHEMBL3730449 & 1537612 & 6.9957 & 6.9308 & TRN \\
\hline CHEMBL3733113 & 1537612 & 8.0 & 7.9236 & TRN \\
\hline CHEMBL3729496 & 1537612 & 8.0 & 8.1657 & TRN \\
\hline CHEMBL3729821 & 1537612 & 8.0 & 7.794 & TRN \\
\hline CHEMBL3727633 & 1537612 & 8.0 & 7.6192 & TRN \\
\hline CHEMBL3728151 & 1537612 & 8.0 & 8.0085 & TRN \\
\hline CHEMBL3732143 & 1537612 & 8.0 & 8.1554 & TRN \\
\hline CHEMBL3729893 & 1537612 & 8.0 & 7.9939 & TRN \\
\hline CHEMBL 3728624 & 1537612 & 6.9957 & 7.2277 & TRN \\
\hline CHEMBL3730249 & 1537612 & 8.0 & 8.0259 & TRN \\
\hline CHEMBL3731824 & 1537612 & 6.9957 & 7.1227 & TRN \\
\hline
\end{tabular}




\begin{tabular}{|c|c|c|c|c|c|}
\hline \multicolumn{6}{|c|}{ Supplemental Table S2.txt } \\
\hline CHEMBL3731935 & 1537612 & 8.0 & 7.8562 & TRN & \\
\hline CHEMBL3731556 & 1537612 & 6.9957 & 7.006 & TRN & \\
\hline CHEMBL3733226 & 1537612 & 8.0 & 8.0579 & TRN & \\
\hline CHEMBL3730879 & 1537612 & 5.9957 & 5.9444 & TST & \\
\hline CHEMBL3730769 & 1537612 & 8.0 & 7.7123 & TRN & \\
\hline CHEMBL3733139 & 1537612 & 6.9957 & 7.1376 & TST & \\
\hline CHEMBL 3729081 & 1537612 & 8.0 & 7.8805 & TRN & \\
\hline CHEMBL 3731834 & 1537612 & 8.0 & 7.8181 & TRN & \\
\hline CHEMBL3729336 & 1537612 & 8.0 & 7.5918 & TRN & \\
\hline CHEMBL3729454 & 1537612 & 8.0 & 7.9996 & TRN & \\
\hline CHEMBL 3730200 & 1537612 & 6.9957 & 7.0154 & TRN & \\
\hline CHEMBL 3727452 & 1537612 & 8.0 & 7.9003 & TRN & \\
\hline CHEMBL3732101 & 1537612 & 8.0 & 8.0225 & TRN & \\
\hline CHEMBL 3729049 & 1537612 & 8.0 & 7.9835 & TRN & \\
\hline CHEMBL3732321 & 1537612 & 5.9957 & 6.24799 & 9999999999 & TRN \\
\hline CHEMBL3731361 & 1537612 & 6.9957 & 7.0475 & TRN & \\
\hline CHEMBL3729906 & 1537612 & 8.0 & 7.9444 & TRN & \\
\hline CHEMBL 3732746 & 1537612 & 8.0 & 7.8659 & TRN & \\
\hline CHEMBL 3731187 & 1537612 & 8.0 & 7.7484 & TRN & \\
\hline CHEMBL3731650 & 1537612 & 5.9957 & 6.4946 & TRN & \\
\hline CHEMBL3728057 & 1537612 & 6.9957 & 7.2983 & TRN & \\
\hline CHEMBL3731897 & 1537612 & 8.0 & 7.9746 & TRN & \\
\hline CHEMBL 3730000 & 1537612 & 6.9957 & 7.6799 & TRN & \\
\hline CHEMBL 3728269 & 1537612 & 8.0 & 7.9606 & TRN & \\
\hline CHEMBL3733100 & 1537612 & 6.9957 & 6.9505 & TST & \\
\hline CHEMBL3731482 & 1537612 & 8.0 & 7.9113 & TRN & \\
\hline CHEMBL 3732129 & 1537612 & 6.9957 & 6.9805 & TRN & \\
\hline CHEMBL 3727380 & 1537612 & 8.0 & 7.858 & TRN & \\
\hline CHEMBL3733161 & 1537612 & 8.0 & 8.0034 & TRN & \\
\hline CHEMBL3731627 & 1537612 & 6.9957 & 7.0323 & TRN & \\
\hline CHEMBL3729712 & 1537612 & 6.9957 & 7.143 & TRN & \\
\hline CHEMBL 3727540 & 1537612 & 5.9957 & 5.0192 & TRN & \\
\hline CHEMBL3732945 & 1537612 & 8.0 & 7.8771 & TRN & \\
\hline CHEMBL 3728388 & 1537612 & 8.0 & 7.9986 & TRN & \\
\hline CHEMBL3729860 & 1537612 & 8.0 & 7.8653 & TRN & \\
\hline CHEMBL 3727945 & 1537612 & 8.0 & 7.8964 & TRN & \\
\hline CHEMBL3731444 & 1537612 & 6.9957 & 7.1717 & TRN & \\
\hline CHEMBL3731425 & 1537612 & 6.9957 & 7.0985 & TRN & \\
\hline CHEMBL3732664 & 1537612 & 5.9957 & 6.0593 & TST & \\
\hline CHEMBL3732412 & 1537612 & 8.0 & 8.1292 & TRN & \\
\hline CHEMBL3731500 & 1537612 & 5.9957 & 6.1632 & TST & \\
\hline CHEMBL3732790 & 1537612 & 6.9957 & 7.2873 & TRN & \\
\hline CHEMBL3729598 & 1537612 & 6.9957 & 7.2089 & TRN & \\
\hline CHEMBL 3729444 & 1537612 & 6.9957 & 7.229 & TRN & \\
\hline CHEMBL3728122 & 1537612 & 8.0 & 7.7719 & TRN & \\
\hline CHEMBL 3728243 & 1537612 & 8.0 & 7.9802 & TRN & \\
\hline CHEMBL3729011 & 1537612 & 8.0 & 7.9419 & TRN & \\
\hline CHEMBL 3732520 & 1537612 & 6.9957 & 7.3444 & TRN & \\
\hline
\end{tabular}




\begin{tabular}{|c|c|c|c|c|}
\hline \multicolumn{5}{|c|}{ Supplemental Table S2.txt } \\
\hline CHEMBL3732573 & 1537612 & 8.0 & 8.0502 & TRN \\
\hline CHEMBL3731601 & 1537612 & 6.9957 & 7.1822 & TRN \\
\hline CHEMBL3731301 & 1537612 & 6.9957 & 7.2795 & TRN \\
\hline CHEMBL 3730677 & 1537612 & 8.0 & 7.9298 & TRN \\
\hline CHEMBL 3727867 & 1537612 & 8.0 & 8.0035 & TRN \\
\hline CHEMBL 3730127 & 1537612 & 6.9957 & 6.9392 & TRN \\
\hline CHEMBL3729438 & 1537612 & 8.0 & 7.311 & TRN \\
\hline CHEMBL3727804 & 1537612 & 8.0 & 7.9406 & TRN \\
\hline CHEMBL3733360 & 1537612 & 8.0 & 7.8799 & TRN \\
\hline CHEMBL3732458 & 1537612 & 6.9957 & 7.2409 & TRN \\
\hline CHEMBL3728691 & 1537612 & 8.0 & 7.9217 & TRN \\
\hline CHEMBL3729684 & 1537612 & 8.0 & 7.8939 & TST \\
\hline CHEMBL3730486 & 1537612 & 3.9996 & 4.8631 & TST \\
\hline CHEMBL3728569 & 1537612 & 8.0 & 7.7065 & TRN \\
\hline CHEMBL3728461 & 1537612 & 6.9957 & 6.9556 & TRN \\
\hline CHEMBL3732133 & 1537612 & 8.0 & 8.1489 & TRN \\
\hline CHEMBL3732647 & 1537612 & 8.0 & 7.8783 & TRN \\
\hline CHEMBL3728504 & 1537612 & 8.0 & 7.2318 & TRN \\
\hline CHEMBL3730388 & 1537612 & 8.0 & 7.8267 & TRN \\
\hline CHEMBL3728102 & 1537612 & 6.9957 & 7.068 & TST \\
\hline CHEMBL3729745 & 1537612 & 8.0 & 7.2231 & TRN \\
\hline CHEMBL3733328 & 1537612 & 6.9957 & 7.1943 & TRN \\
\hline CHEMBL3729704 & 1537612 & 8.0 & 7.6939 & TST \\
\hline CHEMBL3732332 & 1537612 & 8.0 & 7.8139 & TRN \\
\hline CHEMBL3731420 & 1537612 & 8.0 & 7.8592 & TRN \\
\hline CHEMBL3729685 & 1537612 & 8.0 & 7.9745 & TRN \\
\hline CHEMBL3732710 & 1537612 & 8.0 & 8.1265 & TRN \\
\hline CHEMBL3731412 & 1537612 & 3.9996 & 4.7496 & TRN \\
\hline CHEMBL3731941 & 1537612 & 6.9957 & 6.6716 & TRN \\
\hline CHEMBL3730602 & 1537612 & 6.9957 & 6.624 & TST \\
\hline CHEMBL3730872 & 1537612 & 6.9957 & 7.2089 & TRN \\
\hline CHEMBL3727977 & 1537612 & 8.0 & 7.8657 & TRN \\
\hline CHEMBL3732372 & 1537612 & 8.0 & 7.6101 & TRN \\
\hline CHEMBL3729310 & 1537612 & 6.9957 & 7.0885 & TRN \\
\hline CHEMBL3730648 & 1537612 & 6.9957 & 6.9841 & TRN \\
\hline CHEMBL3729057 & 1537612 & 8.0 & 7.8952 & TRN \\
\hline CHEMBL3730300 & 1537612 & 5.9957 & 4.8498 & TRN \\
\hline CHEMBL3729795 & 1537612 & 5.9957 & 6.1482 & TST \\
\hline CHEMBL3728064 & 1537612 & 6.9957 & 7.2095 & TRN \\
\hline CHEMBL3732561 & 1537612 & 8.0 & 8.0602 & TRN \\
\hline CHEMBL3732452 & 1537612 & 6.9957 & 7.2919 & TRN \\
\hline CHEMBL3733051 & 1537612 & 8.0 & 7.8694 & TRN \\
\hline CHEMBL3731126 & 1537612 & 6.9957 & 7.1768 & TRN \\
\hline CHEMBL3731801 & 1537612 & 8.0 & 7.419 & TRN \\
\hline CHEMBL 3727743 & 1537612 & 6.9957 & 7.6794 & TRN \\
\hline CHEMBL3732867 & 1537612 & 8.0 & 7.945 & TRN \\
\hline CHEMBL3733188 & 1537612 & 8.0 & 7.9059 & TST \\
\hline CHEMBL3732713 & 1537612 & 6.9957 & 7.2103 & TRN \\
\hline
\end{tabular}




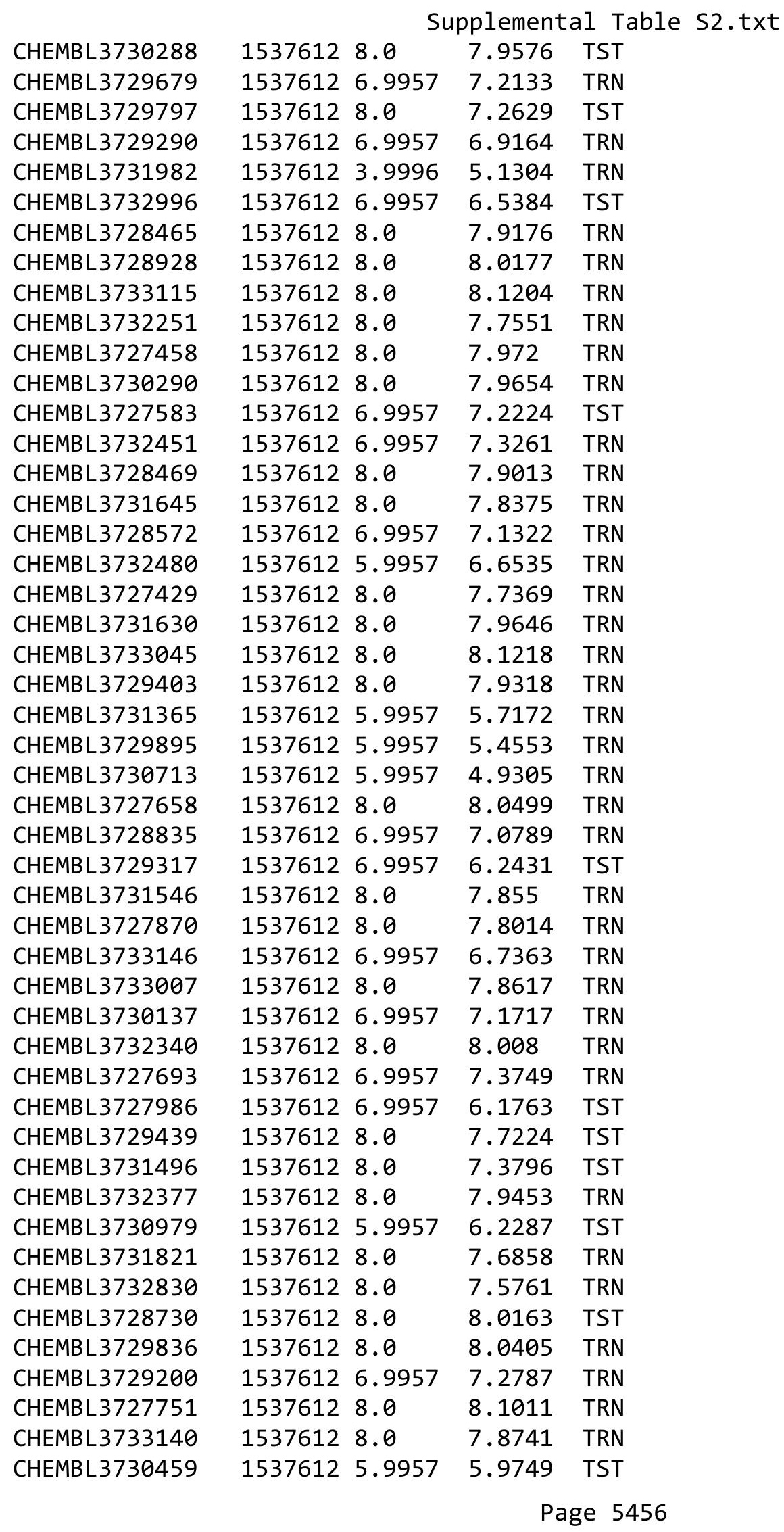


Supplemental Table S2.txt

\begin{tabular}{|c|c|c|c|c|}
\hline CHEMBL3729790 & 1537612 & 6.9957 & 7.0566 & TRN \\
\hline CHEMBL3730709 & 1537612 & 8.0 & 7.5609 & TST \\
\hline CHEMBL3732662 & 1537612 & 8.0 & 7.9078 & TRN \\
\hline CHEMBL3728962 & 1537612 & 8.0 & 7.5794 & TRN \\
\hline CHEMBL3731540 & 1537612 & 8.0 & 8.05 & TRN \\
\hline CHEMBL3728733 & 1537612 & 3.9996 & 4.3974 & TST \\
\hline CHEMBL3729450 & 1537612 & 8.0 & 8.0213 & TST \\
\hline CHEMBL3732176 & 1537612 & 8.0 & 8.0669 & TRN \\
\hline CHEMBL3732405 & 1537612 & 8.0 & 7.9745 & TRN \\
\hline CHEMBL3730039 & 1537612 & 8.0 & 8.0783 & TRN \\
\hline CHEMBL3731479 & 1537612 & 5.9957 & 7.0305 & TRN \\
\hline CHEMBL3728537 & 1537612 & 6.9957 & 6.7228 & TST \\
\hline CHEMBL3730421 & 1537612 & 6.9957 & 6.5582 & TST \\
\hline CHEMBL3729727 & 1537612 & 8.0 & 8.1611 & TRN \\
\hline CHEMBL3732749 & 1537612 & 8.0 & 7.971 & TST \\
\hline CHEMBL3732439 & 1537612 & 3.9996 & 6.7885 & TRN \\
\hline CHEMBL3731643 & 1537612 & 8.0 & 7.9339 & TRN \\
\hline CHEMBL3732933 & 1537612 & 5.9957 & 4.6934 & TST \\
\hline CHEMBL3728568 & 1537612 & 6.9957 & 7.0459 & TRN \\
\hline CHEMBL3732950 & 1537612 & 3.9996 & 4.6948 & TST \\
\hline CHEMBL3729451 & 1537612 & 6.9957 & 6.9142 & TRN \\
\hline CHEMBL3729025 & 1537612 & 8.0 & 7.9363 & TRN \\
\hline CHEMBL3728828 & 1537612 & 8.0 & 8.0245 & TRN \\
\hline CHEMBL3732399 & 1537612 & 8.0 & 7.7773 & TRN \\
\hline CHEMBL3732233 & 1537612 & 5.9957 & 6.1739 & TST \\
\hline CHEMBL3727585 & 1537612 & 6.9957 & 6.9641 & TST \\
\hline CHEMBL3728230 & 1537612 & 6.9957 & 7.062 & TST \\
\hline CHEMBL3727953 & 1537612 & 5.9957 & 6.1031 & TST \\
\hline CHEMBL3731625 & 1537612 & 6.9957 & 6.2025 & TST \\
\hline CHEMBL3728823 & 1537612 & 8.0 & 7.8153 & TST \\
\hline CHEMBL3728498 & 1537612 & 8.0 & 7.86299 & 99999999995 \\
\hline CHEMBL3729506 & 1537612 & 8.0 & 7.7506 & TST \\
\hline CHEMBL3728233 & 1537612 & 8.0 & 7.9582 & TST \\
\hline CHEMBL3729298 & 1537612 & 6.9957 & 7.0705 & TST \\
\hline CHEMBL3733291 & 1537612 & 8.0 & 7.9235 & TST \\
\hline CHEMBL3730243 & 1537612 & 6.9957 & 7.0352 & TST \\
\hline CHEMBL3731856 & 1537612 & 8.0 & 7.9636 & TST \\
\hline CHEMBL3731336 & 1537612 & 5.9957 & 6.2093 & TST \\
\hline CHEMBL3732598 & 1537612 & 8.0 & 7.8693 & TST \\
\hline CHEMBL3732873 & 1537612 & 5.9957 & 6.3358 & TST \\
\hline CHEMBL3727915 & 1537612 & 8.0 & 7.7476 & TST \\
\hline CHEMBL3728131 & 1537612 & 8.0 & 7.807 & TST \\
\hline CHEMBL3731909 & 1537612 & 8.0 & 7.8958 & TST \\
\hline CHEMBL3728124 & 1537612 & 8.0 & 8.0366 & TST \\
\hline CHEMBL3729108 & 1537612 & 6.9957 & 7.7926 & TST \\
\hline CHEMBL3729357 & 1537612 & 5.9957 & 6.356 & TST \\
\hline CHEMBL3731218 & 1537612 & 8.0 & 7.7896 & TST \\
\hline CHEMBL 3729041 & 1537612 & 8.0 & 8.0018 & TST \\
\hline
\end{tabular}




\begin{tabular}{|c|c|c|c|c|c|}
\hline \multicolumn{6}{|c|}{ Supplemental Table S2.txt } \\
\hline CHEMBL3731863 & 1537612 & 8.0 & 8.0799 & TST & \\
\hline CHEMBL3732331 & 1537612 & 5.9957 & 6.3421 & TST & \\
\hline CHEMBL3729570 & 1537612 & 8.0 & 8.0103 & TST & \\
\hline CHEMBL3729924 & 1537612 & 3.9996 & 5.1905 & TST & \\
\hline CHEMBL3730556 & 1537612 & 3.9996 & 4.9224 & TST & \\
\hline CHEMBL3730232 & 1537612 & 8.0 & 7.8181 & TST & \\
\hline CHEMBL 2170511 & 864762 & 6.2218 & 6.329 & TRN & \\
\hline CHEMBL 2170335 & 864762 & 5.0458 & 5.1987 & TRN & \\
\hline CHEMBL 2170362 & 864762 & 5.301 & 5.3385 & TRN & \\
\hline CHEMBL 2170358 & 864762 & 4.4225 & 4.3756 & TRN & \\
\hline CHEMBL 2170508 & 864762 & 6.699 & 6.629 & TRN & \\
\hline CHEMBL 2170319 & 864762 & 5.2147 & 5.0884 & TRN & \\
\hline CHEMBL 2170513 & 864762 & 6.0 & 6.0479 & TRN & \\
\hline CHEMBL 2170328 & 864762 & 4.8153 & 4.6958 & TRN & \\
\hline CHEMBL 2170344 & 864762 & 4.3439 & 5.51200 & 00000000005 & TST \\
\hline CHEMBL 2170356 & 864762 & 4.8356 & 4.8963 & TRN & \\
\hline CHEMBL 2170341 & 864762 & 4.7959 & 5.3145 & TST & \\
\hline CHEMBL 2170321 & 864762 & 5.1487 & 5.0175 & TRN & \\
\hline CHEMBL 2170357 & 864762 & 5.0458 & 5.1317 & TRN & \\
\hline CHEMBL 2170510 & 864762 & 6.301 & 6.2827 & TRN & \\
\hline CHEMBL 2170316 & 864762 & 5.4685 & 5.4293 & TRN & \\
\hline CHEMBL 2170506 & 864762 & 3.5331 & 3.5388 & TRN & \\
\hline CHEMBL 2170324 & 864762 & 4.9706 & 4.7576 & TRN & \\
\hline CHEMBL 2170512 & 864762 & 6.0969 & 5.9212 & TRN & \\
\hline CHEMBL 2170503 & 864762 & 5.0969 & 4.979 & TRN & \\
\hline CHEMBL 2170340 & 864762 & 4.8069 & 4.6357 & TRN & \\
\hline CHEMBL 2170336 & 864762 & 5.0458 & 4.5328 & TST & \\
\hline CHEMBL 2170507 & 864762 & 7.0 & 6.0013 & TST & \\
\hline CHEMBL 2170354 & 864762 & 4.5768 & 4.5254 & TRN & \\
\hline CHEMBL 2169887 & 864762 & 5.9208 & 5.2883 & TST & \\
\hline CHEMBL 2170350 & 864762 & 2.9 & 5.5665 & TST & \\
\hline CHEMBL 2170334 & 864762 & 5.0915 & 5.1084 & TRN & \\
\hline CHEMBL 2170329 & 864762 & 4.5918 & 4.499 & TRN & \\
\hline CHEMBL 2170504 & 864762 & 4.9706 & 4.4945 & TST & \\
\hline CHEMBL 2170339 & 864762 & 4.8416 & 4.8369 & TST & \\
\hline CHEMBL 2170505 & 864762 & 3.8041 & 3.906 & TRN & \\
\hline CHEMBL 2170326 & 864762 & 4.9318 & 5.0779 & TRN & \\
\hline CHEMBL 2170338 & 864762 & 4.8729 & 4.8803 & TRN & \\
\hline CHEMBL 2170327 & 864762 & 4.857 & 5.0843 & TRN & \\
\hline CHEMBL 2170514 & 864762 & 5.9586 & 6.0514 & TRN & \\
\hline CHEMBL 2170353 & 864762 & $4.8210 e$ & 00000000 & 4.6813 & $1 \mathrm{NT}$ \\
\hline CHEMBL 2170359 & 864762 & 4.3645 & 4.6504 & TST & \\
\hline CHEMBL 2170516 & 864762 & 5.4685 & 5.6072 & TRN & \\
\hline CHEMBL 2170317 & 864762 & 5.3565 & 5.484 & TRN & \\
\hline CHEMBL 2170351 & 864762 & 2.983 & 4.1098 & TST & \\
\hline CHEMBL 2170325 & 864762 & 4.9626 & 4.8946 & TRN & \\
\hline CHEMBL 2170337 & 864762 & 5.0315 & 4.8511 & TST & \\
\hline CHEMBL 2170330 & 864762 & 4.2358 & 4.0618 & TRN & \\
\hline
\end{tabular}




\begin{tabular}{|c|c|c|c|c|c|}
\hline & & \multicolumn{4}{|c|}{ Supplemental Table S2.txt } \\
\hline CHEMBL 2170323 & 864762 & 5.0088 & 5.8699 & TRN & \\
\hline CHEMBL 2170318 & 864762 & 5.2596 & 5.1854 & TRN & \\
\hline CHEMBL 2170347 & 864762 & 2.5421 & 2.8155 & TRN & \\
\hline CHEMBL 2170515 & 864762 & 5.9208 & 5.8282 & TRN & \\
\hline CHEMBL2170331 & 864762 & 5.7696 & 5.0696 & TST & \\
\hline CHEMBL 2170360 & 864762 & 4.1694 & 4.998 & TST & \\
\hline CHEMBL2170509 & 864762 & 6.3979 & 6.3095 & TRN & \\
\hline CHEMBL 2170346 & 864762 & 3.6712 & 3.9052 & TRN & \\
\hline CHEMBL 2170352 & 864762 & 2.0996 & 3.534 & TST & \\
\hline CHEMBL2170332 & 864762 & 5.4559 & 4.7093 & TRN & \\
\hline CHEMBL 2170361 & 864762 & 5.4089 & 5.5123 & TST & \\
\hline CHEMBL 2170343 & 864762 & 4.6478 & 4.5856 & TRN & \\
\hline CHEMBL 2170349 & 864762 & 2.4248 & 2.5757 & TRN & \\
\hline CHEMBL 2170348 & 864762 & 2.4584 & 2.5207 & TRN & \\
\hline CHEMBL2170355 & 864762 & 2.9547 & 3.2585 & TST & \\
\hline CHEMBL 2170342 & 864762 & 4.6517 & 4.5416 & TRN & \\
\hline CHEMBL 2170320 & 864762 & 5.1805 & 5.1854 & TRN & \\
\hline CHEMBL 2169892 & 864762 & 5.301 & 5.3037 & TRN & \\
\hline CHEMBL 2170322 & 864762 & 5.0506 & 4.8989 & TRN & \\
\hline CHEMBL 2170345 & 864762 & 3.7438 & 3.78800 & 00000000003 & TRN \\
\hline CHEMBL 2170333 & 864762 & 5.3468 & 5.438 & TRN & \\
\hline CHEMBL2311982 & 936415 & 3.0 & 2.7251 & TST & \\
\hline CHEMBL 2312366 & 936415 & 6.0362 & 5.8835 & TRN & \\
\hline CHEMBL 2312354 & 936415 & 5.0783 & 4.9811 & TRN & \\
\hline CHEMBL2312352 & 936415 & 5.2782 & 5.5212 & TRN & \\
\hline CHEMBL2312363 & 936415 & 3.0 & 2.85100 & 00000000004 & TRN \\
\hline CHEMBL2312365 & 936415 & 3.0 & 3.44100 & 00000000003 & TRN \\
\hline CHEMBL2312362 & 936415 & 3.0 & 3.0066 & TRN & \\
\hline CHEMBL2312345 & 936415 & 3.0 & 3.4574 & TST & \\
\hline CHEMBL 2312390 & 936415 & 3.0 & 3.6686 & TST & \\
\hline CHEMBL2312385 & 936415 & 3.0 & 3.352 & TRN & \\
\hline CHEMBL2311977 & 936415 & 3.0 & 2.3399 & TRN & \\
\hline CHEMBL2312376 & 936415 & 5.857 & 6.25200 & 0000000001 & TRN \\
\hline CHEMBL 2312360 & 936415 & 3.0 & 2.6018 & TRN & \\
\hline CHEMBL2312347 & 936415 & 4.6126 & 5.4119 & TST & \\
\hline CHEMBL 2312370 & 936415 & 6.4815 & 6.6825 & TRN & \\
\hline CHEMBL 2312361 & 936415 & 6.5376 & 6.5807 & TRN & \\
\hline CHEMBL2311980 & 936415 & 3.0 & 2.6672 & TST & \\
\hline CHEMBL 2312382 & 936415 & 6.3872 & 6.2053 & TRN & \\
\hline CHEMBL 2312373 & 936415 & 6.6198 & 6.4868 & TRN & \\
\hline CHEMBL 2312383 & 936415 & 6.4318 & 6.7948 & TRN & \\
\hline CHEMBL 2312392 & 936415 & 7.0 & 6.5861 & TRN & \\
\hline CHEMBL2312377 & 936415 & 6.699 & 6.5253 & TRN & \\
\hline CHEMBL 2312371 & 936415 & 5.5686 & 5.9106 & TRN & \\
\hline CHEMBL2311979 & 936415 & 3.0 & 2.7363 & TRN & \\
\hline CHEMBL2312386 & 936415 & 5.76200 & 30000000 & 5.6562 & TRN \\
\hline CHEMBL123099 & 936415 & 6.7696 & 5.9741 & TRN & \\
\hline CHEMBL2312358 & 936415 & 7.699 & 6.6534 & TRN & \\
\hline
\end{tabular}




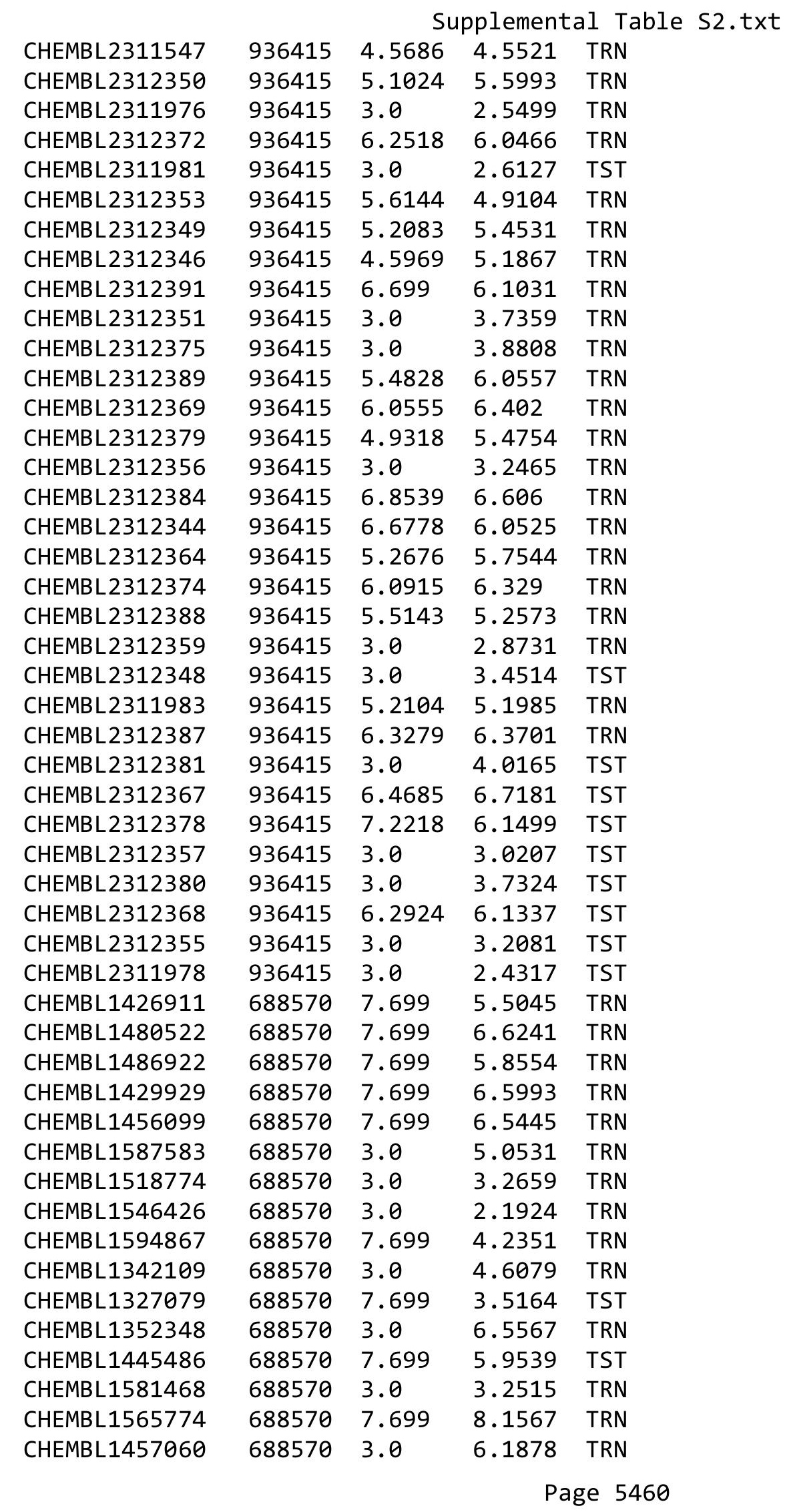




\begin{tabular}{|c|c|c|c|c|}
\hline \multicolumn{5}{|c|}{ Supplemental Table S2.txt } \\
\hline CHEMBL1382028 & 688570 & 7.699 & 6.646 & TRN \\
\hline CHEMBL1544823 & 688570 & 7.699 & 6.4819 & TRN \\
\hline CHEMBL1427979 & 688570 & 3.0 & 3.2504 & TRN \\
\hline CHEMBL1453291 & 688570 & 3.0 & 4.074 & TRN \\
\hline CHEMBL1327749 & 688570 & 3.0 & 4.0934 & TRN \\
\hline CHEMBL1369691 & 688570 & 3.0 & 2.1465 & TRN \\
\hline CHEMBL1504592 & 688570 & 3.0 & 6.807 & TRN \\
\hline CHEMBL1427279 & 688570 & 3.0 & 5.7725 & TRN \\
\hline CHEMBL191750 & 688570 & 3.0 & 4.8311 & TRN \\
\hline CHEMBL1568558 & 688570 & 7.699 & 6.0676 & TRN \\
\hline CHEMBL1978424 & 688570 & 7.699 & 6.5902 & TRN \\
\hline CHEMBL1464941 & 688570 & 7.699 & 7.5197 & TRN \\
\hline CHEMBL1988310 & 688570 & 3.0 & 4.6138 & TST \\
\hline CHEMBL1450119 & 688570 & 7.699 & 7.3267 & TRN \\
\hline CHEMBL1301573 & 688570 & 7.699 & 4.2227 & TRN \\
\hline CHEMBL1332688 & 688570 & 3.0 & 3.6907 & TRN \\
\hline CHEMBL1454247 & 688570 & 7.699 & 5.2018 & TRN \\
\hline CHEMBL210730 & 688570 & 7.699 & 5.8462 & TRN \\
\hline CHEMBL1516729 & 688570 & 7.699 & 5.6799 & TRN \\
\hline CHEMBL1307919 & 688570 & 7.699 & 6.9306 & TRN \\
\hline CHEMBL1389449 & 688570 & 3.0 & 4.1988 & TRN \\
\hline CHEMBL1384654 & 688570 & 7.699 & 5.7844 & TRN \\
\hline CHEMBL1585105 & 688570 & 3.0 & 3.6929 & TRN \\
\hline CHEMBL1471717 & 688570 & 3.0 & 3.7263 & TRN \\
\hline CHEMBL1309232 & 688570 & 7.699 & 5.5982 & TRN \\
\hline CHEMBL1521476 & 688570 & 3.0 & 5.3272 & TRN \\
\hline CHEMBL1453801 & 688570 & 3.0 & 4.5676 & TRN \\
\hline CHEMBL1403048 & 688570 & 7.699 & 6.345 & TRN \\
\hline CHEMBL1452967 & 688570 & 7.699 & 8.555 & TRN \\
\hline CHEMBL1459767 & 688570 & 3.0 & 3.7486 & TRN \\
\hline CHEMBL1304398 & 688570 & 7.699 & 8.0692 & TRN \\
\hline CHEMBL1307028 & 688570 & 3.0 & 5.8896 & TRN \\
\hline CHEMBL1409173 & 688570 & 3.0 & 4.1713 & TRN \\
\hline CHEMBL1369231 & 688570 & 3.0 & 3.5198 & TRN \\
\hline CHEMBL1492738 & 688570 & 7.699 & 4.7153 & TRN \\
\hline CHEMBL1606813 & 688570 & 3.0 & 2.8169 & TRN \\
\hline CHEMBL1303835 & 688570 & 3.0 & 4.8425 & TRN \\
\hline CHEMBL1564077 & 688570 & 7.699 & 4.8286 & TST \\
\hline CHEMBL1313891 & 688570 & 7.699 & 7.0916 & TRN \\
\hline CHEMBL1502354 & 688570 & 3.0 & 5.098 & TST \\
\hline CHEMBL1329235 & 688570 & 3.0 & 7.2579 & TST \\
\hline CHEMBL3213419 & 688570 & 3.0 & 3.175 & TST \\
\hline CHEMBL374632 & 688570 & 7.699 & 5.082 & TST \\
\hline CHEMBL1345388 & 688570 & 7.699 & 6.1006 & TST \\
\hline CHEMBL547833 & 688570 & 7.699 & 6.0233 & TST \\
\hline CHEMBL1904348 & 688570 & 7.699 & 5.7185 & TST \\
\hline CHEMBL1438451 & 688570 & 7.699 & 3.5522 & TST \\
\hline CHEMBL1450780 & 688570 & 3.0 & 5.8109 & TST \\
\hline
\end{tabular}




\begin{tabular}{|c|c|c|c|c|c|}
\hline \\
\hline CHEMBL1595336 & 688570 & 3.0 & 3.6159 & TST & \\
\hline CHEMBL1527447 & 688570 & 7.699 & 6.3114 & TST & \\
\hline CHEMBL1526910 & 688570 & 7.699 & 6.5279 & TST & \\
\hline CHEMBL1374135 & 688570 & 3.0 & 6.1882 & TST & \\
\hline CHEMBL142926 & 302754 & 7.3979 & 7.3973 & TRN & \\
\hline CHEMBL145767 & 302754 & 9.8539 & 9.7817 & TRN & \\
\hline CHEMBL179133 & 302754 & 8.0013 & 7.8933 & TRN & \\
\hline CHEMBL349611 & 302754 & 9.2441 & 9.2879 & TRN & \\
\hline CHEMBL164686 & 302754 & 9.1308 & 9.1963 & TRN & \\
\hline CHEMBL358735 & 302754 & 7.5229 & 7.7437 & TRN & \\
\hline CHEMBL423542 & 302754 & 6.3665 & 6.8802 & TST & \\
\hline CHEMBL175494 & 302754 & 8.3098 & 8.2681 & TRN & \\
\hline CHEMBL137879 & 302754 & 6.4802 & 8.2691 & TST & \\
\hline CHEMBL180583 & 302754 & 7.7881 & 7.7741 & TRN & \\
\hline CHEMBL165600 & 302754 & 9.4318 & 9.3543 & TRN & \\
\hline CHEMBL355415 & 302754 & 9.0915 & 9.1963 & TRN & \\
\hline CHEMBL350830 & 302754 & 9.041 & 9.2458 & TRN & \\
\hline CHEMBL175474 & 302754 & 8.3487 & 8.3282 & TRN & \\
\hline CHEMBL349019 & 302754 & 8.4685 & 8.601 & TRN & \\
\hline CHEMBL352192 & 302754 & 9.301 & 9.3994 & TRN & \\
\hline CHEMBL349716 & 302754 & 9.0655 & 9.1445 & TRN & \\
\hline CHEMBL350205 & 302754 & 9.3468 & 9.3002 & TRN & \\
\hline CHEMBL164905 & 302754 & 9.4685 & 9.585 & TRN & \\
\hline CHEMBL164685 & 302754 & 9.0655 & 9.3311 & TRN & \\
\hline CHEMBL16867 & 302754 & 6.5528 & 7.8768 & TST & \\
\hline CHEMBL164509 & 302754 & 9.2924 & 9.1592 & TRN & \\
\hline CHEMBL 342500 & 302754 & 7.2596 & 7.2723 & TRN & \\
\hline CHEMBL165778 & 302754 & 9.5376 & 9.3442 & TRN & \\
\hline CHEMBL139182 & 302754 & 7.3979 & 7.6697 & TRN & \\
\hline CHEMBL341852 & 302754 & 7.1487 & 7.1241 & TRN & \\
\hline CHEMBL164281 & 302754 & 9.041 & 9.1042 & TRN & \\
\hline CHEMBL423934 & 302754 & 9.2218 & 8.9906 & TRN & \\
\hline CHEMBL348925 & 302754 & 9.3372 & 9.3229 & TRN & \\
\hline CHEMBL330286 & 302754 & 9.4949 & 9.3888 & TRN & \\
\hline CHEMBL 359531 & 302754 & 5.8297 & 8.3632 & TST & \\
\hline CHEMBL141550 & 302754 & 9.7212 & 9.8509 & TST & \\
\hline CHEMBL424161 & 302754 & 9.3665 & 9.51700 & 3000000001 & TRN \\
\hline CHEMBL 324735 & 302754 & 9.7959 & 9.8449 & TRN & \\
\hline CHEMBL354161 & 302754 & 9.3665 & 9.1464 & TRN & \\
\hline CHEMBL164647 & 302754 & 9.2518 & 9.2777 & TRN & \\
\hline CHEMBL137950 & 302754 & 8.0969 & 8.3001 & TRN & \\
\hline CHEMBL 366396 & 302754 & 8.0921 & 8.0503 & TRN & \\
\hline CHEMBL359473 & 302754 & 8.2262 & 8.1613 & TRN & \\
\hline CHEMBL165044 & 302754 & 9.0132 & 9.1632 & TRN & \\
\hline CHEMBL 350042 & 302754 & 9.1487 & 9.11399 & 9999999999 & TRN \\
\hline CHEMBL572765 & 302754 & 9.4685 & 9.3403 & TRN & \\
\hline CHEMBL177066 & 302754 & 8.1062 & 8.1791 & TRN & \\
\hline CHEMBL164275 & 302754 & 8.5229 & 8.5726 & TRN & \\
\hline
\end{tabular}




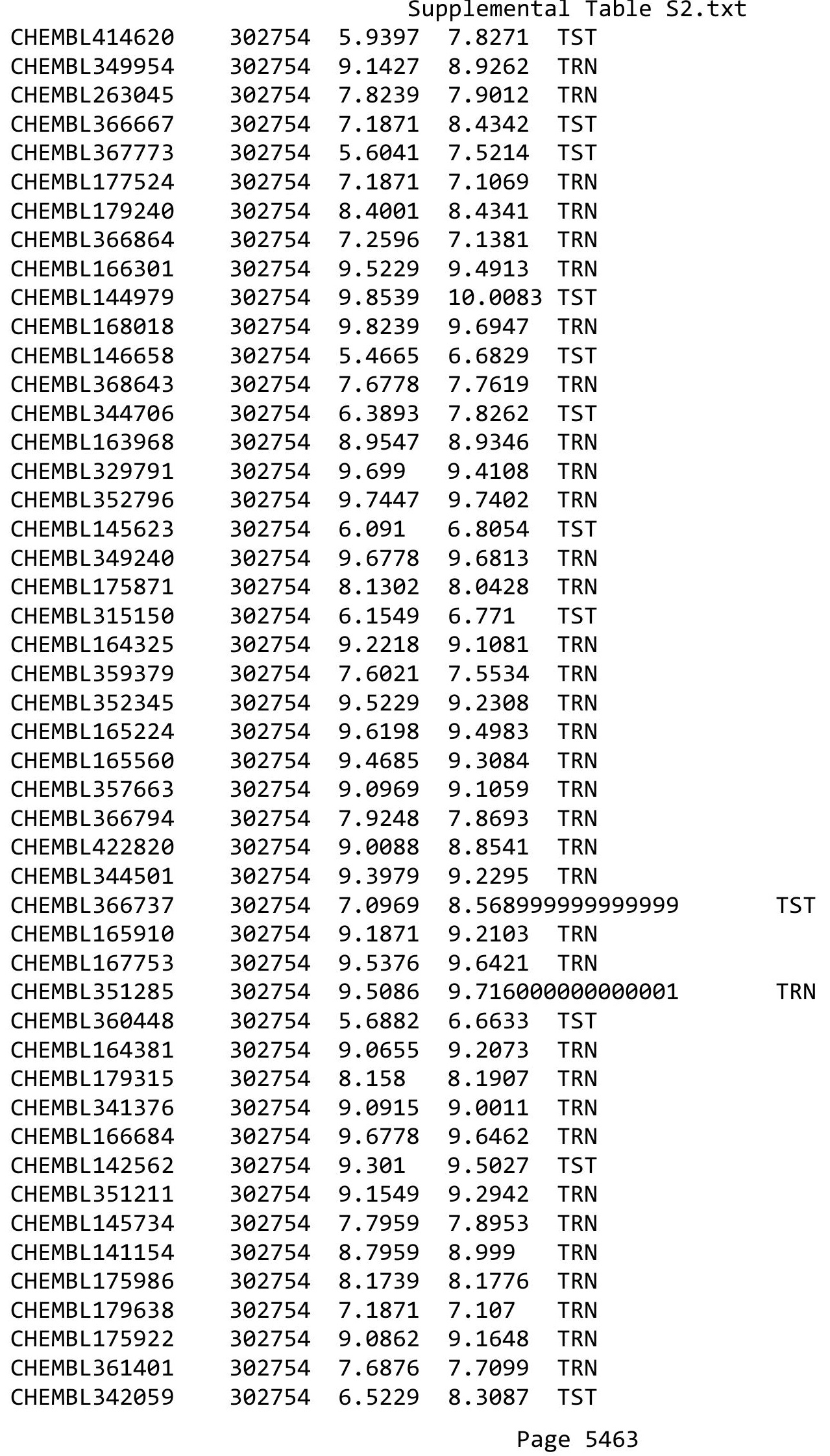


Supplemental Table S2.txt

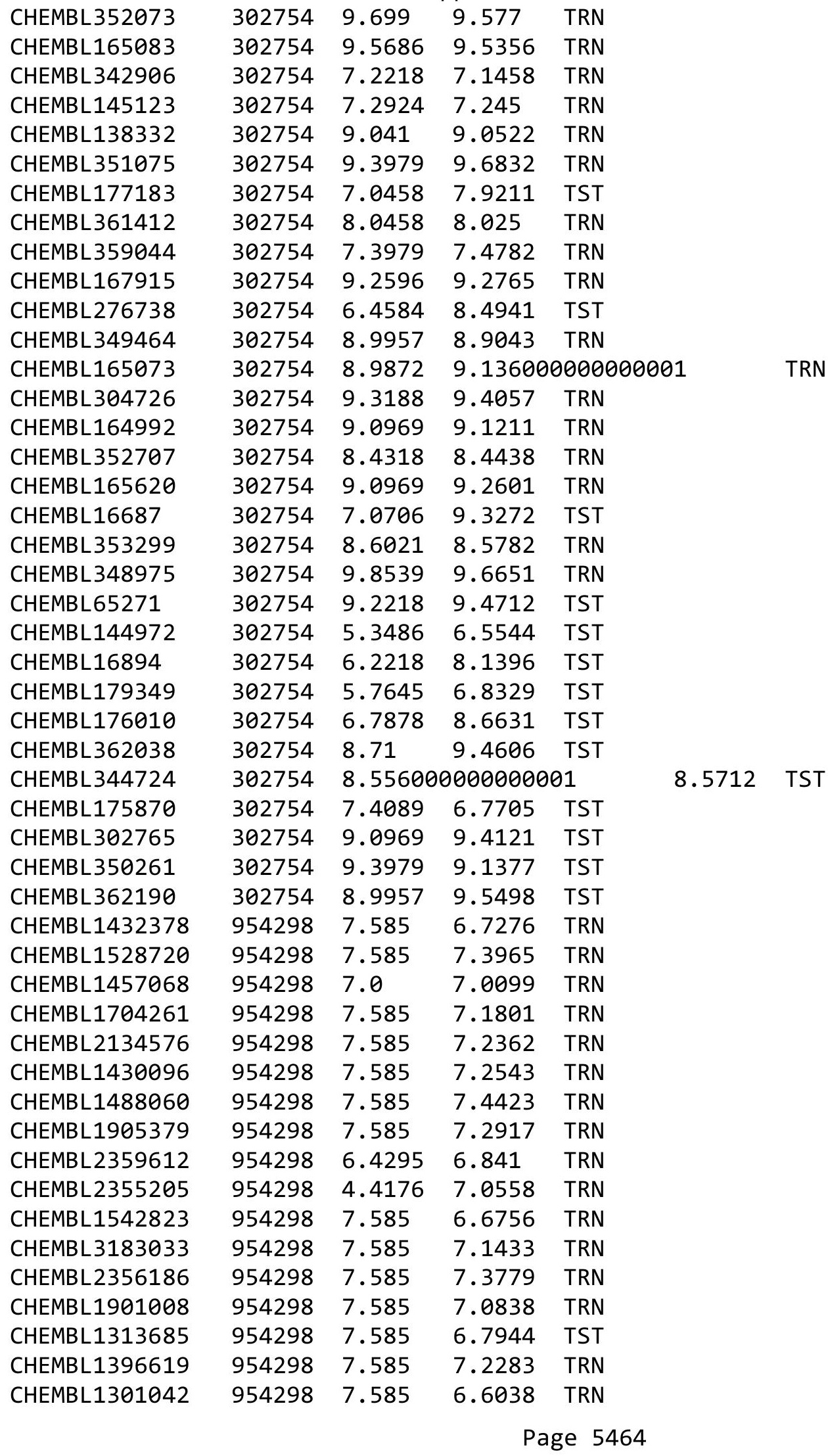


Supplemental Table S2.txt

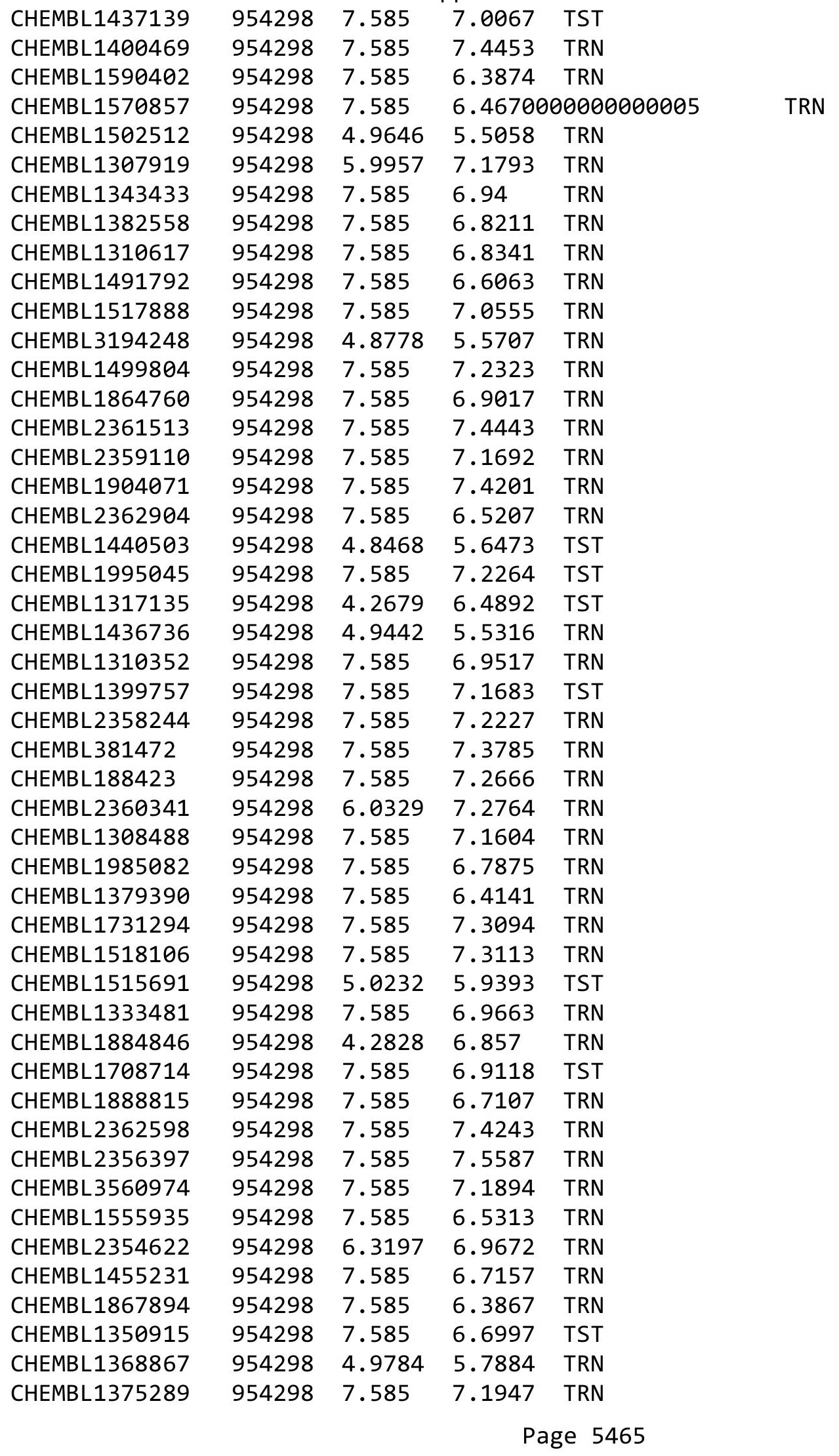




\begin{tabular}{|c|c|c|c|c|c|}
\hline & & \multicolumn{4}{|c|}{ Supplemental Table S2.txt } \\
\hline CHEMBL1414970 & 954298 & 7.585 & 7.2566 & TRN & \\
\hline CHEMBL 2360303 & 954298 & 7.585 & 7.4683 & TRN & \\
\hline CHEMBL1459468 & 954298 & 4.9097 & 5.8319 & TRN & \\
\hline CHEMBL1445297 & 954298 & 6.4248 & 6.5471 & TRN & \\
\hline CHEMBL 2357173 & 954298 & 4.4499 & 7.461 & TRN & \\
\hline CHEMBL1478578 & 954298 & 4.9083 & 5.9143 & TRN & \\
\hline CHEMBL1438210 & 954298 & 7.585 & 7.246 & TRN & \\
\hline CHEMBL1404301 & 954298 & 7.585 & 6.4938 & TRN & \\
\hline CHEMBL 2358509 & 954298 & 5.3665 & 7.4031 & TRN & \\
\hline CHEMBL1484139 & 954298 & 7.585 & 7.1835 & TST & \\
\hline CHEMBL 2357404 & 954298 & 4.1917 & 7.2347 & TRN & \\
\hline CHEMBL1599994 & 954298 & 4.9535 & 5.7441 & TRN & \\
\hline CHEMBL 2356010 & 954298 & 4.3539 & 7.3207 & TRN & \\
\hline CHEMBL1486332 & 954298 & 5.0022 & 5.5767 & TRN & \\
\hline CHEMBL1520276 & 954298 & 7.585 & 7.3377 & TRN & \\
\hline CHEMBL1871451 & 954298 & 7.585 & 7.2648 & TRN & \\
\hline CHEMBL1542312 & 954298 & 4.909 & 5.7334 & TST & \\
\hline CHEMBL1899873 & 954298 & 7.585 & 7.0257 & TRN & \\
\hline CHEMBL1595930 & 954298 & 5.8477 & 7.3475 & TRN & \\
\hline CHEMBL1457201 & 954298 & 4.8847 & 5.5573 & TRN & \\
\hline CHEMBL1456324 & 954298 & 7.585 & 7.1929 & TST & \\
\hline CHEMBL1348874 & 954298 & 7.585 & 6.6421 & TRN & \\
\hline CHEMBL1486546 & 954298 & 7.585 & 7.4041 & TRN & \\
\hline CHEMBL1584985 & 954298 & 7.585 & 6.6719 & TRN & \\
\hline CHEMBL 2358490 & 954298 & 7.585 & 7.4612 & TRN & \\
\hline CHEMBL1709094 & 954298 & 4.1924 & 6.7754 & TST & \\
\hline CHEMBL1570743 & 954298 & 7.585 & 7.4643 & TST & \\
\hline CHEMBL1699228 & 954298 & 7.585 & 7.0581 & TST & \\
\hline CHEMBL1704298 & 954298 & 7.585 & 6.6594 & TRN & \\
\hline CHEMBL1561102 & 954298 & 4.9066 & 5.5859 & TRN & \\
\hline CHEMBL1311838 & 954298 & 7.585 & 6.4285 & TRN & \\
\hline CHEMBL1970422 & 954298 & 7.585 & 6.8085 & TST & \\
\hline CHEMBL1971018 & 954298 & 7.585 & 6.6814 & TRN & \\
\hline CHEMBL1350357 & 954298 & 7.585 & 6.711 & TRN & \\
\hline CHEMBL1387923 & 954298 & 7.585 & 6.5338 & TRN & \\
\hline CHEMBL1361883 & 954298 & 7.585 & 6.9495 & TRN & \\
\hline CHEMBL580955 & 954298 & 7.585 & 7.38700 & 00000000005 & TRN \\
\hline CHEMBL 2133790 & 954298 & 7.585 & 6.4933 & TRN & \\
\hline CHEMBL1361509 & 954298 & 7.585 & 7.1688 & TRN & \\
\hline CHEMBL1728992 & 954298 & 4.7044 & 5.7309 & TST & \\
\hline CHEMBL1405122 & 954298 & 7.585 & 6.6011 & TST & \\
\hline CHEMBL1321427 & 954298 & 7.585 & 7.3159 & TRN & \\
\hline CHEMBL1711200 & 954298 & 4.1674 & 7.3736 & TRN & \\
\hline CHEMBL1378392 & 954298 & 4.9905 & 5.3323 & TRN & \\
\hline CHEMBL 2354739 & 954298 & 7.585 & 7.481 & TRN & \\
\hline CHEMBL1898104 & 954298 & 4.8894 & 6.018 & TRN & \\
\hline CHEMBL1522047 & 954298 & 7.585 & 7.3308 & TRN & \\
\hline CHEMBL465843 & 954298 & 4.218 & 6.7402 & TRN & \\
\hline
\end{tabular}




\begin{tabular}{|c|c|c|c|c|}
\hline & & & oplement & al Ta \\
\hline CHEMBL1559813 & 954298 & 5.0283 & 5.8595 & TRN \\
\hline CHEMBL1873438 & 954298 & 7.585 & 7.2833 & TRN \\
\hline CHEMBL1735419 & 954298 & 6.5607 & 7.341 & TST \\
\hline CHEMBL1607801 & 954298 & 7.585 & 7.2432 & TRN \\
\hline CHEMBL1384253 & 954298 & 7.585 & 6.9562 & TRN \\
\hline CHEMBL1376166 & 954298 & 7.585 & 7.1576 & TRN \\
\hline CHEMBL1580784 & 954298 & 7.585 & 6.9155 & TRN \\
\hline CHEMBL1468323 & 954298 & 7.585 & 7.1141 & TRN \\
\hline CHEMBL1589062 & 954298 & 4.6724 & 5.6346 & TRN \\
\hline CHEMBL1402010 & 954298 & 7.585 & 7.0194 & TRN \\
\hline CHEMBL1448282 & 954298 & 7.585 & 7.0421 & TRN \\
\hline CHEMBL1983234 & 954298 & 7.585 & 7.1457 & TRN \\
\hline CHEMBL1303426 & 954298 & 4.2984 & 7.0461 & TRN \\
\hline CHEMBL 2358011 & 954298 & 4.2033 & 7.2641 & TRN \\
\hline CHEMBL1446377 & 954298 & 7.585 & 6.5108 & TRN \\
\hline CHEMBL1347349 & 954298 & 7.585 & 7.3343 & TST \\
\hline CHEMBL1416856 & 954298 & 7.585 & 6.5871 & TST \\
\hline CHEMBL 2359072 & 954298 & 7.585 & 6.391 & TST \\
\hline CHEMBL1350432 & 954298 & 7.585 & 7.3521 & TST \\
\hline CHEMBL1500335 & 954298 & 7.585 & 7.3369 & TST \\
\hline CHEMBL1564801 & 954298 & 7.585 & 6.4027 & TST \\
\hline CHEMBL1900730 & 954298 & 7.585 & 7.222 & TST \\
\hline CHEMBL3196994 & 954298 & 5.0778 & 5.6865 & TST \\
\hline CHEMBL 2360775 & 954298 & 7.585 & 7.2544 & TST \\
\hline CHEMBL1359982 & 954298 & 4.1601 & 6.4261 & TST \\
\hline CHEMBL1384845 & 954298 & 7.585 & 7.2102 & TST \\
\hline CHEMBL1873119 & 954298 & 7.585 & 7.2158 & TST \\
\hline CHEMBL1401040 & 954298 & 7.585 & 7.4479 & TST \\
\hline CHEMBL509617 & 954298 & 7.585 & 6.8233 & TST \\
\hline CHEMBL1561133 & 954298 & 4.9017 & 5.495 & TST \\
\hline CHEMBL3192873 & 954298 & 4.8921 & 5.657 & TST \\
\hline CHEMBL 26260 & 954298 & 7.585 & 7.2557 & TST \\
\hline CHEMBL1589168 & 954298 & 7.585 & 7.11 & TST \\
\hline CHEMBL1258350 & 665227 & 6.6021 & 7.0215 & TRN \\
\hline CHEMBL379511 & 665227 & 7.5229 & 6.9313 & TST \\
\hline CHEMBL 215780 & 665227 & 6.4318 & 6.6263 & TRN \\
\hline CHEMBL1257889 & 665227 & 5.6383 & 6.5052 & TRN \\
\hline CHEMBL 385390 & 665227 & 7.1427 & 6.5696 & TRN \\
\hline CHEMBL384161 & 665227 & 6.2924 & 6.2259 & TRN \\
\hline CHEMBL1257529 & 665227 & 6.284 & 6.0887 & TRN \\
\hline CHEMBL 215083 & 665227 & 7.1024 & 6.7139 & TRN \\
\hline CHEMBL1257299 & 665227 & 6.1427 & 6.4171 & TRN \\
\hline CHEMBL1256439 & 665227 & 7.1938 & 6.4515 & TRN \\
\hline CHEMBL 214605 & 665227 & 6.4089 & 6.6979 & TRN \\
\hline CHEMBL1258351 & 665227 & 6.4559 & 6.7568 & TRN \\
\hline CHEMBL379766 & 665227 & 7.2218 & 6.5273 & TRN \\
\hline CHEMBL 386292 & 665227 & 5.7696 & 6.2066 & TRN \\
\hline CHEMBL1258797 & 665227 & 7.3188 & 7.359 & TRN \\
\hline
\end{tabular}




\begin{tabular}{|c|c|c|c|c|c|}
\hline \multicolumn{6}{|c|}{ supplemental } \\
\hline CHEMBL215390 & 665227 & 6.4318 & 6.5581 & TRN & \\
\hline CHEMBL383966 & 665227 & 6.7959 & 7.1078 & TST & \\
\hline CHEMBL215475 & 665227 & 7.301 & 7.2602 & TRN & \\
\hline CHEMBL 386462 & 665227 & 6.1367 & 6.6025 & TST & \\
\hline CHEMBL384373 & 665227 & 7.3872 & 7.4007 & TRN & \\
\hline CHEMBL211989 & 665227 & 5.8539 & 5.50899 & 99999999995 & TRN \\
\hline CHEMBL1258682 & 665227 & 6.2291 & 6.4074 & TRN & \\
\hline CHEMBL1258798 & 665227 & 7.0706 & 7.3022 & TRN & \\
\hline CHEMBL1256438 & 665227 & 6.6383 & 6.1772 & TRN & \\
\hline CHEMBL385072 & 665227 & 5.4318 & 5.098 & TRN & \\
\hline CHEMBL1257300 & 665227 & 4.0 & 4.6908 & TRN & \\
\hline CHEMBL1257770 & 665227 & 6.0605 & 6.381 & TRN & \\
\hline CHEMBL 214501 & 665227 & 7.1079 & 7.04700 & 0000000001 & TRN \\
\hline CHEMBL385596 & 665227 & 7.5229 & 6.8149 & TRN & \\
\hline CHEMBL452318 & 665227 & 6.3768 & 6.57 & TRN & \\
\hline CHEMBL1257416 & 665227 & 5.1643 & 5.7943 & TRN & \\
\hline CHEMBL 214610 & 665227 & 7.2924 & 6.7439 & TRN & \\
\hline CHEMBL214659 & 665227 & 7.2676 & 7.0733 & TRN & \\
\hline CHEMBL1257183 & 665227 & 5.2676 & 4.7712 & TRN & \\
\hline CHEMBL1257647 & 665227 & 6.4949 & 6.4723 & TRN & \\
\hline CHEMBL1257301 & 665227 & 5.2757 & 5.1303 & TRN & \\
\hline CHEMBL1258232 & 665227 & 6.3979 & 6.7893 & TRN & \\
\hline CHEMBL1256437 & 665227 & 6.2596 & 6.3636 & TRN & \\
\hline CHEMBL214449 & 665227 & 6.6383 & 6.7714 & TRN & \\
\hline CHEMBL1258000 & 665227 & 5.2757 & 6.2194 & TRN & \\
\hline CHEMBL 215487 & 665227 & 6.7447 & 6.4812 & TRN & \\
\hline CHEMBL452319 & 665227 & 7.1739 & 6.6757 & TRN & \\
\hline CHEMBL215476 & 665227 & 7.6021 & 7.0556 & TST & \\
\hline CHEMBL 379869 & 665227 & 6.9431 & 6.45 & TST & \\
\hline CHEMBL1257999 & 665227 & 5.2076 & 6.4933 & TST & \\
\hline CHEMBL1257648 & 665227 & 6.9586 & 6.2143 & TST & \\
\hline CHEMBL212863 & 665227 & 7.2676 & 6.4261 & TST & \\
\hline CHEMBL1257771 & 665227 & 6.2076 & 6.1115 & TST & \\
\hline CHEMBL 215665 & 665227 & 5.2007 & 6.2312 & TST & \\
\hline CHEMBL215769 & 665227 & 7.2518 & 6.8735 & TST & \\
\hline CHEMBL1256440 & 665227 & 6.5376 & 6.3712 & TST & \\
\hline CHEMBL1256441 & 665227 & 6.3098 & 6.2798 & TST & \\
\hline CHEMBL1257890 & 665227 & 6.2924 & 6.4198 & TST & \\
\hline CHEMBL1964290 & 809231 & 6.8 & 7.4035 & TRN & \\
\hline CHEMBL 2003768 & 809231 & 4.1 & 4.0992 & TRN & \\
\hline CHEMBL 213505 & 809231 & 5.1 & 4.3676 & TRN & \\
\hline CHEMBL1982880 & 809231 & 5.6 & 4.7736 & TRN & \\
\hline CHEMBL1987034 & 809231 & 5.6 & 5.5539 & TRN & \\
\hline CHEMBL1993941 & 809231 & 4.1 & 4.6283 & TRN & \\
\hline CHEMBL 377383 & 809231 & 4.1 & 4.5143 & TRN & \\
\hline CHEMBL 2005886 & 809231 & 4.1 & 4.6234 & TRN & \\
\hline CHEMBL481491 & 809231 & 4.1 & 4.4105 & TST & \\
\hline CHEMBL1682345 & 809231 & 5.7 & 4.7827 & TRN & \\
\hline
\end{tabular}




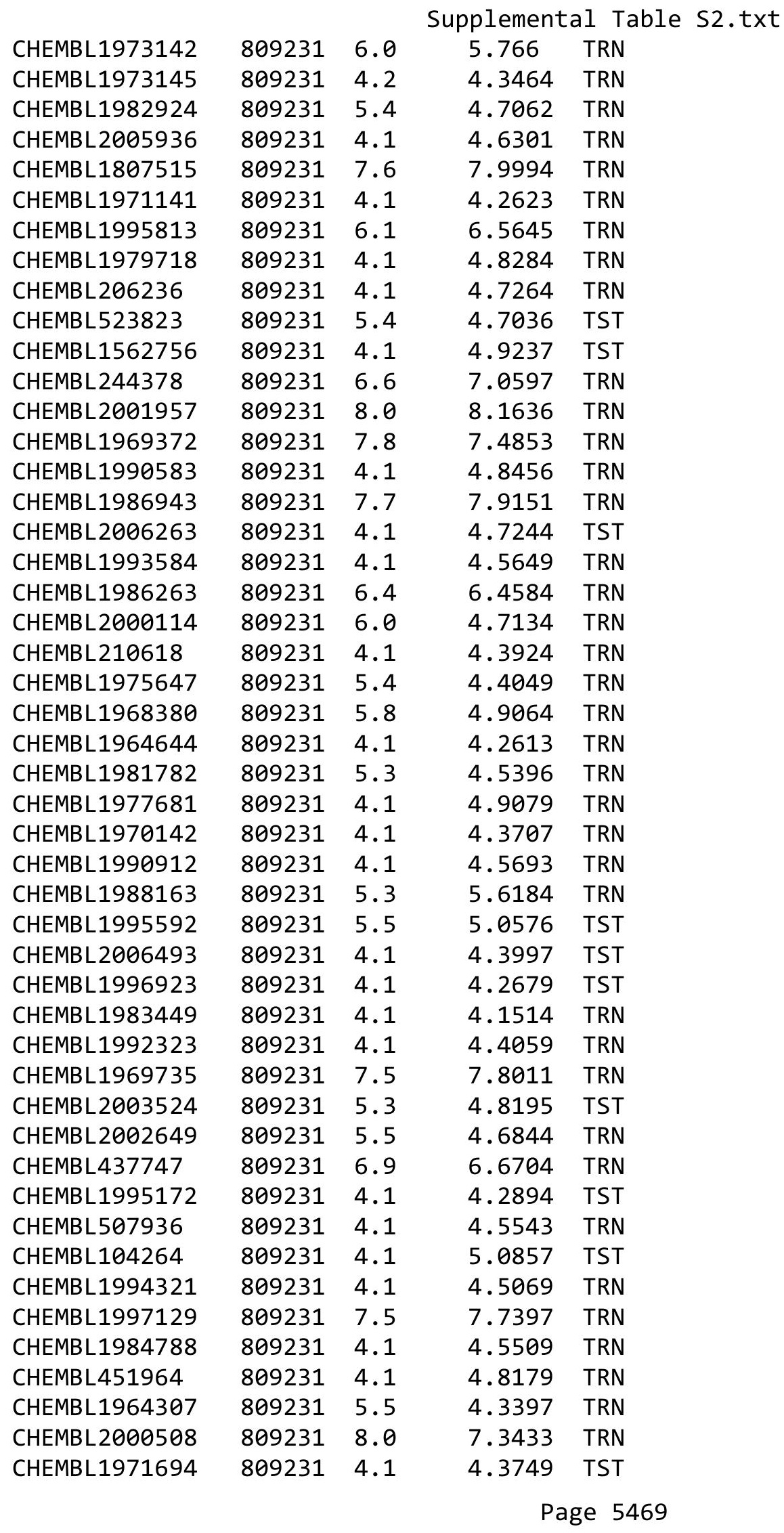




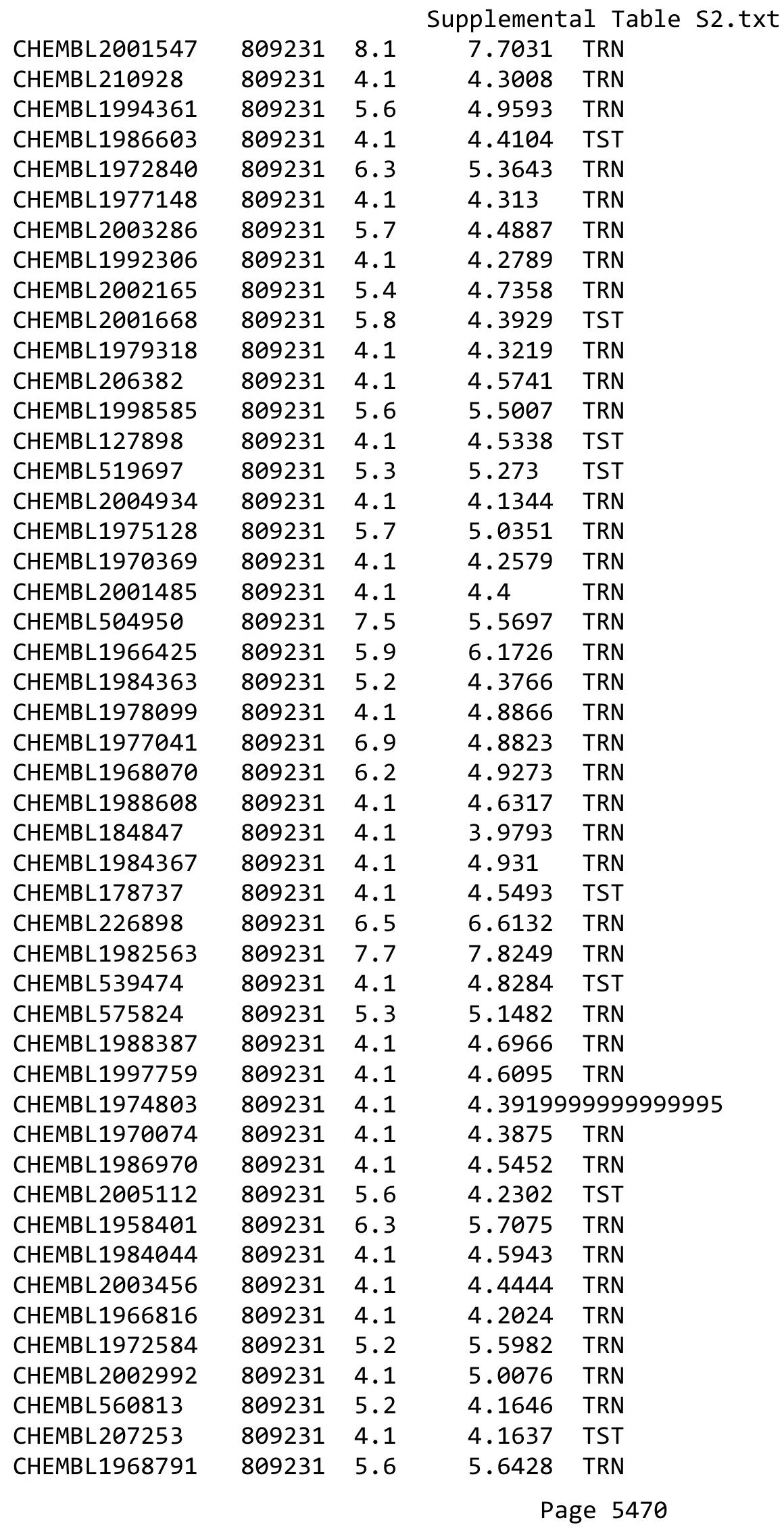




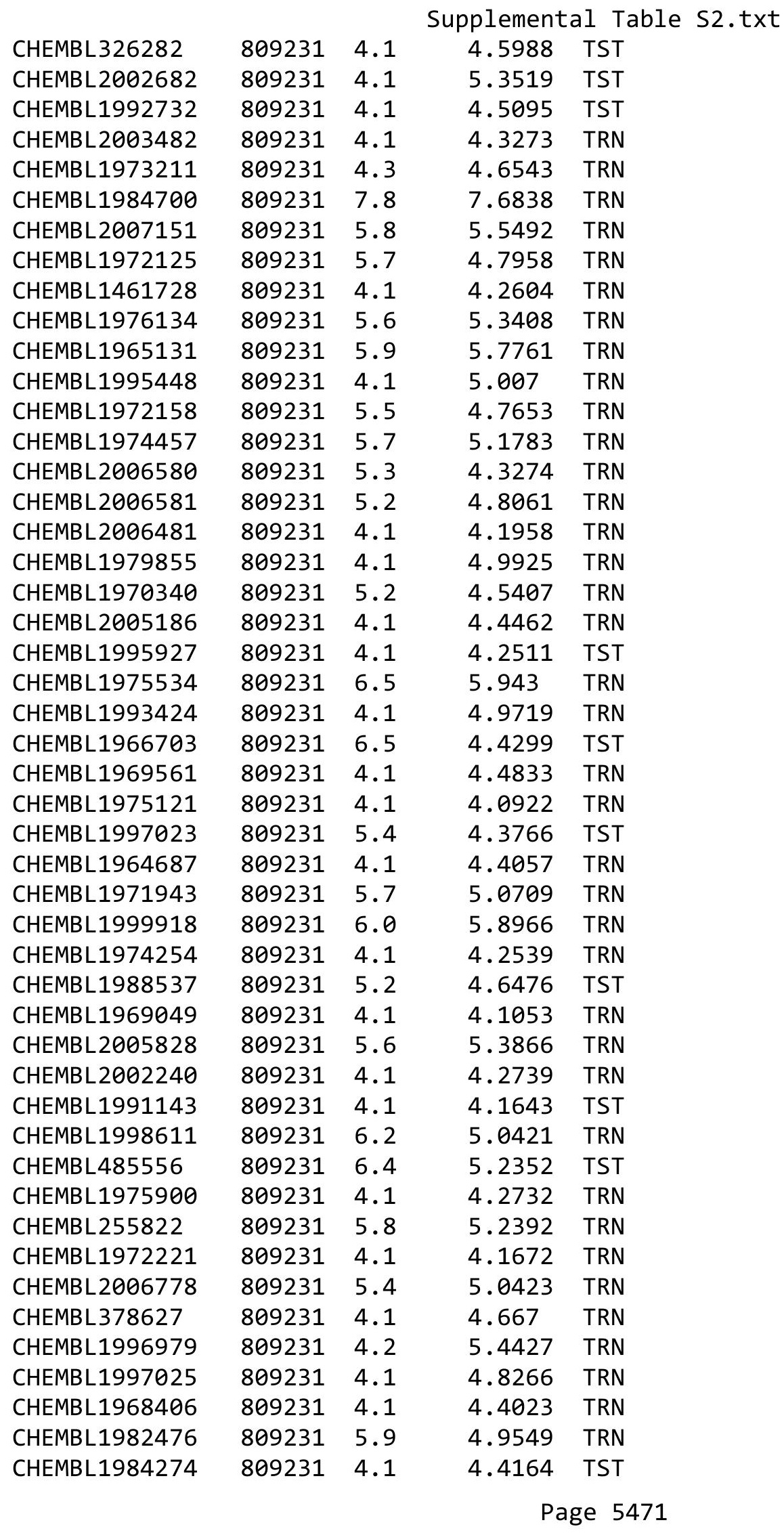




\begin{tabular}{|c|c|c|c|c|c|}
\hline \multicolumn{6}{|c|}{ Supplemental Table S2.txt } \\
\hline CHEMBL1998545 & 809231 & 4.1 & 4.1352 & TRN & \\
\hline CHEMBL1986869 & 809231 & 4.1 & 4.6069 & TRN & \\
\hline CHEMBL 2006010 & 809231 & 4.1 & 4.1706 & TRN & \\
\hline CHEMBL1682558 & 809231 & 6.9 & 4.7586 & TRN & \\
\hline CHEMBL1990496 & 809231 & 7.0 & 6.96399 & 99999999995 & TRN \\
\hline CHEMBL1997623 & 809231 & 4.1 & 4.4484 & TRN & \\
\hline CHEMBL 2002479 & 809231 & 5.5 & 5.1573 & TRN & \\
\hline CHEMBL1980371 & 809231 & 5.4 & 5.2638 & TST & \\
\hline CHEMBL1993166 & 809231 & 4.1 & 4.885 & TRN & \\
\hline CHEMBL1967094 & 809231 & 4.1 & 4.9372 & TRN & \\
\hline CHEMBL1966035 & 809231 & 4.1 & 4.1286 & TRN & \\
\hline CHEMBL 2003341 & 809231 & 4.1 & 4.1985 & TRN & \\
\hline CHEMBL1992645 & 809231 & 4.1 & 5.2055 & TST & \\
\hline CHEMBL1982992 & 809231 & 5.6 & 4.2771 & TRN & \\
\hline CHEMBL1999590 & 809231 & 5.8 & 4.4125 & TST & \\
\hline CHEMBL1981079 & 809231 & 7.6 & 8.2785 & TRN & \\
\hline CHEMBL1972276 & 809231 & 4.1 & 4.5517 & TRN & \\
\hline CHEMBL1980489 & 809231 & 4.1 & 4.1263 & TRN & \\
\hline CHEMBL 2000832 & 809231 & 5.2 & 4.4246 & TRN & \\
\hline CHEMBL1967116 & 809231 & 4.1 & 4.5197 & TRN & \\
\hline CHEMBL1977814 & 809231 & 4.1 & 4.3345 & TST & \\
\hline CHEMBL513846 & 809231 & 5.2 & 4.68199 & 99999999995 & TRN \\
\hline CHEMBL1970709 & 809231 & 4.1 & 4.2257 & TRN & \\
\hline CHEMBL1965660 & 809231 & 7.8 & 8.3724 & TRN & \\
\hline CHEMBL1998112 & 809231 & 4.1 & 4.7584 & TRN & \\
\hline CHEMBL1969126 & 809231 & 6.4 & 5.9522 & TRN & \\
\hline CHEMBL1980896 & 809231 & 5.5 & 4.7014 & TRN & \\
\hline CHEMBL1975208 & 809231 & 4.1 & 4.5617 & TST & \\
\hline CHEMBL1970104 & 809231 & 6.6 & 5.6107 & TRN & \\
\hline CHEMBL1991429 & 809231 & 6.2 & 5.0466 & TRN & \\
\hline CHEMBL1964777 & 809231 & 5.8 & 5.4022 & TRN & \\
\hline CHEMBL1971149 & 809231 & 6.9 & 6.9576 & TRN & \\
\hline CHEMBL1999714 & 809231 & 4.1 & 4.1187 & TRN & \\
\hline CHEMBL1987533 & 809231 & 4.1 & 4.2837 & TRN & \\
\hline CHEMBL1994040 & 809231 & 8.1 & 7.4889 & TRN & \\
\hline CHEMBL388978 & 809231 & 4.6 & 6.2583 & TST & \\
\hline CHEMBL579246 & 809231 & 4.1 & 5.3179 & TRN & \\
\hline CHEMBL398951 & 809231 & 4.1 & 4.2699 & TRN & \\
\hline CHEMBL1982506 & 809231 & 5.4 & 4.4799 & TST & \\
\hline CHEMBL 2004716 & 809231 & 5.1 & 4.9312 & TRN & \\
\hline CHEMBL1968127 & 809231 & 7.6 & 7.2015 & TRN & \\
\hline CHEMBL1975233 & 809231 & 4.1 & 4.3158 & TRN & \\
\hline CHEMBL1985406 & 809231 & 4.1 & 4.3052 & TRN & \\
\hline CHEMBL207400 & 809231 & 4.1 & 4.2736 & TST & \\
\hline CHEMBL 2000894 & 809231 & 5.9 & 4.7736 & TST & \\
\hline CHEMBL1982135 & 809231 & 4.1 & 4.4095 & TRN & \\
\hline CHEMBL1976090 & 809231 & 7.3 & 5.9724 & TRN & \\
\hline CHEMBL1993243 & 809231 & 5.4 & 4.9575 & TRN & \\
\hline
\end{tabular}




\begin{tabular}{|c|c|c|c|c|c|}
\hline \multicolumn{6}{|c|}{ Supplemental Table S2.txt } \\
\hline CHEMBL1992922 & 809231 & 4.1 & 4.5512 & TRN & \\
\hline CHEMBL 2004771 & 809231 & 4.1 & 4.4537 & TRN & \\
\hline CHEMBL399021 & 809231 & 6.0 & 5.6569 & TRN & \\
\hline CHEMBL1997597 & 809231 & 4.1 & 4.4062 & TRN & \\
\hline CHEMBL1969537 & 809231 & 4.1 & 4.6126 & TST & \\
\hline CHEMBL1976093 & 809231 & 7.8 & 7.0683 & TRN & \\
\hline CHEMBL210032 & 809231 & 4.1 & 4.333 & TRN & \\
\hline CHEMBL1996543 & 809231 & 4.1 & 5.3379 & TRN & \\
\hline CHEMBL1975256 & 809231 & 4.1 & 4.2079 & TST & \\
\hline CHEMBL508928 & 809231 & 5.7 & 4.2292 & TRN & \\
\hline CHEMBL1991356 & 809231 & 6.8 & 4.3621 & TST & \\
\hline CHEMBL1983309 & 809231 & 4.1 & 4.3461 & TRN & \\
\hline CHEMBL 2004892 & 809231 & 4.1 & 4.5461 & TRN & \\
\hline CHEMBL1999126 & 809231 & 5.3 & 4.1468 & TST & \\
\hline CHEMBL1997503 & 809231 & 4.1 & 4.4934 & TST & \\
\hline CHEMBL116070 & 809231 & 5.7 & 5.4626 & TRN & \\
\hline CHEMBL1990821 & 809231 & 4.1 & 4.382 & TST & \\
\hline CHEMBL1968340 & 809231 & 5.6 & 5.2341 & TRN & \\
\hline CHEMBL1970314 & 809231 & 4.1 & 4.4632 & TRN & \\
\hline CHEMBL 2004871 & 809231 & 7.1 & 6.0154 & TRN & \\
\hline CHEMBL 2004872 & 809231 & 4.1 & 4.2665 & TRN & \\
\hline CHEMBL1727312 & 809231 & 4.1 & 4.1912 & TRN & \\
\hline CHEMBL1969879 & 809231 & 4.1 & 4.2678 & TRN & \\
\hline CHEMBL1981720 & 809231 & 5.7 & 4.7086 & TRN & \\
\hline CHEMBL419932 & 809231 & 6.1 & 5.4526 & TRN & \\
\hline CHEMBL262433 & 809231 & 4.1 & 4.5325 & TRN & \\
\hline CHEMBL 306380 & 809231 & 6.7 & 6.16299 & 9999999999 & TRN \\
\hline CHEMBL1966722 & 809231 & 4.1 & 4.59399 & 9999999999 & TST \\
\hline CHEMBL1975500 & 809231 & 4.1 & 4.4436 & TRN & \\
\hline CHEMBL1976328 & 809231 & 4.1 & 4.5614 & TRN & \\
\hline CHEMBL394619 & 809231 & 5.6 & 5.4649 & TRN & \\
\hline CHEMBL1964399 & 809231 & 4.1 & 5.1196 & TRN & \\
\hline CHEMBL1996831 & 809231 & 4.1 & 4.7783 & TST & \\
\hline CHEMBL411903 & 809231 & 4.1 & 4.99 & TRN & \\
\hline CHEMBL1965988 & 809231 & 4.1 & 5.3783 & TRN & \\
\hline CHEMBL418203 & 809231 & 4.1 & 5.083 & TST & \\
\hline CHEMBL1989646 & 809231 & 5.7 & 5.7439 & TRN & \\
\hline CHEMBL1682357 & 809231 & 4.1 & 4.5158 & TRN & \\
\hline CHEMBL 225519 & 809231 & 7.3 & 7.0644 & TRN & \\
\hline CHEMBL209534 & 809231 & 5.3 & 4.853 & TRN & \\
\hline CHEMBL1978200 & 809231 & 7.5 & 8.0184 & TRN & \\
\hline CHEMBL 2006631 & 809231 & 4.1 & 4.4711 & TRN & \\
\hline CHEMBL1970522 & 809231 & 6.0 & 5.3512 & TRN & \\
\hline CHEMBL402846 & 809231 & 6.0 & 5.7406 & TRN & \\
\hline CHEMBL1990415 & 809231 & 4.1 & 4.2951 & TRN & \\
\hline CHEMBL1966087 & 809231 & 4.1 & 4.3855 & TRN & \\
\hline CHEMBL1964692 & 809231 & 6.8 & 5.7639 & TRN & \\
\hline CHEMBL1996931 & 809231 & 4.1 & 4.2668 & TRN & \\
\hline
\end{tabular}




\begin{tabular}{|c|c|c|c|c|}
\hline \multicolumn{5}{|c|}{ Supplemental Table S2.txt } \\
\hline CHEMBL1964413 & 809231 & 4.1 & 4.4081 & TRN \\
\hline CHEMBL1973483 & 809231 & 4.1 & 4.4955 & TRN \\
\hline CHEMBL1984432 & 809231 & 4.1 & 4.5508 & TRN \\
\hline CHEMBL1970735 & 809231 & 4.1 & 4.5167 & TRN \\
\hline CHEMBL 219722 & 809231 & 5.3 & 4.2894 & TRN \\
\hline CHEMBL1997340 & 809231 & 4.1 & 4.1637 & TRN \\
\hline CHEMBL 2004365 & 809231 & 4.1 & 4.5425 & TST \\
\hline CHEMBL1522508 & 809231 & 4.1 & 4.1818 & TRN \\
\hline CHEMBL1989474 & 809231 & 4.3 & 5.6936 & TRN \\
\hline CHEMBL1090360 & 809231 & 6.2 & 4.8939 & TRN \\
\hline CHEMBL210887 & 809231 & 6.4 & 5.5754 & TST \\
\hline CHEMBL458997 & 809231 & 5.2 & 5.5498 & TRN \\
\hline CHEMBL1971021 & 809231 & 4.1 & 3.9374 & TRN \\
\hline CHEMBL 227271 & 809231 & 6.9 & 7.1377 & TRN \\
\hline CHEMBL583144 & 809231 & 5.6 & 4.561 & TRN \\
\hline CHEMBL1974310 & 809231 & 5.9 & 6.1282 & TRN \\
\hline CHEMBL1982660 & 809231 & 4.1 & 4.2664 & TRN \\
\hline CHEMBL1994693 & 809231 & 5.4 & 4.3306 & TRN \\
\hline CHEMBL1982957 & 809231 & 5.7 & 5.0422 & TRN \\
\hline CHEMBL1725279 & 809231 & 7.5 & 6.1728 & TST \\
\hline CHEMBL1975138 & 809231 & 4.1 & 4.6054 & TST \\
\hline CHEMBL424872 & 809231 & 4.1 & 4.704 & TRN \\
\hline CHEMBL 2006836 & 809231 & 5.2 & 4.1732 & TST \\
\hline CHEMBL1971947 & 809231 & 4.1 & 4.863 & TRN \\
\hline CHEMBL412142 & 809231 & 4.1 & 4.7873 & TST \\
\hline CHEMBL1980704 & 809231 & 4.1 & 4.4204 & TST \\
\hline CHEMBL 2003271 & 809231 & 6.3 & 5.9753 & TRN \\
\hline CHEMBL1966808 & 809231 & 5.5 & 4.1547 & TST \\
\hline CHEMBL 2004447 & 809231 & 4.1 & 4.3438 & TRN \\
\hline CHEMBL1983111 & 809231 & 5.5 & 5.32 & TST \\
\hline CHEMBL1973860 & 809231 & 4.1 & 4.5506 & TRN \\
\hline CHEMBL1977713 & 809231 & 4.1 & 4.4162 & TRN \\
\hline CHEMBL 260135 & 809231 & 4.1 & 4.362 & TRN \\
\hline CHEMBL 220241 & 809231 & 4.1 & 4.7654 & TRN \\
\hline CHEMBL 2004544 & 809231 & 4.1 & 4.7185 & TST \\
\hline CHEMBL1982610 & 809231 & 5.7 & 4.4729 & TST \\
\hline CHEMBL1999496 & 809231 & 4.1 & 4.3504 & TRN \\
\hline CHEMBL 2006933 & 809231 & 6.1 & 5.0716 & TST \\
\hline CHEMBL375293 & 809231 & 5.7 & 5.232 & TST \\
\hline CHEMBL1988300 & 809231 & 6.0 & 4.6884 & TRN \\
\hline CHEMBL1991078 & 809231 & 6.0 & 6.4746 & TRN \\
\hline CHEMBL1987359 & 809231 & 4.1 & 4.2033 & TST \\
\hline CHEMBL 2000685 & 809231 & 5.7 & 4.8585 & TRN \\
\hline CHEMBL1985311 & 809231 & 5.6 & 4.4548 & TRN \\
\hline CHEMBL1989265 & 809231 & 4.1 & 4.4968 & TST \\
\hline CHEMBL 2004647 & 809231 & 4.1 & 4.5672 & TST \\
\hline CHEMBL1969502 & 809231 & 4.1 & 4.7776 & TRN \\
\hline CHEMBL1965910 & 809231 & 6.4 & 5.7439 & TRN \\
\hline
\end{tabular}




\begin{tabular}{|c|c|c|c|c|c|}
\hline \multicolumn{6}{|c|}{ Supplemental Table S2.txt } \\
\hline CHEMBL1682553 & 809231 & 5.9 & 5.6161 & TRN & \\
\hline CHEMBL1971430 & 809231 & 6.7 & 7.2378 & TRN & \\
\hline CHEMBL1997764 & 809231 & 5.2 & 4.6586 & TRN & \\
\hline CHEMBL1983963 & 809231 & 5.9 & 4.5684 & TRN & \\
\hline CHEMBL 2000271 & 809231 & 6.9 & 6.4557 & TRN & \\
\hline CHEMBL1985092 & 809231 & 5.6 & 4.779 & TST & \\
\hline CHEMBL 2004692 & 809231 & 4.1 & 4.2396 & TST & \\
\hline CHEMBL1981410 & 809231 & 4.1 & 4.6865 & TRN & \\
\hline CHEMBL1996234 & 809231 & 4.1 & 4.6881 & TRN & \\
\hline CHEMBL1991434 & 809231 & 4.1 & 4.3561 & TST & \\
\hline CHEMBL1967544 & 809231 & 4.1 & 4.8584 & TRN & \\
\hline CHEMBL223367 & 809231 & 4.1 & 4.394 & TST & \\
\hline CHEMBL340384 & 809231 & 6.4 & 6.1267 & TST & \\
\hline CHEMBL1996587 & 809231 & 5.8 & 5.1786 & TRN & \\
\hline CHEMBL1964804 & 809231 & 4.1 & 4.8373 & TRN & \\
\hline CHEMBL443962 & 809231 & 4.1 & 4.3438 & TST & \\
\hline CHEMBL 2000354 & 809231 & 5.6 & 5.48600 & 0000000001 & TRN \\
\hline CHEMBL1965507 & 809231 & 4.1 & 4.2382 & TRN & \\
\hline CHEMBL 274064 & 809231 & 7.9 & 8.1846 & TRN & \\
\hline CHEMBL1967564 & 809231 & 4.1 & 4.1663 & TRN & \\
\hline CHEMBL592030 & 809231 & 6.9 & 5.2254 & TST & \\
\hline CHEMBL 2000071 & 809231 & 5.4 & 4.5793 & TRN & \\
\hline CHEMBL1979176 & 809231 & 4.1 & 4.1913 & TRN & \\
\hline CHEMBL1970317 & 809231 & 5.9 & 4.8216 & TRN & \\
\hline CHEMBL 2000408 & 809231 & 7.7 & 7.886 & TRN & \\
\hline CHEMBL248757 & 809231 & 4.1 & 4.3815 & TST & \\
\hline CHEMBL1978014 & 809231 & 4.1 & 4.5888 & TRN & \\
\hline CHEMBL1994538 & 809231 & 5.3 & 4.3604 & TRN & \\
\hline CHEMBL1983195 & 809231 & 4.1 & 4.3203 & TST & \\
\hline CHEMBL1975490 & 809231 & 5.6 & 6.3272 & TRN & \\
\hline CHEMBL1964444 & 809231 & 4.1 & 4.3872 & TRN & \\
\hline CHEMBL1989957 & 809231 & 4.1 & 4.2689 & TRN & \\
\hline CHEMBL 2006567 & 809231 & 4.1 & 4.6483 & TRN & \\
\hline CHEMBL1986139 & 809231 & 4.1 & 4.1674 & TRN & \\
\hline CHEMBL 383527 & 809231 & 4.1 & 4.6957 & TRN & \\
\hline CHEMBL1980540 & 809231 & 4.1 & 4.1944 & TRN & \\
\hline CHEMBL1979883 & 809231 & 4.2 & 4.7197 & TRN & \\
\hline CHEMBL1984162 & 809231 & 6.7 & 4.9188 & TRN & \\
\hline CHEMBL491758 & 809231 & 5.5 & 4.61 & TRN & \\
\hline CHEMBL86066 & 809231 & 5.6 & 4.8594 & TST & \\
\hline CHEMBL549730 & 809231 & 4.1 & 4.1014 & TRN & \\
\hline CHEMBL1682360 & 809231 & 4.1 & 4.5788 & TRN & \\
\hline CHEMBL1970189 & 809231 & 4.1 & 4.2145 & TRN & \\
\hline CHEMBL1996791 & 809231 & 7.0 & 6.5235 & TRN & \\
\hline CHEMBL371206 & 809231 & 5.6 & 5.2416 & TRN & \\
\hline CHEMBL1974664 & 809231 & 4.1 & 4.4103 & TST & \\
\hline CHEMBL1974288 & 809231 & 4.1 & 4.0868 & TRN & \\
\hline CHEMBL196363 & 809231 & 4.1 & 4.3459 & TRN & \\
\hline
\end{tabular}




\begin{tabular}{|c|c|c|c|c|c|}
\hline \multicolumn{6}{|c|}{ Supplemental Table S2.txt } \\
\hline CHEMBL1190711 & 809231 & 4.1 & 5.1598 & TRN & \\
\hline CHEMBL1968705 & 809231 & 4.1 & 4.5794 & TRN & \\
\hline CHEMBL404367 & 809231 & 6.2 & 5.7226 & TRN & \\
\hline CHEMBL1966343 & 809231 & 4.1 & 4.7704 & TRN & \\
\hline CHEMBL1967887 & 809231 & 6.8 & 6.0644 & TRN & \\
\hline CHEMBL 2000568 & 809231 & 5.3 & 4.5846 & TRN & \\
\hline CHEMBL 2000335 & 809231 & 5.4 & 4.4306 & TRN & \\
\hline CHEMBL1977604 & 809231 & 4.1 & 4.3839 & TST & \\
\hline CHEMBL1988717 & 809231 & 4.1 & 4.2613 & TRN & \\
\hline CHEMBL1974328 & 809231 & 4.1 & 6.199 & TRN & \\
\hline CHEMBL509032 & 809231 & 4.1 & 5.1752 & TRN & \\
\hline CHEMBL573339 & 809231 & 4.1 & 5.024 & TRN & \\
\hline CHEMBL1973808 & 809231 & 4.1 & 4.3609 & TRN & \\
\hline CHEMBL 2000429 & 809231 & 8.0 & 8.1005 & TRN & \\
\hline CHEMBL1972576 & 809231 & 4.1 & 4.1646 & TRN & \\
\hline CHEMBL1992555 & 809231 & 4.1 & 4.48600 & 0000000001 & TST \\
\hline CHEMBL1992342 & 809231 & 4.1 & 4.5222 & TRN & \\
\hline CHEMBL1988173 & 809231 & 4.1 & 4.6925 & TST & \\
\hline CHEMBL535331 & 809231 & 4.1 & 4.2993 & TRN & \\
\hline CHEMBL1989805 & 809231 & 4.1 & 4.8047 & TST & \\
\hline CHEMBL1965423 & 809231 & 6.7 & 5.7883 & TRN & \\
\hline CHEMBL1982980 & 809231 & 4.1 & 4.5574 & TST & \\
\hline CHEMBL1983025 & 809231 & 4.1 & 4.7387 & TRN & \\
\hline CHEMBL205415 & 809231 & 5.7 & 4.6811 & TRN & \\
\hline CHEMBL1977135 & 809231 & 4.1 & 4.104 & TRN & \\
\hline CHEMBL 2001920 & 809231 & 5.3 & 4.5711 & TRN & \\
\hline CHEMBL 2002322 & 809231 & 4.1 & 5.9202 & TRN & \\
\hline CHEMBL 2002323 & 809231 & 4.1 & 4.7897 & TRN & \\
\hline CHEMBL1241473 & 809231 & 7.2 & 6.42299 & 9999999999 & TRN \\
\hline CHEMBL1978448 & 809231 & 4.1 & 4.8509 & TST & \\
\hline CHEMBL 2004513 & 809231 & 4.1 & 4.4981 & TRN & \\
\hline CHEMBL1972258 & 809231 & 4.1 & 4.4144 & TRN & \\
\hline CHEMBL 2001257 & 809231 & 4.1 & 4.6233 & TRN & \\
\hline CHEMBL 2005548 & 809231 & 4.1 & 4.6257 & TRN & \\
\hline CHEMBL1992536 & 809231 & 4.1 & 4.1947 & TRN & \\
\hline CHEMBL1987793 & 809231 & 4.1 & 5.3207 & TST & \\
\hline CHEMBL1992740 & 809231 & 4.1 & 4.1582 & TRN & \\
\hline CHEMBL 2002373 & 809231 & 6.8 & 5.9635 & TRN & \\
\hline CHEMBL439340 & 809231 & 4.2 & 4.6291 & TRN & \\
\hline CHEMBL 2006188 & 809231 & 4.1 & 4.2268 & TRN & \\
\hline CHEMBL1967531 & 809231 & 5.8 & 5.6445 & TRN & \\
\hline CHEMBL1970913 & 809231 & 4.1 & 4.3044 & TRN & \\
\hline CHEMBL1973893 & 809231 & 4.1 & 4.2201 & TRN & \\
\hline CHEMBL1995736 & 809231 & 4.1 & 4.7625 & TRN & \\
\hline CHEMBL1997534 & 809231 & 4.1 & 4.7846 & TRN & \\
\hline CHEMBL1996500 & 809231 & 7.5 & 7.9519 & TRN & \\
\hline CHEMBL1985095 & 809231 & 5.5 & 5.0615 & TST & \\
\hline CHEMBL1998551 & 809231 & 6.1 & 4.9085 & TRN & \\
\hline
\end{tabular}




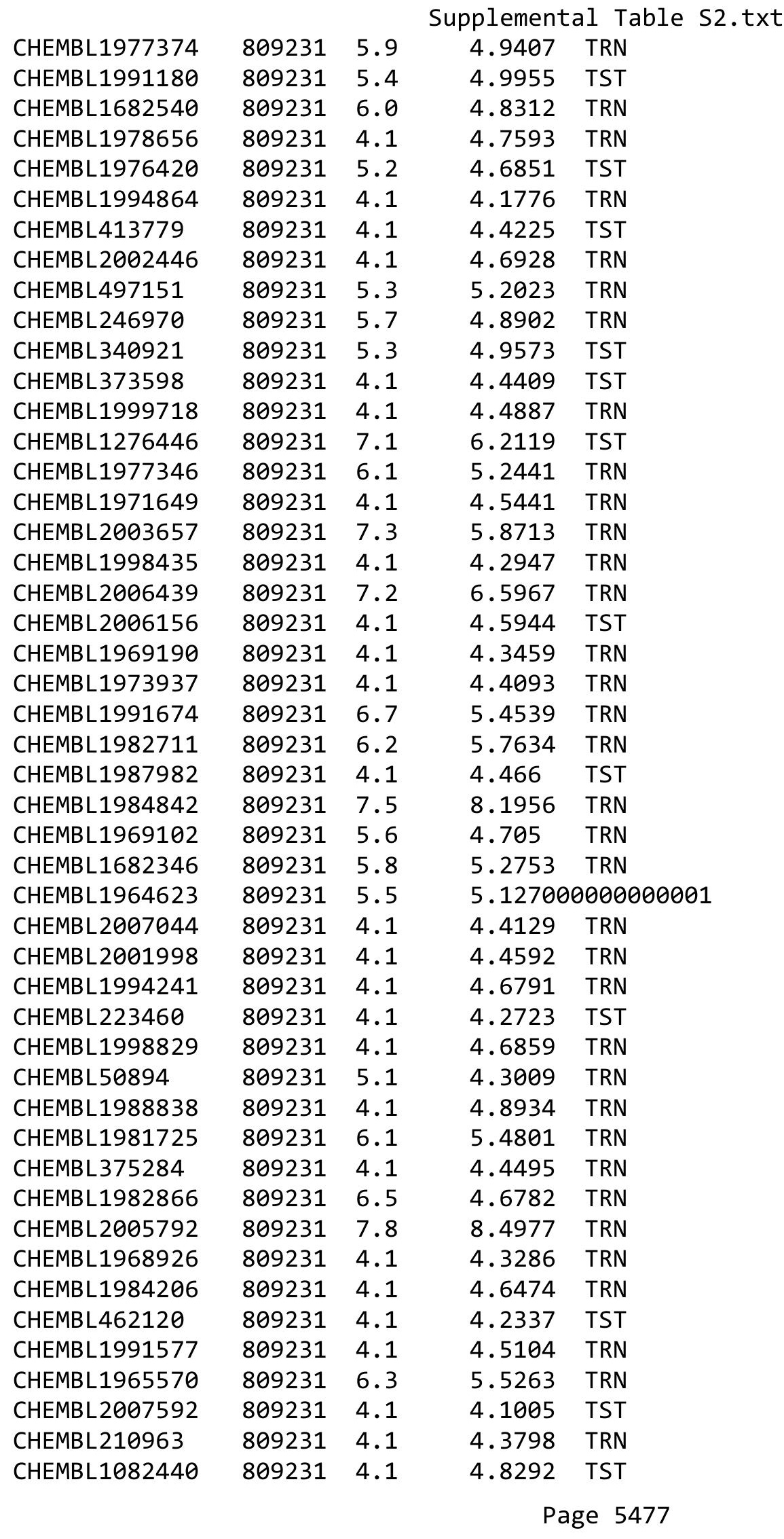




\begin{tabular}{|c|c|c|c|c|c|}
\hline \multirow{3}{*}{$\begin{array}{l}\text { CHEMBL1614705 } \\
\text { CHEMBL1972362 }\end{array}$} & \multirow{3}{*}{$\begin{array}{l}809231 \\
809231\end{array}$} & \multicolumn{4}{|c|}{ Supplemental Table S2.txt } \\
\hline & & 7.0 & 5.4639 & 99999999995 & TRN \\
\hline & & 5.8 & 5.8159 & TRN & \\
\hline CHEMBL1984633 & 809231 & 4.1 & 4.3239 & TRN & \\
\hline CHEMBL 2007372 & 809231 & 6.6 & 6.6964 & TRN & \\
\hline CHEMBL1965845 & 809231 & 4.1 & 4.9662 & TRN & \\
\hline CHEMBL1982167 & 809231 & 4.1 & 4.5949 & TRN & \\
\hline CHEMBL 2006715 & 809231 & 5.5 & 5.2254 & TRN & \\
\hline CHEMBL1986597 & 809231 & 5.4 & 5.1602 & TRN & \\
\hline CHEMBL1971017 & 809231 & 6.2 & 5.8415 & TRN & \\
\hline CHEMBL1990482 & 809231 & 5.7 & 4.8542 & TRN & \\
\hline CHEMBL1990904 & 809231 & 8.1 & 7.7276 & TRN & \\
\hline CHEMBL 2005475 & 809231 & 4.1 & 5.0496 & TRN & \\
\hline CHEMBL 2000104 & 809231 & 5.5 & 5.9684 & TRN & \\
\hline CHEMBL1997349 & 809231 & 4.1 & 4.2375 & TST & \\
\hline CHEMBL183844 & 809231 & 4.1 & 4.1094 & TRN & \\
\hline CHEMBL220057 & 809231 & 5.3 & 4.2379 & TRN & \\
\hline CHEMBL1682545 & 809231 & 4.1 & 4.5127 & TRN & \\
\hline CHEMBL383541 & 809231 & 5.5 & 5.4139 & TRN & \\
\hline CHEMBL 2001224 & 809231 & 4.1 & 4.1916 & TRN & \\
\hline CHEMBL10 & 809231 & 7.4 & 7.7552 & TRN & \\
\hline CHEMBL1976732 & 809231 & 5.5 & 5.2753 & TRN & \\
\hline CHEMBL1969506 & 809231 & 4.1 & 4.3917 & TRN & \\
\hline CHEMBL1964937 & 809231 & 5.2 & 4.9053 & TRN & \\
\hline CHEMBL1980163 & 809231 & 4.1 & 4.3132 & TRN & \\
\hline CHEMBL590109 & 809231 & 6.4 & 5.0931 & TST & \\
\hline CHEMBL1972218 & 809231 & 5.5 & 4.7037 & TST & \\
\hline CHEMBL1970879 & 809231 & 4.1 & 5.551 & TRN & \\
\hline CHEMBL1989856 & 809231 & 5.7 & 4.2831 & TST & \\
\hline CHEMBL2005899 & 809231 & 4.1 & 4.3215 & TRN & \\
\hline CHEMBL1682552 & 809231 & 6.1 & 5.8927 & TRN & \\
\hline CHEMBL259850 & 809231 & 4.1 & 4.3456 & TRN & \\
\hline CHEMBL1972568 & 809231 & 4.1 & 4.1698 & TRN & \\
\hline CHEMBL1996155 & 809231 & 4.1 & 4.755 & TRN & \\
\hline CHEMBL229799 & 809231 & 7.5 & 7.7284 & TRN & \\
\hline CHEMBL1682359 & 809231 & 4.1 & 4.787 & TRN & \\
\hline CHEMBL105739 & 809231 & 6.5 & 5.619 & TRN & \\
\hline CHEMBL379300 & 809231 & 6.5 & 6.6199 & TRN & \\
\hline CHEMBL203673 & 809231 & 5.1 & 4.9416 & TRN & \\
\hline CHEMBL1969523 & 809231 & 4.1 & 5.0099 & TRN & \\
\hline CHEMBL 207995 & 809231 & 4.1 & 4.5806 & TRN & \\
\hline CHEMBL1988995 & 809231 & 5.8 & 5.1191 & TRN & \\
\hline CHEMBL 2001923 & 809231 & 4.1 & 4.6105 & TRN & \\
\hline CHEMBL1986781 & 809231 & 8.1 & 7.4344 & TRN & \\
\hline CHEMBL526133 & 809231 & 6.2 & 5.2947 & TRN & \\
\hline CHEMBL1979057 & 809231 & 5.2 & 4.1232 & TRN & \\
\hline CHEMBL1981045 & 809231 & 4.1 & 4.5151 & TRN & \\
\hline CHEMBL387971 & 809231 & 4.1 & 4.4889 & TRN & \\
\hline CHEMBL1975418 & 809231 & 5.7 & 4.8361 & TRN & \\
\hline
\end{tabular}




\begin{tabular}{|c|c|c|c|c|}
\hline & & & Supplement & \\
\hline CHEMBL1992796 & 809231 & 4.1 & 4.6278 & TST \\
\hline CHEMBL1999428 & 809231 & 4.1 & 4.0634 & TRN \\
\hline CHEMBL223257 & 809231 & 4.1 & 4.481 & TST \\
\hline CHEMBL1967560 & 809231 & 4.1 & 4.4897 & TRN \\
\hline CHEMBL1516890 & 809231 & 6.9 & 5.7444 & TRN \\
\hline CHEMBL 211378 & 809231 & 4.1 & 4.3399 & TRN \\
\hline CHEMBL1982465 & 809231 & 5.3 & 4.4376 & TRN \\
\hline CHEMBL2001751 & 809231 & 6.4 & 6.9203 & TRN \\
\hline CHEMBL 2003420 & 809231 & 4.1 & 4.1651 & TRN \\
\hline CHEMBL1984586 & 809231 & 5.4 & 5.4397 & TRN \\
\hline CHEMBL1999774 & 809231 & 4.1 & 4.9161 & TST \\
\hline CHEMBL1972659 & 809231 & 4.1 & 4.3385 & TST \\
\hline CHEMBL1973395 & 809231 & 4.1 & 4.921 & TRN \\
\hline CHEMBL 272453 & 809231 & 4.1 & 4.2569 & TRN \\
\hline CHEMBL1970217 & 809231 & 4.1 & 4.0798 & TRN \\
\hline CHEMBL1971801 & 809231 & 6.3 & 4.6491 & TRN \\
\hline CHEMBL1968850 & 809231 & 6.8 & 4.8202 & TRN \\
\hline CHEMBL 2005528 & 809231 & 4.1 & 4.8383 & TST \\
\hline CHEMBL185569 & 809231 & 4.1 & 4.0601 & TRN \\
\hline CHEMBL1969843 & 809231 & 4.1 & 4.3594 & TRN \\
\hline CHEMBL 2007002 & 809231 & 4.1 & 4.2446 & TRN \\
\hline CHEMBL1987007 & 809231 & 5.3 & 4.9073 & TRN \\
\hline CHEMBL1969588 & 809231 & 7.2 & 7.0324 & TRN \\
\hline CHEMBL1984711 & 809231 & 4.1 & 4.579 & TRN \\
\hline CHEMBL1990212 & 809231 & 4.1 & 4.8659 & TRN \\
\hline CHEMBL484390 & 809231 & 5.3 & 5.2707 & TST \\
\hline CHEMBL1983255 & 809231 & 5.4 & 5.4794 & TST \\
\hline CHEMBL1979252 & 809231 & 4.1 & 4.1936 & TRN \\
\hline CHEMBL1682341 & 809231 & 5.3 & 4.5424 & TRN \\
\hline CHEMBL 2004290 & 809231 & 4.1 & 4.4086 & TRN \\
\hline CHEMBL1986499 & 809231 & 4.1 & 4.9872 & TRN \\
\hline CHEMBL1972937 & 809231 & 4.1 & 4.4861 & TRN \\
\hline CHEMBL1972250 & 809231 & 4.1 & 4.56 & TRN \\
\hline CHEMBL 2000393 & 809231 & 4.1 & 4.8815 & TST \\
\hline CHEMBL 2004072 & 809231 & 5.5 & 5.2151 & TRN \\
\hline CHEMBL 2004311 & 809231 & 4.1 & 3.9314 & TRN \\
\hline CHEMBL1992634 & 809231 & 4.1 & 4.8495 & TRN \\
\hline CHEMBL1242373 & 809231 & 4.1 & 4.3566 & TRN \\
\hline CHEMBL 2000433 & 809231 & 4.1 & 4.6544 & TST \\
\hline CHEMBL56543 & 809231 & 4.1 & 4.6559 & TRN \\
\hline CHEMBL316264 & 809231 & 7.2 & 7.4779 & TRN \\
\hline CHEMBL1988075 & 809231 & 4.1 & 4.6846 & TRN \\
\hline CHEMBL1991678 & 809231 & 7.9 & 7.7345 & TRN \\
\hline CHEMBL 2001239 & 809231 & 4.1 & 5.9502 & TST \\
\hline CHEMBL1988594 & 809231 & 4.1 & 4.3815 & TRN \\
\hline CHEMBL 2001288 & 809231 & 6.0 & 5.6604 & TRN \\
\hline CHEMBL 260092 & 809231 & 5.6 & 4.8667 & TRN \\
\hline CHEMBL1999811 & 809231 & 4.1 & 5.4947 & TST \\
\hline
\end{tabular}




\begin{tabular}{|c|c|c|c|c|c|}
\hline \multicolumn{6}{|c|}{ Supplemental Table S2.txt } \\
\hline CHEMBL1965495 & 809231 & 5.6 & 4.4854 & TRN & \\
\hline CHEMBL1985074 & 809231 & 4.1 & 5.2695 & TST & \\
\hline CHEMBL1982874 & 809231 & 6.5 & 5.6961 & TRN & \\
\hline CHEMBL 2000481 & 809231 & 4.1 & 4.4657 & TRN & \\
\hline CHEMBL1991725 & 809231 & 4.1 & 4.8092 & TRN & \\
\hline CHEMBL1992242 & 809231 & 4.1 & 4.4202 & TRN & \\
\hline CHEMBL 2007296 & 809231 & 4.1 & 4.118 & TRN & \\
\hline CHEMBL208637 & 809231 & 4.1 & 4.5074 & TRN & \\
\hline CHEMBL396523 & 809231 & 6.8 & 7.1676 & TRN & \\
\hline CHEMBL1970203 & 809231 & 4.1 & 4.1481 & TRN & \\
\hline CHEMBL1986530 & 809231 & 4.1 & 4.4388 & TST & \\
\hline CHEMBL1999321 & 809231 & 4.1 & 4.2272 & TRN & \\
\hline CHEMBL1968590 & 809231 & 5.3 & 5.1098 & TRN & \\
\hline CHEMBL1999749 & 809231 & 4.1 & 5.0615 & TRN & \\
\hline CHEMBL 2005375 & 809231 & 4.1 & 4.7547 & TRN & \\
\hline CHEMBL1984191 & 809231 & 4.3 & 5.1918 & TRN & \\
\hline CHEMBL1983006 & 809231 & 4.1 & 4.5014 & TRN & \\
\hline CHEMBL1972183 & 809231 & 4.1 & 4.2965 & TRN & \\
\hline CHEMBL1971029 & 809231 & 4.1 & 5.3442 & TRN & \\
\hline CHEMBL394790 & 809231 & 5.6 & 5.2931 & TRN & \\
\hline CHEMBL226471 & 809231 & 6.0 & 6.5073 & TRN & \\
\hline CHEMBL1974702 & 809231 & 4.1 & 4.3177 & TRN & \\
\hline CHEMBL1996111 & 809231 & 4.1 & 4.5424 & TRN & \\
\hline CHEMBL1965589 & 809231 & 7.6 & 7.756 & TRN & \\
\hline CHEMBL1998193 & 809231 & 4.1 & 4.1892 & TRN & \\
\hline CHEMBL474432 & 809231 & 4.1 & 4.4738 & TST & \\
\hline CHEMBL1988153 & 809231 & 4.1 & 5.3065 & TRN & \\
\hline CHEMBL1999556 & 809231 & 6.3 & 5.8927 & TRN & \\
\hline CHEMBL1988437 & 809231 & 4.1 & 4.6989 & TST & \\
\hline CHEMBL1968245 & 809231 & 4.1 & 5.2614 & TRN & \\
\hline CHEMBL1968646 & 809231 & 5.2 & 4.9225 & TST & \\
\hline CHEMBL1998121 & 809231 & 4.1 & 4.9217 & TRN & \\
\hline CHEMBL1979577 & 809231 & 4.1 & 5.32799 & & TRN \\
\hline CHEMBL1991800 & 809231 & 8.0 & 7.5753 & TRN & \\
\hline CHEMBL1985566 & 809231 & 4.1 & 4.4619 & TRN & \\
\hline CHEMBL52387 & 809231 & 5.9 & 4.5715 & TST & \\
\hline CHEMBL379835 & 809231 & 4.1 & 4.1204 & TST & \\
\hline CHEMBL1979357 & 809231 & 4.1 & 4.3739 & TRN & \\
\hline CHEMBL1980802 & 809231 & 4.1 & 4.4229 & TST & \\
\hline CHEMBL1979554 & 809231 & 4.1 & 4.6117 & TRN & \\
\hline CHEMBL1996817 & 809231 & 6.2 & 4.7124 & TRN & \\
\hline CHEMBL3197315 & 809231 & 4.1 & 4.3353 & TST & \\
\hline CHEMBL 2004355 & 809231 & 5.2 & 4.7728 & TRN & \\
\hline CHEMBL468280 & 809231 & 4.1 & 4.3243 & TST & \\
\hline CHEMBL1990884 & 809231 & 4.1 & 4.6509 & TRN & \\
\hline CHEMBL3109278 & 809231 & 7.0 & 4.9164 & TRN & \\
\hline CHEMBL256835 & 809231 & 7.6 & 6.8698 & TRN & \\
\hline CHEMBL1980142 & 809231 & 4.1 & 4.0886 & TRN & \\
\hline
\end{tabular}




\begin{tabular}{|c|c|c|c|c|c|}
\hline \multicolumn{6}{|c|}{ Supplemental Table S2.txt } \\
\hline CHEMBL41783 & 809231 & 4.1 & 4.1605 & TRN & \\
\hline CHEMBL 2004438 & 809231 & 4.1 & 4.8243 & TRN & \\
\hline CHEMBL 2006276 & 809231 & 4.1 & 4.4248 & TRN & \\
\hline CHEMBL 271381 & 809231 & 4.1 & 4.2077 & TRN & \\
\hline CHEMBL 2006785 & 809231 & 4.1 & 4.5791 & TRN & \\
\hline CHEMBL1982466 & 809231 & 4.1 & 4.3167 & TRN & \\
\hline CHEMBL249697 & 809231 & 5.2 & 4.9829 & TST & \\
\hline CHEMBL1995740 & 809231 & 4.1 & 4.3049 & TRN & \\
\hline CHEMBL1996390 & 809231 & 6.1 & 5.1896 & TRN & \\
\hline CHEMBL234085 & 809231 & 4.1 & 4.3643 & TRN & \\
\hline CHEMBL1995832 & 809231 & 7.9 & 8.4871 & TRN & \\
\hline CHEMBL1998414 & 809231 & 4.1 & 4.5178 & TRN & \\
\hline CHEMBL1969042 & 809231 & 4.1 & 4.7447 & TST & \\
\hline CHEMBL 2000345 & 809231 & 4.1 & 4.6914 & TRN & \\
\hline CHEMBL1999931 & 809231 & 6.5 & 6.7558 & TRN & \\
\hline CHEMBL1991640 & 809231 & 4.1 & 4.8376 & TST & \\
\hline CHEMBL1375418 & 809231 & 4.1 & 4.52800 & 00000000005 & TRN \\
\hline CHEMBL302449 & 809231 & 4.1 & 5.4328 & TST & \\
\hline CHEMBL 2007064 & 809231 & 5.9 & 4.6671 & TRN & \\
\hline CHEMBL1981047 & 809231 & 4.1 & 4.966 & TST & \\
\hline CHEMBL229968 & 809231 & 7.4 & 7.5826 & TRN & \\
\hline CHEMBL1976240 & 809231 & 4.1 & 4.2224 & TRN & \\
\hline CHEMBL1979093 & 809231 & 4.1 & 4.3435 & TRN & \\
\hline CHEMBL1968151 & 809231 & 4.1 & 4.1584 & TST & \\
\hline CHEMBL1381197 & 809231 & 4.1 & 4.5933 & TRN & \\
\hline CHEMBL1987009 & 809231 & 5.3 & 4.9781 & TRN & \\
\hline CHEMBL379218 & 809231 & 6.6 & 6.9454 & TRN & \\
\hline CHEMBL 2003817 & 809231 & 4.1 & 4.5861 & TRN & \\
\hline CHEMBL336961 & 809231 & 4.1 & 4.7903 & TRN & \\
\hline CHEMBL1994830 & 809231 & 4.1 & 5.6865 & TRN & \\
\hline CHEMBL1987054 & 809231 & 6.7 & 5.0561 & TRN & \\
\hline CHEMBL1970083 & 809231 & 6.2 & 5.087 & TRN & \\
\hline CHEMBL226403 & 809231 & 6.7 & 6.9173 & TRN & \\
\hline CHEMBL 2005631 & 809231 & 5.5 & 5.2436 & TRN & \\
\hline CHEMBL1994938 & 809231 & 5.8 & 4.9752 & TRN & \\
\hline CHEMBL1825138 & 809231 & 4.1 & 5.5038 & TST & \\
\hline CHEMBL1977223 & 809231 & 5.6 & 5.5655 & TRN & \\
\hline CHEMBL1236126 & 809231 & 6.9 & 4.9159 & TST & \\
\hline CHEMBL1966279 & 809231 & 4.1 & 4.4139 & TRN & \\
\hline CHEMBL1997846 & 809231 & 5.9 & 5.0116 & TRN & \\
\hline CHEMBL2004419 & 809231 & 6.1 & 6.273 & TRN & \\
\hline CHEMBL1991728 & 809231 & 4.1 & 4.9043 & TRN & \\
\hline CHEMBL1975787 & 809231 & 6.5 & 5.9594 & TRN & \\
\hline CHEMBL 2002407 & 809231 & 5.3 & 4.9304 & TRN & \\
\hline CHEMBL1972489 & 809231 & 4.1 & 4.2308 & TRN & \\
\hline CHEMBL1994074 & 809231 & 5.5 & 4.6917 & TRN & \\
\hline CHEMBL1992937 & 809231 & 6.1 & 5.4199 & TST & \\
\hline CHEMBL1972119 & 809231 & 4.1 & 4.1948 & TRN & \\
\hline
\end{tabular}




\begin{tabular}{|c|c|c|c|c|c|}
\hline \multicolumn{6}{|c|}{ Supplemental Table S2.txt } \\
\hline CHEMBL1986328 & 809231 & 4.1 & 4.3499 & TST & \\
\hline CHEMBL95692 & 809231 & 7.7 & 6.9239 & TRN & \\
\hline CHEMBL1090356 & 809231 & 4.3 & 5.0673 & TRN & \\
\hline CHEMBL1976455 & 809231 & 5.8 & 5.2353 & TRN & \\
\hline CHEMBL1983923 & 809231 & 4.1 & 4.4727 & TST & \\
\hline CHEMBL1983534 & 809231 & 5.3 & 4.3092 & TRN & \\
\hline CHEMBL1982361 & 809231 & 4.1 & 4.1846 & TRN & \\
\hline CHEMBL1999112 & 809231 & 4.1 & 4.4655 & TST & \\
\hline CHEMBL1982122 & 809231 & 5.6 & 4.3822 & TRN & \\
\hline CHEMBL 2000801 & 809231 & 4.1 & 4.4629 & TRN & \\
\hline CHEMBL1682546 & 809231 & 4.1 & 4.2874 & TRN & \\
\hline CHEMBL1991395 & 809231 & 7.8 & 7.59200 & 00000000005 & TRN \\
\hline CHEMBL1971245 & 809231 & 4.1 & 4.9595 & TRN & \\
\hline CHEMBL1987648 & 809231 & 7.8 & 7.7459 & TRN & \\
\hline CHEMBL1996780 & 809231 & 5.2 & 4.7144 & TST & \\
\hline CHEMBL1972142 & 809231 & 4.1 & 4.2417 & TRN & \\
\hline CHEMBL1966514 & 809231 & 5.7 & 5.7866 & TRN & \\
\hline CHEMBL 2003638 & 809231 & 5.9 & 6.8888 & TRN & \\
\hline CHEMBL296586 & 809231 & 4.1 & 4.5347 & TRN & \\
\hline CHEMBL1996066 & 809231 & 7.1 & 5.9642 & TST & \\
\hline CHEMBL516429 & 809231 & 6.1 & 5.4979 & TRN & \\
\hline CHEMBL1993722 & 809231 & 5.3 & 4.333 & TRN & \\
\hline CHEMBL1970806 & 809231 & 4.1 & 4.2526 & TST & \\
\hline CHEMBL1375640 & 809231 & 7.0 & 6.1866 & TST & \\
\hline CHEMBL1979970 & 809231 & 4.1 & 4.0899 & TRN & \\
\hline CHEMBL249282 & 809231 & 4.1 & 4.2097 & TRN & \\
\hline CHEMBL1969264 & 809231 & 5.9 & 4.5007 & TRN & \\
\hline CHEMBL1973711 & 809231 & 4.1 & 4.6724 & TRN & \\
\hline CHEMBL 2006237 & 809231 & 4.1 & 4.7107 & TST & \\
\hline CHEMBL1967720 & 809231 & 5.8 & 5.5413 & TST & \\
\hline CHEMBL1572266 & 809231 & 4.1 & 4.5278 & TST & \\
\hline CHEMBL1991138 & 809231 & 4.3 & 5.066 & TST & \\
\hline CHEMBL1969755 & 809231 & 4.1 & 4.2054 & TST & \\
\hline CHEMBL1979516 & 809231 & 4.1 & 4.5415 & TST & \\
\hline CHEMBL1605605 & 809231 & 4.1 & 4.4944 & TST & \\
\hline CHEMBL1972820 & 809231 & 4.1 & 4.3137 & TST & \\
\hline CHEMBL1996208 & 809231 & 4.1 & 4.5314 & TST & \\
\hline CHEMBL1989029 & 809231 & 5.4 & 4.6083 & TST & \\
\hline CHEMBL392642 & 809231 & 5.8 & 4.9122 & TST & \\
\hline CHEMBL514499 & 809231 & 4.1 & 4.2868 & TST & \\
\hline CHEMBL1965631 & 809231 & 5.3 & 4.7627 & TST & \\
\hline CHEMBL1980144 & 809231 & 4.1 & 4.2597 & TST & \\
\hline CHEMBL1991188 & 809231 & 4.1 & 4.2435 & TST & \\
\hline CHEMBL1972849 & 809231 & 5.3 & 5.5096 & TST & \\
\hline CHEMBL 377408 & 809231 & 5.6 & 4.8995 & TST & \\
\hline CHEMBL215152 & 809231 & 5.3 & 4.5247 & TST & \\
\hline CHEMBL231209 & 809231 & 5.7 & 5.456 & TST & \\
\hline CHEMBL1975357 & 809231 & 4.1 & 4.4542 & TST & \\
\hline
\end{tabular}




\begin{tabular}{|c|c|c|c|c|c|}
\hline \\
\hline CHEMBL1976220 & 809231 & 5.6 & 5.4289 & TST & \\
\hline CHEMBL259922 & 809231 & 4.1 & 4.4261 & TST & \\
\hline CHEMBL1997617 & 809231 & 7.6 & 6.0945 & TST & \\
\hline CHEMBL1982383 & 809231 & 8.1 & 8.3027 & TST & \\
\hline CHEMBL1969301 & 809231 & 6.7 & 5.5557 & TST & \\
\hline CHEMBL17370 & 809231 & 7.6 & 7.4591 & TST & \\
\hline CHEMBL1987910 & 809231 & 5.8 & 5.3965 & TST & \\
\hline CHEMBL1983932 & 809231 & 4.1 & 4.2786 & TST & \\
\hline CHEMBL1966069 & 809231 & 4.1 & 4.6504 & TST & \\
\hline CHEMBL1997822 & 809231 & 4.1 & 4.8487 & TST & \\
\hline CHEMBL1991285 & 809231 & 4.1 & 4.3494 & TST & \\
\hline CHEMBL 243088 & 809231 & 6.6 & 7.105 & TST & \\
\hline CHEMBL1984038 & 809231 & 4.1 & 4.3473 & TST & \\
\hline CHEMBL1993661 & 809231 & 4.1 & 5.1839 & TST & \\
\hline CHEMBL1974416 & 809231 & 5.7 & 4.77800 & 20000000005 & TST \\
\hline CHEMBL 2004615 & 809231 & 6.1 & 4.4445 & TST & \\
\hline CHEMBL1984039 & 809231 & 4.1 & 4.46 & TST & \\
\hline CHEMBL1997872 & 809231 & 4.1 & 4.4096 & TST & \\
\hline CHEMBL313025 & 911177 & 8.4949 & 8.4936 & TRN & \\
\hline CHEMBL86255 & 911177 & 7.8239 & 7.9544 & TRN & \\
\hline CHEMBL85765 & 911177 & 8.2218 & 8.0324 & TRN & \\
\hline CHEMBL314447 & 911177 & 7.9586 & 8.0538 & TRN & \\
\hline CHEMBL87074 & 911177 & 9.0706 & 9.0087 & TST & \\
\hline CHEMBL87129 & 911177 & 7.9208 & 7.9455 & TRN & \\
\hline CHEMBL69508 & 911177 & 7.2218 & 7.308 & TST & \\
\hline CHEMBL86084 & 911177 & 8.0 & 8.0336 & TRN & \\
\hline CHEMBL 86613 & 911177 & 7.5686 & 7.5947 & TRN & \\
\hline CHEMBL315615 & 911177 & 7.7447 & 7.6368 & TRN & \\
\hline CHEMBL86143 & 911177 & 7.1675 & 7.3757 & TST & \\
\hline CHEMBL 83248 & 911177 & 8.1805 & 8.1455 & TRN & \\
\hline CHEMBL424053 & 911177 & 7.0 & 7.0095 & TRN & \\
\hline CHEMBL84627 & 911177 & 8.301 & 8.2346 & TRN & \\
\hline CHEMBL87392 & 911177 & 8.0223 & 8.2045 & TST & \\
\hline CHEMBL87057 & 911177 & 8.4949 & 8.5094 & TRN & \\
\hline CHEMBL87073 & 911177 & 7.4815 & 7.5167 & TRN & \\
\hline CHEMBL315128 & 911177 & 7.8539 & 7.79799 & 9999999999 & TRN \\
\hline CHEMBL87239 & 911177 & 8.5376 & 8.5145 & TST & \\
\hline CHEMBL314179 & 911177 & 7.7696 & 7.8017 & TRN & \\
\hline CHEMBL 85545 & 911177 & 8.3098 & 8.4108 & TST & \\
\hline CHEMBL86440 & 911177 & 7.1612 & 7.0859 & TRN & \\
\hline CHEMBL316052 & 911177 & 8.2441 & 8.3688 & TRN & \\
\hline CHEMBL87778 & 911177 & 8.5376 & 8.4288 & TRN & \\
\hline CHEMBL83180 & 911177 & 8.3872 & 8.4068 & TRN & \\
\hline CHEMBL 87275 & 911177 & 6.9208 & 6.9557 & TRN & \\
\hline CHEMBL86906 & 911177 & 7.7959 & 7.7741 & TRN & \\
\hline CHEMBL313017 & 911177 & 7.1549 & 7.1659 & TRN & \\
\hline CHEMBL19018 & 911177 & 8.9208 & 8.9802 & TRN & \\
\hline CHEMBL422593 & 911177 & 8.3372 & 8.2647 & TRN & \\
\hline
\end{tabular}




\begin{tabular}{|c|c|c|c|c|c|c|}
\hline & & \multicolumn{5}{|c|}{ Supplemental Table S2.txt } \\
\hline CHEMBL83182 & 911177 & 6.9586 & 6.9139 & TRN & & \\
\hline CHEMBL84630 & 911177 & 7.0969 & 7.1428 & TRN & & \\
\hline CHEMBL420970 & 911177 & 7.3665 & 7.3036 & TRN & & \\
\hline CHEMBL278741 & 911177 & 8.2366 & 8.2502 & TRN & & \\
\hline CHEMBL85704 & 911177 & 6.9393 & 6.9153 & TRN & & \\
\hline CHEMBL 87885 & 911177 & 7.6383 & 7.5974 & TRN & & \\
\hline CHEMBL312921 & 911177 & 7.9586 & 7.9381 & TRN & & \\
\hline CHEMBL85541 & 911177 & 7.7696 & 7.9029 & TRN & & \\
\hline CHEMBL87798 & 911177 & 7.9208 & 7.7845 & TST & & \\
\hline CHEMBL85876 & 911177 & 7.6576 & 7.6569 & TRN & & \\
\hline CHEMBL431411 & 911177 & 8.8539 & 8.745 & TRN & & \\
\hline CHEMBL85596 & 911177 & 7.6778 & 7.7061 & TRN & & \\
\hline CHEMBL87985 & 911177 & 8.1135 & 8.2316 & TST & & \\
\hline CHEMBL313579 & 911177 & 8.1135 & 8.1878 & TRN & & \\
\hline CHEMBL18287 & 911177 & 8.6198 & 8.574 & TRN & & \\
\hline CHEMBL407827 & 911177 & 7.9586 & 7.9916 & TRN & & \\
\hline CHEMBL314042 & 911177 & 8.2518 & 8.2837 & TRN & & \\
\hline CHEMBL312913 & 911177 & 9.0315 & 9.0328 & TST & & \\
\hline CHEMBL87964 & 911177 & 8.7447 & 8.6274 & TST & & \\
\hline CHEMBL82797 & 911177 & 8.0862 & 8.1212 & TRN & & \\
\hline CHEMBL314590 & 911177 & 6.3098 & 6.3456 & TRN & & \\
\hline CHEMBL419483 & 911177 & 9.1308 & 9.2315 & TST & & \\
\hline CHEMBL86741 & 911177 & 7.1024 & 6.9931 & TST & & \\
\hline CHEMBL315776 & 911177 & 8.4437 & 8.5341 & TST & & \\
\hline CHEMBL87513 & 911177 & 8.699 & 8.5827 & TST & & \\
\hline CHEMBL221137 & 954479 & 4.918 & 4.3065 & TST & & \\
\hline CHEMBL1190711 & 954479 & 3.8827 & 3.9907 & TRN & & \\
\hline CHEMBL472940 & 954479 & 3.0126 & 2.8987 & TRN & & \\
\hline CHEMBL449158 & 954479 & 6.8356 & 6.7619 & TST & & \\
\hline CHEMBL209148 & 954479 & 3.1711 & 3.4981 & TRN & & \\
\hline CHEMBL3349342 & 954479 & 5.2966 & 4.9996 & TRN & & \\
\hline CHEMBL515416 & 954479 & 4.0052 & 4.228 & TRN & & \\
\hline CHEMBL1970879 & 954479 & 3.3485 & 3.4699 & TRN & & \\
\hline CHEMBL258844 & 954479 & 5.0338 & 4.5691 & TRN & & \\
\hline CHEMBL509032 & 954479 & 3.8832 & 3.8661 & TRN & & \\
\hline CHEMBL1516890 & 954479 & 4.4269 & 4.1751 & TRN & & \\
\hline CHEMBL483847 & 954479 & 4.0671 & 4.0219 & TRN & & \\
\hline CHEMBL1256459 & 954479 & 7.1077 & 7.029 & TRN & & \\
\hline CHEMBL222102 & 954479 & 3.7485 & 3.6755 & TRN & & \\
\hline CHEMBL3392440 & 954479 & 3.5833 & 3.7799 & TRN & & \\
\hline CHEMBL135561 & 954479 & 4.4436 & 4.3388 & TRN & & \\
\hline CHEMBL1186585 & 954479 & 3.7923 & 3.7212 & TRN & & \\
\hline CHEMBL558642 & 954479 & 3.5768 & 3.3539 & TRN & & \\
\hline CHEMBL1788116 & 954479 & 3.37899 & 99999999 & 996 & 3.9419 & TRN \\
\hline CHEMBL202721 & 954479 & 3.2725 & 3.5787 & TRN & & \\
\hline CHEMBL220241 & 954479 & 3.4905 & 3.3206 & TRN & & \\
\hline CHEMBL189584 & 954479 & 3.5593 & 3.747 & TRN & & \\
\hline CHEMBL1909414 & 954479 & 3.2906 & 3.3568 & TRN & & \\
\hline
\end{tabular}




\begin{tabular}{|c|c|c|c|c|c|c|}
\hline \multicolumn{7}{|c|}{ Supplemental Table S2.txt } \\
\hline CHEMBL259181 & 954479 & 3.7255 & 3.8774 & TRN & & \\
\hline CHEMBL392695 & 954479 & 4.0911 & 4.6341 & TRN & & \\
\hline CHEMBL512504 & 954479 & 4.3671 & 4.2258 & TRN & & \\
\hline CHEMBL577784 & 954479 & 4.5544 & 4.3708 & TRN & & \\
\hline CHEMBL379300 & 954479 & 6.7192 & 6.5651 & TRN & & \\
\hline CHEMBL1673039 & 954479 & 3.7643 & 3.6467 & TRN & & \\
\hline CHEMBL210618 & 954479 & 2.8557 & 2.9464 & TRN & & \\
\hline CHEMBL255342 & 954479 & 3.4445 & 3.2515 & TRN & & \\
\hline CHEMBL3186408 & 954479 & 3.3223 & 2.9855 & TST & & \\
\hline CHEMBL 213100 & 954479 & 3.5868 & 3.3052 & TRN & & \\
\hline CHEMBL483849 & 954479 & 2.438 & 1.9771 & TST & & \\
\hline CHEMBL373751 & 954479 & 3.2047 & 3.3684 & TRN & & \\
\hline CHEMBL188678 & 954479 & 4.2214 & 4.1819 & TRN & & \\
\hline CHEMBL1242367 & 954479 & 3.8171 & 3.7898 & TRN & & \\
\hline CHEMBL379975 & 954479 & 4.3425 & 4.3947 & TRN & & \\
\hline CHEMBL412142 & 954479 & 3.8357 & 3.8038 & TRN & & \\
\hline CHEMBL300389 & 954479 & 6.9217 & 6.8712 & TRN & & \\
\hline CHEMBL 2134202 & 954479 & 3.8867 & 3.853 & TRN & & \\
\hline CHEMBL65 & 954479 & 7.1067 & 6.7493 & TRN & & \\
\hline CHEMBL191334 & 954479 & 2.9311 & 2.7096 & TRN & & \\
\hline CHEMBL9470 & 954479 & 5.7572 & 5.4716 & TST & & \\
\hline CHEMBL 2137530 & 954479 & 4.5004 & 4.4392 & TRN & & \\
\hline CHEMBL514499 & 954479 & 6.1782 & 6.6198 & TRN & & \\
\hline CHEMBL573107 & 954479 & 5.1969 & 4.9139 & TRN & & \\
\hline CHEMBL1404918 & 954479 & 2.7179 & 2.782 & TRN & & \\
\hline CHEMBL1643959 & 954479 & 3.31399 & 99999999 & 996 & 3.4141 & TRN \\
\hline CHEMBL585951 & 954479 & 5.4017 & 5.8815 & TRN & & \\
\hline CHEMBL 2144069 & 954479 & 3.2498 & 3.1509 & TRN & & \\
\hline CHEMBL180127 & 954479 & 3.2395 & 3.5856 & TST & & \\
\hline CHEMBL3199475 & 954479 & 3.7422 & 4.2477 & TST & & \\
\hline CHEMBL1357247 & 954479 & 3.1541 & 2.9 & TST & & \\
\hline CHEMBL393929 & 954479 & 4.5766 & 3.5013 & TST & & \\
\hline CHEMBL1230020 & 954479 & 3.1536 & 3.7593 & TST & & \\
\hline CHEMBL92309 & 954479 & 3.6046 & 2.3501 & TST & & \\
\hline CHEMBL 2005886 & 954479 & 4.6338 & 4.1951 & TST & & \\
\hline CHEMBL1590308 & 954479 & 2.6964 & 2.7496 & TST & & \\
\hline CHEMBL 217354 & 954479 & 6.2476 & 5.8198 & TST & & \\
\hline CHEMBL192566 & 954479 & 7.0811 & 7.5521 & TST & & \\
\hline CHEMBL 2363137 & 954479 & 5.0668 & 4.6015 & TST & & \\
\hline CHEMBL3680727 & 1527682 & 9.3468 & 9.129 & TRN & & \\
\hline CHEMBL 3680743 & 1527682 & 7.7696 & 8.1125 & TST & & \\
\hline CHEMBL 3680702 & 1527682 & 7.6021 & 7.9629 & TST & & \\
\hline CHEMBL3680698 & 1527682 & 9.6778 & 8.8619 & TRN & & \\
\hline CHEMBL 3680729 & 1527682 & 8.9208 & 8.6907 & TRN & & \\
\hline CHEMBL 3680786 & 1527682 & 9.4685 & 9.9329 & TRN & & \\
\hline CHEMBL3680732 & 1527682 & 7.9208 & 7.7757 & TST & & \\
\hline CHEMBL 3680737 & 1527682 & 8.8539 & 8.9154 & TRN & & \\
\hline CHEMBL 3680803 & 1527682 & 7.1427 & 7.6837 & TRN & & \\
\hline
\end{tabular}


Supplemental Table S2.txt

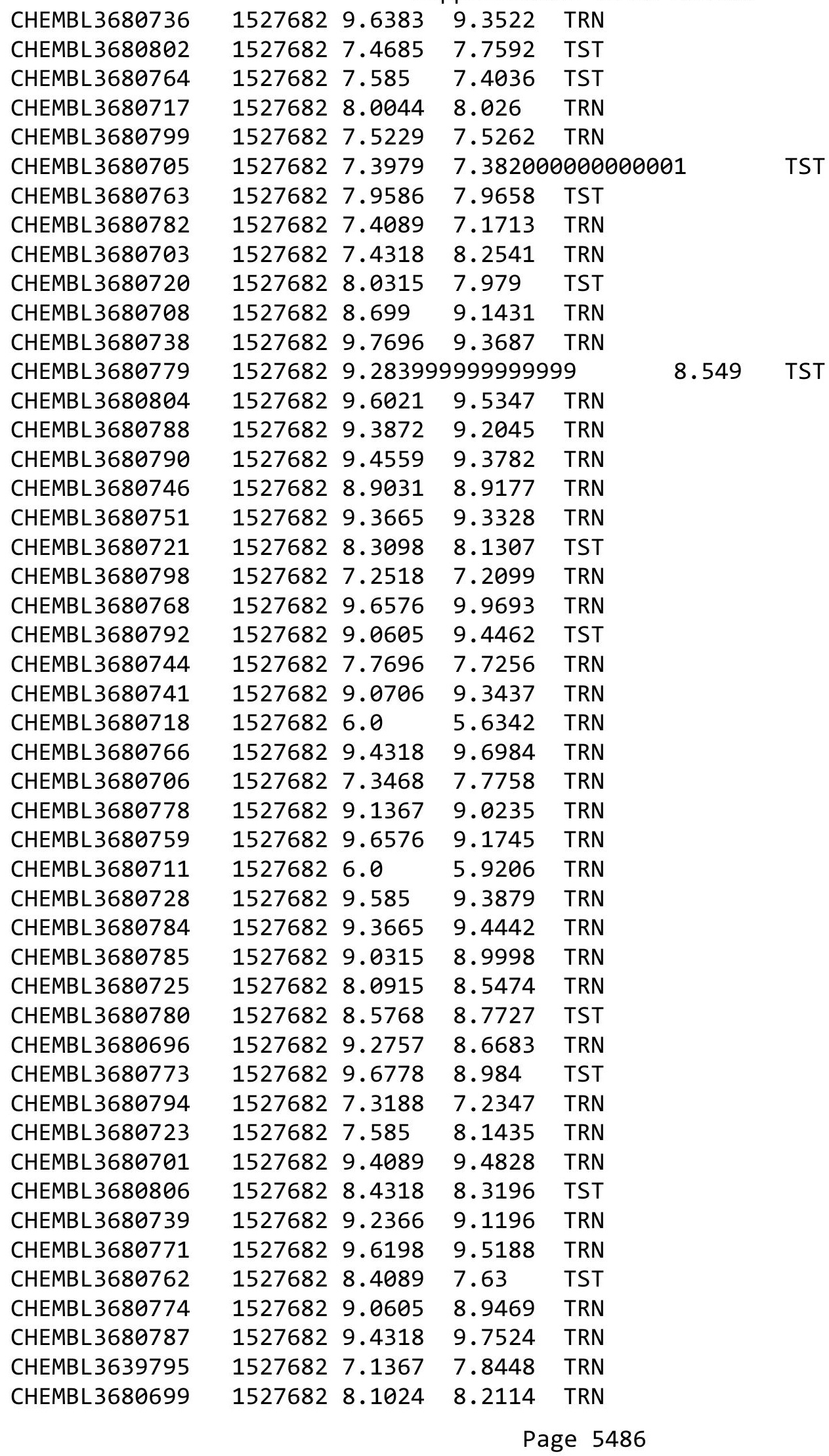


Supplemental Table S2.txt

\begin{tabular}{|c|c|c|c|c|}
\hline CHEMBL 3680805 & 1527682 & 9.699 & 9.9138 & TRN \\
\hline CHEMBL 3680753 & 1527682 & 9.4949 & 9.0051 & TRN \\
\hline CHEMBL 3680731 & 1527682 & 9.0 & 8.7471 & TRN \\
\hline CHEMBL 3680755 & 1527682 & 9.7447 & 9.4652 & TRN \\
\hline CHEMBL 3680765 & 1527682 & 9.5686 & 10.0116 & TRN \\
\hline CHEMBL 3680747 & 1527682 & 7.9119 & 8.0705 & TRN \\
\hline CHEMBL 3680752 & 1527682 & 9.6576 & 9.9593 & TRN \\
\hline CHEMBL 3680740 & 1527682 & 9.585 & 8.2556 & TST \\
\hline CHEMBL 3680775 & 1527682 & 9.4815 & 8.8803 & TST \\
\hline CHEMBL 3680697 & 1527682 & 8.0088 & 8.3453 & TRN \\
\hline CHEMBL 3680707 & 1527682 & 6.0 & 6.1818 & TRN \\
\hline CHEMBL 3680756 & 1527682 & 9.3468 & 9.0775 & TRN \\
\hline CHEMBL 3680748 & 1527682 & 9.5686 & 8.6549 & TST \\
\hline CHEMBL 3680789 & 1527682 & 9.4202 & 9.3471 & TRN \\
\hline CHEMBL 3680801 & 1527682 & 8.7959 & 8.4844 & TRN \\
\hline CHEMBL 3680769 & 1527682 & 9.4949 & 9.1728 & TRN \\
\hline CHEMBL 3680772 & 1527682 & 9.699 & 9.482999 & 9999999999 \\
\hline CHEMBL 3680776 & 1527682 & 8.3615 & 8.5145 & TRN \\
\hline CHEMBL 3680695 & 1527682 & 8.2924 & 8.1612 & TRN \\
\hline CHEMBL 3680694 & 1527682 & 8.7212 & 8.6162 & TRN \\
\hline CHEMBL 3680767 & 1527682 & 9.71 & 9.1321 & TRN \\
\hline CHEMBL 3680781 & 1527682 & 9.2441 & 8.8739 & TST \\
\hline CHEMBL 3680710 & 1527682 & 8.3372 & 8.2808 & TRN \\
\hline CHEMBL 3680745 & 1527682 & 7.3372 & 7.6393 & TST \\
\hline CHEMBL 3680749 & 1527682 & 8.585 & 8.7665 & TST \\
\hline CHEMBL 3680735 & 1527682 & 9.6021 & 9.4729 & TRN \\
\hline CHEMBL 3680760 & 1527682 & 9.1135 & 9.5096 & TRN \\
\hline CHEMBL 3680724 & 1527682 & 7.9586 & 7.6025 & TST \\
\hline CHEMBL445335 & 544730 & 10.1367 & 10.1104 & TRN \\
\hline CHEMBL456064 & 544730 & 10.69900 & 00000000 & 10.7451 \\
\hline CHEMBL459102 & 544730 & 8.9586 & 9.0141 & TST \\
\hline CHEMBL464756 & 544730 & 9.4437 & 9.3756 & TRN \\
\hline CHEMBL518253 & 544730 & 10.3188 & 10.3501 & TRN \\
\hline CHEMBL515383 & 544730 & 9.0 & 9.0058 & TRN \\
\hline CHEMBL461667 & 544730 & 10.2924 & 9.8936 & TST \\
\hline CHEMBL461453 & 544730 & 10.0757 & 10.0412 & TRN \\
\hline CHEMBL517748 & 544730 & 7.9586 & 7.956 & TRN \\
\hline CHEMBL461668 & 544730 & 9.1308 & 9.1807 & TRN \\
\hline CHEMBL504703 & 544730 & 10.1024 & 10.0807 & TRN \\
\hline CHEMBL465794 & 544730 & 8.1192 & 8.2044 & TRN \\
\hline CHEMBL518401 & 544730 & 9.7959 & 9.7608 & TRN \\
\hline CHEMBL446752 & 544730 & 10.5686 & 10.4852 & TRN \\
\hline CHEMBL515066 & 544730 & 8.9586 & 9.587 & TST \\
\hline CHEMBL464555 & 544730 & 10.1871 & 10.1818 & TRN \\
\hline CHEMBL465499 & 544730 & 10.1675 & 10.1838 & TRN \\
\hline CHEMBL462084 & 544730 & 8.5229 & 8.5324 & TRN \\
\hline CHEMBL461091 & 544730 & 10.6778 & 10.7208 & TRN \\
\hline CHEMBL451053 & 544730 & 10.1308 & 10.2 & TRN \\
\hline
\end{tabular}




\begin{tabular}{|c|c|c|c|c|c|c|}
\hline & & \multicolumn{5}{|c|}{ Supplemental Table S2.txt } \\
\hline CHEMBL512287 & 544730 & 9.5376 & 9.5356 & TRN & & \\
\hline CHEMBL468782 & 544730 & 10.0706 & 10.0093 & TRN & & \\
\hline CHEMBL461454 & 544730 & 9.8539 & 9.8657 & TRN & & \\
\hline CHEMBL461297 & 544730 & 10.4559 & 10.4755 & TRN & & \\
\hline CHEMBL456677 & 544730 & 10.0315 & 10.0019 & TRN & & \\
\hline CHEMBL467576 & 544730 & 9.2291 & 9.2057 & TRN & & \\
\hline CHEMBL462710 & 544730 & 9.2596 & 9.2088 & TRN & & \\
\hline CHEMBL510030 & 544730 & 9.9586 & 9.9737 & TRN & & \\
\hline CHEMBL463521 & 544730 & 8.5376 & 8.5588 & TRN & & \\
\hline CHEMBL471550 & 544730 & 10.6021 & 10.6212 & TRN & & \\
\hline CHEMBL471565 & 544730 & 10.1938 & 10.1942 & TRN & & \\
\hline CHEMBL459286 & 544730 & 9.7447 & 9.7352 & TRN & & \\
\hline CHEMBL460884 & 544730 & 9.7447 & 9.8024 & TRN & & \\
\hline CHEMBL456676 & 544730 & 10.3768 & 10.368 & TRN & & \\
\hline CHEMBL457549 & 544730 & 9.4949 & 9.4791 & TRN & & \\
\hline CHEMBL516512 & 544730 & 7.699 & 7.6344 & TRN & & \\
\hline CHEMBL515847 & 544730 & 9.1079 & 9.0914 & TRN & & \\
\hline CHEMBL456034 & 544730 & 9.6198 & 9.6523 & TRN & & \\
\hline CHEMBL458426 & 544730 & 8.1938 & 9.2942 & TST & & \\
\hline CHEMBL462293 & 544730 & 8.8239 & 8.8453 & TRN & & \\
\hline CHEMBL516297 & 544730 & 9.7959 & 9.5985 & TST & & \\
\hline CHEMBL514567 & 544730 & 9.5086 & 9.5723 & TRN & & \\
\hline CHEMBL540198 & 544730 & 10.6990 & 000000000 & 002 & 10.6519 & TRN \\
\hline CHEMBL518473 & 544730 & 10.3665 & 10.38 & TRN & & \\
\hline CHEMBL456932 & 544730 & 8.6021 & 9.4333 & TST & & \\
\hline CHEMBL456931 & 544730 & 8.3098 & 9.1721 & TST & & \\
\hline CHEMBL452793 & 544730 & 8.8239 & 8.8251 & TRN & & \\
\hline CHEMBL513954 & 544730 & 9.2518 & 9.8127 & TST & & \\
\hline CHEMBL512288 & 544730 & 9.8539 & 9.8246 & TRN & & \\
\hline CHEMBL512467 & 544730 & 9.6198 & 9.2931 & TST & & \\
\hline CHEMBL465584 & 544730 & 9.6778 & 9.6768 & TRN & & \\
\hline CHEMBL453208 & 544730 & 10.2676 & 10.0361 & TST & & \\
\hline CHEMBL517714 & 544730 & 8.2924 & 8.301 & TRN & & \\
\hline CHEMBL457774 & 544730 & 10.1487 & 10.1433 & TRN & & \\
\hline CHEMBL516771 & 544730 & 9.8239 & 9.5931 & TST & & \\
\hline CHEMBL468792 & 544730 & 10.2596 & 9.9817 & TST & & \\
\hline CHEMBL456498 & 544730 & 10.6778 & 9.5499 & TST & & \\
\hline CHEMBL468783 & 544730 & 9.9208 & 9.7123 & TST & & \\
\hline CHEMBL460385 & 544730 & 10.3872 & 10.5894 & TST & & \\
\hline CHEMBL1368604 & 688799 & 5.1 & 5.1734 & TRN & & \\
\hline CHEMBL1612050 & 688799 & 7.3002 & 7.1511 & TRN & & \\
\hline CHEMBL221733 & 688799 & 5.5 & 5.5803 & TRN & & \\
\hline CHEMBL242341 & 688799 & 5.1 & 5.3034 & TRN & & \\
\hline CHEMBL1565567 & 688799 & 9.0 & 5.3858 & TRN & & \\
\hline CHEMBL1406556 & 688799 & 5.5 & 5.5447 & TRN & & \\
\hline CHEMBL1569400 & 688799 & 4.4 & 4.5742 & TRN & & \\
\hline CHEMBL332898 & 688799 & 6.1 & 6.0051 & TRN & & \\
\hline CHEMBL1533932 & 688799 & 4.6 & 4.4939 & TRN & & \\
\hline
\end{tabular}




\begin{tabular}{|c|c|c|c|c|}
\hline \\
\hline CHEMBL1476267 & 688799 & 5.4 & 5.2578 & TRN \\
\hline CHEMBL1473191 & 688799 & 5.2 & 5.3458 & TST \\
\hline CHEMBL1476266 & 688799 & 4.4 & 4.6209 & TRN \\
\hline CHEMBL1551548 & 688799 & 4.4 & 4.3791 & TRN \\
\hline CHEMBL1330251 & 688799 & 4.4 & 4.488 & TRN \\
\hline CHEMBL1314799 & 688799 & 5.3 & 5.4441 & TRN \\
\hline CHEMBL1591556 & 688799 & 4.9 & 5.5769 & TST \\
\hline CHEMBL1256957 & 688799 & 5.3 & 5.2147 & TRN \\
\hline CHEMBL1590909 & 688799 & 5.8 & 5.8288 & TRN \\
\hline CHEMBL1443741 & 688799 & 4.4 & 4.3504 & TRN \\
\hline CHEMBL1529452 & 688799 & 5.4 & 5.6734 & TST \\
\hline CHEMBL1334255 & 688799 & 6.0 & 5.995 & TRN \\
\hline CHEMBL1182777 & 688799 & 5.4 & 5.3617 & TST \\
\hline CHEMBL1553498 & 688799 & 7.8013 & 7.4946 & TST \\
\hline CHEMBL1479470 & 688799 & 5.2 & 5.0529 & TRN \\
\hline CHEMBL1414232 & 688799 & 6.6 & 6.473 & TRN \\
\hline CHEMBL1519261 & 688799 & 5.5 & 5.4074 & TRN \\
\hline CHEMBL1601957 & 688799 & 5.2 & 5.3075 & TST \\
\hline CHEMBL1356041 & 688799 & 5.1 & 5.0023 & TRN \\
\hline CHEMBL1552329 & 688799 & 5.0 & 5.1175 & TRN \\
\hline CHEMBL1568178 & 688799 & 5.4 & 5.6375 & TRN \\
\hline CHEMBL1438164 & 688799 & 4.9 & 5.157 & TRN \\
\hline CHEMBL475198 & 688799 & 5.1 & 5.1628 & TRN \\
\hline CHEMBL1320904 & 688799 & 5.0 & 5.5749 & TRN \\
\hline CHEMBL1489836 & 688799 & 5.4 & 5.392 & TRN \\
\hline CHEMBL1592760 & 688799 & 4.4 & 4.5012 & TRN \\
\hline CHEMBL1317533 & 688799 & 4.6 & 4.7901 & TRN \\
\hline CHEMBL1332592 & 688799 & 5.4 & 5.4963 & TRN \\
\hline CHEMBL29726 & 688799 & 4.7 & 5.0064 & TST \\
\hline CHEMBL1438690 & 688799 & 5.8 & 6.0649 & TRN \\
\hline CHEMBL1318789 & 688799 & 4.9 & 4.9163 & TRN \\
\hline CHEMBL1561366 & 688799 & 6.3 & 6.5206 & TRN \\
\hline CHEMBL1415100 & 688799 & 5.5 & 5.6132 & TRN \\
\hline CHEMBL1396754 & 688799 & 5.9 & 5.5269 & TRN \\
\hline CHEMBL119264 & 688799 & 4.5 & 4.6959 & TST \\
\hline CHEMBL400875 & 688799 & 5.8 & 5.785 & TRN \\
\hline CHEMBL1398518 & 688799 & 4.5 & 5.4815 & TST \\
\hline CHEMBL1409547 & 688799 & 4.6 & 4.7982 & TRN \\
\hline CHEMBL1437990 & 688799 & 6.2 & 6.2505 & TRN \\
\hline CHEMBL1553056 & 688799 & 5.9 & 5.6088 & TRN \\
\hline CHEMBL1399135 & 688799 & 5.3 & 5.2091 & TRN \\
\hline CHEMBL1574106 & 688799 & 4.7 & 4.6377 & TRN \\
\hline CHEMBL1554817 & 688799 & 6.9 & 7.0925 & TRN \\
\hline CHEMBL1567569 & 688799 & 5.2 & 5.3373 & TRN \\
\hline CHEMBL1480903 & 688799 & 5.5 & 5.5939 & TRN \\
\hline CHEMBL1318056 & 688799 & 5.6 & 5.0387 & TRN \\
\hline CHEMBL1607830 & 688799 & 5.6 & 5.5914 & TST \\
\hline CHEMBL1377805 & 688799 & 5.2 & 5.5878 & TRN \\
\hline
\end{tabular}




\begin{tabular}{|c|c|c|c|c|c|}
\hline & & & & & \\
\hline CHEMBL1448974 & 688799 & 6.1 & 7.0848 & TRN & \\
\hline CHEMBL1324530 & 688799 & 5.8 & 4.9958 & TRN & \\
\hline CHEMBL1364168 & 688799 & 4.6 & 4.5706 & TRN & \\
\hline CHEMBL3213748 & 688799 & 5.2 & 5.93 & TRN & \\
\hline CHEMBL1314453 & 688799 & 4.8 & 4.9313 & TRN & \\
\hline CHEMBL1201074 & 688799 & 5.5 & 5.6699 & TRN & \\
\hline CHEMBL1494099 & 688799 & 5.8 & 5.9344 & TRN & \\
\hline CHEMBL1590982 & 688799 & 4.6 & 4.7349 & TRN & \\
\hline CHEMBL18132 & 688799 & 5.3 & 5.4272 & TST & \\
\hline CHEMBL1358568 & 688799 & 6.0 & 6.0856 & TRN & \\
\hline CHEMBL1545634 & 688799 & 5.9 & 5.7694 & TRN & \\
\hline CHEMBL1446324 & 688799 & 4.4 & 4.3959 & TRN & \\
\hline CHEMBL63426 & 688799 & 4.5 & 4.9321 & TST & \\
\hline CHEMBL1397833 & 688799 & 6.0 & 5.3862 & TST & \\
\hline CHEMBL198159 & 688799 & 5.7 & 5.7841 & TRN & \\
\hline CHEMBL1590123 & 688799 & 4.4 & 4.6434 & TRN & \\
\hline CHEMBL1486304 & 688799 & 5.6 & 5.7526 & TRN & \\
\hline CHEMBL1594372 & 688799 & 6.9 & 6.6167 & TRN & \\
\hline CHEMBL 1318140 & 688799 & 7.1002 & 5.4495 & TRN & \\
\hline CHEMBL1355227 & 688799 & 4.9 & 4.9553 & TRN & \\
\hline CHEMBL1435604 & 688799 & 5.0 & 5.211 & TRN & \\
\hline CHEMBL1601416 & 688799 & 4.8 & 4.8163 & TRN & \\
\hline CHEMBL1395769 & 688799 & 5.5 & 5.5654 & TST & \\
\hline CHEMBL1316294 & 688799 & 6.1 & 5.5819 & TRN & \\
\hline CHEMBL1415465 & 688799 & 4.4 & 4.2704 & TRN & \\
\hline CHEMBL1416829 & 688799 & 4.6 & 4.7225 & TRN & \\
\hline CHEMBL1600497 & 688799 & 5.3 & 5.5654 & TRN & \\
\hline CHEMBL1328536 & 688799 & 6.0 & 6.0057 & TRN & \\
\hline CHEMBL 291536 & 688799 & 5.0 & 5.9844 & TST & \\
\hline CHEMBL1334327 & 688799 & 6.0 & 5.9549 & TRN & \\
\hline CHEMBL 269366 & 688799 & 5.9 & 5.8676 & TST & \\
\hline CHEMBL1314451 & 688799 & 6.2 & 6.0482 & TRN & \\
\hline CHEMBL1456312 & 688799 & 5.3 & 5.4664 & TRN & \\
\hline CHEMBL1335890 & 688799 & 6.0 & 6.1714 & TRN & \\
\hline CHEMBL1314971 & 688799 & 4.4 & 4.3285 & TRN & \\
\hline CHEMBL1528848 & 688799 & 5.8 & 5.9438 & TRN & \\
\hline CHEMBL1370296 & 688799 & 5.1 & 5.0967 & TRN & \\
\hline CHEMBL1484120 & 688799 & 7.3002 & 5.1397 & TRN & \\
\hline CHEMBL1318104 & 688799 & 5.8 & 5.8261 & TRN & \\
\hline CHEMBL1531299 & 688799 & 6.6 & 6.6408 & TRN & \\
\hline CHEMBL1571391 & 688799 & 6.4 & 5.5462 & TRN & \\
\hline CHEMBL1493369 & 688799 & 5.6 & 5.6273 & TRN & \\
\hline CHEMBL1489212 & 688799 & 4.6 & 4.8617 & TRN & \\
\hline CHEMBL1410910 & 688799 & 6.0 & 6.0339 & TRN & \\
\hline CHEMBL1329940 & 688799 & 6.6 & 6.4125 & TST & \\
\hline CHEMBL1599014 & 688799 & 4.6 & 4.6572 & TRN & \\
\hline CHEMBL1256814 & 688799 & 5.0 & 5.17700 & 00000000005 & TRN \\
\hline CHEMBL1435381 & 688799 & 4.4 & 4.3663 & TST & \\
\hline
\end{tabular}




\begin{tabular}{|c|c|c|c|c|}
\hline \multicolumn{5}{|c|}{ emental T } \\
\hline CHEMBL1355736 & 688799 & 5.0 & 5.0381 & TST \\
\hline CHEMBL1395235 & 688799 & 5.5 & 5.75 & TRN \\
\hline CHEMBL1356748 & 688799 & 5.1 & 5.3233 & TRN \\
\hline CHEMBL1552953 & 688799 & 5.5 & 5.749 & TRN \\
\hline CHEMBL1323905 & 688799 & 5.5 & 5.5499 & TRN \\
\hline CHEMBL1449371 & 688799 & 4.4 & 4.7047 & TRN \\
\hline CHEMBL1398540 & 688799 & 6.1 & 5.9795 & TRN \\
\hline CHEMBL428814 & 688799 & 5.0 & 5.114 & TRN \\
\hline CHEMBL1474795 & 688799 & 4.4 & 3.9676 & TRN \\
\hline CHEMBL1457550 & 688799 & 6.0 & 6.1433 & TRN \\
\hline CHEMBL1327681 & 688799 & 5.2 & 5.2099 & TRN \\
\hline CHEMBL1331004 & 688799 & 4.6 & 4.6676 & TRN \\
\hline CHEMBL1446467 & 688799 & 5.5 & 5.6236 & TRN \\
\hline CHEMBL1452199 & 688799 & 4.7 & 4.4223 & TRN \\
\hline CHEMBL15192 & 688799 & 5.4 & 5.4636 & TST \\
\hline CHEMBL1396377 & 688799 & 5.0 & 4.9945 & TRN \\
\hline CHEMBL153648 & 688799 & 7.2 & 6.9984 & TST \\
\hline CHEMBL1518035 & 688799 & 4.6 & 4.7824 & TRN \\
\hline CHEMBL1366926 & 688799 & 5.0 & 5.1207 & TRN \\
\hline CHEMBL1516103 & 688799 & 4.6 & 4.63 & TRN \\
\hline CHEMBL1597434 & 688799 & 4.6 & 4.7337 & TRN \\
\hline CHEMBL247378 & 688799 & 5.8 & 5.9147 & TRN \\
\hline CHEMBL1512023 & 688799 & 4.8 & 4.9949 & TRN \\
\hline CHEMBL1475108 & 688799 & 8.1024 & 5.5214 & TRN \\
\hline CHEMBL1356733 & 688799 & 5.1 & 5.0663 & TRN \\
\hline CHEMBL611494 & 688799 & 6.0 & 5.2263 & TST \\
\hline CHEMBL534084 & 688799 & 4.6 & 4.9091 & TRN \\
\hline CHEMBL1401672 & 688799 & 5.5 & 5.6494 & TRN \\
\hline CHEMBL1589942 & 688799 & 5.6 & 5.6489 & TST \\
\hline CHEMBL1436049 & 688799 & 5.0 & 5.11 & TRN \\
\hline CHEMBL1496934 & 688799 & 5.5 & 5.7312 & TRN \\
\hline CHEMBL1590059 & 688799 & 4.4 & 4.5534 & TRN \\
\hline CHEMBL1394113 & 688799 & 5.1 & 5.105 & TRN \\
\hline CHEMBL42485 & 688799 & 5.3 & 5.4144 & TST \\
\hline CHEMBL441282 & 688799 & 5.0 & 5.3686 & TST \\
\hline CHEMBL258893 & 688799 & 5.0 & 5.1806 & TRN \\
\hline CHEMBL1570285 & 688799 & 4.6 & 4.6443 & TRN \\
\hline CHEMBL 3350578 & 688799 & 5.4 & 5.4812 & TST \\
\hline CHEMBL1337108 & 688799 & 4.9 & 4.862 & TRN \\
\hline CHEMBL395808 & 688799 & 5.2 & 5.4227 & TRN \\
\hline CHEMBL556001 & 688799 & 6.1 & 6.1451 & TST \\
\hline CHEMBL1317451 & 688799 & 4.4 & 4.3002 & TRN \\
\hline CHEMBL1331351 & 688799 & 4.7 & 4.7699 & TRN \\
\hline CHEMBL1477727 & 688799 & 5.1 & 5.1915 & TRN \\
\hline CHEMBL1334277 & 688799 & 7.0 & 5.4086 & TRN \\
\hline CHEMBL1357574 & 688799 & 5.6 & 5.5703 & TRN \\
\hline CHEMBL1256876 & 688799 & 5.1 & 5.3018 & TRN \\
\hline CHEMBL1514016 & 688799 & 4.7 & 4.6871 & TRN \\
\hline
\end{tabular}




\begin{tabular}{|c|c|c|c|c|}
\hline \multicolumn{5}{|c|}{ Supplemental Table s2.txt } \\
\hline CHEMBL1529490 & 688799 & 6.0 & 5.2486 & TRN \\
\hline CHEMBL1330763 & 688799 & 7.3002 & 7.0561 & TRN \\
\hline CHEMBL1590038 & 688799 & 4.9 & 4.8931 & TRN \\
\hline CHEMBL1452910 & 688799 & 4.6 & 4.2493 & TRN \\
\hline CHEMBL1373773 & 688799 & 5.1 & 5.0817 & TRN \\
\hline CHEMBL1557048 & 688799 & 6.1 & 6.3554 & TRN \\
\hline CHEMBL1329166 & 688799 & 5.4 & 5.6109 & TRN \\
\hline CHEMBL1554567 & 688799 & 4.8 & 5.0791 & TRN \\
\hline CHEMBL 279556 & 688799 & 5.1 & 5.2521 & TST \\
\hline CHEMBL1357168 & 688799 & 4.9 & 4.8821 & TRN \\
\hline CHEMBL1526053 & 688799 & 5.2 & 5.4271 & TRN \\
\hline CHEMBL1594058 & 688799 & 4.4 & 4.5374 & TRN \\
\hline CHEMBL1436925 & 688799 & 5.1 & 5.2269 & TRN \\
\hline CHEMBL1522897 & 688799 & 7.4001 & 6.6489 & TRN \\
\hline CHEMBL3189190 & 688799 & 5.3 & 5.5881 & TRN \\
\hline CHEMBL1565342 & 688799 & 6.0 & 6.1063 & TRN \\
\hline CHEMBL1319626 & 688799 & 5.4 & 5.5238 & TRN \\
\hline CHEMBL123904 & 688799 & 6.4 & 6.289 & TST \\
\hline CHEMBL1396261 & 688799 & 7.1002 & 7.5432 & TRN \\
\hline CHEMBL1452408 & 688799 & 4.9 & 4.8578 & TRN \\
\hline CHEMBL1378764 & 688799 & 5.0 & 4.9291 & TRN \\
\hline CHEMBL1354414 & 688799 & 5.5 & 5.5971 & TRN \\
\hline CHEMBL39317 & 688799 & 4.8 & 5.0772 & TRN \\
\hline CHEMBL1554664 & 688799 & 5.0 & 4.9493 & TRN \\
\hline CHEMBL1529857 & 688799 & 7.6003 & 5.4708 & TRN \\
\hline CHEMBL1335862 & 688799 & 5.8 & 5.777 & TST \\
\hline CHEMBL1316055 & 688799 & 5.4 & 5.4446 & TRN \\
\hline CHEMBL1330587 & 688799 & 7.3002 & 7.2087 & TRN \\
\hline CHEMBL1409613 & 688799 & 4.5 & 4.7627 & TRN \\
\hline CHEMBL1367222 & 688799 & 5.0 & 5.1336 & TRN \\
\hline CHEMBL 328710 & 688799 & 4.7 & 5.1694 & TRN \\
\hline CHEMBL1256646 & 688799 & 4.5 & 4.9385 & TST \\
\hline CHEMBL1435254 & 688799 & 4.4 & 4.5009 & TRN \\
\hline CHEMBL1378667 & 688799 & 5.5 & 5.5042 & TRN \\
\hline CHEMBL1374334 & 688799 & 6.1 & 5.9791 & TST \\
\hline CHEMBL1599748 & 688799 & 6.0 & 5.8263 & TRN \\
\hline CHEMBL1357130 & 688799 & 5.1 & 5.2925 & TST \\
\hline CHEMBL1360942 & 688799 & 5.5 & 5.6186 & TRN \\
\hline CHEMBL1396546 & 688799 & 5.3 & 5.46700 & 00000000005 \\
\hline CHEMBL1515698 & 688799 & 4.4 & 6.1302 & TRN \\
\hline CHEMBL1551503 & 688799 & 5.5 & 5.3887 & TRN \\
\hline CHEMBL1593623 & 688799 & 6.1 & 5.5713 & TST \\
\hline CHEMBL1372627 & 688799 & 5.8 & 5.5848 & TRN \\
\hline CHEMBL1476851 & 688799 & 6.0 & 5.6442 & TRN \\
\hline CHEMBL17002 & 688799 & 5.1 & 5.2068 & TRN \\
\hline CHEMBL44297 & 688799 & 5.0 & 5.1477 & TST \\
\hline CHEMBL1517099 & 688799 & 4.7 & 4.8448 & TRN \\
\hline CHEMBL1333454 & 688799 & 5.3 & 5.557 & TRN \\
\hline
\end{tabular}




\begin{tabular}{|c|c|c|c|c|}
\hline & & & lement & al Ta \\
\hline CHEMBL1485000 & 688799 & 6.0 & 6.155 & TRN \\
\hline CHEMBL1434848 & 688799 & 4.4 & 4.5645 & TRN \\
\hline CHEMBL1570921 & 688799 & 5.0 & 5.1886 & TRN \\
\hline CHEMBL1318004 & 688799 & 5.5 & 5.2443 & TRN \\
\hline CHEMBL1371458 & 688799 & 5.7 & 5.1014 & TRN \\
\hline CHEMBL1326322 & 688799 & 4.7 & 4.7075 & TRN \\
\hline CHEMBL1491744 & 688799 & 6.6 & 6.3375 & TRN \\
\hline CHEMBL1395344 & 688799 & 4.7 & 4.8317 & TRN \\
\hline CHEMBL1534735 & 688799 & 9.0 & 5.3465 & TRN \\
\hline CHEMBL1354913 & 688799 & 5.1 & 5.1206 & TST \\
\hline CHEMBL1398488 & 688799 & 4.4 & 4.4192 & TRN \\
\hline CHEMBL1516787 & 688799 & 5.1 & 5.1115 & TRN \\
\hline CHEMBL1396203 & 688799 & 5.0 & 4.9415 & TRN \\
\hline CHEMBL1360310 & 688799 & 4.8 & 4.6953 & TRN \\
\hline CHEMBL605003 & 688799 & 5.1 & 5.2623 & TRN \\
\hline CHEMBL271165 & 688799 & 6.4 & 6.4865 & TRN \\
\hline CHEMBL1591714 & 688799 & 5.5 & 5.6188 & TRN \\
\hline CHEMBL1330422 & 688799 & 4.4 & 4.8583 & TRN \\
\hline CHEMBL1318137 & 688799 & 5.4 & 5.4375 & TRN \\
\hline CHEMBL1557564 & 688799 & 5.7 & 5.5393 & TRN \\
\hline CHEMBL 291278 & 688799 & 4.5 & 5.2552 & TST \\
\hline CHEMBL462880 & 688799 & 4.9 & 5.0946 & TRN \\
\hline CHEMBL268609 & 688799 & 6.0 & 6.0879 & TRN \\
\hline CHEMBL1610944 & 688799 & 6.3 & 6.35 & TRN \\
\hline CHEMBL250053 & 688799 & 4.8 & 5.0978 & TST \\
\hline CHEMBL1564864 & 688799 & 4.5 & 5.2817 & TRN \\
\hline CHEMBL1322545 & 688799 & 4.8 & 4.9808 & TRN \\
\hline CHEMBL1331031 & 688799 & 5.0 & 5.1845 & TRN \\
\hline CHEMBL1603884 & 688799 & 5.4 & 5.4603 & TRN \\
\hline CHEMBL1553114 & 688799 & 5.8 & 5.9988 & TRN \\
\hline CHEMBL1515559 & 688799 & 4.6 & 5.0256 & TRN \\
\hline CHEMBL3212645 & 688799 & 5.9 & 6.0956 & TRN \\
\hline CHEMBL528080 & 688799 & 4.9 & 5.3126 & TRN \\
\hline CHEMBL77030 & 688799 & 4.6 & 4.8628 & TRN \\
\hline CHEMBL1474410 & 688799 & 5.2 & 5.2453 & TRN \\
\hline CHEMBL1552540 & 688799 & 5.0 & 5.1196 & TRN \\
\hline CHEMBL1451823 & 688799 & 6.0 & 5.6978 & TRN \\
\hline CHEMBL1599118 & 688799 & 5.0 & 4.9453 & TRN \\
\hline CHEMBL596674 & 688799 & 4.5 & 5.0063 & TRN \\
\hline CHEMBL 388054 & 688799 & 4.9 & 5.3442 & TST \\
\hline CHEMBL1448547 & 688799 & 6.1 & 5.284 & TST \\
\hline CHEMBL148296 & 688799 & 5.3 & 5.3893 & TRN \\
\hline CHEMBL1371311 & 688799 & 5.3 & 5.4914 & TST \\
\hline CHEMBL287327 & 688799 & 4.6 & 4.879 & TST \\
\hline CHEMBL1487801 & 688799 & 5.5 & 5.5722 & TRN \\
\hline CHEMBL1489659 & 688799 & 5.1 & 5.0545 & TRN \\
\hline CHEMBL1439665 & 688799 & 4.4 & 4.5558 & TRN \\
\hline CHEMBL1496576 & 688799 & 4.4 & 4.5476 & TRN \\
\hline
\end{tabular}




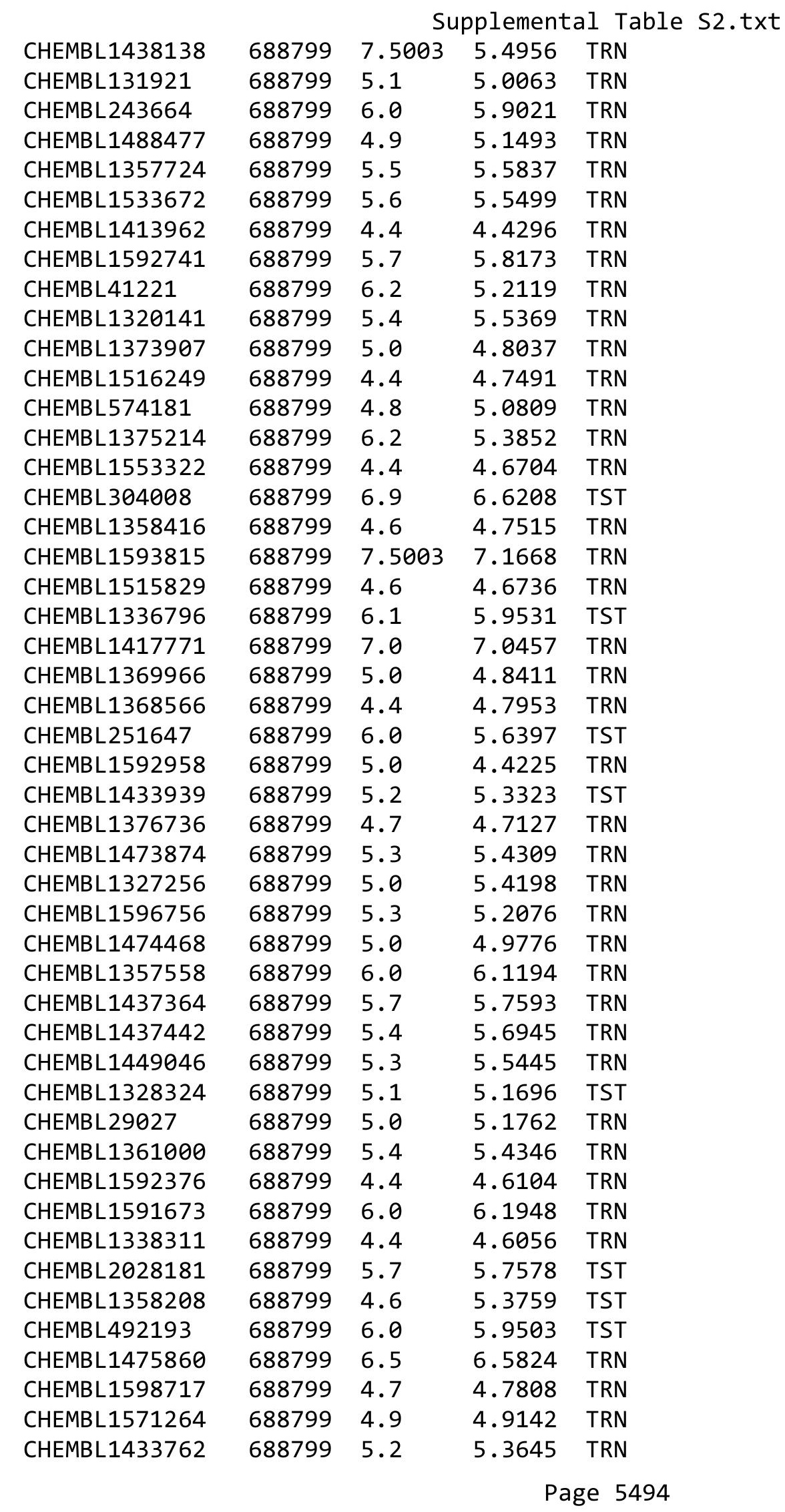




\begin{tabular}{|c|c|c|c|c|c|}
\hline & & & & & \\
\hline CHEMBL1316463 & 688799 & 5.1 & 5.4273 & TRN & \\
\hline CHEMBL221137 & 688799 & 4.4 & 5.2979 & TST & \\
\hline CHEMBL1370698 & 688799 & 5.4 & 5.5067 & TRN & \\
\hline CHEMBL1568080 & 688799 & 5.6 & 5.481 & TRN & \\
\hline CHEMBL1433950 & 688799 & 4.5 & 4.2389 & TRN & \\
\hline CHEMBL325238 & 688799 & 4.8 & 4.99100 & 00000000005 & TRN \\
\hline CHEMBL1450573 & 688799 & 5.8 & 5.9694 & TRN & \\
\hline CHEMBL1397636 & 688799 & 4.9 & 4.9789 & TRN & \\
\hline CHEMBL 317757 & 688799 & 5.0 & 5.15 & TST & \\
\hline CHEMBL3211338 & 688799 & 6.0 & 6.2638 & TRN & \\
\hline CHEMBL1442770 & 688799 & 4.4 & 4.6183 & TST & \\
\hline CHEMBL1396559 & 688799 & 5.6 & 5.5249 & TRN & \\
\hline CHEMBL1395281 & 688799 & 5.5 & 5.4942 & TRN & \\
\hline CHEMBL577455 & 688799 & 4.9 & 5.2468 & TST & \\
\hline CHEMBL1516622 & 688799 & 5.5 & 5.6775 & TRN & \\
\hline CHEMBL1316317 & 688799 & 4.8 & 4.846 & TRN & \\
\hline CHEMBL1437064 & 688799 & 5.0 & 5.1741 & TRN & \\
\hline CHEMBL405912 & 688799 & 5.6 & 5.6196 & TRN & \\
\hline CHEMBL1363622 & 688799 & 4.4 & 4.3007 & TRN & \\
\hline CHEMBL67311 & 688799 & 4.4 & 5.2749 & TST & \\
\hline CHEMBL1553274 & 688799 & 4.9 & 5.3873 & TST & \\
\hline CHEMBL1565578 & 688799 & 5.0 & 5.3041 & TRN & \\
\hline CHEMBL1490024 & 688799 & 5.2 & 5.602 & TRN & \\
\hline CHEMBL1481378 & 688799 & 5.8 & 5.564 & TRN & \\
\hline CHEMBL1565333 & 688799 & 5.7 & 5.7078 & TST & \\
\hline CHEMBL1610350 & 688799 & 6.5 & 6.46700 & 00000000005 & TRN \\
\hline CHEMBL576349 & 688799 & 4.5 & 4.8066 & TRN & \\
\hline CHEMBL 1558480 & 688799 & 4.7 & 4.863 & TRN & \\
\hline CHEMBL1478226 & 688799 & 5.2 & 5.0724 & TRN & \\
\hline CHEMBL1314222 & 688799 & 4.8 & 4.8499 & TRN & \\
\hline CHEMBL1395297 & 688799 & 4.5 & 4.3744 & TRN & \\
\hline CHEMBL1331914 & 688799 & 7.0 & 6.9472 & TST & \\
\hline CHEMBL1447481 & 688799 & 5.7 & 5.6911 & TRN & \\
\hline CHEMBL1436817 & 688799 & 4.8 & 4.7673 & TRN & \\
\hline CHEMBL1188431 & 688799 & 6.0 & 6.1465 & TRN & \\
\hline CHEMBL454761 & 688799 & 4.6 & 5.3744 & TST & \\
\hline CHEMBL1439183 & 688799 & 4.9 & 5.136 & TRN & \\
\hline CHEMBL1487140 & 688799 & 8.2007 & 5.1167 & TST & \\
\hline CHEMBL1331634 & 688799 & 6.0 & 6.1646 & TRN & \\
\hline CHEMBL20562 & 688799 & 4.6 & 4.8708 & TST & \\
\hline CHEMBL1321884 & 688799 & 5.7 & 5.3307 & TRN & \\
\hline CHEMBL1594075 & 688799 & 7.0 & 5.8352 & TRN & \\
\hline CHEMBL1555067 & 688799 & 4.5 & 4.7238 & TST & \\
\hline CHEMBL1525813 & 688799 & 5.4 & 5.5717 & TRN & \\
\hline CHEMBL1433726 & 688799 & 4.9 & 4.9872 & TST & \\
\hline CHEMBL1476170 & 688799 & 5.0 & 5.1487 & TRN & \\
\hline CHEMBL 2374087 & 688799 & 5.5 & 5.445 & TRN & \\
\hline CHEMBL45891 & 688799 & 7.6003 & 7.1074 & TRN & \\
\hline & & & & e 5495 & \\
\hline
\end{tabular}




\begin{tabular}{|c|c|c|c|c|}
\hline \multicolumn{5}{|c|}{ Supplemental Table S2.txt } \\
\hline CHEMBL1475951 & 688799 & 6.5 & 6.5704 & TRN \\
\hline CHEMBL1591635 & 688799 & 5.2 & 4.7485 & TRN \\
\hline CHEMBL1411609 & 688799 & 7.1002 & 6.7796 & TRN \\
\hline CHEMBL34704 & 688799 & 4.6 & 4.9819 & TST \\
\hline CHEMBL1553990 & 688799 & 4.4 & 4.4288 & TRN \\
\hline CHEMBL1317148 & 688799 & 4.5 & 4.9053 & TST \\
\hline CHEMBL1514604 & 688799 & 7.8996 & 7.4511 & TRN \\
\hline CHEMBL1317458 & 688799 & 6.7001 & 6.7245 & TRN \\
\hline CHEMBL1595328 & 688799 & 4.4 & 4.3979 & TRN \\
\hline CHEMBL1371957 & 688799 & 9.0 & 5.6433 & TST \\
\hline CHEMBL1454224 & 688799 & 4.7 & 4.8048 & TRN \\
\hline CHEMBL1485850 & 688799 & 4.4 & 4.688 & TRN \\
\hline CHEMBL 242384 & 688799 & 5.0 & 5.3717 & TRN \\
\hline CHEMBL1359691 & 688799 & 5.1 & 5.284 & TRN \\
\hline CHEMBL1257014 & 688799 & 5.0 & 5.206 & TRN \\
\hline CHEMBL270299 & 688799 & 6.0 & 5.1234 & TRN \\
\hline CHEMBL22870 & 688799 & 5.1 & 5.2933 & TRN \\
\hline CHEMBL1370189 & 688799 & 5.4 & 5.4104 & TRN \\
\hline CHEMBL448602 & 688799 & 6.5 & 6.5742 & TRN \\
\hline CHEMBL1611062 & 688799 & 4.6 & 4.6027 & TRN \\
\hline CHEMBL1398608 & 688799 & 6.4 & 6.1801 & TRN \\
\hline CHEMBL1435080 & 688799 & 6.1 & 5.901 & TRN \\
\hline CHEMBL1612675 & 688799 & 5.1 & 5.2535 & TRN \\
\hline CHEMBL1444914 & 688799 & 5.5 & 5.6679 & TRN \\
\hline CHEMBL545050 & 688799 & 6.0 & 5.3599 & TST \\
\hline CHEMBL1397225 & 688799 & 4.7 & 4.7917 & TRN \\
\hline CHEMBL1442011 & 688799 & 5.0 & 5.2437 & TRN \\
\hline CHEMBL1514953 & 688799 & 5.4 & 5.5059 & TRN \\
\hline CHEMBL1476430 & 688799 & 5.6 & 5.4811 & TRN \\
\hline CHEMBL1494196 & 688799 & 5.2 & 5.2939 & TRN \\
\hline CHEMBL1355849 & 688799 & 5.5 & 5.3321 & TST \\
\hline CHEMBL1611496 & 688799 & 5.2 & 5.3757 & TRN \\
\hline CHEMBL200309 & 688799 & 4.4 & 4.6703 & TST \\
\hline CHEMBL1595377 & 688799 & 4.7 & 4.6419 & TRN \\
\hline CHEMBL1865547 & 688799 & 5.6 & 5.8148 & TRN \\
\hline CHEMBL1415488 & 688799 & 5.6 & 5.751 & TRN \\
\hline CHEMBL1320469 & 688799 & 5.3 & 5.3607 & TRN \\
\hline CHEMBL66654 & 688799 & 5.1 & 5.3234 & TRN \\
\hline CHEMBL1476791 & 688799 & 4.4 & 4.5951 & TRN \\
\hline CHEMBL1566074 & 688799 & 6.4 & 5.1462 & TST \\
\hline CHEMBL1591860 & 688799 & 6.3 & 6.104 & TRN \\
\hline CHEMBL1593889 & 688799 & 6.2 & 6.2194 & TRN \\
\hline CHEMBL1567020 & 688799 & 6.2 & 6.1048 & TST \\
\hline CHEMBL1372850 & 688799 & 5.5 & 5.6053 & TRN \\
\hline CHEMBL1331426 & 688799 & 5.2 & 5.4074 & TST \\
\hline CHEMBL1366068 & 688799 & 4.6 & 5.0415 & TRN \\
\hline CHEMBL1526429 & 688799 & 5.6 & 5.8387 & TRN \\
\hline CHEMBL1415569 & 688799 & 4.8 & 4.7704 & TRN \\
\hline
\end{tabular}




\begin{tabular}{|c|c|c|c|c|}
\hline \multicolumn{5}{|c|}{ Lemental T } \\
\hline CHEMBL1372371 & 688799 & 5.5 & 5.4524 & TRN \\
\hline CHEMBL1433805 & 688799 & 5.4 & 5.56 & TRN \\
\hline CHEMBL287689 & 688799 & 5.4 & 5.5822 & TRN \\
\hline CHEMBL1434369 & 688799 & 5.4 & 5.5203 & TRN \\
\hline CHEMBL1531070 & 688799 & 6.4 & 6.1168 & TRN \\
\hline CHEMBL1571929 & 688799 & 7.1002 & 6.813 & TST \\
\hline CHEMBL117 & 688799 & 6.1 & 5.9679 & TRN \\
\hline CHEMBL1321899 & 688799 & 4.6 & 4.6806 & TRN \\
\hline CHEMBL1512909 & 688799 & 5.1 & 5.7014 & TST \\
\hline CHEMBL1339065 & 688799 & 6.0 & 5.6741 & TRN \\
\hline CHEMBL453066 & 688799 & 5.4 & 5.4396 & TRN \\
\hline CHEMBL1593371 & 688799 & 5.0 & 5.2713 & TRN \\
\hline CHEMBL317221 & 688799 & 5.8 & 5.6074 & TRN \\
\hline CHEMBL1473743 & 688799 & 5.8 & 5.2744 & TST \\
\hline CHEMBL1358614 & 688799 & 5.7 & 5.9652 & TRN \\
\hline CHEMBL1332591 & 688799 & 5.6 & 5.4712 & TRN \\
\hline CHEMBL1552680 & 688799 & 5.3 & 5.2038 & TRN \\
\hline CHEMBL1533895 & 688799 & 7.2 & 5.2874 & TST \\
\hline CHEMBL1492669 & 688799 & 5.4 & 5.5005 & TST \\
\hline CHEMBL77971 & 688799 & 5.0 & 5.1657 & TST \\
\hline CHEMBL1354243 & 688799 & 5.5 & 5.2461 & TST \\
\hline CHEMBL1517793 & 688799 & 7.2 & 5.565 & TST \\
\hline CHEMBL1568575 & 688799 & 4.5 & 4.6005 & TRN \\
\hline CHEMBL1518689 & 688799 & 5.3 & 5.073 & TRN \\
\hline CHEMBL1327793 & 688799 & 5.6 & 5.7005 & TST \\
\hline CHEMBL1324178 & 688799 & 5.9 & 5.7724 & TRN \\
\hline CHEMBL1448552 & 688799 & 5.3 & 5.5023 & TRN \\
\hline CHEMBL1604366 & 688799 & 5.4 & 5.4936 & TRN \\
\hline CHEMBL1438688 & 688799 & 5.0 & 4.9533 & TRN \\
\hline CHEMBL1436024 & 688799 & 5.1 & 5.2627 & TRN \\
\hline CHEMBL446315 & 688799 & 5.7 & 5.6491 & TRN \\
\hline CHEMBL1369796 & 688799 & 5.3 & 5.2275 & TRN \\
\hline CHEMBL1435235 & 688799 & 4.8 & 4.7664 & TRN \\
\hline CHEMBL1478761 & 688799 & 4.9 & 5.0022 & TRN \\
\hline CHEMBL1593432 & 688799 & 5.3 & 5.1248 & TRN \\
\hline CHEMBL1495875 & 688799 & 4.9 & 4.8356 & TRN \\
\hline CHEMBL1592470 & 688799 & 5.7 & 5.4677 & TRN \\
\hline CHEMBL1374028 & 688799 & 8.0 & 5.3664 & TRN \\
\hline CHEMBL1395605 & 688799 & 4.5 & 4.7569 & TRN \\
\hline CHEMBL 267548 & 688799 & 5.6 & 5.3072 & TST \\
\hline CHEMBL1593511 & 688799 & 5.1 & 5.1415 & TRN \\
\hline CHEMBL1372873 & 688799 & 5.4 & 5.2364 & TST \\
\hline CHEMBL1450903 & 688799 & 4.6 & 4.4793 & TRN \\
\hline CHEMBL323197 & 688799 & 5.0 & 5.2791 & TRN \\
\hline CHEMBL1406028 & 688799 & 6.5 & 5.2502 & TRN \\
\hline CHEMBL1317010 & 688799 & 5.9 & 6.0545 & TRN \\
\hline CHEMBL1526543 & 688799 & 6.0 & 6.2857 & TST \\
\hline CHEMBL1363142 & 688799 & 5.5 & 5.3594 & TRN \\
\hline
\end{tabular}




\begin{tabular}{|c|c|c|c|c|c|}
\hline \\
\hline CHEMBL1594405 & 688799 & 5.6 & 5.6249 & TRN & \\
\hline CHEMBL1368942 & 688799 & 5.6 & 5.5111 & TRN & \\
\hline CHEMBL1452389 & 688799 & 6.9 & 6.7522 & TRN & \\
\hline CHEMBL1436882 & 688799 & 6.2 & 6.1635 & TRN & \\
\hline CHEMBL1359917 & 688799 & 5.5 & 5.9149 & TRN & \\
\hline CHEMBL1527221 & 688799 & 4.8 & 4.9202 & TRN & \\
\hline CHEMBL1490477 & 688799 & 4.5 & 4.6512 & TRN & \\
\hline CHEMBL1434747 & 688799 & 5.0 & 5.275 & TRN & \\
\hline CHEMBL9225 & 688799 & 5.5 & 5.4806 & TRN & \\
\hline CHEMBL1395421 & 688799 & 5.3 & 5.3035 & TST & \\
\hline CHEMBL1410367 & 688799 & 6.1 & 5.9208 & TRN & \\
\hline CHEMBL1574196 & 688799 & 4.8 & 4.9364 & TRN & \\
\hline CHEMBL16751 & 688799 & 5.5 & 5.48799 & 99999999995 & TRN \\
\hline CHEMBL434063 & 688799 & 5.4 & 5.6459 & TST & \\
\hline CHEMBL1324494 & 688799 & 5.0 & 5.07 & TRN & \\
\hline CHEMBL1409320 & 688799 & 4.8 & 4.6562 & TRN & \\
\hline CHEMBL1437522 & 688799 & 5.8 & 5.2759 & TRN & \\
\hline CHEMBL1600612 & 688799 & 4.9 & 4.9822 & TRN & \\
\hline CHEMBL429711 & 688799 & 6.0 & 5.3541 & TRN & \\
\hline CHEMBL1567176 & 688799 & 4.8 & 4.8014 & TRN & \\
\hline CHEMBL1325701 & 688799 & 5.3 & 5.5511 & TRN & \\
\hline CHEMBL1483700 & 688799 & 5.0 & 5.4536 & TRN & \\
\hline CHEMBL1376212 & 688799 & 6.0 & 6.0816 & TRN & \\
\hline CHEMBL44 & 688799 & 6.0 & 5.0337 & TRN & \\
\hline CHEMBL1571995 & 688799 & 5.4 & 5.5745 & TRN & \\
\hline CHEMBL1555118 & 688799 & 5.2 & 5.1743 & TRN & \\
\hline CHEMBL83899 & 688799 & 5.0 & 4.9595 & TST & \\
\hline CHEMBL1317696 & 688799 & 6.1 & 5.20700 & 0000000001 & TRN \\
\hline CHEMBL1555713 & 688799 & 4.8 & 4.9744 & TRN & \\
\hline CHEMBL1304918 & 688799 & 5.8 & 5.8374 & TRN & \\
\hline CHEMBL1603803 & 688799 & 5.8 & 6.1088 & TRN & \\
\hline CHEMBL1232474 & 688799 & 7.2 & 7.5261 & TST & \\
\hline CHEMBL1328784 & 688799 & 5.3 & 5.5485 & TRN & \\
\hline CHEMBL1593071 & 688799 & 4.5 & 4.84699 & 99999999995 & TRN \\
\hline CHEMBL1398138 & 688799 & 6.1 & 6.1709 & TST & \\
\hline CHEMBL1555164 & 688799 & 7.8996 & 7.6406 & TRN & \\
\hline CHEMBL1441724 & 688799 & 5.2 & 5.4791 & TRN & \\
\hline CHEMBL1406851 & 688799 & 5.3 & 5.4757 & TRN & \\
\hline CHEMBL1484337 & 688799 & 4.6 & 4.668 & TRN & \\
\hline CHEMBL1562420 & 688799 & 5.3 & 5.3783 & TRN & \\
\hline CHEMBL1372997 & 688799 & 5.0 & 5.1932 & TST & \\
\hline CHEMBL490742 & 688799 & 5.1 & 5.1724 & TRN & \\
\hline CHEMBL1557821 & 688799 & 5.0 & 5.0488 & TRN & \\
\hline CHEMBL1317494 & 688799 & 5.4 & 5.3145 & TRN & \\
\hline CHEMBL3210244 & 688799 & 6.1 & 6.3522 & TRN & \\
\hline CHEMBL1472880 & 688799 & 5.1 & 5.2255 & TRN & \\
\hline CHEMBL1515324 & 688799 & 4.7 & 4.9144 & TRN & \\
\hline CHEMBL512908 & 688799 & 6.4 & 6.3317 & TRN & \\
\hline
\end{tabular}




\begin{tabular}{|c|c|c|c|c|c|}
\hline \multicolumn{6}{|c|}{ Supplemental Table S2.txt } \\
\hline CHEMBL1395415 & 688799 & 4.9 & 4.9424 & TRN & \\
\hline CHEMBL1474603 & 688799 & 6.1 & 4.7075 & TRN & \\
\hline CHEMBL1437226 & 688799 & 4.9 & 4.9909 & TRN & \\
\hline CHEMBL1325408 & 688799 & 5.6 & 5.7119 & TRN & \\
\hline CHEMBL1337978 & 688799 & 7.6003 & 5.8379 & TRN & \\
\hline CHEMBL1326360 & 688799 & 4.8 & 4.8598 & TRN & \\
\hline CHEMBL1398185 & 688799 & 4.9 & 4.6673 & TRN & \\
\hline CHEMBL1514090 & 688799 & 5.6 & 5.6223 & TST & \\
\hline CHEMBL222993 & 688799 & 5.4 & 5.5744 & TRN & \\
\hline CHEMBL1563047 & 688799 & 4.4 & 4.5982 & TRN & \\
\hline CHEMBL1478530 & 688799 & 4.9 & 5.0762 & TRN & \\
\hline CHEMBL2373653 & 688799 & 5.5 & 5.2393 & TRN & \\
\hline CHEMBL1477383 & 688799 & 5.3 & 5.4674 & TRN & \\
\hline CHEMBL1526068 & 688799 & 5.3 & 5.59200 & 00000000005 & TRN \\
\hline CHEMBL1594421 & 688799 & 5.2 & 5.2253 & TRN & \\
\hline CHEMBL1332504 & 688799 & 6.6 & 6.4891 & TRN & \\
\hline CHEMBL1476021 & 688799 & 5.6 & 5.71700 & 00000000005 & TRN \\
\hline CHEMBL536950 & 688799 & 5.5 & 5.478 & TST & \\
\hline CHEMBL243663 & 688799 & 5.3 & 5.3733 & TRN & \\
\hline CHEMBL1436324 & 688799 & 5.4 & 5.5247 & TST & \\
\hline CHEMBL522311 & 688799 & 6.4 & 6.3331 & TRN & \\
\hline CHEMBL1316557 & 688799 & 4.6 & 4.5725 & TRN & \\
\hline CHEMBL1473133 & 688799 & 5.2 & 5.2107 & TRN & \\
\hline CHEMBL278041 & 688799 & 6.0 & 5.7199 & TST & \\
\hline CHEMBL1372657 & 688799 & 5.2 & 5.3545 & TST & \\
\hline CHEMBL333985 & 688799 & 5.0 & 5.4182 & TST & \\
\hline CHEMBL1475146 & 688799 & 5.1 & 4.9905 & TRN & \\
\hline CHEMBL294747 & 688799 & 4.8 & 5.1189 & TRN & \\
\hline CHEMBL1434072 & 688799 & 6.0 & 5.8812 & TRN & \\
\hline CHEMBL501701 & 688799 & 5.3 & 5.3665 & TST & \\
\hline CHEMBL1552051 & 688799 & 6.2 & 4.4289 & TRN & \\
\hline CHEMBL1534082 & 688799 & 4.9 & 5.16200 & 0000000001 & TRN \\
\hline CHEMBL188 & 688799 & 5.0 & 5.0162 & TRN & \\
\hline CHEMBL1411049 & 688799 & 4.5 & 4.6084 & TRN & \\
\hline CHEMBL1516514 & 688799 & 6.4 & 5.3996 & TRN & \\
\hline CHEMBL1449528 & 688799 & 5.9 & 5.7907 & TRN & \\
\hline CHEMBL1319120 & 688799 & 4.6 & 4.7914 & TRN & \\
\hline CHEMBL1394533 & 688799 & 4.4 & 4.6005 & TRN & \\
\hline CHEMBL1455200 & 688799 & 4.7 & 4.9752 & TRN & \\
\hline CHEMBL1358708 & 688799 & 7.0 & 6.7571 & TST & \\
\hline CHEMBL540294 & 688799 & 4.4 & 4.6559 & TST & \\
\hline CHEMBL1473875 & 688799 & 5.4 & 5.4756 & TRN & \\
\hline CHEMBL1481127 & 688799 & 4.8 & 4.7967 & TRN & \\
\hline CHEMBL1488420 & 688799 & 6.1 & 6.0219 & TRN & \\
\hline CHEMBL1343047 & 688799 & 5.4 & 5.4187 & TRN & \\
\hline CHEMBL1490919 & 688799 & 4.9 & 5.9183 & TST & \\
\hline CHEMBL1456872 & 688799 & 4.9 & 4.8802 & TRN & \\
\hline CHEMBL1474625 & 688799 & 5.0 & 5.1049 & TRN & \\
\hline
\end{tabular}




\begin{tabular}{|c|c|c|c|c|c|}
\hline \multicolumn{6}{|c|}{ Supplemental Table S2.txt } \\
\hline CHEMBL1554888 & 688799 & 5.0 & 5.1199 & TRN & \\
\hline CHEMBL1558135 & 688799 & 4.7 & 4.8012 & TRN & \\
\hline CHEMBL1365882 & 688799 & 5.5 & 5.8303 & TRN & \\
\hline CHEMBL1436169 & 688799 & 8.1024 & 8.0352 & TRN & \\
\hline CHEMBL1608975 & 688799 & 4.9 & 5.2383 & TRN & \\
\hline CHEMBL1410398 & 688799 & 5.1 & 5.3769 & TST & \\
\hline CHEMBL1564508 & 688799 & 5.2 & 5.6934 & TST & \\
\hline CHEMBL1323204 & 688799 & 5.9 & 5.8613 & TRN & \\
\hline CHEMBL1395417 & 688799 & 5.4 & 5.4321 & TRN & \\
\hline CHEMBL1446185 & 688799 & 4.4 & 4.9165 & TRN & \\
\hline CHEMBL1317961 & 688799 & 5.0 & 5.3794 & TRN & \\
\hline CHEMBL1436540 & 688799 & 4.5 & 4.626 & TRN & \\
\hline CHEMBL1473707 & 688799 & 6.6 & 5.5347 & TRN & \\
\hline CHEMBL1441981 & 688799 & 4.9 & 4.8714 & TRN & \\
\hline CHEMBL123433 & 688799 & 4.8 & 4.9864 & TST & \\
\hline CHEMBL111545 & 688799 & 4.4 & 4.59 & TST & \\
\hline CHEMBL1514819 & 688799 & 8.2007 & 7.6881 & TRN & \\
\hline CHEMBL1475562 & 688799 & 4.4 & 4.5372 & TRN & \\
\hline CHEMBL1552150 & 688799 & 5.0 & 5.08899 & 99999999995 & TRN \\
\hline CHEMBL3392074 & 688799 & 4.9 & 4.9409 & TST & \\
\hline CHEMBL1256392 & 688799 & 8.6021 & 8.6164 & TRN & \\
\hline CHEMBL1409109 & 688799 & 6.8 & 4.7423 & TST & \\
\hline CHEMBL90769 & 688799 & 6.0 & 5.9278 & TST & \\
\hline CHEMBL1191027 & 688799 & 5.2 & 5.0601 & TST & \\
\hline CHEMBL1435426 & 688799 & 5.7 & 5.4958 & TST & \\
\hline CHEMBL1553731 & 688799 & 5.7 & 5.3729 & TRN & \\
\hline CHEMBL1451057 & 688799 & 7.0 & 6.8298 & TRN & \\
\hline CHEMBL1456755 & 688799 & 5.3 & 5.5768 & TRN & \\
\hline CHEMBL1494529 & 688799 & 5.4 & 5.1937 & TRN & \\
\hline CHEMBL1555567 & 688799 & 6.1 & 6.0351 & TRN & \\
\hline CHEMBL275097 & 688799 & 5.9 & 5.8855 & TRN & \\
\hline CHEMBL1324405 & 688799 & 6.0 & 5.9392 & TRN & \\
\hline CHEMBL1474445 & 688799 & 4.8 & 5.2821 & TST & \\
\hline CHEMBL1409689 & 688799 & 5.1 & 5.1728 & TRN & \\
\hline CHEMBL1335595 & 688799 & 5.8 & 6.496 & TRN & \\
\hline CHEMBL1457317 & 688799 & 4.7 & 4.7439 & TRN & \\
\hline CHEMBL1357151 & 688799 & 4.6 & 5.3008 & TST & \\
\hline CHEMBL311158 & 688799 & 5.0 & 5.2354 & TRN & \\
\hline CHEMBL1593774 & 688799 & 5.9 & 5.8317 & TRN & \\
\hline CHEMBL1333362 & 688799 & 6.8 & 5.1997 & TST & \\
\hline CHEMBL497170 & 688799 & 6.4 & 5.3719 & TRN & \\
\hline CHEMBL1567236 & 688799 & 4.8 & 4.7691 & TRN & \\
\hline CHEMBL491578 & 688799 & 5.9 & 6.0452 & TRN & \\
\hline CHEMBL1390509 & 688799 & 5.8 & 5.5266 & TST & \\
\hline CHEMBL1413102 & 688799 & 5.4 & 5.4538 & TST & \\
\hline CHEMBL1361847 & 688799 & 5.7 & 5.6503 & TRN & \\
\hline CHEMBL1484006 & 688799 & 6.0 & 6.1705 & TRN & \\
\hline CHEMBL492610 & 688799 & 5.1 & 5.0812 & TRN & \\
\hline
\end{tabular}




\begin{tabular}{|c|c|c|c|c|}
\hline & & & & \\
\hline CHEMBL1553700 & 688799 & 6.3 & 6.1713 & TST \\
\hline CHEMBL1435823 & 688799 & 4.9 & 5.15 & TRN \\
\hline CHEMBL1489663 & 688799 & 5.5 & 5.6898 & TRN \\
\hline CHEMBL407874 & 688799 & 5.2 & 5.4742 & TRN \\
\hline CHEMBL1593853 & 688799 & 5.7 & 5.7427 & TRN \\
\hline CHEMBL1356652 & 688799 & 5.0 & 4.9951 & TRN \\
\hline CHEMBL1357444 & 688799 & 5.7 & 5.7904 & TRN \\
\hline CHEMBL1450334 & 688799 & 4.8 & 5.4181 & TRN \\
\hline CHEMBL1567251 & 688799 & 4.7 & 4.7165 & TRN \\
\hline CHEMBL1357676 & 688799 & 5.1 & 5.1284 & TRN \\
\hline CHEMBL345124 & 688799 & 5.8 & 5.7687 & TST \\
\hline CHEMBL1395137 & 688799 & 5.7 & 5.3388 & TRN \\
\hline CHEMBL1449602 & 688799 & 6.0 & 5.2512 & TST \\
\hline CHEMBL1319251 & 688799 & 5.8 & 5.4112 & TRN \\
\hline CHEMBL31741 & 688799 & 4.5 & 4.8729 & TST \\
\hline CHEMBL112816 & 688799 & 5.3 & 5.5241 & TRN \\
\hline CHEMBL3192742 & 688799 & 6.2 & 6.1933 & TRN \\
\hline CHEMBL1611823 & 688799 & 5.6 & 5.3018 & TRN \\
\hline CHEMBL1526486 & 688799 & 4.4 & 4.5574 & TRN \\
\hline CHEMBL1488574 & 688799 & 6.6 & 6.2036 & TRN \\
\hline CHEMBL1413098 & 688799 & 5.5 & 5.1707 & TRN \\
\hline CHEMBL1398528 & 688799 & 5.0 & 5.0883 & TRN \\
\hline CHEMBL1366766 & 688799 & 5.8 & 5.9607 & TRN \\
\hline CHEMBL1398543 & 688799 & 4.7 & 4.7065 & TRN \\
\hline CHEMBL1484447 & 688799 & 4.7 & 4.687 & TRN \\
\hline CHEMBL1597366 & 688799 & 4.6 & 4.6114 & TRN \\
\hline CHEMBL1476830 & 688799 & 5.1 & 5.4472 & TRN \\
\hline CHEMBL1441737 & 688799 & 4.9 & 5.018 & TRN \\
\hline CHEMBL1515221 & 688799 & 4.9 & 4.8651 & TRN \\
\hline CHEMBL1554194 & 688799 & 5.1 & 5.1134 & TRN \\
\hline CHEMBL1553577 & 688799 & 4.6 & 4.8394 & TRN \\
\hline CHEMBL1452894 & 688799 & 4.8 & 4.0669 & TRN \\
\hline CHEMBL1449082 & 688799 & 4.4 & 4.3987 & TRN \\
\hline CHEMBL1361839 & 688799 & 4.6 & 4.7047 & TRN \\
\hline CHEMBL1446335 & 688799 & 4.4 & 4.6379 & TRN \\
\hline CHEMBL1486915 & 688799 & 4.8 & 4.8173 & TRN \\
\hline CHEMBL1373151 & 688799 & 4.9 & 4.9777 & TRN \\
\hline CHEMBL1457043 & 688799 & 4.5 & 5.0678 & TST \\
\hline CHEMBL1329927 & 688799 & 4.8 & 5.0064 & TRN \\
\hline CHEMBL1441607 & 688799 & 5.4 & 5.4545 & TRN \\
\hline CHEMBL1552249 & 688799 & 6.0 & 6.16 & TST \\
\hline CHEMBL323542 & 688799 & 4.7 & 4.9085 & TRN \\
\hline CHEMBL1552707 & 688799 & 5.1 & 5.2408 & TRN \\
\hline CHEMBL1493707 & 688799 & 5.6 & 5.7261 & TRN \\
\hline CHEMBL1361446 & 688799 & 4.7 & 5.1881 & TRN \\
\hline CHEMBL1591189 & 688799 & 6.3 & 5.7642 & TRN \\
\hline CHEMBL1394353 & 688799 & 5.5 & 5.4806 & TRN \\
\hline CHEMBL1357956 & 688799 & 4.9 & 5.1094 & TRN \\
\hline
\end{tabular}




\begin{tabular}{|c|c|c|c|c|c|}
\hline & & \multicolumn{4}{|c|}{ Supplemental Table S2.txt } \\
\hline CHEMBL1410057 & 688799 & 7.4001 & 5.2741 & TRN & \\
\hline CHEMBL1489182 & 688799 & 5.0 & 5.7129 & TRN & \\
\hline CHEMBL8747 & 688799 & 5.2 & 5.3685 & TST & \\
\hline CHEMBL1356118 & 688799 & 4.7 & 4.7986 & TRN & \\
\hline CHEMBL1356304 & 688799 & 5.5 & 5.5377 & TRN & \\
\hline CHEMBL1451904 & 688799 & 5.3 & 5.3191 & TST & \\
\hline CHEMBL1369822 & 688799 & 4.7 & 4.7464 & TRN & \\
\hline CHEMBL1395089 & 688799 & 5.0 & 5.0999 & TRN & \\
\hline CHEMBL1485629 & 688799 & 5.2 & 5.2731 & TST & \\
\hline CHEMBL1354432 & 688799 & 5.7 & 5.5391 & TRN & \\
\hline CHEMBL1200766 & 688799 & 5.9 & 5.9751 & TRN & \\
\hline CHEMBL1531727 & 688799 & 6.3 & 6.1112 & TRN & \\
\hline CHEMBL1606591 & 688799 & 4.7 & 4.8295 & TRN & \\
\hline CHEMBL1472765 & 688799 & 4.7 & 4.8898 & TRN & \\
\hline CHEMBL479014 & 688799 & 6.0 & 6.399 & TRN & \\
\hline CHEMBL492132 & 688799 & 4.9 & 5.1055 & TRN & \\
\hline CHEMBL158507 & 688799 & 5.0 & 5.0701 & TRN & \\
\hline CHEMBL1318553 & 688799 & 6.0 & 5.146 & TST & \\
\hline CHEMBL1401455 & 688799 & 5.6 & 5.6081 & TRN & \\
\hline CHEMBL1488171 & 688799 & 5.3 & 5.3116 & TRN & \\
\hline CHEMBL1318041 & 688799 & 5.1 & 5.0636 & TRN & \\
\hline CHEMBL598263 & 688799 & 5.5 & 5.5069 & TRN & \\
\hline CHEMBL68500 & 688799 & 4.4 & 5.6099 & TST & \\
\hline CHEMBL1610082 & 688799 & 5.1 & 5.1265 & TRN & \\
\hline CHEMBL 272005 & 688799 & 5.2 & 5.1654 & TRN & \\
\hline CHEMBL1437011 & 688799 & 4.5 & 4.7205 & TRN & \\
\hline CHEMBL1448325 & 688799 & 8.1024 & 5.4073 & TRN & \\
\hline CHEMBL1513347 & 688799 & 5.2 & 5.225 & TRN & \\
\hline CHEMBL1317885 & 688799 & 4.9 & 5.0972 & TRN & \\
\hline CHEMBL1437142 & 688799 & 5.1 & 5.1708 & TST & \\
\hline CHEMBL1437013 & 688799 & 5.3 & 5.4522 & TRN & \\
\hline CHEMBL1590601 & 688799 & 5.8 & 5.6368 & TRN & \\
\hline CHEMBL1356834 & 688799 & 4.6 & 4.6844 & TRN & \\
\hline CHEMBL1402827 & 688799 & 4.5 & 4.9474 & TRN & \\
\hline CHEMBL1339015 & 688799 & 5.0 & 5.6433 & TRN & \\
\hline CHEMBL1437448 & 688799 & 4.8 & 4.73 & TRN & \\
\hline CHEMBL1487735 & 688799 & 5.5 & 5.1476 & TRN & \\
\hline CHEMBL1493939 & 688799 & 5.0 & 6.09399 & 9999999999 & TRN \\
\hline CHEMBL1560551 & 688799 & 5.7 & 5.3699 & TRN & \\
\hline CHEMBL1396090 & 688799 & 4.9 & 5.2026 & TRN & \\
\hline CHEMBL1490904 & 688799 & 6.4 & 6.3404 & TRN & \\
\hline CHEMBL1521274 & 688799 & 5.3 & 5.5564 & TRN & \\
\hline CHEMBL1354186 & 688799 & 5.4 & 5.7053 & TRN & \\
\hline CHEMBL1473996 & 688799 & 5.1 & 5.2966 & TRN & \\
\hline CHEMBL1490139 & 688799 & 5.2 & 4.9731 & TRN & \\
\hline CHEMBL1591190 & 688799 & 5.0 & 5.1912 & TRN & \\
\hline CHEMBL1358276 & 688799 & 4.8 & 4.7489 & TRN & \\
\hline CHEMBL565654 & 688799 & 5.0 & 5.0716 & TRN & \\
\hline
\end{tabular}




\begin{tabular}{|c|c|c|c|c|c|}
\hline \\
\hline CHEMBL1256914 & 688799 & 5.0 & 5.4906 & TRN & \\
\hline CHEMBL1333651 & 688799 & 5.6 & 5.3163 & TRN & \\
\hline CHEMBL1590259 & 688799 & 4.9 & 4.9282 & TRN & \\
\hline CHEMBL1591238 & 688799 & 5.4 & 5.3821 & TRN & \\
\hline CHEMBL1515246 & 688799 & 5.4 & 5.5371 & TRN & \\
\hline CHEMBL1475395 & 688799 & 5.8 & 5.98799 & 99999999995 & TRN \\
\hline CHEMBL1192187 & 688799 & 4.8 & 5.0112 & TST & \\
\hline CHEMBL253998 & 688799 & 6.0 & 5.3181 & TRN & \\
\hline CHEMBL1437054 & 688799 & 8.4949 & 7.5683 & TRN & \\
\hline CHEMBL1373428 & 688799 & 5.8 & 5.7587 & TRN & \\
\hline CHEMBL1314486 & 688799 & 6.2 & 6.4043 & TRN & \\
\hline CHEMBL1554622 & 688799 & 4.9 & 4.9214 & TRN & \\
\hline CHEMBL1486808 & 688799 & 4.7 & 4.7076 & TRN & \\
\hline CHEMBL1516468 & 688799 & 6.0 & 6.1482 & TRN & \\
\hline CHEMBL140 & 688799 & 5.6 & 5.4338 & TRN & \\
\hline CHEMBL 1358722 & 688799 & 4.8 & 4.9962 & TST & \\
\hline CHEMBL1565125 & 688799 & 4.4 & 4.4735 & TRN & \\
\hline CHEMBL1552133 & 688799 & 4.8 & 5.2136 & TST & \\
\hline CHEMBL3348998 & 688799 & 6.0 & 5.9209 & TST & \\
\hline CHEMBL1594947 & 688799 & 6.5 & 6.563 & TRN & \\
\hline CHEMBL1475015 & 688799 & 5.5 & 5.4568 & TST & \\
\hline CHEMBL1396898 & 688799 & 5.1 & 5.3614 & TRN & \\
\hline CHEMBL1208858 & 688799 & 4.6 & 5.1799 & TST & \\
\hline CHEMBL1320943 & 688799 & 7.699 & 5.6711 & TRN & \\
\hline CHEMBL1400788 & 688799 & 6.4 & 6.4258 & TRN & \\
\hline CHEMBL3209943 & 688799 & 5.5 & 5.6954 & TRN & \\
\hline CHEMBL1373466 & 688799 & 5.1 & 5.2312 & TST & \\
\hline CHEMBL58033 & 688799 & 6.0 & 6.0092 & TRN & \\
\hline CHEMBL1327243 & 688799 & 4.9 & 5.1654 & TST & \\
\hline CHEMBL1371127 & 688799 & 5.9 & 5.8622 & TRN & \\
\hline CHEMBL1326466 & 688799 & 5.1 & 5.4085 & TRN & \\
\hline CHEMBL1566556 & 688799 & 5.1 & 5.0635 & TRN & \\
\hline CHEMBL567331 & 688799 & 5.4 & 5.4315 & TRN & \\
\hline CHEMBL1433696 & 688799 & 4.8 & 4.9048 & TRN & \\
\hline CHEMBL1324667 & 688799 & 5.8 & 5.5841 & TRN & \\
\hline CHEMBL1255837 & 688799 & 6.0 & 6.1013 & TRN & \\
\hline CHEMBL1530982 & 688799 & 4.9 & 4.7423 & TRN & \\
\hline CHEMBL1514910 & 688799 & 4.8 & 5.3283 & TST & \\
\hline CHEMBL1370467 & 688799 & 6.0 & 6.0878 & TRN & \\
\hline CHEMBL1369874 & 688799 & 6.0 & 6.3566 & TRN & \\
\hline CHEMBL239439 & 688799 & 5.5 & 5.6301 & TST & \\
\hline CHEMBL1452111 & 688799 & 6.0 & 5.9956 & TRN & \\
\hline CHEMBL1551321 & 688799 & 4.7 & 4.7257 & TRN & \\
\hline CHEMBL1321470 & 688799 & 6.0 & 5.7347 & TRN & \\
\hline CHEMBL1394137 & 688799 & 5.7 & 5.8094 & TRN & \\
\hline CHEMBL1554590 & 688799 & 5.6 & 5.5317 & TRN & \\
\hline CHEMBL1356630 & 688799 & 5.5 & 5.7283 & TRN & \\
\hline CHEMBL1562612 & 688799 & 6.0 & 6.0345 & TRN & \\
\hline
\end{tabular}




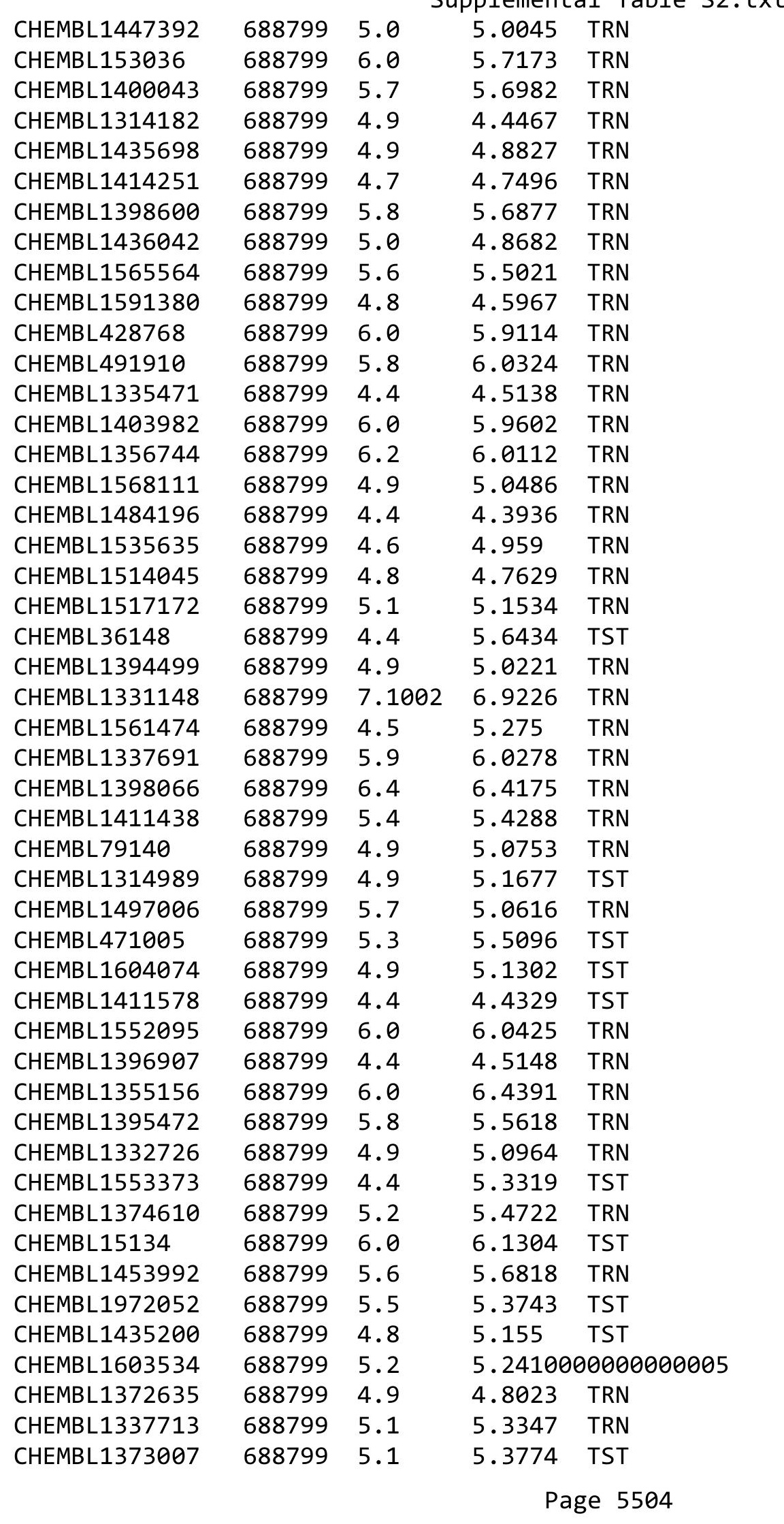




\begin{tabular}{|c|c|c|c|c|c|}
\hline \\
\hline CHEMBL1330020 & 688799 & 5.4 & 5.5611 & TRN & \\
\hline CHEMBL1358449 & 688799 & 6.8 & 6.8457 & TST & \\
\hline CHEMBL1552194 & 688799 & 5.5 & 5.6273 & TRN & \\
\hline CHEMBL1370214 & 688799 & 5.4 & 5.5818 & TST & \\
\hline CHEMBL105739 & 688799 & 5.1 & 5.2047 & TRN & \\
\hline CHEMBL1473317 & 688799 & 5.2 & 5.4137 & TRN & \\
\hline CHEMBL1374585 & 688799 & 5.6 & 5.9252 & TRN & \\
\hline CHEMBL362223 & 688799 & 6.0 & 5.6017 & TRN & \\
\hline CHEMBL1512780 & 688799 & 5.1 & 5.0502 & TRN & \\
\hline CHEMBL1474475 & 688799 & 4.6 & 4.533 & TRN & \\
\hline CHEMBL544713 & 688799 & 5.9 & 5.9981 & TST & \\
\hline CHEMBL1552551 & 688799 & 6.0 & 6.2606 & TRN & \\
\hline CHEMBL1481510 & 688799 & 4.4 & 4.2081 & TRN & \\
\hline CHEMBL164 & 688799 & 6.0 & 5.7702 & TRN & \\
\hline CHEMBL1483625 & 688799 & 4.7 & 4.9423 & TRN & \\
\hline CHEMBL50267 & 688799 & 4.4 & 5.3711 & TST & \\
\hline CHEMBL1407670 & 688799 & 7.3002 & 7.0502 & TRN & \\
\hline CHEMBL1566620 & 688799 & 5.2 & 5.5298 & TST & \\
\hline CHEMBL1450521 & 688799 & 6.6 & 6.859 & TRN & \\
\hline CHEMBL151 & 688799 & 4.8 & 5.5305 & TRN & \\
\hline CHEMBL1492411 & 688799 & 4.5 & 4.8048 & TRN & \\
\hline CHEMBL1358197 & 688799 & 4.8 & 4.9061 & TRN & \\
\hline CHEMBL1449918 & 688799 & 6.4 & 6.4458 & TST & \\
\hline CHEMBL1533853 & 688799 & 6.1 & 6.3013 & TRN & \\
\hline CHEMBL1572988 & 688799 & 4.4 & 4.4716 & TRN & \\
\hline CHEMBL1476280 & 688799 & 5.9 & 6.20100 & 00000000005 & TRN \\
\hline CHEMBL1601019 & 688799 & 5.1 & 5.2553 & TRN & \\
\hline CHEMBL1369212 & 688799 & 6.0 & 6.1784 & TRN & \\
\hline CHEMBL1478504 & 688799 & 5.9 & 5.9634 & TRN & \\
\hline CHEMBL1553173 & 688799 & 5.8 & 5.796 & TRN & \\
\hline CHEMBL1474185 & 688799 & 4.5 & 4.6058 & TRN & \\
\hline CHEMBL1610375 & 688799 & 4.6 & 4.6214 & TRN & \\
\hline CHEMBL1316190 & 688799 & 4.5 & 5.4597 & TRN & \\
\hline CHEMBL1554798 & 688799 & 5.4 & 5.4725 & TRN & \\
\hline CHEMBL260374 & 688799 & 6.0 & 5.8804 & TST & \\
\hline CHEMBL1491966 & 688799 & 5.0 & 5.1119 & TRN & \\
\hline CHEMBL1476108 & 688799 & 5.0 & 5.17200 & 0000000001 & TST \\
\hline CHEMBL1256660 & 688799 & 4.6 & 4.9414 & TRN & \\
\hline CHEMBL1512594 & 688799 & 4.4 & 4.8097 & TRN & \\
\hline CHEMBL1512562 & 688799 & 4.7 & 4.7818 & TRN & \\
\hline CHEMBL1479372 & 688799 & 5.6 & 5.3504 & TRN & \\
\hline CHEMBL1369062 & 688799 & 4.6 & 4.7741 & TRN & \\
\hline CHEMBL1519490 & 688799 & 6.0 & 5.7202 & TRN & \\
\hline CHEMBL22304 & 688799 & 5.6 & 5.1457 & TST & \\
\hline CHEMBL1415790 & 688799 & 4.4 & 4.534 & TRN & \\
\hline CHEMBL1367944 & 688799 & 5.1 & 5.4252 & TRN & \\
\hline CHEMBL491977 & 688799 & 4.9 & 5.0955 & TRN & \\
\hline CHEMBL1335229 & 688799 & 5.8 & 5.5881 & TRN & \\
\hline
\end{tabular}




\begin{tabular}{|c|c|c|c|c|c|}
\hline & & \multicolumn{4}{|c|}{ Supplemental Table S2.txt } \\
\hline CHEMBL1552314 & 688799 & 8.2007 & 7.6346 & TRN & \\
\hline CHEMBL1526229 & 688799 & 6.0 & 5.8131 & TST & \\
\hline CHEMBL1397293 & 688799 & 4.8 & 4.9317 & TRN & \\
\hline CHEMBL1320206 & 688799 & 4.4 & 4.3179 & TRN & \\
\hline CHEMBL1356067 & 688799 & 5.0 & 5.1074 & TRN & \\
\hline CHEMBL1476527 & 688799 & 6.6 & 5.3315 & TST & \\
\hline CHEMBL1566936 & 688799 & 4.6 & 4.9853 & TRN & \\
\hline CHEMBL1255867 & 688799 & 5.2 & 5.854 & TRN & \\
\hline CHEMBL1397079 & 688799 & 4.9 & 5.0157 & TRN & \\
\hline CHEMBL1599647 & 688799 & 6.5 & 5.7552 & TRN & \\
\hline CHEMBL1436957 & 688799 & 4.9 & 5.1195 & TRN & \\
\hline CHEMBL489943 & 688799 & 5.8 & 5.925 & TRN & \\
\hline CHEMBL182310 & 688799 & 4.6 & 4.6939 & TRN & \\
\hline CHEMBL1433785 & 688799 & 4.8 & 4.8803 & TRN & \\
\hline CHEMBL 98350 & 688799 & 5.0 & 5.1198 & TRN & \\
\hline CHEMBL1591374 & 688799 & 4.7 & 4.6292 & TRN & \\
\hline CHEMBL1568233 & 688799 & 6.8 & 5.4633 & TRN & \\
\hline CHEMBL50112 & 688799 & 4.8 & 5.0883 & TRN & \\
\hline CHEMBL1371698 & 688799 & 6.5 & 6.6276 & TRN & \\
\hline CHEMBL1317473 & 688799 & 5.4 & 5.1372 & TRN & \\
\hline CHEMBL1355537 & 688799 & 5.1 & 5.3698 & TST & \\
\hline CHEMBL1395088 & 688799 & 6.4 & 6.4978 & TRN & \\
\hline CHEMBL1488010 & 688799 & 5.1 & 5.3311 & TRN & \\
\hline CHEMBL1476711 & 688799 & 4.4 & 4.5274 & TRN & \\
\hline CHEMBL1255650 & 688799 & 4.4 & 4.7029 & TST & \\
\hline CHEMBL1535884 & 688799 & 5.1 & 5.4718 & TST & \\
\hline CHEMBL1447438 & 688799 & 4.4 & 4.5148 & TRN & \\
\hline CHEMBL1357294 & 688799 & 4.9 & 4.9324 & TRN & \\
\hline CHEMBL1358092 & 688799 & 5.5 & 5.439 & TRN & \\
\hline CHEMBL1322549 & 688799 & 5.3 & 5.4598 & TST & \\
\hline CHEMBL1374863 & 688799 & 6.4 & 6.4342 & TRN & \\
\hline CHEMBL1513740 & 688799 & 5.2 & 5.0859 & TRN & \\
\hline CHEMBL1474402 & 688799 & 5.2 & 5.1503 & TRN & \\
\hline CHEMBL1516211 & 688799 & 5.1 & 5.1172 & TRN & \\
\hline CHEMBL1330087 & 688799 & 6.0 & 6.16100 & 00000000005 & TRN \\
\hline CHEMBL1269022 & 688799 & 6.0 & 6.0423 & TST & \\
\hline CHEMBL406835 & 688799 & 4.9 & 5.5089 & TRN & \\
\hline CHEMBL66105 & 688799 & 6.0 & 6.0214 & TRN & \\
\hline CHEMBL9352 & 688799 & 6.0 & 5.4515 & TRN & \\
\hline CHEMBL1361855 & 688799 & 5.8 & 5.87299 & 9999999999 & TRN \\
\hline CHEMBL1529093 & 688799 & 5.6 & 5.7308 & TST & \\
\hline CHEMBL1410635 & 688799 & 4.9 & 4.8514 & TRN & \\
\hline CHEMBL1359843 & 688799 & 5.0 & 5.0253 & TRN & \\
\hline CHEMBL1322864 & 688799 & 5.8 & 5.822 & TST & \\
\hline CHEMBL1331288 & 688799 & 4.8 & 5.055 & TRN & \\
\hline CHEMBL273481 & 688799 & 4.4 & 5.4225 & TST & \\
\hline CHEMBL1377106 & 688799 & 4.4 & 4.5883 & TRN & \\
\hline CHEMBL1447758 & 688799 & 6.3 & 6.2561 & TRN & \\
\hline
\end{tabular}




\begin{tabular}{|c|c|c|c|c|}
\hline \multicolumn{5}{|c|}{ Supplemental Table S2.txt } \\
\hline CHEMBL1318495 & 688799 & 7.1002 & 7.3025 & TRN \\
\hline CHEMBL1398050 & 688799 & 4.7 & 4.6782 & TRN \\
\hline CHEMBL1396230 & 688799 & 4.9 & 5.1345 & TRN \\
\hline CHEMBL 3207783 & 688799 & 5.6 & 5.8948 & TRN \\
\hline CHEMBL1371547 & 688799 & 5.3 & 5.5184 & TRN \\
\hline CHEMBL1514572 & 688799 & 5.3 & 5.8395 & TRN \\
\hline CHEMBL1512708 & 688799 & 6.6 & 6.6233 & TRN \\
\hline CHEMBL1592327 & 688799 & 5.1 & 5.2024 & TRN \\
\hline CHEMBL1593321 & 688799 & 6.1 & 5.4653 & TRN \\
\hline CHEMBL1356657 & 688799 & 4.4 & 4.422 & TRN \\
\hline CHEMBL1593001 & 688799 & 5.5 & 5.5543 & TRN \\
\hline CHEMBL1321660 & 688799 & 6.0 & 6.0696 & TRN \\
\hline CHEMBL1433783 & 688799 & 4.9 & 4.9763 & TRN \\
\hline CHEMBL1435276 & 688799 & 4.6 & 4.612 & TRN \\
\hline CHEMBL1532230 & 688799 & 5.1 & 5.1784 & TRN \\
\hline CHEMBL1369951 & 688799 & 4.4 & 5.2298 & TRN \\
\hline CHEMBL145725 & 688799 & 6.0 & 5.7591 & TST \\
\hline CHEMBL1514219 & 688799 & 4.7 & 4.9465 & TRN \\
\hline CHEMBL1555058 & 688799 & 5.8 & 5.4663 & TRN \\
\hline CHEMBL1362892 & 688799 & 5.3 & 5.3166 & TRN \\
\hline CHEMBL1551652 & 688799 & 5.4 & 5.42 & TRN \\
\hline CHEMBL1256656 & 688799 & 4.9 & 5.0086 & TRN \\
\hline CHEMBL1591543 & 688799 & 5.9 & 5.8703 & TRN \\
\hline CHEMBL1552028 & 688799 & 5.5 & 5.2006 & TRN \\
\hline CHEMBL45281 & 688799 & 6.0 & 4.6601 & TST \\
\hline CHEMBL1525602 & 688799 & 5.1 & 5.1873 & TRN \\
\hline CHEMBL1317358 & 688799 & 4.9 & 5.0492 & TRN \\
\hline CHEMBL1604135 & 688799 & 7.0 & 5.2082 & TST \\
\hline CHEMBL1416207 & 688799 & 5.5 & 5.3661 & TRN \\
\hline CHEMBL1446323 & 688799 & 5.0 & 5.0885 & TRN \\
\hline CHEMBL1317747 & 688799 & 5.4 & 5.2224 & TRN \\
\hline CHEMBL1317714 & 688799 & 5.1 & 5.9551 & TRN \\
\hline CHEMBL3207899 & 688799 & 5.8 & 6.09 & TRN \\
\hline CHEMBL1334465 & 688799 & 4.8 & 5.0009 & TST \\
\hline CHEMBL1488918 & 688799 & 5.2 & 5.0309 & TRN \\
\hline CHEMBL1531767 & 688799 & 6.5 & 5.4279 & TRN \\
\hline CHEMBL1370622 & 688799 & 5.9 & 6.0088 & TRN \\
\hline CHEMBL1315920 & 688799 & 5.5 & 5.4561 & TRN \\
\hline CHEMBL1594648 & 688799 & 7.0 & 6.218 & TRN \\
\hline CHEMBL1437597 & 688799 & 5.6 & 5.5012 & TST \\
\hline CHEMBL1334397 & 688799 & 5.4 & 5.3363 & TRN \\
\hline CHEMBL1572239 & 688799 & 7.5003 & 7.3792 & TRN \\
\hline CHEMBL1322233 & 688799 & 5.3 & 5.3891 & TRN \\
\hline CHEMBL1514740 & 688799 & 4.4 & 4.7924 & TRN \\
\hline CHEMBL1411055 & 688799 & 5.8 & 5.6617 & TST \\
\hline CHEMBL1573554 & 688799 & 7.8013 & 5.3485 & TST \\
\hline CHEMBL1371944 & 688799 & 4.9 & 4.914 & TRN \\
\hline CHEMBL3392050 & 688799 & 4.4 & 4.5233 & TST \\
\hline
\end{tabular}




\begin{tabular}{|c|c|c|c|c|}
\hline \multicolumn{5}{|c|}{ Supplemental Table s2.txt } \\
\hline CHEMBL1405762 & 688799 & 7.1002 & 6.7392 & TST \\
\hline CHEMBL1377727 & 688799 & 4.8 & 5.1025 & TRN \\
\hline CHEMBL472994 & 688799 & 5.8 & 5.8655 & TST \\
\hline CHEMBL1520442 & 688799 & 8.2007 & 7.5702 & TRN \\
\hline CHEMBL1515804 & 688799 & 4.9 & 4.8408 & TRN \\
\hline CHEMBL 73310 & 688799 & 4.8 & 5.0456 & TRN \\
\hline CHEMBL1520216 & 688799 & 5.2 & 5.4099 & TRN \\
\hline CHEMBL489935 & 688799 & 5.3 & 5.4909 & TRN \\
\hline CHEMBL391997 & 688799 & 6.0 & 6.5833 & TST \\
\hline CHEMBL1354864 & 688799 & 4.4 & 4.4331 & TRN \\
\hline CHEMBL1401793 & 688799 & 5.5 & 5.641 & TST \\
\hline CHEMBL1315609 & 688799 & 5.1 & 5.2005 & TRN \\
\hline CHEMBL1611630 & 688799 & 6.4 & 5.2342 & TRN \\
\hline CHEMBL1436992 & 688799 & 4.4 & 4.4973 & TRN \\
\hline CHEMBL1531837 & 688799 & 4.9 & 4.9155 & TRN \\
\hline CHEMBL1315417 & 688799 & 4.9 & 5.0654 & TST \\
\hline CHEMBL1408422 & 688799 & 5.0 & 4.9525 & TRN \\
\hline CHEMBL1373998 & 688799 & 6.3 & 6.2604 & TRN \\
\hline CHEMBL1603186 & 688799 & 5.9 & 5.7709 & TRN \\
\hline CHEMBL1372037 & 688799 & 5.5 & 5.7571 & TRN \\
\hline CHEMBL1518301 & 688799 & 5.5 & 5.2679 & TRN \\
\hline CHEMBL1590031 & 688799 & 5.5 & 5.2864 & TST \\
\hline CHEMBL1479036 & 688799 & 5.9 & 5.8818 & TST \\
\hline CHEMBL1483801 & 688799 & 5.5 & 5.6976 & TRN \\
\hline CHEMBL186872 & 688799 & 6.2 & 5.8821 & TST \\
\hline CHEMBL1533572 & 688799 & 4.9 & 5.0202 & TRN \\
\hline CHEMBL1256851 & 688799 & 7.2 & 6.7692 & TRN \\
\hline CHEMBL1474890 & 688799 & 5.1 & 5.0402 & TRN \\
\hline CHEMBL1530645 & 688799 & 5.5 & 5.8988 & TRN \\
\hline CHEMBL1555369 & 688799 & 5.8 & 5.8852 & TRN \\
\hline CHEMBL1566101 & 688799 & 4.9 & 4.8972 & TRN \\
\hline CHEMBL1397221 & 688799 & 5.3 & 5.2961 & TRN \\
\hline CHEMBL 2373288 & 688799 & 6.2 & 5.2392 & TST \\
\hline CHEMBL457665 & 688799 & 5.1 & 5.3374 & TRN \\
\hline CHEMBL63154 & 688799 & 6.0 & 5.4561 & TRN \\
\hline CHEMBL1592388 & 688799 & 4.8 & 4.8216 & TRN \\
\hline CHEMBL229907 & 688799 & 6.4 & 5.6057 & TRN \\
\hline CHEMBL1367076 & 688799 & 5.4 & 5.5925 & TRN \\
\hline CHEMBL1403793 & 688799 & 4.4 & 4.5634 & TRN \\
\hline CHEMBL546257 & 688799 & 5.0 & 5.2157 & TST \\
\hline CHEMBL1446731 & 688799 & 5.7 & 5.8604 & TRN \\
\hline CHEMBL1404954 & 688799 & 5.0 & 4.9805 & TRN \\
\hline CHEMBL1514129 & 688799 & 5.3 & 5.2544 & TRN \\
\hline CHEMBL1415728 & 688799 & 4.9 & 5.034 & TRN \\
\hline CHEMBL1450716 & 688799 & 5.1 & 5.2115 & TRN \\
\hline CHEMBL1437783 & 688799 & 6.5 & 6.5749 & TRN \\
\hline CHEMBL1356022 & 688799 & 5.4 & 5.8107 & TRN \\
\hline CHEMBL1436195 & 688799 & 4.9 & 4.9137 & TRN \\
\hline
\end{tabular}




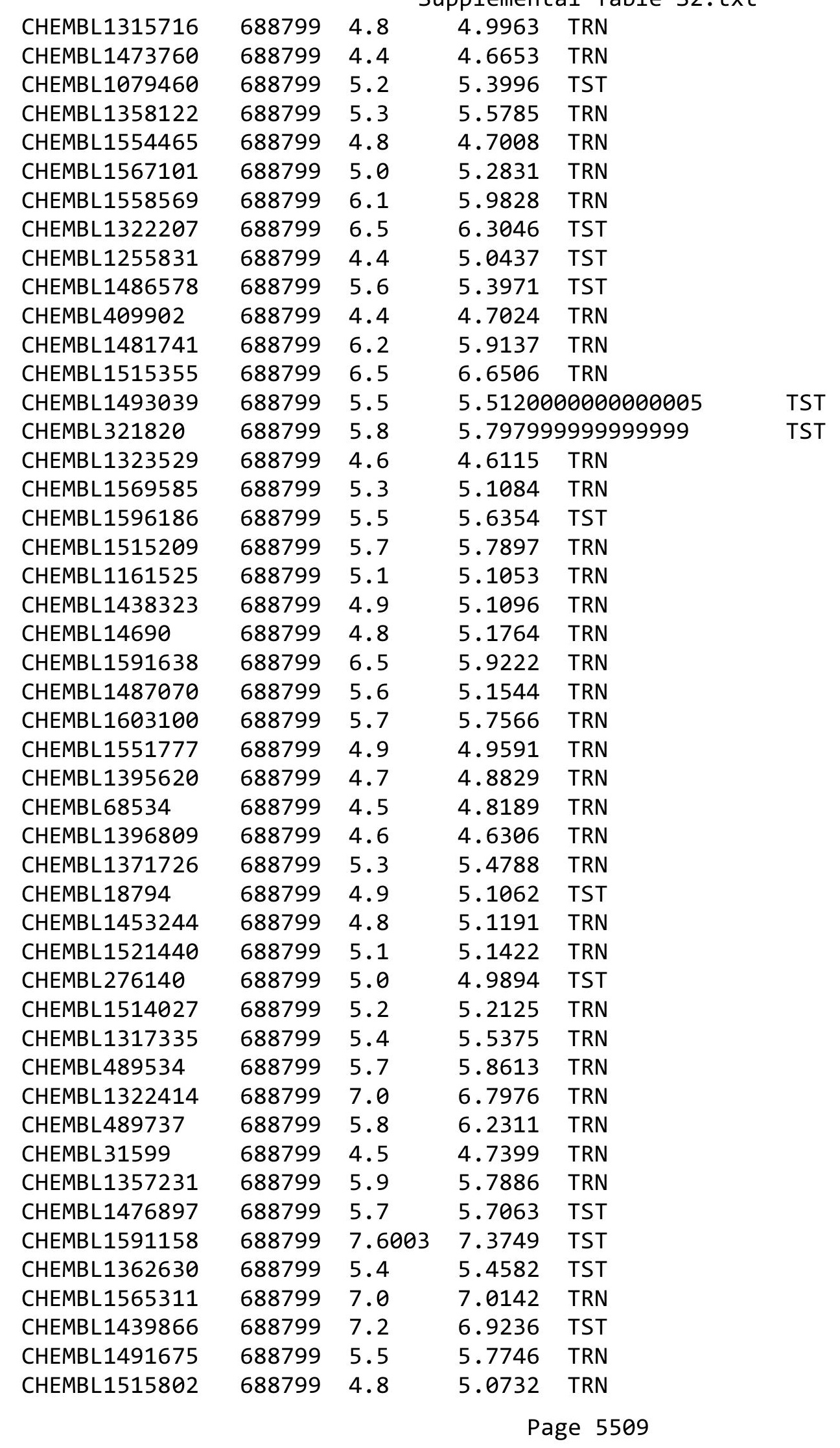




\begin{tabular}{|c|c|c|c|c|}
\hline & & & & \\
\hline CHEMBL1417333 & 688799 & 5.1 & 5.6784 & TST \\
\hline CHEMBL1437047 & 688799 & 4.8 & 5.2911 & TST \\
\hline CHEMBL1354706 & 688799 & 5.6 & 5.419 & TRN \\
\hline CHEMBL1398878 & 688799 & 6.0 & 5.5459 & TRN \\
\hline CHEMBL1609700 & 688799 & 4.9 & 4.9469 & TRN \\
\hline CHEMBL1555014 & 688799 & 5.7 & 5.8453 & TRN \\
\hline CHEMBL1489353 & 688799 & 5.0 & 5.1214 & TST \\
\hline CHEMBL1374335 & 688799 & 5.9 & 6.0104 & TRN \\
\hline CHEMBL1434715 & 688799 & 5.8 & 5.3822 & TRN \\
\hline CHEMBL1514923 & 688799 & 4.8 & 5.0327 & TRN \\
\hline CHEMBL1355387 & 688799 & 5.1 & 5.1674 & TRN \\
\hline CHEMBL1516179 & 688799 & 4.8 & 5.2063 & TST \\
\hline CHEMBL1531294 & 688799 & 6.0 & 5.8778 & TRN \\
\hline CHEMBL27403 & 688799 & 4.9 & 5.0089 & TRN \\
\hline CHEMBL1516232 & 688799 & 6.4 & 6.6741 & TRN \\
\hline CHEMBL1365609 & 688799 & 4.9 & 4.9722 & TRN \\
\hline CHEMBL1482968 & 688799 & 4.4 & 4.5946 & TRN \\
\hline CHEMBL1555466 & 688799 & 5.4 & 5.7614 & TRN \\
\hline CHEMBL1409720 & 688799 & 5.5 & 5.7213 & TRN \\
\hline CHEMBL1329939 & 688799 & 5.8 & 5.8907 & TRN \\
\hline CHEMBL1527565 & 688799 & 6.1 & 6.0064 & TST \\
\hline CHEMBL450493 & 688799 & 5.7 & 5.8892 & TRN \\
\hline CHEMBL1413701 & 688799 & 5.5 & 5.688 & TRN \\
\hline CHEMBL1495251 & 688799 & 4.7 & 4.7486 & TRN \\
\hline CHEMBL1514153 & 688799 & 5.0 & 5.1385 & TRN \\
\hline CHEMBL1435907 & 688799 & 4.8 & 4.9554 & TRN \\
\hline CHEMBL1437488 & 688799 & 6.0 & 7.2628 & TRN \\
\hline CHEMBL1361406 & 688799 & 5.0 & 4.8103 & TRN \\
\hline CHEMBL1317344 & 688799 & 5.3 & 5.6066 & TRN \\
\hline CHEMBL1529330 & 688799 & 4.8 & 4.7702 & TRN \\
\hline CHEMBL1318425 & 688799 & 4.5 & 5.465 & TST \\
\hline CHEMBL1513845 & 688799 & 4.4 & 5.6182 & TRN \\
\hline CHEMBL1446523 & 688799 & 5.4 & 5.4314 & TRN \\
\hline CHEMBL1397353 & 688799 & 4.7 & 4.7931 & TRN \\
\hline CHEMBL1360650 & 688799 & 4.9 & 5.2831 & TRN \\
\hline CHEMBL1475200 & 688799 & 8.0 & 7.9632 & TRN \\
\hline CHEMBL1554577 & 688799 & 7.3002 & 7.2575 & TRN \\
\hline CHEMBL1401324 & 688799 & 5.3 & 5.4068 & TRN \\
\hline CHEMBL1446716 & 688799 & 8.0 & 7.907 & TST \\
\hline CHEMBL1491853 & 688799 & 5.9 & 5.8543 & TST \\
\hline CHEMBL1256695 & 688799 & 4.6 & 4.9611 & TRN \\
\hline CHEMBL1405627 & 688799 & 4.7 & 4.9522 & TRN \\
\hline CHEMBL1437690 & 688799 & 4.9 & 4.7074 & TRN \\
\hline CHEMBL1515874 & 688799 & 4.9 & 5.2328 & TRN \\
\hline CHEMBL1600187 & 688799 & 5.7 & 5.3241 & TRN \\
\hline CHEMBL1456015 & 688799 & 5.3 & 5.3247 & TRN \\
\hline CHEMBL1598228 & 688799 & 6.6 & 6.5029 & TRN \\
\hline CHEMBL1377301 & 688799 & 6.4 & 6.3408 & TRN \\
\hline
\end{tabular}




\begin{tabular}{|c|c|c|c|c|c|}
\hline \multicolumn{6}{|c|}{ Supplemental Table S2.txt } \\
\hline CHEMBL16671 & 688799 & 5.8 & 5.893 & TRN & \\
\hline CHEMBL1363594 & 688799 & 4.8 & 4.8821 & TRN & \\
\hline CHEMBL1358865 & 688799 & 5.2 & 5.44 & TRN & \\
\hline CHEMBL1481029 & 688799 & 5.5 & 5.6827 & TRN & \\
\hline CHEMBL1335634 & 688799 & 5.1 & 5.8203 & TST & \\
\hline CHEMBL1328339 & 688799 & 4.4 & 4.6394 & TRN & \\
\hline CHEMBL1552623 & 688799 & 5.8 & 6.1601 & TRN & \\
\hline CHEMBL1493040 & 688799 & 5.2 & 5.4548 & TRN & \\
\hline CHEMBL1551445 & 688799 & 4.5 & 4.8611 & TRN & \\
\hline CHEMBL1551567 & 688799 & 7.4001 & 6.6453 & TRN & \\
\hline CHEMBL1338095 & 688799 & 4.8 & 4.7332 & TRN & \\
\hline CHEMBL1334103 & 688799 & 4.5 & 4.9422 & TRN & \\
\hline CHEMBL1515717 & 688799 & 5.1 & 5.1155 & TRN & \\
\hline CHEMBL1478772 & 688799 & 4.7 & 4.8313 & TRN & \\
\hline CHEMBL1594704 & 688799 & 5.8 & 4.9232 & TRN & \\
\hline CHEMBL1361656 & 688799 & 4.9 & 5.1619 & TRN & \\
\hline CHEMBL1447946 & 688799 & 5.0 & 4.90300 & 00000000005 & TRN \\
\hline CHEMBL1417013 & 688799 & 5.6 & 5.2751 & TST & \\
\hline CHEMBL1601662 & 688799 & 5.0 & 5.3347 & TRN & \\
\hline CHEMBL1490268 & 688799 & 4.4 & 4.6196 & TRN & \\
\hline CHEMBL7162 & 688799 & 7.1002 & 6.8419 & TST & \\
\hline CHEMBL1398460 & 688799 & 5.2 & 5.4528 & TRN & \\
\hline CHEMBL 8145 & 688799 & 5.0 & 5.1187 & TRN & \\
\hline CHEMBL1514431 & 688799 & 4.5 & 4.6314 & TRN & \\
\hline CHEMBL1515449 & 688799 & 8.0 & 8.0554 & TRN & \\
\hline CHEMBL486817 & 688799 & 4.6 & 5.2442 & TST & \\
\hline CHEMBL1434235 & 688799 & 7.1002 & 6.026 & TRN & \\
\hline CHEMBL1603852 & 688799 & 7.3002 & 7.1875 & TRN & \\
\hline CHEMBL1481361 & 688799 & 5.1 & 5.1598 & TRN & \\
\hline CHEMBL1590919 & 688799 & 4.8 & 4.9039 & TRN & \\
\hline CHEMBL1370891 & 688799 & 5.2 & 5.3737 & TST & \\
\hline CHEMBL1416055 & 688799 & 6.1 & 6.2453 & TRN & \\
\hline CHEMBL1317986 & 688799 & 5.8 & 5.8964 & TST & \\
\hline CHEMBL1454730 & 688799 & 5.5 & 5.5746 & TRN & \\
\hline CHEMBL1357759 & 688799 & 5.1 & 5.1193 & TRN & \\
\hline CHEMBL478 & 688799 & 4.6 & 4.8187 & TRN & \\
\hline CHEMBL1600394 & 688799 & 4.9 & 4.869 & TRN & \\
\hline CHEMBL1476687 & 688799 & 5.2 & 5.3757 & TRN & \\
\hline CHEMBL1357167 & 688799 & 6.3 & 6.16299 & 9999999999 & TRN \\
\hline CHEMBL1315618 & 688799 & 5.3 & 5.3369 & TRN & \\
\hline CHEMBL1335220 & 688799 & 5.5 & 5.6368 & TRN & \\
\hline CHEMBL1516477 & 688799 & 5.1 & 5.318 & TST & \\
\hline CHEMBL1517852 & 688799 & 6.8 & 6.3577 & TRN & \\
\hline CHEMBL1556431 & 688799 & 4.6 & 4.4461 & TRN & \\
\hline CHEMBL1256869 & 688799 & 5.4 & 5.3976 & TRN & \\
\hline CHEMBL1332759 & 688799 & 4.4 & 4.5506 & TRN & \\
\hline CHEMBL1598974 & 688799 & 6.7001 & 6.3793 & TRN & \\
\hline CHEMBL189438 & 688799 & 4.4 & 5.3095 & TRN & \\
\hline
\end{tabular}




\begin{tabular}{|c|c|c|c|c|}
\hline & & & ient & $a \perp 1 a$ \\
\hline CHEMBL1356439 & 688799 & 5.5 & 5.5493 & TRN \\
\hline CHEMBL1513643 & 688799 & 5.6 & 5.7969 & TRN \\
\hline CHEMBL1472753 & 688799 & 4.4 & 4.4791 & TRN \\
\hline CHEMBL1513149 & 688799 & 6.1 & 5.3856 & TST \\
\hline CHEMBL1397177 & 688799 & 5.5 & 5.5714 & TRN \\
\hline CHEMBL1607133 & 688799 & 4.6 & 4.6824 & TRN \\
\hline CHEMBL1553751 & 688799 & 4.7 & 4.8656 & TRN \\
\hline CHEMBL1433724 & 688799 & 5.6 & 5.8583 & TRN \\
\hline CHEMBL1334357 & 688799 & 5.9 & 5.7899 & TRN \\
\hline CHEMBL1408520 & 688799 & 4.6 & 4.8263 & TRN \\
\hline CHEMBL1478153 & 688799 & 5.2 & 5.4971 & TRN \\
\hline CHEMBL321691 & 688799 & 4.8 & 5.026 & TST \\
\hline CHEMBL 376103 & 688799 & 5.3 & 5.5016 & TRN \\
\hline CHEMBL1421016 & 688799 & 4.9 & 5.0491 & TST \\
\hline CHEMBL299613 & 688799 & 4.4 & 4.7851 & TST \\
\hline CHEMBL1333556 & 688799 & 5.1 & 5.2503 & TST \\
\hline CHEMBL1594134 & 688799 & 5.3 & 5.4699 & TRN \\
\hline CHEMBL552439 & 688799 & 5.5 & 5.5886 & TST \\
\hline CHEMBL1592211 & 688799 & 6.4 & 6.3551 & TRN \\
\hline CHEMBL1398137 & 688799 & 4.6 & 4.0236 & TRN \\
\hline CHEMBL1396374 & 688799 & 5.5 & 5.4984 & TRN \\
\hline CHEMBL1488679 & 688799 & 5.5 & 5.6202 & TST \\
\hline CHEMBL1415521 & 688799 & 5.4 & 5.5048 & TRN \\
\hline CHEMBL1327945 & 688799 & 4.9 & 5.2542 & TRN \\
\hline CHEMBL1356485 & 688799 & 4.8 & 5.1585 & TRN \\
\hline CHEMBL1590077 & 688799 & 5.3 & 5.3752 & TRN \\
\hline CHEMBL1323124 & 688799 & 4.6 & 4.2281 & TRN \\
\hline CHEMBL1396577 & 688799 & 5.1 & 5.4657 & TRN \\
\hline CHEMBL1566670 & 688799 & 4.4 & 4.8326 & TRN \\
\hline CHEMBL1570633 & 688799 & 5.0 & 5.1944 & TRN \\
\hline CHEMBL1441891 & 688799 & 4.6 & 4.8461 & TRN \\
\hline CHEMBL315268 & 688799 & 4.9 & 5.0782 & TRN \\
\hline CHEMBL1445893 & 688799 & 4.8 & 4.8248 & TRN \\
\hline CHEMBL1553926 & 688799 & 5.9 & 5.8286 & TRN \\
\hline CHEMBL1318799 & 688799 & 4.9 & 4.9764 & TRN \\
\hline CHEMBL21241 & 688799 & 4.6 & 4.8044 & TST \\
\hline CHEMBL1442106 & 688799 & 5.0 & 4.784 & TRN \\
\hline CHEMBL1324889 & 688799 & 5.4 & 5.5593 & TRN \\
\hline CHEMBL1481608 & 688799 & 5.2 & 5.3267 & TRN \\
\hline CHEMBL1607616 & 688799 & 4.7 & 5.2684 & TRN \\
\hline CHEMBL1395882 & 688799 & 6.2 & 6.226 & TRN \\
\hline CHEMBL1602710 & 688799 & 4.4 & 4.6951 & TRN \\
\hline CHEMBL1600520 & 688799 & 5.1 & 5.5014 & TRN \\
\hline CHEMBL1354145 & 688799 & 4.8 & 4.9737 & TST \\
\hline CHEMBL539947 & 688799 & 5.0 & 4.9797 & TRN \\
\hline CHEMBL1400667 & 688799 & 4.5 & 4.8046 & TST \\
\hline CHEMBL1553635 & 688799 & 5.5 & 5.4524 & TST \\
\hline CHEMBL1551575 & 688799 & 5.3 & 5.3795 & TRN \\
\hline
\end{tabular}




\begin{tabular}{|c|c|c|c|c|}
\hline \multicolumn{5}{|c|}{ plemental T } \\
\hline CHEMBL1532023 & 688799 & 5.8 & 6.0816 & TRN \\
\hline CHEMBL1513077 & 688799 & 4.8 & 4.9523 & TRN \\
\hline CHEMBL1551122 & 688799 & 4.4 & 4.3807 & TRN \\
\hline CHEMBL1328943 & 688799 & 5.8 & 6.151 & TRN \\
\hline CHEMBL1255583 & 688799 & 6.0 & 5.3265 & TRN \\
\hline CHEMBL1434895 & 688799 & 5.6 & 5.4799 & TRN \\
\hline CHEMBL1354357 & 688799 & 4.5 & 5.0618 & TST \\
\hline CHEMBL1487748 & 688799 & 6.0 & 6.1755 & TRN \\
\hline CHEMBL1603518 & 688799 & 6.0 & 6.0735 & TRN \\
\hline CHEMBL1085765 & 688799 & 5.6 & 5.6954 & TRN \\
\hline CHEMBL 310578 & 688799 & 4.4 & 5.0906 & TST \\
\hline CHEMBL1358583 & 688799 & 4.4 & 4.6142 & TRN \\
\hline CHEMBL582444 & 688799 & 5.0 & 4.9782 & TST \\
\hline CHEMBL1517765 & 688799 & 4.8 & 5.1721 & TRN \\
\hline CHEMBL1364871 & 688799 & 4.6 & 4.7486 & TRN \\
\hline CHEMBL1317039 & 688799 & 5.1 & 4.9475 & TRN \\
\hline CHEMBL1454049 & 688799 & 5.4 & 5.2522 & TRN \\
\hline CHEMBL1490209 & 688799 & 5.3 & 5.8928 & TRN \\
\hline CHEMBL1590550 & 688799 & 5.1 & 5.2178 & TRN \\
\hline CHEMBL1366106 & 688799 & 4.7 & 4.7196 & TRN \\
\hline CHEMBL 254348 & 688799 & 4.5 & 5.4308 & TRN \\
\hline CHEMBL1482790 & 688799 & 4.9 & 5.119 & TRN \\
\hline CHEMBL1394640 & 688799 & 6.0 & 6.1116 & TRN \\
\hline CHEMBL1435654 & 688799 & 6.5 & 6.3632 & TRN \\
\hline CHEMBL1512444 & 688799 & 4.5 & 4.4973 & TRN \\
\hline CHEMBL1436832 & 688799 & 4.5 & 4.702 & TRN \\
\hline CHEMBL1603394 & 688799 & 5.2 & 5.2188 & TRN \\
\hline CHEMBL1336155 & 688799 & 5.6 & 5.6029 & TST \\
\hline CHEMBL1357186 & 688799 & 6.6 & 4.9948 & TRN \\
\hline CHEMBL1316456 & 688799 & 6.9 & 6.5499 & TRN \\
\hline CHEMBL1594149 & 688799 & 4.6 & 4.8324 & TST \\
\hline CHEMBL1512895 & 688799 & 6.8 & 4.3689 & TRN \\
\hline CHEMBL1551161 & 688799 & 5.1 & 5.6417 & TRN \\
\hline CHEMBL1443163 & 688799 & 7.0 & 6.8853 & TRN \\
\hline CHEMBL1551200 & 688799 & 5.4 & 5.3898 & TRN \\
\hline CHEMBL1400491 & 688799 & 4.6 & 4.5436 & TRN \\
\hline CHEMBL303516 & 688799 & 5.9 & 5.7412 & TST \\
\hline CHEMBL1373818 & 688799 & 5.1 & 5.1504 & TST \\
\hline CHEMBL1436228 & 688799 & 4.9 & 4.8586 & TRN \\
\hline CHEMBL1440704 & 688799 & 5.5 & 5.6506 & TRN \\
\hline CHEMBL64569 & 688799 & 6.0 & 6.0682 & TRN \\
\hline CHEMBL 72410 & 688799 & 5.0 & 5.0665 & TRN \\
\hline CHEMBL1520593 & 688799 & 5.4 & 5.4591 & TRN \\
\hline CHEMBL1613358 & 688799 & 5.5 & 5.1589 & TST \\
\hline CHEMBL1473029 & 688799 & 6.1 & 5.3927 & TRN \\
\hline CHEMBL1408856 & 688799 & 6.3 & 5.9839 & TRN \\
\hline CHEMBL1314273 & 688799 & 7.2 & 7.0661 & TRN \\
\hline CHEMBL1358402 & 688799 & 4.5 & 4.927 & TST \\
\hline
\end{tabular}




\begin{tabular}{|c|c|c|c|c|c|}
\hline \multicolumn{6}{|c|}{ Supplemental Table s2.txt } \\
\hline CHEMBL1479506 & 688799 & 4.8 & 4.3122 & TRN & \\
\hline CHEMBL13791 & 688799 & 6.0 & 5.9875 & TRN & \\
\hline CHEMBL1399994 & 688799 & 7.699 & 7.3589 & TRN & \\
\hline CHEMBL1321154 & 688799 & 5.0 & 5.5992 & TRN & \\
\hline CHEMBL1433752 & 688799 & 5.1 & 5.1672 & TRN & \\
\hline CHEMBL1363367 & 688799 & 6.0 & 6.0045 & TST & \\
\hline CHEMBL1592876 & 688799 & 5.2 & 5.5461 & TRN & \\
\hline CHEMBL1320474 & 688799 & 8.1024 & 7.8196 & TRN & \\
\hline CHEMBL1317537 & 688799 & 4.7 & 4.8128 & TRN & \\
\hline CHEMBL541847 & 688799 & 5.3 & 5.1796 & TRN & \\
\hline CHEMBL1358731 & 688799 & 4.4 & 4.8378 & TRN & \\
\hline CHEMBL1358409 & 688799 & 5.5 & 5.4251 & TRN & \\
\hline CHEMBL1200938 & 688799 & 6.9 & 6.4741 & TRN & \\
\hline CHEMBL1437713 & 688799 & 4.9 & 4.8852 & TRN & \\
\hline CHEMBL1521490 & 688799 & 4.7 & 5.035 & TRN & \\
\hline CHEMBL1451119 & 688799 & 5.6 & 5.5153 & TRN & \\
\hline CHEMBL1355371 & 688799 & 5.6 & 5.1077 & TST & \\
\hline CHEMBL1512190 & 688799 & 4.9 & 4.7652 & TRN & \\
\hline CHEMBL492122 & 688799 & 4.9 & 4.7361 & TRN & \\
\hline CHEMBL1371510 & 688799 & 5.6 & 5.7495 & TST & \\
\hline CHEMBL587849 & 688799 & 5.5 & 5.63700 & 00000000005 & TRN \\
\hline CHEMBL1488167 & 688799 & 5.9 & 6.1047 & TRN & \\
\hline CHEMBL490706 & 688799 & 5.4 & 5.1517 & TRN & \\
\hline CHEMBL1356094 & 688799 & 5.4 & 5.5367 & TST & \\
\hline CHEMBL 28140 & 688799 & 5.2 & 5.2565 & TRN & \\
\hline CHEMBL1356135 & 688799 & 4.8 & 4.8861 & TRN & \\
\hline CHEMBL1493496 & 688799 & 5.7 & 5.7864 & TRN & \\
\hline CHEMBL1559404 & 688799 & 4.4 & 4.4085 & TRN & \\
\hline CHEMBL1357157 & 688799 & 5.1 & 5.2795 & TRN & \\
\hline CHEMBL1439631 & 688799 & 5.1 & 5.2456 & TRN & \\
\hline CHEMBL1608125 & 688799 & 5.5 & 5.5045 & TRN & \\
\hline CHEMBL275516 & 688799 & 4.8 & 5.1334 & TST & \\
\hline CHEMBL1474326 & 688799 & 4.4 & 4.4523 & TRN & \\
\hline CHEMBL1453872 & 688799 & 5.6 & 6.2655 & TRN & \\
\hline CHEMBL1355644 & 688799 & 8.4949 & 8.4225 & TRN & \\
\hline CHEMBL1403154 & 688799 & 5.9 & 5.7868 & TRN & \\
\hline CHEMBL1472703 & 688799 & 5.1 & 5.2801 & TRN & \\
\hline CHEMBL1555610 & 688799 & 4.6 & 4.7174 & TRN & \\
\hline CHEMBL129795 & 688799 & 6.0 & 5.3932 & TRN & \\
\hline CHEMBL 78150 & 688799 & 5.1 & 5.0801 & TRN & \\
\hline CHEMBL1591336 & 688799 & 5.0 & 5.1913 & TRN & \\
\hline CHEMBL1410759 & 688799 & 5.2 & 5.4499 & TST & \\
\hline CHEMBL1396680 & 688799 & 5.2 & 6.1327 & TRN & \\
\hline CHEMBL1514307 & 688799 & 5.0 & 4.8139 & TRN & \\
\hline CHEMBL565856 & 688799 & 5.3 & 5.3118 & TRN & \\
\hline CHEMBL1361596 & 688799 & 4.9 & 5.4294 & TRN & \\
\hline CHEMBL1367656 & 688799 & 6.1 & 6.135 & TRN & \\
\hline CHEMBL405358 & 688799 & 5.4 & 5.3921 & TST & \\
\hline
\end{tabular}




\begin{tabular}{|c|c|c|c|c|c|}
\hline & & & & & \\
\hline CHEMBL1316839 & 688799 & 5.9 & 5.749 & TRN & \\
\hline CHEMBL1590081 & 688799 & 5.0 & 5.0873 & TRN & \\
\hline CHEMBL1354563 & 688799 & 5.1 & 5.1216 & TRN & \\
\hline CHEMBL1434833 & 688799 & 5.6 & 5.5629 & TRN & \\
\hline CHEMBL1455570 & 688799 & 5.7 & 5.6727 & TRN & \\
\hline CHEMBL1600564 & 688799 & 5.2 & 5.3989 & TRN & \\
\hline CHEMBL1535372 & 688799 & 5.7 & 5.1457 & TRN & \\
\hline CHEMBL1412519 & 688799 & 5.4 & 5.4738 & TRN & \\
\hline CHEMBL1516107 & 688799 & 6.4 & 5.6658 & TRN & \\
\hline CHEMBL1434042 & 688799 & 4.7 & 5.5639 & TRN & \\
\hline CHEMBL1565293 & 688799 & 6.0 & 5.2962 & TST & \\
\hline CHEMBL1553902 & 688799 & 4.7 & 4.7162 & TRN & \\
\hline CHEMBL1611471 & 688799 & 5.9 & 5.4754 & TRN & \\
\hline CHEMBL1590857 & 688799 & 4.7 & 4.7475 & TRN & \\
\hline CHEMBL1378208 & 688799 & 4.8 & 4.9499 & TRN & \\
\hline CHEMBL432527 & 688799 & 8.0 & 7.5397 & TST & \\
\hline CHEMBL1452850 & 688799 & 5.5 & 5.5391 & TRN & \\
\hline CHEMBL407232 & 688799 & 6.0 & 5.35 & TRN & \\
\hline CHEMBL1377526 & 688799 & 4.7 & 4.6684 & TRN & \\
\hline CHEMBL249669 & 688799 & 6.0 & 6.0099 & TST & \\
\hline CHEMBL23327 & 688799 & 4.5 & 5.6827 & TRN & \\
\hline CHEMBL1517241 & 688799 & 4.9 & 5.1484 & TRN & \\
\hline CHEMBL453019 & 688799 & 5.0 & 5.7581 & TRN & \\
\hline CHEMBL1437259 & 688799 & 5.0 & 4.9409 & TRN & \\
\hline CHEMBL1335140 & 688799 & 6.8 & 5.5578 & TRN & \\
\hline CHEMBL1552362 & 688799 & 4.6 & 4.9915 & TRN & \\
\hline CHEMBL1317950 & 688799 & 8.6021 & 8.1035 & TST & \\
\hline CHEMBL1486399 & 688799 & 5.9 & 6.0082 & TRN & \\
\hline CHEMBL1590877 & 688799 & 5.4 & 5.517 & TRN & \\
\hline CHEMBL1357338 & 688799 & 5.0 & 4.8408 & TRN & \\
\hline CHEMBL1326204 & 688799 & 5.5 & 5.50700 & 2000000001 & TST \\
\hline CHEMBL1370805 & 688799 & 5.6 & 5.6667 & TRN & \\
\hline CHEMBL1356060 & 688799 & 7.4001 & 7.5975 & TRN & \\
\hline CHEMBL1524370 & 688799 & 5.2 & 5.3347 & TRN & \\
\hline CHEMBL1609160 & 688799 & 5.1 & 5.40600 & 0000000001 & TRN \\
\hline CHEMBL242171 & 688799 & 4.9 & 5.4036 & TRN & \\
\hline CHEMBL1320989 & 688799 & 4.4 & 4.4599 & TRN & \\
\hline CHEMBL490913 & 688799 & 5.2 & 5.1679 & TRN & \\
\hline CHEMBL1396015 & 688799 & 5.4 & 5.7386 & TRN & \\
\hline CHEMBL1436532 & 688799 & 5.4 & 5.9179 & TRN & \\
\hline CHEMBL1570716 & 688799 & 6.0 & 5.9852 & TRN & \\
\hline CHEMBL1559279 & 688799 & 4.8 & 4.5413 & TRN & \\
\hline CHEMBL259389 & 688799 & 6.2 & 6.5128 & TST & \\
\hline CHEMBL1515540 & 688799 & 4.7 & 4.6501 & TRN & \\
\hline CHEMBL1533335 & 688799 & 5.4 & 5.4066 & TRN & \\
\hline CHEMBL1596872 & 688799 & 4.9 & 5.0999 & TRN & \\
\hline CHEMBL 258465 & 688799 & 6.9 & 6.5781 & TST & \\
\hline CHEMBL1589879 & 688799 & 5.9 & 6.3749 & TRN & \\
\hline
\end{tabular}




\begin{tabular}{|c|c|c|c|c|c|}
\hline \multicolumn{6}{|c|}{ Supplemental Table S2.txt } \\
\hline CHEMBL1356106 & 688799 & 5.4 & 5.6721 & TST & \\
\hline CHEMBL1554745 & 688799 & 6.2 & 6.1466 & TRN & \\
\hline CHEMBL1591876 & 688799 & 7.6003 & 6.9554 & TRN & \\
\hline CHEMBL1566458 & 688799 & 5.4 & 5.3991 & TRN & \\
\hline CHEMBL103469 & 688799 & 4.9 & 4.9794 & TRN & \\
\hline CHEMBL1607623 & 688799 & 6.0 & 5.9866 & TRN & \\
\hline CHEMBL1413489 & 688799 & 6.0 & 6.0432 & TRN & \\
\hline CHEMBL515505 & 688799 & 5.8 & 5.8494 & TRN & \\
\hline CHEMBL1551962 & 688799 & 6.1 & 5.9758 & TRN & \\
\hline CHEMBL1395564 & 688799 & 4.4 & 4.7083 & TRN & \\
\hline CHEMBL1475255 & 688799 & 5.6 & 5.4046 & TRN & \\
\hline CHEMBL1377686 & 688799 & 5.6 & 5.63 & TRN & \\
\hline CHEMBL567175 & 688799 & 6.0 & 5.86799 & 9999999999 & TST \\
\hline CHEMBL1364404 & 688799 & 5.6 & 5.4096 & TRN & \\
\hline CHEMBL1409852 & 688799 & 5.9 & 5.1623 & TRN & \\
\hline CHEMBL1561829 & 688799 & 6.5 & 6.4018 & TRN & \\
\hline CHEMBL1554723 & 688799 & 5.0 & 4.9612 & TRN & \\
\hline CHEMBL1314674 & 688799 & 4.5 & 4.5843 & TRN & \\
\hline CHEMBL1520347 & 688799 & 4.7 & 4.7957 & TRN & \\
\hline CHEMBL8565 & 688799 & 5.1 & 5.0996 & TRN & \\
\hline CHEMBL1408604 & 688799 & 5.6 & 5.7384 & TST & \\
\hline CHEMBL1526213 & 688799 & 6.1 & 6.1519 & TRN & \\
\hline CHEMBL1314288 & 688799 & 4.4 & 4.7135 & TRN & \\
\hline CHEMBL1442425 & 688799 & 4.6 & 4.7628 & TRN & \\
\hline CHEMBL1574103 & 688799 & 5.2 & 5.5973 & TRN & \\
\hline CHEMBL1319672 & 688799 & 5.9 & 5.9389 & TRN & \\
\hline CHEMBL1412163 & 688799 & 7.3002 & 5.3253 & TRN & \\
\hline CHEMBL1417025 & 688799 & 4.8 & 4.8718 & TRN & \\
\hline CHEMBL1356242 & 688799 & 5.1 & 5.1746 & TRN & \\
\hline CHEMBL1395997 & 688799 & 6.5 & 6.1438 & TRN & \\
\hline CHEMBL1451986 & 688799 & 5.7 & 5.7071 & TST & \\
\hline CHEMBL1366296 & 688799 & 4.4 & 4.3125 & TRN & \\
\hline CHEMBL1368895 & 688799 & 5.2 & 5.0072 & TRN & \\
\hline CHEMBL1433705 & 688799 & 4.9 & 4.6652 & TRN & \\
\hline CHEMBL1590974 & 688799 & 4.5 & 4.4996 & TRN & \\
\hline CHEMBL1571705 & 688799 & 4.8 & 5.0424 & TRN & \\
\hline CHEMBL1434817 & 688799 & 5.0 & 4.9519 & TRN & \\
\hline CHEMBL1356505 & 688799 & 5.3 & 5.28299 & 99999999995 & TRN \\
\hline CHEMBL24909 & 688799 & 6.2 & 6.0915 & TRN & \\
\hline CHEMBL1491288 & 688799 & 5.5 & 5.5411 & TRN & \\
\hline CHEMBL1356497 & 688799 & 4.9 & 4.6378 & TRN & \\
\hline CHEMBL1373954 & 688799 & 5.2 & 5.32100 & 0000000001 & TRN \\
\hline CHEMBL1607885 & 688799 & 5.1 & 5.1508 & TRN & \\
\hline CHEMBL1559654 & 688799 & 5.1 & 5.2572 & TRN & \\
\hline CHEMBL1557809 & 688799 & 6.7001 & 5.32 & TRN & \\
\hline CHEMBL94734 & 688799 & 4.9 & 5.2554 & TRN & \\
\hline CHEMBL1396407 & 688799 & 4.5 & 4.7571 & TRN & \\
\hline CHEMBL1514804 & 688799 & 4.8 & 4.8812 & TRN & \\
\hline
\end{tabular}




\begin{tabular}{|c|c|c|c|c|}
\hline \multicolumn{5}{|c|}{ Supplemental Table S2.txt } \\
\hline CHEMBL469309 & 688799 & 5.5 & 5.7482 & TRN \\
\hline CHEMBL1399528 & 688799 & 5.7 & 5.5847 & TRN \\
\hline CHEMBL1591908 & 688799 & 4.8 & 4.8603 & TRN \\
\hline CHEMBL1554982 & 688799 & 6.0 & 5.8111 & TRN \\
\hline CHEMBL 2373554 & 688799 & 5.9 & 5.2803 & TRN \\
\hline CHEMBL1318448 & 688799 & 4.4 & 4.5581 & TRN \\
\hline CHEMBL1601163 & 688799 & 5.4 & 5.8386 & TRN \\
\hline CHEMBL1316213 & 688799 & 7.1002 & 7.1634 & TRN \\
\hline CHEMBL172064 & 688799 & 7.3002 & 6.9562 & TST \\
\hline CHEMBL 384903 & 688799 & 6.9 & 6.4924 & TST \\
\hline CHEMBL1451058 & 688799 & 5.3 & 5.4016 & TRN \\
\hline CHEMBL1374913 & 688799 & 5.3 & 5.3856 & TRN \\
\hline CHEMBL1331657 & 688799 & 4.6 & 4.7499 & TRN \\
\hline CHEMBL1320947 & 688799 & 5.6 & 5.6732 & TRN \\
\hline CHEMBL1553694 & 688799 & 6.3 & 6.1582 & TRN \\
\hline CHEMBL1255659 & 688799 & 5.0 & 5.2005 & TRN \\
\hline CHEMBL1315268 & 688799 & 5.4 & 4.9005 & TRN \\
\hline CHEMBL1316760 & 688799 & 4.6 & 4.6689 & TRN \\
\hline CHEMBL1607106 & 688799 & 5.5 & 5.6793 & TRN \\
\hline CHEMBL1554914 & 688799 & 5.9 & 6.0644 & TRN \\
\hline CHEMBL1600340 & 688799 & 4.7 & 4.3264 & TRN \\
\hline CHEMBL1590821 & 688799 & 4.9 & 5.1546 & TRN \\
\hline CHEMBL1594227 & 688799 & 5.3 & 5.4237 & TRN \\
\hline CHEMBL1522128 & 688799 & 6.2 & 5.5083 & TST \\
\hline CHEMBL1435509 & 688799 & 5.8 & 5.9544 & TRN \\
\hline CHEMBL1476049 & 688799 & 4.9 & 4.857 & TRN \\
\hline CHEMBL1442087 & 688799 & 5.6 & 5.7317 & TRN \\
\hline CHEMBL1602394 & 688799 & 5.9 & 6.1375 & TRN \\
\hline CHEMBL1436125 & 688799 & 5.7 & 5.7341 & TRN \\
\hline CHEMBL1553436 & 688799 & 5.4 & 5.5832 & TST \\
\hline CHEMBL 313938 & 688799 & 6.0 & 4.9832 & TRN \\
\hline CHEMBL1315072 & 688799 & 4.4 & 4.5744 & TRN \\
\hline CHEMBL1366511 & 688799 & 4.4 & 5.2188 & TST \\
\hline CHEMBL6634 & 688799 & 4.4 & 5.2093 & TST \\
\hline CHEMBL1487219 & 688799 & 4.9 & 4.9838 & TST \\
\hline CHEMBL3208021 & 688799 & 5.8 & 5.8797 & TRN \\
\hline CHEMBL1332450 & 688799 & 5.4 & 5.2765 & TRN \\
\hline CHEMBL 285932 & 688799 & 5.1 & 5.1273 & TST \\
\hline CHEMBL1473188 & 688799 & 4.9 & 4.871 & TRN \\
\hline CHEMBL 243677 & 688799 & 4.8 & 5.5131 & TRN \\
\hline CHEMBL1560095 & 688799 & 4.9 & 5.1291 & TRN \\
\hline CHEMBL1378237 & 688799 & 4.8 & 4.81 & TRN \\
\hline CHEMBL1527466 & 688799 & 6.0 & 6.1905 & TRN \\
\hline CHEMBL1358560 & 688799 & 4.9 & 4.8452 & TRN \\
\hline CHEMBL1413343 & 688799 & 5.2 & 5.2076 & TRN \\
\hline CHEMBL1512540 & 688799 & 5.4 & 5.4848 & TRN \\
\hline CHEMBL1255940 & 688799 & 4.9 & 5.1418 & TRN \\
\hline CHEMBL490749 & 688799 & 6.0 & 6.147 & TRN \\
\hline
\end{tabular}




\begin{tabular}{|c|c|c|c|c|}
\hline \multicolumn{5}{|c|}{ Supplemental Table s2.txt } \\
\hline CHEMBL1513121 & 688799 & 4.9 & 4.9441 & TRN \\
\hline CHEMBL1397902 & 688799 & 5.6 & 5.775 & TRN \\
\hline CHEMBL1527622 & 688799 & 5.6 & 5.67899 & 9999999999 \\
\hline CHEMBL1409148 & 688799 & 6.0 & 5.9685 & TRN \\
\hline CHEMBL1436811 & 688799 & 4.4 & 4.6813 & TRN \\
\hline CHEMBL107528 & 688799 & 5.7 & 5.6282 & TRN \\
\hline CHEMBL1329419 & 688799 & 5.2 & 5.6075 & TST \\
\hline CHEMBL1320662 & 688799 & 4.7 & 4.7197 & TRN \\
\hline CHEMBL1375753 & 688799 & 5.4 & 5.2698 & TRN \\
\hline CHEMBL1594054 & 688799 & 6.4 & 6.4365 & TRN \\
\hline CHEMBL1403310 & 688799 & 6.0 & 5.4606 & TRN \\
\hline CHEMBL1481465 & 688799 & 5.0 & 5.0325 & TRN \\
\hline CHEMBL1410139 & 688799 & 5.4 & 5.312 & TRN \\
\hline CHEMBL1525438 & 688799 & 8.3979 & 5.4596 & TST \\
\hline CHEMBL1567472 & 688799 & 4.4 & 4.6154 & TRN \\
\hline CHEMBL1551294 & 688799 & 4.4 & 4.5502 & TRN \\
\hline CHEMBL8488 & 688799 & 4.5 & 5.1814 & TRN \\
\hline CHEMBL1435373 & 688799 & 4.8 & 4.7909 & TRN \\
\hline CHEMBL34730 & 688799 & 5.3 & 5.4193 & TRN \\
\hline CHEMBL1555233 & 688799 & 5.4 & 5.5138 & TRN \\
\hline CHEMBL393417 & 688799 & 5.3 & 5.6152 & TRN \\
\hline CHEMBL1562786 & 688799 & 4.6 & 4.6301 & TRN \\
\hline CHEMBL1328979 & 688799 & 4.8 & 4.2576 & TRN \\
\hline CHEMBL1475381 & 688799 & 4.4 & 4.4312 & TRN \\
\hline CHEMBL1318045 & 688799 & 4.8 & 4.7128 & TRN \\
\hline CHEMBL1590106 & 688799 & 4.6 & 4.7349 & TRN \\
\hline CHEMBL1474287 & 688799 & 6.0 & 5.1527 & TRN \\
\hline CHEMBL 279841 & 688799 & 5.0 & 5.0799 & TRN \\
\hline CHEMBL1356879 & 688799 & 5.5 & 5.6544 & TST \\
\hline CHEMBL1331579 & 688799 & 5.6 & 5.6118 & TRN \\
\hline CHEMBL1473754 & 688799 & 5.2 & 5.1826 & TRN \\
\hline CHEMBL1590261 & 688799 & 5.2 & 5.2369 & TRN \\
\hline CHEMBL1371696 & 688799 & 5.5 & 5.7273 & TRN \\
\hline CHEMBL1596170 & 688799 & 4.8 & 4.808 & TRN \\
\hline CHEMBL 277525 & 688799 & 4.8 & 5.5885 & TRN \\
\hline CHEMBL1434199 & 688799 & 6.6 & 6.6231 & TRN \\
\hline CHEMBL1604063 & 688799 & 5.4 & 5.5766 & TST \\
\hline CHEMBL1554637 & 688799 & 4.7 & 4.7035 & TRN \\
\hline CHEMBL1319049 & 688799 & 6.0 & 6.2081 & TRN \\
\hline CHEMBL1355896 & 688799 & 6.0 & 5.9911 & TRN \\
\hline CHEMBL1557466 & 688799 & 5.4 & 5.2353 & TRN \\
\hline CHEMBL1519978 & 688799 & 5.0 & 5.0868 & TRN \\
\hline CHEMBL1474114 & 688799 & 5.0 & 5.2225 & TRN \\
\hline CHEMBL1515452 & 688799 & 5.5 & 5.7031 & TRN \\
\hline CHEMBL1552181 & 688799 & 4.4 & 4.3788 & TRN \\
\hline CHEMBL1592464 & 688799 & 7.2 & 7.2488 & TRN \\
\hline CHEMBL1413340 & 688799 & 5.1 & 5.3059 & TRN \\
\hline CHEMBL1316219 & 688799 & 5.4 & 5.5142 & TST \\
\hline
\end{tabular}




\begin{tabular}{|c|c|c|c|c|}
\hline \multicolumn{5}{|c|}{ lemental Ta } \\
\hline CHEMBL1403121 & 688799 & 4.9 & 4.9825 & TRN \\
\hline CHEMBL1558843 & 688799 & 5.3 & 5.50700 & 0000000001 \\
\hline CHEMBL495068 & 688799 & 4.8 & 4.8716 & TRN \\
\hline CHEMBL1494182 & 688799 & 5.1 & 5.2433 & TST \\
\hline CHEMBL1502697 & 688799 & 5.3 & 5.4679 & TST \\
\hline CHEMBL1474987 & 688799 & 5.7 & 5.4401 & TRN \\
\hline CHEMBL1357018 & 688799 & 5.3 & 5.5277 & TRN \\
\hline CHEMBL1434308 & 688799 & 4.4 & 5.2995 & TRN \\
\hline CHEMBL1415957 & 688799 & 4.4 & 4.5322 & TRN \\
\hline CHEMBL1368892 & 688799 & 6.2 & 6.4404 & TRN \\
\hline CHEMBL1397860 & 688799 & 4.7 & 4.8021 & TRN \\
\hline CHEMBL1323956 & 688799 & 5.0 & 4.9322 & TRN \\
\hline CHEMBL 75773 & 688799 & 5.0 & 5.0472 & TRN \\
\hline CHEMBL1600620 & 688799 & 4.5 & 4.5609 & TRN \\
\hline CHEMBL1409961 & 688799 & 6.4 & 6.6316 & TRN \\
\hline CHEMBL 1256693 & 688799 & 5.1 & 5.2398 & TST \\
\hline CHEMBL516075 & 688799 & 5.5 & 5.5234 & TRN \\
\hline CHEMBL1324775 & 688799 & 5.4 & 5.4635 & TRN \\
\hline CHEMBL1327203 & 688799 & 7.1002 & 7.4301 & TST \\
\hline CHEMBL1405461 & 688799 & 5.6 & 5.6405 & TRN \\
\hline CHEMBL 1476206 & 688799 & 4.6 & 4.6458 & TRN \\
\hline CHEMBL 383475 & 688799 & 5.4 & 5.2449 & TRN \\
\hline CHEMBL1591508 & 688799 & 4.9 & 5.1609 & TST \\
\hline CHEMBL1394187 & 688799 & 4.9 & 4.8341 & TRN \\
\hline CHEMBL1375723 & 688799 & 5.7 & 5.931 & TRN \\
\hline CHEMBL 1255578 & 688799 & 5.1 & 5.3453 & TST \\
\hline CHEMBL1570894 & 688799 & 6.9 & 6.4105 & TRN \\
\hline CHEMBL1518718 & 688799 & 6.2 & 6.0959 & TRN \\
\hline CHEMBL1593547 & 688799 & 5.0 & 4.8971 & TRN \\
\hline CHEMBL1554936 & 688799 & 6.3 & 6.2487 & TRN \\
\hline CHEMBL1611225 & 688799 & 5.9 & 6.0347 & TRN \\
\hline CHEMBL1731472 & 688799 & 5.3 & 5.5508 & TST \\
\hline CHEMBL446774 & 688799 & 5.4 & 5.4615 & TST \\
\hline CHEMBL1395974 & 688799 & 4.5 & 4.6848 & TRN \\
\hline CHEMBL434119 & 688799 & 4.6 & 5.3085 & TRN \\
\hline CHEMBL1597474 & 688799 & 4.6 & 4.5191 & TRN \\
\hline CHEMBL1451697 & 688799 & 6.3 & 5.3085 & TRN \\
\hline CHEMBL1606727 & 688799 & 5.1 & 5.2063 & TRN \\
\hline CHEMBL1552284 & 688799 & 5.6 & 5.0975 & TST \\
\hline CHEMBL1515341 & 688799 & 5.4 & 5.3989 & TRN \\
\hline CHEMBL1355708 & 688799 & 4.7 & 4.9359 & TRN \\
\hline CHEMBL1472898 & 688799 & 4.5 & 4.5215 & TRN \\
\hline CHEMBL1256364 & 688799 & 5.0 & 5.1775 & TRN \\
\hline CHEMBL299155 & 688799 & 4.7 & 5.2595 & TRN \\
\hline CHEMBL1355855 & 688799 & 6.1 & 6.1704 & TRN \\
\hline CHEMBL1484738 & 688799 & 5.3 & 5.3771 & TST \\
\hline CHEMBL1370229 & 688799 & 6.9 & 6.8916 & TRN \\
\hline CHEMBL1369008 & 688799 & 4.4 & 4.4673 & TRN \\
\hline
\end{tabular}

TRN 


\begin{tabular}{|c|c|c|c|c|c|}
\hline \\
\hline CHEMBL2373583 & 688799 & 6.6 & 5.5661 & TRN & \\
\hline CHEMBL10009 & 688799 & 6.4 & 6.3214 & TRN & \\
\hline CHEMBL491978 & 688799 & 4.8 & 4.8429 & TRN & \\
\hline CHEMBL1435227 & 688799 & 4.6 & 4.7293 & TRN & \\
\hline CHEMBL1398031 & 688799 & 4.4 & 5.4378 & TST & \\
\hline CHEMBL1554976 & 688799 & 5.7 & 5.5474 & TRN & \\
\hline CHEMBL1256984 & 688799 & 5.7 & 5.7787 & TRN & \\
\hline CHEMBL1394956 & 688799 & 5.5 & 5.3092 & TRN & \\
\hline CHEMBL1606018 & 688799 & 7.5003 & 4.9734 & TRN & \\
\hline CHEMBL1591275 & 688799 & 4.6 & 4.5019 & TRN & \\
\hline CHEMBL1561402 & 688799 & 5.5 & 5.598 & TRN & \\
\hline CHEMBL1555559 & 688799 & 6.0 & 5.2952 & TST & \\
\hline CHEMBL1555480 & 688799 & 4.6 & 4.652 & TRN & \\
\hline CHEMBL491771 & 688799 & 5.1 & 5.1292 & TRN & \\
\hline CHEMBL1449417 & 688799 & 5.4 & 5.3288 & TRN & \\
\hline CHEMBL1318765 & 688799 & 6.9 & 5.8068 & TRN & \\
\hline CHEMBL1535796 & 688799 & 5.3 & 5.3674 & TRN & \\
\hline CHEMBL1528688 & 688799 & 5.4 & 5.4676 & TST & \\
\hline CHEMBL1320315 & 688799 & 6.2 & 6.0463 & TST & \\
\hline CHEMBL1363513 & 688799 & 4.4 & 4.4692 & TRN & \\
\hline CHEMBL1727680 & 688799 & 6.3 & 6.2085 & TRN & \\
\hline CHEMBL1322976 & 688799 & 5.7 & 5.3527 & TST & \\
\hline CHEMBL1594350 & 688799 & 5.4 & 5.688 & TRN & \\
\hline CHEMBL303579 & 688799 & 5.3 & 5.4769 & TRN & \\
\hline CHEMBL1437906 & 688799 & 4.8 & 4.9101 & TRN & \\
\hline CHEMBL1563840 & 688799 & 5.2 & 5.7411 & TRN & \\
\hline CHEMBL1359713 & 688799 & 8.0 & 8.0467 & TST & \\
\hline CHEMBL1517187 & 688799 & 4.6 & 4.3663 & TST & \\
\hline CHEMBL1551834 & 688799 & 5.3 & 5.3817 & TRN & \\
\hline CHEMBL1335397 & 688799 & 5.6 & 5.4212 & TST & \\
\hline CHEMBL1608678 & 688799 & 4.6 & 5.2274 & TRN & \\
\hline CHEMBL1454949 & 688799 & 5.6 & 5.7821 & TST & \\
\hline CHEMBL1356346 & 688799 & 4.5 & 4.6859 & TRN & \\
\hline CHEMBL1453542 & 688799 & 4.8 & 4.8749 & TRN & \\
\hline CHEMBL362863 & 688799 & 8.1024 & 7.5384 & TST & \\
\hline CHEMBL1601630 & 688799 & 5.0 & 5.1078 & TRN & \\
\hline CHEMBL1448138 & 688799 & 4.6 & 4.6141 & TRN & \\
\hline CHEMBL1371160 & 688799 & 5.4 & 5.5425 & TST & \\
\hline CHEMBL1394456 & 688799 & 5.4 & 5.8035 & TRN & \\
\hline CHEMBL1532720 & 688799 & 7.5003 & 6.9718 & TRN & \\
\hline CHEMBL1448896 & 688799 & 5.7 & 5.7795 & TRN & \\
\hline CHEMBL1395196 & 688799 & 5.1 & 5.1544 & TST & \\
\hline CHEMBL1356395 & 688799 & 5.2 & 5.3687 & TRN & \\
\hline CHEMBL1365082 & 688799 & 5.8 & 5.92200 & 0000000001 & TRN \\
\hline CHEMBL1395429 & 688799 & 4.4 & 4.5667 & TRN & \\
\hline CHEMBL1434643 & 688799 & 5.0 & 5.5579 & TRN & \\
\hline CHEMBL1475311 & 688799 & 4.5 & 4.3753 & TRN & \\
\hline CHEMBL1314367 & 688799 & 7.8996 & 8.0073 & TRN & \\
\hline
\end{tabular}




\begin{tabular}{|c|c|c|c|c|c|}
\hline \\
\hline CHEMBL1368286 & 688799 & 5.2 & 5.4177 & TRN & \\
\hline CHEMBL1487191 & 688799 & 7.6003 & 6.9723 & TRN & \\
\hline CHEMBL1372282 & 688799 & 6.3 & 5.965 & TST & \\
\hline CHEMBL1494697 & 688799 & 5.8 & 5.7521 & TRN & \\
\hline CHEMBL1592964 & 688799 & 5.2 & 5.1126 & TRN & \\
\hline CHEMBL1316470 & 688799 & 4.9 & 5.1311 & TRN & \\
\hline CHEMBL1377908 & 688799 & 5.9 & 5.49299 & 9999999999 & TRN \\
\hline CHEMBL1405922 & 688799 & 5.3 & 5.4922 & TRN & \\
\hline CHEMBL1444270 & 688799 & 5.3 & 5.3907 & TRN & \\
\hline CHEMBL1256735 & 688799 & 5.1 & 5.1423 & TRN & \\
\hline CHEMBL1357199 & 688799 & 4.5 & 4.6674 & TRN & \\
\hline CHEMBL250428 & 688799 & 4.6 & 4.8481 & TRN & \\
\hline CHEMBL1358570 & 688799 & 5.5 & 5.6099 & TST & \\
\hline CHEMBL1597397 & 688799 & 4.4 & 4.3307 & TRN & \\
\hline CHEMBL1374784 & 688799 & 5.4 & 5.8012 & TRN & \\
\hline CHEMBL1406764 & 688799 & 6.2 & 5.6665 & TRN & \\
\hline CHEMBL1492801 & 688799 & 4.8 & 4.7424 & TRN & \\
\hline CHEMBL3192674 & 688799 & 6.4 & 6.4212 & TRN & \\
\hline CHEMBL255027 & 688799 & 5.2 & 5.3406 & TRN & \\
\hline CHEMBL1789995 & 688799 & 5.4 & 5.6139 & TRN & \\
\hline CHEMBL1446009 & 688799 & 5.4 & 5.2695 & TRN & \\
\hline CHEMBL1526455 & 688799 & 7.0 & 7.2454 & TRN & \\
\hline CHEMBL1434098 & 688799 & 4.7 & 4.9624 & TRN & \\
\hline CHEMBL1591971 & 688799 & 5.7 & 5.8294 & TRN & \\
\hline CHEMBL1558777 & 688799 & 5.1 & 5.336 & TRN & \\
\hline CHEMBL1356372 & 688799 & 4.8 & 4.7785 & TRN & \\
\hline CHEMBL1488845 & 688799 & 5.1 & 4.9417 & TRN & \\
\hline CHEMBL1596241 & 688799 & 4.5 & 4.6195 & TRN & \\
\hline CHEMBL123 & 688799 & 6.0 & 6.4181 & TST & \\
\hline CHEMBL1448562 & 688799 & 5.3 & 5.4571 & TRN & \\
\hline CHEMBL1318421 & 688799 & 5.8 & 5.5499 & TRN & \\
\hline CHEMBL1434006 & 688799 & 4.9 & 4.8229 & TRN & \\
\hline CHEMBL1316337 & 688799 & 5.8 & 5.4606 & TRN & \\
\hline CHEMBL1408735 & 688799 & 5.5 & 5.2345 & TRN & \\
\hline CHEMBL1317373 & 688799 & 5.3 & 5.2841 & TRN & \\
\hline CHEMBL1337128 & 688799 & 6.0 & 6.3612 & TRN & \\
\hline CHEMBL1554593 & 688799 & 6.4 & 6.3183 & TRN & \\
\hline CHEMBL1404317 & 688799 & 5.0 & 4.915 & TRN & \\
\hline CHEMBL1521391 & 688799 & 4.4 & 4.3631 & TRN & \\
\hline CHEMBL 1448712 & 688799 & 5.6 & 5.4993 & TRN & \\
\hline CHEMBL289233 & 688799 & 5.1 & 5.2102 & TRN & \\
\hline CHEMBL1434801 & 688799 & 5.5 & 4.9702 & TRN & \\
\hline CHEMBL1357909 & 688799 & 4.4 & 4.2326 & TRN & \\
\hline CHEMBL1373147 & 688799 & 4.4 & 4.6167 & TRN & \\
\hline CHEMBL1323549 & 688799 & 7.4001 & 7.0174 & TRN & \\
\hline CHEMBL1480350 & 688799 & 4.9 & 4.9058 & TRN & \\
\hline CHEMBL1399058 & 688799 & 5.3 & 5.5183 & TRN & \\
\hline CHEMBL1356115 & 688799 & 4.7 & 5.3201 & TST & \\
\hline
\end{tabular}




\begin{tabular}{|c|c|c|c|c|}
\hline & & & & al Table \\
\hline CHEMBL1515352 & 688799 & 6.3 & 5.5863 & TRN \\
\hline CHEMBL1316759 & 688799 & 5.3 & 4.7206 & TRN \\
\hline CHEMBL1436045 & 688799 & 6.6 & 6.624 & TRN \\
\hline CHEMBL1484422 & 688799 & 5.9 & 5.9589 & TRN \\
\hline CHEMBL1607228 & 688799 & 6.0 & 5.9769 & TRN \\
\hline CHEMBL 2373281 & 688799 & 5.8 & 5.2664 & TST \\
\hline CHEMBL1555190 & 688799 & 4.4 & 4.9481 & TRN \\
\hline CHEMBL168279 & 688799 & 4.5 & 5.3259 & TST \\
\hline CHEMBL1334477 & 688799 & 5.4 & 5.2553 & TRN \\
\hline CHEMBL47 & 688799 & 4.8 & 5.2675 & TST \\
\hline CHEMBL1395337 & 688799 & 5.6 & 5.4333 & TRN \\
\hline CHEMBL1338163 & 688799 & 5.6 & 5.7001 & TRN \\
\hline CHEMBL1325335 & 688799 & 4.4 & 4.4844 & TRN \\
\hline CHEMBL1366732 & 688799 & 6.2 & 6.2101 & TRN \\
\hline CHEMBL1329583 & 688799 & 5.2 & 5.5955 & TRN \\
\hline CHEMBL1534376 & 688799 & 5.4 & 5.4227 & TRN \\
\hline CHEMBL1736254 & 688799 & 6.3 & 6.1502 & TST \\
\hline CHEMBL1407445 & 688799 & 4.6 & 4.5021 & TRN \\
\hline CHEMBL1356391 & 688799 & 5.5 & 5.601 & TRN \\
\hline CHEMBL1402799 & 688799 & 4.6 & 4.7583 & TRN \\
\hline CHEMBL 32142 & 688799 & 6.0 & 5.0984 & TST \\
\hline CHEMBL475375 & 688799 & 5.4 & 5.2143 & TRN \\
\hline CHEMBL69234 & 688799 & 7.8996 & 7.29799 & 9999999999 \\
\hline CHEMBL1512171 & 688799 & 4.4 & 5.073 & TRN \\
\hline CHEMBL1369871 & 688799 & 4.4 & 4.4816 & TRN \\
\hline CHEMBL1450026 & 688799 & 4.4 & 4.4389 & TRN \\
\hline CHEMBL1327697 & 688799 & 4.4 & 4.9925 & TRN \\
\hline CHEMBL1394437 & 688799 & 5.5 & 5.3208 & TST \\
\hline CHEMBL1592500 & 688799 & 6.0 & 5.8019 & TRN \\
\hline CHEMBL1515774 & 688799 & 5.8 & 5.772 & TRN \\
\hline CHEMBL1553185 & 688799 & 5.7 & 5.6929 & TRN \\
\hline CHEMBL1552985 & 688799 & 6.5 & 6.2747 & TRN \\
\hline CHEMBL1406971 & 688799 & 5.5 & 5.2409 & TST \\
\hline CHEMBL1318066 & 688799 & 5.5 & 5.6197 & TRN \\
\hline CHEMBL1566105 & 688799 & 6.0 & 5.8288 & TST \\
\hline CHEMBL1324334 & 688799 & 5.4 & 5.737 & TRN \\
\hline CHEMBL1355909 & 688799 & 4.6 & 4.5877 & TRN \\
\hline CHEMBL275006 & 688799 & 5.1 & 5.3449 & TRN \\
\hline CHEMBL1495773 & 688799 & 4.6 & 4.6604 & TRN \\
\hline CHEMBL 21396 & 688799 & 5.0 & 5.2966 & TST \\
\hline CHEMBL1448726 & 688799 & 4.4 & 4.4081 & TRN \\
\hline CHEMBL1515194 & 688799 & 4.9 & 4.8608 & TRN \\
\hline CHEMBL1474302 & 688799 & 5.2 & 5.2329 & TRN \\
\hline CHEMBL1335967 & 688799 & 4.5 & 4.3261 & TRN \\
\hline CHEMBL1475541 & 688799 & 4.7 & 4.6475 & TRN \\
\hline CHEMBL1475010 & 688799 & 4.4 & 4.7275 & TRN \\
\hline CHEMBL 2448607 & 688799 & 4.4 & 5.3171 & TRN \\
\hline CHEMBL1562791 & 688799 & 5.0 & 5.0764 & TRN \\
\hline
\end{tabular}




\begin{tabular}{|c|c|c|c|c|c|}
\hline \\
\hline CHEMBL1369515 & 688799 & 4.9 & 4.6831 & TRN & \\
\hline CHEMBL429095 & 688799 & 6.0 & 7.2159 & TRN & \\
\hline CHEMBL1399922 & 688799 & 4.7 & 4.9606 & TST & \\
\hline CHEMBL1574160 & 688799 & 4.9 & 4.8276 & TRN & \\
\hline CHEMBL1375469 & 688799 & 6.0 & 6.1004 & TRN & \\
\hline CHEMBL1317795 & 688799 & 5.0 & 5.0588 & TRN & \\
\hline CHEMBL1356262 & 688799 & 4.5 & 4.6383 & TRN & \\
\hline CHEMBL280563 & 688799 & 4.4 & 4.9682 & TST & \\
\hline CHEMBL53898 & 688799 & 6.0 & 5.6285 & TRN & \\
\hline CHEMBL1365537 & 688799 & 6.4 & 6.7765 & TRN & \\
\hline CHEMBL1374355 & 688799 & 4.4 & 4.6247 & TRN & \\
\hline CHEMBL1452722 & 688799 & 5.8 & 5.7224 & TST & \\
\hline CHEMBL1371303 & 688799 & 5.7 & 5.5113 & TST & \\
\hline CHEMBL1330594 & 688799 & 5.2 & 5.6115 & TRN & \\
\hline CHEMBL1374763 & 688799 & 5.4 & 6.3998 & TRN & \\
\hline CHEMBL10347 & 688799 & 6.0 & 6.1063 & TST & \\
\hline CHEMBL1516701 & 688799 & 4.6 & 4.5331 & TRN & \\
\hline CHEMBL1561927 & 688799 & 5.4 & 6.0432 & TST & \\
\hline CHEMBL1527958 & 688799 & 5.8 & 6.001 & TRN & \\
\hline CHEMBL1480880 & 688799 & 5.8 & 5.8595 & TRN & \\
\hline CHEMBL1555348 & 688799 & 4.8 & 4.9547 & TRN & \\
\hline CHEMBL11471 & 688799 & 4.6 & 4.9219 & TRN & \\
\hline CHEMBL1443628 & 688799 & 6.4 & 6.3323 & TRN & \\
\hline CHEMBL283196 & 688799 & 5.7 & 5.7021 & TRN & \\
\hline CHEMBL1574956 & 688799 & 4.4 & 4.5499 & TRN & \\
\hline CHEMBL1333445 & 688799 & 5.6 & 5.5189 & TRN & \\
\hline CHEMBL23731 & 688799 & 5.3 & 5.4701 & TRN & \\
\hline CHEMBL47940 & 688799 & 4.6 & 4.7873 & TST & \\
\hline CHEMBL1556004 & 688799 & 5.5 & 5.4097 & TRN & \\
\hline CHEMBL1329218 & 688799 & 5.0 & 5.1628 & TST & \\
\hline CHEMBL1433730 & 688799 & 4.9 & 5.0847 & TRN & \\
\hline CHEMBL1479792 & 688799 & 5.4 & 5.4549 & TRN & \\
\hline CHEMBL1491258 & 688799 & 5.1 & 5.32700 & 0000000001 & TRN \\
\hline CHEMBL1595282 & 688799 & 5.5 & 5.351 & TRN & \\
\hline CHEMBL1256359 & 688799 & 5.4 & 5.5572 & TRN & \\
\hline CHEMBL242172 & 688799 & 4.6 & 5.3221 & TRN & \\
\hline CHEMBL1356690 & 688799 & 4.6 & 4.5985 & TRN & \\
\hline CHEMBL3145217 & 688799 & 5.3 & 5.2952 & TRN & \\
\hline CHEMBL1410399 & 688799 & 5.5 & 5.5089 & TRN & \\
\hline CHEMBL1317932 & 688799 & 6.9 & 6.7532 & TRN & \\
\hline CHEMBL1557696 & 688799 & 5.4 & 5.476 & TRN & \\
\hline CHEMBL1590397 & 688799 & 6.0 & 6.2048 & TRN & \\
\hline CHEMBL1395241 & 688799 & 5.1 & 4.9328 & TRN & \\
\hline CHEMBL 244707 & 688799 & 5.9 & 5.4815 & TRN & \\
\hline CHEMBL1315700 & 688799 & 6.0 & 5.824 & TRN & \\
\hline CHEMBL1592438 & 688799 & 5.1 & 5.2454 & TRN & \\
\hline CHEMBL 238624 & 688799 & 5.6 & 5.6727 & TST & \\
\hline CHEMBL1454544 & 688799 & 5.1 & 5.2676 & TRN & \\
\hline
\end{tabular}




\begin{tabular}{|c|c|c|c|c|c|}
\hline & & & & & \\
\hline CHEMBL1451303 & 688799 & 5.4 & 5.3011 & TST & \\
\hline CHEMBL1606380 & 688799 & 5.4 & 6.1115 & TRN & \\
\hline CHEMBL1563795 & 688799 & 5.2 & 5.5718 & TRN & \\
\hline CHEMBL1316353 & 688799 & 6.5 & 6.2977 & TRN & \\
\hline CHEMBL1521453 & 688799 & 6.0 & 6.1815 & TST & \\
\hline CHEMBL3661417 & 688799 & 5.2 & 5.3661 & TRN & \\
\hline CHEMBL1373723 & 688799 & 4.8 & 4.8821 & TRN & \\
\hline CHEMBL1592663 & 688799 & 5.4 & 5.4881 & TST & \\
\hline CHEMBL398673 & 688799 & 5.5 & 5.5138 & TST & \\
\hline CHEMBL1485853 & 688799 & 6.5 & 5.4456 & TST & \\
\hline CHEMBL242383 & 688799 & 4.8 & 5.1742 & TRN & \\
\hline CHEMBL 2373651 & 688799 & 6.8 & 6.6267 & TST & \\
\hline CHEMBL1455018 & 688799 & 4.6 & 4.6175 & TRN & \\
\hline CHEMBL1474875 & 688799 & 5.1 & 5.2511 & TRN & \\
\hline CHEMBL192566 & 688799 & 4.9 & 5.1353 & TST & \\
\hline CHEMBL1360434 & 688799 & 5.1 & 5.4258 & TRN & \\
\hline CHEMBL1329786 & 688799 & 5.1 & 5.3428 & TRN & \\
\hline CHEMBL1355263 & 688799 & 4.4 & 4.614 & TRN & \\
\hline CHEMBL1322979 & 688799 & 5.4 & 5.5803 & TRN & \\
\hline CHEMBL265177 & 688799 & 5.5 & 5.5893 & TST & \\
\hline CHEMBL1591140 & 688799 & 4.9 & 5.1997 & TRN & \\
\hline CHEMBL87385 & 688799 & 5.6 & 5.6164 & TRN & \\
\hline CHEMBL1371217 & 688799 & 8.699 & 5.4193 & TRN & \\
\hline CHEMBL1592651 & 688799 & 4.9 & 4.9902 & TRN & \\
\hline CHEMBL1568735 & 688799 & 5.3 & 5.3736 & TRN & \\
\hline CHEMBL1609324 & 688799 & 4.8 & 4.815 & TRN & \\
\hline CHEMBL1552864 & 688799 & 4.4 & 4.4982 & TRN & \\
\hline CHEMBL 1357180 & 688799 & 4.6 & 4.5882 & TRN & \\
\hline CHEMBL1454284 & 688799 & 4.9 & 5.0616 & TST & \\
\hline CHEMBL1288014 & 688799 & 5.9 & 6.2772 & TRN & \\
\hline CHEMBL1364366 & 688799 & 4.8 & 4.67899 & 9999999999 & TRN \\
\hline CHEMBL1553941 & 688799 & 5.9 & 5.6722 & TRN & \\
\hline CHEMBL1598680 & 688799 & 6.0 & 6.0415 & TRN & \\
\hline CHEMBL1452561 & 688799 & 4.5 & 5.0736 & TRN & \\
\hline CHEMBL1486659 & 688799 & 5.6 & 5.4729 & TRN & \\
\hline CHEMBL1474906 & 688799 & 5.5 & 5.1086 & TRN & \\
\hline CHEMBL1536058 & 688799 & 5.6 & 5.4459 & TST & \\
\hline CHEMBL15927 & 688799 & 4.5 & 4.5437 & TRN & \\
\hline CHEMBL567332 & 688799 & 5.3 & 5.3152 & TRN & \\
\hline CHEMBL1554844 & 688799 & 5.5 & 5.1341 & TST & \\
\hline CHEMBL1411314 & 688799 & 5.4 & 5.5114 & TRN & \\
\hline CHEMBL1435738 & 688799 & 5.6 & 5.5279 & TRN & \\
\hline CHEMBL1401859 & 688799 & 5.5 & 5.519 & TRN & \\
\hline CHEMBL1437007 & 688799 & 4.5 & 4.4167 & TRN & \\
\hline CHEMBL1612506 & 688799 & 5.4 & 5.2234 & TRN & \\
\hline CHEMBL1507262 & 688799 & 5.2 & 5.5225 & TST & \\
\hline CHEMBL1597410 & 688799 & 4.9 & 4.9375 & TRN & \\
\hline CHEMBL1338229 & 688799 & 5.0 & 5.24799 & 9999999999 & TST \\
\hline & & & & e 5524 & \\
\hline
\end{tabular}




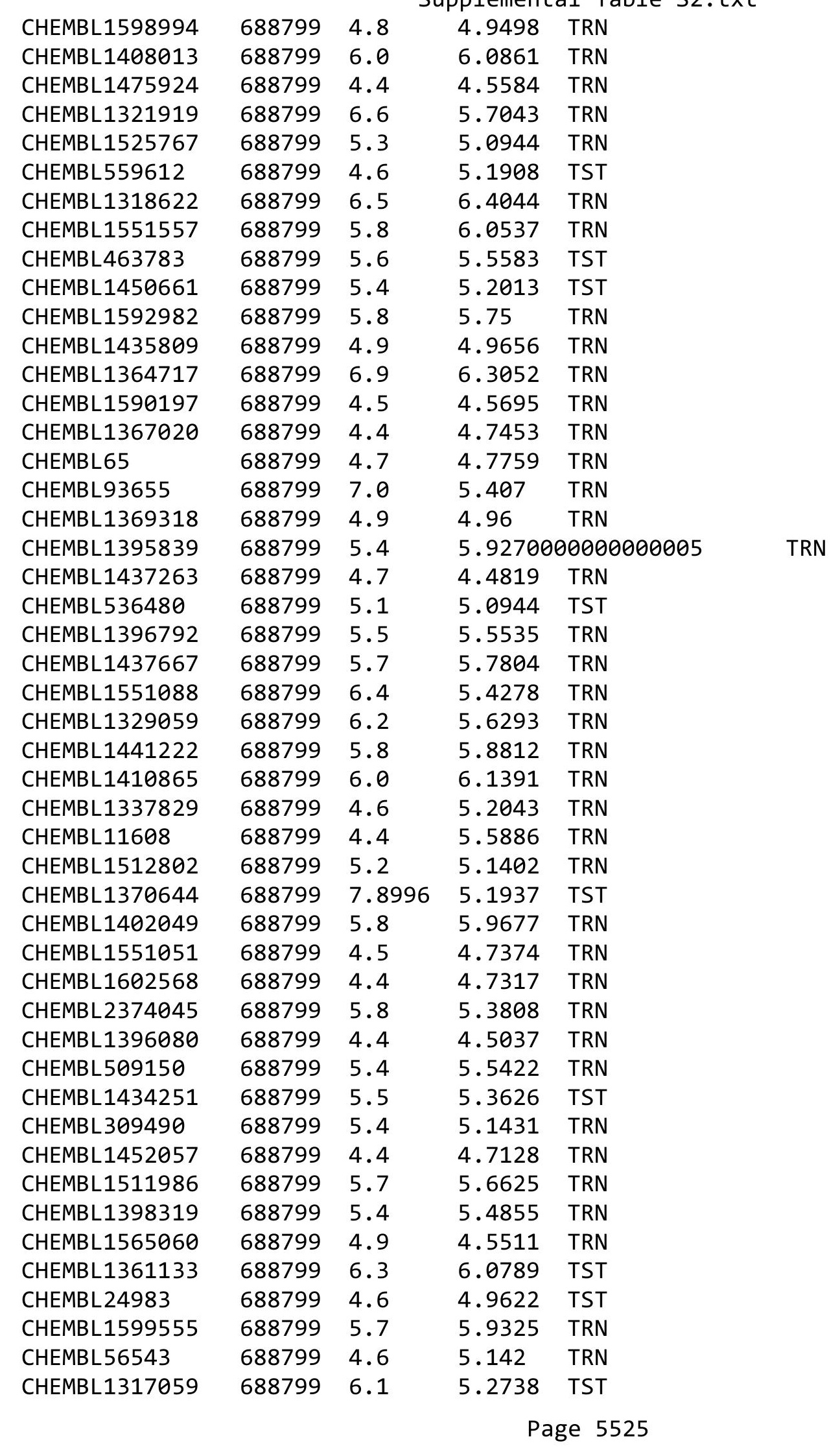




\begin{tabular}{|c|c|c|c|c|c|}
\hline \multicolumn{6}{|c|}{ Supplemental Table S2.txt } \\
\hline CHEMBL76143 & 688799 & 5.5 & 5.2828 & TRN & \\
\hline CHEMBL1552478 & 688799 & 4.5 & 4.355 & TRN & \\
\hline CHEMBL1531108 & 688799 & 4.8 & 4.9224 & TRN & \\
\hline CHEMBL1403488 & 688799 & 5.3 & 5.0977 & TRN & \\
\hline CHEMBL1317076 & 688799 & 4.8 & 4.9597 & TRN & \\
\hline CHEMBL349384 & 688799 & 4.4 & 4.8758 & TST & \\
\hline CHEMBL1417552 & 688799 & 5.2 & 5.2819 & TRN & \\
\hline CHEMBL1358487 & 688799 & 6.3 & 5.9977 & TRN & \\
\hline CHEMBL1436536 & 688799 & 6.0 & 5.7975 & TRN & \\
\hline CHEMBL1458713 & 688799 & 4.4 & 5.3085 & TST & \\
\hline CHEMBL1445399 & 688799 & 5.0 & 5.2326 & TST & \\
\hline CHEMBL1494832 & 688799 & 4.4 & 4.4051 & TRN & \\
\hline CHEMBL1331122 & 688799 & 5.9 & 5.8906 & TST & \\
\hline CHEMBL1529205 & 688799 & 5.7 & 5.2308 & TST & \\
\hline CHEMBL259388 & 688799 & 4.8 & 4.84399 & 7999999999 & TST \\
\hline CHEMBL1554612 & 688799 & 7.0 & 6.9451 & TRN & \\
\hline CHEMBL1446743 & 688799 & 5.3 & 5.3896 & TRN & \\
\hline CHEMBL1551065 & 688799 & 5.5 & 5.1938 & TRN & \\
\hline CHEMBL1603627 & 688799 & 5.0 & 4.9988 & TRN & \\
\hline CHEMBL1436323 & 688799 & 5.9 & 5.6155 & TRN & \\
\hline CHEMBL1529478 & 688799 & 5.1 & 5.171 & TRN & \\
\hline CHEMBL1552517 & 688799 & 5.0 & 5.0526 & TRN & \\
\hline CHEMBL1434550 & 688799 & 4.9 & 5.0844 & TRN & \\
\hline CHEMBL 23194 & 688799 & 5.1 & 5.3682 & TST & \\
\hline CHEMBL433461 & 688799 & 4.4 & 5.5801 & TRN & \\
\hline CHEMBL136906 & 688799 & 5.9 & 5.9149 & TRN & \\
\hline CHEMBL1479727 & 688799 & 5.5 & 5.6104 & TRN & \\
\hline CHEMBL1331280 & 688799 & 4.9 & 5.1572 & TRN & \\
\hline CHEMBL1476712 & 688799 & 4.8 & 4.9267 & TRN & \\
\hline CHEMBL1378758 & 688799 & 6.2 & 6.1119 & TRN & \\
\hline CHEMBL1354596 & 688799 & 5.0 & 5.1205 & TRN & \\
\hline CHEMBL1321422 & 688799 & 5.5 & 5.7123 & TRN & \\
\hline CHEMBL1516170 & 688799 & 5.3 & 5.4931 & TRN & \\
\hline CHEMBL1591459 & 688799 & 6.4 & 6.4396 & TRN & \\
\hline CHEMBL1591956 & 688799 & 4.9 & 5.0526 & TRN & \\
\hline CHEMBL90882 & 688799 & 5.4 & 5.5177 & TRN & \\
\hline CHEMBL1404660 & 688799 & 4.9 & 5.1092 & TRN & \\
\hline CHEMBL1554851 & 688799 & 5.3 & 5.3676 & TRN & \\
\hline CHEMBL1315457 & 688799 & 4.5 & 4.8343 & TST & \\
\hline CHEMBL1256243 & 688799 & 4.5 & 4.7247 & TST & \\
\hline CHEMBL1606796 & 688799 & 4.4 & 4.4372 & TRN & \\
\hline CHEMBL1591209 & 688799 & 7.4001 & 8.13 & TRN & \\
\hline CHEMBL3213163 & 688799 & 5.9 & 5.8747 & TRN & \\
\hline CHEMBL1436506 & 688799 & 5.3 & 5.5773 & TRN & \\
\hline CHEMBL1476348 & 688799 & 4.4 & 4.2188 & TRN & \\
\hline CHEMBL1571785 & 688799 & 8.0 & 6.0702 & TRN & \\
\hline CHEMBL1481847 & 688799 & 4.4 & 4.5394 & TRN & \\
\hline CHEMBL1532016 & 688799 & 5.4 & 5.3431 & TRN & \\
\hline
\end{tabular}




\begin{tabular}{|c|c|c|c|c|}
\hline \multicolumn{5}{|c|}{ Supplemental Table S2.txt } \\
\hline CHEMBL475376 & 688799 & 5.5 & 5.3565 & TRN \\
\hline CHEMBL1335617 & 688799 & 4.9 & 5.0558 & TRN \\
\hline CHEMBL1525822 & 688799 & 6.0 & 6.0526 & TRN \\
\hline CHEMBL608555 & 688799 & 5.6 & 5.5222 & TRN \\
\hline CHEMBL 1314286 & 688799 & 6.0 & 6.0012 & TST \\
\hline CHEMBL1356132 & 688799 & 4.6 & 4.7297 & TRN \\
\hline CHEMBL286615 & 688799 & 4.6 & 4.8002 & TRN \\
\hline CHEMBL1604983 & 688799 & 5.5 & 5.6967 & TST \\
\hline CHEMBL1558418 & 688799 & 5.5 & 5.9032 & TRN \\
\hline CHEMBL1417646 & 688799 & 4.4 & 4.478 & TRN \\
\hline CHEMBL1414269 & 688799 & 4.6 & 4.6743 & TRN \\
\hline CHEMBL1489551 & 688799 & 5.8 & 5.9345 & TRN \\
\hline CHEMBL1405546 & 688799 & 4.4 & 4.6449 & TRN \\
\hline CHEMBL1358628 & 688799 & 6.1 & 5.8231 & TST \\
\hline CHEMBL1514149 & 688799 & 5.3 & 5.4628 & TRN \\
\hline CHEMBL1443323 & 688799 & 5.4 & 5.3448 & TRN \\
\hline CHEMBL1412825 & 688799 & 5.3 & 5.4642 & TRN \\
\hline CHEMBL1318307 & 688799 & 5.1 & 4.9675 & TST \\
\hline CHEMBL1590968 & 688799 & 5.0 & 5.2528 & TRN \\
\hline CHEMBL1444608 & 688799 & 6.0 & 5.4205 & TST \\
\hline CHEMBL1486638 & 688799 & 5.1 & 5.2638 & TRN \\
\hline CHEMBL1401243 & 688799 & 4.4 & 4.4002 & TRN \\
\hline CHEMBL1442355 & 688799 & 4.4 & 5.1681 & TST \\
\hline CHEMBL1362931 & 688799 & 4.8 & 4.8548 & TRN \\
\hline CHEMBL1364980 & 688799 & 4.7 & 5.0417 & TRN \\
\hline CHEMBL 2373630 & 688799 & 5.8 & 5.7017 & TST \\
\hline CHEMBL1492346 & 688799 & 5.0 & 5.0455 & TRN \\
\hline CHEMBL1317009 & 688799 & 4.7 & 4.753 & TRN \\
\hline CHEMBL1476871 & 688799 & 4.4 & 4.7134 & TST \\
\hline CHEMBL1493037 & 688799 & 6.0 & 5.84 & TST \\
\hline CHEMBL1530832 & 688799 & 5.5 & 5.5478 & TRN \\
\hline CHEMBL1367030 & 688799 & 6.0 & 6.0637 & TRN \\
\hline CHEMBL1256687 & 688799 & 8.3979 & 7.7393 & TRN \\
\hline CHEMBL1437138 & 688799 & 6.0 & 5.9118 & TRN \\
\hline CHEMBL313833 & 688799 & 6.0 & 6.0049 & TRN \\
\hline CHEMBL1398321 & 688799 & 5.2 & 5.3383 & TST \\
\hline CHEMBL 1315820 & 688799 & 7.6003 & 7.2668 & TRN \\
\hline CHEMBL1355712 & 688799 & 5.5 & 5.5806 & TRN \\
\hline CHEMBL1569972 & 688799 & 4.7 & 4.7322 & TRN \\
\hline CHEMBL1436997 & 688799 & 6.1 & 5.5621 & TRN \\
\hline CHEMBL1532426 & 688799 & 4.4 & 4.3676 & TRN \\
\hline CHEMBL1397548 & 688799 & 5.0 & 5.8059 & TRN \\
\hline CHEMBL1435647 & 688799 & 4.4 & 4.4477 & TRN \\
\hline CHEMBL1415777 & 688799 & 4.7 & 4.9576 & TST \\
\hline CHEMBL1439455 & 688799 & 5.8 & 5.4652 & TST \\
\hline CHEMBL1370526 & 688799 & 5.7 & 5.8163 & TRN \\
\hline CHEMBL1318114 & 688799 & 6.3 & 6.3166 & TRN \\
\hline CHEMBL1325735 & 688799 & 5.4 & 5.4783 & TRN \\
\hline
\end{tabular}




\begin{tabular}{|c|c|c|c|c|c|}
\hline & & & & & \\
\hline CHEMBL1359181 & 688799 & 5.0 & 5.2104 & TRN & \\
\hline CHEMBL1599378 & 688799 & 5.0 & 5.0973 & TRN & \\
\hline CHEMBL1527443 & 688799 & 5.1 & 4.8193 & TRN & \\
\hline CHEMBL1161936 & 688799 & 5.6 & 5.5254 & TST & \\
\hline CHEMBL1573862 & 688799 & 4.7 & 4.7227 & TRN & \\
\hline CHEMBL1568369 & 688799 & 5.5 & 5.5498 & TST & \\
\hline CHEMBL1397825 & 688799 & 5.3 & 5.2752 & TRN & \\
\hline CHEMBL1473331 & 688799 & 4.4 & 4.1765 & TRN & \\
\hline CHEMBL1396773 & 688799 & 4.6 & 4.6588 & TRN & \\
\hline CHEMBL34241 & 688799 & 5.7 & 5.5824 & TRN & \\
\hline CHEMBL1318340 & 688799 & 4.9 & 5.0099 & TRN & \\
\hline CHEMBL1611856 & 688799 & 6.4 & 6.231 & TRN & \\
\hline CHEMBL1331410 & 688799 & 4.4 & 4.417 & TRN & \\
\hline CHEMBL1593466 & 688799 & 6.1 & 6.1296 & TRN & \\
\hline CHEMBL3213894 & 688799 & 6.0 & 6.7101 & TRN & \\
\hline CHEMBL1316749 & 688799 & 5.9 & 6.0002 & TRN & \\
\hline CHEMBL1435450 & 688799 & 5.5 & 5.4345 & TRN & \\
\hline CHEMBL1365367 & 688799 & 5.6 & 5.6266 & TRN & \\
\hline CHEMBL1256916 & 688799 & 5.0 & 5.2913 & TRN & \\
\hline CHEMBL1454280 & 688799 & 5.3 & 5.5294 & TRN & \\
\hline CHEMBL1361902 & 688799 & 8.0 & 5.7744 & TRN & \\
\hline CHEMBL1366433 & 688799 & 4.9 & 4.86100 & 2000000001 & TRN \\
\hline CHEMBL1472955 & 688799 & 5.3 & 5.1988 & TRN & \\
\hline CHEMBL1495854 & 688799 & 4.5 & 4.7055 & TRN & \\
\hline CHEMBL1318411 & 688799 & 4.4 & 4.6399 & TRN & \\
\hline CHEMBL1597812 & 688799 & 4.9 & 5.1845 & TST & \\
\hline CHEMBL409024 & 688799 & 5.1 & 5.3472 & TRN & \\
\hline CHEMBL1357293 & 688799 & 5.0 & 5.0196 & TRN & \\
\hline CHEMBL1408343 & 688799 & 5.4 & 5.7293 & TRN & \\
\hline CHEMBL1590270 & 688799 & 4.8 & 4.8922 & TRN & \\
\hline CHEMBL606675 & 688799 & 5.5 & 5.5908 & TST & \\
\hline CHEMBL491748 & 688799 & 5.3 & 5.239 & TRN & \\
\hline CHEMBL554041 & 688799 & 5.4 & 5.4212 & TRN & \\
\hline CHEMBL1375474 & 688799 & 4.5 & 4.6123 & TRN & \\
\hline CHEMBL1611220 & 688799 & 6.0 & 6.2056 & TST & \\
\hline CHEMBL1514639 & 688799 & 4.8 & 5.1157 & TRN & \\
\hline CHEMBL365739 & 688799 & 6.0 & 5.949 & TST & \\
\hline CHEMBL1322757 & 688799 & 5.7 & 5.9642 & TRN & \\
\hline CHEMBL1397517 & 688799 & 4.6 & 4.7658 & TRN & \\
\hline CHEMBL51085 & 688799 & 6.0 & 5.6379 & TST & \\
\hline CHEMBL76904 & 688799 & 4.8 & 5.0406 & TRN & \\
\hline CHEMBL1354262 & 688799 & 4.4 & 4.2536 & TRN & \\
\hline CHEMBL1321655 & 688799 & 7.699 & 7.4786 & TRN & \\
\hline CHEMBL87285 & 688799 & 6.0 & 5.9665 & TST & \\
\hline CHEMBL1443713 & 688799 & 5.1 & 5.3635 & TRN & \\
\hline CHEMBL1479625 & 688799 & 5.1 & 5.2463 & TST & \\
\hline CHEMBL1491340 & 688799 & 4.8 & 5.8835 & TST & \\
\hline CHEMBL1473753 & 688799 & 5.5 & 6.00299 & 9999999999 & TRN \\
\hline & & & & 5528 & \\
\hline
\end{tabular}




\begin{tabular}{|c|c|c|c|c|}
\hline \multicolumn{5}{|c|}{ Supplemental Table S2.txt } \\
\hline CHEMBL 279731 & 688799 & 5.1 & 5.1366 & TST \\
\hline CHEMBL1314906 & 688799 & 5.1 & 4.9522 & TRN \\
\hline CHEMBL490577 & 688799 & 5.3 & 5.7058 & TRN \\
\hline CHEMBL1482119 & 688799 & 5.1 & 5.3001 & TRN \\
\hline CHEMBL1599266 & 688799 & 6.3 & 6.1387 & TST \\
\hline CHEMBL1592160 & 688799 & 5.4 & 5.6109 & TRN \\
\hline CHEMBL1162107 & 688799 & 5.6 & 5.5769 & TST \\
\hline CHEMBL1554408 & 688799 & 6.7001 & 5.5038 & TRN \\
\hline CHEMBL1394419 & 688799 & 5.1 & 5.1377 & TST \\
\hline CHEMBL1314388 & 688799 & 5.5 & 5.4889 & TRN \\
\hline CHEMBL1487111 & 688799 & 4.5 & 4.1776 & TRN \\
\hline CHEMBL523464 & 688799 & 4.5 & 4.7391 & TRN \\
\hline CHEMBL1551066 & 688799 & 4.8 & 4.7867 & TRN \\
\hline CHEMBL1374903 & 688799 & 6.2 & 5.6853 & TRN \\
\hline CHEMBL1613725 & 688799 & 4.8 & 4.7983 & TRN \\
\hline CHEMBL507 & 688799 & 4.4 & 5.1907 & TST \\
\hline CHEMBL1451315 & 688799 & 6.0 & 6.0351 & TRN \\
\hline CHEMBL1476632 & 688799 & 7.4001 & 7.1301 & TRN \\
\hline CHEMBL1434111 & 688799 & 4.7 & 4.6571 & TRN \\
\hline CHEMBL1516068 & 688799 & 5.2 & 5.4027 & TRN \\
\hline CHEMBL1358029 & 688799 & 5.9 & 5.2853 & TRN \\
\hline CHEMBL1173475 & 688799 & 4.8 & 5.4019 & TRN \\
\hline CHEMBL1369940 & 688799 & 5.9 & 6.1511 & TRN \\
\hline CHEMBL1789998 & 688799 & 5.0 & 5.0931 & TST \\
\hline CHEMBL1516005 & 688799 & 6.0 & 5.8818 & TRN \\
\hline CHEMBL322970 & 688799 & 4.4 & 5.5938 & TST \\
\hline CHEMBL1371604 & 688799 & 5.4 & 5.5765 & TRN \\
\hline CHEMBL545523 & 688799 & 4.4 & 4.6165 & TRN \\
\hline CHEMBL1354355 & 688799 & 4.5 & 4.5658 & TRN \\
\hline CHEMBL585861 & 688799 & 7.699 & 7.504 & TRN \\
\hline CHEMBL1411094 & 688799 & 4.5 & 4.6329 & TRN \\
\hline CHEMBL1314434 & 688799 & 4.8 & 4.9301 & TRN \\
\hline CHEMBL1354751 & 688799 & 5.7 & 5.6687 & TRN \\
\hline CHEMBL1553741 & 688799 & 4.5 & 4.5985 & TRN \\
\hline CHEMBL1574543 & 688799 & 6.8 & 5.4851 & TRN \\
\hline CHEMBL1569485 & 688799 & 4.9 & 4.8994 & TRN \\
\hline CHEMBL1551633 & 688799 & 4.4 & 4.3788 & TRN \\
\hline CHEMBL1592371 & 688799 & 5.0 & 5.1391 & TRN \\
\hline CHEMBL1522752 & 688799 & 5.7 & 5.7936 & TRN \\
\hline CHEMBL1322026 & 688799 & 6.5 & 6.4334 & TST \\
\hline CHEMBL1396508 & 688799 & 5.9 & 5.5471 & TRN \\
\hline CHEMBL1516265 & 688799 & 4.9 & 4.9877 & TRN \\
\hline CHEMBL1325766 & 688799 & 5.7 & 5.9061 & TRN \\
\hline CHEMBL1434882 & 688799 & 5.0 & 5.0359 & TRN \\
\hline CHEMBL1574297 & 688799 & 5.4 & 5.2448 & TST \\
\hline CHEMBL1518415 & 688799 & 5.0 & 5.0548 & TRN \\
\hline CHEMBL14276 & 688799 & 6.0 & 5.1124 & TST \\
\hline CHEMBL1399489 & 688799 & 5.3 & 5.2771 & TRN \\
\hline
\end{tabular}




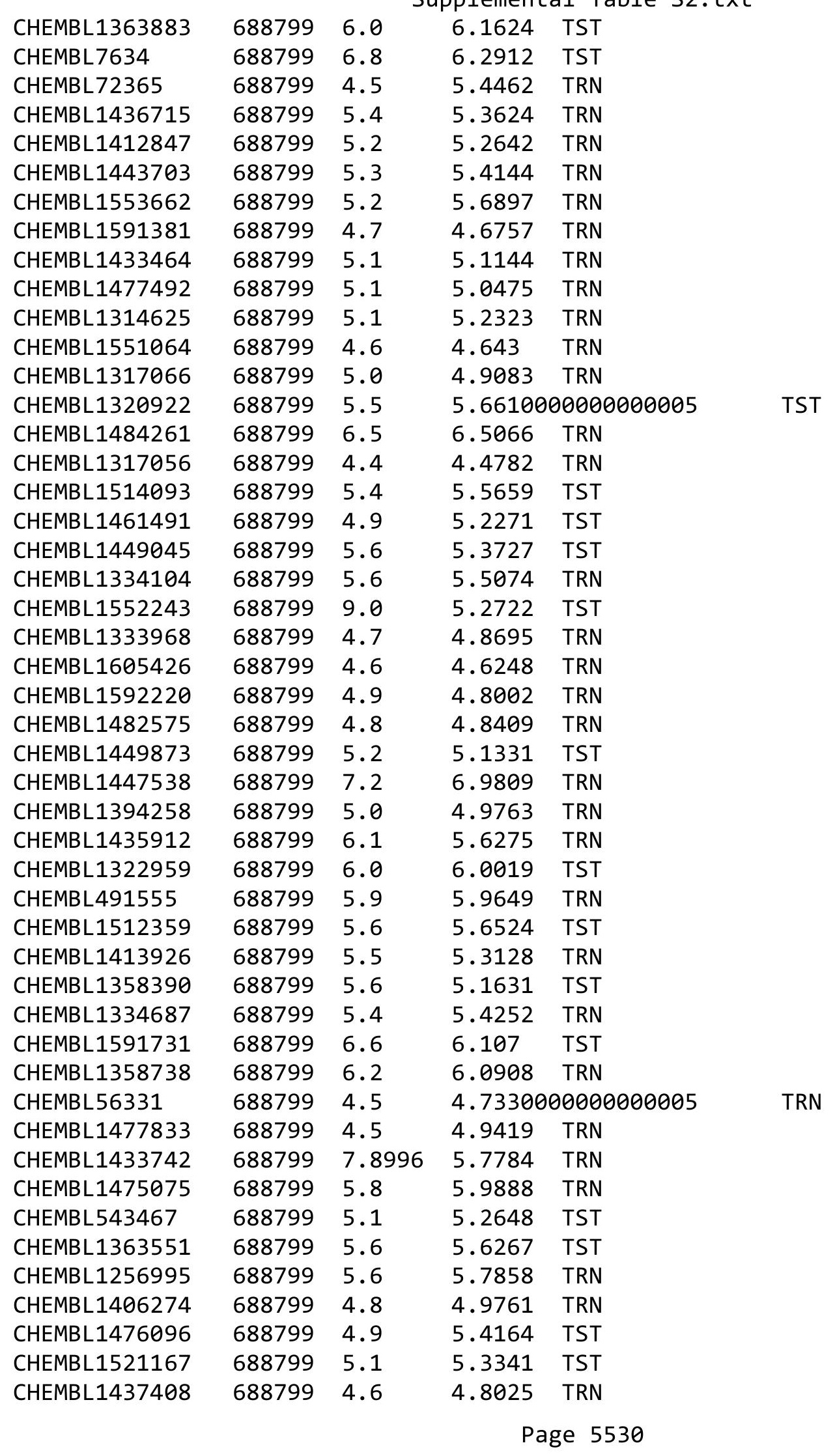




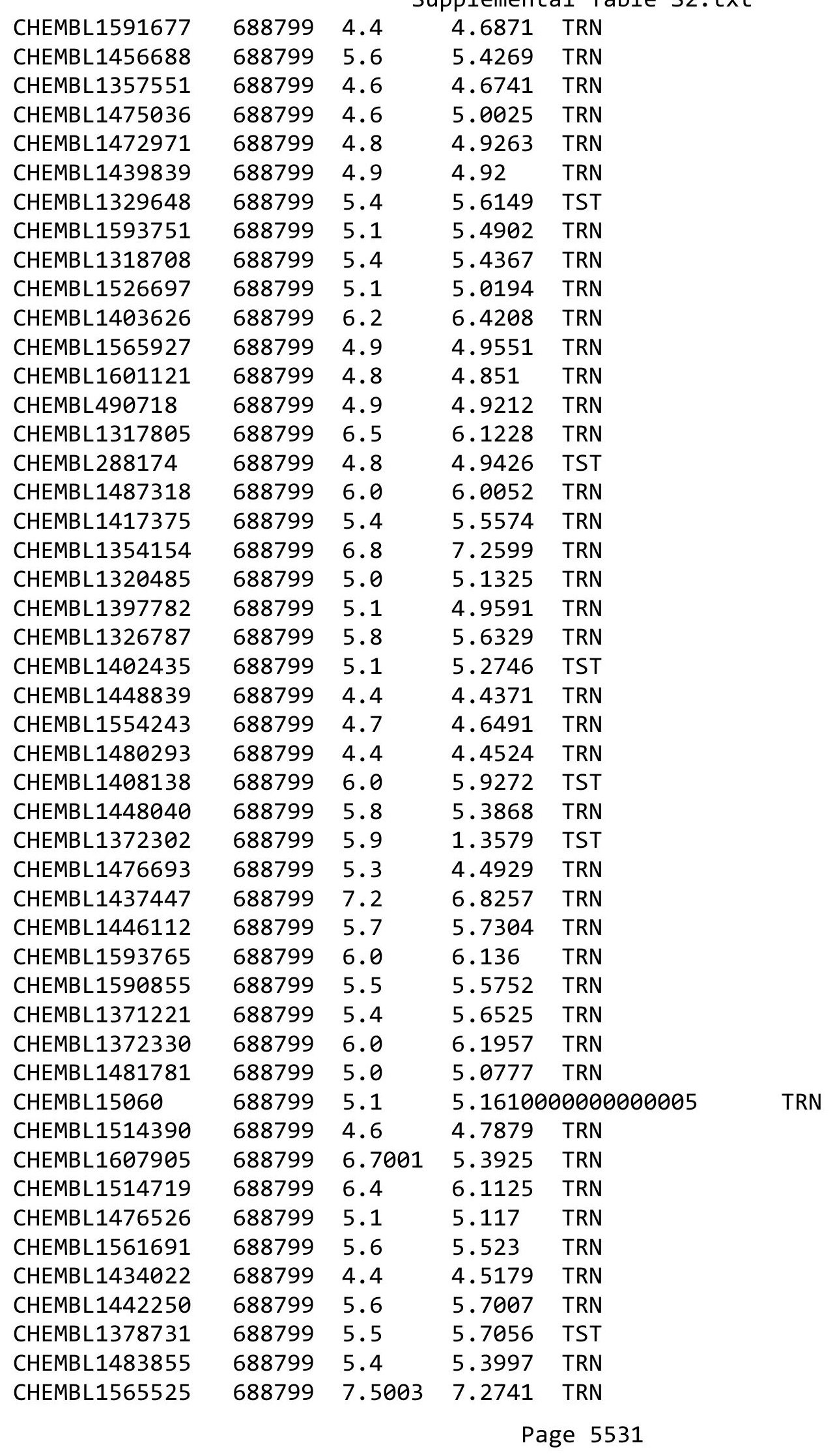




\begin{tabular}{|c|c|c|c|c|}
\hline \multicolumn{5}{|c|}{ mental Table s2.t } \\
\hline CHEMBL1395899 & 688799 & 4.6 & 4.6395 & TRN \\
\hline CHEMBL1513115 & 688799 & 7.2 & 5.7324 & TRN \\
\hline CHEMBL1435885 & 688799 & 5.9 & 5.9663 & TST \\
\hline CHEMBL1337629 & 688799 & 5.2 & 5.3333 & TRN \\
\hline CHEMBL1396949 & 688799 & 5.3 & 5.3367 & TRN \\
\hline CHEMBL1454855 & 688799 & 5.5 & 5.7004 & TRN \\
\hline CHEMBL1435028 & 688799 & 4.9 & 5.0048 & TRN \\
\hline CHEMBL1437088 & 688799 & 4.6 & 4.72 & TRN \\
\hline CHEMBL1394048 & 688799 & 6.8 & 5.6901 & TRN \\
\hline CHEMBL1437876 & 688799 & 5.0 & 5.4562 & TRN \\
\hline CHEMBL1473430 & 688799 & 5.6 & 5.5164 & TRN \\
\hline CHEMBL1559126 & 688799 & 5.3 & 5.3585 & TRN \\
\hline CHEMBL1409756 & 688799 & 6.2 & 6.2194 & TRN \\
\hline CHEMBL1314211 & 688799 & 5.7 & 5.6038 & TRN \\
\hline CHEMBL1358115 & 688799 & 5.2 & 5.4631 & TRN \\
\hline CHEMBL104264 & 688799 & 4.8 & 5.2055 & TRN \\
\hline CHEMBL1329102 & 688799 & 7.699 & 7.5646 & TST \\
\hline CHEMBL264931 & 688799 & 5.0 & 5.3809 & TST \\
\hline CHEMBL429023 & 688799 & 6.0 & 5.9429 & TRN \\
\hline CHEMBL1612582 & 688799 & 4.8 & 4.6431 & TRN \\
\hline CHEMBL1450317 & 688799 & 6.1 & 5.9688 & TRN \\
\hline CHEMBL1356113 & 688799 & 5.6 & 5.8729 & TRN \\
\hline CHEMBL1447959 & 688799 & 5.4 & 5.4904 & TRN \\
\hline CHEMBL1567516 & 688799 & 5.9 & 5.9417 & TST \\
\hline CHEMBL1475375 & 688799 & 5.4 & 5.4425 & TST \\
\hline CHEMBL1530613 & 688799 & 6.8 & 6.4921 & TST \\
\hline CHEMBL1517935 & 688799 & 4.9 & 4.8618 & TRN \\
\hline CHEMBL1513063 & 688799 & 5.5 & 5.4015 & TRN \\
\hline CHEMBL1474230 & 688799 & 5.6 & 5.33799 & 9999999999 \\
\hline CHEMBL1374218 & 688799 & 5.1 & 5.4674 & TRN \\
\hline CHEMBL1401483 & 688799 & 4.5 & 4.677 & TRN \\
\hline CHEMBL1551824 & 688799 & 5.2 & 5.3567 & TRN \\
\hline CHEMBL1567160 & 688799 & 5.6 & 5.7821 & TST \\
\hline CHEMBL491953 & 688799 & 5.4 & 5.4077 & TRN \\
\hline CHEMBL69367 & 688799 & 4.5 & 4.7681 & TRN \\
\hline CHEMBL1414073 & 688799 & 4.4 & 4.4636 & TRN \\
\hline CHEMBL433238 & 688799 & 4.5 & 5.4597 & TRN \\
\hline CHEMBL1315091 & 688799 & 4.6 & 4.6774 & TRN \\
\hline CHEMBL1491574 & 688799 & 4.4 & 4.4532 & TRN \\
\hline CHEMBL1371756 & 688799 & 5.7 & 5.7484 & TRN \\
\hline CHEMBL1437325 & 688799 & 4.9 & 5.0123 & TRN \\
\hline CHEMBL1445792 & 688799 & 6.0 & 5.875 & TRN \\
\hline CHEMBL1315725 & 688799 & 6.1 & 6.0575 & TST \\
\hline CHEMBL1569001 & 688799 & 5.1 & 5.1999 & TRN \\
\hline CHEMBL18879 & 688799 & 5.9 & 5.87 & TST \\
\hline CHEMBL1473489 & 688799 & 5.6 & 5.5467 & TRN \\
\hline CHEMBL1442987 & 688799 & 6.0 & 6.2283 & TRN \\
\hline CHEMBL1572834 & 688799 & 4.4 & 4.6294 & TRN \\
\hline
\end{tabular}




\begin{tabular}{|c|c|c|c|c|}
\hline \multicolumn{5}{|c|}{ splemental T } \\
\hline CHEMBL1554158 & 688799 & 4.9 & 4.9332 & TRN \\
\hline CHEMBL1355370 & 688799 & 5.0 & 5.0258 & TRN \\
\hline CHEMBL1398456 & 688799 & 5.0 & 5.2027 & TST \\
\hline CHEMBL245121 & 688799 & 4.8 & 5.601 & TRN \\
\hline CHEMBL1397257 & 688799 & 5.3 & 5.5467 & TRN \\
\hline CHEMBL1334543 & 688799 & 4.4 & 4.7189 & TRN \\
\hline CHEMBL1529543 & 688799 & 4.8 & 4.8056 & TRN \\
\hline CHEMBL1324882 & 688799 & 5.6 & 5.5236 & TRN \\
\hline CHEMBL165 & 688799 & 6.0 & 8.2648 & TRN \\
\hline CHEMBL1513648 & 688799 & 8.2007 & 5.0943 & TRN \\
\hline CHEMBL1605356 & 688799 & 4.8 & 5.073 & TRN \\
\hline CHEMBL1436054 & 688799 & 5.1 & 5.1072 & TRN \\
\hline CHEMBL1333156 & 688799 & 6.1 & 6.0874 & TRN \\
\hline CHEMBL1328319 & 688799 & 4.5 & 4.598 & TRN \\
\hline CHEMBL1318316 & 688799 & 6.3 & 6.3586 & TRN \\
\hline CHEMBL1357722 & 688799 & 4.4 & 4.4416 & TRN \\
\hline CHEMBL1410859 & 688799 & 5.2 & 5.2884 & TRN \\
\hline CHEMBL1473834 & 688799 & 6.8 & 5.0874 & TRN \\
\hline CHEMBL1595404 & 688799 & 5.5 & 5.2704 & TRN \\
\hline CHEMBL 221300 & 688799 & 4.8 & 5.4967 & TRN \\
\hline CHEMBL1396693 & 688799 & 4.4 & 4.5763 & TRN \\
\hline CHEMBL1488305 & 688799 & 4.7 & 4.8826 & TRN \\
\hline CHEMBL1435216 & 688799 & 4.9 & 4.8898 & TRN \\
\hline CHEMBL1552752 & 688799 & 5.8 & 5.9135 & TRN \\
\hline CHEMBL 274438 & 688799 & 6.8 & 6.7637 & TRN \\
\hline CHEMBL1327772 & 688799 & 6.1 & 5.4636 & TRN \\
\hline CHEMBL1877767 & 688799 & 5.4 & 5.6015 & TRN \\
\hline CHEMBL1330385 & 688799 & 5.0 & 5.0137 & TRN \\
\hline CHEMBL1358263 & 688799 & 4.7 & 5.0598 & TRN \\
\hline CHEMBL319244 & 688799 & 4.9 & 5.2089 & TRN \\
\hline CHEMBL1473849 & 688799 & 5.3 & 5.5811 & TST \\
\hline CHEMBL1408031 & 688799 & 5.5 & 5.4887 & TST \\
\hline CHEMBL447507 & 688799 & 6.1 & 6.1845 & TRN \\
\hline CHEMBL1355693 & 688799 & 5.4 & 5.5121 & TRN \\
\hline CHEMBL1256776 & 688799 & 5.3 & 5.43 & TRN \\
\hline CHEMBL1512683 & 688799 & 4.8 & 5.047 & TRN \\
\hline CHEMBL1316265 & 688799 & 4.5 & 4.5688 & TRN \\
\hline CHEMBL 1407440 & 688799 & 4.4 & 4.3965 & TRN \\
\hline CHEMBL1611820 & 688799 & 4.4 & 4.3803 & TRN \\
\hline CHEMBL1322760 & 688799 & 6.5 & 6.4663 & TRN \\
\hline CHEMBL39878 & 688799 & 5.3 & 5.2437 & TRN \\
\hline CHEMBL92708 & 688799 & 5.0 & 5.148 & TRN \\
\hline CHEMBL1328545 & 688799 & 5.5 & 5.5028 & TRN \\
\hline CHEMBL421215 & 688799 & 5.8 & 5.8499 & TRN \\
\hline CHEMBL1357850 & 688799 & 5.0 & 5.1749 & TRN \\
\hline CHEMBL1396142 & 688799 & 4.4 & 4.5785 & TRN \\
\hline CHEMBL22075 & 688799 & 6.3 & 6.3279 & TRN \\
\hline CHEMBL1445094 & 688799 & 5.1 & 5.0887 & TRN \\
\hline
\end{tabular}




\begin{tabular}{|c|c|c|c|c|c|}
\hline \multicolumn{6}{|c|}{ Supplemental Table S2.txt } \\
\hline CHEMBL1316656 & 688799 & 5.3 & 5.6368 & TRN & \\
\hline CHEMBL150 & 688799 & 6.0 & 4.8844 & TRN & \\
\hline CHEMBL1532597 & 688799 & 6.3 & 5.8617 & TRN & \\
\hline CHEMBL540848 & 688799 & 4.5 & 4.59 & TRN & \\
\hline CHEMBL1317096 & 688799 & 5.4 & 5.4726 & TST & \\
\hline CHEMBL1524331 & 688799 & 4.7 & 4.8258 & TRN & \\
\hline CHEMBL1454033 & 688799 & 5.5 & 5.5784 & TRN & \\
\hline CHEMBL423429 & 688799 & 5.1 & 5.4381 & TST & \\
\hline CHEMBL1361725 & 688799 & 4.8 & 4.5573 & TRN & \\
\hline CHEMBL1256816 & 688799 & 5.7 & 5.7252 & TST & \\
\hline CHEMBL1437095 & 688799 & 5.7 & 5.8212 & TRN & \\
\hline CHEMBL1556701 & 688799 & 4.7 & 4.8407 & TRN & \\
\hline CHEMBL1318310 & 688799 & 5.2 & 5.2941 & TRN & \\
\hline CHEMBL1355835 & 688799 & 4.8 & 4.8836 & TRN & \\
\hline CHEMBL447347 & 688799 & 6.5 & 6.5068 & TRN & \\
\hline CHEMBL1590980 & 688799 & 7.8996 & 7.5394 & TRN & \\
\hline CHEMBL1354934 & 688799 & 5.3 & 5.6745 & TRN & \\
\hline CHEMBL1319783 & 688799 & 5.3 & 5.0624 & TRN & \\
\hline CHEMBL1366020 & 688799 & 5.8 & 5.83700 & 0000000001 & TRN \\
\hline CHEMBL1316979 & 688799 & 5.5 & 5.4092 & TRN & \\
\hline CHEMBL1478249 & 688799 & 5.8 & 5.7219 & TRN & \\
\hline CHEMBL1354344 & 688799 & 6.1 & 5.7363 & TRN & \\
\hline CHEMBL1483716 & 688799 & 7.4001 & 5.4443 & TRN & \\
\hline CHEMBL1437486 & 688799 & 5.5 & 5.3636 & TRN & \\
\hline CHEMBL1555368 & 688799 & 4.9 & 5.1334 & TRN & \\
\hline CHEMBL1531342 & 688799 & 5.2 & 5.5153 & TST & \\
\hline CHEMBL1528540 & 688799 & 7.4001 & 5.3705 & TST & \\
\hline CHEMBL1323488 & 688799 & 4.9 & 4.8565 & TRN & \\
\hline CHEMBL2374062 & 688799 & 4.8 & 5.0337 & TST & \\
\hline CHEMBL1412842 & 688799 & 6.0 & 6.3376 & TRN & \\
\hline CHEMBL26915 & 688799 & 5.1 & 5.25 & TST & \\
\hline CHEMBL225513 & 688799 & 4.8 & 5.5363 & TRN & \\
\hline CHEMBL1448288 & 688799 & 5.0 & 5.0309 & TRN & \\
\hline CHEMBL1435409 & 688799 & 5.7 & 5.5539 & TRN & \\
\hline CHEMBL1255836 & 688799 & 5.0 & 5.0723 & TRN & \\
\hline CHEMBL1551274 & 688799 & 6.0 & 6.1362 & TRN & \\
\hline CHEMBL1354941 & 688799 & 4.8 & 5.1283 & TRN & \\
\hline CHEMBL1513324 & 688799 & 5.0 & 5.0652 & TRN & \\
\hline CHEMBL1446621 & 688799 & 5.4 & 5.6967 & TRN & \\
\hline CHEMBL1190214 & 688799 & 5.9 & 5.8892 & TST & \\
\hline CHEMBL1338347 & 688799 & 9.0 & 5.3907 & TST & \\
\hline CHEMBL1361449 & 688799 & 5.7 & 5.9891 & TRN & \\
\hline CHEMBL1452250 & 688799 & 6.9 & 6.7243 & TRN & \\
\hline CHEMBL1514098 & 688799 & 7.5003 & 7.2134 & TST & \\
\hline CHEMBL1235001 & 688799 & 4.8 & 4.9612 & TST & \\
\hline CHEMBL1489528 & 688799 & 5.1 & 5.1812 & TRN & \\
\hline CHEMBL1564426 & 688799 & 5.6 & 5.7603 & TRN & \\
\hline CHEMBL1395098 & 688799 & 4.8 & 4.918 & TRN & \\
\hline
\end{tabular}




\begin{tabular}{|c|c|c|c|c|}
\hline & & & pplement & al $\mathrm{Ta}$ \\
\hline CHEMBL1557498 & 688799 & 4.4 & 4.7008 & TRN \\
\hline CHEMBL1329823 & 688799 & 4.9 & 5.1963 & TRN \\
\hline CHEMBL1323684 & 688799 & 5.1 & 5.6673 & TRN \\
\hline CHEMBL1512250 & 688799 & 5.0 & 4.9782 & TRN \\
\hline CHEMBL1596698 & 688799 & 6.6 & 6.3334 & TST \\
\hline CHEMBL1554693 & 688799 & 4.7 & 4.9917 & TRN \\
\hline CHEMBL1316956 & 688799 & 7.1002 & 7.2237 & TRN \\
\hline CHEMBL1316893 & 688799 & 4.6 & 4.6964 & TRN \\
\hline CHEMBL1536169 & 688799 & 6.0 & 5.5138 & TST \\
\hline CHEMBL1552677 & 688799 & 5.2 & 5.2198 & TRN \\
\hline CHEMBL1358359 & 688799 & 5.2 & 5.4882 & TRN \\
\hline CHEMBL1327505 & 688799 & 5.9 & 5.8391 & TRN \\
\hline CHEMBL1358132 & 688799 & 5.1 & 5.4279 & TST \\
\hline CHEMBL1526170 & 688799 & 4.6 & 4.6239 & TRN \\
\hline CHEMBL1355935 & 688799 & 4.6 & 4.7685 & TRN \\
\hline CHEMBL1411164 & 688799 & 5.0 & 5.3976 & TRN \\
\hline CHEMBL1496596 & 688799 & 4.6 & 4.738 & TRN \\
\hline CHEMBL1256180 & 688799 & 4.5 & 4.8632 & TST \\
\hline CHEMBL1568071 & 688799 & 4.4 & 4.489 & TRN \\
\hline CHEMBL1376952 & 688799 & 5.5 & 5.9464 & TRN \\
\hline CHEMBL1446990 & 688799 & 6.0 & 6.1248 & TRN \\
\hline CHEMBL1396595 & 688799 & 5.0 & 5.1022 & TRN \\
\hline CHEMBL1551979 & 688799 & 5.0 & 4.9326 & TRN \\
\hline CHEMBL1369186 & 688799 & 5.3 & 5.0585 & TST \\
\hline CHEMBL306764 & 688799 & 5.0 & 5.2508 & TRN \\
\hline CHEMBL3198273 & 688799 & 8.301 & 8.1615 & TRN \\
\hline CHEMBL1485361 & 688799 & 4.4 & 4.4417 & TRN \\
\hline CHEMBL1436525 & 688799 & 6.1 & 5.4696 & TRN \\
\hline CHEMBL512832 & 688799 & 5.9 & 5.965 & TRN \\
\hline CHEMBL1315504 & 688799 & 4.9 & 4.9147 & TRN \\
\hline CHEMBL1331913 & 688799 & 5.5 & 5.5973 & TST \\
\hline CHEMBL1315318 & 688799 & 4.8 & 4.8205 & TRN \\
\hline CHEMBL1374143 & 688799 & 5.5 & 5.2552 & TST \\
\hline CHEMBL1592558 & 688799 & 4.8 & 5.0151 & TST \\
\hline CHEMBL1626274 & 688799 & 6.0 & 5.1249 & TST \\
\hline CHEMBL1366393 & 688799 & 5.4 & 5.2217 & TRN \\
\hline CHEMBL1256697 & 688799 & 4.6 & 5.1195 & TRN \\
\hline CHEMBL1477964 & 688799 & 5.2 & 4.9675 & TRN \\
\hline CHEMBL1338358 & 688799 & 5.1 & 5.6922 & TRN \\
\hline CHEMBL1365712 & 688799 & 5.3 & 5.5051 & TRN \\
\hline CHEMBL1514221 & 688799 & 7.8996 & 7.517 & TRN \\
\hline CHEMBL1356943 & 688799 & 4.4 & 4.5013 & TRN \\
\hline CHEMBL1595524 & 688799 & 4.6 & 4.8984 & TRN \\
\hline CHEMBL1491245 & 688799 & 7.8996 & 5.2941 & TRN \\
\hline CHEMBL1399481 & 688799 & 4.9 & 4.8331 & TRN \\
\hline CHEMBL1436059 & 688799 & 5.4 & 5.4468 & TRN \\
\hline CHEMBL1473405 & 688799 & 5.4 & 5.6177 & TRN \\
\hline CHEMBL1354190 & 688799 & 7.2 & 6.9722 & TST \\
\hline
\end{tabular}




\begin{tabular}{|c|c|c|c|c|c|}
\hline \\
\hline CHEMBL909 & 688799 & 6.1 & 6.0957 & TRN & \\
\hline CHEMBL1331521 & 688799 & 5.0 & 5.1086 & TRN & \\
\hline CHEMBL399249 & 688799 & 6.2 & 5.4553 & TRN & \\
\hline CHEMBL1437681 & 688799 & 5.4 & 5.7122 & TRN & \\
\hline CHEMBL1551732 & 688799 & 7.4001 & 5.6591 & TRN & \\
\hline CHEMBL1256865 & 688799 & 4.6 & 4.887 & TRN & \\
\hline CHEMBL1553804 & 688799 & 4.4 & 4.2675 & TRN & \\
\hline CHEMBL1517724 & 688799 & 5.4 & 5.4295 & TST & \\
\hline CHEMBL1403333 & 688799 & 5.1 & 4.9671 & TRN & \\
\hline CHEMBL256835 & 688799 & 5.1 & 5.1715 & TRN & \\
\hline CHEMBL1327247 & 688799 & 4.7 & 4.8549 & TRN & \\
\hline CHEMBL 299683 & 688799 & 6.0 & 5.0487 & TRN & \\
\hline CHEMBL1354112 & 688799 & 6.2 & 5.4152 & TRN & \\
\hline CHEMBL1571027 & 688799 & 5.2 & 5.9324 & TRN & \\
\hline CHEMBL1513656 & 688799 & 5.7 & 5.8329 & TRN & \\
\hline CHEMBL1593589 & 688799 & 7.4001 & 6.9094 & TRN & \\
\hline CHEMBL474415 & 688799 & 4.8 & 4.8123 & TRN & \\
\hline CHEMBL1435210 & 688799 & 6.0 & 7.1091 & TRN & \\
\hline CHEMBL32503 & 688799 & 6.8 & 6.5147 & TRN & \\
\hline CHEMBL1483110 & 688799 & 5.6 & 5.8741 & TRN & \\
\hline CHEMBL1446649 & 688799 & 4.9 & 5.0044 & TRN & \\
\hline CHEMBL1407527 & 688799 & 4.9 & 4.9584 & TRN & \\
\hline CHEMBL1572173 & 688799 & 6.2 & 6.1102 & TRN & \\
\hline CHEMBL 250711 & 688799 & 4.9 & 5.0055 & TRN & \\
\hline CHEMBL1476298 & 688799 & 4.4 & 4.4638 & TRN & \\
\hline CHEMBL1590060 & 688799 & 4.4 & 4.8917 & TRN & \\
\hline CHEMBL1594258 & 688799 & 5.3 & 5.6138 & TRN & \\
\hline CHEMBL492127 & 688799 & 5.7 & 5.9412 & TRN & \\
\hline CHEMBL1489708 & 688799 & 4.9 & 4.8331 & TRN & \\
\hline CHEMBL1528915 & 688799 & 5.8 & 5.3418 & TST & \\
\hline CHEMBL1564477 & 688799 & 4.5 & 4.3144 & TRN & \\
\hline CHEMBL1438371 & 688799 & 4.9 & 4.8846 & TRN & \\
\hline CHEMBL1527209 & 688799 & 4.4 & 3.8559 & TRN & \\
\hline CHEMBL1451411 & 688799 & 4.4 & 4.8801 & TRN & \\
\hline CHEMBL1396010 & 688799 & 4.9 & 4.9074 & TRN & \\
\hline CHEMBL1604036 & 688799 & 5.5 & 5.6872 & TRN & \\
\hline CHEMBL1451562 & 688799 & 4.5 & 4.5216 & TRN & \\
\hline CHEMBL1565160 & 688799 & 6.1 & 6.1113 & TRN & \\
\hline CHEMBL1364859 & 688799 & 5.0 & 5.67299 & 9999999999 & TRN \\
\hline CHEMBL1418094 & 688799 & 5.5 & 5.5373 & TST & \\
\hline CHEMBL1374799 & 688799 & 6.6 & 5.7002 & TRN & \\
\hline CHEMBL1371789 & 688799 & 4.9 & 5.475 & TRN & \\
\hline CHEMBL1396463 & 688799 & 4.6 & 4.9231 & TST & \\
\hline CHEMBL464176 & 688799 & 5.7 & 5.1302 & TST & \\
\hline CHEMBL1591745 & 688799 & 6.4 & 6.3376 & TRN & \\
\hline CHEMBL1404451 & 688799 & 6.0 & 6.1001 & TRN & \\
\hline CHEMBL1533413 & 688799 & 5.4 & 5.4184 & TST & \\
\hline CHEMBL1413165 & 688799 & 5.6 & 6.0151 & TRN & \\
\hline
\end{tabular}




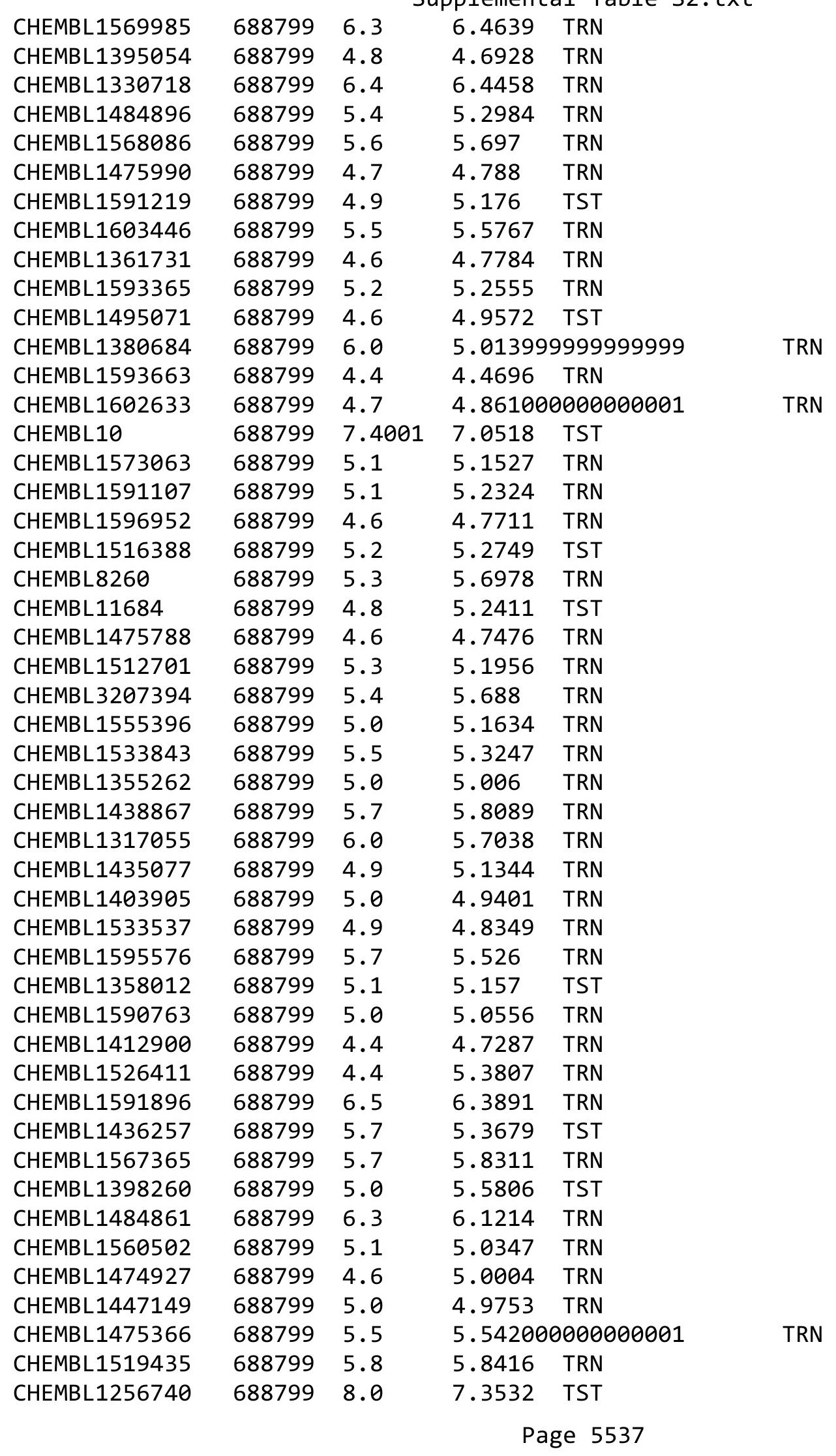




\begin{tabular}{|c|c|c|c|c|c|}
\hline \multicolumn{6}{|c|}{ Supplemental Table S2.txt } \\
\hline CHEMBL1551133 & 688799 & 6.2 & 6.3695 & TRN & \\
\hline CHEMBL1473755 & 688799 & 5.8 & 5.7641 & TRN & \\
\hline CHEMBL402063 & 688799 & 4.9 & 5.4553 & TST & \\
\hline CHEMBL1314564 & 688799 & 5.8 & 5.6532 & TRN & \\
\hline CHEMBL60718 & 688799 & 5.0 & 5.2238 & TRN & \\
\hline CHEMBL1552172 & 688799 & 4.4 & 4.4744 & TRN & \\
\hline CHEMBL1394135 & 688799 & 5.5 & 5.8291 & TRN & \\
\hline CHEMBL1333056 & 688799 & 6.0 & 5.8905 & TST & \\
\hline CHEMBL1450117 & 688799 & 8.2007 & 6.2044 & TRN & \\
\hline CHEMBL1496350 & 688799 & 5.2 & 5.4183 & TRN & \\
\hline CHEMBL1592202 & 688799 & 4.4 & 4.513 & TRN & \\
\hline CHEMBL1434957 & 688799 & 5.2 & 5.4599 & TRN & \\
\hline CHEMBL72631 & 688799 & 5.8 & 5.6525 & TRN & \\
\hline CHEMBL1317461 & 688799 & 5.6 & 5.7402 & TRN & \\
\hline CHEMBL1527086 & 688799 & 6.0 & 5.9463 & TRN & \\
\hline CHEMBL1318447 & 688799 & 4.5 & 4.5508 & TRN & \\
\hline CHEMBL489934 & 688799 & 5.8 & 5.9764 & TRN & \\
\hline CHEMBL1335033 & 688799 & 5.4 & 5.6012 & TST & \\
\hline CHEMBL1557383 & 688799 & 5.3 & 5.7555 & TST & \\
\hline CHEMBL1375127 & 688799 & 7.0 & 6.6077 & TRN & \\
\hline CHEMBL1413858 & 688799 & 5.1 & 5.3305 & TRN & \\
\hline CHEMBL1374696 & 688799 & 5.5 & 5.4961 & TRN & \\
\hline CHEMBL1411201 & 688799 & 4.8 & 4.8865 & TRN & \\
\hline CHEMBL1436259 & 688799 & 5.5 & 5.91100 & 00000000005 & TRN \\
\hline CHEMBL1354281 & 688799 & 4.9 & 4.8561 & TRN & \\
\hline CHEMBL1337781 & 688799 & 5.9 & 5.9471 & TRN & \\
\hline CHEMBL1606292 & 688799 & 4.9 & 5.12 & TRN & \\
\hline CHEMBL1534630 & 688799 & 4.4 & 4.5271 & TST & \\
\hline CHEMBL242948 & 688799 & 4.5 & 5.3165 & TST & \\
\hline CHEMBL1437428 & 688799 & 5.4 & 5.5595 & TST & \\
\hline CHEMBL1553404 & 688799 & 4.8 & 4.7662 & TRN & \\
\hline CHEMBL86931 & 688799 & 6.0 & 5.9434 & TRN & \\
\hline CHEMBL1356842 & 688799 & 6.7001 & 6.2522 & TRN & \\
\hline CHEMBL1315292 & 688799 & 4.8 & 4.9572 & TRN & \\
\hline CHEMBL3207903 & 688799 & 7.0 & 6.9289 & TRN & \\
\hline CHEMBL1375243 & 688799 & 6.3 & 6.3571 & TST & \\
\hline CHEMBL1592571 & 688799 & 4.9 & 5.0295 & TRN & \\
\hline CHEMBL1480806 & 688799 & 8.0 & 8.1667 & TRN & \\
\hline CHEMBL1514739 & 688799 & 5.1 & 4.9932 & TST & \\
\hline CHEMBL1399619 & 688799 & 5.6 & 5.6187 & TRN & \\
\hline CHEMBL188641 & 688799 & 5.8 & 6.0013 & TRN & \\
\hline CHEMBL1612410 & 688799 & 4.6 & 4.6834 & TRN & \\
\hline CHEMBL323356 & 688799 & 5.5 & 5.4482 & TST & \\
\hline CHEMBL1606199 & 688799 & 5.4 & 5.5302 & TRN & \\
\hline CHEMBL1479817 & 688799 & 4.9 & 4.8709 & TRN & \\
\hline CHEMBL1358631 & 688799 & 5.1 & 4.9785 & TRN & \\
\hline CHEMBL1551139 & 688799 & 5.7 & 5.9139 & TRN & \\
\hline CHEMBL1321118 & 688799 & 4.9 & 4.8105 & TRN & \\
\hline
\end{tabular}




\begin{tabular}{|c|c|c|c|c|c|}
\hline \multicolumn{6}{|c|}{ Supplemental Table S2.txt } \\
\hline CHEMBL1517965 & 688799 & 5.8 & 5.6126 & TRN & \\
\hline CHEMBL85194 & 688799 & 5.4 & 5.4582 & TST & \\
\hline CHEMBL1573964 & 688799 & 4.6 & 4.7297 & TRN & \\
\hline CHEMBL1374426 & 688799 & 8.699 & 8.3452 & TST & \\
\hline CHEMBL259073 & 688799 & 4.4 & 4.4822 & TRN & \\
\hline CHEMBL1357553 & 688799 & 4.9 & 5.0082 & TRN & \\
\hline CHEMBL1334106 & 688799 & 5.0 & 5.37299 & 9999999999 & TRN \\
\hline CHEMBL9666 & 688799 & 4.4 & 5.2543 & TRN & \\
\hline CHEMBL1373414 & 688799 & 7.4001 & 5.7902 & TRN & \\
\hline CHEMBL1489668 & 688799 & 8.699 & 5.2717 & TRN & \\
\hline CHEMBL428901 & 688799 & 5.7 & 5.8166 & TRN & \\
\hline CHEMBL1452221 & 688799 & 5.6 & 5.6493 & TRN & \\
\hline CHEMBL1476892 & 688799 & 5.2 & 7.0601 & TRN & \\
\hline CHEMBL1592812 & 688799 & 4.5 & 5.2764 & TRN & \\
\hline CHEMBL 275854 & 688799 & 5.1 & 5.3414 & TRN & \\
\hline CHEMBL1371397 & 688799 & 4.4 & 4.4942 & TST & \\
\hline CHEMBL1592213 & 688799 & 4.4 & 4.3437 & TRN & \\
\hline CHEMBL1411059 & 688799 & 5.6 & 5.3952 & TRN & \\
\hline CHEMBL491547 & 688799 & 5.6 & 5.3467 & TRN & \\
\hline CHEMBL1515287 & 688799 & 5.0 & 4.9335 & TRN & \\
\hline CHEMBL1551308 & 688799 & 7.1002 & 6.6049 & TRN & \\
\hline CHEMBL2373557 & 688799 & 6.0 & 5.4665 & TRN & \\
\hline CHEMBL1473990 & 688799 & 5.0 & 5.7214 & TRN & \\
\hline CHEMBL1409830 & 688799 & 5.0 & 5.0469 & TRN & \\
\hline CHEMBL1397283 & 688799 & 5.5 & 5.5941 & TST & \\
\hline CHEMBL106437 & 688799 & 4.8 & 5.1553 & TRN & \\
\hline CHEMBL1332463 & 688799 & 4.4 & 5.1275 & TRN & \\
\hline CHEMBL1256749 & 688799 & 6.0 & 5.9856 & TST & \\
\hline CHEMBL1517650 & 688799 & 5.6 & 5.4696 & TRN & \\
\hline CHEMBL1322608 & 688799 & 5.0 & 5.4031 & TST & \\
\hline CHEMBL1516028 & 688799 & 5.6 & 5.5662 & TRN & \\
\hline CHEMBL1533680 & 688799 & 6.0 & 6.0031 & TRN & \\
\hline CHEMBL1595002 & 688799 & 5.1 & 5.2866 & TRN & \\
\hline CHEMBL1515295 & 688799 & 4.6 & 4.6265 & TRN & \\
\hline CHEMBL1412390 & 688799 & 6.1 & 6.1495 & TRN & \\
\hline CHEMBL1328265 & 688799 & 5.7 & 5.6516 & TST & \\
\hline CHEMBL208484 & 688799 & 5.4 & 5.3743 & TRN & \\
\hline CHEMBL1435947 & 688799 & 4.9 & 5.008 & TRN & \\
\hline CHEMBL1214274 & 688799 & 6.1 & 6.1288 & TRN & \\
\hline CHEMBL1529265 & 688799 & 5.1 & 5.3621 & TST & \\
\hline CHEMBL1435727 & 688799 & 7.0 & 5.6878 & TRN & \\
\hline CHEMBL1456454 & 688799 & 4.6 & 4.9287 & TRN & \\
\hline CHEMBL1395992 & 688799 & 5.5 & 5.6944 & TRN & \\
\hline CHEMBL1514071 & 688799 & 4.7 & 4.7284 & TRN & \\
\hline CHEMBL1358266 & 688799 & 5.1 & 5.3184 & TRN & \\
\hline CHEMBL1558526 & 688799 & 4.8 & 4.8094 & TRN & \\
\hline CHEMBL1551981 & 688799 & 5.3 & 5.4213 & TRN & \\
\hline CHEMBL1594020 & 688799 & 5.0 & 4.9688 & TRN & \\
\hline
\end{tabular}




\begin{tabular}{|c|c|c|c|c|c|}
\hline \multicolumn{6}{|c|}{ Supplemental Table S2.txt } \\
\hline CHEMBL26320 & 688799 & 6.0 & 5.9127 & TRN & \\
\hline CHEMBL464467 & 688799 & 4.9 & 5.1825 & TST & \\
\hline CHEMBL3210890 & 688799 & 5.3 & 5.5126 & TRN & \\
\hline CHEMBL1398067 & 688799 & 6.4 & 6.4274 & TRN & \\
\hline CHEMBL1314768 & 688799 & 5.2 & 5.362 & TRN & \\
\hline CHEMBL305881 & 688799 & 6.0 & 5.7444 & TST & \\
\hline CHEMBL1518182 & 688799 & 4.4 & 4.7315 & TRN & \\
\hline CHEMBL1400050 & 688799 & 6.0 & 6.0649 & TRN & \\
\hline CHEMBL1492205 & 688799 & 5.3 & 5.1506 & TRN & \\
\hline CHEMBL491960 & 688799 & 7.1002 & 6.8538 & TRN & \\
\hline CHEMBL1609624 & 688799 & 4.4 & 4.95100 & 00000000005 & TRN \\
\hline CHEMBL1395029 & 688799 & 4.8 & 4.7258 & TRN & \\
\hline CHEMBL1513508 & 688799 & 5.9 & 5.9328 & TRN & \\
\hline CHEMBL1418655 & 688799 & 5.4 & 5.5624 & TRN & \\
\hline CHEMBL1454052 & 688799 & 5.5 & 5.7113 & TRN & \\
\hline CHEMBL1326346 & 688799 & 5.5 & 5.6657 & TRN & \\
\hline CHEMBL1451768 & 688799 & 5.6 & 5.5037 & TRN & \\
\hline CHEMBL372797 & 688799 & 7.0 & 6.7616 & TST & \\
\hline CHEMBL1514398 & 688799 & 8.6021 & 8.2991 & TRN & \\
\hline CHEMBL1453208 & 688799 & 4.6 & 4.9013 & TRN & \\
\hline CHEMBL1590663 & 688799 & 4.8 & 4.7568 & TRN & \\
\hline CHEMBL1370938 & 688799 & 6.0 & 5.6928 & TRN & \\
\hline CHEMBL1601908 & 688799 & 4.9 & 4.8462 & TRN & \\
\hline CHEMBL414400 & 688799 & 5.0 & 5.2651 & TRN & \\
\hline CHEMBL1593199 & 688799 & 4.4 & 4.7821 & TRN & \\
\hline CHEMBL 258405 & 688799 & 5.2 & 5.2807 & TST & \\
\hline CHEMBL1514440 & 688799 & 6.0 & 6.1426 & TRN & \\
\hline CHEMBL250447 & 688799 & 4.8 & 5.4478 & TST & \\
\hline CHEMBL1515777 & 688799 & 5.1 & 5.2468 & TRN & \\
\hline CHEMBL1490786 & 688799 & 4.6 & 4.5786 & TRN & \\
\hline CHEMBL1457332 & 688799 & 4.9 & 4.99 & TRN & \\
\hline CHEMBL1596743 & 688799 & 4.4 & 4.5888 & TRN & \\
\hline CHEMBL1378755 & 688799 & 6.3 & 6.1107 & TRN & \\
\hline CHEMBL1358796 & 688799 & 5.5 & 5.4993 & TRN & \\
\hline CHEMBL1473472 & 688799 & 4.8 & 4.8138 & TRN & \\
\hline CHEMBL1409097 & 688799 & 7.5003 & 5.2552 & TRN & \\
\hline CHEMBL1256911 & 688799 & 8.6021 & 5.3203 & TRN & \\
\hline CHEMBL131171 & 688799 & 4.7 & 5.4536 & TRN & \\
\hline CHEMBL1355408 & 688799 & 5.0 & 5.2484 & TRN & \\
\hline CHEMBL464859 & 688799 & 4.4 & 4.9846 & TRN & \\
\hline CHEMBL1436976 & 688799 & 4.4 & 4.5005 & TRN & \\
\hline CHEMBL1490386 & 688799 & 4.9 & 4.819 & TRN & \\
\hline CHEMBL1442094 & 688799 & 5.8 & 6.005 & TRN & \\
\hline CHEMBL28 & 688799 & 6.0 & 5.4938 & TRN & \\
\hline CHEMBL1557234 & 688799 & 4.9 & 4.3679 & TRN & \\
\hline CHEMBL1364611 & 688799 & 4.7 & 4.7574 & TRN & \\
\hline CHEMBL1552973 & 688799 & 4.8 & 4.9437 & TST & \\
\hline CHEMBL1597107 & 688799 & 4.6 & 4.6647 & TRN & \\
\hline
\end{tabular}




\begin{tabular}{|c|c|c|c|c|c|}
\hline \multicolumn{6}{|c|}{ Supplemental Table S2.txt } \\
\hline CHEMBL56731 & 688799 & 4.9 & 5.1245 & TRN & \\
\hline CHEMBL1331525 & 688799 & 6.7001 & 6.7653 & TRN & \\
\hline CHEMBL1495213 & 688799 & 4.4 & 4.6505 & TRN & \\
\hline CHEMBL1533923 & 688799 & 7.1002 & 7.0754 & TRN & \\
\hline CHEMBL1331118 & 688799 & 4.4 & 4.5469 & TRN & \\
\hline CHEMBL1335654 & 688799 & 4.5 & 4.7237 & TRN & \\
\hline CHEMBL1354693 & 688799 & 4.4 & 4.1456 & TRN & \\
\hline CHEMBL523283 & 688799 & 6.0 & 6.1115 & TRN & \\
\hline CHEMBL 1418420 & 688799 & 5.1 & 5.4036 & TRN & \\
\hline CHEMBL1495077 & 688799 & 4.8 & 4.84399 & 9999999999 & TRN \\
\hline CHEMBL1474989 & 688799 & 5.1 & 4.8368 & TRN & \\
\hline CHEMBL1334959 & 688799 & 6.6 & 6.6859 & TRN & \\
\hline CHEMBL1395219 & 688799 & 4.4 & 4.2056 & TRN & \\
\hline CHEMBL1314185 & 688799 & 4.4 & 4.5436 & TRN & \\
\hline CHEMBL1482184 & 688799 & 6.0 & 5.6137 & TST & \\
\hline CHEMBL1318658 & 688799 & 7.0 & 5.8025 & TRN & \\
\hline CHEMBL1479771 & 688799 & 4.9 & 4.9861 & TRN & \\
\hline CHEMBL1605632 & 688799 & 4.5 & 4.5593 & TRN & \\
\hline CHEMBL52 & 688799 & 6.0 & 5.3668 & TRN & \\
\hline CHEMBL598270 & 688799 & 4.9 & 5.0323 & TST & \\
\hline CHEMBL1564194 & 688799 & 4.7 & 4.7677 & TRN & \\
\hline CHEMBL1515401 & 688799 & 6.5 & 6.267 & TRN & \\
\hline CHEMBL399121 & 688799 & 6.0 & 5.5965 & TRN & \\
\hline CHEMBL1494408 & 688799 & 4.9 & 4.8989 & TRN & \\
\hline CHEMBL1437128 & 688799 & 5.5 & 5.6108 & TRN & \\
\hline CHEMBL 75967 & 688799 & 5.2 & 5.4765 & TST & \\
\hline CHEMBL1437778 & 688799 & 4.6 & 4.8591 & TRN & \\
\hline CHEMBL1410602 & 688799 & 5.1 & 5.3438 & TRN & \\
\hline CHEMBL1332929 & 688799 & 5.0 & 5.1823 & TRN & \\
\hline CHEMBL1373621 & 688799 & 7.0 & 6.5594 & TRN & \\
\hline CHEMBL1257078 & 688799 & 6.0 & 5.5531 & TRN & \\
\hline CHEMBL1417636 & 688799 & 5.6 & 5.6802 & TRN & \\
\hline CHEMBL1532615 & 688799 & 5.0 & 5.6099 & TST & \\
\hline CHEMBL1477140 & 688799 & 4.8 & 4.7894 & TRN & \\
\hline CHEMBL1324697 & 688799 & 4.7 & 4.792 & TRN & \\
\hline CHEMBL275311 & 688799 & 6.0 & 5.4322 & TRN & \\
\hline CHEMBL1601805 & 688799 & 5.9 & 5.3229 & TRN & \\
\hline CHEMBL1436464 & 688799 & 5.5 & 5.1363 & TST & \\
\hline CHEMBL1593596 & 688799 & 5.4 & 5.7182 & TST & \\
\hline CHEMBL1328802 & 688799 & 9.0 & 5.3047 & TRN & \\
\hline CHEMBL1487164 & 688799 & 5.7 & 5.7872 & TRN & \\
\hline CHEMBL1476939 & 688799 & 5.4 & 5.6032 & TST & \\
\hline CHEMBL1489941 & 688799 & 7.8996 & 5.0666 & TST & \\
\hline CHEMBL1288013 & 688799 & 6.1 & 6.0026 & TRN & \\
\hline CHEMBL1520292 & 688799 & 4.5 & 4.5375 & TRN & \\
\hline CHEMBL1400309 & 688799 & 4.9 & 4.9201 & TRN & \\
\hline CHEMBL1414185 & 688799 & 5.8 & 5.8761 & TST & \\
\hline CHEMBL1457123 & 688799 & 7.3002 & 6.8512 & TRN & \\
\hline
\end{tabular}




\begin{tabular}{|c|c|c|c|c|}
\hline & & & premer & \\
\hline CHEMBL1332033 & 688799 & 5.3 & 5.2286 & TRN \\
\hline CHEMBL1514333 & 688799 & 5.9 & 5.3686 & TRN \\
\hline CHEMBL1395009 & 688799 & 6.2 & 6.1814 & TST \\
\hline CHEMBL1496194 & 688799 & 5.3 & 5.5145 & TRN \\
\hline CHEMBL1524520 & 688799 & 6.6 & 6.403 & TRN \\
\hline CHEMBL1475131 & 688799 & 6.8 & 6.3712 & TRN \\
\hline CHEMBL1411146 & 688799 & 5.1 & 5.3023 & TRN \\
\hline CHEMBL1325879 & 688799 & 5.6 & 4.5983 & TRN \\
\hline CHEMBL 97760 & 688799 & 6.1 & 5.5709 & TRN \\
\hline CHEMBL1366061 & 688799 & 6.3 & 6.1662 & TRN \\
\hline CHEMBL1591272 & 688799 & 5.8 & 5.4756 & TRN \\
\hline CHEMBL1358137 & 688799 & 5.4 & 5.5363 & TRN \\
\hline CHEMBL1590360 & 688799 & 4.6 & 5.3328 & TRN \\
\hline CHEMBL1475620 & 688799 & 4.6 & 4.8317 & TRN \\
\hline CHEMBL1404490 & 688799 & 4.5 & 5.232 & TST \\
\hline CHEMBL1396109 & 688799 & 5.4 & 5.3152 & TRN \\
\hline CHEMBL1552922 & 688799 & 4.7 & 4.8043 & TRN \\
\hline CHEMBL1322958 & 688799 & 5.4 & 5.5901 & TST \\
\hline CHEMBL1336085 & 688799 & 6.0 & 5.3289 & TST \\
\hline CHEMBL1358341 & 688799 & 7.4001 & 5.3847 & TRN \\
\hline CHEMBL1407012 & 688799 & 4.9 & 4.9952 & TRN \\
\hline CHEMBL473136 & 688799 & 5.5 & 5.5956 & TST \\
\hline CHEMBL399491 & 688799 & 6.0 & 5.6676 & TST \\
\hline CHEMBL1593440 & 688799 & 5.6 & 5.6977 & TRN \\
\hline CHEMBL1482582 & 688799 & 5.5 & 5.4123 & TRN \\
\hline CHEMBL1559127 & 688799 & 5.0 & 4.8946 & TRN \\
\hline CHEMBL1473448 & 688799 & 5.0 & 4.8009 & TRN \\
\hline CHEMBL1592493 & 688799 & 5.9 & 5.6774 & TRN \\
\hline CHEMBL523167 & 688799 & 5.7 & 5.557 & TRN \\
\hline CHEMBL1319093 & 688799 & 6.1 & 6.0169 & TRN \\
\hline CHEMBL1476078 & 688799 & 4.4 & 4.5874 & TRN \\
\hline CHEMBL1323759 & 688799 & 4.5 & 4.5652 & TRN \\
\hline CHEMBL1451788 & 688799 & 4.7 & 4.7386 & TRN \\
\hline CHEMBL1447147 & 688799 & 7.3002 & 5.4102 & TRN \\
\hline CHEMBL1528170 & 688799 & 4.8 & 4.8682 & TRN \\
\hline CHEMBL1479912 & 688799 & 4.9 & 4.7141 & TRN \\
\hline CHEMBL3351080 & 688799 & 6.0 & 5.9468 & TST \\
\hline CHEMBL1314935 & 688799 & 5.4 & 5.5107 & TST \\
\hline CHEMBL1554826 & 688799 & 4.4 & 4.6841 & TRN \\
\hline CHEMBL1235966 & 688799 & 5.1 & 5.3003 & TRN \\
\hline CHEMBL1524211 & 688799 & 4.8 & 4.336 & TRN \\
\hline CHEMBL1568854 & 688799 & 4.8 & 4.7259 & TRN \\
\hline CHEMBL1408954 & 688799 & 5.8 & 5.8059 & TRN \\
\hline CHEMBL1373326 & 688799 & 6.2 & 5.8875 & TRN \\
\hline CHEMBL1318400 & 688799 & 6.0 & 6.1357 & TRN \\
\hline CHEMBL1513334 & 688799 & 6.0 & 5.4981 & TRN \\
\hline CHEMBL1592227 & 688799 & 4.7 & 4.947 & TRN \\
\hline CHEMBL 38576 & 688799 & 6.5 & 6.3512 & TRN \\
\hline
\end{tabular}




\begin{tabular}{|c|c|c|c|c|}
\hline \multicolumn{5}{|c|}{ Supplemental Table s2.txt } \\
\hline CHEMBL1593827 & 688799 & 5.1 & 5.4254 & TRN \\
\hline CHEMBL1395277 & 688799 & 5.6 & 5.7502 & TRN \\
\hline CHEMBL1257081 & 688799 & 5.5 & 4.8423 & TRN \\
\hline CHEMBL1335332 & 688799 & 4.9 & 4.9594 & TRN \\
\hline CHEMBL566899 & 688799 & 7.8996 & 8.0922 & TRN \\
\hline CHEMBL1376543 & 688799 & 4.7 & 4.8653 & TST \\
\hline CHEMBL1593269 & 688799 & 5.2 & 5.0494 & TRN \\
\hline CHEMBL1536007 & 688799 & 7.1002 & 6.789 & TRN \\
\hline CHEMBL1433687 & 688799 & 6.6 & 6.6985 & TRN \\
\hline CHEMBL1480885 & 688799 & 5.5 & 5.6634 & TRN \\
\hline CHEMBL1523579 & 688799 & 4.8 & 4.8559 & TRN \\
\hline CHEMBL345083 & 688799 & 4.7 & 5.3438 & TST \\
\hline CHEMBL1483693 & 688799 & 5.4 & 5.7271 & TRN \\
\hline CHEMBL33171 & 688799 & 5.0 & 5.1971 & TRN \\
\hline CHEMBL1607167 & 688799 & 5.4 & 5.5528 & TRN \\
\hline CHEMBL1512740 & 688799 & 4.4 & 4.388 & TRN \\
\hline CHEMBL311226 & 688799 & 4.4 & 4.6942 & TST \\
\hline CHEMBL1369863 & 688799 & 5.3 & 5.2613 & TRN \\
\hline CHEMBL1161461 & 688799 & 4.5 & 5.0877 & TST \\
\hline CHEMBL29197 & 688799 & 5.7 & 5.6999 & TRN \\
\hline CHEMBL1606892 & 688799 & 4.9 & 5.0051 & TRN \\
\hline CHEMBL441618 & 688799 & 6.0 & 5.5842 & TRN \\
\hline CHEMBL1323563 & 688799 & 6.4 & 6.3153 & TRN \\
\hline CHEMBL1315079 & 688799 & 4.4 & 4.9755 & TRN \\
\hline CHEMBL1594612 & 688799 & 5.7 & 5.6073 & TRN \\
\hline CHEMBL1435384 & 688799 & 4.6 & 4.7415 & TRN \\
\hline CHEMBL1410676 & 688799 & 6.0 & 6.3353 & TRN \\
\hline CHEMBL1520727 & 688799 & 5.0 & 5.0378 & TRN \\
\hline CHEMBL513116 & 688799 & 6.0 & 6.9226 & TRN \\
\hline CHEMBL1396615 & 688799 & 4.6 & 4.9215 & TRN \\
\hline CHEMBL1447663 & 688799 & 5.0 & 5.2273 & TRN \\
\hline CHEMBL1454793 & 688799 & 5.1 & 5.5094 & TRN \\
\hline CHEMBL1435293 & 688799 & 5.5 & 5.3727 & TRN \\
\hline CHEMBL1554721 & 688799 & 7.8996 & 8.2068 & TRN \\
\hline CHEMBL1602632 & 688799 & 7.8996 & 5.4764 & TRN \\
\hline CHEMBL1256139 & 688799 & 5.1 & 5.33700 & 0000000001 \\
\hline CHEMBL102714 & 688799 & 5.1 & 5.6129 & TRN \\
\hline CHEMBL1322137 & 688799 & 5.4 & 5.5139 & TST \\
\hline CHEMBL1606337 & 688799 & 5.7 & 5.682 & TST \\
\hline CHEMBL1529028 & 688799 & 7.0 & 5.7882 & TRN \\
\hline CHEMBL559934 & 688799 & 7.1002 & 5.0971 & TST \\
\hline CHEMBL1257002 & 688799 & 6.0 & 4.7704 & TST \\
\hline CHEMBL1449517 & 688799 & 5.7 & 5.7976 & TRN \\
\hline CHEMBL1375285 & 688799 & 6.0 & 5.9065 & TRN \\
\hline CHEMBL1565724 & 688799 & 8.1024 & 7.1979 & TRN \\
\hline CHEMBL1436661 & 688799 & 5.3 & 5.2954 & TRN \\
\hline CHEMBL1404408 & 688799 & 4.8 & 4.9727 & TRN \\
\hline CHEMBL1440842 & 688799 & 5.9 & 6.151 & TRN \\
\hline
\end{tabular}




\begin{tabular}{|c|c|c|c|c|c|}
\hline & & \\
\hline CHEMBL1515918 & 688799 & 6.6 & 4.7767 & TRN & \\
\hline CHEMBL1358707 & 688799 & 5.8 & 5.2771 & TST & \\
\hline CHEMBL1396211 & 688799 & 5.6 & 5.4821 & TRN & \\
\hline CHEMBL 2373622 & 688799 & 5.4 & 5.3848 & TST & \\
\hline CHEMBL595227 & 688799 & 5.2 & 5.4037 & TST & \\
\hline CHEMBL1230276 & 688799 & 5.5 & 5.50700 & 0000000001 & TRN \\
\hline CHEMBL1321338 & 688799 & 4.4 & 3.7395 & TRN & \\
\hline CHEMBL292477 & 688799 & 5.6 & 5.5954 & TRN & \\
\hline CHEMBL1358503 & 688799 & 4.8 & 4.9177 & TRN & \\
\hline CHEMBL1370480 & 688799 & 5.6 & 5.3271 & TRN & \\
\hline CHEMBL1562337 & 688799 & 5.8 & 5.782 & TRN & \\
\hline CHEMBL1440145 & 688799 & 6.0 & 6.2137 & TRN & \\
\hline CHEMBL1322756 & 688799 & 5.7 & 5.6883 & TRN & \\
\hline CHEMBL580421 & 688799 & 4.5 & 4.8252 & TRN & \\
\hline CHEMBL1256667 & 688799 & 4.6 & 4.7931 & TST & \\
\hline CHEMBL113180 & 688799 & 4.9 & 5.1094 & TRN & \\
\hline CHEMBL1551919 & 688799 & 5.1 & 5.1178 & TRN & \\
\hline CHEMBL1356138 & 688799 & 4.6 & 4.8906 & TRN & \\
\hline CHEMBL1316408 & 688799 & 5.6 & 5.6972 & TRN & \\
\hline CHEMBL1602926 & 688799 & 7.5003 & 7.3205 & TRN & \\
\hline CHEMBL510009 & 688799 & 4.8 & 5.0119 & TRN & \\
\hline CHEMBL1232313 & 688799 & 4.6 & 5.2032 & TST & \\
\hline CHEMBL1489432 & 688799 & 5.0 & 5.3785 & TST & \\
\hline CHEMBL491548 & 688799 & 4.4 & 4.4955 & TRN & \\
\hline CHEMBL491940 & 688799 & 5.5 & 5.4027 & TRN & \\
\hline CHEMBL1358105 & 688799 & 5.8 & 5.8349 & TST & \\
\hline CHEMBL1396108 & 688799 & 5.3 & 5.1425 & TRN & \\
\hline CHEMBL1370553 & 688799 & 4.6 & 4.6908 & TRN & \\
\hline CHEMBL1434082 & 688799 & 5.3 & 5.4471 & TRN & \\
\hline CHEMBL1437776 & 688799 & 4.9 & 4.9625 & TRN & \\
\hline CHEMBL425403 & 688799 & 5.4 & 5.5024 & TST & \\
\hline CHEMBL1404882 & 688799 & 5.2 & 5.4389 & TRN & \\
\hline CHEMBL416657 & 688799 & 4.4 & 4.8202 & TRN & \\
\hline CHEMBL1332636 & 688799 & 5.6 & 5.9848 & TRN & \\
\hline CHEMBL1593134 & 688799 & 4.4 & 4.4596 & TRN & \\
\hline CHEMBL262083 & 688799 & 4.5 & 6.2891 & TRN & \\
\hline CHEMBL1453216 & 688799 & 5.2 & 5.3057 & TRN & \\
\hline CHEMBL1418144 & 688799 & 6.0 & 5.6874 & TST & \\
\hline CHEMBL241862 & 688799 & 5.9 & 5.6979 & TRN & \\
\hline CHEMBL1318544 & 688799 & 4.5 & 4.5718 & TRN & \\
\hline CHEMBL1515789 & 688799 & 5.9 & 5.2112 & TRN & \\
\hline CHEMBL1526964 & 688799 & 6.0 & 6.0638 & TST & \\
\hline CHEMBL1397009 & 688799 & 4.5 & 4.7313 & TRN & \\
\hline CHEMBL1454512 & 688799 & 5.6 & 5.5351 & TRN & \\
\hline CHEMBL994 & 688799 & 5.4 & 5.4987 & TST & \\
\hline CHEMBL276727 & 688799 & 4.4 & 4.7317 & TST & \\
\hline CHEMBL440084 & 688799 & 5.6 & 5.6109 & TRN & \\
\hline CHEMBL1456337 & 688799 & 5.4 & 5.5582 & TRN & \\
\hline & & & & 5544 & \\
\hline
\end{tabular}




\begin{tabular}{|c|c|c|c|c|c|}
\hline & & & & & \\
\hline CHEMBL1336787 & 688799 & 5.3 & 5.4295 & TRN & \\
\hline CHEMBL1365665 & 688799 & 5.8 & 6.1296 & TRN & \\
\hline CHEMBL1397913 & 688799 & 6.9 & 6.8014 & TRN & \\
\hline CHEMBL279218 & 688799 & 4.8 & 5.0319 & TRN & \\
\hline CHEMBL1378440 & 688799 & 4.9 & 4.853 & TRN & \\
\hline CHEMBL1437176 & 688799 & 5.0 & 5.0265 & TRN & \\
\hline CHEMBL1593582 & 688799 & 5.6 & 4.6197 & TRN & \\
\hline CHEMBL1608337 & 688799 & 5.7 & 5.9025 & TRN & \\
\hline CHEMBL1330614 & 688799 & 5.6 & 5.6791 & TRN & \\
\hline CHEMBL1438674 & 688799 & 4.4 & 4.75899 & 99999999995 & TRN \\
\hline CHEMBL1513392 & 688799 & 6.1 & 6.0539 & TRN & \\
\hline CHEMBL1365701 & 688799 & 6.1 & 6.3511 & TRN & \\
\hline CHEMBL1590886 & 688799 & 4.9 & 4.8176 & TRN & \\
\hline CHEMBL1601824 & 688799 & 7.6003 & 5.5189 & TRN & \\
\hline CHEMBL1457544 & 688799 & 4.4 & 4.4348 & TRN & \\
\hline CHEMBL1553488 & 688799 & 5.5 & 5.4589 & TRN & \\
\hline CHEMBL1611974 & 688799 & 8.699 & 5.1207 & TST & \\
\hline CHEMBL1412477 & 688799 & 6.8 & 6.6137 & TRN & \\
\hline CHEMBL1591460 & 688799 & 6.8 & 6.5596 & TRN & \\
\hline CHEMBL1356628 & 688799 & 4.6 & 4.4928 & TRN & \\
\hline CHEMBL1513876 & 688799 & 5.0 & 4.8803 & TRN & \\
\hline CHEMBL1516382 & 688799 & 5.9 & 5.6883 & TRN & \\
\hline CHEMBL1479741 & 688799 & 4.7 & 4.7265 & TRN & \\
\hline CHEMBL1529625 & 688799 & 4.4 & 4.5003 & TST & \\
\hline CHEMBL1416476 & 688799 & 5.8 & 5.6636 & TRN & \\
\hline CHEMBL1556742 & 688799 & 5.4 & 5.3883 & TST & \\
\hline CHEMBL1439400 & 688799 & 6.3 & 5.4321 & TRN & \\
\hline CHEMBL1554717 & 688799 & 6.3 & 6.08799 & 9999999999 & TRN \\
\hline CHEMBL1332735 & 688799 & 5.2 & 5.7034 & TRN & \\
\hline CHEMBL1554935 & 688799 & 4.7 & 4.9168 & TRN & \\
\hline CHEMBL98572 & 688799 & 5.0 & 5.1822 & TRN & \\
\hline CHEMBL269733 & 688799 & 4.6 & 4.9076 & TST & \\
\hline CHEMBL1318454 & 688799 & 4.7 & 4.6137 & TRN & \\
\hline CHEMBL1475617 & 688799 & 4.6 & 4.6866 & TRN & \\
\hline CHEMBL1355135 & 688799 & 4.8 & 4.9595 & TRN & \\
\hline CHEMBL1499077 & 688799 & 7.0 & 7.1318 & TRN & \\
\hline CHEMBL1602812 & 688799 & 4.6 & 4.5696 & TRN & \\
\hline CHEMBL180966 & 688799 & 5.2 & 5.395 & TRN & \\
\hline CHEMBL267373 & 688799 & 6.6 & 5.3079 & TRN & \\
\hline CHEMBL1552720 & 688799 & 6.2 & 6.131 & TRN & \\
\hline CHEMBL1560445 & 688799 & 6.8 & 6.5444 & TRN & \\
\hline CHEMBL1473055 & 688799 & 4.8 & 4.743 & TRN & \\
\hline CHEMBL281622 & 688799 & 6.6 & 6.5416 & TST & \\
\hline CHEMBL419815 & 688799 & 4.6 & 4.8077 & TST & \\
\hline CHEMBL1437314 & 688799 & 5.5 & 5.7944 & TRN & \\
\hline CHEMBL522600 & 688799 & 5.9 & 6.129 & TRN & \\
\hline CHEMBL1487561 & 688799 & 5.2 & 5.3271 & TRN & \\
\hline CHEMBL1534872 & 688799 & 4.8 & 4.8298 & TST & \\
\hline
\end{tabular}




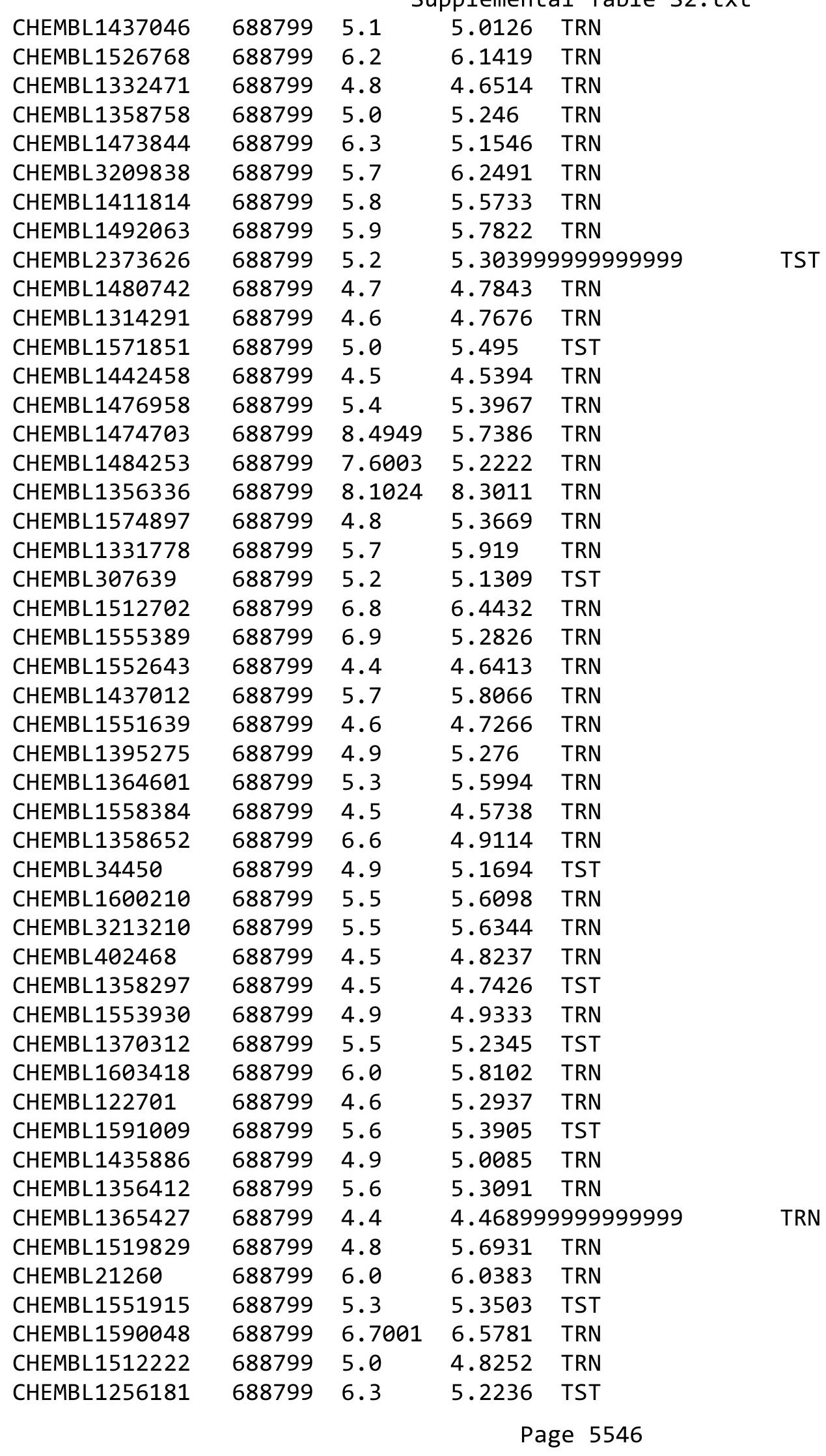




\begin{tabular}{|c|c|c|c|c|c|}
\hline & & \multicolumn{4}{|c|}{ Supplemental Table S2.txt } \\
\hline CHEMBL1355088 & 688799 & 7.1002 & 5.4964 & TRN & \\
\hline CHEMBL1355701 & 688799 & 5.9 & 5.8376 & TRN & \\
\hline CHEMBL1446774 & 688799 & 5.1 & 5.1674 & TRN & \\
\hline CHEMBL1365616 & 688799 & 4.7 & 4.7283 & TRN & \\
\hline CHEMBL242385 & 688799 & 5.4 & 5.6277 & TRN & \\
\hline CHEMBL28992 & 688799 & 4.8 & 5.0718 & TST & \\
\hline CHEMBL1594030 & 688799 & 5.0 & 5.0522 & TRN & \\
\hline CHEMBL1319286 & 688799 & 4.4 & 4.2171 & TRN & \\
\hline CHEMBL 1417140 & 688799 & 4.9 & 4.9559 & TRN & \\
\hline CHEMBL1513665 & 688799 & 4.6 & 4.5121 & TRN & \\
\hline CHEMBL491742 & 688799 & 5.1 & 5.1883 & TRN & \\
\hline CHEMBL1329026 & 688799 & 6.0 & 5.9689 & TST & \\
\hline CHEMBL1407011 & 688799 & 5.3 & 5.449 & TST & \\
\hline CHEMBL1354363 & 688799 & 5.0 & 5.1803 & TST & \\
\hline CHEMBL1552403 & 688799 & 5.3 & 5.51399 & 9999999999 & TST \\
\hline CHEMBL1320525 & 688799 & 4.6 & 4.6024 & TRN & \\
\hline CHEMBL1489392 & 688799 & 4.4 & 4.6517 & TST & \\
\hline CHEMBL1472922 & 688799 & 4.9 & 5.3612 & TRN & \\
\hline CHEMBL1590962 & 688799 & 4.4 & 4.8847 & TRN & \\
\hline CHEMBL1573532 & 688799 & 7.2 & 7.0719 & TRN & \\
\hline CHEMBL1564927 & 688799 & 5.4 & 5.4845 & TST & \\
\hline CHEMBL1552294 & 688799 & 4.4 & 4.5685 & TRN & \\
\hline CHEMBL1564813 & 688799 & 4.7 & 4.6531 & TRN & \\
\hline CHEMBL1513990 & 688799 & 7.1002 & 7.4468 & TRN & \\
\hline CHEMBL1514765 & 688799 & 5.5 & 5.6895 & TST & \\
\hline CHEMBL1610945 & 688799 & 5.4 & 5.4789 & TST & \\
\hline CHEMBL1096400 & 688799 & 6.0 & 5.9811 & TRN & \\
\hline CHEMBL1474317 & 688799 & 4.8 & 4.9744 & TRN & \\
\hline CHEMBL 1437158 & 688799 & 4.6 & 4.83899 & 99999999995 & TRN \\
\hline CHEMBL1445772 & 688799 & 4.5 & 4.5436 & TRN & \\
\hline CHEMBL1487929 & 688799 & 5.7 & 5.558 & TRN & \\
\hline CHEMBL1335466 & 688799 & 6.3 & 5.5526 & TRN & \\
\hline CHEMBL1355139 & 688799 & 6.3 & 6.5629 & TRN & \\
\hline CHEMBL1525024 & 688799 & 5.5 & 5.5608 & TST & \\
\hline CHEMBL1435544 & 688799 & 4.7 & 4.7978 & TRN & \\
\hline CHEMBL1377668 & 688799 & 4.4 & 4.5158 & TRN & \\
\hline CHEMBL1233960 & 688799 & 5.7 & 5.6329 & TRN & \\
\hline CHEMBL1592556 & 688799 & 6.5 & 6.3496 & TRN & \\
\hline CHEMBL1335409 & 688799 & 5.6 & 5.6674 & TST & \\
\hline CHEMBL164841 & 688799 & 6.4 & 5.6457 & TRN & \\
\hline CHEMBL1408238 & 688799 & 5.4 & 5.5719 & TST & \\
\hline CHEMBL1358467 & 688799 & 5.9 & 5.4581 & TRN & \\
\hline CHEMBL1359613 & 688799 & 4.9 & 4.9375 & TRN & \\
\hline CHEMBL1531754 & 688799 & 6.0 & 6.1859 & TRN & \\
\hline CHEMBL1321511 & 688799 & 5.5 & 5.8627 & TRN & \\
\hline CHEMBL1396791 & 688799 & 5.5 & 5.5716 & TRN & \\
\hline CHEMBL393136 & 688799 & 5.7 & 5.7074 & TST & \\
\hline CHEMBL1356844 & 688799 & 6.5 & 6.1946 & TRN & \\
\hline
\end{tabular}




\begin{tabular}{|c|c|c|c|c|c|}
\hline & & & & & \\
\hline CHEMBL1270168 & 688799 & 5.6 & 5.8026 & TRN & \\
\hline CHEMBL476135 & 688799 & 6.3 & 6.3848 & TST & \\
\hline CHEMBL1609403 & 688799 & 5.3 & 5.4018 & TST & \\
\hline CHEMBL1330388 & 688799 & 5.9 & 5.8475 & TST & \\
\hline CHEMBL1316711 & 688799 & 5.6 & 5.6212 & TRN & \\
\hline CHEMBL126077 & 688799 & 6.0 & 4.7642 & TST & \\
\hline CHEMBL1476604 & 688799 & 5.0 & 5.0277 & TRN & \\
\hline CHEMBL1590552 & 688799 & 5.5 & 5.5077 & TRN & \\
\hline CHEMBL1396862 & 688799 & 6.5 & 6.24100 & 30000000005 & TRN \\
\hline CHEMBL1370924 & 688799 & 5.8 & 5.2878 & TRN & \\
\hline CHEMBL1436355 & 688799 & 5.1 & 5.1364 & TRN & \\
\hline CHEMBL159096 & 688799 & 5.3 & 5.3369 & TST & \\
\hline CHEMBL1482581 & 688799 & 5.8 & 5.21200 & 0000000001 & TRN \\
\hline CHEMBL1559023 & 688799 & 5.1 & 5.0694 & TRN & \\
\hline CHEMBL1590156 & 688799 & 8.0 & 7.9528 & TRN & \\
\hline CHEMBL137803 & 688799 & 5.6 & 5.1972 & TST & \\
\hline CHEMBL1605882 & 688799 & 5.2 & 5.3585 & TRN & \\
\hline CHEMBL 289277 & 688799 & 6.0 & 5.5566 & TST & \\
\hline CHEMBL1555156 & 688799 & 5.5 & 5.7046 & TRN & \\
\hline CHEMBL1416009 & 688799 & 6.2 & 5.9677 & TST & \\
\hline CHEMBL 269550 & 688799 & 4.8 & 4.9842 & TRN & \\
\hline CHEMBL1551477 & 688799 & 5.4 & 5.316 & TRN & \\
\hline CHEMBL86537 & 688799 & 7.1002 & 6.9575 & TRN & \\
\hline CHEMBL507112 & 688799 & 6.6 & 6.7613 & TRN & \\
\hline CHEMBL1315184 & 688799 & 6.3 & 6.0517 & TRN & \\
\hline CHEMBL120806 & 688799 & 6.0 & 6.0216 & TRN & \\
\hline CHEMBL1317860 & 688799 & 5.1 & 5.4134 & TRN & \\
\hline CHEMBL1408730 & 688799 & 6.6 & 5.6403 & TRN & \\
\hline CHEMBL1356772 & 688799 & 5.4 & 5.4831 & TRN & \\
\hline CHEMBL1496125 & 688799 & 5.6 & 5.6665 & TRN & \\
\hline CHEMBL1413637 & 688799 & 4.8 & 5.0965 & TRN & \\
\hline CHEMBL68423 & 688799 & 4.5 & 4.8998 & TRN & \\
\hline CHEMBL1590378 & 688799 & 6.0 & 5.9462 & TST & \\
\hline CHEMBL1594329 & 688799 & 5.0 & 4.7987 & TRN & \\
\hline CHEMBL471225 & 688799 & 5.4 & 5.5314 & TRN & \\
\hline CHEMBL1331443 & 688799 & 6.0 & 5.8691 & TRN & \\
\hline CHEMBL1314247 & 688799 & 5.0 & 5.0198 & TRN & \\
\hline CHEMBL1554569 & 688799 & 5.3 & 5.2583 & TRN & \\
\hline CHEMBL1475574 & 688799 & 7.5003 & 6.7519 & TRN & \\
\hline CHEMBL1356302 & 688799 & 4.4 & 4.5193 & TRN & \\
\hline CHEMBL1553001 & 688799 & 4.5 & 4.6849 & TRN & \\
\hline CHEMBL1475689 & 688799 & 4.6 & 4.9492 & TRN & \\
\hline CHEMBL1474522 & 688799 & 6.0 & 5.4986 & TST & \\
\hline CHEMBL1554170 & 688799 & 5.5 & 5.2307 & TRN & \\
\hline CHEMBL1408922 & 688799 & 5.1 & 5.3018 & TST & \\
\hline CHEMBL1527722 & 688799 & 6.0 & 5.8638 & TRN & \\
\hline CHEMBL 88147 & 688799 & 5.8 & 5.8542 & TST & \\
\hline CHEMBL1555823 & 688799 & 5.4 & 5.4346 & TRN & \\
\hline & & & & e 5548 & \\
\hline
\end{tabular}




\begin{tabular}{|c|c|c|c|c|}
\hline \multicolumn{5}{|c|}{ splemental T } \\
\hline CHEMBL1396358 & 688799 & 4.8 & 4.9062 & TRN \\
\hline CHEMBL410873 & 688799 & 4.4 & 4.6965 & TRN \\
\hline CHEMBL1357770 & 688799 & 7.2 & 6.2725 & TST \\
\hline CHEMBL1566442 & 688799 & 6.1 & 5.9815 & TRN \\
\hline CHEMBL3210161 & 688799 & 7.0 & 7.0688 & TRN \\
\hline CHEMBL1439040 & 688799 & 5.9 & 5.5131 & TST \\
\hline CHEMBL1436507 & 688799 & 4.9 & 4.8923 & TRN \\
\hline CHEMBL1256737 & 688799 & 6.0 & 5.9775 & TRN \\
\hline CHEMBL1395107 & 688799 & 7.4001 & 5.2409 & TRN \\
\hline CHEMBL1490528 & 688799 & 4.6 & 4.4099 & TRN \\
\hline CHEMBL1513511 & 688799 & 5.4 & 5.4447 & TRN \\
\hline CHEMBL1456076 & 688799 & 5.4 & 5.4935 & TRN \\
\hline CHEMBL1488179 & 688799 & 5.1 & 5.1219 & TRN \\
\hline CHEMBL1437075 & 688799 & 5.0 & 4.8473 & TRN \\
\hline CHEMBL1331980 & 688799 & 5.6 & 5.7092 & TST \\
\hline CHEMBL1354725 & 688799 & 5.7 & 5.7765 & TRN \\
\hline CHEMBL1435919 & 688799 & 4.9 & 4.9915 & TRN \\
\hline CHEMBL1397308 & 688799 & 4.6 & 5.1064 & TRN \\
\hline CHEMBL1413132 & 688799 & 5.7 & 5.8954 & TRN \\
\hline CHEMBL1475969 & 688799 & 5.4 & 5.5093 & TST \\
\hline CHEMBL1483427 & 688799 & 4.5 & 4.7052 & TRN \\
\hline CHEMBL1370903 & 688799 & 7.1002 & 6.8633 & TRN \\
\hline CHEMBL1566987 & 688799 & 7.3002 & 7.2198 & TRN \\
\hline CHEMBL1368965 & 688799 & 4.4 & 4.4399 & TRN \\
\hline CHEMBL1355351 & 688799 & 5.1 & 5.3314 & TRN \\
\hline CHEMBL1563304 & 688799 & 6.4 & 6.3732 & TRN \\
\hline CHEMBL1318616 & 688799 & 4.4 & 4.4781 & TRN \\
\hline CHEMBL1513985 & 688799 & 4.6 & 4.8958 & TRN \\
\hline CHEMBL1408259 & 688799 & 6.0 & 6.1046 & TRN \\
\hline CHEMBL1565302 & 688799 & 4.8 & 4.7132 & TRN \\
\hline CHEMBL1457262 & 688799 & 5.0 & 5.2187 & TRN \\
\hline CHEMBL489738 & 688799 & 7.2 & 7.0583 & TRN \\
\hline CHEMBL1605152 & 688799 & 6.6 & 7.1103 & TRN \\
\hline CHEMBL586946 & 688799 & 4.8 & 4.922 & TST \\
\hline CHEMBL1450936 & 688799 & 5.5 & 5.5384 & TRN \\
\hline CHEMBL258767 & 688799 & 6.0 & 6.1251 & TRN \\
\hline CHEMBL1476084 & 688799 & 8.2007 & 7.7565 & TRN \\
\hline CHEMBL1441920 & 688799 & 6.0 & 4.7596 & TRN \\
\hline CHEMBL1533139 & 688799 & 5.2 & 5.3546 & TRN \\
\hline CHEMBL1558303 & 688799 & 7.0 & 6.8393 & TRN \\
\hline CHEMBL1364182 & 688799 & 4.6 & 5.0063 & TRN \\
\hline CHEMBL227725 & 688799 & 5.2 & 5.465 & TRN \\
\hline CHEMBL1323438 & 688799 & 4.8 & 4.8204 & TRN \\
\hline CHEMBL1357872 & 688799 & 4.8 & 4.8977 & TRN \\
\hline CHEMBL1324022 & 688799 & 5.1 & 5.3734 & TST \\
\hline CHEMBL1358462 & 688799 & 5.2 & 5.0442 & TRN \\
\hline CHEMBL143360 & 688799 & 5.0 & 5.3727 & TRN \\
\hline CHEMBL1411543 & 688799 & 5.8 & 6.0461 & TRN \\
\hline
\end{tabular}




\begin{tabular}{|c|c|c|c|c|}
\hline \multicolumn{5}{|r|}{ al Table S } \\
\hline CHEMBL1371781 & 688799 & 4.4 & 4.5123 & TRN \\
\hline CHEMBL1589897 & 688799 & 4.4 & 4.6293 & TRN \\
\hline CHEMBL1435702 & 688799 & 5.9 & 5.7191 & TRN \\
\hline CHEMBL1333783 & 688799 & 4.8 & 4.7506 & TRN \\
\hline CHEMBL521970 & 688799 & 5.0 & 5.0147 & TRN \\
\hline CHEMBL 1444652 & 688799 & 6.4 & 5.4723 & TRN \\
\hline CHEMBL1554743 & 688799 & 4.6 & 4.8747 & TRN \\
\hline CHEMBL1447721 & 688799 & 7.2 & 5.5304 & TST \\
\hline CHEMBL1357969 & 688799 & 5.7 & 5.3088 & TRN \\
\hline CHEMBL455185 & 688799 & 4.9 & 5.1794 & TRN \\
\hline CHEMBL 1358033 & 688799 & 5.0 & 4.9607 & TRN \\
\hline CHEMBL41680 & 688799 & 4.6 & 4.9516 & TST \\
\hline CHEMBL1330951 & 688799 & 5.4 & 5.6288 & TRN \\
\hline CHEMBL1326815 & 688799 & 5.8 & 5.8858 & TRN \\
\hline CHEMBL1551841 & 688799 & 5.0 & 4.9546 & TRN \\
\hline CHEMBL 1371572 & 688799 & 5.9 & 5.8247 & TRN \\
\hline CHEMBL1605255 & 688799 & 4.9 & 4.8612 & TRN \\
\hline CHEMBL1315316 & 688799 & 5.8 & 5.7888 & TRN \\
\hline CHEMBL1062 & 688799 & 5.3 & 5.6564 & TST \\
\hline CHEMBL1256709 & 688799 & 4.4 & 5.1707 & TST \\
\hline CHEMBL1592803 & 688799 & 5.0 & 5.1012 & TRN \\
\hline CHEMBL171064 & 688799 & 5.2 & 5.3047 & TRN \\
\hline CHEMBL1515131 & 688799 & 5.4 & 5.4808 & TST \\
\hline CHEMBL1496744 & 688799 & 5.1 & 5.0523 & TRN \\
\hline CHEMBL1441649 & 688799 & 4.4 & 5.091 & TRN \\
\hline CHEMBL1568744 & 688799 & 6.0 & 6.0542 & TRN \\
\hline CHEMBL1446815 & 688799 & 4.6 & 4.2343 & TRN \\
\hline CHEMBL1554659 & 688799 & 4.6 & 4.5899 & TRN \\
\hline CHEMBL1474498 & 688799 & 4.9 & 5.24100 & 00000000005 \\
\hline CHEMBL 282489 & 688799 & 4.9 & 4.9755 & TST \\
\hline CHEMBL285843 & 688799 & 7.8996 & 7.2181 & TRN \\
\hline CHEMBL1552277 & 688799 & 4.8 & 4.7953 & TRN \\
\hline CHEMBL277127 & 688799 & 4.8 & 5.0405 & TRN \\
\hline CHEMBL1415406 & 688799 & 5.2 & 5.2166 & TRN \\
\hline CHEMBL1328533 & 688799 & 5.0 & 5.1086 & TRN \\
\hline CHEMBL1570196 & 688799 & 4.9 & 5.1685 & TST \\
\hline CHEMBL1569497 & 688799 & 5.0 & 4.9443 & TRN \\
\hline CHEMBL86676 & 688799 & 6.0 & 5.7843 & TRN \\
\hline CHEMBL1439882 & 688799 & 4.8 & 4.7849 & TRN \\
\hline CHEMBL1599163 & 688799 & 4.9 & 5.0755 & TRN \\
\hline CHEMBL1481747 & 688799 & 5.0 & 5.0456 & TRN \\
\hline CHEMBL1595166 & 688799 & 4.6 & 4.7052 & TRN \\
\hline CHEMBL1554411 & 688799 & 6.4 & 6.3287 & TRN \\
\hline CHEMBL1574626 & 688799 & 5.6 & 5.5421 & TRN \\
\hline CHEMBL1513800 & 688799 & 4.5 & 4.5759 & TRN \\
\hline CHEMBL1448192 & 688799 & 7.1002 & 5.6755 & TRN \\
\hline CHEMBL1514748 & 688799 & 5.8 & 5.9026 & TRN \\
\hline CHEMBL1566017 & 688799 & 5.2 & 5.2269 & TRN \\
\hline
\end{tabular}




\begin{tabular}{|c|c|c|c|c|c|}
\hline & & & & & \\
\hline CHEMBL269521 & 688799 & 5.2 & 5.1698 & TRN & \\
\hline CHEMBL1433598 & 688799 & 5.5 & 5.8373 & TRN & \\
\hline CHEMBL1398646 & 688799 & 6.0 & 5.2067 & TRN & \\
\hline CHEMBL118109 & 688799 & 5.5 & 5.67700 & 20000000005 & TRN \\
\hline CHEMBL1474483 & 688799 & 5.6 & 5.6603 & TRN & \\
\hline CHEMBL1316402 & 688799 & 4.4 & 4.7935 & TRN & \\
\hline CHEMBL1474695 & 688799 & 4.6 & 4.6782 & TRN & \\
\hline CHEMBL1374501 & 688799 & 5.6 & 5.5844 & TRN & \\
\hline CHEMBL1256913 & 688799 & 4.5 & 5.1199 & TRN & \\
\hline CHEMBL1488990 & 688799 & 4.8 & 4.6767 & TRN & \\
\hline CHEMBL1609896 & 688799 & 4.9 & 4.8758 & TRN & \\
\hline CHEMBL1358807 & 688799 & 4.8 & 4.8111 & TRN & \\
\hline CHEMBL1358272 & 688799 & 5.8 & 5.6703 & TRN & \\
\hline CHEMBL1411389 & 688799 & 4.4 & 4.4087 & TRN & \\
\hline CHEMBL1316075 & 688799 & 5.1 & 5.2904 & TRN & \\
\hline CHEMBL1436361 & 688799 & 4.5 & 4.6278 & TRN & \\
\hline CHEMBL1334847 & 688799 & 4.9 & 4.9207 & TRN & \\
\hline CHEMBL1404598 & 688799 & 7.3002 & 7.6396 & TRN & \\
\hline CHEMBL1315373 & 688799 & 5.0 & 5.2872 & TRN & \\
\hline CHEMBL1411608 & 688799 & 5.6 & 5.6659 & TST & \\
\hline CHEMBL1339209 & 688799 & 6.3 & 6.2136 & TRN & \\
\hline CHEMBL1356923 & 688799 & 5.7 & 5.4926 & TRN & \\
\hline CHEMBL1593997 & 688799 & 4.4 & 4.455 & TRN & \\
\hline CHEMBL1409996 & 688799 & 4.6 & 4.4905 & TRN & \\
\hline CHEMBL491952 & 688799 & 4.7 & 4.6335 & TRN & \\
\hline CHEMBL236789 & 688799 & 4.6 & 4.8649 & TRN & \\
\hline CHEMBL1565842 & 688799 & 4.4 & 4.4834 & TRN & \\
\hline CHEMBL1411360 & 688799 & 5.6 & 6.1251 & TRN & \\
\hline CHEMBL1572655 & 688799 & 6.2 & 5.7936 & TST & \\
\hline CHEMBL1339099 & 688799 & 5.5 & 5.7617 & TRN & \\
\hline CHEMBL1441287 & 688799 & 4.6 & 4.3067 & TRN & \\
\hline CHEMBL1533516 & 688799 & 4.4 & 4.3104 & TRN & \\
\hline CHEMBL1489424 & 688799 & 5.7 & 5.8352 & TRN & \\
\hline CHEMBL1593707 & 688799 & 4.7 & 4.6428 & TRN & \\
\hline CHEMBL1357982 & 688799 & 5.3 & 5.1734 & TRN & \\
\hline CHEMBL1563497 & 688799 & 4.8 & 4.9972 & TST & \\
\hline CHEMBL45068 & 688799 & 6.0 & 5.2144 & TST & \\
\hline CHEMBL1483672 & 688799 & 6.0 & 5.6908 & TST & \\
\hline CHEMBL1357968 & 688799 & 4.7 & 4.8951 & TST & \\
\hline CHEMBL1453840 & 688799 & 5.3 & 5.7443 & TST & \\
\hline CHEMBL608109 & 688799 & 6.0 & 5.9552 & TST & \\
\hline CHEMBL476833 & 688799 & 5.1 & 5.1332 & TST & \\
\hline CHEMBL1590975 & 688799 & 4.6 & 4.9868 & TST & \\
\hline CHEMBL1321459 & 688799 & 5.4 & 5.3574 & TST & \\
\hline CHEMBL1331618 & 688799 & 6.2 & 6.3156 & TST & \\
\hline CHEMBL1472926 & 688799 & 5.9 & 5.8829 & TST & \\
\hline CHEMBL1449777 & 688799 & 5.4 & 5.4515 & TST & \\
\hline CHEMBL1529665 & 688799 & 6.2 & 6.0689 & TST & \\
\hline & & & & e 5551 & \\
\hline
\end{tabular}




\begin{tabular}{|c|c|c|c|c|c|}
\hline \multirow[b]{2}{*}{ CHEMBL1408427 } & \multicolumn{5}{|c|}{ Supplemental Table S2.txt } \\
\hline & 688799 & 7.6003 & 7.7631 & TST & \\
\hline CHEMBL543557 & 688799 & 5.1 & 5.1135 & TST & \\
\hline CHEMBL1611218 & 688799 & 5.0 & 5.0203 & TST & \\
\hline CHEMBL1527132 & 688799 & 6.5 & 6.1363 & TST & \\
\hline CHEMBL35482 & 688799 & 6.0 & 5.3672 & TST & \\
\hline CHEMBL1403388 & 688799 & 6.7001 & 6.5663 & TST & \\
\hline CHEMBL1555132 & 688799 & 4.7 & 4.9874 & TST & \\
\hline CHEMBL1395138 & 688799 & 6.0 & 5.74299 & 9999999999 & TST \\
\hline CHEMBL1354272 & 688799 & 4.4 & 4.8818 & TST & \\
\hline CHEMBL1604095 & 688799 & 4.9 & 4.7509 & TST & \\
\hline CHEMBL 1407257 & 688799 & 5.0 & 5.0484 & TST & \\
\hline CHEMBL492611 & 688799 & 4.8 & 4.7138 & TST & \\
\hline CHEMBL10284 & 688799 & 4.6 & 5.2913 & TST & \\
\hline CHEMBL1532921 & 688799 & 5.6 & 5.7137 & TST & \\
\hline CHEMBL1396630 & 688799 & 6.6 & 5.6038 & TST & \\
\hline CHEMBL 1473420 & 688799 & 4.4 & 4.4147 & TST & \\
\hline CHEMBL411502 & 688799 & 4.4 & 4.4656 & TST & \\
\hline CHEMBL1514587 & 688799 & 5.5 & 5.5015 & TST & \\
\hline CHEMBL1440157 & 688799 & 6.4 & 6.6319 & TST & \\
\hline CHEMBL1434149 & 688799 & 5.5 & 5.54700 & 0000000001 & TST \\
\hline CHEMBL 23507 & 688799 & 4.5 & 5.2844 & TST & \\
\hline CHEMBL1450395 & 688799 & 5.5 & 5.54899 & 99999999995 & TST \\
\hline CHEMBL 32147 & 688799 & 5.4 & 5.5873 & TST & \\
\hline CHEMBL1552066 & 688799 & 5.9 & 5.8822 & TST & \\
\hline CHEMBL1491104 & 688799 & 6.5 & 6.6511 & TST & \\
\hline CHEMBL1592754 & 688799 & 4.4 & 4.3801 & TST & \\
\hline CHEMBL1395226 & 688799 & 4.4 & 4.2297 & TST & \\
\hline CHEMBL1330317 & 688799 & 5.5 & 5.47 & TST & \\
\hline CHEMBL1336782 & 688799 & 5.3 & 5.2646 & TST & \\
\hline CHEMBL1439893 & 688799 & 5.1 & 5.0463 & TST & \\
\hline CHEMBL1567295 & 688799 & 5.4 & 5.5352 & TST & \\
\hline CHEMBL1490195 & 688799 & 5.0 & 5.2245 & TST & \\
\hline CHEMBL1318042 & 688799 & 5.3 & 5.449 & TST & \\
\hline CHEMBL1361226 & 688799 & 8.2007 & 7.9544 & TST & \\
\hline CHEMBL1330957 & 688799 & 5.3 & 5.51 & TST & \\
\hline CHEMBL1396384 & 688799 & 5.5 & 5.5195 & TST & \\
\hline CHEMBL1591874 & 688799 & 4.4 & 5.2472 & TST & \\
\hline CHEMBL1559163 & 688799 & 7.2 & 6.91299 & 9999999999 & TST \\
\hline CHEMBL1612346 & 688799 & 5.4 & 5.5065 & TST & \\
\hline CHEMBL1402106 & 688799 & 9.0 & 5.6031 & TST & \\
\hline CHEMBL1730100 & 688799 & 5.2 & 5.3365 & TST & \\
\hline CHEMBL1522155 & 688799 & 5.2 & 5.3961 & TST & \\
\hline CHEMBL1551090 & 688799 & 4.8 & 5.0537 & TST & \\
\hline CHEMBL1527332 & 688799 & 4.9 & 4.802 & TST & \\
\hline CHEMBL1566780 & 688799 & 5.2 & 5.4847 & TST & \\
\hline CHEMBL 1437650 & 688799 & 4.4 & 4.126 & TST & \\
\hline CHEMBL1324418 & 688799 & 4.6 & 4.7996 & TST & \\
\hline CHEMBL1366961 & 688799 & 4.4 & 5.1704 & TST & \\
\hline
\end{tabular}




\begin{tabular}{|c|c|c|c|c|c|}
\hline CHEMBL1528708 & 688799 & 5.6 & \multicolumn{2}{|c|}{5.531000000000001} & \multirow[t]{2}{*}{ TST } \\
\hline CHEMBL1333384 & 688799 & 6.2 & 6.0783 & TST & \\
\hline CHEMBL37081 & 688799 & 5.2 & 5.36 & TST & \\
\hline CHEMBL1317769 & 688799 & 5.7 & 4.6042 & TST & \\
\hline CHEMBL1572747 & 688799 & 6.1 & 6.0865 & TST & \\
\hline CHEMBL1318228 & 688799 & 4.6 & 4.8526 & TST & \\
\hline CHEMBL1441593 & 688799 & 5.8 & 6.1462 & TST & \\
\hline CHEMBL1688558 & 688799 & 5.4 & 5.5847 & TST & \\
\hline CHEMBL 259325 & 688799 & 5.5 & 5.7517 & TST & \\
\hline CHEMBL1433559 & 688799 & 4.8 & 4.8203 & TST & \\
\hline CHEMBL1597037 & 688799 & 5.9 & 5.8801 & TST & \\
\hline CHEMBL1395850 & 688799 & 4.7 & 4.9145 & TST & \\
\hline CHEMBL1435638 & 688799 & 5.8 & 5.8804 & TST & \\
\hline CHEMBL164660 & 688799 & 5.4 & 5.5211 & TST & \\
\hline CHEMBL74121 & 688799 & 5.3 & 5.341 & TST & \\
\hline CHEMBL1356843 & 688799 & 4.8 & 4.7348 & TST & \\
\hline CHEMBL1514272 & 688799 & 4.6 & 5.1959 & TST & \\
\hline CHEMBL1332937 & 688799 & 4.6 & 4.6076 & TST & \\
\hline CHEMBL1488197 & 688799 & 4.8 & 5.26 & TST & \\
\hline CHEMBL1411045 & 688799 & 5.8 & 5.7704 & TST & \\
\hline CHEMBL1568250 & 688799 & 5.4 & 5.3275 & TST & \\
\hline CHEMBL1553243 & 688799 & 7.5003 & 5.2566 & TST & \\
\hline CHEMBL1553070 & 688799 & 5.1 & 5.2676 & TST & \\
\hline CHEMBL1447333 & 688799 & 5.7 & 5.7359 & TST & \\
\hline CHEMBL1368572 & 688799 & 5.8 & 6.0916 & TST & \\
\hline CHEMBL1562334 & 688799 & 5.4 & 5.4392 & TST & \\
\hline CHEMBL369142 & 688799 & 8.6021 & 8.0602 & TST & \\
\hline CHEMBL1512385 & 688799 & 4.9 & 4.9668 & TST & \\
\hline CHEMBL1486734 & 688799 & 5.8 & 7.6716 & TST & \\
\hline CHEMBL1385840 & 688799 & 4.9 & 5.4027 & TST & \\
\hline CHEMBL1534566 & 688799 & 4.9 & 4.7872 & TST & \\
\hline CHEMBL1607868 & 688799 & 4.9 & 4.9449 & TST & \\
\hline CHEMBL1530445 & 688799 & 6.0 & 6.3509 & TST & \\
\hline CHEMBL1475079 & 688799 & 4.7 & 4.8074 & TST & \\
\hline CHEMBL1394949 & 688799 & 5.5 & 5.3374 & TST & \\
\hline CHEMBL1356808 & 688799 & 4.9 & 5.1605 & TST & \\
\hline CHEMBL1397443 & 688799 & 5.4 & 5.621 & TST & \\
\hline CHEMBL1316056 & 688799 & 5.5 & 5.3992 & TST & \\
\hline CHEMBL1563507 & 688799 & 5.1 & 5.3724 & TST & \\
\hline CHEMBL1395869 & 688799 & 5.9 & 6.2697 & TST & \\
\hline CHEMBL1357289 & 688799 & 4.9 & 4.8368 & TST & \\
\hline CHEMBL521971 & 688799 & 4.6 & 4.7711 & TST & \\
\hline CHEMBL1405744 & 688799 & 6.0 & 5.9041 & TST & \\
\hline CHEMBL375270 & 688799 & 6.1 & 6.01399 & 9999999999 & TST \\
\hline CHEMBL1552854 & 688799 & 5.1 & 5.2162 & TST & \\
\hline CHEMBL1482426 & 688799 & 4.9 & 4.7231 & TST & \\
\hline CHEMBL1327466 & 688799 & 5.9 & 6.1942 & TST & \\
\hline CHEMBL1434447 & 688799 & 6.5 & 5.4523 & TST & \\
\hline & & & & 5553 & \\
\hline
\end{tabular}




\begin{tabular}{|c|c|c|c|c|}
\hline \multicolumn{5}{|c|}{ Supplemental Table S2.txt } \\
\hline CHEMBL1528565 & 688799 & 4.4 & 5.5281 & TST \\
\hline CHEMBL 1447550 & 688799 & 5.6 & 5.7723 & TST \\
\hline CHEMBL1534591 & 688799 & 4.7 & 4.7749 & TST \\
\hline CHEMBL1361905 & 688799 & 5.0 & 5.2853 & TST \\
\hline CHEMBL119841 & 688799 & 4.8 & 4.816 & TST \\
\hline CHEMBL1492577 & 688799 & 7.2 & 5.5738 & TST \\
\hline CHEMBL568379 & 688799 & 5.9 & 5.7321 & TST \\
\hline CHEMBL1593981 & 688799 & 5.6 & 5.71200 & 0000000001 \\
\hline CHEMBL1376143 & 688799 & 4.4 & 4.5652 & TST \\
\hline CHEMBL1554579 & 688799 & 5.2 & 5.3894 & TST \\
\hline CHEMBL1604421 & 688799 & 5.0 & 4.9179 & TST \\
\hline CHEMBL1356771 & 688799 & 5.9 & 5.7368 & TST \\
\hline CHEMBL490717 & 688799 & 4.9 & 5.1938 & TST \\
\hline CHEMBL1397892 & 688799 & 4.4 & 5.0973 & TST \\
\hline CHEMBL1253351 & 688799 & 4.9 & 5.0344 & TST \\
\hline CHEMBL331372 & 688799 & 4.9 & 4.9648 & TST \\
\hline CHEMBL30432 & 688799 & 4.6 & 4.9488 & TST \\
\hline CHEMBL41040 & 688799 & 4.4 & 5.3994 & TST \\
\hline CHEMBL1514143 & 688799 & 5.3 & 5.2085 & TST \\
\hline CHEMBL1565169 & 688799 & 5.6 & 5.7773 & TST \\
\hline CHEMBL1487450 & 688799 & 8.301 & 5.3305 & TST \\
\hline CHEMBL467085 & 688799 & 5.1 & 5.305 & TST \\
\hline CHEMBL1336932 & 688799 & 5.0 & 4.8272 & TST \\
\hline CHEMBL1362562 & 688799 & 5.5 & 5.4951 & TST \\
\hline CHEMBL1316108 & 688799 & 4.5 & 4.7041 & TST \\
\hline CHEMBL222519 & 688799 & 4.6 & 4.939 & TST \\
\hline CHEMBL1397334 & 688799 & 8.3979 & 8.0517 & TST \\
\hline CHEMBL1316828 & 688799 & 4.8 & 4.9549 & TST \\
\hline CHEMBL1609178 & 688799 & 5.4 & 5.6556 & TST \\
\hline CHEMBL1364243 & 688799 & 6.0 & 6.1832 & TST \\
\hline CHEMBL1377111 & 688799 & 6.0 & 5.8165 & TST \\
\hline CHEMBL1316629 & 688799 & 6.0 & 6.2698 & TST \\
\hline CHEMBL1360778 & 688799 & 4.8 & 5.4862 & TST \\
\hline CHEMBL1603802 & 688799 & 5.5 & 5.6582 & TST \\
\hline CHEMBL1476850 & 688799 & 5.4 & 5.4954 & TST \\
\hline CHEMBL1354626 & 688799 & 5.6 & 5.669 & TST \\
\hline CHEMBL1337479 & 688799 & 4.4 & 4.5832 & TST \\
\hline CHEMBL1602329 & 688799 & 4.6 & 5.1228 & TST \\
\hline CHEMBL1474294 & 688799 & 5.5 & 5.5207 & TST \\
\hline CHEMBL1355256 & 688799 & 5.4 & 5.5414 & TST \\
\hline CHEMBL1331112 & 688799 & 4.6 & 4.7885 & TST \\
\hline CHEMBL1437692 & 688799 & 5.3 & 5.7281 & TST \\
\hline CHEMBL1439401 & 688799 & 4.6 & 4.79 & TST \\
\hline CHEMBL1553399 & 688799 & 4.9 & 5.1558 & TST \\
\hline CHEMBL 1371710 & 688799 & 6.0 & 6.0703 & TST \\
\hline CHEMBL1562088 & 688799 & 5.8 & 5.5982 & TST \\
\hline CHEMBL1555255 & 688799 & 6.0 & 5.3376 & TST \\
\hline CHEMBL1488304 & 688799 & 5.5 & 5.2451 & TST \\
\hline
\end{tabular}




\begin{tabular}{|c|c|c|c|c|}
\hline \multicolumn{5}{|c|}{ lemental Ta } \\
\hline CHEMBL1476139 & 688799 & 4.4 & 4.4408 & TST \\
\hline CHEMBL1361807 & 688799 & 5.5 & 5.037 & TST \\
\hline CHEMBL1330692 & 688799 & 6.5 & 6.56 & TST \\
\hline CHEMBL1473099 & 688799 & 6.4 & 6.3262 & TST \\
\hline CHEMBL392394 & 688799 & 5.3 & 5.3263 & TST \\
\hline CHEMBL280065 & 688799 & 4.7 & 4.7948 & TST \\
\hline CHEMBL1552201 & 688799 & 4.7 & 4.829 & TST \\
\hline CHEMBL1406879 & 688799 & 5.1 & 4.9644 & TST \\
\hline CHEMBL1435079 & 688799 & 5.5 & 5.3731 & TST \\
\hline CHEMBL1406936 & 688799 & 5.2 & 5.3531 & TST \\
\hline CHEMBL 1445026 & 688799 & 5.6 & 5.7246 & TST \\
\hline CHEMBL1532103 & 688799 & 7.0 & 5.5425 & TST \\
\hline CHEMBL491909 & 688799 & 5.1 & 5.2773 & TST \\
\hline CHEMBL1603393 & 688799 & 4.9 & 4.9277 & TST \\
\hline CHEMBL1377591 & 688799 & 5.2 & 5.3667 & TST \\
\hline CHEMBL1363413 & 688799 & 5.1 & 5.5536 & TST \\
\hline CHEMBL1332346 & 688799 & 4.9 & 4.8943 & TST \\
\hline CHEMBL1533232 & 688799 & 5.4 & 5.2096 & TST \\
\hline CHEMBL1475789 & 688799 & 5.5 & 5.5678 & TST \\
\hline CHEMBL1374544 & 688799 & 6.2 & 5.984 & TST \\
\hline CHEMBL1436644 & 688799 & 5.0 & 5.49299 & 9999999999 \\
\hline CHEMBL1606094 & 688799 & 5.7 & 5.7008 & TST \\
\hline CHEMBL1256835 & 688799 & 5.2 & 5.3444 & TST \\
\hline CHEMBL1357429 & 688799 & 4.6 & 4.7577 & TST \\
\hline CHEMBL1608410 & 688799 & 5.4 & 5.2534 & TST \\
\hline CHEMBL1256910 & 688799 & 4.5 & 4.6632 & TST \\
\hline CHEMBL1436743 & 688799 & 6.0 & 5.7972 & TST \\
\hline CHEMBL1516187 & 688799 & 5.9 & 6.0121 & TST \\
\hline CHEMBL1562589 & 688799 & 6.5 & 6.6553 & TST \\
\hline CHEMBL1515310 & 688799 & 8.699 & 5.0206 & TST \\
\hline CHEMBL1317913 & 688799 & 4.9 & 4.935 & TST \\
\hline CHEMBL1410926 & 688799 & 4.8 & 4.9426 & TST \\
\hline CHEMBL137648 & 688799 & 5.1 & 5.0031 & TST \\
\hline CHEMBL1328369 & 688799 & 5.9 & 5.9883 & TST \\
\hline CHEMBL1535470 & 688799 & 5.8 & 5.3227 & TST \\
\hline CHEMBL1159900 & 688799 & 4.6 & 4.8925 & TST \\
\hline CHEMBL1555314 & 688799 & 4.6 & 4.689 & TST \\
\hline CHEMBL1592209 & 688799 & 5.4 & 5.5028 & TST \\
\hline CHEMBL275938 & 688799 & 4.6 & 5.0273 & TST \\
\hline CHEMBL1570851 & 688799 & 5.7 & 5.8255 & TST \\
\hline CHEMBL1453641 & 688799 & 5.3 & 5.3755 & TST \\
\hline CHEMBL1441415 & 688799 & 5.0 & 5.0033 & TST \\
\hline CHEMBL1516415 & 688799 & 5.1 & 5.4189 & TST \\
\hline CHEMBL1591368 & 688799 & 5.3 & 5.6138 & TST \\
\hline CHEMBL1316165 & 688799 & 4.4 & 4.4801 & TST \\
\hline CHEMBL1449838 & 688799 & 5.5 & 5.7145 & TST \\
\hline CHEMBL1415053 & 688799 & 5.8 & 5.7217 & TST \\
\hline CHEMBL491943 & 688799 & 4.8 & 4.8119 & TST \\
\hline
\end{tabular}




\begin{tabular}{|c|c|c|c|c|c|}
\hline \multicolumn{6}{|c|}{ splemental } \\
\hline CHEMBL1405464 & 688799 & 5.3 & 5.3127 & TST & \\
\hline CHEMBL1496315 & 688799 & 5.8 & 6.0471 & TST & \\
\hline CHEMBL44083 & 688799 & 5.2 & 5.1165 & TST & \\
\hline CHEMBL1490740 & 688799 & 4.4 & 4.6391 & TST & \\
\hline CHEMBL1414641 & 688799 & 5.5 & 5.3328 & TST & \\
\hline CHEMBL1393664 & 688799 & 5.2 & 5.3624 & TST & \\
\hline CHEMBL1512122 & 688799 & 5.2 & 5.5102 & TST & \\
\hline CHEMBL1981840 & 688799 & 5.3 & 5.5622 & TST & \\
\hline CHEMBL3207894 & 688799 & 6.0 & 6.0119 & TST & \\
\hline CHEMBL1318509 & 688799 & 5.0 & 5.1079 & TST & \\
\hline CHEMBL1568019 & 688799 & 5.0 & 5.0052 & TST & \\
\hline CHEMBL1474681 & 688799 & 5.8 & 5.8523 & TST & \\
\hline CHEMBL1474479 & 688799 & 4.9 & 5.0444 & TST & \\
\hline CHEMBL1338985 & 688799 & 5.0 & 5.2012 & TST & \\
\hline CHEMBL467706 & 688799 & 5.2 & 5.4279 & TST & \\
\hline CHEMBL1475338 & 688799 & 6.3 & 6.1962 & TST & \\
\hline CHEMBL88272 & 688799 & 5.7 & 5.7422 & TST & \\
\hline CHEMBL1335195 & 688799 & 5.0 & 5.1689 & TST & \\
\hline CHEMBL1516054 & 688799 & 5.5 & 5.4697 & TST & \\
\hline CHEMBL1515417 & 688799 & 6.0 & 5.8589 & TST & \\
\hline CHEMBL1589925 & 688799 & 5.1 & 5.2367 & TST & \\
\hline CHEMBL54909 & 688799 & 4.4 & 5.38200 & 0000000001 & TST \\
\hline CHEMBL1440943 & 688799 & 5.1 & 5.2329 & TST & \\
\hline CHEMBL1327355 & 688799 & 5.9 & 5.7332 & TST & \\
\hline CHEMBL1569592 & 688799 & 5.1 & 4.9864 & TST & \\
\hline CHEMBL1551749 & 688799 & 4.9 & 4.8226 & TST & \\
\hline CHEMBL1455438 & 688799 & 4.4 & 4.2665 & TST & \\
\hline CHEMBL1362501 & 688799 & 5.9 & 5.5291 & TST & \\
\hline CHEMBL1394728 & 688799 & 5.2 & 5.6044 & TST & \\
\hline CHEMBL1516015 & 688799 & 4.8 & 5.0585 & TST & \\
\hline CHEMBL1401298 & 688799 & 5.1 & 5.2902 & TST & \\
\hline CHEMBL1520907 & 688799 & 7.6003 & 5.7544 & TST & \\
\hline CHEMBL1397634 & 688799 & 6.3 & 6.4277 & TST & \\
\hline CHEMBL1315083 & 688799 & 5.4 & 5.4424 & TST & \\
\hline CHEMBL1376005 & 688799 & 5.3 & 5.5097 & TST & \\
\hline CHEMBL1456420 & 688799 & 5.1 & 5.1186 & TST & \\
\hline CHEMBL1318105 & 688799 & 5.3 & 5.0485 & TST & \\
\hline CHEMBL1439625 & 688799 & 5.3 & 5.2159 & TST & \\
\hline CHEMBL1328109 & 688799 & 6.3 & 6.2665 & TST & \\
\hline CHEMBL102740 & 688799 & 5.6 & 5.3893 & TST & \\
\hline CHEMBL1409396 & 688799 & 5.6 & 5.8438 & TST & \\
\hline CHEMBL1314371 & 688799 & 5.9 & 5.5064 & TST & \\
\hline CHEMBL1457143 & 688799 & 5.6 & 5.6092 & TST & \\
\hline CHEMBL491976 & 688799 & 5.8 & 5.9152 & TST & \\
\hline CHEMBL1524650 & 688799 & 4.4 & 4.5693 & TST & \\
\hline CHEMBL1474471 & 688799 & 6.0 & 5.9827 & TST & \\
\hline CHEMBL470881 & 688799 & 4.9 & 5.2452 & TST & \\
\hline CHEMBL1358983 & 688799 & 5.0 & 4.8309 & TST & \\
\hline
\end{tabular}




\begin{tabular}{|c|c|c|c|c|c|}
\hline \multicolumn{6}{|c|}{ plemental } \\
\hline CHEMBL1485069 & 688799 & 6.8 & 6.0605 & TST & \\
\hline CHEMBL1331363 & 688799 & 5.1 & 5.2357 & TST & \\
\hline CHEMBL1440487 & 688799 & 5.1 & 5.1269 & TST & \\
\hline CHEMBL 297717 & 69638 & 5.8539 & 5.8562 & TRN & \\
\hline CHEMBL52818 & 69638 & 6.0177 & 6.0134 & TRN & \\
\hline CHEMBL441978 & 69638 & 6.7959 & 6.794 & TRN & \\
\hline CHEMBL53977 & 69638 & 5.0 & 5.0025 & TRN & \\
\hline CHEMBL13662 & 69638 & 7.2441 & 4.8035 & TST & \\
\hline CHEMBL55081 & 69638 & 5.0 & 5.0016 & TRN & \\
\hline CHEMBL296383 & 69638 & 7.4949 & 7.4972 & TRN & \\
\hline CHEMBL50320 & 69638 & 7.7447 & 7.7466 & TRN & \\
\hline CHEMBL54211 & 69638 & 6.4202 & 6.4232 & TRN & \\
\hline CHEMBL 273680 & 69638 & 5.0 & 4.9973 & TRN & \\
\hline CHEMBL301063 & 69638 & 7.7959 & 7.7881 & TRN & \\
\hline CHEMBL 300497 & 69638 & 8.3188 & 8.3204 & TRN & \\
\hline CHEMBL 297481 & 69638 & 6.5229 & 6.5194 & TRN & \\
\hline CHEMBL 300867 & 69638 & 6.699 & 6.6936 & TRN & \\
\hline CHEMBL50402 & 69638 & 7.7447 & 7.744 & TRN & \\
\hline CHEMBL 297958 & 69638 & 6.301 & 6.0174 & TST & \\
\hline CHEMBL53642 & 69638 & 6.1367 & 6.1328 & TRN & \\
\hline CHEMBL52696 & 69638 & 6.3188 & 6.3204 & TRN & \\
\hline CHEMBL 292380 & 69638 & 8.6383 & 8.6286 & TRN & \\
\hline CHEMBL 299995 & 69638 & 5.0 & 5.4341 & TST & \\
\hline CHEMBL 299882 & 69638 & 5.0 & 4.9961 & TRN & \\
\hline CHEMBL53528 & 69638 & 5.0 & 5.0066 & TRN & \\
\hline CHEMBL 298386 & 69638 & 8.6198 & 8.617 & TRN & \\
\hline CHEMBL 299736 & 69638 & 6.6021 & 6.605 & TRN & \\
\hline CHEMBL54859 & 69638 & 5.1938 & 5.1299 & TST & \\
\hline CHEMBL 301181 & 69638 & 7.3872 & 7.3987 & TRN & \\
\hline CHEMBL 299437 & 69638 & 7.7212 & 7.7281 & TRN & \\
\hline CHEMBL53729 & 69638 & 6.0458 & 6.0426 & TRN & \\
\hline CHEMBL52962 & 69638 & 5.0 & 4.7668 & TST & \\
\hline CHEMBL301336 & 69638 & 6.585 & 6.5822 & TRN & \\
\hline CHEMBL445358 & 69638 & 6.6198 & 6.6251 & TRN & \\
\hline CHEMBL 300862 & 69638 & 8.699 & 8.7028 & TRN & \\
\hline CHEMBL 296607 & 69638 & 8.6576 & 8.6653 & TRN & \\
\hline CHEMBL51911 & 69638 & 6.8539 & 6.8569 & TRN & \\
\hline CHEMBL 298501 & 69638 & 6.6021 & 6.599 & TRN & \\
\hline CHEMBL 299642 & 69638 & 7.2518 & 7.2557 & TRN & \\
\hline CHEMBL299210 & 69638 & 9.2924 & 9.292 & TRN & \\
\hline CHEMBL 300690 & 69638 & 6.1487 & 6.148 & TRN & \\
\hline CHEMBL 292462 & 69638 & 8.4089 & 8.40899 & 9999999999 & TRN \\
\hline CHEMBL50581 & 69638 & 6.5528 & 6.5493 & TRN & \\
\hline CHEMBL52014 & 69638 & 5.0 & 4.9978 & TRN & \\
\hline CHEMBL 298730 & 69638 & 5.0 & 4.9982 & TRN & \\
\hline CHEMBL 301104 & 69638 & 5.0 & 5.0007 & TRN & \\
\hline CHEMBL 273456 & 69638 & 7.4202 & 7.4227 & TRN & \\
\hline CHEMBL52672 & 69638 & 7.6198 & 7.6236 & TRN & \\
\hline
\end{tabular}




\begin{tabular}{|c|c|c|c|c|c|}
\hline \multicolumn{6}{|c|}{ Supplemental Table S2.txt } \\
\hline CHEMBL53238 & 69638 & 8.3665 & 8.356 & TRN & \\
\hline CHEMBL 299802 & 69638 & 7.3098 & 7.308 & TRN & \\
\hline CHEMBL 298760 & 69638 & 7.2518 & 7.2538 & TRN & \\
\hline CHEMBL 300951 & 69638 & 8.9208 & 8.9182 & TRN & \\
\hline CHEMBL55450 & 69638 & 7.4949 & 7.4965 & TRN & \\
\hline CHEMBL 300018 & 69638 & 6.8539 & 6.0809 & TST & \\
\hline CHEMBL53587 & 69638 & 7.1487 & 7.774 & TST & \\
\hline CHEMBL52640 & 69638 & 6.0969 & 6.5415 & TST & \\
\hline CHEMBL 300615 & 69638 & 9.0862 & 8.7723 & TST & \\
\hline CHEMBL52030 & 69638 & 7.3565 & 7.9318 & TST & \\
\hline CHEMBL416659 & 69638 & 8.0757 & 7.914 & TST & \\
\hline CHEMBL52310 & 69638 & 7.585 & 7.1058 & TST & \\
\hline CHEMBL299611 & 69638 & 8.5686 & 8.5016 & TST & \\
\hline CHEMBL441612 & 69638 & 7.7447 & 7.3119 & TST & \\
\hline CHEMBL53529 & 69638 & 6.7959 & 6.5723 & TST & \\
\hline CHEMBL 2442381 & 992679 & 5.1249 & 5.1093 & TRN & \\
\hline CHEMBL 2442411 & 992679 & 5.7959 & 5.9328 & TRN & \\
\hline CHEMBL1324368 & 992679 & 3.5229 & 3.4038 & TRN & \\
\hline CHEMBL1951825 & 992679 & 5.5229 & 5.523 & TRN & \\
\hline CHEMBL 2442533 & 992679 & 5.699 & 5.7906 & TRN & \\
\hline CHEMBL 2442380 & 992679 & 3.5229 & 3.5766 & TRN & \\
\hline CHEMBL 2442426 & 992679 & 7.9208 & 7.8042 & TRN & \\
\hline CHEMBL519022 & 992679 & 4.585 & 4.511 & TRN & \\
\hline CHEMBL1414686 & 992679 & 3.5229 & 3.5254 & TRN & \\
\hline CHEMBL 2442386 & 992679 & 4.585 & 4.5135 & TRN & \\
\hline CHEMBL1339927 & 992679 & 4.5229 & 4.4873 & TRN & \\
\hline CHEMBL 2442416 & 992679 & 6.6198 & 6.7182 & TRN & \\
\hline CHEMBL 2442406 & 992679 & 4.9208 & 4.9618 & TST & \\
\hline CHEMBL 2442382 & 992679 & 3.5229 & 3.0985 & TRN & \\
\hline CHEMBL2442379 & 992679 & 3.5229 & 3.5663 & TRN & \\
\hline CHEMBL 2442417 & 992679 & 6.9208 & 7.0364 & TRN & \\
\hline CHEMBL 2442410 & 992679 & 5.6576 & 5.6873 & TRN & \\
\hline CHEMBL 2442409 & 992679 & 3.5229 & 3.5529 & TRN & \\
\hline CHEMBL 2442393 & 992679 & 3.5229 & 3.5906 & TRN & \\
\hline CHEMBL1356298 & 992679 & 4.6383 & 4.4506 & TRN & \\
\hline CHEMBL 2442390 & 992679 & 3.5229 & 3.7132 & TRN & \\
\hline CHEMBL 2442424 & 992679 & 8.0 & 8.1776 & TRN & \\
\hline CHEMBL 2442391 & 992679 & 3.5229 & 3.5457 & TRN & \\
\hline CHEMBL2442526 & 992679 & 7.1079 & 7.1452 & TRN & \\
\hline CHEMBL 2442389 & 992679 & 7.0 & 6.9794 & TRN & \\
\hline CHEMBL 2442376 & 992679 & 3.5229 & 3.63199 & 99999999997 & TRN \\
\hline CHEMBL 2442425 & 992679 & 7.699 & 7.5735 & TRN & \\
\hline CHEMBL 2442385 & 992679 & 3.5229 & 3.7643 & TRN & \\
\hline CHEMBL 2442531 & 992679 & 8.3979 & 8.1946 & TRN & \\
\hline CHEMBL1463081 & 992679 & 3.5229 & 3.5266 & TRN & \\
\hline CHEMBL 2442532 & 992679 & 7.0605 & 6.9548 & TRN & \\
\hline CHEMBL 2442394 & 992679 & 4.7212 & 4.7919 & TRN & \\
\hline CHEMBL 2442399 & 992679 & 4.6778 & 5.0235 & TST & \\
\hline
\end{tabular}


Supplemental Table S2.txt

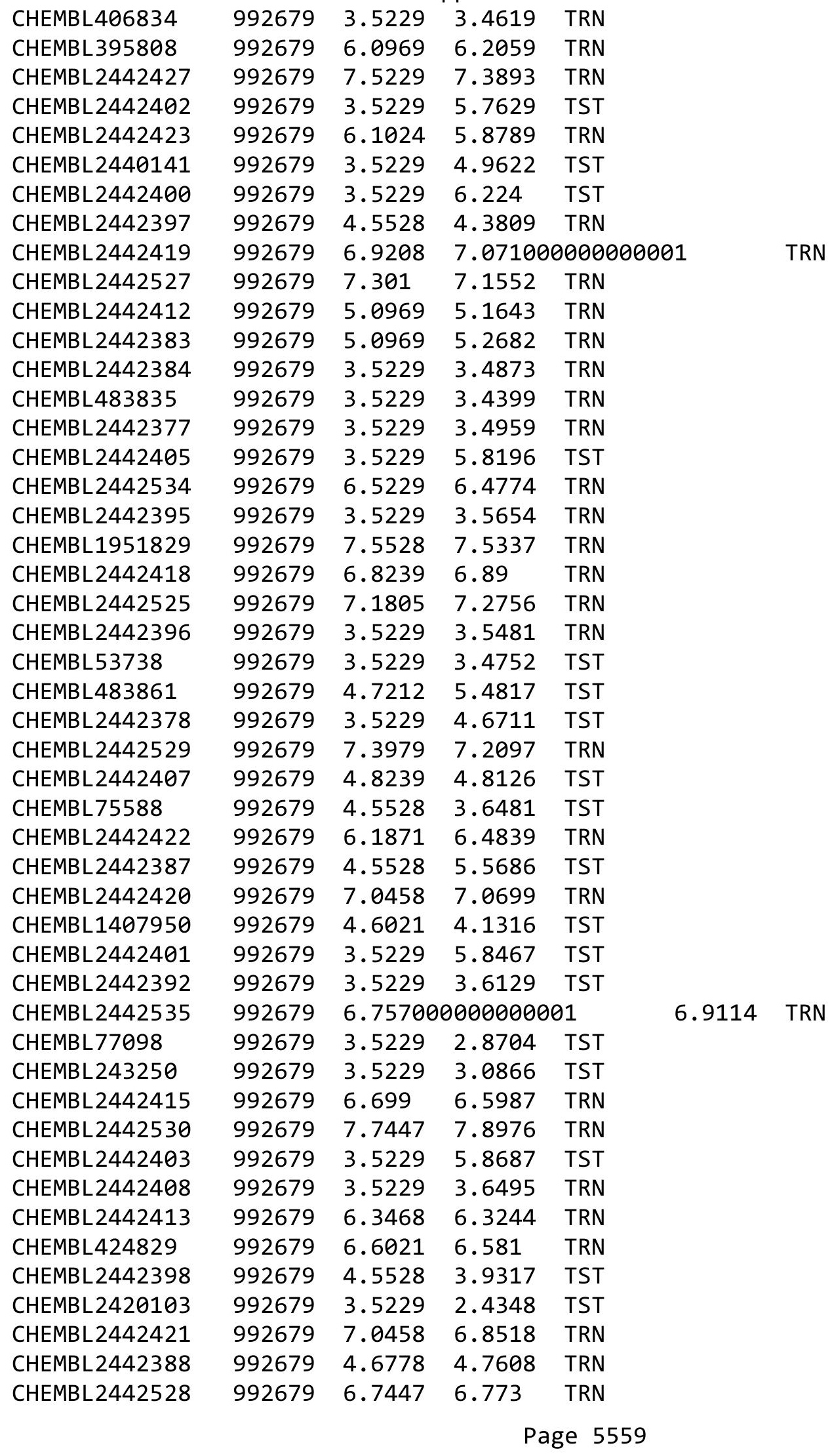




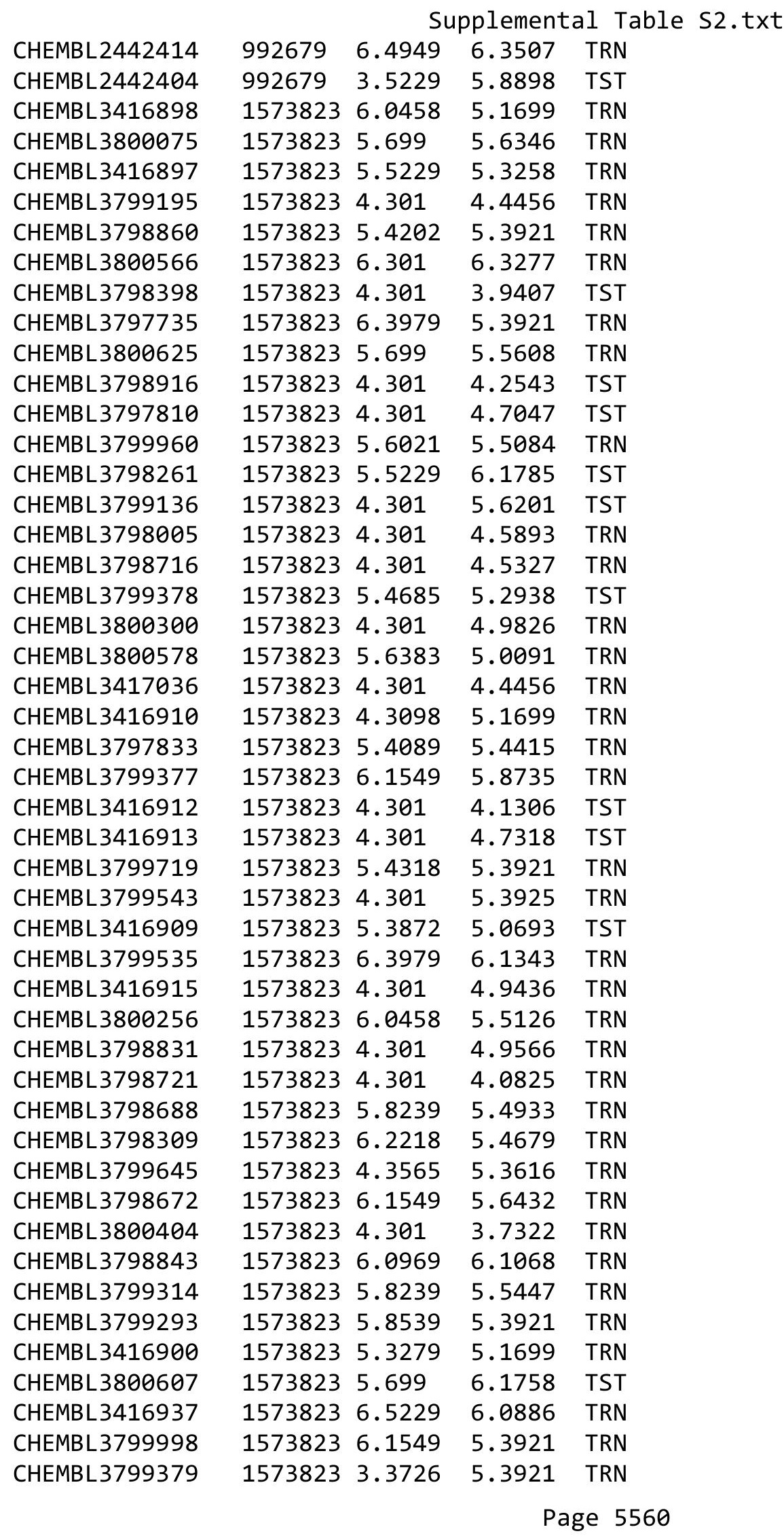


Supplemental Table S2.txt

\begin{tabular}{|c|c|c|c|c|c|}
\hline CHEMBL3800498 & 1573823 & 5.5686 & 5.6201 & TST & \\
\hline CHEMBL3417035 & 1573823 & 5.5528 & 5.3921 & TRN & \\
\hline CHEMBL3800461 & 1573823 & 5.4685 & 5.5608 & TRN & \\
\hline CHEMBL3800504 & 1573823 & 6.2218 & 5.9104 & TST & \\
\hline CHEMBL3798023 & 1573823 & 6.0 & 5.6432 & TRN & \\
\hline CHEMBL3416891 & 1573823 & 4.5229 & 5.1592 & TRN & \\
\hline CHEMBL3797965 & 1573823 & 4.3979 & 5.3921 & TRN & \\
\hline CHEMBL3800477 & 1573823 & 4.301 & 5.4682 & TST & \\
\hline CHEMBL3798549 & 1573823 & 5.8539 & 5.8046 & TST & \\
\hline CHEMBL 3800184 & 1573823 & 6.1549 & 5.8735 & TRN & \\
\hline CHEMBL3798929 & 1573823 & 5.8539 & 5.6041 & TRN & \\
\hline CHEMBL3797956 & 1573823 & 4.301 & 3.716 & TRN & \\
\hline CHEMBL3800588 & 1573823 & 5.6383 & 6.1343 & TST & \\
\hline CHEMBL 3800234 & 1573823 & 5.7447 & 5.3921 & TRN & \\
\hline CHEMBL 3798970 & 1573823 & 4.4202 & 5.2938 & TST & \\
\hline CHEMBL3799005 & 1573823 & 4.3872 & 5.3921 & TRN & \\
\hline CHEMBL3799839 & 1573823 & 4.301 & 4.4456 & TRN & \\
\hline CHEMBL3798829 & 1573823 & 4.301 & 4.5139 & TST & \\
\hline CHEMBL 3797578 & 1573823 & 5.8239 & 5.5511 & TRN & \\
\hline CHEMBL3797934 & 1573823 & 4.3098 & 5.302006 & 0000000005 & TST \\
\hline CHEMBL3416892 & 1573823 & 5.4949 & 5.2891 & TRN & \\
\hline CHEMBL3799846 & 1573823 & 5.7212 & 5.3921 & TRN & \\
\hline CHEMBL3416899 & 1573823 & 5.5686 & 5.1699 & TRN & \\
\hline CHEMBL3800058 & 1573823 & 5.3979 & 5.4737 & TRN & \\
\hline CHEMBL 3798008 & 1573823 & 5.6021 & 5.3921 & TRN & \\
\hline CHEMBL3798546 & 1573823 & 5.5376 & 5.4762 & TST & \\
\hline CHEMBL3797247 & 1573823 & 5.6383 & 4.4456 & TRN & \\
\hline CHEMBL3799101 & 1573823 & 5.585 & 5.1642 & TST & \\
\hline CHEMBL 3800274 & 1573823 & 4.3279 & 5.5199 & TST & \\
\hline CHEMBL3799797 & 1573823 & 4.301 & 3.7314 & TRN & \\
\hline CHEMBL 3800248 & 1573823 & 4.301 & 5.4679 & TRN & \\
\hline CHEMBL3799794 & 1573823 & 5.9208 & 5.5475 & TRN & \\
\hline CHEMBL3416944 & 1573823 & 6.2218 & 5.8735 & TRN & \\
\hline CHEMBL 3416903 & 1573823 & 4.301 & 5.1699 & TRN & \\
\hline CHEMBL 3416886 & 1573823 & 5.5686 & 5.3921 & TRN & \\
\hline CHEMBL3800343 & 1573823 & 4.301 & $3.98100 e$ & 0000000003 & TRN \\
\hline CHEMBL3416905 & 1573823 & 5.4318 & 5.2315 & TRN & \\
\hline CHEMBL3797725 & 1573823 & 4.301 & 5.2374 & TST & \\
\hline CHEMBL 3797709 & 1573823 & 4.301 & 3.7314 & TRN & \\
\hline CHEMBL3797359 & 1573823 & 4.301 & 5.0326 & TRN & \\
\hline CHEMBL3797912 & 1573823 & 4.301 & 4.4456 & TRN & \\
\hline CHEMBL3416901 & 1573823 & 5.5229 & 5.4542 & TRN & \\
\hline CHEMBL3798639 & 1573823 & 6.1549 & 5.5608 & TRN & \\
\hline CHEMBL 3416894 & 1573823 & 5.4202 & 4.8048 & TRN & \\
\hline CHEMBL3416890 & 1573823 & 5.7447 & 5.5534 & TST & \\
\hline CHEMBL3799705 & 1573823 & 5.9586 & 5.5976 & TRN & \\
\hline CHEMBL3797233 & 1573823 & 4.3098 & 5.1642 & TST & \\
\hline CHEMBL3416945 & 1573823 & 4.301 & 4.6665 & TRN & \\
\hline
\end{tabular}




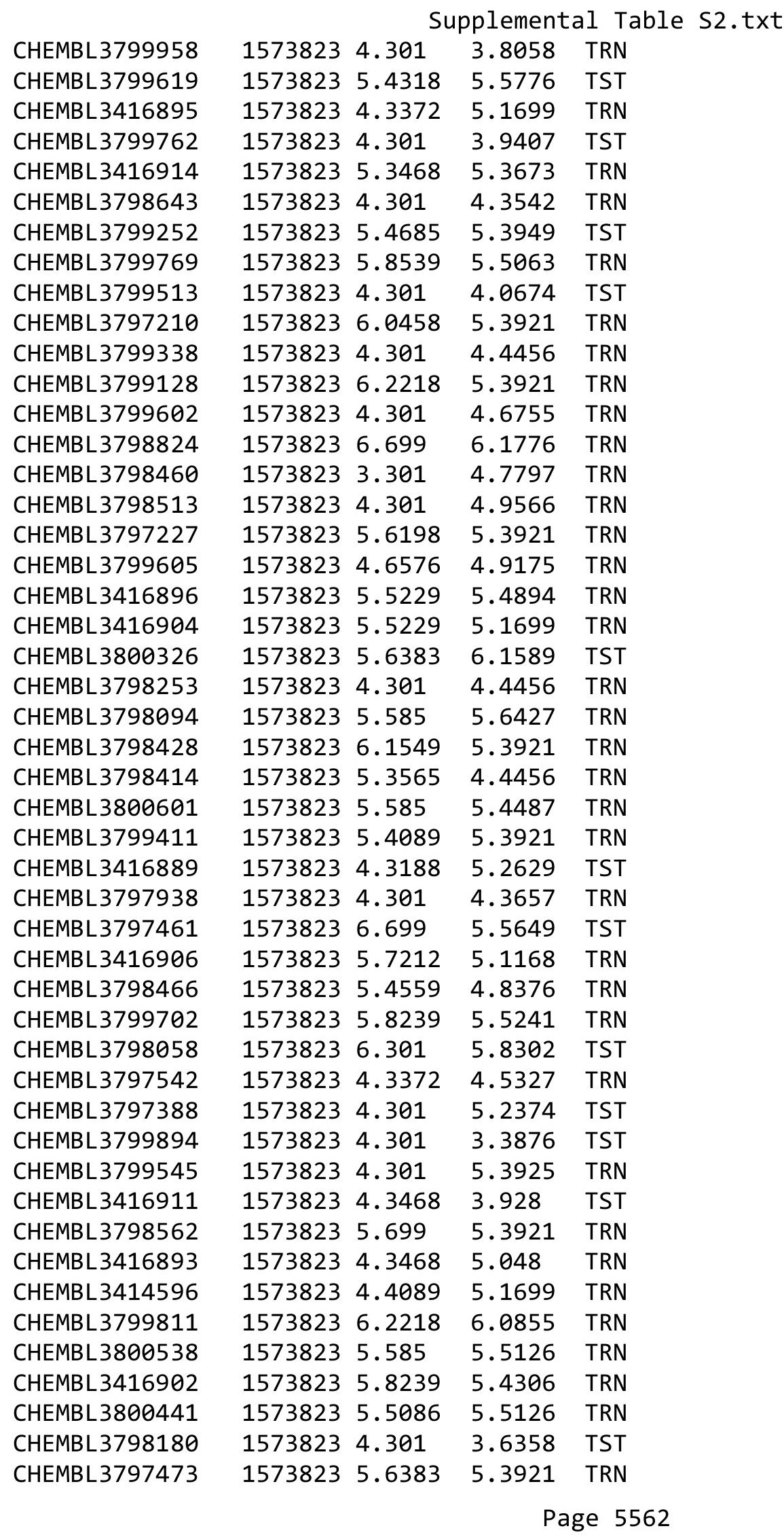


Supplemental Table S2.txt

\begin{tabular}{|c|c|c|c|c|}
\hline CHEMBL3799721 & 1573823 & 5.9586 & 5.6432 & TRN \\
\hline CHEMBL3800494 & 1573823 & 4.4685 & 5.5063 & TRN \\
\hline CHEMBL3799874 & 1573823 & 4.3188 & 4.4456 & TRN \\
\hline CHEMBL3800396 & 1573823 & 4.301 & 3.7612 & TST \\
\hline CHEMBL3798793 & 1573823 & 5.6198 & 6.1343 & TST \\
\hline CHEMBL3797204 & 1573823 & 5.585 & 5.1642 & TST \\
\hline CHEMBL3416907 & 1573823 & 4.301 & 5.1699 & TRN \\
\hline CHEMBL 3800425 & 1573823 & 4.301 & 5.0091 & TRN \\
\hline CHEMBL 3800426 & 1573823 & 4.301 & 4.0825 & TRN \\
\hline CHEMBL3799942 & 1573823 & 5.3565 & \multicolumn{2}{|c|}{5.7170000000000005} \\
\hline CHEMBL3416916 & 1573823 & 4.301 & 4.9436 & TRN \\
\hline CHEMBL3798194 & 1573823 & 4.301 & 4.4456 & TRN \\
\hline CHEMBL3798248 & 1573823 & 4.301 & 4.8001 & TRN \\
\hline CHEMBL3798479 & 1573823 & 6.301 & 6.1343 & TST \\
\hline CHEMBL3798733 & 1573823 & 5.6198 & 5.4905 & TRN \\
\hline CHEMBL3798267 & 1573823 & 4.301 & 4.7903 & TRN \\
\hline CHEMBL3799757 & 1573823 & 5.3468 & 4.9668 & TRN \\
\hline CHEMBL3416908 & 1573823 & 5.4949 & 5.4733 & TRN \\
\hline CHEMBL3799550 & 1573823 & 4.4318 & 5.4679 & TRN \\
\hline CHEMBL1967116 & 809158 & 4.2 & 4.2795 & TRN \\
\hline CHEMBL 2000832 & 809158 & 5.6 & 5.8893 & TRN \\
\hline CHEMBL513846 & 809158 & 4.2 & 4.418 & TRN \\
\hline CHEMBL1970709 & 809158 & 4.2 & 4.0715 & TRN \\
\hline CHEMBL1965660 & 809158 & 5.2 & 4.9587 & TRN \\
\hline CHEMBL1998112 & 809158 & 4.2 & 4.1232 & TRN \\
\hline CHEMBL1969126 & 809158 & 4.2 & 4.1564 & TRN \\
\hline CHEMBL1980896 & 809158 & 5.4 & 5.2453 & TRN \\
\hline CHEMBL1975208 & 809158 & 4.2 & 4.3027 & TST \\
\hline CHEMBL1970104 & 809158 & 5.5 & 5.2748 & TRN \\
\hline CHEMBL1991429 & 809158 & 4.2 & 4.1554 & TRN \\
\hline CHEMBL1964777 & 809158 & 5.4 & 4.9046 & TST \\
\hline CHEMBL1971149 & 809158 & 4.2 & 4.1615 & TRN \\
\hline CHEMBL1999714 & 809158 & 4.2 & 4.3054 & TRN \\
\hline CHEMBL1987533 & 809158 & 4.2 & 4.6384 & TRN \\
\hline CHEMBL1994040 & 809158 & 4.2 & 4.0417 & TRN \\
\hline CHEMBL579246 & 809158 & 5.7 & 6.1937 & TRN \\
\hline CHEMBL398951 & 809158 & 6.5 & 5.9578 & TRN \\
\hline CHEMBL1982506 & 809158 & 4.2 & \multicolumn{2}{|c|}{4.4910000000000005} \\
\hline CHEMBL2004716 & 809158 & 6.0 & 5.5155 & TRN \\
\hline CHEMBL1968127 & 809158 & 4.2 & 4.1628 & TRN \\
\hline CHEMBL1975233 & 809158 & 4.2 & 4.3017 & TRN \\
\hline CHEMBL1985406 & 809158 & 5.4 & 4.4468 & TRN \\
\hline CHEMBL 207400 & 809158 & 4.2 & 4.0939 & TST \\
\hline CHEMBL 2000894 & 809158 & 5.5 & 5.5209 & TST \\
\hline CHEMBL1982135 & 809158 & 4.2 & 4.2179 & TRN \\
\hline CHEMBL1976090 & 809158 & 5.6 & 5.7185 & TRN \\
\hline CHEMBL1993243 & 809158 & 4.2 & 4.4106 & TRN \\
\hline CHEMBL1992922 & 809158 & 6.7 & 7.0504 & TRN \\
\hline
\end{tabular}




\begin{tabular}{|c|c|c|c|c|c|}
\hline \multirow{2}{*}{ CHEMBL2004771 } & \multirow{2}{*}{809158} & \multirow{2}{*}{4.2} & \\
\hline & & & 4.5576 & TRN & \\
\hline CHEMBL1997597 & 809158 & 4.2 & 4.4281 & TRN & \\
\hline CHEMBL1969537 & 809158 & 6.0 & 5.8572 & TST & \\
\hline CHEMBL1976093 & 809158 & 4.2 & 4.1203 & TRN & \\
\hline CHEMBL210032 & 809158 & 4.2 & 4.1612 & TRN & \\
\hline CHEMBL1975256 & 809158 & 4.2 & 3.9148 & TST & \\
\hline CHEMBL508928 & 809158 & 5.6 & 4.7675 & TRN & \\
\hline CHEMBL1991356 & 809158 & 4.2 & 4.2597 & TRN & \\
\hline CHEMBL1983309 & 809158 & 4.2 & 4.0303 & TRN & \\
\hline CHEMBL 2004892 & 809158 & 5.6 & 5.1438 & TRN & \\
\hline CHEMBL1999126 & 809158 & 4.2 & 4.0951 & TST & \\
\hline CHEMBL1997503 & 809158 & 4.2 & 4.3797 & TST & \\
\hline CHEMBL116070 & 809158 & 5.2 & 4.3438 & TST & \\
\hline CHEMBL1990821 & 809158 & 5.3 & 4.7853 & TST & \\
\hline CHEMBL1970314 & 809158 & 4.2 & 4.2214 & TRN & \\
\hline CHEMBL 2004871 & 809158 & 4.2 & 4.1424 & TRN & \\
\hline CHEMBL 2004872 & 809158 & 4.2 & 4.075 & TRN & \\
\hline CHEMBL1727312 & 809158 & 4.2 & 4.3555 & TRN & \\
\hline CHEMBL1969879 & 809158 & 4.2 & 4.3227 & TRN & \\
\hline CHEMBL1981720 & 809158 & 4.2 & 4.3554 & TRN & \\
\hline CHEMBL419932 & 809158 & 5.2 & 4.8784 & TRN & \\
\hline CHEMBL262433 & 809158 & 4.2 & 4.6252 & TRN & \\
\hline CHEMBL306380 & 809158 & 4.2 & 4.691 & TRN & \\
\hline CHEMBL1966722 & 809158 & 5.5 & 5.7124 & TRN & \\
\hline CHEMBL1975500 & 809158 & 6.1 & 5.8325 & TRN & \\
\hline CHEMBL394619 & 809158 & 5.4 & 5.2055 & TRN & \\
\hline CHEMBL1996831 & 809158 & 5.9 & 5.2962 & TST & \\
\hline CHEMBL411903 & 809158 & 4.2 & 5.2676 & TRN & \\
\hline CHEMBL1965988 & 809158 & 5.8 & 5.5106 & TRN & \\
\hline CHEMBL418203 & 809158 & 6.0 & 5.1586 & TST & \\
\hline CHEMBL1989646 & 809158 & 5.5 & 5.4374 & TRN & \\
\hline CHEMBL225519 & 809158 & 4.5 & 4.8651 & TRN & \\
\hline CHEMBL1978200 & 809158 & 4.2 & 4.1201 & TRN & \\
\hline CHEMBL1970522 & 809158 & 5.7 & 5.4762 & TRN & \\
\hline CHEMBL402846 & 809158 & 4.2 & 4.2511 & TRN & \\
\hline CHEMBL1990415 & 809158 & 5.6 & 5.1368 & TRN & \\
\hline CHEMBL1966087 & 809158 & 4.2 & 4.2966 & TRN & \\
\hline CHEMBL1964692 & 809158 & 4.2 & 4.3547 & TRN & \\
\hline CHEMBL1996931 & 809158 & 4.2 & 4.1129 & TRN & \\
\hline CHEMBL1973483 & 809158 & 4.2 & 4.2455 & TRN & \\
\hline CHEMBL1970735 & 809158 & 4.2 & 4.109 & TRN & \\
\hline CHEMBL1997340 & 809158 & 4.2 & 4.0422 & TRN & \\
\hline CHEMBL 2004365 & 809158 & 4.2 & 4.3705 & TST & \\
\hline CHEMBL1522508 & 809158 & 4.2 & 4.0804 & TRN & \\
\hline CHEMBL1989474 & 809158 & 4.2 & 4.1284 & TRN & \\
\hline CHEMBL1090360 & 809158 & 4.2 & 4.0788 & TRN & \\
\hline CHEMBL210887 & 809158 & 4.2 & 5.0327 & TRN & \\
\hline CHEMBL458997 & 809158 & 6.1 & 6.78606 & 00000000005 & TRN \\
\hline & & & & e 5564 & \\
\hline
\end{tabular}




\begin{tabular}{|c|c|c|c|c|c|}
\hline \multicolumn{6}{|c|}{ Supplemental Table S2.txt } \\
\hline CHEMBL227271 & 809158 & 7.3 & 7.811 & TRN & \\
\hline CHEMBL1971021 & 809158 & 4.2 & 4.1223 & TRN & \\
\hline CHEMBL583144 & 809158 & 5.4 & 5.0421 & TRN & \\
\hline CHEMBL1974310 & 809158 & 5.8 & 5.2318 & TST & \\
\hline CHEMBL1982660 & 809158 & 4.2 & 4.4544 & TRN & \\
\hline CHEMBL1994693 & 809158 & 4.2 & 4.4831 & TRN & \\
\hline CHEMBL1982957 & 809158 & 7.3 & 7.0552 & TRN & \\
\hline CHEMBL1725279 & 809158 & 5.8 & 5.8604 & TST & \\
\hline CHEMBL1975138 & 809158 & 5.5 & 5.5015 & TRN & \\
\hline CHEMBL424872 & 809158 & 4.2 & 4.2697 & TRN & \\
\hline CHEMBL 2006836 & 809158 & 4.2 & 4.081 & TST & \\
\hline CHEMBL412142 & 809158 & 4.2 & 4.238 & TST & \\
\hline CHEMBL1980704 & 809158 & 4.2 & 4.3225 & TST & \\
\hline CHEMBL 2003271 & 809158 & 5.8 & 5.3428 & TRN & \\
\hline CHEMBL1966808 & 809158 & 4.2 & 4.0033 & TST & \\
\hline CHEMBL 2004447 & 809158 & 4.2 & 4.1243 & TST & \\
\hline CHEMBL1983111 & 809158 & 6.6 & 6.3386 & TST & \\
\hline CHEMBL1973860 & 809158 & 5.2 & 4.6538 & TRN & \\
\hline CHEMBL260135 & 809158 & 4.2 & 4.5185 & TRN & \\
\hline CHEMBL220241 & 809158 & 4.2 & 4.3623 & TRN & \\
\hline CHEMBL 2004544 & 809158 & 5.9 & 5.3004 & TST & \\
\hline CHEMBL1982610 & 809158 & 4.2 & 4.4884 & TRN & \\
\hline CHEMBL1999496 & 809158 & 4.2 & 4.1141 & TRN & \\
\hline CHEMBL1988300 & 809158 & 4.2 & 4.9368 & TRN & \\
\hline CHEMBL1991078 & 809158 & 6.5 & 6.2313 & TRN & \\
\hline CHEMBL1987359 & 809158 & 4.2 & 4.3712 & TST & \\
\hline CHEMBL1989265 & 809158 & 4.2 & 4.2119 & TST & \\
\hline CHEMBL1969502 & 809158 & 5.4 & 4.921 & TRN & \\
\hline CHEMBL1682553 & 809158 & 4.2 & 4.4759 & TRN & \\
\hline CHEMBL1971430 & 809158 & 4.2 & 4.4194 & TRN & \\
\hline CHEMBL1997764 & 809158 & 6.1 & 6.0865 & TRN & \\
\hline CHEMBL1983963 & 809158 & 4.2 & 4.5323 & TRN & \\
\hline CHEMBL1985092 & 809158 & 5.6 & 5.3441 & TST & \\
\hline CHEMBL 2004692 & 809158 & 4.2 & 3.9422 & TST & \\
\hline CHEMBL1981410 & 809158 & 4.2 & 4.3068 & TRN & \\
\hline CHEMBL1996234 & 809158 & 4.2 & 4.23300 & 00000000005 & TRN \\
\hline CHEMBL1991434 & 809158 & 4.2 & 4.242 & TRN & \\
\hline CHEMBL1967544 & 809158 & 5.3 & 5.2091 & TRN & \\
\hline CHEMBL340384 & 809158 & 6.0 & 6.0837 & TST & \\
\hline CHEMBL1996587 & 809158 & 4.2 & 4.3172 & TRN & \\
\hline CHEMBL1964804 & 809158 & 4.2 & 5.0862 & TRN & \\
\hline CHEMBL443962 & 809158 & 4.2 & 4.566 & TST & \\
\hline CHEMBL 2000354 & 809158 & 5.8 & 5.5206 & TRN & \\
\hline CHEMBL1965507 & 809158 & 5.9 & 5.6956 & TRN & \\
\hline CHEMBL1967564 & 809158 & 4.2 & 4.1229 & TRN & \\
\hline CHEMBL592030 & 809158 & 6.3 & 6.2152 & TST & \\
\hline CHEMBL 2000071 & 809158 & 6.6 & 6.8016 & TRN & \\
\hline CHEMBL1979176 & 809158 & 4.2 & 4.1388 & TRN & \\
\hline
\end{tabular}




\begin{tabular}{|c|c|c|c|c|}
\hline \multicolumn{5}{|c|}{ ipplemental T } \\
\hline CHEMBL 2000408 & 809158 & 4.2 & 4.1763 & TRN \\
\hline CHEMBL1978014 & 809158 & 4.2 & 4.3435 & TRN \\
\hline CHEMBL1994538 & 809158 & 4.2 & 4.2232 & TRN \\
\hline CHEMBL1983195 & 809158 & 5.5 & 5.0819 & TST \\
\hline CHEMBL1975490 & 809158 & 6.0 & 5.3472 & TRN \\
\hline CHEMBL1964444 & 809158 & 4.2 & 4.2687 & TRN \\
\hline CHEMBL1986139 & 809158 & 4.2 & 4.4428 & TRN \\
\hline CHEMBL1980540 & 809158 & 4.2 & 4.1915 & TRN \\
\hline CHEMBL1979883 & 809158 & 5.9 & 5.3403 & TRN \\
\hline CHEMBL1984162 & 809158 & 4.2 & 5.2408 & TRN \\
\hline CHEMBL491758 & 809158 & 4.2 & 5.4402 & TRN \\
\hline CHEMBL549730 & 809158 & 4.2 & 4.0047 & TRN \\
\hline CHEMBL1970189 & 809158 & 4.2 & 4.3143 & TST \\
\hline CHEMBL1996791 & 809158 & 4.2 & 4.7412 & TRN \\
\hline CHEMBL371206 & 809158 & 6.3 & 5.2659 & TRN \\
\hline CHEMBL1974664 & 809158 & 4.2 & 4.5013 & TRN \\
\hline CHEMBL1974288 & 809158 & 4.2 & 4.2237 & TRN \\
\hline CHEMBL196363 & 809158 & 5.8 & 5.3547 & TRN \\
\hline CHEMBL1190711 & 809158 & 5.6 & 4.6472 & TRN \\
\hline CHEMBL1968705 & 809158 & 5.5 & 5.129 & TRN \\
\hline CHEMBL404367 & 809158 & 4.2 & 4.4494 & TRN \\
\hline CHEMBL1966343 & 809158 & 5.9 & 5.5386 & TRN \\
\hline CHEMBL1967887 & 809158 & 6.4 & 6.4987 & TRN \\
\hline CHEMBL 2000568 & 809158 & 4.2 & 4.4587 & TRN \\
\hline CHEMBL 2000335 & 809158 & 6.3 & 5.7192 & TRN \\
\hline CHEMBL1977604 & 809158 & 4.2 & 4.1695 & TST \\
\hline CHEMBL1988717 & 809158 & 4.2 & 4.2443 & TRN \\
\hline CHEMBL1974328 & 809158 & 6.4 & 6.1386 & TRN \\
\hline CHEMBL509032 & 809158 & 7.9 & 7.8798 & TRN \\
\hline CHEMBL1973808 & 809158 & 4.2 & 4.1664 & TRN \\
\hline CHEMBL 2000429 & 809158 & 4.2 & 4.1037 & TRN \\
\hline CHEMBL1972576 & 809158 & 5.6 & 5.3715 & TRN \\
\hline CHEMBL1992555 & 809158 & 4.2 & 4.2758 & TRN \\
\hline CHEMBL1992342 & 809158 & 5.6 & 4.2594 & TRN \\
\hline CHEMBL1988173 & 809158 & 6.1 & 5.8924 & TRN \\
\hline CHEMBL535331 & 809158 & 4.2 & 4.3819 & TRN \\
\hline CHEMBL1989805 & 809158 & 5.6 & 5.3446 & TST \\
\hline CHEMBL1965423 & 809158 & 5.2 & 4.5052 & TRN \\
\hline CHEMBL1982980 & 809158 & 5.7 & 5.0886 & TST \\
\hline CHEMBL1983025 & 809158 & 5.5 & 5.3233 & TRN \\
\hline CHEMBL205415 & 809158 & 5.6 & 5.1012 & TRN \\
\hline CHEMBL1977135 & 809158 & 4.2 & 4.0961 & TRN \\
\hline CHEMBL 2001920 & 809158 & 6.3 & 5.5039 & TRN \\
\hline CHEMBL1978448 & 809158 & 6.6 & 5.925 & TST \\
\hline CHEMBL1972258 & 809158 & 4.2 & 4.2063 & TRN \\
\hline CHEMBL 2001257 & 809158 & 5.8 & 5.2014 & TRN \\
\hline CHEMBL1992536 & 809158 & 4.2 & 4.085 & TRN \\
\hline CHEMBL1987793 & 809158 & 5.6 & 5.205 & TST \\
\hline
\end{tabular}




\begin{tabular}{|c|c|c|c|c|}
\hline \multicolumn{5}{|c|}{ Supplemental Table S2.txt } \\
\hline CHEMBL439340 & 809158 & 4.2 & 4.2054 & TRN \\
\hline CHEMBL 2002373 & 809158 & 4.2 & 4.273 & TRN \\
\hline CHEMBL 2006188 & 809158 & 4.2 & 4.1906 & TRN \\
\hline CHEMBL1967531 & 809158 & 5.3 & 5.454 & TRN \\
\hline CHEMBL1973893 & 809158 & 4.2 & 4.0493 & TRN \\
\hline CHEMBL1970913 & 809158 & 4.2 & 4.0945 & TRN \\
\hline CHEMBL1995736 & 809158 & 4.2 & 4.7156 & TRN \\
\hline CHEMBL1997534 & 809158 & 5.3 & 4.7568 & TRN \\
\hline CHEMBL1996500 & 809158 & 4.2 & 4.0914 & TRN \\
\hline CHEMBL1985095 & 809158 & 5.2 & 5.6306 & TST \\
\hline CHEMBL1977374 & 809158 & 4.2 & 4.1941 & TRN \\
\hline CHEMBL1998551 & 809158 & 4.2 & 4.1446 & TRN \\
\hline CHEMBL1989708 & 809158 & 4.2 & 4.4044 & TRN \\
\hline CHEMBL1682540 & 809158 & 4.2 & 4.69 & TRN \\
\hline CHEMBL1976420 & 809158 & 5.2 & 4.4853 & TST \\
\hline CHEMBL1994864 & 809158 & 4.2 & 4.0198 & TRN \\
\hline CHEMBL 2002446 & 809158 & 5.5 & 5.3517 & TRN \\
\hline CHEMBL497151 & 809158 & 5.6 & 5.0405 & TST \\
\hline CHEMBL246970 & 809158 & 6.1 & 5.6098 & TST \\
\hline CHEMBL340921 & 809158 & 5.6 & 5.5887 & TST \\
\hline CHEMBL1999718 & 809158 & 4.2 & 4.0931 & TRN \\
\hline CHEMBL1276446 & 809158 & 6.7 & 6.6267 & TST \\
\hline CHEMBL1977346 & 809158 & 5.3 & 5.1207 & TRN \\
\hline CHEMBL1971649 & 809158 & 4.2 & 4.1965 & TRN \\
\hline CHEMBL1998435 & 809158 & 4.2 & 4.1087 & TRN \\
\hline CHEMBL 2006439 & 809158 & 6.3 & 6.3217 & TRN \\
\hline CHEMBL 2006156 & 809158 & 4.2 & 5.065 & TST \\
\hline CHEMBL1969190 & 809158 & 4.2 & 4.3205 & TRN \\
\hline CHEMBL1973937 & 809158 & 4.2 & 4.5907 & TRN \\
\hline CHEMBL1991674 & 809158 & 6.1 & 5.4233 & TRN \\
\hline CHEMBL1982711 & 809158 & 6.7 & 6.5703 & TRN \\
\hline CHEMBL1987982 & 809158 & 5.5 & 5.0906 & TST \\
\hline CHEMBL1998829 & 809158 & 5.8 & 5.5339 & TRN \\
\hline CHEMBL50894 & 809158 & 4.2 & 5.346 & TRN \\
\hline CHEMBL1988838 & 809158 & 6.0 & 6.2861 & TRN \\
\hline CHEMBL1981725 & 809158 & 5.5 & 5.0515 & TRN \\
\hline CHEMBL1982866 & 809158 & 4.2 & 4.0986 & TRN \\
\hline CHEMBL1968926 & 809158 & 4.2 & 4.1977 & TRN \\
\hline CHEMBL462120 & 809158 & 5.4 & 4.8743 & TRN \\
\hline CHEMBL1997839 & 809158 & 5.4 & 5.0776 & TST \\
\hline CHEMBL1965570 & 809158 & 4.2 & 4.1931 & TRN \\
\hline CHEMBL 2007592 & 809158 & 4.2 & 4.035 & TST \\
\hline CHEMBL210963 & 809158 & 4.2 & 4.0469 & TRN \\
\hline CHEMBL1614705 & 809158 & 4.2 & 4.1698 & TRN \\
\hline CHEMBL1984633 & 809158 & 4.2 & 4.3164 & TRN \\
\hline CHEMBL1994214 & 809158 & 5.8 & 5.0171 & TST \\
\hline CHEMBL 2007372 & 809158 & 4.2 & 4.1294 & TRN \\
\hline CHEMBL1965845 & 809158 & 5.3 & 4.8863 & TRN \\
\hline
\end{tabular}




\begin{tabular}{|c|c|c|c|c|c|}
\hline \multicolumn{6}{|c|}{ Supplemental Table S2.txt } \\
\hline CHEMBL 2006715 & 809158 & 4.2 & 4.2577 & TRN & \\
\hline CHEMBL1986597 & 809158 & 4.2 & 4.2747 & TRN & \\
\hline CHEMBL1990482 & 809158 & 5.4 & 4.8597 & TRN & \\
\hline CHEMBL1990904 & 809158 & 4.2 & 4.1449 & TRN & \\
\hline CHEMBL1975121 & 809158 & 4.2 & 4.0953 & TRN & \\
\hline CHEMBL 2005475 & 809158 & 4.2 & 5.1563 & TRN & \\
\hline CHEMBL183844 & 809158 & 4.2 & 4.1596 & TRN & \\
\hline CHEMBL1997349 & 809158 & 4.2 & 4.2426 & TST & \\
\hline CHEMBL220057 & 809158 & 5.3 & 5.3529 & TRN & \\
\hline CHEMBL1682545 & 809158 & 4.2 & 4.2785 & TRN & \\
\hline CHEMBL383541 & 809158 & 5.3 & 5.25299 & 9999999999 & TRN \\
\hline CHEMBL 2001224 & 809158 & 4.2 & 4.1426 & TRN & \\
\hline CHEMBL10 & 809158 & 4.2 & 4.2327 & TRN & \\
\hline CHEMBL1976732 & 809158 & 4.2 & 4.2075 & TRN & \\
\hline CHEMBL1964937 & 809158 & 4.2 & 5.3203 & TRN & \\
\hline CHEMBL1969506 & 809158 & 4.2 & 4.5682 & TRN & \\
\hline CHEMBL1980163 & 809158 & 4.2 & 4.2523 & TRN & \\
\hline CHEMBL2005899 & 809158 & 4.2 & 4.1209 & TRN & \\
\hline CHEMBL1682552 & 809158 & 4.2 & 4.4654 & TRN & \\
\hline CHEMBL1972568 & 809158 & 4.2 & 4.0508 & TRN & \\
\hline CHEMBL229799 & 809158 & 8.4 & 7.9709 & TRN & \\
\hline CHEMBL105739 & 809158 & 6.1 & 5.9378 & TRN & \\
\hline CHEMBL379300 & 809158 & 7.9 & 7.5908 & TRN & \\
\hline CHEMBL1988995 & 809158 & 4.2 & 4.1213 & TRN & \\
\hline CHEMBL1986781 & 809158 & 4.2 & 4.1699 & TRN & \\
\hline CHEMBL526133 & 809158 & 4.2 & 4.5473 & TRN & \\
\hline CHEMBL387971 & 809158 & 5.3 & 5.0702 & TRN & \\
\hline CHEMBL1979057 & 809158 & 4.2 & 4.3839 & TRN & \\
\hline CHEMBL1999428 & 809158 & 4.2 & 4.0923 & TRN & \\
\hline CHEMBL1967560 & 809158 & 4.2 & 4.6116 & TRN & \\
\hline CHEMBL211378 & 809158 & 4.2 & 4.3816 & TRN & \\
\hline CHEMBL1516890 & 809158 & 5.4 & 5.4876 & TRN & \\
\hline CHEMBL1982465 & 809158 & 5.3 & 5.0937 & TRN & \\
\hline CHEMBL 2001751 & 809158 & 7.6 & 7.3308 & TRN & \\
\hline CHEMBL 2003420 & 809158 & 4.2 & 4.3669 & TRN & \\
\hline CHEMBL1984586 & 809158 & 4.2 & 4.3479 & TRN & \\
\hline CHEMBL1972659 & 809158 & 4.2 & 4.1625 & TST & \\
\hline CHEMBL 272453 & 809158 & 4.2 & 4.138 & TRN & \\
\hline CHEMBL1970217 & 809158 & 4.2 & 4.2207 & TRN & \\
\hline CHEMBL 2005528 & 809158 & 4.2 & 4.5135 & TST & \\
\hline CHEMBL185569 & 809158 & 4.2 & 4.3203 & TRN & \\
\hline CHEMBL1969843 & 809158 & 4.2 & 4.3123 & TRN & \\
\hline CHEMBL 2007002 & 809158 & 5.3 & 5.059 & TRN & \\
\hline CHEMBL1990288 & 809158 & 4.2 & 4.1042 & TRN & \\
\hline CHEMBL1987007 & 809158 & 5.4 & 5.0413 & TRN & \\
\hline CHEMBL1969588 & 809158 & 7.0 & 7.1582 & TRN & \\
\hline CHEMBL1984711 & 809158 & 4.2 & 4.6717 & TRN & \\
\hline CHEMBL484390 & 809158 & 5.3 & 4.91 & TRN & \\
\hline
\end{tabular}




\begin{tabular}{|c|c|c|c|c|c|}
\hline \multicolumn{6}{|c|}{ Supplemental Table S2.txt } \\
\hline CHEMBL1983255 & 809158 & 5.5 & 4.9119 & TRN & \\
\hline CHEMBL1979252 & 809158 & 4.2 & 4.2134 & TRN & \\
\hline CHEMBL1986499 & 809158 & 5.8 & 5.7681 & TRN & \\
\hline CHEMBL 2004290 & 809158 & 4.2 & 4.0566 & TRN & \\
\hline CHEMBL1972937 & 809158 & 4.2 & 4.4132 & TRN & \\
\hline CHEMBL 2000393 & 809158 & 6.3 & 5.8345 & TST & \\
\hline CHEMBL 2004311 & 809158 & 4.2 & 4.0278 & TRN & \\
\hline CHEMBL1992634 & 809158 & 6.5 & 6.4705 & TRN & \\
\hline CHEMBL1242373 & 809158 & 4.2 & 4.4523 & TRN & \\
\hline CHEMBL56543 & 809158 & 4.2 & 4.2017 & TRN & \\
\hline CHEMBL1988075 & 809158 & 4.2 & 4.2004 & TRN & \\
\hline CHEMBL316264 & 809158 & 4.2 & 4.2048 & TRN & \\
\hline CHEMBL1991678 & 809158 & 4.2 & 4.1234 & TRN & \\
\hline CHEMBL2001239 & 809158 & 5.2 & 5.6232 & TST & \\
\hline CHEMBL1976396 & 809158 & 5.4 & 5.1733 & TST & \\
\hline CHEMBL1988594 & 809158 & 5.3 & 5.6084 & TRN & \\
\hline CHEMBL2001288 & 809158 & 4.2 & 4.7853 & TRN & \\
\hline CHEMBL1999811 & 809158 & 4.2 & 5.2376 & TST & \\
\hline CHEMBL1985074 & 809158 & 4.2 & 4.3727 & TST & \\
\hline CHEMBL1982874 & 809158 & 4.2 & 4.1596 & TRN & \\
\hline CHEMBL 2000481 & 809158 & 4.2 & 4.5893 & TRN & \\
\hline CHEMBL1991725 & 809158 & 4.2 & 4.5191 & TRN & \\
\hline CHEMBL1992242 & 809158 & 4.2 & 4.2464 & TRN & \\
\hline CHEMBL2007296 & 809158 & 4.2 & 4.1559 & TRN & \\
\hline CHEMBL396523 & 809158 & 5.8 & 6.1417 & TRN & \\
\hline CHEMBL 208637 & 809158 & 4.2 & 4.058 & TRN & \\
\hline CHEMBL1970203 & 809158 & 4.2 & 4.4869 & TRN & \\
\hline CHEMBL1986530 & 809158 & 4.2 & 4.6657 & TST & \\
\hline CHEMBL1999321 & 809158 & 4.2 & 4.0482 & TRN & \\
\hline CHEMBL1968590 & 809158 & 4.2 & 4.3476 & TRN & \\
\hline CHEMBL 2005375 & 809158 & 5.6 & 5.3927 & TRN & \\
\hline CHEMBL1984191 & 809158 & 4.2 & 4.2461 & TRN & \\
\hline CHEMBL1972183 & 809158 & 4.2 & 4.3929 & TST & \\
\hline CHEMBL394790 & 809158 & 5.2 & 4.9638 & TRN & \\
\hline CHEMBL 226471 & 809158 & 4.2 & 4.4797 & TRN & \\
\hline CHEMBL1996111 & 809158 & 4.2 & 4.3908 & TRN & \\
\hline CHEMBL1974702 & 809158 & 5.3 & 4.92399 & 99999999995 & TRN \\
\hline CHEMBL1965589 & 809158 & 4.2 & 4.2197 & TRN & \\
\hline CHEMBL1998193 & 809158 & 4.2 & 4.1731 & TRN & \\
\hline CHEMBL474432 & 809158 & 4.2 & 4.8252 & TST & \\
\hline CHEMBL1988153 & 809158 & 4.2 & 4.5727 & TST & \\
\hline CHEMBL1972584 & 809158 & 4.2 & 5.1243 & TRN & \\
\hline CHEMBL1988437 & 809158 & 5.2 & 5.0426 & TST & \\
\hline CHEMBL1998121 & 809158 & 5.5 & 5.7669 & TRN & \\
\hline CHEMBL1979577 & 809158 & 5.8 & 5.6672 & TRN & \\
\hline CHEMBL52387 & 809158 & 4.2 & 4.6515 & TST & \\
\hline CHEMBL379835 & 809158 & 4.2 & 4.0867 & TST & \\
\hline CHEMBL1979357 & 809158 & 4.2 & 4.0442 & TRN & \\
\hline
\end{tabular}




\begin{tabular}{|c|c|c|c|c|c|}
\hline \multicolumn{6}{|c|}{ Supplemental Table S2.txt } \\
\hline CHEMBL1996817 & 809158 & 7.3 & 7.2962 & TRN & \\
\hline CHEMBL3197315 & 809158 & 4.2 & 4.0327 & TST & \\
\hline CHEMBL468280 & 809158 & 4.2 & 4.0562 & TST & \\
\hline CHEMBL1990884 & 809158 & 5.2 & 4.3256 & TRN & \\
\hline CHEMBL 3109278 & 809158 & 7.4 & 6.777 & TRN & \\
\hline CHEMBL256835 & 809158 & 4.2 & 4.1124 & TRN & \\
\hline CHEMBL1980142 & 809158 & 4.2 & 4.1431 & TRN & \\
\hline CHEMBL41783 & 809158 & 4.2 & 4.3381 & TRN & \\
\hline CHEMBL 2006276 & 809158 & 4.2 & 4.3974 & TRN & \\
\hline CHEMBL271381 & 809158 & 4.2 & 4.2685 & TRN & \\
\hline CHEMBL 2006785 & 809158 & 4.2 & 4.2344 & TRN & \\
\hline CHEMBL1982466 & 809158 & 4.2 & 3.9494 & TRN & \\
\hline CHEMBL1995740 & 809158 & 4.2 & 5.0746 & TRN & \\
\hline CHEMBL1986943 & 809158 & 7.5 & 7.5506 & TRN & \\
\hline CHEMBL234085 & 809158 & 4.4 & 4.9679 & TRN & \\
\hline CHEMBL1995832 & 809158 & 4.2 & 4.1598 & TRN & \\
\hline CHEMBL1998414 & 809158 & 4.2 & 4.5135 & TRN & \\
\hline CHEMBL1969042 & 809158 & 5.5 & 5.3747 & TST & \\
\hline CHEMBL1999931 & 809158 & 6.5 & 6.2749 & TRN & \\
\hline CHEMBL1375418 & 809158 & 4.2 & 4.1949 & TRN & \\
\hline CHEMBL 2007064 & 809158 & 5.7 & 5.6882 & TRN & \\
\hline CHEMBL1981047 & 809158 & 5.7 & 5.5226 & TST & \\
\hline CHEMBL229968 & 809158 & 7.8 & 8.0541 & TRN & \\
\hline CHEMBL1976240 & 809158 & 4.2 & 4.2147 & TRN & \\
\hline CHEMBL1979093 & 809158 & 5.5 & 4.28600 & 00000000005 & TRN \\
\hline CHEMBL1968151 & 809158 & 4.2 & 4.1542 & TST & \\
\hline CHEMBL1987009 & 809158 & 4.2 & 5.1547 & TRN & \\
\hline CHEMBL379218 & 809158 & 7.6 & 7.7661 & TRN & \\
\hline CHEMBL2003817 & 809158 & 4.2 & 4.3104 & TRN & \\
\hline CHEMBL1994830 & 809158 & 4.2 & 4.2327 & TST & \\
\hline CHEMBL226403 & 809158 & 5.4 & 5.2158 & TRN & \\
\hline CHEMBL 2005631 & 809158 & 4.2 & 4.3567 & TRN & \\
\hline CHEMBL1994938 & 809158 & 4.2 & 5.0937 & TRN & \\
\hline CHEMBL1825138 & 809158 & 4.2 & 4.9472 & TST & \\
\hline CHEMBL1966279 & 809158 & 4.2 & 4.3227 & TRN & \\
\hline CHEMBL1997846 & 809158 & 5.8 & 5.221 & TRN & \\
\hline CHEMBL 2004419 & 809158 & 5.2 & 4.2314 & TRN & \\
\hline CHEMBL1972489 & 809158 & 4.2 & 4.2346 & TRN & \\
\hline CHEMBL1994074 & 809158 & 5.5 & 4.6446 & TRN & \\
\hline CHEMBL1992937 & 809158 & 4.2 & 5.3212 & TRN & \\
\hline CHEMBL1972119 & 809158 & 4.2 & 4.2505 & TRN & \\
\hline CHEMBL1090356 & 809158 & 4.2 & 4.1957 & TRN & \\
\hline CHEMBL95692 & 809158 & 4.2 & 4.1172 & TRN & \\
\hline CHEMBL1986328 & 809158 & 5.4 & 5.2087 & TST & \\
\hline CHEMBL1976455 & 809158 & 4.2 & 4.4876 & TRN & \\
\hline CHEMBL1983923 & 809158 & 4.2 & 4.5599 & TST & \\
\hline CHEMBL1982361 & 809158 & 4.2 & 4.055 & TRN & \\
\hline CHEMBL1983534 & 809158 & 4.2 & 4.2448 & TRN & \\
\hline
\end{tabular}




\begin{tabular}{|c|c|c|c|c|}
\hline \multicolumn{5}{|c|}{ Supplemental Table S2.txt } \\
\hline CHEMBL1982122 & 809158 & 4.2 & 4.2216 & TRN \\
\hline CHEMBL 2000801 & 809158 & 4.2 & 4.6894 & TRN \\
\hline CHEMBL1999112 & 809158 & 4.2 & 4.4233 & TST \\
\hline CHEMBL1682546 & 809158 & 4.2 & 4.2027 & TRN \\
\hline CHEMBL1991395 & 809158 & 4.2 & 4.1336 & TRN \\
\hline CHEMBL1971245 & 809158 & 4.2 & 4.5746 & TRN \\
\hline CHEMBL1972142 & 809158 & 4.2 & 3.9824 & TRN \\
\hline CHEMBL1966514 & 809158 & 4.2 & 4.3885 & TRN \\
\hline CHEMBL2003638 & 809158 & 6.3 & 6.2126 & TRN \\
\hline CHEMBL1996066 & 809158 & 4.2 & 4.4542 & TST \\
\hline CHEMBL1993722 & 809158 & 4.2 & 4.8289 & TRN \\
\hline CHEMBL1970806 & 809158 & 4.2 & 4.0741 & TST \\
\hline CHEMBL1979970 & 809158 & 4.2 & 4.2604 & TRN \\
\hline CHEMBL1375640 & 809158 & 5.2 & 4.5618 & TST \\
\hline CHEMBL 2006237 & 809158 & 4.2 & 4.2706 & TRN \\
\hline CHEMBL1967720 & 809158 & 5.2 & 5.0239 & TRN \\
\hline CHEMBL1572266 & 809158 & 4.2 & 4.2626 & TST \\
\hline CHEMBL1991138 & 809158 & 4.2 & 4.2991 & TRN \\
\hline CHEMBL1969755 & 809158 & 4.2 & 4.0384 & TRN \\
\hline CHEMBL1979516 & 809158 & 4.2 & 4.2696 & TRN \\
\hline CHEMBL1605605 & 809158 & 4.2 & 4.1708 & TRN \\
\hline CHEMBL1972820 & 809158 & 4.2 & 4.2894 & TST \\
\hline CHEMBL1996208 & 809158 & 4.2 & 4.6715 & TST \\
\hline CHEMBL1989029 & 809158 & 5.4 & 4.3938 & TRN \\
\hline CHEMBL392642 & 809158 & 6.2 & 5.5202 & TST \\
\hline CHEMBL514499 & 809158 & 4.2 & 4.4873 & TST \\
\hline CHEMBL1980144 & 809158 & 4.2 & 4.5737 & TRN \\
\hline CHEMBL1991188 & 809158 & 4.2 & 4.2939 & TRN \\
\hline CHEMBL1972849 & 809158 & 4.2 & 4.1028 & TRN \\
\hline CHEMBL 231209 & 809158 & 5.2 & 4.9562 & TRN \\
\hline CHEMBL1975357 & 809158 & 4.2 & 4.5387 & TST \\
\hline CHEMBL1976220 & 809158 & 5.5 & 5.0995 & TRN \\
\hline CHEMBL 259922 & 809158 & 4.2 & 4.2612 & TST \\
\hline CHEMBL1997617 & 809158 & 5.4 & 5.6274 & TRN \\
\hline CHEMBL1982383 & 809158 & 4.2 & 4.2138 & TRN \\
\hline CHEMBL1969301 & 809158 & 5.3 & 5.1692 & TRN \\
\hline CHEMBL17370 & 809158 & 4.2 & 4.1849 & TRN \\
\hline CHEMBL1987910 & 809158 & 4.2 & 4.474 & TRN \\
\hline CHEMBL1983932 & 809158 & 4.2 & 4.1766 & TRN \\
\hline CHEMBL1997822 & 809158 & 4.2 & 4.3228 & TRN \\
\hline CHEMBL1991285 & 809158 & 4.2 & 4.2628 & TRN \\
\hline CHEMBL1985690 & 809158 & 5.2 & 5.2864 & TRN \\
\hline CHEMBL1984038 & 809158 & 4.2 & 4.4688 & TRN \\
\hline CHEMBL 243088 & 809158 & 5.7 & 5.9425 & TRN \\
\hline CHEMBL1993661 & 809158 & 7.4 & 7.1955 & TRN \\
\hline CHEMBL1974416 & 809158 & 6.1 & 6.0063 & TRN \\
\hline CHEMBL 2004615 & 809158 & 6.0 & 5.17 & TST \\
\hline CHEMBL1984039 & 809158 & 5.2 & 4.9973 & TST \\
\hline
\end{tabular}




\begin{tabular}{|c|c|c|c|c|c|}
\hline \\
\hline CHEMBL1997872 & 809158 & 4.2 & 4.2557 & TRN & \\
\hline CHEMBL1964290 & 809158 & 5.7 & 4.8315 & TRN & \\
\hline CHEMBL 2003768 & 809158 & 4.2 & 4.0338 & TRN & \\
\hline CHEMBL 213505 & 809158 & 4.2 & 4.4632 & TRN & \\
\hline CHEMBL1987034 & 809158 & 7.2 & 7.1574 & TRN & \\
\hline CHEMBL1993941 & 809158 & 4.2 & 4.2504 & TRN & \\
\hline CHEMBL377383 & 809158 & 4.2 & 4.2499 & TRN & \\
\hline CHEMBL 2005886 & 809158 & 6.0 & 5.9631 & TRN & \\
\hline CHEMBL481491 & 809158 & 5.4 & 4.7796 & TST & \\
\hline CHEMBL1973142 & 809158 & 5.8 & 5.2513 & TRN & \\
\hline CHEMBL1973145 & 809158 & 4.2 & 4.3923 & TRN & \\
\hline CHEMBL1982924 & 809158 & 6.2 & 6.1455 & TRN & \\
\hline CHEMBL2005936 & 809158 & 5.9 & 5.5238 & TRN & \\
\hline CHEMBL1807515 & 809158 & 8.4 & 6.851 & TRN & \\
\hline CHEMBL1971141 & 809158 & 4.2 & 4.1279 & TRN & \\
\hline CHEMBL1995813 & 809158 & 7.1 & 7.3589 & TRN & \\
\hline CHEMBL206236 & 809158 & 4.2 & 4.3144 & TRN & \\
\hline CHEMBL 244378 & 809158 & 6.2 & 6.3904 & TRN & \\
\hline CHEMBL 2001957 & 809158 & 4.2 & 4.2097 & TRN & \\
\hline CHEMBL1969372 & 809158 & 4.2 & 4.3299 & TRN & \\
\hline CHEMBL 2006263 & 809158 & 5.7 & 5.4165 & TRN & \\
\hline CHEMBL1993584 & 809158 & 4.2 & 4.8741 & TRN & \\
\hline CHEMBL1986263 & 809158 & 6.5 & 5.9836 & TRN & \\
\hline CHEMBL 2000114 & 809158 & 5.8 & 5.7008 & TRN & \\
\hline CHEMBL210618 & 809158 & 4.2 & 4.0529 & TRN & \\
\hline CHEMBL1975647 & 809158 & 4.2 & 4.4152 & TRN & \\
\hline CHEMBL1968380 & 809158 & 6.7 & 6.1014 & TRN & \\
\hline CHEMBL1964644 & 809158 & 4.2 & 4.2149 & TRN & \\
\hline CHEMBL1981782 & 809158 & 4.2 & 4.3194 & TRN & \\
\hline CHEMBL1977681 & 809158 & 5.5 & 5.5954 & TRN & \\
\hline CHEMBL1970142 & 809158 & 4.2 & 3.8631 & TRN & \\
\hline CHEMBL1990912 & 809158 & 4.2 & 4.416 & TRN & \\
\hline CHEMBL1988163 & 809158 & 6.9 & 6.7553 & TRN & \\
\hline CHEMBL1975128 & 809158 & 4.2 & 5.92299 & & TRN \\
\hline CHEMBL 2006493 & 809158 & 4.2 & 4.2379 & TST & \\
\hline CHEMBL1996923 & 809158 & 4.2 & 4.05399 & 7999999999 & TST \\
\hline CHEMBL1983449 & 809158 & 4.2 & 4.0135 & TRN & \\
\hline CHEMBL1992323 & 809158 & 4.2 & 4.3472 & TRN & \\
\hline CHEMBL1969735 & 809158 & 4.2 & 4.1665 & TRN & \\
\hline CHEMBL 2002649 & 809158 & 5.7 & 5.9423 & TRN & \\
\hline CHEMBL1995172 & 809158 & 4.2 & 4.3204 & TST & \\
\hline CHEMBL1994321 & 809158 & 4.2 & 4.7746 & TRN & \\
\hline CHEMBL1984788 & 809158 & 4.2 & 4.2917 & TRN & \\
\hline CHEMBL 2000508 & 809158 & 4.2 & 4.1833 & TRN & \\
\hline CHEMBL1971694 & 809158 & 4.2 & 4.2454 & TST & \\
\hline CHEMBL 2001547 & 809158 & 4.2 & 4.0596 & TRN & \\
\hline CHEMBL 210928 & 809158 & 4.2 & 4.0444 & TRN & \\
\hline CHEMBL1986603 & 809158 & 4.2 & 4.3205 & TST & \\
\hline
\end{tabular}




\begin{tabular}{|c|c|c|c|c|c|}
\hline \\
\hline CHEMBL1977148 & 809158 & 4.2 & 4.0919 & TRN & \\
\hline CHEMBL 2003286 & 809158 & 4.2 & 4.971 & TRN & \\
\hline CHEMBL1992306 & 809158 & 4.2 & 4.2484 & TRN & \\
\hline CHEMBL 2002165 & 809158 & 4.2 & 4.9316 & TRN & \\
\hline CHEMBL 2001668 & 809158 & 4.2 & 4.4816 & TRN & \\
\hline CHEMBL1979318 & 809158 & 4.2 & 4.3516 & TST & \\
\hline CHEMBL206382 & 809158 & 4.2 & 4.2359 & TRN & \\
\hline CHEMBL1998585 & 809158 & 5.9 & 5.4821 & TRN & \\
\hline CHEMBL127898 & 809158 & 4.2 & 4.3353 & TST & \\
\hline CHEMBL519697 & 809158 & 5.4 & 4.7573 & TRN & \\
\hline CHEMBL 2004934 & 809158 & 4.2 & 4.1689 & TRN & \\
\hline CHEMBL1970369 & 809158 & 4.2 & 4.0356 & TRN & \\
\hline CHEMBL 2001485 & 809158 & 4.2 & 4.093 & TRN & \\
\hline CHEMBL1966425 & 809158 & 5.4 & 5.6317 & TRN & \\
\hline CHEMBL1984363 & 809158 & 5.2 & 4.4768 & TRN & \\
\hline CHEMBL1978099 & 809158 & 6.1 & 5.8622 & TRN & \\
\hline CHEMBL1988608 & 809158 & 4.2 & 4.3039 & TRN & \\
\hline CHEMBL184847 & 809158 & 4.2 & 4.0913 & TRN & \\
\hline CHEMBL1984367 & 809158 & 4.2 & 4.5296 & TRN & \\
\hline CHEMBL178737 & 809158 & 5.4 & 5.0343 & TST & \\
\hline CHEMBL226898 & 809158 & 8.0 & 8.0171 & TRN & \\
\hline CHEMBL1982563 & 809158 & 4.2 & 4.1478 & TRN & \\
\hline CHEMBL539474 & 809158 & 4.2 & 5.5377 & TST & \\
\hline CHEMBL575824 & 809158 & 5.3 & 5.7777 & TRN & \\
\hline CHEMBL1988387 & 809158 & 4.2 & 4.7833 & TRN & \\
\hline CHEMBL1974803 & 809158 & 5.9 & 5.1805 & TRN & \\
\hline CHEMBL1970074 & 809158 & 4.2 & 4.4904 & TRN & \\
\hline CHEMBL1986970 & 809158 & 4.2 & 4.3536 & TRN & \\
\hline CHEMBL 2005112 & 809158 & 4.2 & 4.2172 & TST & \\
\hline CHEMBL1958401 & 809158 & 4.2 & 4.6839 & TRN & \\
\hline CHEMBL1984044 & 809158 & 4.2 & 4.5347 & TRN & \\
\hline CHEMBL 2003456 & 809158 & 4.2 & 4.9422 & TRN & \\
\hline CHEMBL1966816 & 809158 & 4.2 & 4.9867 & TRN & \\
\hline CHEMBL 2002992 & 809158 & 4.2 & 4.9907 & TRN & \\
\hline CHEMBL560813 & 809158 & 4.2 & 4.6139 & TRN & \\
\hline CHEMBL207253 & 809158 & 4.2 & 4.2683 & TST & \\
\hline CHEMBL1990635 & 809158 & 5.4 & 5.0164 & TST & \\
\hline CHEMBL1968791 & 809158 & 5.6 & 5.3952 & TRN & \\
\hline CHEMBL 2002682 & 809158 & 5.7 & 5.3985 & TST & \\
\hline CHEMBL1971186 & 809158 & 4.2 & 4.1857 & TRN & \\
\hline CHEMBL 2003482 & 809158 & 4.2 & 4.1189 & TRN & \\
\hline CHEMBL1973211 & 809158 & 5.7 & 5.3492 & TRN & \\
\hline CHEMBL1984700 & 809158 & 4.2 & 4.0651 & TRN & \\
\hline CHEMBL1972125 & 809158 & 5.7 & $4.4110 e$ & 00000000005 & TRN \\
\hline CHEMBL1461728 & 809158 & 4.2 & 4.29899 & 99999999995 & TRN \\
\hline CHEMBL1976134 & 809158 & 5.5 & 5.0487 & TRN & \\
\hline CHEMBL1965131 & 809158 & 5.6 & 5.194 & TRN & \\
\hline CHEMBL1972158 & 809158 & 5.9 & 6.0058 & TRN & \\
\hline
\end{tabular}




\begin{tabular}{|c|c|c|c|c|c|}
\hline \\
\hline CHEMBL 2006580 & 809158 & 4.2 & 4.2657 & TRN & \\
\hline CHEMBL2006481 & 809158 & 4.2 & 3.9729 & TRN & \\
\hline CHEMBL1979855 & 809158 & 4.2 & 4.2976 & TRN & \\
\hline CHEMBL1970340 & 809158 & 5.2 & 4.7585 & TRN & \\
\hline CHEMBL 2005186 & 809158 & 4.2 & 4.4109 & TST & \\
\hline CHEMBL1995927 & 809158 & 4.2 & 4.1739 & TST & \\
\hline CHEMBL1975534 & 809158 & 5.6 & 5.6212 & TST & \\
\hline CHEMBL1993424 & 809158 & 6.5 & 6.3041 & TST & \\
\hline CHEMBL1966703 & 809158 & 4.2 & 4.3914 & TST & \\
\hline CHEMBL1969561 & 809158 & 4.2 & 4.1497 & TST & \\
\hline CHEMBL1997023 & 809158 & 4.2 & 4.337 & TST & \\
\hline CHEMBL1964687 & 809158 & 4.2 & 4.4265 & TST & \\
\hline CHEMBL1971943 & 809158 & 5.5 & 5.6913 & TST & \\
\hline CHEMBL1974254 & 809158 & 4.2 & 4.1581 & TST & \\
\hline CHEMBL1988537 & 809158 & 6.8 & 5.7239 & TST & \\
\hline CHEMBL1969049 & 809158 & 4.2 & 4.0839 & TST & \\
\hline CHEMBL 2005828 & 809158 & 4.2 & 4.4492 & TST & \\
\hline CHEMBL 2002240 & 809158 & 4.2 & 4.0356 & TST & \\
\hline CHEMBL 2003405 & 809158 & 5.4 & 4.968 & TST & \\
\hline CHEMBL1991143 & 809158 & 4.2 & 4.0711 & TST & \\
\hline CHEMBL1998611 & 809158 & 5.7 & 5.5364 & TST & \\
\hline CHEMBL1975900 & 809158 & 4.2 & 4.0656 & TST & \\
\hline CHEMBL255822 & 809158 & 5.3 & 5.2457 & TST & \\
\hline CHEMBL1972221 & 809158 & 4.2 & 4.079 & TST & \\
\hline CHEMBL 2006778 & 809158 & 5.3 & 4.7896 & TST & \\
\hline CHEMBL 378627 & 809158 & 4.2 & 4.0932 & TST & \\
\hline CHEMBL1996979 & 809158 & 6.3 & 6.1387 & TST & \\
\hline CHEMBL1997025 & 809158 & 4.2 & 4.4122 & TST & \\
\hline CHEMBL1968406 & 809158 & 4.2 & 4.6615 & TST & \\
\hline CHEMBL1984274 & 809158 & 4.2 & 5.0302 & TST & \\
\hline CHEMBL1998545 & 809158 & 4.2 & 4.104 & TST & \\
\hline CHEMBL1986869 & 809158 & 4.2 & 4.18199 & 99999999995 & TST \\
\hline CHEMBL 2006010 & 809158 & 4.2 & 4.1396 & TST & \\
\hline CHEMBL1682558 & 809158 & 4.2 & 4.2521 & TST & \\
\hline CHEMBL1990496 & 809158 & 5.3 & 4.7558 & TST & \\
\hline CHEMBL2002479 & 809158 & 5.6 & 5.7704 & TST & \\
\hline CHEMBL1967094 & 809158 & 4.2 & 4.6604 & TST & \\
\hline CHEMBL1966035 & 809158 & 4.2 & 4.0156 & TST & \\
\hline CHEMBL 2003341 & 809158 & 4.2 & 4.1606 & TST & \\
\hline CHEMBL1982992 & 809158 & 5.6 & 5.1875 & TST & \\
\hline CHEMBL1999590 & 809158 & 4.2 & 4.3007 & TST & \\
\hline CHEMBL1981079 & 809158 & 5.2 & 4.9785 & TST & \\
\hline CHEMBL1972276 & 809158 & 4.2 & 4.1195 & TST & \\
\hline CHEMBL1980489 & 809158 & 4.2 & 4.0048 & TST & \\
\hline CHEMBL1418095 & 737014 & 3.0969 & 3.105 & TRN & \\
\hline CHEMBL1569585 & 737014 & 3.0969 & 3.367 & TRN & \\
\hline CHEMBL1328466 & 737014 & 3.0969 & 3.1556 & TRN & \\
\hline CHEMBL1339830 & 737014 & 3.0969 & 3.5822 & TRN & \\
\hline
\end{tabular}


Supplemental Table S2.txt

\begin{tabular}{|c|c|c|c|c|}
\hline CHEMBL1427457 & 737014 & 3.0969 & 3.418 & TRN \\
\hline CHEMBL1402010 & 737014 & 3.0969 & 3.4313 & TRN \\
\hline CHEMBL1348332 & 737014 & 3.0969 & 3.3741 & TST \\
\hline CHEMBL1375045 & 737014 & 4.2993 & 3.812 & TRN \\
\hline CHEMBL1497939 & 737014 & 3.0969 & 3.1093 & TRN \\
\hline CHEMBL1332347 & 737014 & 3.0969 & 3.45399 & 99999999997 \\
\hline CHEMBL1708144 & 737014 & 3.0969 & 3.3468 & TRN \\
\hline CHEMBL1475884 & 737014 & 3.0969 & 3.6377 & TST \\
\hline CHEMBL1461730 & 737014 & 3.0969 & 3.042 & TRN \\
\hline CHEMBL78150 & 737014 & 3.0969 & 3.037 & TST \\
\hline CHEMBL1332139 & 737014 & 3.0969 & 3.6446 & TRN \\
\hline CHEMBL1456851 & 737014 & 3.0969 & 3.8726 & TRN \\
\hline CHEMBL1332878 & 737014 & 3.0969 & 3.0154 & TRN \\
\hline CHEMBL1491637 & 737014 & 3.0969 & 3.2264 & TRN \\
\hline CHEMBL1460440 & 737014 & 3.0969 & 3.3202 & TRN \\
\hline CHEMBL1347071 & 737014 & 4.3028 & 3.9742 & TRN \\
\hline CHEMBL1573050 & 737014 & 3.0969 & 3.4328 & TRN \\
\hline CHEMBL1467999 & 737014 & 5.6289 & 4.2755 & TRN \\
\hline CHEMBL1548471 & 737014 & 3.0969 & 3.1334 & TRN \\
\hline CHEMBL1327496 & 737014 & 3.0969 & 2.9949 & TRN \\
\hline CHEMBL1979536 & 737014 & 3.0969 & 3.6856 & TRN \\
\hline CHEMBL2360527 & 737014 & 3.0969 & 3.4036 & TRN \\
\hline CHEMBL1501091 & 737014 & 3.0969 & 2.8381 & TRN \\
\hline CHEMBL1577720 & 737014 & 3.0969 & 3.4836 & TST \\
\hline CHEMBL1590016 & 737014 & 3.0969 & 3.4116 & TRN \\
\hline CHEMBL1720152 & 737014 & 4.1864 & 3.3367 & TST \\
\hline CHEMBL1396209 & 737014 & 4.5867 & 4.1013 & TRN \\
\hline CHEMBL590665 & 737014 & 3.0969 & 3.0599 & TRN \\
\hline CHEMBL1305054 & 737014 & 3.0969 & 3.6507 & TRN \\
\hline CHEMBL1609686 & 737014 & 3.0969 & 2.9837 & TRN \\
\hline CHEMBL 299613 & 737014 & 3.0969 & 3.1216 & TST \\
\hline CHEMBL1411639 & 737014 & 3.0969 & 3.0419 & TRN \\
\hline CHEMBL1306816 & 737014 & 3.0969 & 3.0487 & TST \\
\hline CHEMBL1506503 & 737014 & 3.0969 & 3.0936 & TRN \\
\hline CHEMBL1600855 & 737014 & 4.2321 & 3.782 & TRN \\
\hline CHEMBL1717082 & 737014 & 3.0969 & 3.3793 & TRN \\
\hline CHEMBL1344225 & 737014 & 4.5258 & 4.7618 & TRN \\
\hline CHEMBL1432186 & 737014 & 3.0969 & 2.7555 & TRN \\
\hline CHEMBL1451893 & 737014 & 3.0969 & 3.1887 & TST \\
\hline CHEMBL1304363 & 737014 & 4.4342 & 3.9853 & TRN \\
\hline CHEMBL1393671 & 737014 & 3.0969 & 3.1461 & TRN \\
\hline CHEMBL486504 & 737014 & 3.0969 & 3.1172 & TRN \\
\hline CHEMBL1515368 & 737014 & 3.0969 & 3.1168 & TRN \\
\hline CHEMBL3197483 & 737014 & 3.0969 & 3.9262 & TST \\
\hline CHEMBL1714459 & 737014 & 3.0969 & 2.8956 & TRN \\
\hline CHEMBL1440300 & 737014 & 4.2083 & 4.1023 & TRN \\
\hline CHEMBL1341270 & 737014 & 3.0969 & 3.426 & TST \\
\hline CHEMBL1702373 & 737014 & 3.0969 & 2.8544 & TRN \\
\hline
\end{tabular}


Supplemental Table S2.txt

\begin{tabular}{|c|c|c|c|c|}
\hline CHEMBL1348108 & 737014 & 3.0969 & 3.4388 & TRN \\
\hline CHEMBL1491847 & 737014 & 4.6421 & 3.714 & TST \\
\hline CHEMBL1537124 & 737014 & 3.0969 & 3.4237 & TRN \\
\hline CHEMBL1458747 & 737014 & 3.0969 & 2.8875 & TRN \\
\hline CHEMBL455284 & 737014 & 3.0969 & 2.9974 & TRN \\
\hline CHEMBL1526767 & 737014 & 3.0969 & 3.3166 & TRN \\
\hline CHEMBL1382884 & 737014 & 4.6055 & 4.0536 & TRN \\
\hline CHEMBL1545191 & 737014 & 3.0969 & 3.1449 & TRN \\
\hline CHEMBL1405288 & 737014 & 3.0969 & 3.8067 & TRN \\
\hline CHEMBL1584985 & 737014 & 3.0969 & 3.3402 & TST \\
\hline CHEMBL1453108 & 737014 & 3.0969 & 3.3437 & TRN \\
\hline CHEMBL1427279 & 737014 & 3.0969 & 3.4768 & TRN \\
\hline CHEMBL1568923 & 737014 & 3.0969 & 3.301 & TRN \\
\hline CHEMBL1561596 & 737014 & 3.0969 & 2.9034 & TRN \\
\hline CHEMBL1535161 & 737014 & 3.0969 & 3.2646 & TRN \\
\hline CHEMBL1399125 & 737014 & 3.0969 & 3.5267 & TRN \\
\hline CHEMBL1450653 & 737014 & 3.0969 & 2.7583 & TRN \\
\hline CHEMBL1470568 & 737014 & 3.0969 & 3.0103 & TRN \\
\hline CHEMBL1437139 & 737014 & 3.0969 & 3.5445 & TST \\
\hline CHEMBL1489779 & 737014 & 3.0969 & 3.4733 & TRN \\
\hline CHEMBL 261114 & 737014 & 3.0969 & 2.6758 & TRN \\
\hline CHEMBL1376759 & 737014 & 4.2899 & 3.9648 & TRN \\
\hline CHEMBL1392776 & 737014 & 3.0969 & 3.2412 & TRN \\
\hline CHEMBL1390968 & 737014 & 3.0969 & 3.0676 & TRN \\
\hline CHEMBL 2135351 & 737014 & 3.0969 & 3.1926 & TRN \\
\hline CHEMBL1591205 & 737014 & 3.0969 & 3.7891 & TST \\
\hline CHEMBL603129 & 737014 & 4.1656 & 3.59899 & э99999999998 \\
\hline CHEMBL1988042 & 737014 & 3.0969 & 2.9727 & TRN \\
\hline CHEMBL601180 & 737014 & 3.0969 & 3.3219 & TRN \\
\hline CHEMBL1379970 & 737014 & 3.0969 & 3.2215 & TRN \\
\hline CHEMBL1484487 & 737014 & 3.0969 & 3.3972 & TST \\
\hline CHEMBL1411912 & 737014 & 3.0969 & 3.5022 & TRN \\
\hline CHEMBL1452130 & 737014 & 4.3002 & 3.7753 & TRN \\
\hline CHEMBL1459140 & 737014 & 4.209 & 3.6091 & TRN \\
\hline CHEMBL1976638 & 737014 & 3.0969 & 3.9145 & TST \\
\hline CHEMBL1464071 & 737014 & 3.0969 & 3.0777 & TRN \\
\hline CHEMBL1460612 & 737014 & 3.0969 & 2.6542 & TST \\
\hline CHEMBL551783 & 737014 & 4.5482 & 3.8408 & TRN \\
\hline CHEMBL1362490 & 737014 & 3.0969 & 3.2271 & TST \\
\hline CHEMBL1420462 & 737014 & 3.0969 & 2.6618 & TST \\
\hline CHEMBL1353271 & 737014 & 3.0969 & 3.2286 & TRN \\
\hline CHEMBL1613639 & 737014 & 3.0969 & 3.0119 & TRN \\
\hline CHEMBL3189873 & 737014 & 3.0969 & 3.5332 & TRN \\
\hline CHEMBL1602808 & 737014 & 3.0969 & 2.6342 & TRN \\
\hline CHEMBL1445707 & 737014 & 3.0969 & 2.8958 & TRN \\
\hline CHEMBL1467599 & 737014 & 3.0969 & 3.2943 & TST \\
\hline CHEMBL1412002 & 737014 & 3.0969 & 2.8112 & TRN \\
\hline CHEMBL1564737 & 737014 & 4.9914 & 4.4044 & TRN \\
\hline
\end{tabular}


Supplemental Table S2.txt

\begin{tabular}{|c|c|c|c|c|c|}
\hline CHEMBL1300908 & 737014 & 3.0969 & 3.3195 & TRN & \\
\hline CHEMBL1531170 & 737014 & 3.0969 & 2.9522 & TRN & \\
\hline CHEMBL1383397 & 737014 & 3.0969 & 3.2043 & TST & \\
\hline CHEMBL1451284 & 737014 & 3.0969 & 3.025 & TRN & \\
\hline CHEMBL1396619 & 737014 & 3.0969 & 3.2163 & TRN & \\
\hline CHEMBL1359789 & 737014 & 3.0969 & 3.5913 & TRN & \\
\hline CHEMBL1321754 & 737014 & 3.0969 & 3.733 & TRN & \\
\hline CHEMBL 261115 & 737014 & 3.0969 & 2.6678 & TRN & \\
\hline CHEMBL1594114 & 737014 & 4.158 & 3.7886 & TRN & \\
\hline CHEMBL1322272 & 737014 & 3.0969 & 2.9073 & TRN & \\
\hline CHEMBL1397089 & 737014 & 3.0969 & 3.4226 & TRN & \\
\hline CHEMBL1505088 & 737014 & 3.0969 & 3.7147 & TRN & \\
\hline CHEMBL1368007 & 737014 & 3.0969 & 2.9741 & TRN & \\
\hline CHEMBL1609770 & 737014 & 3.0969 & 2.9876 & TRN & \\
\hline CHEMBL1555271 & 737014 & 3.0969 & 3.1839 & TRN & \\
\hline CHEMBL1714557 & 737014 & 3.0969 & 2.8897 & TRN & \\
\hline CHEMBL1377693 & 737014 & 3.0969 & 3.6929 & TRN & \\
\hline CHEMBL1392527 & 737014 & 3.0969 & 3.0639 & TST & \\
\hline CHEMBL1479240 & 737014 & 3.0969 & 3.0637 & TRN & \\
\hline CHEMBL 3195749 & 737014 & 6.0088 & 5.6632 & TRN & \\
\hline CHEMBL1448945 & 737014 & 3.0969 & 3.1805 & TRN & \\
\hline CHEMBL1457403 & 737014 & 4.1694 & 3.594 & TRN & \\
\hline CHEMBL1544634 & 737014 & 3.0969 & 2.6988 & TST & \\
\hline CHEMBL1558285 & 737014 & 4.3116 & 3.6756 & TRN & \\
\hline CHEMBL1513046 & 737014 & 3.0969 & 2.7612 & TRN & \\
\hline CHEMBL1451921 & 737014 & 3.0969 & 3.3884 & TRN & \\
\hline CHEMBL1488760 & 737014 & 3.0969 & 2.9537 & TST & \\
\hline CHEMBL1491324 & 737014 & 4.4647 & 4.3511 & TRN & \\
\hline CHEMBL1525381 & 737014 & 3.0969 & 3.2382 & TRN & \\
\hline CHEMBL1497681 & 737014 & 3.0969 & 3.6039 & TST & \\
\hline CHEMBL1412127 & 737014 & 3.0969 & 3.5705 & TRN & \\
\hline CHEMBL1729978 & 737014 & 3.0969 & 3.3962 & TRN & \\
\hline CHEMBL1410350 & 737014 & 4.3288 & 3.82800 & 00000000003 & TRN \\
\hline CHEMBL 3145303 & 737014 & 3.0969 & 3.4634 & TRN & \\
\hline CHEMBL1461400 & 737014 & 3.0969 & 3.1449 & TRN & \\
\hline CHEMBL147514 & 737014 & 3.0969 & 3.7394 & TRN & \\
\hline CHEMBL1364793 & 737014 & 3.0969 & 2.7171 & TRN & \\
\hline CHEMBL1587218 & 737014 & 3.0969 & 2.5707 & TRN & \\
\hline CHEMBL2359467 & 737014 & 3.0969 & 2.9751 & TRN & \\
\hline CHEMBL1367034 & 737014 & 3.0969 & 3.2708 & TRN & \\
\hline CHEMBL1387181 & 737014 & 3.0969 & 3.2982 & TST & \\
\hline CHEMBL1524791 & 737014 & 3.0969 & 3.1974 & TRN & \\
\hline CHEMBL1344025 & 737014 & 3.0969 & 3.3791 & TST & \\
\hline CHEMBL1317996 & 737014 & 3.0969 & 3.4148 & TRN & \\
\hline CHEMBL1970422 & 737014 & 3.0969 & 3.5626 & TST & \\
\hline CHEMBL1525220 & 737014 & 3.0969 & 3.0021 & TRN & \\
\hline CHEMBL1524095 & 737014 & 3.0969 & 3.5028 & TRN & \\
\hline CHEMBL1986418 & 737014 & 3.0969 & 3.3626 & TRN & \\
\hline
\end{tabular}


Supplemental Table S2.txt

\begin{tabular}{|c|c|c|c|c|}
\hline 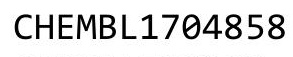 & & & & \\
\hline HEMBL518292 & 37014 & 969 & 0134 & \\
\hline HEMBL1409398 & 37014 & 969 & 778 & \\
\hline 792 & 3014 & & 684 & \\
\hline IEMBL15 & 37014 & & & \\
\hline AEMBL1452379 & 37014 & 969 & 732 & \\
\hline AEMBL1473701 & 37014 & 969 & 433 & \\
\hline HEMBL1415844 & & & & \\
\hline IEMBL14 & 37014 & & & \\
\hline AEMBL1331593 & 37014 & & & \\
\hline AEMBL1519651 & 37014 & 69 & 68 & \\
\hline AEMBL1565636 & 37014 & & & \\
\hline AEMBL1536342 & 14 & & & \\
\hline AEMBL1551000 & 37014 & & & \\
\hline HEMBL578502 & 37014 & & & \\
\hline AEMBL1542955 & 14 & 69 & 24 & \\
\hline AEMBL1546843 & 4 & & & \\
\hline HEMBL1361989 & 4 & & & \\
\hline AEMBL1336485 & 4 & & & \\
\hline AEMBL1588217 & 4 & & & \\
\hline AEMBL3191855 & -4 & 78 & & \\
\hline AEMBL1170485 & & & & \\
\hline HEMBL13094 & 4 & & & \\
\hline AEMBL15977 & 4 & & & \\
\hline AEMBL576349 & & & & \\
\hline AEMBL1483201 & & & & \\
\hline IEMBL1569988 & & & & \\
\hline IEMBL15770 & 4 & & & \\
\hline AFMRI 1690 & 4 & & & \\
\hline AEMBL3199403 & & & & \\
\hline AEMBL1502133 & & & & \\
\hline HEMBL1304383 & 4 & & & \\
\hline 9 & & & & \\
\hline 1235 & 4 & & & \\
\hline HEMBL1462064 & & & & RN \\
\hline AEMBL1424468 & 37 & & & F \\
\hline AEMBL1337659 & 4 & & & \\
\hline & 4 & & & \\
\hline 12215 & 4 & & & RN \\
\hline HEMBL1318350 & & & & IST \\
\hline AEMBL1391387 & 37 & & 94 & $\Gamma R$ \\
\hline AEMBL1511029 & 4 & & & TP \\
\hline ПLIIDL $144 / 442$ & 737 & & & \\
\hline CHEMBL1419096 & & & & r \\
\hline HEMBL1468181 & 737014 & & .1493 & $\mathrm{R}$ \\
\hline AEMBL 265686 & 7376 & 69 & 25 & TR \\
\hline 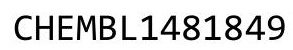 & & & & \\
\hline HEMBL141073 & & & 3.2839 & \\
\hline
\end{tabular}

Page 5578 
Supplemental Table S2.txt

\begin{tabular}{|c|c|c|c|c|c|}
\hline CHEMBL1424127 & 737014 & 3.0969 & \multicolumn{2}{|c|}{3.0839999999999996} & TRN \\
\hline CHEMBL3196351 & 737014 & 3.0969 & 3.0147 & TRN & \\
\hline CHEMBL1574879 & 737014 & 4.4815 & 4.4506 & TRN & \\
\hline CHEMBL1713509 & 737014 & 3.0969 & 2.9945 & TRN & \\
\hline CHEMBL3193419 & 737014 & 3.0969 & 3.1434 & TRN & \\
\hline CHEMBL1490339 & 737014 & 3.0969 & 3.3256 & TRN & \\
\hline CHEMBL1417428 & 737014 & 3.0969 & 3.2249 & TST & \\
\hline CHEMBL1362055 & 737014 & 3.0969 & 3.0371 & TRN & \\
\hline CHEMBL1537452 & 737014 & 3.0969 & 2.9661 & TRN & \\
\hline CHEMBL562566 & 737014 & 4.4449 & 4.0733 & TRN & \\
\hline CHEMBL1332916 & 737014 & 3.0969 & 3.1695 & TRN & \\
\hline CHEMBL1538267 & 737014 & 3.0969 & 3.4148 & TRN & \\
\hline CHEMBL3195389 & 737014 & 3.0969 & 3.0977 & TRN & \\
\hline CHEMBL1393480 & 737014 & 3.0969 & 3.747 & TRN & \\
\hline CHEMBL1430060 & 737014 & 3.0969 & 2.9318 & TRN & \\
\hline CHEMBL3191453 & 737014 & 3.0969 & 3.0032 & TRN & \\
\hline CHEMBL1369930 & 737014 & 3.0969 & 3.2425 & TRN & \\
\hline CHEMBL 2000440 & 737014 & 3.0969 & 3.1436 & TRN & \\
\hline CHEMBL1587868 & 737014 & 3.0969 & 3.5043 & TRN & \\
\hline CHEMBL1531851 & 737014 & 3.0969 & 3.1631 & TRN & \\
\hline CHEMBL3209306 & 737014 & 3.0969 & 3.299 & TRN & \\
\hline CHEMBL15968 & 737014 & 3.0969 & 2.9306 & TRN & \\
\hline CHEMBL1354093 & 737014 & 3.0969 & 3.5792 & TRN & \\
\hline CHEMBL1450116 & 737014 & 3.0969 & 3.537 & TRN & \\
\hline CHEMBL580918 & 737014 & 4.1319 & 3.9656 & TRN & \\
\hline CHEMBL1608078 & 737014 & 3.0969 & 3.7398 & TRN & \\
\hline CHEMBL1491981 & 737014 & 3.0969 & 3.3082 & TRN & \\
\hline CHEMBL1592124 & 737014 & 3.0969 & 3.3463 & TRN & \\
\hline CHEMBL1570647 & 737014 & 3.0969 & 3.0507 & TRN & \\
\hline CHEMBL1600688 & 737014 & 3.0969 & 2.9138 & TRN & \\
\hline CHEMBL1532525 & 737014 & 4.2226 & 3.7457 & TRN & \\
\hline CHEMBL1998940 & 737014 & 3.0969 & 4.2613 & TST & \\
\hline CHEMBL1518625 & 737014 & 4.2262 & 3.7752 & TRN & \\
\hline CHEMBL1521217 & 737014 & 3.0969 & 3.3401 & TRN & \\
\hline CHEMBL1479301 & 737014 & 3.0969 & 3.7589 & TST & \\
\hline CHEMBL1309059 & 737014 & 4.3197 & 3.7189 & TRN & \\
\hline CHEMBL1602086 & 737014 & 3.0969 & 3.365 & TRN & \\
\hline CHEMBL1507250 & 737014 & 3.0969 & 3.7013 & TRN & \\
\hline CHEMBL1481122 & 737014 & 3.0969 & 3.0343 & TST & \\
\hline CHEMBL1520424 & 737014 & 3.0969 & 3.0308 & TRN & \\
\hline CHEMBL1422513 & 737014 & 3.0969 & 2.9975 & TRN & \\
\hline CHEMBL1538784 & 737014 & 3.0969 & 3.4621 & TRN & \\
\hline CHEMBL1537481 & 737014 & 4.4191 & 4.2418 & TRN & \\
\hline CHEMBL1544486 & 737014 & 3.0969 & 3.3135 & TRN & \\
\hline CHEMBL1564136 & 737014 & 3.0969 & 3.9462 & TST & \\
\hline CHEMBL1994193 & 737014 & 3.0969 & 3.0981 & TRN & \\
\hline CHEMBL1590553 & 737014 & 3.0969 & 3.4499 & TRN & \\
\hline CHEMBL279539 & 737014 & 3.0969 & 3.042 & TRN & \\
\hline
\end{tabular}


Supplemental Table S2.txt

\begin{tabular}{|c|c|c|c|c|}
\hline CHEMBL1308547 & 737014 & 3.0969 & 3.4777 & TST \\
\hline CHEMBL1575557 & 737014 & 3.0969 & 3.2911 & TST \\
\hline CHEMBL585502 & 737014 & 3.0969 & \multicolumn{2}{|c|}{3.4160000000000004} \\
\hline CHEMBL3198633 & 737014 & 3.0969 & 3.2147 & TST \\
\hline CHEMBL601757 & 737014 & 5.0264 & 5.5608 & TRN \\
\hline CHEMBL1448627 & 737014 & 4.4001 & 3.8381 & TST \\
\hline CHEMBL1450086 & 737014 & 4.1284 & 4.0141 & TRN \\
\hline CHEMBL1558156 & 737014 & 4.1385 & 3.4096 & TRN \\
\hline CHEMBL1504565 & 737014 & 3.0969 & \multicolumn{2}{|c|}{3.0580000000000003} \\
\hline CHEMBL1393625 & 737014 & 4.1918 & 3.7234 & TRN \\
\hline CHEMBL1565007 & 737014 & 3.0969 & 3.0807 & TRN \\
\hline CHEMBL1971727 & 737014 & 4.7423 & 4.124 & TRN \\
\hline CHEMBL1429782 & 737014 & 3.0969 & 3.2708 & TRN \\
\hline CHEMBL1571885 & 737014 & 4.7721 & 3.903 & TRN \\
\hline CHEMBL1401272 & 737014 & 4.556 & 4.3106 & TRN \\
\hline CHEMBL1325943 & 737014 & 3.0969 & 3.5976 & TRN \\
\hline CHEMBL1493731 & 737014 & 3.0969 & 3.7362 & TRN \\
\hline CHEMBL1486664 & 737014 & 3.0969 & 3.2539 & TRN \\
\hline CHEMBL1608412 & 737014 & 3.0969 & 2.8666 & TRN \\
\hline CHEMBL1567899 & 737014 & 3.0969 & 3.8103 & TRN \\
\hline CHEMBL579318 & 737014 & 5.1152 & 4.8039 & TRN \\
\hline CHEMBL1547979 & 737014 & 3.0969 & 3.4002 & TST \\
\hline CHEMBL131037 & 737014 & 4.3161 & 3.6872 & TRN \\
\hline CHEMBL1439227 & 737014 & 3.0969 & 3.0593 & TRN \\
\hline CHEMBL 3197908 & 737014 & 3.0969 & 3.3809 & TRN \\
\hline CHEMBL1381439 & 737014 & 3.0969 & 3.6179 & TST \\
\hline CHEMBL1720876 & 737014 & 3.0969 & 4.2095 & TST \\
\hline CHEMBL547285 & 737014 & 3.0969 & 3.1849 & TRN \\
\hline CHEMBL1482542 & 737014 & 3.0969 & 3.2776 & TRN \\
\hline CHEMBL1606309 & 737014 & 4.4763 & 3.6173 & TRN \\
\hline CHEMBL1536981 & 737014 & 3.0969 & 3.7299 & TRN \\
\hline CHEMBL1407659 & 737014 & 4.5287 & 3.9528 & TRN \\
\hline CHEMBL1735990 & 737014 & 3.0969 & 3.4904 & TRN \\
\hline CHEMBL408702 & 737014 & 3.0969 & 2.8552 & TRN \\
\hline CHEMBL1372082 & 737014 & 3.0969 & 2.9032 & TRN \\
\hline CHEMBL1417726 & 737014 & 3.0969 & 3.1036 & TRN \\
\hline CHEMBL1339678 & 737014 & 3.0969 & 3.0126 & TRN \\
\hline CHEMBL1585715 & 737014 & 3.0969 & 2.9141 & TRN \\
\hline CHEMBL1993194 & 737014 & 3.0969 & 3.0945 & TRN \\
\hline CHEMBL1995045 & 737014 & 3.0969 & 3.536 & TST \\
\hline CHEMBL1491534 & 737014 & 3.0969 & 2.9962 & TRN \\
\hline CHEMBL1342029 & 737014 & 3.0969 & 3.0298 & TST \\
\hline CHEMBL1611985 & 737014 & 3.0969 & 3.0338 & TRN \\
\hline CHEMBL1335846 & 737014 & 4.6925 & 3.9302 & TRN \\
\hline CHEMBL1599776 & 737014 & 3.0969 & 2.9899 & TRN \\
\hline CHEMBL1576251 & 737014 & 3.0969 & 3.4389 & TRN \\
\hline CHEMBL3199673 & 737014 & 3.0969 & 3.1435 & TRN \\
\hline CHEMBL1507347 & 737014 & 3.0969 & 3.1389 & TRN \\
\hline
\end{tabular}


Supplemental Table S2.txt

\begin{tabular}{|c|c|c|c|c|c|c|}
\hline CHEMBL1484459 & 737014 & 3.0969 & 3.0271 & TRN & & \\
\hline CHEMBL1420393 & 737014 & 3.0969 & 3.268006 & 00000000 & 002 & TRN \\
\hline CHEMBL1596798 & 737014 & 4.1707 & 3.6979 & TRN & & \\
\hline CHEMBL1367311 & 737014 & 3.0969 & 3.1361 & TRN & & \\
\hline CHEMBL1256655 & 737014 & 3.0969 & 3.7772 & TRN & & \\
\hline CHEMBL1610821 & 737014 & 3.0969 & 3.3971 & TRN & & \\
\hline CHEMBL1365398 & 737014 & 3.0969 & 2.9442 & TRN & & \\
\hline CHEMBL1444542 & 737014 & 3.0969 & 3.3455 & TST & & \\
\hline CHEMBL1504701 & 737014 & 3.0969 & 2.9154 & TRN & & \\
\hline CHEMBL1380723 & 737014 & 3.0969 & 3.0707 & TRN & & \\
\hline CHEMBL1450748 & 737014 & 3.0969 & 3.1558 & TRN & & \\
\hline CHEMBL1705098 & 737014 & 3.0969 & 3.4904 & TRN & & \\
\hline CHEMBL1723033 & 737014 & 3.0969 & 2.9259 & TRN & & \\
\hline CHEMBL3190028 & 737014 & 3.0969 & 2.9982 & TRN & & \\
\hline CHEMBL1309521 & 737014 & 3.0969 & 3.5468 & TRN & & \\
\hline CHEMBL1346112 & 737014 & 3.0969 & 3.2546 & TRN & & \\
\hline CHEMBL1966890 & 737014 & 3.0969 & 3.0928 & TRN & & \\
\hline CHEMBL1524014 & 737014 & 3.0969 & 3.1469 & TST & & \\
\hline CHEMBL1346039 & 737014 & 3.0969 & 3.2308 & TRN & & \\
\hline CHEMBL274070 & 737014 & 3.0969 & 3.9609 & TST & & \\
\hline CHEMBL1425889 & 737014 & 4.3507 & 4.2702 & TRN & & \\
\hline CHEMBL482116 & 737014 & 3.0969 & 2.8231 & TRN & & \\
\hline CHEMBL1582099 & 737014 & 3.0969 & 3.2731 & TST & & \\
\hline CHEMBL1310479 & 737014 & 3.0969 & 3.2302 & TRN & & \\
\hline CHEMBL1468435 & 737014 & 3.0969 & 3.0336 & TRN & & \\
\hline CHEMBL1483112 & 737014 & 3.0969 & 3.1959 & TRN & & \\
\hline CHEMBL1400298 & 737014 & 3.0969 & 3.1399 & TRN & & \\
\hline CHEMBL1418432 & 737014 & 3.0969 & 3.3356 & TRN & & \\
\hline CHEMBL1558755 & 737014 & 4.1707 & 3.702 & TRN & & \\
\hline CHEMBL1382128 & 737014 & 4.0975 & 3.9952 & TRN & & \\
\hline CHEMBL1987894 & 737014 & 5.4023 & 5.8033 & TRN & & \\
\hline CHEMBL1505209 & 737014 & 3.0969 & 3.5056 & TST & & \\
\hline CHEMBL1519279 & 737014 & 3.0969 & 3.1652 & TRN & & \\
\hline CHEMBL1497989 & 737014 & 3.0969 & 3.3066 & TRN & & \\
\hline CHEMBL1469379 & 737014 & 3.0969 & 3.4793 & TRN & & \\
\hline CHEMBL1569543 & 737014 & \multicolumn{3}{|c|}{ 4. 2139999999999995} & 3.7531 & TRN \\
\hline CHEMBL1432507 & 737014 & 4.3625 & 3.8608 & TRN & & \\
\hline CHEMBL1432638 & 737014 & 3.0969 & 3.4737 & TRN & & \\
\hline CHEMBL1397445 & 737014 & 4.3045 & 3.7262 & TRN & & \\
\hline CHEMBL1359872 & 737014 & 3.0969 & 2.9869 & TRN & & \\
\hline CHEMBL1596681 & 737014 & 4.3206 & 3.865 & TRN & & \\
\hline CHEMBL1322738 & 737014 & 3.0969 & 2.8344 & TRN & & \\
\hline CHEMBL1537680 & 737014 & 3.0969 & 3.3309 & TRN & & \\
\hline CHEMBL1492399 & 737014 & 3.0969 & 2.6273 & TRN & & \\
\hline CHEMBL1403322 & 737014 & 3.0969 & 3.1975 & TRN & & \\
\hline CHEMBL1352521 & 737014 & 3.0969 & 3.2539 & TRN & & \\
\hline CHEMBL1732859 & 737014 & 3.0969 & 3.2476 & TRN & & \\
\hline CHEMBL1468786 & 737014 & 3.0969 & 3.8081 & TST & & \\
\hline
\end{tabular}


Supplemental Table S2.txt

\begin{tabular}{|c|c|c|c|c|}
\hline CHEMBL1515116 & 737014 & 4.1643 & 3.7783 & TRN \\
\hline CHEMBL1344838 & 737014 & 4.4202 & 4.1675 & TRN \\
\hline CHEMBL1357385 & 737014 & 4.4881 & 4.2872 & TRN \\
\hline CHEMBL1533161 & 737014 & 3.0969 & 3.272 & TRN \\
\hline CHEMBL1445650 & 737014 & 3.0969 & 3.9412 & TRN \\
\hline CHEMBL1500188 & 737014 & 3.0969 & 3.4567 & TRN \\
\hline CHEMBL1333930 & 737014 & 3.0969 & 3.1443 & TRN \\
\hline CHEMBL3194964 & 737014 & 3.0969 & 3.0854 & TRN \\
\hline CHEMBL1409606 & 737014 & 4.762 & 3.9588 & TST \\
\hline CHEMBL1606115 & 737014 & 3.0969 & 2.9982 & TRN \\
\hline CHEMBL1372199 & 737014 & 3.0969 & 3.365 & TRN \\
\hline CHEMBL1565338 & 737014 & 3.0969 & 3.5462 & TRN \\
\hline CHEMBL1363043 & 737014 & 3.0969 & 3.1966 & TRN \\
\hline CHEMBL1432368 & 737014 & 3.0969 & 3.1507 & TRN \\
\hline CHEMBL1524929 & 737014 & 3.0969 & 3.2249 & TRN \\
\hline CHEMBL1456060 & 737014 & 3.0969 & 2.7984 & TST \\
\hline CHEMBL 252387 & 737014 & 3.0969 & 3.6455 & TRN \\
\hline CHEMBL1444020 & 737014 & 3.0969 & 3.5953 & TRN \\
\hline CHEMBL1548492 & 737014 & 3.0969 & 2.8864 & TRN \\
\hline CHEMBL261113 & 737014 & 3.0969 & 2.8857 & TRN \\
\hline CHEMBL1463659 & 737014 & 5.3706 & 5.3269 & TRN \\
\hline CHEMBL1531073 & 737014 & 4.2652 & 3.9799 & TRN \\
\hline CHEMBL303579 & 737014 & 3.0969 & 3.4894 & TRN \\
\hline CHEMBL1377737 & 737014 & 4.5017 & 4.4918 & TRN \\
\hline CHEMBL 3197767 & 737014 & 3.0969 & 2.9037 & TRN \\
\hline CHEMBL1595169 & 737014 & 3.0969 & 3.3957 & TRN \\
\hline CHEMBL1338667 & 737014 & 3.0969 & 2.9975 & TRN \\
\hline CHEMBL154358 & 737014 & 3.0969 & 2.9283 & TRN \\
\hline CHEMBL1995692 & 737014 & 3.0969 & 3.163006 & 0000000003 \\
\hline CHEMBL1563483 & 737014 & 4.279 & 3.3606 & TST \\
\hline CHEMBL89445 & 737014 & 3.0969 & 3.08699 & 9999999997 \\
\hline CHEMBL1528469 & 737014 & 3.0969 & 3.3818 & TST \\
\hline CHEMBL1466542 & 737014 & 3.0969 & 3.3416 & TRN \\
\hline CHEMBL578487 & 737014 & 3.0969 & 3.3151 & TRN \\
\hline CHEMBL1509493 & 737014 & 3.0969 & 3.3922 & TRN \\
\hline CHEMBL1578527 & 737014 & 3.0969 & 3.0936 & TRN \\
\hline CHEMBL1335110 & 737014 & 4.1198 & 3.89 & TRN \\
\hline CHEMBL1333294 & 737014 & 3.0969 & 2.8096 & TRN \\
\hline CHEMBL1374527 & 737014 & 4.4377 & 3.8939 & TRN \\
\hline CHEMBL1407572 & 737014 & 3.0969 & 3.3304 & TST \\
\hline CHEMBL1598986 & 737014 & 3.0969 & 3.2166 & TRN \\
\hline CHEMBL585071 & 737014 & 4.2676 & 3.5321 & TST \\
\hline CHEMBL1510984 & 737014 & 3.0969 & 3.5532 & TRN \\
\hline CHEMBL1487720 & 737014 & 3.0969 & 2.858 & TRN \\
\hline CHEMBL1488472 & 737014 & 3.0969 & 3.4463 & TRN \\
\hline CHEMBL1978733 & 737014 & 4.5513 & 3.4592 & TRN \\
\hline CHEMBL1460007 & 737014 & 4.1051 & 3.5062 & TRN \\
\hline CHEMBL1966865 & 737014 & 3.0969 & 2.9157 & TRN \\
\hline
\end{tabular}


Supplemental Table S2.txt

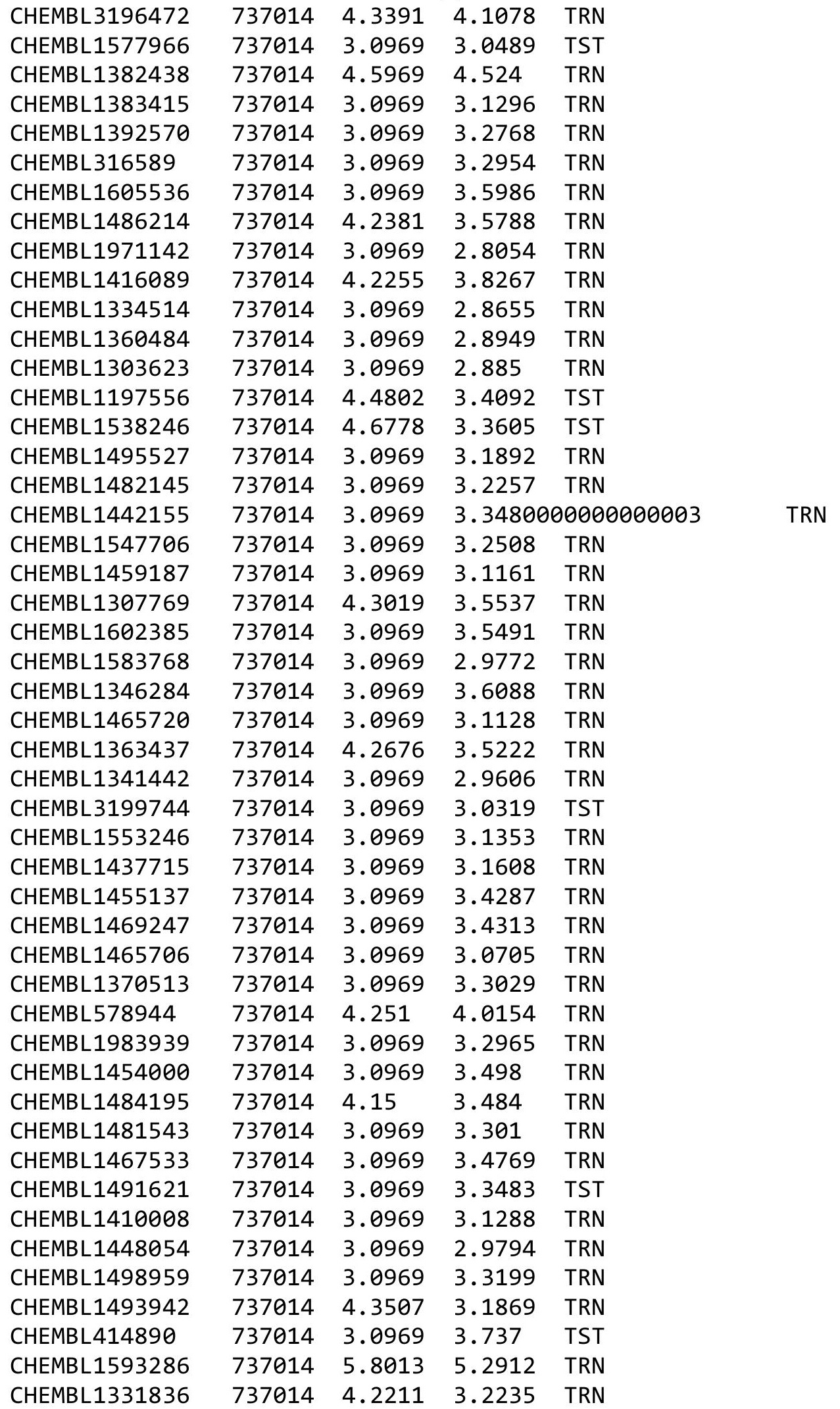

Page 5583 
Supplemental Table S2.txt

\begin{tabular}{|c|c|c|c|c|c|}
\hline CHEMBL1457201 & 737014 & 3.0969 & 3.3319 & TRN & \\
\hline CHEMBL1448642 & 737014 & 4.5654 & 3.7342 & TRN & \\
\hline CHEMBL1444065 & 737014 & 3.0969 & 3.1837 & TRN & \\
\hline CHEMBL1326803 & 737014 & 3.0969 & 3.1099 & TRN & \\
\hline CHEMBL1499414 & 737014 & 3.0969 & 3.2698 & TRN & \\
\hline CHEMBL1441701 & 737014 & 3.0969 & 2.9941 & TST & \\
\hline CHEMBL1610875 & 737014 & 3.0969 & 3.1097 & TRN & \\
\hline CHEMBL1352801 & 737014 & 3.0969 & 3.43899 & 99999999996 & TRN \\
\hline CHEMBL577635 & 737014 & 3.0969 & 3.1875 & TST & \\
\hline CHEMBL1564935 & 737014 & 3.0969 & 3.2185 & TRN & \\
\hline CHEMBL1736070 & 737014 & 3.0969 & 2.9488 & TRN & \\
\hline CHEMBL1387338 & 737014 & 3.0969 & 3.5091 & TRN & \\
\hline CHEMBL1333314 & 737014 & 3.0969 & 3.3085 & TRN & \\
\hline CHEMBL1306460 & 737014 & 4.2306 & 3.4164 & TST & \\
\hline CHEMBL1455279 & 737014 & 3.0969 & 2.9864 & TRN & \\
\hline CHEMBL1374718 & 737014 & 3.0969 & 3.4215 & TRN & \\
\hline CHEMBL1362402 & 737014 & 3.0969 & 2.9598 & TRN & \\
\hline CHEMBL1727333 & 737014 & 3.0969 & 3.6736 & TRN & \\
\hline CHEMBL1711969 & 737014 & 3.0969 & 3.5385 & TST & \\
\hline CHEMBL1469224 & 737014 & 3.0969 & 3.18399 & 99999999997 & TRN \\
\hline CHEMBL1469102 & 737014 & 3.0969 & 3.3272 & TST & \\
\hline CHEMBL1703925 & 737014 & 3.0969 & 3.0483 & TRN & \\
\hline CHEMBL602722 & 737014 & 3.0969 & 3.5224 & TRN & \\
\hline CHEMBL1426762 & 737014 & 3.0969 & 3.2238 & TST & \\
\hline CHEMBL1486874 & 737014 & 3.0969 & 3.0038 & TRN & \\
\hline CHEMBL1429850 & 737014 & 4.1439 & 3.4928 & TST & \\
\hline CHEMBL1476734 & 737014 & 3.0969 & 3.4172 & TRN & \\
\hline CHEMBL1435226 & 737014 & 3.0969 & 3.787 & TRN & \\
\hline CHEMBL1465527 & 737014 & 4.1733 & 3.5675 & TST & \\
\hline CHEMBL1330459 & 737014 & 3.0969 & \multicolumn{2}{|c|}{3.4810000000000003} & TST \\
\hline CHEMBL1509896 & 737014 & 3.0969 & 3.1428 & TRN & \\
\hline CHEMBL1438667 & 737014 & 3.0969 & 3.6344 & TRN & \\
\hline CHEMBL1300558 & 737014 & 3.0969 & 2.9438 & TRN & \\
\hline CHEMBL1364681 & 737014 & 3.0969 & 3.2488 & TRN & \\
\hline CHEMBL1464206 & 737014 & 4.1203 & 4.0457 & TRN & \\
\hline CHEMBL1408150 & 737014 & 4.2062 & 3.3251 & TRN & \\
\hline CHEMBL590927 & 737014 & 3.0969 & 2.97 & TRN & \\
\hline CHEMBL1543337 & 737014 & 3.0969 & 3.7414 & TST & \\
\hline CHEMBL1310753 & 737014 & 3.0969 & 3.2893 & TRN & \\
\hline CHEMBL1426542 & 737014 & 3.0969 & 3.0729 & TRN & \\
\hline CHEMBL1556278 & 737014 & 3.0969 & 2.9979 & TRN & \\
\hline CHEMBL1459767 & 737014 & 3.0969 & 2.7928 & TRN & \\
\hline CHEMBL1459746 & 737014 & 3.0969 & 3.4182 & TRN & \\
\hline CHEMBL1371989 & 737014 & 3.0969 & 3.0119 & TRN & \\
\hline CHEMBL1566488 & 737014 & 3.0969 & 3.4428 & TRN & \\
\hline CHEMBL1309091 & 737014 & 3.0969 & 3.8883 & TRN & \\
\hline CHEMBL1714537 & 737014 & 3.0969 & 3.4016 & TST & \\
\hline CHEMBL1497812 & 737014 & 4.6498 & 3.7978 & TRN & \\
\hline
\end{tabular}


Supplemental Table S2.txt

\begin{tabular}{|c|c|c|c|c|c|}
\hline CHEMBL592600 & 737014 & 3.0969 & 2.9608 & TRN & \\
\hline CHEMBL1392611 & 737014 & 3.0969 & 3.14 & TRN & \\
\hline CHEMBL1476264 & 737014 & 3.0969 & 2.6721 & TST & \\
\hline CHEMBL1312935 & 737014 & 3.0969 & 3.2271 & TRN & \\
\hline CHEMBL1299946 & 737014 & 3.0969 & 2.9371 & TRN & \\
\hline CHEMBL1533321 & 737014 & 3.0969 & 3.1757 & TST & \\
\hline CHEMBL1528118 & 737014 & 3.0969 & 3.0312 & TRN & \\
\hline CHEMBL1486253 & 737014 & 3.0969 & 3.3029 & TST & \\
\hline CHEMBL1448282 & 737014 & 3.0969 & 3.2418 & TRN & \\
\hline CHEMBL 3196754 & 737014 & 4.2041 & 3.7849 & TRN & \\
\hline CHEMBL600100 & 737014 & 3.0969 & 3.1779 & TRN & \\
\hline CHEMBL 2002162 & 737014 & 3.0969 & 3.6518 & TST & \\
\hline CHEMBL428064 & 737014 & 3.0969 & 3.819 & TRN & \\
\hline CHEMBL1514530 & 737014 & 3.0969 & 2.9097 & TRN & \\
\hline CHEMBL 373137 & 737014 & 3.0969 & 3.1294 & TRN & \\
\hline CHEMBL1468134 & 737014 & 3.0969 & 3.5288 & TRN & \\
\hline CHEMBL1568294 & 737014 & 3.0969 & 2.9529 & TRN & \\
\hline CHEMBL1391582 & 737014 & 3.0969 & 3.1795 & TST & \\
\hline CHEMBL1303161 & 737014 & 3.0969 & 3.3973 & TRN & \\
\hline CHEMBL1331733 & 737014 & 3.0969 & 2.7453 & TRN & \\
\hline CHEMBL297323 & 737014 & 3.0969 & 3.138 & TRN & \\
\hline CHEMBL1540682 & 737014 & 4.2472 & 3.562 & TST & \\
\hline CHEMBL1349116 & 737014 & 3.0969 & 3.39 & TRN & \\
\hline CHEMBL1422378 & 737014 & 3.0969 & 3.3592 & TRN & \\
\hline CHEMBL1398260 & 737014 & 3.0969 & 3.6831 & TST & \\
\hline CHEMBL222409 & 737014 & 4.3936 & 3.3002 & TRN & \\
\hline CHEMBL 3194944 & 737014 & 3.0969 & 3.2559 & TRN & \\
\hline CHEMBL1586489 & 737014 & 3.0969 & 3.405 & TRN & \\
\hline CHEMBL1329237 & 737014 & 4.21399 & 79999999 & 3.5738 & TRN \\
\hline CHEMBL1326180 & 737014 & 4.172 & 4.0382 & TRN & \\
\hline CHEMBL1422453 & 737014 & 4.2366 & 4.046 & TRN & \\
\hline CHEMBL1586581 & 737014 & 3.0969 & 3.7016 & TST & \\
\hline CHEMBL532160 & 737014 & 3.0969 & 3.0909 & TRN & \\
\hline CHEMBL1482052 & 737014 & 3.0969 & 3.0145 & TRN & \\
\hline CHEMBL1492096 & 737014 & 3.0969 & 2.9653 & TRN & \\
\hline CHEMBL1319414 & 737014 & 3.0969 & 3.43600 & 00000000004 & TRN \\
\hline CHEMBL1300273 & 737014 & 3.0969 & 3.2413 & TRN & \\
\hline CHEMBL1723154 & 737014 & 3.0969 & 3.0708 & TRN & \\
\hline CHEMBL1989858 & 737014 & 4.3298 & 3.3398 & TST & \\
\hline CHEMBL1373096 & 737014 & 3.0969 & 3.1321 & TRN & \\
\hline CHEMBL1491238 & 737014 & 4.0996 & 3.8727 & TRN & \\
\hline CHEMBL1501242 & 737014 & 3.0969 & 2.8329 & TST & \\
\hline CHEMBL2007135 & 737014 & 3.0969 & 2.85 & TRN & \\
\hline CHEMBL1562664 & 737014 & 3.0969 & 3.37100 & 00000000004 & TRN \\
\hline CHEMBL1391377 & 737014 & 3.0969 & 2.9549 & TRN & \\
\hline CHEMBL1533166 & 737014 & 3.0969 & 2.9087 & TRN & \\
\hline CHEMBL1302238 & 737014 & 4.3696 & 4.1155 & TRN & \\
\hline CHEMBL 3198970 & 737014 & 3.0969 & 2.9361 & TRN & \\
\hline
\end{tabular}


Supplemental Table S2.txt

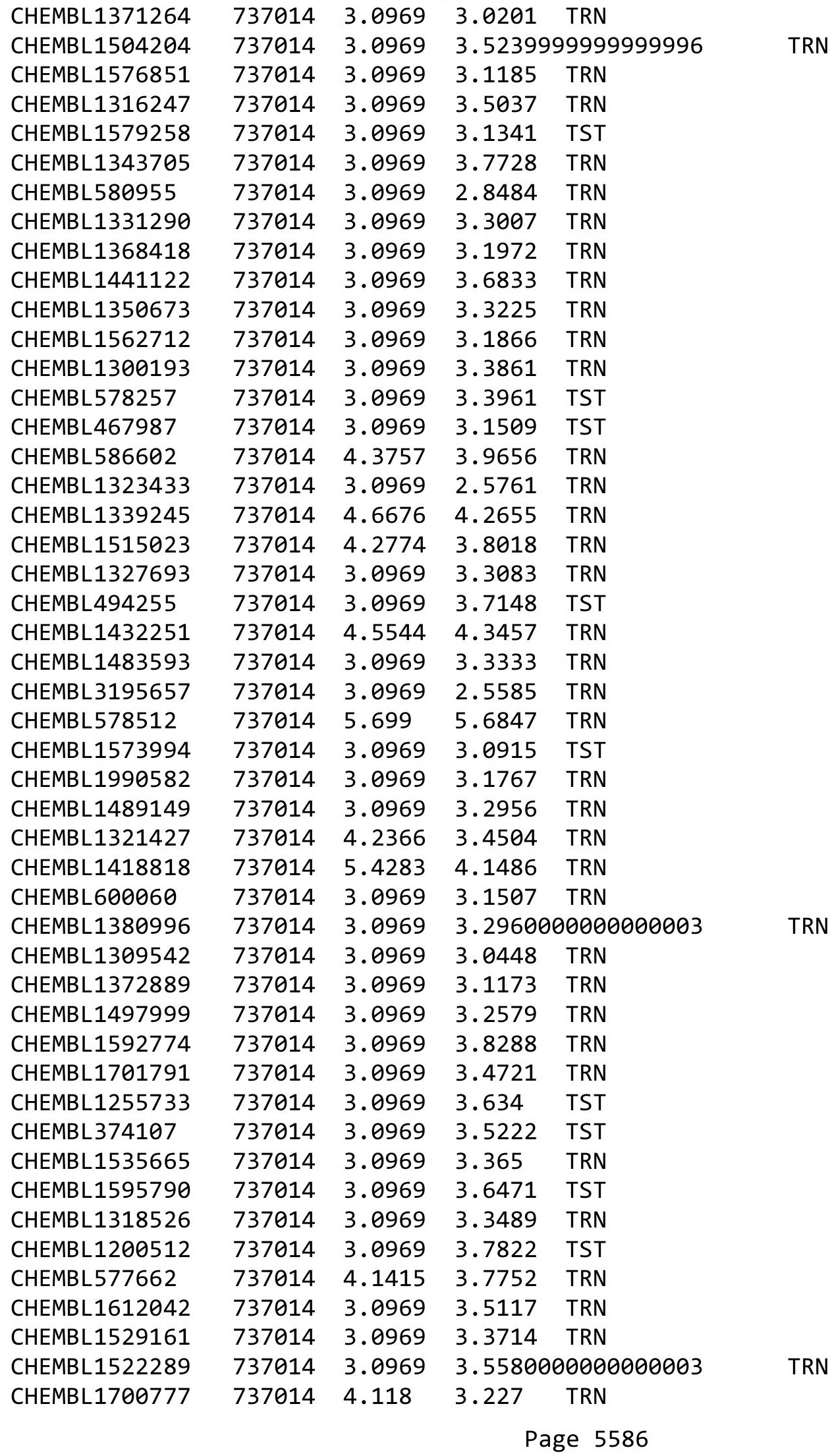


Supplemental Table S2.txt

\begin{tabular}{|c|c|c|c|c|}
\hline CHEMBL1494120 & 737014 & 4.3799 & 4.5342 & TRN \\
\hline CHEMBL1572746 & 737014 & 3.0969 & 3.1125 & TRN \\
\hline CHEMBL3199286 & 737014 & 3.0969 & 3.3114 & TRN \\
\hline CHEMBL1343823 & 737014 & 4.2565 & 3.7675 & TRN \\
\hline CHEMBL1387172 & 737014 & 3.0969 & 3.4393 & TRN \\
\hline CHEMBL1357620 & 737014 & 3.0969 & 3.6001 & TST \\
\hline CHEMBL1602083 & 737014 & 3.0969 & 3.2626 & TRN \\
\hline CHEMBL1610510 & 737014 & 3.0969 & 2.6687 & TST \\
\hline CHEMBL1596740 & 737014 & 4.098 & 3.4972 & TRN \\
\hline CHEMBL1385053 & 737014 & 3.0969 & 2.8619 & TRN \\
\hline CHEMBL1486690 & 737014 & 3.0969 & 3.0651 & TST \\
\hline CHEMBL1517461 & 737014 & 3.0969 & 3.0037 & TRN \\
\hline CHEMBL1998531 & 737014 & 3.0969 & 2.9305 & TRN \\
\hline CHEMBL1452795 & 737014 & 5.4949 & 4.2133 & TRN \\
\hline CHEMBL1346034 & 737014 & 3.0969 & 3.5083 & TRN \\
\hline CHEMBL1319502 & 737014 & 4.3179 & 3.7698 & TRN \\
\hline CHEMBL3189714 & 737014 & 6.3565 & 5.8355 & TRN \\
\hline CHEMBL 2004141 & 737014 & 3.0969 & 3.0946 & TRN \\
\hline CHEMBL1346432 & 737014 & 3.0969 & 3.4436 & TRN \\
\hline CHEMBL1553738 & 737014 & 3.0969 & 3.2172 & TRN \\
\hline CHEMBL1989603 & 737014 & 3.0969 & 2.9071 & TRN \\
\hline CHEMBL3196124 & 737014 & 3.0969 & 3.5815 & TRN \\
\hline CHEMBL1514534 & 737014 & 4.5452 & 3.9302 & TRN \\
\hline CHEMBL1411388 & 737014 & 3.0969 & 3.3121 & TRN \\
\hline CHEMBL1515626 & 737014 & 3.0969 & 3.3129 & TRN \\
\hline CHEMBL193872 & 737014 & 4.1911 & 3.5174 & TST \\
\hline CHEMBL1734695 & 737014 & 3.0969 & 2.852 & TRN \\
\hline CHEMBL 2005364 & 737014 & 4.1574 & 2.6239 & TST \\
\hline CHEMBL1491079 & 737014 & 4.1778 & 3.5651 & TST \\
\hline CHEMBL1369033 & 737014 & 3.0969 & 3.1123 & TST \\
\hline CHEMBL1343568 & 737014 & 3.0969 & 3.98 & TST \\
\hline CHEMBL1401965 & 737014 & 3.0969 & 3.2978 & TST \\
\hline CHEMBL1310995 & 737014 & 3.0969 & 2.8699 & TST \\
\hline CHEMBL1339270 & 737014 & 3.0969 & 3.2206 & TST \\
\hline CHEMBL600862 & 737014 & 3.0969 & 3.0057 & TST \\
\hline CHEMBL1528487 & 737014 & 3.0969 & 3.718 & TST \\
\hline CHEMBL3191151 & 737014 & 3.0969 & 3.2554 & TST \\
\hline CHEMBL1370884 & 737014 & 4.2197 & 3.9965 & TST \\
\hline CHEMBL1412747 & 737014 & 3.0969 & 3.0069 & TST \\
\hline CHEMBL1301125 & 737014 & 3.0969 & 3.5222 & TST \\
\hline CHEMBL586135 & 737014 & 3.0969 & 3.9058 & TST \\
\hline CHEMBL1445297 & 737014 & 3.0969 & 3.5279 & TST \\
\hline CHEMBL1532328 & 737014 & 3.0969 & 2.7409 & TST \\
\hline CHEMBL2003909 & 737014 & 3.0969 & 3.4058 & TST \\
\hline CHEMBL3196134 & 737014 & 3.0969 & 2.951 & TST \\
\hline CHEMBL1540099 & 737014 & 3.0969 & 3.1932 & TST \\
\hline CHEMBL1354927 & 737014 & 3.0969 & 3.59899 & 99999999998 \\
\hline CHEMBL1560061 & 737014 & 3.0969 & 2.9083 & TST \\
\hline
\end{tabular}


Supplemental Table S2.txt

\begin{tabular}{|c|c|c|c|c|}
\hline CHEMBL579322 & 737014 & 3.0969 & 3.1622 & TST \\
\hline CHEMBL1400322 & 737014 & 3.0969 & 3.7233 & TST \\
\hline CHEMBL 2359072 & 737014 & 3.0969 & 3.3745 & TST \\
\hline CHEMBL1475824 & 737014 & 3.0969 & \multicolumn{2}{|c|}{2.9960000000000004} \\
\hline CHEMBL1481347 & 737014 & 4.4157 & 3.865 & TST \\
\hline CHEMBL 2094567 & 737014 & 3.0969 & 3.0269 & TST \\
\hline CHEMBL1535490 & 737014 & 3.0969 & 3.2823 & TST \\
\hline CHEMBL1544465 & 737014 & 3.0969 & 2.853 & TST \\
\hline CHEMBL1530673 & 737014 & 3.0969 & 3.6291 & TST \\
\hline CHEMBL1332565 & 737014 & 3.0969 & 2.8348 & TST \\
\hline CHEMBL1368103 & 737014 & 3.0969 & 3.2836 & TST \\
\hline CHEMBL1422161 & 737014 & 3.0969 & 3.0459 & TST \\
\hline CHEMBL1324319 & 737014 & 3.0969 & \multicolumn{2}{|c|}{2.6919999999999997} \\
\hline CHEMBL1542713 & 737014 & 3.0969 & 4.0826 & TST \\
\hline CHEMBL1484623 & 737014 & 3.0969 & 3.2087 & TST \\
\hline CHEMBL1511424 & 737014 & 3.0969 & 3.9806 & TST \\
\hline CHEMBL1380507 & 737014 & 3.0969 & 3.1772 & TST \\
\hline CHEMBL1324011 & 737014 & 3.0969 & 3.1917 & TST \\
\hline CHEMBL1550278 & 737014 & 3.0969 & 2.9293 & TST \\
\hline CHEMBL1716112 & 737014 & 4.7305 & 3.9447 & TST \\
\hline CHEMBL1480238 & 737014 & 3.0969 & 3.0362 & TST \\
\hline CHEMBL1712891 & 737014 & 3.0969 & 3.5525 & TST \\
\hline CHEMBL 277148 & 737014 & 3.0969 & 3.1792 & TST \\
\hline CHEMBL1410857 & 737014 & 3.0969 & 3.5984 & TST \\
\hline CHEMBL1457561 & 737014 & 3.0969 & 3.1594 & TST \\
\hline CHEMBL1565526 & 737014 & 3.0969 & 3.3525 & TST \\
\hline CHEMBL1387610 & 737014 & 3.0969 & 3.0159 & TST \\
\hline CHEMBL3190965 & 737014 & 4.327 & 3.6747 & TST \\
\hline CHEMBL 2002169 & 737014 & 3.0969 & 3.2546 & TST \\
\hline CHEMBL1300302 & 737014 & 3.0969 & 3.4613 & TST \\
\hline CHEMBL1521172 & 737014 & 3.0969 & 3.5143 & TST \\
\hline CHEMBL1314757 & 737014 & 4.2013 & 3.1787 & TST \\
\hline CHEMBL1566108 & 737014 & 3.0969 & 2.9969 & TST \\
\hline CHEMBL1595952 & 737014 & 3.0969 & 3.0304 & TST \\
\hline CHEMBL1529115 & 737014 & 3.0969 & 3.7886 & TST \\
\hline CHEMBL1964614 & 737014 & 4.2676 & 3.677 & TST \\
\hline CHEMBL1519450 & 737014 & 3.0969 & 3.0316 & TST \\
\hline CHEMBL1563899 & 737014 & 4.1739 & 3.6243 & TST \\
\hline CHEMBL1400459 & 737014 & 3.0969 & 3.2385 & TST \\
\hline CHEMBL1542868 & 737014 & 3.0969 & 2.8855 & TST \\
\hline CHEMBL1570491 & 737014 & 3.0969 & 3.2324 & TST \\
\hline CHEMBL1332955 & 737014 & 3.0969 & 3.5759 & TST \\
\hline CHEMBL1393195 & 737014 & 3.0969 & 3.3973 & TST \\
\hline CHEMBL1571901 & 737014 & 3.0969 & 3.364 & TST \\
\hline CHEMBL1547232 & 737014 & 3.0969 & 3.0291 & TST \\
\hline CHEMBL1420037 & 737014 & 3.0969 & 3.76 & TST \\
\hline CHEMBL122997 & 89542 & 5.6576 & 4.7871 & TRN \\
\hline CHEMBL125054 & 89542 & 5.8665 & 5.2017 & TRN \\
\hline
\end{tabular}




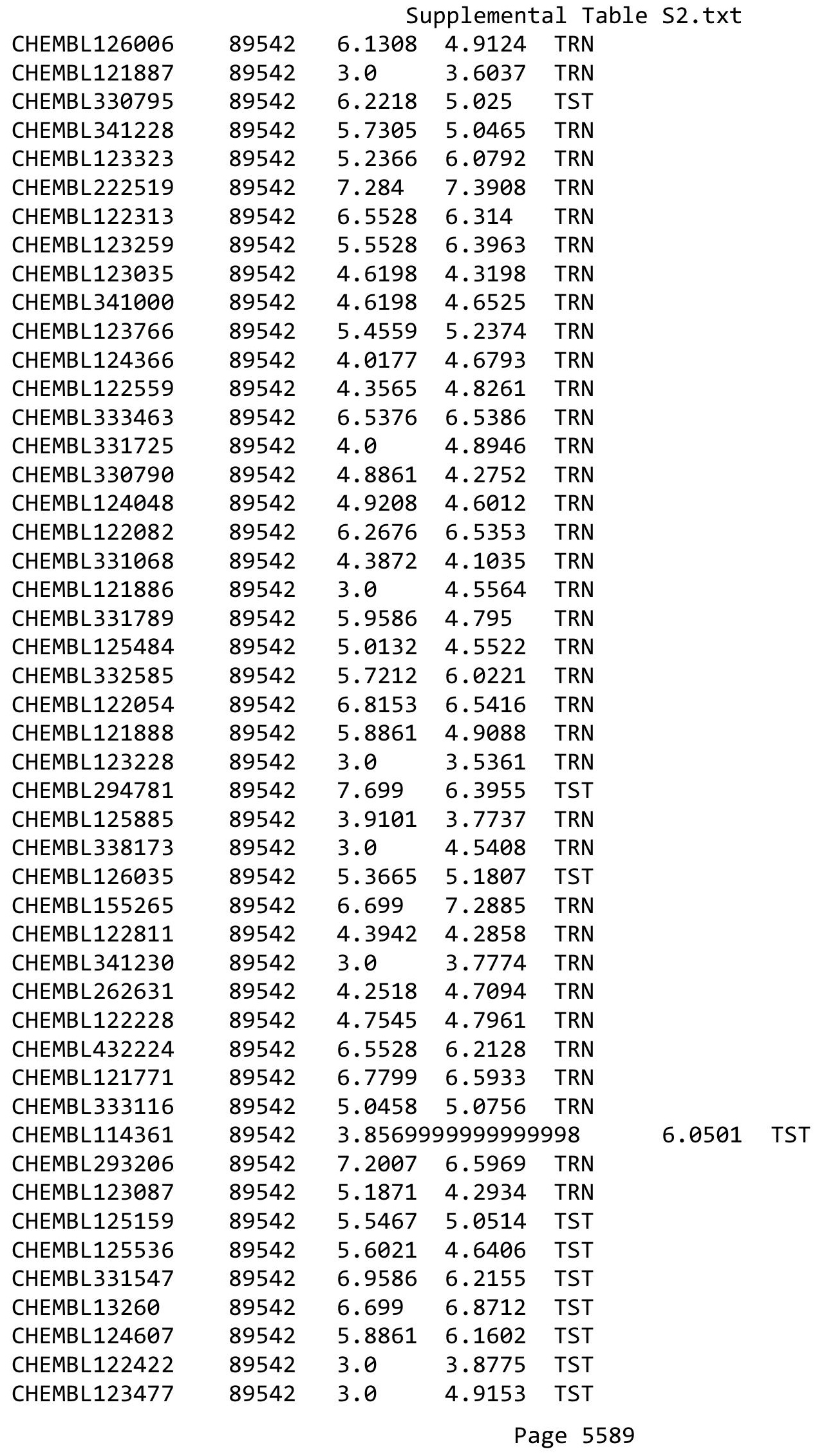


Supplemental Table S2.txt

\begin{tabular}{|c|c|c|c|c|}
\hline HEMBL: & & 4.6778 & 19 & TS \\
\hline HEMPI & 9542 & 4.7447 & 3.8267 & \\
\hline HEMBL; & $\partial 548$ & 3862 & & \\
\hline HEMBL3984285 & 040548 & 9.2218 & & \\
\hline HEMBL3984160 & 640548 & 8.2518 & 6134 & \\
\hline HEMBL3926966 & 540548 & 8.5376 & 082 & \\
\hline AEMBL3891175 & & & & \\
\hline HEMBL3975431 & 48 & 46 & & \\
\hline HEMBL3895954 & 640548 & 7.6345 & 9935 & \\
\hline HEMBL3909547 & 640548 & 8.7959 & 8469 & \\
\hline AEMBL3977360 & 548 & 8.3979 & 51 & \\
\hline AEMBL39 & & & & \\
\hline HEMBL39 & 48 & 78 & & \\
\hline HEMBL3946948 & 548 & & & \\
\hline AEMBL3932007 & 548 & 8. & 48 & \\
\hline EMBL: & 18 & 59 & 01 & \\
\hline AEMBL: & & & & \\
\hline HEMBL39 & 48 & 72 & & \\
\hline HEMBL3931919 & 548 & & & \\
\hline AEMBL38 & 48 & 8. & 52 & \\
\hline EMBL & 8 & & & \\
\hline IEM & & & & \\
\hline HEMBI= & & & & \\
\hline AEMBL & & & & \\
\hline AEMBL39 & 48 & 8. & 94 & RIN \\
\hline EMBL3 & & 83 & & \\
\hline FM & & & & \\
\hline 72 & & & & \\
\hline AEMBL3 & & & & KIV \\
\hline AEMBL3898981 & 48 & 6. & 79 & ST \\
\hline IFMBI 30 & & & & ST \\
\hline 9 & & & & KIV \\
\hline & & & & 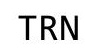 \\
\hline AEMBL3982879 & & & & RN \\
\hline HEMBL3889691 & 48 & & 95 & RI \\
\hline AFMRI 30 & & & & \\
\hline & & & & RIV \\
\hline HEMBL39 & & & & RN \\
\hline HEMBL3924607 & 48 & & & $\Gamma R$ \\
\hline EMBL3 & & & & $S 1$ \\
\hline HEMBL3S & & & & \\
\hline HEMBL3 & & & & ST \\
\hline HEMBL3940155 & & & & RN \\
\hline AEMBL3297851 & 48 & & 88 & $\mathrm{R}$ \\
\hline 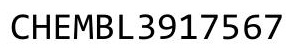 & & & & \\
\hline HEMBL 3895078 & & & & \\
\hline CHEMBL 3961480 & & 8.0088 & .1484 & \\
\hline CHEMBL3943907 & 1640548 & 8.6198 & 8.6473 & \\
\hline
\end{tabular}

Page 5590 
Supplemental Table S2.txt

\begin{tabular}{|c|c|c|c|c|c|}
\hline CHEMBL3934934 & 1640548 & 8.6383 & 8.2712 & TRN & \\
\hline CHEMBL3923055 & 1640548 & 8.585 & 8.4815 & TRN & \\
\hline CHEMBL3968878 & 1640548 & 8.8239 & 8.8902 & TRN & \\
\hline CHEMBL3922027 & 1640548 & 7.8125 & 7.7392 & TRN & \\
\hline CHEMBL3946975 & 1640548 & 7.2147 & 7.2574 & TST & \\
\hline CHEMBL3933990 & 1640548 & 6.9097 & 7.5016 & TST & \\
\hline CHEMBL3954135 & 1640548 & 7.75200 & 00000000 & & 7.7713 \\
\hline CHEMBL3945407 & 1640548 & 7.4168 & 6.9623 & TST & \\
\hline CHEMBL3955661 & 1640548 & 8.4815 & 8.6374 & TRN & \\
\hline CHEMBL3970890 & 1640548 & 8.3279 & 8.6939 & TRN & \\
\hline CHEMBL3937485 & 1640548 & 8.7447 & 8.6578 & TRN & \\
\hline CHEMBL3979742 & 1640548 & 7.2774 & 7.2439 & TRN & \\
\hline CHEMBL3919801 & 1640548 & 6.5791 & 7.7648 & TST & \\
\hline CHEMBL3298567 & 1640548 & 7.5867 & 7.631 & TRN & \\
\hline CHEMBL3915387 & 1640548 & 8.6576 & 8.7786 & TRN & \\
\hline CHEMBL3906468 & 1640548 & 8.7959 & 9.0227 & TST & \\
\hline CHEMBL3927988 & 1640548 & 7.6676 & 7.9036 & TRN & \\
\hline CHEMBL3906714 & 1640548 & 8.9586 & 8.8634 & TRN & \\
\hline CHEMBL3952565 & 1640548 & 6.6778 & 6.6988 & TRN & \\
\hline CHEMBL3920078 & 1640548 & 8.8239 & 8.8482 & TRN & \\
\hline CHEMBL3892311 & 1640548 & 8.8539 & 8.8184 & TRN & \\
\hline CHEMBL3968586 & 1640548 & 8.6216 & 8.5517 & TRN & \\
\hline CHEMBL3985162 & 1640548 & 8.1612 & 8.0909 & TRN & \\
\hline CHEMBL3977524 & 1640548 & 6.7097 & 6.7517 & TRN & \\
\hline CHEMBL3978075 & 1640548 & 8.6383 & 8.618 & TRN & \\
\hline CHEMBL3959595 & 1640548 & 8.1427 & 8.2906 & TRN & \\
\hline CHEMBL3979810 & 1640548 & 8.6383 & 8.9257 & TRN & \\
\hline CHEMBL3928991 & 1640548 & 8.9586 & 8.8299 & TRN & \\
\hline CHEMBL3967253 & 1640548 & 8.6383 & 9.0896 & TST & \\
\hline CHEMBL3940795 & 1640548 & 8.6198 & 8.1486 & TST & \\
\hline CHEMBL3915708 & 1640548 & 8.4949 & 8.4097 & TST & \\
\hline CHEMBL3297858 & 1640548 & 8.1487 & 7.8797 & TST & \\
\hline CHEMBL3969711 & 1640548 & 8.3979 & 8.5974 & TST & \\
\hline CHEMBL 3921444 & 1640548 & 6.9477 & 9.0834 & TST & \\
\hline CHEMBL3910034 & 1640548 & 9.1549 & 8.545 & TST & \\
\hline CHEMBL3900510 & 1640548 & 8.6576 & 8.6157 & TST & \\
\hline CHEMBL3932120 & 1640548 & 7.6968 & 8.3526 & TST & \\
\hline CHEMBL3904925 & 1642280 & 5.6198 & 6.0883 & TRN & \\
\hline CHEMBL 3898375 & 1642280 & 6.5346 & 6.1477 & TRN & \\
\hline CHEMBL3933335 & 1642280 & 5.7423 & 5.7253 & TRN & \\
\hline CHEMBL3982253 & 1642280 & 6.6198 & 6.1198 & TRN & \\
\hline CHEMBL3896677 & 1642280 & 6.7235 & 6.4143 & TRN & \\
\hline CHEMBL3919279 & 1642280 & 6.2418 & 5.8137 & TRN & \\
\hline CHEMBL3916289 & 1642280 & 7.1791 & 7.3583 & TRN & \\
\hline CHEMBL3898964 & 1642280 & 7.1226 & 7.2036 & TRN & \\
\hline CHEMBL3970167 & 1642280 & 7.3298 & 7.3433 & TRN & \\
\hline CHEMBL3973275 & 1642280 & 6.7144 & 6.2429 & TRN & \\
\hline CHEMBL3891867 & 1642280 & 7.4112 & 7.3578 & TRN & \\
\hline
\end{tabular}


Supplemental Table s2.txt

\begin{tabular}{|c|c|c|c|c|c|c|}
\hline CHEMBL3926727 & 1642280 & 7.4377 & 7.399 & TRN & & \\
\hline CHEMBL3904841 & 1642280 & 7.295 & 7.4055 & TRN & & \\
\hline CHEMBL3958787 & 1642280 & 6.3107 & 6.096 & TST & & \\
\hline CHEMBL3915556 & 1642280 & 7.1096 & 7.2386 & TRN & & \\
\hline CHEMBL 3983275 & 1642280 & 6.1415 & 6.0849 & TST & & \\
\hline CHEMBL3935928 & 1642280 & 7.1215 & 7.4119 & TRN & & \\
\hline CHEMBL3893378 & 1642280 & 7.0921 & 7.1878 & TRN & & \\
\hline CHEMBL 3889747 & 1642280 & 6.0438 & 6.0586 & TST & & \\
\hline CHEMBL3958010 & 1642280 & 7.0101 & 7.245 & TST & & \\
\hline CHEMBL 3983754 & 1642280 & 7.6091 & 7.3319 & TRN & & \\
\hline CHEMBL3952227 & 1642280 & 7.0395 & 7.1646 & TRN & & \\
\hline CHEMBL3891194 & 1642280 & 5.71899 & 99999999 & 99 & 5.5825 & TRN \\
\hline CHEMBL3907998 & 1642280 & 6.7545 & 6.2649 & TST & & \\
\hline CHEMBL 3978823 & 1642280 & 7.2668 & 7.1328 & TRN & & \\
\hline CHEMBL 3889469 & 1642280 & 4.3893 & 5.3183 & TRN & & \\
\hline CHEMBL3928315 & 1642280 & 6.7328 & 6.9549 & TRN & & \\
\hline CHEMBL3964429 & 1642280 & 7.2104 & 6.0387 & TST & & \\
\hline CHEMBL 3962469 & 1642280 & 7.9666 & 7.5146 & TRN & & \\
\hline CHEMBL3950632 & 1642280 & 8.0287 & 7.4881 & TRN & & \\
\hline CHEMBL 3940775 & 1642280 & 7.1586 & 7.1389 & TRN & & \\
\hline CHEMBL 3950098 & 1642280 & 6.5331 & 6.2635 & TST & & \\
\hline CHEMBL3923520 & 1642280 & 6.9586 & 7.2093 & TRN & & \\
\hline CHEMBL3959335 & 1642280 & 7.433 & 7.1337 & TRN & & \\
\hline CHEMBL3897197 & 1642280 & 6.6021 & 6.068 & TST & & \\
\hline CHEMBL 3916873 & 1642280 & 7.3215 & 7.3189 & TRN & & \\
\hline CHEMBL3922908 & 1642280 & 6.9666 & 7.2168 & TRN & & \\
\hline CHEMBL3965144 & 1642280 & 6.1656 & 5.5983 & TRN & & \\
\hline CHEMBL 3894687 & 1642280 & 7.1463 & 7.2222 & TRN & & \\
\hline CHEMBL3922445 & 1642280 & 6.2403 & 6.2356 & TST & & \\
\hline CHEMBL3913456 & 1642280 & 6.4698 & 6.2258 & TST & & \\
\hline CHEMBL 3926440 & 1642280 & 6.8697 & 6.2409 & TST & & \\
\hline CHEMBL3986608 & 1642280 & 7.2464 & 7.3299 & TRN & & \\
\hline CHEMBL 3921387 & 1642280 & 6.8928 & 7.2986 & TRN & & \\
\hline CHEMBL3975290 & 1642280 & 6.4498 & 6.305 & TST & & \\
\hline CHEMBL 3960107 & 1642280 & 6.8097 & 7.2056 & TRN & & \\
\hline CHEMBL3904538 & 1642280 & 7.2211 & 6.3121 & TST & & \\
\hline CHEMBL 3981925 & 1642280 & 7.4101 & 7.2318 & TRN & & \\
\hline CHEMBL 3895771 & 1642280 & 6.9508 & 7.2487 & TRN & & \\
\hline CHEMBL 3889934 & 1642280 & 7.266 & 7.3901 & TRN & & \\
\hline CHEMBL 3932535 & 1642280 & 6.7447 & 6.4484 & TST & & \\
\hline CHEMBL3975712 & 1642280 & 7.5498 & 6.4496 & TRN & & \\
\hline CHEMBL 3928182 & 1642280 & 4.3893 & 5.3991 & TRN & & \\
\hline CHEMBL 3943520 & 1642280 & 7.025 & 7.2409 & TRN & & \\
\hline CHEMBL3967046 & 1642280 & 7.2373 & 7.3958 & TRN & & \\
\hline CHEMBL 2012977 & 810063 & 7.6021 & 7.1348 & TST & & \\
\hline CHEMBL2012967 & 810063 & 4.699 & 4.6877 & TRN & & \\
\hline CHEMBL1771387 & 810063 & 7.3979 & 7.5705 & TST & & \\
\hline CHEMBL2012994 & 810063 & 7.301 & 8.1507 & TST & & \\
\hline
\end{tabular}




\begin{tabular}{|c|c|c|c|c|c|}
\hline & & \multicolumn{4}{|c|}{ Supplemental Table s2.txt } \\
\hline CHEMBL 2013007 & 810063 & 5.301 & 5.3021 & TRN & \\
\hline CHEMBL 2012998 & 810063 & 6.1249 & 6.1247 & TRN & \\
\hline CHEMBL 2013115 & 810063 & 6.8239 & 6.8604 & TRN & \\
\hline CHEMBL 2013114 & 810063 & 7.699 & 7.7113 & TRN & \\
\hline CHEMBL2013003 & 810063 & 6.5229 & 6.4966 & TRN & \\
\hline CHEMBL 2012987 & 810063 & 5.6021 & 5.8822 & TST & \\
\hline CHEMBL 2012974 & 810063 & 6.1249 & 6.1776 & TST & \\
\hline CHEMBL 2013113 & 810063 & 6.8239 & 6.8017 & TRN & \\
\hline CHEMBL 2013001 & 810063 & 5.6021 & 5.63399 & 99999999995 & TRN \\
\hline CHEMBL2013112 & 810063 & 7.699 & 7.6909 & TRN & \\
\hline CHEMBL 2012979 & 810063 & 5.5229 & 5.5141 & TRN & \\
\hline CHEMBL 2013005 & 810063 & 6.5229 & 6.5458 & TRN & \\
\hline CHEMBL 2012993 & 810063 & 4.8239 & 5.2233 & TST & \\
\hline CHEMBL 2012978 & 810063 & 6.6021 & 6.6171 & TRN & \\
\hline CHEMBL 2012980 & 810063 & 5.1249 & 5.6647 & TST & \\
\hline CHEMBL 2012990 & 810063 & 5.699 & 5.6984 & TRN & \\
\hline CHEMBL 2013111 & 810063 & 6.8239 & 6.819 & TRN & \\
\hline CHEMBL1771376 & 810063 & 8.3979 & 8.4349 & TRN & \\
\hline CHEMBL 2012983 & 810063 & 4.6021 & 4.5973 & TRN & \\
\hline CHEMBL 2012999 & 810063 & 6.6021 & 6.5984 & TRN & \\
\hline CHEMBL 2012971 & 810063 & 4.301 & 4.2728 & TRN & \\
\hline CHEMBL 2012973 & 810063 & 6.1249 & 6.1395 & TRN & \\
\hline CHEMBL 2012989 & 810063 & 5.6021 & 5.6215 & TRN & \\
\hline CHEMBL 2012975 & 810063 & 4.6021 & 5.0196 & TST & \\
\hline CHEMBL 2013117 & 810063 & 6.5229 & 6.4967 & TRN & \\
\hline CHEMBL 2013008 & 810063 & 5.301 & 5.3141 & TRN & \\
\hline CHEMBL 2013110 & 810063 & 7.6021 & 7.5858 & TRN & \\
\hline CHEMBL 2012997 & 810063 & 5.8239 & 5.8291 & TRN & \\
\hline CHEMBL1771372 & 810063 & 5.6021 & 5.5479 & TRN & \\
\hline CHEMBL 2013116 & 810063 & 6.3979 & 6.3991 & TRN & \\
\hline CHEMBL 2012972 & 810063 & 6.301 & 6.2935 & TRN & \\
\hline CHEMBL2012985 & 810063 & 6.1249 & 6.1176 & TRN & \\
\hline CHEMBL 2012996 & 810063 & 4.1249 & 4.117 & TRN & \\
\hline CHEMBL 2013118 & 810063 & 7.0 & 6.9973 & TRN & \\
\hline CHEMBL 2012992 & 810063 & 5.301 & 5.7608 & TST & \\
\hline CHEMBL 2012981 & 810063 & 5.301 & 5.3022 & TRN & \\
\hline CHEMBL 2012991 & 810063 & 5.301 & 5.2895 & TRN & \\
\hline CHEMBL 2012968 & 810063 & 5.1249 & 5.1235 & TRN & \\
\hline CHEMBL2012969 & 810063 & 4.6021 & 4.6339 & TRN & \\
\hline CHEMBL 2012988 & 810063 & 4.6021 & 4.5969 & TRN & \\
\hline CHEMBL 2013006 & 810063 & 6.6021 & 6.53299 & 99999999995 & TST \\
\hline CHEMBL 2012976 & 810063 & 4.699 & 4.7124 & TRN & \\
\hline CHEMBL 2013000 & 810063 & 6.6021 & 6.7757 & TST & \\
\hline CHEMBL 2013004 & 810063 & 6.3979 & 6.5059 & TST & \\
\hline CHEMBL 2012984 & 810063 & 4.6021 & 4.6008 & TRN & \\
\hline CHEMBL 2013002 & 810063 & 7.1249 & 7.7085 & TST & \\
\hline CHEMBL 2012995 & 810063 & 7.0 & 6.5558 & TST & \\
\hline CHEMBL 2012986 & 810063 & 8.0 & 7.9887 & TRN & \\
\hline
\end{tabular}




\begin{tabular}{|c|c|c|c|c|}
\hline & & & pplement & al $\mathrm{T}$ \\
\hline CHEMBL1771374 & 810063 & 4.699 & 4.7513 & TRN \\
\hline CHEMBL 2012970 & 810063 & 5.6021 & 5.5875 & TRN \\
\hline CHEMBL1771378 & 810063 & 7.301 & 7.275 & TRN \\
\hline CHEMBL2012982 & 810063 & 6.699 & 6.7023 & TRN \\
\hline CHEMBL3190827 & 737030 & 3.4948 & 4.8301 & TST \\
\hline CHEMBL1726168 & 737030 & 3.4948 & 3.5157 & TRN \\
\hline CHEMBL1388755 & 737030 & 5.2749 & 5.2852 & TRN \\
\hline CHEMBL1706477 & 737030 & 3.4948 & 3.5011 & TRN \\
\hline CHEMBL1719035 & 737030 & 3.4948 & 3.4676 & TRN \\
\hline CHEMBL1461661 & 737030 & 3.4948 & 3.3145 & TST \\
\hline CHEMBL1720217 & 737030 & 3.4948 & 4.1997 & TST \\
\hline CHEMBL1726942 & 737030 & 4.9957 & 4.9926 & TRN \\
\hline CHEMBL1588996 & 737030 & 3.4948 & 3.4861 & TRN \\
\hline CHEMBL1348399 & 737030 & 3.4948 & 3.4913 & TRN \\
\hline CHEMBL1359415 & 737030 & 3.4948 & 3.5041 & TRN \\
\hline CHEMBL1564473 & 737030 & 5.4401 & 5.3992 & TRN \\
\hline CHEMBL1416769 & 737030 & 3.4948 & 3.6308 & TST \\
\hline CHEMBL1333440 & 737030 & 8.2218 & 8.3184 & TRN \\
\hline CHEMBL1417841 & 737030 & 5.3072 & 5.2977 & TRN \\
\hline CHEMBL 3145240 & 737030 & 5.4141 & 4.8824 & TST \\
\hline CHEMBL1568059 & 737030 & 4.7011 & 4.7183 & TRN \\
\hline CHEMBL3193664 & 737030 & 3.4948 & 4.1467 & TST \\
\hline CHEMBL1705910 & 737030 & 3.4948 & 3.5175 & TRN \\
\hline CHEMBL1493386 & 737030 & 6.8508 & 6.7317 & TRN \\
\hline CHEMBL1440728 & 737030 & 3.4948 & 3.4968 & TRN \\
\hline CHEMBL1707460 & 737030 & 3.4948 & 3.9729 & TST \\
\hline CHEMBL1710676 & 737030 & 3.4948 & 2.8554 & TST \\
\hline CHEMBL1585267 & 737030 & 6.032 & 6.0405 & TRN \\
\hline CHEMBL1723909 & 737030 & 7.0074 & 7.0302 & TRN \\
\hline CHEMBL1478375 & 737030 & 3.4948 & 3.4959 & TRN \\
\hline CHEMBL1493095 & 737030 & 6.7747 & 6.7376 & TRN \\
\hline CHEMBL1729385 & 737030 & 3.4948 & 3.4818 & TRN \\
\hline CHEMBL1362498 & 737030 & 3.4948 & 3.4416 & TRN \\
\hline CHEMBL1508445 & 737030 & 6.0937 & 6.0814 & TRN \\
\hline CHEMBL1490629 & 737030 & 5.8447 & 5.8408 & TRN \\
\hline CHEMBL1455762 & 737030 & 3.4948 & 3.5247 & TRN \\
\hline CHEMBL1343080 & 737030 & 3.4948 & 3.4377 & TRN \\
\hline CHEMBL1712643 & 737030 & 3.4948 & 3.5382 & TRN \\
\hline CHEMBL1569631 & 737030 & 5.9547 & 5.9335 & TRN \\
\hline CHEMBL1716867 & 737030 & 3.4948 & 3.2425 & TST \\
\hline CHEMBL1718305 & 737030 & 3.4948 & 3.3461 & TST \\
\hline CHEMBL1602191 & 737030 & 4.7423 & 4.7526 & TRN \\
\hline CHEMBL1455766 & 737030 & 3.4948 & 3.5582 & TRN \\
\hline CHEMBL1524012 & 737030 & 3.4948 & 3.4947 & TRN \\
\hline CHEMBL1455045 & 737030 & 3.4948 & 3.4774 & TRN \\
\hline CHEMBL1731800 & 737030 & 3.4948 & 3.4608 & TRN \\
\hline CHEMBL1384726 & 737030 & 3.4948 & 3.4958 & TRN \\
\hline CHEMBL1371990 & 737030 & 3.4948 & 3.5386 & TRN \\
\hline
\end{tabular}




\begin{tabular}{|c|c|c|c|c|c|c|}
\hline \multicolumn{7}{|c|}{ supplemental a } \\
\hline CHEMBL1511139 & 737030 & 3.4948 & 3.4528 & \multicolumn{3}{|l|}{ TRN } \\
\hline CHEMBL1342964 & 737030 & 5.3116 & 5.2997 & \multicolumn{3}{|l|}{ TRN } \\
\hline CHEMBL1710618 & 737030 & 3.4948 & 3.5324 & \multicolumn{3}{|l|}{ TST } \\
\hline CHEMBL1391476 & 737030 & 5.8665 & 5.9294 & \multicolumn{3}{|l|}{ TRN } \\
\hline CHEMBL1403666 & 737030 & 5.1158 & 5.1234 & \multicolumn{3}{|l|}{ TRN } \\
\hline CHEMBL1430337 & 737030 & 3.4948 & 3.7877 & \multicolumn{3}{|l|}{ TST } \\
\hline CHEMBL1430524 & 737030 & 3.4948 & 3.4894 & \multicolumn{3}{|l|}{ TRN } \\
\hline CHEMBL1505687 & 737030 & 6.2218 & 6.1998 & \multicolumn{3}{|l|}{ TRN } \\
\hline CHEMBL1565651 & 737030 & 3.4948 & 3.531 & \multicolumn{3}{|l|}{ TRN } \\
\hline CHEMBL1732148 & 737030 & 3.4948 & 3.6361 & \multicolumn{3}{|l|}{ TST } \\
\hline CHEMBL1480657 & 737030 & 6.9031 & 6.857 & \multicolumn{3}{|l|}{ TRN } \\
\hline CHEMBL1445729 & 737030 & 4.7878 & 4.8151 & \multicolumn{3}{|l|}{ TRN } \\
\hline CHEMBL3190555 & 737030 & 3.4948 & 4.1603 & \multicolumn{3}{|l|}{ TST } \\
\hline CHEMBL1412822 & 737030 & \multicolumn{4}{|c|}{4.9830000000000005} & TRN \\
\hline CHEMBL1724710 & 737030 & 5.2351 & 5.1641 & \\
\hline CHEMBL1311570 & 737030 & 5.8665 & 5.904 & \multicolumn{3}{|l|}{ TRN } \\
\hline CHEMBL1346675 & 737030 & 3.4948 & 3.5038 & \multicolumn{3}{|l|}{ TRN } \\
\hline CHEMBL1405968 & 737030 & 3.4948 & 3.5393 & \multicolumn{3}{|l|}{ TST } \\
\hline CHEMBL3642933 & 1527965 & 9.6383 & 8.5017 & \multicolumn{3}{|l|}{ TST } \\
\hline CHEMBL3642935 & 1527965 & 9.5229 & 8.5189 & \multicolumn{3}{|l|}{ TST } \\
\hline CHEMBL 3642889 & 1527965 & 9.0655 & 9.156 & TRN & & \\
\hline CHEMBL 3642888 & 1527965 & 8.8356 & 9.1751 & TRN & & \\
\hline CHEMBL3642973 & 1527965 & 9.5686 & 8.3495 & TST & & \\
\hline CHEMBL3639418 & 1527965 & 9.301 & 9.1834 & TRN & & \\
\hline CHEMBL3642968 & 1527965 & 9.2924 & 9.2066 & TRN & & \\
\hline CHEMBL 3642895 & 1527965 & 9.6576 & 9.0067 & TST & & \\
\hline CHEMBL3642920 & 1527965 & 8.8539 & 8.8563 & TRN & & \\
\hline CHEMBL3642893 & 1527965 & 8.1433 & 8.6061 & TRN & & \\
\hline CHEMBL3642870 & 1527965 & 6.0 & 6.2186 & TRN & & \\
\hline CHEMBL3642887 & 1527965 & 8.8761 & 9.087 & TRN & & \\
\hline CHEMBL 3642932 & 1527965 & 9.699 & 8.8426 & TRN & & \\
\hline CHEMBL3642969 & 1527965 & 8.0706 & 8.1989 & TRN & & \\
\hline CHEMBL3642892 & 1527965 & 8.3224 & 8.1385 & TST & & \\
\hline CHEMBL3642949 & 1527965 & 8.4437 & 7.9937 & TRN & & \\
\hline CHEMBL3642897 & 1527965 & 8.2403 & 8.5397 & TRN & & \\
\hline CHEMBL3642915 & 1527965 & 8.4685 & 8.13600 & 0000000001 & TRN & \\
\hline CHEMBL3642857 & 1527965 & 9.3565 & 8.5426 & TST & & \\
\hline CHEMBL3642926 & 1527965 & 8.4318 & 8.98299 & 9999999999 & TRN & \\
\hline CHEMBL 3642981 & 1527965 & 8.9208 & 8.9276 & TRN & & \\
\hline CHEMBL3642872 & 1527965 & 6.0 & 6.279 & TRN & & \\
\hline CHEMBL3642939 & 1527965 & 8.4202 & 8.4801 & TRN & & \\
\hline CHEMBL3642961 & 1527965 & 8.9586 & 9.1714 & TRN & & \\
\hline CHEMBL3642864 & 1527965 & 8.0386 & 8.1755 & TST & & \\
\hline CHEMBL3642866 & 1527965 & 9.3188 & 8.385 & TST & & \\
\hline CHEMBL 3642884 & 1527965 & 9.1024 & 9.1595 & TRN & & \\
\hline CHEMBL 3642959 & 1527965 & 9.3098 & 9.4671 & TRN & & \\
\hline CHEMBL3642913 & 1527965 & 8.2441 & 8.5908 & TRN & & \\
\hline CHEMBL3642876 & 1527965 & 6.0 & 5.78600 & 00000000005 & TRN & \\
\hline & & & & e 5595 & & \\
\hline
\end{tabular}


Supplemental Table S2.txt

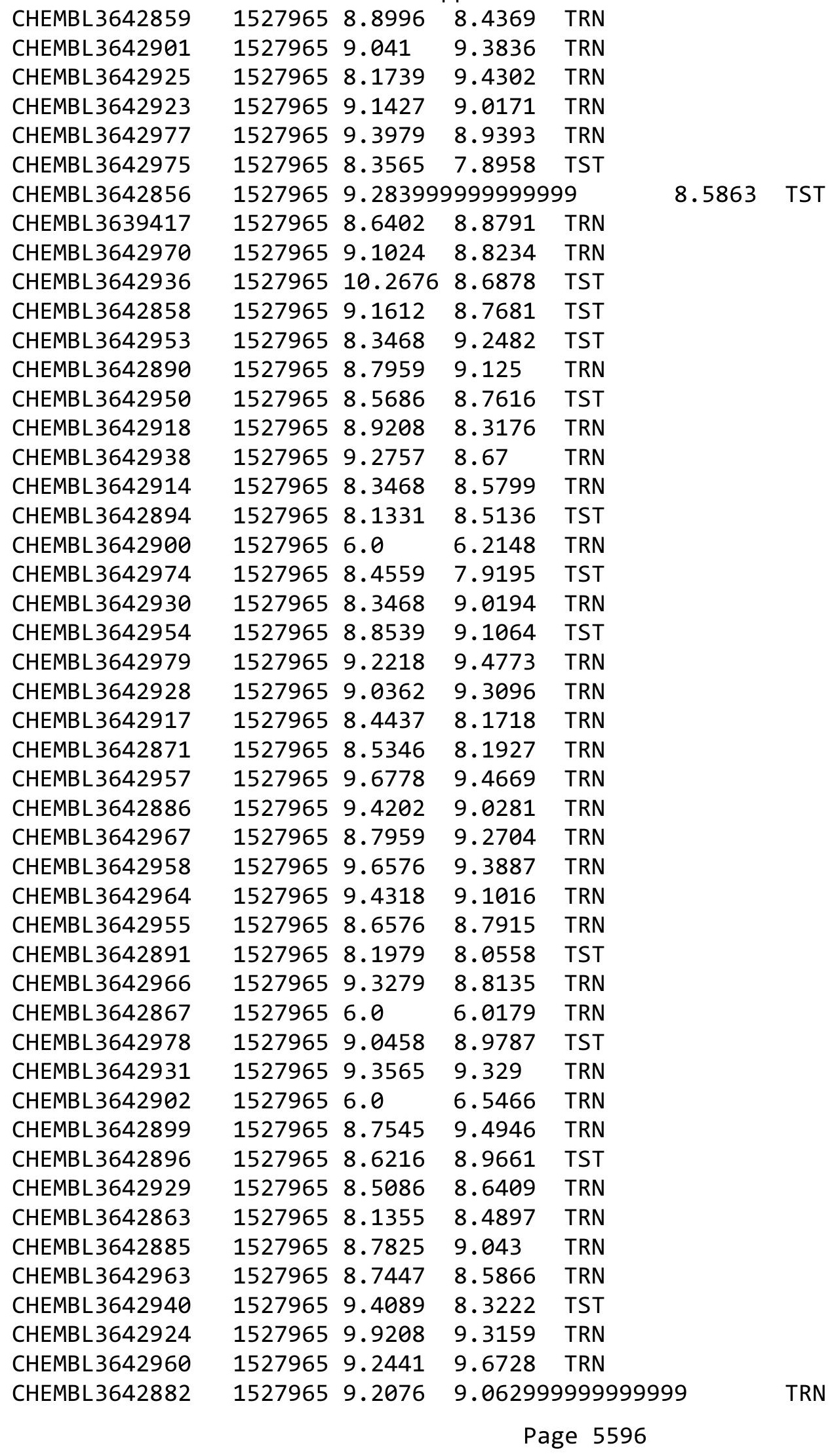


Supplemental Table S2.txt

\begin{tabular}{|c|c|c|c|c|}
\hline CHEMBL3642937 & 1527965 & 8.6383 & 8.8053 & TRN \\
\hline CHEMBL3642948 & 1527965 & 6.0 & 6.6618 & TRN \\
\hline CHEMBL3642869 & 1527965 & 8.7545 & 8.4026 & TRN \\
\hline CHEMBL3642922 & 1527965 & 8.699 & 8.9742 & TRN \\
\hline CHEMBL3642982 & 1527965 & 9.699 & 8.2668 & TRN \\
\hline CHEMBL3642942 & 1527965 & 6.0 & 6.1048 & TRN \\
\hline CHEMBL3642865 & 1527965 & 8.9469 & 8.4929 & TST \\
\hline CHEMBL3642962 & 1527965 & 9.3565 & 9.3578 & TRN \\
\hline CHEMBL3642965 & 1527965 & 9.7447 & 8.8168 & TRN \\
\hline CHEMBL3642916 & 1527965 & 8.6383 & 8.3024 & TRN \\
\hline CHEMBL3642971 & 1527965 & 8.301 & 8.5817 & TRN \\
\hline CHEMBL3642898 & 1527965 & 8.821 & 9.4681 & TRN \\
\hline CHEMBL3642927 & 1527965 & 8.3768 & 8.3879 & TRN \\
\hline CHEMBL 3642862 & 1527965 & 8.9957 & 8.6758 & TST \\
\hline CHEMBL 3642860 & 1527965 & 8.9469 & 8.2974 & TRN \\
\hline CHEMBL 3642980 & 1527965 & 8.4318 & 8.4963 & TRN \\
\hline CHEMBL3642906 & 1527965 & 9.0809 & 9.2825 & TRN \\
\hline CHEMBL3642951 & 1527965 & 9.0132 & 9.1852 & TRN \\
\hline CHEMBL3642868 & 1527965 & 8.7352 & 8.4535 & TRN \\
\hline CHEMBL 3642972 & 1527965 & 9.1549 & 7.849 & TST \\
\hline CHEMBL3642946 & 1527965 & 9.4815 & 8.4968 & TRN \\
\hline CHEMBL3642956 & 1527965 & 8.7447 & 8.6594 & TRN \\
\hline CHEMBL3642861 & 1527965 & 6.0 & 6.7899 & TRN \\
\hline CHEMBL3642919 & 1527965 & 8.8861 & 9.1329 & TRN \\
\hline CHEMBL3642934 & 1527965 & 9.2076 & 8.3457 & TST \\
\hline CHEMBL3642903 & 1527965 & 9.8239 & 8.8705 & TRN \\
\hline CHEMBL3642880 & 1527965 & 8.7773 & 9.0525 & TRN \\
\hline CHEMBL3642881 & 1527965 & 8.8928 & 8.5398 & TRN \\
\hline CHEMBL3642921 & 1527965 & 8.7696 & 8.7545 & TRN \\
\hline CHEMBL 3642883 & 1527965 & 8.5391 & 9.1264 & TST \\
\hline CHEMBL3642976 & 1527965 & 8.4949 & 8.7201 & TST \\
\hline CHEMBL3642947 & 1527965 & 9.1805 & 8.9169 & TST \\
\hline CHEMBL147321 & 1520 & 6.19 & 7.3125 & TRN \\
\hline CHEMBL357655 & 1520 & 8.04 & 7.4481 & TRN \\
\hline CHEMBL347060 & 1520 & 7.88 & 7.5292 & TRN \\
\hline CHEMBL358808 & 1520 & 7.87 & 8.0939 & TRN \\
\hline CHEMBL414623 & 1520 & 8.22 & 8.5595 & TRN \\
\hline CHEMBL358312 & 1520 & 6.39 & 7.6553 & TRN \\
\hline CHEMBL357773 & 1520 & 8.85 & 7.9354 & TRN \\
\hline CHEMBL45101 & 1520 & 9.27 & 8.8879 & TRN \\
\hline CHEMBL356134 & 1520 & 7.56 & 7.63700 & 00000000005 \\
\hline CHEMBL146394 & 1520 & 7.75 & 7.8735 & TRN \\
\hline CHEMBL147522 & 1520 & 6.88 & 7.1348 & TRN \\
\hline CHEMBL357522 & 1520 & 8.04 & 8.1314 & TRN \\
\hline CHEMBL46467 & 1520 & 9.46 & 8.9856 & TRN \\
\hline CHEMBL146297 & 1520 & 8.34 & 8.4888 & TRN \\
\hline CHEMBL148618 & 1520 & 7.0 & 6.3568 & TRN \\
\hline CHEMBL149208 & 1520 & 6.18 & 7.9521 & TST \\
\hline
\end{tabular}




\begin{tabular}{|c|c|c|c|c|c|}
\hline \multirow[b]{2}{*}{ CHEMBL423575 } & \multirow[b]{2}{*}{1520} & \multicolumn{4}{|c|}{ Supplemental Table S2.txt } \\
\hline & & 6.82 & 7.6174 & TST & \\
\hline CHEMBL424309 & 1520 & 7.0 & 7.2896 & TRN & \\
\hline CHEMBL149120 & 1520 & 7.73 & 8.4806 & TRN & \\
\hline CHEMBL280516 & 1520 & 8.57 & 8.4671 & TRN & \\
\hline CHEMBL358258 & 1520 & 8.13 & 8.6128 & TRN & \\
\hline CHEMBL146868 & 1520 & 8.46 & 8.59700 & 3000000001 & TRN \\
\hline CHEMBL147869 & 1520 & 7.75 & 7.1798 & TRN & \\
\hline CHEMBL147172 & 1520 & 8.39 & 8.4782 & TRN & \\
\hline CHEMBL146563 & 1520 & 7.48 & 7.8201 & TRN & \\
\hline CHEMBL56 & 1520 & 8.85 & 7.3526 & TST & \\
\hline CHEMBL149648 & 1520 & 8.64 & 7.6773 & TRN & \\
\hline CHEMBL344303 & 1520 & 5.58 & 6.9789 & TRN & \\
\hline CHEMBL147947 & 1520 & 5.55 & 6.7872 & TRN & \\
\hline CHEMBL149148 & 1520 & 7.53 & 7.2116 & TRN & \\
\hline CHEMBL42994 & 1520 & 8.85 & 8.2378 & TRN & \\
\hline CHEMBL149209 & 1520 & 5.69 & 7.2597 & TST & \\
\hline CHEMBL414443 & 1520 & 7.33 & 8.3192 & TRN & \\
\hline CHEMBL149302 & 1520 & 8.37 & 8.1303 & TRN & \\
\hline CHEMBL148493 & 1520 & 7.33 & 8.2902 & TRN & \\
\hline CHEMBL436615 & 1520 & 6.03 & 5.9611 & TRN & \\
\hline CHEMBL147341 & 1520 & 8.45 & 7.6212 & TRN & \\
\hline CHEMBL146589 & 1520 & 8.13 & 7.8166 & TRN & \\
\hline CHEMBL343671 & 1520 & 7.37 & 7.3658 & TRN & \\
\hline CHEMBL359444 & 1520 & 8.59 & 8.6221 & TRN & \\
\hline CHEMBL146412 & 1520 & 7.3 & 8.3777 & TRN & \\
\hline CHEMBL150184 & 1520 & 7.85 & 7.8048 & TST & \\
\hline CHEMBL297138 & 1520 & 9.03 & 8.6063 & TRN & \\
\hline CHEMBL148901 & 1520 & 6.61 & 7.5591 & TST & \\
\hline CHEMBL295025 & 1520 & 8.78 & 7.8616 & TRN & \\
\hline CHEMBL341628 & 1520 & 7.58 & 7.739 & TRN & \\
\hline CHEMBL298260 & 1520 & 9.43 & 8.5729 & TRN & \\
\hline CHEMBL42294 & 1520 & 9.14 & 9.2047 & TRN & \\
\hline CHEMBL149733 & 1520 & 7.12 & 6.5829 & TRN & \\
\hline CHEMBL146124 & 1520 & 7.31 & 7.4266 & TRN & \\
\hline CHEMBL148908 & 1520 & 6.96 & 7.2605 & TST & \\
\hline CHEMBL149760 & 1520 & 6.78 & 7.6176 & TRN & \\
\hline CHEMBL146669 & 1520 & 8.8 & 8.5258 & TRN & \\
\hline CHEMBL42618 & 1520 & 8.86 & 8.9937 & TRN & \\
\hline CHEMBL439631 & 1520 & 6.38 & 6.1123 & TRN & \\
\hline CHEMBL150109 & 1520 & 6.53 & 6.8547 & TRN & \\
\hline CHEMBL149093 & 1520 & 6.0 & 7.0617 & TST & \\
\hline CHEMBL145863 & 1520 & 8.46 & 8.1196 & TRN & \\
\hline CHEMBL44904 & 1520 & 8.76 & 8.4968 & TRN & \\
\hline CHEMBL148902 & 1520 & 6.77 & 7.0592 & TST & \\
\hline CHEMBL348191 & 1520 & 8.92 & 7.485 & TRN & \\
\hline CHEMBL262431 & 1520 & 8.45 & 8.0787 & TRN & \\
\hline CHEMBL147479 & 1520 & 7.97 & 7.6889 & TST & \\
\hline CHEMBL149069 & 1520 & 7.93 & 8.0208 & TST & \\
\hline
\end{tabular}




\begin{tabular}{|c|c|c|c|c|c|}
\hline \multicolumn{6}{|c|}{ Supplemental Table S2.txt } \\
\hline CHEMBL46697 & 1520 & 7.58 & 7.6135 & TST & \\
\hline CHEMBL342754 & 1520 & 8.5 & 8.2997 & TST & \\
\hline CHEMBL146514 & 1520 & 8.05 & 8.5453 & TST & \\
\hline CHEMBL149785 & 1520 & 7.83 & 7.3099 & TST & \\
\hline CHEMBL147810 & 1520 & 6.7 & 7.4212 & TST & \\
\hline CHEMBL147922 & 1520 & 8.81 & 7.825 & TST & \\
\hline CHEMBL147119 & 1520 & 9.2 & 8.6883 & TST & \\
\hline CHEMBL1463885 & 737541 & 3.0969 & 3.4407 & TST & \\
\hline CHEMBL1605722 & 737541 & 3.0969 & 3.6855 & TRN & \\
\hline CHEMBL1549419 & 737541 & 3.0969 & 4.0814 & TRN & \\
\hline CHEMBL1417204 & 737541 & 3.0969 & 2.8109 & TRN & \\
\hline CHEMBL1576754 & 737541 & 5.2343 & 4.1022 & TRN & \\
\hline CHEMBL1366286 & 737541 & 3.0969 & 3.2709 & TST & \\
\hline CHEMBL1431684 & 737541 & 3.0969 & 3.1034 & TRN & \\
\hline CHEMBL1528569 & 737541 & 3.0969 & 3.0925 & TRN & \\
\hline CHEMBL1452943 & 737541 & 3.0969 & 3.0387 & TST & \\
\hline CHEMBL1573242 & 737541 & 3.0969 & 3.1521 & TRN & \\
\hline CHEMBL1309068 & 737541 & 3.0969 & 3.4782 & TST & \\
\hline CHEMBL1455137 & 737541 & 3.0969 & 3.0827 & TRN & \\
\hline CHEMBL1328473 & 737541 & 3.0969 & 4.1134 & TRN & \\
\hline CHEMBL1373339 & 737541 & 3.0969 & 3.1543 & TRN & \\
\hline CHEMBL1391484 & 737541 & 4.7375 & 3.7277 & TRN & \\
\hline CHEMBL1469171 & 737541 & 3.0969 & 3.0402 & TRN & \\
\hline CHEMBL1432815 & 737541 & 3.0969 & 2.7197 & TRN & \\
\hline CHEMBL1967775 & 737541 & 4.1373 & 3.7436 & TRN & \\
\hline CHEMBL1304363 & 737541 & 4.5258 & 3.049 & TRN & \\
\hline CHEMBL1587596 & 737541 & 3.0969 & 3.1499 & TRN & \\
\hline CHEMBL1305525 & 737541 & 3.0969 & 3.4785 & TST & \\
\hline CHEMBL 2094484 & 737541 & 3.0969 & 3.3939 & TRN & \\
\hline CHEMBL1509061 & 737541 & 3.0969 & 3.0871 & TRN & \\
\hline CHEMBL1548542 & 737541 & 3.0969 & 3.5788 & TST & \\
\hline CHEMBL 2000633 & 737541 & 3.0969 & 4.1967 & TRN & \\
\hline CHEMBL1343814 & 737541 & 3.0969 & 3.1306 & TRN & \\
\hline CHEMBL3193533 & 737541 & 4.9355 & 4.3995 & TRN & \\
\hline CHEMBL1872457 & 737541 & 4.5686 & 4.1127 & TRN & \\
\hline CHEMBL1348169 & 737541 & 5.2534 & 4.6762 & TST & \\
\hline CHEMBL1716112 & 737541 & 4.8069 & 4.9002 & TST & \\
\hline CHEMBL1370810 & 737541 & 5.0306 & 4.5265 & TRN & \\
\hline CHEMBL1583715 & 737541 & 3.0969 & 3.5259 & TRN & \\
\hline CHEMBL3189322 & 737541 & 3.0969 & 3.4621 & TRN & \\
\hline CHEMBL1720448 & 737541 & 5.4841 & 4.6799 & TRN & \\
\hline CHEMBL1370183 & 737541 & 3.0969 & 3.1172 & TRN & \\
\hline CHEMBL1603700 & 737541 & 3.0969 & 3.34800 & 00000000003 & TRN \\
\hline CHEMBL1449008 & 737541 & 3.0969 & 3.4823 & TRN & \\
\hline CHEMBL1415412 & 737541 & 3.0969 & 3.0459 & TRN & \\
\hline CHEMBL1431928 & 737541 & 3.0969 & 3.1072 & TRN & \\
\hline CHEMBL1480798 & 737541 & 3.0969 & 3.4335 & TRN & \\
\hline CHEMBL581860 & 737541 & 3.0969 & 3.4637 & TRN & \\
\hline
\end{tabular}


Supplemental Table S2.txt

\begin{tabular}{|c|c|c|c|c|}
\hline CHEMBL1404067 & 737541 & 3.0969 & 3.5889 & TRN \\
\hline CHEMBL319244 & 737541 & 3.0969 & 3.7864 & TRN \\
\hline CHEMBL1518291 & 737541 & 3.0969 & 2.8069 & TRN \\
\hline CHEMBL1303914 & 737541 & 3.0969 & 3.4212 & TRN \\
\hline CHEMBL1504035 & 737541 & 3.0969 & 2.9688 & TRN \\
\hline CHEMBL1538775 & 737541 & 3.0969 & 3.7743 & TRN \\
\hline CHEMBL1443205 & 737541 & 3.0969 & 3.1567 & TRN \\
\hline CHEMBL1563861 & 737541 & 4.3429 & 3.5252 & TRN \\
\hline CHEMBL1487639 & 737541 & 3.0969 & 3.0566 & TRN \\
\hline CHEMBL1504616 & 737541 & 3.0969 & \multicolumn{2}{|c|}{2.9210000000000003} \\
\hline CHEMBL1564543 & 737541 & 3.0969 & 3.0834 & TRN \\
\hline CHEMBL3190220 & 737541 & 3.0969 & 3.0515 & TST \\
\hline CHEMBL1323696 & 737541 & 5.3696 & 3.9746 & TRN \\
\hline CHEMBL 1400548 & 737541 & 3.0969 & \multicolumn{2}{|c|}{3.7439999999999998} \\
\hline CHEMBL1326587 & 737541 & 3.0969 & 3.2243 & TRN \\
\hline CHEMBL1439210 & 737541 & 3.0969 & 2.9378 & TRN \\
\hline CHEMBL1534959 & 737541 & 3.0969 & 2.9934 & TRN \\
\hline CHEMBL1372421 & 737541 & 3.0969 & 3.0935 & TRN \\
\hline CHEMBL365161 & 737541 & 3.0969 & 2.8519 & TST \\
\hline CHEMBL1542039 & 737541 & 3.0969 & 3.4034 & TRN \\
\hline CHEMBL1362566 & 737541 & 3.0969 & 3.3994 & TRN \\
\hline CHEMBL1565444 & 737541 & 3.0969 & 3.1281 & TRN \\
\hline CHEMBL1447324 & 737541 & 3.0969 & 3.4482 & TRN \\
\hline CHEMBL1419414 & 737541 & 3.0969 & 3.5393 & TRN \\
\hline CHEMBL1582121 & 737541 & 3.0969 & 3.4882 & TRN \\
\hline CHEMBL1728032 & 737541 & 4.9508 & 3.9791 & TST \\
\hline CHEMBL1478382 & 737541 & 4.7747 & 3.6469 & TRN \\
\hline CHEMBL1987579 & 737541 & 3.0969 & 3.6638 & TRN \\
\hline CHEMBL1599458 & 737541 & 3.0969 & \multicolumn{2}{|c|}{3.5669999999999997} \\
\hline CHEMBL1509946 & 737541 & 3.0969 & 3.4367 & TST \\
\hline CHEMBL1970621 & 737541 & 3.0969 & 3.2025 & TRN \\
\hline CHEMBL1421441 & 737541 & 3.0969 & 3.2355 & TRN \\
\hline CHEMBL1435487 & 737541 & 3.0969 & 2.9937 & TRN \\
\hline CHEMBL1533823 & 737541 & 5.0424 & \multicolumn{2}{|c|}{4.196000000000001} \\
\hline CHEMBL1429636 & 737541 & 3.0969 & 3.4587 & TRN \\
\hline CHEMBL1407826 & 737541 & 3.0969 & 3.0759 & TRN \\
\hline CHEMBL1505060 & 737541 & 3.0969 & 3.4616 & TRN \\
\hline CHEMBL1547295 & 737541 & 3.0969 & 3.4421 & TST \\
\hline CHEMBL1538474 & 737541 & 3.0969 & 3.3052 & TST \\
\hline CHEMBL3197076 & 737541 & 4.3507 & 2.969 & TST \\
\hline CHEMBL1472013 & 737541 & 3.0969 & 3.0447 & TRN \\
\hline CHEMBL3195760 & 737541 & 3.0969 & 3.1793 & TRN \\
\hline CHEMBL1580134 & 737541 & 3.0969 & 3.3737 & TRN \\
\hline CHEMBL1376861 & 737541 & 3.0969 & 3.0247 & TRN \\
\hline CHEMBL 3208035 & 737541 & 3.0969 & 3.0276 & TRN \\
\hline CHEMBL1991234 & 737541 & 5.3458 & 4.0978 & TRN \\
\hline CHEMBL1382562 & 737541 & 3.0969 & 3.1406 & TRN \\
\hline CHEMBL1550676 & 737541 & 3.0969 & 3.3959 & TRN \\
\hline
\end{tabular}


Supplemental Table S2.txt

\begin{tabular}{|c|c|c|c|c|}
\hline CHEMBL3192267 & 737541 & 3.0969 & 3.6968 & TST \\
\hline CHEMBL 2007390 & 737541 & 4.6421 & 4.374 & TRN \\
\hline CHEMBL 2000338 & 737541 & 4.9031 & 4.1257 & TRN \\
\hline CHEMBL1474553 & 737541 & 4.5302 & 3.1509 & TRN \\
\hline CHEMBL3191846 & 737541 & 3.0969 & 3.5567 & TRN \\
\hline CHEMBL1458178 & 737541 & 4.5017 & \multicolumn{2}{|c|}{3.5189999999999997} \\
\hline CHEMBL1424783 & 737541 & 3.0969 & 2.9859 & TRN \\
\hline CHEMBL1333386 & 737541 & 3.0969 & 3.3006 & TRN \\
\hline CHEMBL1423597 & 737541 & 3.0969 & 2.927 & TRN \\
\hline CHEMBL1573496 & 737541 & 4.7375 & 3.5152 & TRN \\
\hline CHEMBL1416713 & 737541 & 3.0969 & 3.0194 & TRN \\
\hline CHEMBL1611543 & 737541 & 4.9788 & 3.7505 & TRN \\
\hline CHEMBL 2369281 & 737541 & 3.0969 & 3.6077 & TRN \\
\hline CHEMBL1547420 & 737541 & 3.0969 & 2.9605 & TRN \\
\hline CHEMBL1525315 & 737541 & 3.0969 & 3.0781 & TRN \\
\hline CHEMBL3193435 & 737541 & 5.3556 & 4.6147 & TRN \\
\hline CHEMBL1564250 & 737541 & 3.0969 & 3.7767 & TST \\
\hline CHEMBL1403955 & 737541 & 3.0969 & 3.389 & TRN \\
\hline CHEMBL1400481 & 737541 & 3.0969 & 2.5792 & TRN \\
\hline CHEMBL1594685 & 737541 & 5.0429 & 3.5505 & TRN \\
\hline CHEMBL1339247 & 737541 & 3.0969 & 3.1025 & TST \\
\hline CHEMBL1361509 & 737541 & 3.0969 & 3.2128 & TRN \\
\hline CHEMBL1311879 & 737541 & 3.0969 & 3.488 & TRN \\
\hline CHEMBL1728459 & 737541 & 3.0969 & 3.4748 & TRN \\
\hline CHEMBL1308151 & 737541 & 3.0969 & 3.33 & TRN \\
\hline CHEMBL1505604 & 737541 & 3.0969 & 2.9931 & TRN \\
\hline CHEMBL1596903 & 737541 & 3.0969 & 3.5282 & TRN \\
\hline CHEMBL1597446 & 737541 & 3.0969 & 3.4068 & TRN \\
\hline CHEMBL1374947 & 737541 & 3.0969 & 3.2725 & TRN \\
\hline CHEMBL1309018 & 737541 & 4.5735 & 4.6227 & TRN \\
\hline CHEMBL1600326 & 737541 & 3.0969 & 3.2741 & TRN \\
\hline CHEMBL1343966 & 737541 & 3.0969 & 2.8966 & TRN \\
\hline CHEMBL1570587 & 737541 & 3.0969 & 2.8601 & TRN \\
\hline CHEMBL1400298 & 737541 & 3.0969 & 3.4689 & TRN \\
\hline CHEMBL1709936 & 737541 & 4.4841 & 4.1565 & TRN \\
\hline CHEMBL1982845 & 737541 & 3.0969 & 3.7669 & TST \\
\hline CHEMBL1362565 & 737541 & 3.0969 & 2.802 & TST \\
\hline CHEMBL1422386 & 737541 & 3.0969 & 3.2559 & TRN \\
\hline CHEMBL3196324 & 737541 & 3.0969 & 3.1672 & TRN \\
\hline CHEMBL1568497 & 737541 & 4.7986 & 3.7279 & TRN \\
\hline CHEMBL1419335 & 737541 & 3.0969 & 3.55899 & 99999999997 \\
\hline CHEMBL1502358 & 737541 & 3.0969 & 3.6289 & TST \\
\hline CHEMBL1469904 & 737541 & 3.0969 & 3.4812 & TRN \\
\hline CHEMBL1522373 & 737541 & 3.0969 & 3.8564 & TRN \\
\hline CHEMBL1718942 & 737541 & 3.0969 & 3.7997 & TST \\
\hline CHEMBL1573661 & 737541 & 4.1543 & 3.4916 & TRN \\
\hline CHEMBL3191958 & 737541 & 3.0969 & 3.47300 & 00000000003 \\
\hline CHEMBL3192235 & 737541 & 3.0969 & 3.1214 & TRN \\
\hline
\end{tabular}




\begin{tabular}{|c|c|c|c|c|c|}
\hline \multicolumn{6}{|c|}{ Supplemental Table S2.txt } \\
\hline CHEMBL 3193378 & 737541 & 3.0969 & 3.3137 & TRN & \\
\hline CHEMBL1377964 & 737541 & 5.1938 & 4.6333 & TRN & \\
\hline CHEMBL1718432 & 737541 & 4.5607 & 4.2801 & TRN & \\
\hline CHEMBL1565623 & 737541 & 3.0969 & 3.1677 & TRN & \\
\hline CHEMBL1518735 & 737541 & 4.3778 & 3.1758 & TRN & \\
\hline CHEMBL1501755 & 737541 & 3.0969 & 3.7687 & TRN & \\
\hline CHEMBL1472426 & 737541 & 3.0969 & 3.0133 & TRN & \\
\hline CHEMBL1567898 & 737541 & 3.0969 & 3.6997 & TST & \\
\hline CHEMBL1430328 & 737541 & 3.0969 & 3.3326 & TRN & \\
\hline CHEMBL1579210 & 737541 & 3.0969 & 2.6225 & TST & \\
\hline CHEMBL532160 & 737541 & 3.0969 & 3.0473 & TRN & \\
\hline CHEMBL1427430 & 737541 & 3.0969 & \multicolumn{2}{|c|}{2.9160000000000004} & TRN \\
\hline CHEMBL1389886 & 737541 & 3.0969 & 4.1922 & TRN & \\
\hline CHEMBL309016 & 737541 & 3.0969 & 3.0914 & TRN & \\
\hline CHEMBL3109023 & 737541 & 3.0969 & 3.8611 & TRN & \\
\hline CHEMBL546170 & 737541 & 3.0969 & \multicolumn{2}{|c|}{3.0260000000000002} & TRN \\
\hline CHEMBL3197021 & 737541 & 3.0969 & 3.6554 & TRN & \\
\hline CHEMBL3213030 & 737541 & 4.6364 & 4.2716 & TRN & \\
\hline CHEMBL1383447 & 737541 & 3.0969 & 3.6601 & TST & \\
\hline CHEMBL3192616 & 737541 & 3.0969 & 3.8831 & TRN & \\
\hline CHEMBL3210072 & 737541 & 3.0969 & 2.8131 & TRN & \\
\hline CHEMBL1568934 & 737541 & 3.0969 & 3.3979 & TRN & \\
\hline CHEMBL1587831 & 737541 & 3.0969 & 3.5882 & TST & \\
\hline CHEMBL1511526 & 737541 & 3.0969 & 2.8455 & TRN & \\
\hline CHEMBL1964873 & 737541 & 3.0969 & 3.5305 & TRN & \\
\hline CHEMBL1508402 & 737541 & 3.0969 & 3.2895 & TRN & \\
\hline CHEMBL1334903 & 737541 & 3.0969 & 2.9915 & TRN & \\
\hline CHEMBL607553 & 737541 & 3.0969 & 3.1971 & TRN & \\
\hline CHEMBL1564354 & 737541 & 3.0969 & 3.2849 & TRN & \\
\hline CHEMBL 2002262 & 737541 & 3.0969 & 3.3344 & TRN & \\
\hline CHEMBL1578255 & 737541 & 4. 3161 & 3.5691 & TRN & \\
\hline CHEMBL3197092 & 737541 & 5.3045 & 4.8837 & TRN & \\
\hline CHEMBL1328386 & 737541 & 3.0969 & 3.1235 & TRN & \\
\hline CHEMBL1969303 & 737541 & 4.6144 & 3.738 & TRN & \\
\hline CHEMBL1256364 & 737541 & 3.0969 & 3.1191 & TRN & \\
\hline CHEMBL1410536 & 737541 & 3.0969 & 2.7497 & TRN & \\
\hline CHEMBL1347795 & 737541 & 4.2573 & 3.8636 & TRN & \\
\hline CHEMBL1349590 & 737541 & 3.0969 & 3.0931 & TRN & \\
\hline CHEMBL256042 & 737541 & 3.0969 & 2.995 & TRN & \\
\hline CHEMBL428064 & 737541 & 3.0969 & 3.1433 & TRN & \\
\hline CHEMBL1987938 & 737541 & 3.0969 & 2.9988 & TRN & \\
\hline CHEMBL1556583 & 737541 & 3.0969 & 3.0987 & TRN & \\
\hline CHEMBL1968356 & 737541 & 5.3316 & 4.1496 & TRN & \\
\hline CHEMBL1550076 & 737541 & 3.0969 & 3.4613 & TRN & \\
\hline CHEMBL1341741 & 737541 & 3.0969 & 3.0163 & TRN & \\
\hline CHEMBL1509145 & 737541 & 3.0969 & 3.287 & TRN & \\
\hline CHEMBL579102 & 737541 & 3.0969 & 3.4 & TRN & \\
\hline \multirow[t]{2}{*}{ CHEMBL1364240 } & 737541 & 3.0969 & \multicolumn{2}{|c|}{3.6210000000000004} & TRN \\
\hline & & & & $56 e$ & \\
\hline
\end{tabular}


Supplemental Table S2.txt

\begin{tabular}{|c|c|c|c|c|}
\hline 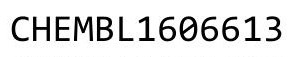 & & & & \\
\hline HEMBL1373880 & 37541 & 0969 & 2328 & \\
\hline & & 969 & 9757 & \\
\hline IFMRI 13 & 1 & 969 & 5919 & \\
\hline IEMBL1537810 & 37541 & 3382 & 2513 & \\
\hline AEMBL1447391 & 37541 & $\partial 969$ & 2307 & \\
\hline HEMBL1546607 & 37541 & 969 & 3417 & \\
\hline IEMBL1 & 37541 & 969 & 386 & \\
\hline IEMBL1523610 & 37541 & 969 & .6623 & \\
\hline AEMBL1584502 & 37541 & 969 & 1653 & \\
\hline HEMBL3190594 & 37541 & 969 & 3969 & \\
\hline AEMBL1578521 & 7541 & 969 & 9069 & \\
\hline IEMBL1 & & & & \\
\hline HEMBL17 & & 969 & 4164 & \\
\hline AEMBL1465511 & 37541 & 969 & 9221 & \\
\hline AEMBL1488408 & 41 & 969 & & \\
\hline JEMBL13 & 41 & 969 & 17 & \\
\hline HEMBL 32 & & & & \\
\hline HEMBL1 1 & 1 & 69 & 67 & \\
\hline AEMBL1410068 & 41 & 22 & 3891 & \\
\hline AEMBL1369124 & 11 & 69 & 3665 & KIV \\
\hline AEMBL13 & 1 & 59 & 897 & RN \\
\hline HEMBL5 & & & & \\
\hline AEMBL3190724 & & & 342 & \\
\hline IEMBL13 & & & 735 & RN \\
\hline AEMBL534353 & 1 & & 2361 & SI \\
\hline HEMBL1594369 & 1 & & 5325 & $R N$ \\
\hline HEMBL13 & & & 8397 & \\
\hline 55 & & & 211 & RN \\
\hline L1446802 & & & 3.134 & I \\
\hline HEMBL146 & 1 & & 257 & RN \\
\hline HEMBL1564403 & 1 & & . 4878 & NIV \\
\hline HEMBL31S & & & 977 & RN \\
\hline 14 & & & & ST \\
\hline AEMBL1973341 & & & 2971 & RN \\
\hline EMBL1546223 & & & 245 & \\
\hline HEMBL1515506 & 1 & & 655 & KIV \\
\hline & & & & RN \\
\hline HEMBL3208237 & & & 3.761 & RN \\
\hline HEMBL3210000 & 1 & & 3099 & $\mathrm{RI}$ \\
\hline IEMBL3195564 & & & 369 & \\
\hline HEMBL1467649 & & & 4.0118 & \\
\hline J & & & & ST \\
\hline HEMBL1533959 & 37 & 969 & 2.8276 & RN \\
\hline HEMBL1491222 & 37 & 969 & 5439 & F \\
\hline & & & .0709 & \\
\hline CHEMBL152 & 737541 & & & \\
\hline 319 & 737541 & 3 . & 3.5765 & \\
\hline
\end{tabular}

Page 5603 
Supplemental Table S2.txt

\begin{tabular}{|c|c|c|c|c|c|}
\hline CHEMBL1499436 & 737541 & 3.0969 & 3.173 & TRN & \\
\hline CHEMBL1548704 & 737541 & 3.0969 & 3.8469 & TRN & \\
\hline CHEMBL1553074 & 737541 & 3.0969 & 2.9762 & TRN & \\
\hline CHEMBL1541405 & 737541 & 3.0969 & 3.3354 & TST & \\
\hline CHEMBL3209511 & 737541 & 3.0969 & 4.1027 & TST & \\
\hline CHEMBL3208014 & 737541 & 4.9666 & 4.5826 & TRN & \\
\hline CHEMBL1414009 & 737541 & 3.0969 & 3.3158 & TRN & \\
\hline CHEMBL1488787 & 737541 & 4.3251 & 3.3489 & TRN & \\
\hline CHEMBL586937 & 737541 & 3.0969 & 3.3242 & TRN & \\
\hline CHEMBL3192900 & 737541 & 4.7447 & 4.1148 & TRN & \\
\hline CHEMBL1392620 & 737541 & 3.0969 & 2.9376 & TRN & \\
\hline CHEMBL1517752 & 737541 & 3.0969 & 3.7519 & TRN & \\
\hline CHEMBL1401059 & 737541 & 3.0969 & 3.1037 & TRN & \\
\hline CHEMBL1519298 & 737541 & 3.0969 & 3.1157 & TRN & \\
\hline CHEMBL3197433 & 737541 & 5.2933 & 3.6979 & TRN & \\
\hline CHEMBL1585527 & 737541 & 3.0969 & 3.1332 & TRN & \\
\hline CHEMBL1527565 & 737541 & 3.0969 & 2.68600 & 00000000004 & TST \\
\hline CHEMBL1424697 & 737541 & 3.0969 & 2.9108 & TRN & \\
\hline CHEMBL1335846 & 737541 & 3.0969 & 2.7179 & TST & \\
\hline CHEMBL1440314 & 737541 & 3.0969 & 3.0891 & TRN & \\
\hline CHEMBL1339562 & 737541 & 3.0969 & 3.1775 & TRN & \\
\hline CHEMBL1505548 & 737541 & 3.0969 & 3.3879 & TRN & \\
\hline CHEMBL1402936 & 737541 & 3.0969 & 3.5889 & TST & \\
\hline CHEMBL1364896 & 737541 & 3.0969 & 3.4805 & TRN & \\
\hline CHEMBL1424951 & 737541 & 3.0969 & 3.6966 & TRN & \\
\hline CHEMBL1367275 & 737541 & 3.0969 & 3.4511 & TRN & \\
\hline CHEMBL3197786 & 737541 & 3.0969 & 2.81100 & 00000000004 & TRN \\
\hline CHEMBL1488192 & 737541 & 3.0969 & 2.8678 & TRN & \\
\hline CHEMBL3144933 & 737541 & 3.0969 & 3.6695 & TST & \\
\hline CHEMBL1352760 & 737541 & 3.0969 & 3.4148 & TRN & \\
\hline CHEMBL1444114 & 737541 & 3.0969 & 3.6609 & TRN & \\
\hline CHEMBL1446060 & 737541 & 3.0969 & 3.0402 & TRN & \\
\hline CHEMBL1426358 & 737541 & 3.0969 & 3.3748 & TRN & \\
\hline CHEMBL1418103 & 737541 & 3.0969 & 3.0896 & TRN & \\
\hline CHEMBL1478237 & 737541 & 3.0969 & 3.0906 & TRN & \\
\hline CHEMBL1480262 & 737541 & 3.0969 & 3.7996 & TRN & \\
\hline CHEMBL363535 & 737541 & 3.0969 & 3.2332 & TST & \\
\hline CHEMBL3191811 & 737541 & 5.0414 & 4.4183 & TRN & \\
\hline CHEMBL1379833 & 737541 & 3.0969 & 2.775 & TRN & \\
\hline CHEMBL1433015 & 737541 & 4.8633 & 3.7322 & TRN & \\
\hline CHEMBL1448503 & 737541 & 3.0969 & 3.15199 & Э99999999997 & TRN \\
\hline CHEMBL1322995 & 737541 & 3.0969 & 3.1351 & TRN & \\
\hline CHEMBL1426440 & 737541 & 3.0969 & 3.4927 & TST & \\
\hline CHEMBL3209920 & 737541 & 4.8794 & 4.6417 & TRN & \\
\hline CHEMBL 3145282 & 737541 & 4.7986 & 3.4424 & TST & \\
\hline CHEMBL1467760 & 737541 & 3.0969 & 3.09800 & 90000000003 & TRN \\
\hline CHEMBL1710243 & 737541 & 3.0969 & 3.2088 & TRN & \\
\hline CHEMBL 2003964 & 737541 & 3.0969 & 3.8743 & TRN & \\
\hline
\end{tabular}


Supplemental Table S2.txt

\begin{tabular}{|c|c|c|c|c|}
\hline CHEMBL3192087 & 737541 & 4.2628 & 3.6324 & TRN \\
\hline CHEMBL1303719 & 737541 & 3.0969 & 4.5483 & TRN \\
\hline CHEMBL1303635 & 737541 & 3.0969 & 3.7145 & TRN \\
\hline CHEMBL1348306 & 737541 & 3.0969 & 3.0541 & TST \\
\hline CHEMBL1430673 & 737541 & 3.0969 & 3.1837 & TRN \\
\hline CHEMBL1427431 & 737541 & 3.0969 & 3.5583 & TRN \\
\hline CHEMBL3195898 & 737541 & 3.0969 & 3.7436 & TRN \\
\hline CHEMBL1421316 & 737541 & 3.0969 & 3.3645 & TST \\
\hline CHEMBL1976317 & 737541 & 3.0969 & 3.326 & TRN \\
\hline CHEMBL1566084 & 737541 & 3.0969 & 3.3249 & TRN \\
\hline CHEMBL1468811 & 737541 & 3.0969 & 3.2724 & TRN \\
\hline CHEMBL1373688 & 737541 & 4.5918 & 3.7136 & TRN \\
\hline CHEMBL1466699 & 737541 & 3.0969 & 3.0969 & TRN \\
\hline CHEMBL1338958 & 737541 & 3.0969 & 3.3219 & TST \\
\hline CHEMBL1600587 & 737541 & 3.0969 & 3.3856 & TRN \\
\hline CHEMBL1443448 & 737541 & 3.0969 & 3.0041 & TRN \\
\hline CHEMBL1567827 & 737541 & 3.0969 & 3.2531 & TRN \\
\hline CHEMBL 2000686 & 737541 & 3.0969 & 3.4048 & TRN \\
\hline CHEMBL1516744 & 737541 & 3.0969 & 3.818 & TRN \\
\hline CHEMBL1556279 & 737541 & 3.0969 & 2.9701 & TRN \\
\hline CHEMBL1334169 & 737541 & 3.0969 & 3.35399 & э99999999996 \\
\hline CHEMBL1487938 & 737541 & 3.0969 & 3.0303 & TRN \\
\hline CHEMBL1598843 & 737541 & 3.0969 & 3.2301 & TRN \\
\hline CHEMBL3212447 & 737541 & 3.0969 & 3.5095 & TRN \\
\hline CHEMBL1535134 & 737541 & 3.0969 & 4.2356 & TRN \\
\hline CHEMBL1307453 & 737541 & 3.0969 & 3.1982 & TRN \\
\hline CHEMBL1984130 & 737541 & 3.0969 & 3.76899 & 99999999997 \\
\hline CHEMBL1465409 & 737541 & 3.0969 & 3.0969 & TRN \\
\hline CHEMBL1563766 & 737541 & 3.0969 & 3.2525 & TRN \\
\hline CHEMBL3208631 & 737541 & 3.0969 & 4.323 & TRN \\
\hline CHEMBL3209000 & 737541 & 3.0969 & 3.43 & TRN \\
\hline CHEMBL1429164 & 737541 & 3.0969 & 2.8046 & TRN \\
\hline CHEMBL1449349 & 737541 & 3.0969 & 2.8219 & TRN \\
\hline CHEMBL1499877 & 737541 & 4.7471 & 3.2125 & TST \\
\hline CHEMBL1531502 & 737541 & 3.0969 & 3.0113 & TRN \\
\hline CHEMBL1497982 & 737541 & 4.4134 & 4.4229 & TST \\
\hline CHEMBL1548898 & 737541 & 3.0969 & 2.802 & TST \\
\hline CHEMBL1300836 & 737541 & 3.0969 & 3.3142 & TRN \\
\hline CHEMBL1372112 & 737541 & 3.0969 & 2.8621 & TRN \\
\hline CHEMBL1414806 & 737541 & 3.0969 & 3.2651 & TRN \\
\hline CHEMBL1501799 & 737541 & 3.0969 & 3.4388 & TRN \\
\hline CHEMBL3145321 & 737541 & 3.0969 & 3.4818 & TST \\
\hline CHEMBL1501376 & 737541 & 3.0969 & 3.1658 & TRN \\
\hline CHEMBL1463564 & 737541 & 3.0969 & 2.9773 & TRN \\
\hline CHEMBL1309127 & 737541 & 3.0969 & 3.1091 & TRN \\
\hline CHEMBL532239 & 737541 & 5.2865 & 3.3741 & TRN \\
\hline CHEMBL1447284 & 737541 & 4.4134 & 3.2504 & TRN \\
\hline CHEMBL3193664 & 737541 & 5.06 & 3.638 & TRN \\
\hline
\end{tabular}


Supplemental Table S2.txt

\begin{tabular}{|c|c|c|c|c|}
\hline CHEMBL1430531 & 737541 & 3.0969 & 3.4231 & TST \\
\hline CHEMBL1517284 & 737541 & 3.0969 & 2.9083 & TRN \\
\hline CHEMBL1504370 & 737541 & 4.6968 & 3.1129 & TST \\
\hline CHEMBL1534922 & 737541 & 3.0969 & 3.3868 & TRN \\
\hline CHEMBL1457472 & 737541 & 3.0969 & 3.4213 & TRN \\
\hline CHEMBL1342156 & 737541 & 3.0969 & 3.7522 & TRN \\
\hline CHEMBL1420406 & 737541 & 4.7144 & 4.3728 & TRN \\
\hline CHEMBL1382870 & 737541 & 3.0969 & 3.1342 & TRN \\
\hline CHEMBL391123 & 737541 & 4.0996 & 3.47600 & 30000000004 \\
\hline CHEMBL1476017 & 737541 & 3.0969 & 3.3621 & TRN \\
\hline CHEMBL1531686 & 737541 & 3.0969 & 2.7505 & TRN \\
\hline CHEMBL1453583 & 737541 & 3.0969 & 3.2032 & TRN \\
\hline CHEMBL 3209897 & 737541 & 4.3143 & 3.9924 & TRN \\
\hline CHEMBL1988579 & 737541 & 3.0969 & 3.5357 & TST \\
\hline CHEMBL3195226 & 737541 & 3.0969 & 3.21 & TRN \\
\hline CHEMBL1979957 & 737541 & 3.0969 & 3.6779 & TRN \\
\hline CHEMBL1433290 & 737541 & 4.7282 & 3.3978 & TRN \\
\hline CHEMBL1477528 & 737541 & 3.0969 & 3.3357 & TRN \\
\hline CHEMBL1323536 & 737541 & 3.0969 & 3.62100 & 00000000004 \\
\hline CHEMBL1466340 & 737541 & 3.0969 & 2.9902 & TRN \\
\hline CHEMBL114544 & 737541 & 3.0969 & 3.0954 & TRN \\
\hline CHEMBL1990659 & 737541 & 4.757 & 4.284 & TRN \\
\hline CHEMBL1984876 & 737541 & 3.0969 & 2.9994 & TRN \\
\hline CHEMBL1716494 & 737541 & 3.0969 & 3.2767 & TRN \\
\hline CHEMBL1985582 & 737541 & 3.0969 & 3.2056 & TRN \\
\hline CHEMBL1440293 & 737541 & 5.0114 & 3.2307 & TST \\
\hline CHEMBL1571290 & 737541 & 3.0969 & 3.7212 & TRN \\
\hline CHEMBL1724535 & 737541 & 4.8239 & 4.1142 & TRN \\
\hline CHEMBL1390785 & 737541 & 3.0969 & 3.2898 & TRN \\
\hline CHEMBL3199323 & 737541 & 3.0969 & 3.233 & TRN \\
\hline CHEMBL1481697 & 737541 & 3.0969 & 3.3778 & TRN \\
\hline CHEMBL3209368 & 737541 & 3.0969 & 3.6341 & TST \\
\hline CHEMBL1332241 & 737541 & 5.104 & 3.7824 & TRN \\
\hline CHEMBL339587 & 737541 & 3.0969 & 3.5873 & TRN \\
\hline CHEMBL455284 & 737541 & 3.0969 & 3.3348 & TRN \\
\hline CHEMBL1572058 & 737541 & 3.0969 & 3.341 & TRN \\
\hline CHEMBL1574219 & 737541 & 3.0969 & 2.886 & TRN \\
\hline CHEMBL1597655 & 737541 & 3.0969 & 3.3442 & TRN \\
\hline CHEMBL1487849 & 737541 & 3.0969 & 3.1675 & TRN \\
\hline CHEMBL1424746 & 737541 & 3.0969 & 3.1261 & TRN \\
\hline CHEMBL1350780 & 737541 & 3.0969 & 3.5118 & TRN \\
\hline CHEMBL1343952 & 737541 & 5.0039 & 4.0933 & TRN \\
\hline CHEMBL1563561 & 737541 & 3.0969 & 3.2038 & TRN \\
\hline CHEMBL1606705 & 737541 & 3.0969 & 3.0206 & TRN \\
\hline CHEMBL1451911 & 737541 & 5.0168 & 3.3654 & TRN \\
\hline CHEMBL1613445 & 737541 & 3.0969 & 3.6555 & TST \\
\hline CHEMBL1332770 & 737541 & 5.3851 & 3.9548 & TRN \\
\hline CHEMBL1323553 & 737541 & 3.0969 & 3.1534 & TRN \\
\hline
\end{tabular}


Supplemental Table S2.txt

\begin{tabular}{|c|c|c|c|c|}
\hline CHEMBL1583292 & 737541 & 3.0969 & 3.4461 & TST \\
\hline CHEMBL1535457 & 737541 & 4.9245 & 4.0634 & TRN \\
\hline CHEMBL112597 & 737541 & 3.0969 & 3.0462 & TRN \\
\hline CHEMBL1511160 & 737541 & 3.0969 & 3.5366 & TRN \\
\hline CHEMBL1347600 & 737541 & 3.0969 & 3.5921 & TST \\
\hline CHEMBL1536606 & 737541 & 3.0969 & 3.2421 & TRN \\
\hline CHEMBL 3192862 & 737541 & 3.0969 & 3.2998 & TRN \\
\hline CHEMBL1305642 & 737541 & 3.0969 & 3.4793 & TRN \\
\hline CHEMBL1377849 & 737541 & 5.0177 & 4.093 & TRN \\
\hline CHEMBL 2005744 & 737541 & 4.6556 & 3.9895 & TRN \\
\hline CHEMBL1300242 & 737541 & 3.0969 & 3.1362 & TRN \\
\hline CHEMBL 3189737 & 737541 & 4.9208 & 4.2604 & TRN \\
\hline CHEMBL1611796 & 737541 & 3.0969 & 3.0891 & TRN \\
\hline CHEMBL1300069 & 737541 & 3.0969 & 3.2223 & TST \\
\hline CHEMBL 3190102 & 737541 & 3.0969 & 3.4588 & TRN \\
\hline CHEMBL 3211540 & 737541 & 3.0969 & 3.1412 & TRN \\
\hline CHEMBL1342821 & 737541 & 3.0969 & 3.6656 & TRN \\
\hline CHEMBL1998940 & 737541 & 3.0969 & 3.896006 & 30000000004 \\
\hline CHEMBL1549657 & 737541 & 3.0969 & 2.8295 & TST \\
\hline CHEMBL3192432 & 737541 & 3.0969 & 2.9616 & TRN \\
\hline CHEMBL1544633 & 737541 & 3.0969 & 3.3649 & TRN \\
\hline CHEMBL1518463 & 737541 & 3.0969 & 3.1982 & TST \\
\hline CHEMBL1542861 & 737541 & 5.0205 & 3.4891 & TRN \\
\hline CHEMBL1342574 & 737541 & 3.0969 & 3.0145 & TRN \\
\hline CHEMBL1488591 & 737541 & 3.0969 & 3.1603 & TST \\
\hline CHEMBL1330558 & 737541 & 3.0969 & 2.9768 & TRN \\
\hline CHEMBL586602 & 737541 & 4.5719 & 4.0755 & TST \\
\hline CHEMBL1502512 & 737541 & 3.0969 & 3.4197 & TRN \\
\hline CHEMBL1548439 & 737541 & 3.0969 & 3.2259 & TRN \\
\hline CHEMBL1539236 & 737541 & 3.0969 & 3.2931 & TRN \\
\hline CHEMBL1544508 & 737541 & 3.0969 & 3.1155 & TRN \\
\hline CHEMBL1499214 & 737541 & 3.0969 & 3.3174 & TST \\
\hline CHEMBL1401040 & 737541 & 3.0969 & 3.2396 & TRN \\
\hline CHEMBL1986073 & 737541 & 4.7167 & 4.2208 & TRN \\
\hline CHEMBL1341553 & 737541 & 3.0969 & 3.5898 & TRN \\
\hline CHEMBL3196363 & 737541 & 4.7258 & 3.5782 & TRN \\
\hline CHEMBL1432327 & 737541 & 3.0969 & 3.2013 & TRN \\
\hline CHEMBL1412972 & 737541 & 3.0969 & 3.3199 & TRN \\
\hline CHEMBL1346233 & 737541 & 3.0969 & 2.9416 & TRN \\
\hline CHEMBL1577986 & 737541 & 3.0969 & 3.9863 & TST \\
\hline CHEMBL1411629 & 737541 & 4.5331 & 4.1663 & TRN \\
\hline CHEMBL1384838 & 737541 & 3.0969 & 3.2564 & TST \\
\hline CHEMBL1725397 & 737541 & 3.0969 & 3.108 & TRN \\
\hline CHEMBL1965132 & 737541 & 3.0969 & 3.4109 & TRN \\
\hline CHEMBL3190198 & 737541 & 3.0969 & 3.7705 & TRN \\
\hline CHEMBL3184145 & 737541 & 3.0969 & 3.2477 & TRN \\
\hline CHEMBL3198576 & 737541 & 3.0969 & 2.7517 & TRN \\
\hline CHEMBL1966869 & 737541 & 4.7595 & 3.5351 & TRN \\
\hline
\end{tabular}


Supplemental Table S2.txt

\begin{tabular}{|c|c|c|c|c|}
\hline CHEMBL1483768 & 737541 & 3.0969 & 3.3086 & TRN \\
\hline CHEMBL1605977 & 737541 & 3.0969 & 3.1268 & TRN \\
\hline CHEMBL1535553 & 737541 & 3.0969 & 3.6188 & TRN \\
\hline CHEMBL1378931 & 737541 & 3.0969 & 3.2979 & TRN \\
\hline CHEMBL1437888 & 737541 & 3.0969 & 3.8314 & TST \\
\hline CHEMBL1972435 & 737541 & 3.0969 & 3.2464 & TRN \\
\hline CHEMBL1535938 & 737541 & 3.0969 & 3.1776 & TRN \\
\hline CHEMBL1566258 & 737541 & 3.0969 & 2.9782 & TRN \\
\hline CHEMBL1526851 & 737541 & 3.0969 & 3.5618 & TRN \\
\hline CHEMBL1522618 & 737541 & 3.0969 & 3.3901 & TRN \\
\hline CHEMBL1338033 & 737541 & 3.0969 & 3.4983 & TRN \\
\hline CHEMBL1494202 & 737541 & 3.0969 & 3.1418 & TRN \\
\hline CHEMBL 2000340 & 737541 & 3.0969 & 3.6045 & TST \\
\hline CHEMBL1608578 & 737541 & 3.0969 & 3.286 & TRN \\
\hline CHEMBL1550485 & 737541 & 3.0969 & 3.2692 & TRN \\
\hline CHEMBL3193422 & 737541 & 3.0969 & 2.9723 & TRN \\
\hline CHEMBL1448982 & 737541 & 3.0969 & 3.0074 & TRN \\
\hline CHEMBL1409219 & 737541 & 3.0969 & 3.5076 & TRN \\
\hline CHEMBL1375884 & 737541 & 3.0969 & 3.3193 & TRN \\
\hline CHEMBL1590745 & 737541 & 3.0969 & 3.175 & TRN \\
\hline CHEMBL1487183 & 737541 & 3.0969 & 3.2616 & TST \\
\hline CHEMBL1558863 & 737541 & 5.1986 & 3.993999 & 99999999998 \\
\hline CHEMBL1517686 & 737541 & 3.0969 & 2.9562 & TRN \\
\hline CHEMBL1567267 & 737541 & 3.0969 & 3.7259 & TRN \\
\hline CHEMBL1544703 & 737541 & 3.0969 & 3.2516 & TRN \\
\hline CHEMBL 260148 & 737541 & 3.0969 & 3.3367 & TST \\
\hline CHEMBL1517763 & 737541 & 5.2757 & 4.6545 & TRN \\
\hline CHEMBL1576094 & 737541 & 3.0969 & 3.2622 & TRN \\
\hline CHEMBL1522846 & 737541 & 3.0969 & 3.291006 & 00000000004 \\
\hline CHEMBL1345877 & 737541 & 3.0969 & 3.3309 & TST \\
\hline CHEMBL1460748 & 737541 & 3.0969 & 3.7277 & TRN \\
\hline CHEMBL1541834 & 737541 & 3.0969 & 3.2163 & TRN \\
\hline CHEMBL1361273 & 737541 & 3.0969 & 3.3812 & TRN \\
\hline CHEMBL1324894 & 737541 & 4.3565 & 4.5125 & TRN \\
\hline CHEMBL1488623 & 737541 & 3.0969 & 3.2893 & TRN \\
\hline CHEMBL3192188 & 737541 & 4.7595 & 3.8881 & TRN \\
\hline CHEMBL3199006 & 737541 & 3.0969 & 3.4793 & TRN \\
\hline CHEMBL1479876 & 737541 & 3.0969 & 3.2799 & TST \\
\hline CHEMBL1330307 & 737541 & 3.0969 & 3.352 & TRN \\
\hline CHEMBL1597580 & 737541 & 3.0969 & 3.8376 & TRN \\
\hline CHEMBL1995152 & 737541 & 3.0969 & 3.4982 & TRN \\
\hline CHEMBL1303953 & 737541 & 3.0969 & 2.8441 & TRN \\
\hline CHEMBL1425921 & 737541 & 3.0969 & 2.853999 & 99999999996 \\
\hline CHEMBL1525546 & 737541 & 3.0969 & 3.1724 & TRN \\
\hline CHEMBL1340619 & 737541 & 3.0969 & 3.0899 & TRN \\
\hline CHEMBL1521373 & 737541 & 3.0969 & 3.6904 & TRN \\
\hline CHEMBL1400005 & 737541 & 3.0969 & 2.9997 & TRN \\
\hline CHEMBL1312672 & 737541 & 3.0969 & 3.9495 & TRN \\
\hline
\end{tabular}


Supplemental Table S2.txt

\begin{tabular}{|c|c|c|c|c|}
\hline CHEMBL1354031 & 737541 & 3.0969 & 2.911 & TRN \\
\hline CHEMBL1439902 & 737541 & 3.0969 & 3.2172 & TST \\
\hline CHEMBL1495072 & 737541 & 4.3904 & 3.5481 & TRN \\
\hline CHEMBL1564522 & 737541 & 3.0969 & 3.1838 & TRN \\
\hline CHEMBL1541379 & 737541 & 3.0969 & 3.1761 & TRN \\
\hline CHEMBL1438319 & 737541 & 3.0969 & 3.4824 & TST \\
\hline CHEMBL1996281 & 737541 & 3.0969 & 3.4994 & TRN \\
\hline CHEMBL 257286 & 737541 & 3.0969 & 3.1107 & TRN \\
\hline CHEMBL1301997 & 737541 & 4.699 & 3.2228 & TRN \\
\hline CHEMBL1968789 & 737541 & 3.0969 & 3.7806 & TRN \\
\hline CHEMBL1604350 & 737541 & 3.0969 & 3.2063 & TRN \\
\hline CHEMBL1366864 & 737541 & 4.5436 & 4.2422 & TRN \\
\hline CHEMBL1359006 & 737541 & 3.0969 & 2.9585 & TRN \\
\hline CHEMBL1396209 & 737541 & 3.0969 & 3.1184 & TST \\
\hline CHEMBL1528581 & 737541 & 3.0969 & 3.4818 & TRN \\
\hline CHEMBL1369594 & 737541 & 3.0969 & 3.6002 & TRN \\
\hline CHEMBL1558070 & 737541 & 4.4855 & 3.49600 & 00000000004 \\
\hline CHEMBL1398450 & 737541 & 3.0969 & 3.407 & TRN \\
\hline CHEMBL1383793 & 737541 & 4.8508 & 4.2966 & TRN \\
\hline CHEMBL1468055 & 737541 & 3.0969 & 3.0386 & TST \\
\hline CHEMBL1417692 & 737541 & 3.0969 & 3.0559 & TRN \\
\hline CHEMBL1986557 & 737541 & 3.0969 & 3.6652 & TRN \\
\hline CHEMBL1422161 & 737541 & 3.0969 & 2.9821 & TRN \\
\hline CHEMBL1309188 & 737541 & 3.0969 & 3.7669 & TRN \\
\hline CHEMBL1398686 & 737541 & 3.0969 & 3.0837 & TRN \\
\hline CHEMBL1311956 & 737541 & 4.9626 & 3.8407 & TRN \\
\hline CHEMBL1387704 & 737541 & 3.0969 & 3.1086 & TRN \\
\hline CHEMBL1562359 & 737541 & 3.0969 & 3.3717 & TST \\
\hline CHEMBL1545927 & 737541 & 3.0969 & 3.8868 & TRN \\
\hline CHEMBL1584597 & 737541 & 3.0969 & 2.9405 & TRN \\
\hline CHEMBL1534218 & 737541 & 3.0969 & 3.5649 & TRN \\
\hline CHEMBL1416566 & 737541 & 3.0969 & 3.3568 & TRN \\
\hline CHEMBL1544114 & 737541 & 3.0969 & 3.5092 & TRN \\
\hline CHEMBL1527739 & 737541 & 4.8182 & 3.7172 & TRN \\
\hline CHEMBL1580083 & 737541 & 3.0969 & 3.0492 & TRN \\
\hline CHEMBL1371774 & 737541 & 3.0969 & 3.3359 & TRN \\
\hline CHEMBL1511063 & 737541 & 3.0969 & 3.623 & TRN \\
\hline CHEMBL 3193391 & 737541 & 3.0969 & 3.0073 & TRN \\
\hline CHEMBL1985343 & 737541 & 3.0969 & 3.7215 & TRN \\
\hline CHEMBL1309573 & 737541 & 3.0969 & 2.9407 & TRN \\
\hline CHEMBL1709004 & 737541 & 4.7696 & 4.3703 & TST \\
\hline CHEMBL 3197860 & 737541 & 3.0969 & 3.77399 & 9999999996 \\
\hline CHEMBL1329046 & 737541 & 3.0969 & 3.4 & TST \\
\hline CHEMBL1492961 & 737541 & 3.0969 & 3.7607 & TRN \\
\hline CHEMBL1565662 & 737541 & 3.0969 & 3.4151 & TRN \\
\hline CHEMBL1385436 & 737541 & 4.5045 & 3.5911 & TST \\
\hline CHEMBL1378118 & 737541 & 3.0969 & 3.0127 & TST \\
\hline CHEMBL1516637 & 737541 & 3.0969 & 3.3129 & TRN \\
\hline
\end{tabular}


Supplemental Table S2.txt

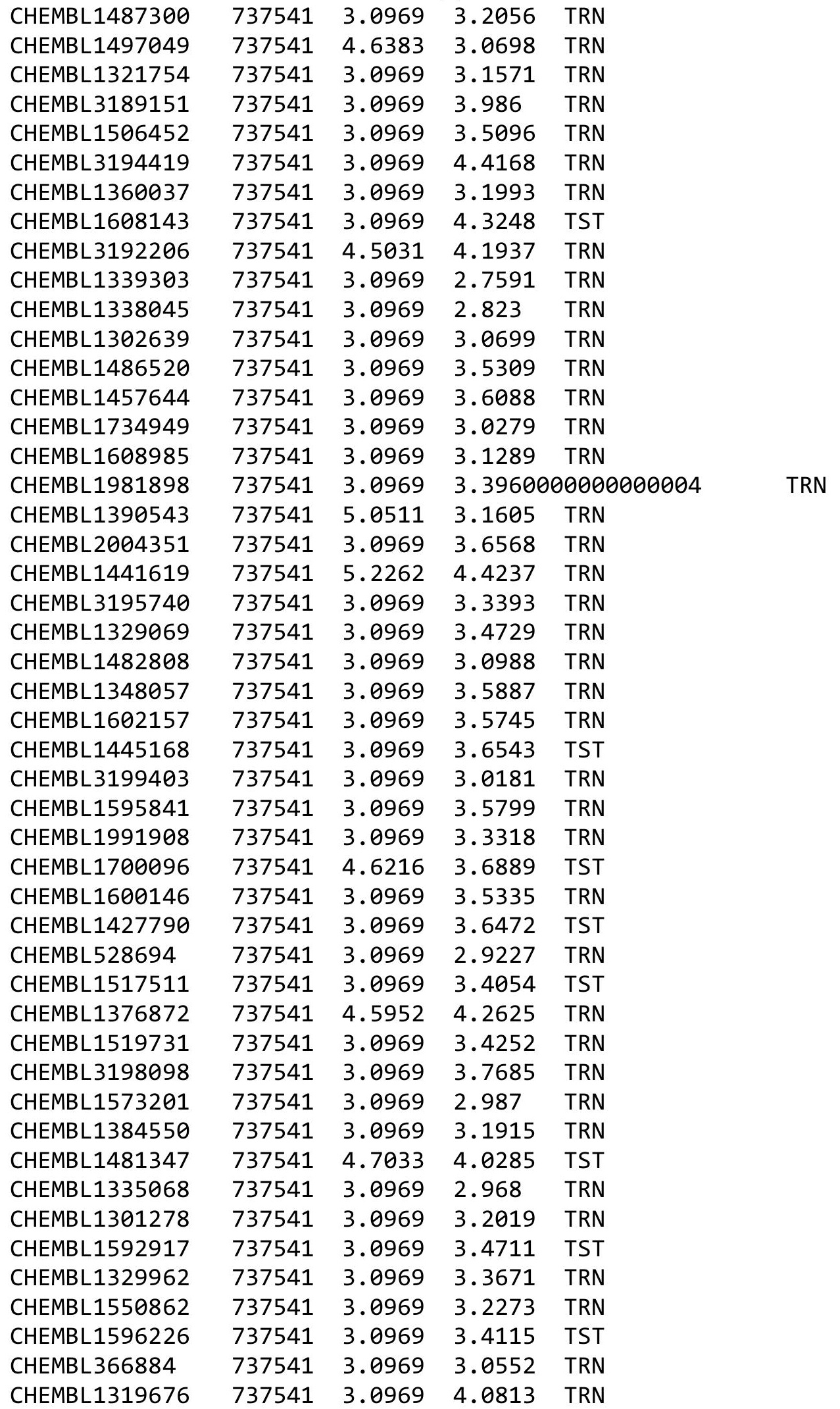

Page 5610 
Supplemental Table S2.txt

\begin{tabular}{|c|c|c|c|c|}
\hline CHEMBL1420031 & 737541 & 3.0969 & 3.388 & TRN \\
\hline CHEMBL1337538 & 737541 & 3.0969 & 3.4605 & TRN \\
\hline CHEMBL1408320 & 737541 & 3.0969 & 3.36 & TRN \\
\hline CHEMBL482050 & 737541 & 3.0969 & 3.4222 & TST \\
\hline CHEMBL 2094567 & 737541 & 3.0969 & 2.9731 & TRN \\
\hline CHEMBL1487635 & 737541 & 3.0969 & 3.1362 & TRN \\
\hline CHEMBL1507407 & 737541 & 5.063 & 3.3779 & TRN \\
\hline CHEMBL1418124 & 737541 & 3.0969 & 3.55 & TRN \\
\hline CHEMBL1386649 & 737541 & 3.0969 & 2.8405 & TRN \\
\hline CHEMBL1527214 & 737541 & 3.0969 & 3.5203 & TRN \\
\hline CHEMBL1981677 & 737541 & 5.21399 & 799999999 & 4.3132 \\
\hline CHEMBL1372492 & 737541 & 4.8097 & 3.543999 & 99999999996 \\
\hline CHEMBL1339270 & 737541 & 3.0969 & 3.2198 & TRN \\
\hline CHEMBL1573909 & 737541 & 3.0969 & 3.2546 & TRN \\
\hline CHEMBL1979800 & 737541 & 3.0969 & 3.5932 & TRN \\
\hline CHEMBL1402909 & 737541 & 3.0969 & 3.4607 & TST \\
\hline CHEMBL1463930 & 737541 & 3.0969 & 3.3528 & TRN \\
\hline CHEMBL1341919 & 737541 & 3.0969 & 3.1904 & TST \\
\hline CHEMBL1346860 & 737541 & 3.0969 & 3.3257 & TRN \\
\hline CHEMBL1610463 & 737541 & 4.475 & 3.4673 & TRN \\
\hline CHEMBL1365235 & 737541 & 3.0969 & 2.9629 & TRN \\
\hline CHEMBL591126 & 737541 & 3.0969 & 2.9633 & TRN \\
\hline CHEMBL3193428 & 737541 & 3.0969 & 3.4939 & TRN \\
\hline CHEMBL3209159 & 737541 & 4.3188 & 3.9574 & TRN \\
\hline CHEMBL1978355 & 737541 & 3.0969 & 3.2526 & TRN \\
\hline CHEMBL1577590 & 737541 & 3.0969 & 3.1216 & TRN \\
\hline CHEMBL1411125 & 737541 & 3.0969 & 3.1549 & TRN \\
\hline CHEMBL1495189 & 737541 & 3.0969 & 3.0049 & TST \\
\hline CHEMBL1586895 & 737541 & 3.0969 & 3.1501 & TRN \\
\hline CHEMBL1612392 & 737541 & 4.6946 & 3.7711 & TRN \\
\hline CHEMBL1607268 & 737541 & 4.1726 & 3.4916 & TRN \\
\hline CHEMBL1991277 & 737541 & 3.0969 & 3.3394 & TRN \\
\hline CHEMBL1299997 & 737541 & 3.0969 & 3.2337 & TRN \\
\hline CHEMBL1400469 & 737541 & 3.0969 & 3.5171 & TRN \\
\hline CHEMBL3209146 & 737541 & 4.6819 & 4.5997 & TRN \\
\hline CHEMBL1321238 & 737541 & 3.0969 & 2.8836 & TRN \\
\hline CHEMBL1544797 & 737541 & 3.0969 & 3.3996 & TRN \\
\hline CHEMBL1494784 & 737541 & 3.0969 & 2.7821 & TST \\
\hline CHEMBL1596681 & 737541 & 3.0969 & 4.0285 & TST \\
\hline CHEMBL19980 & 737541 & 3.0969 & 3.3505 & TST \\
\hline CHEMBL1401951 & 737541 & 3.0969 & 2.9984 & TST \\
\hline CHEMBL1539808 & 737541 & 5.0975 & 4.5493 & TST \\
\hline CHEMBL1611041 & 737541 & 3.0969 & 3.4457 & TST \\
\hline CHEMBL1534503 & 737541 & 3.0969 & 3.6555 & TST \\
\hline CHEMBL1305960 & 737541 & 3.0969 & 3.7662 & TST \\
\hline CHEMBL1324256 & 737541 & 5.2013 & 4.2742 & TST \\
\hline CHEMBL1385413 & 737541 & 3.0969 & 3.2076 & TST \\
\hline CHEMBL1398709 & 737541 & 3.0969 & 3.2368 & TST \\
\hline
\end{tabular}


Supplemental Table S2.txt

\begin{tabular}{|c|c|c|c|c|}
\hline CHEMBL1410897 & 737541 & 3.0969 & 3.5773 & TST \\
\hline CHEMBL1462968 & 737541 & 3.0969 & 3.1109 & TST \\
\hline CHEMBL1403085 & 737541 & 3.0969 & 3.4693 & TST \\
\hline CHEMBL188 & 737541 & 3.0969 & 3.653 & TST \\
\hline CHEMBL1301453 & 737541 & 3.0969 & 3.87100 & 30000000004 \\
\hline CHEMBL1555488 & 737541 & 5.3298 & 3.5412 & TST \\
\hline CHEMBL3197912 & 737541 & 3.0969 & 3.4875 & TST \\
\hline CHEMBL1497243 & 737541 & 3.0969 & 3.5569 & TST \\
\hline CHEMBL1583964 & 737541 & 3.0969 & 3.66899 & \\
\hline CHEMBL1527929 & 737541 & 3.0969 & 3.4847 & TST \\
\hline CHEMBL1500226 & 737541 & 3.0969 & 3.105 & TST \\
\hline CHEMBL1483596 & 737541 & 3.0969 & 3.0935 & TST \\
\hline CHEMBL1391217 & 737541 & 3.0969 & 3.1817 & TST \\
\hline CHEMBL1702699 & 737541 & 4.2277 & 3.5344 & TST \\
\hline CHEMBL453974 & 737541 & 3.0969 & 3.6827 & TST \\
\hline CHEMBL 3193227 & 737541 & 5.0942 & 4.3755 & TST \\
\hline CHEMBL1527447 & 737541 & 3.0969 & 3.6005 & TST \\
\hline CHEMBL1571835 & 737541 & 3.0969 & 2.7596 & TST \\
\hline CHEMBL532363 & 737541 & 3.0969 & 3.2633 & TST \\
\hline CHEMBL1306267 & 737541 & 3.0969 & 3.6598 & TST \\
\hline CHEMBL1413208 & 737541 & 3.0969 & 3.1895 & TST \\
\hline CHEMBL1604863 & 737541 & 3.0969 & 3.4758 & TST \\
\hline CHEMBL1312788 & 737541 & 3.0969 & 2.6494 & TST \\
\hline CHEMBL190880 & 737541 & 3.0969 & 3.1292 & TST \\
\hline CHEMBL1404953 & 737541 & 4.4365 & 3.6077 & TST \\
\hline CHEMBL1539522 & 737541 & 3.0969 & 3.2134 & TST \\
\hline CHEMBL1483562 & 737541 & 3.0969 & 3.7218 & TST \\
\hline CHEMBL3209659 & 737541 & 3.0969 & 4.0372 & TST \\
\hline CHEMBL1322695 & 737541 & 3.0969 & 3.0388 & TST \\
\hline CHEMBL1578962 & 737541 & 3.0969 & 3.22600 & 00000000004 \\
\hline CHEMBL1568646 & 737541 & 3.0969 & 3.1326 & TST \\
\hline CHEMBL1490942 & 737541 & 3.0969 & 3.0642 & TST \\
\hline CHEMBL1529127 & 737541 & 3.0969 & 3.5155 & TST \\
\hline CHEMBL3212519 & 737541 & 4.8125 & 3.7494 & TST \\
\hline CHEMBL3194451 & 737541 & 3.0969 & 3.3829 & TST \\
\hline CHEMBL1477337 & 737541 & 3.0969 & 3.1536 & TST \\
\hline CHEMBL1557820 & 737541 & 3.0969 & 2.8628 & TST \\
\hline CHEMBL 2003511 & 737541 & 4.8477 & 3.8077 & TST \\
\hline CHEMBL1523417 & 737541 & 3.0969 & 3.9545 & TST \\
\hline CHEMBL1612634 & 737541 & 3.0969 & 3.0241 & TST \\
\hline CHEMBL1428507 & 737541 & 3.0969 & 3.1437 & TST \\
\hline CHEMBL1570871 & 737541 & 3.0969 & 3.3376 & TST \\
\hline CHEMBL1565344 & 737541 & 3.0969 & 3.1667 & TST \\
\hline CHEMBL1563323 & 737541 & 3.0969 & 3.1834 & TST \\
\hline CHEMBL1998521 & 737541 & 4.5513 & 3.2727 & TST \\
\hline CHEMBL1330510 & 737541 & 5.007 & 4.9057 & TST \\
\hline CHEMBL1302028 & 737541 & 3.0969 & 3.1638 & TST \\
\hline CHEMBL 270605 & 737541 & 3.0969 & 3.1748 & TST \\
\hline
\end{tabular}


Supplemental Table S2.txt

\begin{tabular}{|c|c|c|c|c|}
\hline CHEMBL1322618 & 737541 & 3.0969 & 2.7665 & TST \\
\hline CHEMBL1408276 & 737541 & 3.0969 & 3.3828 & TST \\
\hline CHEMBL1310701 & 737541 & 3.0969 & 3.2893 & TST \\
\hline CHEMBL1342448 & 737541 & 3.0969 & 3.5099 & TST \\
\hline CHEMBL1485665 & 737541 & 5.251 & 4.0806 & TST \\
\hline CHEMBL1306124 & 737541 & 3.0969 & 3.4697 & TST \\
\hline CHEMBL1990174 & 737541 & 3.0969 & 3.4447 & TST \\
\hline CHEMBL3897582 & 1636903 & 6.2865 & \multicolumn{2}{|c|}{6.292000000000001} \\
\hline CHEMBL3938958 & 1636903 & 6.9031 & 6.9346 & TRN \\
\hline CHEMBL3940649 & 1636903 & 7.3936 & 7.3597 & TRN \\
\hline CHEMBL3898960 & 1636903 & 6.5346 & 7.2958 & TST \\
\hline CHEMBL3912447 & 1636903 & 8.0128 & 8.0114 & TRN \\
\hline CHEMBL3976412 & 1636903 & 7.3726 & 7.4225 & TRN \\
\hline CHEMBL3894575 & 1636903 & 7.7305 & 7.6892 & TRN \\
\hline CHEMBL3983960 & 1636903 & 7.4881 & 7.4892 & TRN \\
\hline CHEMBL3898369 & 1636903 & 7.5622 & 7.4493 & TRN \\
\hline CHEMBL3914026 & 1636903 & 6.6655 & 6.6724 & TRN \\
\hline CHEMBL3931322 & 1636903 & 6.475 & 6.524 & TRN \\
\hline CHEMBL3963371 & 1636903 & 8.1073 & 8.2281 & TRN \\
\hline CHEMBL3976128 & 1636903 & 7.5884 & 7.4922 & TRN \\
\hline CHEMBL3910997 & 1636903 & 7.2557 & 7.3534 & TRN \\
\hline CHEMBL3954822 & 1636903 & 7.5498 & 7.5712 & TRN \\
\hline CHEMBL3935625 & 1636903 & 6.2457 & 7.4683 & TST \\
\hline CHEMBL3945333 & 1636903 & 6.4935 & 6.4832 & TRN \\
\hline CHEMBL3978438 & 1636903 & 6.0386 & 6.0034 & TRN \\
\hline CHEMBL2180073 & 1636903 & 7.6478 & 7.6499 & TRN \\
\hline CHEMBL3964410 & 1636903 & 8.0721 & 8.0793 & TRN \\
\hline CHEMBL3938847 & 1636903 & 8.6498 & 8.5676 & TRN \\
\hline CHEMBL3930242 & 1636903 & 7.1373 & 7.1953 & TRN \\
\hline CHEMBL3937332 & 1636903 & 7.2984 & 7.3506 & TRN \\
\hline CHEMBL3936724 & 1636903 & 6.1469 & 6.1105 & TRN \\
\hline CHEMBL3943350 & 1636903 & 6.4737 & 6.4161 & TRN \\
\hline CHEMBL3961018 & 1636903 & 7.6596 & 7.765 & TRN \\
\hline CHEMBL3931173 & 1636903 & 6.5346 & 6.5825 & TRN \\
\hline CHEMBL 2177503 & 1636903 & 6.5638 & 6.5771 & TRN \\
\hline CHEMBL3931721 & 1636903 & 6.7595 & 6.7586 & TRN \\
\hline CHEMBL3967393 & 1636903 & 7.6144 & 7.5694 & TRN \\
\hline CHEMBL3961293 & 1636903 & 7.3788 & 7.3706 & TRN \\
\hline CHEMBL3905777 & 1636903 & 6.1175 & 7.2778 & TST \\
\hline CHEMBL3939155 & 1636903 & 7.1337 & 7.4983 & TST \\
\hline CHEMBL3961243 & 1636903 & 7.6946 & 7.7442 & TRN \\
\hline CHEMBL3973466 & 1636903 & 7.5258 & 7.5802 & TRN \\
\hline CHEMBL3986634 & 1636903 & 7.8356 & 7.8092 & TRN \\
\hline CHEMBL3953546 & 1636903 & 7.5391 & 7.5102 & TST \\
\hline CHEMBL3936084 & 1636903 & 7.4895 & 7.439 & TRN \\
\hline CHEMBL3907231 & 1636903 & 7.1733 & 6.9436 & TST \\
\hline CHEMBL3926879 & 1636903 & 7.4962 & 7.4898 & TRN \\
\hline CHEMBL3951069 & 1636903 & 7.5058 & 7.5458 & TRN \\
\hline
\end{tabular}


Supplemental Table S2.txt

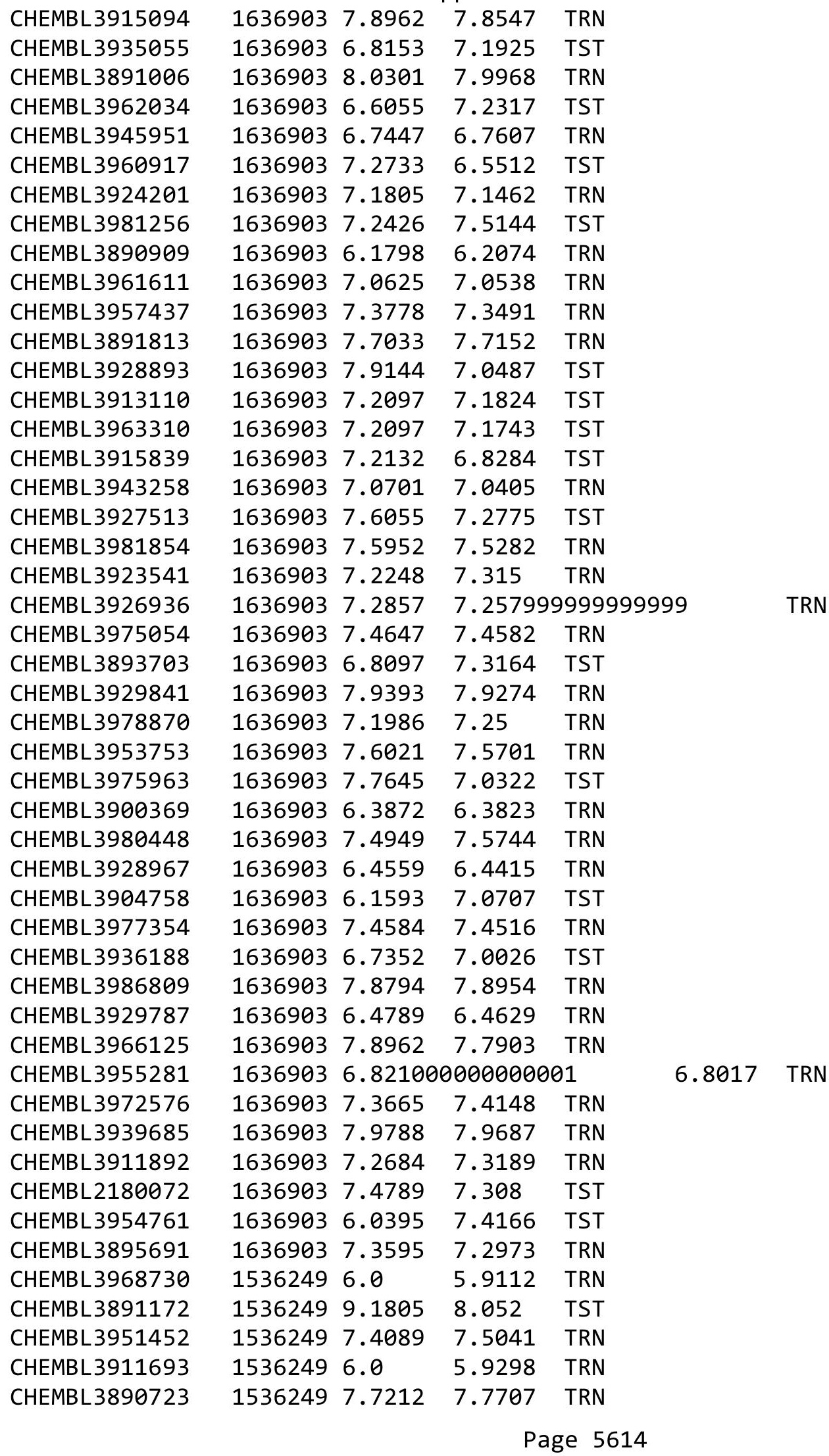




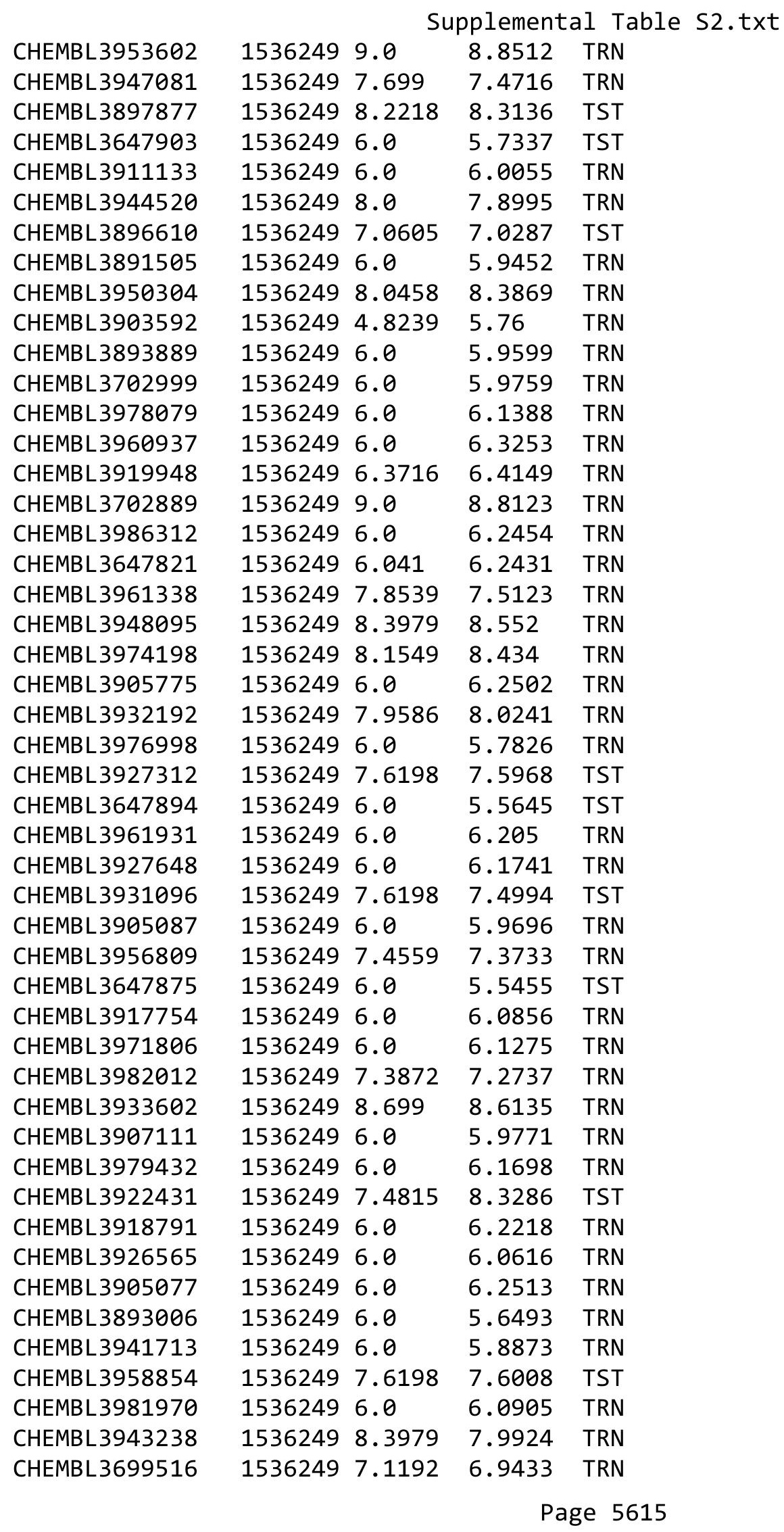


Supplemental Table S2.txt

\begin{tabular}{|c|c|c|c|c|c|}
\hline CHEMBL 3647833 & 1536249 & 7.2291 & 7.1594 & TST & \\
\hline CHEMBL3978330 & 1536249 & 6.0 & 6.1268 & TRN & \\
\hline CHEMBL3699462 & 1536249 & 7.0862 & 7.1876 & TRN & \\
\hline CHEMBL3932785 & 1536249 & 7.4202 & 7.2476 & TRN & \\
\hline CHEMBL3933155 & 1536249 & 7.4685 & 7.475 & TRN & \\
\hline CHEMBL 3965635 & 1536249 & 6.0 & 5.5003 & TST & \\
\hline CHEMBL3699486 & 1536249 & 6.3335 & 6.5036 & TRN & \\
\hline CHEMBL 3973473 & 1536249 & 9.0 & 8.9677 & TRN & \\
\hline CHEMBL 3970898 & 1536249 & 7.5528 & 7.7546 & TRN & \\
\hline CHEMBL3703033 & 1536249 & 6.0 & 6.1545 & TRN & \\
\hline CHEMBL 3904299 & 1536249 & 7.585 & 7.7749 & TRN & \\
\hline CHEMBL 3938888 & 1536249 & 6.301 & 6.5413 & TRN & \\
\hline CHEMBL 3647890 & 1536249 & 6.0 & 5.5801 & TST & \\
\hline CHEMBL 3647828 & 1536249 & 6.0 & \multicolumn{2}{|c|}{5.877000000000001} & TRN \\
\hline CHEMBL3962282 & 1536249 & 6.0 & 6.0614 & TRN & \\
\hline CHEMBL3961410 & 1536249 & 8.699 & 8.4494 & TST & \\
\hline CHEMBL3984856 & 1536249 & 7.3979 & 7.7787 & TRN & \\
\hline CHEMBL3896429 & 1536249 & 8.1549 & 8.0943 & TRN & \\
\hline CHEMBL 3699515 & 1536249 & 6.6459 & 6.7801 & TRN & \\
\hline CHEMBL3647827 & 1536249 & 6.6162 & 7.0971 & TRN & \\
\hline CHEMBL 3909205 & 1536249 & 7.7959 & 7.8096 & TST & \\
\hline CHEMBL3926832 & 1536249 & 7.6383 & 7.5222 & TST & \\
\hline CHEMBL3699487 & 1536249 & 6.9957 & 6.9529 & TRN & \\
\hline CHEMBL3699557 & 1536249 & 6.0 & 5.9248 & TRN & \\
\hline CHEMBL3890956 & 1536249 & 6.0 & 6.1095 & TRN & \\
\hline CHEMBL 3987003 & 1536249 & 7.1938 & 6.8246 & TRN & \\
\hline CHEMBL3986699 & 1536249 & 7.8239 & 7.6555 & TST & \\
\hline CHEMBL3904018 & 1536249 & 7.4949 & 7.4801 & TRN & \\
\hline CHEMBL 3955894 & 1536249 & 7.3768 & 7.2783 & TRN & \\
\hline CHEMBL3925967 & 1536249 & 7.1367 & 7.1324 & TRN & \\
\hline CHEMBL 3968245 & 1536249 & 6.0 & 6.2682 & TRN & \\
\hline CHEMBL3980384 & 1536249 & 7.7447 & 7.6745 & TRN & \\
\hline CHEMBL3911649 & 1536249 & 8.5229 & 8.3311 & TRN & \\
\hline CHEMBL3639467 & 1536249 & 6.0 & 6.0409 & TST & \\
\hline CHEMBL3936080 & 1536249 & 7.9586 & 8.2511 & TRN & \\
\hline CHEMBL3911534 & 1536249 & 7.2218 & 6.9604 & TRN & \\
\hline CHEMBL3983950 & 1536249 & 6.0 & 5.9568 & TRN & \\
\hline CHEMBL3934905 & 1536249 & 6.0 & 5.9849 & TRN & \\
\hline CHEMBL3699472 & 1536249 & 6.0 & 5.96 & TRN & \\
\hline CHEMBL3924444 & 1536249 & 8.2218 & 7.7562 & TRN & \\
\hline CHEMBL3928280 & 1536249 & 6.0 & 6.0535 & TRN & \\
\hline CHEMBL3962315 & 1536249 & 7.2218 & 7.746 & TST & \\
\hline CHEMBL3906629 & 1536249 & 6.8697 & 6.6246 & TRN & \\
\hline CHEMBL3918680 & 1536249 & 6.0 & 6.0582 & TRN & \\
\hline CHEMBL3639466 & 1536249 & 7.7696 & 7.4637 & TRN & \\
\hline CHEMBL3906377 & 1536249 & 7.3768 & 7.2745 & TRN & \\
\hline CHEMBL3953895 & 1536249 & 6.0 & 5.8059 & TST & \\
\hline CHEMBL3647882 & 1536249 & 6.0 & 5.3286 & TST & \\
\hline
\end{tabular}




\begin{tabular}{|c|c|c|c|c|}
\hline \multicolumn{5}{|c|}{ Supplemental Table s2.txt } \\
\hline CHEMBL 3986553 & 1536249 & 6.0 & 6.0876 & TRN \\
\hline CHEMBL3702982 & 1536249 & 7.6383 & 7.7755 & TST \\
\hline CHEMBL3941828 & 1536249 & 8.1549 & 8.1675 & TST \\
\hline CHEMBL 3699460 & 1536249 & 6.0 & 6.0646 & TRN \\
\hline CHEMBL3702936 & 1536249 & 6.6737 & 6.5003 & TRN \\
\hline CHEMBL 3913749 & 1536249 & 6.9245 & 7.1276 & TRN \\
\hline CHEMBL 3920468 & 1536249 & 7.7959 & 7.8533 & TST \\
\hline CHEMBL3984766 & 1536249 & 6.0 & 5.9852 & TRN \\
\hline CHEMBL 3968168 & 1536249 & 6.0 & 5.2444 & TST \\
\hline CHEMBL3699522 & 1536249 & 6.0 & 6.3163 & TST \\
\hline CHEMBL 3986642 & 1536249 & 7.585 & 7.5004 & TRN \\
\hline CHEMBL 3889814 & 1536249 & 6.0 & 6.722 & TRN \\
\hline CHEMBL3966795 & 1536249 & 7.2007 & 7.3256 & TRN \\
\hline CHEMBL3972903 & 1536249 & 6.0 & 5.7367 & TRN \\
\hline CHEMBL3904535 & 1536249 & 6.0 & 5.9996 & TRN \\
\hline CHEMBL 3979847 & 1536249 & 6.0 & 5.7664 & TRN \\
\hline CHEMBL3973226 & 1536249 & 8.0458 & 8.3376 & TRN \\
\hline CHEMBL3926369 & 1536249 & 7.6576 & 7.64 & TRN \\
\hline CHEMBL 3986238 & 1536249 & 6.0 & 6.1106 & TRN \\
\hline CHEMBL3980321 & 1536249 & 7.8539 & 7.8848 & TST \\
\hline CHEMBL3702890 & 1536249 & 7.1739 & 7.0985 & TST \\
\hline CHEMBL 3947625 & 1536249 & 6.0 & 5.8399 & TRN \\
\hline CHEMBL 3650680 & 1536249 & 8.0458 & 7.8064 & TRN \\
\hline CHEMBL 3968714 & 1536249 & 6.0 & 6.1097 & TRN \\
\hline CHEMBL3981024 & 1536249 & 6.0 & 6.1615 & TRN \\
\hline CHEMBL 3983504 & 1536249 & 6.0 & 6.1883 & TRN \\
\hline CHEMBL3647933 & 1536249 & 8.0969 & 7.8617 & TST \\
\hline CHEMBL 3906754 & 1536249 & 7.9586 & 7.5683 & TST \\
\hline CHEMBL 3934454 & 1536249 & 8.0458 & 7.2035 & TST \\
\hline CHEMBL3647919 & 1536249 & 8.699 & 8.1748 & TST \\
\hline CHEMBL 3907979 & 1536249 & 8.3979 & 8.3993 & TRN \\
\hline CHEMBL3904849 & 1536249 & 6.5452 & 6.7584 & TST \\
\hline CHEMBL 3930664 & 1536249 & 6.9957 & 6.9947 & TRN \\
\hline CHEMBL3965680 & 1536249 & 7.9586 & 8.4386 & TST \\
\hline CHEMBL3965754 & 1536249 & 6.0 & 5.6748 & TST \\
\hline CHEMBL 3903540 & 1536249 & 6.0 & 5.8903 & TRN \\
\hline CHEMBL3915734 & 1536249 & 6.0 & 5.9017 & TRN \\
\hline CHEMBL 3927417 & 1536249 & 7.0506 & 7.2948 & TRN \\
\hline CHEMBL3699544 & 1536249 & 6.0 & 5.7955 & TRN \\
\hline CHEMBL3926173 & 1536249 & 7.4559 & 7.388 & TRN \\
\hline CHEMBL 3940826 & 1536249 & 7.5528 & 7.6848 & TRN \\
\hline CHEMBL3926117 & 1536249 & 9.0 & 8.3248 & TST \\
\hline CHEMBL3920925 & 1536249 & 6.0 & 6.2087 & TRN \\
\hline CHEMBL3967801 & 1536249 & 7.3279 & 7.2051 & TRN \\
\hline CHEMBL3889531 & 1536249 & 8.301 & 8.0922 & TRN \\
\hline CHEMBL3971955 & 1536249 & 6.0 & 6.0493 & TRN \\
\hline CHEMBL3940602 & 1536249 & 7.6021 & 7.8453 & TRN \\
\hline CHEMBL 3980187 & 1536249 & 6.0 & 5.6689 & TRN \\
\hline
\end{tabular}




$$
\text { Supplemental Table S2.txt }
$$

\begin{tabular}{|c|c|c|c|c|c|}
\hline CHEMBL 3925986 & 1536249 & 6.9914 & 7.3796 & TRN & \\
\hline CHEMBL 3647899 & 1536249 & 6.0 & 5.4177 & TST & \\
\hline CHEMBL3902031 & 1536249 & 6.0 & 6.2378 & TRN & \\
\hline CHEMBL3937969 & 1536249 & 6.0 & 5.9573 & TRN & \\
\hline CHEMBL 3647880 & 1536249 & 6.0 & 5.7808 & TST & \\
\hline CHEMBL3980805 & 1536249 & 6.0 & 5.9918 & TRN & \\
\hline CHEMBL3974285 & 1536249 & 6.0 & 5.8945 & TST & \\
\hline CHEMBL 3936120 & 1536249 & 6.0 & \multicolumn{2}{|c|}{6.617999999999999} & TRN \\
\hline CHEMBL3937800 & 1536249 & 6.0 & 6.0689 & TRN & \\
\hline CHEMBL3913431 & 1536249 & 8.5229 & 8.5806 & TST & \\
\hline CHEMBL3699517 & 1536249 & 7.4437 & 7.3848 & TRN & \\
\hline CHEMBL3925680 & 1536249 & 6.0 & 5.8386 & TRN & \\
\hline CHEMBL 3949390 & 1536249 & 6.0 & 5.7134 & TST & \\
\hline CHEMBL3980592 & 1536249 & 7.2147 & 7.3604 & TRN & \\
\hline CHEMBL3703007 & 1536249 & 6.0 & 6.0784 & TRN & \\
\hline CHEMBL3944102 & 1536249 & 7.7696 & 7.5086 & TRN & \\
\hline CHEMBL3949858 & 1536249 & 6.0 & 5.8582 & TRN & \\
\hline CHEMBL 3897086 & 1536249 & 6.0 & 6.1992 & TRN & \\
\hline CHEMBL3980251 & 1536249 & 8.1549 & 8.2966 & TRN & \\
\hline CHEMBL3970949 & 1536249 & 7.9586 & 7.9364 & TRN & \\
\hline CHEMBL3647907 & 1536249 & 6.0 & 5.574 & TST & \\
\hline CHEMBL3702964 & 1536249 & 6.0 & 5.8112 & TRN & \\
\hline CHEMBL3915890 & 1536249 & 7.4437 & 7.1352 & TRN & \\
\hline CHEMBL3699491 & 1536249 & 6.7545 & 7.0278 & TRN & \\
\hline CHEMBL 3930691 & 1536249 & 7.6778 & 7.4549 & TRN & \\
\hline CHEMBL3647912 & 1536249 & 7.8861 & 7.4888 & TST & \\
\hline CHEMBL3702983 & 1536249 & 7.1739 & 7.5249 & TST & \\
\hline CHEMBL 3647896 & 1536249 & 6.0 & 5.5769 & TST & \\
\hline CHEMBL3957578 & 1536249 & 7.7696 & 7.8131 & TRN & \\
\hline CHEMBL 3912434 & 1536249 & 7.8539 & 8.0942 & TRN & \\
\hline CHEMBL 3935071 & 1536249 & 8.5229 & 8.6435 & TRN & \\
\hline CHEMBL3949895 & 1536249 & 7.2147 & 7.4819 & TRN & \\
\hline CHEMBL 3939667 & 1536249 & 9.0 & 8.015 & TRN & \\
\hline CHEMBL3699494 & 1536249 & 7.4202 & 7.1594 & TRN & \\
\hline CHEMBL3917069 & 1536249 & 7.5376 & 7.3555 & TRN & \\
\hline CHEMBL3889706 & 1536249 & 8.0 & 7.5474 & TRN & \\
\hline CHEMBL3912739 & 1536249 & 7.8861 & 7.6754 & TRN & \\
\hline CHEMBL 3650677 & 1536249 & 6.0 & 5.9216 & TST & \\
\hline CHEMBL3950555 & 1536249 & 7.3098 & 7.4287 & TRN & \\
\hline CHEMBL 3987188 & 1536249 & 8.5229 & 8.339 & TRN & \\
\hline CHEMBL3963870 & 1536249 & 6.0 & 6.0659 & TRN & \\
\hline CHEMBL3647893 & 1536249 & 6.0 & 5.6505 & TST & \\
\hline CHEMBL3647932 & 1536249 & 8.301 & 8.4253 & TRN & \\
\hline CHEMBL3980212 & 1536249 & 8.699 & 8.2625 & TRN & \\
\hline CHEMBL3702968 & 1536249 & 6.9914 & 6.5434 & TRN & \\
\hline CHEMBL3703086 & 1536249 & 6.0 & 5.671 & TRN & \\
\hline CHEMBL3702928 & 1536249 & 7.6576 & 7.736006 & 0000000001 & TST \\
\hline CHEMBL3699493 & 1536249 & 6.0 & 5.4906 & TST & \\
\hline
\end{tabular}




\begin{tabular}{|c|c|c|c|c|c|}
\hline \multicolumn{6}{|c|}{ Supplemental Table S2.txt } \\
\hline CHEMBL3911297 & 1536249 & 6.0 & 5.9807 & TRN & \\
\hline CHEMBL 3893424 & 1536249 & 7.2924 & 7.2916 & TRN & \\
\hline CHEMBL3986387 & 1536249 & 8.301 & 8.2812 & TRN & \\
\hline CHEMBL 3927307 & 1536249 & 7.7959 & 7.5503 & TRN & \\
\hline CHEMBL3986153 & 1536249 & 6.0 & 5.9437 & TRN & \\
\hline CHEMBL3939393 & 1536249 & 7.4685 & 7.6851 & TRN & \\
\hline CHEMBL3958728 & 1536249 & 7.5086 & 7.7268 & TRN & \\
\hline CHEMBL 3979875 & 1536249 & 6.0 & 5.9319 & TRN & \\
\hline CHEMBL 3940540 & 1536249 & 8.3979 & 8.7388 & TRN & \\
\hline CHEMBL3942197 & 1536249 & 6.0 & 5.7325 & TRN & \\
\hline CHEMBL 3933440 & 1536249 & 6.0 & 5.8026 & TRN & \\
\hline CHEMBL3951734 & 1536249 & 7.3565 & \multicolumn{2}{|c|}{7.593999999999999} & TRN \\
\hline CHEMBL 3930395 & 1536249 & 7.3665 & 7.4419 & TRN & \\
\hline CHEMBL 3894428 & 1536249 & 6.0 & 6.3695 & TRN & \\
\hline CHEMBL 3699504 & 1536249 & 6.3605 & 6.705 & TRN & \\
\hline CHEMBL 3647885 & 1536249 & 6.0 & 5.5374 & TST & \\
\hline CHEMBL3981318 & 1536249 & 8.0458 & 7.5974 & TRN & \\
\hline CHEMBL 3946964 & 1536249 & 7.5229 & 7.3828 & TRN & \\
\hline CHEMBL3699496 & 1536249 & 4.8239 & 5.7514 & TST & \\
\hline CHEMBL3969261 & 1536249 & 6.0 & 6.3845 & TRN & \\
\hline CHEMBL3911301 & 1536249 & 7.9208 & 7.6523 & TRN & \\
\hline CHEMBL3918490 & 1536249 & 6.0 & 5.7576 & TRN & \\
\hline CHEMBL 3892594 & 1536249 & 8.301 & 7.8279 & TRN & \\
\hline CHEMBL3895835 & 1536249 & 6.0 & 5.9592 & TRN & \\
\hline CHEMBL3971368 & 1536249 & 6.0 & 6.9351 & TRN & \\
\hline CHEMBL3935933 & 1536249 & 8.699 & 8.6827 & TRN & \\
\hline CHEMBL3898629 & 1536249 & 7.6021 & 7.9658 & TST & \\
\hline CHEMBL3699490 & 1536249 & 6.4473 & 6.7462 & TRN & \\
\hline CHEMBL3946315 & 1536249 & 6.0 & 6.3357 & TRN & \\
\hline CHEMBL3891136 & 1536249 & 7.301 & 7.0259 & TRN & \\
\hline CHEMBL 3699545 & 1536249 & 6.0 & 6.0386 & TRN & \\
\hline CHEMBL3936365 & 1536249 & 7.8861 & 7.725 & TRN & \\
\hline CHEMBL3986157 & 1536249 & 7.6383 & 8.1021 & TRN & \\
\hline CHEMBL3897122 & 1536249 & 7.4949 & 7.516 & TRN & \\
\hline CHEMBL3905139 & 1536249 & 6.0 & 5.9648 & TRN & \\
\hline CHEMBL3647911 & 1536249 & 6.0 & 5.5176 & TST & \\
\hline CHEMBL3956620 & 1536249 & 8.0 & 7.7711 & TRN & \\
\hline CHEMBL3914361 & 1536249 & 5.9208 & 6.2831 & TRN & \\
\hline CHEMBL3920265 & 1536249 & 6.0 & 5.7073 & TRN & \\
\hline CHEMBL3985892 & 1536249 & 6.0 & 5.7819 & TRN & \\
\hline CHEMBL3942649 & 1536249 & 7.0315 & 7.1346 & TRN & \\
\hline CHEMBL 3969843 & 1536249 & 6.0 & 6.407 & TST & \\
\hline CHEMBL3699488 & 1536249 & 7.6576 & 7.4482 & TRN & \\
\hline CHEMBL3699495 & 1536249 & 7.7212 & 7.6895 & TST & \\
\hline CHEMBL3894776 & 1536249 & 6.0 & 5.4894 & TST & \\
\hline CHEMBL 3978042 & 1536249 & 6.0 & 6.1237 & TRN & \\
\hline CHEMBL 3918625 & 1536249 & 6.0 & 5.9456 & TRN & \\
\hline \multirow[t]{2}{*}{ CHEMBL3949821 } & 1536249 & 8.1549 & \multicolumn{2}{|c|}{7.877000000000001} & TRN \\
\hline & & & \multicolumn{2}{|c|}{ Page 5619} & \\
\hline
\end{tabular}


Supplemental Table S2.txt

\begin{tabular}{|c|c|c|c|c|}
\hline HEMBL & 536249 & 7.7447 & & \\
\hline HEMBL3894309 & 536249 & 6.0 & 5.7042 & \\
\hline 7 & 249 & 6.1574 & & \\
\hline HEMBL 396702 & 5249 & 7.4559 & & \\
\hline AEMBL3977989 & 536249 & 7.7959 & 581 & \\
\hline HEMBL3975046 & 536249 & 6.0 & .1284 & \\
\hline HEMBL & 36249 & 6 & & \\
\hline AEMBL3 & & 7.56 & & \\
\hline HEMBL39 & 536249 & 6.0 & & \\
\hline HEMBL3899369 & 536249 & 7.4318 & . 9892 & \\
\hline HEMBL 3927441 & 536249 & 6.0 & .1301 & \\
\hline AEMBL39 & 49 & 9.0458 & 367 & \\
\hline AEMBL3S & & & & \\
\hline HEMBL396 & 249 & 6.0 & & \\
\hline AEMBL3S & 49 & 7.6778 & & \\
\hline AEMBL39 & 19 & 6.0 & 16 & \\
\hline HEMBL36 & -9 & 7. & & \\
\hline HEMBL36 & & 6 . & & \\
\hline HEMBL3S & 49 & 9.0 & & \\
\hline AEMBL3S & 19 & 8.0 & & \\
\hline HEMBL3 & +9 & 6 & 59 & 1SI \\
\hline HEMBL3 & & 7. & & RN \\
\hline HEMBL3 & & 8 . & & \\
\hline 48 & & 7.3768 & & \\
\hline AEMBL3S & & 6.0 & & I RIV \\
\hline HEMBL37 & +9 & 6 & & RN \\
\hline HEMBL & & & & וד וכ \\
\hline HFMBI 36 & 49 & 8 . & & ST \\
\hline HEMBL3 & & 7.7959 & & IR \\
\hline HEMBL 364 & & 6.6615 & & IS \\
\hline HEMBL3S & & 7.5229 & & $\mathrm{RN}$ \\
\hline HEMBL; & & 8 . & & RN \\
\hline HEMBL. & 19 & 6.0 & & $\mathrm{R}$ \\
\hline HEMBL39e & & 8.09 & & IS \\
\hline HEMBL 397 & 36 & 9.0 & 8 . & TRN \\
\hline HEMBL36 & 49 & 6 & 69 & TRN \\
\hline HFMRI & 9 & 6 . & & $\Gamma \mathrm{RN}$ \\
\hline HEMBL & & 6.60 & & IRN \\
\hline HEMBL3699463 & 536 & 7.2 & 34 & TST \\
\hline AEMBL39 & -0 & 6 . & & TST \\
\hline HEMBL36 & 49 & 6 & 11 & RN \\
\hline CHEMBL 39 & & 6.96 & & ГST \\
\hline HEMBL39 & 536249 & 7.3979 & 7.5479 & TST \\
\hline HEMBL389 & 536249 & 6 & 5.7714 & $\Gamma R$ \\
\hline $1-$ & & & 61 & IRN \\
\hline HEMBL 36 & & דת & 7.1839 & \\
\hline CHEMBL 390 & 536249 & 5.0 & 6.1562 & \\
\hline CHEMBL3981519 & 1536249 & $7.552 \varepsilon$ & 7.3576 & TST \\
\hline
\end{tabular}

Page 5620 


\begin{tabular}{|c|c|c|c|c|c|}
\hline \multicolumn{6}{|c|}{ Supplemental Table S2.txt } \\
\hline CHEMBL3953459 & 1536249 & 6.0 & 5.8444 & TRN & \\
\hline CHEMBL3968521 & 1536249 & 7.6576 & 7.8 & TRN & \\
\hline CHEMBL3955214 & 1536249 & 6.7696 & 6.8654 & TST & \\
\hline CHEMBL3913145 & 1536249 & 6.0 & 5.8323 & TRN & \\
\hline CHEMBL 3983874 & 1536249 & 6.0 & 6.0092 & TRN & \\
\hline CHEMBL3647918 & 1536249 & 8.699 & 8.0743 & TST & \\
\hline CHEMBL3940437 & 1536249 & 8.699 & 8.7305 & TRN & \\
\hline CHEMBL3647763 & 1536249 & 6.0 & 5.7983 & TRN & \\
\hline CHEMBL3903615 & 1536249 & 6.0 & 5.7481 & TRN & \\
\hline CHEMBL3647923 & 1536249 & 6.0 & 6.1943 & TRN & \\
\hline CHEMBL3905747 & 1536249 & 6.0 & 5.92200 & 0000000001 & TRN \\
\hline CHEMBL3931852 & 1536249 & 8.0 & 7.7393 & TRN & \\
\hline CHEMBL3930327 & 1536249 & 8.301 & 8.1515 & TRN & \\
\hline CHEMBL3702888 & 1536249 & 8.0458 & 7.8221 & TST & \\
\hline CHEMBL3650683 & 1536249 & 6.0 & 6.2425 & TRN & \\
\hline CHEMBL3954468 & 1536249 & 7.6778 & 7.4368 & TST & \\
\hline CHEMBL3942620 & 1536249 & 7.2147 & 7.6978 & TRN & \\
\hline CHEMBL3647920 & 1536249 & 6.7352 & 7.0048 & TST & \\
\hline CHEMBL3944704 & 1536249 & 6.0 & 6.2741 & TRN & \\
\hline CHEMBL3954496 & 1536249 & 6.0 & 5.7882 & TRN & \\
\hline CHEMBL3957671 & 1536249 & 6.0 & 5.7264 & TRN & \\
\hline CHEMBL3906102 & 1536249 & 4.8239 & 6.0792 & TST & \\
\hline CHEMBL3949813 & 1536249 & 6.0 & 6.0226 & TRN & \\
\hline CHEMBL 3647817 & 1536249 & 6.1772 & 6.70299 & 9999999999 & TRN \\
\hline CHEMBL3935674 & 1536249 & 8.5229 & 7.36600 & 20000000005 & TST \\
\hline CHEMBL3647819 & 1536249 & 6.3768 & 6.8768 & TRN & \\
\hline CHEMBL3978237 & 1536249 & 7.9586 & 8.0062 & TRN & \\
\hline CHEMBL3934845 & 1536249 & 8.1549 & 8.1966 & TRN & \\
\hline CHEMBL 3937290 & 1536249 & 7.9586 & 8.0093 & TRN & \\
\hline CHEMBL3935016 & 1536249 & 8.699 & 8.9049 & TRN & \\
\hline CHEMBL3978534 & 1536249 & 6.0 & 5.7754 & TRN & \\
\hline CHEMBL3986434 & 1536249 & 7.4559 & 7.2626 & TST & \\
\hline CHEMBL3973400 & 1536249 & 6.0 & 6.0309 & TRN & \\
\hline CHEMBL3928060 & 1536249 & 6.0 & 5.7066 & TRN & \\
\hline CHEMBL3699524 & 1536249 & 6.0 & 6.0505 & TRN & \\
\hline CHEMBL3647922 & 1536249 & 6.0 & 6.3573 & TRN & \\
\hline CHEMBL3647901 & 1536249 & 6.0 & 5.7771 & TST & \\
\hline CHEMBL3947877 & 1536249 & 6.0 & 5.7087 & TRN & \\
\hline CHEMBL 3647820 & 1536249 & 6.6198 & 6.8533 & TRN & \\
\hline CHEMBL 3897014 & 1536249 & 6.0 & 6.1051 & TRN & \\
\hline CHEMBL3946871 & 1536249 & 6.0 & 6.3668 & TST & \\
\hline CHEMBL3907546 & 1536249 & 6.0 & 6.2746 & TRN & \\
\hline CHEMBL3949220 & 1536249 & 8.301 & 8.0326 & TRN & \\
\hline CHEMBL 3962416 & 1536249 & 6.0 & 6.0416 & TRN & \\
\hline CHEMBL3647928 & 1536249 & 7.3098 & 7.6513 & TST & \\
\hline CHEMBL3946519 & 1536249 & 7.4202 & 7.4479 & TRN & \\
\hline CHEMBL3967854 & 1536249 & 7.4202 & 7.3443 & TST & \\
\hline CHEMBL3974844 & 1536249 & 7.3872 & 7.5526 & TRN & \\
\hline
\end{tabular}


Supplemental Table S2.txt

\begin{tabular}{|c|c|c|c|c|c|}
\hline CHEMBL3949116 & 1536249 & 8.5229 & 8.4448 & TRN & \\
\hline CHEMBL3955677 & 1536249 & 7.6383 & 7.3869 & TRN & \\
\hline CHEMBL3904521 & 1536249 & 6.0 & 5.8872 & TST & \\
\hline CHEMBL3918665 & 1536249 & 7.3188 & 7.244 & TRN & \\
\hline CHEMBL3941329 & 1536249 & 6.0 & 5.7684 & TRN & \\
\hline CHEMBL3951386 & 1536249 & 7.4089 & 7.2639 & TST & \\
\hline CHEMBL3902006 & 1536249 & 7.4815 & 7.6343 & TST & \\
\hline CHEMBL3945564 & 1536249 & 6.0 & 5.8557 & TRN & \\
\hline CHEMBL3947274 & 1536249 & 7.0969 & 7.3921 & TRN & \\
\hline CHEMBL3946577 & 1536249 & 6.0 & 5.9276 & TST & \\
\hline CHEMBL 3702887 & 1536249 & 9.0 & 8.432 & TRN & \\
\hline CHEMBL3890435 & 1536249 & 6.0 & 5.8288 & TRN & \\
\hline CHEMBL3914017 & 1536249 & 7.4089 & 7.491006 & 00000000005 & TST \\
\hline CHEMBL3955512 & 1536249 & 6.0 & 5.6197 & TRN & \\
\hline CHEMBL3944882 & 1536249 & 9.0 & 8.8116 & TRN & \\
\hline CHEMBL3963187 & 1536249 & 7.3279 & 7.484 & TRN & \\
\hline CHEMBL3985015 & 1536249 & 8.699 & 7.9327 & TRN & \\
\hline CHEMBL3932800 & 1536249 & 7.5528 & 7.7093 & TST & \\
\hline CHEMBL3919610 & 1536249 & 6.0 & 5.716 & TRN & \\
\hline CHEMBL3897598 & 1536249 & 7.0706 & 7.2265 & TRN & \\
\hline CHEMBL1992342 & 809223 & 4.5 & 4.4444 & TRN & \\
\hline CHEMBL 2002202 & 809223 & 4.2 & 4.03 & TRN & \\
\hline CHEMBL1988173 & 809223 & 4.5 & 4.9572 & TST & \\
\hline CHEMBL1973013 & 809223 & 4.6 & 5.17299 & 9999999999 & TST \\
\hline CHEMBL1164265 & 809223 & 6.9 & 5.7586 & TST & \\
\hline CHEMBL1989805 & 809223 & 4.5 & 4.172 & TST & \\
\hline CHEMBL1965423 & 809223 & 4.5 & 4.5165 & TRN & \\
\hline CHEMBL1983025 & 809223 & 6.2 & 6.2582 & TRN & \\
\hline CHEMBL1975927 & 809223 & 6.2 & 6.0143 & TRN & \\
\hline CHEMBL205415 & 809223 & 4.6 & 4.4355 & TRN & \\
\hline CHEMBL1977135 & 809223 & 4.5 & 4.6996 & TRN & \\
\hline CHEMBL2001920 & 809223 & 4.5 & 4.3841 & TRN & \\
\hline CHEMBL 2002322 & 809223 & 4.5 & 4.1506 & TRN & \\
\hline CHEMBL1977138 & 809223 & 6.3 & 5.7306 & TST & \\
\hline CHEMBL2002323 & 809223 & 4.5 & 4.1978 & TRN & \\
\hline CHEMBL1241473 & 809223 & 7.4 & 7.0066 & TRN & \\
\hline CHEMBL1978448 & 809223 & 4.6 & 4.447 & TST & \\
\hline CHEMBL1972258 & 809223 & 4.5 & 4.5486 & TRN & \\
\hline CHEMBL1969483 & 809223 & 4.6 & 4.862 & TRN & \\
\hline CHEMBL1980329 & 809223 & 5.6 & 5.3558 & TRN & \\
\hline CHEMBL 2004515 & 809223 & 4.4 & 4.3863 & TRN & \\
\hline CHEMBL2001257 & 809223 & 6.0 & 5.9623 & TRN & \\
\hline CHEMBL1992042 & 809223 & 6.5 & 6.4904 & TRN & \\
\hline CHEMBL 2005548 & 809223 & 4.5 & 4.6332 & TRN & \\
\hline CHEMBL1987793 & 809223 & 4.5 & 5.0014 & TST & \\
\hline CHEMBL1992536 & 809223 & 4.5 & 4.7018 & TRN & \\
\hline CHEMBL21156 & 809223 & 4.6 & 5.1743 & TST & \\
\hline CHEMBL1992740 & 809223 & 4.5 & 4.7589 & TRN & \\
\hline
\end{tabular}




\begin{tabular}{|c|c|c|c|c|}
\hline & & & ient & al Ta \\
\hline CHEMBL1994724 & 809223 & 4.6 & 5.072 & TRN \\
\hline CHEMBL1989267 & 809223 & 6.5 & 6.2221 & TRN \\
\hline CHEMBL1997433 & 809223 & 5.6 & 5.0018 & TRN \\
\hline CHEMBL 2002373 & 809223 & 4.5 & 4.5486 & TRN \\
\hline CHEMBL439340 & 809223 & 4.5 & 4.8794 & TRN \\
\hline CHEMBL 2006188 & 809223 & 4.5 & 4.6293 & TRN \\
\hline CHEMBL1970290 & 809223 & 5.9 & 5.5909 & TRN \\
\hline CHEMBL1967531 & 809223 & 6.1 & 5.631 & TRN \\
\hline CHEMBL1970913 & 809223 & 4.5 & 4.7474 & TRN \\
\hline CHEMBL1973893 & 809223 & 4.5 & 4.4723 & TRN \\
\hline CHEMBL1997534 & 809223 & 4.5 & 4.5653 & TRN \\
\hline CHEMBL1993877 & 809223 & 4.6 & 4.8043 & TRN \\
\hline CHEMBL1996500 & 809223 & 4.6 & 4.4767 & TRN \\
\hline CHEMBL1985095 & 809223 & 5.6 & 4.4157 & TST \\
\hline CHEMBL1973363 & 809223 & 5.6 & 5.4861 & TRN \\
\hline CHEMBL1991180 & 809223 & 4.5 & 5.3079 & TST \\
\hline CHEMBL1682540 & 809223 & 4.5 & 4.3618 & TRN \\
\hline CHEMBL1976420 & 809223 & 4.5 & 5.0553 & TST \\
\hline CHEMBL413779 & 809223 & 4.5 & 4.8849 & TST \\
\hline CHEMBL1981744 & 809223 & 4.6 & 4.8401 & TRN \\
\hline CHEMBL1994864 & 809223 & 4.5 & 4.6531 & TRN \\
\hline CHEMBL 2002446 & 809223 & 4.5 & 4.2622 & TST \\
\hline CHEMBL497151 & 809223 & 4.5 & 4.4866 & TRN \\
\hline CHEMBL 2000029 & 809223 & 6.3 & 5.2284 & TRN \\
\hline CHEMBL1973961 & 809223 & 4.6 & 4.9574 & TRN \\
\hline CHEMBL 246970 & 809223 & 4.5 & 4.4625 & TRN \\
\hline CHEMBL340921 & 809223 & 4.5 & 4.189 & TST \\
\hline CHEMBL373598 & 809223 & 4.5 & 4.7803 & TST \\
\hline CHEMBL1999718 & 809223 & 4.5 & 4.2959 & TRN \\
\hline CHEMBL 2000078 & 809223 & 4.6 & 4.9091 & TRN \\
\hline CHEMBL 2005478 & 809223 & 5.7 & 5.3338 & TST \\
\hline CHEMBL1276446 & 809223 & 6.7 & 5.4264 & TST \\
\hline CHEMBL1996646 & 809223 & 6.3 & 6.0655 & TRN \\
\hline CHEMBL1979773 & 809223 & 4.6 & 4.8289 & TRN \\
\hline CHEMBL1977346 & 809223 & 4.5 & 4.3694 & TRN \\
\hline CHEMBL2003657 & 809223 & 4.5 & 4.2828 & TRN \\
\hline CHEMBL1971649 & 809223 & 4.5 & 4.3337 & TRN \\
\hline CHEMBL 2005482 & 809223 & 4.6 & 4.5825 & TRN \\
\hline CHEMBL1996702 & 809223 & 5.7 & 5.3164 & TRN \\
\hline CHEMBL1997909 & 809223 & 4.6 & 4.8588 & TRN \\
\hline CHEMBL 2007124 & 809223 & 4.6 & 4.9502 & TRN \\
\hline CHEMBL 2006439 & 809223 & 4.5 & 4.5996 & TRN \\
\hline CHEMBL1985681 & 809223 & 4.6 & 4.723 & TST \\
\hline CHEMBL1969190 & 809223 & 5.7 & 5.3232 & TRN \\
\hline CHEMBL1973937 & 809223 & 4.5 & 5.2431 & TRN \\
\hline CHEMBL2002099 & 809223 & 4.6 & 4.2377 & TRN \\
\hline CHEMBL1991674 & 809223 & 4.7 & 4.967 & TRN \\
\hline CHEMBL1982711 & 809223 & 4.6 & 4.0977 & TRN \\
\hline
\end{tabular}




\begin{tabular}{|c|c|c|c|c|c|}
\hline \multicolumn{6}{|c|}{ Supplemental Table S2.txt } \\
\hline CHEMBL262623 & 809223 & 4.7 & 4.9877 & TRN & \\
\hline CHEMBL1984842 & 809223 & 4.6 & 4.4183 & TRN & \\
\hline CHEMBL1969102 & 809223 & 7.4 & 7.1774 & TRN & \\
\hline CHEMBL 2004118 & 809223 & 4.6 & 4.7823 & TRN & \\
\hline CHEMBL1682346 & 809223 & 4.5 & 4.4155 & TRN & \\
\hline CHEMBL1996795 & 809223 & 5.6 & 5.0488 & TST & \\
\hline CHEMBL 2007044 & 809223 & 4.5 & 4.0357 & TST & \\
\hline CHEMBL 2001998 & 809223 & 4.5 & 4.3396 & TST & \\
\hline CHEMBL1994241 & 809223 & 4.5 & 4.3611 & TRN & \\
\hline CHEMBL223460 & 809223 & 4.5 & 4.6451 & TST & \\
\hline CHEMBL1998829 & 809223 & 4.5 & 4.3662 & TRN & \\
\hline CHEMBL50894 & 809223 & 4.7 & 4.2978 & TRN & \\
\hline CHEMBL1995211 & 809223 & 4.6 & 5.0231 & TRN & \\
\hline CHEMBL1988838 & 809223 & 5.7 & 5.78100 & 2000000001 & TRN \\
\hline CHEMBL1981725 & 809223 & 6.1 & 5.4405 & TRN & \\
\hline CHEMBL375284 & 809223 & 4.5 & 4.8145 & TRN & \\
\hline CHEMBL2006299 & 809223 & 4.6 & 4.8596 & TRN & \\
\hline CHEMBL1965169 & 809223 & 4.6 & 4.5816 & TST & \\
\hline CHEMBL1991818 & 809223 & 5.6 & 5.0439 & TST & \\
\hline CHEMBL1081312 & 809223 & 4.6 & 4.8812 & TRN & \\
\hline CHEMBL1965170 & 809223 & 8.4 & 8.1118 & TRN & \\
\hline CHEMBL1982866 & 809223 & 4.5 & 4.756 & TRN & \\
\hline CHEMBL 2005792 & 809223 & 4.6 & 4.5964 & TRN & \\
\hline CHEMBL1968926 & 809223 & 4.5 & 4.6436 & TRN & \\
\hline CHEMBL1984206 & 809223 & 4.5 & 4.3996 & TRN & \\
\hline CHEMBL462120 & 809223 & 4.5 & 4.3754 & TRN & \\
\hline CHEMBL1991577 & 809223 & 4.5 & 4.3448 & TRN & \\
\hline CHEMBL1965570 & 809223 & 6.0 & 6.4602 & TRN & \\
\hline CHEMBL 2007592 & 809223 & 4.5 & 4.5668 & TST & \\
\hline CHEMBL1972355 & 809223 & 6.9 & 6.6097 & TRN & \\
\hline CHEMBL1997892 & 809223 & 4.6 & 5.1357 & TRN & \\
\hline CHEMBL 2001641 & 809223 & 4.4 & 4.4043 & TRN & \\
\hline CHEMBL1997193 & 809223 & 4.6 & 5.0195 & TST & \\
\hline CHEMBL210963 & 809223 & 4.5 & 4.5503 & TRN & \\
\hline CHEMBL1964902 & 809223 & 4.6 & 4.5198 & TRN & \\
\hline CHEMBL1082440 & 809223 & 4.5 & 5.055 & TST & \\
\hline CHEMBL1614705 & 809223 & 4.5 & 4.7207 & TRN & \\
\hline CHEMBL1972362 & 809223 & 4.5 & 4.3101 & TRN & \\
\hline CHEMBL1984633 & 809223 & 4.5 & 4.7828 & TRN & \\
\hline CHEMBL1965845 & 809223 & 4.5 & 4.6606 & TRN & \\
\hline CHEMBL 2007372 & 809223 & 4.5 & 4.3369 & TRN & \\
\hline CHEMBL1983715 & 809223 & 6.7 & 6.8046 & TRN & \\
\hline CHEMBL1971017 & 809223 & 4.5 & 4.6661 & TRN & \\
\hline CHEMBL1986597 & 809223 & 4.5 & 4.4502 & TRN & \\
\hline CHEMBL1990482 & 809223 & 4.5 & 4.2186 & TRN & \\
\hline CHEMBL1990904 & 809223 & 4.5 & 4.6226 & TRN & \\
\hline CHEMBL 2000104 & 809223 & 4.5 & 4.708 & TRN & \\
\hline CHEMBL2005475 & 809223 & 4.5 & 4.6258 & TRN & \\
\hline
\end{tabular}




\begin{tabular}{|c|c|c|c|c|c|}
\hline & & & Supplementa & Table S2 & \\
\hline CHEMBL402846 & 809223 & 6.4 & 5.8301 & TRN & \\
\hline CHEMBL1997349 & 809223 & 4.5 & 4.5192 & TST & \\
\hline CHEMBL183844 & 809223 & 4.5 & 4.6709 & TRN & \\
\hline CHEMBL 220057 & 809223 & 6.0 & 5.7244 & TRN & \\
\hline CHEMBL1682545 & 809223 & 4.7 & 4.3903 & TRN & \\
\hline CHEMBL383541 & 809223 & 4.5 & 4.7457 & TRN & \\
\hline CHEMBL 2001224 & 809223 & 4.5 & 4.4141 & TRN & \\
\hline CHEMBL10 & 809223 & 4.6 & 4.3151 & TRN & \\
\hline CHEMBL1976732 & 809223 & 4.5 & 4.3629 & TRN & \\
\hline CHEMBL1969506 & 809223 & 4.5 & 4.374 & TRN & \\
\hline CHEMBL1980763 & 809223 & 4.6 & 4.7898 & TRN & \\
\hline CHEMBL1964937 & 809223 & 4.5 & 4.5422 & TRN & \\
\hline CHEMBL1980163 & 809223 & 4.5 & 3.8952 & TRN & \\
\hline CHEMBL590109 & 809223 & 4.5 & 4.5269 & TST & \\
\hline CHEMBL1977931 & 809223 & 4.4 & 4.3745 & TRN & \\
\hline CHEMBL1970879 & 809223 & 4.5 & 5.0327 & TRN & \\
\hline CHEMBL1989856 & 809223 & 4.5 & 4.4515 & TST & \\
\hline CHEMBL2005899 & 809223 & 4.5 & 4.5593 & TRN & \\
\hline CHEMBL1682552 & 809223 & 4.5 & 4.2052 & TRN & \\
\hline CHEMBL 259850 & 809223 & 4.5 & 4.6417 & TRN & \\
\hline CHEMBL 2007479 & 809223 & 4.6 & 4.7629 & TRN & \\
\hline CHEMBL1996155 & 809223 & 4.5 & $4.45100 e$ & 00000000005 & TRN \\
\hline CHEMBL 229799 & 809223 & 4.5 & 4.6778 & TRN & \\
\hline CHEMBL105739 & 809223 & 4.5 & 4.5914 & TRN & \\
\hline CHEMBL1682359 & 809223 & 4.5 & 4.5825 & TRN & \\
\hline CHEMBL1972220 & 809223 & 8.0 & 8.4859 & TRN & \\
\hline CHEMBL 379300 & 809223 & 4.5 & 4.3896 & TRN & \\
\hline CHEMBL 203673 & 809223 & 4.5 & 4.7242 & TRN & \\
\hline CHEMBL1969523 & 809223 & 6.3 & 5.4223 & TRN & \\
\hline CHEMBL 207995 & 809223 & 4.5 & 4.6006 & TRN & \\
\hline CHEMBL 2001923 & 809223 & 4.6 & 4.3791 & TRN & \\
\hline CHEMBL1986781 & 809223 & 4.5 & 4.4124 & TRN & \\
\hline CHEMBL526133 & 809223 & 4.5 & 4.2824 & TRN & \\
\hline CHEMBL2003514 & 809223 & 4.6 & 4.7223 & TRN & \\
\hline CHEMBL1989043 & 809223 & 4.6 & 4.5148 & TRN & \\
\hline CHEMBL1967538 & 809223 & 3.5 & 3.5551 & TRN & \\
\hline CHEMBL1979057 & 809223 & 4.5 & 4.8359 & TRN & \\
\hline CHEMBL1981045 & 809223 & 4.5 & 4.5469 & TRN & \\
\hline CHEMBL387971 & 809223 & 4.5 & 4.3443 & TST & \\
\hline CHEMBL1975418 & 809223 & 4.5 & 4.7546 & TRN & \\
\hline CHEMBL1992796 & 809223 & 4.5 & 4.7208 & TRN & \\
\hline CHEMBL1164180 & 809223 & 6.6 & 5.9014 & TST & \\
\hline CHEMBL223257 & 809223 & 4.5 & 4.4739 & TST & \\
\hline CHEMBL1999428 & 809223 & 4.5 & 4.3697 & TRN & \\
\hline CHEMBL1967560 & 809223 & 4.5 & 4.5976 & TRN & \\
\hline CHEMBL1997611 & 809223 & 5.6 & 5.2618 & TST & \\
\hline CHEMBL 211378 & 809223 & 4.5 & 4.9003 & TRN & \\
\hline CHEMBL1982465 & 809223 & 7.0 & 7.0754 & TRN & \\
\hline
\end{tabular}




\begin{tabular}{|c|c|c|c|c|}
\hline \multicolumn{5}{|c|}{ Supplemental Table S2.txt } \\
\hline CHEMBL 2001751 & 809223 & 4.5 & 5.1422 & TRN \\
\hline CHEMBL 2003420 & 809223 & 4.5 & 4.3317 & TRN \\
\hline CHEMBL1984586 & 809223 & 5.7 & 4.7731 & TRN \\
\hline CHEMBL1999774 & 809223 & 4.5 & 4.617 & TST \\
\hline CHEMBL1972659 & 809223 & 4.5 & 4.9135 & TST \\
\hline CHEMBL 2002723 & 809223 & 6.0 & 5.3424 & TST \\
\hline CHEMBL1973395 & 809223 & 5.8 & 5.4759 & TRN \\
\hline CHEMBL272453 & 809223 & 4.5 & 4.8169 & TRN \\
\hline CHEMBL1987143 & 809223 & 3.5 & 3.8574 & TRN \\
\hline CHEMBL1970217 & 809223 & 4.5 & 4.3445 & TRN \\
\hline CHEMBL1971801 & 809223 & 4.5 & 4.3403 & TRN \\
\hline CHEMBL1968850 & 809223 & 4.5 & 4.3987 & TRN \\
\hline CHEMBL 2005528 & 809223 & 4.5 & 4.8638 & TST \\
\hline CHEMBL1984686 & 809223 & 4.6 & 4.663 & TRN \\
\hline CHEMBL185569 & 809223 & 6.1 & 5.5322 & TRN \\
\hline CHEMBL1969843 & 809223 & 4.5 & 4.5699 & TRN \\
\hline CHEMBL 2007002 & 809223 & 4.5 & 4.6886 & TRN \\
\hline CHEMBL1987007 & 809223 & 4.5 & 4.1095 & TRN \\
\hline CHEMBL1990288 & 809223 & 4.5 & 4.3123 & TRN \\
\hline CHEMBL1973793 & 809223 & 4.6 & 4.7469 & TST \\
\hline CHEMBL1969588 & 809223 & 4.5 & 4.7314 & TRN \\
\hline CHEMBL1984711 & 809223 & 4.5 & 5.1287 & TRN \\
\hline CHEMBL1992073 & 809223 & 4.6 & 4.8906 & TRN \\
\hline CHEMBL484390 & 809223 & 4.5 & 3.3396 & TST \\
\hline CHEMBL1979252 & 809223 & 4.5 & 4.3822 & TRN \\
\hline CHEMBL1986143 & 809223 & 4.6 & 4.7416 & TRN \\
\hline CHEMBL1972934 & 809223 & 4.6 & 4.4896 & TRN \\
\hline CHEMBL 2007559 & 809223 & 4.6 & 4.6298 & TRN \\
\hline CHEMBL1992581 & 809223 & 4.6 & 4.5578 & TRN \\
\hline CHEMBL1682341 & 809223 & 4.5 & 4.6515 & TRN \\
\hline CHEMBL 2004290 & 809223 & 7.8 & 7.9705 & TRN \\
\hline CHEMBL1986499 & 809223 & 4.5 & 4.8871 & TRN \\
\hline CHEMBL1972937 & 809223 & 4.5 & 4.5027 & TRN \\
\hline CHEMBL1972250 & 809223 & 4.5 & 4.091 & TST \\
\hline CHEMBL 2000393 & 809223 & 4.5 & 5.0672 & TST \\
\hline CHEMBL1983573 & 809223 & 5.7 & 4.5709 & TRN \\
\hline CHEMBL 2004311 & 809223 & 6.3 & 5.6701 & TRN \\
\hline CHEMBL1992634 & 809223 & 4.5 & 4.5248 & TRN \\
\hline CHEMBL1242373 & 809223 & 4.5 & 4.6427 & TRN \\
\hline CHEMBL316264 & 809223 & 4.5 & 4.4902 & TRN \\
\hline CHEMBL1988075 & 809223 & 6.5 & 6.3805 & TRN \\
\hline CHEMBL1996576 & 809223 & 4.6 & 5.1046 & TST \\
\hline CHEMBL1988076 & 809223 & 4.6 & 4.6639 & TRN \\
\hline CHEMBL1991678 & 809223 & 4.6 & 4.4877 & TRN \\
\hline CHEMBL 2001239 & 809223 & 4.5 & 4.7286 & TST \\
\hline CHEMBL1988594 & 809223 & 6.0 & 5.4121 & TRN \\
\hline CHEMBL 2001288 & 809223 & 4.5 & 4.3644 & TRN \\
\hline CHEMBL260092 & 809223 & 6.7 & 6.3337 & TRN \\
\hline
\end{tabular}




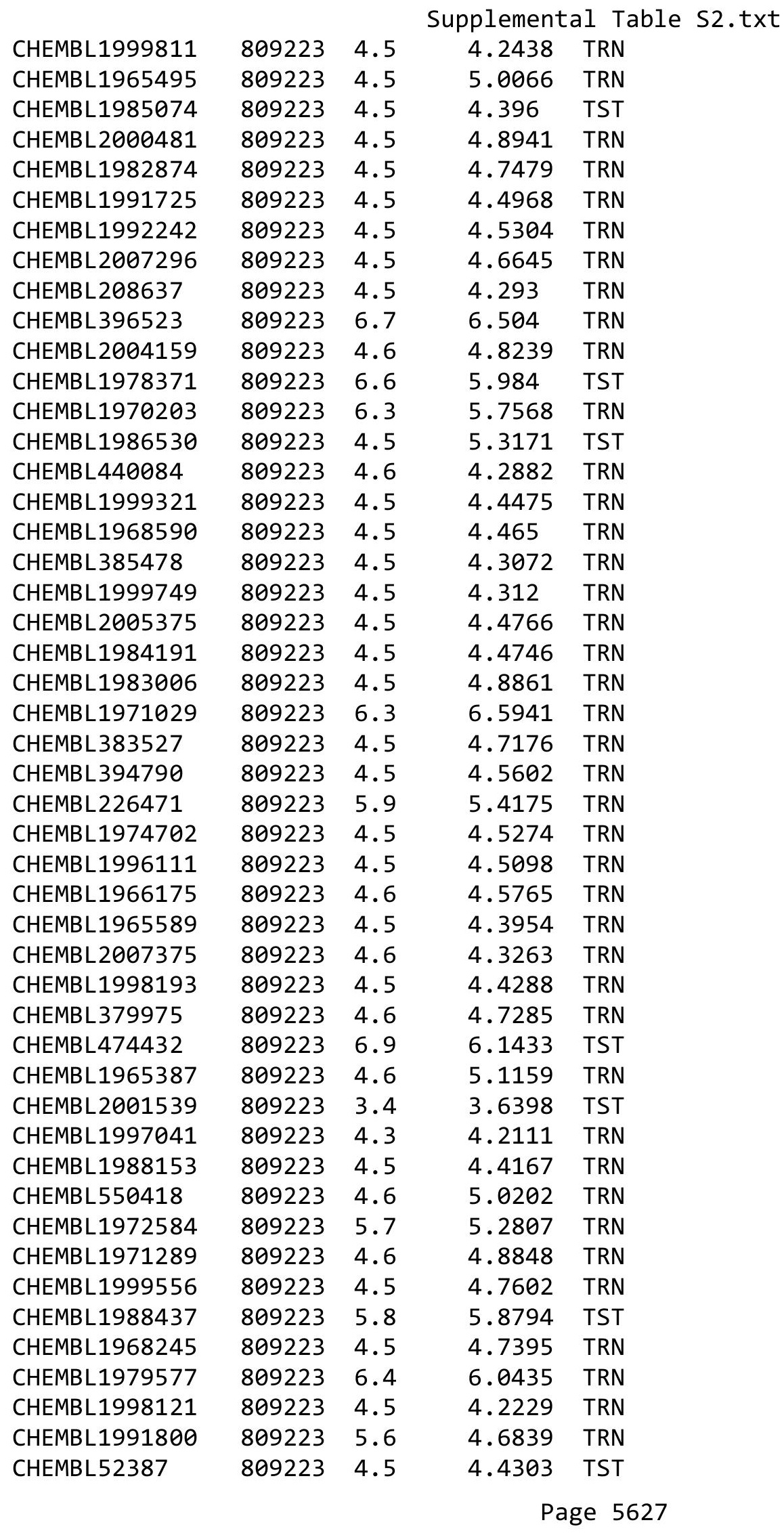




\begin{tabular}{|c|c|c|c|c|c|}
\hline \multicolumn{6}{|c|}{ Supplemental Table S2.txt } \\
\hline CHEMBL379835 & 809223 & 4.5 & 4.5793 & TST & \\
\hline CHEMBL1979357 & 809223 & 4.5 & 4.4324 & TRN & \\
\hline CHEMBL1980802 & 809223 & 4.5 & 4.8864 & TST & \\
\hline CHEMBL1996649 & 809223 & 7.2 & 7.3078 & TRN & \\
\hline CHEMBL1996817 & 809223 & 4.6 & 4.8142 & TRN & \\
\hline CHEMBL1979554 & 809223 & 4.5 & 4.6718 & TRN & \\
\hline CHEMBL1986756 & 809223 & 4.6 & 5.0197 & TRN & \\
\hline CHEMBL 2004355 & 809223 & 4.5 & 4.5484 & TRN & \\
\hline CHEMBL468280 & 809223 & 4.5 & 4.6295 & TST & \\
\hline CHEMBL1990884 & 809223 & 4.5 & 4.5705 & TRN & \\
\hline CHEMBL3109278 & 809223 & 4.6 & 4.65300 & 00000000005 & TRN \\
\hline CHEMBL256835 & 809223 & 4.5 & 4.3096 & TRN & \\
\hline CHEMBL1980142 & 809223 & 4.5 & 4.6102 & TRN & \\
\hline CHEMBL41783 & 809223 & 4.5 & 4.6386 & TRN & \\
\hline CHEMBL 2004438 & 809223 & 4.6 & 4.4092 & TRN & \\
\hline CHEMBL 2006276 & 809223 & 4.5 & 4.6395 & TRN & \\
\hline CHEMBL191003 & 809223 & 6.4 & 5.7715 & TRN & \\
\hline CHEMBL271381 & 809223 & 5.9 & 5.4523 & TRN & \\
\hline CHEMBL 2006785 & 809223 & 4.5 & 4.273 & TRN & \\
\hline CHEMBL1982466 & 809223 & 7.1 & 7.397 & TRN & \\
\hline CHEMBL1973359 & 809223 & 7.3 & 6.2468 & TST & \\
\hline CHEMBL1995740 & 809223 & 4.5 & 4.0946 & TRN & \\
\hline CHEMBL1996390 & 809223 & 4.5 & 4.8193 & TRN & \\
\hline CHEMBL1986943 & 809223 & 4.5 & 5.2312 & TRN & \\
\hline CHEMBL1979690 & 809223 & 6.7 & 6.3329 & TRN & \\
\hline CHEMBL 234085 & 809223 & 4.6 & 4.4557 & TRN & \\
\hline CHEMBL1995832 & 809223 & 4.5 & 4.485 & TRN & \\
\hline CHEMBL1969042 & 809223 & 4.5 & 4.3076 & TRN & \\
\hline CHEMBL 2000345 & 809223 & 4.5 & 4.3034 & TRN & \\
\hline CHEMBL1999931 & 809223 & 4.5 & 4.2147 & TRN & \\
\hline CHEMBL1976376 & 809223 & 4.6 & 4.5892 & TRN & \\
\hline CHEMBL1991640 & 809223 & 4.5 & 4.9287 & TST & \\
\hline CHEMBL1983575 & 809223 & 6.1 & 6.6053 & TRN & \\
\hline CHEMBL1968868 & 809223 & 4.6 & 4.4513 & TRN & \\
\hline CHEMBL1375418 & 809223 & 4.5 & 4.7493 & TRN & \\
\hline CHEMBL302449 & 809223 & 4.5 & 5.5002 & TST & \\
\hline CHEMBL 2007064 & 809223 & 5.6 & 5.5864 & TRN & \\
\hline CHEMBL1981047 & 809223 & 4.6 & 4.9694 & TRN & \\
\hline CHEMBL 229968 & 809223 & 4.5 & 4.4391 & TRN & \\
\hline CHEMBL1976196 & 809223 & 5.7 & 4.8451 & TST & \\
\hline CHEMBL1976240 & 809223 & 4.5 & 4.6343 & TRN & \\
\hline CHEMBL1997197 & 809223 & 4.6 & 4.7109 & TRN & \\
\hline CHEMBL1983630 & 809223 & 4.6 & 4.3862 & TRN & \\
\hline CHEMBL1979093 & 809223 & 4.5 & 5.055 & TRN & \\
\hline CHEMBL1968151 & 809223 & 4.5 & 4.6145 & TST & \\
\hline CHEMBL1381197 & 809223 & 4.5 & 4.5954 & TRN & \\
\hline CHEMBL1987009 & 809223 & 4.5 & 4.8288 & TRN & \\
\hline CHEMBL379218 & 809223 & 4.5 & 4.3865 & TRN & \\
\hline
\end{tabular}




\begin{tabular}{|c|c|c|c|c|c|}
\hline \multirow{2}{*}{ CHEMBL2003817 } & \multirow{2}{*}{809223} & \multirow[b]{2}{*}{4.5} & \\
\hline & & & 4.4757 & TRN & \\
\hline CHEMBL336961 & 809223 & 4.5 & 4.4126 & TRN & \\
\hline CHEMBL1994830 & 809223 & 4.5 & 4.5872 & TRN & \\
\hline CHEMBL1987054 & 809223 & 6.1 & 5.9509 & TRN & \\
\hline CHEMBL1970083 & 809223 & 6.5 & 6.7461 & TRN & \\
\hline CHEMBL 226403 & 809223 & 4.5 & 5.0233 & TRN & \\
\hline CHEMBL 2005631 & 809223 & 7.4 & \multicolumn{2}{|c|}{7.6160000000000005} & TRN \\
\hline CHEMBL1994938 & 809223 & 4.5 & 4.5547 & TRN & \\
\hline CHEMBL1977223 & 809223 & 4.5 & 4.3575 & TRN & \\
\hline CHEMBL1995765 & 809223 & 5.2 & 4.9044 & TST & \\
\hline CHEMBL1966279 & 809223 & 4.5 & 4.8424 & TRN & \\
\hline CHEMBL1236126 & 809223 & 4.5 & \multicolumn{2}{|c|}{3.9810000000000003} & TST \\
\hline CHEMBL1997846 & 809223 & 4.5 & 4.4505 & TRN & \\
\hline CHEMBL1984760 & 809223 & 4.6 & 4.6574 & TRN & \\
\hline CHEMBL2004419 & 809223 & 4.5 & 4.5318 & TRN & \\
\hline CHEMBL1991728 & 809223 & 5.6 & 4.931 & TRN & \\
\hline CHEMBL360847 & 809223 & 4.6 & 5.3483 & TST & \\
\hline CHEMBL1995811 & 809223 & 4.6 & 4.3576 & TRN & \\
\hline CHEMBL1975787 & 809223 & 4.5 & 4.6441 & TRN & \\
\hline CHEMBL 2002407 & 809223 & 4.5 & 4.1269 & TRN & \\
\hline CHEMBL1972489 & 809223 & 4.5 & \multicolumn{2}{|c|}{4.571000000000001} & TRN \\
\hline CHEMBL1994074 & 809223 & 4.5 & 4.5168 & TRN & \\
\hline CHEMBL1992937 & 809223 & 5.7 & 4.1335 & TST & \\
\hline CHEMBL451401 & 809223 & 3.5 & 3.8985 & TRN & \\
\hline CHEMBL1985566 & 809223 & 4.5 & 4.487 & TRN & \\
\hline CHEMBL1986328 & 809223 & 4.5 & 4.6336 & TST & \\
\hline CHEMBL95692 & 809223 & 4.5 & 4.4851 & TRN & \\
\hline CHEMBL1090356 & 809223 & 4.6 & 4.6085 & TRN & \\
\hline CHEMBL 2002450 & 809223 & 4.1 & 4.066 & TRN & \\
\hline CHEMBL1976455 & 809223 & 4.5 & 4.5718 & TRN & \\
\hline CHEMBL261849 & 809223 & 4.6 & 5.0422 & TST & \\
\hline CHEMBL1983923 & 809223 & 4.7 & 4.8875 & TRN & \\
\hline CHEMBL1983534 & 809223 & 4.5 & 4.5205 & TRN & \\
\hline CHEMBL1982361 & 809223 & 4.5 & 4.717 & TRN & \\
\hline CHEMBL1999112 & 809223 & 4.5 & 4.6279 & TST & \\
\hline CHEMBL1982122 & 809223 & 4.5 & 4.2601 & TRN & \\
\hline CHEMBL 2000801 & 809223 & 4.5 & 4.4642 & TRN & \\
\hline CHEMBL1682546 & 809223 & 4.5 & 4.419 & TRN & \\
\hline CHEMBL1991395 & 809223 & 4.5 & 4.3324 & TRN & \\
\hline CHEMBL1971245 & 809223 & 4.5 & 4.0612 & TRN & \\
\hline CHEMBL 2003545 & 809223 & 4.1 & 4.8892 & TST & \\
\hline CHEMBL1987648 & 809223 & 4.5 & 4.4351 & TRN & \\
\hline CHEMBL1996780 & 809223 & 4.5 & 4.3585 & TST & \\
\hline CHEMBL1972142 & 809223 & 4.5 & 3.9861 & TRN & \\
\hline CHEMBL 2002182 & 809223 & 4.1 & 4.1804 & TRN & \\
\hline CHEMBL1966514 & 809223 & 6.9 & 6.5019 & TRN & \\
\hline CHEMBL 2003638 & 809223 & 4.5 & 4.0734 & TRN & \\
\hline \multirow[t]{2}{*}{ CHEMBL296586 } & 809223 & 4.5 & 4.9313 & TRN & \\
\hline & & \multicolumn{4}{|c|}{ Page 5629} \\
\hline
\end{tabular}




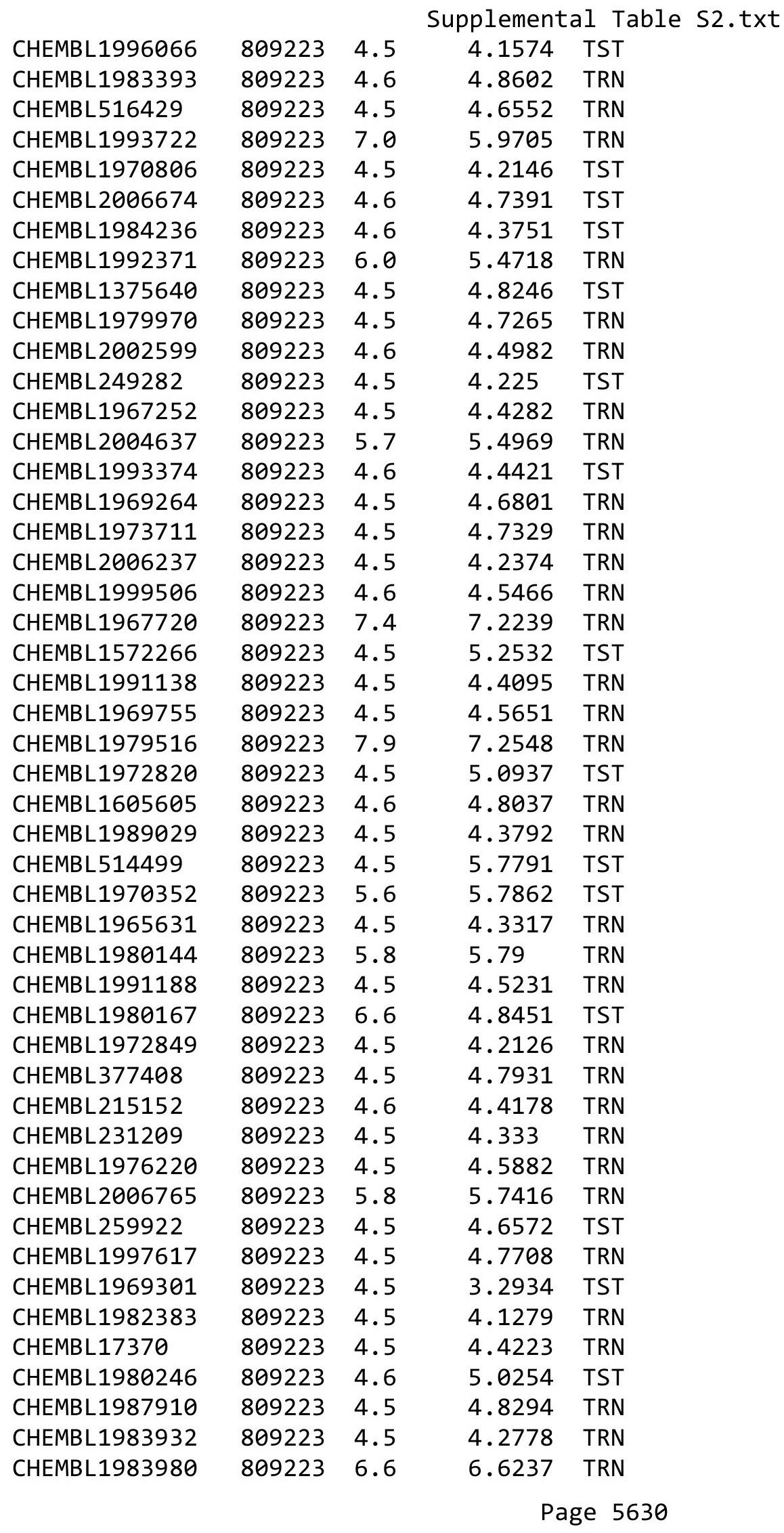




\begin{tabular}{|c|c|c|c|c|c|}
\hline & & & & & \\
\hline CHEMBL1999484 & 809223 & 6.3 & 6.7371 & TRN & \\
\hline CHEMBL1966069 & 809223 & 4.5 & 4.4471 & TRN & \\
\hline CHEMBL1986899 & 809223 & 5.8 & 5.7488 & TRN & \\
\hline CHEMBL1991285 & 809223 & 4.5 & 4.5901 & TRN & \\
\hline CHEMBL1997822 & 809223 & 4.5 & 5.1716 & TRN & \\
\hline CHEMBL 243088 & 809223 & 6.4 & 6.3657 & TRN & \\
\hline CHEMBL1984038 & 809223 & 4.6 & 4.4802 & TRN & \\
\hline CHEMBL1968606 & 809223 & 6.2 & 5.1986 & TRN & \\
\hline CHEMBL1993661 & 809223 & 7.5 & 7.5767 & TRN & \\
\hline CHEMBL1974416 & 809223 & 4.5 & 4.7213 & TRN & \\
\hline CHEMBL1997872 & 809223 & 4.5 & 4.3573 & TRN & \\
\hline CHEMBL1964290 & 809223 & 4.5 & 4.4417 & TRN & \\
\hline CHEMBL 213505 & 809223 & 4.5 & 4.6266 & TRN & \\
\hline CHEMBL 202721 & 809223 & 5.6 & 5.8274 & TRN & \\
\hline CHEMBL1987034 & 809223 & 6.0 & 5.7474 & TRN & \\
\hline CHEMBL1993941 & 809223 & 7.7 & 7.8512 & TRN & \\
\hline CHEMBL 377383 & 809223 & 4.5 & 4.6434 & TRN & \\
\hline CHEMBL 2005886 & 809223 & 4.6 & 4.9247 & TRN & \\
\hline CHEMBL481491 & 809223 & 4.5 & 5.154 & TST & \\
\hline CHEMBL1682345 & 809223 & 4.5 & 4.5461 & TRN & \\
\hline CHEMBL1973142 & 809223 & 4.5 & 4.3925 & TRN & \\
\hline CHEMBL 388311 & 809223 & 6.5 & 6.3703 & TRN & \\
\hline CHEMBL1973145 & 809223 & 4.5 & 4.9978 & TRN & \\
\hline CHEMBL1982924 & 809223 & 4.5 & 4.3687 & TRN & \\
\hline CHEMBL2005936 & 809223 & 4.5 & 4.4127 & TRN & \\
\hline CHEMBL1807515 & 809223 & 4.5 & 4.471 & TRN & \\
\hline CHEMBL1964948 & 809223 & 4.6 & 4.7064 & TRN & \\
\hline CHEMBL1971141 & 809223 & 4.5 & 4.5815 & TRN & \\
\hline CHEMBL1995813 & 809223 & 4.5 & 3.9712 & TRN & \\
\hline CHEMBL1979718 & 809223 & 4.5 & 4.4819 & TRN & \\
\hline CHEMBL206236 & 809223 & 4.5 & 4.5121 & TRN & \\
\hline CHEMBL1989834 & 809223 & 3.9 & 3.9037 & TRN & \\
\hline CHEMBL523823 & 809223 & 5.6 & 4.7717 & TST & \\
\hline CHEMBL1987430 & 809223 & 4.7 & 4.9506 & TRN & \\
\hline CHEMBL 244378 & 809223 & 6.8 & 6.7734 & TRN & \\
\hline CHEMBL 2001957 & 809223 & 4.5 & 4.4356 & TRN & \\
\hline CHEMBL1969372 & 809223 & 4.5 & 4.5275 & TRN & \\
\hline CHEMBL1993413 & 809223 & 4.6 & 4.3187 & TRN & \\
\hline CHEMBL1990583 & 809223 & 4.5 & 5.3421 & TRN & \\
\hline CHEMBL 289959 & 809223 & 3.5 & 3.5975 & TRN & \\
\hline CHEMBL 2006263 & 809223 & 4.5 & 4.89199 & 99999999995 & TST \\
\hline CHEMBL1993584 & 809223 & 4.5 & 4.59399 & 9999999999 & TRN \\
\hline CHEMBL1986263 & 809223 & 4.5 & 5.0484 & TRN & \\
\hline CHEMBL 2000114 & 809223 & 4.5 & 4.3544 & TRN & \\
\hline CHEMBL210618 & 809223 & 4.5 & 4.6239 & TRN & \\
\hline CHEMBL1986265 & 809223 & 4.6 & 4.6262 & TRN & \\
\hline CHEMBL1975647 & 809223 & 4.5 & 4.5548 & TRN & \\
\hline CHEMBL1968380 & 809223 & 4.5 & 4.4491 & TRN & \\
\hline & & & & 5631 & \\
\hline
\end{tabular}




\begin{tabular}{|c|c|c|c|c|}
\hline \multicolumn{5}{|c|}{ Supplemental Tab } \\
\hline CHEMBL1964644 & 809223 & 4.5 & 4.5896 & TRN \\
\hline CHEMBL1991734 & 809223 & 7.0 & 6.7977 & TST \\
\hline CHEMBL1981782 & 809223 & 4.5 & 4.5305 & TRN \\
\hline CHEMBL1977681 & 809223 & 4.5 & 4.2408 & TRN \\
\hline CHEMBL1970142 & 809223 & 7.2 & 7.4756 & TRN \\
\hline CHEMBL1990912 & 809223 & 4.5 & 4.3495 & TRN \\
\hline CHEMBL1991782 & 809223 & 3.3 & 3.4194 & TRN \\
\hline CHEMBL1983348 & 809223 & 4.6 & 5.0911 & TRN \\
\hline CHEMBL1995592 & 809223 & 4.5 & 4.8568 & TST \\
\hline CHEMBL1974480 & 809223 & 5.9 & 5.6913 & TRN \\
\hline CHEMBL1980671 & 809223 & 5.4 & 4.731 & TRN \\
\hline CHEMBL 2006493 & 809223 & 4.5 & 4.7732 & TST \\
\hline CHEMBL1986177 & 809223 & 4.6 & 4.7467 & TRN \\
\hline CHEMBL1983449 & 809223 & 4.5 & 4.4282 & TRN \\
\hline CHEMBL1992323 & 809223 & 4.5 & 4.7415 & TRN \\
\hline CHEMBL1969735 & 809223 & 4.5 & 4.4191 & TRN \\
\hline CHEMBL 2003524 & 809223 & 4.5 & 5.4764 & TST \\
\hline CHEMBL 2002649 & 809223 & 4.5 & 4.7176 & TRN \\
\hline CHEMBL1989423 & 809223 & 3.5 & 3.5254 & TST \\
\hline CHEMBL1985367 & 809223 & 4.6 & 4.4995 & TST \\
\hline CHEMBL1996510 & 809223 & 6.4 & 4.8612 & TST \\
\hline CHEMBL437747 & 809223 & 4.5 & 4.3942 & TRN \\
\hline CHEMBL1995172 & 809223 & 3.9 & 4.0579 & TST \\
\hline CHEMBL 2001584 & 809223 & 4.6 & 4.8996 & TRN \\
\hline CHEMBL507936 & 809223 & 4.5 & 4.4983 & TRN \\
\hline CHEMBL1971227 & 809223 & 6.0 & 4.7243 & TST \\
\hline CHEMBL104264 & 809223 & 4.5 & 4.9216 & TST \\
\hline CHEMBL1967998 & 809223 & 6.9 & 6.553 & TRN \\
\hline CHEMBL1994321 & 809223 & 6.5 & 6.6416 & TRN \\
\hline CHEMBL1978562 & 809223 & 6.1 & 4.6994 & TST \\
\hline CHEMBL1997129 & 809223 & 7.9 & 6.5328 & TRN \\
\hline CHEMBL1984788 & 809223 & 4.5 & 4.4215 & TRN \\
\hline CHEMBL451964 & 809223 & 4.5 & 4.3188 & TRN \\
\hline CHEMBL1974875 & 809223 & 4.9 & 4.6867 & TST \\
\hline CHEMBL1964307 & 809223 & 4.5 & 5.1064 & TRN \\
\hline CHEMBL1989471 & 809223 & 4.6 & 4.7226 & TST \\
\hline CHEMBL 2000508 & 809223 & 4.5 & 4.3883 & TRN \\
\hline CHEMBL1971694 & 809223 & 4.5 & 4.8378 & TST \\
\hline CHEMBL 2001547 & 809223 & 4.5 & 4.3717 & TRN \\
\hline CHEMBL 210928 & 809223 & 4.5 & 4.7947 & TRN \\
\hline CHEMBL1978195 & 809223 & 4.6 & 4.6425 & TRN \\
\hline CHEMBL1994361 & 809223 & 4.5 & 4.7597 & TRN \\
\hline CHEMBL1986603 & 809223 & 4.5 & 5.0304 & TST \\
\hline CHEMBL1972840 & 809223 & 4.5 & 4.362 & TRN \\
\hline CHEMBL1977148 & 809223 & 8.5 & 7.7652 & TRN \\
\hline CHEMBL1966842 & 809223 & 6.4 & 5.425 & TRN \\
\hline CHEMBL 2003286 & 809223 & 4.5 & 4.7221 & TRN \\
\hline CHEMBL 2002165 & 809223 & 7.9 & 7.7538 & TRN \\
\hline
\end{tabular}




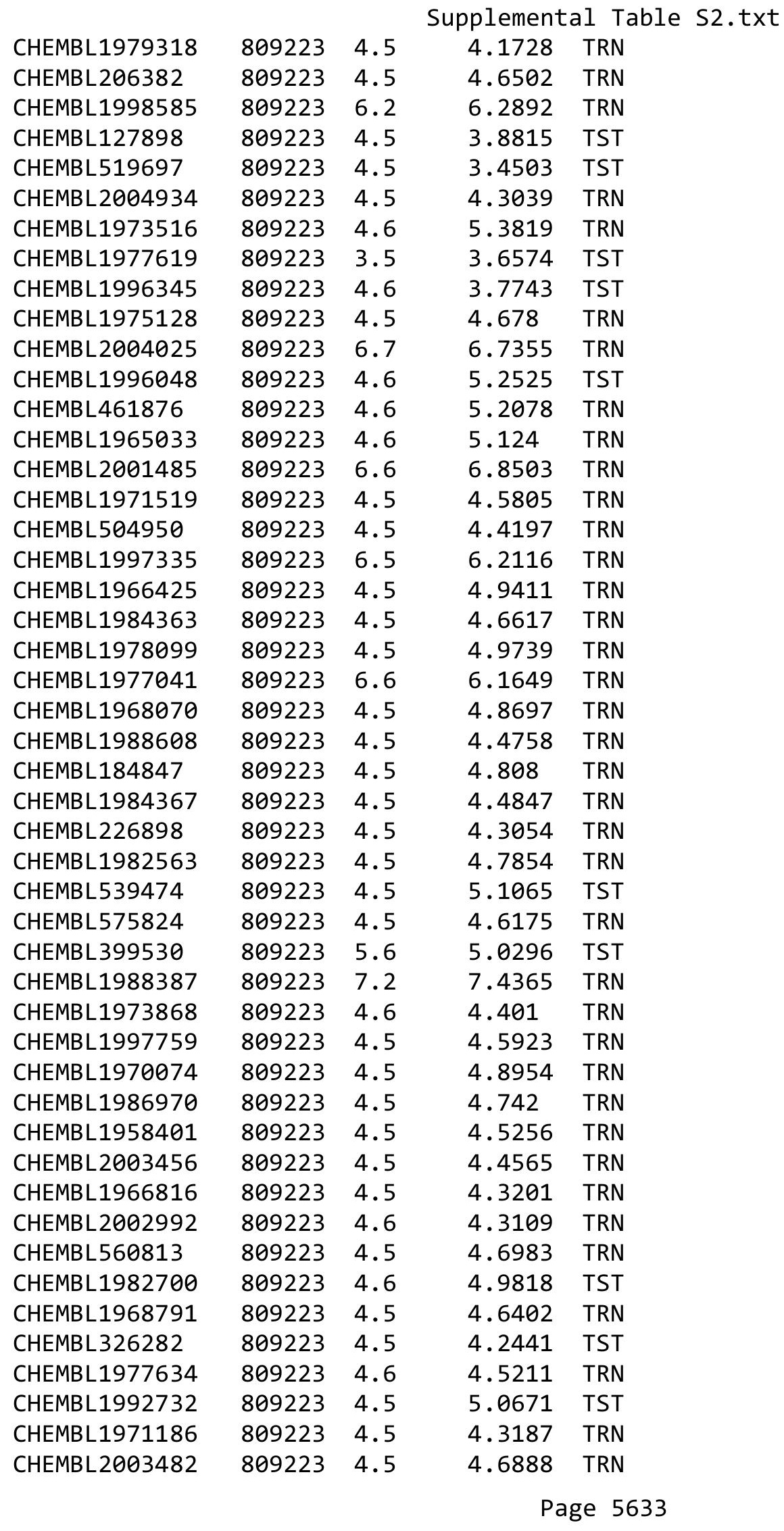




\begin{tabular}{|c|c|c|c|c|}
\hline & & & ient & $a \perp 1 a$ \\
\hline CHEMBL1976872 & 809223 & 3.5 & 3.4865 & TRN \\
\hline CHEMBL1969156 & 809223 & 3.5 & 3.2364 & TRN \\
\hline CHEMBL1973211 & 809223 & 6.4 & 6.6039 & TRN \\
\hline CHEMBL1984700 & 809223 & 4.5 & 4.3374 & TRN \\
\hline CHEMBL2007151 & 809223 & 4.5 & 4.4288 & TRN \\
\hline CHEMBL1971606 & 809223 & 4.6 & 4.5968 & TRN \\
\hline CHEMBL1972125 & 809223 & 4.5 & 4.7017 & TRN \\
\hline CHEMBL1461728 & 809223 & 4.5 & 4.4405 & TRN \\
\hline CHEMBL1999120 & 809223 & 4.2 & 4.4144 & TST \\
\hline CHEMBL1976134 & 809223 & 4.5 & 4.4313 & TRN \\
\hline CHEMBL1965131 & 809223 & 4.5 & 4.5966 & TRN \\
\hline CHEMBL1972158 & 809223 & 4.5 & 4.5399 & TRN \\
\hline CHEMBL1981215 & 809223 & 4.6 & 4.689 & TRN \\
\hline CHEMBL1974457 & 809223 & 4.5 & 4.6631 & TRN \\
\hline CHEMBL2006580 & 809223 & 4.5 & 4.2223 & TRN \\
\hline CHEMBL1999414 & 809223 & 7.3 & 7.4236 & TRN \\
\hline CHEMBL1967336 & 809223 & 4.6 & 4.4751 & TRN \\
\hline CHEMBL 2001228 & 809223 & 4.6 & 4.7214 & TRN \\
\hline CHEMBL 2006581 & 809223 & 4.5 & 4.8783 & TRN \\
\hline CHEMBL1979855 & 809223 & 4.5 & 4.37 & TRN \\
\hline CHEMBL1970340 & 809223 & 3.9 & 4.1724 & TRN \\
\hline CHEMBL1967992 & 809223 & 4.6 & 4.6112 & TRN \\
\hline CHEMBL 2005186 & 809223 & 4.5 & 4.7996 & TRN \\
\hline CHEMBL 2006450 & 809223 & 4.6 & 4.6512 & TRN \\
\hline CHEMBL1975534 & 809223 & 4.5 & 4.4845 & TRN \\
\hline CHEMBL1966703 & 809223 & 4.5 & 4.5826 & TST \\
\hline CHEMBL 2001987 & 809223 & 4.6 & 4.3866 & TRN \\
\hline CHEMBL1969561 & 809223 & 4.5 & 4.59 & TRN \\
\hline CHEMBL1994555 & 809223 & 4.6 & 5.0316 & TST \\
\hline CHEMBL1975121 & 809223 & 4.6 & 4.5112 & TRN \\
\hline CHEMBL1983640 & 809223 & 6.9 & 6.7197 & TRN \\
\hline CHEMBL1997023 & 809223 & 4.5 & 4.3521 & TST \\
\hline CHEMBL1964687 & 809223 & 4.5 & 4.5338 & TRN \\
\hline CHEMBL1971943 & 809223 & 4.6 & 4.3592 & TRN \\
\hline CHEMBL1999918 & 809223 & 4.5 & 4.5981 & TRN \\
\hline CHEMBL1974254 & 809223 & 7.5 & 7.2508 & TRN \\
\hline CHEMBL1997924 & 809223 & 6.1 & 5.7853 & TRN \\
\hline CHEMBL1988537 & 809223 & 4.5 & 4.6842 & TST \\
\hline CHEMBL1969049 & 809223 & 4.5 & 4.3751 & TRN \\
\hline CHEMBL 2005828 & 809223 & 4.5 & 4.5511 & TRN \\
\hline CHEMBL1978267 & 809223 & 4.6 & 4.6435 & TRN \\
\hline CHEMBL1998611 & 809223 & 4.5 & 4.5188 & TRN \\
\hline CHEMBL485556 & 809223 & 4.5 & 3.389 & TST \\
\hline CHEMBL1975900 & 809223 & 4.5 & 4.5216 & TRN \\
\hline CHEMBL 255822 & 809223 & 4.5 & 4.6268 & TRN \\
\hline CHEMBL1972221 & 809223 & 4.5 & 4.5621 & TRN \\
\hline CHEMBL 2006778 & 809223 & 5.7 & 5.4598 & TRN \\
\hline CHEMBL378627 & 809223 & 4.5 & 4.4853 & TRN \\
\hline
\end{tabular}




\begin{tabular}{|c|c|c|c|c|}
\hline & & & ient & al Ta \\
\hline CHEMBL1996979 & 809223 & 4.5 & 4.5064 & TRN \\
\hline CHEMBL1997025 & 809223 & 4.5 & 4.5364 & TRN \\
\hline CHEMBL1968406 & 809223 & 4.5 & 4.3819 & TRN \\
\hline CHEMBL1975921 & 809223 & 4.7 & 4.6149 & TRN \\
\hline CHEMBL1982476 & 809223 & 8.0 & 7.3727 & TRN \\
\hline CHEMBL1998545 & 809223 & 4.5 & 4.6306 & TRN \\
\hline CHEMBL1986869 & 809223 & 4.5 & 4.6378 & TRN \\
\hline CHEMBL1975923 & 809223 & 4.9 & 5.1335 & TST \\
\hline CHEMBL 2005449 & 809223 & 4.6 & 4.9626 & TRN \\
\hline CHEMBL1987998 & 809223 & 4.6 & 4.6392 & TRN \\
\hline CHEMBL 2006010 & 809223 & 4.5 & 4.2844 & TRN \\
\hline CHEMBL1682558 & 809223 & 4.5 & 4.7177 & TRN \\
\hline CHEMBL1990496 & 809223 & 4.6 & 4.5539 & TRN \\
\hline CHEMBL242865 & 809223 & 6.0 & 5.8474 & TRN \\
\hline CHEMBL1997623 & 809223 & 4.5 & 4.7522 & TRN \\
\hline CHEMBL 2002479 & 809223 & 4.5 & 4.7098 & TRN \\
\hline CHEMBL1993166 & 809223 & 4.5 & 4.7527 & TRN \\
\hline CHEMBL1967094 & 809223 & 4.5 & 4.838 & TRN \\
\hline CHEMBL1966035 & 809223 & 4.5 & 4.4661 & TRN \\
\hline CHEMBL 2003341 & 809223 & 4.5 & 4.5085 & TRN \\
\hline CHEMBL1992645 & 809223 & 4.5 & 4.4516 & TST \\
\hline CHEMBL1982992 & 809223 & 4.5 & 4.2183 & TRN \\
\hline CHEMBL1998110 & 809223 & 4.6 & 4.5156 & TRN \\
\hline CHEMBL1999590 & 809223 & 4.5 & 4.2992 & TST \\
\hline CHEMBL1981079 & 809223 & 4.5 & 4.2015 & TRN \\
\hline CHEMBL1978166 & 809223 & 6.5 & 6.4361 & TRN \\
\hline CHEMBL1972276 & 809223 & 4.5 & 4.4419 & TRN \\
\hline CHEMBL1980489 & 809223 & 4.5 & 4.5919 & TRN \\
\hline CHEMBL 2000832 & 809223 & 4.5 & 4.9158 & TRN \\
\hline CHEMBL1967116 & 809223 & 8.1 & 7.8092 & TRN \\
\hline CHEMBL86755 & 809223 & 4.6 & 5.1063 & TRN \\
\hline CHEMBL1970709 & 809223 & 4.5 & 4.8522 & TRN \\
\hline CHEMBL1974617 & 809223 & 4.5 & 4.3985 & TRN \\
\hline CHEMBL1965660 & 809223 & 4.6 & 4.2929 & TRN \\
\hline CHEMBL1992125 & 809223 & 5.6 & 5.9768 & TRN \\
\hline CHEMBL1998112 & 809223 & 4.5 & 4.5452 & TRN \\
\hline CHEMBL1969126 & 809223 & 4.5 & 4.4964 & TRN \\
\hline CHEMBL1980896 & 809223 & 4.5 & 4.6709 & TRN \\
\hline CHEMBL1975208 & 809223 & 4.5 & 4.5936 & TST \\
\hline CHEMBL1970104 & 809223 & 4.5 & 4.8864 & TRN \\
\hline CHEMBL1964777 & 809223 & 4.5 & 4.1088 & TRN \\
\hline CHEMBL1971149 & 809223 & 4.5 & 4.4637 & TRN \\
\hline CHEMBL1999714 & 809223 & 4.5 & 4.2031 & TRN \\
\hline CHEMBL1987533 & 809223 & 4.5 & 4.523 & TRN \\
\hline CHEMBL1994040 & 809223 & 4.5 & 4.5615 & TRN \\
\hline CHEMBL 388978 & 809223 & 7.0 & 7.9242 & TST \\
\hline CHEMBL579246 & 809223 & 4.5 & 4.5697 & TRN \\
\hline CHEMBL398951 & 809223 & 4.6 & 4.2415 & TST \\
\hline
\end{tabular}




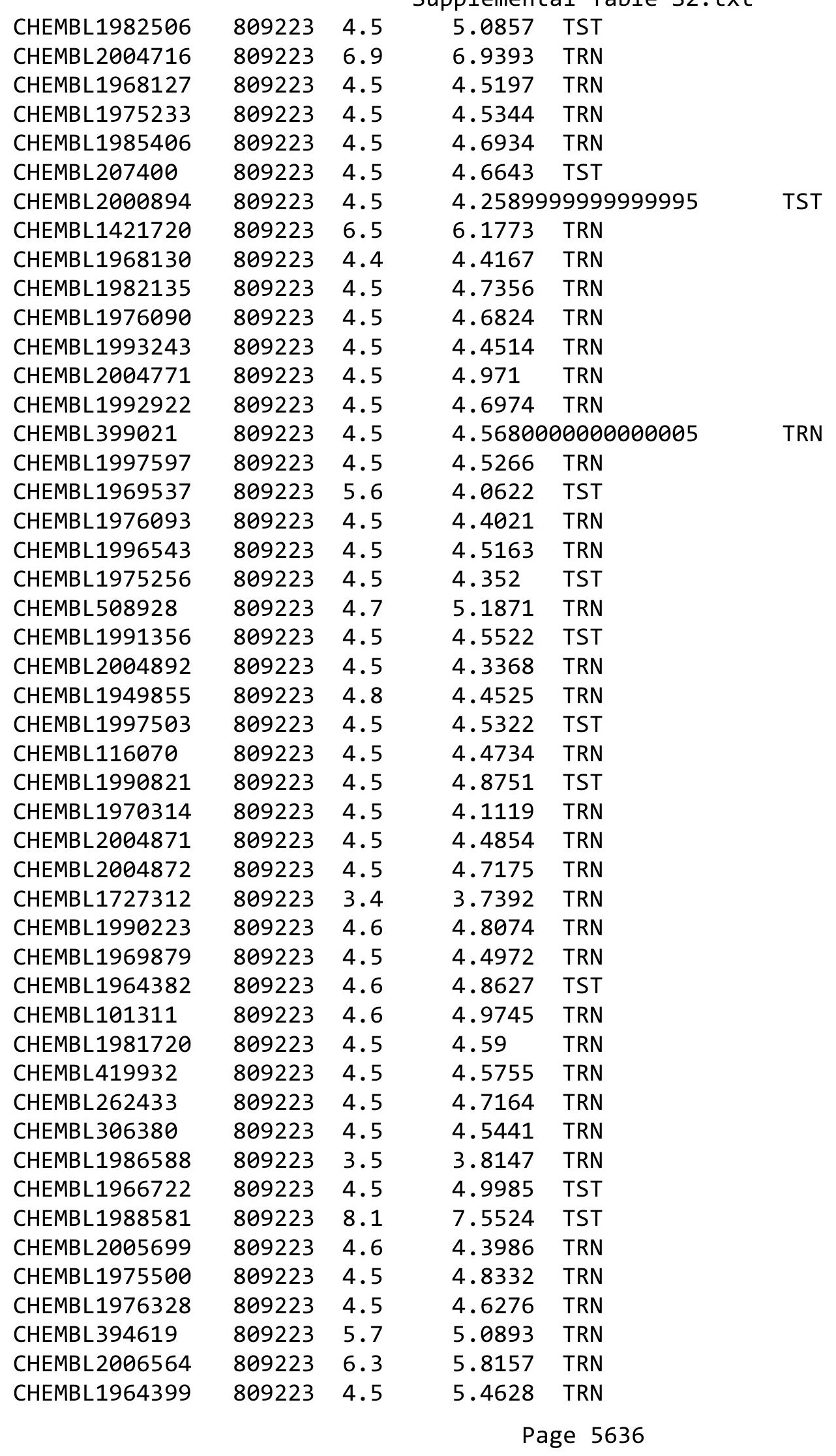




\begin{tabular}{|c|c|c|c|c|c|}
\hline \\
\hline CHEMBL1996831 & 809223 & 4.5 & 4.7057 & TST & \\
\hline CHEMBL411903 & 809223 & 6.6 & 6.3747 & TRN & \\
\hline CHEMBL1965789 & 809223 & 5.9 & 5.3324 & TRN & \\
\hline CHEMBL1978167 & 809223 & 4.6 & 4.8288 & TST & \\
\hline CHEMBL1965988 & 809223 & 6.3 & 6.2436 & TRN & \\
\hline CHEMBL418203 & 809223 & 4.6 & 5.231 & TST & \\
\hline CHEMBL1989646 & 809223 & 4.5 & 4.3582 & TRN & \\
\hline CHEMBL1682357 & 809223 & 4.5 & 4.5284 & TRN & \\
\hline CHEMBL225519 & 809223 & 4.6 & 5.2596 & TRN & \\
\hline CHEMBL209534 & 809223 & 4.5 & 4.2898 & TRN & \\
\hline CHEMBL1978200 & 809223 & 4.5 & 4.282 & TRN & \\
\hline CHEMBL1970522 & 809223 & 4.5 & 4.5273 & TRN & \\
\hline CHEMBL1990415 & 809223 & 4.5 & 4.1471 & TRN & \\
\hline CHEMBL1966087 & 809223 & 4.5 & 4.758 & TRN & \\
\hline CHEMBL1964692 & 809223 & 5.7 & 5.1294 & TRN & \\
\hline CHEMBL1996931 & 809223 & 4.5 & 4.5925 & TRN & \\
\hline CHEMBL1964413 & 809223 & 4.5 & 4.2792 & TRN & \\
\hline CHEMBL1973483 & 809223 & 4.5 & 4.6225 & TRN & \\
\hline CHEMBL1998470 & 809223 & 4.6 & 4.4748 & TRN & \\
\hline CHEMBL1984432 & 809223 & 4.5 & 4.5752 & TRN & \\
\hline CHEMBL1970735 & 809223 & 4.5 & 4.2816 & TRN & \\
\hline CHEMBL219722 & 809223 & 5.6 & 5.5413 & TRN & \\
\hline CHEMBL1975903 & 809223 & 5.6 & 5.0327 & TRN & \\
\hline CHEMBL1997340 & 809223 & 4.5 & 4.23600 & 0000000001 & TRN \\
\hline CHEMBL1522508 & 809223 & 3.4 & 3.8721 & TRN & \\
\hline CHEMBL1989474 & 809223 & 4.5 & 4.5423 & TRN & \\
\hline CHEMBL1988805 & 809223 & 4.6 & 4.0379 & TST & \\
\hline CHEMBL458997 & 809223 & 6.7 & 6.347 & TRN & \\
\hline CHEMBL1971021 & 809223 & 6.5 & 5.8134 & TRN & \\
\hline CHEMBL227271 & 809223 & 4.5 & 4.2463 & TRN & \\
\hline CHEMBL583144 & 809223 & 4.5 & 4.0913 & TRN & \\
\hline CHEMBL1974310 & 809223 & 4.5 & 4.4686 & TRN & \\
\hline CHEMBL1969942 & 809223 & 5.7 & 5.1014 & TRN & \\
\hline CHEMBL1978567 & 809223 & 4.6 & 4.5156 & TRN & \\
\hline CHEMBL1982660 & 809223 & 4.5 & 4.518 & TRN & \\
\hline CHEMBL1994693 & 809223 & 4.5 & 4.7228 & TRN & \\
\hline CHEMBL1965838 & 809223 & 4.1 & 4.6212 & TST & \\
\hline CHEMBL1982957 & 809223 & 4.5 & 4.8729 & TRN & \\
\hline CHEMBL1725279 & 809223 & 6.3 & 5.3242 & TST & \\
\hline CHEMBL 2002346 & 809223 & 5.7 & 5.265 & TRN & \\
\hline CHEMBL1975138 & 809223 & 4.5 & 4.9419 & TST & \\
\hline CHEMBL424872 & 809223 & 4.5 & 4.4695 & TRN & \\
\hline CHEMBL2006836 & 809223 & 4.5 & 4.7579 & TST & \\
\hline CHEMBL1971947 & 809223 & 4.5 & 5.6456 & TRN & \\
\hline CHEMBL412142 & 809223 & 4.5 & 3.9056 & TST & \\
\hline CHEMBL1980704 & 809223 & 4.5 & 4.7196 & TST & \\
\hline CHEMBL 2003271 & 809223 & 4.5 & 4.615 & TRN & \\
\hline CHEMBL1972365 & 809223 & 3.5 & 3.6659 & TRN & \\
\hline & & & & 5637 & \\
\hline
\end{tabular}




\begin{tabular}{|c|c|c|c|c|c|}
\hline \\
\hline CHEMBL1966808 & 809223 & 4.5 & 4.5551 & TST & \\
\hline CHEMBL 2004447 & 809223 & 4.5 & 4.4701 & TRN & \\
\hline CHEMBL1983111 & 809223 & 7.5 & 7.4735 & TRN & \\
\hline CHEMBL1973860 & 809223 & 4.5 & 4.3157 & TRN & \\
\hline CHEMBL 260135 & 809223 & 4.5 & 4.5337 & TRN & \\
\hline CHEMBL 220241 & 809223 & 4.5 & 4.6759 & TRN & \\
\hline CHEMBL 2004544 & 809223 & 4.5 & 4.9326 & TST & \\
\hline CHEMBL1988141 & 809223 & 7.3 & 7.3127 & TST & \\
\hline CHEMBL1982610 & 809223 & 4.5 & 4.6801 & TST & \\
\hline CHEMBL1977134 & 809223 & 4.6 & 4.6872 & TRN & \\
\hline CHEMBL1999496 & 809223 & 4.5 & 4.7477 & TRN & \\
\hline CHEMBL 2006933 & 809223 & 4.5 & 4.5763 & TST & \\
\hline CHEMBL1985206 & 809223 & 4.6 & 4.4938 & TST & \\
\hline CHEMBL1988300 & 809223 & 4.5 & 4.4327 & TRN & \\
\hline CHEMBL1991078 & 809223 & 4.5 & 4.646 & TRN & \\
\hline CHEMBL1987359 & 809223 & 4.5 & 4.7009 & TST & \\
\hline CHEMBL1977749 & 809223 & 6.5 & 5.4212 & TST & \\
\hline CHEMBL1975212 & 809223 & 4.8 & 4.8512 & TRN & \\
\hline CHEMBL2000685 & 809223 & 4.5 & 5.3535 & TRN & \\
\hline CHEMBL2001613 & 809223 & 4.9 & 4.9198 & TRN & \\
\hline CHEMBL1997275 & 809223 & 4.6 & 4.585 & TRN & \\
\hline CHEMBL1993904 & 809223 & 5.8 & 5.45799 & 9999999999 & TRN \\
\hline CHEMBL1980376 & 809223 & 4.5 & 4.3465 & TRN & \\
\hline CHEMBL1967513 & 809223 & 4.6 & 4.71399 & 99999999995 & TRN \\
\hline CHEMBL1985311 & 809223 & 5.9 & 5.8226 & TRN & \\
\hline CHEMBL1989265 & 809223 & 4.5 & 4.5727 & TST & \\
\hline CHEMBL1982413 & 809223 & 6.7 & 5.4502 & TST & \\
\hline CHEMBL1969502 & 809223 & 4.5 & 4.5621 & TRN & \\
\hline CHEMBL1965910 & 809223 & 4.5 & 4.4231 & TRN & \\
\hline CHEMBL1682553 & 809223 & 4.5 & 4.1605 & TRN & \\
\hline CHEMBL1971430 & 809223 & 4.5 & 4.6421 & TRN & \\
\hline CHEMBL1983963 & 809223 & 5.9 & 5.5199 & TRN & \\
\hline CHEMBL1997764 & 809223 & 4.5 & 4.6763 & TRN & \\
\hline CHEMBL 2000271 & 809223 & 4.5 & 4.8203 & TRN & \\
\hline CHEMBL562488 & 809223 & 3.5 & 4.1356 & TRN & \\
\hline CHEMBL1981792 & 809223 & 5.8 & 4.8733 & TRN & \\
\hline CHEMBL1987535 & 809223 & 4.6 & 4.7449 & TRN & \\
\hline CHEMBL1985092 & 809223 & 4.5 & 4.4421 & TRN & \\
\hline CHEMBL2004692 & 809223 & 4.5 & 4.3015 & TST & \\
\hline CHEMBL1981410 & 809223 & 4.5 & 5.1945 & TRN & \\
\hline CHEMBL2002586 & 809223 & 4.6 & 4.5 & TRN & \\
\hline CHEMBL1996234 & 809223 & 4.5 & 4.5545 & TRN & \\
\hline CHEMBL2007421 & 809223 & 4.6 & 5.4861 & TST & \\
\hline CHEMBL1991434 & 809223 & 4.5 & 5.2896 & TST & \\
\hline CHEMBL1967544 & 809223 & 4.5 & 4.3569 & TRN & \\
\hline CHEMBL1973138 & 809223 & 4.6 & 4.8023 & TRN & \\
\hline CHEMBL 223367 & 809223 & 4.5 & 4.7916 & TST & \\
\hline CHEMBL1992673 & 809223 & 4.3 & 4.4771 & TRN & \\
\hline
\end{tabular}




\begin{tabular}{|c|c|c|c|c|c|}
\hline & & & Supplementa & Table S2 & \\
\hline CHEMBL340384 & 809223 & 5.9 & 4.1658 & TST & \\
\hline CHEMBL1996587 & 809223 & 4.5 & 4.5271 & TRN & \\
\hline CHEMBL1981492 & 809223 & 4.1 & 4.0919 & TRN & \\
\hline CHEMBL1993335 & 809223 & 6.0 & 5.6561 & TST & \\
\hline CHEMBL1988692 & 809223 & 4.6 & 4.6156 & TRN & \\
\hline CHEMBL 2007574 & 809223 & 4.6 & 4.8396 & TRN & \\
\hline CHEMBL1964804 & 809223 & 4.5 & 4.2242 & TRN & \\
\hline CHEMBL443962 & 809223 & 4.5 & 4.8914 & TST & \\
\hline CHEMBL 2000354 & 809223 & 4.5 & 4.51 & TRN & \\
\hline CHEMBL1965507 & 809223 & 4.7 & 5.7448 & TRN & \\
\hline CHEMBL 274064 & 809223 & 4.5 & 4.4299 & TRN & \\
\hline CHEMBL1998680 & 809223 & 4.6 & 4.5322 & TRN & \\
\hline CHEMBL1967564 & 809223 & 4.5 & 4.6397 & TRN & \\
\hline CHEMBL592030 & 809223 & 4.7 & 4.1692 & TST & \\
\hline CHEMBL 2000071 & 809223 & 4.5 & 4.5169 & TRN & \\
\hline CHEMBL1979176 & 809223 & 4.5 & 4.5008 & TRN & \\
\hline CHEMBL1970317 & 809223 & 8.1 & 7.1304 & TST & \\
\hline CHEMBL 2000408 & 809223 & 4.5 & 4.3913 & TST & \\
\hline CHEMBL248757 & 809223 & 4.5 & 5.0688 & TST & \\
\hline CHEMBL1978014 & 809223 & 4.5 & 4.3653 & TST & \\
\hline CHEMBL1997007 & 809223 & 4.6 & 4.5951 & TST & \\
\hline CHEMBL1994538 & 809223 & 4.5 & 4.7472 & TST & \\
\hline CHEMBL1983195 & 809223 & 4.5 & 4.9635 & TST & \\
\hline CHEMBL1975490 & 809223 & 4.5 & 4.729 & TST & \\
\hline CHEMBL1964444 & 809223 & 4.5 & 4.5409 & TST & \\
\hline CHEMBL 2002690 & 809223 & 4.6 & 4.6572 & TST & \\
\hline CHEMBL 2006567 & 809223 & 4.5 & 4.0906 & TST & \\
\hline CHEMBL1986139 & 809223 & 4.5 & 4.3804 & TST & \\
\hline CHEMBL1980540 & 809223 & 4.5 & 4.3695 & TST & \\
\hline CHEMBL 278041 & 809223 & 4.6 & 4.5111 & TST & \\
\hline CHEMBL1979883 & 809223 & 6.2 & 6.4166 & TST & \\
\hline CHEMBL1984162 & 809223 & 6.2 & 5.987999 & 99999999995 & TST \\
\hline CHEMBL1997051 & 809223 & 6.3 & 5.4029 & TST & \\
\hline CHEMBL491758 & 809223 & 4.5 & 5.1832 & TST & \\
\hline CHEMBL1986590 & 809223 & 4.6 & 4.5823 & TST & \\
\hline CHEMBL549730 & 809223 & 4.5 & 4.5841 & TST & \\
\hline CHEMBL1682360 & 809223 & 4.5 & 4.6274 & TST & \\
\hline CHEMBL1970189 & 809223 & 4.5 & 4.3079 & TST & \\
\hline CHEMBL1870106 & 809223 & 4.6 & 5.1579 & TST & \\
\hline CHEMBL1996791 & 809223 & 4.5 & 4.4538 & TST & \\
\hline CHEMBL371206 & 809223 & 4.5 & 5.1197 & TST & \\
\hline CHEMBL1974664 & 809223 & 4.5 & 4.8739 & TST & \\
\hline CHEMBL1998477 & 809223 & 5.6 & 4.5124 & TST & \\
\hline CHEMBL406845 & 809223 & 4.6 & 4.6039 & TST & \\
\hline CHEMBL1974288 & 809223 & 4.5 & 4.5309 & TST & \\
\hline CHEMBL1984296 & 809223 & 6.2 & 5.6896 & TST & \\
\hline CHEMBL196363 & 809223 & 6.1 & 6.2223 & TST & \\
\hline CHEMBL1996837 & 809223 & 3.5 & 3.4032 & TST & \\
\hline
\end{tabular}




\begin{tabular}{|c|c|c|c|c|c|}
\hline \multicolumn{6}{|c|}{ Supplemental Table S2.txt } \\
\hline CHEMBL1190711 & 809223 & 6.4 & 4.8433 & TST & \\
\hline CHEMBL1990346 & 809223 & 4.5 & 4.8192 & TST & \\
\hline CHEMBL1964718 & 809223 & 4.3 & 4.4133 & TST & \\
\hline CHEMBL1968705 & 809223 & 4.6 & 4.9245 & TST & \\
\hline CHEMBL1964441 & 809223 & 6.5 & 6.4974 & TST & \\
\hline CHEMBL1991410 & 809223 & 4.6 & 4.55399 & 9999999999 & TST \\
\hline CHEMBL546797 & 809223 & 5.9 & 5.0695 & TST & \\
\hline CHEMBL404367 & 809223 & 6.3 & 5.6211 & TST & \\
\hline CHEMBL1966343 & 809223 & 4.5 & 4.3052 & TST & \\
\hline CHEMBL1978271 & 809223 & 4.6 & 4.7483 & TST & \\
\hline CHEMBL1967887 & 809223 & 4.5 & 4.4922 & TST & \\
\hline CHEMBL 2007266 & 809223 & 4.6 & 5.393 & TST & \\
\hline CHEMBL 2000568 & 809223 & 4.6 & 4.3128 & TST & \\
\hline CHEMBL1994308 & 809223 & 4.6 & 4.2722 & TST & \\
\hline CHEMBL 2000335 & 809223 & 4.5 & 5.4319 & TST & \\
\hline CHEMBL1980161 & 809223 & 3.5 & 4.386 & TST & \\
\hline CHEMBL1988717 & 809223 & 5.6 & 4.9011 & TST & \\
\hline CHEMBL1974328 & 809223 & 6.0 & 4.9745 & TST & \\
\hline CHEMBL509032 & 809223 & 6.6 & 5.9947 & TST & \\
\hline CHEMBL1973808 & 809223 & 4.5 & 4.4744 & TST & \\
\hline CHEMBL 2000429 & 809223 & 4.5 & 4.35800 & 00000000005 & TST \\
\hline CHEMBL1972576 & 809223 & 5.7 & 5.5656 & TST & \\
\hline CHEMBL1992555 & 809223 & 4.5 & 4.2919 & TST & \\
\hline CHEMBL 2311171 & 1555044 & 5.9208 & 6.2637 & TST & \\
\hline CHEMBL1380966 & 1555044 & $4.6110 e$ & 0000000 & 4.6034 & TRN \\
\hline CHEMBL3765224 & 1555044 & 5.1618 & 5.1982 & TRN & \\
\hline CHEMBL3763550 & 1555044 & 6.2076 & 6.1182 & TRN & \\
\hline CHEMBL3764542 & 1555044 & 4.7192 & 5.0586 & TST & \\
\hline CHEMBL3764035 & 1555044 & 4.7261 & 5.6688 & TST & \\
\hline CHEMBL3764619 & 1555044 & 6.8156 & 6.8376 & TRN & \\
\hline CHEMBL1561061 & 1555044 & 5.3002 & 5.2546 & TRN & \\
\hline CHEMBL3764538 & 1555044 & 4.8542 & 4.8543 & TRN & \\
\hline CHEMBL3763793 & 1555044 & 7.9318 & 8.0166 & TRN & \\
\hline CHEMBL3765187 & 1555044 & 5.6345 & 5.6491 & TRN & \\
\hline CHEMBL3764510 & 1555044 & 4.4 & 4.4086 & TRN & \\
\hline CHEMBL3763695 & 1555044 & 7.4318 & 7.3253 & TRN & \\
\hline CHEMBL1623045 & 1555044 & 5.7467 & 5.7613 & TRN & \\
\hline CHEMBL3764651 & 1555044 & 6.1675 & 6.0881 & TRN & \\
\hline CHEMBL3763725 & 1555044 & 7.6556 & 7.5797 & TRN & \\
\hline CHEMBL3763536 & 1555044 & 7.71 & 7.5496 & TRN & \\
\hline CHEMBL3763758 & 1555044 & 7.2211 & 7.2263 & TRN & \\
\hline CHEMBL3765016 & 1555044 & 6.6289 & 6.645 & TRN & \\
\hline CHEMBL3764161 & 1555044 & 4.841 & 4.8319 & TRN & \\
\hline CHEMBL3764753 & 1555044 & 6.6651 & 6.6094 & TRN & \\
\hline CHEMBL3764699 & 1555044 & 5.3072 & 5.3299 & TRN & \\
\hline CHEMBL3764215 & 1555044 & 6.934 & 6.9196 & TRN & \\
\hline CHEMBL1625328 & 1555044 & 3.1549 & 5.8766 & TST & \\
\hline CHEMBL3764324 & 1555044 & 7.4248 & 7.3998 & TRN & \\
\hline
\end{tabular}


Supplemental Table S2.txt

\begin{tabular}{|c|c|c|c|c|c|c|}
\hline CHEMBL1481581 & 1555044 & 5.1938 & 5.1981 & TRN & & \\
\hline CHEMBL481537 & 1555044 & 6.4089 & 4.9618 & TST & & \\
\hline CHEMBL1622371 & 1555044 & 6.16299 & 999999999 & 99 & 6.2105 & TRN \\
\hline CHEMBL 3765064 & 1555044 & 7.6737 & 7.6955 & TRN & & \\
\hline CHEMBL3765163 & 1555044 & 6.5406 & 6.5055 & TRN & & \\
\hline CHEMBL 3764750 & 1555044 & 7.6799 & 7.7669 & TRN & & \\
\hline CHEMBL3763399 & 1555044 & 7.857 & 7.8833 & TRN & & \\
\hline CHEMBL 3764725 & 1555044 & 5.8508 & 5.8262 & TRN & & \\
\hline CHEMBL3763505 & 1555044 & 5.8013 & 5.9606 & TRN & & \\
\hline CHEMBL3764444 & 1555044 & 5.3893 & 5.3995 & TRN & & \\
\hline CHEMBL3763979 & 1555044 & 7.0888 & 7.1822 & TRN & & \\
\hline CHEMBL 3763803 & 1555044 & 6.6038 & 6.6113 & TRN & & \\
\hline CHEMBL3763612 & 1555044 & 4.8871 & 4.8629 & TRN & & \\
\hline CHEMBL 3765243 & 1555044 & 7.15 & 7.1494 & TRN & & \\
\hline CHEMBL3763719 & 1555044 & 5.6861 & 5.6897 & TRN & & \\
\hline CHEMBL 3764168 & 1555044 & 7.61799 & 999999999 & 99 & 7.6726 & TRN \\
\hline CHEMBL3764414 & 1555044 & 4.945 & 4.9547 & TRN & & \\
\hline CHEMBL3765099 & 1555044 & 5.4976 & 5.507999 & 999999999 & & TRN \\
\hline CHEMBL 3764311 & 1555044 & 5.5157 & 5.4977 & TRN & & \\
\hline CHEMBL3763664 & 1555044 & 7.6968 & 7.6775 & TRN & & \\
\hline CHEMBL 3764283 & 1555044 & 5.9872 & 6.0174 & TRN & & \\
\hline CHEMBL3764583 & 1555044 & 7.4962 & 7.7384 & TST & & \\
\hline CHEMBL3765146 & 1555044 & 6.4949 & 6.2202 & TST & & \\
\hline CHEMBL 3765692 & 1555044 & 7.4522 & 6.5346 & TST & & \\
\hline CHEMBL1411493 & 1555044 & 5.6144 & 5.3337 & TST & & \\
\hline CHEMBL3763569 & 1555044 & 6.9355 & 7.5031 & TST & & \\
\hline CHEMBL 3764049 & 1555044 & 6.6778 & 6.9658 & TST & & \\
\hline CHEMBL1622067 & 1555044 & 4.4117 & 5.7819 & TST & & \\
\hline CHEMBL 3764013 & 1555044 & 5.44 & 5.6134 & TST & & \\
\hline CHEMBL1497437 & 1555044 & 3.1549 & 5.6561 & TST & & \\
\hline CHEMBL 3941036 & 1638262 & 8.5686 & 8.889 & TRN & & \\
\hline CHEMBL 3921158 & 1638262 & 8.5686 & 8.5157 & TRN & & \\
\hline CHEMBL3966331 & 1638262 & 8.5686 & 8.5721 & TRN & & \\
\hline CHEMBL 3979096 & 1638262 & 8.5686 & 8.3515 & TRN & & \\
\hline CHEMBL 3896580 & 1638262 & 8.5686 & 8.7807 & TRN & & \\
\hline CHEMBL3902855 & 1638262 & 8.5686 & 8.7751 & TRN & & \\
\hline CHEMBL3932106 & 1638262 & 8.289 & 8.4304 & TRN & & \\
\hline CHEMBL3933131 & 1638262 & 8.5686 & 7.9824 & TST & & \\
\hline CHEMBL 3980758 & 1638262 & 8.5686 & 8.7726 & TRN & & \\
\hline CHEMBL3953739 & 1638262 & 8.5686 & 8.4154 & TRN & & \\
\hline CHEMBL3943791 & 1638262 & 8.5686 & 8.5367 & TRN & & \\
\hline CHEMBL3985726 & 1638262 & 8.5686 & 8.5987 & TRN & & \\
\hline CHEMBL3943011 & 1638262 & 8.5686 & 8.2952 & TRN & & \\
\hline CHEMBL3977761 & 1638262 & 8.5686 & 8.6 & TRN & & \\
\hline CHEMBL 3983767 & 1638262 & 8.5686 & 8.6755 & TRN & & \\
\hline CHEMBL3926491 & 1638262 & 8.5686 & 8.4345 & TST & & \\
\hline CHEMBL3952569 & 1638262 & 8.5686 & 8.6391 & TRN & & \\
\hline CHEMBL 3975263 & 1638262 & 6.0 & 6.3997 & TRN & & \\
\hline
\end{tabular}


Supplemental Table S2.txt

\begin{tabular}{|c|c|c|c|c|c|}
\hline CHEMBL 3975307 & 1638262 & 8.5686 & 8.758 & TRN & \\
\hline CHEMBL3961809 & 1638262 & 8.5686 & 8.7403 & TST & \\
\hline CHEMBL 3957760 & 1638262 & 8.5686 & 8.6279 & TRN & \\
\hline CHEMBL 3926604 & 1638262 & 8.5686 & 8.5182 & TRN & \\
\hline CHEMBL 3934336 & 1638262 & 8.5686 & 8.1412 & TRN & \\
\hline CHEMBL 3939932 & 1638262 & 8.5686 & 8.5088 & TRN & \\
\hline CHEMBL 3955699 & 1638262 & 8.5686 & 8.5383 & TRN & \\
\hline CHEMBL 3918258 & 1638262 & 8.5686 & 8.5435 & TRN & \\
\hline CHEMBL 3893059 & 1638262 & 8.5686 & 8.6216 & TRN & \\
\hline CHEMBL 3931899 & 1638262 & 8.5686 & 8.4936 & TRN & \\
\hline CHEMBL 3900091 & 1638262 & 8.5686 & 8.6284 & TST & \\
\hline CHEMBL3968156 & 1638262 & 8.5686 & 8.3381 & TRN & \\
\hline CHEMBL 3981484 & 1638262 & 8.5686 & 8.6394 & TRN & \\
\hline CHEMBL 3970829 & 1638262 & 8.5686 & 8.2842 & TRN & \\
\hline CHEMBL 3914231 & 1638262 & 8.5686 & 8.6026 & TRN & \\
\hline CHEMBL 3961754 & 1638262 & 7.21399 & 99999999 & 8.0193 & TRN \\
\hline CHEMBL3920236 & 1638262 & 8.5686 & 8.7032 & TRN & \\
\hline CHEMBL 3917503 & 1638262 & 8.5686 & 8.6286 & TST & \\
\hline CHEMBL 3938716 & 1638262 & 8.5686 & 8.3739 & TRN & \\
\hline CHEMBL 3981509 & 1638262 & 8.5686 & 8.6383 & TRN & \\
\hline CHEMBL 3917222 & 1638262 & 8.5686 & 8.5405 & TRN & \\
\hline CHEMBL3957516 & 1638262 & 8.5686 & 8.7098 & TRN & \\
\hline CHEMBL 3890685 & 1638262 & 8.5686 & 8.4289 & TRN & \\
\hline CHEMBL 3926078 & 1638262 & 8.5686 & 8.521 & TRN & \\
\hline CHEMBL 3928658 & 1638262 & 8.5686 & 8.3047 & TRN & \\
\hline CHEMBL 3966307 & 1638262 & 6.0 & 5.9527 & TRN & \\
\hline CHEMBL 3952439 & 1638262 & 8.5686 & 8.6125 & TRN & \\
\hline CHEMBL 3977559 & 1638262 & 8.5686 & 8.405 & TRN & \\
\hline CHEMBL 3952293 & 1638262 & 8.5686 & 7.8749 & TRN & \\
\hline CHEMBL 3964788 & 1638262 & 8.5686 & 8.4695 & TRN & \\
\hline CHEMBL 3934619 & 1638262 & 8.5686 & 8.7613 & TST & \\
\hline CHEMBL 3945849 & 1638262 & 8.5686 & 8.4271 & TRN & \\
\hline CHEMBL 3938313 & 1638262 & 8.5686 & 8.663 & TRN & \\
\hline CHEMBL 3893909 & 1638262 & 8.5686 & 8.687999 & 7999999999 & TST \\
\hline CHEMBL 3917276 & 1638262 & 8.5686 & 8.3069 & TRN & \\
\hline CHEMBL 3959044 & 1638262 & 8.5686 & 8.4323 & TRN & \\
\hline CHEMBL 3900038 & 1638262 & 6.0 & 6.1312 & TRN & \\
\hline CHEMBL 3923745 & 1638262 & 6.0 & 6.0989 & TRN & \\
\hline CHEMBL 3915367 & 1638262 & 8.5686 & 8.2678 & TRN & \\
\hline CHEMBL 3984207 & 1638262 & 8.5686 & 8.2199 & TST & \\
\hline CHEMBL 3981383 & 1638262 & 6.0 & 5.9137 & TRN & \\
\hline CHEMBL 3925563 & 1638262 & 8.5686 & 8.5879 & TRN & \\
\hline CHEMBL 3961361 & 1638262 & 8.5686 & 8.5811 & TRN & \\
\hline CHEMBL 3976286 & 1638262 & 8.5686 & 8.5792 & TRN & \\
\hline CHEMBL 3914443 & 1638262 & 8.5686 & 8.3262 & TRN & \\
\hline CHEMBL 3912947 & 1638262 & 7.71899 & 99999999 & 8.5546 & TRI \\
\hline CHEMBL 3935961 & 1638262 & 8.5686 & 8.6055 & TRN & \\
\hline CHEMBL 3917017 & 1638262 & 8.5686 & 8.5432 & TRN & \\
\hline
\end{tabular}


Supplemental Table S2.txt

\begin{tabular}{|c|c|c|c|c|}
\hline CHEMBL3893346 & 1638262 & 6.0 & 6.0967 & TRN \\
\hline CHEMBL 3960203 & 1638262 & 8.5686 & 8.6223 & TRN \\
\hline CHEMBL 3982288 & 1638262 & 8.5686 & 8.7566 & TRN \\
\hline CHEMBL3914174 & 1638262 & 8.5686 & 8.5564 & TRN \\
\hline CHEMBL 3890828 & 1638262 & 8.5686 & 8.5422 & TRN \\
\hline CHEMBL 3943161 & 1638262 & 8.5686 & 8.1599 & TST \\
\hline CHEMBL3919269 & 1638262 & 8.5686 & 8.5427 & TRN \\
\hline CHEMBL 3961761 & 1638262 & 8.5686 & 8.467 & TRN \\
\hline CHEMBL3968835 & 1638262 & 8.5686 & 8.6149 & TRN \\
\hline CHEMBL 3942683 & 1638262 & 6.0 & 6.3765 & TST \\
\hline CHEMBL3924965 & 1638262 & 8.5686 & 8.4321 & TST \\
\hline CHEMBL 3907754 & 1638262 & 8.5686 & 8.1866 & TST \\
\hline CHEMBL 3914495 & 1638262 & 8.5686 & 7.7869 & TST \\
\hline CHEMBL 3922686 & 1638262 & 8.5686 & 9.0475 & TST \\
\hline CHEMBL 3983200 & 1638262 & 8.5686 & 8.51100 & 0000000001 \\
\hline CHEMBL3896069 & 1638262 & 8.5686 & 8.684 & TST \\
\hline CHEMBL3937089 & 1638262 & 8.5686 & 8.8647 & TST \\
\hline CHEMBL 3977415 & 1638262 & 8.5686 & 8.867 & TST \\
\hline CHEMBL3969137 & 1638262 & 8.5686 & 8.5184 & TST \\
\hline CHEMBL 3902808 & 1638262 & 8.5686 & 8.4246 & TST \\
\hline CHEMBL 3984010 & 1638262 & 8.5686 & 8.6611 & TST \\
\hline CHEMBL 3921534 & 1638262 & 8.5686 & 8.5423 & TST \\
\hline CHEMBL1831196 & 769089 & 6.1487 & 6.1515 & TRN \\
\hline CHEMBL182407 & 769089 & 8.5229 & 6.9662 & TST \\
\hline CHEMBL1831213 & 769089 & 5.2007 & 5.2416 & TRN \\
\hline CHEMBL 207071 & 769089 & 5.301 & 5.1017 & TRN \\
\hline CHEMBL249516 & 769089 & 6.0 & 6.9046 & TRN \\
\hline CHEMBL 207028 & 769089 & 5.0969 & 5.5058 & TRN \\
\hline CHEMBL1831208 & 769089 & 6.4802 & 6.2286 & TRN \\
\hline CHEMBL381932 & 769089 & 4.6289 & 5.3931 & TRN \\
\hline CHEMBL1831206 & 769089 & 6.5638 & 6.6494 & TRN \\
\hline CHEMBL1831204 & 769089 & 7.3979 & 7.818 & TRN \\
\hline CHEMBL1831202 & 769089 & 8.0458 & 7.9727 & TRN \\
\hline CHEMBL1831076 & 769089 & 8.0969 & 7.8312 & TRN \\
\hline CHEMBL 383723 & 769089 & 7.301 & 6.2144 & TRN \\
\hline CHEMBL1831210 & 769089 & 6.3768 & 6.4358 & TRN \\
\hline CHEMBL1831195 & 769089 & 6.2518 & 6.8329 & TRN \\
\hline CHEMBL1831201 & 769089 & 8.0706 & 7.8745 & TRN \\
\hline CHEMBL173050 & 769089 & 5.8239 & 6.6188 & TST \\
\hline CHEMBL181334 & 769089 & 8.301 & 7.0885 & TST \\
\hline CHEMBL1831194 & 769089 & 6.5229 & 6.1554 & TRN \\
\hline CHEMBL1831207 & 769089 & 6.5229 & 6.3088 & TRN \\
\hline CHEMBL1831225 & 769089 & 5.4306 & 6.7238 & TST \\
\hline CHEMBL1831214 & 769089 & 4.9872 & 5.9091 & TRN \\
\hline CHEMBL1831211 & 769089 & 6.2076 & 6.2298 & TRN \\
\hline CHEMBL361171 & 769089 & 6.2518 & 6.455 & TST \\
\hline CHEMBL1831199 & 769089 & 8.1549 & 8.2662 & TRN \\
\hline CHEMBL1831079 & 769089 & 7.0 & 6.2084 & TRN \\
\hline
\end{tabular}




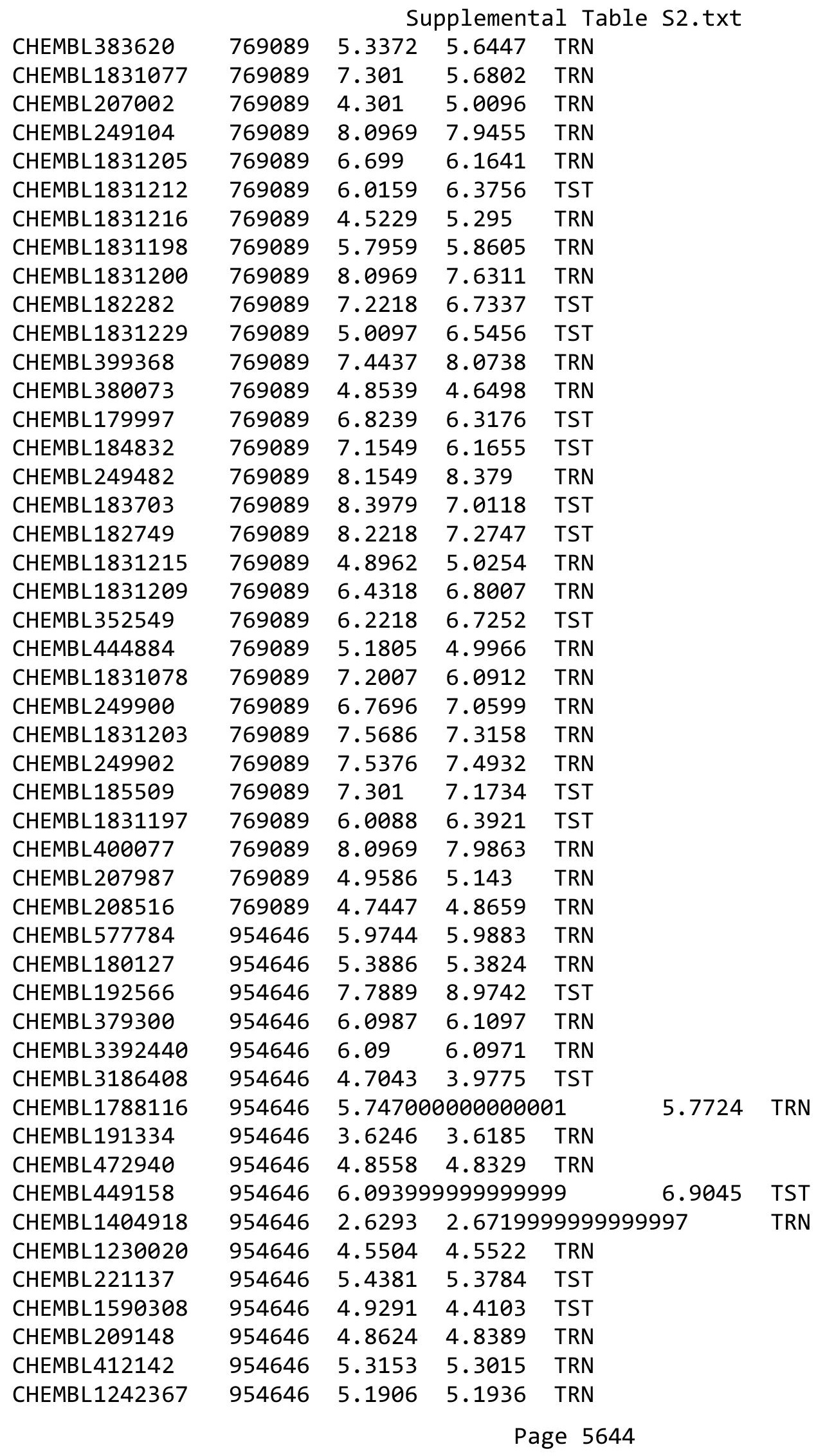




\begin{tabular}{|c|c|c|c|c|c|c|}
\hline & & \multicolumn{5}{|c|}{ Supplemental Table S2.txt } \\
\hline CHEMBL220241 & 954646 & 3.9318 & 3.9389 & TRN & & \\
\hline CHEMBL515416 & 954646 & 3.81399 & 99999999 & 996 & 3.8217 & TRN \\
\hline CHEMBL 213100 & 954646 & 4.5749 & 4.5632 & TRN & & \\
\hline CHEMBL392695 & 954646 & 5.6475 & 5.6622 & TRN & & \\
\hline CHEMBL102714 & 954646 & 4.9852 & 4.9608 & TRN & & \\
\hline CHEMBL1643959 & 954646 & 3.5332 & 3.5444 & TRN & & \\
\hline CHEMBL393929 & 954646 & 5.7194 & 5.7038 & TRN & & \\
\hline CHEMBL3199475 & 954646 & 5.2895 & 5.3157 & TRN & & \\
\hline CHEMBL1357247 & 954646 & 3.7508 & 3.721 & TRN & & \\
\hline CHEMBL9470 & 954646 & 6.5015 & 5.6097 & TST & & \\
\hline CHEMBL240954 & 954646 & 3.9854 & 4.1305 & TST & & \\
\hline CHEMBL512504 & 954646 & 7.2371 & 7.2249 & TRN & & \\
\hline CHEMBL514499 & 954646 & 8.0575 & 8.0453 & TRN & & \\
\hline CHEMBL135561 & 954646 & 4.5943 & 4.6064 & TRN & & \\
\hline CHEMBL558642 & 954646 & 5.2422 & 5.2514 & TRN & & \\
\hline CHEMBL1190711 & 954646 & 6.254 & 6.2703 & TRN & & \\
\hline CHEMBL1256459 & 954646 & 7.3049 & 7.3038 & TRN & & \\
\hline CHEMBL 2005886 & 954646 & 6.4288 & 6.4358 & TRN & & \\
\hline CHEMBL210618 & 954646 & 3.9955 & 3.9737 & TRN & & \\
\hline CHEMBL 258844 & 954646 & 4.7157 & 4.7089 & TRN & & \\
\hline CHEMBL379975 & 954646 & 5.0624 & 5.0373 & TRN & & \\
\hline CHEMBL 222102 & 954646 & 3.9046 & 3.8992 & TRN & & \\
\hline CHEMBL188678 & 954646 & 4.3017 & 4.2935 & TRN & & \\
\hline CHEMBL65 & 954646 & 8.8142 & 8.83 & TRN & & \\
\hline CHEMBL2363137 & 954646 & 5.6306 & 5.65799 & 999999999 & 95 & TRN \\
\hline CHEMBL189584 & 954646 & 3.9316 & 3.9091 & TRN & & \\
\hline CHEMBL483847 & 954646 & 4.2128 & 4.2536 & TRN & & \\
\hline CHEMBL1970879 & 954646 & 4.9403 & 4.9079 & TRN & & \\
\hline CHEMBL 2144069 & 954646 & 5.8701 & 5.8761 & TRN & & \\
\hline CHEMBL585951 & 954646 & 6.17299 & 99999999 & 99 & 6.1552 & TRN \\
\hline CHEMBL259181 & 954646 & 4.7113 & 4.7024 & TRN & & \\
\hline CHEMBL483849 & 954646 & 3.1218 & 3.1381 & TRN & & \\
\hline CHEMBL1909414 & 954646 & 3.4728 & 3.4933 & TRN & & \\
\hline CHEMBL3349342 & 954646 & 3.6339 & 3.6191 & TRN & & \\
\hline CHEMBL1516890 & 954646 & 3.8954 & 5.3067 & TST & & \\
\hline CHEMBL509032 & 954646 & 6.6104 & 5.7823 & TST & & \\
\hline CHEMBL573107 & 954646 & 4.2129 & 5.0827 & TST & & \\
\hline CHEMBL 300389 & 954646 & 7.0967 & 7.2092 & TST & & \\
\hline CHEMBL92309 & 954646 & 4.1554 & 2.6351 & TST & & \\
\hline CHEMBL 373751 & 954646 & 3.248 & 4.5014 & TST & & \\
\hline CHEMBL1673039 & 954646 & 5.2414 & 5.0893 & TST & & \\
\hline CHEMBL 202721 & 954646 & 5.5741 & 5.2034 & TST & & \\
\hline CHEMBL69276 & 221312 & 3.9031 & 4.09 & TRN & & \\
\hline CHEMBL68104 & 221312 & 6.9101 & 6.6737 & TRN & & \\
\hline CHEMBL 304559 & 221312 & 7.5229 & 7.7223 & TRN & & \\
\hline CHEMBL68871 & 221312 & 8.3979 & 7.8419 & TRN & & \\
\hline CHEMBL66047 & 221312 & 3.9031 & 4.2639 & TRN & & \\
\hline CHEMBL 304146 & 221312 & 7.9586 & 7.0102 & TRN & & \\
\hline
\end{tabular}


Supplemental Table S2.txt

\begin{tabular}{|c|c|c|c|c|c|}
\hline CHEMBL 304357 & 221312 & 4.5051 & 5.2342 & TRN & \\
\hline CHEMBL68498 & 221312 & 3.9031 & 5.0976 & TST & \\
\hline CHEMBL70040 & 221312 & 3.9031 & 4.8749 & TRN & \\
\hline CHEMBL 308432 & 221312 & 8.1549 & 8.1603 & TRN & \\
\hline CHEMBL 302119 & 221312 & 7.0458 & 7.7267 & TRN & \\
\hline CHEMBL307976 & 221312 & 5.4949 & 4.8457 & TST & \\
\hline CHEMBL65785 & 221312 & 5.4908 & 5.7042 & TST & \\
\hline CHEMBL 308024 & 221312 & 5.2518 & 5.5514 & TRN & \\
\hline CHEMBL66971 & 221312 & 4.8239 & 4.852 & TRN & \\
\hline CHEMBL 303244 & 221312 & 6.1549 & 5.4829 & TRN & \\
\hline CHEMBL68466 & 221312 & 3.9031 & 4.42 & TRN & \\
\hline CHEMBL 302140 & 221312 & 7.4089 & 7.4722 & TRN & \\
\hline CHEMBL 70244 & 221312 & 3.9031 & 4.1188 & TRN & \\
\hline CHEMBL66283 & 221312 & 7.0969 & 7.5544 & TRN & \\
\hline CHEMBL 304300 & 221312 & 7.7212 & 7.0046 & TRN & \\
\hline CHEMBL 302073 & 221312 & 7.1549 & 6.7764 & TRN & \\
\hline CHEMBL 302107 & 221312 & 3.9031 & 4.6142 & TRN & \\
\hline CHEMBL67558 & 221312 & 6.9586 & 5.1615 & TRN & \\
\hline CHEMBL 302308 & 221312 & 7.0458 & 5.9526 & TRN & \\
\hline CHEMBL 66014 & 221312 & 7.0605 & 7.2627 & TRN & \\
\hline CHEMBL 304789 & 221312 & 6.4815 & 6.5799 & TRN & \\
\hline CHEMBL67167 & 221312 & 7.0 & 7.5082 & TRN & \\
\hline CHEMBL 302108 & 221312 & 6.5086 & 5.7859 & TRN & \\
\hline CHEMBL67292 & 221312 & 6.1765 & 7.2635 & TRN & \\
\hline CHEMBL68398 & 221312 & 6.5654 & 6.9984 & TRN & \\
\hline CHEMBL 67467 & 221312 & 3.9031 & 3.453999 & 99999999997 & TRN \\
\hline CHEMBL67237 & 221312 & 8.3979 & 7.98 & TRN & \\
\hline CHEMBL65941 & 221312 & 5.1397 & 5.3365 & TST & \\
\hline CHEMBL69601 & 221312 & 3.9031 & 4.7182 & TRN & \\
\hline CHEMBL65835 & 221312 & 7.1549 & 6.4666 & TRN & \\
\hline CHEMBL67258 & 221312 & 5.3696 & 5.5095 & TRN & \\
\hline CHEMBL69693 & 221312 & 5.3565 & 4.8077 & TRN & \\
\hline CHEMBL69641 & 221312 & 3.9031 & 5.5718 & TRN & \\
\hline CHEMBL67375 & 221312 & 3.9031 & 4.3489 & TRN & \\
\hline CHEMBL67987 & 221312 & 5.5058 & 5.2485 & TRN & \\
\hline CHEMBL69481 & 221312 & 7.2596 & 7.9835 & TRN & \\
\hline CHEMBL66990 & 221312 & 7.3468 & 7.377000 & 0000000001 & TRN \\
\hline CHEMBL 305399 & 221312 & 5.6968 & 4.6848 & TRN & \\
\hline CHEMBL 70035 & 221312 & 7.0458 & 7.2775 & TRN & \\
\hline CHEMBL 68352 & 221312 & 7.8239 & 7.0899 & TRN & \\
\hline CHEMBL 304497 & 221312 & 3.9031 & 4.1311 & TRN & \\
\hline CHEMBL66109 & 221312 & 5.5229 & 5.4184 & TRN & \\
\hline CHEMBL 303399 & 221312 & 4.6383 & 5.1022 & TST & \\
\hline CHEMBL 305249 & 221312 & \multicolumn{2}{|c|}{5.7620000000000005} & 5.056 & TRN \\
\hline CHEMBL67758 & 221312 & 8.0458 & 7.4012 & TST & \\
\hline CHEMBL67541 & 221312 & 3.9031 & 5.1404 & TST & \\
\hline CHEMBL 304399 & 221312 & \multicolumn{3}{|c|}{6.247999999999999} & TST \\
\hline CHEMBL 302336 & 221312 & 6.5229 & 6.4946 & TST & \\
\hline
\end{tabular}




\begin{tabular}{|c|c|c|c|c|c|}
\hline \multicolumn{6}{|c|}{ Supplemental Table s2.txt } \\
\hline CHEMBL68568 & 221312 & 3.9031 & 4.3181 & TST & \\
\hline CHEMBL 304061 & 221312 & 5.7447 & 6.2292 & TST & \\
\hline CHEMBL303506 & 221312 & 3.9031 & 4.8112 & TST & \\
\hline CHEMBL68645 & 221312 & 3.9031 & 5.8415 & TST & \\
\hline CHEMBL308684 & 221312 & 6.699 & 4.7055 & TST & \\
\hline CHEMBL303686 & 221312 & 6.5376 & 5.2537 & TST & \\
\hline CHEMBL68411 & 221312 & 7.699 & 6.3275 & TST & \\
\hline CHEMBL2362889 & 1301705 & 4.5748 & 4.5264 & TRN & \\
\hline CHEMBL 2357995 & 1301705 & 6.0 & 5.2443 & TRN & \\
\hline CHEMBL1447827 & 1301705 & 4.6096 & 4.6423 & TRN & \\
\hline CHEMBL2354758 & 1301705 & 5.1506 & 4.3865 & TRN & \\
\hline CHEMBL2359510 & 1301705 & 4.58 & 5.1754 & TRN & \\
\hline CHEMBL2362504 & 1301705 & 3.284 & 4.434 & TRN & \\
\hline CHEMBL 2355642 & 1301705 & 4.9442 & 4.9465 & TRN & \\
\hline CHEMBL2357894 & 1301705 & 4.618 & 4.2441 & TRN & \\
\hline CHEMBL 2358205 & 1301705 & 3.284 & 4.4908 & TST & \\
\hline CHEMBL2358709 & 1301705 & 4.5955 & 4.6992 & TRN & \\
\hline CHEMBL2354953 & 1301705 & 3.2441 & 4.1508 & TRN & \\
\hline CHEMBL2360606 & 1301705 & 4.4791 & 4.5897 & TRN & \\
\hline CHEMBL2356799 & 1301705 & 6.0 & 4.8459 & TRN & \\
\hline CHEMBL 2360807 & 1301705 & 4.5578 & 4.5163 & TRN & \\
\hline CHEMBL 2357624 & 1301705 & 4.7033 & 4.4814 & TRN & \\
\hline CHEMBL 2360952 & 1301705 & 4.3311 & 4.8613 & TRN & \\
\hline CHEMBL2359127 & 1301705 & 4.5098 & 4.9124 & TRN & \\
\hline CHEMBL2358333 & 1301705 & 4.8348 & 5.3918 & TRN & \\
\hline CHEMBL 2356371 & 1301705 & 4.6955 & 4.496 & TST & \\
\hline CHEMBL 2354448 & 1301705 & 6.0 & 5.5187 & TRN & \\
\hline CHEMBL 2359550 & 1301705 & 4.6702 & 5.0769 & TRN & \\
\hline CHEMBL1365054 & 1301705 & 4.4955 & 4.3477 & TRN & \\
\hline CHEMBL2355749 & 1301705 & 4.473 & 4.8046 & TRN & \\
\hline CHEMBL1559261 & 1301705 & 3.0362 & 3.9168 & TRN & \\
\hline CHEMBL2360267 & 1301705 & 4.8027 & 5.4977 & TRN & \\
\hline CHEMBL1891222 & 1301705 & 6.0 & 5.2284 & TRN & \\
\hline CHEMBL2359950 & 1301705 & 6.0 & 5.2877 & TRN & \\
\hline CHEMBL2355416 & 1301705 & 4.4438 & 4.8566 & TRN & \\
\hline CHEMBL1470452 & 1301705 & 4.8861 & 4.5907 & TST & \\
\hline CHEMBL2361773 & 1301705 & 4.7149 & 4.7603 & TRN & \\
\hline CHEMBL 2357805 & 1301705 & 4.6688 & 4.8709 & TRN & \\
\hline CHEMBL2361240 & 1301705 & 4.613 & 5.1942 & TRN & \\
\hline CHEMBL2359995 & 1301705 & 4.7298 & 4.8313 & TRN & \\
\hline CHEMBL1505054 & 1301705 & 4.2941 & 4.4467 & TST & \\
\hline CHEMBL2356756 & 1301705 & 4.4477 & 4.038 & TRN & \\
\hline CHEMBL2361971 & 1301705 & 4.5854 & 4.6297 & TRN & \\
\hline CHEMBL2360919 & 1301705 & 4.7503 & 5.286006 & 00000000005 & TRN \\
\hline CHEMBL2362204 & 1301705 & 3.284 & 4.7552 & TRN & \\
\hline CHEMBL 2361534 & 1301705 & 4.8038 & 4.5056 & TRN & \\
\hline CHEMBL2359500 & 1301705 & 4.5524 & 4.3939 & TRN & \\
\hline CHEMBL 2360173 & 1301705 & 4.622 & 4.172 & TRN & \\
\hline
\end{tabular}


Supplemental Table S2.txt

\begin{tabular}{|c|c|c|c|}
\hline HEMBL2359003 & 1301705 & 5.0888 & 5.4837 \\
\hline CHEMBL 2359643 & 1301705 & 5.2097 & 4.988 \\
\hline HEMBL2362046 & L301705 & 3.284 & \\
\hline HEMBL2359303 & 1301705 & 5.3089 & \\
\hline HEMBL2358956 & 301705 & 4.475 & 5225 \\
\hline HEMBL2360305 & 301705 & 4.5485 & 5.1118 \\
\hline HEMBL1452358 & 301705 & 3.284 & 155 \\
\hline AEMBL2358581 & L301705 & 4.6623 & \\
\hline HEMBL2356340 & 1301705 & 4.6645 & \\
\hline HEMBL2357706 & 1301705 & 4.7231 & 4.8432 \\
\hline HEMBL2361873 & 1301705 & 4.7036 & 184 \\
\hline HEMBL2355897 & 1301705 & 5.2967 & 18 \\
\hline HEMBL2357001 & 1301705 & 4.6124 & \\
\hline HEMBL1714379 & 1301705 & 4.4761 & \\
\hline HEMBL2357418 & 1301705 & 4.7224 & \\
\hline HEMBL3184262 & 1301 & 5.0846 & 4. \\
\hline HEMBL2355944 & 1301 & 4.7778 & \\
\hline HEMBL2356101 & 1301 & 5.0182 & \\
\hline HEMBL2362456 & 1301705 & 4.5278 & \\
\hline HEMBL2357707 & 1301705 & 4.547 & \\
\hline HEMBL1865449 & 1301 & 3.284 & \\
\hline HEMBL23 & 1301 & 4.6315 & \\
\hline HEMBL 23 & 1301 & 4.8058 & \\
\hline HEMBL2354976 & 1301705 & 4.6914 & 4. \\
\hline HEMBL2360959 & 1301705 & 6.0 & 4. \\
\hline HEMBL1428940 & 1301 & 4.6975 & \\
\hline HEMBLI & 130 & 4.8119 & \\
\hline 67775 & 1301 & 4.4451 & \\
\hline HEMBL2357722 & 1301 & 4.7873 & \\
\hline HEMBL2359180 & 1301 & 4.5206 & 4. \\
\hline CHEMBL1315275 & 1301 & 4.6891 & \\
\hline HEMBL: & 13 & 4.9442 & 4. \\
\hline CHEMBL 2356982 & 1301 & 4.5799 & \\
\hline CHEMBL 2357888 & 1301705 & 4.5535 & 5.6 \\
\hline HEMBL1389242 & 1301705 & 4.4638 & 4.3 \\
\hline CHEMBL2360064 & 1301 & 4.5776 & 4. \\
\hline CHEMBL2 & 35 & 6. & \\
\hline CHEMBL 2356243 & 1301705 & 4.6413 & 329 \\
\hline CHEMBL 2358214 & 1301705 & 6.0 & 4.9158 \\
\hline CHEMBL 2359733 & 1301705 & 6.0 & 5 . \\
\hline CHEMBL 2356202 & 1301705 & 6 . & 5.6 \\
\hline CHEMBL 2357125 & 1301705 & 5.7932 & \\
\hline CHEMBL 2360317 & 1301705 & 4.2889 & 4.0651 \\
\hline CHEMBL 2354445 & 1301705 & 6.0 & 5.3813 \\
\hline CHEMBL1331798 & 1301705 & 4.5743 & 4.6 \\
\hline CHEMBL 2354443 & 1301705 & 4.4861 & 4.2795 \\
\hline CHEMBL 2361477 & 1301705 & 4.5571 & 4.5507 \\
\hline CHEMBL2358481 & 1301705 & 3.284 & 4.1311 \\
\hline
\end{tabular}


Supplemental Table S2.txt

\begin{tabular}{|c|c|c|c|c|}
\hline CHEMBL 2360390 & 1301705 & 4.8468 & 4.626 & TRN \\
\hline CHEMBL2359386 & 1301705 & 4.4224 & 4.1862 & TST \\
\hline CHEMBL2145398 & 1301705 & 4.8465 & 4.5858 & TST \\
\hline CHEMBL1532941 & 1301705 & 6.0 & 4.8445 & TST \\
\hline CHEMBL2361889 & 1301705 & 4.5989 & 4.6149 & TST \\
\hline CHEMBL2358058 & 1301705 & 4.8297 & 4.6903 & TST \\
\hline CHEMBL2356428 & 1301705 & 4.3949 & 4.7669 & TST \\
\hline CHEMBL2356039 & 1301705 & 5.4949 & 4.0581 & TST \\
\hline CHEMBL1730981 & 1301705 & 3.284 & 4.5346 & TST \\
\hline CHEMBL2356488 & 1301705 & 4.6859 & 5.1173 & TST \\
\hline CHEMBL2356395 & 1301705 & 4.6061 & 4.5303 & TST \\
\hline CHEMBL2354566 & 1301705 & 4.6536 & 4.829 & TST \\
\hline CHEMBL 2354923 & 1301705 & 4.4186 & 4.7027 & TST \\
\hline CHEMBL1451017 & 1301705 & 4.6291 & 4.3547 & TST \\
\hline CHEMBL18718 & 152416 & 5.2218 & 5.1304 & TRN \\
\hline CHEMBL18542 & 152416 & 3.9626 & 3.7767 & TRN \\
\hline CHEMBL18878 & 152416 & 4.1427 & 3.8376 & TRN \\
\hline CHEMBL18444 & 152416 & 3.1778 & 3.2344 & TRN \\
\hline CHEMBL18431 & 152416 & 3.1746 & 3.1265 & TRN \\
\hline CHEMBL18407 & 152416 & 3.6655 & 3.7942 & TRN \\
\hline CHEMBL278921 & 152416 & 4.2441 & 4.2438 & TRN \\
\hline CHEMBL19199 & 152416 & 3.1746 & 3.1051 & TRN \\
\hline CHEMBL278978 & 152416 & 5.2218 & 5.0763 & TRN \\
\hline CHEMBL273782 & 152416 & 3.2636 & 3.0326 & TST \\
\hline CHEMBL18360 & 152416 & 3.0 & 3.0812 & TST \\
\hline CHEMBL18549 & 152416 & 3.1778 & 3.2609 & TRN \\
\hline CHEMBL280477 & 152416 & 5.0969 & 5.0763 & TRN \\
\hline CHEMBL280235 & 152416 & 3.2924 & 3.8376 & TRN \\
\hline CHEMBL276087 & 152416 & 4.7696 & 3.2867 & TST \\
\hline CHEMBL18970 & 152416 & 4.8539 & 5.0763 & TRN \\
\hline CHEMBL18056 & 152416 & 3.5031 & 3.5587 & TRN \\
\hline CHEMBL18686 & 152416 & 5.1549 & 5.0763 & TRN \\
\hline CHEMBL275140 & 152416 & 3.1192 & 3.1119 & TRN \\
\hline CHEMBL18982 & 152416 & 3.3507 & 3.2883 & TRN \\
\hline CHEMBL18638 & 152416 & 3.0 & 3.0467 & TRN \\
\hline CHEMBL280453 & 152416 & 3.0 & 3.0447 & TRN \\
\hline CHEMBL18486 & 152416 & 5.2218 & 4.6348 & TST \\
\hline CHEMBL279363 & 152416 & 5.0458 & 4.6348 & TST \\
\hline CHEMBL18893 & 152416 & 3.1746 & 3.1038 & TRN \\
\hline CHEMBL429382 & 152416 & 3.71 & 3.7272 & TRN \\
\hline CHEMBL18607 & 152416 & 3.2924 & 3.2867 & TST \\
\hline CHEMBL18594 & 152416 & 4.284 & 4.2684 & TRN \\
\hline CHEMBL19155 & 152416 & 3.71 & 3.6135 & TST \\
\hline CHEMBL18294 & 152416 & 3.9626 & 3.7705 & TRN \\
\hline CHEMBL18104 & 152416 & 3.9626 & 3.7942 & TRN \\
\hline CHEMBL278058 & 152416 & 3.71 & 3.6834 & TST \\
\hline CHEMBL280331 & 152416 & 3.5031 & 3.5615 & TRN \\
\hline CHEMBL18585 & 152416 & 2.0 & 3.4646 & TRN \\
\hline
\end{tabular}





\begin{tabular}{|c|c|c|c|c|c|c|}
\hline & & \multicolumn{5}{|c|}{ Supplemental Table s2.txt } \\
\hline CHEMBL355016 & 43024 & 4.76699 & 99999999 & 995 & 4.6226 & TST \\
\hline CHEMBL353817 & 43024 & 4.7375 & 4.3487 & TRN & & \\
\hline CHEMBL170931 & 43024 & 3.6946 & 3.6919 & TRN & & \\
\hline CHEMBL352360 & 43024 & 2.5003 & 2.9909 & TRN & & \\
\hline CHEMBL168321 & 43024 & 4.7545 & 3.9322 & TRN & & \\
\hline CHEMBL171114 & 43024 & 4.3595 & 4.022 & TRN & & \\
\hline CHEMBL418037 & 43024 & 3.6635 & 3.8517 & TRN & & \\
\hline CHEMBL169673 & 43024 & 4.2255 & 3.2375 & TST & & \\
\hline CHEMBL352691 & 43024 & 4.2668 & 3.9301 & TRN & & \\
\hline CHEMBL352352 & 43024 & 2.5003 & 3.7351 & TRN & & \\
\hline CHEMBL169563 & 43024 & 4.2472 & 4.6308 & TST & & \\
\hline CHEMBL170951 & 43024 & 3.7959 & 3.7781 & TRN & & \\
\hline CHEMBL169404 & 43024 & 3.734 & 3.5723 & TRN & & \\
\hline CHEMBL168487 & 43024 & 4.762 & 4.6097 & TST & & \\
\hline CHEMBL353645 & 43024 & 4.7496 & 4.4305 & TRN & & \\
\hline CHEMBL354943 & 43024 & 4.3665 & 4.3136 & TRN & & \\
\hline CHEMBL408162 & 43024 & 2.5003 & 3.0215 & TRN & & \\
\hline CHEMBL368730 & 43024 & 4.3401 & 3.78 & TRN & & \\
\hline CHEMBL169678 & 43024 & 4.2596 & 3.443 & TST & & \\
\hline CHEMBL440929 & 43024 & 4.2628 & 4.6325 & TST & & \\
\hline CHEMBL352423 & 43024 & 4.7423 & 4.4177 & TST & & \\
\hline CHEMBL169773 & 43024 & 4.2798 & 4.5067 & TRN & & \\
\hline CHEMBL424547 & 43024 & 4.7305 & 4.535 & TRN & & \\
\hline CHEMBL264845 & 43024 & 4.0991 & 3.9867 & TRN & & \\
\hline CHEMBL169480 & 43024 & 4.3054 & 4.0969 & TST & & \\
\hline CHEMBL355549 & 43024 & 4.2464 & 4.4925 & TRN & & \\
\hline CHEMBL172615 & 43024 & 4.342 & 3.9686 & TST & & \\
\hline CHEMBL355871 & 43024 & 2.699 & 3.9996 & TRN & & \\
\hline CHEMBL354052 & 43024 & 4.6536 & 4.4208 & TRN & & \\
\hline CHEMBL353103 & 43024 & 4.2411 & 4.6748 & TST & & \\
\hline CHEMBL172036 & 43024 & 3.6882 & 3.3101 & TRN & & \\
\hline CHEMBL443037 & 43024 & 4.2573 & 4.5729 & TST & & \\
\hline CHEMBL353730 & 43024 & 4.6635 & 2.6666 & TRN & & \\
\hline CHEMBL422908 & 43024 & 4.7905 & 4.0221 & TST & & \\
\hline CHEMBL354078 & 43024 & 4.0888 & 3.8958 & TRN & & \\
\hline CHEMBL168996 & 43024 & 4.27 & 3.8434 & TST & & \\
\hline CHEMBL168225 & 43024 & 4.5591 & 4.4987 & TRN & & \\
\hline CHEMBL169755 & 43024 & 3.7258 & 4.2274 & TST & & \\
\hline CHEMBL265230 & 43024 & 2.5003 & 3.0282 & TRN & & \\
\hline CHEMBL355890 & 43024 & 4.3335 & 4.4326 & TRN & & \\
\hline CHEMBL169630 & 43024 & 4.7122 & 4.0526 & TRN & & \\
\hline CHEMBL354765 & 43024 & 4.2941 & 4.5844 & TST & & \\
\hline CHEMBL169499 & 43024 & 4.7167 & 4.4605 & TST & & \\
\hline CHEMBL168937 & 43024 & 4.4685 & 4.1563 & TST & & \\
\hline CHEMBL172395 & 43024 & 3.7212 & 3.6937 & TRN & & \\
\hline CHEMBL169431 & 43024 & 2.5003 & 3.2838 & TRN & & \\
\hline CHEMBL355324 & 43024 & 4.3325 & 4.5123 & TRN & & \\
\hline CHEMBL441495 & 43024 & 4.2464 & 3.8888 & TRN & & \\
\hline
\end{tabular}




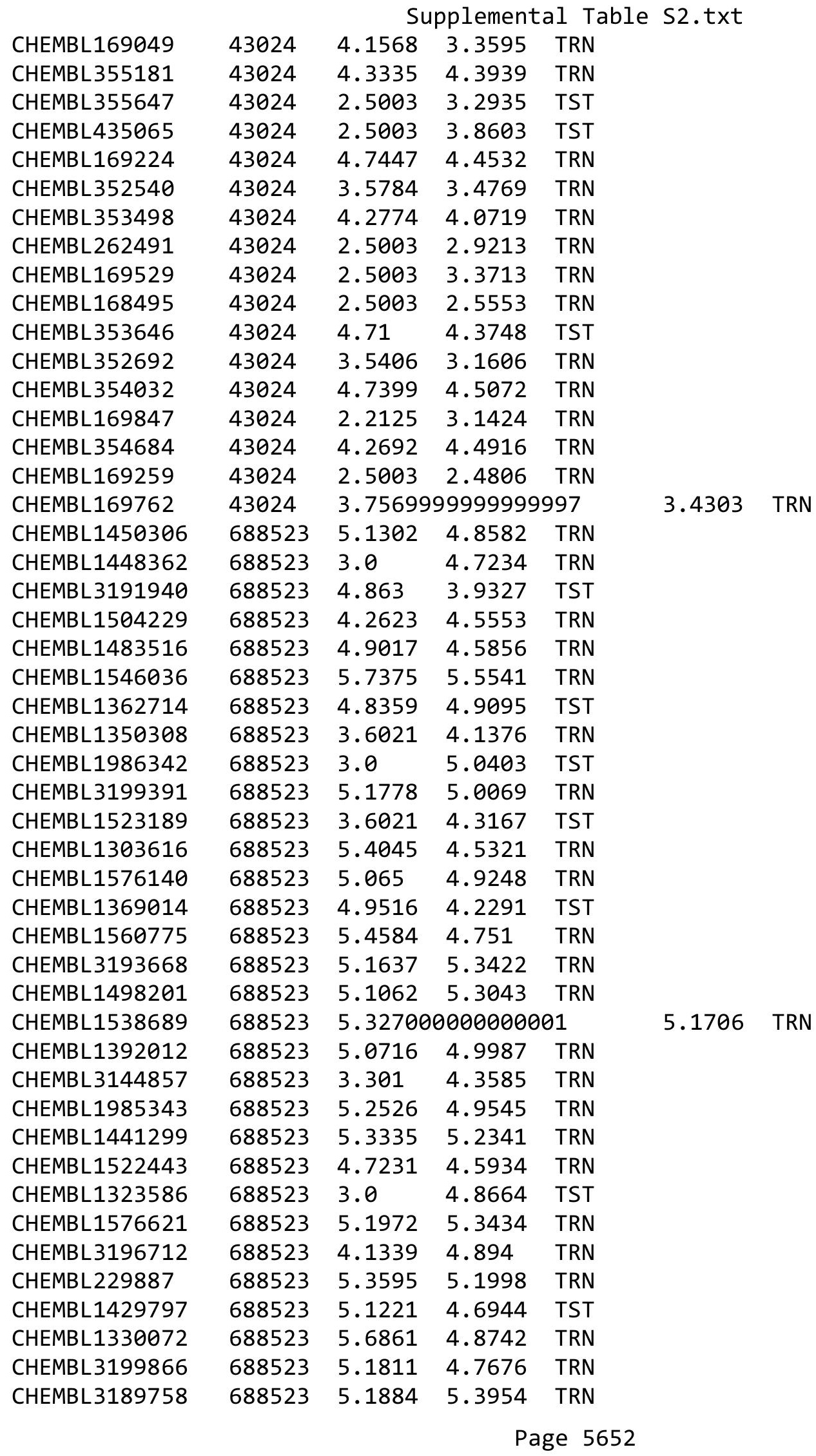




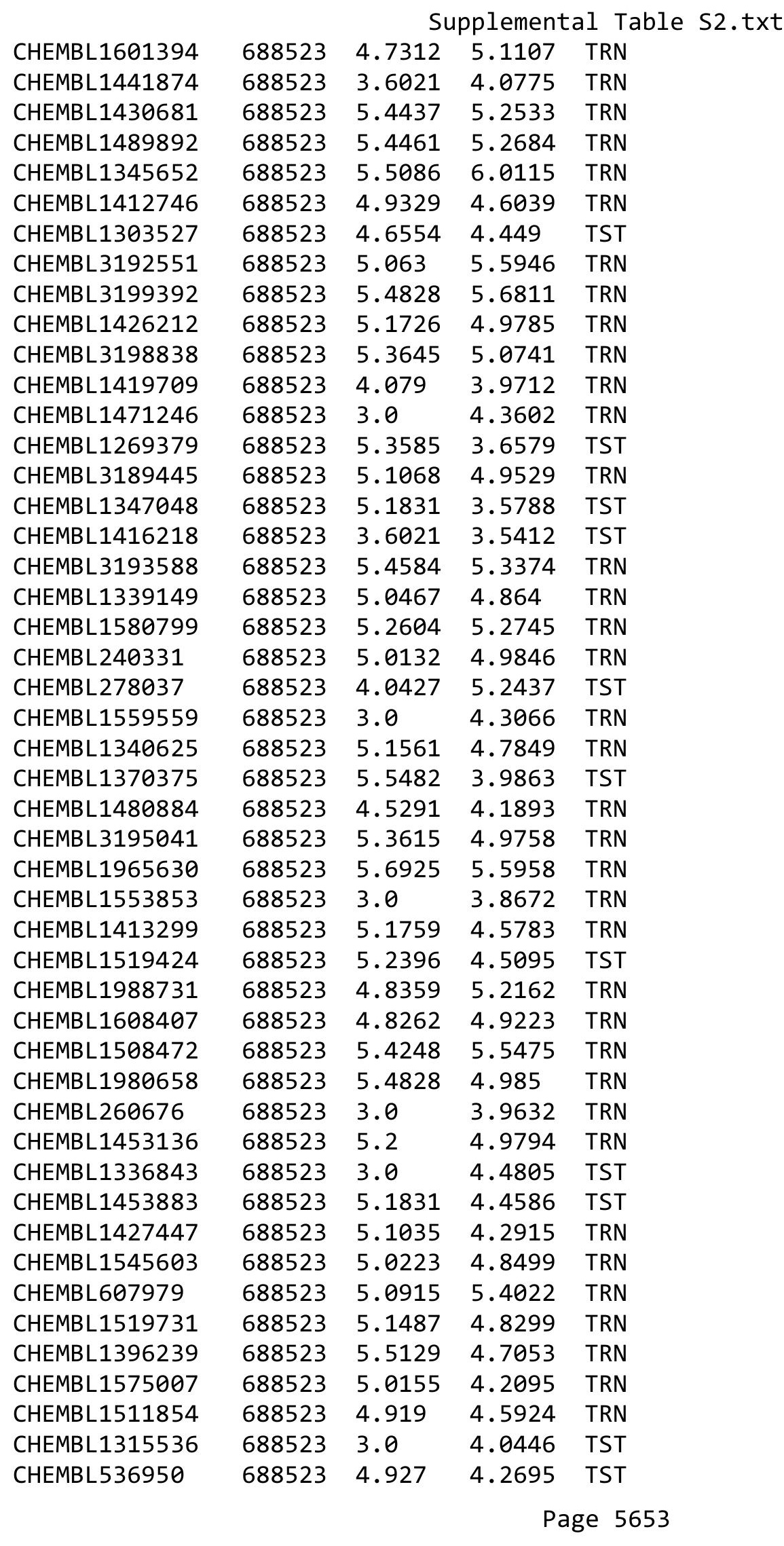




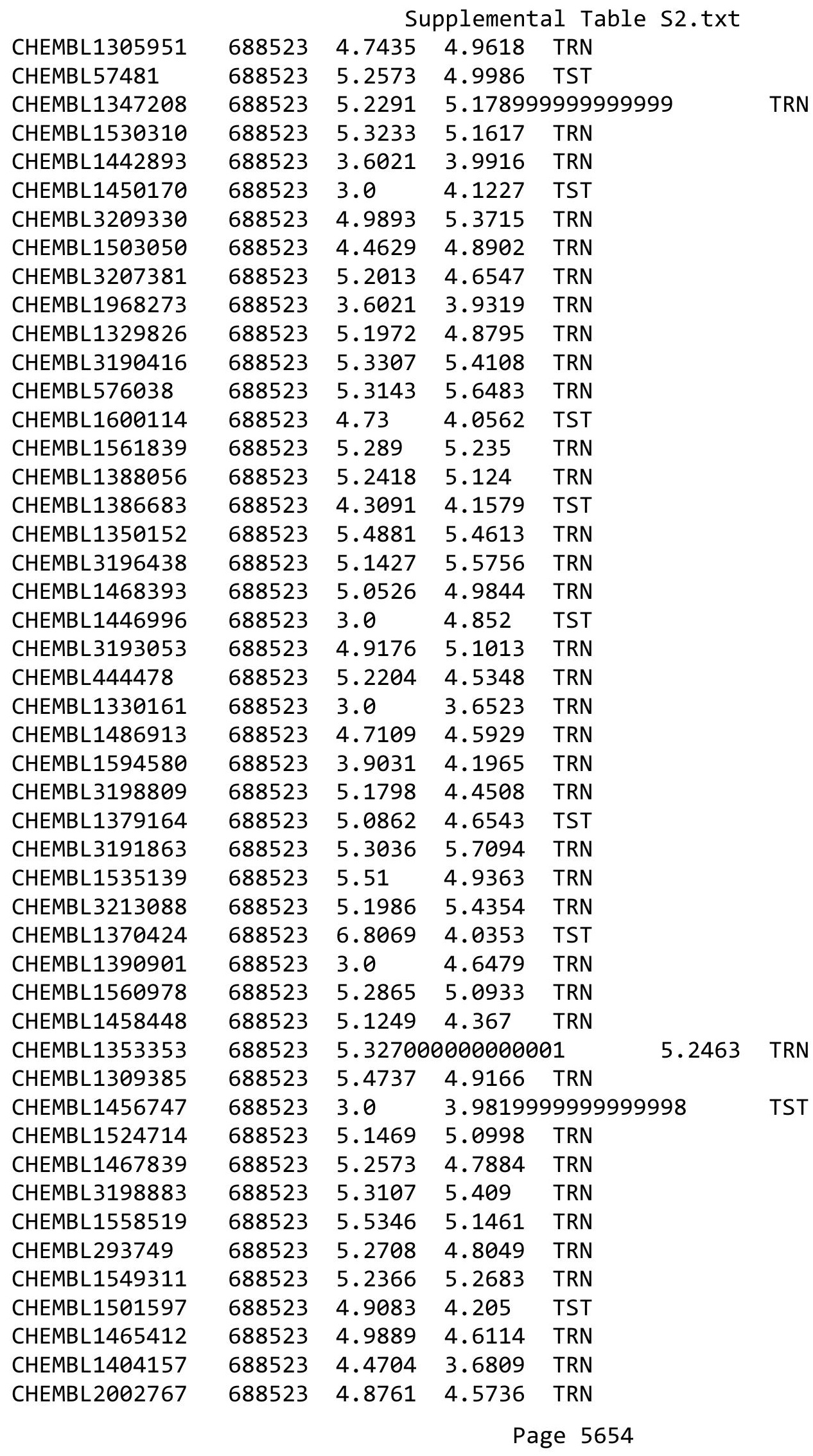




\begin{tabular}{|c|c|c|c|c|c|}
\hline \multicolumn{6}{|c|}{ Supplemental Table S2.txt } \\
\hline CHEMBL1322857 & 688523 & 3.0 & 3.7386 & TRN & \\
\hline CHEMBL 2028186 & 688523 & 4.0903 & 4.535 & TST & \\
\hline CHEMBL1499658 & 688523 & 4.303 & 4.6052 & TRN & \\
\hline CHEMBL1560459 & 688523 & 5.4895 & 4.6826 & TRN & \\
\hline CHEMBL1538616 & 688523 & 5.2048 & 5.008 & TRN & \\
\hline CHEMBL1605916 & 688523 & 3.0 & 4.2199 & TST & \\
\hline CHEMBL1595403 & 688523 & 4.2608 & 4.8372 & TRN & \\
\hline CHEMBL1362221 & 688523 & 5.2336 & 4.2931 & TRN & \\
\hline CHEMBL1455287 & 688523 & 3.0 & 3.8463 & TRN & \\
\hline CHEMBL1613510 & 688523 & 5.7077 & 4.8726 & TRN & \\
\hline CHEMBL3211732 & 688523 & 5.0237 & 4.7171 & TRN & \\
\hline CHEMBL1596766 & 688523 & 3.9031 & 3.8877 & TRN & \\
\hline CHEMBL1365118 & 688523 & 5.2798 & 5.6837 & TRN & \\
\hline CHEMBL 3210920 & 688523 & 4.7926 & 5.0933 & TRN & \\
\hline CHEMBL3191137 & 688523 & 5.1938 & 5.0192 & TRN & \\
\hline CHEMBL1559336 & 688523 & 4.5953 & 5.1158 & TRN & \\
\hline CHEMBL1417963 & 688523 & 5.1255 & 4.5563 & TRN & \\
\hline CHEMBL3196151 & 688523 & 5.4737 & 5.58899 & 99999999995 & TRN \\
\hline CHEMBL1302308 & 688523 & 5.2526 & 5.2835 & TRN & \\
\hline CHEMBL1563898 & 688523 & 5.1409 & 4.755 & TRN & \\
\hline CHEMBL1451040 & 688523 & 4.96899 & 99999999 & 4.9529 & TRN \\
\hline CHEMBL1524690 & 688523 & 4.5777 & 3.9606 & TST & \\
\hline CHEMBL1454442 & 688523 & 4.9212 & 4.5054 & TRN & \\
\hline CHEMBL1342394 & 688523 & 5.5017 & 5.034 & TRN & \\
\hline CHEMBL1405717 & 688523 & 4.6605 & 4.4192 & TRN & \\
\hline CHEMBL1317730 & 688523 & 4.3791 & 4.4198 & TRN & \\
\hline CHEMBL1579884 & 688523 & 5.6055 & 5.3492 & TRN & \\
\hline CHEMBL3198888 & 688523 & 5.1024 & 5.1291 & TRN & \\
\hline CHEMBL1607985 & 688523 & 5.4868 & 5.1572 & TRN & \\
\hline CHEMBL1407714 & 688523 & 5.6364 & 5.1397 & TRN & \\
\hline CHEMBL1312974 & 688523 & 4.7565 & 4.7617 & TST & \\
\hline CHEMBL1364802 & 688523 & 3.0 & 3.8056 & TST & \\
\hline CHEMBL 3214200 & 688523 & 4.9801 & 5.166 & TRN & \\
\hline CHEMBL1372495 & 688523 & 5.1367 & 4.7247 & TRN & \\
\hline CHEMBL1345911 & 688523 & 4.6171 & 5.2847 & TRN & \\
\hline CHEMBL1609006 & 688523 & 5.083 & 4.9629 & TRN & \\
\hline CHEMBL1578535 & 688523 & 5.1707 & 4.7605 & TRN & \\
\hline CHEMBL3191661 & 688523 & 4.3533 & 3.6903 & TRN & \\
\hline CHEMBL1458891 & 688523 & 4.9574 & 4.4445 & TRN & \\
\hline CHEMBL3191670 & 688523 & 5.2676 & 5.4161 & TRN & \\
\hline CHEMBL1468277 & 688523 & 5.4597 & 5.8154 & TRN & \\
\hline CHEMBL1561940 & 688523 & 5.4101 & 5.0526 & TRN & \\
\hline CHEMBL1323774 & 688523 & 5.1427 & 5.4423 & TRN & \\
\hline CHEMBL1595327 & 688523 & 4.8791 & 4.8633 & TRN & \\
\hline CHEMBL1993778 & 688523 & 4.5967 & 4.8588 & TRN & \\
\hline CHEMBL1328295 & 688523 & 3.6021 & 4.5267 & TST & \\
\hline CHEMBL1409586 & 688523 & 4.6047 & 4.0688 & TRN & \\
\hline CHEMBL1501392 & 688523 & 5.2757 & 4.6061 & TRN & \\
\hline
\end{tabular}




\begin{tabular}{|c|c|c|c|c|c|c|}
\hline & & \multicolumn{5}{|c|}{ Supplemental Table S2.txt } \\
\hline CHEMBL1517680 & 688523 & 5.5751 & 5.6635 & TRN & & \\
\hline CHEMBL1418360 & 688523 & 5.2958 & 5.9125 & TRN & & \\
\hline CHEMBL1600874 & 688523 & 5.2366 & 4.3396 & TRN & & \\
\hline CHEMBL3209081 & 688523 & 4.6334 & 4.1382 & TRN & & \\
\hline CHEMBL1384092 & 688523 & 5.2848 & 5.4352 & TRN & & \\
\hline CHEMBL1530229 & 688523 & 5.3197 & 5.2364 & TRN & & \\
\hline CHEMBL1311967 & 688523 & 4.9776 & 5.2344 & TRN & & \\
\hline CHEMBL1350132 & 688523 & 5.5421 & 5.3465 & TRN & & \\
\hline CHEMBL3193934 & 688523 & 5.4078 & 5.3041 & TRN & & \\
\hline CHEMBL1597646 & 688523 & 5.9469 & 5.3679 & TRN & & \\
\hline CHEMBL1432762 & 688523 & 5.4377 & 5.6017 & TRN & & \\
\hline CHEMBL1328065 & 688523 & 3.0 & 4.6614 & TRN & & \\
\hline CHEMBL1365860 & 688523 & 5.1752 & 4.5502 & TST & & \\
\hline CHEMBL1361335 & 688523 & 5.6576 & 5.3677 & TRN & & \\
\hline CHEMBL1406002 & 688523 & 5.3224 & 4.9661 & TRN & & \\
\hline CHEMBL1585679 & 688523 & 4.9706 & 4.5919 & TRN & & \\
\hline CHEMBL1584579 & 688523 & 5.1278 & 4.7453 & TRN & & \\
\hline CHEMBL1542061 & 688523 & 3.0 & 4.1743 & TRN & & \\
\hline CHEMBL1403156 & 688523 & 4.9694 & 4.5493 & TRN & & \\
\hline CHEMBL1517211 & 688523 & 3.0 & 3.5683 & TRN & & \\
\hline CHEMBL1350596 & 688523 & 5.1858 & 4.9141 & TRN & & \\
\hline CHEMBL1385899 & 688523 & 4.4541 & 3.8281 & TRN & & \\
\hline CHEMBL1435590 & 688523 & 5.05699 & 99999999 & 995 & 1.5406 & TRN \\
\hline CHEMBL1400117 & 688523 & 4.9129 & 5.46899 & 9999999999 & & TRN \\
\hline CHEMBL1397072 & 688523 & 5.0947 & 4.6728 & TRN & & \\
\hline CHEMBL1398964 & 688523 & 3.0 & 3.2057 & TRN & & \\
\hline CHEMBL1532298 & 688523 & 3.0 & 3.4087 & TRN & & \\
\hline CHEMBL3209532 & 688523 & 5.3615 & 5.5132 & TRN & & \\
\hline CHEMBL1477219 & 688523 & 5.4001 & 5.1398 & TRN & & \\
\hline CHEMBL1432079 & 688523 & 5.2182 & 5.6104 & TRN & & \\
\hline CHEMBL1507205 & 688523 & 5.24799 & 99999999 & & 4.7048 & TRN \\
\hline CHEMBL1341319 & 688523 & 5.4401 & 5.7155 & TRN & & \\
\hline CHEMBL1304877 & 688523 & 5.3325 & 4.3479 & TST & & \\
\hline CHEMBL3195777 & 688523 & 5.2832 & 5.6085 & TRN & & \\
\hline CHEMBL1548816 & 688523 & 4.87 & 4.8044 & TST & & \\
\hline CHEMBL51085 & 688523 & 4.9642 & 4.74100 & 0000000000 & & TRN \\
\hline CHEMBL1596841 & 688523 & 4.9122 & 4.2439 & TST & & \\
\hline CHEMBL 3194548 & 688523 & 5.1785 & 5.57700 & 0000000001 & & TRN \\
\hline CHEMBL3191546 & 688523 & 5.4045 & 5.6018 & TRN & & \\
\hline CHEMBL1538023 & 688523 & 3.6021 & 3.4715 & TRN & & \\
\hline CHEMBL1498308 & 688523 & 4.9183 & 5.2337 & TRN & & \\
\hline CHEMBL1530272 & 688523 & 5.4895 & 5.3116 & TRN & & \\
\hline CHEMBL1455587 & 688523 & 3.0 & 4.4804 & TRN & & \\
\hline CHEMBL3214433 & 688523 & 5.17200 & 30000000 & & 5.5258 & TRN \\
\hline CHEMBL3189351 & 688523 & 4.0114 & 3.4945 & TRN & & \\
\hline CHEMBL1457008 & 688523 & 5.3134 & 5.175 & TRN & & \\
\hline CHEMBL1379365 & 688523 & 3.6021 & 4.5119 & TST & & \\
\hline CHEMBL1549120 & 688523 & 3.6021 & 4.0321 & TRN & & \\
\hline
\end{tabular}




\begin{tabular}{|c|c|c|c|c|c|}
\hline & & \multicolumn{4}{|c|}{ Supplemental Table S2.txt } \\
\hline CHEMBL1381149 & 688523 & 4.5624 & 3.7643 & TRN & \\
\hline CHEMBL1981464 & 688523 & 5.2396 & 5.3578 & TRN & \\
\hline CHEMBL1603516 & 688523 & 5.06 & 5.0331 & TRN & \\
\hline CHEMBL 3207818 & 688523 & 4.4769 & 4.7211 & TRN & \\
\hline CHEMBL1611743 & 688523 & 3.0 & 3.8115 & TRN & \\
\hline CHEMBL1436318 & 688523 & 5.4353 & 5.8347 & TRN & \\
\hline CHEMBL1507051 & 688523 & 3.0 & 4.9917 & TRN & \\
\hline CHEMBL1466601 & 688523 & 5.3883 & 5.3715 & TRN & \\
\hline CHEMBL1393216 & 688523 & 5.0565 & 4.7559 & TRN & \\
\hline CHEMBL1543989 & 688523 & 5.4157 & 4.8327 & TRN & \\
\hline CHEMBL1381627 & 688523 & 4.9374 & 4.55399 & 9999999999 & TRN \\
\hline CHEMBL1537276 & 688523 & 5.5901 & 5.4998 & TRN & \\
\hline CHEMBL1392552 & 688523 & 3.9031 & 4.8337 & TRN & \\
\hline CHEMBL1315827 & 688523 & 3.0 & 3.5148 & TRN & \\
\hline CHEMBL1334670 & 688523 & 3.0 & 3.8569 & TRN & \\
\hline CHEMBL1351126 & 688523 & 5.4056 & 5.0431 & TRN & \\
\hline CHEMBL1491818 & 688523 & 5.2899 & 5.0982 & TRN & \\
\hline CHEMBL1312334 & 688523 & 5.2111 & 5.1011 & TRN & \\
\hline CHEMBL1546783 & 688523 & 5.3197 & 5.3902 & TRN & \\
\hline CHEMBL1496982 & 688523 & 5.1555 & 4.48600 & 2000000001 & TST \\
\hline CHEMBL1401164 & 688523 & 5.1778 & 5.7179 & TRN & \\
\hline CHEMBL1589547 & 688523 & 5.7011 & 5.0258 & TST & \\
\hline CHEMBL1406481 & 688523 & 3.6021 & 4.1309 & TRN & \\
\hline CHEMBL3198376 & 688523 & 4.2819 & 4.3948 & TRN & \\
\hline CHEMBL266997 & 688523 & 6.0 & 5.6503 & TRN & \\
\hline CHEMBL1565752 & 688523 & 5.4473 & 5.4468 & TRN & \\
\hline CHEMBL1376716 & 688523 & 3.0 & 4.043 & TST & \\
\hline CHEMBL1353516 & 688523 & 5.1931 & 4.9363 & TRN & \\
\hline CHEMBL1540300 & 688523 & 3.0 & 4.47199 & 99999999995 & TRN \\
\hline CHEMBL3210170 & 688523 & 5.1599 & 4.9863 & TRN & \\
\hline CHEMBL1583692 & 688523 & 5.1451 & 5.3814 & TRN & \\
\hline CHEMBL1487716 & 688523 & 5.1918 & 4.91 & TRN & \\
\hline CHEMBL151146 & 688523 & 4.5345 & 4.578 & TRN & \\
\hline CHEMBL1538386 & 688523 & 3.6021 & 3.7202 & TRN & \\
\hline CHEMBL1300059 & 688523 & 3.6021 & 4.5387 & TST & \\
\hline CHEMBL1400620 & 688523 & 4.4959 & 3.69199 & 99999999997 & TRN \\
\hline CHEMBL3214473 & 688523 & 5.38399 & 99999999 & 5.3458 & TRN \\
\hline CHEMBL1592490 & 688523 & 5.063 & 4.7487 & TRN & \\
\hline CHEMBL1304754 & 688523 & 5.0004 & 5.0731 & TRN & \\
\hline CHEMBL1385760 & 688523 & 3.6021 & 4.4278 & TRN & \\
\hline CHEMBL3192269 & 688523 & 5.0395 & 5.7317 & TRN & \\
\hline CHEMBL3190287 & 688523 & 4.3099 & 3.7197 & TRN & \\
\hline CHEMBL1352620 & 688523 & 5.0177 & 5.3676 & TRN & \\
\hline CHEMBL3194268 & 688523 & 5.1733 & 5.1006 & TRN & \\
\hline CHEMBL1310245 & 688523 & 5.6216 & 5.3674 & TRN & \\
\hline CHEMBL395808 & 688523 & 5.5031 & 5.2816 & TRN & \\
\hline CHEMBL1342821 & 688523 & 4.6262 & 5.0718 & TRN & \\
\hline CHEMBL1600228 & 688523 & 4.9859 & 5.2972 & TST & \\
\hline
\end{tabular}




\begin{tabular}{|c|c|c|c|c|c|c|}
\hline & & \multicolumn{5}{|c|}{ Supplemental Table S2.txt } \\
\hline CHEMBL1535285 & 688523 & 4.8642 & 3.9727 & TRN & & \\
\hline CHEMBL1449018 & 688523 & 5.2351 & 4.8514 & TRN & & \\
\hline CHEMBL3197724 & 688523 & 5.2269 & 4.3449 & TST & & \\
\hline CHEMBL1565557 & 688523 & 5.2823 & 5.0983 & TRN & & \\
\hline CHEMBL243596 & 688523 & 5.3197 & 4.4737 & TST & & \\
\hline CHEMBL1598092 & 688523 & 4.391 & 5.46899 & 99999995 & & TRN \\
\hline CHEMBL1406659 & 688523 & 5.4763 & 5.8711 & TRN & & \\
\hline CHEMBL 212504 & 688523 & 3.0 & 3.8159 & TST & & \\
\hline CHEMBL1350320 & 688523 & 5.3449 & 5.3725 & TRN & & \\
\hline CHEMBL353187 & 688523 & 5.767 & 5.1122 & TRN & & \\
\hline CHEMBL1336006 & 688523 & 5.51 & 5.2337 & TRN & & \\
\hline CHEMBL1330886 & 688523 & 4.8292 & 4.3412 & TST & & \\
\hline CHEMBL33103 & 688523 & 5.1549 & 4.7019 & TRN & & \\
\hline CHEMBL3198756 & 688523 & 4.5378 & 4.9938 & TRN & & \\
\hline CHEMBL1974180 & 688523 & 4.9516 & 4.9831 & TRN & & \\
\hline CHEMBL1504194 & 688523 & 5.3788 & 4.4855 & TRN & & \\
\hline CHEMBL1997990 & 688523 & 5.7328 & 5.5633 & TRN & & \\
\hline CHEMBL1257003 & 688523 & 4.909 & 5.2359 & TRN & & \\
\hline CHEMBL1410453 & 688523 & 3.9031 & 4.0138 & TRN & & \\
\hline CHEMBL177987 & 688523 & 4.9408 & 4.7271 & TST & & \\
\hline CHEMBL3191750 & 688523 & 5.4486 & 5.6041 & TRN & & \\
\hline CHEMBL1553654 & 688523 & 4.3818 & 4.1996 & TRN & & \\
\hline CHEMBL1577045 & 688523 & 5.2733 & 4.6945 & TRN & & \\
\hline CHEMBL1502376 & 688523 & 3.0 & 3.5762 & TRN & & \\
\hline CHEMBL3191511 & 688523 & 5.3188 & 4.9065 & TRN & & \\
\hline CHEMBL1482855 & 688523 & 5.3279 & 4.9192 & TRN & & \\
\hline CHEMBL3210076 & 688523 & 5.0535 & 5.6768 & TRN & & \\
\hline CHEMBL1313209 & 688523 & 3.0 & 3.4733 & TRN & & \\
\hline CHEMBL1507662 & 688523 & 3.0 & 4.9923 & TRN & & \\
\hline CHEMBL3208382 & 688523 & 5.426 & 4.8156 & TRN & & \\
\hline CHEMBL1400615 & 688523 & 5.1481 & 5.2114 & TRN & & \\
\hline CHEMBL1442526 & 688523 & 5.3904 & 4.927 & TRN & & \\
\hline CHEMBL1602587 & 688523 & 4.628 & 4.3363 & TRN & & \\
\hline CHEMBL1464039 & 688523 & 4.0971 & 3.8296 & TRN & & \\
\hline CHEMBL3214287 & 688523 & 5.05699 & 99999999 & 995 & 4.5706 & TRN \\
\hline CHEMBL1556611 & 688523 & 5.3458 & 5.5184 & TRN & & \\
\hline CHEMBL1548782 & 688523 & 5.1135 & 4.4492 & TST & & \\
\hline CHEMBL3212209 & 688523 & 5.5086 & 5.0667 & TRN & & \\
\hline CHEMBL1983220 & 688523 & 5.2449 & 4.7357 & TRN & & \\
\hline CHEMBL1380679 & 688523 & 4.8706 & 4.2755 & TRN & & \\
\hline CHEMBL1382785 & 688523 & 4.6379 & 4.1791 & TRN & & \\
\hline CHEMBL1486430 & 688523 & 5.3925 & 4.869 & TRN & & \\
\hline CHEMBL1340288 & 688523 & 3.0 & 3.9751 & TRN & & \\
\hline CHEMBL1306718 & 688523 & 5.1457 & 4.4874 & TST & & \\
\hline CHEMBL1403735 & 688523 & 3.0 & 4.3176 & TST & & \\
\hline CHEMBL1369365 & 688523 & 5.4841 & 5.1815 & TRN & & \\
\hline CHEMBL1344184 & 688523 & 4.6349 & 4.207 & TRN & & \\
\hline CHEMBL1560276 & 688523 & 5.2277 & 4.5573 & TST & & \\
\hline
\end{tabular}




\begin{tabular}{|c|c|c|c|c|}
\hline \multicolumn{5}{|c|}{ Supplemental Table S2.txt } \\
\hline CHEMBL1366767 & 688523 & 3.0 & 3.9751 & TRN \\
\hline CHEMBL1422739 & 688523 & 5.2612 & 4.8385 & TRN \\
\hline CHEMBL1385889 & 688523 & 5.0762 & 4.8249 & TRN \\
\hline CHEMBL 244743 & 688523 & 4.9458 & 4.7593 & TRN \\
\hline CHEMBL3209487 & 688523 & 5.1221 & 5.1003 & TRN \\
\hline CHEMBL1928491 & 688523 & 4.93 & 5.1609 & TRN \\
\hline CHEMBL1430606 & 688523 & 4.2814 & 4.14 & TRN \\
\hline CHEMBL1302927 & 688523 & 4.0407 & 4.3031 & TRN \\
\hline CHEMBL 3193224 & 688523 & 4.8359 & 4.8247 & TRN \\
\hline CHEMBL1508933 & 688523 & 5.3161 & 4.9288 & TRN \\
\hline CHEMBL1587526 & 688523 & 5.056 & 4.2391 & TRN \\
\hline CHEMBL1605436 & 688523 & 5.1959 & 4.9991 & TRN \\
\hline CHEMBL1487562 & 688523 & 3.0 & 4.5803 & TST \\
\hline CHEMBL3193997 & 688523 & 4.8784 & 5.237 & TRN \\
\hline CHEMBL1327880 & 688523 & 4.5521 & 5.5153 & TST \\
\hline CHEMBL3198102 & 688523 & 5.2321 & 5.1781 & TRN \\
\hline CHEMBL1505816 & 688523 & 4.8674 & 5.1517 & TRN \\
\hline CHEMBL3210409 & 688523 & 5.3288 & 5.1549 & TRN \\
\hline CHEMBL1566370 & 688523 & 5.4089 & 5.1175 & TST \\
\hline CHEMBL1485442 & 688523 & 4.0379 & 4.5125 & TRN \\
\hline CHEMBL3191761 & 688523 & 3.6021 & 4.2909 & TRN \\
\hline CHEMBL3189330 & 688523 & 5.0991 & 5.1877 & TRN \\
\hline CHEMBL1308404 & 688523 & 4.5699 & 4.8534 & TRN \\
\hline CHEMBL1996741 & 688523 & 4.9151 & 4.8955 & TST \\
\hline CHEMBL322970 & 688523 & 4.93 & 5.2092 & TRN \\
\hline CHEMBL609036 & 688523 & 5.1993 & 5.4188 & TRN \\
\hline CHEMBL3196732 & 688523 & 5.5003 & 5.0138 & TRN \\
\hline CHEMBL1438778 & 688523 & 3.6021 & 3.6554 & TRN \\
\hline CHEMBL3214106 & 688523 & 5.4921 & 5.2122 & TRN \\
\hline CHEMBL1417628 & 688523 & 5.3224 & 5.0164 & TRN \\
\hline CHEMBL1469246 & 688523 & 5.064 & 4.1674 & TRN \\
\hline CHEMBL3191378 & 688523 & 5.3893 & 5.3762 & TRN \\
\hline CHEMBL1537012 & 688523 & 4.7627 & 4.8499 & TRN \\
\hline CHEMBL1423690 & 688523 & 4.6189 & 4.602 & TRN \\
\hline CHEMBL1331639 & 688523 & 4.2273 & 4.9962 & TRN \\
\hline CHEMBL1518073 & 688523 & 3.9031 & 3.8068 & TRN \\
\hline CHEMBL 2005744 & 688523 & 5.2403 & 5.0313 & TRN \\
\hline CHEMBL1464937 & 688523 & 3.0 & 4.3923 & TST \\
\hline CHEMBL1528749 & 688523 & 5.4413 & 5.2665 & TRN \\
\hline CHEMBL3197494 & 688523 & 5.1163 & 5.4569 & TST \\
\hline CHEMBL1976374 & 688523 & 4.2117 & 4.9305 & TRN \\
\hline CHEMBL1606430 & 688523 & 5.1391 & 4.8818 & TRN \\
\hline CHEMBL1988857 & 688523 & 5.4237 & 5.1351 & TRN \\
\hline CHEMBL1338764 & 688523 & 4.3977 & 4.2734 & TRN \\
\hline CHEMBL3190771 & 688523 & 5.7375 & 5.0172 & TRN \\
\hline CHEMBL1532268 & 688523 & 4.967 & 5.124 & TRN \\
\hline CHEMBL1466237 & 688523 & 3.9031 & 4.3035 & TST \\
\hline CHEMBL3198902 & 688523 & 5.1871 & 5.5759 & TRN \\
\hline
\end{tabular}




\begin{tabular}{|c|c|c|c|c|c|c|}
\hline & & \multicolumn{5}{|c|}{ Supplemental Table S2.txt } \\
\hline CHEMBL3189388 & 688523 & 5.5498 & 5.4118 & TRN & & \\
\hline CHEMBL3213196 & 688523 & 5.1965 & 4.7412 & TRN & & \\
\hline CHEMBL1604427 & 688523 & 5.0453 & 4.7573 & TRN & & \\
\hline CHEMBL1587003 & 688523 & 5.2048 & 5.8878 & TRN & & \\
\hline CHEMBL1458674 & 688523 & 5.7799 & 5.3612 & TRN & & \\
\hline CHEMBL1997491 & 688523 & 4.6302 & 4.5578 & TRN & & \\
\hline CHEMBL1332474 & 688523 & 5.2434 & 4.8345 & TRN & & \\
\hline CHEMBL1602678 & 688523 & \multicolumn{3}{|c|}{5.162999999999999} & 5.2113 & TRN \\
\hline CHEMBL1599030 & 688523 & 3.0 & 4.2595 & TST & & \\
\hline CHEMBL1504378 & 688523 & 4.8422 & 4.9792 & TRN & & \\
\hline CHEMBL1504355 & 688523 & 5.1101 & 5.2441 & TRN & & \\
\hline CHEMBL1396253 & 688523 & 3.9031 & 4.4015 & TRN & & \\
\hline CHEMBL1332872 & 688523 & 5.0783 & 5.6628 & TRN & & \\
\hline CHEMBL1376200 & 688523 & 5.0899 & 4.8241 & TRN & & \\
\hline CHEMBL1466082 & 688523 & 5.1506 & 5.4174 & TRN & & \\
\hline CHEMBL1608115 & 688523 & 4.787 & 4.2467 & TRN & & \\
\hline CHEMBL1451762 & 688523 & 4.8972 & 4.3752 & TRN & & \\
\hline CHEMBL1444764 & 688523 & 5.3788 & 4.5614 & TRN & & \\
\hline CHEMBL1370010 & 688523 & 5.5376 & 5.2312 & TRN & & \\
\hline CHEMBL3196592 & 688523 & 5.3747 & 5.1387 & TRN & & \\
\hline CHEMBL1594057 & 688523 & 5.1669 & 4.5018 & TRN & & \\
\hline CHEMBL1532407 & 688523 & 4.0201 & 3.8089 & TST & & \\
\hline CHEMBL1333363 & 688523 & 4.4035 & 3.9976 & TRN & & \\
\hline CHEMBL1511834 & 688523 & 3.0 & 3.8647 & TST & & \\
\hline CHEMBL1351618 & 688523 & 4.1886 & 5.3378 & TRN & & \\
\hline CHEMBL1559502 & 688523 & 5.3872 & 4.7562 & TRN & & \\
\hline CHEMBL1346564 & 688523 & 5.7545 & 5.7327 & TRN & & \\
\hline CHEMBL1584321 & 688523 & 5.0348 & 4.3907 & TRN & & \\
\hline CHEMBL3197799 & 688523 & 5.6615 & 5.6 & TRN & & \\
\hline CHEMBL3195242 & 688523 & \multicolumn{3}{|c|}{5.382000000000001} & 5.4932 & TRN \\
\hline CHEMBL3199815 & 688523 & 3.301 & 4.3738 & TST & & \\
\hline CHEMBL 3189408 & 688523 & 5.0872 & 4.723 & TRN & & \\
\hline CHEMBL1605787 & 688523 & 4.9722 & 4.4546 & TRN & & \\
\hline CHEMBL1370590 & 688523 & 3.0 & 3.6346 & TRN & & \\
\hline CHEMBL3196335 & 688523 & 5.1046 & 4.9767 & TRN & & \\
\hline CHEMBL1611931 & 688523 & 5.1175 & 4.7943 & TRN & & \\
\hline CHEMBL1367474 & 688523 & 4.7726 & 4.6885 & TST & & \\
\hline CHEMBL1495606 & 688523 & 3.0 & 4.0656 & TRN & & \\
\hline CHEMBL565660 & 688523 & 4.7082 & 5.3937 & TRN & & \\
\hline CHEMBL1351598 & 688523 & 5.3605 & 4.6048 & TRN & & \\
\hline CHEMBL1447743 & 688523 & 4.0411 & 4.9219 & TRN & & \\
\hline CHEMBL1577794 & 688523 & 3.0 & 4.4526 & TRN & & \\
\hline CHEMBL3190975 & 688523 & 5.5129 & 5.4196 & TRN & & \\
\hline CHEMBL1484906 & 688523 & 4.7762 & 4.305 & TST & & \\
\hline CHEMBL1332357 & 688523 & 4.9172 & 5.4952 & TRN & & \\
\hline CHEMBL3199453 & 688523 & 3.0 & 3.6599 & TRN & & \\
\hline CHEMBL1559437 & 688523 & 5.2832 & 5.3187 & TRN & & \\
\hline CHEMBL1327870 & 688523 & 5.4425 & 5.4339 & TRN & & \\
\hline
\end{tabular}




\begin{tabular}{|c|c|c|c|c|c|}
\hline \multicolumn{6}{|c|}{ Supplemental Table S2.txt } \\
\hline CHEMBL1349475 & 688523 & 3.0 & 3.7963 & TRN & \\
\hline CHEMBL 3193400 & 688523 & 5.1319 & 5.1833 & TRN & \\
\hline CHEMBL1455292 & 688523 & 5.0424 & 4.2166 & TST & \\
\hline CHEMBL1564105 & 688523 & 5.2403 & 4.5855 & TRN & \\
\hline CHEMBL1540071 & 688523 & 5.3325 & 5.772 & TRN & \\
\hline CHEMBL 3194421 & 688523 & 5.2262 & 5.4885 & TRN & \\
\hline CHEMBL1432135 & 688523 & 5.0783 & 5.0382 & TRN & \\
\hline CHEMBL1323029 & 688523 & 5.4634 & 5.3572 & TRN & \\
\hline CHEMBL1402845 & 688523 & 4.9987 & 4.8312 & TRN & \\
\hline CHEMBL1456606 & 688523 & 5.3382 & 4.90300 & 00000000005 & TST \\
\hline CHEMBL1407847 & 688523 & 4.9205 & 4.1756 & TST & \\
\hline CHEMBL 1499630 & 688523 & 3.0 & 4.1069 & TRN & \\
\hline CHEMBL 2006519 & 688523 & 3.0 & 3.5098 & TRN & \\
\hline CHEMBL1321811 & 688523 & 4.9658 & 4.0472 & TRN & \\
\hline CHEMBL1319645 & 688523 & 5.0477 & 4.9038 & TRN & \\
\hline CHEMBL1341867 & 688523 & 3.0 & 4.1883 & TST & \\
\hline CHEMBL1586914 & 688523 & 5.4698 & 4.9937 & TRN & \\
\hline CHEMBL1439081 & 688523 & 4.1497 & 3.94199 & 99999999997 & TRN \\
\hline CHEMBL 3199692 & 688523 & 5.1818 & 5.0 & TRN & \\
\hline CHEMBL52 & 688523 & 4.6515 & 4.9301 & TRN & \\
\hline CHEMBL1459258 & 688523 & 3.0 & 3.88100 & 00000000002 & TRN \\
\hline CHEMBL 3197810 & 688523 & 5.4789 & 5.4179 & TRN & \\
\hline CHEMBL1386802 & 688523 & 4.9767 & 4.9298 & TRN & \\
\hline CHEMBL 3210305 & 688523 & 4.9714 & 5.1671 & TRN & \\
\hline CHEMBL 3199610 & 688523 & 5.7033 & 5.2455 & TRN & \\
\hline CHEMBL1173475 & 688523 & 4.0067 & 5.1828 & TRN & \\
\hline CHEMBL1555276 & 688523 & 3.6021 & 4.0028 & TST & \\
\hline CHEMBL1302756 & 688523 & 3.0 & 3.8724 & TRN & \\
\hline CHEMBL1391622 & 688523 & 3.0 & 3.9677 & TST & \\
\hline CHEMBL1329322 & 688523 & 5.6038 & 4.8444 & TRN & \\
\hline CHEMBL3192515 & 688523 & 3.0 & 4.2517 & TRN & \\
\hline CHEMBL1580660 & 688523 & 3.0 & 3.9115 & TST & \\
\hline CHEMBL 250450 & 688523 & 5.1986 & 4.974 & TRN & \\
\hline CHEMBL1350316 & 688523 & 3.0 & 3.8157 & TRN & \\
\hline CHEMBL1343898 & 688523 & 4.9884 & 5.0006 & TRN & \\
\hline CHEMBL3214111 & 688523 & 5.3757 & 5.0915 & TRN & \\
\hline CHEMBL1535485 & 688523 & 4.901 & 5.0455 & TRN & \\
\hline CHEMBL52347 & 688523 & 3.9031 & 4.5876 & TST & \\
\hline CHEMBL1464801 & 688523 & 4.7964 & 3.9996 & TRN & \\
\hline CHEMBL1343259 & 688523 & 5.1818 & 4.6654 & TST & \\
\hline CHEMBL1389127 & 688523 & 5.2132 & 4.6441 & TRN & \\
\hline CHEMBL3194497 & 688523 & 4.8784 & 4.5728 & TRN & \\
\hline CHEMBL3195953 & 688523 & 5.3401 & 4.9247 & TRN & \\
\hline CHEMBL1429158 & 688523 & 5.3716 & 3.9945 & TRN & \\
\hline CHEMBL1384056 & 688523 & 4.8861 & 5.1853 & TRN & \\
\hline CHEMBL1556956 & 688523 & 4.565 & 3.7679 & TRN & \\
\hline CHEMBL1556140 & 688523 & 5.2668 & 5.0187 & TRN & \\
\hline CHEMBL87706 & 688523 & 5.295 & 5.1132 & TRN & \\
\hline
\end{tabular}




\begin{tabular}{|c|c|c|c|c|c|}
\hline \multicolumn{6}{|c|}{ Supplemental Table S2.txt } \\
\hline CHEMBL 3214255 & 688523 & 3.0 & 4.1423 & TST & \\
\hline CHEMBL1309568 & 688523 & 4.2041 & 4.3367 & TRN & \\
\hline CHEMBL1508485 & 688523 & 5.4191 & 5.2618 & TRN & \\
\hline CHEMBL1332506 & 688523 & 4.8739 & 4.0884 & TRN & \\
\hline CHEMBL1385571 & 688523 & 5.5171 & 5.2115 & TRN & \\
\hline CHEMBL1430557 & 688523 & 5.2321 & 5.1762 & TRN & \\
\hline CHEMBL1398648 & 688523 & 5.4498 & 5.4974 & TRN & \\
\hline CHEMBL1975516 & 688523 & 3.0 & 4.1495 & TRN & \\
\hline CHEMBL3189605 & 688523 & 5.2774 & 5.6907 & TRN & \\
\hline CHEMBL1514534 & 688523 & 5.2848 & 4.8261 & TRN & \\
\hline CHEMBL1361740 & 688523 & 3.0 & 4.0007 & TST & \\
\hline CHEMBL1583339 & 688523 & 3.9031 & 3.9361 & TRN & \\
\hline CHEMBL3193202 & 688523 & 5.6234 & 5.7235 & TRN & \\
\hline CHEMBL 3190141 & 688523 & 5.3449 & 5.28700 & 0000000001 & TRN \\
\hline CHEMBL3211836 & 688523 & 5.5331 & 5.3345 & TRN & \\
\hline CHEMBL3190925 & 688523 & 5.2055 & 5.0562 & TRN & \\
\hline CHEMBL1330284 & 688523 & 5.6383 & 5.1907 & TRN & \\
\hline CHEMBL3199380 & 688523 & 5.3002 & 4.5579 & TRN & \\
\hline CHEMBL1444899 & 688523 & 4.5014 & 5.0034 & TRN & \\
\hline CHEMBL1367504 & 688523 & 5.1343 & 4.8804 & TRN & \\
\hline CHEMBL1581335 & 688523 & 4.83 & 4.7673 & TRN & \\
\hline CHEMBL1558577 & 688523 & 5.0506 & 4.8169 & TRN & \\
\hline CHEMBL453038 & 688523 & 3.301 & 4.8107 & TRN & \\
\hline CHEMBL3190343 & 688523 & 4.8351 & 4.6215 & TRN & \\
\hline CHEMBL3208556 & 688523 & 3.0 & 3.6478 & TRN & \\
\hline CHEMBL1528088 & 688523 & 5.3625 & 4.774 & TRN & \\
\hline CHEMBL1557672 & 688523 & 5.32706 & 30000000 & 5.5523 & TRN \\
\hline CHEMBL1472210 & 688523 & 3.6021 & 3.8001 & TRN & \\
\hline CHEMBL1506913 & 688523 & 4.9226 & 4.7914 & TRN & \\
\hline CHEMBL1542301 & 688523 & 3.9031 & 3.7327 & TRN & \\
\hline CHEMBL1327262 & 688523 & 5.5622 & 5.1854 & TRN & \\
\hline CHEMBL1310492 & 688523 & 4.9465 & 4.6955 & TRN & \\
\hline CHEMBL1504284 & 688523 & 4.6613 & 3.9428 & TRN & \\
\hline CHEMBL1425384 & 688523 & 3.0 & 4.6088 & TST & \\
\hline CHEMBL1490436 & 688523 & 5.2373 & 4.7376 & TRN & \\
\hline CHEMBL1447972 & 688523 & 3.0 & 4.1402 & TRN & \\
\hline CHEMBL3212279 & 688523 & 4.9923 & 5.0396 & TRN & \\
\hline CHEMBL1600947 & 688523 & 5.2248 & 5.4061 & TRN & \\
\hline CHEMBL3196947 & 688523 & 5.5058 & 5.2406 & TRN & \\
\hline CHEMBL1594507 & 688523 & 5.0526 & 5.2576 & TRN & \\
\hline CHEMBL78257 & 688523 & 4.8665 & 4.92 & TRN & \\
\hline CHEMBL1468796 & 688523 & 5.3179 & 5.2668 & TRN & \\
\hline CHEMBL1444725 & 688523 & 5.6517 & 4.3054 & TST & \\
\hline CHEMBL 3208427 & 688523 & 5.289 & 5.2762 & TRN & \\
\hline CHEMBL3198029 & 688523 & 4.9714 & 4.9084 & TRN & \\
\hline CHEMBL 2003887 & 688523 & 3.301 & 4.6809 & TST & \\
\hline CHEMBL1577216 & 688523 & 5.3536 & 4.8562 & TRN & \\
\hline CHEMBL1541173 & 688523 & 3.6021 & 4.4344 & TRN & \\
\hline
\end{tabular}




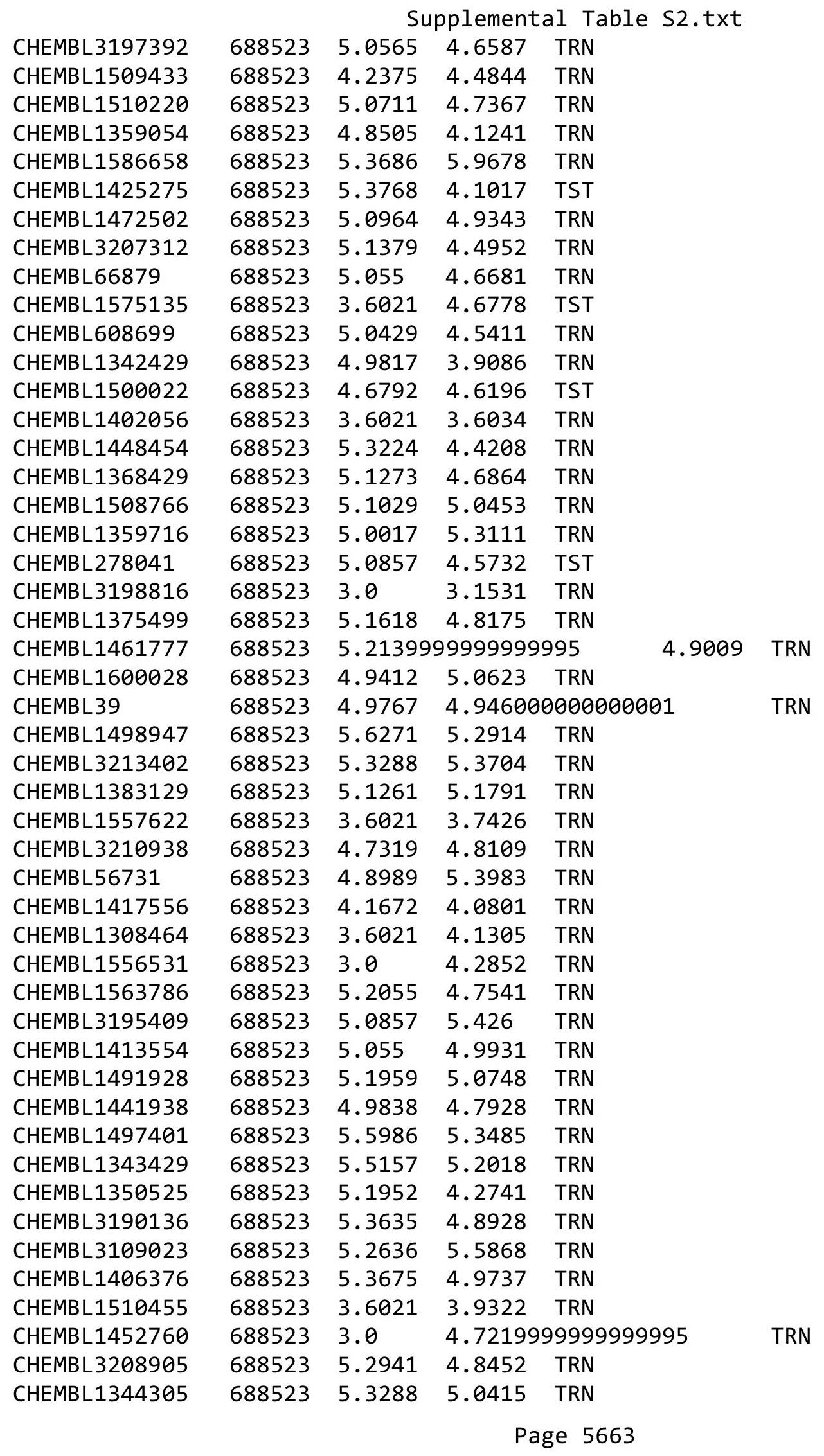




\begin{tabular}{|c|c|c|c|c|c|}
\hline & & \multicolumn{4}{|c|}{ Supplemental Table S2.txt } \\
\hline CHEMBL1471450 & 688523 & 5.1952 & 5.2342 & TRN & \\
\hline CHEMBL1517684 & 688523 & 5.2495 & 4.9436 & TRN & \\
\hline CHEMBL3190655 & 688523 & 5.5436 & 5.5583 & TRN & \\
\hline CHEMBL1320559 & 688523 & 4.3781 & 4.9274 & TRN & \\
\hline CHEMBL1488474 & 688523 & 5.3116 & 5.2491 & TRN & \\
\hline CHEMBL1527214 & 688523 & 5.2503 & 5.1772 & TRN & \\
\hline CHEMBL1561729 & 688523 & 3.0 & 3.9338 & TRN & \\
\hline CHEMBL1571328 & 688523 & 5.3925 & 4.8866 & TRN & \\
\hline CHEMBL307893 & 688523 & 5.3737 & 5.1146 & TRN & \\
\hline CHEMBL1445086 & 688523 & 4.5468 & 4.286006 & 00000000005 & TRN \\
\hline CHEMBL 395590 & 688523 & 5.1445 & 5.3908 & TRN & \\
\hline CHEMBL 3194974 & 688523 & 5.0778 & 5.40799 & 99999999995 & TRN \\
\hline CHEMBL1580019 & 688523 & 3.0 & 3.4313 & TRN & \\
\hline CHEMBL1583337 & 688523 & 3.0 & 4.4437 & TST & \\
\hline CHEMBL1558949 & 688523 & 3.0 & 4.1998 & TST & \\
\hline CHEMBL 3198487 & 688523 & 4.3942 & 4.9186 & TRN & \\
\hline CHEMBL3198277 & 688523 & 5.399 & 5.2023 & TRN & \\
\hline CHEMBL1488896 & 688523 & 3.0 & 4.2343 & TRN & \\
\hline CHEMBL1377923 & 688523 & 4.6328 & 4.5047 & TST & \\
\hline CHEMBL1358014 & 688523 & 3.0 & 4.2858 & TST & \\
\hline CHEMBL1977734 & 688523 & 5.3696 & 5.1063 & TRN & \\
\hline CHEMBL1324819 & 688523 & 3.0 & 4.5462 & TST & \\
\hline CHEMBL3208276 & 688523 & \multicolumn{3}{|c|}{5.382000000000001} & TRN \\
\hline CHEMBL1462372 & 688523 & 4.1079 & 3.4546 & TRN & \\
\hline CHEMBL1426378 & 688523 & 4.2041 & 4.0467 & TST & \\
\hline CHEMBL1595235 & 688523 & 3.0 & 3.45899 & 99999999996 & TRN \\
\hline CHEMBL1570213 & 688523 & 5.3401 & 5.2473 & TRN & \\
\hline CHEMBL1403434 & 688523 & 4.963 & 4.7649 & TRN & \\
\hline CHEMBL 272465 & 688523 & 4.5993 & 4.2976 & TRN & \\
\hline CHEMBL1543965 & 688523 & 5.3072 & 4.6295 & TST & \\
\hline CHEMBL1463203 & 688523 & 4.4845 & 4.7239 & TRN & \\
\hline CHEMBL3195066 & 688523 & 5.5751 & 5.4716 & TRN & \\
\hline CHEMBL358546 & 688523 & 4.9987 & 5.0154 & TRN & \\
\hline CHEMBL3191937 & 688523 & 5.3028 & 5.4695 & TRN & \\
\hline CHEMBL1365341 & 688523 & 5.1331 & 4.5114 & TRN & \\
\hline CHEMBL3194972 & 688523 & 5.4306 & 4.9815 & TRN & \\
\hline CHEMBL1371504 & 688523 & 4.9183 & 5.5394 & TRN & \\
\hline CHEMBL1541882 & 688523 & 4.5436 & 3.9512 & TRN & \\
\hline CHEMBL3207965 & 688523 & 5.567 & 5.2014 & TRN & \\
\hline CHEMBL3392035 & 688523 & 3.0 & 4.2901 & TRN & \\
\hline CHEMBL1352170 & 688523 & 4.2935 & 4.1145 & TRN & \\
\hline CHEMBL1581548 & 688523 & 5.4377 & 5.2326 & TRN & \\
\hline CHEMBL1332029 & 688523 & 5.5406 & 5.5254 & TRN & \\
\hline CHEMBL1424085 & 688523 & 5.2652 & 4.8085 & TRN & \\
\hline CHEMBL1430473 & 688523 & 3.301 & 4.124 & TST & \\
\hline CHEMBL1369958 & 688523 & 3.0 & 3.87600 & 00000000003 & TRN \\
\hline CHEMBL1530356 & 688523 & 5.1244 & 5.5529 & TRN & \\
\hline CHEMBL1427517 & 688523 & 4.7005 & 4.9963 & TST & \\
\hline
\end{tabular}




\begin{tabular}{|c|c|c|c|c|c|c|}
\hline & & \multicolumn{5}{|c|}{ Supplemental Table S2.txt } \\
\hline CHEMBL1570477 & 688523 & 4.1389 & 4.5458 & TST & & \\
\hline CHEMBL3192470 & 688523 & 5.2495 & 5.6094 & TRN & & \\
\hline CHEMBL3195143 & 688523 & 5.4413 & 5.1184 & TRN & & \\
\hline CHEMBL1301573 & 688523 & 5.3089 & 5.1926 & TRN & & \\
\hline CHEMBL1349586 & 688523 & 4.0894 & 4.3016 & TRN & & \\
\hline CHEMBL1351621 & 688523 & 5.0872 & 5.1322 & TRN & & \\
\hline CHEMBL1529946 & 688523 & \multicolumn{3}{|c|}{5.757000000000001} & 4.6933 & TRN \\
\hline CHEMBL1571290 & 688523 & 3.6021 & 3.4036 & TST & & \\
\hline CHEMBL3190174 & 688523 & 5.1561 & 5.2218 & TRN & & \\
\hline CHEMBL1305119 & 688523 & 4.6176 & 4.2253 & TRN & & \\
\hline CHEMBL1529601 & 688523 & 4.2516 & 4.51399 & 9999999999 & & $m$ \\
\hline CHEMBL1468371 & 688523 & 5.098 & 5.0001 & TRN & & \\
\hline CHEMBL1360351 & 688523 & 5.5376 & 5.239 & TRN & & \\
\hline CHEMBL1315133 & 688523 & 5.3947 & 5.1665 & TRN & & \\
\hline CHEMBL3188273 & 688523 & 4.0338 & 3.8281 & TRN & & \\
\hline CHEMBL1455971 & 688523 & 3.0 & 4.0157 & TRN & & \\
\hline CHEMBL1320884 & 688523 & 4.9527 & 5.0482 & TRN & & \\
\hline CHEMBL547833 & 688523 & 5.3915 & 5.3328 & TRN & & \\
\hline CHEMBL1546415 & 688523 & 5.0357 & 5.3217 & TRN & & \\
\hline CHEMBL1455228 & 688523 & 5.3152 & 5.2826 & TRN & & \\
\hline CHEMBL1346456 & 688523 & 4.4021 & 5.1831 & TST & & \\
\hline CHEMBL1333250 & 688523 & 5.0343 & 4.425 & TRN & & \\
\hline CHEMBL3192773 & 688523 & 4.8529 & 5.2496 & TRN & & \\
\hline CHEMBL1309043 & 688523 & 5.3757 & 4.7356 & TST & & \\
\hline CHEMBL1989599 & 688523 & 5.2684 & 5.2731 & TRN & & \\
\hline CHEMBL1578345 & 688523 & 4.4068 & 3.9773 & TRN & & \\
\hline CHEMBL1578506 & 688523 & 5.4237 & 5.0611 & TRN & & \\
\hline CHEMBL1981992 & 688523 & 5.4012 & 5.2354 & TRN & & \\
\hline CHEMBL1468379 & 688523 & 4.9154 & 4.8099 & TST & & \\
\hline CHEMBL1319476 & 688523 & 4.0907 & 4.228 & TRN & & \\
\hline CHEMBL1306105 & 688523 & 5.4342 & 5.0031 & TRN & & \\
\hline CHEMBL1367012 & 688523 & 3.0 & 4.8788 & TRN & & \\
\hline CHEMBL553503 & 688523 & 3.0 & 4.7574 & TST & & \\
\hline CHEMBL3198591 & 688523 & 4.783 & 3.7105 & TRN & & \\
\hline CHEMBL3194343 & 688523 & 4.2957 & 4.59399 & 9999999999 & & TRN \\
\hline CHEMBL1334633 & 688523 & 3.0 & 3.7937 & TST & & \\
\hline CHEMBL1561788 & 688523 & 5.3635 & 4.9606 & TRN & & \\
\hline CHEMBL1423798 & 688523 & 5.2147 & 5.3014 & TRN & & \\
\hline CHEMBL1370184 & 688523 & 4.5653 & 4.433 & TST & & \\
\hline CHEMBL1534784 & 688523 & 6.0458 & 5.251 & TRN & & \\
\hline CHEMBL3214331 & 688523 & 4.3799 & 4.0074 & TRN & & \\
\hline CHEMBL3208456 & 688523 & 5.3862 & 5.4383 & TRN & & \\
\hline CHEMBL1423365 & 688523 & 4.6876 & 4.0522 & TST & & \\
\hline CHEMBL1549745 & 688523 & 4.9176 & 4.551 & TRN & & \\
\hline CHEMBL3191145 & 688523 & 4.5494 & 3.4797 & TRN & & \\
\hline CHEMBL495123 & 688523 & 5.1778 & 5.2064 & TRN & & \\
\hline CHEMBL1300569 & 688523 & 5.3979 & 5.8337 & TRN & & \\
\hline CHEMBL521171 & 688523 & 4.7812 & 4.5384 & TRN & & \\
\hline
\end{tabular}




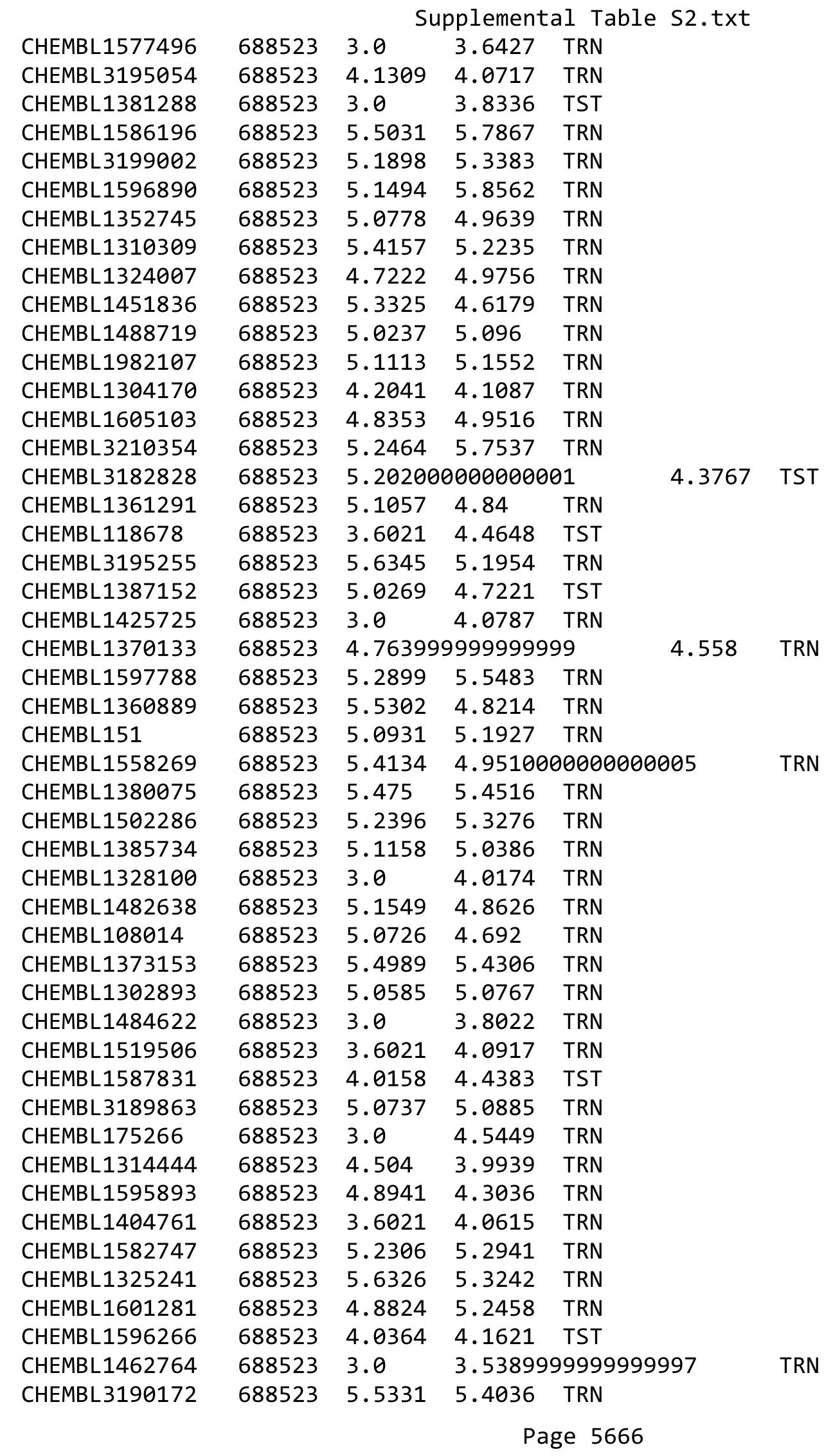


Supplemental Table S2.txt

\begin{tabular}{|c|c|c|c|c|}
\hline HEMB & & & & \\
\hline & 88523 & .0742 & 5.2855 & \\
\hline-5 & & & & \\
\hline AEMBL14 & & $\theta$ & & 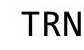 \\
\hline HEMBL 29234 & 8523 & & 5002 & \\
\hline HEMBL1439666 & 88523 & 3.0 & 064 & \\
\hline HEMBL1: & 8523 & & 5405 & \\
\hline IFMBI 14 & 8523 & & & \\
\hline AEMBL1588752 & 88523 & 93 & 5157 & \\
\hline HEMBL1376643 & 88523 & 3687 & 5481 & \\
\hline HEMBL3213847 & 88523 & .2495 & 3573 & \\
\hline EMBL2 & 8523 & 899 & 3996 & \\
\hline AEMBL3 & & & & RN \\
\hline HEMBL13 & 88523 & 15 & 8261 & \\
\hline AEMBL1S & 88523 & 701 & 54 & \\
\hline AEMBL13 & 88523 & 35 & 8218 & \\
\hline HEMBL1: & 8523 & & 529 & \\
\hline HEMBL1: & & & 964 & \\
\hline HEMBL1: & 88523 & 45 & 8066 & \\
\hline AEMBL3: & 885 & 6 & & \\
\hline 化MBLI & 88523 & 7 & 3868 & NIV \\
\hline HEMBLI & 3 & & 714 & 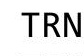 \\
\hline HEMBL165 & 3 & 58 & 3071 & \\
\hline HFMRI 1 & 88523 & & 4814 & \\
\hline AEMBL1 & 3 & 1 & & ( \\
\hline HEMBL3 & 885 & 4 & 091 & KIV \\
\hline HEMBL: & & & 135 & RN \\
\hline HFMBI 1 & 3 & 6 & 883 & \\
\hline HEMBL1 & 88523 & & 3912 & I KIV \\
\hline HEMBL14 & 885 & & & 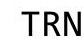 \\
\hline HEMBL1 & 885 & & 729 & RN \\
\hline HEMBL: & & & 824 & RN \\
\hline HFMRI 1 & 3 & 57 & 973 & $\mathrm{RN}$ \\
\hline HEMBL1539393 & 88523 & & 584 & ISI \\
\hline HEMBL1505222 & 88523 & 2 & 886 & TRN \\
\hline HEMBL2 & 885 & 6 & 594 & RN \\
\hline HFMRI 1 & 3 & 9 & 495 & $\Gamma \mathrm{RN}$ \\
\hline HEMBL15 & & & & TRN \\
\hline HEMBL1505196 & 88523 & 157 & 5556 & TRN \\
\hline AEMBL31918 & 88523 & & 57 & $\Gamma \mathrm{RN}$ \\
\hline HEMBL3 & 885 & 2 & 2675 & \\
\hline HEMBL 32 & & .3716 & 1489 & TRN \\
\hline HEMBL339587 & 88523 & & 1083 & RN \\
\hline AEMBL31957 & 88523 & 51 & 9884 & TRN \\
\hline HEMBL1 & 885 & & 8677 & $1 \mathrm{n}$ \\
\hline HEMBL3 & 688523 & & & \\
\hline CHEMBL13187 & 88523 & .019 & .5581 & \\
\hline CHEMBL1469871 & 688523 & 5.2549 & 5.3274 & ГRN \\
\hline
\end{tabular}




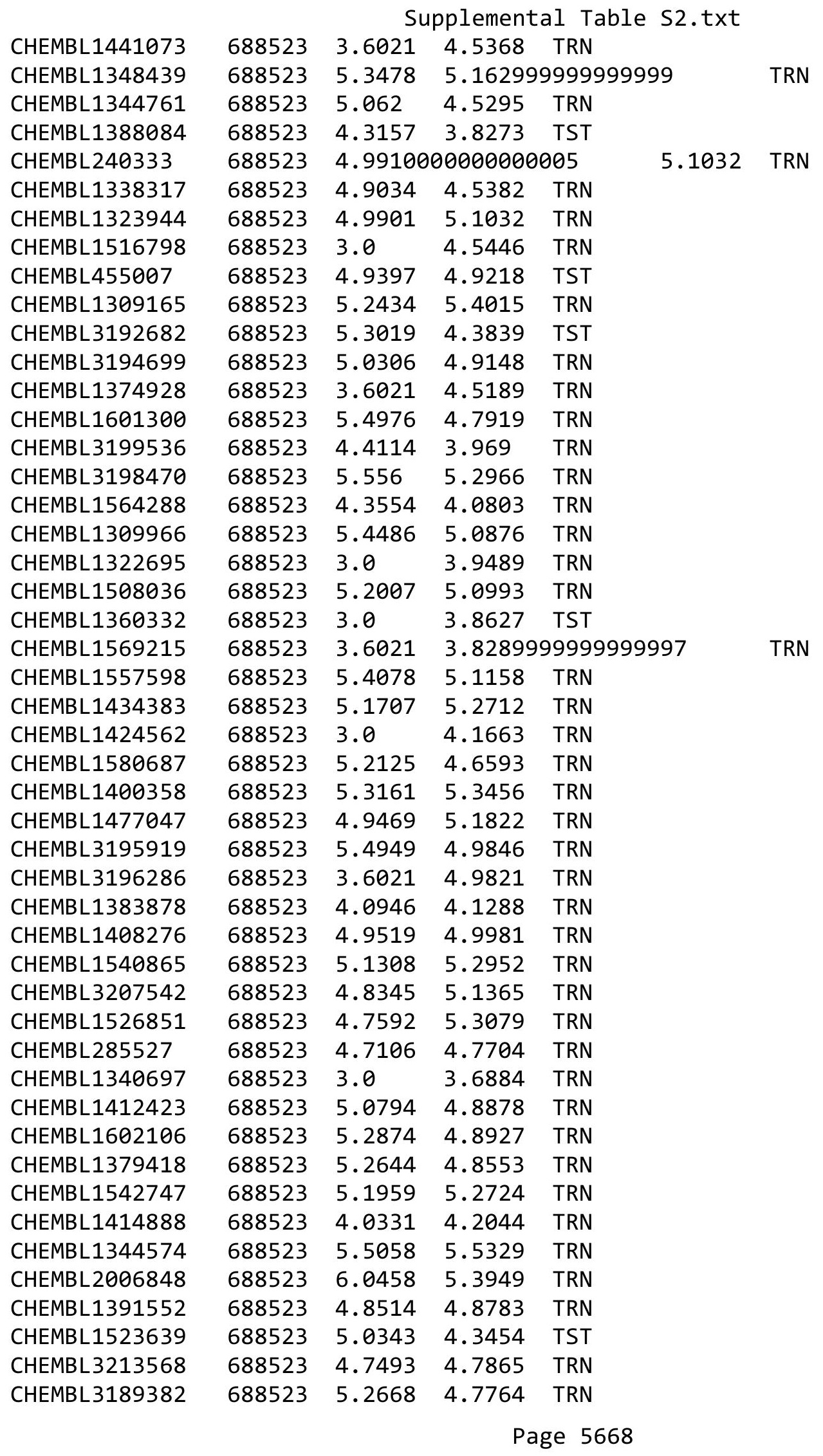




\begin{tabular}{|c|c|c|c|c|c|}
\hline \multicolumn{6}{|c|}{ Supplemental Table s2.txt } \\
\hline CHEMBL1423524 & 688523 & 3.0 & 4.1903 & TST & \\
\hline CHEMBL 3190873 & 688523 & 3.0 & 4.4354 & TRN & \\
\hline CHEMBL145 & 688523 & 5.1701 & 5.0817 & TRN & \\
\hline CHEMBL1448375 & 688523 & 5.2882 & 5.15799 & 99999999995 & TRN \\
\hline CHEMBL3195150 & 688523 & 5.6253 & 5.5962 & TRN & \\
\hline CHEMBL1487698 & 688523 & 5.1605 & 4.1862 & TRN & \\
\hline CHEMBL1447177 & 688523 & 4.9385 & 4.5716 & TRN & \\
\hline CHEMBL 3191986 & 688523 & 5.4089 & 5.4287 & TRN & \\
\hline CHEMBL1546422 & 688523 & 5.0635 & 4.3379 & TST & \\
\hline CHEMBL3209753 & 688523 & 5.4486 & 5.5141 & TRN & \\
\hline CHEMBL1492157 & 688523 & 5.1391 & 4.8161 & TRN & \\
\hline CHEMBL 3191784 & 688523 & 5.3002 & 5.3666 & TRN & \\
\hline CHEMBL1404434 & 688523 & 5.2899 & 4.414 & TRN & \\
\hline CHEMBL1425026 & 688523 & 3.6021 & 4.1225 & TRN & \\
\hline CHEMBL1571034 & 688523 & 5.1463 & 4.8872 & TRN & \\
\hline CHEMBL1312190 & 688523 & 5.1249 & 4.6156 & TRN & \\
\hline CHEMBL3193147 & 688523 & 5.4295 & 4.9567 & TRN & \\
\hline CHEMBL1538161 & 688523 & 3.0 & 3.9596 & TRN & \\
\hline CHEMBL1602105 & 688523 & 4.0991 & 4.0259 & TRN & \\
\hline CHEMBL1489339 & 688523 & 5.4191 & 5.1298 & TRN & \\
\hline CHEMBL1968928 & 688523 & 5.5243 & 5.44600 & 0000000001 & TRN \\
\hline CHEMBL1363382 & 688523 & 5.0867 & 4.577 & TRN & \\
\hline CHEMBL1363493 & 688523 & 3.6021 & 3.9243 & TRN & \\
\hline CHEMBL1307472 & 688523 & 3.0 & 4.0021 & TST & \\
\hline CHEMBL1452301 & 688523 & 4.6617 & 4.738 & TRN & \\
\hline CHEMBL1599381 & 688523 & 3.301 & 3.4188 & TRN & \\
\hline CHEMBL1600782 & 688523 & 3.0 & 4.2073 & TST & \\
\hline CHEMBL1428884 & 688523 & 5.1838 & 5.4326 & TRN & \\
\hline CHEMBL1582192 & 688523 & 3.0 & 4.2893 & TRN & \\
\hline CHEMBL1438191 & 688523 & 4.5715 & 4.7946 & TRN & \\
\hline CHEMBL1324111 & 688523 & 3.9031 & 4.0652 & TRN & \\
\hline CHEMBL1982152 & 688523 & 4.9147 & 4.7736 & TRN & \\
\hline CHEMBL1991669 & 688523 & 5.5702 & 4.7494 & TRN & \\
\hline CHEMBL1567359 & 688523 & 3.0 & 4.3501 & TRN & \\
\hline CHEMBL3191317 & 688523 & 5.3696 & 5.4414 & TRN & \\
\hline CHEMBL530280 & 688523 & 5.2358 & 4.9647 & TRN & \\
\hline CHEMBL1390710 & 688523 & 4.1058 & 4.0435 & TRN & \\
\hline CHEMBL1613444 & 688523 & 5.1752 & 4.4894 & TST & \\
\hline CHEMBL1370054 & 688523 & 3.6021 & 4.6219 & TRN & \\
\hline CHEMBL 3207922 & 688523 & 5.2457 & 4.5021 & TRN & \\
\hline CHEMBL56543 & 688523 & 5.1135 & 4.9384 & TRN & \\
\hline CHEMBL1430778 & 688523 & 4.8327 & 4.6577 & TRN & \\
\hline CHEMBL1611796 & 688523 & 4.7331 & 4.8602 & TRN & \\
\hline CHEMBL1533502 & 688523 & 5.6271 & 5.2342 & TRN & \\
\hline CHEMBL1502018 & 688523 & 5.1238 & 4.2332 & TRN & \\
\hline CHEMBL1571983 & 688523 & 4.7991 & 5.2012 & TRN & \\
\hline CHEMBL1531744 & 688523 & 3.0 & 4.2425 & TRN & \\
\hline CHEMBL1965086 & 688523 & 5.063 & 5.2512 & TRN & \\
\hline
\end{tabular}




\begin{tabular}{|c|c|c|c|c|}
\hline \multicolumn{5}{|c|}{ Supplemental Table S2.txt } \\
\hline CHEMBL1573049 & 688523 & 3.0 & 4.1495 & TRN \\
\hline CHEMBL3199462 & 688523 & 4.7675 & 4.4636 & TRN \\
\hline CHEMBL1473205 & 688523 & 5.3615 & 5.0299 & TST \\
\hline CHEMBL1408320 & 688523 & 3.6021 & 3.3503 & TRN \\
\hline CHEMBL1377903 & 688523 & 4.1116 & 4.6434 & TST \\
\hline CHEMBL1532281 & 688523 & 5.3002 & 5.1106 & TST \\
\hline CHEMBL1982222 & 688523 & 5.2132 & 5.3897 & TRN \\
\hline CHEMBL86966 & 688523 & 4.9952 & 4.0781 & TST \\
\hline CHEMBL445304 & 688523 & 5.1439 & 5.0849 & TRN \\
\hline CHEMBL1379112 & 688523 & 3.0 & 4.176 & TST \\
\hline CHEMBL1449112 & 688523 & 5.1549 & 5.2548 & TRN \\
\hline CHEMBL1595238 & 688523 & 5.063 & 4.8911 & TRN \\
\hline CHEMBL1484288 & 688523 & 3.0 & 4.1196 & TRN \\
\hline CHEMBL1604132 & 688523 & 3.0 & 4.4538 & TST \\
\hline CHEMBL3213898 & 688523 & 5.3449 & 5.5226 & TRN \\
\hline CHEMBL3190282 & 688523 & 4.9805 & 5.3021 & TRN \\
\hline CHEMBL1998254 & 688523 & 4.1287 & 3.8172 & TST \\
\hline CHEMBL142652 & 688523 & 5.1135 & 4.5345 & TRN \\
\hline CHEMBL1970924 & 688523 & 5.1169 & 5.3205 & TRN \\
\hline CHEMBL1519209 & 688523 & 5.3125 & 5.0349 & TRN \\
\hline CHEMBL1347221 & 688523 & 5.2495 & 5.015 & TRN \\
\hline CHEMBL1309877 & 688523 & 5.0278 & 4.7448 & TRN \\
\hline CHEMBL1464009 & 688523 & 5.0883 & 4.952 & TRN \\
\hline CHEMBL84472 & 688523 & 5.3215 & 5.0828 & TST \\
\hline CHEMBL1537352 & 688523 & 5.4711 & 4.7687 & TRN \\
\hline CHEMBL1586611 & 688523 & 5.4647 & 4.6912 & TRN \\
\hline CHEMBL 2007390 & 688523 & 4.994 & 5.2392 & TRN \\
\hline CHEMBL1576346 & 688523 & 5.4045 & 4.5601 & TRN \\
\hline CHEMBL1398855 & 688523 & 5.3958 & 5.2285 & TRN \\
\hline CHEMBL1371792 & 688523 & 4.9038 & 4.6127 & TRN \\
\hline CHEMBL1464022 & 688523 & 5.433 & 4.9105 & TRN \\
\hline CHEMBL3196123 & 688523 & 3.0 & 4.8759 & TRN \\
\hline CHEMBL1504117 & 688523 & 5.3125 & 5.3859 & TRN \\
\hline CHEMBL1424878 & 688523 & 3.0 & 4.1828 & TST \\
\hline CHEMBL3194014 & 688523 & 4.9838 & 5.0208 & TRN \\
\hline CHEMBL1520952 & 688523 & 5.3458 & 4.8819 & TRN \\
\hline CHEMBL 1347279 & 688523 & 5.3575 & 5.409 & TRN \\
\hline CHEMBL1412698 & 688523 & 5.2097 & 5.2062 & TRN \\
\hline CHEMBL1329181 & 688523 & 5.0501 & 4.6746 & TST \\
\hline CHEMBL1445600 & 688523 & 3.6021 & 3.8747 & TRN \\
\hline CHEMBL3198213 & 688523 & 5.1643 & 5.1664 & TST \\
\hline CHEMBL3212429 & 688523 & 5.3206 & 5.0072 & TRN \\
\hline CHEMBL404923 & 688523 & 5.6517 & 5.2615 & TRN \\
\hline CHEMBL1542944 & 688523 & 3.0 & 3.9657 & TRN \\
\hline CHEMBL1598721 & 688523 & 5.3107 & 5.1424 & TRN \\
\hline CHEMBL1585191 & 688523 & 3.0 & 3.7511 & TRN \\
\hline CHEMBL1537130 & 688523 & 4.9634 & 4.4264 & TRN \\
\hline CHEMBL1419228 & 688523 & 4.5095 & 4.5558 & TRN \\
\hline
\end{tabular}




\begin{tabular}{|c|c|c|c|c|c|c|}
\hline & & \multicolumn{5}{|c|}{ Supplemental Table S2.txt } \\
\hline CHEMBL251055 & 688523 & 5.3747 & 4.6039 & TST & & \\
\hline CHEMBL1510704 & 688523 & 4.8655 & 4.1987 & TRN & & \\
\hline CHEMBL1996464 & 688523 & 5.0799 & 4.797 & TST & & \\
\hline CHEMBL1338747 & 688523 & 4.6123 & 4.7343 & TST & & \\
\hline CHEMBL1461891 & 688523 & 5.1824 & 4.6906 & TRN & & \\
\hline CHEMBL1583881 & 688523 & 4.2041 & 4.0161 & TST & & \\
\hline CHEMBL 2007297 & 688523 & 3.0 & 4.2621 & TST & & \\
\hline CHEMBL53898 & 688523 & 5.0768 & 4.7838 & TRN & & \\
\hline CHEMBL3189151 & 688523 & 5.3307 & 5.3953 & TRN & & \\
\hline CHEMBL1307124 & 688523 & 3.0 & 4.6197 & TST & & \\
\hline CHEMBL1582564 & 688523 & 3.0 & 4.1301 & TST & & \\
\hline CHEMBL1540581 & 688523 & 5.266 & 5.0542 & TRN & & \\
\hline CHEMBL3211456 & 688523 & 5.1203 & 5.6677 & TRN & & \\
\hline CHEMBL1409721 & 688523 & 5.2865 & 5.40600 & 000000000 & & TRN \\
\hline CHEMBL1373978 & 688523 & 5.5017 & 5.2778 & TRN & & \\
\hline CHEMBL1608890 & 688523 & 4.5381 & 4.5785 & TRN & & \\
\hline CHEMBL486422 & 688523 & 4.8894 & 4.6026 & TRN & & \\
\hline CHEMBL3210172 & 688523 & 5.2457 & 4.2321 & TRN & & \\
\hline CHEMBL1606809 & 688523 & 3.6021 & 3.6121 & TRN & & \\
\hline CHEMBL1335300 & 688523 & 4.7149 & 4.6264 & TRN & & \\
\hline CHEMBL1526978 & 688523 & 5.0721 & 5.01 & TRN & & \\
\hline CHEMBL3197060 & 688523 & 5.9469 & 4.8895 & TST & & \\
\hline CHEMBL1571743 & 688523 & 5.4724 & 5.4693 & TRN & & \\
\hline CHEMBL1522686 & 688523 & 3.0 & 4.2819 & TRN & & \\
\hline CHEMBL1391193 & 688523 & 4.9154 & 5.1726 & TRN & & \\
\hline CHEMBL1425497 & 688523 & 5.0467 & 4.1008 & TRN & & \\
\hline CHEMBL1588300 & 688523 & 3.9031 & 4.3352 & TST & & \\
\hline CHEMBL1438081 & 688523 & 3.0 & 3.9305 & TST & & \\
\hline CHEMBL1341388 & 688523 & 5.3546 & 5.4047 & TRN & & \\
\hline CHEMBL1533094 & 688523 & 4.9355 & 4.5336 & TRN & & \\
\hline CHEMBL1401307 & 688523 & 4.8371 & 4.121 & TST & & \\
\hline CHEMBL1355173 & 688523 & 3.0 & 3.4561 & TRN & & \\
\hline CHEMBL1543251 & 688523 & 4.0709 & 4.151 & TRN & & \\
\hline CHEMBL458328 & 688523 & 3.9031 & 3.9276 & TST & & \\
\hline CHEMBL1586339 & 688523 & 4.9485 & 5.1939 & TRN & & \\
\hline CHEMBL1440147 & 688523 & 5.466 & 4.8432 & TRN & & \\
\hline CHEMBL3212457 & 688523 & 5.5575 & 5.6675 & TRN & & \\
\hline CHEMBL1410293 & 688523 & 5.7011 & 5.6799 & TRN & & \\
\hline CHEMBL1372012 & 688523 & 5.4078 & 4.9418 & TRN & & \\
\hline CHEMBL1328195 & 688523 & 3.0 & 4.3169 & TRN & & \\
\hline CHEMBL1471374 & 688523 & 3.6021 & 3.6107 & TRN & & \\
\hline CHEMBL1378470 & 688523 & 5.9872 & 5.1009 & TST & & \\
\hline CHEMBL66 & 688523 & 5.2291 & 5.0842 & TRN & & \\
\hline CHEMBL1342528 & 688523 & 5.1831 & 4.4578 & TRN & & \\
\hline CHEMBL3198803 & 688523 & 5.2899 & 5.0858 & TRN & & \\
\hline CHEMBL1358110 & 688523 & 3.301 & 4.1593 & TST & & \\
\hline CHEMBL1306675 & 688523 & 5.21899 & 99999999 & 99 & 5.0999 & TRN \\
\hline CHEMBL1333181 & 688523 & 5.5817 & 4.7427 & TRN & & \\
\hline
\end{tabular}




\begin{tabular}{|c|c|c|c|c|c|c|}
\hline & & \multicolumn{5}{|c|}{ Supplemental Table S2.txt } \\
\hline CHEMBL1482112 & 688523 & 3.9031 & 4.1441 & TRN & & \\
\hline CHEMBL1416049 & 688523 & 4.2779 & 4.4432 & TST & & \\
\hline CHEMBL1339527 & 688523 & 4.9825 & 5.6074 & TRN & & \\
\hline CHEMBL3208563 & 688523 & 5.5751 & 5.0913 & TRN & & \\
\hline CHEMBL1405834 & 688523 & 3.0 & 3.5364 & TRN & & \\
\hline CHEMBL1454784 & 688523 & 5.3261 & 5.153 & TRN & & \\
\hline CHEMBL3192753 & 688523 & 4.0527 & 3.9746 & TRN & & \\
\hline CHEMBL3194330 & 688523 & 5.24799 & 99999999 & & 5.7218 & TRN \\
\hline CHEMBL1561180 & 688523 & 5.17200 & 00000000 & & 5.4503 & TRN \\
\hline CHEMBL1602966 & 688523 & 5.3429 & 4.0396 & TST & & \\
\hline CHEMBL1342868 & 688523 & 4.11 & 4.3275 & TRN & & \\
\hline CHEMBL1425878 & 688523 & 5.3893 & 4.9187 & TRN & & \\
\hline CHEMBL1572785 & 688523 & 4.909 & 4.4498 & TST & & \\
\hline CHEMBL1539778 & 688523 & 4.672 & 4.5509 & TRN & & \\
\hline CHEMBL1563559 & 688523 & 3.0 & 3.8749 & TRN & & \\
\hline CHEMBL3213283 & 688523 & 4.4436 & 4.9328 & TRN & & \\
\hline CHEMBL1537381 & 688523 & 5.5901 & 5.2482 & TRN & & \\
\hline CHEMBL1381116 & 688523 & 4.436 & 4.6801 & TRN & & \\
\hline CHEMBL1486753 & 688523 & 3.9031 & 3.9055 & TRN & & \\
\hline CHEMBL1563045 & 688523 & 5.4318 & 4.9873 & TRN & & \\
\hline CHEMBL1517861 & 688523 & 4.8225 & 4.715 & TRN & & \\
\hline CHEMBL429095 & 688523 & 3.0 & 4.0255 & TRN & & \\
\hline CHEMBL3212501 & 688523 & 5.0013 & 4.7276 & TRN & & \\
\hline CHEMBL3199840 & 688523 & 5.1938 & 4.7337 & TRN & & \\
\hline CHEMBL1537279 & 688523 & 5.0106 & 4.7157 & TST & & \\
\hline CHEMBL1548024 & 688523 & 3.6021 & 4.3779 & TST & & \\
\hline CHEMBL1329587 & 688523 & 3.0 & 3.7992 & TST & & \\
\hline CHEMBL1462120 & 688523 & 5.2933 & 5.3205 & TRN & & \\
\hline CHEMBL3195623 & 688523 & 5.6326 & 5.6347 & TRN & & \\
\hline CHEMBL1446417 & 688523 & 3.0 & 4.4303 & TST & & \\
\hline CHEMBL1372480 & 688523 & 5.0851 & 5.0677 & TRN & & \\
\hline CHEMBL1536107 & 688523 & 5.1079 & 4.5767 & TST & & \\
\hline CHEMBL1971428 & 688523 & 5.5622 & 5.522 & TRN & & \\
\hline CHEMBL3211995 & 688523 & 5.0241 & 5.0846 & TRN & & \\
\hline CHEMBL1457174 & 688523 & 3.0 & 4.0001 & TRN & & \\
\hline CHEMBL3191284 & 688523 & 5.426 & 5.4398 & TRN & & \\
\hline CHEMBL3207980 & 688523 & 5.1798 & 5.6627 & TRN & & \\
\hline CHEMBL1499384 & 688523 & 5.1938 & 5.8515 & TRN & & \\
\hline CHEMBL3190269 & 688523 & 5.4461 & 5.2476 & TRN & & \\
\hline CHEMBL602776 & 688523 & 6.1192 & 5.1488 & TRN & & \\
\hline CHEMBL3196899 & 688523 & 5.0273 & 4.5176 & TRN & & \\
\hline CHEMBL1431711 & 688523 & 4.6588 & 4.3285 & TRN & & \\
\hline CHEMBL1596723 & 688523 & 5.2396 & 4.8058 & TRN & & \\
\hline CHEMBL1304377 & 688523 & 3.6021 & 3.4061 & TRN & & \\
\hline CHEMBL3197485 & 688523 & 5.2765 & 5.50200 & 0000000001 & & KIV \\
\hline CHEMBL224916 & 688523 & 5.8097 & 5.2101 & TRN & & \\
\hline CHEMBL3193483 & 688523 & 5.2125 & 4.684 & TRN & & \\
\hline CHEMBL1364395 & 688523 & 3.0 & 4.229 & TST & & \\
\hline
\end{tabular}




\begin{tabular}{|c|c|c|c|c|}
\hline & & & pplement & al $\mathrm{T}$ \\
\hline CHEMBL1333007 & 688523 & 5.3497 & 5.0456 & TRN \\
\hline CHEMBL1328519 & 688523 & 5.0414 & 4.2718 & TRN \\
\hline CHEMBL1549607 & 688523 & 4.6265 & 4.1192 & TRN \\
\hline CHEMBL1383471 & 688523 & 5.8041 & 5.7343 & TRN \\
\hline CHEMBL598663 & 688523 & 5.3947 & 4.8465 & TRN \\
\hline CHEMBL1583838 & 688523 & 4.8339 & 4.6331 & TRN \\
\hline CHEMBL1568745 & 688523 & 3.9031 & 4.1389 & TST \\
\hline CHEMBL1447364 & 688523 & 3.9031 & 4.2456 & TRN \\
\hline CHEMBL3196800 & 688523 & 5.0825 & 5.6698 & TRN \\
\hline CHEMBL3209878 & 688523 & 5.3372 & 5.1428 & TRN \\
\hline CHEMBL1371841 & 688523 & 5.5031 & 5.4314 & TRN \\
\hline CHEMBL1529366 & 688523 & 3.0 & 3.9742 & TST \\
\hline CHEMBL3191932 & 688523 & 5.1891 & 5.4386 & TRN \\
\hline CHEMBL1872457 & 688523 & 4.4955 & 5.2812 & TRN \\
\hline CHEMBL1522155 & 688523 & 5.1107 & 4.6869 & TST \\
\hline CHEMBL1594342 & 688523 & 4.9187 & 5.2864 & TRN \\
\hline CHEMBL1362572 & 688523 & 3.301 & 4.0069 & TRN \\
\hline CHEMBL1420642 & 688523 & 4.631 & 4.5962 & TRN \\
\hline CHEMBL444357 & 688523 & 5.4868 & 5.5014 & TRN \\
\hline CHEMBL1447034 & 688523 & 3.6021 & 3.6427 & TST \\
\hline CHEMBL1333659 & 688523 & 5.2596 & 5.0453 & TRN \\
\hline CHEMBL1302581 & 688523 & 5.1367 & 4.7355 & TRN \\
\hline CHEMBL1545711 & 688523 & 5.4908 & 5.484 & TRN \\
\hline CHEMBL1444756 & 688523 & 5.4522 & 5.1517 & TRN \\
\hline CHEMBL1412721 & 688523 & 3.6021 & 4.0199 & TRN \\
\hline CHEMBL1607229 & 688523 & 4.8567 & 4.7907 & TRN \\
\hline CHEMBL1510061 & 688523 & 5.0521 & 4.8837 & TST \\
\hline CHEMBL1975361 & 688523 & 3.0 & 4.5441 & TST \\
\hline CHEMBL1360363 & 688523 & 4.9825 & 4.6163 & TST \\
\hline CHEMBL1371614 & 688523 & 5.4306 & 5.3173 & TST \\
\hline CHEMBL3195935 & 688523 & 5.0835 & 4.6388 & TST \\
\hline CHEMBL1559785 & 688523 & 5.4001 & 4.5267 & TST \\
\hline CHEMBL 3213074 & 688523 & 5.1002 & 4.8047 & TST \\
\hline CHEMBL1542507 & 688523 & 3.6021 & 4.0867 & TST \\
\hline CHEMBL1313346 & 688523 & 5.1057 & 4.4286 & TST \\
\hline CHEMBL1510599 & 688523 & 3.0 & 4.357 & TST \\
\hline CHEMBL3198546 & 688523 & 5.1791 & 5.1036 & TST \\
\hline CHEMBL1323320 & 688523 & 3.0 & 3.8565 & TST \\
\hline CHEMBL56542 & 688523 & 5.0362 & 5.065 & TST \\
\hline CHEMBL 3193382 & 688523 & 4.6432 & 5.1759 & TST \\
\hline CHEMBL1603830 & 688523 & 4.9634 & 4.6319 & TST \\
\hline CHEMBL 3199005 & 688523 & 5.5622 & 5.6392 & TST \\
\hline CHEMBL3145028 & 688523 & 3.0 & 4.3886 & TST \\
\hline CHEMBL1413461 & 688523 & 4.9722 & 5.1596 & TST \\
\hline CHEMBL3191078 & 688523 & 5.4202 & 4.8964 & TST \\
\hline CHEMBL1522668 & 688523 & 4.942 & 5.2583 & TST \\
\hline CHEMBL1376865 & 688523 & 4.994 & 3.9017 & TST \\
\hline CHEMBL1442879 & 688523 & 5.2725 & 5.3259 & TST \\
\hline
\end{tabular}




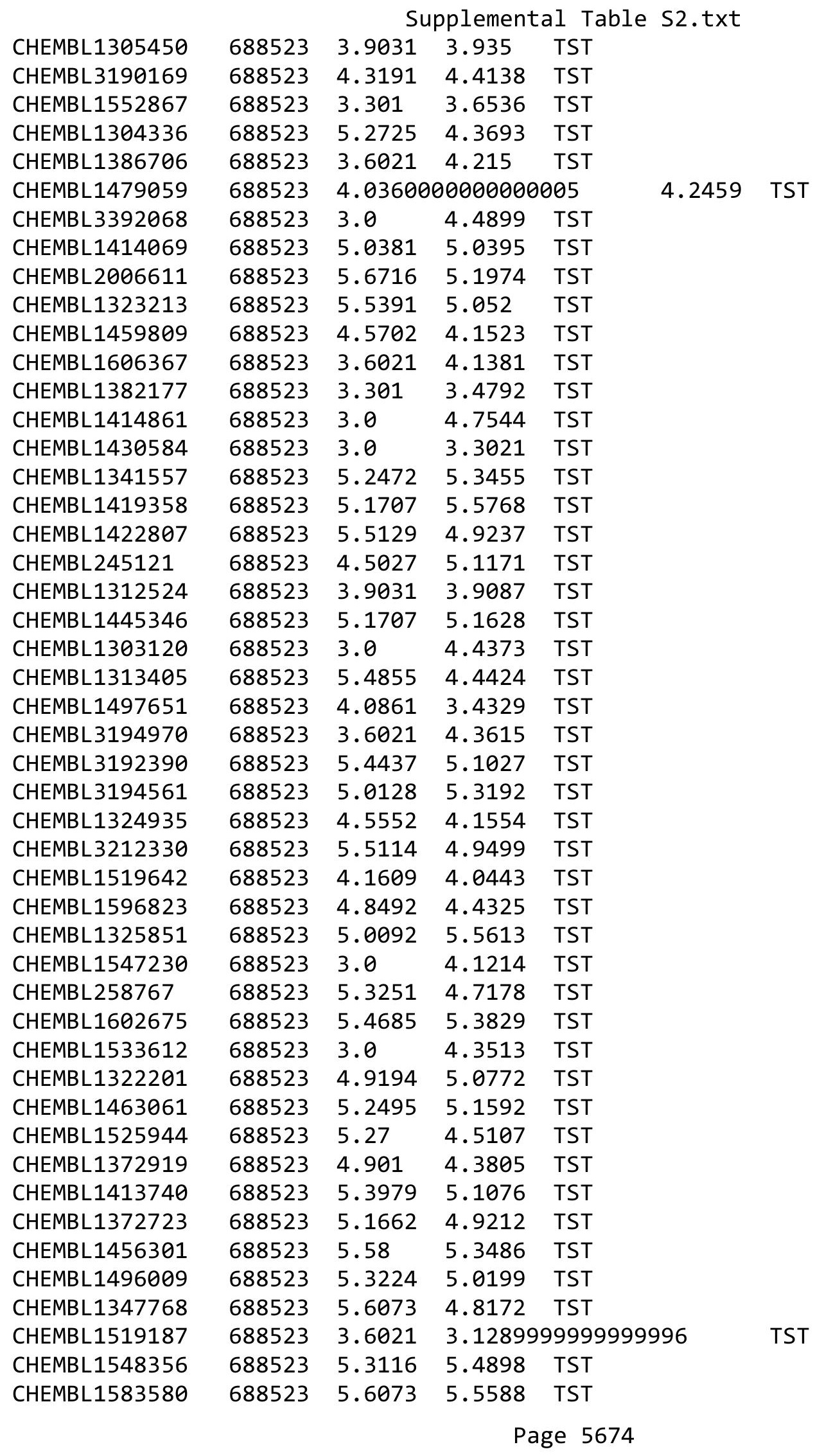




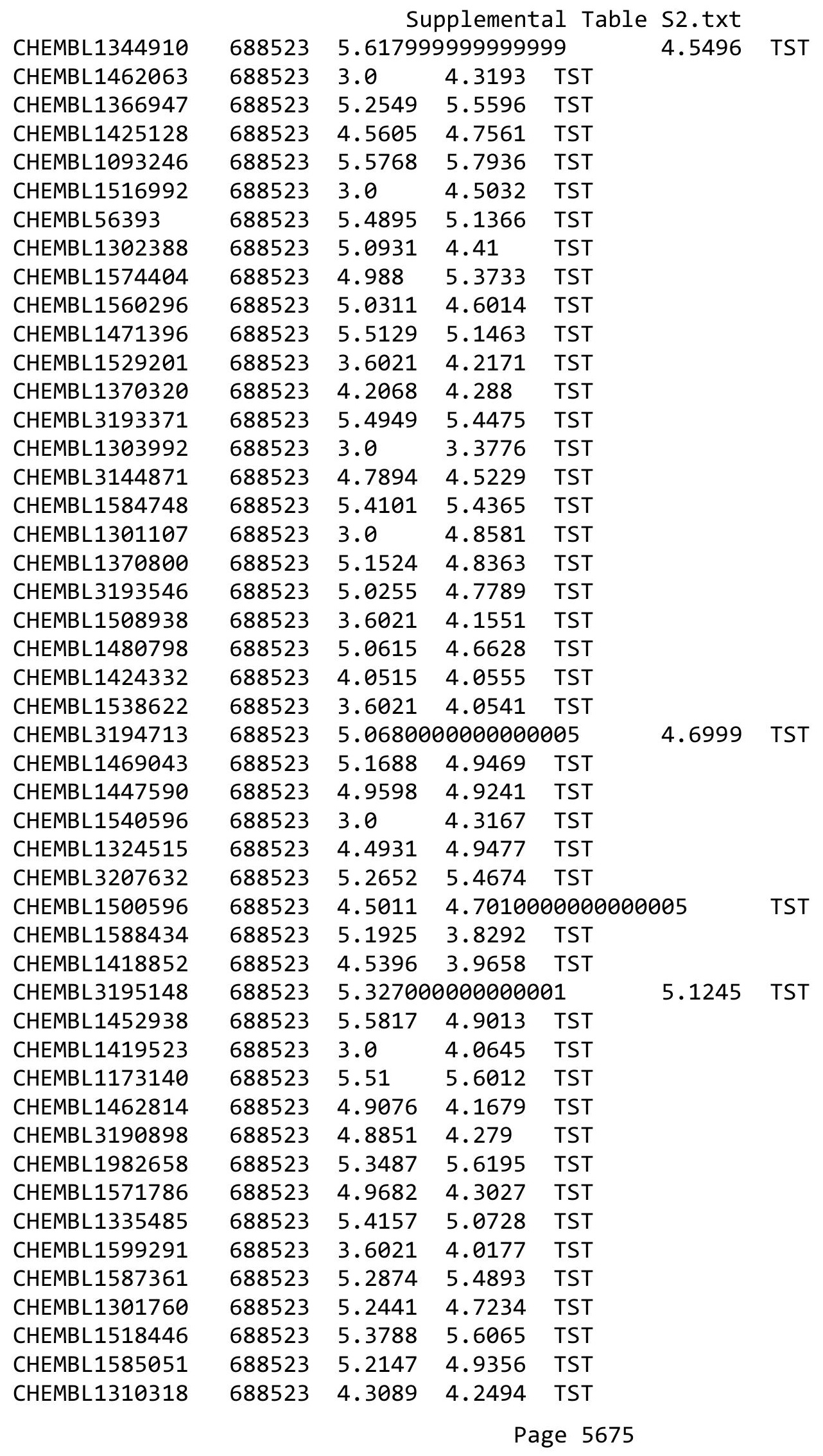




\begin{tabular}{|c|c|c|c|c|c|c|}
\hline \multirow[b]{2}{*}{ CHEMBL 3213248} & & \multicolumn{5}{|c|}{ Supplemental Table S2.txt } \\
\hline & 688523 & 5.5884 & 4.8283 & TST & & \\
\hline CHEMBL3193039 & 688523 & 5.17200 & 30000000 & $\partial 1$ & 4.9629 & TST \\
\hline CHEMBL1487350 & 688523 & 4.9176 & 4.3209 & TST & & \\
\hline CHEMBL1300117 & 688523 & 4.2664 & 3.8246 & TST & & \\
\hline CHEMBL 3210365 & 688523 & 5.3391 & 5.7823 & TST & & \\
\hline CHEMBL1310948 & 688523 & 4.7945 & 4.7222 & TST & & \\
\hline CHEMBL1506144 & 688523 & 4.9759 & 5.5086 & TST & & \\
\hline CHEMBL 2003964 & 688523 & 5.0862 & 4.7935 & TST & & \\
\hline CHEMBL1455637 & 688523 & 4.7245 & 3.7159 & TST & & \\
\hline CHEMBL1406195 & 688523 & 4.3621 & 4.9882 & TST & & \\
\hline CHEMBL229979 & 437192 & 7.585 & 7.3751 & TRN & & \\
\hline CHEMBL 389274 & 437192 & 7.8239 & 7.8905 & TRN & & \\
\hline CHEMBL 388723 & 437192 & 7.8239 & 7.6951 & TRN & & \\
\hline CHEMBL 375465 & 437192 & 7.7447 & 7.7205 & TRN & & \\
\hline CHEMBL229988 & 437192 & 8.0605 & 8.0424 & TRN & & \\
\hline CHEMBL 374844 & 437192 & 8.7212 & 8.5707 & TRN & & \\
\hline CHEMBL 229980 & 437192 & 6.6757 & 7.0514 & TRN & & \\
\hline CHEMBL229925 & 437192 & 8.2676 & 8.2977 & TRN & & \\
\hline CHEMBL 229512 & 437192 & 6.1884 & 7.5477 & TST & & \\
\hline CHEMBL425654 & 437192 & 8.9208 & 8.7301 & TRN & & \\
\hline CHEMBL 389518 & 437192 & 7.0362 & 7.1352 & TRN & & \\
\hline CHEMBL 229350 & 437192 & 5.7058 & 6.9829 & TST & & \\
\hline CHEMBL437544 & 437192 & 8.6198 & 8.6084 & TRN & & \\
\hline CHEMBL 388972 & 437192 & 8.0506 & 7.8061 & TRN & & \\
\hline CHEMBL229339 & 437192 & 6.7423 & 6.9587 & TRN & & \\
\hline CHEMBL 229981 & 437192 & 7.2676 & 7.3662 & TRN & & \\
\hline CHEMBL 389483 & 437192 & 6.4283 & 6.3479 & TRN & & \\
\hline CHEMBL 229557 & 437192 & 6.2684 & 6.3531 & TRN & & \\
\hline CHEMBL387962 & 437192 & 8.3468 & 8.3788 & TRN & & \\
\hline CHEMBL229769 & 437192 & 8.5528 & 8.5285 & TRN & & \\
\hline CHEMBL228289 & 437192 & 7.0969 & 7.2038 & TRN & & \\
\hline CHEMBL 229463 & 437192 & 7.2441 & 7.9131 & TST & & \\
\hline CHEMBL 229715 & 437192 & 8.301 & 8.0751 & TRN & & \\
\hline CHEMBL229461 & 437192 & 8.3768 & 7.6079 & TST & & \\
\hline CHEMBL387961 & 437192 & 8.2441 & 8.3127 & TRN & & \\
\hline CHEMBL229926 & 437192 & 7.6778 & 7.9679 & TRN & & \\
\hline CHEMBL425669 & 437192 & 6.8477 & 6.8964 & TRN & & \\
\hline CHEMBL193260 & 437192 & 8.0458 & 7.5215 & TRN & & \\
\hline CHEMBL229875 & 437192 & 7.5686 & 7.6881 & TRN & & \\
\hline CHEMBL229929 & 437192 & 6.8794 & 6.2205 & TRN & & \\
\hline CHEMBL229767 & 437192 & 8.2218 & 8.4285 & TRN & & \\
\hline CHEMBL229406 & 437192 & 6.9318 & 7.1526 & TST & & \\
\hline CHEMBL229664 & 437192 & 7.8239 & 7.6361 & TRN & & \\
\hline CHEMBL 229223 & 437192 & 7.9586 & 8.2156 & TRN & & \\
\hline CHEMBL229931 & 437192 & 7.3188 & 7.7425 & TRN & & \\
\hline CHEMBL229407 & 437192 & 6.5003 & 6.7291 & TST & & \\
\hline CHEMBL441726 & 437192 & 8.3565 & 8.5363 & TRN & & \\
\hline CHEMBL 229871 & 437192 & 8.1427 & 7.9528 & TRN & & \\
\hline
\end{tabular}


Supplemental Table S2.txt

\begin{tabular}{|c|c|c|c|c|}
\hline CHEMBL 229408 & 437192 & 7.0706 & 7.3416 & TST \\
\hline CHEMBL 229291 & 437192 & 8.4815 & 8.3243 & TRN \\
\hline CHEMBL 389517 & 437192 & 7.2218 & 7.5412 & TRN \\
\hline CHEMBL425664 & 437192 & 7.9586 & 7.795 & TRN \\
\hline CHEMBL 229285 & 437192 & 8.0605 & 7.8619 & TRN \\
\hline CHEMBL 374843 & 437192 & 7.9208 & 7.8808 & TRN \\
\hline CHEMBL538652 & 437192 & 5.655 & 6.9566 & TST \\
\hline CHEMBL 229113 & 437192 & 8.7959 & 8.6861 & TRN \\
\hline CHEMBL 387501 & 437192 & 7.7959 & 7.8754 & TRN \\
\hline CHEMBL 229171 & 437192 & 8.7959 & 7.8843 & TRN \\
\hline CHEMBL 389058 & 437192 & 8.0132 & 8.4086 & TST \\
\hline CHEMBL389059 & 437192 & 6.5302 & 7.7227 & TST \\
\hline CHEMBL 229504 & 437192 & 7.2676 & 7.4614 & TRN \\
\hline CHEMBL 229230 & 437192 & 7.8861 & 7.8104 & TRN \\
\hline CHEMBL 229983 & 437192 & 7.699 & 7.86600 & 00000000005 \\
\hline CHEMBL 229556 & 437192 & 6.8729 & 6.7865 & TRN \\
\hline CHEMBL426369 & 437192 & 8.6778 & 8.6591 & TRN \\
\hline CHEMBL441886 & 437192 & 7.7696 & 7.8487 & TST \\
\hline CHEMBL 390290 & 437192 & 7.5086 & 7.0811 & TST \\
\hline CHEMBL 229229 & 437192 & 7.6778 & 7.3155 & TRN \\
\hline CHEMBL 388302 & 437192 & 5.7249 & 5.7167 & TRN \\
\hline CHEMBL439013 & 437192 & 7.8239 & 7.8587 & TRN \\
\hline CHEMBL 229348 & 437192 & 6.8327 & 7.7706 & TST \\
\hline CHEMBL434747 & 437192 & 8.3872 & 7.2153 & TST \\
\hline CHEMBL 388524 & 437192 & 7.8861 & 7.805 & TST \\
\hline CHEMBL 229930 & 437192 & 7.4685 & 7.3197 & TRN \\
\hline CHEMBL 229505 & 437192 & 7.8239 & 7.6085 & TRN \\
\hline CHEMBL 229986 & 437192 & 7.5376 & 6.9354 & TST \\
\hline CHEMBL 229665 & 437192 & 7.2757 & 7.5667 & TRN \\
\hline CHEMBL 229876 & 437192 & 7.0362 & 7.2438 & TRN \\
\hline CHEMBL426366 & 437192 & 7.6383 & 7.5921 & TRN \\
\hline CHEMBL 229177 & 437192 & 8.6383 & 8.13600 & 0000000001 \\
\hline CHEMBL 229768 & 437192 & 8.1192 & 8.1195 & TRN \\
\hline CHEMBL 229716 & 437192 & 8.5686 & 8.4273 & TRN \\
\hline CHEMBL 390288 & 437192 & 7.5229 & 7.5943 & TST \\
\hline CHEMBL 229824 & 437192 & 7.4685 & 7.4286 & TRN \\
\hline CHEMBL 229178 & 437192 & 7.5086 & 7.4374 & TRN \\
\hline CHEMBL 229870 & 437192 & 6.5058 & 7.723 & TST \\
\hline CHEMBL 229290 & 437192 & 8.0044 & 7.999 & TST \\
\hline CHEMBL 229172 & 437192 & 8.0 & 8.5027 & TRN \\
\hline CHEMBL 390289 & 437192 & 7.2924 & 7.3691 & TST \\
\hline CHEMBL 229112 & 437192 & 6.0 & 7.1077 & TRN \\
\hline CHEMBL 229610 & 437192 & 7.6576 & 7.7676 & TRN \\
\hline CHEMBL 389484 & 437192 & 7.3188 & 7.2277 & TRN \\
\hline CHEMBL426364 & 437192 & 7.699 & 7.8094 & TRN \\
\hline CHEMBL 229822 & 437192 & 7.983 & 8.1977 & TRN \\
\hline CHEMBL 229164 & 437192 & 6.2526 & 7.715 & TST \\
\hline CHEMBL 229462 & 437192 & 8.0862 & 7.5689 & TST \\
\hline
\end{tabular}


Supplemental Table S2.txt

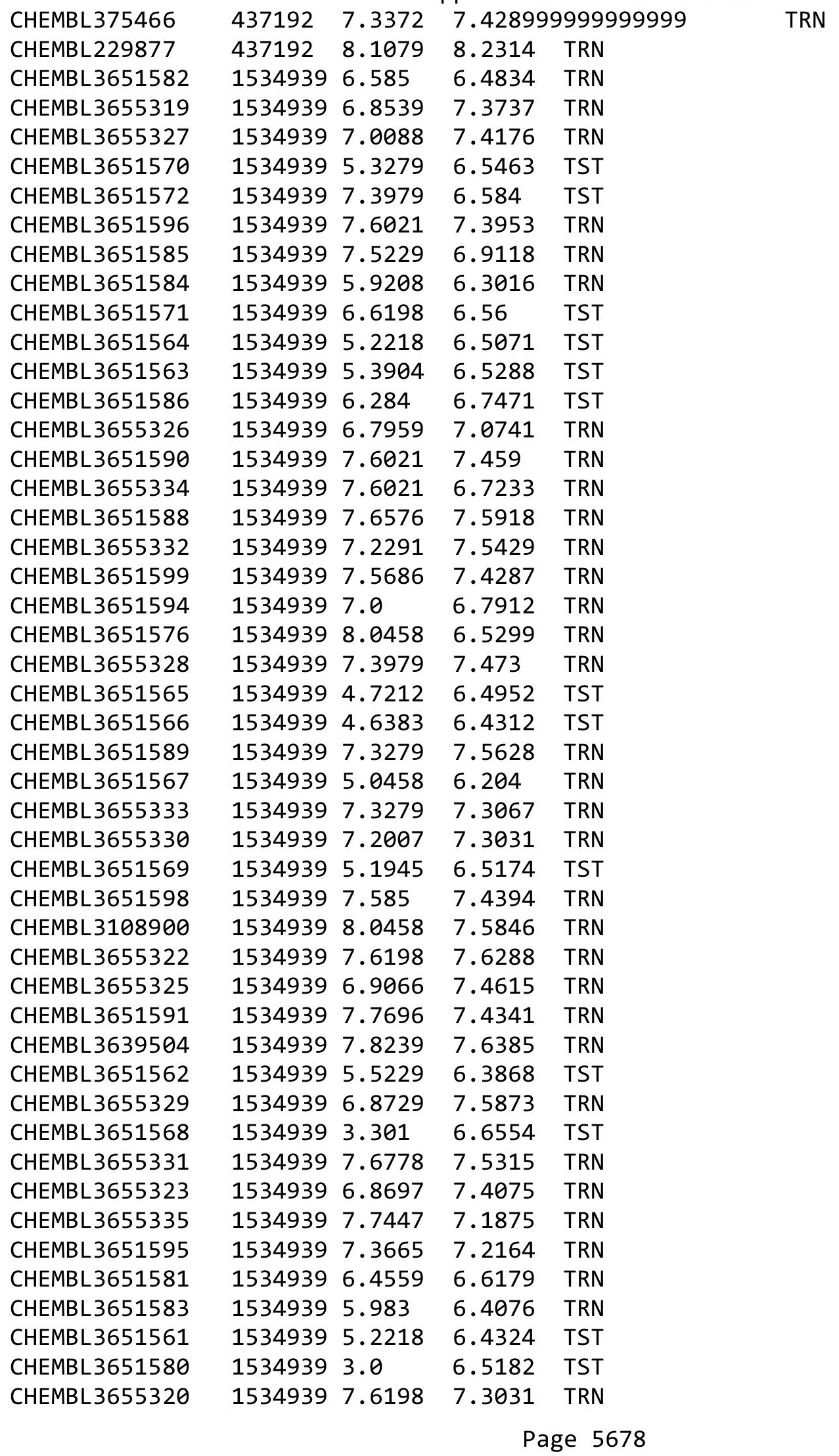


Supplemental Table S2.txt

\begin{tabular}{|c|c|c|c|c|}
\hline HEMBL 3655324 & 534939 & 7.5376 & 7.191 & TRN \\
\hline CHEMBL3651600 & 534939 & 7.3768 & 7.4728 & \\
\hline AFMBI 3 & 39 & 89 & 686 & \\
\hline AEMBL3651592 & 534939 & 7932 & 9108 & \\
\hline AEMBL3651587 & 534939 & 7.7447 & 343 & \\
\hline HEMBL3655321 & 534939 & 7.585 & 7.5848 & \\
\hline HEMBL3651597 & 534939 & 7.5229 & 33 & \\
\hline HEMBL 283181 & 99518 & 4.8861 & & \\
\hline HEMBL512328 & 99518 & 7.2757 & 5 & \\
\hline HEMBL473021 & 99518 & 6.0 & 716 & \\
\hline CHEMBL513985 & 499518 & 6.0 & & \\
\hline CHEMBL30548 & 995 & 7.1427 & 54 & \\
\hline 0518 & 99 & & & \\
\hline CHEMBL472989 & 995 & 104 & & \\
\hline AEMBL511977 & 995 & & & \\
\hline AEMBL512190 & 995 & 5.6 & 66 & \\
\hline CHEMBL104651 & 995 & 6.1 & 23 & \\
\hline CHEMBL514190 & 99 & 6.7 & & \\
\hline CHEMBL460433 & 4995 & & & \\
\hline HEMBL471950 & 99 & & & \\
\hline IEMBL443514 & 995 & 6.3 & 39 & \\
\hline CHEMBL & 499 & 8.5 & 38 & \\
\hline CHEMBL & 499 & & & \\
\hline CHEMBL1972346 & 499 & & & \\
\hline HEMBL504151 & 499 & & & \\
\hline IEMBL474655 & 499 & 8.2 & 23 & \\
\hline CHEMBL: & 499 & $6 . \varepsilon$ & & \\
\hline CHEMBL & 499 & & & \\
\hline CHEMI & 499 & & & \\
\hline CHEMBL30723 & 99 & & & TR \\
\hline CHEMBL105740 & 4995 & 6.6 & & \\
\hline CHEMBL: & 499 & 4. & & \\
\hline 570 & 190 & & & \\
\hline 0736 & 190 & & & \\
\hline CHEMBL474420 & 4995 & & & IR \\
\hline 5868 & 4995 & 6.2 & & TD \\
\hline CHEMBL & 499 & 7. & 7. & \\
\hline & & & & \\
\hline CHEMBL139833 & 4995 & & 19 & TS \\
\hline CHEMBL31141 & 4995 & 6.7959 & & $\mathrm{TR}$ \\
\hline 3216 & 4995 & $6.6-6$ & & n \\
\hline CHEMBL474362 & 4995 & 6.5086 & 6 . & \\
\hline CHEMBL515757 & 4995 & 7.5229 & & 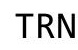 \\
\hline CHEMBL472600 & 4995 & 5.52 & 5.5876 & TR \\
\hline CHEMBL474652 & 4995 & 5.0 & 4.9006 & \\
\hline 588 & 4995 & & & \\
\hline CHEMBL453217 & 499518 & 7.2518 & 7.3308 & \\
\hline CHEMBL515910 & 499518 & 8.7959 & 8.5935 & \\
\hline
\end{tabular}

Page 5679 


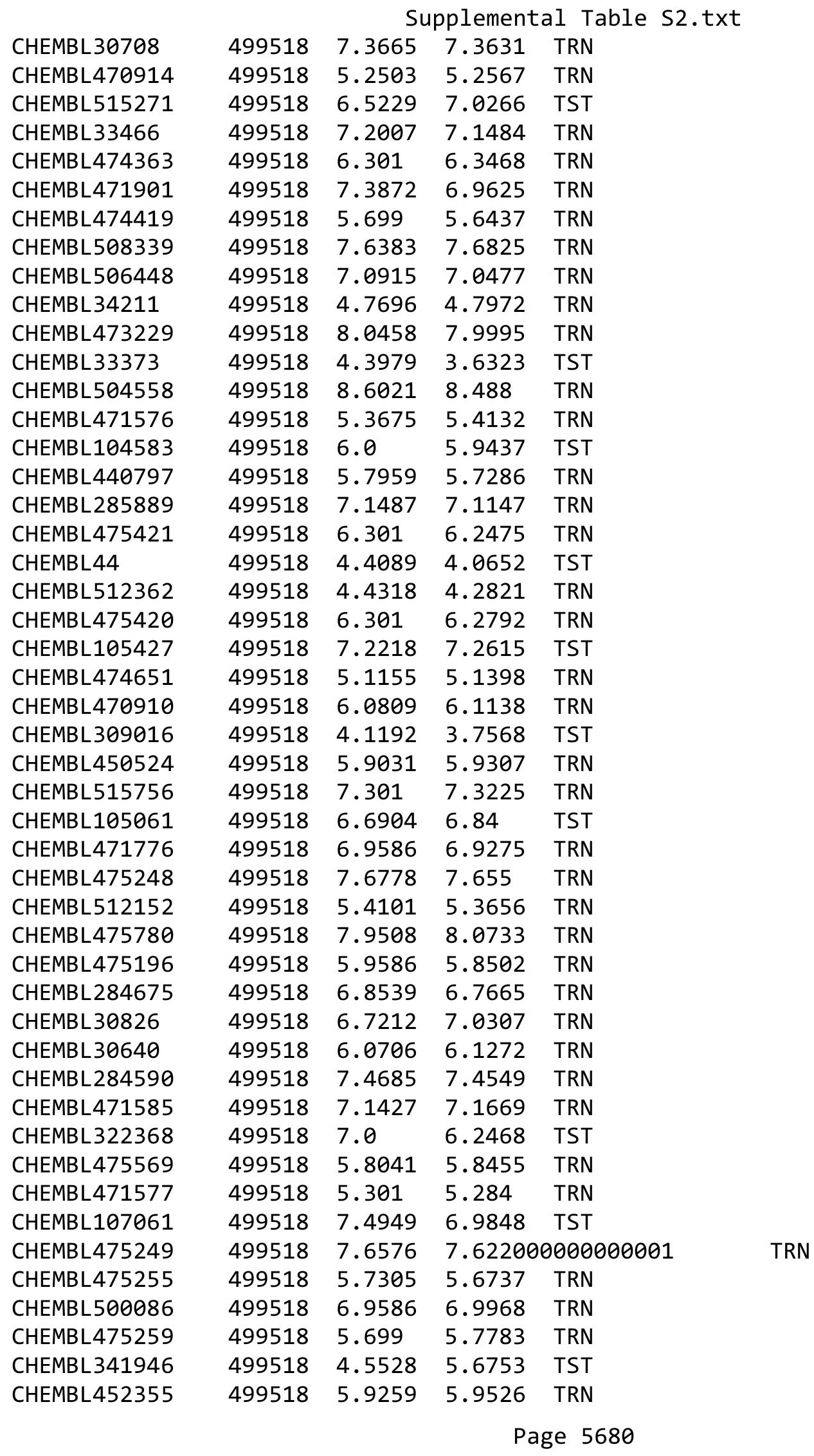




\begin{tabular}{|c|c|c|c|c|c|}
\hline \multicolumn{6}{|c|}{ Supplemental Table S2.txt } \\
\hline CHEMBL322152 & 499518 & 6.8761 & 5.6816 & TST & \\
\hline CHEMBL471727 & 499518 & 7.4949 & 7.5599 & TRN & \\
\hline CHEMBL475180 & 499518 & 6.0 & 6.0093 & TRN & \\
\hline CHEMBL 30885 & 499518 & 6.0706 & 6.0236 & TRN & \\
\hline CHEMBL 30873 & 499518 & 7.0458 & 6.9957 & TRN & \\
\hline CHEMBL 30514 & 499518 & 6.699 & 6.6404 & TRN & \\
\hline CHEMBL450867 & 499518 & 5.301 & 5.3628 & TRN & \\
\hline CHEMBL104691 & 499518 & 6.1818 & 7.0137 & TST & \\
\hline CHEMBL514811 & 499518 & 5.4437 & 5.4255 & TRN & \\
\hline CHEMBL471582 & 499518 & 5.0655 & 5.0514 & TRN & \\
\hline CHEMBL77030 & 499518 & 4.4202 & 4.7331 & TST & \\
\hline CHEMBL475408 & 499518 & 6.301 & 6.2933 & TRN & \\
\hline CHEMBL34104 & 499518 & 6.301 & 6.4036 & TRN & \\
\hline CHEMBL 30678 & 499518 & 7.4685 & 7.1284 & TRN & \\
\hline CHEMBL512364 & 499518 & 5.1186 & 5.0684 & TRN & \\
\hline CHEMBL511829 & 499518 & 6.1612 & 6.1551 & TRN & \\
\hline CHEMBL474582 & 499518 & 8.0458 & 8.0364 & TRN & \\
\hline CHEMBL454012 & 499518 & 7.0362 & 7.1563 & TRN & \\
\hline CHEMBL475014 & 499518 & 4.4389 & 4.5006 & TRN & \\
\hline CHEMBL470717 & 499518 & 5.4202 & 4.0639 & TST & \\
\hline CHEMBL472590 & 499518 & 6.5528 & 6.46899 & 9999999999 & TRN \\
\hline CHEMBL475254 & 499518 & 7.585 & 7.6171 & TRN & \\
\hline CHEMBL475001 & 499518 & 6.0487 & 5.6749 & TST & \\
\hline CHEMBL525222 & 499518 & 5.1851 & 5.6076 & TST & \\
\hline CHEMBL420100 & 499518 & 6.0706 & 6.005 & TST & \\
\hline CHEMBL475416 & 499518 & 5.699 & 5.7403 & TRN & \\
\hline CHEMBL 281696 & 499518 & 6.3872 & 6.3072 & TRN & \\
\hline CHEMBL317197 & 499518 & 5.3979 & 6.2332 & TST & \\
\hline CHEMBL475252 & 499518 & 6.301 & 5.3055 & TST & \\
\hline CHEMBL475195 & 499518 & 6.0 & 6.0284 & TRN & \\
\hline CHEMBL475371 & 499518 & 6.8239 & 6.8293 & TRN & \\
\hline CHEMBL474832 & 499518 & 8.1549 & 8.2546 & TRN & \\
\hline CHEMBL470716 & 499518 & 5.699 & 5.6805 & TRN & \\
\hline CHEMBL 344614 & 499518 & 5.301 & 5.6626 & TST & \\
\hline CHEMBL475250 & 499518 & 7.5229 & 7.5943 & TRN & \\
\hline CHEMBL474361 & 499518 & 6.6383 & 6.5423 & TRN & \\
\hline CHEMBL471753 & 499518 & 6.1249 & 6.1372 & TRN & \\
\hline CHEMBL104813 & 499518 & 6.5638 & 5.7394 & TST & \\
\hline CHEMBL470528 & 499518 & 7.1805 & 7.1849 & TRN & \\
\hline CHEMBL514345 & 499518 & 6.301 & 6.2196 & TRN & \\
\hline CHEMBL470718 & 499518 & 5.1135 & 4.6992 & TST & \\
\hline CHEMBL516060 & 499518 & 5.0004 & 5.197 & TST & \\
\hline CHEMBL 282342 & 499518 & 7.7212 & 7.7193 & TRN & \\
\hline CHEMBL475779 & 499518 & 4.058 & 4.3094 & TST & \\
\hline CHEMBL3968846 & 1640702 & 5.5935 & 5.438 & TRN & \\
\hline CHEMBL 3971002 & 1640702 & 5.466 & 5.5634 & TRN & \\
\hline CHEMBL 1450796 & 1640702 & 8.3979 & 8.0683 & TRN & \\
\hline CHEMBL 2151190 & 1640702 & 8.3979 & 7.6385 & TRN & \\
\hline
\end{tabular}


Supplemental Table S2.txt

\begin{tabular}{|c|c|c|c|c|}
\hline CHEMBL3956648 & 1640702 & 5.5421 & 5.4553 & TRN \\
\hline CHEMBL417727 & 1640702 & 6.1739 & 6.6781 & TST \\
\hline CHEMBL1451931 & 1640702 & 7.0 & 6.3901 & TST \\
\hline CHEMBL3895590 & 1640702 & 5.5317 & 5.4758 & TRN \\
\hline CHEMBL1555938 & 1640702 & 6.284 & 5.7541 & TRN \\
\hline CHEMBL3939309 & 1640702 & 5.6108 & 5.5353 & TRN \\
\hline CHEMBL3932629 & 1640702 & 5.4559 & 5.4744 & TRN \\
\hline CHEMBL3943145 & 1640702 & 5.4168 & 5.4631 & TRN \\
\hline CHEMBL1527391 & 1640702 & 8.3979 & 7.8925 & TRN \\
\hline CHEMBL1096283 & 1640702 & 8.3979 & 7.9617 & TRN \\
\hline CHEMBL3975566 & 1640702 & 5.7825 & 5.716 & TRN \\
\hline CHEMBL3932842 & 1640702 & 5.4389 & 6.29299 & 9999999999 \\
\hline CHEMBL3891183 & 1640702 & 8.3979 & 7.7358 & TRN \\
\hline CHEMBL3922673 & 1640702 & 5.4776 & 5.6389 & TRN \\
\hline CHEMBL3889583 & 1640702 & 5.3665 & 5.5237 & TRN \\
\hline CHEMBL3949529 & 1640702 & 5.52 & 5.5324 & TRN \\
\hline CHEMBL3904842 & 1640702 & 5.6498 & 6.2256 & TST \\
\hline CHEMBL3904392 & 1640702 & 5.4067 & 5.5832 & TRN \\
\hline CHEMBL3913398 & 1640702 & 5.5045 & 5.5094 & TRN \\
\hline CHEMBL3896250 & 1640702 & 5.6737 & 5.6264 & TRN \\
\hline CHEMBL3949128 & 1640702 & 6.1549 & 5.8297 & TST \\
\hline CHEMBL3954473 & 1640702 & 5.5735 & 6.3673 & TST \\
\hline CHEMBL3899280 & 1640702 & 5.9788 & 5.6429 & TRN \\
\hline CHEMBL3922732 & 1640702 & 5.5391 & 6.3608 & TST \\
\hline CHEMBL3930701 & 1640702 & 5.6635 & 5.435 & TRN \\
\hline CHEMBL 2028043 & 1640702 & 8.3979 & 7.5507 & TRN \\
\hline CHEMBL3915173 & 1640702 & 5.5591 & 5.5015 & TRN \\
\hline CHEMBL3971377 & 1640702 & 5.3429 & 5.9854 & TST \\
\hline CHEMBL3973492 & 1640702 & 5.7905 & 6.0077 & TST \\
\hline CHEMBL3893028 & 1640702 & 6.0655 & 6.6111 & TST \\
\hline CHEMBL3942795 & 1640702 & 5.4763 & 5.9303 & TST \\
\hline CHEMBL1605094 & 1640702 & 4.3979 & 5.8604 & TST \\
\hline CHEMBL3967651 & 1640702 & 5.6289 & 5.6156 & TRN \\
\hline CHEMBL3941245 & 1640702 & 5.2958 & 5.4905 & TRN \\
\hline CHEMBL3953375 & 1640702 & 5.6716 & 5.3882 & TRN \\
\hline CHEMBL3984076 & 1640702 & 5.5702 & 5.6232 & TRN \\
\hline CHEMBL555689 & 1640702 & 8.3979 & 7.7166 & TRN \\
\hline CHEMBL3915561 & 1640702 & 8.3979 & 6.7414 & TST \\
\hline CHEMBL1438218 & 1640702 & 8.3979 & 8.0333 & TRN \\
\hline CHEMBL1517074 & 1640702 & 7.1549 & 7.9576 & TRN \\
\hline CHEMBL3964364 & 1640702 & 5.4802 & 5.6783 & TRN \\
\hline CHEMBL3986664 & 1640702 & 5.5544 & 5.6166 & TRN \\
\hline CHEMBL1098317 & 1640702 & 6.8539 & 7.6648 & TRN \\
\hline CHEMBL3942669 & 1640702 & 5.3665 & 5.8447 & TST \\
\hline CHEMBL3967196 & 1640702 & 6.0655 & 5.9623 & TRN \\
\hline CHEMBL3970515 & 1640702 & 5.6536 & 5.5714 & TRN \\
\hline CHEMBL3983497 & 1640702 & 5.5719 & 5.6639 & TRN \\
\hline CHEMBL3929952 & 1640702 & 5.7852 & 6.0806 & TST \\
\hline
\end{tabular}


Supplemental Table S2.txt

\begin{tabular}{|c|c|c|c|c|c|c|}
\hline CHEMBL2094689 & 1640702 & 6.0177 & 7.6975 & TRN & & \\
\hline CHEMBL 3958853 & 1640702 & $5.3420 e$ & 00000000 & 005 & 5.5975 & TRN \\
\hline CHEMBL1325945 & 1640702 & 8.3979 & 7.9148 & TRN & & \\
\hline CHEMBL 3924071 & 1640702 & 5.9666 & 5.8269 & TRN & & \\
\hline CHEMBL3911255 & 1640702 & 5.5157 & 5.6016 & TRN & & \\
\hline CHEMBL 3957146 & 1640702 & 5.5735 & 5.58700 & 0000000001 & & TRN \\
\hline CHEMBL3947991 & 1640702 & 5.5575 & 5.6243 & TRN & & \\
\hline CHEMBL1488035 & 1640702 & 6.6383 & 7.7847 & TRN & & \\
\hline CHEMBL 3920676 & 1640702 & 5.5243 & 5.6511 & TRN & & \\
\hline CHEMBL601757 & 1640702 & 7.0969 & 8.012 & TRN & & \\
\hline CHEMBL3953349 & 1640702 & 5.4921 & 6.0907 & TST & & \\
\hline CHEMBL3957925 & 1640702 & 6.0458 & 5.8998 & TRN & & \\
\hline CHEMBL3890991 & 1640702 & 5.5735 & 5.4936 & TRN & & \\
\hline CHEMBL 3954193 & 1640702 & 5.5143 & 5.6589 & TRN & & \\
\hline CHEMBL3892474 & 1640702 & 5.6364 & 5.6321 & TRN & & \\
\hline CHEMBL 3898920 & 1640702 & 5.7959 & 5.5728 & TRN & & \\
\hline CHEMBL3983097 & 1640702 & 6.0757 & 5.9151 & TST & & \\
\hline CHEMBL3932643 & 1640702 & 5.5834 & 5.5967 & TRN & & \\
\hline CHEMBL 3908323 & 1640702 & 4.3979 & 5.3146 & TRN & & \\
\hline CHEMBL3921213 & 1640702 & 5.4248 & 6.2803 & TST & & \\
\hline CHEMBL1376622 & 1640702 & 6.0605 & 5.6685 & TRN & & \\
\hline CHEMBL3967099 & 1640702 & 5.6655 & 6.6835 & TST & & \\
\hline CHEMBL3910232 & 1640702 & 5.52 & 5.6264 & TRN & & \\
\hline CHEMBL 3918842 & 1640702 & 5.5452 & 5.6343 & TRN & & \\
\hline CHEMBL 3976054 & 1640702 & 5.4012 & 5.5112 & TRN & & \\
\hline CHEMBL3966849 & 1640702 & 5.6421 & 5.5677 & TRN & & \\
\hline CHEMBL 3970460 & 1640702 & 5.8665 & \multicolumn{3}{|c|}{5.752000000000001} & TRN \\
\hline CHEMBL1602578 & 1640702 & 8.3979 & 7.7457 & TRN & & \\
\hline CHEMBL 3929586 & 1640702 & 5.3179 & 5.5637 & TRN & & \\
\hline CHEMBL 3184493 & 1640702 & 6.7212 & 7.6562 & TRN & & \\
\hline CHEMBL 3975252 & 1640702 & 5.7375 & 5.6186 & TRN & & \\
\hline CHEMBL 3905080 & 1640702 & 5.5702 & 5.4872 & TRN & & \\
\hline CHEMBL3891169 & 1640702 & 5.3862 & 5.4894 & TRN & & \\
\hline CHEMBL3961081 & 1640702 & 5.684 & 5.5821 & TRN & & \\
\hline CHEMBL3935059 & 1640702 & 6.0757 & 5.6947 & TST & & \\
\hline CHEMBL3968172 & 1640702 & 5.5376 & 5.4469 & TRN & & \\
\hline CHEMBL3965366 & 1640702 & 5.6478 & 6.0997 & TST & & \\
\hline CHEMBL599924 & 1640702 & 8.3979 & 7.652 & TRN & & \\
\hline CHEMBL 3134043 & 1640702 & 8.3979 & 7.8785 & TRN & & \\
\hline CHEMBL433282 & 1640702 & 6.1938 & 6.5466 & TST & & \\
\hline CHEMBL3918141 & 1640702 & 5.6126 & 5.5447 & TRN & & \\
\hline CHEMBL3905458 & 1640702 & 5.3251 & 6.0212 & TST & & \\
\hline CHEMBL3980446 & 1640702 & 8.3979 & 7.506 & TRN & & \\
\hline CHEMBL3911247 & 1640702 & 5.4078 & 5.5765 & TRN & & \\
\hline CHEMBL3912943 & 1640702 & 5.4685 & 5.6466 & TRN & & \\
\hline CHEMBL1449923 & 1640702 & 5.8827 & 5.7379 & TRN & & \\
\hline CHEMBL 3977238 & 1640702 & 6.0088 & 5.6556 & TRN & & \\
\hline CHEMBL3978673 & 1640702 & 5.4949 & 5.4902 & TRN & & \\
\hline
\end{tabular}


Supplemental Table S2.txt

\begin{tabular}{|c|c|c|c|c|}
\hline - & & 7721 & & \\
\hline & 640702 & 5.4134 & & \\
\hline & & 851 & & \\
\hline AEMBL & 702 & & & $\mathrm{MI}$ \\
\hline AEMBL2086889 & 640702 & 218 & & \\
\hline HEMBL3964262 & 640702 & 5.6091 & 5613 & \\
\hline 13752 & & 905 & & \\
\hline EMBL3983553 & & & & \\
\hline AEMBL3904482 & & & & \\
\hline HEMBL3935233 & 640702 & & 351 & \\
\hline HEMBL3939649 & 702 & 52 & & \\
\hline IEMBL 3917214 & 02 & & 85 & \\
\hline IEMBL: & & & & \\
\hline HEMBL3896702 & 702 & & & \\
\hline AEMBL3971017 & 102 & & & \\
\hline AEMBL3960070 & 64 & 52 & 27 & \\
\hline IEMBL 3981 & 0 & 88 & & \\
\hline AEMBL 3926 & & & & \\
\hline AEMBL2094386 & 02 & 676 & & \\
\hline AEMBL39 & & & & \\
\hline HEIMBL3890091 & 64 & & & Niv \\
\hline IEMBL: & & & & SI \\
\hline AEMBL3 & $\partial 2$ & & & \\
\hline 78318 & 702 & & & \\
\hline HEMBL 398 & & & & TST \\
\hline AEMBL39 & 64 & & & RIV \\
\hline AEMBL & & & & RN \\
\hline $\mathrm{AFMBI}=$ & 82 & & & RN \\
\hline HEMBL3891220 & & & & 15 \\
\hline AEMBL3934132 & & & & RN \\
\hline HEMBL 3984 & & & & RN \\
\hline HEMBL; & & & & RN \\
\hline 38 & 32 & & & RN \\
\hline HEMBL3980959 & & & & IRN \\
\hline HEMBL3936541 & 64 & 71 & & TRN \\
\hline HEMBL3970542 & 6 & & & TRN \\
\hline HFMRI & & & & ГST \\
\hline HEMBL3 & & & & ST \\
\hline HEMBL3937927 & 82 & 38 & & TRN \\
\hline IEMBL 3965809 & & & & $\mathrm{RN}$ \\
\hline HEMBL3976307 & 64 & 87 & & PN \\
\hline HEMBL3901102 & & & & RIN \\
\hline HEMBL3908154 & & & & RN \\
\hline AEMBL3968299 & 782 & 9.0757 & 55 & TR \\
\hline MBL3 & & & & $\mathrm{N}$ \\
\hline HEMBL 3973 & & & & \\
\hline LHEMBL 3910000 & .782 & & & \\
\hline CHEMBL3959085 & 1641782 & 9.3098 & 9.0385 & ГRN \\
\hline
\end{tabular}


Supplemental Table S2.txt

\begin{tabular}{|c|c|c|c|c|c|}
\hline CHEMBL3949681 & 1641782 & 8.9431 & 9.012 & TST & \\
\hline CHEMBL3892717 & 1641782 & 9.0655 & 8.9351 & TRN & \\
\hline CHEMBL3935981 & 1641782 & 9.3468 & 9.245 & TRN & \\
\hline CHEMBL 3974166 & 1641782 & 9.1024 & 9.0316 & TRN & \\
\hline CHEMBL3913096 & 1641782 & 9.0132 & 8.8314 & TRN & \\
\hline CHEMBL 3977237 & 1641782 & 9.28399 & 999999999 & 9.596 & TRN \\
\hline CHEMBL3971083 & 1641782 & 9.4089 & 9.3561 & TST & \\
\hline CHEMBL3975956 & 1641782 & 9.1079 & 8.8542 & TRN & \\
\hline CHEMBL3968781 & 1641782 & 9.4685 & 9.1093 & TRN & \\
\hline CHEMBL3902522 & 1641782 & 8.9706 & 8.8568 & TRN & \\
\hline CHEMBL 3903720 & 1641782 & 9.0862 & 9.1619 & TRN & \\
\hline CHEMBL3956898 & 1641782 & 9.4437 & 9.174 & TRN & \\
\hline CHEMBL3971636 & 1641782 & 9.1938 & 9.7842 & TRN & \\
\hline CHEMBL 3900033 & 1641782 & 9.1249 & 8.934 & TRN & \\
\hline CHEMBL3932229 & 1641782 & 8.1864 & 8.5872 & TRN & \\
\hline CHEMBL3915071 & 1641782 & 9.1487 & 9.2834 & TST & \\
\hline CHEMBL3980934 & 1641782 & 8.382 & 9.0661 & TST & \\
\hline CHEMBL3982069 & 1641782 & 9.2147 & 8.8802 & TRN & \\
\hline CHEMBL 3944383 & 1641782 & 8.5331 & 8.8465 & TRN & \\
\hline CHEMBL 3905546 & 1641782 & 8.9208 & 8.8975 & TRN & \\
\hline CHEMBL3923871 & 1641782 & 9.2924 & 8.94 & TRN & \\
\hline CHEMBL3940929 & 1641782 & 9.2147 & 9.1764 & TRN & \\
\hline CHEMBL3926601 & 1641782 & 9.1427 & 9.3692 & TST & \\
\hline CHEMBL 3977209 & 1641782 & 9.041 & 9.0093 & TRN & \\
\hline CHEMBL3931929 & 1641782 & 7.8526 & 8.652999 & 9999999999 & TRN \\
\hline CHEMBL3927535 & 1641782 & 9.1367 & 9.5906 & TST & \\
\hline CHEMBL 3898868 & 1641782 & 9.3872 & 9.1912 & TRN & \\
\hline CHEMBL 3894548 & 1641782 & 8.6737 & 9.5603 & TRN & \\
\hline CHEMBL 3942241 & 1641782 & 8.9586 & 9.1475 & TST & \\
\hline CHEMBL3946737 & 1641782 & 8.7825 & 9.4498 & TRN & \\
\hline CHEMBL 3892301 & 1641782 & 9.2291 & 8.9019 & TRN & \\
\hline CHEMBL3939892 & 1641782 & 9.5376 & 9.3062 & TST & \\
\hline CHEMBL3979537 & 1641782 & 9.3468 & 9.8333 & TRN & \\
\hline CHEMBL 3950272 & 1641782 & 9.0809 & 8.8604 & TRN & \\
\hline CHEMBL 3956075 & 1641782 & 9.2676 & 9.1466 & TRN & \\
\hline CHEMBL3937898 & 1641782 & 9.3872 & 9.2263 & TRN & \\
\hline CHEMBL3952702 & 1641782 & 9.2366 & 8.8284 & TRN & \\
\hline CHEMBL3984681 & 1641782 & 8.9666 & 9.605 & TRN & \\
\hline CHEMBL 3945615 & 1641782 & 9.2076 & 9.0066 & TRN & \\
\hline CHEMBL3953340 & 1641782 & 8.9172 & 8.8632 & TRN & \\
\hline CHEMBL3900031 & 1641782 & 9.1938 & 9.0823 & TRN & \\
\hline CHEMBL3914623 & 1641782 & 9.4202 & 9.443 & TST & \\
\hline CHEMBL3889937 & 1641782 & 9.3372 & 9.3938 & TRN & \\
\hline CHEMBL3892526 & 1641782 & 9.1308 & 9.1944 & TRN & \\
\hline CHEMBL3956651 & 1641782 & 9.0269 & 9.1516 & TRN & \\
\hline CHEMBL3918538 & 1641782 & 9.2924 & 9.1657 & TRN & \\
\hline CHEMBL3966652 & 1641782 & 8.8268 & 8.8839 & TRN & \\
\hline CHEMBL3926957 & 1641782 & 8.5243 & 8.9653 & TST & \\
\hline
\end{tabular}


Supplemental Table S2.txt

\begin{tabular}{|c|c|c|c|c|c|c|}
\hline CHEMBL3908328 & 1641782 & 9.28399 & 79999999 & & 9.2446 & TRN \\
\hline CHEMBL3959615 & 1641782 & 9.1024 & 8.9292 & TRN & & \\
\hline CHEMBL3923526 & 1641782 & 8.5654 & 8.8766 & TRN & & \\
\hline CHEMBL3965438 & 1641782 & 9.1739 & 8.9027 & TRN & & \\
\hline CHEMBL3974692 & 1641782 & 8.5171 & 9.3139 & TRN & & \\
\hline CHEMBL 3915560 & 1641782 & 9.4815 & 9.3796 & TST & & \\
\hline CHEMBL3951483 & 1641782 & 9.0555 & 8.9638 & TRN & & \\
\hline CHEMBL3933501 & 1641782 & 9.1805 & 9.0042 & TRN & & \\
\hline CHEMBL3975592 & 1641782 & 8.9586 & 8.9757 & TRN & & \\
\hline CHEMBL 3890537 & 1641782 & 9.3979 & 9.1044 & TRN & & \\
\hline CHEMBL 3951397 & 1641782 & 9.5086 & 9.2178 & TRN & & \\
\hline CHEMBL3925466 & 1641782 & 9.0506 & 8.963 & TRN & & \\
\hline CHEMBL3982869 & 1641782 & 9.1024 & 8.8972 & TRN & & \\
\hline CHEMBL 3976520 & 1641782 & 8.7696 & 9.1366 & TRN & & \\
\hline CHEMBL 3925958 & 1641782 & 9.3098 & 9.5355 & TRN & & \\
\hline CHEMBL3908409 & 1641782 & 9.5086 & 9.1846 & TRN & & \\
\hline CHEMBL3900499 & 1641782 & 9.0915 & 9.6699 & TRN & & \\
\hline CHEMBL 3974475 & 1641782 & 9.3188 & 8.9281 & TRN & & \\
\hline CHEMBL3909519 & 1641782 & 9.4089 & 9.1654 & TRN & & \\
\hline CHEMBL 3963271 & 1641782 & 9.6198 & 9.1028 & TRN & & \\
\hline CHEMBL3950688 & 1641782 & 9.2596 & 9.0778 & TRN & & \\
\hline CHEMBL3939335 & 1641782 & 9.0655 & 8.9045 & TRN & & \\
\hline CHEMBL3921889 & 1641782 & 6.0 & 7.1165 & TST & & \\
\hline CHEMBL 3934963 & 1641782 & 9.2596 & 9.4615 & TST & & \\
\hline CHEMBL3912167 & 1641782 & 9.6198 & 9.7064 & TRN & & \\
\hline CHEMBL3952022 & 1641782 & 9.0969 & 9.1871 & TST & & \\
\hline CHEMBL3909533 & 1641782 & 9.2596 & 9.7301 & TRN & & \\
\hline CHEMBL3970070 & 1641782 & 9.4949 & 9.1315 & TRN & & \\
\hline CHEMBL3932430 & 1641782 & \multicolumn{3}{|c|}{9.283999999999999} & 9.5107 & TRN \\
\hline CHEMBL 3946998 & 1641782 & 9.0315 & 8.8776 & TRN & & \\
\hline CHEMBL3890657 & 1641782 & 9.5086 & 9.1135 & TRN & & \\
\hline CHEMBL3903218 & 1641782 & 9.1427 & 9.4506 & TRN & & \\
\hline CHEMBL3892543 & 1641782 & 8.2967 & 8.7709 & TST & & \\
\hline CHEMBL3985677 & 1641782 & 9.1612 & 8.9536 & TRN & & \\
\hline CHEMBL3905167 & 1641782 & 9.2007 & 8.969 & TRN & & \\
\hline CHEMBL3962975 & 1641782 & 9.2218 & 8.8871 & TST & & \\
\hline CHEMBL 3948702 & 1641782 & 8.8894 & 9.116 & TST & & \\
\hline CHEMBL3972830 & 1641782 & 9.3372 & 9.1397 & TRN & & \\
\hline CHEMBL3899509 & 1641782 & 8.5361 & 9.0325 & TST & & \\
\hline CHEMBL3945218 & 1641782 & 9.2676 & 9.2258 & TST & & \\
\hline CHEMBL3915926 & 1641782 & 9.3098 & 9.125 & TRN & & \\
\hline CHEMBL3924255 & 1641782 & 9.1487 & 9.176 & TRN & & \\
\hline CHEMBL3961979 & 1641782 & 8.9626 & 8.851 & TRN & & \\
\hline CHEMBL3934335 & 1641782 & 6.0 & 7.776 & TRN & & \\
\hline CHEMBL3929567 & 1641782 & 9.1871 & 9.1404 & TST & & \\
\hline CHEMBL3952559 & 1641782 & 8.9136 & 8.8881 & TRN & & \\
\hline CHEMBL3929116 & 1641782 & 9.0044 & 9.1491 & TRN & & \\
\hline CHEMBL3932644 & 1641782 & 9.1549 & 9.1695 & TRN & & \\
\hline
\end{tabular}


Supplemental Table S2.txt

\begin{tabular}{|c|c|c|c|c|}
\hline Th & 541782 & & & \\
\hline & & 9.2366 & 8.9771 & \\
\hline & & & & \\
\hline AEMBL3934286 & & & & \\
\hline AEMBL3890487 & 782 & 3279 & 289 & \\
\hline HEMBL3949394 & 641782 & 9.3565 & 9099 & \\
\hline 81 & & & & \\
\hline IFMR| 391 & & & & \\
\hline HEMBL391 & & 1612 & & \\
\hline HEMBL 394 & 782 & 468 & 209 & \\
\hline AEMBL 392 & 782 & 9.6 & 588 & \\
\hline IEMBL39 & 82 & 91 & & \\
\hline AEMBL3S & & & & \\
\hline HEMBL 39 & 82 & 9.2518 & & \\
\hline HEMBL393 & 82 & 9.301 & & \\
\hline AEMBL3S & 32 & 35 & 73 & \\
\hline AEMBL3\& & 32 & 6 & & \\
\hline HEMBL3S & & & & \\
\hline HEMBL3\& & & 96 & & \\
\hline AEMBL3S & & & & \\
\hline HEMBL= & 6 & & & Niv \\
\hline AEMBL: & & & & הות \\
\hline HEMBL & & & & \\
\hline 87 & & & & \\
\hline AEMBL3S & & & & TST \\
\hline HEMBL & 6 & & & 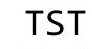 \\
\hline HEMBL; & & & & RN \\
\hline$H F M B I=$ & 82 & $\partial 6$ & & \\
\hline HEMBL3 & & & & $\ln$ \\
\hline HEMBL 389 & & & & 15 \\
\hline HEMBL3S & & & & RN \\
\hline HEMBL; & & & & RN \\
\hline AEMBL; & & & & TRN \\
\hline HEMBL3926 & & & & IRN \\
\hline HEMBL3912946 & 64 & 8. & 3482 & TST \\
\hline HEMBL3 & & & 84 & RN \\
\hline HFMRI: & & & & TRN \\
\hline HEMBL & & & 475 & RN \\
\hline HEMBL3927987 & 82 & 8. & 7819 & TST \\
\hline AEMBL38 & & & & TRN \\
\hline HEMBL3S & 2 & & 75 & \\
\hline CHEMBL 39 & & & & RIV \\
\hline HEMBL39 & & 7.7471 & 8.5564 & TST \\
\hline AEMBL 389 & 782 & 9.2676 & 5378 & TST \\
\hline $\mathrm{MRI}=$ & & & & TST \\
\hline HEMBL3 & & & & \\
\hline CHEMBL 395 & & 9.2441 & 9.0022 & \\
\hline LHEMBL3949479 & 1641782 & 8.4248 & 8.5562 & \\
\hline
\end{tabular}


Supplemental Table S2.txt

\begin{tabular}{|c|c|c|c|c|}
\hline-5 & 32 & & & \\
\hline HEMBL3956152 & 641782 & 9.5229 & 9.5595 & \\
\hline & & 67 & & \\
\hline 32 & 782 & 6.0 & 73 & \\
\hline JEMBL3900004 & 782 & 9.3665 & 0702 & \\
\hline AEMBL3967093 & 641782 & 9.2676 & 0998 & \\
\hline HEMBL3906556 & 782 & 655 & 921 & \\
\hline 83 & 82 & 605 & 562 & \\
\hline IEMBL391 & 882 & 8.9508 & 8095 & \\
\hline AEMBL3915865 & 782 & 9.3565 & 1388 & \\
\hline HEMBL3933698 & 782 & 9.2518 & 9337 & \\
\hline AEMBL3900032 & 82 & 9.2218 & 9446 & \\
\hline AEMBL3S & & 113 & & \\
\hline HEMBL3S & & 3872 & 866 & \\
\hline AEMBL3981362 & 82 & 9.2218 & 625 & \\
\hline AEMBL3932623 & 82 & 9.4089 & 2078 & \\
\hline HEMBL398 & 32 & 223 & 664 & \\
\hline HEMBL 392 & & 596 & & \\
\hline AEMBL3906961 & & 506 & 862 & \\
\hline AEMBL3928370 & & 308 & & \\
\hline AEMBL3963779 & 82 & 218 & 264 & RN \\
\hline HEMBL 398 & 32 & 198 & 681 & \\
\hline HEMBL3 & & & & \\
\hline 82 & & 318 & 2013 & RN \\
\hline HEMBL 389 & 32 & 98 & 982 & RIV \\
\hline 3L390 & & 386 & 375 & RN \\
\hline HEM & & 086 & 603 & - \\
\hline HEN & & 31 & 966 & RN \\
\hline AEMBL39 & & 327 & 95 & RIN \\
\hline HEMBL396 & 2 & 79 & 359 & RN \\
\hline IEMBL396 & & 18 & 752 & ST \\
\hline 81 & & 53 & 33 & RN \\
\hline 8 & & & 353 & RN \\
\hline HEMBL3894688 & & & & RN \\
\hline AEMBL3912892 & 32 & 9.2596 & & RN \\
\hline HEMBL398 & & 212 & 32 & \\
\hline 2 & & 5 & & ST \\
\hline HEMBL3959420 & & & 9.1356 & ST \\
\hline HEMBL3931819 & 82 & 9.5686 & 3255 & TRN \\
\hline AEMBL3899968 & $U^{2}$ & & 165 & RN \\
\hline HEMBL3915304 & 16 & 8.9066 & 25 & I \\
\hline HEMBL3962664 & & & 597 & ST \\
\hline HEMBL3941957 & & 8.8477 & 9.5928 & RN \\
\hline HEMBL3979772 & 882 & 7.0162 & . 1007 & RN \\
\hline EMBL39 & & 9245 & 3.8839 & \\
\hline HEMBL3914779 & 16 & .7696 & 9. 2863 & \\
\hline HEMBL 394 & & 3.8239 & 8.9154 & 1 \\
\hline CHEMBL 3932881 & 1641782 & 9.3372 & 9.137 & RN \\
\hline
\end{tabular}

Page 5688 
Supplemental Table S2.txt

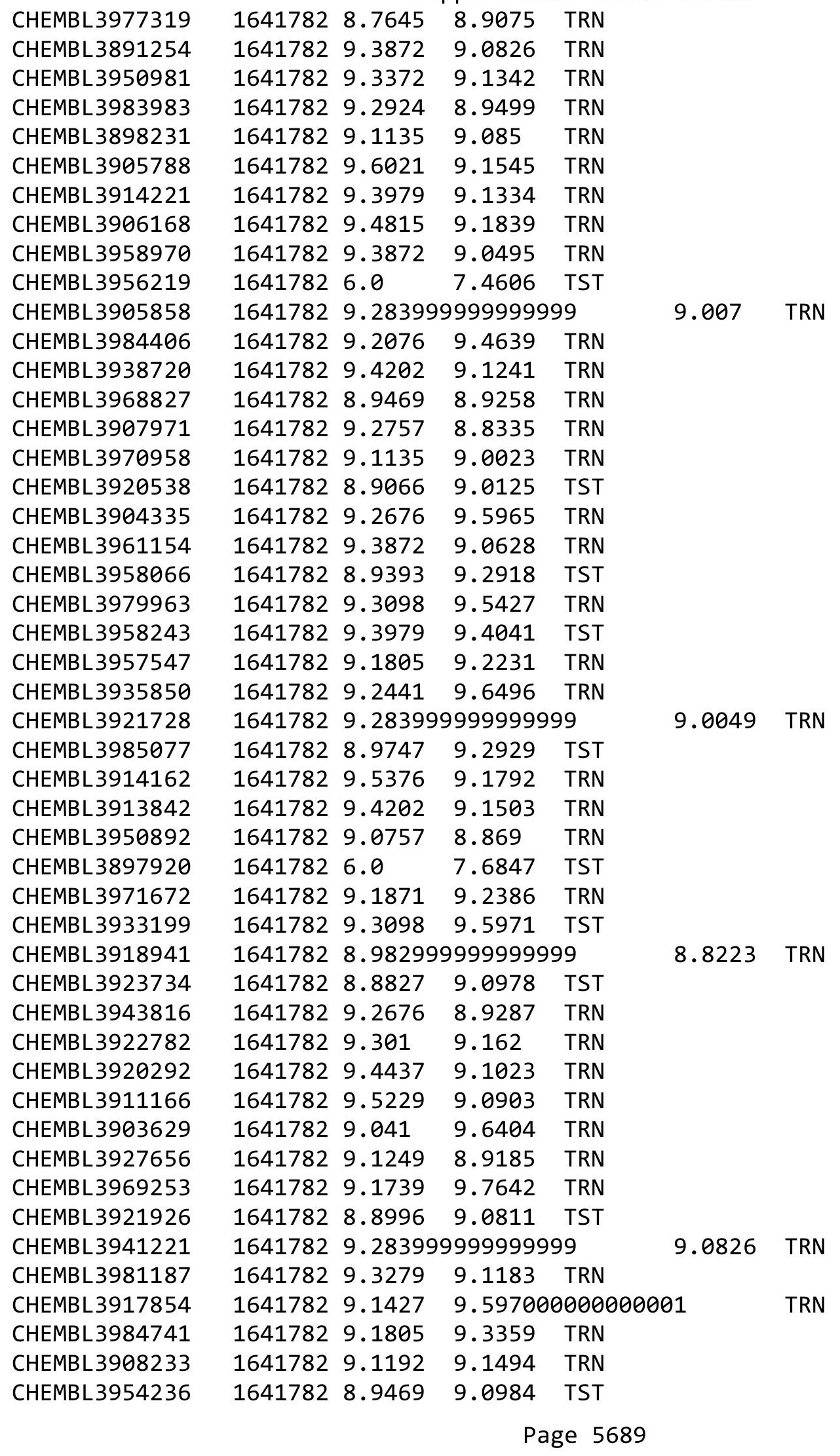


Supplemental Table S2.txt

\begin{tabular}{|c|c|c|c|c|c|}
\hline CHEMBL3920894 & 1641782 & 9.0605 & 9.2393 & TST & \\
\hline CHEMBL3979546 & 1641782 & 9.2366 & 9.2281 & TRN & \\
\hline CHEMBL3943256 & 1641782 & 9.3665 & 9.0024 & TRN & \\
\hline CHEMBL3980794 & 1641782 & 8.9431 & 8.7626 & TRN & \\
\hline CHEMBL 3903778 & 1641782 & 8.9101 & 9.4481 & TRN & \\
\hline CHEMBL3962342 & 1641782 & 9.2924 & 9.1122 & TRN & \\
\hline CHEMBL3950547 & 1641782 & 8.8601 & 9.0208 & TST & \\
\hline CHEMBL3942542 & 1641782 & 6.0 & 7.4545 & TRN & \\
\hline CHEMBL3981642 & 1641782 & 9.3872 & 8.9152 & TRN & \\
\hline CHEMBL3909568 & 1641782 & 9.1487 & 9.4892 & TRN & \\
\hline CHEMBL3890535 & 1641782 & 9.4815 & 9.274 & TRN & \\
\hline CHEMBL3964224 & 1641782 & 8.699 & 9.4748 & TST & \\
\hline CHEMBL3900605 & 1641782 & 9.2757 & 8.8875 & TST & \\
\hline CHEMBL3912919 & 1641782 & 9.6021 & 9.2414 & TRN & \\
\hline CHEMBL3945907 & 1641782 & 8.4828 & 9.1344 & TST & \\
\hline CHEMBL3898055 & 1641782 & 9.1079 & 9.7436 & TRN & \\
\hline CHEMBL3898459 & 1641782 & 8.6421 & 9.0238 & TST & \\
\hline CHEMBL3966860 & 1641782 & 8.9706 & 9.0001 & TRN & \\
\hline CHEMBL 3960123 & 1641782 & 9.2518 & 9.0437 & TRN & \\
\hline CHEMBL3948591 & 1641782 & 9.4815 & 9.1287 & TRN & \\
\hline CHEMBL3968315 & 1641782 & 9.4559 & 9.0834 & TRN & \\
\hline CHEMBL 3898708 & 1641782 & 8.6517 & 8.9314 & TRN & \\
\hline CHEMBL3944331 & 1641782 & 8.9666 & 9.3364 & TRN & \\
\hline CHEMBL3964990 & 1641782 & 9.3979 & 9.1623 & TRN & \\
\hline CHEMBL3901746 & 1641782 & 9.1308 & 8.9339 & TRN & \\
\hline CHEMBL3967830 & 1641782 & 9.4202 & 9.1309 & TRN & \\
\hline CHEMBL3957132 & 1641782 & 9.4089 & 9.1609 & TRN & \\
\hline CHEMBL3975210 & 1641782 & 8.8097 & 8.8539 & TRN & \\
\hline CHEMBL3896141 & 1641782 & 9.3468 & $9.14200 e$ & 2000000001 & TRN \\
\hline CHEMBL3970998 & 1641782 & 9.2757 & 9.2299 & TRN & \\
\hline CHEMBL3924554 & 1641782 & 8.7212 & 8.7624 & TST & \\
\hline CHEMBL3981144 & 1641782 & 9.1427 & 9.1994 & TRN & \\
\hline CHEMBL3970566 & 1641782 & 8.7011 & 9.4029 & TRN & \\
\hline CHEMBL3957195 & 1641782 & 9.4437 & 9.1079 & TRN & \\
\hline CHEMBL 3978448 & 1641782 & 9.3565 & 8.9406 & TRN & \\
\hline CHEMBL3914377 & 1641782 & 9.1675 & 9.3414 & TRN & \\
\hline CHEMBL3901982 & 1641782 & 9.2366 & 9.0948 & TRN & \\
\hline CHEMBL3969424 & 1641782 & 8.9318 & 8.9751 & TRN & \\
\hline CHEMBL3951874 & 1641782 & 9.4949 & 9.3268 & TRN & \\
\hline CHEMBL3910553 & 1641782 & 9.6778 & 9.4641 & TST & \\
\hline CHEMBL 3950200 & 1641782 & 9.0223 & 9.1091 & TRN & \\
\hline CHEMBL 3985468 & 1641782 & 8.7905 & 9.231 & TST & \\
\hline CHEMBL3894603 & 1641782 & 8.8356 & 9.2332 & TST & \\
\hline CHEMBL3924016 & 1641782 & 9.6021 & 9.5875 & TST & \\
\hline CHEMBL 3974690 & 1641782 & 8.699 & 8.9029 & TST & \\
\hline CHEMBL 3957787 & 1641782 & 8.9957 & 8.831 & TRN & \\
\hline CHEMBL3925409 & 1641782 & 8.8633 & 9.0768 & TST & \\
\hline CHEMBL3897207 & 1641782 & 8.8928 & 8.8061 & TRN & \\
\hline
\end{tabular}


Supplemental Table S2.txt

\begin{tabular}{|c|c|c|c|c|}
\hline - & 541782 & & & \\
\hline & & 9.6383 & 5351 & \\
\hline & & & & \\
\hline AEMBL: & & & & \\
\hline AEMBL3920178 & 782 & $\partial 6$ & 302 & \\
\hline HEMBL3928573 & 641782 & 9.3768 & 9986 & \\
\hline HEMBL398 & 782 & 6.0 & 4944 & \\
\hline IFMRI 30 & & 31 & 8981 & \\
\hline AEMBL3892587 & & 98 & 8.9238 & \\
\hline HEMBL3896759 & 782 & & 3687 & \\
\hline HEMBL3931278 & 882 & 9.2 & 127 & \\
\hline IEMBL3S & 82 & & 524 & \\
\hline AEMBL & & & & \\
\hline HEMBL3 & 82 & & 2641 & \\
\hline HEMBL392 & 82 & 24 & 7763 & \\
\hline AEMBL389 & 32 & & 302 & \\
\hline AEMBL3S & 32 & & 794 & \\
\hline HEMBL3S & & & 773 & \\
\hline HEMBL39 & & & 3739 & \\
\hline AEMBL3S & & & & \\
\hline HEMBL= & 82 & & 81 & Niv \\
\hline AEMBL & & & 99 & RN \\
\hline HEMBL3S & & & .72 & \\
\hline 96 & & & & \\
\hline AEMBL3S & & & & TST \\
\hline HEMBL3 & 6 & 9 . & 719 & RN \\
\hline HEMBL & & 6 & 289 & וד וכ \\
\hline$H F M B I=$ & 82 & 6 & 562 & $\sigma-T_{2}$ \\
\hline HEMBL3S & & 6 & 1864 & is \\
\hline HEMBL 391 & & & 556 & I \\
\hline HEMBL3S & 64 & & 998 & ST \\
\hline HEMBL; & & & 147 & RN \\
\hline AEMBL3 & & & 58 & גח \\
\hline HEMBL 390 & & & 578 & IRN \\
\hline HEMBL 3937195 & 2 & 9. & 687 & TRN \\
\hline HEMBL3S & 6 & & 917 & ST \\
\hline HFMRI & & & & $\Gamma \mathrm{RN}$ \\
\hline HEMBL & & & 303 & IRN \\
\hline HEMBL3912800 & 82 & 9. & 7602 & TRN \\
\hline AEMBL3S & 32 & & 757 & TST \\
\hline HEMBL3S & 2 & & 887 & TRN \\
\hline CHEMBL 39 & & & 4858 & RIV \\
\hline HEMBL39 & & & 1309 & TRN \\
\hline HEMBL 389 & 782 & 8. & 3469 & TS \\
\hline MRI $=$ & & & 661 & $\mathrm{~N}$ \\
\hline HEMBL3 & & م & & \\
\hline CHEMBL395 & 782 & 5.0 & 7.8019 & \\
\hline HEMBL3921617 & 1641782 & 9.4202 & 9.6668 & \\
\hline
\end{tabular}

Page 5691 
Supplemental Table S2.txt

\begin{tabular}{|c|c|c|c|c|}
\hline - & 32 & & & \\
\hline & 641782 & 8.301 & 7358 & \\
\hline & & 24 & & \\
\hline 506 & 82 & 132 & 41 & \\
\hline IEMBL3947977 & 782 & 9.5229 & 2004 & \\
\hline AEMBL3924292 & 641782 & 9.3979 & 8249 & \\
\hline HEMBL & 782 & .2441 & 1278 & \\
\hline 66 & 82 & 2757 & 382 & \\
\hline AEMBL3S & & 685 & .1847 & \\
\hline HEMBL 390 & 782 & 9.4089 & 0063 & \\
\hline HEMBL 395 & 782 & 9.0706 & 1948 & \\
\hline AEMBL39 & 82 & 8.6345 & .5583 & \\
\hline AEMBL3 & & & & \\
\hline HEMBL3S & & 6 . & 5252 & \\
\hline HEMBL 389 & 82 & 427 & 929 & \\
\hline AEMBL398 & 82 & 9.0223 & 35 & \\
\hline HEMBL3S & 32 & 188 & 782 & \\
\hline HEMBL3S & & 37 & & \\
\hline AEMBL3 3 & & 098 & $\partial 799$ & \\
\hline AEMBL39 & 32 & 229 & 972 & RN \\
\hline HBL & 82 & 098 & $\partial 23$ & ISI \\
\hline HEMBL3S & 32 & 969 & 3331 & - \\
\hline HEMBL3S & & 901 & & \\
\hline AEMBL & & 229 & & 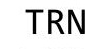 \\
\hline AEMBL3\& & 32 & 098 & 04 & RIN \\
\hline$L 3$ & & 508 & 185 & ST \\
\hline AEMBL3 & & 9 & 047 & RN \\
\hline HEN & & & & ST \\
\hline AEMBL3\& & & & & RN \\
\hline AEMBL3 & 82 & 9. & 549 & RN \\
\hline AEMBL3 & & 586 & & RN \\
\hline 5 & & 47 & & KIV \\
\hline 34 & & 62 & & RN \\
\hline HEMBL3S & & 9 . & & RN \\
\hline HEMBL39 & 32 & 6. & 514 & IST \\
\hline AEMBL3 & & & 278 & rRN \\
\hline $45 M I^{-7}$ & & & 56 & KIV \\
\hline & & & 051 & TST \\
\hline HEMBL396 & 82 & 9.2076 & & TST \\
\hline AEMBL39 & v. & 706 & 791 & 「RN \\
\hline HEMBL39 & 16 & 8. & 9. 226 & SI \\
\hline HEMBL $3 \subseteq$ & & & & RN \\
\hline HEMBL391 & & 8.9586 & 8.8401 & TRN \\
\hline HEMBL396 & 882 & 9.2596 & 9792 & TRN \\
\hline & & 487 & .2028 & \\
\hline HEMBL 39 & & 7959 & 9. 6292 & וצכ \\
\hline HEMBL 39 & & 8.4921 & 8.5487 & \\
\hline CHEMBL 3915738 & 1641782 & 8.7747 & 9.2358 & - \\
\hline
\end{tabular}

Page 5692 
Supplemental Table S2.txt

\begin{tabular}{|c|c|c|c|c|c|}
\hline CHEMBL3895560 & 1641782 & 9.0757 & 8.9173 & TRN & \\
\hline CHEMBL3915972 & 1641782 & 9.6021 & 9.1647 & TRN & \\
\hline CHEMBL3958363 & 1641782 & 9.041 & 8.9069 & TRN & \\
\hline CHEMBL3942091 & 1641782 & 9.3979 & 9.0883 & TRN & \\
\hline CHEMBL3923151 & 1641782 & 9.3768 & 9.0278 & TRN & \\
\hline CHEMBL3952029 & 1641782 & 9.1871 & 9.23899 & э999999999 & TRN \\
\hline CHEMBL 3930303 & 1641782 & 9.2518 & 8.9856 & TRN & \\
\hline CHEMBL3923446 & 1641782 & 6.0 & 7.2335 & TST & \\
\hline CHEMBL3918206 & 1641782 & 8.4401 & 8.7587 & TST & \\
\hline CHEMBL3937077 & 1641782 & 9.2291 & 9.6844 & TRN & \\
\hline CHEMBL 3900819 & 1641782 & 8.9172 & 9.2329 & TRN & \\
\hline CHEMBL3892396 & 1641782 & 9.0362 & 8.9229 & TRN & \\
\hline CHEMBL3942659 & 1641782 & 9.0315 & 8.9954 & TRN & \\
\hline CHEMBL3946308 & 1641782 & 9.2518 & 9.2827 & TST & \\
\hline CHEMBL3926308 & 1641782 & 9.3372 & 9.2807 & TRN & \\
\hline CHEMBL3909091 & 1641782 & 6.0 & 7.6065 & TST & \\
\hline CHEMBL3975506 & 1641782 & 9.4559 & 9.1035 & TRN & \\
\hline CHEMBL 3894756 & 1641782 & 8.8386 & 9.2561 & TST & \\
\hline CHEMBL3919476 & 1641782 & 8.9136 & 9.0456 & TST & \\
\hline CHEMBL3961393 & 1641782 & 9.3372 & 9.2456 & TRN & \\
\hline CHEMBL3914617 & 1641782 & 9.2366 & 9.7163 & TRN & \\
\hline CHEMBL3921497 & 1641782 & 9.6778 & 9.533 & TST & \\
\hline CHEMBL3971137 & 1641782 & 8.9101 & 9.6683 & TRN & \\
\hline CHEMBL3928249 & 1641782 & 9.1427 & 9.4358 & TST & \\
\hline CHEMBL3920142 & 1641782 & 9.6198 & 9.2001 & TRN & \\
\hline CHEMBL3961634 & 1641782 & 8.6073 & 8.7054 & TRN & \\
\hline CHEMBL3970779 & 1641782 & 9.4815 & 9.1635 & TRN & \\
\hline CHEMBL3924451 & 1641782 & 9.2147 & 9.3562 & TST & \\
\hline CHEMBL3916925 & 1641782 & 9.4685 & \multicolumn{2}{|c|}{9.052999999999999} & TRN \\
\hline CHEMBL3901134 & 1641782 & 9.4949 & 9.6185 & TRN & \\
\hline CHEMBL3929644 & 1641782 & 9.4815 & 9.1279 & TRN & \\
\hline CHEMBL1256459 & 955073 & 5.6558 & 5.5726 & TRN & \\
\hline CHEMBL 258844 & 955073 & 3.4321 & 3.4271 & TRN & \\
\hline CHEMBL412142 & 955073 & 3.75 & 3.767 & TRN & \\
\hline CHEMBL393929 & 955073 & 5.0976 & 5.1763 & TRN & \\
\hline CHEMBL585951 & 955073 & 5.8876 & 5.8707 & TRN & \\
\hline CHEMBL 217354 & 955073 & 6.6682 & 6.6578 & TRN & \\
\hline CHEMBL3392440 & 955073 & 3.2295 & 3.1816 & TRN & \\
\hline CHEMBL573107 & 955073 & 5.7505 & 5.7367 & TRN & \\
\hline CHEMBL2363137 & 955073 & 4.7879 & 4.7592 & TRN & \\
\hline CHEMBL 220241 & 955073 & 6.8608 & 6.8293 & TRN & \\
\hline CHEMBL3349342 & 955073 & 4.9217 & 4.9953 & TRN & \\
\hline CHEMBL180127 & 955073 & 3.8461 & 3.8286 & TRN & \\
\hline CHEMBL 213100 & 955073 & 3.0118 & 3.0669 & TRN & \\
\hline CHEMBL65 & 955073 & 9.2116 & 9.2452 & TRN & \\
\hline CHEMBL 202721 & 955073 & 5.144 & 5.0966 & TRN & \\
\hline CHEMBL259181 & 955073 & 3.8065 & 3.7897 & TRN & \\
\hline CHEMBL472940 & 955073 & 3.6296 & 3.6251 & TRN & \\
\hline
\end{tabular}




\begin{tabular}{|c|c|c|c|c|c|}
\hline & & \multicolumn{4}{|c|}{ Supplemental Table S2.txt } \\
\hline CHEMBL1970879 & 955073 & 2.8133 & 2.8689 & TRN & \\
\hline CHEMBL1242367 & 955073 & 2.9926 & 3.0261 & TRN & \\
\hline CHEMBL2137530 & 955073 & 4.7088 & 4.6983 & TRN & \\
\hline CHEMBL483847 & 955073 & 3.7652 & 3.6991 & TRN & \\
\hline CHEMBL379975 & 955073 & 4.4142 & 4.4067 & TRN & \\
\hline CHEMBL 210618 & 955073 & 4.3961 & 4.3891 & TRN & \\
\hline CHEMBL9470 & 955073 & 5.8717 & 4.9907 & TST & \\
\hline CHEMBL300389 & 955073 & 5.9515 & 5.9181 & TRN & \\
\hline CHEMBL 222102 & 955073 & 3.0279 & \multicolumn{2}{|c|}{3.1519999999999997} & TRN \\
\hline CHEMBL189584 & 955073 & 4.5493 & 4.5084 & TRN & \\
\hline CHEMBL 209148 & 955073 & 2.821 & 2.7948 & TRN & \\
\hline CHEMBL577784 & 955073 & 5.3739 & 5.4061 & TRN & \\
\hline CHEMBL379300 & 955073 & 5.1952 & 5.1649 & TRN & \\
\hline CHEMBL192566 & 955073 & 7.1994 & 6.9398 & TST & \\
\hline CHEMBL2005886 & 955073 & 4.5745 & 4.5101 & TRN & \\
\hline CHEMBL 2144069 & 955073 & 4.3571 & 4.276 & TRN & \\
\hline CHEMBL3186408 & 955073 & 4.7146 & 4.223 & TST & \\
\hline CHEMBL255342 & 955073 & 3.346 & 3.2842 & TRN & \\
\hline CHEMBL1909414 & 955073 & 3.4159 & 3.3526 & TRN & \\
\hline CHEMBL1230020 & 955073 & 2.9937 & 3.0503 & TRN & \\
\hline CHEMBL1788116 & 955073 & 4.1583 & 4.1105 & TRN & \\
\hline CHEMBL221137 & 955073 & 4.2053 & 4.6835 & TST & \\
\hline CHEMBL1357247 & 955073 & 2.765 & 2.7556 & TRN & \\
\hline CHEMBL509032 & 955073 & 5.803 & 5.9034 & TRN & \\
\hline CHEMBL512504 & 955073 & 3.7474 & 3.6968 & TRN & \\
\hline CHEMBL515416 & 955073 & 3.193 & 3.2087 & TRN & \\
\hline CHEMBL 2134202 & 955073 & 3.8074 & 3.8727 & TRN & \\
\hline CHEMBL483849 & 955073 & 1.2832 & 1.5756 & TST & \\
\hline CHEMBL399530 & 955073 & \multicolumn{3}{|c|}{4.4239999999999995} & TRN \\
\hline CHEMBL558642 & 955073 & 4.2721 & 4.218 & TRN & \\
\hline CHEMBL3199475 & 955073 & 4.7498 & 4.7994 & TRN & \\
\hline CHEMBL373751 & 955073 & 5.0148 & 4.9027 & TRN & \\
\hline CHEMBL1404918 & 955073 & 3.2452 & 3.2907 & TRN & \\
\hline CHEMBL514499 & 955073 & 5.3957 & 5.4736 & TRN & \\
\hline CHEMBL1190711 & 955073 & 5.276 & 5.3251 & TRN & \\
\hline CHEMBL135561 & 955073 & 3.8886 & 3.93899 & 99999999996 & TRN \\
\hline CHEMBL1516890 & 955073 & 5.5329 & 3.8974 & TST & \\
\hline CHEMBL 240954 & 955073 & 3.5363 & 3.3313 & TST & \\
\hline CHEMBL1643959 & 955073 & 2.6363 & 3.43899 & 99999999996 & TST \\
\hline CHEMBL191334 & 955073 & 5.4935 & 4.2959 & TST & \\
\hline CHEMBL1186585 & 955073 & 4.0754 & 4.4087 & TST & \\
\hline CHEMBL188678 & 955073 & 4.5811 & 4.0257 & TST & \\
\hline CHEMBL92309 & 955073 & 3.2809 & 2.2455 & TST & \\
\hline CHEMBL392695 & 955073 & 4.3191 & 3.6726 & TST & \\
\hline CHEMBL102714 & 955073 & 3.0504 & 2.9353 & TST & \\
\hline CHEMBL1673039 & 955073 & 4.3293 & 4.3017 & TST & \\
\hline CHEMBL1590308 & 955073 & 3.3553 & 3.2073 & TST & \\
\hline CHEMBL449158 & 955073 & 5.9166 & 6.4015 & TST & \\
\hline
\end{tabular}




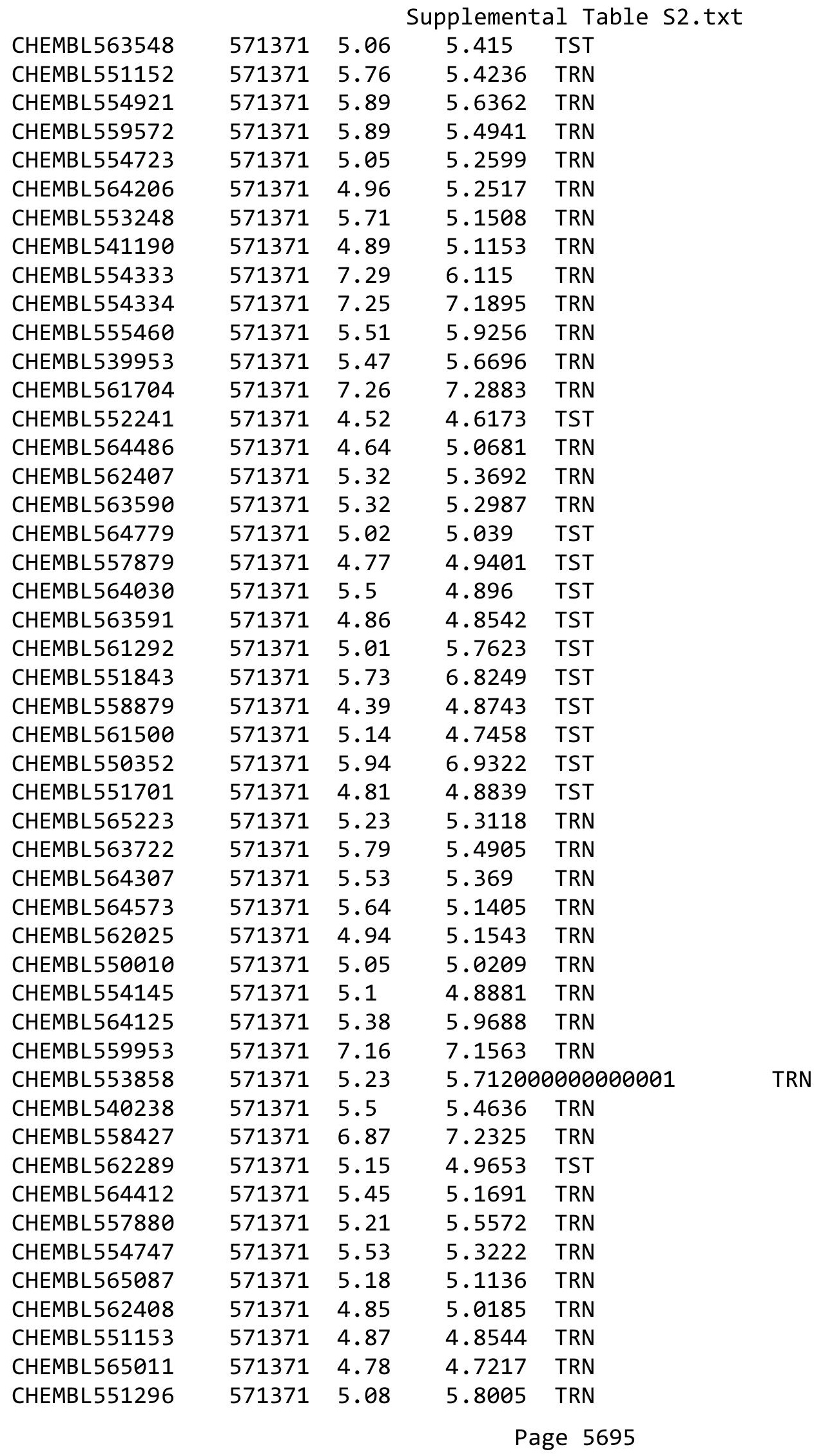




\begin{tabular}{|c|c|c|c|c|c|}
\hline & & \multicolumn{4}{|c|}{ Supplemental Table S2.txt } \\
\hline CHEMBL562026 & 571371 & 6.86 & 6.9821 & TRN & \\
\hline CHEMBL563064 & 571371 & 4.91 & 5.0121 & TRN & \\
\hline CHEMBL560161 & 571371 & 4.71 & 4.883 & TRN & \\
\hline CHEMBL550354 & 571371 & 7.67 & 7.1316 & TRN & \\
\hline CHEMBL515416 & 954788 & 4.0842 & 4.0644 & TRN & \\
\hline CHEMBL573107 & 954788 & 5.6503 & 5.7142 & TRN & \\
\hline CHEMBL379975 & 954788 & 5.3503 & 5.3277 & TRN & \\
\hline CHEMBL258844 & 954788 & 3.3639 & 3.4511 & TRN & \\
\hline CHEMBL1788116 & 954788 & 3.0605 & 3.112 & TRN & \\
\hline CHEMBL399530 & 954788 & 4.7852 & 4.7798 & TRN & \\
\hline CHEMBL1516890 & 954788 & 4.0862 & 4.0071 & TRN & \\
\hline CHEMBL102714 & 954788 & 3.1543 & 3.1623 & TRN & \\
\hline CHEMBL240954 & 954788 & 3.4107 & 2.9249 & TST & \\
\hline CHEMBL393929 & 954788 & 4.5457 & 4.5235 & TRN & \\
\hline CHEMBL1673039 & 954788 & 3.5287 & 3.5744 & TRN & \\
\hline CHEMBL1643959 & 954788 & 3.4226 & 3.4486 & TRN & \\
\hline CHEMBL221137 & 954788 & 4.833 & 4.7887 & TST & \\
\hline CHEMBL 3392440 & 954788 & 3.6334 & 3.6893 & TRN & \\
\hline CHEMBL 209148 & 954788 & \multicolumn{4}{|c|}{4.0889999999999995} \\
\hline CHEMBL180127 & 954788 & 2.6893 & 2.6541 & TRN & \\
\hline CHEMBL192566 & 954788 & 10.0757 & 7.7087 & TST & \\
\hline CHEMBL255342 & 954788 & 3.5742 & 3.5449 & TRN & \\
\hline CHEMBL577784 & 954788 & 5.9832 & 6.1058 & TRN & \\
\hline CHEMBL1909414 & 954788 & 4.3364 & 4.319 & TRN & \\
\hline CHEMBL3349342 & 954788 & 4.1013 & 4.0845 & TRN & \\
\hline CHEMBL 2134202 & 954788 & 3.3096 & 3.3098 & TRN & \\
\hline CHEMBL259181 & 954788 & 3.8781 & 3.9104 & TRN & \\
\hline CHEMBL1186585 & 954788 & 3.4414 & 3.4408 & TRN & \\
\hline CHEMBL 220241 & 954788 & 4.1895 & 4.1584 & TRN & \\
\hline CHEMBL483849 & 954788 & 2.2537 & 1.0652 & TST & \\
\hline CHEMBL300389 & 954788 & 4.738 & 4.7204 & TRN & \\
\hline CHEMBL412142 & 954788 & 3.3108 & 3.2641 & TRN & \\
\hline CHEMBL3186408 & 954788 & 4.5814 & 3.4013 & TST & \\
\hline CHEMBL585951 & 954788 & 5.5923 & 5.6581 & TRN & \\
\hline CHEMBL191334 & 954788 & 5.4461 & 5.4936 & TRN & \\
\hline CHEMBL189584 & 954788 & 5.0426 & 5.0021 & TRN & \\
\hline CHEMBL379300 & 954788 & 4.0155 & 3.9967 & TRN & \\
\hline CHEMBL 2137530 & 954788 & 4.8993 & 4.7873 & TRN & \\
\hline CHEMBL3199475 & 954788 & 3.4673 & 3.5014 & TRN & \\
\hline CHEMBL92309 & 954788 & 3.2832 & 2.53800 & 00000000003 & TST \\
\hline CHEMBL1190711 & 954788 & 4.9988 & 5.058 & TRN & \\
\hline CHEMBL449158 & 954788 & 5.978 & 6.2978 & TST & \\
\hline CHEMBL1230020 & 954788 & 4.1314 & 4.0728 & TRN & \\
\hline CHEMBL1404918 & 954788 & 2.5877 & 2.6453 & TRN & \\
\hline CHEMBL135561 & 954788 & 4.0059 & 4.0037 & TRN & \\
\hline CHEMBL509032 & 954788 & 5.9123 & 5.925 & TRN & \\
\hline CHEMBL373751 & 954788 & 3.6024 & 3.5654 & TRN & \\
\hline CHEMBL202721 & 954788 & 5.0651 & 5.0006 & TRN & \\
\hline
\end{tabular}




\begin{tabular}{|c|c|c|c|c|c|}
\hline & & & & & \\
\hline CHEMBL9470 & 954788 & 6.0782 & 5.0925 & TST & \\
\hline CHEMBL392695 & 954788 & 3.187 & 3.265 & TRN & \\
\hline CHEMBL65 & 954788 & 8.4951 & 8.4937 & TRN & \\
\hline CHEMBL1256459 & 954788 & 5.425 & 5.3463 & TRN & \\
\hline CHEMBL1242367 & 954788 & 3.3953 & 3.3957 & TRN & \\
\hline CHEMBL483847 & 954788 & 4.3579 & 4.2756 & TRN & \\
\hline CHEMBL1970879 & 954788 & 4.0476 & 4.0993 & TRN & \\
\hline CHEMBL558642 & 954788 & 2.7855 & 2.7793 & TRN & \\
\hline CHEMBL210618 & 954788 & 3.105 & 3.1238 & TRN & \\
\hline CHEMBL2363137 & 954788 & 5.4025 & 5.3689 & TRN & \\
\hline CHEMBL213100 & 954788 & 3.4352 & $3.36800 t$ & 00000000003 & TRN \\
\hline CHEMBL 2005886 & 954788 & 3.5018 & 3.56 & TRN & \\
\hline CHEMBL472940 & 954788 & 2.8738 & 3.573 & TST & \\
\hline CHEMBL 2144069 & 954788 & 4.006 & 5.0303 & TST & \\
\hline CHEMBL188678 & 954788 & 4.9188 & 4.4513 & TST & \\
\hline CHEMBL512504 & 954788 & 6.4138 & 4.9816 & TST & \\
\hline CHEMBL1590308 & 954788 & 2.4612 & 3.2922 & TST & \\
\hline CHEMBL514499 & 954788 & 4.2206 & 4.9223 & TST & \\
\hline CHEMBL 217354 & 954788 & 6.5461 & 6.7495 & TST & \\
\hline CHEMBL 222102 & 954788 & 4.6875 & 3.4654 & TST & \\
\hline CHEMBL1357247 & 954788 & 2.4791 & 2.3793 & TST & \\
\hline CHEMBL 2205607 & 885141 & 6.9872 & 6.8145 & TRN & \\
\hline CHEMBL 2205613 & 885141 & 6.0273 & 5.9465 & TRN & \\
\hline CHEMBL2205605 & 885141 & 4.0 & 4.0353 & TRN & \\
\hline CHEMBL2205611 & 885141 & 5.1028 & 5.121 & TRN & \\
\hline CHEMBL2205587 & 885141 & 7.1308 & 7.1453 & TRN & \\
\hline CHEMBL 2204905 & 885141 & 8.3279 & 8.2986 & TRN & \\
\hline CHEMBL 2205581 & 885141 & 8.2291 & 6.9011 & TST & \\
\hline CHEMBL 2204897 & 885141 & 6.6968 & 6.4503 & TST & \\
\hline CHEMBL 2205598 & 885141 & 6.3107 & 6.239 & TST & \\
\hline CHEMBL2205624 & 885141 & 5.029 & 4.9807 & TRN & \\
\hline CHEMBL 2204901 & 885141 & 6.6596 & 6.6063 & TST & \\
\hline CHEMBL2204909 & 885141 & 6.9747 & 6.9566 & TRN & \\
\hline CHEMBL2205619 & 885141 & 7.9586 & 7.7644 & TRN & \\
\hline CHEMBL 2204904 & 885141 & 6.4045 & 6.4948 & TRN & \\
\hline CHEMBL2204896 & 885141 & 7.2007 & 7.1903 & TRN & \\
\hline CHEMBL 2205602 & 885141 & 4.0 & 4.0176 & TRN & \\
\hline CHEMBL2205583 & 885141 & 7.0177 & 7.0535 & TRN & \\
\hline CHEMBL2205586 & 885141 & 6.9957 & 6.9476 & TRN & \\
\hline CHEMBL2204892 & 885141 & 8.2218 & 7.0583 & TST & \\
\hline CHEMBL2204894 & 885141 & 7.3372 & 7.3464 & TRN & \\
\hline CHEMBL 2205620 & 885141 & 7.7696 & 7.8335 & TRN & \\
\hline CHEMBL2204895 & 885141 & 7.7447 & 7.8206 & TRN & \\
\hline CHEMBL 2205580 & 885141 & 8.1938 & 6.9361 & TST & \\
\hline CHEMBL2205582 & 885141 & 7.3979 & 6.7746 & TST & \\
\hline CHEMBL2205596 & 885141 & 8.4437 & 8.4123 & TRN & \\
\hline CHEMBL2205599 & 885141 & 7.1487 & 6.8773 & TST & \\
\hline CHEMBL2204902 & 885141 & 8.2676 & 8.1893 & TRN & \\
\hline
\end{tabular}


Supplemental Table S2.txt

\begin{tabular}{|c|c|c|c|c|c|}
\hline CHEMBL2205609 & 885141 & 7.4559 & 7.5668 & TRN & \\
\hline CHEMBL 2205608 & 885141 & 6.1255 & 6.138 & TRN & \\
\hline CHEMBL 2205606 & 885141 & 6.3116 & 6.4266 & TRN & \\
\hline CHEMBL 2204900 & 885141 & 7.3279 & 7.3281 & TST & \\
\hline CHEMBL 2205601 & 885141 & 5.8474 & 5.8595 & TRN & \\
\hline CHEMBL2205591 & 885141 & 8.6021 & 8.6019 & TRN & \\
\hline CHEMBL 2205585 & 885141 & 7.3872 & 7.3183 & TRN & \\
\hline CHEMBL 2204906 & 885141 & 7.585 & 7.5487 & TRN & \\
\hline CHEMBL 2205617 & 885141 & 7.8539 & 7.9337 & TRN & \\
\hline CHEMBL2205579 & 885141 & 6.8894 & 6.6375 & TST & \\
\hline CHEMBL 2205603 & 885141 & 6.1898 & 6.1779 & TRN & \\
\hline CHEMBL 2204899 & 885141 & 6.4634 & 5.4793 & TST & \\
\hline CHEMBL 2205595 & 885141 & 8.4815 & 8.6288 & TRN & \\
\hline CHEMBL 2205597 & 885141 & 7.6383 & 7.0045 & TST & \\
\hline CHEMBL 2205615 & 885141 & 8.5229 & 8.3678 & TRN & \\
\hline CHEMBL 2205623 & 885141 & 6.15799 & 79999999 & 995 & 6.1282 \\
\hline CHEMBL 2205618 & 885141 & 7.4559 & 7.5962 & TRN & \\
\hline CHEMBL 2205594 & 885141 & 8.8539 & 8.8151 & TRN & \\
\hline CHEMBL2205612 & 885141 & 6.0472 & 6.1571 & TRN & \\
\hline CHEMBL 2204907 & 885141 & 6.6799 & 6.8894 & TST & \\
\hline CHEMBL 2205610 & 885141 & 7.0223 & 7.0567 & TRN & \\
\hline CHEMBL 2205604 & 885141 & 7.4559 & 7.4483 & TRN & \\
\hline CHEMBL2205622 & 885141 & 6.644 & 6.5546 & TRN & \\
\hline CHEMBL 2205584 & 885141 & 7.6198 & 7.6233 & TRN & \\
\hline CHEMBL 2205593 & 885141 & 8.1871 & 8.2387 & TRN & \\
\hline CHEMBL 2205588 & 885141 & 7.8239 & 7.7761 & TRN & \\
\hline CHEMBL 2205616 & 885141 & 8.0223 & 8.0221 & TRN & \\
\hline CHEMBL2205578 & 885141 & 9.2596 & 7.6323 & TST & \\
\hline CHEMBL2205592 & 885141 & 8.3279 & 8.2723 & TRN & \\
\hline CHEMBL 2204893 & 885141 & 7.3098 & 7.3022 & TRN & \\
\hline CHEMBL 2205621 & 885141 & 8.0 & 8.0551 & TRN & \\
\hline CHEMBL 2205614 & 885141 & 4.0 & 3.9479 & TRN & \\
\hline CHEMBL2205600 & 885141 & 6.5045 & 6.6493 & TST & \\
\hline CHEMBL 2205589 & 885141 & 7.4202 & 7.436 & TRN & \\
\hline CHEMBL 2205590 & 885141 & 7.6198 & 7.648 & TRN & \\
\hline CHEMBL 2204898 & 885141 & 6.8182 & 6.2379 & TST & \\
\hline CHEMBL 2204908 & 885141 & 6.8633 & 6.899 & TRN & \\
\hline CHEMBL 2204903 & 885141 & 7.2518 & 6.8679 & TST & \\
\hline CHEMBL3653128 & 1528688 & 7.2924 & 7.3661 & TRN & \\
\hline CHEMBL3653143 & 1528688 & 7.1308 & 7.1298 & TRN & \\
\hline CHEMBL3653116 & 1528688 & 4.0 & 4.0001 & TRN & \\
\hline CHEMBL3653106 & 1528688 & 5.0915 & 5.0957 & TRN & \\
\hline CHEMBL3653093 & 1528688 & 6.2757 & 6.2587 & TRN & \\
\hline CHEMBL3653136 & 1528688 & 7.9586 & 7.9543 & TRN & \\
\hline CHEMBL3653109 & 1528688 & 6.2182 & 6.9039 & TST & \\
\hline CHEMBL3653137 & 1528688 & 7.9586 & 7.9422 & TRN & \\
\hline CHEMBL3653142 & 1528688 & 8.0 & 7.9682 & TRN & \\
\hline CHEMBL3653139 & 1528688 & 7.9208 & 7.915 & TRN & \\
\hline
\end{tabular}


Supplemental Table S2.txt

\begin{tabular}{|c|c|c|c|c|c|}
\hline CHEMBL3653096 & 1528688 & 7.2366 & 7.2415 & TRN & \\
\hline CHEMBL3653110 & 1528688 & 6.0246 & 6.8194 & TST & \\
\hline CHEMBL3653121 & 1528688 & 6.5768 & 6.563 & TST & \\
\hline CHEMBL3653111 & 1528688 & 5.5935 & 6.4048 & TST & \\
\hline CHEMBL3653127 & 1528688 & 7.7959 & 7.7447 & TRN & \\
\hline CHEMBL3653134 & 1528688 & 8.0 & 8.0431 & TRN & \\
\hline CHEMBL3653122 & 1528688 & 7.3565 & 7.3577 & TRN & \\
\hline CHEMBL3653099 & 1528688 & 7.3872 & 7.3845 & TRN & \\
\hline CHEMBL3653129 & 1528688 & 4.0 & 4.0028 & TRN & \\
\hline CHEMBL3653108 & 1528688 & 4.0 & 4.0046 & TRN & \\
\hline CHEMBL3653135 & 1528688 & 7.7959 & 7.791 & TRN & \\
\hline CHEMBL3653133 & 1528688 & 8.1549 & 8.1523 & TRN & \\
\hline CHEMBL 3653124 & 1528688 & 7.4949 & 7.5142 & TRN & \\
\hline CHEMBL 3653140 & 1528688 & 7.1549 & 7.181 & TRN & \\
\hline CHEMBL3653097 & 1528688 & 7.5086 & 7.5144 & TRN & \\
\hline CHEMBL3653102 & 1528688 & 6.5686 & 6.5766 & TRN & \\
\hline CHEMBL3653123 & 1528688 & 8.1549 & 8.1128 & TRN & \\
\hline CHEMBL3653126 & 1528688 & 6.6108 & 6.6113 & TRN & \\
\hline CHEMBL 3653107 & 1528688 & 4.0 & 3.9919 & TRN & \\
\hline CHEMBL3653112 & 1528688 & 6.3143 & 6.7558 & TST & \\
\hline CHEMBL3653114 & 1528688 & 6.058 & 6.0588 & TRN & \\
\hline CHEMBL3653105 & 1528688 & 6.1549 & 6.16100 & 00000000005 & TRN \\
\hline CHEMBL 3653120 & 1528688 & 7.9586 & 7.9072 & TST & \\
\hline CHEMBL3653103 & 1528688 & 7.0605 & 7.0576 & TRN & \\
\hline CHEMBL3653100 & 1528688 & 7.6576 & 7.6825 & TRN & \\
\hline CHEMBL3653101 & 1528688 & 7.2676 & 7.2736 & TRN & \\
\hline CHEMBL3653138 & 1528688 & 8.0458 & 8.0408 & TRN & \\
\hline CHEMBL3653104 & 1528688 & 5.9208 & 5.9161 & TRN & \\
\hline CHEMBL 3653125 & 1528688 & 7.0044 & 6.9559 & TRN & \\
\hline CHEMBL3653113 & 1528688 & 7.3768 & 7.3787 & TRN & \\
\hline CHEMBL3653119 & 1528688 & 7.8539 & 7.8548 & TRN & \\
\hline CHEMBL3653118 & 1528688 & 6.857 & 6.8636 & TRN & \\
\hline CHEMBL3653115 & 1528688 & 5.9788 & 5.9641 & TRN & \\
\hline CHEMBL3653132 & 1528688 & 6.6778 & 6.4255 & TST & \\
\hline CHEMBL 3653141 & 1528688 & 8.0458 & 8.068 & TRN & \\
\hline CHEMBL3653130 & 1528688 & 7.7959 & 7.5555 & TST & \\
\hline CHEMBL3653131 & 1528688 & 8.0 & 7.585 & TST & \\
\hline CHEMBL3653117 & 1528688 & 7.699 & 7.5866 & TST & \\
\hline CHEMBL3653095 & 1528688 & 5.8861 & 6.1745 & TST & \\
\hline CHEMBL 3653094 & 1528688 & 4.0 & 5.8962 & TST & \\
\hline CHEMBL3653098 & 1528688 & 6.2757 & 5.8803 & TST & \\
\hline CHEMBL289651 & 306908 & 8.6576 & 8.7302 & TRN & \\
\hline CHEMBL343570 & 306908 & 9.2441 & 9.3553 & TRN & \\
\hline CHEMBL364335 & 306908 & 9.1427 & 9.148 & TRN & \\
\hline CHEMBL362737 & 306908 & 7.0915 & 7.7838 & TST & \\
\hline CHEMBL140623 & 306908 & 7.8861 & 7.7941 & TRN & \\
\hline CHEMBL335815 & 306908 & 8.8861 & 8.9476 & TRN & \\
\hline CHEMBL189445 & 306908 & 5.8239 & 5.9772 & TRN & \\
\hline
\end{tabular}




\begin{tabular}{|c|c|c|c|c|c|}
\hline & & & & & \\
\hline CHEMBL189765 & 306908 & 7.1675 & 7.2769 & TRN & \\
\hline CHEMBL435288 & 306908 & 4.7212 & 4.6077 & TRN & \\
\hline CHEMBL140461 & 306908 & 8.8239 & 8.791 & TRN & \\
\hline CHEMBL187502 & 306908 & 7.5086 & 7.4192 & TRN & \\
\hline CHEMBL191187 & 306908 & 7.1079 & 7.1151 & TRN & \\
\hline CHEMBL187830 & 306908 & 8.3768 & 8.3618 & TRN & \\
\hline CHEMBL187934 & 306908 & 7.0915 & 7.2776 & TRN & \\
\hline CHEMBL189807 & 306908 & 9.1192 & 8.8493 & TRN & \\
\hline CHEMBL191572 & 306908 & 8.9586 & 8.8515 & TRN & \\
\hline CHEMBL188468 & 306908 & 7.5528 & 7.5412 & TRN & \\
\hline CHEMBL362534 & 306908 & 6.7696 & 6.7915 & TRN & \\
\hline CHEMBL364930 & 306908 & 5.9208 & 5.9282 & TRN & \\
\hline CHEMBL188379 & 306908 & 8.7959 & 8.8304 & TRN & \\
\hline CHEMBL141158 & 306908 & 7.585 & 7.3315 & TRN & \\
\hline CHEMBL343739 & 306908 & 7.1805 & 7.2048 & TRN & \\
\hline CHEMBL364989 & 306908 & 8.8861 & 8.9162 & TRN & \\
\hline CHEMBL534924 & 306908 & 7.4815 & 7.5139 & TRN & \\
\hline CHEMBL362492 & 306908 & 7.8539 & 7.6392 & TRN & \\
\hline CHEMBL435223 & 306908 & 9.4949 & 9.4188 & TRN & \\
\hline CHEMBL79993 & 306908 & 9.4815 & 8.4451 & TST & \\
\hline CHEMBL188390 & 306908 & 6.9586 & 7.1332 & TRN & \\
\hline CHEMBL370320 & 306908 & 9.4089 & 9.4683 & TRN & \\
\hline CHEMBL188259 & 306908 & 7.6383 & 7.58700 & 0000000001 & TRN \\
\hline CHEMBL188317 & 306908 & 7.0605 & 7.0365 & TRN & \\
\hline CHEMBL362971 & 306908 & 9.6576 & 10.022 & TST & \\
\hline CHEMBL 76578 & 306908 & 9.699 & 8.2574 & TST & \\
\hline CHEMBL365969 & 306908 & 7.1871 & 7.1756 & TRN & \\
\hline CHEMBL140310 & 306908 & 7.4089 & 7.5305 & TRN & \\
\hline CHEMBL139617 & 306908 & 6.1938 & 7.2084 & TST & \\
\hline CHEMBL425001 & 306908 & 8.7959 & 8.43700 & 0000000001 & TRN \\
\hline CHEMBL188862 & 306908 & 8.9208 & 8.8735 & TRN & \\
\hline CHEMBL187844 & 306908 & 9.2147 & 9.35700 & 0000000001 & TRN \\
\hline CHEMBL363383 & 306908 & 8.5376 & 8.5651 & TST & \\
\hline CHEMBL190271 & 306908 & 7.3872 & 7.415 & TST & \\
\hline CHEMBL189620 & 306908 & 9.6576 & 9.8275 & TST & \\
\hline CHEMBL191338 & 306908 & 7.3188 & 7.2643 & TST & \\
\hline CHEMBL188710 & 306908 & 8.9208 & 8.9335 & TST & \\
\hline CHEMBL363655 & 306908 & 8.5086 & 8.4863 & TRN & \\
\hline CHEMBL311364 & 306908 & 7.5376 & 6.3796 & TST & \\
\hline CHEMBL187723 & 306908 & 7.7447 & 7.8044 & TRN & \\
\hline CHEMBL191061 & 306908 & 8.1612 & 8.3421 & TRN & \\
\hline CHEMBL370722 & 306908 & 7.1135 & 7.1321 & TST & \\
\hline CHEMBL371853 & 306908 & 6.9586 & 7.7306 & TST & \\
\hline CHEMBL188501 & 306908 & 8.3372 & 8.5996 & TRN & \\
\hline CHEMBL141588 & 306908 & 9.4089 & 9.3418 & TRN & \\
\hline CHEMBL201022 & 330271 & 8.67 & 6.6724 & TRN & \\
\hline CHEMBL199330 & 330271 & 6.69 & 6.4422 & TRN & \\
\hline CHEMBL438071 & 330271 & 6.37 & 6.1836 & TRN & \\
\hline
\end{tabular}




\begin{tabular}{|c|c|c|c|c|}
\hline \multicolumn{5}{|c|}{ Supplemental Table S2.txt } \\
\hline CHEMBL 201145 & 330271 & 7.51 & 7.1277 & TRN \\
\hline CHEMBL 202706 & 330271 & 5.0 & 6.5929 & TST \\
\hline CHEMBL 201796 & 330271 & 6.5 & 6.2859 & TRN \\
\hline CHEMBL 201554 & 330271 & 6.92 & 6.4671 & TRN \\
\hline CHEMBL 201407 & 330271 & 7.96 & 6.5648 & TST \\
\hline CHEMBL199280 & 330271 & 7.1 & 6.5662 & TST \\
\hline CHEMBL 380481 & 330271 & 6.71 & 6.7335 & TRN \\
\hline CHEMBL 381473 & 330271 & 6.14 & 7.1036 & TRN \\
\hline CHEMBL 201447 & 330271 & 6.15 & 7.0757 & TRN \\
\hline CHEMBL203359 & 330271 & 6.58 & 6.9468 & TRN \\
\hline CHEMBL 201024 & 330271 & 6.31 & 7.0593 & TRN \\
\hline CHEMBL 201679 & 330271 & 6.61 & 7.3342 & TRN \\
\hline CHEMBL199722 & 330271 & 6.62 & 7.0759 & TRN \\
\hline CHEMBL199898 & 330271 & 7.0 & 7.0083 & TRN \\
\hline CHEMBL199834 & 330271 & 7.07 & 7.2943 & TRN \\
\hline CHEMBL199327 & 330271 & 7.13 & 7.0847 & TRN \\
\hline CHEMBL198294 & 330271 & 7.04 & 7.1659 & TRN \\
\hline CHEMBL199399 & 330271 & 7.25 & 7.1029 & TRN \\
\hline CHEMBL370629 & 330271 & 6.65 & 7.0455 & TRN \\
\hline CHEMBL 27043 & 330271 & 6.77 & 6.5936 & TST \\
\hline CHEMBL199326 & 330271 & 7.39 & 7.5728 & TRN \\
\hline CHEMBL425395 & 330271 & 7.35 & 7.2709 & TRN \\
\hline CHEMBL 201791 & 330271 & 7.62 & 7.1067 & TRN \\
\hline CHEMBL 203030 & 330271 & 7.37 & 6.9793 & TRN \\
\hline CHEMBL201321 & 330271 & 6.9 & 7.301 & TRN \\
\hline CHEMBL 203148 & 330271 & 7.05 & 7.3953 & TRN \\
\hline CHEMBL381522 & 330271 & 6.8 & 7.0856 & TRN \\
\hline CHEMBL 383321 & 330271 & 7.49 & 6.7353 & TRN \\
\hline CHEMBL 201054 & 330271 & 7.49 & 7.2592 & TRN \\
\hline CHEMBL201042 & 330271 & 6.55 & 6.9488 & TRN \\
\hline CHEMBL199583 & 330271 & 7.16 & 6.9403 & TRN \\
\hline CHEMBL 200967 & 330271 & 7.2 & 7.1155 & TRN \\
\hline CHEMBL 202359 & 330271 & 7.7 & 7.4832 & TRN \\
\hline CHEMBL377434 & 330271 & 6.37 & 7.1118 & TRN \\
\hline CHEMBL202358 & 330271 & 7.7 & 7.0796 & TRN \\
\hline CHEMBL381540 & 330271 & 7.4 & 7.2114 & TRN \\
\hline CHEMBL198338 & 330271 & 7.59 & 6.9461 & TRN \\
\hline CHEMBL 202665 & 330271 & 6.65 & 6.897 & TRN \\
\hline CHEMBL377485 & 330271 & 7.73 & 7.0526 & TRN \\
\hline CHEMBL201128 & 330271 & 7.77 & 7.3427 & TST \\
\hline CHEMBL 201157 & 330271 & 7.27 & 6.8509 & TST \\
\hline CHEMBL 201749 & 330271 & 7.1 & 7.0667 & TRN \\
\hline CHEMBL201008 & 330271 & 7.28 & 7.1842 & TST \\
\hline CHEMBL 201493 & 330271 & 7.5 & 7.1594 & TRN \\
\hline CHEMBL 202767 & 330271 & 7.41 & 7.1329 & TRN \\
\hline CHEMBL 202766 & 330271 & 6.98 & 6.9536 & TRN \\
\hline CHEMBL381091 & 330271 & 7.72 & 7.4428 & TRN \\
\hline CHEMBL201281 & 330271 & 7.92 & 7.4135 & TRN \\
\hline
\end{tabular}




\begin{tabular}{|c|c|c|c|c|c|}
\hline \multicolumn{6}{|c|}{ Supplemental Table S2.txt } \\
\hline CHEMBL 380847 & 330271 & 7.23 & 7.4476 & TRN & \\
\hline CHEMBL 382764 & 330271 & 7.5 & 7.3205 & TRN & \\
\hline CHEMBL201585 & 330271 & 6.24 & 6.7803 & TRN & \\
\hline CHEMBL 200105 & 330271 & 6.78 & 6.7856 & TRN & \\
\hline CHEMBL199354 & 330271 & 6.52 & 6.4112 & TRN & \\
\hline CHEMBL199353 & 330271 & 7.34 & 6.8934 & TRN & \\
\hline CHEMBL 201745 & 330271 & 6.16 & 6.2232 & TRN & \\
\hline CHEMBL426660 & 330271 & 5.98 & 6.3322 & TRN & \\
\hline CHEMBL 201243 & 330271 & 7.09 & 6.6419 & TRN & \\
\hline CHEMBL199485 & 330271 & 7.02 & 6.8183 & TRN & \\
\hline CHEMBL199884 & 330271 & 6.67 & 6.1314 & TST & \\
\hline CHEMBL 201721 & 330271 & 6.11 & 6.5066 & TRN & \\
\hline CHEMBL381214 & 330271 & 7.09 & 6.7688 & TRN & \\
\hline CHEMBL199611 & 330271 & 7.32 & 6.5614 & TST & \\
\hline CHEMBL382135 & 330271 & 7.34 & 6.8877 & TRN & \\
\hline CHEMBL 201750 & 330271 & 5.31 & 6.561 & TRN & \\
\hline CHEMBL199446 & 330271 & 7.19 & 7.0399 & TRN & \\
\hline CHEMBL 370378 & 330271 & 5.91 & 6.75 & TRN & \\
\hline CHEMBL 370588 & 330271 & 7.57 & 6.78799 & 9999999999 & TST \\
\hline CHEMBL 201496 & 330271 & 6.92 & 7.0603 & TRN & \\
\hline CHEMBL 203088 & 330271 & 6.77 & 6.7344 & TRN & \\
\hline CHEMBL 383638 & 330271 & 5.58 & 6.86 & TRN & \\
\hline CHEMBL381538 & 330271 & 6.95 & 7.2603 & TRN & \\
\hline CHEMBL 203413 & 330271 & 6.73 & 6.7634 & TRN & \\
\hline CHEMBL201127 & 330271 & 7.18 & 7.2506 & TRN & \\
\hline CHEMBL 372148 & 330271 & 5.58 & 6.7864 & TRN & \\
\hline CHEMBL199862 & 330271 & 7.81 & 6.8318 & TRN & \\
\hline CHEMBL 382234 & 330271 & 6.8 & 6.551 & TRN & \\
\hline CHEMBL 201006 & 330271 & 7.31 & 7.255 & TRN & \\
\hline CHEMBL201580 & 330271 & 6.73 & 6.4494 & TRN & \\
\hline CHEMBL197605 & 330271 & 7.22 & 6.8409 & TRN & \\
\hline CHEMBL199826 & 330271 & 6.48 & 6.32600 & 00000000005 & TRN \\
\hline CHEMBL199688 & 330271 & 6.74 & 6.2662 & TRN & \\
\hline CHEMBL 202876 & 330271 & 6.05 & 6.1082 & TST & \\
\hline CHEMBL 202828 & 330271 & 6.61 & 6.16700 & 2000000001 & TRN \\
\hline CHEMBL 201323 & 330271 & 7.36 & 6.7198 & TRN & \\
\hline CHEMBL 203305 & 330271 & 7.69 & 6.6506 & TRN & \\
\hline CHEMBL 201028 & 330271 & 7.33 & 7.0537 & TST & \\
\hline CHEMBL 201773 & 330271 & 7.05 & 6.6571 & TRN & \\
\hline CHEMBL 382663 & 330271 & 7.17 & 6.6528 & TRN & \\
\hline CHEMBL 201895 & 330271 & 6.52 & 6.7201 & TRN & \\
\hline CHEMBL424671 & 330271 & 6.51 & 6.6642 & TRN & \\
\hline CHEMBL 201026 & 330271 & 7.8 & 6.5763 & TST & \\
\hline CHEMBL 201329 & 330271 & 6.49 & 6.7813 & TRN & \\
\hline CHEMBL370205 & 330271 & 7.58 & 6.4981 & TST & \\
\hline CHEMBL 378815 & 330271 & 7.79 & 6.3518 & TST & \\
\hline CHEMBL201595 & 330271 & 6.56 & 6.7153 & TRN & \\
\hline CHEMBL 201594 & 330271 & 7.05 & 6.7288 & TRN & \\
\hline
\end{tabular}




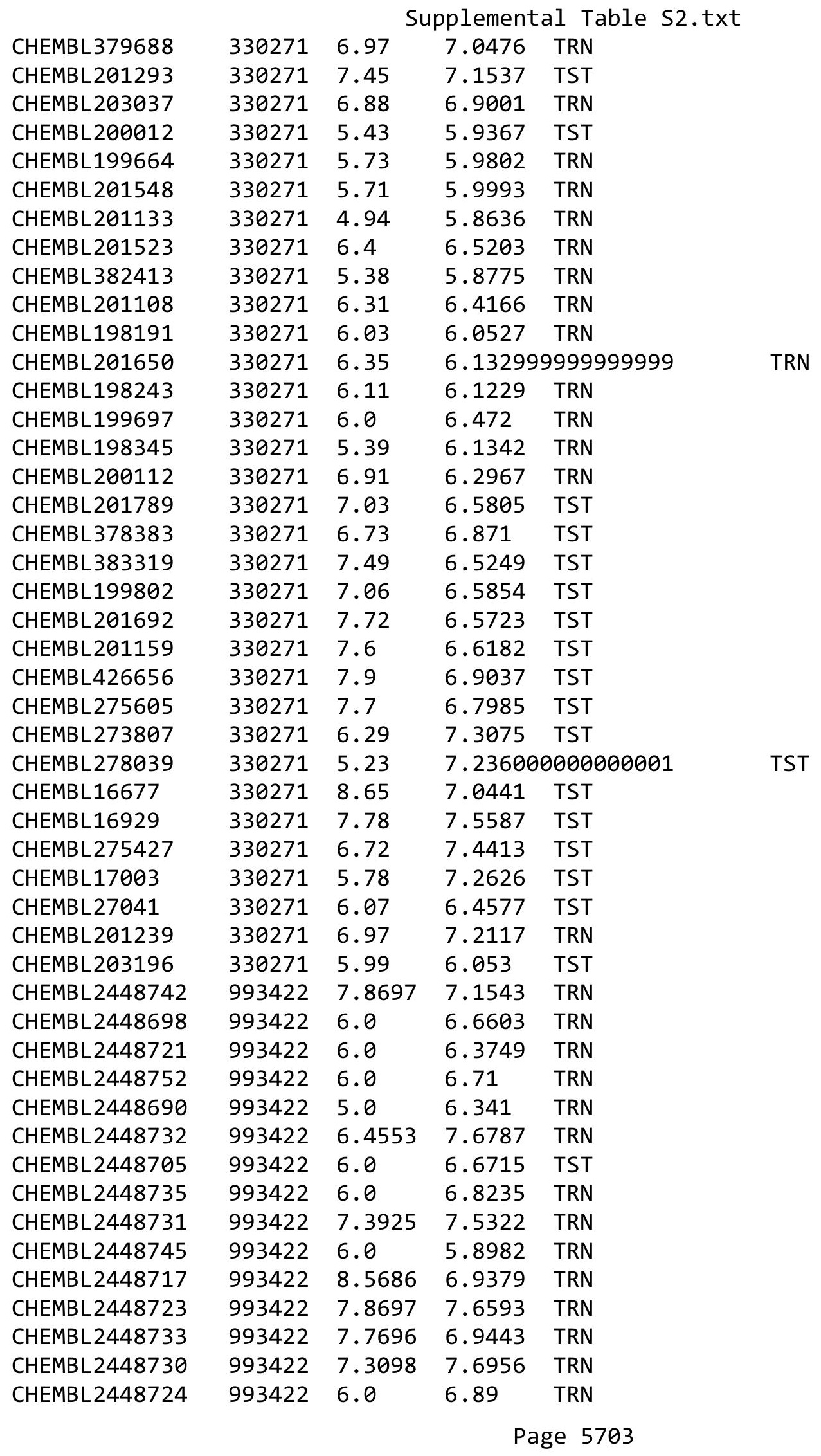




\begin{tabular}{|c|c|c|c|c|c|}
\hline \multicolumn{6}{|c|}{ Supplemental Table S2.txt } \\
\hline CHEMBL 2448696 & 993422 & 5.0 & 6.5193 & TST & \\
\hline CHEMBL 2448711 & 993422 & 7.5376 & 8.133 & TRN & \\
\hline CHEMBL2448706 & 993422 & 6.0 & 6.7108 & TST & \\
\hline CHEMBL2448736 & 993422 & 6.0 & 6.5048 & TRN & \\
\hline CHEMBL2448710 & 993422 & 5.2549 & 6.6101 & TST & \\
\hline CHEMBL 2448713 & 993422 & 7.8861 & 6.8547 & TRN & \\
\hline CHEMBL 2448743 & 993422 & 6.0 & 6.7295 & TRN & \\
\hline CHEMBL 2448734 & 993422 & 7.2716 & 7.0593 & TRN & \\
\hline CHEMBL 2448739 & 993422 & 8.7044 & 7.1653 & TRN & \\
\hline CHEMBL2448701 & 993422 & 7.0458 & 6.6313 & TRN & \\
\hline CHEMBL 2448689 & 993422 & 6.0 & 6.6311 & TRN & \\
\hline CHEMBL1321912 & 993422 & 7.5229 & 6.8487 & TST & \\
\hline CHEMBL 2448700 & 993422 & 5.0 & 6.8243 & TST & \\
\hline CHEMBL 2448744 & 993422 & 7.7696 & 8.0032 & TRN & \\
\hline CHEMBL 2448725 & 993422 & 7.2007 & 6.6982 & TRN & \\
\hline CHEMBL 2448728 & 993422 & 7.699 & 7.8128 & TRN & \\
\hline CHEMBL 2448751 & 993422 & 6.0 & 6.5206 & TRN & \\
\hline CHEMBL 2448693 & 993422 & 6.0 & 7.4148 & TST & \\
\hline CHEMBL2448729 & 993422 & 7.1707 & 6.919 & TRN & \\
\hline CHEMBL 2448749 & 993422 & 6.0 & 6.7544 & TRN & \\
\hline CHEMBL 2448740 & 993422 & 7.8145 & 6.9305 & TRN & \\
\hline CHEMBL 2448737 & 993422 & 7.6383 & 6.9765 & TRN & \\
\hline CHEMBL 2448748 & 993422 & 6.0 & 6.13299 & 9999999999 & TRN \\
\hline CHEMBL 2448741 & 993422 & 6.0 & 6.7429 & TRN & \\
\hline CHEMBL 2448720 & 993422 & 7.8894 & 8.1368 & TRN & \\
\hline CHEMBL 2448694 & 993422 & 8.5229 & 7.0159 & TRN & \\
\hline CHEMBL 2448697 & 993422 & 7.7959 & 6.8389 & TST & \\
\hline CHEMBL 2448702 & 993422 & 6.0 & 6.5221 & TRN & \\
\hline CHEMBL 2448715 & 993422 & 6.767 & 7.7179 & TST & \\
\hline CHEMBL2448718 & 993422 & 7.6904 & 6.5914 & TRN & \\
\hline CHEMBL1552686 & 993422 & 6.515 & 6.5881 & TST & \\
\hline CHEMBL 2448714 & 993422 & 7.6383 & 7.6497 & TST & \\
\hline CHEMBL 2448716 & 993422 & 6.0 & 6.7748 & TRN & \\
\hline CHEMBL 2448712 & 993422 & 6.0 & 6.809 & TRN & \\
\hline CHEMBL2448709 & 993422 & 6.0 & 6.6183 & TST & \\
\hline CHEMBL 2448738 & 993422 & 8.5964 & 6.70700 & 0000000001 & TRN \\
\hline CHEMBL 2448703 & 993422 & 6.7305 & 6.6821 & TST & \\
\hline CHEMBL 2448691 & 993422 & 7.224 & 6.8387 & TRN & \\
\hline CHEMBL 2448727 & 993422 & 7.3279 & 7.42 & TST & \\
\hline CHEMBL331173 & 214553 & 6.0088 & 6.0279 & TRN & \\
\hline CHEMBL118933 & 214553 & 4.9586 & 4.9565 & TRN & \\
\hline CHEMBL119318 & 214553 & 5.585 & 5.5718 & TRN & \\
\hline CHEMBL333055 & 214553 & 5.5686 & 5.5523 & TRN & \\
\hline CHEMBL324251 & 214553 & 6.5376 & 6.5075 & TRN & \\
\hline CHEMBL118829 & 214553 & 5.2924 & 5.2685 & TRN & \\
\hline CHEMBL120449 & 214553 & 5.5528 & 5.5923 & TRN & \\
\hline CHEMBL118805 & 214553 & 4.7212 & 5.28100 & 0000000001 & TST \\
\hline CHEMBL118562 & 214553 & 5.5528 & 5.5238 & TRN & \\
\hline
\end{tabular}




\begin{tabular}{|c|c|c|c|c|c|c|}
\hline \\
\hline CHEMBL119087 & 214553 & 3.0 & 2.983 & TRN & & \\
\hline CHEMBL119291 & 214553 & 4.0555 & 4.2855 & TST & & \\
\hline CHEMBL119442 & 214553 & 5.71899 & 79999999 & 99 & 5.7044 & TRN \\
\hline CHEMBL115434 & 214553 & 5.3665 & 5.3626 & TRN & & \\
\hline CHEMBL118128 & 214553 & 3.0 & 3.0072 & TRN & & \\
\hline CHEMBL118922 & 214553 & 5.7959 & 5.7609 & TRN & & \\
\hline CHEMBL 334225 & 214553 & 5.5229 & 6.7943 & TST & & \\
\hline CHEMBL325819 & 214553 & 4.7959 & 6.2876 & TST & & \\
\hline CHEMBL 324935 & 214553 & 5.6198 & 5.6404 & TRN & & \\
\hline CHEMBL119638 & 214553 & 5.8861 & 3.7171 & TST & & \\
\hline CHEMBL119534 & 214553 & 5.6576 & 5.6661 & TRN & & \\
\hline CHEMBL 332757 & 214553 & 5.6383 & 5.6578 & TRN & & \\
\hline CHEMBL332060 & 214553 & 5.9208 & 6.6687 & TST & & \\
\hline CHEMBL 323802 & 214553 & 5.4949 & 5.5144 & TRN & & \\
\hline CHEMBL118892 & 214553 & 5.3979 & 4.8833 & TST & & \\
\hline CHEMBL333135 & 214553 & 6.2007 & 6.1753 & TRN & & \\
\hline CHEMBL119730 & 214553 & 5.4949 & 5.4565 & TRN & & \\
\hline CHEMBL118878 & 214553 & 5.7212 & 7.2898 & TST & & \\
\hline CHEMBL118271 & 214553 & 6.8539 & 6.8852 & TRN & & \\
\hline CHEMBL115853 & 214553 & 4.585 & 6.4498 & TST & & \\
\hline CHEMBL119806 & 214553 & 6.3872 & 6.4701 & TRN & & \\
\hline CHEMBL119671 & 214553 & 5.5528 & 6.0037 & TST & & \\
\hline CHEMBL121455 & 214553 & 5.1938 & 5.2146 & TRN & & \\
\hline CHEMBL117566 & 214553 & 5.4815 & 5.5002 & TRN & & \\
\hline CHEMBL 324488 & 214553 & 6.1427 & 6.1269 & TRN & & \\
\hline CHEMBL118244 & 214553 & 5.6021 & 6.4118 & TST & & \\
\hline CHEMBL118595 & 214553 & 3.0 & 3.0188 & TRN & & \\
\hline CHEMBL119591 & 214553 & 5.4949 & 5.5079 & TRN & & \\
\hline CHEMBL331098 & 214553 & 5.6198 & 6.6846 & TST & & \\
\hline CHEMBL118863 & 214553 & 5.9208 & 5.9279 & TRN & & \\
\hline CHEMBL331164 & 214553 & 5.8539 & 5.9355 & TRN & & \\
\hline CHEMBL119551 & 214553 & 5.2924 & 5.3035 & TRN & & \\
\hline CHEMBL333597 & 214553 & 5.585 & 6.1498 & TST & & \\
\hline CHEMBL 334009 & 214553 & 5.7696 & 5.7892 & TRN & & \\
\hline CHEMBL119651 & 214553 & 5.0269 & 5.0148 & TRN & & \\
\hline CHEMBL 332090 & 214553 & 5.0 & 5.0039 & TRN & & \\
\hline CHEMBL118270 & 214553 & 5.5229 & 6.4016 & TST & & \\
\hline CHEMBL332450 & 214553 & 6.1192 & 6.1114 & TRN & & \\
\hline CHEMBL331956 & 214553 & 4.1308 & 4.1286 & TRN & & \\
\hline CHEMBL 333652 & 214553 & 5.7447 & 5.7495 & TRN & & \\
\hline CHEMBL 118660 & 214553 & 5.7959 & 5.7906 & TRN & & \\
\hline CHEMBL332685 & 214553 & 6.4202 & 6.4045 & TRN & & \\
\hline CHEMBL116820 & 214553 & 5.1135 & 5.2781 & TST & & \\
\hline CHEMBL 331647 & 214553 & 3.0 & 3.0122 & TRN & & \\
\hline CHEMBL119840 & 214553 & 3.0 & 2.9887 & TRN & & \\
\hline CHEMBL 334082 & 214553 & 6.0 & 6.391 & TST & & \\
\hline CHEMBL331424 & 214553 & 4.7959 & 4.7884 & TRN & & \\
\hline CHEMBL 333201 & 214553 & 7.0223 & 7.0959 & TRN & & \\
\hline
\end{tabular}




\begin{tabular}{|c|c|c|c|c|c|}
\hline \multicolumn{6}{|c|}{ Supplemental Table S2.txt } \\
\hline CHEMBL420880 & 214553 & 6.4089 & 6.396 & TRN & \\
\hline CHEMBL119793 & 214553 & 7.2518 & 7.1169 & TRN & \\
\hline CHEMBL118609 & 214553 & 6.0506 & 6.0464 & TRN & \\
\hline CHEMBL118387 & 214553 & 7.3468 & 7.3687 & TRN & \\
\hline CHEMBL118220 & 214553 & 5.5086 & 5.506 & TRN & \\
\hline CHEMBL 333340 & 214553 & 4.8539 & 4.8505 & TRN & \\
\hline CHEMBL333139 & 214553 & 5.7959 & 5.725 & TRN & \\
\hline CHEMBL 3674657 & 1527801 & 8.0 & 7.9853 & TRN & \\
\hline CHEMBL 3674637 & 1527801 & 6.9245 & 7.5219 & TST & \\
\hline CHEMBL3674649 & 1527801 & 7.8539 & 8.0329 & TRN & \\
\hline CHEMBL 3674653 & 1527801 & 7.4815 & 7.5592 & TRN & \\
\hline CHEMBL 3674643 & 1527801 & 7.6778 & 7.3711 & TRN & \\
\hline CHEMBL 3674659 & 1527801 & 7.4318 & 7.5414 & TRN & \\
\hline CHEMBL 3674667 & 1527801 & 7.2441 & 7.2706 & TRN & \\
\hline CHEMBL3674650 & 1527801 & 6.7212 & 6.7912 & TRN & \\
\hline CHEMBL 3674629 & 1527801 & 7.7447 & 7.4842 & TRN & \\
\hline CHEMBL 3639735 & 1527801 & 7.699 & 7.8376 & TRN & \\
\hline CHEMBL 3674662 & 1527801 & 6.8386 & 6.8534 & TRN & \\
\hline CHEMBL 3674645 & 1527801 & 7.041 & 7.3797 & TRN & \\
\hline CHEMBL 3674673 & 1527801 & 7.4202 & 7.4689 & TRN & \\
\hline CHEMBL 3674644 & 1527801 & 7.7212 & 7.6 & TRN & \\
\hline CHEMBL 3674632 & 1527801 & 7.2076 & 7.2238 & TST & \\
\hline CHEMBL 3674677 & 1527801 & 7.3372 & 7.2393 & TST & \\
\hline CHEMBL 3674669 & 1527801 & 7.9208 & 8.0825 & TRN & \\
\hline CHEMBL 3674635 & 1527801 & 7.5528 & 7.4743 & TRN & \\
\hline CHEMBL 3674661 & 1527801 & 8.1549 & 8.39299 & 9999999999 & TRN \\
\hline CHEMBL 3674672 & 1527801 & 7.9208 & 7.8708 & TRN & \\
\hline CHEMBL 3674678 & 1527801 & 6.8356 & 6.7838 & TRN & \\
\hline CHEMBL 3674646 & 1527801 & 7.2757 & 7.3249 & TRN & \\
\hline CHEMBL 3674676 & 1527801 & 7.1135 & 7.1309 & TRN & \\
\hline CHEMBL 3674651 & 1527801 & 7.0132 & 7.3493 & TST & \\
\hline CHEMBL 3674638 & 1527801 & 6.9626 & 6.9626 & TRN & \\
\hline CHEMBL 3674675 & 1527801 & 8.0969 & 8.141 & TRN & \\
\hline CHEMBL 3674666 & 1527801 & 8.5229 & 8.2691 & TRN & \\
\hline CHEMBL 3674648 & 1527801 & 7.9586 & 8.0253 & TRN & \\
\hline CHEMBL 3674658 & 1527801 & 8.301 & 8.1123 & TRN & \\
\hline CHEMBL 3674674 & 1527801 & 7.6778 & 7.7232 & TRN & \\
\hline CHEMBL 3674670 & 1527801 & 8.0 & 8.0285 & TRN & \\
\hline CHEMBL 3674663 & 1527801 & 8.3979 & 8.379 & TRN & \\
\hline CHEMBL 3674671 & 1527801 & 8.0458 & 8.0017 & TRN & \\
\hline CHEMBL 3674656 & 1527801 & 8.2218 & 8.3422 & TRN & \\
\hline CHEMBL3674639 & 1527801 & 6.7212 & 6.9381 & TRN & \\
\hline CHEMBL3674664 & 1527801 & 7.0458 & 6.848 & TRN & \\
\hline CHEMBL 3674625 & 1527801 & 6.9788 & 7.1012 & TRN & \\
\hline CHEMBL 3674627 & 1527801 & 7.2441 & 7.341 & TRN & \\
\hline CHEMBL 3674626 & 1527801 & 7.0088 & 7.0115 & TST & \\
\hline CHEMBL 3674654 & 1527801 & 7.4949 & 7.3715 & TRN & \\
\hline CHEMBL3674641 & 1527801 & 7.1079 & 7.1452 & TRN & \\
\hline
\end{tabular}


Supplemental Table S2.txt

\begin{tabular}{|c|c|c|c|c|}
\hline CHEMBL3674633 & 1527801 & 8.0 & 7.8873 & TRN \\
\hline CHEMBL3674665 & 1527801 & 7.7212 & 7.5449 & TRN \\
\hline CHEMBL3674628 & 1527801 & 7.3098 & 7.1805 & TRN \\
\hline CHEMBL3674660 & 1527801 & 8.699 & 8.561 & TRN \\
\hline CHEMBL3674636 & 1527801 & 7.3872 & 7.5219 & TST \\
\hline CHEMBL3674634 & 1527801 & 6.9431 & 6.9614 & TRN \\
\hline CHEMBL3674668 & 1527801 & 8.0458 & 7.841 & TST \\
\hline CHEMBL3674655 & 1527801 & 8.301 & 8.7671 & TST \\
\hline CHEMBL3674647 & 1527801 & 7.5528 & 7.695 & TST \\
\hline CHEMBL3674642 & 1527801 & 6.8601 & 7.3129 & TST \\
\hline CHEMBL3674640 & 1527801 & 7.5229 & 7.7621 & TST \\
\hline CHEMBL3674652 & 1527801 & 7.9208 & 7.8524 & TST \\
\hline CHEMBL3674630 & 1527801 & 7.2441 & 7.6528 & TST \\
\hline CHEMBL3674631 & 1527801 & 6.9469 & 7.4511 & TST \\
\hline CHEMBL3126914 & 1294945 & 4.6655 & 6.0711 & TST \\
\hline CHEMBL3126883 & 1294945 & 4.7582 & 4.532 & TRN \\
\hline CHEMBL3126876 & 1294945 & 3.3565 & 3.3431 & TRN \\
\hline CHEMBL3126871 & 1294945 & 4.6849 & 4.8261 & TRN \\
\hline CHEMBL3126901 & 1294945 & 3.3565 & 3.5104 & TRN \\
\hline CHEMBL 3127047 & 1294945 & 3.3565 & 4.3636 & TST \\
\hline CHEMBL3127050 & 1294945 & 3.3565 & 3.5341 & TRN \\
\hline CHEMBL3127057 & 1294945 & 3.3565 & 3.1998 & TST \\
\hline CHEMBL3127060 & 1294945 & 3.3565 & 3.352 & TRN \\
\hline CHEMBL3126873 & 1294945 & 3.3565 & 3.3514 & TRN \\
\hline CHEMBL 3127056 & 1294945 & 3.3565 & 3.9764 & TST \\
\hline CHEMBL3126887 & 1294945 & 3.3565 & $3.52100 e$ & 0000000004 \\
\hline CHEMBL3126897 & 1294945 & 3.3565 & 3.5951 & TST \\
\hline CHEMBL3126899 & 1294945 & 5.8697 & 5.5326 & TRN \\
\hline CHEMBL3126903 & 1294945 & 3.3565 & 3.3935 & TRN \\
\hline CHEMBL 3127053 & 1294945 & 3.3565 & 3.4605 & TRN \\
\hline CHEMBL3126913 & 1294945 & 4.3958 & 4.3857 & TRN \\
\hline CHEMBL3126888 & 1294945 & 3.3565 & 3.5836 & TRN \\
\hline CHEMBL3126910 & 1294945 & 3.3565 & 3.1735 & TRN \\
\hline CHEMBL3126877 & 1294945 & 3.3565 & 3.1433 & TRN \\
\hline CHEMBL 3126894 & 1294945 & 3.3565 & 3.3564 & TRN \\
\hline CHEMBL3126892 & 1294945 & 3.3565 & 3.4566 & TRN \\
\hline CHEMBL3126912 & 1294945 & 3.3565 & 3.2385 & TRN \\
\hline CHEMBL3126907 & 1294945 & 3.3565 & 4.8945 & TST \\
\hline CHEMBL3127067 & 1294945 & 3.3565 & 3.7938 & TRN \\
\hline CHEMBL 3127046 & 1294945 & 4.9901 & 4.9982 & TRN \\
\hline CHEMBL3126872 & 1294945 & 3.3565 & 3.5047 & TST \\
\hline CHEMBL3126878 & 1294945 & 3.3565 & 3.3348 & TRN \\
\hline CHEMBL3126902 & 1294945 & 3.3565 & 3.1483 & TRN \\
\hline CHEMBL3127048 & 1294945 & 3.3565 & 3.3875 & TST \\
\hline CHEMBL 3126874 & 1294945 & 4.3903 & 4.4137 & TRN \\
\hline CHEMBL3126904 & 1294945 & 3.3565 & 3.8625 & TRN \\
\hline CHEMBL3127049 & 1294945 & 7.301 & 7.1698 & TRN \\
\hline CHEMBL 3127051 & 1294945 & 3.3565 & 3.3794 & TRN \\
\hline
\end{tabular}


Supplemental Table S2.txt

\begin{tabular}{|c|c|c|c|c|c|}
\hline CHEMBL3126898 & 1294945 & 3.3565 & 5.059 & TST & \\
\hline CHEMBL319177 & 1294945 & 3.3565 & 3.1689 & TST & \\
\hline CHEMBL1269812 & 1294945 & 7.699 & 6.3887 & TST & \\
\hline CHEMBL3126880 & 1294945 & 4.6509 & 4.331 & TRN & \\
\hline CHEMBL3126908 & 1294945 & 6.8239 & 7.0406 & TRN & \\
\hline CHEMBL3126870 & 1294945 & 3.3565 & 3.2286 & TRN & \\
\hline CHEMBL3127045 & 1294945 & 3.3565 & 3.4032 & TRN & \\
\hline CHEMBL3127064 & 1294945 & 3.3565 & 5.2684 & TST & \\
\hline CHEMBL3126909 & 1294945 & 3.3565 & 3.5047 & TRN & \\
\hline CHEMBL3126911 & 1294945 & 3.3565 & 3.0219 & TRN & \\
\hline CHEMBL3126890 & 1294945 & 3.3565 & 3.319 & TRN & \\
\hline CHEMBL3126905 & 1294945 & 7.0 & 6.6286 & TST & \\
\hline CHEMBL3127066 & 1294945 & 5.082 & 4.5196 & TRN & \\
\hline CHEMBL3126865 & 1294945 & 3.3565 & 4.81 & TST & \\
\hline CHEMBL3127052 & 1294945 & 3.3565 & 3.0653 & TRN & \\
\hline CHEMBL3127068 & 1294945 & 3.3565 & 3.667 & TRN & \\
\hline CHEMBL1814768 & 1294945 & 3.3565 & 2.8401 & TRN & \\
\hline CHEMBL 3127062 & 1294945 & 3.3565 & 3.292 & TRN & \\
\hline CHEMBL3126906 & 1294945 & 6.0132 & \multicolumn{2}{|c|}{5.537000000000001} & TST \\
\hline CHEMBL3126889 & 1294945 & 4.9397 & 4.7623 & TRN & \\
\hline CHEMBL3126891 & 1294945 & 3.3565 & 3.1408 & TRN & \\
\hline CHEMBL 3124960 & 1294945 & 3.3565 & 3.4563 & TRN & \\
\hline CHEMBL3126915 & 1294945 & 5.058 & 3.8585 & TST & \\
\hline CHEMBL3127055 & 1294945 & 3.3565 & 4.8463 & TST & \\
\hline CHEMBL3127065 & 1294945 & 7.5229 & 7.4525 & TRN & \\
\hline CHEMBL3127054 & 1294945 & 4.5281 & 4.2676 & TRN & \\
\hline CHEMBL1814767 & 1294945 & 3.3565 & 3.8871 & TRN & \\
\hline CHEMBL3126895 & 1294945 & 4.7387 & 4.4925 & TRN & \\
\hline CHEMBL3126900 & 1294945 & 3.3565 & 3.5273 & TRN & \\
\hline CHEMBL3126882 & 1294945 & 3.3565 & 3.3896 & TRN & \\
\hline CHEMBL 3127044 & 1294945 & 4.6832 & 3.6177 & TST & \\
\hline CHEMBL3126879 & 1294945 & 3.3565 & 3.5044 & TRN & \\
\hline CHEMBL3126893 & 1294945 & 3.3565 & 3.5492 & TRN & \\
\hline CHEMBL3127058 & 1294945 & 6.8539 & 6.8843 & TRN & \\
\hline CHEMBL3127061 & 1294945 & 3.3565 & 3.1007 & TRN & \\
\hline CHEMBL403715 & 1294945 & 3.3565 & 3.112 & TST & \\
\hline CHEMBL3127059 & 1294945 & 3.3565 & 3.6808 & TRN & \\
\hline CHEMBL3127063 & 1294945 & 4.8674 & 4.9993 & TRN & \\
\hline CHEMBL3126881 & 1294945 & 3.3565 & 3.8235 & TRN & \\
\hline CHEMBL312770 & 106632 & 7.9586 & 7.99 & TRN & \\
\hline CHEMBL 78508 & 106632 & 8.699 & 8.7953 & TRN & \\
\hline CHEMBL312585 & 106632 & 7.3565 & 7.3424 & TRN & \\
\hline CHEMBL78299 & 106632 & 9.0 & 8.4087 & TST & \\
\hline CHEMBL276119 & 106632 & 8.699 & 8.6716 & TRN & \\
\hline CHEMBL76856 & 106632 & 8.699 & 8.7601 & TRN & \\
\hline CHEMBL 76137 & 106632 & 8.5229 & 8.4749 & TRN & \\
\hline CHEMBL 2093894 & 106632 & 8.0969 & 8.5238 & TST & \\
\hline CHEMBL79433 & 106632 & 9.0 & 8.9902 & TRN & \\
\hline
\end{tabular}




\begin{tabular}{|c|c|c|c|c|c|}
\hline \multicolumn{6}{|c|}{ Supplemental Table S2.txt } \\
\hline CHEMBL310057 & 106632 & 8.0458 & 8.1663 & TRN & \\
\hline CHEMBL 309492 & 106632 & 9.0 & 9.0183 & TRN & \\
\hline CHEMBL306617 & 106632 & 8.699 & 8.88600 & 2000000001 & TRN \\
\hline CHEMBL440498 & 106632 & 8.699 & 8.8637 & TST & \\
\hline CHEMBL78255 & 106632 & 8.699 & 8.7414 & TRN & \\
\hline CHEMBL78798 & 106632 & 9.0 & 8.8847 & TRN & \\
\hline CHEMBL 80321 & 106632 & 8.301 & 8.3072 & TRN & \\
\hline CHEMBL80183 & 106632 & 8.5229 & 8.60700 & 0000000001 & TRN \\
\hline CHEMBL 310324 & 106632 & 7.4202 & 7.4488 & TRN & \\
\hline CHEMBL76847 & 106632 & 8.5229 & 8.463 & TRN & \\
\hline CHEMBL78478 & 106632 & 9.0 & 8.9904 & TRN & \\
\hline CHEMBL 80814 & 106632 & 8.699 & 8.51799 & 9999999999 & TRN \\
\hline CHEMBL309311 & 106632 & 9.0 & 8.9305 & TRN & \\
\hline CHEMBL 310342 & 106632 & 7.4815 & 7.4928 & TRN & \\
\hline CHEMBL309416 & 106632 & 8.699 & 8.7508 & TRN & \\
\hline CHEMBL81763 & 106632 & 7.5376 & 7.3173 & TST & \\
\hline CHEMBL77176 & 106632 & 8.699 & 8.7187 & TRN & \\
\hline CHEMBL80969 & 106632 & 8.699 & 8.4823 & TRN & \\
\hline CHEMBL312429 & 106632 & 8.699 & 8.6913 & TRN & \\
\hline CHEMBL 78962 & 106632 & 8.699 & 8.6789 & TRN & \\
\hline CHEMBL80911 & 106632 & 8.699 & 8.6648 & TRN & \\
\hline CHEMBL78709 & 106632 & 7.4685 & 7.4379 & TRN & \\
\hline CHEMBL78909 & 106632 & 9.0 & 9.0451 & TRN & \\
\hline CHEMBL 76836 & 106632 & 8.5229 & 8.6791 & TRN & \\
\hline CHEMBL311436 & 106632 & 9.0 & 8.6506 & TST & \\
\hline CHEMBL 78337 & 106632 & 8.699 & 8.758 & TRN & \\
\hline CHEMBL310684 & 106632 & 8.1549 & 8.1819 & TRN & \\
\hline CHEMBL 78611 & 106632 & 9.0 & 8.9493 & TRN & \\
\hline CHEMBL311357 & 106632 & 9.0 & 8.9453 & TRN & \\
\hline CHEMBL 78549 & 106632 & 9.0 & 8.9636 & TRN & \\
\hline CHEMBL80732 & 106632 & 8.699 & 8.6703 & TRN & \\
\hline CHEMBL80453 & 106632 & 8.3979 & 8.3914 & TRN & \\
\hline CHEMBL 310340 & 106632 & 8.8539 & 8.8282 & TRN & \\
\hline CHEMBL80798 & 106632 & 8.699 & 9.0102 & TST & \\
\hline CHEMBL 79111 & 106632 & 8.699 & 8.4527 & TST & \\
\hline CHEMBL77505 & 106632 & 6.8297 & 7.3495 & TST & \\
\hline CHEMBL420023 & 106632 & 8.699 & 8.7106 & TST & \\
\hline CHEMBL312432 & 106632 & 8.2218 & 9.2286 & TST & \\
\hline CHEMBL80401 & 106632 & 8.301 & 9.0959 & TST & \\
\hline CHEMBL419648 & 106632 & 8.699 & 8.7366 & TST & \\
\hline CHEMBL78934 & 106632 & 8.301 & 8.8375 & TST & \\
\hline CHEMBL3924174 & 1622852 & 7.9586 & 8.0082 & TRN & \\
\hline CHEMBL3949545 & 1622852 & 3.9706 & 3.54600 & 00000000003 & TST \\
\hline CHEMBL3923527 & 1622852 & 5.8268 & 5.9146 & TST & \\
\hline CHEMBL3927837 & 1622852 & 4.1871 & 4.198 & TRN & \\
\hline CHEMBL 3941448 & 1622852 & 7.4202 & 7.4938 & TRN & \\
\hline CHEMBL3969822 & 1622852 & 7.8861 & 7.8532 & TRN & \\
\hline CHEMBL3934795 & 1622852 & 7.1675 & 6.7606 & TRN & \\
\hline
\end{tabular}


Supplemental Table S2.txt

\begin{tabular}{|c|c|c|c|c|c|c|}
\hline CHEMBL3890307 & 1622852 & \multicolumn{3}{|c|}{6.617999999999999} & 6.2858 & TST \\
\hline CHEMBL3958186 & 1622852 & 5.3284 & 4.6206 & TRN & & \\
\hline CHEMBL3969267 & 1622852 & 6.6799 & 5.9844 & TRN & & \\
\hline CHEMBL 3942836 & 1622852 & 7.1427 & 7.3252 & TRN & & \\
\hline CHEMBL3896161 & 1622852 & 7.8539 & 7.9163 & TRN & & \\
\hline CHEMBL 3918060 & 1622852 & 7.8239 & 7.7316 & TRN & & \\
\hline CHEMBL3979902 & 1622852 & 7.3279 & 7.454 & TST & & \\
\hline CHEMBL3925915 & 1622852 & 7.0223 & 7.1729 & TRN & & \\
\hline CHEMBL 3968363 & 1622852 & 7.7447 & 7.6636 & TRN & & \\
\hline CHEMBL3919009 & 1622852 & 6.0888 & 6.1119 & TRN & & \\
\hline CHEMBL 3945715 & 1622852 & 7.6576 & 7.64 & TRN & & \\
\hline CHEMBL3921765 & 1622852 & 7.6021 & 7.5827 & TRN & & \\
\hline CHEMBL3921940 & 1622852 & 7.1805 & 6.9698 & TRN & & \\
\hline CHEMBL 3898772 & 1622852 & 7.2147 & 6.7403 & TST & & \\
\hline CHEMBL3950196 & 1622852 & 7.2596 & 7.5485 & TRN & & \\
\hline CHEMBL3963167 & 1622852 & 6.6737 & 6.2086 & TRN & & \\
\hline CHEMBL3938021 & 1622852 & 7.6198 & 7.5156 & TRN & & \\
\hline CHEMBL3930700 & 1622852 & 3.9374 & 4.2362 & TRN & & \\
\hline CHEMBL3903942 & 1622852 & 6.6364 & 6.4916 & TRN & & \\
\hline CHEMBL3951240 & 1622852 & 6.0783 & 6.0048 & TRN & & \\
\hline CHEMBL3982832 & 1622852 & 4.0969 & 3.8173 & TRN & & \\
\hline CHEMBL3977114 & 1622852 & 7.2366 & 7.3446 & TST & & \\
\hline CHEMBL3906825 & 1622852 & 8.2218 & 7.904 & TRN & & \\
\hline CHEMBL3984761 & 1622852 & 7.284 & 7.42299 & 9999999999 & & TRN \\
\hline CHEMBL 3926201 & 1622852 & 7.2291 & 7.2746 & TRN & & \\
\hline CHEMBL3956823 & 1622852 & 7.3188 & 7.2923 & TRN & & \\
\hline CHEMBL3910085 & 1622852 & 7.2596 & 6.95799 & 9999999999 & & Tro \\
\hline CHEMBL3908881 & 1622852 & 6.6882 & 6.6109 & TRN & & \\
\hline CHEMBL 3889862 & 1622852 & 7.2147 & 7.5827 & TRN & & \\
\hline CHEMBL 3899264 & 1622852 & 6.1662 & 6.0036 & TST & & \\
\hline CHEMBL 3898062 & 1622852 & 6.6198 & 6.6952 & TRN & & \\
\hline CHEMBL3927924 & 1622852 & 6.21899 & 79999999 & 99 & 6.1303 & this \\
\hline CHEMBL3985310 & 1622852 & 7.041 & 7.4438 & TRN & & \\
\hline CHEMBL 3897825 & 1622852 & 7.5528 & 7.3502 & TRN & & \\
\hline CHEMBL 3897240 & 1622852 & 7.5086 & 7.5717 & TRN & & \\
\hline CHEMBL3978193 & 1622852 & 7.3098 & 7.3214 & TRN & & \\
\hline CHEMBL3952664 & 1622852 & 4.1367 & 4.0127 & TRN & & \\
\hline CHEMBL3917820 & 1622852 & 6.5157 & 6.2797 & TRN & & \\
\hline CHEMBL3924956 & 1622852 & 4.1938 & 5.0119 & TRN & & \\
\hline CHEMBL3972450 & 1622852 & 7.0223 & 7.106 & TRN & & \\
\hline CHEMBL3915547 & 1622852 & 7.2076 & 7.2501 & TRN & & \\
\hline CHEMBL3950065 & 1622852 & 6.0353 & 6.1945 & TRN & & \\
\hline CHEMBL3974744 & 1622852 & 5.1302 & 4.7071 & TST & & \\
\hline CHEMBL3933865 & 1622852 & 7.1427 & 7.0081 & TRN & & \\
\hline CHEMBL3974827 & 1622852 & 6.1024 & 5.51399 & 9999999999 & & The \\
\hline CHEMBL3917185 & 1622852 & 6.0655 & 6.1119 & TRN & & \\
\hline CHEMBL3980491 & 1622852 & 6.6383 & 6.652 & TRN & & \\
\hline CHEMBL3952497 & 1622852 & 3.9586 & 4.4026 & TRN & & \\
\hline
\end{tabular}


Supplemental Table S2.txt

\begin{tabular}{|c|c|c|c|c|c|}
\hline CHEMBL 3934860 & 1622852 & 7.8539 & 7.7487 & TRN & \\
\hline CHEMBL3906199 & 1622852 & 8.0458 & 7.9805 & TRN & \\
\hline CHEMBL3950824 & 1622852 & 6.301 & 6.3425 & TRN & \\
\hline CHEMBL3930876 & 1622852 & 7.0315 & 6.888999 & 9999999999 & TRN \\
\hline CHEMBL3948466 & 1622852 & 5.5735 & 6.1347 & TRN & \\
\hline CHEMBL3923097 & 1622852 & 4.0665 & 4.7361 & TRN & \\
\hline CHEMBL3972616 & 1622852 & 7.3768 & 7.2713 & TRN & \\
\hline CHEMBL3961356 & 1622852 & \multicolumn{3}{|c|}{6.1579999999999995} & TRN \\
\hline CHEMBL3986638 & 1622852 & 6.6498 & 6.6146 & TRN & \\
\hline CHEMBL3984489 & 1622852 & 7.2924 & 7.4582 & TST & \\
\hline CHEMBL3936568 & 1622852 & 6.0752 & 6.0685 & TRN & \\
\hline CHEMBL3951580 & 1622852 & 6.6478 & 6.7357 & TRN & \\
\hline CHEMBL3959377 & 1622852 & 6.8508 & 6.815 & TST & \\
\hline CHEMBL3976890 & 1622852 & 6.3197 & 6.2957 & TRN & \\
\hline CHEMBL3970445 & 1622852 & 6.209 & 5.4931 & TST & \\
\hline CHEMBL3947185 & 1622852 & 5.7959 & 5.813 & TRN & \\
\hline CHEMBL3915799 & 1622852 & 7.4437 & 7.4817 & TRN & \\
\hline CHEMBL3916048 & 1622852 & 7.2076 & 7.4603 & TRN & \\
\hline CHEMBL3914936 & 1622852 & 6.9508 & 7.3591 & TRN & \\
\hline CHEMBL3944657 & 1622852 & 6.0655 & 6.0551 & TRN & \\
\hline CHEMBL3974104 & 1622852 & 6.3686 & \multicolumn{2}{|c|}{6.3660000000000005} & TRN \\
\hline CHEMBL3925393 & 1622852 & 6.2757 & 6.2905 & TRN & \\
\hline CHEMBL 3899835 & 1622852 & \multicolumn{3}{|c|}{6.382999999999999} & TRN \\
\hline CHEMBL3926060 & 1622852 & 7.3565 & 7.4148 & TST & \\
\hline CHEMBL3949063 & 1622852 & 7.3768 & 7.2305 & TST & \\
\hline CHEMBL3943761 & 1622852 & 7.5086 & 7.3897 & TST & \\
\hline CHEMBL3931239 & 1622852 & 7.8539 & 7.8754 & TST & \\
\hline CHEMBL3902886 & 1622852 & 7.5229 & 7.272 & TST & \\
\hline CHEMBL3939715 & 1622852 & 7.3565 & 7.153 & TST & \\
\hline CHEMBL3936835 & 1622852 & 7.9208 & 7.7816 & TST & \\
\hline CHEMBL3979642 & 1622852 & 6.4067 & 6.2863 & TST & \\
\hline CHEMBL 3940280 & 1622852 & 7.4815 & 7.3234 & TST & \\
\hline CHEMBL 3912958 & 1622852 & 7.284 & 7.1415 & TST & \\
\hline CHEMBL3916909 & 1622852 & 6.983 & 6.5465 & TST & \\
\hline CHEMBL 3977684 & 1622852 & 7.041 & 7.0256 & TST & \\
\hline CHEMBL586135 & 688854 & 6.1871 & 5.9951 & TST & \\
\hline CHEMBL1573501 & 688854 & 3.301 & 3.9439 & TRN & \\
\hline CHEMBL1531526 & 688854 & 3.301 & 4.1778 & TST & \\
\hline CHEMBL1570249 & 688854 & 3.301 & 4.0735 & TRN & \\
\hline CHEMBL3192690 & 688854 & 4.4106 & 4.3864 & TRN & \\
\hline CHEMBL590666 & 688854 & 4.7208 & 4.7897 & TRN & \\
\hline CHEMBL1584338 & 688854 & 8.0 & 4.3074 & TST & \\
\hline CHEMBL1543340 & 688854 & 4.8353 & 4.4771 & TST & \\
\hline CHEMBL1479637 & 688854 & 5.0752 & 4.7565 & TRN & \\
\hline CHEMBL 3197883 & 688854 & 5.0214 & 4.6305 & TRN & \\
\hline CHEMBL1385701 & 688854 & 4.8164 & 4.7778 & TRN & \\
\hline CHEMBL1984876 & 688854 & 5.8097 & 5.3577 & TRN & \\
\hline CHEMBL1555719 & 688854 & 3.301 & 4.3331 & TRN & \\
\hline
\end{tabular}




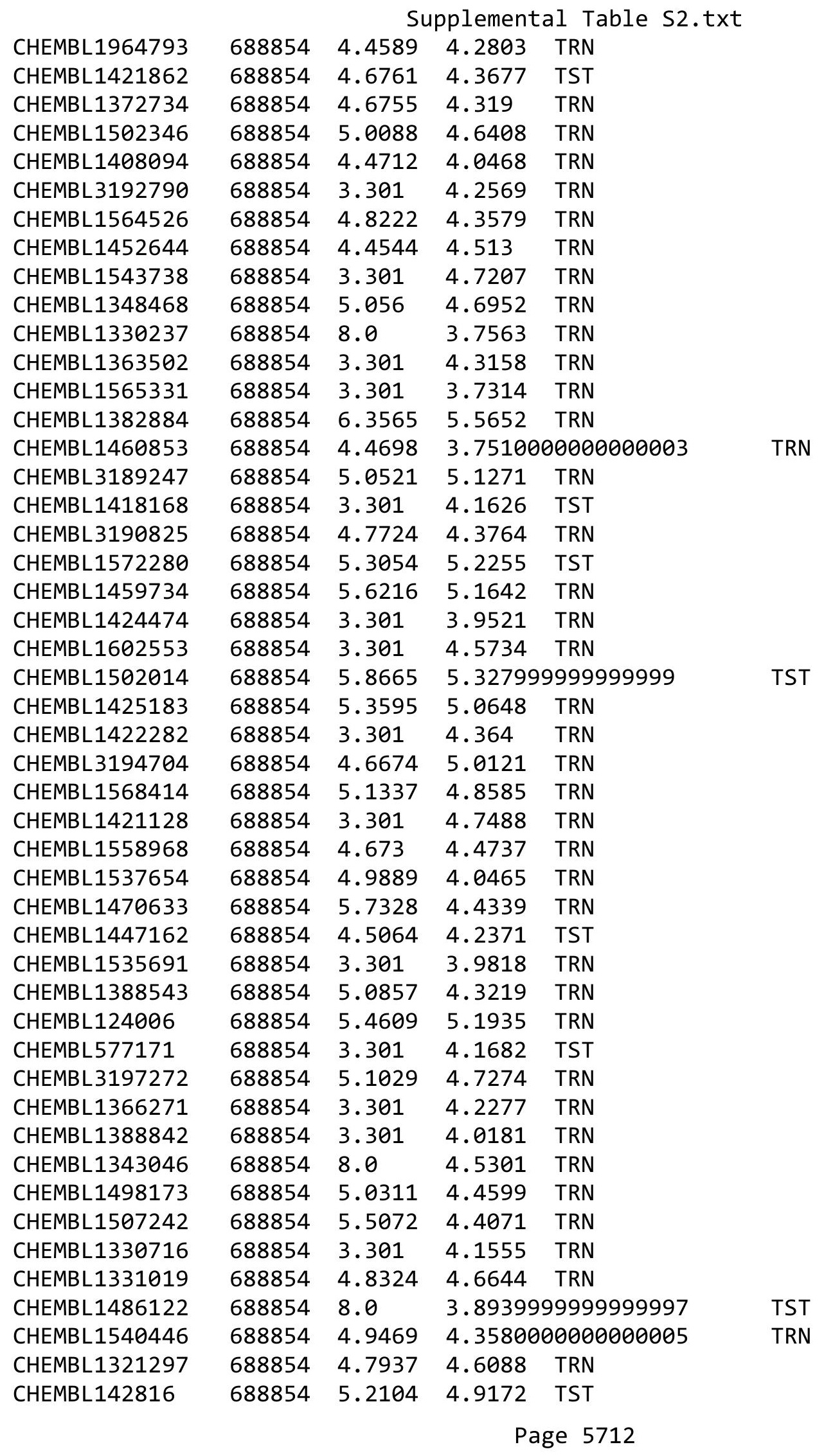




\begin{tabular}{|c|c|c|c|c|c|}
\hline \multicolumn{6}{|c|}{ Supplemental Table S2.txt } \\
\hline CHEMBL3196547 & 688854 & 8.0 & 4.5177 & TRN & \\
\hline CHEMBL1537626 & 688854 & 3.301 & 4.0158 & TRN & \\
\hline CHEMBL1426092 & 688854 & 4.7523 & 4.3331 & TRN & \\
\hline CHEMBL1616787 & 688854 & 4.6914 & 4.5053 & TRN & \\
\hline CHEMBL1388234 & 688854 & 4.8814 & 4.4628 & TRN & \\
\hline CHEMBL1344560 & 688854 & 4.492 & 4.115 & TRN & \\
\hline CHEMBL1371382 & 688854 & 3.301 & 4.0607 & TRN & \\
\hline CHEMBL1431659 & 688854 & 3.301 & 3.90100 & 00000000002 & TRN \\
\hline CHEMBL1304979 & 688854 & 4.6962 & 4.2947 & TRN & \\
\hline CHEMBL1550934 & 688854 & 5.3595 & 4.7552 & TRN & \\
\hline CHEMBL1572436 & 688854 & 4.4204 & 4.5988 & TRN & \\
\hline CHEMBL1992925 & 688854 & 4.7192 & 4.7384 & TRN & \\
\hline CHEMBL1321232 & 688854 & 3.301 & 4.1064 & TRN & \\
\hline CHEMBL1321310 & 688854 & 4.9751 & 4.2255 & TRN & \\
\hline CHEMBL578512 & 688854 & 5.8601 & 4.4591 & TST & \\
\hline CHEMBL1586075 & 688854 & 4.8318 & 4.3263 & TRN & \\
\hline CHEMBL1402405 & 688854 & 4.5206 & 4.5331 & TST & \\
\hline CHEMBL1992490 & 688854 & 4.9821 & 4.4797 & TST & \\
\hline CHEMBL1505314 & 688854 & 8.0 & 4.1125 & TRN & \\
\hline CHEMBL1387321 & 688854 & 4.3445 & 4.36 & TRN & \\
\hline CHEMBL1510095 & 688854 & 3.301 & 4.5471 & TRN & \\
\hline CHEMBL1361227 & 688854 & 5.209 & 4.49 & TRN & \\
\hline CHEMBL1384026 & 688854 & 5.4145 & 4.4416 & TRN & \\
\hline CHEMBL1588561 & 688854 & 3.301 & 4.3535 & TRN & \\
\hline CHEMBL1578031 & 688854 & 3.301 & 4.3971 & TRN & \\
\hline CHEMBL1517889 & 688854 & 4.7298 & 4.6248 & TRN & \\
\hline CHEMBL582030 & 688854 & 5.4365 & 5.0306 & TRN & \\
\hline CHEMBL585622 & 688854 & 5.3615 & 5.1162 & TRN & \\
\hline CHEMBL1446012 & 688854 & 3.301 & 4.4265 & TRN & \\
\hline CHEMBL 2006545 & 688854 & 5.4318 & 4.7285 & TRN & \\
\hline CHEMBL1332756 & 688854 & 6.3279 & 6.1683 & TRN & \\
\hline CHEMBL1504569 & 688854 & 5.8665 & 5.5827 & TRN & \\
\hline CHEMBL1497201 & 688854 & 3.301 & 4.0044 & TRN & \\
\hline CHEMBL186248 & 688854 & 5.0223 & 4.2939 & TRN & \\
\hline CHEMBL453038 & 688854 & 4.6312 & 4.547 & TRN & \\
\hline CHEMBL1306267 & 688854 & 5.5834 & 5.2985 & TRN & \\
\hline CHEMBL 142630 & 688854 & 4.5151 & 4.8337 & TRN & \\
\hline CHEMBL249032 & 688854 & 3.301 & 4.2517 & TRN & \\
\hline CHEMBL1587804 & 688854 & 3.301 & 4.5189 & TRN & \\
\hline CHEMBL1418750 & 688854 & 5.2573 & 4.7336 & TRN & \\
\hline CHEMBL1385808 & 688854 & 6.0 & 5.51 & TST & \\
\hline CHEMBL 2001316 & 688854 & 5.2628 & 4.974 & TRN & \\
\hline CHEMBL1342570 & 688854 & 3.301 & 4.0003 & TRN & \\
\hline CHEMBL1461556 & 688854 & 8.0 & 4.1302 & TST & \\
\hline CHEMBL1581182 & 688854 & 8.0 & 3.8505 & TRN & \\
\hline CHEMBL458019 & 688854 & 4.4662 & 4.622 & TST & \\
\hline CHEMBL 1379846 & 688854 & 3.301 & 4.0427 & TRN & \\
\hline CHEMBL1452426 & 688854 & 3.301 & 4.4175 & TRN & \\
\hline
\end{tabular}




\begin{tabular}{|c|c|c|c|c|}
\hline & & & oplement & al Ta \\
\hline CHEMBL1326083 & 688854 & 5.699 & 5.5962 & TRN \\
\hline CHEMBL1598087 & 688854 & 3.301 & 4.3061 & TRN \\
\hline CHEMBL1375227 & 688854 & 3.301 & 4.1696 & TRN \\
\hline CHEMBL1387500 & 688854 & 4.8928 & 4.0131 & TRN \\
\hline CHEMBL1365988 & 688854 & 4.6409 & 5.3526 & TRN \\
\hline CHEMBL309016 & 688854 & 4.9154 & 4.9737 & TRN \\
\hline CHEMBL1433382 & 688854 & 3.301 & 4.1874 & TRN \\
\hline CHEMBL1562344 & 688854 & 3.301 & 4.1342 & TRN \\
\hline CHEMBL1499914 & 688854 & 5.5544 & 4.7523 & TRN \\
\hline CHEMBL1589539 & 688854 & 8.0 & 4.0543 & TRN \\
\hline CHEMBL1478597 & 688854 & 4.8557 & 5.0914 & TST \\
\hline CHEMBL1989158 & 688854 & 5.0097 & 4.6129 & TST \\
\hline CHEMBL1348352 & 688854 & 8.0 & 4.1268 & TRN \\
\hline CHEMBL1520766 & 688854 & 3.301 & 4.4623 & TST \\
\hline CHEMBL1449161 & 688854 & 3.301 & 4.01 & TRN \\
\hline CHEMBL548294 & 688854 & 4.6728 & 4.4122 & TRN \\
\hline CHEMBL1578054 & 688854 & 4.3302 & 4.5114 & TRN \\
\hline CHEMBL68997 & 688854 & 3.301 & 4.3374 & TRN \\
\hline CHEMBL1608686 & 688854 & 4.5126 & 4.5207 & TRN \\
\hline CHEMBL1606743 & 688854 & 5.067 & 4.5458 & TRN \\
\hline CHEMBL1336261 & 688854 & 3.301 & 4.4278 & TRN \\
\hline CHEMBL1440420 & 688854 & 4.8179 & 4.5978 & TRN \\
\hline CHEMBL1980226 & 688854 & 5.2924 & 5.3324 & TRN \\
\hline CHEMBL1504858 & 688854 & 8.0 & 3.8966 & TRN \\
\hline CHEMBL 290077 & 688854 & 6.4559 & 5.7764 & TST \\
\hline CHEMBL1489524 & 688854 & 3.301 & 3.8682 & TRN \\
\hline CHEMBL1369984 & 688854 & 3.301 & 4.3625 & TST \\
\hline CHEMBL1347193 & 688854 & 4.8684 & 4.709 & TRN \\
\hline CHEMBL1446042 & 688854 & 4.7212 & 4.621 & TRN \\
\hline CHEMBL1388274 & 688854 & 4.5791 & 4.4649 & TRN \\
\hline CHEMBL1511774 & 688854 & 3.301 & 4.1964 & TRN \\
\hline CHEMBL 3195094 & 688854 & 3.301 & 4.5694 & TRN \\
\hline CHEMBL 388978 & 688854 & 8.0 & 5.5786 & TST \\
\hline CHEMBL1405073 & 688854 & 3.301 & 4.0077 & TRN \\
\hline CHEMBL601578 & 688854 & 4.7587 & 4.7698 & TRN \\
\hline CHEMBL1091556 & 688854 & 5.8268 & 5.2877 & TRN \\
\hline CHEMBL582980 & 688854 & 5.153 & 5.2943 & TRN \\
\hline CHEMBL1501300 & 688854 & 4.6101 & 4.4384 & TRN \\
\hline CHEMBL 3208063 & 688854 & 3.301 & 4.3011 & TRN \\
\hline CHEMBL1987472 & 688854 & 5.8327 & 5.0453 & TRN \\
\hline CHEMBL1330963 & 688854 & 4.6338 & 4.2882 & TRN \\
\hline CHEMBL3191530 & 688854 & 3.301 & 4.412 & TRN \\
\hline CHEMBL1388557 & 688854 & 3.301 & 3.8267 & TST \\
\hline CHEMBL1451150 & 688854 & 3.301 & 4.3911 & TRN \\
\hline CHEMBL1510953 & 688854 & 4.3643 & 4.3833 & TRN \\
\hline CHEMBL1301082 & 688854 & 5.3372 & 5.1786 & TRN \\
\hline CHEMBL1484110 & 688854 & 3.301 & 3.9728 & TRN \\
\hline CHEMBL1525481 & 688854 & 3.301 & 4.1711 & TRN \\
\hline
\end{tabular}




\begin{tabular}{|c|c|c|c|c|c|}
\hline & & \multicolumn{4}{|c|}{ Supplemental Table S2.txt } \\
\hline CHEMBL1310009 & 688854 & 4.8778 & 4.9515 & TRN & \\
\hline CHEMBL1431093 & 688854 & 4.8125 & 4.7228 & TRN & \\
\hline CHEMBL1411632 & 688854 & 3.301 & 4.4013 & TRN & \\
\hline CHEMBL1393342 & 688854 & 3.301 & 4.0145 & TRN & \\
\hline CHEMBL51931 & 688854 & 5.6536 & 5.494 & TRN & \\
\hline CHEMBL1582934 & 688854 & 4.5259 & 4.7441 & TRN & \\
\hline CHEMBL 2369168 & 688854 & 5.5017 & 5.0599 & TRN & \\
\hline CHEMBL1605019 & 688854 & 3.301 & 3.9417 & TRN & \\
\hline CHEMBL530281 & 688854 & 3.301 & 4.6525 & TRN & \\
\hline CHEMBL1387313 & 688854 & 4.5139 & 4.6142 & TRN & \\
\hline CHEMBL1344070 & 688854 & 5.0462 & 4.2708 & TRN & \\
\hline CHEMBL600778 & 688854 & 5.1397 & 6.2737 & TRN & \\
\hline CHEMBL528506 & 688854 & 5.0146 & 4.7195 & TRN & \\
\hline CHEMBL 1417383 & 688854 & 4.7005 & 4.4946 & TRN & \\
\hline CHEMBL3213842 & 688854 & 3.301 & 4.6661 & TRN & \\
\hline CHEMBL582444 & 688854 & 5.4473 & 5.0282 & TRN & \\
\hline CHEMBL1462925 & 688854 & 3.301 & 4.2834 & TRN & \\
\hline CHEMBL1350184 & 688854 & 3.301 & 4.2736 & TST & \\
\hline CHEMBL1365234 & 688854 & 3.301 & 4.5309 & TST & \\
\hline CHEMBL1544371 & 688854 & 5.9066 & 5.3897 & TRN & \\
\hline CHEMBL570345 & 688854 & 5.7235 & 4.9623 & TRN & \\
\hline CHEMBL1308088 & 688854 & 5.3161 & 4.73 & TRN & \\
\hline CHEMBL1399925 & 688854 & 3.301 & 4.5972 & TST & \\
\hline CHEMBL1556805 & 688854 & 5.8447 & 5.746 & TST & \\
\hline CHEMBL3190268 & 688854 & 4.9226 & 5.2263 & TRN & \\
\hline CHEMBL581870 & 688854 & 5.3372 & 5.0457 & TRN & \\
\hline CHEMBL1986678 & 688854 & 5.4737 & 5.28600 & 00000000005 & TRN \\
\hline CHEMBL1531172 & 688854 & 4.7825 & 4.5048 & TRN & \\
\hline CHEMBL1904459 & 688854 & 4.9055 & 4.791 & TRN & \\
\hline CHEMBL1337086 & 688854 & 3.301 & 3.8786 & TRN & \\
\hline CHEMBL1379600 & 688854 & 4.8719 & 4.33899 & 99999999995 & TRN \\
\hline CHEMBL1447782 & 688854 & 5.0259 & 4.2062 & TRN & \\
\hline CHEMBL3196813 & 688854 & 5.4145 & 5.1507 & TRN & \\
\hline CHEMBL1337939 & 688854 & 4.6546 & 3.7534 & TRN & \\
\hline CHEMBL1420083 & 688854 & 3.301 & 3.8479 & TRN & \\
\hline CHEMBL3213394 & 688854 & 5.1391 & 4.9723 & TRN & \\
\hline CHEMBL3211290 & 688854 & 4.8778 & 4.9422 & TRN & \\
\hline CHEMBL1572031 & 688854 & 5.1669 & 4.4008 & TRN & \\
\hline CHEMBL1882125 & 688854 & 5.6904 & 4.3898 & TRN & \\
\hline CHEMBL1518866 & 688854 & 5.4789 & 4.973 & TRN & \\
\hline CHEMBL1595024 & 688854 & 4.3492 & 4.342 & TRN & \\
\hline CHEMBL1348555 & 688854 & 4.9485 & 5.2154 & TRN & \\
\hline CHEMBL1542057 & 688854 & 4.4176 & 4.1775 & TRN & \\
\hline CHEMBL1411646 & 688854 & 5.6536 & 5.6925 & TRN & \\
\hline CHEMBL1427000 & 688854 & 4.626 & 4.5148 & TRN & \\
\hline CHEMBL3191242 & 688854 & 5.4413 & 5.4669 & TRN & \\
\hline CHEMBL1450086 & 688854 & 6.1675 & 5.6639 & TRN & \\
\hline CHEMBL1426423 & 688854 & 8.0 & 3.9902 & TRN & \\
\hline
\end{tabular}




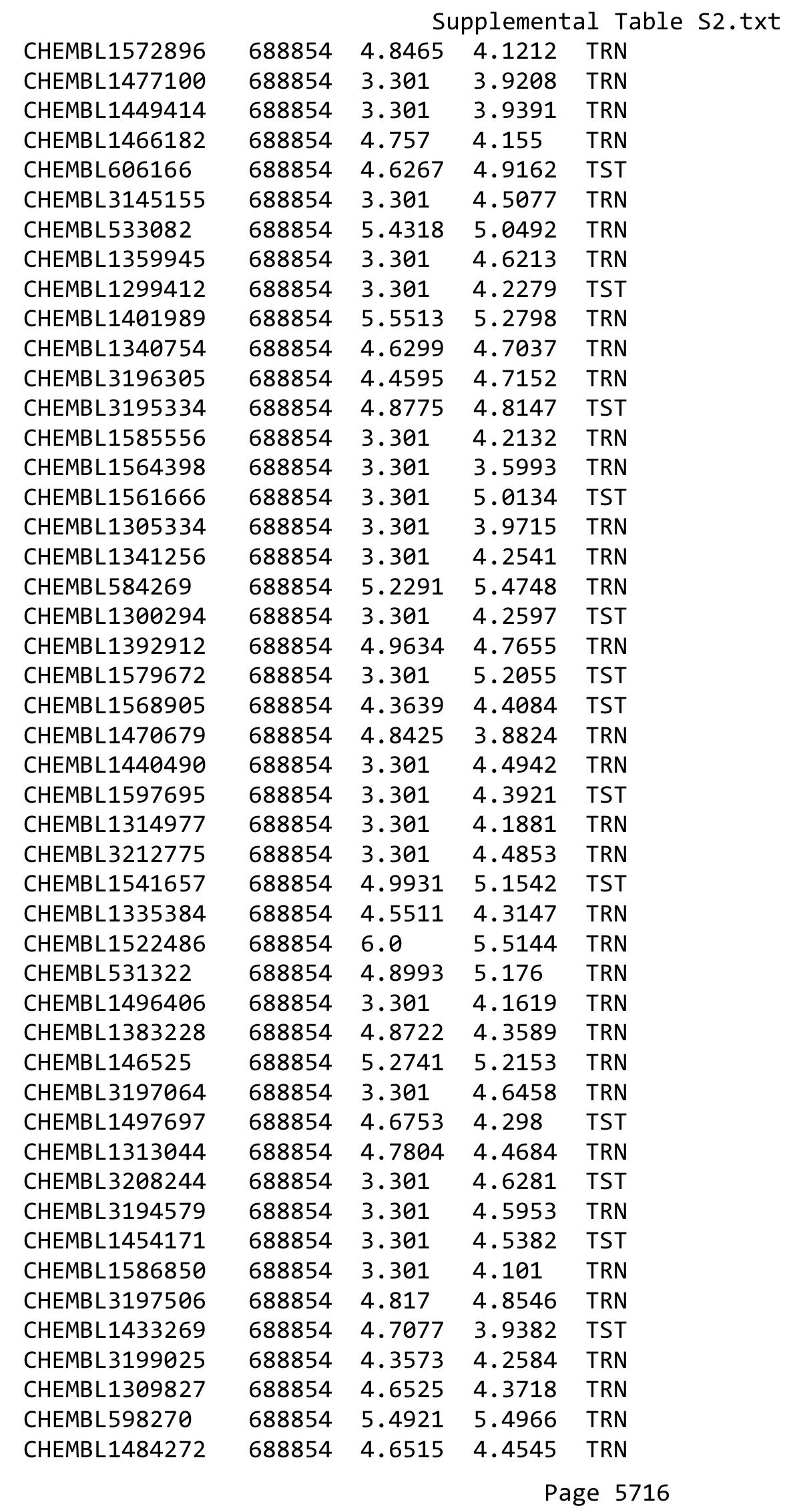





\begin{tabular}{|c|c|c|c|c|c|}
\hline & & \multicolumn{4}{|c|}{ Supplemental Table S2.txt } \\
\hline CHEMBL579111 & 688854 & 3.301 & 3.6579 & TRN & \\
\hline CHEMBL1387404 & 688854 & 4.5615 & 4.52 & TRN & \\
\hline CHEMBL1495602 & 688854 & 5.0804 & 4.5358 & TRN & \\
\hline CHEMBL1389534 & 688854 & 3.301 & 3.9612 & TRN & \\
\hline CHEMBL1605784 & 688854 & 4.574 & 4.0963 & TRN & \\
\hline CHEMBL1536493 & 688854 & 5.5258 & 4.8236 & TRN & \\
\hline CHEMBL1558535 & 688854 & 4.4536 & 4.0571 & TRN & \\
\hline CHEMBL1566203 & 688854 & 3.301 & 4.2542 & TST & \\
\hline CHEMBL 1488580 & 688854 & 3.301 & 4.0902 & TST & \\
\hline CHEMBL1368458 & 688854 & 5.0862 & 4.6408 & TRN & \\
\hline CHEMBL1600940 & 688854 & 4.6054 & 4.1134 & TRN & \\
\hline CHEMBL1555931 & 688854 & 3.301 & 4.1889 & TST & \\
\hline CHEMBL1522083 & 688854 & 4.7815 & 5.2919 & TRN & \\
\hline CHEMBL441986 & 688854 & 3.301 & 4.8696 & TRN & \\
\hline CHEMBL3198074 & 688854 & 4.5865 & 4.7199 & TRN & \\
\hline CHEMBL1464975 & 688854 & 4.7399 & 4.444 & TRN & \\
\hline CHEMBL1505620 & 688854 & 4.565 & 4.4152 & TRN & \\
\hline CHEMBL591137 & 688854 & 5.7595 & 4.7255 & TRN & \\
\hline CHEMBL1596917 & 688854 & 3.301 & 4.4286 & TRN & \\
\hline CHEMBL1509072 & 688854 & 4.7937 & 4.3042 & TRN & \\
\hline CHEMBL1497059 & 688854 & 3.301 & 4.172 & TRN & \\
\hline CHEMBL1406274 & 688854 & 6.0 & 4.5163 & TRN & \\
\hline CHEMBL1606890 & 688854 & 5.209 & 4.832 & TRN & \\
\hline CHEMBL1597279 & 688854 & 3.301 & 3.7048 & TRN & \\
\hline CHEMBL226876 & 688854 & 4.776 & 4.3632 & TRN & \\
\hline CHEMBL1554214 & 688854 & 4.8545 & 4.371 & TST & \\
\hline CHEMBL1485084 & 688854 & 4.4549 & 3.7959 & TRN & \\
\hline CHEMBL588250 & 688854 & 4.8502 & 4.9486 & TRN & \\
\hline CHEMBL1531524 & 688854 & 3.301 & 3.7303 & TRN & \\
\hline CHEMBL1315701 & 688854 & 4.8807 & 4.5802 & TRN & \\
\hline CHEMBL1413504 & 688854 & 4.9706 & 4.3264 & TRN & \\
\hline CHEMBL1607938 & 688854 & 4.3862 & 4.5367 & TRN & \\
\hline CHEMBL1557101 & 688854 & 4.3585 & 4.2368 & TRN & \\
\hline CHEMBL1404984 & 688854 & 3.301 & 4.1429 & TRN & \\
\hline CHEMBL299228 & 688854 & 5.0768 & 4.82600 & 00000000005 & TRN \\
\hline CHEMBL1575914 & 688854 & 3.301 & 4.1979 & TRN & \\
\hline CHEMBL1564542 & 688854 & 5.2749 & 4.3661 & TRN & \\
\hline CHEMBL3193022 & 688854 & 3.301 & 4.4386 & TRN & \\
\hline CHEMBL1578997 & 688854 & 4.9382 & 4.7191 & TRN & \\
\hline CHEMBL1374964 & 688854 & 3.301 & 4.5138 & TST & \\
\hline CHEMBL1568934 & 688854 & 3.301 & 4.1221 & TRN & \\
\hline CHEMBL1602593 & 688854 & 3.301 & 3.7965 & TRN & \\
\hline CHEMBL1413726 & 688854 & 4.9523 & 4.8106 & TRN & \\
\hline CHEMBL1355537 & 688854 & 3.301 & 4.7214 & TST & \\
\hline CHEMBL1467551 & 688854 & 3.301 & 3.7283 & TRN & \\
\hline CHEMBL1349832 & 688854 & 5.6596 & 5.3409 & TRN & \\
\hline CHEMBL1486170 & 688854 & 3.301 & 4.207 & TRN & \\
\hline CHEMBL1309229 & 688854 & 5.1073 & 4.9091 & TRN & \\
\hline
\end{tabular}




\begin{tabular}{|c|c|c|c|c|c|c|}
\hline \multirow[b]{2}{*}{ CHEMBL1578469 } & & \multicolumn{5}{|c|}{ Supplemental Table S2.txt } \\
\hline & 688854 & 4.7484 & 4.2259 & TRN & & \\
\hline CHEMBL1535809 & 688854 & 4.5892 & 4.029 & TRN & & \\
\hline CHEMBL578928 & 688854 & 4.8277 & 4.7708 & TRN & & \\
\hline CHEMBL187866 & 688854 & 5.05399 & 99999999 & 99 & 4.2856 & TRN \\
\hline CHEMBL1420037 & 688854 & 5.9788 & 4.5642 & TRN & & \\
\hline CHEMBL1487935 & 688854 & 3.301 & 4.0051 & TRN & & \\
\hline CHEMBL1386521 & 688854 & 3.301 & 4.0126 & TRN & & \\
\hline CHEMBL1557142 & 688854 & 4.3213 & 4.7392 & TRN & & \\
\hline CHEMBL1504410 & 688854 & 3.301 & 4.0827 & TRN & & \\
\hline CHEMBL1456530 & 688854 & 4.7535 & 4.3995 & TRN & & \\
\hline CHEMBL1539637 & 688854 & 3.301 & 4.1978 & TST & & \\
\hline CHEMBL1568110 & 688854 & 3.301 & 3.7983 & TRN & & \\
\hline CHEMBL1390072 & 688854 & 3.301 & 4.4559 & TRN & & \\
\hline CHEMBL1421395 & 688854 & 4.6664 & 4.0891 & TRN & & \\
\hline CHEMBL1478172 & 688854 & 3.301 & 4.212 & TRN & & \\
\hline CHEMBL1508347 & 688854 & 4.3692 & 4.4373 & TRN & & \\
\hline CHEMBL1326817 & 688854 & 5.0501 & 4.3271 & TRN & & \\
\hline CHEMBL1738986 & 688854 & 4.8908 & 4.7529 & TRN & & \\
\hline CHEMBL1546826 & 688854 & 3.301 & 4.1045 & TRN & & \\
\hline CHEMBL1540426 & 688854 & 3.301 & 3.8896 & TRN & & \\
\hline CHEMBL1490728 & 688854 & 4.8342 & 4.6806 & TRN & & \\
\hline CHEMBL1404349 & 688854 & 3.301 & 4.015 & TRN & & \\
\hline CHEMBL 3194740 & 688854 & 4.5334 & 4.3999 & TRN & & \\
\hline CHEMBL1590547 & 688854 & 5.3904 & 4.8505 & TRN & & \\
\hline CHEMBL1537184 & 688854 & 3.301 & 3.8027 & TRN & & \\
\hline CHEMBL1496555 & 688854 & 4.3181 & 4.2959 & TRN & & \\
\hline CHEMBL1418814 & 688854 & 4.6523 & 4.8118 & TRN & & \\
\hline CHEMBL1481347 & 688854 & 6.6778 & 6.7299 & TRN & & \\
\hline CHEMBL581257 & 688854 & 5.6108 & 5.3111 & TST & & \\
\hline CHEMBL1456519 & 688854 & 8.0 & 3.9116 & TST & & \\
\hline CHEMBL1336446 & 688854 & 4.9245 & 4.2591 & TRN & & \\
\hline CHEMBL1582216 & 688854 & 3.301 & 4.4612 & TST & & \\
\hline CHEMBL1514790 & 688854 & 5.2321 & 5.1021 & TRN & & \\
\hline CHEMBL1304172 & 688854 & 4.9957 & 4.7857 & TRN & & \\
\hline CHEMBL405110 & 688854 & 6.1427 & 4.6447 & TST & & \\
\hline CHEMBL1419585 & 688854 & 5.1135 & 4.729 & TRN & & \\
\hline CHEMBL1498511 & 688854 & 4.6155 & 4.3089 & TRN & & \\
\hline CHEMBL1580083 & 688854 & 5.3958 & 4.2518 & TRN & & \\
\hline CHEMBL1299618 & 688854 & 3.301 & 3.821 & TRN & & \\
\hline CHEMBL3194327 & 688854 & 4.8125 & 5.0406 & TRN & & \\
\hline CHEMBL1559388 & 688854 & 3.301 & 4.1044 & TRN & & \\
\hline CHEMBL1492696 & 688854 & 5.2027 & 5.0067 & TRN & & \\
\hline CHEMBL525826 & 688854 & 5.6459 & 5.2761 & TRN & & \\
\hline CHEMBL1329977 & 688854 & 3.301 & 3.8841 & TRN & & \\
\hline CHEMBL3214537 & 688854 & 4.48 & 4.2943 & TRN & & \\
\hline CHEMBL3189184 & 688854 & 3.301 & 4.4567 & TRN & & \\
\hline CHEMBL3195943 & 688854 & 4.9183 & 4.2848 & TRN & & \\
\hline CHEMBL582877 & 688854 & 3.301 & 5.1836 & TRN & & \\
\hline
\end{tabular}


Supplemental Table S2.txt

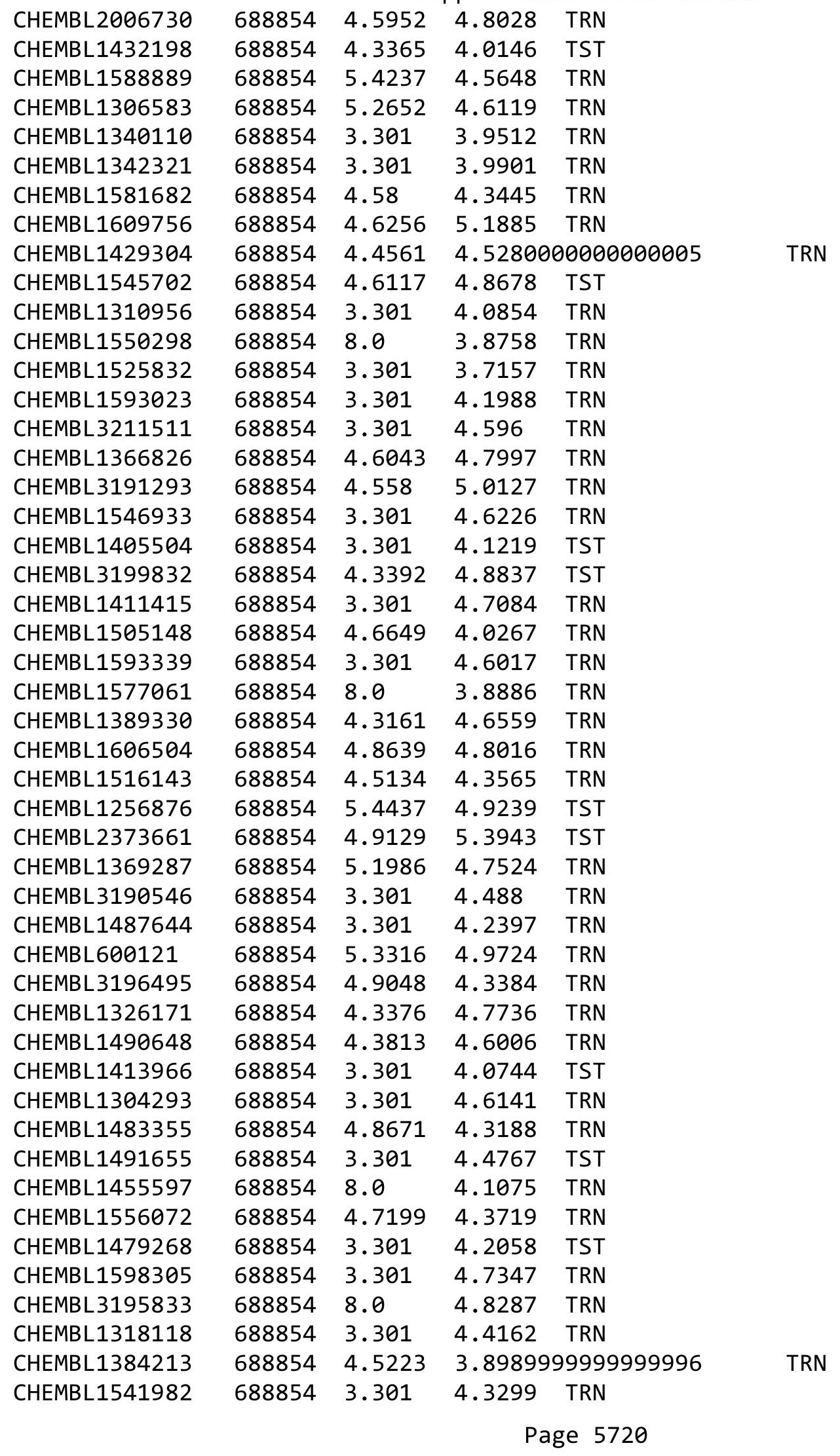




\begin{tabular}{|c|c|c|c|c|c|}
\hline & & & & & \\
\hline CHEMBL1587980 & 688854 & 4.3067 & 4.9208 & TRN & \\
\hline CHEMBL1425080 & 688854 & 3.301 & 4.5377 & TRN & \\
\hline CHEMBL1300557 & 688854 & 4.6635 & 4.3209 & TRN & \\
\hline CHEMBL1430117 & 688854 & 3.301 & 4.229 & TST & \\
\hline CHEMBL1548109 & 688854 & 5.2716 & 5.079 & TRN & \\
\hline CHEMBL1974537 & 688854 & 5.0013 & 4.4316 & TST & \\
\hline CHEMBL1359367 & 688854 & 3.301 & 4.0549 & TRN & \\
\hline CHEMBL1311609 & 688854 & 3.301 & 4.4432 & TST & \\
\hline CHEMBL584626 & 688854 & 3.301 & 4.9617 & TRN & \\
\hline CHEMBL1314743 & 688854 & 3.301 & 4.3647 & TRN & \\
\hline CHEMBL1315061 & 688854 & 3.301 & 5.0923 & TST & \\
\hline CHEMBL3212846 & 688854 & 4.3123 & 4.3798 & TRN & \\
\hline CHEMBL52101 & 688854 & 5.0462 & 5.0886 & TRN & \\
\hline CHEMBL1541209 & 688854 & 5.0731 & 4.33899 & 99999999995 & TRN \\
\hline CHEMBL1440781 & 688854 & 4.3936 & 4.0237 & TRN & \\
\hline CHEMBL1368160 & 688854 & 3.301 & 4.0335 & TRN & \\
\hline CHEMBL1363212 & 688854 & 3.301 & 4.385 & TRN & \\
\hline CHEMBL1535991 & 688854 & 4.8164 & 4.3493 & TRN & \\
\hline CHEMBL530609 & 688854 & 5.1574 & 5.0786 & TRN & \\
\hline CHEMBL1432654 & 688854 & 3.301 & 4.228 & TRN & \\
\hline CHEMBL1401191 & 688854 & 4.3419 & 4.2168 & TST & \\
\hline CHEMBL1594325 & 688854 & 3.301 & 4.1734 & TRN & \\
\hline CHEMBL1583127 & 688854 & 4.7647 & 4.8172 & TRN & \\
\hline CHEMBL3196838 & 688854 & 3.301 & 4.5587 & TRN & \\
\hline CHEMBL1964909 & 688854 & 4.4191 & 4.9 & TRN & \\
\hline CHEMBL1484352 & 688854 & 3.301 & 4.2002 & TRN & \\
\hline CHEMBL1521960 & 688854 & 6.699 & 5.8587 & TST & \\
\hline CHEMBL1359729 & 688854 & 3.301 & 4.6278 & TST & \\
\hline CHEMBL532641 & 688854 & 5.8665 & 5.5534 & TRN & \\
\hline CHEMBL3193714 & 688854 & 8.0 & 5.2178 & TRN & \\
\hline CHEMBL1471353 & 688854 & 3.301 & 4.2182 & TST & \\
\hline CHEMBL1600854 & 688854 & 4.3461 & 3.9564 & TRN & \\
\hline CHEMBL1464537 & 688854 & 3.301 & 3.9509 & TST & \\
\hline CHEMBL1391306 & 688854 & 4.8294 & 4.0562 & TST & \\
\hline CHEMBL3196358 & 688854 & 3.301 & 4.7299 & TRN & \\
\hline CHEMBL193872 & 688854 & 6.1427 & 5.2208 & TST & \\
\hline CHEMBL1465152 & 688854 & 4.7038 & 4.5259 & TRN & \\
\hline CHEMBL1382760 & 688854 & 4.3846 & 4.7 & TRN & \\
\hline CHEMBL3199335 & 688854 & 5.8356 & 4.86100 & 3000000001 & TRN \\
\hline CHEMBL1416618 & 688854 & 4.5698 & 4.623 & TST & \\
\hline CHEMBL1430824 & 688854 & 3.301 & 4.1213 & TRN & \\
\hline CHEMBL1318861 & 688854 & 3.301 & 4.6893 & TST & \\
\hline CHEMBL3209306 & 688854 & 5.7905 & 5.6674 & TRN & \\
\hline CHEMBL1331050 & 688854 & 5.1232 & 4.4415 & TRN & \\
\hline CHEMBL1400005 & 688854 & 4.8918 & 4.5202 & TST & \\
\hline CHEMBL1542644 & 688854 & 5.0119 & 4.0389 & TRN & \\
\hline CHEMBL 2005743 & 688854 & 5.0788 & 4.9371 & TRN & \\
\hline CHEMBL1575043 & 688854 & 3.301 & 4.0581 & TRN & \\
\hline
\end{tabular}





\begin{tabular}{|c|c|c|c|c|c|}
\hline \multicolumn{6}{|c|}{ Supplemental Table S2.txt } \\
\hline CHEMBL3195264 & 688854 & 8.0 & 4.5538 & TST & \\
\hline CHEMBL1382479 & 688854 & 3.301 & 4.5109 & TRN & \\
\hline CHEMBL592842 & 688854 & 4.3379 & 4.525 & TRN & \\
\hline CHEMBL1379994 & 688854 & 5.0467 & 4.0136 & TRN & \\
\hline CHEMBL1422539 & 688854 & 3.301 & 4.0942 & TST & \\
\hline CHEMBL1484218 & 688854 & 3.301 & 4.2249 & TRN & \\
\hline CHEMBL1337563 & 688854 & 4.8259 & 4.1333 & TST & \\
\hline CHEMBL1375045 & 688854 & 6.3188 & 5.996 & TRN & \\
\hline CHEMBL3189342 & 688854 & 5.3788 & 5.5011 & TRN & \\
\hline CHEMBL1386044 & 688854 & 4.8359 & 4.319 & TRN & \\
\hline CHEMBL1169627 & 688854 & 5.0555 & 4.6444 & TST & \\
\hline CHEMBL601737 & 688854 & 3.301 & 4.2918 & TST & \\
\hline CHEMBL1362904 & 688854 & 3.301 & 4.1454 & TRN & \\
\hline CHEMBL254576 & 688854 & 4.5698 & 4.6028 & TRN & \\
\hline CHEMBL1602447 & 688854 & 4.3558 & 4.2613 & TST & \\
\hline CHEMBL1513639 & 688854 & 3.301 & 3.6251 & TRN & \\
\hline CHEMBL1988121 & 688854 & 5.71899 & 99999999 & 5.0438 & TRN \\
\hline CHEMBL1579630 & 688854 & 3.301 & 3.7509 & TST & \\
\hline CHEMBL591126 & 688854 & 5.5768 & 5.4817 & TRN & \\
\hline CHEMBL1333742 & 688854 & 4.6139 & 4.0335 & TRN & \\
\hline CHEMBL589694 & 688854 & 5.0491 & 4.2638 & TRN & \\
\hline CHEMBL1542590 & 688854 & 4.5807 & 4.8852 & TRN & \\
\hline CHEMBL1415035 & 688854 & 4.6611 & 4.6622 & TRN & \\
\hline CHEMBL1430019 & 688854 & 3.301 & 3.88100 & 20000000002 & TRN \\
\hline CHEMBL1358400 & 688854 & 3.301 & 3.5905 & TRN & \\
\hline CHEMBL587892 & 688854 & 4.8636 & 4.9988 & TRN & \\
\hline CHEMBL1309128 & 688854 & 5.0237 & 4.305 & TRN & \\
\hline CHEMBL1529086 & 688854 & 4.7073 & 4.0044 & TRN & \\
\hline CHEMBL1526798 & 688854 & 3.301 & 3.8976 & TRN & \\
\hline CHEMBL1428494 & 688854 & 8.0 & 4.2209 & TST & \\
\hline CHEMBL1342728 & 688854 & 8.0 & 4.3637 & TRN & \\
\hline CHEMBL1353553 & 688854 & 5.0721 & 4.709 & TRN & \\
\hline CHEMBL492886 & 688854 & 3.301 & 4.627 & TRN & \\
\hline CHEMBL1971727 & 688854 & 5.71899 & 79999999 & 5.1869 & TRN \\
\hline CHEMBL1606583 & 688854 & 5.7852 & 5.2433 & TRN & \\
\hline CHEMBL1303009 & 688854 & 4.5777 & 4.5348 & TRN & \\
\hline CHEMBL258767 & 688854 & 4.8182 & 4.4808 & TRN & \\
\hline CHEMBL1451888 & 688854 & 4.7739 & 4.6919 & TRN & \\
\hline CHEMBL1505192 & 688854 & 5.8297 & 6.0833 & TRN & \\
\hline CHEMBL1477689 & 688854 & 3.301 & 3.7499 & TRN & \\
\hline CHEMBL1437542 & 688854 & 5.02 & 4.3912 & TRN & \\
\hline CHEMBL524376 & 688854 & 5.5143 & 5.1918 & TRN & \\
\hline CHEMBL1382066 & 688854 & 3.301 & 4.2873 & TST & \\
\hline CHEMBL 2003973 & 688854 & 5.0044 & 4.4282 & TST & \\
\hline CHEMBL1987461 & 688854 & 6.0458 & 5.0767 & TRN & \\
\hline CHEMBL1373503 & 688854 & 4.3145 & 4.529 & TRN & \\
\hline CHEMBL1369623 & 688854 & 5.2984 & 5.1325 & TRN & \\
\hline CHEMBL1415239 & 688854 & 3.301 & 4.3652 & TST & \\
\hline
\end{tabular}




\begin{tabular}{|c|c|c|c|c|c|}
\hline & & \multicolumn{4}{|c|}{ Supplemental Table S2.txt } \\
\hline CHEMBL1346596 & 688854 & 4.6521 & 4.349 & TRN & \\
\hline CHEMBL1481342 & 688854 & 4.5131 & 4.7617 & TRN & \\
\hline CHEMBL3212049 & 688854 & 4.3932 & 4.3958 & TRN & \\
\hline CHEMBL3196535 & 688854 & 3.301 & 4.8128 & TRN & \\
\hline CHEMBL1406235 & 688854 & 4.3923 & 4.0584 & TRN & \\
\hline CHEMBL603020 & 688854 & 5.4168 & 5.4305 & TRN & \\
\hline CHEMBL602363 & 688854 & 4.9382 & 5.5455 & TRN & \\
\hline CHEMBL1964405 & 688854 & 3.301 & 4.3282 & TRN & \\
\hline CHEMBL1342852 & 688854 & 3.301 & 4.0203 & TRN & \\
\hline CHEMBL1500188 & 688854 & 5.3958 & 5.0478 & TST & \\
\hline CHEMBL1518557 & 688854 & 4.9066 & 4.5506 & TRN & \\
\hline CHEMBL1327813 & 688854 & 3.301 & 4.1327 & TRN & \\
\hline CHEMBL1412114 & 688854 & 4.7387 & 4.5451 & TRN & \\
\hline CHEMBL1390000 & 688854 & 5.4067 & 4.5877 & TRN & \\
\hline CHEMBL1496705 & 688854 & 5.6271 & 5.33 & TRN & \\
\hline CHEMBL1323552 & 688854 & 4.4963 & 4.0363 & TST & \\
\hline CHEMBL1579686 & 688854 & 3.301 & 4.13399 & 99999999995 & TRN \\
\hline CHEMBL1612112 & 688854 & 4.3885 & 4.3019 & TRN & \\
\hline CHEMBL1382265 & 688854 & 5.2299 & 4.3442 & TRN & \\
\hline CHEMBL104270 & 688854 & 3.301 & 4.623 & TRN & \\
\hline CHEMBL1564901 & 688854 & 3.301 & 4.3016 & TST & \\
\hline CHEMBL1982032 & 688854 & 5.3546 & 5.0681 & TST & \\
\hline CHEMBL1575531 & 688854 & 4.5743 & 4.43 & TRN & \\
\hline CHEMBL 1376706 & 688854 & 3.301 & 3.9416 & TRN & \\
\hline CHEMBL1386615 & 688854 & 3.301 & 3.9566 & TRN & \\
\hline CHEMBL3191149 & 688854 & 5.251 & 5.3282 & TRN & \\
\hline CHEMBL1982308 & 688854 & 4.30699 & 99999999 & 4.3703 & Tा \\
\hline CHEMBL357794 & 688854 & 8.0 & 4.2979 & TRN & \\
\hline CHEMBL1382939 & 688854 & 4.6619 & 4.4037 & TRN & \\
\hline CHEMBL1496812 & 688854 & 3.301 & 3.6544 & TRN & \\
\hline CHEMBL3199527 & 688854 & 3.301 & 4.1262 & TRN & \\
\hline CHEMBL27403 & 688854 & 4.3738 & 4.2953 & TRN & \\
\hline CHEMBL1464303 & 688854 & 4.4881 & 4.4099 & TRN & \\
\hline CHEMBL1981667 & 688854 & 5.8182 & 5.1185 & TRN & \\
\hline CHEMBL1353697 & 688854 & 3.301 & 4.5843 & TRN & \\
\hline CHEMBL1329197 & 688854 & 4.4531 & 4.0335 & TRN & \\
\hline CHEMBL1447259 & 688854 & 4.6739 & 4.5558 & TRN & \\
\hline CHEMBL1321808 & 688854 & 3.301 & 3.892 & TST & \\
\hline CHEMBL1527664 & 688854 & 4.8216 & 4.8224 & TST & \\
\hline CHEMBL1339676 & 688854 & 5.1308 & 4.6288 & TRN & \\
\hline CHEMBL3192021 & 688854 & 4.8368 & 4.7482 & TRN & \\
\hline CHEMBL1508833 & 688854 & 3.301 & 4.0439 & TRN & \\
\hline CHEMBL1984793 & 688854 & 3.301 & 4.7079 & TRN & \\
\hline CHEMBL1411779 & 688854 & 4.6981 & 4.4661 & TRN & \\
\hline CHEMBL1984581 & 688854 & 5.0453 & 4.5724 & TST & \\
\hline CHEMBL1322308 & 688854 & 4.3619 & 4.2655 & TRN & \\
\hline CHEMBL546344 & 688854 & 5.2175 & 4.9934 & TRN & \\
\hline CHEMBL1565401 & 688854 & 3.301 & 4.6656 & TST & \\
\hline
\end{tabular}




\begin{tabular}{|c|c|c|c|c|}
\hline \multicolumn{5}{|c|}{ Supplemental Table S2.txt } \\
\hline CHEMBL1414543 & 688854 & 8.0 & 4.4858 & TRN \\
\hline CHEMBL1440636 & 688854 & 4.4907 & 4.5808 & TRN \\
\hline CHEMBL1491847 & 688854 & 5.4572 & 5.2798 & TRN \\
\hline CHEMBL1609529 & 688854 & 5.0526 & 5.0948 & TRN \\
\hline CHEMBL1387884 & 688854 & 3.301 & 4.0643 & TRN \\
\hline CHEMBL1303357 & 688854 & 4.8444 & 4.6993 & TRN \\
\hline CHEMBL1594055 & 688854 & 4.8719 & 5.0323 & TST \\
\hline CHEMBL1423463 & 688854 & 6.0132 & 5.8177 & TRN \\
\hline CHEMBL1562169 & 688854 & 3.301 & 3.7448 & TRN \\
\hline CHEMBL3210835 & 688854 & 4.3012 & 4.8522 & TRN \\
\hline CHEMBL1303745 & 688854 & 4.7953 & 4.5095 & TRN \\
\hline CHEMBL1455197 & 688854 & 4.706 & 4.3479 & TRN \\
\hline CHEMBL1613582 & 688854 & 4.6381 & 4.3711 & TRN \\
\hline CHEMBL 3145245 & 688854 & 5.1637 & 4.4358 & TRN \\
\hline CHEMBL1308783 & 688854 & 4.9045 & 4.4903 & TRN \\
\hline CHEMBL1605080 & 688854 & 3.301 & 4.5019 & TRN \\
\hline CHEMBL1520233 & 688854 & 3.301 & 3.8663 & TRN \\
\hline CHEMBL1401657 & 688854 & 4.5388 & 4.8677 & TRN \\
\hline CHEMBL1440235 & 688854 & 5.1057 & 3.9649 & TRN \\
\hline CHEMBL1598775 & 688854 & 4.9274 & 4.5298 & TRN \\
\hline CHEMBL3189461 & 688854 & 3.301 & 4.2952 & TST \\
\hline CHEMBL3191805 & 688854 & 4.369 & 5.0731 & TRN \\
\hline CHEMBL1533029 & 688854 & 3.301 & 3.984 & TRN \\
\hline CHEMBL1349146 & 688854 & 5.8962 & 4.8358 & TRN \\
\hline CHEMBL1534778 & 688854 & 3.301 & 3.9028 & TRN \\
\hline CHEMBL1375232 & 688854 & 4.3123 & 4.3908 & TRN \\
\hline CHEMBL3198170 & 688854 & 4.3017 & 4.6751 & TRN \\
\hline CHEMBL1393472 & 688854 & 3.301 & 4.1613 & TRN \\
\hline CHEMBL1312441 & 688854 & 5.0921 & 4.6492 & TRN \\
\hline CHEMBL1468275 & 688854 & 3.301 & 4.2747 & TST \\
\hline CHEMBL1524052 & 688854 & 5.4191 & 4.7708 & TRN \\
\hline CHEMBL1540231 & 688854 & 5.0218 & 5.1073 & TST \\
\hline CHEMBL1574090 & 688854 & 3.301 & 4.3816 & TST \\
\hline CHEMBL1330220 & 688854 & 4.7873 & 4.6024 & TST \\
\hline CHEMBL1569989 & 688854 & 5.6498 & 5.3973 & TRN \\
\hline CHEMBL1458960 & 688854 & 3.301 & 3.6837 & TRN \\
\hline CHEMBL1387629 & 688854 & 3.301 & 4.0293 & TRN \\
\hline CHEMBL3195570 & 688854 & 5.1791 & 4.8626 & TRN \\
\hline CHEMBL1327825 & 688854 & 8.0 & 4.073 & TRN \\
\hline CHEMBL153535 & 688854 & 3.301 & 4.5862 & TRN \\
\hline CHEMBL3198400 & 688854 & 4.6637 & 4.6261 & TRN \\
\hline CHEMBL1345775 & 688854 & 4.7409 & 4.2624 & TRN \\
\hline CHEMBL1558367 & 688854 & 4.7983 & 4.1046 & TST \\
\hline CHEMBL1334561 & 688854 & 3.301 & 4.2613 & TRN \\
\hline CHEMBL3195685 & 688854 & 4.7479 & 4.785 & TRN \\
\hline CHEMBL1485551 & 688854 & 4.8716 & 4.4335 & TRN \\
\hline CHEMBL3199512 & 688854 & 4.808 & 5.2263 & TRN \\
\hline CHEMBL1574187 & 688854 & 4.4167 & 4.0247 & TRN \\
\hline
\end{tabular}




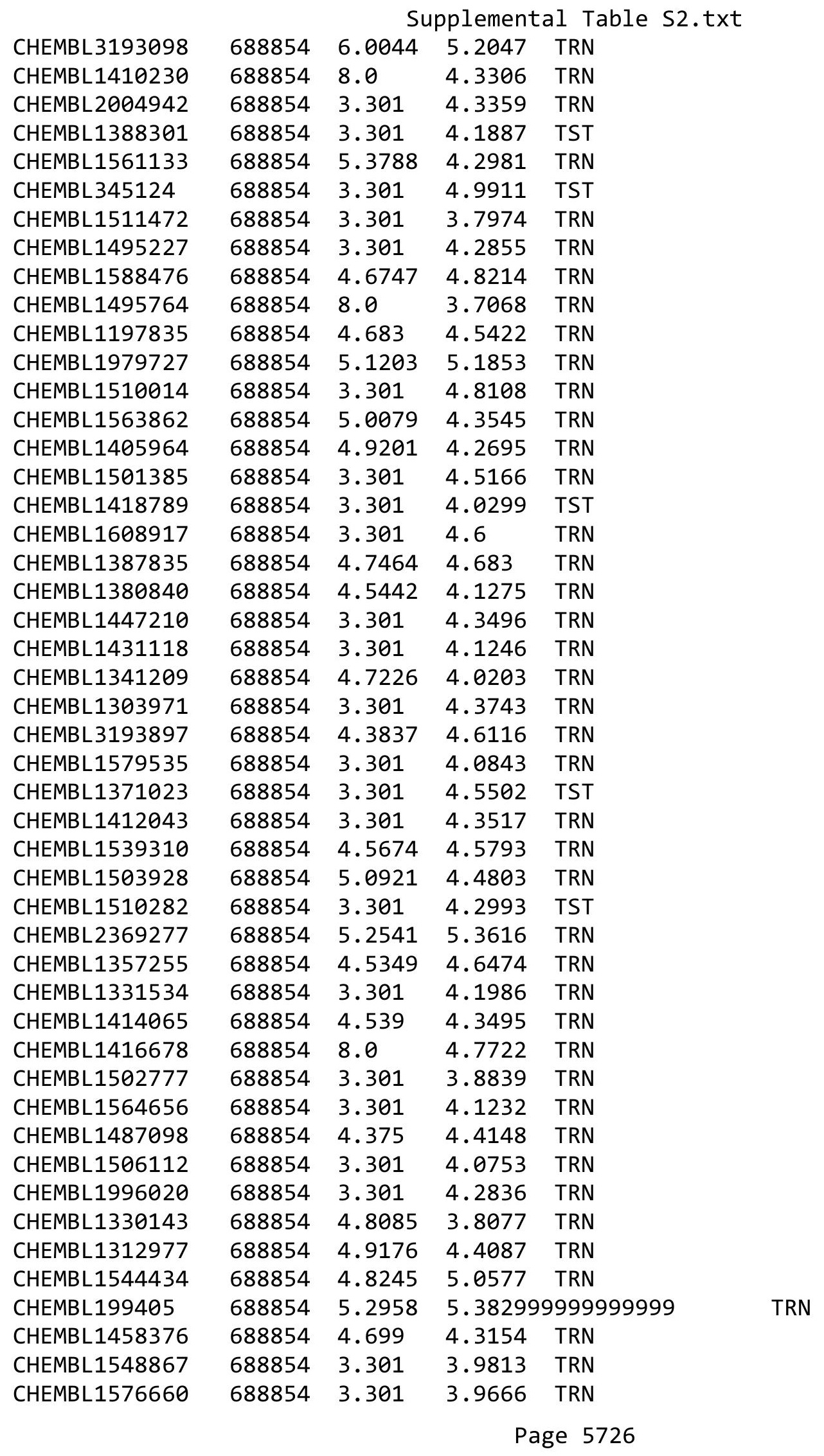


Supplemental Table S2.txt

\begin{tabular}{|c|c|c|c|c|c|}
\hline CHEMBL 3192557 & 688854 & 4.5952 & 4.7932 & TRN & \\
\hline CHEMBL1433109 & 688854 & 4.8431 & 3.8471 & TRN & \\
\hline CHEMBL1600851 & 688854 & 4.3691 & 3.8321 & TRN & \\
\hline CHEMBL1387317 & 688854 & 3.301 & 4.3189 & TST & \\
\hline CHEMBL601547 & 688854 & 5.644 & 5.4089 & TRN & \\
\hline CHEMBL1524783 & 688854 & 4.3591 & 4.4147 & TRN & \\
\hline CHEMBL1441677 & 688854 & 5.0953 & 4.2466 & TRN & \\
\hline CHEMBL578872 & 688854 & 4.7525 & 4.6777 & TST & \\
\hline CHEMBL1328629 & 688854 & 4.4465 & 4.915 & TRN & \\
\hline CHEMBL1601270 & 688854 & 4.3389 & 3.8662 & TRN & \\
\hline CHEMBL1328118 & 688854 & 4.8413 & 4.4367 & TRN & \\
\hline CHEMBL1373244 & 688854 & 3.301 & 4.0055 & TRN & \\
\hline CHEMBL1463600 & 688854 & 4.8752 & 5.0959 & TRN & \\
\hline CHEMBL1604894 & 688854 & 3.301 & 4.1023 & TRN & \\
\hline CHEMBL1352234 & 688854 & 5.4559 & 5.12299 & 9999999999 & TRN \\
\hline CHEMBL1415720 & 688854 & 5.1549 & 5.0603 & TST & \\
\hline CHEMBL1545044 & 688854 & 4.5864 & 4.6131 & TRN & \\
\hline CHEMBL1424695 & 688854 & 3.301 & 3.9836 & TRN & \\
\hline CHEMBL1405683 & 688854 & 8.0 & 4.0633 & TRN & \\
\hline CHEMBL3197991 & 688854 & 4.5613 & 4.8018 & TRN & \\
\hline CHEMBL1600462 & 688854 & 3.301 & 4.1185 & TRN & \\
\hline CHEMBL1438127 & 688854 & 4.3563 & 4.8766 & TRN & \\
\hline CHEMBL1335846 & 688854 & 6.3098 & 4.5792 & TRN & \\
\hline CHEMBL1502340 & 688854 & 4.808 & 3.7142 & TRN & \\
\hline CHEMBL66953 & 688854 & 4.6171 & 4.2013 & TST & \\
\hline CHEMBL 3194737 & 688854 & 5.1367 & 5.3378 & TRN & \\
\hline CHEMBL1389994 & 688854 & 4.7945 & 4.253 & TRN & \\
\hline CHEMBL1333597 & 688854 & 4.543 & 4.4146 & TST & \\
\hline CHEMBL1522007 & 688854 & 5.644 & 4.9534 & TRN & \\
\hline CHEMBL1384387 & 688854 & 5.2684 & 5.5438 & TRN & \\
\hline CHEMBL1563084 & 688854 & 8.0 & 4.5303 & TRN & \\
\hline CHEMBL1324093 & 688854 & 4.6336 & 4.6002 & TRN & \\
\hline CHEMBL1308975 & 688854 & 4.9698 & 4.6683 & TRN & \\
\hline CHEMBL1486325 & 688854 & 3.301 & 4.0039 & TRN & \\
\hline CHEMBL1435878 & 688854 & 4.7402 & 4.3958 & TRN & \\
\hline CHEMBL1350506 & 688854 & 3.301 & 4.1767 & TRN & \\
\hline CHEMBL1542014 & 688854 & 3.301 & 3.9912 & TRN & \\
\hline CHEMBL1326203 & 688854 & 3.301 & 5.1404 & TRN & \\
\hline CHEMBL1971316 & 688854 & 4.3056 & 4.6481 & TRN & \\
\hline CHEMBL1553717 & 688854 & 5.5171 & 4.3531 & TRN & \\
\hline CHEMBL 3198588 & 688854 & 5.279 & 4.5447 & TRN & \\
\hline CHEMBL1553855 & 688854 & 5.1506 & 4.7365 & TRN & \\
\hline CHEMBL 3195766 & 688854 & 4.5381 & 4.4732 & TRN & \\
\hline CHEMBL 1484943 & 688854 & 3.301 & 3.8715 & TRN & \\
\hline CHEMBL1457644 & 688854 & 5.2306 & 5.3683 & TRN & \\
\hline CHEMBL1528481 & 688854 & 5.2588 & 4.7006 & TRN & \\
\hline CHEMBL1322929 & 688854 & 3.301 & 4.5644 & TRN & \\
\hline CHEMBL1393559 & 688854 & 3.301 & 4.2761 & TRN & \\
\hline
\end{tabular}




\begin{tabular}{|c|c|c|c|c|}
\hline & & & pplement & al $\mathrm{Tc}$ \\
\hline CHEMBL1471206 & 688854 & 5.2154 & 4.2223 & TRN \\
\hline CHEMBL1958251 & 688854 & 5.2125 & 5.3133 & TRN \\
\hline CHEMBL1480796 & 688854 & 8.0 & 3.9053 & TRN \\
\hline CHEMBL 204914 & 688854 & 4.9172 & 4.3022 & TRN \\
\hline CHEMBL1330068 & 688854 & 4.6496 & 4.8701 & TRN \\
\hline CHEMBL1538399 & 688854 & 5.4023 & 4.2458 & TRN \\
\hline CHEMBL123 & 688854 & 5.5654 & 5.7587 & TRN \\
\hline CHEMBL1623028 & 688854 & 5.0531 & 4.8957 & TRN \\
\hline CHEMBL1448018 & 688854 & 3.301 & 4.1474 & TRN \\
\hline CHEMBL1548538 & 688854 & 4.4262 & 4.1246 & TRN \\
\hline CHEMBL1490337 & 688854 & 3.301 & 3.7199 & TRN \\
\hline CHEMBL1420418 & 688854 & 4.6749 & 4.3073 & TRN \\
\hline CHEMBL1201074 & 688854 & 4.8921 & 4.348 & TRN \\
\hline CHEMBL1440518 & 688854 & 5.2495 & 4.6907 & TRN \\
\hline CHEMBL1335077 & 688854 & 3.301 & 3.8885 & TRN \\
\hline CHEMBL3197410 & 688854 & 3.301 & 4.4888 & TRN \\
\hline CHEMBL1487428 & 688854 & 3.301 & 4.0622 & TRN \\
\hline CHEMBL1388616 & 688854 & 3.301 & 3.897 & TRN \\
\hline CHEMBL1385558 & 688854 & 5.4828 & 4.7435 & TRN \\
\hline CHEMBL1486960 & 688854 & 3.301 & 4.7409 & TRN \\
\hline CHEMBL1600045 & 688854 & 4.306 & 4.6473 & TRN \\
\hline CHEMBL1398181 & 688854 & 5.0883 & 4.3876 & TRN \\
\hline CHEMBL3192605 & 688854 & 4.7833 & 5.187 & TRN \\
\hline CHEMBL 2004056 & 688854 & 5.1129 & 4.3657 & TRN \\
\hline CHEMBL1598350 & 688854 & 3.301 & 4.0272 & TRN \\
\hline CHEMBL3198649 & 688854 & 3.301 & 4.2645 & TRN \\
\hline CHEMBL1597839 & 688854 & 4.9059 & 4.0551 & TRN \\
\hline CHEMBL1301975 & 688854 & 3.301 & 4.6938 & TRN \\
\hline CHEMBL1514381 & 688854 & 3.301 & 4.8417 & TRN \\
\hline CHEMBL461579 & 688854 & 6.3565 & 5.6585 & TST \\
\hline CHEMBL1483235 & 688854 & 5.6144 & 5.271 & TRN \\
\hline CHEMBL1493890 & 688854 & 3.301 & 4.0106 & TRN \\
\hline CHEMBL1548206 & 688854 & 3.301 & 4.3663 & TRN \\
\hline CHEMBL1346881 & 688854 & 4.8742 & 4.6377 & TRN \\
\hline CHEMBL1416387 & 688854 & 8.0 & 4.4158 & TRN \\
\hline CHEMBL172 & 688854 & 5.4001 & 5.3833 & TST \\
\hline CHEMBL1308845 & 688854 & 4.669 & 4.5252 & TRN \\
\hline CHEMBL1306460 & 688854 & 5.9957 & 4.5433 & TST \\
\hline CHEMBL1542582 & 688854 & 3.301 & 4.5203 & TRN \\
\hline CHEMBL1359781 & 688854 & 3.301 & 4.0916 & TRN \\
\hline CHEMBL3213802 & 688854 & 4.8419 & 4.5505 & TRN \\
\hline CHEMBL609606 & 688854 & 5.1688 & 5.3921 & TST \\
\hline CHEMBL1585197 & 688854 & 4.9821 & 3.9057 & TRN \\
\hline CHEMBL1449349 & 688854 & 5.1612 & 3.9567 & TRN \\
\hline CHEMBL1332978 & 688854 & 4.4905 & 4.8711 & TRN \\
\hline CHEMBL1606918 & 688854 & 4.6336 & 4.8987 & TST \\
\hline CHEMBL1978888 & 688854 & 4.671 & 4.9135 & TRN \\
\hline CHEMBL1363219 & 688854 & 6.0458 & 4.845 & TRN \\
\hline
\end{tabular}




\begin{tabular}{|c|c|c|c|c|c|}
\hline & & \multicolumn{4}{|c|}{ Supplemental Table S2.txt } \\
\hline CHEMBL7747 & 688854 & 3.301 & 4.7434 & TRN & \\
\hline CHEMBL3189405 & 688854 & 6.2441 & 4.9644 & TRN & \\
\hline CHEMBL1419803 & 688854 & 3.301 & 4.3266 & TRN & \\
\hline CHEMBL1312242 & 688854 & 3.301 & 4.3034 & TRN & \\
\hline CHEMBL1551525 & 688854 & 3.301 & 4.5361 & TRN & \\
\hline CHEMBL3197651 & 688854 & 3.301 & 5.1012 & TRN & \\
\hline CHEMBL1468953 & 688854 & 3.301 & 4.3288 & TRN & \\
\hline CHEMBL1495072 & 688854 & 5.5498 & 5.3344 & TRN & \\
\hline CHEMBL1501558 & 688854 & 5.2147 & 5.2526 & TRN & \\
\hline CHEMBL1398171 & 688854 & 4.5414 & 4.5747 & TRN & \\
\hline CHEMBL1455993 & 688854 & 5.3969 & 4.5208 & TRN & \\
\hline CHEMBL 3207320 & 688854 & 3.301 & 3.9337 & TRN & \\
\hline CHEMBL1351158 & 688854 & 5.6421 & 5.2524 & TRN & \\
\hline CHEMBL1301160 & 688854 & 8.0 & 4.1489 & TRN & \\
\hline CHEMBL1396209 & 688854 & 6.6576 & 4.708 & TRN & \\
\hline CHEMBL1598081 & 688854 & 3.301 & 4.34399 & 9999999999 & TST \\
\hline CHEMBL1450959 & 688854 & 4.6897 & 4.0024 & TRN & \\
\hline CHEMBL1318993 & 688854 & 5.0061 & 4.7204 & TRN & \\
\hline CHEMBL1567389 & 688854 & 4.7967 & 4.2644 & TRN & \\
\hline CHEMBL3210919 & 688854 & 5.6655 & 4.5587 & TRN & \\
\hline CHEMBL1527367 & 688854 & 3.301 & 4.0249 & TRN & \\
\hline CHEMBL1527341 & 688854 & 5.7852 & 5.4645 & TRN & \\
\hline CHEMBL1403875 & 688854 & 3.301 & 4.1206 & TRN & \\
\hline CHEMBL334707 & 688854 & 4.5417 & 5.0087 & TRN & \\
\hline CHEMBL1391048 & 688854 & 5.1884 & 4.8534 & TRN & \\
\hline CHEMBL1415140 & 688854 & 4.6055 & 4.3983 & TRN & \\
\hline CHEMBL1603731 & 688854 & 4.5405 & 4.5182 & TRN & \\
\hline CHEMBL1451628 & 688854 & 4.923 & 4.6011 & TST & \\
\hline CHEMBL2359911 & 688854 & 5.8894 & 5.4662 & TRN & \\
\hline CHEMBL1610357 & 688854 & 3.301 & 4.2307 & TRN & \\
\hline CHEMBL1532668 & 688854 & 5.5638 & 5.1758 & TRN & \\
\hline CHEMBL1596066 & 688854 & 4.9618 & 4.3041 & TRN & \\
\hline CHEMBL1326318 & 688854 & 5.0545 & 4.4528 & TRN & \\
\hline CHEMBL1545719 & 688854 & 3.301 & 4.1317 & TRN & \\
\hline CHEMBL1471699 & 688854 & 3.301 & 3.6873 & TRN & \\
\hline CHEMBL3196837 & 688854 & 3.301 & 4.8157 & TRN & \\
\hline CHEMBL530963 & 688854 & 3.301 & 4.5941 & TRN & \\
\hline CHEMBL1586727 & 688854 & 8.0 & 4.7221 & TRN & \\
\hline CHEMBL1411762 & 688854 & 3.301 & 4.0105 & TST & \\
\hline CHEMBL1602189 & 688854 & 3.301 & 4.1246 & TST & \\
\hline CHEMBL1325629 & 688854 & 3.301 & 4.3923 & TRN & \\
\hline CHEMBL1365170 & 688854 & 8.0 & 3.9249 & TRN & \\
\hline CHEMBL1308051 & 688854 & 4.5411 & 4.4229 & TRN & \\
\hline CHEMBL1590885 & 688854 & 3.301 & 4.4156 & TRN & \\
\hline CHEMBL1966824 & 688854 & 5.2097 & 4.6679 & TST & \\
\hline CHEMBL1302458 & 688854 & 8.0 & 3.9528 & TRN & \\
\hline CHEMBL1528746 & 688854 & 8.0 & 4.1939 & TST & \\
\hline CHEMBL1600807 & 688854 & 3.301 & 4.0906 & TRN & \\
\hline
\end{tabular}




\begin{tabular}{|c|c|c|c|c|c|c|}
\hline & & \multicolumn{5}{|c|}{ Supplemental Table S2.txt } \\
\hline CHEMBL1478652 & 688854 & 4.5928 & 5.2079 & TRN & & \\
\hline CHEMBL1550442 & 688854 & 5.2765 & 4.6508 & TRN & & \\
\hline CHEMBL3213632 & 688854 & 4.4998 & 4.4054 & TRN & & \\
\hline CHEMBL1609350 & 688854 & 3.301 & 4.1142 & TRN & & \\
\hline CHEMBL1570336 & 688854 & 4.5322 & 4.2703 & TRN & & \\
\hline CHEMBL1375300 & 688854 & 3.301 & 4.1734 & TRN & & \\
\hline CHEMBL1308879 & 688854 & 5.3054 & 5.4526 & TRN & & \\
\hline CHEMBL1466593 & 688854 & 5.2182 & 4.1804 & TRN & & \\
\hline CHEMBL1484565 & 688854 & 3.301 & 4.1366 & TRN & & \\
\hline CHEMBL1584438 & 688854 & 3.301 & 4.3402 & TRN & & \\
\hline CHEMBL1358278 & 688854 & 5.5969 & 4.8203 & TRN & & \\
\hline CHEMBL1468104 & 688854 & 4.3214 & 4.8673 & TST & & \\
\hline CHEMBL1716494 & 688854 & 3.301 & 4.3045 & TRN & & \\
\hline CHEMBL3190482 & 688854 & 4.5536 & 4.6278 & TRN & & \\
\hline CHEMBL1965204 & 688854 & 3.301 & 4.6388 & TRN & & \\
\hline CHEMBL1595509 & 688854 & 3.301 & 3.8488 & TRN & & \\
\hline CHEMBL1486163 & 688854 & 4.3584 & 4.5487 & TRN & & \\
\hline CHEMBL1540555 & 688854 & 4.6623 & 4.4572 & TRN & & \\
\hline CHEMBL1607500 & 688854 & 3.301 & 4.0251 & TRN & & \\
\hline CHEMBL1429241 & 688854 & 4.7503 & 4.8737 & TRN & & \\
\hline CHEMBL1508956 & 688854 & 3.301 & 3.9732 & TRN & & \\
\hline CHEMBL3199489 & 688854 & 3.301 & 4.864 & TRN & & \\
\hline CHEMBL1482046 & 688854 & 5.1891 & 4.4288 & TRN & & \\
\hline CHEMBL1369492 & 688854 & 3.301 & 4.3089 & TRN & & \\
\hline CHEMBL1503034 & 688854 & 4.8891 & 5.1416 & TRN & & \\
\hline CHEMBL1493728 & 688854 & 8.0 & 4.0141 & TRN & & \\
\hline CHEMBL1546176 & 688854 & 3.301 & 4.0935 & TRN & & \\
\hline CHEMBL1380774 & 688854 & 3.301 & 4.0854 & TRN & & \\
\hline CHEMBL1378768 & 688854 & 4.9462 & 4.5791 & TRN & & \\
\hline CHEMBL 235891 & 688854 & 5.0259 & 4.46 & TST & & \\
\hline CHEMBL1557547 & 688854 & 3.301 & 4.1725 & TRN & & \\
\hline CHEMBL1596605 & 688854 & 3.301 & 3.9199 & TRN & & \\
\hline CHEMBL3195779 & 688854 & 3.301 & 4.4855 & TRN & & \\
\hline CHEMBL1583765 & 688854 & 3.301 & 4.1639 & TST & & \\
\hline CHEMBL1200792 & 688854 & 4.8979 & 4.603 & TRN & & \\
\hline CHEMBL1501424 & 688854 & 3.301 & 4.6374 & TST & & \\
\hline CHEMBL1311878 & 688854 & 4.5797 & 4.2244 & TRN & & \\
\hline CHEMBL1392466 & 688854 & 3.301 & 3.9797 & TRN & & \\
\hline CHEMBL1542594 & 688854 & 5.4101 & 5.1028 & TST & & \\
\hline CHEMBL1549420 & 688854 & 8.0 & 4.2936 & TRN & & \\
\hline CHEMBL1339092 & 688854 & 5.2314 & 4.4698 & TST & & \\
\hline CHEMBL1373898 & 688854 & 3.301 & 4.4848 & TRN & & \\
\hline CHEMBL3196295 & 688854 & 4.5694 & 4.625 & TRN & & \\
\hline CHEMBL1428563 & 688854 & 4.9442 & 4.4644 & TST & & \\
\hline CHEMBL1306425 & 688854 & 3.301 & 4.5266 & TRN & & \\
\hline CHEMBL3190330 & 688854 & 4.5926 & 4.2428 & TRN & & \\
\hline CHEMBL548619 & 688854 & 5.26200 & $\partial 0000000$ & 005 & .5167 & TRN \\
\hline CHEMBL1353959 & 688854 & 8.0 & 3.7508 & TRN & & \\
\hline
\end{tabular}




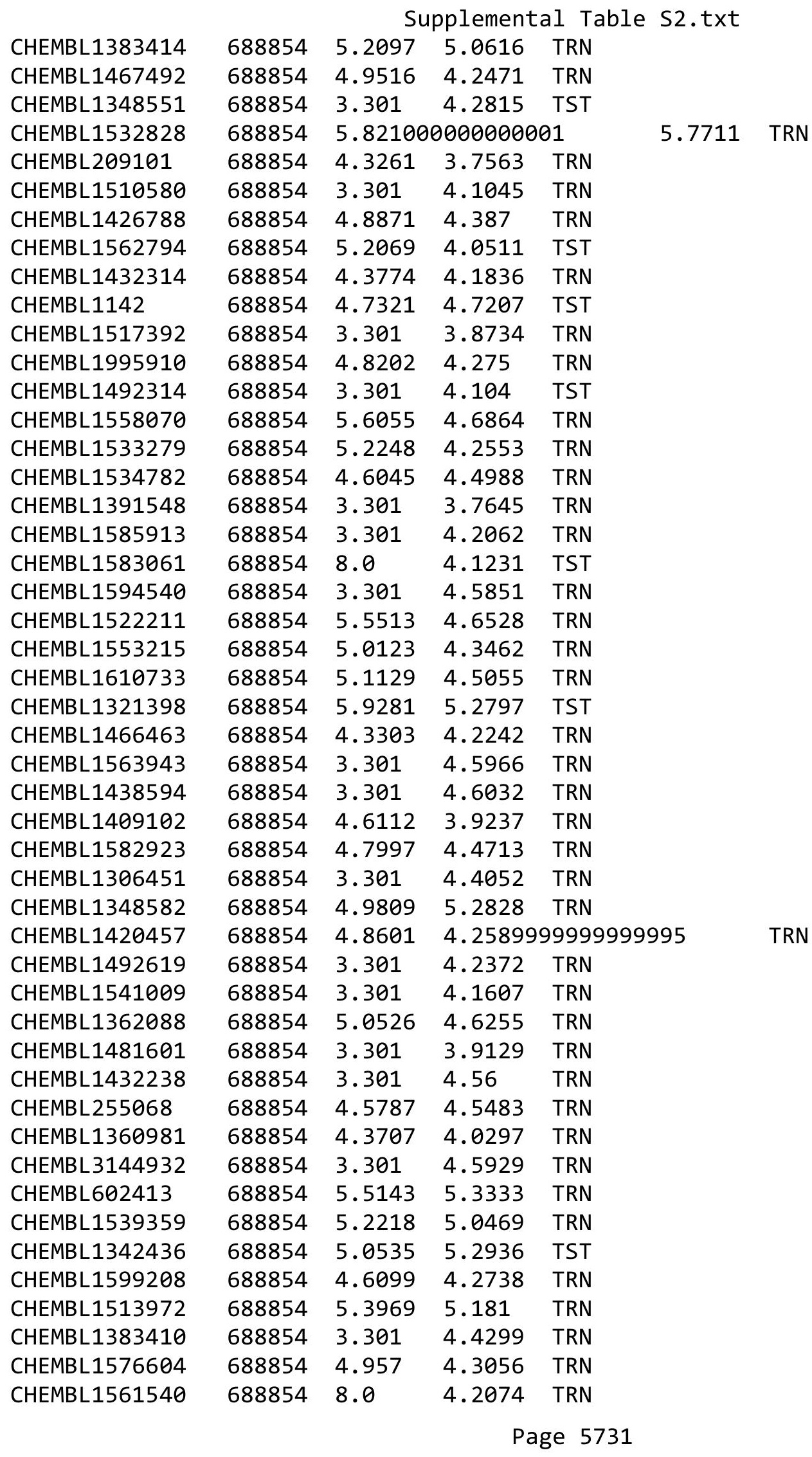


Supplemental Table S2.txt

\begin{tabular}{|c|c|c|c|c|}
\hline CHEMBL1531676 & 688854 & 5.1979 & 4.3628 & TRN \\
\hline CHEMBL1556844 & 688854 & 4.5501 & 4.6196 & TRN \\
\hline CHEMBL1581095 & 688854 & 3.301 & 4.1334 & TST \\
\hline CHEMBL578061 & 688854 & 4.3804 & 4.6989 & TRN \\
\hline CHEMBL3195608 & 688854 & 4.6054 & 4.7533 & TRN \\
\hline CHEMBL1509380 & 688854 & 5.7167 & 5.5219 & TRN \\
\hline CHEMBL1333472 & 688854 & 3.301 & 4.4286 & TST \\
\hline CHEMBL581868 & 688854 & 5.9788 & 5.7141 & TRN \\
\hline CHEMBL1524515 & 688854 & 5.0975 & 4.8306 & TRN \\
\hline CHEMBL1425188 & 688854 & 3.301 & 4.6661 & TRN \\
\hline CHEMBL1455636 & 688854 & 3.301 & 4.2745 & TRN \\
\hline CHEMBL532239 & 688854 & 6.2076 & 5.0709 & TRN \\
\hline CHEMBL1541964 & 688854 & 3.301 & 3.8629 & TRN \\
\hline CHEMBL1449930 & 688854 & 5.1475 & 4.4491 & TRN \\
\hline CHEMBL606167 & 688854 & 4.8592 & 4.7926 & TST \\
\hline CHEMBL1335088 & 688854 & 4.8748 & 3.9645 & TRN \\
\hline CHEMBL1373096 & 688854 & 6.4437 & 6.2788 & TRN \\
\hline CHEMBL1486382 & 688854 & 3.301 & 4.3549 & TST \\
\hline CHEMBL580340 & 688854 & 5.3536 & 5.4516 & TRN \\
\hline CHEMBL1483252 & 688854 & 5.3054 & 5.6817 & TRN \\
\hline CHEMBL445102 & 688854 & 5.011 & 4.4689 & TRN \\
\hline CHEMBL1435343 & 688854 & 5.0921 & 4.5077 & TRN \\
\hline CHEMBL3197662 & 688854 & 4.8576 & 4.6132 & TRN \\
\hline CHEMBL1304292 & 688854 & 3.301 & 5.1306 & TST \\
\hline CHEMBL1360870 & 688854 & 4.9776 & 4.372 & TST \\
\hline CHEMBL1324598 & 688854 & 3.301 & 4.3678 & TRN \\
\hline CHEMBL1360037 & 688854 & 5.0017 & 5.3211 & TRN \\
\hline CHEMBL1594766 & 688854 & 5.2434 & 4.6833 & TRN \\
\hline CHEMBL1508159 & 688854 & 3.301 & 3.9904 & TRN \\
\hline CHEMBL1373650 & 688854 & 4.4662 & 5.1285 & TRN \\
\hline CHEMBL1561308 & 688854 & 3.301 & 4.0437 & TST \\
\hline CHEMBL1306438 & 688854 & 4.5608 & 4.3015 & TRN \\
\hline CHEMBL1574121 & 688854 & 4.8456 & 4.2919 & TRN \\
\hline CHEMBL1370471 & 688854 & 5.8894 & 5.4326 & TRN \\
\hline CHEMBL580183 & 688854 & 4.856 & 4.2217 & TRN \\
\hline CHEMBL1399190 & 688854 & 4.8921 & 4.7381 & TRN \\
\hline CHEMBL139935 & 688854 & 4.6398 & 4.9207 & TRN \\
\hline CHEMBL1580770 & 688854 & 3.301 & 4.193006 & 00000000005 \\
\hline CHEMBL1385873 & 688854 & 3.301 & 4.1565 & TRN \\
\hline CHEMBL1928491 & 688854 & 5.7878 & 5.6617 & TRN \\
\hline CHEMBL1448592 & 688854 & 6.1308 & 6.1491 & TRN \\
\hline CHEMBL1459114 & 688854 & 3.301 & 3.8985 & TRN \\
\hline CHEMBL1498307 & 688854 & 3.301 & 4.4991 & TRN \\
\hline CHEMBL3190958 & 688854 & 4.4757 & 4.9067 & TRN \\
\hline CHEMBL1467064 & 688854 & 3.301 & 4.1153 & TRN \\
\hline CHEMBL1597177 & 688854 & 4.7242 & 4.6332 & TRN \\
\hline CHEMBL1565416 & 688854 & 3.301 & 3.8959 & TRN \\
\hline CHEMBL1311401 & 688854 & 3.301 & 4.4012 & TST \\
\hline
\end{tabular}




\begin{tabular}{|c|c|c|c|c|c|}
\hline \multicolumn{6}{|c|}{ Supplemental Table S2.txt } \\
\hline CHEMBL1489929 & 688854 & 3.301 & 4.4819 & TRN & \\
\hline CHEMBL1198307 & 688854 & 5.6038 & 5.3725 & TRN & \\
\hline CHEMBL3194811 & 688854 & 3.301 & 4.8767 & TRN & \\
\hline CHEMBL585828 & 688854 & 3.301 & 4.6373 & TST & \\
\hline CHEMBL581346 & 688854 & 4.9974 & 5.1724 & TRN & \\
\hline CHEMBL3197818 & 688854 & 4.4653 & 4.4415 & TRN & \\
\hline CHEMBL1450094 & 688854 & 5.466 & 4.9725 & TRN & \\
\hline CHEMBL1455056 & 688854 & 4.7953 & 4.3156 & TRN & \\
\hline CHEMBL 2369209 & 688854 & 4.8976 & 4.4174 & TRN & \\
\hline CHEMBL3199665 & 688854 & 6.4202 & 5.3199 & TRN & \\
\hline CHEMBL1432642 & 688854 & 5.0348 & 3.7629 & TRN & \\
\hline CHEMBL3197284 & 688854 & 4.4787 & 4.7278 & TST & \\
\hline CHEMBL3193049 & 688854 & 5.4776 & 5.0947 & TRN & \\
\hline CHEMBL1464725 & 688854 & 3.301 & 4.1351 & TRN & \\
\hline CHEMBL3194689 & 688854 & 3.301 & 4.9208 & TRN & \\
\hline CHEMBL1583206 & 688854 & 8.0 & 3.9779 & TRN & \\
\hline CHEMBL1443977 & 688854 & 3.301 & 4.21399 & 99999999995 & TRN \\
\hline CHEMBL1389315 & 688854 & 4.9083 & 4.5859 & TRN & \\
\hline CHEMBL1598120 & 688854 & 3.301 & 3.8175 & TRN & \\
\hline CHEMBL1485793 & 688854 & 5.7986 & 6.0309 & TRN & \\
\hline CHEMBL1343203 & 688854 & 3.301 & 4.577 & TST & \\
\hline CHEMBL1975118 & 688854 & 5.0942 & 5.1619 & TRN & \\
\hline CHEMBL1397507 & 688854 & 5.1965 & 4.6573 & TST & \\
\hline CHEMBL1562814 & 688854 & 3.301 & 3.7261 & TRN & \\
\hline CHEMBL19954 & 688854 & 5.8386 & 5.6768 & TRN & \\
\hline CHEMBL1390995 & 688854 & 3.301 & 4.5353 & TRN & \\
\hline CHEMBL1380091 & 688854 & 5.2716 & 4.6391 & TRN & \\
\hline CHEMBL1380367 & 688854 & 3.301 & 3.9387 & TST & \\
\hline CHEMBL1449971 & 688854 & 4.8576 & 4.2994 & TRN & \\
\hline CHEMBL1341906 & 688854 & 4.5096 & 4.1628 & TST & \\
\hline CHEMBL1506281 & 688854 & 5.0953 & 3.72600 & 00000000004 & TRN \\
\hline CHEMBL1610574 & 688854 & 3.301 & 4.2229 & TST & \\
\hline CHEMBL1341871 & 688854 & 3.301 & 4.2765 & TRN & \\
\hline CHEMBL3196074 & 688854 & 8.0 & 4.5404 & TST & \\
\hline CHEMBL1322008 & 688854 & 4.9586 & 4.5004 & TRN & \\
\hline CHEMBL1565483 & 688854 & 8.0 & 4.06 & TRN & \\
\hline CHEMBL1587932 & 688854 & 4.7375 & 3.9922 & TRN & \\
\hline CHEMBL3192818 & 688854 & 3.301 & 4.1561 & TRN & \\
\hline CHEMBL1388845 & 688854 & 8.0 & 4.0642 & TRN & \\
\hline CHEMBL1574076 & 688854 & 3.301 & 4.0909 & TST & \\
\hline CHEMBL1981612 & 688854 & 3.301 & 4.753 & TRN & \\
\hline CHEMBL1604283 & 688854 & 4.3725 & 5.109 & TST & \\
\hline CHEMBL1415758 & 688854 & 3.301 & 4.2703 & TRN & \\
\hline CHEMBL3192398 & 688854 & 4.4853 & 4.2793 & TRN & \\
\hline CHEMBL67311 & 688854 & 3.301 & 4.6822 & TST & \\
\hline CHEMBL1422217 & 688854 & 5.2161 & 4.8804 & TRN & \\
\hline CHEMBL1538493 & 688854 & 4.5089 & 4.197 & TST & \\
\hline CHEMBL1457590 & 688854 & 4.7731 & 4.4999 & TST & \\
\hline
\end{tabular}




\begin{tabular}{|c|c|c|c|c|c|c|}
\hline & & \multicolumn{5}{|c|}{ Supplemental Table S2.txt } \\
\hline CHEMBL1607160 & 688854 & 3.301 & 4.2099 & TRN & & \\
\hline CHEMBL1338743 & 688854 & \multicolumn{3}{|c|}{4.513999999999999} & 4.6746 & TRN \\
\hline CHEMBL1532953 & 688854 & 3.301 & 4.2695 & TRN & & \\
\hline CHEMBL1483161 & 688854 & 5.2857 & 4.6357 & TST & & \\
\hline CHEMBL1339036 & 688854 & 4.6708 & 4.6352 & TRN & & \\
\hline CHEMBL 3195549 & 688854 & 4.7467 & 4.5624 & TRN & & \\
\hline CHEMBL1309278 & 688854 & 3.301 & 4.3961 & TRN & & \\
\hline CHEMBL599890 & 688854 & 4.3907 & 4.7909 & TRN & & \\
\hline CHEMBL1460004 & 688854 & 5.7878 & 5.7469 & TRN & & \\
\hline CHEMBL1370194 & 688854 & 3.301 & 4.1023 & TRN & & \\
\hline CHEMBL1336722 & 688854 & 5.1469 & 5.1642 & TRN & & \\
\hline CHEMBL1503590 & 688854 & 3.301 & 3.9819 & TRN & & \\
\hline CHEMBL1569910 & 688854 & 5.9031 & 4.7256 & TRN & & \\
\hline CHEMBL1335155 & 688854 & 4.7899 & 4.5001 & TRN & & \\
\hline CHEMBL1507898 & 688854 & 3.301 & 4.1454 & TRN & & \\
\hline CHEMBL1588107 & 688854 & 3.301 & 4.0252 & TRN & & \\
\hline CHEMBL1387989 & 688854 & 3.301 & 3.9647 & TRN & & \\
\hline CHEMBL544584 & 688854 & 5.7645 & 5.2225 & TRN & & \\
\hline CHEMBL1424773 & 688854 & 3.301 & 3.8885 & TRN & & \\
\hline CHEMBL1338769 & 688854 & 3.301 & 4.4828 & TRN & & \\
\hline CHEMBL1350245 & 688854 & 5.6655 & 5.7139 & TRN & & \\
\hline CHEMBL1472455 & 688854 & 4.3358 & 4.109 & TRN & & \\
\hline CHEMBL1500500 & 688854 & 4.9876 & 4.7427 & TRN & & \\
\hline CHEMBL1458403 & 688854 & 5.0061 & 4.5528 & TRN & & \\
\hline CHEMBL1522450 & 688854 & 3.301 & 3.8828 & TRN & & \\
\hline CHEMBL1382434 & 688854 & 4.9136 & 4.5856 & TRN & & \\
\hline CHEMBL1565898 & 688854 & 4.9965 & 4.7365 & TRN & & \\
\hline CHEMBL1542560 & 688854 & 4.9682 & 4.4699 & TRN & & \\
\hline CHEMBL1601781 & 688854 & 5.2857 & 4.8973 & TRN & & \\
\hline CHEMBL1478908 & 688854 & 3.301 & 4.269 & TST & & \\
\hline CHEMBL3192856 & 688854 & 5.091 & 5.1035 & TRN & & \\
\hline CHEMBL1378952 & 688854 & 5.5072 & 5.7683 & TRN & & \\
\hline CHEMBL3193701 & 688854 & 4.8761 & 4.8079 & TRN & & \\
\hline CHEMBL1568370 & 688854 & 3.301 & 4.2794 & TRN & & \\
\hline CHEMBL1377841 & 688854 & 4.4056 & 4.5501 & TRN & & \\
\hline CHEMBL3191432 & 688854 & 4.9477 & 4.8468 & TRN & & \\
\hline CHEMBL3039775 & 688854 & 5.2692 & 5.0528 & TRN & & \\
\hline CHEMBL1520276 & 688854 & \multicolumn{3}{|c|}{5.752000000000001} & 4.5065 & TRN \\
\hline CHEMBL1424729 & 688854 & 5.3575 & 4.6479 & TST & & \\
\hline CHEMBL1507990 & 688854 & 5.2684 & 5.003 & TRN & & \\
\hline CHEMBL1459764 & 688854 & 5.0794 & 4.8118 & TRN & & \\
\hline CHEMBL1491778 & 688854 & 4.4607 & 4.629 & TRN & & \\
\hline CHEMBL530049 & 688854 & \multicolumn{3}{|c|}{5.757000000000001} & 5.8892 & TRN \\
\hline CHEMBL1200344 & 688854 & 3.301 & 4.7989 & TST & & \\
\hline CHEMBL1386054 & 688854 & 4.4901 & 4.5958 & TRN & & \\
\hline CHEMBL1360904 & 688854 & 8.0 & 4.2268 & TRN & & \\
\hline CHEMBL1541943 & 688854 & 3.301 & 3.95300 & $\partial 000000$ & 03 & TRN \\
\hline CHEMBL1443946 & 688854 & 5.4776 & 5.3887 & TRN & & \\
\hline
\end{tabular}




\begin{tabular}{|c|c|c|c|c|}
\hline \multicolumn{5}{|c|}{ Supplemental Table s2.txt } \\
\hline CHEMBL1587205 & 688854 & 5.3565 & 4.9449 & TRN \\
\hline CHEMBL1410089 & 688854 & 3.301 & 3.7886 & TRN \\
\hline CHEMBL1564731 & 688854 & 3.301 & 4.7481 & TRN \\
\hline CHEMBL1331702 & 688854 & 4.9073 & 4.6105 & TRN \\
\hline CHEMBL1499792 & 688854 & 6.5229 & 6.274 & TRN \\
\hline CHEMBL1376732 & 688854 & 5.6716 & 4.9501 & TRN \\
\hline CHEMBL3191363 & 688854 & 4.5274 & 4.9056 & TRN \\
\hline CHEMBL1432427 & 688854 & 5.1249 & 5.3638 & TRN \\
\hline CHEMBL56393 & 688854 & 4.4076 & 4.6804 & TRN \\
\hline CHEMBL3199413 & 688854 & 4.3768 & 4.8702 & TRN \\
\hline CHEMBL1585141 & 688854 & 4.4459 & 4.3697 & TRN \\
\hline CHEMBL520667 & 688854 & 4.5009 & 4.6605 & TRN \\
\hline CHEMBL3189889 & 688854 & 3.301 & 4.4281 & TRN \\
\hline CHEMBL548615 & 688854 & 5.9245 & 5.2177 & TRN \\
\hline CHEMBL1409001 & 688854 & 4.4325 & 4.6912 & TRN \\
\hline CHEMBL1406717 & 688854 & 3.301 & 4.3594 & TRN \\
\hline CHEMBL1528900 & 688854 & 3.301 & 4.2372 & TST \\
\hline CHEMBL1492458 & 688854 & 3.301 & 4.0278 & TRN \\
\hline CHEMBL1984298 & 688854 & 4.3236 & 4.7757 & TRN \\
\hline CHEMBL1350342 & 688854 & 3.301 & 4.1915 & TRN \\
\hline CHEMBL1965069 & 688854 & 4.8398 & 4.5341 & TRN \\
\hline CHEMBL1348232 & 688854 & 4.5555 & 5.0581 & TST \\
\hline CHEMBL1458379 & 688854 & 3.301 & 4.588 & TST \\
\hline CHEMBL1560519 & 688854 & 3.301 & 4.4768 & TRN \\
\hline CHEMBL1999984 & 688854 & 3.301 & 4.8531 & TRN \\
\hline CHEMBL1528425 & 688854 & 4.9348 & 4.8775 & TRN \\
\hline CHEMBL1559564 & 688854 & 4.8545 & 5.0097 & TRN \\
\hline CHEMBL1453671 & 688854 & 3.301 & 3.8273 & TRN \\
\hline CHEMBL3196257 & 688854 & 4.9292 & 4.9663 & TRN \\
\hline CHEMBL 3192432 & 688854 & 6.0132 & 5.4249 & TRN \\
\hline CHEMBL1469216 & 688854 & 5.0255 & 4.2486 & TRN \\
\hline CHEMBL1336951 & 688854 & 3.301 & 4.0959 & TRN \\
\hline CHEMBL1416171 & 688854 & 5.4547 & 4.6464 & TRN \\
\hline CHEMBL1332952 & 688854 & 5.1439 & 4.8636 & TRN \\
\hline CHEMBL1479316 & 688854 & 5.684 & 5.7789 & TRN \\
\hline CHEMBL1355961 & 688854 & 4.9363 & 4.6094 & TRN \\
\hline CHEMBL1420648 & 688854 & 3.301 & 4.1665 & TRN \\
\hline CHEMBL1395962 & 688854 & 5.2373 & 4.574 & TRN \\
\hline CHEMBL1432157 & 688854 & 3.301 & 4.037 & TRN \\
\hline CHEMBL1362990 & 688854 & 5.1062 & 4.3093 & TRN \\
\hline CHEMBL1458722 & 688854 & 4.5632 & 4.7668 & TRN \\
\hline CHEMBL1304297 & 688854 & 3.301 & 4.09 & TRN \\
\hline CHEMBL3197977 & 688854 & 4.584 & 4.937 & TRN \\
\hline CHEMBL3190599 & 688854 & 4.3978 & 4.428 & TRN \\
\hline CHEMBL1353752 & 688854 & 3.301 & 4.9156 & TRN \\
\hline CHEMBL1504729 & 688854 & 3.301 & 3.8077 & TRN \\
\hline CHEMBL1324794 & 688854 & 3.301 & 4.0002 & TRN \\
\hline CHEMBL1416897 & 688854 & 3.301 & 4.1347 & TRN \\
\hline
\end{tabular}


Supplemental Table S2.txt

\begin{tabular}{|c|c|c|c|c|}
\hline CHEMBL1406234 & 688854 & 4.3477 & 4.0912 & TRN \\
\hline CHEMBL1426748 & 688854 & 4.6747 & 4.2917 & TRN \\
\hline CHEMBL591404 & 688854 & 5.2321 & 5.1252 & TRN \\
\hline CHEMBL1478826 & 688854 & 5.4622 & 5.1858 & TRN \\
\hline CHEMBL1340751 & 688854 & 3.301 & 4.2209 & TRN \\
\hline CHEMBL1526392 & 688854 & 3.301 & 4.4374 & TRN \\
\hline CHEMBL1511404 & 688854 & 3.301 & 3.5724 & TRN \\
\hline CHEMBL1567519 & 688854 & 4.3883 & 3.7867 & TRN \\
\hline CHEMBL1370181 & 688854 & 3.301 & 4.3384 & TRN \\
\hline CHEMBL 3195484 & 688854 & 8.0 & 4.3307 & TST \\
\hline CHEMBL1370697 & 688854 & 8.0 & 4.5366 & TST \\
\hline CHEMBL1422255 & 688854 & 3.301 & 4.0675 & TRN \\
\hline CHEMBL1969543 & 688854 & 4.5117 & 4.507 & TRN \\
\hline CHEMBL1430795 & 688854 & 5.0022 & 4.5059 & TRN \\
\hline CHEMBL56543 & 688854 & 4.5667 & 4.4573 & TRN \\
\hline CHEMBL 3213479 & 688854 & 3.301 & 4.3606 & TRN \\
\hline CHEMBL1586895 & 688854 & 5.109 & 4.3532 & TRN \\
\hline CHEMBL1587596 & 688854 & 6.1487 & 5.3499 & TRN \\
\hline CHEMBL1472369 & 688854 & 4.4876 & 4.3267 & TRN \\
\hline CHEMBL1338624 & 688854 & 4.4268 & 3.9767 & TST \\
\hline CHEMBL1513816 & 688854 & 3.301 & 3.9591 & TRN \\
\hline CHEMBL1551552 & 688854 & 3.301 & 3.8783 & TRN \\
\hline CHEMBL1366004 & 688854 & 4.6889 & 4.5635 & TRN \\
\hline CHEMBL1451978 & 688854 & 3.301 & 4.0196 & TRN \\
\hline CHEMBL1993190 & 688854 & 5.3665 & 5.0667 & TRN \\
\hline CHEMBL1408162 & 688854 & 3.301 & 4.0684 & TST \\
\hline CHEMBL1385206 & 688854 & 3.301 & 4.1054 & TRN \\
\hline CHEMBL1472891 & 688854 & 4.8608 & 4.4251 & TRN \\
\hline CHEMBL1410641 & 688854 & 5.0066 & 4.8515 & TRN \\
\hline CHEMBL1430673 & 688854 & 4.9512 & 4.3191 & TRN \\
\hline CHEMBL1363656 & 688854 & 3.301 & 4.7595 & TRN \\
\hline CHEMBL1996376 & 688854 & 4.9658 & 4.9429 & TRN \\
\hline CHEMBL1403240 & 688854 & 4.8595 & 3.9377 & TRN \\
\hline CHEMBL 3212684 & 688854 & 4.5538 & 4.4839 & TRN \\
\hline CHEMBL1485275 & 688854 & 6.0 & 5.8612 & TST \\
\hline CHEMBL1300831 & 688854 & 5.1965 & 5.114 & TRN \\
\hline CHEMBL1498274 & 688854 & 3.301 & 3.6988 & TRN \\
\hline CHEMBL1499869 & 688854 & 3.301 & 3.5904 & TRN \\
\hline CHEMBL1424404 & 688854 & 4.4833 & 4.3536 & TRN \\
\hline CHEMBL1532900 & 688854 & 3.301 & 3.7797 & TRN \\
\hline CHEMBL1439433 & 688854 & 3.301 & 4.1549 & TST \\
\hline CHEMBL463175 & 688854 & 8.0 & 4.6615 & TST \\
\hline CHEMBL567422 & 688854 & 5.4828 & 4.2553 & TST \\
\hline CHEMBL1613425 & 688854 & 3.301 & 3.8777 & TRN \\
\hline CHEMBL1373533 & 688854 & 4.7404 & 4.3695 & TRN \\
\hline CHEMBL1524986 & 688854 & 6.1549 & 5.0143 & TRN \\
\hline CHEMBL1325192 & 688854 & 5.6253 & 5.6899 & TRN \\
\hline CHEMBL1312571 & 688854 & 4.3336 & 4.6134 & TST \\
\hline
\end{tabular}




\begin{tabular}{|c|c|c|c|c|c|}
\hline & & \multicolumn{4}{|c|}{ Supplemental Table S2.txt } \\
\hline CHEMBL1546374 & 688854 & 6.1192 & 5.1257 & TST & \\
\hline CHEMBL3211198 & 688854 & 4.4936 & 4.4074 & TST & \\
\hline CHEMBL1581550 & 688854 & 3.301 & 4.5025 & TST & \\
\hline CHEMBL1580272 & 688854 & 4.8345 & 4.7477 & TRN & \\
\hline CHEMBL1364879 & 688854 & 3.301 & 4.131 & TRN & \\
\hline CHEMBL1474571 & 688854 & 4.9666 & 4.4276 & TRN & \\
\hline CHEMBL1600259 & 688854 & 3.301 & 4.0786 & TRN & \\
\hline CHEMBL1305911 & 688854 & 4.7688 & 4.1489 & TRN & \\
\hline CHEMBL 3194910 & 688854 & 4.3983 & 4.7003 & TRN & \\
\hline CHEMBL580609 & 688854 & 4.8684 & 4.8099 & TRN & \\
\hline CHEMBL1487183 & 688854 & 6.0809 & 5.3759 & TST & \\
\hline CHEMBL1543104 & 688854 & 3.301 & 4.01 & TST & \\
\hline CHEMBL3190369 & 688854 & 8.0 & 4.3018 & TST & \\
\hline CHEMBL 1242180 & 688854 & 6.1487 & 6.1756 & TST & \\
\hline CHEMBL1555739 & 688854 & 4.7799 & 4.7199 & TRN & \\
\hline CHEMBL1573630 & 688854 & 4.6544 & 4.4267 & TRN & \\
\hline CHEMBL1200567 & 688854 & 4.5379 & 5.2727 & TST & \\
\hline CHEMBL1578188 & 688854 & 3.301 & 3.8008 & TRN & \\
\hline CHEMBL1446900 & 688854 & 4.569 & 4.86100 & 2000000001 & TRN \\
\hline CHEMBL3195459 & 688854 & 4.8256 & 4.7953 & TRN & \\
\hline CHEMBL1506978 & 688854 & 4.777 & 4.1228 & TST & \\
\hline CHEMBL1583082 & 688854 & 5.0931 & 4.4564 & TRN & \\
\hline CHEMBL1390750 & 688854 & 4.3783 & 4.3154 & TRN & \\
\hline CHEMBL1382900 & 688854 & 3.301 & 3.8429 & TRN & \\
\hline CHEMBL1496066 & 688854 & 3.301 & 4.1605 & TST & \\
\hline CHEMBL1326121 & 688854 & 3.301 & 3.9771 & TRN & \\
\hline CHEMBL1562066 & 688854 & 4.7523 & 4.6439 & TRN & \\
\hline CHEMBL1424607 & 688854 & 5.1733 & 4.5086 & TRN & \\
\hline CHEMBL1470441 & 688854 & 3.301 & 3.99399 & 99999999998 & TRN \\
\hline CHEMBL1966224 & 688854 & 5.1267 & 4.8466 & TRN & \\
\hline CHEMBL1369758 & 688854 & 3.301 & 3.763 & TRN & \\
\hline CHEMBL1605613 & 688854 & 3.301 & 4.1491 & TRN & \\
\hline CHEMBL1543780 & 688854 & 3.301 & 3.8852 & TRN & \\
\hline CHEMBL1425521 & 688854 & 5.2269 & 5.1863 & TRN & \\
\hline CHEMBL1443984 & 688854 & 5.3716 & 4.4822 & TRN & \\
\hline CHEMBL1560273 & 688854 & 5.4365 & 4.68 & TST & \\
\hline CHEMBL1561153 & 688854 & 3.301 & 3.8314 & TRN & \\
\hline CHEMBL3193808 & 688854 & 4.8837 & 4.4496 & TRN & \\
\hline CHEMBL1539127 & 688854 & 4.7899 & 4.2922 & TRN & \\
\hline CHEMBL1412497 & 688854 & 5.2248 & 4.5139 & TRN & \\
\hline CHEMBL1544341 & 688854 & 3.301 & 4.3932 & TRN & \\
\hline CHEMBL1395220 & 688854 & 4.7891 & 4.5248 & TRN & \\
\hline CHEMBL1499014 & 688854 & 4.8342 & 4.618 & TRN & \\
\hline CHEMBL3198512 & 688854 & 5.1331 & 4.3745 & TST & \\
\hline CHEMBL1321283 & 688854 & 4.669 & 4.4195 & TRN & \\
\hline CHEMBL1315948 & 688854 & 5.426 & 4.6425 & TRN & \\
\hline CHEMBL1361678 & 688854 & 3.301 & 3.8471 & TRN & \\
\hline CHEMBL1425495 & 688854 & 8.0 & 4.1771 & TST & \\
\hline
\end{tabular}




\begin{tabular}{|c|c|c|c|c|}
\hline & & & oplement & al $\mathrm{T}$ \\
\hline CHEMBL1495292 & 688854 & 4.4057 & 4.5172 & TRN \\
\hline CHEMBL1339613 & 688854 & 4.8063 & 3.8278 & TRN \\
\hline CHEMBL1256737 & 688854 & 5.0301 & 4.8326 & TRN \\
\hline CHEMBL1403744 & 688854 & 4.7921 & 4.4797 & TST \\
\hline CHEMBL1469710 & 688854 & 4.556 & 3.8811 & TRN \\
\hline CHEMBL1349892 & 688854 & 4.5591 & 4.3672 & TRN \\
\hline CHEMBL1354583 & 688854 & 3.301 & 4.2597 & TST \\
\hline CHEMBL1382949 & 688854 & 3.301 & 4.6516 & TST \\
\hline CHEMBL1520808 & 688854 & 4.6529 & 4.2715 & TRN \\
\hline CHEMBL1462016 & 688854 & 3.301 & 4.9032 & TRN \\
\hline CHEMBL578294 & 688854 & 5.3197 & 5.1237 & TRN \\
\hline CHEMBL1555833 & 688854 & 5.1979 & 4.5169 & TRN \\
\hline CHEMBL1568848 & 688854 & 5.6819 & 5.3314 & TRN \\
\hline CHEMBL1463724 & 688854 & 3.301 & 4.1019 & TRN \\
\hline CHEMBL1438546 & 688854 & 3.301 & 3.7826 & TRN \\
\hline CHEMBL1472253 & 688854 & 5.4157 & 4.5605 & TST \\
\hline CHEMBL1345320 & 688854 & 4.4859 & 5.0215 & TST \\
\hline CHEMBL3213876 & 688854 & 4.8897 & 4.8572 & TST \\
\hline CHEMBL1427617 & 688854 & 4.9311 & 4.5055 & TST \\
\hline CHEMBL1971965 & 688854 & 4.3114 & 4.6306 & TST \\
\hline CHEMBL1423828 & 688854 & 4.5501 & 4.5557 & TST \\
\hline CHEMBL1458046 & 688854 & 4.4817 & 4.166 & TST \\
\hline CHEMBL1466790 & 688854 & 4.3036 & 4.3085 & TST \\
\hline CHEMBL1437560 & 688854 & 5.3019 & 4.3682 & TST \\
\hline CHEMBL1322645 & 688854 & 5.2757 & 4.2888 & TST \\
\hline CHEMBL1330113 & 688854 & 6.0 & 4.5472 & TST \\
\hline CHEMBL1330835 & 688854 & 3.301 & 4.2092 & TST \\
\hline CHEMBL1493994 & 688854 & 8.0 & 4.1179 & TST \\
\hline CHEMBL1967479 & 688854 & 4.8881 & 5.0498 & TST \\
\hline CHEMBL1445085 & 688854 & 4.6979 & 4.8236 & TST \\
\hline CHEMBL1461004 & 688854 & 3.301 & 4.1085 & TST \\
\hline CHEMBL1393092 & 688854 & 3.301 & 4.2089 & TST \\
\hline CHEMBL1350693 & 688854 & 5.0101 & 4.5203 & TST \\
\hline CHEMBL1548026 & 688854 & 4.7575 & 4.3344 & TST \\
\hline CHEMBL1609273 & 688854 & 3.301 & 3.9594 & TST \\
\hline CHEMBL1407165 & 688854 & 3.301 & 4.3093 & TST \\
\hline CHEMBL1313410 & 688854 & 4.7462 & 4.5364 & TST \\
\hline CHEMBL1592917 & 688854 & 5.4486 & 5.0848 & TST \\
\hline CHEMBL1517411 & 688854 & 4.4778 & 4.0704 & TST \\
\hline CHEMBL1428566 & 688854 & 5.2636 & 4.9404 & TST \\
\hline CHEMBL428064 & 688854 & 5.9208 & 5.5427 & TST \\
\hline CHEMBL1310458 & 688854 & 8.0 & 3.6255 & TST \\
\hline CHEMBL935 & 688854 & 4.8179 & 5.5694 & TST \\
\hline CHEMBL1327205 & 688854 & 4.8348 & 4.3295 & TST \\
\hline CHEMBL1411080 & 688854 & 3.301 & 4.9545 & TST \\
\hline CHEMBL1384700 & 688854 & 4.5824 & 4.5214 & TST \\
\hline CHEMBL1509398 & 688854 & 3.301 & 4.2504 & TST \\
\hline CHEMBL1498743 & 688854 & 3.301 & 3.8284 & TST \\
\hline
\end{tabular}


Supplemental Table S2.txt

\begin{tabular}{|c|c|c|c|c|}
\hline CHEMBL1428245 & 688854 & 4.5622 & 4.3264 & TST \\
\hline CHEMBL1477547 & 688854 & 5.0132 & 4.4111 & TST \\
\hline CHEMBL1567574 & 688854 & 3.301 & 3.8211 & TST \\
\hline CHEMBL1521896 & 688854 & 3.301 & 4.1138 & TST \\
\hline CHEMBL1409245 & 688854 & 4.957 & 3.8423 & TST \\
\hline CHEMBL 3214243 & 688854 & 3.301 & 4.3784 & TST \\
\hline CHEMBL1466652 & 688854 & 3.301 & 4.3114 & TST \\
\hline CHEMBL1499662 & 688854 & 4.4719 & 4.3755 & TST \\
\hline CHEMBL1322906 & 688854 & 3.301 & 4.3076 & TST \\
\hline CHEMBL1331185 & 688854 & 3.301 & 3.9258 & TST \\
\hline CHEMBL1200847 & 688854 & 3.301 & 5.0006 & TST \\
\hline CHEMBL1449490 & 688854 & 5.1198 & 4.0222 & TST \\
\hline CHEMBL1382320 & 688854 & 4.6144 & 4.2942 & TST \\
\hline CHEMBL1441888 & 688854 & 4.7003 & 3.8516 & TST \\
\hline CHEMBL1977877 & 688854 & 6.4437 & 5.6142 & TST \\
\hline CHEMBL1468954 & 688854 & 5.0458 & 4.8238 & TST \\
\hline CHEMBL1444767 & 688854 & 4.7555 & 4.3651 & TST \\
\hline CHEMBL1307641 & 688854 & 8.0 & 3.8847 & TST \\
\hline CHEMBL1516070 & 688854 & 3.301 & 3.7164 & TST \\
\hline CHEMBL1373181 & 688854 & 3.301 & 4.5025 & TST \\
\hline CHEMBL1971144 & 688854 & 5.5421 & 5.57799 & 9999999999 \\
\hline CHEMBL1983839 & 688854 & 5.5436 & 5.4707 & TST \\
\hline CHEMBL1549574 & 688854 & 5.1586 & 4.3272 & TST \\
\hline CHEMBL1570706 & 688854 & 5.3546 & 4.1939 & TST \\
\hline CHEMBL1414846 & 688854 & 4.4511 & 3.8533 & TST \\
\hline CHEMBL1478496 & 688854 & 3.301 & 4.4126 & TST \\
\hline CHEMBL1430820 & 688854 & 4.8548 & 4.7018 & TST \\
\hline CHEMBL1415585 & 688854 & 3.301 & 4.0373 & TST \\
\hline CHEMBL1418885 & 688854 & 4.9776 & 4.7638 & TST \\
\hline CHEMBL3193651 & 688854 & 4.6474 & 4.8052 & TST \\
\hline CHEMBL1986151 & 688854 & 4.7752 & 4.9189 & TST \\
\hline CHEMBL1393283 & 688854 & 5.1215 & 4.1294 & TST \\
\hline CHEMBL1300729 & 688854 & 4.8236 & 4.2432 & TST \\
\hline CHEMBL1429048 & 688854 & 3.301 & 4.3687 & TST \\
\hline CHEMBL1304363 & 688854 & 6.0757 & 5.3948 & TST \\
\hline CHEMBL 2004417 & 688854 & 5.7696 & 5.7477 & TST \\
\hline CHEMBL1487460 & 688854 & 4.9481 & 4.3735 & TST \\
\hline CHEMBL1427763 & 688854 & 4.8697 & 4.2138 & TST \\
\hline CHEMBL1339039 & 688854 & 3.301 & 3.7674 & TST \\
\hline CHEMBL1342184 & 688854 & 3.301 & 4.1993 & TST \\
\hline CHEMBL3192078 & 688854 & 5.8508 & 5.3228 & TST \\
\hline CHEMBL1600855 & 688854 & 5.8447 & 5.9565 & TST \\
\hline CHEMBL1484627 & 688854 & 4.7523 & 4.3692 & TST \\
\hline CHEMBL1605239 & 688854 & 3.301 & 4.3914 & TST \\
\hline CHEMBL1375576 & 688854 & 4.316 & 4.6305 & TST \\
\hline CHEMBL1491389 & 688854 & 3.301 & 3.8563 & TST \\
\hline CHEMBL1380943 & 688854 & 4.7572 & 4.4942 & TST \\
\hline CHEMBL169662 & 688854 & 3.301 & 4.1563 & TST \\
\hline
\end{tabular}


Supplemental Table S2.txt

\begin{tabular}{|c|c|c|c|c|}
\hline 809 & & 4.6271 & 4.4097 & \\
\hline & & & 4.2044 & \\
\hline 2 & & & & \\
\hline IEMBL 2000750 & & & & \\
\hline AEMBL1444520 & 38854 & & 679 & \\
\hline 58260 & 38854 & 62 & 844 & \\
\hline 438 & 8854 & & & \\
\hline 8019 & 854 & & & \\
\hline IEMBL3194449 & 88854 & 5.2125 & 2767 & \\
\hline HEMBL1328510 & 88854 & 6.0 & 887 & \\
\hline 9045 & & & & \\
\hline 2820 & 354 & & & \\
\hline 1080 & 354 & & & \\
\hline AEMBL1368756 & 88854 & & & \\
\hline 05943 & 354 & & & \\
\hline 835 & 54 & & & \\
\hline 3236 & & & & \\
\hline 7028 & 354 & & & \\
\hline 02465 & 354 & 969 & & \\
\hline 21414 & & & & \\
\hline 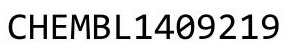 & & & & \\
\hline & & & & \\
\hline 740 & 54 & 27 & & \\
\hline 10 & & 384 & & \\
\hline-5 & & & & \\
\hline- & & & 21 & \\
\hline & & & & \\
\hline 6 & 54 & 96 & 11 & \\
\hline 08 & & & & TS \\
\hline 78707 & & & & \\
\hline & & & & \\
\hline & & & & \\
\hline 7 & & 31 & 28 & \\
\hline 23989 & & & & TS \\
\hline 105259 & & & & TS \\
\hline & & & & $S$ \\
\hline 0 & & & & \\
\hline & & & & TS \\
\hline 23096 & & & & TC \\
\hline 8774 & 4 & & & S \\
\hline 26 & & & & $\mathrm{~S}$ \\
\hline CHEME & & 368 & 01 & \\
\hline 97445 & & & & S \\
\hline 67072 & 38854 & 979 & 53 & 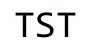 \\
\hline 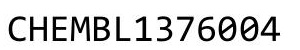 & & & & S \\
\hline $\mathrm{CH}$ & & & & S \\
\hline CHEMBL] & 6888 & 3.301 & 3.8612 & \\
\hline CHEMBL243644 & 688 & .3321 & 3.9556 & \\
\hline
\end{tabular}

Page 5740 



\begin{tabular}{|c|c|c|c|c|c|c|c|}
\hline \multicolumn{8}{|c|}{ Supplemental Table S2.txt } \\
\hline CHEMBL1498431 & 688537 & 5.6139 & 5.7943 & TRN & & & \\
\hline CHEMBL1351542 & 688537 & 6.2534 & 5.946000 & 000000000 & & TRN & \\
\hline CHEMBL 2004918 & 688537 & 5.0726 & 5.3174 & TRN & & & \\
\hline CHEMBL1567674 & 688537 & 5.1181 & 4.5242 & TRN & & & \\
\hline CHEMBL1965814 & 688537 & 5.75200 & 000000000 & 01 & 5.53700 & 0000000001 & TRN \\
\hline CHEMBL1582878 & 688537 & 5.091 & 4.6972 & TRN & & & \\
\hline CHEMBL1515506 & 688537 & 5.6256 & 5.4024 & TRN & & & \\
\hline CHEMBL1351737 & 688537 & 5.1327 & 5.6065 & TRN & & & \\
\hline CHEMBL3197766 & 688537 & 4.9856 & 4.7917 & TRN & & & \\
\hline CHEMBL588804 & 688537 & 6.3809 & 5.7365 & TRN & & & \\
\hline CHEMBL93109 & 688537 & 2.8239 & 3.3588 & TRN & & & \\
\hline CHEMBL1350708 & 688537 & 2.8239 & 3.2646 & TRN & & & \\
\hline CHEMBL1373110 & 688537 & 4.9324 & 5.0373 & TRN & & & \\
\hline CHEMBL1579464 & 688537 & 5.4704 & 5.1694 & TRN & & & \\
\hline CHEMBL1576863 & 688537 & 4.8381 & 4.9716 & TST & & & \\
\hline CHEMBL1503549 & 688537 & 4.0052 & 2.9847 & TST & & & \\
\hline CHEMBL1511033 & 688537 & 5.4173 & 5.2949 & TST & & & \\
\hline CHEMBL1372397 & 688537 & 5.1473 & 5.0868 & TRN & & & \\
\hline CHEMBL1339892 & 688537 & 8.2218 & 7.7482 & TRN & & & \\
\hline CHEMBL1459931 & 688537 & 2.8239 & 2.4074 & TRN & & & \\
\hline CHEMBL1546886 & 688537 & 5.0316 & 5.0831 & TRN & & & \\
\hline CHEMBL3191950 & 688537 & 5.2036 & 5.1937 & TRN & & & \\
\hline CHEMBL1524252 & 688537 & 2.8239 & 3.3779 & TST & & & \\
\hline CHEMBL1510769 & 688537 & 2.8239 & 4.3259 & TST & & & \\
\hline CHEMBL3191871 & 688537 & 5.6135 & 5.6914 & TRN & & & \\
\hline CHEMBL1305997 & 688537 & 5.3357 & 5.44 & TRN & & & \\
\hline CHEMBL1421905 & 688537 & 5.5541 & 5.9746 & TRN & & & \\
\hline CHEMBL1521554 & 688537 & 5.1058 & 4.9926 & TRN & & & \\
\hline CHEMBL1517467 & 688537 & 2.8239 & 2.8184 & TRN & & & \\
\hline CHEMBL3193603 & 688537 & 5.3814 & 4.7319 & TRN & & & \\
\hline CHEMBL1520896 & 688537 & 6.05399 & 999999999 & 99 & 5.8414 & TRN & \\
\hline CHEMBL1468699 & 688537 & 5.3564 & 4.8644 & TRN & & & \\
\hline CHEMBL1310411 & 688537 & 2.8239 & 3.2735 & TRN & & & \\
\hline CHEMBL1519902 & 688537 & 6.7212 & 7.0282 & TRN & & & \\
\hline CHEMBL1609818 & 688537 & 5.2096 & 5.4366 & TRN & & & \\
\hline CHEMBL1607698 & 688537 & 5.1266 & 5.0677 & TRN & & & \\
\hline CHEMBL1388722 & 688537 & 5.33899 & 999999999 & 995 & 5.5999 & TRN & \\
\hline CHEMBL1576710 & 688537 & 4.1775 & 4.5938 & TRN & & & \\
\hline CHEMBL1313887 & 688537 & 4.8913 & 4.5974 & TRN & & & \\
\hline CHEMBL1343326 & 688537 & 6.2557 & 6.1436 & TRN & & & \\
\hline CHEMBL1349635 & 688537 & 4.0726 & 4.5785 & TRN & & & \\
\hline CHEMBL1455577 & 688537 & 2.8239 & 3.1513 & TST & & & \\
\hline CHEMBL1549777 & 688537 & 5.3377 & 5.1033 & TRN & & & \\
\hline CHEMBL1577446 & 688537 & 5.3925 & 5.2614 & TRN & & & \\
\hline CHEMBL1306406 & 688537 & 5.8489 & 6.1345 & TRN & & & \\
\hline CHEMBL 3195778 & 688537 & 5.3305 & 5.2697 & TRN & & & \\
\hline CHEMBL1306283 & 688537 & 6.4535 & 6.7177 & TRN & & & \\
\hline CHEMBL3197099 & 688537 & 6.0788 & 5.4872 & TRN & & & \\
\hline
\end{tabular}


Supplemental Table S2.txt

\begin{tabular}{|c|c|c|c|c|c|c|}
\hline CHEMBL1492642 & 688537 & 5.8523 & 5.4856 & TRN & & \\
\hline CHEMBL1471101 & 688537 & 4.8936 & 4.6659 & TRN & & \\
\hline CHEMBL1377903 & 688537 & 5.3618 & 5.16200 & 0000000001 & & TST \\
\hline CHEMBL1360376 & 688537 & 5.3694 & 5.3332 & TRN & & \\
\hline CHEMBL1366577 & 688537 & 6.3556 & 6.1682 & TRN & & \\
\hline CHEMBL1326634 & 688537 & 5.4715 & 5.2029 & TST & & \\
\hline CHEMBL3197314 & 688537 & 5.96700 & 00000000 & 205 & 5.3433 & TRN \\
\hline CHEMBL1545384 & 688537 & 5.7854 & 5.5803 & TST & & \\
\hline CHEMBL1494458 & 688537 & 5.1756 & 4.7245 & TST & & \\
\hline CHEMBL1456968 & 688537 & 2.8239 & 2.8047 & TRN & & \\
\hline CHEMBL1534035 & 688537 & 6.0088 & 5.8931 & TRN & & \\
\hline CHEMBL3207339 & 688537 & 5.5213 & 5.0664 & TRN & & \\
\hline CHEMBL1575271 & 688537 & 2.8239 & 4.4767 & TRN & & \\
\hline CHEMBL1584456 & 688537 & 2.8239 & 3.3253 & TRN & & \\
\hline CHEMBL1986418 & 688537 & 5.7038 & 5.6803 & TRN & & \\
\hline CHEMBL3189407 & 688537 & 5.1312 & 5.3513 & TRN & & \\
\hline CHEMBL1423338 & 688537 & 4.7923 & 4.632 & TRN & & \\
\hline CHEMBL1448592 & 688537 & 6.0 & 5.2185 & TRN & & \\
\hline CHEMBL1381353 & 688537 & 5.0262 & 4.2788 & TRN & & \\
\hline CHEMBL1502412 & 688537 & 2.8239 & 3.4537 & TRN & & \\
\hline CHEMBL1325982 & 688537 & 4.6682 & 4.4425 & TRN & & \\
\hline CHEMBL1531070 & 688537 & 5.5645 & 5.2319 & TST & & \\
\hline CHEMBL1428166 & 688537 & 5.6887 & 5.4002 & TST & & \\
\hline CHEMBL1586932 & 688537 & 5.0568 & 4.8705 & TRN & & \\
\hline CHEMBL1375172 & 688537 & 4.6152 & 4.9567 & TRN & & \\
\hline CHEMBL1355133 & 688537 & 5.1435 & 5.3695 & TRN & & \\
\hline CHEMBL1388274 & 688537 & 4.9477 & 4.5672 & TST & & \\
\hline CHEMBL1377902 & 688537 & 5.2557 & 4.7869 & TRN & & \\
\hline CHEMBL1604217 & 688537 & 5.5471 & 5.9616 & TRN & & \\
\hline CHEMBL1404493 & 688537 & 5.0853 & 5.635 & TST & & \\
\hline CHEMBL1392637 & 688537 & 6.2441 & 6.0261 & TRN & & \\
\hline CHEMBL1440974 & 688537 & 2.8239 & 3.4326 & TRN & & \\
\hline CHEMBL1377648 & 688537 & 5.2891 & 5.1725 & TRN & & \\
\hline CHEMBL1469656 & 688537 & 5.4312 & 5.5136 & TRN & & \\
\hline CHEMBL1502127 & 688537 & 5.3478 & 5.3986 & TRN & & \\
\hline CHEMBL1972864 & 688537 & 5.6366 & 5.2652 & TRN & & \\
\hline CHEMBL1336052 & 688537 & 5.0114 & 5.2975 & TST & & \\
\hline CHEMBL1449811 & 688537 & 5.4261 & 4.7022 & TRN & & \\
\hline CHEMBL1442280 & 688537 & 6.1367 & 6.4412 & TRN & & \\
\hline CHEMBL1427233 & 688537 & 5.0809 & 4.7814 & TRN & & \\
\hline CHEMBL3197778 & 688537 & 5.3405 & 4.8835 & TRN & & \\
\hline CHEMBL1978479 & 688537 & 6.0106 & 6.0774 & TST & & \\
\hline CHEMBL1387643 & 688537 & 5.178 & 5.0896 & TRN & & \\
\hline CHEMBL1365508 & 688537 & 5.5283 & 5.7636 & TRN & & \\
\hline CHEMBL1466628 & 688537 & 5.6092 & 5.7684 & TRN & & \\
\hline CHEMBL1495893 & 688537 & 5.5305 & 4.9025 & TST & & \\
\hline CHEMBL1322375 & 688537 & 4.8013 & 5.0341 & TRN & & \\
\hline CHEMBL1375734 & 688537 & 2.8239 & 4.7036 & TRN & & \\
\hline
\end{tabular}




\begin{tabular}{|c|c|c|c|c|c|}
\hline \multicolumn{6}{|c|}{ Supplemental Table s2.txt } \\
\hline CHEMBL1425743 & 688537 & 4.8494 & 4.6577 & TST & \\
\hline CHEMBL1606646 & 688537 & 5.8551 & 5.5411 & TRN & \\
\hline CHEMBL1405964 & 688537 & 5.4481 & 5.3223 & TRN & \\
\hline CHEMBL1605854 & 688537 & 4.8366 & 4.7607 & TRN & \\
\hline CHEMBL1534368 & 688537 & 2.8239 & 3.0173 & TRN & \\
\hline CHEMBL1506394 & 688537 & 4.3522 & 4.8078 & TRN & \\
\hline CHEMBL1544679 & 688537 & 6.475 & 6.4177 & TRN & \\
\hline CHEMBL1396500 & 688537 & 4.703 & 4.9275 & TRN & \\
\hline CHEMBL547285 & 688537 & 5.1774 & 5.432 & TRN & \\
\hline CHEMBL3199364 & 688537 & 5.1264 & 5.26 & TRN & \\
\hline CHEMBL1376130 & 688537 & 4.6237 & 5.1115 & TRN & \\
\hline CHEMBL1345195 & 688537 & 5.5567 & 5.7417 & TRN & \\
\hline CHEMBL1480313 & 688537 & 4.9345 & 4.7863 & TRN & \\
\hline CHEMBL1473799 & 688537 & 2.8239 & 4.1624 & TRN & \\
\hline CHEMBL1595700 & 688537 & 5.3033 & 4.6989 & TRN & \\
\hline CHEMBL1580555 & 688537 & 5.16 & 5.2907 & TRN & \\
\hline CHEMBL1593815 & 688537 & 5.4947 & 5.0307 & TST & \\
\hline CHEMBL1366206 & 688537 & 5.0235 & 5.318 & TRN & \\
\hline CHEMBL1517683 & 688537 & 5.2177 & 5.1403 & TRN & \\
\hline CHEMBL1304970 & 688537 & 5.3597 & 5.3672 & TRN & \\
\hline CHEMBL1562776 & 688537 & 2.8239 & 3.3635 & TRN & \\
\hline CHEMBL1431953 & 688537 & 5.4526 & 5.3169 & TST & \\
\hline CHEMBL1478456 & 688537 & 5.73799 & 99999999 & 4.9304 & TRN \\
\hline CHEMBL1469901 & 688537 & 2.8239 & 2.9796 & TRN & \\
\hline CHEMBL1595152 & 688537 & 5.336 & 5.1871 & TST & \\
\hline CHEMBL1406762 & 688537 & 5.4336 & 4.8899 & TRN & \\
\hline CHEMBL1539595 & 688537 & 6.51 & 7.0462 & TRN & \\
\hline CHEMBL1343618 & 688537 & 3.9419 & 3.2678 & TRN & \\
\hline CHEMBL1480812 & 688537 & 5.6115 & 5.55200 & 00000000005 & TRN \\
\hline CHEMBL1456639 & 688537 & 2.8239 & 2.8566 & TRN & \\
\hline CHEMBL1466186 & 688537 & 5.595 & 5.4977 & TRN & \\
\hline CHEMBL1604622 & 688537 & 4.8414 & 5.0911 & TST & \\
\hline CHEMBL1605739 & 688537 & 4.9269 & 4.7662 & TRN & \\
\hline CHEMBL1435487 & 688537 & 5.3901 & 5.3786 & TRN & \\
\hline CHEMBL1370995 & 688537 & 4.6357 & 4.6201 & TRN & \\
\hline CHEMBL1426149 & 688537 & 4.8721 & 4.654 & TRN & \\
\hline CHEMBL 1487432 & 688537 & 2.8239 & 3.2622 & TST & \\
\hline CHEMBL1381360 & 688537 & 5.2842 & 4.9832 & TST & \\
\hline CHEMBL1542682 & 688537 & 5.039 & 5.1466 & TRN & \\
\hline CHEMBL1302865 & 688537 & 5.0004 & 4.8784 & TRN & \\
\hline CHEMBL1441897 & 688537 & 5.1575 & 5.3273 & TRN & \\
\hline CHEMBL1414817 & 688537 & 5.7371 & 5.3589 & TRN & \\
\hline CHEMBL1398664 & 688537 & 5.5209 & 5.6803 & TRN & \\
\hline CHEMBL1528043 & 688537 & 5.1297 & 5.2625 & TRN & \\
\hline CHEMBL544584 & 688537 & 5.5899 & 6.0918 & TRN & \\
\hline CHEMBL1342028 & 688537 & 5.0319 & 5.4128 & TRN & \\
\hline CHEMBL1529601 & 688537 & 4.7731 & 4.6464 & TRN & \\
\hline CHEMBL1965821 & 688537 & 5.1324 & 5.1857 & TRN & \\
\hline
\end{tabular}




\begin{tabular}{|c|c|c|c|c|c|c|}
\hline & & \multicolumn{5}{|c|}{ Supplemental Table S2.txt } \\
\hline CHEMBL1611364 & 688537 & 4.9754 & 5.1463 & TRN & & \\
\hline CHEMBL1973886 & 688537 & 5.0046 & 4.7867 & TRN & & \\
\hline CHEMBL1491847 & 688537 & \multicolumn{3}{|c|}{5.486000000000001} & 5.2588 & TST \\
\hline CHEMBL1542604 & 688537 & 5.0059 & 5.2957 & TRN & & \\
\hline CHEMBL1428730 & 688537 & 5.0821 & 4.7606 & TST & & \\
\hline CHEMBL1340487 & 688537 & 5.3824 & 5.1121 & TRN & & \\
\hline CHEMBL1544188 & 688537 & 5.1752 & 4.9282 & TRN & & \\
\hline CHEMBL1404750 & 688537 & 5.479 & 4.7872 & TST & & \\
\hline CHEMBL1384341 & 688537 & 4.72 & 4.6754 & TRN & & \\
\hline CHEMBL1972915 & 688537 & 5.7296 & 5.7997 & TRN & & \\
\hline CHEMBL1499490 & 688537 & 5.8655 & 5.7924 & TRN & & \\
\hline CHEMBL1328350 & 688537 & 5.3602 & 5.5023 & TRN & & \\
\hline CHEMBL1385676 & 688537 & 5.4134 & 5.4539 & TRN & & \\
\hline CHEMBL3190880 & 688537 & 5.9007 & 5.8911 & TRN & & \\
\hline CHEMBL1345584 & 688537 & 4.6614 & 4.8534 & TRN & & \\
\hline CHEMBL1332450 & 688537 & 5.8333 & 5.8004 & TRN & & \\
\hline CHEMBL1422105 & 688537 & 6.0182 & 4.705 & TRN & & \\
\hline CHEMBL1533269 & 688537 & 5.2892 & 5.2397 & TRN & & \\
\hline CHEMBL1353666 & 688537 & 4.9298 & 5.1113 & TRN & & \\
\hline CHEMBL3198425 & 688537 & 5.6737 & 5.834 & TRN & & \\
\hline CHEMBL1523242 & 688537 & 4.9379 & 4.6281 & TRN & & \\
\hline CHEMBL1585321 & 688537 & 2.8239 & \multicolumn{3}{|c|}{3.0210000000000004} & TST \\
\hline CHEMBL1335383 & 688537 & 5.2947 & 4.9695 & TST & & \\
\hline CHEMBL1420253 & 688537 & 4.494 & 4.2925 & TST & & \\
\hline CHEMBL1540682 & 688537 & 5.3655 & 5.07100 & 0000000001 & & TST \\
\hline CHEMBL1425861 & 688537 & 6.0209 & 5.5545 & TRN & & \\
\hline CHEMBL3195381 & 688537 & 5.019 & 5.0326 & TRN & & \\
\hline CHEMBL1485168 & 688537 & 5.7503 & 5.5746 & TRN & & \\
\hline CHEMBL1354909 & 688537 & 6.0386 & 5.8298 & TRN & & \\
\hline CHEMBL1453208 & 688537 & 5.8184 & 5.439 & TST & & \\
\hline CHEMBL1478241 & 688537 & 5.1436 & 5.1241 & TRN & & \\
\hline CHEMBL1575707 & 688537 & 2.8239 & 3.3443 & TRN & & \\
\hline CHEMBL 3199665 & 688537 & 5.5358 & 5.5952 & TRN & & \\
\hline CHEMBL1353166 & 688537 & 2.8239 & 2.8072 & TRN & & \\
\hline CHEMBL3196810 & 688537 & \multicolumn{3}{|c|}{5.452000000000001} & 5.3961 & TRN \\
\hline CHEMBL1540014 & 688537 & 4.6754 & 4.1562 & TRN & & \\
\hline CHEMBL1604283 & 688537 & 8.2218 & 8.1307 & TST & & \\
\hline CHEMBL1551880 & 688537 & 5.1875 & 5.2401 & TST & & \\
\hline CHEMBL1351309 & 688537 & 5.6678 & 5.4789 & TST & & \\
\hline CHEMBL1550672 & 688537 & 5.2842 & 5.7083 & TRN & & \\
\hline CHEMBL1570705 & 688537 & 6.1415 & 6.2837 & TRN & & \\
\hline CHEMBL1544460 & 688537 & 5.9678 & 5.9783 & TRN & & \\
\hline CHEMBL1496635 & 688537 & 5.3143 & 4.7742 & TST & & \\
\hline CHEMBL3189714 & 688537 & 6.1543 & 5.9402 & TRN & & \\
\hline CHEMBL1391287 & 688537 & 6.3635 & 7.2643 & TRN & & \\
\hline CHEMBL1487834 & 688537 & 4.8855 & 5.0473 & TRN & & \\
\hline CHEMBL1305787 & 688537 & 5.4653 & 5.2252 & TRN & & \\
\hline CHEMBL1354488 & 688537 & 2.8239 & 3.1341 & TRN & & \\
\hline
\end{tabular}


Supplemental Table S2.txt

\begin{tabular}{|c|c|c|c|c|c|}
\hline CHEMBL3189613 & 688537 & 5.6091 & 5.7497 & TRN & \\
\hline CHEMBL1409680 & 688537 & 5.5139 & 5.5283 & TRN & \\
\hline CHEMBL1971033 & 688537 & 5.2701 & 5.5384 & TRN & \\
\hline CHEMBL1329925 & 688537 & 6.1811 & 5.8698 & TRN & \\
\hline CHEMBL1978315 & 688537 & 5.4641 & 4.4886 & TRN & \\
\hline CHEMBL 3192817 & 688537 & 5.5158 & 5.401 & TRN & \\
\hline CHEMBL1546739 & 688537 & 6.6126 & 6.5612 & TRN & \\
\hline CHEMBL1333989 & 688537 & 5.0196 & 4.8464 & TRN & \\
\hline CHEMBL1422386 & 688537 & 5.7404 & 7.38 & TRN & \\
\hline CHEMBL1407688 & 688537 & 2.8239 & 4.7348 & TRN & \\
\hline CHEMBL1568277 & 688537 & 6.0487 & 6.2387 & TRN & \\
\hline CHEMBL1345433 & 688537 & 5.2187 & 4.8857 & TST & \\
\hline CHEMBL1358873 & 688537 & 4.9042 & 4.8348 & TRN & \\
\hline CHEMBL1461193 & 688537 & 5.2212 & 5.1906 & TRN & \\
\hline CHEMBL1466495 & 688537 & 5.0397 & 4.9874 & TRN & \\
\hline CHEMBL1493705 & 688537 & 5.8377 & 5.3222 & TRN & \\
\hline CHEMBL1344339 & 688537 & 6.6946 & 6.5506 & TST & \\
\hline CHEMBL1399731 & 688537 & 5.2232 & 5.0457 & TRN & \\
\hline CHEMBL1479657 & 688537 & 5.5516 & 5.4308 & TRN & \\
\hline CHEMBL1428217 & 688537 & 5.3893 & 5.4275 & TRN & \\
\hline CHEMBL1442742 & 688537 & 5.6887 & 5.7596 & TRN & \\
\hline CHEMBL1424264 & 688537 & 6.0182 & 5.9395 & TRN & \\
\hline CHEMBL1335220 & 688537 & 5.5714 & 5.5078 & TRN & \\
\hline CHEMBL1588702 & 688537 & 5.013 & 5.1486 & TRN & \\
\hline CHEMBL1567899 & 688537 & 5.6415 & 5.7074 & TRN & \\
\hline CHEMBL1421625 & 688537 & 5.8159 & 5.7281 & TRN & \\
\hline CHEMBL1565526 & 688537 & 5.5286 & 5.5374 & TRN & \\
\hline CHEMBL1477597 & 688537 & 4.7019 & 4.3982 & TRN & \\
\hline CHEMBL1500712 & 688537 & 4.4834 & 4.9686 & TST & \\
\hline CHEMBL1390437 & 688537 & 2.8239 & 2.66899 & 99999999996 & TRN \\
\hline CHEMBL1401891 & 688537 & 2.8239 & 4.4125 & TST & \\
\hline CHEMBL1551022 & 688537 & 5.0917 & 4.8958 & TRN & \\
\hline CHEMBL1537431 & 688537 & 2.8239 & 4.021 & TRN & \\
\hline CHEMBL1416666 & 688537 & 4.6354 & 4.4864 & TRN & \\
\hline CHEMBL1466621 & 688537 & 5.8617 & 5.9266 & TRN & \\
\hline CHEMBL1361680 & 688537 & 5.7731 & 5.3938 & TRN & \\
\hline CHEMBL3197982 & 688537 & 2.8239 & 4.458 & TRN & \\
\hline CHEMBL 251148 & 688537 & 2.8239 & 3.1133 & TST & \\
\hline CHEMBL1504588 & 688537 & 2.8239 & 2.7108 & TRN & \\
\hline CHEMBL1454039 & 688537 & 6.3107 & 6.2492 & TRN & \\
\hline CHEMBL1300745 & 688537 & 6.1403 & 5.7437 & TRN & \\
\hline CHEMBL1496705 & 688537 & 5.2075 & 5.2264 & TRN & \\
\hline CHEMBL1406224 & 688537 & 2.8239 & 3.0017 & TRN & \\
\hline CHEMBL1420800 & 688537 & 5.1989 & 4.9857 & TRN & \\
\hline CHEMBL1347270 & 688537 & 5.4688 & 5.0294 & TRN & \\
\hline CHEMBL1975801 & 688537 & \multicolumn{4}{|c|}{5.0089999999999995} \\
\hline CHEMBL1555899 & 688537 & 5.1685 & 4.7334 & TRN & \\
\hline CHEMBL1584002 & 688537 & 4.8819 & 5.3966 & TRN & \\
\hline
\end{tabular}




\begin{tabular}{|c|c|c|c|c|c|c|}
\hline & & \multicolumn{5}{|c|}{ Supplemental Table S2.txt } \\
\hline CHEMBL390559 & 688537 & 5.2793 & 5.5156 & TRN & & \\
\hline CHEMBL1333826 & 688537 & 5.1111 & 5.2061 & TRN & & \\
\hline CHEMBL1599401 & 688537 & 6.5287 & 6.4148 & TRN & & \\
\hline CHEMBL1533459 & 688537 & 6.2596 & 6.2556 & TRN & & \\
\hline CHEMBL1588975 & 688537 & 5.6546 & 5.6577 & TRN & & \\
\hline CHEMBL1540469 & 688537 & 5.186 & 5.3136 & TRN & & \\
\hline CHEMBL1477844 & 688537 & 2.8239 & 2.9103 & TRN & & \\
\hline CHEMBL1466240 & 688537 & 2.8239 & 2.9671 & TRN & & \\
\hline CHEMBL1554002 & 688537 & 6.063 & 6.4629 & TRN & & \\
\hline CHEMBL1517469 & 688537 & 2.8239 & 2.5951 & TRN & & \\
\hline CHEMBL1499320 & 688537 & 6.1831 & 5.6313 & TRN & & \\
\hline CHEMBL1411435 & 688537 & 5.494 & 5.8563 & TRN & & \\
\hline CHEMBL1388295 & 688537 & 2.8239 & 4.8692 & TRN & & \\
\hline CHEMBL1441274 & 688537 & \multicolumn{3}{|c|}{5.172000000000001} & 5.4412 & TRN \\
\hline CHEMBL3213413 & 688537 & 5.2157 & 5.2103 & TRN & & \\
\hline CHEMBL1538099 & 688537 & 5.395 & 5.1871 & TRN & & \\
\hline CHEMBL1604272 & 688537 & 5.0337 & 4.7589 & TRN & & \\
\hline CHEMBL1483287 & 688537 & 2.8239 & 3.1506 & TRN & & \\
\hline CHEMBL3145280 & 688537 & 5.3651 & 5.438 & TRN & & \\
\hline CHEMBL1607568 & 688537 & 5.8526 & 5.852 & TRN & & \\
\hline CHEMBL1984298 & 688537 & 5.6242 & 5.7186 & TRN & & \\
\hline CHEMBL1380762 & 688537 & 5.4074 & 5.5127 & TRN & & \\
\hline CHEMBL1509433 & 688537 & 4.9489 & 5.0069 & TRN & & \\
\hline CHEMBL 1432380 & 688537 & 2.8239 & 2.8114 & TRN & & \\
\hline CHEMBL1602590 & 688537 & 5.1984 & 5.2242 & TRN & & \\
\hline CHEMBL1516527 & 688537 & 5.4234 & 5.2202 & TST & & \\
\hline CHEMBL1383137 & 688537 & 4.6462 & 4.6251 & TRN & & \\
\hline CHEMBL1487434 & 688537 & 2.8239 & 3.0352 & TRN & & \\
\hline CHEMBL590665 & 688537 & 5.8904 & 5.8253 & TRN & & \\
\hline CHEMBL1585843 & 688537 & 2.8239 & 5.1139 & TRN & & \\
\hline CHEMBL1460352 & 688537 & 5.2106 & 5.261 & TRN & & \\
\hline CHEMBL1504469 & 688537 & 5.0305 & 5.0881 & TRN & & \\
\hline CHEMBL 3197371 & 688537 & 5.5575 & 5.5652 & TRN & & \\
\hline CHEMBL 1567518 & 688537 & 6.0645 & 5.8344 & TRN & & \\
\hline CHEMBL1395871 & 688537 & 5.0337 & 5.2676 & TRN & & \\
\hline CHEMBL1453572 & 688537 & 5.7934 & 5.8181 & TRN & & \\
\hline CHEMBL1438582 & 688537 & 2.8239 & 3.0796 & TRN & & \\
\hline CHEMBL1559496 & 688537 & 5.5217 & 4.7268 & TST & & \\
\hline CHEMBL3208443 & 688537 & 5.5822 & 5.641 & TRN & & \\
\hline CHEMBL1565280 & 688537 & 4.3228 & 4.4783 & TRN & & \\
\hline CHEMBL1327706 & 688537 & 6.1244 & 5.778 & TRN & & \\
\hline CHEMBL1511380 & 688537 & 2.8239 & 3.2543 & TST & & \\
\hline CHEMBL1369724 & 688537 & 5.1706 & 5.3418 & TRN & & \\
\hline CHEMBL1444958 & 688537 & 5.5232 & 5.3885 & TRN & & \\
\hline CHEMBL1471046 & 688537 & 2.8239 & 2.8175 & TRN & & \\
\hline CHEMBL1462007 & 688537 & 4.5678 & 4.8198 & TST & & \\
\hline CHEMBL1382763 & 688537 & 4.9189 & 4.4877 & TRN & & \\
\hline CHEMBL1373166 & 688537 & 5.0903 & 5.2154 & TRN & & \\
\hline
\end{tabular}


Supplemental Table S2.txt

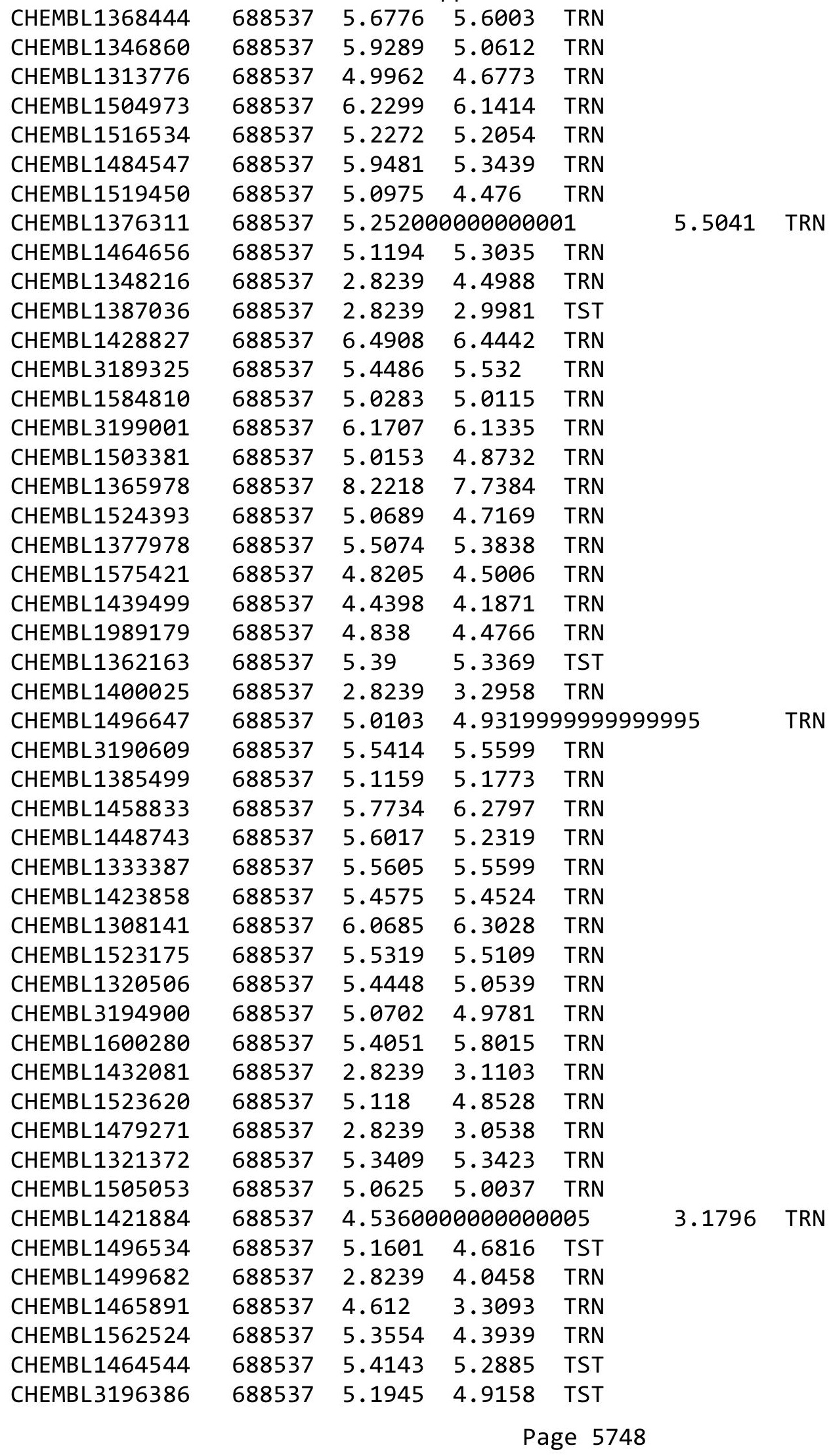


Supplemental Table S2.txt

\begin{tabular}{|c|c|c|c|c|c|}
\hline CHEMBL1420131 & 688537 & 4.3281 & 4.2551 & TRN & \\
\hline CHEMBL1415494 & 688537 & 2.8239 & 3.1033 & TRN & \\
\hline CHEMBL1320170 & 688537 & 5.2169 & 4.7671 & TST & \\
\hline CHEMBL 2006503 & 688537 & 6.3696 & 6.1053 & TRN & \\
\hline CHEMBL1416018 & 688537 & 5.5504 & 5.7944 & TRN & \\
\hline CHEMBL1530220 & 688537 & 5.5804 & 5.6059 & TRN & \\
\hline CHEMBL1557756 & 688537 & 5.1475 & 5.0361 & TRN & \\
\hline CHEMBL1359788 & 688537 & 5.3276 & 5.3634 & TRN & \\
\hline CHEMBL1302551 & 688537 & 5.2195 & 5.2486 & TRN & \\
\hline CHEMBL268356 & 688537 & 6.8962 & 6.7367 & TRN & \\
\hline CHEMBL1476225 & 688537 & 5.1642 & 5.3114 & TRN & \\
\hline CHEMBL1560329 & 688537 & 4.3422 & 4.8893 & TST & \\
\hline CHEMBL1520325 & 688537 & 5.3943 & 4.899 & TRN & \\
\hline CHEMBL1344082 & 688537 & 5.5418 & 5.4146 & TRN & \\
\hline CHEMBL1419323 & 688537 & 2.8239 & 3.0372 & TST & \\
\hline CHEMBL1418178 & 688537 & 4.7749 & 4.8739 & TST & \\
\hline CHEMBL3209772 & 688537 & 5.4277 & 5.28700 & 0000000001 & TRN \\
\hline CHEMBL1420365 & 688537 & 5.4594 & 4.9513 & TRN & \\
\hline CHEMBL1597967 & 688537 & 4.7871 & 4.4713 & TRN & \\
\hline CHEMBL1378131 & 688537 & 6.1024 & 6.191 & TRN & \\
\hline CHEMBL1367313 & 688537 & 5.1409 & 5.0312 & TRN & \\
\hline CHEMBL1468929 & 688537 & 4.6021 & 5.3825 & TRN & \\
\hline CHEMBL1468541 & 688537 & 2.8239 & 2.4603 & TRN & \\
\hline CHEMBL1708832 & 688537 & 2.8239 & 4.8811 & TRN & \\
\hline CHEMBL1588234 & 688537 & 5.2241 & 5.2684 & TRN & \\
\hline CHEMBL1459494 & 688537 & 5.3212 & 5.3923 & TST & \\
\hline CHEMBL570400 & 688537 & 5.5948 & 5.5201 & TRN & \\
\hline CHEMBL1504569 & 688537 & 5.5348 & 5.6261 & TRN & \\
\hline CHEMBL1435933 & 688537 & 5.6144 & 5.1259 & TRN & \\
\hline CHEMBL3190608 & 688537 & 6.0752 & 5.8424 & TRN & \\
\hline CHEMBL1452261 & 688537 & 7.2007 & 5.3228 & TRN & \\
\hline CHEMBL1322304 & 688537 & 5.3424 & 4.9492 & TRN & \\
\hline CHEMBL3197633 & 688537 & 5.7567 & 5.3137 & TRN & \\
\hline CHEMBL1450872 & 688537 & 5.358 & 4.7548 & TST & \\
\hline CHEMBL1510484 & 688537 & 4.2609 & 4.1628 & TRN & \\
\hline CHEMBL1398268 & 688537 & 2.8239 & 4.5563 & TRN & \\
\hline CHEMBL1532148 & 688537 & 5.3665 & 5.2539 & TRN & \\
\hline CHEMBL1896972 & 688537 & 5.0324 & 5.204 & TRN & \\
\hline CHEMBL3145042 & 688537 & 4.7486 & 4.7145 & TRN & \\
\hline CHEMBL1483038 & 688537 & 5.1292 & 4.7248 & TRN & \\
\hline CHEMBL1516396 & 688537 & 6.9957 & 8.2638 & TRN & \\
\hline CHEMBL1480524 & 688537 & 2.8239 & 4.0307 & TST & \\
\hline CHEMBL1425091 & 688537 & 5.2897 & 5.2436 & TRN & \\
\hline CHEMBL1553636 & 688537 & 2.8239 & 4.1401 & TRN & \\
\hline CHEMBL1505192 & 688537 & 5.4144 & 5.3516 & TRN & \\
\hline CHEMBL1455266 & 688537 & 5.8548 & 5.6604 & TST & \\
\hline CHEMBL1374924 & 688537 & 4.8596 & 4.7361 & TRN & \\
\hline CHEMBL1582355 & 688537 & 5.6299 & 5.4743 & TRN & \\
\hline
\end{tabular}




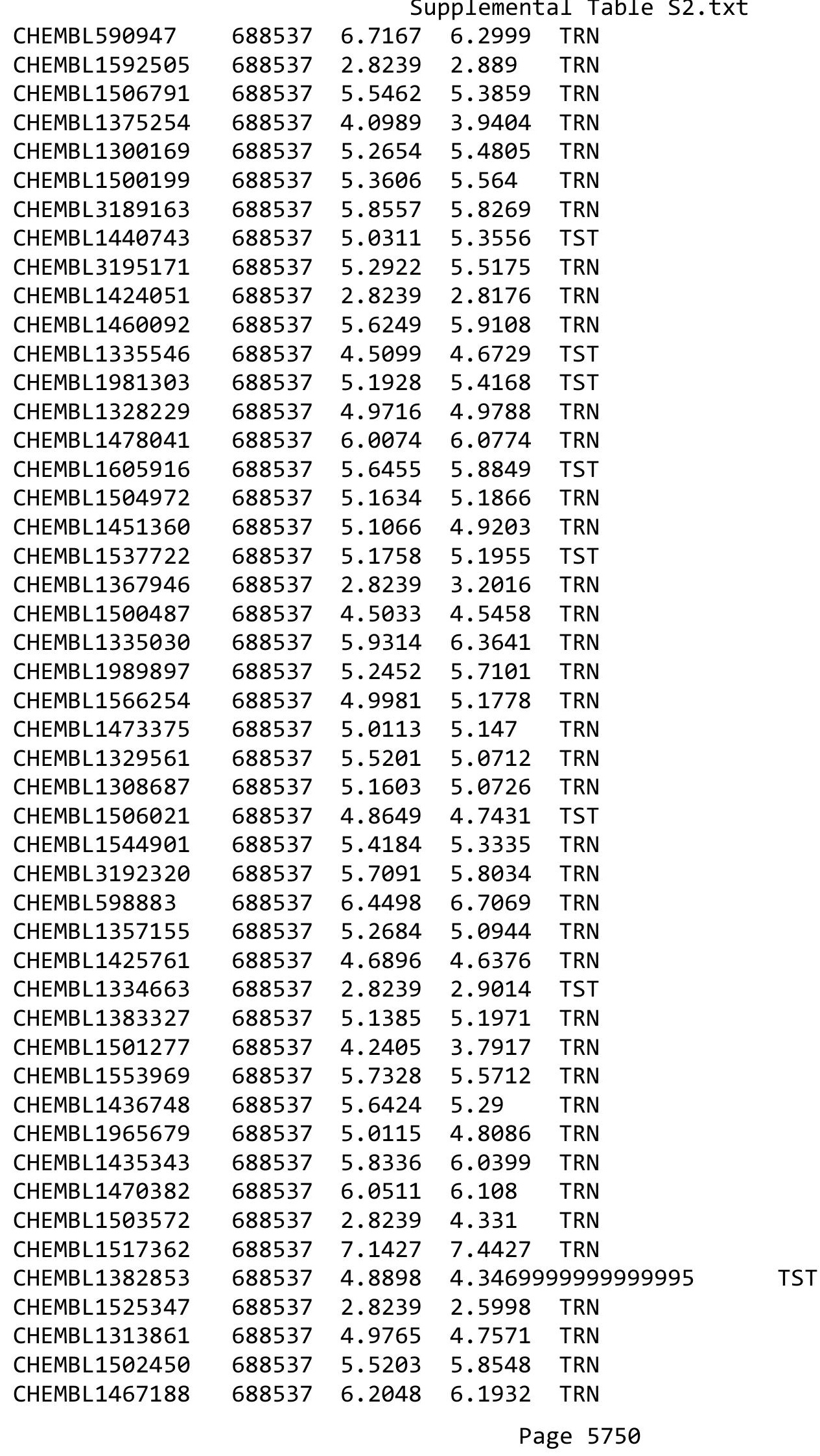




\begin{tabular}{|c|c|c|c|c|}
\hline & & & oplement & al $\mathrm{T}$ \\
\hline CHEMBL1609988 & 688537 & 5.9133 & 5.1977 & TRN \\
\hline CHEMBL1545189 & 688537 & 7.0 & 8.4616 & TRN \\
\hline CHEMBL1308056 & 688537 & 5.4692 & 5.7094 & TST \\
\hline CHEMBL534353 & 688537 & 6.0975 & 5.136 & TST \\
\hline CHEMBL1471371 & 688537 & 4.8593 & 5.0649 & TRN \\
\hline CHEMBL1564731 & 688537 & 5.6155 & 5.6408 & TRN \\
\hline CHEMBL391533 & 688537 & 5.5346 & 5.7959 & TST \\
\hline CHEMBL1611483 & 688537 & 5.0117 & 4.7832 & TST \\
\hline CHEMBL 3195767 & 688537 & 6.9626 & 6.558 & TRN \\
\hline CHEMBL1355233 & 688537 & 5.5535 & 5.3036 & TST \\
\hline CHEMBL1443499 & 688537 & 4.8099 & 4.806 & TRN \\
\hline CHEMBL1578492 & 688537 & 4.7988 & 4.7919 & TRN \\
\hline CHEMBL3214119 & 688537 & 4.854 & 4.5326 & TST \\
\hline CHEMBL1464477 & 688537 & 5.1327 & 5.1891 & TST \\
\hline CHEMBL1341947 & 688537 & 5.3363 & 5.2398 & TST \\
\hline CHEMBL 3195760 & 688537 & 6.3665 & 7.1889 & TRN \\
\hline CHEMBL3199044 & 688537 & 4.9935 & 4.8386 & TRN \\
\hline CHEMBL1991450 & 688537 & 5.3905 & 4.9684 & TRN \\
\hline CHEMBL1506230 & 688537 & 5.3135 & 5.0371 & TRN \\
\hline CHEMBL1568686 & 688537 & 4.663 & 4.2953 & TRN \\
\hline CHEMBL 3198068 & 688537 & 5.4505 & 5.2744 & TRN \\
\hline CHEMBL1482477 & 688537 & 5.6432 & 5.023 & TST \\
\hline CHEMBL1977043 & 688537 & 5.0816 & 5.2608 & TRN \\
\hline CHEMBL1596647 & 688537 & 2.8239 & 4.4801 & TRN \\
\hline CHEMBL1333583 & 688537 & 5.3056 & 4.7942 & TST \\
\hline CHEMBL1982915 & 688537 & 5.145 & 5.2789 & TRN \\
\hline CHEMBL1428514 & 688537 & 5.0254 & 5.2824 & TRN \\
\hline CHEMBL1609420 & 688537 & 2.8239 & 3.0939 & TRN \\
\hline CHEMBL1350869 & 688537 & 5.2252 & 5.5825 & TRN \\
\hline CHEMBL1510905 & 688537 & 5.2544 & 5.2636 & TRN \\
\hline CHEMBL1594517 & 688537 & 5.0027 & 5.0503 & TRN \\
\hline CHEMBL 3145304 & 688537 & 5.8649 & 5.5984 & TRN \\
\hline CHEMBL585591 & 688537 & 5.8233 & 5.5135 & TST \\
\hline CHEMBL1492564 & 688537 & 4.8207 & 5.1601 & TRN \\
\hline CHEMBL1555435 & 688537 & 4.3559 & 4.2296 & TRN \\
\hline CHEMBL3195997 & 688537 & 5.7883 & 5.6872 & TRN \\
\hline CHEMBL1355961 & 688537 & 5.3053 & 5.261 & TST \\
\hline CHEMBL1468672 & 688537 & 5.5699 & 6.2589 & TRN \\
\hline CHEMBL1326194 & 688537 & 5.1043 & 5.4508 & TRN \\
\hline CHEMBL1410901 & 688537 & 4.8022 & 4.3459 & TRN \\
\hline CHEMBL1376810 & 688537 & 5.1416 & 4.7375 & TRN \\
\hline CHEMBL187460 & 688537 & 5.2863 & 5.3333 & TST \\
\hline CHEMBL3199832 & 688537 & 5.1187 & 5.2928 & TRN \\
\hline CHEMBL1582581 & 688537 & 4.7277 & 5.0059 & TRN \\
\hline CHEMBL1536360 & 688537 & 5.7247 & 4.9837 & TRN \\
\hline CHEMBL1540098 & 688537 & 5.3475 & 5.2275 & TRN \\
\hline CHEMBL1479888 & 688537 & 5.3616 & 5.3345 & TRN \\
\hline CHEMBL1438071 & 688537 & 5.1912 & 5.1439 & TRN \\
\hline
\end{tabular}




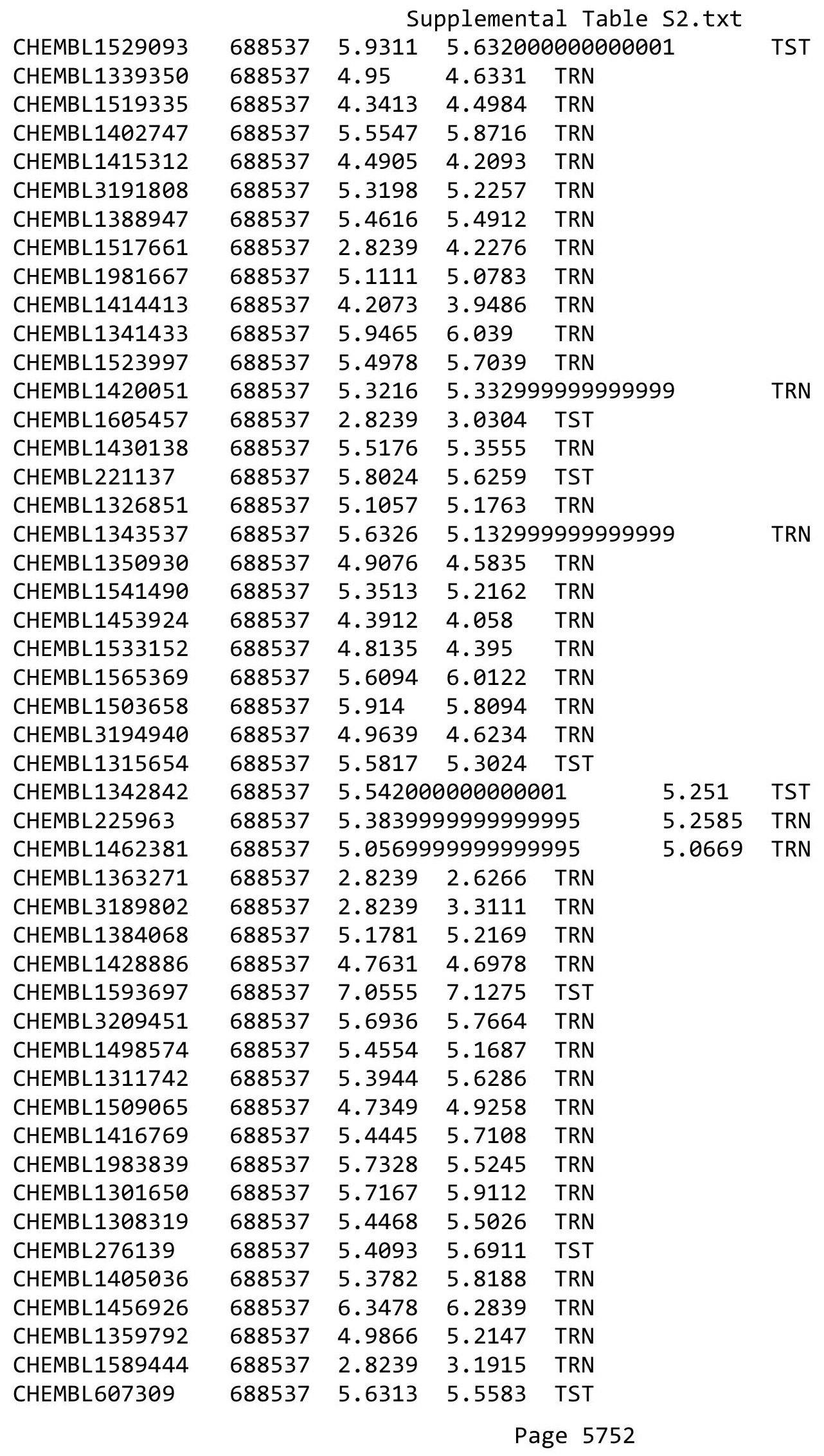




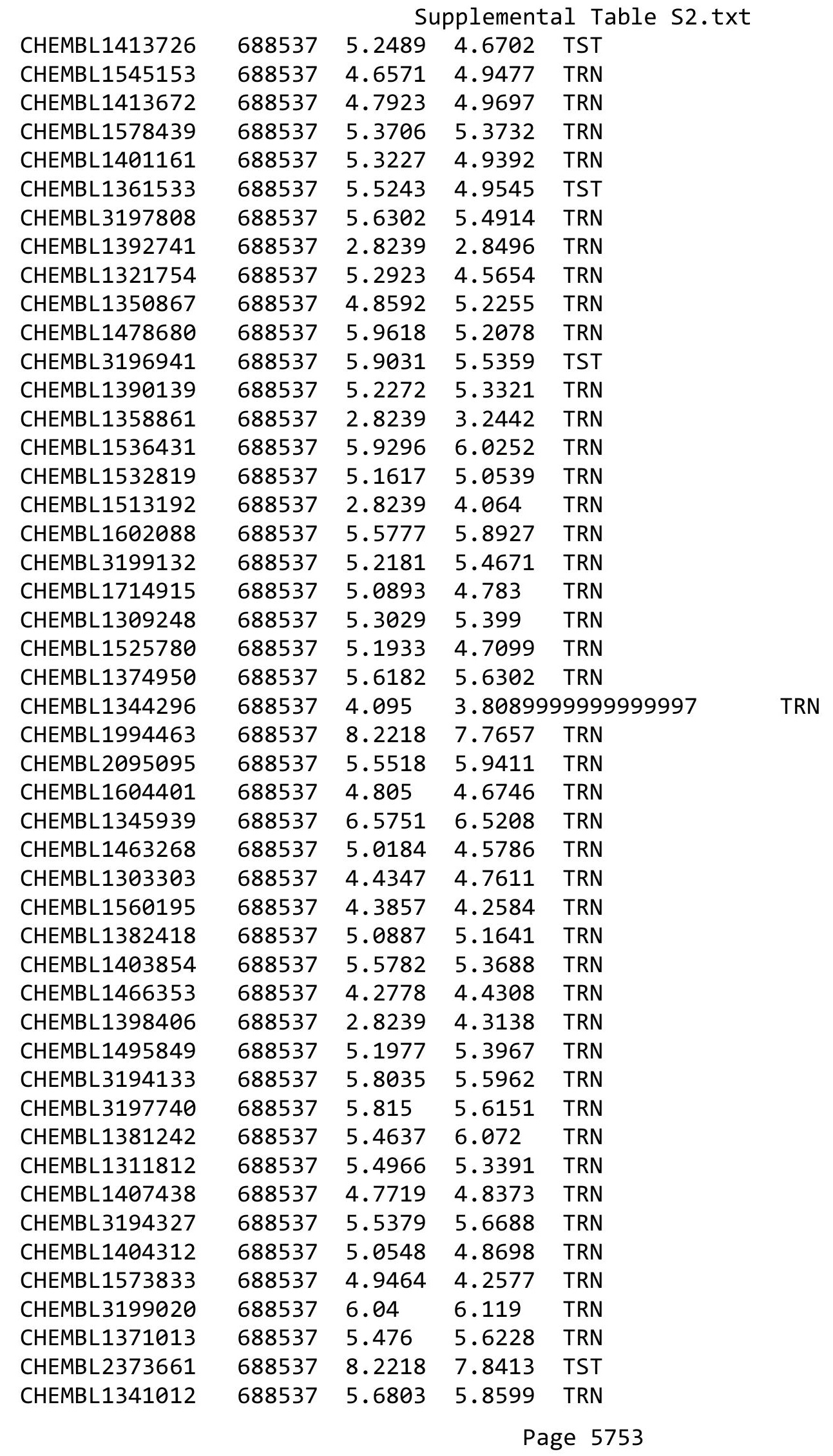




\begin{tabular}{|c|c|c|c|c|c|}
\hline \multirow[b]{2}{*}{ CHEMBL1318412 } & & \multicolumn{4}{|c|}{ Supplemental Table s2.txt } \\
\hline & 688537 & 4.4914 & 4.7449 & TST & \\
\hline CHEMBL1587193 & 688537 & 5.5484 & 4.9833 & TRN & \\
\hline CHEMBL1470925 & 688537 & 5.5391 & 5.3687 & TRN & \\
\hline CHEMBL1426455 & 688537 & 5.434 & 5.1667 & TRN & \\
\hline CHEMBL1584143 & 688537 & 5.3794 & 5.17299 & 9999999999 & TRN \\
\hline CHEMBL3195160 & 688537 & 5.3102 & 4.9306 & TRN & \\
\hline CHEMBL1606837 & 688537 & 5.1769 & 4.7701 & TST & \\
\hline CHEMBL1313281 & 688537 & 2.8239 & 4.3776 & TST & \\
\hline CHEMBL1489407 & 688537 & 5.7665 & 5.5247 & TRN & \\
\hline CHEMBL1566130 & 688537 & 5.447 & 5.5028 & TRN & \\
\hline CHEMBL1601820 & 688537 & 5.9957 & 5.8302 & TRN & \\
\hline CHEMBL1361273 & 688537 & 6.0487 & 5.4236 & TRN & \\
\hline CHEMBL3190644 & 688537 & 5.3246 & 4.7825 & TST & \\
\hline CHEMBL1583060 & 688537 & 5.397 & 5.2982 & TRN & \\
\hline CHEMBL1344875 & 688537 & 4.8762 & 5.0219 & TRN & \\
\hline CHEMBL1299566 & 688537 & 5.6611 & 5.2861 & TRN & \\
\hline CHEMBL1409950 & 688537 & 5.0182 & 4.7825 & TRN & \\
\hline CHEMBL1540901 & 688537 & 2.8239 & 2.5806 & TRN & \\
\hline CHEMBL1566725 & 688537 & 4.8825 & 4.9922 & TRN & \\
\hline CHEMBL1376019 & 688537 & 5.0024 & 5.419 & TRN & \\
\hline CHEMBL1386616 & 688537 & 2.8239 & 3.8159 & TRN & \\
\hline CHEMBL1439833 & 688537 & 5.3886 & 5.7904 & TRN & \\
\hline CHEMBL1564233 & 688537 & 4.7228 & 5.1046 & TRN & \\
\hline CHEMBL1562570 & 688537 & 5.0225 & 4.8034 & TRN & \\
\hline CHEMBL1548017 & 688537 & 2.8239 & 3.3765 & TRN & \\
\hline CHEMBL1396209 & 688537 & 5.4307 & 5.3102 & TRN & \\
\hline CHEMBL1472532 & 688537 & 5.1832 & 4.7737 & TRN & \\
\hline CHEMBL3191406 & 688537 & 5.7452 & 5.6318 & TRN & \\
\hline CHEMBL 299853 & 688537 & 5.75290 & 99999999 & 5.5443 & TRN \\
\hline CHEMBL1319984 & 688537 & 6.4089 & 5.9077 & TRN & \\
\hline CHEMBL1542640 & 688537 & 2.8239 & 3.4046 & TRN & \\
\hline CHEMBL3192977 & 688537 & 5.6358 & 5.5578 & TST & \\
\hline CHEMBL1455024 & 688537 & 4.9704 & 5.0792 & TRN & \\
\hline CHEMBL3191087 & 688537 & 6.0726 & 5.9151 & TRN & \\
\hline CHEMBL1984129 & 688537 & 5.3238 & 5.4159 & TST & \\
\hline CHEMBL1602601 & 688537 & 4.3583 & 3.9903 & TST & \\
\hline CHEMBL1375199 & 688537 & 5.4193 & 5.1363 & TRN & \\
\hline CHEMBL1307769 & 688537 & 5.1637 & 5.2075 & TST & \\
\hline CHEMBL1382325 & 688537 & 5.0096 & 4.827 & TRN & \\
\hline CHEMBL1327172 & 688537 & 5.7783 & 6.0341 & TRN & \\
\hline CHEMBL1533308 & 688537 & 5.1096 & 5.467006 & 00000000005 & TRN \\
\hline CHEMBL1492135 & 688537 & 2.8239 & 3.1826 & TRN & \\
\hline CHEMBL1378331 & 688537 & 4.9147 & 4.9551 & TRN & \\
\hline CHEMBL1324005 & 688537 & 6.7471 & 6.7083 & TRN & \\
\hline CHEMBL1411777 & 688537 & 5.5711 & 5.1241 & TRN & \\
\hline CHEMBL1405262 & 688537 & 5.7515 & 6.0196 & TRN & \\
\hline CHEMBL1360018 & 688537 & 5.4713 & 5.0329 & TRN & \\
\hline CHEMBL1240975 & 688537 & 5.1731 & 4.9797 & TST & \\
\hline
\end{tabular}




\begin{tabular}{|c|c|c|c|c|c|c|}
\hline & & \multicolumn{5}{|c|}{ Supplemental Table s2.txt } \\
\hline CHEMBL1488460 & 688537 & 5.5904 & 4.8217 & TRN & & \\
\hline CHEMBL1537008 & 688537 & 4.2875 & 4.3374 & TRN & & \\
\hline CHEMBL1990783 & 688537 & 5.3711 & 5.1866 & TRN & & \\
\hline CHEMBL1977568 & 688537 & 6.4001 & 6.3407 & TRN & & \\
\hline CHEMBL1331851 & 688537 & 6.4634 & \multicolumn{3}{|c|}{6.4910000000000005} & TRN \\
\hline CHEMBL1509762 & 688537 & 5.0962 & 5.465 & TRN & & \\
\hline CHEMBL1969094 & 688537 & 5.1644 & 4.9215 & TRN & & \\
\hline CHEMBL3199301 & 688537 & 5.53 & 5.5466 & TRN & & \\
\hline CHEMBL1596985 & 688537 & 5.9126 & \multicolumn{3}{|c|}{6.071000000000001} & TRN \\
\hline CHEMBL1527120 & 688537 & 4.9208 & 5.3233 & TST & & \\
\hline CHEMBL1455824 & 688537 & 5.6291 & 5.1798 & TRN & & \\
\hline CHEMBL1518265 & 688537 & 5.7445 & 5.854 & TRN & & \\
\hline CHEMBL1409851 & 688537 & 5.2688 & 5.1358 & TRN & & \\
\hline CHEMBL1349757 & 688537 & 2.8239 & 4.4468 & TRN & & \\
\hline CHEMBL1402051 & 688537 & 2.8239 & 5.141 & TRN & & \\
\hline CHEMBL1533710 & 688537 & 5.5397 & 5.4669 & TRN & & \\
\hline CHEMBL1428875 & 688537 & 5.0737 & 4.9587 & TST & & \\
\hline CHEMBL1359020 & 688537 & 2.8239 & 3.2264 & TRN & & \\
\hline CHEMBL1515140 & 688537 & \multicolumn{3}{|c|}{5.332000000000001} & .4836 & TRN \\
\hline CHEMBL1392501 & 688537 & 5.857 & 6.1489 & TRN & & \\
\hline CHEMBL1462457 & 688537 & 6.2472 & 6.1025 & TRN & & \\
\hline CHEMBL1330307 & 688537 & 5.1286 & 5.1768 & TRN & & \\
\hline CHEMBL1989426 & 688537 & 5.3466 & 5.2477 & TRN & & \\
\hline CHEMBL1481444 & 688537 & 4.961 & 4.8575 & TRN & & \\
\hline CHEMBL1584779 & 688537 & 4.79 & 4.2321 & TRN & & \\
\hline CHEMBL1471788 & 688537 & 5.7791 & 5.138 & TRN & & \\
\hline CHEMBL1459241 & 688537 & 2.8239 & 3.4551 & TRN & & \\
\hline CHEMBL1408463 & 688537 & 5.6584 & 5.6896 & TRN & & \\
\hline CHEMBL1578607 & 688537 & 7.0044 & 6.8967 & TRN & & \\
\hline CHEMBL1378290 & 688537 & 5.2056 & 5.2568 & TRN & & \\
\hline CHEMBL1463761 & 688537 & 5.7528 & 5.1289 & TRN & & \\
\hline CHEMBL1487901 & 688537 & 5.7683 & 5.6838 & TRN & & \\
\hline CHEMBL1602883 & 688537 & 4.936 & 4.8472 & TRN & & \\
\hline CHEMBL1502251 & 688537 & 5.4585 & 5.1234 & TRN & & \\
\hline CHEMBL1478856 & 688537 & 5.2431 & 5.4664 & TRN & & \\
\hline CHEMBL1457515 & 688537 & 5.4541 & 5.3538 & TST & & \\
\hline CHEMBL1415425 & 688537 & 5.4939 & 5.5606 & TRN & & \\
\hline CHEMBL1571208 & 688537 & 4.6507 & 4.6276 & TST & & \\
\hline CHEMBL1434750 & 688537 & 5.8011 & 5.8967 & TRN & & \\
\hline CHEMBL1512198 & 688537 & 8.2218 & 8.1859 & TST & & \\
\hline CHEMBL1387128 & 688537 & 2.8239 & 3.12899 & 99999999996 & & TRN \\
\hline CHEMBL1424907 & 688537 & 5.4145 & 5.3997 & TRN & & \\
\hline CHEMBL1603420 & 688537 & 4.8153 & 4.7602 & TRN & & \\
\hline CHEMBL1301353 & 688537 & 5.6207 & 5.3879 & TRN & & \\
\hline CHEMBL1422976 & 688537 & 5.4722 & 5.256 & TRN & & \\
\hline CHEMBL1333647 & 688537 & 3.93300 & 00000000 & 203 & .0194 & TRN \\
\hline CHEMBL1519235 & 688537 & 5.2139 & 5.358 & TRN & & \\
\hline CHEMBL1481198 & 688537 & 6.1158 & 6.0102 & TRN & & \\
\hline
\end{tabular}




\begin{tabular}{|c|c|c|c|c|c|}
\hline \multicolumn{6}{|c|}{ Supplemental Table s2.txt } \\
\hline CHEMBL1372796 & 688537 & 5.2954 & 5.6531 & TRN & \\
\hline CHEMBL1427185 & 688537 & 4.9838 & 4.6071 & TRN & \\
\hline CHEMBL1586806 & 688537 & 5.6484 & 5.7015 & TRN & \\
\hline CHEMBL1359912 & 688537 & 2.8239 & 3.033 & TST & \\
\hline CHEMBL1495462 & 688537 & 5.5322 & 4.7087 & TST & \\
\hline CHEMBL1371733 & 688537 & 2.8239 & 3.2695 & TRN & \\
\hline CHEMBL1587103 & 688537 & 4.2856 & 3.9044 & TRN & \\
\hline CHEMBL1372388 & 688537 & 4.5705 & 4.7056 & TRN & \\
\hline CHEMBL1518844 & 688537 & 5.8303 & 5.9074 & TRN & \\
\hline CHEMBL1426469 & 688537 & 4.7731 & 4.8686 & TRN & \\
\hline CHEMBL1520696 & 688537 & 5.7523 & 5.6444 & TST & \\
\hline CHEMBL1387953 & 688537 & 4.824 & 4.3354 & TRN & \\
\hline CHEMBL3144931 & 688537 & 5.6008 & 4.9821 & TRN & \\
\hline CHEMBL1523372 & 688537 & 5.3763 & 5.50700 & 3000000001 & TRN \\
\hline CHEMBL1344358 & 688537 & 2.8239 & 3.1583 & TRN & \\
\hline CHEMBL1481616 & 688537 & 6.1512 & 5.8277 & TRN & \\
\hline CHEMBL1968842 & 688537 & 5.0532 & 4.7211 & TRN & \\
\hline CHEMBL1386918 & 688537 & 5.0143 & 5.1153 & TRN & \\
\hline CHEMBL3190404 & 688537 & 4.8419 & 4.6819 & TRN & \\
\hline CHEMBL598903 & 688537 & 5.4855 & 5.3526 & TST & \\
\hline CHEMBL3211496 & 688537 & 2.8239 & 3.1898 & TRN & \\
\hline CHEMBL1320542 & 688537 & 6.2798 & 5.96700 & 00000000005 & TRN \\
\hline CHEMBL1383799 & 688537 & 5.4669 & 5.7075 & TRN & \\
\hline CHEMBL1494569 & 688537 & 2.8239 & 4.2794 & TRN & \\
\hline CHEMBL1535538 & 688537 & 4.7435 & 4.7755 & TRN & \\
\hline CHEMBL1566748 & 688537 & 5.4182 & 4.9259 & TRN & \\
\hline CHEMBL1985629 & 688537 & 5.6216 & 4.897 & TRN & \\
\hline CHEMBL1464202 & 688537 & 4.888 & 4.5651 & TRN & \\
\hline CHEMBL3193491 & 688537 & 2.8239 & 3.0221 & TST & \\
\hline CHEMBL1431875 & 688537 & 7.1427 & 8.4822 & TRN & \\
\hline CHEMBL1501917 & 688537 & 5.4499 & 5.6108 & TRN & \\
\hline CHEMBL1502201 & 688537 & 5.8259 & 5.6751 & TRN & \\
\hline CHEMBL1431676 & 688537 & 5.2622 & 4.8829 & TRN & \\
\hline CHEMBL1387605 & 688537 & 6.2434 & 6.1804 & TRN & \\
\hline CHEMBL1546791 & 688537 & 5.0547 & 4.8426 & TRN & \\
\hline CHEMBL1537118 & 688537 & 5.2128 & 4.9023 & TRN & \\
\hline CHEMBL3193488 & 688537 & 2.8239 & 3.11800 & 00000000003 & TRN \\
\hline CHEMBL1510679 & 688537 & 5.5358 & 5.6779 & TRN & \\
\hline CHEMBL1528933 & 688537 & 5.434 & 5.4692 & TRN & \\
\hline CHEMBL1545468 & 688537 & 5.1946 & 5.4555 & TRN & \\
\hline CHEMBL1541410 & 688537 & 6.1343 & 5.4714 & TST & \\
\hline CHEMBL1434604 & 688537 & 4.6836 & 4.7179 & TST & \\
\hline CHEMBL1390716 & 688537 & 6.7033 & 6.3782 & TRN & \\
\hline CHEMBL1173823 & 688537 & 4.6299 & 4.6981 & TRN & \\
\hline CHEMBL1340458 & 688537 & 5.2377 & 5.1114 & TRN & \\
\hline CHEMBL586135 & 688537 & 8.2218 & 7.5767 & TRN & \\
\hline CHEMBL3213728 & 688537 & 4.7124 & 4.8326 & TRN & \\
\hline CHEMBL1441888 & 688537 & 5.1856 & 4.7555 & TRN & \\
\hline
\end{tabular}




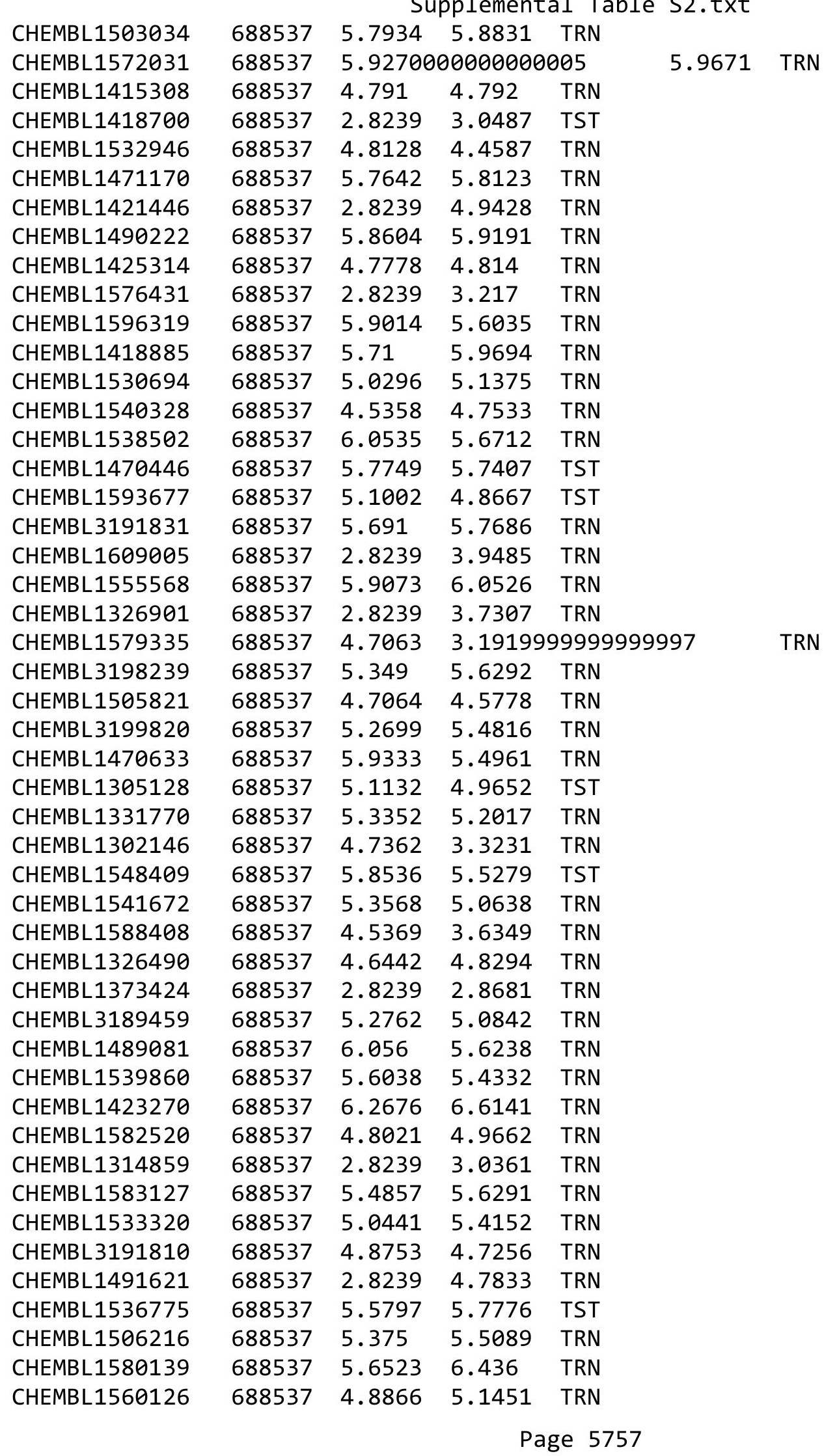




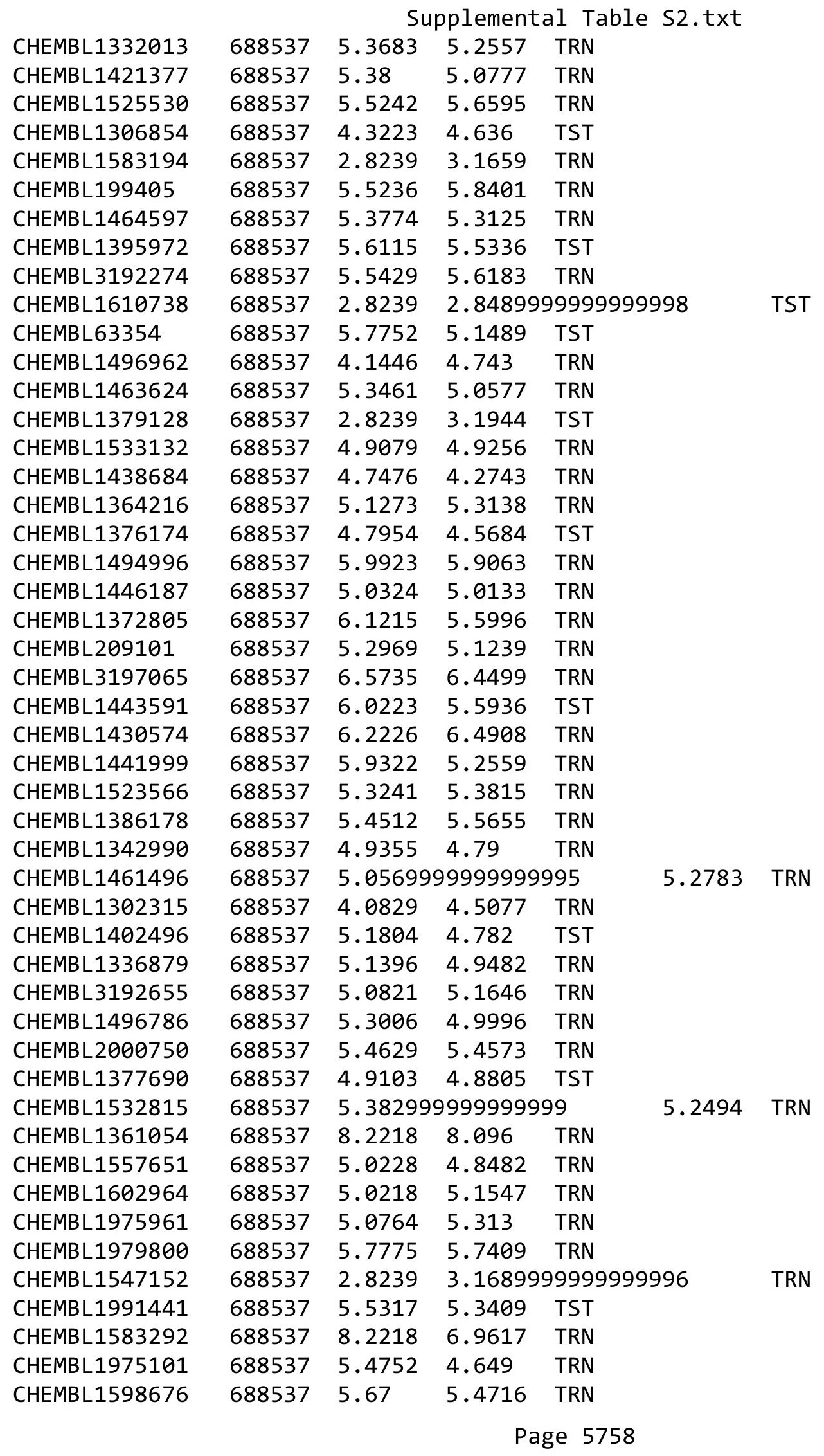




\begin{tabular}{|c|c|c|c|c|c|c|}
\hline & & \multicolumn{5}{|c|}{ Supplemental Table S2.txt } \\
\hline CHEMBL1586774 & 688537 & 2.8239 & 4.7183 & TRN & & \\
\hline CHEMBL1458441 & 688537 & 5.4653 & 5.4771 & TRN & & \\
\hline CHEMBL1461661 & 688537 & 5.782 & 5.5776 & TRN & & \\
\hline CHEMBL1483146 & 688537 & 6.8633 & 6.5471 & TRN & & \\
\hline CHEMBL1546810 & 688537 & 5.5178 & 5.2471 & TRN & & \\
\hline CHEMBL1413355 & 688537 & 4.8986 & 4.5419 & TRN & & \\
\hline CHEMBL1567814 & 688537 & 5.568 & 5.1898 & TRN & & \\
\hline CHEMBL1381704 & 688537 & 4.0767 & 3.5228 & TRN & & \\
\hline CHEMBL3193441 & 688537 & 5.5129 & 5.0866 & TRN & & \\
\hline CHEMBL1477640 & 688537 & 5.4567 & 5.0302 & TRN & & \\
\hline CHEMBL1380621 & 688537 & 5.5784 & 5.7324 & TRN & & \\
\hline CHEMBL1504429 & 688537 & 5.4865 & 5.6125 & TRN & & \\
\hline CHEMBL1405475 & 688537 & 5.5837 & 5.3064 & TRN & & \\
\hline CHEMBL 351660 & 688537 & 5.5074 & 4.8822 & TST & & \\
\hline CHEMBL1340213 & 688537 & 5.0764 & 5.1831 & TRN & & \\
\hline CHEMBL1424836 & 688537 & 2.8239 & 3.472 & TRN & & \\
\hline CHEMBL1391621 & 688537 & 5.2868 & 5.3313 & TRN & & \\
\hline CHEMBL1466644 & 688537 & 5.3832 & 5.5804 & TRN & & \\
\hline CHEMBL1374908 & 688537 & 4.9012 & 4.3465 & TRN & & \\
\hline CHEMBL 2094484 & 688537 & 5.5412 & 5.5493 & TRN & & \\
\hline CHEMBL3193652 & 688537 & 5.5373 & 4.9861 & TRN & & \\
\hline CHEMBL1341308 & 688537 & 5.5724 & 5.8724 & TRN & & \\
\hline CHEMBL 257286 & 688537 & 5.4861 & 5.3543 & TRN & & \\
\hline CHEMBL 1605733 & 688537 & 6.153 & 5.5253 & TST & & \\
\hline CHEMBL1586207 & 688537 & 5.1712 & 4.8441 & TST & & \\
\hline CHEMBL1414361 & 688537 & 2.8239 & 2.9097 & TST & & \\
\hline CHEMBL1477713 & 688537 & 5.1462 & 4.9435 & TST & & \\
\hline CHEMBL3199916 & 688537 & 5.2027 & 5.3192 & TRN & & \\
\hline CHEMBL 1489865 & 688537 & 5.4227 & 5.1239 & TRN & & \\
\hline CHEMBL1383078 & 688537 & 5.4483 & 5.9777 & TRN & & \\
\hline CHEMBL3199217 & 688537 & 5.4504 & 5.2562 & TRN & & \\
\hline CHEMBL1383333 & 688537 & 6.1568 & 6.1774 & TRN & & \\
\hline CHEMBL1564958 & 688537 & $5.5370 e$ & 0000000 & $\partial 1$ & 5.6367 & TRN \\
\hline CHEMBL3195662 & 688537 & 5.6306 & 5.4164 & TST & & \\
\hline CHEMBL1509718 & 688537 & 5.9252 & 5.796 & TST & & \\
\hline CHEMBL1380365 & 688537 & 5.1767 & 5.1606 & TRN & & \\
\hline CHEMBL1580874 & 688537 & 4.9613 & 5.1238 & TRN & & \\
\hline CHEMBL1560577 & 688537 & 5.8677 & 5.9612 & TRN & & \\
\hline CHEMBL1466352 & 688537 & 5.0019 & 4.6672 & TRN & & \\
\hline CHEMBL1382445 & 688537 & 5.0515 & 5.0171 & TRN & & \\
\hline CHEMBL3211464 & 688537 & 5.2029 & 5.1726 & TRN & & \\
\hline CHEMBL1371231 & 688537 & 2.8239 & 3.3054 & TST & & \\
\hline CHEMBL3199856 & 688537 & 5.5176 & 5.301 & TRN & & \\
\hline CHEMBL1308201 & 688537 & 4.9201 & 4.6543 & TST & & \\
\hline CHEMBL1332733 & 688537 & 4.6855 & 4.5249 & TST & & \\
\hline CHEMBL1584229 & 688537 & 4.6774 & 5.2625 & TRN & & \\
\hline CHEMBL1347282 & 688537 & 2.8239 & 3.3374 & TST & & \\
\hline CHEMBL1377629 & 688537 & 5.2887 & 5.5406 & TRN & & \\
\hline
\end{tabular}


Supplemental Table S2.txt

\begin{tabular}{|c|c|c|c|c|c|}
\hline CHEMBL3194563 & 688537 & 5.1427 & 5.0765 & TRN & \\
\hline CHEMBL1327366 & 688537 & 5.1575 & 4.8038 & TRN & \\
\hline CHEMBL1402670 & 688537 & 5.3759 & 5.3852 & TRN & \\
\hline CHEMBL1340114 & 688537 & 4.8125 & 4.765 & TRN & \\
\hline CHEMBL1325258 & 688537 & 4.7039 & 4.7995 & TRN & \\
\hline CHEMBL3197446 & 688537 & 5.301 & 4.9968 & TRN & \\
\hline CHEMBL1416440 & 688537 & 4.9106 & 4.5307 & TRN & \\
\hline CHEMBL1558590 & 688537 & 2.8239 & 4.0754 & TST & \\
\hline CHEMBL1419772 & 688537 & 5.1807 & 5.1441 & TST & \\
\hline CHEMBL1469579 & 688537 & 5.2966 & 5.4824 & TRN & \\
\hline CHEMBL1492510 & 688537 & 4.8879 & 4.6391 & TST & \\
\hline CHEMBL1360393 & 688537 & 4.8361 & 4.7517 & TRN & \\
\hline CHEMBL1366975 & 688537 & 5.7605 & 5.6897 & TRN & \\
\hline CHEMBL1541343 & 688537 & \multicolumn{3}{|c|}{6.4510000000000005} & 6.2321 \\
\hline CHEMBL1560358 & 688537 & 4.9621 & 5.1206 & TRN & \\
\hline CHEMBL1549267 & 688537 & 5.7185 & 5.5663 & TRN & \\
\hline CHEMBL1477881 & 688537 & 5.6855 & 5.6899 & TRN & \\
\hline CHEMBL1471741 & 688537 & 5.4737 & 5.8641 & TRN & \\
\hline CHEMBL528506 & 688537 & 5.3746 & 5.1254 & TRN & \\
\hline CHEMBL1548682 & 688537 & 2.8239 & 3.141 & TST & \\
\hline CHEMBL1984190 & 688537 & 5.7222 & 5.5771 & TRN & \\
\hline CHEMBL3196295 & 688537 & 4.9636 & 4.7768 & TRN & \\
\hline CHEMBL1417780 & 688537 & 5.1645 & 5.1299 & TRN & \\
\hline CHEMBL 254576 & 688537 & 5.8771 & 5.7134 & TRN & \\
\hline CHEMBL586937 & 688537 & 5.2226 & 5.3181 & TRN & \\
\hline CHEMBL1467919 & 688537 & 5.4062 & 5.7509 & TRN & \\
\hline CHEMBL1490966 & 688537 & 2.8239 & 3.2881 & TRN & \\
\hline CHEMBL1442713 & 688537 & 5.2942 & 5.3213 & TST & \\
\hline CHEMBL1482990 & 688537 & 5.1913 & 5.3134 & TRN & \\
\hline CHEMBL1443649 & 688537 & 4.9713 & 4.8451 & TST & \\
\hline CHEMBL1572266 & 688537 & 6.6635 & 6.5247 & TRN & \\
\hline CHEMBL1494433 & 688537 & 5.4312 & 5.4743 & TRN & \\
\hline CHEMBL1433404 & 688537 & 2.8239 & 2.6633 & TRN & \\
\hline CHEMBL1594984 & 688537 & 5.7724 & 6.0395 & TRN & \\
\hline CHEMBL3192616 & 688537 & 5.9694 & 5.9006 & TRN & \\
\hline CHEMBL1433095 & 688537 & 5.2127 & 5.1901 & TRN & \\
\hline CHEMBL3189740 & 688537 & 5.2851 & 5.0135 & TRN & \\
\hline CHEMBL1469460 & 688537 & 5.2436 & 4.5937 & TST & \\
\hline CHEMBL1556925 & 688537 & 5.0118 & 5.0039 & TRN & \\
\hline CHEMBL1513972 & 688537 & 5.3199 & 5.1999 & TST & \\
\hline CHEMBL1476264 & 688537 & 6.5157 & 6.6919 & TRN & \\
\hline CHEMBL1612159 & 688537 & 5.8097 & 5.4359 & TST & \\
\hline CHEMBL1391179 & 688537 & 5.271 & 5.2592 & TST & \\
\hline CHEMBL1464261 & 688537 & 5.2875 & 5.2599 & TST & \\
\hline CHEMBL1334670 & 688537 & 5.2581 & 4.8545 & TRN & \\
\hline CHEMBL1977078 & 688537 & 5.5309 & 5.4696 & TST & \\
\hline CHEMBL1534138 & 688537 & 2.8239 & 2.8778 & TRN & \\
\hline CHEMBL1375468 & 688537 & 5.6737 & 5.1729 & TRN & \\
\hline
\end{tabular}




\begin{tabular}{|c|c|c|c|c|c|c|}
\hline \multirow[b]{2}{*}{ CHEMBL1439185 } & \multicolumn{6}{|c|}{ Supplemental Table S2.txt } \\
\hline & 688537 & 2.8239 & 4.1883 & TST & & \\
\hline CHEMBL1394121 & 688537 & 5.1943 & 4.4907 & TRN & & \\
\hline CHEMBL1367877 & 688537 & 5.2483 & 5.4152 & TRN & & \\
\hline CHEMBL1363543 & 688537 & 5.5447 & 5.3791 & TRN & & \\
\hline CHEMBL1332728 & 688537 & 5.3106 & 5.0521 & TRN & & \\
\hline CHEMBL1505450 & 688537 & 5.1045 & 5.2895 & TRN & & \\
\hline CHEMBL1481301 & 688537 & 5.6716 & 5.8719 & TRN & & \\
\hline CHEMBL1384874 & 688537 & 6.26200 & 30000000 & 005 & .9805 & TRN \\
\hline CHEMBL3198791 & 688537 & 5.8416 & 5.7767 & TST & & \\
\hline CHEMBL1532303 & 688537 & 5.0171 & 4.4877 & TRN & & \\
\hline CHEMBL1361046 & 688537 & 5.3136 & 5.1169 & TRN & & \\
\hline CHEMBL 3194562 & 688537 & 5.6282 & 5.6667 & TRN & & \\
\hline CHEMBL1368435 & 688537 & 5.0852 & 4.4094 & TRN & & \\
\hline CHEMBL1500466 & 688537 & 5.0582 & 5.1863 & TRN & & \\
\hline CHEMBL171637 & 688537 & 5.6275 & 4.7875 & TST & & \\
\hline CHEMBL1431056 & 688537 & 2.8239 & 3.148 & TST & & \\
\hline CHEMBL1501874 & 688537 & 5.0005 & 4.948 & TRN & & \\
\hline CHEMBL1581270 & 688537 & 4.8408 & 4.1961 & TRN & & \\
\hline CHEMBL1384325 & 688537 & 5.1812 & 5.2967 & TST & & \\
\hline CHEMBL1493953 & 688537 & 5.1517 & 5.3738 & TRN & & \\
\hline CHEMBL1563221 & 688537 & 5.5812 & 5.6886 & TRN & & \\
\hline CHEMBL1451125 & 688537 & 5.2332 & 4.8424 & TRN & & \\
\hline CHEMBL355496 & 688537 & 5.5844 & 5.7427 & TRN & & \\
\hline CHEMBL1400406 & 688537 & 6.1152 & 6.0675 & TRN & & \\
\hline CHEMBL1322356 & 688537 & 5.6653 & 5.5753 & TRN & & \\
\hline CHEMBL1316002 & 688537 & 5.7158 & 5.6473 & TRN & & \\
\hline CHEMBL1392200 & 688537 & 5.699 & 6.1534 & TRN & & \\
\hline CHEMBL1342093 & 688537 & 5.9104 & 5.9346 & TRN & & \\
\hline CHEMBL1369492 & 688537 & 5.6223 & 5.3531 & TRN & & \\
\hline CHEMBL1575766 & 688537 & 5.2558 & 5.118 & TRN & & \\
\hline CHEMBL1537518 & 688537 & 4.6355 & 4.7665 & TRN & & \\
\hline CHEMBL1421570 & 688537 & 4.1123 & 3.4304 & TRN & & \\
\hline CHEMBL 3197243 & 688537 & 5.6007 & 5.6391 & TRN & & \\
\hline CHEMBL1364011 & 688537 & 8.2218 & 8.5929 & TRN & & \\
\hline CHEMBL1586809 & 688537 & 4.8234 & 5.106 & TRN & & \\
\hline CHEMBL1572056 & 688537 & 4.6909 & 4.3575 & TRN & & \\
\hline CHEMBL1353643 & 688537 & 5.6962 & 5.92399 & 99999999995 & & TRN \\
\hline CHEMBL1529276 & 688537 & 5.2535 & 5.5231 & TRN & & \\
\hline CHEMBL1385886 & 688537 & 4.7186 & 4.3872 & TRN & & \\
\hline CHEMBL1375045 & 688537 & 5.8854 & 5.58799 & 9999999999 & & TST \\
\hline CHEMBL1485261 & 688537 & 4.5468 & 4.3576 & TRN & & \\
\hline CHEMBL1343101 & 688537 & 5.7233 & 5.4184 & TST & & \\
\hline CHEMBL1531168 & 688537 & 5.1177 & 6.0968 & TRN & & \\
\hline CHEMBL1537032 & 688537 & 4.6013 & 3.234 & TST & & \\
\hline CHEMBL 3189984 & 688537 & 5.99100 & 30000000 & 005 & .9767 & TRN \\
\hline CHEMBL1416184 & 688537 & 5.5638 & 5.7223 & TRN & & \\
\hline CHEMBL 3145287 & 688537 & 5.5261 & 5.3811 & TRN & & \\
\hline CHEMBL1440838 & 688537 & 2.8239 & 2.425 & TRN & & \\
\hline
\end{tabular}




\begin{tabular}{|c|c|c|c|c|c|c|}
\hline & & \multicolumn{5}{|c|}{ Supplemental Table s2.txt } \\
\hline CHEMBL580955 & 688537 & 5.5928 & 5.399 & TRN & & \\
\hline CHEMBL1534716 & 688537 & 5.4585 & 4.8896 & TRN & & \\
\hline CHEMBL1511495 & 688537 & 5.1053 & 5.2005 & TRN & & \\
\hline CHEMBL3197091 & 688537 & 6.251 & 5.98600 & 0000000001 & & TRN \\
\hline CHEMBL1519239 & 688537 & 5.0504 & 5.2758 & TRN & & \\
\hline CHEMBL1599033 & 688537 & 8.2218 & 7.8137 & TST & & \\
\hline CHEMBL1306359 & 688537 & 6.058 & 6.0714 & TRN & & \\
\hline CHEMBL3193092 & 688537 & 4.9439 & 4.7918 & TRN & & \\
\hline CHEMBL 2005246 & 688537 & 6.6289 & 6.4009 & TRN & & \\
\hline CHEMBL1546285 & 688537 & 5.9359 & 5.1727 & TRN & & \\
\hline CHEMBL1486883 & 688537 & $5.2020 €$ & 0000000 & & 4.9523 & TRN \\
\hline CHEMBL1320948 & 688537 & 4.3037 & 4.6273 & TRN & & \\
\hline CHEMBL3196681 & 688537 & 5.1015 & 4.7865 & TRN & & \\
\hline CHEMBL1308873 & 688537 & 5.3699 & 5.5504 & TRN & & \\
\hline CHEMBL1303940 & 688537 & 2.8239 & 3.0252 & TST & & \\
\hline CHEMBL3196513 & 688537 & 4.8854 & 4.6039 & TRN & & \\
\hline CHEMBL1470030 & 688537 & 2.8239 & 2.8358 & TRN & & \\
\hline CHEMBL 2006856 & 688537 & 5.3188 & 5.2286 & TRN & & \\
\hline CHEMBL1382806 & 688537 & 5.6778 & 5.6246 & TRN & & \\
\hline CHEMBL1427455 & 688537 & 4.6157 & 4.3517 & TST & & \\
\hline CHEMBL1540122 & 688537 & 4.7798 & 4.3006 & TRN & & \\
\hline CHEMBL123 & 688537 & 5.6476 & 5.4693 & TST & & \\
\hline CHEMBL1575588 & 688537 & 5.09699 & 79999999ऽ & 995 & 5.0701 & TST \\
\hline CHEMBL1422161 & 688537 & 5.3863 & 5.3246 & TRN & & \\
\hline CHEMBL1304742 & 688537 & 5.7102 & 5.0972 & TST & & \\
\hline CHEMBL1426383 & 688537 & 6.2865 & 6.1026 & TRN & & \\
\hline CHEMBL1436964 & 688537 & 6.0453 & 5.4501 & TRN & & \\
\hline CHEMBL1523312 & 688537 & 2.8239 & 2.7019 & TRN & & \\
\hline CHEMBL1349905 & 688537 & 5.2229 & 5.5502 & TRN & & \\
\hline CHEMBL1416526 & 688537 & 5.5885 & 5.3529 & TRN & & \\
\hline CHEMBL1359157 & 688537 & 5.2595 & 5.4329 & TST & & \\
\hline CHEMBL1328493 & 688537 & 5.2868 & 5.6827 & TRN & & \\
\hline CHEMBL1601265 & 688537 & 5.5787 & 4.9936 & TRN & & \\
\hline CHEMBL1324064 & 688537 & 2.8239 & 2.9132 & TST & & \\
\hline CHEMBL1589425 & 688537 & 5.75799 & 99999999 & 99 & 5.6648 & TST \\
\hline CHEMBL1535539 & 688537 & 6.1124 & 5.7204 & TST & & \\
\hline CHEMBL1459918 & 688537 & 5.4089 & 5.5013 & TRN & & \\
\hline CHEMBL1504848 & 688537 & 2.8239 & 2.8444 & TRN & & \\
\hline CHEMBL1305918 & 688537 & 5.4317 & 5.8904 & TRN & & \\
\hline CHEMBL1354074 & 688537 & 5.3103 & 4.7544 & TRN & & \\
\hline CHEMBL1311826 & 688537 & 6.4473 & 6.6613 & TRN & & \\
\hline CHEMBL3190142 & 688537 & 5.1783 & 5.0968 & TRN & & \\
\hline CHEMBL1331801 & 688537 & 5.5669 & 5.3358 & TST & & \\
\hline CHEMBL1591082 & 688537 & 5.4877 & 5.3286 & TRN & & \\
\hline CHEMBL1345080 & 688537 & 4.6607 & 5.2272 & TRN & & \\
\hline CHEMBL1346307 & 688537 & 4.8947 & 4.9906 & TRN & & \\
\hline CHEMBL1379636 & 688537 & 5.688 & 5.4545 & TST & & \\
\hline CHEMBL1418389 & 688537 & 6.6216 & 6.4784 & TRN & & \\
\hline
\end{tabular}




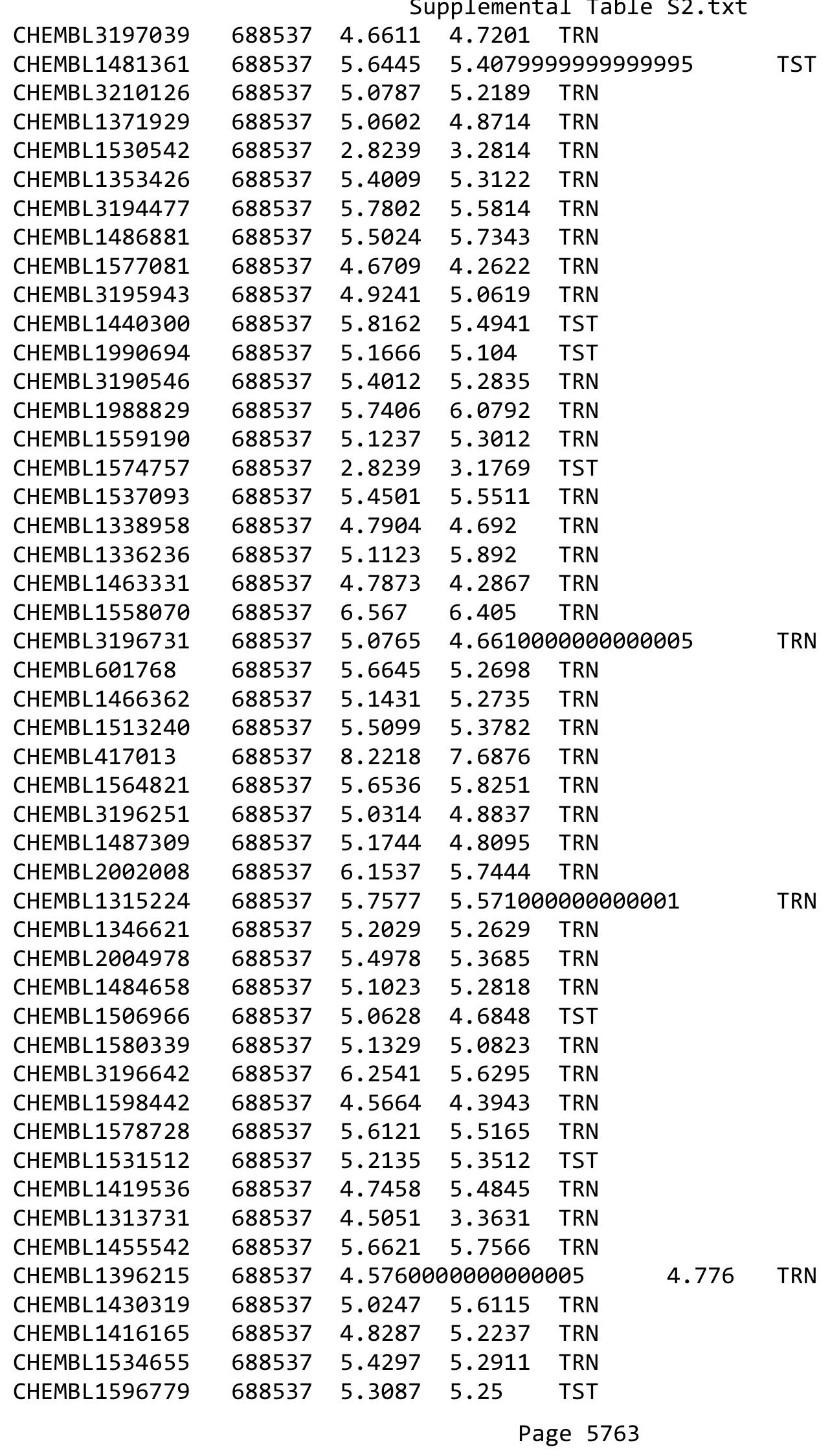


Supplemental Table S2.txt

\begin{tabular}{|c|c|c|c|c|}
\hline 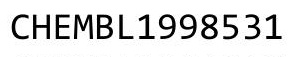 & & & 4471 & \\
\hline HEMBL1344918 & 38537 & 2529 & 8234 & \\
\hline HEMBL1302758 & 88537 & & 806 & \\
\hline IEMBL1 & & & 2773 & \\
\hline EMBL14 & & 56 & .3713 & \\
\hline HEMBL1488035 & 88537 & 595 & .5973 & \\
\hline HEMBL1557952 & 88537 & .4608 & .6835 & \\
\hline HEMBL607 & & 952 & .8981 & \\
\hline IEMBL32 & 37 & & .3828 & \\
\hline IEMBL15 & 37 & & .6862 & \\
\hline HEMBL1423286 & 88537 & .1046 & .4522 & \\
\hline HEMBL1410739 & 88537 & & .4334 & \\
\hline HEMBL504 & 37 & 64 & 9378 & \\
\hline HEMBL13e & 37 & 78 & .2886 & \\
\hline HEMBL152 & 37 & & .2463 & \\
\hline HEMBL151 & 37 & 64 & 2546 & \\
\hline HEMBL318 & 88537 & & 6172 & \\
\hline HEMBL149 & 37 & 7 & 3734 & \\
\hline HEMBL13 & & & 5664 & \\
\hline HEMBL15 & & & .9075 & \\
\hline HEMBL14 & 37 & 96 & 949 & \\
\hline HEMBL15 & 37 & & & \\
\hline HEMBL14 & 7 & & .4192 & Niv \\
\hline HEMBL15 & & & .5156 & \\
\hline 43 & & & 6.1946 & $\mathrm{RN}$ \\
\hline HEMBL13 & & & & N \\
\hline HEMBL139 & 37 & & & Iv \\
\hline HEMBL13 & & & 53 & RN \\
\hline HEM & & & 87 & RN \\
\hline 51 & & 3 & 29 & RN \\
\hline HEMBL15e & & & & $\mathbf{v}$ \\
\hline HEMBL1478314 & 885 & & 4.8393 & ГRN \\
\hline HEMBL1: & & & 933 & 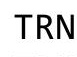 \\
\hline 8 & & & 95 & RN \\
\hline HEMBL153 & & & 3.1596 & RN \\
\hline HEMBL1305375 & 37 & & 5.3713 & Th \\
\hline HEMBL 2006511 & 88537 & & 5.7953 & RN \\
\hline 100 & 37 & & 78 & RIV \\
\hline 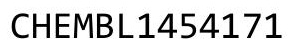 & & & 5.7291 & RN \\
\hline HEMBL 138 & & & 5.6655 & $\mathrm{RN}$ \\
\hline HEMBL148 & 88537 & 2 & 6.1326 & TRN \\
\hline HEMBL 31 & 88537 & & 5.2761 & RN \\
\hline HEMBL15 & & & 4.4751 & \\
\hline HEMBL13 & & & & RN \\
\hline HEMBL1559226 & & & .2618 & RN \\
\hline HEMBL 130 & 38537 & & 5.1096 & \\
\hline 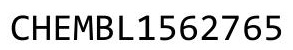 & & & 01 & \\
\hline ר & & & & \\
\hline
\end{tabular}


Supplemental Table S2.txt

\begin{tabular}{|c|c|c|c|c|}
\hline 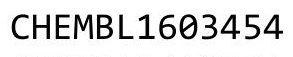 & & o & & \\
\hline HEMBL1412704 & 88537 & 1907 & 8541 & \\
\hline HEMBL1469449 & 7 & 0169 & .123 & \\
\hline 1323 & & 39 & & \\
\hline AEMBL1: & & 3239 & & \\
\hline AEMBL1484438 & 88537 & .9586 & 7.0297 & \\
\hline HEMBL1559624 & 88537 & .5761 & 5.5215 & \\
\hline HEMBL494083 & & 796 & 45 & \\
\hline HEMBL1361740 & & 509 & .2013 & \\
\hline AEMBL13 & & & & \\
\hline HEMBL1391973 & 88537 & .8292 & 4.371 & \\
\hline HEMBL1299389 & 37 & .7055 & 6.6395 & \\
\hline HEMBL1414465 & 37 & 369 & 5.2486 & \\
\hline HEMBL15 & & 864 & & \\
\hline JEMBL14 & & 86 & & \\
\hline HEMBL1353339 & 37 & 9324 & 4.8515 & \\
\hline AEMBL1493101 & 37 & & & \\
\hline HEMBL15 & 58 & 919 & 05 & \\
\hline L14 & & 239 & & \\
\hline AEMBL13 & & 79 & & \\
\hline HEMBL1366319 & & 072 & & \\
\hline AEMBL1426228 & & & & \\
\hline HEMBL15 & 58 & 399 & & \\
\hline L1: & & 946 & & \\
\hline 307 & & 66 & & \\
\hline 1222 & & & & 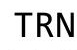 \\
\hline AEMBL1417529 & & & & \\
\hline JEMBL15 & & 235 & & ST \\
\hline HEN & & & & RN \\
\hline L13 & & 257 & & ST \\
\hline AEMBL1331692 & & & & \\
\hline HEMBL1591445 & & 432 & & RN \\
\hline AEMBL1 & & 96 & & RN \\
\hline 5 & & 39 & & RN \\
\hline 4 & & 37 & & $\mathrm{RN}$ \\
\hline AEMBL1546374 & & 863 & & ST \\
\hline AEMBL1346056 & & 931 & 405 & $\mathrm{RN}$ \\
\hline 761 & & & & KIV \\
\hline 8 & & & & RIV \\
\hline & & & 3947 & RN \\
\hline AEMBL494252 & 37 & 751 & 5.8361 & RN \\
\hline AEMBL13 & & & & RN \\
\hline HEMBL1379322 & & & & \\
\hline HEMBL15 & & 239 & & II \\
\hline HEMBL3196125 & & & 4.8718 & ST \\
\hline IEMBL16 & 37 & 478 & .3436 & ST \\
\hline 21 & & & & \\
\hline & & & 5.3499 & \\
\hline
\end{tabular}




\begin{tabular}{|c|c|c|c|c|c|c|}
\hline & & \multicolumn{5}{|c|}{ Supplemental Table S2.txt } \\
\hline CHEMBL1540477 & 688537 & 5.5714 & 5.3251 & TRN & & \\
\hline CHEMBL1582424 & 688537 & 2.8239 & 3.1604 & TRN & & \\
\hline CHEMBL1370838 & 688537 & 5.0711 & 4.5488 & TST & & \\
\hline CHEMBL1431888 & 688537 & 4.7976 & 4.7098 & TRN & & \\
\hline CHEMBL3144976 & 688537 & 5.83 & 6.1543 & TRN & & \\
\hline CHEMBL1518285 & 688537 & 5.4375 & 5.4445 & TRN & & \\
\hline CHEMBL1197556 & 688537 & 5.3242 & 5.1994 & TST & & \\
\hline CHEMBL1508399 & 688537 & 5.5242 & 5.1109 & TRN & & \\
\hline CHEMBL2369316 & 688537 & 4.4867 & 4.6113 & TRN & & \\
\hline CHEMBL1533170 & 688537 & 2.8239 & 4.2998 & TRN & & \\
\hline CHEMBL1329129 & 688537 & 5.6388 & 5.7525 & TRN & & \\
\hline CHEMBL1299640 & 688537 & 5.4703 & 5.0342 & TRN & & \\
\hline CHEMBL1428000 & 688537 & 4.4818 & 3.6253 & TST & & \\
\hline CHEMBL1381257 & 688537 & 4.5995 & 4.3761 & TRN & & \\
\hline CHEMBL1329067 & 688537 & 5.5102 & 5.5106 & TRN & & \\
\hline CHEMBL1994623 & 688537 & 6.6038 & 6.3752 & TRN & & \\
\hline CHEMBL1977301 & 688537 & 5.7073 & 5.8653 & TRN & & \\
\hline CHEMBL1475524 & 688537 & 4.506 & 3.895 & TRN & & \\
\hline CHEMBL1578127 & 688537 & 6.098 & 5.7363 & TST & & \\
\hline CHEMBL1489358 & 688537 & 5.4332 & 5.1578 & TST & & \\
\hline CHEMBL1345063 & 688537 & 5.6417 & 5.5983 & TRN & & \\
\hline CHEMBL1530170 & 688537 & 5.4212 & 5.2114 & TRN & & \\
\hline CHEMBL3190900 & 688537 & 5.2935 & 5.3939 & TRN & & \\
\hline CHEMBL3197439 & 688537 & 4.6954 & 4.8568 & TRN & & \\
\hline CHEMBL1610217 & 688537 & 5.5468 & 5.1261 & TRN & & \\
\hline CHEMBL1368599 & 688537 & 6.0846 & 5.8175 & TRN & & \\
\hline CHEMBL1576647 & 688537 & 5.4777 & 5.1371 & TRN & & \\
\hline CHEMBL1402936 & 688537 & 5.3145 & 5.8642 & TRN & & \\
\hline CHEMBL1302620 & 688537 & 2.8239 & 3.3337 & TST & & \\
\hline CHEMBL1352903 & 688537 & 4.6911 & 4.7703 & TRN & & \\
\hline CHEMBL3195273 & 688537 & 5.0887 & 4.2844 & TRN & & \\
\hline CHEMBL1364447 & 688537 & 6.21899 & 99999999 & 99 & 5.8013 & 151 \\
\hline CHEMBL1336654 & 688537 & 4.9521 & 4.5197 & TST & & \\
\hline CHEMBL1566076 & 688537 & 5.4504 & 5.2595 & TRN & & \\
\hline CHEMBL1531834 & 688537 & 5.8908 & 6.1242 & TRN & & \\
\hline CHEMBL3193792 & 688537 & 5.1123 & 5.1236 & TRN & & \\
\hline CHEMBL1456111 & 688537 & 7.1308 & 6.7132 & TRN & & \\
\hline CHEMBL3192479 & 688537 & 5.0751 & 5.112 & TRN & & \\
\hline CHEMBL 238188 & 688537 & 5.9539 & 6.0266 & TRN & & \\
\hline CHEMBL1517741 & 688537 & 5.9872 & 6.1519 & TRN & & \\
\hline CHEMBL579318 & 688537 & 5.8814 & 5.6767 & TRN & & \\
\hline CHEMBL1596234 & 688537 & 2.8239 & 4.6377 & TRN & & \\
\hline CHEMBL1390546 & 688537 & 5.4067 & 5.1961 & TRN & & \\
\hline CHEMBL1568018 & 688537 & 5.0447 & 5.1131 & TRN & & \\
\hline CHEMBL 2358514 & 688537 & 5.5294 & 5.1433 & TST & & \\
\hline CHEMBL1358093 & 688537 & 5.50700 & 00000000 & 01 & 5.7315 & TRN \\
\hline CHEMBL1594907 & 688537 & 2.8239 & 2.8214 & TRN & & \\
\hline CHEMBL3192194 & 688537 & 5.9122 & 5.7171 & TRN & & \\
\hline
\end{tabular}


Supplemental Table S2.txt

\begin{tabular}{|c|c|c|c|c|c|}
\hline CHEMBL1448584 & 688537 & 6.1605 & 6.2977 & TRN & \\
\hline CHEMBL1310332 & 688537 & 4.9357 & 5.0438 & TRN & \\
\hline CHEMBL1985479 & 688537 & 5.2925 & 5.3061 & TRN & \\
\hline CHEMBL1506765 & 688537 & 4.7648 & 5.0269 & TRN & \\
\hline CHEMBL1518455 & 688537 & 5.0033 & 4.6206 & TRN & \\
\hline CHEMBL1405668 & 688537 & 5.3606 & 5.3738 & TST & \\
\hline CHEMBL1340150 & 688537 & 5.4746 & 5.7502 & TRN & \\
\hline CHEMBL1402267 & 688537 & 5.1132 & 5.084 & TRN & \\
\hline CHEMBL1427178 & 688537 & 6.7399 & 6.8784 & TRN & \\
\hline CHEMBL1587655 & 688537 & 5.1694 & 4.8304 & TRN & \\
\hline CHEMBL1506580 & 688537 & 5.4275 & 5.2802 & TRN & \\
\hline CHEMBL1340154 & 688537 & 2.8239 & 3.1402 & TRN & \\
\hline CHEMBL1499111 & 688537 & 5.2289 & 5.5142 & TRN & \\
\hline CHEMBL1534781 & 688537 & 5.3246 & 5.0703 & TRN & \\
\hline CHEMBL3199104 & 688537 & 5.1462 & 5.3862 & TRN & \\
\hline CHEMBL3194847 & 688537 & 4.9557 & 5.0434 & TRN & \\
\hline CHEMBL3190468 & 688537 & 5.8655 & 6.106 & TRN & \\
\hline CHEMBL1463734 & 688537 & 2.8239 & 2.9988 & TRN & \\
\hline CHEMBL1423839 & 688537 & 5.6021 & 5.5058 & TRN & \\
\hline CHEMBL3191019 & 688537 & 5.0952 & 4.8009 & TRN & \\
\hline CHEMBL3199403 & 688537 & 5.26 & 5.2531 & TRN & \\
\hline CHEMBL3195531 & 688537 & 5.2431 & 5.7859 & TRN & \\
\hline CHEMBL3192555 & 688537 & 5.5239 & 5.926 & TRN & \\
\hline CHEMBL1966798 & 688537 & 5.3869 & 4.9713 & TRN & \\
\hline CHEMBL1588987 & 688537 & 4.8176 & 4.9653 & TRN & \\
\hline CHEMBL1473543 & 688537 & 4.4815 & 4.7628 & TST & \\
\hline CHEMBL3195813 & 688537 & 5.8179 & 5.5501 & TRN & \\
\hline CHEMBL1330556 & 688537 & 5.6084 & 5.4706 & TST & \\
\hline CHEMBL1365611 & 688537 & 5.2447 & 5.1893 & TST & \\
\hline CHEMBL3193378 & 688537 & 5.9805 & 5.841 & TRN & \\
\hline CHEMBL1310101 & 688537 & 5.5804 & 5.65 & TRN & \\
\hline CHEMBL1373002 & 688537 & 5.3771 & 5.2971 & TRN & \\
\hline CHEMBL1467901 & 688537 & 2.8239 & 2.6637 & TRN & \\
\hline CHEMBL1459036 & 688537 & 4.64199 & 999999999 & 995 & 4.3711 \\
\hline CHEMBL1535622 & 688537 & 5.1983 & 4.6536 & TRN & \\
\hline CHEMBL1538328 & 688537 & 5.7545 & 5.8013 & TST & \\
\hline CHEMBL3189599 & 688537 & 5.5214 & 5.3358 & TRN & \\
\hline CHEMBL1345827 & 688537 & 5.1406 & 5.2229 & TRN & \\
\hline CHEMBL1559100 & 688537 & 5.6103 & 5.3873 & TRN & \\
\hline CHEMBL1534433 & 688537 & 2.8239 & 3.114 & TRN & \\
\hline CHEMBL1341979 & 688537 & 5.0278 & 4.7839 & TRN & \\
\hline CHEMBL3193835 & 688537 & 5.1908 & 4.8607 & TRN & \\
\hline CHEMBL473107 & 688537 & 5.3689 & 5.0761 & TRN & \\
\hline CHEMBL1542959 & 688537 & 5.6499 & 5.6459 & TRN & \\
\hline CHEMBL3196867 & 688537 & 5.605 & 5.6658 & TRN & \\
\hline CHEMBL601757 & 688537 & 5.3245 & 5.4772 & TST & \\
\hline CHEMBL1530378 & 688537 & 2.8239 & 3.1419 & TST & \\
\hline CHEMBL1325639 & 688537 & 4.9187 & 4.5925 & TRN & \\
\hline
\end{tabular}


Supplemental Table S2.txt

\begin{tabular}{|c|c|c|c|c|c|}
\hline CHEMBL1604790 & 688537 & 5.6123 & 5.4523 & TRN & \\
\hline CHEMBL1579026 & 688537 & 5.1561 & 5.2366 & TRN & \\
\hline CHEMBL1525259 & 688537 & 5.6242 & 5.3115 & TRN & \\
\hline CHEMBL1982010 & 688537 & 5.7373 & 6.061 & TRN & \\
\hline CHEMBL1546381 & 688537 & 4.9411 & 4.9917 & TRN & \\
\hline CHEMBL1405968 & 688537 & 6.2503 & 5.7334 & TRN & \\
\hline CHEMBL1602058 & 688537 & 4.8495 & 4.9437 & TRN & \\
\hline CHEMBL1485259 & 688537 & 5.9914 & 5.9809 & TRN & \\
\hline CHEMBL1576050 & 688537 & 2.8239 & 2.8725 & TRN & \\
\hline CHEMBL1539510 & 688537 & 4.9428 & 4.7638 & TRN & \\
\hline CHEMBL1306856 & 688537 & 4.6316 & 4.6734 & TRN & \\
\hline CHEMBL1491750 & 688537 & 5.6753 & 5.6535 & TST & \\
\hline CHEMBL584668 & 688537 & 4.9599 & 5.3886 & TRN & \\
\hline CHEMBL 2369184 & 688537 & 5.9 & 5.8212 & TRN & \\
\hline CHEMBL3194209 & 688537 & 4.3505 & 3.465 & TRN & \\
\hline CHEMBL3190827 & 688537 & 5.1137 & 5.4273 & TRN & \\
\hline CHEMBL3190811 & 688537 & 4.0502 & 4.3481 & TRN & \\
\hline CHEMBL3189743 & 688537 & 5.5268 & 5.571000 & 0000000001 & TRN \\
\hline CHEMBL1302815 & 688537 & 5.4139 & 5.6748 & TRN & \\
\hline CHEMBL1469207 & 688537 & 5.1699 & 5.1529 & TRN & \\
\hline CHEMBL1350749 & 688537 & 5.3645 & 5.3595 & TRN & \\
\hline CHEMBL1579693 & 688537 & 5.683 & 5.6951 & TRN & \\
\hline CHEMBL1422465 & 688537 & $5.1560 e$ & 000000000 & 5.1255 & TST \\
\hline CHEMBL1448808 & 688537 & 5.2763 & 5.4037 & TRN & \\
\hline CHEMBL1541862 & 688537 & 5.1062 & 4.9852 & TRN & \\
\hline CHEMBL1447284 & 688537 & 6.71899 & 999999999 & 7.6451 & TRN \\
\hline CHEMBL1605668 & 688537 & 5.3684 & 4.7712 & TRN & \\
\hline CHEMBL1303126 & 688537 & 4.7423 & 4.6574 & TRN & \\
\hline CHEMBL3199756 & 688537 & 6.3778 & 6.3191 & TRN & \\
\hline CHEMBL1418812 & 688537 & 6.3958 & 6.3982 & TRN & \\
\hline CHEMBL1611573 & 688537 & 6.1284 & 6.1208 & TRN & \\
\hline CHEMBL1337445 & 688537 & 5.7029 & 5.7024 & TST & \\
\hline CHEMBL1470475 & 688537 & 2.8239 & 2.8907 & TST & \\
\hline CHEMBL1422170 & 688537 & 2.8239 & 3.1284 & TRN & \\
\hline CHEMBL1976677 & 688537 & 5.7324 & 5.9887 & TRN & \\
\hline CHEMBL1478237 & 688537 & 5.402 & 5.4489 & TRN & \\
\hline CHEMBL1449124 & 688537 & 5.4742 & 5.4161 & TRN & \\
\hline CHEMBL3196139 & 688537 & 4.8463 & 5.0017 & TRN & \\
\hline CHEMBL1451132 & 688537 & 4.4028 & 4.4634 & TRN & \\
\hline CHEMBL1322496 & 688537 & 4.6988 & 5.0911 & TRN & \\
\hline CHEMBL3208968 & 688537 & 6.209 & 5.742999 & 9999999999 & $7 \mathrm{~T}$ \\
\hline CHEMBL1612732 & 688537 & 5.4403 & 5.1222 & TRN & \\
\hline CHEMBL1424933 & 688537 & 5.1162 & 4.8733 & TRN & \\
\hline CHEMBL 2006545 & 688537 & 5.9784 & 5.8668 & TRN & \\
\hline CHEMBL1329336 & 688537 & 5.5397 & 5.3147 & TRN & \\
\hline CHEMBL1392523 & 688537 & 2.8239 & 3.4815 & TST & \\
\hline CHEMBL1365325 & 688537 & 4.8301 & 4.9437 & TRN & \\
\hline CHEMBL1609332 & 688537 & 5.2518 & 5.5179 & TRN & \\
\hline
\end{tabular}


Supplemental Table S2.txt

\begin{tabular}{|c|c|c|c|c|}
\hline CHEMBL1461196 & 688537 & 6.1993 & 6.3019 & TRN \\
\hline CHEMBL1327627 & 688537 & 5.1847 & 5.3565 & TRN \\
\hline CHEMBL3190482 & 688537 & 5.2716 & 5.1285 & TRN \\
\hline CHEMBL1563791 & 688537 & 6.7077 & 6.8061 & TRN \\
\hline CHEMBL1333177 & 688537 & 6.0414 & 6.0231 & TST \\
\hline CHEMBL1552543 & 688537 & 6.1469 & 5.8006 & TRN \\
\hline CHEMBL1598340 & 688537 & 5.6423 & 5.8117 & TRN \\
\hline CHEMBL51085 & 688537 & 5.9602 & 5.9105 & TRN \\
\hline CHEMBL3190739 & 688537 & 5.4862 & 5.2989 & TRN \\
\hline CHEMBL1602581 & 688537 & 5.7077 & 5.3244 & TRN \\
\hline CHEMBL1555719 & 688537 & 5.2892 & 4.9924 & TRN \\
\hline CHEMBL1333978 & 688537 & 4.6896 & 4.8237 & TRN \\
\hline CHEMBL1509051 & 688537 & 6.4647 & 6.2647 & TRN \\
\hline CHEMBL1425166 & 688537 & 5.4582 & 5.5185 & TRN \\
\hline CHEMBL3145320 & 688537 & 5.4508 & 5.6919 & TRN \\
\hline CHEMBL1610654 & 688537 & 6.3125 & 5.3881 & TRN \\
\hline CHEMBL1334968 & 688537 & 5.1479 & 5.4734 & TRN \\
\hline CHEMBL1500382 & 688537 & 4.4824 & 4.5855 & TRN \\
\hline CHEMBL1462889 & 688537 & 2.8239 & 4.5569 & TRN \\
\hline CHEMBL1536256 & 688537 & 5.6694 & 5.6579 & TRN \\
\hline CHEMBL1430104 & 688537 & 5.4388 & 5.2841 & TRN \\
\hline CHEMBL1324944 & 688537 & 6.3072 & 6.3956 & TRN \\
\hline CHEMBL1364119 & 688537 & 5.6332 & 5.7019 & TRN \\
\hline CHEMBL1431751 & 688537 & 2.8239 & 3.3875 & TRN \\
\hline CHEMBL1539579 & 688537 & 6.1284 & 6.0035 & TRN \\
\hline CHEMBL1467238 & 688537 & 2.8239 & 4.5215 & TST \\
\hline CHEMBL1989234 & 688537 & 6.0255 & 5.8399 & TRN \\
\hline CHEMBL1588859 & 688537 & 5.31 & 5.0765 & TST \\
\hline CHEMBL1558361 & 688537 & 5.3499 & 5.3451 & TRN \\
\hline CHEMBL1447076 & 688537 & 5.5825 & 5.5259 & TRN \\
\hline CHEMBL1521230 & 688537 & 5.0229 & 5.5411 & TRN \\
\hline CHEMBL1495254 & 688537 & 5.8811 & 5.564 & TRN \\
\hline CHEMBL1366012 & 688537 & 5.9352 & 6.2985 & TRN \\
\hline CHEMBL1565132 & 688537 & 2.8239 & 4.0813 & TRN \\
\hline CHEMBL1359037 & 688537 & 5.312 & 5.085 & TRN \\
\hline CHEMBL1380959 & 688537 & 4.8409 & 4.4914 & TRN \\
\hline CHEMBL1379467 & 688537 & 4.9952 & 4.9931 & TRN \\
\hline CHEMBL1453857 & 688537 & 6.3487 & 5.9612 & TRN \\
\hline CHEMBL1437942 & 688537 & 5.3831 & 5.1754 & TRN \\
\hline CHEMBL1430107 & 688537 & 5.596 & 5.0251 & TRN \\
\hline CHEMBL1579548 & 688537 & 5.6002 & 5.7352 & TRN \\
\hline CHEMBL3193765 & 688537 & 5.782 & 5.8224 & TRN \\
\hline CHEMBL1461513 & 688537 & 5.2784 & 5.119 & TRN \\
\hline CHEMBL1557782 & 688537 & 5.0587 & 5.1313 & TRN \\
\hline CHEMBL1568971 & 688537 & 5.0439 & 4.9929 & TRN \\
\hline CHEMBL1582537 & 688537 & 5.5824 & 4.763999 & 9999999999 \\
\hline CHEMBL1320543 & 688537 & 2.8239 & 2.4838 & TRN \\
\hline CHEMBL1390121 & 688537 & 5.1825 & 6.0898 & TRN \\
\hline
\end{tabular}


Supplemental Table S2.txt

\begin{tabular}{|c|c|c|c|c|c|}
\hline CHEMBL1516308 & 688537 & 4.7056 & 4.758 & TRN & \\
\hline CHEMBL1496827 & 688537 & 5.026 & 5.0773 & TRN & \\
\hline CHEMBL1310080 & 688537 & 5.7632 & 5.482 & TRN & \\
\hline CHEMBL1571801 & 688537 & 4.9594 & 4.5185 & TRN & \\
\hline CHEMBL1601133 & 688537 & 5.5013 & 5.541 & TRN & \\
\hline CHEMBL1319778 & 688537 & 6.2055 & 6.395 & TRN & \\
\hline CHEMBL1444820 & 688537 & 8.2218 & 8.1973 & TRN & \\
\hline CHEMBL1491019 & 688537 & 6.289 & 5.8769 & TRN & \\
\hline CHEMBL1579796 & 688537 & 5.0443 & 5.0183 & TRN & \\
\hline CHEMBL1508930 & 688537 & 5.5049 & 5.3905 & TST & \\
\hline CHEMBL1383511 & 688537 & 4.9003 & 5.0512 & TST & \\
\hline CHEMBL1504407 & 688537 & 5.6463 & 5.5766 & TST & \\
\hline CHEMBL1453089 & 688537 & 5.5363 & 5.3483 & TRN & \\
\hline CHEMBL528694 & 688537 & 5.9598 & 5.7842 & TRN & \\
\hline CHEMBL1299577 & 688537 & 4.5924 & 5.0292 & TRN & \\
\hline CHEMBL3207920 & 688537 & 4.9751 & 4.9338 & TRN & \\
\hline CHEMBL1455197 & 688537 & 5.9884 & 6.105 & TRN & \\
\hline CHEMBL1498307 & 688537 & 6.3036 & 6.0342 & TRN & \\
\hline CHEMBL1429121 & 688537 & 4.747 & 3.2887 & TRN & \\
\hline CHEMBL1578856 & 688537 & 6.1918 & 5.9545 & TST & \\
\hline CHEMBL1461547 & 688537 & 5.4462 & 5.41200 & 0000000001 & TRN \\
\hline CHEMBL1582690 & 688537 & 5.5077 & 5.7221 & TRN & \\
\hline CHEMBL 29097 & 688537 & 5.9702 & 5.8334 & TST & \\
\hline CHEMBL1451491 & 688537 & 5.7455 & 5.6443 & TRN & \\
\hline CHEMBL1341108 & 688537 & 5.2387 & 5.3391 & TRN & \\
\hline CHEMBL1371337 & 688537 & 4.8835 & 5.074 & TST & \\
\hline CHEMBL1577440 & 688537 & 5.0536 & 5.0195 & TRN & \\
\hline CHEMBL539027 & 688537 & 5.0604 & 5.1106 & TST & \\
\hline CHEMBL1451977 & 688537 & 8.2218 & 7.5483 & TRN & \\
\hline CHEMBL3145107 & 688537 & 5.6137 & 5.4983 & TRN & \\
\hline CHEMBL1421032 & 688537 & 5.6107 & 5.811 & TRN & \\
\hline CHEMBL1525619 & 688537 & 5.919 & 5.6647 & TRN & \\
\hline CHEMBL1488576 & 688537 & 5.0511 & 4.7408 & TRN & \\
\hline CHEMBL1438570 & 688537 & 5.3097 & 5.2921 & TRN & \\
\hline CHEMBL1407094 & 688537 & 5.856 & 5.6026 & TRN & \\
\hline CHEMBL1365902 & 688537 & 5.5514 & 4.9596 & TRN & \\
\hline CHEMBL1304997 & 688537 & 5.454 & 4.8806 & TRN & \\
\hline CHEMBL1326397 & 688537 & 8.2218 & 8.4816 & TRN & \\
\hline CHEMBL1402220 & 688537 & 2.8239 & 3.0806 & TRN & \\
\hline CHEMBL411070 & 688537 & 2.8239 & 3.1622 & TST & \\
\hline CHEMBL1360539 & 688537 & 5.6755 & 5.8208 & TRN & \\
\hline CHEMBL1546382 & 688537 & 5.2689 & 5.4301 & TRN & \\
\hline CHEMBL1600855 & 688537 & 5.6861 & 5.4101 & TST & \\
\hline CHEMBL1980844 & 688537 & 8.2218 & 7.88 & TRN & \\
\hline CHEMBL3199908 & 688537 & 6.1238 & 5.619 & TST & \\
\hline CHEMBL1579808 & 688537 & 5.2412 & 5.1028 & TRN & \\
\hline CHEMBL1400434 & 688537 & 6.0851 & 6.3733 & TRN & \\
\hline CHEMBL 39878 & 688537 & 6.0825 & 5.7853 & TRN & \\
\hline
\end{tabular}


Supplemental Table S2.txt

\begin{tabular}{|c|c|c|c|c|c|}
\hline CHEMBL1501022 & 688537 & 5.4089 & 5.2655 & TRN & \\
\hline CHEMBL1573462 & 688537 & 2.8239 & 3.2959 & TRN & \\
\hline CHEMBL1381519 & 688537 & 2.8239 & 3.2046 & TST & \\
\hline CHEMBL1301734 & 688537 & 5.5511 & 5.3099 & TST & \\
\hline CHEMBL3213606 & 688537 & 5.5622 & 5.7447 & TRN & \\
\hline CHEMBL1467058 & 688537 & 8.2218 & 8.1669 & TST & \\
\hline CHEMBL1348268 & 688537 & 4.3789 & 3.7222 & TRN & \\
\hline CHEMBL1387393 & 688537 & 4.1636 & 4.8162 & TRN & \\
\hline CHEMBL1390021 & 688537 & 5.1851 & 5.027 & TRN & \\
\hline CHEMBL1482979 & 688537 & 5.4151 & 4.8186 & TST & \\
\hline CHEMBL1423933 & 688537 & 5.3453 & 5.1049 & TST & \\
\hline CHEMBL1589029 & 688537 & 5.1529 & 5.2049 & TRN & \\
\hline CHEMBL1305393 & 688537 & 2.8239 & 3.1971 & TRN & \\
\hline CHEMBL1328707 & 688537 & 5.381 & 5.1329 & TRN & \\
\hline CHEMBL1582609 & 688537 & 4.9451 & 4.7372 & TRN & \\
\hline CHEMBL1452235 & 688537 & 6.0004 & 5.7304 & TRN & \\
\hline CHEMBL1561338 & 688537 & 4.8803 & 4.2001 & TRN & \\
\hline CHEMBL1536073 & 688537 & 5.4895 & 5.9996 & TRN & \\
\hline CHEMBL1356182 & 688537 & 5.5096 & 5.4401 & TRN & \\
\hline CHEMBL1540742 & 688537 & 5.1486 & 5.0856 & TST & \\
\hline CHEMBL3190753 & 688537 & 4.9605 & 5.0879 & TRN & \\
\hline CHEMBL3193726 & 688537 & 2.8239 & 3.1819 & TRN & \\
\hline CHEMBL1535252 & 688537 & 5.5409 & 4.962 & TRN & \\
\hline CHEMBL3211198 & 688537 & 5.5039 & 5.3444 & TRN & \\
\hline CHEMBL1987622 & 688537 & 5.8804 & 5.4499 & TRN & \\
\hline CHEMBL1459691 & 688537 & 6.4724 & 6.2251 & TRN & \\
\hline CHEMBL496633 & 688537 & 5.5829 & 5.5152 & TST & \\
\hline CHEMBL1424380 & 688537 & 4.7096 & 4.7685 & TRN & \\
\hline CHEMBL1974063 & 688537 & 5.2842 & 5.5503 & TRN & \\
\hline CHEMBL1378852 & 688537 & 2.8239 & 3.4894 & TRN & \\
\hline CHEMBL3207947 & 688537 & 5.8941 & 5.7266 & TRN & \\
\hline CHEMBL1389982 & 688537 & 4.9984 & 5.0121 & TRN & \\
\hline CHEMBL1544097 & 688537 & 5.614 & 5.7638 & TRN & \\
\hline CHEMBL3195852 & 688537 & 5.3897 & 5.138999 & 999999999 & TRN \\
\hline CHEMBL1332404 & 688537 & 5.3986 & 5.4784 & TRN & \\
\hline CHEMBL1452379 & 688537 & 5.3008 & 5.1824 & TRN & \\
\hline CHEMBL1399332 & 688537 & 5.1826 & 5.1294 & TRN & \\
\hline CHEMBL169 & 688537 & 6.0227 & 5.9868 & TST & \\
\hline CHEMBL1538808 & 688537 & 4.9431 & 5.1521 & TRN & \\
\hline CHEMBL1478211 & 688537 & 5.2013 & 5.4003 & TRN & \\
\hline CHEMBL3197489 & 688537 & 5.0532 & 4.6933 & TRN & \\
\hline CHEMBL1520898 & 688537 & 2.8239 & 3.1139 & TST & \\
\hline CHEMBL1969492 & 688537 & 5.9527 & 5.6062 & TST & \\
\hline CHEMBL3197605 & 688537 & 4.7389 & 4.5268 & TRN & \\
\hline CHEMBL1493766 & 688537 & 5.7878 & 5.6308 & TRN & \\
\hline CHEMBL1502724 & 688537 & 5.3594 & 4.5022 & TRN & \\
\hline CHEMBL1330201 & 688537 & 6.1593 & 5.817 & TRN & \\
\hline CHEMBL1470353 & 688537 & 2.8239 & 3.2965 & TST & \\
\hline
\end{tabular}




\begin{tabular}{|c|c|c|c|c|c|c|}
\hline \multirow{3}{*}{$\begin{array}{l}\text { CHEMBL1557859 } \\
\text { CHFMBI } 1366790\end{array}$} & & \multicolumn{5}{|c|}{ Supplemental Table S2.txt } \\
\hline & 688537 & 4.9406 & \multicolumn{3}{|c|}{5.2620000000000005} & TRN \\
\hline & 688537 & 2.8239 & 3.2929 & TST & & \\
\hline CHEMBL1994815 & 688537 & 5.3022 & 5.2939 & TRN & & \\
\hline CHEMBL1564636 & 688537 & 5.0892 & 5.0078 & TRN & & \\
\hline CHEMBL1410625 & 688537 & 5.4242 & 5.0611 & TRN & & \\
\hline CHEMBL1520328 & 688537 & 5.3796 & 5.5455 & TRN & & \\
\hline CHEMBL1346853 & 688537 & 5.0803 & 4.6304 & TST & & \\
\hline CHEMBL1550334 & 688537 & 5.0417 & 4.8838 & TRN & & \\
\hline CHEMBL1468058 & 688537 & 4.6369 & 4.6587 & TRN & & \\
\hline CHEMBL1374455 & 688537 & 4.08899 & 99999999 & 995 & 4.3131 & TRN \\
\hline CHEMBL1400889 & 688537 & 5.1611 & 5.629 & TRN & & \\
\hline CHEMBL1325303 & 688537 & 4.9354 & 5.5007 & TRN & & \\
\hline CHEMBL1415635 & 688537 & 6.0894 & 5.9337 & TRN & & \\
\hline CHEMBL1310193 & 688537 & 6.0501 & 5.6667 & TRN & & \\
\hline CHEMBL3191692 & 688537 & 5.1985 & 5.1124 & TRN & & \\
\hline CHEMBL1382035 & 688537 & 5.3036 & 5.6929 & TST & & \\
\hline CHEMBL1403442 & 688537 & 5.1372 & 5.2869 & TRN & & \\
\hline CHEMBL1427125 & 688537 & 5.2912 & 5.0242 & TST & & \\
\hline CHEMBL1566084 & 688537 & 5.9876 & 5.7608 & TRN & & \\
\hline CHEMBL1345480 & 688537 & 5.1102 & 5.2414 & TRN & & \\
\hline CHEMBL3209974 & 688537 & 5.5157 & 5.4373 & TRN & & \\
\hline CHEMBL1575578 & 688537 & 5.1558 & 4.8695 & TRN & & \\
\hline CHEMBL1578141 & 688537 & 5.1866 & 5.1642 & TRN & & \\
\hline CHEMBL3192020 & 688537 & 6.068 & 5.8234 & TRN & & \\
\hline CHEMBL589351 & 688537 & 5.0905 & 5.2316 & TRN & & \\
\hline CHEMBL1324181 & 688537 & 4.5913 & 4.6122 & TRN & & \\
\hline CHEMBL1992109 & 688537 & 6.0292 & 5.8904 & TRN & & \\
\hline CHEMBL1453335 & 688537 & 5.5209 & 5.255 & TRN & & \\
\hline CHEMBL3195410 & 688537 & 6.3458 & 6.1241 & TRN & & \\
\hline CHEMBL1310744 & 688537 & 5.3397 & 5.6337 & TRN & & \\
\hline CHEMBL1602599 & 688537 & 4.8812 & 4.7832 & TRN & & \\
\hline CHEMBL1336728 & 688537 & 5.0147 & 5.0812 & TRN & & \\
\hline CHEMBL1518905 & 688537 & 5.2245 & 5.1447 & TST & & \\
\hline CHEMBL601751 & 688537 & 3.8357 & 4.6975 & TRN & & \\
\hline CHEMBL1508055 & 688537 & 5.263 & 4.6978 & TRN & & \\
\hline CHEMBL1392438 & 688537 & 4.2519 & 4.7949 & TST & & \\
\hline CHEMBL3191360 & 688537 & 4.7921 & 4.7012 & TRN & & \\
\hline CHEMBL1481281 & 688537 & 5.6377 & 6.1716 & TRN & & \\
\hline CHEMBL1315795 & 688537 & 5.4959 & 5.2297 & TRN & & \\
\hline CHEMBL1521482 & 688537 & 5.8407 & 5.9774 & TRN & & \\
\hline CHEMBL3197639 & 688537 & 6.2366 & 5.9303 & TRN & & \\
\hline CHEMBL 1427340 & 688537 & 5.029 & 4.9058 & TRN & & \\
\hline CHEMBL1983939 & 688537 & 6.0079 & 5.6606 & TRN & & \\
\hline CHEMBL3196184 & 688537 & 6.1163 & 5.6568 & TRN & & \\
\hline CHEMBL1382213 & 688537 & 5.1355 & 5.334 & TRN & & \\
\hline CHEMBL1327470 & 688537 & 5.4156 & 5.1467 & TST & & \\
\hline CHEMBL1321025 & 688537 & 5.5018 & 6.0309 & TRN & & \\
\hline CHEMBL1403172 & 688537 & 5.3263 & 5.2426 & TRN & & \\
\hline
\end{tabular}


Supplemental Table S2.txt

\begin{tabular}{|c|c|c|c|c|}
\hline CHEMBL1337364 & 688537 & 4.4022 & 4.4724 & TRN \\
\hline CHEMBL1391911 & 688537 & 5.659 & 6.0417 & TRN \\
\hline CHEMBL1316800 & 688537 & 2.8239 & 2.8831 & TRN \\
\hline CHEMBL1984876 & 688537 & 5.8891 & 6.0286 & TRN \\
\hline CHEMBL1544494 & 688537 & 4.5409 & 4.2754 & TST \\
\hline CHEMBL1411063 & 688537 & 2.8239 & 2.4724 & TRN \\
\hline CHEMBL1533489 & 688537 & 2.8239 & 4.3001 & TRN \\
\hline CHEMBL3191762 & 688537 & 5.0524 & 5.0239 & TRN \\
\hline CHEMBL1977995 & 688537 & 5.551 & 5.0785 & TRN \\
\hline CHEMBL1386957 & 688537 & \multicolumn{3}{|c|}{4.8260000000000005} \\
\hline CHEMBL1592387 & 688537 & 4.7694 & 4.53 & TRN \\
\hline CHEMBL1547031 & 688537 & 4.5522 & 3.3501 & TRN \\
\hline CHEMBL1549202 & 688537 & 4.9737 & 5.1235 & TRN \\
\hline CHEMBL1449354 & 688537 & 2.8239 & 4.3879 & TRN \\
\hline CHEMBL1393529 & 688537 & 5.1341 & 5.1227 & TRN \\
\hline CHEMBL1531320 & 688537 & 5.0974 & 5.1491 & TRN \\
\hline CHEMBL1583807 & 688537 & 4.8968 & 4.7938 & TRN \\
\hline CHEMBL1518871 & 688537 & 5.4836 & 5.3755 & TRN \\
\hline CHEMBL1510339 & 688537 & 6.0264 & 5.5979 & TRN \\
\hline CHEMBL1464647 & 688537 & 6.2503 & 5.9693 & TRN \\
\hline CHEMBL1482637 & 688537 & 5.5025 & 4.8265 & TRN \\
\hline CHEMBL1369125 & 688537 & 5.5016 & 5.2396 & TST \\
\hline CHEMBL1502939 & 688537 & 2.8239 & 4.0149 & TRN \\
\hline CHEMBL1390963 & 688537 & 6.5376 & 6.2255 & TRN \\
\hline CHEMBL1522211 & 688537 & 6.2132 & 6.3851 & TRN \\
\hline CHEMBL1522803 & 688537 & 4.7941 & 4.9644 & TRN \\
\hline CHEMBL1598413 & 688537 & 5.9076 & 5.7089 & TRN \\
\hline CHEMBL1378952 & 688537 & 5.7165 & 5.8832 & TRN \\
\hline CHEMBL1477341 & 688537 & 5.7279 & 5.5422 & TST \\
\hline CHEMBL1584684 & 688537 & 5.7645 & 5.8772 & TRN \\
\hline CHEMBL1383406 & 688537 & 4.7714 & 4.4697 & TRN \\
\hline CHEMBL1546249 & 688537 & 4.7347 & 5.0393 & TRN \\
\hline CHEMBL1377316 & 688537 & 5.586 & 5.8188 & TRN \\
\hline CHEMBL1489757 & 688537 & 5.5761 & 5.4654 & TRN \\
\hline CHEMBL1312303 & 688537 & 4.5064 & 5.5336 & TRN \\
\hline CHEMBL1301536 & 688537 & 5.5952 & 5.8491 & TRN \\
\hline CHEMBL1447526 & 688537 & 5.2011 & 5.19600 & 0000000001 \\
\hline CHEMBL1376204 & 688537 & 4.8951 & 4.1812 & TRN \\
\hline CHEMBL1417054 & 688537 & 5.1239 & 4.8051 & TRN \\
\hline CHEMBL1531454 & 688537 & 5.7983 & 6.0499 & TRN \\
\hline CHEMBL1964793 & 688537 & 5.4482 & 5.7742 & TRN \\
\hline CHEMBL104270 & 688537 & 6.5591 & 6.4419 & TRN \\
\hline CHEMBL1609756 & 688537 & 5.4789 & 5.4646 & TST \\
\hline CHEMBL1382575 & 688537 & 5.21 & 5.1131 & TRN \\
\hline CHEMBL1580116 & 688537 & 5.4238 & 5.5718 & TRN \\
\hline CHEMBL1339368 & 688537 & 5.0191 & 4.7434 & TST \\
\hline CHEMBL1510981 & 688537 & 5.2788 & 4.4815 & TST \\
\hline CHEMBL1598569 & 688537 & 6.4622 & 6.626 & TRN \\
\hline
\end{tabular}




\begin{tabular}{|c|c|c|c|c|c|}
\hline & & & & & \\
\hline CHEMBL1481849 & 688537 & 5.5547 & 5.0441 & TST & \\
\hline CHEMBL1571348 & 688537 & 5.1381 & 5.1706 & TRN & \\
\hline CHEMBL1415442 & 688537 & 5.0209 & 5.1022 & TRN & \\
\hline CHEMBL1519807 & 688537 & 5.3931 & 5.2744 & TST & \\
\hline CHEMBL1405781 & 688537 & 2.8239 & 4.7576 & TRN & \\
\hline CHEMBL3191452 & 688537 & 4.7367 & 4.8664 & TRN & \\
\hline CHEMBL1511561 & 688537 & 3.8953 & 4.2729 & TRN & \\
\hline CHEMBL1426435 & 688537 & 6.3279 & 6.3779 & TRN & \\
\hline CHEMBL1423138 & 688537 & 5.8645 & 5.7221 & TRN & \\
\hline CHEMBL1998716 & 688537 & 5.3121 & 5.2325 & TRN & \\
\hline CHEMBL1301717 & 688537 & 5.2577 & 5.0843 & TRN & \\
\hline CHEMBL1391928 & 688537 & 5.3234 & 5.3124 & TRN & \\
\hline CHEMBL1576333 & 688537 & 5.2555 & 4.8121 & TRN & \\
\hline CHEMBL381033 & 688537 & 5.7133 & 5.0573 & TRN & \\
\hline CHEMBL1354346 & 688537 & 4.931 & 4.8 & TRN & \\
\hline CHEMBL1525576 & 688537 & 5.7224 & 5.2732 & TRN & \\
\hline CHEMBL1448732 & 688537 & 5.2879 & 5.4162 & TRN & \\
\hline CHEMBL1613625 & 688537 & 4.8555 & 4.6483 & TRN & \\
\hline CHEMBL1490336 & 688537 & 5.5259 & 5.6085 & TRN & \\
\hline CHEMBL1327389 & 688537 & 5.9512 & 4.7946 & TST & \\
\hline CHEMBL1542263 & 688537 & 6.7932 & 7.7293 & TRN & \\
\hline CHEMBL1528266 & 688537 & 2.8239 & 4.8635 & TRN & \\
\hline CHEMBL1431014 & 688537 & 5.7752 & 6.0603 & TRN & \\
\hline CHEMBL1376578 & 688537 & 5.1328 & 5.329 & TST & \\
\hline CHEMBL1422340 & 688537 & 5.5592 & 5.4193 & TST & \\
\hline CHEMBL1434622 & 688537 & 5.6484 & 4.9122 & TRN & \\
\hline CHEMBL1302158 & 688537 & 5.5027 & 5.2715 & TRN & \\
\hline CHEMBL1611858 & 688537 & 5.0195 & 5.2669 & TRN & \\
\hline CHEMBL1595850 & 688537 & 5.9112 & 5.5529 & TRN & \\
\hline CHEMBL1411001 & 688537 & 4.6239 & 4.1737 & TRN & \\
\hline CHEMBL1466844 & 688537 & 6.20200 & 00000006 & 6.2567 & TRN \\
\hline CHEMBL1553151 & 688537 & 4.6974 & 4.0742 & TRN & \\
\hline CHEMBL1511795 & 688537 & 5.4812 & 5.2466 & TRN & \\
\hline CHEMBL1433263 & 688537 & 4.8848 & 4.446006 & 0000000001 & TRN \\
\hline CHEMBL3189791 & 688537 & 5.4987 & 5.6451 & TRN & \\
\hline CHEMBL1301179 & 688537 & 5.2465 & 5.4586 & TRN & \\
\hline CHEMBL1575038 & 688537 & 5.9801 & 5.5455 & TRN & \\
\hline CHEMBL1532716 & 688537 & 5.1188 & 5.3173 & TRN & \\
\hline CHEMBL1522288 & 688537 & 6.7423 & 6.6902 & TRN & \\
\hline CHEMBL1427004 & 688537 & 5.5382 & 5.4046 & TRN & \\
\hline CHEMBL1476229 & 688537 & 5.3854 & 4.8026 & TRN & \\
\hline CHEMBL 2006634 & 688537 & 5.9485 & 5.5779 & TRN & \\
\hline CHEMBL1507262 & 688537 & 5.0332 & 4.6872 & TST & \\
\hline CHEMBL583584 & 688537 & 8.2218 & 6.4194 & TRN & \\
\hline CHEMBL1435719 & 688537 & 2.8239 & 3.7196 & TRN & \\
\hline CHEMBL1387906 & 688537 & 5.2609 & 5.1864 & TRN & \\
\hline CHEMBL1705518 & 688537 & 5.4435 & 5.4549 & TRN & \\
\hline CHEMBL3190262 & 688537 & 4.9248 & 5.0836 & TRN & \\
\hline
\end{tabular}




\begin{tabular}{|c|c|c|c|c|c|c|}
\hline & & \multicolumn{5}{|c|}{ Supplemental Table S2.txt } \\
\hline CHEMBL1407907 & 688537 & 4.9855 & 5.2879 & TRN & & \\
\hline CHEMBL1430586 & 688537 & 5.2883 & 5.2573 & TRN & & \\
\hline CHEMBL1417731 & 688537 & 6.4989 & 6.7408 & TRN & & \\
\hline CHEMBL1494940 & 688537 & 5.8505 & 5.5643 & TST & & \\
\hline CHEMBL1360618 & 688537 & 5.254 & 5.1654 & TRN & & \\
\hline CHEMBL1606903 & 688537 & 5.4203 & 5.0185 & TRN & & \\
\hline CHEMBL1345800 & 688537 & 5.1174 & 5.3023 & TRN & & \\
\hline CHEMBL1510940 & 688537 & 4.9662 & 5.0046 & TST & & \\
\hline CHEMBL1511193 & 688537 & 5.6085 & 5.7961 & TRN & & \\
\hline CHEMBL1546634 & 688537 & 4.8544 & 4.5465 & TRN & & \\
\hline CHEMBL1375825 & 688537 & 4.8638 & 4.9624 & TRN & & \\
\hline CHEMBL1479116 & 688537 & 4.6737 & 4.7901 & TST & & \\
\hline CHEMBL1550104 & 688537 & 5.8804 & 5.6029 & TRN & & \\
\hline CHEMBL1454278 & 688537 & 5.7095 & 5.4939 & TRN & & \\
\hline CHEMBL 3211808 & 688537 & 4.8018 & 5.0075 & TRN & & \\
\hline CHEMBL1380929 & 688537 & 3.301 & 4.9207 & TRN & & \\
\hline CHEMBL1383044 & 688537 & 5.1478 & 5.0439 & TRN & & \\
\hline CHEMBL1488865 & 688537 & 4.8791 & 4.9765 & TRN & & \\
\hline CHEMBL3199742 & 688537 & $5.4520 e$ & 00000000 & $\partial 1$ & 5.1697 & TRN \\
\hline CHEMBL1304169 & 688537 & 6.4078 & 5.6346 & TRN & & \\
\hline CHEMBL1366997 & 688537 & 6.9066 & 6.5832 & TRN & & \\
\hline CHEMBL1550132 & 688537 & 4.9919 & 5.1417 & TRN & & \\
\hline CHEMBL1242180 & 688537 & 5.1742 & 5.1421 & TST & & \\
\hline CHEMBL1428343 & 688537 & 5.2788 & 4.8892 & TRN & & \\
\hline CHEMBL1349631 & 688537 & 6.7825 & 7.0584 & TRN & & \\
\hline CHEMBL1469980 & 688537 & 5.2244 & 5.3026 & TRN & & \\
\hline CHEMBL1541789 & 688537 & 5.0446 & 4.9064 & TRN & & \\
\hline CHEMBL1526472 & 688537 & 5.0643 & 5.1933 & TRN & & \\
\hline CHEMBL1413629 & 688537 & 5.1376 & 5.0106 & TRN & & \\
\hline CHEMBL1439990 & 688537 & 4.7462 & 4.7842 & TRN & & \\
\hline CHEMBL1327412 & 688537 & 5.5632 & 5.3217 & TRN & & \\
\hline CHEMBL1520849 & 688537 & 5.1735 & 5.4086 & TRN & & \\
\hline CHEMBL1299653 & 688537 & 4.853 & 4.8907 & TST & & \\
\hline CHEMBL1379443 & 688537 & 5.2779 & 5.5018 & TRN & & \\
\hline CHEMBL1383757 & 688537 & 2.8239 & 3.9792 & TRN & & \\
\hline CHEMBL1359321 & 688537 & 5.2978 & 5.7155 & TRN & & \\
\hline CHEMBL1327509 & 688537 & 4.7582 & 5.0711 & TRN & & \\
\hline CHEMBL1466932 & 688537 & 4.8426 & 4.5892 & TRN & & \\
\hline CHEMBL1432888 & 688537 & 5.4508 & 5.4253 & TRN & & \\
\hline CHEMBL1521990 & 688537 & 5.7093 & 5.1718 & TRN & & \\
\hline CHEMBL1444990 & 688537 & 5.0396 & 4.6448 & TRN & & \\
\hline CHEMBL1326371 & 688537 & 5.2329 & 5.6793 & TRN & & \\
\hline CHEMBL1320465 & 688537 & 5.3405 & 5.2245 & TRN & & \\
\hline CHEMBL1309598 & 688537 & 6.2076 & 6.0988 & TRN & & \\
\hline CHEMBL1482127 & 688537 & 5.6542 & 5.3539 & TST & & \\
\hline CHEMBL 3192542 & 688537 & 6.4647 & 6.1575 & TRN & & \\
\hline CHEMBL1598101 & 688537 & 5.3827 & 4.9621 & TRN & & \\
\hline CHEMBL1463714 & 688537 & 5.8162 & 5.8082 & TRN & & \\
\hline
\end{tabular}




\begin{tabular}{|c|c|c|c|c|c|}
\hline \multicolumn{6}{|c|}{ Supplemental Table S2.txt } \\
\hline CHEMBL1547804 & 688537 & 5.2448 & 5.3464 & TRN & \\
\hline CHEMBL1587753 & 688537 & 5.3471 & 5.5222 & TRN & \\
\hline CHEMBL1540340 & 688537 & 5.1917 & 4.9268 & TRN & \\
\hline CHEMBL1497721 & 688537 & 5.6182 & 5.8364 & TRN & \\
\hline CHEMBL3189643 & 688537 & 5.4874 & 5.5594 & TRN & \\
\hline CHEMBL1454827 & 688537 & 5.18 & 5.3041 & TRN & \\
\hline CHEMBL1304605 & 688537 & 5.3825 & 5.4115 & TRN & \\
\hline CHEMBL1500469 & 688537 & 5.8877 & 5.8769 & TRN & \\
\hline CHEMBL606167 & 688537 & 5.0838 & 5.3797 & TST & \\
\hline CHEMBL1372492 & 688537 & 6.3851 & 5.87200 & 2000000001 & TRN \\
\hline CHEMBL1430631 & 688537 & 2.8239 & 4.9642 & TRN & \\
\hline CHEMBL1331239 & 688537 & 5.2821 & 4.8239 & TRN & \\
\hline CHEMBL1606488 & 688537 & 4.5392 & 4.3998 & TST & \\
\hline CHEMBL1334100 & 688537 & 4.9485 & 4.8264 & TST & \\
\hline CHEMBL1466614 & 688537 & 5.6868 & 5.9435 & TRN & \\
\hline CHEMBL1570738 & 688537 & 6.5214 & 6.9397 & TRN & \\
\hline CHEMBL1566530 & 688537 & 5.7066 & 5.7723 & TRN & \\
\hline CHEMBL1404485 & 688537 & 5.8677 & 6.1237 & TRN & \\
\hline CHEMBL3196175 & 688537 & 4.6509 & 5.1524 & TRN & \\
\hline CHEMBL1487657 & 688537 & 5.7886 & 5.61100 & 0000000001 & TRN \\
\hline CHEMBL1562608 & 688537 & 5.191 & 4.897 & TRN & \\
\hline CHEMBL1506533 & 688537 & $5.1620 e$ & 00000000 & 5.0965 & TRN \\
\hline CHEMBL1509258 & 688537 & 5.3583 & 4.7618 & TRN & \\
\hline CHEMBL1605304 & 688537 & 5.1072 & 5.2412 & TRN & \\
\hline CHEMBL1358550 & 688537 & 2.8239 & 2.9111 & TRN & \\
\hline CHEMBL3196688 & 688537 & 5.1267 & 4.9214 & TRN & \\
\hline CHEMBL1427928 & 688537 & 6.1864 & 5.7595 & TRN & \\
\hline CHEMBL1374595 & 688537 & 4.9256 & 4.9247 & TST & \\
\hline CHEMBL1991388 & 688537 & 5.5602 & 5.8316 & TRN & \\
\hline CHEMBL1314461 & 688537 & 5.0875 & 5.3845 & TRN & \\
\hline CHEMBL1970859 & 688537 & 5.2099 & 5.2945 & TRN & \\
\hline CHEMBL1461180 & 688537 & 2.8239 & 4.9517 & TRN & \\
\hline CHEMBL463175 & 688537 & 6.4584 & 6.3143 & TRN & \\
\hline CHEMBL1518085 & 688537 & 6.0381 & 5.98 & TRN & \\
\hline CHEMBL1400092 & 688537 & 2.8239 & 3.3184 & TST & \\
\hline CHEMBL532160 & 688537 & 5.5993 & 5.3051 & TST & \\
\hline CHEMBL3193204 & 688537 & 4.919 & 4.7147 & TRN & \\
\hline CHEMBL1504763 & 688537 & 5.5233 & 5.6284 & TRN & \\
\hline CHEMBL1309059 & 688537 & 5.3054 & 4.902 & TRN & \\
\hline CHEMBL1527478 & 688537 & 3.9147 & 3.2047 & TRN & \\
\hline CHEMBL1384179 & 688537 & 5.487 & 5.1818 & TRN & \\
\hline CHEMBL1600566 & 688537 & 5.6421 & 5.7707 & TRN & \\
\hline CHEMBL1529121 & 688537 & 5.0634 & 4.5921 & TRN & \\
\hline CHEMBL1517104 & 688537 & 5.4789 & 5.669 & TRN & \\
\hline CHEMBL1587142 & 688537 & 2.8239 & 3.0975 & TST & \\
\hline CHEMBL3195933 & 688537 & 4.9974 & 5.3483 & TRN & \\
\hline CHEMBL1541391 & 688537 & 5.477 & 5.7123 & TST & \\
\hline CHEMBL1412087 & 688537 & 5.7496 & 5.8571 & TRN & \\
\hline
\end{tabular}


Supplemental Table S2.txt

\begin{tabular}{|c|c|c|c|c|c|c|}
\hline CHEMBL1581194 & 688537 & 4.6853 & 4.7872 & TRN & & \\
\hline CHEMBL1336205 & 688537 & 5.6048 & 5.3344 & TST & & \\
\hline CHEMBL1585375 & 688537 & 4.728 & 4.4765 & TRN & & \\
\hline CHEMBL1470321 & 688537 & 5.0837 & 5.2236 & TRN & & \\
\hline CHEMBL1544633 & 688537 & 5.7768 & 5.5244 & TRN & & \\
\hline CHEMBL603031 & 688537 & 5.1636 & 4.401 & TRN & & \\
\hline CHEMBL1416124 & 688537 & 6.0894 & 5.649 & TRN & & \\
\hline CHEMBL1478587 & 688537 & 5.8496 & 5.6454 & TRN & & \\
\hline CHEMBL1584753 & 688537 & 5.5188 & 5.7324 & TRN & & \\
\hline CHEMBL1588513 & 688537 & 5.7537 & 5.5454 & TRN & & \\
\hline CHEMBL1606330 & 688537 & 4.7177 & 4.3726 & TST & & \\
\hline CHEMBL1581000 & 688537 & 4.9407 & 4.7187 & TRN & & \\
\hline CHEMBL1583579 & 688537 & 5.1455 & 4.9881 & TRN & & \\
\hline CHEMBL1497898 & 688537 & 4.4563 & 4.231 & TRN & & \\
\hline CHEMBL1312122 & 688537 & 5.6174 & 5.5061 & TRN & & \\
\hline CHEMBL1361693 & 688537 & 4.8949 & 4.8963 & TRN & & \\
\hline CHEMBL 3211356 & 688537 & 5.2858 & 5.4263 & TRN & & \\
\hline CHEMBL1442884 & 688537 & 5.4935 & 5.3631 & TRN & & \\
\hline CHEMBL 2007163 & 688537 & 4.776 & 4.6914 & TRN & & \\
\hline CHEMBL1323151 & 688537 & 4.8107 & 4.8005 & TRN & & \\
\hline CHEMBL1496338 & 688537 & 5.5028 & 5.023 & TRN & & \\
\hline CHEMBL1990772 & 688537 & 5.98799 & 99999999 & 95 & 5.5309 & TRN \\
\hline CHEMBL1600314 & 688537 & 5.7873 & 5.7514 & TRN & & \\
\hline CHEMBL587849 & 688537 & 5.90799 & 99999999 & 95 & 5.6649 & TाNo \\
\hline CHEMBL1371792 & 688537 & 4.9926 & 4.5054 & TRN & & \\
\hline CHEMBL1499233 & 688537 & 5.3984 & 5.8026 & TRN & & \\
\hline CHEMBL1457139 & 688537 & 5.6388 & 5.4947 & TRN & & \\
\hline CHEMBL1334568 & 688537 & 6.6635 & 6.7571 & TRN & & \\
\hline CHEMBL3212285 & 688537 & 5.6498 & 5.7702 & TRN & & \\
\hline CHEMBL1446095 & 688537 & \multicolumn{3}{|c|}{5.4879999999999995} & 5.0865 & TST \\
\hline CHEMBL1412177 & 688537 & 5.0215 & 4.813 & TRN & & \\
\hline CHEMBL1550584 & 688537 & 6.58 & 6.2682 & TRN & & \\
\hline CHEMBL 3194623 & 688537 & 5.8019 & 5.4866 & TRN & & \\
\hline CHEMBL1389269 & 688537 & 5.3659 & 5.0924 & TST & & \\
\hline CHEMBL1320397 & 688537 & 5.178 & 5.2045 & TRN & & \\
\hline CHEMBL1393796 & 688537 & 4.4224 & 3.8929 & TRN & & \\
\hline CHEMBL1613066 & 688537 & 4.9683 & 4.4079 & TRN & & \\
\hline CHEMBL1971370 & 688537 & 2.8239 & 4.2124 & TRN & & \\
\hline CHEMBL1992943 & 688537 & 5.3284 & 5.1137 & TRN & & \\
\hline CHEMBL 3208362 & 688537 & 5.4578 & 5.3089 & TRN & & \\
\hline CHEMBL1416153 & 688537 & 6.0097 & 5.9634 & TRN & & \\
\hline CHEMBL1505044 & 688537 & 5.2171 & 4.7588 & TRN & & \\
\hline CHEMBL581251 & 688537 & 5.5038 & 5.4664 & TST & & \\
\hline CHEMBL1510676 & 688537 & 6.1878 & 6.1018 & TRN & & \\
\hline CHEMBL1307382 & 688537 & 2.8239 & 4.3943 & TST & & \\
\hline CHEMBL1510974 & 688537 & 5.9918 & 5.6724 & TRN & & \\
\hline CHEMBL1562584 & 688537 & 5.4412 & 5.6492 & TRN & & \\
\hline CHEMBL1521418 & 688537 & 5.4135 & 4.8547 & TRN & & \\
\hline
\end{tabular}




\begin{tabular}{|c|c|c|c|c|c|c|}
\hline & & \multicolumn{5}{|c|}{ Supplemental Table s2.txt } \\
\hline CHEMBL31293 & 688537 & 5.9122 & 6.3789 & TRN & & \\
\hline CHEMBL1585681 & 688537 & 5.0689 & 5.8055 & TRN & & \\
\hline CHEMBL1353506 & 688537 & 6.2299 & 5.5726 & TRN & & \\
\hline CHEMBL 3190974 & 688537 & \multicolumn{3}{|c|}{5.486000000000001} & 5.5897 & TRN \\
\hline CHEMBL1428221 & 688537 & 4.7741 & 5.1893 & TST & & \\
\hline CHEMBL1572550 & 688537 & 5.6977 & 5.7151 & TRN & & \\
\hline CHEMBL1483252 & 688537 & 5.8265 & 5.7508 & TRN & & \\
\hline CHEMBL1451873 & 688537 & 2.8239 & 4.5895 & TST & & \\
\hline CHEMBL1449111 & 688537 & 5.2174 & 5.0343 & TRN & & \\
\hline CHEMBL3192533 & 688537 & 5.1728 & 5.29700 & 0000000001 & & TRN \\
\hline CHEMBL1594171 & 688537 & 5.4542 & 5.1107 & TRN & & \\
\hline CHEMBL1580328 & 688537 & 5.9031 & 5.1597 & TRN & & \\
\hline CHEMBL1427991 & 688537 & 6.0264 & 5.7684 & TRN & & \\
\hline CHEMBL1520712 & 688537 & 2.8239 & 3.1997 & TST & & \\
\hline CHEMBL1595444 & 688537 & 5.8582 & 5.4355 & TST & & \\
\hline CHEMBL1582831 & 688537 & 5.8742 & 5.9223 & TRN & & \\
\hline CHEMBL1443205 & 688537 & 6.0237 & 6.0355 & TRN & & \\
\hline CHEMBL1371877 & 688537 & \multicolumn{3}{|c|}{5.361000000000001} & 5.3624 & TRN \\
\hline CHEMBL1999630 & 688537 & 5.7762 & 5.7637 & TRN & & \\
\hline CHEMBL1461674 & 688537 & 2.8239 & 3.1795 & TRN & & \\
\hline CHEMBL1483333 & 688537 & 5.3446 & 4.9553 & TRN & & \\
\hline CHEMBL1514534 & 688537 & 5.5102 & 5.5171 & TRN & & \\
\hline CHEMBL1422471 & 688537 & 2.8239 & 4.9725 & TRN & & \\
\hline CHEMBL1470520 & 688537 & 5.1648 & 5.2789 & TRN & & \\
\hline CHEMBL1384227 & 688537 & 6.3391 & 6.1409 & TRN & & \\
\hline CHEMBL1453837 & 688537 & 5.1122 & 4.6861 & TRN & & \\
\hline CHEMBL1377813 & 688537 & 5.0438 & 5.0562 & TRN & & \\
\hline CHEMBL1305864 & 688537 & 5.0248 & 4.9604 & TST & & \\
\hline CHEMBL1887153 & 688537 & 5.7277 & 5.3856 & TRN & & \\
\hline CHEMBL1563827 & 688537 & \multicolumn{3}{|c|}{5.332000000000001} & 5.4552 & TST \\
\hline CHEMBL1563623 & 688537 & 5.5891 & 5.7113 & TRN & & \\
\hline CHEMBL1511300 & 688537 & 5.763 & 5.7346 & TRN & & \\
\hline CHEMBL1560092 & 688537 & 5.255 & 5.4505 & TRN & & \\
\hline CHEMBL162783 & 688537 & 6.4895 & 6.4742 & TRN & & \\
\hline CHEMBL1425525 & 688537 & 5.6066 & 5.7969 & TRN & & \\
\hline CHEMBL1508232 & 688537 & 5.6 & 5.3167 & TRN & & \\
\hline CHEMBL1334456 & 688537 & 6.7932 & 6.364 & TST & & \\
\hline CHEMBL1335491 & 688537 & 5.9285 & 6.4777 & TRN & & \\
\hline CHEMBL1536372 & 688537 & 2.8239 & 2.4601 & TRN & & \\
\hline CHEMBL1475748 & 688537 & \multicolumn{3}{|c|}{5.9670000000000005} & 5.654 & TRN \\
\hline CHEMBL535315 & 688537 & 5.5061 & 5.3821 & TRN & & \\
\hline CHEMBL 3212523 & 688537 & 2.8239 & 2.9879 & TRN & & \\
\hline CHEMBL1568457 & 688537 & 5.0954 & 4.6924 & TRN & & \\
\hline CHEMBL19954 & 688537 & 5.5979 & 5.5395 & TST & & \\
\hline CHEMBL1487004 & 688537 & 5.4661 & 5.2414 & TST & & \\
\hline CHEMBL1566354 & 688537 & 2.8239 & 3.9051 & TRN & & \\
\hline CHEMBL1465980 & 688537 & 2.8239 & 3.3978 & TST & & \\
\hline CHEMBL1608631 & 688537 & 4.4766 & 4.8513 & TST & & \\
\hline
\end{tabular}




\begin{tabular}{|c|c|c|c|c|c|c|}
\hline \multirow[b]{2}{*}{ CHEMBL1353013 } & \multirow[b]{2}{*}{688537} & \multicolumn{5}{|c|}{ Supplemental Table S2.txt } \\
\hline & & 4.9046 & 5.019 & TRN & & \\
\hline CHEMBL1522807 & 688537 & 6.32700 & 30000000 & & 5.5336 & TRN \\
\hline CHEMBL1380969 & 688537 & 5.19799 & 99999999 & 995 & 5.0374 & TRN \\
\hline CHEMBL1602836 & 688537 & 5.2157 & 5.0347 & TRN & & \\
\hline CHEMBL1609946 & 688537 & 6.9208 & 6.5791 & TRN & & \\
\hline CHEMBL1542652 & 688537 & 5.0437 & 5.0029 & TST & & \\
\hline CHEMBL1478319 & 688537 & 5.4209 & 5.2615 & TST & & \\
\hline CHEMBL1992702 & 688537 & 5.7314 & 5.8942 & TRN & & \\
\hline CHEMBL1572382 & 688537 & 5.9296 & 5.434 & TRN & & \\
\hline CHEMBL1315948 & 688537 & 5.4464 & 5.1618 & TRN & & \\
\hline CHEMBL1991751 & 688537 & 2.8239 & 4.7855 & TRN & & \\
\hline CHEMBL1414460 & 688537 & 5.101 & 5.4776 & TRN & & \\
\hline CHEMBL 256042 & 688537 & 6.1506 & 5.8345 & TRN & & \\
\hline CHEMBL1400432 & 688537 & 5.1904 & 5.2416 & TST & & \\
\hline CHEMBL1462041 & 688537 & 4.8825 & 4.7362 & TRN & & \\
\hline CHEMBL605185 & 688537 & 6.1884 & 5.4901 & TRN & & \\
\hline CHEMBL1391743 & 688537 & 6.1035 & 6.19600 & 0000000001 & & TRN \\
\hline CHEMBL1589298 & 688537 & 6.4214 & 6.1288 & TRN & & \\
\hline CHEMBL1413931 & 688537 & 4.9219 & 5.0277 & TRN & & \\
\hline CHEMBL1576581 & 688537 & 6.7471 & 6.5454 & TRN & & \\
\hline CHEMBL1984315 & 688537 & 4.6444 & 3.577 & TRN & & \\
\hline CHEMBL1510680 & 688537 & 2.8239 & 4.4227 & TRN & & \\
\hline CHEMBL1579217 & 688537 & 5.2787 & 5.3566 & TRN & & \\
\hline CHEMBL1395220 & 688537 & 5.1163 & 4.6787 & TRN & & \\
\hline CHEMBL1386200 & 688537 & 5.5056 & 5.1796 & TRN & & \\
\hline CHEMBL1460624 & 688537 & 6.20200 & 90000000 & $\partial 1$ & 6.1042 & TRN \\
\hline CHEMBL1507404 & 688537 & 5.254 & 5.1254 & TST & & \\
\hline CHEMBL1468737 & 688537 & 5.6794 & 5.2166 & TRN & & \\
\hline CHEMBL1339728 & 688537 & 5.149 & 5.05699 & 9999999999 & 95 & TRN \\
\hline CHEMBL1391069 & 688537 & 2.8239 & 3.3546 & TRN & & \\
\hline CHEMBL1578411 & 688537 & 5.391 & 5.5287 & TRN & & \\
\hline CHEMBL1556350 & 688537 & 6.6038 & 6.485 & TRN & & \\
\hline CHEMBL1379744 & 688537 & 4.07100 & 30000000 & $\partial 1$ & 4.7936 & TRN \\
\hline CHEMBL1473916 & 688537 & 5.1489 & 5.2748 & TST & & \\
\hline CHEMBL1429841 & 688537 & 5.4449 & 5.1541 & TRN & & \\
\hline CHEMBL1965811 & 688537 & 6.3134 & 5.9327 & TRN & & \\
\hline CHEMBL1471698 & 688537 & 6.1959 & 5.6221 & TRN & & \\
\hline CHEMBL1323757 & 688537 & 5.1997 & 5.395 & TRN & & \\
\hline CHEMBL1384094 & 688537 & 4.9522 & 4.9282 & TST & & \\
\hline CHEMBL1335027 & 688537 & 5.706 & 5.0566 & TRN & & \\
\hline CHEMBL1443936 & 688537 & 5.2787 & 4.5766 & TST & & \\
\hline CHEMBL1301919 & 688537 & 2.8239 & 2.8801 & TRN & & \\
\hline CHEMBL1341676 & 688537 & 5.1223 & 4.7482 & TRN & & \\
\hline CHEMBL1600644 & 688537 & 5.7373 & 5.5447 & TRN & & \\
\hline CHEMBL1343073 & 688537 & 5.5131 & 4.7836 & TST & & \\
\hline CHEMBL1321627 & 688537 & 2.8239 & 3.2653 & TRN & & \\
\hline CHEMBL1399543 & 688537 & 6.2218 & 5.8825 & TRN & & \\
\hline CHEMBL1600849 & 688537 & 5.9385 & 5.6743 & TST & & \\
\hline
\end{tabular}




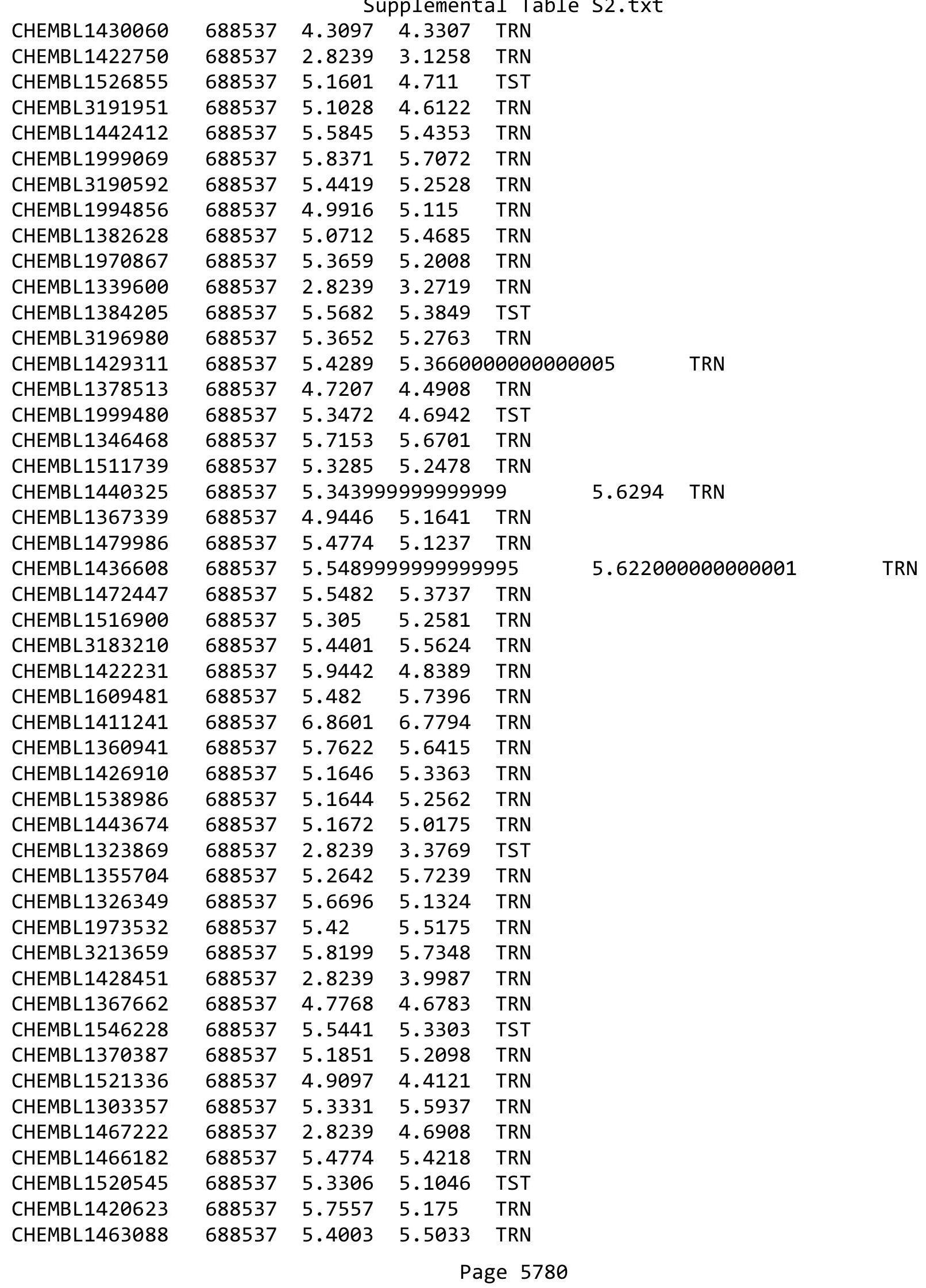


Supplemental Table S2.txt

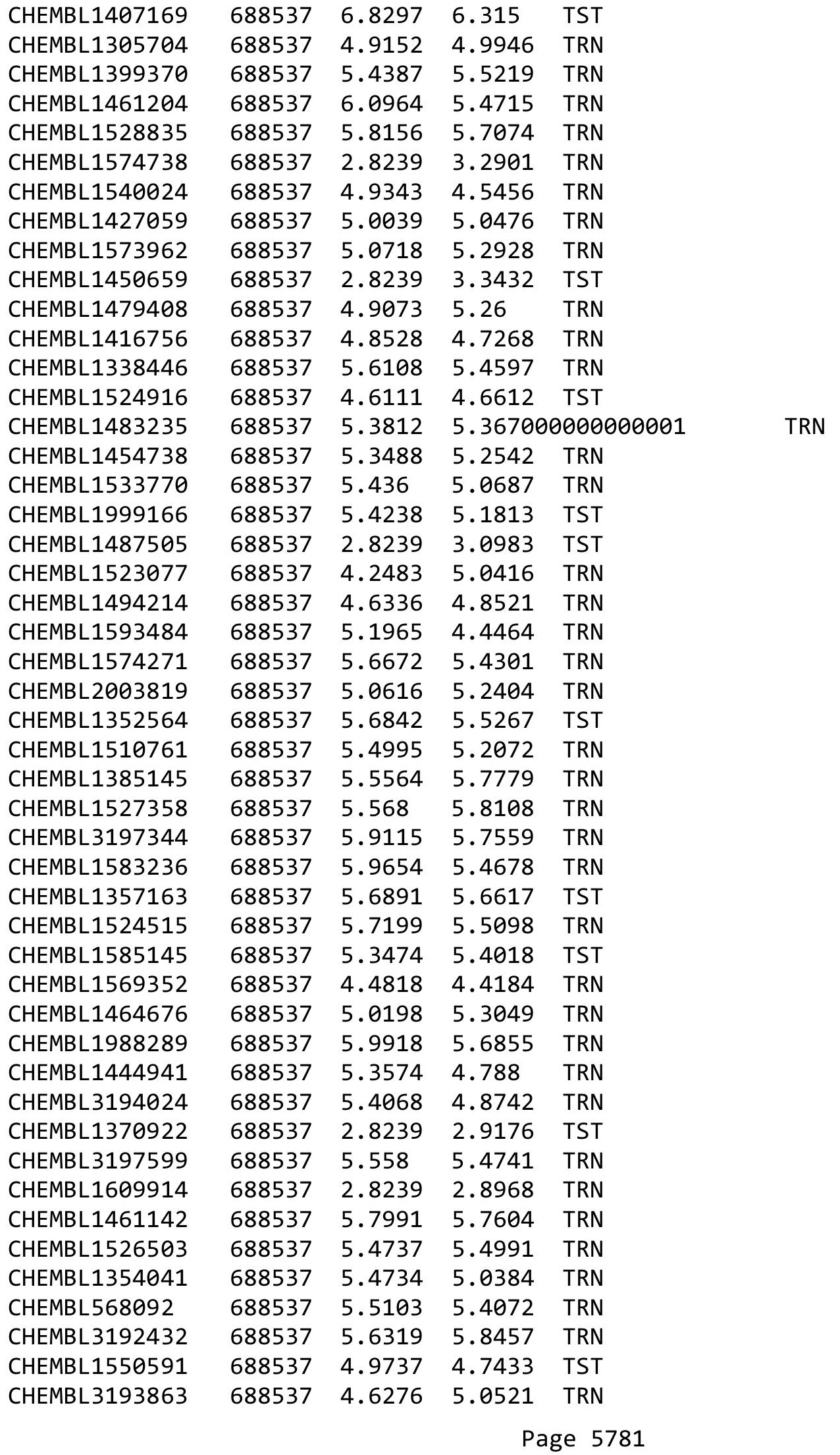




\begin{tabular}{|c|c|c|c|c|c|c|}
\hline & & \multicolumn{5}{|c|}{ Supplemental Table S2.txt } \\
\hline CHEMBL3191846 & 688537 & 5.0144 & 5.1635 & TRN & & \\
\hline CHEMBL1428417 & 688537 & 4.9534 & 5.1158 & TRN & & \\
\hline CHEMBL1470545 & 688537 & 5.08899 & 99999999 & 995 & 4.8718 & TRN \\
\hline CHEMBL1527664 & 688537 & 5.5415 & 5.4653 & TST & & \\
\hline CHEMBL1528965 & 688537 & 5.6975 & 5.5867 & TRN & & \\
\hline CHEMBL1477837 & 688537 & $5.2810 e$ & 00000000 & & 5.3524 & TRN \\
\hline CHEMBL1597758 & 688537 & 5.1535 & 5.1465 & TST & & \\
\hline CHEMBL1372064 & 688537 & 4.8264 & 4.8622 & TRN & & \\
\hline CHEMBL1533835 & 688537 & 4.9707 & 5.1916 & TRN & & \\
\hline CHEMBL1705092 & 688537 & 5.4332 & 4.8441 & TRN & & \\
\hline CHEMBL1605464 & 688537 & 5.244 & 5.2765 & TRN & & \\
\hline CHEMBL1543734 & 688537 & 6.0348 & 6.0854 & TRN & & \\
\hline CHEMBL1977596 & 688537 & 4.837 & 4.7162 & TRN & & \\
\hline CHEMBL1519374 & 688537 & 6.0325 & 5.4963 & TST & & \\
\hline CHEMBL1417620 & 688537 & 5.8274 & 5.6324 & TRN & & \\
\hline CHEMBL1424562 & 688537 & 5.6755 & 5.6154 & TRN & & \\
\hline CHEMBL1456906 & 688537 & 8.2218 & 8.2694 & TST & & \\
\hline CHEMBL1418600 & 688537 & 6.0017 & 5.521 & TST & & \\
\hline CHEMBL1351575 & 688537 & 4.8251 & 4.7973 & TRN & & \\
\hline CHEMBL1600587 & 688537 & 5.4998 & 5.5166 & TST & & \\
\hline CHEMBL550826 & 688537 & 5.334 & 4.7754 & TRN & & \\
\hline CHEMBL3191958 & 688537 & 5.12799 & 99999999 & 99 & 5.2928 & TRN \\
\hline CHEMBL1563370 & 688537 & 5.5127 & 5.6221 & TST & & \\
\hline CHEMBL1594106 & 688537 & 4.9974 & 4.7828 & TRN & & \\
\hline CHEMBL1597435 & 688537 & 5.9935 & 6.0692 & TRN & & \\
\hline CHEMBL1503123 & 688537 & 4.5975 & 4.3243 & TRN & & \\
\hline CHEMBL1531676 & 688537 & 5.0533 & 4.6833 & TST & & \\
\hline CHEMBL1450679 & 688537 & 5.2603 & 5.0538 & TRN & & \\
\hline CHEMBL1550490 & 688537 & 5.6386 & 5.4055 & TRN & & \\
\hline CHEMBL1594567 & 688537 & 5.2784 & 5.2648 & TRN & & \\
\hline CHEMBL1359609 & 688537 & 5.4968 & 4.9816 & TRN & & \\
\hline CHEMBL1428358 & 688537 & 4.623 & 4.5631 & TRN & & \\
\hline CHEMBL1467427 & 688537 & 5.3527 & 4.8503 & TRN & & \\
\hline CHEMBL1361896 & 688537 & 5.6338 & 5.7821 & TRN & & \\
\hline CHEMBL1347120 & 688537 & 4.5557 & 4.6137 & TST & & \\
\hline CHEMBL1321386 & 688537 & 5.3526 & 4.9702 & TRN & & \\
\hline CHEMBL1350984 & 688537 & 5.1693 & 4.6069 & TRN & & \\
\hline CHEMBL1505586 & 688537 & 5.7435 & 5.5704 & TST & & \\
\hline CHEMBL1524431 & 688537 & 5.186 & 4.7072 & TRN & & \\
\hline CHEMBL1980657 & 688537 & 5.9602 & 5.8631 & TRN & & \\
\hline CHEMBL1499084 & 688537 & 5.3688 & 5.2335 & TRN & & \\
\hline CHEMBL1965348 & 688537 & 5.4117 & 5.1375 & TRN & & \\
\hline CHEMBL1975652 & 688537 & 5.1741 & 4.8049 & TRN & & \\
\hline CHEMBL1460903 & 688537 & 5.4223 & 5.3363 & TRN & & \\
\hline CHEMBL1976000 & 688537 & 5.9052 & 5.5411 & TRN & & \\
\hline CHEMBL1366055 & 688537 & 6.1675 & 6.1658 & TRN & & \\
\hline CHEMBL1509878 & 688537 & 6.3675 & 6.1728 & TRN & & \\
\hline CHEMBL1994371 & 688537 & 5.4985 & 5.4954 & TRN & & \\
\hline
\end{tabular}




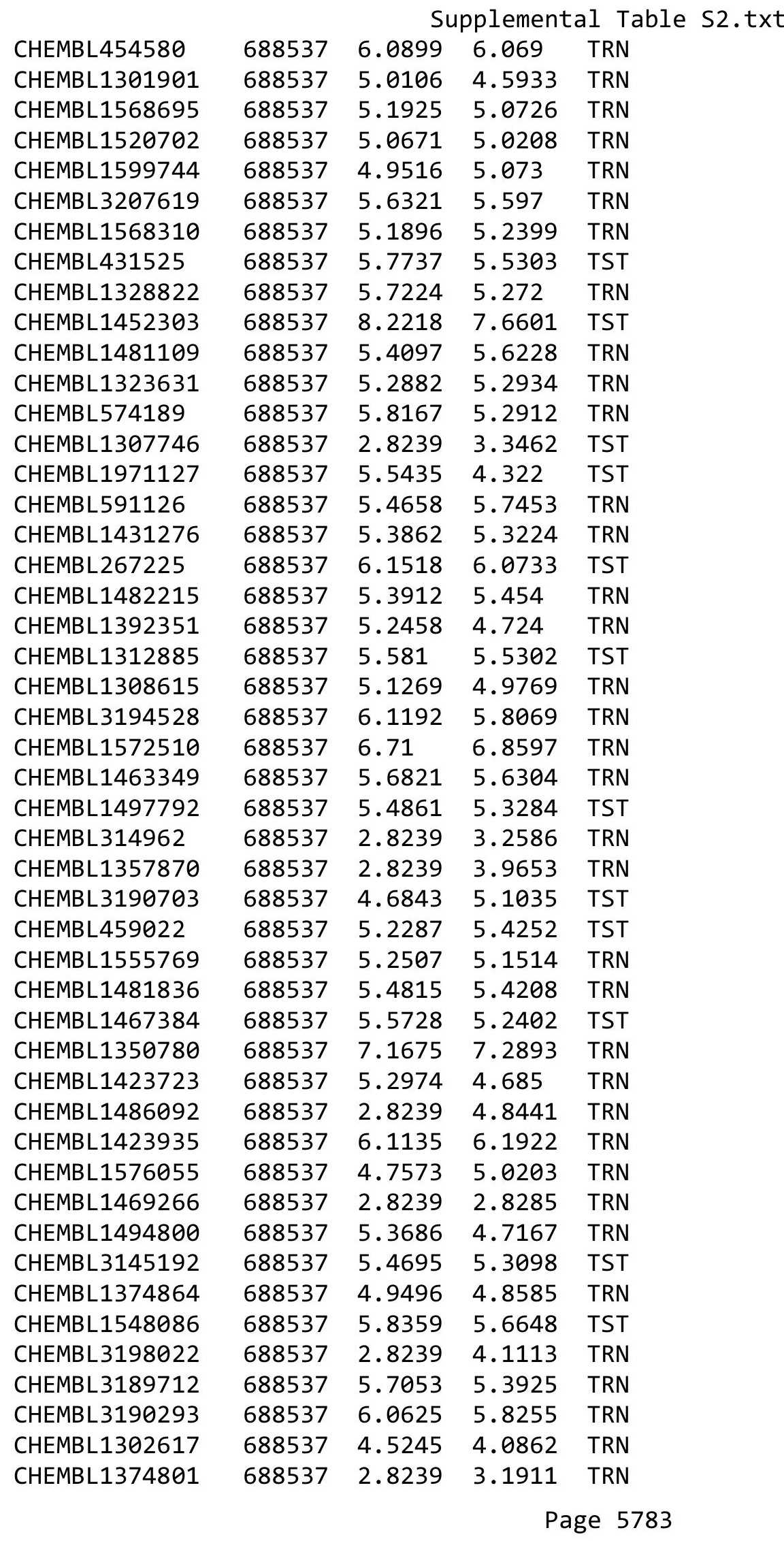


Supplemental Table S2.txt

\begin{tabular}{|c|c|c|c|c|}
\hline CHEMBL 2311878 & 688537 & 6.0969 & 5.9695 & TRN \\
\hline CHEMBL1367033 & 688537 & 2.8239 & 2.4182 & TRN \\
\hline CHEMBL140425 & 688537 & 5.8765 & 5.9424 & TRN \\
\hline CHEMBL1348729 & 688537 & 5.2586 & 5.3067 & TRN \\
\hline CHEMBL1504993 & 688537 & 5.8289 & 5.5001 & TST \\
\hline CHEMBL1428153 & 688537 & 5.8133 & 5.5495 & TST \\
\hline CHEMBL1450241 & 688537 & 5.9172 & 4.9435 & TRN \\
\hline CHEMBL1453391 & 688537 & 2.8239 & 2.9479 & TRN \\
\hline CHEMBL1487959 & 688537 & 5.3682 & 5.541 & TRN \\
\hline CHEMBL 246338 & 688537 & 2.8239 & 3.2684 & TRN \\
\hline CHEMBL1502639 & 688537 & 5.0189 & 4.1334 & TRN \\
\hline CHEMBL1200847 & 688537 & 5.8459 & 5.2637 & TST \\
\hline CHEMBL1523130 & 688537 & 5.2342 & 4.6171 & TST \\
\hline CHEMBL3145296 & 688537 & 6.2269 & 6.0679 & TRN \\
\hline CHEMBL1256686 & 688537 & 8.2218 & 7.3843 & TST \\
\hline CHEMBL1358081 & 688537 & 2.8239 & 2.8782 & TRN \\
\hline CHEMBL1523419 & 688537 & 4.8963 & 5.0734 & TRN \\
\hline CHEMBL3209776 & 688537 & 5.4118 & 5.4586 & TRN \\
\hline CHEMBL1470448 & 688537 & 6.7986 & 6.5705 & TRN \\
\hline CHEMBL1605015 & 688537 & 6.3497 & 5.716 & TRN \\
\hline CHEMBL1579503 & 688537 & 4.8954 & 4.3813 & TRN \\
\hline CHEMBL1310490 & 688537 & 5.1844 & 5.2017 & TRN \\
\hline CHEMBL1450825 & 688537 & 5.3064 & 5.3928 & TRN \\
\hline CHEMBL1347538 & 688537 & 2.8239 & 4.4948 & TST \\
\hline CHEMBL1977376 & 688537 & 2.8239 & 3.2054 & TRN \\
\hline CHEMBL1482975 & 688537 & 6.6968 & 7.2089 & TRN \\
\hline CHEMBL1351562 & 688537 & 5.777 & 5.4275 & TRN \\
\hline CHEMBL1507228 & 688537 & 5.2535 & 5.5576 & TRN \\
\hline CHEMBL1333575 & 688537 & 2.8239 & 3.0044 & TRN \\
\hline CHEMBL1330129 & 688537 & 5.5988 & 5.6738 & TRN \\
\hline CHEMBL1508440 & 688537 & 5.2897 & 4.8282 & TST \\
\hline CHEMBL1428894 & 688537 & 6.0794 & 5.7377 & TRN \\
\hline CHEMBL1498473 & 688537 & 4.6504 & 5.0697 & TST \\
\hline CHEMBL3198554 & 688537 & 5.6356 & 5.6265 & TRN \\
\hline CHEMBL1341945 & 688537 & 4.6725 & 4.551 & TRN \\
\hline CHEMBL3198659 & 688537 & 5.4766 & 5.5373 & TST \\
\hline CHEMBL1340792 & 688537 & 5.0752 & 4.8745 & TST \\
\hline CHEMBL1312717 & 688537 & 4.3549 & 4.6737 & TRN \\
\hline CHEMBL1568771 & 688537 & 4.8441 & 4.4662 & TRN \\
\hline CHEMBL1572768 & 688537 & 2.8239 & 4.5567 & TRN \\
\hline CHEMBL1407237 & 688537 & 5.6509 & 5.7523 & TRN \\
\hline CHEMBL1413243 & 688537 & 5.5178 & 5.6859 & TRN \\
\hline CHEMBL3193666 & 688537 & 5.4018 & 5.4442 & TRN \\
\hline CHEMBL1318350 & 688537 & 5.4831 & 5.7512 & TST \\
\hline CHEMBL590184 & 688537 & 6.6737 & 6.6705 & TRN \\
\hline CHEMBL1560273 & 688537 & 5.3013 & 4.9647 & TST \\
\hline CHEMBL3189161 & 688537 & 5.5378 & 5.6269 & TRN \\
\hline CHEMBL1597510 & 688537 & 4.7463 & 5.36100 & 3000000001 \\
\hline
\end{tabular}




\begin{tabular}{|c|c|c|c|c|}
\hline & & & pplement & al $\mathrm{T}$ \\
\hline CHEMBL458094 & 688537 & 5.5662 & 5.7634 & TRN \\
\hline CHEMBL1967185 & 688537 & 5.5049 & 5.1798 & TRN \\
\hline CHEMBL1447853 & 688537 & 4.6226 & 4.7883 & TST \\
\hline CHEMBL1308179 & 688537 & 5.3071 & 5.5692 & TST \\
\hline CHEMBL1334928 & 688537 & 5.4088 & 5.2022 & TRN \\
\hline CHEMBL3194816 & 688537 & 4.7958 & 4.4156 & TRN \\
\hline CHEMBL1339245 & 688537 & 6.1325 & 5.7318 & TRN \\
\hline CHEMBL1558160 & 688537 & 5.5892 & 5.4918 & TRN \\
\hline CHEMBL1332241 & 688537 & 5.2547 & 4.8596 & TRN \\
\hline CHEMBL1384702 & 688537 & 5.6461 & 5.7111 & TRN \\
\hline CHEMBL1345663 & 688537 & 5.0485 & 4.875 & TRN \\
\hline CHEMBL1334272 & 688537 & 5.2113 & 5.1496 & TRN \\
\hline CHEMBL1473268 & 688537 & 5.5524 & 5.5004 & TRN \\
\hline CHEMBL3195963 & 688537 & 5.7762 & 5.7513 & TST \\
\hline CHEMBL1432065 & 688537 & 5.6962 & 5.0339 & TST \\
\hline CHEMBL1602902 & 688537 & 4.9395 & 4.85 & TRN \\
\hline CHEMBL1584720 & 688537 & 5.0873 & 5.1833 & TRN \\
\hline CHEMBL1550430 & 688537 & 5.6874 & 6.0851 & TRN \\
\hline CHEMBL1432181 & 688537 & 5.9435 & 5.8364 & TRN \\
\hline CHEMBL3195142 & 688537 & 5.6921 & 5.8525 & TRN \\
\hline CHEMBL3189295 & 688537 & 5.3966 & 5.1214 & TRN \\
\hline CHEMBL1347710 & 688537 & 5.6373 & 5.6794 & TRN \\
\hline CHEMBL1574982 & 688537 & 4.5024 & 4.7524 & TRN \\
\hline CHEMBL1573804 & 688537 & 6.2848 & 5.7994 & TRN \\
\hline CHEMBL1437924 & 688537 & 5.0747 & 4.8794 & TST \\
\hline CHEMBL1598311 & 688537 & 5.1358 & 5.2806 & TRN \\
\hline CHEMBL1309958 & 688537 & 2.8239 & 4.8891 & TST \\
\hline CHEMBL1966025 & 688537 & 5.1578 & 5.0755 & TRN \\
\hline CHEMBL 3190621 & 688537 & 5.7001 & 5.6052 & TRN \\
\hline CHEMBL1517264 & 688537 & 4.8483 & 4.9931 & TRN \\
\hline CHEMBL1447251 & 688537 & 5.7133 & 5.6933 & TRN \\
\hline CHEMBL1602141 & 688537 & 4.887 & 5.3049 & TRN \\
\hline CHEMBL3212271 & 688537 & 5.3126 & 5.2445 & TRN \\
\hline CHEMBL1375559 & 688537 & 5.2893 & 4.8993 & TST \\
\hline CHEMBL1561190 & 688537 & 5.0135 & 4.9326 & TRN \\
\hline CHEMBL1514790 & 688537 & 5.319 & 5.2713 & TST \\
\hline CHEMBL1545839 & 688537 & 2.8239 & 3.3693 & TRN \\
\hline CHEMBL3144984 & 688537 & 5.3914 & 5.4778 & TRN \\
\hline CHEMBL3190103 & 688537 & 5.4049 & 5.316 & TST \\
\hline CHEMBL1510086 & 688537 & 5.1521 & 5.4327 & TRN \\
\hline CHEMBL1967772 & 688537 & 4.9663 & 5.232 & TRN \\
\hline CHEMBL1303391 & 688537 & 4.9581 & 4.9361 & TRN \\
\hline CHEMBL1367295 & 688537 & 6.5214 & 5.7806 & TRN \\
\hline CHEMBL1564641 & 688537 & 5.1337 & 5.4478 & TRN \\
\hline CHEMBL1368535 & 688537 & 5.5464 & 5.2336 & TRN \\
\hline CHEMBL1542491 & 688537 & 5.1923 & 5.6282 & TRN \\
\hline CHEMBL1449595 & 688537 & 2.8239 & 3.1876 & TRN \\
\hline CHEMBL1346881 & 688537 & 5.1285 & 5.3228 & TST \\
\hline
\end{tabular}




\begin{tabular}{|c|c|c|c|c|c|c|}
\hline & & \multicolumn{5}{|c|}{ Supplemental Table S2.txt } \\
\hline CHEMBL1482296 & 688537 & 5.6334 & 5.5575 & TRN & & \\
\hline CHEMBL455284 & 688537 & 5.699 & 5.1203 & TRN & & \\
\hline CHEMBL1594317 & 688537 & 5.4177 & 5.1273 & TRN & & \\
\hline CHEMBL81935 & 688537 & 5.092 & 5.3344 & TST & & \\
\hline CHEMBL1441088 & 688537 & 4.9405 & 4.9567 & TRN & & \\
\hline CHEMBL1520777 & 688537 & 5.1915 & 5.0028 & TRN & & \\
\hline CHEMBL1463856 & 688537 & 2.8239 & 3.2389 & TRN & & \\
\hline CHEMBL1303280 & 688537 & 5.4679 & 5.4781 & TRN & & \\
\hline CHEMBL1431705 & 688537 & \multicolumn{3}{|c|}{5.787000000000001} & 5.5717 & TRN \\
\hline CHEMBL1536034 & 688537 & 5.1099 & 4.7478 & TRN & & \\
\hline CHEMBL1605217 & 688537 & 5.0944 & 4.9496 & TRN & & \\
\hline CHEMBL1448529 & 688537 & 5.3901 & 4.9562 & TRN & & \\
\hline CHEMBL1406895 & 688537 & 5.5384 & 5.6922 & TRN & & \\
\hline CHEMBL1304666 & 688537 & 6.6091 & 6.6409 & TRN & & \\
\hline CHEMBL1435818 & 688537 & 5.9965 & 5.4371 & TRN & & \\
\hline CHEMBL1369522 & 688537 & 4.1639 & 4.6565 & TST & & \\
\hline CHEMBL1308594 & 688537 & 5.0488 & 5.2695 & TST & & \\
\hline CHEMBL1585579 & 688537 & 2.8239 & 3.2466 & TRN & & \\
\hline CHEMBL1491933 & 688537 & 5.1976 & 5.3695 & TRN & & \\
\hline CHEMBL1612688 & 688537 & 5.1362 & 4.7427 & TRN & & \\
\hline CHEMBL1596326 & 688537 & 4.9831 & 5.0761 & TRN & & \\
\hline CHEMBL1390702 & 688537 & 5.7104 & 5.0194 & TRN & & \\
\hline CHEMBL3210228 & 688537 & 6.0195 & 5.2009 & TRN & & \\
\hline CHEMBL3198886 & 688537 & 5.9948 & 6.069 & TRN & & \\
\hline CHEMBL1993291 & 688537 & 5.278 & 5.4382 & TRN & & \\
\hline CHEMBL1598882 & 688537 & 4.9487 & 4.539 & TRN & & \\
\hline CHEMBL1332165 & 688537 & 5.5979 & 5.1766 & TRN & & \\
\hline CHEMBL1488021 & 688537 & 5.0462 & 4.7414 & TST & & \\
\hline CHEMBL1406455 & 688537 & 2.8239 & 3.0869 & TRN & & \\
\hline CHEMBL1305498 & 688537 & 2.8239 & 3.3242 & TST & & \\
\hline CHEMBL1314913 & 688537 & 5.9682 & 5.733 & TST & & \\
\hline CHEMBL1331882 & 688537 & 4.6978 & 4.0289 & TRN & & \\
\hline CHEMBL1544371 & 688537 & 5.6702 & 5.7684 & TRN & & \\
\hline CHEMBL1300446 & 688537 & 5.7212 & 6.1074 & TRN & & \\
\hline CHEMBL1569782 & 688537 & 5.3038 & 5.18 & TRN & & \\
\hline CHEMBL1351805 & 688537 & 2.8239 & 3.0642 & TRN & & \\
\hline CHEMBL1372434 & 688537 & 5.138 & 5.4218 & TRN & & \\
\hline CHEMBL1449291 & 688537 & 4.8858 & 4.4447 & TRN & & \\
\hline CHEMBL1499597 & 688537 & 5.1709 & 4.5513 & TRN & & \\
\hline CHEMBL 2002849 & 688537 & 5.5686 & 5.1983 & TRN & & \\
\hline CHEMBL1466887 & 688537 & 6.0 & 5.6057 & TST & & \\
\hline CHEMBL1430636 & 688537 & 5.2723 & 5.3171 & TST & & \\
\hline CHEMBL3191706 & 688537 & 4.9091 & 4.706 & TRN & & \\
\hline CHEMBL1535525 & 688537 & \multicolumn{3}{|c|}{4.5969999999999995} & 4.752 & או \\
\hline CHEMBL1612475 & 688537 & 4.1939 & 4.7439 & TRN & & \\
\hline CHEMBL1369339 & 688537 & 5.4336 & 5.2757 & TRN & & \\
\hline CHEMBL1969647 & 688537 & 5.7981 & 5.9024 & TRN & & \\
\hline CHEMBL1510187 & 688537 & 2.8239 & 3.9314 & TRN & & \\
\hline
\end{tabular}


Supplemental Table S2.txt

\begin{tabular}{|c|c|c|c|c|}
\hline CHEMBL1454212 & 688537 & 5.9747 & 5.4472 & TRN \\
\hline CHEMBL1388702 & 688537 & 2.8239 & 3.0204 & TRN \\
\hline CHEMBL1718568 & 688537 & 6.3546 & 5.9648 & TRN \\
\hline CHEMBL1350336 & 688537 & 5.3892 & 5.5172 & TRN \\
\hline CHEMBL1237072 & 688537 & 8.2218 & 7.8781 & TST \\
\hline CHEMBL1513407 & 688537 & 6.0788 & 5.9777 & TRN \\
\hline CHEMBL1384186 & 688537 & 5.3367 & 5.4012 & TRN \\
\hline CHEMBL1452706 & 688537 & 5.3633 & 5.3716 & TRN \\
\hline CHEMBL1604261 & 688537 & 4.9821 & 4.7715 & TST \\
\hline CHEMBL1379895 & 688537 & 5.6291 & 5.5225 & TRN \\
\hline CHEMBL1426978 & 688537 & 5.1344 & 4.9301 & TRN \\
\hline CHEMBL3195036 & 688537 & 4.5631 & 5.1042 & TRN \\
\hline CHEMBL1459514 & 688537 & 5.4893 & 5.0337 & TRN \\
\hline CHEMBL1494274 & 688537 & 2.8239 & 3.1063 & TRN \\
\hline CHEMBL1333993 & 688537 & 4.6812 & 4.768 & TST \\
\hline CHEMBL1313236 & 688537 & 5.2761 & 5.3056 & TRN \\
\hline CHEMBL1559660 & 688537 & 5.1044 & 4.9734 & TST \\
\hline CHEMBL1344388 & 688537 & 6.1203 & 6.1119 & TRN \\
\hline CHEMBL1320354 & 688537 & 5.6882 & 5.6406 & TRN \\
\hline CHEMBL1306480 & 688537 & 5.3539 & 5.1673 & TRN \\
\hline CHEMBL1501057 & 688537 & 5.6312 & 5.9794 & TRN \\
\hline CHEMBL1992276 & 688537 & 4.809 & 4.8846 & TRN \\
\hline CHEMBL1516792 & 688537 & 4.3157 & 4.3619 & TRN \\
\hline CHEMBL1300408 & 688537 & 5.1708 & \multicolumn{2}{|c|}{5.1339999999999995} \\
\hline CHEMBL1345459 & 688537 & 2.8239 & 2.7139 & TRN \\
\hline CHEMBL1370252 & 688537 & 4.8367 & 5.0333 & TRN \\
\hline CHEMBL1328384 & 688537 & 5.0492 & 4.9279 & TST \\
\hline CHEMBL1518155 & 688537 & 4.9508 & 4.8042 & TST \\
\hline CHEMBL1387737 & 688537 & 2.8239 & 3.0453 & TRN \\
\hline CHEMBL1611182 & 688537 & 5.14 & \multicolumn{2}{|c|}{5.3839999999999995} \\
\hline CHEMBL1559500 & 688537 & 4.9469 & 4.8437 & TRN \\
\hline CHEMBL1444102 & 688537 & 3.9418 & 4.7521 & TST \\
\hline CHEMBL1393914 & 688537 & 5.5232 & 5.5908 & TRN \\
\hline CHEMBL1501558 & 688537 & 5.3289 & 5.7055 & TRN \\
\hline CHEMBL1411744 & 688537 & 2.8239 & 3.1613 & TRN \\
\hline CHEMBL1527573 & 688537 & 2.8239 & 2.9203 & TRN \\
\hline CHEMBL1330453 & 688537 & 4.9888 & 4.9516 & TRN \\
\hline CHEMBL1483261 & 688537 & 5.2752 & 5.1018 & TRN \\
\hline CHEMBL1340482 & 688537 & 5.965 & 5.7395 & TRN \\
\hline CHEMBL1403112 & 688537 & 5.6548 & 5.5017 & TRN \\
\hline CHEMBL1585777 & 688537 & 5.7442 & 6.2218 & TRN \\
\hline CHEMBL1970872 & 688537 & 5.9867 & 5.7535 & TRN \\
\hline CHEMBL1495998 & 688537 & 5.6444 & 5.5413 & TRN \\
\hline CHEMBL1300229 & 688537 & 2.8239 & 3.3959 & TST \\
\hline CHEMBL1492305 & 688537 & 5.4352 & 5.4129 & TRN \\
\hline CHEMBL1577983 & 688537 & 5.1638 & 5.5507 & TRN \\
\hline CHEMBL1995336 & 688537 & 2.8239 & 3.29699 & 99999999997 \\
\hline CHEMBL1401144 & 688537 & 4.8606 & 4.4162 & TRN \\
\hline
\end{tabular}




\begin{tabular}{|c|c|c|c|c|c|c|}
\hline & & \multicolumn{5}{|c|}{ Supplemental Table S2.txt } \\
\hline CHEMBL1526636 & 688537 & 5.1392 & 5.5012 & TRN & & \\
\hline CHEMBL1476032 & 688537 & 2.8239 & 2.7327 & TRN & & \\
\hline CHEMBL1517346 & 688537 & 2.8239 & 3.2806 & TST & & \\
\hline CHEMBL1372421 & 688537 & 6.1586 & 6.1067 & TRN & & \\
\hline CHEMBL1306690 & 688537 & 4.982 & 5.4108 & TST & & \\
\hline CHEMBL3198398 & 688537 & 5.0651 & 4.7964 & TRN & & \\
\hline CHEMBL1346628 & 688537 & 5.0487 & 5.0583 & TST & & \\
\hline CHEMBL1597655 & 688537 & 5.2118 & 5.3835 & TRN & & \\
\hline CHEMBL283849 & 688537 & 5.2534 & 5.3242 & TRN & & \\
\hline CHEMBL510279 & 688537 & 5.5552 & 5.5888 & TRN & & \\
\hline CHEMBL1994902 & 688537 & 6.3279 & 6.0094 & TRN & & \\
\hline CHEMBL1463163 & 688537 & 5.0217 & 5.272 & TRN & & \\
\hline CHEMBL1446290 & 688537 & 2.8239 & 2.9604 & TRN & & \\
\hline CHEMBL1322274 & 688537 & 4.8026 & 5.1298 & TST & & \\
\hline CHEMBL1348356 & 688537 & 4.76399 & 99999999 & 99 & 4.4246 & TRN \\
\hline CHEMBL1365357 & 688537 & 4.7328 & 4.2963 & TRN & & \\
\hline CHEMBL6742 & 688537 & 6.4473 & 6.7386 & TRN & & \\
\hline CHEMBL461820 & 688537 & 5.5299 & 5.7157 & TRN & & \\
\hline CHEMBL1437208 & 688537 & 4.993 & 4.4467 & TRN & & \\
\hline CHEMBL1449956 & 688537 & 2.8239 & 3.2162 & TRN & & \\
\hline CHEMBL1533981 & 688537 & 5.5969 & 5.2917 & TRN & & \\
\hline CHEMBL1330522 & 688537 & 8.2218 & 7.5229 & TRN & & \\
\hline CHEMBL1373646 & 688537 & 6.9508 & 8.2414 & TRN & & \\
\hline CHEMBL1548396 & 688537 & 5.3451 & 5.2354 & TST & & \\
\hline CHEMBL1407260 & 688537 & 5.1363 & 5.0485 & TRN & & \\
\hline CHEMBL1337018 & 688537 & $5.7620 e$ & 00000000 & 005 & 5.3058 & TRN \\
\hline CHEMBL3194106 & 688537 & 2.8239 & 4.623 & TRN & & \\
\hline CHEMBL1586817 & 688537 & 5.061 & 5.4882 & TRN & & \\
\hline CHEMBL1337193 & 688537 & 5.9104 & 5.6324 & TRN & & \\
\hline CHEMBL1419303 & 688537 & 5.1927 & 5.2495 & TST & & \\
\hline CHEMBL1322039 & 688537 & 4.9897 & 5.048 & TRN & & \\
\hline CHEMBL1594349 & 688537 & 5.3846 & 5.1943 & TRN & & \\
\hline CHEMBL1408102 & 688537 & 5.2328 & 5.1781 & TST & & \\
\hline CHEMBL 2003651 & 688537 & 5.2411 & 5.7025 & TRN & & \\
\hline CHEMBL498436 & 688537 & 5.636 & 5.5332 & TST & & \\
\hline CHEMBL1971532 & 688537 & 5.4616 & 5.5439 & TRN & & \\
\hline CHEMBL1553408 & 688537 & 5.1301 & 5.3433 & TRN & & \\
\hline CHEMBL3195074 & 688537 & 6.2976 & 5.919 & TRN & & \\
\hline CHEMBL 1327810 & 688537 & 5.1245 & 5.2084 & TRN & & \\
\hline CHEMBL1542568 & 688537 & 5.2416 & 5.1287 & TRN & & \\
\hline CHEMBL1366168 & 688537 & 5.5669 & 5.6173 & TRN & & \\
\hline CHEMBL1568827 & 688537 & 5.434 & 5.5452 & TRN & & \\
\hline CHEMBL1488172 & 688537 & 5.8193 & 5.6916 & TRN & & \\
\hline CHEMBL1447061 & 688537 & 2.8239 & 2.8711 & TRN & & \\
\hline CHEMBL1326101 & 688537 & 5.4766 & 5.4709 & TRN & & \\
\hline CHEMBL1592582 & 688537 & 2.8239 & 4.2272 & TRN & & \\
\hline CHEMBL482116 & 688537 & 5.2875 & 5.0978 & TRN & & \\
\hline CHEMBL1427079 & 688537 & 5.0169 & 4.8276 & TST & & \\
\hline
\end{tabular}




\begin{tabular}{|c|c|c|c|c|c|c|}
\hline \multicolumn{7}{|c|}{ Supplemental Table S2.txt } \\
\hline CHEMBL1338713 & 688537 & 2.8239 & 4.5075 & TRN & & \\
\hline CHEMBL1556485 & 688537 & 5.4721 & 5.4584 & TRN & & \\
\hline CHEMBL1407235 & 688537 & 5.0167 & 3.6885 & TRN & & \\
\hline CHEMBL1389673 & 688537 & 4.6391 & 4.7748 & TRN & & \\
\hline CHEMBL1347479 & 688537 & 4.6255 & 5.0042 & TST & & \\
\hline CHEMBL3211781 & 688537 & 4.9357 & 5.5619 & TRN & & \\
\hline CHEMBL1353949 & 688537 & 2.8239 & 3.2902 & TST & & \\
\hline CHEMBL3199324 & 688537 & 5.4231 & 5.5722 & TRN & & \\
\hline CHEMBL1586706 & 688537 & 4.9156 & 5.1135 & TRN & & \\
\hline CHEMBL1595276 & 688537 & 2.8239 & 2.9674 & TST & & \\
\hline CHEMBL1550274 & 688537 & 5.6366 & 4.9036 & TRN & & \\
\hline CHEMBL1346232 & 688537 & 5.1309 & 4.9162 & TRN & & \\
\hline CHEMBL1371298 & 688537 & 4.3558 & 5.2233 & TRN & & \\
\hline CHEMBL1535529 & 688537 & 5.0068 & 5.3865 & TRN & & \\
\hline CHEMBL1587181 & 688537 & 5.5281 & 5.171 & TRN & & \\
\hline CHEMBL1475733 & 688537 & 4.6268 & 4.7702 & TRN & & \\
\hline CHEMBL1335724 & 688537 & 5.6373 & 5.1734 & TRN & & \\
\hline CHEMBL1452116 & 688537 & 5.9439 & 5.7764 & TRN & & \\
\hline CHEMBL1557648 & 688537 & 6.585 & 6.6827 & TRN & & \\
\hline CHEMBL1559999 & 688537 & 5.2641 & 4.9647 & TRN & & \\
\hline CHEMBL1328544 & 688537 & 5.7929 & 4.6275 & TRN & & \\
\hline CHEMBL1426440 & 688537 & 5.2286 & 4.9778 & TST & & \\
\hline CHEMBL1544859 & 688537 & 4.5824 & 4.8025 & TRN & & \\
\hline CHEMBL1603550 & 688537 & 2.8239 & 2.8843 & TRN & & \\
\hline CHEMBL1409001 & 688537 & 5.5455 & 5.6004 & TRN & & \\
\hline CHEMBL1303651 & 688537 & 5.7414 & 5.8662 & TRN & & \\
\hline CHEMBL1522645 & 688537 & 4.8864 & 4.886 & TRN & & \\
\hline CHEMBL1336675 & 688537 & 5.724 & 6.0976 & TRN & & \\
\hline CHEMBL1544544 & 688537 & 5.8851 & 5.9866 & TRN & & \\
\hline CHEMBL1361361 & 688537 & 5.3643 & 4.6728 & TRN & & \\
\hline CHEMBL1528206 & 688537 & 8.2218 & 8.1525 & TRN & & \\
\hline CHEMBL3198313 & 688537 & 5.2752 & 4.9799 & TRN & & \\
\hline CHEMBL1534987 & 688537 & 4.5895 & 5.3025 & TRN & & \\
\hline CHEMBL1975032 & 688537 & 5.6313 & 5.4297 & TRN & & \\
\hline CHEMBL1333637 & 688537 & 4.9561 & 4.7413 & TST & & \\
\hline CHEMBL1382674 & 688537 & 8.2218 & 8.5023 & TRN & & \\
\hline CHEMBL1606583 & 688537 & 5.5146 & 5.4356 & TRN & & \\
\hline CHEMBL1419484 & 688537 & 5.6747 & 5.6601 & TRN & & \\
\hline CHEMBL1548142 & 688537 & 2.8239 & 3.5494 & TST & & \\
\hline CHEMBL1348167 & 688537 & 2.8239 & 2.8246 & TRN & & \\
\hline CHEMBL1314141 & 688537 & 6.75700 & 000000000 & 21 & 6.867000000000001 & TRN \\
\hline CHEMBL1604383 & 688537 & 4.9732 & 5.0494 & TRN & & \\
\hline CHEMBL1560408 & 688537 & 5.4456 & 5.1412 & TRN & & \\
\hline CHEMBL1386564 & 688537 & 4.7845 & 5.012 & TST & & \\
\hline CHEMBL1421347 & 688537 & 5.9129 & 5.9089 & TRN & & \\
\hline CHEMBL1982305 & 688537 & 5.3353 & 5.6279 & TRN & & \\
\hline CHEMBL1377417 & 688537 & 4.6222 & 4.5985 & TRN & & \\
\hline CHEMBL1562033 & 688537 & 8.2218 & 6.7449 & TST & & \\
\hline
\end{tabular}


Supplemental Table S2.txt

\begin{tabular}{|c|c|c|c|c|c|}
\hline CHEMBL1453663 & 688537 & 5.2675 & 5.2157 & TST & \\
\hline CHEMBL1532436 & 688537 & 5.0158 & 5.1295 & TRN & \\
\hline CHEMBL1511114 & 688537 & 4.8675 & 4.786000 & 0000000005 & TRN \\
\hline CHEMBL1552296 & 688537 & 5.0742 & 3.9298 & TRN & \\
\hline CHEMBL1584796 & 688537 & 5.1621 & 5.3388 & TRN & \\
\hline CHEMBL1518955 & 688537 & 4.7836 & 4.9037 & TRN & \\
\hline CHEMBL1324032 & 688537 & 5.0991 & 4.9451 & TST & \\
\hline CHEMBL1406942 & 688537 & 5.21299 & 999999999 & 5.1254 & TRN \\
\hline CHEMBL1564099 & 688537 & 4.9937 & 5.108000 & 0000000005 & TRN \\
\hline CHEMBL1482387 & 688537 & 5.3626 & 5.7627 & TRN & \\
\hline CHEMBL 3192972 & 688537 & 5.4614 & 5.282 & TRN & \\
\hline CHEMBL1995800 & 688537 & 4.3477 & 3.5925 & TRN & \\
\hline CHEMBL1494267 & 688537 & 2.8239 & 3.282 & TST & \\
\hline CHEMBL1384748 & 688537 & 5.0548 & 5.1164 & TRN & \\
\hline CHEMBL1383895 & 688537 & 5.4752 & 5.5948 & TRN & \\
\hline CHEMBL1309573 & 688537 & 5.6014 & 5.8273 & TRN & \\
\hline CHEMBL3193184 & 688537 & 5.1501 & 5.195 & TRN & \\
\hline CHEMBL1529106 & 688537 & 4.7152 & 4.5685 & TRN & \\
\hline CHEMBL1610443 & 688537 & 6.0119 & 5.8322 & TRN & \\
\hline CHEMBL1478231 & 688537 & 5.3728 & 4.6851 & TST & \\
\hline CHEMBL1364626 & 688537 & 2.8239 & 3.6689 & TRN & \\
\hline CHEMBL1336274 & 688537 & 4.8872 & 4.902 & TRN & \\
\hline CHEMBL1497725 & 688537 & 2.8239 & 3.1421 & TRN & \\
\hline CHEMBL1359820 & 688537 & 4.9541 & 4.8119 & TRN & \\
\hline CHEMBL1505674 & 688537 & 5.2844 & 5.6301 & TST & \\
\hline CHEMBL1336959 & 688537 & \multicolumn{3}{|c|}{5.9910000000000005} & TRN \\
\hline CHEMBL1480252 & 688537 & 4.4592 & 4.7808 & TRN & \\
\hline CHEMBL3193178 & 688537 & 4.9036 & 4.6083 & TRN & \\
\hline CHEMBL1603637 & 688537 & 6.1891 & 5.9091 & TRN & \\
\hline CHEMBL 2000517 & 688537 & 5.7744 & 5.8065 & TRN & \\
\hline CHEMBL3197433 & 688537 & 5.7696 & 5.7047 & TRN & \\
\hline CHEMBL1611585 & 688537 & 2.8239 & 4.1136 & TRN & \\
\hline CHEMBL1472773 & 688537 & 5.8897 & 5.6706 & TST & \\
\hline CHEMBL1409443 & 688537 & 5.5061 & 4.9722 & TRN & \\
\hline CHEMBL1471286 & 688537 & 6.3675 & \multicolumn{2}{|c|}{5.752999999999999} & TRN \\
\hline CHEMBL1337353 & 688537 & \multicolumn{3}{|c|}{5.202000000000001} & TRN \\
\hline CHEMBL1503359 & 688537 & 5.3735 & 4.8334 & TRN & \\
\hline CHEMBL1307515 & 688537 & 5.7265 & 5.2622 & TST & \\
\hline CHEMBL1310234 & 688537 & 5.2568 & 5.3444 & TRN & \\
\hline CHEMBL1450690 & 688537 & 5.9094 & 5.9497 & TRN & \\
\hline CHEMBL1520217 & 688537 & 4.6643 & 4.1766 & TRN & \\
\hline CHEMBL1384209 & 688537 & 2.8239 & 3.3807 & TRN & \\
\hline CHEMBL1520763 & 688537 & 5.3674 & 5.0973 & TRN & \\
\hline CHEMBL1500050 & 688537 & 5.3779 & 5.2633 & TRN & \\
\hline CHEMBL3192625 & 688537 & 6.6556 & 5.9357 & TRN & \\
\hline CHEMBL1452858 & 688537 & 5.8952 & 6.2906 & TRN & \\
\hline CHEMBL1610002 & 688537 & 5.2701 & 4.7294 & TST & \\
\hline CHEMBL1394159 & 688537 & 5.3275 & 4.482 & TST & \\
\hline
\end{tabular}


Supplemental Table S2.txt

\begin{tabular}{|c|c|c|c|c|}
\hline HEN & & 2971 & & \\
\hline & 88537 & .2218 & & \\
\hline & & & & \\
\hline AEMBL1 & & & & \\
\hline AEMBL1450597 & 537 & 5682 & & \\
\hline HEMBL1572283 & 88537 & .7807 & 5135 & \\
\hline HEMBL14 & 8537 & 239 & & \\
\hline IFMBI 14 & & & & \\
\hline AEMBL1383807 & 88537 & 9121 & 5329 & \\
\hline HEMBL153 & 38537 & 607 & 801 & \\
\hline HEMBL1469791 & 88537 & 1883 & 3033 & \\
\hline IEMBL15 & 37 & 713 & 445 & \\
\hline IEMBL14 & & & & \\
\hline HEMBL18 & 37 & .777 & 5.4384 & \\
\hline IEMBL13 & 37 & 39 & 032 & \\
\hline IEMBL14 & 37 & 862 & 482 & \\
\hline AEMBL16 & & 39 & 58 & \\
\hline HEMBL15 & & & & \\
\hline HEMBL 15 & & & 7408 & \\
\hline IEMBL41 & & & & \\
\hline HEMBLIS & 7 & 6 & 957 & I NIV \\
\hline AEMBL14 & & & & \\
\hline AEMBL5E & & & 275 & \\
\hline AEMBL31 & & 3867 & & \\
\hline HEMBL132 & & & & ras \\
\hline HEMBL15 & 1 & & & RN \\
\hline HEMBL1: & & & & Niv \\
\hline HFMBI 14 & 7 & 35 & 24 & \\
\hline AEMBL14 & & & & +2 \\
\hline HEMBL146 & & & & IRIV \\
\hline HEMBL31 & 7 & & & RN \\
\hline HEMBLI & & & 66 & RN \\
\hline HEMRI - & 7 & 54 & 07 & $\mathrm{RN}$ \\
\hline HEMBL3213534 & & & & $\mathrm{IR}$ \\
\hline HEMBL1515525 & 37 & & 425 & TRN \\
\hline HEMBL & 37 & & 283 & RN \\
\hline HᄃMP 1 & & 9 & 145 & $\Gamma \mathrm{RN}$ \\
\hline HEMBL1 & & & 754 & IST \\
\hline HEMBL1597289 & 88537 & & 8566 & TRN \\
\hline AEMBL15 & 885 & & 2646 & ГRN \\
\hline HEMBL 20 & 88537 & 44 & 122 & \\
\hline CHEMBL137 & & & 5.5677 & TRN \\
\hline HEMBL1441418 & 88537 & & 1989 & RN \\
\hline AEMBL3198440 & 38537 & 79 & 5181 & TRN \\
\hline HEMBL1 & 88537 & & 5174 & $\pi$ \\
\hline HEMBL13 & 588537 & & 1.6231 & \\
\hline CHEMBL140119] & 88537 & & 3.0803 & \\
\hline CHEMBL1583785 & 688537 & 4.5107 & 4.6847 & ГRN \\
\hline
\end{tabular}

Page 5791 


\begin{tabular}{|c|c|c|c|c|c|c|}
\hline & & & & & & \\
\hline CHEMBL1455627 & 688537 & 6.4425 & 6.4706 & TRN & & \\
\hline CHEMBL1394479 & 688537 & 5.3112 & 5.456 & TRN & & \\
\hline CHEMBL1326819 & 688537 & 4.9265 & 4.7759 & TRN & & \\
\hline CHEMBL590887 & 688537 & 5.6209 & 5.3831 & TRN & & \\
\hline CHEMBL1499220 & 688537 & 5.5267 & 5.2934 & TRN & & \\
\hline CHEMBL1599981 & 688537 & 4.9868 & 4.7091 & TRN & & \\
\hline CHEMBL1320940 & 688537 & 5.4147 & 5.337006 & 000000000 & & TRN \\
\hline CHEMBL1445161 & 688537 & 5.3282 & 5.4813 & TST & & \\
\hline CHEMBL1336054 & 688537 & 5.2822 & 5.5389 & TRN & & \\
\hline CHEMBL1374335 & 688537 & 2.8239 & 5.0199 & TRN & & \\
\hline CHEMBL530682 & 688537 & 5.2713 & 4.9626 & TRN & & \\
\hline CHEMBL1477690 & 688537 & 5.2766 & 4.8011 & TRN & & \\
\hline CHEMBL3210860 & 688537 & 5.1445 & 4.7919 & TRN & & \\
\hline CHEMBL1569639 & 688537 & 2.8239 & 2.9387 & TRN & & \\
\hline CHEMBL1410479 & 688537 & 5.5339 & 5.4171 & TRN & & \\
\hline CHEMBL3191818 & 688537 & 4.9886 & 5.1383 & TRN & & \\
\hline CHEMBL1460705 & 688537 & 6.1785 & 5.9606 & TRN & & \\
\hline CHEMBL533226 & 688537 & 5.3523 & 5.4161 & TRN & & \\
\hline CHEMBL1501475 & 688537 & 6.025 & 4.88 & TRN & & \\
\hline CHEMBL1343800 & 688537 & 5.8871 & 5.4242 & TRN & & \\
\hline CHEMBL1542654 & 688537 & 4.9056 & 5.4191 & TRN & & \\
\hline CHEMBL1342436 & 688537 & 8.2218 & 7.2957 & TST & & \\
\hline CHEMBL1349434 & 688537 & 5.9739 & 5.8413 & TRN & & \\
\hline CHEMBL1501495 & 688537 & 5.1921 & 5.3687 & TRN & & \\
\hline CHEMBL1453753 & 688537 & 5.4604 & 4.9778 & TRN & & \\
\hline CHEMBL1467377 & 688537 & 2.8239 & 3.267 & TRN & & \\
\hline CHEMBL3197936 & 688537 & 5.4095 & 5.4188 & TRN & & \\
\hline CHEMBL1581789 & 688537 & 6.0706 & 6.2024 & TRN & & \\
\hline CHEMBL1398910 & 688537 & 4.3221 & 4.8398 & TRN & & \\
\hline CHEMBL1414923 & 688537 & 6.3261 & 6.4506 & TRN & & \\
\hline CHEMBL1449349 & 688537 & 5.2388 & 4.57100 & 000000000 & & TRN \\
\hline CHEMBL1320128 & 688537 & 5.1737 & 5.2273 & TRN & & \\
\hline CHEMBL1518264 & 688537 & 4.6926 & 4.8639 & TRN & & \\
\hline CHEMBL1522582 & 688537 & 5.3322 & 5.4097 & TRN & & \\
\hline CHEMBL1399229 & 688537 & 2.8239 & 3.1568 & TST & & \\
\hline CHEMBL1509590 & 688537 & 5.9512 & 5.7467 & TRN & & \\
\hline CHEMBL3190657 & 688537 & 2.8239 & 4.933 & TRN & & \\
\hline CHEMBL1546607 & 688537 & 5.0844 & 5.1672 & TRN & & \\
\hline CHEMBL1377207 & 688537 & 4.50899 & 99999999 & 995 & 4.2986 & TRN \\
\hline CHEMBL3392057 & 688537 & 5.8002 & 5.3595 & TRN & & \\
\hline CHEMBL 2369228 & 688537 & 5.0337 & 5.0221 & TST & & \\
\hline CHEMBL1300890 & 688537 & 5.6108 & 5.3928 & TRN & & \\
\hline CHEMBL1547542 & 688537 & 2.8239 & 3.2626 & TRN & & \\
\hline CHEMBL1545225 & 688537 & 5.78299 & 99999999 & 995 & 5.728 & TRN \\
\hline CHEMBL1457175 & 688537 & 5.7347 & 5.1206 & TRN & & \\
\hline CHEMBL3192727 & 688537 & 5.5737 & 5.358 & TRN & & \\
\hline CHEMBL1398075 & 688537 & 2.8239 & 3.0338 & TRN & & \\
\hline CHEMBL1367268 & 688537 & 4.9264 & 5.2642 & TRN & & \\
\hline
\end{tabular}


Supplemental Table S2.txt

\begin{tabular}{|c|c|c|c|c|c|}
\hline CHEMBL1443198 & 688537 & 5.5909 & 4.9768 & TRN & \\
\hline CHEMBL1422078 & 688537 & 8.2218 & 7.0317 & TRN & \\
\hline CHEMBL193627 & 688537 & 5.3898 & 5.355 & TST & \\
\hline CHEMBL1326060 & 688537 & 5.7378 & 5.6783 & TRN & \\
\hline CHEMBL1390112 & 688537 & 6.3019 & 5.4811 & TRN & \\
\hline CHEMBL1492045 & 688537 & 5.4931 & 5.6738 & TRN & \\
\hline CHEMBL1558175 & 688537 & 4.8071 & 4.9118 & TRN & \\
\hline CHEMBL1525775 & 688537 & 2.8239 & 4.2347 & TRN & \\
\hline CHEMBL1445659 & 688537 & 5.6782 & 5.3809 & TRN & \\
\hline CHEMBL1486418 & 688537 & 5.3415 & 5.4367 & TRN & \\
\hline CHEMBL1386092 & 688537 & 5.2806 & 5.1901 & TST & \\
\hline CHEMBL1539400 & 688537 & 4.8806 & 5.0144 & TRN & \\
\hline CHEMBL1447772 & 688537 & 4.1484 & 4.6053 & TST & \\
\hline CHEMBL1354211 & 688537 & 5.2729 & 4.9297 & TRN & \\
\hline CHEMBL3189749 & 688537 & 2.8239 & 4.7286 & TRN & \\
\hline CHEMBL1535938 & 688537 & 4.9444 & 5.1727 & TRN & \\
\hline CHEMBL1588500 & 688537 & 5.1876 & 5.2183 & TRN & \\
\hline CHEMBL600778 & 688537 & 5.303 & 5.5302 & TRN & \\
\hline CHEMBL394242 & 688537 & 6.1938 & 6.127999 & 9999999999 & TRN \\
\hline CHEMBL1421316 & 688537 & 4.5469 & 4.4254 & TRN & \\
\hline CHEMBL1368221 & 688537 & 4.9859 & 4.9622 & TRN & \\
\hline CHEMBL1501236 & 688537 & 4.5874 & 5.0208 & TRN & \\
\hline CHEMBL1604723 & 688537 & 2.8239 & 3.0431 & TRN & \\
\hline CHEMBL1422414 & 688537 & 5.2351 & 5.2668 & TRN & \\
\hline CHEMBL1471845 & 688537 & 5.9034 & 6.1079 & TRN & \\
\hline CHEMBL1575634 & 688537 & 6.4413 & 6.731 & TRN & \\
\hline CHEMBL1528869 & 688537 & 5.1388 & 5.1061 & TRN & \\
\hline CHEMBL1606685 & 688537 & 5.83299 & 999999999 & 5.7806 & TRN \\
\hline CHEMBL1606412 & 688537 & 5.7667 & 5.5009 & TRN & \\
\hline CHEMBL1463750 & 688537 & 7.1739 & 7.7014 & TRN & \\
\hline CHEMBL1436772 & 688537 & 6.4225 & 6.6893 & TRN & \\
\hline CHEMBL1478693 & 688537 & 5.3614 & 4.9971 & TRN & \\
\hline CHEMBL1603581 & 688537 & 5.3966 & 5.4419 & TST & \\
\hline CHEMBL1502401 & 688537 & 5.0698 & 5.1885 & TRN & \\
\hline CHEMBL3197459 & 688537 & 6.153 & 6.2501 & TRN & \\
\hline CHEMBL1994179 & 688537 & 6.1073 & 5.86 & TRN & \\
\hline CHEMBL1338335 & 688537 & 5.83 & 5.3132 & TRN & \\
\hline CHEMBL1589219 & 688537 & 5.0704 & 5.0057 & TST & \\
\hline CHEMBL193872 & 688537 & \multicolumn{3}{|c|}{5.667000000000001} & TST \\
\hline CHEMBL 223453 & 688537 & 5.9987 & 5.9927 & TRN & \\
\hline CHEMBL1597234 & 688537 & 4.6003 & 4.7762 & TRN & \\
\hline CHEMBL1500256 & 688537 & 6.3686 & 5.6756 & TRN & \\
\hline CHEMBL3192328 & 688537 & 5.6229 & 5.4562 & TRN & \\
\hline CHEMBL1359345 & 688537 & 2.8239 & 3.2349 & TRN & \\
\hline CHEMBL1360808 & 688537 & 5.4083 & 4.6404 & TRN & \\
\hline CHEMBL 212314 & 688537 & 5.5173 & 5.3085 & TST & \\
\hline CHEMBL1379894 & 688537 & 5.3536 & 5.1257 & TST & \\
\hline CHEMBL1569929 & 688537 & 5.1717 & 4.8736 & TRN & \\
\hline
\end{tabular}


Supplemental Table S2.txt

\begin{tabular}{|c|c|c|c|c|}
\hline & & & & \\
\hline IEMBL1 & 688537 & 8239 & & \\
\hline IEMBL1303164 & 3537 & 3239 & 3502 & \\
\hline AEMBL14 & 537 & 407 & 546 & \\
\hline & 537 & & & \\
\hline IFMRI 15 & 537 & & 479 & \\
\hline AEMBL1363199 & 88537 & 239 & 1999 & \\
\hline AEMBL3198009 & 88537 & 239 & 32 & \\
\hline AEMBL151 & 88537 & & 261 & \\
\hline IEMBL14 & 537 & & 867 & \\
\hline IEMBL13: & & & & \\
\hline AEMBL1361866 & 688537 & & 7073 & \\
\hline HEMBL137 & 537 & & 841 & \\
\hline IEMBL153 & 688 & & & \\
\hline EMBL160 & 37 & & 515 & \\
\hline IEMBL1583914 & & & 908 & \\
\hline AEMBL1986090 & 588537 & & 519 & \\
\hline IEMBL1408962 & 88537 & & 07 & \\
\hline EMBLLIS & 37 & & 82 & \\
\hline EMBL14 & & & 004 & \\
\hline IFMBI 14 & & & 674 & \\
\hline HEMBL15€ & 37 & & 469 & RN \\
\hline AEMBL142 & & & & \\
\hline EMBL15 & 37 & & & \\
\hline IEMBL14 & 37 & & & \\
\hline 1 ICMPI 19 & 37 & & & \\
\hline 152 & & & & RN \\
\hline IEMBL1463272 & & & & ST \\
\hline IEMBL321 & 37 & & 689 & RI \\
\hline 999 & 37 & & 24 & RN \\
\hline 93 & 37 & & 72 & RN \\
\hline AEMBL153 & & & & RN \\
\hline AEMBL1351184 & & & & ST \\
\hline MBL150 & 37 & & 13 & S \\
\hline 117 & 37 & & 44 & Mriv \\
\hline 35 & & & & W. \\
\hline AEMBL1573330 & 688537 & & 386 & $\mathrm{R}$ \\
\hline IEMBL1305871 & & & & $S$ \\
\hline EMBL14 & 7 & & & RI \\
\hline 28 & & & & \\
\hline & & & & RN \\
\hline AEMBL1458785 & 688537 & & 3489 & $\mathrm{R}$ \\
\hline 318 & 688537 & & & TS \\
\hline 19 & & & & TS \\
\hline & & & & \\
\hline HEMBL 156 & & & & +3 \\
\hline AEMBL1529203 & 688537 & 5.6726 & 5.8353 & $\Gamma R$ \\
\hline HFMBI 1461337 & 688537 & 5.1791 & 5.2492 & \\
\hline
\end{tabular}




\begin{tabular}{|c|c|c|c|c|c|c|}
\hline & & \multicolumn{5}{|c|}{ Supplemental Table S2.txt } \\
\hline CHEMBL1482053 & 688537 & 5.0019 & 4.9784 & TRN & & \\
\hline CHEMBL1405220 & 688537 & 5.3817 & 5.5822 & TRN & & \\
\hline CHEMBL1984120 & 688537 & 5.2047 & 5.2678 & TRN & & \\
\hline CHEMBL1542862 & 688537 & 6.2472 & 5.7507 & TRN & & \\
\hline CHEMBL1997052 & 688537 & 5.2596 & 5.018 & TRN & & \\
\hline CHEMBL 3191394 & 688537 & 5.6012 & 5.0018 & TRN & & \\
\hline CHEMBL1409596 & 688537 & 2.8239 & 5.261 & TRN & & \\
\hline CHEMBL1498998 & 688537 & 4.5165 & 4.8082 & TST & & \\
\hline CHEMBL1509369 & 688537 & 6.7721 & 6.9033 & TRN & & \\
\hline CHEMBL1302569 & 688537 & 5.5547 & 5.3987 & TRN & & \\
\hline CHEMBL1483746 & 688537 & 4.6759 & 4.8204 & TRN & & \\
\hline CHEMBL581257 & 688537 & 8.2218 & 7.9585 & TRN & & \\
\hline CHEMBL1432309 & 688537 & 5.1364 & 5.49799 & 9999999999 & & TRN \\
\hline CHEMBL 2005895 & 688537 & 5.3728 & 5.5719 & TRN & & \\
\hline CHEMBL1511893 & 688537 & 5.4281 & 4.7478 & TRN & & \\
\hline CHEMBL1573586 & 688537 & 5.4201 & 4.9631 & TST & & \\
\hline CHEMBL1458877 & 688537 & 5.1925 & 5.0478 & TRN & & \\
\hline CHEMBL3210497 & 688537 & 4.575 & 4.1923 & TST & & \\
\hline CHEMBL1583716 & 688537 & 5.1497 & 4.8623 & TRN & & \\
\hline CHEMBL1347076 & 688537 & 4.1724 & 3.9508 & TRN & & \\
\hline CHEMBL188423 & 688537 & 5.9215 & 5.5869 & TRN & & \\
\hline CHEMBL1505760 & 688537 & 5.5248 & 5.796 & TRN & & \\
\hline CHEMBL1580922 & 688537 & 2.8239 & 4.2945 & TRN & & \\
\hline CHEMBL1360492 & 688537 & 2.8239 & 2.8882 & TRN & & \\
\hline CHEMBL3195885 & 688537 & 4.9992 & 5.4198 & TRN & & \\
\hline CHEMBL1601747 & 688537 & 2.8239 & 3.3028 & TST & & \\
\hline CHEMBL3191218 & 688537 & 5.5361 & 5.0567 & TRN & & \\
\hline CHEMBL1303975 & 688537 & 4.893 & 4.9374 & TRN & & \\
\hline CHEMBL1509694 & 688537 & 4.7571 & 4.2792 & TRN & & \\
\hline CHEMBL3193805 & 688537 & 5.4417 & 5.4523 & TRN & & \\
\hline CHEMBL1505153 & 688537 & 5.5919 & 6.0553 & TRN & & \\
\hline CHEMBL1541350 & 688537 & 4.766 & 5.0016 & TRN & & \\
\hline CHEMBL589238 & 688537 & 6.983 & 6.59399 & 9999999999 & & TRN \\
\hline CHEMBL1585480 & 688537 & 4.6364 & 4.8746 & TRN & & \\
\hline CHEMBL1494782 & 688537 & 2.8239 & 2.9952 & TRN & & \\
\hline CHEMBL1338677 & 688537 & 6.3391 & 5.9655 & TRN & & \\
\hline CHEMBL1445324 & 688537 & 5.8184 & 6.1552 & TRN & & \\
\hline CHEMBL1344667 & 688537 & 5.3001 & 5.1813 & TRN & & \\
\hline CHEMBL1609828 & 688537 & 5.6317 & 5.6016 & TRN & & \\
\hline CHEMBL1539864 & 688537 & 5.7838 & 6.0448 & TRN & & \\
\hline CHEMBL1417167 & 688537 & 6.0825 & 5.8939 & TRN & & \\
\hline CHEMBL1613220 & 688537 & 5.8219 & 5.6382 & TRN & & \\
\hline CHEMBL 2003001 & 688537 & 5.3907 & 5.4473 & TRN & & \\
\hline CHEMBL1417429 & 688537 & 5.12299 & 79999999 & 99 & 5.2159 & TRN \\
\hline CHEMBL1469698 & 688537 & 5.7357 & 5.2883 & TRN & & \\
\hline CHEMBL1495140 & 688537 & 5.3498 & 5.0516 & TRN & & \\
\hline CHEMBL1532727 & 688537 & 4.0742 & 5.2915 & TRN & & \\
\hline CHEMBL1580917 & 688537 & 5.3416 & 5.1117 & TRN & & \\
\hline
\end{tabular}




\begin{tabular}{|c|c|c|c|c|c|}
\hline \multicolumn{6}{|c|}{ Supplemental Table S2.txt } \\
\hline CHEMBL1400768 & 688537 & 5.1257 & 4.5719 & TST & \\
\hline CHEMBL1587283 & 688537 & 2.8239 & 3.3597 & TST & \\
\hline CHEMBL3199654 & 688537 & 4.8791 & 5.0851 & TRN & \\
\hline CHEMBL1526490 & 688537 & 5.1283 & 5.7217 & TRN & \\
\hline CHEMBL1362528 & 688537 & 2.8239 & 3.0333 & TRN & \\
\hline CHEMBL1311547 & 688537 & 4.5799 & 4.4269 & TRN & \\
\hline CHEMBL1326381 & 688537 & 5.261 & 4.8981 & TRN & \\
\hline CHEMBL1562454 & 688537 & 5.0708 & 4.9679 & TRN & \\
\hline CHEMBL448741 & 688537 & 5.8735 & 5.4355 & TST & \\
\hline CHEMBL3194571 & 688537 & 5.9289 & 5.91700 & 0000000001 & TRN \\
\hline CHEMBL1494353 & 688537 & 5.5265 & 5.6082 & TRN & \\
\hline CHEMBL1513743 & 688537 & 5.0097 & 4.8767 & TST & \\
\hline CHEMBL166209 & 688537 & 5.192 & 4.8759 & TST & \\
\hline CHEMBL1312788 & 688537 & 5.4624 & 5.2974 & TRN & \\
\hline CHEMBL1299757 & 688537 & 5.4533 & 5.1455 & TRN & \\
\hline CHEMBL1411449 & 688537 & 5.5572 & 5.6366 & TRN & \\
\hline CHEMBL1300385 & 688537 & 4.7791 & 4.5481 & TRN & \\
\hline CHEMBL1572935 & 688537 & 5.1391 & 4.6279 & TRN & \\
\hline CHEMBL1342423 & 688537 & 5.9352 & 5.7483 & TRN & \\
\hline CHEMBL531401 & 688537 & 4.6641 & 5.0192 & TRN & \\
\hline CHEMBL1300170 & 688537 & 5.1989 & 5.8686 & TRN & \\
\hline CHEMBL1461477 & 688537 & 6.0958 & 6.0097 & TRN & \\
\hline CHEMBL3189832 & 688537 & 5.6321 & 5.3312 & TST & \\
\hline CHEMBL1994935 & 688537 & 4.7773 & 4.5107 & TRN & \\
\hline CHEMBL1523859 & 688537 & 5.1782 & 5.2286 & TRN & \\
\hline CHEMBL1392551 & 688537 & 6.3615 & 6.1813 & TST & \\
\hline CHEMBL1402915 & 688537 & 2.8239 & 3.2782 & TRN & \\
\hline CHEMBL1610489 & 688537 & 4.9092 & 4.4452 & TST & \\
\hline CHEMBL1483809 & 688537 & 5.4072 & 5.1584 & TST & \\
\hline CHEMBL1452449 & 688537 & 6.5436 & 6.88399 & 99999999995 & TRN \\
\hline CHEMBL1597278 & 688537 & 5.5219 & 5.2943 & TRN & \\
\hline CHEMBL1971144 & 688537 & 5.7426 & 5.6654 & TRN & \\
\hline CHEMBL51931 & 688537 & 5.8748 & 5.9013 & TRN & \\
\hline CHEMBL1310223 & 688537 & 2.8239 & 3.3014 & TRN & \\
\hline CHEMBL3196117 & 688537 & 4.927 & 4.9355 & TRN & \\
\hline CHEMBL1543879 & 688537 & 2.8239 & 2.8788 & TRN & \\
\hline CHEMBL1445650 & 688537 & 5.5842 & 5.7391 & TRN & \\
\hline CHEMBL1404929 & 688537 & 5.5867 & 5.4134 & TRN & \\
\hline CHEMBL1578482 & 688537 & 6.3107 & 6.0156 & TRN & \\
\hline CHEMBL3195536 & 688537 & 4.7367 & 4.3358 & TRN & \\
\hline CHEMBL1313588 & 688537 & 5.6165 & 5.562 & TRN & \\
\hline CHEMBL1604302 & 688537 & 5.1158 & 4.5577 & TRN & \\
\hline CHEMBL1330429 & 688537 & 4.4915 & 4.1424 & TRN & \\
\hline CHEMBL1501222 & 688537 & 5.1311 & 4.9006 & TRN & \\
\hline CHEMBL1613678 & 688537 & 5.0326 & 5.1296 & TRN & \\
\hline CHEMBL1341590 & 688537 & 5.2977 & 5.7132 & TRN & \\
\hline CHEMBL 2007218 & 688537 & 6.3757 & 6.3685 & TRN & \\
\hline CHEMBL1600573 & 688537 & 5.2211 & 4.775 & TRN & \\
\hline
\end{tabular}




\begin{tabular}{|c|c|c|c|c|c|}
\hline & & \multicolumn{4}{|c|}{ Supplemental Table S2.txt } \\
\hline CHEMBL1497894 & 688537 & 5.731 & 5.3725 & TRN & \\
\hline CHEMBL1388118 & 688537 & 4.5925 & 4.4644 & TST & \\
\hline CHEMBL1430426 & 688537 & 2.8239 & 3.3314 & TST & \\
\hline CHEMBL1965791 & 688537 & 5.468 & 5.4828 & TRN & \\
\hline CHEMBL1445603 & 688537 & 6.4976 & 6.0166 & TRN & \\
\hline CHEMBL1387503 & 688537 & 2.8239 & 3.0149 & TRN & \\
\hline CHEMBL1533366 & 688537 & 6.0035 & 5.8346 & TRN & \\
\hline CHEMBL1401522 & 688537 & 5.8962 & 5.7132 & TST & \\
\hline CHEMBL597251 & 688537 & 5.4973 & 5.255 & TRN & \\
\hline CHEMBL1588416 & 688537 & 4.9695 & 4.4499 & TRN & \\
\hline CHEMBL1527341 & 688537 & 5.1748 & 5.1535 & TRN & \\
\hline CHEMBL 3213747 & 688537 & 5.2737 & 5.434 & TST & \\
\hline CHEMBL591361 & 688537 & 5.7622 & 6.0212 & TRN & \\
\hline CHEMBL1304179 & 688537 & 4.3818 & 4.5943 & TRN & \\
\hline CHEMBL1536017 & 688537 & 2.8239 & 3.4304 & TRN & \\
\hline CHEMBL1395907 & 688537 & 5.727 & 4.9752 & TRN & \\
\hline CHEMBL1323248 & 688537 & 5.7605 & 5.5748 & TRN & \\
\hline CHEMBL1384359 & 688537 & 4.96399 & 79999999 & 4.5331 & TST \\
\hline CHEMBL1519755 & 688537 & 5.4519 & 5.4533 & TRN & \\
\hline CHEMBL1574283 & 688537 & 5.7518 & 6.1461 & TRN & \\
\hline CHEMBL1539624 & 688537 & 6.1662 & 6.4191 & TRN & \\
\hline CHEMBL1419518 & 688537 & 5.4382 & 5.4866 & TRN & \\
\hline CHEMBL1458809 & 688537 & 5.5505 & 5.8389 & TRN & \\
\hline CHEMBL3145088 & 688537 & 5.6548 & 5.84399 & & TRN \\
\hline CHEMBL1332598 & 688537 & 2.8239 & 4.9195 & TRN & \\
\hline CHEMBL1567571 & 688537 & 5.9991 & 5.7202 & TRN & \\
\hline CHEMBL1483281 & 688537 & 4.7003 & 5.1829 & TRN & \\
\hline CHEMBL1573813 & 688537 & 5.7786 & 5.6777 & TRN & \\
\hline CHEMBL1599708 & 688537 & 6.6757 & 7.2219 & TRN & \\
\hline CHEMBL1601701 & 688537 & 4.9508 & 4.9247 & TST & \\
\hline CHEMBL1547685 & 688537 & 4.9329 & 4.6388 & TRN & \\
\hline CHEMBL1327721 & 688537 & 5.6568 & 5.7813 & TRN & \\
\hline CHEMBL935 & 688537 & 8.2218 & 7.6174 & TST & \\
\hline CHEMBL1549651 & 688537 & 6.2716 & 6.3847 & TRN & \\
\hline CHEMBL3198912 & 688537 & 5.0881 & 5.1403 & TRN & \\
\hline CHEMBL1518515 & 688537 & 5.4916 & 4.967 & TST & \\
\hline CHEMBL3196257 & 688537 & 5.5077 & 5.5776 & TRN & \\
\hline CHEMBL168 & 688537 & 5.5852 & 5.7136 & TST & \\
\hline CHEMBL1525098 & 688537 & 7.1308 & 6.5683 & TRN & \\
\hline CHEMBL1339872 & 688537 & 5.2198 & 4.6902 & TST & \\
\hline CHEMBL530038 & 688537 & 5.1392 & 4.7364 & TRN & \\
\hline CHEMBL1603615 & 688537 & 5.3414 & 5.1419 & TRN & \\
\hline CHEMBL1510346 & 688537 & 2.8239 & 2.9034 & TRN & \\
\hline CHEMBL1467749 & 688537 & 5.8573 & 5.8344 & TRN & \\
\hline CHEMBL1310221 & 688537 & 5.8202 & 5.6597 & TRN & \\
\hline CHEMBL1557920 & 688537 & 5.3571 & 5.0688 & TRN & \\
\hline CHEMBL1511042 & 688537 & 5.5459 & 5.0259 & TST & \\
\hline CHEMBL1498722 & 688537 & 2.8239 & 2.8067 & TRN & \\
\hline
\end{tabular}


Supplemental Table S2.txt

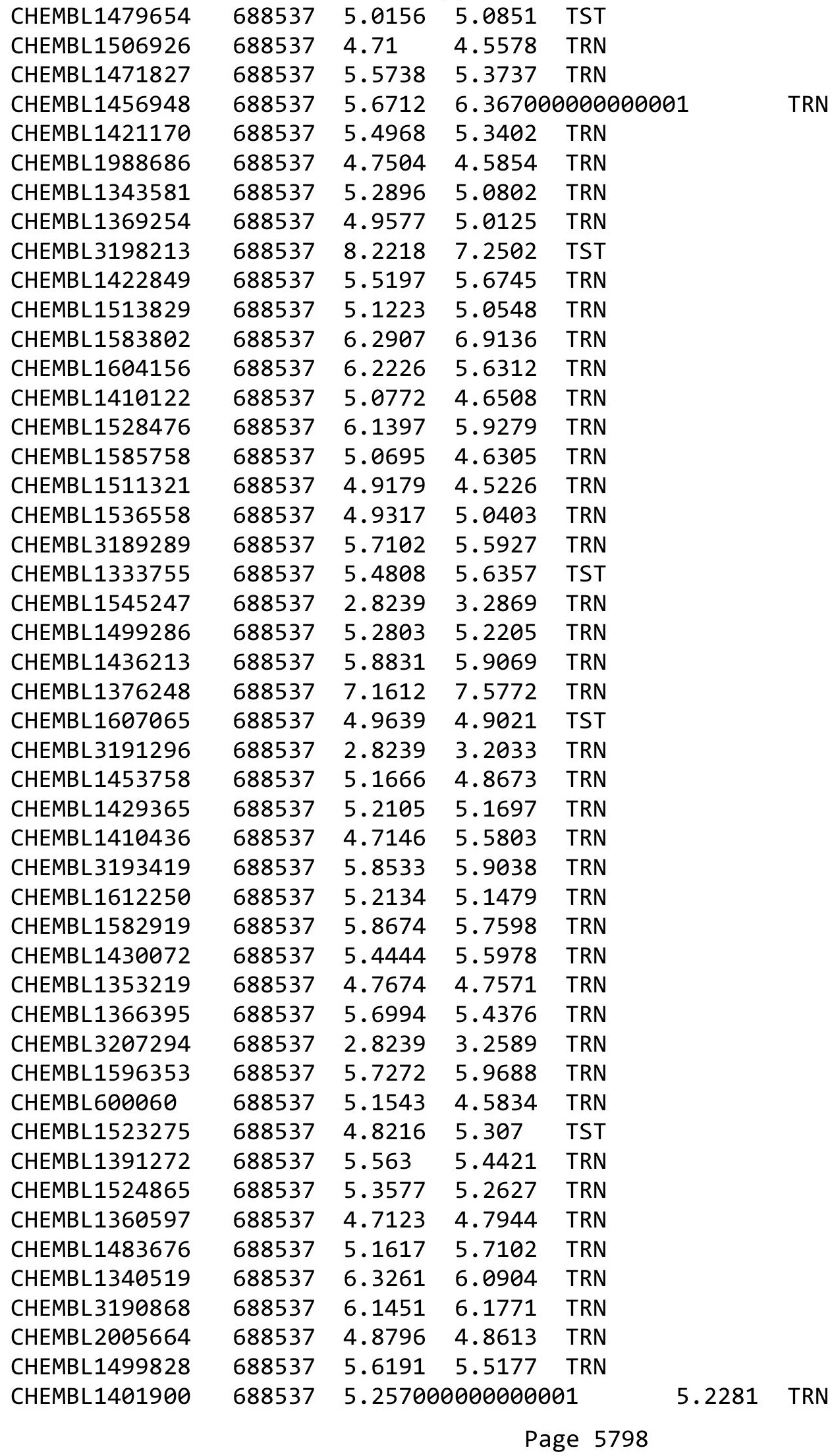




\begin{tabular}{|c|c|c|c|c|c|c|}
\hline & & \multicolumn{5}{|c|}{ Supplemental Table S2.txt } \\
\hline CHEMBL1568696 & 688537 & 2.8239 & 3.1934 & TRN & & \\
\hline CHEMBL1564523 & 688537 & 5.0774 & 5.0467 & TRN & & \\
\hline CHEMBL197014 & 688537 & 5.1978 & 5.1404 & TRN & & \\
\hline CHEMBL1433219 & 688537 & 4.6096 & 4.8451 & TRN & & \\
\hline CHEMBL2004157 & 688537 & 5.8894 & 5.5577 & TRN & & \\
\hline CHEMBL1344556 & 688537 & \multicolumn{3}{|c|}{5.587000000000001} & .4513 & TRN \\
\hline CHEMBL1555602 & 688537 & 2.8239 & 3.2598 & TRN & & \\
\hline CHEMBL1372606 & 688537 & 6.3197 & 5.8095 & TRN & & \\
\hline CHEMBL1493936 & 688537 & 8.2218 & 7.8116 & TRN & & \\
\hline CHEMBL1964891 & 688537 & 5.8431 & 5.0551 & TRN & & \\
\hline CHEMBL1580583 & 688537 & 5.4078 & 4.9734 & TRN & & \\
\hline CHEMBL1472321 & 688537 & 6.0804 & 5.8929 & TRN & & \\
\hline CHEMBL1426113 & 688537 & 5.2588 & 5.1431 & TRN & & \\
\hline CHEMBL1302276 & 688537 & 5.2431 & 4.5056 & TRN & & \\
\hline CHEMBL1450483 & 688537 & 5.4897 & 5.5562 & TRN & & \\
\hline CHEMBL1496648 & 688537 & 4.8593 & 4.7576 & TRN & & \\
\hline CHEMBL1385362 & 688537 & 2.8239 & 2.5399 & TRN & & \\
\hline CHEMBL1470483 & 688537 & 5.6146 & 5.8955 & TRN & & \\
\hline CHEMBL3196614 & 688537 & 4.9977 & 4.8978 & TRN & & \\
\hline CHEMBL3191413 & 688537 & 5.2444 & 5.151 & TRN & & \\
\hline CHEMBL1457644 & 688537 & 5.2615 & 5.4262 & TRN & & \\
\hline CHEMBL1580856 & 688537 & 5.4501 & 5.2421 & TRN & & \\
\hline CHEMBL1505552 & 688537 & 5.8784 & 5.787006 & 0000000001 & & TRN \\
\hline CHEMBL1568852 & 688537 & 5.2677 & 5.2023 & TRN & & \\
\hline CHEMBL1503729 & 688537 & 5.2207 & 5.3087 & TRN & & \\
\hline CHEMBL1326559 & 688537 & 2.8239 & 3.4697 & TST & & \\
\hline CHEMBL1335732 & 688537 & 5.4528 & 5.2775 & TRN & & \\
\hline CHEMBL1329634 & 688537 & 4.8106 & 4.5052 & TRN & & \\
\hline CHEMBL1337203 & 688537 & 3.301 & 4.8073 & TRN & & \\
\hline CHEMBL1571174 & 688537 & 2.8239 & 3.4458 & TRN & & \\
\hline CHEMBL 240546 & 688537 & 5.4229 & 5.3705 & TRN & & \\
\hline CHEMBL1594585 & 688537 & 2.8239 & 3.1818 & TRN & & \\
\hline CHEMBL1318922 & 688537 & 8.2218 & 8.4438 & TRN & & \\
\hline CHEMBL1489078 & 688537 & 2.8239 & 3.0306 & TRN & & \\
\hline CHEMBL1560219 & 688537 & 5.334 & 5.334 & TRN & & \\
\hline CHEMBL3211754 & 688537 & 4.6662 & 4.7965 & TRN & & \\
\hline CHEMBL3191568 & 688537 & 5.8022 & 5.4863 & TRN & & \\
\hline CHEMBL1430495 & 688537 & 5.6426 & 5.0171 & TST & & \\
\hline CHEMBL1454245 & 688537 & 5.2604 & 5.2123 & TRN & & \\
\hline CHEMBL1440277 & 688537 & 5.5453 & 5.6202 & TRN & & \\
\hline CHEMBL577102 & 688537 & 5.4896 & 5.5685 & TRN & & \\
\hline CHEMBL3194704 & 688537 & 5.9935 & 5.9828 & TRN & & \\
\hline CHEMBL1559169 & 688537 & 3.9769 & 3.2726 & TST & & \\
\hline CHEMBL1497685 & 688537 & 4.5783 & 4.6502 & TRN & & \\
\hline CHEMBL1447541 & 688537 & 4.524 & 4.6478 & TRN & & \\
\hline CHEMBL1484169 & 688537 & 5.2476 & 5.326006 & 00000000005 & & TRN \\
\hline CHEMBL1584690 & 688537 & 2.8239 & 3.3158 & TRN & & \\
\hline CHEMBL 2006840 & 688537 & 6.0575 & 5.6918 & TRN & & \\
\hline
\end{tabular}




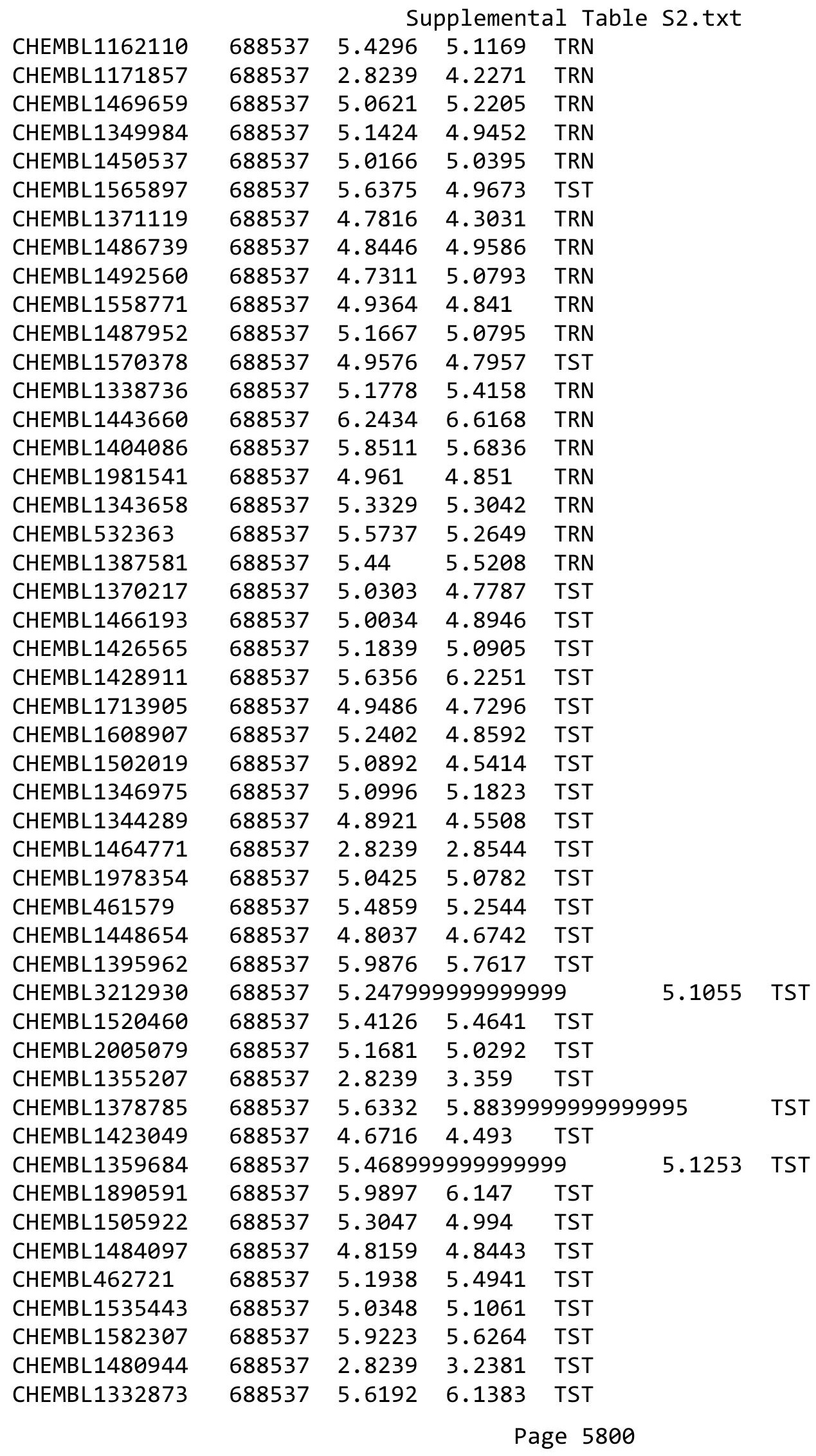




\begin{tabular}{|c|c|c|c|c|c|}
\hline \multicolumn{6}{|c|}{ Supplemental Table S2.txt } \\
\hline CHEMBL1361033 & 688537 & 5.0784 & 5.1526 & TST & \\
\hline CHEMBL1332139 & 688537 & 6.556 & 6.2542 & TST & \\
\hline CHEMBL1468351 & 688537 & 4.6631 & 4.6101 & TST & \\
\hline CHEMBL1500481 & 688537 & 5.0743 & 5.2445 & TST & \\
\hline CHEMBL1505057 & 688537 & 6.0329 & 5.2785 & TST & \\
\hline CHEMBL1452652 & 688537 & 5.2014 & 5.1696 & TST & \\
\hline CHEMBL1508616 & 688537 & 5.1761 & 5.1828 & TST & \\
\hline CHEMBL1531919 & 688537 & 5.4486 & 5.1702 & TST & \\
\hline CHEMBL 3194931 & 688537 & 5.3989 & 4.9034 & TST & \\
\hline CHEMBL1515251 & 688537 & 5.0993 & 4.9918 & TST & \\
\hline CHEMBL1465097 & 688537 & 4.8022 & 5.002 & TST & \\
\hline CHEMBL1521619 & 688537 & 5.5397 & 5.4963 & TST & \\
\hline CHEMBL1530048 & 688537 & 5.1754 & 4.8098 & TST & \\
\hline CHEMBL1433385 & 688537 & 5.1764 & 4.7622 & TST & \\
\hline CHEMBL3199016 & 688537 & 5.4139 & 5.3395 & TST & \\
\hline CHEMBL1990786 & 688537 & 6.0182 & 5.7465 & TST & \\
\hline CHEMBL1418662 & 688537 & 5.4194 & 5.072 & TST & \\
\hline CHEMBL1567034 & 688537 & 4.8335 & 4.996 & TST & \\
\hline CHEMBL1420123 & 688537 & 4.8528 & 4.8561 & TST & \\
\hline CHEMBL1972143 & 688537 & 5.2977 & 5.0782 & TST & \\
\hline CHEMBL1325644 & 688537 & 5.5178 & 5.3791 & TST & \\
\hline CHEMBL1449558 & 688537 & 5.0991 & 4.954 & TST & \\
\hline CHEMBL1443632 & 688537 & 5.8013 & 5.5179 & TST & \\
\hline CHEMBL1427661 & 688537 & 5.487 & 5.7344 & TST & \\
\hline CHEMBL81782 & 688537 & 5.5945 & 5.7516 & TST & \\
\hline CHEMBL1346995 & 688537 & 6.0804 & 4.9444 & TST & \\
\hline CHEMBL1991373 & 688537 & 6.4389 & 6.3533 & TST & \\
\hline CHEMBL1450554 & 688537 & 2.8239 & 2.8819 & TST & \\
\hline CHEMBL1506301 & 688537 & 5.5058 & 5.4342 & TST & \\
\hline CHEMBL1545702 & 688537 & 6.063 & 6.0888 & TST & \\
\hline CHEMBL1495714 & 688537 & 5.7066 & 5.2076 & TST & \\
\hline CHEMBL1557538 & 688537 & 5.0651 & 5.085 & TST & \\
\hline CHEMBL1411838 & 688537 & 2.8239 & 3.0753 & TST & \\
\hline CHEMBL1330113 & 688537 & 6.2865 & 5.9023 & TST & \\
\hline CHEMBL1375741 & 688537 & 5.5014 & 5.3119 & TST & \\
\hline CHEMBL1463571 & 688537 & 6.1791 & 6.2425 & TST & \\
\hline CHEMBL1335214 & 688537 & 4.53 & 4.636 & TST & \\
\hline CHEMBL1354009 & 688537 & 4.4398 & 4.4239 & TST & \\
\hline CHEMBL1497950 & 688537 & 5.3558 & 5.32100 & 0000000001 & TST \\
\hline CHEMBL1603844 & 688537 & 6.2204 & 5.7123 & TST & \\
\hline CHEMBL1475279 & 688537 & 2.8239 & 4.6214 & TST & \\
\hline CHEMBL1408752 & 688537 & 5.1462 & 4.6146 & TST & \\
\hline CHEMBL1991888 & 688537 & 6.4776 & 6.348 & TST & \\
\hline CHEMBL1465660 & 688537 & 2.8239 & 2.6652 & TST & \\
\hline CHEMBL1599495 & 688537 & 2.8239 & 3.0939 & TST & \\
\hline CHEMBL1426136 & 688537 & 2.8239 & 2.3753 & TST & \\
\hline CHEMBL1416159 & 688537 & 2.8239 & 3.1158 & TST & \\
\hline CHEMBL1436666 & 688537 & 5.3538 & 5.7748 & TST & \\
\hline
\end{tabular}


Supplemental Table S2.txt

\begin{tabular}{|c|c|c|c|c|c|c|}
\hline CHEMBL1549870 & 688537 & 5.0757 & 5.2675 & TST & & \\
\hline CHEMBL1534540 & 688537 & 4.2373 & 4.3441 & TST & & \\
\hline CHEMBL3192299 & 688537 & 5.8739 & 5.9334 & TST & & \\
\hline CHEMBL1596066 & 688537 & 5.8962 & 5.80200 & $\partial 0000000$ & $\partial 05$ & TST \\
\hline CHEMBL1338481 & 688537 & 4.6765 & 4.7357 & TST & & \\
\hline CHEMBL1428258 & 688537 & 5.4056 & 5.3204 & TST & & \\
\hline CHEMBL1459313 & 688537 & 4.9825 & 4.9853 & TST & & \\
\hline CHEMBL1450105 & 688537 & 5.4412 & 5.6324 & TST & & \\
\hline CHEMBL1344663 & 688537 & 3.9654 & 4.4334 & TST & & \\
\hline CHEMBL1492017 & 688537 & 5.6761 & 5.50299 & 99999999 & & TC \\
\hline CHEMBL1582575 & 688537 & 2.8239 & 2.5659 & TST & & \\
\hline CHEMBL1582111 & 688537 & 5.2965 & 5.5 & TST & & \\
\hline CHEMBL1407786 & 688537 & 5.3607 & 5.0813 & TST & & \\
\hline CHEMBL1511854 & 688537 & 4.8036 & 4.5263 & TST & & \\
\hline CHEMBL1546139 & 688537 & 5.65799 & 99999999 & 995 & 5.5928 & TST \\
\hline CHEMBL1480647 & 688537 & 2.8239 & 3.5379 & TST & & \\
\hline CHEMBL1536217 & 688537 & 5.1442 & 5.2565 & TST & & \\
\hline CHEMBL1370746 & 688537 & 4.9042 & 5.3881 & TST & & \\
\hline CHEMBL3214096 & 688537 & 4.4745 & 4.5853 & TST & & \\
\hline CHEMBL1572356 & 688537 & 6.0227 & 6.1743 & TST & & \\
\hline CHEMBL1505788 & 688537 & 5.0293 & 4.9853 & TST & & \\
\hline CHEMBL1457780 & 688537 & 4.9933 & 5.1185 & TST & & \\
\hline CHEMBL1371940 & 688537 & 5.4602 & 5.5032 & TST & & \\
\hline CHEMBL1452467 & 688537 & 6.0991 & 6.1844 & TST & & \\
\hline CHEMBL1478826 & 688537 & 5.6052 & 6.2825 & TST & & \\
\hline CHEMBL1450648 & 688537 & 5.2157 & 5.2211 & TST & & \\
\hline CHEMBL1605393 & 688537 & 4.7941 & 5.1903 & TST & & \\
\hline CHEMBL478791 & 688537 & 5.6402 & 5.6384 & TST & & \\
\hline CHEMBL1392311 & 688537 & 2.8239 & 3.2904 & TST & & \\
\hline CHEMBL1453819 & 688537 & 5.9825 & 5.4625 & TST & & \\
\hline CHEMBL1441983 & 688537 & 2.8239 & 3.9832 & TST & & \\
\hline CHEMBL1596460 & 688537 & 4.8264 & 4.7338 & TST & & \\
\hline CHEMBL1354631 & 688537 & 4.9677 & 4.8188 & TST & & \\
\hline CHEMBL1461960 & 688537 & 6.2097 & 6.211 & TST & & \\
\hline CHEMBL1347204 & 688537 & 6.5391 & 6.6282 & TST & & \\
\hline CHEMBL1313074 & 688537 & 4.7811 & 4.9756 & TST & & \\
\hline CHEMBL1519764 & 688537 & 4.7596 & 4.7222 & TST & & \\
\hline CHEMBL1494810 & 688537 & 5.7962 & 5.2481 & TST & & \\
\hline CHEMBL1240788 & 688537 & 5.2387 & 4.9082 & TST & & \\
\hline CHEMBL1587636 & 688537 & 4.9151 & 4.9383 & TST & & \\
\hline CHEMBL1536740 & 688537 & 5.9034 & 5.9569 & TST & & \\
\hline CHEMBL1400237 & 688537 & 5.1381 & 5.5332 & TST & & \\
\hline CHEMBL1541449 & 688537 & \multicolumn{3}{|c|}{4.6819999999999995} & 4.877 & \\
\hline CHEMBL1536606 & 688537 & 5.3654 & 5.3327 & TST & & \\
\hline CHEMBL1460692 & 688537 & 5.3614 & 5.3293 & TST & & \\
\hline CHEMBL1378397 & 688537 & 4.6441 & 4.3402 & TST & & \\
\hline CHEMBL1588472 & 688537 & 5.6021 & 5.9866 & TST & & \\
\hline CHEMBL1429682 & 688537 & 5.6123 & 6.0295 & TST & & \\
\hline
\end{tabular}


Supplemental Table S2.txt

\begin{tabular}{|c|c|c|c|c|c|}
\hline CHEMBL1488364 & 688537 & 5.6686 & 5.2129 & TST & \\
\hline CHEMBL1383321 & 688537 & 5.5482 & 5.5191 & TST & \\
\hline CHEMBL 3213459 & 688537 & 5.1173 & 5.3682 & TST & \\
\hline CHEMBL1343674 & 688537 & 5.2606 & 4.9554 & TST & \\
\hline CHEMBL1537542 & 688537 & 7.0458 & 8.5102 & TST & \\
\hline CHEMBL 3195009 & 688537 & 5.5415 & 5.6711 & TST & \\
\hline CHEMBL1316798 & 688537 & 5.0773 & 5.3852 & TST & \\
\hline CHEMBL1588549 & 688537 & 5.9389 & 5.9847 & TST & \\
\hline CHEMBL1599815 & 688537 & 6.4895 & 6.04799 & э999999999 & TST \\
\hline CHEMBL1384368 & 688537 & 6.699 & 6.5808 & TST & \\
\hline CHEMBL1579058 & 688537 & 5.4047 & 4.7073 & TST & \\
\hline CHEMBL3193989 & 688537 & 5.4921 & 5.2286 & TST & \\
\hline CHEMBL 3193338 & 688537 & 5.3599 & 5.24 & TST & \\
\hline CHEMBL1320562 & 688537 & 5.3751 & 5.4481 & TST & \\
\hline CHEMBL1306986 & 688537 & 5.8837 & 6.4718 & TST & \\
\hline CHEMBL1368833 & 688537 & 5.4536 & 5.2083 & TST & \\
\hline CHEMBL1366987 & 688537 & 5.1858 & 5.1456 & TST & \\
\hline CHEMBL1422253 & 688537 & 8.2218 & 8.1102 & TST & \\
\hline CHEMBL1405059 & 688537 & 4.5272 & 4.4381 & TST & \\
\hline CHEMBL1437052 & 688537 & 5.7001 & 5.5678 & TST & \\
\hline CHEMBL1588660 & 688537 & 5.7491 & 6.0674 & TST & \\
\hline CHEMBL 2007593 & 688537 & 5.0959 & 4.8817 & TST & \\
\hline CHEMBL1371202 & 688537 & 2.8239 & 5.0392 & TST & \\
\hline CHEMBL 3190835 & 688537 & 2.8239 & 3.2271 & TST & \\
\hline CHEMBL1539224 & 688537 & 5.4951 & 5.4437 & TST & \\
\hline CHEMBL517514 & 688537 & 5.9551 & 5.4655 & TST & \\
\hline CHEMBL1533974 & 688537 & 4.8751 & 4.9075 & TST & \\
\hline CHEMBL1471592 & 688537 & 5.6101 & 5.7422 & TST & \\
\hline CHEMBL1531654 & 688537 & 5.2617 & 5.3367 & TST & \\
\hline CHEMBL417727 & 688537 & 6.3372 & 5.9214 & TST & \\
\hline CHEMBL1534816 & 688537 & 4.6413 & 4.8607 & TST & \\
\hline CHEMBL1329980 & 688537 & 4.7502 & 4.8204 & TST & \\
\hline CHEMBL1971379 & 688537 & 5.8277 & 5.7026 & TST & \\
\hline CHEMBL1319643 & 688537 & 6.9626 & 6.8216 & TST & \\
\hline CHEMBL1327034 & 688537 & \multicolumn{2}{|c|}{4.906000000000001} & 4.5593 & TST \\
\hline CHEMBL1545093 & 688537 & 5.6312 & 5.8047 & TST & \\
\hline CHEMBL1334290 & 688537 & 2.8239 & 2.9034 & TST & \\
\hline CHEMBL1469052 & 688537 & 2.8239 & \multicolumn{2}{|c|}{3.0260000000000002} & ובנו \\
\hline CHEMBL1431776 & 688537 & 5.1474 & 5.414 & TST & \\
\hline CHEMBL1387517 & 688537 & 4.7539 & 4.6971 & TST & \\
\hline CHEMBL 3193542 & 688537 & 4.4904 & 4.697 & TST & \\
\hline CHEMBL1442745 & 688537 & 5.5784 & 5.4157 & TST & \\
\hline CHEMBL 3210474 & 688537 & 5.6776 & 5.5824 & TST & \\
\hline CHEMBL518430 & 688537 & 5.4352 & 5.2872 & TST & \\
\hline CHEMBL1452612 & 688537 & 5.6158 & 5.1597 & TST & \\
\hline CHEMBL1602709 & 688537 & \multicolumn{3}{|c|}{5.2860000000000005} & \\
\hline CHEMBL1402502 & 688537 & 5.1815 & 5.0858 & TST & \\
\hline CHEMBL1480439 & 688537 & 5.4138 & 4.9115 & TST & \\
\hline
\end{tabular}


Supplemental Table S2.txt

\begin{tabular}{|c|c|c|c|c|}
\hline CHEMBL1320591 & 688537 & 5.1107 & 4.9625 & TST \\
\hline CHEMBL1984816 & 688537 & 4.6422 & 4.7623 & TST \\
\hline CHEMBL1504806 & 688537 & 4.7355 & 4.3033 & TST \\
\hline CHEMBL1323512 & 688537 & 5.2112 & 5.5994 & TST \\
\hline CHEMBL 3190585 & 688537 & 4.956 & 4.6688 & TST \\
\hline CHEMBL1361520 & 688537 & 2.8239 & 3.2902 & TST \\
\hline CHEMBL1351081 & 688537 & 4.9218 & 4.7492 & TST \\
\hline CHEMBL1391280 & 688537 & 2.8239 & 3.3511 & TST \\
\hline CHEMBL1498273 & 688537 & 4.8935 & 4.8789 & TST \\
\hline CHEMBL1571096 & 688537 & 2.8239 & 2.8217 & TST \\
\hline CHEMBL1453497 & 688537 & 5.1379 & 4.4076 & TST \\
\hline CHEMBL1390565 & 688537 & 5.6071 & 5.4129 & TST \\
\hline CHEMBL1539522 & 688537 & 5.0013 & 5.0246 & TST \\
\hline CHEMBL1609090 & 688537 & 5.0952 & 5.284 & TST \\
\hline CHEMBL1351595 & 688537 & 5.1334 & 5.1312 & TST \\
\hline CHEMBL1376070 & 688537 & 5.3884 & 5.2554 & TST \\
\hline CHEMBL1445257 & 688537 & 5.7249 & 6.2698 & TST \\
\hline CHEMBL1302253 & 688537 & 3.9619 & 4.5076 & TST \\
\hline CHEMBL1589670 & 688537 & 5.7956 & 5.3085 & TST \\
\hline CHEMBL1462906 & 688537 & 5.5807 & 5.5139 & TST \\
\hline CHEMBL391123 & 688537 & 6.556 & 6.7066 & TST \\
\hline CHEMBL1418469 & 688537 & 4.9281 & 4.4678 & TST \\
\hline CHEMBL1430718 & 688537 & 5.9412 & 5.4976 & TST \\
\hline CHEMBL1357862 & 688537 & 4.7018 & 4.2128 & TST \\
\hline CHEMBL1310449 & 688537 & 6.2411 & 6.5988 & TST \\
\hline CHEMBL1558952 & 688537 & 5.83 & 5.4269 & TST \\
\hline CHEMBL1572214 & 688537 & 4.8588 & 4.6044 & TST \\
\hline CHEMBL1588356 & 688537 & 5.3486 & 5.2304 & TST \\
\hline CHEMBL1497196 & 688537 & 5.4384 & 5.6109 & TST \\
\hline CHEMBL1472530 & 688537 & 4.238 & 3.1711 & TST \\
\hline CHEMBL3193769 & 688537 & 2.8239 & 4.4256 & TST \\
\hline CHEMBL1993993 & 688537 & 5.3451 & 5.4316 & TST \\
\hline CHEMBL1302367 & 688537 & 5.278 & 5.4327 & TST \\
\hline CHEMBL3194964 & 688537 & 5.1634 & 5.57700 & 0000000001 \\
\hline CHEMBL1541683 & 688537 & 2.8239 & 4.8276 & TST \\
\hline CHEMBL1520507 & 688537 & 5.1148 & 4.7158 & TST \\
\hline CHEMBL1501158 & 688537 & 4.3775 & 4.5603 & TST \\
\hline CHEMBL1344526 & 688537 & 2.8239 & 2.5256 & TST \\
\hline CHEMBL1503749 & 688537 & 2.8239 & 4.316 & TST \\
\hline CHEMBL1411897 & 688537 & 5.2706 & 5.1583 & TST \\
\hline CHEMBL3194766 & 688537 & 2.8239 & 4.8141 & TST \\
\hline CHEMBL1555793 & 688537 & 5.7165 & 5.8328 & TST \\
\hline CHEMBL1996376 & 688537 & 5.4689 & 5.1594 & TST \\
\hline CHEMBL1510316 & 688537 & 2.8239 & 4.4089 & TST \\
\hline CHEMBL1341913 & 688537 & 4.4514 & 5.1902 & TST \\
\hline CHEMBL1987894 & 688537 & 5.731 & 5.87799 & 9999999999 \\
\hline CHEMBL 80799 & 688537 & 5.0844 & 4.9067 & TST \\
\hline CHEMBL1445327 & 688537 & 5.2132 & 5.0723 & TST \\
\hline
\end{tabular}




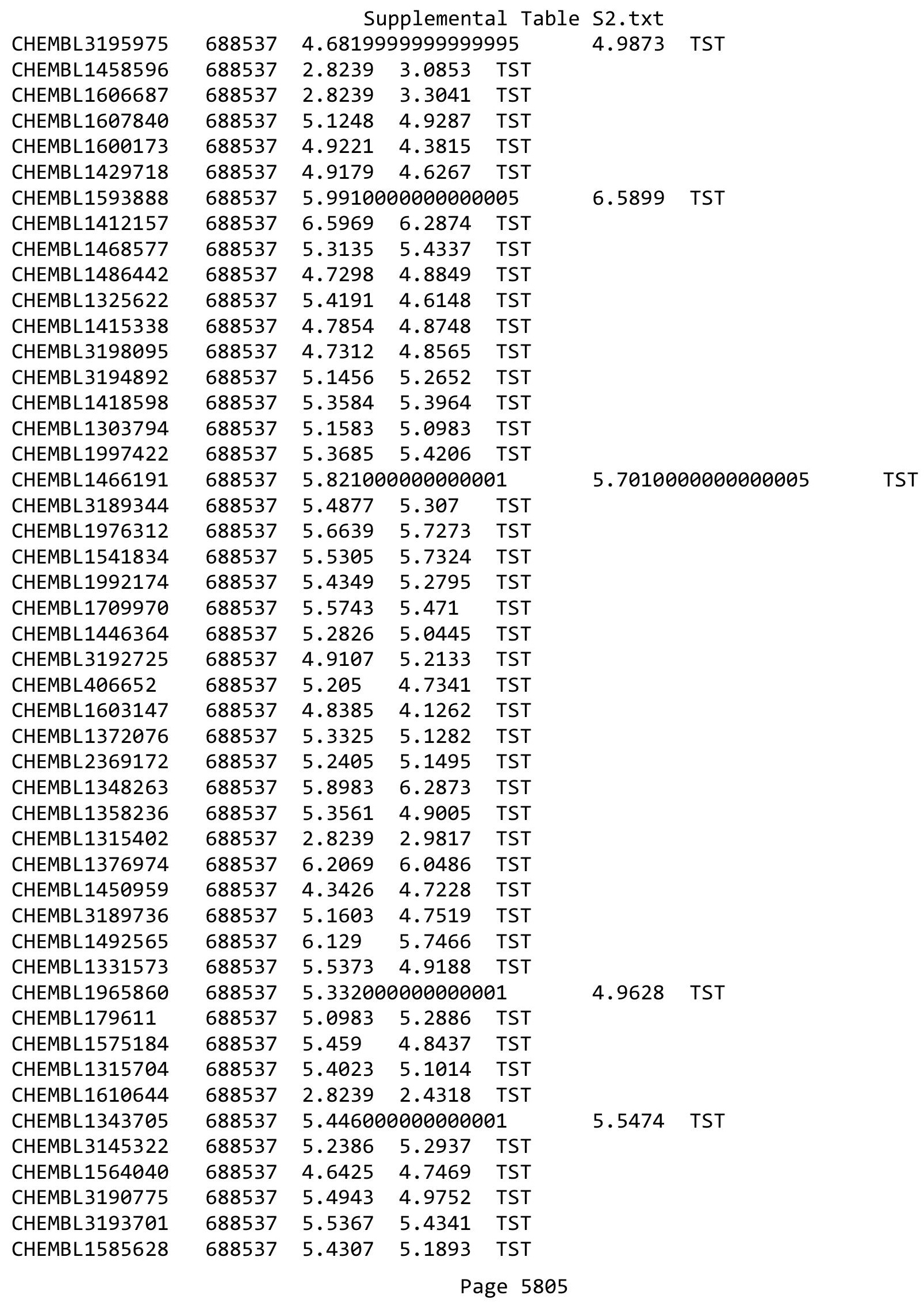




\begin{tabular}{|c|c|c|c|c|c|c|c|}
\hline \\
\hline CHEMBL1532546 & 688537 & 6.4237 & 6.862 & TST & & & \\
\hline CHEMBL1389315 & 688537 & 5.2859 & 5.4498 & TST & & & \\
\hline CHEMBL1595732 & 688537 & 2.8239 & 3.1468 & TST & & & \\
\hline CHEMBL 2003808 & 688537 & 5.7373 & 6.1917 & TST & & & \\
\hline CHEMBL1535900 & 688537 & 4.7617 & 5.2036 & TST & & & \\
\hline CHEMBL1997585 & 688537 & 4.1805 & 4.6989 & TST & & & \\
\hline CHEMBL479765 & 688537 & 5.9586 & 5.7495 & TST & & & \\
\hline CHEMBL1324715 & 688537 & 4.9586 & 4.92 & TST & & & \\
\hline CHEMBL3194214 & 688537 & 5.4803 & 5.2447 & TST & & & \\
\hline CHEMBL1595934 & 688537 & 5.9944 & 6.0399 & TST & & & \\
\hline CHEMBL1359871 & 688537 & 5.7926 & 6.0002 & TST & & & \\
\hline CHEMBL1392828 & 688537 & 4.8261 & 4.3781 & TST & & & \\
\hline CHEMBL221907 & 688537 & 5.4738 & 5.8405 & TST & & & \\
\hline CHEMBL1403620 & 688537 & 2.8239 & 2.9012 & TST & & & \\
\hline CHEMBL1401989 & 688537 & 5.3901 & 5.376 & TST & & & \\
\hline CHEMBL1399698 & 688537 & 8.2218 & 7.4743 & TST & & & \\
\hline CHEMBL1988657 & 688537 & 4.3082 & 4.5435 & TST & & & \\
\hline CHEMBL3208501 & 688537 & 5.7007 & 5.5855 & TST & & & \\
\hline CHEMBL3190533 & 688537 & 2.8239 & 3.0399 & TST & & & \\
\hline CHEMBL2001739 & 688537 & 5.734 & 5.8653 & TST & & & \\
\hline CHEMBL591834 & 688537 & 5.50200 & 00000000 & & $5.3870 e$ & 30000000005 & TST \\
\hline CHEMBL1477091 & 688537 & 2.8239 & 3.2794 & TST & & & \\
\hline CHEMBL1524131 & 688537 & 5.5013 & 5.4385 & TST & & & \\
\hline CHEMBL1415587 & 688537 & 2.8239 & 4.6552 & TST & & & \\
\hline CHEMBL1435040 & 688537 & 2.8239 & 3.0799 & TST & & & \\
\hline CHEMBL1492378 & 688537 & 4.6139 & 4.9969 & TST & & & \\
\hline CHEMBL1379801 & 688537 & 5.2331 & 4.8341 & TST & & & \\
\hline CHEMBL45281 & 688537 & 5.8557 & 5.532 & TST & & & \\
\hline CHEMBL1549391 & 688537 & 4.7438 & 4.2422 & TST & & & \\
\hline CHEMBL45152 & 688537 & 6.0516 & 5.9712 & TST & & & \\
\hline CHEMBL1338825 & 688537 & 5.3676 & 4.9504 & TST & & & \\
\hline CHEMBL3192181 & 688537 & 5.3495 & 5.3969 & TST & & & \\
\hline CHEMBL1471932 & 688537 & 5.1333 & 5.2329 & TST & & & \\
\hline CHEMBL1491007 & 688537 & 5.2763 & 5.28799 & 9999999999 & & TST & \\
\hline CHEMBL1343528 & 688537 & 4.1721 & 4.3396 & TST & & & \\
\hline CHEMBL464006 & 688537 & 5.5662 & 5.8651 & TST & & & \\
\hline CHEMBL1611733 & 688537 & 5.5402 & 5.5908 & TST & & & \\
\hline CHEMBL1561569 & 688537 & 2.8239 & 3.1736 & TST & & & \\
\hline CHEMBL1327628 & 688537 & 5.1065 & 4.766 & TST & & & \\
\hline CHEMBL1580638 & 688537 & 5.8147 & 5.7193 & TST & & & \\
\hline CHEMBL1466712 & 688537 & 5.5028 & 5.4355 & TST & & & \\
\hline CHEMBL1507251 & 688537 & 5.46700 & 00000000 & 205 & 5.7761 & TST & \\
\hline CHEMBL1490049 & 688537 & 2.8239 & 3.4069 & TST & & & \\
\hline CHEMBL1547350 & 688537 & 5.5699 & 5.6989 & TST & & & \\
\hline CHEMBL1503248 & 688537 & 6.2882 & 6.7528 & TST & & & \\
\hline CHEMBL1583801 & 688537 & 5.3755 & 5.2832 & TST & & & \\
\hline CHEMBL1388595 & 688537 & 5.3496 & 5.2119 & TST & & & \\
\hline CHEMBL1353738 & 688537 & 5.5735 & 5.2774 & TST & & & \\
\hline
\end{tabular}




\begin{tabular}{|c|c|c|c|c|c|}
\hline \multicolumn{6}{|c|}{ Supplemental Table S2.txt } \\
\hline CHEMBL1397158 & 688537 & 5.1368 & 5.0517 & TST & \\
\hline CHEMBL1454430 & 688537 & 5.5738 & 5.9665 & TST & \\
\hline CHEMBL567132 & 688537 & 5.5227 & 5.4134 & TST & \\
\hline CHEMBL1985061 & 688537 & 5.2665 & 5.1602 & TST & \\
\hline CHEMBL1418112 & 688537 & 4.2099 & 4.3236 & TST & \\
\hline CHEMBL1427606 & 688537 & 5.315 & 5.2951 & TST & \\
\hline CHEMBL1539127 & 688537 & 5.1538 & 5.1577 & TST & \\
\hline CHEMBL1505275 & 688537 & 5.6432 & 5.2591 & TST & \\
\hline CHEMBL1465946 & 688537 & 6.3851 & 6.34399 & 9999999999 & TST \\
\hline CHEMBL1485275 & 688537 & 8.2218 & 7.8489 & TST & \\
\hline CHEMBL 3105372 & 1284820 & 3.0 & 3.2538 & TRN & \\
\hline CHEMBL 3105368 & 1284820 & 3.0 & 3.0354 & TRN & \\
\hline CHEMBL3105300 & 1284820 & 4.1349 & 3.9641 & TST & \\
\hline CHEMBL3105291 & 1284820 & 4.5467 & 4.6056 & TRN & \\
\hline CHEMBL3105304 & 1284820 & 5.0555 & 5.5502 & TRN & \\
\hline CHEMBL 3105284 & 1284820 & 4.3915 & 4.1083 & TST & \\
\hline CHEMBL3105278 & 1284820 & 3.0 & 3.3834 & TRN & \\
\hline CHEMBL3105288 & 1284820 & 4.8928 & 4.2952 & TRN & \\
\hline CHEMBL3105303 & 1284820 & 4.6615 & 4.6059 & TRN & \\
\hline CHEMBL3105286 & 1284820 & 4.5331 & 4.3639 & TRN & \\
\hline CHEMBL3105377 & 1284820 & 3.0 & 3.3164 & TST & \\
\hline CHEMBL110097 & 1284820 & 3.0 & 3.0366 & TRN & \\
\hline CHEMBL3105302 & 1284820 & 4.567 & 5.0227 & TRN & \\
\hline CHEMBL3105295 & 1284820 & 4.2007 & 4.1149 & TRN & \\
\hline CHEMBL3105379 & 1284820 & 3.0 & 3.1903 & TRN & \\
\hline CHEMBL 3105290 & 1284820 & 4.4609 & 4.4071 & TRN & \\
\hline CHEMBL3105297 & 1284820 & 4.1831 & 4.1122 & TST & \\
\hline CHEMBL 3105381 & 1284820 & 3.0 & 3.2353 & TRN & \\
\hline CHEMBL3105307 & 1284820 & 5.7212 & 5.1963 & TRN & \\
\hline CHEMBL3105311 & 1284820 & 4.2041 & 3.7555 & TRN & \\
\hline CHEMBL 3105374 & 1284820 & 3.0 & 3.7669 & TST & \\
\hline CHEMBL3105285 & 1284820 & 4.341 & 4.3885 & TRN & \\
\hline CHEMBL3105301 & 1284820 & 4.5017 & 3.9025 & TST & \\
\hline CHEMBL3105378 & 1284820 & 3.0 & 3.5329 & TRN & \\
\hline CHEMBL3105305 & 1284820 & 4.6038 & 4.6 & TRN & \\
\hline CHEMBL3105371 & 1284820 & 3.0 & 3.0268 & TRN & \\
\hline CHEMBL3105308 & 1284820 & 4.7282 & 5.0963 & TRN & \\
\hline CHEMBL 3105282 & 1284820 & 5.5229 & 5.5632 & TRN & \\
\hline CHEMBL3105294 & 1284820 & 4.2565 & 4.209 & TRN & \\
\hline CHEMBL3105296 & 1284820 & 4.1871 & 3.9742 & TRN & \\
\hline CHEMBL3102883 & 1284820 & 5.2676 & 5.3332 & TRN & \\
\hline CHEMBL3105292 & 1284820 & 4.0942 & 4.3629 & TRN & \\
\hline CHEMBL2133975 & 1284820 & 3.0 & 2.9094 & TRN & \\
\hline CHEMBL3105380 & 1284820 & 3.0 & 3.2513 & TRN & \\
\hline CHEMBL3105310 & 1284820 & 4.4145 & 4.1242 & TRN & \\
\hline CHEMBL3105289 & 1284820 & 4.6108 & 4.38399 & 99999999995 & $|R|$ \\
\hline CHEMBL3105369 & 1284820 & 3.0 & 3.4451 & TRN & \\
\hline CHEMBL 3105280 & 1284820 & 4.2013 & 3.9101 & TRN & \\
\hline
\end{tabular}


Supplemental Table S2.txt

\begin{tabular}{|c|c|c|c|c|}
\hline CHEMBL3105299 & 1284820 & 4.6289 & 3.5781 & TST \\
\hline CHEMBL3105287 & 1284820 & 4.6904 & 4.2583 & TRN \\
\hline CHEMBL3105375 & 1284820 & 3.0 & 3.7555 & TST \\
\hline CHEMBL 3105283 & 1284820 & 4.4989 & 4.2602 & TRN \\
\hline CHEMBL3105306 & 1284820 & 4.6676 & 4.6479 & TST \\
\hline CHEMBL3105373 & 1284820 & 3.0 & 2.5672 & TRN \\
\hline CHEMBL3105376 & 1284820 & 3.0 & 2.8177 & TST \\
\hline CHEMBL3105309 & 1284820 & 5.1192 & 4.5396 & TST \\
\hline CHEMBL3105279 & 1284820 & 3.0 & 3.0753 & TRN \\
\hline CHEMBL3105298 & 1284820 & 4.6383 & 4.1415 & TST \\
\hline CHEMBL3105367 & 1284820 & 3.0 & 2.9524 & TRN \\
\hline CHEMBL3105370 & 1284820 & 3.0 & 2.9987 & TRN \\
\hline CHEMBL3105293 & 1284820 & 4.0487 & 4.0342 & TRN \\
\hline CHEMBL3105281 & 1284820 & 4.6737 & 4.8609 & TST \\
\hline CHEMBL3923285 & 1637098 & 8.0 & 7.2338 & TST \\
\hline CHEMBL3976027 & 1637098 & 8.0 & 8.286 & TRN \\
\hline CHEMBL3928309 & 1637098 & 7.0 & 5.9932 & TRN \\
\hline CHEMBL3919842 & 1637098 & 4.0 & 4.4112 & TRN \\
\hline CHEMBL3975137 & 1637098 & 7.0 & 6.6616 & TST \\
\hline CHEMBL3894255 & 1637098 & 7.0 & 5.8589 & TRN \\
\hline CHEMBL3973711 & 1637098 & 7.0 & 6.8931 & TRN \\
\hline CHEMBL3938839 & 1637098 & 4.0 & 7.1245 & TST \\
\hline CHEMBL3910833 & 1637098 & 7.0 & 7.0631 & TRN \\
\hline CHEMBL3967525 & 1637098 & 6.0 & 5.7412 & TRN \\
\hline CHEMBL 3949025 & 1637098 & 7.0 & 8.0535 & TRN \\
\hline CHEMBL3951185 & 1637098 & 6.0 & 6.6361 & TRN \\
\hline CHEMBL3984694 & 1637098 & 4.0 & 3.7606 & TST \\
\hline CHEMBL3941546 & 1637098 & 4.0 & 5.8878 & TRN \\
\hline CHEMBL3920250 & 1637098 & 7.0 & 6.4127 & TRN \\
\hline CHEMBL3964912 & 1637098 & 5.0 & 5.6436 & TRN \\
\hline CHEMBL3953679 & 1637098 & 8.0 & 8.2334 & TRN \\
\hline CHEMBL3920754 & 1637098 & 7.0 & 6.5452 & TRN \\
\hline CHEMBL3981735 & 1637098 & 8.0 & 7.3262 & TRN \\
\hline CHEMBL3905598 & 1637098 & 7.0 & 5.9828 & TRN \\
\hline CHEMBL3974628 & 1637098 & 7.0 & 6.636 & TRN \\
\hline CHEMBL3985711 & 1637098 & 7.0 & 7.3612 & TRN \\
\hline CHEMBL3981906 & 1637098 & 8.0 & 7.9394 & TRN \\
\hline CHEMBL 3932332 & 1637098 & 6.0 & 5.1352 & TST \\
\hline CHEMBL3919763 & 1637098 & 8.0 & 6.8928 & TRN \\
\hline CHEMBL3902945 & 1637098 & 7.0 & 7.6796 & TRN \\
\hline CHEMBL3905132 & 1637098 & 8.0 & 7.7364 & TRN \\
\hline CHEMBL3964189 & 1637098 & 8.0 & 8.0531 & TRN \\
\hline CHEMBL3981319 & 1637098 & 8.0 & 7.5364 & TRN \\
\hline CHEMBL3916649 & 1637098 & 8.0 & 7.9765 & TRN \\
\hline CHEMBL3939713 & 1637098 & 8.0 & 7.9547 & TRN \\
\hline CHEMBL3934197 & 1637098 & 7.0 & 7.0657 & TST \\
\hline CHEMBL3969911 & 1637098 & 8.0 & 6.8726 & TRN \\
\hline CHEMBL3979331 & 1637098 & 8.0 & 7.9808 & TRN \\
\hline
\end{tabular}




\begin{tabular}{|c|c|c|c|c|}
\hline CHEMBL 3972202 & 1637098 & 8.0 & 7.535 & TRN \\
\hline CHEMBL 3985764 & 1637098 & 7.0 & 5.9242 & TST \\
\hline CHEMBL3971922 & 1637098 & 8.0 & 7.5695 & TRN \\
\hline CHEMBL 3889687 & 1637098 & 8.0 & 7.2382 & TRN \\
\hline CHEMBL3927115 & 1637098 & 7.0 & 6.2933 & TRN \\
\hline CHEMBL3949031 & 1637098 & 8.0 & 8.0866 & TRN \\
\hline CHEMBL 3918763 & 1637098 & 6.0 & 6.6349 & TRN \\
\hline CHEMBL3949241 & 1637098 & 8.0 & 7.9332 & TRN \\
\hline CHEMBL3948766 & 1637098 & 6.0 & 6.9097 & TRN \\
\hline CHEMBL3920973 & 1637098 & 8.0 & 8.3139 & TRN \\
\hline CHEMBL3934193 & 1637098 & 4.0 & 3.9869 & TST \\
\hline CHEMBL 3977886 & 1637098 & 8.0 & \multicolumn{2}{|c|}{6.9479999999999995} \\
\hline CHEMBL3953621 & 1637098 & 7.0 & 6.5373 & TRN \\
\hline CHEMBL3911034 & 1637098 & 8.0 & 8.1572 & TRN \\
\hline CHEMBL 3965684 & 1637098 & 8.0 & 6.9918 & TRN \\
\hline CHEMBL3905083 & 1637098 & 4.0 & 5.9003 & TRN \\
\hline CHEMBL3969273 & 1637098 & 8.0 & 7.1777 & TST \\
\hline CHEMBL 3978491 & 1637098 & 8.0 & 8.0061 & TRN \\
\hline CHEMBL3915590 & 1637098 & 7.0 & 7.1205 & TST \\
\hline CHEMBL3974179 & 1637098 & 8.0 & 7.1056 & TRN \\
\hline CHEMBL3986855 & 1637098 & 8.0 & 7.4618 & TRN \\
\hline CHEMBL 3962612 & 1637098 & 8.0 & 6.6941 & TRN \\
\hline CHEMBL3918109 & 1637098 & 4.0 & 3.9178 & TST \\
\hline CHEMBL3980396 & 1637098 & 4.0 & 5.8367 & TRN \\
\hline CHEMBL3911175 & 1637098 & 6.0 & 6.8521 & TRN \\
\hline CHEMBL3958796 & 1637098 & 8.0 & 6.2301 & TRN \\
\hline CHEMBL3912775 & 1637098 & 7.0 & 7.4559 & TRN \\
\hline CHEMBL 3908417 & 1637098 & 6.0 & 5.8154 & TRN \\
\hline CHEMBL3937104 & 1637098 & 8.0 & 8.1691 & TRN \\
\hline CHEMBL 3905580 & 1637098 & 4.0 & 6.2927 & TRN \\
\hline CHEMBL3959902 & 1637098 & 8.0 & 7.0866 & TST \\
\hline CHEMBL 3934621 & 1637098 & 6.0 & 5.8656 & TST \\
\hline CHEMBL3931462 & 1637098 & 8.0 & 7.0948 & TST \\
\hline CHEMBL3980892 & 1637098 & 6.0 & 4.9056 & TST \\
\hline CHEMBL 3892265 & 1637098 & 7.0 & 7.2551 & TST \\
\hline CHEMBL3892662 & 1637098 & 6.0 & 6.7197 & TST \\
\hline CHEMBL 3972206 & 1637098 & 8.0 & 8.0358 & TRN \\
\hline CHEMBL3934207 & 1637098 & 4.0 & 5.1479 & TRN \\
\hline CHEMBL3943361 & 1637098 & 7.0 & 6.8268 & TRN \\
\hline CHEMBL 3946559 & 1637098 & 7.0 & 6.4593 & TST \\
\hline CHEMBL3904707 & 1637098 & 8.0 & 8.0336 & TRN \\
\hline CHEMBL3901585 & 1637098 & 8.0 & 7.0126 & TST \\
\hline CHEMBL 3974554 & 1637098 & 4.0 & 4.9739 & TRN \\
\hline CHEMBL3954736 & 1637098 & 6.0 & 5.9563 & TRN \\
\hline CHEMBL 3959833 & 1637098 & 8.0 & 7.8895 & TRN \\
\hline CHEMBL 3912530 & 1637098 & 7.0 & 6.9399 & TRN \\
\hline CHEMBL 3927712 & 1637098 & 8.0 & 7.2207 & TRN \\
\hline CHEMBL3969872 & 1637098 & 8.0 & 7.0697 & TST \\
\hline
\end{tabular}




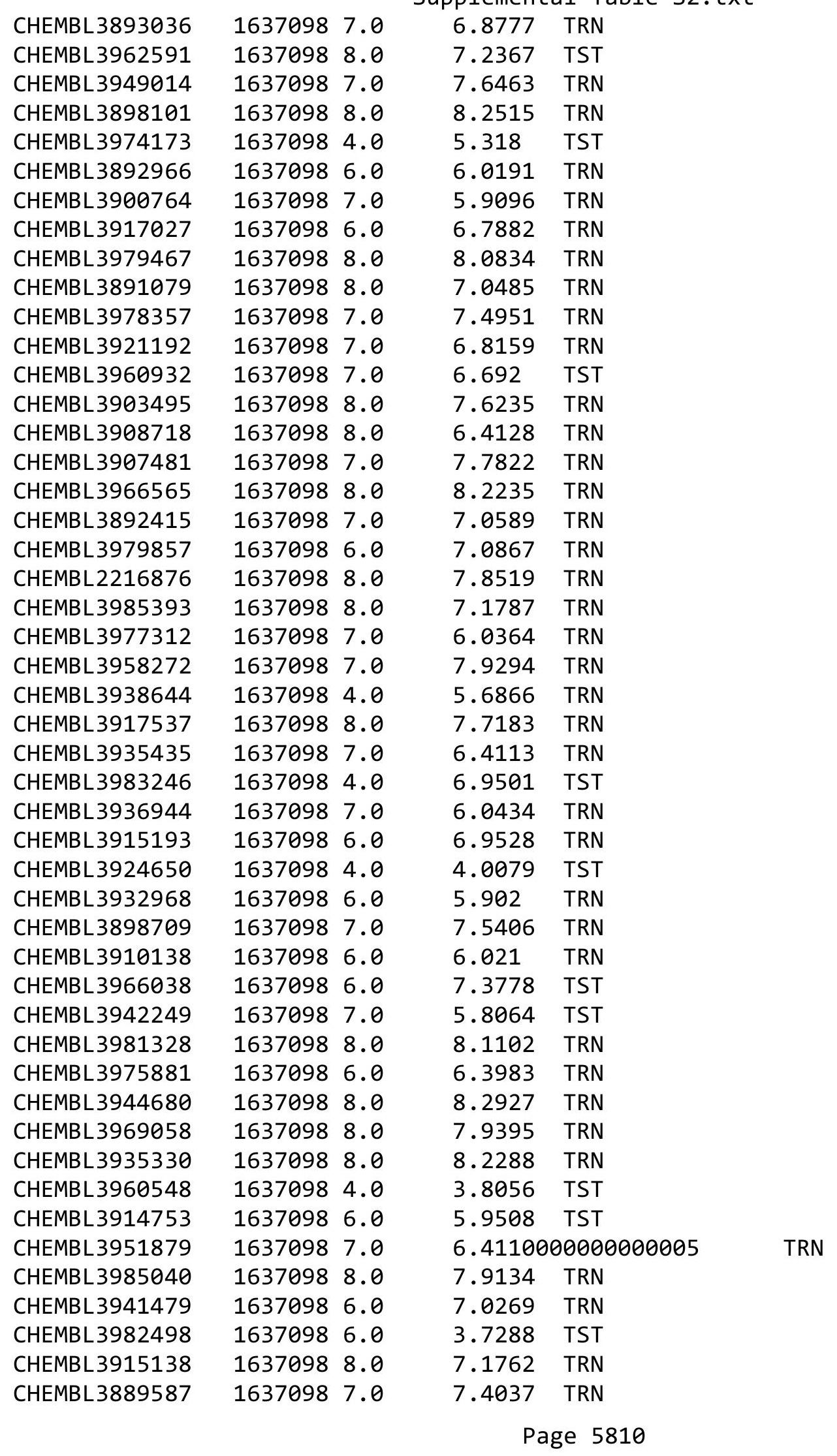




\begin{tabular}{|c|c|c|c|c|}
\hline & & & & \\
\hline CHEMBL3980419 & 1637098 & 4.0 & 4.2942 & TST \\
\hline CHEMBL3946345 & 1637098 & 8.0 & 6.526 & TST \\
\hline CHEMBL3925005 & 1637098 & 7.0 & 6.6198 & TRN \\
\hline CHEMBL3962439 & 1637098 & 4.0 & 5.7094 & TRN \\
\hline CHEMBL3939554 & 1637098 & 8.0 & 8.0513 & TRN \\
\hline CHEMBL3957382 & 1637098 & 6.0 & 6.7026 & TRN \\
\hline CHEMBL3947356 & 1637098 & 4.0 & 6.7756 & TRN \\
\hline CHEMBL3955031 & 1637098 & 8.0 & 7.0936 & TST \\
\hline CHEMBL3961109 & 1637098 & 6.0 & 7.5299 & TRN \\
\hline CHEMBL3907964 & 1637098 & 8.0 & 7.0072 & TRN \\
\hline CHEMBL3903046 & 1637098 & 8.0 & 8.226 & TRN \\
\hline CHEMBL3932626 & 1637098 & 8.0 & 8.1673 & TRN \\
\hline CHEMBL3980844 & 1637098 & 7.0 & 6.7126 & TRN \\
\hline CHEMBL3958075 & 1637098 & 8.0 & 7.9465 & TRN \\
\hline CHEMBL3986480 & 1637098 & 7.0 & 6.5329 & TRN \\
\hline CHEMBL3974367 & 1637098 & 8.0 & 7.8243 & TRN \\
\hline CHEMBL3905246 & 1637098 & 6.0 & 7.1021 & TRN \\
\hline CHEMBL3925129 & 1637098 & 8.0 & 6.9726 & TST \\
\hline CHEMBL3890604 & 1637098 & 4.0 & 3.6839 & TST \\
\hline CHEMBL3966715 & 1637098 & 7.0 & 7.0124 & TRN \\
\hline CHEMBL 3896670 & 1637098 & 6.0 & 6.0212 & TRN \\
\hline CHEMBL3954757 & 1637098 & 8.0 & 6.7797 & TRN \\
\hline CHEMBL3981434 & 1637098 & 8.0 & 6.6771 & TRN \\
\hline CHEMBL3944018 & 1637098 & 8.0 & 8.1242 & TRN \\
\hline CHEMBL 3895608 & 1637098 & 6.0 & 6.4081 & TRN \\
\hline CHEMBL 3913415 & 1637098 & 7.0 & 7.1657 & TRN \\
\hline CHEMBL3967531 & 1637098 & 4.0 & 3.5683 & TST \\
\hline CHEMBL3957119 & 1637098 & 8.0 & 8.2011 & TRN \\
\hline CHEMBL3918112 & 1637098 & 8.0 & 6.723 & TST \\
\hline CHEMBL 3962803 & 1637098 & 7.0 & 7.3876 & TRN \\
\hline CHEMBL3985194 & 1637098 & 6.0 & 5.2428 & TRN \\
\hline CHEMBL3915312 & 1637098 & 8.0 & 7.1592 & TST \\
\hline CHEMBL3945850 & 1637098 & 8.0 & 8.0013 & TRN \\
\hline CHEMBL 3927820 & 1637098 & 4.0 & 5.8339 & TRN \\
\hline CHEMBL3940957 & 1637098 & 8.0 & 7.8623 & TRN \\
\hline CHEMBL3940977 & 1637098 & 8.0 & 7.1949 & TRN \\
\hline CHEMBL3896177 & 1637098 & 8.0 & 7.0439 & TST \\
\hline CHEMBL3920111 & 1637098 & 6.0 & 6.0209 & TRN \\
\hline CHEMBL 3957361 & 1637098 & 8.0 & 7.7304 & TRN \\
\hline CHEMBL3983481 & 1637098 & 7.0 & 6.9301 & TRN \\
\hline CHEMBL3969116 & 1637098 & 8.0 & 7.7107 & TRN \\
\hline CHEMBL3893129 & 1637098 & 6.0 & 5.9017 & TRN \\
\hline CHEMBL3937172 & 1637098 & 6.0 & 6.9378 & TRN \\
\hline CHEMBL 3907233 & 1637098 & 6.0 & 6.9255 & TRN \\
\hline CHEMBL3913845 & 1637098 & 8.0 & 8.0011 & TRN \\
\hline CHEMBL3907079 & 1637098 & 7.0 & 7.1593 & TST \\
\hline CHEMBL3969470 & 1637098 & 6.0 & 5.8195 & TRN \\
\hline CHEMBL3978509 & 1637098 & 6.0 & 5.4831 & TST \\
\hline
\end{tabular}




\begin{tabular}{|c|c|c|c|c|c|}
\hline CHEMBL 3971853 & 1637098 & 7.0 & 6.8339 & TRN & \\
\hline CHEMBL 3907677 & 1637098 & 8.0 & 7.8755 & TRN & \\
\hline CHEMBL3939953 & 1637098 & 8.0 & 8.0202 & TRN & \\
\hline CHEMBL3971985 & 1637098 & 8.0 & \multicolumn{2}{|c|}{7.093999999999999} & TST \\
\hline CHEMBL 3985898 & 1637098 & 7.0 & 7.0703 & TST & \\
\hline CHEMBL3903458 & 1637098 & 4.0 & 5.2242 & TRN & \\
\hline CHEMBL 3969965 & 1637098 & 8.0 & 7.0984 & TST & \\
\hline CHEMBL3933033 & 1637098 & 8.0 & 7.1542 & TST & \\
\hline CHEMBL3932575 & 1637098 & 8.0 & 7.0045 & TST & \\
\hline CHEMBL3986828 & 1637098 & 7.0 & 6.7672 & TRN & \\
\hline CHEMBL3961040 & 1637098 & 7.0 & 7.1181 & TRN & \\
\hline CHEMBL 3986800 & 1637098 & 8.0 & 7.8381 & TRN & \\
\hline CHEMBL3929045 & 1637098 & 4.0 & \multicolumn{2}{|c|}{6.497000000000001} & TST \\
\hline CHEMBL3898290 & 1637098 & 8.0 & 6.3276 & TRN & \\
\hline CHEMBL 3917082 & 1637098 & 6.0 & 5.7672 & TST & \\
\hline CHEMBL3905612 & 1637098 & 7.0 & 7.7708 & TRN & \\
\hline CHEMBL3936676 & 1637098 & 8.0 & 8.2631 & TRN & \\
\hline CHEMBL 3955440 & 1637098 & 8.0 & 8.0874 & TRN & \\
\hline CHEMBL3895375 & 1637098 & 7.0 & 7.1011 & TRN & \\
\hline CHEMBL3901409 & 1637098 & 7.0 & 6.6427 & TRN & \\
\hline CHEMBL3903621 & 1637098 & 4.0 & 3.6235 & TST & \\
\hline CHEMBL 3908820 & 1637098 & 8.0 & 6.9752 & TRN & \\
\hline CHEMBL3966914 & 1637098 & 6.0 & 6.2519 & TRN & \\
\hline CHEMBL3942692 & 1637098 & 8.0 & 7.774 & TRN & \\
\hline CHEMBL 3983816 & 1637098 & 7.0 & 7.6129 & TRN & \\
\hline CHEMBL3951888 & 1637098 & 8.0 & 8.012 & TRN & \\
\hline CHEMBL 3948376 & 1637098 & 8.0 & 7.8145 & TRN & \\
\hline CHEMBL 3982302 & 1637098 & 6.0 & 5.4008 & TRN & \\
\hline CHEMBL3972637 & 1637098 & 7.0 & 6.9305 & TST & \\
\hline CHEMBL 3920543 & 1637098 & 7.0 & 7.1008 & TRN & \\
\hline CHEMBL3900898 & 1637098 & 6.0 & 6.267 & TST & \\
\hline CHEMBL 3922415 & 1637098 & 8.0 & 8.0151 & TRN & \\
\hline CHEMBL3922769 & 1637098 & 7.0 & 6.9522 & TRN & \\
\hline CHEMBL3911538 & 1637098 & 8.0 & 7.7529 & TRN & \\
\hline CHEMBL 3947509 & 1637098 & 6.0 & 7.0288 & TRN & \\
\hline CHEMBL3958438 & 1637098 & 8.0 & 7.9056 & TRN & \\
\hline CHEMBL 3982444 & 1637098 & 6.0 & 5.5508 & TRN & \\
\hline CHEMBL3950901 & 1637098 & 8.0 & 8.1319 & TRN & \\
\hline CHEMBL3952948 & 1637098 & 4.0 & 5.0174 & TRN & \\
\hline CHEMBL3932981 & 1637098 & 7.0 & 6.8084 & TRN & \\
\hline CHEMBL3919689 & 1637098 & 8.0 & 7.9532 & TRN & \\
\hline CHEMBL3955730 & 1637098 & 8.0 & 7.0914 & TRN & \\
\hline CHEMBL2216897 & 1637098 & 8.0 & 8.1711 & TRN & \\
\hline CHEMBL3978013 & 1637098 & 8.0 & 7.6894 & TRN & \\
\hline CHEMBL3911404 & 1637098 & 8.0 & 7.0515 & TST & \\
\hline CHEMBL3929965 & 1637098 & 7.0 & 6.04200 & 0000000001 & TRN \\
\hline CHEMBL 3919824 & 1637098 & 6.0 & 6.8935 & TRN & \\
\hline CHEMBL3919001 & 1637098 & 7.0 & 7.4493 & TST & \\
\hline
\end{tabular}




\begin{tabular}{|c|c|c|c|c|}
\hline & & & 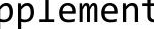 & \\
\hline CHEMBL3981071 & 1637098 & 7.0 & 7.0776 & TST \\
\hline CHEMBL3916328 & 1637098 & 8.0 & 7.0508 & TRN \\
\hline CHEMBL 3895422 & 1637098 & 6.0 & 5.8544 & TRN \\
\hline CHEMBL3972055 & 1637098 & 8.0 & 6.8958 & TRN \\
\hline CHEMBL3941416 & 1637098 & 4.0 & 5.6239 & TST \\
\hline CHEMBL3969492 & 1637098 & 7.0 & 7.6199 & TRN \\
\hline CHEMBL3924404 & 1637098 & 8.0 & 7.0659 & TRN \\
\hline CHEMBL3957623 & 1637098 & 7.0 & 6.0405 & TRN \\
\hline CHEMBL3950924 & 1637098 & 6.0 & 3.4155 & TST \\
\hline CHEMBL3924168 & 1637098 & 8.0 & 7.9637 & TRN \\
\hline CHEMBL3928104 & 1637098 & 8.0 & 8.033 & TRN \\
\hline CHEMBL3961908 & 1637098 & 7.0 & 6.8333 & TRN \\
\hline CHEMBL3917519 & 1637098 & 4.0 & 5.0318 & TST \\
\hline CHEMBL3954505 & 1637098 & 8.0 & 7.9385 & TRN \\
\hline CHEMBL3891083 & 1637098 & 6.0 & 6.1814 & TRN \\
\hline CHEMBL3939576 & 1637098 & 8.0 & 6.9666 & TST \\
\hline CHEMBL3925535 & 1637098 & 6.0 & 6.1084 & TRN \\
\hline CHEMBL 3918477 & 1637098 & 8.0 & 8.0213 & TRN \\
\hline CHEMBL3889919 & 1637098 & 8.0 & 7.3086 & TST \\
\hline CHEMBL3910674 & 1637098 & 8.0 & 8.1297 & TRN \\
\hline CHEMBL3986207 & 1637098 & 6.0 & 6.204 & TST \\
\hline CHEMBL3922817 & 1637098 & 8.0 & 7.2286 & TRN \\
\hline CHEMBL3957628 & 1637098 & 8.0 & 7.1323 & TST \\
\hline CHEMBL3974743 & 1637098 & 8.0 & 8.1018 & TRN \\
\hline CHEMBL 3965714 & 1637098 & 8.0 & 7.1866 & TST \\
\hline CHEMBL3917917 & 1637098 & 8.0 & 7.7638 & TRN \\
\hline CHEMBL3931051 & 1637098 & 8.0 & 6.8342 & TRN \\
\hline CHEMBL3946653 & 1637098 & 6.0 & 4.8832 & TST \\
\hline CHEMBL3922621 & 1637098 & 8.0 & 6.9843 & TST \\
\hline CHEMBL 3944887 & 1637098 & 7.0 & 7.8457 & TRN \\
\hline CHEMBL1342776 & 736980 & 4.4789 & 5.1196 & TRN \\
\hline CHEMBL581449 & 736980 & 4.4789 & 4.8371 & TRN \\
\hline CHEMBL1400385 & 736980 & 3.5243 & 3.2316 & TRN \\
\hline CHEMBL1330018 & 736980 & 3.5243 & 3.7115 & TRN \\
\hline CHEMBL1507439 & 736980 & 3.5243 & 3.9017 & TST \\
\hline CHEMBL1971695 & 736980 & 5.4855 & 5.2386 & TRN \\
\hline CHEMBL1968278 & 736980 & 3.5243 & 4.1631 & TRN \\
\hline CHEMBL1527735 & 736980 & 5.8327 & 4.9463 & TST \\
\hline CHEMBL1428566 & 736980 & 3.5243 & 4.263 & TST \\
\hline CHEMBL1976525 & 736980 & 5.3098 & 4.6397 & TRN \\
\hline CHEMBL455399 & 736980 & 6.1726 & 5.3204 & TRN \\
\hline CHEMBL3194037 & 736980 & 3.5243 & 3.7883 & TRN \\
\hline CHEMBL1351173 & 736980 & 4.6003 & 4.6132 & TRN \\
\hline CHEMBL1560584 & 736980 & 3.5243 & 3.6441 & TRN \\
\hline CHEMBL1319502 & 736980 & 3.5243 & 3.3567 & TRN \\
\hline CHEMBL1377193 & 736980 & 6.7747 & 7.0231 & TRN \\
\hline CHEMBL3715797 & 736980 & 3.5243 & 4.4413 & TRN \\
\hline CHEMBL1412812 & 736980 & 3.5243 & 3.3915 & TRN \\
\hline
\end{tabular}




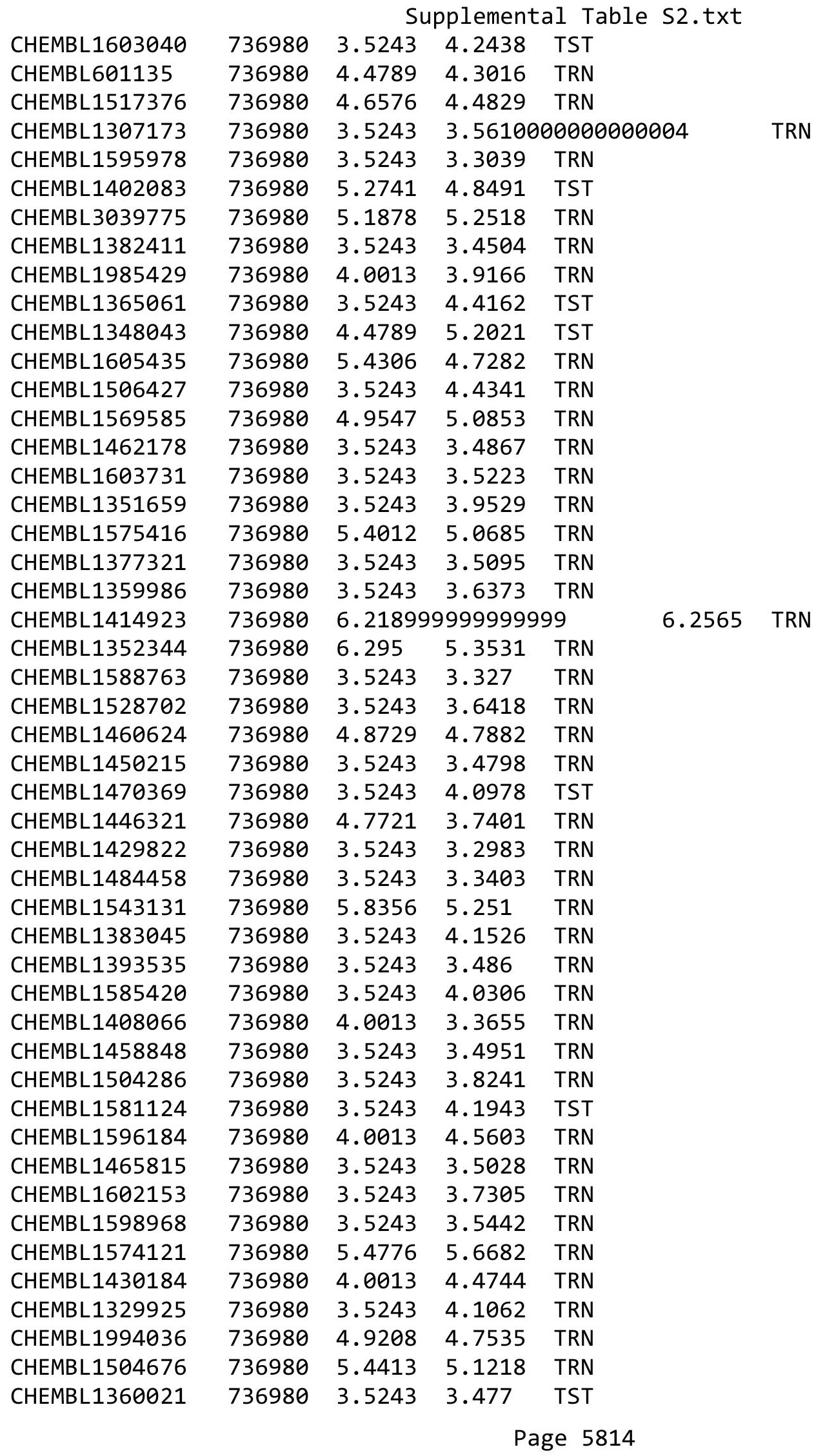




\begin{tabular}{|c|c|c|c|c|c|}
\hline & & \multicolumn{4}{|c|}{ Supplemental Table S2.txt } \\
\hline CHEMBL1389483 & 736980 & 3.5243 & 3.3549 & TST & \\
\hline CHEMBL1494852 & 736980 & 5.4498 & 4.7284 & TST & \\
\hline CHEMBL1509135 & 736980 & 3.5243 & 5.5862 & TST & \\
\hline CHEMBL1419072 & 736980 & 3.5243 & 3.7935 & TST & \\
\hline CHEMBL1490716 & 736980 & 5.8928 & 5.1202 & TST & \\
\hline CHEMBL1542598 & 736980 & 3.5243 & 3.4056 & TST & \\
\hline CHEMBL1516758 & 736980 & 5.7905 & 4.3462 & TST & \\
\hline CHEMBL1602160 & 736980 & 4.0013 & 4.9071 & TST & \\
\hline CHEMBL1421574 & 736980 & 3.5243 & 3.85100 & 00000000004 & TST \\
\hline CHEMBL1215671 & 649313 & 3.301 & 3.7704 & TRN & \\
\hline CHEMBL1215533 & 649313 & 3.3565 & 3.78899 & 99999999997 & TST \\
\hline CHEMBL1215667 & 649313 & 3.3279 & 3.8439 & TRN & \\
\hline CHEMBL1215457 & 649313 & 3.301 & 4.0467 & TRN & \\
\hline CHEMBL1212959 & 649313 & 4.4089 & 4.3498 & TRN & \\
\hline CHEMBL1214817 & 649313 & 4.699 & 4.3303 & TRN & \\
\hline CHEMBL1215528 & 649313 & 4.0 & 3.8108 & TRN & \\
\hline CHEMBL1214665 & 649313 & 4.699 & 3.9041 & TRN & \\
\hline CHEMBL1215530 & 649313 & 4.301 & 4.498 & TST & \\
\hline CHEMBL1215738 & 649313 & 4.3979 & 3.5439 & TRN & \\
\hline CHEMBL1215307 & 649313 & 4.8729 & 4.8148 & TRN & \\
\hline CHEMBL1215383 & 649313 & 4.9469 & 4.43 & TRN & \\
\hline CHEMBL1214885 & 649313 & 4.585 & 4.3072 & TRN & \\
\hline CHEMBL1215386 & 649313 & 3.301 & 4.5261 & TRN & \\
\hline CHEMBL1214822 & 649313 & 3.4685 & 4.3036 & TRN & \\
\hline CHEMBL1215382 & 649313 & 4.7721 & 4.1298 & TST & \\
\hline CHEMBL1215602 & 649313 & 4.301 & 4.2891 & TRN & \\
\hline CHEMBL1214884 & 649313 & 3.4815 & 4.5496 & TRN & \\
\hline CHEMBL1215668 & 649313 & 3.4437 & 3.7587 & TRN & \\
\hline CHEMBL164129 & 649313 & 4.7986 & 4.2101 & TST & \\
\hline CHEMBL1214742 & 649313 & 4.6383 & 4.2678 & TRN & \\
\hline CHEMBL1214819 & 649313 & 4.8861 & 4.4928 & TRN & \\
\hline CHEMBL1215736 & 649313 & 3.4202 & 3.7216 & TRN & \\
\hline CHEMBL1215308 & 649313 & 4.8794 & 4.6785 & TST & \\
\hline CHEMBL1214740 & 649313 & 4.8239 & 4.4319 & TRN & \\
\hline CHEMBL1214818 & 649313 & 5.1135 & 4.7044 & TRN & \\
\hline CHEMBL1214667 & 649313 & 4.7447 & 4.3727 & TRN & \\
\hline CHEMBL1215456 & 649313 & 4.0 & 4.3276 & TRN & \\
\hline CHEMBL1214668 & 649313 & 4.7959 & 4.7384 & TRN & \\
\hline CHEMBL1214821 & 649313 & 4.6383 & 4.3925 & TRN & \\
\hline CHEMBL1215669 & 649313 & 3.585 & 3.667 & TRN & \\
\hline CHEMBL1215734 & 649313 & 4.699 & 4.2287 & TRN & \\
\hline CHEMBL1215534 & 649313 & 3.301 & 3.7126 & TST & \\
\hline CHEMBL1214741 & 649313 & 4.3098 & 4.3457 & TRN & \\
\hline CHEMBL1215384 & 649313 & 4.9355 & 4.2127 & TST & \\
\hline CHEMBL1215598 & 649313 & 3.4685 & 3.9807 & TST & \\
\hline CHEMBL1215460 & 649313 & 3.6576 & 3.7015 & TRN & \\
\hline CHEMBL1215670 & 649313 & 5.0 & 4.0306 & TRN & \\
\hline CHEMBL1215385 & 649313 & 3.301 & 3.7967 & TRN & \\
\hline
\end{tabular}




\begin{tabular}{|c|c|c|c|c|c|}
\hline \multicolumn{6}{|c|}{ Supplemental Table S2.txt } \\
\hline CHEMBL1215666 & 649313 & 4.0458 & 4.0236 & TRN & \\
\hline CHEMBL1214670 & 649313 & 4.6778 & 4.2709 & TRN & \\
\hline CHEMBL1215735 & 649313 & 3.5376 & 3.957 & TRN & \\
\hline CHEMBL1215532 & 649313 & 4.4559 & 4.0086 & TST & \\
\hline CHEMBL1214669 & 649313 & 4.301 & 4.5234 & TRN & \\
\hline CHEMBL1215458 & 649313 & 4.3979 & 3.8886 & TRN & \\
\hline CHEMBL1215599 & 649313 & 4.7212 & 3.7062 & TST & \\
\hline CHEMBL1215459 & 649313 & 4.301 & 3.8104 & TRN & \\
\hline CHEMBL1215737 & 649313 & 3.5229 & 3.636 & TRN & \\
\hline CHEMBL1215381 & 649313 & 4.8041 & 4.1839 & TST & \\
\hline CHEMBL1215529 & 649313 & 3.4437 & 3.6899 & TST & \\
\hline CHEMBL1215531 & 649313 & 4.5086 & 4.2981 & TST & \\
\hline CHEMBL1214883 & 649313 & 4.4815 & 4.2321 & TRN & \\
\hline CHEMBL1212969 & 649313 & 3.5686 & 3.6371 & TRN & \\
\hline CHEMBL1215601 & 649313 & 4.301 & 4.5119 & TRN & \\
\hline CHEMBL1215597 & 649313 & 4.0 & 3.6071 & TST & \\
\hline CHEMBL1215461 & 649313 & 4.301 & 4.0851 & TRN & \\
\hline CHEMBL1214743 & 649313 & 4.7212 & 4.5953 & TRN & \\
\hline CHEMBL1215733 & 649313 & 4.3372 & 4.4533 & TRN & \\
\hline CHEMBL1214820 & 649313 & 3.6778 & 4.2356 & TRN & \\
\hline CHEMBL1214666 & 649313 & 3.301 & 3.6424 & TRN & \\
\hline CHEMBL1215309 & 649313 & 5.1739 & 4.4828 & TST & \\
\hline CHEMBL1215310 & 649313 & 4.9101 & 4.1791 & TST & \\
\hline CHEMBL1215600 & 649313 & 3.4437 & 3.764 & TRN & \\
\hline CHEMBL3121964 & 1291714 & 7.8239 & 7.83799 & & TRN \\
\hline CHEMBL3121985 & 1291714 & 6.7645 & 6.7539 & TRN & \\
\hline CHEMBL3122011 & 1291714 & 4.0 & 3.9916 & TRN & \\
\hline CHEMBL3121968 & 1291714 & 6.6271 & 6.8543 & TST & \\
\hline CHEMBL3121995 & 1291714 & 6.8508 & 6.8571 & TRN & \\
\hline CHEMBL3121971 & 1291714 & 5.9393 & 7.2607 & TST & \\
\hline CHEMBL3121978 & 1291714 & 7.6021 & 7.5826 & TRN & \\
\hline CHEMBL 3122010 & 1291714 & 4.0 & 4.0095 & TRN & \\
\hline CHEMBL3121989 & 1291714 & 6.4067 & 6.4084 & TRN & \\
\hline CHEMBL3121981 & 1291714 & 6.2226 & 6.226 & TRN & \\
\hline CHEMBL3122001 & 1291714 & 8.0506 & 8.0451 & TRN & \\
\hline CHEMBL3121970 & 1291714 & 5.902 & 6.6618 & TST & \\
\hline CHEMBL3122002 & 1291714 & 4.0 & 3.9952 & TRN & \\
\hline CHEMBL3122008 & 1291714 & 4.0 & 4.0123 & TRN & \\
\hline CHEMBL3122000 & 1291714 & 6.9136 & 6.9148 & TRN & \\
\hline CHEMBL3121969 & 1291714 & 6.6073 & 6.8045 & TST & \\
\hline CHEMBL3122009 & 1291714 & 4.0 & 3.9925 & TRN & \\
\hline CHEMBL3121965 & 1291714 & 6.7645 & 6.8905 & TST & \\
\hline CHEMBL3121991 & 1291714 & 5.7557 & 5.7597 & TRN & \\
\hline CHEMBL3121967 & 1291714 & 6.2774 & 6.9459 & TST & \\
\hline CHEMBL3121999 & 1291714 & 6.5031 & 6.5114 & TRN & \\
\hline CHEMBL3121988 & 1291714 & 7.9586 & 7.9723 & TRN & \\
\hline CHEMBL3120183 & 1291714 & 7.8239 & 7.8154 & TRN & \\
\hline CHEMBL3122003 & 1291714 & 5.3519 & 5.3416 & TRN & \\
\hline
\end{tabular}


Supplemental Table S2.txt

\begin{tabular}{|c|c|c|c|c|}
\hline The & 291714 & & & \\
\hline & 291714 & 7.1805 & & \\
\hline & 1714 & & & \\
\hline AEMBL 3121 & 1714 & 4.0 & & \\
\hline AEMBL3121990 & 291714 & 19 & & \\
\hline HEMBL3121966 & 291714 & 7.1308 & .2466 & \\
\hline 184 & & 65 & & \\
\hline 998 & & & & \\
\hline AEMBL3122004 & & 5.3516 & .3567 & \\
\hline HEMBL3121983 & 291714 & 4.0 & .997 & \\
\hline HEMBL3121961 & 714 & 8.2366 & 23 & \\
\hline AEMBL3 & 714 & 48 & .3442 & \\
\hline HEMBL; & & & & \\
\hline HEMBL312 & & 5.2782 & 8469 & \\
\hline AEMBL31 & & $\partial 5$ & & \\
\hline AEMBL3 & & 62 & 74 & \\
\hline AEMBL3 & & & 84 & \\
\hline HEMBL3 & & & & \\
\hline HEMBL3 & & & & \\
\hline AEMBL3 & & & & \\
\hline HEMBL & & 5. & 72 & RIV \\
\hline HEMBL & & $T$ & & 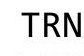 \\
\hline HEMBL & & & & \\
\hline HEMBL & & & & \\
\hline AEMBL3 & & & & N \\
\hline HEMBL; & & 4 & & RN \\
\hline HEMBL & & & & ST \\
\hline AFMBI & & & & \\
\hline HEMBL3 & & & & RIV \\
\hline HEMBL3S & & & & I RIV \\
\hline HEMBL & & & & SI \\
\hline AFMB & & & & RN \\
\hline HEMBL & & & & RN \\
\hline HEMBL3 & & 7. & & IRN \\
\hline HEMBL 3951731 & & 6.6 & 6. & ГRN \\
\hline HEMBL & & 1 & 35 & \\
\hline HEMRI & & 7. & & RN \\
\hline HEMBL & & & & IRN \\
\hline HEMBL3964708 & & 7.699 & 238 & TRN \\
\hline AEMBL & & & & $\Gamma \mathrm{RN}$ \\
\hline HEMBL & & 51 & 51 & \\
\hline CHEMBL3 & & & & RN \\
\hline HEMBL3 & & 7.3098 & 7.1989 & RN \\
\hline HEMBL3 & 919 & 5.971 & 13 & TRN \\
\hline MPI & & & 7. & $\mathrm{~N}$ \\
\hline HEMBL3 & & & 7.8009 & \\
\hline CHEMBL3 & & 5.4698 & 7.2345 & \\
\hline THEMBL3952972 & 1640919 & 8.1024 & 8.5817 & ГRN \\
\hline
\end{tabular}

Page 5817 
Supplemental Table S2.txt

\begin{tabular}{|c|c|c|c|c|c|}
\hline CHEMBL3933043 & 1640919 & 7.699 & 8.0803 & TST & \\
\hline CHEMBL 3978535 & 1640919 & 6.7235 & 6.7446 & TRN & \\
\hline CHEMBL3893518 & 1640919 & 6.0 & 7.4071 & TRN & \\
\hline CHEMBL3935414 & 1640919 & 7.3565 & 7.4057 & TRN & \\
\hline CHEMBL 3905186 & 1640919 & 7.4685 & 7.4059 & TRN & \\
\hline CHEMBL3979582 & 1640919 & 7.1487 & 7.0379 & TRN & \\
\hline CHEMBL 3974402 & 1640919 & 7.8861 & 6.5915 & TST & \\
\hline CHEMBL3957040 & 1640919 & 7.1487 & 7.3833 & TRN & \\
\hline CHEMBL3951121 & 1640919 & 7.7959 & 7.7765 & TRN & \\
\hline CHEMBL3913511 & 1640919 & 7.699 & 7.5714 & TRN & \\
\hline CHEMBL3928633 & 1640919 & 8.28399 & 999999999 & 8.0787 & TRN \\
\hline CHEMBL 3948807 & 1640919 & 9.1487 & 9.2602 & TRN & \\
\hline CHEMBL3914211 & 1640919 & 6.7986 & 7.6527 & TST & \\
\hline CHEMBL3949229 & 1640919 & 7.6021 & 7.3936 & TRN & \\
\hline CHEMBL 3935344 & 1640919 & 7.6778 & 7.4364 & TRN & \\
\hline CHEMBL3890322 & 1640919 & 4.0 & 4.1776 & TRN & \\
\hline CHEMBL3977622 & 1640919 & 6.8794 & 8.3415 & TST & \\
\hline CHEMBL 3981253 & 1640919 & 7.1549 & 8.1315 & TST & \\
\hline CHEMBL3951805 & 1640919 & 8.0809 & 8.0207 & TRN & \\
\hline CHEMBL 3916522 & 1640919 & 6.3089 & 6.3581 & TRN & \\
\hline CHEMBL3949684 & 1640919 & 7.5528 & 7.687 & TRN & \\
\hline CHEMBL3983604 & 1640919 & 7.3872 & 7.327000 & 0000000001 & TRN \\
\hline CHEMBL 3984430 & 1640919 & 7.1938 & 7.3195 & TST & \\
\hline CHEMBL3957691 & 1640919 & 7.0223 & 7.4315 & TST & \\
\hline CHEMBL3964710 & 1640919 & 7.2291 & 7.1292 & TRN & \\
\hline CHEMBL3937605 & 1640919 & 7.2676 & 7.5341 & TRN & \\
\hline CHEMBL3938531 & 1640919 & 7.9586 & 7.2938 & TRN & \\
\hline CHEMBL3942977 & 1640919 & 7.0 & 8.0077 & TST & \\
\hline CHEMBL3930481 & 1640919 & 8.9208 & 8.2262 & TRN & \\
\hline CHEMBL3907937 & 1640919 & 8.3468 & 6.8326 & TST & \\
\hline CHEMBL3931663 & 1640919 & 7.0605 & 7.9863 & TST & \\
\hline CHEMBL3920682 & 1640919 & 7.9586 & 7.9925 & TRN & \\
\hline CHEMBL3969240 & 1640919 & 7.0362 & 6.5275 & TRN & \\
\hline CHEMBL3979133 & 1640919 & 8.4559 & 8.535 & TRN & \\
\hline CHEMBL3965796 & 1640919 & 6.8297 & 6.7602 & TRN & \\
\hline CHEMBL3966653 & 1640919 & 6.82100 & 000000000 & 7.0058 & TRN \\
\hline CHEMBL3936901 & 1640919 & 6.8013 & 6.5298 & TRN & \\
\hline CHEMBL3955765 & 1640919 & 8.2218 & 6.7333 & TST & \\
\hline CHEMBL3977558 & 1640919 & 6.6716 & 6.632999 & 7999999999 & TRN \\
\hline CHEMBL3942526 & 1640919 & 5.449 & 7.4818 & TST & \\
\hline CHEMBL3933938 & 1640919 & 5.5077 & 5.9471 & TRN & \\
\hline CHEMBL3940459 & 1640919 & 6.5017 & 6.5919 & TRN & \\
\hline CHEMBL3941743 & 1640919 & 6.9914 & 7.041 & TRN & \\
\hline CHEMBL3915006 & 1640919 & 7.8861 & 7.7951 & TRN & \\
\hline CHEMBL3956514 & 1640919 & 7.3372 & 7.4304 & TRN & \\
\hline CHEMBL3928516 & 1640919 & 7.5686 & 8.3215 & TST & \\
\hline CHEMBL 3948405 & 1640919 & 8.1192 & 7.5324 & TST & \\
\hline CHEMBL3949075 & 1640919 & 6.8477 & 7.2358 & TST & \\
\hline
\end{tabular}


Supplemental Table S2.txt

\begin{tabular}{|c|c|c|c|c|}
\hline CHEMBL3969242 & 1640919 & 7.0458 & 7.1246 & TRN \\
\hline CHEMBL 3938000 & 1640919 & 6.4342 & 5.2555 & TRN \\
\hline CHEMBL3922502 & 1640919 & 6.8297 & 6.9212 & TRN \\
\hline CHEMBL3976599 & 1640919 & 7.7447 & 8.0891 & TRN \\
\hline CHEMBL 3921273 & 1640919 & 7.0915 & 7.5469 & TST \\
\hline CHEMBL 3960144 & 1640919 & 7.2007 & 7.3239 & TRN \\
\hline CHEMBL3914784 & 1640919 & 7.0362 & 7.2058 & TRN \\
\hline CHEMBL3920207 & 1640919 & 7.2924 & 7.3063 & TRN \\
\hline CHEMBL3930688 & 1640919 & 7.8861 & 7.9153 & TRN \\
\hline CHEMBL 3898046 & 1640919 & 6.7122 & 6.5655 & TRN \\
\hline CHEMBL 3927509 & 1640919 & 7.2924 & 7.2914 & TRN \\
\hline CHEMBL 3947376 & 1640919 & 8.1487 & 8.1904 & TRN \\
\hline CHEMBL 3892964 & 1640919 & 9.7447 & 9.6173 & TRN \\
\hline CHEMBL3961347 & 1640919 & 6.3054 & 6.3696 & TRN \\
\hline CHEMBL 3976592 & 1640919 & 9.2757 & 9.073 & TRN \\
\hline CHEMBL3945596 & 1640919 & 7.1938 & 7.2467 & TRN \\
\hline CHEMBL3967470 & 1640919 & 7.5528 & 7.6581 & TRN \\
\hline CHEMBL 3913232 & 1640919 & 9.3768 & 9.4474 & TRN \\
\hline CHEMBL3979346 & 1640919 & 7.2076 & 7.2549 & TRN \\
\hline CHEMBL 3948839 & 1640919 & 8.301 & 8.2224 & TRN \\
\hline CHEMBL3924095 & 1640919 & 7.2366 & 7.3098 & TRN \\
\hline CHEMBL3950227 & 1640919 & 7.5528 & 7.7042 & TRN \\
\hline CHEMBL 3974291 & 1640919 & 8.2518 & 8.2034 & TRN \\
\hline CHEMBL3935777 & 1640919 & 7.5086 & 7.7098 & TST \\
\hline CHEMBL 3927524 & 1640919 & 6.9586 & 7.9168 & TST \\
\hline CHEMBL3928141 & 1640919 & 7.8239 & 7.8644 & TRN \\
\hline CHEMBL 3941274 & 1640919 & 7.5229 & 7.534 & TST \\
\hline CHEMBL3977179 & 1640919 & 7.2147 & 7.2623 & TRN \\
\hline CHEMBL3915187 & 1640919 & 7.3768 & 7.39 & TRN \\
\hline CHEMBL 3900509 & 1640919 & 8.3665 & 8.237 & TRN \\
\hline CHEMBL3968092 & 1640919 & 8.3565 & 8.4756 & TST \\
\hline CHEMBL 3985701 & 1640919 & 7.3872 & 7.8155 & TST \\
\hline CHEMBL3937483 & 1640919 & 7.4202 & 8.2312 & TST \\
\hline CHEMBL3919257 & 1640919 & 8.6021 & 8.2876 & TRN \\
\hline CHEMBL3958168 & 1640919 & 7.3098 & 7.5804 & TRN \\
\hline CHEMBL3926033 & 1640919 & 5.1216 & 7.199 & TST \\
\hline CHEMBL3921535 & 1640919 & 7.4949 & 7.1991 & TST \\
\hline CHEMBL3923399 & 1640919 & 8.4559 & 8.3152 & TST \\
\hline CHEMBL3975984 & 1640919 & 7.7696 & 7.8074 & TRN \\
\hline CHEMBL 3950748 & 1640919 & 9.0862 & 9.4354 & TRN \\
\hline CHEMBL3981688 & 1640919 & 4.0 & 4.167 & TRN \\
\hline CHEMBL3982390 & 1640919 & 7.6778 & 7.6039 & TRN \\
\hline CHEMBL3956479 & 1640919 & 7.8861 & 7.7992 & TRN \\
\hline CHEMBL3968808 & 1640919 & 7.4949 & 7.57799 & 9999999999 \\
\hline CHEMBL3975155 & 1640919 & 7.0044 & 7.1111 & TRN \\
\hline CHEMBL3974405 & 1640919 & 7.6021 & 7.78 & TRN \\
\hline CHEMBL 3937705 & 1640919 & 7.1135 & 7.2376 & TRN \\
\hline \multirow[t]{2}{*}{ CHEMBL3907474 } & 1640919 & 7.7212 & 7.54299 & 9999999999 \\
\hline & & \multicolumn{3}{|c|}{ Page 5819} \\
\hline
\end{tabular}


Supplemental Table S2.txt

\begin{tabular}{|c|c|c|c|c|c|}
\hline CHEMBL3940365 & 1640919 & 7.2676 & 8.2123 & TST & \\
\hline CHEMBL 3925898 & 1640919 & 6.9788 & 6.7048 & TRN & \\
\hline CHEMBL3957044 & 1640919 & 8.4437 & 8.5115 & TST & \\
\hline CHEMBL3909072 & 1640919 & 7.699 & 7.8212 & TRN & \\
\hline CHEMBL 3943737 & 1640919 & 7.1308 & 8.7777 & TST & \\
\hline CHEMBL3963999 & 1640919 & 6.9626 & 6.4121 & TRN & \\
\hline CHEMBL 3936418 & 1640919 & 6.82100 & 00000000 & & 7.2612 \\
\hline CHEMBL3960506 & 1640919 & 7.7696 & 7.6627 & TRN & \\
\hline CHEMBL3889684 & 1640919 & 4.0 & 4.7065 & TRN & \\
\hline CHEMBL 3931684 & 1640919 & 7.2366 & 7.3324 & TRN & \\
\hline CHEMBL 3944971 & 1640919 & 7.7212 & 7.8906 & TRN & \\
\hline CHEMBL 3955324 & 1640919 & 6.0241 & 6.5473 & TRN & \\
\hline CHEMBL3919272 & 1640919 & 7.4089 & 7.3185 & TRN & \\
\hline CHEMBL 3932761 & 1640919 & 6.7167 & 7.0635 & TRN & \\
\hline CHEMBL 3900137 & 1640919 & 7.3372 & 7.414 & TRN & \\
\hline CHEMBL 3956216 & 1640919 & 7.5086 & 7.8554 & TRN & \\
\hline CHEMBL 3924453 & 1640919 & 7.585 & 7.1607 & TST & \\
\hline CHEMBL3971628 & 1640919 & 7.2676 & 7.666 & TRN & \\
\hline CHEMBL3968597 & 1640919 & 6.4815 & 8.1412 & TST & \\
\hline CHEMBL 3899827 & 1640919 & 8.1871 & 8.1428 & TRN & \\
\hline CHEMBL 3942178 & 1640919 & 8.3098 & 8.0056 & TRN & \\
\hline CHEMBL 3959848 & 1640919 & 7.8239 & 6.9964 & TST & \\
\hline CHEMBL 3945393 & 1640919 & 7.7212 & 7.665 & TRN & \\
\hline CHEMBL3928642 & 1640919 & 7.3768 & 7.4997 & TRN & \\
\hline CHEMBL 3974277 & 1640919 & 7.7447 & 7.7619 & TRN & \\
\hline CHEMBL 3958924 & 1640919 & 7.1871 & 7.311 & TRN & \\
\hline CHEMBL 3892653 & 1640919 & 7.3098 & 7.1013 & TRN & \\
\hline CHEMBL3948369 & 1640919 & 8.2924 & 7.7579 & TST & \\
\hline CHEMBL 3900492 & 1640919 & 7.6383 & 7.607 & TRN & \\
\hline CHEMBL 3912466 & 1640919 & 6.7352 & 7.4162 & TST & \\
\hline CHEMBL 3942119 & 1640919 & 8.1871 & 8.1842 & TRN & \\
\hline CHEMBL 3927902 & 1640919 & 7.699 & 8.0904 & TRN & \\
\hline CHEMBL3958129 & 1640919 & 8.6383 & 8.6278 & TRN & \\
\hline CHEMBL 3937853 & 1640919 & 7.8861 & 7.9214 & TRN & \\
\hline CHEMBL 3950237 & 1640919 & 7.0223 & 7.0789 & TRN & \\
\hline CHEMBL3907941 & 1640919 & 8.0132 & 7.7521 & TRN & \\
\hline CHEMBL 3899450 & 1640919 & 8.5376 & 8.0421 & TRN & \\
\hline CHEMBL 3898914 & 1640919 & 8.1805 & 7.5387 & TRN & \\
\hline CHEMBL 3982449 & 1640919 & 6.6234 & 7.3169 & TST & \\
\hline CHEMBL 3948004 & 1640919 & 6.556 & 7.6696 & TST & \\
\hline CHEMBL 3957155 & 1640919 & 7.4437 & 7.3065 & TRN & \\
\hline CHEMBL 3956213 & 1640919 & 7.1739 & 7.0418 & TRN & \\
\hline CHEMBL 3913977 & 1640919 & 8.0269 & 8.0445 & TRN & \\
\hline CHEMBL3934912 & 1640919 & 5.4984 & 7.1974 & TST & \\
\hline CHEMBL 3896763 & 1640919 & 7.5086 & 7.5498 & TST & \\
\hline CHEMBL 3930383 & 1640919 & 8.1079 & 7.721 & TST & \\
\hline CHEMBL 3926961 & 1640919 & 6.6904 & 6.7924 & TRN & \\
\hline CHEMBL 3952957 & 1640919 & 6.7747 & 6.6892 & TRN & \\
\hline
\end{tabular}




\begin{tabular}{|c|c|c|c|c|}
\hline \multicolumn{5}{|c|}{ Supplemental Table } \\
\hline CHEMBL1719276 & 736850 & 4.1397 & 3.6415 & TRN \\
\hline CHEMBL1569076 & 736850 & 4.9031 & 5.3393 & TRN \\
\hline CHEMBL1717981 & 736850 & 3.0 & 3.015 & TRN \\
\hline CHEMBL1713941 & 736850 & 3.0 & 3.8424 & TRN \\
\hline CHEMBL1672291 & 736850 & 6.0146 & 5.6332 & TRN \\
\hline CHEMBL1708418 & 736850 & 3.0 & 3.3288 & TRN \\
\hline CHEMBL1407368 & 736850 & 5.6198 & 5.8099 & TRN \\
\hline CHEMBL1526088 & 736850 & 5.4413 & 5.6952 & TRN \\
\hline CHEMBL1714877 & 736850 & 3.0 & 4.0059 & TRN \\
\hline CHEMBL1460470 & 736850 & 6.9172 & 5.0325 & TRN \\
\hline CHEMBL1736022 & 736850 & 3.0 & 3.6811 & TRN \\
\hline CHEMBL1304974 & 736850 & 5.7144 & 5.3238 & TRN \\
\hline CHEMBL1708834 & 736850 & 3.0 & 3.8646 & TRN \\
\hline CHEMBL1385949 & 736850 & 5.8996 & 6.0898 & TRN \\
\hline CHEMBL3193786 & 736850 & 5.5031 & 5.3489 & TRN \\
\hline CHEMBL1727475 & 736850 & 4.3979 & 4.484 & TRN \\
\hline CHEMBL1719568 & 736850 & 3.0 & 3.4301 & TRN \\
\hline CHEMBL1407203 & 736850 & 6.1385 & 4.2281 & TRN \\
\hline CHEMBL1732186 & 736850 & 3.0 & 3.175 & TRN \\
\hline CHEMBL1703811 & 736850 & 3.0 & 2.7173 & TRN \\
\hline CHEMBL1725341 & 736850 & 3.0 & 3.1892 & TRN \\
\hline CHEMBL1441524 & 736850 & 3.0 & 4.1156 & TRN \\
\hline CHEMBL1322542 & 736850 & 6.1524 & 5.6877 & TRN \\
\hline CHEMBL1698303 & 736850 & 3.0 & 2.7127 & TRN \\
\hline CHEMBL1721385 & 736850 & 3.0 & 4.0841 & TST \\
\hline CHEMBL1727280 & 736850 & 3.0 & 2.9717 & TRN \\
\hline CHEMBL1605172 & 736850 & 6.6021 & 5.483 & TST \\
\hline CHEMBL1505246 & 736850 & 5.4789 & 5.1559 & TST \\
\hline CHEMBL1393151 & 736850 & 5.475 & 5.5275 & TST \\
\hline CHEMBL1734920 & 736850 & 3.0 & 2.7 & TRN \\
\hline CHEMBL1708751 & 736850 & 3.0 & 2.8473 & TST \\
\hline CHEMBL1484942 & 736850 & 3.0 & 4.3171 & TRN \\
\hline CHEMBL1735040 & 736850 & 3.0 & 3.576 & TRN \\
\hline CHEMBL1445488 & 736850 & 5.9066 & 5.6631 & TST \\
\hline CHEMBL1672292 & 736850 & 5.3737 & 5.5499 & TST \\
\hline CHEMBL1536551 & 736850 & 3.0 & 3.7348 & TST \\
\hline CHEMBL1372387 & 736850 & 5.5817 & 5.2714 & TST \\
\hline CHEMBL1608642 & 736850 & 6.0186 & 3.2981 & TRN \\
\hline CHEMBL1408579 & 736850 & 6.466 & 5.1218 & TST \\
\hline CHEMBL1735408 & 736850 & 3.0 & 3.7075 & TRN \\
\hline CHEMBL1702303 & 736850 & 4.475 & 4.4844 & TRN \\
\hline CHEMBL1578067 & 736850 & 3.0 & 3.2027 & TRN \\
\hline CHEMBL1715328 & 736850 & 4.4306 & 3.4878 & TST \\
\hline CHEMBL1722185 & 736850 & 4.6038 & 4.2522 & TRN \\
\hline CHEMBL1715760 & 736850 & 3.0 & 2.6983 & TRN \\
\hline CHEMBL1536896 & 736850 & 5.8894 & 5.61 & TST \\
\hline CHEMBL1489619 & 736850 & 3.0 & 3.2278 & TRN \\
\hline CHEMBL1702283 & 736850 & 3.0 & 3.0134 & TRN \\
\hline
\end{tabular}




\begin{tabular}{|c|c|c|c|c|c|c|}
\hline \multicolumn{6}{|c|}{ Supplemental Table s2.txt } & \\
\hline CHEMBL1447397 & 736850 & 5.2668 & 5.5514 & TRN & & \\
\hline CHEMBL1717901 & 736850 & 3.0 & 2.8136 & TRN & & \\
\hline CHEMBL1304193 & 736850 & 6.2757 & 5.183 & TST & & \\
\hline CHEMBL 2005886 & 954915 & 5.739 & 5.6887 & TRN & & \\
\hline CHEMBL1788116 & 954915 & 4.9171 & 4.5676 & TRN & & \\
\hline CHEMBL515416 & 954915 & 5.4844 & 5.2247 & TRN & & \\
\hline CHEMBL189584 & 954915 & 4.1422 & 4.5354 & TRN & & \\
\hline CHEMBL1190711 & 954915 & 5.4298 & 5.5127 & TRN & & \\
\hline CHEMBL577784 & 954915 & 5.0247 & 4.9476 & TRN & & \\
\hline CHEMBL412142 & 954915 & 4.4173 & 4.3419 & TRN & & \\
\hline CHEMBL221137 & 954915 & 5.0584 & 5.2808 & TST & & \\
\hline CHEMBL509032 & 954915 & 5.7873 & 5.2945 & TRN & & \\
\hline CHEMBL3199475 & 954915 & 5.6018 & 5.3645 & TRN & & \\
\hline CHEMBL373751 & 954915 & $3.2460 e$ & 00000000 & 204 & 3.6727 TRN & \\
\hline CHEMBL 2137530 & 954915 & 4.7846 & 4.8965 & TRN & & \\
\hline CHEMBL1516890 & 954915 & 3.9842 & 4.1338 & TRN & & \\
\hline CHEMBL483847 & 954915 & 4.6735 & 4.4066 & TRN & & \\
\hline CHEMBL92309 & 954915 & 3.7526 & 3.0663 & TST & & \\
\hline CHEMBL202721 & 954915 & 4.6718 & 5.018 & TRN & & \\
\hline CHEMBL379975 & 954915 & 4.7346 & 5.0651 & TRN & & \\
\hline CHEMBL558642 & 954915 & 4.1683 & 4.2337 & TRN & & \\
\hline CHEMBL 217354 & 954915 & 6.8181 & 6.6129 & TRN & & \\
\hline CHEMBL192566 & 954915 & 9.2854 & 9.3623 & TST & & \\
\hline CHEMBL585951 & 954915 & 6.8339 & 6.8231 & TRN & & \\
\hline CHEMBL472940 & 954915 & 3.8987 & 3.8595 & TRN & & \\
\hline CHEMBL210618 & 954915 & 3.4801 & 3.2738 & TRN & & \\
\hline CHEMBL 259181 & 954915 & 5.0687 & 5.3994 & TRN & & \\
\hline CHEMBL135561 & 954915 & 5.3401 & 5.0102 & TRN & & \\
\hline CHEMBL191334 & 954915 & 5.5774 & 5.4013 & TRN & & \\
\hline CHEMBL449158 & 954915 & 6.5227 & 7.874 & TST & & \\
\hline CHEMBL379300 & 954915 & 6.8165 & 6.8149 & TRN & & \\
\hline CHEMBL 2363137 & 954915 & 5.5318 & 5.6202 & TRN & & \\
\hline CHEMBL1673039 & 954915 & 4.328 & 4.8092 & TRN & & \\
\hline CHEMBL399530 & 954915 & 4.4491 & 4.8397 & TRN & & \\
\hline CHEMBL1404918 & 954915 & $2.7260 e$ & 30000000 & 204 & 3.0589999999999997 & TRN \\
\hline CHEMBL240954 & 954915 & 3.2865 & 3.7767 & TST & & \\
\hline CHEMBL393929 & 954915 & 3.6793 & 3.5293 & TRN & & \\
\hline CHEMBL255342 & 954915 & 3.5985 & 3.6744 & TRN & & \\
\hline CHEMBL 222102 & 954915 & 3.6821 & 3.7053 & TRN & & \\
\hline CHEMBL3392440 & 954915 & 4.8472 & 4.2899 & TRN & & \\
\hline CHEMBL258844 & 954915 & 4.3164 & 4.5604 & TRN & & \\
\hline CHEMBL188678 & 954915 & 4.7272 & 4.52 & TRN & & \\
\hline CHEMBL1186585 & 954915 & 4.1888 & 4.498 & TRN & & \\
\hline CHEMBL 220241 & 954915 & 5.3092 & 4.9405 & TRN & & \\
\hline CHEMBL483849 & 954915 & 2.353 & 2.2146 & TST & & \\
\hline CHEMBL 2144069 & 954915 & 8.1801 & 8.5166 & TRN & & \\
\hline CHEMBL1909414 & 954915 & 6.3618 & 6.0362 & TRN & & \\
\hline CHEMBL180127 & 954915 & 4.5189 & 4.3752 & TRN & & \\
\hline
\end{tabular}




\begin{tabular}{|c|c|c|c|c|c|c|}
\hline \multicolumn{7}{|c|}{ Supplemental Ta } \\
\hline CHEMBL512504 & 954915 & 4.4854 & 4.7391 & TRN & & \\
\hline CHEMBL392695 & 954915 & 6.5091 & 5.9059 & TRN & & \\
\hline CHEMBL514499 & 954915 & 7.7865 & 7.8991 & TRN & & \\
\hline CHEMBL1256459 & 954915 & 7.8383 & 8.1744 & TRN & & \\
\hline CHEMBL573107 & 954915 & 5.2315 & 5.3313 & TRN & & \\
\hline CHEMBL1230020 & 954915 & 6.4397 & 6.3865 & TRN & & \\
\hline CHEMBL 209148 & 954915 & 5.476 & 5.0505 & TRN & & \\
\hline CHEMBL1970879 & 954915 & 4.7879 & 4.6427 & TRN & & \\
\hline CHEMBL102714 & 954915 & 3.2381 & 3.6747 & TRN & & \\
\hline CHEMBL65 & 954915 & 7.7481 & 8.801 & TST & & \\
\hline CHEMBL 2134202 & 954915 & 4.0477 & 4.6092 & TST & & \\
\hline CHEMBL1242367 & 954915 & 5.2826 & 4.4209 & TST & & \\
\hline CHEMBL3186408 & 954915 & 3.4348 & 4.1417 & TST & & \\
\hline CHEMBL300389 & 954915 & 7.6863 & 7.3032 & TST & & \\
\hline CHEMBL1643959 & 954915 & 3.0175 & 3.4647 & TST & & \\
\hline CHEMBL1590308 & 954915 & 3.8756 & 3.1366 & TST & & \\
\hline CHEMBL3349342 & 954915 & 7.3101 & 7.4468 & TST & & \\
\hline CHEMBL9470 & 954915 & 6.2509 & 6.4266 & TST & & \\
\hline CHEMBL 213100 & 954915 & 5.8401 & 5.0212 & TST & & \\
\hline CHEMBL1357247 & 954915 & 3.15 & 3.2015 & TST & & \\
\hline CHEMBL483849 & 954603 & 1.7875 & 2.4784 & TST & & \\
\hline CHEMBL135561 & 954603 & 4.8746 & 4.8746 & TRN & & \\
\hline CHEMBL399530 & 954603 & 4.9671 & 4.9671 & TRN & & \\
\hline CHEMBL1909414 & 954603 & 3.2367 & 3.2367 & TRN & & \\
\hline CHEMBL392695 & 954603 & 5.9438 & 5.9438 & TRN & & \\
\hline CHEMBL573107 & 954603 & 4.89199 & 999999999 & 995 & 4.8919999999999995 & TRN \\
\hline CHEMBL577784 & 954603 & 5.6312 & 5.6312 & TRN & & \\
\hline CHEMBL 2137530 & 954603 & 4.2545 & 4.2545 & TRN & & \\
\hline CHEMBL1357247 & 954603 & 3.4948 & 3.4948 & TRN & & \\
\hline CHEMBL 2134202 & 954603 & 3.4624 & 3.4624 & TRN & & \\
\hline CHEMBL192566 & 954603 & 8.1644 & 9.0065 & TST & & \\
\hline CHEMBL1788116 & 954603 & 4.1448 & 4.1448 & TRN & & \\
\hline CHEMBL1590308 & 954603 & 3.0373 & 3.6386 & TST & & \\
\hline CHEMBL1673039 & 954603 & 4.4279 & 4.4279 & TRN & & \\
\hline CHEMBL65 & 954603 & 7.688 & 7.688 & TRN & & \\
\hline CHEMBL558642 & 954603 & 4.0233 & 4.0233 & TRN & & \\
\hline CHEMBL3349342 & 954603 & 5.8241 & 5.8241 & TRN & & \\
\hline CHEMBL472940 & 954603 & 3.2066 & 3.2066 & TRN & & \\
\hline CHEMBL 300389 & 954603 & 7.3458 & 7.3458 & TRN & & \\
\hline CHEMBL373751 & 954603 & 3.7664 & 3.7664 & TRN & & \\
\hline CHEMBL191334 & 954603 & 3.5157 & 3.5157 & TRN & & \\
\hline CHEMBL202721 & 954603 & 4.8506 & 4.8505 & TRN & & \\
\hline CHEMBL 2144069 & 954603 & 4.0954 & 4.0954 & TRN & & \\
\hline CHEMBL393929 & 954603 & 3.8192 & 3.8192 & TRN & & \\
\hline CHEMBL213100 & 954603 & 5.8737 & 5.8737 & TRN & & \\
\hline CHEMBL 379300 & 954603 & 6.59399 & 999999999 & 99 & 6.593999999999999 & TRN \\
\hline CHEMBL 1230020 & 954603 & 3.1793 & 3.1793 & TRN & & \\
\hline CHEMBL1404918 & 954603 & 3.6412 & 3.6412 & TRN & & \\
\hline
\end{tabular}




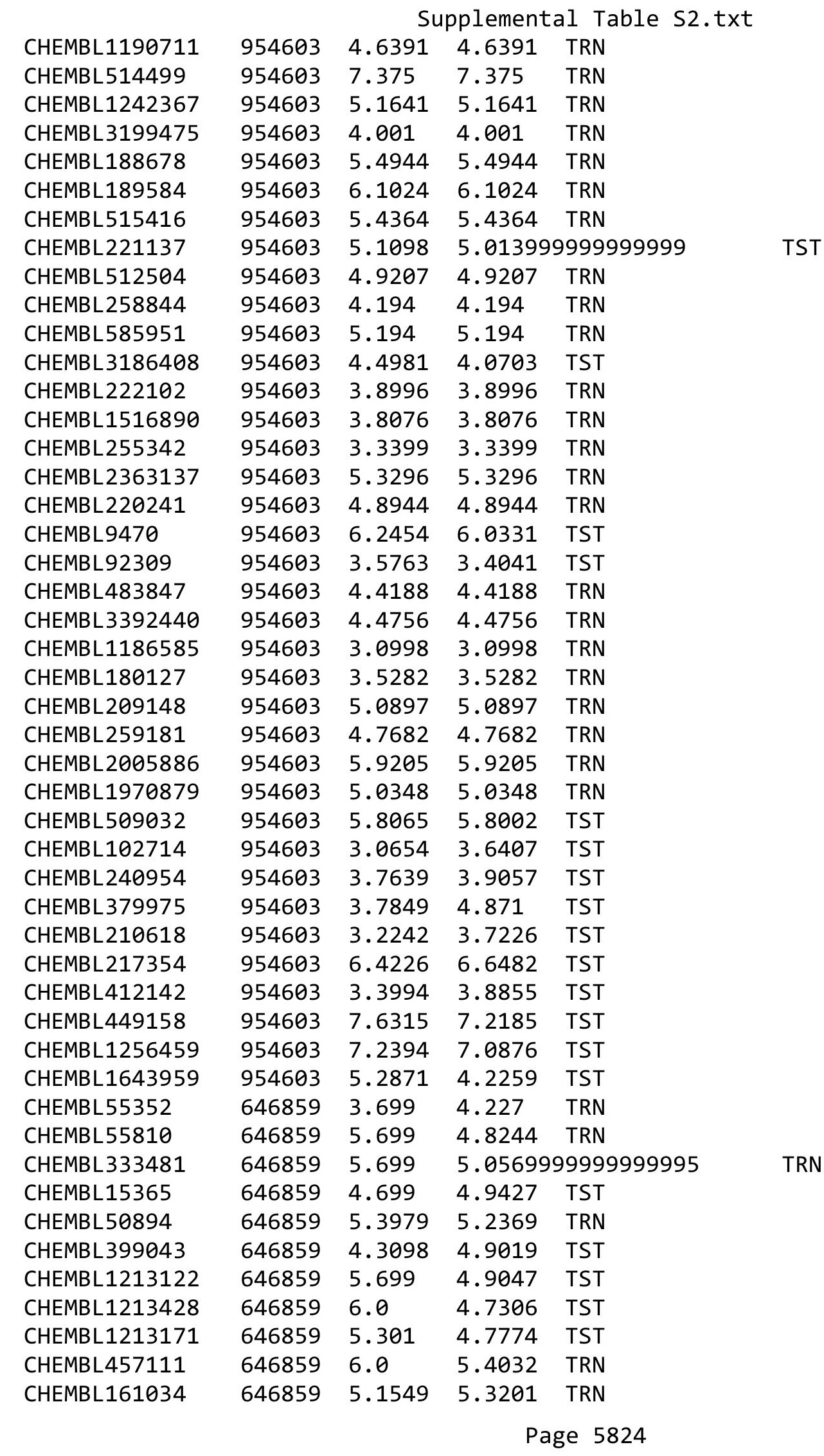




\begin{tabular}{|c|c|c|c|c|}
\hline & & & oplement & al Ta \\
\hline CHEMBL119649 & 646859 & 5.301 & 5.1915 & TRN \\
\hline CHEMBL90753 & 646859 & 6.0 & 4.8095 & TST \\
\hline CHEMBL15688 & 646859 & 5.699 & 5.0918 & TST \\
\hline CHEMBL15321 & 646859 & 4.699 & 5.0931 & TST \\
\hline CHEMBL512200 & 646859 & 6.0 & 5.3719 & TRN \\
\hline CHEMBL325533 & 646859 & 4.6383 & 4.9161 & TRN \\
\hline CHEMBL53982 & 646859 & 4.5086 & 4.4302 & TRN \\
\hline CHEMBL1194310 & 646859 & 4.7959 & 4.8783 & TST \\
\hline CHEMBL1213866 & 646859 & 5.0969 & 4.8567 & TST \\
\hline CHEMBL55959 & 646859 & 3.699 & 3.7214 & TRN \\
\hline CHEMBL55856 & 646859 & 3.699 & 3.8781 & TRN \\
\hline CHEMBL444605 & 646859 & 5.699 & 5.2754 & TRN \\
\hline CHEMBL294191 & 646859 & 3.699 & 3.747 & TRN \\
\hline CHEMBL1213383 & 646859 & 4.3979 & 4.7358 & TRN \\
\hline CHEMBL1213805 & 646859 & 6.0 & 4.8879 & TRN \\
\hline CHEMBL291736 & 646859 & 3.699 & 3.4521 & TRN \\
\hline CHEMBL1213809 & 646859 & 4.3372 & 4.8403 & TST \\
\hline CHEMBL346982 & 646859 & 5.5229 & 5.295 & TRN \\
\hline CHEMBL 278847 & 646859 & 5.0458 & 5.4781 & TRN \\
\hline CHEMBL115585 & 646859 & 4.8539 & 4.9893 & TRN \\
\hline CHEMBL1213047 & 646859 & 4.6198 & 4.6281 & TRN \\
\hline CHEMBL1213871 & 646859 & 5.5229 & 4.9964 & TRN \\
\hline CHEMBL37647 & 646859 & 6.0 & 5.1937 & TRN \\
\hline CHEMBL55886 & 646859 & 3.699 & 4.0056 & TRN \\
\hline CHEMBL298771 & 646859 & 3.699 & 4.5825 & TRN \\
\hline CHEMBL118343 & 646859 & 4.4949 & 5.0834 & TRN \\
\hline CHEMBL 274031 & 646859 & 5.5229 & 5.215 & TRN \\
\hline CHEMBL321034 & 646859 & 5.0 & 4.7952 & TRN \\
\hline CHEMBL1213748 & 646859 & 5.5229 & 5.0748 & TRN \\
\hline CHEMBL 296586 & 646859 & 5.3979 & 5.0971 & TRN \\
\hline CHEMBL117064 & 646859 & 4.7447 & 5.0301 & TRN \\
\hline CHEMBL158570 & 646859 & 5.3979 & 5.4189 & TRN \\
\hline CHEMBL110097 & 646859 & 6.0 & 4.5171 & TRN \\
\hline CHEMBL1213872 & 646859 & 4.6576 & 4.8799 & TRN \\
\hline CHEMBL56704 & 646859 & 3.699 & 3.9707 & TRN \\
\hline CHEMBL54004 & 646859 & 6.0 & 4.8244 & TRN \\
\hline CHEMBL1213868 & 646859 & 4.1487 & 4.8322 & TST \\
\hline CHEMBL 217786 & 646859 & 4.0362 & 4.2587 & TST \\
\hline CHEMBL1213046 & 646859 & 4.3565 & 4.8188 & TRN \\
\hline CHEMBL220698 & 646859 & 3.699 & 3.6729 & TRN \\
\hline CHEMBL417932 & 646859 & 3.699 & 4.4139 & TRN \\
\hline CHEMBL 35439 & 646859 & 6.0 & 5.301 & TRN \\
\hline CHEMBL118916 & 646859 & 4.6778 & 5.1706 & TRN \\
\hline CHEMBL119224 & 646859 & 4.5229 & 5.0358 & TRN \\
\hline CHEMBL417549 & 646859 & 3.9508 & 4.4088 & TRN \\
\hline CHEMBL 300755 & 646859 & 3.699 & 3.8377 & TRN \\
\hline CHEMBL 245179 & 646859 & 5.2218 & 4.1253 & TST \\
\hline CHEMBL117831 & 646859 & 4.8539 & 4.8648 & TRN \\
\hline
\end{tabular}




\begin{tabular}{|c|c|c|c|c|}
\hline & & & oplement & al Ta \\
\hline CHEMBL56011 & 646859 & 3.699 & 3.7465 & TRN \\
\hline CHEMBL 300361 & 646859 & 3.699 & 4.2532 & TST \\
\hline CHEMBL324178 & 646859 & 5.0969 & 4.9024 & TRN \\
\hline CHEMBL1213315 & 646859 & 6.0 & 4.7766 & TST \\
\hline CHEMBL301065 & 646859 & 3.699 & 3.4536 & TRN \\
\hline CHEMBL 301471 & 646859 & 3.699 & 3.6854 & TRN \\
\hline CHEMBL501933 & 646859 & 5.699 & 4.9069 & TST \\
\hline CHEMBL301954 & 646859 & 3.699 & 4.0162 & TRN \\
\hline CHEMBL1213552 & 646859 & 3.699 & 4.5033 & TRN \\
\hline CHEMBL1213749 & 646859 & 5.699 & 5.0824 & TRN \\
\hline CHEMBL337993 & 646859 & 5.3979 & 5.2249 & TRN \\
\hline CHEMBL293116 & 646859 & 5.301 & 3.8865 & TRN \\
\hline CHEMBL1213811 & 646859 & 4.0 & 4.8058 & TST \\
\hline CHEMBL1213316 & 646859 & 4.4815 & 4.6831 & TRN \\
\hline CHEMBL54888 & 646859 & 3.9872 & 4.2222 & TRN \\
\hline CHEMBL346932 & 646859 & 5.0969 & 5.3632 & TRN \\
\hline CHEMBL 324010 & 646859 & 6.0 & 4.675 & TRN \\
\hline CHEMBL119096 & 646859 & 5.699 & 5.0 & TST \\
\hline CHEMBL1213309 & 646859 & 4.5229 & 4.9292 & TRN \\
\hline CHEMBL1235 & 646859 & 4.1367 & 4.6038 & TRN \\
\hline CHEMBL118602 & 646859 & 5.301 & 5.4463 & TRN \\
\hline CHEMBL1214313 & 646859 & 5.5229 & 4.6904 & TST \\
\hline CHEMBL127819 & 646859 & 4.2441 & 4.8294 & TST \\
\hline CHEMBL54056 & 646859 & 3.699 & 3.8529 & TRN \\
\hline CHEMBL1213393 & 646859 & 4.5376 & 4.4728 & TRN \\
\hline CHEMBL1213815 & 646859 & 4.4202 & 5.0939 & TRN \\
\hline CHEMBL485019 & 646859 & 5.301 & 5.1805 & TRN \\
\hline CHEMBL55140 & 646859 & 3.699 & 3.3779 & TRN \\
\hline CHEMBL417419 & 646859 & 3.699 & 3.7838 & TRN \\
\hline CHEMBL354011 & 646859 & 5.0969 & 5.4717 & TRN \\
\hline CHEMBL115433 & 646859 & 4.4949 & 5.0056 & TRN \\
\hline CHEMBL510457 & 646859 & 4.2924 & 4.774 & TRN \\
\hline CHEMBL55608 & 646859 & 3.699 & 4.1338 & TRN \\
\hline CHEMBL54472 & 646859 & 3.699 & 3.8872 & TRN \\
\hline CHEMBL107867 & 646859 & 3.6696 & 4.0129 & TRN \\
\hline CHEMBL55557 & 646859 & 3.699 & 3.5422 & TRN \\
\hline CHEMBL55572 & 646859 & 3.699 & 4.8244 & TRN \\
\hline CHEMBL1213812 & 646859 & 3.7595 & 4.9052 & TRN \\
\hline CHEMBL161009 & 646859 & 5.5229 & 5.5311 & TRN \\
\hline CHEMBL1213307 & 646859 & 6.0 & 4.6507 & TST \\
\hline CHEMBL56254 & 646859 & 4.2441 & 4.4088 & TRN \\
\hline CHEMBL 340803 & 646859 & 4.3768 & 4.5701 & TRN \\
\hline CHEMBL3350390 & 646859 & 6.0 & 4.7222 & TST \\
\hline CHEMBL367788 & 646859 & 4.7959 & 4.1731 & TST \\
\hline CHEMBL52761 & 646859 & 3.8861 & 4.4017 & TRN \\
\hline CHEMBL 301857 & 646859 & 3.699 & 3.4245 & TRN \\
\hline CHEMBL 363491 & 646859 & 5.5229 & 5.0353 & TRN \\
\hline CHEMBL313578 & 646859 & 4.3768 & 4.9274 & TRN \\
\hline
\end{tabular}




\begin{tabular}{|c|c|c|c|c|c|}
\hline & & \multicolumn{4}{|c|}{ Supplemental Table S2.txt } \\
\hline CHEMBL1213354 & 646859 & 4.4437 & 4.607 & TRN & \\
\hline CHEMBL1213394 & 646859 & 5.2218 & 4.9616 & TST & \\
\hline CHEMBL1213507 & 646859 & 3.8386 & 5.1719 & TST & \\
\hline CHEMBL 293522 & 646859 & 3.699 & 3.977 & TRN & \\
\hline CHEMBL55518 & 646859 & 3.699 & 4.0434 & TRN & \\
\hline CHEMBL323158 & 646859 & 5.0458 & 4.8354 & TRN & \\
\hline CHEMBL 324180 & 646859 & 4.6778 & 4.8933 & TRN & \\
\hline CHEMBL108087 & 646859 & 4.7696 & 4.86600 & 00000000005 & TRN \\
\hline CHEMBL18679 & 646859 & 5.0969 & 4.9741 & TRN & \\
\hline CHEMBL431139 & 646859 & 3.983 & 3.9395 & TRN & \\
\hline CHEMBL 279948 & 646859 & 5.5229 & 5.2438 & TRN & \\
\hline CHEMBL 280012 & 646859 & 5.0458 & 5.0218 & TST & \\
\hline CHEMBL54925 & 646859 & 3.699 & 3.7304 & TRN & \\
\hline CHEMBL1213555 & 646859 & 3.6326 & 5.1764 & TST & \\
\hline CHEMBL417198 & 646859 & 3.699 & 3.8278 & TRN & \\
\hline CHEMBL1213546 & 646859 & 6.0 & 4.8851 & TST & \\
\hline CHEMBL56255 & 646859 & 5.301 & 4.3382 & TRN & \\
\hline CHEMBL299717 & 646859 & 3.699 & 3.9111 & TRN & \\
\hline CHEMBL291727 & 646859 & 4.301 & 3.6641 & TRN & \\
\hline CHEMBL293479 & 646859 & 4.1135 & 3.9711 & TRN & \\
\hline CHEMBL55889 & 646859 & 3.699 & 3.7313 & TRN & \\
\hline CHEMBL118066 & 646859 & 4.8239 & 4.8045 & TRN & \\
\hline CHEMBL119102 & 646859 & 4.7959 & 4.6325 & TRN & \\
\hline CHEMBL 280074 & 646859 & 5.5229 & 4.6977 & TST & \\
\hline CHEMBL1213814 & 646859 & 5.699 & 5.1089 & TRN & \\
\hline CHEMBL1214556 & 646859 & 2.6968 & 4.5529 & TST & \\
\hline CHEMBL1213384 & 646859 & 4.4685 & 4.5737 & TRN & \\
\hline CHEMBL1213551 & 646859 & 4.6383 & 4.6698 & TRN & \\
\hline CHEMBL55359 & 646859 & 3.8013 & 4.0468 & TRN & \\
\hline CHEMBL421358 & 646859 & 6.0 & 5.0147 & TST & \\
\hline CHEMBL1213463 & 646859 & 4.7959 & 5.1912 & TRN & \\
\hline CHEMBL54714 & 646859 & 4.9586 & 3.8581 & TRN & \\
\hline CHEMBL298852 & 646859 & 3.699 & 4.8244 & TRN & \\
\hline CHEMBL431735 & 646859 & 3.699 & 4.0057 & TRN & \\
\hline CHEMBL 301244 & 646859 & 4.4685 & 4.4809 & TRN & \\
\hline CHEMBL161757 & 646859 & 5.2218 & 5.3566 & TRN & \\
\hline CHEMBL422005 & 646859 & 6.0 & 5.5665 & TRN & \\
\hline CHEMBL108992 & 646859 & 5.0969 & 4.7669 & TRN & \\
\hline CHEMBL 294478 & 646859 & 3.699 & 3.8265 & TRN & \\
\hline CHEMBL118855 & 646859 & 5.301 & 5.0231 & TRN & \\
\hline CHEMBL119475 & 646859 & 4.4949 & 5.2441 & TRN & \\
\hline CHEMBL1213750 & 646859 & 5.301 & 4.9526 & TRN & \\
\hline CHEMBL416301 & 646859 & 6.0 & 4.8244 & TRN & \\
\hline CHEMBL448594 & 646859 & 4.3565 & 4.6176 & TRN & \\
\hline CHEMBL 328338 & 646859 & 6.0 & 4.3477 & TST & \\
\hline CHEMBL357621 & 646859 & 6.0 & 4.9187 & TST & \\
\hline CHEMBL291931 & 646859 & 5.3979 & 5.2318 & TRN & \\
\hline CHEMBL335121 & 646859 & 4.3872 & 4.8169 & TRN & \\
\hline
\end{tabular}




\begin{tabular}{|c|c|c|c|c|c|}
\hline \multirow{3}{*}{$\begin{array}{l}\text { CHEMBL292224 } \\
\text { CHEMBL352441 }\end{array}$} & & \multicolumn{4}{|c|}{ Supplemental Table S2.txt } \\
\hline & 646859 & 3.699 & \multicolumn{2}{|c|}{3.7060000000000004} & TRN \\
\hline & 646859 & 5.699 & 5.4786 & TRN & \\
\hline CHEMBL55779 & 646859 & 3.699 & 4.0176 & TRN & \\
\hline CHEMBL1213867 & 646859 & 4.2441 & 4.8337 & TST & \\
\hline CHEMBL1213306 & 646859 & 6.0 & 4.5317 & TST & \\
\hline CHEMBL58830 & 646859 & 3.699 & 3.5319 & TRN & \\
\hline CHEMBL54124 & 646859 & 3.699 & 3.6239 & TRN & \\
\hline CHEMBL1213310 & 646859 & 4.4815 & 4.6109 & TRN & \\
\hline CHEMBL1213865 & 646859 & 3.5867 & 4.6063 & TST & \\
\hline CHEMBL 278722 & 646859 & 5.2218 & 5.1432 & TST & \\
\hline CHEMBL56253 & 646859 & 3.699 & 3.5146 & TRN & \\
\hline CHEMBL126652 & 646859 & 4.4318 & 5.1173 & TRN & \\
\hline CHEMBL54344 & 646859 & 4.0458 & 4.0557 & TRN & \\
\hline CHEMBL289191 & 646859 & 4.5528 & 4.9945 & TST & \\
\hline CHEMBL1213806 & 646859 & 4.7696 & 4.9417 & TRN & \\
\hline CHEMBL56078 & 646859 & 3.699 & 3.7278 & TRN & \\
\hline CHEMBL111325 & 646859 & 4.3098 & 4.6087 & TRN & \\
\hline CHEMBL1213862 & 646859 & 4.7212 & 4.8444 & TRN & \\
\hline CHEMBL320546 & 646859 & 4.4949 & 4.4258 & TRN & \\
\hline CHEMBL 22137 & 646859 & 5.5229 & 5.4573 & TRN & \\
\hline CHEMBL1213386 & 646859 & 4.4949 & 4.6168 & TRN & \\
\hline CHEMBL161117 & 646859 & 5.3979 & 5.4003 & TRN & \\
\hline CHEMBL1214554 & 646859 & 4.6383 & 4.7558 & TST & \\
\hline CHEMBL56146 & 646859 & 4.6778 & 5.2302 & TRN & \\
\hline CHEMBL52306 & 646859 & 3.699 & 4.1796 & TST & \\
\hline CHEMBL1213094 & 646859 & 4.3372 & 4.1573 & TRN & \\
\hline CHEMBL44144 & 646859 & 6.0 & 4.6176 & TST & \\
\hline CHEMBL159052 & 646859 & 5.0458 & 5.4056 & TRN & \\
\hline CHEMBL419055 & 646859 & 4.301 & 5.1565 & TRN & \\
\hline CHEMBL418821 & 646859 & 4.4318 & 4.4604 & TRN & \\
\hline CHEMBL1213544 & 646859 & 6.0 & 4.8162 & TST & \\
\hline CHEMBL 323909 & 646859 & 4.4949 & 4.6755 & TRN & \\
\hline CHEMBL111076 & 646859 & 5.0969 & 4.7989 & TRN & \\
\hline CHEMBL52251 & 646859 & 4.8861 & 4.4088 & TRN & \\
\hline CHEMBL416376 & 646859 & 4.6778 & 5.06 & TRN & \\
\hline CHEMBL440898 & 646859 & 5.3979 & 5.0595 & TRN & \\
\hline CHEMBL54747 & 646859 & 3.699 & 4.8159 & TRN & \\
\hline CHEMBL108041 & 646859 & 4.284 & 4.3158 & TRN & \\
\hline CHEMBL55353 & 646859 & 3.699 & 4.4075 & TRN & \\
\hline CHEMBL108191 & 646859 & 4.4559 & 4.8366 & TRN & \\
\hline CHEMBL55837 & 646859 & 4.5376 & 4.8244 & TRN & \\
\hline CHEMBL1213804 & 646859 & 5.3979 & 4.8657 & TRN & \\
\hline CHEMBL14910 & 646859 & 4.699 & 4.9419 & TST & \\
\hline CHEMBL118340 & 646859 & 4.7447 & 5.0914 & TRN & \\
\hline CHEMBL375673 & 646859 & 4.7212 & 4.7033 & TRN & \\
\hline CHEMBL16300 & 646859 & 4.7696 & 4.0722 & TST & \\
\hline CHEMBL23327 & 646859 & 5.5229 & 4.77800 & 0000000000 & TST \\
\hline CHEMBL1213461 & 646859 & 4.5229 & 5.0055 & TRN & \\
\hline
\end{tabular}




\begin{tabular}{|c|c|c|c|c|c|}
\hline & & \multicolumn{4}{|c|}{ Supplemental Table S2.txt } \\
\hline CHEMBL468610 & 646859 & 3.8729 & 4.2835 & TST & \\
\hline CHEMBL190880 & 646859 & 5.3979 & 4.817 & TRN & \\
\hline CHEMBL290691 & 646859 & 6.0 & 4.5614 & TST & \\
\hline CHEMBL52620 & 646859 & 3.699 & 3.784 & TRN & \\
\hline CHEMBL1214555 & 646859 & 3.2299 & 4.6447 & TST & \\
\hline CHEMBL1214553 & 646859 & 4.4202 & 4.7885 & TST & \\
\hline CHEMBL340874 & 646859 & 4.7696 & 4.9565 & TRN & \\
\hline CHEMBL1236 & 646859 & 5.5229 & 4.7363 & TRN & \\
\hline CHEMBL55221 & 646859 & 3.699 & 4.1764 & TST & \\
\hline CHEMBL22811 & 646859 & 4.5086 & 5.0092 & TRN & \\
\hline CHEMBL196358 & 646859 & 3.327 & 4.5863 & TST & \\
\hline CHEMBL 35228 & 646859 & 4.1938 & 4.831 & TRN & \\
\hline CHEMBL 2111067 & 646859 & 3.6108 & 4.3816 & TST & \\
\hline CHEMBL443023 & 646859 & 4.5376 & 5.2975 & TRN & \\
\hline CHEMBL1213810 & 646859 & 4.5229 & 4.8138 & TST & \\
\hline CHEMBL22146 & 646859 & 5.301 & 5.2455 & TRN & \\
\hline CHEMBL323489 & 646859 & 4.5229 & 4.6271 & TRN & \\
\hline CHEMBL 334255 & 646859 & 6.0 & 5.0959 & TST & \\
\hline CHEMBL1213506 & 646859 & 4.1675 & 5.0842 & TST & \\
\hline CHEMBL 9395 & 646859 & 6.0 & 5.375 & TRN & \\
\hline CHEMBL 293798 & 646859 & 5.301 & 4.7208 & TRN & \\
\hline CHEMBL1213807 & 646859 & 6.0 & 5.3168 & TST & \\
\hline CHEMBL55264 & 646859 & 5.3979 & 4.8244 & TRN & \\
\hline CHEMBL1213132 & 646859 & 3.699 & 4.1518 & TST & \\
\hline CHEMBL1213385 & 646859 & 4.4559 & 4.7144 & TRN & \\
\hline CHEMBL299563 & 646859 & 3.699 & 4.0848 & TRN & \\
\hline CHEMBL 299988 & 646859 & 5.2218 & 4.758 & TRN & \\
\hline CHEMBL1213509 & 646859 & 4.1871 & 5.3061 & TST & \\
\hline CHEMBL1213045 & 646859 & 4.4318 & 4.6386 & TRN & \\
\hline CHEMBL55222 & 646859 & 3.699 & 4.1457 & TST & \\
\hline CHEMBL 322320 & 646859 & 5.5229 & 4.9854 & TRN & \\
\hline CHEMBL412889 & 646859 & 3.699 & 3.5146 & TRN & \\
\hline CHEMBL329687 & 646859 & 6.0 & 5.3555 & TRN & \\
\hline CHEMBL100483 & 646859 & 3.699 & 3.6118 & TRN & \\
\hline CHEMBL1213086 & 646859 & 6.0 & 4.7919 & TST & \\
\hline CHEMBL432423 & 646859 & 5.3979 & 4.9644 & TRN & \\
\hline CHEMBL348151 & 646859 & 5.5229 & 5.5145 & TRN & \\
\hline CHEMBL52621 & 646859 & 3.699 & 3.6993 & TRN & \\
\hline CHEMBL36532 & 646859 & 5.1549 & 5.3017 & TRN & \\
\hline CHEMBL324905 & 646859 & 4.301 & 4.6148 & TRN & \\
\hline CHEMBL352195 & 646859 & 5.3979 & 5.3003 & TRN & \\
\hline CHEMBL331251 & 646859 & 4.4949 & 5.23 & TRN & \\
\hline CHEMBL301247 & 646859 & 3.699 & 4.0242 & TRN & \\
\hline CHEMBL1213396 & 646859 & 4.5376 & 4.691 & TST & \\
\hline CHEMBL21921 & 646859 & 5.2218 & 5.6372 & TRN & \\
\hline CHEMBL 294192 & 646859 & 4.7696 & 3.71199 & 99999999997 & TRN \\
\hline CHEMBL15160 & 646859 & 5.0458 & 5.0744 & TST & \\
\hline CHEMBL1213813 & 646859 & 5.301 & 5.2727 & TRN & \\
\hline
\end{tabular}




\begin{tabular}{|c|c|c|c|c|}
\hline & & & pplement & al $\mathrm{Tc}$ \\
\hline CHEMBL299491 & 646859 & 4.2441 & 4.6536 & TRN \\
\hline CHEMBL556120 & 646859 & 3.3372 & 5.1719 & TST \\
\hline CHEMBL56028 & 646859 & 4.5086 & 4.026 & TRN \\
\hline CHEMBL1213508 & 646859 & 3.1068 & 5.3061 & TST \\
\hline CHEMBL322258 & 646859 & 4.4949 & 4.6472 & TRN \\
\hline CHEMBL1213499 & 646859 & 6.0 & 4.8441 & TST \\
\hline CHEMBL1656 & 646859 & 3.8729 & 4.7859 & TRN \\
\hline CHEMBL298547 & 646859 & 4.5686 & 4.8244 & TRN \\
\hline CHEMBL1214608 & 646859 & 3.5214 & 4.6061 & TST \\
\hline CHEMBL1213591 & 646859 & 5.5229 & 4.6691 & TRN \\
\hline CHEMBL434978 & 646859 & 3.699 & 4.0556 & TRN \\
\hline CHEMBL365922 & 646859 & 5.5229 & 4.913 & TRN \\
\hline CHEMBL430963 & 646859 & 3.699 & 3.7251 & TRN \\
\hline CHEMBL108596 & 646859 & 3.301 & 4.1098 & TRN \\
\hline CHEMBL1213308 & 646859 & 4.2924 & 4.6459 & TRN \\
\hline CHEMBL434024 & 646859 & 3.699 & 3.9237 & TRN \\
\hline CHEMBL321924 & 646859 & 5.3979 & 5.1119 & TRN \\
\hline CHEMBL52137 & 646859 & 3.699 & 3.8872 & TRN \\
\hline CHEMBL161451 & 646859 & 5.5229 & 5.3556 & TST \\
\hline CHEMBL1213870 & 646859 & 4.7959 & 4.7236 & TST \\
\hline CHEMBL321238 & 646859 & 6.0 & 4.8395 & TRN \\
\hline CHEMBL54926 & 646859 & 3.699 & 3.4815 & TRN \\
\hline CHEMBL 301572 & 646859 & 4.7447 & 4.0258 & TRN \\
\hline CHEMBL120123 & 646859 & 5.5229 & 5.2348 & TRN \\
\hline CHEMBL111746 & 646859 & 4.6778 & 4.6379 & TRN \\
\hline CHEMBL338983 & 646859 & 4.6778 & 4.8971 & TRN \\
\hline CHEMBL490322 & 646859 & 5.699 & 5.0943 & TST \\
\hline CHEMBL34941 & 646859 & 6.0 & 5.0749 & TRN \\
\hline CHEMBL36404 & 646859 & 6.0 & 5.1664 & TRN \\
\hline CHEMBL55371 & 646859 & 3.699 & 4.086 & TRN \\
\hline CHEMBL1213497 & 646859 & 6.0 & 4.7756 & TST \\
\hline CHEMBL1213627 & 646859 & 3.9872 & 4.2148 & TRN \\
\hline CHEMBL56556 & 646859 & 5.0969 & 4.3603 & TRN \\
\hline CHEMBL424619 & 646859 & 4.1024 & 4.0798 & TRN \\
\hline CHEMBL1213042 & 646859 & 3.699 & 3.8973 & TRN \\
\hline CHEMBL1213265 & 646859 & 3.7055 & 3.7126 & TRN \\
\hline CHEMBL 22138 & 646859 & 5.5229 & 5.2553 & TRN \\
\hline CHEMBL1213869 & 646859 & 5.0969 & 4.8531 & TST \\
\hline CHEMBL55358 & 646859 & 3.699 & 4.3477 & TRN \\
\hline CHEMBL1242973 & 646859 & 4.9208 & 4.7246 & TST \\
\hline CHEMBL1213462 & 646859 & 5.699 & 5.1806 & TRN \\
\hline CHEMBL43929 & 2755 & 8.5 & 8.4661 & TRN \\
\hline CHEMBL 289436 & 2755 & 8.5 & 8.3519 & TRN \\
\hline CHEMBL42257 & 2755 & 7.9 & 7.7605 & TRN \\
\hline CHEMBL 296189 & 2755 & 8.2 & 8.3366 & TRN \\
\hline CHEMBL43496 & 2755 & 7.3 & 7.1274 & TRN \\
\hline CHEMBL42327 & 2755 & 5.9 & 5.9057 & TRN \\
\hline CHEMBL295228 & 2755 & 6.5 & 7.277 & TST \\
\hline
\end{tabular}




\begin{tabular}{|c|c|c|c|c|}
\hline \multicolumn{5}{|c|}{ Supplemental Table s2.txt } \\
\hline CHEMBL265991 & 2755 & 8.2 & 8.1703 & TRN \\
\hline CHEMBL297784 & 2755 & 7.9 & 6.9244 & TST \\
\hline CHEMBL296090 & 2755 & 8.5 & 8.481 & TRN \\
\hline CHEMBL43808 & 2755 & 8.3 & 8.2283 & TRN \\
\hline CHEMBL417713 & 2755 & 8.6 & 8.4987 & TST \\
\hline CHEMBL297445 & 2755 & 7.7 & 7.6761 & TRN \\
\hline CHEMBL295020 & 2755 & 7.3 & 7.6843 & TRN \\
\hline CHEMBL296236 & 2755 & 6.9 & 6.9452 & TRN \\
\hline CHEMBL38027 & 2755 & 7.4 & 7.3628 & TRN \\
\hline CHEMBL288108 & 2755 & 7.3 & 7.3793 & TRN \\
\hline CHEMBL289063 & 2755 & 7.6 & 7.575 & TST \\
\hline CHEMBL40579 & 2755 & 6.9 & 6.8953 & TRN \\
\hline CHEMBL 38407 & 2755 & 6.3 & 7.0709 & TST \\
\hline CHEMBL 290666 & 2755 & 7.7 & 7.6546 & TRN \\
\hline CHEMBL297043 & 2755 & 8.1 & 8.1484 & TRN \\
\hline CHEMBL41792 & 2755 & 8.2 & 8.4278 & TRN \\
\hline CHEMBL14352 & 2755 & 8.0 & 7.9829 & TRN \\
\hline CHEMBL41510 & 2755 & 8.2 & 8.0406 & TRN \\
\hline CHEMBL42681 & 2755 & 8.4 & 8.2598 & TST \\
\hline CHEMBL296687 & 2755 & 7.7 & 7.8233 & TRN \\
\hline CHEMBL44206 & 2755 & 7.6 & 7.7889 & TRN \\
\hline CHEMBL41940 & 2755 & 8.7 & 8.334 & TRN \\
\hline CHEMBL416806 & 2755 & 7.9 & 7.9316 & TRN \\
\hline CHEMBL44015 & 2755 & 8.4 & 8.3303 & TRN \\
\hline CHEMBL42806 & 2755 & 7.5 & 7.4168 & TRN \\
\hline CHEMBL41153 & 2755 & 6.8 & 6.7515 & TRN \\
\hline CHEMBL42276 & 2755 & 7.6 & 7.3141 & TST \\
\hline CHEMBL42273 & 2755 & 6.5 & 7.8509 & TST \\
\hline CHEMBL44095 & 2755 & 8.0 & 8.0222 & TRN \\
\hline CHEMBL42024 & 2755 & 8.2 & 8.151 & TRN \\
\hline CHEMBL40698 & 2755 & 7.1 & 7.1681 & TRN \\
\hline CHEMBL 276140 & 2755 & 8.6 & 8.7381 & TRN \\
\hline CHEMBL40946 & 2755 & 6.5 & 6.4762 & TRN \\
\hline CHEMBL443518 & 2755 & 7.6 & 7.79 & TRN \\
\hline CHEMBL42463 & 2755 & 8.1 & 7.6021 & TST \\
\hline CHEMBL44552 & 2755 & 7.4 & 7.2014 & TST \\
\hline CHEMBL431729 & 2755 & 7.2 & 7.4833 & TST \\
\hline CHEMBL43916 & 2755 & 8.4 & 8.4058 & TRN \\
\hline CHEMBL42758 & 2755 & 7.8 & 7.856 & TRN \\
\hline CHEMBL43633 & 2755 & 7.7 & 7.5399 & TRN \\
\hline CHEMBL288129 & 2755 & 8.7 & 8.664 & TRN \\
\hline CHEMBL290395 & 2755 & 7.1 & 7.2358 & TRN \\
\hline CHEMBL38911 & 2755 & 7.3 & 7.2381 & TRN \\
\hline CHEMBL40342 & 2755 & 7.8 & 7.7322 & TRN \\
\hline CHEMBL41347 & 2755 & 6.1 & 6.7653 & TST \\
\hline CHEMBL296791 & 2755 & 7.6 & 7.5565 & TRN \\
\hline CHEMBL40699 & 2755 & 7.5 & 7.5245 & TRN \\
\hline CHEMBL40341 & 2755 & 7.5 & 7.4176 & TST \\
\hline
\end{tabular}




\begin{tabular}{|c|c|c|c|c|c|c|c|}
\hline \multirow[b]{2}{*}{ CHEMBL41389 } & \multicolumn{6}{|c|}{ Supplemental Table S2.txt } & \\
\hline & 2755 & 8.5 & 7.6928 & TST & & & \\
\hline CHEMBL218408 & 425511 & \multicolumn{3}{|c|}{10.300999999999998} & 10.4372 & TRN & \\
\hline CHEMBL374303 & 425511 & \multicolumn{3}{|c|}{10.300999999999998} & 10.6061 & TRN & \\
\hline CHEMBL373712 & 425511 & 8.7447 & 8.7475 & TRN & & & \\
\hline CHEMBL375628 & 425511 & \multicolumn{3}{|c|}{10.300999999999998} & 9.728 & TRN & \\
\hline CHEMBL374214 & 425511 & \multicolumn{3}{|c|}{10.300999999999998} & 10.0192 & TRN & \\
\hline CHEMBL218524 & 425511 & \multicolumn{3}{|c|}{10.300999999999998} & 10.5452 & TRN & \\
\hline CHEMBL385101 & 425511 & \multicolumn{3}{|c|}{10.300999999999998} & 10.3482 & TRN & \\
\hline CHEMBL374271 & 425511 & 9.0969 & 9.2243 & TRN & & & \\
\hline CHEMBL385104 & 425511 & 10.0 & 9.4481 & TRN & & & \\
\hline CHEMBL221295 & 425511 & 9.0458 & 8.5811 & TRN & & & \\
\hline CHEMBL373544 & 425511 & \multicolumn{3}{|c|}{10.300999999999998} & 9.7691 & TST & \\
\hline CHEMBL375770 & 425511 & \multicolumn{3}{|c|}{10.300999999999998} & 9.6915 & TRN & \\
\hline CHEMBL221708 & 425511 & 8.4437 & 9.4572 & TST & & & \\
\hline CHEMBL221750 & 425511 & \multicolumn{3}{|c|}{10.300999999999998} & 10.2185 & TRN & \\
\hline CHEMBL376409 & 425511 & 9.0 & 9.6313 & TRN & & & \\
\hline CHEMBL426535 & 425511 & \multicolumn{3}{|c|}{10.300999999999998} & 10.3733 & TRN & \\
\hline CHEMBL221805 & 425511 & \multicolumn{3}{|c|}{10.300999999999998} & 10.3129 & 99999999999 & TST \\
\hline CHEMBL437146 & 425511 & 8.6021 & 8.5409 & TRN & & & \\
\hline CHEMBL386955 & 425511 & 8.7696 & 8.9999 & TST & & & \\
\hline CHEMBL374270 & 425511 & 8.8861 & 8.8278 & TRN & & & \\
\hline CHEMBL268908 & 425511 & 8.9586 & 9.9031 & TRN & & & \\
\hline CHEMBL376408 & 425511 & \multicolumn{3}{|c|}{10.300999999999998} & 10.0151 & TRN & \\
\hline CHEMBL376921 & 425511 & 8.585 & 8.6396 & TRN & & & \\
\hline CHEMBL374097 & 425511 & \multicolumn{3}{|c|}{10.300999999999998} & 10.2185 & TRN & \\
\hline CHEMBL385119 & 425511 & \multicolumn{3}{|c|}{10.300999999999998} & 9.9474 & TRN & \\
\hline CHEMBL192571 & 425511 & 9.0969 & 8.8253 & TRN & & & \\
\hline CHEMBL375841 & 425511 & 9.0458 & 9.0365 & TRN & & & \\
\hline CHEMBL376659 & 425511 & 9.2218 & 10.3144 & TST & & & \\
\hline CHEMBL217960 & 425511 & \multicolumn{3}{|c|}{10.300999999999998} & 10.3612 & TRN & \\
\hline CHEMBL384218 & 425511 & \multicolumn{3}{|c|}{10.300999999999998} & 10.1764 & TRN & \\
\hline CHEMBL376696 & 425511 & 8.4318 & 9.0683 & TST & & & \\
\hline CHEMBL374941 & 425511 & \multicolumn{3}{|c|}{$\begin{array}{lll}8.8861 & 9.9204 & \text { TST }\end{array}$} & & & \\
\hline CHEMBL373631 & 425511 & \multicolumn{3}{|c|}{10.300999999999998} & 10.0835 & TST & \\
\hline CHEMBL221856 & 425511 & 9.2218 & 9.698 & TRN & & & \\
\hline CHEMBL384217 & 425511 & 10.3009 & 99999999 & 998 & 10.3903 & TRN & \\
\hline CHEMBL376254 & 425511 & 10.3009 & 99999999 & 998 & 10.4523 & TST & \\
\hline CHEMBL375299 & 425511 & 10.3009 & 79999999 & 998 & 10.1353 & TRN & \\
\hline CHEMBL 376410 & 425511 & 10.3009 & 99999999 & 998 & 10.1667 & TRN & \\
\hline CHEMBL373577 & 425511 & 8.2147 & 8.5301 & TRN & & & \\
\hline CHEMBL387141 & 425511 & 9.0969 & 8.3604 & TST & & & \\
\hline CHEMBL 375842 & 425511 & 9.0458 & 9.7167 & TRN & & & \\
\hline CHEMBL221294 & 425511 & 10.3009 & 79999999 & 998 & 10.0129 & TRN & \\
\hline CHEMBL437148 & 425511 & 9.0458 & 9.0712 & TRN & & & \\
\hline CHEMBL387142 & 425511 & 8.5229 & 9.3776 & TRN & & & \\
\hline CHEMBL426558 & 425511 & 10.3009 & 99999999 & 998 & 10.1385 & TRN & \\
\hline CHEMBL221854 & 425511 & 10.3009 & 99999999 & 998 & 10.3263 & TRN & \\
\hline CHEMBL221855 & 425511 & 10.3009 & 79999999 & 998 & 9.9037 & TRN & \\
\hline & & & & ge & & & \\
\hline
\end{tabular}




\begin{tabular}{|c|c|c|c|c|c|c|}
\hline CHEMBL374309 & 425511 & \multicolumn{4}{|c|}{ Supplemental Table S2.txt } & TRN \\
\hline CHEMBL222069 & 425511 & 8.8539 & 10.0709 & TST & & \\
\hline CHEMBL373713 & 425511 & 8.3565 & 8.9655 & TST & & \\
\hline CHEMBL221218 & 425511 & 8.3372 & 8.6138 & TRN & & \\
\hline CHEMBL439495 & 425511 & 8.3979 & 9.1663 & TST & & \\
\hline CHEMBL2041191 & 823543 & 9.0 & 8.8966 & TRN & & \\
\hline CHEMBL2041169 & 823543 & 9.699 & 9.2934 & TRN & & \\
\hline CHEMBL2041182 & 823543 & 9.699 & 9.7868 & TRN & & \\
\hline CHEMBL 2041167 & 823543 & 8.4089 & 8.3354 & TRN & & \\
\hline CHEMBL2043010 & 823543 & 9.3979 & 8.7801 & TST & & \\
\hline CHEMBL2043328 & 823543 & 7.5086 & 7.6892 & TRN & & \\
\hline CHEMBL 2041179 & 823543 & 8.3279 & 8.5276 & TRN & & \\
\hline CHEMBL2042133 & 823543 & 6.4318 & 5.611006 & 0000000001 & & TRN \\
\hline CHEMBL2042855 & 823543 & 7.9586 & 7.7454 & TST & & \\
\hline CHEMBL2041181 & 823543 & 8.7212 & 8.6423 & TRN & & \\
\hline CHEMBL2043170 & 823543 & 8.301 & 8.2076 & TRN & & \\
\hline CHEMBL2041185 & 823543 & 9.699 & 10.0414 & TRN & & \\
\hline CHEMBL2042269 & 823543 & 3.301 & 3.4741 & TRN & & \\
\hline CHEMBL 2043325 & 823543 & 9.699 & 9.5864 & TRN & & \\
\hline CHEMBL 2042847 & 823543 & 5.2218 & 6.1774 & TRN & & \\
\hline CHEMBL2043007 & 823543 & 8.4685 & 8.279 & TRN & & \\
\hline CHEMBL 2043172 & 823543 & 9.0 & 8.661 & TRN & & \\
\hline CHEMBL2042852 & 823543 & 8.1675 & 7.6222 & TRN & & \\
\hline CHEMBL2042129 & 823543 & 6.0 & 6.2331 & TRN & & \\
\hline CHEMBL 2042840 & 823543 & 3.301 & 5.0269 & TST & & \\
\hline CHEMBL2041173 & 823543 & 8.6383 & 8.9028 & TRN & & \\
\hline CHEMBL2042995 & 823543 & 8.7959 & 7.9225 & TST & & \\
\hline CHEMBL2043003 & 823543 & 8.3665 & 8.1243 & TRN & & \\
\hline CHEMBL2042720 & 823543 & 3.301 & 5.3597 & TST & & \\
\hline CHEMBL 2041190 & 823543 & 9.699 & 9.7741 & TRN & & \\
\hline CHEMBL2043002 & 823543 & 8.5229 & 8.4367 & TRN & & \\
\hline CHEMBL 2043000 & 823543 & 7.5686 & 8.597006 & 2000000001 & & TST \\
\hline CHEMBL2043326 & 823543 & 9.301 & 9.0338 & TRN & & \\
\hline CHEMBL2042132 & 823543 & 5.1079 & 5.7495 & TRN & & \\
\hline CHEMBL 2041178 & 823543 & 9.301 & 9.1065 & TRN & & \\
\hline CHEMBL2042126 & 823543 & 5.1805 & 5.3512 & TRN & & \\
\hline CHEMBL 2041166 & 823543 & 7.8539 & 8.4095 & TRN & & \\
\hline CHEMBL2043011 & 823543 & 8.9586 & 9.3209 & TRN & & \\
\hline CHEMBL2042841 & 823543 & 3.301 & 5.0229 & TST & & \\
\hline CHEMBL2043169 & 823543 & 9.3979 & 9.6362 & TRN & & \\
\hline CHEMBL2042134 & 823543 & 5.585 & 4.9719 & TRN & & \\
\hline CHEMBL 2042994 & 823543 & 8.6778 & 7.9005 & TST & & \\
\hline CHEMBL2041170 & 823543 & 9.2218 & 8.8963 & TRN & & \\
\hline CHEMBL 2042999 & 823543 & 8.0506 & 8.3189 & TST & & \\
\hline CHEMBL2041187 & 823543 & 9.0969 & 9.257 & TRN & & \\
\hline CHEMBL2041186 & 823543 & 9.699 & 9.816 & TRN & & \\
\hline CHEMBL 2042408 & 823543 & 6.3565 & 6.0037 & TRN & & \\
\hline CHEMBL2043168 & 823543 & 9.3979 & 9.2217 & TRN & & \\
\hline
\end{tabular}




\begin{tabular}{|c|c|c|c|c|c|}
\hline & & \multicolumn{4}{|c|}{ Supplemental Table S2.txt } \\
\hline CHEMBL 2041171 & 823543 & 8.9586 & 8.6627 & TRN & \\
\hline CHEMBL 2041175 & 823543 & 9.699 & 9.3826 & TRN & \\
\hline CHEMBL 2042848 & 823543 & 5.9208 & 6.6719 & TRN & \\
\hline CHEMBL 2041180 & 823543 & 8.7959 & 8.8877 & TRN & \\
\hline CHEMBL 2042130 & 823543 & 6.1938 & 6.17399 & 99999999995 & TRN \\
\hline CHEMBL 2042268 & 823543 & 3.301 & 4.0121 & TRN & \\
\hline CHEMBL 2043008 & 823543 & 8.3872 & 8.2366 & TRN & \\
\hline CHEMBL 2042846 & 823543 & 7.3565 & 7.0379 & TRN & \\
\hline CHEMBL 2043005 & 823543 & 8.6778 & 8.3144 & TRN & \\
\hline CHEMBL 2042850 & 823543 & 6.8539 & 7.282 & TRN & \\
\hline CHEMBL 2041177 & 823543 & 9.0969 & 8.8247 & TRN & \\
\hline CHEMBL2042996 & 823543 & 8.4202 & 8.0305 & TST & \\
\hline CHEMBL 2042271 & 823543 & 5.5171 & 4.4907 & TRN & \\
\hline CHEMBL 2042843 & 823543 & 6.7328 & 5.9779 & TRN & \\
\hline CHEMBL 2042998 & 823543 & 7.5086 & 8.4724 & TST & \\
\hline CHEMBL 2042991 & 823543 & 7.7696 & 8.1009 & TST & \\
\hline CHEMBL 2042851 & 823543 & 7.284 & 7.3929 & TRN & \\
\hline CHEMBL 2041183 & 823543 & 9.301 & 9.8729 & TRN & \\
\hline CHEMBL 2041184 & 823543 & 9.699 & 9.8372 & TRN & \\
\hline CHEMBL 2043006 & 823543 & 8.3665 & 8.2677 & TRN & \\
\hline CHEMBL 2040865 & 823543 & 3.301 & 4.2248 & TRN & \\
\hline CHEMBL 2041010 & 823543 & 9.2218 & 8.9933 & TRN & \\
\hline CHEMBL 2043327 & 823543 & 8.301 & 8.1633 & TRN & \\
\hline CHEMBL 2040854 & 823543 & 9.2218 & 8.8837 & TRN & \\
\hline CHEMBL2041189 & 823543 & 9.3979 & 9.221 & TRN & \\
\hline CHEMBL 2040896 & 823543 & 8.0315 & 8.0604 & TRN & \\
\hline CHEMBL 2040894 & 823543 & 7.9586 & 7.979 & TRN & \\
\hline CHEMBL 2041193 & 823543 & 9.699 & 9.929 & TRN & \\
\hline CHEMBL 2041172 & 823543 & 8.699 & 8.9037 & TRN & \\
\hline CHEMBL 2041164 & 823543 & 8.5528 & 8.9965 & TRN & \\
\hline CHEMBL 2042844 & 823543 & 6.0757 & 5.6551 & TRN & \\
\hline CHEMBL 2043171 & 823543 & 9.0969 & 9.1359 & TRN & \\
\hline CHEMBL 2041188 & 823543 & 9.3979 & 9.7722 & TRN & \\
\hline CHEMBL2042993 & 823543 & 9.1549 & 8.9305 & TST & \\
\hline CHEMBL 2042131 & 823543 & 6.1675 & 6.2787 & TRN & \\
\hline CHEMBL 2042849 & 823543 & 7.5229 & 6.4528 & TST & \\
\hline CHEMBL 2043004 & 823543 & 8.6021 & 8.5616 & TRN & \\
\hline CHEMBL 2042997 & 823543 & 7.0088 & 7.6417 & TST & \\
\hline CHEMBL 2041165 & 823543 & 8.3098 & 8.1029 & TRN & \\
\hline CHEMBL 2043324 & 823543 & 9.3979 & 9.4226 & TRN & \\
\hline CHEMBL 2042992 & 823543 & 8.3872 & 7.9213 & TST & \\
\hline CHEMBL 2041174 & 823543 & 8.8239 & 8.7871 & TRN & \\
\hline CHEMBL 2042270 & 823543 & 3.301 & 4.5505 & TST & \\
\hline CHEMBL 2042128 & 823543 & 5.9208 & 6.3747 & TST & \\
\hline CHEMBL 2041192 & 823543 & 9.699 & 9.5006 & TRN & \\
\hline CHEMBL 2040895 & 823543 & 7.1192 & 7.6794 & TRN & \\
\hline CHEMBL 2042853 & 823543 & 8.3979 & 7.9677 & TST & \\
\hline CHEMBL 2042845 & 823543 & 5.3279 & 5.14 & TST & \\
\hline
\end{tabular}


Supplemental Table S2.txt

\begin{tabular}{|c|c|c|c|c|c|}
\hline CHEMBL 2042842 & 823543 & 5.5086 & 5.4075 & TST & \\
\hline CHEMBL 2042127 & 823543 & 5.6576 & 6.8075 & TST & \\
\hline CHEMBL2041194 & 823543 & 9.0969 & 8.9808 & TRN & \\
\hline CHEMBL 2041176 & 823543 & 8.7959 & 8.3177 & TRN & \\
\hline CHEMBL 2042854 & 823543 & 8.1079 & 7.7822 & TST & \\
\hline CHEMBL 2040897 & 823543 & 9.0458 & 9.1094 & TRN & \\
\hline CHEMBL 2042409 & 823543 & 4.8153 & 4.876 & TST & \\
\hline CHEMBL 2041168 & 823543 & 8.2676 & 8.7006 & TRN & \\
\hline CHEMBL 2042267 & 823543 & 6.1024 & 4.4773 & TST & \\
\hline CHEMBL1165089 & 638726 & 6.1739 & 6.0703 & TRN & \\
\hline CHEMBL1165583 & 638726 & 5.301 & 5.8285 & TRN & \\
\hline CHEMBL1163708 & 638726 & 3.301 & 3.4541 & TRN & \\
\hline CHEMBL1163230 & 638726 & 4.0 & 4.1247 & TRN & \\
\hline CHEMBL1164432 & 638726 & 3.301 & 2.9735 & TRN & \\
\hline CHEMBL1164238 & 638726 & 4.0 & 4.4394 & TST & \\
\hline CHEMBL1163703 & 638726 & 4.0 & 4.0935 & TRN & \\
\hline CHEMBL1163218 & 638726 & 4.0 & 3.94199 & 99999999997 & TRN \\
\hline CHEMBL381617 & 638726 & 5.301 & 5.6564 & TRN & \\
\hline CHEMBL 222794 & 638726 & 4.6778 & 4.5943 & TRN & \\
\hline CHEMBL1163547 & 638726 & 4.6021 & 4.7238 & TRN & \\
\hline CHEMBL1163251 & 638726 & 4.0 & 4.0972 & TRN & \\
\hline CHEMBL212873 & 638726 & 5.0 & 5.3471 & TRN & \\
\hline CHEMBL 207083 & 638726 & 6.0 & 6.284 & TRN & \\
\hline CHEMBL1164610 & 638726 & 4.0 & 3.9748 & TRN & \\
\hline CHEMBL1163846 & 638726 & 3.301 & 3.7012 & TST & \\
\hline CHEMBL1163660 & 638726 & 4.0 & 4.0943 & TRN & \\
\hline CHEMBL376277 & 638726 & 4.8539 & 4.7824 & TRN & \\
\hline CHEMBL1164543 & 638726 & 4.52 & 5.0081 & TRN & \\
\hline CHEMBL1164127 & 638726 & 4.0 & 4.1143 & TRN & \\
\hline CHEMBL379820 & 638726 & 7.1675 & 6.6906 & TRN & \\
\hline CHEMBL1164330 & 638726 & 4.0 & 4.123 & TRN & \\
\hline CHEMBL 213904 & 638726 & 7.1024 & 6.4368 & TRN & \\
\hline CHEMBL1164095 & 638726 & 4.0 & 3.7169 & TRN & \\
\hline CHEMBL 211097 & 638726 & 5.4202 & 5.7551 & TRN & \\
\hline CHEMBL1164464 & 638726 & 4.0 & 3.8681 & TRN & \\
\hline CHEMBL1164406 & 638726 & 4.0 & 4.2661 & TRN & \\
\hline CHEMBL1163250 & 638726 & 4.0 & 3.7779 & TRN & \\
\hline CHEMBL 266891 & 638726 & 4.8239 & 4.9157 & TRN & \\
\hline CHEMBL1165722 & 638726 & 4.6861 & 4.47 & TRN & \\
\hline CHEMBL1165364 & 638726 & 4.0 & 4.1285 & TST & \\
\hline CHEMBL380521 & 638726 & 5.301 & 5.7057 & TRN & \\
\hline CHEMBL 209055 & 638726 & 4.0 & 3.9086 & TRN & \\
\hline CHEMBL1165196 & 638726 & 4.0 & 4.9316 & TST & \\
\hline CHEMBL1165791 & 638726 & 4.5544 & 4.273 & TRN & \\
\hline CHEMBL1164643 & 638726 & 5.7212 & 5.63 & TRN & \\
\hline CHEMBL376072 & 638726 & 4.8239 & 4.9271 & TRN & \\
\hline CHEMBL1163704 & 638726 & 4.0 & 4.3071 & TRN & \\
\hline CHEMBL 212627 & 638726 & 7.1024 & 6.4775 & TRN & \\
\hline
\end{tabular}




\begin{tabular}{|c|c|c|c|c|c|}
\hline \multicolumn{6}{|c|}{ Supplemental Table s2.txt } \\
\hline CHEMBL1165202 & 638726 & 4.0 & 3.9391 & TRN & \\
\hline CHEMBL1164462 & 638726 & 4.2007 & 5.0235 & TST & \\
\hline CHEMBL1164946 & 638726 & 3.301 & 3.365 & TST & \\
\hline CHEMBL379100 & 638726 & 5.0 & 5.0505 & TRN & \\
\hline CHEMBL1164306 & 638726 & 4.0 & 4.2005 & TRN & \\
\hline CHEMBL379067 & 638726 & 7.0 & 6.5426 & TRN & \\
\hline CHEMBL1164333 & 638726 & 3.301 & 3.7224 & TST & \\
\hline CHEMBL1164128 & 638726 & 4.0 & 4.0153 & TRN & \\
\hline CHEMBL1164329 & 638726 & 3.301 & 3.4576 & TRN & \\
\hline CHEMBL1163953 & 638726 & 4.0 & 4.1414 & TRN & \\
\hline CHEMBL1164331 & 638726 & 4.0 & 4.0342 & TRN & \\
\hline CHEMBL1164239 & 638726 & 4.0 & 4.1581 & TST & \\
\hline CHEMBL1164618 & 638726 & 3.0 & 4.7586 & TST & \\
\hline CHEMBL 206442 & 638726 & 6.1192 & 6.0116 & TRN & \\
\hline CHEMBL209052 & 638726 & 6.0 & 6.3185 & TRN & \\
\hline CHEMBL1164837 & 638726 & 4.0 & 3.9661 & TRN & \\
\hline CHEMBL1165064 & 638726 & 4.0 & 4.0947 & TST & \\
\hline CHEMBL1165812 & 638726 & 4.0 & 3.5764 & TRN & \\
\hline CHEMBL1163651 & 638726 & 4.0 & 4.3586 & TST & \\
\hline CHEMBL1164540 & 638726 & 5.1487 & 4.4801 & TRN & \\
\hline CHEMBL379334 & 638726 & 5.9031 & 6.2574 & TRN & \\
\hline CHEMBL1164009 & 638726 & 3.301 & 3.5984 & TST & \\
\hline CHEMBL 212578 & 638726 & \multicolumn{3}{|c|}{6.821000000000001} & 6.4764 \\
\hline CHEMBL1164397 & 638726 & 4.0 & 4.048 & TRN & \\
\hline CHEMBL381618 & 638726 & 6.0 & 6.0869 & TRN & \\
\hline CHEMBL1165356 & 638726 & 4.0 & 3.7218 & TRN & \\
\hline CHEMBL1163705 & 638726 & 4.9245 & 4.9025 & TRN & \\
\hline CHEMBL1164743 & 638726 & 4.0 & 3.8562 & TRN & \\
\hline CHEMBL1165815 & 638726 & 4.0 & 3.8927 & TRN & \\
\hline CHEMBL1163649 & 638726 & 4.0 & 4.1459 & TRN & \\
\hline CHEMBL1163845 & 638726 & 4.9208 & 5.1612 & TRN & \\
\hline CHEMBL 378032 & 638726 & 6.0 & 5.9916 & TRN & \\
\hline CHEMBL1163299 & 638726 & 4.0 & 3.9978 & TRN & \\
\hline CHEMBL1163712 & 638726 & 3.301 & 3.4389 & TRN & \\
\hline CHEMBL1164960 & 638726 & 4.0 & 4.1931 & TRN & \\
\hline CHEMBL1163698 & 638726 & 4.0872 & 4.2776 & TRN & \\
\hline CHEMBL1164972 & 638726 & 4.0 & 4.4949 & TST & \\
\hline CHEMBL206854 & 638726 & 6.0 & 5.92 & TRN & \\
\hline CHEMBL1165658 & 638726 & 4.5935 & 4.3847 & TRN & \\
\hline CHEMBL1163707 & 638726 & 4.0 & 4.3599 & TRN & \\
\hline CHEMBL1164434 & 638726 & 3.301 & 3.7184 & TST & \\
\hline CHEMBL1163225 & 638726 & 6.0 & 4.981 & TRN & \\
\hline CHEMBL 225442 & 638726 & 4.6383 & 4.9652 & TST & \\
\hline CHEMBL1165057 & 638726 & 4.0 & 4.1503 & TST & \\
\hline CHEMBL1164612 & 638726 & 6.2366 & 6.4541 & TRN & \\
\hline CHEMBL1164433 & 638726 & 3.301 & 3.7206 & TST & \\
\hline CHEMBL1165724 & 638726 & 3.5969 & 3.9576 & TST & \\
\hline CHEMBL1164363 & 638726 & 4.0 & 3.8747 & TRN & \\
\hline
\end{tabular}




\begin{tabular}{|c|c|c|c|c|c|}
\hline \multicolumn{6}{|c|}{ Supplemental Table S2.txt } \\
\hline CHEMBL1164435 & 638726 & 4.0 & 3.883 & TRN & \\
\hline CHEMBL1165280 & 638726 & 4.0 & 4.1816 & TRN & \\
\hline CHEMBL1164841 & 638726 & 4.0 & 4.1289 & TRN & \\
\hline CHEMBL1165197 & 638726 & 4.0 & 4.1442 & TRN & \\
\hline CHEMBL1164640 & 638726 & 4.8861 & 4.9182 & TRN & \\
\hline CHEMBL1163658 & 638726 & 4.0 & 3.991 & TRN & \\
\hline CHEMBL426717 & 638726 & 5.8539 & 4.7734 & TST & \\
\hline CHEMBL1164690 & 638726 & 4.9508 & 4.5646 & TRN & \\
\hline CHEMBL1165279 & 638726 & 4.0 & 4.1457 & TRN & \\
\hline CHEMBL1165384 & 638726 & 3.8187 & 4.1565 & TRN & \\
\hline CHEMBL1164691 & 638726 & 4.3179 & 4.2117 & TRN & \\
\hline CHEMBL1164096 & 638726 & 4.0 & 3.8777 & TRN & \\
\hline CHEMBL1164242 & 638726 & 3.301 & 4.187 & TST & \\
\hline CHEMBL1163699 & 638726 & 4.0 & 4.163 & TRN & \\
\hline CHEMBL1164617 & 638726 & 4.0 & 3.9438 & TRN & \\
\hline CHEMBL1164697 & 638726 & 4.0 & 3.9781 & TRN & \\
\hline CHEMBL 211256 & 638726 & 7.0458 & 6.8021 & TRN & \\
\hline CHEMBL1165731 & 638726 & 4.0 & 3.8373 & TRN & \\
\hline CHEMBL1163234 & 638726 & 4.0 & 3.8687 & TST & \\
\hline CHEMBL1165549 & 638726 & 4.0 & 3.4966 & TST & \\
\hline CHEMBL1164437 & 638726 & 5.4318 & 5.5964 & TRN & \\
\hline CHEMBL1164644 & 638726 & 4.3497 & 4.8634 & TRN & \\
\hline CHEMBL 377581 & 638726 & 6.9586 & 6.8753 & TRN & \\
\hline CHEMBL1163648 & 638726 & 4.0 & 4.1456 & TRN & \\
\hline CHEMBL 377625 & 638726 & 5.0 & 4.9019 & TST & \\
\hline CHEMBL378225 & 638726 & 4.8239 & 4.7309 & TST & \\
\hline CHEMBL211995 & 638726 & 6.5229 & 6.4373 & TRN & \\
\hline CHEMBL1163263 & 638726 & 3.301 & 3.8743 & TST & \\
\hline CHEMBL1163652 & 638726 & 4.0 & 3.7406 & TRN & \\
\hline CHEMBL1164314 & 638726 & 3.301 & 3.4565 & TST & \\
\hline CHEMBL1163700 & 638726 & 4.0 & 4.3892 & TST & \\
\hline CHEMBL1165270 & 638726 & 4.0 & 3.897 & TST & \\
\hline CHEMBL1165814 & 638726 & 4.0 & 4.1767 & TST & \\
\hline CHEMBL 211214 & 638726 & 6.2007 & 6.6339 & TRN & \\
\hline CHEMBL212681 & 638726 & 4.699 & 5.0087 & TRN & \\
\hline CHEMBL1164332 & 638726 & 4.301 & 4.2019 & TRN & \\
\hline CHEMBL1165526 & 638726 & 4.0 & 3.889 & TST & \\
\hline CHEMBL1164187 & 638726 & 5.6576 & 5.2136 & TRN & \\
\hline CHEMBL1164959 & 638726 & 4.2684 & 4.2744 & TRN & \\
\hline CHEMBL1164405 & 638726 & 4.0 & 4.0501 & TRN & \\
\hline CHEMBL1163776 & 638726 & 5.3979 & 5.36100 & 0000000001 & TRN \\
\hline CHEMBL1164362 & 638726 & 4.0 & 3.7518 & TST & \\
\hline CHEMBL517746 & 638726 & 4.0 & 4.0266 & TST & \\
\hline CHEMBL162970 & 638726 & 4.3872 & 4.6925 & TST & \\
\hline CHEMBL1230020 & 954956 & 3.0959 & 3.0957 & TRN & \\
\hline CHEMBL1673039 & 954956 & 3.8271 & 3.8325 & TRN & \\
\hline CHEMBL483847 & 954956 & 4.3496 & 4.3533 & TRN & \\
\hline CHEMBL1404918 & 954956 & 2.8111 & 2.8094 & TRN & \\
\hline
\end{tabular}




\begin{tabular}{|c|c|c|c|c|c|c|}
\hline & & \multicolumn{5}{|c|}{ Supplemental Table S2.txt } \\
\hline CHEMBL1357247 & 954956 & 3.477 & 3.4798 & TRN & & \\
\hline CHEMBL1186585 & 954956 & 3.8915 & 3.9008 & TRN & & \\
\hline CHEMBL577784 & 954956 & 5.4323 & 5.4556 & TRN & & \\
\hline CHEMBL379975 & 954956 & 4.5584 & 4.5547 & TRN & & \\
\hline CHEMBL2363137 & 954956 & 4.4588 & 4.4628 & TRN & & \\
\hline CHEMBL558642 & 954956 & 2.7627 & 2.7588 & TRN & & \\
\hline CHEMBL585951 & 954956 & 4.8411 & 4.8429 & TRN & & \\
\hline CHEMBL483849 & 954956 & 1.9356 & 2.7069 & TST & & \\
\hline CHEMBL 3186408 & 954956 & 3.6352 & 3.9059 & TST & & \\
\hline CHEMBL412142 & 954956 & 3.7764 & 3.7577 & TRN & & \\
\hline CHEMBL1242367 & 954956 & 4.6534 & 4.6496 & TRN & & \\
\hline CHEMBL 2005886 & 954956 & 5.1734 & 5.169 & TRN & & \\
\hline CHEMBL512504 & 954956 & 4.262 & 4.2467 & TRN & & \\
\hline CHEMBL514499 & 954956 & 6.8274 & 6.8217 & TRN & & \\
\hline CHEMBL573107 & 954956 & 5.0135 & 5.0193 & TRN & & \\
\hline CHEMBL449158 & 954956 & 6.2995 & 6.2974 & TST & & \\
\hline CHEMBL222102 & 954956 & 4.1179 & 4.1559 & TRN & & \\
\hline CHEMBL 2144069 & 954956 & 5.3794 & 5.3816 & TRN & & \\
\hline CHEMBL188678 & 954956 & 4.6649 & 4.6565 & TRN & & \\
\hline CHEMBL102714 & 954956 & 3.9343 & 3.9287 & TRN & & \\
\hline CHEMBL1788116 & 954956 & 3.9549 & 3.9444 & TRN & & \\
\hline CHEMBL3349342 & 954956 & 5.5706 & 5.5677 & TRN & & \\
\hline CHEMBL1643959 & 954956 & 3.7382 & 3.75 & TRN & & \\
\hline CHEMBL509032 & 954956 & 4.9899 & 4.9822 & TRN & & \\
\hline CHEMBL 9470 & 954956 & 4.8515 & 5.058 & TST & & \\
\hline CHEMBL 379300 & 954956 & 6.5348 & 6.5458 & TRN & & \\
\hline CHEMBL 2134202 & 954956 & 3.8918 & 3.9013 & TRN & & \\
\hline CHEMBL258844 & 954956 & 4.3721 & 4.3855 & TRN & & \\
\hline CHEMBL191334 & 954956 & 3.0678 & 3.0661 & TRN & & \\
\hline CHEMBL209148 & 954956 & 4.6151 & 4.6062 & TRN & & \\
\hline CHEMBL240954 & 954956 & 3.0885 & 3.5422 & TST & & \\
\hline CHEMBL180127 & 954956 & 3.7724 & 3.7663 & TRN & & \\
\hline CHEMBL135561 & 954956 & 4.4177 & 4.4 & TRN & & \\
\hline CHEMBL1190711 & 954956 & 3.6356 & 3.6441 & TRN & & \\
\hline CHEMBL393929 & 954956 & 3.359 & 3.3601 & TRN & & \\
\hline CHEMBL92309 & 954956 & 3.2325 & 3.0919 & TST & & \\
\hline CHEMBL192566 & 954956 & 8.1199 & 6.8598 & TST & & \\
\hline CHEMBL202721 & 954956 & 4.7409 & 4.7243 & TRN & & \\
\hline CHEMBL 213100 & 954956 & 5.7058 & 5.7083 & TRN & & \\
\hline CHEMBL1909414 & 954956 & 3.2452 & 3.2466 & TRN & & \\
\hline CHEMBL 210618 & 954956 & 3.2128 & 3.207 & TRN & & \\
\hline CHEMBL3199475 & 954956 & 3.8981 & 3.9116 & TRN & & \\
\hline CHEMBL1256459 & 954956 & 7.2363 & 7.2256 & TRN & & \\
\hline CHEMBL1590308 & 954956 & 3.5077 & 3.3885 & TST & & \\
\hline CHEMBL65 & 954956 & 6.4777 & 6.4811 & TRN & & \\
\hline CHEMBL 2137530 & 954956 & 4.8264 & 4.8285 & TRN & & \\
\hline CHEMBL 300389 & 954956 & 6.98600 & 00000000 & 01 & 6.9798 & TRN \\
\hline CHEMBL221137 & 954956 & 3.8125 & 4.5285 & TST & & \\
\hline
\end{tabular}




\begin{tabular}{|c|c|c|c|c|c|}
\hline \multicolumn{6}{|c|}{ Supplemental Table S2.txt } \\
\hline CHEMBL392695 & 954956 & 5.6655 & 5.678 & TRN & \\
\hline CHEMBL259181 & 954956 & 2.9952 & 2.9923 & TRN & \\
\hline CHEMBL255342 & 954956 & 4.3294 & 4.2998 & TRN & \\
\hline CHEMBL189584 & 954956 & 4.011 & 4.019 & TRN & \\
\hline CHEMBL220241 & 954956 & 4.2807 & 4.2846 & TRN & \\
\hline CHEMBL217354 & 954956 & 5.5611 & 6.3651 & TST & \\
\hline CHEMBL399530 & 954956 & 4.4489 & 4.3464 & TST & \\
\hline CHEMBL1970879 & 954956 & 5.1627 & 5.0916 & TST & \\
\hline CHEMBL373751 & 954956 & 3.4027 & 3.9492 & TST & \\
\hline CHEMBL472940 & 954956 & 2.5987 & 3.6708 & TST & \\
\hline CHEMBL1516890 & 954956 & 5.2014 & 3.8493 & TST & \\
\hline CHEMBL3392440 & 954956 & 6.4448 & 3.7651 & TST & \\
\hline CHEMBL515416 & 954956 & 3.7023 & 4.5899 & TST & \\
\hline CHEMBL3338052 & 1436004 & 4.6364 & 4.4213 & TRN & \\
\hline CHEMBL3338000 & 1436004 & 3.1938 & 3.54600 & 30000000003 & TST \\
\hline CHEMBL3338044 & 1436004 & 5.1844 & 4.9077 & TRN & \\
\hline CHEMBL3338018 & 1436004 & 5.1605 & 5.2171 & TRN & \\
\hline CHEMBL 71728 & 1436004 & 3.1938 & 3.5266 & TRN & \\
\hline CHEMBL3338054 & 1436004 & 4.7409 & 5.0185 & TRN & \\
\hline CHEMBL3338039 & 1436004 & 3.1938 & 3.7335 & TRN & \\
\hline CHEMBL3338025 & 1436004 & 4.8674 & 4.9626 & TRN & \\
\hline CHEMBL578061 & 1436004 & 4.654 & 4.5526 & TST & \\
\hline CHEMBL 3338048 & 1436004 & 5.8239 & 5.1038 & TRN & \\
\hline CHEMBL3338010 & 1436004 & 3.4948 & 3.7317 & TRN & \\
\hline CHEMBL3337461 & 1436004 & 3.4948 & 3.6041 & TRN & \\
\hline CHEMBL3338022 & 1436004 & 4.3872 & 4.3554 & TRN & \\
\hline CHEMBL3338013 & 1436004 & 4.8807 & 4.4173 & TRN & \\
\hline CHEMBL3338007 & 1436004 & 3.1938 & 3.1673 & TRN & \\
\hline CHEMBL3338049 & 1436004 & 4.9208 & 4.4741 & TRN & \\
\hline CHEMBL3338037 & 1436004 & 4.4917 & 3.5268 & TRN & \\
\hline CHEMBL3338034 & 1436004 & 5.3045 & 5.3497 & TRN & \\
\hline CHEMBL3338011 & 1436004 & 3.4948 & 3.6075 & TRN & \\
\hline CHEMBL3338017 & 1436004 & 4.9435 & 3.6437 & TRN & \\
\hline CHEMBL3337999 & 1436004 & 3.1938 & 3.389 & TST & \\
\hline CHEMBL3338031 & 1436004 & 5.2211 & 5.0241 & TRN & \\
\hline CHEMBL3338001 & 1436004 & 3.4948 & 3.2322 & TRN & \\
\hline CHEMBL3338004 & 1436004 & 3.4948 & 3.2874 & TRN & \\
\hline CHEMBL3338016 & 1436004 & 3.4948 & 3.8981 & TRN & \\
\hline CHEMBL3338012 & 1436004 & 4.5274 & 3.66899 & 99999999996 & TRN \\
\hline CHEMBL3338050 & 1436004 & 3.1938 & 3.5421 & TRN & \\
\hline CHEMBL3337998 & 1436004 & 3.1938 & 3.7655 & TST & \\
\hline CHEMBL72529 & 1436004 & 4.5458 & 4.1836 & TRN & \\
\hline CHEMBL470025 & 1436004 & 3.1938 & 4.8858 & TRN & \\
\hline CHEMBL3338021 & 1436004 & 3.1938 & 3.4467 & TRN & \\
\hline CHEMBL3338027 & 1436004 & 5.3143 & 5.5129 & TRN & \\
\hline CHEMBL3338014 & 1436004 & 3.4948 & 3.883 & TRN & \\
\hline CHEMBL3338043 & 1436004 & 5.0438 & 4.8548 & TRN & \\
\hline CHEMBL3338015 & 1436004 & 3.1938 & 3.7786 & TRN & \\
\hline
\end{tabular}


Supplemental Table S2.txt

\begin{tabular}{|c|c|c|c|c|c|}
\hline CHEMBL3338005 & 1436004 & 4.4887 & 3.6933 & TST & \\
\hline CHEMBL3338009 & 1436004 & 5.0155 & 4.7726 & TRN & \\
\hline CHEMBL71659 & 1436004 & 4.5824 & 4.9237 & TRN & \\
\hline CHEMBL 74174 & 1436004 & 4.4184 & 4.5145 & TRN & \\
\hline CHEMBL3338046 & 1436004 & 3.1938 & 3.5231 & TRN & \\
\hline CHEMBL3338030 & 1436004 & 5.2526 & 5.4406 & TRN & \\
\hline CHEMBL3338055 & 1436004 & 3.1938 & 3.5533 & TST & \\
\hline CHEMBL3338036 & 1436004 & 3.1938 & 3.7683 & TRN & \\
\hline CHEMBL3338029 & 1436004 & \multicolumn{3}{|c|}{5.2620000000000005} & 4.9709 \\
\hline CHEMBL3338028 & 1436004 & 4.8955 & 4.9234 & TRN & \\
\hline CHEMBL3338053 & 1436004 & 4.7773 & 4.0192 & TRN & \\
\hline CHEMBL3338033 & 1436004 & 5.2823 & 4.9438 & TRN & \\
\hline CHEMBL 3338023 & 1436004 & 5.0074 & 4.9302 & TRN & \\
\hline CHEMBL3338045 & 1436004 & 4.6234 & 4.6771 & TRN & \\
\hline CHEMBL 3338040 & 1436004 & 4.6189 & 4.7713 & TRN & \\
\hline CHEMBL69503 & 1436004 & 5.0969 & 5.0396 & TRN & \\
\hline CHEMBL3338006 & 1436004 & 3.1938 & 3.3339 & TRN & \\
\hline CHEMBL3338008 & 1436004 & 3.1938 & 3.5011 & TRN & \\
\hline CHEMBL3338042 & 1436004 & 3.1938 & 3.5265 & TRN & \\
\hline CHEMBL 3338019 & 1436004 & 3.4948 & 4.2869 & TRN & \\
\hline CHEMBL3338047 & 1436004 & 5.1439 & 4.6721 & TRN & \\
\hline CHEMBL3338032 & 1436004 & 5.3778 & 5.4926 & TRN & \\
\hline CHEMBL3338024 & 1436004 & 4.8989 & 4.5342 & TRN & \\
\hline CHEMBL3338002 & 1436004 & 3.4948 & 3.5451 & TST & \\
\hline CHEMBL 3338035 & 1436004 & 3.1938 & 4.3137 & TST & \\
\hline CHEMBL421114 & 1436004 & 4.9965 & 3.9899 & TST & \\
\hline CHEMBL3338020 & 1436004 & 4.6741 & 4.5242 & TST & \\
\hline CHEMBL302791 & 1436004 & 4.654 & 4.9944 & TST & \\
\hline CHEMBL3338051 & 1436004 & 3.1938 & 3.7156 & TST & \\
\hline CHEMBL 71521 & 1436004 & 3.1938 & 4.6141 & TST & \\
\hline CHEMBL3338041 & 1436004 & 4.699 & 4.2858 & TST & \\
\hline CHEMBL3338026 & 1436004 & 4.9965 & 4.6479 & TST & \\
\hline CHEMBL3338003 & 1436004 & 3.4948 & 3.4039 & TST & \\
\hline CHEMBL54893 & 1436004 & 3.1938 & 3.6206 & TST & \\
\hline CHEMBL3338038 & 1436004 & 5.2218 & 4.7996 & TST & \\
\hline CHEMBL3718511 & 1537056 & 11.0 & 8.9555 & TST & \\
\hline CHEMBL3718406 & 1537056 & 7.0 & 6.9659 & TRN & \\
\hline CHEMBL3716761 & 1537056 & 11.0 & 9.3297 & TRN & \\
\hline CHEMBL3716242 & 1537056 & 11.0 & 11.0201 & TRN & \\
\hline CHEMBL 3714804 & 1537056 & 7.0 & 6.7437 & TRN & \\
\hline CHEMBL3717472 & 1537056 & 11.0 & 10.8797 & TST & \\
\hline CHEMBL3716438 & 1537056 & 11.0 & 10.3118 & TST & \\
\hline CHEMBL3718572 & 1537056 & 7.0 & 6.5056 & TRN & \\
\hline CHEMBL3718668 & 1537056 & 11.0 & 10.1947 & TRN & \\
\hline CHEMBL3717695 & 1537056 & 11.0 & 10.0289 & TRN & \\
\hline CHEMBL3716734 & 1537056 & 11.0 & 9.6201 & TRN & \\
\hline CHEMBL 3715646 & 1537056 & 11.0 & 10.8929 & TRN & \\
\hline CHEMBL3718064 & 1537056 & 11.0 & 10.0237 & TRN & \\
\hline
\end{tabular}


Supplemental Table S2.txt

\begin{tabular}{|c|c|c|c|c|c|}
\hline CHEMBL3718451 & 1537056 & 7.0 & 6.0802 & TRN & \\
\hline CHEMBL3714918 & 1537056 & 11.0 & 11.2287 & TRN & \\
\hline CHEMBL3714897 & 1537056 & 7.0 & 6.0555 & TRN & \\
\hline CHEMBL 3719047 & 1537056 & 11.0 & 6.7762 & TST & \\
\hline CHEMBL 3715550 & 1537056 & 7.0 & 9.709 & TST & \\
\hline CHEMBL 3718482 & 1537056 & 11.0 & 9.9234 & TRN & \\
\hline CHEMBL3718778 & 1537056 & 7.0 & 8.115 & TRN & \\
\hline CHEMBL 3717594 & 1537056 & 11.0 & 10.5983 & TRN & \\
\hline CHEMBL 3718616 & 1537056 & 7.0 & 7.5427 & TRN & \\
\hline CHEMBL3715086 & 1537056 & 7.0 & 7.9324 & TRN & \\
\hline CHEMBL 3716178 & 1537056 & 11.0 & 9.9952 & TRN & \\
\hline CHEMBL3716482 & 1537056 & 11.0 & 10.2549 & TRN & \\
\hline CHEMBL 3718642 & 1537056 & 11.0 & 11.8625 & TRN & \\
\hline CHEMBL 3715069 & 1537056 & 11.0 & 11.6916 & TST & \\
\hline CHEMBL 3716815 & 1537056 & 11.0 & 10.6649 & TRN & \\
\hline CHEMBL3715016 & 1537056 & 11.0 & 10.7037 & TRN & \\
\hline CHEMBL3716911 & 1537056 & 6.301 & 7.9481 & TRN & \\
\hline CHEMBL 3715513 & 1537056 & 11.0 & 9.3989 & TRN & \\
\hline CHEMBL3718580 & 1537056 & 11.0 & 10.8424 & TST & \\
\hline CHEMBL 3718203 & 1537056 & 11.0 & 8.4603 & TRN & \\
\hline CHEMBL 3717664 & 1537056 & 11.0 & 11.8134 & TRN & \\
\hline CHEMBL3719011 & 1537056 & 11.0 & 10.9953 & TRN & \\
\hline CHEMBL 3715633 & 1537056 & 7.0 & 7.7275 & TRN & \\
\hline CHEMBL3719113 & 1537056 & 11.0 & 8.9121 & TRN & \\
\hline CHEMBL 3718644 & 1537056 & 7.0 & 8.7935 & TRN & \\
\hline CHEMBL 3715047 & 1537056 & 5.0 & 5.5439 & TRN & \\
\hline CHEMBL3716399 & 1537056 & 11.0 & \multicolumn{2}{|c|}{11.030999999999999} & TRN \\
\hline CHEMBL3716925 & 1537056 & 11.0 & 11.185 & TRN & \\
\hline CHEMBL3718158 & 1537056 & 11.0 & 10.021 & TRN & \\
\hline CHEMBL 3717307 & 1537056 & 7.0 & 8.6465 & TRN & \\
\hline CHEMBL 3714981 & 1537056 & 5.0 & 7.0899 & TRN & \\
\hline CHEMBL3715307 & 1537056 & 11.0 & \multicolumn{2}{|c|}{10.585999999999999} & TRN \\
\hline CHEMBL3716125 & 1537056 & 11.0 & 10.33 & TRN & \\
\hline CHEMBL3716166 & 1537056 & 11.0 & 9.8835 & TRN & \\
\hline CHEMBL3716622 & 1537056 & 11.0 & 11.1966 & TRN & \\
\hline CHEMBL3715467 & 1537056 & 5.0 & 5.1072 & TRN & \\
\hline CHEMBL 3715990 & 1537056 & 11.0 & 12.3334 & TST & \\
\hline CHEMBL3716202 & 1537056 & 11.0 & 9.8235 & TRN & \\
\hline CHEMBL3715804 & 1537056 & 5.0 & 5.5751 & TRN & \\
\hline CHEMBL3716913 & 1537056 & 6.301 & 7.6655 & TRN & \\
\hline CHEMBL 3716807 & 1537056 & 7.0 & 6.9883 & TST & \\
\hline CHEMBL 3716781 & 1537056 & 7.0 & 6.0039 & TRN & \\
\hline CHEMBL 3714820 & 1537056 & 7.0 & 9.1956 & TRN & \\
\hline CHEMBL3716185 & 1537056 & 11.0 & 6.3036 & TRN & \\
\hline CHEMBL3718521 & 1537056 & 11.0 & 10.7368 & TRN & \\
\hline CHEMBL3718767 & 1537056 & 11.0 & 10.2007 & TRN & \\
\hline CHEMBL3715684 & 1537056 & 11.0 & 9.9368 & TRN & \\
\hline CHEMBL3715290 & 1537056 & 11.0 & 11.8895 & TRN & \\
\hline
\end{tabular}

Page 5841 
Supplemental Table S2.txt

CHEMBL3719052

CHEMBL 3718814

CHEMBL3717169

CHEMBL3718109

CHEMBL 3715250

CHEMBL 3717323

CHEMBL 3717318

CHEMBL 3715779

CHEMBL 3718687

CHEMBL3719036

CHEMBL3719276

CHEMBL3718246

CHEMBL3716896

CHEMBL 3714778

CHEMBL 3719012

CHEMBL3718652

CHEMBL3717267

CHEMBL 3719084

CHEMBL 3717010

CHEMBL3715962

CHEMBL 3718615

CHEMBL 3715436

CHEMBL 3715943

CHEMBL 3717237

CHEMBL 3718614

CHEMBL 3718258

CHEMBL 3717786

CHEMBL 3718000

CHEMBL 3716443

CHEMBL3718309

CHEMBL3717958

CHEMBL 3717298

CHEMBL3717849

CHEMBL 3718308

CHEMBL 3715925

CHEMBL 3716448

CHEMBL3718169

CHEMBL3717345

CHEMBL3714825

CHEMBL 3717326

CHEMBL3716369

CHEMBL 3718190

CHEMBL 3716875

CHEMBL3719334

CHEMBL3714809

CHEMBL 3717729

CHEMBL3718281

CHEMBL 3717358
153705611.0 153705611.0 153705611.0 15370567.0 15370567.0 153705611.0 153705611.0 153705611.0 153705611.0 153705611.0 153705611.0 153705611.0 $1537056 \quad 6.301$ $1537056 \quad 6.301$ 153705611.0 15370567.0 153705611.0 15370565.0 153705611.0 15370565.0 15370567.0 153705611.0 153705611.0 15370567.0 153705611.0 153705611.0 153705611.0 15370567.0 153705611.0 153705611.0 153705611.0 15370565.0 $1537056 \quad 6.301$ 15370567.0 153705611.0 15370567.0 153705611.0 15370567.0 15370567.0 153705611.0 153705611.0 15370567.0 15370567.0 153705611.0 15370567.0 153705611.0 153705611.0 153705611.0
10.1238 TRN

10.8829 TRN

9.781 TRN

10.078 TRN

8.5345 TRN

10.7726 TRN

12.3173 TRN

10.4483 TRN

10.5898 TRN

9.9696 TRN

10.8065 TRN

10.5481 TST

8.3093 TRN

8.8115 TRN

8.4553 TRN

6.5224 TRN

9.9732 TRN

6.8773 TRN

10.5826 TRN

5.0602 TRN

7.2916 TRN

9.5829 TRN

11.0735 TRN

$6.5489999999999995 \quad$ TRN

10.1128 TRN

9.2093 TRN

10.7458 TRN

8.5412 TRN

11.0997 TRN

11.4587 TRN

10.7875 TST

10.0701 TST

5.4209 TRN

6.9072 TRN

11.5345 TRN

9.3569 TRN

11.1352 TST

9.3269 TST

10.1661 TRN

9.154 TRN

9.3571 TRN

8.145 TRN

8.2836 TRN

10.8698 TRN

9.0003 TRN

7.6061 TRN

10.7534 TRN

12.1171 TRN

Page 5842 


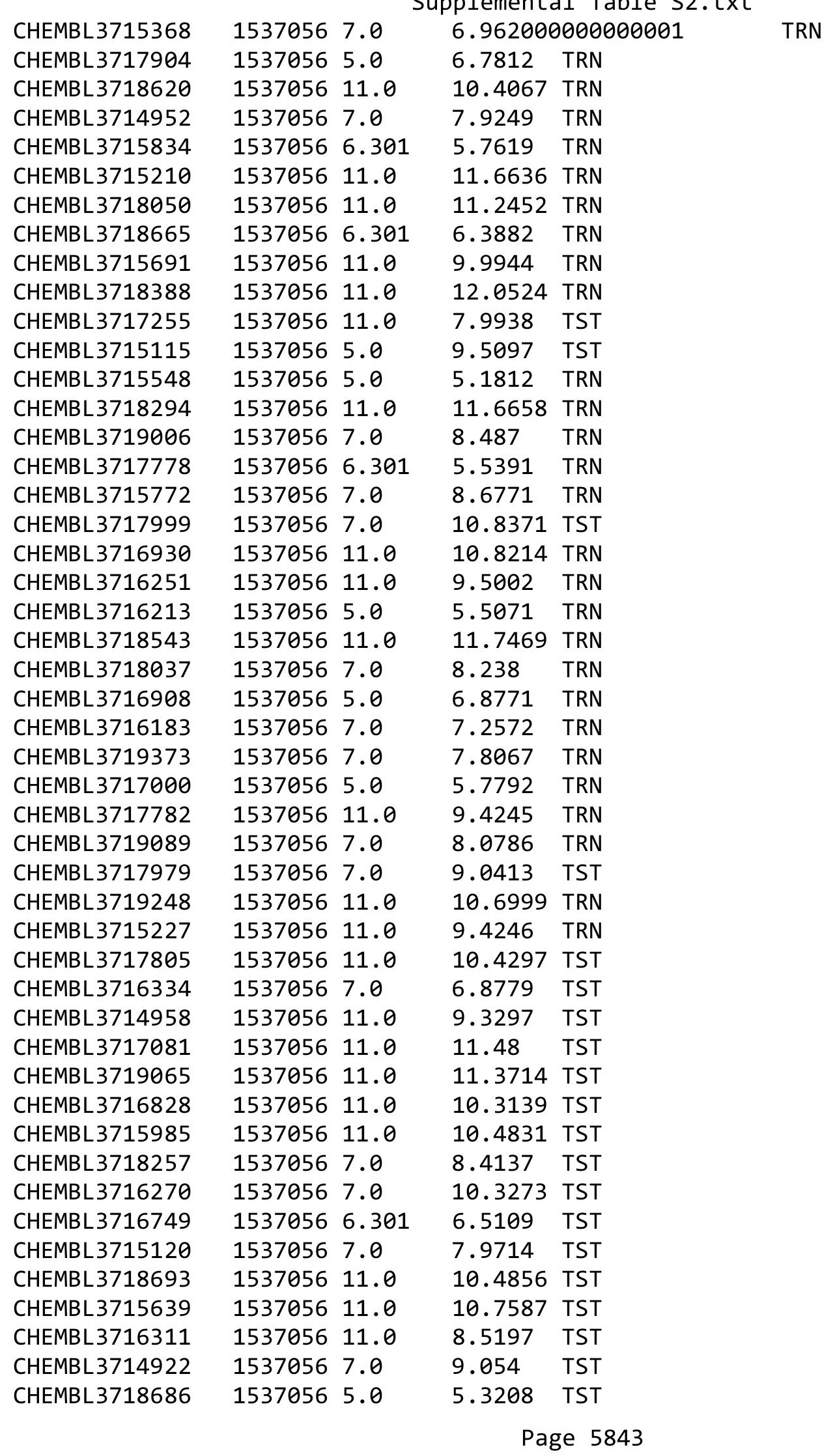


Supplemental Table S2.txt

\begin{tabular}{|c|c|c|c|c|}
\hline HEMBL & 537056 & 11.0 & 10.8586 & TST \\
\hline CHEMBL 3716060 & .537056 & 7.0 & 6.8404 & TS \\
\hline HEMBL3717536 & 537056 & 5.0 & . 3917 & ST \\
\hline HEMBL3719339 & 537056 & 11.0 & 0.1201 & \\
\hline HEMBL3714917 & 537056 & 11.0 & .6466 & ST \\
\hline HEMBL3715903 & 537056 & 7.0 & 8.6206 & \\
\hline HEMBL3715645 & 537056 & 11.0 & 0.538 & \\
\hline HEMBL 263503 & 04160 & 7.9586 & 8.0179 & RN \\
\hline HEMBL 315349 & 104160 & 8.3979 & 8.5093 & PN \\
\hline HEMBL84490 & 04160 & 2.699 & 2.6018 & \\
\hline HEMBL 79291 & 04160 & 3.4948 & 2.9769 & \\
\hline HEMBL 312702 & 04160 & 8.2218 & 8.1218 & \\
\hline HEMBL82106 & 04160 & 9.0 & 8.9366 & RN \\
\hline HEMBL311605 & 104160 & 6.5229 & 6.5638 & RN \\
\hline HEMBL82992 & 04160 & 2.699 & 2.4046 & \\
\hline HEMBL312644 & 04160 & 2.699 & 2.8076 & \\
\hline HEMBL8 & 60 & 2.8239 & 2.6378 & I \\
\hline HEMBL3 & 60 & 3.1249 & 3.0585 & \\
\hline HEMBL 79398 & 104160 & 6.301 & 6.3541 & \\
\hline HEMBL314269 & 60 & 3.8861 & 4.1892 & \\
\hline HEMBL7 & 60 & 5.0 & 4.9873 & TRN \\
\hline HEMBL3 & 50 & 6.5229 & 6.5721 & $\mathrm{RN}$ \\
\hline HEMBL8 & 60 & 5.8239 & 5.6095 & \\
\hline HEMBL83495 & 104160 & 6.5229 & 6.6829 & RN \\
\hline HEMBL84372 & 60 & 5.0809 & 5.2723 & TRN \\
\hline HEMBL8 & 50 & 7.8539 & 7.9638 & RIN \\
\hline HEMBL3 & 50 & 5.8539 & 5.931 & RN \\
\hline HEMBL84101 & 04160 & 6.5229 & 6.6201 & RN \\
\hline HEMBL313011 & 04160 & 5.43 & 5.5424 & TRN \\
\hline CHEMBL 79826 & 04160 & 5.0458 & 4.7154 & IR \\
\hline HEMBL 8 & 50 & 3.37 & 3. & ST \\
\hline HEMBL8 & 10 & 3.5086 & 3.4649 & RN \\
\hline CHEMBL4 & 60 & 6.7447 & 6.7824 & TRN \\
\hline CHEMBL84002 & 04160 & 7.8239 & 7.6452 & IRN \\
\hline HEMBL84217 & 04160 & 8.5229 & 8.5021 & TRN \\
\hline HEMBL 84522 & 60 & 6.8861 & 7.0136 & RN \\
\hline CHEMBL3 & 50 & 2.699 & 49 & 1 \\
\hline CHEMBL82471 & 104160 & 6.301 & 6.41 & TRN \\
\hline CHEMBL419108 & 104160 & 7.301 & 7.1266 & TRN \\
\hline LHEMBL84208 & 04160 & 5.6383 & 5.5678 & TRN \\
\hline CHEMBL 36 & 104160 & 3.2676 & 2.7083 & ST \\
\hline CHEMBL310319 & 104160 & 7.6021 & 7.5271 & RIN \\
\hline CHEMBL83793 & 104160 & 5.7212 & 5.6283 & TRN \\
\hline CHEMBL83981 & 104160 & 2.699 & 2.7866 & TST \\
\hline CHEMBL 314697 & 50 & 7.0969 & 7.3422 & RN \\
\hline CHEMBL82682 & 104160 & 3.0 & 3.0405 & ונ \\
\hline CHEMBL 82415 & 104160 & 5.7447 & 5.1444 & SI \\
\hline CHEMBL84534 & 104160 & 5.9208 & 5.7217 & 「RN \\
\hline
\end{tabular}




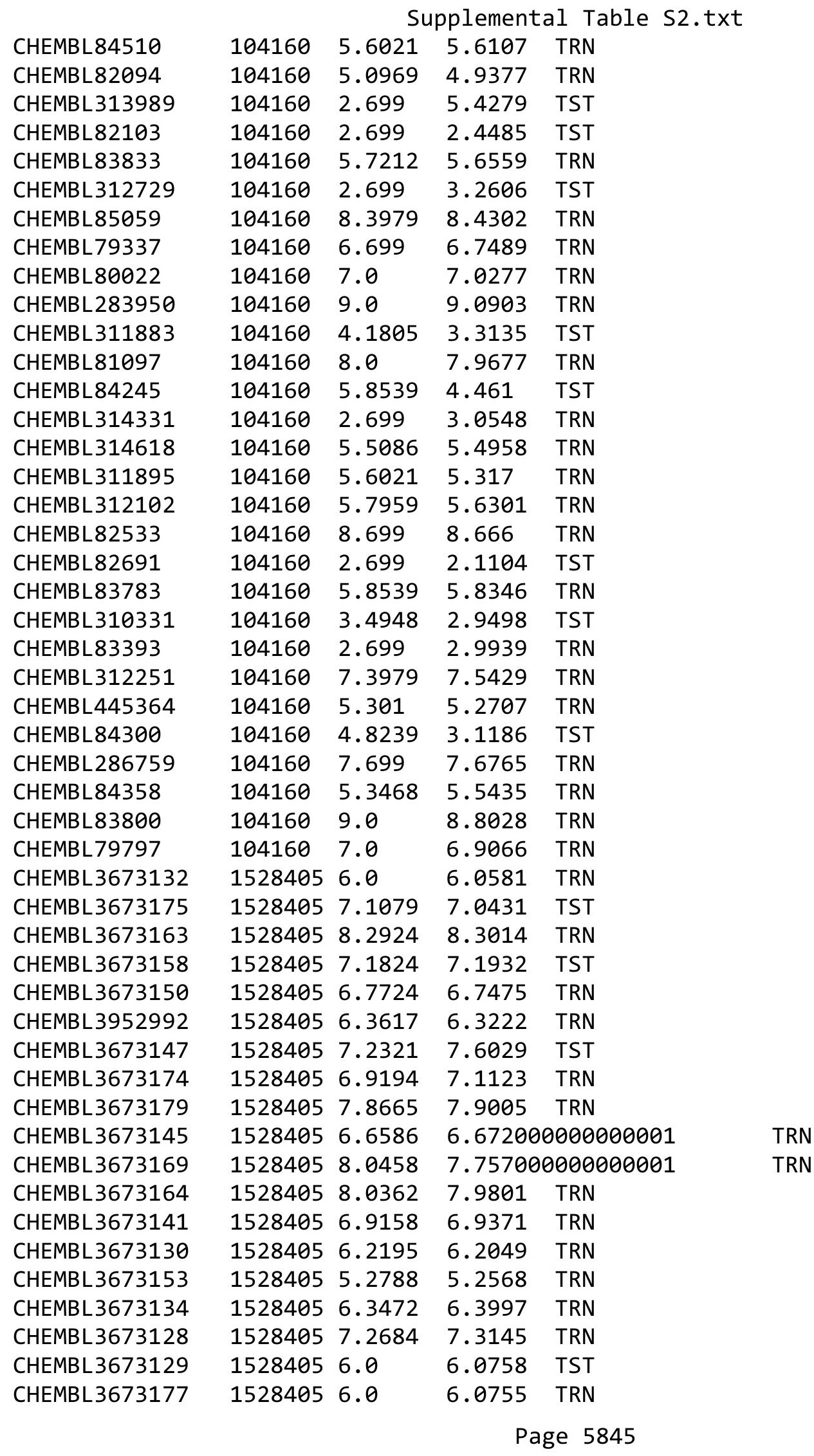


Supplemental Table S2.txt

\begin{tabular}{|c|c|c|c|c|}
\hline CHEMBL3673173 & 1528405 & 7.3686 & 7.385 & TRN \\
\hline CHEMBL3673152 & 1528405 & 6.87 & 6.901 & TRN \\
\hline CHEMBL3673146 & 1528405 & 6.4517 & 6.4236 & TRN \\
\hline CHEMBL 3673142 & 1528405 & 6.806 & 6.8244 & TRN \\
\hline CHEMBL3673149 & 1528405 & 6.0673 & 6.7837 & TST \\
\hline CHEMBL3673144 & 1528405 & 7.3224 & 7.3534 & TRN \\
\hline CHEMBL3673140 & 1528405 & 7.2418 & 7.1201 & TRN \\
\hline CHEMBL3673180 & 1528405 & 5.3961 & 5.3644 & TRN \\
\hline CHEMBL3673170 & 1528405 & 7.9957 & 7.9236 & TRN \\
\hline CHEMBL3673159 & 1528405 & 7.7328 & 7.4126 & TST \\
\hline CHEMBL3673136 & 1528405 & 6.0 & 6.4072 & TST \\
\hline CHEMBL3673165 & 1528405 & 7.3585 & 7.289 & TST \\
\hline CHEMBL3673156 & 1528405 & 6.9851 & 6.9414 & TRN \\
\hline CHEMBL3673161 & 1528405 & 7.5834 & 7.5675 & TRN \\
\hline CHEMBL3673166 & 1528405 & 7.4698 & 7.5467 & TRN \\
\hline CHEMBL3673168 & 1528405 & 7.2581 & 7.2837 & TRN \\
\hline CHEMBL3673139 & 1528405 & 7.6757 & 7.6376 & TRN \\
\hline CHEMBL3673178 & 1528405 & 7.2299 & 7.2347 & TRN \\
\hline CHEMBL3639720 & 1528405 & 6.2119 & 6.2139 & TRN \\
\hline CHEMBL3673127 & 1528405 & 7.0283 & 7.0335 & TRN \\
\hline CHEMBL3673138 & 1528405 & 7.284 & 7.2881 & TRN \\
\hline CHEMBL3673162 & 1528405 & 8.2291 & 8.2758 & TRN \\
\hline CHEMBL3673155 & 1528405 & 6.9348 & 6.8796 & TRN \\
\hline CHEMBL3673160 & 1528405 & 7.5935 & 7.2551 & TST \\
\hline CHEMBL3673172 & 1528405 & 7.1993 & 7.2751 & TRN \\
\hline CHEMBL3673151 & 1528405 & 7.2007 & 7.1901 & TRN \\
\hline CHEMBL3673131 & 1528405 & 7.1296 & 6.9194 & TRN \\
\hline CHEMBL3673143 & 1528405 & 7.0783 & 7.0791 & TRN \\
\hline CHEMBL3673154 & 1528405 & 7.4377 & 7.669 & TRN \\
\hline CHEMBL3673171 & 1528405 & 7.2526 & 7.1628 & TST \\
\hline CHEMBL3673148 & 1528405 & 7.426 & 7.2136 & TST \\
\hline CHEMBL3673157 & 1528405 & 6.6876 & 7.1745 & TST \\
\hline CHEMBL3673167 & 1528405 & 9.1549 & 8.015 & TST \\
\hline CHEMBL3673133 & 1528405 & 6.0 & 6.78100 & 0000000001 \\
\hline CHEMBL3692292 & 1528926 & 6.1675 & 5.1884 & TST \\
\hline CHEMBL3692313 & 1528926 & 6.585 & 6.6808 & TRN \\
\hline CHEMBL3692311 & 1528926 & 6.301 & 6.2517 & TRN \\
\hline CHEMBL3696434 & 1528926 & 6.585 & 5.3695 & TST \\
\hline CHEMBL3692227 & 1528926 & 5.7122 & 5.6773 & TST \\
\hline CHEMBL3696441 & 1528926 & 6.4318 & 6.1831 & TRN \\
\hline CHEMBL3696455 & 1528926 & 5.3915 & 5.3589 & TST \\
\hline CHEMBL3696357 & 1528926 & 3.699 & 4.1037 & TRN \\
\hline CHEMBL3696386 & 1528926 & 3.699 & 3.8866 & TRN \\
\hline CHEMBL3696448 & 1528926 & 6.8861 & 5.7487 & TST \\
\hline CHEMBL3692270 & 1528926 & 5.7496 & 5.7601 & TRN \\
\hline CHEMBL3696407 & 1528926 & 6.7959 & 6.86100 & 0000000001 \\
\hline CHEMBL3696410 & 1528926 & 7.0969 & 6.7313 & TRN \\
\hline CHEMBL3696435 & 1528926 & 5.8761 & 5.7802 & TRN \\
\hline
\end{tabular}


Supplemental Table S2.txt

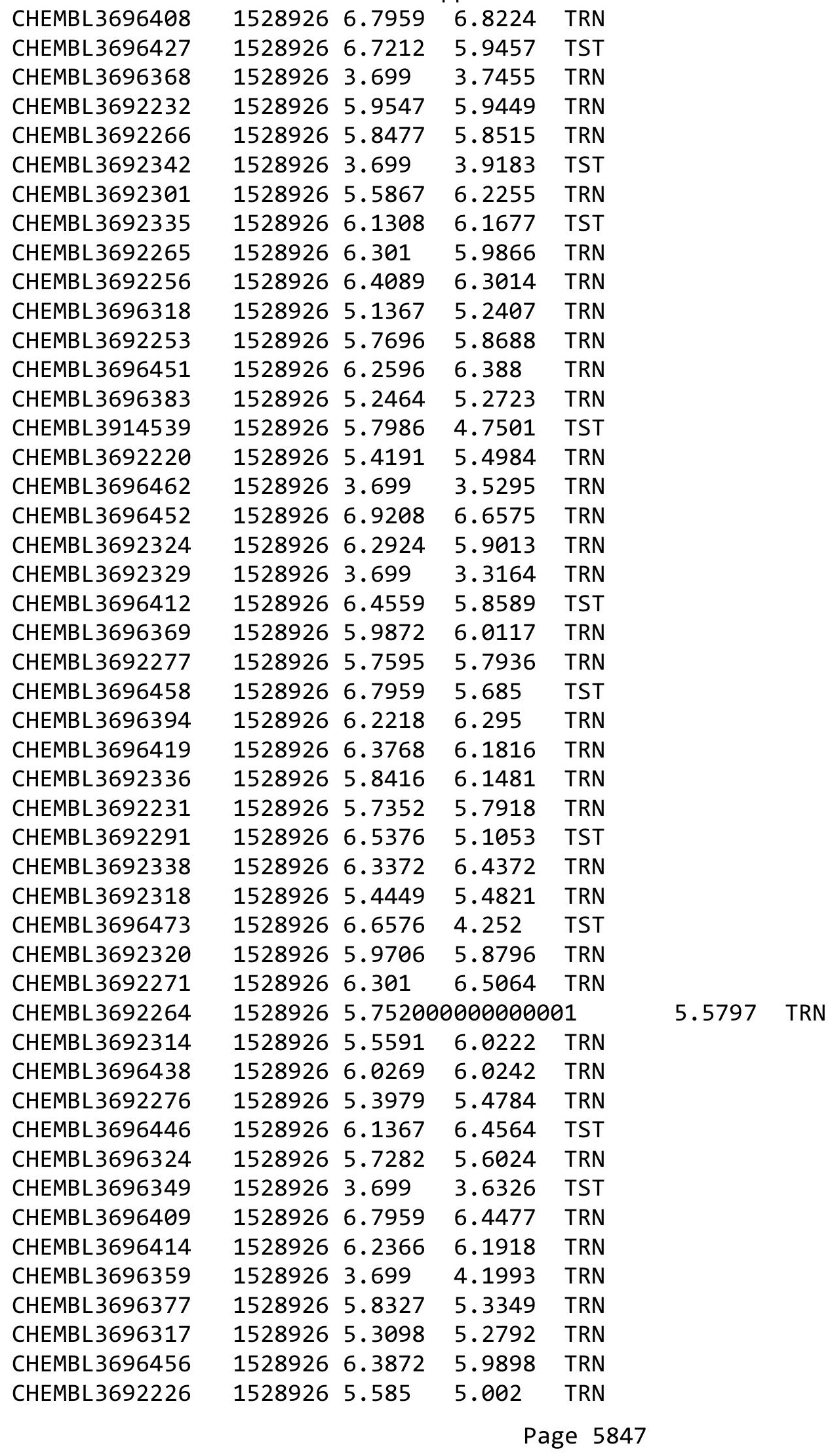


Supplemental Table S2.txt

\begin{tabular}{|c|c|c|c|c|c|}
\hline CHEMBL3696389 & 1528926 & 3.699 & 3.6185 & TRN & \\
\hline CHEMBL 3696363 & 1528926 & 3.699 & 4.3044 & TRN & \\
\hline CHEMBL3692300 & 1528926 & 6.2924 & 5.8492 & TRN & \\
\hline CHEMBL3692289 & 1528926 & 4.9914 & 5.4855 & TRN & \\
\hline CHEMBL 3692278 & 1528926 & 6.3188 & 6.1644 & TRN & \\
\hline CHEMBL3696463 & 1528926 & 3.699 & 3.5139 & TRN & \\
\hline CHEMBL 3692321 & 1528926 & 4.8153 & 5.0558 & TRN & \\
\hline CHEMBL 3692294 & 1528926 & 6.3372 & 6.2752 & TRN & \\
\hline CHEMBL 3696431 & 1528926 & 6.3565 & 6.2969 & TRN & \\
\hline CHEMBL 3692254 & 1528926 & 5.8539 & 5.7772 & TRN & \\
\hline CHEMBL 3692234 & 1528926 & 5.9508 & 6.0268 & TRN & \\
\hline CHEMBL 3692298 & 1528926 & 5.5086 & 5.8037 & TRN & \\
\hline CHEMBL3696423 & 1528926 & 6.5229 & 6.3248 & TRN & \\
\hline CHEMBL 3696442 & 1528926 & 6.585 & 6.7349 & TRN & \\
\hline CHEMBL 3692340 & 1528926 & 5.0306 & 3.9882 & TST & \\
\hline CHEMBL3696467 & 1528926 & 5.9101 & 6.0971 & TRN & \\
\hline CHEMBL 3692238 & 1528926 & 5.8928 & 5.8879 & TRN & \\
\hline CHEMBL 3692262 & 1528926 & 6.4815 & 6.1805 & TRN & \\
\hline CHEMBL 3696437 & 1528926 & 5.5702 & 5.7857 & TRN & \\
\hline CHEMBL 3696428 & 1528926 & 6.4089 & 5.5664 & TST & \\
\hline CHEMBL3696417 & 1528926 & 3.699 & 6.6195 & TST & \\
\hline CHEMBL 3696461 & 1528926 & 5.0926 & 4.7723 & TRN & \\
\hline CHEMBL 3696445 & 1528926 & 6.284 & 5.5608 & TST & \\
\hline CHEMBL 3696360 & 1528926 & 3.699 & 3.2034 & TRN & \\
\hline CHEMBL3696399 & 1528926 & 6.4202 & 5.8478 & TST & \\
\hline CHEMBL 3696424 & 1528926 & 6.1249 & 5.9755 & TRN & \\
\hline CHEMBL 3692345 & 1528926 & 5.5157 & 4.9773 & TRN & \\
\hline CHEMBL3696397 & 1528926 & 6.4318 & 6.3996 & TRN & \\
\hline CHEMBL 3692297 & 1528926 & 6.5229 & 6.5486 & TRN & \\
\hline CHEMBL 3696400 & 1528926 & 5.9547 & 6.0272 & TST & \\
\hline CHEMBL3696439 & 1528926 & 6.6021 & 6.693 & TRN & \\
\hline CHEMBL 3692327 & 1528926 & 3.699 & 4.2197 & TRN & \\
\hline CHEMBL 3692242 & 1528926 & 6.4949 & 6.4021 & TRN & \\
\hline CHEMBL3696387 & 1528926 & 6.1805 & 5.86600 & 00000000005 & TRN \\
\hline CHEMBL 3692246 & 1528926 & 4.9208 & 5.3521 & TRN & \\
\hline CHEMBL3696415 & 1528926 & 3.699 & 6.0547 & TST & \\
\hline CHEMBL 3696316 & 1528926 & 3.699 & 4.0109 & TRN & \\
\hline CHEMBL 3692237 & 1528926 & 5.4815 & 5.8041 & TRN & \\
\hline CHEMBL 3692330 & 1528926 & 5.209 & 5.5542 & TRN & \\
\hline CHEMBL3696385 & 1528926 & 6.4559 & 6.3565 & TRN & \\
\hline CHEMBL3696450 & 1528926 & 6.5528 & 6.2768 & TRN & \\
\hline CHEMBL 3692287 & 1528926 & 5.7959 & 5.83200 & 0000000001 & TRN \\
\hline CHEMBL 3696395 & 1528926 & 5.7447 & 6.2951 & TST & \\
\hline CHEMBL3696372 & 1528926 & 6.2757 & 5.9808 & TRN & \\
\hline CHEMBL3696426 & 1528926 & 6.7696 & 5.2565 & TST & \\
\hline CHEMBL 3696388 & 1528926 & 6.3188 & 5.7045 & TRN & \\
\hline CHEMBL 3696404 & 1528926 & 6.2924 & 6.5222 & TST & \\
\hline CHEMBL 3696405 & 1528926 & 5.7305 & 6.5789 & TST & \\
\hline
\end{tabular}


Supplemental Table S2.txt

\begin{tabular}{|c|c|c|c|c|c|}
\hline CHEMBL3696378 & 1528926 & 4.7328 & 4.9129 & TRN & \\
\hline CHEMBL3696332 & 1528926 & 3.699 & 4.1317 & TRN & \\
\hline CHEMBL 3696370 & 1528926 & 6.1135 & 6.235 & TRN & \\
\hline CHEMBL 3692288 & 1528926 & 6.2676 & 5.9257 & TRN & \\
\hline CHEMBL3696393 & 1528926 & 5.5346 & 5.8246 & TRN & \\
\hline CHEMBL 3692269 & 1528926 & 5.6655 & 5.5646 & TRN & \\
\hline CHEMBL3696398 & 1528926 & 5.8153 & 5.6896 & TRN & \\
\hline CHEMBL 3696443 & 1528926 & 6.284 & 5.4347 & TST & \\
\hline CHEMBL 3692274 & 1528926 & 5.9666 & 6.1196 & TRN & \\
\hline CHEMBL3696411 & 1528926 & 5.8416 & 5.8277 & TRN & \\
\hline CHEMBL 3696335 & 1528926 & 4.7545 & 3.7102 & TST & \\
\hline CHEMBL3696466 & 1528926 & 3.699 & \multicolumn{2}{|c|}{3.4760000000000004} & TRN \\
\hline CHEMBL 3696403 & 1528926 & 6.5376 & 5.9466 & TST & \\
\hline CHEMBL 3692344 & 1528926 & 5.1062 & 5.0346 & TRN & \\
\hline CHEMBL3692303 & 1528926 & 6.0177 & 6.1518 & TRN & \\
\hline CHEMBL 3696382 & 1528926 & 5.082 & 5.3998 & TRN & \\
\hline CHEMBL3692304 & 1528926 & 6.5686 & 6.649 & TRN & \\
\hline CHEMBL3692307 & 1528926 & 6.4815 & 6.6217 & TRN & \\
\hline CHEMBL 3692290 & 1528926 & 6.1549 & 5.0501 & TST & \\
\hline CHEMBL3692343 & 1528926 & 3.699 & 3.9462 & TRN & \\
\hline CHEMBL3696376 & 1528926 & 4.8697 & 4.4281 & TST & \\
\hline CHEMBL3696447 & 1528926 & 6.7696 & 6.416 & TST & \\
\hline CHEMBL3696371 & 1528926 & 6.1024 & 5.9235 & TRN & \\
\hline CHEMBL 3696356 & 1528926 & 3.699 & 3.3481 & TST & \\
\hline CHEMBL 3692296 & 1528926 & 6.284 & 6.2359 & TRN & \\
\hline CHEMBL 3692295 & 1528926 & 6.1549 & 6.2247 & TRN & \\
\hline CHEMBL3692319 & 1528926 & 6.2007 & 5.8689 & TRN & \\
\hline CHEMBL 3696320 & 1528926 & 4.8069 & \multicolumn{2}{|c|}{4.6339999999999995} & TRN \\
\hline CHEMBL 3692293 & 1528926 & 5.7852 & 5.9315 & TRN & \\
\hline CHEMBL3692279 & 1528926 & 6.6576 & 6.3822 & TRN & \\
\hline CHEMBL 3692322 & 1528926 & 5.5768 & 5.8806 & TRN & \\
\hline CHEMBL3692235 & 1528926 & 6.6383 & 6.4293 & TRN & \\
\hline CHEMBL3692251 & 1528926 & 5.9245 & 5.9177 & TRN & \\
\hline CHEMBL3692333 & 1528926 & 6.0362 & 5.8246 & TST & \\
\hline CHEMBL3696342 & 1528926 & 6.0 & 4.3884 & TST & \\
\hline CHEMBL3692308 & 1528926 & 6.9586 & 7.0193 & TRN & \\
\hline CHEMBL3692252 & 1528926 & 5.5452 & 5.8135 & TRN & \\
\hline CHEMBL3692257 & 1528926 & 6.3372 & 6.221 & TRN & \\
\hline CHEMBL3692281 & 1528926 & 5.4295 & 5.6763 & TRN & \\
\hline CHEMBL3692221 & 1528926 & 5.0278 & 6.1029 & TRN & \\
\hline CHEMBL3905536 & 1528926 & 6.7696 & 6.8561 & TRN & \\
\hline CHEMBL3692283 & 1528926 & 5.6216 & 5.4635 & TRN & \\
\hline CHEMBL3692247 & 1528926 & 5.6271 & 5.3511 & TRN & \\
\hline CHEMBL3692323 & 1528926 & 5.6326 & 5.5777 & TRN & \\
\hline CHEMBL3692315 & 1528926 & 5.8996 & 5.7403 & TRN & \\
\hline CHEMBL3692240 & 1528926 & 6.1249 & 5.9268 & TRN & \\
\hline CHEMBL3696381 & 1528926 & 6.1024 & 6.2147 & TRN & \\
\hline CHEMBL3692299 & 1528926 & 6.2441 & 5.8156 & TRN & \\
\hline
\end{tabular}


Supplemental Table S2.txt

\begin{tabular}{|c|c|c|c|c|c|}
\hline CHEMBL3692255 & 1528926 & 5.5272 & 5.7045 & TRN & \\
\hline CHEMBL3696364 & 1528926 & 3.699 & 3.1735 & TST & \\
\hline CHEMBL3696334 & 1528926 & 3.699 & 3.6334 & TST & \\
\hline CHEMBL3692228 & 1528926 & 6.041 & 5.6903 & TST & \\
\hline CHEMBL3696429 & 1528926 & 6.7447 & 6.6061 & TRN & \\
\hline CHEMBL3696358 & 1528926 & 3.699 & 3.806 & TRN & \\
\hline CHEMBL 3692248 & 1528926 & 5.857 & 5.9349 & TRN & \\
\hline CHEMBL3696348 & 1528926 & 3.699 & 3.5298 & TST & \\
\hline CHEMBL3696379 & 1528926 & 3.699 & 4.3152 & TRN & \\
\hline CHEMBL3692273 & 1528926 & 6.2007 & 6.2427 & TRN & \\
\hline CHEMBL3696460 & 1528926 & 5.5935 & 4.2062 & TST & \\
\hline CHEMBL3696402 & 1528926 & 5.2403 & 4.9019 & TST & \\
\hline CHEMBL3692250 & 1528926 & 6.0223 & 6.2785 & TRN & \\
\hline CHEMBL3696436 & 1528926 & 4.9626 & 4.9512 & TRN & \\
\hline CHEMBL3696373 & 1528926 & 3.699 & 4.0618 & TRN & \\
\hline CHEMBL3696416 & 1528926 & 6.1549 & 5.9477 & TRN & \\
\hline CHEMBL3696401 & 1528926 & 6.0088 & 6.3841 & TST & \\
\hline CHEMBL3696380 & 1528926 & 5.5969 & 5.3289 & TRN & \\
\hline CHEMBL3692339 & 1528926 & 3.699 & 3.9068 & TST & \\
\hline CHEMBL3692239 & 1528926 & 6.1549 & 6.1221 & TRN & \\
\hline CHEMBL3692305 & 1528926 & 6.9208 & 6.9716 & TRN & \\
\hline CHEMBL3696418 & 1528926 & 6.6383 & 6.7319 & TRN & \\
\hline CHEMBL3692316 & 1528926 & 6.1549 & 6.5834 & TRN & \\
\hline CHEMBL3696396 & 1528926 & 6.8539 & 6.8893 & TRN & \\
\hline CHEMBL3692309 & 1528926 & 6.4949 & 6.7696 & TRN & \\
\hline CHEMBL3696333 & 1528926 & 3.699 & 3.6543 & TST & \\
\hline CHEMBL3696352 & 1528926 & 3.699 & 4.2252 & TRN & \\
\hline CHEMBL3696444 & 1528926 & 6.0044 & 5.4427 & TST & \\
\hline CHEMBL3639911 & 1528926 & 6.4949 & 6.388 & TRN & \\
\hline CHEMBL3692285 & 1528926 & 5.4342 & 5.5996 & TRN & \\
\hline CHEMBL3943783 & 1528926 & 6.4318 & 6.5876 & TST & \\
\hline CHEMBL3692230 & 1528926 & 6.0915 & 6.3271 & TRN & \\
\hline CHEMBL3696432 & 1528926 & 6.2596 & 6.1147 & TRN & \\
\hline CHEMBL3696367 & 1528926 & 3.699 & 3.748 & TRN & \\
\hline CHEMBL3692259 & 1528926 & 5.4597 & 5.2083 & TRN & \\
\hline CHEMBL3696350 & 1528926 & 3.699 & 3.9917 & TRN & \\
\hline CHEMBL3692261 & 1528926 & 6.5376 & 6.5143 & TRN & \\
\hline CHEMBL3692337 & 1528926 & 6.3188 & 6.3407 & TRN & \\
\hline CHEMBL3696374 & 1528926 & 5.6091 & \multicolumn{2}{|c|}{6.252999999999999} & TRN \\
\hline CHEMBL3692241 & 1528926 & 6.1871 & 6.1494 & TRN & \\
\hline CHEMBL3696433 & 1528926 & 6.9208 & 6.0533 & TST & \\
\hline CHEMBL3692310 & 1528926 & 6.8539 & 6.9499 & TRN & \\
\hline CHEMBL3692263 & 1528926 & 6.3188 & 6.4408 & TRN & \\
\hline CHEMBL3692272 & 1528926 & 5.8268 & 5.7547 & TRN & \\
\hline CHEMBL3692268 & 1528926 & 6.1192 & 5.8539 & TRN & \\
\hline CHEMBL3696362 & 1528926 & 3.699 & 4.1483 & TRN & \\
\hline CHEMBL3696392 & 1528926 & 6.8539 & 6.3835 & TST & \\
\hline CHEMBL3967937 & 1528926 & 6.3872 & 6.0915 & TRN & \\
\hline
\end{tabular}


Supplemental Table S2.txt

\begin{tabular}{|c|c|c|c|c|c|}
\hline CHEMBL 3696322 & 1528926 & 5.063 & 5.1323 & TRN & \\
\hline CHEMBL3696449 & 1528926 & 6.1024 & 5.7443 & TST & \\
\hline CHEMBL3696353 & 1528926 & 3.699 & 3.571 & TRN & \\
\hline CHEMBL 3696366 & 1528926 & 3.699 & 3.4364 & TRN & \\
\hline CHEMBL3696422 & 1528926 & 6.284 & 6.1694 & TST & \\
\hline CHEMBL3696425 & 1528926 & 6.6383 & 5.3502 & TST & \\
\hline CHEMBL 3696440 & 1528926 & 6.4089 & 6.4611 & TRN & \\
\hline CHEMBL 3692280 & 1528926 & 6.3768 & 6.317 & TRN & \\
\hline CHEMBL 3692317 & 1528926 & 6.2676 & 6.2483 & TRN & \\
\hline CHEMBL3696430 & 1528926 & 6.3768 & 5.2626 & TST & \\
\hline CHEMBL3696375 & 1528926 & 6.1675 & 5.9404 & TRN & \\
\hline CHEMBL 3692334 & 1528926 & 5.7878 & 5.9723 & TST & \\
\hline CHEMBL3692258 & 1528926 & 6.0809 & 5.8601 & TRN & \\
\hline CHEMBL 3692245 & 1528926 & 5.6596 & 5.5233 & TRN & \\
\hline CHEMBL3692236 & 1528926 & 5.857 & 6.4636 & TRN & \\
\hline CHEMBL3692341 & 1528926 & 4.9586 & 4.0726 & TST & \\
\hline CHEMBL3696453 & 1528926 & 5.4214 & 5.5448 & TST & \\
\hline CHEMBL3696390 & 1528926 & 6.1487 & 6.0965 & TRN & \\
\hline CHEMBL3696323 & 1528926 & 5.1918 & 5.1288 & TRN & \\
\hline CHEMBL3696365 & 1528926 & 3.699 & 3.7453 & TRN & \\
\hline CHEMBL3938385 & 1528926 & 6.0915 & 6.6878 & TST & \\
\hline CHEMBL3696472 & 1528926 & 6.2366 & 4.7324 & TST & \\
\hline CHEMBL3696361 & 1528926 & 5.0888 & 4.883 & TRN & \\
\hline CHEMBL 3692267 & 1528926 & 6.3372 & 6.2417 & TRN & \\
\hline CHEMBL 3696355 & 1528926 & 5.5317 & 4.7445 & TRN & \\
\hline CHEMBL3692275 & 1528926 & 6.7212 & 6.2293 & TRN & \\
\hline CHEMBL 3696321 & 1528926 & 5.5157 & 4.9279 & TRN & \\
\hline CHEMBL3696406 & 1528926 & 6.4202 & 6.5641 & TRN & \\
\hline CHEMBL 3696391 & 1528926 & 7.0969 & 6.4806 & TST & \\
\hline CHEMBL 3696384 & 1528926 & 6.0 & 5.9297 & TRN & \\
\hline CHEMBL 3692229 & 1528926 & 5.9508 & 6.2742 & TRN & \\
\hline CHEMBL3692312 & 1528926 & 6.4559 & 6.5482 & TRN & \\
\hline CHEMBL 3696347 & 1528926 & 3.699 & 3.7527 & TST & \\
\hline CHEMBL 3696413 & 1528926 & 3.699 & 5.8657 & TST & \\
\hline CHEMBL 3696454 & 1528926 & 5.4377 & 4.8176 & TST & \\
\hline CHEMBL 3692284 & 1528926 & 6.8539 & 6.0647 & TRN & \\
\hline CHEMBL3696319 & 1528926 & 4.9066 & 4.8877 & TRN & \\
\hline CHEMBL3696346 & 1528926 & 3.699 & 3.6696 & TRN & \\
\hline CHEMBL3696457 & 1528926 & 6.2291 & 4.8972 & TST & \\
\hline CHEMBL 3692282 & 1528926 & 6.7447 & 6.79700 & 0000000001 & TRN \\
\hline CHEMBL3692260 & 1528926 & 5.6946 & 5.8917 & TRN & \\
\hline CHEMBL3692325 & 1528926 & 3.699 & 3.38 & TRN & \\
\hline CHEMBL3981408 & 1528926 & 5.8182 & 5.8927 & TRN & \\
\hline CHEMBL3692306 & 1528926 & 6.4685 & 6.4731 & TST & \\
\hline CHEMBL3696459 & 1528926 & 6.4437 & 5.2019 & TST & \\
\hline CHEMBL3639952 & 1528926 & 3.699 & 3.7607 & TRN & \\
\hline CHEMBL3692286 & 1528926 & 5.52 & 5.6333 & TRN & \\
\hline CHEMBL3639953 & 1528926 & 6.1871 & 6.2069 & TRN & \\
\hline
\end{tabular}

Page 5851 


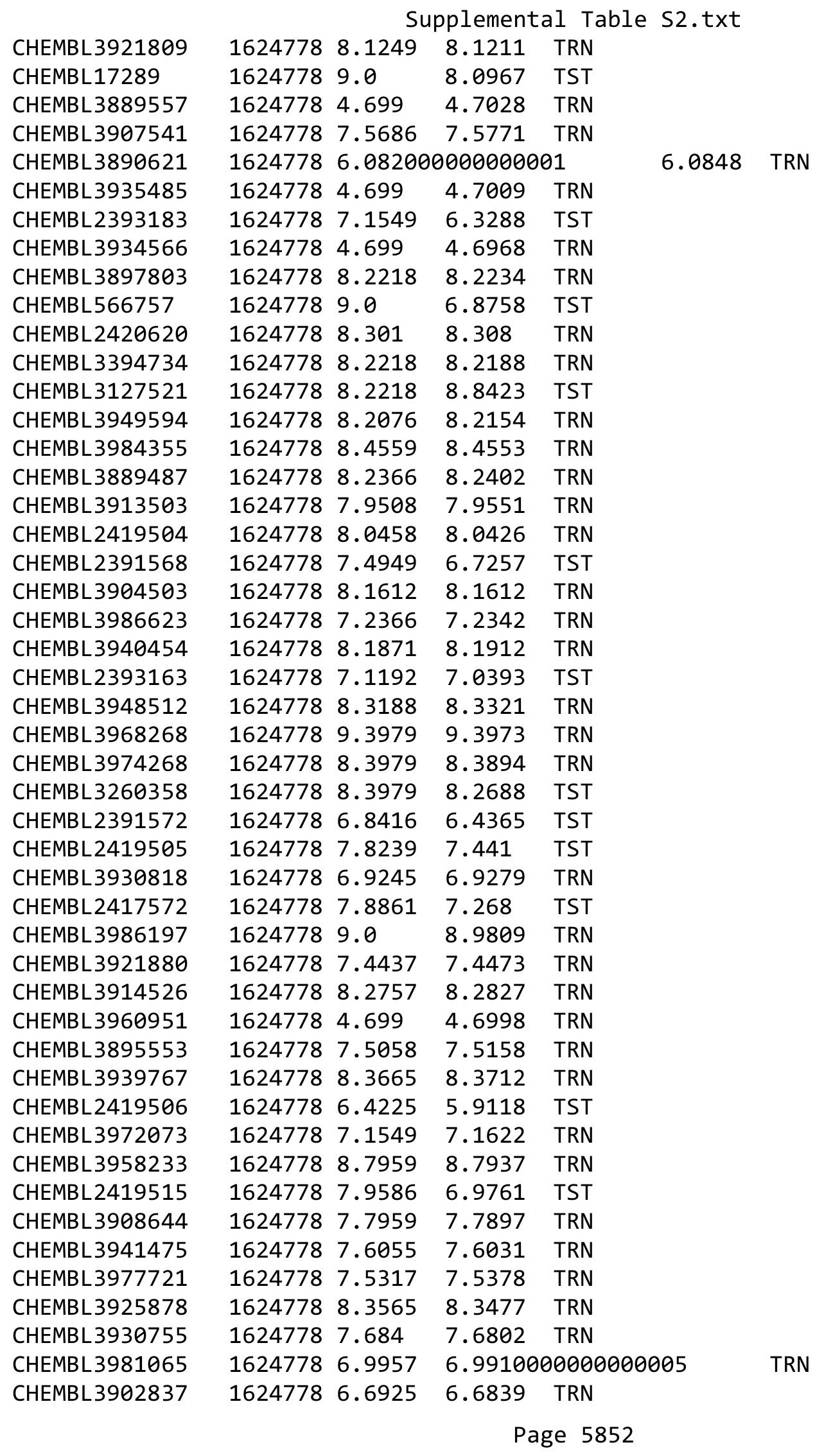


Supplemental Table S2.txt

\begin{tabular}{|c|c|c|c|c|c|}
\hline CHEMBL3958520 & 1624778 & 6.1229 & 6.1162 & TRN & \\
\hline CHEMBL3963163 & 1624778 & 8.7959 & 8.7959 & TRN & \\
\hline CHEMBL3962066 & 1624778 & 4.699 & 4.6968 & TRN & \\
\hline CHEMBL3394738 & 1624778 & 7.9586 & 7.5635 & TST & \\
\hline CHEMBL3959982 & 1624778 & 4.699 & 4.6923 & TRN & \\
\hline CHEMBL3923552 & 1624778 & 8.4202 & 8.4152 & TRN & \\
\hline CHEMBL3932498 & 1624778 & 7.8761 & 7.8781 & TRN & \\
\hline CHEMBL 2393174 & 1624778 & 4.699 & 6.5084 & TST & \\
\hline CHEMBL3913883 & 1624778 & 8.7959 & 8.793 & TRN & \\
\hline CHEMBL 2420629 & 1624778 & 8.699 & 7.7724 & TST & \\
\hline CHEMBL3978768 & 1642193 & 6.1986 & 6.7294 & TST & \\
\hline CHEMBL3903909 & 1642193 & 5.6038 & 5.7553 & TRN & \\
\hline CHEMBL3355549 & 1642193 & 6.8297 & 6.7883 & TRN & \\
\hline CHEMBL3940282 & 1642193 & 7.0809 & 6.1885 & TRN & \\
\hline CHEMBL3949701 & 1642193 & 6.8268 & 6.9497 & TST & \\
\hline CHEMBL3945649 & 1642193 & 7.3872 & 7.1458 & TRN & \\
\hline CHEMBL3922142 & 1642193 & 7.3372 & 7.3069 & TRN & \\
\hline CHEMBL3972198 & 1642193 & 5.7841 & 5.772 & TRN & \\
\hline CHEMBL3930875 & 1642193 & 7.6383 & 7.3824 & TRN & \\
\hline CHEMBL3976290 & 1642193 & 7.2366 & 7.0188 & TRN & \\
\hline CHEMBL3965483 & 1642193 & 5.4036 & 6.0807 & TRN & \\
\hline CHEMBL3935431 & 1642193 & 7.8539 & 7.8819 & TRN & \\
\hline CHEMBL3952816 & 1642193 & 7.7959 & 7.4477 & TRN & \\
\hline CHEMBL3951241 & 1642193 & 7.9208 & \multicolumn{2}{|c|}{7.582999999999999} & TST \\
\hline CHEMBL3956574 & 1642193 & 6.7305 & 6.9376 & TST & \\
\hline CHEMBL3355542 & 1642193 & 8.301 & 8.2656 & TRN & \\
\hline CHEMBL3914589 & 1642193 & 7.8539 & 7.5035 & TST & \\
\hline CHEMBL3961837 & 1642193 & 7.4202 & 7.1617 & TRN & \\
\hline CHEMBL3921058 & 1642193 & 6.9393 & 7.5929 & TRN & \\
\hline CHEMBL 3899481 & 1642193 & 5.7055 & 7.4604 & TST & \\
\hline CHEMBL3355988 & 1642193 & 7.1675 & 7.0744 & TRN & \\
\hline CHEMBL3355555 & 1642193 & 6.9547 & 6.7764 & TRN & \\
\hline CHEMBL3355559 & 1642193 & 6.6253 & \multicolumn{2}{|c|}{7.1370000000000005} & TRN \\
\hline CHEMBL3895053 & 1642193 & 7.8861 & 7.1806 & TRN & \\
\hline CHEMBL3355543 & 1642193 & 6.8794 & 7.3862 & TST & \\
\hline CHEMBL3355547 & 1642193 & 6.4225 & 7.1528 & TRN & \\
\hline CHEMBL3902131 & 1642193 & 6.2857 & 6.0718 & TRN & \\
\hline CHEMBL3915263 & 1642193 & 7.7696 & 7.8034 & TRN & \\
\hline CHEMBL3355550 & 1642193 & 7.6021 & 7.1933 & TRN & \\
\hline CHEMBL1952325 & 1642193 & 7.0915 & 6.9552 & TST & \\
\hline CHEMBL3355987 & 1642193 & 7.6383 & 7.4017 & TRN & \\
\hline CHEMBL3959607 & 1642193 & 7.5229 & 7.0908 & TRN & \\
\hline CHEMBL3978991 & 1642193 & 5.9245 & 6.7803 & TRN & \\
\hline CHEMBL3966574 & 1642193 & 5.4196 & 5.8388 & TST & \\
\hline CHEMBL3355553 & 1642193 & 7.1805 & 7.0299 & TRN & \\
\hline CHEMBL3976705 & 1642193 & 7.7959 & 7.2082 & TRN & \\
\hline CHEMBL3965060 & 1642193 & 7.4815 & 7.3095 & TRN & \\
\hline CHEMBL3953965 & 1642193 & 7.5528 & 7.519 & TRN & \\
\hline
\end{tabular}


Supplemental Table S2.txt

\begin{tabular}{|c|c|c|c|c|c|c|}
\hline CHEMBL3355990 & 1642193 & 6.7852 & 6.7064 & TRN & & \\
\hline CHEMBL3355545 & 1642193 & 6.7055 & 6.7117 & TRN & & \\
\hline CHEMBL3935450 & 1642193 & 6.7747 & 6.9746 & TST & & \\
\hline CHEMBL3941934 & 1642193 & 7.7447 & 7.528 & TRN & & \\
\hline CHEMBL 3938841 & 1642193 & 8.3979 & 7.836 & TRN & & \\
\hline CHEMBL3928943 & 1642193 & 8.699 & 8.3194 & TRN & & \\
\hline CHEMBL 3908640 & 1642193 & 7.2366 & 6.7726 & TRN & & \\
\hline CHEMBL3947584 & 1642193 & 3.5229 & 5.7828 & TST & & \\
\hline CHEMBL3922404 & 1642193 & 5.7878 & 6.9116 & TRN & & \\
\hline CHEMBL3976594 & 1642193 & 8.0969 & 8.2863 & TRN & & \\
\hline CHEMBL 3940944 & 1642193 & 6.6216 & 6.8325 & TRN & & \\
\hline CHEMBL3890318 & 1642193 & 5.4996 & 5.8564 & TRN & & \\
\hline CHEMBL3912135 & 1642193 & 6.9872 & 7.1859 & TRN & & \\
\hline CHEMBL3929683 & 1642193 & 8.1549 & 7.5572 & TST & & \\
\hline CHEMBL 3935594 & 1642193 & 8.0 & 7.1793 & TRN & & \\
\hline CHEMBL3948326 & 1642193 & 6.3116 & 6.2159 & TRN & & \\
\hline CHEMBL3922693 & 1642193 & 6.2815 & 6.4269 & TRN & & \\
\hline CHEMBL 3957249 & 1642193 & 7.4437 & 7.7455 & TRN & & \\
\hline CHEMBL426658 & 1642193 & 7.3188 & 6.8803 & TST & & \\
\hline CHEMBL 3899380 & 1642193 & 7.0506 & 7.4322 & TRN & & \\
\hline CHEMBL 3943090 & 1642193 & 7.7212 & 7.9711 & TRN & & \\
\hline CHEMBL3937592 & 1642193 & \multicolumn{3}{|c|}{6.7620000000000005} & 7.0192 & $T$ \\
\hline CHEMBL3914508 & 1642193 & 7.2518 & 7.7926 & TRN & & \\
\hline CHEMBL3964407 & 1642193 & 8.1549 & 7.6495 & TRN & & \\
\hline CHEMBL3904958 & 1642193 & 6.8153 & 6.9098 & TRN & & \\
\hline CHEMBL3961500 & 1642193 & 7.2757 & 7.1978 & TRN & & \\
\hline CHEMBL3967542 & 1642193 & 6.3279 & 8.0585 & TST & & \\
\hline CHEMBL3973281 & 1642193 & 8.3979 & 8.4669 & TRN & & \\
\hline CHEMBL3947323 & 1642193 & 8.3979 & 8.5512 & TRN & & \\
\hline CHEMBL3911729 & 1642193 & 6.1415 & 6.1885 & TST & & \\
\hline CHEMBL3973693 & 1642193 & 3.5229 & 6.1923 & TST & & \\
\hline CHEMBL3355558 & 1642193 & 7.0269 & 7.4957 & TST & & \\
\hline CHEMBL3897790 & 1642193 & 7.4685 & 7.9335 & TRN & & \\
\hline CHEMBL3966882 & 1642193 & 5.4123 & 6.2428 & TST & & \\
\hline CHEMBL3355546 & 1642193 & 6.6904 & 7.3345 & TRN & & \\
\hline CHEMBL3950665 & 1642193 & 6.6459 & 7.1779 & TST & & \\
\hline CHEMBL3894085 & 1642193 & 6.2984 & 7.1352 & TRN & & \\
\hline CHEMBL3929768 & 1642193 & 7.5229 & 7.5931 & TST & & \\
\hline CHEMBL 3975308 & 1642193 & 9.0 & 7.954 & TRN & & \\
\hline CHEMBL3943200 & 1642193 & 5.5482 & 6.6046 & TST & & \\
\hline CHEMBL3951229 & 1642193 & 6.61799 & 999999999 & 99 & 6.8316 & TRI \\
\hline CHEMBL3986216 & 1642193 & 7.1612 & 7.4291 & TRN & & \\
\hline CHEMBL3355560 & 1642193 & 6.4225 & 6.6733 & TRN & & \\
\hline CHEMBL3979144 & 1642193 & 8.301 & 7.8076 & TRN & & \\
\hline CHEMBL3936197 & 1642193 & 8.0969 & 7.6116 & TRN & & \\
\hline CHEMBL3355552 & 1642193 & 7.7696 & 7.4013 & TRN & & \\
\hline CHEMBL3895282 & 1642193 & 6.1649 & 6.2422 & TST & & \\
\hline CHEMBL3926526 & 1642193 & 6.699 & 6.5881 & TRN & & \\
\hline
\end{tabular}


Supplemental Table S2.txt

\begin{tabular}{|c|c|c|c|c|c|c|}
\hline CHEMBL3956500 & 1642193 & 6.6861 & 7.225 & TRN & & \\
\hline CHEMBL3355544 & 1642193 & 7.5686 & 7.3247 & TRN & & \\
\hline CHEMBL3962567 & 1642193 & 7.4685 & 8.2593 & TST & & \\
\hline CHEMBL3355557 & 1642193 & 7.6198 & 8.2929 & TRN & & \\
\hline CHEMBL3917577 & 1642193 & 8.0458 & 7.8565 & TRN & & \\
\hline CHEMBL3893254 & 1642193 & 7.1549 & 5.6527 & TST & & \\
\hline CHEMBL3980238 & 1642193 & 5.4881 & 5.8752 & TST & & \\
\hline CHEMBL3355541 & 1642193 & 7.3468 & 7.2924 & TRN & & \\
\hline CHEMBL3891871 & 1642193 & 7.8861 & 6.9455 & TRN & & \\
\hline CHEMBL3355551 & 1642193 & 7.2676 & 6.6399 & TRN & & \\
\hline CHEMBL3967586 & 1642193 & 6.16299 & 99999999 & 99 & 7.4945 & TRN \\
\hline CHEMBL3918006 & 1642193 & 7.284 & 7.353 & TRN & & \\
\hline CHEMBL3927091 & 1642193 & 7.5229 & 7.2821 & TRN & & \\
\hline CHEMBL3932320 & 1642193 & 6.2573 & 6.8108 & TST & & \\
\hline CHEMBL3905035 & 1642193 & 6.8386 & 7.1738 & TRN & & \\
\hline CHEMBL1718692 & 812917 & 3.699 & 3.6401 & TRN & & \\
\hline CHEMBL1706542 & 812917 & 3.699 & 3.5486 & TRN & & \\
\hline CHEMBL1569174 & 812917 & 6.8539 & 5.9104 & TRN & & \\
\hline CHEMBL1729147 & 812917 & 3.699 & 3.7144 & TST & & \\
\hline CHEMBL1700889 & 812917 & 4.8508 & 5.0062 & TRN & & \\
\hline CHEMBL1708215 & 812917 & 3.699 & 3.515 & TRN & & \\
\hline CHEMBL1321508 & 812917 & 3.699 & 4.4508 & TST & & \\
\hline CHEMBL1716673 & 812917 & 3.699 & 3.4706 & TRN & & \\
\hline CHEMBL1538784 & 812917 & 3.699 & 5.0929 & TRN & & \\
\hline CHEMBL1723582 & 812917 & 3.699 & 3.4657 & TRN & & \\
\hline CHEMBL1411903 & 812917 & 3.699 & 3.7033 & TST & & \\
\hline CHEMBL1706268 & 812917 & 5.056 & 4.5328 & TRN & & \\
\hline CHEMBL1736791 & 812917 & 3.699 & 4.2332 & TRN & & \\
\hline CHEMBL1316316 & 812917 & 3.699 & 4.4155 & TST & & \\
\hline CHEMBL1363341 & 812917 & 3.699 & 3.7787 & TST & & \\
\hline CHEMBL1706382 & 812917 & 3.699 & 3.4798 & TRN & & \\
\hline CHEMBL1700405 & 812917 & 6.1871 & 5.9041 & TRN & & \\
\hline CHEMBL1720861 & 812917 & 3.699 & 3.8021 & TRN & & \\
\hline CHEMBL1420187 & 812917 & 5.2218 & 5.3349 & TRN & & \\
\hline CHEMBL1728008 & 812917 & 3.699 & 4.8685 & TRN & & \\
\hline CHEMBL1728652 & 812917 & 4.9678 & 4.5586 & TRN & & \\
\hline CHEMBL1521474 & 812917 & 3.699 & 4.8402 & TST & & \\
\hline CHEMBL1710033 & 812917 & 5.8239 & 5.6286 & TRN & & \\
\hline CHEMBL1700826 & 812917 & 3.699 & 3.4501 & TRN & & \\
\hline CHEMBL1450407 & 812917 & 5.4145 & 5.773 & TRN & & \\
\hline CHEMBL1731582 & 812917 & 3.699 & 3.7919 & TRN & & \\
\hline CHEMBL1715638 & 812917 & 3.699 & 3.5131 & TRN & & \\
\hline CHEMBL1732337 & 812917 & 6.6198 & 6.1593 & TRN & & \\
\hline CHEMBL1407805 & 812917 & 3.699 & 4.2332 & TST & & \\
\hline CHEMBL1717116 & 812917 & 5.3665 & 5.4849 & TRN & & \\
\hline CHEMBL1725712 & 812917 & 3.699 & 4.1948 & TRN & & \\
\hline CHEMBL1342760 & 812917 & 3.699 & 4.7974 & TRN & & \\
\hline CHEMBL1731586 & 812917 & 3.699 & 3.6924 & TRN & & \\
\hline
\end{tabular}




\begin{tabular}{|c|c|c|c|c|c|}
\hline & & \multicolumn{4}{|c|}{ Supplemental Table s2.txt } \\
\hline CHEMBL1532328 & 812917 & 5.5406 & 5.3773 & TRN & \\
\hline CHEMBL 2018275 & 812917 & 3.699 & 3.8842 & TST & \\
\hline CHEMBL1535050 & 812917 & 3.699 & 4.0965 & TST & \\
\hline CHEMBL1716972 & 812917 & 3.699 & 3.7694 & TRN & \\
\hline CHEMBL1519988 & 812917 & 3.699 & 4.1345 & TST & \\
\hline CHEMBL1351584 & 812917 & 5.1391 & 5.2205 & TRN & \\
\hline CHEMBL1735926 & 812917 & 5.4855 & 5.7501 & TRN & \\
\hline CHEMBL1721360 & 812917 & 3.699 & 3.4638 & TRN & \\
\hline CHEMBL1569954 & 812917 & 5.6882 & 4.8685 & TRN & \\
\hline CHEMBL1699379 & 812917 & 3.699 & 3.4777 & TRN & \\
\hline CHEMBL1704728 & 812917 & 6.4318 & 6.0395 & TRN & \\
\hline CHEMBL1719579 & 812917 & 3.699 & 4.7812 & TRN & \\
\hline CHEMBL1726725 & 812917 & 3.699 & 3.4386 & TRN & \\
\hline CHEMBL1719980 & 812917 & 3.699 & 4.0886 & TRN & \\
\hline CHEMBL1709705 & 812917 & 6.2366 & 5.8772 & TRN & \\
\hline CHEMBL1729949 & 812917 & 3.699 & 3.6236 & TRN & \\
\hline CHEMBL1712058 & 812917 & 4.8153 & 4.4982 & TRN & \\
\hline CHEMBL1730320 & 812917 & 3.699 & 3.606006 & 00000000003 & TRN \\
\hline CHEMBL 2018276 & 812917 & 3.699 & 4.1609 & TST & \\
\hline CHEMBL1433326 & 812917 & 3.699 & 3.7393 & TST & \\
\hline CHEMBL1412853 & 812917 & 3.699 & 4.4517 & TST & \\
\hline CHEMBL1554526 & 812917 & 5.4949 & 4.9528 & TST & \\
\hline CHEMBL1713298 & 812917 & 7.5229 & 7.1839 & TRN & \\
\hline CHEMBL1717353 & 812917 & 3.699 & 4.5675 & TRN & \\
\hline CHEMBL1720257 & 812917 & 5.2396 & 5.4722 & TRN & \\
\hline CHEMBL1733280 & 812917 & 5.3645 & 5.1657 & TRN & \\
\hline CHEMBL1727158 & 812917 & 3.699 & 3.717 & TRN & \\
\hline CHEMBL1612423 & 812917 & 6.3098 & 4.7812 & TRN & \\
\hline CHEMBL 1700026 & 812917 & 3.699 & 3.5295 & TRN & \\
\hline CHEMBL1364793 & 812917 & 5.308 & 5.9025 & TRN & \\
\hline CHEMBL1314048 & 812917 & 3.699 & 4.4181 & TST & \\
\hline CHEMBL1721926 & 812917 & 5.7878 & 5.6679 & TRN & \\
\hline CHEMBL1732890 & 812917 & 3.699 & 4.0864 & TRN & \\
\hline CHEMBL1710228 & 812917 & 3.699 & 3.8468 & TST & \\
\hline CHEMBL1734509 & 812917 & 5.7375 & 5.4175 & TST & \\
\hline CHEMBL456225 & 540740 & 8.06299 & 99999999 & 8.4447 & I RT \\
\hline CHEMBL510745 & 540740 & 8.301 & 8.4789 & TRN & \\
\hline CHEMBL516187 & 540740 & 7.7986 & 8.8676 & TRN & \\
\hline CHEMBL460636 & 540740 & 8.4559 & 8.0691 & TRN & \\
\hline CHEMBL515575 & 540740 & 9.3979 & 8.8885 & TRN & \\
\hline CHEMBL511161 & 540740 & 8.7447 & 8.8602 & TRN & \\
\hline CHEMBL514606 & 540740 & 7.2441 & 7.0783 & TRN & \\
\hline CHEMBL475096 & 540740 & 8.6778 & 8.2789 & TRN & \\
\hline CHEMBL516389 & 540740 & 9.301 & 8.5532 & TST & \\
\hline CHEMBL473701 & 540740 & 9.0 & 8.2253 & TST & \\
\hline CHEMBL515554 & 540740 & 7.0506 & 7.1273 & TRN & \\
\hline CHEMBL457244 & 540740 & 8.5607 & 8.3601 & TRN & \\
\hline CHEMBL516077 & 540740 & 7.71 & 7.9449 & TRN & \\
\hline
\end{tabular}




\begin{tabular}{|c|c|c|c|c|}
\hline & & & & \\
\hline CHEMBL473068 & 540740 & 8.3925 & 963 & TRA \\
\hline CHEMBL475094 & 540740 & 9.0458 & 8.8961 & \\
\hline HEMBL474485 & 40740 & 8.6778 & .8025 & \\
\hline CHEMBL474096 & 540740 & 9.301 & 8.8977 & \\
\hline CHEMBL471880 & 40740 & 9.2218 & 8.8973 & \\
\hline CHEMBL475496 & 40740 & 7.3125 & 7.7709 & \\
\hline CHEMBL518325 & 40740 & 8.5935 & 8.2779 & \\
\hline CHEMBL473700 & 540740 & 9.3979 & 8.4781 & \\
\hline CHEMBL472867 & 540740 & 7.3206 & 7.8452 & \\
\hline CHEMBL241272 & 40740 & 8.1675 & 7.5606 & \\
\hline CHEMBL501088 & 540740 & 8.4202 & 8.4976 & \\
\hline CHEMBL475707 & 540740 & 9.1549 & 8.3832 & \\
\hline CHEMBL515829 & 540740 & 8.6676 & 8.311 & \\
\hline CHEMBL240657 & 540740 & 7.6383 & 6.8397 & \\
\hline CHEMBL510201 & 40740 & 7.5086 & 7.0046 & \\
\hline CHEMBL473898 & 40 & 8.8539 & 8.7496 & \\
\hline CHEMBL472669 & 540740 & 9.301 & 8.49 & \\
\hline CHEMBL514662 & 540740 & 9.2218 & 8.4234 & TS \\
\hline CHEMBL 4 & 540740 & 7.0809 & 6.9662 & \\
\hline CHEMBL & 40 & 7.4 & 7.0598 & . \\
\hline CHEMBL: & 40 & 8.8539 & 8.8375 & \\
\hline CHEMBL511162 & 740 & 8.4437 & 8.8196 & $\mathrm{TP}$ \\
\hline CHEMBL464191 & 54 & 8.4949 & 8.1563 & $\mathrm{TP}$ \\
\hline CHEMBL5 & 40 & 9.0 & 8.9606 & TRI \\
\hline CHEMBL 2 & 40 & 361 & 8.2949 & \\
\hline CHEMBL & 40 & 8.7696 & 8.5207 & \\
\hline CHEMBL474091 & 54 & 7.0757 & 6.9179 & TF \\
\hline CHEMBL473279 & 540740 & 9.301 & 8.9096 & $\mathrm{TP}$ \\
\hline CHEMBL516024 & 540740 & 7.585 & 7.8827 & TRI \\
\hline CHEMBL4 & 40 & 9.301 & 8.501 & \\
\hline CHEMBL & 40 & 8.7959 & 69 & $\mathrm{TR}$ \\
\hline CHEMBL471882 & $54 e$ & 9.1549 & 9.0012 & TR \\
\hline CHEMBL473272 & 540740 & 9.0 & 8.8635 & TR \\
\hline CHEMBL474092 & 40740 & 8.8239 & 8.9554 & $\mathrm{TR}$ \\
\hline CHEMBL517167 & 40 & 9.0969 & 8.3013 & TS \\
\hline CHEMBL473884 & $54 €$ & 7.7328 & 7.8589 & TRI \\
\hline CHEMBL472676 & 540740 & 7.1805 & 6.9631 & TS \\
\hline CHEMBL473280 & 40740 & 8.1739 & 8.5914 & $\mathrm{TR}$ \\
\hline CHEMBL511649 & 540740 & 8.3468 & 8.4217 & $\mathrm{TR}$ \\
\hline CHEMBL517265 & 540740 & 8.4318 & 8.3036 & TRI \\
\hline CHEMBL514463 & 540740 & 9.0458 & 8.9816 & $\mathrm{TR}$ \\
\hline CHEMBL473904 & 540740 & 8.6383 & 8.1406 & TS \\
\hline CHEMBL515142 & 40740 & 9.1549 & 8.3887 & TS \\
\hline CHEMBL499169 & 540740 & 7.9172 & 8.0162 & $\mathrm{TR}$ \\
\hline CHEMBL474708 & 540740 & 6.6308 & 6.9265 & TRN \\
\hline CHEMBL472086 & 540740 & 7.9136 & 8.8178 & $\mathrm{TR}$ \\
\hline CHEMBL473278 & 540740 & 9.0969 & 8.8402 & $\mathrm{TR}$ \\
\hline CHEMBL457451 & 540740 & 8.6478 & 8.0602 & $\mathrm{TR}$ \\
\hline
\end{tabular}

Page 5857 


\begin{tabular}{|c|c|c|c|c|}
\hline & & & pplement & al $\mathrm{Tc}$ \\
\hline CHEMBL475497 & 540740 & 7.2518 & 7.8591 & TRN \\
\hline CHEMBL471262 & 540740 & 8.2676 & 8.4743 & TST \\
\hline CHEMBL464192 & 540740 & 8.0969 & 8.0777 & TRN \\
\hline CHEMBL514965 & 540740 & 6.6925 & 6.8534 & TRN \\
\hline CHEMBL240215 & 540740 & 8.6383 & 7.8116 & TST \\
\hline CHEMBL515901 & 540740 & 7.2757 & 7.0905 & TRN \\
\hline CHEMBL 2070058 & 834201 & 6.699 & 8.2329 & TRN \\
\hline CHEMBL 2070073 & 834201 & 8.0915 & 8.389 & TRN \\
\hline CHEMBL 2070057 & 834201 & 8.2676 & 8.3398 & TRN \\
\hline CHEMBL 2069958 & 834201 & 8.6021 & 8.1358 & TRN \\
\hline CHEMBL 2070087 & 834201 & 8.5686 & 8.4223 & TRN \\
\hline CHEMBL 2069946 & 834201 & 7.9208 & 7.7055 & TST \\
\hline CHEMBL 2070068 & 834201 & 8.3979 & 8.9525 & TRN \\
\hline CHEMBL 2069952 & 834201 & 8.6021 & 7.9304 & TRN \\
\hline CHEMBL 2070051 & 834201 & 8.4685 & 8.1811 & TRN \\
\hline CHEMBL 2070081 & 834201 & 8.5376 & 8.3966 & TRN \\
\hline CHEMBL 2070077 & 834201 & 8.3665 & 8.4234 & TRN \\
\hline CHEMBL 2070074 & 834201 & 8.585 & 8.3968 & TRN \\
\hline CHEMBL 2070061 & 834201 & 8.4318 & 8.458 & TRN \\
\hline CHEMBL 2070084 & 834201 & 7.4949 & 8.3214 & TRN \\
\hline CHEMBL2069939 & 834201 & 7.2366 & 7.8093 & TRN \\
\hline CHEMBL 2070062 & 834201 & 9.0969 & 8.7785 & TRN \\
\hline CHEMBL 2069938 & 834201 & 8.3468 & 7.6384 & TRN \\
\hline CHEMBL 2070086 & 834201 & 8.6576 & 8.4134 & TRN \\
\hline CHEMBL 2070069 & 834201 & 9.1549 & 9.0549 & TRN \\
\hline CHEMBL 2070048 & 834201 & 8.301 & 8.3299 & TRN \\
\hline CHEMBL 2070076 & 834201 & 8.4685 & 8.3742 & TRN \\
\hline CHEMBL 2070060 & 834201 & 9.0458 & 8.383 & TRN \\
\hline CHEMBL 2070067 & 834201 & 9.1549 & 9.0306 & TRN \\
\hline CHEMBL 2070082 & 834201 & 8.301 & 8.3846 & TRN \\
\hline CHEMBL1231371 & 834201 & 8.1024 & 7.9644 & TRN \\
\hline CHEMBL 2070055 & 834201 & 8.4949 & 8.3722 & TRN \\
\hline CHEMBL 2069943 & 834201 & 8.301 & 8.0718 & TST \\
\hline CHEMBL2069936 & 834201 & 4.301 & 7.4793 & TST \\
\hline CHEMBL 2070080 & 834201 & 8.5528 & 8.323 & TRN \\
\hline CHEMBL2069937 & 834201 & 4.301 & 7.6501 & TST \\
\hline CHEMBL 2069949 & 834201 & 7.7447 & 7.9273 & TRN \\
\hline CHEMBL 2070049 & 834201 & 7.4815 & 8.2441 & TRN \\
\hline CHEMBL 2070052 & 834201 & 8.0 & 8.1875 & TRN \\
\hline CHEMBL1241489 & 834201 & 8.301 & 8.0657 & TRN \\
\hline CHEMBL 2069955 & 834201 & 7.5086 & 7.6401 & TST \\
\hline CHEMBL 2069954 & 834201 & 6.8861 & 7.727 & TST \\
\hline CHEMBL 2070050 & 834201 & 8.6021 & 8.4058 & TRN \\
\hline CHEMBL 2070085 & 834201 & 8.7212 & 8.4383 & TRN \\
\hline CHEMBL 2070071 & 834201 & 7.9208 & 8.3178 & TRN \\
\hline CHEMBL 2070054 & 834201 & 9.2218 & 8.4401 & TRN \\
\hline CHEMBL 2069944 & 834201 & 8.3872 & 7.9948 & TST \\
\hline CHEMBL 2069941 & 834201 & 8.1367 & 7.9023 & TRN \\
\hline
\end{tabular}


Supplemental Table S2.txt

\begin{tabular}{|c|c|c|c|c|c|}
\hline CHEMBL2070083 & 834201 & 7.9586 & 8.3434 & TRN & \\
\hline CHEMBL 2070044 & 834201 & 8.2676 & 8.0862 & TRN & \\
\hline CHEMBL1242847 & 834201 & 7.3979 & 8.0008 & TRN & \\
\hline CHEMBL1242754 & 834201 & 7.6198 & 7.8588 & TST & \\
\hline CHEMBL2070066 & 834201 & 8.2596 & 8.9258 & TST & \\
\hline CHEMBL2069315 & 834201 & 8.5229 & 8.5142 & TRN & \\
\hline CHEMBL 2069960 & 834201 & 7.7447 & 7.8719 & TRN & \\
\hline CHEMBL2069945 & 834201 & 8.6576 & 8.157 & TRN & \\
\hline CHEMBL 2070056 & 834201 & 8.585 & 8.4575 & TRN & \\
\hline CHEMBL 2070078 & 834201 & 8.3665 & 8.4769 & TRN & \\
\hline CHEMBL2070063 & 834201 & 8.6383 & 8.8672 & TRN & \\
\hline CHEMBL 2069940 & 834201 & 7.7212 & 7.9979 & TST & \\
\hline CHEMBL2070089 & 834201 & 8.3665 & 8.5008 & TRN & \\
\hline CHEMBL2069948 & 834201 & 8.041 & 7.9245 & TST & \\
\hline CHEMBL 2070047 & 834201 & 8.3098 & 8.2459 & TRN & \\
\hline CHEMBL2069953 & 834201 & 8.4318 & 8.1093 & TRN & \\
\hline CHEMBL 2070064 & 834201 & 7.9586 & 8.6288 & TST & \\
\hline CHEMBL1242384 & 834201 & 8.4437 & 8.1195 & TST & \\
\hline CHEMBL 2070046 & 834201 & 7.699 & 8.0599 & TST & \\
\hline CHEMBL 2070070 & 834201 & 7.8861 & 8.2896 & TST & \\
\hline CHEMBL 2070088 & 834201 & 8.5229 & 8.4484 & TRN & \\
\hline CHEMBL 2070072 & 834201 & 8.041 & 8.4161 & TRN & \\
\hline CHEMBL 2069947 & 834201 & 7.0915 & 7.7006 & TRN & \\
\hline CHEMBL 2070075 & 834201 & 8.6198 & 8.3901 & TRN & \\
\hline CHEMBL 2069314 & 834201 & 7.8239 & 7.7899 & TST & \\
\hline CHEMBL2070065 & 834201 & 8.8861 & 8.7189 & TRN & \\
\hline CHEMBL2069951 & 834201 & 7.8861 & 8.0215 & TST & \\
\hline CHEMBL 2070079 & 834201 & 8.2147 & 8.3445 & TRN & \\
\hline CHEMBL2070053 & 834201 & 8.4202 & 8.2428 & TRN & \\
\hline CHEMBL 2070059 & 834201 & 8.4318 & 8.3744 & TRN & \\
\hline CHEMBL2070045 & 834201 & 8.2218 & 8.1401 & TST & \\
\hline CHEMBL 2069961 & 834201 & 8.5086 & 7.9408 & TST & \\
\hline CHEMBL88161 & 142338 & 7.1612 & 6.6256 & TRN & \\
\hline CHEMBL89344 & 142338 & 6.9914 & 6.7501 & TST & \\
\hline CHEMBL81070 & 142338 & 4.4685 & 4.3459 & TRN & \\
\hline CHEMBL 81626 & 142338 & 4.6345 & 4.8213 & TRN & \\
\hline CHEMBL 78777 & 142338 & 6.7747 & 6.82700 & 0000000001 & TRN \\
\hline CHEMBL 90643 & 142338 & 5.9872 & 6.3236 & TRN & \\
\hline CHEMBL328986 & 142338 & 6.27 & 6.6367 & TRN & \\
\hline CHEMBL88639 & 142338 & 5.0 & 4.9231 & TRN & \\
\hline CHEMBL78306 & 142338 & 5.8041 & 5.1496 & TST & \\
\hline CHEMBL 81678 & 142338 & 5.9586 & 6.1731 & TRN & \\
\hline CHEMBL421364 & 142338 & 7.0605 & 7.0387 & TRN & \\
\hline CHEMBL 78411 & 142338 & 4.4168 & 4.7959 & TRN & \\
\hline CHEMBL91946 & 142338 & 5.684 & 5.6645 & TRN & \\
\hline CHEMBL 88660 & 142338 & 5.0 & 5.0894 & TRN & \\
\hline CHEMBL 91628 & 142338 & 6.6696 & 6.4378 & TRN & \\
\hline CHEMBL 78083 & 142338 & 4.9872 & 4.9269 & TRN & \\
\hline
\end{tabular}




\begin{tabular}{|c|c|c|c|c|c|}
\hline \multicolumn{6}{|c|}{ Supplemental Table S2.txt } \\
\hline CHEMBL90809 & 142338 & 6.9318 & 6.8942 & TRN & \\
\hline CHEMBL88465 & 142338 & 6.9393 & 6.2956 & TRN & \\
\hline CHEMBL314710 & 142338 & 5.0 & 5.1532 & TRN & \\
\hline CHEMBL91828 & 142338 & 6.066 & 6.2608 & TST & \\
\hline CHEMBL431214 & 142338 & 5.0 & 4.9588 & TRN & \\
\hline CHEMBL312600 & 142338 & 6.6421 & 6.1162 & TRN & \\
\hline CHEMBL310729 & 142338 & 5.7959 & 5.8087 & TRN & \\
\hline CHEMBL90508 & 142338 & 6.6799 & 6.94 & TRN & \\
\hline CHEMBL420245 & 142338 & 7.1367 & 7.3487 & TRN & \\
\hline CHEMBL309603 & 142338 & 6.475 & 6.32100 & 0000000001 & TRN \\
\hline CHEMBL330551 & 142338 & 5.7011 & 5.9032 & TRN & \\
\hline CHEMBL412674 & 142338 & 5.0 & 5.2336 & TRN & \\
\hline CHEMBL430455 & 142338 & 5.2899 & 5.6355 & TRN & \\
\hline CHEMBL91791 & 142338 & 4.8962 & 5.7939 & TST & \\
\hline CHEMBL 81602 & 142338 & 4.8761 & 4.5927 & TRN & \\
\hline CHEMBL313649 & 142338 & 6.3152 & 6.2311 & TRN & \\
\hline CHEMBL88146 & 142338 & 7.0132 & 7.3776 & TRN & \\
\hline CHEMBL 82078 & 142338 & 6.3904 & 6.4463 & TRN & \\
\hline CHEMBL 91145 & 142338 & 5.0 & 5.1532 & TRN & \\
\hline CHEMBL91222 & 142338 & 6.3072 & 6.4086 & TRN & \\
\hline CHEMBL 77675 & 142338 & 5.4622 & 5.2274 & TRN & \\
\hline CHEMBL 89811 & 142338 & 7.0 & 7.2282 & TRN & \\
\hline CHEMBL91713 & 142338 & 7.4089 & 7.4048 & TRN & \\
\hline CHEMBL81594 & 142338 & 5.0 & 5.4086 & TST & \\
\hline CHEMBL280243 & 142338 & 6.6635 & 6.3935 & TRN & \\
\hline CHEMBL441453 & 142338 & 3.0 & 5.2423 & TST & \\
\hline CHEMBL 79509 & 142338 & 6.4815 & 6.6995 & TRN & \\
\hline CHEMBL431462 & 142338 & 5.7721 & 5.9469 & TRN & \\
\hline CHEMBL315051 & 142338 & 6.2958 & 5.2475 & TST & \\
\hline CHEMBL420979 & 142338 & 7.0706 & 6.7728 & TRN & \\
\hline CHEMBL314379 & 142338 & 7.2757 & 6.9211 & TRN & \\
\hline CHEMBL 329623 & 142338 & 5.5952 & 4.5797 & TST & \\
\hline CHEMBL88932 & 142338 & 6.7167 & 6.9604 & TRN & \\
\hline CHEMBL 90326 & 142338 & 7.1871 & 6.5555 & TRN & \\
\hline CHEMBL 90288 & 142338 & 6.3279 & 6.375 & TRN & \\
\hline CHEMBL90975 & 142338 & 5.5376 & 6.3693 & TST & \\
\hline CHEMBL 310170 & 142338 & 6.0862 & 6.3466 & TST & \\
\hline CHEMBL282433 & 142338 & 5.04 & 5.782 & TST & \\
\hline CHEMBL 92095 & 142338 & 5.7258 & 6.3207 & TST & \\
\hline CHEMBL 79437 & 142338 & 5.699 & 6.7101 & TST & \\
\hline CHEMBL314423 & 142338 & 5.7282 & 5.8133 & TST & \\
\hline CHEMBL 265549 & 142338 & 5.5528 & 6.4678 & TST & \\
\hline CHEMBL3976089 & 1639956 & 8.0 & 8.1149 & TRN & \\
\hline CHEMBL3980924 & 1639956 & 7.0 & 7.3581 & TRN & \\
\hline CHEMBL3954626 & 1639956 & 8.0 & 7.7732 & TRN & \\
\hline CHEMBL3966039 & 1639956 & 7.0 & 7.1271 & TRN & \\
\hline CHEMBL3910786 & 1639956 & 8.0 & 8.105 & TRN & \\
\hline CHEMBL3966631 & 1639956 & 8.0 & 7.8072 & TRN & \\
\hline
\end{tabular}




\begin{tabular}{|c|c|c|c|c|}
\hline & & & ent & al T \\
\hline CHEMBL3986486 & 1639956 & 7.0 & 6.9437 & TRN \\
\hline CHEMBL3950710 & 1639956 & 8.0 & 8.0616 & TST \\
\hline CHEMBL3983372 & 1639956 & 8.0 & 7.9685 & TST \\
\hline CHEMBL 3922623 & 1639956 & 8.0 & 7.9542 & TRN \\
\hline CHEMBL3982279 & 1639956 & 8.0 & 6.9487 & TST \\
\hline CHEMBL3930109 & 1639956 & 8.0 & 8.1512 & TRN \\
\hline CHEMBL3950687 & 1639956 & 8.0 & 7.858 & TRN \\
\hline CHEMBL 3944267 & 1639956 & 8.0 & 8.0732 & TRN \\
\hline CHEMBL3921763 & 1639956 & 8.0 & 7.9061 & TRN \\
\hline CHEMBL3948598 & 1639956 & 7.0 & 7.1369 & TRN \\
\hline CHEMBL3946402 & 1639956 & 8.0 & 7.7153 & TST \\
\hline CHEMBL3973278 & 1639956 & 8.0 & 7.954 & TRN \\
\hline CHEMBL3971495 & 1639956 & 8.0 & 8.0846 & TRN \\
\hline CHEMBL 3958040 & 1639956 & 7.0 & 7.0113 & TRN \\
\hline CHEMBL3905798 & 1639956 & 7.0 & 6.9267 & TRN \\
\hline CHEMBL3965479 & 1639956 & 7.0 & 7.1223 & TRN \\
\hline CHEMBL3962661 & 1639956 & 8.0 & 7.8601 & TRN \\
\hline CHEMBL3965473 & 1639956 & 8.0 & 7.2943 & TRN \\
\hline CHEMBL3905821 & 1639956 & 8.0 & 7.7784 & TST \\
\hline CHEMBL3959946 & 1639956 & 8.0 & 8.1318 & TRN \\
\hline CHEMBL3899393 & 1639956 & 8.0 & 8.095 & TRN \\
\hline CHEMBL3903694 & 1639956 & 8.0 & 7.8076 & TRN \\
\hline CHEMBL3933708 & 1639956 & 8.0 & 8.0136 & TST \\
\hline CHEMBL3959511 & 1639956 & 7.0 & 7.1605 & TST \\
\hline CHEMBL3939157 & 1639956 & 8.0 & 7.822 & TRN \\
\hline CHEMBL3986696 & 1639956 & 8.0 & 8.0736 & TRN \\
\hline CHEMBL3899187 & 1639956 & 8.0 & 7.7953 & TRN \\
\hline CHEMBL 3952417 & 1639956 & 8.0 & 7.8695 & TRN \\
\hline CHEMBL3927630 & 1639956 & 8.0 & 8.1352 & TRN \\
\hline CHEMBL3983876 & 1639956 & 8.0 & 8.0248 & TRN \\
\hline CHEMBL 3942022 & 1639956 & 8.0 & 7.9074 & TRN \\
\hline CHEMBL3986419 & 1639956 & 7.0 & 7.1893 & TRN \\
\hline CHEMBL3938334 & 1639956 & 6.0 & 6.2201 & TRN \\
\hline CHEMBL3972256 & 1639956 & 8.0 & 7.9509 & TRN \\
\hline CHEMBL 3948278 & 1639956 & 8.0 & 8.0456 & TRN \\
\hline CHEMBL3926840 & 1639956 & 8.0 & 7.2075 & TRN \\
\hline CHEMBL3912445 & 1639956 & 8.0 & 7.0224 & TRN \\
\hline CHEMBL3903125 & 1639956 & 8.0 & 7.7497 & TRN \\
\hline CHEMBL3915663 & 1639956 & 8.0 & 7.9648 & TST \\
\hline CHEMBL3909078 & 1639956 & 8.0 & 7.8631 & TRN \\
\hline CHEMBL3919707 & 1639956 & 8.0 & 7.2037 & TRN \\
\hline CHEMBL3929514 & 1639956 & 7.0 & 7.1213 & TRN \\
\hline CHEMBL3955058 & 1639956 & 8.0 & 8.0303 & TRN \\
\hline CHEMBL3955346 & 1639956 & 7.0 & 7.2421 & TRN \\
\hline CHEMBL3953389 & 1639956 & 8.0 & 8.0011 & TST \\
\hline CHEMBL3910002 & 1639956 & 6.0 & 6.7374 & TRN \\
\hline CHEMBL3934557 & 1639956 & 8.0 & 7.2129 & TRN \\
\hline CHEMBL3939322 & 1639956 & 7.0 & 7.8592 & TRN \\
\hline
\end{tabular}




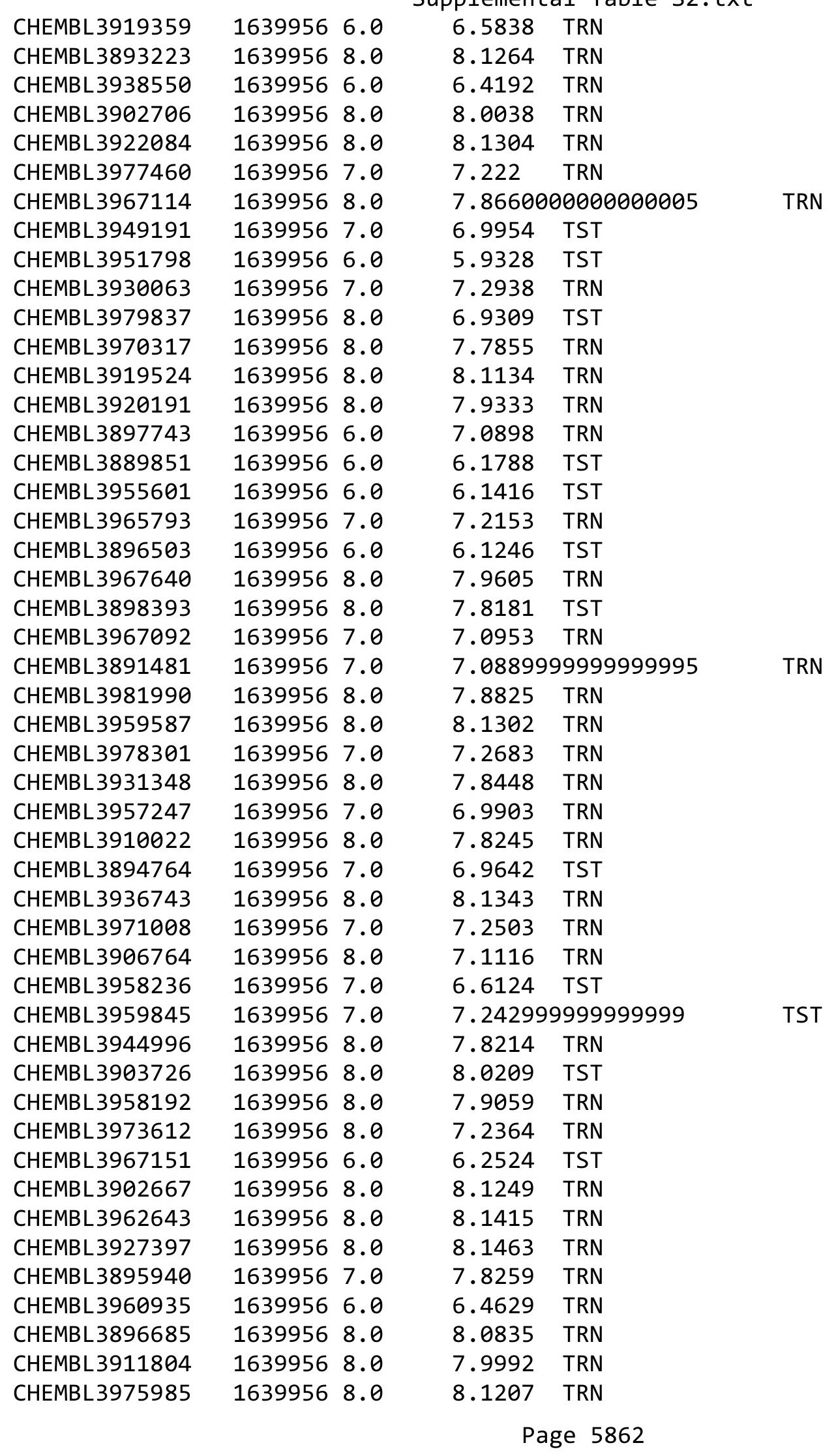




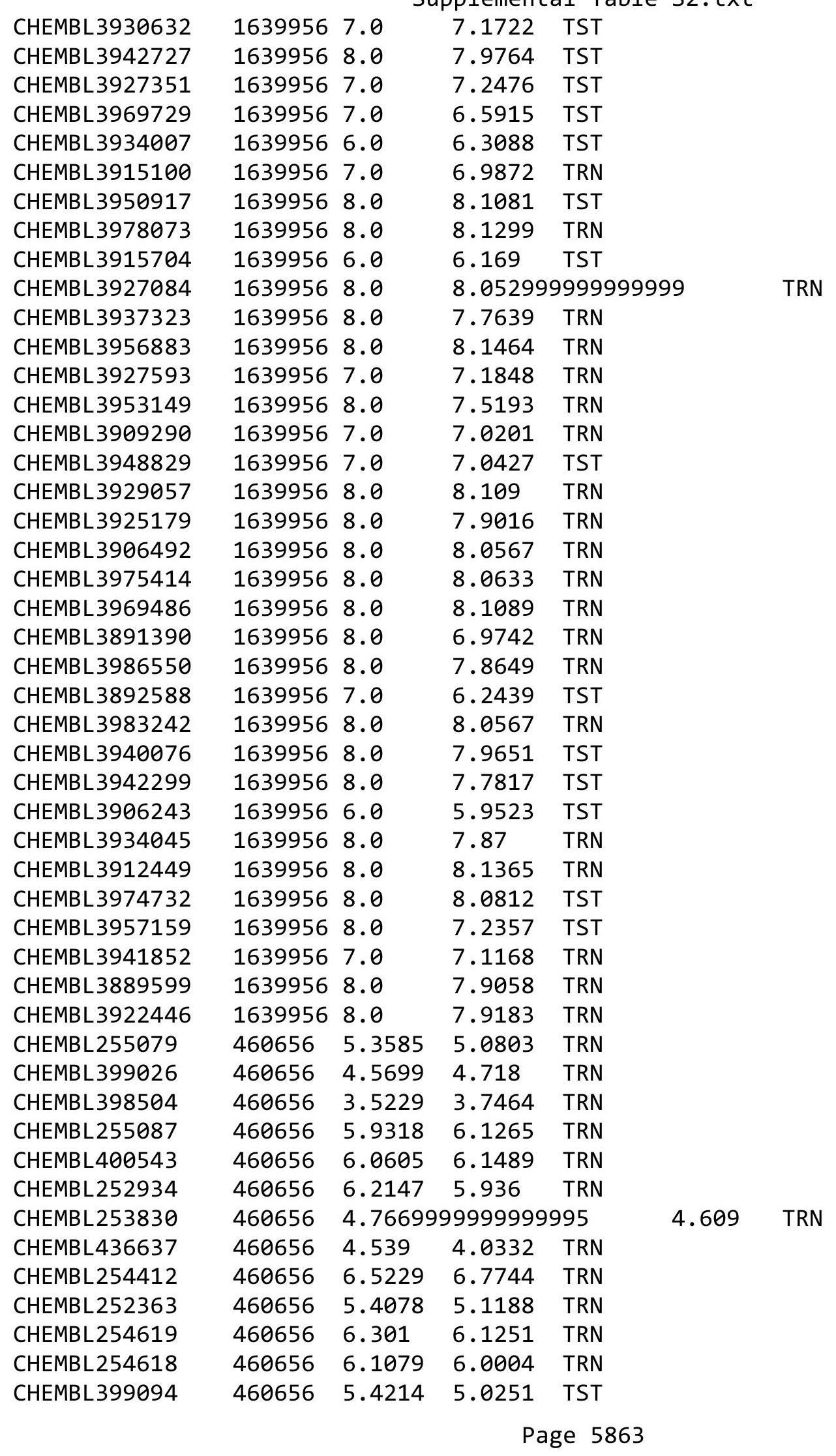




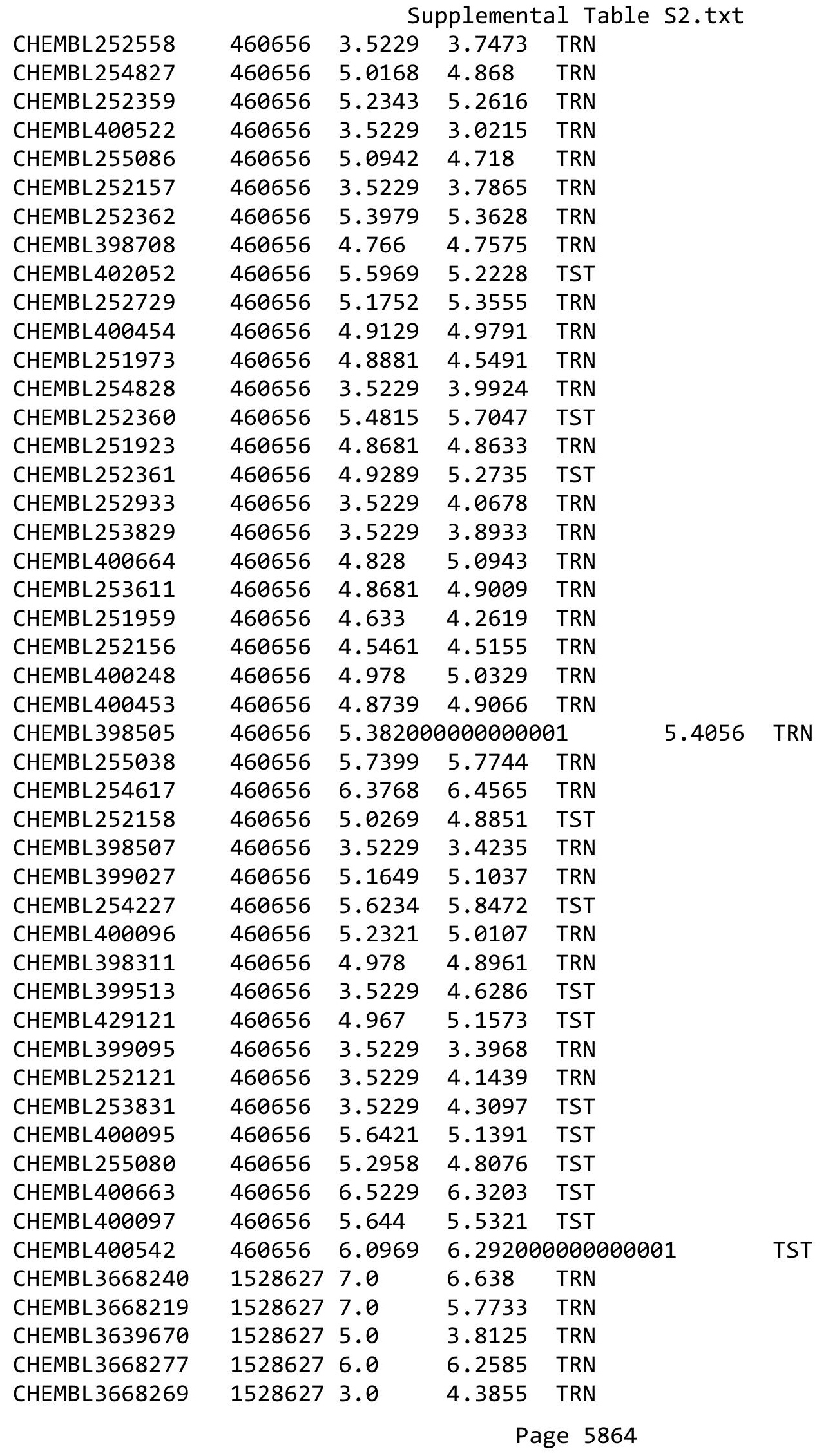




\begin{tabular}{|c|c|c|c|c|}
\hline & & & ıpplement & al Ta \\
\hline CHEMBL3668265 & 1528627 & 7.0 & 6.7338 & TRN \\
\hline CHEMBL3668276 & 1528627 & 7.0 & 6.7407 & TRN \\
\hline CHEMBL3668281 & 1528627 & 6.0 & 5.3675 & TRN \\
\hline CHEMBL3668270 & 1528627 & 4.0 & 5.2886 & TRN \\
\hline CHEMBL 3668213 & 1528627 & 9.0 & 8.7319 & TRN \\
\hline CHEMBL3668225 & 1528627 & 6.0 & 6.0106 & TRN \\
\hline CHEMBL 3668234 & 1528627 & 7.0 & 7.1047 & TRN \\
\hline CHEMBL 3668254 & 1528627 & 8.0 & 7.0923 & TST \\
\hline CHEMBL3668261 & 1528627 & 6.0 & 4.6743 & TRN \\
\hline CHEMBL 3668285 & 1528627 & 4.0 & 4.3822 & TRN \\
\hline CHEMBL3668232 & 1528627 & 5.0 & 6.9326 & TRN \\
\hline CHEMBL3668231 & 1528627 & 4.0 & 4.7247 & TRN \\
\hline CHEMBL3668237 & 1528627 & 9.0 & 8.9436 & TRN \\
\hline CHEMBL 3668273 & 1528627 & 4.0 & 3.9857 & TRN \\
\hline CHEMBL 3668283 & 1528627 & 5.0 & 3.4992 & TRN \\
\hline CHEMBL 3668223 & 1528627 & 4.0 & 4.1122 & TRN \\
\hline CHEMBL3668264 & 1528627 & 8.0 & 7.7779 & TRN \\
\hline CHEMBL 3668267 & 1528627 & 6.0 & 6.3341 & TRN \\
\hline CHEMBL3668256 & 1528627 & 9.0 & 8.7606 & TRN \\
\hline CHEMBL 3668272 & 1528627 & 3.0 & 4.1298 & TRN \\
\hline CHEMBL 3668242 & 1528627 & 7.0 & 6.5093 & TST \\
\hline CHEMBL3668290 & 1528627 & 2.0 & 4.9275 & TRN \\
\hline CHEMBL3668278 & 1528627 & 6.0 & 6.1132 & TRN \\
\hline CHEMBL 3668279 & 1528627 & 7.0 & 7.4026 & TRN \\
\hline CHEMBL3668211 & 1528627 & 4.0 & 4.6906 & TRN \\
\hline CHEMBL 3668249 & 1528627 & 5.0 & 5.5383 & TRN \\
\hline CHEMBL3668226 & 1528627 & 6.0 & 6.1637 & TRN \\
\hline CHEMBL 3668250 & 1528627 & 5.0 & 5.1042 & TRN \\
\hline CHEMBL3668227 & 1528627 & 8.0 & 7.9395 & TRN \\
\hline CHEMBL 3668271 & 1528627 & 4.0 & 4.9981 & TRN \\
\hline CHEMBL3668258 & 1528627 & 5.0 & 4.0757 & TRN \\
\hline CHEMBL3668263 & 1528627 & 3.0 & 4.3943 & TRN \\
\hline CHEMBL3668255 & 1528627 & 7.0 & 5.0744 & TRN \\
\hline CHEMBL3668293 & 1528627 & 6.0 & 5.8866 & TRN \\
\hline CHEMBL 3668218 & 1528627 & 8.0 & 7.0917 & TRN \\
\hline CHEMBL3668236 & 1528627 & 9.0 & 9.071 & TRN \\
\hline CHEMBL 3668262 & 1528627 & 4.0 & 4.4936 & TRN \\
\hline CHEMBL 3668220 & 1528627 & 5.0 & 4.8336 & TRN \\
\hline CHEMBL3668266 & 1528627 & 6.0 & 6.3681 & TRN \\
\hline CHEMBL 3668248 & 1528627 & 4.0 & 4.4414 & TRN \\
\hline CHEMBL3668251 & 1528627 & 8.0 & 6.8967 & TRN \\
\hline CHEMBL 3668228 & 1528627 & 5.0 & 5.5259 & TRN \\
\hline CHEMBL3668216 & 1528627 & 7.0 & 7.0448 & TRN \\
\hline CHEMBL 3668284 & 1528627 & 6.0 & 6.1913 & TRN \\
\hline CHEMBL 3668238 & 1528627 & 5.0 & 4.4005 & TRN \\
\hline CHEMBL 3668217 & 1528627 & 6.0 & 4.8013 & TRN \\
\hline CHEMBL 3668260 & 1528627 & 4.0 & 4.1309 & TRN \\
\hline CHEMBL3668212 & 1528627 & 7.0 & 6.8499 & TRN \\
\hline
\end{tabular}




\begin{tabular}{|c|c|c|c|c|c|}
\hline & & & & & \\
\hline CHEMBL3935638 & 1528627 & 7.0 & 6.8215 & TST & \\
\hline CHEMBL3668235 & 1528627 & 4.0 & 4.6028 & TRN & \\
\hline CHEMBL3668259 & 1528627 & 6.0 & 5.0029 & TRN & \\
\hline CHEMBL 3668287 & 1528627 & 6.0 & 4.7446 & TRN & \\
\hline CHEMBL 3668233 & 1528627 & 6.0 & 6.5883 & TRN & \\
\hline CHEMBL3668257 & 1528627 & 9.0 & 8.924 & TRN & \\
\hline CHEMBL3668246 & 1528627 & 5.0 & 4.6546 & TST & \\
\hline CHEMBL 3668243 & 1528627 & 4.0 & 4.2199 & TRN & \\
\hline CHEMBL3668245 & 1528627 & 6.0 & 4.3056 & TST & \\
\hline CHEMBL3668239 & 1528627 & 5.0 & 4.6859 & TST & \\
\hline CHEMBL3668221 & 1528627 & 7.0 & 7.0296 & TRN & \\
\hline CHEMBL3668215 & 1528627 & 7.0 & 6.523 & TRN & \\
\hline CHEMBL 3668274 & 1528627 & 5.0 & 3.8097 & TRN & \\
\hline CHEMBL 3668252 & 1528627 & 7.0 & 6.7367 & TST & \\
\hline CHEMBL 3668286 & 1528627 & 7.0 & 7.32 & TRN & \\
\hline CHEMBL3668292 & 1528627 & 6.0 & 6.3032 & TST & \\
\hline CHEMBL3668214 & 1528627 & 9.0 & 8.5212 & TRN & \\
\hline CHEMBL 3668288 & 1528627 & 7.0 & 7.1624 & TRN & \\
\hline CHEMBL3668268 & 1528627 & 6.0 & 6.3431 & TST & \\
\hline CHEMBL 3668222 & 1528627 & 4.0 & 4.312 & TST & \\
\hline CHEMBL3668289 & 1528627 & 7.0 & 6.5204 & TST & \\
\hline CHEMBL 3668244 & 1528627 & 5.0 & 3.2169 & TST & \\
\hline CHEMBL 3668241 & 1528627 & 5.0 & 4.1984 & TST & \\
\hline CHEMBL3668230 & 1528627 & 4.0 & 3.9629 & TST & \\
\hline CHEMBL 3668282 & 1528627 & 6.0 & 5.6536 & TST & \\
\hline CHEMBL 3668224 & 1528627 & 7.0 & 6.6323 & TST & \\
\hline CHEMBL3668247 & 1528627 & 5.0 & 3.8942 & TST & \\
\hline CHEMBL3668253 & 1528627 & 8.0 & 6.9939 & TST & \\
\hline CHEMBL3668280 & 1528627 & 8.0 & 8.2448 & TST & \\
\hline CHEMBL 3668275 & 1528627 & 7.0 & 7.7213 & TST & \\
\hline CHEMBL3668229 & 1528627 & 8.0 & 8.3434 & TST & \\
\hline CHEMBL 2170221 & 861906 & 7.8761 & 7.7811 & TRN & \\
\hline CHEMBL 2170203 & 861906 & 7.8297 & 8.0337 & TRN & \\
\hline CHEMBL 2170054 & 861906 & 8.0223 & 7.3034 & TST & \\
\hline CHEMBL 2170047 & 861906 & 5.0 & 5.0133 & TRN & \\
\hline CHEMBL 2170064 & 861906 & 6.857 & 6.7716 & TRN & \\
\hline CHEMBL 2170070 & 861906 & 7.4711 & 7.3679 & TRN & \\
\hline CHEMBL 2170210 & 861906 & 6.6326 & 6.78700 & 0000000001 & TRN \\
\hline CHEMBL 2170211 & 861906 & 8.0506 & 8.0265 & TRN & \\
\hline CHEMBL 2170058 & 861906 & 5.0 & 4.7814 & TRN & \\
\hline CHEMBL2170060 & 861906 & 7.7496 & 7.9208 & TRN & \\
\hline CHEMBL 2170051 & 861906 & 7.8477 & 7.374 & TST & \\
\hline CHEMBL 2170229 & 861906 & 8.0757 & 8.2006 & TRN & \\
\hline CHEMBL 2170056 & 861906 & 6.1302 & 6.4406 & TRN & \\
\hline CHEMBL 2170072 & 861906 & 7.9318 & 7.8884 & TRN & \\
\hline CHEMBL2169891 & 861906 & 7.7932 & 7.9044 & TRN & \\
\hline CHEMBL 2170204 & 861906 & 7.7645 & 7.8436 & TRN & \\
\hline CHEMBL2170050 & 861906 & 6.5287 & 7.00299 & 9999999999 & TRN \\
\hline & & & & 5866 & \\
\hline
\end{tabular}




\begin{tabular}{|c|c|c|c|c|c|c|}
\hline \multirow[b]{2}{*}{ CHEMBL 2170231} & & \multicolumn{5}{|c|}{ Supplemental Table s2.txt } \\
\hline & 861906 & 7.9547 & 7.8357 & TRN & & \\
\hline CHEMBL73824 & 861906 & 8.2007 & 7.5449 & TST & & \\
\hline CHEMBL 2170066 & 861906 & 7.6364 & 6.9 & TST & & \\
\hline CHEMBL 2170065 & 861906 & 5.0 & 6.38399 & 9999999 & 995 & TST \\
\hline CHEMBL 2170052 & 861906 & 7.0926 & 6.7565 & TST & & \\
\hline CHEMBL 2170223 & 861906 & 8.1487 & 7.9298 & TRN & & \\
\hline CHEMBL 2170218 & 861906 & 7.8761 & 8.0902 & TRN & & \\
\hline CHEMBL 2170207 & 861906 & 7.4342 & 7.7956 & TRN & & \\
\hline CHEMBL 2170046 & 861906 & 7.0788 & 6.7693 & TRN & & \\
\hline CHEMBL 2170238 & 861906 & 7.8041 & 8.2214 & TRN & & \\
\hline CHEMBL 2170217 & 861906 & 7.983 & 8.1321 & TRN & & \\
\hline CHEMBL 2170234 & 861906 & 8.0044 & 8.029 & TRN & & \\
\hline CHEMBL 2170215 & 861906 & 6.6498 & 6.8301 & TRN & & \\
\hline CHEMBL 2170206 & 861906 & 8.0862 & 7.7602 & TRN & & \\
\hline CHEMBL 2170230 & 861906 & 7.7959 & 8.0323 & TRN & & \\
\hline CHEMBL 2170220 & 861906 & 7.7825 & 7.8978 & TRN & & \\
\hline CHEMBL 2170073 & 861906 & 5.0 & 4.8205 & TRN & & \\
\hline CHEMBL 2170216 & 861906 & 7.7235 & 7.7832 & TRN & & \\
\hline CHEMBL 2170059 & 861906 & 6.7447 & 6.6733 & TRN & & \\
\hline CHEMBL 2170071 & 861906 & 8.0044 & 8.084 & TRN & & \\
\hline CHEMBL 2170053 & 861906 & 7.4045 & 7.2978 & TST & & \\
\hline CHEMBL 2170063 & 861906 & 7.4776 & 7.0606 & TRN & & \\
\hline CHEMBL 2170237 & 861906 & 8.0862 & 7.9163 & TRN & & \\
\hline CHEMBL 2170076 & 861906 & 7.9914 & 7.95 & TRN & & \\
\hline CHEMBL 2170209 & 861906 & 6.8928 & 6.9038 & TRN & & \\
\hline CHEMBL 2170069 & 861906 & 7.3279 & 7.4253 & TRN & & \\
\hline CHEMBL 2170049 & 861906 & 7.1871 & 7.5366 & TRN & & \\
\hline CHEMBL 2170067 & 861906 & 8.0 & 7.4074 & TRN & & \\
\hline CHEMBL 2170205 & 861906 & 7.6198 & 7.3986 & TRN & & \\
\hline CHEMBL 2170236 & 861906 & 6.5317 & 6.3661 & TRN & & \\
\hline CHEMBL 2170222 & 861906 & 8.1612 & 8.1871 & TRN & & \\
\hline CHEMBL 2170075 & 861906 & 7.7545 & 7.7912 & TRN & & \\
\hline CHEMBL 2170225 & 861906 & 7.9666 & 7.5729 & TRN & & \\
\hline CHEMBL 2170061 & 861906 & 7.3565 & 7.318 & TRN & & \\
\hline CHEMBL 2170233 & 861906 & 7.8297 & 7.9193 & TRN & & \\
\hline CHEMBL 2170074 & 861906 & 6.0685 & 6.2569 & TRN & & \\
\hline CHEMBL 2170214 & 861906 & 6.7645 & 6.8226 & TRN & & \\
\hline CHEMBL 2170228 & 861906 & 8.0269 & 7.9124 & TRN & & \\
\hline CHEMBL 2170227 & 861906 & 8.2596 & 7.9124 & TRN & & \\
\hline CHEMBL 2170045 & 861906 & 5.0 & 5.6927 & TRN & & \\
\hline CHEMBL 2170219 & 861906 & 8.0177 & 7.9261 & TRN & & \\
\hline CHEMBL 2170055 & 861906 & 8.0269 & 7.6557 & TRN & & \\
\hline CHEMBL 2170226 & 861906 & 8.28399 & 9999999 & 99 & 8.0123 & TRN \\
\hline CHEMBL 2170212 & 861906 & 8.0655 & 8.2019 & TST & & \\
\hline CHEMBL 2170224 & 861906 & 7.585 & 8.2399 & TST & & \\
\hline CHEMBL 2170057 & 861906 & 5.0 & 6.6637 & TST & & \\
\hline CHEMBL 2170239 & 861906 & 7.7773 & 8.0265 & TST & & \\
\hline CHEMBL 2170208 & 861906 & 6.056 & 7.2202 & TST & & \\
\hline
\end{tabular}




\begin{tabular}{|c|c|c|c|c|c|}
\hline \multicolumn{6}{|c|}{ Supplemental Table S2.txt } \\
\hline CHEMBL 2170213 & 861906 & 8.1427 & 7.24 & TST & \\
\hline CHEMBL 2170062 & 861906 & 7.7696 & 6.8515 & TST & \\
\hline CHEMBL 2170232 & 861906 & 7.3565 & 7.1826 & TST & \\
\hline CHEMBL 2170235 & 861906 & 8.0706 & 7.6804 & TST & \\
\hline CHEMBL 2170068 & 861906 & 8.0044 & 7.4734 & TST & \\
\hline CHEMBL 2170048 & 861906 & 7.0039 & 7.0245 & TST & \\
\hline CHEMBL3143297 & 209251 & 6.9586 & 6.7885 & TRN & \\
\hline CHEMBL3143251 & 209251 & 7.3979 & 7.4437 & TRN & \\
\hline CHEMBL3143279 & 209251 & 6.4685 & 6.0948 & TRN & \\
\hline CHEMBL3143307 & 209251 & 6.8861 & 6.6238 & TRN & \\
\hline CHEMBL3143255 & 209251 & 6.0605 & 6.46700 & 00000000005 & TRN \\
\hline CHEMBL3143311 & 209251 & 7.6198 & 7.08799 & 9999999999 & TRN \\
\hline CHEMBL3143294 & 209251 & 6.1675 & 6.1344 & TRN & \\
\hline CHEMBL3143321 & 209251 & 7.2076 & 7.3198 & TRN & \\
\hline CHEMBL 3143277 & 209251 & 7.6021 & 6.5383 & TST & \\
\hline CHEMBL3143286 & 209251 & 3.5229 & 5.9799 & TRN & \\
\hline CHEMBL3143283 & 209251 & 6.8861 & 6.2232 & TRN & \\
\hline CHEMBL 3143284 & 209251 & 7.9208 & 7.2256 & TRN & \\
\hline CHEMBL3143293 & 209251 & 6.7959 & 6.396 & TRN & \\
\hline CHEMBL 3143246 & 209251 & 7.6383 & 7.3502 & TRN & \\
\hline CHEMBL3143300 & 209251 & 6.2007 & 5.6512 & TRN & \\
\hline CHEMBL3143281 & 209251 & 7.7212 & 8.0446 & TRN & \\
\hline CHEMBL3143303 & 209251 & 5.6345 & 6.9531 & TST & \\
\hline CHEMBL3143320 & 209251 & 7.6198 & 6.9839 & TRN & \\
\hline CHEMBL 3143308 & 209251 & 5.7878 & 6.9401 & TRN & \\
\hline CHEMBL3143292 & 209251 & 6.0223 & 5.5064 & TRN & \\
\hline CHEMBL3143309 & 209251 & 7.6778 & 7.3584 & TRN & \\
\hline CHEMBL3143296 & 209251 & 5.8996 & 6.8134 & TRN & \\
\hline CHEMBL3143299 & 209251 & 7.2147 & 7.3872 & TRN & \\
\hline CHEMBL3143683 & 209251 & 7.6198 & 6.6309 & TST & \\
\hline CHEMBL3143265 & 209251 & 6.1079 & 6.2942 & TRN & \\
\hline CHEMBL3143301 & 209251 & 5.3635 & 6.6862 & TST & \\
\hline CHEMBL3143319 & 209251 & 6.2518 & 6.2955 & TRN & \\
\hline CHEMBL3143295 & 209251 & 6.5302 & 6.9075 & TRN & \\
\hline CHEMBL3143254 & 209251 & 7.7696 & 7.5648 & TRN & \\
\hline CHEMBL3143326 & 209251 & 6.6576 & 6.2765 & TRN & \\
\hline CHEMBL3143273 & 209251 & 8.3979 & 7.8369 & TRN & \\
\hline CHEMBL3143302 & 209251 & 7.6383 & 7.0182 & TST & \\
\hline CHEMBL 3143253 & 209251 & 7.3565 & 7.7747 & TRN & \\
\hline CHEMBL3143288 & 209251 & 7.3768 & 7.0023 & TRN & \\
\hline CHEMBL3143258 & 209251 & 6.301 & 6.2361 & TRN & \\
\hline CHEMBL3143305 & 209251 & 5.0482 & 6.026 & TST & \\
\hline CHEMBL3143267 & 209251 & 7.0044 & 7.5861 & TRN & \\
\hline CHEMBL 3144093 & 209251 & 7.7212 & 7.266 & TRN & \\
\hline CHEMBL3143306 & 209251 & 6.4559 & 6.2035 & TRN & \\
\hline CHEMBL 3143298 & 209251 & 7.7212 & 6.8305 & TST & \\
\hline CHEMBL3143291 & 209251 & 8.1249 & 8.1601 & TRN & \\
\hline CHEMBL3143324 & 209251 & 5.8153 & 6.6981 & TRN & \\
\hline
\end{tabular}




\begin{tabular}{|c|c|c|c|c|c|c|}
\hline & & \multicolumn{5}{|c|}{ Supplemental Table S2.txt } \\
\hline CHEMBL3143271 & 209251 & 7.5528 & 7.0618 & TRN & & \\
\hline CHEMBL3143263 & 209251 & 6.0 & 7.0164 & TRN & & \\
\hline CHEMBL3143313 & 209251 & 6.6091 & 6.6975 & TRN & & \\
\hline CHEMBL 3143252 & 209251 & 7.6596 & 8.0997 & TRN & & \\
\hline CHEMBL3143317 & 209251 & 5.9508 & 6.419 & TRN & & \\
\hline CHEMBL 3143248 & 209251 & 6.5686 & 7.0735 & TRN & & \\
\hline CHEMBL3143257 & 209251 & 7.3872 & 7.4902 & TRN & & \\
\hline CHEMBL3143684 & 209251 & 7.3768 & 7.2737 & TRN & & \\
\hline CHEMBL3143289 & 209251 & 7.0315 & 6.8162 & TRN & & \\
\hline CHEMBL3143247 & 209251 & 7.5376 & 6.6196 & TST & & \\
\hline CHEMBL 3143280 & 209251 & 8.0458 & 7.572 & TRN & & \\
\hline CHEMBL 3143256 & 209251 & 6.585 & 6.3115 & TRN & & \\
\hline CHEMBL3143304 & 209251 & 6.5086 & 6.1622 & TRN & & \\
\hline CHEMBL 3143287 & 209251 & 5.4634 & 5.8869 & TRN & & \\
\hline CHEMBL3143316 & 209251 & 5.1221 & 5.4532 & TRN & & \\
\hline CHEMBL 3143250 & 209251 & 7.3372 & 6.8525 & TRN & & \\
\hline CHEMBL3143318 & 209251 & \multicolumn{3}{|c|}{5.327000000000001} & 5.5506 & TRN \\
\hline CHEMBL3143269 & 209251 & 5.9281 & 5.5657 & TRN & & \\
\hline CHEMBL 3143270 & 209251 & 6.4949 & 6.3518 & TRN & & \\
\hline CHEMBL3143312 & 209251 & 5.983 & 6.8522 & TST & & \\
\hline CHEMBL3143260 & 209251 & 6.3279 & 6.6435 & TRN & & \\
\hline CHEMBL3143310 & 209251 & 6.7696 & 6.7352 & TST & & \\
\hline CHEMBL3143290 & 209251 & 7.4089 & 6.7502 & TRN & & \\
\hline CHEMBL3143259 & 209251 & 6.4318 & 6.5014 & TRN & & \\
\hline CHEMBL 3143276 & 209251 & 7.6198 & 6.5436 & TST & & \\
\hline CHEMBL 3143282 & 209251 & 7.5528 & 6.7434 & TRN & & \\
\hline CHEMBL3143262 & 209251 & 6.4318 & 6.2806 & TST & & \\
\hline CHEMBL3143268 & 209251 & 7.4559 & 6.9001 & TST & & \\
\hline CHEMBL 3143275 & 209251 & 8.1805 & 8.1405 & TST & & \\
\hline CHEMBL 3143264 & 209251 & 6.9586 & 7.0207 & TST & & \\
\hline CHEMBL3143272 & 209251 & 8.1079 & 7.7326 & TST & & \\
\hline CHEMBL 3143278 & 209251 & 7.6021 & 8.1784 & TST & & \\
\hline CHEMBL3143682 & 209251 & 7.585 & 6.69 & TST & & \\
\hline CHEMBL3143315 & 209251 & 6.4685 & 6.0258 & TST & & \\
\hline CHEMBL 3143274 & 209251 & 7.7799 & 8.1959 & TST & & \\
\hline CHEMBL399673 & 461060 & 5.9355 & 6.7432 & TRN & & \\
\hline CHEMBL 249648 & 461060 & 7.1367 & 7.0428 & TST & & \\
\hline CHEMBL 253977 & 461060 & 7.3279 & 6.6898 & TRN & & \\
\hline CHEMBL252727 & 461060 & 5.6861 & 6.4713 & TST & & \\
\hline CHEMBL251061 & 461060 & 5.8996 & 6.7211 & TST & & \\
\hline CHEMBL251260 & 461060 & 6.4921 & 7.7285 & TRN & & \\
\hline CHEMBL 253972 & 461060 & 6.7447 & 6.6515 & TST & & \\
\hline CHEMBL398699 & 461060 & 5.1101 & 6.3033 & TRN & & \\
\hline CHEMBL251257 & 461060 & 6.6576 & 6.9255 & TRN & & \\
\hline CHEMBL251449 & 461060 & 7.1871 & 6.8068 & TRN & & \\
\hline CHEMBL 250268 & 461060 & 6.6576 & 6.8881 & TRN & & \\
\hline CHEMBL 251632 & 461060 & 7.7959 & 7.2235 & TRN & & \\
\hline CHEMBL404629 & 461060 & 6.6556 & 6.5156 & TRN & & \\
\hline
\end{tabular}




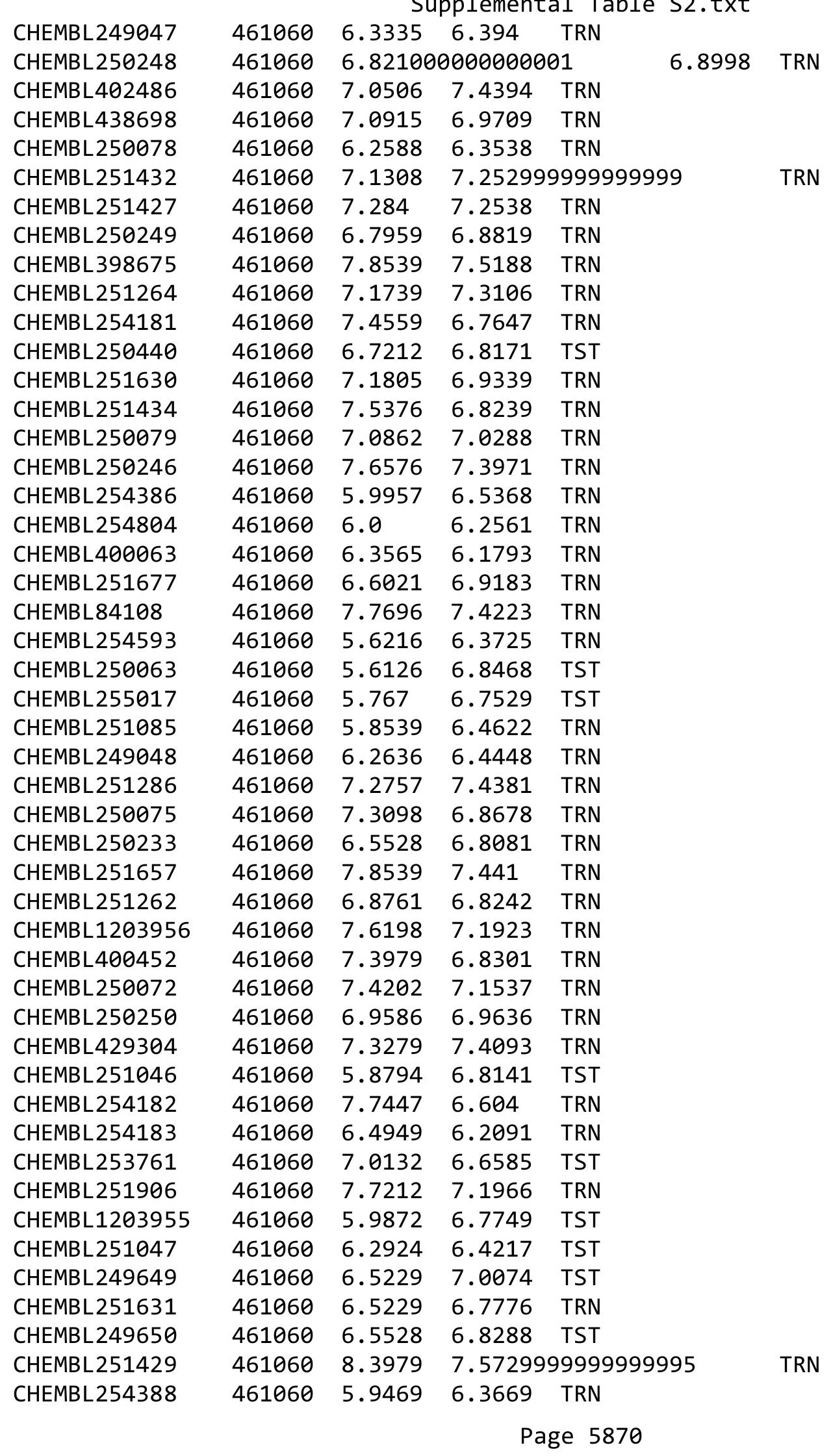




\begin{tabular}{|c|c|c|c|c|c|}
\hline & & & & & \\
\hline CHEMBL 253974 & 461060 & 6.3188 & 6.9952 & TST & \\
\hline CHEMBL341590 & 461060 & 6.8539 & 6.7462 & TST & \\
\hline CHEMBL251676 & 461060 & 6.7212 & 7.2215 & TRN & \\
\hline CHEMBL400348 & 461060 & 7.4202 & 7.6532 & TRN & \\
\hline CHEMBL398417 & 461060 & 7.0969 & 6.2628 & TRN & \\
\hline CHEMBL 249256 & 461060 & 7.6383 & 7.5038 & TRN & \\
\hline CHEMBL 251430 & 461060 & 7.2676 & 7.4782 & TRN & \\
\hline CHEMBL255018 & 461060 & 6.5376 & 6.7354 & TST & \\
\hline CHEMBL413990 & 461060 & 7.2218 & 7.0254 & TRN & \\
\hline CHEMBL139184 & 461060 & 6.7447 & 6.7905 & TST & \\
\hline CHEMBL 253763 & 461060 & 6.3279 & 7.0753 & TST & \\
\hline CHEMBL1203957 & 461060 & 7.7447 & 7.7283 & TRN & \\
\hline CHEMBL251435 & 461060 & 6.7645 & 6.5815 & TRN & \\
\hline CHEMBL254387 & 461060 & 6.5376 & 6.21299 & 9999999999 & TRN \\
\hline CHEMBL251907 & 461060 & 6.7212 & 6.6548 & TRN & \\
\hline CHEMBL401305 & 461060 & 6.4559 & 7.0432 & TRN & \\
\hline CHEMBL400672 & 461060 & 7.2596 & 7.5205 & TRN & \\
\hline CHEMBL 251048 & 461060 & 6.3188 & 6.6587 & TST & \\
\hline CHEMBL 251675 & 461060 & 6.9208 & 7.4263 & TRN & \\
\hline CHEMBL251263 & 461060 & 6.983 & 7.3076 & TRN & \\
\hline CHEMBL399794 & 461060 & 6.8297 & 7.3125 & TRN & \\
\hline CHEMBL 253971 & 461060 & 6.2596 & 6.8175 & TST & \\
\hline CHEMBL 250232 & 461060 & 6.7447 & 7.079 & TRN & \\
\hline CHEMBL 249046 & 461060 & 6.4559 & 6.537006 & 0000000001 & TRN \\
\hline CHEMBL402274 & 461060 & 6.1871 & 6.7498 & TST & \\
\hline CHEMBL343382 & 461060 & 6.7696 & 6.8011 & TST & \\
\hline CHEMBL250076 & 461060 & 7.4559 & 6.995 & TRN & \\
\hline CHEMBL 250895 & 461060 & 6.7696 & 6.4345 & TRN & \\
\hline CHEMBL399880 & 461060 & 6.3872 & 6.4928 & TRN & \\
\hline CHEMBL 250074 & 461060 & 7.3665 & 7.2721 & TRN & \\
\hline CHEMBL 250231 & 461060 & 7.1079 & 7.166 & TRN & \\
\hline CHEMBL251428 & 461060 & 7.3768 & 7.3831 & TRN & \\
\hline CHEMBL413808 & 461060 & 6.9208 & 7.0717 & TRN & \\
\hline CHEMBL249636 & 461060 & 7.6198 & 7.3287 & TRN & \\
\hline CHEMBL255019 & 461060 & 7.3768 & 6.8787 & TRN & \\
\hline CHEMBL400062 & 461060 & 7.301 & 6.6185 & TST & \\
\hline CHEMBL398415 & 461060 & 6.8539 & 7.0413 & TST & \\
\hline CHEMBL400473 & 461060 & 6.8539 & 6.8359 & TRN & \\
\hline CHEMBL251436 & 461060 & 6.0472 & 6.4892 & TRN & \\
\hline CHEMBL 250073 & 461060 & 7.3279 & 7.37799 & 9999999999 & TRN \\
\hline CHEMBL 82334 & 461060 & 5.9172 & 6.3026 & TST & \\
\hline CHEMBL413809 & 461060 & 5.6326 & 6.5933 & TST & \\
\hline CHEMBL 250245 & 461060 & 7.7447 & 7.1782 & TRN & \\
\hline CHEMBL404628 & 461060 & 6.2197 & 6.4846 & TRN & \\
\hline CHEMBL251905 & 461060 & 6.4089 & 6.9493 & TRN & \\
\hline CHEMBL 253762 & 461060 & 5.567 & 7.076006 & 00000000005 & TST \\
\hline CHEMBL597649 & 1301403 & 5.0635 & 5.314 & TRN & \\
\hline CHEMBL600461 & 1301403 & 4.7053 & 4.5576 & TRN & \\
\hline
\end{tabular}


Supplemental Table S2.txt

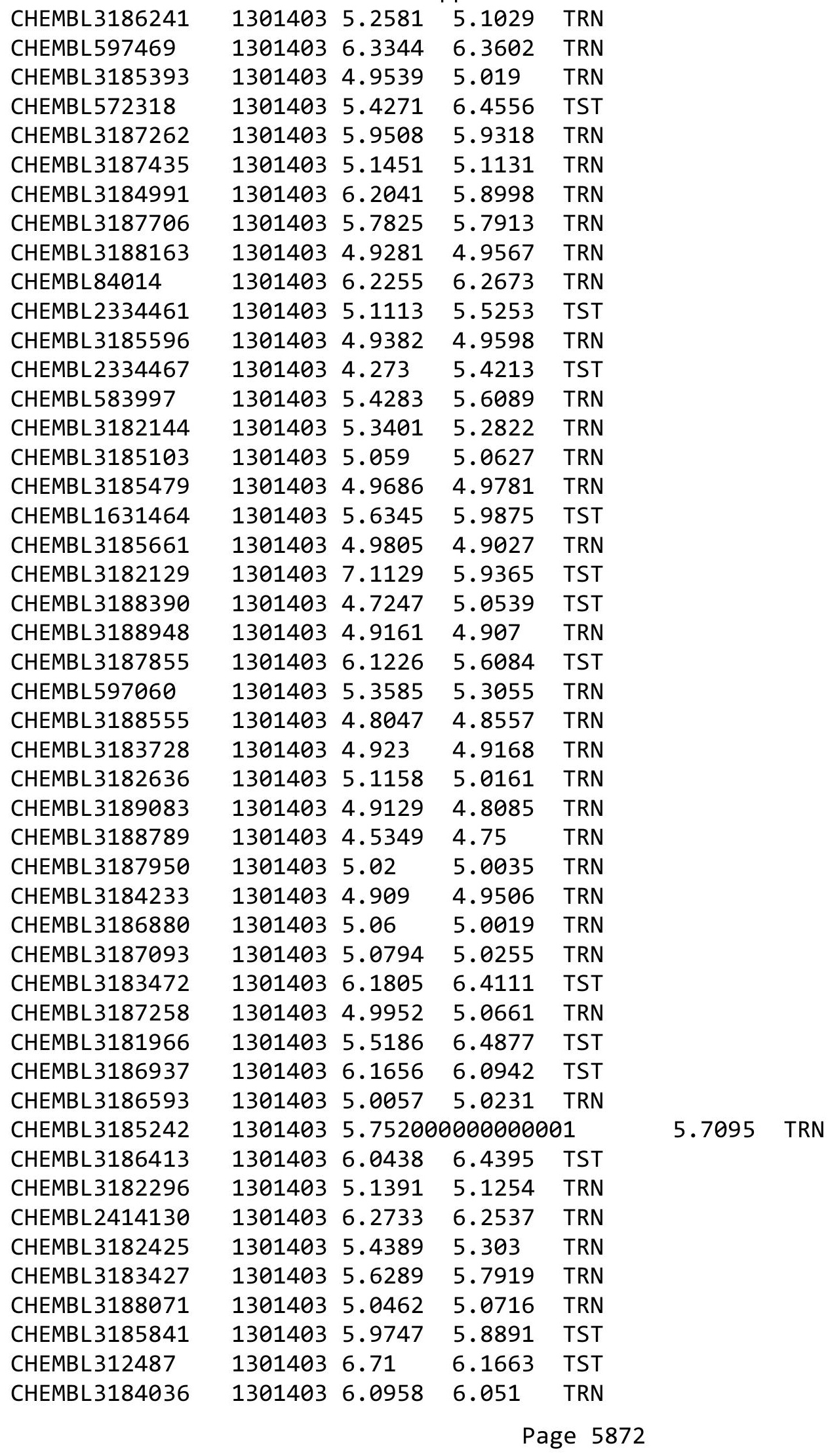


Supplemental Table S2.txt

\begin{tabular}{|c|c|c|c|c|c|}
\hline CHEMBL 3185050 & 1301403 & 4.7794 & 4.8147 & TRN & \\
\hline CHEMBL3187292 & 1301403 & 4.9796 & 5.0288 & TRN & \\
\hline CHEMBL3182615 & 1301403 & 5.0926 & 5.0577 & TRN & \\
\hline CHEMBL3185552 & 1301403 & 5.9066 & 6.6519 & TST & \\
\hline CHEMBL3185435 & 1301403 & 6.7645 & 6.0725 & TST & \\
\hline CHEMBL601071 & 1301403 & 4.7983 & 4.8345 & TRN & \\
\hline CHEMBL3186663 & 1301403 & \multicolumn{3}{|c|}{4.7860000000000005} & TRN \\
\hline CHEMBL 3188422 & 1301403 & 4.9348 & 5.0146 & TRN & \\
\hline CHEMBL1631460 & 1301403 & 6.0768 & 6.5129 & TST & \\
\hline CHEMBL3187431 & 1301403 & 5.065 & 5.1459 & TRN & \\
\hline CHEMBL3186072 & 1301403 & 5.1079 & 5.1838 & TRN & \\
\hline CHEMBL3974505 & 1639639 & 6.301 & 7.2497 & TRN & \\
\hline CHEMBL3969788 & 1639639 & 6.301 & 6.7452 & TRN & \\
\hline CHEMBL3977669 & 1639639 & 6.301 & 6.5784 & TRN & \\
\hline CHEMBL3898799 & 1639639 & 6.301 & 7.2091 & TRN & \\
\hline CHEMBL3919388 & 1639639 & 6.301 & 6.5816 & TRN & \\
\hline CHEMBL3977190 & 1639639 & 7.301 & 7.86799 & 9999999999 & TRN \\
\hline CHEMBL3917091 & 1639639 & 7.301 & 7.28299 & 99999999995 & TRN \\
\hline CHEMBL3900698 & 1639639 & 8.301 & 7.9652 & TRN & \\
\hline CHEMBL3952643 & 1639639 & 6.301 & 6.6638 & TRN & \\
\hline CHEMBL3911864 & 1639639 & 7.301 & 7.5841 & TRN & \\
\hline CHEMBL3907667 & 1639639 & 6.301 & 5.5899 & TST & \\
\hline CHEMBL3900128 & 1639639 & 6.301 & 5.5598 & TRN & \\
\hline CHEMBL 3954797 & 1639639 & 6.301 & 6.25899 & 99999999995 & TRN \\
\hline CHEMBL3970961 & 1639639 & 4.301 & 4.777 & TST & \\
\hline CHEMBL3931926 & 1639639 & 6.301 & 6.791 & TRN & \\
\hline CHEMBL3911118 & 1639639 & 7.301 & 7.6105 & TRN & \\
\hline CHEMBL3915614 & 1639639 & 8.301 & 8.6959 & TRN & \\
\hline CHEMBL3924996 & 1639639 & 8.301 & 7.8996 & TRN & \\
\hline CHEMBL3935778 & 1639639 & 8.301 & 8.5352 & TRN & \\
\hline CHEMBL3966891 & 1639639 & 6.301 & 6.0598 & TRN & \\
\hline CHEMBL3923128 & 1639639 & 4.301 & 4.4308 & TRN & \\
\hline CHEMBL3975233 & 1639639 & 8.301 & 8.4267 & TRN & \\
\hline CHEMBL3960013 & 1639639 & 6.301 & 6.1676 & TRN & \\
\hline CHEMBL3980371 & 1639639 & 8.301 & 8.2687 & TRN & \\
\hline CHEMBL3924790 & 1639639 & 8.301 & 8.1025 & TRN & \\
\hline CHEMBL3959579 & 1639639 & 7.301 & 6.7149 & TRN & \\
\hline CHEMBL3960952 & 1639639 & 8.301 & 8.0258 & TRN & \\
\hline CHEMBL 3971432 & 1639639 & 7.301 & 6.9876 & TRN & \\
\hline CHEMBL3950789 & 1639639 & 6.301 & 7.0996 & TRN & \\
\hline CHEMBL3929393 & 1639639 & 8.301 & 8.0612 & TRN & \\
\hline CHEMBL3907622 & 1639639 & 7.301 & 7.2852 & TRN & \\
\hline CHEMBL3965789 & 1639639 & 7.301 & 7.1707 & TRN & \\
\hline CHEMBL3910573 & 1639639 & 6.301 & 7.5475 & TRN & \\
\hline CHEMBL3979147 & 1639639 & 7.301 & 7.3721 & TRN & \\
\hline CHEMBL3968298 & 1639639 & 8.301 & 8.2242 & TRN & \\
\hline CHEMBL3936222 & 1639639 & 4.301 & 4.0506 & TRN & \\
\hline CHEMBL3933857 & 1639639 & 4.301 & 5.0854 & TRN & \\
\hline
\end{tabular}


Supplemental Table S2.txt

CHEMBL3957213

CHEMBL3896130

CHEMBL3986321

CHEMBL 3965968

CHEMBL3976537

CHEMBL3898893

CHEMBL 3976130

CHEMBL 3955744

CHEMBL3941204

CHEMBL3927723

CHEMBL 3917620

CHEMBL3894207

CHEMBL3909168

CHEMBL3936043

CHEMBL 3974700

CHEMBL3942675

CHEMBL3983956

CHEMBL3958377

CHEMBL 3891746

CHEMBL 3963029

CHEMBL3966779

CHEMBL3938559

CHEMBL3913705

CHEMBL 3893891

CHEMBL 3951073

CHEMBL 3946302

CHEMBL3977566

CHEMBL3937356

CHEMBL 3927018

CHEMBL3937191

CHEMBL3978787

CHEMBL3960387

CHEMBL 3893428

CHEMBL3971803

CHEMBL3898487

CHEMBL 3945808

CHEMBL 3938497

CHEMBL3929699

CHEMBL3940331

CHEMBL3944740

CHEMBL3924119

CHEMBL3916373

CHEMBL3902663

CHEMBL 3959061

CHEMBL3924933

CHEMBL 3960142

CHEMBL3964970

CHEMBL 3907416
16396394.301

16396398.301

16396398.301

16396396.301

16396397.301

16396394.301

16396397.301

16396398.301

16396394.301

16396397.301

16396396.301

16396398.301

16396398.301

16396398.301

16396397.301

16396398.301

16396397.301

16396397.301

16396398.301

16396397.301

16396394.301

16396398.301

16396397.301

16396398.301

16396398.301

16396397.301

16396398.301

16396396.301

16396398.301

16396397.301

16396396.301

16396398.301

16396398.301

16396398.301

16396394.301

16396398.301

16396394.301

16396397.301

16396397.301

16396397.301

16396398.301

16396397.301

16396397.301

16396397.301

16396396.301

16396398.301

16396394.301

16396398.301
5.1661 TST

7.9133 TRN

7.7026 TRN

6.867999999999999

6.7844 TRN

5.0542 TST

7.3688 TRN

7. 292000000000001

4.1397 TST

7.1945 TRN

5.6985 TRN

8.3468 TRN

8.1752 TRN

8.2754 TRN

5.6825 TST

7.9473 TRN

7.9103 TRN

7.0345 TRN

8.4064 TRN

7.9664 TRN

6.2163 TRN

7.6767 TRN

7.1742 TRN

8.4311 TRN

8.3476 TRN

7.6213 TRN

8.3309 TRN

6.3699 TRN

8.3507 TRN

7.4776 TRN

5.468 TST

8.2408 TRN

7.7406 TRN

8.3492 TRN

4.1448 TRN

6.7141 TRN

4.4301 TRN

7.4088 TRN

7.1314 TRN

7.3252 TRN

8.1408 TRN

7.4483 TRN

7.5114 TRN

7.9522 TRN

4.0395 TST

5.4469 TST

4.6692 TRN

7.6881 TRN
TRN

TRN

\section{Page 5874}


Supplemental Table S2.txt

\begin{tabular}{|c|c|c|c|c|c|}
\hline CHEMBL3903945 & 1639639 & 8.301 & 8.0074 & TRN & \\
\hline CHEMBL3903233 & 1639639 & 6.301 & 6.5909 & TRN & \\
\hline CHEMBL3915074 & 1639639 & 7.301 & 7.1471 & TRN & \\
\hline CHEMBL 3953873 & 1639639 & 8.301 & 7.7416 & TRN & \\
\hline CHEMBL3945083 & 1639639 & 8.301 & 7.5873 & TST & \\
\hline CHEMBL3962417 & 1639639 & 8.301 & \multicolumn{2}{|c|}{7.787999999999999} & TRN \\
\hline CHEMBL3917831 & 1639639 & 8.301 & 8.1669 & TRN & \\
\hline CHEMBL 3892784 & 1639639 & 7.301 & 7.6635 & TRN & \\
\hline CHEMBL 3938067 & 1639639 & 7.301 & 5.6568 & TST & \\
\hline CHEMBL3907833 & 1639639 & 6.301 & 7.5045 & TRN & \\
\hline CHEMBL3915700 & 1639639 & 8.301 & 7.9136 & TRN & \\
\hline CHEMBL3962301 & 1639639 & 8.301 & 7.8949 & TRN & \\
\hline CHEMBL3963071 & 1639639 & 6.301 & 6.9096 & TST & \\
\hline CHEMBL3892032 & 1639639 & 6.301 & 4.5264 & TST & \\
\hline CHEMBL3895878 & 1639639 & 6.301 & 6.3888 & TST & \\
\hline CHEMBL3968915 & 1639639 & 6.301 & 5.4614 & TST & \\
\hline CHEMBL3904363 & 1639639 & 7.301 & \multicolumn{2}{|c|}{6.792000000000001} & TRN \\
\hline CHEMBL3923119 & 1639639 & 6.301 & 6.8016 & TRN & \\
\hline CHEMBL3929767 & 1639639 & 8.301 & 8.4519 & TRN & \\
\hline CHEMBL3959219 & 1639639 & 8.301 & 7.8041 & TRN & \\
\hline CHEMBL3926120 & 1639639 & 6.301 & 5.1665 & TST & \\
\hline CHEMBL3967069 & 1639639 & 4.301 & 4.7559 & TST & \\
\hline CHEMBL3921369 & 1639639 & 7.301 & 5.6476 & TST & \\
\hline CHEMBL 3967785 & 1639639 & 7.301 & 7.3157 & TRN & \\
\hline CHEMBL3900099 & 1639639 & 6.301 & 5.8418 & TRN & \\
\hline CHEMBL3904134 & 1639639 & 8.301 & 7.0103 & TST & \\
\hline CHEMBL3931389 & 1639639 & 4.301 & 4.2419 & TRN & \\
\hline CHEMBL 3932122 & 1639639 & 8.301 & 8.3775 & TRN & \\
\hline CHEMBL3980001 & 1639639 & 7.301 & 7.4001 & TRN & \\
\hline CHEMBL3948864 & 1639639 & 7.301 & 6.9872 & TRN & \\
\hline CHEMBL3968710 & 1639639 & 4.301 & 4.1138 & TRN & \\
\hline CHEMBL3986630 & 1639639 & 7.301 & 7.5352 & TRN & \\
\hline CHEMBL 3960888 & 1639639 & 8.301 & 8.2207 & TRN & \\
\hline CHEMBL3900086 & 1639639 & 6.301 & 5.9296 & TST & \\
\hline CHEMBL3945764 & 1639639 & 7.301 & 7.63 & TRN & \\
\hline CHEMBL3966542 & 1639639 & 8.301 & 8.4158 & TRN & \\
\hline CHEMBL3907202 & 1639639 & 6.301 & 5.0891 & TRN & \\
\hline CHEMBL3901428 & 1639639 & 4.301 & 4.4215 & TST & \\
\hline CHEMBL 3947721 & 1639639 & 8.301 & 7.1234 & TRN & \\
\hline CHEMBL3928679 & 1639639 & 8.301 & 8.1061 & TRN & \\
\hline CHEMBL3891318 & 1639639 & 6.301 & 7.5141 & TST & \\
\hline CHEMBL3891852 & 1639639 & 7.301 & 7.1864 & TRN & \\
\hline CHEMBL1241569 & 1639639 & 7.301 & 7.0002 & TST & \\
\hline CHEMBL3911934 & 1639639 & 4.301 & 4.4581 & TST & \\
\hline CHEMBL3905863 & 1639639 & 8.301 & 7.9856 & TRN & \\
\hline CHEMBL3929760 & 1639639 & 7.301 & 6.8406 & TRN & \\
\hline CHEMBL3982159 & 1639639 & 7.301 & 7.0808 & TRN & \\
\hline CHEMBL3902986 & 1639639 & 8.301 & 8.8376 & TRN & \\
\hline
\end{tabular}


Supplemental Table S2.txt

\begin{tabular}{|c|c|c|c|c|}
\hline HEMBL3902178 & 539639 & 301 & 6.7009 & TR \\
\hline HEMBL3895701 & 639639 & 4.301 & 4.4089 & \\
\hline 208 & 39639 & 01 & 3878 & \\
\hline IEMBL3902213 & 539639 & 301 & 7817 & \\
\hline AEMBL3957817 & 539639 & 6.301 & 4704 & \\
\hline AEMBL3929082 & 639639 & 7.301 & 7608 & \\
\hline HEMBL3967190 & 539639 & 8.301 & 124 & \\
\hline IEMBL3983053 & 639639 & 301 & 3133 & \\
\hline AEMBL 3923238 & 639639 & 6.301 & 7732 & \\
\hline HEMBL3952625 & 639639 & 8.301 & 7.4562 & \\
\hline HEMBL3920402 & 639639 & 4.301 & 5223 & \\
\hline IEMBL3918901 & 639639 & 7.301 & 621 & \\
\hline IEMBL3983161 & 39 & 301 & 878 & RN \\
\hline AEMBL3963544 & 639639 & 8.301 & 358 & \\
\hline AEMBL3941940 & 639639 & 8.301 & 5849 & $\mathrm{KIV}$ \\
\hline AEMBL3943198 & 639639 & 301 & 63 & \\
\hline AEMBL3901458 & 63 & 301 & 66 & \\
\hline AEMBL3930472 & 163 & 301 & & \\
\hline HEMBL3936745 & 635 & 4.301 & & \\
\hline AEMBL3901158 & 39 & 8.301 & 349 & RN \\
\hline HEMBL3961573 & 635 & 7.301 & 637 & ГRA \\
\hline AEMBL3974093 & 63 & 7.301 & 883 & RN \\
\hline AEMBL3944113 & 163 & 7.301 & 359 & \\
\hline AEMBL3894607 & 39 & 7.301 & 539 & \\
\hline AEMBL 3919886 & 39 & 301 & 365 & RIV \\
\hline AEMBL 3909945 & 63 & 301 & & RN \\
\hline AEMBL3908741 & 163 & 4.301 & 612 & \\
\hline AEMB & $16=$ & 8.301 & 477 & RN \\
\hline AEMBL3918853 & 39 & 7.301 & 129 & RN \\
\hline AEMBL3897623 & 39 & 301 & 714 & RN \\
\hline AEMBL 3918350 & 163 & 8.301 & & $\mathrm{RI}$ \\
\hline AEMBL3925505 & 163 & 01 & 592 & RN \\
\hline IEMBL3S & 163 & 01 & 367 & ST \\
\hline AEMBL3889739 & 163 & 7.301 & 999 & RN \\
\hline AEMBL3980577 & 1639 & 7.301 & 681 & RN \\
\hline AEMBL3891418 & 163 & 8.301 & 947 & $\mathrm{RN}$ \\
\hline AEMBL3982265 & 163 & 01 & 705 & ST \\
\hline HEMBL3903100 & 163 & 4.301 & 498 & RN \\
\hline HEMBL3952875 & 1639 & 8.301 & 096 & RN \\
\hline AEMBL3922504 & 16396 & 6.301 & 438 & RN \\
\hline CHEMBL3919085 & 1639 & 4.301 & 4.8925 & 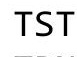 \\
\hline CHEMBL3921351 & 1639 & 4.301 & 4.9405 & RN \\
\hline CHEMBL3965605 & 1639639 & 6.301 & .1731 & RN \\
\hline CHEMBL3905368 & 1639639 & 6.301 & 7.1491 & RN \\
\hline HEMBL3912745 & 16396 & 6.301 & & RN \\
\hline CHEMBL3959418 & 1639639 & 8.301 & 8.3074 & \\
\hline CHEMBL3960772 & 1639 & 7.301 & 6.7871 & \\
\hline CHEMBL3951713 & 163963 & 7.301 & 6.7256 & R \\
\hline
\end{tabular}

Page 5876 
Supplemental Table S2.txt

\begin{tabular}{|c|c|c|c|c|c|}
\hline CHEMBL3957329 & 1639639 & 6.301 & 5.6079 & TRN & \\
\hline CHEMBL3951640 & 1639639 & 8.301 & 8.2052 & TRN & \\
\hline CHEMBL3910428 & 1639639 & 7.301 & 7.7382 & TRN & \\
\hline CHEMBL3913201 & 1639639 & 7.301 & 6.2951 & TRN & \\
\hline CHEMBL3955163 & 1639639 & 7.301 & 6.0536 & TST & \\
\hline CHEMBL3892954 & 1639639 & 8.301 & 8.0573 & TRN & \\
\hline CHEMBL3947072 & 1639639 & 8.301 & 8.2579 & TRN & \\
\hline CHEMBL3964210 & 1639639 & 6.301 & 7.4613 & TST & \\
\hline CHEMBL3982068 & 1639639 & 6.301 & 5.0726 & TST & \\
\hline CHEMBL3942191 & 1639639 & 6.301 & 7.0048 & TRN & \\
\hline CHEMBL 3919140 & 1639639 & 7.301 & 7.541 & TRN & \\
\hline CHEMBL3963474 & 1639639 & 6.301 & 6.7899 & TRN & \\
\hline CHEMBL3943179 & 1639639 & 4.301 & 3.7042 & TST & \\
\hline CHEMBL3963506 & 1639639 & 6.301 & 5.8318 & TRN & \\
\hline CHEMBL 3975149 & 1639639 & 8.301 & 8.4921 & TRN & \\
\hline CHEMBL521895 & 1639639 & 7.301 & 6.8575 & TRN & \\
\hline CHEMBL3962381 & 1639639 & 7.301 & 7.0427 & TRN & \\
\hline CHEMBL3968474 & 1639639 & 7.301 & \multicolumn{2}{|c|}{6.906000000000001} & TRN \\
\hline CHEMBL3969854 & 1639639 & 7.301 & 6.3247 & TST & \\
\hline CHEMBL3919836 & 1639639 & 7.301 & 7.2692 & TRN & \\
\hline CHEMBL3973833 & 1639639 & 4.301 & 4.145 & TST & \\
\hline CHEMBL3983968 & 1639639 & 8.301 & 8.0463 & TRN & \\
\hline CHEMBL3920843 & 1639639 & 7.301 & 7.0136 & TRN & \\
\hline CHEMBL3962143 & 1639639 & 4.301 & 4.9152 & TRN & \\
\hline CHEMBL3965961 & 1639639 & 4.301 & 4.7597 & TST & \\
\hline CHEMBL 3927281 & 1639639 & 4.301 & 4.5939 & TRN & \\
\hline CHEMBL3906354 & 1639639 & 8.301 & 8.2786 & TRN & \\
\hline CHEMBL3932034 & 1639639 & 6.301 & 6.2544 & TST & \\
\hline CHEMBL3947522 & 1639639 & 4.301 & 5.4139 & TST & \\
\hline CHEMBL 3955590 & 1639639 & 6.301 & 6.4084 & TRN & \\
\hline CHEMBL3935077 & 1639639 & 6.301 & 7.1116 & TRN & \\
\hline CHEMBL3953344 & 1639639 & 8.301 & 8.0322 & TRN & \\
\hline CHEMBL3898655 & 1639639 & 8.301 & 8.4531 & TRN & \\
\hline CHEMBL3967198 & 1639639 & 6.301 & \multicolumn{2}{|c|}{6.9270000000000005} & TRN \\
\hline CHEMBL3891655 & 1639639 & 4.301 & 4.7075 & TRN & \\
\hline CHEMBL3966008 & 1639639 & 8.301 & 8.2636 & TRN & \\
\hline CHEMBL3939503 & 1639639 & 4.301 & 5.2912 & TRN & \\
\hline CHEMBL3934603 & 1639639 & 8.301 & 7.3477 & TRN & \\
\hline CHEMBL3943472 & 1639639 & 8.301 & 8.3873 & TRN & \\
\hline CHEMBL3926402 & 1639639 & 4.301 & 4.4647 & TRN & \\
\hline CHEMBL3946421 & 1639639 & 4.301 & 4.9119 & TRN & \\
\hline CHEMBL3964689 & 1639639 & 7.301 & 7.8679 & TRN & \\
\hline CHEMBL3946057 & 1639639 & 4.301 & 5.4497 & TST & \\
\hline CHEMBL3983846 & 1639639 & 4.301 & 4.083 & TRN & \\
\hline CHEMBL3982043 & 1639639 & 6.301 & 6.5938 & TST & \\
\hline CHEMBL399021 & 1639639 & 7.301 & 5.5307 & TST & \\
\hline CHEMBL3914391 & 1639639 & 7.301 & 6.3322 & TRN & \\
\hline CHEMBL3949993 & 1639639 & 8.301 & 8.1535 & TRN & \\
\hline
\end{tabular}


Supplemental Table S2.txt

\begin{tabular}{|c|c|c|c|c|}
\hline HEMBL3 & 639639 & 4.301 & 4.25 & TS \\
\hline HEMBL3959430 & 639639 & 4.301 & 5.2714 & \\
\hline 763 & 39 & 301 & 4091 & \\
\hline IEMBL 3921595 & 539639 & 6.301 & 6577 & \\
\hline HEMBL3952184 & 639639 & 7.301 & .5876 & \\
\hline HEMBL 3924283 & 639639 & 6.301 & .3709 & \\
\hline HEMBL 3954841 & 639639 & 6.301 & 2484 & \\
\hline HEMBL3898390 & 539639 & 8.301 & .7742 & \\
\hline AEMBL3896752 & 639639 & 4.301 & .7323 & RN \\
\hline HEMBL3948639 & 639639 & 4.301 & .1186 & \\
\hline HEMBL 3962888 & 639639 & 7.301 & 4116 & \\
\hline HEMBL3892830 & 639639 & 7.301 & .1775 & \\
\hline HEMBL5E & & 7.301 & 7615 & RN \\
\hline HEMBL3957450 & 639639 & 6.301 & 0871 & \\
\hline HEMBL3966679 & 639639 & 6.301 & 6554 & \\
\hline HEMBL3917671 & 639639 & 7.301 & 3746 & KIV \\
\hline HEMBL3911765 & 639639 & 7.301 & 1687 & \\
\hline HEMBL 396 & 639639 & 4.301 & & \\
\hline HEMBL3927637 & 639639 & 4.301 & 4889 & \\
\hline HEMBL3922065 & 639639 & 6.301 & 9262 & 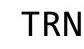 \\
\hline HEMBL464179 & 39639 & 6.301 & 3972 & $\mathrm{I} R \mathrm{IV}$ \\
\hline HEMBL3916643 & 639639 & 6.301 & 7007 & RN \\
\hline HEMBL39 & 639639 & 6.301 & 967 & \\
\hline HEMBL3984067 & 639639 & 8.301 & 966 & RN \\
\hline HEMBL3946610 & 639639 & 6.301 & 97 & $\mathrm{RN}$ \\
\hline HEMBL397 & 39 & 8.301 & 69 & TRN \\
\hline HEMBL 39 & 639639 & 6.301 & .732 & ST \\
\hline HEM & 39 & 4.301 & 087 & RN \\
\hline HEMBL3960458 & 1639639 & 6.301 & & ST \\
\hline HEMBL3969152 & 639639 & 8.301 & & RN \\
\hline HEMBL 392 & 539639 & 4.301 & 1612 & ST \\
\hline HEMBL 39 & 39 & 6.301 & 386 & ST \\
\hline HEMBL39 & 639639 & 8.301 & 995 & RN \\
\hline HEMBL3950975 & 639639 & 6. & 352 & TRN \\
\hline HEMBL 3969671 & 639639 & 4.301 & 8503 & IRN \\
\hline HEMBL3956940 & 639639 & 6 . & 805 & RN \\
\hline HEMBL3 & 39 & 6 . & 715 & RN \\
\hline HEMBL3890207 & 1639639 & 7.301 & 7964 & TST \\
\hline HEMBL3979886 & 639639 & 8.301 & 2782 & TRN \\
\hline HEMBL3913015 & 639639 & 7.301 & 9733 & TRN \\
\hline CHEMBL3922744 & 1639639 & 8.301 & 7.2103 & TST \\
\hline CHEMBL3984411 & 1639639 & 8.301 & 4099 & $\mathrm{RN}$ \\
\hline HEMBL3904364 & 1639639 & 7.301 & 1961 & TRN \\
\hline HEMBL3920121 & 1639639 & 6.301 & 9718 & TST \\
\hline AEMBL3938224 & 639635 & 6.301 & 5381 & RN \\
\hline CHEMBL 3896387 & 1639639 & 7.301 & .7284 & 11 \\
\hline CHEMBL3902712 & 1639639 & 6.301 & .9587 & RN \\
\hline CHEMBL3939968 & 1639639 & 7.301 & 6.8786 & TRN \\
\hline
\end{tabular}

Page 5878 
Supplemental Table S2.txt

\begin{tabular}{|c|c|c|c|c|}
\hline CHEMBL3937923 & 1639639 & 7.301 & 7.8725 & TRN \\
\hline CHEMBL 3987052 & 1639639 & 6.0 & 4.7232 & TST \\
\hline CHEMBL3897581 & 1639639 & 6.301 & \multicolumn{2}{|c|}{6.872000000000001} \\
\hline CHEMBL3918863 & 1639639 & 7.301 & 6.8051 & TRN \\
\hline CHEMBL3966870 & 1639639 & 8.301 & 7.8026 & TRN \\
\hline CHEMBL 3889700 & 1639639 & 8.301 & 8.1267 & TRN \\
\hline CHEMBL 3928120 & 1639639 & 4.301 & 4.402 & TRN \\
\hline CHEMBL3979018 & 1639639 & 7.301 & 7.3589 & TRN \\
\hline CHEMBL3932519 & 1639639 & 7.301 & 8.1214 & TRN \\
\hline CHEMBL3946560 & 1639639 & 6.301 & 6.6621 & TRN \\
\hline CHEMBL3972484 & 1639639 & 6.301 & 6.291 & TRN \\
\hline CHEMBL 3900251 & 1639639 & 8.301 & 8.3197 & TRN \\
\hline CHEMBL 3895910 & 1639639 & 7.301 & 6.3009 & TRN \\
\hline CHEMBL3906841 & 1639639 & 8.301 & 7.6935 & TRN \\
\hline CHEMBL 3969734 & 1639639 & 6.301 & 6.1042 & TRN \\
\hline CHEMBL3938485 & 1639639 & 8.301 & 8.0074 & TRN \\
\hline CHEMBL3923587 & 1639639 & 4.301 & 5.97 & TRN \\
\hline CHEMBL 3894108 & 1639639 & 8.301 & 6.9913 & TST \\
\hline CHEMBL3905214 & 1639639 & 8.301 & 8.3562 & TRN \\
\hline CHEMBL 3909208 & 1639639 & 4.301 & 4.2328 & TRN \\
\hline CHEMBL3895688 & 1639639 & 8.301 & 7.8147 & TRN \\
\hline CHEMBL3943374 & 1639639 & 4.301 & 5.308 & TST \\
\hline CHEMBL3920475 & 1639639 & 8.301 & 8.1607 & TRN \\
\hline CHEMBL3916991 & 1639639 & 8.301 & 8.626 & TRN \\
\hline CHEMBL3901341 & 1639639 & 7.301 & 7.954 & TRN \\
\hline CHEMBL3961783 & 1639639 & 8.301 & 7.3423 & TRN \\
\hline CHEMBL3931212 & 1639639 & 7.301 & 7.2185 & TRN \\
\hline CHEMBL3933451 & 1639639 & 6.301 & 6.8889 & TST \\
\hline CHEMBL3955085 & 1639639 & 6.301 & 6.4004 & TRN \\
\hline CHEMBL3936464 & 1639639 & 8.301 & 7.8724 & TRN \\
\hline CHEMBL3943970 & 1639639 & 4.301 & 5.0552 & TST \\
\hline CHEMBL3928105 & 1639639 & 7.301 & 6.1218 & TRN \\
\hline CHEMBL3966233 & 1639639 & 6.301 & 5.5291 & TRN \\
\hline CHEMBL3972438 & 1639639 & 6.301 & 5.5045 & TST \\
\hline CHEMBL3948347 & 1639639 & 6.301 & 7.0329 & TRN \\
\hline CHEMBL3904605 & 1639639 & 4.301 & 4.2854 & TRN \\
\hline CHEMBL496483 & 1639639 & 6.301 & 6.3514 & TRN \\
\hline CHEMBL3932715 & 1639639 & 7.301 & 7.0401 & TRN \\
\hline CHEMBL3958571 & 1639639 & 4.301 & 3.7793 & TST \\
\hline CHEMBL 3977623 & 1639639 & 7.301 & 6.553 & TST \\
\hline CHEMBL 3986771 & 1639639 & 8.301 & 7.9545 & TRN \\
\hline CHEMBL 3898581 & 1639639 & 6.301 & 7.5818 & TST \\
\hline CHEMBL3980941 & 1639639 & 8.301 & 7.7872 & TRN \\
\hline CHEMBL3902595 & 1639639 & 7.301 & 7.1284 & TST \\
\hline CHEMBL3976513 & 1639639 & 6.301 & 6.7703 & TRN \\
\hline CHEMBL 3913123 & 1639639 & 8.301 & 8.3619 & TRN \\
\hline CHEMBL 3959574 & 1639639 & 8.301 & 7.7886 & TRN \\
\hline \multirow[t]{2}{*}{ CHEMBL3917366 } & 1639639 & 7.301 & 7.3493 & TRN \\
\hline & & & \multicolumn{2}{|c|}{ Page 5879} \\
\hline
\end{tabular}


Supplemental Table S2.txt

\begin{tabular}{|c|c|c|c|c|c|}
\hline CHEMBL3963117 & 1639639 & 8.301 & 8.2338 & TRN & \\
\hline CHEMBL3958220 & 1639639 & 6.301 & 7.3193 & TST & \\
\hline CHEMBL3905592 & 1639639 & 6.301 & 7.1288 & TRN & \\
\hline CHEMBL3895926 & 1639639 & 6.301 & 7.2028 & TRN & \\
\hline CHEMBL464800 & 1639639 & 7.301 & 5.4025 & TRN & \\
\hline CHEMBL3974050 & 1639639 & 6.301 & 5.947 & TST & \\
\hline CHEMBL3949298 & 1639639 & 6.301 & 6.3849 & TRN & \\
\hline CHEMBL3954306 & 1639639 & 6.301 & 7.1788 & TRN & \\
\hline CHEMBL3935718 & 1639639 & 4.301 & \multicolumn{2}{|c|}{5.9910000000000005} & TRN \\
\hline CHEMBL3903907 & 1639639 & 8.301 & 7.2308 & TRN & \\
\hline CHEMBL3892974 & 1639639 & 7.301 & 6.7342 & TRN & \\
\hline CHEMBL3938315 & 1639639 & 8.301 & 7.9246 & TRN & \\
\hline CHEMBL3948442 & 1639639 & 8.301 & 8.2322 & TRN & \\
\hline CHEMBL3952035 & 1639639 & 7.301 & 6.9636 & TRN & \\
\hline CHEMBL 3981560 & 1639639 & 7.301 & 6.6645 & TRN & \\
\hline CHEMBL3974639 & 1639639 & 7.301 & \multicolumn{2}{|c|}{7.207999999999999} & TRN \\
\hline CHEMBL3927102 & 1639639 & 6.301 & 5.8189 & TST & \\
\hline CHEMBL3932387 & 1639639 & 8.301 & 8.137 & TST & \\
\hline CHEMBL3923876 & 1639639 & 8.301 & 8.4353 & TRN & \\
\hline CHEMBL3935438 & 1639639 & 6.301 & \multicolumn{2}{|c|}{6.037999999999999} & TRN \\
\hline CHEMBL3929068 & 1639639 & 4.301 & 4.2173 & TRN & \\
\hline CHEMBL3954598 & 1639639 & 4.301 & 4.305 & TRN & \\
\hline CHEMBL3947526 & 1639639 & 7.301 & 7.1688 & TRN & \\
\hline CHEMBL3961802 & 1639639 & 6.301 & 6.9576 & TST & \\
\hline CHEMBL3939181 & 1639639 & 7.301 & 7.6752 & TRN & \\
\hline CHEMBL3917133 & 1639639 & 6.301 & 7.5899 & TRN & \\
\hline CHEMBL3926606 & 1639639 & 8.301 & 6.7189 & TRN & \\
\hline CHEMBL3983881 & 1639639 & 8.301 & 8.2908 & TRN & \\
\hline CHEMBL3940651 & 1639639 & 7.301 & 6.8384 & TRN & \\
\hline CHEMBL 3944408 & 1639639 & 4.301 & 6.3337 & TRN & \\
\hline CHEMBL3903938 & 1639639 & 7.301 & 7.0801 & TRN & \\
\hline CHEMBL3946334 & 1639639 & 7.301 & 7.9474 & TRN & \\
\hline CHEMBL3941890 & 1639639 & 8.301 & 8.3208 & TRN & \\
\hline CHEMBL 3919940 & 1639639 & 6.301 & 6.3736 & TRN & \\
\hline CHEMBL3950461 & 1639639 & 6.301 & 7.4601 & TRN & \\
\hline CHEMBL3937979 & 1639639 & 6.301 & 6.9414 & TRN & \\
\hline CHEMBL3947733 & 1639639 & 6.301 & 6.995 & TST & \\
\hline CHEMBL3910985 & 1639639 & 4.301 & 5.5971 & TST & \\
\hline CHEMBL3965209 & 1639639 & 6.301 & 6.0017 & TRN & \\
\hline CHEMBL3926344 & 1639639 & 4.301 & 5.6283 & TRN & \\
\hline CHEMBL3901567 & 1639639 & 6.301 & 5.3327 & TRN & \\
\hline CHEMBL3968695 & 1639639 & 7.301 & 7.1919 & TRN & \\
\hline CHEMBL3978974 & 1639639 & 6.301 & 5.3778 & TRN & \\
\hline CHEMBL3948152 & 1639639 & 7.301 & 7.1179 & TRN & \\
\hline CHEMBL3977542 & 1639639 & 7.301 & 7.7667 & TRN & \\
\hline CHEMBL3966630 & 1639639 & 7.301 & 7.1738 & TRN & \\
\hline CHEMBL3913406 & 1639639 & 8.301 & 7.8837 & TRN & \\
\hline CHEMBL3894512 & 1639639 & 7.301 & 6.37 & TRN & \\
\hline
\end{tabular}


Supplemental Table S2.txt

\begin{tabular}{|c|c|c|c|c|}
\hline CHEMBL3922277 & 1639639 & 8.301 & 7.7631 & TRN \\
\hline CHEMBL3947362 & 1639639 & 7.301 & 6.5482 & TRN \\
\hline CHEMBL3935355 & 1639639 & 6.301 & 6.8564 & TRN \\
\hline CHEMBL3929626 & 1639639 & 8.301 & 8.082 & TRN \\
\hline CHEMBL3931884 & 1639639 & 8.301 & 8.51 & TRN \\
\hline CHEMBL3952557 & 1639639 & 7.301 & 6.7346 & TST \\
\hline CHEMBL3948547 & 1639639 & 6.301 & 6.4733 & TRN \\
\hline CHEMBL3916332 & 1639639 & 4.301 & 4.2601 & TRN \\
\hline CHEMBL3949164 & 1639639 & 4.301 & 4.8632 & TRN \\
\hline CHEMBL3900069 & 1639639 & 8.301 & 7.38299 & 9999999999 \\
\hline CHEMBL3906892 & 1639639 & 7.301 & 7.8075 & TRN \\
\hline CHEMBL3932359 & 1639639 & 6.301 & 6.1338 & TST \\
\hline CHEMBL3909920 & 1639639 & 8.301 & 7.4739 & TRN \\
\hline CHEMBL3983006 & 1639639 & 7.301 & 7.0587 & TRN \\
\hline CHEMBL3911710 & 1639639 & 6.301 & 6.1437 & TRN \\
\hline CHEMBL3980420 & 1639639 & 4.301 & 4.7747 & TST \\
\hline CHEMBL3898001 & 1639639 & 7.301 & 6.7766 & TRN \\
\hline CHEMBL3918655 & 1639639 & 6.301 & 6.49 & TRN \\
\hline CHEMBL3916535 & 1639639 & 7.301 & 6.5443 & TRN \\
\hline CHEMBL3915992 & 1639639 & 8.301 & 8.0406 & TRN \\
\hline CHEMBL3893250 & 1639639 & 6.301 & 6.9439 & TST \\
\hline CHEMBL3936663 & 1639639 & 8.301 & 7.6409 & TRN \\
\hline CHEMBL3962213 & 1639639 & 7.301 & 6.2829 & TRN \\
\hline CHEMBL3945893 & 1639639 & 8.301 & 7.3407 & TRN \\
\hline CHEMBL3928421 & 1639639 & 6.301 & 6.6077 & TRN \\
\hline CHEMBL3904158 & 1639639 & 6.301 & 6.3837 & TRN \\
\hline CHEMBL3968205 & 1639639 & 7.301 & 6.2686 & TRN \\
\hline CHEMBL3946622 & 1639639 & 4.301 & 5.0493 & TST \\
\hline CHEMBL3984496 & 1639639 & 8.301 & 7.4342 & TRN \\
\hline CHEMBL 3985074 & 1639639 & 7.301 & 7.6926 & TRN \\
\hline CHEMBL3903431 & 1639639 & 8.301 & 7.6182 & TRN \\
\hline CHEMBL3909730 & 1639639 & 7.301 & 7.5898 & TRN \\
\hline CHEMBL3957063 & 1639639 & 4.301 & 4.2357 & TRN \\
\hline CHEMBL3906390 & 1639639 & 4.301 & 4.9872 & TRN \\
\hline CHEMBL3965491 & 1639639 & 6.301 & 6.8874 & TRN \\
\hline CHEMBL3973663 & 1639639 & 4.301 & 4.396 & TRN \\
\hline CHEMBL3929174 & 1639639 & 7.301 & 7.5279 & TRN \\
\hline CHEMBL3973676 & 1639639 & 7.301 & 7.6807 & TRN \\
\hline CHEMBL3917632 & 1639639 & 7.301 & 6.9818 & TST \\
\hline CHEMBL3963527 & 1639639 & 8.301 & 8.1554 & TRN \\
\hline CHEMBL3896277 & 1639639 & 6.301 & 6.124 & TST \\
\hline CHEMBL3964903 & 1639639 & 7.301 & 7.3398 & TRN \\
\hline CHEMBL3980579 & 1639639 & 8.301 & 8.3653 & TRN \\
\hline CHEMBL3948445 & 1639639 & 8.301 & 7.6827 & TRN \\
\hline CHEMBL3959703 & 1639639 & 8.301 & 7.9007 & TRN \\
\hline CHEMBL3939361 & 1639639 & 7.301 & 7.8643 & TRN \\
\hline CHEMBL3963363 & 1639639 & 8.301 & 7.999 & TRN \\
\hline CHEMBL3930396 & 1639639 & 7.301 & 6.3158 & TRN \\
\hline
\end{tabular}


Supplemental Table S2.txt

\begin{tabular}{|c|c|c|c|c|c|}
\hline CHEMBL3950906 & 1639639 & 8.301 & 7.9482 & TRN & \\
\hline CHEMBL3944239 & 1639639 & 4.301 & 4.6404 & TRN & \\
\hline CHEMBL3920221 & 1639639 & 8.301 & 8.4709 & TRN & \\
\hline CHEMBL3921059 & 1639639 & 6.301 & 4.8779 & TRN & \\
\hline CHEMBL3946147 & 1639639 & 8.301 & 6.4957 & TST & \\
\hline CHEMBL3905265 & 1639639 & 7.301 & 7.8674 & TRN & \\
\hline CHEMBL3904092 & 1639639 & 8.301 & 8.675 & TRN & \\
\hline CHEMBL3933017 & 1639639 & 4.301 & 5.652 & TRN & \\
\hline CHEMBL3937123 & 1639639 & 6.301 & 5.5505 & TRN & \\
\hline CHEMBL3966217 & 1639639 & 4.301 & 4.6414 & TRN & \\
\hline CHEMBL3959585 & 1639639 & 8.301 & 8.5459 & TRN & \\
\hline CHEMBL3894511 & 1639639 & 8.301 & 8.3167 & TRN & \\
\hline CHEMBL3947890 & 1639639 & 8.301 & 8.2709 & TRN & \\
\hline CHEMBL3951485 & 1639639 & 7.301 & 6.7684 & TRN & \\
\hline CHEMBL3934851 & 1639639 & 7.301 & 8.0238 & TRN & \\
\hline CHEMBL3939254 & 1639639 & 8.301 & 7.8641 & TRN & \\
\hline CHEMBL69638 & 1639639 & 4.301 & 3.9077 & TST & \\
\hline CHEMBL 3908210 & 1639639 & 4.301 & 4.8102 & TRN & \\
\hline CHEMBL3903661 & 1639639 & 4.301 & 6.45299 & 9999999999 & TST \\
\hline CHEMBL3924389 & 1639639 & 6.301 & 6.6794 & TRN & \\
\hline CHEMBL3978191 & 1639639 & 7.301 & 7.5211 & TRN & \\
\hline CHEMBL 3902551 & 1639639 & 8.301 & 7.9827 & TRN & \\
\hline CHEMBL3950288 & 1639639 & 7.301 & 7.6424 & TRN & \\
\hline CHEMBL 3923437 & 1639639 & 6.301 & 6.4318 & TRN & \\
\hline CHEMBL3891973 & 1639639 & 4.301 & 5.4756 & TRN & \\
\hline CHEMBL3957551 & 1639639 & 6.301 & 5.9488 & TST & \\
\hline CHEMBL3896196 & 1639639 & 6.301 & 6.9455 & TRN & \\
\hline CHEMBL3975695 & 1639639 & 7.301 & 6.3101 & TRN & \\
\hline CHEMBL3981336 & 1639639 & 4.301 & 5.5236 & TST & \\
\hline CHEMBL3946160 & 1639639 & 4.301 & 4.748 & TRN & \\
\hline CHEMBL3948804 & 1639639 & 4.301 & 4.419 & TST & \\
\hline CHEMBL3962286 & 1639639 & 8.301 & 7.7366 & TRN & \\
\hline CHEMBL3892431 & 1639639 & 6.301 & 7.1359 & TRN & \\
\hline CHEMBL3967928 & 1639639 & 8.301 & 8.3981 & TRN & \\
\hline CHEMBL3897731 & 1639639 & 8.301 & 8.2058 & TRN & \\
\hline CHEMBL3973211 & 1639639 & 7.301 & 7.3535 & TRN & \\
\hline CHEMBL 3946183 & 1639639 & 6.301 & 7.4356 & TRN & \\
\hline CHEMBL3900489 & 1639639 & 6.301 & 6.6598 & TRN & \\
\hline CHEMBL 3894963 & 1639639 & 6.301 & 7.3149 & TST & \\
\hline CHEMBL3939897 & 1639639 & 6.0 & 5.5186 & TST & \\
\hline CHEMBL3949569 & 1639639 & 7.301 & 7.1248 & TRN & \\
\hline CHEMBL3929460 & 1639639 & 8.301 & 8.3306 & TRN & \\
\hline CHEMBL3948500 & 1639639 & 4.301 & 4.3811 & TRN & \\
\hline CHEMBL3910473 & 1639639 & 6.301 & 6.7248 & TRN & \\
\hline CHEMBL3969323 & 1639639 & 7.301 & 7.3733 & TRN & \\
\hline CHEMBL3954655 & 1639639 & 8.301 & 8.1834 & TRN & \\
\hline CHEMBL3927540 & 1639639 & 6.301 & 6.7785 & TRN & \\
\hline CHEMBL3945357 & 1639639 & 7.301 & 7.3186 & TRN & \\
\hline
\end{tabular}


Supplemental Table S2.txt

\begin{tabular}{|c|c|c|c|c|}
\hline HEMBL 3965216 & 9639 & 301 & 15 & TRN \\
\hline HEMBL 3953633 & 639639 & 6.301 & 2776 & \\
\hline HEMBL3932168 & 39639 & 4.301 & 5462 & \\
\hline AEMBL3915864 & 539639 & 4.301 & 3967 & \\
\hline HEMBL3916941 & 639639 & 6.301 & .6375 & \\
\hline HEMBL3965523 & 639639 & 4.301 & 4153 & \\
\hline AEMBL3892480 & 539639 & 6.301 & 2859 & \\
\hline HEMBL3951175 & 639639 & 7.301 & 141 & PN \\
\hline HEMBL3898928 & 639639 & 8.301 & 6141 & \\
\hline HEMBL3942153 & 639639 & 8.301 & .4461 & \\
\hline HEMBL3919732 & 639639 & 8.301 & 7627 & \\
\hline HEMBL3920278 & 639639 & 6.301 & & \\
\hline HEMBL3972005 & 639639 & 6.301 & 6827 & \\
\hline AEMBL3955965 & 639639 & 8.301 & 8781 & \\
\hline HEMBL3914566 & 639639 & 6.301 & 5722 & \\
\hline HEMBL3 & 639639 & 7.301 & 1881 & \\
\hline HEMBL & 39 & 7.301 & & ST \\
\hline HEMBL3 & 639639 & 6.301 & 3774 & \\
\hline HEMBL3914341 & 639639 & 6.301 & 5329 & \\
\hline HEMBL3941712 & 639639 & 4.301 & 411 & TST \\
\hline HEMBL3 & 639 & 7.301 & & SI \\
\hline HEMBL: & 39 & 7. & & ST \\
\hline HEMBL; & 639 & 7.301 & 536 & \\
\hline HEMBL & 639 & 4.301 & & IST \\
\hline AEMBL3 & 639639 & 8.301 & 48 & SI \\
\hline HEMBL3 & 9639 & 6 & 23 & ST \\
\hline HEMBL & 39 & 8. & & ST \\
\hline AFMRI & 39 & 301 & & ST \\
\hline AEMBL3 & 639 & 7. & & is \\
\hline AEMBL3920708 & 639639 & 6.301 & 15 & ГST \\
\hline HEMBL3 & 9639 & 6 & 03 & ST \\
\hline HEME & 39 & 6. & & ST \\
\hline & & & & TST \\
\hline AEMBL3976495 & 639639 & & & TST \\
\hline HEMBL3904218 & 639639 & 7.301 & 706 & TST \\
\hline HEMBL3 & 639639 & 4 . & 302 & IST \\
\hline יחו & & & & ST \\
\hline HEMBL3 & & & & TST \\
\hline HEMBL3921869 & 639639 & 8.301 & 654 & TST \\
\hline IEMBL3 & 639639 & 4.301 & +355 & TST \\
\hline HEMBL3S & 639639 & 7.301 & 808 & וכנו \\
\hline CHEMBL3985643 & & 8.301 & 506 & IST \\
\hline HEMBL3899065 & 1639639 & 8.301 & 013 & TST \\
\hline HEMBL 210618 & 54885 & 3.2331 & 28 & $\mathrm{R}$ \\
\hline EMBL1 & & 5073 & 2042 & RN \\
\hline CHEMBL1590308 & 954885 & 3.5744 & 3.4981 & \\
\hline CHEMBL573107 & 54885 & 4.198 & 4.9804 & \\
\hline CHEMBL412142 & 954885 & 4.3916 & 3.9239 & $2 \mathrm{~N}$ \\
\hline
\end{tabular}

Page 5883 


\begin{tabular}{|c|c|c|c|c|c|c|}
\hline & & \multicolumn{5}{|c|}{ Supplemental Table S2.txt } \\
\hline CHEMBL1230020 & 954885 & 6.0563 & 4.248 & TRN & & \\
\hline CHEMBL379300 & 954885 & 6.575 & 5.9436 & TRN & & \\
\hline CHEMBL1970879 & 954885 & 5.0292 & 4.0657 & TRN & & \\
\hline CHEMBL1242367 & 954885 & 3.43300 & 00000000 & 003 & 4.0162 & TRN \\
\hline CHEMBL240954 & 954885 & 5.416 & 4.013 & TRN & & \\
\hline CHEMBL1643959 & 954885 & 3.8063 & 3.5522 & TRN & & \\
\hline CHEMBL3392440 & 954885 & 3.3594 & 3.8217 & TRN & & \\
\hline CHEMBL 2144069 & 954885 & 3.0209 & 4.3822 & TRN & & \\
\hline CHEMBL1404918 & 954885 & 3.0903 & 3.1183 & TRN & & \\
\hline CHEMBL65 & 954885 & 7.2557 & 7.4998 & TRN & & \\
\hline CHEMBL 2363137 & 954885 & 5.4632 & 4.558 & TRN & & \\
\hline CHEMBL509032 & 954885 & 3.6693 & 4.8528 & TRN & & \\
\hline CHEMBL379975 & 954885 & 4.1979 & 5.1149 & TRN & & \\
\hline CHEMBL192566 & 954885 & 7.2296 & 7.1895 & TST & & \\
\hline CHEMBL483847 & 954885 & 3.95899 & 99999999 & 996 & 4.0681 & TRN \\
\hline CHEMBL1788116 & 954885 & 3.3454 & 4.1068 & TRN & & \\
\hline CHEMBL3199475 & 954885 & 5.3637 & 4.4438 & TRN & & \\
\hline CHEMBL393929 & 954885 & 3.7184 & 4.0365 & TRN & & \\
\hline CHEMBL258844 & 954885 & 4.83 & 4.1556 & TRN & & \\
\hline CHEMBL92309 & 954885 & 1.641 & 3.15 & TST & & \\
\hline CHEMBL213100 & 954885 & 3.1975 & 4.0313 & TRN & & \\
\hline CHEMBL1516890 & 954885 & 3.8609 & 4.0343 & TRN & & \\
\hline CHEMBL180127 & 954885 & 4.6108 & 4.1496 & TRN & & \\
\hline CHEMBL1357247 & 954885 & 3.1742 & 3.1813 & TRN & & \\
\hline CHEMBL 2005886 & 954885 & 3.2986 & 4.6279 & TRN & & \\
\hline CHEMBL1190711 & 954885 & 4.9316 & 4.8877 & TRN & & \\
\hline CHEMBL1909414 & 954885 & 5.9751 & 4.2714 & TRN & & \\
\hline CHEMBL3349342 & 954885 & 4.227 & 4.6133 & TRN & & \\
\hline CHEMBL191334 & 954885 & 5.1175 & 4.3103 & TRN & & \\
\hline CHEMBL512504 & 954885 & 6.4662 & 5.314 & TRN & & \\
\hline CHEMBL449158 & 954885 & 5.9691 & 6.2229 & TST & & \\
\hline CHEMBL9470 & 954885 & 6.3045 & 5.3882 & TST & & \\
\hline CHEMBL392695 & 954885 & 5.0762 & 4.9125 & TRN & & \\
\hline CHEMBL189584 & 954885 & 5.6235 & 4.6991 & TRN & & \\
\hline CHEMBL221137 & 954885 & 4.885 & 4.5651 & TST & & \\
\hline CHEMBL259181 & 954885 & 4.4494 & 4.314 & TRN & & \\
\hline CHEMBL558642 & 954885 & 2.6859 & 3.9265 & TRN & & \\
\hline CHEMBL1256459 & 954885 & 6.3258 & 6.428 & TRN & & \\
\hline CHEMBL514499 & 954885 & 6.239 & 6.4304 & TRN & & \\
\hline CHEMBL3186408 & 954885 & 3.167 & 3.8664 & TST & & \\
\hline CHEMBL209148 & 954885 & 2.3895 & 4.1607 & TRN & & \\
\hline CHEMBL472940 & 954885 & 3.1214 & 3.7633 & TRN & & \\
\hline CHEMBL1673039 & 954885 & 2.972 & 4.4571 & TST & & \\
\hline CHEMBL585951 & 954885 & 5.9642 & 5.7153 & TST & & \\
\hline CHEMBL220241 & 954885 & 4.8734 & 4.4023 & TST & & \\
\hline CHEMBL300389 & 954885 & 6.1486 & 6.2168 & TST & & \\
\hline CHEMBL373751 & 954885 & 3.5646 & 3.7102 & TST & & \\
\hline CHEMBL202721 & 954885 & 5.3342 & 4.8039 & TST & & \\
\hline
\end{tabular}


Supplemental Table S2.txt

\begin{tabular}{|c|c|c|c|c|}
\hline CHEMBL515416 & 954885 & 4.1609 & 4.3541 & TST \\
\hline CHEMBL 304857 & 1614 & 6.8539 & 6.9131 & TRN \\
\hline CHEMBL147961 & 1614 & 6.3979 & 6.3652 & TRN \\
\hline CHEMBL 344537 & 1614 & 5.9208 & 5.96 & TRN \\
\hline CHEMBL146729 & 1614 & 6.8539 & 6.8731 & TRN \\
\hline CHEMBL144002 & 1614 & 6.3768 & 6.4131 & TRN \\
\hline CHEMBL147907 & 1614 & 6.9586 & 7.0039 & TRN \\
\hline CHEMBL147555 & 1614 & 6.8539 & 6.725 & TRN \\
\hline CHEMBL343217 & 1614 & 7.0506 & 7.0285 & TRN \\
\hline CHEMBL146391 & 1614 & 6.0 & 6.001 & TRN \\
\hline CHEMBL146024 & 1614 & 7.4559 & 7.4052 & TRN \\
\hline CHEMBL143952 & 1614 & 7.2218 & 7.3064 & TRN \\
\hline CHEMBL147546 & 1614 & 7.1805 & 7.1538 & TRN \\
\hline CHEMBL143947 & 1614 & 6.0 & 6.0281 & TRN \\
\hline CHEMBL423212 & 1614 & 6.8539 & 6.8833 & TRN \\
\hline CHEMBL148085 & 1614 & 6.699 & 6.725 & TRN \\
\hline CHEMBL146991 & 1614 & 7.1308 & 7.6881 & TST \\
\hline CHEMBL145997 & 1614 & 7.1192 & 7.1788 & TRN \\
\hline CHEMBL434125 & 1614 & 7.0 & 6.9728 & TRN \\
\hline CHEMBL147940 & 1614 & 8.0506 & 7.8666 & TRN \\
\hline CHEMBL333341 & 1614 & 7.5686 & 7.3912 & TRN \\
\hline CHEMBL143951 & 1614 & 7.2007 & 7.1923 & TRN \\
\hline CHEMBL143893 & 1614 & 7.5528 & 7.7106 & TRN \\
\hline CHEMBL434315 & 1614 & 7.0506 & 7.0333 & TRN \\
\hline CHEMBL147148 & 1614 & 8.2076 & 8.166 & TRN \\
\hline CHEMBL313714 & 1614 & 6.8239 & 6.8164 & TRN \\
\hline CHEMBL331970 & 1614 & 7.4559 & 7.4249 & TRN \\
\hline CHEMBL146335 & 1614 & 7.3468 & 7.4256 & TRN \\
\hline CHEMBL116092 & 1614 & 7.5528 & 7.4422 & TST \\
\hline CHEMBL 358072 & 1614 & 8.4815 & 8.5649 & TRN \\
\hline CHEMBL146891 & 1614 & 6.8539 & 6.8099 & TRN \\
\hline CHEMBL145982 & 1614 & 7.7447 & 7.7203 & TRN \\
\hline CHEMBL146129 & 1614 & 6.3372 & 6.2609 & TST \\
\hline CHEMBL343667 & 1614 & 7.1805 & 7.2688 & TRN \\
\hline CHEMBL117046 & 1614 & 6.9208 & 6.9016 & TRN \\
\hline CHEMBL357007 & 1614 & 7.6198 & 7.5456 & TRN \\
\hline CHEMBL147838 & 1614 & 6.3872 & 7.6659 & TST \\
\hline CHEMBL356808 & 1614 & 7.6021 & 7.6296 & TRN \\
\hline CHEMBL147786 & 1614 & 6.585 & 6.7347 & TRN \\
\hline CHEMBL146483 & 1614 & 6.0 & 5.9891 & TRN \\
\hline CHEMBL357408 & 1614 & 7.1079 & 7.00700 & 000000001 \\
\hline CHEMBL145849 & 1614 & 7.0706 & 7.0846 & TRN \\
\hline CHEMBL149488 & 1614 & 7.0 & 6.8932 & TRN \\
\hline CHEMBL147660 & 1614 & 7.6198 & 7.7281 & TRN \\
\hline CHEMBL148325 & 1614 & 6.8539 & 7.815 & TST \\
\hline CHEMBL357634 & 1614 & 8.0 & 7.5552 & TST \\
\hline CHEMBL 341854 & 1614 & 5.8861 & 5.6975 & TST \\
\hline CHEMBL347570 & 1614 & 7.3979 & 7.6094 & TST \\
\hline
\end{tabular}




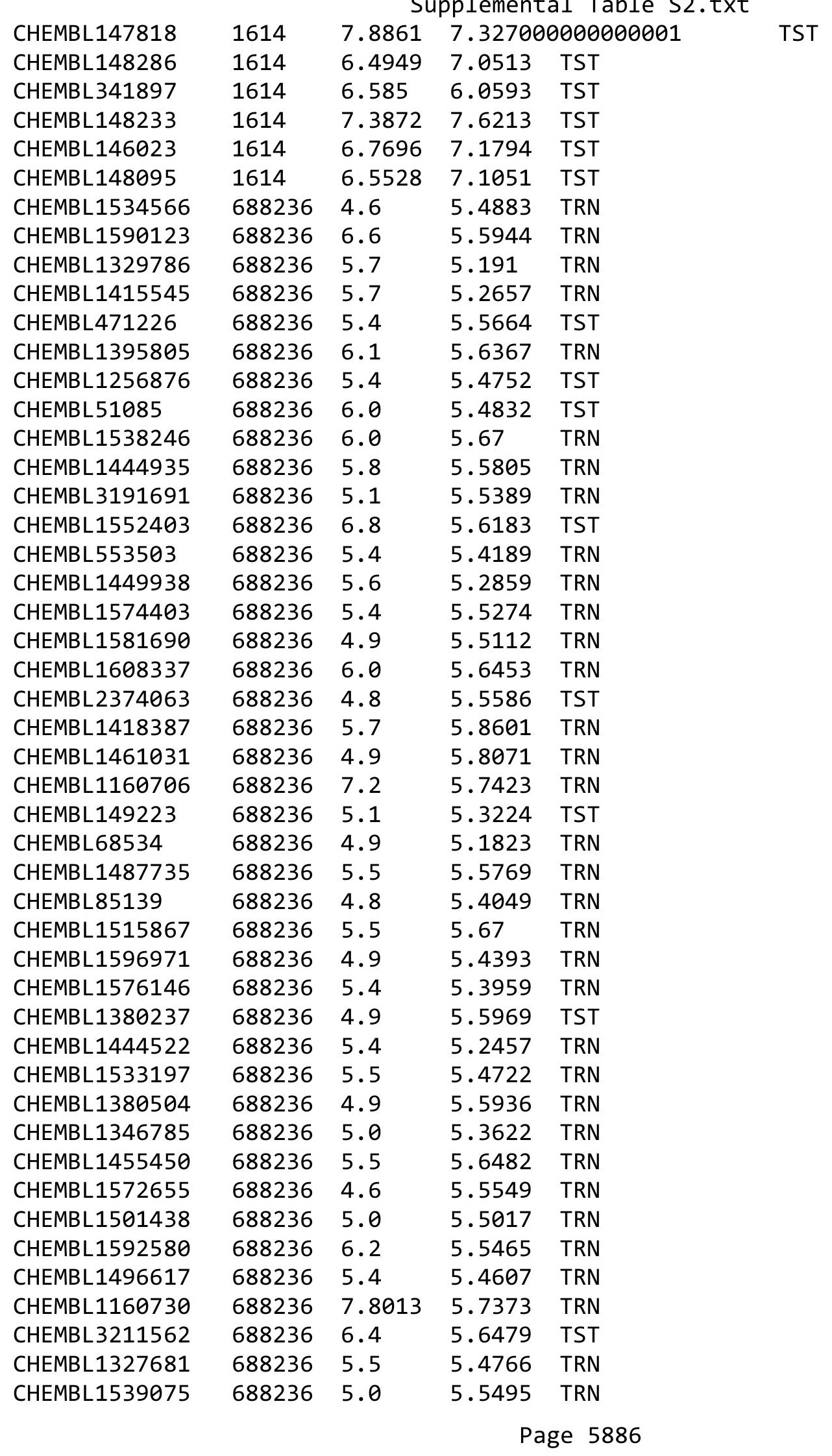




\begin{tabular}{|c|c|c|c|c|c|}
\hline CHEMBL1395417 & 688236 & 5.5 & 5.8224 & TRN & \\
\hline CHEMBL1399181 & 688236 & 5.5 & 5.61799 & 9999999999 & TRN \\
\hline CHEMBL1358395 & 688236 & 6.8 & 5.63200 & 0000000001 & TRN \\
\hline CHEMBL1405744 & 688236 & 6.2 & 5.7578 & TRN & \\
\hline CHEMBL491578 & 688236 & 5.3 & 5.6946 & TRN & \\
\hline CHEMBL1474522 & 688236 & 6.0 & 5.5032 & TST & \\
\hline CHEMBL465843 & 688236 & 5.0 & 5.4804 & TRN & \\
\hline CHEMBL476672 & 688236 & 5.3 & 5.6109 & TRN & \\
\hline CHEMBL1390888 & 688236 & 5.2 & 5.5456 & TRN & \\
\hline CHEMBL1327851 & 688236 & 5.3 & 5.4284 & TRN & \\
\hline CHEMBL1500533 & 688236 & 4.9 & 5.4389 & TST & \\
\hline CHEMBL1736254 & 688236 & 6.8 & 5.6122 & TST & \\
\hline CHEMBL420060 & 688236 & 4.8 & 5.5021 & TRN & \\
\hline CHEMBL1512693 & 688236 & 5.4 & 5.6153 & TRN & \\
\hline CHEMBL1471205 & 688236 & 5.5 & 5.3404 & TRN & \\
\hline CHEMBL1594457 & 688236 & 5.0 & 5.3824 & TRN & \\
\hline CHEMBL1325408 & 688236 & 6.0 & 5.652 & TRN & \\
\hline CHEMBL1257078 & 688236 & 4.9 & 5.5363 & TST & \\
\hline CHEMBL1401031 & 688236 & 6.5 & 5.7532 & TRN & \\
\hline CHEMBL1331657 & 688236 & 5.8 & 5.65 & TRN & \\
\hline CHEMBL1315527 & 688236 & 5.4 & 5.4637 & TRN & \\
\hline CHEMBL1488420 & 688236 & 5.7 & 5.3631 & TRN & \\
\hline CHEMBL1424148 & 688236 & 4.9 & 5.2611 & TRN & \\
\hline CHEMBL1332463 & 688236 & 6.2 & 5.9658 & TRN & \\
\hline CHEMBL119171 & 688236 & 4.9 & 5.5039 & TRN & \\
\hline CHEMBL1575721 & 688236 & 5.0 & 5.2858 & TRN & \\
\hline CHEMBL1571157 & 688236 & 6.4 & 5.8343 & TRN & \\
\hline CHEMBL1358806 & 688236 & 6.3 & 5.5194 & TRN & \\
\hline CHEMBL1365898 & 688236 & 5.8 & 5.2615 & TRN & \\
\hline CHEMBL1512222 & 688236 & 5.5 & 5.5153 & TRN & \\
\hline CHEMBL1424950 & 688236 & 5.3 & 5.5578 & TRN & \\
\hline CHEMBL1485579 & 688236 & 5.3 & 5.6346 & TRN & \\
\hline CHEMBL1481337 & 688236 & 4.9 & 5.2577 & TRN & \\
\hline CHEMBL1486304 & 688236 & 6.1 & 5.5672 & TRN & \\
\hline CHEMBL1437783 & 688236 & 5.5 & 5.4295 & TRN & \\
\hline CHEMBL1256910 & 688236 & 5.2 & 5.5644 & TST & \\
\hline CHEMBL1554131 & 688236 & 6.0 & 5.6013 & TRN & \\
\hline CHEMBL 1447590 & 688236 & 5.5 & 5.5987 & TST & \\
\hline CHEMBL1437648 & 688236 & 5.5 & 5.4483 & TST & \\
\hline CHEMBL1544947 & 688236 & 5.5 & 5.3415 & TRN & \\
\hline CHEMBL1482155 & 688236 & 5.5 & 5.6978 & TRN & \\
\hline CHEMBL1588679 & 688236 & 5.3 & 5.4656 & TRN & \\
\hline CHEMBL1418583 & 688236 & 6.1 & 5.2638 & TRN & \\
\hline CHEMBL1356391 & 688236 & 6.8 & 5.6565 & TRN & \\
\hline CHEMBL1727680 & 688236 & 6.4 & 5.5613 & TRN & \\
\hline CHEMBL 275006 & 688236 & 4.9 & 5.6039 & TST & \\
\hline CHEMBL1438928 & 688236 & 5.5 & 5.6098 & TRN & \\
\hline CHEMBL1397604 & 688236 & 5.5 & 5.4438 & TRN & \\
\hline
\end{tabular}




\begin{tabular}{|c|c|c|c|c|c|}
\hline \\
\hline CHEMBL1545244 & 688236 & 5.0 & 5.4564 & TST & \\
\hline CHEMBL1611308 & 688236 & 5.5 & 5.5349 & TRN & \\
\hline CHEMBL544115 & 688236 & 5.3 & 5.3672 & TRN & \\
\hline CHEMBL1435654 & 688236 & 5.9 & 5.5389 & TRN & \\
\hline CHEMBL1475487 & 688236 & 5.3 & 5.9797 & TRN & \\
\hline CHEMBL1299407 & 688236 & 4.9 & 5.1138 & TRN & \\
\hline CHEMBL1377111 & 688236 & 5.4 & 5.4644 & TST & \\
\hline CHEMBL1380644 & 688236 & 5.3 & 5.4286 & TRN & \\
\hline CHEMBL1570595 & 688236 & 4.9 & 5.5534 & TRN & \\
\hline CHEMBL1559618 & 688236 & 4.9 & 5.6209 & TRN & \\
\hline CHEMBL1390659 & 688236 & 5.0 & 5.3826 & TRN & \\
\hline CHEMBL1593412 & 688236 & 6.0 & 5.5031 & TRN & \\
\hline CHEMBL1319308 & 688236 & 5.6 & 5.51200 & 00000000005 & TST \\
\hline CHEMBL 2373582 & 688236 & 6.5 & 5.4544 & TST & \\
\hline CHEMBL1698288 & 688236 & 5.3 & 5.5811 & TRN & \\
\hline CHEMBL1593589 & 688236 & 6.1 & 5.7196 & TRN & \\
\hline CHEMBL1502888 & 688236 & 5.0 & 5.3828 & TRN & \\
\hline CHEMBL553751 & 688236 & 5.7 & 5.4924 & TRN & \\
\hline CHEMBL1559628 & 688236 & 5.0 & 5.2999 & TRN & \\
\hline CHEMBL1306312 & 688236 & 5.8 & 5.4272 & TRN & \\
\hline CHEMBL1316647 & 688236 & 6.0 & 5.655 & TRN & \\
\hline CHEMBL1571006 & 688236 & 5.9 & 5.2991 & TRN & \\
\hline CHEMBL1461834 & 688236 & 4.9 & 5.3473 & TRN & \\
\hline CHEMBL1407769 & 688236 & 5.0 & 5.5181 & TST & \\
\hline CHEMBL1384200 & 688236 & 6.4 & 5.3475 & TRN & \\
\hline CHEMBL1524001 & 688236 & 5.5 & 5.6371 & TRN & \\
\hline CHEMBL1491965 & 688236 & 5.5 & 5.7395 & TRN & \\
\hline CHEMBL1437523 & 688236 & 5.7 & 5.652 & TRN & \\
\hline CHEMBL1327059 & 688236 & 5.5 & 5.4834 & TRN & \\
\hline CHEMBL1399656 & 688236 & 6.7001 & 5.5734 & TRN & \\
\hline CHEMBL543467 & 688236 & 4.9 & 5.6122 & TST & \\
\hline CHEMBL2373615 & 688236 & 6.0 & 5.5459 & TRN & \\
\hline CHEMBL1356041 & 688236 & 5.5 & 5.8455 & TRN & \\
\hline CHEMBL1390 & 688236 & 7.1002 & 5.4387 & TST & \\
\hline CHEMBL1373796 & 688236 & 5.3 & 5.5749 & TRN & \\
\hline CHEMBL1370698 & 688236 & 5.5 & 5.5697 & TRN & \\
\hline CHEMBL1314182 & 688236 & 5.5 & 5.7868 & TRN & \\
\hline CHEMBL1371355 & 688236 & 6.7001 & 5.5145 & TRN & \\
\hline CHEMBL1255747 & 688236 & 4.9 & 5.4612 & TRN & \\
\hline CHEMBL1519225 & 688236 & 5.6 & 5.6723 & TRN & \\
\hline CHEMBL1467091 & 688236 & 5.0 & 5.5197 & TRN & \\
\hline CHEMBL1526543 & 688236 & 6.0 & 5.5724 & TST & \\
\hline CHEMBL1256943 & 688236 & 4.8 & 5.4384 & TRN & \\
\hline CHEMBL1300217 & 688236 & 6.6 & 5.5131 & TRN & \\
\hline CHEMBL1495685 & 688236 & 5.6 & 5.4239 & TRN & \\
\hline CHEMBL1392030 & 688236 & 5.3 & 5.2841 & TRN & \\
\hline CHEMBL1411314 & 688236 & 5.9 & 5.6674 & TRN & \\
\hline CHEMBL1394095 & 688236 & 6.0 & 5.8319 & TRN & \\
\hline
\end{tabular}




\begin{tabular}{|c|c|c|c|c|}
\hline & & & & $a \perp 1$ \\
\hline CHEMBL1452561 & 688236 & 6.0 & 5.4685 & TRN \\
\hline CHEMBL1445386 & 688236 & 6.1 & 6.1958 & TST \\
\hline CHEMBL1490339 & 688236 & 6.5 & 5.6758 & TRN \\
\hline CHEMBL1256646 & 688236 & 5.1 & 5.4084 & TRN \\
\hline CHEMBL1256283 & 688236 & 4.8 & 5.5088 & TRN \\
\hline CHEMBL1594915 & 688236 & 5.2 & 5.5265 & TRN \\
\hline CHEMBL1464723 & 688236 & 5.3 & 5.51 & TRN \\
\hline CHEMBL1477182 & 688236 & 6.9 & 5.641 & TST \\
\hline CHEMBL1256746 & 688236 & 5.2 & 5.6336 & TRN \\
\hline CHEMBL3212790 & 688236 & 6.1 & 5.4872 & TST \\
\hline CHEMBL1084643 & 688236 & 5.6 & 5.5573 & TST \\
\hline CHEMBL1355010 & 688236 & 5.5 & 5.6427 & TRN \\
\hline CHEMBL1590601 & 688236 & 7.0 & 5.3478 & TRN \\
\hline CHEMBL1377507 & 688236 & 6.0 & 5.6729 & TST \\
\hline CHEMBL1565228 & 688236 & 6.8 & 5.5462 & TRN \\
\hline CHEMBL1544060 & 688236 & 4.9 & 5.4005 & TRN \\
\hline CHEMBL1353175 & 688236 & 5.0 & 5.3002 & TRN \\
\hline CHEMBL1307622 & 688236 & 5.3 & 5.3642 & TRN \\
\hline CHEMBL1513030 & 688236 & 5.3 & 5.7129 & TRN \\
\hline CHEMBL1516495 & 688236 & 4.9 & 5.3748 & TRN \\
\hline CHEMBL1552957 & 688236 & 5.5 & 5.6893 & TRN \\
\hline CHEMBL1396997 & 688236 & 5.6 & 5.7422 & TRN \\
\hline CHEMBL1517852 & 688236 & 5.6 & 5.5392 & TRN \\
\hline CHEMBL3212923 & 688236 & 5.1 & 5.4845 & TRN \\
\hline CHEMBL1505922 & 688236 & 5.5 & 5.4642 & TRN \\
\hline CHEMBL1535395 & 688236 & 5.2 & 5.2919 & TRN \\
\hline CHEMBL1256360 & 688236 & 6.0 & 5.7601 & TRN \\
\hline CHEMBL1450716 & 688236 & 5.5 & 5.8355 & TRN \\
\hline CHEMBL 267014 & 688236 & 4.9 & 5.6453 & TRN \\
\hline CHEMBL1611550 & 688236 & 5.9 & 5.71 & TRN \\
\hline CHEMBL1374996 & 688236 & 4.9 & 5.5118 & TST \\
\hline CHEMBL1567944 & 688236 & 6.0 & 5.7088 & TRN \\
\hline CHEMBL1554236 & 688236 & 5.4 & 5.7131 & TRN \\
\hline CHEMBL1366810 & 688236 & 5.0 & 5.2151 & TRN \\
\hline CHEMBL131921 & 688236 & 5.0 & 5.5425 & TRN \\
\hline CHEMBL258767 & 688236 & 6.0 & 5.3738 & TRN \\
\hline CHEMBL1458826 & 688236 & 5.0 & 5.5136 & TRN \\
\hline CHEMBL1562477 & 688236 & 5.5 & 5.7553 & TRN \\
\hline CHEMBL1420011 & 688236 & 5.0 & 5.5431 & TST \\
\hline CHEMBL1335410 & 688236 & 5.0 & 5.4997 & TST \\
\hline CHEMBL1569814 & 688236 & 4.9 & 5.4093 & TST \\
\hline CHEMBL1476762 & 688236 & 4.6 & 5.5504 & TST \\
\hline CHEMBL566899 & 688236 & 6.4 & 5.99200 & 0000000001 \\
\hline CHEMBL1255866 & 688236 & 4.8 & 5.5282 & TST \\
\hline CHEMBL 282489 & 688236 & 4.6 & 5.5201 & TST \\
\hline CHEMBL1584264 & 688236 & 4.9 & 5.38 & TRN \\
\hline CHEMBL1612410 & 688236 & 6.2 & 5.6599 & TRN \\
\hline CHEMBL1437119 & 688236 & 5.3 & 5.5605 & TRN \\
\hline
\end{tabular}

TRN 


\begin{tabular}{|c|c|c|c|c|c|}
\hline \multirow[b]{2}{*}{ CHEMBL1324529 } & \\
\hline & 688236 & 5.6 & 5.6888 & TRN & \\
\hline CHEMBL1350478 & 688236 & 5.0 & 5.3127 & TRN & \\
\hline CHEMBL1340201 & 688236 & 6.1 & 5.2921 & TRN & \\
\hline CHEMBL1438389 & 688236 & 6.4 & 5.4415 & TRN & \\
\hline CHEMBL1527439 & 688236 & 6.7001 & 5.4464 & TST & \\
\hline CHEMBL1418094 & 688236 & 5.7 & 5.5386 & TST & \\
\hline CHEMBL1496863 & 688236 & 5.0 & 5.2671 & TRN & \\
\hline CHEMBL1473874 & 688236 & 5.0 & 5.4555 & TST & \\
\hline CHEMBL1588762 & 688236 & 5.6 & 5.5821 & TRN & \\
\hline CHEMBL1325297 & 688236 & 5.9 & 5.5324 & TST & \\
\hline CHEMBL1084478 & 688236 & 5.3 & 5.4867 & TRN & \\
\hline CHEMBL1383447 & 688236 & 5.9 & 5.4869 & TST & \\
\hline CHEMBL1426258 & 688236 & 4.9 & 5.2994 & TRN & \\
\hline CHEMBL576349 & 688236 & 7.3002 & 5.5609 & TRN & \\
\hline CHEMBL1386326 & 688236 & 5.6 & 5.5871 & TRN & \\
\hline CHEMBL1592542 & 688236 & 6.0 & 5.4792 & TST & \\
\hline CHEMBL1392350 & 688236 & 5.4 & 5.36799 & 9999999999 & TRN \\
\hline CHEMBL1545211 & 688236 & 5.0 & 5.184 & TRN & \\
\hline CHEMBL1325388 & 688236 & 6.9 & 5.6063 & TRN & \\
\hline CHEMBL56731 & 688236 & 5.0 & 5.2802 & TRN & \\
\hline CHEMBL1436059 & 688236 & 7.1002 & 5.5342 & TRN & \\
\hline CHEMBL7917 & 688236 & 4.8 & 5.8047 & TRN & \\
\hline CHEMBL1368572 & 688236 & 5.5 & 5.5274 & TRN & \\
\hline CHEMBL1437747 & 688236 & 5.5 & 5.7672 & TRN & \\
\hline CHEMBL1451327 & 688236 & 5.2 & 5.3824 & TST & \\
\hline CHEMBL45244 & 688236 & 5.3 & 5.1553 & TRN & \\
\hline CHEMBL188 & 688236 & 4.6 & 5.2956 & TRN & \\
\hline CHEMBL572576 & 688236 & 4.9 & 5.369 & TRN & \\
\hline CHEMBL399121 & 688236 & 5.3 & 5.5634 & TRN & \\
\hline CHEMBL1488918 & 688236 & 5.4 & 5.3984 & TRN & \\
\hline CHEMBL1393480 & 688236 & 6.5 & 5.6852 & TRN & \\
\hline CHEMBL1497731 & 688236 & 4.9 & 5.4869 & TRN & \\
\hline CHEMBL1378073 & 688236 & 4.9 & 5.4034 & TRN & \\
\hline CHEMBL1451733 & 688236 & 5.3 & 5.4029 & TRN & \\
\hline CHEMBL1317451 & 688236 & 5.5 & 5.7038 & TRN & \\
\hline CHEMBL1588305 & 688236 & 5.5 & 5.5211 & TRN & \\
\hline CHEMBL270299 & 688236 & 4.7 & 5.5972 & TST & \\
\hline CHEMBL1462380 & 688236 & 5.0 & 5.4689 & TRN & \\
\hline CHEMBL1579891 & 688236 & 5.4 & 5.28799 & 9999999999 & TRN \\
\hline CHEMBL1480673 & 688236 & 5.3 & 5.5302 & TST & \\
\hline CHEMBL293749 & 688236 & 5.0 & 5.1515 & TRN & \\
\hline CHEMBL1458925 & 688236 & 5.3 & 5.3688 & TRN & \\
\hline CHEMBL1357850 & 688236 & 5.4 & 5.5936 & TRN & \\
\hline CHEMBL1565927 & 688236 & 6.1 & 5.92 & TRN & \\
\hline CHEMBL1595142 & 688236 & 5.5 & 5.9237 & TRN & \\
\hline CHEMBL30432 & 688236 & 6.1 & 5.6672 & TRN & \\
\hline CHEMBL1395297 & 688236 & 5.5 & 5.7054 & TRN & \\
\hline CHEMBL1597390 & 688236 & 7.0 & 5.5255 & TRN & \\
\hline & & & & 8 & \\
\hline
\end{tabular}




\begin{tabular}{|c|c|c|c|c|c|}
\hline \multirow{2}{*}{ CHEMBL1554791 } & \multirow{2}{*}{688236} & \\
\hline & & 5.6 & 5.6294 & TRN & \\
\hline CHEMBL1526927 & 688236 & 7.0 & 5.6164 & TRN & \\
\hline CHEMBL75967 & 688236 & 6.0 & 5.5433 & TST & \\
\hline CHEMBL1393548 & 688236 & 5.0 & 5.4374 & TRN & \\
\hline CHEMBL 288096 & 688236 & 5.6 & 5.3811 & TRN & \\
\hline CHEMBL21260 & 688236 & 6.0 & 5.5895 & TRN & \\
\hline CHEMBL1408760 & 688236 & 6.0 & 5.6423 & TRN & \\
\hline CHEMBL1604377 & 688236 & 6.0 & 5.4835 & TRN & \\
\hline CHEMBL1502224 & 688236 & 6.5 & 5.4626 & TRN & \\
\hline CHEMBL1400411 & 688236 & 5.5 & 5.4922 & TST & \\
\hline CHEMBL1547754 & 688236 & 5.6 & 5.3034 & TRN & \\
\hline CHEMBL 2068217 & 688236 & 5.2 & 5.5677 & TST & \\
\hline CHEMBL1411808 & 688236 & 7.5003 & 5.7451 & TRN & \\
\hline CHEMBL1996233 & 688236 & 5.0 & 5.3679 & TRN & \\
\hline CHEMBL1315743 & 688236 & 4.8 & 5.5314 & TST & \\
\hline CHEMBL1308455 & 688236 & 6.5 & \multicolumn{2}{|c|}{5.3020000000000005} & TRN \\
\hline CHEMBL3190629 & 688236 & 5.5 & 5.477 & TRN & \\
\hline CHEMBL1354281 & 688236 & 5.4 & 5.4001 & TRN & \\
\hline CHEMBL1593219 & 688236 & 5.5 & 5.6992 & TRN & \\
\hline CHEMBL1398137 & 688236 & 5.7 & 5.523 & TRN & \\
\hline CHEMBL1404093 & 688236 & 5.6 & 5.6126 & TRN & \\
\hline CHEMBL1418227 & 688236 & 6.0 & 5.4985 & TRN & \\
\hline CHEMBL1419598 & 688236 & 5.4 & 5.2811 & TRN & \\
\hline CHEMBL1555929 & 688236 & 6.0 & 5.6693 & TST & \\
\hline CHEMBL581886 & 688236 & 7.3002 & 5.6858 & TRN & \\
\hline CHEMBL1384421 & 688236 & 5.5 & 5.4191 & TRN & \\
\hline CHEMBL1590886 & 688236 & 5.5 & 5.5484 & TRN & \\
\hline CHEMBL1455073 & 688236 & 5.9 & 5.5711 & TST & \\
\hline CHEMBL1317647 & 688236 & 5.3 & 5.4191 & TRN & \\
\hline CHEMBL3190482 & 688236 & 5.7 & 5.3541 & TST & \\
\hline CHEMBL1552181 & 688236 & 5.5 & 5.6912 & TRN & \\
\hline CHEMBL1378742 & 688236 & 5.0 & 5.5735 & TRN & \\
\hline CHEMBL1412511 & 688236 & 4.9 & 5.4949 & TRN & \\
\hline CHEMBL1424538 & 688236 & 5.2 & 5.3325 & TRN & \\
\hline CHEMBL340807 & 688236 & 5.0 & 5.487 & TRN & \\
\hline CHEMBL1440588 & 688236 & 5.0 & 5.4154 & TST & \\
\hline CHEMBL261131 & 688236 & 5.3 & 5.3863 & TRN & \\
\hline CHEMBL291481 & 688236 & 4.9 & 5.4636 & TRN & \\
\hline CHEMBL1603692 & 688236 & 5.5 & 5.6442 & TRN & \\
\hline CHEMBL56393 & 688236 & 5.1 & 5.1332 & TRN & \\
\hline CHEMBL1517724 & 688236 & 6.4 & 5.8258 & TRN & \\
\hline CHEMBL1299369 & 688236 & 5.6 & 5.3306 & TRN & \\
\hline CHEMBL1306263 & 688236 & 6.7001 & 5.3139 & TRN & \\
\hline CHEMBL1435994 & 688236 & 5.8 & 5.8489 & TRN & \\
\hline CHEMBL1318114 & 688236 & 5.6 & 5.82299 & 99999999995 & TRN \\
\hline CHEMBL1596391 & 688236 & 5.7 & 5.3842 & TRN & \\
\hline CHEMBL1398518 & 688236 & 4.9 & 5.521 & TST & \\
\hline \multirow[t]{2}{*}{ CHEMBL577635 } & 688236 & 5.6 & 5.4974 & TRN & \\
\hline & & \multicolumn{4}{|c|}{ Page 5891} \\
\hline
\end{tabular}




\begin{tabular}{|c|c|c|c|c|}
\hline \multicolumn{5}{|c|}{ Supplemental Table S2.txt } \\
\hline CHEMBL1394945 & 688236 & 4.9 & 5.6447 & TRN \\
\hline CHEMBL1613194 & 688236 & 5.3 & 5.6295 & TRN \\
\hline CHEMBL1558569 & 688236 & 5.3 & 5.9047 & TRN \\
\hline CHEMBL3189836 & 688236 & 5.0 & 5.3842 & TRN \\
\hline CHEMBL1422158 & 688236 & 5.0 & 5.4938 & TRN \\
\hline CHEMBL1502697 & 688236 & 5.3 & 5.6147 & TST \\
\hline CHEMBL1395277 & 688236 & 5.3 & 5.6101 & TRN \\
\hline CHEMBL1310777 & 688236 & 5.0 & 5.4284 & TRN \\
\hline CHEMBL1357401 & 688236 & 8.0 & 5.8256 & TRN \\
\hline CHEMBL1371947 & 688236 & 5.5 & 5.6253 & TST \\
\hline CHEMBL1441453 & 688236 & 5.4 & 5.4948 & TRN \\
\hline CHEMBL1403769 & 688236 & 5.5 & 5.6976 & TRN \\
\hline CHEMBL1515717 & 688236 & 5.2 & 5.6773 & TRN \\
\hline CHEMBL1455255 & 688236 & 5.5 & 5.8576 & TRN \\
\hline CHEMBL1369796 & 688236 & 5.8 & 5.7761 & TRN \\
\hline CHEMBL19880 & 688236 & 4.9 & 5.5156 & TST \\
\hline CHEMBL1404884 & 688236 & 5.8 & 5.4722 & TRN \\
\hline CHEMBL1333212 & 688236 & 5.3 & 5.6412 & TRN \\
\hline CHEMBL1398713 & 688236 & 5.4 & 5.5784 & TST \\
\hline CHEMBL534084 & 688236 & 4.6 & 5.5465 & TRN \\
\hline CHEMBL1605399 & 688236 & 5.5 & 5.8972 & TRN \\
\hline CHEMBL1403154 & 688236 & 6.0 & 5.6469 & TRN \\
\hline CHEMBL1553635 & 688236 & 8.1024 & 5.5644 & TST \\
\hline CHEMBL1417349 & 688236 & 5.5 & 5.7177 & TRN \\
\hline CHEMBL1520025 & 688236 & 7.3002 & 5.568 & TST \\
\hline CHEMBL1403102 & 688236 & 6.9 & 5.6591 & TRN \\
\hline CHEMBL23236 & 688236 & 5.9 & 5.532 & TST \\
\hline CHEMBL140 & 688236 & 5.2 & 5.4951 & TRN \\
\hline CHEMBL1506496 & 688236 & 5.3 & 5.318 & TRN \\
\hline CHEMBL561589 & 688236 & 5.2 & 5.4157 & TRN \\
\hline CHEMBL1330951 & 688236 & 5.5 & 5.4437 & TRN \\
\hline CHEMBL1328484 & 688236 & 5.6 & 5.6176 & TST \\
\hline CHEMBL1536490 & 688236 & 5.3 & 5.5112 & TRN \\
\hline CHEMBL1510206 & 688236 & 5.6 & 5.4372 & TRN \\
\hline CHEMBL1595377 & 688236 & 5.4 & 5.5964 & TRN \\
\hline CHEMBL1468929 & 688236 & 6.3 & 5.4891 & TST \\
\hline CHEMBL3211772 & 688236 & 5.0 & 5.4379 & TRN \\
\hline CHEMBL1334327 & 688236 & 6.2 & 5.5146 & TRN \\
\hline CHEMBL1371634 & 688236 & 5.5 & 5.4317 & TST \\
\hline CHEMBL1397671 & 688236 & 5.3 & 5.7559 & TRN \\
\hline CHEMBL568379 & 688236 & 5.4 & 5.7969 & TRN \\
\hline CHEMBL1607568 & 688236 & 6.2 & 5.6629 & TRN \\
\hline CHEMBL1257123 & 688236 & 5.0 & 5.5115 & TRN \\
\hline CHEMBL 2373676 & 688236 & 5.6 & 5.5512 & TST \\
\hline CHEMBL 1403112 & 688236 & 5.9 & 5.5772 & TRN \\
\hline CHEMBL1256654 & 688236 & 5.4 & 5.649 & TRN \\
\hline CHEMBL1475589 & 688236 & 5.5 & 5.6378 & TRN \\
\hline CHEMBL1523959 & 688236 & 5.5 & 5.6316 & TRN \\
\hline
\end{tabular}




\begin{tabular}{|c|c|c|c|c|}
\hline \multicolumn{5}{|c|}{ Supplemental Table } \\
\hline CHEMBL1592464 & 688236 & 5.7 & 5.7615 & TRN \\
\hline CHEMBL1477573 & 688236 & 5.1 & 5.4262 & TRN \\
\hline CHEMBL1397965 & 688236 & 5.5 & 5.8007 & TRN \\
\hline CHEMBL251647 & 688236 & 4.9 & 5.6993 & TST \\
\hline CHEMBL1376212 & 688236 & 5.3 & 5.3304 & TRN \\
\hline CHEMBL1516749 & 688236 & 5.1 & 5.2965 & TRN \\
\hline CHEMBL1437846 & 688236 & 5.9 & 5.5098 & TST \\
\hline CHEMBL494887 & 688236 & 5.5 & 5.56 & TST \\
\hline CHEMBL1256984 & 688236 & 4.6 & \multicolumn{2}{|c|}{5.611000000000001} \\
\hline CHEMBL1589897 & 688236 & 5.3 & 5.5345 & TRN \\
\hline CHEMBL1475620 & 688236 & 6.2 & 5.6509 & TRN \\
\hline CHEMBL310798 & 688236 & 5.0 & 5.345 & TRN \\
\hline CHEMBL1097940 & 688236 & 4.6 & 5.6293 & TST \\
\hline CHEMBL1314473 & 688236 & 5.9 & 5.6097 & TRN \\
\hline CHEMBL1363622 & 688236 & 5.5 & 5.5726 & TRN \\
\hline CHEMBL1358722 & 688236 & 7.2 & 5.7116 & TST \\
\hline CHEMBL1358838 & 688236 & 6.2 & 5.5971 & TRN \\
\hline CHEMBL1438041 & 688236 & 5.5 & 5.6284 & TRN \\
\hline CHEMBL1332120 & 688236 & 5.4 & 5.7053 & TRN \\
\hline CHEMBL1609770 & 688236 & 5.4 & 5.5808 & TST \\
\hline CHEMBL1331778 & 688236 & 6.4 & 5.6739 & TRN \\
\hline CHEMBL1597277 & 688236 & 5.9 & 5.5098 & TRN \\
\hline CHEMBL1558246 & 688236 & 5.0 & 5.4838 & TRN \\
\hline CHEMBL1593068 & 688236 & 5.8 & 5.505 & TRN \\
\hline CHEMBL95431 & 688236 & 5.5 & 5.3271 & TST \\
\hline CHEMBL1317950 & 688236 & 4.9 & 5.5205 & TRN \\
\hline CHEMBL1500323 & 688236 & 5.2 & 5.4105 & TST \\
\hline CHEMBL1437522 & 688236 & 7.4001 & 5.5121 & TRN \\
\hline CHEMBL1590911 & 688236 & 5.3 & 5.4342 & TRN \\
\hline CHEMBL1436179 & 688236 & 5.7 & 5.6847 & TRN \\
\hline CHEMBL1421246 & 688236 & 6.6 & 5.4615 & TRN \\
\hline CHEMBL1587764 & 688236 & 4.9 & 5.3183 & TRN \\
\hline CHEMBL1553179 & 688236 & 5.5 & 5.6378 & TRN \\
\hline CHEMBL1366371 & 688236 & 5.5 & 5.7141 & TRN \\
\hline CHEMBL1490456 & 688236 & 4.9 & 5.3332 & TST \\
\hline CHEMBL1434833 & 688236 & 5.5 & 5.5767 & TRN \\
\hline CHEMBL1341664 & 688236 & 5.2 & 5.2665 & TRN \\
\hline CHEMBL1348849 & 688236 & 5.0 & 5.2795 & TRN \\
\hline CHEMBL1357648 & 688236 & 5.3 & 5.6043 & TRN \\
\hline CHEMBL3198611 & 688236 & 6.3 & 5.3771 & TST \\
\hline CHEMBL1518705 & 688236 & 6.1 & 5.6214 & TRN \\
\hline CHEMBL1160709 & 688236 & 6.0 & 5.7375 & TRN \\
\hline CHEMBL539027 & 688236 & 6.0 & 5.5974 & TRN \\
\hline CHEMBL1475698 & 688236 & 8.1024 & 5.6233 & TST \\
\hline CHEMBL1488771 & 688236 & 5.4 & 5.4115 & TRN \\
\hline CHEMBL1516163 & 688236 & 5.5 & 5.7248 & TRN \\
\hline CHEMBL1427851 & 688236 & 4.9 & 5.6164 & TRN \\
\hline CHEMBL1473755 & 688236 & 5.5 & 5.7536 & TRN \\
\hline
\end{tabular}




\begin{tabular}{|c|c|c|c|c|c|}
\hline \\
\hline CHEMBL60718 & 688236 & 4.6 & 5.5192 & TRN & \\
\hline CHEMBL265177 & 688236 & 7.0 & 5.5737 & TST & \\
\hline CHEMBL1589998 & 688236 & 8.6021 & 5.7978 & TRN & \\
\hline CHEMBL1447738 & 688236 & 5.4 & 5.6203 & TRN & \\
\hline CHEMBL1513665 & 688236 & 5.3 & 5.718 & TRN & \\
\hline CHEMBL1391287 & 688236 & 6.5 & 5.7616 & TRN & \\
\hline CHEMBL1452098 & 688236 & 5.5 & 5.49799 & 9999999999 & TRN \\
\hline CHEMBL1256186 & 688236 & 4.8 & 5.4765 & TST & \\
\hline CHEMBL1379653 & 688236 & 4.9 & 5.3259 & TRN & \\
\hline CHEMBL1592452 & 688236 & 5.6 & 5.7158 & TRN & \\
\hline CHEMBL1516622 & 688236 & 6.5 & 5.6227 & TRN & \\
\hline CHEMBL1329033 & 688236 & 5.1 & 5.2608 & TRN & \\
\hline CHEMBL1594437 & 688236 & 5.0 & 5.3373 & TRN & \\
\hline CHEMBL1520216 & 688236 & 5.9 & 5.7516 & TRN & \\
\hline CHEMBL268609 & 688236 & 6.0 & 5.4155 & TRN & \\
\hline CHEMBL1407114 & 688236 & 5.0 & 5.2123 & TRN & \\
\hline CHEMBL1373259 & 688236 & 5.3 & 5.6892 & TRN & \\
\hline CHEMBL1455942 & 688236 & 5.3 & 5.5529 & TRN & \\
\hline CHEMBL1512049 & 688236 & 5.6 & 5.71200 & 0000000001 & TRN \\
\hline CHEMBL93655 & 688236 & 5.6 & 5.4191 & TRN & \\
\hline CHEMBL1499884 & 688236 & 6.4 & 5.3607 & TRN & \\
\hline CHEMBL1355879 & 688236 & 7.8013 & 5.6061 & TST & \\
\hline CHEMBL1349625 & 688236 & 5.0 & 5.4113 & TST & \\
\hline CHEMBL1589942 & 688236 & 5.6 & 5.5247 & TST & \\
\hline CHEMBL17468 & 688236 & 5.0 & 5.5644 & TRN & \\
\hline CHEMBL1492263 & 688236 & 5.8 & 5.2579 & TRN & \\
\hline CHEMBL290077 & 688236 & 5.2 & 5.5668 & TRN & \\
\hline CHEMBL1342336 & 688236 & 7.0 & 5.7185 & TRN & \\
\hline CHEMBL1409046 & 688236 & 4.9 & 5.5289 & TST & \\
\hline CHEMBL1378010 & 688236 & 5.5 & 5.6011 & TRN & \\
\hline CHEMBL1313103 & 688236 & 6.9 & 5.4379 & TRN & \\
\hline CHEMBL1415053 & 688236 & 5.5 & 5.3161 & TRN & \\
\hline CHEMBL1433886 & 688236 & 5.3 & 5.2905 & TRN & \\
\hline CHEMBL1314414 & 688236 & 5.4 & 5.6533 & TRN & \\
\hline CHEMBL994 & 688236 & 5.0 & 5.8226 & TRN & \\
\hline CHEMBL1435823 & 688236 & 5.5 & 5.9653 & TRN & \\
\hline CHEMBL1377807 & 688236 & 6.2 & 5.5367 & TRN & \\
\hline CHEMBL1316222 & 688236 & 5.3 & 5.4715 & TRN & \\
\hline CHEMBL 289277 & 688236 & 5.0 & 5.5219 & TRN & \\
\hline CHEMBL1474922 & 688236 & 7.5003 & 5.482 & TST & \\
\hline CHEMBL271165 & 688236 & 5.5 & 5.4962 & TST & \\
\hline CHEMBL1476170 & 688236 & 6.0 & 5.43 & TST & \\
\hline CHEMBL475375 & 688236 & 5.5 & 5.9192 & TRN & \\
\hline CHEMBL1396665 & 688236 & 4.9 & 5.3638 & TRN & \\
\hline CHEMBL1366433 & 688236 & 5.4 & 5.9604 & TRN & \\
\hline CHEMBL1482649 & 688236 & 5.7 & 5.4039 & TRN & \\
\hline CHEMBL1486659 & 688236 & 5.5 & 5.2788 & TST & \\
\hline CHEMBL1552562 & 688236 & 5.4 & 5.6899 & TRN & \\
\hline
\end{tabular}




\begin{tabular}{|c|c|c|c|c|c|}
\hline & & & & & \\
\hline CHEMBL1472547 & 688236 & 6.0 & 5.5302 & TST & \\
\hline CHEMBL1536379 & 688236 & 5.6 & 5.3577 & TRN & \\
\hline CHEMBL1516068 & 688236 & 5.0 & 5.3445 & TRN & \\
\hline CHEMBL29711 & 688236 & 5.7 & 5.5854 & TST & \\
\hline CHEMBL52 & 688236 & 6.0 & 5.6035 & TRN & \\
\hline CHEMBL1391184 & 688236 & 4.9 & 5.2464 & TRN & \\
\hline CHEMBL1593337 & 688236 & 5.3 & 5.4794 & TRN & \\
\hline CHEMBL15192 & 688236 & 4.5 & 5.53299 & 99999999995 & TRN \\
\hline CHEMBL1476021 & 688236 & 6.5 & 5.6591 & TRN & \\
\hline CHEMBL1503627 & 688236 & 5.7 & 5.7945 & TRN & \\
\hline CHEMBL1613349 & 688236 & 5.2 & 5.3517 & TRN & \\
\hline CHEMBL1445900 & 688236 & 5.5 & 5.5018 & TRN & \\
\hline CHEMBL1316808 & 688236 & 5.3 & 5.5229 & TRN & \\
\hline CHEMBL1514719 & 688236 & 5.7 & 5.8381 & TRN & \\
\hline CHEMBL1256718 & 688236 & 4.6 & 5.5009 & TST & \\
\hline CHEMBL1527317 & 688236 & 6.8 & 5.7475 & TRN & \\
\hline CHEMBL1502154 & 688236 & 5.0 & 5.37799 & 9999999999 & TRN \\
\hline CHEMBL1208858 & 688236 & 4.6 & 5.5694 & TRN & \\
\hline CHEMBL1437213 & 688236 & 7.6003 & 5.5048 & TRN & \\
\hline CHEMBL1566345 & 688236 & 5.0 & 5.3945 & TRN & \\
\hline CHEMBL1404954 & 688236 & 5.8 & 5.8911 & TRN & \\
\hline CHEMBL1460595 & 688236 & 5.0 & 5.5697 & TST & \\
\hline CHEMBL1475008 & 688236 & 4.9 & 5.6697 & TST & \\
\hline CHEMBL3192873 & 688236 & 5.2 & 5.6055 & TRN & \\
\hline CHEMBL1366157 & 688236 & 5.4 & 5.6354 & TRN & \\
\hline CHEMBL1600210 & 688236 & 5.5 & 5.7714 & TRN & \\
\hline CHEMBL1474479 & 688236 & 4.6 & 5.5914 & TRN & \\
\hline CHEMBL1437711 & 688236 & 5.6 & 5.4661 & TRN & \\
\hline CHEMBL1512624 & 688236 & 5.4 & 5.4365 & TRN & \\
\hline CHEMBL1562912 & 688236 & 4.9 & 5.4302 & TST & \\
\hline CHEMBL1533734 & 688236 & 5.5 & 5.739 & TRN & \\
\hline CHEMBL1550296 & 688236 & 5.8 & 5.6112 & TRN & \\
\hline CHEMBL 1457755 & 688236 & 5.7 & 5.1256 & TRN & \\
\hline CHEMBL1473116 & 688236 & 5.3 & 5.5606 & TRN & \\
\hline CHEMBL1315257 & 688236 & 5.6 & 5.7638 & TRN & \\
\hline CHEMBL1586681 & 688236 & 5.0 & 5.3223 & TRN & \\
\hline CHEMBL1318349 & 688236 & 5.4 & 5.5922 & TRN & \\
\hline CHEMBL1789988 & 688236 & 5.6 & 5.5591 & TRN & \\
\hline CHEMBL1551016 & 688236 & 7.0 & 5.5757 & TRN & \\
\hline CHEMBL1253215 & 688236 & 7.0 & 5.4942 & TRN & \\
\hline CHEMBL1333056 & 688236 & 6.0 & 5.4872 & TST & \\
\hline CHEMBL1437325 & 688236 & 6.6 & 5.591 & TRN & \\
\hline CHEMBL1459956 & 688236 & 5.5 & 5.55399 & 9999999999 & TRN \\
\hline CHEMBL1435885 & 688236 & 5.3 & 5.5308 & TST & \\
\hline CHEMBL1326758 & 688236 & 5.0 & 5.2284 & TRN & \\
\hline CHEMBL512908 & 688236 & 5.6 & 5.5326 & TRN & \\
\hline CHEMBL1596241 & 688236 & 5.9 & 5.8679 & TRN & \\
\hline CHEMBL1475999 & 688236 & 6.1 & 5.5875 & TST & \\
\hline
\end{tabular}




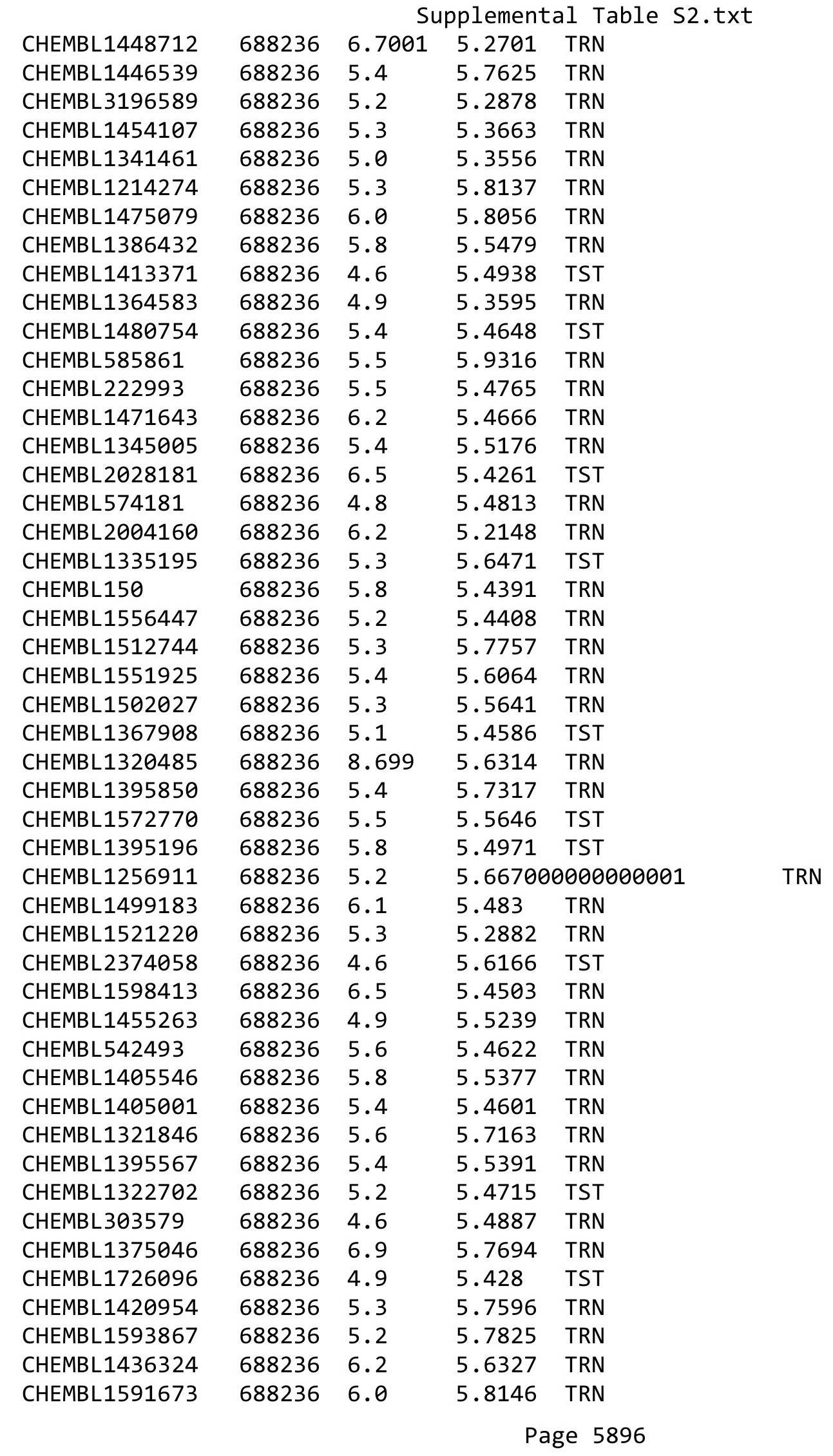




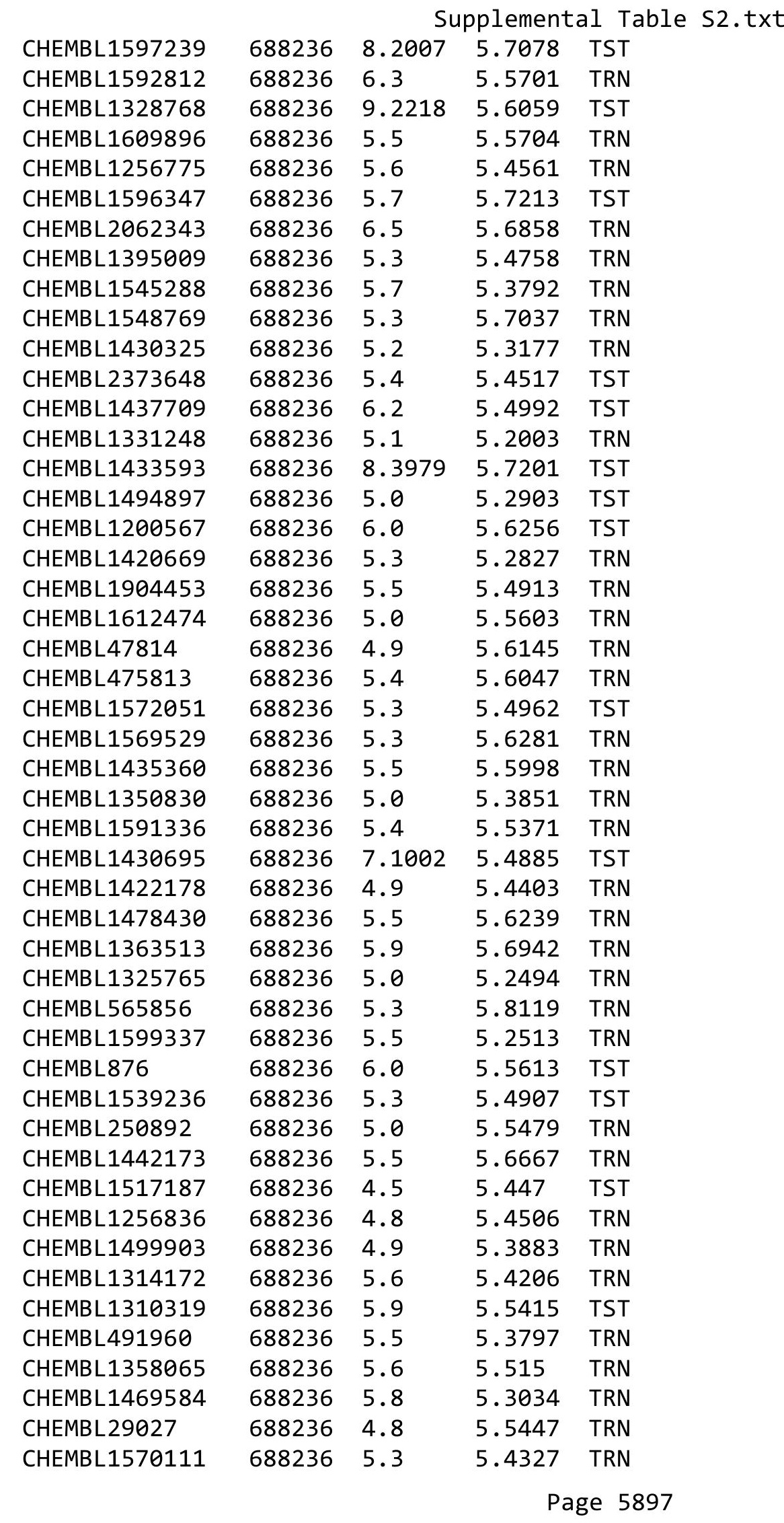




\begin{tabular}{|c|c|c|c|c|}
\hline & & & & \\
\hline CHEMBL1476511 & 688236 & 5.7 & 5.5569 & TRN \\
\hline CHEMBL1514129 & 688236 & 5.4 & 5.7636 & TRN \\
\hline CHEMBL2374259 & 688236 & 4.9 & 5.5639 & TRN \\
\hline CHEMBL1515334 & 688236 & 4.6 & 5.6439 & TST \\
\hline CHEMBL60518 & 688236 & 5.5 & 5.7166 & TRN \\
\hline CHEMBL1333454 & 688236 & 5.9 & 5.5348 & TRN \\
\hline CHEMBL1606369 & 688236 & 6.3 & 5.5738 & TRN \\
\hline CHEMBL1322290 & 688236 & 5.3 & 5.4408 & TST \\
\hline CHEMBL1366296 & 688236 & 5.5 & 5.5306 & TRN \\
\hline CHEMBL1593815 & 688236 & 5.6 & 5.5682 & TRN \\
\hline CHEMBL1439882 & 688236 & 5.5 & 5.6236 & TRN \\
\hline CHEMBL1304582 & 688236 & 5.7 & 5.7345 & TRN \\
\hline CHEMBL1551633 & 688236 & 6.0 & 5.483 & TRN \\
\hline CHEMBL1543216 & 688236 & 5.3 & 5.3715 & TRN \\
\hline CHEMBL67311 & 688236 & 4.6 & 5.5468 & TST \\
\hline CHEMBL1355963 & 688236 & 6.0 & 5.651 & TST \\
\hline CHEMBL1331927 & 688236 & 5.2 & 5.7575 & TRN \\
\hline CHEMBL1256132 & 688236 & 4.8 & 5.5365 & TRN \\
\hline CHEMBL1376239 & 688236 & 5.7 & 5.5027 & TRN \\
\hline CHEMBL1473754 & 688236 & 5.9 & 5.569 & TRN \\
\hline CHEMBL1256835 & 688236 & 5.6 & 5.1902 & TST \\
\hline CHEMBL1520445 & 688236 & 5.4 & 5.6109 & TRN \\
\hline CHEMBL1432338 & 688236 & 5.7 & 5.6082 & TST \\
\hline CHEMBL1394714 & 688236 & 5.8 & 5.7902 & TRN \\
\hline CHEMBL1455438 & 688236 & 5.5 & 5.7687 & TRN \\
\hline CHEMBL1388465 & 688236 & 5.0 & 5.4316 & TRN \\
\hline CHEMBL1316158 & 688236 & 6.2 & 5.7221 & TRN \\
\hline CHEMBL10347 & 688236 & 4.8 & 5.4126 & TRN \\
\hline CHEMBL393136 & 688236 & 5.4 & 5.675 & TST \\
\hline CHEMBL1355323 & 688236 & 5.0 & 5.6536 & TST \\
\hline CHEMBL429095 & 688236 & 5.2 & 5.5798 & TRN \\
\hline CHEMBL1515305 & 688236 & 5.8 & 5.5129 & TRN \\
\hline CHEMBL64391 & 688236 & 5.6 & 5.7131 & TST \\
\hline CHEMBL1344735 & 688236 & 5.3 & 5.3085 & TRN \\
\hline CHEMBL3145312 & 688236 & 5.1 & 5.4158 & TRN \\
\hline CHEMBL1497468 & 688236 & 5.2 & 5.3081 & TRN \\
\hline CHEMBL1445589 & 688236 & 5.0 & 5.4842 & TRN \\
\hline CHEMBL1594030 & 688236 & 5.6 & 5.6326 & TRN \\
\hline CHEMBL1547481 & 688236 & 5.2 & 5.5621 & TRN \\
\hline CHEMBL1301611 & 688236 & 5.3 & 5.2956 & TRN \\
\hline CHEMBL1575892 & 688236 & 6.1 & 5.6231 & TRN \\
\hline CHEMBL1463790 & 688236 & 5.0 & 5.5278 & TRN \\
\hline CHEMBL1546891 & 688236 & 5.0 & 5.2679 & TRN \\
\hline CHEMBL274189 & 688236 & 4.9 & 5.6184 & TRN \\
\hline CHEMBL1588042 & 688236 & 5.4 & 5.2692 & TRN \\
\hline CHEMBL1404660 & 688236 & 5.5 & 5.6173 & TRN \\
\hline CHEMBL1323631 & 688236 & 5.1 & 5.5508 & TRN \\
\hline CHEMBL1445121 & 688236 & 5.0 & 5.5181 & TRN \\
\hline
\end{tabular}




\begin{tabular}{|c|c|c|c|c|c|}
\hline \multicolumn{6}{|c|}{ Supplemental Table S2.txt } \\
\hline CHEMBL8618 & 688236 & 4.8 & 5.4438 & TRN & \\
\hline CHEMBL1331587 & 688236 & 7.0 & 5.5687 & TRN & \\
\hline CHEMBL1591487 & 688236 & 5.5 & 5.4503 & TRN & \\
\hline CHEMBL1406660 & 688236 & 4.9 & 5.4064 & TRN & \\
\hline CHEMBL1344878 & 688236 & 5.0 & 5.5316 & TRN & \\
\hline CHEMBL1378043 & 688236 & 5.6 & 5.5081 & TRN & \\
\hline CHEMBL1407586 & 688236 & 5.5 & 5.3398 & TRN & \\
\hline CHEMBL1790009 & 688236 & 7.4001 & 5.6157 & TRN & \\
\hline CHEMBL1591533 & 688236 & 5.4 & 5.5451 & TRN & \\
\hline CHEMBL1496243 & 688236 & 5.5 & 5.6419 & TRN & \\
\hline CHEMBL1384026 & 688236 & 5.9 & 5.6123 & TRN & \\
\hline CHEMBL1458376 & 688236 & 6.1 & 5.5432 & TRN & \\
\hline CHEMBL1256697 & 688236 & 4.9 & 5.6942 & TRN & \\
\hline CHEMBL1256663 & 688236 & 4.8 & 5.3204 & TRN & \\
\hline CHEMBL1233274 & 688236 & 5.3 & 5.4629 & TST & \\
\hline CHEMBL326967 & 688236 & 4.8 & 5.4668 & TST & \\
\hline CHEMBL1516006 & 688236 & 5.5 & 5.7179 & TRN & \\
\hline CHEMBL1459087 & 688236 & 5.3 & 5.3907 & TST & \\
\hline CHEMBL1354363 & 688236 & 5.5 & 5.6119 & TRN & \\
\hline CHEMBL1609406 & 688236 & 5.6 & 5.7614 & TRN & \\
\hline CHEMBL1355185 & 688236 & 5.8 & 5.6611 & TRN & \\
\hline CHEMBL3351064 & 688236 & 6.0 & 5.5277 & TST & \\
\hline CHEMBL1316463 & 688236 & 6.0 & 5.7944 & TRN & \\
\hline CHEMBL1376572 & 688236 & 5.3 & 5.7185 & TRN & \\
\hline CHEMBL1270168 & 688236 & 5.6 & 5.5912 & TRN & \\
\hline CHEMBL1449517 & 688236 & 5.5 & 5.6033 & TRN & \\
\hline CHEMBL1518338 & 688236 & 5.2 & 5.7874 & TRN & \\
\hline CHEMBL1473205 & 688236 & 5.0 & 5.461 & TRN & \\
\hline CHEMBL1593199 & 688236 & 5.5 & 5.6502 & TRN & \\
\hline CHEMBL475376 & 688236 & 5.4 & 5.86799 & 9999999999 & TRN \\
\hline CHEMBL1518182 & 688236 & 6.3 & 5.6731 & TRN & \\
\hline CHEMBL1255659 & 688236 & 4.6 & 5.4052 & TRN & \\
\hline CHEMBL1373007 & 688236 & 6.6 & 5.3964 & TST & \\
\hline CHEMBL1592470 & 688236 & 5.5 & 5.5986 & TRN & \\
\hline CHEMBL1564545 & 688236 & 5.3 & 5.428 & TRN & \\
\hline CHEMBL1355263 & 688236 & 5.4 & 5.3269 & TRN & \\
\hline CHEMBL1516468 & 688236 & 5.6 & 5.2779 & TRN & \\
\hline CHEMBL1256687 & 688236 & 4.8 & 5.6927 & TRN & \\
\hline CHEMBL1436438 & 688236 & 4.8 & 5.5519 & TRN & \\
\hline CHEMBL1610945 & 688236 & 6.0 & 5.7304 & TRN & \\
\hline CHEMBL1448121 & 688236 & 5.4 & 5.3733 & TRN & \\
\hline CHEMBL1400014 & 688236 & 6.8 & 5.49200 & 0000000001 & TST \\
\hline CHEMBL1433752 & 688236 & 5.7 & 5.9603 & TRN & \\
\hline CHEMBL539947 & 688236 & 6.2 & 5.4745 & TRN & \\
\hline CHEMBL3207894 & 688236 & 5.4 & 5.4251 & TST & \\
\hline CHEMBL1497574 & 688236 & 5.4 & 5.534 & TRN & \\
\hline CHEMBL1366745 & 688236 & 4.9 & 5.2648 & TRN & \\
\hline CHEMBL330320 & 688236 & 6.7001 & 5.6045 & TRN & \\
\hline
\end{tabular}




\begin{tabular}{|c|c|c|c|c|c|}
\hline & & & & & \\
\hline CHEMBL1437139 & 688236 & 6.3 & 5.6228 & TST & \\
\hline CHEMBL1435477 & 688236 & 5.6 & 5.5152 & TRN & \\
\hline CHEMBL1318222 & 688236 & 5.5 & 5.7396 & TRN & \\
\hline CHEMBL1417392 & 688236 & 5.1 & 5.5297 & TRN & \\
\hline CHEMBL1476939 & 688236 & 5.5 & 5.3687 & TRN & \\
\hline CHEMBL1548425 & 688236 & 5.1 & 5.4146 & TRN & \\
\hline CHEMBL475198 & 688236 & 5.7 & 5.6891 & TRN & \\
\hline CHEMBL1591757 & 688236 & 5.5 & 5.6553 & TRN & \\
\hline CHEMBL596674 & 688236 & 4.5 & 5.50299 & 9999999999 & TRN \\
\hline CHEMBL323356 & 688236 & 4.9 & 5.4243 & TRN & \\
\hline CHEMBL434063 & 688236 & 5.7 & 5.5969 & TST & \\
\hline CHEMBL327708 & 688236 & 4.5 & 5.2896 & TST & \\
\hline CHEMBL1565333 & 688236 & 5.4 & 5.5335 & TRN & \\
\hline CHEMBL1318643 & 688236 & 5.0 & 5.2828 & TRN & \\
\hline CHEMBL1528359 & 688236 & 5.3 & 5.6492 & TRN & \\
\hline CHEMBL 275516 & 688236 & 4.9 & 5.3987 & TST & \\
\hline CHEMBL1473331 & 688236 & 5.6 & 5.7746 & TRN & \\
\hline CHEMBL1390316 & 688236 & 5.5 & 5.4491 & TST & \\
\hline CHEMBL1331786 & 688236 & 4.9 & 5.4487 & TST & \\
\hline CHEMBL1354256 & 688236 & 4.9 & 5.4404 & TST & \\
\hline CHEMBL1474016 & 688236 & 5.6 & 5.6828 & TRN & \\
\hline CHEMBL1551548 & 688236 & 5.5 & 5.6551 & TRN & \\
\hline CHEMBL17551 & 688236 & 5.0 & 5.5998 & TST & \\
\hline CHEMBL1556431 & 688236 & 5.4 & 5.6554 & TRN & \\
\hline CHEMBL1436195 & 688236 & 5.7 & 5.5663 & TRN & \\
\hline CHEMBL 26138 & 688236 & 4.6 & 5.4586 & TRN & \\
\hline CHEMBL345083 & 688236 & 6.8 & 5.4862 & TST & \\
\hline CHEMBL1327772 & 688236 & 6.9 & 5.6966 & TRN & \\
\hline CHEMBL1512838 & 688236 & 5.5 & 5.4834 & TRN & \\
\hline CHEMBL1256623 & 688236 & 4.8 & 5.4675 & TRN & \\
\hline CHEMBL1532615 & 688236 & 5.1 & 5.4577 & TST & \\
\hline CHEMBL1537860 & 688236 & 5.1 & 5.2411 & TRN & \\
\hline CHEMBL1376430 & 688236 & 5.2 & 5.3534 & TRN & \\
\hline CHEMBL1326152 & 688236 & 5.5 & 5.5642 & TRN & \\
\hline CHEMBL1589923 & 688236 & 5.3 & 5.2912 & TRN & \\
\hline CHEMBL1396109 & 688236 & 5.9 & 5.70200 & 3000000001 & TRN \\
\hline CHEMBL1366616 & 688236 & 4.8 & 5.6037 & TRN & \\
\hline CHEMBL1474578 & 688236 & 5.5 & 5.6075 & TRN & \\
\hline CHEMBL1481510 & 688236 & 5.5 & 5.6458 & TRN & \\
\hline CHEMBL1566442 & 688236 & 5.8 & 5.6088 & TRN & \\
\hline CHEMBL1329454 & 688236 & 5.3 & 5.3506 & TRN & \\
\hline CHEMBL1514547 & 688236 & 5.4 & 5.5948 & TST & \\
\hline CHEMBL1335944 & 688236 & 5.8 & 5.4143 & TRN & \\
\hline CHEMBL1435259 & 688236 & 5.9 & 5.8388 & TRN & \\
\hline CHEMBL48449 & 688236 & 6.0 & 5.5454 & TST & \\
\hline CHEMBL1529147 & 688236 & 5.2 & 5.395 & TST & \\
\hline CHEMBL458765 & 688236 & 5.8 & 5.4683 & TRN & \\
\hline CHEMBL1397877 & 688236 & 5.4 & 5.65600 & 2000000001 & TRN \\
\hline & & & & 5900 & \\
\hline
\end{tabular}




\begin{tabular}{|c|c|c|c|c|c|}
\hline \multicolumn{6}{|c|}{ Supplemental Table S2.txt } \\
\hline CHEMBL39947 & 688236 & 5.5 & 5.5037 & TST & \\
\hline CHEMBL1410957 & 688236 & 5.0 & 5.3353 & TRN & \\
\hline CHEMBL1435248 & 688236 & 5.8 & 5.5973 & TRN & \\
\hline CHEMBL1536966 & 688236 & 5.7 & 5.3695 & TRN & \\
\hline CHEMBL1599748 & 688236 & 6.6 & 5.535 & TRN & \\
\hline CHEMBL1593374 & 688236 & 6.3 & 5.7704 & TRN & \\
\hline CHEMBL1319604 & 688236 & 5.3 & 5.5334 & TRN & \\
\hline CHEMBL1257080 & 688236 & 5.0 & 5.3723 & TST & \\
\hline CHEMBL1455548 & 688236 & 5.0 & 5.2532 & TRN & \\
\hline CHEMBL319244 & 688236 & 5.3 & 5.3379 & TRN & \\
\hline CHEMBL269277 & 688236 & 4.9 & 5.5087 & TST & \\
\hline CHEMBL1552028 & 688236 & 5.5 & 5.7016 & TRN & \\
\hline CHEMBL1476670 & 688236 & 6.4 & 5.8231 & TRN & \\
\hline CHEMBL1598565 & 688236 & 5.6 & 5.593 & TRN & \\
\hline CHEMBL1484484 & 688236 & 5.1 & 5.66299 & 9999999999 & TRN \\
\hline CHEMBL1574693 & 688236 & 5.6 & 5.4398 & TRN & \\
\hline CHEMBL1565588 & 688236 & 4.9 & 5.6784 & TST & \\
\hline CHEMBL1976489 & 688236 & 5.2 & 5.4694 & TRN & \\
\hline CHEMBL1353094 & 688236 & 5.0 & 5.5627 & TRN & \\
\hline CHEMBL1256698 & 688236 & 4.8 & 5.3551 & TRN & \\
\hline CHEMBL1445473 & 688236 & 5.4 & 5.8428 & TRN & \\
\hline CHEMBL1555480 & 688236 & 5.9 & 5.6282 & TRN & \\
\hline CHEMBL1232207 & 688236 & 5.0 & 5.5651 & TRN & \\
\hline CHEMBL441282 & 688236 & 5.5 & 5.6037 & TST & \\
\hline CHEMBL1528565 & 688236 & 4.5 & 5.5667 & TST & \\
\hline CHEMBL3211052 & 688236 & 5.0 & 5.5617 & TRN & \\
\hline CHEMBL1598680 & 688236 & 4.9 & 5.4631 & TRN & \\
\hline CHEMBL1409222 & 688236 & 4.9 & 5.4582 & TRN & \\
\hline CHEMBL1475191 & 688236 & 5.4 & 5.4806 & TRN & \\
\hline CHEMBL1530236 & 688236 & 5.0 & 5.6359 & TST & \\
\hline CHEMBL1434411 & 688236 & 5.4 & 5.7067 & TRN & \\
\hline CHEMBL1173453 & 688236 & 5.3 & 5.5894 & TRN & \\
\hline CHEMBL1475146 & 688236 & 5.5 & 5.6286 & TRN & \\
\hline CHEMBL1425234 & 688236 & 6.0 & 5.3828 & TRN & \\
\hline CHEMBL554041 & 688236 & 5.3 & 5.6089 & TST & \\
\hline CHEMBL1556733 & 688236 & 5.0 & 5.6156 & TRN & \\
\hline CHEMBL1343731 & 688236 & 5.8 & 5.4953 & TRN & \\
\hline CHEMBL1608984 & 688236 & 7.6003 & 5.2375 & TRN & \\
\hline CHEMBL1445135 & 688236 & 5.3 & 5.2569 & TRN & \\
\hline CHEMBL1534591 & 688236 & 5.4 & 5.8289 & TRN & \\
\hline CHEMBL3192500 & 688236 & 5.0 & 5.5329 & TRN & \\
\hline CHEMBL1312936 & 688236 & 6.0 & 5.4269 & TRN & \\
\hline CHEMBL1602451 & 688236 & 5.1 & 5.3229 & TRN & \\
\hline CHEMBL1397427 & 688236 & 5.8 & 5.7268 & TRN & \\
\hline CHEMBL 2374062 & 688236 & 4.6 & 5.6858 & TST & \\
\hline CHEMBL285819 & 688236 & 6.0 & 5.4453 & TRN & \\
\hline CHEMBL388342 & 688236 & 6.0 & 5.5468 & TRN & \\
\hline CHEMBL1593707 & 688236 & 5.5 & 5.5657 & TRN & \\
\hline
\end{tabular}




\begin{tabular}{|c|c|c|c|c|}
\hline \multicolumn{5}{|c|}{$a \perp$} \\
\hline CHEMBL1374426 & 688236 & 5.5 & 5.4168 & TST \\
\hline CHEMBL1320913 & 688236 & 5.3 & 5.4434 & TST \\
\hline CHEMBL1410826 & 688236 & 7.2 & 5.6322 & TRN \\
\hline CHEMBL1406782 & 688236 & 5.5 & 5.7668 & TRN \\
\hline CHEMBL1476139 & 688236 & 5.4 & 5.54799 & 9999999999 \\
\hline CHEMBL1486465 & 688236 & 6.4 & 5.5233 & TST \\
\hline CHEMBL1449838 & 688236 & 6.0 & 5.6216 & TRN \\
\hline CHEMBL1430077 & 688236 & 4.9 & 5.3839 & TRN \\
\hline CHEMBL1590616 & 688236 & 6.2 & 5.5661 & TRN \\
\hline CHEMBL1317986 & 688236 & 6.1 & 5.6443 & TRN \\
\hline CHEMBL1594350 & 688236 & 6.6 & 5.5721 & TRN \\
\hline CHEMBL1354563 & 688236 & 5.3 & 5.6601 & TRN \\
\hline CHEMBL1376191 & 688236 & 5.5 & 5.6806 & TRN \\
\hline CHEMBL1454730 & 688236 & 6.1 & 5.7097 & TRN \\
\hline CHEMBL1322584 & 688236 & 5.4 & 5.8728 & TRN \\
\hline CHEMBL1406588 & 688236 & 5.6 & 5.4011 & TRN \\
\hline CHEMBL1514604 & 688236 & 6.5 & 5.54 & TST \\
\hline CHEMBL1435374 & 688236 & 5.5 & 5.7283 & TRN \\
\hline CHEMBL1592966 & 688236 & 5.4 & 5.5956 & TRN \\
\hline CHEMBL1538257 & 688236 & 5.0 & 5.5269 & TRN \\
\hline CHEMBL1594881 & 688236 & 5.8 & 5.6383 & TST \\
\hline CHEMBL1336155 & 688236 & 6.3 & 5.6761 & TST \\
\hline CHEMBL1488907 & 688236 & 5.2 & 5.5298 & TRN \\
\hline CHEMBL1350047 & 688236 & 5.2 & 5.2209 & TRN \\
\hline CHEMBL441083 & 688236 & 5.6 & 5.7715 & TRN \\
\hline CHEMBL1357130 & 688236 & 5.3 & 5.4131 & TST \\
\hline CHEMBL1224512 & 688236 & 4.8 & 5.3249 & TRN \\
\hline CHEMBL1360778 & 688236 & 6.7001 & 5.5113 & TST \\
\hline CHEMBL1375094 & 688236 & 5.3 & 5.5328 & TRN \\
\hline CHEMBL1445710 & 688236 & 5.8 & 5.6676 & TRN \\
\hline CHEMBL1393783 & 688236 & 5.5 & 5.7522 & TRN \\
\hline CHEMBL1421867 & 688236 & 5.1 & 5.2757 & TRN \\
\hline CHEMBL1356106 & 688236 & 4.9 & 5.4315 & TST \\
\hline CHEMBL1529543 & 688236 & 5.5 & 5.5694 & TRN \\
\hline CHEMBL1526043 & 688236 & 5.5 & 5.4621 & TRN \\
\hline CHEMBL1514634 & 688236 & 4.9 & 5.3914 & TRN \\
\hline CHEMBL1328339 & 688236 & 5.5 & 5.4952 & TRN \\
\hline CHEMBL1417398 & 688236 & 4.9 & 5.434 & TRN \\
\hline CHEMBL1609595 & 688236 & 5.1 & 5.7736 & TRN \\
\hline CHEMBL1377706 & 688236 & 5.6 & 5.7987 & TRN \\
\hline CHEMBL1358654 & 688236 & 5.7 & 5.6397 & TRN \\
\hline CHEMBL446315 & 688236 & 6.0 & 5.4604 & TST \\
\hline CHEMBL1590242 & 688236 & 5.5 & 5.5451 & TRN \\
\hline CHEMBL1314906 & 688236 & 5.5 & 5.6125 & TRN \\
\hline CHEMBL1369215 & 688236 & 5.6 & 5.5506 & TST \\
\hline CHEMBL1394089 & 688236 & 5.0 & 5.4859 & TST \\
\hline CHEMBL1590980 & 688236 & 4.8 & 5.6042 & TRN \\
\hline CHEMBL1489016 & 688236 & 5.8 & 5.6415 & TRN \\
\hline
\end{tabular}




\begin{tabular}{|c|c|c|c|c|c|}
\hline \multirow[b]{2}{*}{ CHEMBL1331383 } & \multicolumn{5}{|c|}{ plemental } \\
\hline & 688236 & 4.9 & 5.3515 & TRN & \\
\hline CHEMBL1440145 & 688236 & 5.3 & 5.3217 & TRN & \\
\hline CHEMBL1456747 & 688236 & 5.4 & 5.537006 & 0000000001 & TST \\
\hline CHEMBL1481029 & 688236 & 5.3 & 5.6699 & TRN & \\
\hline CHEMBL1479708 & 688236 & 5.3 & 5.426 & TRN & \\
\hline CHEMBL1397548 & 688236 & 5.3 & 5.5865 & TRN & \\
\hline CHEMBL1315530 & 688236 & 5.5 & 5.6683 & TRN & \\
\hline CHEMBL72365 & 688236 & 4.6 & 5.4539 & TRN & \\
\hline CHEMBL1453641 & 688236 & 7.6003 & 5.6767 & TST & \\
\hline CHEMBL1529346 & 688236 & 5.2 & 5.3589 & TRN & \\
\hline CHEMBL1085765 & 688236 & 4.9 & 5.375 & TRN & \\
\hline CHEMBL1406307 & 688236 & 5.7 & 5.5673 & TRN & \\
\hline CHEMBL1607167 & 688236 & 5.9 & 5.7271 & TST & \\
\hline CHEMBL3186408 & 688236 & 6.0 & 5.3618 & TST & \\
\hline CHEMBL1355220 & 688236 & 7.4001 & 5.6613 & TST & \\
\hline CHEMBL1434098 & 688236 & 5.3 & 5.49799 & 9999999999 & TRN \\
\hline CHEMBL1554721 & 688236 & 5.8 & 5.8191 & TRN & \\
\hline CHEMBL1397438 & 688236 & 5.5 & 5.7452 & TRN & \\
\hline CHEMBL1972346 & 688236 & 5.0 & 5.4692 & TRN & \\
\hline CHEMBL126077 & 688236 & 4.6 & 5.497006 & 2000000001 & TRN \\
\hline CHEMBL604119 & 688236 & 4.6 & 5.5993 & TST & \\
\hline CHEMBL1325494 & 688236 & 4.9 & 5.2972 & TRN & \\
\hline CHEMBL1319303 & 688236 & 5.5 & 5.7141 & TRN & \\
\hline CHEMBL1319312 & 688236 & 6.1 & 5.7943 & TRN & \\
\hline CHEMBL1591674 & 688236 & 5.5 & 5.6216 & TRN & \\
\hline CHEMBL1479677 & 688236 & 6.0 & 5.7155 & TRN & \\
\hline CHEMBL1558184 & 688236 & 5.4 & 5.7561 & TRN & \\
\hline CHEMBL1593511 & 688236 & 5.5 & 5.5107 & TRN & \\
\hline CHEMBL1314286 & 688236 & 6.0 & 5.6391 & TST & \\
\hline CHEMBL1335634 & 688236 & 4.9 & 5.4961 & TST & \\
\hline CHEMBL1327487 & 688236 & 5.2 & 5.4819 & TRN & \\
\hline CHEMBL80155 & 688236 & 5.2 & 5.4315 & TRN & \\
\hline CHEMBL1591272 & 688236 & 5.5 & 5.6258 & TRN & \\
\hline CHEMBL429023 & 688236 & 7.1002 & 5.5875 & TST & \\
\hline CHEMBL1341213 & 688236 & 5.5 & 5.4345 & TRN & \\
\hline CHEMBL110739 & 688236 & 6.0 & 5.5223 & TST & \\
\hline CHEMBL1256751 & 688236 & 4.8 & 5.292006 & 0000000001 & TRN \\
\hline CHEMBL1448044 & 688236 & 4.9 & 5.5726 & TRN & \\
\hline CHEMBL1495589 & 688236 & 4.9 & 5.577006 & 3000000001 & TRN \\
\hline CHEMBL1358570 & 688236 & 5.9 & 5.4607 & TST & \\
\hline CHEMBL1408854 & 688236 & 6.2 & 5.6299 & TRN & \\
\hline CHEMBL451226 & 688236 & 4.6 & 5.4364 & TST & \\
\hline CHEMBL1515691 & 688236 & 6.3 & 5.6188 & TRN & \\
\hline CHEMBL1300597 & 688236 & 5.9 & 5.6187 & TRN & \\
\hline CHEMBL1173475 & 688236 & 6.0 & 5.4658 & TRN & \\
\hline CHEMBL1512027 & 688236 & 5.4 & 5.7752 & TRN & \\
\hline CHEMBL1591374 & 688236 & 7.0 & 6.0819 & TRN & \\
\hline CHEMBL491555 & 688236 & 5.4 & 5.8135 & TRN & \\
\hline
\end{tabular}




\begin{tabular}{|c|c|c|c|c|c|}
\hline \multicolumn{6}{|c|}{ Supplemental Table s2.txt } \\
\hline CHEMBL19980 & 688236 & 6.5 & 5.5706 & TST & \\
\hline CHEMBL1409957 & 688236 & 5.5 & 5.4154 & TRN & \\
\hline CHEMBL1417771 & 688236 & 5.5 & 5.8254 & TRN & \\
\hline CHEMBL1399699 & 688236 & 5.6 & 5.3314 & TRN & \\
\hline CHEMBL1450521 & 688236 & 6.2 & 6.0014 & TRN & \\
\hline CHEMBL1474523 & 688236 & 7.699 & 5.6639 & TST & \\
\hline CHEMBL1473149 & 688236 & 5.5 & 5.7101 & TRN & \\
\hline CHEMBL1407440 & 688236 & 5.5 & 5.6771 & TRN & \\
\hline CHEMBL1551841 & 688236 & 5.3 & 5.8157 & TRN & \\
\hline CHEMBL1516232 & 688236 & 5.2 & 5.862 & TRN & \\
\hline CHEMBL3210606 & 688236 & 4.9 & 5.5981 & TRN & \\
\hline CHEMBL1554763 & 688236 & 5.5 & 5.5986 & TRN & \\
\hline CHEMBL1367565 & 688236 & 6.0 & 5.689 & TRN & \\
\hline CHEMBL1362287 & 688236 & 5.5 & 5.5116 & TRN & \\
\hline CHEMBL1376723 & 688236 & 5.1 & 5.3438 & TRN & \\
\hline CHEMBL1316285 & 688236 & 5.5 & 5.564 & TRN & \\
\hline CHEMBL1413630 & 688236 & 5.4 & 5.2299 & TRN & \\
\hline CHEMBL1571851 & 688236 & 6.0 & 5.6181 & TST & \\
\hline CHEMBL1482426 & 688236 & 5.5 & 5.7424 & TRN & \\
\hline CHEMBL1572173 & 688236 & 5.9 & 5.6501 & TRN & \\
\hline CHEMBL1315725 & 688236 & 5.5 & 5.4552 & TST & \\
\hline CHEMBL183 & 688236 & 5.0 & 5.2927 & TST & \\
\hline CHEMBL1433760 & 688236 & 6.3 & 5.6179 & TRN & \\
\hline CHEMBL1408297 & 688236 & 4.9 & 5.6745 & TRN & \\
\hline CHEMBL1408427 & 688236 & 6.0 & 5.9715 & TRN & \\
\hline CHEMBL1387556 & 688236 & 5.0 & 5.3701 & TRN & \\
\hline CHEMBL1440534 & 688236 & 5.3 & 5.3105 & TRN & \\
\hline CHEMBL1591294 & 688236 & 5.9 & 5.4305 & TST & \\
\hline CHEMBL1358562 & 688236 & 5.6 & 5.6329 & TRN & \\
\hline CHEMBL1598394 & 688236 & 5.5 & 5.705 & TRN & \\
\hline CHEMBL1362157 & 688236 & 5.0 & 5.3751 & TRN & \\
\hline CHEMBL1334561 & 688236 & 4.9 & 5.5041 & TRN & \\
\hline CHEMBL1405627 & 688236 & 5.6 & 5.8682 & TRN & \\
\hline CHEMBL1300089 & 688236 & 6.3 & 5.3742 & TRN & \\
\hline CHEMBL1336414 & 688236 & 4.9 & 5.2783 & TRN & \\
\hline CHEMBL1499275 & 688236 & 6.7001 & 5.3461 & TRN & \\
\hline CHEMBL1573094 & 688236 & 5.0 & 5.3692 & TRN & \\
\hline CHEMBL1442094 & 688236 & 7.0 & 5.4116 & TRN & \\
\hline CHEMBL1398425 & 688236 & 5.3 & 5.608 & TRN & \\
\hline CHEMBL1553766 & 688236 & 6.9 & $5.6770 e$ & 00000000005 & TRN \\
\hline CHEMBL1525456 & 688236 & 5.5 & 5.7706 & TRN & \\
\hline CHEMBL1342353 & 688236 & 5.3 & 5.6309 & TRN & \\
\hline CHEMBL1522752 & 688236 & 5.3 & 5.3934 & TRN & \\
\hline CHEMBL1570500 & 688236 & 7.5003 & 5.5432 & TRN & \\
\hline CHEMBL1569893 & 688236 & 6.2 & 5.4692 & TRN & \\
\hline CHEMBL1566428 & 688236 & 5.4 & 5.6856 & TRN & \\
\hline CHEMBL1317924 & 688236 & 5.4 & 5.6017 & TRN & \\
\hline CHEMBL1446139 & 688236 & 5.3 & 5.7224 & TRN & \\
\hline
\end{tabular}




\begin{tabular}{|c|c|c|c|c|c|}
\hline \\
\hline CHEMBL1572807 & 688236 & 5.1 & 5.2966 & TRN & \\
\hline CHEMBL1376987 & 688236 & 5.9 & 5.7831 & TRN & \\
\hline CHEMBL491748 & 688236 & 5.5 & 5.7478 & TRN & \\
\hline CHEMBL1396898 & 688236 & 6.9 & 5.7856 & TRN & \\
\hline CHEMBL372052 & 688236 & 4.8 & 5.5866 & TRN & \\
\hline CHEMBL1391196 & 688236 & 5.4 & 5.5241 & TRN & \\
\hline CHEMBL469309 & 688236 & 5.4 & 5.65799 & 99999999995 & TRN \\
\hline CHEMBL1525024 & 688236 & 6.0 & 5.4353 & TRN & \\
\hline CHEMBL1435404 & 688236 & 6.2 & 5.4895 & TRN & \\
\hline CHEMBL1514560 & 688236 & 5.5 & 5.4184 & TRN & \\
\hline CHEMBL1328690 & 688236 & 4.9 & 5.3028 & TRN & \\
\hline CHEMBL1592227 & 688236 & 5.4 & 6.0045 & TRN & \\
\hline CHEMBL1518154 & 688236 & 7.2 & 6.1039 & TST & \\
\hline CHEMBL1566136 & 688236 & 5.6 & 5.6521 & TST & \\
\hline CHEMBL1489182 & 688236 & 5.8 & 5.977 & TRN & \\
\hline CHEMBL1557383 & 688236 & 5.0 & 5.41799 & 9999999999 & TST \\
\hline CHEMBL1363883 & 688236 & 6.0 & 5.4505 & TST & \\
\hline CHEMBL1571692 & 688236 & 4.9 & 5.6511 & TST & \\
\hline CHEMBL1551051 & 688236 & 5.5 & 5.5671 & TRN & \\
\hline CHEMBL1480806 & 688236 & 5.3 & 5.8966 & TRN & \\
\hline CHEMBL1162107 & 688236 & 5.8 & 5.4758 & TST & \\
\hline CHEMBL1404408 & 688236 & 5.3 & 5.4622 & TRN & \\
\hline CHEMBL1301821 & 688236 & 4.9 & 5.3405 & TRN & \\
\hline CHEMBL1379801 & 688236 & 5.0 & 5.606 & TRN & \\
\hline CHEMBL1354069 & 688236 & 5.0 & 5.2533 & TRN & \\
\hline CHEMBL517186 & 688236 & 5.6 & 5.5711 & TRN & \\
\hline CHEMBL1574390 & 688236 & 5.5 & 5.5525 & TRN & \\
\hline CHEMBL1604925 & 688236 & 5.2 & 5.4063 & TRN & \\
\hline CHEMBL1325511 & 688236 & 5.4 & 5.4986 & TRN & \\
\hline CHEMBL1456481 & 688236 & 5.5 & 5.5555 & TRN & \\
\hline CHEMBL1594086 & 688236 & 5.4 & 5.6883 & TRN & \\
\hline CHEMBL1541618 & 688236 & 6.3 & 5.5575 & TRN & \\
\hline CHEMBL1335455 & 688236 & 8.6021 & 5.5746 & TST & \\
\hline CHEMBL1600497 & 688236 & 5.4 & 5.3875 & TRN & \\
\hline CHEMBL1561474 & 688236 & 4.8 & 5.5714 & TRN & \\
\hline CHEMBL1364012 & 688236 & 5.4 & 5.527 & TRN & \\
\hline CHEMBL1592560 & 688236 & 5.5 & 5.5049 & TRN & \\
\hline CHEMBL1565060 & 688236 & 5.5 & 5.5822 & TRN & \\
\hline CHEMBL1401483 & 688236 & 5.5 & 5.5393 & TRN & \\
\hline CHEMBL1518550 & 688236 & 5.1 & 5.4875 & TRN & \\
\hline CHEMBL1582777 & 688236 & 4.9 & 5.2516 & TRN & \\
\hline CHEMBL1513684 & 688236 & 8.8861 & 5.75200 & 0000000001 & TRN \\
\hline CHEMBL1411609 & 688236 & 5.3 & 5.4449 & TST & \\
\hline CHEMBL1372282 & 688236 & 6.8 & 5.3579 & TST & \\
\hline CHEMBL1436682 & 688236 & 5.8 & 6.0283 & TRN & \\
\hline CHEMBL1336166 & 688236 & 4.5 & 5.5319 & TRN & \\
\hline CHEMBL1487441 & 688236 & 5.9 & 5.5841 & TRN & \\
\hline CHEMBL1569552 & 688236 & 5.2 & 5.5116 & TRN & \\
\hline
\end{tabular}




\begin{tabular}{|c|c|c|c|c|c|}
\hline & & & & & \\
\hline CHEMBL1467629 & 688236 & 6.2 & 5.5535 & TRN & \\
\hline CHEMBL1256851 & 688236 & 4.6 & 5.4194 & TST & \\
\hline CHEMBL1318464 & 688236 & 6.6 & 5.556 & TRN & \\
\hline CHEMBL 76589 & 688236 & 4.8 & 5.3115 & TRN & \\
\hline CHEMBL1395415 & 688236 & 5.8 & 5.9781 & TRN & \\
\hline CHEMBL1160544 & 688236 & 6.0 & 5.805 & TRN & \\
\hline CHEMBL1516388 & 688236 & 5.0 & 5.6282 & TST & \\
\hline CHEMBL399491 & 688236 & 4.7 & 5.4516 & TST & \\
\hline CHEMBL1317135 & 688236 & 6.1 & 5.5111 & TST & \\
\hline CHEMBL1449350 & 688236 & 5.4 & 5.5161 & TRN & \\
\hline CHEMBL 2374026 & 688236 & 6.6 & 5.4392 & TST & \\
\hline CHEMBL1390014 & 688236 & 5.1 & 5.3923 & TRN & \\
\hline CHEMBL1470336 & 688236 & 5.6 & 5.4377 & TRN & \\
\hline CHEMBL1357157 & 688236 & 7.8996 & 5.6334 & TRN & \\
\hline CHEMBL1458643 & 688236 & 5.0 & 5.3641 & TRN & \\
\hline CHEMBL1434882 & 688236 & 5.3 & 5.6796 & TRN & \\
\hline CHEMBL1417025 & 688236 & 5.8 & 5.5455 & TRN & \\
\hline CHEMBL1355708 & 688236 & 7.6003 & 5.6972 & TRN & \\
\hline CHEMBL1524638 & 688236 & 5.3 & 5.4111 & TRN & \\
\hline CHEMBL1200938 & 688236 & 6.0 & 5.5609 & TST & \\
\hline CHEMBL1433939 & 688236 & 6.7001 & 5.4643 & TST & \\
\hline CHEMBL1314222 & 688236 & 5.5 & 5.8298 & TRN & \\
\hline CHEMBL1358756 & 688236 & 5.5 & 5.6005 & TRN & \\
\hline CHEMBL1591380 & 688236 & 5.6 & 5.7163 & TRN & \\
\hline CHEMBL1304237 & 688236 & 4.9 & 5.4735 & TRN & \\
\hline CHEMBL1342837 & 688236 & 5.4 & 5.4697 & TRN & \\
\hline CHEMBL 2006590 & 688236 & 4.9 & 5.4114 & TRN & \\
\hline CHEMBL2068684 & 688236 & 6.7001 & 5.4139 & TRN & \\
\hline CHEMBL407232 & 688236 & 4.6 & 5.5047 & TRN & \\
\hline CHEMBL1564508 & 688236 & 5.7 & 5.4896 & TST & \\
\hline CHEMBL22075 & 688236 & 4.9 & 5.4862 & TRN & \\
\hline CHEMBL1358671 & 688236 & 5.5 & 5.6633 & TRN & \\
\hline CHEMBL1404714 & 688236 & 5.7 & 5.3675 & TRN & \\
\hline CHEMBL1470178 & 688236 & 5.0 & 5.3663 & TRN & \\
\hline CHEMBL418509 & 688236 & 4.5 & 5.5872 & TRN & \\
\hline CHEMBL1563088 & 688236 & 5.3 & 5.6075 & TRN & \\
\hline CHEMBL1492017 & 688236 & 6.0 & 5.5536 & TRN & \\
\hline CHEMBL416657 & 688236 & 4.5 & 5.4404 & TRN & \\
\hline CHEMBL1318495 & 688236 & 5.4 & 5.8946 & TRN & \\
\hline CHEMBL86676 & 688236 & 4.6 & 5.5838 & TST & \\
\hline CHEMBL1554098 & 688236 & 6.5 & 5.4893 & TST & \\
\hline CHEMBL1475695 & 688236 & 5.8 & 5.8171 & TRN & \\
\hline CHEMBL1537507 & 688236 & 5.0 & 5.5578 & TRN & \\
\hline CHEMBL1493700 & 688236 & 4.9 & 5.3325 & TRN & \\
\hline CHEMBL1393872 & 688236 & 4.9 & 5.54799 & 9999999999 & TRN \\
\hline CHEMBL1473919 & 688236 & 5.4 & 5.8377 & TRN & \\
\hline CHEMBL1322719 & 688236 & 5.3 & 5.4612 & TST & \\
\hline CHEMBL1317306 & 688236 & 6.2 & 5.7287 & TRN & \\
\hline
\end{tabular}




\begin{tabular}{|c|c|c|c|c|c|}
\hline \multicolumn{6}{|c|}{ Supplemental Table S2.txt } \\
\hline CHEMBL225230 & 688236 & 5.6 & 5.4249 & TRN & \\
\hline CHEMBL487356 & 688236 & 7.699 & 5.4345 & TRN & \\
\hline CHEMBL3195525 & 688236 & 5.5 & 5.3469 & TRN & \\
\hline CHEMBL1462487 & 688236 & 5.2 & 5.6298 & TRN & \\
\hline CHEMBL1436540 & 688236 & 5.8 & 5.815 & TRN & \\
\hline CHEMBL1438688 & 688236 & 5.7 & 5.8541 & TRN & \\
\hline CHEMBL404613 & 688236 & 7.8013 & 5.4548 & TST & \\
\hline CHEMBL1391679 & 688236 & 5.6 & 5.6438 & TRN & \\
\hline CHEMBL76143 & 688236 & 6.8 & 5.6074 & TRN & \\
\hline CHEMBL1551834 & 688236 & 5.2 & 5.5853 & TRN & \\
\hline CHEMBL1321005 & 688236 & 7.3002 & 5.6405 & TRN & \\
\hline CHEMBL1314451 & 688236 & 5.6 & 5.3871 & TRN & \\
\hline CHEMBL1353983 & 688236 & 5.5 & 5.5152 & TRN & \\
\hline CHEMBL1404315 & 688236 & 5.9 & 5.4811 & TRN & \\
\hline CHEMBL1410119 & 688236 & 5.0 & 5.63200 & 0000000001 & TRN \\
\hline CHEMBL1543205 & 688236 & 5.0 & 5.3353 & TRN & \\
\hline CHEMBL1328265 & 688236 & 5.4 & 5.4063 & TST & \\
\hline CHEMBL1545498 & 688236 & 5.3 & 5.5926 & TRN & \\
\hline CHEMBL1255656 & 688236 & 5.2 & 5.4435 & TRN & \\
\hline CHEMBL3207941 & 688236 & 5.0 & 5.7735 & TST & \\
\hline CHEMBL1551557 & 688236 & 6.5 & 5.79700 & 0000000001 & TRN \\
\hline CHEMBL1448228 & 688236 & 5.5 & 5.6478 & TRN & \\
\hline CHEMBL1358012 & 688236 & 5.1 & 5.4762 & TST & \\
\hline CHEMBL1318316 & 688236 & 6.0 & 5.415 & TRN & \\
\hline CHEMBL1564461 & 688236 & 5.8 & 5.7032 & TRN & \\
\hline CHEMBL1330594 & 688236 & 6.0 & 5.4712 & TRN & \\
\hline CHEMBL1572167 & 688236 & 5.1 & 5.3783 & TST & \\
\hline CHEMBL405358 & 688236 & 4.9 & 5.5098 & TRN & \\
\hline CHEMBL1436272 & 688236 & 5.9 & 5.7228 & TRN & \\
\hline CHEMBL1394456 & 688236 & 6.9 & 5.5756 & TRN & \\
\hline CHEMBL189438 & 688236 & 6.0 & 5.4057 & TST & \\
\hline CHEMBL1611654 & 688236 & 5.5 & 5.3636 & TST & \\
\hline CHEMBL408994 & 688236 & 5.5 & 5.3661 & TRN & \\
\hline CHEMBL1256878 & 688236 & 6.0 & 5.3994 & TRN & \\
\hline CHEMBL516075 & 688236 & 6.1 & 5.9091 & TRN & \\
\hline CHEMBL1365701 & 688236 & 6.0 & 5.5901 & TRN & \\
\hline CHEMBL1429345 & 688236 & 4.9 & 5.2302 & TRN & \\
\hline CHEMBL1236872 & 688236 & 6.0 & 5.591 & TRN & \\
\hline CHEMBL1512708 & 688236 & 5.5 & 5.8528 & TRN & \\
\hline CHEMBL1453673 & 688236 & 4.9 & 5.6386 & TST & \\
\hline CHEMBL1512802 & 688236 & 6.0 & 5.6289 & TRN & \\
\hline CHEMBL1606018 & 688236 & 6.1 & 5.6005 & TRN & \\
\hline CHEMBL1433687 & 688236 & 6.0 & 5.5449 & TRN & \\
\hline CHEMBL1449856 & 688236 & 5.4 & 5.7119 & TRN & \\
\hline CHEMBL1357520 & 688236 & 6.4 & 5.6582 & TRN & \\
\hline CHEMBL1373004 & 688236 & 5.3 & 5.9865 & TRN & \\
\hline CHEMBL1367656 & 688236 & 6.8 & 5.6332 & TRN & \\
\hline CHEMBL1328369 & 688236 & 5.6 & 5.341 & TST & \\
\hline
\end{tabular}




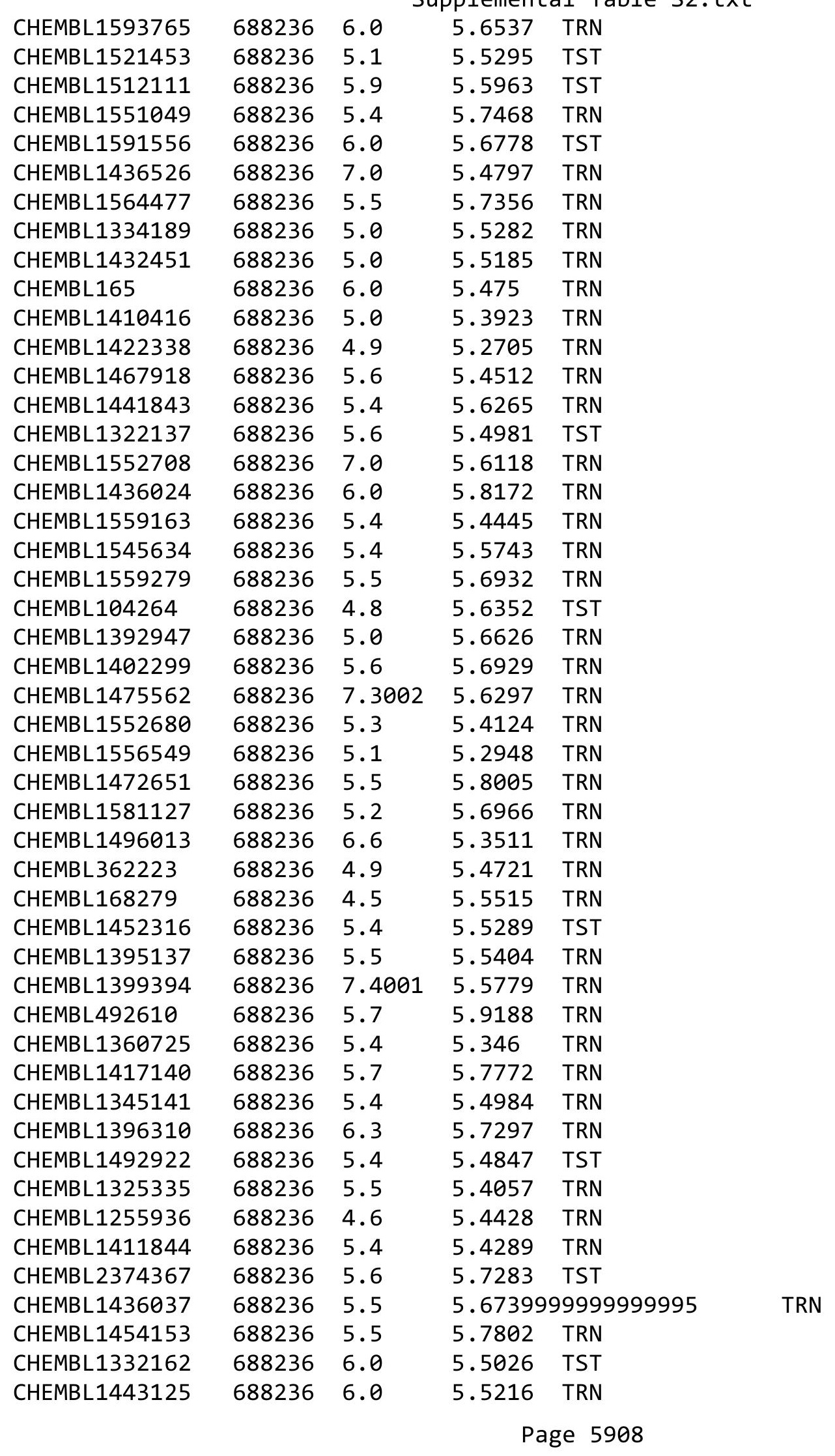




\begin{tabular}{|c|c|c|c|c|c|}
\hline & & \\
\hline CHEMBL1325701 & 688236 & 5.4 & 5.6878 & TRN & \\
\hline CHEMBL1531932 & 688236 & 6.4 & 5.4749 & TST & \\
\hline CHEMBL1593547 & 688236 & 5.5 & 5.6206 & TRN & \\
\hline CHEMBL1518164 & 688236 & 6.1 & 5.4563 & TRN & \\
\hline CHEMBL584759 & 688236 & 6.1 & 5.6892 & TRN & \\
\hline CHEMBL1590831 & 688236 & 5.6 & 5.6773 & TRN & \\
\hline CHEMBL1315716 & 688236 & 5.5 & 5.5947 & TRN & \\
\hline CHEMBL1475257 & 688236 & 5.9 & 5.5865 & TRN & \\
\hline CHEMBL280998 & 688236 & 4.9 & 5.5204 & TRN & \\
\hline CHEMBL151 & 688236 & 6.4 & 5.4649 & TRN & \\
\hline CHEMBL1354693 & 688236 & 5.5 & 5.644 & TRN & \\
\hline CHEMBL1514143 & 688236 & 5.4 & 5.5376 & TRN & \\
\hline CHEMBL 253989 & 688236 & 6.1 & 5.5487 & TST & \\
\hline CHEMBL47940 & 688236 & 4.5 & 5.6376 & TST & \\
\hline CHEMBL1516211 & 688236 & 5.3 & 5.7982 & TRN & \\
\hline CHEMBL1320310 & 688236 & 4.6 & 5.4538 & TST & \\
\hline CHEMBL1475207 & 688236 & 5.4 & 5.5803 & TRN & \\
\hline CHEMBL1527269 & 688236 & 5.5 & 5.5717 & TRN & \\
\hline CHEMBL1257081 & 688236 & 4.8 & 5.3569 & TRN & \\
\hline CHEMBL1394137 & 688236 & 5.6 & 5.5283 & TRN & \\
\hline CHEMBL1562786 & 688236 & 5.4 & 5.5602 & TRN & \\
\hline CHEMBL1468658 & 688236 & 4.9 & 5.4526 & TRN & \\
\hline CHEMBL1531699 & 688236 & 6.9 & 5.6278 & TRN & \\
\hline CHEMBL1397151 & 688236 & 5.5 & 5.7509 & TRN & \\
\hline CHEMBL1569958 & 688236 & 6.4 & 5.4927 & TRN & \\
\hline CHEMBL95606 & 688236 & 5.2 & 5.4326 & TRN & \\
\hline CHEMBL1429863 & 688236 & 6.4 & 5.6635 & TRN & \\
\hline CHEMBL1436042 & 688236 & 5.3 & 5.5945 & TRN & \\
\hline CHEMBL1335406 & 688236 & 4.7 & 5.4856 & TRN & \\
\hline CHEMBL443893 & 688236 & 6.0 & 5.7336 & TRN & \\
\hline CHEMBL1470983 & 688236 & 5.4 & 5.4123 & TST & \\
\hline CHEMBL66 & 688236 & 4.6 & 5.455 & TRN & \\
\hline CHEMBL491771 & 688236 & 5.7 & 5.8725 & TRN & \\
\hline CHEMBL1390386 & 688236 & 5.6 & 5.8848 & TRN & \\
\hline CHEMBL1525813 & 688236 & 6.0 & 5.7939 & TRN & \\
\hline CHEMBL1306570 & 688236 & 5.8 & 5.3748 & TRN & \\
\hline CHEMBL1584312 & 688236 & 5.7 & 5.6226 & TST & \\
\hline CHEMBL1491966 & 688236 & 5.6 & 5.7386 & TRN & \\
\hline CHEMBL1327203 & 688236 & 5.4 & 5.5863 & TRN & \\
\hline CHEMBL1356060 & 688236 & 5.7 & 5.795 & TRN & \\
\hline CHEMBL3216363 & 688236 & 5.2 & 5.3009 & TRN & \\
\hline CHEMBL1406556 & 688236 & 5.4 & 5.6002 & TRN & \\
\hline CHEMBL1449987 & 688236 & 5.0 & 5.4908 & TST & \\
\hline CHEMBL98350 & 688236 & 5.1 & 5.4889 & TRN & \\
\hline CHEMBL304291 & 688236 & 4.9 & 5.6968 & TST & \\
\hline CHEMBL1356497 & 688236 & 5.5 & 5.5577 & TRN & \\
\hline CHEMBL1394118 & 688236 & 5.5 & 5.79700 & 0000000001 & TRN \\
\hline CHEMBL1523296 & 688236 & 5.0 & 5.2395 & TRN & \\
\hline & & & & ge 5909 & \\
\hline
\end{tabular}




\begin{tabular}{|c|c|c|c|c|c|}
\hline \multicolumn{6}{|c|}{ Iemer } \\
\hline CHEMBL1391136 & 688236 & 5.1 & 5.3106 & TRN & \\
\hline CHEMBL1357186 & 688236 & 5.4 & 5.57299 & 99999999995 & TRN \\
\hline CHEMBL1374363 & 688236 & 5.3 & 5.4297 & TST & \\
\hline CHEMBL1439007 & 688236 & 5.2 & 5.3029 & TRN & \\
\hline CHEMBL76904 & 688236 & 5.0 & 5.3228 & TRN & \\
\hline CHEMBL1592584 & 688236 & 5.6 & 5.6238 & TRN & \\
\hline CHEMBL1474471 & 688236 & 5.8 & 5.7109 & TRN & \\
\hline CHEMBL1551151 & 688236 & 5.6 & 5.6502 & TST & \\
\hline CHEMBL521970 & 688236 & 5.4 & 5.9427 & TRN & \\
\hline CHEMBL1880070 & 688236 & 5.5 & 5.5254 & TST & \\
\hline CHEMBL1410841 & 688236 & 5.6 & 5.7211 & TST & \\
\hline CHEMBL1357445 & 688236 & 5.3 & 5.4888 & TRN & \\
\hline CHEMBL1437054 & 688236 & 6.6 & 5.3969 & TST & \\
\hline CHEMBL1570532 & 688236 & 5.3 & 5.629 & TRN & \\
\hline CHEMBL1479767 & 688236 & 5.5 & 5.4745 & TRN & \\
\hline CHEMBL1387249 & 688236 & 5.8 & 5.6689 & TRN & \\
\hline CHEMBL1514416 & 688236 & 7.6003 & 5.7846 & TRN & \\
\hline CHEMBL1458327 & 688236 & 5.4 & 5.4064 & TRN & \\
\hline CHEMBL1414943 & 688236 & 5.8 & 5.4596 & TRN & \\
\hline CHEMBL1591879 & 688236 & 5.5 & 5.4979 & TST & \\
\hline CHEMBL1316796 & 688236 & 5.5 & 5.7326 & TRN & \\
\hline CHEMBL3392071 & 688236 & 5.4 & 5.3707 & TST & \\
\hline CHEMBL291829 & 688236 & 6.0 & 5.5613 & TRN & \\
\hline CHEMBL1525011 & 688236 & 5.1 & 5.7239 & TRN & \\
\hline CHEMBL1535431 & 688236 & 5.4 & 5.7855 & TRN & \\
\hline CHEMBL1398538 & 688236 & 5.4 & 5.5751 & TRN & \\
\hline CHEMBL1600340 & 688236 & 5.6 & 5.7439 & TRN & \\
\hline CHEMBL1328565 & 688236 & 5.5 & 5.63700 & 00000000005 & TRN \\
\hline CHEMBL542700 & 688236 & 4.9 & 5.4259 & TRN & \\
\hline CHEMBL1555823 & 688236 & 5.5 & 5.5025 & TRN & \\
\hline CHEMBL24983 & 688236 & 4.5 & 5.4642 & TST & \\
\hline CHEMBL1300512 & 688236 & 5.1 & 5.3162 & TRN & \\
\hline CHEMBL1596743 & 688236 & 5.4 & 5.6105 & TRN & \\
\hline CHEMBL598270 & 688236 & 4.9 & 5.4456 & TST & \\
\hline CHEMBL71851 & 688236 & 4.9 & 5.3865 & TRN & \\
\hline CHEMBL1560847 & 688236 & 4.9 & 5.3345 & TRN & \\
\hline CHEMBL1468845 & 688236 & 5.1 & 5.3173 & TST & \\
\hline CHEMBL1315072 & 688236 & 5.6 & 5.6645 & TRN & \\
\hline CHEMBL1534710 & 688236 & 5.4 & 5.4835 & TRN & \\
\hline CHEMBL1351918 & 688236 & 5.0 & 5.6139 & TRN & \\
\hline CHEMBL1437488 & 688236 & 5.6 & 5.4597 & TRN & \\
\hline CHEMBL1552720 & 688236 & 6.1 & 5.9816 & TRN & \\
\hline CHEMBL1569307 & 688236 & 6.0 & 5.3881 & TRN & \\
\hline CHEMBL1504792 & 688236 & 5.0 & 5.3157 & TRN & \\
\hline CHEMBL1358402 & 688236 & 6.1 & 5.4919 & TST & \\
\hline CHEMBL598952 & 688236 & 4.9 & 5.6231 & TST & \\
\hline CHEMBL1306749 & 688236 & 5.6 & 5.3526 & TRN & \\
\hline CHEMBL1358252 & 688236 & 5.5 & 5.6909 & TRN & \\
\hline
\end{tabular}




\begin{tabular}{|c|c|c|c|c|c|}
\hline & & & & & \\
\hline CHEMBL1415165 & 688236 & 5.1 & 5.4586 & TRN & \\
\hline CHEMBL1518305 & 688236 & 5.6 & 5.7581 & TRN & \\
\hline CHEMBL1416389 & 688236 & 5.3 & 5.5193 & TRN & \\
\hline CHEMBL1441920 & 688236 & 5.5 & 5.4699 & TST & \\
\hline CHEMBL391997 & 688236 & 5.3 & 5.3662 & TRN & \\
\hline CHEMBL1387946 & 688236 & 5.3 & 5.5466 & TRN & \\
\hline CHEMBL1446970 & 688236 & 5.0 & 5.5137 & TST & \\
\hline CHEMBL1306509 & 688236 & 4.9 & 5.3803 & TST & \\
\hline CHEMBL1501915 & 688236 & 5.0 & 5.3479 & TRN & \\
\hline CHEMBL1558135 & 688236 & 5.5 & 5.7916 & TRN & \\
\hline CHEMBL1326031 & 688236 & 5.5 & 5.55399 & 9999999999 & TRN \\
\hline CHEMBL 2373654 & 688236 & 6.0 & 5.335 & TRN & \\
\hline CHEMBL1555037 & 688236 & 5.5 & 5.7379 & TRN & \\
\hline CHEMBL1605510 & 688236 & 6.4 & 5.9044 & TRN & \\
\hline CHEMBL1406513 & 688236 & 4.9 & 5.3879 & TRN & \\
\hline CHEMBL1339229 & 688236 & 5.0 & 5.6364 & TST & \\
\hline CHEMBL3216873 & 688236 & 5.0 & 5.4231 & TST & \\
\hline CHEMBL117 & 688236 & 5.2 & 5.4168 & TRN & \\
\hline CHEMBL1433897 & 688236 & 6.0 & 5.63700 & 00000000005 & TST \\
\hline CHEMBL1257002 & 688236 & 5.9 & 5.58899 & 99999999995 & TRN \\
\hline CHEMBL1455194 & 688236 & 5.2 & 5.3454 & TRN & \\
\hline CHEMBL1408836 & 688236 & 5.5 & 5.3908 & TRN & \\
\hline CHEMBL1435899 & 688236 & 5.5 & 5.5034 & TRN & \\
\hline CHEMBL418068 & 688236 & 4.9 & 5.54700 & 0000000001 & TRN \\
\hline CHEMBL1484261 & 688236 & 6.6 & 5.87299 & 9999999999 & TRN \\
\hline CHEMBL1433464 & 688236 & 6.1 & 5.6572 & TRN & \\
\hline CHEMBL26915 & 688236 & 5.3 & 5.7779 & TRN & \\
\hline CHEMBL1495077 & 688236 & 5.5 & 5.5495 & TRN & \\
\hline CHEMBL1455570 & 688236 & 5.5 & 5.7106 & TRN & \\
\hline CHEMBL1529365 & 688236 & 5.4 & 5.6464 & TRN & \\
\hline CHEMBL1396010 & 688236 & 5.4 & 5.5862 & TRN & \\
\hline CHEMBL 8747 & 688236 & 5.1 & 5.7288 & TRN & \\
\hline CHEMBL3195219 & 688236 & 5.0 & 5.4549 & TRN & \\
\hline CHEMBL1356135 & 688236 & 5.9 & 5.7313 & TRN & \\
\hline CHEMBL 244743 & 688236 & 5.0 & 5.3477 & TRN & \\
\hline CHEMBL1473934 & 688236 & 5.5 & 5.6052 & TRN & \\
\hline CHEMBL1573732 & 688236 & 5.7 & 5.3634 & TRN & \\
\hline CHEMBL1394348 & 688236 & 5.5 & 5.5355 & TRN & \\
\hline CHEMBL1444371 & 688236 & 5.6 & 5.4142 & TRN & \\
\hline CHEMBL1487340 & 688236 & 6.0 & 5.4228 & TRN & \\
\hline CHEMBL1489769 & 688236 & 5.0 & 5.6404 & TST & \\
\hline CHEMBL1446523 & 688236 & 6.5 & 5.8318 & TRN & \\
\hline CHEMBL1396791 & 688236 & 5.6 & 5.654 & TRN & \\
\hline CHEMBL1541450 & 688236 & 5.2 & 5.3098 & TRN & \\
\hline CHEMBL1411929 & 688236 & 6.0 & 5.44600 & 2000000001 & TST \\
\hline CHEMBL1476383 & 688236 & 7.699 & 5.5455 & TST & \\
\hline CHEMBL1256647 & 688236 & 4.9 & 5.5016 & TST & \\
\hline CHEMBL1256869 & 688236 & 4.5 & 5.3987 & TST & \\
\hline & & & & 5911 & \\
\hline
\end{tabular}




\begin{tabular}{|c|c|c|c|c|c|}
\hline & & & & & \\
\hline CHEMBL1590378 & 688236 & 6.0 & 5.4597 & TST & \\
\hline CHEMBL1243269 & 688236 & 4.9 & 5.3859 & TST & \\
\hline CHEMBL1514307 & 688236 & 5.5 & 5.6202 & TRN & \\
\hline CHEMBL1372723 & 688236 & 4.9 & 5.5362 & TRN & \\
\hline CHEMBL1376954 & 688236 & 6.4 & 5.6915 & TRN & \\
\hline CHEMBL1966792 & 688236 & 5.3 & 5.3588 & TRN & \\
\hline CHEMBL1395226 & 688236 & 5.4 & 5.74799 & 9999999999 & TRN \\
\hline CHEMBL1554577 & 688236 & 5.4 & 5.83299 & 9999999999 & TRN \\
\hline CHEMBL1500231 & 688236 & 4.9 & 5.25899 & 99999999995 & TRN \\
\hline CHEMBL587849 & 688236 & 5.5 & 5.5155 & TRN & \\
\hline CHEMBL1523150 & 688236 & 5.4 & 5.3438 & TRN & \\
\hline CHEMBL1269022 & 688236 & 5.6 & 5.6831 & TST & \\
\hline CHEMBL1375753 & 688236 & 5.4 & 5.6961 & TRN & \\
\hline CHEMBL168276 & 688236 & 4.8 & 5.5276 & TRN & \\
\hline CHEMBL1437007 & 688236 & 5.5 & 5.6627 & TRN & \\
\hline CHEMBL1338095 & 688236 & 5.3 & 5.61700 & 0000000001 & TRN \\
\hline CHEMBL1534849 & 688236 & 5.5 & 5.6094 & TRN & \\
\hline CHEMBL1540350 & 688236 & 5.5 & 5.3897 & TRN & \\
\hline CHEMBL1583392 & 688236 & 5.1 & 5.4218 & TST & \\
\hline CHEMBL1358137 & 688236 & 5.7 & 5.6129 & TRN & \\
\hline CHEMBL1395402 & 688236 & 5.3 & 5.7115 & TRN & \\
\hline CHEMBL1562125 & 688236 & 5.1 & 5.2701 & TRN & \\
\hline CHEMBL1516351 & 688236 & 6.0 & 5.527 & TST & \\
\hline CHEMBL1604036 & 688236 & 6.7001 & 5.7284 & TST & \\
\hline CHEMBL1412519 & 688236 & 5.7 & 5.6275 & TRN & \\
\hline CHEMBL1357676 & 688236 & 5.6 & 5.6437 & TRN & \\
\hline CHEMBL275938 & 688236 & 4.9 & 5.48799 & 99999999995 & TST \\
\hline CHEMBL1532555 & 688236 & 5.6 & 5.5146 & TRN & \\
\hline CHEMBL1508914 & 688236 & 5.5 & 5.5828 & TRN & \\
\hline CHEMBL1328240 & 688236 & 5.2 & 5.5065 & TRN & \\
\hline CHEMBL1522486 & 688236 & 4.9 & 5.7167 & TRN & \\
\hline CHEMBL3191152 & 688236 & 5.2 & 5.6138 & TST & \\
\hline CHEMBL1556023 & 688236 & 8.8861 & 5.7176 & TST & \\
\hline CHEMBL1497991 & 688236 & 5.1 & 5.1724 & TRN & \\
\hline CHEMBL1421193 & 688236 & 5.5 & 5.4019 & TRN & \\
\hline CHEMBL1564501 & 688236 & 5.9 & 5.5928 & TRN & \\
\hline CHEMBL1536971 & 688236 & 4.9 & 5.425 & TRN & \\
\hline CHEMBL1512210 & 688236 & 5.5 & 5.4512 & TRN & \\
\hline CHEMBL1558456 & 688236 & 6.8 & 5.5758 & TRN & \\
\hline CHEMBL1402957 & 688236 & 5.5 & 5.4133 & TST & \\
\hline CHEMBL1321855 & 688236 & 5.9 & 5.5634 & TRN & \\
\hline CHEMBL1363815 & 688236 & 5.0 & 5.4234 & TRN & \\
\hline CHEMBL491953 & 688236 & 5.7 & 5.88 & TRN & \\
\hline CHEMBL1442459 & 688236 & 6.7001 & 5.5163 & TST & \\
\hline CHEMBL1593774 & 688236 & 5.6 & 5.777 & TRN & \\
\hline CHEMBL3210598 & 688236 & 5.1 & 5.3772 & TRN & \\
\hline CHEMBL1593859 & 688236 & 5.4 & 5.4973 & TRN & \\
\hline CHEMBL1303113 & 688236 & 5.2 & 5.3292 & TRN & \\
\hline
\end{tabular}




\begin{tabular}{|c|c|c|c|c|}
\hline & & & & $a \perp 1 a$ \\
\hline CHEMBL28 & 688236 & 6.0 & 5.4452 & TRN \\
\hline CHEMBL1611820 & 688236 & 5.5 & 5.6656 & TRN \\
\hline CHEMBL1315141 & 688236 & 6.0 & 5.6126 & TRN \\
\hline CHEMBL1474795 & 688236 & 5.4 & 5.7006 & TRN \\
\hline CHEMBL1554910 & 688236 & 5.3 & 5.6388 & TRN \\
\hline CHEMBL1437741 & 688236 & 5.3 & 5.6971 & TRN \\
\hline CHEMBL1411543 & 688236 & 5.3 & 5.6992 & TRN \\
\hline CHEMBL1315504 & 688236 & 5.3 & 5.6595 & TRN \\
\hline CHEMBL1329117 & 688236 & 6.2 & 5.5387 & TRN \\
\hline CHEMBL1547696 & 688236 & 5.4 & 5.62700 & 0000000001 \\
\hline CHEMBL1256709 & 688236 & 4.9 & 5.2911 & TRN \\
\hline CHEMBL1597692 & 688236 & 4.8 & 5.5239 & TST \\
\hline CHEMBL1515004 & 688236 & 5.6 & 5.4766 & TRN \\
\hline CHEMBL1591712 & 688236 & 5.0 & 5.4085 & TST \\
\hline CHEMBL1399619 & 688236 & 5.4 & 5.5492 & TRN \\
\hline CHEMBL1529009 & 688236 & 5.0 & 5.5522 & TRN \\
\hline CHEMBL1553825 & 688236 & 5.9 & 5.8802 & TRN \\
\hline CHEMBL3209128 & 688236 & 5.0 & 5.6375 & TST \\
\hline CHEMBL1594107 & 688236 & 5.7 & 5.5922 & TST \\
\hline CHEMBL1554411 & 688236 & 5.5 & 5.5732 & TRN \\
\hline CHEMBL287689 & 688236 & 5.5 & 5.4938 & TRN \\
\hline CHEMBL1513458 & 688236 & 5.3 & 5.7122 & TRN \\
\hline CHEMBL1577982 & 688236 & 5.1 & 5.4843 & TRN \\
\hline CHEMBL1356463 & 688236 & 6.7001 & 5.5453 & TST \\
\hline CHEMBL1377200 & 688236 & 5.0 & 5.4012 & TRN \\
\hline CHEMBL1508743 & 688236 & 5.0 & 5.308 & TRN \\
\hline CHEMBL1538395 & 688236 & 5.1 & 5.5135 & TRN \\
\hline CHEMBL1356783 & 688236 & 8.6021 & 5.5539 & TST \\
\hline CHEMBL1514280 & 688236 & 5.6 & 5.7068 & TRN \\
\hline CHEMBL1327187 & 688236 & 6.0 & 5.5078 & TRN \\
\hline CHEMBL1310973 & 688236 & 5.2 & 5.3881 & TRN \\
\hline CHEMBL56543 & 688236 & 5.0 & 5.1925 & TRN \\
\hline CHEMBL 296586 & 688236 & 5.5 & 5.4548 & TRN \\
\hline CHEMBL1593989 & 688236 & 5.5 & 5.6301 & TRN \\
\hline CHEMBL1494883 & 688236 & 5.4 & 5.5234 & TRN \\
\hline CHEMBL1609341 & 688236 & 5.0 & 5.5487 & TRN \\
\hline CHEMBL1572855 & 688236 & 5.5 & 5.6083 & TRN \\
\hline CHEMBL1496363 & 688236 & 5.5 & 5.5738 & TST \\
\hline CHEMBL1410627 & 688236 & 7.8996 & 5.5106 & TRN \\
\hline CHEMBL1398321 & 688236 & 5.0 & 5.5946 & TRN \\
\hline CHEMBL1361596 & 688236 & 5.4 & 5.4543 & TST \\
\hline CHEMBL1601477 & 688236 & 5.3 & 5.8368 & TRN \\
\hline CHEMBL1552897 & 688236 & 5.2 & 5.5235 & TRN \\
\hline CHEMBL1400543 & 688236 & 4.5 & 5.65 & TST \\
\hline CHEMBL1536363 & 688236 & 5.3 & 5.3402 & TRN \\
\hline CHEMBL1386915 & 688236 & 4.9 & 5.2773 & TRN \\
\hline CHEMBL109037 & 688236 & 4.8 & 5.557 & TRN \\
\hline CHEMBL1571264 & 688236 & 5.7 & 5.8816 & TRN \\
\hline
\end{tabular}

TRN 


\begin{tabular}{|c|c|c|c|c|c|}
\hline \multicolumn{6}{|c|}{ Supplemental Table S2.txt } \\
\hline CHEMBL1403305 & 688236 & 5.4 & 5.5846 & TRN & \\
\hline CHEMBL1337820 & 688236 & 5.3 & 5.4447 & TRN & \\
\hline CHEMBL1414885 & 688236 & 8.1024 & 5.7387 & TST & \\
\hline CHEMBL1355217 & 688236 & 6.7001 & 5.6753 & TRN & \\
\hline CHEMBL1394477 & 688236 & 5.7 & 5.8415 & TRN & \\
\hline CHEMBL1519261 & 688236 & 5.9 & 5.6614 & TRN & \\
\hline CHEMBL578943 & 688236 & 9.0969 & 5.5233 & TST & \\
\hline CHEMBL 304621 & 688236 & 5.0 & 5.5402 & TRN & \\
\hline CHEMBL1381644 & 688236 & 5.6 & \multicolumn{2}{|c|}{5.702000000000001} & TRN \\
\hline CHEMBL1506173 & 688236 & 5.0 & 5.5557 & TRN & \\
\hline CHEMBL1316492 & 688236 & 5.4 & 5.5873 & TRN & \\
\hline CHEMBL1332504 & 688236 & 5.4 & 5.4011 & TRN & \\
\hline CHEMBL1473498 & 688236 & 8.7959 & 5.5954 & TRN & \\
\hline CHEMBL239439 & 688236 & 5.5 & 5.5499 & TRN & \\
\hline CHEMBL1589298 & 688236 & 5.7 & 5.4636 & TRN & \\
\hline CHEMBL1480293 & 688236 & 5.7 & 5.4863 & TRN & \\
\hline CHEMBL 243664 & 688236 & 6.1 & 5.4516 & TRN & \\
\hline CHEMBL1529490 & 688236 & 5.6 & 5.4752 & TRN & \\
\hline CHEMBL522121 & 688236 & 5.7 & 5.6714 & TRN & \\
\hline CHEMBL1423437 & 688236 & 6.3 & 5.5513 & TRN & \\
\hline CHEMBL1358085 & 688236 & 5.5 & 5.5774 & TRN & \\
\hline CHEMBL1256971 & 688236 & 4.6 & 5.4706 & TST & \\
\hline CHEMBL1318789 & 688236 & 8.0 & 5.5735 & TST & \\
\hline CHEMBL1563352 & 688236 & 5.4 & 5.5267 & TST & \\
\hline CHEMBL1256484 & 688236 & 5.2 & 5.5112 & TRN & \\
\hline CHEMBL1592556 & 688236 & 5.6 & 5.6431 & TRN & \\
\hline CHEMBL1325419 & 688236 & 5.1 & 5.5622 & TRN & \\
\hline CHEMBL1559783 & 688236 & 5.4 & 5.4794 & TRN & \\
\hline CHEMBL1417375 & 688236 & 7.0 & \multicolumn{2}{|c|}{5.747000000000001} & TRN \\
\hline CHEMBL1421938 & 688236 & 5.1 & 5.4949 & TRN & \\
\hline CHEMBL1450917 & 688236 & 5.4 & 5.2443 & TRN & \\
\hline CHEMBL1526212 & 688236 & 5.3 & 5.3576 & TRN & \\
\hline CHEMBL1413343 & 688236 & 5.4 & 5.817 & TRN & \\
\hline CHEMBL50378 & 688236 & 5.9 & 5.6793 & TRN & \\
\hline CHEMBL1563047 & 688236 & 5.4 & 5.6802 & TRN & \\
\hline CHEMBL1486555 & 688236 & 7.0 & 5.4286 & TRN & \\
\hline CHEMBL1384211 & 688236 & 5.9 & 5.2779 & TRN & \\
\hline CHEMBL1526697 & 688236 & 5.6 & 5.9045 & TRN & \\
\hline CHEMBL3209312 & 688236 & 6.2 & 5.3695 & TRN & \\
\hline CHEMBL1533853 & 688236 & 5.2 & 5.9482 & TRN & \\
\hline CHEMBL3207906 & 688236 & 6.1 & 5.4791 & TST & \\
\hline CHEMBL1513490 & 688236 & 6.0 & 5.5059 & TST & \\
\hline CHEMBL1522897 & 688236 & 5.4 & 5.8041 & TRN & \\
\hline CHEMBL1487191 & 688236 & 5.4 & 5.6182 & TRN & \\
\hline CHEMBL1413497 & 688236 & 5.6 & 5.6331 & TRN & \\
\hline CHEMBL1479746 & 688236 & 5.2 & 5.5725 & TST & \\
\hline CHEMBL1315382 & 688236 & 5.6 & 5.6476 & TRN & \\
\hline CHEMBL1574404 & 688236 & 5.2 & 5.445 & TST & \\
\hline
\end{tabular}




\begin{tabular}{|c|c|c|c|c|c|}
\hline & & & & & \\
\hline CHEMBL1330020 & 688236 & 6.5 & 5.7507 & TRN & \\
\hline CHEMBL410873 & 688236 & 4.9 & 5.3719 & TRN & \\
\hline CHEMBL3193813 & 688236 & 5.2 & 5.1739 & TRN & \\
\hline CHEMBL495068 & 688236 & 5.6 & 5.9042 & TRN & \\
\hline CHEMBL1488679 & 688236 & 5.7 & 5.5789 & TST & \\
\hline CHEMBL1467406 & 688236 & 5.1 & 5.2998 & TRN & \\
\hline CHEMBL1495171 & 688236 & 5.7 & 5.5119 & TRN & \\
\hline CHEMBL1408879 & 688236 & 6.7001 & 5.2923 & TST & \\
\hline CHEMBL1973435 & 688236 & 6.0 & 5.319 & TRN & \\
\hline CHEMBL374107 & 688236 & 5.1 & 5.6148 & TST & \\
\hline CHEMBL516616 & 688236 & 5.5 & 5.37700 & 0000000001 & TST \\
\hline CHEMBL1503131 & 688236 & 5.1 & 5.4876 & TRN & \\
\hline CHEMBL73310 & 688236 & 5.3 & 5.4939 & TRN & \\
\hline CHEMBL546257 & 688236 & 6.0 & 5.6445 & TRN & \\
\hline CHEMBL1321338 & 688236 & 5.5 & 5.6207 & TRN & \\
\hline CHEMBL1493644 & 688236 & 5.5 & 5.5971 & TRN & \\
\hline CHEMBL1592186 & 688236 & 5.3 & 5.5244 & TRN & \\
\hline CHEMBL1591504 & 688236 & 5.3 & 5.6936 & TRN & \\
\hline CHEMBL1372837 & 688236 & 5.3 & 5.3418 & TRN & \\
\hline CHEMBL1405797 & 688236 & 5.3 & 5.7082 & TRN & \\
\hline CHEMBL1564476 & 688236 & 4.9 & 5.4904 & TRN & \\
\hline CHEMBL1181366 & 688236 & 5.8 & 5.5816 & TST & \\
\hline CHEMBL428496 & 688236 & 6.8 & 5.5221 & TST & \\
\hline CHEMBL1408176 & 688236 & 5.4 & 5.6574 & TRN & \\
\hline CHEMBL1355201 & 688236 & 5.6 & 5.7928 & TRN & \\
\hline CHEMBL1476129 & 688236 & 5.6 & 5.70299 & 9999999999 & TRN \\
\hline CHEMBL1334357 & 688236 & 5.3 & 5.631 & TRN & \\
\hline CHEMBL1256659 & 688236 & 5.5 & 5.3419 & TRN & \\
\hline CHEMBL1311630 & 688236 & 5.1 & 5.38200 & 0000000001 & TRN \\
\hline CHEMBL1473793 & 688236 & 5.5 & 5.6573 & TRN & \\
\hline CHEMBL1552051 & 688236 & 5.5 & 5.8215 & TRN & \\
\hline CHEMBL1371756 & 688236 & 5.1 & 5.5499 & TRN & \\
\hline CHEMBL1315609 & 688236 & 6.0 & 5.8922 & TRN & \\
\hline CHEMBL1494177 & 688236 & 5.5 & 5.4472 & TRN & \\
\hline CHEMBL1398528 & 688236 & 5.8 & 5.3783 & TRN & \\
\hline CHEMBL1610003 & 688236 & 5.5 & 5.5913 & TRN & \\
\hline CHEMBL1284 & 688236 & 4.8 & 5.4135 & TRN & \\
\hline CHEMBL1437142 & 688236 & 7.1002 & 5.5603 & TST & \\
\hline CHEMBL34730 & 688236 & 4.9 & 5.5204 & TRN & \\
\hline CHEMBL1604597 & 688236 & 5.5 & 5.3596 & TRN & \\
\hline CHEMBL1411360 & 688236 & 5.8 & 5.5856 & TRN & \\
\hline CHEMBL1725279 & 688236 & 4.8 & 5.6076 & TST & \\
\hline CHEMBL1401859 & 688236 & 5.3 & 5.8927 & TRN & \\
\hline CHEMBL1508113 & 688236 & 5.0 & 5.5629 & TRN & \\
\hline CHEMBL1585547 & 688236 & 6.5 & 5.2567 & TRN & \\
\hline CHEMBL1471867 & 688236 & 5.6 & 5.5432 & TRN & \\
\hline CHEMBL1467236 & 688236 & 5.5 & 5.3901 & TRN & \\
\hline CHEMBL1328480 & 688236 & 5.4 & 5.4313 & TRN & \\
\hline
\end{tabular}




\begin{tabular}{|c|c|c|c|c|c|}
\hline \\
\hline CHEMBL1534297 & 688236 & 6.0 & 5.5863 & TRN & \\
\hline CHEMBL1372951 & 688236 & 6.0 & 5.6242 & TRN & \\
\hline CHEMBL1508059 & 688236 & 5.0 & 5.5005 & TRN & \\
\hline CHEMBL1356501 & 688236 & 5.4 & 5.6585 & TRN & \\
\hline CHEMBL1324842 & 688236 & 6.3 & 5.5685 & TRN & \\
\hline CHEMBL1469355 & 688236 & 6.3 & 5.5104 & TRN & \\
\hline CHEMBL16671 & 688236 & 6.5 & 5.6102 & TRN & \\
\hline CHEMBL1475617 & 688236 & 6.0 & 5.4677 & TRN & \\
\hline CHEMBL3195914 & 688236 & 5.3 & 5.3587 & TRN & \\
\hline CHEMBL1302135 & 688236 & 6.0 & 5.3872 & TST & \\
\hline CHEMBL1320460 & 688236 & 5.4 & 5.3519 & TRN & \\
\hline CHEMBL535307 & 688236 & 8.0 & 5.6776 & TRN & \\
\hline CHEMBL1496315 & 688236 & 5.3 & 5.7688 & TRN & \\
\hline CHEMBL1468261 & 688236 & 4.9 & 5.5196 & TRN & \\
\hline CHEMBL1351807 & 688236 & 5.4 & 5.2793 & TRN & \\
\hline CHEMBL1530216 & 688236 & 5.4 & 5.3581 & TST & \\
\hline CHEMBL1473285 & 688236 & 5.4 & 5.6505 & TRN & \\
\hline CHEMBL1354119 & 688236 & 5.5 & 5.7066 & TRN & \\
\hline CHEMBL1592717 & 688236 & 6.6 & 5.5241 & TST & \\
\hline CHEMBL1597506 & 688236 & 5.3 & 5.6334 & TST & \\
\hline CHEMBL 8867 & 688236 & 4.5 & 5.3745 & TST & \\
\hline CHEMBL 3214579 & 688236 & 5.2 & 5.3384 & TRN & \\
\hline CHEMBL1343939 & 688236 & 5.0 & 5.4479 & TRN & \\
\hline CHEMBL1335552 & 688236 & 5.0 & 5.3528 & TST & \\
\hline CHEMBL1331037 & 688236 & 5.4 & 5.7243 & TRN & \\
\hline CHEMBL1390418 & 688236 & 5.2 & 5.4111 & TRN & \\
\hline CHEMBL1326723 & 688236 & 5.5 & 5.6279 & TRN & \\
\hline CHEMBL1362714 & 688236 & 5.1 & 5.6333 & TST & \\
\hline CHEMBL1474294 & 688236 & 6.0 & 5.5075 & TST & \\
\hline CHEMBL1475338 & 688236 & 5.5 & 5.5289 & TRN & \\
\hline CHEMBL1496345 & 688236 & 5.3 & 5.7125 & TRN & \\
\hline CHEMBL1435809 & 688236 & 5.4 & 5.58799 & 9999999999 & TRN \\
\hline CHEMBL1315129 & 688236 & 5.8 & 5.7012 & TRN & \\
\hline CHEMBL1515131 & 688236 & 7.6003 & 5.5389 & TST & \\
\hline CHEMBL1479202 & 688236 & 5.8 & 5.7174 & TRN & \\
\hline CHEMBL1452454 & 688236 & 5.9 & 5.329 & TRN & \\
\hline CHEMBL1478627 & 688236 & 5.6 & 5.5014 & TRN & \\
\hline CHEMBL1593661 & 688236 & 5.5 & 5.7054 & TRN & \\
\hline CHEMBL1403982 & 688236 & 5.6 & 5.5395 & TRN & \\
\hline CHEMBL1465739 & 688236 & 5.0 & 5.4038 & TRN & \\
\hline CHEMBL1336469 & 688236 & 5.0 & 5.7494 & TRN & \\
\hline CHEMBL1316956 & 688236 & 5.5 & 5.84200 & 00000000005 & TRN \\
\hline CHEMBL515505 & 688236 & 5.8 & 5.5645 & TRN & \\
\hline CHEMBL1338358 & 688236 & 4.6 & 5.1992 & TRN & \\
\hline CHEMBL1493284 & 688236 & 5.5 & 5.5449 & TRN & \\
\hline CHEMBL1417636 & 688236 & 6.0 & 5.6571 & TRN & \\
\hline CHEMBL1316831 & 688236 & 5.4 & 5.6864 & TRN & \\
\hline CHEMBL1688558 & 688236 & 6.4 & 5.8028 & TRN & \\
\hline
\end{tabular}




\begin{tabular}{|c|c|c|c|c|c|}
\hline \\
\hline CHEMBL1563501 & 688236 & 6.9 & 5.6583 & TRN & \\
\hline CHEMBL1440857 & 688236 & 5.0 & 5.6624 & TRN & \\
\hline CHEMBL3192605 & 688236 & 5.1 & 5.6062 & TRN & \\
\hline CHEMBL1603371 & 688236 & 5.3 & 5.6084 & TRN & \\
\hline CHEMBL1366085 & 688236 & 5.4 & 5.5635 & TRN & \\
\hline CHEMBL1317916 & 688236 & 5.5 & 5.5414 & TRN & \\
\hline CHEMBL1447863 & 688236 & 5.2 & 5.3748 & TRN & \\
\hline CHEMBL1593153 & 688236 & 5.5 & 5.7783 & TRN & \\
\hline CHEMBL1526964 & 688236 & 6.6 & 5.6139 & TST & \\
\hline CHEMBL1390770 & 688236 & 5.8 & 5.3551 & TRN & \\
\hline CHEMBL1531863 & 688236 & 4.5 & 5.4399 & TRN & \\
\hline CHEMBL105739 & 688236 & 6.8 & $5.5870 e$ & 0000000001 & TRN \\
\hline CHEMBL322970 & 688236 & 4.9 & 5.5071 & TRN & \\
\hline CHEMBL1340944 & 688236 & 5.0 & 5.3186 & TRN & \\
\hline CHEMBL1565914 & 688236 & 5.8 & 5.6507 & TRN & \\
\hline CHEMBL1330183 & 688236 & 6.4 & 5.5399 & TRN & \\
\hline CHEMBL1416946 & 688236 & 4.9 & 5.5162 & TRN & \\
\hline CHEMBL1452199 & 688236 & 5.6 & 5.449 & TRN & \\
\hline CHEMBL1501564 & 688236 & 5.4 & 5.4797 & TST & \\
\hline CHEMBL1608811 & 688236 & 5.7 & 5.3271 & TRN & \\
\hline CHEMBL1522370 & 688236 & 6.0 & 5.6961 & TRN & \\
\hline CHEMBL1604074 & 688236 & 5.3 & 5.4358 & TRN & \\
\hline CHEMBL1556610 & 688236 & 5.8 & 5.5866 & TRN & \\
\hline CHEMBL1506225 & 688236 & 5.0 & 5.5552 & TRN & \\
\hline CHEMBL1515385 & 688236 & 6.4 & 5.2294 & TRN & \\
\hline CHEMBL1475366 & 688236 & 5.6 & 5.9704 & TRN & \\
\hline CHEMBL1569232 & 688236 & 5.5 & 5.651 & TRN & \\
\hline CHEMBL1436865 & 688236 & 5.5 & 5.5514 & TRN & \\
\hline CHEMBL1527360 & 688236 & 5.0 & 5.3869 & TRN & \\
\hline CHEMBL1524714 & 688236 & 4.9 & 5.4348 & TRN & \\
\hline CHEMBL265699 & 688236 & 5.7 & 5.7674 & TRN & \\
\hline CHEMBL1515310 & 688236 & 4.5 & 5.5842 & TST & \\
\hline CHEMBL1396742 & 688236 & 5.7 & 5.7335 & TRN & \\
\hline CHEMBL1373587 & 688236 & 5.5 & 5.652 & TRN & \\
\hline CHEMBL1516054 & 688236 & 5.3 & 5.8595 & TRN & \\
\hline CHEMBL507159 & 688236 & 7.0 & $5.6110 e$ & 0000000001 & TRN \\
\hline CHEMBL3192314 & 688236 & 5.0 & 5.50899 & 99999999995 & TRN \\
\hline CHEMBL1519472 & 688236 & 6.4 & 5.5761 & TRN & \\
\hline CHEMBL1435009 & 688236 & 5.6 & 5.8363 & TRN & \\
\hline CHEMBL1455097 & 688236 & 6.6 & 5.6959 & TRN & \\
\hline CHEMBL1350883 & 688236 & 5.2 & 5.7012 & TRN & \\
\hline CHEMBL1449152 & 688236 & 5.6 & 5.3922 & TRN & \\
\hline CHEMBL1324287 & 688236 & 5.4 & 5.4951 & TRN & \\
\hline CHEMBL1385840 & 688236 & 6.4 & 5.4899 & TST & \\
\hline CHEMBL1474475 & 688236 & 5.5 & 5.5694 & TRN & \\
\hline CHEMBL444422 & 688236 & 4.6 & 5.4938 & TST & \\
\hline CHEMBL1496666 & 688236 & 4.9 & 5.331 & TRN & \\
\hline CHEMBL1358092 & 688236 & 5.6 & 5.561 & TRN & \\
\hline
\end{tabular}




\begin{tabular}{|c|c|c|c|c|c|}
\hline \\
\hline CHEMBL1344640 & 688236 & 5.5 & 5.5914 & TRN & \\
\hline CHEMBL1439126 & 688236 & 5.5 & 5.5311 & TST & \\
\hline CHEMBL1395026 & 688236 & 5.5 & 5.6783 & TRN & \\
\hline CHEMBL1395974 & 688236 & 5.4 & 5.7044 & TRN & \\
\hline CHEMBL1338950 & 688236 & 7.8013 & 5.665 & TRN & \\
\hline CHEMBL192566 & 688236 & 4.5 & 6.2508 & TST & \\
\hline CHEMBL1435919 & 688236 & 6.0 & 5.7339 & TRN & \\
\hline CHEMBL1396595 & 688236 & 6.8 & 6.0074 & TRN & \\
\hline CHEMBL1269845 & 688236 & 5.5 & 5.5382 & TRN & \\
\hline CHEMBL1329077 & 688236 & 5.0 & 5.5912 & TRN & \\
\hline CHEMBL1396661 & 688236 & 5.0 & 5.4021 & TST & \\
\hline CHEMBL432527 & 688236 & 5.5 & 5.6353 & TRN & \\
\hline CHEMBL1407953 & 688236 & 5.8 & 5.5882 & TRN & \\
\hline CHEMBL1579427 & 688236 & 4.9 & 5.2732 & TRN & \\
\hline CHEMBL1318616 & 688236 & 5.5 & 5.6427 & TRN & \\
\hline CHEMBL1402856 & 688236 & 4.9 & 5.1973 & TRN & \\
\hline CHEMBL1537294 & 688236 & 5.0 & 5.5381 & TRN & \\
\hline CHEMBL541585 & 688236 & 5.3 & 5.3877 & TRN & \\
\hline CHEMBL123 & 688236 & 6.0 & 5.6679 & TRN & \\
\hline CHEMBL1256974 & 688236 & 4.8 & 5.5282 & TRN & \\
\hline CHEMBL1317498 & 688236 & 5.4 & 5.6716 & TRN & \\
\hline CHEMBL1360942 & 688236 & 5.5 & 5.5115 & TRN & \\
\hline CHEMBL1422043 & 688236 & 7.0 & 5.5055 & TST & \\
\hline CHEMBL1434164 & 688236 & 5.4 & 5.604 & TRN & \\
\hline CHEMBL25236 & 688236 & 6.0 & 5.36799 & 9999999999 & TRN \\
\hline CHEMBL3193689 & 688236 & 5.0 & 5.3105 & TRN & \\
\hline CHEMBL1354355 & 688236 & 5.3 & 5.7197 & TRN & \\
\hline CHEMBL1447051 & 688236 & 5.2 & 5.5737 & TST & \\
\hline CHEMBL1358583 & 688236 & 5.9 & 5.5002 & TRN & \\
\hline CHEMBL 30707 & 688236 & 5.0 & 5.4479 & TRN & \\
\hline CHEMBL1363873 & 688236 & 5.5 & 5.50700 & $\partial 000000001$ & TRN \\
\hline CHEMBL1552839 & 688236 & 6.3 & 5.6318 & TRN & \\
\hline CHEMBL1344787 & 688236 & 5.5 & 5.6057 & TRN & \\
\hline CHEMBL1434022 & 688236 & 5.5 & 5.4446 & TRN & \\
\hline CHEMBL1595910 & 688236 & 5.4 & 5.6028 & TRN & \\
\hline CHEMBL1521681 & 688236 & 6.0 & 5.511 & TST & \\
\hline CHEMBL1255653 & 688236 & 5.0 & 5.6732 & TST & \\
\hline CHEMBL1725507 & 688236 & 5.2 & 5.4285 & TRN & \\
\hline CHEMBL1523314 & 688236 & 5.3 & 5.6477 & TRN & \\
\hline CHEMBL565654 & 688236 & 5.7 & 5.8411 & TRN & \\
\hline CHEMBL1356721 & 688236 & 5.3 & 5.7575 & TRN & \\
\hline CHEMBL1434308 & 688236 & 7.0 & 5.8052 & TRN & \\
\hline CHEMBL10009 & 688236 & 5.0 & 5.47 & TRN & \\
\hline CHEMBL1396282 & 688236 & 5.3 & 5.5075 & TST & \\
\hline CHEMBL1483855 & 688236 & 5.4 & 5.9028 & TRN & \\
\hline CHEMBL1487898 & 688236 & 5.3 & 5.7599 & TRN & \\
\hline CHEMBL1497576 & 688236 & 5.9 & 5.4813 & TRN & \\
\hline CHEMBL1399590 & 688236 & 5.3 & 5.4168 & TRN & \\
\hline
\end{tabular}




\begin{tabular}{|c|c|c|c|c|c|}
\hline \\
\hline CHEMBL3392050 & 688236 & 4.6 & 5.5804 & TST & \\
\hline CHEMBL1481668 & 688236 & 5.5 & 5.5269 & TRN & \\
\hline CHEMBL1357076 & 688236 & 5.5 & 5.6347 & TRN & \\
\hline CHEMBL1330459 & 688236 & 5.1 & 5.6083 & TRN & \\
\hline CHEMBL1426948 & 688236 & 4.9 & 5.3708 & TST & \\
\hline CHEMBL1355200 & 688236 & 5.9 & 5.437 & TRN & \\
\hline CHEMBL137267 & 688236 & 5.7 & 5.5135 & TRN & \\
\hline CHEMBL1515194 & 688236 & 5.5 & 5.5891 & TRN & \\
\hline CHEMBL442581 & 688236 & 7.0 & 5.4459 & TRN & \\
\hline CHEMBL102714 & 688236 & 5.4 & 5.2671 & TRN & \\
\hline CHEMBL1397088 & 688236 & 5.5 & 5.7001 & TRN & \\
\hline CHEMBL1462791 & 688236 & 5.0 & 5.3216 & TRN & \\
\hline CHEMBL1314247 & 688236 & 5.4 & 5.6498 & TRN & \\
\hline CHEMBL1448728 & 688236 & 5.5 & 5.7482 & TRN & \\
\hline CHEMBL1304186 & 688236 & 5.4 & 5.5065 & TRN & \\
\hline CHEMBL1316219 & 688236 & 5.9 & 5.6572 & TRN & \\
\hline CHEMBL288174 & 688236 & 4.5 & 5.4637 & TST & \\
\hline CHEMBL1339227 & 688236 & 5.3 & 5.4105 & TRN & \\
\hline CHEMBL1302071 & 688236 & 5.7 & 5.6409 & TRN & \\
\hline CHEMBL3716478 & 688236 & 5.1 & 5.4814 & TST & \\
\hline CHEMBL1397532 & 688236 & 5.6 & 5.7209 & TRN & \\
\hline CHEMBL1361855 & 688236 & 5.5 & 5.5 & TRN & \\
\hline CHEMBL1496664 & 688236 & 6.1 & 5.5197 & TRN & \\
\hline CHEMBL1302028 & 688236 & 4.9 & 5.3882 & TRN & \\
\hline CHEMBL1395997 & 688236 & 5.3 & 5.5688 & TRN & \\
\hline CHEMBL1370146 & 688236 & 4.9 & 5.2892 & TRN & \\
\hline CHEMBL1475686 & 688236 & 6.1 & 5.78299 & 99999999995 & TRN \\
\hline CHEMBL1561888 & 688236 & 6.0 & 5.8114 & TRN & \\
\hline CHEMBL1523817 & 688236 & 5.4 & 5.4092 & TST & \\
\hline CHEMBL1355970 & 688236 & 5.5 & 5.7421 & TRN & \\
\hline CHEMBL1470039 & 688236 & 5.0 & 5.3043 & TRN & \\
\hline CHEMBL1592754 & 688236 & 5.5 & 5.6266 & TRN & \\
\hline CHEMBL1429627 & 688236 & 5.3 & 5.5159 & TRN & \\
\hline CHEMBL1355262 & 688236 & 5.5 & 5.5114 & TRN & \\
\hline CHEMBL3197198 & 688236 & 5.2 & 5.6081 & TRN & \\
\hline CHEMBL1440617 & 688236 & 5.4 & 5.53700 & $\partial 000000001$ & TRN \\
\hline CHEMBL1476274 & 688236 & 7.2 & 5.4617 & TST & \\
\hline CHEMBL1380403 & 688236 & 5.3 & 5.6102 & TRN & \\
\hline CHEMBL1374585 & 688236 & 5.5 & 5.7309 & TRN & \\
\hline CHEMBL1403333 & 688236 & 5.3 & 5.8104 & TRN & \\
\hline CHEMBL1476712 & 688236 & 5.9 & 5.7706 & TRN & \\
\hline CHEMBL1410838 & 688236 & 5.2 & 5.4145 & TRN & \\
\hline CHEMBL78150 & 688236 & 6.9 & 5.5187 & TRN & \\
\hline CHEMBL1369824 & 688236 & 5.8 & 5.6867 & TRN & \\
\hline CHEMBL 1485000 & 688236 & 6.7001 & 5.4222 & TRN & \\
\hline CHEMBL1257041 & 688236 & 5.6 & 5.4714 & TRN & \\
\hline CHEMBL1327752 & 688236 & 6.4 & 5.7674 & TRN & \\
\hline CHEMBL34704 & 688236 & 5.9 & 5.4316 & TST & \\
\hline
\end{tabular}




\begin{tabular}{|c|c|c|c|c|}
\hline & & & 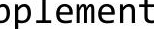 & $1 \mathrm{~T}$ \\
\hline CHEMBL1435381 & 688236 & 4.8 & 5.447 & TST \\
\hline CHEMBL1361438 & 688236 & 5.2 & 5.62700 & 0000000001 \\
\hline CHEMBL1592371 & 688236 & 5.6 & 5.4336 & TRN \\
\hline CHEMBL1569583 & 688236 & 6.0 & 5.5428 & TST \\
\hline CHEMBL1585078 & 688236 & 5.1 & 5.5342 & TRN \\
\hline CHEMBL1608159 & 688236 & 5.4 & 5.2858 & TRN \\
\hline CHEMBL1353133 & 688236 & 6.9 & 5.4873 & TRN \\
\hline CHEMBL1528005 & 688236 & 6.1 & 5.6906 & TST \\
\hline CHEMBL1703229 & 688236 & 6.3 & 5.6088 & TRN \\
\hline CHEMBL598263 & 688236 & 5.8 & 5.4985 & TST \\
\hline CHEMBL1365069 & 688236 & 5.5 & 5.2874 & TRN \\
\hline CHEMBL1354913 & 688236 & 6.8 & 5.7712 & TRN \\
\hline CHEMBL1484944 & 688236 & 5.5 & 5.6474 & TRN \\
\hline CHEMBL1317748 & 688236 & 5.6 & 5.8961 & TRN \\
\hline CHEMBL1553863 & 688236 & 6.2 & 5.4246 & TRN \\
\hline CHEMBL1613623 & 688236 & 5.2 & 5.4509 & TRN \\
\hline CHEMBL1481974 & 688236 & 5.5 & 5.4615 & TST \\
\hline CHEMBL1460909 & 688236 & 5.0 & 5.3515 & TRN \\
\hline CHEMBL1551254 & 688236 & 5.5 & 5.3595 & TRN \\
\hline CHEMBL1330961 & 688236 & 5.9 & 5.7 & TRN \\
\hline CHEMBL1439172 & 688236 & 4.5 & 5.4662 & TRN \\
\hline CHEMBL1257003 & 688236 & 5.0 & 5.2777 & TRN \\
\hline CHEMBL1381989 & 688236 & 5.4 & 5.4854 & TST \\
\hline CHEMBL1349507 & 688236 & 6.8 & 5.5747 & TRN \\
\hline CHEMBL1311586 & 688236 & 6.3 & 5.4024 & TRN \\
\hline CHEMBL1315457 & 688236 & 4.7 & 5.5404 & TST \\
\hline CHEMBL 238624 & 688236 & 5.8 & 5.5784 & TRN \\
\hline CHEMBL1512023 & 688236 & 5.4 & 5.7441 & TRN \\
\hline CHEMBL1331122 & 688236 & 5.5 & 5.4619 & TRN \\
\hline CHEMBL52387 & 688236 & 4.5 & 5.76 & TRN \\
\hline CHEMBL1476521 & 688236 & 5.4 & 5.5718 & TRN \\
\hline CHEMBL1439673 & 688236 & 5.5 & 5.5153 & TRN \\
\hline CHEMBL1523390 & 688236 & 6.3 & 5.6338 & TST \\
\hline CHEMBL1436075 & 688236 & 5.5 & 5.6717 & TRN \\
\hline CHEMBL1577591 & 688236 & 4.9 & 5.5296 & TST \\
\hline CHEMBL1359396 & 688236 & 5.2 & 5.5375 & TRN \\
\hline CHEMBL1559143 & 688236 & 5.3 & 5.2572 & TRN \\
\hline CHEMBL1376253 & 688236 & 5.7 & 5.6141 & TRN \\
\hline CHEMBL1403488 & 688236 & 5.5 & 5.603 & TRN \\
\hline CHEMBL1570996 & 688236 & 7.699 & 5.5656 & TRN \\
\hline CHEMBL1375967 & 688236 & 5.5 & 5.4449 & TRN \\
\hline CHEMBL3198736 & 688236 & 5.0 & 5.5283 & TST \\
\hline CHEMBL1593926 & 688236 & 5.5 & 5.6037 & TRN \\
\hline CHEMBL1399519 & 688236 & 5.3 & 5.2881 & TRN \\
\hline CHEMBL 7644 & 688236 & 5.4 & 5.4738 & TRN \\
\hline CHEMBL1395431 & 688236 & 6.0 & 5.6832 & TRN \\
\hline CHEMBL1593158 & 688236 & 5.5 & 5.8516 & TRN \\
\hline CHEMBL1357381 & 688236 & 6.4 & 5.4967 & TRN \\
\hline
\end{tabular}

TRN 


\begin{tabular}{|c|c|c|c|c|c|}
\hline \\
\hline CHEMBL1309066 & 688236 & 5.2 & 5.5649 & TRN & \\
\hline CHEMBL421215 & 688236 & 5.1 & 5.535 & TST & \\
\hline CHEMBL1589061 & 688236 & 4.9 & 5.2422 & TRN & \\
\hline CHEMBL1569549 & 688236 & 6.4 & 5.6055 & TRN & \\
\hline CHEMBL164 & 688236 & 5.7 & 5.4276 & TRN & \\
\hline CHEMBL3191778 & 688236 & 4.9 & 5.5817 & TRN & \\
\hline CHEMBL1492102 & 688236 & 5.7 & 5.4523 & TRN & \\
\hline CHEMBL1397466 & 688236 & 8.6021 & 5.4724 & TST & \\
\hline CHEMBL1605818 & 688236 & 5.5 & 5.5842 & TRN & \\
\hline CHEMBL1433105 & 688236 & 4.9 & 5.4584 & TRN & \\
\hline CHEMBL1583388 & 688236 & 4.9 & 5.5266 & TST & \\
\hline CHEMBL128427 & 688236 & 5.1 & 5.6741 & TRN & \\
\hline CHEMBL105278 & 688236 & 4.8 & 5.5066 & TST & \\
\hline CHEMBL1511379 & 688236 & 4.9 & 5.5489 & TST & \\
\hline CHEMBL1426207 & 688236 & 5.8 & 5.4746 & TRN & \\
\hline CHEMBL1434334 & 688236 & 6.0 & 5.5059 & TST & \\
\hline CHEMBL1441192 & 688236 & 5.5 & 5.7188 & TRN & \\
\hline CHEMBL1607062 & 688236 & 8.4949 & 5.7896 & TRN & \\
\hline CHEMBL1398260 & 688236 & 6.0 & 5.6484 & TST & \\
\hline CHEMBL1496459 & 688236 & 5.5 & 5.3408 & TRN & \\
\hline CHEMBL1375243 & 688236 & 6.3 & 5.4858 & TST & \\
\hline CHEMBL1338490 & 688236 & 5.1 & 5.5504 & TST & \\
\hline CHEMBL1541211 & 688236 & 5.5 & 5.3254 & TRN & \\
\hline CHEMBL1318927 & 688236 & 5.6 & 5.3761 & TRN & \\
\hline CHEMBL590670 & 688236 & 5.3 & 5.46700 & 00000000005 & TRN \\
\hline CHEMBL1437263 & 688236 & 5.3 & 5.6788 & TRN & \\
\hline CHEMBL124267 & 688236 & 4.6 & 5.4003 & TRN & \\
\hline CHEMBL1417789 & 688236 & 5.5 & 5.6272 & TRN & \\
\hline CHEMBL1325833 & 688236 & 5.3 & 5.6449 & TRN & \\
\hline CHEMBL1471010 & 688236 & 5.2 & 5.2928 & TRN & \\
\hline CHEMBL1435907 & 688236 & 5.5 & 5.4559 & TRN & \\
\hline CHEMBL1357222 & 688236 & 5.4 & 5.669 & TRN & \\
\hline CHEMBL1328509 & 688236 & 5.3 & 5.3947 & TRN & \\
\hline CHEMBL311489 & 688236 & 6.4 & 5.5945 & TRN & \\
\hline CHEMBL1504180 & 688236 & 5.0 & 5.53799 & 9999999999 & TRN \\
\hline CHEMBL1369601 & 688236 & 5.5 & 5.6066 & TRN & \\
\hline CHEMBL1463207 & 688236 & 4.9 & 5.4087 & TRN & \\
\hline CHEMBL333985 & 688236 & 4.9 & 5.4399 & TST & \\
\hline CHEMBL1328109 & 688236 & 5.8 & 5.5184 & TRN & \\
\hline CHEMBL1320129 & 688236 & 5.0 & 5.7436 & TST & \\
\hline CHEMBL1444625 & 688236 & 5.4 & 5.5801 & TRN & \\
\hline CHEMBL1529011 & 688236 & 5.1 & 5.5301 & TRN & \\
\hline CHEMBL1437164 & 688236 & 5.5 & 5.7458 & TRN & \\
\hline CHEMBL1371152 & 688236 & 4.9 & 5.5596 & TRN & \\
\hline CHEMBL10284 & 688236 & 4.7 & 5.5882 & TRN & \\
\hline CHEMBL1327825 & 688236 & 5.0 & 5.3786 & TRN & \\
\hline CHEMBL1328094 & 688236 & 5.1 & 5.58899 & 99999999995 & TST \\
\hline CHEMBL1354262 & 688236 & 5.5 & 5.7089 & TRN & \\
\hline
\end{tabular}




\begin{tabular}{|c|c|c|c|c|c|}
\hline \\
\hline CHEMBL1455614 & 688236 & 6.2 & 5.6064 & TRN & \\
\hline CHEMBL544713 & 688236 & 4.8 & 5.6375 & TST & \\
\hline CHEMBL583849 & 688236 & 6.1 & 5.5418 & TRN & \\
\hline CHEMBL1400198 & 688236 & 6.6 & 5.5098 & TRN & \\
\hline CHEMBL52030 & 688236 & 5.0 & 5.3211 & TRN & \\
\hline CHEMBL1315965 & 688236 & 6.4 & 5.7047 & TRN & \\
\hline CHEMBL 250711 & 688236 & 4.5 & 5.3885 & TRN & \\
\hline CHEMBL1437176 & 688236 & 5.5 & 5.7138 & TRN & \\
\hline CHEMBL1382813 & 688236 & 5.1 & 5.2824 & TRN & \\
\hline CHEMBL1314975 & 688236 & 4.9 & 5.7337 & TRN & \\
\hline CHEMBL1440484 & 688236 & 5.3 & 5.4522 & TRN & \\
\hline CHEMBL1465923 & 688236 & 5.1 & 5.4281 & TRN & \\
\hline CHEMBL1469327 & 688236 & 5.3 & 5.249 & TRN & \\
\hline CHEMBL1356392 & 688236 & 7.1002 & 5.4605 & TRN & \\
\hline CHEMBL1408138 & 688236 & 5.3 & 5.79299 & 9999999999 & TRN \\
\hline CHEMBL1367030 & 688236 & 5.6 & 5.3245 & TRN & \\
\hline CHEMBL 222334 & 688236 & 5.2 & 5.432 & TRN & \\
\hline CHEMBL1416814 & 688236 & 5.8 & 5.8357 & TRN & \\
\hline CHEMBL1420053 & 688236 & 5.0 & 5.3243 & TST & \\
\hline CHEMBL1395219 & 688236 & 5.4 & 5.7896 & TRN & \\
\hline CHEMBL21241 & 688236 & 5.3 & 5.54 & TST & \\
\hline CHEMBL1430891 & 688236 & 4.9 & 5.3412 & TRN & \\
\hline CHEMBL1561363 & 688236 & 5.5 & 5.7241 & TRN & \\
\hline CHEMBL1336793 & 688236 & 5.4 & 5.682 & TRN & \\
\hline CHEMBL1516080 & 688236 & 7.8013 & 5.8786 & TRN & \\
\hline CHEMBL1476851 & 688236 & 6.3 & 6.0175 & TRN & \\
\hline CHEMBL1520199 & 688236 & 5.0 & 5.3468 & TRN & \\
\hline CHEMBL1434715 & 688236 & 6.6 & 5.7886 & TRN & \\
\hline CHEMBL1555118 & 688236 & 6.1 & 5.6155 & TRN & \\
\hline CHEMBL 28140 & 688236 & 8.301 & 5.6786 & TRN & \\
\hline CHEMBL1389338 & 688236 & 5.0 & 5.3296 & TRN & \\
\hline CHEMBL1256885 & 688236 & 5.4 & 5.3539 & TRN & \\
\hline CHEMBL1372997 & 688236 & 5.0 & 5.4635 & TRN & \\
\hline CHEMBL1475750 & 688236 & 6.3 & 5.70200 & 0000000001 & TRN \\
\hline CHEMBL 1487318 & 688236 & 5.8 & 5.7108 & TRN & \\
\hline CHEMBL1256814 & 688236 & 4.9 & 5.312 & TRN & \\
\hline CHEMBL1451357 & 688236 & 6.0 & 5.7449 & TRN & \\
\hline CHEMBL1357553 & 688236 & 5.6 & 5.939 & TRN & \\
\hline CHEMBL1482342 & 688236 & 5.3 & 5.58899 & 99999999995 & TRN \\
\hline CHEMBL1548229 & 688236 & 5.4 & 5.3704 & TRN & \\
\hline CHEMBL1421463 & 688236 & 5.0 & 5.5682 & TST & \\
\hline CHEMBL1406410 & 688236 & 5.5 & 5.6545 & TRN & \\
\hline CHEMBL1611413 & 688236 & 6.0 & 5.5895 & TRN & \\
\hline CHEMBL428768 & 688236 & 6.0 & 5.3539 & TRN & \\
\hline CHEMBL1440148 & 688236 & 5.4 & 5.4125 & TRN & \\
\hline CHEMBL1380755 & 688236 & 4.9 & 5.3442 & TRN & \\
\hline CHEMBL1609790 & 688236 & 4.9 & 5.1589 & TRN & \\
\hline CHEMBL1373998 & 688236 & 5.5 & 5.5047 & TRN & \\
\hline
\end{tabular}




\begin{tabular}{|c|c|c|c|c|c|}
\hline \\
\hline CHEMBL1602568 & 688236 & 5.5 & 5.7605 & TRN & \\
\hline CHEMBL1551036 & 688236 & 6.5 & 5.5449 & TRN & \\
\hline CHEMBL1515315 & 688236 & 6.2 & 5.6505 & TRN & \\
\hline CHEMBL1397293 & 688236 & 5.9 & 5.7835 & TRN & \\
\hline CHEMBL1590270 & 688236 & 6.2 & 5.4805 & TRN & \\
\hline CHEMBL582444 & 688236 & 5.3 & 5.6994 & TRN & \\
\hline CHEMBL1338159 & 688236 & 5.5 & 5.5726 & TRN & \\
\hline CHEMBL1489044 & 688236 & 7.8013 & 5.7463 & TRN & \\
\hline CHEMBL1607443 & 688236 & 5.5 & 5.5468 & TRN & \\
\hline CHEMBL1534248 & 688236 & 6.6 & 5.5061 & TST & \\
\hline CHEMBL1476711 & 688236 & 6.0 & 5.5269 & TRN & \\
\hline CHEMBL1562864 & 688236 & 6.0 & 5.3215 & TRN & \\
\hline CHEMBL1572915 & 688236 & 5.6 & 5.6362 & TRN & \\
\hline CHEMBL1487503 & 688236 & 5.5 & 5.4781 & TST & \\
\hline CHEMBL1512122 & 688236 & 5.8 & 5.3036 & TRN & \\
\hline CHEMBL1488167 & 688236 & 6.4 & 5.4135 & TRN & \\
\hline CHEMBL1574196 & 688236 & 5.3 & 5.6718 & TRN & \\
\hline CHEMBL1515804 & 688236 & 5.4 & 5.6365 & TRN & \\
\hline CHEMBL1577300 & 688236 & 5.0 & 5.2366 & TRN & \\
\hline CHEMBL3195118 & 688236 & 5.0 & 5.4407 & TST & \\
\hline CHEMBL1304256 & 688236 & 8.0 & 5.3762 & TRN & \\
\hline CHEMBL1314956 & 688236 & 5.5 & 5.59200 & 00000000005 & TRN \\
\hline CHEMBL3197899 & 688236 & 5.0 & 5.2373 & TRN & \\
\hline CHEMBL1375431 & 688236 & 5.3 & 5.692 & TRN & \\
\hline CHEMBL1288013 & 688236 & 5.5 & 5.6882 & TST & \\
\hline CHEMBL1385808 & 688236 & 4.9 & 5.5331 & TST & \\
\hline CHEMBL1498734 & 688236 & 5.1 & 5.3273 & TRN & \\
\hline CHEMBL402468 & 688236 & 5.1 & 5.5786 & TRN & \\
\hline CHEMBL1336119 & 688236 & 5.0 & 5.6066 & TRN & \\
\hline CHEMBL1355089 & 688236 & 5.3 & 5.689 & TRN & \\
\hline CHEMBL1591600 & 688236 & 6.4 & 5.8163 & TRN & \\
\hline CHEMBL1533263 & 688236 & 5.5 & 5.3862 & TRN & \\
\hline CHEMBL3199921 & 688236 & 5.0 & 5.4339 & TRN & \\
\hline CHEMBL1554158 & 688236 & 5.3 & 5.8404 & TRN & \\
\hline CHEMBL1410039 & 688236 & 5.5 & 5.38299 & 9999999999 & TRN \\
\hline CHEMBL1493014 & 688236 & 5.2 & 5.2843 & TRN & \\
\hline CHEMBL1320206 & 688236 & 6.4 & 5.6801 & TRN & \\
\hline CHEMBL1971698 & 688236 & 5.0 & 5.3163 & TRN & \\
\hline CHEMBL1607143 & 688236 & 5.1 & 5.4845 & TRN & \\
\hline CHEMBL491547 & 688236 & 5.7 & 5.8932 & TRN & \\
\hline CHEMBL3193278 & 688236 & 5.0 & 5.3988 & TRN & \\
\hline CHEMBL1590855 & 688236 & 5.5 & 5.8189 & TRN & \\
\hline CHEMBL1558165 & 688236 & 5.1 & 5.5668 & TRN & \\
\hline CHEMBL1515526 & 688236 & 5.5 & 5.4692 & TRN & \\
\hline CHEMBL1570993 & 688236 & 5.7 & 5.3863 & TRN & \\
\hline CHEMBL1363920 & 688236 & 5.2 & 5.5425 & TRN & \\
\hline CHEMBL1341397 & 688236 & 5.0 & 5.2165 & TRN & \\
\hline CHEMBL1596698 & 688236 & 6.0 & 5.3395 & TRN & \\
\hline
\end{tabular}




\begin{tabular}{|c|c|c|c|c|c|}
\hline \multicolumn{6}{|c|}{ Supplemental Table S2.txt } \\
\hline CHEMBL309339 & 688236 & 5.4 & 5.4233 & TRN & \\
\hline CHEMBL1318276 & 688236 & 6.0 & 5.8557 & TRN & \\
\hline CHEMBL1367281 & 688236 & 4.9 & 5.6254 & TST & \\
\hline CHEMBL1408498 & 688236 & 6.2 & 5.4851 & TRN & \\
\hline CHEMBL1397406 & 688236 & 5.4 & 5.6844 & TRN & \\
\hline CHEMBL1578279 & 688236 & 5.1 & \multicolumn{2}{|c|}{5.372000000000001} & TRN \\
\hline CHEMBL23327 & 688236 & 5.0 & 5.8312 & TRN & \\
\hline CHEMBL1590645 & 688236 & 5.5 & 5.6554 & TRN & \\
\hline CHEMBL2374368 & 688236 & 5.4 & 5.6622 & TRN & \\
\hline CHEMBL1386172 & 688236 & 6.8 & 5.6003 & TRN & \\
\hline CHEMBL297784 & 688236 & 4.9 & 5.4667 & TRN & \\
\hline CHEMBL1530314 & 688236 & 6.3 & 5.5207 & TST & \\
\hline CHEMBL1612261 & 688236 & 5.7 & 5.4666 & TRN & \\
\hline CHEMBL1611496 & 688236 & 6.0 & 5.8671 & TRN & \\
\hline CHEMBL1079460 & 688236 & 4.6 & 5.6282 & TST & \\
\hline CHEMBL1348647 & 688236 & 5.1 & 5.3771 & TRN & \\
\hline CHEMBL1498117 & 688236 & 5.3 & 5.4942 & TRN & \\
\hline CHEMBL1483133 & 688236 & 5.5 & 5.8198 & TRN & \\
\hline CHEMBL16687 & 688236 & 5.3 & 5.5108 & TRN & \\
\hline CHEMBL1370296 & 688236 & 5.8 & 5.8769 & TRN & \\
\hline CHEMBL476135 & 688236 & 5.5 & 5.5992 & TST & \\
\hline CHEMBL1511046 & 688236 & 5.2 & 5.5138 & TRN & \\
\hline CHEMBL1397634 & 688236 & 5.4 & 5.5205 & TRN & \\
\hline CHEMBL1299470 & 688236 & 6.5 & 5.6642 & TRN & \\
\hline CHEMBL1354600 & 688236 & 5.5 & 5.6437 & TRN & \\
\hline CHEMBL1360151 & 688236 & 7.699 & 5.6202 & TRN & \\
\hline CHEMBL1502538 & 688236 & 5.6 & 5.4492 & TST & \\
\hline CHEMBL1310378 & 688236 & 4.9 & 5.3086 & TRN & \\
\hline CHEMBL145 & 688236 & 5.1 & 5.4045 & TRN & \\
\hline CHEMBL3392051 & 688236 & 5.6 & 5.5285 & TST & \\
\hline CHEMBL1311072 & 688236 & 6.4 & 5.3929 & TRN & \\
\hline CHEMBL1482759 & 688236 & 5.5 & 5.6376 & TRN & \\
\hline CHEMBL1315690 & 688236 & 5.5 & 5.4811 & TRN & \\
\hline CHEMBL1514090 & 688236 & 5.0 & 5.3994 & TST & \\
\hline CHEMBL1554717 & 688236 & 4.8 & 5.5366 & TRN & \\
\hline CHEMBL1528007 & 688236 & 5.0 & 5.6882 & TRN & \\
\hline CHEMBL1563566 & 688236 & 6.0 & 5.7231 & TRN & \\
\hline CHEMBL1355909 & 688236 & 5.5 & 5.6857 & TRN & \\
\hline CHEMBL1316779 & 688236 & 5.5 & 5.5785 & TRN & \\
\hline CHEMBL1256660 & 688236 & 4.6 & 5.4233 & TST & \\
\hline CHEMBL137743 & 688236 & 4.9 & 5.4443 & TRN & \\
\hline CHEMBL1547901 & 688236 & 5.0 & 5.2121 & TRN & \\
\hline CHEMBL1407527 & 688236 & 5.6 & 5.7534 & TRN & \\
\hline CHEMBL1561738 & 688236 & 5.1 & 5.3228 & TRN & \\
\hline CHEMBL471225 & 688236 & 6.2 & 5.7528 & TRN & \\
\hline CHEMBL1518237 & 688236 & 5.0 & 5.3527 & TRN & \\
\hline CHEMBL1356134 & 688236 & 5.5 & 5.57100 & 0000000001 & TRN \\
\hline CHEMBL164269 & 688236 & 5.5 & 5.8038 & TST & \\
\hline
\end{tabular}




\begin{tabular}{|c|c|c|c|c|c|}
\hline \multirow[b]{2}{*}{ CHEMBL1376696 } & \multirow[b]{2}{*}{688236} & \\
\hline & & 5.0 & 5.1448 & TRN & \\
\hline CHEMBL1330357 & 688236 & 4.8 & 5.4673 & TST & \\
\hline CHEMBL1515635 & 688236 & 5.5 & 5.6485 & TRN & \\
\hline CHEMBL1352377 & 688236 & 6.1 & 5.5497 & TRN & \\
\hline CHEMBL1552542 & 688236 & 5.5 & 5.6366 & TRN & \\
\hline CHEMBL1570413 & 688236 & 5.8 & 5.7811 & TRN & \\
\hline CHEMBL1327989 & 688236 & 5.5 & 5.6737 & TRN & \\
\hline CHEMBL1301473 & 688236 & 5.4 & \multicolumn{2}{|c|}{5.406000000000001} & TRN \\
\hline CHEMBL1603418 & 688236 & 5.6 & 5.9838 & TRN & \\
\hline CHEMBL363332 & 688236 & 5.3 & 5.5203 & TRN & \\
\hline CHEMBL1487323 & 688236 & 4.9 & 5.4362 & TRN & \\
\hline CHEMBL1491288 & 688236 & 5.2 & 5.4078 & TRN & \\
\hline CHEMBL1515410 & 688236 & 5.9 & 5.5535 & TRN & \\
\hline CHEMBL1490528 & 688236 & 5.5 & 5.5985 & TRN & \\
\hline CHEMBL1372650 & 688236 & 5.5 & 5.2208 & TRN & \\
\hline CHEMBL1552353 & 688236 & 5.6 & 5.5636 & TRN & \\
\hline CHEMBL1316980 & 688236 & 5.9 & 5.6758 & TRN & \\
\hline CHEMBL1444339 & 688236 & 4.9 & 5.3903 & TRN & \\
\hline CHEMBL1414867 & 688236 & 5.6 & 5.3932 & TRN & \\
\hline CHEMBL1511034 & 688236 & 5.6 & 5.8342 & TST & \\
\hline CHEMBL1593545 & 688236 & 5.5 & 5.8038 & TST & \\
\hline CHEMBL1398185 & 688236 & 5.6 & 5.6352 & TST & \\
\hline CHEMBL1320662 & 688236 & 6.3 & 5.6786 & TST & \\
\hline CHEMBL1365983 & 688236 & 5.5 & 5.4942 & TST & \\
\hline CHEMBL1355762 & 688236 & 5.1 & 5.5366 & TST & \\
\hline CHEMBL1593056 & 688236 & 5.5 & 5.6135 & TST & \\
\hline CHEMBL1355537 & 688236 & 6.2 & 5.5406 & TST & \\
\hline CHEMBL190259 & 688236 & 7.4001 & 5.5954 & TST & \\
\hline CHEMBL1561148 & 688236 & 7.0 & \multicolumn{2}{|c|}{5.5489999999999995} & TST \\
\hline CHEMBL1352733 & 688236 & 5.2 & 5.3173 & TST & \\
\hline CHEMBL3304020 & 688236 & 6.1 & 5.6358 & TST & \\
\hline CHEMBL1476288 & 688236 & 5.5 & 5.5996 & TST & \\
\hline CHEMBL1334162 & 688236 & 5.3 & 5.3561 & TST & \\
\hline CHEMBL1489424 & 688236 & 6.6 & \multicolumn{2}{|c|}{5.5489999999999995} & TST \\
\hline CHEMBL1466877 & 688236 & 6.1 & 5.5997 & TST & \\
\hline CHEMBL1315316 & 688236 & 5.9 & 5.5107 & TST & \\
\hline CHEMBL1493388 & 688236 & 8.0 & 5.6422 & TST & \\
\hline CHEMBL1567032 & 688236 & 5.7 & \multicolumn{2}{|c|}{5.547999999999999} & TST \\
\hline CHEMBL14276 & 688236 & 5.4 & 5.7538 & TST & \\
\hline CHEMBL1403793 & 688236 & 5.4 & 5.7679 & TST & \\
\hline CHEMBL1322545 & 688236 & 5.9 & 5.763 & TST & \\
\hline CHEMBL1332182 & 688236 & 5.2 & 5.6241 & TST & \\
\hline CHEMBL1586241 & 688236 & 4.9 & 5.4244 & TST & \\
\hline CHEMBL1493585 & 688236 & 5.6 & 5.3862 & TST & \\
\hline CHEMBL44 & 688236 & 5.3 & 5.5622 & TST & \\
\hline CHEMBL1402241 & 688236 & 5.8 & 5.6493 & TST & \\
\hline CHEMBL1566105 & 688236 & 5.3 & 5.5096 & TST & \\
\hline \multirow[t]{2}{*}{ CHEMBL1512701 } & 688236 & 5.3 & 5.6567 & TST & \\
\hline & & \multicolumn{4}{|c|}{ Page 5925} \\
\hline
\end{tabular}




\begin{tabular}{|c|c|c|c|c|c|}
\hline \\
\hline CHEMBL1256291 & 688236 & 5.3 & 5.3857 & TST & \\
\hline CHEMBL1383144 & 688236 & 5.5 & 5.347 & TST & \\
\hline CHEMBL1442458 & 688236 & 5.5 & 5.6894 & TST & \\
\hline CHEMBL1316709 & 688236 & 6.1 & 5.8348 & TST & \\
\hline CHEMBL63154 & 688236 & 4.6 & 5.5543 & TST & \\
\hline CHEMBL1492000 & 688236 & 5.0 & 5.6147 & TST & \\
\hline CHEMBL3212171 & 688236 & 5.6 & 5.3535 & TST & \\
\hline CHEMBL1256735 & 688236 & 4.9 & 5.5415 & TST & \\
\hline CHEMBL1553218 & 688236 & 5.4 & 5.7783 & TST & \\
\hline CHEMBL1718952 & 688236 & 5.5 & 5.5405 & TST & \\
\hline CHEMBL1369825 & 688236 & 5.4 & 5.5593 & TST & \\
\hline CHEMBL1335967 & 688236 & 5.5 & 5.6655 & TST & \\
\hline CHEMBL1611619 & 688236 & 5.4 & 5.3758 & TST & \\
\hline CHEMBL1590321 & 688236 & 5.6 & 5.9254 & TST & \\
\hline CHEMBL18132 & 688236 & 4.5 & 5.6227 & TST & \\
\hline CHEMBL 389390 & 688236 & 6.1 & 5.7481 & TST & \\
\hline CHEMBL1399561 & 688236 & 5.5 & 5.7115 & TST & \\
\hline CHEMBL1355203 & 688236 & 5.5 & 5.7668 & TST & \\
\hline CHEMBL1367665 & 688236 & 4.9 & 5.5175 & TST & \\
\hline CHEMBL269733 & 688236 & 5.0 & 5.465 & TST & \\
\hline CHEMBL559612 & 688236 & 4.5 & 5.5473 & TST & \\
\hline CHEMBL1324032 & 688236 & 6.3 & 5.7685 & TST & \\
\hline CHEMBL1370644 & 688236 & 5.5 & 5.50899 & 99999999995 & TST \\
\hline CHEMBL1515858 & 688236 & 5.4 & 5.6752 & TST & \\
\hline CHEMBL1591581 & 688236 & 7.5003 & 5.5393 & TST & \\
\hline CHEMBL1512605 & 688236 & 5.2 & 5.33799 & 9999999999 & TST \\
\hline CHEMBL1301935 & 688236 & 5.0 & 5.4637 & TST & \\
\hline CHEMBL1518035 & 688236 & 5.5 & 5.449 & TST & \\
\hline CHEMBL1472732 & 688236 & 5.5 & 5.6072 & TST & \\
\hline CHEMBL1310585 & 688236 & 5.9 & 5.3533 & TST & \\
\hline CHEMBL1375314 & 688236 & 5.1 & 5.2704 & TST & \\
\hline CHEMBL1443628 & 688236 & 5.5 & 5.5227 & TST & \\
\hline CHEMBL1497316 & 688236 & 5.1 & 5.4552 & TST & \\
\hline CHEMBL1414842 & 688236 & 5.0 & 5.3544 & TST & \\
\hline CHEMBL1368286 & 688236 & 6.2 & 5.4578 & TST & \\
\hline CHEMBL24510 & 688236 & 6.0 & 5.5492 & TST & \\
\hline CHEMBL1440100 & 688236 & 5.0 & 5.3025 & TST & \\
\hline CHEMBL1465394 & 688236 & 5.0 & 5.3719 & TST & \\
\hline CHEMBL1409720 & 688236 & 6.6 & 5.4818 & TST & \\
\hline CHEMBL1450455 & 688236 & 5.5 & 5.4737 & TST & \\
\hline CHEMBL1369009 & 688236 & 7.3002 & 5.5897 & TST & \\
\hline CHEMBL1513633 & 688236 & 5.6 & 5.6717 & TST & \\
\hline CHEMBL1464354 & 688236 & 5.4 & 5.4521 & TST & \\
\hline CHEMBL1575588 & 688236 & 6.3 & 5.7843 & TST & \\
\hline CHEMBL1437990 & 688236 & 7.0 & 5.5576 & TST & \\
\hline CHEMBL1420083 & 688236 & 5.0 & 5.206 & TST & \\
\hline CHEMBL1422573 & 688236 & 5.1 & 5.5191 & TST & \\
\hline CHEMBL1415465 & 688236 & 5.5 & 5.6678 & TST & \\
\hline
\end{tabular}




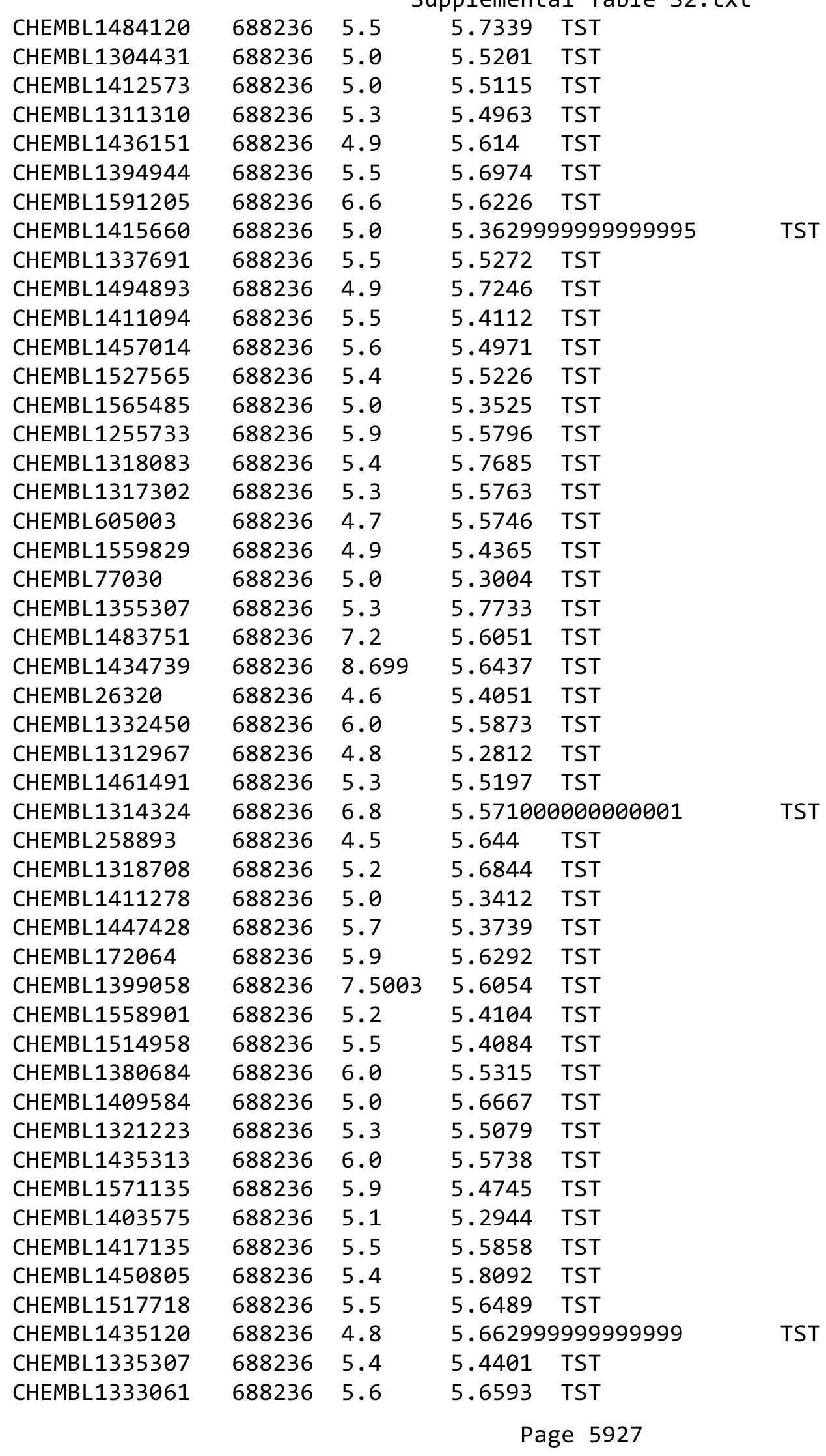




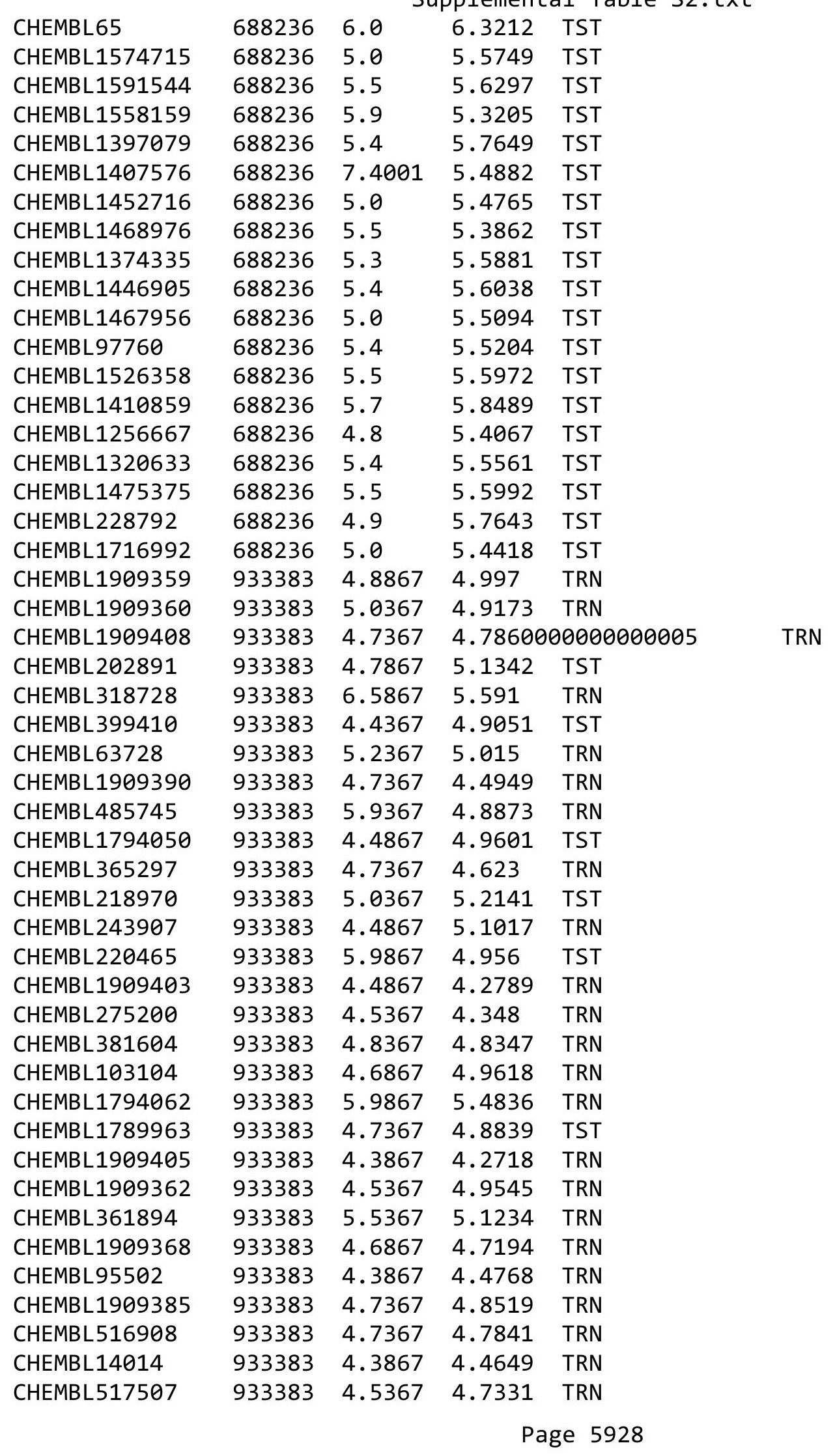


Supplemental Table S2.txt

\begin{tabular}{|c|c|c|c|c|}
\hline CHEMBL218932 & 933383 & 4.5367 & 5.1153 & TST \\
\hline CHEMBL188426 & 933383 & 4.8367 & 4.7067 & TRN \\
\hline CHEMBL157258 & 933383 & 4.4867 & 5.0516 & TRN \\
\hline CHEMBL 234838 & 933383 & 6.0867 & 4.9811 & TST \\
\hline CHEMBL192417 & 933383 & 6.2366 & 5.5328 & TRN \\
\hline CHEMBL102936 & 933383 & 4.6867 & 4.677 & TRN \\
\hline CHEMBL407113 & 933383 & 4.6867 & 4.7153 & TRN \\
\hline CHEMBL 397570 & 933383 & 6.0367 & 4.7988 & TST \\
\hline CHEMBL529066 & 933383 & 4.6867 & 4.7312 & TRN \\
\hline CHEMBL409892 & 933383 & 4.5367 & 4.9256 & TRN \\
\hline CHEMBL1909381 & 933383 & 5.8367 & 5.3129 & TRN \\
\hline CHEMBL 275724 & 933383 & 4.5367 & 4.4554 & TRN \\
\hline CHEMBL 215993 & 933383 & 4.5367 & 4.9696 & TRN \\
\hline CHEMBL1794053 & 933383 & 4.5367 & 4.8024 & TST \\
\hline CHEMBL 206010 & 933383 & 5.2367 & 5.0573 & TRN \\
\hline CHEMBL408732 & 933383 & 5.6367 & 4.7212 & TRN \\
\hline CHEMBL1909371 & 933383 & 4.8367 & 5.2879 & TRN \\
\hline CHEMBL 273611 & 933383 & 4.4867 & 4.3631 & TRN \\
\hline CHEMBL176553 & 933383 & 5.1867 & 5.4432 & TRN \\
\hline CHEMBL65884 & 933383 & 4.4867 & 4.8985 & TRN \\
\hline CHEMBL1794058 & 933383 & 4.7867 & 5.1235 & TRN \\
\hline CHEMBL 274064 & 933383 & 4.6367 & 4.4591 & TRN \\
\hline CHEMBL1794052 & 933383 & 4.6867 & 5.0063 & TST \\
\hline CHEMBL434729 & 933383 & 4.3867 & 4.8839 & TRN \\
\hline CHEMBL458865 & 933383 & 4.5867 & 4.6301 & TST \\
\hline CHEMBL230911 & 933383 & 4.3867 & 5.2939 & TST \\
\hline CHEMBL 251549 & 933383 & 4.8867 & 5.1872 & TRN \\
\hline CHEMBL 270054 & 933383 & 4.3867 & 4.76399 & 9999999999 \\
\hline CHEMBL263796 & 933383 & 4.7867 & 5.1879 & TST \\
\hline CHEMBL1794059 & 933383 & 4.7367 & 5.0865 & TRN \\
\hline CHEMBL 233001 & 933383 & 4.7367 & 5.0448 & TST \\
\hline CHEMBL359963 & 933383 & 4.6867 & 5.0732 & TRN \\
\hline CHEMBL1794061 & 933383 & 5.9867 & 5.4689 & TRN \\
\hline CHEMBL175321 & 933383 & 5.2867 & 5.0663 & TRN \\
\hline CHEMBL507329 & 933383 & 4.6867 & 4.5289 & TRN \\
\hline CHEMBL419903 & 933383 & 4.7867 & 4.5715 & TRN \\
\hline CHEMBL1909414 & 933383 & 4.8367 & 4.6433 & TST \\
\hline CHEMBL189353 & 933383 & 6.2366 & 5.0343 & TRN \\
\hline CHEMBL65945 & 933383 & 4.5367 & 5.0473 & TRN \\
\hline CHEMBL1909388 & 933383 & 4.6867 & 4.816 & TRN \\
\hline CHEMBL417804 & 933383 & 4.4367 & 4.5348 & TRN \\
\hline CHEMBL 237347 & 933383 & 4.3867 & 4.9861 & TST \\
\hline CHEMBL1909394 & 933383 & 4.6867 & 4.489 & TRN \\
\hline CHEMBL156263 & 933383 & 4.4367 & 5.2421 & TRN \\
\hline CHEMBL410072 & 933383 & 4.3867 & 4.6816 & TRN \\
\hline CHEMBL1909369 & 933383 & 4.8867 & 4.8197 & TRN \\
\hline CHEMBL405021 & 933383 & 4.7367 & 4.91 & TRN \\
\hline CHEMBL1794056 & 933383 & 4.7367 & 5.0718 & TRN \\
\hline
\end{tabular}


Supplemental Table S2.txt

\begin{tabular}{|c|c|c|c|c|}
\hline CHEMBL468963 & 933383 & 5.4367 & 4.8365 & TRN \\
\hline CHEMBL1909379 & 933383 & 4.7867 & 5.0276 & TRN \\
\hline CHEMBL 373073 & 933383 & 5.1867 & 5.1249 & TRN \\
\hline CHEMBL188381 & 933383 & 4.7367 & 4.9791 & TRN \\
\hline CHEMBL 268885 & 933383 & 4.5367 & 4.7786 & TST \\
\hline CHEMBL495902 & 933383 & 4.7367 & 4.6788 & TRN \\
\hline CHEMBL1909361 & 933383 & 4.6867 & 4.9184 & TRN \\
\hline CHEMBL346551 & 933383 & 4.4867 & 5.3847 & TRN \\
\hline CHEMBL1909392 & 933383 & 4.6867 & 4.7856 & TRN \\
\hline CHEMBL531804 & 933383 & 4.7867 & 4.9662 & TRN \\
\hline CHEMBL156524 & 933383 & 5.1867 & 4.8572 & TST \\
\hline CHEMBL 204934 & 933383 & 4.7867 & 5.1222 & TRN \\
\hline CHEMBL260417 & 933383 & 4.6867 & 4.65300 & 00000000005 \\
\hline CHEMBL581096 & 933383 & 4.6867 & 5.0476 & TST \\
\hline CHEMBL330422 & 933383 & 4.4367 & 4.3143 & TRN \\
\hline CHEMBL1909386 & 933383 & 4.8867 & 4.8517 & TRN \\
\hline CHEMBL385426 & 933383 & 4.4367 & 5.1846 & TST \\
\hline CHEMBL1794057 & 933383 & 5.3867 & 5.0419 & TRN \\
\hline CHEMBL306865 & 933383 & 5.1867 & 5.1462 & TRN \\
\hline CHEMBL1909351 & 933383 & 4.9367 & 4.7504 & TRN \\
\hline CHEMBL405042 & 933383 & 5.4367 & 5.0903 & TRN \\
\hline CHEMBL517171 & 933383 & 6.5367 & 4.5715 & TST \\
\hline CHEMBL441702 & 933383 & 4.3867 & 4.9536 & TRN \\
\hline CHEMBL66004 & 933383 & 5.4367 & 4.989 & TST \\
\hline CHEMBL485598 & 933383 & 4.3867 & 4.449 & TRN \\
\hline CHEMBL1516890 & 933383 & 4.8367 & 5.1523 & TST \\
\hline CHEMBL1794060 & 933383 & 5.2367 & 5.4504 & TRN \\
\hline CHEMBL 275168 & 933383 & 4.7867 & 4.3091 & TRN \\
\hline CHEMBL1909366 & 933383 & 4.7867 & 4.7933 & TRN \\
\hline CHEMBL182283 & 933383 & 4.7367 & 4.8872 & TRN \\
\hline CHEMBL1909382 & 933383 & 6.1367 & 5.278 & TRN \\
\hline CHEMBL181361 & 933383 & 4.4867 & 5.2042 & TST \\
\hline CHEMBL66292 & 933383 & 4.7367 & 5.0565 & TST \\
\hline CHEMBL176857 & 933383 & 4.3867 & 5.0024 & TST \\
\hline CHEMBL408564 & 933383 & 4.6867 & 4.8331 & TRN \\
\hline CHEMBL14212 & 933383 & 4.3367 & 4.4655 & TRN \\
\hline CHEMBL1909393 & 933383 & 4.8367 & 4.6735 & TRN \\
\hline CHEMBL479079 & 933383 & 4.7367 & 5.0478 & TRN \\
\hline CHEMBL38425 & 933383 & 4.3867 & 4.6 & TST \\
\hline CHEMBL479038 & 933383 & 5.0367 & 4.9327 & TRN \\
\hline CHEMBL1909352 & 933383 & 4.5367 & 4.9601 & TST \\
\hline CHEMBL1909364 & 933383 & 4.6867 & 5.0569 & TRN \\
\hline CHEMBL 261440 & 933383 & 4.7867 & 4.4633 & TRN \\
\hline CHEMBL517666 & 933383 & 4.7367 & 4.7849 & TRN \\
\hline CHEMBL103080 & 933383 & 4.6867 & 4.7989 & TRN \\
\hline CHEMBL1909373 & 933383 & 6.9367 & 5.2449 & TRN \\
\hline CHEMBL 270164 & 933383 & 4.3867 & 4.9802 & TRN \\
\hline CHEMBL495771 & 933383 & 5.3367 & 4.9727 & TRN \\
\hline
\end{tabular}


Supplemental Table S2.txt

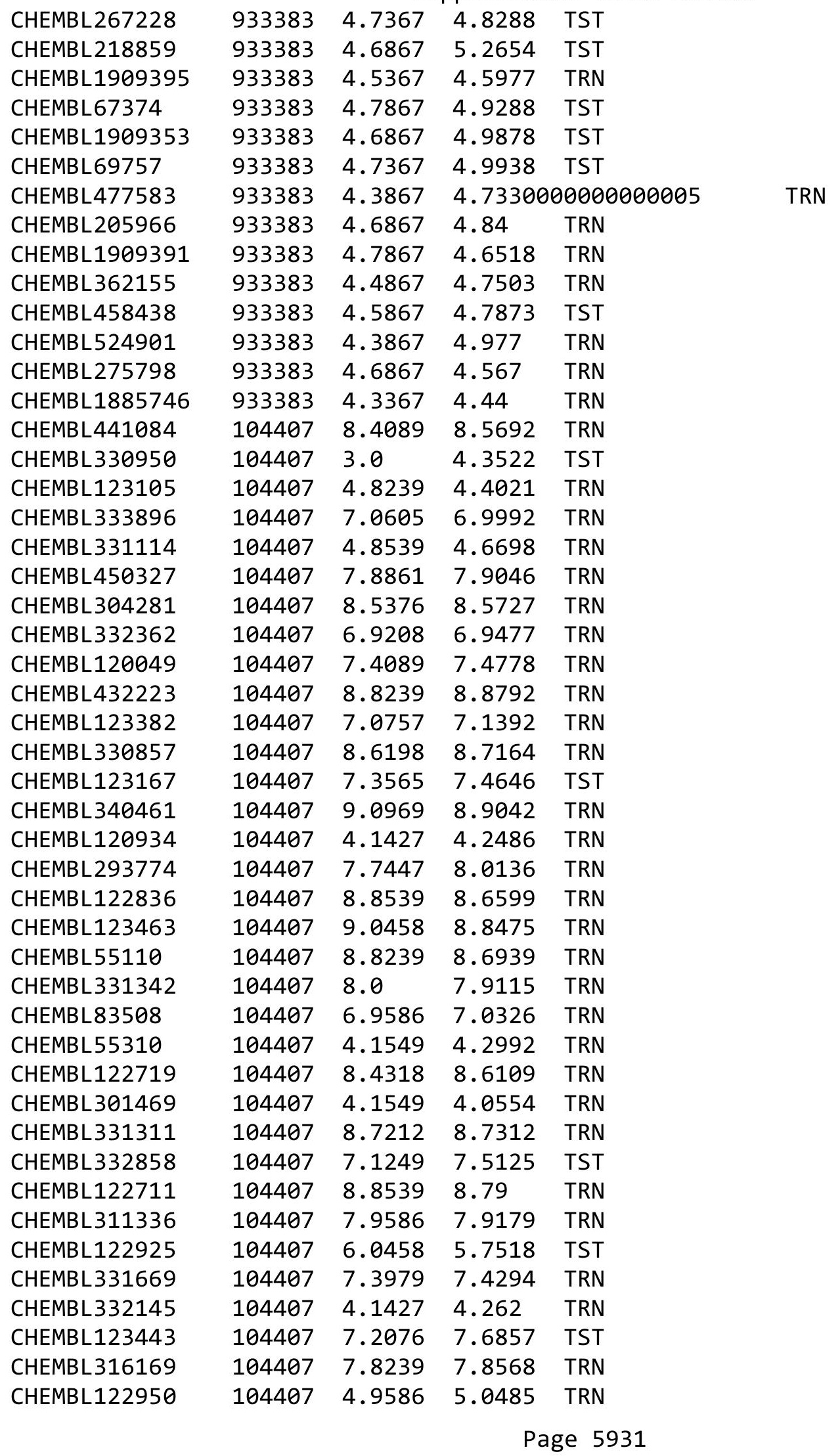




\begin{tabular}{|c|c|c|c|c|}
\hline \multicolumn{5}{|c|}{ Supplemental Table S2.txt } \\
\hline CHEMBL122109 & 104407 & 4.8539 & 5.5623 & TST \\
\hline CHEMBL121501 & 104407 & 4.4202 & 5.119 & TST \\
\hline CHEMBL440714 & 104407 & 7.9208 & 7.9549 & TRN \\
\hline CHEMBL124237 & 104407 & 3.0 & 4.3608 & TST \\
\hline CHEMBL332429 & 104407 & 7.1612 & 7.6013 & TST \\
\hline CHEMBL122831 & 104407 & 8.4318 & 8.654 & TRN \\
\hline CHEMBL262676 & 104407 & 8.8239 & 8.7311 & TRN \\
\hline CHEMBL332120 & 104407 & 7.8239 & 8.13 & TRN \\
\hline CHEMBL121559 & 104407 & 4.1135 & 3.99 & TRN \\
\hline CHEMBL123233 & 104407 & 5.0458 & 5.103 & TRN \\
\hline CHEMBL331308 & 104407 & 3.0 & 4.958 & TST \\
\hline CHEMBL121592 & 104407 & 4.6383 & 4.873 & TRN \\
\hline CHEMBL123404 & 104407 & 4.1871 & 4.2064 & TRN \\
\hline CHEMBL333532 & 104407 & 7.0458 & 6.8601 & TRN \\
\hline CHEMBL121729 & 104407 & 4.6778 & 4.5573 & TRN \\
\hline CHEMBL123775 & 104407 & 9.1549 & 8.9807 & TRN \\
\hline CHEMBL122868 & 104407 & 4.8539 & 4.9551 & TRN \\
\hline CHEMBL122651 & 104407 & 7.8239 & 7.8434 & TRN \\
\hline CHEMBL 82868 & 104407 & 7.7447 & 7.7083 & TRN \\
\hline CHEMBL333122 & 104407 & 4.1367 & 5.3834 & TST \\
\hline CHEMBL332406 & 104407 & 7.3872 & 7.4641 & TRN \\
\hline CHEMBL293503 & 104407 & 9.1549 & 8.9826 & TRN \\
\hline CHEMBL332439 & 104407 & 4.7212 & 5.4947 & TST \\
\hline CHEMBL123041 & 104407 & 8.4949 & 8.6269 & TRN \\
\hline CHEMBL121916 & 104407 & 7.0862 & 7.0613 & TRN \\
\hline CHEMBL333248 & 104407 & 7.1805 & 7.5991 & TST \\
\hline CHEMBL332755 & 104407 & 9.0969 & 8.9179 & TRN \\
\hline CHEMBL98328 & 104407 & 6.0 & 4.824 & TST \\
\hline CHEMBL306726 & 104407 & 9.0969 & 8.7756 & TST \\
\hline CHEMBL123064 & 104407 & 4.6778 & 4.8553 & TST \\
\hline CHEMBL145991 & 91747 & 4.0 & 4.3608 & TRN \\
\hline CHEMBL436408 & 91747 & 4.0 & 4.6289 & TST \\
\hline CHEMBL357869 & 91747 & 4.9101 & 4.1619 & TRN \\
\hline CHEMBL358496 & 91747 & 4.0 & 3.9203 & TRN \\
\hline CHEMBL342308 & 91747 & 5.8539 & 5.6536 & TRN \\
\hline CHEMBL149767 & 91747 & 4.0 & 2.9156 & TST \\
\hline CHEMBL145900 & 91747 & 4.0 & 3.8311 & TST \\
\hline CHEMBL357802 & 91747 & 4.0 & 3.8701 & TRN \\
\hline CHEMBL440175 & 91747 & 4.0 & 4.0162 & TST \\
\hline CHEMBL357480 & 91747 & 4.0 & 3.8115 & TST \\
\hline CHEMBL146662 & 91747 & 4.0 & 4.3048 & TRN \\
\hline CHEMBL148717 & 91747 & 5.1135 & 4.3818 & TST \\
\hline CHEMBL146698 & 91747 & 5.4437 & 5.1757 & TRN \\
\hline CHEMBL147813 & 91747 & 5.3468 & 5.5983 & TRN \\
\hline CHEMBL145858 & 91747 & 5.4318 & 5.5983 & TRN \\
\hline CHEMBL422658 & 91747 & 4.9547 & 4.9126 & TRN \\
\hline CHEMBL439992 & 91747 & 4.0 & 4.2779 & TRN \\
\hline CHEMBL346400 & 91747 & 4.0 & 3.699 & TRN \\
\hline
\end{tabular}




\begin{tabular}{|c|c|c|c|c|c|}
\hline \\
\hline CHEMBL356617 & 91747 & 4.0 & 4.2785 & TRN & \\
\hline CHEMBL357481 & 91747 & 4.0 & 4.1132 & TRN & \\
\hline CHEMBL146543 & 91747 & 4.0 & 4.7993 & TST & \\
\hline CHEMBL147701 & 91747 & 5.3872 & 5.1757 & TRN & \\
\hline CHEMBL148554 & 91747 & 5.3872 & 5.146 & TRN & \\
\hline CHEMBL146040 & 91747 & 4.0 & 5.1547 & TST & \\
\hline CHEMBL145993 & 91747 & 5.0088 & 4.3008 & TST & \\
\hline CHEMBL149840 & 91747 & 5.2147 & 5.1465 & TRN & \\
\hline CHEMBL146041 & 91747 & 6.0 & 5.4162 & TRN & \\
\hline CHEMBL150186 & 91747 & 4.8861 & 4.5 & TRN & \\
\hline CHEMBL356795 & 91747 & 5.0269 & 5.1555 & TRN & \\
\hline CHEMBL149946 & 91747 & 4.0 & 4.35 & TRN & \\
\hline CHEMBL146337 & 91747 & 4.9393 & 3.7934 & TST & \\
\hline CHEMBL357980 & 91747 & 4.9245 & 4.9972 & TRN & \\
\hline CHEMBL150051 & 91747 & 5.4202 & 4.9492 & TRN & \\
\hline CHEMBL 2112019 & 91747 & 4.9355 & 4.9731 & TST & \\
\hline CHEMBL149386 & 91747 & 4.0 & 3.904 & TRN & \\
\hline CHEMBL148790 & 91747 & 4.0 & 4.1068 & TRN & \\
\hline CHEMBL148782 & 91747 & 4.0 & 4.0983 & TRN & \\
\hline CHEMBL148897 & 91747 & 5.3279 & 5.6363 & TRN & \\
\hline CHEMBL150108 & 91747 & 4.0 & 4.5152 & TRN & \\
\hline CHEMBL147874 & 91747 & 5.1871 & 4.95100 & 00000000005 & TRN \\
\hline CHEMBL146463 & 91747 & 5.2757 & 5.3341 & TRN & \\
\hline CHEMBL149885 & 91747 & 4.0 & 4.7993 & TST & \\
\hline CHEMBL148696 & 91747 & 4.8827 & 4.7416 & TRN & \\
\hline CHEMBL147229 & 91747 & 4.0 & 3.9215 & TRN & \\
\hline CHEMBL148362 & 91747 & 4.9245 & 4.926 & TRN & \\
\hline CHEMBL146261 & 91747 & 4.0 & 4.0121 & TRN & \\
\hline CHEMBL150171 & 91747 & 4.0 & 4.7097 & TRN & \\
\hline CHEMBL355963 & 91747 & 4.0 & 3.9986 & TRN & \\
\hline CHEMBL149899 & 91747 & 4.0 & 3.6643 & TST & \\
\hline CHEMBL359036 & 91747 & 5.6021 & 5.7709 & TRN & \\
\hline CHEMBL1446560 & 737357 & 2.585 & 2.8057 & TRN & \\
\hline CHEMBL1467309 & 737357 & 2.585 & 3.2875 & TRN & \\
\hline CHEMBL1703819 & 737357 & 2.585 & 2.7992 & TST & \\
\hline CHEMBL1412954 & 737357 & 4.3288 & 2.9876 & TRN & \\
\hline CHEMBL1578341 & 737357 & 5.4773 & 3.8086 & TRN & \\
\hline CHEMBL1371491 & 737357 & 2.585 & 3.3405 & TRN & \\
\hline CHEMBL1600836 & 737357 & 2.585 & 3.1251 & TRN & \\
\hline CHEMBL1328569 & 737357 & 2.585 & 3.5154 & TRN & \\
\hline CHEMBL1339303 & 737357 & 5.0432 & 3.5094 & TRN & \\
\hline CHEMBL1421199 & 737357 & 2.585 & 3.6716 & TRN & \\
\hline CHEMBL3192833 & 737357 & 2.585 & 3.1926 & TRN & \\
\hline CHEMBL1984179 & 737357 & 2.585 & 3.4705 & TRN & \\
\hline CHEMBL1455208 & 737357 & 2.585 & 2.87399 & 99999999997 & TRN \\
\hline CHEMBL1470562 & 737357 & 2.585 & 4.056 & TRN & \\
\hline CHEMBL1497119 & 737357 & 4.3727 & 3.4341 & TRN & \\
\hline CHEMBL1405075 & 737357 & 2.585 & 3.2797 & TRN & \\
\hline
\end{tabular}




\begin{tabular}{|c|c|c|c|c|c|}
\hline & & \multicolumn{4}{|c|}{ Supplemental Table S2.txt } \\
\hline CHEMBL1467484 & 737357 & 2.585 & 3.467 & TRN & \\
\hline CHEMBL1509648 & 737357 & 3.6415 & 3.8109 & TRN & \\
\hline CHEMBL1309794 & 737357 & 2.585 & 2.7806 & TRN & \\
\hline CHEMBL1610796 & 737357 & 2.585 & 2.9118 & TST & \\
\hline CHEMBL1429606 & 737357 & 5.0919 & 3.1805 & TRN & \\
\hline CHEMBL1515801 & 737357 & 2.585 & 3.2891 & TRN & \\
\hline CHEMBL1538601 & 737357 & 2.585 & 3.3842 & TST & \\
\hline CHEMBL1442166 & 737357 & 2.585 & 3.2529 & TRN & \\
\hline CHEMBL1459341 & 737357 & 2.585 & 3.1665 & TRN & \\
\hline CHEMBL1411871 & 737357 & 2.585 & 3.0217 & TRN & \\
\hline CHEMBL1405957 & 737357 & 5.3265 & 2.9504 & TRN & \\
\hline CHEMBL1469517 & 737357 & 4.4666 & 3.2687 & TRN & \\
\hline CHEMBL1446821 & 737357 & 2.585 & 3.1866 & TRN & \\
\hline CHEMBL1410337 & 737357 & 2.585 & 2.9447 & TRN & \\
\hline CHEMBL1530922 & 737357 & 4.449 & 2.7879 & TRN & \\
\hline CHEMBL1584954 & 737357 & 3.8821 & 3.6121 & TRN & \\
\hline CHEMBL1560341 & 737357 & 4.777 & 3.4198 & TRN & \\
\hline CHEMBL1568761 & 737357 & 2.585 & 2.9063 & TRN & \\
\hline CHEMBL1405835 & 737357 & 2.585 & 3.0558 & TRN & \\
\hline CHEMBL1605052 & 737357 & 2.585 & 2.8173 & TRN & \\
\hline CHEMBL1468876 & 737357 & 2.585 & 3.2168 & TRN & \\
\hline CHEMBL1384091 & 737357 & 2.585 & 2.6803 & TRN & \\
\hline CHEMBL1595088 & 737357 & 2.585 & 3.75399 & 99999999996 & TRN \\
\hline CHEMBL1707652 & 737357 & 2.585 & 3.1448 & TRN & \\
\hline CHEMBL1985705 & 737357 & 2.585 & 3.1995 & TRN & \\
\hline CHEMBL1492967 & 737357 & 2.585 & 3.2127 & TRN & \\
\hline CHEMBL1530097 & 737357 & 4.1262 & 4.158 & TRN & \\
\hline CHEMBL1704918 & 737357 & 4.2052 & 2.7437 & TRN & \\
\hline CHEMBL1456624 & 737357 & 3.7878 & 3.2904 & TRN & \\
\hline CHEMBL1398673 & 737357 & 2.585 & 2.8211 & TRN & \\
\hline CHEMBL1363439 & 737357 & 2.585 & 3.0395 & TRN & \\
\hline CHEMBL1327717 & 737357 & 3.9045 & 3.7102 & TRN & \\
\hline CHEMBL3212519 & 737357 & 5.5525 & 3.6405 & TRN & \\
\hline CHEMBL1500746 & 737357 & 2.585 & 2.9222 & TRN & \\
\hline CHEMBL45007 & 737357 & 2.585 & 2.69199 & 99999999997 & TRN \\
\hline CHEMBL1557144 & 737357 & 2.585 & 2.5989 & TRN & \\
\hline CHEMBL1542755 & 737357 & 2.585 & 3.16300 & 00000000003 & TRN \\
\hline CHEMBL1388764 & 737357 & 2.585 & 3.6572 & TRN & \\
\hline CHEMBL1579126 & 737357 & 2.585 & 3.2769 & TRN & \\
\hline CHEMBL1550185 & 737357 & 2.585 & 2.83 & TRN & \\
\hline CHEMBL1361740 & 737357 & 5.5372 & 4.747 & TRN & \\
\hline CHEMBL1491626 & 737357 & 2.585 & 3.7089 & TRN & \\
\hline CHEMBL1540177 & 737357 & 2.585 & 3.0508 & TRN & \\
\hline CHEMBL1400717 & 737357 & 2.585 & 3.2382 & TST & \\
\hline CHEMBL1390836 & 737357 & 2.585 & 3.3424 & TRN & \\
\hline CHEMBL1456739 & 737357 & 2.585 & 2.3913 & TRN & \\
\hline CHEMBL1363127 & 737357 & 2.585 & 3.3623 & TRN & \\
\hline CHEMBL1492274 & 737357 & 4.9322 & 3.2807 & TRN & \\
\hline
\end{tabular}




\begin{tabular}{|c|c|c|c|c|c|}
\hline \multirow[b]{2}{*}{ CHEMBL 2000342} & \multicolumn{5}{|c|}{ Supplemental Table S2.txt } \\
\hline & 737357 & 4.7951 & 3.2702 & TST & \\
\hline CHEMBL1462274 & 737357 & 2.585 & 3.0142 & TRN & \\
\hline CHEMBL3194505 & 737357 & 2.585 & 3.54 & TST & \\
\hline CHEMBL3208299 & 737357 & 2.585 & 3.1039 & TRN & \\
\hline CHEMBL1580566 & 737357 & 2.585 & 2.87899 & 99999999996 & TRN \\
\hline CHEMBL1527007 & 737357 & 2.585 & 3.1754 & TRN & \\
\hline CHEMBL1402363 & 737357 & 2.585 & 2.9254 & TRN & \\
\hline CHEMBL1735809 & 737357 & 2.585 & 3.6279 & TST & \\
\hline CHEMBL1366189 & 737357 & 4.2507 & 2.8057 & TRN & \\
\hline CHEMBL1557405 & 737357 & 2.585 & 2.6939 & TRN & \\
\hline CHEMBL1598716 & 737357 & 2.585 & 3.3133 & TRN & \\
\hline CHEMBL1494692 & 737357 & 2.585 & 2.7241 & TRN & \\
\hline CHEMBL1339270 & 737357 & 5.3393 & 4.4005 & TRN & \\
\hline CHEMBL1416858 & 737357 & 2.585 & 3.049 & TRN & \\
\hline CHEMBL1338100 & 737357 & 2.585 & 3.5787 & TRN & \\
\hline CHEMBL1983075 & 737357 & 2.585 & 3.61899 & 99999999998 & TRN \\
\hline CHEMBL1515661 & 737357 & 2.585 & 3.0581 & TRN & \\
\hline CHEMBL1363040 & 737357 & 2.585 & 3.1798 & TRN & \\
\hline CHEMBL1735995 & 737357 & 2.585 & 2.9502 & TRN & \\
\hline CHEMBL1410332 & 737357 & 2.585 & 3.0339 & TRN & \\
\hline CHEMBL1328161 & 737357 & 2.585 & 3.404 & TRN & \\
\hline CHEMBL1534498 & 737357 & 2.585 & 3.40100 & 00000000002 & TRN \\
\hline CHEMBL1588145 & 737357 & 2.585 & 3.033 & TRN & \\
\hline CHEMBL1430372 & 737357 & 3.8125 & 3.6879 & TRN & \\
\hline CHEMBL1313460 & 737357 & 2.585 & 3.14399 & 99999999997 & TRN \\
\hline CHEMBL1594182 & 737357 & 2.585 & 4.1308 & TRN & \\
\hline CHEMBL1500316 & 737357 & 5.4742 & 4.4935 & TST & \\
\hline CHEMBL1426992 & 737357 & 2.585 & 3.1455 & TRN & \\
\hline CHEMBL 2000340 & 737357 & 5.5759 & 3.3294 & TRN & \\
\hline CHEMBL1452115 & 737357 & 2.9208 & 2.714 & TRN & \\
\hline CHEMBL1548492 & 737357 & 2.585 & 4.9422 & TRN & \\
\hline CHEMBL1568913 & 737357 & 2.585 & 3.3084 & TRN & \\
\hline CHEMBL1376285 & 737357 & 2.585 & 2.9768 & TRN & \\
\hline CHEMBL1303885 & 737357 & 2.585 & 3.054 & TRN & \\
\hline CHEMBL1460763 & 737357 & 2.585 & 3.1041 & TRN & \\
\hline CHEMBL1483112 & 737357 & 4.657 & 3.1502 & TRN & \\
\hline CHEMBL 1734647 & 737357 & 2.585 & 2.5952 & TRN & \\
\hline CHEMBL1540061 & 737357 & 2.585 & 2.5481 & TRN & \\
\hline CHEMBL1326230 & 737357 & 2.585 & 2.3602 & TRN & \\
\hline CHEMBL3391716 & 737357 & 2.585 & 3.1136 & TST & \\
\hline CHEMBL1380057 & 737357 & 2.585 & 3.49600 & 00000000004 & TRN \\
\hline CHEMBL1493171 & 737357 & 5.1792 & 3.7144 & TRN & \\
\hline CHEMBL1482414 & 737357 & 2.585 & 2.6205 & TRN & \\
\hline CHEMBL1581193 & 737357 & 4.8289 & 3.0037 & TRN & \\
\hline CHEMBL1607095 & 737357 & 2.585 & 2.6761 & TRN & \\
\hline CHEMBL1734949 & 737357 & 4.6836 & 3.4567 & TRN & \\
\hline CHEMBL1467135 & 737357 & 2.585 & 3.2756 & TST & \\
\hline CHEMBL1520825 & 737357 & 2.585 & 3.4177 & TST & \\
\hline
\end{tabular}


Supplemental Table S2.txt

\begin{tabular}{|c|c|c|c|c|c|}
\hline CHEMBL1368224 & 737357 & 2.585 & 2.7219 & TRN & \\
\hline CHEMBL1585794 & 737357 & 2.585 & 2.6559 & TRN & \\
\hline CHEMBL1445629 & 737357 & 4.8758 & 3.3719 & TRN & \\
\hline CHEMBL1493936 & 737357 & 5.2687 & 3.8535 & TRN & \\
\hline CHEMBL1723450 & 737357 & 2.585 & 2.4876 & TRN & \\
\hline CHEMBL3199573 & 737357 & 2.585 & 3.2653 & TST & \\
\hline CHEMBL1736193 & 737357 & 2.585 & 2.8694 & TRN & \\
\hline CHEMBL1429219 & 737357 & 2.585 & 3.3128 & TRN & \\
\hline CHEMBL1413626 & 737357 & 2.585 & 3.6026 & TST & \\
\hline CHEMBL1595458 & 737357 & 2.585 & 2.5989 & TRN & \\
\hline CHEMBL1499014 & 737357 & 2.585 & 2.9945 & TRN & \\
\hline CHEMBL 2002806 & 737357 & 2.585 & 3.1097 & TRN & \\
\hline CHEMBL1698769 & 737357 & 2.585 & 2.9987 & TST & \\
\hline CHEMBL1537039 & 737357 & 4.7399 & 3.6257 & TRN & \\
\hline CHEMBL1388999 & 737357 & 2.585 & 2.9238 & TRN & \\
\hline CHEMBL1998436 & 737357 & 3.9739 & 3.3887 & TRN & \\
\hline CHEMBL1510068 & 737357 & 2.585 & 3.4994 & TRN & \\
\hline CHEMBL1357411 & 737357 & 2.585 & 2.6105 & TRN & \\
\hline CHEMBL1564365 & 737357 & 2.585 & 3.0048 & TRN & \\
\hline CHEMBL1342386 & 737357 & 2.585 & 2.87899 & 99999999996 & TRN \\
\hline CHEMBL3195663 & 737357 & 2.9208 & 3.4594 & TRN & \\
\hline CHEMBL1700020 & 737357 & 2.585 & 2.6398 & TRN & \\
\hline CHEMBL1532249 & 737357 & 2.585 & 2.9379 & TRN & \\
\hline CHEMBL1378952 & 737357 & 2.585 & 5.6064 & TRN & \\
\hline CHEMBL3196958 & 737357 & 2.585 & 3.3701 & TRN & \\
\hline CHEMBL3197993 & 737357 & 2.585 & 3.4546 & TST & \\
\hline CHEMBL1580622 & 737357 & 4.862 & 3.123 & TST & \\
\hline CHEMBL1339675 & 737357 & 2.585 & 3.4767 & TRN & \\
\hline CHEMBL1372952 & 737357 & 5.0787 & 3.4384 & TRN & \\
\hline CHEMBL1404327 & 737357 & 5.3017 & 3.4183 & TST & \\
\hline CHEMBL1717570 & 737357 & 2.585 & 3.2097 & TRN & \\
\hline CHEMBL 2004475 & 737357 & 5.2046 & 3.6917 & TST & \\
\hline CHEMBL3211094 & 737357 & 2.585 & 3.2461 & TRN & \\
\hline CHEMBL1571968 & 737357 & 2.585 & 2.9523 & TRN & \\
\hline CHEMBL1719459 & 737357 & 3.8671 & 3.7154 & TST & \\
\hline CHEMBL1698748 & 737357 & 2.585 & 3.1596 & TRN & \\
\hline CHEMBL1400481 & 737357 & 5.178 & 4.3039 & TRN & \\
\hline CHEMBL1522618 & 737357 & 5.1476 & 3.7743 & TRN & \\
\hline CHEMBL566068 & 737357 & 2.585 & 3.5935 & TRN & \\
\hline CHEMBL3209226 & 737357 & 2.585 & 3.0254 & TRN & \\
\hline CHEMBL1562436 & 737357 & 2.585 & 2.4563 & TRN & \\
\hline CHEMBL1570930 & 737357 & 2.585 & 2.6218 & TRN & \\
\hline CHEMBL1338775 & 737357 & 2.585 & 2.8761 & TRN & \\
\hline CHEMBL1497134 & 737357 & 2.585 & 2.9561 & TRN & \\
\hline CHEMBL1503030 & 737357 & 2.585 & 3.2084 & TRN & \\
\hline CHEMBL1992631 & 737357 & 2.585 & 3.965 & TRN & \\
\hline CHEMBL1465021 & 737357 & 2.585 & 2.8595 & TRN & \\
\hline CHEMBL1349151 & 737357 & 4.8016 & 3.426 & TRN & \\
\hline
\end{tabular}




\begin{tabular}{|c|c|c|c|c|}
\hline \multicolumn{5}{|c|}{ Supplemental Table S2.txt } \\
\hline CHEMBL1484878 & 737357 & 2.585 & 3.3043 & TST \\
\hline CHEMBL587389 & 737357 & 4.2373 & 3.6422 & TRN \\
\hline CHEMBL1517491 & 737357 & 2.585 & 3.3291 & TRN \\
\hline CHEMBL1407564 & 737357 & 2.585 & 3.0819 & TST \\
\hline CHEMBL1566928 & 737357 & 5.5604 & 3.8313 & TST \\
\hline CHEMBL1600188 & 737357 & 2.585 & 3.2668 & TRN \\
\hline CHEMBL1376516 & 737357 & 4.6019 & 2.9322 & TRN \\
\hline CHEMBL1326104 & 737357 & 2.585 & 3.0669 & TRN \\
\hline CHEMBL1451923 & 737357 & 2.585 & 2.6455 & TRN \\
\hline CHEMBL1585674 & 737357 & 4.3467 & 3.0001 & TRN \\
\hline CHEMBL1443896 & 737357 & 4.4122 & 3.3055 & TRN \\
\hline CHEMBL1587764 & 737357 & 4.2408 & 3.5023 & TRN \\
\hline CHEMBL1573434 & 737357 & 2.585 & 2.7686 & TRN \\
\hline CHEMBL1604009 & 737357 & 2.585 & 3.4508 & TRN \\
\hline CHEMBL1326754 & 737357 & 2.585 & 2.83 & TRN \\
\hline CHEMBL1533979 & 737357 & 3.9201 & 3.0885 & TRN \\
\hline CHEMBL1414816 & 737357 & 2.585 & 2.9831 & TRN \\
\hline CHEMBL1354031 & 737357 & 2.585 & 3.361 & TRN \\
\hline CHEMBL1387362 & 737357 & 4.1662 & 2.8913 & TRN \\
\hline CHEMBL1362832 & 737357 & 2.585 & 2.7888 & TRN \\
\hline CHEMBL1522198 & 737357 & 4.6105 & 3.3066 & TRN \\
\hline CHEMBL1999149 & 737357 & 2.585 & 3.3882 & TRN \\
\hline CHEMBL1463077 & 737357 & 5.0946 & 4.0991 & TRN \\
\hline CHEMBL1576217 & 737357 & 2.585 & 3.2959 & TRN \\
\hline CHEMBL1735901 & 737357 & 2.585 & 2.6961 & TRN \\
\hline CHEMBL1455507 & 737357 & 5.107 & 3.2589 & TRN \\
\hline CHEMBL582478 & 737357 & 2.585 & 3.0903 & TRN \\
\hline CHEMBL1431107 & 737357 & 2.585 & 2.8576 & TRN \\
\hline CHEMBL556001 & 737357 & 2.585 & 3.0813 & TRN \\
\hline CHEMBL 1727810 & 737357 & 2.585 & 3.1212 & TRN \\
\hline CHEMBL1433035 & 737357 & 2.585 & 2.9569 & TST \\
\hline CHEMBL1546853 & 737357 & 4.9223 & 3.3025 & TRN \\
\hline CHEMBL1517214 & 737357 & 2.585 & 2.9968 & TRN \\
\hline CHEMBL1440945 & 737357 & 2.585 & 2.9769 & TRN \\
\hline CHEMBL1587108 & 737357 & 2.585 & 3.3165 & TRN \\
\hline CHEMBL1393564 & 737357 & 4.4983 & 3.3541 & TST \\
\hline CHEMBL1340821 & 737357 & 2.585 & 2.5359 & TRN \\
\hline CHEMBL3193887 & 737357 & 2.585 & 3.5195 & TRN \\
\hline CHEMBL1383719 & 737357 & 2.585 & 2.7747 & TRN \\
\hline CHEMBL1490777 & 737357 & 2.585 & 2.8098 & TRN \\
\hline CHEMBL1367842 & 737357 & 2.585 & 2.8637 & TRN \\
\hline CHEMBL1598592 & 737357 & 2.585 & 3.2434 & TST \\
\hline CHEMBL1722276 & 737357 & 2.585 & 3.0248 & TRN \\
\hline CHEMBL1462065 & 737357 & 2.585 & 2.8538 & TRN \\
\hline CHEMBL1558070 & 737357 & 5.4803 & 3.3163 & TRN \\
\hline CHEMBL1359384 & 737357 & 2.585 & 3.7312 & TRN \\
\hline CHEMBL1309333 & 737357 & 2.585 & 3.2629 & TRN \\
\hline CHEMBL1970274 & 737357 & 2.585 & 2.9859 & TRN \\
\hline
\end{tabular}


Supplemental Table S2.txt

\begin{tabular}{|c|c|c|c|c|c|}
\hline CHEMBL3209950 & 737357 & 2.585 & 3.142 & TST & \\
\hline CHEMBL1524247 & 737357 & 2.585 & 2.8983 & TRN & \\
\hline CHEMBL1322591 & 737357 & 2.585 & 3.0681 & TRN & \\
\hline CHEMBL1340943 & 737357 & 2.585 & 3.0119 & TRN & \\
\hline CHEMBL1350432 & 737357 & 4.7537 & 3.9931 & TST & \\
\hline CHEMBL1337904 & 737357 & 2.585 & 2.6691 & TRN & \\
\hline CHEMBL1341865 & 737357 & 2.585 & 3.4822 & TRN & \\
\hline CHEMBL1367316 & 737357 & 5.181 & 4.2315 & TRN & \\
\hline CHEMBL 3208674 & 737357 & 2.585 & 3.259 & TRN & \\
\hline CHEMBL1444045 & 737357 & 4.9363 & 3.0356 & TRN & \\
\hline CHEMBL3198554 & 737357 & 2.585 & 3.4229 & TRN & \\
\hline CHEMBL1341202 & 737357 & 2.585 & 3.0377 & TRN & \\
\hline CHEMBL1471847 & 737357 & 2.585 & 2.6073 & TRN & \\
\hline CHEMBL1724131 & 737357 & 2.585 & 2.6523 & TRN & \\
\hline CHEMBL1347369 & 737357 & 4.763 & 3.2852 & TRN & \\
\hline CHEMBL1602684 & 737357 & 2.585 & 3.3313 & TRN & \\
\hline CHEMBL1604912 & 737357 & 2.585 & 2.8051 & TRN & \\
\hline CHEMBL1482265 & 737357 & 2.585 & 3.0503 & TST & \\
\hline CHEMBL1484007 & 737357 & 2.585 & 2.9484 & TRN & \\
\hline CHEMBL1459325 & 737357 & 2.585 & 3.1652 & TST & \\
\hline CHEMBL1374864 & 737357 & 2.585 & 2.7816 & TRN & \\
\hline CHEMBL1439064 & 737357 & 2.585 & 3.0545 & TRN & \\
\hline CHEMBL1525745 & 737357 & 2.585 & 2.8489 & TRN & \\
\hline CHEMBL1412901 & 737357 & 2.585 & 3.52399 & 99999999996 & TRN \\
\hline CHEMBL1567443 & 737357 & 2.585 & 2.9458 & TRN & \\
\hline CHEMBL1561326 & 737357 & 2.585 & 3.1199 & TST & \\
\hline CHEMBL1467615 & 737357 & 2.585 & 2.9349 & TST & \\
\hline CHEMBL1391757 & 737357 & 2.585 & 3.362 & TRN & \\
\hline CHEMBL1604694 & 737357 & 2.585 & 3.2556 & TRN & \\
\hline CHEMBL1426451 & 737357 & 2.585 & 3.0597 & TRN & \\
\hline CHEMBL1418582 & 737357 & 2.585 & 3.3766 & TRN & \\
\hline CHEMBL1967479 & 737357 & 2.585 & 4.0097 & TRN & \\
\hline CHEMBL1705190 & 737357 & 2.585 & 2.8285 & TRN & \\
\hline CHEMBL1701229 & 737357 & 2.585 & 3.3297 & TST & \\
\hline CHEMBL1303791 & 737357 & 2.585 & 2.7932 & TRN & \\
\hline CHEMBL1703552 & 737357 & 2.585 & 2.7235 & TRN & \\
\hline CHEMBL1588229 & 737357 & 2.585 & 3.3618 & TRN & \\
\hline CHEMBL3189715 & 737357 & 2.585 & 3.1623 & TRN & \\
\hline CHEMBL1451736 & 737357 & 4.4072 & 3.6373 & TRN & \\
\hline CHEMBL1443824 & 737357 & 2.585 & 3.0393 & TRN & \\
\hline CHEMBL1333687 & 737357 & 4.901 & 3.4404 & TRN & \\
\hline CHEMBL1300242 & 737357 & 5.0288 & 3.4802 & TRN & \\
\hline CHEMBL1374398 & 737357 & 4.9586 & 2.8496 & TRN & \\
\hline CHEMBL1529882 & 737357 & 4.3504 & 3.1611 & TRN & \\
\hline CHEMBL1558024 & 737357 & 2.585 & 3.339 & TRN & \\
\hline CHEMBL1710589 & 737357 & 2.585 & 2.8105 & TRN & \\
\hline CHEMBL1412884 & 737357 & 2.585 & 2.8628 & TRN & \\
\hline CHEMBL3189902 & 737357 & 2.585 & 3.3383 & TRN & \\
\hline
\end{tabular}




\begin{tabular}{|c|c|c|c|c|c|}
\hline & & \multicolumn{4}{|c|}{ Supplemental Table S2.txt } \\
\hline CHEMBL1428823 & 737357 & 4.1843 & 3.7537 & TRN & \\
\hline CHEMBL1996698 & 737357 & 2.585 & 3.2119 & TRN & \\
\hline CHEMBL1303265 & 737357 & 2.585 & 2.8931 & TRN & \\
\hline CHEMBL1304384 & 737357 & 4.9492 & 3.1384 & TRN & \\
\hline CHEMBL1559782 & 737357 & 4.2341 & 3.0622 & TST & \\
\hline CHEMBL1422520 & 737357 & 2.585 & 3.0559 & TRN & \\
\hline CHEMBL1358680 & 737357 & 2.585 & 2.5855 & TRN & \\
\hline CHEMBL1393596 & 737357 & 5.1076 & 2.9455 & TRN & \\
\hline CHEMBL1367444 & 737357 & 2.585 & 3.3572 & TRN & \\
\hline CHEMBL602314 & 737357 & 2.585 & 2.7959 & TRN & \\
\hline CHEMBL1606353 & 737357 & 2.585 & 3.0031 & TRN & \\
\hline CHEMBL1460949 & 737357 & 2.585 & 2.8268 & TRN & \\
\hline CHEMBL1429794 & 737357 & 2.585 & 2.8495 & TRN & \\
\hline CHEMBL1532309 & 737357 & 2.585 & 3.0331 & TRN & \\
\hline CHEMBL1588456 & 737357 & 2.585 & 3.1189 & TRN & \\
\hline CHEMBL1722942 & 737357 & 2.585 & 2.6287 & TRN & \\
\hline CHEMBL1491029 & 737357 & 2.585 & 3.35100 & 00000000004 & TST \\
\hline CHEMBL1375589 & 737357 & 2.585 & 3.1267 & TST & \\
\hline CHEMBL1334022 & 737357 & 2.585 & 2.714 & TRN & \\
\hline CHEMBL1367994 & 737357 & 2.585 & 3.1801 & TRN & \\
\hline CHEMBL1542124 & 737357 & 4.5187 & 2.9088 & TRN & \\
\hline CHEMBL1573651 & 737357 & 2.585 & 2.4961 & TRN & \\
\hline CHEMBL1437869 & 737357 & 2.585 & 3.0512 & TRN & \\
\hline CHEMBL1410982 & 737357 & 2.585 & 3.0583 & TRN & \\
\hline CHEMBL1342719 & 737357 & 2.585 & 2.7142 & TST & \\
\hline CHEMBL1612673 & 737357 & 4.3563 & 2.8847 & TRN & \\
\hline CHEMBL1539505 & 737357 & 2.585 & 2.9474 & TRN & \\
\hline CHEMBL1565175 & 737357 & 2.585 & 3.2722 & TRN & \\
\hline CHEMBL1979106 & 737357 & 2.585 & 4.3018 & TRN & \\
\hline CHEMBL1525994 & 737357 & 2.585 & 3.7674 & TST & \\
\hline CHEMBL1505964 & 737357 & 4.7333 & 2.55800 & 00000000003 & TRN \\
\hline CHEMBL1562839 & 737357 & 4.5031 & 3.4308 & TRN & \\
\hline CHEMBL1608331 & 737357 & 2.585 & 2.9845 & TRN & \\
\hline CHEMBL1478366 & 737357 & 2.585 & 3.4756 & TRN & \\
\hline CHEMBL1422726 & 737357 & 2.585 & 3.6134 & TRN & \\
\hline CHEMBL1716125 & 737357 & 2.585 & 3.2501 & TRN & \\
\hline CHEMBL1412322 & 737357 & 2.585 & 2.7827 & TRN & \\
\hline CHEMBL1442265 & 737357 & 2.585 & 2.7856 & TRN & \\
\hline CHEMBL1441382 & 737357 & 2.585 & 3.4109 & TRN & \\
\hline CHEMBL1455037 & 737357 & 2.585 & 3.5594 & TRN & \\
\hline CHEMBL1422998 & 737357 & 2.585 & 2.8659 & TRN & \\
\hline CHEMBL1431255 & 737357 & 2.585 & 3.2372 & TRN & \\
\hline CHEMBL1457855 & 737357 & 2.585 & 3.1108 & TRN & \\
\hline CHEMBL1713901 & 737357 & 4.5583 & 3.2629 & TRN & \\
\hline CHEMBL1602218 & 737357 & 2.585 & 3.0578 & TRN & \\
\hline CHEMBL1575613 & 737357 & 4.4459 & 2.3876 & TRN & \\
\hline CHEMBL1704911 & 737357 & 2.585 & 2.9256 & TRN & \\
\hline CHEMBL197131 & 737357 & 2.585 & 2.7953 & TRN & \\
\hline
\end{tabular}




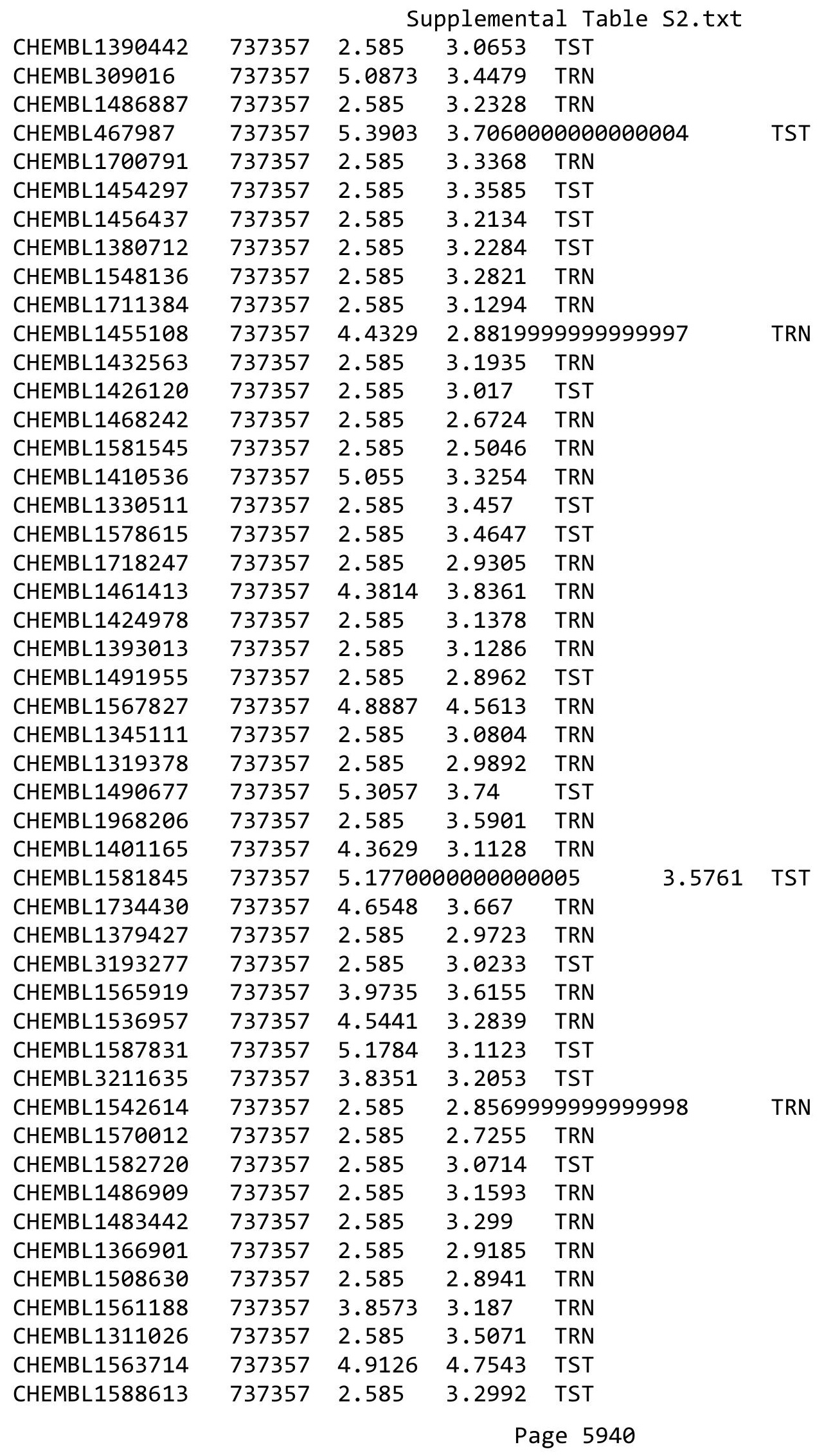


Supplemental Table S2.txt

\begin{tabular}{|c|c|c|c|c|}
\hline-3 & & & & \\
\hline HEMBL1324240 & 37357 & .585 & 2.6985 & \\
\hline 2518 & & & & \\
\hline 7005 & 357 & 85 & 351 & \\
\hline JEMBL1699304 & 37357 & 585 & 5502 & \\
\hline AEMBL3214139 & 37357 & 585 & 1119 & \\
\hline HEMBL1421219 & 37357 & .585 & .7074 & \\
\hline AEMBL1527671 & & 85 & 0914 & \\
\hline IEMBL 14 & 37357 & 3967 & .3863 & \\
\hline AEMBL1569203 & 37357 & 585 & . 7797 & \\
\hline HEMBL 523200 & 37357 & 9329 & .9869 & \\
\hline AEMBL1567814 & 37357 & 85 & .3655 & \\
\hline AEMBL15 & & & & \\
\hline AEMBL1C & 357 & 58 & 1979 & \\
\hline AEMBL3193858 & 357 & 58 & 1711 & \\
\hline AEMBL3194508 & 37357 & & 3017 & \\
\hline HEMBL1407600 & 57 & 85 & 6215 & \\
\hline HEMBL1305462 & & 953 & 7733 & \\
\hline HEMBL 14 & 357 & 85 & .8798 & \\
\hline HEMBL137 & & & 628 & \\
\hline AEMBL1380509 & 57 & 85 & .7812 & KIN \\
\hline HEMBL15€ & 57 & 85 & .0769 & RIN \\
\hline HEMBL14 & & 491 & .5287 & \\
\hline AEMBL1727710 & & & .4088 & \\
\hline IEMBL15 & & & 968 & II \\
\hline MBL13 & 57 & ה ה & 56 & ST \\
\hline AEMBL1: & 57 & & 322 & RN \\
\hline 93 & & & 325 & RN \\
\hline 336 & & 397 & 141 & $\mathrm{RN}$ \\
\hline HEMBL134 & & & 163 & RN \\
\hline AEMBL1585511 & 57 & 079 & 15 & $\mathrm{RN}$ \\
\hline HEMBL1612514 & 57 & & 67 & RN \\
\hline 35 & & & & ST \\
\hline HEMBL151 & & & & RN \\
\hline AEMBL172 & & & 105 & IST \\
\hline JEMBL14 & & & 913 & RN \\
\hline 1 & & 62 & 53 & RN \\
\hline & & & 2.8794 & $\mathrm{RN}$ \\
\hline HEMBL1550048 & 37357 & 2 . & 3.3559 & RN \\
\hline AEMBL3209624 & & & 3.5332 & RN \\
\hline HEMBL1321644 & 57 & & 2.9027 & RN \\
\hline & & & 3.3765 & RN \\
\hline HEMBL1736799 & 37357 & & 2.5502 & $\mathrm{RN}$ \\
\hline AEMBL1701459 & 37357 & 85 & .0134 & RN \\
\hline EMBL1529381 & & & . .8957 & RN \\
\hline HEMBL1987784 & 37357 & 901 & 2.8222 & \\
\hline HEMBL132 & 737357 & & 1.0679 & \\
\hline CHEMBL1308088 & 737357 & 4.3836 & 3.6504 & \\
\hline
\end{tabular}

Page 5941 
Supplemental Table S2.txt

\begin{tabular}{|c|c|c|c|c|}
\hline CHEMBL1387592 & 737357 & 2.585 & 3.5604 & TRN \\
\hline CHEMBL1520220 & 737357 & 2.585 & 3.0527 & TRN \\
\hline CHEMBL1510666 & 737357 & 2.585 & 3.3409 & TRN \\
\hline CHEMBL1498575 & 737357 & 2.585 & 2.8672 & TRN \\
\hline CHEMBL1427679 & 737357 & 2.585 & 3.0894 & TRN \\
\hline CHEMBL1582116 & 737357 & 2.585 & 2.7958 & TRN \\
\hline CHEMBL1366836 & 737357 & 4.7749 & 3.0272 & TRN \\
\hline CHEMBL1564145 & 737357 & 2.585 & 2.8451 & TRN \\
\hline CHEMBL1424881 & 737357 & 2.585 & 2.8297 & TRN \\
\hline CHEMBL1575235 & 737357 & 2.585 & 3.3789 & TST \\
\hline CHEMBL 2004226 & 737357 & 2.585 & 3.7174 & TRN \\
\hline CHEMBL1495630 & 737357 & 2.585 & 3.1419 & TRN \\
\hline CHEMBL1426686 & 737357 & 2.585 & 3.1671 & TRN \\
\hline CHEMBL1570304 & 737357 & 2.585 & 2.7813 & TRN \\
\hline CHEMBL 3212241 & 737357 & 2.585 & 3.2379 & TST \\
\hline CHEMBL1724320 & 737357 & 2.585 & 2.5853 & TRN \\
\hline CHEMBL3189419 & 737357 & 2.585 & 3.4083 & TRN \\
\hline CHEMBL3212625 & 737357 & 5.4269 & 3.3527 & TRN \\
\hline CHEMBL3392077 & 737357 & 2.585 & 3.1466 & TRN \\
\hline CHEMBL1967901 & 737357 & 3.8722 & 3.0953 & TRN \\
\hline CHEMBL1581131 & 737357 & 2.585 & 3.464 & TRN \\
\hline CHEMBL1481417 & 737357 & 4.8088 & 3.6238 & TRN \\
\hline CHEMBL1364330 & 737357 & 2.585 & 2.8206 & TRN \\
\hline CHEMBL1595183 & 737357 & 4.9017 & 3.1886 & TRN \\
\hline CHEMBL3194415 & 737357 & 2.585 & 2.9931 & TRN \\
\hline CHEMBL1545491 & 737357 & 2.585 & 2.89 & TRN \\
\hline CHEMBL1486174 & 737357 & 2.585 & 3.25399 & 99999999996 \\
\hline CHEMBL1424673 & 737357 & 2.585 & 3.4092 & TST \\
\hline CHEMBL1461750 & 737357 & 2.585 & 3.3303 & TRN \\
\hline CHEMBL1975622 & 737357 & 2.585 & 3.3 & TRN \\
\hline CHEMBL1726576 & 737357 & 2.585 & 3.3477 & TST \\
\hline CHEMBL1594870 & 737357 & 2.585 & 3.4253 & TST \\
\hline CHEMBL1596646 & 737357 & 4.6383 & 3.3471 & TRN \\
\hline CHEMBL1990081 & 737357 & 2.585 & 3.4315 & TRN \\
\hline CHEMBL1969492 & 737357 & 4.1473 & 3.7835 & TST \\
\hline CHEMBL1527010 & 737357 & 2.585 & 3.0886 & TST \\
\hline CHEMBL1431099 & 737357 & 2.585 & 2.7593 & TRN \\
\hline CHEMBL1382170 & 737357 & 2.585 & 2.8444 & TRN \\
\hline CHEMBL1992715 & 737357 & 2.585 & 3.1026 & TRN \\
\hline CHEMBL1460692 & 737357 & 4.5688 & 3.4164 & TRN \\
\hline CHEMBL1469821 & 737357 & 5.1135 & 3.4335 & TRN \\
\hline CHEMBL1320305 & 737357 & 2.585 & 2.7606 & TRN \\
\hline CHEMBL3195699 & 737357 & 2.585 & 3.0477 & TRN \\
\hline CHEMBL1463463 & 737357 & 2.585 & 2.8771 & TRN \\
\hline CHEMBL1444576 & 737357 & 2.585 & 3.3292 & TRN \\
\hline CHEMBL1342059 & 737357 & 2.585 & 3.0262 & TRN \\
\hline CHEMBL1368203 & 737357 & 2.585 & 3.445 & TRN \\
\hline CHEMBL52 & 737357 & 5.6347 & 3.3166 & TST \\
\hline
\end{tabular}




\begin{tabular}{|c|c|c|c|c|}
\hline \multicolumn{5}{|c|}{ Supplemental Table S2.txt } \\
\hline CHEMBL1528478 & 737357 & 3.7552 & 3.7496 & TRN \\
\hline CHEMBL1707489 & 737357 & 2.585 & 3.1226 & TRN \\
\hline CHEMBL1354121 & 737357 & 2.585 & 2.5344 & TRN \\
\hline CHEMBL1584367 & 737357 & 2.585 & 2.9494 & TRN \\
\hline CHEMBL1579364 & 737357 & 2.585 & 2.9136 & TRN \\
\hline CHEMBL1503368 & 737357 & 2.585 & 3.5038 & TRN \\
\hline CHEMBL3195126 & 737357 & 2.585 & 3.2412 & TRN \\
\hline CHEMBL1729739 & 737357 & 2.585 & 3.0723 & TST \\
\hline CHEMBL1415811 & 737357 & 2.585 & 2.6729 & TRN \\
\hline CHEMBL1458638 & 737357 & 2.585 & 2.7588 & TRN \\
\hline CHEMBL1369984 & 737357 & 4.376 & 3.2382 & TRN \\
\hline CHEMBL1537562 & 737357 & 2.585 & 2.7233 & TRN \\
\hline CHEMBL1481680 & 737357 & 2.585 & 2.8946 & TRN \\
\hline CHEMBL1310609 & 737357 & 2.585 & 2.8629 & TRN \\
\hline CHEMBL1462152 & 737357 & 2.585 & 2.7912 & TRN \\
\hline CHEMBL1339211 & 737357 & 2.585 & 2.9556 & TRN \\
\hline CHEMBL1603493 & 737357 & 4.3706 & 3.3758 & TRN \\
\hline CHEMBL1341981 & 737357 & 2.585 & 3.7164 & TRN \\
\hline CHEMBL1592105 & 737357 & 2.585 & 3.3814 & TRN \\
\hline CHEMBL1486682 & 737357 & 2.585 & 2.9423 & TRN \\
\hline CHEMBL1505902 & 737357 & 4.8459 & 3.7295 & TRN \\
\hline CHEMBL3192842 & 737357 & 4.2131 & 3.7102 & TRN \\
\hline CHEMBL1562312 & 737357 & 3.8027 & 2.9446 & TRN \\
\hline CHEMBL1306347 & 737357 & 4.669 & 3.5527 & TST \\
\hline CHEMBL1417768 & 737357 & 2.585 & 3.103 & TRN \\
\hline CHEMBL 1413540 & 737357 & 2.585 & 2.9701 & TRN \\
\hline CHEMBL1567036 & 737357 & 2.585 & 2.707 & TRN \\
\hline CHEMBL3199812 & 737357 & 4.3792 & 3.5194 & TRN \\
\hline CHEMBL1391718 & 737357 & 2.585 & 3.235 & TRN \\
\hline CHEMBL1607495 & 737357 & 2.585 & 2.8535 & TRN \\
\hline CHEMBL1610868 & 737357 & 2.585 & 3.0671 & TRN \\
\hline CHEMBL1419656 & 737357 & 2.585 & 2.82 & TRN \\
\hline CHEMBL1438451 & 737357 & 2.585 & 3.1152 & TRN \\
\hline CHEMBL1558306 & 737357 & 5.0731 & 4.0865 & TRN \\
\hline CHEMBL1570004 & 737357 & 4.1774 & 3.6944 & TST \\
\hline CHEMBL1428226 & 737357 & 2.585 & 3.1166 & TRN \\
\hline CHEMBL1428980 & 737357 & 2.585 & 2.4405 & TST \\
\hline CHEMBL1534012 & 737357 & 6.0811 & 2.8554 & TRN \\
\hline CHEMBL1506505 & 737357 & 4.8687 & 3.6166 & TRN \\
\hline CHEMBL 2001024 & 737357 & 2.585 & 3.2018 & TRN \\
\hline CHEMBL1489011 & 737357 & 2.585 & 2.7177 & TRN \\
\hline CHEMBL1361055 & 737357 & 2.585 & 3.4279 & TRN \\
\hline CHEMBL1318971 & 737357 & 4.8969 & 3.1503 & TRN \\
\hline CHEMBL1349962 & 737357 & 4.8351 & 3.363 & TST \\
\hline CHEMBL261692 & 737357 & 4.7557 & 3.4295 & TRN \\
\hline CHEMBL1366834 & 737357 & 2.585 & 3.2647 & TRN \\
\hline CHEMBL 270672 & 737357 & 2.585 & 3.1667 & TRN \\
\hline CHEMBL1361013 & 737357 & 2.585 & 3.1134 & TRN \\
\hline
\end{tabular}


Supplemental Table S2.txt

\begin{tabular}{|c|c|c|c|c|}
\hline CHEMBL1301107 & 737357 & 2.585 & 3.7806 & TRN \\
\hline CHEMBL1592941 & 737357 & 2.585 & 2.7388 & TRN \\
\hline CHEMBL1387109 & 737357 & 2.585 & 3.365 & TRN \\
\hline CHEMBL1605033 & 737357 & 2.585 & 3.1364 & TST \\
\hline CHEMBL3193814 & 737357 & 2.585 & 3.4164 & TRN \\
\hline CHEMBL1430631 & 737357 & 2.585 & 2.8278 & TRN \\
\hline CHEMBL1497010 & 737357 & 5.037 & 3.255 & TRN \\
\hline CHEMBL1351102 & 737357 & 4.734 & 3.3592 & TRN \\
\hline CHEMBL1990342 & 737357 & 5.0279 & 3.1242 & TRN \\
\hline CHEMBL1360875 & 737357 & 4.5334 & 3.0787 & TRN \\
\hline CHEMBL1419866 & 737357 & 2.585 & 3.1349 & TST \\
\hline CHEMBL1407015 & 737357 & 2.585 & 2.7089 & TRN \\
\hline CHEMBL1376715 & 737357 & 2.585 & 2.7835 & TRN \\
\hline CHEMBL1453386 & 737357 & 5.1628 & 3.3117 & TRN \\
\hline CHEMBL1583531 & 737357 & 3.7044 & 3.4457 & TRN \\
\hline CHEMBL1483818 & 737357 & 2.585 & 2.9354 & TRN \\
\hline CHEMBL1385433 & 737357 & 4.7326 & 3.029 & TRN \\
\hline CHEMBL1531952 & 737357 & 2.585 & 3.1984 & TRN \\
\hline CHEMBL1493957 & 737357 & 4.8834 & 3.6157 & TRN \\
\hline CHEMBL1338940 & 737357 & 2.585 & 3.1531 & TRN \\
\hline CHEMBL1299804 & 737357 & 2.585 & 2.4697 & TRN \\
\hline CHEMBL1559741 & 737357 & 4.1819 & 3.3363 & TRN \\
\hline CHEMBL1541239 & 737357 & 2.585 & 2.9806 & TRN \\
\hline CHEMBL1717183 & 737357 & 2.585 & 2.9045 & TST \\
\hline CHEMBL1501706 & 737357 & 2.585 & 2.812 & TRN \\
\hline CHEMBL1588072 & 737357 & 4.7929 & 2.8553 & TRN \\
\hline CHEMBL1326110 & 737357 & 5.4743 & 4.4126 & TRN \\
\hline CHEMBL1468471 & 737357 & 2.585 & 3.12899 & 99999999996 \\
\hline CHEMBL1486140 & 737357 & 2.585 & 2.9849 & TRN \\
\hline CHEMBL1510474 & 737357 & 2.585 & 2.7832 & TRN \\
\hline CHEMBL1346973 & 737357 & 2.585 & 3.1243 & TRN \\
\hline CHEMBL1567531 & 737357 & 2.585 & 3.1281 & TRN \\
\hline CHEMBL1351290 & 737357 & 2.585 & 3.0137 & TST \\
\hline CHEMBL1534669 & 737357 & 2.585 & 3.0879 & TRN \\
\hline CHEMBL1975721 & 737357 & 4.7496 & 3.2867 & TST \\
\hline CHEMBL1311899 & 737357 & 2.585 & 3.3827 & TRN \\
\hline CHEMBL1444441 & 737357 & 2.585 & 3.0186 & TRN \\
\hline CHEMBL1584304 & 737357 & 3.6091 & 3.0725 & TST \\
\hline CHEMBL1305759 & 737357 & 2.585 & 2.6596 & TRN \\
\hline CHEMBL1564306 & 737357 & 2.585 & 3.5041 & TRN \\
\hline CHEMBL1478237 & 737357 & 5.4647 & 4.6651 & TRN \\
\hline CHEMBL1304131 & 737357 & 2.585 & 2.8644 & TRN \\
\hline CHEMBL1335959 & 737357 & 2.585 & 3.3996 & TRN \\
\hline CHEMBL1585783 & 737357 & 2.585 & 3.0736 & TRN \\
\hline CHEMBL1393154 & 737357 & 2.585 & 3.1988 & TRN \\
\hline CHEMBL1613195 & 737357 & 2.585 & 2.6447 & TRN \\
\hline CHEMBL1384349 & 737357 & 4.4916 & 3.4514 & TRN \\
\hline CHEMBL1362814 & 737357 & 4.5 & 2.9161 & TRN \\
\hline
\end{tabular}


Supplemental Table S2.txt

\begin{tabular}{|c|c|c|c|c|}
\hline I & & & & 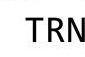 \\
\hline HEMBL1526313 & 37357 & 2.585 & 3.4223 & \\
\hline & & & & \\
\hline EMBL542493 & 57 & 85 & 48 & \\
\hline AEMBL1556242 & 37357 & 585 & 3362 & \\
\hline HEMBL1493488 & 37357 & 585 & 6492 & \\
\hline HEMBL1300861 & 37357 & .585 & .5344 & \\
\hline IEMBL1537211 & 57 & 85 & 05 & \\
\hline IEMBL1402449 & 37357 & 585 & .0752 & \\
\hline HEMBL1499742 & 37357 & 585 & .0019 & \\
\hline HEMBL1416441 & 37357 & .585 & 9979 & \\
\hline AEMBL1403842 & 37357 & 85 & .093 & \\
\hline AEMBL1531811 & & & & \\
\hline AEMBL1356192 & 357 & 585 & .9874 & \\
\hline AEMBL1383782 & 357 & 85 & .7425 & \\
\hline AEMBL1433144 & 37357 & & .4246 & \\
\hline HEMBL1600730 & 57 & 85 & 33 & \\
\hline HEMBL3209416 & & 85 & 89 & \\
\hline HEMBL 159 & 57 & 58 & .9223 & RN \\
\hline IEMBL17 & 57 & 85 & . 7987 & RIV \\
\hline AEMBL1345523 & 57 & 702 & 3.0299 & IRN \\
\hline HEMBL15 & 57 & 85 & .0665 & RN \\
\hline HEMBL15 & & & & RN \\
\hline$\partial 07$ & & & .2114 & ST \\
\hline HEMBL199 & & 85 & 2 & RIN \\
\hline MBL31 & 57 & 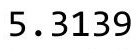 & 12 & ГRN \\
\hline HEMBL14 & 57 & 3 & 78 & RN \\
\hline 332 & & & 55 & RN \\
\hline 889 & & & & RN \\
\hline AEMBL1458565 & & r & 2.7945 & RN \\
\hline AEMBL1332712 & 57 & & 3.2244 & RN \\
\hline AFMBI 15 & & & .8146 & RN \\
\hline 72 & & & 29 & RN \\
\hline HEMBL1408350 & & & & RN \\
\hline AEMBL1334307 & & 50 & 3.1005 & RN \\
\hline HEMBL1712472 & & & 3.3773 & RN \\
\hline HEMRI 13 & & & 2.8745 & RN \\
\hline L1537062 & & & 3.2459 & ST \\
\hline HEMBL1438361 & 37357 & 85 & 2.2979 & TRN \\
\hline AEMBL1310319 & & & 3.7699 & RN \\
\hline HEMBL1304081 & 57 & 2 . & 3.5366 & RN \\
\hline HEMBL1578101 & & 548 & & RN \\
\hline HEMBL1369402 & 37357 & 2.585 & 2.9706 & TRN \\
\hline AEMBL1556937 & 37357 & 2.585 & . . 9894 & RN \\
\hline L3190375 & & & 3.4958 & IRI \\
\hline HEMBL1303670 & & & 2.7244 & \\
\hline CHEMBL1382672 & 737357 & 2.585 & 2.8706 & RN \\
\hline CHEMBL1483028 & 737357 & 3.997 & 3.4985 & 3 \\
\hline
\end{tabular}

Page 5945 


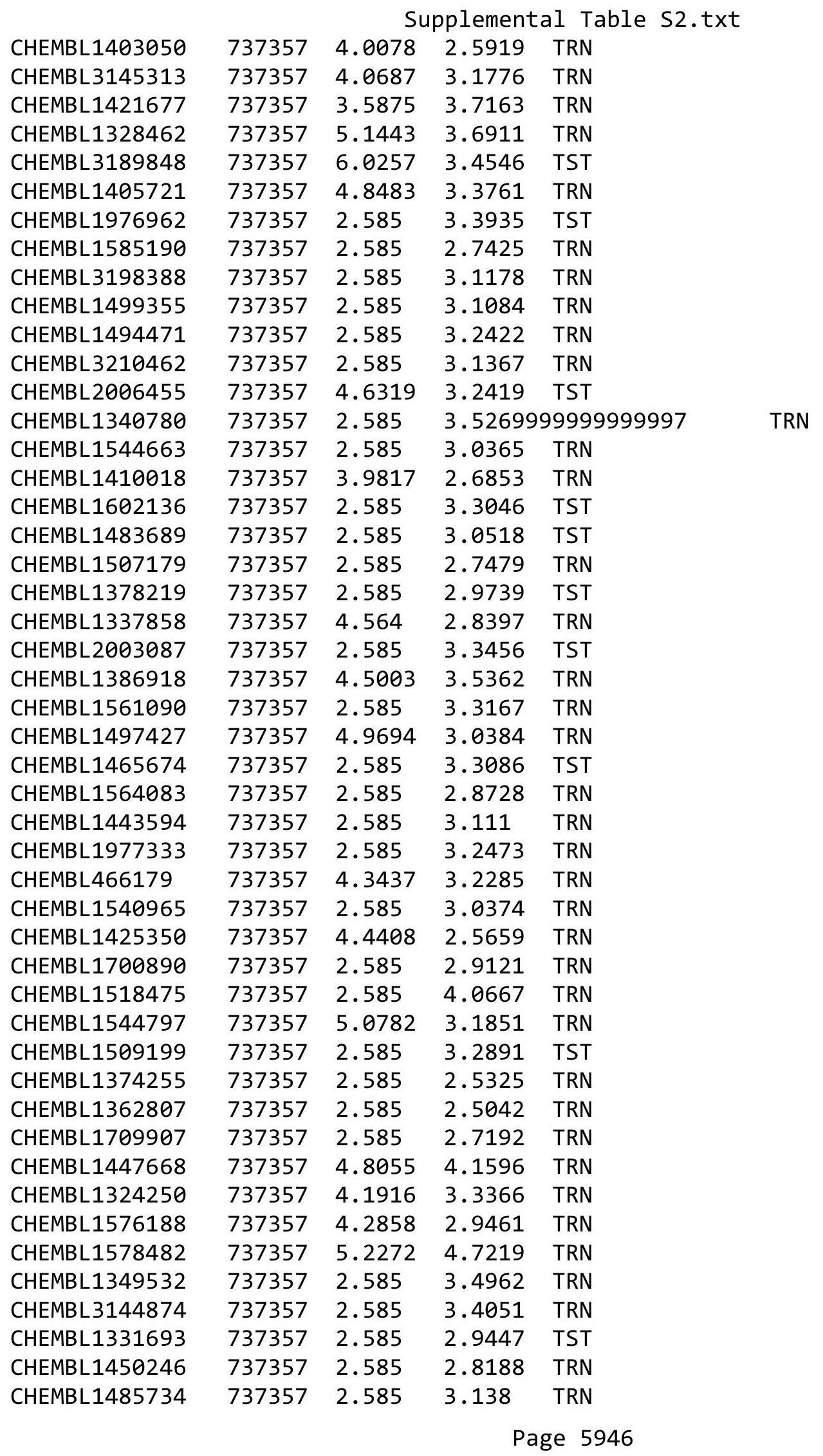




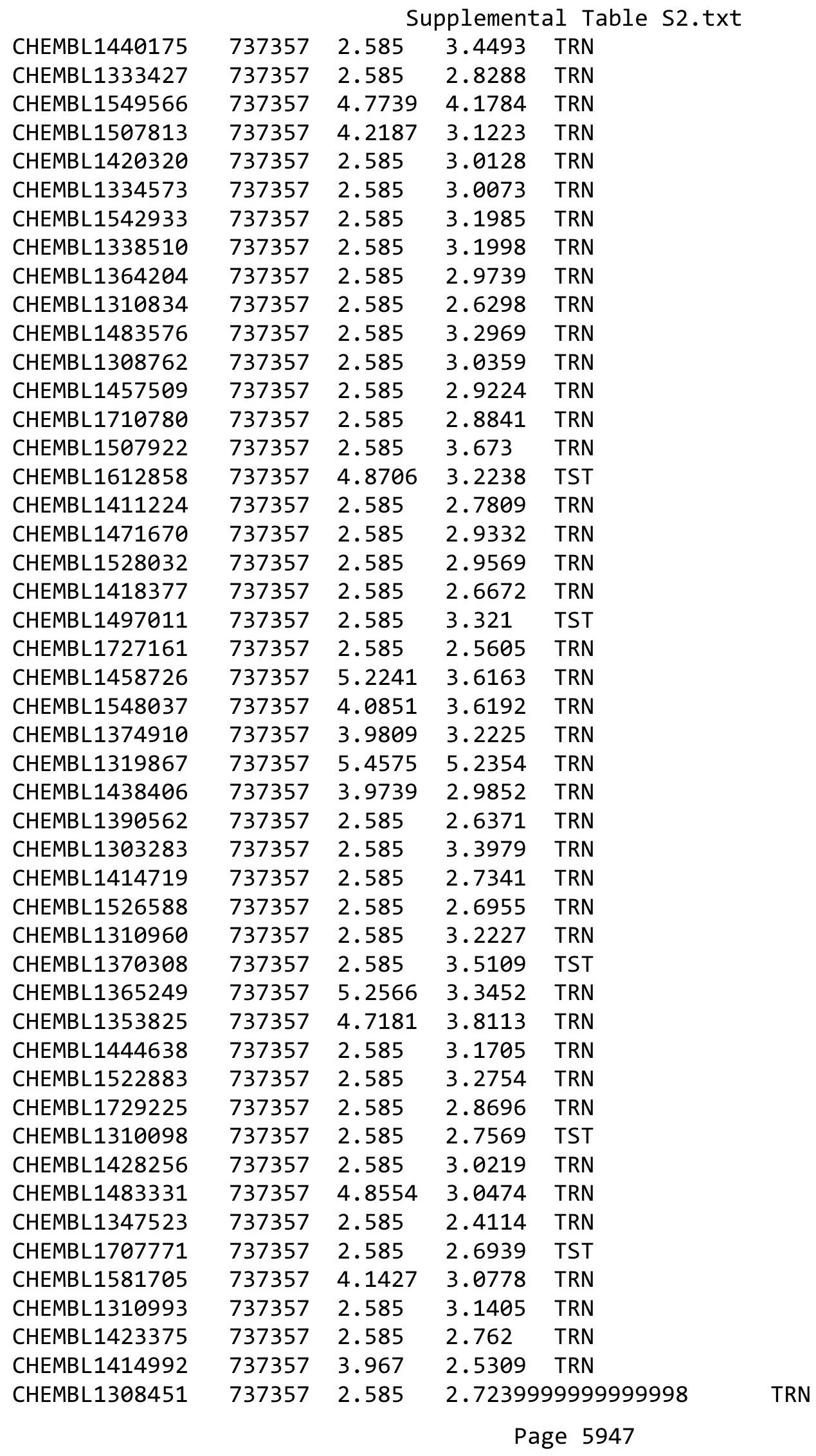




\begin{tabular}{|c|c|c|c|c|c|c|}
\hline & & \multicolumn{5}{|c|}{ Supplemental Table S2.txt } \\
\hline CHEMBL1701332 & 737357 & 2.585 & 3.1306 & TST & & \\
\hline CHEMBL1589399 & 737357 & 2.585 & 2.7411 & TST & & \\
\hline CHEMBL1966948 & 737357 & 2.585 & 2.7923 & TRN & & \\
\hline CHEMBL1321469 & 737357 & 4.8459 & 3.0824 & TRN & & \\
\hline CHEMBL1581444 & 737357 & 2.585 & 3.208 & TRN & & \\
\hline CHEMBL1431975 & 737357 & 2.585 & 3.3016 & TRN & & \\
\hline CHEMBL1604632 & 737357 & \multicolumn{3}{|c|}{4.593999999999999} & 2.8158 & TRN \\
\hline CHEMBL1549738 & 737357 & 4.4111 & 3.0962 & TST & & \\
\hline CHEMBL1374285 & 737357 & 2.585 & 3.0444 & TRN & & \\
\hline CHEMBL1458812 & 737357 & 5.1651 & 3.8827 & TST & & \\
\hline CHEMBL1472092 & 737357 & 2.585 & 3.3579 & TRN & & \\
\hline CHEMBL1734350 & 737357 & 2.585 & 3.3131 & TRN & & \\
\hline CHEMBL1378203 & 737357 & 3.9838 & 2.9134 & TRN & & \\
\hline CHEMBL1581068 & 737357 & 2.585 & 3.8399 & TRN & & \\
\hline CHEMBL1451869 & 737357 & 2.585 & 3.1464 & TRN & & \\
\hline CHEMBL1504075 & 737357 & 2.585 & 2.623 & TRN & & \\
\hline CHEMBL1511306 & 737357 & 2.585 & 3.2191 & TRN & & \\
\hline CHEMBL1566084 & 737357 & 5.1262 & 4.07 & TRN & & \\
\hline CHEMBL1531727 & 737357 & 2.585 & 3.0386 & TRN & & \\
\hline CHEMBL1343925 & 737357 & 4.6558 & 3.3318 & TST & & \\
\hline CHEMBL1403085 & 737357 & 5.3934 & 4.4259 & TRN & & \\
\hline CHEMBL1423337 & 737357 & 2.585 & 2.7317 & TRN & & \\
\hline CHEMBL1351519 & 737357 & 5.0412 & 3.3079 & TRN & & \\
\hline CHEMBL1476946 & 737357 & 2.585 & 2.9738 & TRN & & \\
\hline CHEMBL1467155 & 737357 & 2.585 & 2.639 & TRN & & \\
\hline CHEMBL1368375 & 737357 & 2.585 & 3.2236 & TRN & & \\
\hline CHEMBL1312227 & 737357 & 2.585 & 3.0836 & TRN & & \\
\hline CHEMBL1597158 & 737357 & 4.2243 & 3.228 & TRN & & \\
\hline CHEMBL1715193 & 737357 & 2.585 & 2.7563 & TRN & & \\
\hline CHEMBL1701649 & 737357 & 2.585 & 2.7759 & TRN & & \\
\hline CHEMBL1515217 & 737357 & 2.585 & 2.8006 & TRN & & \\
\hline CHEMBL1507022 & 737357 & 2.585 & 3.2134 & TRN & & \\
\hline CHEMBL1336098 & 737357 & 6.4175 & 3.738 & TRN & & \\
\hline CHEMBL1414079 & 737357 & 4.1622 & 2.9317 & TRN & & \\
\hline CHEMBL1548253 & 737357 & 4.6844 & 4.0007 & TST & & \\
\hline CHEMBL1452398 & 737357 & 2.585 & 2.9658 & TRN & & \\
\hline CHEMBL1484362 & 737357 & 2.585 & 3.3227 & TRN & & \\
\hline CHEMBL1528987 & 737357 & 2.585 & 2.8824 & TST & & \\
\hline CHEMBL1607008 & 737357 & 2.585 & 3.1602 & TRN & & \\
\hline CHEMBL1368609 & 737357 & 4.6688 & 3.3815 & TST & & \\
\hline CHEMBL1371117 & 737357 & 4.3937 & 2.6943 & TRN & & \\
\hline CHEMBL1578445 & 737357 & 2.585 & 2.9804 & TRN & & \\
\hline CHEMBL1413901 & 737357 & 2.585 & 3.5577 & TRN & & \\
\hline CHEMBL1439834 & 737357 & 2.585 & 3.0254 & TRN & & \\
\hline CHEMBL1470207 & 737357 & 2.585 & 3.2613 & TST & & \\
\hline CHEMBL1301976 & 737357 & 4.2138 & 2.9194 & TRN & & \\
\hline CHEMBL1383158 & 737357 & 2.585 & 3.2414 & TRN & & \\
\hline CHEMBL 3198705 & 737357 & 2.585 & 3.5179 & TST & & \\
\hline
\end{tabular}




\begin{tabular}{|c|c|c|c|c|c|c|}
\hline & & \multicolumn{5}{|c|}{ Supplemental Table S2.txt } \\
\hline CHEMBL3207493 & 737357 & 2.585 & 3.2753 & TRN & & \\
\hline CHEMBL1425530 & 737357 & 2.585 & 3.2835 & TST & & \\
\hline CHEMBL3198851 & 737357 & 4.6996 & 3.4479 & TRN & & \\
\hline CHEMBL1732524 & 737357 & 2.585 & 2.9581 & TST & & \\
\hline CHEMBL1556394 & 737357 & 2.585 & 3.1133 & TRN & & \\
\hline CHEMBL1363898 & 737357 & 2.585 & 3.2571 & TRN & & \\
\hline CHEMBL1565883 & 737357 & \multicolumn{3}{|c|}{5.382000000000001} & 3.2724 & TRN \\
\hline CHEMBL1541405 & 737357 & 5.3745 & 3.4432 & TRN & & \\
\hline CHEMBL 3197574 & 737357 & 2.585 & 3.4851 & TRN & & \\
\hline CHEMBL1488224 & 737357 & 2.585 & 2.685 & TRN & & \\
\hline CHEMBL1387407 & 737357 & 2.585 & 2.8147 & TST & & \\
\hline CHEMBL1994506 & 737357 & 2.585 & 3.1655 & TST & & \\
\hline CHEMBL1420268 & 737357 & 4.817 & 3.0482 & TRN & & \\
\hline CHEMBL 1453774 & 737357 & 2.585 & 3.0004 & TST & & \\
\hline CHEMBL1536637 & 737357 & 2.585 & 2.9482 & TRN & & \\
\hline CHEMBL1700197 & 737357 & 2.585 & 3.1425 & TRN & & \\
\hline CHEMBL1532741 & 737357 & 2.585 & 3.0285 & TRN & & \\
\hline CHEMBL1328807 & 737357 & 3.6921 & 3.299 & TRN & & \\
\hline CHEMBL1301273 & 737357 & 5.4265 & 3.1278 & TRN & & \\
\hline CHEMBL1448109 & 737357 & 2.585 & 3.0618 & TST & & \\
\hline CHEMBL1574366 & 737357 & 2.585 & 2.7192 & TRN & & \\
\hline CHEMBL1424928 & 737357 & 2.585 & 3.0267 & TRN & & \\
\hline CHEMBL1360868 & 737357 & 2.585 & 3.2522 & TRN & & \\
\hline CHEMBL1461905 & 737357 & 2.585 & 2.9241 & TRN & & \\
\hline CHEMBL1541243 & 737357 & 2.585 & 2.9284 & TRN & & \\
\hline CHEMBL1506321 & 737357 & 2.585 & 3.0232 & TRN & & \\
\hline CHEMBL1509496 & 737357 & 2.585 & 3.4016 & TRN & & \\
\hline CHEMBL1699011 & 737357 & 2.585 & 2.9773 & TRN & & \\
\hline CHEMBL1417204 & 737357 & 5.9646 & 3.977 & TRN & & \\
\hline CHEMBL1603183 & 737357 & 4.2049 & 2.6944 & TRN & & \\
\hline CHEMBL1608439 & 737357 & 2.585 & 2.7583 & TRN & & \\
\hline CHEMBL1455481 & 737357 & 2.585 & 2.97 & TRN & & \\
\hline CHEMBL1470696 & 737357 & 2.585 & 3.0445 & TRN & & \\
\hline CHEMBL1422947 & 737357 & 4.5834 & 3.2887 & TRN & & \\
\hline CHEMBL1703804 & 737357 & 2.585 & 2.7517 & TRN & & \\
\hline CHEMBL1537615 & 737357 & 4.9698 & 3.8684 & TRN & & \\
\hline CHEMBL1419266 & 737357 & 2.585 & 3.2949 & TRN & & \\
\hline CHEMBL1302170 & 737357 & 2.585 & 3.0533 & TRN & & \\
\hline CHEMBL1340713 & 737357 & 2.585 & 3.6784 & TST & & \\
\hline CHEMBL1410986 & 737357 & 4.4376 & 3.3804 & TRN & & \\
\hline CHEMBL1461000 & 737357 & 4.6874 & 3.2883 & TRN & & \\
\hline CHEMBL1735093 & 737357 & 2.585 & 2.6437 & TRN & & \\
\hline CHEMBL1485646 & 737357 & 2.585 & 3.0666 & TRN & & \\
\hline CHEMBL1486612 & 737357 & 2.585 & 3.1229 & TRN & & \\
\hline CHEMBL1326559 & 737357 & 2.585 & 3.1306 & TRN & & \\
\hline CHEMBL19954 & 737357 & 2.585 & 4.2252 & TRN & & \\
\hline CHEMBL1333624 & 737357 & 2.585 & 2.931 & TRN & & \\
\hline CHEMBL1419844 & 737357 & 2.585 & 2.8747 & TRN & & \\
\hline
\end{tabular}




\begin{tabular}{|c|c|c|c|c|c|}
\hline & & \multicolumn{4}{|c|}{ Supplemental Table S2.txt } \\
\hline CHEMBL1415620 & 737357 & 2.585 & 2.9503 & TRN & \\
\hline CHEMBL1707896 & 737357 & 3.6101 & 3.0564 & TRN & \\
\hline CHEMBL1215474 & 737357 & 4.0757 & 3.0436 & TRN & \\
\hline CHEMBL1720173 & 737357 & 2.585 & 3.1302 & TST & \\
\hline CHEMBL1725843 & 737357 & 2.585 & 2.9129 & TRN & \\
\hline CHEMBL1355233 & 737357 & 4.3302 & 3.2461 & TRN & \\
\hline CHEMBL1508314 & 737357 & 2.585 & 2.825 & TRN & \\
\hline CHEMBL1548265 & 737357 & 4.0941 & 3.1584 & TRN & \\
\hline CHEMBL1699067 & 737357 & 2.585 & 2.7508 & TRN & \\
\hline CHEMBL1362349 & 737357 & 2.585 & 2.8914 & TRN & \\
\hline CHEMBL1606065 & 737357 & 2.585 & 3.3438 & TRN & \\
\hline CHEMBL1302598 & 737357 & 6.0474 & 3.5369 & TRN & \\
\hline CHEMBL1531100 & 737357 & 2.585 & 2.9889 & TRN & \\
\hline CHEMBL1319842 & 737357 & 2.585 & 3.0027 & TRN & \\
\hline CHEMBL1497281 & 737357 & 2.585 & 3.3094 & TST & \\
\hline CHEMBL1716830 & 737357 & 2.585 & 2.7831 & TRN & \\
\hline CHEMBL1586843 & 737357 & 3.5928 & 2.9585 & TRN & \\
\hline CHEMBL1728201 & 737357 & 2.585 & 3.0097 & TRN & \\
\hline CHEMBL1308037 & 737357 & 3.8184 & 3.0654 & TRN & \\
\hline CHEMBL1550950 & 737357 & 2.585 & 3.1771 & TRN & \\
\hline CHEMBL1303115 & 737357 & 4.6269 & 3.6735 & TRN & \\
\hline CHEMBL1436621 & 737357 & 2.585 & 2.658 & TRN & \\
\hline CHEMBL1480756 & 737357 & 4.9706 & 3.1793 & TRN & \\
\hline CHEMBL1352919 & 737357 & 5.3871 & 3.7955 & TRN & \\
\hline CHEMBL1453045 & 737357 & 2.585 & 2.6982 & TRN & \\
\hline CHEMBL1426998 & 737357 & 2.585 & 2.8842 & TRN & \\
\hline CHEMBL1350672 & 737357 & 2.585 & 3.1705 & TRN & \\
\hline CHEMBL1965780 & 737357 & 2.585 & 3.2621 & TRN & \\
\hline CHEMBL1520852 & 737357 & 4.6637 & 4.5635 & TRN & \\
\hline CHEMBL1508017 & 737357 & 2.585 & 3.0676 & TRN & \\
\hline CHEMBL1504819 & 737357 & 2.585 & 3.4019 & TST & \\
\hline CHEMBL1608392 & 737357 & 5.2973 & 3.2621 & TRN & \\
\hline CHEMBL1522395 & 737357 & 2.585 & 2.9984 & TRN & \\
\hline CHEMBL1503283 & 737357 & 2.585 & 3.1038 & TST & \\
\hline CHEMBL3197098 & 737357 & 4.8851 & 3.88199 & 99999999997 & TRN \\
\hline CHEMBL1438038 & 737357 & 4.7667 & 3.4862 & TRN & \\
\hline CHEMBL1720278 & 737357 & 2.585 & 2.8616 & TRN & \\
\hline CHEMBL1493173 & 737357 & 2.585 & 2.3959 & TRN & \\
\hline CHEMBL1462847 & 737357 & 2.585 & 3.3402 & TRN & \\
\hline CHEMBL1313242 & 737357 & 3.927 & 2.8947 & TRN & \\
\hline CHEMBL1532546 & 737357 & 3.6091 & 3.5086 & TST & \\
\hline CHEMBL1499699 & 737357 & 2.585 & 2.7885 & TRN & \\
\hline CHEMBL1336226 & 737357 & 2.585 & 3.2013 & TRN & \\
\hline CHEMBL1330929 & 737357 & 4.6173 & 3.01800 & 00000000002 & TRN \\
\hline CHEMBL1426404 & 737357 & 2.585 & 3.0869 & TST & \\
\hline CHEMBL1429274 & 737357 & 2.585 & 3.2618 & TRN & \\
\hline CHEMBL1372625 & 737357 & 4.1763 & 3.2735 & TRN & \\
\hline CHEMBL3195079 & 737357 & 2.585 & 3.4139 & TRN & \\
\hline
\end{tabular}




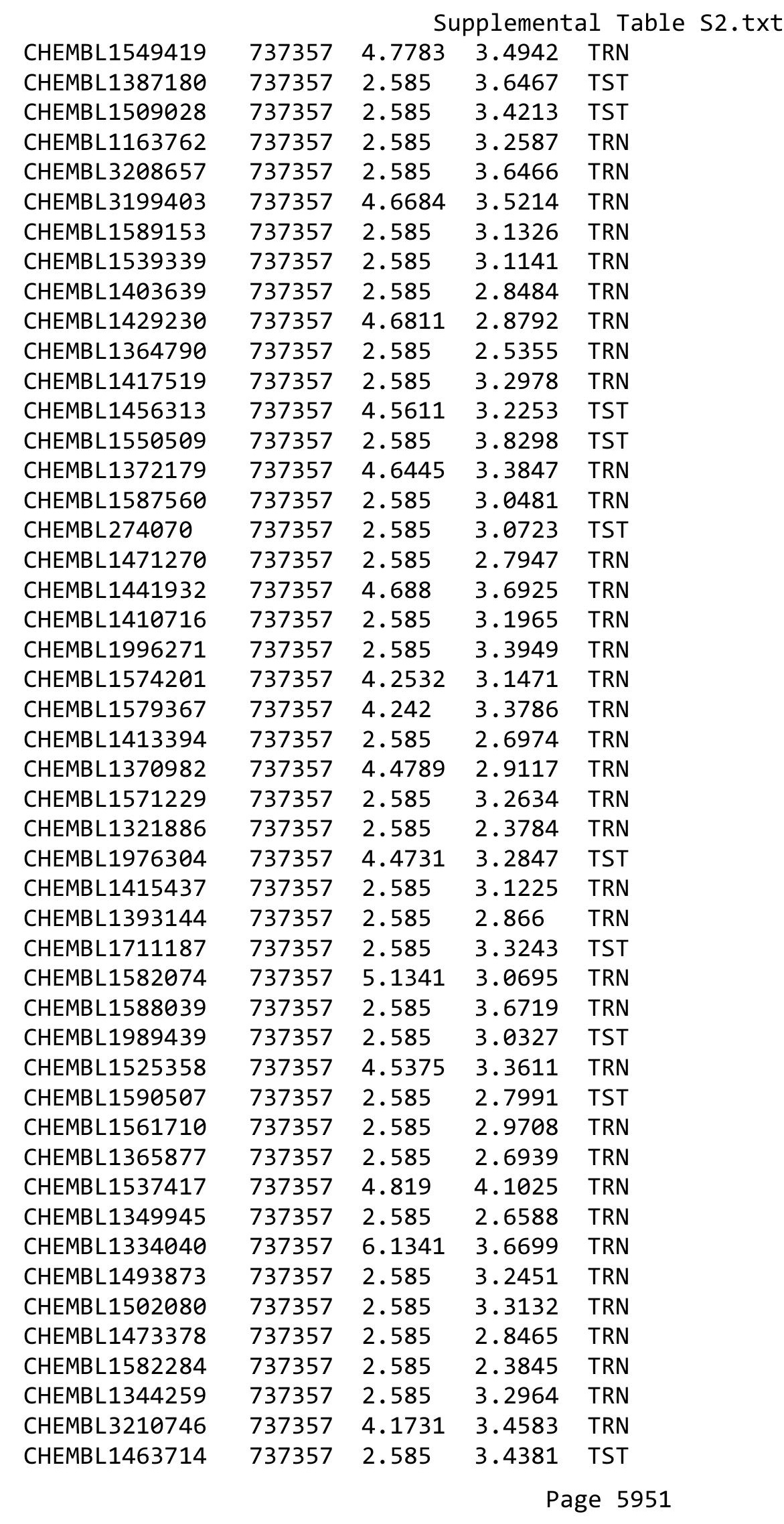


Supplemental Table S2.txt

\begin{tabular}{|c|c|c|c|c|c|}
\hline CHEMBL1523580 & 737357 & 2.585 & 2.9024 & TRN & \\
\hline CHEMBL1734761 & 737357 & 2.585 & 2.596 & TRN & \\
\hline CHEMBL1370493 & 737357 & 2.585 & 2.967 & TRN & \\
\hline CHEMBL1700485 & 737357 & 2.585 & 2.9325 & TRN & \\
\hline CHEMBL1309926 & 737357 & 2.585 & 3.1019 & TRN & \\
\hline CHEMBL1496836 & 737357 & 2.585 & 3.1808 & TST & \\
\hline CHEMBL1368420 & 737357 & 2.585 & 3.5053 & TRN & \\
\hline CHEMBL1587718 & 737357 & 2.585 & 3.4988 & TST & \\
\hline CHEMBL1339051 & 737357 & 2.585 & 2.8689 & TRN & \\
\hline CHEMBL 2003214 & 737357 & 2.585 & 3.5894 & TRN & \\
\hline CHEMBL1367574 & 737357 & 2.585 & 2.8492 & TRN & \\
\hline CHEMBL1461733 & 737357 & 2.585 & 3.5414 & TRN & \\
\hline CHEMBL1452842 & 737357 & 4.763 & 2.81699 & 99999999997 & TRN \\
\hline CHEMBL410484 & 737357 & 4.8389 & 2.8287 & TRN & \\
\hline CHEMBL1347326 & 737357 & 2.585 & 2.7309 & TRN & \\
\hline CHEMBL1534683 & 737357 & 2.585 & 3.0108 & TRN & \\
\hline CHEMBL1443778 & 737357 & 2.585 & 3.2582 & TST & \\
\hline CHEMBL1442786 & 737357 & 2.585 & 3.14399 & 99999999997 & TST \\
\hline CHEMBL1310887 & 737357 & 2.585 & 2.6743 & TRN & \\
\hline CHEMBL1342171 & 737357 & 3.6659 & 2.9237 & TRN & \\
\hline CHEMBL1999049 & 737357 & 2.585 & 4.0677 & TST & \\
\hline CHEMBL1563558 & 737357 & 2.585 & 2.9715 & TRN & \\
\hline CHEMBL1566193 & 737357 & 2.585 & 3.3276 & TRN & \\
\hline CHEMBL 2003086 & 737357 & 2.585 & 3.5807 & TRN & \\
\hline CHEMBL1371252 & 737357 & 4.1287 & 3.5681 & TRN & \\
\hline CHEMBL1379921 & 737357 & 2.585 & 3.0223 & TRN & \\
\hline CHEMBL1586980 & 737357 & 4.8765 & 2.9369 & TRN & \\
\hline CHEMBL1369247 & 737357 & 2.585 & 2.6782 & TRN & \\
\hline CHEMBL1384477 & 737357 & 2.585 & 3.1454 & TRN & \\
\hline CHEMBL1710267 & 737357 & 2.585 & 3.3222 & TRN & \\
\hline CHEMBL1702712 & 737357 & 2.585 & 2.9014 & TST & \\
\hline CHEMBL1542331 & 737357 & 2.585 & 3.3766 & TRN & \\
\hline CHEMBL1406565 & 737357 & 2.585 & 3.32800 & 00000000003 & TRN \\
\hline CHEMBL1541671 & 737357 & 2.585 & 3.0844 & TRN & \\
\hline CHEMBL1446280 & 737357 & 2.585 & 3.0624 & TRN & \\
\hline CHEMBL1713576 & 737357 & 2.585 & 3.4732 & TRN & \\
\hline CHEMBL1460017 & 737357 & 2.585 & 2.8207 & TRN & \\
\hline CHEMBL1531633 & 737357 & 5.862 & 3.6429 & TRN & \\
\hline CHEMBL1575872 & 737357 & \multicolumn{3}{|c|}{3.9589999999999996} & TRN \\
\hline CHEMBL1417223 & 737357 & 2.585 & 2.7394 & TRN & \\
\hline CHEMBL1553738 & 737357 & 4.4162 & 3.2129 & TRN & \\
\hline CHEMBL1536624 & 737357 & 2.585 & 3.2178 & TRN & \\
\hline CHEMBL1536878 & 737357 & 4.4913 & 3.9533 & TRN & \\
\hline CHEMBL1531278 & 737357 & 2.585 & 3.1297 & TRN & \\
\hline CHEMBL1418903 & 737357 & 2.585 & 2.8058 & TRN & \\
\hline CHEMBL1433224 & 737357 & 2.585 & 2.653 & TRN & \\
\hline CHEMBL1359540 & 737357 & 2.585 & 3.6921 & TST & \\
\hline CHEMBL1529788 & 737357 & 2.585 & 3.1804 & TRN & \\
\hline
\end{tabular}




\begin{tabular}{|c|c|c|c|c|c|}
\hline \multirow[b]{2}{*}{ CHEMBL1379214 } & & \multicolumn{4}{|c|}{ Supplemental Table S2.txt } \\
\hline & 737357 & 2.585 & 3.0562 & TRN & \\
\hline CHEMBL1466846 & 737357 & 4.1895 & 3.1666 & TRN & \\
\hline CHEMBL1358016 & 737357 & 2.585 & 3.6556 & TRN & \\
\hline CHEMBL1495987 & 737357 & 2.585 & 2.763 & TRN & \\
\hline CHEMBL3194353 & 737357 & 4.2858 & 3.8472 & TRN & \\
\hline CHEMBL1506862 & 737357 & 2.585 & 2.6168 & TRN & \\
\hline CHEMBL1717893 & 737357 & 2.585 & 3.5661 & TRN & \\
\hline CHEMBL1490332 & 737357 & 2.585 & 3.397 & TRN & \\
\hline CHEMBL584444 & 737357 & 2.585 & 3.3331 & TRN & \\
\hline CHEMBL1969548 & 737357 & 3.8499 & 3.6677 & TRN & \\
\hline CHEMBL1342953 & 737357 & 2.585 & 3.0416 & TRN & \\
\hline CHEMBL1337630 & 737357 & 4.1711 & 3.1401 & TRN & \\
\hline CHEMBL1546757 & 737357 & 2.585 & 3.2964 & TRN & \\
\hline CHEMBL3210212 & 737357 & 2.585 & 3.1501 & TRN & \\
\hline CHEMBL1576332 & 737357 & 2.585 & 2.9714 & TRN & \\
\hline CHEMBL 1726302 & 737357 & 2.585 & 3.1159 & TRN & \\
\hline CHEMBL1482595 & 737357 & 2.585 & 3.0739 & TRN & \\
\hline CHEMBL3208143 & 737357 & 2.585 & 3.2465 & TRN & \\
\hline CHEMBL1429298 & 737357 & 2.585 & 3.2405 & TRN & \\
\hline CHEMBL1603635 & 737357 & 2.585 & 2.8557 & TRN & \\
\hline CHEMBL1543024 & 737357 & 2.585 & 2.9722 & TRN & \\
\hline CHEMBL1576490 & 737357 & 2.585 & 3.3764 & TRN & \\
\hline CHEMBL1735257 & 737357 & 2.585 & 2.9686 & TRN & \\
\hline CHEMBL1391180 & 737357 & 4.7029 & 3.4334 & TRN & \\
\hline CHEMBL1549840 & 737357 & 5.0696 & 3.278 & TRN & \\
\hline CHEMBL 1345216 & 737357 & 2.585 & 2.8068 & TRN & \\
\hline CHEMBL1407727 & 737357 & 2.585 & 2.489 & TRN & \\
\hline CHEMBL1716182 & 737357 & 2.585 & 2.5366 & TRN & \\
\hline CHEMBL1491932 & 737357 & 4.5583 & 4.1481 & TRN & \\
\hline CHEMBL1342903 & 737357 & 2.585 & 3.16300 & 00000000003 & TRN \\
\hline CHEMBL1402150 & 737357 & 2.585 & 2.8189 & TRN & \\
\hline CHEMBL1383966 & 737357 & 2.585 & 3.3812 & TRN & \\
\hline CHEMBL1721115 & 737357 & 2.585 & 2.5218 & TRN & \\
\hline CHEMBL3199539 & 737357 & 4.7314 & 3.9683 & TRN & \\
\hline CHEMBL1311879 & 737357 & 5.0077 & 4.6398 & TRN & \\
\hline CHEMBL1607482 & 737357 & 2.585 & 2.9428 & TRN & \\
\hline CHEMBL3191942 & 737357 & 2.585 & 3.8045 & TRN & \\
\hline CHEMBL1597960 & 737357 & 4.0416 & 3.0573 & TRN & \\
\hline CHEMBL1416741 & 737357 & 2.585 & 3.188 & TRN & \\
\hline CHEMBL3212708 & 737357 & 2.585 & 3.4908 & TRN & \\
\hline CHEMBL3192693 & 737357 & 2.585 & 4.2059 & TRN & \\
\hline CHEMBL 2003651 & 737357 & 2.585 & 3.9752 & TRN & \\
\hline CHEMBL1386302 & 737357 & 4.71899 & 99999999 & 3.1118 & TRN \\
\hline CHEMBL1597102 & 737357 & 2.585 & 2.8718 & TRN & \\
\hline CHEMBL1708951 & 737357 & 2.585 & 3.4414 & TRN & \\
\hline CHEMBL 1545632 & 737357 & 4.3207 & 3.0951 & TRN & \\
\hline CHEMBL1729142 & 737357 & 3.8623 & 2.7095 & TRN & \\
\hline CHEMBL1507939 & 737357 & 2.585 & 3.0145 & TRN & \\
\hline
\end{tabular}




\begin{tabular}{|c|c|c|c|c|c|}
\hline & & \multicolumn{4}{|c|}{ Supplemental Table S2.txt } \\
\hline CHEMBL1371816 & 737357 & 4.9618 & 3.3539 & TRN & \\
\hline CHEMBL1597479 & 737357 & 2.585 & 2.8679 & TRN & \\
\hline CHEMBL1437900 & 737357 & 2.585 & 2.4434 & TRN & \\
\hline CHEMBL1347913 & 737357 & 2.585 & 2.8087 & TRN & \\
\hline CHEMBL1353046 & 737357 & 2.585 & 3.0198 & TRN & \\
\hline CHEMBL1550221 & 737357 & 2.585 & 3.6228 & TRN & \\
\hline CHEMBL1502104 & 737357 & 5.0499 & 3.4308 & TRN & \\
\hline CHEMBL1319028 & 737357 & 2.585 & 3.3489 & TRN & \\
\hline CHEMBL1527421 & 737357 & 2.585 & 3.0994 & TRN & \\
\hline CHEMBL1411303 & 737357 & 2.585 & 3.2509 & TRN & \\
\hline CHEMBL1452235 & 737357 & 3.6133 & 3.7262 & TRN & \\
\hline CHEMBL1352394 & 737357 & 2.585 & 2.8102 & TRN & \\
\hline CHEMBL1306520 & 737357 & 2.585 & 3.12600 & 00000000003 & TST \\
\hline CHEMBL1418885 & 737357 & 4.7972 & 4.586 & TRN & \\
\hline CHEMBL1381710 & 737357 & 2.585 & 3.1392 & TRN & \\
\hline CHEMBL1722514 & 737357 & 4.673 & 3.1356 & TST & \\
\hline CHEMBL1424739 & 737357 & 2.585 & 3.7206 & TST & \\
\hline CHEMBL1351165 & 737357 & 2.585 & 2.9856 & TRN & \\
\hline CHEMBL528694 & 737357 & 5.4774 & 4.6474 & TRN & \\
\hline CHEMBL1507740 & 737357 & 4.6419 & 3.0134 & TRN & \\
\hline CHEMBL1313582 & 737357 & 2.585 & 3.2328 & TRN & \\
\hline CHEMBL1370794 & 737357 & 2.585 & 3.2045 & TRN & \\
\hline CHEMBL1526681 & 737357 & 2.585 & 3.5535 & TRN & \\
\hline CHEMBL1536585 & 737357 & 2.585 & 3.3933 & TRN & \\
\hline CHEMBL1611722 & 737357 & 2.585 & 3.0182 & TRN & \\
\hline CHEMBL1534346 & 737357 & 2.585 & 2.6527 & TRN & \\
\hline CHEMBL1492999 & 737357 & 2.585 & 3.4 & TST & \\
\hline CHEMBL1705884 & 737357 & 2.585 & 2.6744 & TRN & \\
\hline CHEMBL1311570 & 737357 & 4.4368 & 3.1488 & TRN & \\
\hline CHEMBL1443890 & 737357 & 2.585 & 3.23199 & 99999999998 & TRN \\
\hline CHEMBL1988303 & 737357 & 2.585 & 3.6154 & TRN & \\
\hline CHEMBL1483859 & 737357 & 2.585 & 2.7203 & TRN & \\
\hline CHEMBL1976412 & 737357 & 5.3576 & 3.8327 & TRN & \\
\hline CHEMBL1468562 & 737357 & 5.1854 & 2.9609 & TRN & \\
\hline CHEMBL1565623 & 737357 & 5.1115 & 3.7673 & TRN & \\
\hline CHEMBL1373085 & 737357 & 2.585 & 3.2209 & TST & \\
\hline CHEMBL1585797 & 737357 & 2.585 & 2.526 & TRN & \\
\hline CHEMBL3207638 & 737357 & 2.585 & 3.0565 & TRN & \\
\hline CHEMBL1393257 & 737357 & 2.585 & 3.1608 & TRN & \\
\hline CHEMBL1466526 & 737357 & 4.4593 & 2.9292 & TRN & \\
\hline CHEMBL1965975 & 737357 & 2.585 & 3.1879 & TRN & \\
\hline CHEMBL1380335 & 737357 & 2.585 & 2.9881 & TRN & \\
\hline CHEMBL3209735 & 737357 & 2.585 & 2.7006 & TRN & \\
\hline CHEMBL1587057 & 737357 & 2.585 & 2.8225 & TRN & \\
\hline CHEMBL1328731 & 737357 & 2.585 & 2.4995 & TRN & \\
\hline CHEMBL1331071 & 737357 & 2.585 & 3.2923 & TRN & \\
\hline CHEMBL1422161 & 737357 & 4.5855 & 3.4163 & TRN & \\
\hline CHEMBL1488346 & 737357 & 4.225 & 2.9806 & TRN & \\
\hline
\end{tabular}




\begin{tabular}{|c|c|c|c|c|c|}
\hline & & \multicolumn{4}{|c|}{ Supplemental Table S2.txt } \\
\hline CHEMBL1511419 & 737357 & 2.585 & 2.9021 & TRN & \\
\hline CHEMBL1332139 & 737357 & 4.5852 & 4.3323 & TST & \\
\hline CHEMBL1726845 & 737357 & 2.585 & 3.0553 & TRN & \\
\hline CHEMBL1562349 & 737357 & 2.585 & 2.6211 & TRN & \\
\hline CHEMBL1561457 & 737357 & 2.585 & 3.5609 & TRN & \\
\hline CHEMBL1299616 & 737357 & 2.585 & 3.1672 & TRN & \\
\hline CHEMBL1998461 & 737357 & 4.3679 & 3.5619 & TRN & \\
\hline CHEMBL1703988 & 737357 & 2.585 & 2.9819 & TRN & \\
\hline CHEMBL1448698 & 737357 & 4.2152 & 3.7498 & TRN & \\
\hline CHEMBL1457472 & 737357 & 2.585 & 3.4301 & TRN & \\
\hline CHEMBL1549996 & 737357 & 4.3363 & 3.2518 & TRN & \\
\hline CHEMBL1321387 & 737357 & 2.585 & 3.1139 & TRN & \\
\hline CHEMBL1528835 & 737357 & 4.2208 & 3.2758 & TST & \\
\hline CHEMBL1445106 & 737357 & 2.585 & 2.4718 & TRN & \\
\hline CHEMBL1547243 & 737357 & 2.585 & 3.2351 & TRN & \\
\hline CHEMBL1592785 & 737357 & 4.4309 & 3.0531 & TRN & \\
\hline CHEMBL1375659 & 737357 & 4.5549 & 3.6744 & TST & \\
\hline CHEMBL1384182 & 737357 & 2.585 & 3.2933 & TRN & \\
\hline CHEMBL1519457 & 737357 & 2.585 & 3.2166 & TRN & \\
\hline CHEMBL1732007 & 737357 & 2.585 & 2.6755 & TRN & \\
\hline CHEMBL1991523 & 737357 & 2.585 & 3.0648 & TRN & \\
\hline CHEMBL1993447 & 737357 & 4.4989 & 3.2712 & TRN & \\
\hline CHEMBL1582756 & 737357 & 4.2248 & 2.9048 & TRN & \\
\hline CHEMBL1414859 & 737357 & 2.585 & 2.8542 & TRN & \\
\hline CHEMBL1485267 & 737357 & 2.585 & 3.3263 & TRN & \\
\hline CHEMBL1716699 & 737357 & 2.585 & 3.4328 & TRN & \\
\hline CHEMBL3197844 & 737357 & 2.585 & 2.8008 & TRN & \\
\hline CHEMBL1717544 & 737357 & 2.585 & 2.7012 & TRN & \\
\hline CHEMBL1983220 & 737357 & 5.2714 & 3.4337 & TST & \\
\hline CHEMBL1348535 & 737357 & 2.585 & 3.0369 & TRN & \\
\hline CHEMBL1420086 & 737357 & 2.585 & 3.6236 & TRN & \\
\hline CHEMBL1390623 & 737357 & 2.585 & 2.9743 & TRN & \\
\hline CHEMBL1985310 & 737357 & 2.585 & 3.7952 & TRN & \\
\hline CHEMBL1604719 & 737357 & 2.585 & 3.5807 & TRN & \\
\hline CHEMBL3197001 & 737357 & 2.585 & 3.25600 & 00000000002 & TRN \\
\hline CHEMBL1382886 & 737357 & 2.585 & 3.4307 & TRN & \\
\hline CHEMBL1488300 & 737357 & 3.6957 & 3.1779 & TRN & \\
\hline CHEMBL1439950 & 737357 & 2.585 & 2.5846 & TRN & \\
\hline CHEMBL1549231 & 737357 & 2.585 & 3.415 & TRN & \\
\hline CHEMBL1558434 & 737357 & 2.585 & 3.0166 & TRN & \\
\hline CHEMBL1400769 & 737357 & 2.585 & 2.9631 & TRN & \\
\hline CHEMBL241987 & 737357 & 3.9014 & 3.32899 & 99999999997 & TRN \\
\hline CHEMBL1609678 & 737357 & 2.585 & 3.2583 & TRN & \\
\hline CHEMBL1460791 & 737357 & 4.4082 & 3.1246 & TRN & \\
\hline CHEMBL3208046 & 737357 & 2.585 & 3.5562 & TRN & \\
\hline CHEMBL1336419 & 737357 & 4.3658 & 3.1176 & TRN & \\
\hline CHEMBL1526966 & 737357 & 5.1128 & 4.2193 & TRN & \\
\hline CHEMBL1545282 & 737357 & 2.585 & 3.1213 & TRN & \\
\hline
\end{tabular}




\begin{tabular}{|c|c|c|c|c|c|}
\hline & & \multicolumn{4}{|c|}{ Supplemental Table S2.txt } \\
\hline CHEMBL1594253 & 737357 & 2.585 & 2.948 & TRN & \\
\hline CHEMBL1607877 & 737357 & 4.9337 & 3.1102 & TRN & \\
\hline CHEMBL1547627 & 737357 & 2.585 & 3.1146 & TST & \\
\hline CHEMBL1558252 & 737357 & 2.585 & 2.5924 & TRN & \\
\hline CHEMBL1322901 & 737357 & 2.585 & 3.2237 & TRN & \\
\hline CHEMBL1359631 & 737357 & 2.585 & 3.071 & TRN & \\
\hline CHEMBL1721867 & 737357 & 2.585 & 2.6095 & TRN & \\
\hline CHEMBL1503292 & 737357 & 4.7994 & 3.6388 & TRN & \\
\hline CHEMBL1420854 & 737357 & 2.585 & 3.2296 & TRN & \\
\hline CHEMBL1543886 & 737357 & 2.585 & 2.77100 & 00000000004 & TRN \\
\hline CHEMBL1608893 & 737357 & 2.585 & 2.9822 & TRN & \\
\hline CHEMBL1413661 & 737357 & 4.8661 & 3.6148 & TRN & \\
\hline CHEMBL1377240 & 737357 & 2.585 & 3.0343 & TRN & \\
\hline CHEMBL1540204 & 737357 & 2.585 & 3.3019 & TRN & \\
\hline CHEMBL1331197 & 737357 & 2.585 & 2.7726 & TRN & \\
\hline CHEMBL1487918 & 737357 & 2.585 & 2.9033 & TST & \\
\hline CHEMBL1392869 & 737357 & 2.585 & 3.03 & TRN & \\
\hline CHEMBL 3208922 & 737357 & 2.585 & 3.2636 & TRN & \\
\hline CHEMBL1523239 & 737357 & 2.585 & 2.5874 & TRN & \\
\hline CHEMBL532776 & 737357 & 2.585 & 3.2654 & TRN & \\
\hline CHEMBL1371372 & 737357 & 2.585 & 3.1813 & TRN & \\
\hline CHEMBL1454585 & 737357 & 2.585 & 3.9927 & TST & \\
\hline CHEMBL1548439 & 737357 & 5.0393 & 3.737 & TRN & \\
\hline CHEMBL1380541 & 737357 & 2.585 & 2.9265 & TRN & \\
\hline CHEMBL1529455 & 737357 & 4.828 & 3.6174 & TRN & \\
\hline CHEMBL1421284 & 737357 & 2.585 & 3.0955 & TRN & \\
\hline CHEMBL1369432 & 737357 & 2.585 & 3.2026 & TRN & \\
\hline CHEMBL1490060 & 737357 & 6.0056 & 3.58100 & 00000000004 & TRN \\
\hline CHEMBL1464236 & 737357 & 2.585 & 3.4868 & TST & \\
\hline CHEMBL1493256 & 737357 & 4.7421 & 2.9039 & TST & \\
\hline CHEMBL1577495 & 737357 & 4.2378 & 2.9346 & TRN & \\
\hline CHEMBL1360715 & 737357 & 2.585 & 3.0195 & TRN & \\
\hline CHEMBL1464723 & 737357 & 4.9154 & 3.3175 & TRN & \\
\hline CHEMBL1441784 & 737357 & 2.585 & 3.0512 & TRN & \\
\hline CHEMBL 2004711 & 737357 & 2.585 & 3.2443 & TST & \\
\hline CHEMBL1415691 & 737357 & 2.585 & 3.0874 & TRN & \\
\hline CHEMBL3192106 & 737357 & 4.9512 & 3.2884 & TRN & \\
\hline CHEMBL1299358 & 737357 & 2.585 & 3.3305 & TRN & \\
\hline CHEMBL1547101 & 737357 & 2.585 & 3.6394 & TST & \\
\hline CHEMBL1725923 & 737357 & 2.585 & 3.0879 & TST & \\
\hline CHEMBL1582834 & 737357 & 4.4984 & 3.2794 & TRN & \\
\hline CHEMBL1310221 & 737357 & 4.2827 & 3.4816 & TRN & \\
\hline CHEMBL1402703 & 737357 & 2.585 & 2.478 & TRN & \\
\hline CHEMBL1598313 & 737357 & 4.2752 & 2.8465 & TRN & \\
\hline CHEMBL3144995 & 737357 & 2.585 & 3.4129 & TRN & \\
\hline CHEMBL1460483 & 737357 & 2.585 & 2.9011 & TRN & \\
\hline CHEMBL1601549 & 737357 & 2.585 & 3.4117 & TRN & \\
\hline CHEMBL1594719 & 737357 & 2.585 & 3.1735 & TRN & \\
\hline
\end{tabular}


Supplemental Table S2.txt

\begin{tabular}{|c|c|c|c|c|c|}
\hline CHEMBL1704554 & 737357 & 2.585 & 2.9165 & TRN & \\
\hline CHEMBL1598116 & 737357 & 4.2303 & 3.3611 & TRN & \\
\hline CHEMBL1582305 & 737357 & 4.1535 & 3.3633 & TRN & \\
\hline CHEMBL1721381 & 737357 & 2.585 & 2.964 & TRN & \\
\hline CHEMBL1312089 & 737357 & 2.585 & 3.0569 & TRN & \\
\hline CHEMBL1503966 & 737357 & 2.585 & 3.2338 & TRN & \\
\hline CHEMBL1349110 & 737357 & 2.585 & 2.6341 & TRN & \\
\hline CHEMBL1541081 & 737357 & 2.585 & 3.1544 & TRN & \\
\hline CHEMBL1309987 & 737357 & 2.585 & \multicolumn{2}{|c|}{ 3.3139999999999996 } & TST \\
\hline CHEMBL1381235 & 737357 & 2.585 & 2.7255 & TRN & \\
\hline CHEMBL1400217 & 737357 & 2.585 & 3.2141 & TRN & \\
\hline CHEMBL3198929 & 737357 & 3.9477 & 3.0449 & TRN & \\
\hline CHEMBL1566835 & 737357 & 5.0681 & 3.105 & TRN & \\
\hline CHEMBL1569836 & 737357 & 2.585 & 3.056 & TRN & \\
\hline CHEMBL1504294 & 737357 & 2.585 & 3.2837 & TRN & \\
\hline CHEMBL1483662 & 737357 & 2.585 & 3.0464 & TRN & \\
\hline CHEMBL1555759 & 737357 & 2.585 & 3.091 & TST & \\
\hline CHEMBL1510661 & 737357 & 4.2573 & 3.2209 & TRN & \\
\hline CHEMBL1517563 & 737357 & 2.585 & 2.8801 & TRN & \\
\hline CHEMBL1576473 & 737357 & 2.585 & 2.9 & TRN & \\
\hline CHEMBL1586722 & 737357 & 4.1533 & \multicolumn{2}{|c|}{3.0839999999999996} & TRN \\
\hline CHEMBL1388499 & 737357 & 2.585 & 3.1145 & TST & \\
\hline CHEMBL1434250 & 737357 & 4.8941 & 3.0787 & TRN & \\
\hline CHEMBL1597676 & 737357 & 2.585 & 2.6507 & TRN & \\
\hline CHEMBL1474894 & 737357 & 2.585 & 2.6272 & TRN & \\
\hline CHEMBL1533067 & 737357 & 4.556 & 3.7293 & TST & \\
\hline CHEMBL1723366 & 737357 & 2.585 & 2.9568 & TRN & \\
\hline CHEMBL1432239 & 737357 & 2.585 & 3.0345 & TRN & \\
\hline CHEMBL1589402 & 737357 & 2.585 & 3.6643 & TRN & \\
\hline CHEMBL1426814 & 737357 & 4.1869 & 2.8005 & TRN & \\
\hline CHEMBL1486503 & 737357 & 4.5214 & 3.8541 & TRN & \\
\hline CHEMBL1322579 & 737357 & 2.585 & 2.7484 & TRN & \\
\hline CHEMBL1997928 & 737357 & 5.4655 & 3.0881 & TRN & \\
\hline CHEMBL1427882 & 737357 & 2.585 & 2.9166 & TRN & \\
\hline CHEMBL1700396 & 737357 & 2.585 & 2.2691 & TRN & \\
\hline CHEMBL1613090 & 737357 & 5.3366 & 3.2772 & TRN & \\
\hline CHEMBL1497238 & 737357 & 2.585 & 2.8818 & TRN & \\
\hline CHEMBL1596521 & 737357 & 2.585 & 3.1387 & TRN & \\
\hline CHEMBL1441339 & 737357 & 2.585 & 2.7946 & TRN & \\
\hline CHEMBL1365853 & 737357 & 2.585 & 3.0119 & TRN & \\
\hline CHEMBL1471293 & 737357 & 2.585 & 3.0627 & TRN & \\
\hline CHEMBL1539684 & 737357 & 2.585 & 3.5652 & TST & \\
\hline CHEMBL596271 & 737357 & 2.585 & 2.9019 & TRN & \\
\hline CHEMBL1305054 & 737357 & 4.4209 & 3.0639 & TRN & \\
\hline CHEMBL1470758 & 737357 & 2.585 & 3.0437 & TRN & \\
\hline CHEMBL1401342 & 737357 & 4.699 & 3.6781 & TST & \\
\hline CHEMBL1455930 & 737357 & 2.585 & 2.784 & TRN & \\
\hline CHEMBL1596063 & 737357 & 2.585 & 3.0794 & TST & \\
\hline
\end{tabular}


Supplemental Table S2.txt

\begin{tabular}{|c|c|c|c|c|c|c|}
\hline CHEMBL1390038 & 737357 & 2.585 & 2.9512 & TRN & & \\
\hline CHEMBL1510511 & 737357 & 2.585 & 3.1411 & TRN & & \\
\hline CHEMBL1727372 & 737357 & 2.585 & 3.2777 & TRN & & \\
\hline CHEMBL1579659 & 737357 & 2.585 & 2.8401 & TRN & & \\
\hline CHEMBL1405421 & 737357 & 2.585 & 2.4325 & TRN & & \\
\hline CHEMBL1498383 & 737357 & 2.585 & 2.4878 & TRN & & \\
\hline CHEMBL1447281 & 737357 & 4.4083 & 3.7478 & TRN & & \\
\hline CHEMBL1543224 & 737357 & 2.585 & 3.016 & TRN & & \\
\hline CHEMBL1539941 & 737357 & 2.585 & 2.7874 & TRN & & \\
\hline CHEMBL1303162 & 737357 & 2.585 & 2.9482 & TRN & & \\
\hline CHEMBL1421868 & 737357 & 4.6077 & 3.0255 & TRN & & \\
\hline CHEMBL1731709 & 737357 & 2.585 & 2.9535 & TRN & & \\
\hline CHEMBL1299552 & 737357 & 2.585 & 2.9208 & TRN & & \\
\hline CHEMBL1588004 & 737357 & 2.585 & 3.3642 & TRN & & \\
\hline CHEMBL1525668 & 737357 & 2.585 & 2.6326 & TRN & & \\
\hline CHEMBL1364018 & 737357 & 4.447 & 3.7426 & TRN & & \\
\hline CHEMBL1407509 & 737357 & 2.585 & 2.7547 & TRN & & \\
\hline CHEMBL1998379 & 737357 & 2.585 & 3.42199 & 99999999997 & TST & \\
\hline CHEMBL1312931 & 737357 & 2.585 & 2.867 & TRN & & \\
\hline CHEMBL1437061 & 737357 & 2.585 & 2.9035 & TRN & & \\
\hline CHEMBL1500144 & 737357 & 4.5772 & 3.1035 & TRN & & \\
\hline CHEMBL1710035 & 737357 & 2.585 & 3.1447 & TRN & & \\
\hline CHEMBL1478031 & 737357 & 2.585 & 3.1299 & TRN & & \\
\hline CHEMBL1502717 & 737357 & 2.585 & 3.0926 & TRN & & \\
\hline CHEMBL1527964 & 737357 & \multicolumn{4}{|c|}{3.7430000000000003} & TRN \\
\hline CHEMBL1546298 & 737357 & 2.585 & 2.9618 & TRN & & \\
\hline CHEMBL1698244 & 737357 & 2.585 & 3.2227 & TRN & & \\
\hline CHEMBL1720952 & 737357 & 2.585 & 2.971 & TRN & & \\
\hline CHEMBL1398826 & 737357 & 4.8342 & 3.6501 & TRN & & \\
\hline CHEMBL1331599 & 737357 & 2.585 & 3.1911 & TST & & \\
\hline CHEMBL1448959 & 737357 & 2.585 & 2.8911 & TRN & & \\
\hline CHEMBL1416175 & 737357 & 2.585 & 2.6696 & TRN & & \\
\hline CHEMBL1509699 & 737357 & 2.585 & 3.1996 & TST & & \\
\hline CHEMBL 2003935 & 737357 & 2.585 & 3.7992 & TRN & & \\
\hline CHEMBL1502802 & 737357 & 2.585 & 2.8357 & TRN & & \\
\hline CHEMBL1728448 & 737357 & 2.585 & 2.7532 & TRN & & \\
\hline CHEMBL1534158 & 737357 & 2.585 & 2.7315 & TRN & & \\
\hline CHEMBL1493700 & 737357 & 2.585 & 3.3422 & TRN & & \\
\hline CHEMBL1470914 & 737357 & 5.0903 & 3.05899 & 99999999997 & TRN & \\
\hline CHEMBL1586147 & 737357 & 2.585 & 3.4299 & TRN & & \\
\hline CHEMBL1531815 & 737357 & 2.585 & 2.7275 & TRN & & \\
\hline CHEMBL1348298 & 737357 & 2.585 & 3.2024 & TRN & & \\
\hline CHEMBL1970272 & 737357 & 4.351 & 2.9976 & TRN & & \\
\hline CHEMBL 1702320 & 737357 & 2.585 & 2.6185 & TRN & & \\
\hline CHEMBL3144967 & 737357 & 5.4126 & 3.3753 & TRN & & \\
\hline CHEMBL1589470 & 737357 & 2.585 & 2.9813 & TRN & & \\
\hline CHEMBL1520210 & 737357 & 4.5016 & 2.8394 & TRN & & \\
\hline CHEMBL1567513 & 737357 & 2.585 & 3.0765 & TRN & & \\
\hline
\end{tabular}




\begin{tabular}{|c|c|c|c|c|c|}
\hline & & \multicolumn{4}{|c|}{ Supplemental Table S2.txt } \\
\hline CHEMBL1585081 & 737357 & 2.585 & 3.1572 & TRN & \\
\hline CHEMBL1597459 & 737357 & 4.8345 & 3.7136 & TRN & \\
\hline CHEMBL1583930 & 737357 & 2.585 & 3.2589 & TST & \\
\hline CHEMBL1727651 & 737357 & 2.585 & 3.5377 & TRN & \\
\hline CHEMBL1392679 & 737357 & 2.585 & 3.1342 & TRN & \\
\hline CHEMBL1389050 & 737357 & 2.585 & 2.8474 & TST & \\
\hline CHEMBL1368851 & 737357 & 2.585 & 2.8439 & TRN & \\
\hline CHEMBL1305650 & 737357 & 2.585 & 2.9034 & TST & \\
\hline CHEMBL1570958 & 737357 & 5.347 & 4.6819 & TRN & \\
\hline CHEMBL1711427 & 737357 & 2.585 & 2.376 & TRN & \\
\hline CHEMBL1555655 & 737357 & 2.585 & 3.1194 & TRN & \\
\hline CHEMBL1497197 & 737357 & 2.585 & 3.5029 & TRN & \\
\hline CHEMBL1498398 & 737357 & 2.585 & 3.0656 & TST & \\
\hline CHEMBL1714153 & 737357 & 2.585 & 3.0403 & TRN & \\
\hline CHEMBL3212311 & 737357 & 4.997 & 3.28800 & 00000000003 & TRN \\
\hline CHEMBL1467978 & 737357 & 2.585 & 2.8774 & TST & \\
\hline CHEMBL1563453 & 737357 & 2.585 & 2.8833 & TRN & \\
\hline CHEMBL1352415 & 737357 & 2.585 & 3.8308 & TRN & \\
\hline CHEMBL1529401 & 737357 & 2.585 & 3.3801 & TRN & \\
\hline CHEMBL1382564 & 737357 & 2.585 & 3.5493 & TRN & \\
\hline CHEMBL1734729 & 737357 & 2.585 & 2.5794 & TRN & \\
\hline CHEMBL1304807 & 737357 & 2.585 & 3.11899 & 99999999998 & TRN \\
\hline CHEMBL1566160 & 737357 & 2.585 & 2.8096 & TRN & \\
\hline CHEMBL1431696 & 737357 & 2.585 & 3.0018 & TRN & \\
\hline CHEMBL265515 & 737357 & 5.0364 & 3.4117 & TRN & \\
\hline CHEMBL1364584 & 737357 & 2.585 & 3.824 & TRN & \\
\hline CHEMBL1548389 & 737357 & 2.585 & 3.3021 & TRN & \\
\hline CHEMBL1472413 & 737357 & 2.585 & 3.0623 & TRN & \\
\hline CHEMBL1371774 & 737357 & 5.2621 & 3.6948 & TRN & \\
\hline CHEMBL1508051 & 737357 & 5.2624 & 3.3186 & TRN & \\
\hline CHEMBL1547940 & 737357 & 4.8729 & 3.1189 & TRN & \\
\hline CHEMBL1980604 & 737357 & 4.7794 & 3.3407 & TRN & \\
\hline CHEMBL1422741 & 737357 & 2.585 & 3.0474 & TRN & \\
\hline CHEMBL1587078 & 737357 & 5.4483 & 3.7751 & TST & \\
\hline CHEMBL1533036 & 737357 & 2.585 & 3.0415 & TRN & \\
\hline CHEMBL1579986 & 737357 & 2.585 & 2.5749 & TRN & \\
\hline CHEMBL1326836 & 737357 & 2.585 & 2.9346 & TST & \\
\hline CHEMBL1522943 & 737357 & 2.585 & 3.1279 & TRN & \\
\hline CHEMBL1580538 & 737357 & 2.585 & 2.9974 & TRN & \\
\hline CHEMBL1450034 & 737357 & 2.585 & 2.801 & TRN & \\
\hline CHEMBL1599408 & 737357 & 2.585 & 3.2113 & TRN & \\
\hline CHEMBL1414684 & 737357 & 2.585 & 3.1882 & TRN & \\
\hline CHEMBL1464470 & 737357 & 2.585 & 3.0528 & TRN & \\
\hline CHEMBL1511719 & 737357 & 2.585 & 2.986 & TRN & \\
\hline CHEMBL1421803 & 737357 & 2.585 & 2.8849 & TRN & \\
\hline CHEMBL1447194 & 737357 & 2.585 & 3.4803 & TST & \\
\hline CHEMBL1360156 & 737357 & 2.585 & 2.9197 & TRN & \\
\hline CHEMBL1508896 & 737357 & 4.7488 & 4.4058 & TRN & \\
\hline
\end{tabular}




\begin{tabular}{|c|c|c|c|c|c|c|}
\hline \multirow[b]{2}{*}{ CHEMBL1306502 } & & \multicolumn{5}{|c|}{ Supplemental Table S2.txt } \\
\hline & 737357 & 2.585 & 2.9465 & TRN & & \\
\hline CHEMBL1572955 & 737357 & 4.8505 & 3.45399 & 99999999997 & & TRN \\
\hline CHEMBL1371925 & 737357 & 4.6142 & 3.5786 & TRN & & \\
\hline CHEMBL 3211670 & 737357 & 2.585 & 3.1796 & TRN & & \\
\hline CHEMBL1594896 & 737357 & 5.1655 & 3.96100 & 00000000003 & & TRN \\
\hline CHEMBL1443501 & 737357 & 2.585 & 2.8668 & TRN & & \\
\hline CHEMBL1599819 & 737357 & 2.585 & 2.8509 & TRN & & \\
\hline CHEMBL1543295 & 737357 & 5.0133 & 3.8804 & TST & & \\
\hline CHEMBL1412381 & 737357 & 2.585 & 3.5452 & TRN & & \\
\hline CHEMBL1334794 & 737357 & 4.5438 & 2.9129 & TRN & & \\
\hline CHEMBL1422795 & 737357 & 2.585 & 2.6836 & TRN & & \\
\hline CHEMBL1439269 & 737357 & 2.585 & 3.3484 & TST & & \\
\hline CHEMBL1727601 & 737357 & 2.585 & 2.8821 & TST & & \\
\hline CHEMBL1489165 & 737357 & 2.585 & 2.6791 & TRN & & \\
\hline CHEMBL1481525 & 737357 & 5.6635 & 3.2797 & TRN & & \\
\hline CHEMBL1533776 & 737357 & 2.585 & 3.3462 & TRN & & \\
\hline CHEMBL1334950 & 737357 & 2.585 & 2.8258 & TRN & & \\
\hline CHEMBL1461400 & 737357 & 2.585 & 3.3877 & TRN & & \\
\hline CHEMBL1390998 & 737357 & 2.585 & 3.0664 & TRN & & \\
\hline CHEMBL1533164 & 737357 & 2.585 & 3.2766 & TRN & & \\
\hline CHEMBL1533738 & 737357 & 4.5546 & 3.386 & TRN & & \\
\hline CHEMBL1482927 & 737357 & 2.585 & 2.7833 & TRN & & \\
\hline CHEMBL1709573 & 737357 & 2.585 & 3.2732 & TST & & \\
\hline CHEMBL1536327 & 737357 & 4.8 & 2.8032 & TRN & & \\
\hline CHEMBL1421061 & 737357 & 2.585 & 3.0297 & TRN & & \\
\hline CHEMBL1701768 & 737357 & 2.585 & 3.0911 & TRN & & \\
\hline CHEMBL3195728 & 737357 & 2.585 & 3.5554 & TST & & \\
\hline CHEMBL1970784 & 737357 & 2.585 & 3.4611 & TRN & & \\
\hline CHEMBL1350826 & 737357 & 2.585 & 3.412 & TRN & & \\
\hline CHEMBL1535706 & 737357 & 2.585 & 3.3559 & TRN & & \\
\hline CHEMBL1550022 & 737357 & 2.585 & 2.8933 & TRN & & \\
\hline CHEMBL1726195 & 737357 & 2.585 & 3.09800 & 00000000003 & & TRN \\
\hline CHEMBL1368809 & 737357 & 3.957 & 2.8235 & TRN & & \\
\hline CHEMBL1535991 & 737357 & 4.2167 & 3.053 & TRN & & \\
\hline CHEMBL1451883 & 737357 & 2.585 & 3.4073 & TRN & & \\
\hline CHEMBL1728155 & 737357 & 2.585 & 2.95300 & 00000000003 & & TRN \\
\hline CHEMBL1414077 & 737357 & 2.585 & 2.6424 & TRN & & \\
\hline CHEMBL1564801 & 737357 & 4.1712 & 3.4209 & TRN & & \\
\hline CHEMBL1404515 & 737357 & 2.585 & 3.0743 & TRN & & \\
\hline CHEMBL1494935 & 737357 & 3.8665 & 2.95300 & 00000000003 & & TRN \\
\hline CHEMBL1461393 & 737357 & 3.8824 & 3.7418 & TRN & & \\
\hline CHEMBL1446474 & 737357 & 2.585 & 2.7219 & TRN & & \\
\hline CHEMBL1734401 & 737357 & 2.585 & 2.9731 & TRN & & \\
\hline CHEMBL1496051 & 737357 & 3.75600 & 30000000 & 002 & .6137 & TRN \\
\hline CHEMBL1516783 & 737357 & 4.60800 & 30000000 & 005 & .0419 & TRN \\
\hline CHEMBL1459535 & 737357 & 2.585 & 3.0162 & TRN & & \\
\hline CHEMBL1337780 & 737357 & 2.585 & 3.1239 & TST & & \\
\hline CHEMBL1466048 & 737357 & 2.585 & 3.2791 & TRN & & \\
\hline
\end{tabular}




\begin{tabular}{|c|c|c|c|c|c|}
\hline & & \multicolumn{4}{|c|}{ Supplemental Table S2.txt } \\
\hline CHEMBL1519014 & 737357 & 4.8645 & 3.5526 & TRN & \\
\hline CHEMBL1607789 & 737357 & 2.585 & 3.1194 & TRN & \\
\hline CHEMBL1425824 & 737357 & 2.585 & 3.3913 & TST & \\
\hline CHEMBL1413508 & 737357 & 2.585 & 3.48199 & 99999999998 & TRN \\
\hline CHEMBL1518131 & 737357 & 2.585 & 2.8166 & TRN & \\
\hline CHEMBL1584009 & 737357 & 2.585 & 2.5478 & TRN & \\
\hline CHEMBL1349753 & 737357 & 2.585 & 2.7766 & TRN & \\
\hline CHEMBL1365990 & 737357 & 3.6996 & 3.0416 & TRN & \\
\hline CHEMBL1401525 & 737357 & 2.585 & 2.7176 & TRN & \\
\hline CHEMBL1432578 & 737357 & 2.585 & 3.2362 & TST & \\
\hline CHEMBL1363346 & 737357 & 5.1797 & 3.7351 & TRN & \\
\hline CHEMBL1312253 & 737357 & 2.585 & 2.9044 & TRN & \\
\hline CHEMBL1494225 & 737357 & 3.6171 & 2.6616 & TRN & \\
\hline CHEMBL1521074 & 737357 & 4.6916 & 3.4818 & TRN & \\
\hline CHEMBL1401891 & 737357 & 2.585 & 3.3408 & TST & \\
\hline CHEMBL1610322 & 737357 & 2.585 & 3.0133 & TRN & \\
\hline CHEMBL1520053 & 737357 & 2.585 & 3.2994 & TST & \\
\hline CHEMBL1723458 & 737357 & 2.585 & 2.4779 & TRN & \\
\hline CHEMBL1480950 & 737357 & 2.585 & 3.6514 & TST & \\
\hline CHEMBL1367472 & 737357 & 2.585 & 2.7346 & TRN & \\
\hline CHEMBL1373040 & 737357 & 2.585 & 2.7096 & TRN & \\
\hline CHEMBL1374935 & 737357 & 2.585 & 2.9715 & TRN & \\
\hline CHEMBL1510143 & 737357 & 2.585 & 2.8323 & TRN & \\
\hline CHEMBL1564889 & 737357 & 2.585 & 2.822 & TRN & \\
\hline CHEMBL1303858 & 737357 & 2.585 & 2.8701 & TRN & \\
\hline CHEMBL1341201 & 737357 & 4.4702 & 2.9933 & TRN & \\
\hline CHEMBL1539531 & 737357 & 2.585 & 3.3058 & TRN & \\
\hline CHEMBL1598720 & 737357 & 2.585 & 3.0214 & TRN & \\
\hline CHEMBL1307662 & 737357 & 2.585 & 3.5809 & TRN & \\
\hline CHEMBL1606171 & 737357 & 2.585 & 2.9081 & TRN & \\
\hline CHEMBL1549401 & 737357 & 5.0725 & 3.3878 & TRN & \\
\hline CHEMBL1603688 & 737357 & 4.2621 & 3.2091 & TST & \\
\hline CHEMBL1431638 & 737357 & 2.585 & 2.9671 & TRN & \\
\hline CHEMBL1471709 & 737357 & 2.585 & 2.9249 & TST & \\
\hline CHEMBL1402163 & 737357 & 2.585 & 2.9543 & TRN & \\
\hline CHEMBL1519469 & 737357 & 2.585 & 3.0457 & TRN & \\
\hline CHEMBL1401349 & 737357 & 2.585 & 2.8188 & TRN & \\
\hline CHEMBL1602522 & 737357 & 2.585 & 3.1508 & TST & \\
\hline CHEMBL1443601 & 737357 & 5.4281 & 3.5558 & TRN & \\
\hline CHEMBL1305804 & 737357 & 4.3655 & 3.3719 & TRN & \\
\hline CHEMBL1563440 & 737357 & 2.585 & 3.0847 & TRN & \\
\hline CHEMBL1537077 & 737357 & 2.585 & 2.8368 & TRN & \\
\hline CHEMBL1444561 & 737357 & 2.585 & 2.9077 & TRN & \\
\hline CHEMBL1485168 & 737357 & 5.4076 & 3.6825 & TRN & \\
\hline CHEMBL1722985 & 737357 & 2.585 & 3.0538 & TST & \\
\hline CHEMBL1560679 & 737357 & 4.4935 & 4.1105 & TRN & \\
\hline CHEMBL1422613 & 737357 & 4.4965 & 3.532 & TRN & \\
\hline CHEMBL1505474 & 737357 & 5.102 & 3.1649 & TRN & \\
\hline
\end{tabular}




\begin{tabular}{|c|c|c|c|c|c|}
\hline & & \multicolumn{4}{|c|}{ Supplemental Table S2.txt } \\
\hline CHEMBL1492697 & 737357 & 2.585 & 3.4166 & TST & \\
\hline CHEMBL1539823 & 737357 & 2.585 & 3.1169 & TRN & \\
\hline CHEMBL1313626 & 737357 & 4.0278 & 3.2606 & TST & \\
\hline CHEMBL1304541 & 737357 & 2.585 & 3.1264 & TRN & \\
\hline CHEMBL1490496 & 737357 & 2.585 & 3.0486 & TRN & \\
\hline CHEMBL1362096 & 737357 & 4.9041 & 4.0788 & TRN & \\
\hline CHEMBL1371966 & 737357 & 4.1586 & 2.9317 & TRN & \\
\hline CHEMBL3196809 & 737357 & 2.585 & 4.4994 & TRN & \\
\hline CHEMBL1307424 & 737357 & 2.585 & 2.6338 & TRN & \\
\hline CHEMBL1603090 & 737357 & 2.585 & 2.9049 & TST & \\
\hline CHEMBL1522758 & 737357 & 4.8242 & 2.963 & TRN & \\
\hline CHEMBL1371804 & 737357 & 2.585 & 2.9353 & TRN & \\
\hline CHEMBL1969984 & 737357 & 2.585 & 3.4808 & TRN & \\
\hline CHEMBL1549594 & 737357 & 2.585 & 2.7581 & TRN & \\
\hline CHEMBL1403700 & 737357 & 2.585 & 2.9444 & TRN & \\
\hline CHEMBL1984065 & 737357 & 2.585 & 2.9822 & TRN & \\
\hline CHEMBL528506 & 737357 & 2.585 & 3.3451 & TRN & \\
\hline CHEMBL1495202 & 737357 & 4.4909 & 3.3086 & TRN & \\
\hline CHEMBL1351135 & 737357 & 4.3302 & 3.5837 & TRN & \\
\hline CHEMBL1325094 & 737357 & 2.585 & 2.8575 & TRN & \\
\hline CHEMBL1980448 & 737357 & 2.585 & 3.721 & TRN & \\
\hline CHEMBL1453591 & 737357 & 2.585 & 2.9851 & TRN & \\
\hline CHEMBL1460081 & 737357 & 2.585 & 2.8408 & TRN & \\
\hline CHEMBL1714564 & 737357 & 2.585 & 3.0606 & TRN & \\
\hline CHEMBL1320042 & 737357 & 4.33899 & 99999999 & 2.8611 & TRN \\
\hline CHEMBL1442339 & 737357 & 2.585 & 3.2891 & TRN & \\
\hline CHEMBL1360658 & 737357 & 2.585 & 3.0596 & TRN & \\
\hline CHEMBL 3190256 & 737357 & 2.585 & 3.6107 & TRN & \\
\hline CHEMBL1370565 & 737357 & 2.585 & 2.8739 & TST & \\
\hline CHEMBL1504855 & 737357 & 4.1432 & 3.2458 & TRN & \\
\hline CHEMBL1302460 & 737357 & 5.1731 & 3.3782 & TRN & \\
\hline CHEMBL1486221 & 737357 & 2.585 & 3.4841 & TRN & \\
\hline CHEMBL1376438 & 737357 & 2.585 & 3.3726 & TRN & \\
\hline CHEMBL1332462 & 737357 & 2.585 & 2.9507 & TST & \\
\hline CHEMBL1579521 & 737357 & 4.3611 & 3.3715 & TRN & \\
\hline CHEMBL1404107 & 737357 & 2.585 & 3.3827 & TRN & \\
\hline CHEMBL1598844 & 737357 & 2.585 & 3.2126 & TRN & \\
\hline CHEMBL1605723 & 737357 & 2.585 & 3.0279 & TRN & \\
\hline CHEMBL1411172 & 737357 & 2.585 & 3.35100 & 00000000004 & TRN \\
\hline CHEMBL1448295 & 737357 & 3.6262 & 3.1394 & TST & \\
\hline CHEMBL1579211 & 737357 & 2.585 & 3.24399 & 99999999998 & TST \\
\hline CHEMBL1331672 & 737357 & 2.585 & 2.5971 & TRN & \\
\hline CHEMBL1430669 & 737357 & 2.585 & 3.1212 & TRN & \\
\hline CHEMBL1420393 & 737357 & 5.7905 & 3.6379 & TRN & \\
\hline CHEMBL1329464 & 737357 & 2.585 & 2.7186 & TRN & \\
\hline CHEMBL1340587 & 737357 & 2.585 & 3.2822 & TRN & \\
\hline CHEMBL266997 & 737357 & 2.585 & 3.1092 & TRN & \\
\hline CHEMBL1541779 & 737357 & 2.585 & 2.9743 & TRN & \\
\hline
\end{tabular}




\begin{tabular}{|c|c|c|c|c|c|}
\hline \multirow[b]{2}{*}{ CHEMBL1334228 } & \multicolumn{5}{|c|}{ Supplemental Table S2.txt } \\
\hline & 737357 & 3.9066 & 3.2414 & TRN & \\
\hline CHEMBL1726392 & 737357 & 2.585 & 3.1087 & TRN & \\
\hline CHEMBL1598774 & 737357 & 5.1244 & 3.7543 & TRN & \\
\hline CHEMBL1536129 & 737357 & 4.308 & 3.0036 & TRN & \\
\hline CHEMBL1572459 & 737357 & 2.585 & 2.9258 & TRN & \\
\hline CHEMBL1585296 & 737357 & 2.585 & 3.242 & TRN & \\
\hline CHEMBL1479472 & 737357 & 4.9991 & 3.2613 & TRN & \\
\hline CHEMBL1385123 & 737357 & 2.585 & 3.008 & TRN & \\
\hline CHEMBL1502712 & 737357 & 4.6972 & 3.4318 & TRN & \\
\hline CHEMBL1459480 & 737357 & 2.585 & 2.9579 & TRN & \\
\hline CHEMBL1509034 & 737357 & 2.585 & 3.1829 & TRN & \\
\hline CHEMBL1330828 & 737357 & 2.585 & 2.9561 & TRN & \\
\hline CHEMBL1506967 & 737357 & 5.0301 & 3.0254 & TST & \\
\hline CHEMBL1376824 & 737357 & 2.585 & 3.1092 & TRN & \\
\hline CHEMBL2005991 & 737357 & 4.4674 & 3.5671 & TRN & \\
\hline CHEMBL1537911 & 737357 & 2.585 & 2.4577 & TRN & \\
\hline CHEMBL1308659 & 737357 & 2.585 & 3.2793 & TRN & \\
\hline CHEMBL1463006 & 737357 & 2.585 & 2.5821 & TRN & \\
\hline CHEMBL1424118 & 737357 & 2.585 & 3.9174 & TRN & \\
\hline CHEMBL1520457 & 737357 & 4.1959 & 3.2185 & TRN & \\
\hline CHEMBL1423288 & 737357 & 2.585 & 2.8316 & TRN & \\
\hline CHEMBL1387904 & 737357 & 4.7359 & 3.4577 & TRN & \\
\hline CHEMBL3195455 & 737357 & 5.1228 & 3.5097 & TRN & \\
\hline CHEMBL1412252 & 737357 & 2.585 & 3.3265 & TRN & \\
\hline CHEMBL1427814 & 737357 & 4.2274 & 3.1111 & TST & \\
\hline CHEMBL1502550 & 737357 & 4.7452 & 3.4141 & TRN & \\
\hline CHEMBL1556478 & 737357 & 2.585 & 2.9773 & TRN & \\
\hline CHEMBL1360299 & 737357 & 2.585 & 3.0928 & TRN & \\
\hline CHEMBL1977659 & 737357 & 2.585 & 2.9818 & TRN & \\
\hline CHEMBL1531750 & 737357 & 2.585 & 2.94100 & 00000000003 & TRN \\
\hline CHEMBL1354696 & 737357 & 2.585 & 2.448 & TRN & \\
\hline CHEMBL1422933 & 737357 & 2.585 & 3.3736 & TRN & \\
\hline CHEMBL1700932 & 737357 & 2.585 & 2.6718 & TRN & \\
\hline CHEMBL1557083 & 737357 & 4.4917 & 2.4867 & TRN & \\
\hline CHEMBL1468811 & 737357 & 5.3746 & 5.0183 & TRN & \\
\hline CHEMBL1550567 & 737357 & 2.585 & 2.8726 & TRN & \\
\hline CHEMBL3197396 & 737357 & 4.0411 & 4.2786 & TRN & \\
\hline CHEMBL1501553 & 737357 & 2.585 & 3.1743 & TST & \\
\hline CHEMBL1445150 & 737357 & 2.585 & 2.9236 & TRN & \\
\hline CHEMBL1488465 & 737357 & 2.585 & 2.8381 & TRN & \\
\hline CHEMBL1345688 & 737357 & 2.585 & 2.5066 & TRN & \\
\hline CHEMBL1537461 & 737357 & 2.585 & 3.3923 & TRN & \\
\hline CHEMBL1444756 & 737357 & 4.957 & 3.2796 & TST & \\
\hline CHEMBL1579167 & 737357 & 2.585 & 2.8378 & TRN & \\
\hline CHEMBL1549387 & 737357 & 2.585 & 2.9095 & TRN & \\
\hline CHEMBL1463878 & 737357 & 2.585 & 2.7938 & TST & \\
\hline CHEMBL1392339 & 737357 & 2.585 & 3.7459 & TRN & \\
\hline CHEMBL1430071 & 737357 & 2.585 & 2.9928 & TST & \\
\hline
\end{tabular}




\begin{tabular}{|c|c|c|c|c|c|}
\hline & & \multicolumn{4}{|c|}{ Supplemental Table S2.txt } \\
\hline CHEMBL1594789 & 737357 & 3.9355 & 3.2803 & TRN & \\
\hline CHEMBL1331628 & 737357 & 2.585 & 3.1106 & TRN & \\
\hline CHEMBL1572420 & 737357 & 4.8499 & 3.3636 & TRN & \\
\hline CHEMBL1311731 & 737357 & 2.585 & 2.4576 & TRN & \\
\hline CHEMBL1506239 & 737357 & 2.585 & 2.8691 & TRN & \\
\hline CHEMBL 248654 & 737357 & 2.585 & 3.3082 & TRN & \\
\hline CHEMBL1507468 & 737357 & 4.7533 & 3.3064 & TRN & \\
\hline CHEMBL1408691 & 737357 & 2.585 & 2.9213 & TRN & \\
\hline CHEMBL1428587 & 737357 & 4.0061 & 2.8356 & TRN & \\
\hline CHEMBL1611170 & 737357 & 5.1857 & 3.5925 & TRN & \\
\hline CHEMBL3207337 & 737357 & 2.585 & 2.7748 & TRN & \\
\hline CHEMBL1728869 & 737357 & 2.585 & 2.9918 & TRN & \\
\hline CHEMBL1362248 & 737357 & 4.731 & 3.4273 & TRN & \\
\hline CHEMBL1448812 & 737357 & 2.585 & 2.7046 & TRN & \\
\hline CHEMBL1422886 & 737357 & 2.585 & 3.00699 & 99999999997 & TRN \\
\hline CHEMBL1605816 & 737357 & 2.585 & 3.3454 & TRN & \\
\hline CHEMBL1439807 & 737357 & 2.585 & 3.2394 & TST & \\
\hline CHEMBL1607464 & 737357 & 2.585 & 3.2328 & TRN & \\
\hline CHEMBL1302314 & 737357 & 2.585 & 2.9994 & TRN & \\
\hline CHEMBL1538073 & 737357 & 2.585 & 3.0246 & TRN & \\
\hline CHEMBL1735927 & 737357 & 3.7836 & 3.8149 & TRN & \\
\hline CHEMBL1338045 & 737357 & 2.585 & 3.99600 & 00000000004 & TRN \\
\hline CHEMBL1613033 & 737357 & 2.585 & 3.2661 & TRN & \\
\hline CHEMBL1393638 & 737357 & 2.585 & 3.1901 & TRN & \\
\hline CHEMBL1719460 & 737357 & 2.585 & 2.9538 & TRN & \\
\hline CHEMBL1431655 & 737357 & 2.585 & 3.1355 & TRN & \\
\hline CHEMBL1974501 & 737357 & 5.1621 & 3.4933 & TRN & \\
\hline CHEMBL1442678 & 737357 & 2.585 & 3.0663 & TRN & \\
\hline CHEMBL1363446 & 737357 & 2.585 & 2.9568 & TRN & \\
\hline CHEMBL1332589 & 737357 & 5.0024 & 3.5332 & TRN & \\
\hline CHEMBL1338723 & 737357 & 4.8719 & 3.1606 & TRN & \\
\hline CHEMBL428064 & 737357 & 5.5589 & 3.9028 & TRN & \\
\hline CHEMBL1353556 & 737357 & 2.585 & 3.4305 & TRN & \\
\hline CHEMBL2369309 & 737357 & 2.585 & 3.5929 & TRN & \\
\hline CHEMBL1409202 & 737357 & 2.585 & 2.7473 & TRN & \\
\hline CHEMBL1736275 & 737357 & 2.585 & 2.7103 & TRN & \\
\hline CHEMBL1439210 & 737357 & 2.585 & 4.6057 & TRN & \\
\hline CHEMBL1601397 & 737357 & 2.585 & 3.2499 & TRN & \\
\hline CHEMBL1566183 & 737357 & 2.585 & 3.0586 & TRN & \\
\hline CHEMBL1471418 & 737357 & 4.766 & 3.0351 & TRN & \\
\hline CHEMBL1611063 & 737357 & 2.585 & 2.7948 & TRN & \\
\hline CHEMBL1541045 & 737357 & 2.585 & 3.0578 & TRN & \\
\hline CHEMBL1496329 & 737357 & 4.6819 & 3.3436 & TRN & \\
\hline CHEMBL 2002898 & 737357 & 4.1245 & 3.6773 & TRN & \\
\hline CHEMBL1600741 & 737357 & 2.585 & 3.3055 & TRN & \\
\hline CHEMBL3214618 & 737357 & 2.585 & 3.0289 & TRN & \\
\hline CHEMBL1454951 & 737357 & 5.5626 & 3.5202 & TRN & \\
\hline CHEMBL1714049 & 737357 & 2.585 & 3.2096 & TST & \\
\hline
\end{tabular}




\begin{tabular}{|c|c|c|c|c|c|}
\hline & & \multicolumn{4}{|c|}{ Supplemental Table S2.txt } \\
\hline CHEMBL2007553 & 737357 & 3.7742 & 3.0148 & TRN & \\
\hline CHEMBL1388936 & 737357 & 2.585 & 2.8151 & TRN & \\
\hline CHEMBL1390804 & 737357 & 4.9126 & 3.0493 & TST & \\
\hline CHEMBL1326677 & 737357 & 2.585 & 3.22 & TRN & \\
\hline CHEMBL1407928 & 737357 & 3.9416 & 2.7792 & TST & \\
\hline CHEMBL3193428 & 737357 & 2.585 & 3.7926 & TRN & \\
\hline CHEMBL1504272 & 737357 & 2.585 & 2.9198 & TRN & \\
\hline CHEMBL1536140 & 737357 & 3.9825 & 3.4608 & TRN & \\
\hline CHEMBL1467668 & 737357 & 2.585 & 3.25100 & 20000000003 & TST \\
\hline CHEMBL3145378 & 737357 & 2.585 & 3.2799 & TST & \\
\hline CHEMBL1704255 & 737357 & 2.585 & 2.8581 & TRN & \\
\hline CHEMBL1308875 & 737357 & 2.585 & 3.3517 & TRN & \\
\hline CHEMBL1524737 & 737357 & 2.585 & 2.9469 & TRN & \\
\hline CHEMBL1497977 & 737357 & 2.585 & 3.0358 & TRN & \\
\hline CHEMBL1455533 & 737357 & 2.585 & 3.4487 & TRN & \\
\hline CHEMBL1505182 & 737357 & 2.585 & 3.37100 & 30000000004 & TST \\
\hline CHEMBL1464445 & 737357 & 2.585 & 2.6327 & TRN & \\
\hline CHEMBL1706586 & 737357 & 2.585 & 3.0034 & TRN & \\
\hline CHEMBL3191525 & 737357 & 2.585 & 3.6237 & TRN & \\
\hline CHEMBL1352608 & 737357 & 2.585 & 3.1245 & TRN & \\
\hline CHEMBL1368591 & 737357 & 2.585 & 2.9213 & TRN & \\
\hline CHEMBL1544208 & 737357 & 2.585 & 3.0 & TRN & \\
\hline CHEMBL1362563 & 737357 & 2.585 & 2.6803 & TRN & \\
\hline CHEMBL1449719 & 737357 & 3.9739 & 2.924 & TRN & \\
\hline CHEMBL1346722 & 737357 & 2.585 & 2.6917 & TRN & \\
\hline CHEMBL1716154 & 737357 & 2.585 & 2.7708 & TRN & \\
\hline CHEMBL1340923 & 737357 & 2.585 & 2.4072 & TRN & \\
\hline CHEMBL1419366 & 737357 & 2.585 & 3.33399 & 99999999996 & TST \\
\hline CHEMBL1313581 & 737357 & 2.585 & 3.1048 & TST & \\
\hline CHEMBL1730001 & 737357 & 2.585 & 2.8064 & TRN & \\
\hline CHEMBL3209625 & 737357 & 2.585 & 3.6806 & TRN & \\
\hline CHEMBL1613111 & 737357 & 2.585 & 3.0522 & TRN & \\
\hline CHEMBL1424727 & 737357 & 2.585 & 2.9885 & TRN & \\
\hline CHEMBL1722135 & 737357 & 2.585 & 2.7678 & TRN & \\
\hline CHEMBL1482877 & 737357 & 2.585 & 2.7546 & TST & \\
\hline CHEMBL1421614 & 737357 & 2.585 & 3.1302 & TST & \\
\hline CHEMBL1608740 & 737357 & 2.585 & 2.9343 & TRN & \\
\hline CHEMBL3194229 & 737357 & 2.585 & 3.0171 & TRN & \\
\hline CHEMBL1326503 & 737357 & 2.585 & 3.319 & TRN & \\
\hline CHEMBL1447324 & 737357 & 5.5255 & 3.5651 & TRN & \\
\hline CHEMBL1492017 & 737357 & 4.9535 & 3.7307 & TRN & \\
\hline CHEMBL1719850 & 737357 & 2.585 & 3.188 & TRN & \\
\hline CHEMBL1462498 & 737357 & 4.2734 & 2.839 & TRN & \\
\hline CHEMBL1526816 & 737357 & 2.585 & 2.6637 & TRN & \\
\hline CHEMBL1516822 & 737357 & 2.585 & 2.6083 & TRN & \\
\hline CHEMBL1417777 & 737357 & 2.585 & 2.5859 & TRN & \\
\hline CHEMBL1515256 & 737357 & 2.585 & 2.8802 & TRN & \\
\hline CHEMBL1702777 & 737357 & 2.585 & 2.9819 & TRN & \\
\hline
\end{tabular}


Supplemental Table S2.txt

\begin{tabular}{|c|c|c|c|c|c|c|}
\hline CHEMBL1527583 & 737357 & 2.585 & 3.1036 & TRN & & \\
\hline CHEMBL3196084 & 737357 & 2.585 & 3.366 & TST & & \\
\hline CHEMBL1990694 & 737357 & 4.248 & 3.324 & TST & & \\
\hline CHEMBL1734210 & 737357 & 2.585 & 3.0283 & TRN & & \\
\hline CHEMBL3199020 & 737357 & 5.5119 & 4.7873 & TRN & & \\
\hline CHEMBL1600794 & 737357 & 2.585 & 3.0911 & TRN & & \\
\hline CHEMBL1321453 & 737357 & 2.585 & 3.8246 & TRN & & \\
\hline CHEMBL1347325 & 737357 & 2.585 & 3.0733 & TRN & & \\
\hline CHEMBL1714560 & 737357 & 2.585 & 2.858 & TST & & \\
\hline CHEMBL1524542 & 737357 & 4.8259 & 3.5615 & TRN & & \\
\hline CHEMBL1730719 & 737357 & 2.585 & 2.9315 & TRN & & \\
\hline CHEMBL1600974 & 737357 & 2.585 & 2.8929 & TRN & & \\
\hline CHEMBL1417867 & 737357 & 4.5449 & 3.2295 & TRN & & \\
\hline CHEMBL1609851 & 737357 & 2.585 & 3.2176 & TRN & & \\
\hline CHEMBL1527691 & 737357 & 4.5592 & 3.5977 & TST & & \\
\hline CHEMBL1504724 & 737357 & 2.585 & 3.282 & TST & & \\
\hline CHEMBL1579505 & 737357 & 4.5122 & 3.1759 & TRN & & \\
\hline CHEMBL1706575 & 737357 & 2.585 & 3.3336 & TRN & & \\
\hline CHEMBL1449128 & 737357 & 2.585 & 2.6571 & TRN & & \\
\hline CHEMBL1385219 & 737357 & \multicolumn{3}{|c|}{3.7439999999999998} & 2.9883 & TRN \\
\hline CHEMBL1516865 & 737357 & 4.9355 & 2.9875 & TRN & & \\
\hline CHEMBL1510249 & 737357 & 2.585 & 2.8994 & TRN & & \\
\hline CHEMBL1332822 & 737357 & 2.585 & 2.7176 & TRN & & \\
\hline CHEMBL1546622 & 737357 & 2.585 & 3.0094 & TRN & & \\
\hline CHEMBL1423204 & 737357 & 2.585 & 2.8328 & TRN & & \\
\hline CHEMBL1583292 & 737357 & 2.585 & 3.5439 & TRN & & \\
\hline CHEMBL3196975 & 737357 & 2.585 & 2.9878 & TRN & & \\
\hline CHEMBL1542693 & 737357 & 4.51 & 3.2397 & TRN & & \\
\hline CHEMBL1334178 & 737357 & 4.4113 & 3.9216 & TRN & & \\
\hline CHEMBL1507215 & 737357 & 2.585 & 3.3094 & TRN & & \\
\hline CHEMBL1520176 & 737357 & 4.1528 & 3.0936 & TRN & & \\
\hline CHEMBL1704717 & 737357 & 2.585 & 3.1632 & TRN & & \\
\hline CHEMBL1320946 & 737357 & 4.4607 & 3.3054 & TRN & & \\
\hline CHEMBL1562304 & 737357 & 4.8245 & 3.8474 & TRN & & \\
\hline CHEMBL3190636 & 737357 & 2.585 & 3.4734 & TRN & & \\
\hline CHEMBL1568851 & 737357 & 2.585 & 3.2546 & TRN & & \\
\hline CHEMBL1500868 & 737357 & 2.585 & 3.1043 & TRN & & \\
\hline CHEMBL1525858 & 737357 & 4.353 & 3.0656 & TRN & & \\
\hline CHEMBL1381333 & 737357 & 2.585 & 3.267 & TRN & & \\
\hline CHEMBL1988536 & 737357 & 2.585 & 3.0222 & TRN & & \\
\hline CHEMBL1352525 & 737357 & 3.6146 & 2.6554 & TRN & & \\
\hline CHEMBL1421294 & 737357 & 2.585 & 3.1657 & TRN & & \\
\hline CHEMBL1504710 & 737357 & 2.585 & 3.2906 & TRN & & \\
\hline CHEMBL1500214 & 737357 & 2.585 & 2.8795 & TRN & & \\
\hline CHEMBL1325823 & 737357 & 5.569 & 3.5668 & TRN & & \\
\hline CHEMBL 3213103 & 737357 & 5.0003 & 3.1992 & TRN & & \\
\hline CHEMBL1432918 & 737357 & 2.585 & 2.8828 & TRN & & \\
\hline CHEMBL1322482 & 737357 & 4.3375 & 2.6702 & TRN & & \\
\hline
\end{tabular}




\begin{tabular}{|c|c|c|c|c|c|}
\hline & & \multicolumn{4}{|c|}{ Supplemental Table S2.txt } \\
\hline CHEMBL1730375 & 737357 & 2.585 & 2.6834 & TRN & \\
\hline CHEMBL 2006131 & 737357 & 4.7788 & 3.5758 & TRN & \\
\hline CHEMBL1518247 & 737357 & 2.585 & 2.3995 & TRN & \\
\hline CHEMBL1483015 & 737357 & 2.585 & 3.3999 & TRN & \\
\hline CHEMBL1392590 & 737357 & 5.5624 & 3.0963 & TRN & \\
\hline CHEMBL1304653 & 737357 & 2.585 & 2.9555 & TRN & \\
\hline CHEMBL1462844 & 737357 & 2.585 & 3.0736 & TRN & \\
\hline CHEMBL1338590 & 737357 & 2.585 & 2.8794 & TRN & \\
\hline CHEMBL1367075 & 737357 & 2.585 & 3.4824 & TRN & \\
\hline CHEMBL1487320 & 737357 & 5.1428 & 3.6538 & TRN & \\
\hline CHEMBL1525923 & 737357 & 2.585 & 2.5829 & TRN & \\
\hline CHEMBL1502358 & 737357 & 5.251 & 3.7957 & TST & \\
\hline CHEMBL1334903 & 737357 & 2.585 & 3.7286 & TRN & \\
\hline CHEMBL1543273 & 737357 & 2.585 & 2.9866 & TRN & \\
\hline CHEMBL1383842 & 737357 & 2.585 & 3.4068 & TRN & \\
\hline CHEMBL1541118 & 737357 & 4.4157 & 3.0358 & TRN & \\
\hline CHEMBL1313328 & 737357 & 2.585 & 3.0716 & TRN & \\
\hline CHEMBL1517959 & 737357 & 2.585 & 2.9822 & TRN & \\
\hline CHEMBL1416493 & 737357 & 4.4433 & 3.5898 & TRN & \\
\hline CHEMBL1352555 & 737357 & 5.2346 & 3.623 & TRN & \\
\hline CHEMBL1416271 & 737357 & 2.585 & 3.1456 & TRN & \\
\hline CHEMBL1605477 & 737357 & 2.585 & 3.2254 & TST & \\
\hline CHEMBL1331573 & 737357 & 2.585 & 4.1811 & TRN & \\
\hline CHEMBL1555960 & 737357 & 2.585 & 3.3135 & TRN & \\
\hline CHEMBL1420629 & 737357 & 2.585 & 3.0737 & TRN & \\
\hline CHEMBL 1302326 & 737357 & 2.585 & 3.0795 & TRN & \\
\hline CHEMBL1433203 & 737357 & 2.585 & 3.1338 & TRN & \\
\hline CHEMBL1543866 & 737357 & 2.585 & 3.2822 & TRN & \\
\hline CHEMBL1359404 & 737357 & 2.585 & 3.3615 & TRN & \\
\hline CHEMBL1387152 & 737357 & 4.3945 & 3.2645 & TST & \\
\hline CHEMBL1459074 & 737357 & 2.585 & 2.6368 & TRN & \\
\hline CHEMBL1351491 & 737357 & 2.585 & 2.889 & TST & \\
\hline CHEMBL1411344 & 737357 & 4.9763 & 3.4777 & TST & \\
\hline CHEMBL1715505 & 737357 & 2.585 & 2.4588 & TRN & \\
\hline CHEMBL1367505 & 737357 & 2.585 & 2.7733 & TST & \\
\hline CHEMBL1700605 & 737357 & 2.585 & 3.2849 & TRN & \\
\hline CHEMBL1362659 & 737357 & 3.9212 & 2.8493 & TRN & \\
\hline CHEMBL1305307 & 737357 & 5.0716 & 3.2481 & TRN & \\
\hline CHEMBL1566417 & 737357 & 2.585 & 3.0766 & TRN & \\
\hline CHEMBL1605430 & 737357 & 2.585 & 3.2055 & TRN & \\
\hline CHEMBL1485869 & 737357 & 2.585 & 3.1042 & TRN & \\
\hline CHEMBL1502054 & 737357 & 4.2602 & 2.9268 & TST & \\
\hline CHEMBL1302213 & 737357 & 2.585 & 3.0824 & TRN & \\
\hline CHEMBL1570898 & 737357 & 4.0887 & 3.6112 & TRN & \\
\hline CHEMBL1424003 & 737357 & 2.585 & 3.4316 & TRN & \\
\hline CHEMBL1540861 & 737357 & 4.9187 & 3.4413 & TRN & \\
\hline CHEMBL1566393 & 737357 & 2.585 & 3.08699 & 99999999997 & TRN \\
\hline CHEMBL1540377 & 737357 & 5.4314 & 3.8837 & TRN & \\
\hline
\end{tabular}


Supplemental Table S2.txt

\begin{tabular}{|c|c|c|c|c|}
\hline 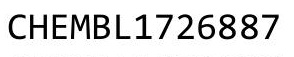 & 37357 & & & 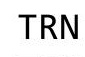 \\
\hline HEMBL1550028 & 37357 & 2.585 & 3.449 & \\
\hline HEMBL1483018 & 37357 & 821 & 604 & \\
\hline AEMBL1466782 & 37357 & 585 & 221 & \\
\hline FMBL 2000945 & 7357 & & 537 & \\
\hline EMBL1482357 & 37357 & 585 & 554 & \\
\hline HEMBL1302969 & 37357 & 585 & 7388 & \\
\hline AEMBL1347500 & 37357 & .585 & 409 & \\
\hline EMBL1698278 & 37357 & 585 & 447 & \\
\hline IEMBL13 & 37357 & & & RN \\
\hline AEMBL1604371 & 37357 & .8345 & 414 & \\
\hline AEMBL1575149 & 37357 & .585 & 742 & \\
\hline AEMBL1: & 37 & .585 & & \\
\hline IEMBL151 & 37357 & 585 & & RN \\
\hline IEMBL1414103 & & .585 & & \\
\hline IEMBL1305075 & 37357 & 0285 & 685 & ST \\
\hline IEMBL1452672 & 357 & 585 & & \\
\hline AEMBL1498002 & 37357 & 2.585 & 527 & \\
\hline EMBL1 & & 85 & 286 & RN \\
\hline 720 & & 85 & 75 & \\
\hline IEMBL1404932 & 37357 & 4166 & 925 & \\
\hline IEMBL1506351 & & 98 & & N \\
\hline IEMBL1410641 & 57 & 4.8745 & & RN \\
\hline EMBL14 & & & & $\mathrm{RN}$ \\
\hline 362 & 57 & 35 & & \\
\hline 969 & 57 & 585 & & RN \\
\hline IEMBL134 & & & & N \\
\hline IEMBL1429884 & 57 & 2. & 54 & RN \\
\hline 28 & & 35 & 57 & $\mathrm{RN}$ \\
\hline 35 & 57 & 85 & & RN \\
\hline & & & & RN \\
\hline IEMBL1467760 & & 20 & & in \\
\hline IEMBL1468055 & 57 & 5.1 & & RN \\
\hline 66 & 57 & 85 & 97 & RN \\
\hline 50 & 57 & 35 & 65 & RN \\
\hline EMBL1403779 & & 2.585 & 666 & RN \\
\hline IEMBL1468522 & 57 & 4.82 & 95 & 「RN \\
\hline MBL1 & 7 & & 324 & ST \\
\hline 5329 & 57 & 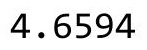 & & RN \\
\hline 17 & 57 & 2.5 & 32 & IST \\
\hline IEMBL1510852 & 37357 & 5.2042 & 638 & RN \\
\hline AEMBL1511777 & 57 & 2.585 & 88 & TRN \\
\hline & & & & TST \\
\hline HEMBL1333268 & 57 & 5.7345 & 3.2105 & TST \\
\hline HEMBL1393888 & 37357 & 2.585 & 2.9367 & ST \\
\hline EMBL1546373 & 37357 & .585 & .1468 & TST \\
\hline HEMBL1544468 & 57 & 5.0724 & 4.0815 & TST \\
\hline CHEMBL1588058 & 37357 & & 3.1562 & \\
\hline
\end{tabular}

Page 5968 
Supplemental Table S2.txt

\begin{tabular}{|c|c|c|c|c|}
\hline 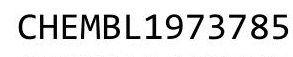 & 37357 & 2.585 & 5056 & \\
\hline HEMBL1568437 & 37357 & 2.585 & & \\
\hline HEMBL1462918 & 37357 & 585 & 1745 & \\
\hline HEMBL1584315 & 37357 & .585 & 1393 & \\
\hline HEMBL1705578 & 7357 & & & \\
\hline AEMBL1703781 & 37357 & .585 & 0922 & \\
\hline HEMBL1329938 & 37357 & .5948 & .2141 & \\
\hline HEMBL1392359 & 37357 & 2.585 & .2042 & \\
\hline HEMBL1391217 & 37357 & 9527 & 2333 & \\
\hline HEMBL1493353 & & 3636 & & \\
\hline HEMBL1500020 & 37357 & 4607 & 4412 & \\
\hline HEMBL1373692 & 37357 & .585 & 9761 & \\
\hline HEMBL1586141 & 357 & 2.585 & .4841 & \\
\hline AEMBL146 & 57 & 979 & 1492 & \\
\hline HEM & & 85 & & \\
\hline HEMBL1436003 & 37357 & 2.585 & .0265 & \\
\hline AEMBL147 & & & & \\
\hline AEMBL15 & 57 & 2. & 7684 & \\
\hline L14 & 57 & 096 & 983 & \\
\hline AEN & & & & \\
\hline HEMBL1371 & 37357 & & 5013 & \\
\hline HEMBL130 & & 58 & & \\
\hline HEMBL 14 & 57 & 437 & 63 & \\
\hline HEN & & & 46 & \\
\hline HEN & & & & \\
\hline 150 & & & & \\
\hline HEMBL136 & & & & \\
\hline HEMBL116 & 57 & & 58 & \\
\hline HEM & & & 28 & \\
\hline L15 & 57 & 85 & 87 & \\
\hline-153 & & & & \\
\hline AEMBL170 & & & & \\
\hline EEMBL14 & & & 3201 & \\
\hline 14 & & 048 & 227 & \\
\hline 1 & 57 & 144 & 434 & \\
\hline HEMBL600008 & & & 3.5405 & \\
\hline AEMBL1702394 & & & 997 & ST \\
\hline HEMBL14 & & & & \\
\hline 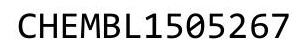 & & & 53 & \\
\hline HEMBL160 & 57 & & 438 & ST \\
\hline HEMBL 3197171 & 37357 & 2.585 & 3.0659 & ST \\
\hline HEMBL14333 & 57 & 872 & 484 & ST \\
\hline HEMBL13 & 57 & & & \\
\hline CHEMBL172 & 57 & & 2.7111 & \\
\hline HEMBL1422867 & 737357 & 2.585 & 3.4459 & ST \\
\hline AEMBL1342574 & 37357 & 4.9784 & 3.4494 & \\
\hline EMBL14 & & & & \\
\hline CHEMBL146767 & 737357 & & 3.2497 & \\
\hline
\end{tabular}

Page 5969 


\begin{tabular}{|c|c|c|c|c|c|}
\hline & & \multicolumn{4}{|c|}{ Supplemental Table S2.txt } \\
\hline CHEMBL1980614 & 737357 & 2.585 & 3.0913 & TST & \\
\hline CHEMBL1575978 & 737357 & 4.5196 & 3.1745 & TST & \\
\hline CHEMBL1546136 & 737357 & 2.585 & 3.4992 & TST & \\
\hline CHEMBL1477889 & 737357 & 3.8441 & 3.1376 & TST & \\
\hline CHEMBL1433182 & 737357 & 4.833 & 4.0188 & TST & \\
\hline CHEMBL1419117 & 737357 & 4.143 & 3.1218 & TST & \\
\hline CHEMBL1511811 & 737357 & 2.585 & 2.7396 & TST & \\
\hline CHEMBL1561206 & 737357 & 2.585 & 3.4557 & TST & \\
\hline CHEMBL1309737 & 737357 & 4.9083 & 2.638 & TST & \\
\hline CHEMBL1302352 & 737357 & 2.585 & 3.2967 & TST & \\
\hline CHEMBL1510455 & 737357 & 5.0679 & 3.8517 & TST & \\
\hline CHEMBL1416244 & 737357 & 2.585 & 3.1304 & TST & \\
\hline CHEMBL1555770 & 737357 & 2.585 & 3.2754 & TST & \\
\hline CHEMBL1579198 & 737357 & 2.585 & 3.4184 & TST & \\
\hline CHEMBL1347469 & 737357 & 3.9876 & 3.2301 & TST & \\
\hline CHEMBL1715252 & 737357 & 2.585 & 3.013 & TST & \\
\hline CHEMBL1986765 & 737357 & 4.251 & 3.705 & TST & \\
\hline CHEMBL1300087 & 737357 & 2.585 & 3.1157 & TST & \\
\hline CHEMBL1520936 & 737357 & 2.585 & 3.3077 & TST & \\
\hline CHEMBL1438342 & 737357 & 2.585 & 2.8681 & TST & \\
\hline CHEMBL1564367 & 737357 & 2.585 & 3.1066 & TST & \\
\hline CHEMBL1456289 & 737357 & 2.585 & 2.9605 & TST & \\
\hline CHEMBL1432553 & 737357 & 2.585 & 3.2464 & TST & \\
\hline CHEMBL1543012 & 737357 & 2.585 & 2.9844 & TST & \\
\hline CHEMBL1415864 & 737357 & 2.585 & 3.2348 & TST & \\
\hline CHEMBL1387351 & 737357 & 2.585 & 3.343 & TST & \\
\hline CHEMBL1613275 & 737357 & 2.585 & 3.2296 & TST & \\
\hline CHEMBL1438290 & 737357 & 2.585 & 3.1396 & TST & \\
\hline CHEMBL1732921 & 737357 & 3.6434 & 2.8309 & TST & \\
\hline CHEMBL1322780 & 737357 & 4.4626 & 3.3408 & TST & \\
\hline CHEMBL1365850 & 737357 & 4.7178 & 3.4008 & TST & \\
\hline CHEMBL3193644 & 737357 & 2.585 & 3.3812 & TST & \\
\hline CHEMBL1331211 & 737357 & 2.585 & 3.7086 & TST & \\
\hline CHEMBL1570697 & 737357 & 2.585 & 3.3255 & TST & \\
\hline CHEMBL1388600 & 737357 & 2.585 & 3.0536 & TST & \\
\hline CHEMBL1729218 & 737357 & 2.585 & 3.2056 & TST & \\
\hline CHEMBL1507840 & 737357 & 2.585 & 2.6141 & TST & \\
\hline CHEMBL1980665 & 737357 & 2.585 & 3.2271 & TST & \\
\hline CHEMBL1306480 & 737357 & 3.6434 & 2.9722 & TST & \\
\hline CHEMBL3213960 & 737357 & 2.585 & 3.0593 & TST & \\
\hline CHEMBL1563248 & 737357 & 2.585 & 2.8438 & TST & \\
\hline CHEMBL1430403 & 737357 & 2.585 & 3.3027 & TST & \\
\hline CHEMBL1345223 & 737357 & 2.585 & 3.0707 & TST & \\
\hline CHEMBL3194361 & 737357 & 2.585 & 3.50399 & 99999999996 & TST \\
\hline CHEMBL1429684 & 737357 & 2.585 & 3.2011 & TST & \\
\hline CHEMBL1573219 & 737357 & 2.585 & 3.1979 & TST & \\
\hline CHEMBL1731010 & 737357 & 2.585 & 2.9779 & TST & \\
\hline CHEMBL1341555 & 737357 & 2.585 & 2.8012 & TST & \\
\hline
\end{tabular}


Supplemental Table S2.txt

\begin{tabular}{|c|c|c|c|c|}
\hline HEN & 7 & .585 & 3.4762 & . \\
\hline HEMBL1708785 & 37357 & 2.585 & 2.6369 & \\
\hline 368 & & & & \\
\hline AEMBL1431005 & 7357 & 585 & & \\
\hline HEMBL1392956 & 37357 & 292 & 8317 & \\
\hline HEMBL1423085 & 37357 & .585 & .1685 & \\
\hline HEMBL1 & 7357 & 778 & & \\
\hline AEMBL3 & & & .4161 & \\
\hline AEMBL13 & 357 & 585 & 3.2518 & \\
\hline HEMBL1384026 & 357 & 85 & .1025 & \\
\hline AEMBL16 & 357 & 585 & .0255 & \\
\hline IEMBL1 & 7357 & & 1663 & \\
\hline AEMBL1 & & & & \\
\hline HEMBL1: & 357 & & 5.566 & \\
\hline AEMBL1: & & & 3699 & \\
\hline AEMBL1 & 57 & & 1564 & \\
\hline HEMBL1 & 57 & 26 & .1313 & \\
\hline HEMBL1 & & & 3.5103 & \\
\hline HEMBL1 & & & .0535 & \\
\hline AEMBL1 & & & & \\
\hline HEMBL= & 7 & & .7535 & \\
\hline HEMBLI & & & 753 & \\
\hline HEMBL1 & & & 177 & \\
\hline AEMBL1. & & & 7539 & \\
\hline AEMBL1: & & 535 & & \\
\hline HEMBL1 & & & 23 & \\
\hline AEMBL: & & & 377 & \\
\hline HFMBI 1 & & 24 & 3.1266 & \\
\hline AEMBL3 & & & 6634 & \\
\hline HEMBL15 & & 59 & 3.0753 & ГST \\
\hline HEMBL1 & & & 3.3562 & ST \\
\hline HEMBL 1 & & & 756 & וע \\
\hline 4 & & 64 & 975 & \\
\hline HEMBL14 & & & & $\mid$ \\
\hline HEMBL1383876 & & 327 & 2.9097 & TST \\
\hline HEMBL1 & & & 3.0529 & \\
\hline HFMRI & & & 3.1251 & \\
\hline HEMBL1 & & & 2.7056 & ST \\
\hline HEMBL1495939 & 37357 & 3 . & 3.2359 & TS \\
\hline IEMBL1 & & & 3.1662 & TST \\
\hline HEMBL1. & 57 & 143 & 3.4403 & \\
\hline CHEMBL1: & & & & SI \\
\hline HEMBL1 & 37357 & 2.585 & 3.0839 & TST \\
\hline AEMBL13 & 37357 & 85 & .5923 & TS \\
\hline EBL1 & & & 3.2001 & 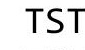 \\
\hline HEMBL1 & 57 & 358 & 3.2569 & \\
\hline CHEMBL17 & 37357 & & 2.6773 & \\
\hline SHEMBL1380514 & 737357 & 4.4503 & 3.6626 & ГST \\
\hline
\end{tabular}

Page 5971 
Supplemental Table S2.txt

\begin{tabular}{|c|c|c|c|c|}
\hline CHEMBL1349590 & 737357 & 5.0712 & 3.6668 & TST \\
\hline CHEMBL1369920 & 737357 & 2.585 & 3.2374 & TST \\
\hline CHEMBL1299406 & 737357 & 2.585 & 3.1214 & TST \\
\hline CHEMBL1561977 & 737357 & 2.585 & 2.944 & TST \\
\hline CHEMBL1967395 & 737357 & 4.7749 & 2.95600 & 00000000004 \\
\hline CHEMBL1351255 & 737357 & 2.585 & 3.2663 & TST \\
\hline CHEMBL1563746 & 737357 & 2.585 & 3.2307 & TST \\
\hline CHEMBL1471326 & 737357 & 2.585 & 3.3147 & TST \\
\hline CHEMBL1340685 & 737357 & 2.585 & 3.1554 & TST \\
\hline CHEMBL1699188 & 737357 & 2.585 & 2.7242 & TST \\
\hline CHEMBL1506071 & 737357 & 2.585 & 3.1516 & TST \\
\hline CHEMBL1510485 & 737357 & 2.585 & 3.1262 & TST \\
\hline CHEMBL1498418 & 737357 & 2.585 & 3.0054 & TST \\
\hline CHEMBL1504331 & 737357 & 2.585 & 2.6106 & TST \\
\hline CHEMBL1299288 & 737357 & 2.585 & 3.4563 & TST \\
\hline CHEMBL1320470 & 737357 & 4.3399 & 3.3783 & TST \\
\hline CHEMBL1460350 & 737357 & 3.6182 & 3.1262 & TST \\
\hline CHEMBL1353664 & 737357 & 2.585 & 3.1879 & TST \\
\hline CHEMBL1304363 & 737357 & 5.6863 & 4.6584 & TST \\
\hline CHEMBL1391931 & 737357 & 4.453 & 2.7458 & TST \\
\hline CHEMBL3193915 & 737357 & 4.1695 & 3.2503 & TST \\
\hline CHEMBL1559129 & 737357 & 4.9543 & 3.0615 & TST \\
\hline CHEMBL1976526 & 737357 & 2.585 & 3.4152 & TST \\
\hline CHEMBL1343101 & 737357 & 2.585 & 3.2655 & TST \\
\hline CHEMBL1608578 & 737357 & 4.8665 & 3.9127 & TST \\
\hline CHEMBL1309847 & 737357 & 2.585 & 3.8287 & TST \\
\hline CHEMBL1311109 & 737357 & 3.8636 & 3.1361 & TST \\
\hline CHEMBL1409186 & 737357 & 2.585 & 2.4044 & TST \\
\hline CHEMBL1423113 & 737357 & 2.585 & 3.2524 & TST \\
\hline CHEMBL1451669 & 737357 & 2.585 & 2.8035 & TST \\
\hline CHEMBL1408404 & 737357 & 4.3777 & 3.0239 & TST \\
\hline CHEMBL1420325 & 737357 & 4.7503 & 3.7638 & TST \\
\hline CHEMBL1425909 & 737357 & 2.585 & 3.3819 & TST \\
\hline CHEMBL1328748 & 737357 & 2.585 & 3.5076 & TST \\
\hline CHEMBL1364445 & 737357 & 4.3147 & 2.9011 & TST \\
\hline CHEMBL1734693 & 737357 & 2.585 & 2.7693 & TST \\
\hline CHEMBL1348834 & 737357 & 2.585 & 2.4564 & TST \\
\hline CHEMBL1455957 & 737357 & 5.1177 & 3.4848 & TST \\
\hline CHEMBL1403692 & 737357 & 2.585 & 3.2808 & TST \\
\hline CHEMBL1373780 & 737357 & 4.0199 & 3.3929 & TST \\
\hline CHEMBL1698706 & 737357 & 2.585 & 3.0914 & TST \\
\hline CHEMBL1611616 & 737357 & 2.585 & 3.3874 & TST \\
\hline CHEMBL1499076 & 737357 & 2.585 & \multicolumn{2}{|c|}{3.5639999999999996} \\
\hline CHEMBL1448962 & 737357 & 3.782 & 3.3434 & TST \\
\hline CHEMBL1508167 & 737357 & 2.585 & 3.1378 & TST \\
\hline CHEMBL 2000686 & 737357 & 5.1556 & 3.3507 & TST \\
\hline CHEMBL1463492 & 737357 & 2.585 & 3.0734 & TST \\
\hline CHEMBL1419567 & 737357 & 2.585 & 2.9755 & TST \\
\hline
\end{tabular}


Supplemental Table S2.txt

\begin{tabular}{|c|c|c|c|c|}
\hline 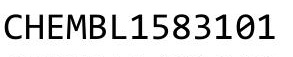 & 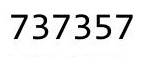 & & & \\
\hline CHEMBL1481940 & 37357 & .585 & 9116 & \\
\hline HEMBL1565392 & 7357 & 5 & & \\
\hline HEMBL15 & & & & \\
\hline IEMBL14 & 7357 & 85 & & \\
\hline AEMBL1600334 & 37357 & 585 & 979 & \\
\hline HEMBL1380076 & 37357 & .585 & 4967 & \\
\hline HEMBL137 & 37357 & .1524 & & \\
\hline AEMBL13 & 37357 & .585 & 367 & \\
\hline HEMBL14 & 37357 & 375 & & \\
\hline HEMBL1446402 & 37357 & .585 & 569 & \\
\hline HEMBL14C & 37357 & .585 & 231 & \\
\hline HEMBL14 & 37357 & 179 & 78 & \\
\hline AEMBL] & 37357 & .585 & & \\
\hline AEMBL] & 37357 & .585 & & \\
\hline AEMBL13 & 37357 & .6243 & 2891 & \\
\hline HEMBL14 & & 85 & & \\
\hline HEMBL1 & 37357 & 85 & & \\
\hline AEMBLE & 57 & 996 & & \\
\hline AEMBL: & 57 & 85 & & \\
\hline IEMBL14 & 37357 & 585 & & \\
\hline AEMBL13 & & 85 & & \\
\hline HEMBL1 & 37357 & 4.8044 & & \\
\hline AEMBL: & 57 & e & & \\
\hline EMB & 357 & 2.585 & & \\
\hline IEMBL] & 357 & .585 & & \\
\hline IEMBL15 & & 2.585 & & \\
\hline HEMBL1C & 37357 & 4.569 & & \\
\hline AEMB & 57 & 85 & & \\
\hline IEMB & 57 & 2.585 & & \\
\hline 58 & & 2.585 & & \\
\hline AEMBL1 & 57 & 5.8274 & & S1 1 \\
\hline AEMBL] & 57 & 2.585 & & S1 1 \\
\hline 2 & 57 & 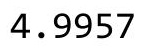 & & \\
\hline 33 & 57 & 2. & & TST \\
\hline IEMBL1 & & 4.1959 & & \\
\hline AEMBL13 & 37357 & 2.585 & 56 & S \\
\hline 44 & 57 & & & בת \\
\hline 57 & 57 & 2.585 & & \\
\hline$\theta 0$ & 57 & & & IST \\
\hline IEMBL1 & 37357 & 2.585 & 96 & $\mathrm{~S}$ \\
\hline AEMBL: & 37357 & 4.6805 & & S \\
\hline CHEMBL & 37357 & 5.6 & & \\
\hline & & & & \\
\hline CHEMBL15 & 37357 & 4.5018 & 3.3427 & $\mathrm{~S}$ \\
\hline AEMBL3 & 37357 & 2.585 & . 4946 & \\
\hline CHEMB & & & & \\
\hline & רסכרכי & & 3.4135 & \\
\hline
\end{tabular}

Page 5973 


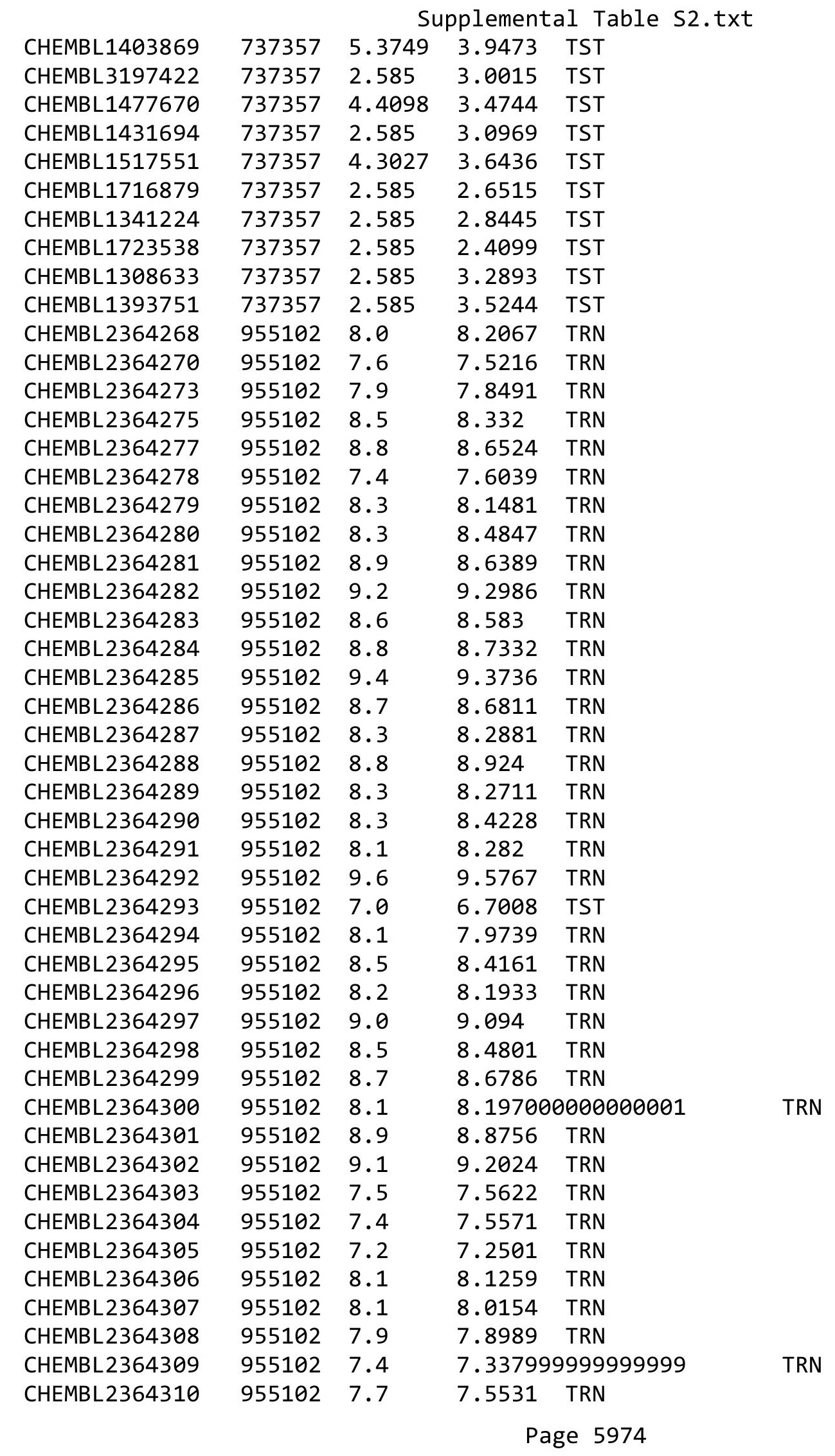




\begin{tabular}{|c|c|c|c|c|c|}
\hline \multicolumn{6}{|c|}{ Supplemental Table S2.txt } \\
\hline CHEMBL 2364311 & 955102 & 8.1 & 7.9528 & TRN & \\
\hline CHEMBL 2364312 & 955102 & 9.6 & 9.6913 & TRN & \\
\hline CHEMBL 2364313 & 955102 & 7.8 & 7.8418 & TRN & \\
\hline CHEMBL 2364314 & 955102 & 6.8 & 8.4106 & TST & \\
\hline CHEMBL 2364315 & 955102 & 8.8 & 9.5806 & TST & \\
\hline CHEMBL 2364316 & 955102 & 7.8 & 7.8472 & TRN & \\
\hline CHEMBL 2364317 & 955102 & 9.5 & 9.5133 & TRN & \\
\hline CHEMBL 2364318 & 955102 & 9.4 & 9.2703 & TRN & \\
\hline CHEMBL 2364319 & 955102 & 7.1 & 7.1602 & TRN & \\
\hline CHEMBL 2364320 & 955102 & 8.8 & 8.9864 & TST & \\
\hline CHEMBL 2364321 & 955102 & 8.7 & 8.6399 & TRN & \\
\hline CHEMBL 2364322 & 955102 & 7.7 & 8.9186 & TST & \\
\hline CHEMBL 2364323 & 955102 & 8.7 & 8.3737 & TST & \\
\hline CHEMBL 2364324 & 955102 & 7.6 & 8.4574 & TST & \\
\hline CHEMBL 2364325 & 955102 & 7.7 & 8.1012 & TST & \\
\hline CHEMBL 2364326 & 955102 & 9.0 & 8.0924 & TST & \\
\hline CHEMBL 2364327 & 955102 & 8.2 & 8.2184 & TST & \\
\hline CHEMBL 2364328 & 955102 & 8.6 & 8.6273 & TST & \\
\hline CHEMBL 2364329 & 955102 & 8.9 & 8.4324 & TST & \\
\hline CHEMBL 2364330 & 955102 & 9.1 & 8.6431 & TST & \\
\hline CHEMBL 2364331 & 955102 & 7.4 & 7.7148 & TST & \\
\hline CHEMBL 2364332 & 955102 & 7.8 & 8.282 & TST & \\
\hline CHEMBL 2364333 & 955102 & 7.6 & 8.6185 & TST & \\
\hline CHEMBL 3697665 & 1528234 & 7.4685 & 7.5508 & TST & \\
\hline CHEMBL3697673 & 1528234 & 7.8539 & 7.2486 & TST & \\
\hline CHEMBL3697679 & 1528234 & 6.7447 & 6.71899 & 9999999999 & TRN \\
\hline CHEMBL3697657 & 1528234 & 7.9586 & 7.9694 & TRN & \\
\hline CHEMBL3697653 & 1528234 & 7.699 & 7.7141 & TRN & \\
\hline CHEMBL 3697646 & 1528234 & 7.6198 & 7.6134 & TRN & \\
\hline CHEMBL3697691 & 1528234 & 7.1675 & 7.1909 & TRN & \\
\hline CHEMBL3697697 & 1528234 & 7.4559 & 7.45799 & 9999999999 & TRN \\
\hline CHEMBL 3697667 & 1528234 & 7.5086 & 7.4889 & TRN & \\
\hline CHEMBL3697696 & 1528234 & 6.5452 & 6.5341 & TRN & \\
\hline CHEMBL 3697662 & 1528234 & 7.3372 & 7.0011 & TST & \\
\hline CHEMBL3697688 & 1528234 & 6.3665 & 6.3684 & TRN & \\
\hline CHEMBL3697660 & 1528234 & 7.301 & 7.3322 & TRN & \\
\hline CHEMBL3697681 & 1528234 & 6.6021 & 6.5835 & TRN & \\
\hline CHEMBL3697675 & 1528234 & 6.8861 & 6.7166 & TST & \\
\hline CHEMBL3697630 & 1528234 & 7.2366 & 7.2241 & TRN & \\
\hline CHEMBL3697700 & 1528234 & 6.9666 & 6.945 & TRN & \\
\hline CHEMBL3697687 & 1528234 & 6.4318 & 6.4398 & TRN & \\
\hline CHEMBL3697631 & 1528234 & 7.2218 & 7.206 & TRN & \\
\hline CHEMBL3697666 & 1528234 & 7.9208 & 7.8785 & TRN & \\
\hline CHEMBL3697639 & 1528234 & 7.2366 & 7.2106 & TRN & \\
\hline CHEMBL 3697644 & 1528234 & 7.9586 & 7.9392 & TRN & \\
\hline CHEMBL3697634 & 1528234 & 6.3925 & 6.8875 & TST & \\
\hline CHEMBL3697647 & 1528234 & 7.5686 & 7.6343 & TRN & \\
\hline CHEMBL3697632 & 1528234 & 6.8386 & 6.8845 & TRN & \\
\hline
\end{tabular}


Supplemental Table S2.txt

\begin{tabular}{|c|c|c|c|c|c|}
\hline CHEMBL3697655 & 1528234 & 7.4685 & 7.5324 & TRN & \\
\hline CHEMBL3697670 & 1528234 & 7.1938 & 6.5399 & TST & \\
\hline CHEMBL3697668 & 1528234 & 7.1871 & 7.2421 & TRN & \\
\hline CHEMBL3697693 & 1528234 & 6.8697 & 6.8647 & TRN & \\
\hline CHEMBL3697652 & 1528234 & 7.6198 & 7.6248 & TRN & \\
\hline CHEMBL3697680 & 1528234 & 5.3615 & 5.3682 & TRN & \\
\hline CHEMBL3697664 & 1528234 & 7.8239 & 7.7919 & TRN & \\
\hline CHEMBL3697698 & 1528234 & 6.9586 & 6.9726 & TRN & \\
\hline CHEMBL3697658 & 1528234 & 6.7212 & 6.7016 & TRN & \\
\hline CHEMBL3697695 & 1528234 & 6.0066 & \multicolumn{2}{|c|}{6.007000000000001} & TRN \\
\hline CHEMBL3697699 & 1528234 & 6.3925 & 7.1371 & TST & \\
\hline CHEMBL3697685 & 1528234 & 6.1871 & 6.1845 & TRN & \\
\hline CHEMBL3697633 & 1528234 & 7.4318 & 7.097 & TST & \\
\hline CHEMBL 3697672 & 1528234 & 7.3768 & 7.1695 & TST & \\
\hline CHEMBL 3697683 & 1528234 & 7.0969 & 7.0818 & TRN & \\
\hline CHEMBL3697682 & 1528234 & 7.0177 & 7.026 & TRN & \\
\hline CHEMBL3697638 & 1528234 & 7.9586 & \multicolumn{2}{|c|}{7.922000000000001} & TRN \\
\hline CHEMBL3697627 & 1528234 & 7.7696 & 7.7764 & TRN & \\
\hline CHEMBL3697641 & 1528234 & 6.5376 & 6.5372 & TRN & \\
\hline CHEMBL 3697640 & 1528234 & 7.8239 & 7.8271 & TRN & \\
\hline CHEMBL3697674 & 1528234 & 8.2218 & 7.5167 & TST & \\
\hline CHEMBL3697650 & 1528234 & 7.2757 & 7.2821 & TRN & \\
\hline CHEMBL3697637 & 1528234 & 6.5157 & 6.7037 & TST & \\
\hline CHEMBL3697651 & 1528234 & 7.0362 & 6.977 & TRN & \\
\hline CHEMBL3697669 & 1528234 & 7.699 & 7.685 & TRN & \\
\hline CHEMBL3697663 & 1528234 & 7.1308 & 7.1069 & TRN & \\
\hline CHEMBL3697645 & 1528234 & 7.1805 & 6.7394 & TST & \\
\hline CHEMBL3697642 & 1528234 & 6.9393 & \multicolumn{2}{|c|}{6.946000000000001} & TRN \\
\hline CHEMBL3697694 & 1528234 & 6.8697 & 6.8675 & TRN & \\
\hline CHEMBL 3697677 & 1528234 & 7.5086 & 7.4884 & TRN & \\
\hline CHEMBL3697636 & 1528234 & 7.4318 & 7.35 & TST & \\
\hline CHEMBL3697686 & 1528234 & 6.8386 & 6.855 & TRN & \\
\hline CHEMBL3697648 & 1528234 & 7.1079 & 7.2983 & TST & \\
\hline CHEMBL 3697628 & 1528234 & 7.4949 & 7.4527 & TRN & \\
\hline CHEMBL3697659 & 1528234 & 7.284 & 7.2805 & TRN & \\
\hline CHEMBL3697692 & 1528234 & 7.1024 & 7.0969 & TRN & \\
\hline CHEMBL 3697649 & 1528234 & 7.4815 & 7.5356 & TRN & \\
\hline CHEMBL3697656 & 1528234 & 6.0 & 7.4626 & TST & \\
\hline CHEMBL 3697678 & 1528234 & 7.3372 & 7.3753 & TRN & \\
\hline CHEMBL3697689 & 1528234 & 6.1221 & 6.1367 & TRN & \\
\hline CHEMBL3697671 & 1528234 & 7.1805 & 6.9349 & TST & \\
\hline CHEMBL3697629 & 1528234 & 7.6576 & 7.6788 & TRN & \\
\hline CHEMBL3697635 & 1528234 & 6.8861 & 7.2803 & TST & \\
\hline CHEMBL3697643 & 1528234 & 7.2076 & 7.1986 & TRN & \\
\hline CHEMBL3697661 & 1528234 & 7.4089 & 7.4204 & TRN & \\
\hline CHEMBL3697690 & 1528234 & 7.4089 & 7.3826 & TRN & \\
\hline CHEMBL 3697684 & 1528234 & 6.1308 & 7.0004 & TST & \\
\hline CHEMBL258844 & 954762 & 4.0032 & 4.6386 & TRN & \\
\hline
\end{tabular}




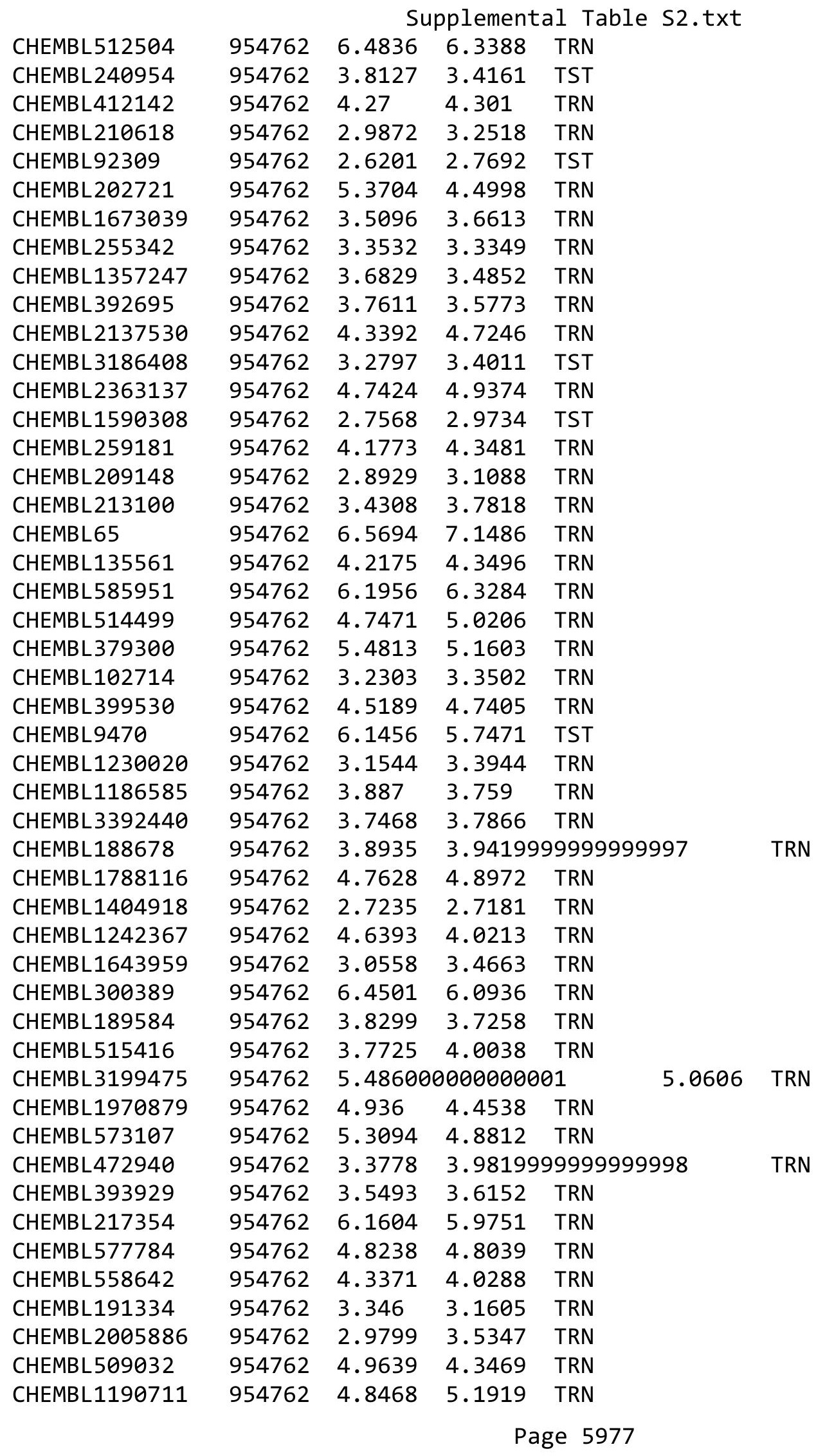




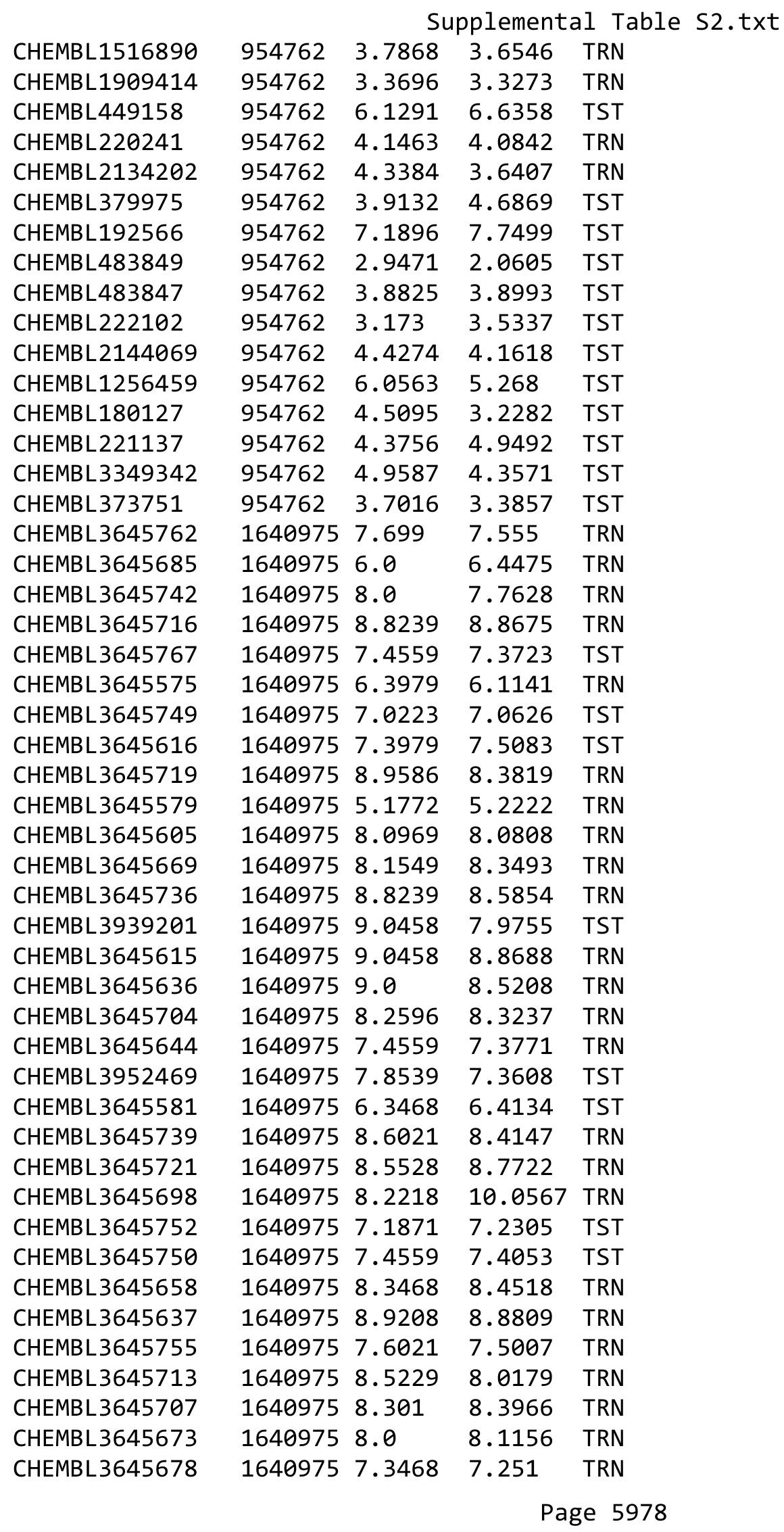


Supplemental Table S2.txt

\begin{tabular}{|c|c|c|c|c|c|}
\hline CHEMBL 3645746 & 1640975 & 7.6021 & 7.5318 & TRN & \\
\hline CHEMBL3645593 & 1640975 & 7.2596 & 7.1884 & TRN & \\
\hline CHEMBL3645731 & 1640975 & 8.0969 & 7.7971 & TRN & \\
\hline CHEMBL3645711 & 1640975 & 8.0969 & 7.5323 & TRN & \\
\hline CHEMBL3980438 & 1640975 & 8.699 & 7.931 & TST & \\
\hline CHEMBL3645607 & 1640975 & 8.4559 & 7.9435 & TRN & \\
\hline CHEMBL3645689 & 1640975 & 8.3468 & 7.6769 & TRN & \\
\hline CHEMBL3645628 & 1640975 & 8.6021 & 8.5037 & TRN & \\
\hline CHEMBL3645610 & 1640975 & 6.0 & 6.2418 & TRN & \\
\hline CHEMBL3645651 & 1640975 & 6.1871 & 6.2703 & TST & \\
\hline CHEMBL3645733 & 1640975 & 8.0 & 8.1543 & TST & \\
\hline CHEMBL3639446 & 1640975 & 7.1549 & 7.1985 & TRN & \\
\hline CHEMBL3981947 & 1640975 & 8.2596 & 7.892 & TST & \\
\hline CHEMBL 3645676 & 1640975 & 7.699 & 7.645 & TRN & \\
\hline CHEMBL3645656 & 1640975 & 8.699 & 8.4091 & TRN & \\
\hline CHEMBL3645645 & 1640975 & 7.3979 & 7.4552 & TRN & \\
\hline CHEMBL3897794 & 1640975 & 8.4559 & 7.3013 & TST & \\
\hline CHEMBL3645657 & 1640975 & 8.2218 & 8.3743 & TRN & \\
\hline CHEMBL 3645583 & 1640975 & 7.0 & 6.8017 & TST & \\
\hline CHEMBL3645618 & 1640975 & 7.8239 & 7.7863 & TRN & \\
\hline CHEMBL3645712 & 1640975 & 8.0 & 7.5214 & TRN & \\
\hline CHEMBL3645695 & 1640975 & 8.8539 & 8.7376 & TRN & \\
\hline CHEMBL3645591 & 1640975 & 6.0 & 6.4777 & TRN & \\
\hline CHEMBL 3645766 & 1640975 & 8.0969 & 7.88399 & 99999999995 & TRN \\
\hline CHEMBL3645664 & 1640975 & 8.301 & 7.8358 & TRN & \\
\hline CHEMBL3645667 & 1640975 & 8.8239 & 8.7106 & TRN & \\
\hline CHEMBL3645759 & 1640975 & 7.6021 & 7.5486 & TST & \\
\hline CHEMBL 3645756 & 1640975 & 7.699 & 7.6044 & TRN & \\
\hline CHEMBL 3645666 & 1640975 & 8.699 & 8.4511 & TRN & \\
\hline CHEMBL3645614 & 1640975 & 8.2218 & 7.9616 & TRN & \\
\hline CHEMBL3645734 & 1640975 & 9.2218 & 9.0086 & TST & \\
\hline CHEMBL3645612 & 1640975 & 6.0 & 7.0035 & TRN & \\
\hline CHEMBL3645725 & 1640975 & 7.6576 & 8.3819 & TRN & \\
\hline CHEMBL 3645690 & 1640975 & 8.2596 & 7.7498 & TRN & \\
\hline CHEMBL3645631 & 1640975 & 8.1871 & 8.3185 & TRN & \\
\hline CHEMBL3645654 & 1640975 & 8.3979 & 8.5792 & TRN & \\
\hline CHEMBL3645727 & 1640975 & 8.5229 & 8.5198 & TRN & \\
\hline CHEMBL3645699 & 1640975 & 8.2218 & 8.2947 & TRN & \\
\hline CHEMBL 3924781 & 1640975 & 10.5229 & 8.0809 & TST & \\
\hline CHEMBL 3645617 & 1640975 & 7.2218 & 7.2176 & TST & \\
\hline CHEMBL3645641 & 1640975 & 7.699 & 7.8678 & TRN & \\
\hline CHEMBL3645674 & 1640975 & 8.6021 & 8.6932 & TRN & \\
\hline CHEMBL3899422 & 1640975 & 7.3979 & 7.1937 & TST & \\
\hline CHEMBL 3645714 & 1640975 & 8.0458 & 7.7133 & TRN & \\
\hline CHEMBL 3645730 & 1640975 & 5.8239 & 6.31 & TRN & \\
\hline CHEMBL3645745 & 1640975 & 7.0969 & 7.0991 & TRN & \\
\hline CHEMBL3645585 & 1640975 & 6.0 & 6.2702 & TRN & \\
\hline CHEMBL3645589 & 1640975 & 6.0 & 6.1725 & TRN & \\
\hline
\end{tabular}




\begin{tabular}{|c|c|c|c|c|c|}
\hline \multicolumn{6}{|c|}{ Supplemental Table S2.txt } \\
\hline CHEMBL3645619 & 1640975 & 6.0 & 6.3315 & TRN & \\
\hline CHEMBL 3645577 & 1640975 & 6.0 & 7.6879 & TRN & \\
\hline CHEMBL3645626 & 1640975 & 8.6021 & 8.4006 & TRN & \\
\hline CHEMBL3645661 & 1640975 & 6.301 & 6.1615 & TST & \\
\hline CHEMBL3645744 & 1640975 & 7.6021 & 7.5073 & TRN & \\
\hline CHEMBL3645705 & 1640975 & 8.5528 & 8.3416 & TRN & \\
\hline CHEMBL3905595 & 1640975 & 8.6021 & 7.4669 & TST & \\
\hline CHEMBL3933617 & 1640975 & 8.8239 & 7.857 & TST & \\
\hline CHEMBL3645701 & 1640975 & 8.8539 & 8.6354 & TRN & \\
\hline CHEMBL3931905 & 1640975 & 8.0 & 7.6695 & TST & \\
\hline CHEMBL3645665 & 1640975 & 6.0 & 6.6683 & TRN & \\
\hline CHEMBL3645629 & 1640975 & 8.8539 & 8.6501 & TRN & \\
\hline CHEMBL3645584 & 1640975 & 7.1871 & 6.9811 & TRN & \\
\hline CHEMBL3645633 & 1640975 & 8.4559 & 7.8547 & TRN & \\
\hline CHEMBL 3645598 & 1640975 & 7.1871 & 7.0505 & TRN & \\
\hline CHEMBL3912001 & 1640975 & 8.4202 & 7.7026 & TST & \\
\hline CHEMBL3645578 & 1640975 & 7.4559 & 7.06 & TST & \\
\hline CHEMBL3645694 & 1640975 & 6.0 & 6.4282 & TRN & \\
\hline CHEMBL3645761 & 1640975 & 7.1249 & 7.1897 & TRN & \\
\hline CHEMBL 3645632 & 1640975 & 8.4559 & 7.75899 & 99999999995 & TRN \\
\hline CHEMBL3645764 & 1640975 & 7.3979 & 7.36799 & 9999999999 & TRN \\
\hline CHEMBL3645758 & 1640975 & 7.6021 & 7.4959 & TRN & \\
\hline CHEMBL3645768 & 1640975 & 7.699 & 7.6411 & TRN & \\
\hline CHEMBL 3645743 & 1640975 & 7.6021 & 7.51 & TST & \\
\hline CHEMBL 3645729 & 1640975 & 6.0 & 8.7084 & TRN & \\
\hline CHEMBL 3645720 & 1640975 & 8.7447 & 8.9524 & TRN & \\
\hline CHEMBL3645622 & 1640975 & 6.0 & 6.3893 & TRN & \\
\hline CHEMBL3645609 & 1640975 & 8.5229 & 8.3648 & TRN & \\
\hline CHEMBL 3645748 & 1640975 & 7.0458 & 7.0502 & TST & \\
\hline CHEMBL 3645600 & 1640975 & 7.8239 & 7.5278 & TRN & \\
\hline CHEMBL 3645576 & 1640975 & 6.1249 & 5.8509 & TRN & \\
\hline CHEMBL3645717 & 1640975 & 8.6198 & 8.6736 & TRN & \\
\hline CHEMBL3645760 & 1640975 & 8.0 & 7.8814 & TRN & \\
\hline CHEMBL3645738 & 1640975 & 9.0 & 8.6454 & TRN & \\
\hline CHEMBL 3645625 & 1640975 & 5.9393 & 6.154 & TST & \\
\hline CHEMBL3645703 & 1640975 & 8.0969 & 8.3189 & TRN & \\
\hline CHEMBL3645683 & 1640975 & 6.0 & 6.2189 & TRN & \\
\hline CHEMBL3645582 & 1640975 & 6.5229 & 6.6119 & TRN & \\
\hline CHEMBL 3645753 & 1640975 & 7.6021 & 7.4777 & TRN & \\
\hline CHEMBL 3645682 & 1640975 & 8.6021 & 8.4948 & TRN & \\
\hline CHEMBL3645602 & 1640975 & 8.699 & 8.7349 & TRN & \\
\hline CHEMBL3645735 & 1640975 & 7.5229 & 7.9593 & TST & \\
\hline CHEMBL3645740 & 1640975 & 8.5229 & 8.6511 & TST & \\
\hline CHEMBL3645599 & 1640975 & 8.0969 & 8.2442 & TRN & \\
\hline CHEMBL 3645723 & 1640975 & 8.8861 & 8.3226 & TRN & \\
\hline CHEMBL 3645726 & 1640975 & 7.9586 & 8.2597 & TRN & \\
\hline CHEMBL3645638 & 1640975 & 8.699 & 8.4999 & TRN & \\
\hline CHEMBL3645606 & 1640975 & 9.0 & 8.8893 & TRN & \\
\hline
\end{tabular}


Supplemental Table S2.txt

\begin{tabular}{|c|c|c|c|c|}
\hline CHEMBL 3639445 & 1640975 & 7.0969 & 7.3565 & TRN \\
\hline CHEMBL3645586 & 1640975 & 6.0 & 6.0598 & TRN \\
\hline CHEMBL 3645587 & 1640975 & 6.0 & 5.9719 & TRN \\
\hline CHEMBL 3645672 & 1640975 & 7.699 & 7.6685 & TRN \\
\hline CHEMBL 3645597 & 1640975 & 6.3979 & 6.33700 & 0000000001 \\
\hline CHEMBL 3645659 & 1640975 & 8.3468 & 8.3153 & TRN \\
\hline CHEMBL 3645709 & 1640975 & 8.1549 & 8.1067 & TRN \\
\hline CHEMBL 3645732 & 1640975 & 8.2076 & 8.2241 & TST \\
\hline CHEMBL 3645594 & 1640975 & 7.1549 & 7.0703 & TRN \\
\hline CHEMBL 3645706 & 1640975 & 8.5229 & 8.4228 & TRN \\
\hline CHEMBL 3645754 & 1640975 & 7.699 & 7.4908 & TST \\
\hline CHEMBL 3645677 & 1640975 & 7.8239 & 7.7986 & TRN \\
\hline CHEMBL 3645671 & 1640975 & 8.1549 & 8.1354 & TRN \\
\hline CHEMBL 3645747 & 1640975 & 7.5229 & 7.3368 & TST \\
\hline CHEMBL 3645647 & 1640975 & 7.8239 & 7.6718 & TRN \\
\hline CHEMBL 3645580 & 1640975 & 7.3468 & 7.3269 & TRN \\
\hline CHEMBL3645642 & 1640975 & 6.0223 & 6.0375 & TST \\
\hline CHEMBL 3645680 & 1640975 & 8.0458 & 8.2276 & TRN \\
\hline CHEMBL 3645691 & 1640975 & 8.3468 & 8.3325 & TRN \\
\hline CHEMBL 3645715 & 1640975 & 8.5229 & 8.7936 & TRN \\
\hline CHEMBL 3645700 & 1640975 & 8.3979 & 8.6254 & TRN \\
\hline CHEMBL 3645708 & 1640975 & 8.3468 & 8.1363 & TRN \\
\hline CHEMBL 3645649 & 1640975 & 7.5229 & 7.5618 & TRN \\
\hline CHEMBL 3645757 & 1640975 & 7.2596 & 7.23799 & 99999999995 \\
\hline CHEMBL 3645588 & 1640975 & 8.5229 & 8.2442 & TRN \\
\hline CHEMBL 3645643 & 1640975 & 7.301 & 7.3152 & TST \\
\hline CHEMBL3645697 & 1640975 & 8.8239 & 8.9845 & TRN \\
\hline CHEMBL 3645751 & 1640975 & 7.3979 & 7.291 & TST \\
\hline CHEMBL 3645728 & 1640975 & 7.1871 & 7.0566 & TST \\
\hline CHEMBL 3645660 & 1640975 & 8.1549 & 7.7739 & TRN \\
\hline CHEMBL 3645646 & 1640975 & 7.1549 & 7.1781 & TRN \\
\hline CHEMBL 3645663 & 1640975 & 8.1871 & 8.1 & TRN \\
\hline CHEMBL 3645686 & 1640975 & 6.0 & 5.9719 & TRN \\
\hline CHEMBL 3645718 & 1640975 & 8.699 & 8.843 & TRN \\
\hline CHEMBL 3930203 & 1640975 & 8.5229 & 7.4192 & TST \\
\hline CHEMBL3965801 & 1640975 & 8.2291 & 7.7033 & TST \\
\hline CHEMBL3906713 & 1640975 & 8.0 & 7.8954 & TST \\
\hline CHEMBL 3645722 & 1640975 & 8.3565 & 7.9992 & TRN \\
\hline CHEMBL 3645634 & 1640975 & 5.9031 & 5.8787 & TST \\
\hline CHEMBL 3645684 & 1640975 & 8.0969 & 7.9372 & TRN \\
\hline CHEMBL 3645627 & 1640975 & 8.7696 & 8.6627 & TRN \\
\hline CHEMBL 3645635 & 1640975 & 6.1249 & 5.9995 & TST \\
\hline CHEMBL3645662 & 1640975 & 7.5229 & 7.3531 & TRN \\
\hline CHEMBL 3645681 & 1640975 & 6.0 & 6.625 & TRN \\
\hline CHEMBL 3645763 & 1640975 & 7.3979 & 7.3196 & TST \\
\hline CHEMBL 3645668 & 1640975 & 8.301 & 7.0035 & TRN \\
\hline CHEMBL 3973938 & 1640975 & 8.4815 & 7.6805 & TST \\
\hline CHEMBL 3968741 & 1640975 & 8.6021 & 7.8679 & TST \\
\hline
\end{tabular}


Supplemental Table S2.txt

\begin{tabular}{|c|c|c|c|c|c|}
\hline CHEMBL 3645648 & 1640975 & 7.1871 & 7.1915 & TRN & \\
\hline CHEMBL 3645630 & 1640975 & 8.0969 & 8.0957 & TRN & \\
\hline CHEMBL 3645724 & 1640975 & 9.0 & 8.9524 & TRN & \\
\hline CHEMBL 3645675 & 1640975 & 8.0969 & 7.94799 & 99999999995 & TRN \\
\hline CHEMBL 3645639 & 1640975 & 6.0 & 6.631 & TRN & \\
\hline CHEMBL574981 & 588489 & 4.0 & 4.0003 & TRN & \\
\hline CHEMBL574977 & 588489 & 5.4183 & 5.4161 & TRN & \\
\hline CHEMBL573598 & 588489 & 6.0778 & 6.0769 & TRN & \\
\hline CHEMBL572663 & 588489 & 7.061 & 7.0525 & TRN & \\
\hline CHEMBL577900 & 588489 & 4.0 & 4.0025 & TRN & \\
\hline CHEMBL574548 & 588489 & 4.0 & 4.0031 & TRN & \\
\hline CHEMBL574749 & 588489 & \multicolumn{2}{|c|}{5.587000000000001} & 5.5883 & TRN \\
\hline CHEMBL572430 & 588489 & 4.0 & 3.9966 & TRN & \\
\hline CHEMBL574303 & 588489 & 4.0 & 3.9984 & TRN & \\
\hline CHEMBL572429 & 588489 & 4.0 & 4.6744 & TST & \\
\hline CHEMBL 72187 & 588489 & 5.2916 & 5.2921 & TRN & \\
\hline CHEMBL584357 & 588489 & 4.0 & 4.3533 & TST & \\
\hline CHEMBL574253 & 588489 & 5.6992 & 5.7024 & TRN & \\
\hline CHEMBL576732 & 588489 & 5.9646 & 5.9749 & TRN & \\
\hline CHEMBL573317 & 588489 & 5.5635 & 5.5621 & TRN & \\
\hline CHEMBL572660 & 588489 & 4.0 & 4.005 & TRN & \\
\hline CHEMBL573305 & 588489 & 5.1086 & 5.11100 & 0000000001 & TRN \\
\hline CHEMBL574547 & 588489 & 4.0 & 4.0012 & TRN & \\
\hline CHEMBL573617 & 588489 & 5.9285 & 5.9304 & TRN & \\
\hline CHEMBL584575 & 588489 & 5.8861 & 5.887006 & 30000000005 & TRN \\
\hline CHEMBL574994 & 588489 & 4.0 & 4.001 & TRN & \\
\hline CHEMBL576566 & 588489 & 6.3063 & 6.3151 & TRN & \\
\hline CHEMBL564496 & 588489 & 4.0 & 4.0033 & TRN & \\
\hline CHEMBL578225 & 588489 & 5.7632 & 5.7566 & TRN & \\
\hline CHEMBL583145 & 588489 & 5.0492 & 5.0459 & TRN & \\
\hline CHEMBL584574 & 588489 & 4.0 & 4.0175 & TRN & \\
\hline CHEMBL573538 & 588489 & 4.0 & 3.9953 & TRN & \\
\hline CHEMBL574099 & 588489 & 4.0 & 3.9833 & TRN & \\
\hline CHEMBL583365 & 588489 & 4.0 & 3.9956 & TRN & \\
\hline CHEMBL574980 & 588489 & 6.3809 & 6.3748 & TRN & \\
\hline CHEMBL575852 & 588489 & 5.38 & 5.3761 & TRN & \\
\hline CHEMBL575851 & 588489 & 4.0 & 3.99899 & 99999999997 & TRN \\
\hline CHEMBL574763 & 588489 & 4.0 & 3.9955 & TRN & \\
\hline CHEMBL575812 & 588489 & 5.6878 & 5.6858 & TRN & \\
\hline CHEMBL572665 & 588489 & 4.0 & 4.6036 & TST & \\
\hline CHEMBL573596 & 588489 & 4.0 & 4.374 & TST & \\
\hline CHEMBL574770 & 588489 & 4.0 & 4.0022 & TRN & \\
\hline CHEMBL583777 & 588489 & 5.4807 & 5.5055 & TRN & \\
\hline CHEMBL574080 & 588489 & 5.3485 & 5.3524 & TRN & \\
\hline CHEMBL572661 & 588489 & 4.0 & 4.002 & TRN & \\
\hline CHEMBL575603 & 588489 & 5.2762 & 5.2799 & TRN & \\
\hline CHEMBL573863 & 588489 & 4.0 & 3.9915 & TRN & \\
\hline CHEMBL574984 & 588489 & 5.2658 & 5.2628 & TRN & \\
\hline
\end{tabular}




\begin{tabular}{|c|c|c|c|c|c|c|}
\hline & & \multicolumn{5}{|c|}{ t. } \\
\hline CHEMBL574532 & 588489 & 5.2497 & 4.5848 & TST & & \\
\hline CHEMBL584388 & 588489 & 4.0 & 3.9968 & TRN & & \\
\hline CHEMBL573862 & 588489 & \multicolumn{3}{|c|}{5.071000000000001} & 5.0758 & TRN \\
\hline CHEMBL583287 & 588489 & 4.0 & 4.8947 & TST & & \\
\hline CHEMBL584205 & 588489 & 6.0039 & 5.9903 & TRN & & \\
\hline CHEMBL573553 & 588489 & 6.2299 & 4.2185 & TST & & \\
\hline CHEMBL576552 & 588489 & 5.2341 & 5.228 & TRN & & \\
\hline CHEMBL573597 & 588489 & 4.0 & 4.6447 & TST & & \\
\hline CHEMBL572664 & 588489 & 6.8297 & 6.8182 & TRN & & \\
\hline CHEMBL574098 & 588489 & 5.8239 & 5.8256 & TRN & & \\
\hline CHEMBL575848 & 588489 & 5.395 & 5.3928 & TRN & & \\
\hline CHEMBL583764 & 588489 & 4.0 & 4.0023 & TRN & & \\
\hline CHEMBL575853 & 588489 & 4.0 & 4.9225 & TST & & \\
\hline CHEMBL584389 & 588489 & 7.5317 & 7.5415 & TRN & & \\
\hline CHEMBL579267 & 588489 & 4.0 & 4.0023 & TRN & & \\
\hline CHEMBL583787 & 588489 & 6.3726 & 6.3713 & TRN & & \\
\hline CHEMBL573835 & 588489 & 6.6536 & 6.6539 & TRN & & \\
\hline CHEMBL574769 & 588489 & 6.6162 & 5.332006 & 0000000001 & & TST \\
\hline CHEMBL578653 & 588489 & 7.6968 & 7.1122 & TST & & \\
\hline CHEMBL574750 & 588489 & 4.0 & 4.6051 & TST & & \\
\hline CHEMBL577181 & 588489 & 5.6838 & 5.9181 & TST & & \\
\hline CHEMBL584187 & 588489 & 5.2431 & 4.7231 & TST & & \\
\hline CHEMBL574533 & 588489 & 8.1079 & 6.6003 & TST & & \\
\hline CHEMBL574327 & 588489 & 4.0 & 4.0846 & TST & & \\
\hline CHEMBL572904 & 588489 & 4.0 & 3.6394 & TST & & \\
\hline CHEMBL564497 & 588489 & 5.0351 & 4.9914 & TST & & \\
\hline CHEMBL3694235 & 1528030 & 3.5229 & 3.4609 & TRN & & \\
\hline CHEMBL3690150 & 1528030 & 3.5229 & 3.3983 & TRN & & \\
\hline CHEMBL 2012829 & 1528030 & 6.0 & 6.1468 & TRN & & \\
\hline CHEMBL 3694243 & 1528030 & 6.9172 & 6.7233 & TRN & & \\
\hline CHEMBL3690112 & 1528030 & 4.71899 & 79999999 & 99 & 5.8535 & TST \\
\hline CHEMBL 3690131 & 1528030 & 6.7852 & 6.6007 & TRN & & \\
\hline CHEMBL3690147 & 1528030 & 6.6576 & 6.3897 & TRN & & \\
\hline CHEMBL3690117 & 1528030 & 3.5229 & 4.1984 & TST & & \\
\hline CHEMBL 3694245 & 1528030 & 6.5986 & 6.4919 & TRN & & \\
\hline CHEMBL3694241 & 1528030 & 3.5229 & 3.5973 & TRN & & \\
\hline CHEMBL3690129 & 1528030 & 6.6216 & 6.2445 & TRN & & \\
\hline CHEMBL3694247 & 1528030 & 7.0506 & 6.9368 & TRN & & \\
\hline CHEMBL3690146 & 1528030 & 5.3218 & 5.2872 & TRN & & \\
\hline CHEMBL 3694239 & 1528030 & 6.9355 & 7.0434 & TRN & & \\
\hline CHEMBL600689 & 1528030 & 7.0809 & 5.7689 & TST & & \\
\hline CHEMBL 3694252 & 1528030 & 6.4685 & 1.6265 & TST & & \\
\hline CHEMBL3690152 & 1528030 & 3.5229 & 3.5868 & TRN & & \\
\hline CHEMBL3690121 & 1528030 & 3.5229 & 3.5464 & TRN & & \\
\hline CHEMBL3690136 & 1528030 & 7.4202 & 7.3986 & TRN & & \\
\hline CHEMBL 2012940 & 1528030 & 3.5229 & 3.5893 & TRN & & \\
\hline CHEMBL3690127 & 1528030 & 3.5229 & 3.4925 & TRN & & \\
\hline CHEMBL3690135 & 1528030 & 6.4763 & 6.4782 & TRN & & \\
\hline
\end{tabular}


Supplemental Table S2.txt

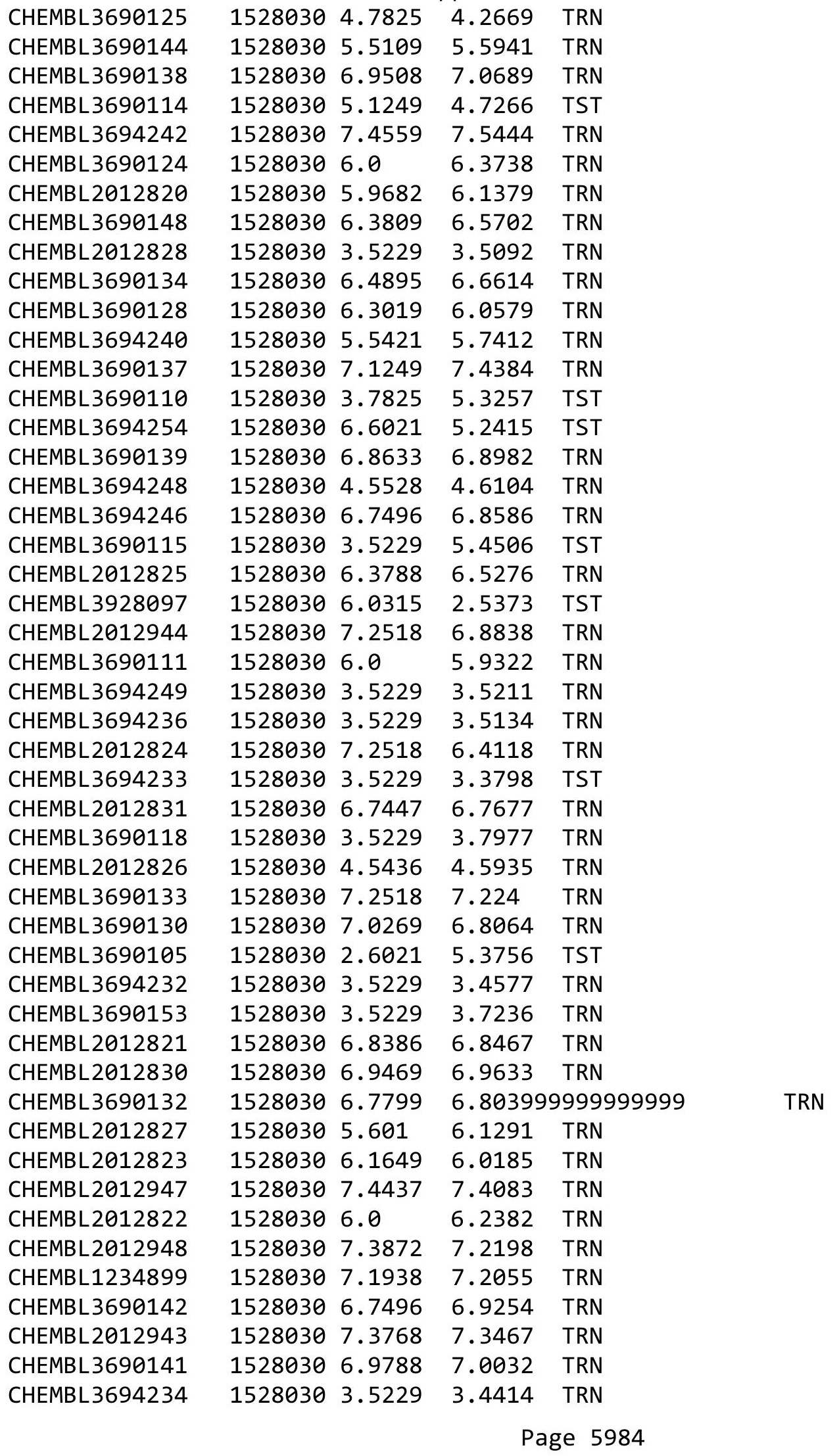


Supplemental Table S2.txt

\begin{tabular}{|c|c|c|c|c|c|c|c|}
\hline CHEMBL2012956 & 1528030 & 6.0 & 6.4097 & TRN & & & \\
\hline CHEMBL3690140 & 1528030 & 7.1739 & 7.0783 & TRN & & & \\
\hline CHEMBL3690120 & 1528030 & 6.71899 & 999999999 & & 6.54706 & 0000000001 & TRN \\
\hline CHEMBL3690149 & 1528030 & 6.6198 & 6.5902 & TRN & & & \\
\hline CHEMBL3690113 & 1528030 & 5.0362 & 5.2641 & TST & & & \\
\hline CHEMBL3690151 & 1528030 & 5.7696 & 5.8919 & TRN & & & \\
\hline CHEMBL3928365 & 1528030 & 3.5229 & 3.5605 & TST & & & \\
\hline CHEMBL3690123 & 1528030 & 6.6737 & 7.341 & TST & & & \\
\hline CHEMBL 2012819 & 1528030 & 3.5229 & 4.2184 & TST & & & \\
\hline CHEMBL3690145 & 1528030 & 5.9516 & 5.3787 & TST & & & \\
\hline CHEMBL3690143 & 1528030 & 7.2366 & 6.6898 & TST & & & \\
\hline CHEMBL3694244 & 1528030 & 6.9788 & 7.5555 & TST & & & \\
\hline CHEMBL3690106 & 1528030 & 2.6021 & 5.3387 & TST & & & \\
\hline CHEMBL3690116 & 1528030 & 4.8601 & 4.8954 & TST & & & \\
\hline CHEMBL3690119 & 1528030 & 4.8539 & 5.2548 & TST & & & \\
\hline CHEMBL3694250 & 1528030 & 6.2366 & 5.3782 & TST & & & \\
\hline CHEMBL 211678 & 379744 & \multicolumn{3}{|c|}{ 7. 752000000000001} & 7.595 & TRN & \\
\hline CHEMBL 377875 & 379744 & 7.7375 & 8.0253 & TRN & & & \\
\hline CHEMBL 212795 & 379744 & 7.0799 & 7.0412 & TRN & & & \\
\hline CHEMBL 384795 & 379744 & 8.9586 & 8.4974 & TST & & & \\
\hline CHEMBL 215899 & 379744 & 8.6383 & 8.2014 & TST & & & \\
\hline CHEMBL378934 & 379744 & 7.9066 & 7.7721 & TRN & & & \\
\hline CHEMBL 215680 & 379744 & 7.2636 & 7.3309 & TRN & & & \\
\hline CHEMBL194322 & 379744 & 8.301 & 7.8491 & TRN & & & \\
\hline CHEMBL 211735 & 379744 & 8.2676 & 7.7933 & TRN & & & \\
\hline CHEMBL 213522 & 379744 & 7.6655 & 7.3507 & TRN & & & \\
\hline CHEMBL386742 & 379744 & 7.71 & 7.0535 & TST & & & \\
\hline CHEMBL209644 & 379744 & 9.3979 & 9.0895 & TRN & & & \\
\hline CHEMBL379394 & 379744 & 8.4559 & 8.0306 & TRN & & & \\
\hline CHEMBL 213521 & 379744 & 6.5452 & 6.9269 & TRN & & & \\
\hline CHEMBL 213159 & 379744 & 8.6021 & 8.3105 & TST & & & \\
\hline CHEMBL 212294 & 379744 & 8.5229 & 8.5099 & TRN & & & \\
\hline CHEMBL 212238 & 379744 & 8.2924 & 8.2777 & TRN & & & \\
\hline CHEMBL378328 & 379744 & \multicolumn{3}{|c|}{7.752000000000001} & 7.6815 & TRN & \\
\hline CHEMBL 212038 & 379744 & 7.8356 & 8.082 & TRN & & & \\
\hline CHEMBL 213374 & 379744 & 8.3872 & 7.6435 & TRN & & & \\
\hline CHEMBL 211151 & 379744 & 7.5784 & 7.6772 & TRN & & & \\
\hline CHEMBL379866 & 379744 & 8.2366 & 8.1978 & TRN & & & \\
\hline CHEMBL386360 & 379744 & 7.8539 & 7.8002 & TST & & & \\
\hline CHEMBL379374 & 379744 & 8.426 & 8.2489 & TRN & & & \\
\hline CHEMBL 215858 & 379744 & 8.1805 & 7.9835 & TRN & & & \\
\hline CHEMBL 213002 & 379744 & 7.9281 & 7.1315 & TST & & & \\
\hline CHEMBL 214152 & 379744 & 8.2076 & 8.1621 & TST & & & \\
\hline CHEMBL386869 & 379744 & 7.3261 & 7.4429 & TRN & & & \\
\hline CHEMBL377538 & 379744 & 7.7799 & 7.5632 & TRN & & & \\
\hline CHEMBL377757 & 379744 & 8.041 & 8.0285 & TRN & & & \\
\hline CHEMBL439321 & 379744 & 8.8239 & 8.1715 & TST & & & \\
\hline CHEMBL377319 & 379744 & 8.5229 & 8.029 & TST & & & \\
\hline
\end{tabular}




\begin{tabular}{|c|c|c|c|c|c|}
\hline \multicolumn{6}{|c|}{ Supplemental Table S2.txt } \\
\hline CHEMBL212898 & 379744 & 8.4559 & 8.1698 & TRN & \\
\hline CHEMBL211362 & 379744 & 8.0809 & 8.3118 & TRN & \\
\hline CHEMBL377841 & 379744 & 8.0362 & 7.6139 & TST & \\
\hline CHEMBL379112 & 379744 & 7.0794 & 7.8172 & TRN & \\
\hline CHEMBL 379590 & 379744 & 8.6576 & 8.4542 & TRN & \\
\hline CHEMBL384967 & 379744 & 7.3645 & 7.621 & TRN & \\
\hline CHEMBL213501 & 379744 & 7.7471 & 7.84399 & 9999999999 & TRN \\
\hline CHEMBL439540 & 379744 & 8.0969 & 7.7014 & TRN & \\
\hline CHEMBL212239 & 379744 & 7.8697 & 7.8539 & TRN & \\
\hline CHEMBL379929 & 379744 & 8.0177 & 7.7828 & TRN & \\
\hline CHEMBL386807 & 379744 & 7.8125 & 7.6069 & TST & \\
\hline CHEMBL214114 & 379744 & 7.6198 & 7.8431 & TRN & \\
\hline CHEMBL213258 & 379744 & 8.3665 & 8.4548 & TRN & \\
\hline CHEMBL380030 & 379744 & 8.3372 & 8.5873 & TRN & \\
\hline CHEMBL378922 & 379744 & 6.7033 & 7.4507 & TRN & \\
\hline CHEMBL379783 & 379744 & 7.9101 & 7.7706 & TRN & \\
\hline CHEMBL386033 & 379744 & 7.4789 & 8.013 & TST & \\
\hline CHEMBL212382 & 379744 & 8.9586 & 8.7349 & TRN & \\
\hline CHEMBL 378919 & 379744 & 9.3979 & 9.7582 & TRN & \\
\hline CHEMBL213451 & 379744 & 8.1192 & 7.7852 & TRN & \\
\hline CHEMBL384990 & 379744 & 7.2557 & 7.7228 & TRN & \\
\hline CHEMBL 385352 & 379744 & 7.9547 & 8.105 & TRN & \\
\hline CHEMBL213598 & 379744 & 8.2518 & 8.1733 & TRN & \\
\hline CHEMBL211679 & 379744 & 7.9626 & 7.4592 & TST & \\
\hline CHEMBL386904 & 379744 & 7.8153 & 7.7125 & TST & \\
\hline CHEMBL214310 & 379744 & 8.0132 & 7.8926 & TST & \\
\hline CHEMBL 378920 & 379744 & 7.6108 & 8.1966 & TRN & \\
\hline CHEMBL214198 & 379744 & 8.5528 & 8.4619 & TST & \\
\hline CHEMBL211628 & 379744 & 9.1549 & 8.3829 & TST & \\
\hline CHEMBL377606 & 379744 & 7.6021 & 8.0436 & TRN & \\
\hline CHEMBL210060 & 379744 & 8.1427 & 7.856 & TRN & \\
\hline CHEMBL377165 & 379744 & 7.7011 & 7.1398 & TRN & \\
\hline CHEMBL378752 & 379744 & 7.6517 & 7.7547 & TRN & \\
\hline CHEMBL 213423 & 379744 & 8.4949 & 8.3352 & TRN & \\
\hline CHEMBL215652 & 379744 & 8.6021 & 8.3718 & TRN & \\
\hline CHEMBL211919 & 379744 & 8.3279 & 7.5875 & TST & \\
\hline CHEMBL 212341 & 379744 & 8.1079 & 7.9835 & TST & \\
\hline CHEMBL213055 & 379744 & 6.2644 & 7.1837 & TRN & \\
\hline CHEMBL 212708 & 379744 & 8.0555 & 8.3466 & TRN & \\
\hline CHEMBL212968 & 379744 & 8.7447 & 8.5409 & TRN & \\
\hline CHEMBL212655 & 379744 & 8.0555 & 7.6576 & TRN & \\
\hline CHEMBL384117 & 379744 & 7.4225 & 7.734 & TRN & \\
\hline CHEMBL212849 & 379744 & 8.2596 & 7.8529 & TRN & \\
\hline CHEMBL 378697 & 379744 & 7.8386 & 8.3256 & TRN & \\
\hline CHEMBL10009 & 688447 & 6.5501 & 5.9517 & TRN & \\
\hline CHEMBL1256737 & 688447 & 5.65 & 5.7264 & TRN & \\
\hline CHEMBL1338900 & 688447 & 4.55 & 5.5917 & TST & \\
\hline CHEMBL539947 & 688447 & 4.95 & 5.6013 & TRN & \\
\hline
\end{tabular}




\begin{tabular}{|c|c|c|c|c|c|}
\hline \multicolumn{6}{|c|}{ Supplemental Table s2.txt } \\
\hline CHEMBL1605605 & 688447 & 5.1 & 5.8863 & TRN & \\
\hline CHEMBL1400543 & 688447 & 6.0 & 5.0293 & TRN & \\
\hline CHEMBL429095 & 688447 & 5.4 & 5.3718 & TRN & \\
\hline CHEMBL21241 & 688447 & 4.85 & 6.0913 & TRN & \\
\hline CHEMBL216504 & 688447 & 6.6499 & 5.6996 & TRN & \\
\hline CHEMBL2374058 & 688447 & 8.0 & 6.4728 & TST & \\
\hline CHEMBL595227 & 688447 & 5.7 & 5.365 & TRN & \\
\hline CHEMBL1315457 & 688447 & 5.0 & 5.0778 & TST & \\
\hline CHEMBL1534566 & 688447 & 5.9 & 6.0037 & TRN & \\
\hline CHEMBL1398537 & 688447 & 6.25 & 5.5382 & TRN & \\
\hline CHEMBL1320485 & 688447 & 8.0506 & 5.8321 & TRN & \\
\hline CHEMBL1365553 & 688447 & 5.0 & 5.4769 & TRN & \\
\hline CHEMBL1256625 & 688447 & 6.8499 & 5.5675 & TRN & \\
\hline CHEMBL1562 & 688447 & 8.4559 & 6.0123 & TRN & \\
\hline CHEMBL410873 & 688447 & 5.0 & 5.5191 & TRN & \\
\hline CHEMBL1435313 & 688447 & 8.0 & 6.782 & TRN & \\
\hline CHEMBL1338358 & 688447 & 4.6 & 5.1931 & TRN & \\
\hline CHEMBL110739 & 688447 & 7.699 & 6.3337 & TRN & \\
\hline CHEMBL 275854 & 688447 & 6.45 & 5.9857 & TRN & \\
\hline CHEMBL 258767 & 688447 & 6.0 & 5.6986 & TRN & \\
\hline CHEMBL56543 & 688447 & 5.2 & 5.4824 & TRN & \\
\hline CHEMBL1585944 & 688447 & 8.0 & 6.6178 & TRN & \\
\hline CHEMBL1256514 & 688447 & 4.85 & 5.49799 & 9999999999 & TRN \\
\hline CHEMBL1255837 & 688447 & 5.35 & 6.5454 & TRN & \\
\hline CHEMBL1255649 & 688447 & 4.65 & 6.0052 & TRN & \\
\hline CHEMBL1522486 & 688447 & 5.3 & 4.6863 & TRN & \\
\hline CHEMBL544115 & 688447 & 4.9 & 5.9075 & TRN & \\
\hline CHEMBL17331 & 688447 & 4.9 & 5.1039 & TRN & \\
\hline CHEMBL1514440 & 688447 & 5.15 & 5.8671 & TRN & \\
\hline CHEMBL1256139 & 688447 & 7.5498 & 5.7718 & TRN & \\
\hline CHEMBL1595524 & 688447 & 4.95 & 5.3868 & TRN & \\
\hline CHEMBL1200462 & 688447 & 5.1 & 5.66700 & 0000000001 & TRN \\
\hline CHEMBL 6640 & 688447 & 4.9 & 5.0621 & TRN & \\
\hline CHEMBL1255733 & 688447 & 6.7001 & 6.6694 & TRN & \\
\hline CHEMBL1552165 & 688447 & 5.55 & 5.0998 & TRN & \\
\hline CHEMBL288096 & 688447 & 5.25 & 6.2118 & TRN & \\
\hline CHEMBL1255655 & 688447 & 5.45 & 5.4919 & TRN & \\
\hline CHEMBL 294590 & 688447 & 6.0 & 5.3383 & TRN & \\
\hline CHEMBL1257075 & 688447 & 5.05 & 5.1255 & TRN & \\
\hline CHEMBL129795 & 688447 & 5.5 & 5.8648 & TRN & \\
\hline CHEMBL1514375 & 688447 & 5.95 & 6.1073 & TST & \\
\hline CHEMBL51085 & 688447 & 4.9 & 5.0218 & TRN & \\
\hline CHEMBL1256674 & 688447 & 5.25 & 5.6218 & TST & \\
\hline CHEMBL111545 & 688447 & 7.5003 & 5.5597 & TRN & \\
\hline CHEMBL1367076 & 688447 & 5.85 & 5.5609 & TRN & \\
\hline CHEMBL60518 & 688447 & 6.35 & 5.3513 & TRN & \\
\hline CHEMBL1255656 & 688447 & 5.45 & 5.9245 & TRN & \\
\hline CHEMBL327708 & 688447 & 5.0 & 5.8738 & TRN & \\
\hline
\end{tabular}




\begin{tabular}{|c|c|c|c|c|c|}
\hline \\
\hline CHEMBL122270 & 688447 & 4.9 & 5.864 & TRN & \\
\hline CHEMBL1357016 & 688447 & 5.6 & 6.1083 & TRN & \\
\hline CHEMBL68534 & 688447 & 4.95 & 5.3669 & TRN & \\
\hline CHEMBL1191361 & 688447 & 4.8 & 5.2951 & TST & \\
\hline CHEMBL285819 & 688447 & 5.45 & 5.1146 & TRN & \\
\hline CHEMBL1433897 & 688447 & 6.2 & 5.6034 & TRN & \\
\hline CHEMBL1255936 & 688447 & 4.75 & 5.1627 & TRN & \\
\hline CHEMBL251647 & 688447 & 5.9 & 5.3065 & TST & \\
\hline CHEMBL 260374 & 688447 & 6.5 & 5.8115 & TST & \\
\hline CHEMBL399491 & 688447 & 5.5 & 5.6945 & TST & \\
\hline CHEMBL1435120 & 688447 & 5.4 & 5.4216 & TRN & \\
\hline CHEMBL 2374062 & 688447 & 6.0 & 6.3512 & TST & \\
\hline CHEMBL1355710 & 688447 & 5.45 & 5.5686 & TRN & \\
\hline CHEMBL1355963 & 688447 & 4.95 & 6.90799 & 99999999995 & TST \\
\hline CHEMBL1372302 & 688447 & 5.55 & 5.4883 & TRN & \\
\hline CHEMBL27403 & 688447 & 5.0 & 5.6611 & TRN & \\
\hline CHEMBL1096400 & 688447 & 6.35 & 5.6221 & TRN & \\
\hline CHEMBL1435477 & 688447 & 5.95 & 5.53700 & 0000000001 & TRN \\
\hline CHEMBL 275006 & 688447 & 5.3 & 5.7384 & TRN & \\
\hline CHEMBL1333056 & 688447 & 6.0 & 6.0787 & TST & \\
\hline CHEMBL395915 & 688447 & 5.25 & 5.7998 & TRN & \\
\hline CHEMBL1208858 & 688447 & 4.95 & 5.8026 & TST & \\
\hline CHEMBL3186408 & 688447 & 5.0 & 5.7555 & TST & \\
\hline CHEMBL1255650 & 688447 & 4.9 & 5.36700 & 0000000001 & TRN \\
\hline CHEMBL1256835 & 688447 & 4.9 & 5.7226 & TRN & \\
\hline CHEMBL333985 & 688447 & 5.05 & 5.2141 & TRN & \\
\hline CHEMBL14276 & 688447 & 5.95 & 6.1109 & TRN & \\
\hline CHEMBL 296586 & 688447 & 5.7 & 5.3018 & TRN & \\
\hline CHEMBL 303579 & 688447 & 5.5 & 5.4667 & TRN & \\
\hline CHEMBL1529217 & 688447 & 8.4559 & 5.7207 & TST & \\
\hline CHEMBL77456 & 688447 & 5.05 & 5.2524 & TRN & \\
\hline CHEMBL1284 & 688447 & 5.85 & 5.7354 & TRN & \\
\hline CHEMBL86676 & 688447 & 5.3 & 5.6446 & TST & \\
\hline CHEMBL1399702 & 688447 & 4.65 & 5.4183 & TRN & \\
\hline CHEMBL 1256177 & 688447 & 5.0 & 5.2906 & TRN & \\
\hline CHEMBL17468 & 688447 & 5.25 & 5.749 & TRN & \\
\hline CHEMBL1256851 & 688447 & 6.35 & 5.3783 & TRN & \\
\hline CHEMBL282489 & 688447 & 5.0 & 5.8651 & TRN & \\
\hline CHEMBL1256186 & 688447 & 8.3979 & 6.5903 & TRN & \\
\hline CHEMBL1476170 & 688447 & 6.6 & 6.6056 & TRN & \\
\hline CHEMBL1366616 & 688447 & 4.55 & 4.9521 & TRN & \\
\hline CHEMBL1358402 & 688447 & 6.7501 & 6.4638 & TST & \\
\hline CHEMBL405358 & 688447 & 4.5 & 5.4452 & TRN & \\
\hline CHEMBL362863 & 688447 & 5.2 & 5.6736 & TRN & \\
\hline CHEMBL1329033 & 688447 & 5.0 & 5.8455 & TRN & \\
\hline CHEMBL1336727 & 688447 & 8.1024 & 5.7572 & TRN & \\
\hline CHEMBL 293749 & 688447 & 5.85 & 5.4865 & TRN & \\
\hline CHEMBL 8145 & 688447 & 5.35 & 5.7967 & TRN & \\
\hline
\end{tabular}




\begin{tabular}{|c|c|c|c|c|c|}
\hline \multicolumn{6}{|c|}{ Supplemental Table S2.txt } \\
\hline CHEMBL336467 & 688447 & 5.0 & 4.8388 & TST & \\
\hline CHEMBL1323714 & 688447 & 7.699 & 5.5481 & TST & \\
\hline CHEMBL 278755 & 688447 & 4.6 & 5.0461 & TRN & \\
\hline CHEMBL 388054 & 688447 & 6.6 & 5.8397 & TRN & \\
\hline CHEMBL538595 & 688447 & 6.0 & 5.9338 & TRN & \\
\hline CHEMBL542700 & 688447 & 4.95 & 5.6183 & TRN & \\
\hline CHEMBL56731 & 688447 & 6.0 & 5.5188 & TRN & \\
\hline CHEMBL 375270 & 688447 & 6.95 & 5.581 & TRN & \\
\hline CHEMBL1320310 & 688447 & 5.05 & 6.3235 & TRN & \\
\hline CHEMBL1418227 & 688447 & 5.7 & 6.2348 & TRN & \\
\hline CHEMBL322970 & 688447 & 5.2 & 5.468 & TRN & \\
\hline CHEMBL1256775 & 688447 & 5.1 & 5.3154 & TRN & \\
\hline CHEMBL1255662 & 688447 & 5.1 & 5.4124 & TRN & \\
\hline CHEMBL1236872 & 688447 & 5.35 & 5.3476 & TRN & \\
\hline CHEMBL1361446 & 688447 & 4.7 & 5.6892 & TRN & \\
\hline CHEMBL428496 & 688447 & 6.8499 & 6.365 & TST & \\
\hline CHEMBL24983 & 688447 & 5.2 & 4.9255 & TRN & \\
\hline CHEMBL1436121 & 688447 & 7.1002 & 5.2105 & TST & \\
\hline CHEMBL1571692 & 688447 & 5.7 & 5.9171 & TRN & \\
\hline CHEMBL578741 & 688447 & 5.95 & 5.0077 & TRN & \\
\hline CHEMBL1256191 & 688447 & 6.0 & 5.88 & TRN & \\
\hline CHEMBL1413371 & 688447 & 5.0 & 5.0019 & TRN & \\
\hline CHEMBL319244 & 688447 & 5.65 & 5.6577 & TRN & \\
\hline CHEMBL1567944 & 688447 & 5.2 & 6.2278 & TRN & \\
\hline CHEMBL275311 & 688447 & 5.0 & 6.013 & TRN & \\
\hline CHEMBL 258893 & 688447 & 4.95 & 5.8038 & TST & \\
\hline CHEMBL47814 & 688447 & 5.5 & 5.4231 & TRN & \\
\hline CHEMBL1395737 & 688447 & 4.9 & 5.63299 & 9999999999 & TRN \\
\hline CHEMBL1256623 & 688447 & 5.95 & 5.7403 & TRN & \\
\hline CHEMBL10284 & 688447 & 4.9 & 5.295 & TRN & \\
\hline CHEMBL60718 & 688447 & 5.5 & 5.2963 & TRN & \\
\hline CHEMBL 8488 & 688447 & 6.8499 & 5.3934 & TRN & \\
\hline CHEMBL 2449003 & 688447 & 6.0 & 5.8291 & TRN & \\
\hline CHEMBL 268868 & 688447 & 5.0 & 5.0946 & TRN & \\
\hline CHEMBL1256359 & 688447 & 4.75 & 5.5203 & TRN & \\
\hline CHEMBL1452561 & 688447 & 5.75 & 5.7961 & TRN & \\
\hline CHEMBL 22870 & 688447 & 5.0 & 5.7723 & TRN & \\
\hline CHEMBL1336166 & 688447 & 4.85 & 5.5244 & TRN & \\
\hline CHEMBL 58343 & 688447 & 6.45 & 5.5257 & TRN & \\
\hline CHEMBL1255836 & 688447 & 4.55 & 5.7851 & TRN & \\
\hline CHEMBL1256390 & 688447 & 4.55 & 5.5663 & TRN & \\
\hline CHEMBL 28626 & 688447 & 5.0 & 5.8246 & TRN & \\
\hline CHEMBL1520394 & 688447 & 5.3 & 6.0396 & TRN & \\
\hline CHEMBL 34241 & 688447 & 6.1 & 6.1363 & TRN & \\
\hline CHEMBL1472989 & 688447 & 5.45 & 5.897 & TRN & \\
\hline CHEMBL1552095 & 688447 & 5.9 & 6.4475 & TRN & \\
\hline CHEMBL 1257013 & 688447 & 4.95 & 5.2896 & TRN & \\
\hline CHEMBL1354145 & 688447 & 4.95 & 5.4115 & TRN & \\
\hline
\end{tabular}




\begin{tabular}{|c|c|c|c|c|c|}
\hline \multirow[b]{2}{*}{ CHEMBL441282 } & \multicolumn{5}{|c|}{ Supplemental Table S2.txt } \\
\hline & 688447 & 4.55 & 5.5902 & TRN & \\
\hline CHEMBL105739 & 688447 & 4.95 & 5.3102 & TRN & \\
\hline CHEMBL192566 & 688447 & 4.95 & 7.80200 & 00000000005 & TST \\
\hline CHEMBL1440857 & 688447 & 5.4 & 6.638 & TST & \\
\hline CHEMBL 275516 & 688447 & 5.2 & 5.6544 & TST & \\
\hline CHEMBL546257 & 688447 & 4.95 & 5.6794 & TRN & \\
\hline CHEMBL1256776 & 688447 & 5.45 & 5.83299 & 9999999999 & TRN \\
\hline CHEMBL310798 & 688447 & 5.45 & 5.4601 & TRN & \\
\hline CHEMBL168279 & 688447 & 8.0 & 5.8891 & TRN & \\
\hline CHEMBL53898 & 688447 & 5.95 & 5.5556 & TRN & \\
\hline CHEMBL1473712 & 688447 & 5.3 & 5.8348 & TRN & \\
\hline CHEMBL109037 & 688447 & 5.15 & 5.8833 & TRN & \\
\hline CHEMBL28140 & 688447 & 5.35 & 6.1264 & TRN & \\
\hline CHEMBL1256667 & 688447 & 4.55 & 5.9435 & TST & \\
\hline CHEMBL1517187 & 688447 & 4.8 & 5.6675 & TRN & \\
\hline CHEMBL268609 & 688447 & 4.85 & 5.6859 & TRN & \\
\hline CHEMBL1331383 & 688447 & 5.0 & 5.1697 & TRN & \\
\hline CHEMBL106265 & 688447 & 4.95 & 5.5623 & TRN & \\
\hline CHEMBL 266084 & 688447 & 5.3 & 5.6296 & TRN & \\
\hline CHEMBL1368961 & 688447 & 8.5528 & 5.7578 & TRN & \\
\hline CHEMBL 260629 & 688447 & 6.4 & 5.7374 & TRN & \\
\hline CHEMBL330129 & 688447 & 5.95 & 5.6751 & TRN & \\
\hline CHEMBL1493117 & 688447 & 5.55 & 5.2824 & TRN & \\
\hline CHEMBL1591158 & 688447 & 7.15 & 5.6056 & TRN & \\
\hline CHEMBL1607062 & 688447 & 8.301 & 5.6445 & TRN & \\
\hline CHEMBL541585 & 688447 & 7.7496 & 6.0098 & TRN & \\
\hline CHEMBL18701 & 688447 & 5.65 & 5.7354 & TRN & \\
\hline CHEMBL164747 & 688447 & 5.9 & 5.6606 & TRN & \\
\hline CHEMBL1256660 & 688447 & 4.6 & 5.5897 & TRN & \\
\hline CHEMBL 376505 & 688447 & 6.3 & 5.2062 & TST & \\
\hline CHEMBL 2110371 & 688447 & 7.6003 & 5.5478 & TRN & \\
\hline CHEMBL51697 & 688447 & 4.95 & 5.4144 & TRN & \\
\hline CHEMBL23507 & 688447 & 5.35 & 5.5592 & TRN & \\
\hline CHEMBL1256656 & 688447 & 6.8499 & 6.3037 & TRN & \\
\hline CHEMBL 267014 & 688447 & 4.55 & 5.26200 & 00000000005 & TRN \\
\hline CHEMBL1377507 & 688447 & 8.0 & 6.9372 & TRN & \\
\hline CHEMBL 24510 & 688447 & 5.5 & 5.6064 & TRN & \\
\hline CHEMBL1591556 & 688447 & 7.0 & 6.8392 & TRN & \\
\hline CHEMBL1316222 & 688447 & 5.2 & 5.7049 & TRN & \\
\hline CHEMBL1356777 & 688447 & 6.5 & 6.2507 & TST & \\
\hline CHEMBL52 & 688447 & 5.1 & 5.7315 & TRN & \\
\hline CHEMBL1255867 & 688447 & 5.05 & 4.9998 & TRN & \\
\hline CHEMBL1512111 & 688447 & 6.6499 & 6.6948 & TRN & \\
\hline CHEMBL574181 & 688447 & 4.95 & 5.4063 & TRN & \\
\hline CHEMBL1395661 & 688447 & 5.5 & 5.7673 & TRN & \\
\hline CHEMBL1515691 & 688447 & 5.3 & 6.2667 & TST & \\
\hline CHEMBL1256974 & 688447 & 4.95 & 5.4671 & TRN & \\
\hline CHEMBL23957 & 688447 & 4.55 & 5.8582 & TST & \\
\hline & & & & 5990 & \\
\hline
\end{tabular}




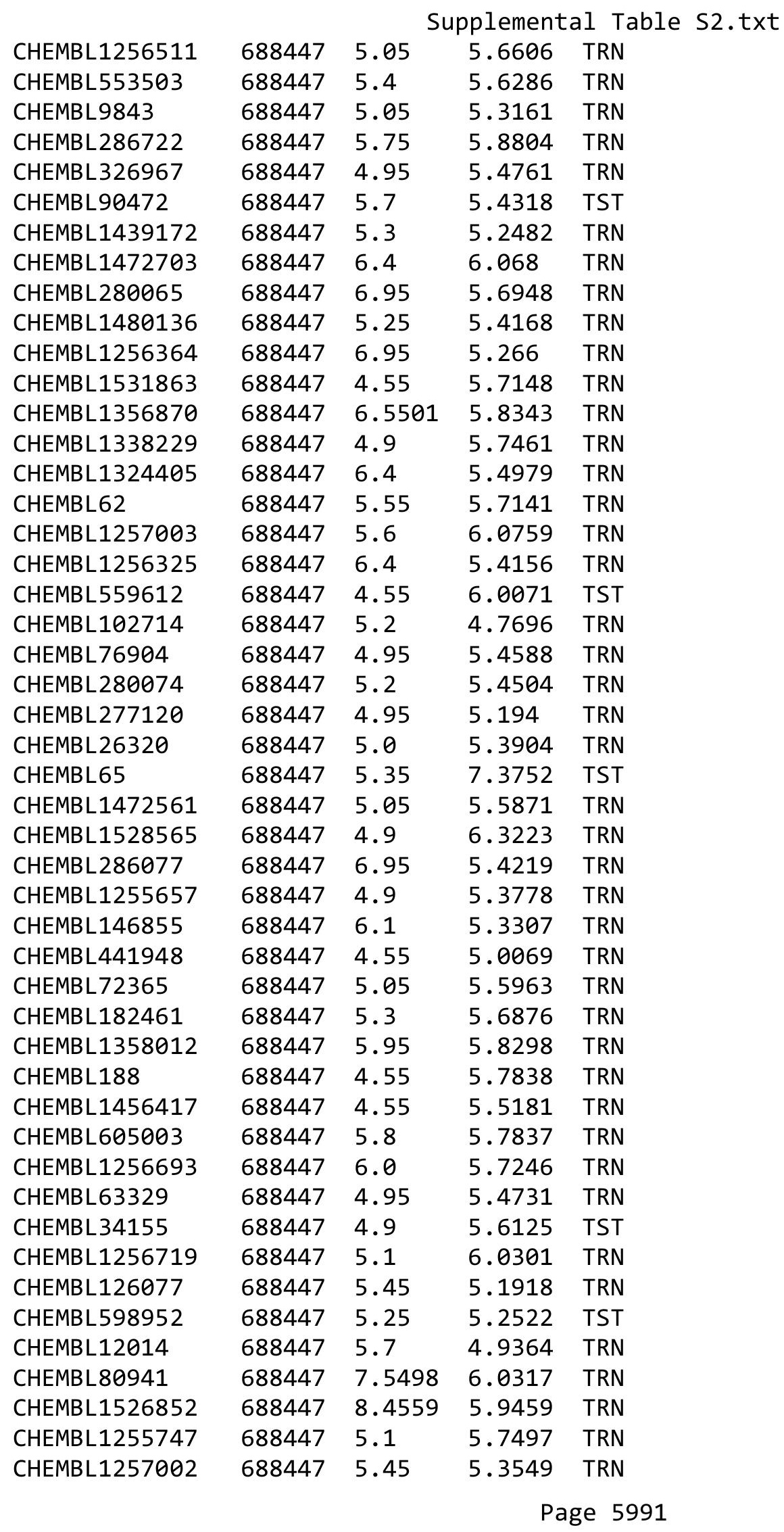




\begin{tabular}{|c|c|c|c|c|c|}
\hline \multicolumn{6}{|c|}{ Supplemental Table S2.txt } \\
\hline CHEMBL1559663 & 688447 & 6.8 & 6.3773 & TRN & \\
\hline CHEMBL1590980 & 688447 & 5.35 & 5.5069 & TRN & \\
\hline CHEMBL1373007 & 688447 & 5.85 & 5.9627 & TST & \\
\hline CHEMBL1394757 & 688447 & 6.6 & 5.7101 & TST & \\
\hline CHEMBL113830 & 688447 & 6.0 & 6.0923 & TRN & \\
\hline CHEMBL1097940 & 688447 & 5.45 & 5.3552 & TRN & \\
\hline CHEMBL428768 & 688447 & 6.9 & 5.62200 & 0000000001 & TRN \\
\hline CHEMBL543557 & 688447 & 4.5 & 5.8394 & TRN & \\
\hline CHEMBL288174 & 688447 & 6.25 & 5.8555 & TST & \\
\hline CHEMBL143324 & 688447 & 6.8 & 5.7662 & TRN & \\
\hline CHEMBL270299 & 688447 & 4.7 & 5.2659 & TST & \\
\hline CHEMBL107251 & 688447 & 6.5 & 5.37 & TRN & \\
\hline CHEMBL1372997 & 688447 & 8.4559 & 6.2074 & TRN & \\
\hline CHEMBL484928 & 688447 & 5.3 & 5.4843 & TRN & \\
\hline CHEMBL66 & 688447 & 5.8 & 5.9734 & TRN & \\
\hline CHEMBL1256995 & 688447 & 7.6498 & 5.9499 & TRN & \\
\hline CHEMBL98350 & 688447 & 5.15 & 5.5414 & TRN & \\
\hline CHEMBL1400884 & 688447 & 6.95 & 5.7946 & TRN & \\
\hline CHEMBL13791 & 688447 & 5.0 & 5.2678 & TRN & \\
\hline CHEMBL1256697 & 688447 & 5.1 & 5.7711 & TRN & \\
\hline CHEMBL1256484 & 688447 & 5.65 & 5.6781 & TRN & \\
\hline CHEMBL1554789 & 688447 & 6.0 & 4.9693 & TRN & \\
\hline CHEMBL153036 & 688447 & 5.3 & 5.4967 & TRN & \\
\hline CHEMBL1380684 & 688447 & 7.8996 & 6.2282 & TRN & \\
\hline CHEMBL408982 & 688447 & 6.7501 & 5.7787 & TRN & \\
\hline CHEMBL416657 & 688447 & 4.9 & 5.4956 & TRN & \\
\hline CHEMBL3216928 & 688447 & 4.95 & 5.9322 & TRN & \\
\hline CHEMBL7917 & 688447 & 4.8 & 5.4755 & TRN & \\
\hline CHEMBL278041 & 688447 & 4.95 & 5.2074 & TRN & \\
\hline CHEMBL1256148 & 688447 & 6.0 & 5.7795 & TRN & \\
\hline CHEMBL67535 & 688447 & 5.25 & 5.6186 & TRN & \\
\hline CHEMBL34730 & 688447 & 5.5 & 5.9525 & TRN & \\
\hline CHEMBL145 & 688447 & 6.8499 & 5.7417 & TRN & \\
\hline CHEMBL3392050 & 688447 & 4.95 & 5.8249 & TRN & \\
\hline CHEMBL32590 & 688447 & 6.7001 & 6.2511 & TRN & \\
\hline CHEMBL1256836 & 688447 & 5.0 & 6.4974 & TRN & \\
\hline CHEMBL1256646 & 688447 & 4.95 & 5.886 & TRN & \\
\hline CHEMBL604119 & 688447 & 4.95 & 6.3356 & TRN & \\
\hline CHEMBL1255935 & 688447 & 4.95 & 5.6724 & TRN & \\
\hline CHEMBL1520976 & 688447 & 4.7 & 5.3967 & TST & \\
\hline CHEMBL1255841 & 688447 & 7.6003 & 6.0859 & TRN & \\
\hline CHEMBL 8080 & 688447 & 8.4559 & 5.642 & TST & \\
\hline CHEMBL88621 & 688447 & 4.6 & 5.6854 & TRN & \\
\hline CHEMBL1256911 & 688447 & 5.7 & 5.7887 & TRN & \\
\hline CHEMBL1407012 & 688447 & 5.65 & 5.1709 & TRN & \\
\hline CHEMBL47940 & 688447 & 4.95 & 5.2579 & TRN & \\
\hline CHEMBL15192 & 688447 & 5.05 & 5.3939 & TRN & \\
\hline CHEMBL1237212 & 688447 & 4.55 & 5.5052 & TST & \\
\hline
\end{tabular}




\begin{tabular}{|c|c|c|c|c|c|}
\hline \multicolumn{6}{|c|}{ Supplemental Table s2.txt } \\
\hline CHEMBL1256923 & 688447 & 6.05 & 5.8744 & TRN & \\
\hline CHEMBL1234696 & 688447 & 6.3 & 5.9092 & TRN & \\
\hline CHEMBL1256751 & 688447 & 5.6 & 5.6627 & TRN & \\
\hline CHEMBL177820 & 688447 & 5.3 & 5.3937 & TST & \\
\hline CHEMBL72631 & 688447 & 7.7496 & 6.0309 & TRN & \\
\hline CHEMBL1329218 & 688447 & 7.6498 & 5.6008 & TST & \\
\hline CHEMBL1521453 & 688447 & 8.4559 & 6.4248 & TRN & \\
\hline CHEMBL1526455 & 688447 & 4.75 & 5.1247 & TRN & \\
\hline CHEMBL1256291 & 688447 & 6.25 & 5.6322 & TRN & \\
\hline CHEMBL1461491 & 688447 & 5.2 & 5.8102 & TRN & \\
\hline CHEMBL1316314 & 688447 & 4.85 & 6.1203 & TRN & \\
\hline CHEMBL310310 & 688447 & 5.0 & 5.4278 & TRN & \\
\hline CHEMBL596674 & 688447 & 5.55 & 5.66299 & 9999999999 & TRN \\
\hline CHEMBL543 & 688447 & 8.2007 & 5.0539 & TST & \\
\hline CHEMBL1256686 & 688447 & 5.25 & 6.2998 & TST & \\
\hline CHEMBL104264 & 688447 & 4.9 & 4.9234 & TRN & \\
\hline CHEMBL1256687 & 688447 & 5.6 & 5.355 & TRN & \\
\hline CHEMBL299613 & 688447 & 7.0501 & 6.495 & TRN & \\
\hline CHEMBL40998 & 688447 & 5.05 & 5.4988 & TRN & \\
\hline CHEMBL1395058 & 688447 & 5.0 & 4.9263 & TRN & \\
\hline CHEMBL10347 & 688447 & 4.55 & 5.8705 & TRN & \\
\hline CHEMBL67378 & 688447 & 5.3 & 5.9988 & TRN & \\
\hline CHEMBL1527442 & 688447 & 4.9 & 5.46700 & 00000000005 & TST \\
\hline CHEMBL52387 & 688447 & 4.95 & 5.5065 & TRN & \\
\hline CHEMBL1553428 & 688447 & 7.7496 & 6.1369 & TRN & \\
\hline CHEMBL355496 & 688447 & 5.65 & 5.2598 & TRN & \\
\hline CHEMBL1435381 & 688447 & 4.95 & 5.6675 & TRN & \\
\hline CHEMBL 267548 & 688447 & 6.5 & 5.8354 & TST & \\
\hline CHEMBL 30432 & 688447 & 5.1 & 5.3293 & TRN & \\
\hline CHEMBL261642 & 688447 & 6.0 & 5.8625 & TRN & \\
\hline CHEMBL 258405 & 688447 & 4.55 & 5.8015 & TRN & \\
\hline CHEMBL280998 & 688447 & 5.65 & 5.1609 & TRN & \\
\hline CHEMBL540848 & 688447 & 4.8 & 5.1373 & TRN & \\
\hline CHEMBL153057 & 688447 & 5.0 & 5.7599 & TRN & \\
\hline CHEMBL1314286 & 688447 & 5.25 & 5.8903 & TRN & \\
\hline CHEMBL611494 & 688447 & 6.0 & 5.5619 & TST & \\
\hline CHEMBL1561474 & 688447 & 5.3 & 5.6955 & TRN & \\
\hline CHEMBL391997 & 688447 & 5.4 & 5.869 & TRN & \\
\hline CHEMBL1256876 & 688447 & 5.2 & 6.1021 & TST & \\
\hline CHEMBL77030 & 688447 & 5.25 & 5.50299 & 9999999999 & TRN \\
\hline CHEMBL1256749 & 688447 & 5.05 & 5.3534 & TRN & \\
\hline CHEMBL1253351 & 688447 & 5.9 & 5.7784 & TRN & \\
\hline CHEMBL1256916 & 688447 & 6.45 & 5.6574 & TRN & \\
\hline CHEMBL407874 & 688447 & 5.25 & 5.04899 & 99999999995 & TRN \\
\hline CHEMBL1336469 & 688447 & 5.1 & 6.1058 & TRN & \\
\hline CHEMBL 80155 & 688447 & 5.5 & 5.8105 & TRN & \\
\hline CHEMBL1256754 & 688447 & 4.65 & 6.1666 & TRN & \\
\hline CHEMBL1436438 & 688447 & 5.3 & 5.5464 & TRN & \\
\hline
\end{tabular}




\begin{tabular}{|c|c|c|c|c|}
\hline \multicolumn{5}{|c|}{ Supplemental Table S2.txt } \\
\hline CHEMBL876 & 688447 & 5.0 & 5.7155 & TRN \\
\hline CHEMBL 250892 & 688447 & 5.2 & 5.8389 & TRN \\
\hline CHEMBL48449 & 688447 & 5.2 & 5.8757 & TST \\
\hline CHEMBL87285 & 688447 & 5.8 & 6.0667 & TRN \\
\hline CHEMBL 269733 & 688447 & 8.1487 & 5.8189 & TRN \\
\hline CHEMBL48278 & 688447 & 6.4 & 5.4359 & TRN \\
\hline CHEMBL407232 & 688447 & 6.1 & 4.9826 & TRN \\
\hline CHEMBL8747 & 688447 & 6.05 & 5.5366 & TRN \\
\hline CHEMBL1436268 & 688447 & 4.85 & 5.754 & TST \\
\hline CHEMBL1256910 & 688447 & 5.25 & 6.0543 & TST \\
\hline CHEMBL1335406 & 688447 & 4.9 & 6.0739 & TST \\
\hline CHEMBL1457550 & 688447 & 5.5 & 5.4807 & TST \\
\hline CHEMBL 262083 & 688447 & 5.65 & 5.3241 & TST \\
\hline CHEMBL45281 & 688447 & 5.0 & 5.669 & TST \\
\hline CHEMBL23832 & 688447 & 6.2 & 5.6686 & TST \\
\hline CHEMBL 2374259 & 688447 & 4.65 & 6.4752 & TST \\
\hline CHEMBL 263972 & 688447 & 7.15 & 5.2555 & TST \\
\hline CHEMBL1523894 & 688447 & 5.05 & 5.6217 & TST \\
\hline CHEMBL 305195 & 688447 & 5.1 & 6.1892 & TST \\
\hline CHEMBL1256814 & 688447 & 5.0 & 5.6497 & TST \\
\hline CHEMBL1257041 & 688447 & 5.05 & 6.2984 & TST \\
\hline CHEMBL8165 & 688447 & 5.3 & 5.5044 & TST \\
\hline CHEMBL46257 & 688447 & 4.55 & 5.2236 & TST \\
\hline CHEMBL1200450 & 688447 & 4.55 & 5.5276 & TST \\
\hline CHEMBL1360725 & 688447 & 8.1024 & 6.0548 & TST \\
\hline CHEMBL 903 & 688447 & 5.0 & 5.4409 & TST \\
\hline CHEMBL123 & 688447 & 5.85 & 4.8679 & TST \\
\hline CHEMBL1255749 & 688447 & 4.9 & 5.4126 & TST \\
\hline CHEMBL434063 & 688447 & 4.9 & 5.6719 & TST \\
\hline CHEMBL 28862 & 688447 & 5.3 & 5.7524 & TST \\
\hline CHEMBL64239 & 688447 & 5.95 & 5.5016 & TST \\
\hline CHEMBL1173475 & 688447 & 5.25 & 5.8224 & TST \\
\hline CHEMBL 28 & 688447 & 4.7 & 5.7958 & TST \\
\hline CHEMBL252909 & 688447 & 5.45 & 5.5418 & TST \\
\hline CHEMBL 1256360 & 688447 & 6.0 & 6.0894 & TST \\
\hline CHEMBL384903 & 688447 & 5.0 & 5.9402 & TST \\
\hline CHEMBL1598680 & 688447 & 5.05 & 5.8671 & TST \\
\hline CHEMBL1224512 & 688447 & 5.9 & 5.8079 & TST \\
\hline CHEMBL1322959 & 688447 & 4.55 & 5.8878 & TST \\
\hline CHEMBL33884 & 688447 & 5.0 & 5.5444 & TST \\
\hline CHEMBL78150 & 688447 & 5.0 & 5.6037 & TST \\
\hline CHEMBL1256943 & 688447 & 7.0 & 5.7654 & TST \\
\hline CHEMBL1367565 & 688447 & 5.3 & 5.7284 & TST \\
\hline CHEMBL1330357 & 688447 & 4.75 & 6.28700 & 0000000001 \\
\hline CHEMBL 77971 & 688447 & 5.5 & 5.9869 & TST \\
\hline CHEMBL1398031 & 688447 & 5.5 & 5.4724 & TST \\
\hline CHEMBL25236 & 688447 & 5.6 & 6.0188 & TST \\
\hline CHEMBL1256984 & 688447 & 5.2 & 5.5952 & TST \\
\hline
\end{tabular}




\begin{tabular}{|c|c|c|c|c|c|}
\hline \multicolumn{6}{|c|}{ Supplemental Table S2.txt } \\
\hline CHEMBL1515334 & 688447 & 6.6 & 4.8374 & TST & \\
\hline CHEMBL1256663 & 688447 & 7.5003 & 6.146 & TST & \\
\hline CHEMBL1256878 & 688447 & 6.2 & 5.2029 & TST & \\
\hline CHEMBL93655 & 688447 & 4.55 & 5.5029 & TST & \\
\hline CHEMBL543467 & 688447 & 5.1 & 5.4988 & TST & \\
\hline CHEMBL1256624 & 688447 & 6.0 & 6.0388 & TST & \\
\hline CHEMBL18238 & 688447 & 5.1 & 5.4303 & TST & \\
\hline CHEMBL250711 & 688447 & 4.7 & 5.8932 & TST & \\
\hline CHEMBL 2334392 & 948451 & 7.4685 & 7.4094 & TRN & \\
\hline CHEMBL 2331582 & 948451 & 7.9208 & 8.106 & TRN & \\
\hline CHEMBL 2334401 & 948451 & 8.0 & 7.2714 & TRN & \\
\hline CHEMBL 2334386 & 948451 & 5.301 & 5.6377 & TST & \\
\hline CHEMBL 2334393 & 948451 & 7.9208 & 7.7073 & TRN & \\
\hline CHEMBL 2334041 & 948451 & 8.4815 & 8.5957 & TRN & \\
\hline CHEMBL 2334053 & 948451 & 6.5229 & 6.5484 & TRN & \\
\hline CHEMBL 2334032 & 948451 & 5.301 & 5.8805 & TRN & \\
\hline CHEMBL 2334022 & 948451 & 8.2291 & 7.7623 & TRN & \\
\hline CHEMBL 2334050 & 948451 & 7.8861 & 7.9675 & TRN & \\
\hline CHEMBL 2334389 & 948451 & 7.1805 & 6.9651 & TRN & \\
\hline CHEMBL 2334023 & 948451 & 7.2924 & 7.1953 & TRN & \\
\hline CHEMBL 2334044 & 948451 & 5.301 & 5.32100 & 0000000001 & TRN \\
\hline CHEMBL 2334371 & 948451 & 6.5302 & 6.3173 & TRN & \\
\hline CHEMBL 2334390 & 948451 & 6.8239 & 6.7676 & TRN & \\
\hline CHEMBL 2334375 & 948451 & 6.9586 & 6.8745 & TRN & \\
\hline CHEMBL 2334057 & 948451 & 7.5376 & 8.01100 & 0000000001 & TST \\
\hline CHEMBL 2334049 & 948451 & 8.0315 & 7.75899 & 99999999995 & TRN \\
\hline CHEMBL 2334046 & 948451 & 6.9914 & 6.9538 & TRN & \\
\hline CHEMBL 2334367 & 948451 & 7.4559 & 7.51200 & 00000000005 & TST \\
\hline CHEMBL 2334400 & 948451 & 7.3979 & 7.2171 & TRN & \\
\hline CHEMBL 2334034 & 948451 & 6.4134 & 6.4034 & TRN & \\
\hline CHEMBL 2334377 & 948451 & 7.3565 & 7.1349 & TRN & \\
\hline CHEMBL 2334372 & 948451 & 8.0655 & 8.3636 & TRN & \\
\hline CHEMBL 2334396 & 948451 & 5.301 & 5.6589 & TRN & \\
\hline CHEMBL 2334378 & 948451 & 6.3615 & 6.4605 & TRN & \\
\hline CHEMBL 2334033 & 948451 & 6.4763 & 6.4173 & TRN & \\
\hline CHEMBL 2334374 & 948451 & 7.301 & 7.2749 & TRN & \\
\hline CHEMBL 2334054 & 948451 & 7.4089 & 7.6959 & TRN & \\
\hline CHEMBL 2334040 & 948451 & 7.699 & 8.1589 & TRN & \\
\hline CHEMBL 2334029 & 948451 & 6.7773 & 6.6845 & TRN & \\
\hline CHEMBL 2334025 & 948451 & 7.0969 & 7.244 & TST & \\
\hline CHEMBL 2334056 & 948451 & 7.6383 & 7.7848 & TST & \\
\hline CHEMBL 2334047 & 948451 & 6.8601 & 6.6362 & TST & \\
\hline CHEMBL 2334045 & 948451 & 10.2218 & 8.4527 & TST & \\
\hline CHEMBL 2334388 & 948451 & 5.301 & 5.7699 & TST & \\
\hline CHEMBL 2334370 & 948451 & 7.2076 & 7.3224 & TRN & \\
\hline CHEMBL 2334031 & 948451 & 7.3768 & 7.441 & TRN & \\
\hline CHEMBL 2334042 & 948451 & 5.301 & 5.9864 & TST & \\
\hline CHEMBL 2334038 & 948451 & 8.3098 & 7.936 & TRN & \\
\hline
\end{tabular}




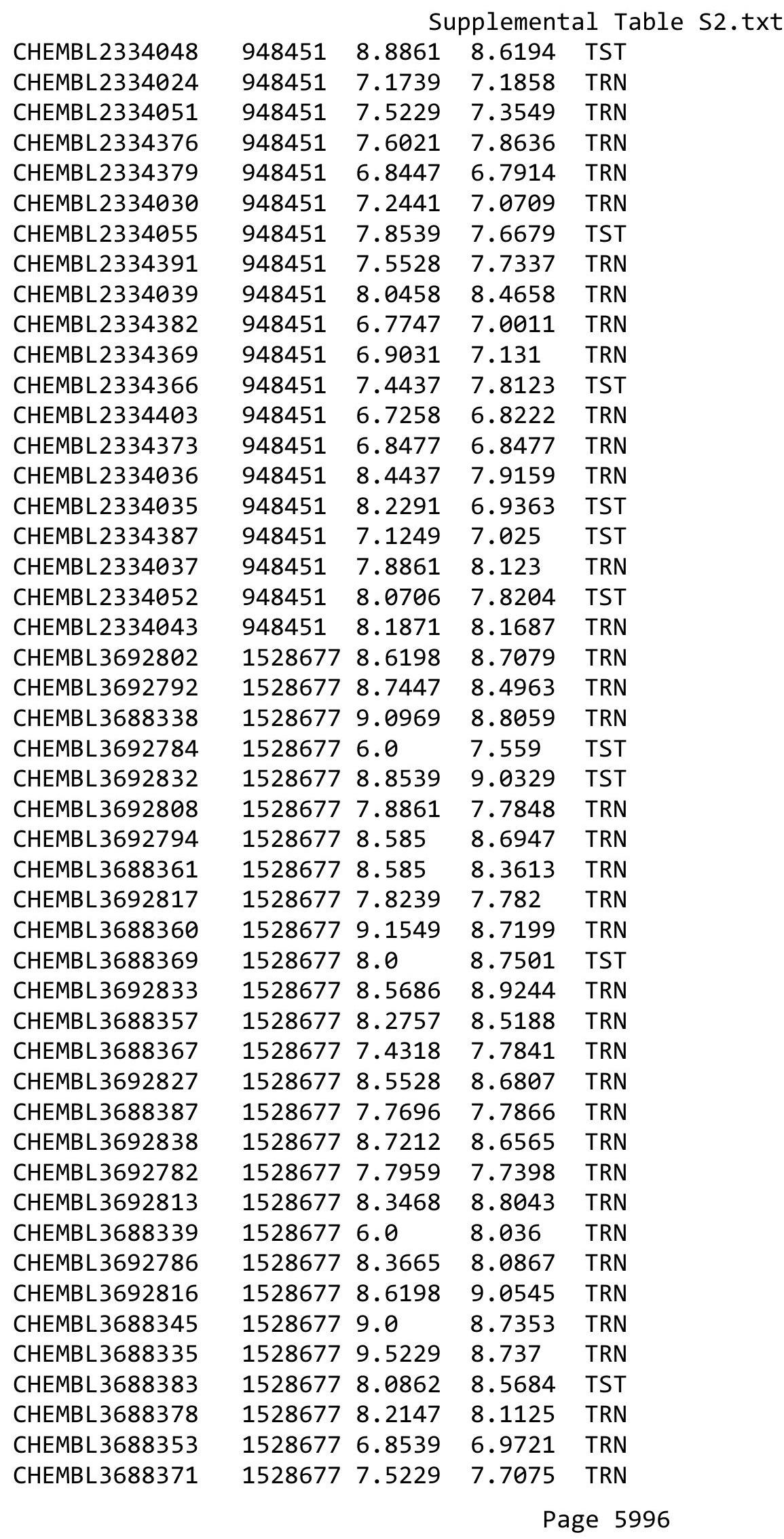


Supplemental Table S2.txt

\begin{tabular}{|c|c|c|c|c|}
\hline CHEMBL3688342 & 1528677 & 9.1549 & 8.9726 & TRN \\
\hline CHEMBL3692834 & 1528677 & 8.7959 & 8.7722 & TRN \\
\hline CHEMBL3692814 & 1528677 & 8.3468 & 8.4997 & TRN \\
\hline CHEMBL3692793 & 1528677 & 8.9208 & 8.3823 & TRN \\
\hline CHEMBL3688370 & 1528677 & 7.9586 & 7.9082 & TRN \\
\hline CHEMBL3688349 & 1528677 & 8.5528 & 8.5718 & TRN \\
\hline CHEMBL3688386 & 1528677 & 7.9208 & 8.1269 & TST \\
\hline CHEMBL3688377 & 1528677 & 8.2366 & 8.23 & TRN \\
\hline CHEMBL3688375 & 1528677 & 8.5086 & 8.5412 & TRN \\
\hline CHEMBL3688340 & 1528677 & 6.0 & 7.8933 & TRN \\
\hline CHEMBL 3688347 & 1528677 & 9.0458 & 8.8927 & TRN \\
\hline CHEMBL3688366 & 1528677 & 8.2147 & 7.9463 & TRN \\
\hline CHEMBL3688365 & 1528677 & 8.1079 & 8.3648 & TST \\
\hline CHEMBL 3688364 & 1528677 & 8.7959 & 9.1639 & TRN \\
\hline CHEMBL3692783 & 1528677 & 8.9208 & 8.5821 & TRN \\
\hline CHEMBL3688363 & 1528677 & 8.4318 & 8.5159 & TRN \\
\hline CHEMBL3692789 & 1528677 & 9.0969 & 8.8389 & TRN \\
\hline CHEMBL3692788 & 1528677 & 9.0458 & 8.8622 & TRN \\
\hline CHEMBL3692826 & 1528677 & 8.8861 & 8.7316 & TRN \\
\hline CHEMBL3692805 & 1528677 & 8.7959 & 8.7305 & TRN \\
\hline CHEMBL3688372 & 1528677 & 6.0 & 9.2863 & TST \\
\hline CHEMBL3692812 & 1528677 & 7.9586 & 8.2564 & TRN \\
\hline CHEMBL3692804 & 1528677 & 5.699 & 7.6644 & TST \\
\hline CHEMBL3692806 & 1528677 & 9.2218 & 9.6342 & TRN \\
\hline CHEMBL 3688376 & 1528677 & 9.5229 & 8.8884 & TRN \\
\hline CHEMBL3688346 & 1528677 & 8.8539 & 8.5731 & TRN \\
\hline CHEMBL3692800 & 1528677 & 8.585 & 8.4218 & TRN \\
\hline CHEMBL3688359 & 1528677 & 8.0 & 8.6541 & TRN \\
\hline CHEMBL3692807 & 1528677 & 9.301 & 9.4828 & TRN \\
\hline CHEMBL 3688352 & 1528677 & 7.4949 & 7.0766 & TRN \\
\hline CHEMBL3692811 & 1528677 & 6.9208 & 7.0914 & TRN \\
\hline CHEMBL3688379 & 1528677 & 8.0 & 8.3228 & TRN \\
\hline CHEMBL3692787 & 1528677 & 9.3979 & 8.986 & TRN \\
\hline CHEMBL3688385 & 1528677 & 8.8239 & 8.2565 & TST \\
\hline CHEMBL3688355 & 1528677 & 7.8239 & 7.7369 & TRN \\
\hline CHEMBL3692830 & 1528677 & 6.0 & 9.0255 & TST \\
\hline CHEMBL3692796 & 1528677 & 9.2218 & 9.1893 & TRN \\
\hline CHEMBL3692809 & 1528677 & 6.0 & 9.13600 & 0000000001 \\
\hline CHEMBL3692803 & 1528677 & 6.1308 & 7.5062 & TST \\
\hline CHEMBL3688358 & 1528677 & 7.7212 & 8.321 & TST \\
\hline CHEMBL 3688344 & 1528677 & 8.5686 & 8.9311 & TST \\
\hline CHEMBL3688384 & 1528677 & 7.5686 & 8.39299 & 9999999999 \\
\hline CHEMBL3692810 & 1528677 & 7.5086 & 7.5278 & TRN \\
\hline CHEMBL3688368 & 1528677 & 8.6778 & 8.8907 & TST \\
\hline CHEMBL3688373 & 1528677 & 8.7696 & 8.4425 & TST \\
\hline CHEMBL3688380 & 1528677 & 9.2218 & 8.9924 & TRN \\
\hline CHEMBL 3688341 & 1528677 & 8.8239 & 8.2527 & TRN \\
\hline CHEMBL 3688356 & 1528677 & 8.0506 & 8.1184 & TST \\
\hline
\end{tabular}


Supplemental Table S2.txt

\begin{tabular}{|c|c|c|c|c|}
\hline HEMBL & & & & \\
\hline HFMRI 3602891 & 528677 & 9.0 & $0 \quad 8170$ & \\
\hline HEMBL & 28677 & 8.8861 & 8257 & \\
\hline AEMBL3692795 & 528677 & 8.9208 & 613 & \\
\hline HEMBL3959392 & 528677 & 8.1871 & .3888 & \\
\hline HEMBL & 528677 & 8.9208 & & \\
\hline HEMBL; & 528677 & & & \\
\hline HEMBL & .528677 & 9.301 & & PN \\
\hline HEMBL3688334 & 528677 & 6.5086 & 55 & \\
\hline HEMBL3688354 & 528677 & 8.3372 & 94 & \\
\hline HEMBL36 & 528677 & 8.8239 & 67 & \\
\hline HEMBL; & 8677 & & & RN \\
\hline HEMBL3 & 528677 & 8.7212 & & \\
\hline HEMBL3 & 528677 & 7.7696 & & \\
\hline HEMBL 368 & 528677 & 9.301 & & \\
\hline AEMBL: & 8677 & 8. & & \\
\hline AEMBL & 3677 & 9.0 & & $2 \mathrm{~N}$ \\
\hline HEMBL; & 528677 & 8.74 & & \\
\hline HEMBL3 & 3677 & 8 . & & \\
\hline AEMBL36 & 528677 & 8. & 31 & ISI \\
\hline AEMBL & 3677 & 8. & & ST \\
\hline AEME & 677 & & & ST \\
\hline HEMBL & 677 & 8 . & & RN \\
\hline HEMBL & 677 & & & \\
\hline AEMBL3 & 702 & 3.0 & & SI \\
\hline IEMBL: & 702 & & & RN \\
\hline AEM & 702 & & & $\mathrm{RN}$ \\
\hline HEMPI & 702 & 3. & & RN \\
\hline IEMBL: & & & & IRN \\
\hline HEMBL39 & 517702 & 4.8861 & 73 & $\mathrm{RN}$ \\
\hline AEMBL: & 702 & 3 & & $\mathrm{RN}$ \\
\hline 0 & 02 & 3 & & RN \\
\hline & & & & RN \\
\hline AEMBL3 & 702 & 3. & & ГST \\
\hline AEMBL39 & 517702 & & & ГST \\
\hline$A F M B$ & 702 & 3 & & IST \\
\hline & & & & RN \\
\hline HEMBL3 & 702 & & & RN \\
\hline HEMBL 389 & 702 & & & 「RN \\
\hline EMBL3 & 702 & 4. & & IST \\
\hline HEMBL3 & 702 & & & TRN \\
\hline HEMBL3 & & 4.3372 & & 「RN \\
\hline HEMBL36 & 1617702 & 3.0 & & TST \\
\hline AEMBL3 & 702 & 4. & & TR \\
\hline HEMBL 389 & & & & \\
\hline HEMBL 3904891 & 617702 & 4.6778 & & \\
\hline HEMBL 3978830 & 617702 & 4.1024 & 4.0728 & \\
\hline CHEMBL3947198 & 1617702 & 4.0555 & 4.1126 & \\
\hline
\end{tabular}

Page 5998 
Supplemental Table S2.txt

\begin{tabular}{|c|c|c|c|c|}
\hline CHEMBL3979736 & 1617702 & 4.6576 & 4.6779 & TRN \\
\hline CHEMBL3907505 & 1617702 & 3.0 & 2.9613 & TRN \\
\hline CHEMBL3899371 & 1617702 & 4.1805 & 4.1818 & TRN \\
\hline CHEMBL3910488 & 1617702 & 4.7447 & 4.7491 & TRN \\
\hline CHEMBL3952045 & 1617702 & 3.0 & 2.9877 & TRN \\
\hline CHEMBL3919412 & 1617702 & 4.5528 & 4.5084 & TRN \\
\hline CHEMBL3924343 & 1617702 & 3.0 & 3.0478 & TRN \\
\hline CHEMBL3950773 & 1617702 & 4.6021 & 4.6164 & TRN \\
\hline CHEMBL3960743 & 1617702 & 3.0 & 2.9663 & TRN \\
\hline CHEMBL3906378 & 1617702 & 4.3468 & 4.3238 & TRN \\
\hline CHEMBL3938421 & 1617702 & 4.4437 & 4.4249 & TRN \\
\hline CHEMBL3966262 & 1617702 & 4.2366 & 4.263 & TRN \\
\hline CHEMBL3913878 & 1617702 & 4.6778 & 4.6952 & TRN \\
\hline CHEMBL3978029 & 1617702 & 3.0 & 2.9905 & TRN \\
\hline CHEMBL3922861 & 1617702 & 4.5086 & 4.5503 & TRN \\
\hline CHEMBL3951335 & 1617702 & 4.0223 & 4.0156 & TRN \\
\hline CHEMBL3912547 & 1617702 & 4.284 & 4.2959 & TRN \\
\hline CHEMBL3967047 & 1617702 & 4.2218 & 4.2492 & TRN \\
\hline CHEMBL3980253 & 1617702 & 4.1192 & 4.0987 & TRN \\
\hline CHEMBL3970551 & 1617702 & 4.8239 & 3.4975 & TST \\
\hline CHEMBL3942054 & 1617702 & 4.6021 & 4.5029 & TST \\
\hline CHEMBL3952406 & 1617702 & 3.0 & 3.8594 & TST \\
\hline CHEMBL3986320 & 1617702 & 4.4202 & 4.4335 & TST \\
\hline CHEMBL3983061 & 1617702 & 4.5528 & 4.7793 & TST \\
\hline CHEMBL3115908 & 1617702 & 4.4685 & 4.6702 & TST \\
\hline CHEMBL3934352 & 1617702 & 4.3468 & 4.3365 & TST \\
\hline CHEMBL3703303 & 1641174 & 5.0 & 5.1656 & TRN \\
\hline CHEMBL3703259 & 1641174 & 5.2358 & 5.1461 & TRN \\
\hline CHEMBL3703270 & 1641174 & 4.0 & 3.7383 & TRN \\
\hline CHEMBL3650774 & 1641174 & 5.0 & 4.657 & TRN \\
\hline CHEMBL3703233 & 1641174 & 4.0 & 3.7234 & TRN \\
\hline CHEMBL3703301 & 1641174 & 5.5361 & 5.6294 & TRN \\
\hline CHEMBL3703235 & 1641174 & 4.0 & 4.2101 & TRN \\
\hline CHEMBL3703264 & 1641174 & 5.3487 & 5.2843 & TRN \\
\hline CHEMBL3650822 & 1641174 & 4.0 & 3.9383 & TRN \\
\hline CHEMBL3650837 & 1641174 & 4.0 & 4.3733 & TRN \\
\hline CHEMBL3703282 & 1641174 & 4.0 & 4.5471 & TRN \\
\hline CHEMBL3703222 & 1641174 & 4.0 & 4.2852 & TRN \\
\hline CHEMBL3924870 & 1641174 & 4.0 & 3.984 & TST \\
\hline CHEMBL3703278 & 1641174 & 4.0 & 3.6671 & TRN \\
\hline CHEMBL3650827 & 1641174 & 5.4377 & 4.7207 & TRN \\
\hline CHEMBL3703298 & 1641174 & 5.4881 & 5.0782 & TRN \\
\hline CHEMBL3703292 & 1641174 & 4.0 & 4.1223 & TRN \\
\hline CHEMBL3703296 & 1641174 & 4.0 & 4.2358 & TRN \\
\hline CHEMBL3650849 & 1641174 & 4.0 & 4.1326 & TRN \\
\hline CHEMBL3703263 & 1641174 & 5.3536 & 5.5075 & TST \\
\hline CHEMBL3650830 & 1641174 & 5.3716 & 4.1963 & TST \\
\hline CHEMBL3703309 & 1641174 & 4.0 & 3.8815 & TRN \\
\hline
\end{tabular}




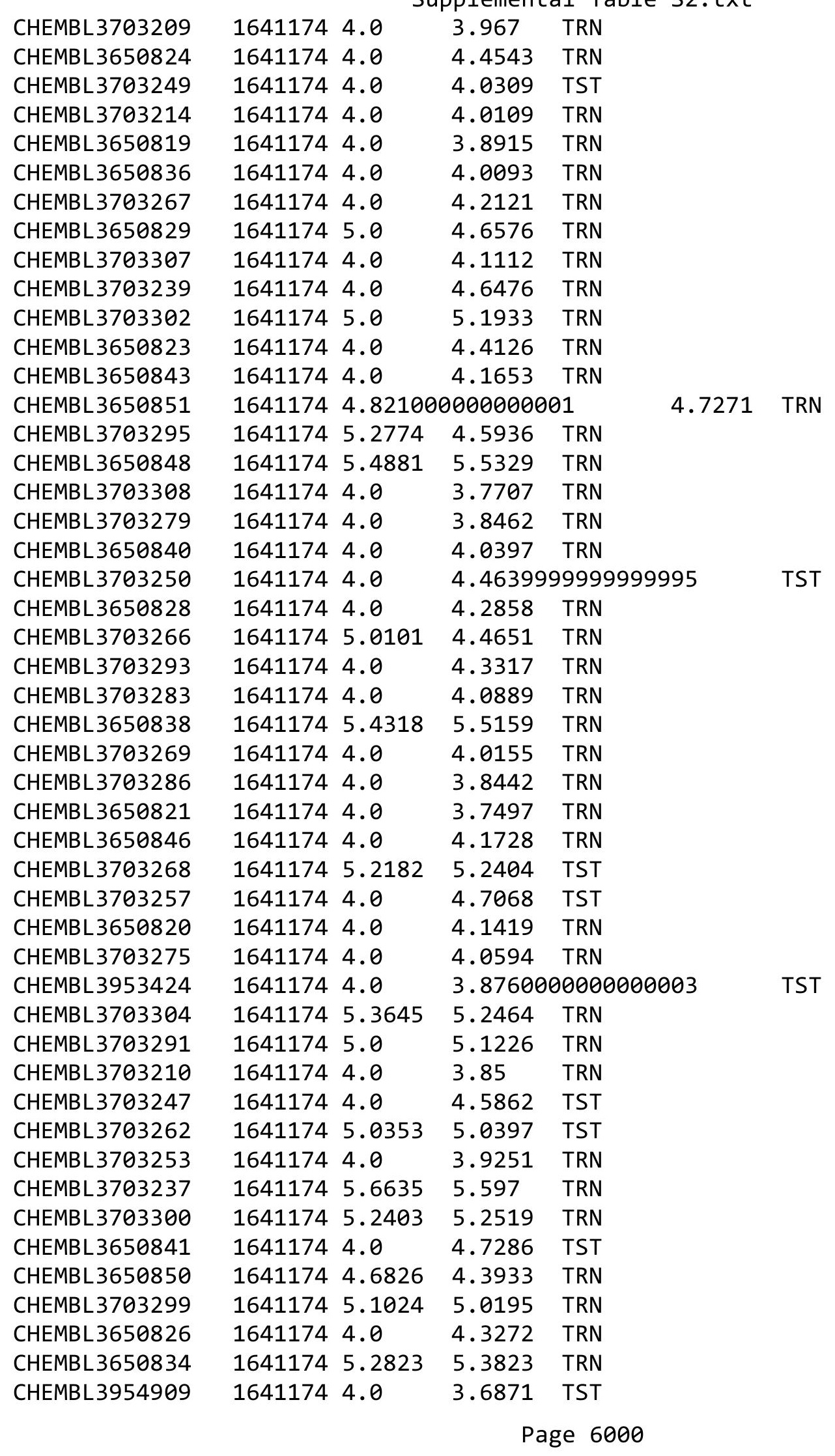


Supplemental Table S2.txt

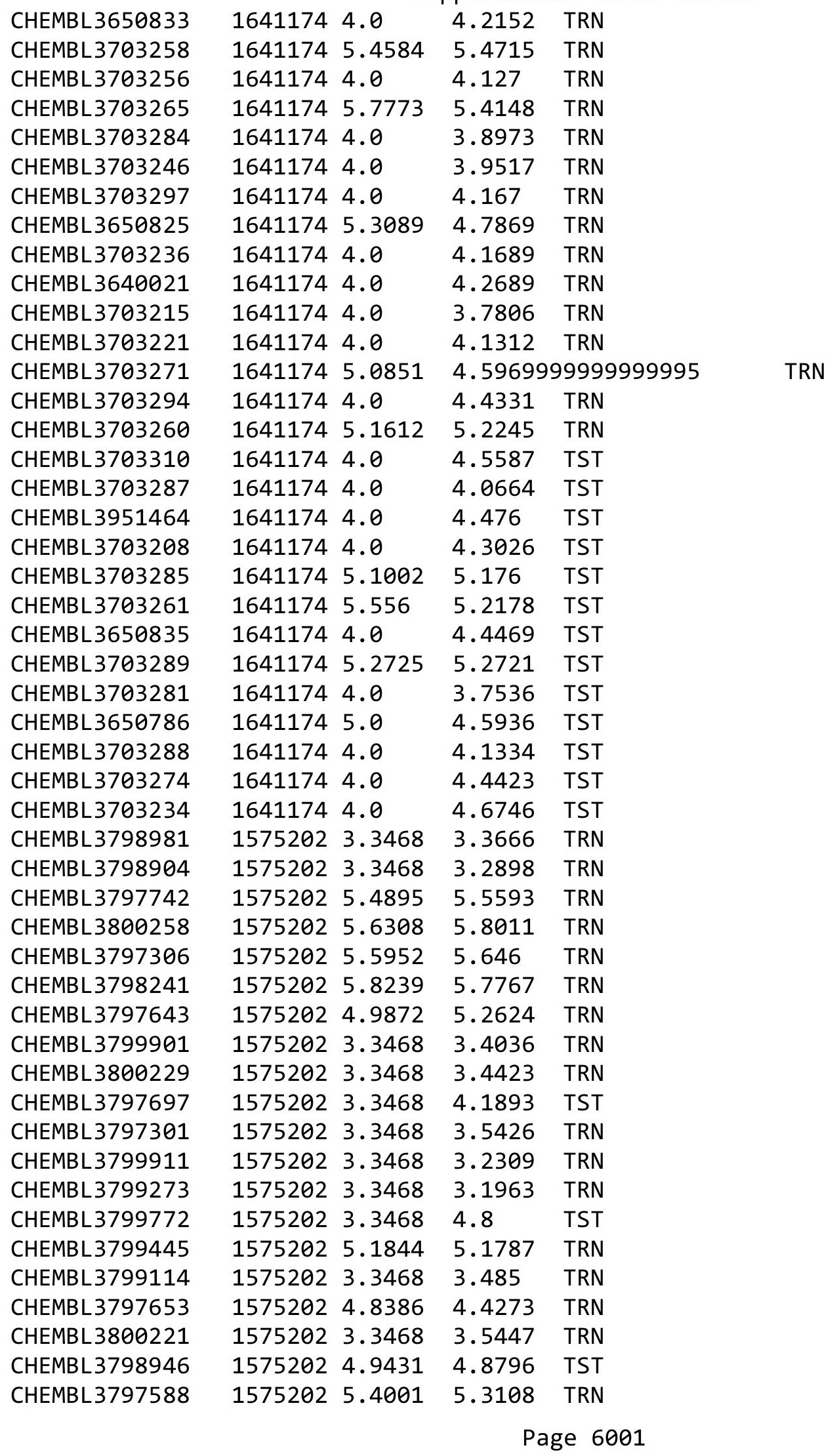


Supplemental Table S2.txt

\begin{tabular}{|c|c|c|c|c|c|}
\hline CHEMBL3797894 & 1575202 & 5.1871 & 4.981 & TST & \\
\hline CHEMBL3797438 & 1575202 & 5.58 & 5.6278 & TRN & \\
\hline CHEMBL3799566 & 1575202 & 5.3288 & 5.3906 & TRN & \\
\hline CHEMBL 3798653 & 1575202 & 3.3468 & 3.6658 & TRN & \\
\hline CHEMBL3797664 & 1575202 & 3.3468 & 3.4453 & TRN & \\
\hline CHEMBL3798251 & 1575202 & 3.3468 & 3.0541 & TRN & \\
\hline CHEMBL3797218 & 1575202 & 5.8761 & 5.91299 & 9999999999 & TRN \\
\hline CHEMBL3797730 & 1575202 & 5.3915 & 5.5049 & TRN & \\
\hline CHEMBL3797909 & 1575202 & $5.7620 e$ & 00000000 & 5.6739 & TRN \\
\hline CHEMBL3797448 & 1575202 & 3.3468 & 3.2675 & TRN & \\
\hline CHEMBL3799688 & 1575202 & 3.3468 & 3.3014 & TRN & \\
\hline CHEMBL 3800124 & 1575202 & 4.6289 & 4.5745 & TRN & \\
\hline CHEMBL3797794 & 1575202 & 5.4157 & 4.7621 & TST & \\
\hline CHEMBL 3800323 & 1575202 & 5.6478 & 5.4359 & TRN & \\
\hline CHEMBL3799541 & 1575202 & 5.585 & 5.5334 & TRN & \\
\hline CHEMBL3799717 & 1575202 & 3.3468 & 3.3266 & TST & \\
\hline CHEMBL3799484 & 1575202 & 5.2097 & 4.6802 & TST & \\
\hline CHEMBL3798893 & 1575202 & 3.3468 & 5.2827 & TST & \\
\hline CHEMBL3799322 & 1575202 & 3.3468 & 3.2848 & TST & \\
\hline CHEMBL3797847 & 1575202 & 4.5003 & 4.3422 & TRN & \\
\hline CHEMBL3799974 & 1575202 & 3.3468 & 3.3271 & TST & \\
\hline CHEMBL3798765 & 1575202 & 3.3468 & 3.3178 & TRN & \\
\hline CHEMBL3799272 & 1575202 & 3.3468 & 4.3123 & TST & \\
\hline CHEMBL3797517 & 1575202 & 5.6326 & 5.6169 & TRN & \\
\hline CHEMBL3798898 & 1575202 & 3.3468 & 3.3746 & TRN & \\
\hline CHEMBL3800319 & 1575202 & 3.3468 & 3.35 & TRN & \\
\hline CHEMBL3798009 & 1575202 & 3.3468 & 3.4481 & TRN & \\
\hline CHEMBL3797970 & 1575202 & 4.857 & 4.7854 & TRN & \\
\hline CHEMBL 3799922 & 1575202 & 5.4342 & 5.4588 & TRN & \\
\hline CHEMBL3798678 & 1575202 & 5.2573 & 5.284 & TRN & \\
\hline CHEMBL3799353 & 1575202 & 3.3468 & 3.3511 & TRN & \\
\hline CHEMBL3800536 & 1575202 & 3.3468 & 3.377 & TRN & \\
\hline CHEMBL 3797564 & 1575202 & 5.5969 & 5.4057 & TRN & \\
\hline CHEMBL 3798291 & 1575202 & 5.5072 & 5.2754 & TST & \\
\hline CHEMBL3799000 & 1575202 & 3.3468 & 4.3376 & TST & \\
\hline CHEMBL3799588 & 1575202 & 5.1409 & 5.1955 & TST & \\
\hline CHEMBL3924829 & 1642538 & 8.2218 & 7.6395 & TST & \\
\hline CHEMBL3893301 & 1642538 & 7.4634 & 7.6908 & TST & \\
\hline CHEMBL3975103 & 1642538 & 7.699 & 7.6832 & TRN & \\
\hline CHEMBL3925264 & 1642538 & 4.699 & 6.614 & TST & \\
\hline CHEMBL3923163 & 1642538 & 7.6216 & 8.4008 & TRN & \\
\hline CHEMBL3939825 & 1642538 & 7.6402 & 7.7025 & TRN & \\
\hline CHEMBL3977152 & 1642538 & 6.9431 & 7.233 & TST & \\
\hline CHEMBL 3942825 & 1642538 & 8.585 & 8.6166 & TRN & \\
\hline CHEMBL3935382 & 1642538 & 8.5086 & 8.6717 & TST & \\
\hline CHEMBL3949680 & 1642538 & 6.8153 & 7.3203 & TST & \\
\hline CHEMBL3916526 & 1642538 & 8.4815 & 8.6181 & TST & \\
\hline CHEMBL3961316 & 1642538 & 8.7447 & 8.7315 & TRN & \\
\hline
\end{tabular}


Supplemental Table S2.txt

\begin{tabular}{|c|c|c|c|c|}
\hline CHEMBL 3947948 & 1642538 & 8.1024 & 8.4188 & TRN \\
\hline CHEMBL 3977481 & 1642538 & 8.2147 & 7.9321 & TRN \\
\hline CHEMBL 3904017 & 1642538 & 7.8386 & 7.694 & TST \\
\hline CHEMBL 3959158 & 1642538 & 8.3279 & 8.2243 & TRN \\
\hline CHEMBL3987018 & 1642538 & 6.2565 & 6.9264 & TST \\
\hline CHEMBL 3903330 & 1642538 & 7.9957 & 8.0212 & TRN \\
\hline CHEMBL 3936532 & 1642538 & 7.9957 & 8.5036 & TRN \\
\hline CHEMBL 3895913 & 1642538 & 7.5406 & 7.582999 & 7999999999 \\
\hline CHEMBL 3889723 & 1642538 & 7.9469 & 7.7137 & TRN \\
\hline CHEMBL3899986 & 1642538 & 6.3428 & 6.9288 & TRN \\
\hline CHEMBL 3985580 & 1642538 & 7.3768 & 7.4745 & TRN \\
\hline CHEMBL 3958331 & 1642538 & 6.9914 & 7.4355 & TST \\
\hline CHEMBL3951296 & 1642538 & 7.9208 & 8.4222 & TRN \\
\hline CHEMBL 3967723 & 1642538 & 8.0044 & 7.5154 & TRN \\
\hline CHEMBL3960818 & 1642538 & 7.8182 & 7.565 & TRN \\
\hline CHEMBL 3907925 & 1642538 & 8.7447 & 8.3374 & TRN \\
\hline CHEMBL3916882 & 1642538 & 7.7496 & 7.6308 & TRN \\
\hline CHEMBL 3891165 & 1642538 & 6.9825 & 7.1021 & TRN \\
\hline CHEMBL 3952882 & 1642538 & 8.4318 & 6.9045 & TRN \\
\hline CHEMBL3893155 & 1642538 & 7.1457 & 7.7719 & TST \\
\hline CHEMBL3946336 & 1642538 & 8.0655 & 7.8656 & TRN \\
\hline CHEMBL3927972 & 1642538 & 7.7282 & 7.6541 & TRN \\
\hline CHEMBL 3969521 & 1642538 & 7.1141 & 7.3351 & TRN \\
\hline CHEMBL 3919122 & 1642538 & 7.5513 & 7.4166 & TRN \\
\hline CHEMBL 3957543 & 1642538 & 8.8239 & 8.5614 & TRN \\
\hline CHEMBL 3986343 & 1642538 & 7.8633 & 7.7697 & TRN \\
\hline CHEMBL 3944359 & 1642538 & 6.5901 & 7.12 & TST \\
\hline CHEMBL 3916656 & 1642538 & 8.0915 & 8.4549 & TRN \\
\hline CHEMBL 3976515 & 1642538 & 8.0088 & 8.3687 & TST \\
\hline CHEMBL 3971152 & 1642538 & 8.6576 & 8.7319 & TRN \\
\hline CHEMBL 3980426 & 1642538 & 7.4672 & 7.4824 & TRN \\
\hline CHEMBL 3937466 & 1642538 & 7.1391 & 7.5063 & TRN \\
\hline CHEMBL3962919 & 1642538 & 7.4145 & 7.8366 & TRN \\
\hline CHEMBL 3974872 & 1642538 & 7.8633 & 7.9284 & TRN \\
\hline CHEMBL 3972492 & 1642538 & 7.6402 & 7.6234 & TRN \\
\hline CHEMBL 3915283 & 1642538 & 7.75700 & 000000000 & 8.3877 \\
\hline CHEMBL 3889846 & 1642538 & 8.4815 & 8.4411 & TST \\
\hline CHEMBL 3910319 & 1642538 & 9.0458 & 8.3646 & TRN \\
\hline CHEMBL 3900211 & 1642538 & 7.9101 & 7.854 & TRN \\
\hline CHEMBL 3913000 & 1642538 & 7.1209 & 7.2942 & TST \\
\hline CHEMBL 3894100 & 1642538 & 7.3188 & 7.2645 & TST \\
\hline CHEMBL 3969763 & 1642538 & 8.0809 & 7.4538 & TRN \\
\hline CHEMBL3940555 & 1642538 & 8.0915 & 8.1354 & TRN \\
\hline CHEMBL 3943891 & 1642538 & 7.8013 & 7.7137 & TRN \\
\hline CHEMBL 3899096 & 1642538 & 7.983 & 8.0635 & TST \\
\hline CHEMBL 3965423 & 1642538 & 4.699 & 6.9937 & TST \\
\hline CHEMBL 3889710 & 1642538 & 7.2204 & 7.3549 & TRN \\
\hline CHEMBL 3926825 & 1642538 & 8.4089 & 8.6522 & TRN \\
\hline
\end{tabular}


Supplemental Table S2.txt

\begin{tabular}{|c|c|c|c|c|c|}
\hline CHEMBL3987095 & 1642538 & 6.769 & 6.8541 & TRN & \\
\hline CHEMBL 3939027 & 1642538 & 8.8861 & 8.9041 & TRN & \\
\hline CHEMBL3951534 & 1642538 & 7.5406 & 7.6497 & TRN & \\
\hline CHEMBL3900391 & 1642538 & 8.8861 & 9.0288 & TRN & \\
\hline CHEMBL 3895186 & 1642538 & 7.4868 & 7.797006 & 0000000001 & TRN \\
\hline CHEMBL 3895315 & 1642538 & 7.4559 & 7.5324 & TRN & \\
\hline CHEMBL3981157 & 1642538 & 7.8447 & 7.8539 & TRN & \\
\hline CHEMBL3915816 & 1642538 & 8.6576 & 8.8309 & TRN & \\
\hline CHEMBL3930261 & 1642538 & 7.8601 & 7.6052 & TST & \\
\hline CHEMBL3983364 & 1642538 & 7.1938 & 7.239 & TRN & \\
\hline CHEMBL 3925387 & 1642538 & 8.301 & 8.06299 & 9999999999 & ST \\
\hline CHEMBL3953610 & 1642538 & 8.3372 & 8.4764 & TRN & \\
\hline CHEMBL 3895083 & 1642538 & 8.8239 & 8.0955 & TST & \\
\hline CHEMBL3903967 & 1642538 & 8.0315 & 8.1647 & TRN & \\
\hline CHEMBL3922374 & 1642538 & 8.0315 & 7.7708 & TRN & \\
\hline CHEMBL 3986585 & 1642538 & 8.6383 & 8.8499 & TRN & \\
\hline CHEMBL3931942 & 1642538 & 8.1308 & 8.5424 & TRN & \\
\hline CHEMBL3915828 & 1642538 & 7.7645 & 7.2171 & TST & \\
\hline CHEMBL3978386 & 1642538 & 7.8665 & 7.7228 & TRN & \\
\hline CHEMBL3923060 & 1642538 & 8.1135 & 8.1339 & TST & \\
\hline CHEMBL 3954265 & 1642538 & 7.7496 & 8.2004 & TRN & \\
\hline CHEMBL3941685 & 1642538 & 8.1024 & 7.6159 & TRN & \\
\hline CHEMBL3889600 & 1642538 & 6.0 & 6.3323 & TRN & \\
\hline CHEMBL 3984487 & 1642538 & 7.4584 & 7.3005 & TRN & \\
\hline CHEMBL3910210 & 1642538 & \multicolumn{2}{|c|}{6.6339999999999995} & 6.5458 & \\
\hline CHEMBL 3946925 & 1642538 & 7.8761 & 7.2345 & TRN & \\
\hline CHEMBL 3970297 & 1642538 & 7.9318 & 8.1168 & TST & \\
\hline CHEMBL3960227 & 1642538 & 7.6696 & 7.6107 & TRN & \\
\hline CHEMBL3922511 & 1642538 & 8.8861 & 8.9067 & TRN & \\
\hline CHEMBL3919335 & 1642538 & 7.1972 & 7.3794 & TST & \\
\hline CHEMBL3912546 & 1642538 & 7.5513 & 7.4954 & TRN & \\
\hline CHEMBL3949881 & 1642538 & 7.8125 & 8.0516 & TRN & \\
\hline CHEMBL 3893731 & 1642538 & 8.7447 & 8.5603 & TRN & \\
\hline CHEMBL 3909456 & 1642538 & 7.7305 & 8.22299 & 7999999999 & N \\
\hline CHEMBL 3982877 & 1642538 & 7.7447 & 7.5617 & TRN & \\
\hline CHEMBL3903876 & 1642538 & 8.1308 & 8.0876 & TST & \\
\hline CHEMBL3932369 & 1642538 & 8.0915 & 8.4158 & TST & \\
\hline CHEMBL 3981324 & 1642538 & 8.041 & 7.8716 & TRN & \\
\hline CHEMBL 3893281 & 1642538 & 8.3098 & 8.5464 & TRN & \\
\hline CHEMBL 3950183 & 1642538 & 8.1739 & 8.0149 & TST & \\
\hline CHEMBL3981818 & 1642538 & 7.6326 & 7.4426 & TST & \\
\hline CHEMBL3932533 & 1642538 & 8.7212 & 8.9011 & TRN & \\
\hline CHEMBL 3896785 & 1642538 & 7.7011 & 7.7001 & TRN & \\
\hline CHEMBL3913183 & 1642538 & 7.3883 & 7.69 & TRN & \\
\hline CHEMBL 3921603 & 1642538 & 8.1024 & 8.2032 & TRN & \\
\hline CHEMBL3907589 & 1642538 & 7.8041 & 7.6375 & TRN & \\
\hline CHEMBL3937324 & 1642538 & 7.3179 & 7.3538 & TRN & \\
\hline CHEMBL 3935757 & 1642538 & 8.1675 & 7.7849 & TRN & \\
\hline
\end{tabular}

Page 6004 
Supplemental Table S2.txt

\begin{tabular}{|c|c|c|c|c|c|}
\hline CHEMBL 3938867 & 1642538 & 8.3188 & 8.5682 & TRN & \\
\hline CHEMBL 3912884 & 1642538 & 9.3979 & 8.5565 & TRN & \\
\hline CHEMBL3952116 & 1642538 & 7.8539 & 7.7055 & TRN & \\
\hline CHEMBL 3917728 & 1642538 & 7.9788 & 7.7137 & TRN & \\
\hline CHEMBL 3953061 & 1642538 & 8.1805 & 8.0121 & TRN & \\
\hline CHEMBL 3976870 & 1642538 & 7.1255 & 7.0862 & TRN & \\
\hline CHEMBL 3913546 & 1642538 & 6.4401 & 6.9067 & TRN & \\
\hline CHEMBL3951515 & 1642538 & \multicolumn{2}{|c|}{7.7620000000000005} & 7.8823 & TRN \\
\hline CHEMBL 3967195 & 1642538 & 6.0464 & 6.9249 & TRN & \\
\hline CHEMBL 3963973 & 1642538 & 7.5702 & 8.229 & TRN & \\
\hline CHEMBL 3909525 & 1642538 & 7.8182 & 7.7229 & TST & \\
\hline CHEMBL3966079 & 1642538 & 7.5031 & 7.3589 & TRN & \\
\hline CHEMBL 3981952 & 1642538 & 8.9208 & 8.8412 & TRN & \\
\hline CHEMBL 3902286 & 1642538 & 7.9788 & 7.8046 & TST & \\
\hline CHEMBL 3955665 & 1642538 & 7.5003 & 7.4746 & TRN & \\
\hline CHEMBL3963771 & 1642538 & 7.6556 & 7.5255 & TRN & \\
\hline CHEMBL3939255 & 1642538 & 7.5884 & 7.5363 & TRN & \\
\hline CHEMBL 3972305 & 1642538 & 7.7905 & \multicolumn{2}{|c|}{7.6160000000000005} & TRN \\
\hline CHEMBL 3936095 & 1642538 & 8.6198 & 8.3378 & TRN & \\
\hline CHEMBL 3963299 & 1642538 & 7.6517 & 7.6431 & TRN & \\
\hline CHEMBL 3940974 & 1642538 & 7.7282 & 7.7404 & TRN & \\
\hline CHEMBL 3986616 & 1642538 & 7.6402 & 7.7403 & TRN & \\
\hline CHEMBL 3907683 & 1642538 & 7.3449 & \multicolumn{2}{|c|}{ 7.212999999999999 } & ISI \\
\hline CHEMBL 3940237 & 1642538 & 8.1308 & 7.6678 & TST & \\
\hline CHEMBL 3932365 & 1642538 & 7.8827 & 7.6182 & TRN & \\
\hline CHEMBL 3958671 & 1642538 & 8.2518 & 7.6225 & TRN & \\
\hline CHEMBL3898566 & 1642538 & \multicolumn{2}{|c|}{5.9910000000000005} & 6.5345 & TRN \\
\hline CHEMBL 3944464 & 1642538 & 9.2218 & 8.758 & TRN & \\
\hline CHEMBL3905231 & 1642538 & 8.0315 & 8.0973 & TRN & \\
\hline CHEMBL 3902265 & 1642538 & 9.0 & 8.5273 & TRN & \\
\hline CHEMBL 3948521 & 1642538 & 8.4949 & 8.328 & TST & \\
\hline CHEMBL 3907142 & 1642538 & 8.3188 & 7.9504 & TRN & \\
\hline CHEMBL 3892824 & 1642538 & 8.1805 & 7.6801 & TST & \\
\hline CHEMBL3901909 & 1642538 & 6.8633 & 7.0924 & TST & \\
\hline CHEMBL3910924 & 1642538 & 8.7447 & 8.622 & TST & \\
\hline CHEMBL3938335 & 1642538 & 7.3478 & \multicolumn{2}{|c|}{7.537000000000001} & NI \\
\hline CHEMBL 3928838 & 1642538 & 6.8027 & 6.7312 & TST & \\
\hline CHEMBL 3910402 & 1642538 & 7.9172 & 7.8218 & TRN & \\
\hline CHEMBL 3975556 & 1642538 & 7.6308 & 7.5884 & TRN & \\
\hline CHEMBL 3932627 & 1642538 & \multicolumn{3}{|c|}{7.7620000000000005} & 5 \\
\hline CHEMBL 3933511 & 1642538 & 8.1487 & 8.1496 & TRN & \\
\hline CHEMBL 3939036 & 1642538 & 7.9788 & 7.9153 & TRN & \\
\hline CHEMBL 3899562 & 1642538 & 7.7167 & 7.8611 & TRN & \\
\hline CHEMBL 3909877 & 1642538 & 7.8416 & 7.9343 & TRN & \\
\hline CHEMBL 3982144 & 1642538 & 7.9586 & 7.8825 & TRN & \\
\hline CHEMBL 3900216 & 1642538 & 7.9393 & 7.75 & TRN & \\
\hline CHEMBL 3964687 & 1642538 & 7.556 & 7.6412 & TST & \\
\hline CHEMBL 3914746 & 1642538 & 7.8633 & 7.6262 & TRN & \\
\hline
\end{tabular}


Supplemental Table S2.txt

\begin{tabular}{|c|c|c|c|c|c|}
\hline CHEMBL3978116 & 1642538 & 9.5229 & 8.8614 & TRN & \\
\hline CHEMBL3902838 & 1642538 & 9.0 & 8.4915 & TRN & \\
\hline CHEMBL3969708 & 1642538 & 7.6737 & 7.605 & TRN & \\
\hline CHEMBL3925884 & 1642538 & 7.8539 & 7.8206 & TRN & \\
\hline CHEMBL3943491 & 1642538 & 8.5686 & 8.758 & TRN & \\
\hline CHEMBL3929204 & 1642538 & 8.0362 & 7.7009 & TRN & \\
\hline CHEMBL3909742 & 1642538 & 7.6421 & 7.907 & TRN & \\
\hline CHEMBL3941721 & 1642538 & 7.5406 & 7.4304 & TRN & \\
\hline CHEMBL 3930043 & 1642538 & 8.2007 & 7.4655 & TST & \\
\hline CHEMBL3909481 & 1642538 & 7.4949 & 7.5232 & TRN & \\
\hline CHEMBL 3902451 & 1642538 & 7.6308 & 7.7596 & TRN & \\
\hline CHEMBL3923511 & 1642538 & 7.0004 & 7.1286 & TRN & \\
\hline CHEMBL3981677 & 1642538 & 9.0969 & 8.2484 & TST & \\
\hline CHEMBL3965134 & 1642538 & 7.6289 & 7.6911 & TST & \\
\hline CHEMBL3897438 & 1642538 & 7.3625 & 7.4276 & TST & \\
\hline CHEMBL3921458 & 1642538 & 7.3251 & 7.0303 & TST & \\
\hline CHEMBL3896955 & 1642538 & 7.6326 & 7.8325 & TRN & \\
\hline CHEMBL3890290 & 1642538 & 8.1938 & 8.0267 & TST & \\
\hline CHEMBL3982756 & 1642538 & 8.3979 & 8.2339 & TRN & \\
\hline CHEMBL3926405 & 1642538 & 8.699 & 8.7911 & TRN & \\
\hline CHEMBL3970214 & 1642538 & 6.9066 & 7.7799 & TRN & \\
\hline CHEMBL3962177 & 1642538 & 9.699 & 8.8902 & TRN & \\
\hline CHEMBL3922012 & 1642538 & 8.7212 & 8.1493 & TST & \\
\hline CHEMBL3905181 & 1642538 & 7.9914 & 7.9715 & TRN & \\
\hline CHEMBL3959875 & 1642538 & 7.8386 & 7.8089 & TRN & \\
\hline CHEMBL3914705 & 1642538 & 6.87 & 7.1487 & TRN & \\
\hline CHEMBL3921992 & 1642538 & 6.9374 & 7.1609 & TST & \\
\hline CHEMBL3924423 & 1642538 & 7.3325 & 7.4385 & TRN & \\
\hline CHEMBL3949364 & 1642538 & 7.6576 & 8.0135 & TRN & \\
\hline CHEMBL3947732 & 1642538 & 8.6198 & 8.5562 & TRN & \\
\hline CHEMBL3895318 & 1642538 & 8.2441 & 8.2493 & TRN & \\
\hline CHEMBL3936977 & 1642538 & 7.0074 & 7.0151 & TRN & \\
\hline CHEMBL3906580 & 1642538 & 8.5229 & 8.7724 & TRN & \\
\hline CHEMBL 3893406 & 1642538 & 7.9957 & 8.335 & TRN & \\
\hline CHEMBL3981164 & 1642538 & 7.3002 & 7.4238 & TRN & \\
\hline CHEMBL3974768 & 1642538 & 7.9136 & $8.07200 t$ & 0000000001 & TRN \\
\hline CHEMBL3936537 & 1642538 & 7.4559 & 7.4639 & TRN & \\
\hline CHEMBL3933835 & 1642538 & 8.4437 & 8.5038 & TRN & \\
\hline CHEMBL 3941604 & 1642538 & 8.1938 & 7.9334 & TRN & \\
\hline CHEMBL1964290 & 809220 & 6.1 & 6.13399 & 99999999995 & TRN \\
\hline CHEMBL 2003768 & 809220 & 4.2 & 4.0779 & TRN & \\
\hline CHEMBL213505 & 809220 & 6.4 & 5.8428 & TRN & \\
\hline CHEMBL202721 & 809220 & 4.6 & 5.1061 & TRN & \\
\hline CHEMBL1987034 & 809220 & 7.2 & 7.82 & TRN & \\
\hline CHEMBL1993941 & 809220 & 7.2 & 7.1044 & TRN & \\
\hline CHEMBL1980435 & 809220 & 5.8 & 5.3549 & TRN & \\
\hline CHEMBL377383 & 809220 & 4.2 & 3.9909 & TRN & \\
\hline CHEMBL 2005886 & 809220 & 6.5 & 6.4075 & TRN & \\
\hline
\end{tabular}




\begin{tabular}{|c|c|c|c|c|c|}
\hline \\
\hline CHEMBL481491 & 809220 & 4.2 & 5.3638 & TST & \\
\hline CHEMBL1973142 & 809220 & 5.7 & 5.6843 & TRN & \\
\hline CHEMBL388311 & 809220 & 7.8 & 7.8618 & TRN & \\
\hline CHEMBL1973145 & 809220 & 4.2 & 4.4622 & TRN & \\
\hline CHEMBL1982924 & 809220 & 5.6 & 5.6677 & TRN & \\
\hline CHEMBL2005936 & 809220 & 5.8 & 5.8003 & TRN & \\
\hline CHEMBL1807515 & 809220 & 7.3 & 7.09399 & 9999999999 & TRN \\
\hline CHEMBL1964948 & 809220 & 4.6 & 4.8048 & TRN & \\
\hline CHEMBL1971141 & 809220 & 4.2 & 4.1895 & TRN & \\
\hline CHEMBL1995813 & 809220 & 7.1 & 6.8397 & TRN & \\
\hline CHEMBL206236 & 809220 & 4.2 & 4.5418 & TRN & \\
\hline CHEMBL1989834 & 809220 & 3.9 & 4.5527 & TRN & \\
\hline CHEMBL1987430 & 809220 & 4.6 & 4.3637 & TRN & \\
\hline CHEMBL 244378 & 809220 & 8.5 & 8.5184 & TRN & \\
\hline CHEMBL 2001957 & 809220 & 4.2 & 4.2405 & TRN & \\
\hline CHEMBL1969372 & 809220 & 4.2 & 4.252 & TRN & \\
\hline CHEMBL1993413 & 809220 & 4.6 & 4.5142 & TRN & \\
\hline CHEMBL1986943 & 809220 & 7.4 & 7.4764 & TRN & \\
\hline CHEMBL289959 & 809220 & 4.3 & 3.8925 & TRN & \\
\hline CHEMBL 2006263 & 809220 & 4.2 & 5.2959 & TST & \\
\hline CHEMBL 2001646 & 809220 & 5.4 & 5.2805 & TRN & \\
\hline CHEMBL1993584 & 809220 & 5.6 & 5.3944 & TRN & \\
\hline CHEMBL1986263 & 809220 & 7.7 & 6.6994 & TRN & \\
\hline CHEMBL 2000114 & 809220 & 5.5 & 5.2393 & TRN & \\
\hline CHEMBL 210618 & 809220 & 4.2 & 4.0946 & TRN & \\
\hline CHEMBL1986265 & 809220 & 4.6 & 4.7105 & TRN & \\
\hline CHEMBL1971172 & 809220 & 6.0 & 6.3167 & TRN & \\
\hline CHEMBL1975647 & 809220 & 4.2 & 4.9511 & TRN & \\
\hline CHEMBL1968380 & 809220 & 4.2 & 4.0335 & TRN & \\
\hline CHEMBL1964644 & 809220 & 4.2 & 4.3961 & TRN & \\
\hline CHEMBL1991734 & 809220 & 6.6 & 5.9626 & TST & \\
\hline CHEMBL1981782 & 809220 & 4.2 & 3.9907 & TRN & \\
\hline CHEMBL1977681 & 809220 & 6.1 & 5.3559 & TRN & \\
\hline CHEMBL1970142 & 809220 & 7.9 & 7.3209 & TRN & \\
\hline CHEMBL1990912 & 809220 & 5.3 & 5.58200 & 0000000001 & TRN \\
\hline CHEMBL1991782 & 809220 & 3.3 & 3.7788 & TRN & \\
\hline CHEMBL 2002105 & 809220 & 4.8 & 4.6695 & TRN & \\
\hline CHEMBL1983348 & 809220 & 5.8 & 6.3883 & TRN & \\
\hline CHEMBL1988163 & 809220 & 7.8 & 7.3016 & TRN & \\
\hline CHEMBL1980671 & 809220 & 4.0 & 4.6471 & TRN & \\
\hline CHEMBL2006493 & 809220 & 4.2 & 4.2038 & TST & \\
\hline CHEMBL1986177 & 809220 & 4.6 & 4.6914 & TRN & \\
\hline CHEMBL1996923 & 809220 & 4.2 & 4.2586 & TST & \\
\hline CHEMBL1983449 & 809220 & 4.2 & 4.1052 & TRN & \\
\hline CHEMBL1992323 & 809220 & 4.2 & 4.1823 & TRN & \\
\hline CHEMBL1969735 & 809220 & 4.2 & 4.4063 & TRN & \\
\hline CHEMBL 2002649 & 809220 & 6.4 & 6.1953 & TRN & \\
\hline CHEMBL1983589 & 809220 & 6.8 & 7.1329 & TRN & \\
\hline
\end{tabular}




\begin{tabular}{|c|c|c|c|c|}
\hline & & & plem & \\
\hline CHEMBL1989423 & 809220 & 4.0 & 4.1209 & TRN \\
\hline CHEMBL1985367 & 809220 & 4.6 & 4.8403 & TST \\
\hline CHEMBL1996510 & 809220 & 6.0 & 6.0361 & TST \\
\hline CHEMBL 2005718 & 809220 & 6.6 & 6.5474 & TRN \\
\hline CHEMBL1995172 & 809220 & 4.3 & 4.3157 & TST \\
\hline CHEMBL 2001584 & 809220 & 4.6 & 4.2653 & TRN \\
\hline CHEMBL1971227 & 809220 & 5.7 & 5.3117 & TST \\
\hline CHEMBL1967998 & 809220 & 6.3 & 6.5943 & TRN \\
\hline CHEMBL1994321 & 809220 & 6.9 & 6.4384 & TRN \\
\hline CHEMBL1978562 & 809220 & 5.8 & 5.2661 & TST \\
\hline CHEMBL1997129 & 809220 & 8.3 & 7.5439 & TRN \\
\hline CHEMBL1984788 & 809220 & 5.9 & 5.2604 & TRN \\
\hline CHEMBL1974875 & 809220 & 4.4 & 4.6361 & TST \\
\hline CHEMBL1989471 & 809220 & 5.9 & 5.2383 & TST \\
\hline CHEMBL 2002099 & 809220 & 4.6 & 5.2729 & TRN \\
\hline CHEMBL 2000508 & 809220 & 4.2 & 4.6862 & TRN \\
\hline CHEMBL1971694 & 809220 & 4.2 & 4.0416 & TST \\
\hline CHEMBL 2001547 & 809220 & 4.2 & 4.2983 & TRN \\
\hline CHEMBL210928 & 809220 & 4.2 & 4.086 & TRN \\
\hline CHEMBL1978195 & 809220 & 6.6 & 5.7247 & TRN \\
\hline CHEMBL1986603 & 809220 & 4.2 & 4.9034 & TST \\
\hline CHEMBL1977148 & 809220 & 4.2 & 5.9727 & TRN \\
\hline CHEMBL1966842 & 809220 & 6.3 & 5.5748 & TRN \\
\hline CHEMBL 2003286 & 809220 & 4.2 & 4.7238 & TRN \\
\hline CHEMBL1992306 & 809220 & 4.2 & 5.3425 & TRN \\
\hline CHEMBL 2002165 & 809220 & 6.9 & 7.1125 & TRN \\
\hline CHEMBL 2001668 & 809220 & 4.2 & 4.1179 & TST \\
\hline CHEMBL1979318 & 809220 & 4.2 & 4.1371 & TST \\
\hline CHEMBL206382 & 809220 & 4.2 & 4.7226 & TRN \\
\hline CHEMBL1998585 & 809220 & 6.6 & 6.751 & TRN \\
\hline CHEMBL127898 & 809220 & 4.2 & 4.6959 & TST \\
\hline CHEMBL519697 & 809220 & 5.3 & 5.4036 & TST \\
\hline CHEMBL 2004934 & 809220 & 4.2 & 4.4859 & TRN \\
\hline CHEMBL1987261 & 809220 & 6.3 & 6.4358 & TRN \\
\hline CHEMBL1973516 & 809220 & 4.6 & 5.9547 & TRN \\
\hline CHEMBL1996345 & 809220 & 4.6 & 4.7941 & TST \\
\hline CHEMBL1975128 & 809220 & 6.1 & 6.5207 & TRN \\
\hline CHEMBL 2004025 & 809220 & 6.1 & 5.4466 & TRN \\
\hline CHEMBL1996048 & 809220 & 6.8 & 5.8947 & TST \\
\hline CHEMBL1970369 & 809220 & 4.2 & 3.697 & TRN \\
\hline CHEMBL461876 & 809220 & 4.6 & 5.0373 & TRN \\
\hline CHEMBL1965033 & 809220 & 4.6 & 4.7016 & TRN \\
\hline CHEMBL 2001485 & 809220 & 7.2 & 7.1296 & TRN \\
\hline CHEMBL1971519 & 809220 & 4.5 & 4.6133 & TRN \\
\hline CHEMBL1997335 & 809220 & 5.7 & 6.1757 & TRN \\
\hline CHEMBL1966425 & 809220 & 5.7 & 5.496 & TRN \\
\hline CHEMBL1984363 & 809220 & 6.3 & 5.294 & TRN \\
\hline CHEMBL1978099 & 809220 & 5.9 & 6.4774 & TRN \\
\hline
\end{tabular}




\begin{tabular}{|c|c|c|c|c|}
\hline & & & ient & al Ta \\
\hline CHEMBL1988608 & 809220 & 4.2 & 4.8738 & TRN \\
\hline CHEMBL184847 & 809220 & 4.2 & 5.5321 & TRN \\
\hline CHEMBL1994808 & 809220 & 4.2 & 4.5852 & TRN \\
\hline CHEMBL1984367 & 809220 & 4.2 & 4.7235 & TRN \\
\hline CHEMBL1985723 & 809220 & 6.5 & 6.4598 & TRN \\
\hline CHEMBL 178737 & 809220 & 4.2 & 5.3079 & TST \\
\hline CHEMBL 226898 & 809220 & 7.2 & 6.7533 & TRN \\
\hline CHEMBL1982563 & 809220 & 4.2 & 4.3782 & TRN \\
\hline CHEMBL539474 & 809220 & 4.2 & 5.0407 & TST \\
\hline CHEMBL575824 & 809220 & 4.3 & 5.3333 & TRN \\
\hline CHEMBL1988387 & 809220 & 7.5 & 7.5388 & TRN \\
\hline CHEMBL1973868 & 809220 & 4.6 & 4.819 & TRN \\
\hline CHEMBL1977128 & 809220 & 4.6 & 5.3604 & TRN \\
\hline CHEMBL1974803 & 809220 & 5.8 & 5.3107 & TRN \\
\hline CHEMBL1970074 & 809220 & 5.8 & 4.8245 & TRN \\
\hline CHEMBL1965702 & 809220 & 6.1 & 6.1203 & TRN \\
\hline CHEMBL1986970 & 809220 & 5.5 & 5.1313 & TRN \\
\hline CHEMBL 2005112 & 809220 & 4.2 & 4.7986 & TST \\
\hline CHEMBL1958401 & 809220 & 6.0 & 5.3604 & TRN \\
\hline CHEMBL1984044 & 809220 & 6.0 & 5.0818 & TRN \\
\hline CHEMBL 2003456 & 809220 & 6.1 & 5.4337 & TRN \\
\hline CHEMBL1966816 & 809220 & 5.2 & 4.7386 & TRN \\
\hline CHEMBL1972584 & 809220 & 5.6 & 6.1281 & TRN \\
\hline CHEMBL 2002992 & 809220 & 4.7 & 5.4594 & TRN \\
\hline CHEMBL560813 & 809220 & 4.2 & 5.1479 & TRN \\
\hline CHEMBL207253 & 809220 & 5.3 & 4.6696 & TST \\
\hline CHEMBL1982700 & 809220 & 4.6 & 4.5773 & TST \\
\hline CHEMBL1990635 & 809220 & 5.3 & 5.0697 & TST \\
\hline CHEMBL1968791 & 809220 & 5.5 & 4.5549 & TRN \\
\hline CHEMBL 2002682 & 809220 & 5.6 & 5.4433 & TRN \\
\hline CHEMBL1977634 & 809220 & 4.6 & 4.5675 & TRN \\
\hline CHEMBL1971186 & 809220 & 4.2 & 4.397 & TRN \\
\hline CHEMBL 2003482 & 809220 & 4.2 & 4.18 & TRN \\
\hline CHEMBL 2006456 & 809220 & 6.7 & 6.7597 & TRN \\
\hline CHEMBL1973211 & 809220 & 6.5 & 6.2873 & TRN \\
\hline CHEMBL1984700 & 809220 & 4.2 & 4.5832 & TRN \\
\hline CHEMBL1971606 & 809220 & 4.6 & 4.5878 & TRN \\
\hline CHEMBL1972125 & 809220 & 4.2 & 4.621 & TRN \\
\hline CHEMBL1461728 & 809220 & 4.2 & 4.1642 & TRN \\
\hline CHEMBL1976134 & 809220 & 6.9 & 6.4372 & TRN \\
\hline CHEMBL1965131 & 809220 & 5.9 & 5.8646 & TRN \\
\hline CHEMBL1972158 & 809220 & 6.2 & 6.1984 & TRN \\
\hline CHEMBL1981215 & 809220 & 4.6 & 4.8186 & TRN \\
\hline CHEMBL 2006580 & 809220 & 5.6 & 5.1493 & TRN \\
\hline CHEMBL1999414 & 809220 & 6.5 & 6.7865 & TRN \\
\hline CHEMBL1967336 & 809220 & 4.6 & 4.5207 & TRN \\
\hline CHEMBL 2001228 & 809220 & 4.6 & 4.9963 & TRN \\
\hline CHEMBL1994056 & 809220 & 4.2 & 4.5345 & TST \\
\hline
\end{tabular}




\begin{tabular}{|c|c|c|c|c|}
\hline & & & ient & al Ta \\
\hline CHEMBL 2006481 & 809220 & 4.2 & 3.8722 & TRN \\
\hline CHEMBL1979855 & 809220 & 5.4 & 4.0848 & TRN \\
\hline CHEMBL1970340 & 809220 & 4.8 & 4.5306 & TRN \\
\hline CHEMBL1967992 & 809220 & 4.6 & 4.5333 & TRN \\
\hline CHEMBL 2005186 & 809220 & 4.2 & 4.305 & TRN \\
\hline CHEMBL1995927 & 809220 & 5.2 & 4.1812 & TRN \\
\hline CHEMBL 2006450 & 809220 & 4.6 & 4.6504 & TRN \\
\hline CHEMBL1975534 & 809220 & 5.5 & 4.8384 & TRN \\
\hline CHEMBL1993424 & 809220 & 7.1 & 7.1372 & TRN \\
\hline CHEMBL1966703 & 809220 & 4.2 & 4.3501 & TST \\
\hline CHEMBL2001987 & 809220 & 4.6 & 4.2749 & TRN \\
\hline CHEMBL1969561 & 809220 & 5.7 & 5.5594 & TRN \\
\hline CHEMBL1994555 & 809220 & 4.6 & 5.5838 & TRN \\
\hline CHEMBL1983640 & 809220 & 6.2 & 5.8753 & TRN \\
\hline CHEMBL1997023 & 809220 & 4.2 & 4.7309 & TST \\
\hline CHEMBL1964687 & 809220 & 5.4 & 5.6584 & TRN \\
\hline CHEMBL1971943 & 809220 & 4.8 & 4.6972 & TRN \\
\hline CHEMBL1974254 & 809220 & 6.8 & 7.0869 & TRN \\
\hline CHEMBL1997924 & 809220 & 7.2 & 6.9333 & TRN \\
\hline CHEMBL1988537 & 809220 & 4.2 & 5.1446 & TST \\
\hline CHEMBL1969049 & 809220 & 4.2 & 4.3921 & TRN \\
\hline CHEMBL 2005828 & 809220 & 6.4 & 6.6272 & TRN \\
\hline CHEMBL 2002240 & 809220 & 4.2 & 4.5785 & TRN \\
\hline CHEMBL1978267 & 809220 & 6.0 & 4.9084 & TRN \\
\hline CHEMBL1991143 & 809220 & 4.2 & 4.476 & TST \\
\hline CHEMBL1980178 & 809220 & 6.2 & 6.2569 & TRN \\
\hline CHEMBL1998611 & 809220 & 4.2 & 5.0087 & TRN \\
\hline CHEMBL1975900 & 809220 & 4.2 & 4.5497 & TRN \\
\hline CHEMBL 255822 & 809220 & 4.2 & 4.9988 & TRN \\
\hline CHEMBL1972221 & 809220 & 4.2 & 5.1677 & TRN \\
\hline CHEMBL 2006778 & 809220 & 7.1 & 6.4923 & TRN \\
\hline CHEMBL 378627 & 809220 & 4.2 & 4.0695 & TRN \\
\hline CHEMBL1996979 & 809220 & 6.7 & 5.7118 & TRN \\
\hline CHEMBL1997025 & 809220 & 5.6 & 5.1132 & TRN \\
\hline CHEMBL1968406 & 809220 & 6.3 & 5.8318 & TRN \\
\hline CHEMBL1975921 & 809220 & 4.9 & 5.0303 & TRN \\
\hline CHEMBL1984274 & 809220 & 4.2 & 5.3095 & TRN \\
\hline CHEMBL117217 & 809220 & 5.3 & 4.8964 & TST \\
\hline CHEMBL1998545 & 809220 & 4.2 & 3.8959 & TRN \\
\hline CHEMBL1986869 & 809220 & 4.2 & 4.3437 & TRN \\
\hline CHEMBL 2004033 & 809220 & 5.6 & 4.574 & TST \\
\hline CHEMBL1975923 & 809220 & 4.9 & 5.2144 & TST \\
\hline CHEMBL2005449 & 809220 & 4.6 & 5.5981 & TRN \\
\hline CHEMBL1987998 & 809220 & 4.6 & 4.6307 & TRN \\
\hline CHEMBL 2006010 & 809220 & 4.2 & 4.1043 & TRN \\
\hline CHEMBL1682558 & 809220 & 4.2 & 4.2675 & TRN \\
\hline CHEMBL1971534 & 809220 & 5.0 & 5.1806 & TRN \\
\hline CHEMBL1990496 & 809220 & 4.3 & 4.7219 & TRN \\
\hline
\end{tabular}




\begin{tabular}{|c|c|c|c|c|c|}
\hline \multicolumn{6}{|c|}{ Supplemental Table S2.txt } \\
\hline CHEMBL242865 & 809220 & 6.4 & 7.2164 & TRN & \\
\hline CHEMBL 2002479 & 809220 & 5.8 & 5.5621 & TRN & \\
\hline CHEMBL 2002480 & 809220 & 4.1 & 4.5357 & TRN & \\
\hline CHEMBL1967094 & 809220 & 5.7 & 5.4276 & TRN & \\
\hline CHEMBL1966035 & 809220 & 4.2 & 4.0628 & TRN & \\
\hline CHEMBL2003341 & 809220 & 4.2 & 4.2765 & TRN & \\
\hline CHEMBL1982992 & 809220 & 5.3 & 5.2085 & TRN & \\
\hline CHEMBL1998110 & 809220 & 4.6 & 4.1746 & TRN & \\
\hline CHEMBL1999590 & 809220 & 4.2 & $4.8260 e$ & 00000000005 & TST \\
\hline CHEMBL1981079 & 809220 & 6.4 & 5.8862 & TRN & \\
\hline CHEMBL1978166 & 809220 & 6.5 & 6.8305 & TRN & \\
\hline CHEMBL1972276 & 809220 & 4.2 & 4.545 & TRN & \\
\hline CHEMBL1980489 & 809220 & 4.2 & 4.4736 & TRN & \\
\hline CHEMBL2000832 & 809220 & 7.0 & 6.5592 & TRN & \\
\hline CHEMBL1967116 & 809220 & 7.5 & 7.6494 & TRN & \\
\hline CHEMBL1990590 & 809220 & 4.6 & 4.1972 & TRN & \\
\hline CHEMBL513846 & 809220 & 4.2 & 4.4759 & TRN & \\
\hline CHEMBL1970709 & 809220 & 4.2 & 3.6736 & TRN & \\
\hline CHEMBL1974617 & 809220 & 4.4 & 4.4739 & TRN & \\
\hline CHEMBL1965660 & 809220 & 6.7 & 6.5546 & TRN & \\
\hline CHEMBL1992125 & 809220 & 5.8 & 5.6652 & TRN & \\
\hline CHEMBL1998112 & 809220 & 6.9 & 5.6822 & TRN & \\
\hline CHEMBL1972290 & 809220 & 6.5 & 6.5888 & TRN & \\
\hline CHEMBL1969126 & 809220 & 4.2 & 4.8743 & TRN & \\
\hline CHEMBL1980896 & 809220 & 5.2 & 5.1821 & TRN & \\
\hline CHEMBL1975208 & 809220 & 4.2 & 3.8529 & TST & \\
\hline CHEMBL1970104 & 809220 & 7.4 & 6.4998 & TRN & \\
\hline CHEMBL1991429 & 809220 & 6.6 & 6.4577 & TRN & \\
\hline CHEMBL1964777 & 809220 & 6.2 & 5.8103 & TRN & \\
\hline CHEMBL1971149 & 809220 & 4.2 & 4.1716 & TRN & \\
\hline CHEMBL1999714 & 809220 & 4.2 & 3.7524 & TRN & \\
\hline CHEMBL1987533 & 809220 & 4.2 & 4.2232 & TRN & \\
\hline CHEMBL1994040 & 809220 & 4.2 & 4.4638 & TRN & \\
\hline CHEMBL388978 & 809220 & 8.3 & 7.6913 & TST & \\
\hline CHEMBL1984548 & 809220 & 8.5 & 7.7522 & TRN & \\
\hline CHEMBL579246 & 809220 & 4.2 & 5.4207 & TRN & \\
\hline CHEMBL398951 & 809220 & 4.4 & 4.4815 & TST & \\
\hline CHEMBL1982506 & 809220 & 4.2 & 4.9911 & TST & \\
\hline CHEMBL2004716 & 809220 & 7.4 & 6.8747 & TRN & \\
\hline CHEMBL1968127 & 809220 & 4.2 & 3.9548 & TRN & \\
\hline CHEMBL1975233 & 809220 & 4.2 & 4.5248 & TRN & \\
\hline CHEMBL1985406 & 809220 & 5.9 & 5.6815 & TRN & \\
\hline CHEMBL207400 & 809220 & 4.2 & 4.26399 & 9999999999 & TST \\
\hline CHEMBL2000894 & 809220 & 4.2 & 5.2378 & TST & \\
\hline CHEMBL1421720 & 809220 & 5.7 & 5.7214 & TRN & \\
\hline CHEMBL1982135 & 809220 & 6.7 & 6.0625 & TRN & \\
\hline CHEMBL1976090 & 809220 & 5.8 & 5.4259 & TRN & \\
\hline CHEMBL1993243 & 809220 & 5.9 & 5.6639 & TRN & \\
\hline
\end{tabular}




\begin{tabular}{|c|c|c|c|c|}
\hline \\
\hline CHEMBL2004771 & 809220 & 6.5 & 5.5144 & TRN \\
\hline CHEMBL1992922 & 809220 & 6.8 & 6.1826 & TRN \\
\hline CHEMBL1997597 & 809220 & 5.6 & 5.2232 & TRN \\
\hline CHEMBL1969537 & 809220 & 5.8 & 4.7899 & TST \\
\hline CHEMBL1976093 & 809220 & 4.2 & 3.9273 & TRN \\
\hline CHEMBL 210032 & 809220 & 5.4 & 4.6201 & TRN \\
\hline CHEMBL1975256 & 809220 & 4.2 & 4.315 & TST \\
\hline CHEMBL508928 & 809220 & 5.8 & 5.9867 & TRN \\
\hline CHEMBL1991356 & 809220 & 4.2 & 4.9036 & TST \\
\hline CHEMBL1983309 & 809220 & 6.2 & 5.0135 & TRN \\
\hline CHEMBL 2004892 & 809220 & 4.2 & 5.0864 & TRN \\
\hline CHEMBL1949855 & 809220 & 5.0 & 4.6595 & TRN \\
\hline CHEMBL1999126 & 809220 & 4.2 & 4.8483 & TST \\
\hline CHEMBL1997503 & 809220 & 4.2 & 5.1349 & TST \\
\hline CHEMBL1972339 & 809220 & 6.4 & 6.544 & TRN \\
\hline CHEMBL116070 & 809220 & 5.7 & 5.5204 & TRN \\
\hline CHEMBL1990821 & 809220 & 5.7 & 5.0994 & TRN \\
\hline CHEMBL1970314 & 809220 & 5.4 & 5.1012 & TRN \\
\hline CHEMBL 2004871 & 809220 & 4.2 & 4.5839 & TRN \\
\hline CHEMBL 2004872 & 809220 & 4.2 & 4.1299 & TRN \\
\hline CHEMBL1727312 & 809220 & 4.2 & 3.5881 & TRN \\
\hline CHEMBL1990223 & 809220 & 4.6 & 4.4678 & TRN \\
\hline CHEMBL1969879 & 809220 & 4.2 & 4.8122 & TRN \\
\hline CHEMBL1964382 & 809220 & 4.6 & 4.8461 & TST \\
\hline CHEMBL101311 & 809220 & 6.0 & 5.5616 & TRN \\
\hline CHEMBL1981720 & 809220 & 4.2 & 5.4871 & TRN \\
\hline CHEMBL419932 & 809220 & 5.5 & 5.1759 & TRN \\
\hline CHEMBL 262433 & 809220 & 5.7 & 5.5806 & TRN \\
\hline CHEMBL 306380 & 809220 & 4.2 & 4.3105 & TRN \\
\hline CHEMBL1966722 & 809220 & 6.1 & 5.3909 & TST \\
\hline CHEMBL1983595 & 809220 & 4.6 & 5.2211 & TRN \\
\hline CHEMBL1988581 & 809220 & 7.1 & 6.681 & TST \\
\hline CHEMBL 2005699 & 809220 & 4.6 & 4.3835 & TRN \\
\hline CHEMBL1975500 & 809220 & 6.9 & 5.894 & TRN \\
\hline CHEMBL394619 & 809220 & 5.9 & 6.0026 & TRN \\
\hline CHEMBL 2006564 & 809220 & 6.6 & 6.3977 & TRN \\
\hline CHEMBL1996831 & 809220 & 4.2 & 4.6014 & TST \\
\hline CHEMBL411903 & 809220 & 6.7 & 7.2438 & TRN \\
\hline CHEMBL1980253 & 809220 & 6.7 & 6.6202 & TRN \\
\hline CHEMBL1965789 & 809220 & 5.6 & 5.1552 & TST \\
\hline CHEMBL1978167 & 809220 & 4.6 & 5.0971 & TST \\
\hline CHEMBL1965988 & 809220 & 6.3 & 6.5401 & TRN \\
\hline CHEMBL418203 & 809220 & 6.0 & 5.6441 & TST \\
\hline CHEMBL1989646 & 809220 & 5.6 & 5.75200 & 0000000001 \\
\hline CHEMBL225519 & 809220 & 5.9 & 5.9778 & TRN \\
\hline CHEMBL1978200 & 809220 & 4.2 & 4.3541 & TRN \\
\hline CHEMBL 2006631 & 809220 & 5.3 & 4.1174 & TRN \\
\hline CHEMBL1970522 & 809220 & 4.2 & 4.6215 & TRN \\
\hline
\end{tabular}

TRN 


\begin{tabular}{|c|c|c|c|c|c|}
\hline \\
\hline CHEMBL1990415 & 809220 & 5.5 & 4.5814 & TRN & \\
\hline CHEMBL1966087 & 809220 & 4.2 & 4.5767 & TRN & \\
\hline CHEMBL1964692 & 809220 & 7.2 & 6.2798 & TRN & \\
\hline CHEMBL1996931 & 809220 & 4.2 & 4.0721 & TRN & \\
\hline CHEMBL1964413 & 809220 & 4.2 & 3.6262 & TRN & \\
\hline CHEMBL1973483 & 809220 & 4.2 & 4.562 & TRN & \\
\hline CHEMBL1998470 & 809220 & 4.6 & 5.1622 & TRN & \\
\hline CHEMBL1996980 & 809220 & 7.3 & 7.5892 & TRN & \\
\hline CHEMBL1970735 & 809220 & 5.7 & 4.4475 & TRN & \\
\hline CHEMBL1975903 & 809220 & 4.6 & 5.5923 & TRN & \\
\hline CHEMBL1994669 & 809220 & 8.7 & 8.0563 & TRN & \\
\hline CHEMBL1997340 & 809220 & 4.2 & 3.8267 & TRN & \\
\hline CHEMBL2004365 & 809220 & 5.4 & 5.5932 & TST & \\
\hline CHEMBL1522508 & 809220 & 3.5 & 3.912 & TRN & \\
\hline CHEMBL1989474 & 809220 & 4.2 & 4.1645 & TRN & \\
\hline CHEMBL1090360 & 809220 & 7.1 & 6.0034 & TRN & \\
\hline CHEMBL210887 & 809220 & 5.3 & 5.2838 & TST & \\
\hline CHEMBL1988805 & 809220 & 4.6 & 5.1458 & TST & \\
\hline CHEMBL458997 & 809220 & 4.3 & 5.8169 & TRN & \\
\hline CHEMBL1971021 & 809220 & 4.2 & 4.2645 & TRN & \\
\hline CHEMBL227271 & 809220 & 6.5 & $6.8720 e$ & 0000000001 & TRN \\
\hline CHEMBL583144 & 809220 & 4.2 & 4.64199 & 99999999995 & TRN \\
\hline CHEMBL1974310 & 809220 & 7.3 & 6.1336 & TRN & \\
\hline CHEMBL1969942 & 809220 & 4.6 & 5.131 & TRN & \\
\hline CHEMBL1978567 & 809220 & 4.6 & 4.1746 & TRN & \\
\hline CHEMBL1982660 & 809220 & 4.6 & 5.8122 & TRN & \\
\hline CHEMBL1994693 & 809220 & 7.1 & 6.3619 & TRN & \\
\hline CHEMBL1982957 & 809220 & 4.2 & 5.6543 & TRN & \\
\hline CHEMBL1725279 & 809220 & 7.3 & 5.657 & TST & \\
\hline CHEMBL1975138 & 809220 & 5.8 & 5.2675 & TST & \\
\hline CHEMBL424872 & 809220 & 4.2 & $3.8760 e$ & 00000000003 & TRN \\
\hline CHEMBL2006836 & 809220 & 4.2 & 4.3437 & TST & \\
\hline CHEMBL412142 & 809220 & 4.2 & 4.143 & TST & \\
\hline CHEMBL1980704 & 809220 & 4.2 & 4.0773 & TST & \\
\hline CHEMBL2003271 & 809220 & 6.3 & 6.0675 & TRN & \\
\hline CHEMBL1966808 & 809220 & 4.2 & 4.2264 & TST & \\
\hline CHEMBL2004447 & 809220 & 4.2 & 3.8627 & TST & \\
\hline CHEMBL1992231 & 809220 & 4.6 & 5.5894 & TRN & \\
\hline CHEMBL1983111 & 809220 & 7.4 & 7.2361 & TRN & \\
\hline CHEMBL1973860 & 809220 & 4.2 & 4.953 & TRN & \\
\hline CHEMBL 260135 & 809220 & 4.2 & 4.3951 & TRN & \\
\hline CHEMBL220241 & 809220 & 4.2 & 5.3956 & TRN & \\
\hline CHEMBL 2004544 & 809220 & 4.2 & 4.8167 & TST & \\
\hline CHEMBL1988141 & 809220 & 6.4 & 6.0159 & TST & \\
\hline CHEMBL1982610 & 809220 & 4.2 & 4.2351 & TST & \\
\hline CHEMBL1977134 & 809220 & 4.6 & 4.7943 & TRN & \\
\hline CHEMBL1999496 & 809220 & 4.2 & 4.2664 & TRN & \\
\hline CHEMBL1985206 & 809220 & 4.6 & 4.6069 & TST & \\
\hline
\end{tabular}




\begin{tabular}{|c|c|c|c|c|}
\hline & & & upplement & al $\mathrm{Ta}$ \\
\hline CHEMBL1988300 & 809220 & 5.7 & 5.7477 & TRN \\
\hline CHEMBL1991078 & 809220 & 6.4 & 6.1801 & TRN \\
\hline CHEMBL1987359 & 809220 & 4.2 & 4.1587 & TST \\
\hline CHEMBL1977749 & 809220 & 5.9 & 5.9395 & TST \\
\hline CHEMBL1975212 & 809220 & 4.6 & 5.1684 & TRN \\
\hline CHEMBL2001613 & 809220 & 4.5 & 4.8556 & TRN \\
\hline CHEMBL1997275 & 809220 & 4.6 & 5.0413 & TRN \\
\hline CHEMBL1993904 & 809220 & 7.4 & 6.0756 & TRN \\
\hline CHEMBL1994438 & 809220 & 7.5 & 6.2954 & TRN \\
\hline CHEMBL1980376 & 809220 & 5.5 & 4.3882 & TRN \\
\hline CHEMBL1967513 & 809220 & 4.6 & 4.2631 & TRN \\
\hline CHEMBL 2000724 & 809220 & 4.6 & 4.1836 & TRN \\
\hline CHEMBL1989265 & 809220 & 4.2 & 4.2808 & TST \\
\hline CHEMBL1982413 & 809220 & 6.3 & 5.3368 & TRN \\
\hline CHEMBL1969502 & 809220 & 6.5 & 6.1309 & TRN \\
\hline CHEMBL1682553 & 809220 & 4.2 & 4.0311 & TRN \\
\hline CHEMBL1971430 & 809220 & 4.2 & 4.3716 & TRN \\
\hline CHEMBL1983963 & 809220 & 5.6 & 6.2924 & TRN \\
\hline CHEMBL1997764 & 809220 & 5.4 & 5.6592 & TRN \\
\hline CHEMBL1981792 & 809220 & 4.6 & 4.6852 & TRN \\
\hline CHEMBL1987535 & 809220 & 4.6 & 5.7477 & TRN \\
\hline CHEMBL1985092 & 809220 & 5.8 & 5.4239 & TRN \\
\hline CHEMBL 2004692 & 809220 & 4.2 & 4.05 & TST \\
\hline CHEMBL1981410 & 809220 & 5.8 & 5.3696 & TRN \\
\hline CHEMBL2002586 & 809220 & 6.5 & 5.061 & TRN \\
\hline CHEMBL1996234 & 809220 & 6.1 & 4.6421 & TRN \\
\hline CHEMBL383264 & 809220 & 5.7 & 5.8529 & TRN \\
\hline CHEMBL 2007421 & 809220 & 4.6 & 5.1832 & TRN \\
\hline CHEMBL1991434 & 809220 & 4.2 & 4.6371 & TST \\
\hline CHEMBL1967544 & 809220 & 4.2 & 4.7497 & TRN \\
\hline CHEMBL1973138 & 809220 & 4.6 & 4.2496 & TRN \\
\hline CHEMBL223367 & 809220 & 4.2 & 4.867 & TST \\
\hline CHEMBL1992673 & 809220 & 4.2 & 4.2549 & TRN \\
\hline CHEMBL340384 & 809220 & 5.3 & 5.86 & TST \\
\hline CHEMBL1969151 & 809220 & 6.5 & 6.9224 & TRN \\
\hline CHEMBL1996587 & 809220 & 4.2 & 4.4804 & TRN \\
\hline CHEMBL1981492 & 809220 & 4.3 & 4.4422 & TRN \\
\hline CHEMBL1993335 & 809220 & 6.4 & 5.4479 & TST \\
\hline CHEMBL1988692 & 809220 & 4.6 & 5.205 & TRN \\
\hline CHEMBL2007574 & 809220 & 6.1 & 6.199 & TRN \\
\hline CHEMBL1964804 & 809220 & 5.4 & 5.336 & TRN \\
\hline CHEMBL443962 & 809220 & 5.8 & 5.5145 & TRN \\
\hline CHEMBL 2000354 & 809220 & 5.9 & 5.2228 & TRN \\
\hline CHEMBL1965507 & 809220 & 7.4 & 7.2442 & TRN \\
\hline CHEMBL 274064 & 809220 & 4.2 & 4.9054 & TRN \\
\hline CHEMBL1998680 & 809220 & 4.6 & 4.4016 & TRN \\
\hline CHEMBL1967564 & 809220 & 4.2 & 4.4434 & TRN \\
\hline CHEMBL592030 & 809220 & 4.8 & 6.2039 & TST \\
\hline
\end{tabular}




\begin{tabular}{|c|c|c|c|c|c|}
\hline & & & & & \\
\hline CHEMBL2000071 & 809220 & 6.5 & 6.5489 & TRN & \\
\hline CHEMBL1979176 & 809220 & 5.5 & 4.7855 & TRN & \\
\hline CHEMBL2002613 & 809220 & 4.6 & 4.9087 & TRN & \\
\hline CHEMBL2000408 & 809220 & 4.2 & 4.5278 & TRN & \\
\hline CHEMBL 248757 & 809220 & 4.2 & 5.2541 & TST & \\
\hline CHEMBL1978014 & 809220 & 4.2 & 4.2453 & TRN & \\
\hline CHEMBL1997007 & 809220 & 5.9 & 5.7949 & TRN & \\
\hline CHEMBL1994538 & 809220 & 4.2 & 4.4962 & TRN & \\
\hline CHEMBL1983195 & 809220 & 5.3 & 5.0872 & TST & \\
\hline CHEMBL1975490 & 809220 & 5.4 & 5.472 & TRN & \\
\hline CHEMBL1964444 & 809220 & 4.2 & 4.7835 & TRN & \\
\hline CHEMBL 2002690 & 809220 & 4.6 & 4.7275 & TRN & \\
\hline CHEMBL1986139 & 809220 & 5.2 & 4.7211 & TRN & \\
\hline CHEMBL1980540 & 809220 & 4.2 & 4.2507 & TRN & \\
\hline CHEMBL 278041 & 809220 & 4.6 & 4.551 & TRN & \\
\hline CHEMBL1979883 & 809220 & 6.4 & 6.4892 & TRN & \\
\hline CHEMBL1984162 & 809220 & 7.1 & 6.4787 & TRN & \\
\hline CHEMBL1997051 & 809220 & 6.1 & 5.6048 & TRN & \\
\hline CHEMBL1998432 & 809220 & 6.7 & 6.8388 & TRN & \\
\hline CHEMBL491758 & 809220 & 5.7 & 6.1759 & TRN & \\
\hline CHEMBL1986590 & 809220 & 6.2 & 5.3724 & TRN & \\
\hline CHEMBL549730 & 809220 & 4.2 & 4.082 & TRN & \\
\hline CHEMBL1970189 & 809220 & 4.2 & 4.3405 & TST & \\
\hline CHEMBL1870106 & 809220 & 4.6 & 4.9274 & TRN & \\
\hline CHEMBL1996791 & 809220 & 5.4 & 5.2765 & TRN & \\
\hline CHEMBL371206 & 809220 & 6.3 & 6.4114 & TRN & \\
\hline CHEMBL1974664 & 809220 & 4.2 & 4.7889 & TRN & \\
\hline CHEMBL406845 & 809220 & 4.6 & 4.0429 & TRN & \\
\hline CHEMBL482538 & 809220 & 5.0 & 5.4202 & TRN & \\
\hline CHEMBL1974288 & 809220 & 4.2 & 4.5192 & TRN & \\
\hline CHEMBL196363 & 809220 & 5.6 & 6.0298 & TRN & \\
\hline CHEMBL1190711 & 809220 & 7.8 & 5.8053 & TRN & \\
\hline CHEMBL1964718 & 809220 & 4.1 & 4.4734 & TST & \\
\hline CHEMBL1968705 & 809220 & 5.8 & 4.7361 & TRN & \\
\hline CHEMBL1991410 & 809220 & 4.6 & 4.2553 & TRN & \\
\hline CHEMBL1964441 & 809220 & 6.3 & 6.1683 & TRN & \\
\hline CHEMBL546797 & 809220 & 4.6 & 5.0525 & TRN & \\
\hline CHEMBL404367 & 809220 & 5.8 & 5.9044 & TRN & \\
\hline CHEMBL1966343 & 809220 & 4.2 & 5.3405 & TRN & \\
\hline CHEMBL1978271 & 809220 & 4.6 & 4.4383 & TRN & \\
\hline CHEMBL1967887 & 809220 & 6.0 & 5.9166 & TRN & \\
\hline CHEMBL 2007266 & 809220 & 4.6 & 4.8081 & TRN & \\
\hline CHEMBL2000568 & 809220 & 4.5 & 5.7977 & TRN & \\
\hline CHEMBL1994308 & 809220 & 4.6 & 4.5615 & TRN & \\
\hline CHEMBL2000335 & 809220 & 6.3 & 6.6826 & TRN & \\
\hline CHEMBL1977604 & 809220 & 4.2 & 4.1666 & TST & \\
\hline CHEMBL1985507 & 809220 & 5.3 & 4.207 & TST & \\
\hline CHEMBL1988717 & 809220 & 5.7 & $5.4110 e$ & 20000000005 & TRN \\
\hline & & & & e 6015 & \\
\hline
\end{tabular}




\begin{tabular}{|c|c|c|c|c|}
\hline \multicolumn{5}{|c|}{ Supplemental Table S2.txt } \\
\hline CHEMBL1974328 & 809220 & 7.7 & 6.3914 & TRN \\
\hline CHEMBL509032 & 809220 & 6.4 & 6.5469 & TRN \\
\hline CHEMBL243298 & 809220 & 7.1 & 6.9763 & TRN \\
\hline CHEMBL1973808 & 809220 & 4.2 & 3.9833 & TRN \\
\hline CHEMBL 2000429 & 809220 & 4.2 & 4.5889 & TRN \\
\hline CHEMBL1972576 & 809220 & 7.1 & 7.7329 & TRN \\
\hline CHEMBL1992555 & 809220 & 4.2 & 4.3894 & TST \\
\hline CHEMBL1992342 & 809220 & 5.3 & 5.3727 & TRN \\
\hline CHEMBL1988173 & 809220 & 6.3 & 6.1444 & TST \\
\hline CHEMBL1973013 & 809220 & 4.6 & 5.3099 & TRN \\
\hline CHEMBL1164265 & 809220 & 6.2 & 6.0031 & TST \\
\hline CHEMBL535331 & 809220 & 5.6 & 4.7873 & TRN \\
\hline CHEMBL1989805 & 809220 & 4.2 & 5.0252 & TST \\
\hline CHEMBL1966204 & 809220 & 5.7 & 5.9166 & TRN \\
\hline CHEMBL1982980 & 809220 & 5.7 & 5.0395 & TRN \\
\hline CHEMBL1965423 & 809220 & 6.1 & 5.1586 & TRN \\
\hline CHEMBL1983025 & 809220 & 6.0 & 6.0939 & TRN \\
\hline CHEMBL1975927 & 809220 & 4.6 & 5.581 & TRN \\
\hline CHEMBL 205415 & 809220 & 4.3 & 4.7903 & TRN \\
\hline CHEMBL1977135 & 809220 & 4.2 & 4.4388 & TRN \\
\hline CHEMBL 2001920 & 809220 & 4.2 & 5.1486 & TRN \\
\hline CHEMBL1997119 & 809220 & 4.4 & 4.303 & TRN \\
\hline CHEMBL1977138 & 809220 & 6.3 & 6.0902 & TST \\
\hline CHEMBL1241473 & 809220 & 8.1 & 7.6554 & TRN \\
\hline CHEMBL1978448 & 809220 & 4.7 & 4.5326 & TST \\
\hline CHEMBL1972258 & 809220 & 4.2 & 4.5707 & TRN \\
\hline CHEMBL1969483 & 809220 & 4.6 & 4.789 & TRN \\
\hline CHEMBL1980329 & 809220 & 7.5 & 6.8906 & TRN \\
\hline CHEMBL 2004515 & 809220 & 4.4 & 5.1999 & TRN \\
\hline CHEMBL 2001257 & 809220 & 6.0 & 5.9869 & TRN \\
\hline CHEMBL1992042 & 809220 & 5.9 & 5.5183 & TRN \\
\hline CHEMBL1987793 & 809220 & 5.8 & 5.0438 & TRN \\
\hline CHEMBL1992536 & 809220 & 4.2 & 3.9287 & TRN \\
\hline CHEMBL 21156 & 809220 & 5.6 & 5.7813 & TST \\
\hline CHEMBL1992740 & 809220 & 4.2 & 4.3526 & TRN \\
\hline CHEMBL1994724 & 809220 & 4.6 & 4.9106 & TRN \\
\hline CHEMBL1989267 & 809220 & 6.4 & 6.2335 & TRN \\
\hline CHEMBL 2002373 & 809220 & 4.2 & 4.6338 & TRN \\
\hline CHEMBL439340 & 809220 & 4.2 & 4.4311 & TRN \\
\hline CHEMBL 2006188 & 809220 & 4.2 & 4.2079 & TRN \\
\hline CHEMBL1970290 & 809220 & 6.5 & 4.915 & TRN \\
\hline CHEMBL1967531 & 809220 & 6.6 & 6.8164 & TRN \\
\hline CHEMBL1970913 & 809220 & 4.2 & 4.6316 & TRN \\
\hline CHEMBL1973893 & 809220 & 5.2 & 5.2107 & TRN \\
\hline CHEMBL1995736 & 809220 & 5.3 & 4.7182 & TRN \\
\hline CHEMBL1997534 & 809220 & 7.4 & 5.9985 & TRN \\
\hline CHEMBL1993877 & 809220 & 6.2 & 5.1781 & TRN \\
\hline CHEMBL1996500 & 809220 & 4.5 & 4.3909 & TRN \\
\hline
\end{tabular}




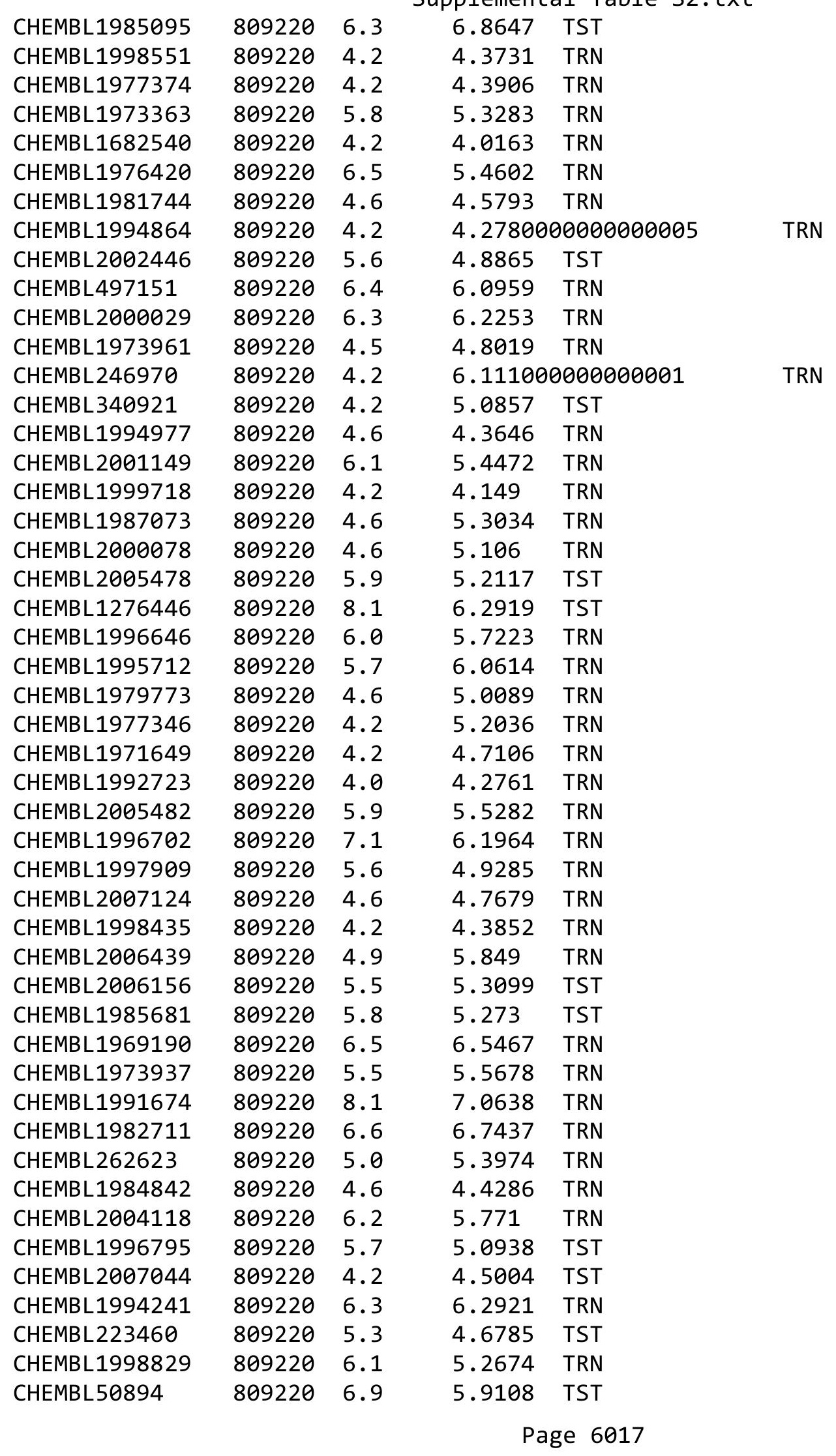




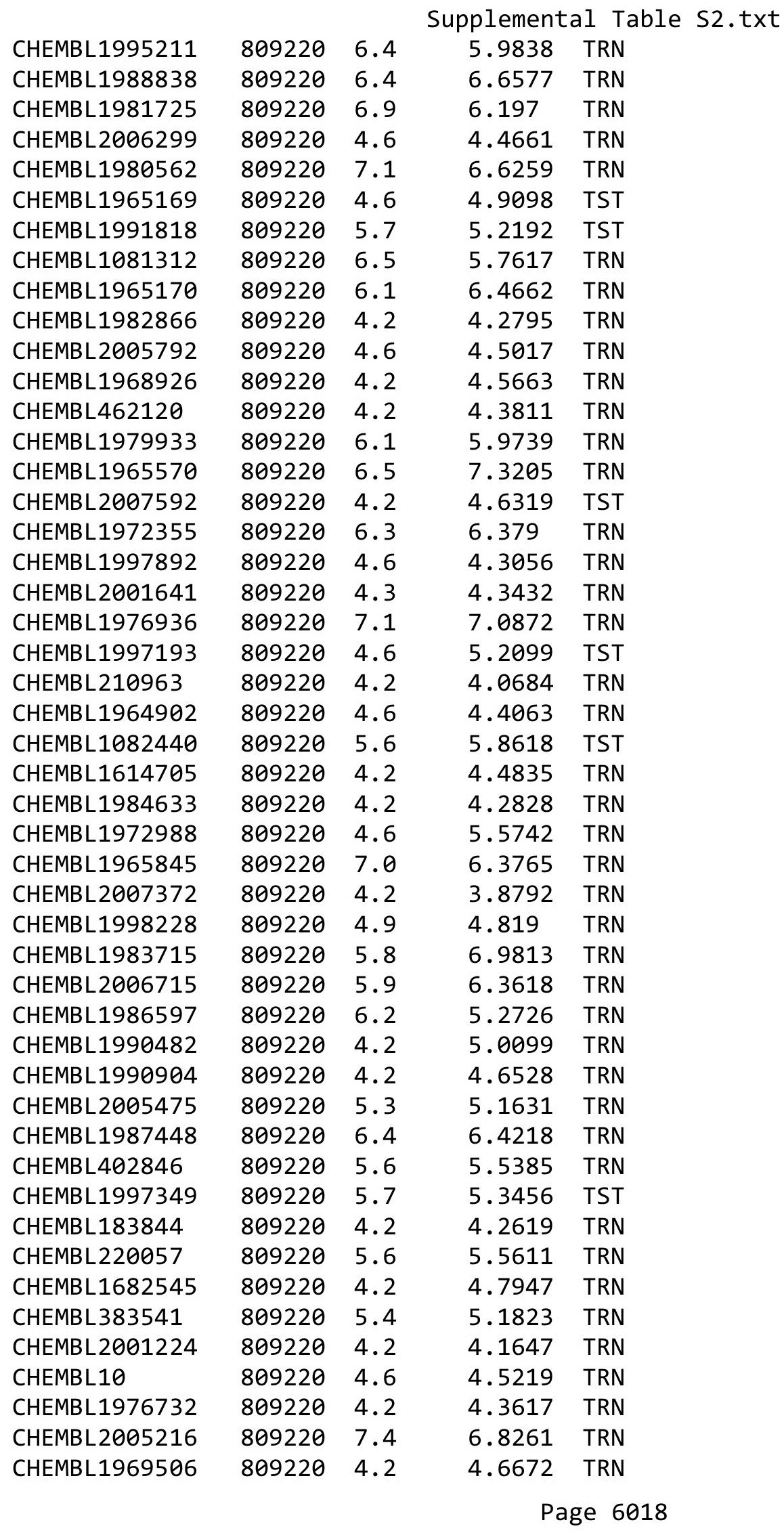




\begin{tabular}{|c|c|c|c|c|}
\hline & & & ient & al Ta \\
\hline CHEMBL1980763 & 809220 & 5.9 & 5.5707 & TRN \\
\hline CHEMBL1964937 & 809220 & 6.4 & 5.8786 & TRN \\
\hline CHEMBL1980163 & 809220 & 4.2 & 4.1712 & TRN \\
\hline CHEMBL1977931 & 809220 & 4.6 & 4.526 & TRN \\
\hline CHEMBL2005899 & 809220 & 4.2 & 4.2113 & TRN \\
\hline CHEMBL1682552 & 809220 & 4.2 & 4.1029 & TRN \\
\hline CHEMBL1972568 & 809220 & 4.2 & 4.5056 & TRN \\
\hline CHEMBL 2007479 & 809220 & 4.6 & 4.5264 & TRN \\
\hline CHEMBL229799 & 809220 & 7.2 & 7.3294 & TRN \\
\hline CHEMBL105739 & 809220 & 5.8 & 5.5821 & TRN \\
\hline CHEMBL1972220 & 809220 & 7.7 & 7.2383 & TRN \\
\hline CHEMBL 379300 & 809220 & 7.6 & 6.8844 & TRN \\
\hline CHEMBL 2003785 & 809220 & 4.1 & 4.2981 & TST \\
\hline CHEMBL1973720 & 809220 & 7.2 & 7.2682 & TRN \\
\hline CHEMBL1969523 & 809220 & 4.2 & 5.8797 & TRN \\
\hline CHEMBL1988995 & 809220 & 4.2 & 4.2548 & TRN \\
\hline CHEMBL2001923 & 809220 & 4.6 & 4.6576 & TST \\
\hline CHEMBL1986781 & 809220 & 4.2 & 4.4347 & TRN \\
\hline CHEMBL1983070 & 809220 & 4.6 & 4.3621 & TRN \\
\hline CHEMBL526133 & 809220 & 4.2 & 4.8249 & TRN \\
\hline CHEMBL 2003514 & 809220 & 4.6 & 4.2582 & TRN \\
\hline CHEMBL1989043 & 809220 & 4.6 & 4.9029 & TRN \\
\hline CHEMBL1979057 & 809220 & 5.7 & 5.8213 & TRN \\
\hline CHEMBL387971 & 809220 & 4.2 & 4.649 & TST \\
\hline CHEMBL1164180 & 809220 & 6.2 & 5.8618 & TST \\
\hline CHEMBL1999428 & 809220 & 4.2 & 4.3244 & TRN \\
\hline CHEMBL1967560 & 809220 & 4.2 & 3.8196 & TRN \\
\hline CHEMBL1997611 & 809220 & 4.6 & 4.973 & TST \\
\hline CHEMBL1516890 & 809220 & 6.3 & 5.9928 & TRN \\
\hline CHEMBL 211378 & 809220 & 4.2 & 5.0227 & TRN \\
\hline CHEMBL1982465 & 809220 & 6.3 & 6.3082 & TRN \\
\hline CHEMBL 2001751 & 809220 & 7.4 & 7.5112 & TRN \\
\hline CHEMBL 2003420 & 809220 & 4.2 & 4.2351 & TRN \\
\hline CHEMBL1984586 & 809220 & 6.3 & 6.6793 & TRN \\
\hline CHEMBL1972659 & 809220 & 5.2 & 4.3614 & TST \\
\hline CHEMBL 272453 & 809220 & 5.3 & 5.5794 & TRN \\
\hline CHEMBL1970217 & 809220 & 4.2 & 4.6969 & TRN \\
\hline CHEMBL 2005528 & 809220 & 4.2 & 4.923 & TST \\
\hline CHEMBL1984686 & 809220 & 4.6 & 4.5847 & TRN \\
\hline CHEMBL185569 & 809220 & 5.2 & 5.2504 & TRN \\
\hline CHEMBL1969843 & 809220 & 4.2 & 3.984 & TRN \\
\hline CHEMBL 2007002 & 809220 & 6.5 & 6.1503 & TRN \\
\hline CHEMBL1987007 & 809220 & 4.2 & 4.423 & TRN \\
\hline CHEMBL1973793 & 809220 & 4.6 & 5.3609 & TST \\
\hline CHEMBL1984711 & 809220 & 4.2 & 5.365 & TRN \\
\hline CHEMBL1992073 & 809220 & 4.6 & 5.6574 & TRN \\
\hline CHEMBL484390 & 809220 & 5.4 & 5.2976 & TST \\
\hline CHEMBL1979252 & 809220 & 4.2 & 4.3283 & TRN \\
\hline
\end{tabular}




\begin{tabular}{|c|c|c|c|c|}
\hline \multicolumn{5}{|c|}{ lemental T } \\
\hline CHEMBL1986143 & 809220 & 4.6 & 4.3501 & TRN \\
\hline CHEMBL1972934 & 809220 & 4.7 & 4.6071 & TRN \\
\hline CHEMBL2007559 & 809220 & 4.6 & 4.8741 & TRN \\
\hline CHEMBL1992581 & 809220 & 6.6 & 4.9688 & TRN \\
\hline CHEMBL 2004290 & 809220 & 6.9 & 6.6995 & TRN \\
\hline CHEMBL1986499 & 809220 & 5.9 & 5.9396 & TRN \\
\hline CHEMBL1972937 & 809220 & 4.2 & 4.0963 & TRN \\
\hline CHEMBL 2000393 & 809220 & 6.9 & 6.5016 & TST \\
\hline CHEMBL1089101 & 809220 & 5.2 & 5.0707 & TRN \\
\hline CHEMBL 2004311 & 809220 & 5.4 & 5.1699 & TRN \\
\hline CHEMBL1992634 & 809220 & 7.7 & 6.9732 & TRN \\
\hline CHEMBL1242373 & 809220 & 5.7 & 5.9355 & TRN \\
\hline CHEMBL56543 & 809220 & 5.7 & 5.4161 & TRN \\
\hline CHEMBL1984847 & 809220 & 4.6 & 4.6604 & TST \\
\hline CHEMBL316264 & 809220 & 4.2 & 4.2816 & TRN \\
\hline CHEMBL1988075 & 809220 & 7.0 & 6.8653 & TRN \\
\hline CHEMBL1996576 & 809220 & 4.6 & 4.5559 & TST \\
\hline CHEMBL1988076 & 809220 & 5.6 & 5.14 & TRN \\
\hline CHEMBL1991678 & 809220 & 4.5 & 4.2783 & TRN \\
\hline CHEMBL2001239 & 809220 & 5.7 & 5.2303 & TRN \\
\hline CHEMBL1988594 & 809220 & 7.0 & 7.7983 & TRN \\
\hline CHEMBL 2001288 & 809220 & 4.2 & 4.7933 & TRN \\
\hline CHEMBL1992363 & 809220 & 7.4 & 6.1275 & TRN \\
\hline CHEMBL1999811 & 809220 & 6.1 & 5.591 & TRN \\
\hline CHEMBL235157 & 809220 & 4.6 & 4.6542 & TST \\
\hline CHEMBL1985074 & 809220 & 4.2 & 4.6939 & TST \\
\hline CHEMBL 2000481 & 809220 & 4.2 & 5.5797 & TRN \\
\hline CHEMBL1982874 & 809220 & 6.1 & 5.2332 & TRN \\
\hline CHEMBL1991725 & 809220 & 5.9 & 4.9883 & TRN \\
\hline CHEMBL1992242 & 809220 & 4.2 & 3.9907 & TRN \\
\hline CHEMBL1982271 & 809220 & 6.9 & 7.2197 & TRN \\
\hline CHEMBL 2007296 & 809220 & 4.2 & 4.6594 & TRN \\
\hline CHEMBL208637 & 809220 & 5.3 & 4.1317 & TRN \\
\hline CHEMBL2004159 & 809220 & 4.6 & 4.457 & TRN \\
\hline CHEMBL396523 & 809220 & 8.3 & 8.5518 & TRN \\
\hline CHEMBL1978371 & 809220 & 6.0 & 5.4545 & TST \\
\hline CHEMBL1970203 & 809220 & 7.2 & 7.5003 & TRN \\
\hline CHEMBL1986530 & 809220 & 6.5 & 5.1259 & TST \\
\hline CHEMBL1999321 & 809220 & 4.2 & 4.0803 & TRN \\
\hline CHEMBL1968590 & 809220 & 6.3 & 5.4342 & TRN \\
\hline CHEMBL 2005375 & 809220 & 4.2 & 3.98 & TRN \\
\hline CHEMBL1984191 & 809220 & 4.2 & 4.9183 & TRN \\
\hline CHEMBL1972183 & 809220 & 4.2 & 3.9908 & TST \\
\hline CHEMBL1971029 & 809220 & 8.0 & 7.6204 & TRN \\
\hline CHEMBL394790 & 809220 & 6.2 & 6.1321 & TRN \\
\hline CHEMBL226471 & 809220 & 6.0 & 5.9509 & TRN \\
\hline CHEMBL1974702 & 809220 & 4.2 & 4.6146 & TRN \\
\hline CHEMBL1996111 & 809220 & 6.2 & 5.3256 & TRN \\
\hline
\end{tabular}




\begin{tabular}{|c|c|c|c|c|c|}
\hline \\
\hline CHEMBL1966175 & 809220 & 4.6 & 5.3305 & TRN & \\
\hline CHEMBL1965589 & 809220 & 4.2 & 4.2622 & TRN & \\
\hline CHEMBL2007375 & 809220 & 4.6 & 4.3133 & TRN & \\
\hline CHEMBL1998193 & 809220 & 4.2 & 4.3627 & TRN & \\
\hline CHEMBL379975 & 809220 & 6.9 & 7.3635 & TRN & \\
\hline CHEMBL474432 & 809220 & 4.3 & 5.6316 & TST & \\
\hline CHEMBL1965387 & 809220 & 4.6 & 4.8041 & TRN & \\
\hline CHEMBL2001539 & 809220 & 5.2 & 4.2872 & TST & \\
\hline CHEMBL1997041 & 809220 & 4.2 & 4.8435 & TRN & \\
\hline CHEMBL1988153 & 809220 & 5.7 & 5.6597 & TRN & \\
\hline CHEMBL550418 & 809220 & 5.6 & 5.4643 & TRN & \\
\hline CHEMBL1986666 & 809220 & 6.5 & 6.6252 & TRN & \\
\hline CHEMBL1971289 & 809220 & 4.6 & 5.0675 & TRN & \\
\hline CHEMBL1988437 & 809220 & 6.5 & 6.3333 & TST & \\
\hline CHEMBL1979577 & 809220 & 6.5 & 6.3296 & TRN & \\
\hline CHEMBL1998121 & 809220 & 4.2 & 5.0692 & TRN & \\
\hline CHEMBL1233887 & 809220 & 4.6 & 4.7411 & TST & \\
\hline CHEMBL1991800 & 809220 & 4.2 & 4.5999 & TRN & \\
\hline CHEMBL52387 & 809220 & 4.2 & 4.4801 & TST & \\
\hline CHEMBL 379835 & 809220 & 4.2 & 4.3473 & TST & \\
\hline CHEMBL1979357 & 809220 & 4.2 & 4.6706 & TRN & \\
\hline CHEMBL1996649 & 809220 & 6.5 & 6.7838 & TRN & \\
\hline CHEMBL1996817 & 809220 & 7.1 & 6.5282 & TRN & \\
\hline CHEMBL1986756 & 809220 & 4.6 & 4.5874 & TRN & \\
\hline CHEMBL3197315 & 809220 & 4.2 & 4.115 & TST & \\
\hline CHEMBL468280 & 809220 & 4.2 & 4.2123 & TST & \\
\hline CHEMBL1990884 & 809220 & 4.2 & 4.5563 & TRN & \\
\hline CHEMBL3109278 & 809220 & 4.8 & 5.1724 & TRN & \\
\hline CHEMBL 256835 & 809220 & 4.2 & 5.0803 & TRN & \\
\hline CHEMBL1980142 & 809220 & 4.2 & 4.0019 & TRN & \\
\hline CHEMBL41783 & 809220 & 4.2 & 4.4423 & TRN & \\
\hline CHEMBL 2004438 & 809220 & 4.6 & 4.4563 & TRN & \\
\hline CHEMBL2006276 & 809220 & 5.4 & 4.8707 & TRN & \\
\hline CHEMBL191003 & 809220 & 5.8 & 6.1032 & TRN & \\
\hline CHEMBL 271381 & 809220 & 6.2 & 6.50799 & 9999999999 & TRN \\
\hline CHEMBL 2002471 & 809220 & 5.6 & 5.2138 & TRN & \\
\hline CHEMBL 2006785 & 809220 & 4.2 & 4.3723 & TRN & \\
\hline CHEMBL1982466 & 809220 & 7.7 & 7.296 & TRN & \\
\hline CHEMBL1973359 & 809220 & 6.6 & 6.4397 & TST & \\
\hline CHEMBL1995740 & 809220 & 4.2 & 5.4741 & TRN & \\
\hline CHEMBL1990162 & 809220 & 5.6 & 5.5647 & TRN & \\
\hline CHEMBL1992220 & 809220 & 7.3 & 7.5617 & TRN & \\
\hline CHEMBL1979690 & 809220 & 6.3 & 6.7939 & TRN & \\
\hline CHEMBL234085 & 809220 & 4.5 & 4.9272 & TRN & \\
\hline CHEMBL1998414 & 809220 & 4.2 & 4.4723 & TRN & \\
\hline CHEMBL1995832 & 809220 & 4.2 & 4.6615 & TRN & \\
\hline CHEMBL1969042 & 809220 & 5.7 & 5.51 & TRN & \\
\hline CHEMBL 2000345 & 809220 & 6.4 & 6.3304 & TRN & \\
\hline
\end{tabular}




\begin{tabular}{|c|c|c|c|c|}
\hline & & & nent & al Table \\
\hline CHEMBL1999931 & 809220 & 7.1 & 6.5247 & TRN \\
\hline CHEMBL1976376 & 809220 & 4.6 & 4.54 & TRN \\
\hline CHEMBL1983575 & 809220 & 7.9 & 6.629 & TRN \\
\hline CHEMBL1968868 & 809220 & 4.6 & 4.5319 & TRN \\
\hline CHEMBL1375418 & 809220 & 4.2 & 4.4839 & TRN \\
\hline CHEMBL 2007064 & 809220 & 5.4 & 5.6765 & TRN \\
\hline CHEMBL1981047 & 809220 & 6.4 & 6.3351 & TRN \\
\hline CHEMBL229968 & 809220 & 7.2 & 7.1914 & TRN \\
\hline CHEMBL1976196 & 809220 & 6.0 & 5.3265 & TST \\
\hline CHEMBL 2002432 & 809220 & 4.6 & 5.0331 & TRN \\
\hline CHEMBL1976240 & 809220 & 4.2 & 4.8705 & TRN \\
\hline CHEMBL1987948 & 809220 & 6.2 & 6.0925 & TRN \\
\hline CHEMBL1997197 & 809220 & 4.6 & 4.675 & TRN \\
\hline CHEMBL1983630 & 809220 & 4.5 & 4.6537 & TRN \\
\hline CHEMBL1979093 & 809220 & 6.3 & 6.3372 & TRN \\
\hline CHEMBL1968151 & 809220 & 4.2 & 4.2746 & TST \\
\hline CHEMBL1987009 & 809220 & 6.0 & 5.8939 & TRN \\
\hline CHEMBL379218 & 809220 & 7.2 & 6.7662 & TRN \\
\hline CHEMBL 2003817 & 809220 & 4.2 & 4.6887 & TRN \\
\hline CHEMBL1994830 & 809220 & 6.4 & 5.6165 & TRN \\
\hline CHEMBL 226403 & 809220 & 5.7 & 5.5806 & TRN \\
\hline CHEMBL 2005631 & 809220 & 7.0 & 7.1765 & TRN \\
\hline CHEMBL1994938 & 809220 & 5.8 & 5.8058 & TRN \\
\hline CHEMBL1977223 & 809220 & 5.3 & 5.0252 & TRN \\
\hline CHEMBL1995765 & 809220 & 5.0 & 4.7532 & TST \\
\hline CHEMBL1966279 & 809220 & 4.2 & 5.3442 & TRN \\
\hline CHEMBL1236126 & 809220 & 4.2 & 4.5628 & TST \\
\hline CHEMBL1997846 & 809220 & 6.4 & 6.0042 & TRN \\
\hline CHEMBL1984760 & 809220 & 5.8 & 5.5462 & TRN \\
\hline CHEMBL 2004419 & 809220 & 5.2 & 4.7662 & TRN \\
\hline CHEMBL360847 & 809220 & 4.6 & 5.1312 & TST \\
\hline CHEMBL1995811 & 809220 & 4.6 & 5.1999 & TRN \\
\hline CHEMBL1972489 & 809220 & 4.2 & 4.1798 & TRN \\
\hline CHEMBL1994074 & 809220 & 5.3 & 5.4207 & TRN \\
\hline CHEMBL1992937 & 809220 & 5.7 & 5.3668 & TST \\
\hline CHEMBL1968930 & 809220 & 7.3 & 6.8503 & TRN \\
\hline CHEMBL1972119 & 809220 & 4.2 & 3.8043 & TRN \\
\hline CHEMBL1986328 & 809220 & 5.4 & 5.0064 & TST \\
\hline CHEMBL95692 & 809220 & 4.2 & 4.8704 & TRN \\
\hline CHEMBL1090356 & 809220 & 4.2 & 5.5542 & TRN \\
\hline CHEMBL 2002450 & 809220 & 4.2 & 4.7331 & TRN \\
\hline CHEMBL1976455 & 809220 & 5.7 & $5.2470 e$ & 0000000001 \\
\hline CHEMBL261849 & 809220 & 4.6 & 4.3948 & TST \\
\hline CHEMBL1983923 & 809220 & 5.6 & 5.5463 & TRN \\
\hline CHEMBL1983534 & 809220 & 4.2 & 5.0217 & TST \\
\hline CHEMBL1982361 & 809220 & 4.2 & 4.6107 & TST \\
\hline CHEMBL1999112 & 809220 & 5.4 & 5.7065 & TST \\
\hline CHEMBL1982122 & 809220 & 5.4 & 5.1751 & TST \\
\hline
\end{tabular}

TRN 


\begin{tabular}{|c|c|c|c|c|c|}
\hline \\
\hline CHEMBL 2000801 & 809220 & 4.2 & 4.1324 & TST & \\
\hline CHEMBL1682546 & 809220 & 4.2 & 4.2923 & TST & \\
\hline CHEMBL1991395 & 809220 & 4.2 & 4.4069 & TST & \\
\hline CHEMBL1971245 & 809220 & 4.2 & 5.0105 & TST & \\
\hline CHEMBL1972142 & 809220 & 7.6 & 6.2732 & TST & \\
\hline CHEMBL1966514 & 809220 & 6.8 & 7.0824 & TST & \\
\hline CHEMBL 2003638 & 809220 & 6.5 & 5.9834 & TST & \\
\hline CHEMBL1996066 & 809220 & 6.7 & 5.1984 & TST & \\
\hline CHEMBL1983393 & 809220 & 4.6 & 4.9002 & TST & \\
\hline CHEMBL1993722 & 809220 & 6.5 & 5.8239 & TST & \\
\hline CHEMBL1970806 & 809220 & 4.2 & 4.3102 & TST & \\
\hline CHEMBL 2006674 & 809220 & 4.6 & 4.5626 & TST & \\
\hline CHEMBL1984236 & 809220 & 4.6 & 4.5944 & TST & \\
\hline CHEMBL1992371 & 809220 & 4.6 & 5.6311 & TST & \\
\hline CHEMBL1375640 & 809220 & 5.3 & 5.4943 & TST & \\
\hline CHEMBL1979970 & 809220 & 4.2 & 4.4181 & TST & \\
\hline CHEMBL2002599 & 809220 & 4.6 & 4.7882 & TST & \\
\hline CHEMBL249282 & 809220 & 4.2 & 4.665 & TST & \\
\hline CHEMBL1967252 & 809220 & 5.4 & 5.5658 & TST & \\
\hline CHEMBL 2004637 & 809220 & 6.3 & 5.1829 & TST & \\
\hline CHEMBL1993374 & 809220 & 4.6 & 4.7245 & TST & \\
\hline CHEMBL 2006237 & 809220 & 4.2 & 4.2205 & TST & \\
\hline CHEMBL1999506 & 809220 & 4.6 & 4.3897 & TST & \\
\hline CHEMBL1967720 & 809220 & 7.0 & 6.8885 & TST & \\
\hline CHEMBL2005509 & 809220 & 7.3 & 7.519 & TST & \\
\hline CHEMBL1572266 & 809220 & 4.2 & 4.2698 & TST & \\
\hline CHEMBL1991138 & 809220 & 4.2 & 4.1623 & TST & \\
\hline CHEMBL1969755 & 809220 & 4.2 & 3.8417 & TST & \\
\hline CHEMBL1979516 & 809220 & 6.8 & 6.7811 & TST & \\
\hline CHEMBL1972820 & 809220 & 4.2 & 4.5289 & TST & \\
\hline CHEMBL1605605 & 809220 & 4.6 & 4.76399 & 9999999999 & TST \\
\hline CHEMBL1996208 & 809220 & 4.3 & 4.3167 & TST & \\
\hline CHEMBL1989029 & 809220 & 5.6 & 5.4999 & TST & \\
\hline CHEMBL392642 & 809220 & 4.2 & 6.0601 & TST & \\
\hline CHEMBL514499 & 809220 & 4.2 & 5.4378 & TST & \\
\hline CHEMBL1970352 & 809220 & 5.7 & 5.3116 & TST & \\
\hline CHEMBL1965631 & 809220 & 4.2 & 4.7711 & TST & \\
\hline CHEMBL1980144 & 809220 & 7.2 & 7.5681 & TST & \\
\hline CHEMBL1991188 & 809220 & 5.2 & 4.5859 & TST & \\
\hline CHEMBL1980167 & 809220 & 5.6 & 5.5097 & TST & \\
\hline CHEMBL1972849 & 809220 & 4.2 & 4.3755 & TST & \\
\hline CHEMBL377408 & 809220 & 5.5 & 3.9471 & TST & \\
\hline CHEMBL1986855 & 809220 & 7.8 & 7.1584 & TST & \\
\hline CHEMBL 215152 & 809220 & 5.6 & 5.2675 & TST & \\
\hline CHEMBL231209 & 809220 & 6.3 & 6.21899 & 9999999999 & TST \\
\hline CHEMBL1975357 & 809220 & 5.2 & 4.3394 & TST & \\
\hline CHEMBL1976220 & 809220 & 6.3 & 6.1989 & TST & \\
\hline CHEMBL 2006765 & 809220 & 7.2 & 6.2713 & TST & \\
\hline
\end{tabular}




\begin{tabular}{|c|c|c|c|c|c|}
\hline \multicolumn{6}{|c|}{ Supplemental Table S2.txt } \\
\hline CHEMBL259922 & 809220 & 4.2 & 3.9906 & TST & \\
\hline CHEMBL1997617 & 809220 & 5.5 & 5.308 & TST & \\
\hline CHEMBL1969301 & 809220 & 5.7 & 5.5992 & TST & \\
\hline CHEMBL1982383 & 809220 & 4.2 & 4.6928 & TST & \\
\hline CHEMBL17370 & 809220 & 4.2 & 4.3775 & TST & \\
\hline CHEMBL1980246 & 809220 & 4.6 & 4.9741 & TST & \\
\hline CHEMBL1987910 & 809220 & 6.0 & 5.6096 & TST & \\
\hline CHEMBL1983932 & 809220 & 4.2 & 6.3404 & TST & \\
\hline CHEMBL1983980 & 809220 & 5.9 & 5.9505 & TST & \\
\hline CHEMBL1999484 & 809220 & 6.1 & 6.8656 & TST & \\
\hline CHEMBL1986899 & 809220 & 5.6 & 4.8596 & TST & \\
\hline CHEMBL1991285 & 809220 & 4.2 & 4.4459 & TST & \\
\hline CHEMBL1997822 & 809220 & 7.6 & 6.0284 & TST & \\
\hline CHEMBL 243088 & 809220 & 7.7 & 7.8635 & TST & \\
\hline CHEMBL1984038 & 809220 & 4.3 & 4.6765 & TST & \\
\hline CHEMBL1974416 & 809220 & 5.2 & 5.5511 & TST & \\
\hline CHEMBL1993661 & 809220 & 7.3 & 7.3337 & TST & \\
\hline CHEMBL2004615 & 809220 & 5.2 & 4.607 & TST & \\
\hline CHEMBL1984039 & 809220 & 4.2 & 4.6915 & TST & \\
\hline CHEMBL1997872 & 809220 & 6.5 & 5.2909 & TST & \\
\hline CHEMBL51085 & 737627 & 6.9547 & 4.9581 & TST & \\
\hline CHEMBL1790038 & 737627 & 5.3019 & 5.3459 & TST & \\
\hline CHEMBL1406130 & 737627 & 6.1013 & 5.6078 & TRN & \\
\hline CHEMBL1714665 & 737627 & 7.0 & 6.6452 & TRN & \\
\hline CHEMBL1731796 & 737627 & 4.4437 & 4.7417 & TST & \\
\hline CHEMBL1601716 & 737627 & 5.129 & 5.7179 & TRN & \\
\hline CHEMBL1720377 & 737627 & 4.2652 & 5.109 & TRN & \\
\hline CHEMBL1717022 & 737627 & 6.6326 & 6.8489 & TRN & \\
\hline CHEMBL1705022 & 737627 & 6.4449 & 5.6913 & TRN & \\
\hline CHEMBL1726776 & 737627 & 6.2557 & 6.3821 & TST & \\
\hline CHEMBL1732623 & 737627 & 7.6326 & 6.8095 & TST & \\
\hline CHEMBL1712661 & 737627 & 6.2388 & 6.3284 & TST & \\
\hline CHEMBL1702227 & 737627 & 5.2069 & 5.2873 & TRN & \\
\hline CHEMBL1371792 & 737627 & 5.8962 & 5.3997 & TRN & \\
\hline CHEMBL1720939 & 737627 & 5.9066 & 6.6005 & TRN & \\
\hline CHEMBL1790035 & 737627 & 5.5867 & 5.3129 & TST & \\
\hline CHEMBL1712495 & 737627 & 4.4045 & 5.2907 & TRN & \\
\hline CHEMBL1713178 & 737627 & 6.2555 & 5.0987 & TRN & \\
\hline CHEMBL1530439 & 737627 & 4.4101 & 5.2039 & TRN & \\
\hline CHEMBL1369613 & 737627 & 6.0841 & 5.8216 & TRN & \\
\hline CHEMBL1333250 & 737627 & 6.0926 & 5.82700 & 2000000001 & TRN \\
\hline CHEMBL1423690 & 737627 & 5.7352 & 4.7413 & TRN & \\
\hline CHEMBL1606007 & 737627 & 7.1397 & 6.5931 & TST & \\
\hline CHEMBL1722737 & 737627 & 6.2491 & 5.8633 & TRN & \\
\hline CHEMBL1449845 & 737627 & 5.2976 & 5.2732 & TRN & \\
\hline CHEMBL1520143 & 737627 & 5.3143 & 5.2137 & TRN & \\
\hline CHEMBL1712882 & 737627 & 4.4685 & 5.2304 & TRN & \\
\hline CHEMBL1737005 & 737627 & 5.7471 & 5.0198 & TRN & \\
\hline
\end{tabular}


Supplemental Table S2.txt

\begin{tabular}{|c|c|c|c|c|}
\hline CHEMBL1734915 & 737627 & 6.2725 & 6.0809 & TRN \\
\hline CHEMBL45152 & 737627 & 6.0264 & 5.1529 & TRN \\
\hline CHEMBL1338317 & 737627 & 4.9706 & 5.3135 & TRN \\
\hline CHEMBL1600114 & 737627 & 5.3497 & 5.5835 & TST \\
\hline CHEMBL1725120 & 737627 & 5.3872 & 5.6889 & TRN \\
\hline CHEMBL1708710 & 737627 & 4.9355 & 5.2296 & TRN \\
\hline CHEMBL1725457 & 737627 & 6.7156 & 6.5807 & TST \\
\hline CHEMBL1731467 & 737627 & 6.3032 & 6.4592 & TRN \\
\hline CHEMBL1706034 & 737627 & 5.266 & 5.3231 & TRN \\
\hline CHEMBL1725977 & 737627 & 5.0862 & 5.4476 & TRN \\
\hline CHEMBL1704299 & 737627 & 6.0862 & 4.817 & TST \\
\hline CHEMBL1709105 & 737627 & 6.1221 & 6.1068 & TRN \\
\hline CHEMBL1728593 & 737627 & 6.2636 & 5.2548 & TRN \\
\hline CHEMBL1609086 & 737627 & 3.0 & 5.0406 & TST \\
\hline CHEMBL1700715 & 737627 & 5.5638 & 5.075 & TRN \\
\hline CHEMBL1720245 & 737627 & 5.4437 & 5.2989 & TST \\
\hline CHEMBL1727796 & 737627 & 6.5986 & 6.1736 & TRN \\
\hline CHEMBL1314602 & 737627 & 5.1759 & 5.3992 & TRN \\
\hline CHEMBL1733472 & 737627 & 6.4151 & 5.6737 & TRN \\
\hline CHEMBL1790032 & 737627 & 5.9031 & 5.7802 & TST \\
\hline CHEMBL1570441 & 737627 & 6.857 & 5.6467 & TRN \\
\hline CHEMBL1702821 & 737627 & 5.1073 & 4.9549 & TRN \\
\hline CHEMBL1708115 & 737627 & 5.9706 & 4.8841 & TRN \\
\hline CHEMBL1701478 & 737627 & 5.1844 & 5.7405 & TRN \\
\hline CHEMBL1708860 & 737627 & 3.0 & 4.8872 & TRN \\
\hline CHEMBL1698123 & 737627 & 5.2832 & 4.8835 & TRN \\
\hline CHEMBL1732571 & 737627 & 5.6946 & 4.6106 & TST \\
\hline CHEMBL1709252 & 737627 & 5.7077 & 4.8213 & TST \\
\hline CHEMBL1712029 & 737627 & 3.0 & 4.9998 & TRN \\
\hline CHEMBL1711440 & 737627 & 5.8153 & 5.59399 & 9999999999 \\
\hline CHEMBL1392315 & 737627 & 6.3107 & 5.2039 & TRN \\
\hline CHEMBL1411202 & 737627 & 5.6326 & 5.6129 & TRN \\
\hline CHEMBL1724427 & 737627 & 7.4584 & 6.6763 & TST \\
\hline CHEMBL1714438 & 737627 & 4.9431 & 5.0692 & TRN \\
\hline CHEMBL1354431 & 737627 & 5.9431 & 6.1673 & TRN \\
\hline CHEMBL1708335 & 737627 & 4.2765 & 5.0478 & TRN \\
\hline CHEMBL1553163 & 737627 & 4.0 & 5.4094 & TRN \\
\hline CHEMBL1701021 & 737627 & 5.3737 & 5.754 & TRN \\
\hline CHEMBL1524484 & 737313 & 3.3032 & 3.3033 & TRN \\
\hline CHEMBL1377656 & 737313 & 3.3032 & 3.8585 & TRN \\
\hline CHEMBL1419029 & 737313 & 3.3035 & 3.8442 & TRN \\
\hline CHEMBL1357156 & 737313 & 3.3033 & 3.1936 & TRN \\
\hline CHEMBL1536921 & 737313 & 3.3032 & 3.7408 & TRN \\
\hline CHEMBL1520346 & 737313 & 3.3032 & 3.3874 & TRN \\
\hline CHEMBL1526729 & 737313 & 3.3033 & 3.3091 & TRN \\
\hline CHEMBL1594672 & 737313 & 4.6752 & 3.6359 & TRN \\
\hline CHEMBL1715597 & 737313 & 3.3033 & 3.6914 & TRN \\
\hline CHEMBL1463349 & 737313 & 3.3034 & 3.3379 & TRN \\
\hline
\end{tabular}


Supplemental Table S2.txt

\begin{tabular}{|c|c|c|c|c|}
\hline 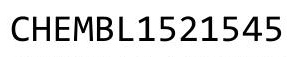 & & & & \\
\hline HГMDI 1456056 & & 3.3034 & & \\
\hline & & $\partial 35$ & & \\
\hline AEMBL1 & 7313 & 3032 & & \\
\hline AEMBL15 & 37313 & 3028 & 254 & \\
\hline HEMBL1496820 & 37313 & 3027 & 3781 & \\
\hline HEMBL1 & 7313 & 033 & & \\
\hline 815 & & & & \\
\hline HEMBL1722330 & 37313 & 3032 & & \\
\hline HEMBL1327720 & 37313 & 3031 & 88 & \\
\hline AEMBL17 & 7313 & 032 & & \\
\hline IEMBL1 & 13 & 029 & & \\
\hline IEMBL1 & & & & \\
\hline HEMBL15 & 37313 & 296 & & \\
\hline AEMBL13 & 13 & 032 & & \\
\hline AEMBL1 & 3 & 032 & 27 & \\
\hline HEMBL1 & 13 & 35 & & \\
\hline HEMBL1 & & & & \\
\hline HEMBL1C & & 032 & & \\
\hline AEMBL1; & & & & \\
\hline IEMBL: & 3 & 33 & 65 & Trv \\
\hline AEMBLI & & & & RN \\
\hline HEMBLI & & & & \\
\hline 566 & & 031 & & \\
\hline AEMBL17 & & & & \\
\hline HEMBLI & & 32 & & RN \\
\hline HEMBLI & & & & TRN \\
\hline HFMRI 1 & & & & \\
\hline HEMBL1 & & & & $T_{2}$ \\
\hline HEMBL1C & & & & 15 \\
\hline HEMBL1 & 3 & 39 & & RN \\
\hline HEMBL & & 32 & & RN \\
\hline 41 & & & & \\
\hline HEMBL14 & & & & 15 \\
\hline HEMBL1964878 & בר & 31 & & TST \\
\hline HEMBL: & & & & RN \\
\hline HFMRI 1 & 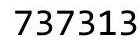 & & & $\operatorname{RiN}$ \\
\hline HEMBL1: & & & & ГRN \\
\hline HEMBL1430677 & 373 & & & TR \\
\hline AEMBL1 & & & & 「RN \\
\hline HEMBL1 & & 32 & & TRN \\
\hline HEMBL1 & 13 & 032 & & TRN \\
\hline HEMBL1S & 37313 & 3.3032 & 932 & $\Gamma R$ \\
\hline AEMBL15 & 37313 & 3032 & & TR \\
\hline AEMBL1 & ל ד בדי & 035 & & $T$ \\
\hline HEMBL1 & & & & \\
\hline CHEMBL13 & 37313 & 3.3032 & 3.5198 & \\
\hline CHEMBL1433931 & 737313 & 3.3031 & 3.9081 & S \\
\hline
\end{tabular}

Page 6026 


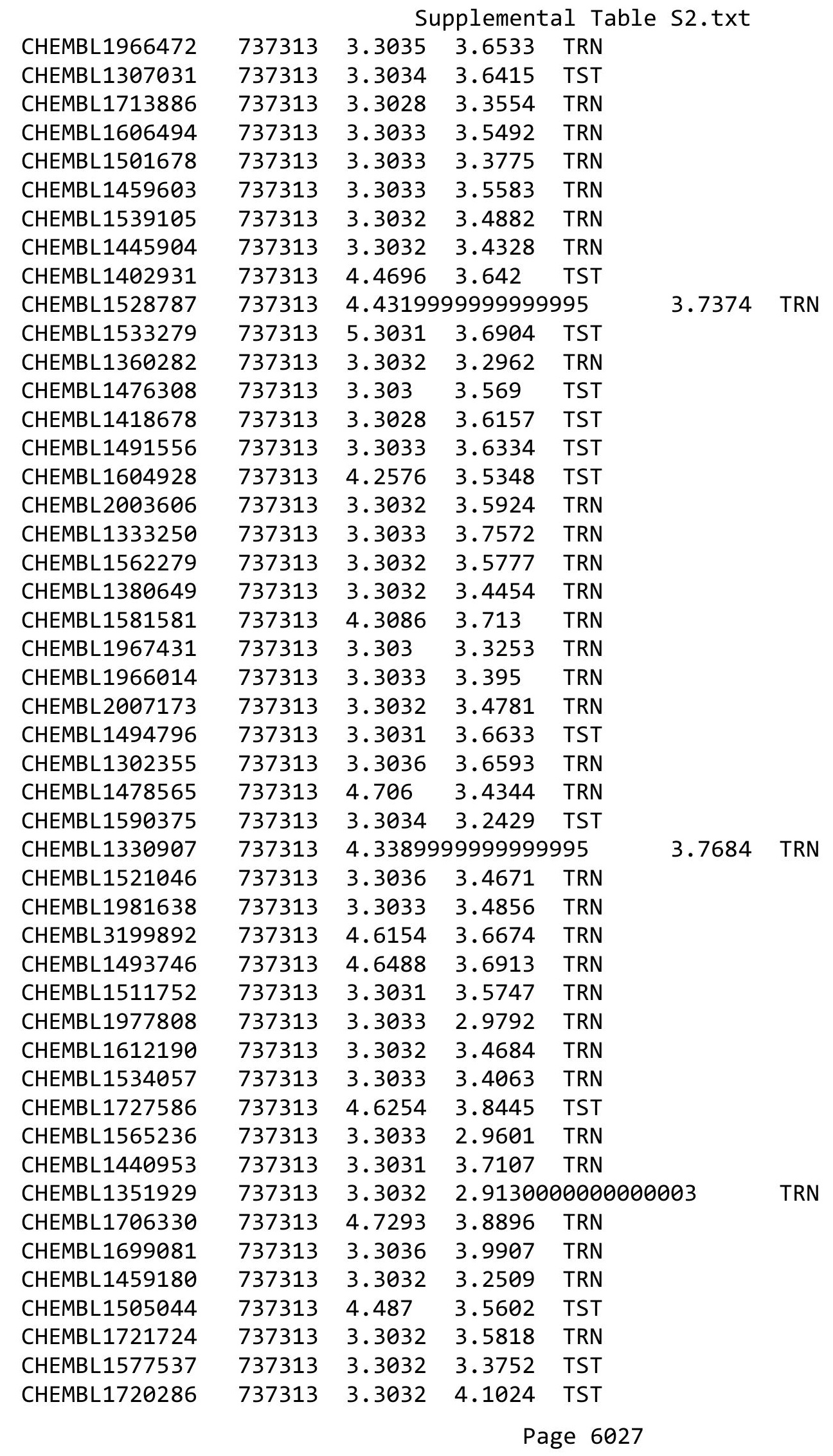


Supplemental Table S2.txt

\begin{tabular}{|c|c|c|c|c|}
\hline CHEMBL1735531 & 737313 & 3.3033 & 3.8272 & TRN \\
\hline CHEMBL1330311 & 737313 & 3.3032 & 3.3183 & TRN \\
\hline CHEMBL1334210 & 737313 & 3.3032 & 3.174 & TRN \\
\hline CHEMBL1590005 & 737313 & 3.3032 & 3.2537 & TRN \\
\hline CHEMBL1343392 & 737313 & 3.3032 & 3.6072 & TRN \\
\hline CHEMBL1348119 & 737313 & 4.3591 & \multicolumn{2}{|c|}{3.3689999999999998} \\
\hline CHEMBL1583293 & 737313 & 3.3032 & 3.4555 & TRN \\
\hline CHEMBL1344470 & 737313 & 4.4773 & 3.8868 & TRN \\
\hline CHEMBL1709502 & 737313 & 3.3032 & 3.5395 & TRN \\
\hline CHEMBL1605702 & 737313 & 3.3032 & 3.5127 & TST \\
\hline CHEMBL1571574 & 737313 & 3.3031 & 3.0848 & TRN \\
\hline CHEMBL1367399 & 737313 & 4.7496 & 3.428 & TST \\
\hline CHEMBL1351110 & 737313 & 3.3032 & 3.7448 & TRN \\
\hline CHEMBL3214429 & 737313 & 4.6071 & 3.6461 & TST \\
\hline CHEMBL1565349 & 737313 & 3.7804 & 3.6404 & TRN \\
\hline CHEMBL1983843 & 737313 & 3.3033 & 3.4391 & TRN \\
\hline CHEMBL1440341 & 737313 & 3.3033 & 3.1391 & TRN \\
\hline CHEMBL1270809 & 737313 & 3.3032 & 3.4628 & TRN \\
\hline CHEMBL1464571 & 737313 & 4.3101 & 3.4522 & TRN \\
\hline CHEMBL1720383 & 737313 & 3.3029 & 3.5394 & TRN \\
\hline CHEMBL1422276 & 737313 & 3.3034 & 3.3713 & TRN \\
\hline CHEMBL1548353 & 737313 & 3.3035 & 3.4307 & TRN \\
\hline CHEMBL1418095 & 737313 & 3.3032 & 3.1402 & TRN \\
\hline CHEMBL1326648 & 737313 & 3.3032 & 3.753 & TRN \\
\hline CHEMBL1520702 & 737313 & 4.3117 & 3.3668 & TRN \\
\hline CHEMBL1388463 & 737313 & 3.303 & 3.5023 & TRN \\
\hline CHEMBL1546895 & 737313 & 3.3033 & 3.2776 & TRN \\
\hline CHEMBL1421498 & 737313 & 3.3032 & 3.8765 & TRN \\
\hline CHEMBL1588229 & 737313 & 4.6707 & 3.6577 & TST \\
\hline CHEMBL1553774 & 737313 & 3.3035 & 3.33 & TRN \\
\hline CHEMBL1557141 & 737313 & 3.3035 & 3.6661 & TRN \\
\hline CHEMBL1575576 & 737313 & 3.3032 & 3.2151 & TRN \\
\hline CHEMBL1572758 & 737313 & 3.3032 & 3.7076 & TRN \\
\hline CHEMBL1426481 & 737313 & 3.3032 & 3.6506 & TRN \\
\hline CHEMBL1369963 & 737313 & 3.3029 & 3.5343 & TRN \\
\hline CHEMBL1344555 & 737313 & 3.3033 & 2.9994 & TRN \\
\hline CHEMBL1988282 & 737313 & 3.3032 & 3.4502 & TRN \\
\hline CHEMBL1308855 & 737313 & 3.303 & 3.4446 & TST \\
\hline CHEMBL1438417 & 737313 & 4.4408 & 3.6686 & TRN \\
\hline CHEMBL1970286 & 737313 & 3.3032 & 3.4744 & TRN \\
\hline CHEMBL2006840 & 737313 & 3.3032 & 3.3376 & TRN \\
\hline CHEMBL1375038 & 737313 & 3.3032 & 3.6253 & TRN \\
\hline CHEMBL1477093 & 737313 & 3.3032 & 3.6319 & TRN \\
\hline CHEMBL1328144 & 737313 & 3.3031 & 3.3931 & TRN \\
\hline CHEMBL1480014 & 737313 & 3.3033 & 3.6092 & TRN \\
\hline CHEMBL1401331 & 737313 & 3.3032 & 3.63199 & 799999999997 \\
\hline CHEMBL1432793 & 737313 & 3.3032 & 3.5645 & TRN \\
\hline CHEMBL1595012 & 737313 & 3.3037 & 3.412 & TRN \\
\hline
\end{tabular}


Supplemental Table S2.txt

\begin{tabular}{|c|c|c|c|c|c|}
\hline CHEMBL1416951 & 737313 & 3.3032 & 3.5653 & TRN & \\
\hline CHEMBL1542157 & 737313 & 3.3032 & 3.4623 & TRN & \\
\hline CHEMBL1399190 & 737313 & 4.6562 & 3.4512 & TST & \\
\hline CHEMBL1409330 & 737313 & 3.3032 & 3.3065 & TRN & \\
\hline CHEMBL1498924 & 737313 & 4.6016 & 3.7211 & TST & \\
\hline CHEMBL1364699 & 737313 & 3.3032 & 3.3691 & TRN & \\
\hline CHEMBL1597288 & 737313 & 4.5997 & 4.0624 & TRN & \\
\hline CHEMBL1514800 & 737313 & 3.3028 & 3.3814 & TRN & \\
\hline CHEMBL1336039 & 737313 & 3.3032 & 3.2813 & TRN & \\
\hline CHEMBL1400350 & 737313 & 4.7548 & 4.0002 & TRN & \\
\hline CHEMBL1335338 & 737313 & 3.3032 & 3.7091 & TRN & \\
\hline CHEMBL1418004 & 737313 & 3.3032 & 3.588 & TRN & \\
\hline CHEMBL1572480 & 737313 & 4.4072 & 3.7339 & TRN & \\
\hline CHEMBL1460004 & 737313 & 4.8151 & 3.6031 & TST & \\
\hline CHEMBL1560993 & 737313 & 3.3036 & 3.2973 & TRN & \\
\hline CHEMBL1588363 & 737313 & 3.3032 & 3.4394 & TRN & \\
\hline CHEMBL1335116 & 737313 & 3.3032 & 3.668 & TRN & \\
\hline CHEMBL1501952 & 737313 & 3.3032 & 3.5857 & TRN & \\
\hline CHEMBL1333148 & 737313 & 3.3032 & 3.4618 & TRN & \\
\hline CHEMBL1342815 & 737313 & 3.3036 & 3.8058 & TRN & \\
\hline CHEMBL1582623 & 737313 & 3.3032 & 3.4158 & TRN & \\
\hline CHEMBL1552334 & 737313 & 3.3033 & 3.6141 & TRN & \\
\hline CHEMBL1354074 & 737313 & 4.6343 & 4.0807 & TRN & \\
\hline CHEMBL1508525 & 737313 & 3.3031 & 3.3186 & TRN & \\
\hline CHEMBL1722206 & 737313 & 4.7569 & 3.6934 & TRN & \\
\hline CHEMBL1363571 & 737313 & 3.3033 & 3.8734 & TRN & \\
\hline CHEMBL1556254 & 737313 & 4.3096 & 3.4324 & TRN & \\
\hline CHEMBL1579404 & 737313 & 3.3035 & 3.5002 & TRN & \\
\hline CHEMBL1997993 & 737313 & 3.3032 & 3.33399 & 99999999996 & TRN \\
\hline CHEMBL3199868 & 737313 & 3.3033 & 3.7195 & TRN & \\
\hline CHEMBL1330781 & 737313 & 3.3033 & 3.4518 & TST & \\
\hline CHEMBL1706285 & 737313 & 3.3031 & 3.6239 & TRN & \\
\hline CHEMBL1967103 & 737313 & 3.3032 & 3.1343 & TRN & \\
\hline CHEMBL1507474 & 737313 & 3.3033 & 3.3522 & TRN & \\
\hline CHEMBL1518032 & 737313 & 3.3032 & 3.264 & TRN & \\
\hline CHEMBL 2004183 & 737313 & 3.3032 & 3.0597 & TRN & \\
\hline CHEMBL1399289 & 737313 & 3.3032 & 3.3796 & TRN & \\
\hline CHEMBL1575559 & 737313 & 4.8321 & 4.1758 & TRN & \\
\hline CHEMBL1434457 & 737313 & 4.592 & 4.2458 & TRN & \\
\hline CHEMBL1409773 & 737313 & 3.3033 & 3.2868 & TRN & \\
\hline CHEMBL1493516 & 737313 & 3.3032 & 3.3136 & TRN & \\
\hline CHEMBL1466997 & 737313 & 3.3032 & 3.2972 & TRN & \\
\hline CHEMBL1304258 & 737313 & 3.3036 & 2.9816 & TRN & \\
\hline CHEMBL1487872 & 737313 & 3.3036 & 3.0989 & TRN & \\
\hline CHEMBL1558506 & 737313 & 3.303 & 3.32 & TRN & \\
\hline CHEMBL1481716 & 737313 & 3.3032 & 3.6436 & TRN & \\
\hline CHEMBL1458511 & 737313 & 3.3031 & 3.3909 & TRN & \\
\hline CHEMBL1714024 & 737313 & 4.3119 & 3.8288 & TRN & \\
\hline
\end{tabular}


Supplemental Table S2.txt

\begin{tabular}{|c|c|c|c|c|c|c|}
\hline CHEMBL1977763 & 737313 & 3.3036 & 3.5202 & TRN & & \\
\hline CHEMBL1355104 & 737313 & 3.3034 & 3.1493 & TRN & & \\
\hline CHEMBL1337585 & 737313 & 3.3032 & 3.6588 & TRN & & \\
\hline CHEMBL1726432 & 737313 & 3.3028 & 3.4265 & TRN & & \\
\hline CHEMBL1503548 & 737313 & 3.303 & 3.4367 & TRN & & \\
\hline CHEMBL1378896 & 737313 & 3.303 & 3.3756 & TRN & & \\
\hline CHEMBL1572095 & 737313 & 4.7375 & 3.8935 & TRN & & \\
\hline CHEMBL1327065 & 737313 & 3.3035 & 3.6811 & TRN & & \\
\hline CHEMBL1382624 & 737313 & 3.3031 & 3.7736 & TRN & & \\
\hline CHEMBL1365949 & 737313 & 4.7404 & 4.0004 & TRN & & \\
\hline CHEMBL1384723 & 737313 & 3.3035 & 3.4218 & TRN & & \\
\hline CHEMBL1461147 & 737313 & 4.672 & 4.0706 & TRN & & \\
\hline CHEMBL1493493 & 737313 & 3.3032 & 3.6203 & TRN & & \\
\hline CHEMBL1714525 & 737313 & 4.3631 & 3.6271 & TST & & \\
\hline CHEMBL1532403 & 737313 & 3.3029 & 3.6453 & TST & & \\
\hline CHEMBL1995997 & 737313 & 3.3032 & 3.3833 & TST & & \\
\hline CHEMBL1482828 & 737313 & 3.3033 & 3.5647 & TST & & \\
\hline CHEMBL1595403 & 737313 & 3.3031 & 3.6551 & TST & & \\
\hline CHEMBL1704083 & 737313 & 3.3031 & 3.6796 & TST & & \\
\hline CHEMBL1588256 & 737313 & 3.3032 & 3.7587 & TST & & \\
\hline CHEMBL1559065 & 737313 & 3.3032 & 3.529 & TST & & \\
\hline CHEMBL1584180 & 737313 & 3.3033 & 3.7846 & TST & & \\
\hline CHEMBL1527445 & 737313 & 3.3032 & 3.5102 & TST & & \\
\hline CHEMBL1536442 & 737313 & 4.6016 & 3.3874 & TST & & \\
\hline CHEMBL1980584 & 737313 & 3.3029 & 3.4708 & TST & & \\
\hline CHEMBL1978193 & 737313 & 3.3032 & 3.6511 & TST & & \\
\hline CHEMBL1342888 & 737313 & 3.3032 & 3.6434 & TST & & \\
\hline CHEMBL1481095 & 737313 & 3.3034 & 3.139 & TST & & \\
\hline CHEMBL1583817 & 737313 & 3.3031 & 3.7076 & TST & & \\
\hline CHEMBL1724205 & 737313 & \multicolumn{3}{|c|}{4.8919999999999995} & 3.5460000000000003 & TST \\
\hline CHEMBL3667549 & 737313 & 4.5558 & 3.5389 & TST & & \\
\hline CHEMBL1331281 & 737313 & 3.303 & 3.4343 & TST & & \\
\hline CHEMBL1372776 & 737313 & 3.3032 & 3.5664 & TST & & \\
\hline CHEMBL1406761 & 737313 & 3.3035 & 3.4843 & TST & & \\
\hline CHEMBL1485238 & 737313 & 3.3032 & 3.4371 & TST & & \\
\hline CHEMBL1733477 & 737313 & 3.3035 & 3.0451 & TST & & \\
\hline CHEMBL1438621 & 737313 & 3.3032 & 3.4142 & TST & & \\
\hline CHEMBL1979844 & 737313 & 3.3032 & 3.3299 & TST & & \\
\hline CHEMBL1468272 & 737313 & 3.3031 & 3.6625 & TST & & \\
\hline CHEMBL199868 & 737313 & 3.303 & 3.4614 & TST & & \\
\hline CHEMBL1526293 & 737313 & 3.3032 & 3.6207 & TST & & \\
\hline CHEMBL1502107 & 737313 & 4.3184 & 3.6 & TST & & \\
\hline CHEMBL1582357 & 737313 & 3.3032 & 3.5301 & TST & & \\
\hline CHEMBL1438796 & 737313 & 3.3028 & 3.2858 & TST & & \\
\hline CHEMBL1512498 & 737313 & 3.3034 & 3.4287 & TST & & \\
\hline CHEMBL2205623 & 885135 & 5.3336 & 4.7186 & TRN & & \\
\hline CHEMBL2205622 & 885135 & 5.4855 & 4.9129 & TRN & & \\
\hline CHEMBL 2205590 & 885135 & 5.1797 & 5.3789 & TRN & & \\
\hline
\end{tabular}




\begin{tabular}{|c|c|c|c|c|c|}
\hline & & \multicolumn{4}{|c|}{ Supplemental Table S2.txt } \\
\hline CHEMBL2205616 & 885135 & 6.0339 & 5.9279 & TRN & \\
\hline CHEMBL2205615 & 885135 & 6.2168 & 6.4986 & TRN & \\
\hline CHEMBL2204892 & 885135 & 6.6635 & 5.5582 & TST & \\
\hline CHEMBL2205620 & 885135 & 5.06 & 4.7141 & TRN & \\
\hline CHEMBL2205598 & 885135 & 4.0 & 3.4506 & TST & \\
\hline CHEMBL2204902 & 885135 & 6.4737 & 5.7465 & TRN & \\
\hline CHEMBL2205617 & 885135 & 6.0 & 6.1852 & TRN & \\
\hline CHEMBL 2205586 & 885135 & 4.0 & 4.0074 & TRN & \\
\hline CHEMBL 2204897 & 885135 & 4.0 & 3.7844 & TST & \\
\hline CHEMBL2205601 & 885135 & 4.0 & 4.308 & TRN & \\
\hline CHEMBL 2205578 & 885135 & 7.7959 & 4.979 & TST & \\
\hline CHEMBL2205621 & 885135 & 6.6003 & 5.6599 & TRN & \\
\hline CHEMBL 2205597 & 885135 & 5.7201 & 3.8847 & TST & \\
\hline CHEMBL 2204903 & 885135 & 4.0 & 5.4968 & TRN & \\
\hline CHEMBL2205587 & 885135 & 4.0 & 4.244 & TRN & \\
\hline CHEMBL 2204895 & 885135 & 6.857 & 6.33799 & 9999999999 & TRN \\
\hline CHEMBL2205612 & 885135 & 4.0 & 4.4281 & TRN & \\
\hline CHEMBL 2205624 & 885135 & 4.0 & 4.2006 & TRN & \\
\hline CHEMBL 2204898 & 885135 & 4.0 & 3.8127 & TST & \\
\hline CHEMBL2204896 & 885135 & 4.0 & 4.8622 & TRN & \\
\hline CHEMBL2205596 & 885135 & 6.6003 & 6.648 & TRN & \\
\hline CHEMBL 2205604 & 885135 & 5.8239 & 5.2755 & TRN & \\
\hline CHEMBL 2204900 & 885135 & 5.401 & 4.4331 & TST & \\
\hline CHEMBL2205599 & 885135 & 5.0953 & $4.02800 t$ & 00000000005 & TST \\
\hline CHEMBL2204906 & 885135 & 5.4925 & 5.6607 & TRN & \\
\hline CHEMBL 2205600 & 885135 & 4.0 & 3.8379 & TST & \\
\hline CHEMBL2205585 & 885135 & 4.0 & 4.3169 & TRN & \\
\hline CHEMBL2205609 & 885135 & 5.7562 & 5.8188 & TRN & \\
\hline CHEMBL2205583 & 885135 & 4.0 & 4.2662 & TRN & \\
\hline CHEMBL2204909 & 885135 & 4.0 & 4.6625 & TRN & \\
\hline CHEMBL2205594 & 885135 & 7.0969 & 6.9702 & TRN & \\
\hline CHEMBL2205579 & 885135 & 4.0 & 5.011 & TRN & \\
\hline CHEMBL2205603 & 885135 & 5.1277 & 4.6058 & TRN & \\
\hline CHEMBL2204901 & 885135 & 4.0 & 4.2764 & TST & \\
\hline CHEMBL2205581 & 885135 & 6.4342 & 3.9454 & TST & \\
\hline CHEMBL2205608 & 885135 & 4.0 & 4.4759 & TRN & \\
\hline CHEMBL 2205593 & 885135 & 6.098 & 6.62799 & 9999999999 & TRN \\
\hline CHEMBL2205595 & 885135 & 6.9031 & 6.4361 & TRN & \\
\hline CHEMBL 2205592 & 885135 & 5.7047 & 6.3696 & TRN & \\
\hline CHEMBL 2205582 & 885135 & 5.7809 & 5.0296 & TST & \\
\hline CHEMBL2204904 & 885135 & 4.0 & 5.3549 & TST & \\
\hline CHEMBL2204899 & 885135 & 4.0 & 3.6741 & TST & \\
\hline CHEMBL2204908 & 885135 & 4.0 & 4.2553 & TRN & \\
\hline CHEMBL 2204905 & 885135 & 6.9469 & 5.7494 & TST & \\
\hline CHEMBL 2205602 & 885135 & 4.0 & 3.8973 & TRN & \\
\hline CHEMBL 2205610 & 885135 & 5.3431 & 5.5331 & TRN & \\
\hline CHEMBL2205589 & 885135 & 5.8489 & 5.1685 & TRN & \\
\hline CHEMBL2204894 & 885135 & 6.0186 & 4.8914 & TRN & \\
\hline
\end{tabular}




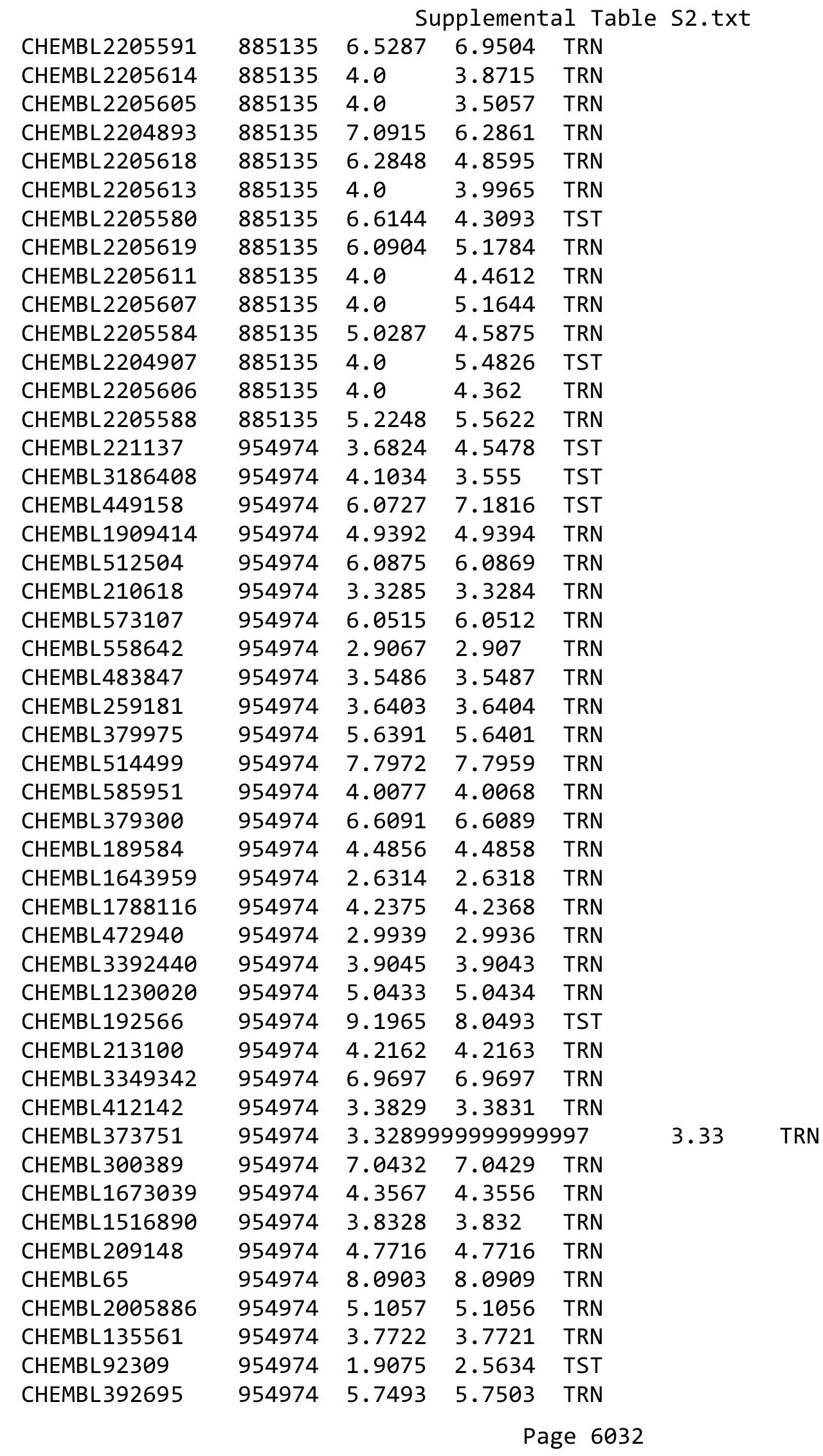


Supplemental Table S2.txt

\begin{tabular}{|c|c|c|c|c|}
\hline CHEMBL191334 & 954974 & 3.8083 & 3.8088 & TRN \\
\hline CHEMBL1970879 & 954974 & 5.4382 & 5.4383 & TRN \\
\hline CHEMBL 2363137 & 954974 & 3.8665 & 3.8664 & TRN \\
\hline CHEMBL258844 & 954974 & 3.2252 & 3.2251 & TRN \\
\hline CHEMBL1190711 & 954974 & 4.2804 & 4.2812 & TRN \\
\hline CHEMBL1256459 & 954974 & 6.6567 & 6.6577 & TRN \\
\hline CHEMBL393929 & 954974 & 3.8509 & 3.8507 & TRN \\
\hline CHEMBL 2144069 & 954974 & 4.7338 & 4.7336 & TRN \\
\hline CHEMBL1357247 & 954974 & 2.405 & 2.4043 & TRN \\
\hline CHEMBL1404918 & 954974 & 2.9497 & 2.9496 & TRN \\
\hline CHEMBL3199475 & 954974 & 3.8556 & 3.8563 & TRN \\
\hline CHEMBL509032 & 954974 & 4.4338 & 5.5119 & TST \\
\hline CHEMBL240954 & 954974 & 4.4547 & 3.8258 & TST \\
\hline CHEMBL180127 & 954974 & 4.2125 & 4.2188 & TST \\
\hline CHEMBL220241 & 954974 & 3.543 & 3.9982 & TST \\
\hline CHEMBL515416 & 954974 & 5.4342 & 4.8283 & TST \\
\hline CHEMBL1590308 & 954974 & 3.4729 & 3.0687 & TST \\
\hline CHEMBL202721 & 954974 & 5.22 & 4.4953 & TST \\
\hline CHEMBL1242367 & 954974 & 4.4896 & 3.5022 & TST \\
\hline CHEMBL 9470 & 954974 & 6.1268 & 5.7396 & TST \\
\hline CHEMBL3954993 & 1641399 & 7.1938 & 7.4349 & TST \\
\hline CHEMBL3958048 & 1641399 & 6.3206 & 7.1154 & TRN \\
\hline CHEMBL3890277 & 1641399 & 7.0969 & 6.8612 & TRN \\
\hline CHEMBL3897537 & 1641399 & 6.5622 & 6.9754 & TRN \\
\hline CHEMBL3914040 & 1641399 & 7.3768 & 7.5568 & TRN \\
\hline CHEMBL3976206 & 1641399 & 6.3233 & 7.5858 & TST \\
\hline CHEMBL3954035 & 1641399 & 8.0458 & 7.631 & TRN \\
\hline CHEMBL3909260 & 1641399 & 6.7235 & 7.1731 & TRN \\
\hline CHEMBL3903459 & 1641399 & 6.0 & 6.91 & TRN \\
\hline CHEMBL3959134 & 1641399 & 8.0969 & 7.3856 & TRN \\
\hline CHEMBL3893078 & 1641399 & 7.3665 & 7.364 & TST \\
\hline CHEMBL3922743 & 1641399 & 7.0315 & 7.0243 & TRN \\
\hline CHEMBL3935751 & 1641399 & 6.0851 & 7.57700 & 0000000001 \\
\hline CHEMBL3923360 & 1641399 & 7.0555 & 7.2048 & TRN \\
\hline CHEMBL3978239 & 1641399 & 6.2306 & 7.4542 & TST \\
\hline CHEMBL3899261 & 1641399 & 7.8861 & 7.1022 & TRN \\
\hline CHEMBL3952287 & 1641399 & 7.0915 & 7.0889 & TRN \\
\hline CHEMBL3983863 & 1641399 & 8.2218 & 7.6427 & TRN \\
\hline CHEMBL3961948 & 1641399 & 7.5376 & 7.4582 & TST \\
\hline CHEMBL3981623 & 1641399 & 7.3565 & 7.6841 & TRN \\
\hline CHEMBL3970177 & 1641399 & 6.9031 & 7.1091 & TST \\
\hline CHEMBL3946909 & 1641399 & 7.6021 & 7.4373 & TRN \\
\hline CHEMBL3904529 & 1641399 & 6.3809 & 7.5941 & TST \\
\hline CHEMBL3922052 & 1641399 & 7.6021 & 7.694 & TRN \\
\hline CHEMBL3924490 & 1641399 & 6.0 & 7.2834 & TRN \\
\hline CHEMBL3970688 & 1641399 & 6.4711 & 7.6419 & TST \\
\hline CHEMBL3958094 & 1641399 & 7.4089 & 7.6259 & TRN \\
\hline CHEMBL3982294 & 1641399 & 7.3188 & 7.6026 & TRN \\
\hline
\end{tabular}


Supplemental Table S2.txt

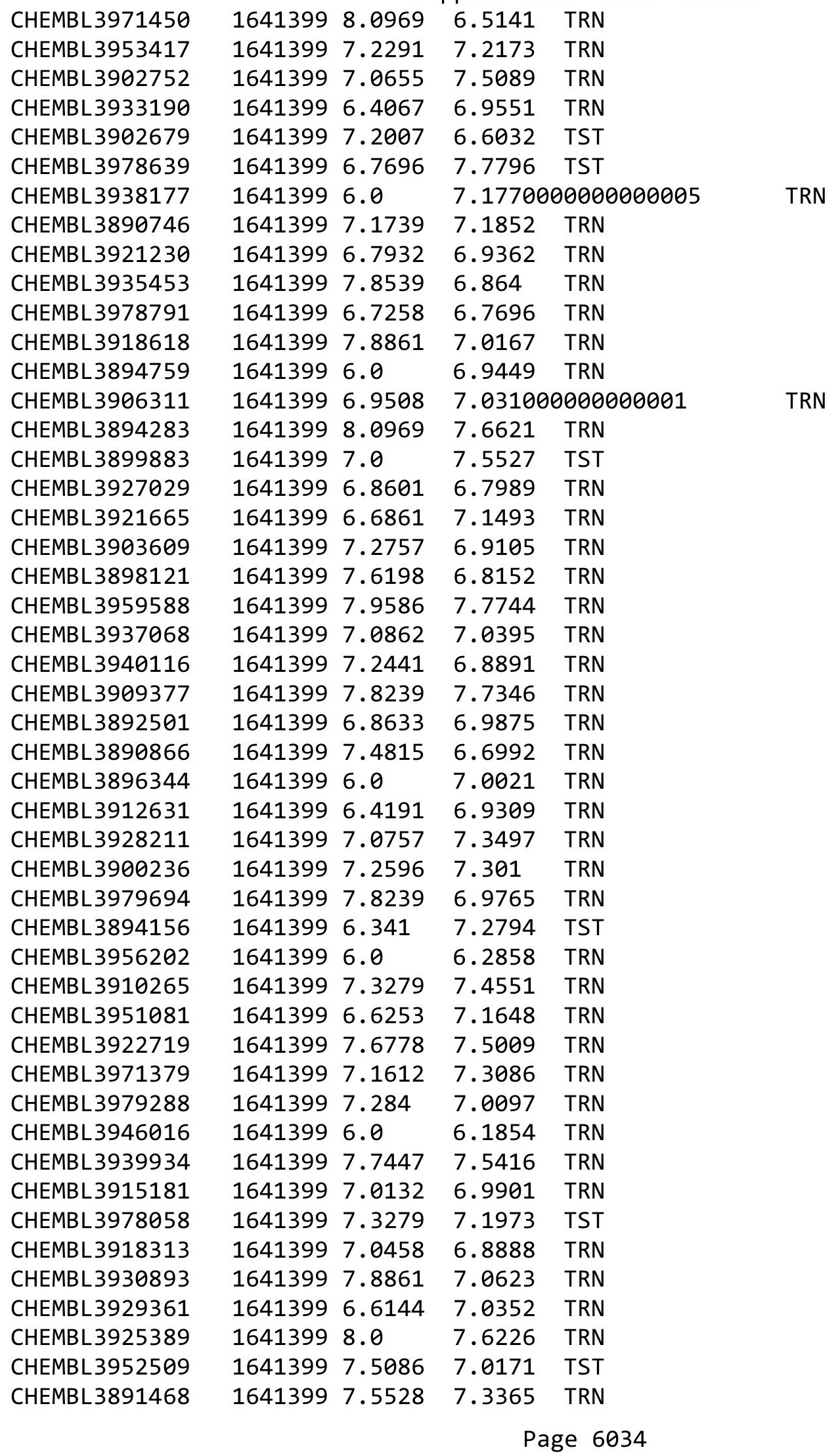


Supplemental Table S2.txt

\begin{tabular}{|c|c|c|c|c|c|}
\hline CHEMBL 3986471 & 1641399 & 6.8268 & 7.0994 & TRN & \\
\hline CHEMBL3969392 & 1641399 & 6.9066 & 7.7725 & TST & \\
\hline CHEMBL3945166 & 1641399 & 7.4437 & 7.5535 & TRN & \\
\hline CHEMBL 3950572 & 1641399 & 8.1549 & 7.7004 & TRN & \\
\hline CHEMBL 3923126 & 1641399 & 8.301 & 7.8069 & TRN & \\
\hline CHEMBL3940665 & 1641399 & 6.0 & 6.3884 & TRN & \\
\hline CHEMBL 3970463 & 1641399 & 6.0 & 6.2528 & TRN & \\
\hline CHEMBL3951983 & 1641399 & 7.6778 & 7.5292 & TRN & \\
\hline CHEMBL3972456 & 1641399 & 5.5144 & 7.3031 & TST & \\
\hline CHEMBL3956019 & 1641399 & 7.0915 & 6.5574 & TRN & \\
\hline CHEMBL3961107 & 1641399 & 7.8539 & 6.6944 & TRN & \\
\hline CHEMBL3963813 & 1641399 & 6.8268 & 7.3164 & TRN & \\
\hline CHEMBL3958138 & 1641399 & 8.1549 & 7.2278 & TST & \\
\hline CHEMBL 3983614 & 1641399 & 7.5086 & 6.8441 & TST & \\
\hline CHEMBL 3946344 & 1641399 & 6.1805 & 7.18 & TST & \\
\hline CHEMBL 3897362 & 1641399 & 7.1192 & 7.6595 & TRN & \\
\hline CHEMBL3945813 & 1641399 & 7.6778 & 6.8859 & TST & \\
\hline CHEMBL3946940 & 1641399 & 6.0 & 6.5642 & TRN & \\
\hline CHEMBL3922089 & 1641399 & 7.2596 & 7.0264 & TRN & \\
\hline CHEMBL 3974279 & 1641399 & 6.4342 & 7.7194 & TST & \\
\hline CHEMBL 3970507 & 1641399 & 6.0 & 6.86600 & 00000000005 & TRN \\
\hline CHEMBL3976706 & 1641399 & 7.6198 & 7.2742 & TRN & \\
\hline CHEMBL 3953345 & 1641399 & 7.0757 & 7.1325 & TST & \\
\hline CHEMBL 3973949 & 1641399 & 7.6383 & 7.4668 & TRN & \\
\hline CHEMBL 3895854 & 1641399 & 5.7881 & 6.9301 & TRN & \\
\hline CHEMBL3925507 & 1641399 & 7.5086 & 7.5658 & TRN & \\
\hline CHEMBL 3922857 & 1641399 & 6.0 & 6.4967 & TRN & \\
\hline CHEMBL3942629 & 1641399 & 7.5229 & 7.0822 & TRN & \\
\hline CHEMBL3953060 & 1641399 & 7.1308 & 7.6116 & TRN & \\
\hline CHEMBL 3913806 & 1641399 & 6.7375 & 6.9683 & TRN & \\
\hline CHEMBL3945965 & 1641399 & 7.0655 & 7.0428 & TRN & \\
\hline CHEMBL 3950438 & 1641399 & 7.5528 & 7.53700 & 0000000001 & TRN \\
\hline CHEMBL 3936247 & 1641399 & 7.8539 & 7.6215 & TRN & \\
\hline CHEMBL3967755 & 1641399 & 7.1805 & 6.7623 & TRN & \\
\hline CHEMBL 3939827 & 1641399 & 7.8861 & 7.5948 & TST & \\
\hline CHEMBL3897968 & 1641399 & 7.8861 & 7.6291 & TRN & \\
\hline CHEMBL 3908309 & 1641399 & 7.4089 & 7.7213 & TRN & \\
\hline CHEMBL3969686 & 1641399 & 7.5086 & 7.2564 & TST & \\
\hline CHEMBL 3944124 & 1641399 & 7.6778 & 7.0835 & TRN & \\
\hline CHEMBL 3907349 & 1641399 & 6.8697 & 7.7159 & TST & \\
\hline CHEMBL3954377 & 1641399 & 7.3372 & 7.1773 & TRN & \\
\hline CHEMBL3969213 & 1641399 & 7.1308 & 7.2107 & TST & \\
\hline CHEMBL 3912824 & 1641399 & 6.3904 & 7.6576 & TST & \\
\hline CHEMBL3957842 & 1641399 & 6.1759 & 7.751 & TST & \\
\hline CHEMBL 3903111 & 1641399 & 7.1367 & 6.5503 & TRN & \\
\hline CHEMBL3961599 & 1641399 & 8.1549 & 7.4453 & TRN & \\
\hline CHEMBL 3983396 & 1641399 & 6.6234 & 7.2113 & TRN & \\
\hline CHEMBL 3966866 & 1641399 & 6.0 & 6.4902 & TRN & \\
\hline
\end{tabular}


Supplemental Table S2.txt

\begin{tabular}{|c|c|c|c|c|}
\hline CHEMBL 3912490 & 1641399 & 7.2596 & 6.9571 & TRN \\
\hline CHEMBL3958113 & 1641399 & 6.0 & 6.8225 & TRN \\
\hline CHEMBL3894556 & 1641399 & 6.0 & 6.9278 & TRN \\
\hline CHEMBL 3900813 & 1641399 & 6.0 & 6.2341 & TRN \\
\hline CHEMBL3952222 & 1641399 & 7.1487 & 7.3522 & TRN \\
\hline CHEMBL 3961788 & 1641399 & 7.7696 & 7.3253 & TRN \\
\hline CHEMBL 3899807 & 1641399 & 6.617999 & 999999999 & 7.3506 \\
\hline CHEMBL3971590 & 1641399 & 5.9626 & 6.4235 & TRN \\
\hline CHEMBL3949126 & 1641399 & 7.6021 & 6.9624 & TRN \\
\hline CHEMBL3919306 & 1641399 & 7.2147 & 7.039 & TRN \\
\hline CHEMBL3925652 & 1641399 & 7.1938 & 7.4078 & TRN \\
\hline CHEMBL 3907626 & 1641399 & 6.9281 & 7.1789 & TRN \\
\hline CHEMBL3892073 & 1641399 & 8.0458 & 7.5271 & TRN \\
\hline CHEMBL3905282 & 1641399 & 6.0 & 6.9766 & TRN \\
\hline CHEMBL3913733 & 1641399 & 6.6696 & 7.5248 & TST \\
\hline CHEMBL3960845 & 1641399 & 7.0506 & 7.0374 & TRN \\
\hline CHEMBL3901084 & 1641399 & 7.7447 & 7.1501 & TRN \\
\hline CHEMBL3933004 & 1641399 & 6.6108 & 7.2597 & TRN \\
\hline CHEMBL3965606 & 1641399 & 7.9208 & 7.5468 & TRN \\
\hline CHEMBL3895570 & 1641399 & 7.6576 & 7.667000 & 000000001 \\
\hline CHEMBL3986465 & 1641399 & 6.4001 & 7.435 & TST \\
\hline CHEMBL3895775 & 1641399 & 6.9355 & 6.4879 & TRN \\
\hline CHEMBL3894799 & 1641399 & 7.6383 & 7.297999 & 999999999 \\
\hline CHEMBL3892899 & 1641399 & 8.0 & 7.1686 & TST \\
\hline CHEMBL3979211 & 1641399 & 6.7878 & 7.0333 & TRN \\
\hline CHEMBL3971819 & 1641399 & 7.6198 & 7.3046 & TST \\
\hline CHEMBL 3908110 & 1641399 & 7.1367 & 7.1155 & TRN \\
\hline CHEMBL 3972468 & 1641399 & 7.3768 & 6.9006 & TRN \\
\hline CHEMBL3930529 & 1641399 & 7.2007 & 6.9174 & TRN \\
\hline CHEMBL3973721 & 1641399 & 6.0 & 6.4395 & TRN \\
\hline CHEMBL3892604 & 1641399 & 7.9208 & 7.3349 & TRN \\
\hline CHEMBL3929304 & 1641399 & 7.0706 & 7.2993 & TST \\
\hline CHEMBL3900371 & 1641399 & 7.4559 & 7.6313 & TRN \\
\hline CHEMBL3983820 & 1641399 & 8.0458 & 7.5314 & TRN \\
\hline CHEMBL3954634 & 1641399 & 7.9586 & 7.1099 & TRN \\
\hline CHEMBL3971388 & 1641399 & 8.301 & 7.5976 & TRN \\
\hline CHEMBL3974648 & 1641399 & 6.7878 & 7.0299 & TRN \\
\hline CHEMBL3925177 & 1641399 & 8.1549 & 7.4763 & TST \\
\hline CHEMBL3949512 & 1641399 & 6.7721 & 7.2448 & TRN \\
\hline CHEMBL3959505 & 1641399 & 7.8239 & 7.5271 & TRN \\
\hline CHEMBL3930631 & 1641399 & 6.8665 & 7.0539 & TRN \\
\hline CHEMBL3926436 & 1641399 & 7.2757 & 6.6748 & TRN \\
\hline CHEMBL3923798 & 1641399 & 7.5229 & 7.4515 & TRN \\
\hline CHEMBL3960284 & 1641399 & 7.2676 & 7.3818 & TST \\
\hline CHEMBL3962095 & 1641399 & 7.6021 & 7.3092 & TST \\
\hline CHEMBL3945590 & 1641399 & 8.3979 & 7.6474 & TRN \\
\hline CHEMBL3890814 & 1641399 & 7.4437 & 7.2928 & TST \\
\hline CHEMBL3941663 & 1641399 & 7.8861 & 7.58 & TST \\
\hline
\end{tabular}


Supplemental Table S2.txt

\begin{tabular}{|c|c|c|c|c|c|}
\hline CHEMBL3968972 & 1641399 & 7.2518 & 7.1117 & TRN & \\
\hline CHEMBL3936318 & 1641399 & 6.0 & 7.0199 & TRN & \\
\hline CHEMBL3930919 & 1641399 & 7.2518 & 7.4096 & TRN & \\
\hline CHEMBL3954534 & 1641399 & 6.8386 & 7.7397 & TRN & \\
\hline CHEMBL3940628 & 1641399 & 6.5243 & 7.1464 & TST & \\
\hline CHEMBL3972918 & 1641399 & 6.5654 & 7.0006 & TRN & \\
\hline CHEMBL3912111 & 1641399 & 7.041 & 6.6758 & TRN & \\
\hline CHEMBL3907125 & 1641399 & 6.6289 & 6.8571 & TRN & \\
\hline CHEMBL3947441 & 1641399 & 7.3768 & 7.2256 & TRN & \\
\hline CHEMBL3985872 & 1641399 & 8.0458 & 6.726 & TRN & \\
\hline CHEMBL3978978 & 1641399 & 7.6383 & 7.3656 & TST & \\
\hline CHEMBL3917237 & 1641399 & 6.7645 & 6.8045 & TRN & \\
\hline CHEMBL3930820 & 1641399 & 7.699 & 7.4163 & TRN & \\
\hline CHEMBL3935571 & 1641399 & 7.284 & 7.7628 & TRN & \\
\hline CHEMBL3929631 & 1641399 & 7.7959 & 7.1468 & TST & \\
\hline CHEMBL3896042 & 1641399 & 5.0 & 6.9977 & TRN & \\
\hline CHEMBL3981039 & 1641399 & 7.5086 & 7.4161 & TRN & \\
\hline CHEMBL3985577 & 1641399 & 6.7721 & 7.5703 & TST & \\
\hline CHEMBL3969476 & 1641399 & 7.1192 & 7.6032 & TRN & \\
\hline CHEMBL3929001 & 1641399 & 7.6778 & 7.5265 & TRN & \\
\hline CHEMBL3939409 & 1641399 & 6.0057 & 7.0407 & TST & \\
\hline CHEMBL3921799 & 1641399 & 6.4237 & 7.5334 & TST & \\
\hline CHEMBL3926904 & 1641399 & 7.2596 & 7.6383 & TRN & \\
\hline CHEMBL3945170 & 1641399 & 6.7721 & 7.5907 & TST & \\
\hline CHEMBL3894724 & 1641399 & 7.3768 & 7.0651 & TRN & \\
\hline CHEMBL3939839 & 1641399 & 6.2967 & 7.6361 & TST & \\
\hline CHEMBL3983624 & 1641399 & 6.9788 & 7.0785 & TRN & \\
\hline CHEMBL3982968 & 1641399 & 6.4815 & 6.8393 & TRN & \\
\hline CHEMBL3973004 & 1641399 & 6.7986 & \multicolumn{2}{|c|}{6.888999999999999} & TRN \\
\hline CHEMBL3953821 & 1641399 & 6.9101 & 7.0952 & TRN & \\
\hline CHEMBL 3912345 & 1641399 & 6.1669 & 7.7475 & TST & \\
\hline CHEMBL3909273 & 1641399 & 7.7696 & 7.4791 & TST & \\
\hline CHEMBL3972217 & 1641399 & 7.8861 & 6.7654 & TRN & \\
\hline CHEMBL3948794 & 1641399 & 6.7212 & 7.6947 & TST & \\
\hline CHEMBL3936050 & 1641399 & 6.7696 & 6.9678 & TRN & \\
\hline CHEMBL3924450 & 1641399 & 7.3372 & 7.1263 & TRN & \\
\hline CHEMBL3936939 & 1641399 & 7.3372 & 7.3148 & TRN & \\
\hline CHEMBL3902047 & 1641399 & 6.7167 & 6.5325 & TST & \\
\hline CHEMBL3939455 & 1641399 & 6.0 & 6.2862 & TRN & \\
\hline CHEMBL3941798 & 1641399 & 6.9281 & 6.9056 & TRN & \\
\hline CHEMBL3903327 & 1641399 & 7.2366 & 7.6797 & TST & \\
\hline CHEMBL3924585 & 1641399 & 6.0 & 6.9834 & TRN & \\
\hline CHEMBL3953282 & 1641399 & 7.2291 & 7.374 & TRN & \\
\hline CHEMBL3916486 & 1641399 & 6.9508 & 7.1555 & TST & \\
\hline CHEMBL3894815 & 1641399 & 6.8894 & 7.2673 & TST & \\
\hline CHEMBL3939979 & 1641399 & 6.1688 & 7.6786 & TST & \\
\hline CHEMBL3953648 & 1641399 & 6.0 & 6.5674 & TRN & \\
\hline CHEMBL3942209 & 1641399 & 7.0177 & 7.6585 & TRN & \\
\hline
\end{tabular}


Supplemental Table S2.txt

CHEMBL3982636

CHEMBL3965612

CHEMBL3926942

CHEMBL3974523

CHEMBL3920092

CHEMBL3950864

CHEMBL 3947898

CHEMBL3974406

CHEMBL 3928272

CHEMBL3950507

CHEMBL 3955040

CHEMBL3889906

CHEMBL3912634

CHEMBL 3979547

CHEMBL3968939

CHEMBL3893351

CHEMBL 3930346

CHEMBL3947299

CHEMBL 3913090

CHEMBL3909827

CHEMBL3960294

CHEMBL 3935153

CHEMBL3982696

CHEMBL 3954513

CHEMBL3941863

CHEMBL 3937038

CHEMBL 3964644

CHEMBL3949122

CHEMBL 3904730

CHEMBL 3928860

CHEMBL3931394

CHEMBL 3972482

CHEMBL3949371

CHEMBL3917921

CHEMBL3954371

CHEMBL3946509

CHEMBL 3985765

CHEMBL 3949476

CHEMBL3891986

CHEMBL3978247

CHEMBL 3946311

CHEMBL 3955188

CHEMBL 3937970

CHEMBL 3903901

CHEMBL 3924055

CHEMBL 3897268

CHEMBL 3965748

CHEMBL 3914560

$\begin{array}{llll}1641399 & 7.5686 & 7.1315 & \text { TRN }\end{array}$

$\begin{array}{lll}16413996.0 & 6.8118 & \text { TRN }\end{array}$

$\begin{array}{lll}16413996.0 & 6.2243 & \text { TRN }\end{array}$

$\begin{array}{llll}1641399 & 7.4202 & 7.0697 & \text { TST }\end{array}$

$\begin{array}{llll}1641399 & 7.4202 & 7.3366 & \text { TRN }\end{array}$

$\begin{array}{llll}1641399 & 7.5686 & 7.6872 & \text { TRN }\end{array}$

$\begin{array}{llll}1641399 & 7.3279 & 7.3222 & \text { TRN }\end{array}$

$\begin{array}{llll}1641399 & 7.6198 & 6.4912 & \text { TRN }\end{array}$

$16413996.0 \quad 7.0585$ TST

$\begin{array}{llll}1641399 & 7.1079 & 6.9465 & \text { TRN }\end{array}$

$\begin{array}{llll}1641399 & 6.7986 & 7.6231 & \text { TST }\end{array}$

$\begin{array}{llll}1641399 & 8.0969 & 7.1549 & \text { TRN }\end{array}$

$\begin{array}{llll}1641399 & 7.0862 & 7.4444 & \text { TRN }\end{array}$

$\begin{array}{lll}16413998.0 & 7.5209 & \text { TRN }\end{array}$

$\begin{array}{llll}1641399 & 7.3372 & 7.3749 & \text { TRN }\end{array}$

$16413996.0 \quad 6.9091$ TRN

$\begin{array}{lll}1641399 & 6.1931 & 7.662000000000001\end{array}$

$16413996.5834 \quad 6.6196 \quad$ TRN

$\begin{array}{llll}1641399 & 6.7282 & 6.8815 & \text { TRN }\end{array}$

$\begin{array}{llll}1641399 & 7.1192 & 7.0538 & \text { TRN }\end{array}$

$\begin{array}{llll}1641399 & 6.9626 & 7.2469 & \text { TRN }\end{array}$

$\begin{array}{llll}16413998.0 & 7.2599 & \text { TST }\end{array}$

$\begin{array}{llll}1641399 & 6.6635 & 7.5573 & \text { TST }\end{array}$

$\begin{array}{llll}1641399 & 7.5686 & 7.5288 & \text { TRN }\end{array}$

$\begin{array}{llll}1641399 & 8.2218 & 7.932 & \text { TRN }\end{array}$

$\begin{array}{llll}1641399 & 8.0969 & 7.5785 & \text { TRN }\end{array}$

$\begin{array}{llll}1641399 & 8.301 & 6.5426 & \text { TRN }\end{array}$

$\begin{array}{llll}1641399 & 7.5686 & 7.3595 & \text { TRN }\end{array}$

$\begin{array}{llll}1641399 & 6.0 & 6.2393 & \text { TRN }\end{array}$

$\begin{array}{llll}1641399 & 7.4685 & 7.6419 & \text { TRN }\end{array}$

$\begin{array}{llll}1641399 & 6.857 & 7.6623 & \text { TST }\end{array}$

$\begin{array}{llll}1641399 & 6.767 & 7.6985 & \text { TST }\end{array}$

$\begin{array}{llll}1641399 & 7.9586 & 6.6967 & \text { TRN }\end{array}$

$\begin{array}{llll}1641399 & 6.585 & 6.9077 & \text { TRN }\end{array}$

$\begin{array}{llll}1641399 & 7.5528 & 7.4794 & \text { TRN }\end{array}$

$\begin{array}{llll}1641399 & 6.5986 & 7.1832 & \text { TRN }\end{array}$

$\begin{array}{llll}1641399 & 7.1805 & 6.9397 & \text { TRN }\end{array}$

$\begin{array}{llll}1641399 & 7.7959 & 7.5406 & \text { TST }\end{array}$

$\begin{array}{llll}1641399 & 7.6778 & 7.1368 & \text { TST }\end{array}$

$\begin{array}{llll}1641399 & 6.9431 & 7.0594 & \text { TRN }\end{array}$

$\begin{array}{llll}1641399 & 6.6421 & 7.4016 & \text { TRN }\end{array}$

$\begin{array}{llll}1641399 & 8.2218 & 7.7742 & \text { TRN }\end{array}$

$\begin{array}{lllll}1641399 & 8.1549 & 7.8256 & \text { TRN }\end{array}$

$\begin{array}{llll}1641399 & 7.6778 & 7.3926 & \text { TRN }\end{array}$

$\begin{array}{llll}1641399 & 6.8477 & 6.9353 & \text { TRN }\end{array}$

$\begin{array}{llll}1641399 & 6.4056 & 7.7906 & \text { TST }\end{array}$

$\begin{array}{llll}1641399 & 7.6778 & 7.4998 & \text { TRN }\end{array}$

$\begin{array}{llll}1641399 & 7.5229 & 7.4388 & \text { TRN }\end{array}$ 
Supplemental Table S2.txt

\begin{tabular}{|c|c|c|c|c|c|}
\hline CHEMBL3907527 & 1641399 & 7.3979 & \multicolumn{2}{|c|}{7.172000000000001} & TST \\
\hline CHEMBL3958736 & 1641399 & 7.3872 & 7.6891 & TRN & \\
\hline CHEMBL3956161 & 1641399 & 8.0969 & 7.1894 & TRN & \\
\hline CHEMBL3698702 & 1528842 & 8.3872 & 7.4359 & TRN & \\
\hline CHEMBL 3642031 & 1528842 & 8.7696 & 7.9998 & TRN & \\
\hline CHEMBL3642030 & 1528842 & 6.0 & 5.7303 & TRN & \\
\hline CHEMBL3702248 & 1528842 & 7.7696 & 7.9523 & TRN & \\
\hline CHEMBL3702198 & 1528842 & 7.3979 & 8.2126 & TRN & \\
\hline CHEMBL3698679 & 1528842 & 7.9586 & 7.4506 & TST & \\
\hline CHEMBL3641978 & 1528842 & 7.0969 & 6.6791 & TRN & \\
\hline CHEMBL3702191 & 1528842 & 8.4089 & \multicolumn{2}{|c|}{8.107000000000001} & TST \\
\hline CHEMBL3641909 & 1528842 & 7.1308 & 6.3705 & TRN & \\
\hline CHEMBL3698703 & 1528842 & 8.6383 & 7.3256 & TRN & \\
\hline CHEMBL 3641924 & 1528842 & 6.7986 & 6.7972 & TRN & \\
\hline CHEMBL 3702206 & 1528842 & 7.8861 & 7.1608 & TRN & \\
\hline CHEMBL3702035 & 1528842 & 8.2757 & 7.5964 & TST & \\
\hline CHEMBL3642021 & 1528842 & 8.3279 & 8.1929 & TRN & \\
\hline CHEMBL3641955 & 1528842 & 6.4685 & \multicolumn{2}{|c|}{6.417999999999999} & TRN \\
\hline CHEMBL3702037 & 1528842 & 7.7959 & 6.711 & TST & \\
\hline CHEMBL 3237448 & 1528842 & 7.4437 & 7.8965 & TRN & \\
\hline CHEMBL3702233 & 1528842 & 6.0 & 6.5127 & TRN & \\
\hline CHEMBL3642036 & 1528842 & 6.0 & 6.4825 & TRN & \\
\hline CHEMBL3698718 & 1528842 & 6.3215 & 7.3142 & TRN & \\
\hline CHEMBL3702046 & 1528842 & 8.9208 & 7.761 & TRN & \\
\hline CHEMBL3702136 & 1528842 & 7.8239 & 6.4631 & TST & \\
\hline CHEMBL3698746 & 1528842 & 8.699 & 7.6022 & TRN & \\
\hline CHEMBL3702211 & 1528842 & 8.0655 & 7.3177 & TRN & \\
\hline CHEMBL3698656 & 1528842 & 8.0915 & 7.4676 & TRN & \\
\hline CHEMBL3698685 & 1528842 & 7.1805 & 6.9638 & TST & \\
\hline CHEMBL 3642012 & 1528842 & 6.9586 & 6.7043 & TRN & \\
\hline CHEMBL3940640 & 1528842 & 6.0 & \multicolumn{2}{|c|}{6.696000000000001} & TRN \\
\hline CHEMBL3702147 & 1528842 & 8.1308 & 8.5579 & TRN & \\
\hline CHEMBL3702043 & 1528842 & 5.0 & 6.3376 & TST & \\
\hline CHEMBL 3237446 & 1528842 & 8.3279 & 7.9923 & TRN & \\
\hline CHEMBL3698682 & 1528842 & 8.699 & 8.6628 & TRN & \\
\hline CHEMBL3702176 & 1528842 & 6.0 & 7.2202 & TST & \\
\hline CHEMBL 3698644 & 1528842 & 9.8861 & 9.0542 & TRN & \\
\hline CHEMBL3642039 & 1528842 & 6.0315 & 7.6593 & TRN & \\
\hline CHEMBL3642023 & 1528842 & 8.3768 & 8.3136 & TRN & \\
\hline CHEMBL3698684 & 1528842 & 8.6021 & 7.5212 & TST & \\
\hline CHEMBL3702182 & 1528842 & 7.9586 & 7.9157 & TRN & \\
\hline CHEMBL3642034 & 1528842 & 8.0969 & 7.8381 & TRN & \\
\hline CHEMBL3237702 & 1528842 & 8.9208 & 7.8354 & TRN & \\
\hline CHEMBL3702082 & 1528842 & 6.0 & 7.1642 & TRN & \\
\hline CHEMBL3641969 & 1528842 & 6.0 & 6.4348 & TRN & \\
\hline CHEMBL3702062 & 1528842 & 8.3872 & 8.17 & TST & \\
\hline CHEMBL3702142 & 1528842 & 8.3565 & 7.9889 & TST & \\
\hline CHEMBL3702028 & 1528842 & 7.7212 & 7.1247 & TRN & \\
\hline
\end{tabular}


Supplemental Table S2.txt

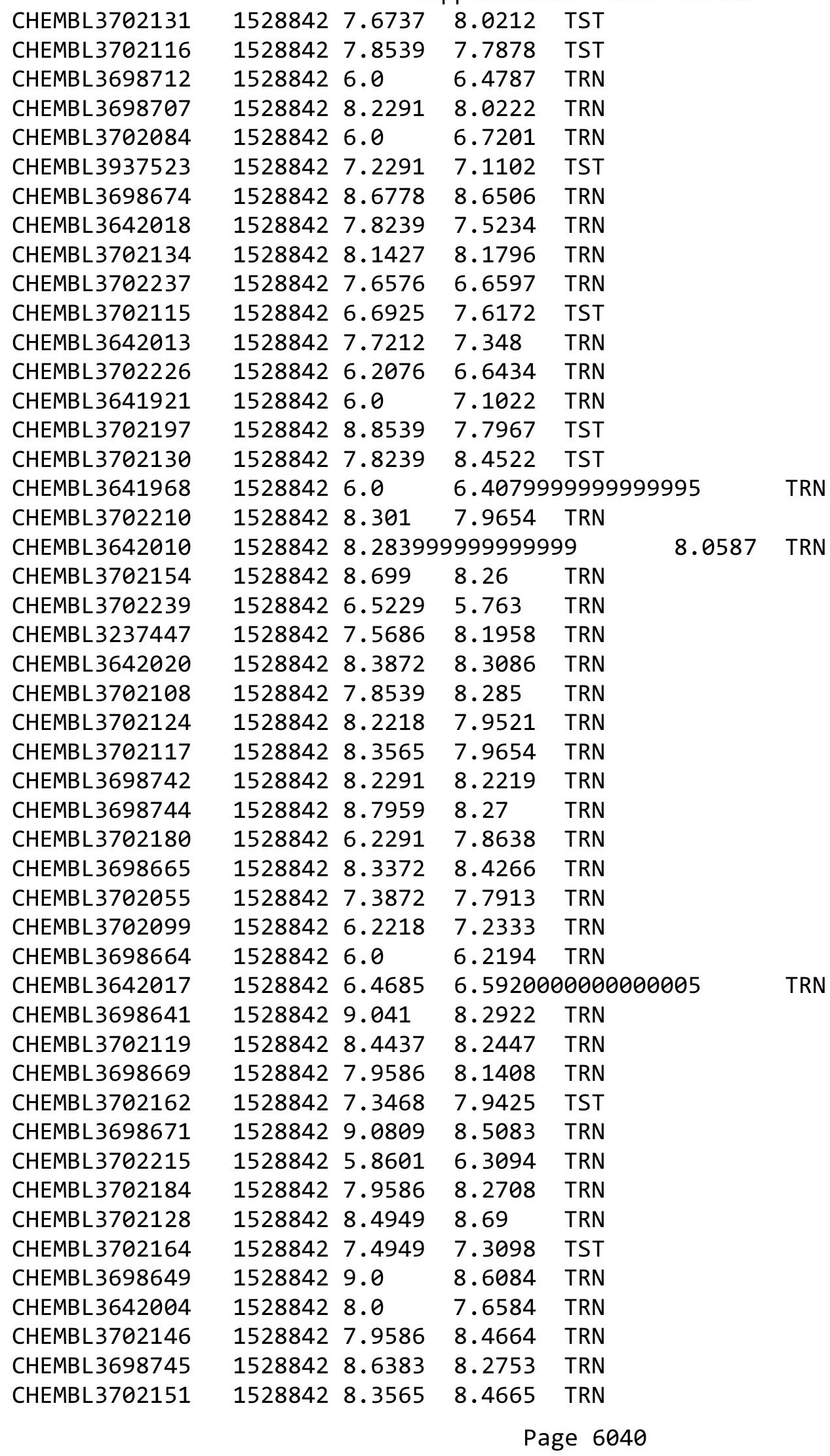




\begin{tabular}{|c|c|c|c|c|c|c|}
\hline \multicolumn{7}{|c|}{ Supplemental Table S2.txt } \\
\hline CHEMBL3702040 & 1528842 & 6.52 & 7.5499 & TST & & \\
\hline CHEMBL3941146 & 1528842 & 6.8416 & 6.0958 & TRN & & \\
\hline CHEMBL3702080 & 1528842 & 7.4815 & 7.8651 & TRN & & \\
\hline CHEMBL3642029 & 1528842 & 8.301 & 7.8343 & TRN & & \\
\hline CHEMBL3698699 & 1528842 & 8.3872 & 7.2351 & TST & & \\
\hline CHEMBL3639408 & 1528842 & 7.0362 & 6.1937 & TRN & & \\
\hline CHEMBL3642011 & 1528842 & 8.1549 & 7.8232 & TRN & & \\
\hline CHEMBL3702032 & 1528842 & 7.7696 & 6.9732 & TST & & \\
\hline CHEMBL3702158 & 1528842 & 8.8861 & 8.2666 & TST & & \\
\hline CHEMBL3641939 & 1528842 & 5.699 & 6.2869 & TRN & & \\
\hline CHEMBL3698695 & 1528842 & 6.0 & 6.4104 & TRN & & \\
\hline CHEMBL3698673 & 1528842 & 8.6778 & 7.8019 & TRN & & \\
\hline CHEMBL3642027 & 1528842 & 7.6198 & 7.8999 & TRN & & \\
\hline CHEMBL3702152 & 1528842 & 7.7959 & 8.3915 & TST & & \\
\hline CHEMBL3642028 & 1528842 & 8.0132 & 7.6554 & TRN & & \\
\hline CHEMBL3641952 & 1528842 & 6.0 & 7.1472 & TRN & & \\
\hline CHEMBL3698696 & 1528842 & 8.0177 & 7.4874 & TST & & \\
\hline CHEMBL3698652 & 1528842 & 8.0 & 7.1872 & TST & & \\
\hline CHEMBL3698733 & 1528842 & 8.2518 & 8.5505 & TRN & & \\
\hline CHEMBL3698726 & 1528842 & 7.7905 & 8.2304 & TRN & & \\
\hline CHEMBL3698689 & 1528842 & 8.28399 & 99999999 & 99 & 8.5145 & TRN \\
\hline CHEMBL3702200 & 1528842 & 7.6576 & 7.4827 & TRN & & \\
\hline CHEMBL3641995 & 1528842 & 6.0 & 6.3727 & TRN & & \\
\hline CHEMBL3702029 & 1528842 & 8.3665 & 7.2365 & TRN & & \\
\hline CHEMBL3698655 & 1528842 & 6.0 & 6.5578 & TRN & & \\
\hline CHEMBL3642035 & 1528842 & 8.3098 & 8.1272 & TRN & & \\
\hline CHEMBL3702050 & 1528842 & 8.7447 & 8.7701 & TRN & & \\
\hline CHEMBL3942636 & 1528842 & 6.8386 & 6.835 & TST & & \\
\hline CHEMBL 3702098 & 1528842 & 7.1675 & 7.6706 & TRN & & \\
\hline CHEMBL 3702230 & 1528842 & 6.0 & 7.1132 & TRN & & \\
\hline CHEMBL3702231 & 1528842 & 6.0 & 6.8609 & TRN & & \\
\hline CHEMBL 3702245 & 1528842 & 7.6778 & 7.9106 & TRN & & \\
\hline CHEMBL3702072 & 1528842 & 8.0706 & 7.9224 & TST & & \\
\hline CHEMBL 3938092 & 1528842 & 6.7905 & 6.5914 & TST & & \\
\hline CHEMBL 3698675 & 1528842 & 8.3098 & 8.0104 & TRN & & \\
\hline CHEMBL3702071 & 1528842 & 8.4437 & 8.2525 & TST & & \\
\hline CHEMBL3698709 & 1528842 & 7.8239 & 8.1537 & TRN & & \\
\hline CHEMBL3698735 & 1528842 & 6.0 & 6.4381 & TRN & & \\
\hline CHEMBL3702132 & 1528842 & 7.7959 & 7.9067 & TRN & & \\
\hline CHEMBL3698672 & 1528842 & 8.3665 & 8.9177 & TRN & & \\
\hline CHEMBL3641931 & 1528842 & 6.0 & 6.7564 & TRN & & \\
\hline CHEMBL3702063 & 1528842 & 8.1549 & 7.2832 & TST & & \\
\hline CHEMBL3702060 & 1528842 & 9.0 & 8.664 & TRN & & \\
\hline CHEMBL3702141 & 1528842 & 8.1675 & 7.1852 & TST & & \\
\hline CHEMBL3702059 & 1528842 & 8.5229 & 8.0772 & TRN & & \\
\hline CHEMBL3702064 & 1528842 & 7.5229 & 7.0191 & TST & & \\
\hline CHEMBL3702186 & 1528842 & 8.585 & 8.1908 & TRN & & \\
\hline CHEMBL3702096 & 1528842 & 8.3565 & 8.3875 & TRN & & \\
\hline
\end{tabular}


Supplemental Table S2.txt

\begin{tabular}{|c|c|c|c|c|}
\hline CHEMBL3702041 & 1528842 & 7.0 & 7.2981 & TST \\
\hline CHEMBL 3702227 & 1528842 & 6.0 & 6.7106 & TRN \\
\hline CHEMBL 3702171 & 1528842 & 7.4559 & 7.8202 & TST \\
\hline CHEMBL 3237443 & 1528842 & 8.699 & 8.0261 & TRN \\
\hline CHEMBL3702106 & 1528842 & 6.8508 & 6.6176 & TRN \\
\hline CHEMBL 3702030 & 1528842 & 8.0605 & 7.7691 & TST \\
\hline CHEMBL3698686 & 1528842 & 6.8996 & 7.3842 & TST \\
\hline CHEMBL 3641910 & 1528842 & 7.0969 & 5.9164 & TRN \\
\hline CHEMBL3702061 & 1528842 & 7.699 & 8.502 & TRN \\
\hline CHEMBL 3698639 & 1528842 & 9.3468 & 8.7436 & TRN \\
\hline CHEMBL3702079 & 1528842 & 8.2518 & 7.6682 & TRN \\
\hline CHEMBL 3702188 & 1528842 & 6.0 & 7.7484 & TRN \\
\hline CHEMBL 3702244 & 1528842 & 6.0 & 6.1716 & TRN \\
\hline CHEMBL3698668 & 1528842 & 8.2757 & 7.9806 & TST \\
\hline CHEMBL 3641967 & 1528842 & 6.0 & 6.1708 & TRN \\
\hline CHEMBL3702192 & 1528842 & 8.3098 & 7.978 & TST \\
\hline CHEMBL3981417 & 1528842 & 8.2924 & 7.9288 & TST \\
\hline CHEMBL 3698716 & 1528842 & 8.1938 & 8.4889 & TRN \\
\hline CHEMBL3641936 & 1528842 & 6.0 & 6.4365 & TRN \\
\hline CHEMBL3702178 & 1528842 & 7.0177 & 7.5795 & TRN \\
\hline CHEMBL 3698724 & 1528842 & 8.3098 & 8.3423 & TRN \\
\hline CHEMBL 3702221 & 1528842 & 6.0 & 6.5665 & TRN \\
\hline CHEMBL 3698748 & 1528842 & 8.3768 & 7.7209 & TRN \\
\hline CHEMBL3641970 & 1528842 & 7.8539 & 6.0226 & TRN \\
\hline CHEMBL3702078 & 1528842 & 7.7212 & 7.6619 & TST \\
\hline CHEMBL3702056 & 1528842 & 7.8239 & 8.0909 & TRN \\
\hline CHEMBL 3702073 & 1528842 & 8.2596 & 8.366 & TRN \\
\hline CHEMBL 3698743 & 1528842 & 8.3768 & 7.135 & TRN \\
\hline CHEMBL3698687 & 1528842 & 7.9208 & 7.9276 & TRN \\
\hline CHEMBL3972254 & 1528842 & 5.0 & 6.44 & TST \\
\hline CHEMBL 3237442 & 1528842 & 8.4949 & 8.617 & TRN \\
\hline CHEMBL 3698747 & 1528842 & 8.2596 & 8.6693 & TRN \\
\hline CHEMBL 3640009 & 1528842 & 7.2518 & 8.2397 & TRN \\
\hline CHEMBL3698700 & 1528842 & 7.7696 & 7.9528 & TRN \\
\hline CHEMBL3702089 & 1528842 & 8.0655 & 7.8254 & TST \\
\hline CHEMBL3702058 & 1528842 & 7.9586 & 8.156 & TRN \\
\hline CHEMBL 3946387 & 1528842 & 6.9393 & 5.9084 & TRN \\
\hline CHEMBL3702181 & 1528842 & 7.2291 & 7.4889 & TRN \\
\hline CHEMBL 3698732 & 1528842 & 8.5086 & 7.8845 & TRN \\
\hline CHEMBL 3698740 & 1528842 & 8.4685 & 7.721 & TRN \\
\hline CHEMBL3702185 & 1528842 & 8.301 & 7.8463 & TRN \\
\hline CHEMBL 3702247 & 1528842 & 7.5686 & 7.9122 & TRN \\
\hline CHEMBL 3698657 & 1528842 & 9.0 & 9.0228 & TRN \\
\hline CHEMBL3702179 & 1528842 & 8.3372 & 8.3559 & TRN \\
\hline CHEMBL3698659 & 1528842 & 9.0269 & 7.8872 & TRN \\
\hline CHEMBL3641922 & 1528842 & 6.0 & 6.0765 & TRN \\
\hline CHEMBL 3641911 & 1528842 & 6.8356 & $6.71700 e$ & 30000000005 \\
\hline CHEMBL 3698677 & 1528842 & 6.6253 & 6.6096 & TRN \\
\hline
\end{tabular}


Supplemental Table S2.txt

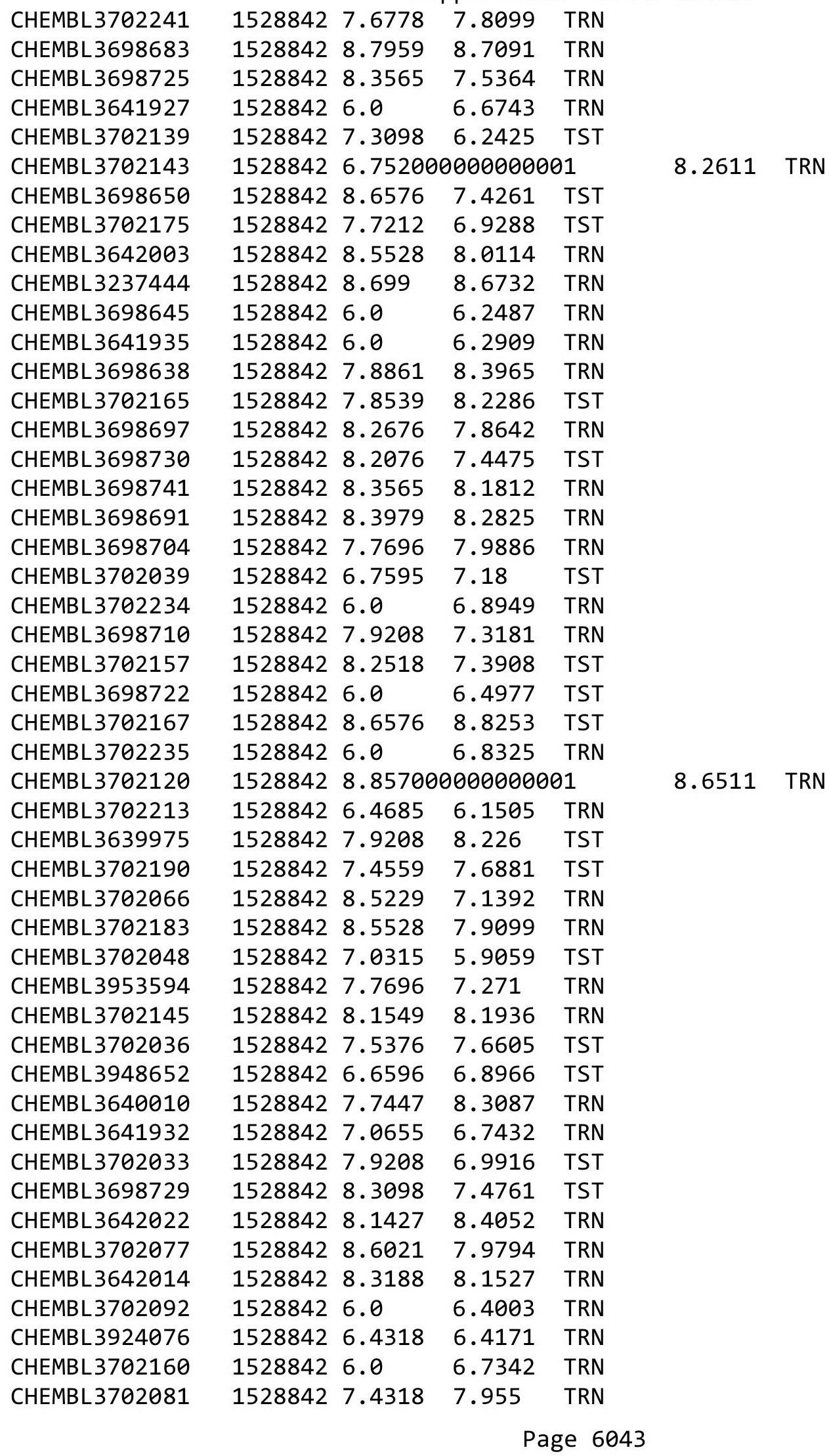


Supplemental Table S2.txt

\begin{tabular}{|c|c|c|c|c|c|}
\hline CHEMBL3702052 & 1528842 & 8.4685 & \multicolumn{2}{|c|}{8.552999999999999} & TRN \\
\hline CHEMBL3702209 & 1528842 & 7.9586 & 7.7732 & TRN & \\
\hline CHEMBL3702125 & 1528842 & 7.8861 & 7.8899 & TRN & \\
\hline CHEMBL3698662 & 1528842 & 8.2596 & 7.3791 & TST & \\
\hline CHEMBL3698731 & 1528842 & 8.3979 & 8.4117 & TRN & \\
\hline CHEMBL3698670 & 1528842 & 8.0862 & 8.0405 & TRN & \\
\hline CHEMBL3975692 & 1528842 & 7.6198 & 7.4627 & TST & \\
\hline CHEMBL3698676 & 1528842 & 8.5686 & 7.9384 & TST & \\
\hline CHEMBL3641920 & 1528842 & 6.0 & 7.1098 & TRN & \\
\hline CHEMBL3641996 & 1528842 & 8.2366 & 7.7378 & TRN & \\
\hline CHEMBL3698727 & 1528842 & 6.3665 & 7.0292 & TST & \\
\hline CHEMBL3698667 & 1528842 & 7.8861 & 7.2731 & TST & \\
\hline CHEMBL3702065 & 1528842 & 8.2676 & 8.08 & TRN & \\
\hline CHEMBL 3698717 & 1528842 & 7.3665 & 7.7574 & TRN & \\
\hline CHEMBL3698646 & 1528842 & 8.6576 & 7.9809 & TRN & \\
\hline CHEMBL3641954 & 1528842 & 6.6234 & 6.7524 & TRN & \\
\hline CHEMBL3702194 & 1528842 & 6.0 & 6.0794 & TST & \\
\hline CHEMBL3642015 & 1528842 & 6.0 & 6.4353 & TRN & \\
\hline CHEMBL3702212 & 1528842 & 6.4318 & 5.8763 & TRN & \\
\hline CHEMBL 3698728 & 1528842 & 8.6021 & 7.4917 & TST & \\
\hline CHEMBL3237704 & 1528842 & 8.4559 & 8.7886 & TRN & \\
\hline CHEMBL3702095 & 1528842 & 8.1938 & 7.7741 & TRN & \\
\hline CHEMBL3702246 & 1528842 & 7.2676 & 8.2141 & TRN & \\
\hline CHEMBL3702161 & 1528842 & 7.3098 & 7.5165 & TST & \\
\hline CHEMBL3702049 & 1528842 & 8.6576 & 8.7553 & TRN & \\
\hline CHEMBL3702068 & 1528842 & 8.4437 & 6.9863 & TRN & \\
\hline CHEMBL3641930 & 1528842 & 6.0 & 6.7155 & TRN & \\
\hline CHEMBL3702140 & 1528842 & 7.4559 & 6.2155 & TST & \\
\hline CHEMBL3698708 & 1528842 & 8.5229 & 8.165 & TRN & \\
\hline CHEMBL 3698653 & 1528842 & 9.4949 & 8.3997 & TST & \\
\hline CHEMBL3642024 & 1528842 & 8.2441 & 7.6269 & TRN & \\
\hline CHEMBL3702148 & 1528842 & 7.1549 & 8.0984 & TRN & \\
\hline CHEMBL3961274 & 1528842 & 6.8447 & 6.4915 & TST & \\
\hline CHEMBL 3702177 & 1528842 & 7.7696 & 7.9306 & TRN & \\
\hline CHEMBL3702111 & 1528842 & 7.9586 & 7.9851 & TRN & \\
\hline CHEMBL3641980 & 1528842 & 6.0 & 6.1148 & TRN & \\
\hline CHEMBL3702074 & 1528842 & 7.9586 & 7.6716 & TRN & \\
\hline CHEMBL3702103 & 1528842 & 6.0 & 7.4974 & TRN & \\
\hline CHEMBL3702093 & 1528842 & 8.5376 & 8.3292 & TRN & \\
\hline CHEMBL3702076 & 1528842 & 6.8539 & 6.6393 & TST & \\
\hline CHEMBL3641913 & 1528842 & 6.0 & 5.8957 & TRN & \\
\hline CHEMBL3702172 & 1528842 & 7.3979 & 7.9416 & TST & \\
\hline CHEMBL3702199 & 1528842 & 7.2218 & 7.5311 & TRN & \\
\hline CHEMBL3702201 & 1528842 & 7.5086 & 7.7386 & TRN & \\
\hline CHEMBL3702045 & 1528842 & 7.9586 & 8.0956 & TRN & \\
\hline CHEMBL3702202 & 1528842 & 7.3279 & 7.1845 & TRN & \\
\hline CHEMBL3641998 & 1528842 & 6.0 & 5.7918 & TRN & \\
\hline CHEMBL 3698737 & 1528842 & 8.0757 & 7.9327 & TRN & \\
\hline
\end{tabular}


Supplemental Table S2.txt

\begin{tabular}{|c|c|c|c|c|c|}
\hline CHEMBL3702144 & 1528842 & 7.2076 & 8.3487 & TRN & \\
\hline CHEMBL3702088 & 1528842 & 6.8477 & 7.4092 & TRN & \\
\hline CHEMBL3702243 & 1528842 & 7.3565 & 7.6925 & TRN & \\
\hline CHEMBL3698688 & 1528842 & 9.0132 & 8.3878 & TRN & \\
\hline CHEMBL3702153 & 1528842 & 8.4949 & 8.6104 & TST & \\
\hline CHEMBL3641993 & 1528842 & 7.6383 & 7.8973 & TRN & \\
\hline CHEMBL3702135 & 1528842 & 8.3372 & 6.9313 & TST & \\
\hline CHEMBL3702086 & 1528842 & 7.8239 & 7.5421 & TST & \\
\hline CHEMBL 3702044 & 1528842 & 8.1612 & 7.8554 & TRN & \\
\hline CHEMBL3698642 & 1528842 & 8.8239 & 8.5424 & TRN & \\
\hline CHEMBL3971812 & 1528842 & 8.6021 & 7.9552 & TRN & \\
\hline CHEMBL3702170 & 1528842 & 7.9586 & 7.9701 & TST & \\
\hline CHEMBL3641958 & 1528842 & 6.0 & 6.5061 & TRN & \\
\hline CHEMBL3641979 & 1528842 & 6.0 & 6.0075 & TRN & \\
\hline CHEMBL 3641972 & 1528842 & 8.585 & 6.5884 & TRN & \\
\hline CHEMBL3698661 & 1528842 & 8.7959 & 7.9813 & TST & \\
\hline CHEMBL3702150 & 1528842 & 7.7447 & 8.0321 & TRN & \\
\hline CHEMBL3702214 & 1528842 & 6.4202 & 5.7753 & TRN & \\
\hline CHEMBL3642032 & 1528842 & 8.699 & 8.2102 & TRN & \\
\hline CHEMBL3698660 & 1528842 & 7.5229 & 7.3194 & TST & \\
\hline CHEMBL3702126 & 1528842 & 6.284 & 6.7818 & TRN & \\
\hline CHEMBL3702137 & 1528842 & 6.9031 & 5.5493 & TST & \\
\hline CHEMBL3702166 & 1528842 & 8.0315 & 8.0823 & TST & \\
\hline CHEMBL3642001 & 1528842 & 8.6576 & 8.2804 & TRN & \\
\hline CHEMBL 3642019 & 1528842 & 8.699 & 8.3879 & TRN & \\
\hline CHEMBL 3702127 & 1528842 & 8.3979 & 8.7023 & TRN & \\
\hline CHEMBL3641990 & 1528842 & 7.8861 & 7.9136 & TRN & \\
\hline CHEMBL3702112 & 1528842 & 8.1805 & 7.7285 & TRN & \\
\hline CHEMBL3702105 & 1528842 & 7.585 & 7.6251 & TRN & \\
\hline CHEMBL3702138 & 1528842 & 7.4685 & 7.4123 & TST & \\
\hline CHEMBL3698701 & 1528842 & 8.4437 & 7.3745 & TST & \\
\hline CHEMBL3702168 & 1528842 & 8.5086 & 8.5842 & TST & \\
\hline CHEMBL3641994 & 1528842 & 8.3768 & 7.9859 & TRN & \\
\hline CHEMBL 3702114 & 1528842 & 7.4685 & 8.0469 & TRN & \\
\hline CHEMBL3702042 & 1528842 & 6.7212 & 7.2151 & TST & \\
\hline CHEMBL3698714 & 1528842 & 7.6576 & 8.0436 & TRN & \\
\hline CHEMBL3702034 & 1528842 & 8.699 & 7.6663 & TST & \\
\hline CHEMBL3237449 & 1528842 & 6.0 & 6.7171 & TRN & \\
\hline CHEMBL3957477 & 1528842 & 7.6778 & 7.2548 & TST & \\
\hline CHEMBL3698643 & 1528842 & 8.8539 & 8.9288 & TRN & \\
\hline CHEMBL3926468 & 1528842 & 7.9208 & 7.36299 & 99999999995 & TRN \\
\hline CHEMBL3698713 & 1528842 & 8.585 & 8.0062 & TRN & \\
\hline CHEMBL3702205 & 1528842 & 6.0 & 6.2029 & TRN & \\
\hline CHEMBL3642006 & 1528842 & 6.0 & 6.7135 & TRN & \\
\hline CHEMBL3977134 & 1528842 & 7.3768 & 6.9017 & TRN & \\
\hline CHEMBL3702156 & 1528842 & 7.6576 & 8.0515 & TRN & \\
\hline CHEMBL3702149 & 1528842 & 8.4685 & 8.1551 & TRN & \\
\hline CHEMBL 3642025 & 1528842 & 7.9586 & 7.3 & TRN & \\
\hline
\end{tabular}


Supplemental Table S2.txt

\begin{tabular}{|c|c|c|c|c|}
\hline CHEMBL3698681 & 1528842 & 8.699 & 8.4715 & TRN \\
\hline CHEMBL 3702203 & 1528842 & 7.5086 & 7.2464 & TRN \\
\hline CHEMBL 3702104 & 1528842 & 6.0 & 7.3219 & TRN \\
\hline CHEMBL 3698648 & 1528842 & 8.0177 & 7.9878 & TRN \\
\hline CHEMBL 3642026 & 1528842 & 8.3872 & 7.6852 & TRN \\
\hline CHEMBL 3698736 & 1528842 & 8.3979 & 8.0355 & TRN \\
\hline CHEMBL3698705 & 1528842 & 7.2518 & 7.46200 & 3000000001 \\
\hline CHEMBL 3702187 & 1528842 & 6.9101 & 7.319 & TRN \\
\hline CHEMBL 3702054 & 1528842 & 7.301 & 7.8175 & TRN \\
\hline CHEMBL3702057 & 1528842 & 7.7696 & 7.5307 & TRN \\
\hline CHEMBL 3702228 & 1528842 & 6.0 & 6.4219 & TRN \\
\hline CHEMBL3641981 & 1528842 & 7.1249 & 5.725 & TRN \\
\hline CHEMBL 3641926 & 1528842 & 6.0 & 6.6328 & TRN \\
\hline CHEMBL 3983722 & 1528842 & 7.1367 & 6.2111 & TRN \\
\hline CHEMBL 3702097 & 1528842 & 7.5817 & 7.4674 & TRN \\
\hline CHEMBL 3702094 & 1528842 & 7.699 & 7.255 & TRN \\
\hline CHEMBL3702107 & 1528842 & 8.585 & 8.0896 & TRN \\
\hline CHEMBL3702163 & 1528842 & 6.6326 & 7.1546 & TST \\
\hline CHEMBL 3702110 & 1528842 & 8.7447 & 8.103 & TRN \\
\hline CHEMBL3698651 & 1528842 & 8.1249 & 7.7648 & TST \\
\hline CHEMBL 3237445 & 1528842 & 7.699 & 7.5682 & TRN \\
\hline CHEMBL 3938566 & 1528842 & 6.52 & 6.3803 & TRN \\
\hline CHEMBL 3907280 & 1528842 & 7.6576 & 6.7047 & TST \\
\hline CHEMBL3698680 & 1528842 & 7.1367 & 6.233 & TRN \\
\hline CHEMBL 3702038 & 1528842 & 7.699 & 7.4997 & TST \\
\hline CHEMBL 3237451 & 1528842 & 7.9586 & 8.1408 & TRN \\
\hline CHEMBL 3702070 & 1528842 & 7.7696 & 7.0526 & TRN \\
\hline CHEMBL3641953 & 1528842 & 6.0 & 7.5131 & TRN \\
\hline CHEMBL3641918 & 1528842 & 6.0 & 6.0485 & TRN \\
\hline CHEMBL 3698723 & 1528842 & 8.5086 & 7.7111 & TST \\
\hline CHEMBL 3698706 & 1528842 & 8.8539 & 8.0809 & TRN \\
\hline CHEMBL3641964 & 1528842 & 6.0 & 6.6288 & TRN \\
\hline CHEMBL3923921 & 1528842 & 6.0 & 7.00799 & э999999999 \\
\hline CHEMBL 3702100 & 1528842 & 7.8861 & 7.5698 & TRN \\
\hline CHEMBL3702113 & 1528842 & 8.0088 & 7.5987 & TST \\
\hline CHEMBL 3702051 & 1528842 & 8.4202 & 8.4554 & TRN \\
\hline CHEMBL3702087 & 1528842 & 6.9469 & 7.7947 & TRN \\
\hline CHEMBL 3641928 & 1528842 & 6.0 & 6.4956 & TRN \\
\hline CHEMBL 3702173 & 1528842 & 7.7959 & 8.3258 & TST \\
\hline CHEMBL3641937 & 1528842 & 6.0 & 6.6652 & TRN \\
\hline CHEMBL 3642008 & 1528842 & 6.0 & 6.1272 & TRN \\
\hline CHEMBL3702123 & 1528842 & 8.8539 & 8.4057 & TRN \\
\hline CHEMBL3702169 & 1528842 & 7.1367 & 7.8098 & TST \\
\hline CHEMBL 3702208 & 1528842 & 7.9586 & 7.9405 & TRN \\
\hline CHEMBL 3698678 & 1528842 & 6.8665 & 7.2129 & TRN \\
\hline CHEMBL 3698715 & 1528842 & 7.699 & 8.0232 & TRN \\
\hline CHEMBL3702129 & 1528842 & 8.5229 & 8.7232 & TST \\
\hline CHEMBL3698658 & 1528842 & 8.8861 & 8.6506 & TRN \\
\hline
\end{tabular}


Supplemental Table S2.txt

\begin{tabular}{|c|c|c|c|c|c|}
\hline CHEMBL3642033 & 1528842 & 8.699 & 8.3625 & TRN & \\
\hline CHEMBL3944755 & 1528842 & 6.7799 & 6.8037 & TST & \\
\hline CHEMBL3702067 & 1528842 & 8.6021 & 7.5532 & TRN & \\
\hline CHEMBL3702174 & 1528842 & 7.5686 & 7.3547 & TRN & \\
\hline CHEMBL3702053 & 1528842 & 9.0 & 8.5474 & TRN & \\
\hline CHEMBL3698647 & 1528842 & 8.5086 & 8.1863 & TRN & \\
\hline CHEMBL3702031 & 1528842 & 7.3179 & 7.4966 & TST & \\
\hline CHEMBL3641971 & 1528842 & 6.0 & 6.2268 & TRN & \\
\hline CHEMBL3702121 & 1528842 & 8.2757 & 8.2482 & TRN & \\
\hline CHEMBL3698719 & 1528842 & 6.0 & 7.7112 & TRN & \\
\hline CHEMBL3698690 & 1528842 & 7.8239 & 7.8997 & TRN & \\
\hline CHEMBL3702236 & 1528842 & 6.0 & 6.67899 & 9999999999 & TRN \\
\hline CHEMBL3702196 & 1528842 & 6.0 & 5.4989 & TST & \\
\hline CHEMBL3702159 & 1528842 & 8.1549 & 8.5361 & TST & \\
\hline CHEMBL3641999 & 1528842 & 8.3188 & 8.1706 & TRN & \\
\hline CHEMBL3702109 & 1528842 & 8.0 & 8.1178 & TRN & \\
\hline CHEMBL3955164 & 1528842 & 7.0458 & 6.7897 & TST & \\
\hline CHEMBL 3698738 & 1528842 & 6.0 & 7.6346 & TRN & \\
\hline CHEMBL3920794 & 1528842 & 8.4089 & 7.0435 & TST & \\
\hline CHEMBL3698698 & 1528842 & 8.8861 & 7.9066 & TRN & \\
\hline CHEMBL3702207 & 1528842 & 7.9586 & 8.1958 & TRN & \\
\hline CHEMBL3642009 & 1528842 & 8.3372 & 7.9418 & TRN & \\
\hline CHEMBL3702133 & 1528842 & 8.4815 & 8.1975 & TRN & \\
\hline CHEMBL3698693 & 1528842 & 6.0 & 6.4671 & TRN & \\
\hline CHEMBL3702075 & 1528842 & 5.0 & 5.6171 & TST & \\
\hline CHEMBL3702122 & 1528842 & 9.0 & 8.6661 & TRN & \\
\hline CHEMBL 3702232 & 1528842 & 6.0 & 6.8266 & TRN & \\
\hline CHEMBL3702047 & 1528842 & 7.7959 & 8.5102 & TRN & \\
\hline CHEMBL3702118 & 1528842 & 8.0 & 7.9957 & TRN & \\
\hline CHEMBL3641960 & 1528842 & 6.0 & 6.6247 & TRN & \\
\hline CHEMBL446240 & 688476 & 4.3 & 4.7502 & TST & \\
\hline CHEMBL1511602 & 688476 & 4.3 & 4.245 & TRN & \\
\hline CHEMBL1518792 & 688476 & 3.85 & 4.9583 & TRN & \\
\hline CHEMBL1586339 & 688476 & 4.7 & 4.6364 & TRN & \\
\hline CHEMBL1440951 & 688476 & 4.2 & 4.463 & TRN & \\
\hline CHEMBL1455554 & 688476 & 3.9 & 4.5916 & TRN & \\
\hline CHEMBL1514486 & 688476 & 6.05 & 6.3596 & TRN & \\
\hline CHEMBL1559691 & 688476 & 3.85 & 4.2253 & TRN & \\
\hline CHEMBL109037 & 688476 & 4.7 & 5.0563 & TRN & \\
\hline CHEMBL1532515 & 688476 & 4.05 & 4.2772 & TRN & \\
\hline CHEMBL1597993 & 688476 & 4.5 & 5.0037 & TST & \\
\hline CHEMBL1510562 & 688476 & 4.65 & 4.7659 & TRN & \\
\hline CHEMBL1402871 & 688476 & 5.35 & 5.4066 & TRN & \\
\hline CHEMBL1474286 & 688476 & 5.0 & 5.2921 & TRN & \\
\hline CHEMBL1607723 & 688476 & 5.55 & \multicolumn{2}{|c|}{5.8020000000000005} & TRN \\
\hline CHEMBL1471965 & 688476 & 5.05 & 4.9874 & TRN & \\
\hline CHEMBL3195977 & 688476 & 5.2 & 4.6031 & TST & \\
\hline CHEMBL1385694 & 688476 & 5.15 & 4.7572 & TRN & \\
\hline
\end{tabular}




\begin{tabular}{|c|c|c|c|c|c|}
\hline \multicolumn{6}{|c|}{ Supplemental Table S2.txt } \\
\hline CHEMBL1526663 & 688476 & 3.85 & 5.2012 & TRN & \\
\hline CHEMBL1381551 & 688476 & 4.35 & 4.6086 & TST & \\
\hline CHEMBL1441990 & 688476 & 3.95 & 4.8084 & TRN & \\
\hline CHEMBL286494 & 688476 & 6.8499 & 4.4394 & TST & \\
\hline CHEMBL1493466 & 688476 & 4.0 & 4.6424 & TRN & \\
\hline CHEMBL504791 & 688476 & 4.3 & 4.607 & TRN & \\
\hline CHEMBL1391063 & 688476 & 4.5 & 5.4866 & TRN & \\
\hline CHEMBL1479248 & 688476 & 4.15 & 4.9704 & TRN & \\
\hline CHEMBL1530437 & 688476 & 4.4 & 4.5479 & TRN & \\
\hline CHEMBL1471579 & 688476 & 4.0 & 3.9476 & TRN & \\
\hline CHEMBL1390427 & 688476 & 6.35 & 4.8384 & TRN & \\
\hline CHEMBL1393131 & 688476 & 4.4 & 4.298 & TRN & \\
\hline CHEMBL1580779 & 688476 & 4.65 & 5.228 & TRN & \\
\hline CHEMBL1559225 & 688476 & 5.8 & 5.5617 & TRN & \\
\hline CHEMBL1981243 & 688476 & 4.35 & 4.132 & TRN & \\
\hline CHEMBL1571649 & 688476 & 5.95 & 4.4704 & TRN & \\
\hline CHEMBL1527095 & 688476 & 4.3 & 4.2561 & TRN & \\
\hline CHEMBL1516388 & 688476 & 4.85 & 5.1001 & TST & \\
\hline CHEMBL1425636 & 688476 & 4.55 & 4.945 & TRN & \\
\hline CHEMBL1200938 & 688476 & 6.05 & 5.6431 & TST & \\
\hline CHEMBL1403572 & 688476 & 4.5 & 4.512 & TRN & \\
\hline CHEMBL1589385 & 688476 & 4.9 & 3.8673 & TRN & \\
\hline CHEMBL1589017 & 688476 & 4.2 & 4.7223 & TRN & \\
\hline CHEMBL1445850 & 688476 & 4.35 & 4.1906 & TRN & \\
\hline CHEMBL1334484 & 688476 & 4.4 & 4.3096 & TST & \\
\hline CHEMBL52 & 688476 & 5.05 & 5.5696 & TRN & \\
\hline CHEMBL1515873 & 688476 & 3.95 & 5.2276 & TRN & \\
\hline CHEMBL1508406 & 688476 & 4.35 & 5.10800 & 00000000005 & TRN \\
\hline CHEMBL1343341 & 688476 & 3.85 & 4.1065 & TRN & \\
\hline CHEMBL1308842 & 688476 & 4.35 & 4.8024 & TRN & \\
\hline CHEMBL1401747 & 688476 & 4.9 & 4.3883 & TRN & \\
\hline CHEMBL1558621 & 688476 & 5.2 & 5.1552 & TST & \\
\hline CHEMBL1305393 & 688476 & 4.25 & 4.9504 & TRN & \\
\hline CHEMBL1542916 & 688476 & 3.95 & 4.7738 & TRN & \\
\hline CHEMBL1539325 & 688476 & 7.8508 & 4.3475 & TST & \\
\hline CHEMBL1560884 & 688476 & 6.0 & 6.3591 & TRN & \\
\hline CHEMBL1308015 & 688476 & 4.1 & 5.4794 & TST & \\
\hline CHEMBL1325440 & 688476 & 4.35 & 5.1684 & TRN & \\
\hline CHEMBL1606794 & 688476 & 4.15 & 5.1053 & TRN & \\
\hline CHEMBL 3189657 & 688476 & 4.45 & 5.5909 & TRN & \\
\hline CHEMBL1973050 & 688476 & 4.6 & 5.1436 & TRN & \\
\hline CHEMBL1704267 & 688476 & 4.4 & 4.5621 & TRN & \\
\hline CHEMBL1574133 & 688476 & 4.35 & 4.7829 & TRN & \\
\hline CHEMBL1427330 & 688476 & 5.0 & 4.0651 & TRN & \\
\hline CHEMBL1572334 & 688476 & 4.4 & 5.2844 & TRN & \\
\hline CHEMBL1416563 & 688476 & 4.95 & 5.2795 & TRN & \\
\hline CHEMBL1595235 & 688476 & 4.85 & 4.3894 & TRN & \\
\hline CHEMBL1353907 & 688476 & 4.3 & 4.1006 & TRN & \\
\hline
\end{tabular}




\begin{tabular}{|c|c|c|c|c|c|}
\hline \multicolumn{6}{|c|}{ Supplemental Table S2.txt } \\
\hline CHEMBL1965155 & 688476 & 4.1 & 4.2777 & TRN & \\
\hline CHEMBL1445030 & 688476 & 4.45 & 5.5083 & TRN & \\
\hline CHEMBL1532477 & 688476 & 8.7447 & 4.6059 & TRN & \\
\hline CHEMBL351042 & 688476 & 6.0 & 5.6395 & TRN & \\
\hline CHEMBL1402957 & 688476 & 5.1 & 5.9026 & TST & \\
\hline CHEMBL1532234 & 688476 & 3.9 & 4.2771 & TRN & \\
\hline CHEMBL160053 & 688476 & 5.2 & 4.6948 & TST & \\
\hline CHEMBL1367444 & 688476 & 4.25 & 4.1498 & TRN & \\
\hline CHEMBL1451790 & 688476 & 5.15 & 5.5397 & TRN & \\
\hline CHEMBL1498884 & 688476 & 4.4 & 4.8428 & TRN & \\
\hline CHEMBL1478395 & 688476 & 4.35 & 4.098 & TRN & \\
\hline CHEMBL1314174 & 688476 & 5.0 & 4.4665 & TST & \\
\hline CHEMBL1316831 & 688476 & 6.05 & 6.76200 & 00000000005 & TRN \\
\hline CHEMBL1701224 & 688476 & 5.0 & 4.7559 & TRN & \\
\hline CHEMBL1366929 & 688476 & 5.15 & 4.976 & TRN & \\
\hline CHEMBL1527684 & 688476 & 4.15 & 4.5831 & TRN & \\
\hline CHEMBL1454643 & 688476 & 3.85 & 4.447 & TRN & \\
\hline CHEMBL1463964 & 688476 & 4.85 & 4.4736 & TRN & \\
\hline CHEMBL1481914 & 688476 & 4.4 & 4.5961 & TRN & \\
\hline CHEMBL3213527 & 688476 & 6.15 & 5.8108 & TRN & \\
\hline CHEMBL1604163 & 688476 & 4.35 & 4.4515 & TRN & \\
\hline CHEMBL1423705 & 688476 & 4.35 & 4.2743 & TST & \\
\hline CHEMBL1301115 & 688476 & 4.75 & 4.8792 & TRN & \\
\hline CHEMBL1397270 & 688476 & 5.2 & 4.5507 & TST & \\
\hline CHEMBL1328010 & 688476 & 3.95 & 4.8279 & TRN & \\
\hline CHEMBL1320902 & 688476 & 6.0 & 5.6639 & TRN & \\
\hline CHEMBL1454269 & 688476 & 4.25 & 5.2101 & TRN & \\
\hline CHEMBL1310907 & 688476 & 4.3 & 4.0702 & TRN & \\
\hline CHEMBL3198782 & 688476 & 4.2 & 5.2006 & TST & \\
\hline CHEMBL418068 & 688476 & 5.1 & 5.7518 & TRN & \\
\hline CHEMBL1461136 & 688476 & 6.6499 & 6.0534 & TRN & \\
\hline CHEMBL1349382 & 688476 & 4.85 & 4.3966 & TRN & \\
\hline CHEMBL1366812 & 688476 & 5.35 & 6.3593 & TRN & \\
\hline CHEMBL1392900 & 688476 & 4.3 & 4.5088 & TRN & \\
\hline CHEMBL1609550 & 688476 & 4.3 & 4.5645 & TRN & \\
\hline CHEMBL1422559 & 688476 & 5.95 & 4.8604 & TRN & \\
\hline CHEMBL1362935 & 688476 & 5.15 & 5.8263 & TRN & \\
\hline CHEMBL1527799 & 688476 & 5.2 & 5.1652 & TRN & \\
\hline CHEMBL1522761 & 688476 & 5.2 & 4.1848 & TRN & \\
\hline CHEMBL3195611 & 688476 & 4.45 & 4.9409 & TRN & \\
\hline CHEMBL1600012 & 688476 & 3.95 & 4.6533 & TRN & \\
\hline CHEMBL1523286 & 688476 & 5.15 & 4.9968 & TST & \\
\hline CHEMBL1365599 & 688476 & 4.45 & 5.2078 & TST & \\
\hline CHEMBL1530561 & 688476 & 5.35 & 5.0195 & TRN & \\
\hline CHEMBL408702 & 688476 & 4.45 & 5.0429 & TRN & \\
\hline CHEMBL1606751 & 688476 & 6.8499 & 5.54299 & 9999999999 & TRN \\
\hline CHEMBL340807 & 688476 & 4.75 & 4.4634 & TRN & \\
\hline CHEMBL3190370 & 688476 & 4.05 & 4.43 & TRN & \\
\hline
\end{tabular}




\begin{tabular}{|c|c|c|c|c|c|}
\hline \multicolumn{6}{|c|}{ Supplemental Table S2.txt } \\
\hline CHEMBL1494334 & 688476 & 4.35 & 4.7724 & TRN & \\
\hline CHEMBL1426001 & 688476 & 4.15 & 5.50200 & 0000000001 & TRN \\
\hline CHEMBL1352844 & 688476 & 4.85 & 4.9569 & TRN & \\
\hline CHEMBL1460436 & 688476 & 4.5 & 4.336 & TRN & \\
\hline CHEMBL1555752 & 688476 & 3.9 & 5.1764 & TST & \\
\hline CHEMBL1332402 & 688476 & 4.75 & 4.9334 & TRN & \\
\hline CHEMBL1408991 & 688476 & 4.35 & 5.2706 & TRN & \\
\hline CHEMBL1452561 & 688476 & 5.4 & 5.2106 & TRN & \\
\hline CHEMBL1521196 & 688476 & 5.65 & 4.9965 & TRN & \\
\hline CHEMBL1539384 & 688476 & 4.4 & 5.118 & TRN & \\
\hline CHEMBL1364573 & 688476 & 4.85 & 4.5717 & TRN & \\
\hline CHEMBL1462793 & 688476 & 6.1 & 5.0865 & TRN & \\
\hline CHEMBL43612 & 688476 & 5.7 & 5.7235 & TRN & \\
\hline CHEMBL1427289 & 688476 & 4.25 & 4.6359 & TRN & \\
\hline CHEMBL189438 & 688476 & 4.65 & 4.9519 & TST & \\
\hline CHEMBL3192084 & 688476 & 4.25 & 5.2039 & TRN & \\
\hline CHEMBL530280 & 688476 & 8.1024 & 5.6463 & TRN & \\
\hline CHEMBL1491095 & 688476 & 4.05 & 4.57600 & 00000000005 & TRN \\
\hline CHEMBL1431875 & 688476 & 4.2 & 4.949 & TST & \\
\hline CHEMBL1353420 & 688476 & 4.3 & 4.7398 & TRN & \\
\hline CHEMBL1429158 & 688476 & 4.45 & 4.0487 & TRN & \\
\hline CHEMBL1390419 & 688476 & 7.1002 & 5.8219 & TRN & \\
\hline CHEMBL1358777 & 688476 & 5.55 & 4.9079 & TRN & \\
\hline CHEMBL1565805 & 688476 & 4.4 & 4.3974 & TRN & \\
\hline CHEMBL1526624 & 688476 & 5.6 & 5.726 & TRN & \\
\hline CHEMBL1581156 & 688476 & 8.4949 & 5.5035 & TRN & \\
\hline CHEMBL1424340 & 688476 & 4.35 & 4.3017 & TRN & \\
\hline CHEMBL1560128 & 688476 & 4.05 & 5.09699 & 99999999995 & TRN \\
\hline CHEMBL1313635 & 688476 & 9.301 & 5.8796 & TRN & \\
\hline CHEMBL1592095 & 688476 & 6.0 & 6.2034 & TRN & \\
\hline CHEMBL1486827 & 688476 & 8.6576 & 5.79 & TRN & \\
\hline CHEMBL1480797 & 688476 & 4.2 & 4.4625 & TRN & \\
\hline CHEMBL1585318 & 688476 & 4.3 & 5.0832 & TRN & \\
\hline CHEMBL1391256 & 688476 & 4.3 & 4.8806 & TST & \\
\hline CHEMBL1553873 & 688476 & 3.9 & 4.7564 & TRN & \\
\hline CHEMBL1346592 & 688476 & 4.35 & 5.4622 & TRN & \\
\hline CHEMBL3199475 & 688476 & 4.95 & 5.2706 & TRN & \\
\hline CHEMBL1571704 & 688476 & 4.15 & 5.2218 & TRN & \\
\hline CHEMBL1365380 & 688476 & 5.65 & 4.7966 & TRN & \\
\hline CHEMBL1432332 & 688476 & 5.0 & 4.7376 & TRN & \\
\hline CHEMBL1491702 & 688476 & 4.65 & 4.8197 & TST & \\
\hline CHEMBL1578687 & 688476 & 4.3 & 4.9676 & TRN & \\
\hline CHEMBL1730100 & 688476 & 5.5 & 5.2488 & TST & \\
\hline CHEMBL1535956 & 688476 & 8.7447 & 5.5504 & TRN & \\
\hline CHEMBL1333879 & 688476 & 4.0 & 4.4532 & TRN & \\
\hline CHEMBL1344810 & 688476 & 4.0 & 4.2914 & TRN & \\
\hline CHEMBL1580036 & 688476 & 4.25 & 4.0632 & TRN & \\
\hline CHEMBL1572280 & 688476 & 4.4 & 5.0703 & TRN & \\
\hline
\end{tabular}




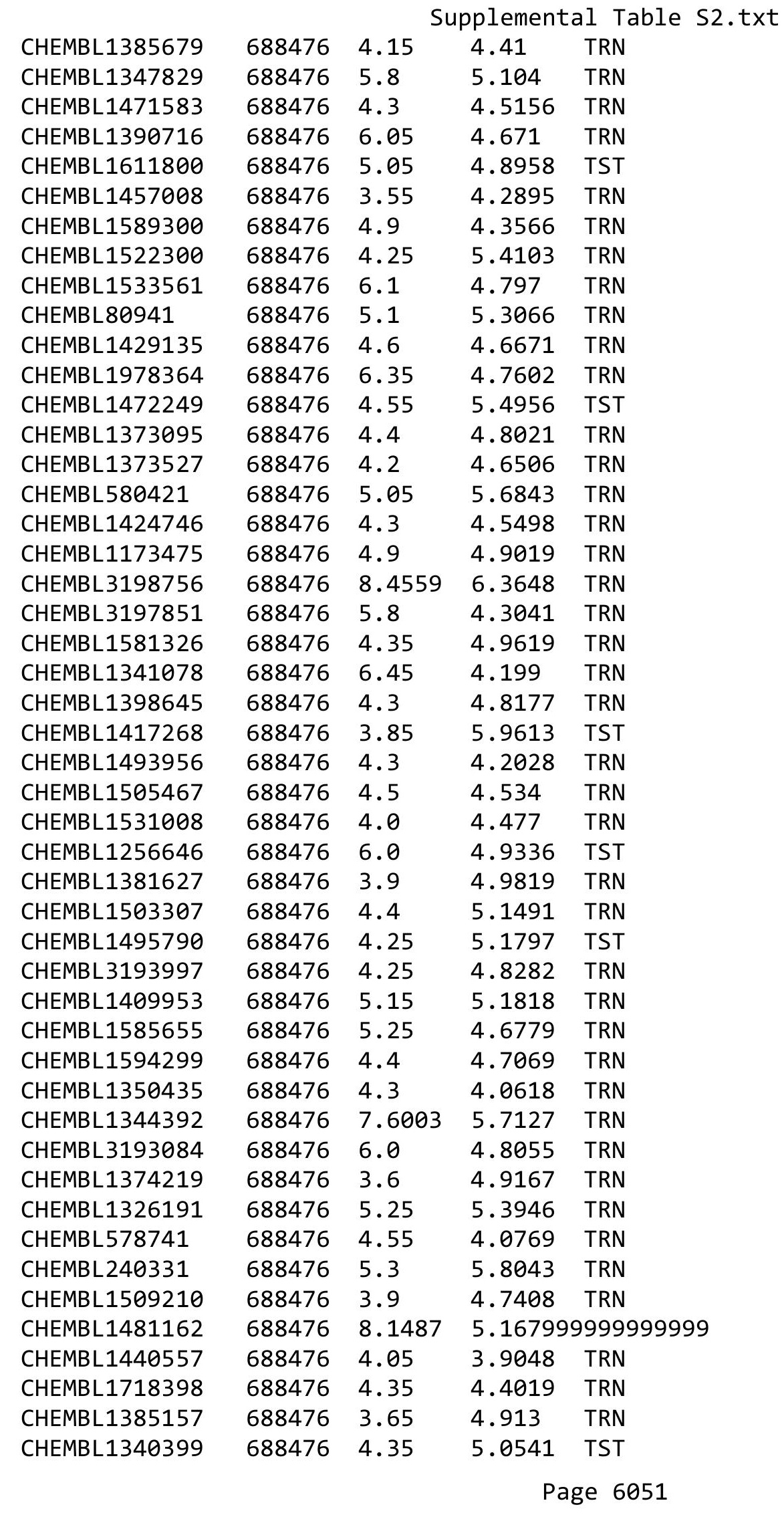

TRN 


\begin{tabular}{|c|c|c|c|c|c|}
\hline \\
\hline CHEMBL1574820 & 688476 & 4.8 & 5.2226 & TRN & \\
\hline CHEMBL3192701 & 688476 & 4.2 & 5.3636 & TRN & \\
\hline CHEMBL1412163 & 688476 & 4.6 & 4.8346 & TST & \\
\hline CHEMBL1993613 & 688476 & 4.35 & 5.1347 & TRN & \\
\hline CHEMBL1550228 & 688476 & 3.85 & 4.7193 & TRN & \\
\hline CHEMBL97453 & 688476 & 4.35 & 4.8667 & TRN & \\
\hline CHEMBL1449836 & 688476 & 4.3 & 4.4939 & TRN & \\
\hline CHEMBL1469647 & 688476 & 4.35 & 4.4629 & TRN & \\
\hline CHEMBL493863 & 688476 & 7.6003 & 5.5591 & TRN & \\
\hline CHEMBL15192 & 688476 & 5.0 & 5.0003 & TRN & \\
\hline CHEMBL1423129 & 688476 & 3.95 & 4.8823 & TRN & \\
\hline CHEMBL1324853 & 688476 & 3.7 & 4.5443 & TRN & \\
\hline CHEMBL3194626 & 688476 & 4.05 & 4.716 & TRN & \\
\hline CHEMBL1502839 & 688476 & 5.7 & 5.4256 & TRN & \\
\hline CHEMBL584759 & 688476 & 6.0 & 6.7424 & TRN & \\
\hline CHEMBL1324247 & 688476 & 6.25 & 4.7641 & TRN & \\
\hline CHEMBL1373950 & 688476 & 4.8 & 4.404 & TST & \\
\hline CHEMBL1364011 & 688476 & 4.9 & 5.1372 & TST & \\
\hline CHEMBL1429273 & 688476 & 3.6 & 4.58899 & 99999999995 & TRN \\
\hline CHEMBL1341927 & 688476 & 6.4 & 5.4435 & TRN & \\
\hline CHEMBL1419637 & 688476 & 6.05 & 4.4379 & TRN & \\
\hline CHEMBL1518838 & 688476 & 4.55 & 5.045 & TRN & \\
\hline CHEMBL1562712 & 688476 & 7.2503 & 6.0264 & TRN & \\
\hline CHEMBL1312514 & 688476 & 6.7501 & 5.7377 & TRN & \\
\hline CHEMBL399043 & 688476 & 4.95 & 4.7431 & TST & \\
\hline CHEMBL1346456 & 688476 & 4.3 & 5.3378 & TST & \\
\hline CHEMBL546257 & 688476 & 5.2 & 5.1481 & TST & \\
\hline CHEMBL1557372 & 688476 & 4.4 & 3.9897 & TRN & \\
\hline CHEMBL1464373 & 688476 & 4.4 & 4.4015 & TST & \\
\hline CHEMBL1451483 & 688476 & 5.35 & 5.1044 & TST & \\
\hline CHEMBL1462808 & 688476 & 4.4 & 4.2859 & TST & \\
\hline CHEMBL1443157 & 688476 & 4.8 & 5.5534 & TST & \\
\hline CHEMBL1548055 & 688476 & 8.0506 & 4.8471 & TST & \\
\hline CHEMBL1546656 & 688476 & 4.3 & 4.8783 & TST & \\
\hline CHEMBL1407306 & 688476 & 8.0506 & 4.6358 & TST & \\
\hline CHEMBL1520155 & 688476 & 4.5 & 4.5565 & TST & \\
\hline CHEMBL1320230 & 688476 & 4.85 & 5.1718 & TST & \\
\hline CHEMBL187460 & 688476 & 4.55 & 5.1348 & TST & \\
\hline CHEMBL1567099 & 688476 & 4.55 & 5.3021 & TST & \\
\hline CHEMBL 1706577 & 688476 & 4.75 & 4.6562 & TST & \\
\hline CHEMBL1388659 & 688476 & 4.2 & 4.6867 & TST & \\
\hline CHEMBL1424412 & 688476 & 4.3 & 5.4184 & TST & \\
\hline CHEMBL1578278 & 688476 & 8.4559 & 4.4635 & TST & \\
\hline CHEMBL1968540 & 688476 & 8.7447 & 5.2982 & TST & \\
\hline CHEMBL1522129 & 688476 & 4.35 & 4.3512 & TST & \\
\hline CHEMBL599013 & 688476 & 4.4 & 4.7021 & TST & \\
\hline CHEMBL1224512 & 688476 & 5.35 & 4.9746 & TST & \\
\hline CHEMBL106525 & 688476 & 4.45 & 5.1539 & TST & \\
\hline
\end{tabular}




\begin{tabular}{|c|c|c|c|c|c|}
\hline \multicolumn{6}{|c|}{ Supplemental Table S2.txt } \\
\hline CHEMBL1309506 & 688476 & 4.05 & 4.8275 & TST & \\
\hline CHEMBL1588434 & 688476 & 5.45 & 4.3841 & TST & \\
\hline CHEMBL1465322 & 688476 & 5.5 & 4.7865 & TST & \\
\hline CHEMBL1434137 & 688476 & 3.95 & 5.5323 & TST & \\
\hline CHEMBL1511287 & 688476 & 6.9 & 4.2265 & TST & \\
\hline CHEMBL1374242 & 688476 & 4.55 & 4.5551 & TST & \\
\hline CHEMBL1397833 & 688476 & 4.35 & 5.4201 & TST & \\
\hline CHEMBL78573 & 688476 & 5.35 & 5.3463 & TST & \\
\hline CHEMBL1538232 & 688476 & 5.65 & 4.5814 & TST & \\
\hline CHEMBL1305289 & 688476 & 4.25 & 5.2567 & TST & \\
\hline CHEMBL1464853 & 688476 & 4.35 & 4.8729 & TST & \\
\hline CHEMBL1452561 & 688334 & 5.75 & 5.6072 & TRN & \\
\hline CHEMBL28626 & 688334 & 5.0 & 5.5555 & TRN & \\
\hline CHEMBL574181 & 688334 & 4.95 & 5.4787 & TRN & \\
\hline CHEMBL1356777 & 688334 & 6.5 & 5.4968 & TST & \\
\hline CHEMBL98350 & 688334 & 5.15 & 5.5396 & TRN & \\
\hline CHEMBL1527442 & 688334 & 4.9 & 5.5945 & TST & \\
\hline CHEMBL1480136 & 688334 & 5.25 & 5.54799 & 9999999999 & TRN \\
\hline CHEMBL10284 & 688334 & 4.9 & 5.1465 & TRN & \\
\hline CHEMBL1354145 & 688334 & 4.95 & 5.4961 & TRN & \\
\hline CHEMBL280065 & 688334 & 6.95 & 5.6372 & TRN & \\
\hline CHEMBL1439172 & 688334 & 5.3 & 5.5212 & TRN & \\
\hline CHEMBL78150 & 688334 & 5.0 & 5.6801 & TRN & \\
\hline CHEMBL1367076 & 688334 & 5.85 & 5.7888 & TRN & \\
\hline CHEMBL52 & 688334 & 5.1 & 5.6101 & TRN & \\
\hline CHEMBL258767 & 688334 & 6.0 & 5.4667 & TRN & \\
\hline CHEMBL1255747 & 688334 & 5.1 & 5.7495 & TRN & \\
\hline CHEMBL113830 & 688334 & 6.0 & 5.84 & TRN & \\
\hline CHEMBL153057 & 688334 & 5.0 & 5.8626 & TRN & \\
\hline CHEMBL275006 & 688334 & 5.3 & 5.6624 & TRN & \\
\hline CHEMBL28 & 688334 & 4.7 & 5.495 & TRN & \\
\hline CHEMBL1435477 & 688334 & 5.95 & 5.3262 & TRN & \\
\hline CHEMBL3392050 & 688334 & 4.95 & 5.645 & TRN & \\
\hline CHEMBL8488 & 688334 & 6.8499 & 5.6924 & TRN & \\
\hline CHEMBL362863 & 688334 & 5.2 & 6.1227 & TRN & \\
\hline CHEMBL1400543 & 688334 & 6.0 & 5.4744 & TRN & \\
\hline CHEMBL1256359 & 688334 & 4.75 & 5.5153 & TRN & \\
\hline CHEMBL33884 & 688334 & 5.0 & 5.7122 & TRN & \\
\hline CHEMBL1255657 & 688334 & 4.9 & 5.3387 & TRN & \\
\hline CHEMBL 72631 & 688334 & 7.7496 & 5.7571 & TRN & \\
\hline CHEMBL64239 & 688334 & 5.95 & 5.8719 & TRN & \\
\hline CHEMBL326967 & 688334 & 4.95 & 5.5913 & TRN & \\
\hline CHEMBL 2374058 & 688334 & 8.0 & 5.9469 & TST & \\
\hline CHEMBL1607062 & 688334 & 8.301 & 5.4364 & TRN & \\
\hline CHEMBL1567944 & 688334 & 5.2 & 5.9039 & TRN & \\
\hline CHEMBL 6640 & 688334 & 4.9 & 5.4154 & TRN & \\
\hline CHEMBL1256916 & 688334 & 6.45 & 5.5166 & TRN & \\
\hline CHEMBL286722 & 688334 & 5.75 & 5.7136 & TRN & \\
\hline
\end{tabular}




\begin{tabular}{|c|c|c|c|c|}
\hline \multicolumn{5}{|c|}{ Supplemental Table S2.txt } \\
\hline CHEMBL1585944 & 688334 & 8.0 & 5.7491 & TRN \\
\hline CHEMBL143324 & 688334 & 6.8 & 5.4674 & TRN \\
\hline CHEMBL1377507 & 688334 & 8.0 & 6.0075 & TRN \\
\hline CHEMBL153036 & 688334 & 5.3 & 5.4576 & TRN \\
\hline CHEMBL1435313 & 688334 & 8.0 & 6.0729 & TRN \\
\hline CHEMBL1256749 & 688334 & 5.05 & 5.1003 & TRN \\
\hline CHEMBL32590 & 688334 & 6.7001 & 5.8337 & TRN \\
\hline CHEMBL546257 & 688334 & 4.95 & 5.4121 & TRN \\
\hline CHEMBL1256984 & 688334 & 5.2 & 5.6335 & TRN \\
\hline CHEMBL1256514 & 688334 & 4.85 & 5.6182 & TRN \\
\hline CHEMBL1256719 & 688334 & 5.1 & 6.0132 & TRN \\
\hline CHEMBL56543 & 688334 & 5.2 & 5.5842 & TRN \\
\hline CHEMBL538595 & 688334 & 6.0 & 5.1812 & TRN \\
\hline CHEMBL1512111 & 688334 & 6.6499 & 6.0441 & TRN \\
\hline CHEMBL 288096 & 688334 & 5.25 & 5.5276 & TRN \\
\hline CHEMBL9843 & 688334 & 5.05 & 5.1809 & TRN \\
\hline CHEMBL22870 & 688334 & 5.0 & 5.7231 & TRN \\
\hline CHEMBL1591556 & 688334 & 7.0 & 6.1072 & TRN \\
\hline CHEMBL1256177 & 688334 & 5.0 & 5.5362 & TRN \\
\hline CHEMBL1461491 & 688334 & 5.2 & 5.9705 & TRN \\
\hline CHEMBL1097940 & 688334 & 5.45 & 5.7339 & TRN \\
\hline CHEMBL 303579 & 688334 & 5.5 & 5.3832 & TRN \\
\hline CHEMBL1373007 & 688334 & 5.85 & 5.6413 & TST \\
\hline CHEMBL1534566 & 688334 & 5.9 & 5.3761 & TRN \\
\hline CHEMBL1522486 & 688334 & 5.3 & 5.3277 & TRN \\
\hline CHEMBL258405 & 688334 & 4.55 & 5.1979 & TRN \\
\hline CHEMBL1256751 & 688334 & 5.6 & 5.6619 & TRN \\
\hline CHEMBL1256687 & 688334 & 5.6 & 5.6265 & TRN \\
\hline CHEMBL8747 & 688334 & 6.05 & 5.7921 & TRN \\
\hline CHEMBL1256775 & 688334 & 5.1 & 5.34 & TRN \\
\hline CHEMBL1191361 & 688334 & 4.8 & 5.6214 & TST \\
\hline CHEMBL53898 & 688334 & 5.95 & 5.6321 & TRN \\
\hline CHEMBL1338229 & 688334 & 4.9 & 5.53299 & 99999999995 \\
\hline CHEMBL1515691 & 688334 & 5.3 & 5.82299 & 99999999995 \\
\hline CHEMBL1255836 & 688334 & 4.55 & 5.5718 & TRN \\
\hline CHEMBL1323714 & 688334 & 7.699 & 5.5159 & TST \\
\hline CHEMBL111545 & 688334 & 7.5003 & 5.2885 & TRN \\
\hline CHEMBL40998 & 688334 & 5.05 & 5.0095 & TRN \\
\hline CHEMBL252909 & 688334 & 5.45 & 5.6834 & TRN \\
\hline CHEMBL 250892 & 688334 & 5.2 & 5.584 & TRN \\
\hline CHEMBL559612 & 688334 & 4.55 & 5.8998 & TST \\
\hline CHEMBL110739 & 688334 & 7.699 & 6.0349 & TRN \\
\hline CHEMBL93655 & 688334 & 4.55 & 5.1845 & TRN \\
\hline CHEMBL66 & 688334 & 5.8 & 5.7274 & TRN \\
\hline CHEMBL107251 & 688334 & 6.5 & 5.5784 & TRN \\
\hline CHEMBL72365 & 688334 & 5.05 & 5.7269 & TRN \\
\hline CHEMBL1256674 & 688334 & 5.25 & 5.4764 & TST \\
\hline CHEMBL428768 & 688334 & 6.9 & 5.6895 & TRN \\
\hline
\end{tabular}




\begin{tabular}{|c|c|c|c|c|c|}
\hline & & \multicolumn{4}{|c|}{ Supplemental Table s2.txt } \\
\hline CHEMBL1336727 & 688334 & 8.1024 & 5.4917 & TRN & \\
\hline CHEMBL1515334 & 688334 & 6.6 & 5.145 & TRN & \\
\hline CHEMBL188 & 688334 & 4.55 & 5.4734 & TRN & \\
\hline CHEMBL543467 & 688334 & 5.1 & 5.4621 & TRN & \\
\hline CHEMBL1322959 & 688334 & 4.55 & 5.6116 & TRN & \\
\hline CHEMBL1256390 & 688334 & 4.55 & 5.4176 & TRN & \\
\hline CHEMBL330129 & 688334 & 5.95 & 5.6204 & TRN & \\
\hline CHEMBL391997 & 688334 & 5.4 & 5.7044 & TRN & \\
\hline CHEMBL67535 & 688334 & 5.25 & 5.7283 & TRN & \\
\hline CHEMBL8080 & 688334 & 8.4559 & 5.8317 & TST & \\
\hline CHEMBL 2110371 & 688334 & 7.6003 & 5.4282 & TRN & \\
\hline CHEMBL544115 & 688334 & 4.9 & 5.483 & TRN & \\
\hline CHEMBL278755 & 688334 & 4.6 & 5.2368 & TRN & \\
\hline CHEMBL1394757 & 688334 & 6.6 & 5.7666 & TST & \\
\hline CHEMBL267548 & 688334 & 6.5 & 5.4551 & TST & \\
\hline CHEMBL261642 & 688334 & 6.0 & 5.449 & TRN & \\
\hline CHEMBL319244 & 688334 & 5.65 & 5.7334 & TRN & \\
\hline CHEMBL 2449003 & 688334 & 6.0 & 5.6639 & TRN & \\
\hline CHEMBL 275854 & 688334 & 6.45 & 5.7707 & TRN & \\
\hline CHEMBL1224512 & 688334 & 5.9 & 5.6715 & TRN & \\
\hline CHEMBL1330357 & 688334 & 4.75 & 5.7852 & TRN & \\
\hline CHEMBL1529217 & 688334 & 8.4559 & 5.805 & TST & \\
\hline CHEMBL60518 & 688334 & 6.35 & 5.6335 & TRN & \\
\hline CHEMBL541585 & 688334 & 7.7496 & 5.65600 & 0000000001 & TRN \\
\hline CHEMBL1472703 & 688334 & 6.4 & 5.7316 & TRN & \\
\hline CHEMBL65 & 688334 & 5.35 & 5.5591 & TST & \\
\hline CHEMBL1255656 & 688334 & 5.45 & 5.9106 & TRN & \\
\hline CHEMBL1400884 & 688334 & 6.95 & 5.7426 & TRN & \\
\hline CHEMBL327708 & 688334 & 5.0 & 6.0964 & TRN & \\
\hline CHEMBL1257002 & 688334 & 5.45 & 5.6812 & TRN & \\
\hline CHEMBL23507 & 688334 & 5.35 & 5.5839 & TRN & \\
\hline CHEMBL1436268 & 688334 & 4.85 & 5.6943 & TST & \\
\hline CHEMBL63329 & 688334 & 4.95 & 5.2597 & TRN & \\
\hline CHEMBL12014 & 688334 & 5.7 & 5.2897 & TRN & \\
\hline CHEMBL48278 & 688334 & 6.4 & 5.7917 & TRN & \\
\hline CHEMBL 277120 & 688334 & 4.95 & 5.3728 & TRN & \\
\hline CHEMBL1320310 & 688334 & 5.05 & 5.9625 & TRN & \\
\hline CHEMBL10347 & 688334 & 4.55 & 5.8012 & TRN & \\
\hline CHEMBL1256686 & 688334 & 5.25 & 5.8806 & TST & \\
\hline CHEMBL1526852 & 688334 & 8.4559 & 5.9277 & TRN & \\
\hline CHEMBL30432 & 688334 & 5.1 & 5.3695 & TRN & \\
\hline CHEMBL1324405 & 688334 & 6.4 & 5.6019 & TRN & \\
\hline CHEMBL86676 & 688334 & 5.3 & 5.678 & TST & \\
\hline CHEMBL553503 & 688334 & 5.4 & 5.475 & TRN & \\
\hline CHEMBL262083 & 688334 & 5.65 & 5.5901 & TRN & \\
\hline CHEMBL 260374 & 688334 & 6.5 & 6.1097 & TST & \\
\hline CHEMBL275516 & 688334 & 5.2 & 5.7453 & TST & \\
\hline CHEMBL48449 & 688334 & 5.2 & 5.6816 & TST & \\
\hline
\end{tabular}




\begin{tabular}{|c|c|c|c|c|}
\hline \multicolumn{5}{|c|}{ Supplemental Table S2.txt } \\
\hline CHEMBL17468 & 688334 & 5.25 & 5.9615 & TRN \\
\hline CHEMBL1457550 & 688334 & 5.5 & 5.3406 & TRN \\
\hline CHEMBL269733 & 688334 & 8.1487 & 5.7671 & TRN \\
\hline CHEMBL1256836 & 688334 & 5.0 & 5.6091 & TRN \\
\hline CHEMBL1256667 & 688334 & 4.55 & 5.6121 & TST \\
\hline CHEMBL1329218 & 688334 & 7.6498 & 5.7626 & TST \\
\hline CHEMBL1571692 & 688334 & 5.7 & 6.1914 & TRN \\
\hline CHEMBL2374259 & 688334 & 4.65 & 6.0714 & TRN \\
\hline CHEMBL441948 & 688334 & 4.55 & 5.1405 & TRN \\
\hline CHEMBL45281 & 688334 & 5.0 & 5.5141 & TRN \\
\hline CHEMBL1526455 & 688334 & 4.75 & 5.2565 & TRN \\
\hline CHEMBL1395058 & 688334 & 5.0 & 5.1165 & TRN \\
\hline CHEMBL76904 & 688334 & 4.95 & 5.6994 & TRN \\
\hline CHEMBL1316222 & 688334 & 5.2 & 5.5013 & TRN \\
\hline CHEMBL1173475 & 688334 & 5.25 & 5.6427 & TRN \\
\hline CHEMBL1520394 & 688334 & 5.3 & 6.075 & TRN \\
\hline CHEMBL51697 & 688334 & 4.95 & 5.4058 & TRN \\
\hline CHEMBL333985 & 688334 & 5.05 & 5.2364 & TRN \\
\hline CHEMBL 216504 & 688334 & 6.6499 & 5.7759 & TRN \\
\hline CHEMBL1395661 & 688334 & 5.5 & 5.9716 & TRN \\
\hline CHEMBL1315457 & 688334 & 5.0 & 5.2655 & TST \\
\hline CHEMBL1521453 & 688334 & 8.4559 & 6.1513 & TRN \\
\hline CHEMBL1257075 & 688334 & 5.05 & 5.5084 & TRN \\
\hline CHEMBL1456417 & 688334 & 4.55 & 6.0099 & TRN \\
\hline CHEMBL 21241 & 688334 & 4.85 & 6.1977 & TRN \\
\hline CHEMBL 275311 & 688334 & 5.0 & 5.6329 & TRN \\
\hline CHEMBL 280074 & 688334 & 5.2 & 5.3717 & TRN \\
\hline CHEMBL1329033 & 688334 & 5.0 & 5.5593 & TRN \\
\hline CHEMBL146855 & 688334 & 6.1 & 5.6134 & TRN \\
\hline CHEMBL67378 & 688334 & 5.3 & 6.0339 & TRN \\
\hline CHEMBL1472989 & 688334 & 5.45 & 6.2322 & TRN \\
\hline CHEMBL1256623 & 688334 & 5.95 & 5.7402 & TRN \\
\hline CHEMBL1255841 & 688334 & 7.6003 & 5.8334 & TRN \\
\hline CHEMBL1208858 & 688334 & 4.95 & 5.4924 & TST \\
\hline CHEMBL1200450 & 688334 & 4.55 & 5.2863 & TRN \\
\hline CHEMBL1355710 & 688334 & 5.45 & 5.4082 & TRN \\
\hline CHEMBL1591158 & 688334 & 7.15 & 5.154 & TRN \\
\hline CHEMBL1605605 & 688334 & 5.1 & 5.5904 & TRN \\
\hline CHEMBL52387 & 688334 & 4.95 & 5.4964 & TRN \\
\hline CHEMBL263972 & 688334 & 7.15 & 5.3078 & TRN \\
\hline CHEMBL51085 & 688334 & 4.9 & 5.5833 & TRN \\
\hline CHEMBL1436438 & 688334 & 5.3 & 6.0005 & TRN \\
\hline CHEMBL611494 & 688334 & 6.0 & 5.6002 & TST \\
\hline CHEMBL1255733 & 688334 & 6.7001 & 6.0723 & TRN \\
\hline CHEMBL1257013 & 688334 & 4.95 & 5.5514 & TRN \\
\hline CHEMBL1200462 & 688334 & 5.1 & 5.5166 & TRN \\
\hline CHEMBL1256974 & 688334 & 4.95 & 5.0445 & TRN \\
\hline CHEMBL7917 & 688334 & 4.8 & 5.8412 & TRN \\
\hline
\end{tabular}




\begin{tabular}{|c|c|c|c|c|c|}
\hline \multicolumn{6}{|c|}{ Supplemental Table S2.txt } \\
\hline CHEMBL1255649 & 688334 & 4.65 & 5.5845 & TRN & \\
\hline CHEMBL294590 & 688334 & 6.0 & 5.9258 & TRN & \\
\hline CHEMBL484928 & 688334 & 5.3 & 5.3881 & TRN & \\
\hline CHEMBL1380684 & 688334 & 7.8996 & 5.5798 & TRN & \\
\hline CHEMBL123 & 688334 & 5.85 & 5.2368 & TRN & \\
\hline CHEMBL1559663 & 688334 & 6.8 & 6.1108 & TRN & \\
\hline CHEMBL595227 & 688334 & 5.7 & 5.4214 & TRN & \\
\hline CHEMBL80941 & 688334 & 7.5498 & 5.7764 & TRN & \\
\hline CHEMBL1256995 & 688334 & 7.6498 & 5.6086 & TRN & \\
\hline CHEMBL8165 & 688334 & 5.3 & 5.5459 & TRN & \\
\hline CHEMBL1595524 & 688334 & 4.95 & 5.2915 & TRN & \\
\hline CHEMBL1237212 & 688334 & 4.55 & 5.8616 & TST & \\
\hline CHEMBL1316314 & 688334 & 4.85 & 6.0162 & TRN & \\
\hline CHEMBL1590980 & 688334 & 5.35 & 5.61299 & 99999999995 & TRN \\
\hline CHEMBL1398537 & 688334 & 6.25 & 5.5288 & TRN & \\
\hline CHEMBL182461 & 688334 & 5.3 & 5.5281 & TRN & \\
\hline CHEMBL1358012 & 688334 & 5.95 & 5.6843 & TRN & \\
\hline CHEMBL1372997 & 688334 & 8.4559 & 5.9898 & TRN & \\
\hline CHEMBL 280998 & 688334 & 5.65 & 5.5257 & TRN & \\
\hline CHEMBL13791 & 688334 & 5.0 & 5.6034 & TRN & \\
\hline CHEMBL1336166 & 688334 & 4.85 & 5.4285 & TRN & \\
\hline CHEMBL293749 & 688334 & 5.85 & 5.6219 & TRN & \\
\hline CHEMBL1528565 & 688334 & 4.9 & 5.7396 & TRN & \\
\hline CHEMBL 77456 & 688334 & 5.05 & 5.6329 & TRN & \\
\hline CHEMBL578741 & 688334 & 5.95 & 5.4855 & TRN & \\
\hline CHEMBL540848 & 688334 & 4.8 & 5.3758 & TRN & \\
\hline CHEMBL1255936 & 688334 & 4.75 & 5.4831 & TRN & \\
\hline CHEMBL355496 & 688334 & 5.65 & 5.5792 & TRN & \\
\hline CHEMBL1514440 & 688334 & 5.15 & 5.1813 & TRN & \\
\hline CHEMBL1561474 & 688334 & 5.3 & 5.4447 & TRN & \\
\hline CHEMBL56731 & 688334 & 6.0 & 5.711 & TRN & \\
\hline CHEMBL258893 & 688334 & 4.95 & 6.0001 & TST & \\
\hline CHEMBL1256814 & 688334 & 5.0 & 5.6301 & TRN & \\
\hline CHEMBL1256186 & 688334 & 8.3979 & 5.7123 & TRN & \\
\hline CHEMBL1514375 & 688334 & 5.95 & 5.4772 & TST & \\
\hline CHEMBL395915 & 688334 & 5.25 & 5.6863 & TRN & \\
\hline CHEMBL286077 & 688334 & 6.95 & 5.5117 & TRN & \\
\hline CHEMBL1367565 & 688334 & 5.3 & 5.7109 & TRN & \\
\hline CHEMBL1256754 & 688334 & 4.65 & 5.8425 & TRN & \\
\hline CHEMBL1517187 & 688334 & 4.8 & 5.7074 & TRN & \\
\hline CHEMBL106265 & 688334 & 4.95 & 5.8349 & TRN & \\
\hline CHEMBL77971 & 688334 & 5.5 & 6.0406 & TRN & \\
\hline CHEMBL 388054 & 688334 & 6.6 & 5.8496 & TRN & \\
\hline CHEMBL434063 & 688334 & 4.9 & 5.4614 & TRN & \\
\hline CHEMBL876 & 688334 & 5.0 & 5.4239 & TRN & \\
\hline CHEMBL1096400 & 688334 & 6.35 & 5.8279 & TRN & \\
\hline CHEMBL1395737 & 688334 & 4.9 & 5.6036 & TRN & \\
\hline CHEMBL88621 & 688334 & 4.6 & 5.3984 & TRN & \\
\hline
\end{tabular}




\begin{tabular}{|c|c|c|c|c|c|}
\hline \multicolumn{6}{|c|}{ Supplemental Table s2.txt } \\
\hline CHEMBL441282 & 688334 & 4.55 & 5.568 & TRN & \\
\hline CHEMBL 28140 & 688334 & 5.35 & 5.5965 & TRN & \\
\hline CHEMBL1493117 & 688334 & 5.55 & 5.5712 & TRN & \\
\hline CHEMBL15192 & 688334 & 5.05 & 5.396 & TRN & \\
\hline CHEMBL1361446 & 688334 & 4.7 & 5.5318 & TRN & \\
\hline CHEMBL1520976 & 688334 & 4.7 & 5.5391 & TST & \\
\hline CHEMBL1257041 & 688334 & 5.05 & 5.5402 & TRN & \\
\hline CHEMBL428496 & 688334 & 6.8499 & 5.81 & TST & \\
\hline CHEMBL1256876 & 688334 & 5.2 & 6.0191 & TST & \\
\hline CHEMBL1531863 & 688334 & 4.55 & 5.6344 & TRN & \\
\hline CHEMBL270299 & 688334 & 4.7 & 5.5991 & TST & \\
\hline CHEMBL3216928 & 688334 & 4.95 & 5.7393 & TRN & \\
\hline CHEMBL1598680 & 688334 & 5.05 & 5.0796 & TRN & \\
\hline CHEMBL 26320 & 688334 & 5.0 & 5.5181 & TRN & \\
\hline CHEMBL17331 & 688334 & 4.9 & 5.3081 & TRN & \\
\hline CHEMBL1357016 & 688334 & 5.6 & 5.9591 & TRN & \\
\hline CHEMBL1256646 & 688334 & 4.95 & 5.7238 & TRN & \\
\hline CHEMBL90472 & 688334 & 5.7 & 5.5174 & TST & \\
\hline CHEMBL1336469 & 688334 & 5.1 & 5.82600 & 00000000005 & TRN \\
\hline CHEMBL1256484 & 688334 & 5.65 & 5.5413 & TRN & \\
\hline CHEMBL10009 & 688334 & 6.5501 & 5.858 & TRN & \\
\hline CHEMBL1435120 & 688334 & 5.4 & 5.41799 & 9999999999 & TRN \\
\hline CHEMBL14276 & 688334 & 5.95 & 5.9103 & TRN & \\
\hline CHEMBL410873 & 688334 & 5.0 & 5.7241 & TRN & \\
\hline CHEMBL34241 & 688334 & 6.1 & 5.5344 & TRN & \\
\hline CHEMBL47814 & 688334 & 5.5 & 5.5493 & TRN & \\
\hline CHEMBL336467 & 688334 & 5.0 & 5.1512 & TST & \\
\hline CHEMBL177820 & 688334 & 5.3 & 5.4633 & TST & \\
\hline CHEMBL1256737 & 688334 & 5.65 & 5.4214 & TRN & \\
\hline CHEMBL1236872 & 688334 & 5.35 & 5.6443 & TRN & \\
\hline CHEMBL1256624 & 688334 & 6.0 & 6.1819 & TRN & \\
\hline CHEMBL1255749 & 688334 & 4.9 & 5.54899 & 99999999995 & TRN \\
\hline CHEMBL305195 & 688334 & 5.1 & 5.7242 & TRN & \\
\hline CHEMBL1256191 & 688334 & 6.0 & 5.8455 & TRN & \\
\hline CHEMBL1256625 & 688334 & 6.8499 & 5.6906 & TRN & \\
\hline CHEMBL1407012 & 688334 & 5.65 & 5.5825 & TRN & \\
\hline CHEMBL1256148 & 688334 & 6.0 & 5.724 & TRN & \\
\hline CHEMBL1553428 & 688334 & 7.7496 & 6.0292 & TRN & \\
\hline CHEMBL46257 & 688334 & 4.55 & 5.4537 & TRN & \\
\hline CHEMBL299613 & 688334 & 7.0501 & 6.1536 & TRN & \\
\hline CHEMBL3186408 & 688334 & 5.0 & 5.5851 & TST & \\
\hline CHEMBL1399702 & 688334 & 4.65 & 5.585 & TRN & \\
\hline CHEMBL 278041 & 688334 & 4.95 & 5.5584 & TRN & \\
\hline CHEMBL539947 & 688334 & 4.95 & 5.76200 & 00000000005 & TRN \\
\hline CHEMBL267014 & 688334 & 4.55 & 5.4848 & TRN & \\
\hline CHEMBL1433897 & 688334 & 6.2 & 5.6414 & TRN & \\
\hline CHEMBL1256943 & 688334 & 7.0 & 5.6303 & TRN & \\
\hline CHEMBL1256656 & 688334 & 6.8499 & 6.3468 & TRN & \\
\hline
\end{tabular}




\begin{tabular}{|c|c|c|c|c|c|}
\hline \multicolumn{6}{|c|}{ Supplemental Table S2.txt } \\
\hline CHEMBL1257003 & 688334 & 5.6 & 6.1279 & TRN & \\
\hline CHEMBL1552165 & 688334 & 5.55 & 5.4263 & TRN & \\
\hline CHEMBL1552095 & 688334 & 5.9 & 5.843 & TRN & \\
\hline CHEMBL1256360 & 688334 & 6.0 & 5.8575 & TRN & \\
\hline CHEMBL1473712 & 688334 & 5.3 & 5.3461 & TRN & \\
\hline CHEMBL68534 & 688334 & 4.95 & 5.895 & TRN & \\
\hline CHEMBL1355963 & 688334 & 4.95 & 6.0666 & TST & \\
\hline CHEMBL87285 & 688334 & 5.8 & 5.7805 & TRN & \\
\hline CHEMBL1562 & 688334 & 8.4559 & 6.0045 & TRN & \\
\hline CHEMBL 2374062 & 688334 & 6.0 & 5.8453 & TST & \\
\hline CHEMBL1331383 & 688334 & 5.0 & 5.7291 & TRN & \\
\hline CHEMBL24983 & 688334 & 5.2 & 5.2975 & TRN & \\
\hline CHEMBL 282489 & 688334 & 5.0 & 5.69600 & 0000000001 & TRN \\
\hline CHEMBL129795 & 688334 & 5.5 & 5.6661 & TRN & \\
\hline CHEMBL1256693 & 688334 & 6.0 & 5.6796 & TRN & \\
\hline CHEMBL77030 & 688334 & 5.25 & 5.7579 & TRN & \\
\hline CHEMBL58343 & 688334 & 6.45 & 5.6156 & TRN & \\
\hline CHEMBL 268868 & 688334 & 5.0 & 5.4794 & TRN & \\
\hline CHEMBL109037 & 688334 & 5.15 & 5.5689 & TRN & \\
\hline CHEMBL145 & 688334 & 6.8499 & 5.7169 & TRN & \\
\hline CHEMBL416657 & 688334 & 4.9 & 5.5547 & TRN & \\
\hline CHEMBL903 & 688334 & 5.0 & 5.605 & TRN & \\
\hline CHEMBL1256291 & 688334 & 6.25 & 5.4644 & TRN & \\
\hline CHEMBL1255650 & 688334 & 4.9 & 5.4597 & TRN & \\
\hline CHEMBL80155 & 688334 & 5.5 & 5.9787 & TRN & \\
\hline CHEMBL1366616 & 688334 & 4.55 & 5.4712 & TRN & \\
\hline CHEMBL1436121 & 688334 & 7.1002 & 5.3134 & TST & \\
\hline CHEMBL1253351 & 688334 & 5.9 & 5.8756 & TRN & \\
\hline CHEMBL310798 & 688334 & 5.45 & 5.6921 & TRN & \\
\hline CHEMBL102714 & 688334 & 5.2 & 5.182 & TRN & \\
\hline CHEMBL268609 & 688334 & 4.85 & 5.1418 & TRN & \\
\hline CHEMBL1256697 & 688334 & 5.1 & 5.73799 & 99999999995 & TRN \\
\hline CHEMBL598952 & 688334 & 5.25 & 5.3427 & TST & \\
\hline CHEMBL605003 & 688334 & 5.8 & 5.8573 & TRN & \\
\hline CHEMBL 266084 & 688334 & 5.3 & 5.8101 & TRN & \\
\hline CHEMBL1256851 & 688334 & 6.35 & 5.5034 & TRN & \\
\hline CHEMBL 250711 & 688334 & 4.7 & 5.6589 & TRN & \\
\hline CHEMBL251647 & 688334 & 5.9 & 5.3855 & TST & \\
\hline CHEMBL1234696 & 688334 & 6.3 & 5.67299 & 9999999999 & TRN \\
\hline CHEMBL168279 & 688334 & 8.0 & 5.4908 & TRN & \\
\hline CHEMBL1338900 & 688334 & 4.55 & 5.5916 & TST & \\
\hline CHEMBL24510 & 688334 & 5.5 & 5.603 & TRN & \\
\hline CHEMBL1472561 & 688334 & 5.05 & 5.8227 & TRN & \\
\hline CHEMBL1440857 & 688334 & 5.4 & 6.28700 & 3000000001 & TST \\
\hline CHEMBL1256835 & 688334 & 4.9 & 5.4315 & TRN & \\
\hline CHEMBL543557 & 688334 & 4.5 & 5.7309 & TRN & \\
\hline CHEMBL 288174 & 688334 & 6.25 & 5.8453 & TST & \\
\hline CHEMBL296586 & 688334 & 5.7 & 5.6177 & TRN & \\
\hline
\end{tabular}




\begin{tabular}{|c|c|c|c|c|c|}
\hline \multicolumn{6}{|c|}{ Supplemental Table S2.txt } \\
\hline CHEMBL1255837 & 688334 & 5.35 & 5.9788 & TRN & \\
\hline CHEMBL1476170 & 688334 & 6.6 & 6.0233 & TRN & \\
\hline CHEMBL1256364 & 688334 & 6.95 & 5.4814 & TRN & \\
\hline CHEMBL1413371 & 688334 & 5.0 & 5.5316 & TRN & \\
\hline CHEMBL27403 & 688334 & 5.0 & 5.5076 & TRN & \\
\hline CHEMBL407232 & 688334 & 6.1 & 5.2933 & TRN & \\
\hline CHEMBL18238 & 688334 & 5.1 & 5.5519 & TRN & \\
\hline CHEMBL1256923 & 688334 & 6.05 & 5.5755 & TRN & \\
\hline CHEMBL1255655 & 688334 & 5.45 & 5.1551 & TRN & \\
\hline CHEMBL596674 & 688334 & 5.55 & 5.7113 & TRN & \\
\hline CHEMBL60718 & 688334 & 5.5 & 4.9048 & TRN & \\
\hline CHEMBL408982 & 688334 & 6.7501 & 5.6909 & TRN & \\
\hline CHEMBL1256511 & 688334 & 5.05 & 5.5099 & TRN & \\
\hline CHEMBL 25236 & 688334 & 5.6 & 6.0411 & TRN & \\
\hline CHEMBL1418227 & 688334 & 5.7 & 5.8921 & TRN & \\
\hline CHEMBL192566 & 688334 & 4.95 & 6.3396 & TST & \\
\hline CHEMBL 23957 & 688334 & 4.55 & 5.6896 & TST & \\
\hline CHEMBL34730 & 688334 & 5.5 & 5.8631 & TRN & \\
\hline CHEMBL104264 & 688334 & 4.9 & 5.4 & TST & \\
\hline CHEMBL1554789 & 688334 & 6.0 & 5.2413 & TST & \\
\hline CHEMBL1256325 & 688334 & 6.4 & 5.5575 & TST & \\
\hline CHEMBL1435381 & 688334 & 4.95 & 5.7074 & TST & \\
\hline CHEMBL1335406 & 688334 & 4.9 & 5.7489 & TST & \\
\hline CHEMBL1372302 & 688334 & 5.55 & 5.3105 & TST & \\
\hline CHEMBL28862 & 688334 & 5.3 & 5.2977 & TST & \\
\hline CHEMBL399491 & 688334 & 5.5 & 5.6712 & TST & \\
\hline CHEMBL1358402 & 688334 & 6.7501 & 6.1863 & TST & \\
\hline CHEMBL543 & 688334 & 8.2007 & 5.2671 & TST & \\
\hline CHEMBL1256910 & 688334 & 5.25 & 5.8603 & TST & \\
\hline CHEMBL310310 & 688334 & 5.0 & 5.4151 & TST & \\
\hline CHEMBL407874 & 688334 & 5.25 & 5.5888 & TST & \\
\hline CHEMBL1256139 & 688334 & 7.5498 & 5.5212 & TST & \\
\hline CHEMBL18701 & 688334 & 5.65 & 6.2453 & TST & \\
\hline CHEMBL429095 & 688334 & 5.4 & 5.4069 & TST & \\
\hline CHEMBL1255867 & 688334 & 5.05 & 5.1269 & TST & \\
\hline CHEMBL1284 & 688334 & 5.85 & 5.6665 & TST & \\
\hline CHEMBL604119 & 688334 & 4.95 & 5.9993 & TST & \\
\hline CHEMBL1256878 & 688334 & 6.2 & 5.1853 & TST & \\
\hline CHEMBL34155 & 688334 & 4.9 & 5.7796 & TST & \\
\hline CHEMBL1398031 & 688334 & 5.5 & 5.45100 & 00000000005 & \\
\hline CHEMBL1256663 & 688334 & 7.5003 & 5.973 & TST & \\
\hline CHEMBL405358 & 688334 & 4.5 & 5.499 & TST & \\
\hline CHEMBL 23832 & 688334 & 6.2 & 5.6792 & TST & \\
\hline CHEMBL1256911 & 688334 & 5.7 & 5.8617 & TST & \\
\hline CHEMBL1368961 & 688334 & 8.5528 & 5.6023 & TST & \\
\hline CHEMBL1523894 & 688334 & 5.05 & 5.3611 & TST & \\
\hline CHEMBL1333056 & 688334 & 6.0 & 5.73 & TST & \\
\hline CHEMBL322970 & 688334 & 5.2 & 5.1724 & TST & \\
\hline
\end{tabular}




\begin{tabular}{|c|c|c|c|c|c|}
\hline \multicolumn{6}{|c|}{ pıementa } \\
\hline CHEMBL260629 & 688334 & 6.4 & 5.5776 & TST & \\
\hline CHEMBL384903 & 688334 & 5.0 & 5.6737 & TST & \\
\hline CHEMBL105739 & 688334 & 4.95 & 5.5398 & TST & \\
\hline CHEMBL1256660 & 688334 & 4.6 & 5.3751 & TST & \\
\hline CHEMBL1314286 & 688334 & 5.25 & 5.967006 & 20000000005 & TST \\
\hline CHEMBL1365553 & 688334 & 5.0 & 5.46299 & 9999999999 & TST \\
\hline CHEMBL1338358 & 688334 & 4.6 & 5.3661 & TST & \\
\hline CHEMBL62 & 688334 & 5.55 & 5.255 & TST & \\
\hline CHEMBL122270 & 688334 & 4.9 & 5.6058 & TST & \\
\hline CHEMBL1320485 & 688334 & 8.0506 & 5.4798 & TST & \\
\hline CHEMBL8145 & 688334 & 5.35 & 5.6868 & TST & \\
\hline CHEMBL285819 & 688334 & 5.45 & 5.5169 & TST & \\
\hline CHEMBL164747 & 688334 & 5.9 & 5.6434 & TST & \\
\hline CHEMBL1360725 & 688334 & 8.1024 & 5.7577 & TST & \\
\hline CHEMBL1255662 & 688334 & 5.1 & 5.5055 & TST & \\
\hline CHEMBL47940 & 688334 & 4.95 & 5.8344 & TST & \\
\hline CHEMBL376505 & 688334 & 6.3 & 5.4711 & TST & \\
\hline CHEMBL126077 & 688334 & 5.45 & 5.5759 & TST & \\
\hline CHEMBL1256776 & 688334 & 5.45 & 5.2291 & TST & \\
\hline CHEMBL1356870 & 688334 & 6.5501 & 5.9848 & TST & \\
\hline CHEMBL1255935 & 688334 & 4.95 & 5.6946 & TST & \\
\hline CHEMBL542700 & 688334 & 4.95 & 5.746 & TST & \\
\hline CHEMBL 375270 & 688334 & 6.95 & 5.1387 & TST & \\
\hline CHEMBL 3648255 & 1527782 & 7.2218 & 7.2103 & TRN & \\
\hline CHEMBL 3648224 & 1527782 & 7.5686 & 7.9016 & TRN & \\
\hline CHEMBL 3648246 & 1527782 & 8.0458 & 7.1899 & TRN & \\
\hline CHEMBL 3648227 & 1527782 & 8.7447 & 8.6778 & TRN & \\
\hline CHEMBL3651415 & 1527782 & 6.0 & 6.8406 & TRN & \\
\hline CHEMBL 3651410 & 1527782 & 6.8962 & 7.4495 & TRN & \\
\hline CHEMBL3651419 & 1527782 & 8.1487 & 7.902 & TRN & \\
\hline CHEMBL 3648232 & 1527782 & 7.2924 & 7.6139 & TRN & \\
\hline CHEMBL3969740 & 1527782 & 9.3188 & 7.1565 & TRN & \\
\hline CHEMBL 3648248 & 1527782 & 6.2291 & 6.9666 & TRN & \\
\hline CHEMBL 3648223 & 1527782 & 8.0969 & 7.9422 & TRN & \\
\hline CHEMBL3651408 & 1527782 & 8.0969 & 7.8791 & TRN & \\
\hline CHEMBL 3648226 & 1527782 & 7.2291 & 7.4011 & TRN & \\
\hline CHEMBL3651411 & 1527782 & 8.1549 & 7.6934 & TRN & \\
\hline CHEMBL3651418 & 1527782 & 9.3979 & 7.7865 & TST & \\
\hline CHEMBL 3651388 & 1527782 & 7.5376 & 6.7619 & TRN & \\
\hline CHEMBL3648261 & 1527782 & 7.1675 & 7.7138 & TRN & \\
\hline CHEMBL 3648262 & 1527782 & 8.0 & 7.4643 & TRN & \\
\hline CHEMBL3648251 & 1527782 & 7.5528 & 7.8495 & TRN & \\
\hline CHEMBL3651407 & 1527782 & 7.3768 & 8.1002 & TRN & \\
\hline CHEMBL 3648235 & 1527782 & 8.1367 & 8.1245 & TRN & \\
\hline CHEMBL3648256 & 1527782 & 7.4559 & 7.2405 & TRN & \\
\hline CHEMBL 3651430 & 1527782 & 8.4202 & 7.5197 & TRN & \\
\hline CHEMBL 3648245 & 1527782 & 7.699 & 7.4674 & TRN & \\
\hline CHEMBL 3648250 & 1527782 & 6.7959 & 7.1481 & TRN & \\
\hline
\end{tabular}


Supplemental Table S2.txt

\begin{tabular}{|c|c|c|c|c|c|}
\hline CHEMBL 3651387 & 1527782 & 8.1549 & 7.2121 & TRN & \\
\hline CHEMBL3651401 & 1527782 & 6.8069 & 7.3039 & TST & \\
\hline CHEMBL3651399 & 1527782 & 7.8539 & 7.9729 & TRN & \\
\hline CHEMBL 3651422 & 1527782 & 7.9208 & 7.5796 & TRN & \\
\hline CHEMBL3648259 & 1527782 & 8.4437 & 7.8859 & TRN & \\
\hline CHEMBL 3651417 & 1527782 & 7.699 & 7.3953 & TRN & \\
\hline CHEMBL3651390 & 1527782 & 7.4685 & 6.9913 & TRN & \\
\hline CHEMBL 3651395 & 1527782 & 6.0 & 8.1927 & TRN & \\
\hline CHEMBL 3648234 & 1527782 & 8.5528 & 8.07 & TRN & \\
\hline CHEMBL3651428 & 1527782 & 6.0 & 6.441 & TRN & \\
\hline CHEMBL 3648229 & 1527782 & 7.6198 & 7.516 & TRN & \\
\hline CHEMBL 3651425 & 1527782 & 7.7212 & 6.4008 & TST & \\
\hline CHEMBL3651414 & 1527782 & 6.0 & 7.4071 & TST & \\
\hline CHEMBL3648237 & 1527782 & 7.5376 & 7.5835 & TRN & \\
\hline CHEMBL3651406 & 1527782 & 7.8239 & 8.0228 & TRN & \\
\hline CHEMBL 3648230 & 1527782 & 6.0 & 6.4366 & TRN & \\
\hline CHEMBL3648225 & 1527782 & 8.2596 & 7.795 & TRN & \\
\hline CHEMBL 3648242 & 1527782 & 8.6576 & 7.9226 & TRN & \\
\hline CHEMBL3648260 & 1527782 & 6.3526 & 6.2251 & TRN & \\
\hline CHEMBL3651413 & 1527782 & 7.7696 & 7.7635 & TST & \\
\hline CHEMBL3639470 & 1527782 & 7.1367 & 7.6351 & TRN & \\
\hline CHEMBL3639502 & 1527782 & 6.4202 & 6.5832 & TRN & \\
\hline CHEMBL3651389 & 1527782 & 7.8861 & 7.416 & TRN & \\
\hline CHEMBL3651392 & 1527782 & 6.3565 & 6.6485 & TRN & \\
\hline CHEMBL3651396 & 1527782 & 8.4202 & 8.199 & TRN & \\
\hline CHEMBL3648236 & 1527782 & 7.3372 & 7.5838 & TRN & \\
\hline CHEMBL 3651412 & 1527782 & 7.9586 & 7.6769 & TST & \\
\hline CHEMBL3651394 & 1527782 & 7.9586 & 7.8181 & TRN & \\
\hline CHEMBL3648231 & 1527782 & 6.0 & 7.0678 & TRN & \\
\hline CHEMBL3648222 & 1527782 & 8.0 & 8.0615 & TRN & \\
\hline CHEMBL 3648233 & 1527782 & 7.2596 & 6.5887 & TRN & \\
\hline CHEMBL 3651398 & 1527782 & 7.5528 & 7.582999 & & TRN \\
\hline CHEMBL3651429 & 1527782 & 6.0 & 6.7089 & TRN & \\
\hline CHEMBL3648253 & 1527782 & 7.1549 & 7.4267 & TST & \\
\hline CHEMBL3648257 & 1527782 & 7.7825 & 7.8617 & TST & \\
\hline CHEMBL3651397 & 1527782 & 8.6021 & 8.0952 & TRN & \\
\hline CHEMBL3648241 & 1527782 & 8.6198 & 7.9581 & TST & \\
\hline CHEMBL3651404 & 1527782 & 8.2218 & 7.1109 & TST & \\
\hline CHEMBL 3648228 & 1527782 & 8.1739 & 8.5464 & TRN & \\
\hline CHEMBL3651391 & 1527782 & 5.4437 & 5.6896 & TRN & \\
\hline CHEMBL3648249 & 1527782 & 6.4437 & 7.3841 & TST & \\
\hline CHEMBL3651400 & 1527782 & 6.8153 & 7.1099 & TST & \\
\hline CHEMBL3648238 & 1527782 & 6.0 & 7.4008 & TST & \\
\hline CHEMBL3648243 & 1527782 & 8.5229 & 7.5175 & TST & \\
\hline CHEMBL3648252 & 1527782 & 7.4881 & 7.7989 & TST & \\
\hline CHEMBL 3648258 & 1527782 & 8.4089 & 7.9217 & TST & \\
\hline CHEMBL3651402 & 1527782 & 7.0809 & 7.3189 & TRN & \\
\hline CHEMBL3648247 & 1527782 & 6.3565 & 7.1615 & TST & \\
\hline
\end{tabular}


Supplemental Table S2.txt

\begin{tabular}{|c|c|c|c|c|}
\hline CHEMBL3648244 & 32 & 7 & 65 & TST \\
\hline CHEMBL3651405 & 527782 & 7.7447 & 7.3405 & CPN \\
\hline HEMBL3651426 & .527782 & 6.0 & .2102 & N \\
\hline HEMBL3648240 & .527782 & 8.2924 & 7.409 & \\
\hline HEMBL3648221 & 527782 & 7.4437 & 7.7975 & \\
\hline HEMBL3648254 & .527782 & 7.9208 & 7.8439 & \\
\hline HEMBL 251037 & 58680 & 4.7447 & 4.7324 & \\
\hline HEMBL 399996 & 58680 & 3.0 & 2.9303 & \\
\hline HEMBL401375 & 458680 & 3.0 & 5.2996 & \\
\hline HEMBL398867 & 58680 & 3.0 & .0243 & \\
\hline HEMBL 249411 & 458680 & 5.1549 & 5.1708 & נח \\
\hline HEMBL 250664 & 458680 & 5.3872 & 5.3871 & \\
\hline HEMBL 399552 & 58680 & 5.0269 & 5.029 & \\
\hline HEMBL 398868 & 458680 & 4.699 & 4.6928 & \\
\hline HEMBL 251612 & 458680 & 3.0 & 2.9986 & \\
\hline HEMBL 249403 & 458680 & 3.0 & 2.9845 & \\
\hline HEMBL400070 & 458680 & 5.2218 & 5.1938 & \\
\hline HEMBL 248818 & 458680 & 5.4089 & 5.4252 & \\
\hline HEMBL 399869 & 458680 & 6 & 6.2496 & \\
\hline HEMBL 399553 & 458680 & 18 & 5.4203 & \\
\hline HEMBL 251614 & 458680 & 4.5686 & 4.5774 & \\
\hline HEMBL 248973 & 458680 & 6.284 & 6.2845 & \\
\hline HEMBL 399551 & 458680 & 5.2924 & 5.2823 & \\
\hline HEMBL400168 & 458680 & 3. & 3.0111 & $\mathrm{R} N$ \\
\hline HEMBL 248572 & 458680 & 3.0 & 3.0117 & \\
\hline HEMBL 251606 & 458680 & 5.8239 & 5.7907 & \\
\hline HEMBL 250825 & 458680 & 6.3188 & 6.3239 & RN \\
\hline HEMBL 249404 & 458680 & 3.0 & 3.0046 & RN \\
\hline HEMBL 399488 & 458680 & 5.2218 & 5.2764 & RN \\
\hline HEMBL399489 & 458 & 5.8239 & 5.8494 & RN \\
\hline HEMBL 248780 & 458680 & 3.0 & 2.9962 & RN \\
\hline HEMBL 248579 & 458680 & 3.0 & 2.9973 & RN \\
\hline HEMBL 251038 & 458680 & 3.0 & 3.0136 & $\Gamma R N$ \\
\hline HEMBL 250860 & 458680 & 6. & 6.2892 & RN \\
\hline HEMBL401413 & 458 & 5 . & 5.9277 & RN \\
\hline HEMBL 250480 & 45 & 4. & 4.2814 & ST \\
\hline HEMBL401384 & 458680 & 5.0177 & 5.0066 & TRN \\
\hline HEMBL 249200 & 458680 & 3.0 & 3.5617 & TS \\
\hline LHEMBL400730 & 458680 & 5.4089 & 3.5025 & TST \\
\hline CHEMBL 251607 & 458680 & 5.0 & 4.9784 & $\mathrm{RN}$ \\
\hline CHEMBL248974 & 458680 & 6.74 & 6.7567 & RN \\
\hline HEMBL402497 & 458680 & 5.0177 & 5.02 & RN \\
\hline HEMBL251019 & 458680 & 5 . & 5.4002 & $\Gamma R N$ \\
\hline CHEMBL 250861 & 458680 & 5 . & 5.7392 & $\mathrm{~N}$ \\
\hline CHEMBL399995 & 458680 & 5.4559 & 5.4614 & \\
\hline CHEMBL250479 & 458680 & 4.9586 & 4.9417 & RN \\
\hline CHEMBL 250827 & 458680 & 3.0 & 2.9982 & RN \\
\hline CHEMBL 249419 & 458680 & 5.8861 & 5.8853 & TRN \\
\hline
\end{tabular}

Page 6063 


\begin{tabular}{|c|c|c|c|c|c|}
\hline \multirow[b]{2}{*}{ CHEMBL541724 } & \multicolumn{5}{|c|}{ Supplemental Table S2.txt } \\
\hline & 458680 & 4.3979 & 4.3818 & TRN & \\
\hline CHEMBL 249405 & 458680 & 3.0 & 3.0078 & TRN & \\
\hline CHEMBL398682 & 458680 & 6.0 & 5.9785 & TRN & \\
\hline CHEMBL 248975 & 458680 & 4.7959 & 5.0281 & TST & \\
\hline CHEMBL399870 & 458680 & 6.2218 & 6.0584 & TST & \\
\hline CHEMBL251613 & 458680 & 3.0 & 3.6476 & TST & \\
\hline CHEMBL399691 & 458680 & 3.0 & 2.7946 & TST & \\
\hline CHEMBL251608 & 458680 & 3.0 & 5.7339 & TST & \\
\hline CHEMBL249409 & 458680 & 3.0 & 4.968 & TST & \\
\hline CHEMBL250226 & 458680 & 4.8861 & 5.9407 & TST & \\
\hline CHEMBL93774 & 48534 & 6.5528 & 6.6032 & TRN & \\
\hline CHEMBL90339 & 48534 & 4.0 & 4.0449 & TRN & \\
\hline CHEMBL415311 & 48534 & 6.3372 & 6.3673 & TRN & \\
\hline CHEMBL90819 & 48534 & 5.4089 & 5.3485 & TRN & \\
\hline CHEMBL89974 & 48534 & 4.0 & 4.008 & TRN & \\
\hline CHEMBL313316 & 48534 & 4.0 & 4.0039 & TRN & \\
\hline CHEMBL91644 & 48534 & 4.0 & 3.8996 & TRN & \\
\hline CHEMBL 327582 & 48534 & 4.0 & 3.9576 & TRN & \\
\hline CHEMBL90181 & 48534 & 5.7212 & 5.6862 & TRN & \\
\hline CHEMBL92099 & 48534 & 7.699 & 7.5119 & TRN & \\
\hline CHEMBL242103 & 48534 & 4.0 & 4.251 & TST & \\
\hline CHEMBL328234 & 48534 & 4.0 & 3.9962 & TRN & \\
\hline CHEMBL 90354 & 48534 & 5.7696 & 5.791 & TRN & \\
\hline CHEMBL90371 & 48534 & 4.0 & 3.9789 & TRN & \\
\hline CHEMBL90023 & 48534 & 4.0 & 4.0949 & TRN & \\
\hline CHEMBL91887 & 48534 & 4.0 & 3.9783 & TRN & \\
\hline CHEMBL89915 & 48534 & 4.0 & 4.3078 & TRN & \\
\hline CHEMBL 91643 & 48534 & 4.0 & 3.9825 & TRN & \\
\hline CHEMBL88354 & 48534 & 4.0 & 3.9957 & TRN & \\
\hline CHEMBL92375 & 48534 & 4.0 & 4.0543 & TRN & \\
\hline CHEMBL421363 & 48534 & 6.2518 & 6.1435 & TRN & \\
\hline CHEMBL315862 & 48534 & 4.0 & 4.0408 & TRN & \\
\hline CHEMBL 90866 & 48534 & 6.6576 & 6.9366 & TRN & \\
\hline CHEMBL91195 & 48534 & 4.0 & 3.9473 & TRN & \\
\hline CHEMBL93490 & 48534 & 4.0 & 4.0517 & TRN & \\
\hline CHEMBL330453 & 48534 & 4.0 & 4.4062 & TST & \\
\hline CHEMBL91003 & 48534 & 7.3979 & 7.4843 & TRN & \\
\hline CHEMBL90859 & 48534 & 4.0 & 3.984 & TRN & \\
\hline CHEMBL329128 & 48534 & 6.8539 & 6.6953 & TRN & \\
\hline CHEMBL89990 & 48534 & 5.4202 & 5.42899 & 9999999999 & TRN \\
\hline CHEMBL91640 & 48534 & 7.0969 & 7.0748 & TRN & \\
\hline CHEMBL329346 & 48534 & 7.2218 & 7.1909 & TRN & \\
\hline CHEMBL330503 & 48534 & 4.0 & 3.8512 & TRN & \\
\hline CHEMBL91266 & 48534 & 4.0 & 4.0824 & TST & \\
\hline CHEMBL93125 & 48534 & 4.0 & 4.0852 & TRN & \\
\hline CHEMBL313679 & 48534 & 7.0 & 7.0622 & TRN & \\
\hline CHEMBL440504 & 48534 & 4.0 & 3.9183 & TRN & \\
\hline CHEMBL90060 & 48534 & 6.5528 & 6.5631 & TRN & \\
\hline
\end{tabular}




\begin{tabular}{|c|c|c|c|c|c|}
\hline \multicolumn{6}{|c|}{ Supplemental Table S2.txt } \\
\hline CHEMBL91267 & 48534 & 4.0 & 4.0076 & TRN & \\
\hline CHEMBL90197 & 48534 & 6.5686 & 6.3078 & TST & \\
\hline CHEMBL91201 & 48534 & 4.0 & 4.5944 & TST & \\
\hline CHEMBL90948 & 48534 & 4.0 & 3.5737 & TST & \\
\hline CHEMBL91322 & 48534 & 4.0 & 4.0281 & TRN & \\
\hline CHEMBL327902 & 48534 & 4.0 & 3.8601 & TRN & \\
\hline CHEMBL 328370 & 48534 & 4.0 & 4.1264 & TST & \\
\hline CHEMBL92376 & 48534 & 7.301 & 7.2885 & TRN & \\
\hline CHEMBL92579 & 48534 & 4.0 & 4.0466 & TRN & \\
\hline CHEMBL90688 & 48534 & 6.3188 & 4.1663 & TST & \\
\hline CHEMBL91844 & 48534 & 5.8861 & 5.82100 & 0000000001 & TRN \\
\hline CHEMBL88307 & 48534 & 4.0 & 4.1201 & TRN & \\
\hline CHEMBL94235 & 48534 & 5.5528 & 3.4039 & TST & \\
\hline CHEMBL89973 & 48534 & 7.2218 & 7.3063 & TRN & \\
\hline CHEMBL 88782 & 48534 & 4.0 & 4.1718 & TRN & \\
\hline CHEMBL91344 & 48534 & 4.0 & 3.8179 & TRN & \\
\hline CHEMBL90311 & 48534 & 4.0 & 3.4565 & TST & \\
\hline CHEMBL314026 & 48534 & 6.699 & 6.2283 & TST & \\
\hline CHEMBL 88586 & 48534 & 4.0 & 3.8389 & TRN & \\
\hline CHEMBL92903 & 48534 & 4.0 & 4.2192 & TST & \\
\hline CHEMBL90250 & 48534 & 4.0 & 3.9305 & TRN & \\
\hline CHEMBL91439 & 48534 & 4.0 & 4.0086 & TRN & \\
\hline CHEMBL91893 & 48534 & 4.0 & 3.9406 & TRN & \\
\hline CHEMBL 90772 & 48534 & 6.4949 & 4.8429 & TST & \\
\hline CHEMBL90428 & 48534 & 6.6383 & 6.3565 & TST & \\
\hline CHEMBL90235 & 48534 & 4.0 & 3.9995 & TRN & \\
\hline CHEMBL 330050 & 48534 & 6.7696 & 6.8355 & TRN & \\
\hline CHEMBL 90475 & 48534 & 6.0 & 5.178 & TST & \\
\hline CHEMBL91347 & 48534 & 5.8539 & 4.7728 & TST & \\
\hline CHEMBL93166 & 48534 & 7.699 & 7.5508 & TRN & \\
\hline CHEMBL421737 & 48534 & 4.0 & 4.2388 & TRN & \\
\hline CHEMBL90867 & 48534 & 6.2518 & 6.0897 & TRN & \\
\hline CHEMBL 90808 & 48534 & 5.5528 & 5.5045 & TST & \\
\hline CHEMBL406038 & 48534 & 7.0969 & 6.5507 & TST & \\
\hline CHEMBL 88734 & 48534 & 6.699 & 6.7872 & TRN & \\
\hline CHEMBL91830 & 48534 & 5.1549 & 6.9339 & TST & \\
\hline CHEMBL91544 & 48534 & 7.1549 & 7.5055 & TST & \\
\hline CHEMBL327577 & 48534 & 6.5229 & 6.6079 & TRN & \\
\hline CHEMBL90512 & 48534 & 7.301 & 7.2292 & TRN & \\
\hline CHEMBL570045 & 595036 & 8.585 & 8.5781 & TRN & \\
\hline CHEMBL569988 & 595036 & 8.5376 & 8.4822 & TRN & \\
\hline CHEMBL566913 & 595036 & 9.0809 & 9.1792 & TRN & \\
\hline CHEMBL567189 & 595036 & 8.3872 & 8.272 & TST & \\
\hline CHEMBL570386 & 595036 & 8.6021 & 8.8938 & TRN & \\
\hline CHEMBL565300 & 595036 & 8.1308 & 7.9739 & TRN & \\
\hline CHEMBL569914 & 595036 & 9.0 & 8.548 & TRN & \\
\hline CHEMBL570263 & 595036 & 7.9914 & 8.5567 & TRN & \\
\hline CHEMBL566745 & 595036 & 8.9208 & 8.551 & TRN & \\
\hline
\end{tabular}




\begin{tabular}{|c|c|c|c|c|}
\hline & & & pplement & al $\mathrm{T}$ \\
\hline CHEMBL567064 & 595036 & 8.2757 & 8.6117 & TRN \\
\hline CHEMBL569617 & 595036 & 7.1427 & 7.7226 & TRN \\
\hline CHEMBL570289 & 595036 & 8.8861 & 8.7837 & TRN \\
\hline CHEMBL570151 & 595036 & 8.6778 & 8.8338 & TRN \\
\hline CHEMBL568498 & 595036 & 7.4559 & 7.7268 & TST \\
\hline CHEMBL570384 & 595036 & 8.0915 & 7.9099 & TRN \\
\hline CHEMBL567915 & 595036 & 9.3979 & 9.071 & TRN \\
\hline CHEMBL569781 & 595036 & 7.8239 & 7.8675 & TRN \\
\hline CHEMBL567416 & 595036 & 8.9208 & 8.7648 & TRN \\
\hline CHEMBL566520 & 595036 & 8.6021 & 8.4898 & TRN \\
\hline CHEMBL568059 & 595036 & 9.1612 & 8.7264 & TRN \\
\hline CHEMBL570149 & 595036 & 7.6576 & 7.9423 & TRN \\
\hline CHEMBL569742 & 595036 & 8.0269 & 8.2112 & TST \\
\hline CHEMBL569910 & 595036 & 8.2441 & 7.9377 & TRN \\
\hline CHEMBL571929 & 595036 & 8.1249 & 8.5402 & TRN \\
\hline CHEMBL571584 & 595036 & 8.5229 & 8.7556 & TRN \\
\hline CHEMBL569911 & 595036 & 7.6576 & 8.0641 & TST \\
\hline CHEMBL565836 & 595036 & 9.1739 & 8.8169 & TRN \\
\hline CHEMBL569681 & 595036 & 7.2596 & 8.1282 & TST \\
\hline CHEMBL570128 & 595036 & 8.9208 & 8.5483 & TRN \\
\hline CHEMBL570064 & 595036 & 8.7696 & 8.9094 & TRN \\
\hline CHEMBL569771 & 595036 & 7.5086 & 7.6773 & TST \\
\hline CHEMBL565249 & 595036 & 7.7212 & 7.7801 & TST \\
\hline CHEMBL571599 & 595036 & 9.0362 & 8.9641 & TRN \\
\hline CHEMBL567772 & 595036 & 8.4437 & 8.3828 & TRN \\
\hline CHEMBL570150 & 595036 & 8.2366 & 7.9553 & TRN \\
\hline CHEMBL567883 & 595036 & 8.301 & 8.6126 & TRN \\
\hline CHEMBL568384 & 595036 & 8.3768 & 8.4409 & TRN \\
\hline CHEMBL565542 & 595036 & 8.2291 & 8.2439 & TRN \\
\hline CHEMBL570285 & 595036 & 8.4559 & 8.3449 & TRN \\
\hline CHEMBL570271 & 595036 & 8.0757 & 7.9498 & TRN \\
\hline CHEMBL570242 & 595036 & 8.3665 & 8.5467 & TRN \\
\hline CHEMBL566176 & 595036 & 8.1308 & 8.4276 & TRN \\
\hline CHEMBL570154 & 595036 & 8.5686 & 8.7519 & TRN \\
\hline CHEMBL566613 & 595036 & 8.5229 & 8.1887 & TRN \\
\hline CHEMBL569815 & 595036 & 7.9208 & 7.6159 & TST \\
\hline CHEMBL568128 & 595036 & 7.9586 & 8.2401 & TRN \\
\hline CHEMBL570156 & 595036 & 8.1487 & 8.0268 & TRN \\
\hline CHEMBL570093 & 595036 & 8.699 & 8.5263 & TRN \\
\hline CHEMBL570053 & 595036 & 8.1675 & 7.9844 & TRN \\
\hline CHEMBL567468 & 595036 & 8.0757 & 8.5521 & TRN \\
\hline CHEMBL569127 & 595036 & 7.3768 & 8.0194 & TST \\
\hline CHEMBL569722 & 595036 & 7.9586 & 8.2176 & TRN \\
\hline CHEMBL570275 & 595036 & 9.0044 & 8.9141 & TRN \\
\hline CHEMBL567271 & 595036 & 8.5528 & 8.7583 & TRN \\
\hline CHEMBL570153 & 595036 & 8.6576 & 8.7916 & TRN \\
\hline CHEMBL565470 & 595036 & 8.5686 & 8.4364 & TRN \\
\hline CHEMBL569915 & 595036 & 8.3188 & 8.0733 & TST \\
\hline
\end{tabular}




\begin{tabular}{|c|c|c|c|c|c|}
\hline \multicolumn{6}{|c|}{ Supplemental Table S2.txt } \\
\hline CHEMBL569913 & 595036 & 7.1549 & 8.3174 & TST & \\
\hline CHEMBL569909 & 595036 & 7.7212 & 8.0988 & TRN & \\
\hline CHEMBL569319 & 595036 & 7.9208 & 7.6767 & TRN & \\
\hline CHEMBL571812 & 595036 & 7.9208 & 7.9759 & TRN & \\
\hline CHEMBL568250 & 595036 & 8.9208 & 7.9939 & TST & \\
\hline CHEMBL566720 & 595036 & 6.9101 & 7.9032 & TST & \\
\hline CHEMBL569732 & 595036 & 7.9586 & 8.1427 & TST & \\
\hline CHEMBL569764 & 595036 & 8.6576 & 8.0415 & TST & \\
\hline CHEMBL565974 & 595036 & 9.2147 & 8.7155 & TRN & \\
\hline CHEMBL567050 & 595036 & 8.0269 & 8.1983 & TRN & \\
\hline CHEMBL570155 & 595036 & 8.8539 & 8.5392 & TRN & \\
\hline CHEMBL568824 & 595036 & 7.7959 & 7.9694 & TST & \\
\hline CHEMBL567280 & 595036 & 8.6778 & 8.9813 & TRN & \\
\hline CHEMBL570060 & 595036 & 7.9208 & 7.8136 & TRN & \\
\hline CHEMBL566753 & 595036 & 7.4202 & 7.5515 & TST & \\
\hline CHEMBL570387 & 595036 & 8.8239 & 8.9547 & TRN & \\
\hline CHEMBL570028 & 595036 & 8.6383 & 8.3658 & TRN & \\
\hline CHEMBL569629 & 595036 & 8.4318 & 8.4637 & TRN & \\
\hline CHEMBL570388 & 595036 & 8.4437 & 8.5599 & TRN & \\
\hline CHEMBL569053 & 595036 & 7.5686 & 7.7735 & TST & \\
\hline CHEMBL568257 & 595036 & 8.28399 & 99999999 & 7.4826 & TST \\
\hline CHEMBL569884 & 595036 & 8.5528 & 7.9089 & TST & \\
\hline CHEMBL567709 & 595036 & 9.1487 & 8.7635 & TRN & \\
\hline CHEMBL570256 & 595036 & 8.699 & 8.5121 & TRN & \\
\hline CHEMBL567133 & 595036 & 9.1549 & 9.05600 & 2000000001 & TRN \\
\hline CHEMBL570108 & 595036 & 7.5376 & 7.8681 & TRN & \\
\hline CHEMBL567740 & 595036 & 9.2218 & 8.9667 & TRN & \\
\hline CHEMBL569680 & 595036 & 8.9208 & 7.3313 & TST & \\
\hline CHEMBL569908 & 595036 & 6.7352 & 7.3923 & TST & \\
\hline CHEMBL566599 & 595036 & 8.5376 & 8.8034 & TRN & \\
\hline CHEMBL570152 & 595036 & 8.8239 & 8.9985 & TRN & \\
\hline CHEMBL570295 & 595036 & 9.4202 & 8.3836 & TST & \\
\hline CHEMBL569995 & 595036 & 8.8861 & 8.7224 & TRN & \\
\hline CHEMBL565409 & 595036 & 9.0458 & 8.8362 & TRN & \\
\hline CHEMBL569912 & 595036 & 7.7696 & 8.2772 & TST & \\
\hline CHEMBL565573 & 595036 & 8.0 & 8.1103 & TRN & \\
\hline CHEMBL570020 & 595036 & 7.8539 & 7.8098 & TRN & \\
\hline CHEMBL570238 & 595036 & 8.5086 & 8.7512 & TRN & \\
\hline CHEMBL567840 & 595036 & 7.9586 & 7.8399 & TRN & \\
\hline CHEMBL568211 & 595036 & 9.1024 & 8.8797 & TRN & \\
\hline CHEMBL570423 & 595036 & 8.3468 & 7.9886 & TST & \\
\hline CHEMBL567561 & 595036 & 9.3372 & 9.1561 & TRN & \\
\hline CHEMBL566309 & 595036 & 7.9586 & 7.9248 & TRN & \\
\hline CHEMBL569679 & 595036 & 8.9208 & 7.7341 & TST & \\
\hline CHEMBL565363 & 595036 & 8.7959 & 9.0563 & TRN & \\
\hline CHEMBL571583 & 595036 & 8.0757 & 8.151 & TRN & \\
\hline CHEMBL569889 & 595036 & 7.9586 & 7.5858 & TST & \\
\hline CHEMBL570385 & 595036 & 8.699 & 8.9166 & TRN & \\
\hline
\end{tabular}




\begin{tabular}{|c|c|c|c|c|c|}
\hline \multicolumn{6}{|c|}{ Supplemental Table S2.txt } \\
\hline CHEMBL284405 & 96109 & 4.2857 & 4.5761 & TRN & \\
\hline CHEMBL 29351 & 96109 & 3.9281 & 3.9521 & TRN & \\
\hline CHEMBL28189 & 96109 & 3.6635 & 3.5196 & TRN & \\
\hline CHEMBL286704 & 96109 & 4.2933 & 4.3758 & TRN & \\
\hline CHEMBL28613 & 96109 & 3.5482 & 3.9087 & TST & \\
\hline CHEMBL282399 & 96109 & 4.3116 & 4.0461 & TRN & \\
\hline CHEMBL29701 & 96109 & 3.5834 & 3.2678 & TST & \\
\hline CHEMBL28251 & 96109 & 4.757 & 4.9546 & TRN & \\
\hline CHEMBL283707 & 96109 & 4.2924 & 4.197 & TRN & \\
\hline CHEMBL28755 & 96109 & 4.3072 & 4.277 & TRN & \\
\hline CHEMBL 28855 & 96109 & 4.2097 & 4.294 & TRN & \\
\hline CHEMBL 29493 & 96109 & 3.983 & 3.0497 & TST & \\
\hline CHEMBL29787 & 96109 & 4.2644 & 4.19 & TRN & \\
\hline CHEMBL 29251 & 96109 & 4.1355 & 4.04899 & 99999999995 & TRN \\
\hline CHEMBL 28591 & 96109 & 3.9508 & 3.8948 & TRN & \\
\hline CHEMBL 30145 & 96109 & 4.3391 & 4.2739 & TRN & \\
\hline CHEMBL281551 & 96109 & 3.4179 & 2.8056 & TST & \\
\hline CHEMBL417294 & 96109 & 3.9747 & 4.0182 & TRN & \\
\hline CHEMBL282326 & 96109 & 2.301 & 2.3992 & TRN & \\
\hline CHEMBL30247 & 96109 & 4.2132 & 3.87899 & 99999999996 & TRN \\
\hline CHEMBL282962 & 96109 & 3.7423 & 3.9906 & TRN & \\
\hline CHEMBL29733 & 96109 & 3.7932 & 3.7962 & TRN & \\
\hline CHEMBL 29563 & 96109 & 3.8013 & 4.0612 & TRN & \\
\hline CHEMBL 28471 & 96109 & 4.6021 & 4.6782 & TRN & \\
\hline CHEMBL 28614 & 96109 & 2.301 & 3.2868 & TST & \\
\hline CHEMBL 28667 & 96109 & 4.1649 & 4.2384 & TST & \\
\hline CHEMBL 29845 & 96109 & 4.1605 & 4.0964 & TRN & \\
\hline CHEMBL282831 & 96109 & 3.7905 & 3.8025 & TST & \\
\hline CHEMBL444786 & 96109 & 3.5361 & 3.4533 & TST & \\
\hline CHEMBL28190 & 96109 & 4.2284 & 4.2337 & TRN & \\
\hline CHEMBL 30022 & 96109 & 5.7282 & 5.4479 & TRN & \\
\hline CHEMBL281870 & 96109 & 4.3565 & 4.6228 & TRN & \\
\hline CHEMBL281704 & 96109 & 3.58 & 3.5244 & TST & \\
\hline CHEMBL29077 & 96109 & 3.5143 & 4.2571 & TST & \\
\hline CHEMBL286526 & 96109 & 3.8416 & 3.6208 & TST & \\
\hline CHEMBL413538 & 96109 & 4.3851 & 4.4033 & TRN & \\
\hline CHEMBL30095 & 96109 & 3.5952 & 3.8859 & TRN & \\
\hline CHEMBL 28861 & 96109 & 2.301 & 2.5593 & TRN & \\
\hline CHEMBL29542 & 96109 & 4.2168 & 4.1635 & TRN & \\
\hline CHEMBL282171 & 96109 & 3.8729 & 3.8494 & TRN & \\
\hline CHEMBL29539 & 96109 & 6.4685 & 6.1111 & TRN & \\
\hline CHEMBL30096 & 96109 & 3.6091 & 3.6172 & TST & \\
\hline CHEMBL30098 & 96109 & 4.0506 & 4.0991 & TRN & \\
\hline CHEMBL 27535 & 96109 & 4.2197 & 4.3634 & TRN & \\
\hline CHEMBL280639 & 96109 & 4.2668 & 4.1905 & TRN & \\
\hline CHEMBL282370 & 96109 & 4.1884 & 3.9844 & TRN & \\
\hline CHEMBL29737 & 96109 & 4.1018 & 4.4143 & TST & \\
\hline CHEMBL29170 & 96109 & 4.3635 & 4.463 & TRN & \\
\hline
\end{tabular}




\begin{tabular}{|c|c|c|c|c|}
\hline \multirow[b]{2}{*}{ CHEMBL284878 } & \multicolumn{4}{|c|}{ Supplemental } \\
\hline & 96109 & 4.2976 & 4.3359 & TRN \\
\hline CHEMBL28689 & 96109 & 3.9172 & 3.884 & TRN \\
\hline CHEMBL287179 & 96109 & 3.6946 & 3.5772 & TRN \\
\hline CHEMBL281980 & 96109 & 2.301 & 1.9828 & TRN \\
\hline CHEMBL29042 & 96109 & 3.5918 & 3.5412 & TRN \\
\hline CHEMBL25902 & 96109 & 4.0809 & 4.3141 & TST \\
\hline CHEMBL417299 & 96109 & 4.2495 & 4.6241 & TRN \\
\hline CHEMBL29573 & 96109 & 4.2815 & 4.0598 & TRN \\
\hline CHEMBL308429 & 105401 & 8.1024 & 7.77 & TST \\
\hline CHEMBL303918 & 105401 & 7.0 & 7.311 & TST \\
\hline CHEMBL303155 & 105401 & 8.8239 & 9.0341 & TRN \\
\hline CHEMBL306524 & 105401 & 8.9586 & 9.2713 & TRN \\
\hline CHEMBL 70426 & 105401 & 8.0605 & 8.0261 & TRN \\
\hline CHEMBL 71014 & 105401 & 7.585 & 7.8592 & TRN \\
\hline CHEMBL306912 & 105401 & 9.0809 & 9.0735 & TRN \\
\hline CHEMBL306224 & 105401 & 8.9208 & 8.8402 & TRN \\
\hline CHEMBL68890 & 105401 & 9.2676 & 9.146 & TRN \\
\hline CHEMBL308012 & 105401 & 8.7696 & 8.3687 & TRN \\
\hline CHEMBL 74175 & 105401 & 8.5528 & 8.8302 & TRN \\
\hline CHEMBL68149 & 105401 & 8.4559 & 8.3629 & TRN \\
\hline CHEMBL 70570 & 105401 & 8.6021 & 8.8289 & TST \\
\hline CHEMBL 72743 & 105401 & 8.5229 & 8.538 & TRN \\
\hline CHEMBL70398 & 105401 & 8.6383 & 8.8482 & TST \\
\hline CHEMBL 70354 & 105401 & 8.4437 & 8.0536 & TRN \\
\hline CHEMBL 71482 & 105401 & 9.3872 & 9.2016 & TRN \\
\hline CHEMBL 71713 & 105401 & 8.1487 & 8.4588 & TRN \\
\hline CHEMBL70639 & 105401 & 7.7447 & 7.7368 & TRN \\
\hline CHEMBL 302954 & 105401 & 8.1612 & 7.9579 & TRN \\
\hline CHEMBL 72337 & 105401 & 8.2757 & 8.1684 & TRN \\
\hline CHEMBL71618 & 105401 & 9.0044 & 8.7335 & TRN \\
\hline CHEMBL70315 & 105401 & 9.1549 & 8.9199 & TRN \\
\hline CHEMBL70049 & 105401 & 7.6576 & 7.9457 & TRN \\
\hline CHEMBL152104 & 105401 & 6.0 & 6.7669 & TRN \\
\hline CHEMBL422948 & 105401 & 8.7212 & 8.8237 & TRN \\
\hline CHEMBL302311 & 105401 & 8.7696 & 8.8982 & TRN \\
\hline CHEMBL74182 & 105401 & 8.9586 & 8.7066 & TRN \\
\hline CHEMBL 71800 & 105401 & 8.5229 & 8.2069 & TRN \\
\hline CHEMBL 302368 & 105401 & 8.301 & 8.8148 & TRN \\
\hline CHEMBL420932 & 105401 & 9.1192 & 8.978 & TRN \\
\hline CHEMBL68049 & 105401 & 7.1612 & 7.2594 & TRN \\
\hline CHEMBL 70430 & 105401 & 9.2366 & 9.0593 & TRN \\
\hline CHEMBL70406 & 105401 & 8.2007 & 7.829 & TRN \\
\hline CHEMBL 308032 & 105401 & 6.2366 & 6.2223 & TST \\
\hline CHEMBL69024 & 105401 & 8.8239 & 8.7501 & TRN \\
\hline CHEMBL70571 & 105401 & 8.7696 & 8.6458 & TST \\
\hline CHEMBL 305780 & 105401 & 8.3872 & 8.3696 & TRN \\
\hline CHEMBL308228 & 105401 & 8.6021 & 8.5733 & TRN \\
\hline CHEMBL 70492 & 105401 & 8.8861 & 9.1062 & TRN \\
\hline
\end{tabular}




\begin{tabular}{|c|c|c|c|c|c|}
\hline \multicolumn{6}{|c|}{ Supplemental Table S2.txt } \\
\hline CHEMBL69506 & 105401 & 8.5686 & 8.8521 & TRN & \\
\hline CHEMBL 305222 & 105401 & 9.0177 & 8.7945 & TRN & \\
\hline CHEMBL308397 & 105401 & 8.7696 & 8.26700 & 0000000001 & TRN \\
\hline CHEMBL 71468 & 105401 & 7.3768 & 7.4811 & TST & \\
\hline CHEMBL72678 & 105401 & 8.7959 & 9.0579 & TST & \\
\hline CHEMBL 307090 & 105401 & 8.9586 & 8.9995 & TRN & \\
\hline CHEMBL71630 & 105401 & 8.1871 & 8.1855 & TRN & \\
\hline CHEMBL70417 & 105401 & 9.1079 & 9.2823 & TRN & \\
\hline CHEMBL69072 & 105401 & 7.585 & 7.6363 & TRN & \\
\hline CHEMBL308598 & 105401 & 7.8861 & 7.5152 & TRN & \\
\hline CHEMBL310249 & 105401 & 8.8239 & 9.13 & TRN & \\
\hline CHEMBL71071 & 105401 & 8.4318 & 8.6722 & TRN & \\
\hline CHEMBL306189 & 105401 & 9.2007 & 9.2016 & TST & \\
\hline CHEMBL71995 & 105401 & 9.0458 & 9.0167 & TST & \\
\hline CHEMBL 72788 & 105401 & 8.7696 & 8.9198 & TST & \\
\hline CHEMBL 306470 & 105401 & 8.5229 & 8.4993 & TST & \\
\hline CHEMBL70965 & 105401 & 9.1675 & 9.0326 & TST & \\
\hline CHEMBL430612 & 105401 & 7.8861 & 7.6434 & TST & \\
\hline CHEMBL 306871 & 105401 & 8.8539 & 9.0223 & TST & \\
\hline CHEMBL 2448582 & 752588 & 3.0044 & 3.3622 & TRN & \\
\hline CHEMBL1864262 & 752588 & 3.0044 & 3.1216 & TRN & \\
\hline CHEMBL1891751 & 752588 & 5.585 & 5.0588 & TRN & \\
\hline CHEMBL1883060 & 752588 & 3.0044 & 3.1011 & TRN & \\
\hline CHEMBL1877442 & 752588 & 4.4711 & 4.886 & TRN & \\
\hline CHEMBL1877822 & 752588 & 3.0044 & 3.6047 & TRN & \\
\hline CHEMBL1886662 & 752588 & 5.6021 & 6.2517 & TRN & \\
\hline CHEMBL1873177 & 752588 & 3.0044 & 3.5631 & TST & \\
\hline CHEMBL1873053 & 752588 & 3.0044 & 3.2431 & TRN & \\
\hline CHEMBL1379448 & 752588 & 5.6144 & 4.8555 & TRN & \\
\hline CHEMBL1414729 & 752588 & 5.4841 & 4.422 & TST & \\
\hline CHEMBL1333222 & 752588 & 5.1427 & 4.7466 & TRN & \\
\hline CHEMBL1773702 & 752588 & 5.8827 & 5.5026 & TRN & \\
\hline CHEMBL1510959 & 752588 & 3.0044 & 3.6531 & TST & \\
\hline CHEMBL1477200 & 752588 & 4.2373 & 3.5031 & TRN & \\
\hline CHEMBL1613216 & 752588 & 5.7852 & 6.1453 & TST & \\
\hline CHEMBL1895018 & 752588 & 3.0044 & 4.0626 & TRN & \\
\hline CHEMBL576846 & 752588 & 5.6326 & 4.4459 & TRN & \\
\hline CHEMBL1896157 & 752588 & 3.0044 & 3.6432 & TRN & \\
\hline CHEMBL1370991 & 752588 & 5.2472 & 4.6053 & TRN & \\
\hline CHEMBL1483649 & 752588 & 5.7696 & 6.2517 & TRN & \\
\hline CHEMBL1866482 & 752588 & 4.0825 & 3.4669 & TRN & \\
\hline CHEMBL1899086 & 752588 & 3.0044 & 3.1842 & TRN & \\
\hline CHEMBL1867839 & 752588 & 3.0044 & 3.0648 & TRN & \\
\hline CHEMBL1865625 & 752588 & 4.9586 & 4.2613 & TRN & \\
\hline CHEMBL1864057 & 752588 & 3.0044 & 3.8775 & TRN & \\
\hline CHEMBL1532745 & 752588 & 3.0044 & 2.9759 & TRN & \\
\hline CHEMBL1882443 & 752588 & 5.4815 & 5.9355 & TRN & \\
\hline CHEMBL1871228 & 752588 & 6.0362 & 6.2941 & TRN & \\
\hline
\end{tabular}


Supplemental Table S2.txt

\begin{tabular}{|c|c|c|c|c|}
\hline CHEMBL1553773 & 752588 & 5.7959 & 5.5882 & TRN \\
\hline CHEMBL1905640 & 752588 & 3.0044 & 3.287 & TST \\
\hline CHEMBL1613411 & 752588 & 5.4045 & 5.1653 & TRN \\
\hline CHEMBL1904202 & 752588 & 3.0044 & 3.1301 & TST \\
\hline CHEMBL1892775 & 752588 & 3.0044 & 3.2601 & TRN \\
\hline CHEMBL546865 & 752588 & 5.5272 & 4.773 & TST \\
\hline CHEMBL1898553 & 752588 & 4.2007 & 3.438 & TST \\
\hline CHEMBL1898076 & 752588 & 3.0044 & 2.9593 & TRN \\
\hline CHEMBL1609828 & 752588 & 5.1952 & 5.2691 & TST \\
\hline CHEMBL1302779 & 752588 & 6.0 & 5.9854 & TRN \\
\hline CHEMBL1869875 & 752588 & 6.0066 & 5.6175 & TRN \\
\hline CHEMBL1864637 & 752588 & 3.0044 & 3.4809 & TST \\
\hline CHEMBL1867387 & 752588 & 3.0044 & 3.2168 & TRN \\
\hline CHEMBL1863714 & 752588 & 3.0044 & 3.373999 & 99999999997 \\
\hline CHEMBL1866663 & 752588 & 3.0044 & 3.5947 & TRN \\
\hline CHEMBL1575970 & 752588 & 5.75200 & 00000000 & 5.3429 \\
\hline CHEMBL1897477 & 752588 & 3.0044 & 3.2321 & TRN \\
\hline CHEMBL1875316 & 752588 & 3.0044 & 3.298 & TST \\
\hline CHEMBL1901962 & 752588 & 3.0044 & 3.2598 & TRN \\
\hline CHEMBL1892979 & 752588 & 3.0044 & 3.2014 & TRN \\
\hline CHEMBL1884507 & 752588 & 5.301 & 5.1015 & TRN \\
\hline CHEMBL1880304 & 752588 & 3.0044 & 3.4181 & TRN \\
\hline CHEMBL1871327 & 752588 & 5.0555 & 4.5529 & TRN \\
\hline CHEMBL1495113 & 752588 & 3.0044 & 3.4853 & TRN \\
\hline CHEMBL1902007 & 752588 & 5.2596 & 4.8559 & TRN \\
\hline CHEMBL1494979 & 752588 & 4.9208 & 4.7245 & TST \\
\hline CHEMBL1888363 & 752588 & 3.0044 & 3.6118 & TRN \\
\hline CHEMBL1864348 & 752588 & 3.0044 & 3.5891 & TRN \\
\hline CHEMBL1880833 & 752588 & 3.0044 & 3.9408 & TRN \\
\hline CHEMBL1883288 & 752588 & 3.0044 & 3.377 & TST \\
\hline CHEMBL1468256 & 752588 & 4.8894 & 5.1073 & TRN \\
\hline CHEMBL1881590 & 752588 & 4.0137 & 3.2549 & TRN \\
\hline CHEMBL1425795 & 752588 & 5.3665 & 5.5298 & TRN \\
\hline CHEMBL1866613 & 752588 & 5.8539 & 6.4938 & TRN \\
\hline CHEMBL1898479 & 752588 & 4.3036 & 3.5484 & TRN \\
\hline CHEMBL1565912 & 752588 & 5.6655 & 5.9389 & TST \\
\hline CHEMBL1881903 & 752588 & 3.0044 & 3.3422 & TRN \\
\hline CHEMBL1902151 & 752588 & 3.0044 & 3.1145 & TRN \\
\hline CHEMBL1542557 & 752588 & 5.5143 & 4.388 & TST \\
\hline CHEMBL1880791 & 752588 & 3.0044 & 3.2157 & TRN \\
\hline CHEMBL1897885 & 752588 & 4.7959 & 4.3963 & TRN \\
\hline CHEMBL1893046 & 752588 & 3.0044 & 3.4002 & TRN \\
\hline CHEMBL1869506 & 752588 & 5.6778 & 5.4844 & TST \\
\hline CHEMBL1894672 & 752588 & 3.0044 & 3.3926 & TRN \\
\hline CHEMBL1888458 & 752588 & 3.0044 & 3.1126 & TST \\
\hline CHEMBL1892270 & 752588 & 5.6459 & 4.7672 & TRN \\
\hline CHEMBL1405521 & 752588 & 5.341 & 4.4046 & TST \\
\hline CHEMBL1895014 & 752588 & 3.0044 & 3.3816 & TRN \\
\hline
\end{tabular}


Supplemental Table S2.txt

\begin{tabular}{|c|c|c|c|c|c|}
\hline CHEMBL3195749 & 752588 & 5.6162 & 5.0454 & TST & \\
\hline CHEMBL1892009 & 752588 & 4.4078 & 3.3396 & TRN & \\
\hline CHEMBL1319405 & 752588 & 6.0 & 6.0982 & TRN & \\
\hline CHEMBL1886078 & 752588 & 4.7447 & 3.7064 & TRN & \\
\hline CHEMBL1365469 & 752588 & 5.2757 & 5.095 & TRN & \\
\hline CHEMBL1884442 & 752588 & 6.041 & 6.7392 & TRN & \\
\hline CHEMBL1477061 & 752588 & 5.1146 & 4.0754 & TRN & \\
\hline CHEMBL1870597 & 752588 & 3.0044 & 3.1381 & TRN & \\
\hline CHEMBL1345096 & 752588 & 5.3565 & 5.131 & TST & \\
\hline CHEMBL1903194 & 752588 & 3.0044 & 3.0574 & TRN & \\
\hline CHEMBL1866897 & 752588 & 3.0044 & 3.4149 & TRN & \\
\hline CHEMBL1906326 & 752588 & 3.0044 & 3.213 & TST & \\
\hline CHEMBL1876157 & 752588 & 3.0044 & 2.97399 & 99999999998 & TRN \\
\hline CHEMBL1598762 & 752588 & 5.5243 & 4.6483 & TST & \\
\hline CHEMBL1435486 & 752588 & 5.3872 & 4.5577 & TRN & \\
\hline CHEMBL1416561 & 752588 & 3.0044 & 2.9759 & TRN & \\
\hline CHEMBL1886235 & 752588 & 3.0044 & 2.9554 & TRN & \\
\hline CHEMBL 2448581 & 752588 & 3.0044 & 3.2128 & TRN & \\
\hline CHEMBL1408953 & 752588 & 4.1701 & 3.6639 & TST & \\
\hline CHEMBL1903946 & 752588 & 3.0044 & 3.1576 & TRN & \\
\hline CHEMBL1875486 & 752588 & 3.0044 & 3.4625 & TRN & \\
\hline CHEMBL1879394 & 752588 & 6.0685 & 6.66299 & 9999999999 & TRN \\
\hline CHEMBL1544489 & 752588 & 5.7696 & 5.3478 & TST & \\
\hline CHEMBL1880043 & 752588 & 4.2441 & 3.2352 & TRN & \\
\hline CHEMBL1898951 & 752588 & 3.0044 & 3.2695 & TRN & \\
\hline CHEMBL1887272 & 752588 & 5.4202 & 4.5624 & TRN & \\
\hline CHEMBL1865088 & 752588 & 3.0044 & 3.1868 & TRN & \\
\hline CHEMBL1906504 & 752588 & 3.0044 & 3.2186 & TRN & \\
\hline CHEMBL1871384 & 752588 & 3.0044 & 2.9998 & TRN & \\
\hline CHEMBL1873019 & 752588 & 3.0044 & 3.5626 & TRN & \\
\hline CHEMBL1902852 & 752588 & 3.0044 & 3.2967 & TRN & \\
\hline CHEMBL1882084 & 752588 & 3.0044 & 3.5736 & TRN & \\
\hline CHEMBL1870914 & 752588 & 6.3098 & 6.4441 & TRN & \\
\hline CHEMBL1888528 & 752588 & 4.7905 & 4.3295 & TRN & \\
\hline CHEMBL1881878 & 752588 & 3.0044 & 3.2309 & TRN & \\
\hline CHEMBL1886693 & 752588 & 4.9431 & 4.5769 & TRN & \\
\hline CHEMBL1901827 & 752588 & 5.699 & 6.2989 & TRN & \\
\hline CHEMBL1309254 & 752588 & 3.0044 & 4.0397 & TST & \\
\hline CHEMBL1888478 & 752588 & 3.0044 & 3.1684 & TRN & \\
\hline CHEMBL1883428 & 752588 & 3.0044 & 3.2195 & TRN & \\
\hline CHEMBL1895637 & 752588 & 5.284 & 4.6187 & TRN & \\
\hline CHEMBL1876946 & 752588 & 3.0044 & 3.1829 & TRN & \\
\hline CHEMBL1873238 & 752588 & 4.0691 & 3.8989 & TST & \\
\hline CHEMBL1877317 & 752588 & 3.0044 & 3.1582 & TRN & \\
\hline CHEMBL1869120 & 752588 & 3.0044 & 3.3909 & TRN & \\
\hline CHEMBL1705186 & 752588 & 5.7959 & 5.0026 & TRN & \\
\hline CHEMBL1867373 & 752588 & 3.0044 & 3.2192 & TRN & \\
\hline CHEMBL1902173 & 752588 & 5.5607 & 5.8507 & TRN & \\
\hline
\end{tabular}




\begin{tabular}{|c|c|c|c|c|c|}
\hline & & \multicolumn{4}{|c|}{ Supplemental Table S2.txt } \\
\hline CHEMBL1876647 & 752588 & 3.0044 & 3.1555 & TRN & \\
\hline CHEMBL1878172 & 752588 & 3.0044 & 3.1934 & TST & \\
\hline CHEMBL1880875 & 752588 & 3.0044 & 3.6331 & TST & \\
\hline CHEMBL1599544 & 752588 & 3.0044 & 3.29600 & 00000000003 & TST \\
\hline CHEMBL1322834 & 752588 & 5.5452 & 5.7594 & TRN & \\
\hline CHEMBL1892156 & 752588 & 4.6696 & 3.8873 & TRN & \\
\hline CHEMBL1873343 & 752588 & 3.0044 & 3.3013 & TRN & \\
\hline CHEMBL1432044 & 752588 & 4.8962 & 3.8535 & TST & \\
\hline CHEMBL1879541 & 752588 & 3.0044 & 3.4266 & TRN & \\
\hline CHEMBL1901952 & 752588 & 5.8539 & 5.4313 & TRN & \\
\hline CHEMBL1884495 & 752588 & 5.9586 & 6.1747 & TRN & \\
\hline CHEMBL1506656 & 752588 & 3.0044 & 3.4058 & TST & \\
\hline CHEMBL1892340 & 752588 & 3.0044 & 3.0156 & TRN & \\
\hline CHEMBL1864747 & 752588 & 5.5528 & 5.66700 & 0000000001 & TRN \\
\hline CHEMBL1883257 & 752588 & 5.1938 & 4.2684 & TRN & \\
\hline CHEMBL1890253 & 752588 & 3.0044 & 3.3729 & TRN & \\
\hline CHEMBL1867713 & 752588 & 3.0044 & 3.5432 & TRN & \\
\hline CHEMBL1885498 & 752588 & 3.0044 & 3.0485 & TRN & \\
\hline CHEMBL1869876 & 752588 & 3.0044 & 3.6236 & TRN & \\
\hline CHEMBL1870966 & 752588 & 5.2941 & 4.3225 & TRN & \\
\hline CHEMBL1906573 & 752588 & 4.4647 & 3.1449 & TRN & \\
\hline CHEMBL1877788 & 752588 & 3.0044 & 3.2192 & TST & \\
\hline CHEMBL1905817 & 752588 & 5.5129 & 5.1271 & TRN & \\
\hline CHEMBL1898718 & 752588 & 3.0044 & 3.1818 & TST & \\
\hline CHEMBL1904443 & 752588 & 3.0044 & 3.5127 & TRN & \\
\hline CHEMBL1877931 & 752588 & 3.0044 & 2.9645 & TRN & \\
\hline CHEMBL1901170 & 752588 & 5.7077 & 5.9582 & TRN & \\
\hline CHEMBL1885025 & 752588 & 3.0044 & 3.5156 & TRN & \\
\hline CHEMBL1316867 & 752588 & 6.3098 & 6.4697 & TRN & \\
\hline CHEMBL1890186 & 752588 & 4.4949 & 3.6674 & TST & \\
\hline CHEMBL1866145 & 752588 & 3.0044 & 3.0523 & TRN & \\
\hline CHEMBL1904348 & 752588 & 4.6326 & 5.4367 & TST & \\
\hline CHEMBL1897044 & 752588 & 4.059 & 4.6286 & TST & \\
\hline CHEMBL1525161 & 752588 & 6.1972 & 6.2838 & TST & \\
\hline CHEMBL1866357 & 752588 & 4.0985 & 3.6145 & TRN & \\
\hline CHEMBL1877777 & 752588 & 5.9208 & 6.0353 & TRN & \\
\hline CHEMBL1885482 & 752588 & 4.8539 & 4.982 & TRN & \\
\hline CHEMBL1892075 & 752588 & 3.0044 & 3.7427 & TRN & \\
\hline CHEMBL1449672 & 752588 & 5.3516 & 5.0507 & TRN & \\
\hline CHEMBL1868306 & 752588 & 3.0044 & 3.4661 & TRN & \\
\hline CHEMBL1899771 & 752588 & 4.4828 & 3.6803 & TRN & \\
\hline CHEMBL1877261 & 752588 & 4.1469 & 3.4439 & TRN & \\
\hline CHEMBL1534143 & 752588 & 5.7696 & 6.0272 & TRN & \\
\hline CHEMBL1893535 & 752588 & 4.5331 & 4.4756 & TST & \\
\hline CHEMBL1894125 & 752588 & 3.0044 & 3.5759 & TST & \\
\hline CHEMBL1898423 & 752588 & 4.8539 & 4.3774 & TRN & \\
\hline CHEMBL1885809 & 752588 & 5.5751 & 4.3086 & TRN & \\
\hline CHEMBL1879256 & 752588 & 3.0044 & 3.498 & TRN & \\
\hline
\end{tabular}




\begin{tabular}{|c|c|c|c|c|c|}
\hline \multicolumn{6}{|c|}{ Supplemental Table S2.txt } \\
\hline CHEMBL1892809 & 752588 & 3.0044 & 3.8033 & TST & \\
\hline CHEMBL1486906 & 752588 & 3.0044 & 3.1888 & TRN & \\
\hline CHEMBL1864818 & 752588 & 3.0044 & 3.2612 & TRN & \\
\hline CHEMBL1906451 & 752588 & 3.0044 & 3.469 & TST & \\
\hline CHEMBL1890591 & 752588 & 5.8539 & 5.3726 & TST & \\
\hline CHEMBL1889650 & 752588 & 5.9747 & 5.8972 & TRN & \\
\hline CHEMBL1894366 & 752588 & 3.0044 & 3.4075 & TRN & \\
\hline CHEMBL1881371 & 752588 & 3.0044 & 3.201 & TRN & \\
\hline CHEMBL1863755 & 752588 & 3.0044 & 3.4429 & TRN & \\
\hline CHEMBL1874319 & 752588 & 5.4935 & 4.8178 & TRN & \\
\hline CHEMBL1874506 & 752588 & 5.7447 & 5.7643 & TRN & \\
\hline CHEMBL1898917 & 752588 & 3.0044 & 3.2728 & TRN & \\
\hline CHEMBL1888321 & 752588 & 3.0044 & 3.0608 & TRN & \\
\hline CHEMBL1547213 & 752588 & 4.4609 & 4.6766 & TRN & \\
\hline CHEMBL1875168 & 752588 & 3.0044 & 3.575 & TRN & \\
\hline CHEMBL1888516 & 752588 & 5.8153 & 5.273 & TST & \\
\hline CHEMBL1900453 & 752588 & 4.7496 & 4.6991 & TST & \\
\hline CHEMBL1897633 & 752588 & 4.5901 & 3.3695 & TRN & \\
\hline CHEMBL1893952 & 752588 & 3.0044 & 3.5719 & TRN & \\
\hline CHEMBL1564500 & 752588 & 5.2291 & 4.2303 & TRN & \\
\hline CHEMBL1883904 & 752588 & 3.0044 & 3.1676 & TST & \\
\hline CHEMBL1586985 & 752588 & 6.0477 & 5.6585 & TRN & \\
\hline CHEMBL1514860 & 752588 & 3.0044 & 3.5554 & TRN & \\
\hline CHEMBL1886476 & 752588 & 3.0044 & 3.2115 & TRN & \\
\hline CHEMBL1896895 & 752588 & 4.3325 & 3.8014 & TRN & \\
\hline CHEMBL1322894 & 752588 & 5.6799 & 5.2867 & TRN & \\
\hline CHEMBL1905576 & 752588 & 3.0044 & 3.3034 & TRN & \\
\hline CHEMBL1876316 & 752588 & 4.9626 & 4.2626 & TRN & \\
\hline CHEMBL1878043 & 752588 & 5.1938 & 5.0075 & TRN & \\
\hline CHEMBL1868274 & 752588 & 5.6021 & 4.9828 & TRN & \\
\hline CHEMBL1497617 & 752588 & 5.5607 & 4.4629 & TST & \\
\hline CHEMBL1872249 & 752588 & 4.0462 & 3.5722 & TRN & \\
\hline CHEMBL1884437 & 752588 & 4.5654 & 3.56100 & 00000000004 & TRN \\
\hline CHEMBL1517170 & 752588 & 3.0044 & 3.5259 & TRN & \\
\hline CHEMBL1891588 & 752588 & 6.1249 & 6.7988 & TRN & \\
\hline CHEMBL1900215 & 752588 & 3.0044 & 3.12600 & 00000000003 & TRN \\
\hline CHEMBL1897928 & 752588 & 3.0044 & 3.5237 & TST & \\
\hline CHEMBL1893628 & 752588 & 3.0044 & 3.1971 & TRN & \\
\hline CHEMBL1871956 & 752588 & 3.0044 & 4.0823 & TST & \\
\hline CHEMBL1408676 & 752588 & 4.2782 & 3.9549 & TRN & \\
\hline CHEMBL1905093 & 752588 & 4.4559 & 3.9945 & TRN & \\
\hline CHEMBL1887414 & 752588 & 3.0044 & 4.2539 & TST & \\
\hline CHEMBL1469489 & 752588 & 4.1068 & 3.5891 & TST & \\
\hline CHEMBL1883048 & 752588 & 3.0044 & 3.1109 & TRN & \\
\hline CHEMBL1870930 & 752588 & 5.5768 & 4.9658 & TRN & \\
\hline CHEMBL1905211 & 752588 & 3.0044 & 3.4973 & TRN & \\
\hline CHEMBL1870590 & 752588 & 3.0044 & 3.3469 & TST & \\
\hline CHEMBL1880120 & 752588 & 4.9355 & 4.9929 & TRN & \\
\hline
\end{tabular}




\begin{tabular}{|c|c|c|c|c|c|}
\hline & & & & & \\
\hline CHEMBL1887007 & 752588 & 3.0044 & 3.0841 & TRN & \\
\hline CHEMBL1874988 & 752588 & 4.7447 & 4.52800 & 00000000005 & TRN \\
\hline CHEMBL1620972 & 752588 & 3.0044 & 3.3486 & TRN & \\
\hline CHEMBL1577231 & 752588 & 5.9586 & 6.1572 & TRN & \\
\hline CHEMBL1879721 & 752588 & 4.0506 & 4.6315 & TRN & \\
\hline CHEMBL1554455 & 752588 & 3.0044 & 3.4174 & TRN & \\
\hline CHEMBL1899595 & 752588 & 5.699 & 5.59399 & 9999999999 & TRN \\
\hline CHEMBL1876217 & 752588 & 5.8097 & 6.4472 & TRN & \\
\hline CHEMBL1876373 & 752588 & 3.0044 & 3.4219 & TRN & \\
\hline CHEMBL1306211 & 752588 & 3.0044 & 3.7607 & TST & \\
\hline CHEMBL1884064 & 752588 & 3.0044 & 3.2858 & TRN & \\
\hline CHEMBL1872841 & 752588 & 4.8539 & 4.4366 & TRN & \\
\hline CHEMBL1899989 & 752588 & 5.8239 & 5.8093 & TRN & \\
\hline CHEMBL1868902 & 752588 & 5.7212 & 5.7935 & TRN & \\
\hline CHEMBL1865565 & 752588 & 3.0044 & 3.2745 & TST & \\
\hline CHEMBL1470146 & 752588 & 5.2472 & 5.4488 & TST & \\
\hline CHEMBL1865265 & 752588 & 3.0044 & 3.245 & TST & \\
\hline CHEMBL3144856 & 752588 & 4.9101 & 4.5488 & TST & \\
\hline CHEMBL1904648 & 752588 & 5.7696 & 5.4104 & TRN & \\
\hline CHEMBL1460250 & 752588 & 5.2815 & 4.4201 & TST & \\
\hline CHEMBL1582654 & 752588 & 5.8697 & 5.7232 & TRN & \\
\hline CHEMBL1886298 & 752588 & 3.0044 & 3.1538 & TRN & \\
\hline CHEMBL1571012 & 752588 & 5.1656 & 4.3651 & TST & \\
\hline CHEMBL1902079 & 752588 & 4.1079 & 3.4677 & TST & \\
\hline CHEMBL1872062 & 752588 & 5.5436 & 5.1033 & TST & \\
\hline CHEMBL1893076 & 752588 & 3.0044 & 3.1089 & TST & \\
\hline CHEMBL1878061 & 752588 & 5.9586 & 6.4042 & TRN & \\
\hline CHEMBL1897015 & 752588 & 4.3325 & 3.4026 & TRN & \\
\hline CHEMBL1877896 & 752588 & 3.0044 & 3.1235 & TST & \\
\hline CHEMBL1471498 & 752588 & 4.6091 & 3.6865 & TST & \\
\hline CHEMBL1885269 & 752588 & 5.8861 & 6.3645 & TRN & \\
\hline CHEMBL1896263 & 752588 & 5.7959 & 5.79799 & 9999999999 & TRN \\
\hline CHEMBL1898778 & 752588 & 3.0044 & 3.3766 & TRN & \\
\hline CHEMBL1892581 & 752588 & 3.0044 & 3.307 & TST & \\
\hline CHEMBL1891206 & 752588 & 6.0506 & 6.914 & TRN & \\
\hline CHEMBL1412015 & 752588 & 5.8827 & 5.9369 & TST & \\
\hline CHEMBL1869393 & 752588 & 6.0177 & 6.601 & TRN & \\
\hline CHEMBL1890161 & 752588 & 4.0942 & 3.3887 & TST & \\
\hline CHEMBL233119 & 752588 & 5.5686 & 4.5638 & TRN & \\
\hline CHEMBL68442 & 752588 & 3.0044 & 3.2047 & TRN & \\
\hline CHEMBL 2028088 & 752588 & 3.0044 & 3.1158 & TRN & \\
\hline CHEMBL1413278 & 752588 & 5.6021 & 5.1232 & TRN & \\
\hline CHEMBL1886317 & 752588 & 5.3098 & 4.9097 & TRN & \\
\hline CHEMBL1903693 & 752588 & 3.0044 & 3.1953 & TST & \\
\hline CHEMBL3410603 & 1470242 & 4.0 & 3.9146 & TRN & \\
\hline CHEMBL 3410578 & 1470242 & 4.0 & 3.9835 & TRN & \\
\hline CHEMBL3410606 & 1470242 & 4.0 & 3.9281 & TST & \\
\hline CHEMBL3410589 & 1470242 & 4.0 & 3.9962 & TRN & \\
\hline
\end{tabular}




\begin{tabular}{|c|c|c|c|c|c|}
\hline & & & & & \\
\hline CHEMBL3410579 & 1470242 & 4.0 & 3.9713 & TRN & \\
\hline CHEMBL3410598 & 1470242 & 4.0 & 3.9564 & TRN & \\
\hline CHEMBL3410582 & 1470242 & 4.0 & 3.986 & TRN & \\
\hline CHEMBL3410615 & 1470242 & 4.0 & 3.9306 & TRN & \\
\hline CHEMBL3410610 & 1470242 & 4.0 & 4.4671 & TRN & \\
\hline CHEMBL3410574 & 1470242 & 5.3701 & 4.1451 & TST & \\
\hline CHEMBL3410604 & 1470242 & 4.0 & 3.8978 & TRN & \\
\hline CHEMBL 3410588 & 1470242 & 4.0 & 3.9925 & TRN & \\
\hline CHEMBL3410605 & 1470242 & 4.0 & 3.9323 & TRN & \\
\hline CHEMBL3410595 & 1470242 & 4.0 & 3.9121 & TRN & \\
\hline CHEMBL3410573 & 1470242 & 4.0 & 4.1613 & TRN & \\
\hline CHEMBL3410576 & 1470242 & 6.06 & 4.689 & TRN & \\
\hline CHEMBL3410607 & 1470242 & 4.0 & 3.9188 & TRN & \\
\hline CHEMBL3410592 & 1470242 & 4.0 & 3.95899 & 99999999996 & TRN \\
\hline CHEMBL 3410583 & 1470242 & 4.0 & 3.9722 & TRN & \\
\hline CHEMBL 3410600 & 1470242 & 4.0 & 4.0959 & TRN & \\
\hline CHEMBL3410591 & 1470242 & 4.0 & 3.9647 & TRN & \\
\hline CHEMBL3410617 & 1470242 & 4.0 & 3.9761 & TRN & \\
\hline CHEMBL3410570 & 1470242 & 4.0 & 4.1685 & TRN & \\
\hline CHEMBL3410584 & 1470242 & 4.0 & 4.0338 & TRN & \\
\hline CHEMBL3410611 & 1470242 & 4.0 & 4.2419 & TRN & \\
\hline CHEMBL3410616 & 1470242 & 4.0 & 3.9881 & TRN & \\
\hline CHEMBL3410587 & 1470242 & 4.0 & 3.9763 & TRN & \\
\hline CHEMBL3410612 & 1470242 & 4.0 & 3.9625 & TRN & \\
\hline CHEMBL3410577 & 1470242 & 4.0 & 4.4842 & TRN & \\
\hline CHEMBL1235108 & 1470242 & 4.0 & 4.178 & TRN & \\
\hline CHEMBL3410608 & 1470242 & 4.0 & 3.94 & TRN & \\
\hline CHEMBL3410596 & 1470242 & 4.0 & 3.9544 & TRN & \\
\hline CHEMBL3410593 & 1470242 & 4.0 & 3.9917 & TRN & \\
\hline CHEMBL3410609 & 1470242 & 4.0 & 3.9271 & TRN & \\
\hline CHEMBL3410581 & 1470242 & 4.0 & 4.4753 & TRN & \\
\hline CHEMBL3410613 & 1470242 & 4.0 & 3.9467 & TRN & \\
\hline CHEMBL3410571 & 1470242 & 4.0 & 4.1735 & TRN & \\
\hline CHEMBL1460972 & 1470242 & 5.6105 & 3.9869 & TST & \\
\hline CHEMBL3410586 & 1470242 & 4.0 & 4.0219 & TST & \\
\hline CHEMBL475813 & 1470242 & 7.6021 & 4.6098 & TST & \\
\hline CHEMBL3410590 & 1470242 & 4.0 & 4.0316 & TRN & \\
\hline CHEMBL 3410597 & 1470242 & 4.0 & 3.9227 & TRN & \\
\hline CHEMBL3410618 & 1470242 & 4.0 & 4.0388 & TRN & \\
\hline CHEMBL3410619 & 1470242 & 4.0 & 4.0294 & TRN & \\
\hline CHEMBL3410594 & 1470242 & 4.0 & 3.9182 & TRN & \\
\hline CHEMBL 3410580 & 1470242 & 4.0 & 4.0082 & TST & \\
\hline CHEMBL3410572 & 1470242 & 5.8271 & 4.1619 & TST & \\
\hline CHEMBL3410585 & 1470242 & 4.0 & 4.0001 & TST & \\
\hline CHEMBL3410599 & 1470242 & 4.0 & 3.9392 & TST & \\
\hline CHEMBL3410602 & 1470242 & 4.0 & 3.9146 & TST & \\
\hline CHEMBL 2178108 & 1470242 & 6.2007 & 4.2004 & TST & \\
\hline CHEMBL3410575 & 1470242 & 4.0 & 4.1523 & TST & \\
\hline
\end{tabular}




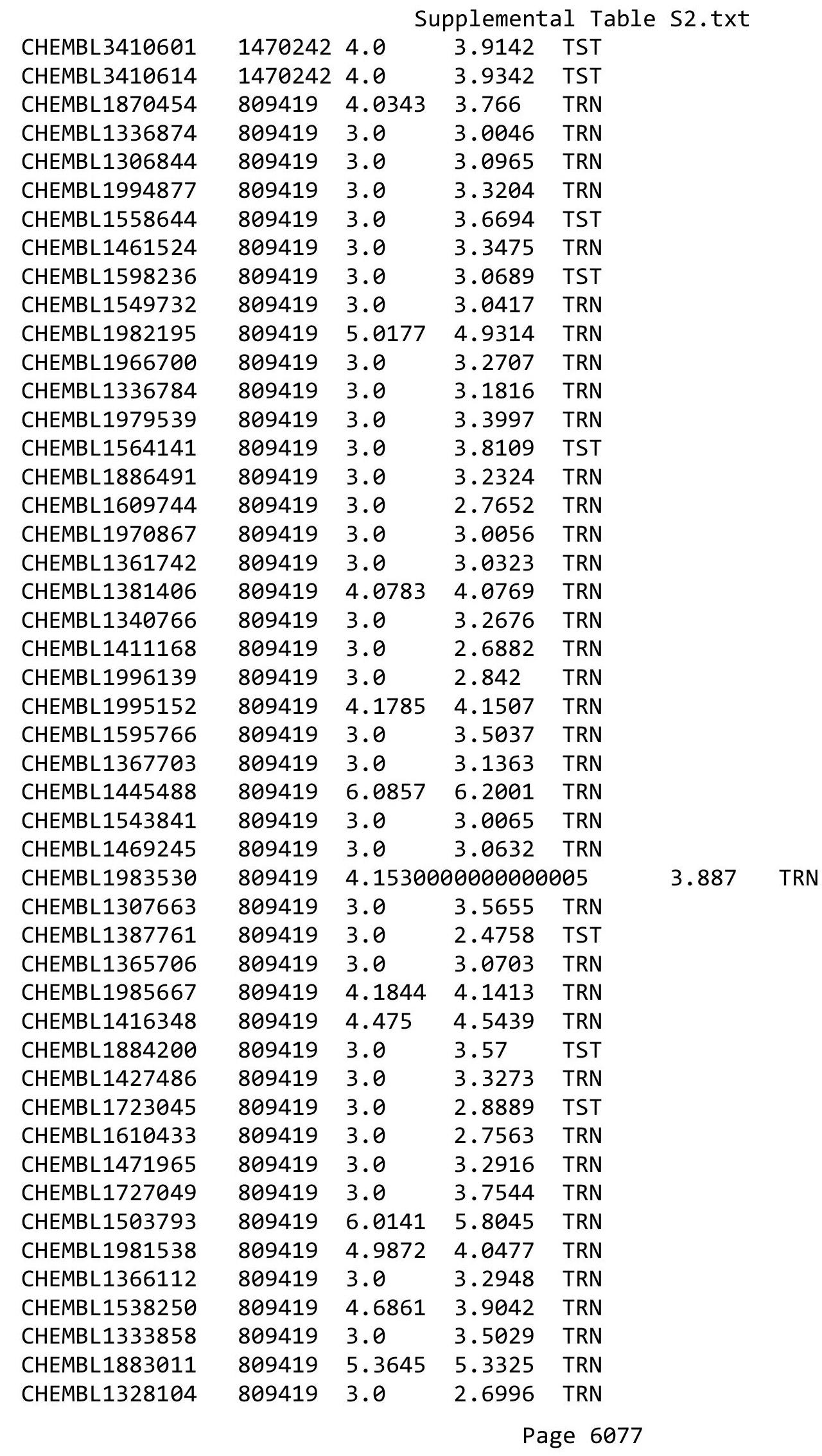




\begin{tabular}{|c|c|c|c|c|c|}
\hline & & \multicolumn{4}{|c|}{ Supplemental Table S2.txt } \\
\hline CHEMBL1333181 & 809419 & 4.3757 & 3.7603 & TRN & \\
\hline CHEMBL1421745 & 809419 & 3.0 & 2.8484 & TRN & \\
\hline CHEMBL1505300 & 809419 & 5.2373 & 4.6766 & TRN & \\
\hline CHEMBL1973435 & 809419 & 3.0 & 3.2359 & TST & \\
\hline CHEMBL1454680 & 809419 & 3.0 & 2.7578 & TRN & \\
\hline CHEMBL2004916 & 809419 & 3.0 & 3.0797 & TST & \\
\hline CHEMBL1315298 & 809419 & 3.0 & 3.6833 & TST & \\
\hline CHEMBL1473121 & 809419 & 4.1898 & 3.3123 & TST & \\
\hline CHEMBL1727678 & 809419 & 3.0 & 4.0718 & TST & \\
\hline CHEMBL1393151 & 809419 & 5.4342 & 5.2648 & TRN & \\
\hline CHEMBL1479139 & 809419 & 3.0 & 2.9277 & TRN & \\
\hline CHEMBL1447158 & 809419 & 5.0894 & 4.5726 & TRN & \\
\hline CHEMBL 2000877 & 809419 & 3.0 & 3.3138 & TRN & \\
\hline CHEMBL1545689 & 809419 & 3.0 & 2.66899 & 99999999996 & TRN \\
\hline CHEMBL579028 & 809419 & 3.0 & 3.4038 & TRN & \\
\hline CHEMBL1709966 & 809419 & 3.0 & 3.0167 & TST & \\
\hline CHEMBL1993978 & 809419 & 3.0 & 2.8141 & TRN & \\
\hline CHEMBL1564058 & 809419 & 3.0 & 3.0828 & TRN & \\
\hline CHEMBL1717770 & 809419 & 4.0372 & 2.5485 & TST & \\
\hline CHEMBL1309895 & 809419 & 4.9208 & 4.966 & TRN & \\
\hline CHEMBL1491272 & 809419 & 3.0 & 2.935 & TRN & \\
\hline CHEMBL1428997 & 809419 & 4.6737 & 5.0186 & TRN & \\
\hline CHEMBL1481077 & 809419 & 4.5331 & 4.3916 & TRN & \\
\hline CHEMBL1532025 & 809419 & 4.3665 & 3.9126 & TRN & \\
\hline CHEMBL1306897 & 809419 & 3.0 & 2.8705 & TST & \\
\hline CHEMBL1362650 & 809419 & 3.0 & 3.2304 & TST & \\
\hline CHEMBL1487024 & 809419 & 3.0 & 3.3843 & TRN & \\
\hline CHEMBL1405120 & 809419 & 3.0 & 3.4657 & TRN & \\
\hline CHEMBL1876111 & 809419 & 3.0 & 2.9731 & TRN & \\
\hline CHEMBL1453126 & 809419 & 3.0 & 2.7977 & TRN & \\
\hline CHEMBL1482795 & 809419 & 3.0 & 2.545 & TRN & \\
\hline CHEMBL1414513 & 809419 & 3.0 & 3.3309 & TRN & \\
\hline CHEMBL1409822 & 809419 & 3.0 & 3.0749 & TRN & \\
\hline CHEMBL1974063 & 809419 & 3.0 & 3.6759 & TRN & \\
\hline CHEMBL1299478 & 809419 & 3.0 & 2.7768 & TRN & \\
\hline CHEMBL1362445 & 809419 & 4.6383 & 4.1067 & TRN & \\
\hline CHEMBL473314 & 809419 & 3.0 & 2.9241 & TST & \\
\hline CHEMBL1975054 & 809419 & 3.0 & 3.5645 & TRN & \\
\hline CHEMBL1313324 & 809419 & 3.0 & 3.0225 & TRN & \\
\hline CHEMBL1975801 & 809419 & 3.0 & 2.6265 & TRN & \\
\hline CHEMBL1545846 & 809419 & 3.0 & 2.7075 & TRN & \\
\hline CHEMBL1422807 & 809419 & 5.0311 & 4.6367 & TRN & \\
\hline CHEMBL1998061 & 809419 & 3.0 & 3.4322 & TRN & \\
\hline CHEMBL1366289 & 809419 & 3.0 & 3.1759 & TST & \\
\hline CHEMBL1443088 & 809419 & 3.0 & 3.1037 & TRN & \\
\hline CHEMBL1997827 & 809419 & 3.0 & 3.2445 & TRN & \\
\hline CHEMBL1448606 & 809419 & 4.0232 & 3.615 & TRN & \\
\hline CHEMBL1427763 & 809419 & 3.0 & 3.0431 & TRN & \\
\hline
\end{tabular}




\begin{tabular}{|c|c|c|c|c|c|}
\hline \multicolumn{6}{|c|}{ Supplemental Table s2.txt } \\
\hline CHEMBL1537847 & 809419 & 3.0 & 3.2984 & TRN & \\
\hline CHEMBL1576310 & 809419 & 3.0 & 2.5786 & TRN & \\
\hline CHEMBL2359510 & 809419 & 3.0 & 2.8844 & TRN & \\
\hline CHEMBL1444386 & 809419 & 3.0 & 2.4455 & TRN & \\
\hline CHEMBL1898074 & 809419 & 5.2668 & 4.4378 & TRN & \\
\hline CHEMBL1580664 & 809419 & 3.0 & 3.2325 & TRN & \\
\hline CHEMBL1470199 & 809419 & 3.0 & 3.1457 & TRN & \\
\hline CHEMBL1726180 & 809419 & 4.1319 & 3.7603 & TRN & \\
\hline CHEMBL1369893 & 809419 & 5.2284 & 5.3264 & TRN & \\
\hline CHEMBL1482926 & 809419 & 3.0 & 3.0584 & TRN & \\
\hline CHEMBL1604122 & 809419 & 4.2612 & 4.1538 & TRN & \\
\hline CHEMBL1329487 & 809419 & 4.1878 & 4.0137 & TRN & \\
\hline CHEMBL1351704 & 809419 & 3.0 & 3.1945 & TRN & \\
\hline CHEMBL1509867 & 809419 & 3.0 & 3.117 & TRN & \\
\hline CHEMBL1384550 & 809419 & 3.0 & 3.1192 & TRN & \\
\hline CHEMBL1542128 & 809419 & 5.1979 & 5.0669 & TRN & \\
\hline CHEMBL1308195 & 809419 & 3.0 & 2.9445 & TRN & \\
\hline CHEMBL1482670 & 809419 & 3.0 & 3.1169 & TRN & \\
\hline CHEMBL1350703 & 809419 & 3.0 & 3.0511 & TRN & \\
\hline CHEMBL1583854 & 809419 & 3.0 & 3.1011 & TRN & \\
\hline CHEMBL1317897 & 809419 & 3.0 & 3.2707 & TRN & \\
\hline CHEMBL1497731 & 809419 & 3.0 & 2.9434 & TRN & \\
\hline CHEMBL1450813 & 809419 & 3.0 & 2.6694 & TRN & \\
\hline CHEMBL1548770 & 809419 & 4.2048 & 4.0121 & TRN & \\
\hline CHEMBL1520551 & 809419 & 3.0 & 3.7768 & TST & \\
\hline CHEMBL1493011 & 809419 & 6.52 & 6.0581 & TRN & \\
\hline CHEMBL1385587 & 809419 & 4.0883 & 4.2339 & TRN & \\
\hline CHEMBL1982308 & 809419 & 3.0 & 2.6223 & TST & \\
\hline CHEMBL1884782 & 809419 & 4.0665 & 2.9613 & TST & \\
\hline CHEMBL1351925 & 809419 & 3.0 & 3.2746 & TRN & \\
\hline CHEMBL1339485 & 809419 & 3.0 & 2.9137 & TRN & \\
\hline CHEMBL1971127 & 809419 & 3.0 & 2.9308 & TST & \\
\hline CHEMBL1438370 & 809419 & 3.0 & 2.822 & TRN & \\
\hline CHEMBL1480073 & 809419 & 3.0 & 3.1592 & TRN & \\
\hline CHEMBL1534006 & 809419 & 4.0506 & 3.5428 & TRN & \\
\hline CHEMBL 2005671 & 809419 & 3.0 & 3.0753 & TRN & \\
\hline CHEMBL1544407 & 809419 & 3.0 & 3.0099 & TRN & \\
\hline CHEMBL1460857 & 809419 & 3.0 & 3.3056 & TRN & \\
\hline CHEMBL1320702 & 809419 & 4.5544 & 4.5646 & TRN & \\
\hline CHEMBL1985696 & 809419 & 5.0888 & 4.6004 & TRN & \\
\hline CHEMBL1313755 & 809419 & 3.0 & 3.0232 & TRN & \\
\hline CHEMBL1474528 & 809419 & 3.0 & 4.1146 & TST & \\
\hline CHEMBL1443805 & 809419 & 3.0 & 3.0518 & TST & \\
\hline CHEMBL1537775 & 809419 & 3.0 & 3.26899 & 99999999997 & TRN \\
\hline CHEMBL1971033 & 809419 & 5.4214 & 4.414 & TRN & \\
\hline CHEMBL1573804 & 809419 & 3.0 & 3.4481 & TRN & \\
\hline CHEMBL1888496 & 809419 & 3.0 & 2.7972 & TRN & \\
\hline CHEMBL1873140 & 809419 & 3.0 & 3.0782 & TRN & \\
\hline
\end{tabular}




\begin{tabular}{|c|c|c|c|c|}
\hline \multicolumn{5}{|c|}{ Supplemental Table S2.txt } \\
\hline CHEMBL1320653 & 809419 & 3.0 & 3.0236 & TRN \\
\hline CHEMBL2005518 & 809419 & 3.0 & 3.3921 & TRN \\
\hline CHEMBL1497338 & 809419 & 3.0 & 3.2786 & TST \\
\hline CHEMBL1545927 & 809419 & 3.0 & 2.9648 & TRN \\
\hline CHEMBL2003445 & 809419 & 3.0 & 2.5904 & TRN \\
\hline CHEMBL1306521 & 809419 & 3.0 & 2.7374 & TRN \\
\hline CHEMBL1555317 & 809419 & 3.0 & 2.6242 & TRN \\
\hline CHEMBL1481605 & 809419 & 3.0 & 3.1637 & TRN \\
\hline CHEMBL1993220 & 809419 & 3.0 & 2.9932 & TST \\
\hline CHEMBL1970785 & 809419 & 3.0 & 2.698 & TRN \\
\hline CHEMBL 2003808 & 809419 & 3.0 & 3.8748 & TRN \\
\hline CHEMBL1491016 & 809419 & 3.0 & 3.2218 & TRN \\
\hline CHEMBL1992681 & 809419 & 3.0 & 2.6682 & TRN \\
\hline CHEMBL1986889 & 809419 & 3.0 & 3.0852 & TRN \\
\hline CHEMBL1976161 & 809419 & 3.0 & 3.2728 & TRN \\
\hline CHEMBL1555215 & 809419 & 3.0 & 3.0308 & TRN \\
\hline CHEMBL1564638 & 809419 & 4.6904 & 5.078 & TRN \\
\hline CHEMBL1342085 & 809419 & 3.0 & 2.8649 & TRN \\
\hline CHEMBL1308055 & 809419 & 3.0 & 3.7338 & TRN \\
\hline CHEMBL1498705 & 809419 & 3.0 & 2.5801 & TST \\
\hline CHEMBL56542 & 809419 & 3.0 & 2.7384 & TRN \\
\hline CHEMBL1881326 & 809419 & 3.0 & 2.8982 & TST \\
\hline CHEMBL1875123 & 809419 & 3.0 & 3.33 & TRN \\
\hline CHEMBL1484632 & 809419 & 3.0 & 2.7239 & TRN \\
\hline CHEMBL1864040 & 809419 & 3.0 & 2.8981 & TRN \\
\hline CHEMBL1375814 & 809419 & 3.0 & 2.8776 & TRN \\
\hline CHEMBL1505688 & 809419 & 4.9872 & 3.8499 & TRN \\
\hline CHEMBL1504166 & 809419 & 3.0 & 3.2267 & TRN \\
\hline CHEMBL1378952 & 809419 & 4.8297 & 4.8532 & TRN \\
\hline CHEMBL1364454 & 809419 & 3.0 & 2.9333 & TRN \\
\hline CHEMBL1518206 & 809419 & 3.0 & 3.255 & TST \\
\hline CHEMBL2007227 & 809419 & 3.0 & 3.1239 & TRN \\
\hline CHEMBL1591691 & 809419 & 3.0 & 2.7526 & TRN \\
\hline CHEMBL1446094 & 809419 & 3.0 & 3.5016 & TRN \\
\hline CHEMBL1613540 & 809419 & 3.0 & 3.135 & TRN \\
\hline CHEMBL1363662 & 809419 & 3.0 & 2.6583 & TRN \\
\hline CHEMBL1982202 & 809419 & 3.0 & 3.2463 & TST \\
\hline CHEMBL1985795 & 809419 & 3.0 & 2.8643 & TRN \\
\hline CHEMBL1404120 & 809419 & 3.0 & 2.8339 & TRN \\
\hline CHEMBL1610506 & 809419 & 4.3625 & 3.6053 & TST \\
\hline CHEMBL1996136 & 809419 & 3.0 & 3.0885 & TRN \\
\hline CHEMBL 2002565 & 809419 & 3.0 & 3.4196 & TRN \\
\hline CHEMBL1528977 & 809419 & 3.0 & 3.0079 & TRN \\
\hline CHEMBL 2001433 & 809419 & 3.0 & 2.7463 & TRN \\
\hline CHEMBL1340228 & 809419 & 3.0 & 3.6377 & TRN \\
\hline CHEMBL1401522 & 809419 & 3.0 & 2.8446 & TRN \\
\hline CHEMBL1481627 & 809419 & 3.0 & 2.5729 & TRN \\
\hline CHEMBL1460896 & 809419 & 3.0 & 3.3457 & TRN \\
\hline
\end{tabular}




\begin{tabular}{|c|c|c|c|c|c|}
\hline \multirow{3}{*}{$\begin{array}{l}\text { CHEMBL1550553 } \\
\text { CHEMBL1980308 }\end{array}$} & \multirow{3}{*}{$\begin{array}{l}809419 \\
809419\end{array}$} & \multicolumn{4}{|c|}{ Supplemental Table S2.txt } \\
\hline & & 3.0 & \multicolumn{2}{|c|}{3.1310000000000002} & TRN \\
\hline & & 3.0 & 3.0804 & TRN & \\
\hline CHEMBL1364731 & 809419 & 3.0 & 3.2219 & TRN & \\
\hline CHEMBL1706207 & 809419 & 4.1057 & 3.7761 & TST & \\
\hline CHEMBL1591174 & 809419 & 4.3936 & 4.0861 & TRN & \\
\hline CHEMBL1590386 & 809419 & 3.0 & 2.7172 & TRN & \\
\hline CHEMBL1320535 & 809419 & 3.0 & 2.7147 & TRN & \\
\hline CHEMBL1979696 & 809419 & 3.0 & 2.9673 & TRN & \\
\hline CHEMBL1325757 & 809419 & 3.0 & 2.6602 & TRN & \\
\hline CHEMBL1983460 & 809419 & 3.0 & 2.9197 & TRN & \\
\hline CHEMBL1529328 & 809419 & 3.0 & 2.88199 & 99999999997 & TRN \\
\hline CHEMBL1569215 & 809419 & 4.2464 & 4.4348 & TRN & \\
\hline CHEMBL1899457 & 809419 & 3.0 & 2.8989 & TRN & \\
\hline CHEMBL1343853 & 809419 & 3.0 & 2.8596 & TRN & \\
\hline CHEMBL1302696 & 809419 & 3.0 & 2.9171 & TRN & \\
\hline CHEMBL1427330 & 809419 & 4.8182 & 5.2414 & TRN & \\
\hline CHEMBL1335064 & 809419 & 4.2426 & 4.2339 & TRN & \\
\hline CHEMBL1709846 & 809419 & 3.0 & 4.2499 & TST & \\
\hline CHEMBL1699206 & 809419 & 3.0 & 3.2458 & TRN & \\
\hline CHEMBL 2006357 & 809419 & 3.0 & 2.5412 & TRN & \\
\hline CHEMBL1344023 & 809419 & 3.0 & 3.0805 & TRN & \\
\hline CHEMBL1316472 & 809419 & 3.0 & 2.925 & TRN & \\
\hline CHEMBL56731 & 809419 & 3.0 & 3.1221 & TRN & \\
\hline CHEMBL1972506 & 809419 & 3.0 & 3.0491 & TST & \\
\hline CHEMBL1439933 & 809419 & 3.0 & 3.1103 & TRN & \\
\hline CHEMBL1464805 & 809419 & 5.0773 & 4.6657 & TRN & \\
\hline CHEMBL1988376 & 809419 & 3.0 & 3.5492 & TRN & \\
\hline CHEMBL1976677 & 809419 & 4.9031 & 4.0633 & TRN & \\
\hline CHEMBL1428264 & 809419 & 3.0 & 2.8608 & TRN & \\
\hline CHEMBL1458593 & 809419 & 3.0 & 2.7315 & TRN & \\
\hline CHEMBL1540680 & 809419 & 3.0 & 3.8688 & TRN & \\
\hline CHEMBL1532956 & 809419 & 4.6234 & 4.8912 & TRN & \\
\hline CHEMBL1977596 & 809419 & 3.0 & 3.2038 & TST & \\
\hline CHEMBL1452158 & 809419 & 3.0 & 3.3272 & TRN & \\
\hline CHEMBL1325818 & 809419 & 4.7258 & 4.3884 & TRN & \\
\hline CHEMBL1418430 & 809419 & 3.0 & 3.1691 & TRN & \\
\hline CHEMBL1992308 & 809419 & 3.0 & 3.67 & TST & \\
\hline CHEMBL1966202 & 809419 & 3.0 & 3.3046 & TRN & \\
\hline CHEMBL1378569 & 809419 & 4.4123 & 4.4643 & TRN & \\
\hline CHEMBL1337267 & 809419 & 3.0 & 2.7039 & TRN & \\
\hline CHEMBL1541480 & 809419 & 3.0 & 2.8725 & TRN & \\
\hline CHEMBL1299980 & 809419 & 3.0 & 2.9686 & TRN & \\
\hline CHEMBL1596745 & 809419 & 3.0 & 3.4706 & TRN & \\
\hline CHEMBL1347547 & 809419 & 3.0 & 2.907 & TRN & \\
\hline CHEMBL1351250 & 809419 & 3.0 & 3.0721 & TRN & \\
\hline CHEMBL1509380 & 809419 & 3.0 & 2.9652 & TRN & \\
\hline CHEMBL1612000 & 809419 & 3.0 & 3.1649 & TRN & \\
\hline CHEMBL1345800 & 809419 & 4.3449 & 4.1173 & TRN & \\
\hline
\end{tabular}




\begin{tabular}{|c|c|c|c|c|c|}
\hline & & \multicolumn{4}{|c|}{ Supplemental Table S2.txt } \\
\hline CHEMBL1536896 & 809419 & 5.983 & 5.968 & TRN & \\
\hline CHEMBL1467881 & 809419 & 3.0 & 3.1995 & TRN & \\
\hline CHEMBL1994463 & 809419 & 6.9136 & 3.2447 & TST & \\
\hline CHEMBL1602055 & 809419 & 3.0 & 3.3592 & TRN & \\
\hline CHEMBL1360824 & 809419 & 3.0 & 3.1642 & TRN & \\
\hline CHEMBL1376556 & 809419 & 3.0 & 2.792 & TRN & \\
\hline CHEMBL1537781 & 809419 & 3.0 & 2.2455 & TST & \\
\hline CHEMBL1560147 & 809419 & 3.0 & 3.0003 & TRN & \\
\hline CHEMBL1548928 & 809419 & 3.0 & 3.0374 & TRN & \\
\hline CHEMBL1459808 & 809419 & 3.0 & 3.3945 & TRN & \\
\hline CHEMBL1580600 & 809419 & 3.0 & 3.3308 & TRN & \\
\hline CHEMBL1996548 & 809419 & 3.0 & 3.0912 & TRN & \\
\hline CHEMBL1350299 & 809419 & 3.0 & 3.0085 & TRN & \\
\hline CHEMBL1968356 & 809419 & 3.0 & 3.2449 & TRN & \\
\hline CHEMBL1535349 & 809419 & 3.0 & 3.30899 & 99999999997 & TRN \\
\hline CHEMBL1556531 & 809419 & 5.6345 & 5.0567 & TRN & \\
\hline CHEMBL1429479 & 809419 & 5.4622 & 5.038 & TRN & \\
\hline CHEMBL1556780 & 809419 & 3.0 & 2.8271 & TRN & \\
\hline CHEMBL1326349 & 809419 & 3.0 & 2.6203 & TRN & \\
\hline CHEMBL1719956 & 809419 & 3.0 & 3.3782 & TRN & \\
\hline CHEMBL1980844 & 809419 & 7.1169 & 3.3496 & TST & \\
\hline CHEMBL1566994 & 809419 & 5.6676 & 5.78100 & 0000000001 & TRN \\
\hline CHEMBL1538897 & 809419 & 3.0 & 3.8879 & TRN & \\
\hline CHEMBL1597650 & 809419 & 3.0 & 3.4107 & TRN & \\
\hline CHEMBL1526150 & 809419 & 3.0 & 2.8328 & TRN & \\
\hline CHEMBL1538322 & 809419 & 3.0 & 3.1582 & TRN & \\
\hline CHEMBL1480510 & 809419 & 3.0 & 3.0223 & TRN & \\
\hline CHEMBL1511181 & 809419 & 3.0 & 3.1075 & TRN & \\
\hline CHEMBL1381815 & 809419 & 3.0 & 2.8345 & TRN & \\
\hline CHEMBL1303333 & 809419 & 4.1475 & 3.6517 & TRN & \\
\hline CHEMBL1999908 & 809419 & 4.5229 & 3.9271 & TRN & \\
\hline CHEMBL1431909 & 809419 & 3.0 & 2.69 & TRN & \\
\hline CHEMBL1600901 & 809419 & 3.0 & 3.3601 & TRN & \\
\hline CHEMBL1972750 & 809419 & 3.0 & 2.9805 & TST & \\
\hline CHEMBL1484595 & 809419 & 3.0 & 2.7966 & TRN & \\
\hline CHEMBL1873454 & 809419 & 3.0 & 4.7136 & TST & \\
\hline CHEMBL1342836 & 809419 & 3.0 & 2.1106 & TST & \\
\hline CHEMBL1316089 & 809419 & 3.0 & 3.5022 & TRN & \\
\hline CHEMBL1437190 & 809419 & 3.0 & 2.9838 & TRN & \\
\hline CHEMBL1346724 & 809419 & 4.51 & 3.8501 & TRN & \\
\hline CHEMBL1522018 & 809419 & 3.0 & 2.5433 & TRN & \\
\hline CHEMBL1501577 & 809419 & 4.6478 & 4.0954 & TRN & \\
\hline CHEMBL1438210 & 809419 & 3.0 & 2.9308 & TRN & \\
\hline CHEMBL1463203 & 809419 & 4.4855 & 3.8274 & TRN & \\
\hline CHEMBL1398357 & 809419 & 3.0 & 2.8497 & TRN & \\
\hline CHEMBL1332854 & 809419 & 3.0 & 2.9699 & TRN & \\
\hline CHEMBL1361889 & 809419 & 3.0 & 2.9394 & TRN & \\
\hline CHEMBL1528476 & 809419 & 3.0 & 3.3496 & TRN & \\
\hline
\end{tabular}




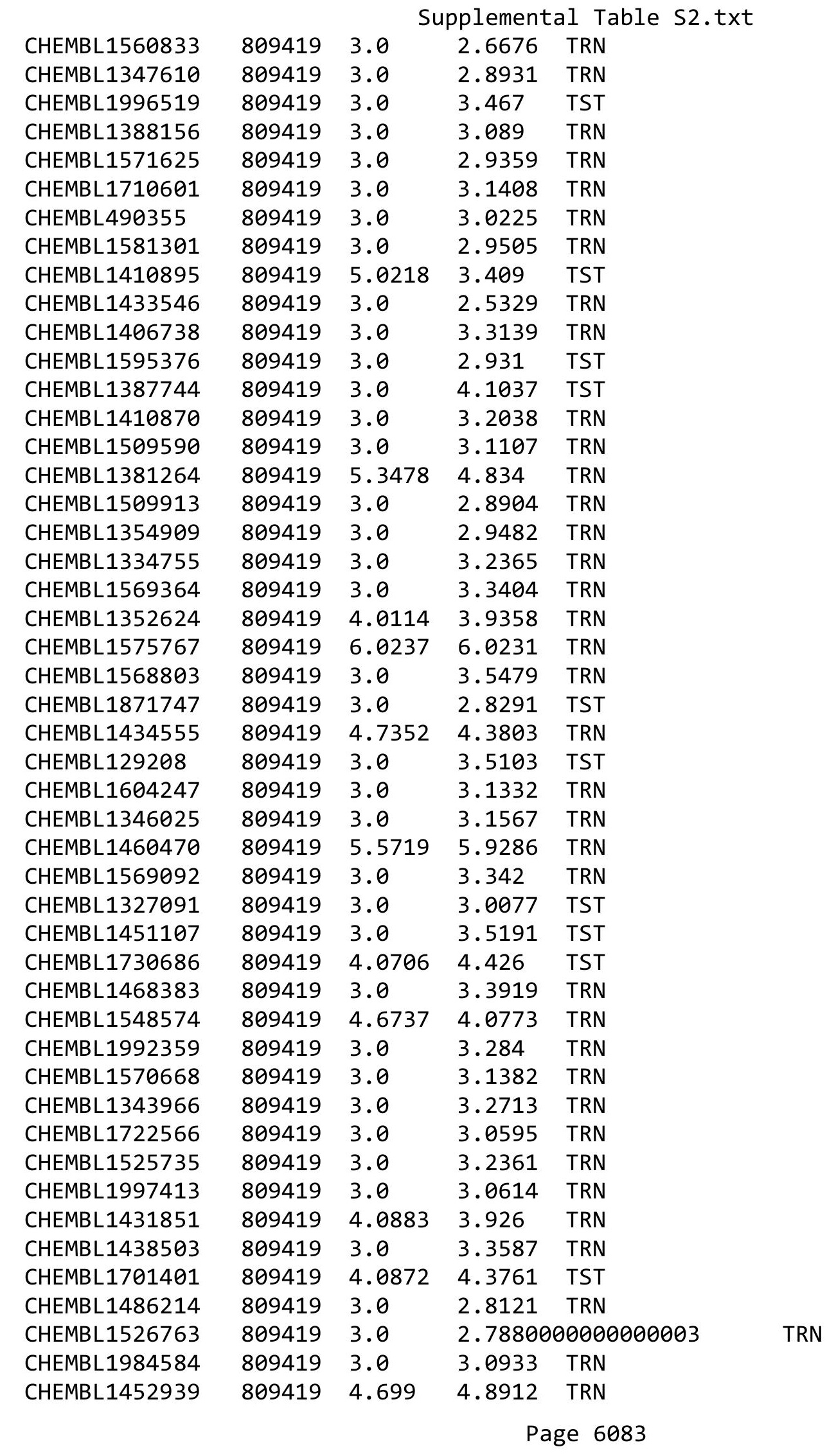




\begin{tabular}{|c|c|c|c|c|}
\hline \multicolumn{5}{|c|}{ Supplemental Table s2.txt } \\
\hline CHEMBL1546767 & 809419 & 5.4868 & 5.2263 & TRN \\
\hline CHEMBL1531824 & 809419 & 4.3468 & 2.9619 & TST \\
\hline CHEMBL1302889 & 809419 & 3.0 & 3.4508 & TRN \\
\hline CHEMBL 2006338 & 809419 & 3.0 & 3.2301 & TRN \\
\hline CHEMBL1528327 & 809419 & 3.0 & 3.38 & TRN \\
\hline CHEMBL1396811 & 809419 & 3.0 & 3.2115 & TST \\
\hline CHEMBL1991303 & 809419 & 3.0 & 3.7226 & TRN \\
\hline CHEMBL1411673 & 809419 & 4.8962 & 4.8639 & TRN \\
\hline CHEMBL1552304 & 809419 & 3.0 & 3.3355 & TRN \\
\hline CHEMBL244645 & 809419 & 3.0 & 2.6611 & TRN \\
\hline CHEMBL1994935 & 809419 & 3.0 & 2.9192 & TST \\
\hline CHEMBL1375551 & 809419 & 3.0 & 3.4481 & TST \\
\hline CHEMBL1586269 & 809419 & 4.8069 & 3.5496 & TST \\
\hline CHEMBL1705518 & 809419 & 3.0 & 3.4575 & TST \\
\hline CHEMBL1548704 & 809419 & 4.0177 & 3.1238 & TST \\
\hline CHEMBL1976919 & 809419 & 3.0 & 3.7425 & TST \\
\hline CHEMBL1988686 & 809419 & 3.0 & 2.5192 & TST \\
\hline CHEMBL1581048 & 809419 & 3.0 & 2.7663 & TST \\
\hline CHEMBL1726773 & 809419 & 3.0 & 1.8267 & TST \\
\hline CHEMBL1348946 & 809419 & 5.4045 & 3.2499 & TST \\
\hline CHEMBL 1480262 & 809419 & 3.0 & 2.688 & TST \\
\hline CHEMBL1990774 & 809419 & 3.0 & 2.5969 & TST \\
\hline CHEMBL1414362 & 809419 & 3.0 & 3.9066 & TST \\
\hline CHEMBL1984772 & 809419 & 3.0 & 3.1313 & TST \\
\hline CHEMBL1610814 & 809419 & 3.0 & 2.9523 & TST \\
\hline CHEMBL 1578629 & 809419 & 3.0 & 3.4473 & TST \\
\hline CHEMBL1552672 & 809419 & 3.0 & 2.594 & TST \\
\hline CHEMBL1997797 & 809419 & 3.0 & 3.0576 & TST \\
\hline CHEMBL1969992 & 809419 & 3.0 & 3.5911 & TST \\
\hline CHEMBL1552053 & 809419 & 3.0 & 3.085 & TST \\
\hline CHEMBL 1403497 & 809419 & 5.983 & 4.7973 & TST \\
\hline CHEMBL1971051 & 809419 & 3.0 & 2.9934 & TST \\
\hline CHEMBL1964690 & 809419 & 3.0 & 2.8795 & TST \\
\hline CHEMBL1402117 & 809419 & 7.7721 & 3.2992 & TST \\
\hline CHEMBL1326271 & 809419 & 3.0 & 3.0514 & TST \\
\hline CHEMBL1982026 & 809419 & 3.0 & 3.3755 & TST \\
\hline CHEMBL1702964 & 809419 & 3.0 & 3.4292 & TST \\
\hline CHEMBL1518982 & 809419 & 3.0 & 3.9679 & TST \\
\hline CHEMBL1318608 & 809419 & 4.6271 & 2.9108 & TST \\
\hline CHEMBL1711830 & 809419 & 3.0 & 3.477 & TST \\
\hline CHEMBL1568373 & 809419 & 3.0 & 2.8947 & TST \\
\hline CHEMBL1422472 & 809419 & 3.0 & 2.1337 & TST \\
\hline CHEMBL1976317 & 809419 & 3.0 & 3.4226 & TST \\
\hline CHEMBL1983001 & 809419 & 5.3468 & 4.8287 & TST \\
\hline CHEMBL1612291 & 809419 & 3.0 & 3.1471 & TST \\
\hline CHEMBL 1434377 & 809419 & 3.0 & 3.0455 & TST \\
\hline CHEMBL1461270 & 809419 & 4.8962 & 3.4267 & TST \\
\hline CHEMBL1425576 & 809419 & 3.0 & 2.1501 & TST \\
\hline
\end{tabular}




\begin{tabular}{|c|c|c|c|c|c|}
\hline \multicolumn{6}{|c|}{ Supplemental Table S2.txt } \\
\hline CHEMBL1471990 & 809419 & 3.0 & 2.9244 & TST & \\
\hline CHEMBL1587149 & 809419 & 3.0 & 2.8536 & TST & \\
\hline CHEMBL1384373 & 809419 & 3.0 & 4.015 & TST & \\
\hline CHEMBL1412423 & 809419 & 4.4012 & 4.4066 & TST & \\
\hline CHEMBL1345911 & 809419 & 3.0 & 2.9199 & TST & \\
\hline CHEMBL1966168 & 809419 & 3.0 & 3.2121 & TST & \\
\hline CHEMBL1288186 & 687740 & 3.301 & 3.3024 & TRN & \\
\hline CHEMBL1288129 & 687740 & 5.1192 & 5.1204 & TRN & \\
\hline CHEMBL1288299 & 687740 & 3.301 & 3.3009 & TRN & \\
\hline CHEMBL1288100 & 687740 & 6.5686 & 6.5715 & TRN & \\
\hline CHEMBL1288099 & 687740 & 6.1487 & 5.3581 & TST & \\
\hline CHEMBL1287857 & 687740 & 3.301 & 3.3014 & TRN & \\
\hline CHEMBL1288156 & 687740 & 4.8508 & 4.8509 & TRN & \\
\hline CHEMBL1288297 & 687740 & 3.301 & 3.2988 & TRN & \\
\hline CHEMBL1288128 & 687740 & 5.585 & 5.58700 & 0000000001 & TRN \\
\hline CHEMBL1287915 & 687740 & 3.301 & 3.3014 & TRN & \\
\hline CHEMBL1288098 & 687740 & 5.2441 & 5.3398 & TST & \\
\hline CHEMBL1287858 & 687740 & 4.8827 & 4.8808 & TRN & \\
\hline CHEMBL1288127 & 687740 & 5.2757 & 5.2785 & TRN & \\
\hline CHEMBL1288068 & 687740 & 4.9245 & 5.6509 & TST & \\
\hline CHEMBL1288160 & 687740 & 6.3279 & 6.3263 & TRN & \\
\hline CHEMBL1288930 & 687740 & 4.6421 & 4.6427 & TRN & \\
\hline CHEMBL1287886 & 687740 & 4.5735 & 4.5717 & TRN & \\
\hline CHEMBL1288993 & 687740 & 3.301 & 3.3025 & TRN & \\
\hline CHEMBL1288966 & 687740 & 4.3316 & 4.3315 & TRN & \\
\hline CHEMBL1287914 & 687740 & 3.301 & 2.9325 & TST & \\
\hline CHEMBL1288039 & 687740 & 5.0605 & 5.0555 & TST & \\
\hline CHEMBL1288037 & 687740 & 3.301 & 3.2999 & TRN & \\
\hline CHEMBL1288158 & 687740 & 3.301 & 3.3 & TRN & \\
\hline CHEMBL1288298 & 687740 & 3.301 & 3.3012 & TRN & \\
\hline CHEMBL1288214 & 687740 & 4.4559 & 4.4569 & TRN & \\
\hline CHEMBL1288187 & 687740 & 3.301 & 3.301 & TRN & \\
\hline CHEMBL1287916 & 687740 & 5.5229 & 5.5196 & TRN & \\
\hline CHEMBL1287974 & 687740 & 5.6198 & 5.6194 & TRN & \\
\hline CHEMBL1287888 & 687740 & 4.567 & 4.4203 & TST & \\
\hline CHEMBL1288159 & 687740 & 5.699 & 5.6973 & TRN & \\
\hline CHEMBL1288005 & 687740 & 3.301 & 3.3027 & TRN & \\
\hline CHEMBL1288069 & 687740 & 3.301 & 4.3603 & TST & \\
\hline CHEMBL1288157 & 687740 & 3.301 & 3.3003 & TRN & \\
\hline CHEMBL1288245 & 687740 & 3.301 & 3.3014 & TRN & \\
\hline CHEMBL1288271 & 687740 & 3.301 & 3.3002 & TRN & \\
\hline CHEMBL1288004 & 687740 & 5.8239 & 4.3118 & TST & \\
\hline CHEMBL1287975 & 687740 & 3.301 & 3.8224 & TST & \\
\hline CHEMBL1288244 & 687740 & 3.301 & 3.2996 & TRN & \\
\hline CHEMBL1287887 & 687740 & 4.6271 & 4.6277 & TRN & \\
\hline CHEMBL1288038 & 687740 & 4.8239 & 4.6869 & TST & \\
\hline CHEMBL1287859 & 687740 & 5.0044 & 5.0074 & TRN & \\
\hline CHEMBL1287944 & 687740 & 4.7878 & 4.6074 & TST & \\
\hline
\end{tabular}




\begin{tabular}{|c|c|c|c|c|c|}
\hline & & \multicolumn{4}{|c|}{ Supplemental Table S2.txt } \\
\hline CHEMBL1288243 & 687740 & 4.3215 & 4.3203 & TRN & \\
\hline CHEMBL1288272 & 687740 & 3.301 & 3.3021 & TRN & \\
\hline CHEMBL1288067 & 687740 & 3.301 & 3.9815 & TST & \\
\hline CHEMBL1288932 & 687740 & 3.301 & 3.3003 & TRN & \\
\hline CHEMBL1288188 & 687740 & 4.8356 & 4.8419 & TRN & \\
\hline CHEMBL1288215 & 687740 & 5.5086 & 5.5033 & TRN & \\
\hline CHEMBL1288006 & 687740 & 5.301 & 5.301 & TRN & \\
\hline CHEMBL1288931 & 687740 & 3.301 & 3.301 & TRN & \\
\hline CHEMBL1288895 & 687740 & 4.6696 & 4.6697 & TRN & \\
\hline CHEMBL1287945 & 687740 & 3.301 & 3.8054 & TST & \\
\hline CHEMBL1288273 & 687740 & 3.301 & 3.1293 & TST & \\
\hline CHEMBL1288216 & 687740 & 5.5229 & 5.5212 & TRN & \\
\hline CHEMBL2315493 & 933806 & 6.4559 & 5.0999 & TRN & \\
\hline CHEMBL2315488 & 933806 & 6.8539 & 6.1375 & TRN & \\
\hline CHEMBL 2315498 & 933806 & 7.7696 & 6.7872 & TRN & \\
\hline CHEMBL 2315495 & 933806 & 5.9586 & 6.5662 & TRN & \\
\hline CHEMBL2315478 & 933806 & 5.6576 & 6.3431 & TRN & \\
\hline CHEMBL2315179 & 933806 & 9.0 & 8.76799 & 9999999999 & TRN \\
\hline CHEMBL2315518 & 933806 & 4.0 & 3.8356 & TRN & \\
\hline CHEMBL444433 & 933806 & 3.5834 & 7.3197 & TST & \\
\hline CHEMBL2315516 & 933806 & 4.0 & 4.5515 & TRN & \\
\hline CHEMBL 2315482 & 933806 & 5.4815 & 5.9646 & TRN & \\
\hline CHEMBL 2315181 & 933806 & 8.5229 & 8.3301 & TRN & \\
\hline CHEMBL2315477 & 933806 & 6.0315 & 7.9019 & TRN & \\
\hline CHEMBL2315513 & 933806 & 5.9208 & 5.9584 & TRN & \\
\hline CHEMBL 2315480 & 933806 & 8.3979 & 7.3221 & TRN & \\
\hline CHEMBL2315497 & 933806 & 7.3768 & 6.1759 & TRN & \\
\hline CHEMBL 2315517 & 933806 & 5.7959 & 5.2436 & TRN & \\
\hline CHEMBL2315479 & 933806 & 7.9208 & 7.0072 & TRN & \\
\hline CHEMBL 2315504 & 933806 & 6.3372 & 6.3553 & TRN & \\
\hline CHEMBL 2315491 & 933806 & 6.4202 & 5.7759 & TRN & \\
\hline CHEMBL2315489 & 933806 & 5.8239 & 5.647 & TRN & \\
\hline CHEMBL 2315473 & 933806 & 8.5229 & 8.3601 & TRN & \\
\hline CHEMBL2315506 & 933806 & 4.0 & 5.4848 & TRN & \\
\hline CHEMBL2315474 & 933806 & 5.3279 & 7.1881 & TRN & \\
\hline CHEMBL2315487 & 933806 & 5.0862 & 5.2327 & TRN & \\
\hline CHEMBL2315499 & 933806 & 4.0 & 5.1588 & TRN & \\
\hline CHEMBL2315509 & 933806 & 6.3665 & 5.6559 & TRN & \\
\hline CHEMBL2315475 & 933806 & 8.0 & 7.4637 & TRN & \\
\hline CHEMBL1683577 & 933806 & 4.9318 & 6.7124 & TST & \\
\hline CHEMBL2315519 & 933806 & 5.5229 & 5.0387 & TST & \\
\hline CHEMBL 2315180 & 933806 & 8.0969 & 7.9533 & TRN & \\
\hline CHEMBL2315485 & 933806 & 5.6108 & 5.8328 & TRN & \\
\hline CHEMBL2315486 & 933806 & 6.7447 & 5.7501 & TRN & \\
\hline CHEMBL2315515 & 933806 & 4.0 & 5.2727 & TRN & \\
\hline CHEMBL 2315502 & 933806 & 6.1675 & 6.2327 & TRN & \\
\hline CHEMBL 2315501 & 933806 & 5.7447 & 5.5307 & TRN & \\
\hline CHEMBL 2315503 & 933806 & 7.4949 & 6.5733 & TRN & \\
\hline
\end{tabular}




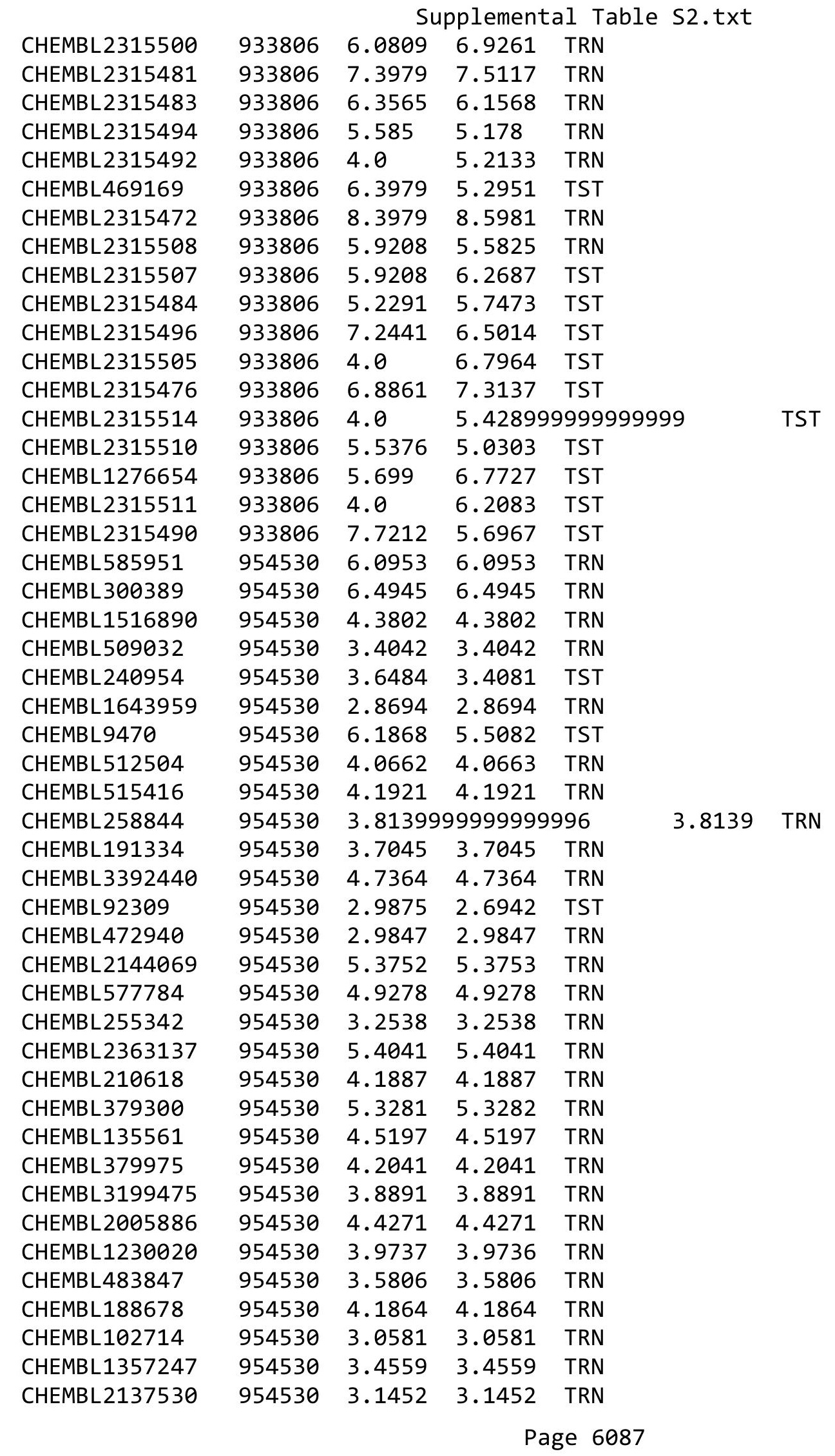


Supplemental Table S2.txt

\begin{tabular}{|c|c|c|c|c|c|c|}
\hline CHEMBL392695 & 954530 & 4.0932 & 4.0932 & TRN & & \\
\hline CHEMBL202721 & 954530 & 5.4284 & 5.4283 & TRN & & \\
\hline CHEMBL259181 & 954530 & 4.1904 & 4.1904 & TRN & & \\
\hline CHEMBL558642 & 954530 & 2.9472 & 2.9472 & TRN & & \\
\hline CHEMBL1788116 & 954530 & 3.6878 & 3.6878 & TRN & & \\
\hline CHEMBL 2134202 & 954530 & 3.4703 & 3.4703 & TRN & & \\
\hline CHEMBL373751 & 954530 & 2.9657 & 2.9657 & TRN & & \\
\hline CHEMBL393929 & 954530 & 3.5405 & 3.5405 & TRN & & \\
\hline CHEMBL 3349342 & 954530 & 4.8964 & 4.8964 & TRN & & \\
\hline CHEMBL573107 & 954530 & 5.052 & 5.052 & TRN & & \\
\hline CHEMBL514499 & 954530 & 5.5288 & 5.5288 & TRN & & \\
\hline CHEMBL221137 & 954530 & 5.1074 & 4.2948 & TST & & \\
\hline CHEMBL213100 & 954530 & 3.5711 & 3.5711 & TRN & & \\
\hline CHEMBL65 & 954530 & 7.7312 & 7.7312 & TRN & & \\
\hline CHEMBL180127 & 954530 & 3.5616 & 3.5616 & TRN & & \\
\hline CHEMBL449158 & 954530 & 6.20799 & 79999999 & 99 & 6.7892 & TST \\
\hline CHEMBL1256459 & 954530 & 3.9321 & 3.932 & TRN & & \\
\hline CHEMBL1673039 & 954530 & 3.7189 & 3.7189 & TRN & & \\
\hline CHEMBL1590308 & 954530 & 2.3218 & 3.0769 & TST & & \\
\hline CHEMBL399530 & 954530 & 4.7216 & 4.7215 & TRN & & \\
\hline CHEMBL217354 & 954530 & 6.652 & 6.652 & TRN & & \\
\hline CHEMBL1242367 & 954530 & 3.5763 & 3.5763 & TRN & & \\
\hline CHEMBL189584 & 954530 & 4.0554 & 4.0554 & TRN & & \\
\hline CHEMBL1186585 & 954530 & 4.129 & 3.7819 & TST & & \\
\hline CHEMBL192566 & 954530 & 8.9504 & 7.8707 & TST & & \\
\hline CHEMBL483849 & 954530 & 3.3314 & 1.7021 & TST & & \\
\hline CHEMBL412142 & 954530 & 3.5143 & 3.7171 & TST & & \\
\hline CHEMBL1970879 & 954530 & 2.7432 & 2.9915 & TST & & \\
\hline CHEMBL1190711 & 954530 & 4.789 & 4.4007 & TST & & \\
\hline CHEMBL209148 & 954530 & 4.0619 & 4.1694 & TST & & \\
\hline CHEMBL1404918 & 954530 & 2.8908 & 3.1384 & TST & & \\
\hline CHEMBL1909414 & 954530 & 3.8957 & 3.5027 & TST & & \\
\hline CHEMBL222102 & 954530 & 4.2554 & 3.904 & TST & & \\
\hline CHEMBL3960154 & 1640187 & 9.1701 & 8.9235 & TST & & \\
\hline CHEMBL120413 & 1640187 & 7.3002 & 7.0674 & TST & & \\
\hline CHEMBL381866 & 1640187 & 8.3675 & 8.351 & TRN & & \\
\hline CHEMBL93087 & 1640187 & 7.1175 & 7.1307 & TST & & \\
\hline CHEMBL3942651 & 1640187 & 5.4271 & 5.4161 & TST & & \\
\hline CHEMBL436293 & 1640187 & 7.1203 & 6.9211 & TRN & & \\
\hline CHEMBL3972969 & 1640187 & 8.1238 & 8.2265 & TRN & & \\
\hline CHEMBL190142 & 1640187 & 8.8297 & 8.4842 & TRN & & \\
\hline CHEMBL3907419 & 1640187 & 8.4685 & 8.664 & TRN & & \\
\hline CHEMBL196162 & 1640187 & 8.4342 & 7.7672 & TRN & & \\
\hline CHEMBL 3968842 & 1640187 & 8.5272 & 8.6891 & TRN & & \\
\hline CHEMBL 3979386 & 1640187 & 8.9872 & 8.988 & TRN & & \\
\hline CHEMBL3966335 & 1640187 & 6.1331 & 5.9943 & TST & & \\
\hline CHEMBL196539 & 1640187 & 9.0926 & 9.2618 & TRN & & \\
\hline CHEMBL198654 & 1640187 & 8.2924 & 8.3563 & TRN & & \\
\hline
\end{tabular}

Page 6088 
Supplemental Table S2.txt

\begin{tabular}{|c|c|c|c|c|c|}
\hline CHEMBL 364284 & 1640187 & 9.6536 & 9.7983 & TRN & \\
\hline CHEMBL 3955803 & 1640187 & 8.8416 & 8.7474 & TRN & \\
\hline CHEMBL316053 & 1640187 & 7.3675 & 7.1425 & TST & \\
\hline CHEMBL197547 & 1640187 & 7.3936 & 7.2427 & TRN & \\
\hline CHEMBL 3961484 & 1640187 & 9.0443 & 8.9325 & TRN & \\
\hline CHEMBL197624 & 1640187 & 7.4597 & 7.5385 & TRN & \\
\hline CHEMBL 3957468 & 1640187 & 7.8761 & 7.7775 & TRN & \\
\hline CHEMBL196589 & 1640187 & 7.1209 & 7.3149 & TRN & \\
\hline CHEMBL194186 & 1640187 & 9.1624 & 9.3797 & TRN & \\
\hline CHEMBL 3958789 & 1640187 & 8.4841 & 8.4384 & TRN & \\
\hline CHEMBL 3910588 & 1640187 & 9.1209 & 9.0664 & TRN & \\
\hline CHEMBL194889 & 1640187 & 6.3161 & 6.3335 & TRN & \\
\hline CHEMBL48813 & 1640187 & 8.7932 & 8.6177 & TST & \\
\hline CHEMBL370176 & 1640187 & \multicolumn{3}{|c|}{6.7620000000000005} & TRN \\
\hline CHEMBL 3972799 & 1640187 & 9.1433 & 9.0519 & TRN & \\
\hline CHEMBL557915 & 1640187 & 8.7235 & 8.7128 & TRN & \\
\hline CHEMBL 3974641 & 1640187 & 7.5513 & 7.3167 & TST & \\
\hline CHEMBL1235423 & 1640187 & 7.5867 & 7.205 & TST & \\
\hline CHEMBL 3912108 & 1640187 & 8.7852 & 8.5406 & TRN & \\
\hline CHEMBL194810 & 1640187 & 7.8182 & 7.9617 & TRN & \\
\hline CHEMBL 3956658 & 1640187 & 8.061 & 8.2633 & TRN & \\
\hline CHEMBL198421 & 1640187 & 6.6144 & 6.8174 & TRN & \\
\hline CHEMBL370614 & 1640187 & 8.9747 & 8.8602 & TRN & \\
\hline CHEMBL550453 & 1640187 & \multicolumn{2}{|c|}{8.091000000000001} & 8.2685 & TRN \\
\hline CHEMBL196492 & 1640187 & 8.3696 & 8.0718 & TRN & \\
\hline CHEMBL3305961 & 1640187 & 7.6234 & 7.7969 & TRN & \\
\hline CHEMBL564248 & 1640187 & 8.8153 & 8.8739 & TRN & \\
\hline CHEMBL 3959350 & 1640187 & 7.4921 & 7.22 & TRN & \\
\hline CHEMBL3928201 & 1640187 & 7.644 & 7.242000 & 000000001 & TST \\
\hline CHEMBL 371106 & 1640187 & 7.5243 & 7.7801 & TRN & \\
\hline CHEMBL 372568 & 1640187 & 6.3883 & 6.4877 & TRN & \\
\hline CHEMBL 3986101 & 1640187 & 9.0061 & 9.0771 & TRN & \\
\hline CHEMBL197377 & 1640187 & 9.1555 & 9.0661 & TRN & \\
\hline CHEMBL 3904655 & 1640187 & 8.5768 & 8.4717 & TRN & \\
\hline CHEMBL196669 & 1640187 & 5.2336 & 5.2997 & TRN & \\
\hline CHEMBL 3304291 & 1640187 & 8.2291 & 8.3433 & TST & \\
\hline CHEMBL196551 & 1640187 & 8.059 & 8.0452 & TST & \\
\hline CHEMBL383361 & 1640187 & 9.0164 & 9.0956 & TST & \\
\hline CHEMBL372956 & 1640187 & 8.6345 & 8.4828 & TST & \\
\hline CHEMBL412250 & 147673 & 2.0 & 0.422000 & 000000000004 & ובני \\
\hline CHEMBL440613 & 147673 & 5.5702 & 4.4045 & TRN & \\
\hline CHEMBL409291 & 147673 & 5.2366 & 4.7032 & TRN & \\
\hline CHEMBL438032 & 147673 & 2.0 & 1.4541 & TST & \\
\hline CHEMBL 276022 & 147673 & 5.2581 & 5.9234 & TRN & \\
\hline CHEMBL415650 & 147673 & 5.8861 & 4.7032 & TRN & \\
\hline CHEMBL437906 & 147673 & 2.0 & 1.4738 & TRN & \\
\hline CHEMBL428821 & 147673 & 5.6799 & 4.8063 & TRN & \\
\hline CHEMBL263625 & 147673 & 5.3152 & 4.6707 & TRN & \\
\hline
\end{tabular}




\begin{tabular}{|c|c|c|c|c|c|}
\hline \multirow[b]{2}{*}{ CHEMBL425940 } & \multicolumn{5}{|c|}{ Supplemental Table s2.txt } \\
\hline & 147673 & 5.082 & 4.7945 & TRN & \\
\hline CHEMBL384249 & 147673 & 2.0 & 1.63800 & 00000000001 & TRN \\
\hline CHEMBL2370341 & 147673 & 5.8729 & 6.0397 & TRN & \\
\hline CHEMBL411048 & 147673 & 5.7852 & 4.7032 & TRN & \\
\hline CHEMBL441924 & 147673 & 5.9208 & 4.4015 & TRN & \\
\hline CHEMBL430144 & 147673 & 2.0 & 0.5604 & TST & \\
\hline CHEMBL382561 & 147673 & 5.7696 & 4.6739 & TRN & \\
\hline CHEMBL265747 & 147673 & 6.0915 & 6.3488 & TRN & \\
\hline CHEMBL428140 & 147673 & 5.7852 & 4.7032 & TRN & \\
\hline CHEMBL265993 & 147673 & 2.0 & 3.3215 & TRN & \\
\hline CHEMBL 217721 & 147673 & 2.0 & 3.7859 & TRN & \\
\hline CHEMBL384047 & 147673 & 2.0 & 1.1773 & TST & \\
\hline CHEMBL204810 & 147673 & 5.0773 & 4.1983 & TRN & \\
\hline CHEMBL412247 & 147673 & 2.0 & 4.0534 & TRN & \\
\hline CHEMBL428626 & 147673 & 4.8976 & 4.2329 & TRN & \\
\hline CHEMBL439110 & 147673 & 5.7235 & 3.9471 & TRN & \\
\hline CHEMBL411361 & 147673 & 5.1302 & 4.6957 & TRN & \\
\hline CHEMBL409322 & 147673 & 4.9431 & 4.7032 & TRN & \\
\hline CHEMBL441585 & 147673 & 5.3507 & 4.2989 & TRN & \\
\hline CHEMBL429376 & 147673 & 5.1612 & 5.5772 & TRN & \\
\hline CHEMBL410918 & 147673 & 6.1079 & 3.824 & TST & \\
\hline CHEMBL429242 & 147673 & 2.0 & 4.4241 & TRN & \\
\hline CHEMBL411934 & 147673 & 2.0 & 1.6565 & TST & \\
\hline CHEMBL428126 & 147673 & 5.8356 & 4.987 & TRN & \\
\hline CHEMBL2370375 & 147673 & 2.0 & 1.6923 & TST & \\
\hline CHEMBL441942 & 147673 & 6.7959 & 6.4653 & TRN & \\
\hline CHEMBL409323 & 147673 & 5.7212 & 4.0965 & TRN & \\
\hline CHEMBL411914 & 147673 & 2.0 & 4.7032 & TRN & \\
\hline CHEMBL 269724 & 147673 & 5.3625 & 4.7032 & TRN & \\
\hline CHEMBL268346 & 147673 & 2.0 & 3.7812 & TRN & \\
\hline CHEMBL440826 & 147673 & 7.0458 & 6.5319 & TST & \\
\hline CHEMBL406777 & 147673 & 5.9872 & 6.1175 & TRN & \\
\hline CHEMBL408086 & 147673 & 5.7471 & 5.8217 & TRN & \\
\hline CHEMBL429205 & 147673 & 2.0 & 1.0189 & TST & \\
\hline CHEMBL409392 & 147673 & 2.0 & 3.8259 & TRN & \\
\hline CHEMBL411589 & 147673 & 5.6383 & 4.7032 & TRN & \\
\hline CHEMBL406591 & 147673 & 2.0 & 1.7157 & TRN & \\
\hline CHEMBL409745 & 147673 & 2.0 & 3.3823 & TRN & \\
\hline CHEMBL407866 & 147673 & 4.7491 & 4.2989 & TRN & \\
\hline CHEMBL411097 & 147673 & 2.0 & 4.0734 & TRN & \\
\hline CHEMBL 280472 & 147673 & 2.0 & 1.0451 & TST & \\
\hline CHEMBL440426 & 147673 & 6.1367 & 4.7032 & TRN & \\
\hline CHEMBL268347 & 147673 & 5.9172 & 6.2112 & TRN & \\
\hline CHEMBL427980 & 147673 & 5.3449 & 5.6422 & TRN & \\
\hline CHEMBL408467 & 147673 & 5.6556 & 4.6957 & TRN & \\
\hline CHEMBL409188 & 147673 & 2.0 & 0.42200 & 000000000004 & TST \\
\hline CHEMBL438779 & 147673 & 6.0315 & 4.6064 & TRN & \\
\hline CHEMBL379910 & 147673 & 2.0 & 3.6304 & TRN & \\
\hline
\end{tabular}




\begin{tabular}{|c|c|c|c|c|c|c|}
\hline \multicolumn{7}{|c|}{$p+c$} \\
\hline CHEMBL410749 & 147673 & 2.0 & 4.2989 & TRN & & \\
\hline CHEMBL439123 & 147673 & 6.1938 & 6.5136 & TRN & & \\
\hline CHEMBL409269 & 147673 & 6.0655 & 6.0054 & TRN & & \\
\hline CHEMBL410690 & 147673 & 2.0 & 4.7032 & TRN & & \\
\hline CHEMBL413009 & 147673 & 6.1675 & 6.4471 & TST & & \\
\hline CHEMBL386724 & 147673 & 2.0 & 0.42200 & 0000 & 0004 & TST \\
\hline CHEMBL 2370351 & 147673 & 2.0 & 1.7253 & TST & & \\
\hline CHEMBL267350 & 147673 & 2.0 & 0.5545 & TST & & \\
\hline CHEMBL214619 & 147673 & 2.0 & 1.1517 & TRN & & \\
\hline CHEMBL439311 & 147673 & 2.0 & 2.4079 & TST & & \\
\hline CHEMBL430345 & 147673 & 2.0 & 1.37 & TST & & \\
\hline CHEMBL437920 & 147673 & 5.15799 & 99999999 & 995 & 4.6957 & TRN \\
\hline CHEMBL437533 & 147673 & 2.0 & 4.2989 & TRN & & \\
\hline CHEMBL427206 & 147673 & 5.8477 & 5.9158 & TST & & \\
\hline CHEMBL439525 & 147673 & 5.05699 & 99999999 & 995 & 4.0755 & TRN \\
\hline CHEMBL439167 & 147673 & 2.0 & 1.1592 & TST & & \\
\hline CHEMBL266189 & 147673 & 4.6531 & 4.466 & TRN & & \\
\hline CHEMBL438276 & 147673 & 5.0227 & 3.838 & TRN & & \\
\hline CHEMBL429374 & 147673 & 5.5003 & 4.6728 & TRN & & \\
\hline CHEMBL 3890621 & 1624777 & 7.0088 & 7.0482 & TRN & & \\
\hline CHEMBL 3977721 & 1624777 & 7.4123 & 7.3074 & TRN & & \\
\hline CHEMBL 2393163 & 1624777 & 8.2218 & 7.4835 & TST & & \\
\hline CHEMBL 3963163 & 1624777 & 7.6737 & 7.6237 & TRN & & \\
\hline CHEMBL 3900937 & 1624777 & 4.699 & 4.9474 & TRN & & \\
\hline CHEMBL 3904503 & 1624777 & 7.6596 & 7.7405 & TRN & & \\
\hline CHEMBL 3972073 & 1624777 & 7.6198 & 7.6591 & TRN & & \\
\hline CHEMBL 3260358 & 1624777 & 8.2218 & 6.1537 & TST & & \\
\hline CHEMBL 3935485 & 1624777 & 6.3737 & 6.5668 & TRN & & \\
\hline CHEMBL 3984355 & 1624777 & 7.6778 & 7.5245 & TRN & & \\
\hline CHEMBL 3974268 & 1624777 & 7.6904 & 7.936 & TRN & & \\
\hline CHEMBL566757 & 1624777 & 8.5229 & 6.7816 & TST & & \\
\hline CHEMBL 3958520 & 1624777 & 6.2554 & 6.1294 & TRN & & \\
\hline CHEMBL 2419506 & 1624777 & 7.1308 & 6.7679 & TRN & & \\
\hline CHEMBL 3923552 & 1624777 & 7.8477 & 8.088 & TRN & & \\
\hline CHEMBL 3914526 & 1624777 & 8.2147 & 8.2708 & TRN & & \\
\hline CHEMBL 2419504 & 1624777 & 7.8239 & 8.1474 & TRN & & \\
\hline CHEMBL 3932498 & 1624777 & 7.2299 & 7.4017 & TRN & & \\
\hline CHEMBL 3908644 & 1624777 & 7.6778 & 7.6593 & TRN & & \\
\hline CHEMBL 3940454 & 1624777 & 7.5622 & 7.4696 & TRN & & \\
\hline CHEMBL 2420629 & 1624777 & 8.301 & 8.8124 & TST & & \\
\hline CHEMBL 3978996 & 1624777 & 4.699 & 4.8584 & TRN & & \\
\hline CHEMBL 2420620 & 1624777 & 8.0969 & 7.8245 & TRN & & \\
\hline CHEMBL 3889557 & 1624777 & 6.3958 & 6.6415 & TRN & & \\
\hline CHEMBL 3913503 & 1624777 & 7.3206 & 7.5991 & TRN & & \\
\hline CHEMBL 3959982 & 1624777 & 6.3251 & 6.5173 & TRN & & \\
\hline CHEMBL 3907541 & 1624777 & 7.8539 & 7.5311 & TRN & & \\
\hline CHEMBL 2417572 & 1624777 & 8.699 & 7.7485 & TST & & \\
\hline CHEMBL 3897803 & 1624777 & 8.0 & 8.54 & TST & & \\
\hline
\end{tabular}


Supplemental Table S2.txt

\begin{tabular}{|c|c|c|c|c|}
\hline CHEMBL 3394738 & 1624777 & 7.4089 & 8.7244 & TST \\
\hline CHEMBL 3981065 & 1624777 & 7.1308 & 6.5983 & TRN \\
\hline CHEMBL 2419515 & 1624777 & 7.9586 & 8.3406 & TST \\
\hline CHEMBL 3948512 & 1624777 & 7.6536 & 7.9072 & TRN \\
\hline CHEMBL 3921809 & 1624777 & 7.3851 & 7.5852 & TRN \\
\hline CHEMBL17289 & 1624777 & 8.699 & 6.9619 & TST \\
\hline CHEMBL 2391568 & 1624777 & 8.1549 & 7.4987 & TST \\
\hline CHEMBL 3941475 & 1624777 & 7.5768 & 7.4863 & TRN \\
\hline CHEMBL3930818 & 1624777 & 7.7447 & \multicolumn{2}{|c|}{7.662999999999999} \\
\hline CHEMBL 3958233 & 1624777 & 8.3565 & 7.9224 & TRN \\
\hline CHEMBL 3986623 & 1624777 & 7.1938 & \multicolumn{2}{|c|}{7.252000000000001} \\
\hline CHEMBL 3939767 & 1624777 & \multicolumn{2}{|c|}{7.821000000000001} & 7.7325 \\
\hline CHEMBL 3986197 & 1624777 & 7.9245 & 8.0561 & TRN \\
\hline CHEMBL 2393183 & 1624777 & 8.5229 & 7.4937 & TST \\
\hline CHEMBL 3394734 & 1624777 & 8.0 & 9.1298 & TST \\
\hline CHEMBL 2393174 & 1624777 & 7.2291 & 7.1194 & TST \\
\hline CHEMBL3962066 & 1624777 & 4.699 & 4.5925 & TRN \\
\hline CHEMBL 3921880 & 1624777 & 8.0 & 7.9476 & TRN \\
\hline CHEMBL3889487 & 1624777 & 7.7932 & 7.5709 & TRN \\
\hline CHEMBL 3913883 & 1624777 & 8.1739 & 8.1749 & TRN \\
\hline CHEMBL 3925878 & 1624777 & 7.8928 & 7.5932 & TRN \\
\hline CHEMBL3930755 & 1624777 & 7.3179 & 7.4377 & TRN \\
\hline CHEMBL 3968268 & 1624777 & 8.2218 & 8.1661 & TRN \\
\hline CHEMBL3127521 & 1624777 & 8.3979 & 8.2001 & TST \\
\hline CHEMBL 3895553 & 1624777 & 7.3872 & 7.5042 & TRN \\
\hline CHEMBL 3952257 & 1624777 & 4.7696 & 4.9796 & TRN \\
\hline CHEMBL 3902837 & 1624777 & 8.0458 & 8.0924 & TRN \\
\hline CHEMBL 3949594 & 1624777 & 8.0655 & 7.8607 & TRN \\
\hline CHEMBL3943545 & 1624777 & 6.0809 & 5.9821 & TRN \\
\hline CHEMBL 3960951 & 1624777 & 7.2291 & 7.5331 & TRN \\
\hline CHEMBL 2419505 & 1624777 & 7.8539 & 7.2656 & TST \\
\hline CHEMBL 2391572 & 1624777 & 8.5229 & 7.4478 & TST \\
\hline CHEMBL 3934566 & 1624777 & 4.699 & 4.6336 & TRN \\
\hline CHEMBL3891956 & 1624777 & 4.699 & 4.5787 & TRN \\
\hline CHEMBL583110 & 608993 & 5.3 & 4.868 & TRN \\
\hline CHEMBL601448 & 608993 & 5.6 & 5.7796 & TRN \\
\hline CHEMBL604752 & 608993 & 6.2 & 6.06 & TRN \\
\hline CHEMBL601449 & 608993 & 6.3 & 6.5508 & TRN \\
\hline CHEMBL600624 & 608993 & 5.7 & 5.811 & TRN \\
\hline CHEMBL590739 & 608993 & 6.2 & 5.9025 & TRN \\
\hline CHEMBL575966 & 608993 & 7.5 & 6.9826 & TRN \\
\hline CHEMBL600827 & 608993 & 7.8 & 8.4325 & TRN \\
\hline CHEMBL600421 & 608993 & 6.9 & 6.7722 & TRN \\
\hline CHEMBL605986 & 608993 & 6.4 & 6.5352 & TRN \\
\hline CHEMBL600422 & 608993 & 5.9 & 5.5438 & TRN \\
\hline CHEMBL600629 & 608993 & 6.9 & 6.3963 & TRN \\
\hline CHEMBL603107 & 608993 & 5.6 & 5.852 & TRN \\
\hline CHEMBL600410 & 608993 & 5.9 & 6.1265 & TRN \\
\hline
\end{tabular}




\begin{tabular}{|c|c|c|c|c|c|}
\hline \\
\hline CHEMBL604751 & 608993 & 6.4 & 6.0073 & TRN & \\
\hline CHEMBL600020 & 608993 & 7.2 & 7.4208 & TRN & \\
\hline CHEMBL600021 & 608993 & 6.6 & 6.8707 & TRN & \\
\hline CHEMBL590982 & 608993 & 7.0 & 6.8768 & TRN & \\
\hline CHEMBL604520 & 608993 & 5.6 & 6.0975 & TRN & \\
\hline CHEMBL576138 & 608993 & 7.1 & 7.2188 & TRN & \\
\hline CHEMBL590495 & 608993 & 7.9 & 7.68 & TRN & \\
\hline CHEMBL598743 & 608993 & 7.7 & 7.811 & TRN & \\
\hline CHEMBL611676 & 608993 & 5.4 & 5.8863 & TRN & \\
\hline CHEMBL599126 & 608993 & 6.0 & 6.0115 & TRN & \\
\hline CHEMBL604524 & 608993 & 5.2 & 5.5039 & TRN & \\
\hline CHEMBL599127 & 608993 & 5.9 & 5.8424 & TRN & \\
\hline CHEMBL604734 & 608993 & 5.1 & 5.0931 & TRN & \\
\hline CHEMBL599328 & 608993 & 7.7 & 6.3675 & TRN & \\
\hline CHEMBL599347 & 608993 & 6.5 & 6.1784 & TRN & \\
\hline CHEMBL605356 & 608993 & 6.5 & 6.8694 & TRN & \\
\hline CHEMBL598120 & 608993 & 5.4 & 5.9661 & TRN & \\
\hline CHEMBL605554 & 608993 & 4.9 & 5.0578 & TRN & \\
\hline CHEMBL598118 & 608993 & 4.1 & 3.9651 & TRN & \\
\hline CHEMBL602273 & 608993 & 5.1 & 5.0342 & TRN & \\
\hline CHEMBL601233 & 608993 & 6.8 & 6.7798 & TRN & \\
\hline CHEMBL601440 & 608993 & 8.1 & 7.9268 & TRN & \\
\hline CHEMBL591455 & 608993 & 6.3 & 6.5764 & TRN & \\
\hline CHEMBL601441 & 608993 & 7.9 & 7.8643 & TRN & \\
\hline CHEMBL600821 & 608993 & 7.9 & 6.6803 & TRN & \\
\hline CHEMBL604537 & 608993 & 7.9 & 7.9516 & TRN & \\
\hline CHEMBL602892 & 608993 & 7.1 & 7.3065 & TRN & \\
\hline CHEMBL603096 & 608993 & 6.0 & 6.5661 & TRN & \\
\hline CHEMBL603500 & 608993 & 7.2 & 6.9897 & TRN & \\
\hline CHEMBL612138 & 608993 & 9.0 & 8.4321 & TRN & \\
\hline CHEMBL602690 & 608993 & 5.3 & 6.0093 & TRN & \\
\hline CHEMBL604543 & 608993 & 7.5 & 7.3563 & TRN & \\
\hline CHEMBL602691 & 608993 & 6.5 & 6.8773 & TRN & \\
\hline CHEMBL603706 & 608993 & 5.9 & 6.20100 & 00000000005 & TRN \\
\hline CHEMBL601882 & 608993 & 7.7 & 7.7113 & TRN & \\
\hline CHEMBL591927 & 608993 & 6.2 & 7.0389 & TST & \\
\hline CHEMBL 601670 & 608993 & 6.2 & 6.9051 & TST & \\
\hline CHEMBL601671 & 608993 & 5.5 & 6.1632 & TST & \\
\hline CHEMBL600833 & 608993 & 7.5 & 6.0651 & TST & \\
\hline CHEMBL600834 & 608993 & 7.4 & 5.9262 & TST & \\
\hline CHEMBL608867 & 608993 & 6.5 & 6.0081 & TST & \\
\hline CHEMBL600835 & 608993 & 5.5 & 6.4937 & TST & \\
\hline CHEMBL592158 & 608993 & 5.9 & 7.0239 & TST & \\
\hline CHEMBL603112 & 608993 & 8.4 & 6.16 & TST & \\
\hline CHEMBL603921 & 608993 & 7.7 & 6.2353 & TST & \\
\hline CHEMBL601637 & 608993 & 8.0 & 5.9254 & TST & \\
\hline CHEMBL601638 & 608993 & 8.4 & 6.2048 & TST & \\
\hline CHEMBL605367 & 608993 & 8.0 & 5.7093 & TST & \\
\hline
\end{tabular}




\begin{tabular}{|c|c|c|c|c|c|}
\hline \multicolumn{6}{|c|}{ Supplemental Table s2.txt } \\
\hline CHEMBL592645 & 608993 & 6.1 & 5.5524 & TST & \\
\hline CHEMBL601218 & 608993 & 5.5 & 5.8042 & TST & \\
\hline CHEMBL604131 & 608993 & 7.9 & 6.4029 & TST & \\
\hline CHEMBL601428 & 608993 & 7.2 & 6.9091 & TST & \\
\hline CHEMBL2322974 & 941182 & 3.4815 & 3.6536 & TRN & \\
\hline CHEMBL2325792 & 941182 & 5.0915 & 5.4161 & TST & \\
\hline CHEMBL 2325781 & 941182 & 6.3188 & 6.49299 & 9999999999 & TRN \\
\hline CHEMBL2324288 & 941182 & 6.301 & 6.6318 & TRN & \\
\hline CHEMBL2322971 & 941182 & 6.9208 & 7.0102 & TRN & \\
\hline CHEMBL2325793 & 941182 & 4.9208 & 5.2554 & TST & \\
\hline CHEMBL2324281 & 941182 & 6.9586 & 6.9968 & TRN & \\
\hline CHEMBL2325795 & 941182 & 6.7212 & 6.939 & TRN & \\
\hline CHEMBL2325788 & 941182 & 5.4559 & 6.5441 & TST & \\
\hline CHEMBL 2324286 & 941182 & 6.4815 & 6.2012 & TRN & \\
\hline CHEMBL 2325786 & 941182 & 5.9586 & 6.3577 & TST & \\
\hline CHEMBL 2324292 & 941182 & 6.1367 & 6.0524 & TRN & \\
\hline CHEMBL2325804 & 941182 & 6.5229 & 6.4327 & TRN & \\
\hline CHEMBL2325796 & 941182 & 3.4815 & 3.8471 & TRN & \\
\hline CHEMBL2324296 & 941182 & 5.2218 & 8.1716 & TST & \\
\hline CHEMBL 2324294 & 941182 & 3.4815 & 3.5362 & TRN & \\
\hline CHEMBL 2322975 & 941182 & 6.7959 & 6.8029 & TRN & \\
\hline CHEMBL2325789 & 941182 & 5.6021 & 7.1857 & TST & \\
\hline CHEMBL 2324287 & 941182 & 6.3279 & 6.6123 & TRN & \\
\hline CHEMBL2325797 & 941182 & 3.7959 & 3.6524 & TRN & \\
\hline CHEMBL2324284 & 941182 & 6.6576 & 6.521 & TRN & \\
\hline CHEMBL2322979 & 941182 & 7.5686 & 7.7067 & TRN & \\
\hline CHEMBL2322977 & 941182 & 6.6198 & 6.4257 & TRN & \\
\hline CHEMBL 2324290 & 941182 & 6.1938 & 6.0236 & TRN & \\
\hline CHEMBL 2325790 & 941182 & 5.3372 & 6.4894 & TST & \\
\hline CHEMBL2322969 & 941182 & 8.2218 & 8.1824 & TRN & \\
\hline CHEMBL 2322976 & 941182 & 6.6021 & 6.7029 & TRN & \\
\hline CHEMBL2324280 & 941182 & 7.2366 & 6.8425 & TRN & \\
\hline CHEMBL2322968 & 941182 & 6.7696 & 6.9026 & TRN & \\
\hline CHEMBL2324291 & 941182 & 6.1427 & 6.0588 & TRN & \\
\hline CHEMBL2325801 & 941182 & 7.699 & 7.9022 & TRN & \\
\hline CHEMBL2325800 & 941182 & 5.9208 & 5.84399 & 9999999999 & TRN \\
\hline CHEMBL591552 & 941182 & 6.0362 & 5.8232 & TRN & \\
\hline CHEMBL 2324283 & 941182 & 6.7212 & 6.8767 & TRN & \\
\hline CHEMBL2322970 & 941182 & 6.1675 & 5.9908 & TRN & \\
\hline CHEMBL2322978 & 941182 & 6.4949 & 5.8972 & TRN & \\
\hline CHEMBL 2324293 & 941182 & 6.0969 & 6.3391 & TRN & \\
\hline CHEMBL2325791 & 941182 & 5.2518 & 6.3778 & TST & \\
\hline CHEMBL2325802 & 941182 & 6.9208 & 6.7473 & TRN & \\
\hline CHEMBL2322972 & 941182 & 5.4437 & 5.5255 & TRN & \\
\hline CHEMBL2325799 & 941182 & 5.7212 & 5.7098 & TRN & \\
\hline CHEMBL 2325787 & 941182 & 5.0177 & 6.1466 & TST & \\
\hline CHEMBL2325794 & 941182 & 5.9586 & 6.2174 & TRN & \\
\hline CHEMBL2324282 & 941182 & 6.8539 & 6.6494 & TRN & \\
\hline
\end{tabular}




\begin{tabular}{|c|c|c|c|c|c|}
\hline & & \multicolumn{4}{|c|}{ Supplemental Table S2.txt } \\
\hline CHEMBL 2325798 & 941182 & 4.585 & 4.6108 & TRN & \\
\hline CHEMBL 2325221 & 941182 & 7.3872 & 7.3838 & TRN & \\
\hline CHEMBL 2322973 & 941182 & 4.0 & 5.722 & TST & \\
\hline CHEMBL 2324285 & 941182 & 6.5086 & 6.9185 & TST & \\
\hline CHEMBL2324289 & 941182 & 6.284 & 6.8925 & TST & \\
\hline CHEMBL 2325803 & 941182 & 6.6576 & 6.0337 & TST & \\
\hline CHEMBL303504 & 48628 & 7.9586 & 7.9649 & TRN & \\
\hline CHEMBL294594 & 48628 & 6.6198 & 6.8404 & TST & \\
\hline CHEMBL65343 & 48628 & 7.0458 & 7.2636 & TRN & \\
\hline CHEMBL291429 & 48628 & 8.1549 & 8.1367 & TRN & \\
\hline CHEMBL63475 & 48628 & 7.5686 & 7.3081 & TRN & \\
\hline CHEMBL64947 & 48628 & 3.9586 & 5.3415 & TRN & \\
\hline CHEMBL294121 & 48628 & 8.301 & 6.7348 & TRN & \\
\hline CHEMBL65816 & 48628 & 7.9208 & 7.3002 & TRN & \\
\hline CHEMBL291430 & 48628 & 7.5376 & 7.7223 & TRN & \\
\hline CHEMBL66583 & 48628 & 8.301 & 8.1381 & TRN & \\
\hline CHEMBL65219 & 48628 & 7.8239 & 8.0443 & TRN & \\
\hline CHEMBL62656 & 48628 & 8.0969 & 7.5667 & TRN & \\
\hline CHEMBL65978 & 48628 & 7.5686 & 7.3446 & TRN & \\
\hline CHEMBL63307 & 48628 & 7.8861 & 8.04 & TRN & \\
\hline CHEMBL63518 & 48628 & 8.0 & 8.1391 & TRN & \\
\hline CHEMBL63690 & 48628 & 6.3665 & 6.7629 & TST & \\
\hline CHEMBL302968 & 48628 & 7.3468 & 7.1363 & TST & \\
\hline CHEMBL65544 & 48628 & 6.2757 & 6.7005 & TST & \\
\hline CHEMBL64904 & 48628 & 7.8539 & 8.0215 & TRN & \\
\hline CHEMBL305379 & 48628 & 7.4318 & 7.6628 & TRN & \\
\hline CHEMBL65146 & 48628 & 8.5229 & 8.0689 & TRN & \\
\hline CHEMBL293682 & 48628 & 6.5686 & 6.62799 & & TRN \\
\hline CHEMBL 294782 & 48628 & 7.2441 & 7.1437 & TST & \\
\hline CHEMBL 303790 & 48628 & 6.8239 & 7.5459 & TRN & \\
\hline CHEMBL 62563 & 48628 & 6.1938 & 6.9684 & TST & \\
\hline CHEMBL445616 & 48628 & 7.9586 & 8.044 & TRN & \\
\hline CHEMBL291644 & 48628 & 7.7212 & 8.0666 & TRN & \\
\hline CHEMBL293248 & 48628 & 7.7447 & 7.8821 & TRN & \\
\hline CHEMBL62279 & 48628 & 8.1549 & 8.1159 & TRN & \\
\hline CHEMBL65877 & 48628 & 6.6383 & 7.1489 & TST & \\
\hline CHEMBL417738 & 48628 & 7.6198 & 7.2566 & TRN & \\
\hline CHEMBL302178 & 48628 & 6.7959 & 7.0575 & TST & \\
\hline CHEMBL 292941 & 48628 & 7.3872 & 7.7434 & TRN & \\
\hline CHEMBL66362 & 48628 & 7.1549 & 7.1959 & TRN & \\
\hline CHEMBL65506 & 48628 & 8.2218 & 8.1432 & TRN & \\
\hline CHEMBL305097 & 48628 & 7.0 & 7.5432 & TRN & \\
\hline CHEMBL61950 & 48628 & 7.9208 & 7.3285 & TRN & \\
\hline CHEMBL436356 & 48628 & 7.4437 & 7.2735 & TRN & \\
\hline CHEMBL292254 & 48628 & 7.0757 & 7.2168 & TRN & \\
\hline CHEMBL66535 & 48628 & 7.5086 & 6.5518 & TST & \\
\hline CHEMBL304859 & 48628 & 7.1487 & 7.2273 & TRN & \\
\hline CHEMBL66030 & 48628 & 8.0 & 8.014 & TRN & \\
\hline
\end{tabular}




\begin{tabular}{|c|c|c|c|c|c|}
\hline \multicolumn{6}{|c|}{ Supplemental Table s2.txt } \\
\hline CHEMBL305394 & 48628 & 8.0969 & 8.2801 & TRN & \\
\hline CHEMBL65128 & 48628 & 7.6021 & 7.23 & TRN & \\
\hline CHEMBL304080 & 48628 & 8.2218 & 8.1244 & TRN & \\
\hline CHEMBL65637 & 48628 & 6.6383 & 6.8903 & TST & \\
\hline CHEMBL62870 & 48628 & 7.5686 & 7.4433 & TRN & \\
\hline CHEMBL446398 & 48628 & 6.4089 & 7.0271 & TST & \\
\hline CHEMBL292305 & 48628 & 8.1549 & 7.9964 & TRN & \\
\hline CHEMBL64994 & 48628 & 8.0969 & 8.2644 & TRN & \\
\hline CHEMBL293217 & 48628 & 7.699 & 7.3598 & TRN & \\
\hline CHEMBL293423 & 48628 & 6.6198 & 7.5287 & TRN & \\
\hline CHEMBL65394 & 48628 & 7.5229 & 7.62799 & 9999999999 & TRN \\
\hline CHEMBL303345 & 48628 & 8.0969 & 8.1367 & TRN & \\
\hline CHEMBL293425 & 48628 & 6.2291 & 6.5906 & TRN & \\
\hline CHEMBL293462 & 48628 & 8.0458 & 6.7233 & TRN & \\
\hline CHEMBL65613 & 48628 & 6.9208 & 7.2457 & TRN & \\
\hline CHEMBL62758 & 48628 & 7.1739 & 7.1233 & TST & \\
\hline CHEMBL63369 & 48628 & 6.8539 & 7.522 & TST & \\
\hline CHEMBL294115 & 48628 & 7.9586 & 7.5574 & TST & \\
\hline CHEMBL63672 & 48628 & 8.0969 & 8.2737 & TRN & \\
\hline CHEMBL65010 & 48628 & 5.8861 & 6.8387 & TST & \\
\hline CHEMBL62746 & 48628 & 7.1938 & 6.87200 & 0000000001 & TST \\
\hline CHEMBL560813 & 570759 & 6.9 & 7.697 & TRN & \\
\hline CHEMBL551086 & 570759 & 8.7 & 7.8576 & TRN & \\
\hline CHEMBL572125 & 570759 & 6.4 & 7.0903 & TST & \\
\hline CHEMBL552355 & 570759 & 7.1 & 6.4196 & TRN & \\
\hline CHEMBL558077 & 570759 & 8.8 & 8.6034 & TRN & \\
\hline CHEMBL220035 & 570759 & 7.9 & 9.0697 & TRN & \\
\hline CHEMBL540992 & 570759 & 8.2 & 8.1546 & TRN & \\
\hline CHEMBL241966 & 570759 & 7.1 & 6.647 & TRN & \\
\hline CHEMBL558070 & 570759 & 4.9 & 5.777 & TST & \\
\hline CHEMBL549660 & 570759 & 8.2 & 7.6444 & TRN & \\
\hline CHEMBL554904 & 570759 & 7.7 & 7.8558 & TRN & \\
\hline CHEMBL560149 & 570759 & 7.8 & 7.7679 & TRN & \\
\hline CHEMBL559425 & 570759 & 8.6 & 7.6737 & TRN & \\
\hline CHEMBL563331 & 570759 & 8.0 & 8.2686 & TRN & \\
\hline CHEMBL549662 & 570759 & 7.1 & 7.5336 & TRN & \\
\hline CHEMBL396034 & 570759 & 4.8 & 4.9106 & TRN & \\
\hline CHEMBL558209 & 570759 & 6.6 & 6.721 & TST & \\
\hline CHEMBL549525 & 570759 & 6.9 & 6.1395 & TRN & \\
\hline CHEMBL549526 & 570759 & 7.5 & 7.0654 & TRN & \\
\hline CHEMBL538899 & 570759 & 6.0 & 6.4368 & TRN & \\
\hline CHEMBL560150 & 570759 & 6.8 & 7.1418 & TRN & \\
\hline CHEMBL438485 & 570759 & 8.2 & 7.4174 & TRN & \\
\hline CHEMBL563452 & 570759 & 7.2 & 6.9334 & TRN & \\
\hline CHEMBL550209 & 570759 & 8.5 & 7.8539 & TRN & \\
\hline CHEMBL248194 & 570759 & 10.0 & 9.0035 & TRN & \\
\hline CHEMBL557757 & 570759 & 7.8 & 7.7926 & TRN & \\
\hline CHEMBL559818 & 570759 & 4.4 & 6.3862 & TST & \\
\hline
\end{tabular}




\begin{tabular}{|c|c|c|c|c|}
\hline & & & upplement & al $\mathrm{Ta}$ \\
\hline CHEMBL549730 & 570759 & 4.8 & 4.9342 & TRN \\
\hline CHEMBL550071 & 570759 & 7.1 & 5.7806 & TST \\
\hline CHEMBL556619 & 570759 & 6.4 & 5.9831 & TRN \\
\hline CHEMBL249363 & 570759 & 9.5 & 9.6774 & TRN \\
\hline CHEMBL563639 & 570759 & 6.9 & 8.1513 & TRN \\
\hline CHEMBL563792 & 570759 & 8.3 & 8.3942 & TRN \\
\hline CHEMBL245605 & 570759 & 7.9 & 8.3585 & TRN \\
\hline CHEMBL558271 & 570759 & 7.8 & 7.8462 & TRN \\
\hline CHEMBL564952 & 570759 & 8.0 & 8.1672 & TRN \\
\hline CHEMBL550073 & 570759 & 7.1 & 7.8493 & TRN \\
\hline CHEMBL540922 & 570759 & 5.7 & 5.5545 & TRN \\
\hline CHEMBL555947 & 570759 & 7.2 & 7.7999 & TRN \\
\hline CHEMBL541259 & 570759 & 6.3 & 6.1995 & TST \\
\hline CHEMBL564542 & 570759 & 8.0 & 7.5992 & TRN \\
\hline CHEMBL559695 & 570759 & 7.1 & 6.7432 & TRN \\
\hline CHEMBL383264 & 570759 & 5.3 & 5.6857 & TRN \\
\hline CHEMBL207994 & 570759 & 8.0 & 7.835 & TRN \\
\hline CHEMBL538900 & 570759 & 4.9 & 6.0929 & TST \\
\hline CHEMBL207596 & 570759 & 8.4 & 8.3541 & TRN \\
\hline CHEMBL538671 & 570759 & 9.2 & 8.3651 & TRN \\
\hline CHEMBL550819 & 570759 & 6.6 & 6.7377 & TRN \\
\hline CHEMBL559918 & 570759 & 5.6 & 5.7739 & TST \\
\hline CHEMBL559696 & 570759 & 5.5 & 6.0855 & TST \\
\hline CHEMBL542007 & 570759 & 8.8 & 8.9192 & TRN \\
\hline CHEMBL562875 & 570759 & 8.2 & 8.2729 & TRN \\
\hline CHEMBL22336 & 570759 & 6.3 & 5.8613 & TRN \\
\hline CHEMBL550820 & 570759 & 8.3 & 7.9886 & TRN \\
\hline CHEMBL550821 & 570759 & 7.7 & 7.004 & TRN \\
\hline CHEMBL560210 & 570759 & 8.4 & 7.8185 & TRN \\
\hline CHEMBL560211 & 570759 & 7.4 & 7.657 & TRN \\
\hline CHEMBL551025 & 570759 & 5.9 & 6.7827 & TST \\
\hline CHEMBL558868 & 570759 & 5.5 & 7.5231 & TRN \\
\hline CHEMBL550479 & 570759 & 9.3 & 8.5905 & TRN \\
\hline CHEMBL559893 & 570759 & 6.4 & 6.9558 & TST \\
\hline CHEMBL559063 & 570759 & 7.3 & 7.8312 & TRN \\
\hline CHEMBL202930 & 570759 & 7.5 & 7.3882 & TRN \\
\hline CHEMBL559064 & 570759 & 6.3 & 6.5066 & TRN \\
\hline CHEMBL560413 & 570759 & 7.0 & 7.5317 & TRN \\
\hline CHEMBL541515 & 570759 & 8.7 & 8.3969 & TRN \\
\hline CHEMBL565046 & 570759 & 5.4 & 5.8903 & TRN \\
\hline CHEMBL550680 & 570759 & 6.8 & 6.6144 & TRN \\
\hline CHEMBL379914 & 570759 & 5.5 & 5.5137 & TRN \\
\hline CHEMBL555940 & 570759 & 8.3 & 8.1223 & TRN \\
\hline CHEMBL560749 & 570759 & 6.9 & 7.9216 & TRN \\
\hline CHEMBL563187 & 570759 & 6.4 & 5.9176 & TRN \\
\hline CHEMBL389816 & 570759 & 8.0 & 7.0867 & TRN \\
\hline CHEMBL551085 & 570759 & 5.7 & 6.3143 & TRN \\
\hline CHEMBL553642 & 570759 & 6.1 & 6.796 & TRN \\
\hline
\end{tabular}




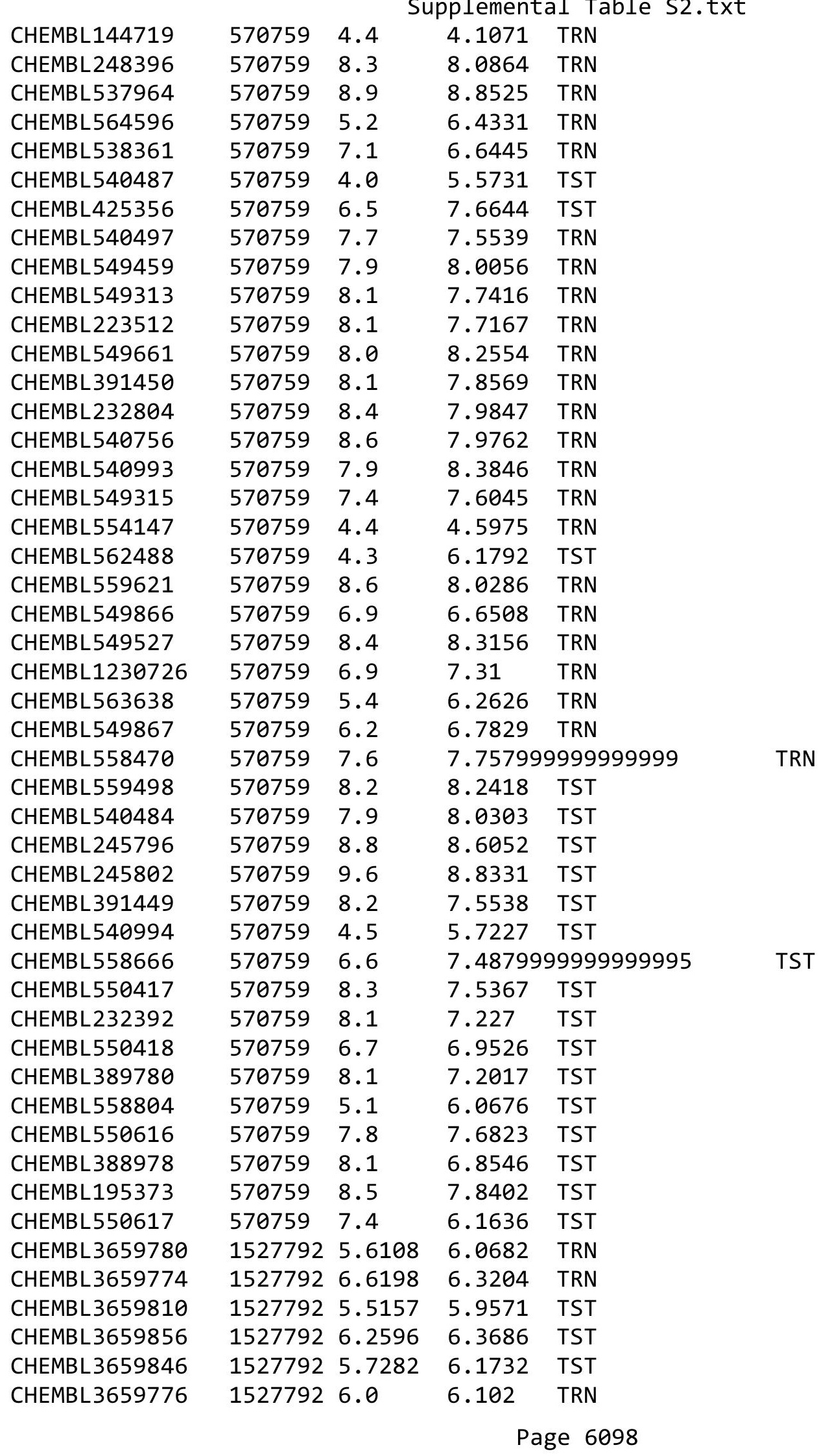


Supplemental Table S2.txt

\begin{tabular}{|c|c|c|c|c|c|}
\hline CHEMBL 3659809 & 1527792 & 6.5376 & 6.3362 & TST & \\
\hline CHEMBL 3659786 & 1527792 & 5.9747 & 6.115 & TST & \\
\hline CHEMBL 3659878 & 1527792 & 6.3768 & 6.1133 & TRN & \\
\hline CHEMBL 3659888 & 1527792 & 7.0 & 6.8094 & TRN & \\
\hline CHEMBL 3659864 & 1527792 & 6.4559 & 6.087006 & 0000000001 & TRN \\
\hline CHEMBL 3659708 & 1527792 & 6.3468 & 6.3329 & TRN & \\
\hline CHEMBL 3659830 & 1527792 & 5.75200 & 00000006 & 5.8659 & TRN \\
\hline CHEMBL 3659802 & 1527792 & 5.9318 & 5.9333 & TRN & \\
\hline CHEMBL 3659754 & 1527792 & 5.5361 & 5.8742 & TRN & \\
\hline CHEMBL 3659842 & 1527792 & 6.1308 & 6.0232 & TRN & \\
\hline CHEMBL 3659701 & 1527792 & 6.0 & 6.178 & TRN & \\
\hline CHEMBL 3659788 & 1527792 & 5.21399 & 99999999 & 5.6654 & TRN \\
\hline CHEMBL 3659765 & 1527792 & 5.5935 & 5.5516 & TRN & \\
\hline CHEMBL 3659783 & 1527792 & 6.6198 & 6.7394 & TRN & \\
\hline CHEMBL 3659704 & 1527792 & 5.6556 & 5.2003 & TRN & \\
\hline CHEMBL 3659785 & 1527792 & 6.4318 & 6.5794 & TST & \\
\hline CHEMBL3659779 & 1527792 & 5.399 & 5.4912 & TRN & \\
\hline CHEMBL 3659853 & 1527792 & 6.3872 & 5.9981 & TRN & \\
\hline CHEMBL 3659882 & 1527792 & 4.93 & 5.0184 & TRN & \\
\hline CHEMBL 3659706 & 1527792 & 7.1549 & 6.9676 & TRN & \\
\hline CHEMBL 3659736 & 1527792 & 6.6021 & 6.4661 & TRN & \\
\hline CHEMBL 3659757 & 1527792 & 6.6198 & 6.7289 & TRN & \\
\hline CHEMBL 3659771 & 1527792 & 6.699 & 6.0094 & TRN & \\
\hline CHEMBL 3659822 & 1527792 & 5.8416 & 5.7589 & TRN & \\
\hline CHEMBL 3659871 & 1527792 & 5.71899 & 99999999 & 5.8709 & TRN \\
\hline CHEMBL 3659742 & 1527792 & 6.0506 & 5.6653 & TRN & \\
\hline CHEMBL 3659850 & 1527792 & 5.556 & $5.79700 €$ & 0000000001 & TRN \\
\hline CHEMBL 3659838 & 1527792 & 5.6478 & 5.8104 & TRN & \\
\hline CHEMBL3659873 & 1527792 & 6.4685 & 6.3606 & TRN & \\
\hline CHEMBL 3659823 & 1527792 & 5.9031 & 6.0599 & TRN & \\
\hline CHEMBL 3659762 & 1527792 & 5.3872 & 5.3521 & TRN & \\
\hline CHEMBL 3659887 & 1527792 & 6.1549 & 5.5404 & TST & \\
\hline CHEMBL 3659712 & 1527792 & 6.3098 & 6.1444 & TRN & \\
\hline CHEMBL 3659794 & 1527792 & 6.1135 & 6.0609 & TRN & \\
\hline CHEMBL 3659748 & 1527792 & 6.8239 & 6.3124 & TRN & \\
\hline CHEMBL 3659772 & 1527792 & 5.4112 & 5.862 & TRN & \\
\hline CHEMBL3659839 & 1527792 & 5.7595 & 5.9503 & TRN & \\
\hline CHEMBL 3659876 & 1527792 & 6.3565 & 6.3167 & TRN & \\
\hline CHEMBL 3659826 & 1527792 & 5.6253 & 5.7159 & TRN & \\
\hline CHEMBL 3659722 & 1527792 & 6.1739 & 5.5928 & TRN & \\
\hline CHEMBL 3659875 & 1527792 & 6.1739 & 6.5296 & TRN & \\
\hline CHEMBL3659861 & 1527792 & 5.6861 & 5.822999 & 99999999995 & TRN \\
\hline CHEMBL3659696 & 1527792 & 6.2757 & 6.8245 & TRN & \\
\hline CHEMBL 3659847 & 1527792 & 5.2373 & 5.4957 & TRN & \\
\hline CHEMBL 3659868 & 1527792 & 6.0315 & 5.9308 & TRN & \\
\hline CHEMBL3659768 & 1527792 & 5.9508 & 5.9434 & TRN & \\
\hline CHEMBL 3659857 & 1527792 & 6.7212 & 6.3472 & TRN & \\
\hline CHEMBL3659746 & 1527792 & 7.3979 & 7.1831 & TRN & \\
\hline
\end{tabular}


Supplemental Table S2.txt

\begin{tabular}{|c|c|c|c|c|c|}
\hline CHEMBL3659815 & 1527792 & 6.2757 & 6.4554 & TRN & \\
\hline CHEMBL3659756 & 1527792 & 7.2218 & 6.9471 & TRN & \\
\hline CHEMBL 3659818 & 1527792 & 5.6615 & 5.9486 & TRN & \\
\hline CHEMBL 3659729 & 1527792 & 5.644 & 5.6978 & TRN & \\
\hline CHEMBL 3659717 & 1527792 & 6.2366 & 6.3331 & TRN & \\
\hline CHEMBL 3659797 & 1527792 & 5.9281 & 6.2926 & TST & \\
\hline CHEMBL3659727 & 1527792 & 7.2218 & 6.6598 & TRN & \\
\hline CHEMBL 3659825 & 1527792 & 5.1135 & 5.769 & TRN & \\
\hline CHEMBL 3659866 & 1527792 & 5.7721 & 5.9068 & TRN & \\
\hline CHEMBL3659695 & 1527792 & 6.0 & 6.301 & TRN & \\
\hline CHEMBL 3659835 & 1527792 & 5.5467 & 5.7098 & TRN & \\
\hline CHEMBL3659726 & 1527792 & 6.4685 & 6.4492 & TRN & \\
\hline CHEMBL 3659769 & 1527792 & 6.0 & 5.8491 & TRN & \\
\hline CHEMBL 3659752 & 1527792 & 6.1871 & 6.1206 & TRN & \\
\hline CHEMBL 3659820 & 1527792 & 5.7595 & 5.5336 & TRN & \\
\hline CHEMBL 3659877 & 1527792 & 6.3188 & 6.0792 & TRN & \\
\hline CHEMBL 3659737 & 1527792 & 6.8861 & 6.787999 & 9999999999 & TRN \\
\hline CHEMBL 3659848 & 1527792 & 5.4045 & 4.8969 & TRN & \\
\hline CHEMBL 3659792 & 1527792 & 5.7447 & 5.6175 & TRN & \\
\hline CHEMBL 3659758 & 1527792 & 5.2118 & 5.978 & TRN & \\
\hline CHEMBL 3659858 & 1527792 & 6.0915 & 6.1332 & TST & \\
\hline CHEMBL 3659855 & 1527792 & 5.9626 & 6.106 & TRN & \\
\hline CHEMBL3659813 & 1527792 & 5.9788 & 6.0453 & TRN & \\
\hline CHEMBL 3639585 & 1527792 & 6.7447 & 6.7414 & TRN & \\
\hline CHEMBL 3659801 & 1527792 & 6.4437 & 6.0409 & TST & \\
\hline CHEMBL 3659724 & 1527792 & 6.7212 & 6.8679 & TRN & \\
\hline CHEMBL 3659719 & 1527792 & 5.75700 & 000000000 & 5.7295 & TST \\
\hline CHEMBL3659705 & 1527792 & 5.2725 & 5.2841 & TRN & \\
\hline CHEMBL 3659870 & 1527792 & 5.9245 & 5.8844 & TRN & \\
\hline CHEMBL 3659851 & 1527792 & 6.1192 & 6.1686 & TRN & \\
\hline CHEMBL 3659827 & 1527792 & 5.9626 & 6.2641 & TRN & \\
\hline CHEMBL 3659845 & 1527792 & 6.5229 & 6.4737 & TRN & \\
\hline CHEMBL3659883 & 1527792 & 5.6216 & 5.3037 & TRN & \\
\hline CHEMBL 3659777 & 1527792 & 5.6904 & 5.5585 & TST & \\
\hline CHEMBL3659732 & 1527792 & 5.9872 & 6.2996 & TRN & \\
\hline CHEMBL 3659725 & 1527792 & 6.699 & 6.75 & TRN & \\
\hline CHEMBL3659766 & 1527792 & 5.3468 & 5.774 & TRN & \\
\hline CHEMBL3659867 & 1527792 & 5.6308 & 5.633999 & & $\mathrm{K}$ \\
\hline CHEMBL 3659824 & 1527792 & 6.1079 & 6.2179 & TRN & \\
\hline CHEMBL 3659750 & 1527792 & 5.857 & 5.8986 & TRN & \\
\hline CHEMBL 3659837 & 1527792 & 6.3468 & 6.1202 & TRN & \\
\hline CHEMBL3659859 & 1527792 & 5.5003 & 6.171 & TST & \\
\hline CHEMBL 3659720 & 1527792 & 5.7905 & 6.0775 & TST & \\
\hline CHEMBL3659800 & 1527792 & 6.2441 & 6.2451 & TRN & \\
\hline CHEMBL 3659886 & 1527792 & 5.3851 & 5.3547 & TRN & \\
\hline CHEMBL 3659784 & 1527792 & 6.1427 & 5.8593 & TRN & \\
\hline CHEMBL3659759 & 1527792 & 6.7696 & 6.6008 & TRN & \\
\hline CHEMBL3659709 & 1527792 & 5.7235 & 5.6347 & TRN & \\
\hline
\end{tabular}


Supplemental Table S2.txt

\begin{tabular}{|c|c|c|c|c|c|}
\hline CHEMBL3659791 & 1527792 & 6.5376 & \multicolumn{2}{|c|}{6.122000000000001} & TRN \\
\hline CHEMBL3659773 & 1527792 & 6.3279 & 6.1487 & TRN & \\
\hline CHEMBL3659804 & 1527792 & 6.7212 & 6.5311 & TRN & \\
\hline CHEMBL3659834 & 1527792 & 6.4318 & 6.0917 & TST & \\
\hline CHEMBL3659699 & 1527792 & 7.0969 & 7.1517 & TRN & \\
\hline CHEMBL3659884 & 1527792 & 5.4949 & 5.8847 & TRN & \\
\hline CHEMBL3659755 & 1527792 & 6.0555 & 6.2779 & TRN & \\
\hline CHEMBL3659843 & 1527792 & 6.1612 & 6.2451 & TRN & \\
\hline CHEMBL3659782 & 1527792 & 5.4597 & 5.4708 & TRN & \\
\hline CHEMBL3659795 & 1527792 & 6.3872 & 5.9724 & TST & \\
\hline CHEMBL3659739 & 1527792 & 6.3979 & 6.108 & TRN & \\
\hline CHEMBL3659734 & 1527792 & 5.9788 & 6.0188 & TRN & \\
\hline CHEMBL3659805 & 1527792 & 7.0 & 6.0258 & TST & \\
\hline CHEMBL3659763 & 1527792 & 4.9735 & 4.9997 & TRN & \\
\hline CHEMBL3659778 & 1527792 & 6.3188 & 5.7067 & TST & \\
\hline CHEMBL3659803 & 1527792 & 5.8601 & 5.8927 & TRN & \\
\hline CHEMBL3659840 & 1527792 & 6.1549 & 6.349 & TRN & \\
\hline CHEMBL 3659790 & 1527792 & 6.3279 & 6.3628 & TRN & \\
\hline CHEMBL 3659787 & 1527792 & 6.6021 & \multicolumn{2}{|c|}{6.138999999999999} & TST \\
\hline CHEMBL3659890 & 1527792 & 5.4413 & \multicolumn{2}{|c|}{5.327000000000001} & TRN \\
\hline CHEMBL3659700 & 1527792 & 5.9031 & 6.3494 & TRN & \\
\hline CHEMBL 3659747 & 1527792 & 6.9586 & 7.0515 & TRN & \\
\hline CHEMBL3659874 & 1527792 & 5.9318 & 6.1312 & TRN & \\
\hline CHEMBL 3659854 & 1527792 & 6.1739 & 6.115 & TRN & \\
\hline CHEMBL3659885 & 1527792 & 5.082 & 5.461 & TRN & \\
\hline CHEMBL3659738 & 1527792 & 6.7696 & 6.4247 & TRN & \\
\hline CHEMBL 3659745 & 1527792 & 6.1192 & 6.0753 & TRN & \\
\hline CHEMBL3659863 & 1527792 & 5.284 & 5.5446 & TRN & \\
\hline CHEMBL3659775 & 1527792 & 5.4179 & 6.0068 & TST & \\
\hline CHEMBL3659798 & 1527792 & 6.1249 & 5.6779 & TST & \\
\hline CHEMBL3659849 & 1527792 & 6.2757 & 6.1866 & TRN & \\
\hline CHEMBL3659836 & 1527792 & 6.0 & 6.1269 & TRN & \\
\hline CHEMBL3659761 & 1527792 & 5.6861 & 5.3861 & TRN & \\
\hline CHEMBL 3659710 & 1527792 & 6.8539 & 6.6859 & TRN & \\
\hline CHEMBL3659713 & 1527792 & 6.7212 & 6.0712 & TRN & \\
\hline CHEMBL3659781 & 1527792 & 5.2055 & 5.6702 & TST & \\
\hline CHEMBL3659697 & 1527792 & 6.8861 & 7.0774 & TRN & \\
\hline CHEMBL3659740 & 1527792 & 5.9914 & 6.0189 & TRN & \\
\hline CHEMBL3659869 & 1527792 & 5.6364 & \multicolumn{2}{|c|}{5.547000000000001} & TRN \\
\hline CHEMBL3659793 & 1527792 & 6.699 & 6.3574 & TRN & \\
\hline CHEMBL 3659841 & 1527792 & 5.5544 & 6.0249 & TRN & \\
\hline CHEMBL3659789 & 1527792 & 6.1612 & 5.604 & TST & \\
\hline CHEMBL3659881 & 1527792 & 4.9747 & 5.1762 & TRN & \\
\hline CHEMBL3659860 & 1527792 & 5.5171 & 5.8242 & TRN & \\
\hline CHEMBL3659751 & 1527792 & 6.5229 & 6.2806 & TRN & \\
\hline CHEMBL3659796 & 1527792 & 6.3468 & 5.1182 & TST & \\
\hline CHEMBL3659811 & 1527792 & 6.2441 & 6.5138 & TRN & \\
\hline CHEMBL3659819 & 1527792 & 7.0458 & 7.4313 & TRN & \\
\hline
\end{tabular}


Supplemental Table S2.txt

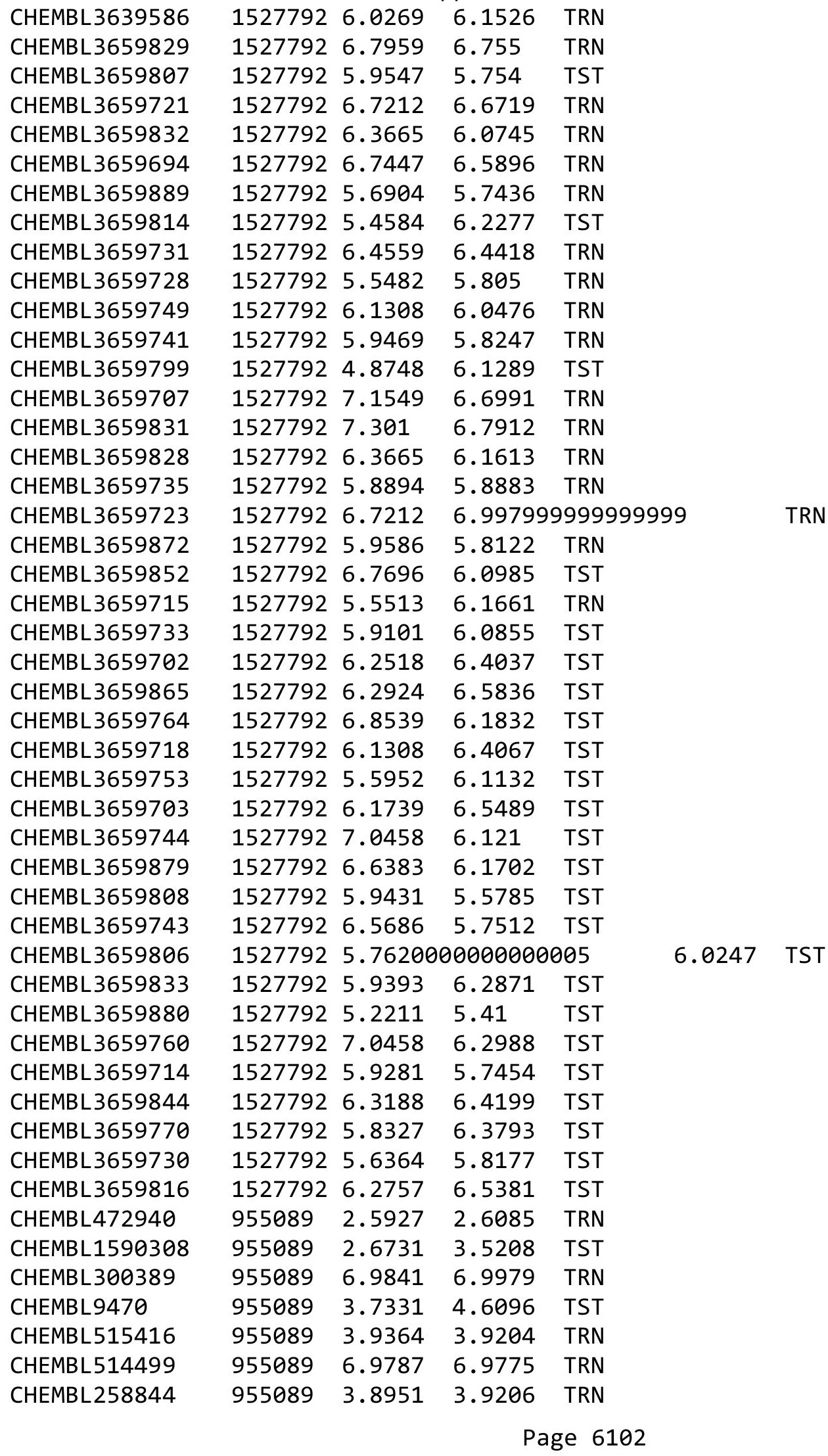




\begin{tabular}{|c|c|c|c|c|c|c|}
\hline & & \multicolumn{5}{|c|}{ Supplemental Table s2.txt } \\
\hline CHEMBL102714 & 955089 & 3.2812 & 3.2779 & TRN & & \\
\hline CHEMBL191334 & 955089 & 3.7227 & 3.7237 & TRN & & \\
\hline CHEMBL1673039 & 955089 & 4.7298 & 4.7184 & TRN & & \\
\hline CHEMBL240954 & 955089 & 4.601 & 4.4302 & TST & & \\
\hline CHEMBL210618 & 955089 & 4.1731 & 4.1878 & TRN & & \\
\hline CHEMBL1256459 & 955089 & 5.7676 & 5.7666 & TRN & & \\
\hline CHEMBL1643959 & 955089 & 3.6647 & 3.6734 & TRN & & \\
\hline CHEMBL1242367 & 955089 & 3.502 & 3.5207 & TRN & & \\
\hline CHEMBL392695 & 955089 & 4.9667 & 4.957 & TRN & & \\
\hline CHEMBL3199475 & 955089 & 4.1177 & 4.1163 & TRN & & \\
\hline CHEMBL1404918 & 955089 & 3.1457 & 3.1144 & TRN & & \\
\hline CHEMBL188678 & 955089 & 4.7988 & 4.7821 & TRN & & \\
\hline CHEMBL1970879 & 955089 & 3.8858 & 3.8894 & TRN & & \\
\hline CHEMBL512504 & 955089 & \multicolumn{3}{|c|}{6.1979999999999995} & 6.2042 & TRN \\
\hline CHEMBL180127 & 955089 & 2.7821 & 2.7805 & TRN & & \\
\hline CHEMBL3349342 & 955089 & 3.5727 & 3.5822 & TRN & & \\
\hline CHEMBL135561 & 955089 & 4.3858 & \multicolumn{3}{|c|}{ 4. 3919999999999995} & TRN \\
\hline CHEMBL 379975 & 955089 & 5.294 & 5.2769 & TRN & & \\
\hline CHEMBL3392440 & 955089 & 3.3503 & 3.3599 & TRN & & \\
\hline CHEMBL1230020 & 955089 & 4.4904 & 4.4826 & TRN & & \\
\hline CHEMBL573107 & 955089 & 4.4736 & 4.4681 & TRN & & \\
\hline CHEMBL483849 & 955089 & 2.3758 & 2.3796 & TRN & & \\
\hline CHEMBL577784 & 955089 & 3.8747 & 3.8765 & TRN & & \\
\hline CHEMBL1909414 & 955089 & 4.178 & 4.1746 & TRN & & \\
\hline CHEMBL209148 & 955089 & 3.2365 & 3.2345 & TRN & & \\
\hline CHEMBL585951 & 955089 & 5.8447 & 5.8677 & TRN & & \\
\hline CHEMBL202721 & 955089 & 3.9952 & 3.9877 & TRN & & \\
\hline CHEMBL483847 & 955089 & 3.7388 & 3.7188 & TRN & & \\
\hline CHEMBL 2005886 & 955089 & 3.3125 & 3.2976 & TRN & & \\
\hline CHEMBL92309 & 955089 & 3.273 & 2.8585 & TST & & \\
\hline CHEMBL 259181 & 955089 & 4.1984 & 4.1768 & TRN & & \\
\hline CHEMBL509032 & 955089 & 5.9456 & 5.9276 & TRN & & \\
\hline CHEMBL3186408 & 955089 & 4.6351 & 3.7981 & TST & & \\
\hline CHEMBL449158 & 955089 & 6.4581 & 5.9022 & TST & & \\
\hline CHEMBL222102 & 955089 & 4.1412 & 4.1648 & TRN & & \\
\hline CHEMBL558642 & 955089 & 4.5411 & 4.5562 & TRN & & \\
\hline CHEMBL65 & 955089 & 7.2271 & 7.2299 & TRN & & \\
\hline CHEMBL 213100 & 955089 & 3.2805 & 3.29 & TRN & & \\
\hline CHEMBL1357247 & 955089 & 3.1929 & 3.2015 & TRN & & \\
\hline CHEMBL189584 & 955089 & 4.474 & 4.4706 & TRN & & \\
\hline CHEMBL1788116 & 955089 & 3.8668 & 3.8647 & TRN & & \\
\hline CHEMBL192566 & 955089 & 7.2286 & 6.7865 & TST & & \\
\hline CHEMBL220241 & 955089 & 4.9245 & 4.923 & TRN & & \\
\hline CHEMBL1190711 & 955089 & 5.0241 & 5.0207 & TRN & & \\
\hline CHEMBL412142 & 955089 & 3.5966 & 3.8254 & TST & & \\
\hline CHEMBL 379300 & 955089 & \multicolumn{3}{|c|}{6.787000000000001} & 5.7664 & TST \\
\hline CHEMBL 2363137 & 955089 & 3.9464 & 4.1938 & TST & & \\
\hline CHEMBL393929 & 955089 & 3.6803 & 4.0466 & TST & & \\
\hline
\end{tabular}


Supplemental Table S2.txt

\begin{tabular}{|c|c|c|c|c|}
\hline CHEMBL373751 & 955089 & 3.9798 & 4.3533 & TST \\
\hline CHEMBL221137 & 955089 & 4.4612 & 4.0991 & TST \\
\hline CHEMBL1516890 & 955089 & 3.951 & 3.5844 & TST \\
\hline CHEMBL 2144069 & 955089 & 3.8103 & 3.6993 & TST \\
\hline CHEMBL3719056 & 1536778 & 8.0 & 7.5952 & TRN \\
\hline CHEMBL3716042 & 1536778 & 8.0 & 7.6935 & TST \\
\hline CHEMBL3715221 & 1536778 & 8.0 & 7.6676 & TRN \\
\hline CHEMBL3718571 & 1536778 & 6.0 & 6.044 & TRN \\
\hline CHEMBL3716824 & 1536778 & 8.0 & 7.44 & TRN \\
\hline CHEMBL3717232 & 1536778 & 8.0 & 7.6721 & TRN \\
\hline CHEMBL3715287 & 1536778 & 7.0 & 7.6935 & TST \\
\hline CHEMBL3717556 & 1536778 & 6.0 & 6.0226 & TST \\
\hline CHEMBL3716345 & 1536778 & 6.0 & 6.3206 & TRN \\
\hline CHEMBL3717238 & 1536778 & 8.0 & 7.6573 & TRN \\
\hline CHEMBL3719300 & 1536778 & 6.0 & 6.0157 & TST \\
\hline CHEMBL3717896 & 1536778 & 7.0 & 7.6676 & TRN \\
\hline CHEMBL3715487 & 1536778 & 8.0 & 7.6142 & TRN \\
\hline CHEMBL3716181 & 1536778 & 8.0 & 7.6687 & TRN \\
\hline CHEMBL3714925 & 1536778 & 8.0 & 7.6358 & TRN \\
\hline CHEMBL3718322 & 1536778 & 8.0 & 7.6779 & TST \\
\hline CHEMBL3719297 & 1536778 & 6.0 & 6.401 & TRN \\
\hline CHEMBL3715269 & 1536778 & 8.0 & 7.6676 & TST \\
\hline CHEMBL3719122 & 1536778 & 7.0 & 7.653 & TRN \\
\hline CHEMBL3717474 & 1536778 & 7.0 & 7.6607 & TRN \\
\hline CHEMBL3719382 & 1536778 & 7.0 & 7.5797 & TRN \\
\hline CHEMBL3717984 & 1536778 & 7.0 & 7.6831 & TST \\
\hline CHEMBL3716905 & 1536778 & 7.0 & 7.3745 & TST \\
\hline CHEMBL3716706 & 1536778 & 7.0 & 7.6296 & TRN \\
\hline CHEMBL3719028 & 1536778 & 7.0 & 7.4685 & TRN \\
\hline CHEMBL3715204 & 1536778 & 7.0 & 7.6314 & TRN \\
\hline CHEMBL3718370 & 1536778 & 8.0 & 7.4814 & TRN \\
\hline CHEMBL3718339 & 1536778 & 8.0 & 7.6778 & TRN \\
\hline CHEMBL3717793 & 1536778 & 8.0 & 7.6883 & TST \\
\hline CHEMBL3716210 & 1536778 & 7.0 & 7.4523 & TRN \\
\hline CHEMBL3718207 & 1536778 & 8.0 & 7.5952 & TRN \\
\hline CHEMBL3718491 & 1536778 & 6.0 & 6.5094 & TRN \\
\hline CHEMBL3718056 & 1536778 & 8.0 & 7.6514 & TST \\
\hline CHEMBL3717223 & 1536778 & 8.0 & 7.6883 & TRN \\
\hline CHEMBL3719064 & 1536778 & 7.0 & 7.621 & TRN \\
\hline CHEMBL3717222 & 1536778 & 8.0 & 7.6986 & TRN \\
\hline CHEMBL3717576 & 1536778 & 7.0 & 7.6986 & TST \\
\hline CHEMBL3715268 & 1536778 & 8.0 & 7.6883 & TST \\
\hline CHEMBL3715272 & 1536778 & 8.0 & 7.5331 & TRN \\
\hline CHEMBL3716748 & 1536778 & 7.0 & 7.5447 & TRN \\
\hline CHEMBL3717501 & 1536778 & 8.0 & 7.6986 & TRN \\
\hline CHEMBL3717165 & 1536778 & 6.0 & 6.3491 & TST \\
\hline CHEMBL3717061 & 1536778 & 7.0 & 7.6573 & TRN \\
\hline CHEMBL3717320 & 1536778 & 8.0 & 7.3358 & TRN \\
\hline
\end{tabular}




\begin{tabular}{|c|c|c|c|c|}
\hline & & & & $a \perp 1 a$ \\
\hline CHEMBL3718394 & 1536778 & 8.0 & 7.6057 & TRN \\
\hline CHEMBL3714947 & 1536778 & 8.0 & 7.6623 & TST \\
\hline CHEMBL3715242 & 1536778 & 6.0 & 7.3486 & TRN \\
\hline CHEMBL 3718419 & 1536778 & 7.0 & 7.6107 & TST \\
\hline CHEMBL3716267 & 1536778 & 8.0 & 7.6917 & TRN \\
\hline CHEMBL3714920 & 1536778 & 7.0 & 7.5952 & TRN \\
\hline CHEMBL3717749 & 1536778 & 7.0 & 7.6675 & TRN \\
\hline CHEMBL3715444 & 1536778 & 8.0 & 7.6883 & TRN \\
\hline CHEMBL 3716880 & 1536778 & 8.0 & 7.6313 & TRN \\
\hline CHEMBL3718270 & 1536778 & 7.0 & 7.3505 & TRN \\
\hline CHEMBL3718031 & 1536778 & 8.0 & 7.4607 & TRN \\
\hline CHEMBL3718191 & 1536778 & 6.0 & 6.1162 & TRN \\
\hline CHEMBL3715591 & 1536778 & 7.0 & 7.3323 & TRN \\
\hline CHEMBL3718779 & 1536778 & 6.0 & 5.9629 & TRN \\
\hline CHEMBL3715314 & 1536778 & 6.0 & 6.3213 & TST \\
\hline CHEMBL3715810 & 1536778 & 7.0 & 7.2409 & TRN \\
\hline CHEMBL3719213 & 1536778 & 7.0 & 7.678 & TRN \\
\hline CHEMBL3716297 & 1536778 & 8.0 & 7.6573 & TRN \\
\hline CHEMBL 3717715 & 1536778 & 8.0 & 6.9714 & TRN \\
\hline CHEMBL3716295 & 1536778 & 8.0 & 7.6882 & TRN \\
\hline CHEMBL3714992 & 1536778 & 8.0 & 7.6218 & TRN \\
\hline CHEMBL3716513 & 1536778 & 8.0 & 7.5073 & TRN \\
\hline CHEMBL 3714848 & 1536778 & 8.0 & 7.6986 & TST \\
\hline CHEMBL3718967 & 1536778 & 8.0 & 7.6264 & TRN \\
\hline CHEMBL 3718414 & 1536778 & 8.0 & 7.6986 & TST \\
\hline CHEMBL3715827 & 1536778 & 8.0 & 7.6468 & TST \\
\hline CHEMBL3715134 & 1536778 & 6.0 & 6.3749 & TRN \\
\hline CHEMBL3718089 & 1536778 & 8.0 & 7.6986 & TRN \\
\hline CHEMBL3718525 & 1536778 & 8.0 & 7.6986 & TRN \\
\hline CHEMBL3716651 & 1536778 & 8.0 & 7.6883 & TRN \\
\hline CHEMBL3717859 & 1536778 & 8.0 & 7.4245 & TRN \\
\hline CHEMBL3715301 & 1536778 & 8.0 & 7.6073 & TRN \\
\hline CHEMBL3716303 & 1536778 & 6.0 & 6.3681 & TRN \\
\hline CHEMBL 3718738 & 1536778 & 6.0 & 6.04 & TST \\
\hline CHEMBL3718417 & 1536778 & 7.0 & 7.5641 & TRN \\
\hline CHEMBL3718822 & 1536778 & 8.0 & 6.4139 & TRN \\
\hline CHEMBL3714940 & 1536778 & 7.0 & 7.6986 & TST \\
\hline CHEMBL3719306 & 1536778 & 7.0 & 7.6883 & TST \\
\hline CHEMBL 3718096 & 1536778 & 6.0 & 6.0199 & TRN \\
\hline CHEMBL3716851 & 1536778 & 7.0 & 7.6658 & TRN \\
\hline CHEMBL 3715881 & 1536778 & 8.0 & 7.6314 & TRN \\
\hline CHEMBL3719367 & 1536778 & 8.0 & 7.6831 & TRN \\
\hline CHEMBL3718816 & 1536778 & 7.0 & 7.6504 & TRN \\
\hline CHEMBL 3718771 & 1536778 & 8.0 & 7.5539 & TRN \\
\hline CHEMBL 3717380 & 1536778 & 8.0 & 7.5763 & TRN \\
\hline CHEMBL 3714927 & 1536778 & 8.0 & 7.1611 & TRN \\
\hline CHEMBL3715565 & 1536778 & 7.0 & 7.5987 & TRN \\
\hline CHEMBL 3716542 & 1536778 & 8.0 & 7.6572 & TRN \\
\hline
\end{tabular}




\begin{tabular}{|c|c|c|c|c|}
\hline & & & oplement & $d \perp$ \\
\hline CHEMBL3716565 & 1536778 & 7.0 & 7.6986 & TRN \\
\hline CHEMBL3719075 & 1536778 & 7.0 & 7.6831 & TRN \\
\hline CHEMBL3718112 & 1536778 & 7.0 & 7.5884 & TST \\
\hline CHEMBL3716071 & 1536778 & 6.0 & 7.6418 & TRN \\
\hline CHEMBL3717340 & 1536778 & 6.0 & 6.1389 & TRN \\
\hline CHEMBL3715191 & 1536778 & 8.0 & 7.6064 & TRN \\
\hline CHEMBL 3715768 & 1536778 & 6.0 & 5.8216 & TST \\
\hline CHEMBL 3717351 & 1536778 & 8.0 & 7.678 & TRN \\
\hline CHEMBL 3717342 & 1536778 & 8.0 & 7.5744 & TRN \\
\hline CHEMBL3719098 & 1536778 & 8.0 & 7.6607 & TST \\
\hline CHEMBL 3714868 & 1536778 & 8.0 & 7.6418 & TST \\
\hline CHEMBL129795 & 3921 & 4.4559 & 4.2321 & TRN \\
\hline CHEMBL105310 & 3921 & 3.3979 & 3.2189 & TRN \\
\hline CHEMBL 340783 & 3921 & 8.1079 & 7.4687 & TRN \\
\hline CHEMBL129644 & 3921 & 7.6576 & 7.276 & TRN \\
\hline CHEMBL125633 & 3921 & 7.6198 & 7.4201 & TRN \\
\hline CHEMBL128000 & 3921 & 8.3372 & 7.4884 & TRN \\
\hline CHEMBL128990 & 3921 & 7.3872 & 8.0628 & TRN \\
\hline CHEMBL126657 & 3921 & 5.0506 & 5.723 & TRN \\
\hline CHEMBL1173475 & 3921 & 6.699 & 6.5577 & TST \\
\hline CHEMBL338066 & 3921 & 4.0 & 4.1355 & TRN \\
\hline CHEMBL85000 & 3921 & 8.1612 & 3.9691 & TST \\
\hline CHEMBL126647 & 3921 & 6.4318 & 7.0651 & TRN \\
\hline CHEMBL129590 & 3921 & 8.3979 & 8.0257 & TRN \\
\hline CHEMBL52 & 3921 & 7.0 & 6.6699 & TST \\
\hline CHEMBL126252 & 3921 & 7.8539 & 7.5896 & TRN \\
\hline CHEMBL341135 & 3921 & 8.3979 & 7.8406 & TRN \\
\hline CHEMBL126940 & 3921 & 7.699 & 7.7065 & TRN \\
\hline CHEMBL126669 & 3921 & 8.3768 & 8.0212 & TRN \\
\hline CHEMBL126894 & 3921 & 8.1871 & 7.664 & TRN \\
\hline CHEMBL 340140 & 3921 & 7.5686 & 7.7262 & TRN \\
\hline CHEMBL126804 & 3921 & 4.3768 & 3.8738 & TRN \\
\hline CHEMBL 145 & 3921 & 4.3665 & 7.3002 & TRN \\
\hline CHEMBL 7660 & 3921 & 6.0 & 3.557 & TST \\
\hline CHEMBL129371 & 3921 & 3.8539 & 3.4696 & TRN \\
\hline CHEMBL127064 & 3921 & 7.7959 & 7.5987 & TRN \\
\hline CHEMBL125800 & 3921 & 7.1938 & 7.4258 & TRN \\
\hline CHEMBL340911 & 3921 & 7.9586 & 7.7825 & TRN \\
\hline CHEMBL 127593 & 3921 & 8.0706 & 7.7666 & TRN \\
\hline CHEMBL129510 & 3921 & 7.3665 & 7.1367 & TRN \\
\hline CHEMBL127409 & 3921 & 6.8539 & 7.2368 & TRN \\
\hline CHEMBL129160 & 3921 & 8.0458 & 7.5656 & TRN \\
\hline CHEMBL130639 & 3921 & 4.9208 & 5.825 & TRN \\
\hline CHEMBL339587 & 3921 & 7.6383 & 7.3081 & TRN \\
\hline CHEMBL128012 & 3921 & 7.0362 & 7.0965 & TRN \\
\hline CHEMBL125854 & 3921 & 7.5686 & 6.9785 & TRN \\
\hline CHEMBL126597 & 3921 & 7.5686 & 7.8851 & TRN \\
\hline CHEMBL 262892 & 3921 & 8.3279 & 8.2148 & TRN \\
\hline
\end{tabular}




\begin{tabular}{|c|c|c|c|c|c|}
\hline & & \multicolumn{4}{|c|}{ Supplemental Table s2.txt } \\
\hline CHEMBL126617 & 3921 & 7.7959 & 7.6596 & TRN & \\
\hline CHEMBL338199 & 3921 & 8.2757 & 7.9487 & TRN & \\
\hline CHEMBL340418 & 3921 & 7.1192 & 7.9696 & TRN & \\
\hline CHEMBL130239 & 3921 & 6.3979 & 7.4175 & TRN & \\
\hline CHEMBL129523 & 3921 & 8.0 & 7.5694 & TRN & \\
\hline CHEMBL130640 & 3921 & 4.7696 & 5.1507 & TRN & \\
\hline CHEMBL125415 & 3921 & 8.4202 & 7.7061 & TRN & \\
\hline CHEMBL129765 & 3921 & 7.7447 & 7.7218 & TRN & \\
\hline CHEMBL276473 & 3921 & 3.6383 & 3.2472 & TST & \\
\hline CHEMBL126499 & 3921 & 7.7696 & 7.8907 & TRN & \\
\hline CHEMBL126631 & 3921 & 7.4089 & 7.5829 & TST & \\
\hline CHEMBL340244 & 3921 & 7.8239 & 7.5534 & TST & \\
\hline CHEMBL126838 & 3921 & 8.6198 & 7.9906 & TST & \\
\hline CHEMBL338169 & 3921 & 6.6778 & 7.1916 & TST & \\
\hline CHEMBL128605 & 3921 & 6.0 & 7.8456 & TST & \\
\hline CHEMBL126774 & 3921 & 7.2366 & 7.1559 & TST & \\
\hline CHEMBL339029 & 3921 & 7.6383 & 7.9615 & TST & \\
\hline CHEMBL339788 & 3921 & 8.0088 & 8.0352 & TST & \\
\hline CHEMBL126621 & 3921 & 7.3872 & 7.4792 & TST & \\
\hline CHEMBL1964290 & 809143 & 6.1 & 5.4441 & TRN & \\
\hline CHEMBL213505 & 809143 & 4.7 & 4.5562 & TRN & \\
\hline CHEMBL1987034 & 809143 & 5.9 & 6.0617 & TRN & \\
\hline CHEMBL1993941 & 809143 & 4.7 & 4.7134 & TRN & \\
\hline CHEMBL377383 & 809143 & 4.7 & 4.5012 & TRN & \\
\hline CHEMBL 2005886 & 809143 & 6.4 & 5.5392 & TRN & \\
\hline CHEMBL481491 & 809143 & 4.7 & 4.8654 & TST & \\
\hline CHEMBL1973142 & 809143 & 6.3 & 5.3031 & TRN & \\
\hline CHEMBL1973145 & 809143 & 4.7 & 4.6995 & TRN & \\
\hline CHEMBL1982924 & 809143 & 4.7 & 4.9773 & TRN & \\
\hline CHEMBL 2005936 & 809143 & 7.0 & 6.7841 & TRN & \\
\hline CHEMBL1807515 & 809143 & 7.0 & 7.3808 & TRN & \\
\hline CHEMBL1971141 & 809143 & 4.7 & 4.6561 & TRN & \\
\hline CHEMBL1995813 & 809143 & 6.8 & 7.3188 & TRN & \\
\hline CHEMBL206236 & 809143 & 7.1 & 6.8388 & TRN & \\
\hline CHEMBL244378 & 809143 & 4.7 & 5.59200 & 00000000005 & TRN \\
\hline CHEMBL 2001957 & 809143 & 4.7 & 4.4444 & TRN & \\
\hline CHEMBL1969372 & 809143 & 4.7 & 4.6144 & TRN & \\
\hline CHEMBL1986943 & 809143 & 7.0 & 7.2982 & TRN & \\
\hline CHEMBL 2006263 & 809143 & 4.7 & 5.2159 & TST & \\
\hline CHEMBL1993584 & 809143 & 6.2 & 6.6884 & TRN & \\
\hline CHEMBL1986263 & 809143 & 4.7 & 4.9739 & TRN & \\
\hline CHEMBL 2000114 & 809143 & 4.7 & 4.9642 & TRN & \\
\hline CHEMBL210618 & 809143 & 4.7 & 4.5014 & TRN & \\
\hline CHEMBL1975647 & 809143 & 5.8 & 4.6163 & TRN & \\
\hline CHEMBL1968380 & 809143 & 4.7 & 4.6886 & TRN & \\
\hline CHEMBL1964644 & 809143 & 4.7 & 4.6907 & TRN & \\
\hline CHEMBL1981782 & 809143 & 7.3 & 6.9069 & TRN & \\
\hline CHEMBL1977681 & 809143 & 4.7 & 5.1053 & TRN & \\
\hline
\end{tabular}




\begin{tabular}{|c|c|c|c|c|c|}
\hline \multicolumn{6}{|c|}{ Supplemental Table S2.txt } \\
\hline CHEMBL1970142 & 809143 & 4.7 & 4.7048 & TRN & \\
\hline CHEMBL1990912 & 809143 & 4.7 & 4.5919 & TRN & \\
\hline CHEMBL1988163 & 809143 & 4.7 & 5.4006 & TRN & \\
\hline CHEMBL2006493 & 809143 & 4.7 & 4.6822 & TST & \\
\hline CHEMBL1983449 & 809143 & 6.6 & 6.2668 & TRN & \\
\hline CHEMBL1992323 & 809143 & 4.7 & 4.8495 & TRN & \\
\hline CHEMBL1969735 & 809143 & 4.7 & 4.5848 & TRN & \\
\hline CHEMBL2002649 & 809143 & 4.7 & 4.8337 & TRN & \\
\hline CHEMBL1994321 & 809143 & 4.7 & 4.8611 & TRN & \\
\hline CHEMBL1997129 & 809143 & 4.7 & 5.3815 & TRN & \\
\hline CHEMBL2000508 & 809143 & 4.7 & 4.6349 & TRN & \\
\hline CHEMBL1971694 & 809143 & 4.7 & 4.809 & TST & \\
\hline CHEMBL2001547 & 809143 & 4.7 & 4.547 & TRN & \\
\hline CHEMBL210928 & 809143 & 4.7 & 4.5566 & TRN & \\
\hline CHEMBL1986603 & 809143 & 4.7 & 4.7592 & TST & \\
\hline CHEMBL1977148 & 809143 & 4.7 & 4.756 & TRN & \\
\hline CHEMBL2003286 & 809143 & 4.7 & 4.7077 & TRN & \\
\hline CHEMBL1992306 & 809143 & 4.7 & 4.6378 & TRN & \\
\hline CHEMBL2002165 & 809143 & 4.7 & 4.8049 & TRN & \\
\hline CHEMBL206382 & 809143 & 6.6 & 6.4042 & TRN & \\
\hline CHEMBL1998585 & 809143 & 4.7 & 4.8169 & TRN & \\
\hline CHEMBL127898 & 809143 & 4.7 & 5.0517 & TST & \\
\hline CHEMBL519697 & 809143 & 4.7 & 4.8691 & TST & \\
\hline CHEMBL2004934 & 809143 & 6.7 & 7.1514 & TRN & \\
\hline CHEMBL1975128 & 809143 & 8.0 & 7.1944 & TRN & \\
\hline CHEMBL 2001485 & 809143 & 4.7 & 4.7543 & TRN & \\
\hline CHEMBL1984363 & 809143 & 6.4 & 5.9663 & TRN & \\
\hline CHEMBL1978099 & 809143 & 4.7 & 5.3526 & TRN & \\
\hline CHEMBL1988608 & 809143 & 8.3 & 6.5315 & TRN & \\
\hline CHEMBL184847 & 809143 & 4.7 & 4.58 & TRN & \\
\hline CHEMBL1984367 & 809143 & 4.7 & 4.7919 & TRN & \\
\hline CHEMBL226898 & 809143 & 7.8 & 6.9679 & TRN & \\
\hline CHEMBL1982563 & 809143 & 4.7 & 4.5363 & TRN & \\
\hline CHEMBL539474 & 809143 & 6.0 & 5.2813 & TST & \\
\hline CHEMBL575824 & 809143 & 6.1 & 6.4683 & TRN & \\
\hline CHEMBL1988387 & 809143 & 4.7 & 4.8811 & TRN & \\
\hline CHEMBL1989708 & 809143 & 4.7 & 4.8312 & TRN & \\
\hline CHEMBL1990288 & 809143 & 4.7 & 4.715 & TRN & \\
\hline CHEMBL1970074 & 809143 & 4.7 & 5.3406 & TRN & \\
\hline CHEMBL1986970 & 809143 & 6.1 & 6.7802 & TRN & \\
\hline CHEMBL1958401 & 809143 & 4.7 & 5.1184 & TRN & \\
\hline CHEMBL 2003456 & 809143 & 4.7 & 4.6433 & TRN & \\
\hline CHEMBL1966816 & 809143 & 4.7 & 4.6819 & TRN & \\
\hline CHEMBL1972584 & 809143 & 4.7 & 4.9772 & TRN & \\
\hline CHEMBL 2002992 & 809143 & 6.2 & 6.13299 & 9999999999 & TRN \\
\hline CHEMBL560813 & 809143 & 4.7 & 4.6872 & TRN & \\
\hline CHEMBL1968791 & 809143 & 4.7 & 4.8315 & TRN & \\
\hline CHEMBL1971186 & 809143 & 4.7 & 4.5296 & TRN & \\
\hline
\end{tabular}




\begin{tabular}{|c|c|c|c|c|c|}
\hline \multicolumn{6}{|c|}{ Supplemental Table S2.txt } \\
\hline CHEMBL2003482 & 809143 & 4.7 & 4.7086 & TRN & \\
\hline CHEMBL1973211 & 809143 & 4.7 & 4.8224 & TRN & \\
\hline CHEMBL1984700 & 809143 & 4.7 & 4.5085 & TRN & \\
\hline CHEMBL1972125 & 809143 & 4.8 & 4.9814 & TRN & \\
\hline CHEMBL1976134 & 809143 & 6.1 & 5.0868 & TRN & \\
\hline CHEMBL1965131 & 809143 & 6.5 & 5.3047 & TRN & \\
\hline CHEMBL1972158 & 809143 & 6.5 & 7.0195 & TRN & \\
\hline CHEMBL1979855 & 809143 & 4.7 & 4.7588 & TRN & \\
\hline CHEMBL1970340 & 809143 & 4.7 & 5.2334 & TRN & \\
\hline CHEMBL 2005186 & 809143 & 4.7 & 5.0471 & TRN & \\
\hline CHEMBL1975534 & 809143 & 4.7 & 5.0559 & TRN & \\
\hline CHEMBL1993424 & 809143 & 4.7 & 5.0166 & TRN & \\
\hline CHEMBL1966703 & 809143 & 4.7 & 4.7418 & TST & \\
\hline CHEMBL1969561 & 809143 & 7.1 & 6.9986 & TRN & \\
\hline CHEMBL1975121 & 809143 & 8.1 & 7.1632 & TRN & \\
\hline CHEMBL1997023 & 809143 & 4.7 & 5.0839 & TST & \\
\hline CHEMBL1964687 & 809143 & 4.7 & 4.9282 & TRN & \\
\hline CHEMBL1971943 & 809143 & 7.4 & 6.3825 & TST & \\
\hline CHEMBL1974254 & 809143 & 4.7 & 5.3211 & TRN & \\
\hline CHEMBL1988537 & 809143 & 4.7 & 5.99 & TST & \\
\hline CHEMBL1969049 & 809143 & 7.2 & 7.1146 & TRN & \\
\hline CHEMBL2005828 & 809143 & 4.7 & 4.9608 & TRN & \\
\hline CHEMBL1998611 & 809143 & 6.0 & 5.6511 & TRN & \\
\hline CHEMBL1975900 & 809143 & 6.9 & 7.1369 & TRN & \\
\hline CHEMBL255822 & 809143 & 4.7 & 4.6986 & TRN & \\
\hline CHEMBL1972221 & 809143 & 4.7 & 4.7807 & TRN & \\
\hline CHEMBL 2006778 & 809143 & 4.7 & 4.747 & TRN & \\
\hline CHEMBL378627 & 809143 & 4.7 & 4.5302 & TRN & \\
\hline CHEMBL1996979 & 809143 & 4.7 & 5.1834 & TRN & \\
\hline CHEMBL1968406 & 809143 & 4.7 & 4.8051 & TRN & \\
\hline CHEMBL1998545 & 809143 & 6.2 & 6.2064 & TRN & \\
\hline CHEMBL1986869 & 809143 & 4.7 & 5.138 & TRN & \\
\hline CHEMBL1682558 & 809143 & 4.7 & 4.7086 & TRN & \\
\hline CHEMBL1990496 & 809143 & 4.7 & 5.3764 & TRN & \\
\hline CHEMBL2002479 & 809143 & 6.5 & 5.5349 & TRN & \\
\hline CHEMBL1967094 & 809143 & 4.7 & 5.336 & TRN & \\
\hline CHEMBL 2003341 & 809143 & 6.9 & 6.7195 & TRN & \\
\hline CHEMBL1982992 & 809143 & 4.7 & 5.1302 & TRN & \\
\hline CHEMBL1999590 & 809143 & 4.7 & 4.7113 & TST & \\
\hline CHEMBL1981079 & 809143 & 6.3 & 5.5346 & TRN & \\
\hline CHEMBL1980489 & 809143 & 7.5 & 6.8582 & TRN & \\
\hline CHEMBL1967116 & 809143 & 4.7 & 4.6735 & TRN & \\
\hline CHEMBL2000832 & 809143 & 4.7 & 5.8367 & TRN & \\
\hline CHEMBL1970709 & 809143 & 4.7 & 6.7465 & TRN & \\
\hline CHEMBL1965660 & 809143 & 6.1 & 5.9883 & TRN & \\
\hline CHEMBL1998112 & 809143 & 4.7 & 4.9589 & TRN & \\
\hline CHEMBL1969126 & 809143 & 4.7 & 4.6208 & TRN & \\
\hline CHEMBL1980896 & 809143 & 4.7 & $4.7360 e$ & 2000000001 & TRN \\
\hline & & & & 6109 & \\
\hline
\end{tabular}




\begin{tabular}{|c|c|c|c|c|c|}
\hline \multicolumn{6}{|c|}{ Supplemental Table S2.txt } \\
\hline CHEMBL1970104 & 809143 & 4.7 & 5.2943 & TRN & \\
\hline CHEMBL1991429 & 809143 & 4.7 & 5.0217 & TRN & \\
\hline CHEMBL1999714 & 809143 & 4.7 & 4.4378 & TRN & \\
\hline CHEMBL1971149 & 809143 & 4.7 & 4.8027 & TRN & \\
\hline CHEMBL1994040 & 809143 & 4.7 & 4.5452 & TRN & \\
\hline CHEMBL579246 & 809143 & 6.5 & 6.6676 & TRN & \\
\hline CHEMBL398951 & 809143 & 4.7 & 4.6404 & TRN & \\
\hline CHEMBL1982506 & 809143 & 4.7 & 4.6568 & TST & \\
\hline CHEMBL 2004716 & 809143 & 4.7 & 5.0227 & TRN & \\
\hline CHEMBL1968127 & 809143 & 4.7 & 4.5621 & TRN & \\
\hline CHEMBL1975233 & 809143 & 4.7 & 4.6285 & TRN & \\
\hline CHEMBL1985406 & 809143 & 4.7 & 4.7374 & TRN & \\
\hline CHEMBL207400 & 809143 & 4.7 & 4.6995 & TST & \\
\hline CHEMBL 2000894 & 809143 & 5.9 & 6.4342 & TST & \\
\hline CHEMBL1982135 & 809143 & 4.7 & 5.03600 & 00000000005 & TRN \\
\hline CHEMBL1976090 & 809143 & 4.7 & 5.3043 & TRN & \\
\hline CHEMBL1993243 & 809143 & 4.7 & 4.6917 & TRN & \\
\hline CHEMBL1992922 & 809143 & 4.7 & 5.5503 & TRN & \\
\hline CHEMBL 2004771 & 809143 & 4.7 & 4.8992 & TRN & \\
\hline CHEMBL1997597 & 809143 & 4.7 & 4.9934 & TRN & \\
\hline CHEMBL1969537 & 809143 & 4.7 & 4.805 & TST & \\
\hline CHEMBL1976093 & 809143 & 4.7 & 4.6075 & TRN & \\
\hline CHEMBL1975256 & 809143 & 4.7 & 5.0007 & TST & \\
\hline CHEMBL508928 & 809143 & 4.7 & 4.602 & TRN & \\
\hline CHEMBL1991356 & 809143 & 4.7 & 4.6984 & TRN & \\
\hline CHEMBL 2004892 & 809143 & 4.7 & 5.0077 & TRN & \\
\hline CHEMBL116070 & 809143 & 4.7 & 5.4696 & TST & \\
\hline CHEMBL1970314 & 809143 & 4.7 & 4.7606 & TRN & \\
\hline CHEMBL 2004871 & 809143 & 4.7 & 4.6364 & TRN & \\
\hline CHEMBL 2004872 & 809143 & 6.7 & 6.4661 & TRN & \\
\hline CHEMBL1969879 & 809143 & 4.7 & 4.8758 & TRN & \\
\hline CHEMBL1981720 & 809143 & 4.7 & 4.7288 & TRN & \\
\hline CHEMBL419932 & 809143 & 7.3 & 6.7873 & TRN & \\
\hline CHEMBL262433 & 809143 & 4.7 & 4.7305 & TRN & \\
\hline CHEMBL306380 & 809143 & 4.7 & 5.1578 & TRN & \\
\hline CHEMBL1966722 & 809143 & 4.7 & 5.151 & TST & \\
\hline CHEMBL1975500 & 809143 & 4.7 & 5.0754 & TRN & \\
\hline CHEMBL394619 & 809143 & 4.7 & 4.7527 & TRN & \\
\hline CHEMBL1996831 & 809143 & 4.7 & 4.7736 & TST & \\
\hline CHEMBL411903 & 809143 & 5.9 & 4.8439 & TRN & \\
\hline CHEMBL1965988 & 809143 & 4.7 & 5.2765 & TRN & \\
\hline CHEMBL418203 & 809143 & 4.7 & 4.9392 & TST & \\
\hline CHEMBL1989646 & 809143 & 6.6 & 6.6248 & TRN & \\
\hline CHEMBL225519 & 809143 & 7.7 & 5.8674 & TRN & \\
\hline CHEMBL1978200 & 809143 & 4.7 & 4.6184 & TRN & \\
\hline CHEMBL1970522 & 809143 & 4.7 & 4.7938 & TRN & \\
\hline CHEMBL1966087 & 809143 & 6.2 & 6.1115 & TRN & \\
\hline CHEMBL1964692 & 809143 & 4.7 & 4.6612 & TRN & \\
\hline
\end{tabular}




\begin{tabular}{|c|c|c|c|c|c|}
\hline \multicolumn{6}{|c|}{ Supplemental Table S2.txt } \\
\hline CHEMBL1996931 & 809143 & 6.7 & 6.1094 & TRN & \\
\hline CHEMBL1964413 & 809143 & 4.7 & 5.0387 & TRN & \\
\hline CHEMBL1973483 & 809143 & 4.7 & 4.6628 & TRN & \\
\hline CHEMBL1997340 & 809143 & 4.7 & 4.6522 & TRN & \\
\hline CHEMBL1522508 & 809143 & 4.7 & 4.6103 & TRN & \\
\hline CHEMBL1989474 & 809143 & 4.7 & 4.6186 & TRN & \\
\hline CHEMBL1090360 & 809143 & 4.7 & 4.6413 & TRN & \\
\hline CHEMBL210887 & 809143 & 4.7 & 4.5029 & TST & \\
\hline CHEMBL458997 & 809143 & 5.9 & 4.9306 & TRN & \\
\hline CHEMBL227271 & 809143 & 8.1 & 7.7195 & TRN & \\
\hline CHEMBL1971021 & 809143 & 4.7 & 4.5007 & TRN & \\
\hline CHEMBL583144 & 809143 & 5.9 & 5.3373 & TRN & \\
\hline CHEMBL1974310 & 809143 & 4.7 & 5.16299 & 9999999999 & TST \\
\hline CHEMBL1982660 & 809143 & 4.7 & 4.8402 & TRN & \\
\hline CHEMBL1994693 & 809143 & 4.7 & 4.8657 & TRN & \\
\hline CHEMBL1982957 & 809143 & 4.7 & 5.46200 & 0000000001 & TRN \\
\hline CHEMBL1725279 & 809143 & 4.7 & 4.7406 & TST & \\
\hline CHEMBL1975138 & 809143 & 4.7 & 4.9412 & TST & \\
\hline CHEMBL424872 & 809143 & 4.7 & 4.3724 & TRN & \\
\hline CHEMBL412142 & 809143 & 4.7 & 4.8803 & TST & \\
\hline CHEMBL1980704 & 809143 & 4.7 & 4.6304 & TST & \\
\hline CHEMBL 2003271 & 809143 & 6.3 & 5.4193 & TRN & \\
\hline CHEMBL1966808 & 809143 & 4.7 & 4.6255 & TST & \\
\hline CHEMBL 2004447 & 809143 & 4.7 & 4.6887 & TST & \\
\hline CHEMBL1983111 & 809143 & 4.7 & 5.8617 & TST & \\
\hline CHEMBL1973860 & 809143 & 4.7 & 4.8515 & TRN & \\
\hline CHEMBL260135 & 809143 & 4.7 & 5.1846 & TRN & \\
\hline CHEMBL220241 & 809143 & 6.8 & 6.7469 & TRN & \\
\hline CHEMBL1982610 & 809143 & 4.7 & 4.8176 & TST & \\
\hline CHEMBL1999496 & 809143 & 4.7 & 5.3371 & TRN & \\
\hline CHEMBL1988300 & 809143 & 4.7 & 4.7752 & TRN & \\
\hline CHEMBL1991078 & 809143 & 6.2 & 6.3659 & TRN & \\
\hline CHEMBL1987359 & 809143 & 4.7 & 4.6384 & TST & \\
\hline CHEMBL1969502 & 809143 & 7.0 & 6.6527 & TST & \\
\hline CHEMBL1682553 & 809143 & 7.5 & 6.1885 & TRN & \\
\hline CHEMBL1997764 & 809143 & 4.7 & 4.9518 & TRN & \\
\hline CHEMBL1983963 & 809143 & 4.7 & 4.6852 & TRN & \\
\hline CHEMBL1985092 & 809143 & 5.8 & 5.5669 & TST & \\
\hline CHEMBL1981410 & 809143 & 4.7 & 4.7111 & TRN & \\
\hline CHEMBL1996234 & 809143 & 4.7 & 4.8225 & TRN & \\
\hline CHEMBL1991434 & 809143 & 4.7 & 4.7764 & TRN & \\
\hline CHEMBL1967544 & 809143 & 7.1 & 6.7109 & TRN & \\
\hline CHEMBL223367 & 809143 & 4.7 & 4.8418 & TST & \\
\hline CHEMBL340384 & 809143 & 6.7 & 6.8529 & TST & \\
\hline CHEMBL1996587 & 809143 & 4.7 & 4.6168 & TRN & \\
\hline CHEMBL1964804 & 809143 & 6.6 & 6.0064 & TRN & \\
\hline CHEMBL443962 & 809143 & 4.7 & 4.7855 & TST & \\
\hline CHEMBL2000354 & 809143 & 4.7 & 4.7958 & TRN & \\
\hline
\end{tabular}




\begin{tabular}{|c|c|c|c|c|}
\hline & & & $=1$ & al Ta \\
\hline CHEMBL1965507 & 809143 & 6.8 & 4.9799 & TRN \\
\hline CHEMBL 274064 & 809143 & 4.7 & 4.9837 & TRN \\
\hline CHEMBL1967564 & 809143 & 4.7 & 4.6339 & TRN \\
\hline CHEMBL592030 & 809143 & 8.2 & 7.2762 & TST \\
\hline CHEMBL 2000071 & 809143 & 4.7 & 5.4439 & TRN \\
\hline CHEMBL1979176 & 809143 & 4.7 & 4.6915 & TRN \\
\hline CHEMBL 2000408 & 809143 & 4.7 & 4.5636 & TRN \\
\hline CHEMBL248757 & 809143 & 4.7 & 4.7031 & TST \\
\hline CHEMBL1978014 & 809143 & 5.9 & 4.8494 & TRN \\
\hline CHEMBL1994538 & 809143 & 4.7 & 4.629 & TRN \\
\hline CHEMBL1975490 & 809143 & 4.7 & 5.1034 & TRN \\
\hline CHEMBL1964444 & 809143 & 4.7 & 4.6414 & TRN \\
\hline CHEMBL1986139 & 809143 & 4.7 & 4.7373 & TRN \\
\hline CHEMBL1980540 & 809143 & 4.7 & 4.6382 & TRN \\
\hline CHEMBL1979883 & 809143 & 4.7 & 4.9 & TRN \\
\hline CHEMBL1984162 & 809143 & 4.7 & 5.2522 & TRN \\
\hline CHEMBL491758 & 809143 & 4.7 & 4.7652 & TRN \\
\hline CHEMBL549730 & 809143 & 4.7 & 5.4747 & TRN \\
\hline CHEMBL1970189 & 809143 & 4.7 & 4.6409 & TST \\
\hline CHEMBL371206 & 809143 & 4.7 & 4.6477 & TRN \\
\hline CHEMBL1996791 & 809143 & 4.7 & 4.9469 & TRN \\
\hline CHEMBL1974664 & 809143 & 4.7 & 4.8479 & TST \\
\hline CHEMBL1974288 & 809143 & 7.8 & 7.3139 & TRN \\
\hline CHEMBL196363 & 809143 & 4.7 & 4.723 & TRN \\
\hline CHEMBL1190711 & 809143 & 4.7 & 4.9903 & TRN \\
\hline CHEMBL1968705 & 809143 & 5.9 & 4.9408 & TRN \\
\hline CHEMBL404367 & 809143 & 4.7 & 4.7276 & TRN \\
\hline CHEMBL1966343 & 809143 & 6.9 & 5.7529 & TRN \\
\hline CHEMBL1967887 & 809143 & 6.6 & 6.7079 & TRN \\
\hline CHEMBL 2000568 & 809143 & 4.7 & 4.9007 & TRN \\
\hline CHEMBL 2000335 & 809143 & 4.7 & 5.2888 & TRN \\
\hline CHEMBL1988717 & 809143 & 4.7 & 4.5268 & TRN \\
\hline CHEMBL1974328 & 809143 & 4.7 & 5.6629 & TRN \\
\hline CHEMBL509032 & 809143 & 5.8 & 5.7581 & TRN \\
\hline CHEMBL1973808 & 809143 & 5.9 & 4.8188 & TRN \\
\hline CHEMBL 2000429 & 809143 & 4.7 & 4.4466 & TRN \\
\hline CHEMBL1972576 & 809143 & 4.7 & 4.9243 & TRN \\
\hline CHEMBL1992342 & 809143 & 6.3 & 5.2452 & TRN \\
\hline CHEMBL1988173 & 809143 & 4.7 & 5.3596 & TST \\
\hline CHEMBL1989805 & 809143 & 4.7 & 5.2327 & TST \\
\hline CHEMBL1965423 & 809143 & 4.7 & 4.6235 & TRN \\
\hline CHEMBL1983025 & 809143 & 4.7 & 4.8718 & TRN \\
\hline CHEMBL205415 & 809143 & 6.6 & 6.7712 & TRN \\
\hline CHEMBL1977135 & 809143 & 7.0 & 6.7334 & TRN \\
\hline CHEMBL 2001920 & 809143 & 4.7 & 4.7784 & TRN \\
\hline CHEMBL1241473 & 809143 & 4.7 & 5.8039 & TRN \\
\hline CHEMBL1978448 & 809143 & 6.6 & 4.9165 & TST \\
\hline CHEMBL1972258 & 809143 & 5.8 & 6.2412 & TRN \\
\hline
\end{tabular}




\begin{tabular}{|c|c|c|c|c|c|}
\hline \\
\hline CHEMBL 2001257 & 809143 & 4.7 & 4.8547 & TRN & \\
\hline CHEMBL1992536 & 809143 & 6.8 & 5.57299 & 99999999995 & TRN \\
\hline CHEMBL1992740 & 809143 & 4.7 & 4.6582 & TRN & \\
\hline CHEMBL439340 & 809143 & 4.7 & 4.7971 & TRN & \\
\hline CHEMBL 2002373 & 809143 & 4.7 & 4.7401 & TRN & \\
\hline CHEMBL 2006188 & 809143 & 7.7 & 6.9078 & TRN & \\
\hline CHEMBL1967531 & 809143 & 4.7 & 4.6664 & TRN & \\
\hline CHEMBL1973893 & 809143 & 4.7 & 4.8294 & TRN & \\
\hline CHEMBL1970913 & 809143 & 4.7 & 4.6681 & TRN & \\
\hline CHEMBL1997534 & 809143 & 5.9 & 6.2437 & TRN & \\
\hline CHEMBL1996500 & 809143 & 4.7 & 4.6426 & TRN & \\
\hline CHEMBL1985095 & 809143 & 6.4 & 6.7451 & TST & \\
\hline CHEMBL1682540 & 809143 & 4.7 & 5.3004 & TRN & \\
\hline CHEMBL1976420 & 809143 & 4.7 & 4.8334 & TST & \\
\hline CHEMBL1994864 & 809143 & 6.9 & 6.5276 & TRN & \\
\hline CHEMBL 2002446 & 809143 & 6.0 & 5.2658 & TRN & \\
\hline CHEMBL497151 & 809143 & 4.7 & 6.0003 & TST & \\
\hline CHEMBL246970 & 809143 & 4.7 & 5.1925 & TRN & \\
\hline CHEMBL340921 & 809143 & 5.8 & 6.3714 & TST & \\
\hline CHEMBL1999718 & 809143 & 4.7 & 4.6525 & TRN & \\
\hline CHEMBL1276446 & 809143 & 6.9 & 5.4756 & TST & \\
\hline CHEMBL1977346 & 809143 & 4.7 & 4.6139 & TRN & \\
\hline CHEMBL1971649 & 809143 & 4.7 & 4.5327 & TRN & \\
\hline CHEMBL 2006439 & 809143 & 6.1 & 6.4107 & TRN & \\
\hline CHEMBL1969190 & 809143 & 4.7 & 4.6893 & TRN & \\
\hline CHEMBL1973937 & 809143 & 4.7 & 5.1638 & TRN & \\
\hline CHEMBL1991674 & 809143 & 4.9 & 7.0296 & TRN & \\
\hline CHEMBL1982711 & 809143 & 7.9 & 6.3908 & TRN & \\
\hline CHEMBL 2007044 & 809143 & 4.7 & 4.6064 & TRN & \\
\hline CHEMBL1994241 & 809143 & 4.7 & 4.9022 & TST & \\
\hline CHEMBL223460 & 809143 & 4.7 & 4.6253 & TST & \\
\hline CHEMBL1998829 & 809143 & 4.7 & 4.9853 & TRN & \\
\hline CHEMBL50894 & 809143 & 4.7 & 4.995 & TST & \\
\hline CHEMBL1988838 & 809143 & 4.7 & 5.5083 & TRN & \\
\hline CHEMBL1981725 & 809143 & 4.7 & 4.9767 & TRN & \\
\hline CHEMBL1982866 & 809143 & 4.7 & 4.7166 & TRN & \\
\hline CHEMBL1965570 & 809143 & 4.7 & 4.7326 & TRN & \\
\hline CHEMBL 2007592 & 809143 & 4.7 & 4.6207 & TST & \\
\hline CHEMBL210963 & 809143 & 4.7 & 4.4873 & TRN & \\
\hline CHEMBL 1082440 & 809143 & 6.0 & 6.2929 & TST & \\
\hline CHEMBL1614705 & 809143 & 4.7 & 5.218 & TRN & \\
\hline CHEMBL1984633 & 809143 & 6.4 & 5.9537 & TRN & \\
\hline CHEMBL1965845 & 809143 & 6.5 & 7.2284 & TRN & \\
\hline CHEMBL 2006715 & 809143 & 5.9 & 4.71399 & 99999999995 & TRN \\
\hline CHEMBL1986597 & 809143 & 4.7 & 4.6694 & TRN & \\
\hline CHEMBL1990482 & 809143 & 6.5 & 5.7224 & TRN & \\
\hline CHEMBL1990904 & 809143 & 4.7 & 4.5148 & TRN & \\
\hline CHEMBL 2005475 & 809143 & 4.7 & 5.0423 & TRN & \\
\hline
\end{tabular}




\begin{tabular}{|c|c|c|c|c|c|}
\hline \multicolumn{6}{|c|}{ Supplemental Table S2.txt } \\
\hline CHEMBL402846 & 809143 & 4.7 & 4.8085 & TRN & \\
\hline CHEMBL183844 & 809143 & 4.7 & 4.3354 & TRN & \\
\hline CHEMBL220057 & 809143 & 6.1 & 5.465 & TRN & \\
\hline CHEMBL1682545 & 809143 & 4.7 & 5.0476 & TRN & \\
\hline CHEMBL 383541 & 809143 & 7.5 & 7.2563 & TRN & \\
\hline CHEMBL 2001224 & 809143 & 4.7 & 4.63899 & 9999999999 & TRN \\
\hline CHEMBL10 & 809143 & 4.7 & 4.7398 & TRN & \\
\hline CHEMBL1976732 & 809143 & 4.7 & 4.5992 & TRN & \\
\hline CHEMBL1964937 & 809143 & 7.0 & 6.6462 & TRN & \\
\hline CHEMBL1969506 & 809143 & 4.7 & 5.6204 & TRN & \\
\hline CHEMBL1980163 & 809143 & 4.7 & 4.7504 & TRN & \\
\hline CHEMBL 2005899 & 809143 & 5.8 & 5.2781 & TRN & \\
\hline CHEMBL1682552 & 809143 & 7.6 & 5.7192 & TRN & \\
\hline CHEMBL229799 & 809143 & 8.0 & 7.9224 & TRN & \\
\hline CHEMBL105739 & 809143 & 4.7 & 4.9655 & TRN & \\
\hline CHEMBL 379300 & 809143 & 6.6 & 7.6177 & TRN & \\
\hline CHEMBL1969523 & 809143 & 4.7 & 5.3559 & TRN & \\
\hline CHEMBL1986781 & 809143 & 4.7 & 4.5062 & TRN & \\
\hline CHEMBL526133 & 809143 & 4.7 & 4.8868 & TRN & \\
\hline CHEMBL387971 & 809143 & 4.7 & 4.8281 & TRN & \\
\hline CHEMBL1979057 & 809143 & 4.7 & 4.6463 & TRN & \\
\hline CHEMBL1999428 & 809143 & 7.4 & 7.2224 & TRN & \\
\hline CHEMBL1967560 & 809143 & 4.7 & 4.6705 & TRN & \\
\hline CHEMBL211378 & 809143 & 4.7 & 4.4434 & TRN & \\
\hline CHEMBL1516890 & 809143 & 4.7 & 4.9668 & TRN & \\
\hline CHEMBL1982465 & 809143 & 4.7 & 4.8225 & TRN & \\
\hline CHEMBL 2001751 & 809143 & 8.9 & 7.46200 & 0000000001 & TRN \\
\hline CHEMBL 2003420 & 809143 & 4.7 & 4.8787 & TRN & \\
\hline CHEMBL1984586 & 809143 & 4.7 & 4.7679 & TRN & \\
\hline CHEMBL1972659 & 809143 & 5.9 & 5.9979 & TST & \\
\hline CHEMBL 272453 & 809143 & 4.7 & 4.8161 & TRN & \\
\hline CHEMBL1970217 & 809143 & 6.0 & 7.2664 & TRN & \\
\hline CHEMBL 2005528 & 809143 & 4.7 & 4.6268 & TST & \\
\hline CHEMBL185569 & 809143 & 4.7 & 4.4294 & TRN & \\
\hline CHEMBL1969843 & 809143 & 6.2 & 4.8994 & TRN & \\
\hline CHEMBL 2007002 & 809143 & 4.7 & 4.836 & TRN & \\
\hline CHEMBL1987007 & 809143 & 4.7 & 5.1204 & TRN & \\
\hline CHEMBL1969588 & 809143 & 6.7 & 7.4723 & TRN & \\
\hline CHEMBL1984711 & 809143 & 4.7 & 4.8164 & TRN & \\
\hline CHEMBL484390 & 809143 & 4.7 & 4.7971 & TST & \\
\hline CHEMBL1979252 & 809143 & 7.5 & 6.5224 & TRN & \\
\hline CHEMBL1986499 & 809143 & 6.5 & 6.9857 & TRN & \\
\hline CHEMBL 2004290 & 809143 & 4.7 & 4.8237 & TRN & \\
\hline CHEMBL1972937 & 809143 & 4.7 & 4.6885 & TRN & \\
\hline CHEMBL 2000393 & 809143 & 4.7 & 5.2201 & TST & \\
\hline CHEMBL 2004311 & 809143 & 4.7 & 4.5045 & TRN & \\
\hline CHEMBL1992634 & 809143 & 4.7 & 4.919 & TRN & \\
\hline CHEMBL1242373 & 809143 & 4.7 & 4.6917 & TRN & \\
\hline
\end{tabular}




\begin{tabular}{|c|c|c|c|c|c|}
\hline \multicolumn{6}{|c|}{ Supplemental Table S2.txt } \\
\hline CHEMBL1988075 & 809143 & 4.7 & 4.5884 & TRN & \\
\hline CHEMBL316264 & 809143 & 4.7 & 4.6906 & TRN & \\
\hline CHEMBL1991678 & 809143 & 4.7 & 4.6162 & TRN & \\
\hline CHEMBL 2001239 & 809143 & 5.8 & 5.3091 & TST & \\
\hline CHEMBL1988594 & 809143 & 6.7 & 4.8225 & TRN & \\
\hline CHEMBL 2001288 & 809143 & 4.7 & 4.7407 & TRN & \\
\hline CHEMBL1999811 & 809143 & 6.0 & 5.3229 & TST & \\
\hline CHEMBL1985074 & 809143 & 4.7 & 4.6823 & TST & \\
\hline CHEMBL1982874 & 809143 & 4.7 & 4.613 & TRN & \\
\hline CHEMBL 2000481 & 809143 & 4.7 & 4.9953 & TRN & \\
\hline CHEMBL1991725 & 809143 & 4.7 & 6.17299 & 9999999999 & TRN \\
\hline CHEMBL1992242 & 809143 & 4.7 & 4.6455 & TRN & \\
\hline CHEMBL 2007296 & 809143 & 7.5 & 6.7744 & TRN & \\
\hline CHEMBL396523 & 809143 & 4.7 & 5.4538 & TRN & \\
\hline CHEMBL1970203 & 809143 & 4.7 & 4.68199 & 99999999995 & TRN \\
\hline CHEMBL1999321 & 809143 & 4.7 & 5.0547 & TRN & \\
\hline CHEMBL1986530 & 809143 & 4.7 & 4.8248 & TST & \\
\hline CHEMBL1968590 & 809143 & 4.7 & 4.6732 & TRN & \\
\hline CHEMBL 2005375 & 809143 & 4.7 & 4.6479 & TRN & \\
\hline CHEMBL1984191 & 809143 & 4.7 & 5.2352 & TRN & \\
\hline CHEMBL1971029 & 809143 & 4.7 & 5.6439 & TRN & \\
\hline CHEMBL394790 & 809143 & 4.7 & 4.7373 & TRN & \\
\hline CHEMBL226471 & 809143 & 4.7 & 4.6722 & TRN & \\
\hline CHEMBL1996111 & 809143 & 6.3 & 6.9044 & TRN & \\
\hline CHEMBL1974702 & 809143 & 4.7 & 4.8295 & TRN & \\
\hline CHEMBL1965589 & 809143 & 4.7 & 4.665 & TRN & \\
\hline CHEMBL1998193 & 809143 & 4.7 & 4.6788 & TRN & \\
\hline CHEMBL474432 & 809143 & 4.7 & 4.7837 & TST & \\
\hline CHEMBL1988153 & 809143 & 4.7 & 5.3775 & TST & \\
\hline CHEMBL1988437 & 809143 & 4.7 & 4.9488 & TST & \\
\hline CHEMBL1998121 & 809143 & 8.9 & 6.8524 & TRN & \\
\hline CHEMBL1979577 & 809143 & 4.7 & 4.9241 & TRN & \\
\hline CHEMBL1991800 & 809143 & 4.7 & 4.4848 & TRN & \\
\hline CHEMBL379835 & 809143 & 4.7 & 4.6542 & TST & \\
\hline CHEMBL1979357 & 809143 & 7.4 & 6.2835 & TRN & \\
\hline CHEMBL1996817 & 809143 & 5.9 & 5.5679 & TRN & \\
\hline CHEMBL468280 & 809143 & 4.7 & 4.6791 & TST & \\
\hline CHEMBL1990884 & 809143 & 4.7 & 4.8054 & TRN & \\
\hline CHEMBL3109278 & 809143 & 4.7 & 4.9332 & TRN & \\
\hline CHEMBL 256835 & 809143 & 4.7 & 4.6548 & TRN & \\
\hline CHEMBL1980142 & 809143 & 5.9 & 4.88399 & 79999999995 & TRN \\
\hline CHEMBL41783 & 809143 & 4.7 & 4.782 & TRN & \\
\hline CHEMBL 2006276 & 809143 & 4.7 & 5.3077 & TRN & \\
\hline CHEMBL271381 & 809143 & 4.7 & 4.7666 & TRN & \\
\hline CHEMBL 2006785 & 809143 & 4.7 & 4.7321 & TRN & \\
\hline CHEMBL1982466 & 809143 & 4.7 & 4.7183 & TRN & \\
\hline CHEMBL1995740 & 809143 & 4.7 & 5.0798 & TRN & \\
\hline CHEMBL234085 & 809143 & 4.7 & 5.0783 & TRN & \\
\hline
\end{tabular}




\begin{tabular}{|c|c|c|c|c|c|}
\hline \multicolumn{6}{|c|}{ Supplemental Table S2.txt } \\
\hline CHEMBL1995832 & 809143 & 4.7 & 4.5104 & TRN & \\
\hline CHEMBL1969042 & 809143 & 6.2 & 4.8799 & TST & \\
\hline CHEMBL1999931 & 809143 & 6.5 & 6.5062 & TRN & \\
\hline CHEMBL 2000345 & 809143 & 4.7 & 4.9333 & TST & \\
\hline CHEMBL 2007064 & 809143 & 4.7 & 4.9671 & TRN & \\
\hline CHEMBL229968 & 809143 & 8.1 & 7.6701 & TRN & \\
\hline CHEMBL1981047 & 809143 & 4.7 & 5.0425 & TST & \\
\hline CHEMBL1976240 & 809143 & 8.6 & 7.3158 & TRN & \\
\hline CHEMBL1979093 & 809143 & 4.7 & 4.813 & TRN & \\
\hline CHEMBL1968151 & 809143 & 4.7 & 4.7929 & TST & \\
\hline CHEMBL1987009 & 809143 & 4.7 & 5.3069 & TRN & \\
\hline CHEMBL379218 & 809143 & 6.8 & 7.7593 & TRN & \\
\hline CHEMBL 2003817 & 809143 & 4.7 & 4.6546 & TRN & \\
\hline CHEMBL1994830 & 809143 & 4.7 & 5.687 & TST & \\
\hline CHEMBL 226403 & 809143 & 4.7 & 4.658 & TRN & \\
\hline CHEMBL 2005631 & 809143 & 4.7 & 4.802 & TRN & \\
\hline CHEMBL1994938 & 809143 & 4.7 & 4.9346 & TRN & \\
\hline CHEMBL1977223 & 809143 & 4.7 & 5.37200 & 0000000001 & TRN \\
\hline CHEMBL1825138 & 809143 & 4.7 & 5.2429 & TST & \\
\hline CHEMBL1236126 & 809143 & 4.7 & 4.6509 & TST & \\
\hline CHEMBL1966279 & 809143 & 4.7 & 4.7711 & TRN & \\
\hline CHEMBL1997846 & 809143 & 6.3 & 6.7664 & TRN & \\
\hline CHEMBL 2004419 & 809143 & 4.7 & 4.5956 & TRN & \\
\hline CHEMBL1972489 & 809143 & 4.7 & 4.9343 & TRN & \\
\hline CHEMBL1994074 & 809143 & 4.7 & 4.7866 & TRN & \\
\hline CHEMBL1992937 & 809143 & 4.7 & 4.7867 & TST & \\
\hline CHEMBL1972119 & 809143 & 4.7 & 4.6729 & TRN & \\
\hline CHEMBL1090356 & 809143 & 4.7 & 4.6274 & TRN & \\
\hline CHEMBL95692 & 809143 & 4.7 & 4.9763 & TRN & \\
\hline CHEMBL1986328 & 809143 & 4.7 & 4.7963 & TST & \\
\hline CHEMBL1976455 & 809143 & 4.7 & 4.6673 & TRN & \\
\hline CHEMBL1982361 & 809143 & 7.1 & 6.5817 & TRN & \\
\hline CHEMBL1983534 & 809143 & 4.7 & 6.0977 & TRN & \\
\hline CHEMBL1983923 & 809143 & 4.7 & 4.9331 & TST & \\
\hline CHEMBL1982122 & 809143 & 5.8 & 6.4594 & TST & \\
\hline CHEMBL 2000801 & 809143 & 4.7 & 4.6566 & TST & \\
\hline CHEMBL1999112 & 809143 & 4.7 & 4.7569 & TST & \\
\hline CHEMBL1682546 & 809143 & 4.7 & 5.9793 & TST & \\
\hline CHEMBL1991395 & 809143 & 4.7 & 4.5951 & TST & \\
\hline CHEMBL1971245 & 809143 & 4.7 & 4.7287 & TST & \\
\hline CHEMBL1972142 & 809143 & 4.7 & 5.2695 & TST & \\
\hline CHEMBL1966514 & 809143 & 4.7 & 4.6703 & TST & \\
\hline CHEMBL 2003638 & 809143 & 6.8 & 6.2058 & TST & \\
\hline CHEMBL1996066 & 809143 & 4.7 & 4.8231 & TST & \\
\hline CHEMBL1993722 & 809143 & 6.1 & 5.8301 & TST & \\
\hline CHEMBL1970806 & 809143 & 4.7 & 4.6289 & TST & \\
\hline CHEMBL1979970 & 809143 & 4.7 & 4.5993 & TST & \\
\hline CHEMBL1375640 & 809143 & 4.7 & 5.5658 & TST & \\
\hline
\end{tabular}




\begin{tabular}{|c|c|c|c|c|c|}
\hline \multicolumn{6}{|c|}{ Supplemental Table s2.txt } \\
\hline CHEMBL249282 & 809143 & 4.7 & 4.6092 & TST & \\
\hline CHEMBL 2006237 & 809143 & 4.7 & 4.7696 & TST & \\
\hline CHEMBL1967720 & 809143 & 4.7 & 4.5978 & TST & \\
\hline CHEMBL1572266 & 809143 & 4.7 & 4.8467 & TST & \\
\hline CHEMBL1969755 & 809143 & 5.9 & 5.8711 & TST & \\
\hline CHEMBL1979516 & 809143 & 4.7 & 4.6261 & TST & \\
\hline CHEMBL1991138 & 809143 & 4.7 & 4.6545 & TST & \\
\hline CHEMBL1605605 & 809143 & 4.7 & 6.0466 & TST & \\
\hline CHEMBL1989029 & 809143 & 4.7 & 4.7354 & TST & \\
\hline CHEMBL392642 & 809143 & 4.7 & 5.1033 & TST & \\
\hline CHEMBL514499 & 809143 & 6.5 & 5.0874 & TST & \\
\hline CHEMBL1965631 & 809143 & 4.7 & 5.2199 & TST & \\
\hline CHEMBL1980144 & 809143 & 6.3 & 4.9465 & TST & \\
\hline CHEMBL1991188 & 809143 & 7.6 & 6.7437 & TST & \\
\hline CHEMBL1972849 & 809143 & 4.7 & 4.5485 & TST & \\
\hline CHEMBL 377408 & 809143 & 4.7 & 4.4164 & TST & \\
\hline CHEMBL231209 & 809143 & 4.7 & 4.7371 & TST & \\
\hline CHEMBL1976220 & 809143 & 4.7 & 4.8067 & TST & \\
\hline CHEMBL1997617 & 809143 & 4.7 & 4.8904 & TST & \\
\hline CHEMBL 259922 & 809143 & 4.7 & 4.7578 & TST & \\
\hline CHEMBL1982383 & 809143 & 4.7 & 4.5548 & TST & \\
\hline CHEMBL1969301 & 809143 & 4.7 & 4.8369 & TST & \\
\hline CHEMBL17370 & 809143 & 4.7 & 4.9691 & TST & \\
\hline CHEMBL1987910 & 809143 & 4.7 & 4.7794 & TST & \\
\hline CHEMBL1983932 & 809143 & 4.7 & 4.7177 & TST & \\
\hline CHEMBL1997822 & 809143 & 4.7 & 5.0453 & TST & \\
\hline CHEMBL1991285 & 809143 & 4.7 & 4.6774 & TST & \\
\hline CHEMBL1984038 & 809143 & 4.7 & 4.7473 & TST & \\
\hline CHEMBL 243088 & 809143 & 4.7 & 5.2471 & TST & \\
\hline CHEMBL1993661 & 809143 & 4.7 & 6.48600 & 0000000001 & TST \\
\hline CHEMBL1974416 & 809143 & 4.7 & 4.9271 & TST & \\
\hline CHEMBL1997872 & 809143 & 4.7 & 4.8533 & TST & \\
\hline CHEMBL123458 & 930033 & 6.7447 & 6.8135 & TRN & \\
\hline CHEMBL122747 & 930033 & 6.6383 & 6.5866 & TRN & \\
\hline CHEMBL123219 & 930033 & 7.699 & 7.7165 & TRN & \\
\hline CHEMBL339908 & 930033 & 7.1427 & 7.2158 & TRN & \\
\hline CHEMBL123174 & 930033 & 5.7212 & 5.7425 & TRN & \\
\hline CHEMBL122809 & 930033 & 7.2366 & 7.3991 & TRN & \\
\hline CHEMBL414425 & 930033 & 7.2676 & 7.1028 & TRN & \\
\hline CHEMBL331788 & 930033 & 5.4559 & 5.3482 & TST & \\
\hline CHEMBL340821 & 930033 & 6.4089 & 6.4364 & TRN & \\
\hline CHEMBL 2296151 & 930033 & 6.7447 & 6.8072 & TRN & \\
\hline CHEMBL123283 & 930033 & 7.2076 & 7.2238 & TRN & \\
\hline CHEMBL2296150 & 930033 & 6.7959 & 6.7825 & TRN & \\
\hline CHEMBL331305 & 930033 & 7.0 & 7.0843 & TRN & \\
\hline CHEMBL 333044 & 930033 & 7.2218 & 7.2282 & TRN & \\
\hline CHEMBL421278 & 930033 & 7.2366 & 7.1104 & TRN & \\
\hline CHEMBL123079 & 930033 & 5.0269 & 4.856 & TRN & \\
\hline
\end{tabular}




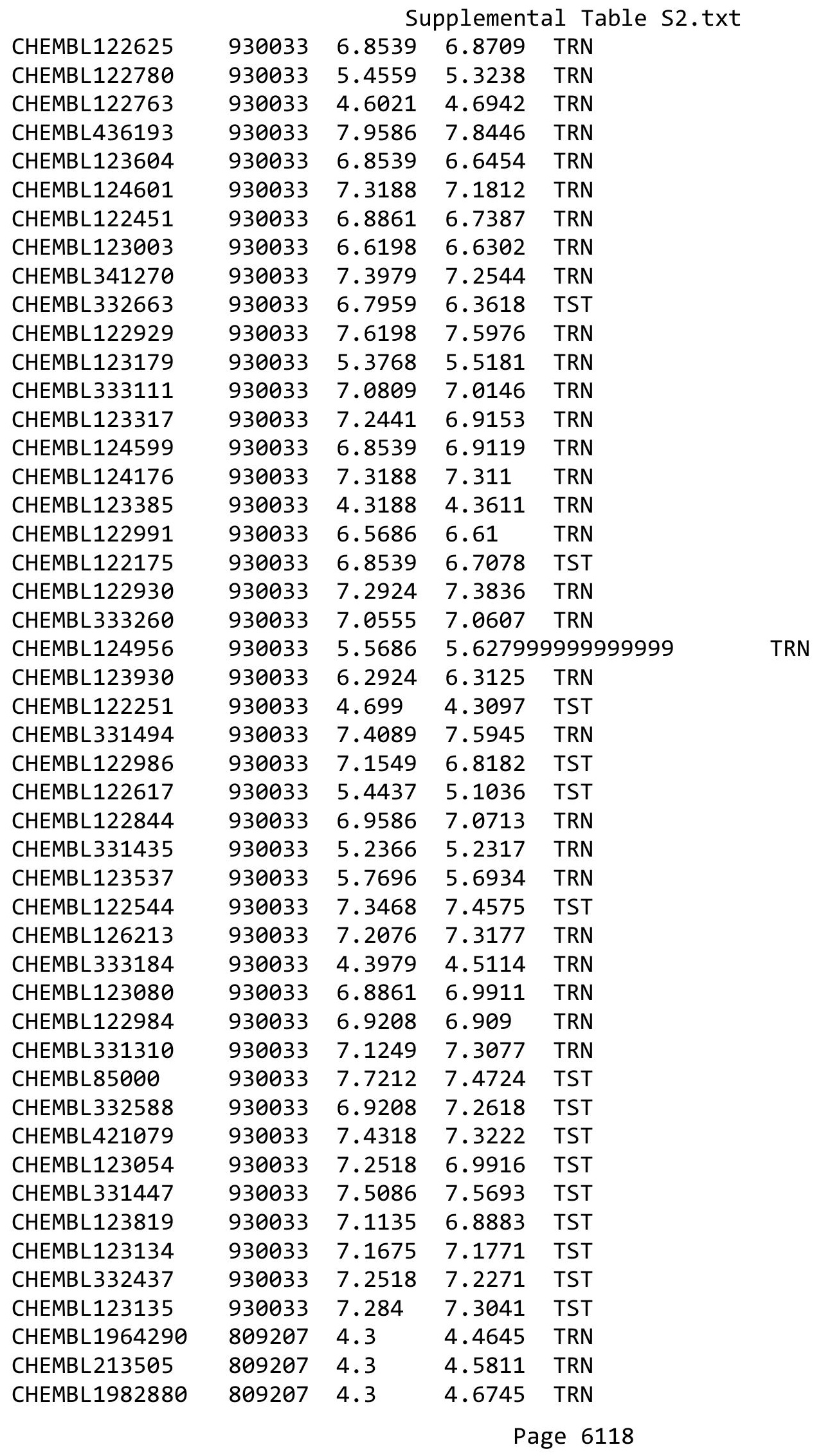




\begin{tabular}{|c|c|c|c|c|}
\hline & & & & \\
\hline CHEMBL1987034 & 809207 & 7.4 & 7.0408 & TRN \\
\hline CHEMBL1993941 & 809207 & 6.9 & 6.6474 & TRN \\
\hline CHEMBL377383 & 809207 & 4.3 & 4.3545 & TRN \\
\hline CHEMBL 2005886 & 809207 & 7.6 & 7.8059 & TRN \\
\hline CHEMBL481491 & 809207 & 4.3 & 4.9377 & TST \\
\hline CHEMBL1682345 & 809207 & 4.3 & 4.1705 & TRN \\
\hline CHEMBL1973142 & 809207 & 6.0 & 5.5692 & TRN \\
\hline CHEMBL1973145 & 809207 & 4.3 & 4.3095 & TRN \\
\hline CHEMBL1982924 & 809207 & 4.3 & 4.3717 & TRN \\
\hline CHEMBL 2005936 & 809207 & 4.3 & 4.3857 & TRN \\
\hline CHEMBL1807515 & 809207 & 6.3 & 5.4638 & TRN \\
\hline CHEMBL1971141 & 809207 & 4.3 & 4.0258 & TRN \\
\hline CHEMBL1995813 & 809207 & 4.3 & 4.9953 & TRN \\
\hline CHEMBL1979718 & 809207 & 4.3 & 4.3706 & TRN \\
\hline CHEMBL206236 & 809207 & 4.3 & 4.5132 & TRN \\
\hline CHEMBL1989834 & 809207 & 3.3 & 4.0543 & TRN \\
\hline CHEMBL523823 & 809207 & 4.3 & 4.4628 & TST \\
\hline CHEMBL1562756 & 809207 & 4.3 & 4.7757 & TST \\
\hline CHEMBL244378 & 809207 & 7.0 & 6.9551 & TRN \\
\hline CHEMBL 2001957 & 809207 & 4.3 & 4.5115 & TRN \\
\hline CHEMBL1969372 & 809207 & 4.3 & 4.3774 & TRN \\
\hline CHEMBL1990583 & 809207 & 4.3 & 4.6505 & TRN \\
\hline CHEMBL1986943 & 809207 & 6.4 & 5.937 & TRN \\
\hline CHEMBL289959 & 809207 & 3.3 & 3.3197 & TRN \\
\hline CHEMBL 2006263 & 809207 & 4.3 & 4.1956 & TST \\
\hline CHEMBL1993584 & 809207 & 4.3 & 4.1479 & TRN \\
\hline CHEMBL1986263 & 809207 & 5.4 & 5.4485 & TRN \\
\hline CHEMBL 2000114 & 809207 & 4.3 & 4.4836 & TRN \\
\hline CHEMBL210618 & 809207 & 4.3 & 4.28100 & 0000000001 \\
\hline CHEMBL1975647 & 809207 & 4.3 & 4.3727 & TRN \\
\hline CHEMBL1968380 & 809207 & 5.5 & 4.3971 & TRN \\
\hline CHEMBL1964644 & 809207 & 4.3 & 4.1075 & TRN \\
\hline CHEMBL1981782 & 809207 & 4.3 & 3.8852 & TRN \\
\hline CHEMBL1977681 & 809207 & 4.3 & 4.2146 & TRN \\
\hline CHEMBL1970142 & 809207 & 5.6 & 6.3519 & TRN \\
\hline CHEMBL1990912 & 809207 & 4.3 & 4.1997 & TRN \\
\hline CHEMBL1988163 & 809207 & 6.9 & 6.5689 & TRN \\
\hline CHEMBL1995592 & 809207 & 5.6 & 5.641 & TST \\
\hline CHEMBL 2006493 & 809207 & 4.3 & 4.5895 & TST \\
\hline CHEMBL1996923 & 809207 & 4.3 & 4.3579 & TST \\
\hline CHEMBL1983449 & 809207 & 4.3 & 4.3133 & TRN \\
\hline CHEMBL1992323 & 809207 & 4.3 & 4.4569 & TRN \\
\hline CHEMBL1969735 & 809207 & 4.3 & 4.4563 & TRN \\
\hline CHEMBL 2003524 & 809207 & 4.3 & 4.6895 & TST \\
\hline CHEMBL 2002649 & 809207 & 4.3 & 5.1276 & TRN \\
\hline CHEMBL1989423 & 809207 & 3.3 & 4.1702 & TST \\
\hline CHEMBL437747 & 809207 & 4.3 & 5.1444 & TRN \\
\hline CHEMBL1995172 & 809207 & 3.8 & 4.0923 & TST \\
\hline
\end{tabular}

TRN 


\begin{tabular}{|c|c|c|c|c|}
\hline & & & nent & al Ts \\
\hline CHEMBL507936 & 809207 & 4.3 & 3.8127 & TRN \\
\hline CHEMBL104264 & 809207 & 4.3 & 4.0365 & TST \\
\hline CHEMBL1994321 & 809207 & 6.3 & 5.6113 & TRN \\
\hline CHEMBL1997129 & 809207 & 5.3 & 5.0687 & TRN \\
\hline CHEMBL1984788 & 809207 & 6.0 & 5.2457 & TRN \\
\hline CHEMBL451964 & 809207 & 4.3 & 4.1846 & TRN \\
\hline CHEMBL1964307 & 809207 & 4.3 & 4.4697 & TRN \\
\hline CHEMBL 2000508 & 809207 & 4.3 & 4.5032 & TRN \\
\hline CHEMBL1971694 & 809207 & 4.3 & 4.1505 & TST \\
\hline CHEMBL 2001547 & 809207 & 4.3 & 4.3918 & TRN \\
\hline CHEMBL 210928 & 809207 & 4.3 & 4.2648 & TRN \\
\hline CHEMBL1994361 & 809207 & 4.3 & 4.3992 & TRN \\
\hline CHEMBL1986603 & 809207 & 4.3 & 4.2177 & TST \\
\hline CHEMBL1972840 & 809207 & 4.3 & 4.4468 & TRN \\
\hline CHEMBL1977148 & 809207 & 7.6 & 6.6931 & TRN \\
\hline CHEMBL 2003286 & 809207 & 4.3 & 4.0159 & TRN \\
\hline CHEMBL 2002165 & 809207 & 6.9 & 6.7772 & TRN \\
\hline CHEMBL 2001668 & 809207 & 4.3 & 4.6703 & TST \\
\hline CHEMBL1979318 & 809207 & 4.3 & 4.5919 & TRN \\
\hline CHEMBL 206382 & 809207 & 4.3 & 4.4456 & TRN \\
\hline CHEMBL1998585 & 809207 & 5.8 & 5.665 & TRN \\
\hline CHEMBL127898 & 809207 & 4.3 & 4.2223 & TST \\
\hline CHEMBL519697 & 809207 & 4.3 & 4.5781 & TST \\
\hline CHEMBL 2004934 & 809207 & 4.3 & 4.0957 & TRN \\
\hline CHEMBL1977619 & 809207 & 3.3 & 4.0254 & TST \\
\hline CHEMBL1975128 & 809207 & 4.3 & 4.6512 & TRN \\
\hline CHEMBL1970369 & 809207 & 4.3 & 4.2342 & TRN \\
\hline CHEMBL 2001485 & 809207 & 5.6 & 5.8947 & TRN \\
\hline CHEMBL504950 & 809207 & 4.3 & 4.5622 & TRN \\
\hline CHEMBL1966425 & 809207 & 5.3 & 4.7774 & TRN \\
\hline CHEMBL1984363 & 809207 & 4.3 & 4.5698 & TRN \\
\hline CHEMBL1978099 & 809207 & 6.3 & 6.0934 & TRN \\
\hline CHEMBL1977041 & 809207 & 6.6 & 5.7342 & TRN \\
\hline CHEMBL1968070 & 809207 & 4.3 & 4.8139 & TRN \\
\hline CHEMBL1988608 & 809207 & 4.3 & 4.1586 & TRN \\
\hline CHEMBL184847 & 809207 & 4.3 & 4.0537 & TRN \\
\hline CHEMBL1984367 & 809207 & 4.3 & 4.0809 & TRN \\
\hline CHEMBL178737 & 809207 & 4.3 & 4.5343 & TST \\
\hline CHEMBL226898 & 809207 & 4.3 & 4.5339 & TRN \\
\hline CHEMBL1982563 & 809207 & 4.3 & 4.3712 & TRN \\
\hline CHEMBL539474 & 809207 & 4.3 & 4.5539 & TST \\
\hline CHEMBL575824 & 809207 & 4.3 & 4.4469 & TRN \\
\hline CHEMBL1988387 & 809207 & 6.8 & 7.0225 & TRN \\
\hline CHEMBL1997759 & 809207 & 4.3 & 3.9987 & TRN \\
\hline CHEMBL1990288 & 809207 & 4.3 & 4.5389 & TRN \\
\hline CHEMBL1974803 & 809207 & 4.3 & 4.721 & TST \\
\hline CHEMBL1970074 & 809207 & 4.3 & 4.1291 & TRN \\
\hline CHEMBL1986970 & 809207 & 4.3 & 4.1467 & TRN \\
\hline
\end{tabular}




\begin{tabular}{|c|c|c|c|c|}
\hline & & & promer & $a \perp 1 a$ \\
\hline CHEMBL 2005112 & 809207 & 4.3 & 4.35 & TST \\
\hline CHEMBL1958401 & 809207 & 4.3 & 4.652 & TRN \\
\hline CHEMBL1984044 & 809207 & 4.3 & 4.9183 & TRN \\
\hline CHEMBL 2003456 & 809207 & 4.3 & 4.4416 & TRN \\
\hline CHEMBL1966816 & 809207 & 4.3 & 4.4395 & TRN \\
\hline CHEMBL1972584 & 809207 & 6.6 & 6.0241 & TRN \\
\hline CHEMBL2002992 & 809207 & 4.3 & 4.676 & TRN \\
\hline CHEMBL560813 & 809207 & 4.3 & 4.0853 & TRN \\
\hline CHEMBL1968791 & 809207 & 7.8 & 6.7865 & TRN \\
\hline CHEMBL326282 & 809207 & 4.3 & 4.541 & TST \\
\hline CHEMBL 2002682 & 809207 & 4.3 & 4.9027 & TST \\
\hline CHEMBL1992732 & 809207 & 4.3 & 4.1645 & TST \\
\hline CHEMBL1971186 & 809207 & 4.3 & 4.6823 & TRN \\
\hline CHEMBL 2003482 & 809207 & 4.3 & 4.4766 & TRN \\
\hline CHEMBL1976872 & 809207 & 3.3 & 3.6747 & TRN \\
\hline CHEMBL1969156 & 809207 & 3.3 & 4.064 & TST \\
\hline CHEMBL1973211 & 809207 & 6.0 & 5.9485 & TRN \\
\hline CHEMBL1984700 & 809207 & 4.3 & 4.4419 & TRN \\
\hline CHEMBL 2007151 & 809207 & 6.7 & 6.6832 & TRN \\
\hline CHEMBL1972125 & 809207 & 4.3 & 4.1847 & TRN \\
\hline CHEMBL1461728 & 809207 & 4.3 & 3.9447 & TRN \\
\hline CHEMBL1976134 & 809207 & 5.8 & 5.2288 & TRN \\
\hline CHEMBL1965131 & 809207 & 6.1 & 5.4491 & TRN \\
\hline CHEMBL1972158 & 809207 & 4.3 & 4.5419 & TRN \\
\hline CHEMBL1974457 & 809207 & 4.3 & 4.4356 & TRN \\
\hline CHEMBL 2006580 & 809207 & 4.3 & 4.1725 & TRN \\
\hline CHEMBL 2006581 & 809207 & 4.3 & 4.4543 & TRN \\
\hline CHEMBL 2006481 & 809207 & 4.3 & 4.2644 & TRN \\
\hline CHEMBL1979855 & 809207 & 4.3 & 4.0295 & TRN \\
\hline CHEMBL1970340 & 809207 & 4.3 & 4.4111 & TRN \\
\hline CHEMBL 2005186 & 809207 & 4.3 & 4.5596 & TRN \\
\hline CHEMBL1995927 & 809207 & 4.3 & 4.5938 & TST \\
\hline CHEMBL1975534 & 809207 & 4.3 & 4.468 & TRN \\
\hline CHEMBL1993424 & 809207 & 4.3 & 6.0999 & TRN \\
\hline CHEMBL1966703 & 809207 & 4.3 & 4.8795 & TST \\
\hline CHEMBL1969561 & 809207 & 4.3 & 4.1236 & TRN \\
\hline CHEMBL1975121 & 809207 & 4.3 & 4.0802 & TRN \\
\hline CHEMBL1997023 & 809207 & 4.3 & 4.2732 & TST \\
\hline CHEMBL1964687 & 809207 & 4.3 & 4.1284 & TRN \\
\hline CHEMBL1971943 & 809207 & 6.3 & 4.5634 & TST \\
\hline CHEMBL1999918 & 809207 & 4.3 & 4.8474 & TRN \\
\hline CHEMBL1974254 & 809207 & 6.5 & 6.6532 & TRN \\
\hline CHEMBL1988537 & 809207 & 4.3 & 5.2378 & TST \\
\hline CHEMBL1969049 & 809207 & 4.3 & 4.1073 & TRN \\
\hline CHEMBL 2005828 & 809207 & 4.3 & 4.1899 & TRN \\
\hline CHEMBL 2002240 & 809207 & 4.3 & 4.412 & TRN \\
\hline CHEMBL1998611 & 809207 & 6.2 & 5.2859 & TRN \\
\hline CHEMBL485556 & 809207 & 5.3 & 4.9279 & TST \\
\hline
\end{tabular}




\begin{tabular}{|c|c|c|c|c|c|}
\hline \\
\hline CHEMBL1975900 & 809207 & 4.3 & 4.2341 & TRN & \\
\hline CHEMBL255822 & 809207 & 4.3 & 3.9503 & TRN & \\
\hline CHEMBL1972221 & 809207 & 4.3 & 4.2425 & TRN & \\
\hline CHEMBL 2006778 & 809207 & 5.4 & 6.1232 & TRN & \\
\hline CHEMBL378627 & 809207 & 4.3 & 3.998 & TRN & \\
\hline CHEMBL1996979 & 809207 & 4.3 & 4.999 & TRN & \\
\hline CHEMBL1997025 & 809207 & 5.5 & 5.05 & TRN & \\
\hline CHEMBL1968406 & 809207 & 4.3 & 4.3998 & TRN & \\
\hline CHEMBL1982476 & 809207 & 6.7 & 6.7368 & TRN & \\
\hline CHEMBL1984274 & 809207 & 4.3 & 4.5087 & TST & \\
\hline CHEMBL1998545 & 809207 & 4.3 & 4.2571 & TRN & \\
\hline CHEMBL1986869 & 809207 & 4.3 & 4.2538 & TRN & \\
\hline CHEMBL2006010 & 809207 & 4.3 & 4.4921 & TRN & \\
\hline CHEMBL1682558 & 809207 & 4.3 & 4.3593 & TRN & \\
\hline CHEMBL1990496 & 809207 & 4.3 & 4.353 & TRN & \\
\hline CHEMBL1997623 & 809207 & 4.3 & 4.6633 & TRN & \\
\hline CHEMBL 2002479 & 809207 & 4.3 & 4.7128 & TRN & \\
\hline CHEMBL1993166 & 809207 & 4.3 & 4.331 & TRN & \\
\hline CHEMBL1967094 & 809207 & 4.3 & 4.2865 & TRN & \\
\hline CHEMBL1966035 & 809207 & 4.3 & 4.3807 & TRN & \\
\hline CHEMBL 2003341 & 809207 & 4.3 & 4.51699 & 99999999995 & TRN \\
\hline CHEMBL1992645 & 809207 & 4.3 & 4.2836 & TST & \\
\hline CHEMBL1982992 & 809207 & 4.3 & 4.2882 & TRN & \\
\hline CHEMBL1999590 & 809207 & 4.3 & 4.4732 & TST & \\
\hline CHEMBL1981079 & 809207 & 4.3 & 4.4278 & TRN & \\
\hline CHEMBL1972276 & 809207 & 4.3 & 4.4983 & TRN & \\
\hline CHEMBL1980489 & 809207 & 4.3 & 4.2582 & TRN & \\
\hline CHEMBL 2000832 & 809207 & 4.3 & 4.2134 & TRN & \\
\hline CHEMBL1967116 & 809207 & 7.2 & 6.5734 & TRN & \\
\hline CHEMBL1977814 & 809207 & 4.3 & 4.2219 & TST & \\
\hline CHEMBL513846 & 809207 & 4.3 & 4.8476 & TRN & \\
\hline CHEMBL1970709 & 809207 & 4.3 & 3.6084 & TRN & \\
\hline CHEMBL1965660 & 809207 & 4.3 & 4.6678 & TRN & \\
\hline CHEMBL1998112 & 809207 & 6.3 & 5.3308 & TRN & \\
\hline CHEMBL1969126 & 809207 & 4.3 & 4.3113 & TRN & \\
\hline CHEMBL1980896 & 809207 & 4.3 & 4.53100 & $\partial 000000001$ & TRN \\
\hline CHEMBL1975208 & 809207 & 4.3 & 4.4185 & TST & \\
\hline CHEMBL1970104 & 809207 & 6.2 & 5.7066 & TRN & \\
\hline CHEMBL1991429 & 809207 & 7.4 & 6.5336 & TRN & \\
\hline CHEMBL1964777 & 809207 & 4.3 & 4.2253 & TRN & \\
\hline CHEMBL1971149 & 809207 & 4.3 & 4.3694 & TRN & \\
\hline CHEMBL1999714 & 809207 & 4.3 & 3.7918 & TRN & \\
\hline CHEMBL1987533 & 809207 & 4.3 & 4.3309 & TRN & \\
\hline CHEMBL1994040 & 809207 & 4.3 & 4.5753 & TRN & \\
\hline CHEMBL 388978 & 809207 & 7.9 & 8.3413 & TST & \\
\hline CHEMBL579246 & 809207 & 4.3 & 4.3405 & TRN & \\
\hline CHEMBL398951 & 809207 & 4.3 & 4.7344 & TST & \\
\hline CHEMBL1982506 & 809207 & 4.3 & 4.6538 & TST & \\
\hline
\end{tabular}




\begin{tabular}{|c|c|c|c|c|}
\hline \multicolumn{5}{|c|}{ Supplemental Table S2.tx } \\
\hline CHEMBL 2004716 & 809207 & 6.7 & 5.9766 & TRN \\
\hline CHEMBL1968127 & 809207 & 4.3 & 4.3223 & TRN \\
\hline CHEMBL1975233 & 809207 & 4.3 & 4.1244 & TRN \\
\hline CHEMBL1985406 & 809207 & 4.3 & 4.4132 & TRN \\
\hline CHEMBL 207400 & 809207 & 4.3 & 4.1833 & TST \\
\hline CHEMBL 2000894 & 809207 & 4.3 & 4.5662 & TST \\
\hline CHEMBL1982135 & 809207 & 5.5 & 4.3724 & TRN \\
\hline CHEMBL1976090 & 809207 & 4.3 & 4.5439 & TRN \\
\hline CHEMBL1993243 & 809207 & 4.3 & 5.3974 & TRN \\
\hline CHEMBL1992922 & 809207 & 5.5 & 5.1705 & TRN \\
\hline CHEMBL 2004771 & 809207 & 6.3 & 4.8668 & TRN \\
\hline CHEMBL399021 & 809207 & 7.4 & 6.7041 & TRN \\
\hline CHEMBL1997597 & 809207 & 4.3 & 4.1786 & TRN \\
\hline CHEMBL1969537 & 809207 & 4.3 & 4.8822 & TST \\
\hline CHEMBL1976093 & 809207 & 4.3 & 4.2442 & TRN \\
\hline CHEMBL1996543 & 809207 & 4.3 & 4.0384 & TRN \\
\hline CHEMBL1975256 & 809207 & 4.3 & 4.3009 & TST \\
\hline CHEMBL508928 & 809207 & 4.3 & 5.3232 & TRN \\
\hline CHEMBL1991356 & 809207 & 4.3 & 4.683 & TST \\
\hline CHEMBL1983309 & 809207 & 4.3 & 4.4925 & TRN \\
\hline CHEMBL 2004892 & 809207 & 4.3 & 4.1853 & TRN \\
\hline CHEMBL1997503 & 809207 & 4.3 & 4.5556 & TST \\
\hline CHEMBL116070 & 809207 & 4.3 & 4.1791 & TRN \\
\hline CHEMBL1990821 & 809207 & 4.3 & 4.4724 & TST \\
\hline CHEMBL1970314 & 809207 & 4.3 & 4.5139 & TRN \\
\hline CHEMBL 2004871 & 809207 & 4.3 & 4.0654 & TRN \\
\hline CHEMBL 2004872 & 809207 & 4.3 & 4.1149 & TRN \\
\hline CHEMBL1727312 & 809207 & 3.5 & 3.8529 & TRN \\
\hline CHEMBL1969879 & 809207 & 4.3 & 4.1452 & TRN \\
\hline CHEMBL1981720 & 809207 & 4.3 & 4.0931 & TRN \\
\hline CHEMBL419932 & 809207 & 4.3 & 4.4253 & TRN \\
\hline CHEMBL 262433 & 809207 & 4.3 & 4.3747 & TRN \\
\hline CHEMBL 306380 & 809207 & 5.4 & 5.2371 & TRN \\
\hline CHEMBL1986588 & 809207 & 3.3 & 3.6039 & TRN \\
\hline CHEMBL1966722 & 809207 & 4.3 & 4.4503 & TRN \\
\hline CHEMBL1975500 & 809207 & 4.3 & 4.4856 & TRN \\
\hline CHEMBL1976328 & 809207 & 4.3 & 4.0874 & TRN \\
\hline CHEMBL394619 & 809207 & 4.3 & 4.7196 & TRN \\
\hline CHEMBL1964399 & 809207 & 4.3 & 4.9029 & TRN \\
\hline CHEMBL1996831 & 809207 & 4.3 & 4.5497 & TST \\
\hline CHEMBL411903 & 809207 & 4.3 & 5.2729 & TRN \\
\hline CHEMBL1965988 & 809207 & 6.2 & 5.6496 & TRN \\
\hline CHEMBL418203 & 809207 & 4.3 & 4.8702 & TST \\
\hline CHEMBL1989646 & 809207 & 4.3 & 4.1988 & TRN \\
\hline CHEMBL1682357 & 809207 & 4.3 & 4.3826 & TRN \\
\hline CHEMBL225519 & 809207 & 4.3 & 4.1492 & TRN \\
\hline CHEMBL209534 & 809207 & 4.3 & 4.1054 & TRN \\
\hline CHEMBL1978200 & 809207 & 4.3 & 4.3772 & TRN \\
\hline
\end{tabular}




\begin{tabular}{|c|c|c|c|c|}
\hline \multicolumn{5}{|c|}{ lemental T } \\
\hline CHEMBL1970522 & 809207 & 4.3 & 4.2608 & TRN \\
\hline CHEMBL402846 & 809207 & 4.3 & 4.5719 & TRN \\
\hline CHEMBL1990415 & 809207 & 4.3 & 4.4843 & TRN \\
\hline CHEMBL1966087 & 809207 & 4.3 & 4.419 & TRN \\
\hline CHEMBL1964692 & 809207 & 5.6 & 4.7829 & TRN \\
\hline CHEMBL1996931 & 809207 & 4.3 & 4.3748 & TRN \\
\hline CHEMBL1964413 & 809207 & 4.3 & 4.0742 & TRN \\
\hline CHEMBL1973483 & 809207 & 4.3 & 4.3755 & TRN \\
\hline CHEMBL1984432 & 809207 & 4.3 & 3.8213 & TRN \\
\hline CHEMBL1970735 & 809207 & 4.3 & 4.3083 & TRN \\
\hline CHEMBL 219722 & 809207 & 5.9 & 5.0452 & TRN \\
\hline CHEMBL1997340 & 809207 & 4.3 & 4.1453 & TRN \\
\hline CHEMBL 2004365 & 809207 & 4.3 & 4.3967 & TST \\
\hline CHEMBL1522508 & 809207 & 4.3 & 3.4253 & TRN \\
\hline CHEMBL1989474 & 809207 & 4.3 & 3.8846 & TRN \\
\hline CHEMBL 1090360 & 809207 & 7.4 & 6.9528 & TRN \\
\hline CHEMBL458997 & 809207 & 8.3 & 7.2538 & TRN \\
\hline CHEMBL1971021 & 809207 & 4.3 & 4.566 & TRN \\
\hline CHEMBL227271 & 809207 & 4.3 & 4.8927 & TRN \\
\hline CHEMBL583144 & 809207 & 4.3 & 4.7409 & TRN \\
\hline CHEMBL 1974310 & 809207 & 4.3 & 4.1039 & TRN \\
\hline CHEMBL1982660 & 809207 & 4.3 & 4.7401 & TRN \\
\hline CHEMBL1994693 & 809207 & 5.3 & 4.3291 & TRN \\
\hline CHEMBL1982957 & 809207 & 5.8 & 5.5503 & TRN \\
\hline CHEMBL1725279 & 809207 & 6.3 & 5.5828 & TST \\
\hline CHEMBL 2002346 & 809207 & 5.7 & 4.8 & TRN \\
\hline CHEMBL1975138 & 809207 & 4.3 & 4.045 & TRN \\
\hline CHEMBL424872 & 809207 & 4.3 & 4.136 & TRN \\
\hline CHEMBL 2006836 & 809207 & 4.3 & 4.5453 & TST \\
\hline CHEMBL1971947 & 809207 & 4.3 & 5.3081 & TRN \\
\hline CHEMBL412142 & 809207 & 4.3 & 4.4659 & TST \\
\hline CHEMBL1980704 & 809207 & 4.3 & 4.5869 & TST \\
\hline CHEMBL 2003271 & 809207 & 5.7 & 5.6063 & TRN \\
\hline CHEMBL1972365 & 809207 & 3.3 & 4.4498 & TST \\
\hline CHEMBL1966808 & 809207 & 4.3 & 4.4269 & TST \\
\hline CHEMBL 2004447 & 809207 & 4.3 & 4.3238 & TRN \\
\hline CHEMBL1983111 & 809207 & 7.6 & 7.1789 & TST \\
\hline CHEMBL1973860 & 809207 & 4.3 & 4.2808 & TRN \\
\hline CHEMBL260135 & 809207 & 4.3 & 4.5121 & TRN \\
\hline CHEMBL 220241 & 809207 & 4.3 & 4.9 & TST \\
\hline CHEMBL 2004544 & 809207 & 4.3 & 4.0824 & TST \\
\hline CHEMBL1982610 & 809207 & 4.3 & 4.8205 & TST \\
\hline CHEMBL1999496 & 809207 & 4.3 & 4.0783 & TRN \\
\hline CHEMBL1970873 & 809207 & 3.5 & 3.7615 & TRN \\
\hline CHEMBL 2006933 & 809207 & 4.3 & 4.5129 & TST \\
\hline CHEMBL1988300 & 809207 & 4.3 & 5.0515 & TRN \\
\hline CHEMBL1991078 & 809207 & 5.9 & 4.81 & TRN \\
\hline CHEMBL1987359 & 809207 & 4.3 & 4.0979 & TST \\
\hline
\end{tabular}




\begin{tabular}{|c|c|c|c|c|c|}
\hline \\
\hline CHEMBL 2000685 & 809207 & 4.3 & 4.7753 & TRN & \\
\hline CHEMBL1985311 & 809207 & 4.3 & 5.0104 & TRN & \\
\hline CHEMBL1989265 & 809207 & 4.3 & 4.6944 & TST & \\
\hline CHEMBL1969502 & 809207 & 4.3 & 5.0896 & TRN & \\
\hline CHEMBL1965910 & 809207 & 6.9 & 6.6548 & TRN & \\
\hline CHEMBL1682553 & 809207 & 4.3 & 4.2427 & TRN & \\
\hline CHEMBL1971430 & 809207 & 4.3 & 4.2155 & TRN & \\
\hline CHEMBL1997764 & 809207 & 4.3 & 4.602 & TRN & \\
\hline CHEMBL1983963 & 809207 & 4.3 & 4.7517 & TRN & \\
\hline CHEMBL 2000271 & 809207 & 8.6 & 5.6914 & TRN & \\
\hline CHEMBL562488 & 809207 & 3.3 & 3.6968 & TRN & \\
\hline CHEMBL354676 & 809207 & 3.3 & 3.6923 & TRN & \\
\hline CHEMBL1985092 & 809207 & 4.3 & 4.2165 & TST & \\
\hline CHEMBL2004692 & 809207 & 4.3 & 4.3148 & TST & \\
\hline CHEMBL1981410 & 809207 & 4.3 & 3.9602 & TRN & \\
\hline CHEMBL1996234 & 809207 & 8.2 & 5.5188 & TRN & \\
\hline CHEMBL1991434 & 809207 & 4.3 & 4.1462 & TST & \\
\hline CHEMBL1967544 & 809207 & 4.3 & 4.4829 & TRN & \\
\hline CHEMBL223367 & 809207 & 4.3 & 4.4922 & TST & \\
\hline CHEMBL340384 & 809207 & 5.5 & 5.079 & TST & \\
\hline CHEMBL1996587 & 809207 & 4.3 & 4.2685 & TRN & \\
\hline CHEMBL1964804 & 809207 & 4.3 & 4.4128 & TRN & \\
\hline CHEMBL443962 & 809207 & 5.7 & 4.5706 & TST & \\
\hline CHEMBL 2000354 & 809207 & 4.3 & 4.1395 & TRN & \\
\hline CHEMBL1965507 & 809207 & 4.3 & 3.6803 & TRN & \\
\hline CHEMBL 274064 & 809207 & 4.3 & 4.43199 & 99999999995 & TRN \\
\hline CHEMBL1967564 & 809207 & 4.3 & 4.3082 & TRN & \\
\hline CHEMBL592030 & 809207 & 4.3 & 4.1384 & TST & \\
\hline CHEMBL 2000071 & 809207 & 4.3 & 4.9837 & TRN & \\
\hline CHEMBL1979176 & 809207 & 4.3 & 4.1738 & TRN & \\
\hline CHEMBL1970317 & 809207 & 6.9 & 6.5328 & TRN & \\
\hline CHEMBL2000408 & 809207 & 4.3 & 4.3654 & TRN & \\
\hline CHEMBL248757 & 809207 & 4.3 & 4.5928 & TST & \\
\hline CHEMBL1978014 & 809207 & 4.3 & 3.5996 & TRN & \\
\hline CHEMBL1994538 & 809207 & 4.3 & 4.2093 & TRN & \\
\hline CHEMBL1983195 & 809207 & 4.3 & 4.1251 & TST & \\
\hline CHEMBL1975490 & 809207 & 5.3 & 4.8845 & TRN & \\
\hline CHEMBL1964444 & 809207 & 4.3 & 3.9952 & TRN & \\
\hline CHEMBL2006567 & 809207 & 4.3 & 4.4438 & TRN & \\
\hline CHEMBL1986139 & 809207 & 4.3 & 3.8708 & TRN & \\
\hline CHEMBL 383527 & 809207 & 4.3 & 4.186 & TRN & \\
\hline CHEMBL1980540 & 809207 & 4.3 & 4.4159 & TRN & \\
\hline CHEMBL1979883 & 809207 & 5.8 & 5.6252 & TRN & \\
\hline CHEMBL1984162 & 809207 & 7.0 & 7.2767 & TRN & \\
\hline CHEMBL491758 & 809207 & 6.1 & 6.2282 & TRN & \\
\hline CHEMBL549730 & 809207 & 4.3 & 4.0504 & TRN & \\
\hline CHEMBL1682360 & 809207 & 4.3 & 4.5495 & TRN & \\
\hline CHEMBL1970189 & 809207 & 4.3 & 4.6681 & TRN & \\
\hline
\end{tabular}




\begin{tabular}{|c|c|c|c|c|}
\hline & & & ement & al Ta \\
\hline CHEMBL1996791 & 809207 & 6.0 & 5.1406 & TRN \\
\hline CHEMBL371206 & 809207 & 4.3 & 4.5584 & TRN \\
\hline CHEMBL1974664 & 809207 & 4.3 & 5.0375 & TST \\
\hline CHEMBL1974288 & 809207 & 4.3 & 4.3511 & TRN \\
\hline CHEMBL196363 & 809207 & 5.5 & 4.9061 & TRN \\
\hline CHEMBL1996837 & 809207 & 3.3 & 3.5547 & TRN \\
\hline CHEMBL1190711 & 809207 & 4.3 & 4.7969 & TRN \\
\hline CHEMBL1990346 & 809207 & 4.3 & 4.5489 & TRN \\
\hline CHEMBL1968705 & 809207 & 4.3 & 4.3918 & TRN \\
\hline CHEMBL404367 & 809207 & 4.3 & 4.3843 & TRN \\
\hline CHEMBL1966343 & 809207 & 4.3 & 4.2904 & TRN \\
\hline CHEMBL1967887 & 809207 & 4.3 & 4.9646 & TRN \\
\hline CHEMBL 2000568 & 809207 & 5.5 & 4.7045 & TRN \\
\hline CHEMBL 2000335 & 809207 & 4.3 & 4.8881 & TRN \\
\hline CHEMBL1980161 & 809207 & 3.3 & 4.467 & TRN \\
\hline CHEMBL1988717 & 809207 & 4.3 & 5.4566 & TRN \\
\hline CHEMBL1974328 & 809207 & 4.3 & 5.0753 & TRN \\
\hline CHEMBL509032 & 809207 & 6.3 & 7.3925 & TRN \\
\hline CHEMBL143703 & 809207 & 3.3 & 3.4808 & TRN \\
\hline CHEMBL1973808 & 809207 & 4.3 & 4.3252 & TRN \\
\hline CHEMBL 2000429 & 809207 & 4.3 & 4.4577 & TRN \\
\hline CHEMBL1972576 & 809207 & 4.3 & 3.8058 & TRN \\
\hline CHEMBL1992555 & 809207 & 4.3 & 4.87 & TST \\
\hline CHEMBL1990254 & 809207 & 4.3 & 4.3807 & TRN \\
\hline CHEMBL1992342 & 809207 & 4.3 & 4.2757 & TRN \\
\hline CHEMBL1988173 & 809207 & 4.3 & 4.4393 & TRN \\
\hline CHEMBL535331 & 809207 & 4.3 & 4.4454 & TRN \\
\hline CHEMBL1989805 & 809207 & 4.3 & 4.37 & TST \\
\hline CHEMBL1965423 & 809207 & 4.3 & 4.3304 & TRN \\
\hline CHEMBL1982980 & 809207 & 4.3 & 4.8572 & TST \\
\hline CHEMBL1983025 & 809207 & 5.5 & 5.2842 & TRN \\
\hline CHEMBL 205415 & 809207 & 4.3 & 3.8724 & TRN \\
\hline CHEMBL1977135 & 809207 & 4.3 & 4.1924 & TRN \\
\hline CHEMBL 2001920 & 809207 & 4.3 & 4.49 & TRN \\
\hline CHEMBL 2002322 & 809207 & 4.3 & 4.0244 & TRN \\
\hline CHEMBL 2002323 & 809207 & 4.3 & 3.9448 & TST \\
\hline CHEMBL1241473 & 809207 & 8.2 & 7.7693 & TRN \\
\hline CHEMBL1978448 & 809207 & 4.3 & 4.3952 & TST \\
\hline CHEMBL1972258 & 809207 & 4.3 & 4.4401 & TRN \\
\hline CHEMBL 2001257 & 809207 & 5.5 & 5.2344 & TRN \\
\hline CHEMBL 2005548 & 809207 & 4.3 & 4.1245 & TRN \\
\hline CHEMBL1992536 & 809207 & 4.3 & 4.2578 & TRN \\
\hline CHEMBL1987793 & 809207 & 4.3 & 4.7917 & TST \\
\hline CHEMBL1992740 & 809207 & 4.3 & 4.3637 & TRN \\
\hline CHEMBL 2002373 & 809207 & 4.3 & 4.3573 & TRN \\
\hline CHEMBL439340 & 809207 & 4.3 & 4.2345 & TRN \\
\hline CHEMBL 2006188 & 809207 & 4.3 & 4.2 & TRN \\
\hline CHEMBL1967531 & 809207 & 4.3 & 4.6998 & TRN \\
\hline
\end{tabular}




\begin{tabular}{|c|c|c|c|c|}
\hline \multicolumn{5}{|c|}{ plemental $\mathrm{T}$} \\
\hline CHEMBL1970913 & 809207 & 4.3 & 4.3682 & TRN \\
\hline CHEMBL1973893 & 809207 & 4.3 & 4.2215 & TRN \\
\hline CHEMBL1995736 & 809207 & 4.3 & 4.9871 & TRN \\
\hline CHEMBL1997534 & 809207 & 4.3 & 4.4155 & TRN \\
\hline CHEMBL1996500 & 809207 & 4.3 & 4.2958 & TRN \\
\hline CHEMBL1985095 & 809207 & 4.3 & 4.4855 & TST \\
\hline CHEMBL1977374 & 809207 & 4.3 & 4.4946 & TRN \\
\hline CHEMBL1991180 & 809207 & 4.3 & 5.0214 & TST \\
\hline CHEMBL1682540 & 809207 & 4.3 & 4.1578 & TRN \\
\hline CHEMBL1976420 & 809207 & 4.3 & 5.0911 & TST \\
\hline CHEMBL1994864 & 809207 & 4.3 & 3.8803 & TRN \\
\hline CHEMBL413779 & 809207 & 4.3 & 4.5462 & TST \\
\hline CHEMBL 2002446 & 809207 & 4.3 & 5.0406 & TST \\
\hline CHEMBL497151 & 809207 & 4.3 & 4.2638 & TRN \\
\hline CHEMBL246970 & 809207 & 4.3 & 4.8103 & TRN \\
\hline CHEMBL340921 & 809207 & 4.3 & 4.4848 & TST \\
\hline CHEMBL373598 & 809207 & 4.3 & 4.5007 & TST \\
\hline CHEMBL1999718 & 809207 & 4.3 & 4.1299 & TRN \\
\hline CHEMBL1276446 & 809207 & 5.8 & 5.9495 & TST \\
\hline CHEMBL1977346 & 809207 & 4.3 & 4.8895 & TRN \\
\hline CHEMBL1971649 & 809207 & 4.3 & 3.8787 & TRN \\
\hline CHEMBL 2003657 & 809207 & 4.3 & 4.277 & TRN \\
\hline CHEMBL 2006439 & 809207 & 5.5 & 4.8702 & TRN \\
\hline CHEMBL 2006156 & 809207 & 4.3 & 4.0968 & TST \\
\hline CHEMBL1969190 & 809207 & 5.5 & 4.9432 & TRN \\
\hline CHEMBL1973937 & 809207 & 4.3 & 4.543 & TRN \\
\hline CHEMBL1991674 & 809207 & 4.4 & 5.2877 & TRN \\
\hline CHEMBL1982711 & 809207 & 4.3 & 4.7881 & TRN \\
\hline CHEMBL1984842 & 809207 & 4.3 & 4.329 & TRN \\
\hline CHEMBL1969102 & 809207 & 6.8 & 6.1981 & TRN \\
\hline CHEMBL1682346 & 809207 & 4.3 & 4.2149 & TRN \\
\hline CHEMBL 2007044 & 809207 & 4.3 & 4.301 & TST \\
\hline CHEMBL 2001998 & 809207 & 4.3 & 4.6706 & TST \\
\hline CHEMBL1994241 & 809207 & 4.3 & 4.3129 & TRN \\
\hline CHEMBL 223460 & 809207 & 4.3 & 4.4722 & TST \\
\hline CHEMBL1998829 & 809207 & 4.3 & 4.4202 & TRN \\
\hline CHEMBL50894 & 809207 & 4.3 & 5.2656 & TRN \\
\hline CHEMBL1988838 & 809207 & 6.7 & 6.6773 & TRN \\
\hline CHEMBL1981725 & 809207 & 8.6 & 7.8068 & TRN \\
\hline CHEMBL 375284 & 809207 & 4.3 & 3.7452 & TRN \\
\hline CHEMBL1982866 & 809207 & 4.3 & 4.2786 & TRN \\
\hline CHEMBL 2005792 & 809207 & 4.3 & 4.3622 & TRN \\
\hline CHEMBL1968926 & 809207 & 4.3 & 4.4392 & TRN \\
\hline CHEMBL1984206 & 809207 & 4.3 & 4.1769 & TRN \\
\hline CHEMBL462120 & 809207 & 4.3 & 4.7142 & TST \\
\hline CHEMBL1991577 & 809207 & 4.3 & 4.4099 & TRN \\
\hline CHEMBL1991867 & 809207 & 3.3 & 4.356 & TST \\
\hline CHEMBL1965570 & 809207 & 5.8 & 6.1621 & TRN \\
\hline
\end{tabular}




\begin{tabular}{|c|c|c|c|c|}
\hline & & & & al \\
\hline CHEMBL 2007592 & 809207 & 4.3 & 4.5031 & TST \\
\hline CHEMBL210963 & 809207 & 4.3 & 3.9987 & TRN \\
\hline CHEMBL1082440 & 809207 & 4.3 & 4.6859 & TST \\
\hline CHEMBL1614705 & 809207 & 4.3 & 4.5641 & TRN \\
\hline CHEMBL1972362 & 809207 & 4.3 & 4.1872 & TRN \\
\hline CHEMBL1984633 & 809207 & 4.3 & 4.1053 & TRN \\
\hline CHEMBL 2007372 & 809207 & 4.3 & 4.2949 & TRN \\
\hline CHEMBL1965845 & 809207 & 4.3 & 4.067 & TRN \\
\hline CHEMBL1982167 & 809207 & 4.3 & 4.2856 & TRN \\
\hline CHEMBL2006715 & 809207 & 6.5 & 6.485 & TRN \\
\hline CHEMBL1986597 & 809207 & 4.3 & 4.8922 & TRN \\
\hline CHEMBL1971017 & 809207 & 4.3 & 4.6441 & TRN \\
\hline CHEMBL1990482 & 809207 & 4.3 & 4.6801 & TRN \\
\hline CHEMBL1990904 & 809207 & 4.3 & 4.5586 & TRN \\
\hline CHEMBL 2005475 & 809207 & 4.3 & 4.633 & TRN \\
\hline CHEMBL 2000104 & 809207 & 4.3 & 4.3051 & TRN \\
\hline CHEMBL1997349 & 809207 & 4.3 & 4.655 & TST \\
\hline CHEMBL183844 & 809207 & 4.3 & 4.2576 & TRN \\
\hline CHEMBL220057 & 809207 & 5.6 & 4.8148 & TRN \\
\hline CHEMBL1682545 & 809207 & 4.3 & 4.1649 & TRN \\
\hline CHEMBL 383541 & 809207 & 4.3 & 4.081 & TRN \\
\hline CHEMBL 2001224 & 809207 & 4.3 & 4.2589 & TRN \\
\hline CHEMBL10 & 809207 & 4.3 & 4.3824 & TRN \\
\hline CHEMBL1976732 & 809207 & 4.3 & 4.2137 & TRN \\
\hline CHEMBL1969506 & 809207 & 4.3 & 3.9456 & TRN \\
\hline CHEMBL1964937 & 809207 & 4.3 & 4.144 & TRN \\
\hline CHEMBL1980163 & 809207 & 4.3 & 4.1949 & TRN \\
\hline CHEMBL590109 & 809207 & 4.3 & 4.4079 & TST \\
\hline CHEMBL1970879 & 809207 & 5.4 & 6.0143 & TRN \\
\hline CHEMBL1989856 & 809207 & 4.3 & 4.6393 & TST \\
\hline CHEMBL2005899 & 809207 & 4.3 & 4.0556 & TRN \\
\hline CHEMBL1682552 & 809207 & 4.3 & 4.3931 & TRN \\
\hline CHEMBL 259850 & 809207 & 4.3 & 4.1803 & TRN \\
\hline CHEMBL1972568 & 809207 & 4.3 & 4.2429 & TRN \\
\hline CHEMBL1996155 & 809207 & 4.3 & 4.2822 & TRN \\
\hline CHEMBL229799 & 809207 & 5.5 & 5.3313 & TRN \\
\hline CHEMBL1682359 & 809207 & 4.3 & 4.2313 & TRN \\
\hline CHEMBL105739 & 809207 & 6.8 & 6.0297 & TRN \\
\hline CHEMBL 379300 & 809207 & 5.4 & 5.0288 & TRN \\
\hline CHEMBL 203673 & 809207 & 4.3 & 4.4956 & TRN \\
\hline CHEMBL1969523 & 809207 & 4.3 & 4.7212 & TRN \\
\hline CHEMBL207995 & 809207 & 4.3 & 4.0683 & TRN \\
\hline CHEMBL1988995 & 809207 & 4.3 & 4.3768 & TRN \\
\hline CHEMBL 2001923 & 809207 & 4.3 & 4.1474 & TRN \\
\hline CHEMBL1986781 & 809207 & 4.3 & 4.5964 & TRN \\
\hline CHEMBL526133 & 809207 & 4.3 & 4.2323 & TRN \\
\hline CHEMBL1967538 & 809207 & 3.3 & 3.6328 & TRN \\
\hline CHEMBL1979057 & 809207 & 4.3 & 4.5217 & TRN \\
\hline
\end{tabular}




\begin{tabular}{|c|c|c|c|c|}
\hline & & & pplement & al $\mathrm{Ta}$ \\
\hline CHEMBL1981045 & 809207 & 4.3 & 4.6751 & TRN \\
\hline CHEMBL387971 & 809207 & 4.3 & 4.8645 & TST \\
\hline CHEMBL1975418 & 809207 & 4.3 & 4.7172 & TRN \\
\hline CHEMBL1992796 & 809207 & 4.3 & 4.6868 & TST \\
\hline CHEMBL1999428 & 809207 & 4.3 & 4.3642 & TRN \\
\hline CHEMBL223257 & 809207 & 4.3 & 4.4962 & TST \\
\hline CHEMBL1967560 & 809207 & 4.3 & 4.4747 & TRN \\
\hline CHEMBL1516890 & 809207 & 5.6 & 4.9831 & TRN \\
\hline CHEMBL211378 & 809207 & 4.3 & 4.1133 & TRN \\
\hline CHEMBL1982465 & 809207 & 6.3 & 6.2683 & TRN \\
\hline CHEMBL 2001751 & 809207 & 4.3 & 5.5133 & TRN \\
\hline CHEMBL 2003420 & 809207 & 4.3 & 3.9346 & TRN \\
\hline CHEMBL1984586 & 809207 & 4.3 & 4.5542 & TRN \\
\hline CHEMBL1999774 & 809207 & 4.3 & 4.3846 & TST \\
\hline CHEMBL1972659 & 809207 & 4.3 & 4.3768 & TST \\
\hline CHEMBL1973395 & 809207 & 5.7 & 5.5665 & TRN \\
\hline CHEMBL 272453 & 809207 & 4.3 & 4.7866 & TRN \\
\hline CHEMBL1987143 & 809207 & 3.3 & 4.3292 & TST \\
\hline CHEMBL1970217 & 809207 & 4.3 & 3.9223 & TRN \\
\hline CHEMBL1971801 & 809207 & 4.3 & 4.717 & TRN \\
\hline CHEMBL1968850 & 809207 & 4.3 & 4.657 & TRN \\
\hline CHEMBL 2005528 & 809207 & 4.3 & 4.3673 & TST \\
\hline CHEMBL185569 & 809207 & 4.3 & 4.4241 & TRN \\
\hline CHEMBL1969843 & 809207 & 4.3 & 4.3854 & TRN \\
\hline CHEMBL 2007002 & 809207 & 4.3 & 3.6887 & TRN \\
\hline CHEMBL1987007 & 809207 & 4.3 & 4.2111 & TRN \\
\hline CHEMBL1969588 & 809207 & 4.3 & 5.2612 & TRN \\
\hline CHEMBL1984711 & 809207 & 7.4 & 6.4125 & TRN \\
\hline CHEMBL1990212 & 809207 & 4.3 & 4.7323 & TRN \\
\hline CHEMBL484390 & 809207 & 4.3 & 4.5697 & TST \\
\hline CHEMBL1979252 & 809207 & 4.3 & 4.1715 & TRN \\
\hline CHEMBL1682341 & 809207 & 4.3 & 4.5142 & TRN \\
\hline CHEMBL 2004290 & 809207 & 7.3 & 6.5459 & TRN \\
\hline CHEMBL1986499 & 809207 & 4.3 & 4.4913 & TRN \\
\hline CHEMBL1972937 & 809207 & 4.3 & 4.3655 & TRN \\
\hline CHEMBL1972250 & 809207 & 4.3 & 4.3398 & TST \\
\hline CHEMBL 2000393 & 809207 & 4.3 & 5.6603 & TST \\
\hline CHEMBL 2004311 & 809207 & 4.3 & 4.8372 & TRN \\
\hline CHEMBL1992634 & 809207 & 6.2 & 4.8446 & TRN \\
\hline CHEMBL1242373 & 809207 & 4.3 & 4.2072 & TRN \\
\hline CHEMBL316264 & 809207 & 4.3 & 4.3361 & TRN \\
\hline CHEMBL1988075 & 809207 & 4.3 & 5.6282 & TRN \\
\hline CHEMBL1991678 & 809207 & 4.3 & 4.4017 & TRN \\
\hline CHEMBL 2001239 & 809207 & 4.3 & 4.51 & TST \\
\hline CHEMBL1988594 & 809207 & 4.3 & 3.9397 & TRN \\
\hline CHEMBL 2001288 & 809207 & 4.3 & 4.5108 & TRN \\
\hline CHEMBL 260092 & 809207 & 4.3 & 5.0303 & TRN \\
\hline CHEMBL1999811 & 809207 & 5.3 & 4.5884 & TST \\
\hline
\end{tabular}




\begin{tabular}{|c|c|c|c|c|c|}
\hline \\
\hline CHEMBL1965495 & 809207 & 5.6 & 5.1943 & TRN & \\
\hline CHEMBL1985074 & 809207 & 4.3 & 4.2372 & TST & \\
\hline CHEMBL1982874 & 809207 & 5.6 & 4.7451 & TRN & \\
\hline CHEMBL 2000481 & 809207 & 4.3 & 4.1522 & TRN & \\
\hline CHEMBL1991725 & 809207 & 4.3 & 4.4713 & TRN & \\
\hline CHEMBL1992242 & 809207 & 4.3 & 3.6633 & TRN & \\
\hline CHEMBL 2007296 & 809207 & 4.3 & 4.3867 & TRN & \\
\hline CHEMBL 208637 & 809207 & 4.3 & 4.2333 & TRN & \\
\hline CHEMBL396523 & 809207 & 6.5 & 6.8113 & TRN & \\
\hline CHEMBL1970203 & 809207 & 4.3 & 3.8765 & TRN & \\
\hline CHEMBL 1986530 & 809207 & 4.3 & 4.6888 & TST & \\
\hline CHEMBL1999321 & 809207 & 4.3 & 4.5762 & TRN & \\
\hline CHEMBL 385478 & 809207 & 6.8 & 5.2748 & TRN & \\
\hline CHEMBL1968590 & 809207 & 4.3 & 5.54700 & $\partial 000000001$ & TRN \\
\hline CHEMBL1999749 & 809207 & 4.3 & 4.0764 & TRN & \\
\hline CHEMBL 2005375 & 809207 & 4.3 & 4.3074 & TRN & \\
\hline CHEMBL1984191 & 809207 & 4.3 & 4.3878 & TRN & \\
\hline CHEMBL1983006 & 809207 & 4.3 & 4.2715 & TRN & \\
\hline CHEMBL1972183 & 809207 & 4.3 & 4.3916 & TRN & \\
\hline CHEMBL394790 & 809207 & 4.3 & 4.7911 & TRN & \\
\hline CHEMBL 226471 & 809207 & 4.3 & 4.2019 & TRN & \\
\hline CHEMBL1974702 & 809207 & 4.3 & 4.7321 & TRN & \\
\hline CHEMBL1996111 & 809207 & 4.3 & 3.9967 & TRN & \\
\hline CHEMBL1965589 & 809207 & 4.3 & 4.6004 & TRN & \\
\hline CHEMBL1998193 & 809207 & 4.3 & 3.7569 & TRN & \\
\hline CHEMBL474432 & 809207 & 5.5 & 5.7839 & TST & \\
\hline CHEMBL 2001539 & 809207 & 3.3 & 4.1968 & TST & \\
\hline CHEMBL1988153 & 809207 & 4.3 & 4.2972 & TRN & \\
\hline CHEMBL1999556 & 809207 & 4.3 & 4.6494 & TRN & \\
\hline CHEMBL1988437 & 809207 & 4.3 & 5.5469 & TST & \\
\hline CHEMBL1968245 & 809207 & 4.3 & 4.1513 & TRN & \\
\hline CHEMBL1998121 & 809207 & 4.3 & 4.5251 & TRN & \\
\hline CHEMBL1979577 & 809207 & 5.6 & 5.3358 & TRN & \\
\hline CHEMBL1991800 & 809207 & 4.3 & 4.4832 & TRN & \\
\hline CHEMBL52387 & 809207 & 4.3 & 4.3984 & TST & \\
\hline CHEMBL379835 & 809207 & 4.3 & 4.5101 & TST & \\
\hline CHEMBL1979357 & 809207 & 4.3 & 4.3174 & TRN & \\
\hline CHEMBL1980802 & 809207 & 4.3 & 4.4233 & TST & \\
\hline CHEMBL1979554 & 809207 & 4.3 & 4.3856 & TRN & \\
\hline CHEMBL1996817 & 809207 & 6.3 & 5.6975 & TRN & \\
\hline CHEMBL 3197315 & 809207 & 4.3 & 4.3184 & TST & \\
\hline CHEMBL 2004355 & 809207 & 4.3 & 4.1817 & TRN & \\
\hline CHEMBL468280 & 809207 & 4.3 & 4.3686 & TST & \\
\hline CHEMBL1990884 & 809207 & 4.3 & 5.0935 & TRN & \\
\hline CHEMBL 3109278 & 809207 & 6.7 & 5.901 & TRN & \\
\hline CHEMBL 256835 & 809207 & 4.3 & 4.4322 & TRN & \\
\hline CHEMBL1980142 & 809207 & 4.3 & 4.2255 & TRN & \\
\hline CHEMBL41783 & 809207 & 4.3 & 4.1394 & TRN & \\
\hline
\end{tabular}




\begin{tabular}{|c|c|c|c|c|c|}
\hline \\
\hline CHEMBL 2004438 & 809207 & 4.3 & 4.0413 & TRN & \\
\hline CHEMBL 2006276 & 809207 & 4.3 & 3.9419 & TRN & \\
\hline CHEMBL271381 & 809207 & 5.3 & 4.8702 & TRN & \\
\hline CHEMBL 2006785 & 809207 & 4.3 & 4.6875 & TRN & \\
\hline CHEMBL1982466 & 809207 & 6.0 & 6.3304 & TRN & \\
\hline CHEMBL1995740 & 809207 & 4.3 & 4.0864 & TRN & \\
\hline CHEMBL1996390 & 809207 & 4.3 & 4.3496 & TRN & \\
\hline CHEMBL234085 & 809207 & 4.3 & 4.2934 & TRN & \\
\hline CHEMBL1995832 & 809207 & 4.3 & 4.5115 & TRN & \\
\hline CHEMBL1998414 & 809207 & 4.3 & 4.209 & TRN & \\
\hline CHEMBL1969042 & 809207 & 4.3 & 4.3524 & TST & \\
\hline CHEMBL 2000345 & 809207 & 4.3 & 4.1204 & TRN & \\
\hline CHEMBL1999931 & 809207 & 4.3 & 4.8273 & TRN & \\
\hline CHEMBL1991640 & 809207 & 4.3 & 4.71399 & 99999999995 & TST \\
\hline CHEMBL1375418 & 809207 & 4.3 & 4.078 & TRN & \\
\hline CHEMBL302449 & 809207 & 5.8 & 6.0974 & TST & \\
\hline CHEMBL2007064 & 809207 & 6.1 & 6.1444 & TRN & \\
\hline CHEMBL1981047 & 809207 & 4.3 & 6.7086 & TST & \\
\hline CHEMBL229968 & 809207 & 5.6 & 5.3213 & TRN & \\
\hline CHEMBL1976240 & 809207 & 4.3 & 4.3654 & TRN & \\
\hline CHEMBL1979093 & 809207 & 4.3 & 4.9547 & TRN & \\
\hline CHEMBL1968151 & 809207 & 4.3 & 4.3272 & TST & \\
\hline CHEMBL1381197 & 809207 & 4.3 & 4.5781 & TRN & \\
\hline CHEMBL1987009 & 809207 & 4.3 & 4.4825 & TRN & \\
\hline CHEMBL379218 & 809207 & 4.3 & 5.1766 & TRN & \\
\hline CHEMBL 2003817 & 809207 & 4.3 & 4.2431 & TRN & \\
\hline CHEMBL336961 & 809207 & 4.3 & 4.1516 & TRN & \\
\hline CHEMBL1994830 & 809207 & 4.3 & 4.3024 & TRN & \\
\hline CHEMBL1987054 & 809207 & 7.0 & 7.2379 & TRN & \\
\hline CHEMBL1970083 & 809207 & 5.7 & 6.4257 & TRN & \\
\hline CHEMBL 226403 & 809207 & 4.3 & 4.1185 & TRN & \\
\hline CHEMBL 2005631 & 809207 & 6.4 & 6.3793 & TRN & \\
\hline CHEMBL1994938 & 809207 & 4.3 & 5.4215 & TRN & \\
\hline CHEMBL1825138 & 809207 & 6.4 & 4.9417 & TST & \\
\hline CHEMBL1977223 & 809207 & 4.3 & 4.0293 & TRN & \\
\hline CHEMBL1236126 & 809207 & 4.3 & 4.5119 & TST & \\
\hline CHEMBL1966279 & 809207 & 4.3 & 4.0774 & TRN & \\
\hline CHEMBL1997846 & 809207 & 4.3 & 4.7234 & TRN & \\
\hline CHEMBL 2004419 & 809207 & 4.3 & 4.3769 & TRN & \\
\hline CHEMBL1991728 & 809207 & 4.3 & 4.3792 & TRN & \\
\hline CHEMBL1975787 & 809207 & 4.3 & 4.6451 & TRN & \\
\hline CHEMBL 2002407 & 809207 & 4.3 & 4.3357 & TRN & \\
\hline CHEMBL1972489 & 809207 & 4.3 & 4.3573 & TRN & \\
\hline CHEMBL1994074 & 809207 & 4.3 & 4.4848 & TRN & \\
\hline CHEMBL1992937 & 809207 & 4.3 & 4.5416 & TST & \\
\hline CHEMBL451401 & 809207 & 3.3 & 4.3446 & TRN & \\
\hline CHEMBL1985566 & 809207 & 4.3 & 4.6323 & TRN & \\
\hline CHEMBL1972119 & 809207 & 4.3 & 4.6016 & TRN & \\
\hline & & & & 6131 & \\
\hline
\end{tabular}




\begin{tabular}{|c|c|c|c|c|}
\hline \multicolumn{5}{|c|}{ Supplemental Table S2.txt } \\
\hline CHEMBL1986328 & 809207 & 4.3 & 3.9812 & TST \\
\hline CHEMBL95692 & 809207 & 4.3 & 4.2296 & TRN \\
\hline CHEMBL1090356 & 809207 & 7.4 & 6.8673 & TRN \\
\hline CHEMBL1976455 & 809207 & 4.3 & 3.9583 & TRN \\
\hline CHEMBL1983923 & 809207 & 5.7 & 6.1756 & TST \\
\hline CHEMBL1983534 & 809207 & 4.3 & 4.2368 & TRN \\
\hline CHEMBL1982361 & 809207 & 4.3 & 4.484 & TRN \\
\hline CHEMBL1999112 & 809207 & 4.3 & 4.5438 & TST \\
\hline CHEMBL1982122 & 809207 & 4.3 & 4.185 & TRN \\
\hline CHEMBL 2000801 & 809207 & 4.3 & 4.1395 & TRN \\
\hline CHEMBL1682546 & 809207 & 4.3 & 4.0121 & TRN \\
\hline CHEMBL1991395 & 809207 & 4.3 & 4.2138 & TRN \\
\hline CHEMBL1971245 & 809207 & 4.3 & 5.5953 & TRN \\
\hline CHEMBL1987648 & 809207 & 4.3 & 4.2531 & TRN \\
\hline CHEMBL1996780 & 809207 & 4.3 & 4.444 & TST \\
\hline CHEMBL1972142 & 809207 & 4.3 & 4.5723 & TRN \\
\hline CHEMBL1966514 & 809207 & 6.3 & 6.0571 & TRN \\
\hline CHEMBL 2003638 & 809207 & 4.3 & 4.5945 & TRN \\
\hline CHEMBL 296586 & 809207 & 4.3 & 4.9609 & TRN \\
\hline CHEMBL1996066 & 809207 & 4.3 & 5.1416 & TST \\
\hline CHEMBL516429 & 809207 & 4.3 & 4.6233 & TRN \\
\hline CHEMBL1993722 & 809207 & 4.3 & 4.8115 & TRN \\
\hline CHEMBL1970806 & 809207 & 4.3 & 4.2671 & TST \\
\hline CHEMBL1375640 & 809207 & 4.3 & 4.6898 & TST \\
\hline CHEMBL1979970 & 809207 & 4.3 & 4.3101 & TRN \\
\hline CHEMBL 249282 & 809207 & 4.3 & 4.7244 & TST \\
\hline CHEMBL1969264 & 809207 & 4.3 & 4.2943 & TRN \\
\hline CHEMBL1973711 & 809207 & 4.3 & 4.55399 & 9999999999 \\
\hline CHEMBL 2006237 & 809207 & 4.3 & 4.4719 & TST \\
\hline CHEMBL1967720 & 809207 & 6.7 & 6.5342 & TST \\
\hline CHEMBL1572266 & 809207 & 4.3 & 4.7871 & TST \\
\hline CHEMBL1991138 & 809207 & 7.1 & 5.9145 & TST \\
\hline CHEMBL1969755 & 809207 & 4.3 & 4.2613 & TST \\
\hline CHEMBL1979516 & 809207 & 6.5 & 6.3877 & TST \\
\hline CHEMBL1605605 & 809207 & 4.3 & 4.4155 & TST \\
\hline CHEMBL1972820 & 809207 & 4.3 & 4.5079 & TST \\
\hline CHEMBL1996208 & 809207 & 4.3 & 5.0037 & TST \\
\hline CHEMBL1989029 & 809207 & 4.3 & 4.7474 & TST \\
\hline CHEMBL 392642 & 809207 & 4.3 & 4.4903 & TST \\
\hline CHEMBL514499 & 809207 & 4.3 & 5.5355 & TST \\
\hline CHEMBL1965631 & 809207 & 4.3 & 3.9865 & TST \\
\hline CHEMBL1980144 & 809207 & 4.3 & 4.3038 & TST \\
\hline CHEMBL1991188 & 809207 & 4.3 & 3.9202 & TST \\
\hline CHEMBL1972849 & 809207 & 4.3 & 4.0473 & TST \\
\hline CHEMBL377408 & 809207 & 4.3 & 4.3358 & TST \\
\hline CHEMBL215152 & 809207 & 4.3 & 4.6081 & TST \\
\hline CHEMBL231209 & 809207 & 4.3 & 4.5558 & TST \\
\hline CHEMBL1976220 & 809207 & 5.3 & 4.6414 & TST \\
\hline
\end{tabular}




\begin{tabular}{|c|c|c|c|c|c|}
\hline & & & & & \\
\hline CHEMBL 259922 & 809207 & 4.3 & 4.7393 & TST & \\
\hline CHEMBL1997617 & 809207 & 6.6 & 6.4939 & TST & \\
\hline CHEMBL1982383 & 809207 & 4.3 & 4.3244 & TST & \\
\hline CHEMBL1969301 & 809207 & 4.3 & 4.5423 & TST & \\
\hline CHEMBL17370 & 809207 & 4.3 & 4.3315 & TST & \\
\hline CHEMBL1987910 & 809207 & 4.3 & 4.8898 & TST & \\
\hline CHEMBL1983932 & 809207 & 4.3 & 4.4795 & TST & \\
\hline CHEMBL1973399 & 809207 & 3.3 & 4.1049 & TST & \\
\hline CHEMBL1966069 & 809207 & 4.3 & 4.5688 & TST & \\
\hline CHEMBL1997822 & 809207 & 5.4 & 5.4984 & TST & \\
\hline CHEMBL1991285 & 809207 & 4.3 & 4.6587 & TST & \\
\hline CHEMBL 243088 & 809207 & 6.4 & 6.934 & TST & \\
\hline CHEMBL1984038 & 809207 & 4.3 & 4.1953 & TST & \\
\hline CHEMBL1993661 & 809207 & 7.2 & 7.96899 & 9999999999 & TST \\
\hline CHEMBL1974416 & 809207 & 4.3 & 5.1044 & TST & \\
\hline CHEMBL 2004615 & 809207 & 5.8 & 4.42399 & 99999999995 & TST \\
\hline CHEMBL1997872 & 809207 & 4.3 & 5.2743 & TST & \\
\hline CHEMBL434573 & 429455 & 6.8239 & 6.7362 & TRN & \\
\hline CHEMBL374918 & 429455 & 6.1938 & 6.2173 & TRN & \\
\hline CHEMBL 374643 & 429455 & 8.2218 & 7.8229 & TRN & \\
\hline CHEMBL 222622 & 429455 & 6.8386 & 7.6777 & TRN & \\
\hline CHEMBL 375162 & 429455 & 7.4815 & 8.1016 & TRN & \\
\hline CHEMBL 222498 & 429455 & 6.6198 & 6.6632 & TRN & \\
\hline CHEMBL 385803 & 429455 & 7.2218 & 6.8322 & TRN & \\
\hline CHEMBL 223725 & 429455 & 7.9586 & 7.2185 & TRN & \\
\hline CHEMBL 221517 & 429455 & 5.0 & 6.8027 & TST & \\
\hline CHEMBL 376471 & 429455 & 7.6576 & 7.6709 & TRN & \\
\hline CHEMBL 373993 & 429455 & 6.0706 & 6.3707 & TST & \\
\hline CHEMBL373507 & 429455 & 6.2518 & 6.6164 & TRN & \\
\hline CHEMBL 375103 & 429455 & 7.5528 & 7.3702 & TRN & \\
\hline CHEMBL 375408 & 429455 & 7.0969 & 7.1852 & TRN & \\
\hline CHEMBL 222789 & 429455 & 7.0 & 7.0856 & TRN & \\
\hline CHEMBL 375859 & 429455 & 7.9586 & 7.2816 & TRN & \\
\hline CHEMBL221674 & 429455 & 6.9586 & 6.0221 & TRN & \\
\hline CHEMBL 222518 & 429455 & 6.9172 & 7.0416 & TRN & \\
\hline CHEMBL223638 & 429455 & 6.1938 & 6.2734 & TRN & \\
\hline CHEMBL 373995 & 429455 & 5.7696 & 5.6256 & TRN & \\
\hline CHEMBL 221662 & 429455 & 6.8239 & 7.059 & TRN & \\
\hline CHEMBL 373393 & 429455 & 6.5229 & 6.1672 & TRN & \\
\hline CHEMBL 223239 & 429455 & 6.3565 & 6.216 & TRN & \\
\hline CHEMBL 375102 & 429455 & 7.8539 & 7.0727 & TRN & \\
\hline CHEMBL 221723 & 429455 & 5.0 & 5.7195 & TRN & \\
\hline CHEMBL375972 & 429455 & 7.1079 & 6.9422 & TRN & \\
\hline CHEMBL434738 & 429455 & 6.7696 & 6.3876 & TRN & \\
\hline CHEMBL 373392 & 429455 & 7.2596 & 6.899 & TRN & \\
\hline CHEMBL 223532 & 429455 & 7.2518 & 6.8727 & TRN & \\
\hline CHEMBL 266199 & 429455 & 6.3768 & 6.5866 & TST & \\
\hline CHEMBL 376258 & 429455 & 7.7447 & 7.7665 & TRN & \\
\hline
\end{tabular}




\begin{tabular}{|c|c|c|c|c|c|}
\hline \multicolumn{6}{|c|}{ Supplemental Table S2 } \\
\hline CHEMBL223269 & 429455 & 6.284 & 5.8046 & TST & \\
\hline CHEMBL 385131 & 429455 & 7.6778 & 7.4385 & TRN & \\
\hline CHEMBL426905 & 429455 & 6.2441 & 6.5129 & TST & \\
\hline CHEMBL 374920 & 429455 & 6.8539 & 7.0155 & TRN & \\
\hline CHEMBL 387109 & 429455 & 6.8539 & 6.7533 & TRN & \\
\hline CHEMBL 374655 & 429455 & 7.9208 & 7.8654 & TRN & \\
\hline CHEMBL 374921 & 429455 & 6.8861 & 6.7742 & TRN & \\
\hline CHEMBL 222912 & 429455 & 6.71 & 6.8196 & TRN & \\
\hline CHEMBL374919 & 429455 & 6.6576 & 6.4768 & TRN & \\
\hline CHEMBL413856 & 429455 & 6.2366 & 6.2937 & TRN & \\
\hline CHEMBL427076 & 429455 & 6.2596 & 6.4654 & TRN & \\
\hline CHEMBL 374501 & 429455 & 5.0 & 6.15600 & 0000000001 & TRN \\
\hline CHEMBL 375568 & 429455 & 5.6576 & 5.9748 & TST & \\
\hline CHEMBL221996 & 429455 & 6.5086 & 6.4641 & TRN & \\
\hline CHEMBL 223726 & 429455 & 6.9031 & 7.0714 & TRN & \\
\hline CHEMBL 221569 & 429455 & 6.1549 & 6.2908 & TRN & \\
\hline CHEMBL223810 & 429455 & 6.0757 & 6.4346 & TRN & \\
\hline CHEMBL 374992 & 429455 & 7.3565 & 7.4854 & TRN & \\
\hline CHEMBL 374073 & 429455 & 7.8239 & 8.1423 & TRN & \\
\hline CHEMBL 376736 & 429455 & 7.1805 & 7.2477 & TRN & \\
\hline CHEMBL375150 & 429455 & 6.3872 & 6.6037 & TRN & \\
\hline CHEMBL 222610 & 429455 & 7.0177 & 7.1583 & TRN & \\
\hline CHEMBL 222710 & 429455 & 6.3979 & 6.6776 & TRN & \\
\hline CHEMBL 376459 & 429455 & 5.0 & 5.0912 & TRN & \\
\hline CHEMBL 373772 & 429455 & 6.301 & 6.8944 & TST & \\
\hline CHEMBL 223586 & 429455 & 5.0 & 4.8285 & TST & \\
\hline CHEMBL386218 & 429455 & 6.9666 & 7.1633 & TST & \\
\hline CHEMBL 374917 & 429455 & 5.0 & 5.4887 & TST & \\
\hline CHEMBL 390503 & 429455 & 6.1805 & 6.9528 & TST & \\
\hline CHEMBL 222835 & 429455 & 6.1249 & 7.0664 & TST & \\
\hline CHEMBL224921 & 429455 & 6.9208 & 6.7453 & TST & \\
\hline CHEMBL 376735 & 429455 & 6.8239 & 7.0499 & TST & \\
\hline CHEMBL 374757 & 429455 & 6.8539 & 6.5165 & TST & \\
\hline CHEMBL 375161 & 429455 & 6.0 & 6.3161 & TST & \\
\hline CHEMBL 223323 & 429455 & 6.3279 & 6.0982 & TST & \\
\hline CHEMBL485410 & 537479 & 6.9031 & 6.9753 & TRN & \\
\hline CHEMBL458959 & 537479 & 7.0809 & 7.16799 & 9999999999 & TRN \\
\hline CHEMBL485424 & 537479 & 5.9978 & 6.4956 & TRN & \\
\hline CHEMBL485414 & 537479 & 6.6038 & 6.9481 & TRN & \\
\hline CHEMBL484195 & 537479 & 7.5528 & 7.6313 & TRN & \\
\hline CHEMBL506885 & 537479 & 6.8297 & 6.6372 & TRN & \\
\hline CHEMBL520335 & 537479 & 6.8097 & 6.6591 & TRN & \\
\hline CHEMBL484563 & 537479 & 7.5686 & 7.2002 & TRN & \\
\hline CHEMBL456434 & 537479 & 5.2923 & 6.08899 & 99999999995 & TRN \\
\hline CHEMBL484548 & 537479 & 8.3979 & 7.9495 & TRN & \\
\hline CHEMBL464397 & 537479 & 8.3979 & 8.452 & TRN & \\
\hline CHEMBL458546 & 537479 & 7.9586 & 7.8173 & TRN & \\
\hline CHEMBL485225 & 537479 & 7.6383 & 7.5568 & TRN & \\
\hline
\end{tabular}




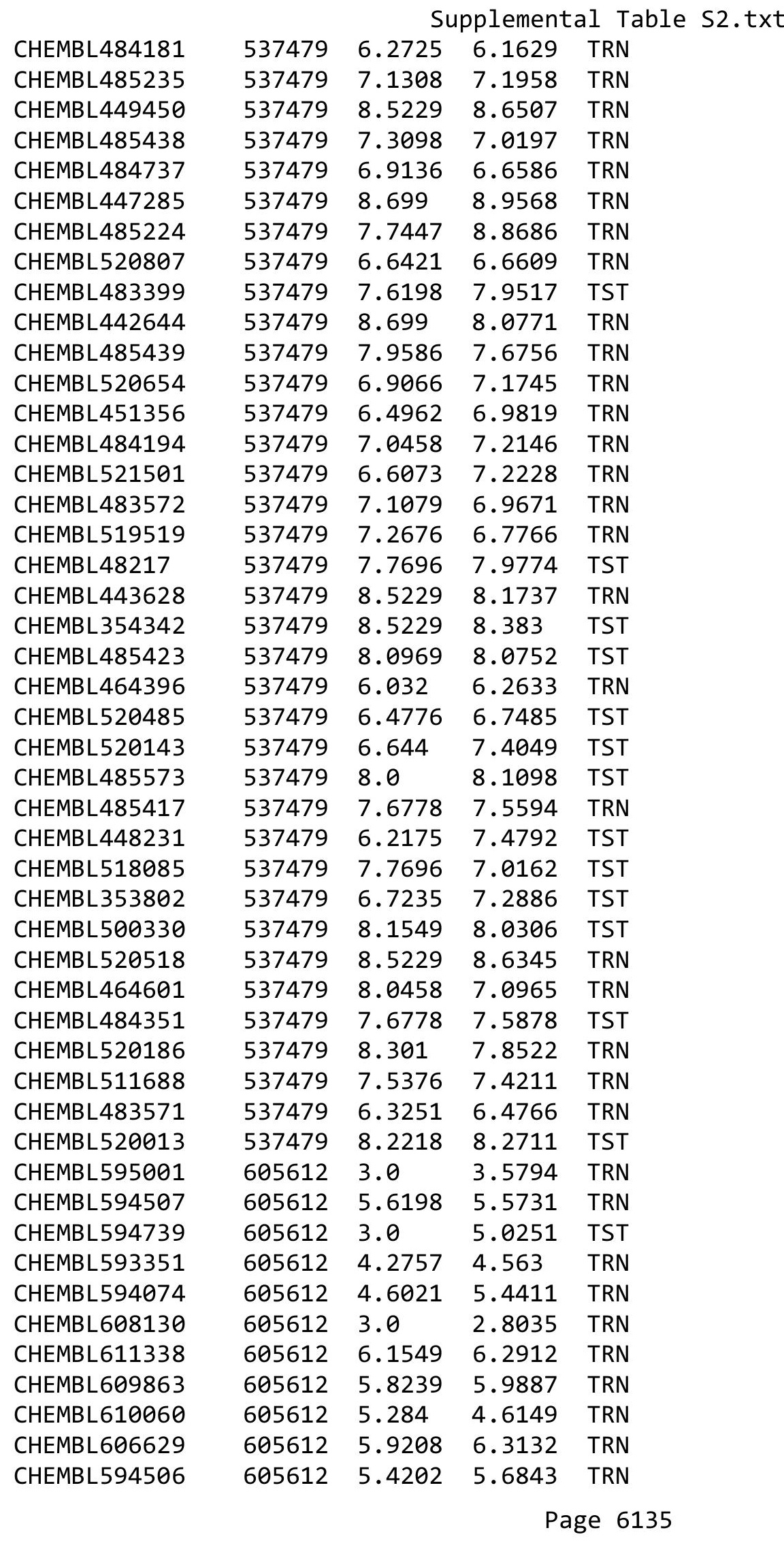




\begin{tabular}{|c|c|c|c|c|c|}
\hline \multirow[b]{2}{*}{ CHEMBL611339 } & \multicolumn{5}{|c|}{ Supplemental Table S2.txt } \\
\hline & 605612 & 6.1549 & 5.5159 & TRN & \\
\hline CHEMBL604059 & 605612 & 5.7959 & 5.629 & TRN & \\
\hline CHEMBL594528 & 605612 & 4.3468 & 3.8489 & TRN & \\
\hline CHEMBL594302 & 605612 & 5.0555 & 4.7437 & TST & \\
\hline CHEMBL608384 & 605612 & 4.4437 & 4.7536 & TRN & \\
\hline CHEMBL594738 & 605612 & 5.9586 & 4.9005 & TST & \\
\hline CHEMBL593365 & 605612 & 3.0 & 4.0621 & TST & \\
\hline CHEMBL593344 & 605612 & 6.1549 & 6.21299 & 9999999999 & TRN \\
\hline CHEMBL607315 & 605612 & 6.1549 & 5.4818 & TRN & \\
\hline CHEMBL594746 & 605612 & 5.9586 & 5.4465 & TRN & \\
\hline CHEMBL595000 & 605612 & 5.0706 & 5.2204 & TST & \\
\hline CHEMBL594140 & 605612 & 4.1024 & 5.0077 & TRN & \\
\hline CHEMBL596152 & 605612 & 3.0 & 3.1279 & TRN & \\
\hline CHEMBL593203 & 605612 & 3.0 & 3.1456 & TRN & \\
\hline CHEMBL594998 & 605612 & 5.9208 & 5.2586 & TRN & \\
\hline CHEMBL610740 & 605612 & 5.3665 & 4.6285 & TST & \\
\hline CHEMBL608129 & 605612 & 3.0 & 3.9916 & TST & \\
\hline CHEMBL594524 & 605612 & 6.0969 & 5.6483 & TRN & \\
\hline CHEMBL594762 & 605612 & 5.2596 & 5.0342 & TST & \\
\hline CHEMBL593826 & 605612 & 4.0 & 4.2407 & TRN & \\
\hline CHEMBL594771 & 605612 & 5.699 & 5.3844 & TRN & \\
\hline CHEMBL593435 & 605612 & 5.6383 & 4.7624 & TRN & \\
\hline CHEMBL594514 & 605612 & 3.0 & 3.6903 & TRN & \\
\hline CHEMBL594537 & 605612 & 4.9208 & 4.6644 & TRN & \\
\hline CHEMBL594761 & 605612 & 4.3372 & 5.086 & TST & \\
\hline CHEMBL610741 & 605612 & 5.7447 & 5.2695 & TRN & \\
\hline CHEMBL593827 & 605612 & 4.0 & 4.5047 & TRN & \\
\hline CHEMBL608696 & 605612 & 6.2218 & 4.8251 & TST & \\
\hline CHEMBL607691 & 605612 & 4.1487 & 5.0689 & TRN & \\
\hline CHEMBL593733 & 605612 & 4.0757 & 4.4671 & TST & \\
\hline CHEMBL593120 & 605612 & 5.6778 & 5.2413 & TRN & \\
\hline CHEMBL594745 & 605612 & 5.8539 & 5.5853 & TRN & \\
\hline CHEMBL594744 & 605612 & 4.3098 & 4.0919 & TRN & \\
\hline CHEMBL594525 & 605612 & 6.301 & 5.7257 & TRN & \\
\hline CHEMBL609870 & 605612 & 5.301 & 5.1927 & TST & \\
\hline CHEMBL594505 & 605612 & 5.699 & 5.3708 & TRN & \\
\hline CHEMBL609584 & 605612 & 5.8861 & 5.9102 & TRN & \\
\hline CHEMBL611948 & 605612 & 4.301 & 5.7508 & TRN & \\
\hline CHEMBL593517 & 605612 & 3.0 & 4.60800 & 00000000005 & TST \\
\hline CHEMBL610333 & 605612 & 6.0 & 6.1116 & TRN & \\
\hline CHEMBL593436 & 605612 & 4.6021 & 4.886 & TRN & \\
\hline CHEMBL596153 & 605612 & 4.9586 & 4.0681 & TRN & \\
\hline CHEMBL594737 & 605612 & 5.7959 & 5.9668 & TRN & \\
\hline CHEMBL596580 & 605612 & 4.2441 & 4.9947 & TRN & \\
\hline CHEMBL611340 & 605612 & 5.8239 & 6.3864 & TRN & \\
\hline CHEMBL594278 & 605612 & 3.0 & 4.1308 & TRN & \\
\hline CHEMBL596151 & 605612 & 3.0 & 4.0104 & TST & \\
\hline CHEMBL595235 & 605612 & 4.7959 & 4.4804 & TRN & \\
\hline
\end{tabular}




\begin{tabular}{|c|c|c|c|c|c|c|}
\hline \multicolumn{7}{|c|}{ Supplemental Table S2.txt } \\
\hline CHEMBL594740 & 605612 & 3.0 & 5.3388 & TST & & \\
\hline CHEMBL594758 & 605612 & 6.301 & 6.2624 & TRN & & \\
\hline CHEMBL593433 & 605612 & 4.2518 & 4.474 & TRN & & \\
\hline CHEMBL594052 & 605612 & 5.1024 & 5.3492 & TRN & & \\
\hline CHEMBL594974 & 605612 & 5.301 & 5.257000 & 0000000001 & & TST \\
\hline CHEMBL594838 & 605612 & 3.0 & 4.2395 & TST & & \\
\hline CHEMBL609852 & 605612 & 5.5229 & 5.3322 & TRN & & \\
\hline CHEMBL608697 & 605612 & 5.9586 & 4.5645 & TRN & & \\
\hline CHEMBL593839 & 605612 & 5.699 & 5.3511 & TRN & & \\
\hline CHEMBL609586 & 605612 & 5.4685 & 5.7534 & TRN & & \\
\hline CHEMBL594770 & 605612 & 5.7212 & 4.9408 & TRN & & \\
\hline CHEMBL609291 & 605612 & 5.8239 & 5.3117 & TST & & \\
\hline CHEMBL611632 & 605612 & 5.2441 & 4.7442 & TRN & & \\
\hline CHEMBL593607 & 605612 & 4.699 & 4.5832 & TRN & & \\
\hline CHEMBL594760 & 605612 & 4.0 & 4.2776 & TST & & \\
\hline CHEMBL596154 & 605612 & 3.0 & 4.0774 & TRN & & \\
\hline CHEMBL594597 & 605612 & 3.7696 & 5.0586 & TST & & \\
\hline CHEMBL608991 & 605612 & 4.7696 & 5.0083 & TRN & & \\
\hline CHEMBL595715 & 605612 & 5.8539 & 5.1098 & TRN & & \\
\hline CHEMBL609861 & 605612 & 5.8239 & 6.065 & TRN & & \\
\hline CHEMBL593121 & 605612 & 4.699 & 4.9157 & TRN & & \\
\hline CHEMBL3652652 & 1527604 & 9.5376 & 9.4677 & TRN & & \\
\hline CHEMBL3652658 & 1527604 & 9.3665 & 9.4361 & TRN & & \\
\hline CHEMBL3649455 & 1527604 & 8.6003 & 6.8886 & TST & & \\
\hline CHEMBL 3652657 & 1527604 & 9.6576 & 9.3673 & TRN & & \\
\hline CHEMBL3652667 & 1527604 & 9.7696 & 9.9894 & TRN & & \\
\hline CHEMBL3652678 & 1527604 & 7.8567 & 7.7652 & TRN & & \\
\hline CHEMBL3652653 & 1527604 & 9.7447 & 9.9738 & TRN & & \\
\hline CHEMBL3652649 & 1527604 & 7.699 & 7.1488 & TST & & \\
\hline CHEMBL 3652654 & 1527604 & 10.0458 & 10.0017 & TRN & & \\
\hline CHEMBL3649450 & 1527604 & 7.5683 & 6.2796 & TST & & \\
\hline CHEMBL3649448 & 1527604 & 7.301 & 6.6144 & TST & & \\
\hline CHEMBL3649452 & 1527604 & 5.9014 & 6.6056 & TST & & \\
\hline CHEMBL3652681 & 1527604 & 9.0223 & 9.1424 & TRN & & \\
\hline CHEMBL3652674 & 1527604 & 7.95700 & 000000000 & & 7.9995 & TRN \\
\hline CHEMBL3639515 & 1527604 & 7.8948 & 8.2839 & TRN & & \\
\hline CHEMBL3652656 & 1527604 & 10.0458 & 9.7197 & TRN & & \\
\hline CHEMBL3652676 & 1527604 & 7.5474 & 7.8294 & TRN & & \\
\hline CHEMBL 3649454 & 1527604 & 7.7392 & 6.965 & TST & & \\
\hline CHEMBL3652661 & 1527604 & 9.2441 & 9.3775 & TRN & & \\
\hline CHEMBL3652673 & 1527604 & 7.98799 & 999999999 & 995 & 8.1525 & TRN \\
\hline CHEMBL3649451 & 1527604 & 7.9367 & 6.5342 & TST & & \\
\hline CHEMBL3652662 & 1527604 & 9.6198 & 9.3816 & TRN & & \\
\hline CHEMBL3652664 & 1527604 & 9.2518 & 9.2961 & TRN & & \\
\hline CHEMBL 3652677 & 1527604 & 8.1113 & 7.427000 & 000000000 & 305 & TRN \\
\hline CHEMBL3652666 & 1527604 & 8.9469 & 9.0164 & TRN & & \\
\hline CHEMBL3649458 & 1527604 & 6.1577 & 7.066 & TST & & \\
\hline CHEMBL3652655 & 1527604 & 9.4437 & 9.4907 & TRN & & \\
\hline
\end{tabular}


Supplemental Table S2.txt

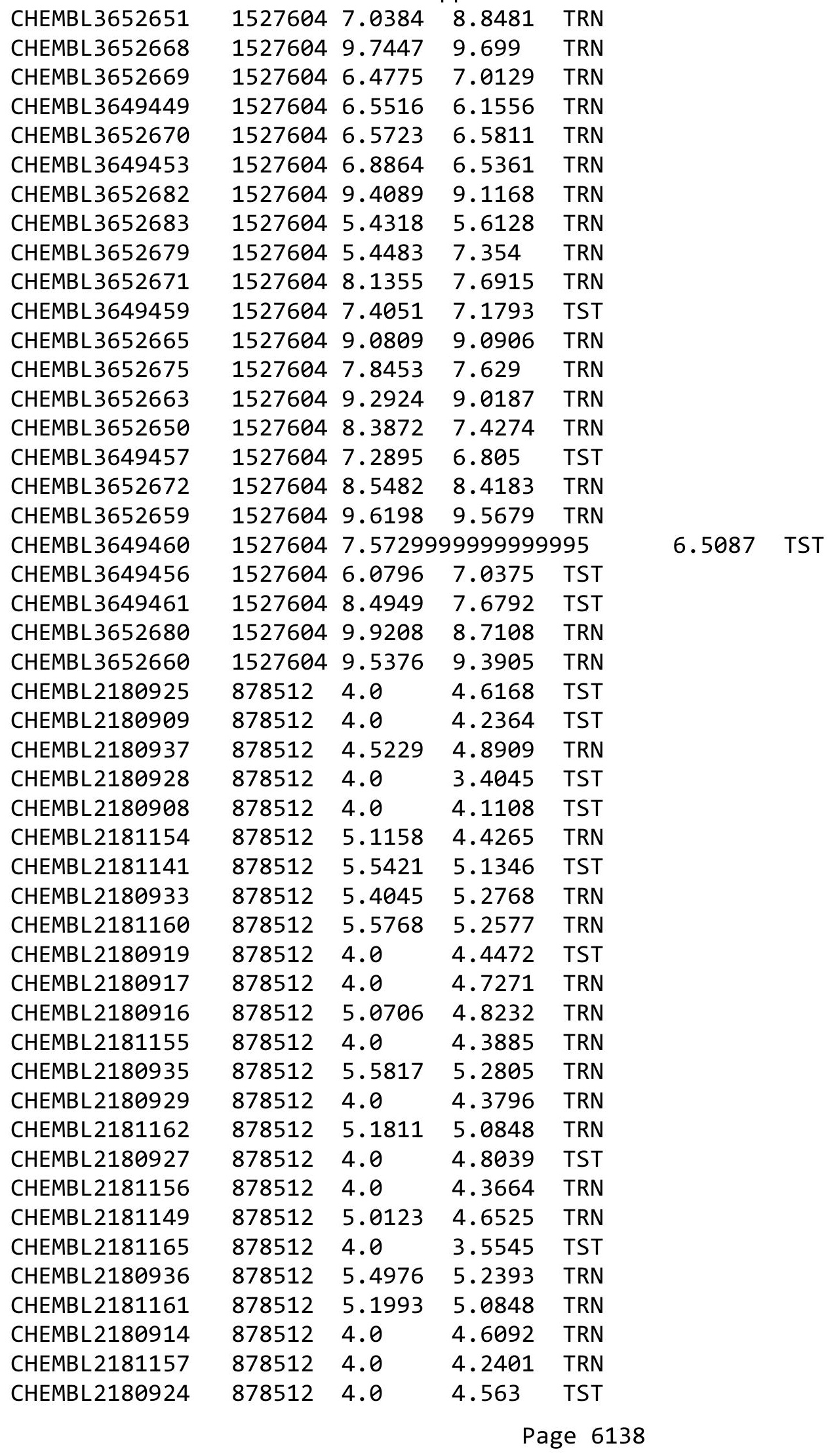




\begin{tabular}{|c|c|c|c|c|c|c|}
\hline & & \multicolumn{5}{|c|}{ Supplemental Table s2.txt } \\
\hline CHEMBL 2181148 & 878512 & 5.6655 & 4.9085 & TRN & & \\
\hline CHEMBL 2181143 & 878512 & 5.0315 & 4.6133 & TRN & & \\
\hline CHEMBL 2180926 & 878512 & 4.0 & 3.9079 & TST & & \\
\hline CHEMBL 2181142 & 878512 & 5.1267 & 4.8171 & TRN & & \\
\hline CHEMBL 2180930 & 878512 & 5.4776 & 5.319 & TRN & & \\
\hline CHEMBL 2180939 & 878512 & 4.0 & 4.9375 & TRN & & \\
\hline CHEMBL 2180940 & 878512 & 5.5544 & 5.4691 & TRN & & \\
\hline CHEMBL 2181158 & 878512 & \multicolumn{3}{|c|}{5.757000000000001} & 5.2508 & TRN \\
\hline CHEMBL 2180913 & 878512 & 4.0 & 4.4973 & TRN & & \\
\hline CHEMBL 2180934 & 878512 & 5.007 & 5.0681 & TRN & & \\
\hline CHEMBL 2181147 & 878512 & 5.6757 & 4.9502 & TRN & & \\
\hline CHEMBL 2181145 & 878512 & 4.0 & 3.2182 & TRN & & \\
\hline CHEMBL 2181163 & 878512 & 4.0 & 5.0848 & TRN & & \\
\hline CHEMBL 2181144 & 878512 & 4.0 & 3.7504 & TRN & & \\
\hline CHEMBL 2180906 & 878512 & 4.0 & 4.2826 & TRN & & \\
\hline CHEMBL 2181146 & 878512 & 4.0 & 3.6962 & TRN & & \\
\hline CHEMBL 2180938 & 878512 & 4.5229 & 5.2635 & TRN & & \\
\hline CHEMBL 2181139 & 878512 & 5.4112 & 5.2747 & TRN & & \\
\hline CHEMBL 2181140 & 878512 & 5.279 & 5.2017 & TRN & & \\
\hline CHEMBL 2180915 & 878512 & 4.0 & 4.6092 & TRN & & \\
\hline CHEMBL 2180922 & 878512 & 4.0 & 3.9804 & TST & & \\
\hline CHEMBL 2180907 & 878512 & 4.0 & 4.6915 & TST & & \\
\hline CHEMBL 2180911 & 878512 & 4.0 & 4.4379 & TRN & & \\
\hline CHEMBL 2180912 & 878512 & 4.0 & 4.4708 & TRN & & \\
\hline CHEMBL 2181159 & 878512 & 5.9547 & 5.4171 & TRN & & \\
\hline CHEMBL 2181164 & 878512 & 5.0155 & 4.8434 & TRN & & \\
\hline CHEMBL 2180920 & 878512 & 4.0 & 4.0941 & TST & & \\
\hline CHEMBL 2180923 & 878512 & 4.0 & 4.501 & TST & & \\
\hline CHEMBL 2180910 & 878512 & 4.5229 & 4.6975 & TRN & & \\
\hline CHEMBL 2180918 & 878512 & 5.1249 & 5.0992 & TRN & & \\
\hline CHEMBL 2181153 & 878512 & 5.4001 & 4.7827 & TRN & & \\
\hline CHEMBL 2180921 & 878512 & 4.0 & 4.3657 & TST & & \\
\hline CHEMBL 3652404 & 1534978 & 11.7011 & 11.3228 & TRN & & \\
\hline CHEMBL3652367 & 1534978 & 7.7144 & 8.1813 & TRN & & \\
\hline CHEMBL3652325 & 1534978 & 7.6421 & 7.5303 & TRN & & \\
\hline CHEMBL3927234 & 1534978 & 7.3507 & 7.9631 & TST & & \\
\hline CHEMBL3652351 & 1534978 & 8.5186 & 8.937000 & 0000000001 & & $1 \mathrm{~K}$ \\
\hline CHEMBL3652353 & 1534978 & 8.1343 & 8.3405 & TRN & & \\
\hline CHEMBL3652378 & 1534978 & 8.5952 & 8.7584 & TRN & & \\
\hline CHEMBL3652334 & 1534978 & 8.0516 & 7.9162 & TRN & & \\
\hline CHEMBL3652293 & 1534978 & 8.7799 & 8.3526 & TRN & & \\
\hline CHEMBL3652294 & 1534978 & 7.9469 & 8.1445 & TRN & & \\
\hline CHEMBL3652283 & 1534978 & 8.2757 & 7.8827 & TRN & & \\
\hline CHEMBL3652338 & 1534978 & 7.6861 & 7.6386 & TRN & & \\
\hline CHEMBL3652409 & 1534978 & 10.6289 & 10.9765 & TRN & & \\
\hline CHEMBL3652399 & 1534978 & 8.1302 & 8.0301 & TRN & & \\
\hline CHEMBL3652362 & 1534978 & 8.7167 & 8.6451 & TRN & & \\
\hline CHEMBL 3652384 & 1534978 & 8.5157 & 8.6582 & TRN & & \\
\hline
\end{tabular}


Supplemental Table S2.txt

\begin{tabular}{|c|c|c|c|c|c|}
\hline CHEMBL3652382 & 1534978 & 7.9031 & 8.0145 & TRN & \\
\hline CHEMBL3652331 & 1534978 & 8.7696 & 8.7484 & TRN & \\
\hline CHEMBL3652277 & 1534978 & 8.9208 & 9.3824 & TRN & \\
\hline CHEMBL3652324 & 1534978 & 7.6459 & 7.5845 & TRN & \\
\hline CHEMBL3652329 & 1534978 & 8.1135 & 8.0137 & TRN & \\
\hline CHEMBL3652408 & 1534978 & 11.9031 & 11.9775 & TRN & \\
\hline CHEMBL3652288 & 1534978 & 8.2284 & 8.4637 & TRN & \\
\hline CHEMBL3652386 & 1534978 & 7.9706 & 7.9323 & TRN & \\
\hline CHEMBL3652316 & 1534978 & 8.0964 & 7.7925 & TRN & \\
\hline CHEMBL3652289 & 1534978 & 8.6716 & 8.8055 & TRN & \\
\hline CHEMBL3652299 & 1534978 & 8.8416 & 7.7997 & TRN & \\
\hline CHEMBL3652319 & 1534978 & 7.8697 & 7.6929 & TRN & \\
\hline CHEMBL3652361 & 1534978 & 8.7447 & 8.5675 & TRN & \\
\hline CHEMBL3652295 & 1534978 & 6.0 & 5.9789 & TRN & \\
\hline CHEMBL3652403 & 1534978 & 10.644 & 10.4748 & TRN & \\
\hline CHEMBL3652343 & 1534978 & 6.0 & 6.3191 & TRN & \\
\hline CHEMBL3652376 & 1534978 & 7.7496 & 7.5683 & TRN & \\
\hline CHEMBL 3652290 & 1534978 & 8.2175 & 7.847 & TRN & \\
\hline CHEMBL3652359 & 1534978 & 8.172 & 8.2785 & TST & \\
\hline CHEMBL3652366 & 1534978 & 7.9031 & 7.9254 & TRN & \\
\hline CHEMBL3652355 & 1534978 & 8.5058 & 8.1752 & TST & \\
\hline CHEMBL 3652360 & 1534978 & 8.3516 & 8.3586 & TRN & \\
\hline CHEMBL3652392 & 1534978 & 7.9172 & 8.3686 & TRN & \\
\hline CHEMBL 3652292 & 1534978 & 7.8297 & 8.0564 & TST & \\
\hline CHEMBL3639511 & 1534978 & 8.0372 & 7.6034 & TRN & \\
\hline CHEMBL 3652340 & 1534978 & 8.02 & 7.9072 & TRN & \\
\hline CHEMBL 3652314 & 1534978 & 7.7825 & 7.4772 & TRN & \\
\hline CHEMBL3652394 & 1534978 & 8.0555 & 7.9079 & TRN & \\
\hline CHEMBL 3652284 & 1534978 & 7.3737 & 7.5821 & TRN & \\
\hline CHEMBL3652281 & 1534978 & 8.5287 & 8.8114 & TRN & \\
\hline CHEMBL 3652354 & 1534978 & 8.3197 & 8.3972 & TRN & \\
\hline CHEMBL 3652372 & 1534978 & 8.3134 & 8.2011 & TRN & \\
\hline CHEMBL3652380 & 1534978 & 7.8447 & 7.9306 & TRN & \\
\hline CHEMBL3652313 & 1534978 & 7.6556 & 7.4989 & TRN & \\
\hline CHEMBL3652364 & 1534978 & 8.2596 & 7.9442 & TRN & \\
\hline CHEMBL3652374 & 1534978 & 7.9747 & 8.1833 & TRN & \\
\hline CHEMBL3652335 & 1534978 & 6.0 & 6.3385 & TRN & \\
\hline CHEMBL3652336 & 1534978 & 8.1192 & 7.888999 & 9999999999 & TRN \\
\hline CHEMBL3652352 & 1534978 & 8.556000 & 00000006 & 8.0104 & TRN \\
\hline CHEMBL3652308 & 1534978 & 6.0 & 6.3534 & TRN & \\
\hline CHEMBL3652381 & 1534978 & 7.7852 & 8.4469 & TRN & \\
\hline CHEMBL3916507 & 1534978 & 7.9586 & 7.702006 & 0000000001 & TRN \\
\hline CHEMBL 3652370 & 1534978 & 6.0 & 7.8251 & TRN & \\
\hline CHEMBL3652390 & 1534978 & 8.0742 & 8.2789 & TRN & \\
\hline CHEMBL 3652348 & 1534978 & 7.9957 & 8.0818 & TRN & \\
\hline CHEMBL3652312 & 1534978 & 6.0 & 6.3001 & TRN & \\
\hline CHEMBL3901124 & 1534978 & 11.2941 & 10.8038 & TST & \\
\hline \multirow[t]{2}{*}{ CHEMBL 3652344} & 1534978 & 8.7721 & 8.027006 & $\partial 000000001$ & TRN \\
\hline & & \multicolumn{4}{|c|}{ Page 6140} \\
\hline
\end{tabular}


Supplemental Table S2.txt

\begin{tabular}{|c|c|c|c|c|c|c|}
\hline CHEMBL3652393 & 1534978 & 7.8633 & 8.0083 & TRN & & \\
\hline CHEMBL3931018 & 1534978 & 7.8416 & 8.2675 & TST & & \\
\hline CHEMBL3652410 & 1534978 & 10.58 & 10.7483 & TRN & & \\
\hline CHEMBL3652280 & 1534978 & 8.1397 & 7.9125 & TRN & & \\
\hline CHEMBL3652327 & 1534978 & 7.6968 & 7.558 & TRN & & \\
\hline CHEMBL3652297 & 1534978 & 8.2984 & 8.6983 & TRN & & \\
\hline CHEMBL3652322 & 1534978 & 8.0794 & 7.7504 & TST & & \\
\hline CHEMBL3652345 & 1534978 & \multicolumn{3}{|c|}{7.7620000000000005} & 7.8554 & TRN \\
\hline CHEMBL3652373 & 1534978 & 7.7011 & 7.9611 & TRN & & \\
\hline CHEMBL3652383 & 1534978 & 8.8097 & 8.5427 & TRN & & \\
\hline CHEMBL3652309 & 1534978 & 8.2716 & 7.7631 & TRN & & \\
\hline CHEMBL3652375 & 1534978 & 7.7447 & 7.8777 & TRN & & \\
\hline CHEMBL3652368 & 1534978 & 8.8665 & 8.4736 & TST & & \\
\hline CHEMBL3652349 & 1534978 & 7.8601 & 7.9874 & TRN & & \\
\hline CHEMBL3652371 & 1534978 & 8.1618 & 8.0435 & TRN & & \\
\hline CHEMBL3652315 & 1534978 & 7.8928 & 7.7107 & TRN & & \\
\hline CHEMBL3652385 & 1534978 & 7.9706 & 7.6511 & TRN & & \\
\hline CHEMBL3652363 & 1534978 & 8.1605 & 7.6547 & TRN & & \\
\hline CHEMBL3652279 & 1534978 & 8.1506 & 8.2725 & TRN & & \\
\hline CHEMBL3652357 & 1534978 & 8.1891 & 7.9296 & TRN & & \\
\hline CHEMBL3652396 & 1534978 & 7.7122 & 8.0484 & TRN & & \\
\hline CHEMBL3652397 & 1534978 & 7.8416 & 7.8173 & TST & & \\
\hline CHEMBL3652317 & 1534978 & 8.7986 & 8.5591 & TRN & & \\
\hline CHEMBL3652321 & 1534978 & 7.9318 & 7.5328 & TRN & & \\
\hline CHEMBL3652407 & 1534978 & 11.8761 & 11.667 & TRN & & \\
\hline CHEMBL3652358 & 1534978 & 8.4855 & 8.7077 & TRN & & \\
\hline CHEMBL3652350 & 1534978 & 7.8416 & 7.8622 & TRN & & \\
\hline CHEMBL3652365 & 1534978 & \multicolumn{3}{|c|}{7.757000000000001} & 8.0162 & ובו \\
\hline CHEMBL3652369 & 1534978 & 8.3595 & 8.3074 & TRN & & \\
\hline CHEMBL3652339 & 1534978 & 7.9245 & 7.8849 & TRN & & \\
\hline CHEMBL3639512 & 1534978 & 7.644 & 8.1375 & TRN & & \\
\hline CHEMBL3652303 & 1534978 & 6.0 & 6.7129 & TRN & & \\
\hline CHEMBL3652326 & 1534978 & 7.6576 & 7.8153 & TRN & & \\
\hline CHEMBL3652298 & 1534978 & 6.0 & 6.1179 & TRN & & \\
\hline CHEMBL3652337 & 1534978 & 8.5086 & 7.9097 & TRN & & \\
\hline CHEMBL3652401 & 1534978 & 8.1871 & 8.1039 & TRN & & \\
\hline CHEMBL3652302 & 1534978 & 8.2823 & 8.1021 & TRN & & \\
\hline CHEMBL3652310 & 1534978 & 7.9431 & 7.8333 & TRN & & \\
\hline CHEMBL3652389 & 1534978 & 8.1884 & 8.414 & TRN & & \\
\hline CHEMBL3652306 & 1534978 & 7.983 & 8.3013 & TST & & \\
\hline CHEMBL3929066 & 1534978 & 8.2 & 8.9113 & TST & & \\
\hline CHEMBL3652318 & 1534978 & 8.2233 & 8.3423 & TST & & \\
\hline CHEMBL3652282 & 1534978 & 7.8297 & 7.6573 & TST & & \\
\hline CHEMBL3652388 & 1534978 & 7.7773 & 7.8995 & TST & & \\
\hline CHEMBL3652323 & 1534978 & 7.7852 & 7.6183 & TST & & \\
\hline CHEMBL3652320 & 1534978 & 7.644 & 7.6743 & TST & & \\
\hline CHEMBL3652391 & 1534978 & 7.983 & 8.0475 & TST & & \\
\hline CHEMBL3652356 & 1534978 & 7.9788 & 7.9426 & TST & & \\
\hline
\end{tabular}


Supplemental Table S2.txt

\begin{tabular}{|c|c|c|c|c|c|c|}
\hline CHEMBL3652296 & 1534978 & 8.1113 & 7.8921 & TST & & \\
\hline CHEMBL3652379 & 1534978 & 8.3251 & 8.0145 & TST & & \\
\hline CHEMBL 3652387 & 1534978 & 7.9586 & 8.1549 & TST & & \\
\hline CHEMBL 3652347 & 1534978 & 8.5258 & 7.9659 & TST & & \\
\hline CHEMBL 3652346 & 1534978 & 7.718999 & 999999999 & 99 & 7.6556 & TST \\
\hline CHEMBL 3652405 & 1534978 & 10.6108 & 10.2492 & TST & & \\
\hline CHEMBL3969771 & 1534978 & 7.9547 & 7.9214 & TST & & \\
\hline CHEMBL 3652291 & 1534978 & 8.01100 & 000000000 & $\partial 1$ & 8.3297 & TST \\
\hline CHEMBL 3652377 & 1534978 & 8.4437 & 8.3601 & TST & & \\
\hline CHEMBL3652328 & 1534978 & 8.3904 & 7.6535 & TST & & \\
\hline CHEMBL 3652333 & 1534978 & 8.6198 & 8.0282 & TST & & \\
\hline CHEMBL 3652332 & 1534978 & 7.9666 & 7.725 & TST & & \\
\hline CHEMBL3652330 & 1534978 & 8.1904 & 8.2827 & TST & & \\
\hline CHEMBL 3946084 & 1642462 & 6.0 & 5.9114 & TRN & & \\
\hline CHEMBL3985772 & 1642462 & 8.0 & 8.3151 & TRN & & \\
\hline CHEMBL3957730 & 1642462 & 7.3002 & 6.9182 & TRN & & \\
\hline CHEMBL3963276 & 1642462 & 5.9547 & 6.086 & TST & & \\
\hline CHEMBL3952741 & 1642462 & 7.3635 & 7.2592 & TRN & & \\
\hline CHEMBL 3906029 & 1642462 & 6.2549 & 6.3379 & TST & & \\
\hline CHEMBL3954595 & 1642462 & 8.1433 & 7.9391 & TRN & & \\
\hline CHEMBL3923381 & 1642462 & 7.0044 & 6.7162 & TST & & \\
\hline CHEMBL3945324 & 1642462 & 6.5467 & 6.818 & TRN & & \\
\hline CHEMBL3969325 & 1642462 & 8.6091 & 8.896 & TST & & \\
\hline CHEMBL 3974729 & 1642462 & 6.8386 & 6.631 & TRN & & \\
\hline CHEMBL 3891623 & 1642462 & 6.0 & 6.0295 & TRN & & \\
\hline CHEMBL 3946874 & 1642462 & 8.6536 & 7.8717 & TRN & & \\
\hline CHEMBL 3905628 & 1642462 & 7.1343 & 7.3105 & TRN & & \\
\hline CHEMBL3977577 & 1642462 & 8.4711 & 8.9816 & TST & & \\
\hline CHEMBL 3912670 & 1642462 & 6.0 & 5.9471 & TRN & & \\
\hline CHEMBL 3913767 & 1642462 & 5.7696 & 5.7047 & TRN & & \\
\hline CHEMBL3916429 & 1642462 & 4.699 & 6.087000 & 0000000001 & & \\
\hline CHEMBL 3895792 & 1642462 & 7.767 & 7.8596 & TRN & & \\
\hline CHEMBL3982579 & 1642462 & 7.1118 & 7.0972 & TRN & & \\
\hline CHEMBL 3943648 & 1642462 & 7.6615 & 7.7311 & TRN & & \\
\hline CHEMBL3919291 & 1642462 & 6.7447 & 6.4994 & TRN & & \\
\hline CHEMBL 3897427 & 1642462 & 6.8761 & 7.3958 & TRN & & \\
\hline CHEMBL 3965294 & 1642462 & 7.5214 & 7.6815 & TST & & \\
\hline CHEMBL3960736 & 1642462 & 8.3696 & 8.4042 & TRN & & \\
\hline CHEMBL 3928198 & 1642462 & 8.1851 & 8.0775 & TRN & & \\
\hline CHEMBL3905905 & 1642462 & 7.1925 & 7.1045 & TRN & & \\
\hline CHEMBL3930451 & 1642462 & 6.0 & 5.9243 & TRN & & \\
\hline CHEMBL3956876 & 1642462 & 6.4214 & 6.1994 & TST & & \\
\hline CHEMBL3983453 & 1642462 & 8.068 & 8.0864 & TRN & & \\
\hline CHEMBL3937334 & 1642462 & 7.2549 & 7.5552 & TRN & & \\
\hline CHEMBL 3944777 & 1642462 & 7.0701 & 6.7953 & TRN & & \\
\hline CHEMBL 3952342 & 1642462 & 8.1331 & 8.1651 & TRN & & \\
\hline CHEMBL3899127 & 1642462 & 6.4012 & 6.3211 & TRN & & \\
\hline CHEMBL3896691 & 1642462 & 6.0 & 6.5258 & TRN & & \\
\hline
\end{tabular}


Supplemental Table S2.txt

\begin{tabular}{|c|c|c|c|c|c|}
\hline CHEMBL3914478 & 1642462 & 7.4868 & 7.2446 & TRN & \\
\hline CHEMBL3932451 & 1642462 & 7.4389 & 7.5614 & TRN & \\
\hline CHEMBL3919941 & 1642462 & 6.8097 & 6.3367 & TRN & \\
\hline CHEMBL3949136 & 1642462 & 9.3665 & 9.1664 & TRN & \\
\hline CHEMBL3986100 & 1642462 & 6.6882 & 6.6175 & TRN & \\
\hline CHEMBL3931902 & 1642462 & 8.1791 & 8.1389 & TRN & \\
\hline CHEMBL3923391 & 1642462 & 7.857 & 8.2802 & TST & \\
\hline CHEMBL3948586 & 1642462 & 8.0726 & 7.7763 & TRN & \\
\hline CHEMBL3908187 & 1642462 & 7.2248 & 7.3042 & TRN & \\
\hline CHEMBL3969563 & 1642462 & 8.6676 & 8.6026 & TRN & \\
\hline CHEMBL3969951 & 1642462 & 8.1752 & 7.9405 & TRN & \\
\hline CHEMBL3947008 & 1642462 & 8.6126 & 8.9908 & TRN & \\
\hline CHEMBL3943121 & 1642462 & 6.6144 & 6.931 & TRN & \\
\hline CHEMBL3902021 & 1642462 & 6.0 & 5.7266 & TRN & \\
\hline CHEMBL3971299 & 1642462 & 7.2581 & 7.2458 & TRN & \\
\hline CHEMBL3963293 & 1642462 & 6.7799 & 6.9064 & TRN & \\
\hline CHEMBL3918529 & 1642462 & 9.699 & 6.3971 & TST & \\
\hline CHEMBL3916608 & 1642462 & 7.4401 & 7.3472 & TRN & \\
\hline CHEMBL3961538 & 1642462 & 9.4089 & 8.4832 & TST & \\
\hline CHEMBL3980770 & 1642462 & 6.3019 & 6.4077 & TRN & \\
\hline CHEMBL3899661 & 1642462 & 6.0 & 5.7136 & TRN & \\
\hline CHEMBL3900840 & 1642462 & 6.8097 & 6.6973 & TRN & \\
\hline CHEMBL3927282 & 1642462 & 7.9586 & 7.9185 & TST & \\
\hline CHEMBL3916624 & 1642462 & 6.6696 & 6.5125 & TST & \\
\hline CHEMBL3973474 & 1642462 & 7.4145 & 7.4386 & TRN & \\
\hline CHEMBL3907133 & 1642462 & 8.2716 & 8.1153 & TRN & \\
\hline CHEMBL3936330 & 1642462 & 6.0 & 5.7926 & TRN & \\
\hline CHEMBL3936240 & 1642462 & 7.3788 & 7.5342 & TRN & \\
\hline CHEMBL3985261 & 1642462 & 7.2118 & 7.6197 & TST & \\
\hline CHEMBL3901295 & 1642462 & 6.0 & 5.9375 & TRN & \\
\hline CHEMBL3920062 & 1642462 & 8.5003 & 8.2728 & TRN & \\
\hline CHEMBL3934418 & 1642462 & 7.857 & 7.7774 & TST & \\
\hline CHEMBL3982864 & 1642462 & 7.1494 & 6.8981 & TRN & \\
\hline CHEMBL3967606 & 1642462 & 7.7721 & 7.7978 & TST & \\
\hline CHEMBL3961024 & 1642462 & 8.4895 & 8.7136 & TRN & \\
\hline CHEMBL3974586 & 1642462 & 6.1403 & 6.295 & TRN & \\
\hline CHEMBL3965274 & 1642462 & 6.0 & 6.0628 & TRN & \\
\hline CHEMBL3895453 & 1642462 & 7.4572 & 7.2326 & TRN & \\
\hline CHEMBL3945260 & 1642462 & 6.059 & \multicolumn{2}{|c|}{6.196000000000001} & TRN \\
\hline CHEMBL3949659 & 1642462 & 5.8013 & 6.2585 & TRN & \\
\hline CHEMBL3931254 & 1642462 & 6.8356 & 7.5303 & TST & \\
\hline CHEMBL3976502 & 1642462 & 6.1013 & 5.9424 & TST & \\
\hline CHEMBL3973591 & 1642462 & 6.1296 & 6.2604 & TRN & \\
\hline CHEMBL 3925445 & 1642462 & 6.9666 & 7.1648 & TRN & \\
\hline CHEMBL3918029 & 1642462 & 7.3635 & 7.2447 & TRN & \\
\hline CHEMBL3937215 & 1642462 & 7.4498 & 7.1614 & TRN & \\
\hline CHEMBL3943471 & 1642462 & 7.8794 & 7.891 & TRN & \\
\hline CHEMBL3965615 & 1642462 & 5.7258 & 5.1792 & TST & \\
\hline
\end{tabular}


Supplemental Table S2.txt

\begin{tabular}{|c|c|c|c|c|c|}
\hline CHEMBL 3985775 & 1642462 & 7.585 & 7.8754 & TRN & \\
\hline CHEMBL 3957411 & 1642462 & 7.4045 & 7.0753 & TST & \\
\hline CHEMBL 3959242 & 1642462 & 7.279 & 7.4042 & TST & \\
\hline CHEMBL 3939581 & 1642462 & 8.3747 & 8.7616 & TST & \\
\hline CHEMBL 3921599 & 1642462 & 7.7305 & 7.8002 & TRN & \\
\hline CHEMBL 3938539 & 1642462 & 7.9872 & 7.81 & TRN & \\
\hline CHEMBL 3947868 & 1642462 & 5.6003 & 5.6327 & TRN & \\
\hline CHEMBL 3968042 & 1642462 & 5.3893 & \multicolumn{2}{|c|}{5.507999999999999} & TRN \\
\hline CHEMBL 3939661 & 1642462 & \multicolumn{3}{|c|}{7.757000000000001} & TRN \\
\hline CHEMBL3979159 & 1642462 & 8.4711 & 8.7142 & TST & \\
\hline CHEMBL 3928122 & 1642462 & 7.0241 & 6.9794 & TRN & \\
\hline CHEMBL 3950030 & 1642462 & 8.0061 & 8.3644 & TRN & \\
\hline CHEMBL 3967386 & 1642462 & 8.0747 & 7.9072 & TRN & \\
\hline CHEMBL 3942539 & 1642462 & 6.3363 & 6.5307 & TST & \\
\hline CHEMBL 3928583 & 1642462 & 6.983 & 7.0482 & TRN & \\
\hline CHEMBL 3976118 & 1642462 & 7.6676 & \multicolumn{2}{|c|}{8.152000000000001} & TRN \\
\hline CHEMBL 3986802 & 1642462 & 9.0706 & 8.5852 & TRN & \\
\hline CHEMBL 3952575 & 1642462 & 7.6478 & 7.8177 & TRN & \\
\hline CHEMBL 3953574 & 1642462 & 4.699 & \multicolumn{2}{|c|}{5.872999999999999} & \\
\hline CHEMBL 3963314 & 1642462 & 7.5513 & 7.8885 & TRN & \\
\hline CHEMBL 3986370 & 1642462 & 7.9281 & 8.2795 & TST & \\
\hline CHEMBL 3938075 & 1642462 & 4.699 & 5.9758 & TST & \\
\hline CHEMBL 3914458 & 1642462 & 7.0031 & 7.0414 & TRN & \\
\hline CHEMBL 3926788 & 1642462 & 7.8297 & 7.6227 & TRN & \\
\hline CHEMBL 3898965 & 1642462 & 6.0 & 5.9114 & TRN & \\
\hline CHEMBL 3970956 & 1642462 & 7.6517 & 7.5071 & TRN & \\
\hline CHEMBL 3957117 & 1642462 & 6.4306 & 6.2527 & TRN & \\
\hline CHEMBL 3939886 & 1642462 & 8.3716 & 7.6611 & TST & \\
\hline CHEMBL 3928475 & 1642462 & 7.2882 & 7.7529 & TRN & \\
\hline CHEMBL 3957651 & 1642462 & 8.8125 & 8.7448 & TRN & \\
\hline CHEMBL 3896978 & 1642462 & 7.7496 & 7.9233 & TRN & \\
\hline CHEMBL 3915741 & 1642462 & 4.699 & 6.1296 & TST & \\
\hline CHEMBL 3965517 & 1642462 & 8.1314 & 7.8352 & TRN & \\
\hline CHEMBL3956525 & 1642462 & 5.9318 & 6.3207 & TST & \\
\hline CHEMBL 3974675 & 1642462 & 7.2941 & 7.2778 & TRN & \\
\hline CHEMBL3928424 & 1642462 & 6.0 & 5.9307 & TRN & \\
\hline CHEMBL 3983535 & 1642462 & 6.6904 & 6.7134 & TRN & \\
\hline CHEMBL 3964232 & 1642462 & 7.4067 & 7.7006 & TRN & \\
\hline CHEMBL 3896967 & 1642462 & 7.8125 & 7.6842 & TRN & \\
\hline CHEMBL 3979165 & 1642462 & 7.6757 & 7.8683 & TRN & \\
\hline CHEMBL3926967 & 1642462 & 7.7747 & 7.8991 & TRN & \\
\hline CHEMBL 3985933 & 1642462 & 7.6596 & 7.5168 & TRN & \\
\hline CHEMBL3921882 & 1642462 & 8.1135 & 8.2089 & TRN & \\
\hline CHEMBL3920786 & 1642462 & 7.7825 & 8.1057 & TRN & \\
\hline CHEMBL 3941476 & 1642462 & 6.8327 & 7.3071 & TST & \\
\hline CHEMBL 3965403 & 1642462 & 7.6091 & 7.3374 & TRN & \\
\hline CHEMBL 3964418 & 1642462 & 8.98299 & 999999999 & 8.8276 & $1 \times 1$ \\
\hline CHEMBL 3907466 & 1642462 & 6.3261 & 6.5056 & TST & \\
\hline
\end{tabular}


Supplemental Table S2.txt

\begin{tabular}{|c|c|c|c|c|c|}
\hline CHEMBL3978630 & 1642462 & 7.2581 & 7.3776 & TST & \\
\hline CHEMBL3917947 & 1642462 & 7.0123 & 7.7029 & TST & \\
\hline CHEMBL3922917 & 1642462 & 6.7595 & 7.0338 & TST & \\
\hline CHEMBL3965594 & 1642462 & 6.0 & 5.9443 & TRN & \\
\hline CHEMBL3960761 & 1642462 & 6.8827 & 6.6476 & TST & \\
\hline CHEMBL3942625 & 1642462 & 6.3925 & 7.1407 & TST & \\
\hline CHEMBL3946401 & 1642462 & 7.4306 & 7.3172 & TST & \\
\hline CHEMBL3969281 & 1642462 & 7.4461 & 7.2189 & TRN & \\
\hline CHEMBL3908339 & 1642462 & 5.7545 & 6.1916 & TRN & \\
\hline CHEMBL3950612 & 1642462 & 7.0851 & 7.1623 & TRN & \\
\hline CHEMBL3982665 & 1642462 & 6.2924 & 6.5341 & TRN & \\
\hline CHEMBL3893355 & 1642462 & 7.1403 & 7.2241 & TRN & \\
\hline CHEMBL3922402 & 1642462 & 5.7471 & 5.9098 & TRN & \\
\hline CHEMBL3953239 & 1642462 & 7.4672 & 7.3406 & TRN & \\
\hline CHEMBL3911734 & 1642462 & 7.3737 & 7.3573 & TRN & \\
\hline CHEMBL3890180 & 1642462 & 7.1959 & 7.3401 & TRN & \\
\hline CHEMBL3893663 & 1642462 & 6.2204 & 6.4276 & TRN & \\
\hline CHEMBL3953311 & 1642462 & 6.4377 & 6.5059 & TRN & \\
\hline CHEMBL3956875 & 1642462 & 8.3372 & 8.4821 & TRN & \\
\hline CHEMBL3929051 & 1642462 & 5.7258 & 5.5058 & TRN & \\
\hline CHEMBL3964822 & 1642462 & 8.1838 & 7.9139 & TRN & \\
\hline CHEMBL3904054 & 1642462 & 8.4868 & 8.2826 & TST & \\
\hline CHEMBL3954919 & 1642462 & 8.3354 & 7.9876 & TRN & \\
\hline CHEMBL3903654 & 1642462 & 5.644 & 5.7142 & TRN & \\
\hline CHEMBL3896915 & 1642462 & 6.0 & 5.8417 & TRN & \\
\hline CHEMBL3921975 & 1642462 & 7.5143 & 7.5672 & TRN & \\
\hline CHEMBL3903819 & 1642462 & 7.4123 & 7.0191 & TRN & \\
\hline CHEMBL3925017 & 1642462 & 8.9066 & 8.8314 & TRN & \\
\hline CHEMBL3957110 & 1642462 & 7.8827 & 7.2408 & TST & \\
\hline CHEMBL3918124 & 1642462 & 7.4271 & 7.6462 & TRN & \\
\hline CHEMBL3889653 & 1642462 & 8.1549 & 7.6497 & TRN & \\
\hline CHEMBL3917158 & 1642462 & 8.1198 & 8.2461 & TRN & \\
\hline CHEMBL3901566 & 1642462 & 8.0443 & 7.7615 & TRN & \\
\hline CHEMBL3938495 & 1642462 & 7.8013 & 8.0369 & TRN & \\
\hline CHEMBL3975539 & 1642462 & 6.8861 & 7.3282 & TST & \\
\hline CHEMBL3890248 & 1642462 & 6.0 & 6.0031 & TRN & \\
\hline CHEMBL3910168 & 1642462 & 7.8928 & 7.967006 & 00000000005 & TRN \\
\hline CHEMBL3956238 & 1642462 & 8.6216 & 8.6985 & TRN & \\
\hline CHEMBL3964562 & 1642462 & 6.2765 & 6.5418 & TRN & \\
\hline CHEMBL3947211 & 1642462 & 6.0 & 6.0957 & TRN & \\
\hline CHEMBL3911197 & 1642462 & 5.9066 & 5.95200 & 3000000001 & TST \\
\hline CHEMBL3934001 & 1642462 & 7.5768 & 7.6724 & TRN & \\
\hline CHEMBL3915928 & 1642462 & 7.8182 & 8.1427 & TRN & \\
\hline CHEMBL3892417 & 1642462 & 5.4622 & 6.3496 & TRN & \\
\hline CHEMBL3906535 & 1642462 & 7.7721 & 7.5166 & TRN & \\
\hline CHEMBL3898415 & 1642462 & 6.0 & 6.0836 & TRN & \\
\hline CHEMBL3891447 & 1642462 & 6.5467 & 6.4209 & TRN & \\
\hline CHEMBL3967402 & 1642462 & 6.7144 & 6.8473 & TRN & \\
\hline
\end{tabular}


Supplemental Table S2.txt

\begin{tabular}{|c|c|c|c|c|}
\hline CHEMBL3965912 & 1642462 & 7.032 & 7.1046 & TRN \\
\hline CHEMBL3893554 & 1642462 & 6.0 & 5.7033 & TRN \\
\hline CHEMBL3955506 & 1642462 & 4.699 & 4.7459 & TRN \\
\hline CHEMBL3914530 & 1642462 & 7.9469 & 8.1309 & TST \\
\hline CHEMBL3902850 & 1642462 & 6.0762 & 6.1188 & TST \\
\hline CHEMBL3912625 & 1642462 & 6.9031 & 6.7974 & TRN \\
\hline CHEMBL 3908876 & 1642462 & 8.0048 & 8.1905 & TRN \\
\hline CHEMBL 3951004 & 1642462 & 7.1938 & 7.0941 & TRN \\
\hline CHEMBL 3904808 & 1642462 & 5.8729 & 6.0718 & TST \\
\hline CHEMBL3951271 & 1642462 & 8.1746 & 8.0249 & TRN \\
\hline CHEMBL 3965260 & 1642462 & 8.6459 & 8.3929 & TRN \\
\hline CHEMBL3950431 & 1642462 & 6.4935 & 6.6378 & TST \\
\hline CHEMBL3935094 & 1642462 & 7.1918 & 7.2383 & TRN \\
\hline CHEMBL3965554 & 1642462 & 7.6402 & 7.7566 & TRN \\
\hline CHEMBL3951573 & 1642462 & 6.7399 & 7.0128 & TRN \\
\hline CHEMBL3984075 & 1642462 & 6.0 & 6.2327 & TRN \\
\hline CHEMBL3894920 & 1642462 & 4.699 & 5.1269 & TRN \\
\hline CHEMBL3955445 & 1642462 & 8.0173 & 7.7706 & TRN \\
\hline CHEMBL3932327 & 1642462 & 7.6271 & 7.74200 & 0000000001 \\
\hline CHEMBL3910152 & 1642462 & 8.7471 & 8.8027 & TRN \\
\hline CHEMBL3969934 & 1642462 & 8.4724 & 8.2207 & TRN \\
\hline CHEMBL3956456 & 1642462 & 6.9706 & 6.9845 & TRN \\
\hline CHEMBL3962377 & 1642462 & 6.0 & 5.8247 & TRN \\
\hline CHEMBL3902471 & 1642462 & 9.585 & 8.7149 & TST \\
\hline CHEMBL3907073 & 1642462 & 6.9706 & 6.8563 & TRN \\
\hline CHEMBL3958747 & 1642462 & 7.9469 & 8.1028 & TRN \\
\hline CHEMBL3987039 & 1642462 & 7.6904 & 7.3356 & TRN \\
\hline CHEMBL 3890038 & 1642462 & 4.699 & 5.4772 & TST \\
\hline CHEMBL3954535 & 1642462 & 7.3862 & 7.5398 & TST \\
\hline CHEMBL3899293 & 1642462 & 6.0 & 6.1403 & TRN \\
\hline CHEMBL3915532 & 1642462 & 8.2388 & 8.0483 & TRN \\
\hline CHEMBL3975031 & 1642462 & 8.0937 & 7.6948 & TST \\
\hline CHEMBL3975905 & 1642462 & 6.7595 & 7.1455 & TRN \\
\hline CHEMBL3979701 & 1642462 & 8.2233 & 8.1731 & TST \\
\hline CHEMBL3890689 & 1642462 & 6.4622 & 7.4516 & TRN \\
\hline CHEMBL3926252 & 1642462 & 5.6126 & 5.0386 & TRN \\
\hline CHEMBL3902479 & 1642462 & 7.27 & 7.3208 & TRN \\
\hline CHEMBL3900611 & 1642462 & 6.4763 & 6.3541 & TRN \\
\hline CHEMBL3960608 & 1642462 & 7.9318 & 7.9961 & TRN \\
\hline CHEMBL3950642 & 1642462 & 6.0 & 6.3673 & TST \\
\hline CHEMBL3933653 & 1642462 & 8.1494 & 8.2421 & TRN \\
\hline CHEMBL3922088 & 1642462 & 8.1124 & 7.9058 & TRN \\
\hline CHEMBL3972689 & 1642462 & 6.7352 & 7.0063 & TRN \\
\hline CHEMBL3950542 & 1642462 & 7.0825 & 6.9602 & TRN \\
\hline CHEMBL3959761 & 1642462 & 8.0088 & 7.415 & TRN \\
\hline CHEMBL3939992 & 1642462 & 7.1952 & 7.301 & TST \\
\hline CHEMBL3944065 & 1642462 & 7.6716 & \multicolumn{2}{|c|}{ 7. 3629999999999995} \\
\hline CHEMBL3981704 & 1642462 & 6.4413 & 7.0214 & TRN \\
\hline
\end{tabular}


Supplemental Table S2.txt

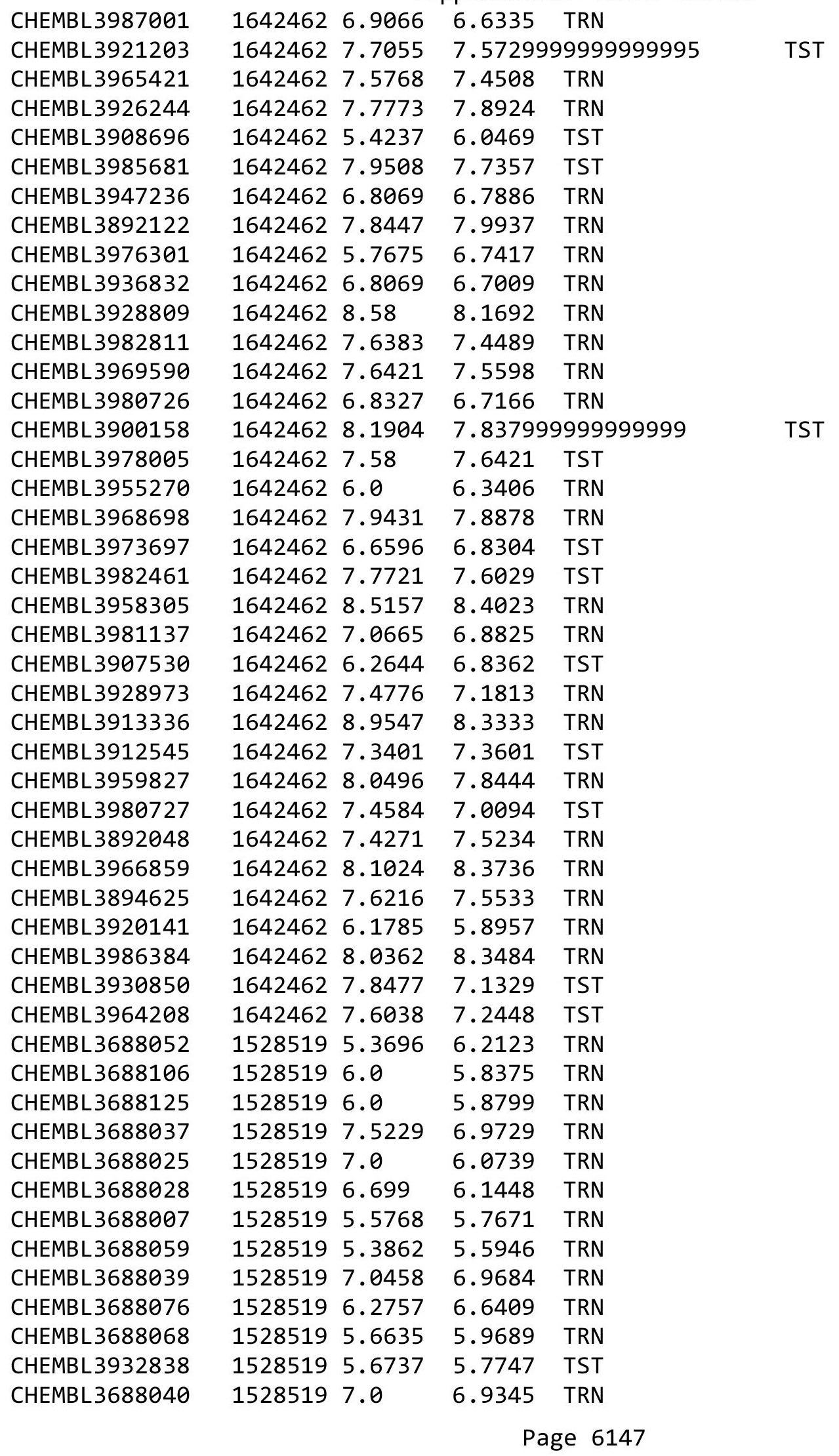


Supplemental Table S2.txt

\begin{tabular}{|c|c|c|c|c|}
\hline CHEMBL3688061 & 1528519 & 5.0357 & 6.2821 & TST \\
\hline CHEMBL 3687994 & 1528519 & 6.0 & 5.7391 & TRN \\
\hline CHEMBL3688086 & 1528519 & 7.0969 & 5.9181 & TRN \\
\hline CHEMBL 3688064 & 1528519 & 5.1469 & 5.5709 & TRN \\
\hline CHEMBL 3688114 & 1528519 & 5.9031 & 5.6715 & TRN \\
\hline CHEMBL 3688032 & 1528519 & 6.5086 & 5.9181 & TRN \\
\hline CHEMBL 3688084 & 1528519 & 6.4437 & 5.6873 & TRN \\
\hline CHEMBL3687999 & 1528519 & 5.5575 & 5.5851 & TRN \\
\hline CHEMBL 3688071 & 1528519 & 6.6576 & 5.7913 & TRN \\
\hline CHEMBL 3688097 & 1528519 & 5.9788 & 5.9788 & TST \\
\hline CHEMBL 3688043 & 1528519 & 6.7696 & 7.1064 & TRN \\
\hline CHEMBL 3688104 & 1528519 & 5.5114 & 5.6423 & TRN \\
\hline CHEMBL 3639869 & 1528519 & 5.7282 & 5.8877 & TRN \\
\hline CHEMBL3688107 & 1528519 & 3.699 & 5.4466 & TRN \\
\hline CHEMBL 3688087 & 1528519 & 5.567 & 5.715 & TRN \\
\hline CHEMBL 3688120 & 1528519 & 6.7959 & 6.0193 & TRN \\
\hline CHEMBL 3688048 & 1528519 & 6.1192 & 6.4732 & TRN \\
\hline CHEMBL 3688072 & 1528519 & 7.0 & 5.8791 & TST \\
\hline CHEMBL3953183 & 1528519 & 3.699 & 5.49299 & 9999999999 \\
\hline CHEMBL 3639868 & 1528519 & 6.8239 & 6.096 & TRN \\
\hline CHEMBL3688055 & 1528519 & 5.8861 & 6.1391 & TRN \\
\hline CHEMBL3688021 & 1528519 & 5.4828 & 5.7079 & TRN \\
\hline CHEMBL 3688002 & 1528519 & 5.5272 & 5.9865 & TRN \\
\hline CHEMBL3975873 & 1528519 & 6.6198 & 5.752006 & 0000000001 \\
\hline CHEMBL 3687985 & 1528519 & 6.0 & 5.6022 & TRN \\
\hline CHEMBL3688093 & 1528519 & 6.8539 & 5.8336 & TST \\
\hline CHEMBL3687992 & 1528519 & 6.284 & 5.6796 & TRN \\
\hline CHEMBL 3688134 & 1528519 & 6.1367 & 5.4199 & TRN \\
\hline CHEMBL 3688054 & 1528519 & 6.3872 & 6.3502 & TST \\
\hline CHEMBL 3688050 & 1528519 & 7.0458 & 6.0495 & TRN \\
\hline CHEMBL3687997 & 1528519 & 5.8477 & 5.9174 & TRN \\
\hline CHEMBL 3688031 & 1528519 & 6.6383 & 5.9474 & TRN \\
\hline CHEMBL 3688074 & 1528519 & 6.5686 & 5.9468 & TST \\
\hline CHEMBL3688020 & 1528519 & 6.0315 & 5.4752 & TRN \\
\hline CHEMBL3688099 & 1528519 & 5.8894 & 5.8272 & TRN \\
\hline CHEMBL3688110 & 1528519 & 7.1549 & 5.8708 & TRN \\
\hline CHEMBL 3688133 & 1528519 & 5.3645 & 5.4862 & TRN \\
\hline CHEMBL 3688027 & 1528519 & 6.7447 & 6.1845 & TRN \\
\hline CHEMBL 3687991 & 1528519 & 6.0 & 5.7669 & TRN \\
\hline CHEMBL3688029 & 1528519 & 6.6576 & 6.5227 & TRN \\
\hline CHEMBL3688098 & 1528519 & 6.0 & 5.68 & TRN \\
\hline CHEMBL 3688056 & 1528519 & 5.8356 & 6.0923 & TST \\
\hline CHEMBL3688058 & 1528519 & 5.71 & 6.1558 & TRN \\
\hline CHEMBL3945921 & 1528519 & 5.6021 & \multicolumn{2}{|c|}{5.492999999999999} \\
\hline CHEMBL 3688078 & 1528519 & 6.3979 & 6.0748 & TST \\
\hline CHEMBL 3688131 & 1528519 & 6.0 & 5.8345 & TRN \\
\hline CHEMBL 3688012 & 1528519 & 6.0 & \multicolumn{2}{|c|}{5.781000000000001} \\
\hline CHEMBL3688112 & 1528519 & 3.699 & 5.7646 & TRN \\
\hline
\end{tabular}


Supplemental Table S2.txt

\begin{tabular}{|c|c|c|c|c|}
\hline TLר & 528519 & & 5572 & \\
\hline & & 6.6576 & & \\
\hline EN & 28519 & & & \\
\hline IEMBL & 28519 & 6.0 & & \\
\hline AEMBL3688053 & 528519 & 4.8239 & 0311 & \\
\hline AEMBL 3 & 528519 & 6.72 & 07 & \\
\hline 016 & 28519 & 6.0 & & \\
\hline AEMBL & 8519 & 5 & & נMP \\
\hline HEMBL3688067 & 528519 & 3.699 & 4 & \\
\hline HEMBL3688026 & 528519 & 6.8539 & 47 & \\
\hline HEMBL3688121 & 528519 & & 27 & \\
\hline 082 & 519 & 487 & & \\
\hline AEMBL: & & & & \\
\hline HEMBL3688057 & 528519 & 5.7122 & & \\
\hline AEMBL3688033 & 528519 & 6.0809 & & \\
\hline AEMBL3 & 19 & 959 & & RIN \\
\hline AEMBL & 19 & 048 & & 年 \\
\hline AEMBL & 19 & 239 & & \\
\hline 88030 & 3519 & 576 & & \\
\hline HEMBL3688115 & & & & I KIV \\
\hline HEMBL & 19 & & & RN \\
\hline IEM & & & & RN \\
\hline AEMBL & 19 & 7. & & $\mathrm{RN}$ \\
\hline 663 & & 6 . & & IST \\
\hline AEMBL3 & 19 & 686 & & |S| \\
\hline AEMBL3 & 19 & 56 & & RN \\
\hline HEM & & 7 & & RN \\
\hline 70 & 19 & 6. & & RN \\
\hline HEMBL & & & & IRN \\
\hline HEMBL3688022 & 519 & 6. & 65 & TRN \\
\hline AEMB & 19 & 8 & & RN \\
\hline$\Delta 5 M$ & & & & 「RN \\
\hline 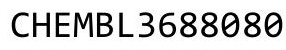 & & & & ГST \\
\hline HEMBL3688094 & & & & 「RN \\
\hline HEMBL3688063 & 519 & & 301 & ГST \\
\hline 090 & 19 & 1 & & TRN \\
\hline 9 & & & & ГRN \\
\hline HEMBL3 & & 5 . & & TST \\
\hline HEMBL3688129 & 519 & 6. & & $\Gamma \mathrm{R}$ \\
\hline EMBL & & & & ГST \\
\hline HEMBL3 & & 5 . & & TRN \\
\hline HEMBL3 & 19 & 3.699 & .04 & 「RN \\
\hline HEMBL3688091 & & & 7089 & TST \\
\hline HEMBL3688044 & 19 & & & $\mathrm{R}$ \\
\hline 34 & & 3041 & & $\mathrm{~N}$ \\
\hline HEMBL3687998 & 519 & & & \\
\hline CHEMBL 3938626 & 519 & .96 & 5.2315 & ו \\
\hline CHEMBL3688066 & 1528519 & 5.4168 & 5.7067 & 3 \\
\hline
\end{tabular}

Page 6149 
Supplemental Table S2.txt

\begin{tabular}{|c|c|c|c|c|}
\hline 342 & 528519 & 6.8861 & & \\
\hline 5501 & 528519 & 3.699 & & \\
\hline & 28519 & & & \\
\hline EMBL: & & & & \\
\hline 3047 & 528519 & 559 & & \\
\hline AEMBL3688035 & 528519 & 5.6421 & & \\
\hline 261 & 528519 & 959 & & \\
\hline EMB & 528519 & & & RN \\
\hline AEMBL3688113 & 528519 & 99 & & \\
\hline AEMBL3910673 & 528519 & 5198 & & \\
\hline AEMBL 3688075 & 528519 & 6886 & & \\
\hline 3088 & 528519 & 99 & 204 & \\
\hline 079 & 528519 & 861 & & \\
\hline 588049 & 528519 & 2458 & & \\
\hline 88081 & 528519 & 076 & & \\
\hline IEMBL3688117 & 19 & 021 & & \\
\hline EMBL & 528519 & 575 & & \\
\hline 077 & 528519 & 968 & & \\
\hline 985309 & 640977 & 198 & & \\
\hline IEMBL & 977 & 326 & & \\
\hline 723 & 1 & 8 & & \\
\hline 916 & 77 & 6 & & 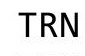 \\
\hline 23 & 77 & 49 & & \\
\hline 673 & 977 & 586 & & \\
\hline IEMBL & & & & \\
\hline IEMBL & 640 & 54 & & RI \\
\hline 21 & 77 & 28 & & 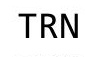 \\
\hline 734 & 77 & 47 & 71 & \\
\hline 937 & 640977 & 318 & & RN \\
\hline IEMBL3 & 77 & & & R \\
\hline IEMBL & 640977 & 969 & & RI \\
\hline 79 & 77 & 399 & & 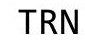 \\
\hline 27 & 77 & & & 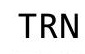 \\
\hline 398131 & 640977 & & & RI \\
\hline AEMBL3985879 & 640977 & & & KI \\
\hline 5342 & 977 & 665 & & RI \\
\hline 34 & 77 & 3 & & RN \\
\hline & & & & RN \\
\hline IEMBL3893883 & 640977 & & & RN \\
\hline 98765 & 540977 & 086 & & RI \\
\hline 08238 & 540977 & 017 & & \\
\hline HEMBL3952573 & & & & RI \\
\hline AEMBL3972250 & 540977 & 6.9747 & 118 & RI \\
\hline IEMBL3967886 & 540977 & 6.2518 & & $\mathrm{R}$ \\
\hline 399 & & 559 & & $\mathbf{K}$ \\
\hline HEMBL3896129 & 640977 & 7.8539 & & \\
\hline CHEMBL 3928143 & 540977 & & 6.5206 & \\
\hline CHEMBL3959744 & 164097 & 6.6459 & 6.8165 & TR \\
\hline
\end{tabular}

Page 6150 
Supplemental Table S2.txt

\begin{tabular}{|c|c|c|c|c|c|}
\hline CHEMBL3956172 & 1640977 & 7.0605 & 6.5703 & TRN & \\
\hline CHEMBL3893638 & 1640977 & 6.1972 & 6.3444 & TST & \\
\hline CHEMBL3944069 & 1640977 & 7.2147 & 7.0077 & TRN & \\
\hline CHEMBL3936398 & 1640977 & 8.0458 & 7.6605 & TST & \\
\hline CHEMBL 3916151 & 1640977 & 6.5086 & 6.7635 & TRN & \\
\hline CHEMBL 3953267 & 1640977 & 6.3605 & 6.4818 & TST & \\
\hline CHEMBL3951607 & 1640977 & 6.9788 & 6.9339 & TRN & \\
\hline CHEMBL3896517 & 1640977 & 7.0269 & 7.1685 & TRN & \\
\hline CHEMBL3913269 & 1640977 & 8.2218 & 8.2198 & TRN & \\
\hline CHEMBL 3972784 & 1640977 & 6.2299 & 6.1673 & TRN & \\
\hline CHEMBL 3985829 & 1640977 & 8.2218 & 8.089 & TRN & \\
\hline CHEMBL 3890620 & 1640977 & 6.4168 & 6.3637 & TRN & \\
\hline CHEMBL 3905308 & 1640977 & 6.9208 & 6.7463 & TRN & \\
\hline CHEMBL 3895407 & 1640977 & 7.2596 & 7.1331 & TRN & \\
\hline CHEMBL3949649 & 1640977 & 8.301 & 7.834 & TRN & \\
\hline CHEMBL 3899500 & 1640977 & 6.9393 & 6.5574 & TST & \\
\hline CHEMBL3904328 & 1640977 & 7.8239 & 7.775 & TRN & \\
\hline CHEMBL3941665 & 1640977 & 6.8794 & 6.8766 & TRN & \\
\hline CHEMBL 3891765 & 1640977 & 8.699 & 8.6546 & TRN & \\
\hline CHEMBL3929289 & 1640977 & 6.3439 & 6.5386 & TRN & \\
\hline CHEMBL3901780 & 1640977 & 8.5229 & 8.4018 & TRN & \\
\hline CHEMBL3985303 & 1640977 & 7.1739 & 7.3853 & TRN & \\
\hline CHEMBL 3910720 & 1640977 & 6.3635 & 6.3197 & TRN & \\
\hline CHEMBL 3916344 & 1640977 & 6.1701 & 5.949 & TRN & \\
\hline CHEMBL3981680 & 1640977 & 6.7959 & \multicolumn{2}{|c|}{7.0760000000000005} & TST \\
\hline CHEMBL3926669 & 1640977 & 7.1487 & \multicolumn{2}{|c|}{7.0329999999999995} & TRN \\
\hline CHEMBL3904601 & 1640977 & 7.5086 & 6.8739 & TST & \\
\hline CHEMBL 3897022 & 1640977 & 6.3936 & 6.006 & TST & \\
\hline CHEMBL3917090 & 1640977 & 8.3979 & 8.6139 & TRN & \\
\hline CHEMBL3936591 & 1640977 & 8.0969 & 7.3775 & TST & \\
\hline CHEMBL 3898383 & 1640977 & 6.6402 & 6.6158 & TRN & \\
\hline CHEMBL3935739 & 1640977 & 6.2708 & 6.7035 & TRN & \\
\hline CHEMBL 3969973 & 1640977 & 8.3979 & 8.2549 & TRN & \\
\hline CHEMBL3895492 & 1640977 & 6.684 & 6.9235 & TST & \\
\hline CHEMBL 3889935 & 1640977 & 8.3979 & 8.2713 & TRN & \\
\hline CHEMBL3938800 & 1640977 & 7.9586 & 7.8045 & TRN & \\
\hline CHEMBL3974014 & 1640977 & 6.7258 & \multicolumn{2}{|c|}{6.2410000000000005} & TST \\
\hline CHEMBL3970429 & 1640977 & 7.5376 & 7.4128 & TRN & \\
\hline CHEMBL 3977425 & 1640977 & 6.8761 & 7.2233 & TST & \\
\hline CHEMBL3961137 & 1640977 & 7.6198 & 7.2851 & TRN & \\
\hline CHEMBL3960770 & 1640977 & 8.2218 & 8.4731 & TRN & \\
\hline CHEMBL3913736 & 1640977 & 6.2857 & 6.5132 & TST & \\
\hline CHEMBL3922706 & 1640977 & 7.7696 & 7.8078 & TRN & \\
\hline CHEMBL 3925514 & 1640977 & 7.301 & 7.0776 & TRN & \\
\hline CHEMBL 3950544 & 1640977 & 6.1403 & 6.5357 & TRN & \\
\hline CHEMBL3902839 & 1640977 & 8.0 & 7.1306 & TRN & \\
\hline CHEMBL3909816 & 1640977 & 6.0 & 7.0727 & TRN & \\
\hline CHEMBL3952981 & 1640977 & 6.3958 & 6.5938 & TST & \\
\hline
\end{tabular}


Supplemental Table S2.txt

\begin{tabular}{|c|c|c|c|c|}
\hline 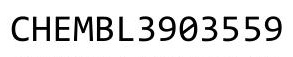 & 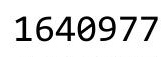 & 8.0 & & \\
\hline HEMBL3920643 & 640977 & 7.14 & 1926 & \\
\hline & & & & \\
\hline 731 & 977 & & 734 & \\
\hline AEMBL3965098 & 540977 & & 9496 & \\
\hline AEMBL3927447 & 640977 & 8.0458 & 8335 & \\
\hline HEMBL3979348 & 640977 & 391 & .3069 & \\
\hline IEMBL3S & 977 & & 591 & \\
\hline EMBL3S & 977 & & 5642 & \\
\hline AEMBL3951022 & 640977 & 8.1549 & 5147 & \\
\hline HEMBL3901252 & 640977 & 6.684 & 654 & \\
\hline HEMBL3977217 & 640977 & 8 . & 8395 & \\
\hline AEMBL3 & & & & \\
\hline HEMBL & & & 1815 & \\
\hline AEMBL3S & 977 & & 1898 & \\
\hline AEMBL39 & 977 & 7 & 7766 & \\
\hline AEMBL3 & 77 & 8 . & 2522 & \\
\hline HEMBL; & & & 924 & \\
\hline HEMBL & & & 1841 & \\
\hline HEMBL3 & & & 4689 & 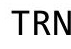 \\
\hline HEMBL3910668 & 77 & 8. & 5451 & NIV \\
\hline HEMBL3 & 77 & 7. & 3323 & 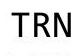 \\
\hline HEMBL3 & & & 664 & \\
\hline 373 & & & 2722 & RN \\
\hline AEMBL3S & & 9 & 506 & RIV \\
\hline $\mathrm{EEMBL} 39$ & 7 & 8. & 307 & RIN \\
\hline HEMBL3S & 77 & & 285 & 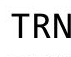 \\
\hline HEMBL3 & & & 056 & \\
\hline 112 & & & 686 & RN \\
\hline IEMBL3S & & & 391 & RN \\
\hline AEMBL39 & 77 & 6. & 1956 & RN \\
\hline HEMBL39 & 77 & 7. & 234 & Nov \\
\hline HEMBL3 & & & 023 & ST \\
\hline 70 & & & & RN \\
\hline AEMBL39 & 77 & 7. & 3665 & RN \\
\hline EMBL3903279 & 77 & & 662 & \\
\hline HEMBL3930713 & 77 & & 9842 & II \\
\hline & & & & RN \\
\hline HEMBL3889788 & 77 & & 409 & $\mathrm{RN}$ \\
\hline HEMBL3919243 & 77 & & 704 & ST \\
\hline AEMBL39 & 77 & & 387 & \\
\hline HEMBL3897072 & & & 871 & \\
\hline HEMBL 38 & & & & RN \\
\hline HEMBL3930778 & 977 & 7. & 518 & ST \\
\hline HEMBL3982091 & 977 & & & F \\
\hline & & & & \\
\hline CHEMBL 39 & & 5.1624 & 5.835 & \\
\hline 392390 & 640977 & 7.6198 & 7.5384 & \\
\hline
\end{tabular}

Page 6152 
Supplemental Table S2.txt

\begin{tabular}{|c|c|c|c|c|c|}
\hline CHEMBL3959741 & 1640977 & 7.2076 & 6.9934 & TRN & \\
\hline CHEMBL3946566 & 1640977 & 6.9101 & 7.1677 & TST & \\
\hline CHEMBL3979169 & 1640977 & 8.0458 & 7.9801 & TRN & \\
\hline CHEMBL3913722 & 1640977 & 6.6253 & 6.502999 & 9999999999 & TRN \\
\hline CHEMBL3976416 & 1640977 & 6.2916 & 6.3818 & TRN & \\
\hline CHEMBL3898075 & 1640977 & 6.0453 & 6.646 & TST & \\
\hline CHEMBL3936334 & 1640977 & 7.7959 & 7.6554 & TRN & \\
\hline CHEMBL3895452 & 1640977 & 6.6861 & 6.4863 & TRN & \\
\hline CHEMBL3926910 & 1640977 & 7.6021 & 7.5396 & TRN & \\
\hline CHEMBL3904878 & 1640977 & 8.5229 & 7.5466 & TST & \\
\hline CHEMBL3944921 & 1640977 & 8.5229 & 8.75 & TRN & \\
\hline CHEMBL3955483 & 1640977 & 6.8356 & 6.7622 & TRN & \\
\hline CHEMBL3901112 & 1640977 & 7.7212 & 7.6745 & TRN & \\
\hline CHEMBL3903511 & 1640977 & 7.2291 & 7.3667 & TRN & \\
\hline CHEMBL3950942 & 1640977 & 6.1851 & 7.4318 & TST & \\
\hline CHEMBL3982020 & 1640977 & 6.2976 & 6.4059 & TST & \\
\hline CHEMBL3961792 & 1640977 & 7.9586 & 7.5004 & TST & \\
\hline CHEMBL3963842 & 1640977 & 6.9788 & 7.1536 & TRN & \\
\hline CHEMBL3980926 & 1640977 & 6.4145 & 6.4226 & TRN & \\
\hline CHEMBL3980790 & 1640977 & 7.8539 & 7.8464 & TRN & \\
\hline CHEMBL3894301 & 1640977 & 7.3979 & 6.7588 & TST & \\
\hline CHEMBL3898435 & 1640977 & 6.062 & 6.5467 & TST & \\
\hline CHEMBL3926723 & 1640977 & 6.2882 & 6.4373 & TST & \\
\hline CHEMBL3963037 & 1640977 & 6.6596 & 6.5949 & TRN & \\
\hline CHEMBL3908912 & 1640977 & 7.2676 & 7.3201 & TRN & \\
\hline CHEMBL3912081 & 1640977 & 6.4559 & 5.5661 & TST & \\
\hline CHEMBL3907557 & 1640977 & 6.0044 & 6.4389 & TST & \\
\hline CHEMBL3979986 & 1640977 & 8.5229 & 8.533 & TRN & \\
\hline CHEMBL3984951 & 1640977 & 7.0362 & 6.9741 & TST & \\
\hline CHEMBL3964730 & 1640977 & 6.857 & 7.2107 & TRN & \\
\hline CHEMBL3938658 & 1640977 & 6.3925 & 6.6161 & TST & \\
\hline CHEMBL3958086 & 1640977 & 7.1805 & 7.218999 & 9999999999 & TRN \\
\hline CHEMBL3926963 & 1640977 & 6.9666 & 6.4422 & TST & \\
\hline CHEMBL 3914288 & 1640977 & 6.4962 & 6.4415 & TRN & \\
\hline CHEMBL3957725 & 1640977 & 6.1261 & 6.2511 & TRN & \\
\hline CHEMBL3905050 & 1640977 & 8.0458 & 8.0303 & TRN & \\
\hline CHEMBL 3985030 & 1640977 & 7.3279 & 7.0404 & TRN & \\
\hline CHEMBL3907806 & 1640977 & 6.5129 & 6.3134 & TST & \\
\hline CHEMBL3911709 & 1640977 & 7.2924 & 6.9198 & TST & \\
\hline CHEMBL3950132 & 1640977 & 7.8539 & 7.885 & TRN & \\
\hline CHEMBL3978632 & 1640977 & 7.6383 & 7.9094 & TRN & \\
\hline CHEMBL3936860 & 1640977 & 7.699 & 7.6173 & TRN & \\
\hline CHEMBL3958199 & 1640977 & 6.2993 & 6.4524 & TST & \\
\hline CHEMBL3971364 & 1640977 & 6.4895 & 6.9081 & TST & \\
\hline CHEMBL3899402 & 1640977 & 6.9788 & 7.0969 & TRN & \\
\hline CHEMBL3962334 & 1640977 & 6.3851 & 6.7355 & TRN & \\
\hline CHEMBL 3905444 & 1640977 & 6.6144 & 6.7315 & TST & \\
\hline CHEMBL3959244 & 1640977 & 6.0114 & 7.2856 & TST & \\
\hline
\end{tabular}


Supplemental Table S2.txt

\begin{tabular}{|c|c|c|c|c|c|}
\hline CHEMBL3949765 & 1640977 & 6.4012 & 6.631 & TST & \\
\hline CHEMBL3335144 & 1433006 & 5.585 & 5.5919 & TRN & \\
\hline CHEMBL3335157 & 1433006 & 5.3872 & 5.3516 & TRN & \\
\hline CHEMBL3334507 & 1433006 & 5.1739 & 5.1532 & TRN & \\
\hline CHEMBL3335168 & 1433006 & 5.1938 & 5.1628 & TRN & \\
\hline CHEMBL3335129 & 1433006 & 5.3565 & 5.3775 & TRN & \\
\hline CHEMBL3335161 & 1433006 & 5.2291 & 5.2542 & TRN & \\
\hline CHEMBL3335153 & 1433006 & 6.5229 & 6.5519 & TRN & \\
\hline CHEMBL3335160 & 1433006 & 4.301 & 4.345 & TRN & \\
\hline CHEMBL3335167 & 1433006 & 3.301 & 3.2939 & TRN & \\
\hline CHEMBL3335149 & 1433006 & 5.9208 & 5.8623 & TRN & \\
\hline CHEMBL3335152 & 1433006 & 5.5376 & 4.9776 & TST & \\
\hline CHEMBL3335128 & 1433006 & 6.0458 & 6.1548 & TRN & \\
\hline CHEMBL3335150 & 1433006 & 5.7212 & 5.4873 & TST & \\
\hline CHEMBL3335178 & 1433006 & 3.301 & 3.2569 & TRN & \\
\hline CHEMBL3335142 & 1433006 & 5.2291 & 5.2603 & TRN & \\
\hline CHEMBL3335145 & 1433006 & 5.0177 & 4.9534 & TRN & \\
\hline CHEMBL3335143 & 1433006 & 5.4202 & 5.3781 & TRN & \\
\hline CHEMBL3335122 & 1433006 & 4.6576 & 4.6111 & TRN & \\
\hline CHEMBL3335166 & 1433006 & 5.0862 & 5.0644 & TRN & \\
\hline CHEMBL3335121 & 1433006 & 4.6383 & 4.70100 & 00000000005 & TRN \\
\hline CHEMBL3335146 & 1433006 & 5.9586 & 6.0153 & TRN & \\
\hline CHEMBL3335156 & 1433006 & 4.9208 & 4.8439 & TRN & \\
\hline CHEMBL3335165 & 1433006 & 4.9393 & 4.8675 & TRN & \\
\hline CHEMBL3335162 & 1433006 & 4.699 & 4.6999 & TRN & \\
\hline CHEMBL3335151 & 1433006 & 5.585 & 5.0683 & TST & \\
\hline CHEMBL3335158 & 1433006 & 5.3468 & 5.3516 & TRN & \\
\hline CHEMBL3335164 & 1433006 & 5.1135 & 5.1422 & TRN & \\
\hline CHEMBL3335154 & 1433006 & 3.301 & 3.2802 & TRN & \\
\hline CHEMBL3335125 & 1433006 & 6.3979 & 6.3789 & TRN & \\
\hline CHEMBL3335147 & 1433006 & 5.5686 & 5.5619 & TRN & \\
\hline CHEMBL3335123 & 1433006 & 5.1367 & 5.2157 & TRN & \\
\hline CHEMBL3335141 & 1433006 & 6.301 & 6.0455 & TRN & \\
\hline CHEMBL3335124 & 1433006 & 5.8861 & 5.9094 & TRN & \\
\hline CHEMBL3335140 & 1433006 & 5.2366 & 5.1732 & TRN & \\
\hline CHEMBL3335159 & 1433006 & 4.7959 & 4.857 & TRN & \\
\hline CHEMBL3335171 & 1433006 & 4.3665 & 4.4011 & TRN & \\
\hline CHEMBL3335170 & 1433006 & 5.0506 & 5.7542 & TST & \\
\hline CHEMBL3335163 & 1433006 & 3.301 & 3.8956 & TST & \\
\hline CHEMBL3335174 & 1433006 & 3.301 & 4.3901 & TST & \\
\hline CHEMBL3335169 & 1433006 & 4.9208 & 4.9352 & TRN & \\
\hline CHEMBL3335119 & 1433006 & 4.7959 & 4.7768 & TST & \\
\hline CHEMBL3335126 & 1433006 & 5.6383 & 5.7173 & TRN & \\
\hline CHEMBL3335175 & 1433006 & 3.301 & 5.1404 & TST & \\
\hline CHEMBL3335177 & 1433006 & 3.301 & 3.478 & TST & \\
\hline CHEMBL3335173 & 1433006 & 5.1805 & 5.1177 & TST & \\
\hline CHEMBL3335127 & 1433006 & 5.5528 & 5.4781 & TRN & \\
\hline CHEMBL3335155 & 1433006 & 4.7212 & 4.9817 & TRN & \\
\hline
\end{tabular}


Supplemental Table S2.txt

\begin{tabular}{|c|c|c|c|c|}
\hline CHEMBL3335172 & 1433006 & 5.1367 & 4.8652 & TST \\
\hline CHEMBL3335120 & 1433006 & 4.4949 & 4.5457 & TST \\
\hline CHEMBL3335176 & 1433006 & 3.301 & 5.0237 & TST \\
\hline CHEMBL3335148 & 1433006 & 5.699 & 5.6878 & TRN \\
\hline CHEMBL 3093244 & 1280628 & 5.7645 & \multicolumn{2}{|c|}{5.622000000000001} \\
\hline CHEMBL3093149 & 1280628 & 4.9957 & 5.4624 & TRN \\
\hline CHEMBL3093156 & 1280628 & 5.0 & 5.0185 & TRN \\
\hline CHEMBL 3093257 & 1280628 & 5.0381 & 5.0978 & TST \\
\hline CHEMBL3093162 & 1280628 & 4.7696 & 4.66 & TRN \\
\hline CHEMBL 3093256 & 1280628 & 4.0 & 5.1463 & TST \\
\hline CHEMBL3093147 & 1280628 & 5.4962 & 5.2545 & TRN \\
\hline CHEMBL 2079522 & 1280628 & 5.3747 & 5.0168 & TRN \\
\hline CHEMBL 3093254 & 1280628 & 5.1871 & 5.2779 & TST \\
\hline CHEMBL 2079397 & 1280628 & 5.2076 & 4.9682 & TRN \\
\hline CHEMBL 3093148 & 1280628 & 4.0 & 4.7512 & TRN \\
\hline CHEMBL 3093144 & 1280628 & 5.3098 & 5.1022 & TRN \\
\hline CHEMBL3093154 & 1280628 & 4.9393 & 5.2617 & TRN \\
\hline CHEMBL 2032289 & 1280628 & 5.0315 & 5.2503 & TRN \\
\hline CHEMBL 2032299 & 1280628 & 5.5143 & 5.5242 & TRN \\
\hline CHEMBL3093152 & 1280628 & 4.0 & 5.1886 & TRN \\
\hline CHEMBL3093246 & 1280628 & 5.4949 & 5.7833 & TRN \\
\hline CHEMBL 3093251 & 1280628 & 4.0 & 5.2392 & TST \\
\hline CHEMBL3093260 & 1280628 & 5.7825 & 5.5009 & TRN \\
\hline CHEMBL3093158 & 1280628 & 4.0 & 4.3025 & TRN \\
\hline CHEMBL 3093250 & 1280628 & 5.5143 & 4.6272 & TRN \\
\hline CHEMBL3093161 & 1280628 & 4.0 & 4.5642 & TRN \\
\hline CHEMBL 2079392 & 1280628 & 4.0 & 4.522 & TRN \\
\hline CHEMBL3093255 & 1280628 & 4.0 & 4.8292 & TST \\
\hline CHEMBL 2078645 & 1280628 & 5.1993 & 5.2166 & TRN \\
\hline CHEMBL3093146 & 1280628 & 5.0825 & 4.9978 & TRN \\
\hline CHEMBL 2032286 & 1280628 & 5.58 & 5.4265 & TRN \\
\hline CHEMBL3093252 & 1280628 & 4.0 & 4.5397 & TST \\
\hline CHEMBL3093258 & 1280628 & 6.0706 & 5.5257 & TRN \\
\hline CHEMBL 2079205 & 1280628 & 5.0132 & 4.9401 & TST \\
\hline CHEMBL3093153 & 1280628 & 5.2441 & 5.397 & TRN \\
\hline CHEMBL3093150 & 1280628 & 5.2757 & 5.4114 & TRN \\
\hline CHEMBL3093151 & 1280628 & 6.3372 & 5.4539 & TRN \\
\hline CHEMBL3093259 & 1280628 & 5.1918 & 5.4549 & TRN \\
\hline CHEMBL3093145 & 1280628 & 5.2581 & 5.2946 & TRN \\
\hline CHEMBL3093160 & 1280628 & 4.9245 & 4.5416 & TRN \\
\hline CHEMBL3093249 & 1280628 & 4.0 & 4.6772 & TRN \\
\hline CHEMBL 3093163 & 1280628 & 5.0915 & 4.6079 & TRN \\
\hline CHEMBL 3093248 & 1280628 & 5.4012 & 5.2849 & TRN \\
\hline CHEMBL3093159 & 1280628 & 5.3925 & 5.1238 & TRN \\
\hline CHEMBL3093245 & 1280628 & 5.4962 & 5.4156 & TRN \\
\hline CHEMBL3093253 & 1280628 & 4.0 & 5.3428 & TST \\
\hline CHEMBL 3093157 & 1280628 & 4.0 & 4.2595 & TRN \\
\hline CHEMBL3093164 & 1280628 & 5.4202 & 4.504 & TRN \\
\hline
\end{tabular}


Supplemental Table S2.txt

\begin{tabular}{|c|c|c|c|c|}
\hline & & & & \\
\hline 32290 & 6628 & 5.0809 & 18 & \\
\hline 3261 & 628 & 3861 & & \\
\hline & & & & \\
\hline 243 & 628 & 305 & & \\
\hline IEMBL 3093155 & 280628 & 5.6459 & 742 & \\
\hline AEMBL 2079395 & 280628 & 5.6696 & 181 & \\
\hline 247 & 0628 & 177 & & \\
\hline 94 & 78482 & 21 & & \\
\hline EMBL & 78482 & 21 & & \\
\hline IEMBL 2418167 & 78482 & 021 & 462 & \\
\hline IEMBL 2418176 & 78482 & 757 & & \\
\hline 7LIMDL $\angle 6$ & 978482 & 4.7721 & & \\
\hline 181 & 78482 & 528 & & \\
\hline 186 & 78482 & 21 & & \\
\hline IEMBL2. & 78482 & & & \\
\hline IEMBL & 82 & 21 & & \\
\hline IEIME & 32 & 21 & & \\
\hline 9 & 82 & & & \\
\hline FMB & 82 & 21 & & \\
\hline 59 & 82 & 21 & & \\
\hline & 32 & 21 & & \\
\hline 5 & 82 & 21 & & \\
\hline & 78482 & & & \\
\hline 45 & 82 & 21 & & \\
\hline 88 & & & & \\
\hline & 82 & & & \\
\hline & 82 & & & \\
\hline 5 & 32 & 96 & & \\
\hline 5 & & 21 & & \\
\hline & & & & \\
\hline 16 & 182 & 21 & & \\
\hline & & & & \\
\hline 2 & 32 & & & \\
\hline & & & & \\
\hline & & & & \\
\hline 174 & 978482 & 367 & & \\
\hline & 078 & 3. & & \\
\hline 7 & 2 & & & \\
\hline & & 5.0605 & & \\
\hline EMBL & 978482 & 3.6021 & & \\
\hline & 978 & 21 & & \\
\hline & 978482 & & & \\
\hline CHEMBL 2 & 978482 & 21 & & \\
\hline 73 & 978482 & 6.3665 & 832 & $1 \mathrm{k}$ \\
\hline 149 & 978482 & 5.6383 & 21 & TS \\
\hline & & & & \\
\hline & 978482 & סחתר & $4 . \varepsilon$ & \\
\hline
\end{tabular}

Page 6156 
Supplemental Table S2.txt

\begin{tabular}{|c|c|c|c|c|}
\hline CHEMBL2418144 & 978482 & 3.6021 & 3.3215 & TST \\
\hline CHEMBL 2418183 & 978482 & 3.6021 & 3.5789 & TRN \\
\hline HEMBL2418190 & 78482 & 3.6021 & 5933 & \\
\hline HEMBL2418171 & 78482 & 3.6021 & 6659 & \\
\hline HEMBL 2418148 & 78482 & 5.0862 & .9343 & \\
\hline HEMBL2418177 & 978482 & 3.6021 & 3.6151 & 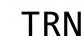 \\
\hline HEMBL 2418168 & 978482 & 3.6021 & 3.5517 & \\
\hline HEMBL 2418192 & 978482 & 3.6021 & 4345 & \\
\hline HEMBL 2418162 & 978482 & 3.6021 & 3.5914 & RN \\
\hline HEMBL 2418166 & 978482 & 3.6021 & 3.6256 & 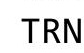 \\
\hline HEMBL 2418156 & 978482 & 3.6021 & 5445 & - \\
\hline HEMBL 2418151 & 978482 & 3.6021 & 3.6532 & \\
\hline CHEMBL 2418193 & 978482 & 3.6021 & .6367 & \\
\hline HEMBL 2418141 & 978482 & 3.6021 & .6114 & KIV \\
\hline HEMBL 2418172 & 978482 & 5.4559 & 5.5824 & \\
\hline HEMBL 2418152 & 978482 & 3.6021 & 4.0589 & ST \\
\hline CHEMBL2418164 & 78482 & 3.6021 & 3.5959 & TRN \\
\hline CHEMBL 91401 & 06 & 3.7825 & 3.6446 & RN \\
\hline CHEMBL91 & 9 & 2.301 & 2.4208 & RN \\
\hline CHEMBL 91262 & 9 & 2.301 & 2.5568 & \\
\hline LHEMBL91958 & 29 & 3.301 & 3504 & N \\
\hline CHEMBL 90982 & 06 & .301 & 2.2263 & $\mathrm{~N}$ \\
\hline CHEMBL91 & 506 & 2.30 & 2.3242 & RN \\
\hline CHEMBL90 & 9 & 2.301 & 2.2327 & TRN \\
\hline CHEMBL 31 & 9 & 2.301 & 3.3833 & TST \\
\hline LHEMBL89434 & 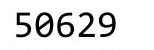 & 2.301 & 5597 & TST \\
\hline CHEMBL88552 & 06 & 2.301 & 2.2609 & TRN \\
\hline CHEMBL90 & $\theta 6$ & 2.301 & 2.4815 & TRN \\
\hline CHEMBL 31 & 9 & 2.301 & 1058 & TRN \\
\hline CHEMBL 92 & 0 & 2.301 & 2.235 & TRN \\
\hline CHEMBL90135 & 9 & 2.30 & 2797 & TRN \\
\hline CHEMBL 91834 & 9 & 4.1024 & 4.0795 & TRN \\
\hline CHEMBL41 & 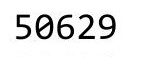 & 2 . & 2.3541 & TRN \\
\hline CHEMBL 96 & 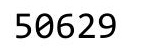 & 2.301 & 2.3497 & TRN \\
\hline CHEMBL 90370 & & 2.301 & 2.3129 & TRN \\
\hline CHEMBL329550 & 50629 & 2.30 & 2.2903 & TRN \\
\hline CHEMBL 91679 & 50629 & 4.3565 & 4.3578 & TRN \\
\hline CHEMBL $9 e$ & & 2. & & TRN \\
\hline CHEMBL90 & 9 & 4.0605 & 4.0704 & TRN \\
\hline CHEMBL 91590 & 9 & 2.301 & 1.8169 & TST \\
\hline CHEMBL91202 & 0629 & 2.301 & 2.7164 & TST \\
\hline CHEMBL 92372 & 50629 & 2.301 & 2.3846 & TRN \\
\hline CHEMBL273301 & & 4.284 & 4.2905 & TRN \\
\hline CHEMBL91564 & 50629 & 2.301 & 3.333 & TST \\
\hline CHEMBL 91500 & 50629 & 2.301 & 1.9722 & TST \\
\hline CHEMBL 89780 & 50629 & 2.301 & 2.3721 & TRN \\
\hline CHEMBL91954 & 50629 & 2.301 & 2.3928 & $\mathrm{IRN}$ \\
\hline CHEMBL261980 & 50629 & 2.301 & 1.9127 & \\
\hline
\end{tabular}

Page 6157 


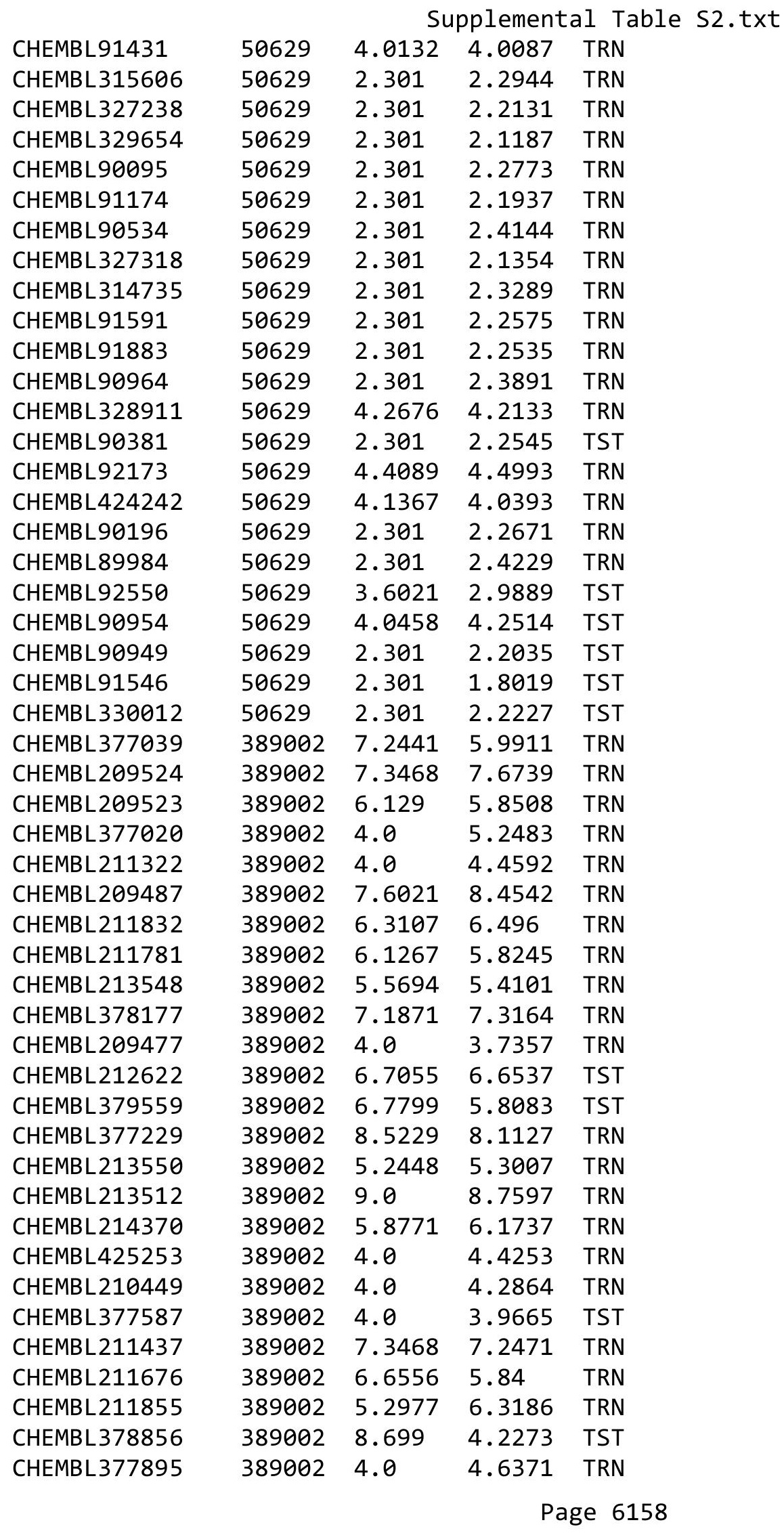




\begin{tabular}{|c|c|c|c|c|c|c|}
\hline & & \multicolumn{5}{|c|}{ Supplemental Table S2.txt } \\
\hline CHEMBL211780 & 389002 & 7.9208 & 6.7791 & TRN & & \\
\hline CHEMBL211892 & 389002 & 6.5768 & 5.8553 & TRN & & \\
\hline CHEMBL212058 & 389002 & 9.0 & 7.766 & TRN & & \\
\hline CHEMBL213242 & 389002 & 4.0 & 4.4375 & TRN & & \\
\hline CHEMBL211630 & 389002 & 6.7959 & 6.4085 & TRN & & \\
\hline CHEMBL209499 & 389002 & 5.0831 & 5.496 & TRN & & \\
\hline CHEMBL208792 & 389002 & 9.0 & 8.4486 & TRN & & \\
\hline CHEMBL210171 & 389002 & 7.4318 & 7.3873 & TRN & & \\
\hline CHEMBL437689 & 389002 & 5.7662 & 5.5398 & TRN & & \\
\hline CHEMBL210506 & 389002 & 9.0 & 8.4058 & TRN & & \\
\hline CHEMBL213028 & 389002 & 5.9606 & 7.2389 & TRN & & \\
\hline CHEMBL211728 & 389002 & 5.4884 & 4.1214 & TRN & & \\
\hline CHEMBL213513 & 389002 & 6.9469 & 8.3782 & TRN & & \\
\hline CHEMBL277505 & 389002 & 5.5567 & 5.2986 & TRN & & \\
\hline CHEMBL379301 & 389002 & 6.9914 & 7.2211 & TRN & & \\
\hline CHEMBL211261 & 389002 & 5.2007 & 5.8363 & TRN & & \\
\hline CHEMBL210064 & 389002 & 4.0 & 6.3018 & TST & & \\
\hline CHEMBL211825 & 389002 & 4.0 & 5.3032 & TST & & \\
\hline CHEMBL209925 & 389002 & 5.8545 & 6.8055 & TST & & \\
\hline CHEMBL377980 & 389002 & 5.5496 & 4.3258 & TST & & \\
\hline CHEMBL378948 & 389002 & 6.6198 & 8.0366 & TST & & \\
\hline CHEMBL379859 & 389002 & 4.0 & 4.385 & TST & & \\
\hline CHEMBL426512 & 389002 & 5.6269 & 8.5255 & TST & & \\
\hline CHEMBL211433 & 389002 & 5.3419 & 5.8497 & TST & & \\
\hline CHEMBL379208 & 389002 & 4.0 & 3.9666 & TST & & \\
\hline CHEMBL1909414 & 954630 & 5.0687 & 5.0626 & TRN & & \\
\hline CHEMBL300389 & 954630 & 7.1877 & 7.2031 & TRN & & \\
\hline CHEMBL92309 & 954630 & 3.6344 & 2.9466 & TST & & \\
\hline CHEMBL180127 & 954630 & 3.8252 & 3.8155 & TRN & & \\
\hline CHEMBL1186585 & 954630 & 3.4942 & 3.4787 & TRN & & \\
\hline CHEMBL483847 & 954630 & 4.0373 & 4.0398 & TRN & & \\
\hline CHEMBL 2144069 & 954630 & 4.482 & 4.4864 & TRN & & \\
\hline CHEMBL259181 & 954630 & 4.6094 & 4.6034 & TRN & & \\
\hline CHEMBL512504 & 954630 & 5.6471 & 5.6399 & TRN & & \\
\hline CHEMBL258844 & 954630 & 4.9834 & 4.9827 & TRN & & \\
\hline CHEMBL192566 & 954630 & 8.7625 & 9.4971 & TST & & \\
\hline CHEMBL393929 & 954630 & 4.8158 & 4.805 & TRN & & \\
\hline CHEMBL379300 & 954630 & $6.4060 e$ & j00000006 & 01 & 6.3902 & TRN \\
\hline CHEMBL 209148 & 954630 & 3.9494 & 3.9549 & TRN & & \\
\hline CHEMBL412142 & 954630 & 3.9567 & 3.9481 & TRN & & \\
\hline CHEMBL240954 & 954630 & 3.3609 & 3.8129 & TST & & \\
\hline CHEMBL3349342 & 954630 & 5.4786 & 5.4714 & TRN & & \\
\hline CHEMBL558642 & 954630 & 4.0886 & 4.0771 & TRN & & \\
\hline CHEMBL1190711 & 954630 & 3.8753 & 3.8757 & TRN & & \\
\hline CHEMBL217354 & 954630 & 6.244 & 6.2276 & TRN & & \\
\hline CHEMBL1590308 & 954630 & 2.9126 & 3.1313 & TST & & \\
\hline CHEMBL1788116 & 954630 & 5.0894 & 5.1112 & TRN & & \\
\hline CHEMBL255342 & 954630 & 3.8064 & 3.7973 & TRN & & \\
\hline
\end{tabular}


Supplemental Table S2.txt

\begin{tabular}{|c|c|c|c|c|}
\hline CHEMBL 202721 & 954630 & 5.1692 & 5.1511 & TRN \\
\hline CHEMBL509032 & 954630 & 4.4565 & 4.4538 & TRN \\
\hline CHEMBL585951 & 954630 & 6.5832 & 6.5724 & TRN \\
\hline CHEMBL1357247 & 954630 & 3.9962 & 3.9978 & TRN \\
\hline CHEMBL135561 & 954630 & 4.1931 & 4.2077 & TRN \\
\hline CHEMBL577784 & 954630 & 5.3779 & 5.36299 & 99999999995 \\
\hline CHEMBL3186408 & 954630 & 3.3419 & 3.3935 & TST \\
\hline CHEMBL 3199475 & 954630 & 3.9822 & 3.9705 & TRN \\
\hline CHEMBL 2137530 & 954630 & 4.5539 & 4.6089 & TRN \\
\hline CHEMBL 2134202 & 954630 & 3.9158 & 3.9402 & TRN \\
\hline CHEMBL191334 & 954630 & 3.2753 & 3.2622 & TRN \\
\hline CHEMBL 2363137 & 954630 & 5.2272 & 5.2539 & TRN \\
\hline CHEMBL1230020 & 954630 & 3.57899 & 99999999 & 3.588 \\
\hline CHEMBL1643959 & 954630 & 4.9863 & 4.9999 & TRN \\
\hline CHEMBL 220241 & 954630 & 3.6321 & 3.6455 & TRN \\
\hline CHEMBL514499 & 954630 & 7.2742 & 7.2835 & TRN \\
\hline CHEMBL1970879 & 954630 & 4.1412 & 4.1156 & TRN \\
\hline CHEMBL392695 & 954630 & 5.4304 & 5.4242 & TRN \\
\hline CHEMBL 399530 & 954630 & 4.8772 & 4.8775 & TRN \\
\hline CHEMBL189584 & 954630 & 4.8128 & 4.8134 & TRN \\
\hline CHEMBL449158 & 954630 & 7.8033 & 7.6025 & TST \\
\hline CHEMBL 373751 & 954630 & 3.2849 & 3.2897 & TRN \\
\hline CHEMBL 213100 & 954630 & 4.2597 & 4.2649 & TRN \\
\hline CHEMBL 2005886 & 954630 & 4.2524 & 4.2623 & TRN \\
\hline CHEMBL1673039 & 954630 & 4.3281 & 4.3342 & TRN \\
\hline CHEMBL1404918 & 954630 & 3.3461 & 3.3456 & TRN \\
\hline CHEMBL1242367 & 954630 & 3.9876 & 3.9574 & TRN \\
\hline CHEMBL 222102 & 954630 & 3.4174 & 3.4314 & TRN \\
\hline CHEMBL188678 & 954630 & 4.6686 & 3.9255 & TST \\
\hline CHEMBL 210618 & 954630 & 3.1415 & 3.4365 & TST \\
\hline CHEMBL 9470 & 954630 & 8.1253 & 6.6161 & TST \\
\hline CHEMBL573107 & 954630 & 4.8469 & 5.1905 & TST \\
\hline CHEMBL515416 & 954630 & 5.0431 & 4.6903 & TST \\
\hline CHEMBL221137 & 954630 & 5.1109 & 4.8691 & TST \\
\hline CHEMBL3392440 & 954630 & 3.8992 & 3.7144 & TST \\
\hline CHEMBL1256459 & 954630 & 6.0049 & 7.16 & TST \\
\hline CHEMBL 379975 & 954630 & 5.1733 & 4.7975 & TST \\
\hline CHEMBL472940 & 954630 & 3.2857 & 3.2799 & TST \\
\hline CHEMBL 3665052 & 1641143 & 5.5519 & 5.6231 & TRN \\
\hline CHEMBL 3660309 & 1641143 & 6.0 & 5.9419 & TRN \\
\hline CHEMBL 3660467 & 1641143 & 6.1986 & 6.2097 & TRN \\
\hline CHEMBL 3665044 & 1641143 & 6.9031 & 7.0373 & TRN \\
\hline CHEMBL 3660330 & 1641143 & 6.0 & 6.0331 & TRN \\
\hline CHEMBL 3660311 & 1641143 & 6.0 & 6.2489 & TRN \\
\hline CHEMBL 3660316 & 1641143 & 6.0 & 6.1582 & TRN \\
\hline CHEMBL 3665062 & 1641143 & 6.7696 & 6.6306 & TST \\
\hline CHEMBL3665026 & 1641143 & 6.1904 & 6.3076 & TRN \\
\hline CHEMBL 3660385 & 1641143 & 6.4776 & 5.468 & TRN \\
\hline
\end{tabular}


Supplemental Table S2.txt

\begin{tabular}{|c|c|c|c|c|c|}
\hline CHEMBL3660365 & 1641143 & 5.1979 & 5.1829 & TRN & \\
\hline CHEMBL3660409 & 1641143 & 6.1555 & \multicolumn{2}{|c|}{6.257000000000001} & TRN \\
\hline CHEMBL3665070 & 1641143 & 3.699 & \multicolumn{2}{|c|}{ 2.97899999999999996 } & TST \\
\hline CHEMBL3665099 & 1641143 & 6.9666 & 6.6557 & TRN & \\
\hline CHEMBL3660313 & 1641143 & 6.9586 & 6.8691 & TRN & \\
\hline CHEMBL3660439 & 1641143 & 6.4584 & 6.5134 & TRN & \\
\hline CHEMBL3660478 & 1641143 & 7.0 & 7.1873 & TRN & \\
\hline CHEMBL3665019 & 1641143 & 6.4056 & 6.4256 & TRN & \\
\hline CHEMBL3660393 & 1641143 & 7.3372 & 7.3409 & TRN & \\
\hline CHEMBL3660451 & 1641143 & 6.3054 & 6.4059 & TRN & \\
\hline CHEMBL 3665102 & 1641143 & 6.8928 & 6.7863 & TRN & \\
\hline CHEMBL3660352 & 1641143 & 5.7986 & 5.681 & TRN & \\
\hline CHEMBL3660372 & 1641143 & 5.0329 & 5.1856 & TRN & \\
\hline CHEMBL3660328 & 1641143 & 6.3979 & 6.2424 & TRN & \\
\hline CHEMBL3665078 & 1641143 & 6.6556 & 6.3952 & TRN & \\
\hline CHEMBL3665094 & 1641143 & 5.8173 & 5.3626 & TST & \\
\hline CHEMBL3660446 & 1641143 & 5.7667 & 5.7824 & TRN & \\
\hline CHEMBL 3660388 & 1641143 & 5.6254 & 5.5473 & TRN & \\
\hline CHEMBL3665076 & 1641143 & 3.699 & 3.0253 & TST & \\
\hline CHEMBL3665027 & 1641143 & 7.6383 & \multicolumn{2}{|c|}{ 7.502999999999999 } & TRN \\
\hline CHEMBL3665046 & 1641143 & 3.699 & 3.9278 & TRN & \\
\hline CHEMBL3660473 & 1641143 & \multicolumn{2}{|c|}{6.3420000000000005} & 6.4123 & TRN \\
\hline CHEMBL3665033 & 1641143 & 5.6955 & 5.4425 & TRN & \\
\hline CHEMBL93215 & 1641143 & 7.0969 & 6.9577 & TST & \\
\hline CHEMBL3939769 & 1641143 & 5.8703 & 6.6258 & TRN & \\
\hline CHEMBL3660433 & 1641143 & 6.4214 & 6.1825 & TRN & \\
\hline CHEMBL3660461 & 1641143 & 6.4547 & 6.4524 & TRN & \\
\hline CHEMBL 3660400 & 1641143 & 5.1341 & 5.7103 & TRN & \\
\hline CHEMBL3660381 & 1641143 & 7.0132 & 7.0675 & TRN & \\
\hline CHEMBL3660390 & 1641143 & 6.0026 & 6.0375 & TST & \\
\hline CHEMBL3660412 & 1641143 & 5.7455 & \multicolumn{2}{|c|}{5.7989999999999995} & TRN \\
\hline CHEMBL3665029 & 1641143 & 7.1308 & 7.1688 & TRN & \\
\hline CHEMBL3660345 & 1641143 & 5.8928 & 5.7098 & TRN & \\
\hline CHEMBL3665048 & 1641143 & 4.8079 & 4.9272 & TRN & \\
\hline CHEMBL3665063 & 1641143 & 7.3468 & 6.9896 & TST & \\
\hline CHEMBL3660420 & 1641143 & 6.6517 & 6.6973 & TRN & \\
\hline CHEMBL3897991 & 1641143 & 4.8079 & 4.8208 & TRN & \\
\hline CHEMBL3660442 & 1641143 & 5.4803 & 5.3684 & TRN & \\
\hline CHEMBL3665072 & 1641143 & 3.699 & 2.9567 & TST & \\
\hline CHEMBL3665023 & 1641143 & 6.4023 & 6.3853 & TRN & \\
\hline CHEMBL3665053 & 1641143 & 8.5229 & 8.4169 & TRN & \\
\hline CHEMBL 3660429 & 1641143 & \multicolumn{2}{|c|}{6.3839999999999995} & 6.4341 & TRN \\
\hline CHEMBL3660371 & 1641143 & 5.0531 & 5.0578 & TST & \\
\hline CHEMBL3660456 & 1641143 & 7.4949 & 7.5016 & TRN & \\
\hline CHEMBL3660424 & 1641143 & 5.7899 & 5.769 & TRN & \\
\hline CHEMBL3660406 & 1641143 & 5.4083 & 5.405 & TRN & \\
\hline CHEMBL3665084 & 1641143 & 5.0212 & 4.5595 & TST & \\
\hline CHEMBL3660432 & 1641143 & 6.76200 & 00000000 & 7.0054 & TRN \\
\hline
\end{tabular}


Supplemental Table S2.txt

\begin{tabular}{|c|c|c|c|}
\hline HEMBL3660340 & 1641143 & 6.0044 & 5.8164 \\
\hline HEMBL3660326 & 1641143 & 6.4089 & 6.3766 \\
\hline HEMBL3665069 & 1641143 & 5.3824 & \\
\hline CHEMBL 3660338 & 1641143 & 6.1249 & \\
\hline HEMBL3660458 & 641143 & 5.9059 & 649 \\
\hline HEMBL3660455 & 1641143 & 7.6778 & 7.4584 \\
\hline HEMBL3660415 & 641143 & 3.699 & 098 \\
\hline AEMBL3660342 & 1641143 & 5.9706 & \\
\hline HEMBL3660449 & 1641143 & 6.6716 & 267 \\
\hline HEMBL 229251 & 1641143 & 6.1427 & 5.9851 \\
\hline CHEMBL3660394 & 1641143 & 6.983 & 6.977 \\
\hline HEMBL3660471 & 1641143 & 6.4001 & 222 \\
\hline HEMBL3660423 & 1641143 & 7.0555 & \\
\hline HEMBL3665054 & 1641143 & 7.3279 & 7.5487 \\
\hline HEMBL3660327 & 1641143 & 6.3979 & 201 \\
\hline FEMBL3660408 & 1641143 & 6.7011 & 6.6477 \\
\hline HEMBL3660399 & 164 & 6.2716 & 6 . \\
\hline HEMBL3660427 & 164 & 6.3363 & 07 \\
\hline HEMBL3660335 & 1641143 & 6.2441 & 6.2101 \\
\hline HEMBL3665043 & 1641143 & 7.585 & \\
\hline HEMBL3660310 & 164 & 6.0 & 54 \\
\hline HEMBL3660397 & 164 & 6.5086 & 33 \\
\hline CHEMBL & 164 & 24 & 35 \\
\hline HEMBL3660373 & 1641143 & 5.0269 & 851 \\
\hline HEMBL3911792 & 164 & 6.0975 & \\
\hline CHEMBL3665075 & 164 & 3. & 67 \\
\hline HEMBL3 & 164 & 8 . & 14 \\
\hline HEMBL3660445 & 164 & 5.3202 & 64 \\
\hline HEMBL3665050 & 1641143 & 5.8713 & 75 \\
\hline CHEMBL 3660317 & 1641143 & 6.6198 & 57 \\
\hline CHEMBL 3660379 & 1641143 & 6.129 & \\
\hline CHEMBL & 164 & 88 & 36 \\
\hline CHEMBL 3660479 & 164 & 6.9747 & 03 \\
\hline CHEMBL 3665103 & 1641143 & 6.2933 & 588 \\
\hline CHEMBL 3660351 & 1641143 & 5.8297 & 5.8077 \\
\hline CHEMBL 3660426 & 1641143 & 6.8508 & 31 \\
\hline CHEMBL: & 164 & 6.3768 & \\
\hline CHEMBL3934961 & 1641143 & 6.8041 & 6.7124 \\
\hline CHEMBL207194 & 1641143 & 5.8761 & 5.7783 \\
\hline CHEMBL 3660324 & 1641143 & 6.4202 & 721 \\
\hline CHEMBL 3665037 & 1641143 & 5.2022 & 545 \\
\hline CHEMBL3660407 & 1641143 & 5.8321 & 5.6977 \\
\hline CHEMBL3660463 & 1641143 & 6.6517 & 6.6694 \\
\hline CHEMBL 3665082 & 1641143 & 7.6383 & 7.3649 \\
\hline CHEMBL3660416 & 164 & 5.3465 & \\
\hline CHEMBL 3660380 & 1641143 & 6.7747 & 6.8667 \\
\hline CHEMBL3665035 & 1641143 & 5.0282 & 5.1028 \\
\hline CHEMBL3665101 & 1641143 & 5.8011 & 5.7941 \\
\hline
\end{tabular}

Page 6162 
Supplemental Table S2.txt

\begin{tabular}{|c|c|c|c|c|c|}
\hline CHEMBL3660376 & 1641143 & 6.8327 & 6.7305 & TRN & \\
\hline CHEMBL3660368 & 1641143 & 6.0 & 5.5995 & TRN & \\
\hline CHEMBL3660375 & 1641143 & 3.699 & 3.803 & TRN & \\
\hline CHEMBL3665093 & 1641143 & 3.699 & 3.3353 & TST & \\
\hline CHEMBL3660468 & 1641143 & 6.3757 & 6.3697 & TRN & \\
\hline CHEMBL3665098 & 1641143 & 6.279 & 6.249 & TST & \\
\hline CHEMBL3660336 & 1641143 & 6.0 & 6.1458 & TRN & \\
\hline CHEMBL3660421 & 1641143 & 7.0915 & 7.0267 & TRN & \\
\hline CHEMBL 3660448 & 1641143 & 6.8827 & 6.9794 & TRN & \\
\hline CHEMBL3660329 & 1641143 & 6.3979 & 6.2518 & TRN & \\
\hline CHEMBL 3665064 & 1641143 & 5.9066 & 5.7901 & TST & \\
\hline CHEMBL 3660378 & 1641143 & 6.8268 & 6.9383 & TRN & \\
\hline CHEMBL3665065 & 1641143 & 6.3696 & 6.3689 & TRN & \\
\hline CHEMBL 3660350 & 1641143 & 5.8539 & 5.7927 & TST & \\
\hline CHEMBL3665077 & 1641143 & 5.6743 & 5.8902 & TRN & \\
\hline CHEMBL 3660325 & 1641143 & 6.4202 & 6.3136 & TRN & \\
\hline CHEMBL3660422 & 1641143 & 6.3768 & 6.1202 & TRN & \\
\hline CHEMBL3660386 & 1641143 & 7.0 & 6.9091 & TRN & \\
\hline CHEMBL3665049 & 1641143 & 6.9031 & 6.9459 & TRN & \\
\hline CHEMBL3660447 & 1641143 & 6.6383 & 6.6506 & TRN & \\
\hline CHEMBL3665061 & 1641143 & 6.82100 & 000000006 & 6.6898 & TRN \\
\hline CHEMBL3665051 & 1641143 & 6.8041 & 6.9254 & TRN & \\
\hline CHEMBL3660453 & 1641143 & 6.8327 & 6.7708 & TRN & \\
\hline CHEMBL 3660348 & 1641143 & 5.8827 & 5.7905 & TRN & \\
\hline CHEMBL3660354 & 1641143 & 5.7375 & 5.7315 & TRN & \\
\hline CHEMBL3665071 & 1641143 & 3.699 & 3.1749 & TST & \\
\hline CHEMBL3660477 & 1641143 & 6.8013 & 7.1223 & TRN & \\
\hline CHEMBL3660384 & 1641143 & 6.5157 & 6.3138 & TRN & \\
\hline CHEMBL3660418 & 1641143 & 6.9431 & 6.8468 & TRN & \\
\hline CHEMBL3660360 & 1641143 & 5.5143 & 5.6365 & TST & \\
\hline CHEMBL3665097 & 1641143 & 7.3279 & 7.1295 & TST & \\
\hline CHEMBL3639639 & 1641143 & 5.4206 & 5.4371 & TRN & \\
\hline CHEMBL 3660315 & 1641143 & 6.7696 & 6.7224 & TST & \\
\hline CHEMBL 3660474 & 1641143 & 6.0969 & 6.3299 & TRN & \\
\hline CHEMBL3660358 & 1641143 & 5.5686 & 5.48 & TRN & \\
\hline CHEMBL3660322 & 1641143 & 6.0 & 6.1733 & TRN & \\
\hline CHEMBL3660454 & 1641143 & 6.8794 & 6.8416 & TRN & \\
\hline CHEMBL3920586 & 1641143 & 6.8097 & 5.9675 & TST & \\
\hline CHEMBL 3660434 & 1641143 & 7.3372 & 7.4369 & TRN & \\
\hline CHEMBL3665020 & 1641143 & 7.1805 & 7.3277 & TRN & \\
\hline CHEMBL 3665034 & 1641143 & 5.0586 & 4.9636 & TRN & \\
\hline CHEMBL3665041 & 1641143 & 3.699 & 4.0064 & TRN & \\
\hline CHEMBL3665036 & 1641143 & 4.9164 & 5.132006 & 0000000001 & TRN \\
\hline CHEMBL 3665038 & 1641143 & 3.699 & 3.665 & TRN & \\
\hline CHEMBL3660435 & 1641143 & 6.6289 & 6.8287 & TRN & \\
\hline CHEMBL3660337 & 1641143 & 6.1249 & 6.0907 & TRN & \\
\hline CHEMBL3660441 & 1641143 & 5.4353 & 5.6028 & TRN & \\
\hline CHEMBL3665096 & 1641143 & 4.913 & 4.6574 & TST & \\
\hline
\end{tabular}


Supplemental Table S2.txt

\begin{tabular}{|c|c|c|c|c|c|}
\hline CHEMBL3665104 & 1641143 & 4.4393 & 4.4883 & TST & \\
\hline CHEMBL 3660382 & 1641143 & 6.4609 & 6.5918 & TRN & \\
\hline CHEMBL3660470 & 1641143 & 6.1824 & 6.2717 & TRN & \\
\hline CHEMBL3665068 & 1641143 & 4.753 & 4.4628 & TST & \\
\hline CHEMBL 3665017 & 1641143 & 7.0757 & 7.2736 & TRN & \\
\hline CHEMBL 3665040 & 1641143 & 3.699 & 3.4477 & TRN & \\
\hline CHEMBL 3665045 & 1641143 & 6.2262 & 6.2183 & TRN & \\
\hline CHEMBL3660428 & 1641143 & 7.0862 & 7.1569 & TRN & \\
\hline CHEMBL3660319 & 1641143 & 6.6021 & 6.5923 & TRN & \\
\hline CHEMBL3660341 & 1641143 & 5.9957 & 5.9571 & TRN & \\
\hline CHEMBL 3660437 & 1641143 & 5.5536 & 5.6479 & TRN & \\
\hline CHEMBL 3660331 & 1641143 & 6.3565 & 6.263999 & 9999999999 & TST \\
\hline CHEMBL 3660417 & 1641143 & 6.3556 & 6.4451 & TRN & \\
\hline CHEMBL3660419 & 1641143 & 7.2924 & 7.0896 & TRN & \\
\hline CHEMBL3919666 & 1641143 & 5.5144 & 5.7918 & TST & \\
\hline CHEMBL3660369 & 1641143 & 5.0862 & 4.8215 & TRN & \\
\hline CHEMBL3665089 & 1641143 & 6.1931 & 6.0948 & TST & \\
\hline CHEMBL 3660443 & 1641143 & 6.7167 & 6.6177 & TRN & \\
\hline CHEMBL 3665088 & 1641143 & 6.8125 & 6.8234 & TRN & \\
\hline CHEMBL 3660387 & 1641143 & 7.1308 & 7.126 & TRN & \\
\hline CHEMBL 3660410 & 1641143 & 5.9952 & 5.8709 & TST & \\
\hline CHEMBL3660475 & 1641143 & 5.7122 & 5.8316 & TRN & \\
\hline CHEMBL 3665055 & 1641143 & 6.1904 & 6.4232 & TRN & \\
\hline CHEMBL3265258 & 1641143 & 5.2468 & 5.3524 & TRN & \\
\hline CHEMBL 3660466 & 1641143 & 7.0706 & 7.2454 & TRN & \\
\hline CHEMBL 3660402 & 1641143 & 6.4802 & 6.5153 & TRN & \\
\hline CHEMBL3660361 & 1641143 & 5.5058 & 5.4322 & TST & \\
\hline CHEMBL 3665090 & 1641143 & 3.699 & 3.5693 & TST & \\
\hline CHEMBL3660465 & 1641143 & 6.6696 & 6.7213 & TRN & \\
\hline CHEMBL3660362 & 1641143 & 5.3936 & 5.297000 & 0000000001 & TRN \\
\hline CHEMBL3660395 & 1641143 & 6.1226 & 6.2164 & TRN & \\
\hline CHEMBL 3660430 & 1641143 & 6.7905 & 6.6743 & TRN & \\
\hline CHEMBL3660353 & 1641143 & 5.7852 & 5.6951 & TRN & \\
\hline CHEMBL3660346 & 1641143 & 5.8861 & 5.7931 & TRN & \\
\hline CHEMBL3665059 & 1641143 & 6.8041 & 7.1978 & TRN & \\
\hline CHEMBL3665042 & 1641143 & 6.0565 & 6.2421 & TRN & \\
\hline CHEMBL3660452 & 1641143 & 6.7055 & 6.9908 & TRN & \\
\hline CHEMBL 3660403 & 1641143 & 5.9539 & 5.8821 & TST & \\
\hline CHEMBL 3665031 & 1641143 & 7.4437 & 7.2029 & TRN & \\
\hline CHEMBL3660355 & 1641143 & 5.7167 & 5.638999 & 9999999999 & TRN \\
\hline CHEMBL 2063877 & 1641143 & 5.75700 & 000000000 & 5.7334 & TRN \\
\hline CHEMBL 3665095 & 1641143 & 4.944 & 4.7355 & TST & \\
\hline CHEMBL 3660464 & 1641143 & 6.4353 & 6.1497 & TRN & \\
\hline CHEMBL3665028 & 1641143 & 7.1805 & 6.8742 & TRN & \\
\hline CHEMBL 3665058 & 1641143 & 6.4101 & 6.5846 & TRN & \\
\hline CHEMBL 3660347 & 1641143 & 5.8861 & 5.711 & TRN & \\
\hline CHEMBL 3660450 & 1641143 & 6.32700 & 000000000 & .4158 & TRN \\
\hline CHEMBL3895174 & 1641143 & 6.8041 & 6.359 & TRN & \\
\hline
\end{tabular}


Supplemental Table S2.txt

\begin{tabular}{|c|c|c|c|c|}
\hline-1 & 1143 & & 5.7349 & \\
\hline & 641143 & & 6.5384 & \\
\hline-1 & & & & \\
\hline AEMB & & & & \\
\hline HEMBL & 641143 & & 4288 & \\
\hline HEMBL3660444 & 641143 & 6.1331 & 3767 & \\
\hline 50405 & & 69 & 32 & \\
\hline |FMRI & & & & \\
\hline HEMBL3665092 & & & 3938 & \\
\hline HEMBL3665080 & 143 & 3703 & 1865 & \\
\hline HEMBL3660367 & 143 & 5.1656 & 1982 & \\
\hline IEMBL & 3 & 024 & .762 & \\
\hline HEMBL; & & & & \\
\hline HEMBL3 & 43 & 4089 & 2952 & \\
\hline AEMBL3 & 43 & 57 & 282 & \\
\hline AEMBL3 & 6 & 3. & 3886 & \\
\hline HEMBL3 & 6 & & 465 & \\
\hline HEMBL3 & & & 262 & \\
\hline HEMBL3 & & 47 & 1435 & \\
\hline IEMBL3 & & & 322 & \\
\hline HEMBL & 6 & & 466 & \\
\hline HEMBL: & & & 397 & \\
\hline HEMBL; & & & 18 & \\
\hline 60370 & & 721 & 618 & \\
\hline AEMBL3 & & & 81 & ISI \\
\hline HEMBL & 6 & & 7206 & RN \\
\hline HEMBL & & & 842 & וד וכ \\
\hline HFMBI : & & 45 & 909 & \\
\hline HEMBL3 & & & 657 & RIV \\
\hline HEMBL3660391 & & 6.7212 & 972 & I RN \\
\hline HEMBL36603 & $\sigma$ & & 985 & RIV \\
\hline HEMBL & & & 55 & ST \\
\hline HEMBL & & 76 & 109 & -3 \\
\hline HEMBL3639592 & & & 331 & IRN \\
\hline HEMBL3665079 & & & 3495 & TST \\
\hline HEMBL 366037 & & 78 & & TRN \\
\hline HFMRI & 6 & & 853 & KIV \\
\hline HEMBL: & & & 222 & RN \\
\hline HEMBL3660359 & & 5.5452 & 3532 & TST \\
\hline AEMBL36604 & & & 5274 & TRN \\
\hline HEMBL366e & 16 & & 372 & \\
\hline CHEMBL3665060 & & 8.30 & 3.0195 & RIN \\
\hline HEMBL3660425 & & 6.1524 & 1143 & RN \\
\hline HEMBL3665047 & 16 & 5 . & 218 & TRN \\
\hline HEMBL36650 & & & 1379 & $\mathrm{~N}$ \\
\hline LHEMBL 3660332 & & 924 & 9131 & \\
\hline CHEMBL 3665022 & & .7212 & .7182 & \\
\hline CHEMBL3660457 & 1641143 & 7.2676 & 7.1461 & \\
\hline
\end{tabular}

Page 6165 
Supplemental Table S2.txt

\begin{tabular}{|c|c|c|}
\hline (1) & & \\
\hline CHEMBL & 1143 & \\
\hline AEMBL3 & 541143 & SO \\
\hline AEMBL3660436 & 641143 & 5 \\
\hline 60414 & 41143 & 136 \\
\hline AFMRI 366 & 641143 & 6.410 \\
\hline AEMBL3665039 & 1641143 & 3.699 \\
\hline HEMBL3 & 641143 & 5.376 \\
\hline AEMBL 3660392 & 1641143 & 6.096 \\
\hline 374 & 1641143 & 5.011 \\
\hline$\partial 21$ & 1641143 & 7.397 \\
\hline AEMBL3660396 & 1641143 & 6.785 \\
\hline 398 & 1641143 & 6.627 \\
\hline 383 & 1641143 & 6.03 \\
\hline 89 & 143 & 7.086 \\
\hline 97 & 143 & 6.926 \\
\hline 364 & 1641143 & 5.255 \\
\hline$\partial 81$ & 143 & 7.468 \\
\hline 62 & & 4 \\
\hline 24 & 143 & 7.026 \\
\hline 13 & 143 & 6.419 \\
\hline 82 & 143 & 231 \\
\hline 80 & 143 & 996 \\
\hline HEN & & 6 \\
\hline 27 & 16 & 7.055 \\
\hline 55 & 56 & 8.148 \\
\hline 46 & 956 & 7.640 \\
\hline 35 & 956 & 6.73 \\
\hline 204 & & 83 \\
\hline HEN & 16 & 7.076 \\
\hline & 16 & 7.101 \\
\hline & & 7.368 \\
\hline 16 & $16<$ & 6. \\
\hline 386 & 1640956 & 5.652 \\
\hline 401 & 956 & 5.970 \\
\hline & 16 & 8.045 \\
\hline HEMBL3956596 & & 8.366 \\
\hline HEMBL3931806 & 1640956 & 7.742 \\
\hline CHEMBL 3915571 & 1640956 & 6.892 \\
\hline 74 & 956 & 6.689 \\
\hline Curmor & 956 & 6.273 \\
\hline CHEMBL3959669 & 1640956 & 7.950 \\
\hline CHEMBL3952447 & 1640956 & 7.253 \\
\hline CHEMBL3980965 & 16 & $6.18 \varepsilon$ \\
\hline CHEMBL3925076 & 1640956 & 6.246 \\
\hline CHEMBL 3939252 & 1640956 & 7.146 \\
\hline CHEMBL3930246 & 1640956 & 7.11 \\
\hline CHEMBL3656247 & 1640956 & 6.0 \\
\hline
\end{tabular}

$\begin{array}{ll}6.3925 & \text { TRN } \\ 6.5291 & \text { TRN } \\ 6.4011 & \text { TRN } \\ 5.9265 & \text { TRN } \\ 7.0723 & \text { TRN } \\ 6.574 & \text { TST }\end{array}$

3.418 TST

5.3096 TST

6.3372 TST

4.843 TST

7.4262 TST

6.7696 TST

6.5671 TST

5.9823 TST

6.8391 TST

6.0161 TST

5.2343 TST

7.2943 TST

4.7755 TST

7.2258 TST

6.364 TST

6.3985 TST

6.7978 TST

6.117999999999999

TST

7.3246 TST

7.7096 TRN

7.1243 TRN

6.7934 TRN

6.9162 TST

7.3006 TRN

7.416 TST

7.5785 TST

6.3556 TRN

7.2046 TRN

7.1299 TRN

7.6529 TRN

7.5108 TRN

7.5321 TRN

7.2281 TRN

6.8306 TST

6.5852 TST

7.0879 TRN

6.5467 TST

7.1116 TRN

7.0513 TRN

7.2551 TRN

7.5381 TRN

7.4281 TST

Page 6166 
Supplemental Table S2.txt

\begin{tabular}{|c|c|c|c|c|c|}
\hline CHEMBL 3935455 & 1640956 & 7.983 & 6.3475 & TRN & \\
\hline CHEMBL 3943370 & 1640956 & 5.4553 & 6.9851 & TST & \\
\hline CHEMBL 3893167 & 1640956 & 7.9508 & 7.3722 & TRN & \\
\hline CHEMBL 3909268 & 1640956 & 8.0555 & 7.2154 & TRN & \\
\hline CHEMBL 3939118 & 1640956 & 6.1605 & 7.4899 & TST & \\
\hline CHEMBL 3946645 & 1640956 & 7.9208 & 6.9526 & TST & \\
\hline CHEMBL 3900213 & 1640956 & 4.6582 & 7.0807 & TST & \\
\hline CHEMBL 3897128 & 1640956 & 7.7399 & 7.1527 & TRN & \\
\hline CHEMBL 3974233 & 1640956 & 7.6345 & 7.04299 & 7999999999 & TRN \\
\hline CHEMBL 3953496 & 1640956 & 6.8722 & 7.4134 & TRN & \\
\hline CHEMBL 3925501 & 1640956 & 8.0605 & 6.9903 & TRN & \\
\hline CHEMBL 3656188 & 1640956 & 7.0039 & 7.3429 & TST & \\
\hline CHEMBL 3656205 & 1640956 & 7.4089 & 7.66 & TST & \\
\hline CHEMBL 3656186 & 1640956 & 6.5629 & 7.0863 & TST & \\
\hline CHEMBL 3982045 & 1640956 & 7.4647 & 7.6343 & TRN & \\
\hline CHEMBL 3969124 & 1640956 & 7.4908 & 7.03600 & 00000000005 & TRN \\
\hline CHEMBL 3916361 & 1640956 & 8.3468 & 8.4097 & TRN & \\
\hline CHEMBL 3907588 & 1640956 & 6.8392 & 7.1917 & TRN & \\
\hline CHEMBL 3909862 & 1640956 & 7.5186 & 7.1184 & TRN & \\
\hline CHEMBL 3920999 & 1640956 & 6.3249 & 7.0051 & TRN & \\
\hline CHEMBL 3921241 & 1640956 & 7.6676 & 6.9114 & TRN & \\
\hline CHEMBL 3903793 & 1640956 & 7.6904 & 7.3201 & TRN & \\
\hline CHEMBL 3944116 & 1640956 & 7.8013 & 7.1069 & TRN & \\
\hline CHEMBL 3972526 & 1640956 & 6.3392 & 6.7874 & TRN & \\
\hline CHEMBL 3967330 & 1640956 & 7.1397 & 7.2508 & TRN & \\
\hline CHEMBL 3941103 & 1640956 & 4.8697 & 6.4728 & TRN & \\
\hline CHEMBL 3889795 & 1640956 & 6.9393 & 7.2911 & TST & \\
\hline CHEMBL 3953190 & 1640956 & 7.8894 & 6.875 & TRN & \\
\hline CHEMBL 3942229 & 1640956 & 6.0 & 7.6556 & TRN & \\
\hline CHEMBL 3904142 & 1640956 & 6.0 & 7.4801 & TRN & \\
\hline CHEMBL 3656191 & 1640956 & 7.0325 & 7.3072 & TST & \\
\hline CHEMBL 3902558 & 1640956 & 6.0 & 7.2759 & TRN & \\
\hline CHEMBL 3952491 & 1640956 & 7.6021 & 7.7865 & TRN & \\
\hline CHEMBL 3936827 & 1640956 & 6.0 & 7.2841 & TRN & \\
\hline CHEMBL 3962306 & 1640956 & 5.7102 & 7.3964 & TRN & \\
\hline CHEMBL 3986110 & 1640956 & 7.6778 & 7.9608 & TRN & \\
\hline CHEMBL 3917982 & 1640956 & 6.7263 & 7.0776 & TRN & \\
\hline CHEMBL 3940181 & 1640956 & 7.4425 & 7.0946 & TRN & \\
\hline CHEMBL 3937749 & 1640956 & 5.6315 & 6.4441 & TST & \\
\hline CHEMBL 3898784 & 1640956 & 8.0 & 6.8157 & TRN & \\
\hline CHEMBL 3969552 & 1640956 & 7.1068 & 7.3212 & TRN & \\
\hline CHEMBL 3897669 & 1640956 & 5.8674 & 6.3582 & TRN & \\
\hline CHEMBL 3916104 & 1640956 & 6.0 & 6.9723 & TST & \\
\hline CHEMBL 3907808 & 1640956 & 6.8271 & 7.1828 & TRN & \\
\hline CHEMBL 3950945 & 1640956 & 6.4336 & 7.1847 & TRN & \\
\hline CHEMBL 3919711 & 1640956 & 7.6055 & 7.2735 & TRN & \\
\hline CHEMBL 3923021 & 1640956 & 6.8041 & 7.1286 & TRN & \\
\hline CHEMBL 3965121 & 1640956 & 6.75299 & 9999999 & 7.0066 & TRN \\
\hline
\end{tabular}


Supplemental Table S2.txt

\begin{tabular}{|c|c|c|c|c|}
\hline HEMBL 39 & 640956 & 7.7077 & 7.3675 & \\
\hline HEMBL3977850 & 640956 & 7.9872 & 7.3997 & \\
\hline HEMBL3903963 & 56 & 7.0391 & & \\
\hline AEMBL3906323 & 640956 & 8.1675 & & \\
\hline HEMBL3976150 & 646956 & 8.1308 & .4846 & \\
\hline HEMBL3944387 & 640956 & 7.9355 & .9539 & \\
\hline JEMBL396 & 56 & 6.2623 & .7855 & \\
\hline HEMBL395 & 956 & & 2769 & \\
\hline HEMBL3891866 & L640956 & 6.0 & 7.5162 & \\
\hline HEMBL3955331 & 1640956 & 7.4145 & 7.3543 & \\
\hline HEMBL3980763 & 640956 & 7.6904 & 7.3181 & \\
\hline IEMBL397 & 64 & 7.8013 & 7.2289 & \\
\hline HEMBL392 & & 86 & 7.7354 & \\
\hline HEMBL3902306 & 164 & 6.4949 & 7.0613 & \\
\hline HEMBL3927824 & 56 & 7.7932 & 7.6615 & \\
\hline IEMBL393 & 164 & 7.1605 & 7.1102 & \\
\hline IEMBL393 & 6 & 697 & .3067 & \\
\hline HEMBL 390 & 6 & 089 & 541 & \\
\hline HEMBL 389 & 56 & 6.7924 & 7.2688 & \\
\hline HEMBL 397 & 6 & 6.0 & & \\
\hline JEMBL39 & 64 & 331 & 7.2525 & \\
\hline JEMBL39 & U & 7. & 889 & \\
\hline HEMBL 39 & 6 & 31 & 381 & \\
\hline HEMBL 391 & 56 & 7.3107 & 7.3691 & \\
\hline HEMBL 390 & 6 & 79 & 7.6453 & \\
\hline HEMBL 390 & 164 & 041 & 7.4231 & \\
\hline HEMBL39 & 16 & 15 & 105 & \\
\hline JEMBL 38 & 6 & 63 & .78 & \\
\hline HEMBL 398 & 56 & 6.9788 & 7.2963 & \\
\hline HEMBL3913436 & 64 & 7. & 7.2067 & \\
\hline HEMBL392 & 64 & 7.0405 & 7.155 & \\
\hline HEMBL3S & 6 & 24 & 705 & \\
\hline HEMBL3S & 6 & 39 & 002 & \\
\hline HEMBL3904617 & 64 & 6.739 & 6.5391 & \\
\hline HEMBL3925344 & $64 t$ & 8.0269 & 7.9873 & \\
\hline HEMBL398 & 64 & 7.4685 & 7.7106 & \\
\hline HEMBL 39 & 6 & 76 & .4289 & \\
\hline CHEMBL396 & 16 & 7.8097 & 7.222 & \\
\hline HEMBL3933950 & 164 & 7.9031 & 7.1796 & \\
\hline HEMBL3938356 & 64 & 5.3894 & 6.4535 & \\
\hline HEMBL396 & 164 & 7.9318 & 8.0626 & \\
\hline CHEMBL397 & 164 & 8.301 & 8.3038 & \\
\hline CHEMBL3656276 & 164 & 8.2076 & 8.0874 & \\
\hline CHEMBL3964102 & 1640956 & 7.2373 & 7.4612 & \\
\hline EMBL391 & 64 & 8.0506 & 7.2804 & \\
\hline CHEMBL3903080 & $164 t$ & 7.9393 & 7.2309 & \\
\hline CHEMBL3905149 & 164 & 7.3665 & 7.1376 & \\
\hline CHEMBL3965828 & 1640956 & 7.426 & 7.4552 & \\
\hline
\end{tabular}

Page 6168 


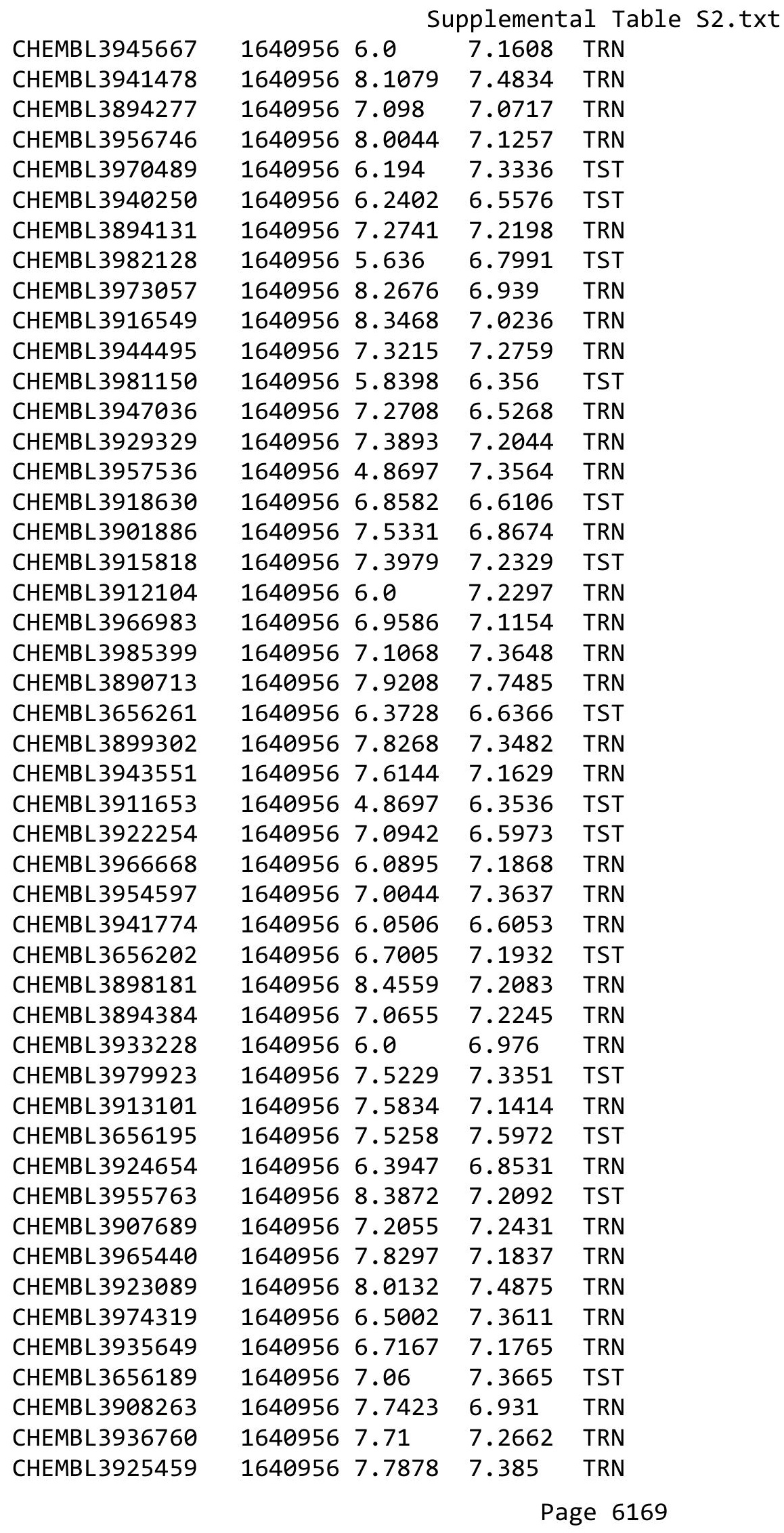


Supplemental Table S2.txt

\begin{tabular}{|c|c|c|c|c|c|c|}
\hline CHEMBL 3976065 & 1640956 & 8.0506 & 7.2181 & TRN & & \\
\hline CHEMBL 3949357 & 1640956 & 5.8013 & 6.3751 & TRN & & \\
\hline CHEMBL3925451 & 1640956 & 7.6925 & 7.0891 & TRN & & \\
\hline CHEMBL3958997 & 1640956 & 7.5003 & 7.0162 & TRN & & \\
\hline CHEMBL3896298 & 1640956 & 6.0931 & 6.8034 & TRN & & \\
\hline CHEMBL3973828 & 1640956 & 5.9215 & 6.8924 & TRN & & \\
\hline CHEMBL 3910670 & 1640956 & 7.9469 & 7.3029 & TRN & & \\
\hline CHEMBL3926999 & 1640956 & 7.4572 & 7.4156 & TRN & & \\
\hline CHEMBL3980312 & 1640956 & 5.7764 & 6.5011 & TST & & \\
\hline CHEMBL3940036 & 1640956 & 7.8297 & 7.4706 & TRN & & \\
\hline CHEMBL3924326 & 1640956 & 7.7959 & 7.5014 & TST & & \\
\hline CHEMBL3927975 & 1640956 & 6.5792 & 6.3777 & TRN & & \\
\hline CHEMBL 3984957 & 1640956 & 7.8697 & 7.3991 & TRN & & \\
\hline CHEMBL3980777 & 1640956 & 6.0 & 6.9872 & TRN & & \\
\hline CHEMBL3919628 & 1640956 & 7.1135 & 7.5784 & TRN & & \\
\hline CHEMBL3925553 & 1640956 & 6.0 & 7.0869 & TRN & & \\
\hline CHEMBL 3983723 & 1640956 & 6.9007 & 7.0329 & TST & & \\
\hline CHEMBL 3931664 & 1640956 & 8.1549 & 7.2748 & TST & & \\
\hline CHEMBL3980812 & 1640956 & 5.9331 & 7.0899 & TST & & \\
\hline CHEMBL3903027 & 1640956 & \multicolumn{3}{|c|}{7.7620000000000005} & 7.3647 & TRN \\
\hline CHEMBL 3908822 & 1640956 & 7.3686 & 7.6165 & TRN & & \\
\hline CHEMBL3938713 & 1640956 & 6.0 & 7.1816 & TRN & & \\
\hline CHEMBL3971649 & 1640956 & 8.1367 & 7.1239 & TRN & & \\
\hline CHEMBL 3947797 & 1640956 & 7.5834 & 6.3471 & TRN & & \\
\hline CHEMBL3922159 & 1640956 & 6.0 & 7.1815 & TRN & & \\
\hline CHEMBL 3946221 & 1640956 & 8.0969 & 7.3389 & TRN & & \\
\hline CHEMBL3950163 & 1640956 & 7.8069 & 7.683 & TRN & & \\
\hline CHEMBL 3905251 & 1640956 & 7.51 & 6.3682 & TRN & & \\
\hline CHEMBL3920773 & 1640956 & 7.5391 & 7.5384 & TRN & & \\
\hline CHEMBL3932723 & 1640956 & 7.7595 & 7.7144 & TRN & & \\
\hline CHEMBL3980458 & 1640956 & 5.3741 & 6.0529 & TRN & & \\
\hline CHEMBL3922042 & 1640956 & 7.3161 & 7.3167 & TST & & \\
\hline CHEMBL 3902253 & 1640956 & 6.4689 & 7.1691 & TST & & \\
\hline CHEMBL3959903 & 1640956 & \multicolumn{3}{|c|}{6.3420000000000005} & 6.8565 & TRN \\
\hline CHEMBL3966722 & 1640956 & 7.5498 & 7.2237 & TRN & & \\
\hline CHEMBL 3953186 & 1640956 & 7.7959 & 6.874 & TRN & & \\
\hline CHEMBL3943052 & 1640956 & 7.5918 & 6.8876 & TRN & & \\
\hline CHEMBL 3952078 & 1640956 & 7.7932 & 7.3779 & TST & & \\
\hline CHEMBL3908843 & 1640956 & 8.2218 & 8.0064 & TRN & & \\
\hline CHEMBL3911294 & 1640956 & 7.7696 & 7.5663 & TRN & & \\
\hline CHEMBL 3962090 & 1640956 & 6.8395 & 7.0408 & TRN & & \\
\hline CHEMBL3895666 & 1640956 & 7.8996 & 7.3239 & TRN & & \\
\hline CHEMBL 3656245 & 1640956 & 6.0 & 6.7942 & TST & & \\
\hline CHEMBL3935652 & 1640956 & 7.6198 & 7.6486 & TRN & & \\
\hline CHEMBL 3933588 & 1640956 & 6.0834 & 7.0901 & TRN & & \\
\hline CHEMBL 3920748 & 1640956 & 8.1079 & 7.2622 & TRN & & \\
\hline CHEMBL3905707 & 1640956 & 7.6383 & 7.3698 & TRN & & \\
\hline CHEMBL 3985282 & 1640956 & 7.8182 & 7.2769 & TRN & & \\
\hline
\end{tabular}




\begin{tabular}{|c|c|c|c|c|c|c|}
\hline \multicolumn{7}{|c|}{ Supplemental Table S2.txt } \\
\hline CHEMBL3906842 & 1640956 & 6.75299 & (99999999 & & 7.355 & TRN \\
\hline CHEMBL 3890022 & 1640956 & 5.6968 & 6.8229 & TST & & \\
\hline CHEMBL3930777 & 1640956 & 6.2118 & 6.739 & TRN & & \\
\hline CHEMBL 3944604 & 1640956 & 7.8508 & 7.17299 & 9999999999 & & TRN \\
\hline CHEMBL 3656215 & 1640956 & 8.0458 & 8.0634 & TST & & \\
\hline CHEMBL 3933242 & 1640956 & 6.768 & 7.1422 & TRN & & \\
\hline CHEMBL 3967730 & 1640956 & 6.0 & 7.2434 & TRN & & \\
\hline CHEMBL 3943546 & 1640956 & 7.9136 & 7.235 & TRN & & \\
\hline CHEMBL 3894862 & 1640956 & 5.5947 & 7.1583 & TRN & & \\
\hline CHEMBL 3945122 & 1640956 & 8.1549 & 7.5256 & TRN & & \\
\hline CHEMBL 3656196 & 1640956 & 7.2652 & 7.5291 & TST & & \\
\hline CHEMBL 3935889 & 1640956 & 7.6144 & 7.2939 & TRN & & \\
\hline CHEMBL3895197 & 1640956 & 4.5229 & 6.4975 & TST & & \\
\hline CHEMBL 3986229 & 1640956 & 6.6012 & 7.021 & TRN & & \\
\hline CHEMBL 3934573 & 1640956 & 7.76200 & 90000000 & 005 & 7.2551 & TRN \\
\hline CHEMBL 3984177 & 1640956 & 7.8794 & 7.3174 & TRN & & \\
\hline CHEMBL 3912922 & 1640956 & 7.1273 & 6.8023 & TRN & & \\
\hline CHEMBL3963268 & 1640956 & 7.699 & 6.9529 & TRN & & \\
\hline CHEMBL 3955352 & 1640956 & 8.0 & 7.4426 & TST & & \\
\hline CHEMBL3945502 & 1640956 & 7.2534 & 7.1591 & TRN & & \\
\hline CHEMBL 3889964 & 1640956 & 6.8407 & 7.1315 & TRN & & \\
\hline CHEMBL 3975135 & 1640956 & 7.567 & 7.6824 & TRN & & \\
\hline CHEMBL3909616 & 1640956 & 6.5735 & 7.0444 & TRN & & \\
\hline CHEMBL3930915 & 1640956 & 7.6364 & 6.9761 & TRN & & \\
\hline CHEMBL 3982284 & 1640956 & 8.1549 & 7.9958 & TRN & & \\
\hline CHEMBL 3940969 & 1640956 & 6.9559 & 7.0313 & TRN & & \\
\hline CHEMBL 3656225 & 1640956 & 6.8928 & 7.3005 & TST & & \\
\hline CHEMBL3978356 & 1640956 & 6.4931 & 7.1066 & TRN & & \\
\hline CHEMBL 3899206 & 1640956 & 7.5346 & 7.3701 & TRN & & \\
\hline CHEMBL3981106 & 1640956 & 6.209 & 7.3257 & TRN & & \\
\hline CHEMBL 3920806 & 1640956 & 7.8013 & 7.291 & TRN & & \\
\hline CHEMBL 3943420 & 1640956 & 8.0 & 7.1816 & TRN & & \\
\hline CHEMBL 3971782 & 1640956 & 5.6276 & 6.3636 & TST & & \\
\hline CHEMBL3949906 & 1640956 & 7.091 & 7.2865 & TRN & & \\
\hline CHEMBL3890041 & 1640956 & 6.0 & 6.3472 & TRN & & \\
\hline CHEMBL 3656148 & 1640956 & 8.2757 & 7.9356 & TST & & \\
\hline CHEMBL3915238 & 1640956 & 7.9586 & 8.1834 & TRN & & \\
\hline CHEMBL3914985 & 1640956 & 7.4711 & 6.864 & TRN & & \\
\hline CHEMBL3977859 & 1640956 & 7.9788 & 7.0764 & TRN & & \\
\hline CHEMBL3930721 & 1640956 & 7.6478 & 7.2613 & TRN & & \\
\hline CHEMBL 3956802 & 1640956 & 6.9654 & 7.1438 & TRN & & \\
\hline CHEMBL3906599 & 1640956 & 6.4651 & 7.081 & TRN & & \\
\hline CHEMBL3922515 & 1640956 & 7.6737 & 7.5302 & TRN & & \\
\hline CHEMBL3968144 & 1640956 & 8.1308 & 7.3944 & TRN & & \\
\hline CHEMBL3929655 & 1640956 & 7.7645 & 6.5341 & TST & & \\
\hline CHEMBL 3952868 & 1640956 & 6.0 & 7.2498 & TRN & & \\
\hline CHEMBL3961892 & 1640956 & 7.8297 & 6.9836 & TRN & & \\
\hline CHEMBL 3938722 & 1640956 & 6.2472 & 7.0202 & TST & & \\
\hline
\end{tabular}


Supplemental Table S2.txt

\begin{tabular}{|c|c|c|c|c|c|}
\hline CHEMBL 3957218 & 1640956 & 7.8125 & 7.3781 & TRN & \\
\hline CHEMBL 3931617 & 1640956 & 7.3478 & 7.3426 & TRN & \\
\hline CHEMBL 3978048 & 1640956 & 8.0132 & 7.0715 & TRN & \\
\hline CHEMBL 3910708 & 1640956 & 6.4522 & 6.5959 & TST & \\
\hline CHEMBL3926530 & 1640956 & 6.0 & 6.3039 & TRN & \\
\hline CHEMBL3945730 & 1640956 & 6.9821 & 6.4628 & TRN & \\
\hline CHEMBL 3924244 & 1640956 & 8.2676 & 7.4483 & TRN & \\
\hline CHEMBL 3656212 & 1640956 & 7.2147 & 7.4024 & TST & \\
\hline CHEMBL 3656210 & 1640956 & 7.3188 & 7.6035 & TST & \\
\hline CHEMBL3980268 & 1640956 & 7.4535 & 7.2833 & TRN & \\
\hline CHEMBL3907597 & 1640956 & 7.9208 & 7.9363 & TRN & \\
\hline CHEMBL 3910995 & 1640956 & 7.3716 & 7.2504 & TRN & \\
\hline CHEMBL3918779 & 1640956 & 5.2055 & 6.3009 & TST & \\
\hline CHEMBL 3964951 & 1640956 & 4.8697 & 7.1608 & TST & \\
\hline CHEMBL3904189 & 1640956 & 8.1549 & 7.9323 & TRN & \\
\hline CHEMBL3910301 & 1640956 & 7.1175 & 7.3447 & TRN & \\
\hline CHEMBL 3656218 & 1640956 & 6.057 & 6.7118 & TST & \\
\hline CHEMBL 3907226 & 1640956 & 7.1007 & 7.3333 & TST & \\
\hline CHEMBL 3902793 & 1640956 & 5.6126 & 6.1665 & TST & \\
\hline CHEMBL3973871 & 1640956 & 6.7263 & 7.0498 & TRN & \\
\hline CHEMBL3974295 & 1640956 & 7.2757 & 7.3687 & TST & \\
\hline CHEMBL3931613 & 1640956 & 8.0315 & 7.5245 & TRN & \\
\hline CHEMBL 3958576 & 1640956 & 7.61799 & 999999999 & 7.2379 & TRN \\
\hline CHEMBL 3965117 & 1640956 & 8.8239 & 7.1917 & TRN & \\
\hline CHEMBL 3919180 & 1640956 & 7.8539 & 7.6913 & TRN & \\
\hline CHEMBL3939930 & 1640956 & 8.2007 & 7.0814 & TST & \\
\hline CHEMBL 3927467 & 1640956 & 4.7109 & 6.5066 & TST & \\
\hline CHEMBL 3934567 & 1640956 & 7.3072 & 7.2207 & TRN & \\
\hline CHEMBL 3948874 & 1640956 & 8.1308 & 7.1433 & TRN & \\
\hline CHEMBL 3900970 & 1640956 & 6.8216 & 6.4928 & TRN & \\
\hline CHEMBL 3947627 & 1640956 & 7.2111 & 7.3554 & TRN & \\
\hline CHEMBL 3929053 & 1640956 & 6.8928 & 7.2603 & TST & \\
\hline CHEMBL 3960538 & 1640956 & 7.0472 & 6.9122 & TRN & \\
\hline CHEMBL 3978126 & 1640956 & 7.8239 & 7.6346 & TRN & \\
\hline CHEMBL 3953152 & 1640956 & 6.87 & 7.3678 & TRN & \\
\hline CHEMBL 3972752 & 1640956 & 7.7696 & 7.3941 & TRN & \\
\hline CHEMBL 3941308 & 1640956 & 8.1675 & 7.5242 & TRN & \\
\hline CHEMBL 3899247 & 1640956 & 6.0 & 7.4754 & TRN & \\
\hline CHEMBL 3656277 & 1640956 & 6.9914 & 7.5514 & TST & \\
\hline CHEMBL 3915130 & 1640956 & 7.9101 & 7.3506 & TRN & \\
\hline CHEMBL 3980499 & 1640956 & 8.2757 & 7.5309 & TRN & \\
\hline CHEMBL 3955360 & 1640956 & 6.1366 & 7.1421 & TST & \\
\hline CHEMBL 3979334 & 1640956 & 7.3536 & 7.555 & TRN & \\
\hline CHEMBL3962901 & 1640956 & 6.7387 & 6.6012 & TST & \\
\hline CHEMBL 3948290 & 1640956 & 7.7959 & 7.257999 & 9999999999 & TRN \\
\hline CHEMBL 3958023 & 1640956 & 8.28399 & 999999999 & 7.566 & TRN \\
\hline CHEMBL 3961260 & 1640956 & 6.7721 & 7.1265 & TRN & \\
\hline CHEMBL 3939788 & 1640956 & 6.8601 & 7.3203 & TRN & \\
\hline
\end{tabular}


Supplemental Table S2.txt

\begin{tabular}{|c|c|c|c|c|}
\hline 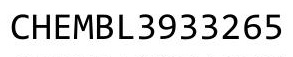 & & 6.0 & & \\
\hline HEMBL3934938 & 9956 & 8.0458 & 0107 & \\
\hline HEMBL3949804 & & 6.5328 & 9998 & \\
\hline 166 & & 298 & & \\
\hline IEMBL 3922032 & 56 & 6.0 & 3974 & \\
\hline HEMBL3977470 & 640956 & 6.0 & 9519 & \\
\hline HEMBL3963820 & 640956 & 5.5008 & 1211 & \\
\hline HEMBL & 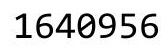 & .3979 & 2498 & \\
\hline AEMBL & 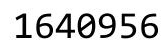 & 6.9519 & .3611 & \\
\hline AEMBL & 64 & 6.145 & & \\
\hline HEMBL3963104 & 640 & 6.1978 & . 4597 & \\
\hline HEMBL3983940 & 646 & 6.0 & & \\
\hline HEMBL3933493 & 54 & 699 & 0814 & \\
\hline HEMBL39 & & & 2799 & \\
\hline HEMBL36 & 62 & 722 & 0534 & \\
\hline HEMBL3971949 & 6 & 7.399 & 9461 & \\
\hline HEMBL3893841 & 64 & 6.6737 & 7.0651 & \\
\hline HEMBL36 & 64 & 59 & 1902 & \\
\hline HEMBL36 & & & & \\
\hline HEMBL & 6 & & 339 & \\
\hline HEMBL3S & 6 & & 49 & \\
\hline HEMBL3921657 & 64 & 7.4 & 752 & 151 \\
\hline HEMBL39 & 64 & $7 . \varepsilon$ & 527 & \\
\hline HEMBL3S & & & & \\
\hline 337 & 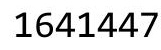 & 39 & 363 & RN \\
\hline HEMBL12 & 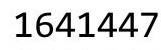 & & & RN \\
\hline HEMBL1257757 & 64 & 8. & 333 & $R / N$ \\
\hline HEMBL12 & 54 & 99 & 329 & $\mathrm{RN}$ \\
\hline HEM & 7 & 5 & 49 & RN \\
\hline HEMBL12 & 6 & & & RN \\
\hline HEMBL1257634 & & & & IRN \\
\hline HEMBL1257405 & 641 & 9.3979 & 827 & RN \\
\hline HEMBL12 & 64 & 39 & 591 & 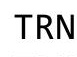 \\
\hline 6 & & & & RN \\
\hline HEMBL1256165 & & & & RN \\
\hline HEMBL1257518 & 64 & 8.5 & & ГRN \\
\hline HEMBL1257877 & 641 & 8. & 7101 & $\mathrm{RN}$ \\
\hline HEMBL1257286 & 6 & 7. & 88 & RN \\
\hline 6 & & & & RN \\
\hline HEMBL1257515 & & & 8777 & ST \\
\hline HEMBL1257170 & 641 & & 162 & RN \\
\hline HEMBL 21 & 64 & & 758 & ST \\
\hline HEMBL12 & & & 261 & \\
\hline CHEMBL1257879 & & & 8.9086 & RN \\
\hline HEMBL1258106 & 64 & 7.0132 & 2892 & RN \\
\hline HEMBL1258107 & 1641 & 7.1938 & 133 & N \\
\hline$\llcorner 1$ & & & & \\
\hline & & & & \\
\hline
\end{tabular}

Page 6173 
Supplemental Table S2.txt

\begin{tabular}{|c|c|c|c|c|c|}
\hline CHEMBL1258221 & 1641447 & 6.9586 & 7.0057 & TRN & \\
\hline CHEMBL1258556 & 1641447 & 5.5376 & 5.3835 & TRN & \\
\hline CHEMBL1258219 & 1641447 & 6.0 & 6.0556 & TRN & \\
\hline CHEMBL1257633 & 1641447 & 5.2924 & 5.5494 & TRN & \\
\hline CHEMBL1257635 & 1641447 & 9.1549 & 9.2025 & TRN & \\
\hline CHEMBL1258669 & 1641447 & 8.6383 & 8.5917 & TRN & \\
\hline CHEMBL1258904 & 1641447 & 8.5528 & 8.4913 & TRN & \\
\hline CHEMBL1256164 & 1641447 & 8.4559 & 7.9935 & TST & \\
\hline CHEMBL1257989 & 1641447 & 7.0 & 7.0448 & TST & \\
\hline CHEMBL1257632 & 1641447 & 9.0458 & 7.9935 & TST & \\
\hline CHEMBL1258336 & 1641447 & 7.8239 & \multicolumn{2}{|c|}{8.312000000000001} & TRN \\
\hline CHEMBL1257517 & 1641447 & 9.3979 & 9.2472 & TRN & \\
\hline CHEMBL1258668 & 1641447 & 4.4202 & 4.4773 & TRN & \\
\hline CHEMBL1258785 & 1641447 & 9.1549 & 8.7987 & TRN & \\
\hline CHEMBL1258784 & 1641447 & 8.0555 & 8.2114 & TRN & \\
\hline CHEMBL1258670 & 1641447 & 8.1871 & 8.7662 & TRN & \\
\hline CHEMBL1256163 & 1641447 & 7.3098 & 6.9296 & TRN & \\
\hline CHEMBL1258335 & 1641447 & 7.6383 & 8.206 & TRN & \\
\hline CHEMBL1258558 & 1641447 & 9.0 & 9.1459 & TRN & \\
\hline CHEMBL1257404 & 1641447 & 8.9208 & \multicolumn{2}{|c|}{8.722999999999999} & TST \\
\hline CHEMBL1257758 & 1641447 & 9.3979 & 8.7149 & TST & \\
\hline CHEMBL1257759 & 1641447 & 9.3979 & 9.1162 & TST & \\
\hline CHEMBL1258447 & 1641447 & 7.699 & 7.6713 & TST & \\
\hline CHEMBL1257285 & 1641447 & 8.301 & 8.2432 & TST & \\
\hline CHEMBL1257514 & 1641447 & 9.3979 & 8.1695 & TST & \\
\hline CHEMBL1258105 & 1641447 & 6.1871 & 5.7579 & TST & \\
\hline CHEMBL1258903 & 1641447 & 7.5528 & 7.7754 & TST & \\
\hline CHEMBL 363434 & 396850 & 4.1739 & 4.2032 & TRN & \\
\hline CHEMBL386831 & 396850 & 4.6345 & 4.5466 & TRN & \\
\hline CHEMBL56073 & 396850 & 4.308 & 4.3581 & TST & \\
\hline CHEMBL 377025 & 396850 & 1.0 & 1.0365 & TRN & \\
\hline CHEMBL215413 & 396850 & 3.5186 & 3.4713 & TRN & \\
\hline CHEMBL212835 & 396850 & 6.1871 & 6.9317 & TST & \\
\hline CHEMBL213059 & 396850 & 1.0 & 0.9792 & TRN & \\
\hline CHEMBL212662 & 396850 & 5.1871 & 5.1686 & TRN & \\
\hline CHEMBL373332 & 396850 & 4.8827 & 4.8412 & TRN & \\
\hline CHEMBL215472 & 396850 & 3.3605 & 3.3449 & TRN & \\
\hline CHEMBL384601 & 396850 & 4.3487 & 4.3643 & TRN & \\
\hline CHEMBL212895 & 396850 & 3.5901 & 3.5838 & TRN & \\
\hline CHEMBL215664 & 396850 & 1.0 & 0.8882 & TRN & \\
\hline CHEMBL386386 & 396850 & 4.1385 & 4.0769 & TRN & \\
\hline CHEMBL378256 & 396850 & 5.8447 & 6.8382 & TST & \\
\hline CHEMBL190258 & 396850 & 3.9547 & 3.8929 & TRN & \\
\hline CHEMBL385291 & 396850 & 4.3497 & 4.2788 & TRN & \\
\hline CHEMBL212792 & 396850 & 5.1096 & 4.7173 & TST & \\
\hline CHEMBL436939 & 396850 & 3.5376 & 3.6944 & TRN & \\
\hline CHEMBL213343 & 396850 & 4.3507 & 4.4243 & TRN & \\
\hline CHEMBL378858 & 396850 & 1.0 & 0.9901 & TRN & \\
\hline
\end{tabular}




\begin{tabular}{|c|c|c|c|c|c|c|}
\hline \multicolumn{7}{|c|}{ Supplemental Table S2.txt } \\
\hline CHEMBL386646 & 396850 & 1.0 & 1.0895 & TRN & & \\
\hline CHEMBL52621 & 396850 & 3.39899 & 99999999 & 996 & 3.6782 & TST \\
\hline CHEMBL436772 & 396850 & 3.8761 & 3.9259 & TRN & & \\
\hline CHEMBL215119 & 396850 & 4.2343 & 4.2737 & TRN & & \\
\hline CHEMBL212843 & 396850 & 4.5482 & 4.8626 & TST & & \\
\hline CHEMBL215608 & 396850 & 4.2366 & 4.1325 & TRN & & \\
\hline CHEMBL384308 & 396850 & 4.1864 & 4.2484 & TRN & & \\
\hline CHEMBL193722 & 396850 & 4.3072 & 4.2922 & TRN & & \\
\hline CHEMBL193356 & 396850 & 4.279 & 4.2595 & TRN & & \\
\hline CHEMBL383957 & 396850 & 4.618 & 4.6559 & TRN & & \\
\hline CHEMBL385542 & 396850 & 3.2076 & 3.2221 & TRN & & \\
\hline CHEMBL384162 & 396850 & 3.5834 & 3.6371 & TRN & & \\
\hline CHEMBL213470 & 396850 & 3.9626 & 3.8727 & TRN & & \\
\hline CHEMBL193619 & 396850 & 4.5129 & 4.513 & TRN & & \\
\hline CHEMBL 213327 & 396850 & 5.1029 & 6.3655 & TST & & \\
\hline CHEMBL294191 & 396850 & 4.8416 & 4.9545 & TST & & \\
\hline CHEMBL 378940 & 396850 & 4.0491 & 4.0321 & TRN & & \\
\hline CHEMBL 212842 & 396850 & 5.3206 & 5.9103 & TST & & \\
\hline CHEMBL192342 & 396850 & 4.5654 & 4.4552 & TRN & & \\
\hline CHEMBL378354 & 396850 & 4.2541 & 4.313 & TRN & & \\
\hline CHEMBL 213280 & 396850 & 3.6144 & 3.5534 & TRN & & \\
\hline CHEMBL217805 & 396850 & 3.8794 & 3.9219 & TRN & & \\
\hline CHEMBL213463 & 396850 & 3.8447 & 3.9332 & TRN & & \\
\hline CHEMBL192043 & 396850 & 4.3391 & 4.3315 & TRN & & \\
\hline CHEMBL214851 & 396850 & 5.209 & 4.9016 & TST & & \\
\hline CHEMBL213489 & 396850 & 1.0 & 0.9953 & TRN & & \\
\hline CHEMBL213206 & 396850 & 5.6234 & 6.601 & TST & & \\
\hline CHEMBL191634 & 396850 & 4.3298 & 4.2551 & TRN & & \\
\hline CHEMBL56011 & 396850 & 3.5214 & 4.0292 & TST & & \\
\hline CHEMBL213289 & 396850 & 2.0 & 2.2274 & TST & & \\
\hline CHEMBL294192 & 396850 & 3.8327 & 4.5498 & TST & & \\
\hline CHEMBL 216027 & 396850 & 3.3233 & 3.3381 & TRN & & \\
\hline CHEMBL214544 & 396850 & 3.75699 & 99999999 & 997 & 3.7544 & $1 \mathrm{~K}$ \\
\hline CHEMBL215490 & 396850 & 3.6345 & 3.6799 & TRN & & \\
\hline CHEMBL192017 & 396850 & 3.7595 & 3.8822 & TRN & & \\
\hline CHEMBL383962 & 396850 & 4.98306 & 00000000 & 005 & 5.0107 & Th \\
\hline CHEMBL425896 & 396850 & 3.585 & 3.5394 & TRN & & \\
\hline CHEMBL213490 & 396850 & 3.8861 & 3.9414 & TRN & & \\
\hline CHEMBL214519 & 396850 & 1.0 & 0.991 & TRN & & \\
\hline CHEMBL212182 & 396850 & 3.4572 & 3.1579 & TST & & \\
\hline CHEMBL441692 & 396850 & 4.3605 & 4.5793 & TST & & \\
\hline CHEMBL 3909757 & 1528051 & 7.2652 & 7.0691 & TRN & & \\
\hline CHEMBL3986222 & 1528051 & 7.2255 & 6.1245 & TRN & & \\
\hline CHEMBL 3940573 & 1528051 & 6.4859 & 6.1104 & TRN & & \\
\hline CHEMBL3912389 & 1528051 & 7.3233 & 7.7045 & TRN & & \\
\hline CHEMBL3916463 & 1528051 & 5.2208 & 6.7749 & TRN & & \\
\hline CHEMBL 3894612 & 1528051 & 7.2941 & 7.3297 & TRN & & \\
\hline CHEMBL3921239 & 1528051 & 5.9367 & 7.1507 & TRN & & \\
\hline
\end{tabular}


Supplemental Table S2.txt

\begin{tabular}{|c|c|c|c|c|}
\hline CHEMBL3965119 & 1528051 & 7.0182 & 6.2352 & TRN \\
\hline CHEMBL3685395 & 1528051 & 6.0 & 7.4869 & TST \\
\hline CHEMBL 3892957 & 1528051 & 6.5444 & 7.1962 & TRN \\
\hline CHEMBL3933006 & 1528051 & 5.5498 & 5.8761 & TRN \\
\hline CHEMBL3912799 & 1528051 & 4.9318 & 4.8449 & TRN \\
\hline CHEMBL3924057 & 1528051 & 6.8649 & 6.6876 & TRN \\
\hline CHEMBL3909353 & 1528051 & 7.0246 & 6.9481 & TRN \\
\hline CHEMBL 3945911 & 1528051 & 7.2596 & 7.0704 & TRN \\
\hline CHEMBL3981817 & 1528051 & 8.1805 & 7.4701 & TRN \\
\hline CHEMBL3917486 & 1528051 & 6.5085 & 6.1691 & TST \\
\hline CHEMBL 3983443 & 1528051 & 7.2396 & 6.9588 & TRN \\
\hline CHEMBL3910953 & 1528051 & 5.611006 & 000000000 & 6.6357 \\
\hline CHEMBL3938171 & 1528051 & 6.5116 & 6.9378 & TST \\
\hline CHEMBL 3937824 & 1528051 & 5.7838 & 6.5791 & TRN \\
\hline CHEMBL 3981848 & 1528051 & 6.1664 & 6.3714 & TRN \\
\hline CHEMBL3968502 & 1528051 & 5.8622 & 6.2092 & TST \\
\hline CHEMBL3918247 & 1528051 & 5.0303 & 6.5375 & TRN \\
\hline CHEMBL3980059 & 1528051 & 7.3028 & 7.0637 & TRN \\
\hline CHEMBL3924777 & 1528051 & 4.699 & 5.6697 & TRN \\
\hline CHEMBL3916752 & 1528051 & 6.7496 & 6.6845 & TRN \\
\hline CHEMBL3897974 & 1528051 & 6.8128 & 6.9737 & TRN \\
\hline CHEMBL3962637 & 1528051 & 5.9813 & 6.4123 & TRN \\
\hline CHEMBL3987015 & 1528051 & 7.5702 & 7.6112 & TRN \\
\hline CHEMBL3954210 & 1528051 & 7.7033 & 7.5875 & TRN \\
\hline CHEMBL 3901500 & 1528051 & 7.2958 & 7.0973 & TRN \\
\hline CHEMBL3909946 & 1528051 & 5.8462 & 6.4819 & TST \\
\hline CHEMBL3961155 & 1528051 & 6.6478 & 6.9985 & TRN \\
\hline CHEMBL3685399 & 1528051 & 6.4008 & 7.0363 & TST \\
\hline CHEMBL3971641 & 1528051 & 6.3125 & 6.2637 & TRN \\
\hline CHEMBL 3899972 & 1528051 & 7.0915 & 6.8012 & TRN \\
\hline CHEMBL3931547 & 1528051 & 7.1433 & 7.4131 & TRN \\
\hline CHEMBL3946700 & 1528051 & 6.8283 & 6.2833 & TRN \\
\hline CHEMBL3951543 & 1528051 & 5.5626 & 6.6057 & TRN \\
\hline CHEMBL3910557 & 1528051 & 7.6556 & 7.0274 & TRN \\
\hline CHEMBL3948769 & 1528051 & 5.7267 & 5.9094 & TRN \\
\hline CHEMBL3964643 & 1528051 & 6.6741 & 6.3533 & TRN \\
\hline CHEMBL3907344 & 1528051 & 6.9048 & 6.1905 & TRN \\
\hline CHEMBL3889464 & 1528051 & 7.3716 & 6.832000 & 0000000001 \\
\hline CHEMBL3895385 & 1528051 & 7.6383 & 7.2817 & TRN \\
\hline CHEMBL3954608 & 1528051 & 5.5825 & 6.5311 & TRN \\
\hline CHEMBL3685401 & 1528051 & 6.8019 & 7.0458 & TST \\
\hline CHEMBL3955403 & 1528051 & 6.2275 & 5.6593 & TRN \\
\hline CHEMBL3920768 & 1528051 & 5.9611 & 5.9394 & TRN \\
\hline CHEMBL3903946 & 1528051 & 5.4389 & 5.4417 & TRN \\
\hline CHEMBL3968693 & 1528051 & 5.2023 & 5.3901 & TRN \\
\hline CHEMBL3899441 & 1528051 & 6.8697 & 6.7045 & TRN \\
\hline CHEMBL 3925449 & 1528051 & 6.0853 & 6.2272 & TRN \\
\hline CHEMBL3685402 & 1528051 & 6.1756 & 7.0442 & TST \\
\hline
\end{tabular}


Supplemental Table S2.txt

\begin{tabular}{|c|c|c|c|c|c|}
\hline CHEMBL3933696 & 1528051 & 6.7305 & 7.0628 & TRN & \\
\hline CHEMBL3685403 & 1528051 & 5.9667 & 6.0588 & TST & \\
\hline CHEMBL3685396 & 1528051 & 6.0 & 6.91100 & 30000000005 & TST \\
\hline CHEMBL 3942749 & 1528051 & 6.6631 & 6.8985 & TRN & \\
\hline CHEMBL3913297 & 1528051 & 6.6007 & 6.1039 & TRN & \\
\hline CHEMBL3940793 & 1528051 & 6.6326 & 6.5587 & TRN & \\
\hline CHEMBL3949675 & 1528051 & 8.1427 & 7.6447 & TRN & \\
\hline CHEMBL3903555 & 1528051 & 6.1615 & 6.9123 & TST & \\
\hline CHEMBL3893640 & 1528051 & 5.2869 & 5.6724 & TRN & \\
\hline CHEMBL3919126 & 1528051 & 7.7471 & 7.0271 & TRN & \\
\hline CHEMBL3942124 & 1528051 & 6.9129 & 6.954 & TRN & \\
\hline CHEMBL3685393 & 1528051 & 5.3912 & 6.8914 & TST & \\
\hline CHEMBL3898315 & 1528051 & 7.5031 & 7.2156 & TRN & \\
\hline CHEMBL3942016 & 1528051 & 7.4191 & 7.7664 & TRN & \\
\hline CHEMBL3917508 & 1528051 & 7.2933 & 6.8917 & TRN & \\
\hline CHEMBL3905170 & 1528051 & 6.407 & 6.1259 & TRN & \\
\hline CHEMBL3918864 & 1528051 & 6.2884 & 6.2063 & TST & \\
\hline CHEMBL3961940 & 1528051 & 7.0031 & 7.5896 & TRN & \\
\hline CHEMBL3915344 & 1528051 & 5.2467 & 6.3049 & TST & \\
\hline CHEMBL3980950 & 1528051 & 7.1778 & 6.6301 & TRN & \\
\hline CHEMBL3896633 & 1528051 & 7.2291 & 7.0188 & TRN & \\
\hline CHEMBL3916364 & 1528051 & 4.9871 & 5.7492 & TRN & \\
\hline CHEMBL3685398 & 1528051 & 6.7622 & 7.5458 & TST & \\
\hline CHEMBL3944653 & 1528051 & 7.284 & 6.8622 & TRN & \\
\hline CHEMBL3966462 & 1528051 & 7.6904 & 6.7638 & TRN & \\
\hline CHEMBL3902889 & 1528051 & 6.2623 & 6.1064 & TST & \\
\hline CHEMBL3685385 & 1528051 & 5.777 & 6.6546 & TST & \\
\hline CHEMBL3685394 & 1528051 & 6.0 & 6.8303 & TST & \\
\hline CHEMBL3923828 & 1528051 & 7.0752 & 6.9475 & TRN & \\
\hline CHEMBL87706 & 1528051 & 4.9975 & 6.1754 & TST & \\
\hline CHEMBL598787 & 1528051 & 6.279 & 7.1737 & TST & \\
\hline CHEMBL3955852 & 1528051 & 6.9318 & 6.8948 & TRN & \\
\hline CHEMBL3947687 & 1528051 & 6.7625 & 5.9297 & TRN & \\
\hline CHEMBL3983048 & 1528051 & 7.3478 & 7.1403 & TRN & \\
\hline CHEMBL3967227 & 1528051 & \multicolumn{3}{|c|}{5.611000000000001} & נד \\
\hline CHEMBL3958327 & 1528051 & 7.3107 & 6.9619 & TRN & \\
\hline CHEMBL3919332 & 1528051 & 6.9817 & 7.0705 & TRN & \\
\hline CHEMBL3928937 & 1528051 & 6.9594 & 6.8012 & TRN & \\
\hline CHEMBL3916400 & 1528051 & 6.9408 & 6.8302 & TRN & \\
\hline CHEMBL3971722 & 1528051 & 6.5901 & 6.5211 & TRN & \\
\hline CHEMBL3938491 & 1528051 & 7.5467 & 6.0109 & TST & \\
\hline CHEMBL3983148 & 1528051 & 5.5169 & 6.3144 & TST & \\
\hline CHEMBL3925347 & 1528051 & 7.0246 & 6.899 & TRN & \\
\hline CHEMBL3972837 & 1528051 & 7.9872 & 7.6259 & TRN & \\
\hline CHEMBL3955243 & 1528051 & 7.3233 & 7.1867 & TRN & \\
\hline CHEMBL3972270 & 1528051 & 5.4483 & 6.1805 & TRN & \\
\hline CHEMBL3914326 & 1528051 & 7.7077 & 6.6928 & TRN & \\
\hline CHEMBL3922200 & 1528051 & 6.0893 & 6.0671 & TRN & \\
\hline
\end{tabular}




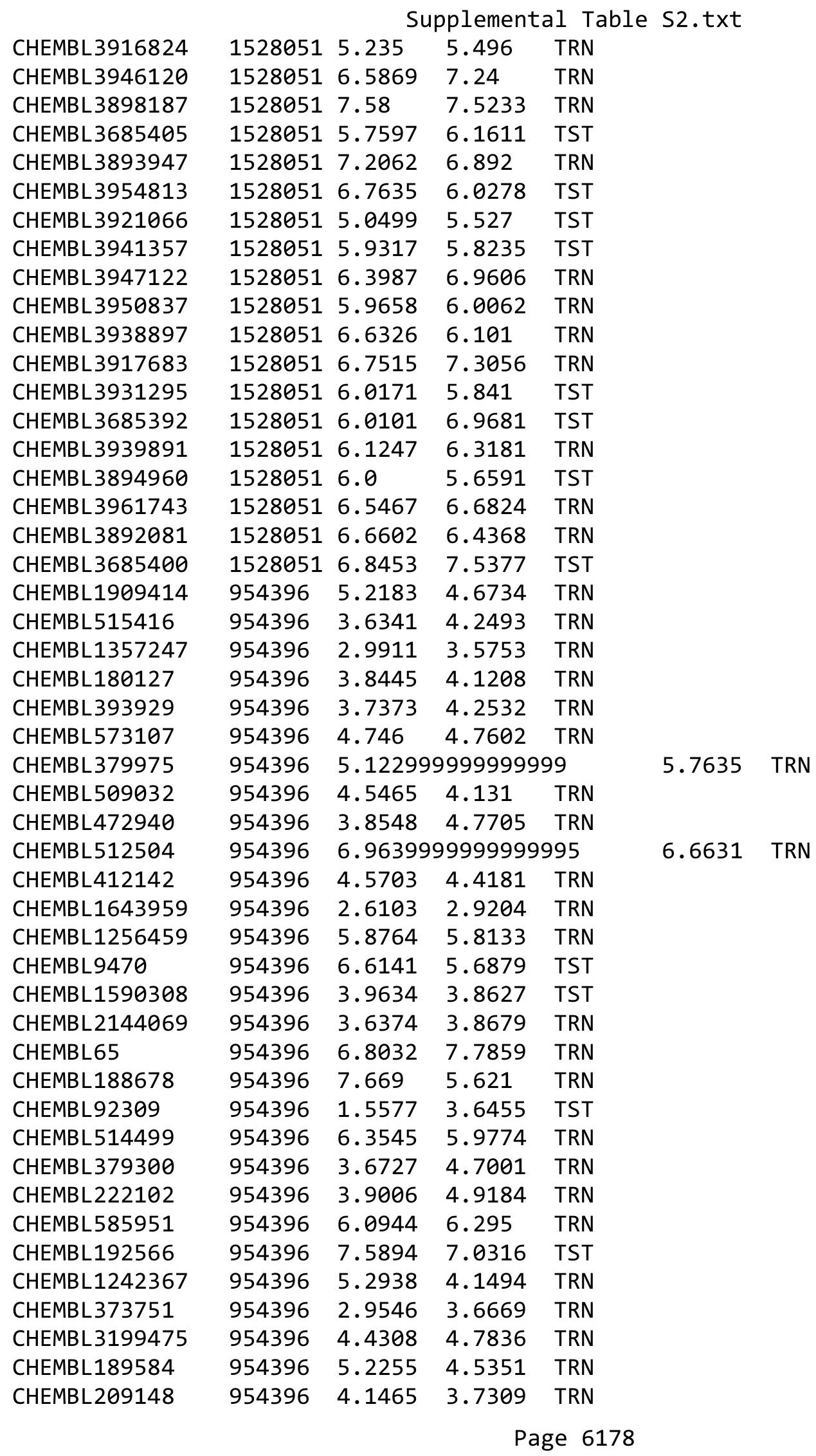




\begin{tabular}{|c|c|c|c|c|}
\hline \multicolumn{5}{|c|}{ Supplemental Table s2.txt } \\
\hline CHEMBL 2005886 & 954396 & 4.9346 & 4.6396 & TRN \\
\hline CHEMBL221137 & 954396 & 3.8298 & 5.0995 & TST \\
\hline CHEMBL1673039 & 954396 & 5.3246 & 4.3915 & TRN \\
\hline CHEMBL202721 & 954396 & 4.1628 & 4.3869 & TRN \\
\hline CHEMBL1404918 & 954396 & 2.9142 & 3.468 & TRN \\
\hline CHEMBL 258844 & 954396 & 4.4662 & 4.6547 & TRN \\
\hline CHEMBL213100 & 954396 & 3.1414 & 3.1037 & TRN \\
\hline CHEMBL392695 & 954396 & 4.8035 & 5.1776 & TRN \\
\hline CHEMBL1190711 & 954396 & 5.5832 & 4.9658 & TRN \\
\hline CHEMBL2363137 & 954396 & 4.7673 & 4.8451 & TRN \\
\hline CHEMBL 3186408 & 954396 & 4.6657 & 4.3786 & TST \\
\hline CHEMBL1788116 & 954396 & 4.9539 & 4.4691 & TRN \\
\hline CHEMBL1516890 & 954396 & 3.9537 & 4.2358 & TRN \\
\hline CHEMBL577784 & 954396 & 4.1508 & 4.4268 & TRN \\
\hline CHEMBL300389 & 954396 & 6.5155 & 6.1599 & TRN \\
\hline CHEMBL483849 & 954396 & 3.3139 & 3.1644 & TRN \\
\hline CHEMBL558642 & 954396 & 4.9985 & 4.4229 & TRN \\
\hline CHEMBL1230020 & 954396 & 4.4793 & 4.1869 & TRN \\
\hline CHEMBL 220241 & 954396 & 4.2362 & 3.68 & TRN \\
\hline CHEMBL483847 & 954396 & 3.5086 & 3.6999 & TRN \\
\hline CHEMBL210618 & 954396 & 3.8583 & 3.7436 & TRN \\
\hline CHEMBL 3392440 & 954396 & 4.2442 & 3.8329 & TST \\
\hline CHEMBL102714 & 954396 & 6.5318 & 4.623 & TST \\
\hline CHEMBL1970879 & 954396 & 3.6829 & 3.5761 & TST \\
\hline CHEMBL259181 & 954396 & 5.0507 & 4.6382 & TST \\
\hline CHEMBL3349342 & 954396 & 5.2481 & 4.4908 & TST \\
\hline CHEMBL449158 & 954396 & 6.6266 & 5.9136 & TST \\
\hline CHEMBL240954 & 954396 & 3.7619 & 4.4441 & TST \\
\hline CHEMBL191334 & 954396 & 3.3243 & 4.4509 & TST \\
\hline CHEMBL135561 & 954396 & 4.1636 & 4.3552 & TST \\
\hline CHEMBL1495233 & 688687 & 4.6 & 4.8246 & TRN \\
\hline CHEMBL1439331 & 688687 & 4.7 & 4.8065 & TRN \\
\hline CHEMBL1560298 & 688687 & 4.5 & 4.6809 & TRN \\
\hline CHEMBL1584692 & 688687 & 5.6 & 5.485 & TRN \\
\hline CHEMBL1412263 & 688687 & 4.5 & 4.8024 & TRN \\
\hline CHEMBL1364182 & 688687 & 4.4 & 4.8072 & TRN \\
\hline CHEMBL1424414 & 688687 & 5.1 & 5.0934 & TRN \\
\hline CHEMBL1584434 & 688687 & 4.5 & 4.7183 & TRN \\
\hline CHEMBL1369854 & 688687 & 4.6 & 4.9125 & TRN \\
\hline CHEMBL1365686 & 688687 & 5.5 & 4.7442 & TRN \\
\hline CHEMBL1539024 & 688687 & 4.8 & 4.8654 & TST \\
\hline CHEMBL1344668 & 688687 & 4.7 & 4.8247 & TST \\
\hline CHEMBL1530687 & 688687 & 4.5 & 4.5999 & TRN \\
\hline CHEMBL1335490 & 688687 & 4.5 & 5.4345 & TST \\
\hline CHEMBL1611608 & 688687 & 4.5 & 5.0813 & TST \\
\hline CHEMBL1522434 & 688687 & 4.7 & 4.7847 & TRN \\
\hline CHEMBL1399518 & 688687 & 4.4 & 4.7295 & TRN \\
\hline CHEMBL1595831 & 688687 & 5.5 & 5.3407 & TRN \\
\hline
\end{tabular}




\begin{tabular}{|c|c|c|c|c|c|}
\hline \\
\hline CHEMBL1504634 & 688687 & 6.6 & 5.8189 & TRN & \\
\hline CHEMBL1578717 & 688687 & 5.3 & 5.7582 & TRN & \\
\hline CHEMBL1607897 & 688687 & 4.6 & 4.9185 & TRN & \\
\hline CHEMBL136906 & 688687 & 5.4 & 5.3842 & TST & \\
\hline CHEMBL1313756 & 688687 & 6.0 & 4.8323 & TRN & \\
\hline CHEMBL1316470 & 688687 & 4.5 & 5.0594 & TST & \\
\hline CHEMBL1299837 & 688687 & 5.2 & 4.6724 & TRN & \\
\hline CHEMBL77030 & 688687 & 6.0 & 6.1472 & TRN & \\
\hline CHEMBL1334083 & 688687 & 4.4 & 4.8487 & TRN & \\
\hline CHEMBL1524015 & 688687 & 5.1 & 4.9021 & TRN & \\
\hline CHEMBL1417829 & 688687 & 4.4 & 4.9869 & TRN & \\
\hline CHEMBL1599808 & 688687 & 4.5 & 4.987 & TST & \\
\hline CHEMBL1531515 & 688687 & 5.2 & 5.0853 & TRN & \\
\hline CHEMBL1528235 & 688687 & 4.6 & 4.7623 & TRN & \\
\hline CHEMBL1422670 & 688687 & 5.2 & 4.8722 & TRN & \\
\hline CHEMBL1399391 & 688687 & 4.4 & 4.7673 & TST & \\
\hline CHEMBL1525080 & 688687 & 4.5 & 4.8082 & TRN & \\
\hline CHEMBL1496932 & 688687 & 4.5 & 4.7876 & TRN & \\
\hline CHEMBL1377727 & 688687 & 4.5 & 4.9164 & TRN & \\
\hline CHEMBL75913 & 688687 & 6.2 & 4.9875 & TST & \\
\hline CHEMBL1330951 & 688687 & 5.5 & 5.434 & TST & \\
\hline CHEMBL1606327 & 688687 & 4.4 & 4.852 & TRN & \\
\hline CHEMBL1576456 & 688687 & 4.8 & 4.919 & TRN & \\
\hline CHEMBL1582379 & 688687 & 5.0 & 5.0118 & TRN & \\
\hline CHEMBL1324121 & 688687 & 5.4 & 4.737 & TRN & \\
\hline CHEMBL1331278 & 688687 & 5.1 & 4.9952 & TRN & \\
\hline CHEMBL1547182 & 688687 & 4.4 & 4.7284 & TRN & \\
\hline CHEMBL1478743 & 688687 & 4.4 & 4.801 & TRN & \\
\hline CHEMBL1305632 & 688687 & 4.9 & 4.7293 & TRN & \\
\hline CHEMBL1444643 & 688687 & 4.8 & 4.8148 & TRN & \\
\hline CHEMBL1322030 & 688687 & 6.0 & 5.0828 & TRN & \\
\hline CHEMBL1405223 & 688687 & 4.9 & 4.7439 & TRN & \\
\hline CHEMBL1556692 & 688687 & 5.2 & 4.7829 & TRN & \\
\hline CHEMBL1415521 & 688687 & 4.5 & 4.5934 & TRN & \\
\hline CHEMBL1325408 & 688687 & 5.6 & 5.13200 & 0000000001 & TST \\
\hline CHEMBL1541330 & 688687 & 4.9 & 4.9199 & TRN & \\
\hline CHEMBL1368848 & 688687 & 4.5 & 5.0797 & TRN & \\
\hline CHEMBL56543 & 688687 & 4.8 & 5.6824 & TRN & \\
\hline CHEMBL3199227 & 688687 & 4.6 & 4.3689 & TRN & \\
\hline CHEMBL1301151 & 688687 & 4.4 & 4.4354 & TRN & \\
\hline CHEMBL1585166 & 688687 & 4.6 & 4.6743 & TRN & \\
\hline CHEMBL1477336 & 688687 & 4.4 & 4.575 & TRN & \\
\hline CHEMBL1385476 & 688687 & 4.8 & 4.65600 & 2000000001 & TST \\
\hline CHEMBL1491332 & 688687 & 5.5 & 5.0467 & TRN & \\
\hline CHEMBL1384445 & 688687 & 5.4 & 5.0108 & TRN & \\
\hline CHEMBL1565681 & 688687 & 5.5 & 4.8759 & TRN & \\
\hline CHEMBL1377070 & 688687 & 8.2007 & 5.1994 & TRN & \\
\hline CHEMBL1536142 & 688687 & 4.5 & 4.9321 & TRN & \\
\hline
\end{tabular}




\begin{tabular}{|c|c|c|c|c|}
\hline \multirow[b]{2}{*}{ CHEMBL1567185 } & \multicolumn{4}{|c|}{ Supplemental Table S2.tx } \\
\hline & 688687 & 4.8 & 4.79 & TRN \\
\hline CHEMBL1550510 & 688687 & 5.1 & 4.6676 & TRN \\
\hline CHEMBL1479991 & 688687 & 4.4 & 5.1716 & TRN \\
\hline CHEMBL419045 & 688687 & 4.5 & 5.0842 & TST \\
\hline CHEMBL 259388 & 688687 & 4.4 & 4.9243 & TST \\
\hline CHEMBL1502667 & 688687 & 4.4 & 4.4824 & TRN \\
\hline CHEMBL1472216 & 688687 & 4.7 & 4.7756 & TRN \\
\hline CHEMBL1329823 & 688687 & 4.4 & 4.8453 & TRN \\
\hline CHEMBL1340509 & 688687 & 4.5 & 4.6434 & TRN \\
\hline CHEMBL1339773 & 688687 & 4.6 & 4.7007 & TRN \\
\hline CHEMBL1469508 & 688687 & 4.5 & 4.7147 & TRN \\
\hline CHEMBL1587381 & 688687 & 4.6 & 4.9388 & TRN \\
\hline CHEMBL1561750 & 688687 & 5.2 & 4.9662 & TRN \\
\hline CHEMBL1454569 & 688687 & 5.0 & 4.8279 & TRN \\
\hline CHEMBL1587216 & 688687 & 4.5 & 4.9546 & TRN \\
\hline CHEMBL1607247 & 688687 & 4.6 & 4.7949 & TRN \\
\hline CHEMBL1339724 & 688687 & 4.4 & 4.862 & TRN \\
\hline CHEMBL1538650 & 688687 & 4.4 & 4.85 & TST \\
\hline CHEMBL1596629 & 688687 & 4.4 & 4.6274 & TRN \\
\hline CHEMBL251389 & 688687 & 5.6 & 5.3299 & TRN \\
\hline CHEMBL1472193 & 688687 & 4.9 & 5.0099 & TRN \\
\hline CHEMBL1311011 & 688687 & 4.5 & 4.8559 & TRN \\
\hline CHEMBL1607113 & 688687 & 6.5 & 4.4407 & TRN \\
\hline CHEMBL1555348 & 688687 & 4.5 & 4.6895 & TRN \\
\hline CHEMBL1408846 & 688687 & 4.9 & 4.7129 & TRN \\
\hline CHEMBL 24850 & 688687 & 4.5 & 4.8869 & TRN \\
\hline CHEMBL605747 & 688687 & 4.7 & 4.5845 & TRN \\
\hline CHEMBL1973226 & 688687 & 4.4 & 4.7596 & TRN \\
\hline CHEMBL462227 & 688687 & 5.2 & 4.7569 & TRN \\
\hline CHEMBL1403761 & 688687 & 4.4 & 4.7227 & TRN \\
\hline CHEMBL1354547 & 688687 & 4.5 & 4.8094 & TRN \\
\hline CHEMBL1423097 & 688687 & 5.6 & 4.6172 & TRN \\
\hline CHEMBL1517595 & 688687 & 4.4 & 4.5338 & TRN \\
\hline CHEMBL1530938 & 688687 & 4.4 & 4.9357 & TRN \\
\hline CHEMBL1546370 & 688687 & 5.9 & 4.5252 & TRN \\
\hline CHEMBL1489409 & 688687 & 5.6 & 4.8573 & TRN \\
\hline CHEMBL1381306 & 688687 & 5.8 & 4.8585 & TRN \\
\hline CHEMBL1605678 & 688687 & 4.4 & 4.6929 & TRN \\
\hline CHEMBL1373584 & 688687 & 4.9 & 4.9644 & TRN \\
\hline CHEMBL1540273 & 688687 & 5.4 & 4.7738 & TRN \\
\hline CHEMBL1430900 & 688687 & 4.7 & 4.7603 & TRN \\
\hline CHEMBL1603505 & 688687 & 4.9 & 4.6124 & TRN \\
\hline CHEMBL1559657 & 688687 & 7.4001 & 5.1649 & TST \\
\hline CHEMBL1597845 & 688687 & 4.8 & 4.8287 & TRN \\
\hline CHEMBL352396 & 688687 & 4.4 & 5.0908 & TST \\
\hline CHEMBL1356485 & 688687 & 4.4 & 4.8684 & TRN \\
\hline CHEMBL1318447 & 688687 & 4.6 & 5.0951 & TRN \\
\hline CHEMBL1365394 & 688687 & 4.9 & 4.6522 & TRN \\
\hline
\end{tabular}




\begin{tabular}{|c|c|c|c|c|}
\hline & & & ent & al Ta \\
\hline CHEMBL1529809 & 688687 & 5.5 & 5.5966 & TRN \\
\hline CHEMBL1565158 & 688687 & 5.1 & 4.9181 & TRN \\
\hline CHEMBL1501264 & 688687 & 4.5 & 4.7872 & TRN \\
\hline CHEMBL1585118 & 688687 & 5.4 & 4.8428 & TRN \\
\hline CHEMBL1564940 & 688687 & 4.7 & 4.7956 & TST \\
\hline CHEMBL1393509 & 688687 & 4.4 & 4.9117 & TRN \\
\hline CHEMBL1490678 & 688687 & 5.9 & 4.7368 & TRN \\
\hline CHEMBL1486934 & 688687 & 5.8 & 5.0635 & TRN \\
\hline CHEMBL1546947 & 688687 & 4.8 & 4.8029 & TRN \\
\hline CHEMBL1508334 & 688687 & 4.4 & 4.8209 & TRN \\
\hline CHEMBL1577538 & 688687 & 4.5 & 4.6134 & TRN \\
\hline CHEMBL1542271 & 688687 & 6.0 & 5.1955 & TRN \\
\hline CHEMBL416657 & 688687 & 4.4 & 4.825 & TST \\
\hline CHEMBL1388271 & 688687 & 4.4 & 4.4275 & TRN \\
\hline CHEMBL1532361 & 688687 & 4.5 & 4.9062 & TRN \\
\hline CHEMBL1387744 & 688687 & 4.4 & 4.9462 & TRN \\
\hline CHEMBL1559014 & 688687 & 4.4 & 4.5249 & TRN \\
\hline CHEMBL1330094 & 688687 & 5.9 & 4.7393 & TRN \\
\hline CHEMBL1344836 & 688687 & 4.5 & 4.7736 & TRN \\
\hline CHEMBL1582127 & 688687 & 4.4 & 4.8998 & TRN \\
\hline CHEMBL1427645 & 688687 & 4.4 & 5.0036 & TST \\
\hline CHEMBL1570699 & 688687 & 4.9 & 4.8568 & TRN \\
\hline CHEMBL1455000 & 688687 & 4.6 & 5.01 & TST \\
\hline CHEMBL1604563 & 688687 & 4.9 & 4.728 & TRN \\
\hline CHEMBL1483593 & 688687 & 4.7 & 4.5213 & TRN \\
\hline CHEMBL1890597 & 688687 & 5.1 & 5.0376 & TRN \\
\hline CHEMBL1517843 & 688687 & 5.1 & 4.7085 & TRN \\
\hline CHEMBL1581512 & 688687 & 6.1 & 5.0389 & TRN \\
\hline CHEMBL1441395 & 688687 & 5.3 & 5.1394 & TST \\
\hline CHEMBL1379048 & 688687 & 6.5 & 4.8194 & TST \\
\hline CHEMBL1429929 & 688687 & 4.8 & 4.985 & TRN \\
\hline CHEMBL1373353 & 688687 & 5.2 & 5.0207 & TRN \\
\hline CHEMBL1569439 & 688687 & 4.4 & 5.1907 & TST \\
\hline CHEMBL1542627 & 688687 & 4.4 & 4.7862 & TRN \\
\hline CHEMBL1417719 & 688687 & 4.6 & 4.8277 & TRN \\
\hline CHEMBL243676 & 688687 & 4.5 & 4.9815 & TRN \\
\hline CHEMBL1415754 & 688687 & 4.5 & 4.5471 & TRN \\
\hline CHEMBL1437075 & 688687 & 4.4 & 4.1881 & TRN \\
\hline CHEMBL1300503 & 688687 & 4.6 & 5.2517 & TST \\
\hline CHEMBL1201091 & 688687 & 6.0 & 4.7311 & TRN \\
\hline CHEMBL1407576 & 688687 & 5.7 & 5.1762 & TST \\
\hline CHEMBL1522440 & 688687 & 5.9 & 4.788 & TST \\
\hline CHEMBL587259 & 688687 & 4.7 & 4.6768 & TRN \\
\hline CHEMBL1460807 & 688687 & 4.6 & 4.4751 & TRN \\
\hline CHEMBL1595490 & 688687 & 4.4 & 4.7808 & TST \\
\hline CHEMBL1361177 & 688687 & 4.7 & 4.4975 & TRN \\
\hline CHEMBL 245264 & 688687 & 4.8 & 4.9551 & TRN \\
\hline CHEMBL1585266 & 688687 & 4.5 & 4.7388 & TRN \\
\hline
\end{tabular}




\begin{tabular}{|c|c|c|c|c|c|}
\hline \\
\hline CHEMBL1586326 & 688687 & 4.7 & 4.8016 & TRN & \\
\hline CHEMBL1365253 & 688687 & 5.5 & 4.8536 & TRN & \\
\hline CHEMBL1333056 & 688687 & 4.5 & 5.3588 & TST & \\
\hline CHEMBL1333563 & 688687 & 4.7 & 5.0578 & TRN & \\
\hline CHEMBL522140 & 688687 & 4.5 & 4.8102 & TRN & \\
\hline CHEMBL3192913 & 688687 & 4.5 & 4.7348 & TST & \\
\hline CHEMBL1319389 & 688687 & 6.0 & 4.8973 & TRN & \\
\hline CHEMBL1334430 & 688687 & 4.5 & 5.0523 & TRN & \\
\hline CHEMBL1362196 & 688687 & 4.7 & 4.6998 & TRN & \\
\hline CHEMBL1584479 & 688687 & 5.6 & 5.4902 & TRN & \\
\hline CHEMBL1523194 & 688687 & 4.5 & 4.7897 & TST & \\
\hline CHEMBL1423096 & 688687 & 4.8 & 4.6529 & TRN & \\
\hline CHEMBL1454682 & 688687 & 5.2 & 4.6447 & TRN & \\
\hline CHEMBL1399505 & 688687 & 5.2 & 4.4446 & TRN & \\
\hline CHEMBL1467824 & 688687 & 4.5 & 4.8569 & TRN & \\
\hline CHEMBL1347312 & 688687 & 4.5 & 4.6889 & TRN & \\
\hline CHEMBL1400057 & 688687 & 4.6 & 5.1122 & TRN & \\
\hline CHEMBL3191031 & 688687 & 4.6 & 4.7255 & TRN & \\
\hline CHEMBL1443569 & 688687 & 5.5 & 4.9861 & TRN & \\
\hline CHEMBL1567191 & 688687 & 5.4 & 5.1509 & TRN & \\
\hline CHEMBL1475142 & 688687 & 4.4 & 4.6165 & TRN & \\
\hline CHEMBL1513077 & 688687 & 5.3 & 4.7066 & TRN & \\
\hline CHEMBL1384025 & 688687 & 5.1 & 4.8697 & TRN & \\
\hline CHEMBL3191725 & 688687 & 4.4 & 4.4421 & TRN & \\
\hline CHEMBL1346385 & 688687 & 5.5 & 4.928 & TRN & \\
\hline CHEMBL1307970 & 688687 & 4.5 & 4.8666 & TST & \\
\hline CHEMBL1302995 & 688687 & 4.7 & 4.8461 & TRN & \\
\hline CHEMBL1464093 & 688687 & 4.4 & 4.77 & TRN & \\
\hline CHEMBL461431 & 688687 & 6.4 & 5.2289 & TRN & \\
\hline CHEMBL1322051 & 688687 & 4.6 & 4.8334 & TST & \\
\hline CHEMBL1394002 & 688687 & 4.6 & 4.8004 & TRN & \\
\hline CHEMBL1593866 & 688687 & 4.4 & 4.2626 & TRN & \\
\hline CHEMBL1503882 & 688687 & 4.4 & 4.46899 & 9999999999 & TRN \\
\hline CHEMBL510009 & 688687 & 4.6 & 4.4283 & TRN & \\
\hline CHEMBL1482064 & 688687 & 4.4 & 4.3961 & TRN & \\
\hline CHEMBL116541 & 688687 & 5.0 & 4.625 & TRN & \\
\hline CHEMBL1585404 & 688687 & 4.5 & 4.7582 & TRN & \\
\hline CHEMBL1565213 & 688687 & 4.7 & 4.8998 & TRN & \\
\hline CHEMBL1601910 & 688687 & 4.4 & 4.8686 & TRN & \\
\hline CHEMBL 1451110 & 688687 & 4.5 & 4.5395 & TRN & \\
\hline CHEMBL1308447 & 688687 & 4.5 & 4.8363 & TRN & \\
\hline CHEMBL491953 & 688687 & 4.4 & 4.2968 & TRN & \\
\hline CHEMBL1373487 & 688687 & 4.5 & 5.0068 & TRN & \\
\hline CHEMBL1382392 & 688687 & 5.8 & 4.9648 & TRN & \\
\hline CHEMBL1596014 & 688687 & 4.4 & 4.7362 & TST & \\
\hline CHEMBL1499041 & 688687 & 4.6 & 4.7772 & TRN & \\
\hline CHEMBL1610581 & 688687 & 4.4 & 4.7511 & TRN & \\
\hline CHEMBL1536593 & 688687 & 5.9 & 5.1724 & TRN & \\
\hline
\end{tabular}




\begin{tabular}{|c|c|c|c|c|c|}
\hline & & & & & \\
\hline CHEMBL1336032 & 688687 & 4.4 & 4.7105 & TRN & \\
\hline CHEMBL1587788 & 688687 & 4.7 & 4.6696 & TRN & \\
\hline CHEMBL1423954 & 688687 & 4.4 & 5.221 & TRN & \\
\hline CHEMBL1409089 & 688687 & 5.7 & 4.9404 & TRN & \\
\hline CHEMBL1313053 & 688687 & 4.4 & 4.9022 & TRN & \\
\hline CHEMBL1408894 & 688687 & 5.5 & 4.9882 & TRN & \\
\hline CHEMBL1568791 & 688687 & 4.5 & 4.6836 & TRN & \\
\hline CHEMBL1501019 & 688687 & 4.8 & 4.6906 & TRN & \\
\hline CHEMBL154762 & 688687 & 4.4 & 4.6564 & TRN & \\
\hline CHEMBL1385946 & 688687 & 4.6 & 4.7985 & TRN & \\
\hline CHEMBL1482818 & 688687 & 4.4 & 4.9776 & TST & \\
\hline CHEMBL1373816 & 688687 & 4.5 & 4.9959 & TRN & \\
\hline CHEMBL1491767 & 688687 & 5.7 & 4.8627 & TRN & \\
\hline CHEMBL1364110 & 688687 & 4.4 & 4.6248 & TRN & \\
\hline CHEMBL1447188 & 688687 & 4.5 & 4.7727 & TRN & \\
\hline CHEMBL1357199 & 688687 & 4.5 & 4.2892 & TRN & \\
\hline CHEMBL1417986 & 688687 & 5.4 & 4.4181 & TRN & \\
\hline CHEMBL1528164 & 688687 & 4.5 & 4.9836 & TRN & \\
\hline CHEMBL1383269 & 688687 & 4.6 & 4.9668 & TRN & \\
\hline CHEMBL1512210 & 688687 & 4.5 & 4.8689 & TRN & \\
\hline CHEMBL1384562 & 688687 & 5.3 & 5.1112 & TRN & \\
\hline CHEMBL1518703 & 688687 & 4.5 & 4.8191 & TRN & \\
\hline CHEMBL1451343 & 688687 & 4.5 & 4.4946 & TRN & \\
\hline CHEMBL1583365 & 688687 & 4.5 & 4.65600 & $\partial 000000001$ & TRN \\
\hline CHEMBL1532732 & 688687 & 4.4 & 4.89 & TRN & \\
\hline CHEMBL1518503 & 688687 & 5.5 & 5.9858 & TRN & \\
\hline CHEMBL1331252 & 688687 & 7.5003 & 5.1418 & TRN & \\
\hline CHEMBL1532745 & 688687 & 4.8 & 4.6833 & TRN & \\
\hline CHEMBL1604939 & 688687 & 5.3 & 4.8234 & TRN & \\
\hline CHEMBL1351338 & 688687 & 4.8 & 4.5795 & TRN & \\
\hline CHEMBL1462825 & 688687 & 4.8 & 4.6419 & TRN & \\
\hline CHEMBL192009 & 688687 & 5.0 & 4.71399 & 99999999995 & TRN \\
\hline CHEMBL1529777 & 688687 & 5.0 & 4.8411 & TRN & \\
\hline CHEMBL1439995 & 688687 & 4.6 & 4.5857 & TRN & \\
\hline CHEMBL1508148 & 688687 & 4.9 & 5.0515 & TRN & \\
\hline CHEMBL1346410 & 688687 & 5.4 & 4.8049 & TRN & \\
\hline CHEMBL1507590 & 688687 & 5.0 & 4.6759 & TRN & \\
\hline CHEMBL1370884 & 688687 & 6.3 & 5.2193 & TRN & \\
\hline CHEMBL451748 & 688687 & 4.4 & 4.6633 & TRN & \\
\hline CHEMBL1584578 & 688687 & 4.5 & 4.9609 & TRN & \\
\hline CHEMBL 78150 & 688687 & 4.8 & 5.2285 & TRN & \\
\hline CHEMBL1363562 & 688687 & 4.6 & 4.6908 & TRN & \\
\hline CHEMBL1543399 & 688687 & 4.4 & 4.8194 & TST & \\
\hline CHEMBL1436169 & 688687 & 4.5 & 4.5397 & TRN & \\
\hline CHEMBL1306280 & 688687 & 4.6 & 4.5533 & TRN & \\
\hline CHEMBL1455516 & 688687 & 4.6 & 4.9001 & TRN & \\
\hline CHEMBL1484989 & 688687 & 4.6 & 4.8936 & TRN & \\
\hline CHEMBL1421681 & 688687 & 4.5 & 5.3503 & TRN & \\
\hline
\end{tabular}




\begin{tabular}{|c|c|c|c|c|}
\hline \multicolumn{5}{|c|}{ Supplemental Table S2.txt } \\
\hline CHEMBL1446630 & 688687 & 4.5 & 4.6503 & TRN \\
\hline CHEMBL1428812 & 688687 & 5.2 & 5.0595 & TRN \\
\hline CHEMBL1558123 & 688687 & 4.6 & 4.5761 & TRN \\
\hline CHEMBL1448734 & 688687 & 4.4 & 4.4929 & TRN \\
\hline CHEMBL1517767 & 688687 & 4.6 & 4.6543 & TRN \\
\hline CHEMBL1611681 & 688687 & 5.6 & 4.8259 & TRN \\
\hline CHEMBL 1438740 & 688687 & 4.9 & 4.7983 & TRN \\
\hline CHEMBL1594948 & 688687 & 4.6 & 4.8158 & TRN \\
\hline CHEMBL1469464 & 688687 & 5.0 & 4.5841 & TRN \\
\hline CHEMBL1563398 & 688687 & 4.6 & 4.6525 & TRN \\
\hline CHEMBL1572390 & 688687 & 4.6 & 4.7516 & TRN \\
\hline CHEMBL1564324 & 688687 & 4.4 & 4.8124 & TRN \\
\hline CHEMBL1407267 & 688687 & 5.5 & 4.7443 & TRN \\
\hline CHEMBL1424501 & 688687 & 4.5 & 4.8602 & TRN \\
\hline CHEMBL1398638 & 688687 & 5.4 & 4.8181 & TRN \\
\hline CHEMBL1509339 & 688687 & 4.5 & 4.6071 & TRN \\
\hline CHEMBL1336650 & 688687 & 4.6 & 5.0799 & TRN \\
\hline CHEMBL 242172 & 688687 & 5.0 & 4.8962 & TRN \\
\hline CHEMBL1519218 & 688687 & 4.5 & 4.4193 & TRN \\
\hline CHEMBL1444424 & 688687 & 4.8 & 4.9904 & TRN \\
\hline CHEMBL1442284 & 688687 & 4.6 & 5.1565 & TST \\
\hline CHEMBL1449836 & 688687 & 5.3 & 5.1488 & TRN \\
\hline CHEMBL 3198121 & 688687 & 5.5 & 4.7449 & TRN \\
\hline CHEMBL 269550 & 688687 & 4.5 & 5.0549 & TST \\
\hline CHEMBL1333430 & 688687 & 4.4 & 4.8971 & TRN \\
\hline CHEMBL1391159 & 688687 & 5.8 & 5.1143 & TRN \\
\hline CHEMBL1326823 & 688687 & 4.4 & 4.4714 & TRN \\
\hline CHEMBL1482262 & 688687 & 4.4 & 4.7302 & TRN \\
\hline CHEMBL1412835 & 688687 & 7.1002 & 5.2788 & TRN \\
\hline CHEMBL1388969 & 688687 & 4.6 & 4.7261 & TRN \\
\hline CHEMBL1359468 & 688687 & 4.5 & 4.7266 & TRN \\
\hline CHEMBL1471841 & 688687 & 6.7001 & 5.8416 & TRN \\
\hline CHEMBL1305411 & 688687 & 4.5 & 4.5117 & TRN \\
\hline CHEMBL1340379 & 688687 & 4.4 & 4.565 & TRN \\
\hline CHEMBL1308965 & 688687 & 5.5 & 5.1992 & TRN \\
\hline CHEMBL1400304 & 688687 & 4.6 & 4.9986 & TRN \\
\hline CHEMBL 1458280 & 688687 & 4.7 & 4.6134 & TRN \\
\hline CHEMBL1506423 & 688687 & 4.8 & 4.646 & TRN \\
\hline CHEMBL1462695 & 688687 & 4.5 & 4.7769 & TRN \\
\hline CHEMBL1380816 & 688687 & 4.5 & 4.6065 & TRN \\
\hline CHEMBL1572253 & 688687 & 4.5 & 4.5601 & TRN \\
\hline CHEMBL1472513 & 688687 & 5.5 & 5.4537 & TRN \\
\hline CHEMBL1339597 & 688687 & 4.5 & 4.8213 & TRN \\
\hline CHEMBL1479917 & 688687 & 4.6 & 4.9832 & TST \\
\hline CHEMBL1517870 & 688687 & 4.4 & 4.8621 & TRN \\
\hline CHEMBL1426501 & 688687 & 4.5 & 4.6006 & TRN \\
\hline CHEMBL1353353 & 688687 & 4.5 & 4.96899 & 9999999999 \\
\hline CHEMBL454173 & 688687 & 6.0 & 5.065 & TST \\
\hline
\end{tabular}




\begin{tabular}{|c|c|c|c|c|}
\hline \multicolumn{5}{|r|}{ L Table } \\
\hline CHEMBL1428815 & 688687 & 4.7 & 4.5162 & TRN \\
\hline CHEMBL1323974 & 688687 & 4.9 & 5.2595 & TRN \\
\hline CHEMBL1501547 & 688687 & 4.6 & 4.8945 & TRN \\
\hline CHEMBL1514071 & 688687 & 4.4 & 4.9115 & TRN \\
\hline CHEMBL1483112 & 688687 & 5.5 & 5.0197 & TRN \\
\hline CHEMBL 2373629 & 688687 & 4.4 & 4.7643 & TST \\
\hline CHEMBL1512208 & 688687 & 4.4 & 4.4903 & TRN \\
\hline CHEMBL1348280 & 688687 & 7.2 & 4.766 & TRN \\
\hline CHEMBL1328864 & 688687 & 5.4 & 4.6021 & TRN \\
\hline CHEMBL1341867 & 688687 & 4.6 & 4.7978 & TRN \\
\hline CHEMBL1468210 & 688687 & 4.6 & 4.7844 & TRN \\
\hline CHEMBL155320 & 688687 & 4.4 & 4.7783 & TRN \\
\hline CHEMBL464251 & 688687 & 4.6 & 4.88899 & 9999999999 \\
\hline CHEMBL1579143 & 688687 & 6.1 & 5.3182 & TRN \\
\hline CHEMBL1414001 & 688687 & 5.7 & 4.9252 & TST \\
\hline CHEMBL1571220 & 688687 & 4.8 & 4.65 & TRN \\
\hline CHEMBL1442011 & 688687 & 4.5 & 4.7906 & TRN \\
\hline CHEMBL1471531 & 688687 & 4.9 & 4.7236 & TRN \\
\hline CHEMBL1320092 & 688687 & 4.8 & 4.6358 & TRN \\
\hline CHEMBL1447750 & 688687 & 5.2 & 4.871 & TRN \\
\hline CHEMBL1589363 & 688687 & 4.4 & 4.5186 & TRN \\
\hline CHEMBL1334552 & 688687 & 6.7001 & 4.8306 & TRN \\
\hline CHEMBL 1417158 & 688687 & 7.3002 & 4.7238 & TST \\
\hline CHEMBL1549476 & 688687 & 4.8 & 4.8739 & TRN \\
\hline CHEMBL1484464 & 688687 & 4.6 & 5.0286 & TRN \\
\hline CHEMBL491978 & 688687 & 5.3 & 4.6889 & TRN \\
\hline CHEMBL1336812 & 688687 & 4.9 & 5.0314 & TST \\
\hline CHEMBL1401137 & 688687 & 4.4 & 4.6286 & TRN \\
\hline CHEMBL1565861 & 688687 & 6.0 & 5.0581 & TST \\
\hline CHEMBL1502936 & 688687 & 5.4 & 4.7739 & TRN \\
\hline CHEMBL1420887 & 688687 & 4.5 & 4.9471 & TRN \\
\hline CHEMBL1409795 & 688687 & 4.4 & 4.9953 & TRN \\
\hline CHEMBL1530185 & 688687 & 4.4 & 4.6948 & TRN \\
\hline CHEMBL1605526 & 688687 & 6.0 & 4.9659 & TRN \\
\hline CHEMBL1402379 & 688687 & 5.2 & 4.8127 & TRN \\
\hline CHEMBL1390759 & 688687 & 4.6 & 4.6025 & TRN \\
\hline CHEMBL1515918 & 688687 & 4.6 & 4.5798 & TRN \\
\hline CHEMBL1453953 & 688687 & 4.5 & 4.655 & TRN \\
\hline CHEMBL1526260 & 688687 & 5.5 & 5.1822 & TRN \\
\hline CHEMBL1300161 & 688687 & 4.6 & 4.6016 & TST \\
\hline CHEMBL1507584 & 688687 & 5.5 & 4.6666 & TRN \\
\hline CHEMBL1593068 & 688687 & 4.8 & 4.8368 & TRN \\
\hline CHEMBL1596172 & 688687 & 4.7 & 4.5844 & TRN \\
\hline CHEMBL1609128 & 688687 & 5.3 & 5.0796 & TRN \\
\hline CHEMBL1552051 & 688687 & 4.9 & 4.8845 & TRN \\
\hline CHEMBL1313433 & 688687 & 4.5 & 4.9883 & TRN \\
\hline CHEMBL1607485 & 688687 & 4.8 & 4.8475 & TRN \\
\hline CHEMBL1414563 & 688687 & 5.6 & 5.7808 & TRN \\
\hline
\end{tabular}




\begin{tabular}{|c|c|c|c|c|c|}
\hline \multirow{2}{*}{ CHEMBL1404421 } & \multirow{2}{*}{688687} & \\
\hline & & 4.9 & 4.8 & TST & \\
\hline CHEMBL1374939 & 688687 & 4.6 & 4.6315 & TRN & \\
\hline CHEMBL1143 & 688687 & 4.4 & 5.1704 & TRN & \\
\hline CHEMBL1446972 & 688687 & 5.0 & 5.0252 & TRN & \\
\hline CHEMBL1332775 & 688687 & 4.6 & 4.9369 & TRN & \\
\hline CHEMBL1524927 & 688687 & 5.4 & 4.7023 & TST & \\
\hline CHEMBL44201 & 688687 & 4.4 & 4.8064 & TRN & \\
\hline CHEMBL1173475 & 688687 & 6.0 & 5.8204 & TRN & \\
\hline CHEMBL1416611 & 688687 & 4.5 & 4.8131 & TRN & \\
\hline CHEMBL1489619 & 688687 & 5.1 & \multicolumn{2}{|c|}{5.297999999999999} & TRN \\
\hline CHEMBL45068 & 688687 & 4.9 & 5.6044 & TRN & \\
\hline CHEMBL1310190 & 688687 & 4.5 & 4.8961 & TRN & \\
\hline CHEMBL1405810 & 688687 & 4.6 & 4.9623 & TRN & \\
\hline CHEMBL1545362 & 688687 & 4.5 & 5.0244 & TRN & \\
\hline CHEMBL355014 & 688687 & 4.4 & 4.692 & TRN & \\
\hline CHEMBL1333431 & 688687 & 5.2 & 4.7617 & TST & \\
\hline CHEMBL1509360 & 688687 & 5.2 & 4.8648 & TRN & \\
\hline CHEMBL1427720 & 688687 & 4.8 & 4.6222 & TRN & \\
\hline CHEMBL1357491 & 688687 & 4.5 & 4.4121 & TRN & \\
\hline CHEMBL1484823 & 688687 & 5.5 & 5.0494 & TST & \\
\hline CHEMBL1463665 & 688687 & 4.4 & 4.6473 & TRN & \\
\hline CHEMBL1304452 & 688687 & 4.6 & 4.5029 & TRN & \\
\hline CHEMBL1458755 & 688687 & 4.5 & 4.9243 & TRN & \\
\hline CHEMBL1526281 & 688687 & 4.6 & 5.005 & TRN & \\
\hline CHEMBL1355693 & 688687 & 5.1 & 5.1124 & TRN & \\
\hline CHEMBL1599413 & 688687 & 4.6 & 4.9203 & TRN & \\
\hline CHEMBL1474169 & 688687 & 4.6 & 4.7249 & TRN & \\
\hline CHEMBL1519306 & 688687 & 4.5 & 4.8098 & TRN & \\
\hline CHEMBL1595818 & 688687 & 4.8 & 4.7591 & TRN & \\
\hline CHEMBL1427602 & 688687 & 4.5 & 4.5789 & TRN & \\
\hline CHEMBL1730100 & 688687 & 6.9 & 5.3994 & TST & \\
\hline CHEMBL1388070 & 688687 & 4.5 & 4.5722 & TRN & \\
\hline CHEMBL1468309 & 688687 & 4.5 & 4.8058 & TRN & \\
\hline CHEMBL1594240 & 688687 & 4.7 & 4.8375 & TRN & \\
\hline CHEMBL1370467 & 688687 & 5.3 & 4.8409 & TST & \\
\hline CHEMBL1466604 & 688687 & 4.4 & 4.7941 & TRN & \\
\hline CHEMBL1566202 & 688687 & 4.6 & 4.4735 & TRN & \\
\hline CHEMBL1363367 & 688687 & 5.1 & 4.9034 & TST & \\
\hline CHEMBL1565782 & 688687 & 5.2 & 4.84699 & 99999999995 & TRN \\
\hline CHEMBL1409812 & 688687 & 4.6 & 4.8323 & TRN & \\
\hline CHEMBL1498052 & 688687 & 4.6 & 4.6021 & TRN & \\
\hline CHEMBL1562104 & 688687 & 6.2 & 4.9046 & TST & \\
\hline CHEMBL1577176 & 688687 & 4.4 & 4.8888 & TRN & \\
\hline CHEMBL1498634 & 688687 & 4.6 & 4.8693 & TRN & \\
\hline CHEMBL1355835 & 688687 & 4.8 & 4.7361 & TRN & \\
\hline CHEMBL1487182 & 688687 & 4.8 & 4.6007 & TRN & \\
\hline CHEMBL1494965 & 688687 & 4.5 & 4.4959 & TRN & \\
\hline \multirow[t]{2}{*}{ CHEMBL1454860 } & 688687 & 4.6 & 4.7974 & TRN & \\
\hline & & \multicolumn{4}{|c|}{ Page 6187} \\
\hline
\end{tabular}




\begin{tabular}{|c|c|c|c|c|c|}
\hline \\
\hline CHEMBL1379838 & 688687 & 4.5 & 4.5833 & TRN & \\
\hline CHEMBL1460674 & 688687 & 5.2 & 4.8069 & TRN & \\
\hline CHEMBL1612408 & 688687 & 4.6 & 4.7919 & TRN & \\
\hline CHEMBL1429218 & 688687 & 5.1 & 4.9195 & TRN & \\
\hline CHEMBL1555629 & 688687 & 4.5 & 4.5205 & TRN & \\
\hline CHEMBL1532177 & 688687 & 6.1 & 4.8039 & TRN & \\
\hline CHEMBL1438442 & 688687 & 4.6 & 5.4539 & TRN & \\
\hline CHEMBL1491939 & 688687 & 4.4 & 4.4747 & TRN & \\
\hline CHEMBL1374260 & 688687 & 4.4 & 4.5586 & TRN & \\
\hline CHEMBL1612031 & 688687 & 4.5 & 4.8425 & TST & \\
\hline CHEMBL1404303 & 688687 & 4.8 & 4.6611 & TST & \\
\hline CHEMBL1464091 & 688687 & 4.6 & 4.9552 & TRN & \\
\hline CHEMBL1488918 & 688687 & 4.4 & 4.8437 & TRN & \\
\hline CHEMBL1413167 & 688687 & 5.5 & 4.9385 & TRN & \\
\hline CHEMBL1584350 & 688687 & 4.9 & 4.909 & TRN & \\
\hline CHEMBL1345961 & 688687 & 4.7 & 4.4616 & TRN & \\
\hline CHEMBL1526580 & 688687 & 4.8 & 4.822 & TRN & \\
\hline CHEMBL1318908 & 688687 & 5.2 & 4.6971 & TRN & \\
\hline CHEMBL310798 & 688687 & 5.4 & 5.38399 & 99999999995 & TRN \\
\hline CHEMBL 2004070 & 688687 & 5.0 & 4.7432 & TRN & \\
\hline CHEMBL1378659 & 688687 & 5.7 & 5.4748 & TST & \\
\hline CHEMBL1542501 & 688687 & 4.5 & 4.5678 & TRN & \\
\hline CHEMBL1597840 & 688687 & 4.4 & 4.7834 & TRN & \\
\hline CHEMBL1178 & 688687 & 4.5 & 4.7638 & TST & \\
\hline CHEMBL1516370 & 688687 & 4.6 & 5.0382 & TRN & \\
\hline CHEMBL1363697 & 688687 & 4.4 & 4.6013 & TST & \\
\hline CHEMBL1589625 & 688687 & 5.2 & 4.7084 & TRN & \\
\hline CHEMBL1302158 & 688687 & 4.6 & 4.8807 & TRN & \\
\hline CHEMBL1400874 & 688687 & 5.1 & 4.8541 & TRN & \\
\hline CHEMBL3196182 & 688687 & 4.8 & 5.0109 & TRN & \\
\hline CHEMBL1375240 & 688687 & 4.5 & 4.6915 & TRN & \\
\hline CHEMBL1474890 & 688687 & 4.4 & 4.8414 & TRN & \\
\hline CHEMBL1407054 & 688687 & 4.5 & 4.8747 & TRN & \\
\hline CHEMBL1463073 & 688687 & 5.1 & 4.7931 & TRN & \\
\hline CHEMBL1337581 & 688687 & 5.5 & 5.1897 & TRN & \\
\hline CHEMBL1565539 & 688687 & 5.1 & 4.7181 & TRN & \\
\hline CHEMBL550826 & 688687 & 4.4 & 4.7314 & TRN & \\
\hline CHEMBL1335319 & 688687 & 6.2 & 4.9787 & TRN & \\
\hline CHEMBL1590663 & 688687 & 4.6 & 4.7771 & TRN & \\
\hline CHEMBL1504007 & 688687 & 4.4 & 4.6091 & TRN & \\
\hline CHEMBL1402952 & 688687 & 4.9 & 4.8674 & TRN & \\
\hline CHEMBL1419260 & 688687 & 4.5 & 5.0493 & TRN & \\
\hline CHEMBL1342074 & 688687 & 5.5 & 4.5565 & TRN & \\
\hline CHEMBL1365972 & 688687 & 4.5 & 4.6298 & TRN & \\
\hline CHEMBL1331573 & 688687 & 5.0 & 4.8559 & TST & \\
\hline CHEMBL1376954 & 688687 & 6.1 & 5.1531 & TRN & \\
\hline CHEMBL1308001 & 688687 & 4.6 & 4.8201 & TRN & \\
\hline CHEMBL1444260 & 688687 & 5.9 & 4.8078 & TRN & \\
\hline
\end{tabular}




\begin{tabular}{|c|c|c|c|c|c|}
\hline & & & & & \\
\hline CHEMBL1303204 & 688687 & 4.4 & 4.5022 & TST & \\
\hline CHEMBL503470 & 688687 & 5.0 & 4.6345 & TRN & \\
\hline CHEMBL1485331 & 688687 & 6.5 & 4.9539 & TRN & \\
\hline CHEMBL1326738 & 688687 & 4.4 & 4.646 & TRN & \\
\hline CHEMBL 275311 & 688687 & 4.6 & 5.3146 & TST & \\
\hline CHEMBL1332059 & 688687 & 5.2 & 4.9915 & TST & \\
\hline CHEMBL1305284 & 688687 & 5.0 & 4.9608 & TRN & \\
\hline CHEMBL1601992 & 688687 & 6.9 & 4.6985 & TRN & \\
\hline CHEMBL1552286 & 688687 & 4.4 & 4.60800 & 00000000005 & TRN \\
\hline CHEMBL1490628 & 688687 & 6.6 & 5.3127 & TRN & \\
\hline CHEMBL1409613 & 688687 & 4.5 & 4.8176 & TRN & \\
\hline CHEMBL1448969 & 688687 & 5.1 & 4.5267 & TST & \\
\hline CHEMBL1503776 & 688687 & 4.5 & 4.5205 & TRN & \\
\hline CHEMBL1413521 & 688687 & 4.4 & 4.512 & TRN & \\
\hline CHEMBL1398019 & 688687 & 5.4 & 4.5603 & TST & \\
\hline CHEMBL1350275 & 688687 & 4.5 & 4.647 & TRN & \\
\hline CHEMBL1581228 & 688687 & 4.5 & 4.7683 & TRN & \\
\hline CHEMBL1325403 & 688687 & 4.6 & 4.725 & TRN & \\
\hline CHEMBL1483629 & 688687 & 4.4 & 4.8635 & TRN & \\
\hline CHEMBL1585629 & 688687 & 4.5 & 4.7144 & TRN & \\
\hline CHEMBL1471947 & 688687 & 4.4 & 4.8357 & TRN & \\
\hline CHEMBL1502028 & 688687 & 4.6 & 4.7096 & TRN & \\
\hline CHEMBL1444639 & 688687 & 5.1 & 4.94300 & j0000000005 & TRN \\
\hline CHEMBL1540098 & 688687 & 4.4 & 4.4291 & TRN & \\
\hline CHEMBL1605094 & 688687 & 4.5 & 4.6365 & TRN & \\
\hline CHEMBL1350980 & 688687 & 4.9 & 4.9585 & TRN & \\
\hline CHEMBL1509065 & 688687 & 5.2 & 4.8025 & TRN & \\
\hline CHEMBL1550728 & 688687 & 4.7 & 4.7051 & TRN & \\
\hline CHEMBL1394469 & 688687 & 4.5 & 4.7598 & TRN & \\
\hline CHEMBL1417349 & 688687 & 4.9 & 4.7337 & TRN & \\
\hline CHEMBL1466241 & 688687 & 5.0 & 4.6211 & TRN & \\
\hline CHEMBL1505049 & 688687 & 5.4 & 4.8107 & TRN & \\
\hline CHEMBL1486640 & 688687 & 4.5 & 4.5602 & TRN & \\
\hline CHEMBL1382707 & 688687 & 4.5 & 5.024 & TST & \\
\hline CHEMBL1400386 & 688687 & 6.4 & 4.9347 & TST & \\
\hline CHEMBL1317279 & 688687 & 4.5 & 4.5279 & TRN & \\
\hline CHEMBL1325152 & 688687 & 4.5 & 4.7341 & TRN & \\
\hline CHEMBL399491 & 688687 & 6.0 & 5.3902 & TST & \\
\hline CHEMBL1505858 & 688687 & 4.6 & 4.8229 & TST & \\
\hline CHEMBL1347058 & 688687 & 7.2 & 5.2349 & TRN & \\
\hline CHEMBL1302845 & 688687 & 4.4 & 4.4709 & TRN & \\
\hline CHEMBL1299509 & 688687 & 4.6 & 4.5682 & TRN & \\
\hline CHEMBL1337039 & 688687 & 4.6 & 4.7332 & TRN & \\
\hline CHEMBL3195009 & 688687 & 5.4 & 4.9552 & TST & \\
\hline CHEMBL1510630 & 688687 & 4.6 & 4.7537 & TRN & \\
\hline CHEMBL3210593 & 688687 & 4.5 & 4.5534 & TRN & \\
\hline CHEMBL1347319 & 688687 & 4.5 & 4.7944 & TRN & \\
\hline CHEMBL1512919 & 688687 & 4.6 & 4.7805 & TRN & \\
\hline & & & & 6189 & \\
\hline
\end{tabular}




\begin{tabular}{|c|c|c|c|c|c|}
\hline \\
\hline CHEMBL1449573 & 688687 & 4.6 & 4.8603 & TST & \\
\hline CHEMBL1505246 & 688687 & 6.2 & 5.4129 & TRN & \\
\hline CHEMBL1462157 & 688687 & 5.4 & 4.6389 & TRN & \\
\hline CHEMBL1438876 & 688687 & 4.5 & 4.9078 & TST & \\
\hline CHEMBL1407066 & 688687 & 4.8 & 4.6868 & TRN & \\
\hline CHEMBL1532319 & 688687 & 5.5 & 4.9422 & TST & \\
\hline CHEMBL1553721 & 688687 & 6.2 & 5.5151 & TRN & \\
\hline CHEMBL1524453 & 688687 & 5.8 & 5.0122 & TST & \\
\hline CHEMBL1603700 & 688687 & 4.5 & 5.3453 & TST & \\
\hline CHEMBL1596228 & 688687 & 5.4 & 5.2997 & TRN & \\
\hline CHEMBL1375780 & 688687 & 4.5 & 4.9611 & TST & \\
\hline CHEMBL1487974 & 688687 & 5.2 & 4.592 & TRN & \\
\hline CHEMBL1404231 & 688687 & 6.0 & 5.1423 & TRN & \\
\hline CHEMBL1523338 & 688687 & 4.8 & 4.9355 & TRN & \\
\hline CHEMBL1336047 & 688687 & 4.5 & 4.8883 & TRN & \\
\hline CHEMBL1364258 & 688687 & 4.6 & 5.0086 & TRN & \\
\hline CHEMBL1520719 & 688687 & 5.1 & 4.8266 & TRN & \\
\hline CHEMBL1478482 & 688687 & 4.5 & 4.7622 & TRN & \\
\hline CHEMBL1545747 & 688687 & 4.5 & 4.4075 & TRN & \\
\hline CHEMBL1524788 & 688687 & 4.9 & 5.0279 & TRN & \\
\hline CHEMBL1607155 & 688687 & 5.1 & 4.8951 & TRN & \\
\hline CHEMBL1503929 & 688687 & 4.5 & 4.7136 & TRN & \\
\hline CHEMBL1342674 & 688687 & 5.1 & 4.9664 & TST & \\
\hline CHEMBL1529671 & 688687 & 4.5 & 4.6321 & TRN & \\
\hline CHEMBL1561495 & 688687 & 4.8 & 4.6789 & TRN & \\
\hline CHEMBL1586310 & 688687 & 6.0 & 5.0745 & TRN & \\
\hline CHEMBL168461 & 688687 & 5.7 & 5.0933 & TST & \\
\hline CHEMBL1393994 & 688687 & 4.5 & 4.7474 & TRN & \\
\hline CHEMBL1455628 & 688687 & 4.4 & 4.9196 & TRN & \\
\hline CHEMBL1332732 & 688687 & 6.2 & 4.8608 & TRN & \\
\hline CHEMBL1466155 & 688687 & 4.4 & 4.7207 & TRN & \\
\hline CHEMBL1367450 & 688687 & 4.6 & 4.7973 & TST & \\
\hline CHEMBL1540503 & 688687 & 4.6 & 4.7954 & TRN & \\
\hline CHEMBL1446323 & 688687 & 4.5 & 4.42899 & 9999999999 & TRN \\
\hline CHEMBL1339329 & 688687 & 4.5 & 4.5324 & TRN & \\
\hline CHEMBL1328827 & 688687 & 4.5 & 4.6807 & TRN & \\
\hline CHEMBL1409359 & 688687 & 4.7 & 4.5189 & TRN & \\
\hline CHEMBL1408965 & 688687 & 4.8 & 4.734 & TRN & \\
\hline CHEMBL117 & 688687 & 5.0 & 5.2217 & TRN & \\
\hline CHEMBL1460721 & 688687 & 4.8 & 4.7352 & TRN & \\
\hline CHEMBL1549698 & 688687 & 4.4 & 4.7138 & TRN & \\
\hline CHEMBL1365166 & 688687 & 4.5 & 4.9893 & TRN & \\
\hline CHEMBL1313988 & 688687 & 4.6 & 4.6925 & TRN & \\
\hline CHEMBL1430008 & 688687 & 4.6 & 4.8042 & TRN & \\
\hline CHEMBL69086 & 688687 & 5.5 & 4.9124 & TRN & \\
\hline CHEMBL 276727 & 688687 & 4.8 & 4.9958 & TST & \\
\hline CHEMBL1452250 & 688687 & 4.5 & 4.8095 & TRN & \\
\hline CHEMBL1523881 & 688687 & 4.4 & 4.738 & TRN & \\
\hline
\end{tabular}




\begin{tabular}{|c|c|c|c|c|c|}
\hline \multicolumn{6}{|c|}{ בد שעם } \\
\hline CHEMBL1340569 & 688687 & 4.6 & 4.8248 & TRN & \\
\hline CHEMBL1475788 & 688687 & 4.4 & 4.626 & TRN & \\
\hline CHEMBL1341531 & 688687 & 4.8 & 4.9346 & TRN & \\
\hline CHEMBL1489184 & 688687 & 4.6 & 4.772 & TST & \\
\hline CHEMBL1561281 & 688687 & 4.5 & 4.7547 & TRN & \\
\hline CHEMBL1200471 & 688687 & 5.9 & 5.4362 & TST & \\
\hline CHEMBL1570457 & 688687 & 4.6 & 4.8675 & TST & \\
\hline CHEMBL1545156 & 688687 & 4.9 & 5.2784 & TRN & \\
\hline CHEMBL1401891 & 688687 & 4.5 & 5.1402 & TST & \\
\hline CHEMBL1585413 & 688687 & 5.4 & 4.8092 & TRN & \\
\hline CHEMBL1343200 & 688687 & 4.6 & 4.7425 & TRN & \\
\hline CHEMBL1544999 & 688687 & 4.5 & 4.7091 & TRN & \\
\hline CHEMBL1532288 & 688687 & 5.0 & 4.7362 & TRN & \\
\hline CHEMBL1312033 & 688687 & 4.7 & 4.6535 & TRN & \\
\hline CHEMBL1470269 & 688687 & 4.5 & 4.8748 & TRN & \\
\hline CHEMBL1588504 & 688687 & 4.5 & 5.061 & TRN & \\
\hline CHEMBL1571817 & 688687 & 4.5 & 4.6597 & TRN & \\
\hline CHEMBL473107 & 688687 & 4.7 & 4.6956 & TRN & \\
\hline CHEMBL1428100 & 688687 & 4.4 & 4.5405 & TRN & \\
\hline CHEMBL1354563 & 688687 & 4.4 & 4.4119 & TRN & \\
\hline CHEMBL1319990 & 688687 & 4.8 & 4.8216 & TST & \\
\hline CHEMBL1328210 & 688687 & 4.7 & 4.92 & TST & \\
\hline CHEMBL1479550 & 688687 & 4.9 & 4.9641 & TRN & \\
\hline CHEMBL3190449 & 688687 & 4.8 & $4.6160 e$ & 00000000005 & TRN \\
\hline CHEMBL1487683 & 688687 & 4.7 & 4.6442 & TRN & \\
\hline CHEMBL1326063 & 688687 & 4.5 & 4.4107 & TRN & \\
\hline CHEMBL1555046 & 688687 & 4.4 & 4.9767 & TST & \\
\hline CHEMBL1389547 & 688687 & 4.4 & 4.5358 & TRN & \\
\hline CHEMBL1551618 & 688687 & 4.8 & 4.9598 & TRN & \\
\hline CHEMBL1541733 & 688687 & 4.6 & 5.2524 & TRN & \\
\hline CHEMBL1371143 & 688687 & 4.6 & 4.5442 & TRN & \\
\hline CHEMBL1584661 & 688687 & 4.9 & 4.4424 & TRN & \\
\hline CHEMBL1603776 & 688687 & 5.5 & 5.2347 & TST & \\
\hline CHEMBL1455061 & 688687 & 4.5 & 4.6792 & TRN & \\
\hline CHEMBL1432150 & 688687 & 4.4 & 4.8717 & TRN & \\
\hline CHEMBL 234583 & 688687 & 4.5 & 4.6983 & TRN & \\
\hline CHEMBL1324099 & 688687 & 4.5 & 4.5972 & TRN & \\
\hline CHEMBL1559765 & 688687 & 4.4 & 5.0304 & TRN & \\
\hline CHEMBL1421346 & 688687 & 4.5 & 4.5678 & TRN & \\
\hline CHEMBL1329712 & 688687 & 5.4 & 5.1672 & TRN & \\
\hline CHEMBL1546753 & 688687 & 4.6 & 5.0638 & TST & \\
\hline CHEMBL1574909 & 688687 & 4.8 & 4.8923 & TST & \\
\hline CHEMBL1460341 & 688687 & 4.5 & 4.6677 & TRN & \\
\hline CHEMBL1606900 & 688687 & 5.6 & 5.109 & TST & \\
\hline CHEMBL3208887 & 688687 & 5.0 & 4.5556 & TRN & \\
\hline CHEMBL571296 & 688687 & 4.9 & 4.5537 & TRN & \\
\hline CHEMBL1405411 & 688687 & 4.6 & 4.865 & TRN & \\
\hline CHEMBL 3213260 & 688687 & 4.8 & 4.7895 & TRN & \\
\hline & & & & 6191 & \\
\hline
\end{tabular}




\begin{tabular}{|c|c|c|c|c|}
\hline & & & & \\
\hline CHEMBL1454211 & 688687 & 4.6 & 4.9557 & TRN \\
\hline CHEMBL 3207598 & 688687 & 6.0 & 4.6351 & TRN \\
\hline CHEMBL1388479 & 688687 & 4.9 & 5.0097 & TRN \\
\hline CHEMBL1387274 & 688687 & 4.5 & 4.6677 & TRN \\
\hline CHEMBL1454529 & 688687 & 4.4 & 4.628 & TRN \\
\hline CHEMBL1549732 & 688687 & 4.5 & 4.7296 & TRN \\
\hline CHEMBL3208629 & 688687 & 4.4 & 4.9029 & TRN \\
\hline CHEMBL1384120 & 688687 & 4.5 & 4.6602 & TST \\
\hline CHEMBL1364961 & 688687 & 4.4 & 4.8665 & TRN \\
\hline CHEMBL1387066 & 688687 & 4.7 & 4.7289 & TRN \\
\hline CHEMBL1456026 & 688687 & 4.4 & 4.6392 & TRN \\
\hline CHEMBL1332587 & 688687 & 4.4 & 4.854 & TST \\
\hline CHEMBL1325068 & 688687 & 4.4 & 4.7221 & TRN \\
\hline CHEMBL530664 & 688687 & 4.7 & 4.593 & TRN \\
\hline CHEMBL1493138 & 688687 & 4.5 & 4.7219 & TRN \\
\hline CHEMBL1602901 & 688687 & 5.9 & 5.2585 & TRN \\
\hline CHEMBL1390278 & 688687 & 4.5 & 5.0954 & TRN \\
\hline CHEMBL454746 & 688687 & 4.6 & 4.8764 & TRN \\
\hline CHEMBL1500066 & 688687 & 5.2 & 4.7697 & TRN \\
\hline CHEMBL1349303 & 688687 & 4.6 & 4.8937 & TST \\
\hline CHEMBL1497417 & 688687 & 4.9 & 4.9809 & TRN \\
\hline CHEMBL466930 & 688687 & 5.4 & 4.8678 & TRN \\
\hline CHEMBL1584069 & 688687 & 4.4 & 4.5282 & TRN \\
\hline CHEMBL1326041 & 688687 & 4.9 & 4.7894 & TRN \\
\hline CHEMBL1224512 & 688687 & 6.6 & 5.9598 & TRN \\
\hline CHEMBL1416867 & 688687 & 4.5 & 4.4714 & TRN \\
\hline CHEMBL1425342 & 688687 & 5.3 & 4.9282 & TRN \\
\hline CHEMBL1310701 & 688687 & 4.5 & 5.2159 & TST \\
\hline CHEMBL1368776 & 688687 & 4.4 & 4.7723 & TRN \\
\hline CHEMBL1698217 & 688687 & 4.7 & 4.6189 & TRN \\
\hline CHEMBL1550642 & 688687 & 5.5 & 5.0087 & TRN \\
\hline CHEMBL1511063 & 688687 & 4.8 & 4.8349 & TRN \\
\hline CHEMBL1585086 & 688687 & 4.6 & 4.6012 & TRN \\
\hline CHEMBL1375306 & 688687 & 4.7 & 4.685 & TRN \\
\hline CHEMBL1449269 & 688687 & 4.6 & 4.5658 & TRN \\
\hline CHEMBL1329850 & 688687 & 5.6 & 5.7648 & TRN \\
\hline CHEMBL1439795 & 688687 & 5.0 & 5.0644 & TRN \\
\hline CHEMBL1457624 & 688687 & 4.4 & 4.4592 & TRN \\
\hline CHEMBL1550829 & 688687 & 4.5 & 4.453 & TRN \\
\hline CHEMBL1604108 & 688687 & 4.4 & 4.7701 & TRN \\
\hline CHEMBL1412622 & 688687 & 4.4 & 4.8402 & TRN \\
\hline CHEMBL1322401 & 688687 & 4.6 & 4.732 & TRN \\
\hline CHEMBL1571084 & 688687 & 4.7 & 4.9177 & TRN \\
\hline CHEMBL1418460 & 688687 & 4.6 & 4.525 & TRN \\
\hline CHEMBL1313689 & 688687 & 5.1 & 4.7938 & TRN \\
\hline CHEMBL1569931 & 688687 & 4.9 & 4.8664 & TRN \\
\hline CHEMBL 1474278 & 688687 & 6.5 & 5.2014 & TST \\
\hline CHEMBL 3190147 & 688687 & 4.8 & 4.8201 & TST \\
\hline
\end{tabular}




\begin{tabular}{|c|c|c|c|c|}
\hline & & & ient & $a \perp 1 a$ \\
\hline CHEMBL1324817 & 688687 & 4.5 & 4.4473 & TRN \\
\hline CHEMBL1600790 & 688687 & 4.8 & 4.8484 & TRN \\
\hline CHEMBL1563916 & 688687 & 4.8 & 4.6577 & TST \\
\hline CHEMBL1345749 & 688687 & 4.6 & 5.0744 & TST \\
\hline CHEMBL1553179 & 688687 & 5.0 & 4.8472 & TRN \\
\hline CHEMBL1413805 & 688687 & 4.6 & 4.529 & TRN \\
\hline CHEMBL1534471 & 688687 & 4.5 & 5.1591 & TRN \\
\hline CHEMBL1386455 & 688687 & 5.5 & 4.9339 & TRN \\
\hline CHEMBL1419335 & 688687 & 6.9 & 5.8189 & TRN \\
\hline CHEMBL1507195 & 688687 & 4.8 & 4.8327 & TRN \\
\hline CHEMBL1548414 & 688687 & 5.1 & 4.7529 & TST \\
\hline CHEMBL1483733 & 688687 & 4.6 & 4.7686 & TRN \\
\hline CHEMBL3193049 & 688687 & 4.8 & 5.1027 & TRN \\
\hline CHEMBL1484081 & 688687 & 4.4 & 4.6684 & TRN \\
\hline CHEMBL1441846 & 688687 & 4.9 & 4.7495 & TRN \\
\hline CHEMBL1379517 & 688687 & 4.8 & 4.8959 & TRN \\
\hline CHEMBL1526365 & 688687 & 4.9 & 4.6834 & TST \\
\hline CHEMBL1569535 & 688687 & 5.1 & 5.1838 & TRN \\
\hline CHEMBL1325637 & 688687 & 4.5 & 4.6503 & TRN \\
\hline CHEMBL1579276 & 688687 & 4.5 & 4.9669 & TRN \\
\hline CHEMBL1461201 & 688687 & 4.5 & 4.6451 & TRN \\
\hline CHEMBL1543896 & 688687 & 4.6 & 5.3802 & TST \\
\hline CHEMBL1417759 & 688687 & 4.6 & 4.4956 & TRN \\
\hline CHEMBL1336572 & 688687 & 4.9 & 4.6324 & TRN \\
\hline CHEMBL1538446 & 688687 & 4.4 & 4.6151 & TRN \\
\hline CHEMBL1474471 & 688687 & 4.9 & 5.0067 & TRN \\
\hline CHEMBL1610645 & 688687 & 4.5 & 4.5549 & TRN \\
\hline CHEMBL1386123 & 688687 & 4.7 & 4.8331 & TRN \\
\hline CHEMBL1558288 & 688687 & 4.4 & 4.6893 & TRN \\
\hline CHEMBL1525872 & 688687 & 4.6 & 4.8251 & TRN \\
\hline CHEMBL1608641 & 688687 & 4.5 & 4.9368 & TRN \\
\hline CHEMBL1567481 & 688687 & 5.3 & 4.8049 & TRN \\
\hline CHEMBL1341450 & 688687 & 5.5 & 4.5481 & TRN \\
\hline CHEMBL1573102 & 688687 & 4.5 & 4.7851 & TRN \\
\hline CHEMBL1465913 & 688687 & 4.4 & 4.5071 & TRN \\
\hline CHEMBL1446623 & 688687 & 4.4 & 4.4513 & TRN \\
\hline CHEMBL1424486 & 688687 & 4.9 & 5.0116 & TRN \\
\hline CHEMBL1328574 & 688687 & 4.8 & 4.7584 & TRN \\
\hline CHEMBL1339243 & 688687 & 5.7 & 4.8069 & TRN \\
\hline CHEMBL1307791 & 688687 & 4.5 & 4.8038 & TRN \\
\hline CHEMBL1481573 & 688687 & 4.9 & 5.3215 & TRN \\
\hline CHEMBL1459784 & 688687 & 4.6 & 4.5466 & TRN \\
\hline CHEMBL1586633 & 688687 & 4.4 & 4.6816 & TRN \\
\hline CHEMBL1437158 & 688687 & 5.5 & 4.996 & TRN \\
\hline CHEMBL1352349 & 688687 & 4.4 & 4.6926 & TRN \\
\hline CHEMBL1521456 & 688687 & 4.4 & 4.4628 & TRN \\
\hline CHEMBL1577537 & 688687 & 4.5 & 5.4527 & TST \\
\hline CHEMBL1364714 & 688687 & 4.9 & 4.8717 & TRN \\
\hline
\end{tabular}




\begin{tabular}{|c|c|c|c|c|c|}
\hline & & & & & \\
\hline CHEMBL1576363 & 688687 & 5.3 & 5.0112 & TRN & \\
\hline CHEMBL1531439 & 688687 & 4.4 & 4.5191 & TRN & \\
\hline CHEMBL1538805 & 688687 & 4.6 & 4.5331 & TRN & \\
\hline CHEMBL1493367 & 688687 & 4.5 & 4.4923 & TRN & \\
\hline CHEMBL1602728 & 688687 & 5.1 & 4.8452 & TRN & \\
\hline CHEMBL1349765 & 688687 & 4.4 & 4.3953 & TRN & \\
\hline CHEMBL1577903 & 688687 & 4.6 & 4.5996 & TRN & \\
\hline CHEMBL1448824 & 688687 & 5.0 & 4.9016 & TST & \\
\hline CHEMBL1425332 & 688687 & 4.6 & 5.0132 & TRN & \\
\hline CHEMBL1365762 & 688687 & 4.5 & 4.7981 & TRN & \\
\hline CHEMBL1542925 & 688687 & 4.8 & 4.6745 & TRN & \\
\hline CHEMBL 221300 & 688687 & 4.4 & 4.881 & TST & \\
\hline CHEMBL1418089 & 688687 & 4.4 & 4.747 & TRN & \\
\hline CHEMBL1491507 & 688687 & 4.6 & 4.8735 & TRN & \\
\hline CHEMBL1425227 & 688687 & 4.5 & 4.8301 & TRN & \\
\hline CHEMBL364032 & 688687 & 4.8 & 4.9649 & TRN & \\
\hline CHEMBL1322641 & 688687 & 4.4 & 4.7631 & TRN & \\
\hline CHEMBL1507067 & 688687 & 4.5 & 4.7001 & TRN & \\
\hline CHEMBL1429741 & 688687 & 4.4 & 4.6028 & TRN & \\
\hline CHEMBL1517727 & 688687 & 4.6 & 4.8873 & TRN & \\
\hline CHEMBL 244743 & 688687 & 4.9 & 5.3516 & TRN & \\
\hline CHEMBL1528023 & 688687 & 4.4 & 4.489 & TRN & \\
\hline CHEMBL3198038 & 688687 & 4.4 & 4.9781 & TST & \\
\hline CHEMBL1531735 & 688687 & 4.8 & 4.9268 & TRN & \\
\hline CHEMBL1547211 & 688687 & 4.5 & 4.7134 & TRN & \\
\hline CHEMBL1586525 & 688687 & 4.7 & 4.6307 & TRN & \\
\hline CHEMBL1340593 & 688687 & 4.5 & 4.48600 & 0000000001 & TRN \\
\hline CHEMBL1534325 & 688687 & 4.5 & 4.8125 & TRN & \\
\hline CHEMBL1501214 & 688687 & 5.7 & 5.0442 & TRN & \\
\hline CHEMBL1606020 & 688687 & 5.0 & 4.6754 & TRN & \\
\hline CHEMBL1409762 & 688687 & 5.6 & 5.3003 & TST & \\
\hline CHEMBL1607104 & 688687 & 4.4 & 4.603 & TRN & \\
\hline CHEMBL1425704 & 688687 & 4.5 & 4.9149 & TRN & \\
\hline CHEMBL1355644 & 688687 & 4.6 & 4.7718 & TRN & \\
\hline CHEMBL1542510 & 688687 & 5.8 & 5.9115 & TRN & \\
\hline CHEMBL1390901 & 688687 & 5.5 & 5.9174 & TRN & \\
\hline CHEMBL81753 & 688687 & 6.0 & 5.501 & TST & \\
\hline CHEMBL1394939 & 688687 & 4.4 & 4.5968 & TRN & \\
\hline CHEMBL1562810 & 688687 & 4.6 & 4.7809 & TRN & \\
\hline CHEMBL1338095 & 688687 & 4.4 & 4.6233 & TRN & \\
\hline CHEMBL3197105 & 688687 & 4.6 & 4.9548 & TST & \\
\hline CHEMBL1521551 & 688687 & 4.5 & 4.5355 & TRN & \\
\hline CHEMBL3198329 & 688687 & 4.6 & 4.4147 & TRN & \\
\hline CHEMBL1563643 & 688687 & 4.6 & 4.6499 & TRN & \\
\hline CHEMBL1499631 & 688687 & 4.4 & 4.8394 & TRN & \\
\hline CHEMBL1455073 & 688687 & 6.0 & 4.8822 & TST & \\
\hline CHEMBL553751 & 688687 & 6.6 & 5.1794 & TST & \\
\hline CHEMBL1357167 & 688687 & 4.4 & 4.2662 & TRN & \\
\hline
\end{tabular}




\begin{tabular}{|c|c|c|c|c|}
\hline \multicolumn{5}{|c|}{ plemental Table } \\
\hline CHEMBL1604045 & 688687 & 5.4 & 5.0031 & TRN \\
\hline CHEMBL1561864 & 688687 & 4.8 & 4.9539 & TRN \\
\hline CHEMBL1473793 & 688687 & 4.6 & 4.8645 & TRN \\
\hline CHEMBL1349136 & 688687 & 4.7 & 4.6536 & TRN \\
\hline CHEMBL1529858 & 688687 & 5.9 & 4.7363 & TST \\
\hline CHEMBL1359989 & 688687 & 4.8 & 4.7519 & TRN \\
\hline CHEMBL1605759 & 688687 & 4.4 & 5.0216 & TRN \\
\hline CHEMBL1256484 & 688687 & 5.9 & 5.6206 & TRN \\
\hline CHEMBL1430785 & 688687 & 4.5 & 4.9435 & TRN \\
\hline CHEMBL157351 & 688687 & 5.5 & 4.9829 & TST \\
\hline CHEMBL1490639 & 688687 & 5.5 & 4.7067 & TRN \\
\hline CHEMBL1409384 & 688687 & 6.3 & 5.1235 & TRN \\
\hline CHEMBL1364904 & 688687 & 5.6 & 4.7757 & TST \\
\hline CHEMBL1394118 & 688687 & 5.6 & 5.2668 & TRN \\
\hline CHEMBL1388947 & 688687 & 4.6 & 4.7727 & TRN \\
\hline CHEMBL1436272 & 688687 & 4.5 & 4.4658 & TRN \\
\hline CHEMBL1477337 & 688687 & 4.9 & 4.6335 & TRN \\
\hline CHEMBL1453592 & 688687 & 4.4 & 4.6471 & TRN \\
\hline CHEMBL1496732 & 688687 & 4.8 & 5.0136 & TRN \\
\hline CHEMBL1342654 & 688687 & 4.5 & 4.917 & TRN \\
\hline CHEMBL1456747 & 688687 & 6.0 & 5.2432 & TST \\
\hline CHEMBL1391498 & 688687 & 4.6 & 4.9303 & TST \\
\hline CHEMBL1707275 & 688687 & 4.7 & 4.5698 & TRN \\
\hline CHEMBL1444201 & 688687 & 5.5 & 4.522 & TRN \\
\hline CHEMBL1486729 & 688687 & 6.7001 & 5.4816 & TRN \\
\hline CHEMBL1403458 & 688687 & 5.5 & 4.9291 & TRN \\
\hline CHEMBL1457833 & 688687 & 4.4 & 4.5994 & TRN \\
\hline CHEMBL1336289 & 688687 & 4.4 & 4.7461 & TRN \\
\hline CHEMBL1510237 & 688687 & 4.5 & 4.8067 & TRN \\
\hline CHEMBL1604473 & 688687 & 4.9 & 4.6646 & TRN \\
\hline CHEMBL1378138 & 688687 & 4.4 & 4.7182 & TRN \\
\hline CHEMBL1324085 & 688687 & 4.6 & 4.9468 & TRN \\
\hline CHEMBL1411349 & 688687 & 4.4 & 4.9166 & TRN \\
\hline CHEMBL1613092 & 688687 & 5.1 & 4.9158 & TRN \\
\hline CHEMBL1500633 & 688687 & 4.4 & 4.8339 & TRN \\
\hline CHEMBL1507474 & 688687 & 4.9 & 4.7939 & TRN \\
\hline CHEMBL1492270 & 688687 & 4.4 & 4.6671 & TRN \\
\hline CHEMBL1522515 & 688687 & 5.4 & 4.5922 & TRN \\
\hline CHEMBL1498339 & 688687 & 4.5 & 4.6659 & TRN \\
\hline CHEMBL1487347 & 688687 & 5.2 & 4.7084 & TRN \\
\hline CHEMBL1508430 & 688687 & 5.4 & 4.8127 & TRN \\
\hline CHEMBL1530531 & 688687 & 5.8 & 5.4029 & TRN \\
\hline CHEMBL1602857 & 688687 & 5.2 & 5.255 & TRN \\
\hline CHEMBL1340322 & 688687 & 4.6 & 4.6317 & TRN \\
\hline CHEMBL1471193 & 688687 & 4.4 & 4.8872 & TRN \\
\hline CHEMBL1556512 & 688687 & 4.4 & 4.6702 & TRN \\
\hline CHEMBL1484419 & 688687 & 5.1 & 4.8383 & TRN \\
\hline CHEMBL1463801 & 688687 & 4.8 & 4.7006 & TRN \\
\hline
\end{tabular}




\begin{tabular}{|c|c|c|c|c|c|}
\hline \\
\hline CHEMBL1409230 & 688687 & 4.4 & 5.0227 & TRN & \\
\hline CHEMBL1363513 & 688687 & 4.4 & 4.899 & TRN & \\
\hline CHEMBL464467 & 688687 & 4.4 & 5.1708 & TST & \\
\hline CHEMBL1513495 & 688687 & 4.5 & 4.9495 & TRN & \\
\hline CHEMBL1568059 & 688687 & 4.8 & 4.7808 & TRN & \\
\hline CHEMBL1430269 & 688687 & 4.4 & 4.3956 & TRN & \\
\hline CHEMBL1309082 & 688687 & 5.4 & 4.8421 & TRN & \\
\hline CHEMBL1562425 & 688687 & 4.6 & 4.7842 & TRN & \\
\hline CHEMBL444236 & 688687 & 4.6 & 4.9422 & TST & \\
\hline CHEMBL1459185 & 688687 & 4.9 & 4.5106 & TRN & \\
\hline CHEMBL1455283 & 688687 & 4.4 & 4.7605 & TRN & \\
\hline CHEMBL1371774 & 688687 & 4.9 & 5.011 & TRN & \\
\hline CHEMBL1610721 & 688687 & 4.5 & 4.913 & TRN & \\
\hline CHEMBL1310041 & 688687 & 4.4 & 4.7131 & TRN & \\
\hline CHEMBL1365444 & 688687 & 4.9 & 4.5893 & TRN & \\
\hline CHEMBL1360235 & 688687 & 4.6 & 4.7339 & TRN & \\
\hline CHEMBL1412519 & 688687 & 6.1 & 4.6714 & TST & \\
\hline CHEMBL1600996 & 688687 & 5.5 & 4.8925 & TRN & \\
\hline CHEMBL1412261 & 688687 & 4.9 & 4.9889 & TST & \\
\hline CHEMBL18840 & 688687 & 4.9 & 5.0268 & TST & \\
\hline CHEMBL1362317 & 688687 & 4.5 & 5.2731 & TRN & \\
\hline CHEMBL1516957 & 688687 & 4.7 & 4.90300 & 00000000005 & TRN \\
\hline CHEMBL1395974 & 688687 & 5.0 & 5.0538 & TRN & \\
\hline CHEMBL1323090 & 688687 & 4.6 & 4.5316 & TRN & \\
\hline CHEMBL565755 & 688687 & 4.5 & 4.6994 & TRN & \\
\hline CHEMBL1464482 & 688687 & 5.2 & 4.9585 & TRN & \\
\hline CHEMBL1494470 & 688687 & 5.2 & 4.9232 & TRN & \\
\hline CHEMBL1603415 & 688687 & 4.6 & 4.7361 & TRN & \\
\hline CHEMBL 225012 & 688687 & 4.6 & 4.54 & TRN & \\
\hline CHEMBL1439247 & 688687 & 4.4 & 4.9488 & TST & \\
\hline CHEMBL1256686 & 688687 & 6.0 & 4.7096 & TST & \\
\hline CHEMBL1460224 & 688687 & 4.6 & 4.6888 & TRN & \\
\hline CHEMBL1573995 & 688687 & 5.1 & 4.8099 & TRN & \\
\hline CHEMBL1588808 & 688687 & 5.1 & 5.0446 & TRN & \\
\hline CHEMBL1503672 & 688687 & 4.4 & 4.88399 & 99999999995 & TRN \\
\hline CHEMBL1351018 & 688687 & 5.4 & 4.7828 & TRN & \\
\hline CHEMBL1312599 & 688687 & 4.7 & 4.4945 & TRN & \\
\hline CHEMBL1307167 & 688687 & 4.6 & 4.8414 & TRN & \\
\hline CHEMBL1342976 & 688687 & 4.5 & 4.7078 & TRN & \\
\hline CHEMBL1411492 & 688687 & 4.4 & 4.5328 & TRN & \\
\hline CHEMBL1350476 & 688687 & 4.6 & 4.583 & TRN & \\
\hline CHEMBL1510411 & 688687 & 4.5 & 4.9311 & TRN & \\
\hline CHEMBL1429397 & 688687 & 4.5 & 4.5513 & TRN & \\
\hline CHEMBL1478081 & 688687 & 4.8 & 4.8236 & TRN & \\
\hline CHEMBL1345240 & 688687 & 4.6 & 4.6196 & TRN & \\
\hline CHEMBL1513030 & 688687 & 5.0 & 4.998 & TRN & \\
\hline CHEMBL1425085 & 688687 & 4.5 & 4.6193 & TRN & \\
\hline CHEMBL1324955 & 688687 & 4.6 & 4.8673 & TRN & \\
\hline
\end{tabular}




\begin{tabular}{|c|c|c|c|c|c|}
\hline & & & & & \\
\hline CHEMBL1455467 & 688687 & 5.6 & 5.5725 & TRN & \\
\hline CHEMBL1381209 & 688687 & 5.0 & 4.9828 & TRN & \\
\hline CHEMBL1465105 & 688687 & 5.4 & 4.8244 & TRN & \\
\hline CHEMBL1577485 & 688687 & 5.8 & 4.8581 & TST & \\
\hline CHEMBL1326569 & 688687 & 5.5 & 5.2643 & TRN & \\
\hline CHEMBL1466569 & 688687 & 4.6 & 5.1522 & TRN & \\
\hline CHEMBL1493942 & 688687 & 4.4 & 4.5527 & TRN & \\
\hline CHEMBL1363056 & 688687 & 6.0 & 5.2182 & TRN & \\
\hline CHEMBL1308751 & 688687 & 4.4 & 4.9682 & TRN & \\
\hline CHEMBL1610207 & 688687 & 5.3 & 4.9044 & TRN & \\
\hline CHEMBL1374942 & 688687 & 4.6 & 4.4363 & TRN & \\
\hline CHEMBL1528346 & 688687 & 4.4 & 4.7266 & TRN & \\
\hline CHEMBL1602731 & 688687 & 4.9 & 5.0877 & TST & \\
\hline CHEMBL1594281 & 688687 & 5.3 & 4.7941 & TRN & \\
\hline CHEMBL1540347 & 688687 & 5.1 & 5.008 & TRN & \\
\hline CHEMBL1424034 & 688687 & 4.9 & 4.90600 & 0000000001 & TRN \\
\hline CHEMBL1560630 & 688687 & 4.7 & 4.6887 & TRN & \\
\hline CHEMBL1526245 & 688687 & 4.5 & 4.8599 & TRN & \\
\hline CHEMBL1310614 & 688687 & 4.6 & 4.5718 & TRN & \\
\hline CHEMBL1390194 & 688687 & 4.6 & 5.0037 & TRN & \\
\hline CHEMBL1559787 & 688687 & 4.6 & 4.4352 & TRN & \\
\hline CHEMBL1369152 & 688687 & 4.6 & 4.9509 & TRN & \\
\hline CHEMBL1489484 & 688687 & 4.6 & 4.8005 & TRN & \\
\hline CHEMBL429095 & 688687 & 6.0 & 5.1174 & TST & \\
\hline CHEMBL1480902 & 688687 & 6.2 & 5.2035 & TST & \\
\hline CHEMBL1337533 & 688687 & 4.4 & 4.9068 & TRN & \\
\hline CHEMBL1442387 & 688687 & 4.6 & 4.7248 & TST & \\
\hline CHEMBL1419588 & 688687 & 4.4 & 4.4975 & TRN & \\
\hline CHEMBL1309404 & 688687 & 4.4 & 4.6653 & TRN & \\
\hline CHEMBL1556821 & 688687 & 4.4 & 4.8029 & TRN & \\
\hline CHEMBL1559558 & 688687 & 4.5 & 4.4425 & TRN & \\
\hline CHEMBL1321310 & 688687 & 4.5 & 4.4457 & TRN & \\
\hline CHEMBL1556237 & 688687 & 4.6 & 4.7107 & TST & \\
\hline CHEMBL1333007 & 688687 & 4.8 & 4.9758 & TST & \\
\hline CHEMBL1548137 & 688687 & 4.5 & 4.4893 & TRN & \\
\hline CHEMBL1330486 & 688687 & 5.6 & 5.3502 & TRN & \\
\hline CHEMBL1611618 & 688687 & 4.7 & 4.8392 & TRN & \\
\hline CHEMBL1521192 & 688687 & 5.2 & 4.885 & TRN & \\
\hline CHEMBL1454136 & 688687 & 4.5 & 4.9104 & TRN & \\
\hline CHEMBL1312334 & 688687 & 4.5 & 4.7515 & TRN & \\
\hline CHEMBL1313141 & 688687 & 4.9 & 5.0325 & TRN & \\
\hline CHEMBL1414282 & 688687 & 4.9 & 4.808 & TRN & \\
\hline CHEMBL1521142 & 688687 & 7.0 & 4.938 & TRN & \\
\hline CHEMBL1387876 & 688687 & 4.7 & 4.7125 & TRN & \\
\hline CHEMBL1594707 & 688687 & 5.5 & 5.045 & TRN & \\
\hline CHEMBL1541064 & 688687 & 4.4 & 4.8803 & TRN & \\
\hline CHEMBL1536946 & 688687 & 6.3 & 4.9789 & TRN & \\
\hline CHEMBL1173823 & 688687 & 4.5 & 4.5872 & TRN & \\
\hline & & & & e 6197 & \\
\hline
\end{tabular}




\begin{tabular}{|c|c|c|c|c|c|}
\hline \\
\hline CHEMBL1404104 & 688687 & 4.5 & 4.8897 & TST & \\
\hline CHEMBL1532805 & 688687 & 4.5 & 4.7242 & TRN & \\
\hline CHEMBL1482002 & 688687 & 4.5 & 4.5709 & TST & \\
\hline CHEMBL1443403 & 688687 & 5.3 & 5.1496 & TRN & \\
\hline CHEMBL1578151 & 688687 & 4.4 & 4.4502 & TRN & \\
\hline CHEMBL1457550 & 688687 & 4.4 & 5.3389 & TST & \\
\hline CHEMBL1521813 & 688687 & 5.2 & 5.2215 & TRN & \\
\hline CHEMBL1554664 & 688687 & 4.4 & 4.647 & TRN & \\
\hline CHEMBL1353661 & 688687 & 5.4 & 4.6728 & TRN & \\
\hline CHEMBL1356748 & 688687 & 6.1 & 5.2065 & TST & \\
\hline CHEMBL1337886 & 688687 & 4.4 & 4.6881 & TRN & \\
\hline CHEMBL3197851 & 688687 & 4.6 & 4.9625 & TST & \\
\hline CHEMBL1452838 & 688687 & 5.5 & 5.0083 & TRN & \\
\hline CHEMBL1488204 & 688687 & 4.6 & 4.4937 & TRN & \\
\hline CHEMBL1450920 & 688687 & 4.4 & 5.03100 & 0000000001 & TST \\
\hline CHEMBL1330161 & 688687 & 5.5 & 5.8528 & TRN & \\
\hline CHEMBL2132953 & 688687 & 6.1 & 4.8022 & TST & \\
\hline CHEMBL1380684 & 688687 & 6.0 & 5.3452 & TST & \\
\hline CHEMBL1303480 & 688687 & 5.3 & 4.6308 & TRN & \\
\hline CHEMBL1448912 & 688687 & 4.6 & 4.8116 & TRN & \\
\hline CHEMBL1499736 & 688687 & 4.7 & 4.5421 & TRN & \\
\hline CHEMBL1316796 & 688687 & 5.4 & 5.1604 & TRN & \\
\hline CHEMBL1432701 & 688687 & 4.5 & 4.773 & TRN & \\
\hline CHEMBL1603991 & 688687 & 5.7 & 5.7547 & TRN & \\
\hline CHEMBL1421164 & 688687 & 4.6 & 4.8561 & TRN & \\
\hline CHEMBL1596039 & 688687 & 4.5 & 4.8863 & TRN & \\
\hline CHEMBL1389294 & 688687 & 5.3 & 5.2001 & TRN & \\
\hline CHEMBL1438761 & 688687 & 4.4 & 4.5626 & TRN & \\
\hline CHEMBL1483442 & 688687 & 5.3 & 5.1467 & TRN & \\
\hline CHEMBL1383181 & 688687 & 5.5 & 5.0907 & TRN & \\
\hline CHEMBL3196180 & 688687 & 4.5 & 4.8083 & TRN & \\
\hline CHEMBL1496596 & 688687 & 5.4 & 5.0208 & TRN & \\
\hline CHEMBL1312156 & 688687 & 4.6 & 4.6227 & TRN & \\
\hline CHEMBL1518794 & 688687 & 5.3 & 4.782 & TRN & \\
\hline CHEMBL1323989 & 688687 & 4.5 & 4.548 & TRN & \\
\hline CHEMBL1521872 & 688687 & 4.9 & 4.7484 & TST & \\
\hline CHEMBL1352912 & 688687 & 4.9 & 4.5381 & TRN & \\
\hline CHEMBL1412232 & 688687 & 4.5 & 4.6782 & TRN & \\
\hline CHEMBL1561533 & 688687 & 4.5 & 4.7923 & TRN & \\
\hline CHEMBL1392054 & 688687 & 4.7 & 5.0756 & TRN & \\
\hline CHEMBL1552707 & 688687 & 4.5 & 4.8006 & TRN & \\
\hline CHEMBL1457187 & 688687 & 4.7 & 4.6342 & TRN & \\
\hline CHEMBL1493034 & 688687 & 4.4 & 4.8992 & TST & \\
\hline CHEMBL1574825 & 688687 & 4.7 & 5.2793 & TRN & \\
\hline CHEMBL1485581 & 688687 & 4.9 & 4.8733 & TRN & \\
\hline CHEMBL1556800 & 688687 & 4.4 & 4.8119 & TST & \\
\hline CHEMBL1308901 & 688687 & 4.5 & 4.9322 & TRN & \\
\hline CHEMBL1403455 & 688687 & 4.5 & 4.8247 & TRN & \\
\hline
\end{tabular}




\begin{tabular}{|c|c|c|c|c|}
\hline \multicolumn{5}{|c|}{ pplemental Table S2.t } \\
\hline CHEMBL 3197840 & 688687 & 4.5 & 4.9765 & TRN \\
\hline CHEMBL1569933 & 688687 & 4.6 & 5.1684 & TRN \\
\hline CHEMBL1382866 & 688687 & 4.9 & 4.8446 & TRN \\
\hline CHEMBL 1477840 & 688687 & 5.0 & 4.5844 & TRN \\
\hline CHEMBL1371943 & 688687 & 4.4 & 4.8761 & TRN \\
\hline CHEMBL3194854 & 688687 & 4.4 & 4.8171 & TST \\
\hline CHEMBL1500905 & 688687 & 5.4 & 5.0549 & TRN \\
\hline CHEMBL1360009 & 688687 & 4.5 & 4.6799 & TRN \\
\hline CHEMBL1342136 & 688687 & 4.5 & 4.5865 & TRN \\
\hline CHEMBL1538757 & 688687 & 4.6 & 4.8295 & TRN \\
\hline CHEMBL1255656 & 688687 & 6.1 & 5.2644 & TST \\
\hline CHEMBL577887 & 688687 & 4.6 & 4.697 & TRN \\
\hline CHEMBL1531788 & 688687 & 4.5 & 4.8891 & TRN \\
\hline CHEMBL1322862 & 688687 & 4.6 & 4.6919 & TRN \\
\hline CHEMBL1588531 & 688687 & 4.4 & 4.7515 & TRN \\
\hline CHEMBL1439904 & 688687 & 4.7 & 5.0317 & TRN \\
\hline CHEMBL1256646 & 688687 & 6.0 & 5.271 & TST \\
\hline CHEMBL1492428 & 688687 & 6.2 & 5.1563 & TRN \\
\hline CHEMBL1597774 & 688687 & 4.6 & 4.4223 & TRN \\
\hline CHEMBL1409974 & 688687 & 4.5 & 4.6124 & TRN \\
\hline CHEMBL1321811 & 688687 & 4.6 & 5.0666 & TRN \\
\hline CHEMBL1384354 & 688687 & 4.5 & 5.1476 & TRN \\
\hline CHEMBL1370648 & 688687 & 5.4 & 4.6987 & TRN \\
\hline CHEMBL1364375 & 688687 & 4.8 & 4.6964 & TRN \\
\hline CHEMBL1517045 & 688687 & 4.5 & 4.8636 & TST \\
\hline CHEMBL1477842 & 688687 & 4.6 & 4.6127 & TRN \\
\hline CHEMBL1352118 & 688687 & 4.4 & 4.4949 & TRN \\
\hline CHEMBL1688558 & 688687 & 6.5 & 5.2044 & TST \\
\hline CHEMBL1460182 & 688687 & 4.5 & 4.7042 & TRN \\
\hline CHEMBL1407483 & 688687 & 6.8 & 4.9295 & TST \\
\hline CHEMBL1520159 & 688687 & 4.6 & 4.8395 & TRN \\
\hline CHEMBL1407885 & 688687 & 4.7 & 5.2292 & TRN \\
\hline CHEMBL1594307 & 688687 & 4.4 & 4.6287 & TRN \\
\hline CHEMBL1418522 & 688687 & 4.5 & 4.9889 & TRN \\
\hline CHEMBL1305649 & 688687 & 4.4 & 5.0084 & TRN \\
\hline CHEMBL1524482 & 688687 & 4.5 & 4.8663 & TRN \\
\hline CHEMBL1557048 & 688687 & 4.9 & 4.6477 & TRN \\
\hline CHEMBL1521658 & 688687 & 4.4 & 4.4625 & TRN \\
\hline CHEMBL294209 & 688687 & 4.6 & 5.0614 & TST \\
\hline CHEMBL1478258 & 688687 & 4.8 & 4.6623 & TRN \\
\hline CHEMBL1375636 & 688687 & 4.5 & 4.5801 & TST \\
\hline CHEMBL1594554 & 688687 & 5.1 & 4.8113 & TRN \\
\hline CHEMBL1563518 & 688687 & 4.6 & 4.8827 & TRN \\
\hline CHEMBL1419259 & 688687 & 5.5 & 4.8453 & TRN \\
\hline CHEMBL1161936 & 688687 & 7.3002 & 5.1559 & TST \\
\hline CHEMBL1386243 & 688687 & 5.1 & 4.7299 & TST \\
\hline CHEMBL1501861 & 688687 & 6.1 & 4.9109 & TRN \\
\hline CHEMBL1577248 & 688687 & 4.6 & 4.6855 & TST \\
\hline
\end{tabular}




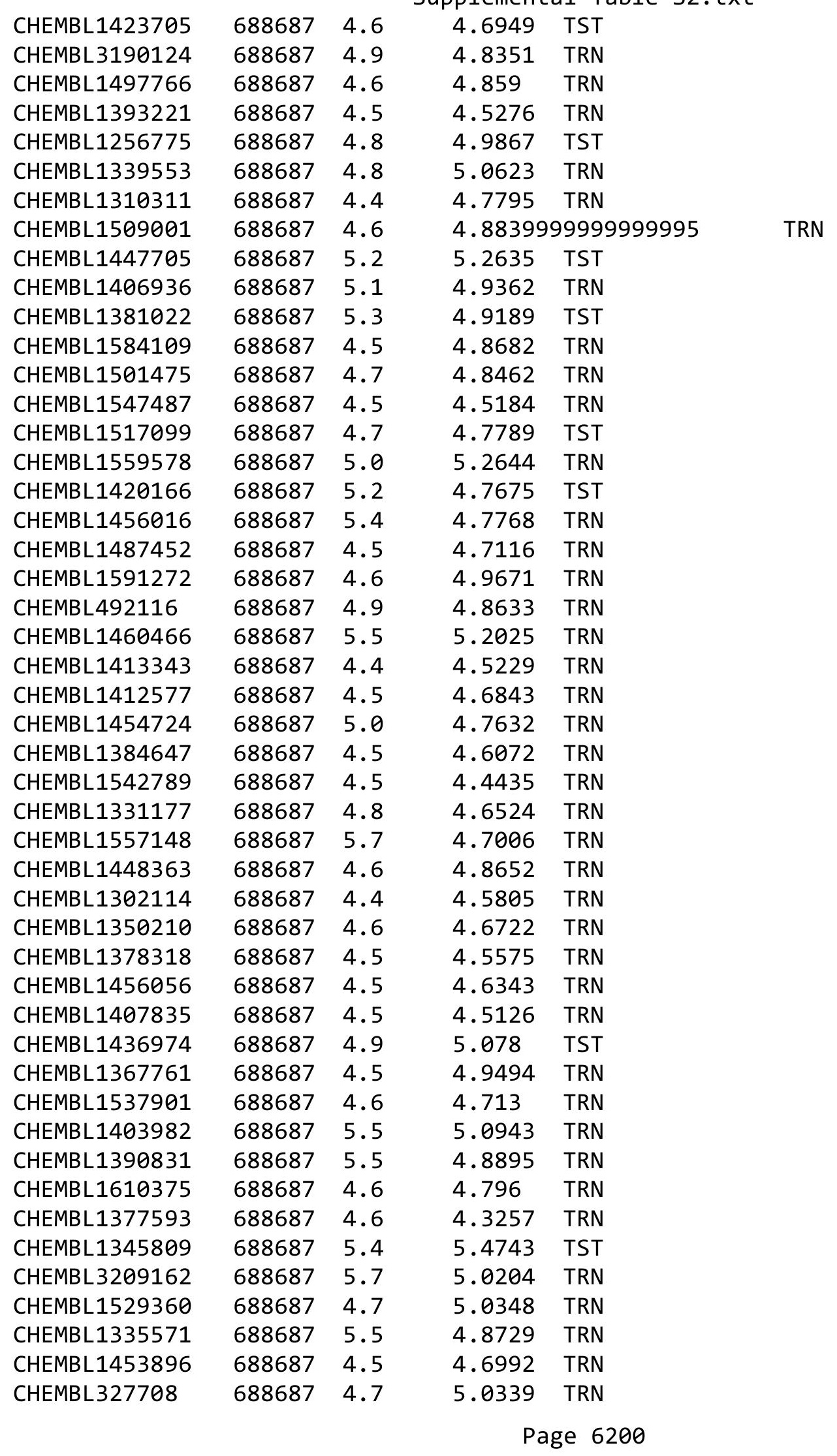




\begin{tabular}{|c|c|c|c|c|c|}
\hline \\
\hline CHEMBL1565585 & 688687 & 4.9 & 4.9498 & TST & \\
\hline CHEMBL1406871 & 688687 & 6.0 & 4.9281 & TRN & \\
\hline CHEMBL1523699 & 688687 & 5.3 & 5.313 & TRN & \\
\hline CHEMBL282003 & 688687 & 4.4 & 4.6254 & TRN & \\
\hline CHEMBL500430 & 688687 & 6.1 & 4.8808 & TRN & \\
\hline CHEMBL517444 & 688687 & 4.7 & 4.6784 & TRN & \\
\hline CHEMBL1406829 & 688687 & 4.6 & 4.8351 & TST & \\
\hline CHEMBL1440430 & 688687 & 4.8 & 4.6592 & TRN & \\
\hline CHEMBL1597242 & 688687 & 4.6 & 4.8974 & TRN & \\
\hline CHEMBL1407247 & 688687 & 4.6 & 4.8763 & TRN & \\
\hline CHEMBL1588931 & 688687 & 4.6 & 4.9458 & TRN & \\
\hline CHEMBL1331289 & 688687 & 5.2 & 4.8847 & TRN & \\
\hline CHEMBL1562619 & 688687 & 4.6 & 4.7402 & TRN & \\
\hline CHEMBL1524353 & 688687 & 4.5 & 4.9862 & TST & \\
\hline CHEMBL1346587 & 688687 & 5.6 & 4.9894 & TRN & \\
\hline CHEMBL1392265 & 688687 & 4.9 & 4.8633 & TRN & \\
\hline CHEMBL1303766 & 688687 & 4.6 & 4.8706 & TRN & \\
\hline CHEMBL1491440 & 688687 & 4.5 & 4.7803 & TRN & \\
\hline CHEMBL261889 & 688687 & 5.5 & 4.9876 & TRN & \\
\hline CHEMBL1576347 & 688687 & 5.5 & 5.0117 & TRN & \\
\hline CHEMBL1438567 & 688687 & 5.0 & 5.0631 & TRN & \\
\hline CHEMBL1581568 & 688687 & 4.6 & 4.8135 & TST & \\
\hline CHEMBL1454803 & 688687 & 5.6 & 5.0722 & TRN & \\
\hline CHEMBL1522100 & 688687 & 4.6 & 4.6524 & TRN & \\
\hline CHEMBL1451429 & 688687 & 5.6 & 4.7711 & TRN & \\
\hline CHEMBL1576107 & 688687 & 4.5 & 4.7733 & TRN & \\
\hline CHEMBL1336666 & 688687 & 4.5 & 4.7378 & TST & \\
\hline CHEMBL1332019 & 688687 & 4.5 & 4.70100 & 00000000005 & TRN \\
\hline CHEMBL1399829 & 688687 & 5.2 & 5.15 & TRN & \\
\hline CHEMBL1407754 & 688687 & 4.4 & 4.9257 & TRN & \\
\hline CHEMBL1515961 & 688687 & 5.5 & 4.8597 & TST & \\
\hline CHEMBL1432442 & 688687 & 4.5 & 4.685 & TRN & \\
\hline CHEMBL1380940 & 688687 & 5.6 & 4.8538 & TRN & \\
\hline CHEMBL1306731 & 688687 & 5.5 & 5.3443 & TRN & \\
\hline CHEMBL1339706 & 688687 & 4.7 & 4.6091 & TRN & \\
\hline CHEMBL1392825 & 688687 & 4.5 & 4.8773 & TRN & \\
\hline CHEMBL1537276 & 688687 & 5.0 & 4.9467 & TRN & \\
\hline CHEMBL1608211 & 688687 & 4.5 & 5.0447 & TRN & \\
\hline CHEMBL1329801 & 688687 & 4.6 & 4.7618 & TRN & \\
\hline CHEMBL2028181 & 688687 & 5.5 & 4.837 & TST & \\
\hline CHEMBL1586148 & 688687 & 4.4 & 4.6407 & TST & \\
\hline CHEMBL1562710 & 688687 & 4.4 & 4.6211 & TRN & \\
\hline CHEMBL1406292 & 688687 & 4.6 & 5.4875 & TST & \\
\hline CHEMBL1561273 & 688687 & 4.6 & 4.5301 & TRN & \\
\hline CHEMBL1369588 & 688687 & 5.1 & 4.8215 & TST & \\
\hline CHEMBL1528624 & 688687 & 4.4 & 4.7924 & TRN & \\
\hline CHEMBL71460 & 688687 & 4.4 & 5.2349 & TST & \\
\hline CHEMBL1569493 & 688687 & 4.5 & 5.1489 & TRN & \\
\hline
\end{tabular}




\begin{tabular}{|c|c|c|c|c|}
\hline & & & IIETा & al Ta \\
\hline CHEMBL1558990 & 688687 & 4.4 & 4.6401 & TRN \\
\hline CHEMBL1435409 & 688687 & 4.6 & 4.4447 & TRN \\
\hline CHEMBL1367825 & 688687 & 5.1 & 4.8296 & TRN \\
\hline CHEMBL1376804 & 688687 & 4.5 & 4.5823 & TRN \\
\hline CHEMBL1450380 & 688687 & 5.4 & 4.6364 & TRN \\
\hline CHEMBL1469487 & 688687 & 5.0 & 4.8061 & TRN \\
\hline CHEMBL1604441 & 688687 & 5.0 & 4.9202 & TST \\
\hline CHEMBL1372272 & 688687 & 4.8 & 4.7994 & TRN \\
\hline CHEMBL1419791 & 688687 & 4.6 & 4.9289 & TRN \\
\hline CHEMBL1573353 & 688687 & 4.6 & 4.9199 & TRN \\
\hline CHEMBL1503046 & 688687 & 4.5 & 4.6538 & TRN \\
\hline CHEMBL1527929 & 688687 & 4.6 & 5.0664 & TST \\
\hline CHEMBL1601757 & 688687 & 4.6 & 4.5423 & TRN \\
\hline CHEMBL1362622 & 688687 & 5.2 & 4.7082 & TRN \\
\hline CHEMBL1486659 & 688687 & 6.0 & 5.3901 & TRN \\
\hline CHEMBL1335141 & 688687 & 4.4 & 4.7856 & TRN \\
\hline CHEMBL1534725 & 688687 & 5.2 & 4.5721 & TST \\
\hline CHEMBL1596656 & 688687 & 5.5 & 4.6799 & TRN \\
\hline CHEMBL1446626 & 688687 & 5.1 & 5.1399 & TRN \\
\hline CHEMBL1468479 & 688687 & 4.5 & 4.9738 & TRN \\
\hline CHEMBL1312338 & 688687 & 4.5 & 4.7418 & TRN \\
\hline CHEMBL1406745 & 688687 & 4.5 & 4.5884 & TRN \\
\hline CHEMBL1505947 & 688687 & 5.8 & 5.1847 & TRN \\
\hline CHEMBL1561369 & 688687 & 6.8 & 5.3293 & TRN \\
\hline CHEMBL1438164 & 688687 & 5.5 & 4.8276 & TRN \\
\hline CHEMBL1576154 & 688687 & 5.0 & 4.7607 & TRN \\
\hline CHEMBL1609334 & 688687 & 4.7 & 4.8344 & TRN \\
\hline CHEMBL1549225 & 688687 & 4.7 & 4.9059 & TRN \\
\hline CHEMBL45245 & 688687 & 5.1 & 4.9659 & TRN \\
\hline CHEMBL1494458 & 688687 & 5.5 & 5.3006 & TRN \\
\hline CHEMBL1560320 & 688687 & 5.4 & 5.1059 & TRN \\
\hline CHEMBL1323669 & 688687 & 5.7 & 4.6309 & TST \\
\hline CHEMBL1388879 & 688687 & 5.4 & 4.9397 & TRN \\
\hline CHEMBL1411085 & 688687 & 4.4 & 4.6786 & TRN \\
\hline CHEMBL1587501 & 688687 & 4.5 & 4.5955 & TRN \\
\hline CHEMBL1456042 & 688687 & 4.5 & 4.8784 & TRN \\
\hline CHEMBL1487016 & 688687 & 5.4 & 4.8687 & TRN \\
\hline CHEMBL1352734 & 688687 & 4.4 & 4.7346 & TRN \\
\hline CHEMBL1306697 & 688687 & 6.0 & 4.9644 & TRN \\
\hline CHEMBL1347042 & 688687 & 4.5 & 4.8783 & TRN \\
\hline CHEMBL1604063 & 688687 & 6.2 & 5.5995 & TST \\
\hline CHEMBL1354243 & 688687 & 4.4 & 4.7304 & TST \\
\hline CHEMBL1579385 & 688687 & 4.8 & 4.6374 & TST \\
\hline CHEMBL1491075 & 688687 & 4.6 & 4.6584 & TRN \\
\hline CHEMBL1470737 & 688687 & 5.9 & 4.9203 & TRN \\
\hline CHEMBL1540534 & 688687 & 4.5 & 4.5523 & TRN \\
\hline CHEMBL1412273 & 688687 & 4.4 & 5.0735 & TRN \\
\hline CHEMBL522311 & 688687 & 4.4 & 4.5031 & TRN \\
\hline
\end{tabular}




\begin{tabular}{|c|c|c|c|c|c|}
\hline & & & & & \\
\hline CHEMBL1333251 & 688687 & 4.6 & 4.993 & TRN & \\
\hline CHEMBL1315373 & 688687 & 4.7 & 4.7278 & TRN & \\
\hline CHEMBL1612710 & 688687 & 6.0 & 4.8651 & TRN & \\
\hline CHEMBL1463681 & 688687 & 4.5 & 4.7122 & TRN & \\
\hline CHEMBL1363103 & 688687 & 4.6 & 4.8883 & TST & \\
\hline CHEMBL1311029 & 688687 & 5.2 & 4.6664 & TRN & \\
\hline CHEMBL1372115 & 688687 & 4.4 & 4.3061 & TRN & \\
\hline CHEMBL1517847 & 688687 & 4.5 & 4.8564 & TRN & \\
\hline CHEMBL1388009 & 688687 & 4.5 & 4.3925 & TRN & \\
\hline CHEMBL1410534 & 688687 & 4.4 & 4.863 & TRN & \\
\hline CHEMBL1383415 & 688687 & 4.6 & 5.1775 & TRN & \\
\hline CHEMBL1344908 & 688687 & 4.4 & 4.6876 & TRN & \\
\hline CHEMBL1375455 & 688687 & 4.6 & 4.7887 & TRN & \\
\hline CHEMBL1441622 & 688687 & 4.4 & 5.1258 & TRN & \\
\hline CHEMBL1573204 & 688687 & 4.4 & 4.8052 & TST & \\
\hline CHEMBL1539325 & 688687 & 4.9 & 4.7206 & TRN & \\
\hline CHEMBL1508968 & 688687 & 4.5 & 5.1288 & TST & \\
\hline CHEMBL1325774 & 688687 & 4.6 & 4.7948 & TST & \\
\hline CHEMBL1422702 & 688687 & 4.4 & 4.5324 & TRN & \\
\hline CHEMBL1534893 & 688687 & 4.4 & 4.51699 & 99999999995 & TRN \\
\hline CHEMBL1518533 & 688687 & 4.4 & 4.7942 & TRN & \\
\hline CHEMBL1564905 & 688687 & 5.4 & 4.88899 & 9999999999 & TRN \\
\hline CHEMBL1256914 & 688687 & 4.6 & 4.9363 & TST & \\
\hline CHEMBL1330114 & 688687 & 5.9 & 5.3201 & TRN & \\
\hline CHEMBL1488031 & 688687 & 4.6 & 4.9203 & TST & \\
\hline CHEMBL1329798 & 688687 & 4.7 & 5.1749 & TST & \\
\hline CHEMBL1568808 & 688687 & 4.6 & 4.4354 & TRN & \\
\hline CHEMBL1531336 & 688687 & 4.6 & 4.783 & TRN & \\
\hline CHEMBL1463494 & 688687 & 4.5 & 4.652 & TRN & \\
\hline CHEMBL 3190100 & 688687 & 5.5 & 5.0021 & TRN & \\
\hline CHEMBL1309772 & 688687 & 4.9 & 4.8326 & TRN & \\
\hline CHEMBL1344444 & 688687 & 4.4 & 4.7946 & TRN & \\
\hline CHEMBL1421334 & 688687 & 4.8 & 5.1219 & TRN & \\
\hline CHEMBL1378382 & 688687 & 5.5 & 4.7679 & TRN & \\
\hline CHEMBL1518611 & 688687 & 4.5 & 4.9418 & TRN & \\
\hline CHEMBL1574559 & 688687 & 5.4 & 4.8817 & TRN & \\
\hline CHEMBL9352 & 688687 & 4.7 & 5.2422 & TST & \\
\hline CHEMBL3194435 & 688687 & 4.9 & 4.8737 & TRN & \\
\hline CHEMBL1470981 & 688687 & 4.4 & 4.9018 & TRN & \\
\hline CHEMBL 259615 & 688687 & 4.4 & 5.0298 & TRN & \\
\hline CHEMBL1445260 & 688687 & 4.4 & 4.7942 & TRN & \\
\hline CHEMBL1411084 & 688687 & 5.4 & 4.8189 & TRN & \\
\hline CHEMBL1320319 & 688687 & 5.6 & 4.8038 & TST & \\
\hline CHEMBL1476722 & 688687 & 5.0 & 4.6346 & TRN & \\
\hline CHEMBL69151 & 688687 & 4.4 & 4.9053 & TRN & \\
\hline CHEMBL 3207786 & 688687 & 5.5 & 5.0338 & TST & \\
\hline CHEMBL1319503 & 688687 & 4.4 & 4.8341 & TST & \\
\hline CHEMBL1367966 & 688687 & 4.4 & 5.0332 & TST & \\
\hline
\end{tabular}


Supplemental Table S2.txt

\begin{tabular}{|c|c|c|c|c|}
\hline CHEMBL1408532 & 688687 & 6.7001 & 4.7296 & TRN \\
\hline CHEMBL1401091 & 688687 & 4.8 & 4.8096 & TST \\
\hline CHEMBL1527930 & 688687 & 4.4 & 4.7552 & TST \\
\hline CHEMBL222519 & 688687 & 6.2 & 5.1806 & TST \\
\hline CHEMBL1491979 & 688687 & 4.5 & 4.8202 & TRN \\
\hline CHEMBL1448531 & 688687 & 4.4 & 4.7679 & TRN \\
\hline CHEMBL1562591 & 688687 & 6.8 & 5.0199 & TST \\
\hline CHEMBL1545634 & 688687 & 6.0 & 5.0418 & TST \\
\hline CHEMBL1529229 & 688687 & 4.4 & 4.5795 & TRN \\
\hline CHEMBL1409440 & 688687 & 4.4 & 4.7561 & TRN \\
\hline CHEMBL1493117 & 688687 & 4.7 & 4.8829 & TST \\
\hline CHEMBL1489965 & 688687 & 4.6 & 4.6392 & TRN \\
\hline CHEMBL1491807 & 688687 & 4.5 & 4.6043 & TRN \\
\hline CHEMBL1456621 & 688687 & 6.1 & 5.1741 & TRN \\
\hline CHEMBL1470077 & 688687 & 4.5 & 4.9719 & TST \\
\hline CHEMBL1427752 & 688687 & 6.2 & 5.8003 & TRN \\
\hline CHEMBL112597 & 688687 & 5.2 & 5.1852 & TRN \\
\hline CHEMBL1313788 & 688687 & 4.8 & 4.9052 & TRN \\
\hline CHEMBL1552973 & 688687 & 5.3 & 5.2442 & TST \\
\hline CHEMBL1332602 & 688687 & 5.1 & 4.8511 & TRN \\
\hline CHEMBL3212191 & 688687 & 5.6 & 4.9721 & TRN \\
\hline CHEMBL1607919 & 688687 & 4.5 & 4.4584 & TRN \\
\hline CHEMBL1567220 & 688687 & 4.6 & 4.9785 & TRN \\
\hline CHEMBL1491745 & 688687 & 4.6 & 4.5382 & TRN \\
\hline CHEMBL1173522 & 688687 & 4.4 & 4.622 & TRN \\
\hline CHEMBL1556956 & 688687 & 4.6 & 4.7987 & TRN \\
\hline CHEMBL1333797 & 688687 & 5.5 & 4.8178 & TRN \\
\hline CHEMBL1391366 & 688687 & 4.5 & 5.0618 & TRN \\
\hline CHEMBL1564698 & 688687 & 5.2 & 4.9772 & TRN \\
\hline CHEMBL1366858 & 688687 & 5.7 & 5.1774 & TRN \\
\hline CHEMBL1365213 & 688687 & 4.4 & 4.8956 & TST \\
\hline CHEMBL1532633 & 688687 & 5.5 & 5.0121 & TRN \\
\hline CHEMBL1414244 & 688687 & 4.8 & 4.9085 & TRN \\
\hline CHEMBL1528418 & 688687 & 4.6 & 4.6179 & TRN \\
\hline CHEMBL1509447 & 688687 & 4.6 & 4.96899 & 9999999999 \\
\hline CHEMBL1597742 & 688687 & 4.4 & 4.4535 & TRN \\
\hline CHEMBL1421495 & 688687 & 4.7 & 4.7107 & TRN \\
\hline CHEMBL1479872 & 688687 & 4.7 & 4.8366 & TRN \\
\hline CHEMBL1427588 & 688687 & 4.5 & 4.6761 & TRN \\
\hline CHEMBL1420368 & 688687 & 4.5 & 4.5677 & TRN \\
\hline CHEMBL601528 & 688687 & 4.5 & 4.9618 & TST \\
\hline CHEMBL1598114 & 688687 & 4.4 & 4.5656 & TRN \\
\hline CHEMBL471005 & 688687 & 6.0 & 5.0156 & TST \\
\hline CHEMBL1411491 & 688687 & 5.5 & 4.7896 & TRN \\
\hline CHEMBL1372037 & 688687 & 4.6 & 4.815 & TRN \\
\hline CHEMBL1589593 & 688687 & 6.2 & 4.6124 & TRN \\
\hline CHEMBL1477620 & 688687 & 4.7 & 4.6899 & TRN \\
\hline CHEMBL1372465 & 688687 & 4.6 & 4.5735 & TRN \\
\hline
\end{tabular}




\begin{tabular}{|c|c|c|c|c|}
\hline & & & ient & al Ta \\
\hline CHEMBL1456872 & 688687 & 4.5 & 4.7147 & TRN \\
\hline CHEMBL1496832 & 688687 & 6.0 & 5.0111 & TRN \\
\hline CHEMBL1489874 & 688687 & 5.1 & 4.5965 & TRN \\
\hline CHEMBL1547865 & 688687 & 4.6 & 4.7925 & TRN \\
\hline CHEMBL1506979 & 688687 & 4.4 & 4.9733 & TST \\
\hline CHEMBL1310655 & 688687 & 4.9 & 4.9862 & TRN \\
\hline CHEMBL1449939 & 688687 & 5.5 & 5.3492 & TRN \\
\hline CHEMBL1380195 & 688687 & 4.4 & 4.8168 & TRN \\
\hline CHEMBL1475207 & 688687 & 4.9 & 4.7916 & TRN \\
\hline CHEMBL1546699 & 688687 & 4.5 & 4.9254 & TRN \\
\hline CHEMBL 3190584 & 688687 & 4.4 & 4.5054 & TRN \\
\hline CHEMBL1594705 & 688687 & 5.2 & 4.9964 & TRN \\
\hline CHEMBL1421740 & 688687 & 4.5 & 4.6852 & TRN \\
\hline CHEMBL1571088 & 688687 & 4.6 & 4.9538 & TRN \\
\hline CHEMBL1589751 & 688687 & 5.1 & 5.0113 & TRN \\
\hline CHEMBL1402888 & 688687 & 4.8 & 4.8262 & TRN \\
\hline CHEMBL1403235 & 688687 & 4.6 & 4.7191 & TRN \\
\hline CHEMBL1516787 & 688687 & 4.4 & 4.6924 & TST \\
\hline CHEMBL1530449 & 688687 & 5.3 & 5.2742 & TRN \\
\hline CHEMBL1324939 & 688687 & 5.4 & 4.953 & TRN \\
\hline CHEMBL1449575 & 688687 & 4.9 & 4.7797 & TRN \\
\hline CHEMBL1576725 & 688687 & 4.6 & 4.9285 & TRN \\
\hline CHEMBL1402107 & 688687 & 4.7 & 4.5966 & TRN \\
\hline CHEMBL1456620 & 688687 & 4.6 & 4.7421 & TRN \\
\hline CHEMBL1548655 & 688687 & 4.6 & 4.8402 & TRN \\
\hline CHEMBL1560539 & 688687 & 4.7 & 4.5199 & TST \\
\hline CHEMBL1556412 & 688687 & 4.5 & 4.7065 & TRN \\
\hline CHEMBL1458407 & 688687 & 4.4 & 5.1256 & TST \\
\hline CHEMBL1404364 & 688687 & 4.5 & 4.9338 & TRN \\
\hline CHEMBL1322844 & 688687 & 4.4 & 4.7193 & TRN \\
\hline CHEMBL1406976 & 688687 & 4.4 & 4.5265 & TRN \\
\hline CHEMBL1550188 & 688687 & 5.4 & 5.1997 & TRN \\
\hline CHEMBL1551557 & 688687 & 5.1 & 4.6931 & TRN \\
\hline CHEMBL1334570 & 688687 & 4.7 & 5.0384 & TRN \\
\hline CHEMBL1550366 & 688687 & 5.7 & 5.0583 & TRN \\
\hline CHEMBL1372555 & 688687 & 4.4 & 4.8071 & TRN \\
\hline CHEMBL1996867 & 688687 & 4.5 & 4.651 & TRN \\
\hline CHEMBL1557435 & 688687 & 4.4 & 4.9022 & TRN \\
\hline CHEMBL1371247 & 688687 & 4.4 & 4.7233 & TRN \\
\hline CHEMBL1571563 & 688687 & 4.5 & 5.1298 & TRN \\
\hline CHEMBL1311840 & 688687 & 4.9 & 4.6987 & TRN \\
\hline CHEMBL1431070 & 688687 & 4.5 & 4.8904 & TRN \\
\hline CHEMBL1372490 & 688687 & 4.5 & 4.9725 & TRN \\
\hline CHEMBL1400537 & 688687 & 4.5 & 4.6369 & TRN \\
\hline CHEMBL1399093 & 688687 & 4.5 & 4.5921 & TRN \\
\hline CHEMBL1474633 & 688687 & 5.1 & 4.7727 & TRN \\
\hline CHEMBL1348151 & 688687 & 4.8 & 5.18 & TRN \\
\hline CHEMBL1311100 & 688687 & 4.6 & 5.1344 & TRN \\
\hline
\end{tabular}




\begin{tabular}{|c|c|c|c|c|}
\hline & & & 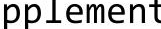 & al Ta \\
\hline CHEMBL539947 & 688687 & 4.9 & 5.3212 & TRN \\
\hline CHEMBL1472046 & 688687 & 4.4 & 4.7762 & TRN \\
\hline CHEMBL1440902 & 688687 & 4.5 & 4.738 & TRN \\
\hline CHEMBL1337781 & 688687 & 5.4 & 5.1776 & TRN \\
\hline CHEMBL1526168 & 688687 & 4.5 & 4.5887 & TRN \\
\hline CHEMBL1486645 & 688687 & 4.6 & 5.0243 & TRN \\
\hline CHEMBL1355139 & 688687 & 4.6 & 4.667 & TRN \\
\hline CHEMBL3208302 & 688687 & 4.6 & 4.684 & TRN \\
\hline CHEMBL1582079 & 688687 & 4.5 & 4.8172 & TRN \\
\hline CHEMBL1320722 & 688687 & 4.6 & 4.7298 & TRN \\
\hline CHEMBL1576395 & 688687 & 5.3 & 4.6539 & TST \\
\hline CHEMBL1507132 & 688687 & 5.6 & 4.9222 & TRN \\
\hline CHEMBL1502892 & 688687 & 5.0 & 4.8739 & TRN \\
\hline CHEMBL1608067 & 688687 & 4.6 & 4.7902 & TRN \\
\hline CHEMBL1550267 & 688687 & 4.8 & 4.7565 & TRN \\
\hline CHEMBL1343543 & 688687 & 4.5 & 4.9249 & TST \\
\hline CHEMBL601952 & 688687 & 4.9 & 4.9918 & TST \\
\hline CHEMBL1491146 & 688687 & 4.8 & 5.0775 & TST \\
\hline CHEMBL1387089 & 688687 & 4.9 & 4.9497 & TST \\
\hline CHEMBL1460023 & 688687 & 5.2 & 4.6555 & TRN \\
\hline CHEMBL1497269 & 688687 & 4.5 & 4.6493 & TRN \\
\hline CHEMBL1541222 & 688687 & 4.9 & 4.8319 & TRN \\
\hline CHEMBL1528527 & 688687 & 5.4 & 4.5882 & TRN \\
\hline CHEMBL1458968 & 688687 & 4.4 & 4.5482 & TRN \\
\hline CHEMBL1451317 & 688687 & 4.6 & 4.4431 & TRN \\
\hline CHEMBL1560147 & 688687 & 5.3 & 4.8212 & TRN \\
\hline CHEMBL1598352 & 688687 & 4.9 & 4.7457 & TRN \\
\hline CHEMBL1523098 & 688687 & 4.5 & 4.5258 & TRN \\
\hline CHEMBL1473434 & 688687 & 4.5 & 4.6069 & TRN \\
\hline CHEMBL3210542 & 688687 & 4.5 & 4.8306 & TST \\
\hline CHEMBL1540672 & 688687 & 4.4 & 4.7082 & TRN \\
\hline CHEMBL1375397 & 688687 & 5.8 & 4.742 & TRN \\
\hline CHEMBL1510821 & 688687 & 4.7 & 5.1221 & TRN \\
\hline CHEMBL1407017 & 688687 & 4.4 & 4.6727 & TRN \\
\hline CHEMBL489940 & 688687 & 4.7 & 4.9099 & TRN \\
\hline CHEMBL576317 & 688687 & 5.0 & 4.7566 & TRN \\
\hline CHEMBL1306138 & 688687 & 5.9 & 4.7842 & TST \\
\hline CHEMBL256250 & 688687 & 4.4 & 5.0846 & TST \\
\hline CHEMBL1425333 & 688687 & 4.4 & 4.5747 & TRN \\
\hline CHEMBL1305500 & 688687 & 4.6 & 4.7788 & TRN \\
\hline CHEMBL1538088 & 688687 & 5.5 & 4.9648 & TRN \\
\hline CHEMBL1528479 & 688687 & 4.5 & 4.9322 & TRN \\
\hline CHEMBL1414793 & 688687 & 4.4 & 5.0377 & TST \\
\hline CHEMBL1390386 & 688687 & 4.4 & 4.6013 & TRN \\
\hline CHEMBL1608535 & 688687 & 5.5 & 5.3037 & TRN \\
\hline CHEMBL1551294 & 688687 & 4.4 & 4.6928 & TRN \\
\hline CHEMBL561936 & 688687 & 4.6 & 4.717 & TRN \\
\hline CHEMBL1525769 & 688687 & 4.9 & 4.7304 & TRN \\
\hline
\end{tabular}




\begin{tabular}{|c|c|c|c|c|}
\hline & & & & \\
\hline CHEMBL1528890 & 688687 & 4.5 & 4.8348 & TRN \\
\hline CHEMBL1551518 & 688687 & 4.7 & 4.4927 & TRN \\
\hline CHEMBL1367899 & 688687 & 4.4 & 4.3898 & TRN \\
\hline CHEMBL1368796 & 688687 & 5.6 & 4.6847 & TST \\
\hline CHEMBL1547349 & 688687 & 4.5 & 4.5588 & TRN \\
\hline CHEMBL1443114 & 688687 & 4.8 & 4.7989 & TRN \\
\hline CHEMBL1382476 & 688687 & 5.5 & 5.3033 & TRN \\
\hline CHEMBL3198927 & 688687 & 4.6 & 4.769 & TRN \\
\hline CHEMBL1586034 & 688687 & 4.5 & 4.4832 & TRN \\
\hline CHEMBL1456526 & 688687 & 5.9 & 4.711 & TRN \\
\hline CHEMBL1391889 & 688687 & 4.4 & 4.6706 & TRN \\
\hline CHEMBL1417101 & 688687 & 5.2 & 4.9146 & TRN \\
\hline CHEMBL1491478 & 688687 & 4.5 & 4.7616 & TRN \\
\hline CHEMBL1416838 & 688687 & 4.5 & 4.8552 & TRN \\
\hline CHEMBL1347556 & 688687 & 5.5 & 4.6714 & TST \\
\hline CHEMBL1479543 & 688687 & 4.7 & 4.9877 & TRN \\
\hline CHEMBL1482094 & 688687 & 4.5 & 4.5842 & TRN \\
\hline CHEMBL1607559 & 688687 & 4.5 & 5.0056 & TRN \\
\hline CHEMBL1388974 & 688687 & 4.4 & 4.7561 & TRN \\
\hline CHEMBL1577245 & 688687 & 5.9 & 5.2655 & TRN \\
\hline CHEMBL1480041 & 688687 & 4.6 & 4.792 & TRN \\
\hline CHEMBL1484276 & 688687 & 4.6 & 4.5355 & TRN \\
\hline CHEMBL1484199 & 688687 & 4.5 & 5.0654 & TRN \\
\hline CHEMBL1527694 & 688687 & 5.5 & 4.8293 & TRN \\
\hline CHEMBL1316956 & 688687 & 5.2 & 4.6731 & TRN \\
\hline CHEMBL1310219 & 688687 & 4.9 & 4.7488 & TRN \\
\hline CHEMBL1389951 & 688687 & 8.0 & 5.1744 & TRN \\
\hline CHEMBL1410996 & 688687 & 4.5 & 4.7884 & TRN \\
\hline CHEMBL1484731 & 688687 & 5.9 & 5.1955 & TRN \\
\hline CHEMBL1567437 & 688687 & 4.5 & 5.1103 & TRN \\
\hline CHEMBL1443662 & 688687 & 4.6 & 5.308 & TRN \\
\hline CHEMBL1569501 & 688687 & 5.2 & 5.0303 & TRN \\
\hline CHEMBL1312348 & 688687 & 5.2 & 4.6252 & TRN \\
\hline CHEMBL1323403 & 688687 & 5.0 & 4.8858 & TST \\
\hline CHEMBL1321649 & 688687 & 4.4 & 4.5992 & TRN \\
\hline CHEMBL1302960 & 688687 & 5.5 & 4.7584 & TRN \\
\hline CHEMBL1382110 & 688687 & 4.5 & 4.751 & TRN \\
\hline CHEMBL1348912 & 688687 & 4.7 & 4.7628 & TRN \\
\hline CHEMBL1577147 & 688687 & 4.5 & 4.7923 & TRN \\
\hline CHEMBL1336373 & 688687 & 5.2 & 4.6425 & TRN \\
\hline CHEMBL1706619 & 688687 & 4.4 & 4.2775 & TRN \\
\hline CHEMBL1557910 & 688687 & 6.0 & 5.1406 & TRN \\
\hline CHEMBL265698 & 688687 & 5.4 & 4.8371 & TRN \\
\hline CHEMBL 258893 & 688687 & 4.7 & 4.6418 & TST \\
\hline CHEMBL1499130 & 688687 & 4.4 & 4.4567 & TRN \\
\hline CHEMBL1417392 & 688687 & 6.5 & 5.5452 & TRN \\
\hline CHEMBL1510959 & 688687 & 4.5 & 5.1709 & TST \\
\hline CHEMBL1332208 & 688687 & 4.5 & 4.4811 & TRN \\
\hline
\end{tabular}




\begin{tabular}{|c|c|c|c|c|}
\hline & & & pplement & al Tá \\
\hline CHEMBL1556251 & 688687 & 4.7 & 4.9765 & TRN \\
\hline CHEMBL1412619 & 688687 & 4.5 & 4.5298 & TRN \\
\hline CHEMBL1256740 & 688687 & 5.0 & 5.1323 & TST \\
\hline CHEMBL1340804 & 688687 & 4.4 & 4.7843 & TRN \\
\hline CHEMBL 313833 & 688687 & 5.3 & 5.0224 & TST \\
\hline CHEMBL1428178 & 688687 & 4.5 & 5.0624 & TRN \\
\hline CHEMBL1557315 & 688687 & 4.6 & 4.5384 & TRN \\
\hline CHEMBL1613682 & 688687 & 4.4 & 4.5792 & TRN \\
\hline CHEMBL1402520 & 688687 & 5.1 & 4.7382 & TRN \\
\hline CHEMBL1509460 & 688687 & 4.5 & 4.5678 & TRN \\
\hline CHEMBL1572834 & 688687 & 4.6 & 4.391 & TRN \\
\hline CHEMBL1443284 & 688687 & 5.5 & 4.6349 & TRN \\
\hline CHEMBL1535449 & 688687 & 5.4 & 5.0252 & TRN \\
\hline CHEMBL1449759 & 688687 & 4.6 & 4.7895 & TRN \\
\hline CHEMBL1423165 & 688687 & 4.4 & 4.8119 & TRN \\
\hline CHEMBL1447735 & 688687 & 4.6 & 4.7973 & TRN \\
\hline CHEMBL1556323 & 688687 & 5.1 & 5.1485 & TST \\
\hline CHEMBL1595178 & 688687 & 4.6 & 4.8434 & TRN \\
\hline CHEMBL1363313 & 688687 & 4.4 & 4.8679 & TRN \\
\hline CHEMBL1606451 & 688687 & 5.4 & 4.989 & TRN \\
\hline CHEMBL1611680 & 688687 & 4.6 & 4.452 & TST \\
\hline CHEMBL1531365 & 688687 & 4.5 & 4.4591 & TRN \\
\hline CHEMBL1302244 & 688687 & 4.4 & 4.831 & TRN \\
\hline CHEMBL1406851 & 688687 & 4.8 & 4.7477 & TRN \\
\hline CHEMBL1404301 & 688687 & 5.2 & 5.2748 & TRN \\
\hline CHEMBL1401860 & 688687 & 5.0 & 5.0668 & TRN \\
\hline CHEMBL1348610 & 688687 & 4.6 & 4.8861 & TST \\
\hline CHEMBL1331521 & 688687 & 4.4 & 4.6957 & TRN \\
\hline CHEMBL1449253 & 688687 & 4.9 & 4.6498 & TRN \\
\hline CHEMBL1543402 & 688687 & 4.4 & 4.8019 & TRN \\
\hline CHEMBL1339446 & 688687 & 5.5 & 4.8887 & TRN \\
\hline CHEMBL1400051 & 688687 & 4.5 & 4.6353 & TRN \\
\hline CHEMBL1599574 & 688687 & 4.5 & 4.6865 & TRN \\
\hline CHEMBL1479720 & 688687 & 4.5 & 4.6435 & TRN \\
\hline CHEMBL1336716 & 688687 & 4.4 & 4.8658 & TRN \\
\hline CHEMBL1509357 & 688687 & 4.4 & 5.0161 & TRN \\
\hline CHEMBL1486840 & 688687 & 4.5 & 4.8514 & TRN \\
\hline CHEMBL1347531 & 688687 & 4.9 & 5.3487 & TRN \\
\hline CHEMBL1404569 & 688687 & 4.4 & 4.7134 & TRN \\
\hline CHEMBL1394765 & 688687 & 4.5 & 4.6463 & TRN \\
\hline CHEMBL1403032 & 688687 & 4.5 & 4.8314 & TRN \\
\hline CHEMBL1572857 & 688687 & 5.5 & 4.9248 & TRN \\
\hline CHEMBL1426497 & 688687 & 5.1 & 5.0374 & TST \\
\hline CHEMBL1358503 & 688687 & 4.9 & 4.737 & TRN \\
\hline CHEMBL1386232 & 688687 & 4.8 & 5.0224 & TRN \\
\hline CHEMBL1508994 & 688687 & 5.1 & 4.6982 & TRN \\
\hline CHEMBL1449478 & 688687 & 5.0 & 4.8472 & TRN \\
\hline CHEMBL1305427 & 688687 & 5.5 & 5.0967 & TST \\
\hline
\end{tabular}




\begin{tabular}{|c|c|c|c|c|c|}
\hline \multirow{3}{*}{$\begin{array}{l}\text { CHEMBL471225 } \\
\text { CHEMBL1329433 }\end{array}$} & \multirow{3}{*}{$\begin{array}{l}688687 \\
688687\end{array}$} & \multicolumn{4}{|c|}{ Supplemental Table S2.txt } \\
\hline & & 5.3 & \multicolumn{2}{|c|}{5.382999999999999} & \multirow[t]{2}{*}{ TST } \\
\hline & & 4.5 & 5.0514 & TRN & \\
\hline CHEMBL1551015 & 688687 & 5.7 & 5.768 & TRN & \\
\hline CHEMBL1595142 & 688687 & 4.7 & \multicolumn{2}{|c|}{5.252000000000001} & TRN \\
\hline CHEMBL1517939 & 688687 & 4.6 & 4.8909 & TRN & \\
\hline CHEMBL1488715 & 688687 & 4.4 & 5.1499 & TRN & \\
\hline CHEMBL1574004 & 688687 & 5.0 & 4.7206 & TRN & \\
\hline CHEMBL1569541 & 688687 & 4.4 & 5.0219 & TRN & \\
\hline CHEMBL1569991 & 688687 & 5.9 & 4.8913 & TRN & \\
\hline CHEMBL1409060 & 688687 & 6.6 & 5.0444 & TST & \\
\hline CHEMBL1504172 & 688687 & 4.6 & 4.6702 & TRN & \\
\hline CHEMBL1444960 & 688687 & 5.7 & 4.4604 & TST & \\
\hline CHEMBL1388603 & 688687 & 4.5 & 4.5651 & TRN & \\
\hline CHEMBL1347052 & 688687 & 4.5 & 4.5758 & TRN & \\
\hline CHEMBL1554936 & 688687 & 5.1 & 5.0489 & TST & \\
\hline CHEMBL63154 & 688687 & 6.0 & 4.755 & TST & \\
\hline CHEMBL1387738 & 688687 & 4.6 & 4.8625 & TRN & \\
\hline CHEMBL1381002 & 688687 & 5.1 & 4.6965 & TRN & \\
\hline CHEMBL1581701 & 688687 & 4.9 & 4.7609 & TRN & \\
\hline CHEMBL1348753 & 688687 & 4.5 & 4.7438 & TRN & \\
\hline CHEMBL1340563 & 688687 & 5.5 & 5.1685 & TRN & \\
\hline CHEMBL 2006154 & 688687 & 5.2 & 4.7759 & TST & \\
\hline CHEMBL1531156 & 688687 & 4.6 & 5.0893 & TRN & \\
\hline CHEMBL1390346 & 688687 & 4.6 & 4.8756 & TRN & \\
\hline CHEMBL1490150 & 688687 & 4.4 & 4.6859 & TRN & \\
\hline CHEMBL1359152 & 688687 & 7.5003 & 5.1747 & TST & \\
\hline CHEMBL1405133 & 688687 & 4.6 & 4.8579 & TRN & \\
\hline CHEMBL1471467 & 688687 & 4.4 & 4.7008 & TRN & \\
\hline CHEMBL1380300 & 688687 & 4.5 & 4.7194 & TRN & \\
\hline CHEMBL1446802 & 688687 & 6.5 & 5.0906 & TRN & \\
\hline CHEMBL1547507 & 688687 & 4.8 & 4.6161 & TRN & \\
\hline CHEMBL1390216 & 688687 & 4.5 & 4.586 & TRN & \\
\hline CHEMBL1587160 & 688687 & 5.0 & 4.801 & TST & \\
\hline CHEMBL1318206 & 688687 & 4.6 & 4.7247 & TRN & \\
\hline CHEMBL1486138 & 688687 & 4.9 & 5.0428 & TRN & \\
\hline CHEMBL1300158 & 688687 & 4.4 & 4.5552 & TRN & \\
\hline CHEMBL242080 & 688687 & 6.0 & 5.4529 & TRN & \\
\hline CHEMBL1596675 & 688687 & 7.1002 & 5.1775 & TST & \\
\hline CHEMBL1567732 & 688687 & 4.5 & 4.8227 & TRN & \\
\hline CHEMBL1300266 & 688687 & 6.3 & 5.3369 & TRN & \\
\hline CHEMBL1426299 & 688687 & 4.5 & 5.1983 & TRN & \\
\hline CHEMBL1440540 & 688687 & 4.5 & 4.5391 & TRN & \\
\hline CHEMBL1523094 & 688687 & 4.9 & 4.7426 & TRN & \\
\hline CHEMBL546597 & 688687 & 5.1 & 4.9779 & TRN & \\
\hline CHEMBL1376733 & 688687 & 6.0 & 5.04899 & 99999999995 & TST \\
\hline CHEMBL428496 & 688687 & 6.0 & 4.886 & TST & \\
\hline CHEMBL1557507 & 688687 & 4.6 & 4.797 & TRN & \\
\hline CHEMBL1579414 & 688687 & 4.8 & 4.7948 & TRN & \\
\hline
\end{tabular}





\begin{tabular}{|c|c|c|c|c|c|}
\hline \multicolumn{6}{|c|}{ Supplemental Table S2.txt } \\
\hline CHEMBL3191143 & 688687 & 4.7 & 4.8041 & TST & \\
\hline CHEMBL1376310 & 688687 & 4.5 & 4.8465 & TRN & \\
\hline CHEMBL1573269 & 688687 & 4.5 & 4.6666 & TRN & \\
\hline CHEMBL1334940 & 688687 & 4.4 & 4.4267 & TRN & \\
\hline CHEMBL 3214149 & 688687 & 4.5 & 4.3818 & TRN & \\
\hline CHEMBL1334591 & 688687 & 4.9 & 4.6011 & TRN & \\
\hline CHEMBL520107 & 688687 & 4.4 & 4.8721 & TRN & \\
\hline CHEMBL1470504 & 688687 & 4.9 & 4.6127 & TRN & \\
\hline CHEMBL1334094 & 688687 & 4.5 & 4.5753 & TRN & \\
\hline CHEMBL1566624 & 688687 & 4.5 & 4.9829 & TRN & \\
\hline CHEMBL1573611 & 688687 & 5.5 & 4.7716 & TRN & \\
\hline CHEMBL1522059 & 688687 & 5.5 & 4.8773 & TRN & \\
\hline CHEMBL1550158 & 688687 & 4.8 & 4.7551 & TRN & \\
\hline CHEMBL1349172 & 688687 & 4.5 & 4.9221 & TRN & \\
\hline CHEMBL64239 & 688687 & 8.3979 & 4.7864 & TST & \\
\hline CHEMBL1424367 & 688687 & 4.4 & 4.9206 & TRN & \\
\hline CHEMBL1363362 & 688687 & 4.4 & 4.2485 & TRN & \\
\hline CHEMBL1543552 & 688687 & 4.4 & 4.6533 & TRN & \\
\hline CHEMBL1547380 & 688687 & 4.4 & 4.8399 & TRN & \\
\hline CHEMBL1373217 & 688687 & 4.5 & 4.7751 & TRN & \\
\hline CHEMBL3191913 & 688687 & 4.7 & 4.4869 & TRN & \\
\hline CHEMBL1325523 & 688687 & 4.5 & 5.0425 & TST & \\
\hline CHEMBL1555882 & 688687 & 4.5 & 4.7374 & TRN & \\
\hline CHEMBL1458422 & 688687 & 4.9 & 4.996 & TST & \\
\hline CHEMBL1373107 & 688687 & 5.1 & 4.8825 & TST & \\
\hline CHEMBL1529449 & 688687 & 5.1 & 4.8965 & TST & \\
\hline CHEMBL1598411 & 688687 & 5.9 & 4.6813 & TRN & \\
\hline CHEMBL1564708 & 688687 & 4.6 & 4.5477 & TRN & \\
\hline CHEMBL1373994 & 688687 & 4.6 & 4.8517 & TRN & \\
\hline CHEMBL428768 & 688687 & 4.6 & 4.6815 & TRN & \\
\hline CHEMBL1494499 & 688687 & 4.5 & 4.5731 & TRN & \\
\hline CHEMBL1399909 & 688687 & 4.4 & 4.6341 & TRN & \\
\hline CHEMBL1565595 & 688687 & 4.5 & 4.9773 & TRN & \\
\hline CHEMBL1447034 & 688687 & 5.0 & 5.2364 & TST & \\
\hline CHEMBL1330166 & 688687 & 4.5 & 4.71399 & 99999999995 & TRN \\
\hline CHEMBL1350054 & 688687 & 4.5 & 4.7593 & TRN & \\
\hline CHEMBL398363 & 688687 & 4.5 & 4.7819 & TRN & \\
\hline CHEMBL1372535 & 688687 & 4.4 & 4.8052 & TRN & \\
\hline CHEMBL1418227 & 688687 & 4.4 & 5.1777 & TST & \\
\hline CHEMBL1373076 & 688687 & 5.2 & 4.6682 & TRN & \\
\hline CHEMBL1573906 & 688687 & 4.9 & 4.8319 & TST & \\
\hline CHEMBL1312649 & 688687 & 4.9 & 5.0895 & TRN & \\
\hline CHEMBL1327601 & 688687 & 4.5 & 4.7826 & TRN & \\
\hline CHEMBL1409564 & 688687 & 4.6 & 4.4683 & TRN & \\
\hline CHEMBL1541505 & 688687 & 4.5 & 5.0435 & TST & \\
\hline CHEMBL1459280 & 688687 & 5.5 & 5.3437 & TRN & \\
\hline CHEMBL1584569 & 688687 & 6.5 & 5.0732 & TRN & \\
\hline CHEMBL1588598 & 688687 & 4.6 & 5.0045 & TST & \\
\hline
\end{tabular}




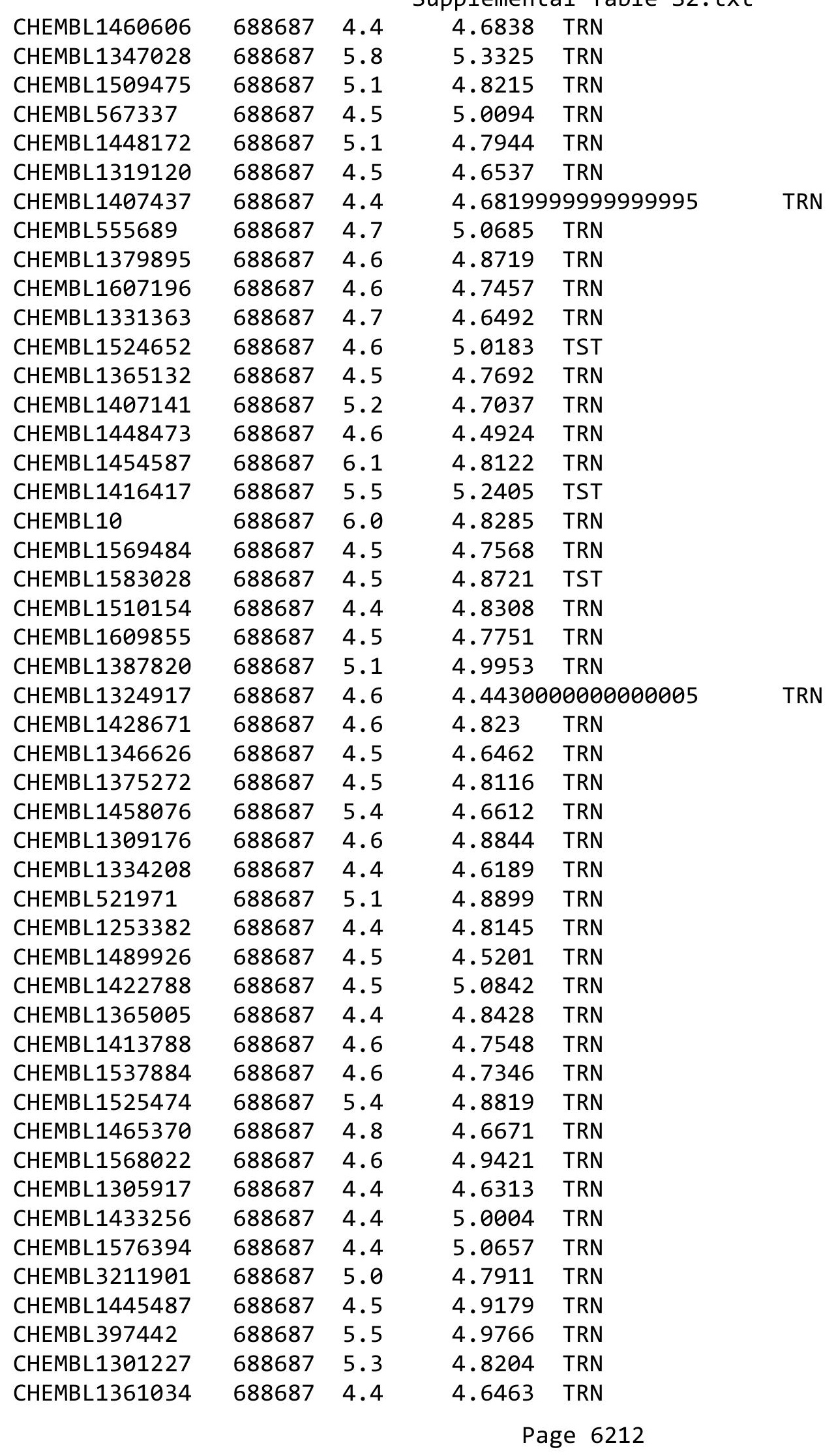




\begin{tabular}{|c|c|c|c|c|}
\hline & & & ient & al Ta \\
\hline CHEMBL1426439 & 688687 & 6.1 & 4.8269 & TRN \\
\hline CHEMBL1332597 & 688687 & 4.4 & 4.6699 & TRN \\
\hline CHEMBL1464220 & 688687 & 4.5 & 4.6399 & TRN \\
\hline CHEMBL1352738 & 688687 & 4.4 & 4.6167 & TRN \\
\hline CHEMBL1495845 & 688687 & 4.8 & 4.8685 & TRN \\
\hline CHEMBL1469865 & 688687 & 5.5 & 4.7492 & TRN \\
\hline CHEMBL1480098 & 688687 & 4.8 & 4.9151 & TRN \\
\hline CHEMBL1311755 & 688687 & 4.6 & 5.0966 & TRN \\
\hline CHEMBL1567266 & 688687 & 4.5 & 4.9562 & TRN \\
\hline CHEMBL216504 & 688687 & 4.6 & 4.8868 & TST \\
\hline CHEMBL 250711 & 688687 & 4.7 & 5.2614 & TRN \\
\hline CHEMBL1471203 & 688687 & 4.4 & 4.7947 & TRN \\
\hline CHEMBL1490294 & 688687 & 5.2 & 4.8571 & TST \\
\hline CHEMBL1452426 & 688687 & 4.7 & 4.7549 & TRN \\
\hline CHEMBL1411544 & 688687 & 5.5 & 4.8523 & TRN \\
\hline CHEMBL1335784 & 688687 & 5.5 & 4.7129 & TST \\
\hline CHEMBL1592289 & 688687 & 5.1 & 4.7974 & TRN \\
\hline CHEMBL1596886 & 688687 & 4.6 & 5.131 & TST \\
\hline CHEMBL1464266 & 688687 & 5.1 & 4.8443 & TRN \\
\hline CHEMBL1405700 & 688687 & 5.0 & 4.7572 & TRN \\
\hline CHEMBL1558544 & 688687 & 4.5 & 4.8703 & TST \\
\hline CHEMBL1324769 & 688687 & 5.0 & 4.6132 & TRN \\
\hline CHEMBL1500184 & 688687 & 4.6 & 4.8765 & TRN \\
\hline CHEMBL1322374 & 688687 & 5.0 & 4.7233 & TRN \\
\hline CHEMBL1356505 & 688687 & 4.6 & 4.976 & TRN \\
\hline CHEMBL1446009 & 688687 & 4.4 & 4.4418 & TRN \\
\hline CHEMBL1546783 & 688687 & 5.0 & 4.9277 & TST \\
\hline CHEMBL1516442 & 688687 & 4.6 & 5.0059 & TRN \\
\hline CHEMBL1559601 & 688687 & 5.2 & 4.8001 & TRN \\
\hline CHEMBL1420038 & 688687 & 4.6 & 5.1507 & TST \\
\hline CHEMBL1350860 & 688687 & 5.7 & 4.9403 & TRN \\
\hline CHEMBL1548717 & 688687 & 4.4 & 4.5927 & TRN \\
\hline CHEMBL1401985 & 688687 & 5.5 & 4.8176 & TRN \\
\hline CHEMBL1425335 & 688687 & 4.5 & 4.7301 & TRN \\
\hline CHEMBL1371927 & 688687 & 4.5 & 5.1116 & TRN \\
\hline CHEMBL1601623 & 688687 & 4.5 & 4.9709 & TRN \\
\hline CHEMBL1348223 & 688687 & 4.5 & 4.6918 & TRN \\
\hline CHEMBL1502290 & 688687 & 4.4 & 4.4492 & TRN \\
\hline CHEMBL1446961 & 688687 & 5.4 & 4.7722 & TRN \\
\hline CHEMBL1333688 & 688687 & 4.5 & 4.8065 & TRN \\
\hline CHEMBL1510035 & 688687 & 5.7 & 5.1932 & TRN \\
\hline CHEMBL1425096 & 688687 & 4.6 & 5.0435 & TRN \\
\hline CHEMBL1500660 & 688687 & 4.5 & 4.822 & TRN \\
\hline CHEMBL1327059 & 688687 & 4.6 & 4.7692 & TRN \\
\hline CHEMBL1531191 & 688687 & 4.4 & 4.6668 & TRN \\
\hline CHEMBL1608868 & 688687 & 4.4 & 4.8568 & TRN \\
\hline CHEMBL1352405 & 688687 & 4.6 & 4.9596 & TRN \\
\hline CHEMBL1543339 & 688687 & 4.4 & 4.51 & TRN \\
\hline
\end{tabular}




\begin{tabular}{|c|c|c|c|c|c|}
\hline & & & & & \\
\hline CHEMBL1325975 & 688687 & 4.4 & 4.5245 & TRN & \\
\hline CHEMBL1489522 & 688687 & 4.4 & 4.8642 & TRN & \\
\hline CHEMBL1527722 & 688687 & 6.0 & 5.074 & TST & \\
\hline CHEMBL1411832 & 688687 & 5.2 & 4.8739 & TRN & \\
\hline CHEMBL1554960 & 688687 & 4.8 & 4.86100 & 0000000001 & TRN \\
\hline CHEMBL1530653 & 688687 & 5.9 & 4.7503 & TRN & \\
\hline CHEMBL 3193792 & 688687 & 4.4 & 4.6209 & TRN & \\
\hline CHEMBL1581825 & 688687 & 4.6 & 4.7293 & TRN & \\
\hline CHEMBL1540513 & 688687 & 6.0 & 4.9561 & TRN & \\
\hline CHEMBL1369619 & 688687 & 6.9 & 4.9625 & TRN & \\
\hline CHEMBL1307204 & 688687 & 4.4 & 4.6047 & TRN & \\
\hline CHEMBL1565563 & 688687 & 5.4 & 4.7583 & TRN & \\
\hline CHEMBL1484447 & 688687 & 5.9 & 4.8328 & TST & \\
\hline CHEMBL1299416 & 688687 & 4.5 & 4.6755 & TRN & \\
\hline CHEMBL1447746 & 688687 & 5.4 & 4.9842 & TRN & \\
\hline CHEMBL3190797 & 688687 & 4.5 & 4.7109 & TRN & \\
\hline CHEMBL1606527 & 688687 & 4.8 & 5.3027 & TRN & \\
\hline CHEMBL1572921 & 688687 & 4.4 & 4.6862 & TRN & \\
\hline CHEMBL602213 & 688687 & 5.1 & 5.7704 & TRN & \\
\hline CHEMBL1600989 & 688687 & 4.6 & 4.9082 & TST & \\
\hline CHEMBL1440326 & 688687 & 4.6 & 4.8577 & TRN & \\
\hline CHEMBL1531320 & 688687 & 5.3 & 4.6687 & TRN & \\
\hline CHEMBL1523263 & 688687 & 4.8 & 5.0385 & TST & \\
\hline CHEMBL1545559 & 688687 & 5.5 & 5.0414 & TRN & \\
\hline CHEMBL1545285 & 688687 & 5.0 & 4.9003 & TRN & \\
\hline CHEMBL1276244 & 688687 & 4.6 & 5.1285 & TRN & \\
\hline CHEMBL1410602 & 688687 & 5.5 & 5.3796 & TRN & \\
\hline CHEMBL1609002 & 688687 & 5.4 & 4.7546 & TST & \\
\hline CHEMBL1452243 & 688687 & 4.5 & 4.8552 & TRN & \\
\hline CHEMBL1601822 & 688687 & 5.5 & 4.9806 & TST & \\
\hline CHEMBL1559164 & 688687 & 5.1 & 5.13700 & 00000000005 & TRN \\
\hline CHEMBL1383468 & 688687 & 4.4 & 4.8278 & TRN & \\
\hline CHEMBL1582610 & 688687 & 5.8 & 5.2289 & TRN & \\
\hline CHEMBL1530061 & 688687 & 4.6 & 4.6361 & TRN & \\
\hline CHEMBL1568111 & 688687 & 4.7 & 4.8402 & TRN & \\
\hline CHEMBL1560244 & 688687 & 5.7 & 4.8725 & TST & \\
\hline CHEMBL1407257 & 688687 & 4.5 & 4.7716 & TRN & \\
\hline CHEMBL1388564 & 688687 & 4.7 & 4.8638 & TST & \\
\hline CHEMBL1398000 & 688687 & 5.4 & 5.2274 & TRN & \\
\hline CHEMBL1535796 & 688687 & 4.8 & 4.5005 & TRN & \\
\hline CHEMBL1486366 & 688687 & 5.1 & 5.33899 & 99999999995 & TST \\
\hline CHEMBL88961 & 688687 & 4.7 & 5.1598 & TRN & \\
\hline CHEMBL1477856 & 688687 & 4.4 & 4.4828 & TRN & \\
\hline CHEMBL1341668 & 688687 & 4.4 & 4.747 & TRN & \\
\hline CHEMBL1448041 & 688687 & 5.5 & 4.9428 & TST & \\
\hline CHEMBL1450936 & 688687 & 4.8 & 4.97199 & 99999999995 & TRN \\
\hline CHEMBL1499592 & 688687 & 4.5 & 4.893 & TRN & \\
\hline CHEMBL1565531 & 688687 & 4.5 & 4.7069 & TRN & \\
\hline
\end{tabular}




\begin{tabular}{|c|c|c|c|c|}
\hline & & & ment & al Ta \\
\hline CHEMBL1332851 & 688687 & 4.4 & 4.654 & TRN \\
\hline CHEMBL1433024 & 688687 & 4.5 & 4.6382 & TRN \\
\hline CHEMBL1378655 & 688687 & 5.5 & 4.9507 & TRN \\
\hline CHEMBL1518784 & 688687 & 4.6 & 4.6351 & TRN \\
\hline CHEMBL1435381 & 688687 & 5.2 & 4.8664 & TST \\
\hline CHEMBL1457783 & 688687 & 4.9 & 4.9304 & TST \\
\hline CHEMBL1426747 & 688687 & 5.1 & 5.1636 & TST \\
\hline CHEMBL1336485 & 688687 & 4.7 & 4.9643 & TRN \\
\hline CHEMBL1312571 & 688687 & 5.4 & 5.0899 & TST \\
\hline CHEMBL1532613 & 688687 & 5.1 & 5.0254 & TRN \\
\hline CHEMBL3192690 & 688687 & 5.9 & 5.0592 & TST \\
\hline CHEMBL1375019 & 688687 & 4.6 & 5.2078 & TRN \\
\hline CHEMBL1457008 & 688687 & 4.8 & 4.7809 & TRN \\
\hline CHEMBL1369392 & 688687 & 5.1 & 4.7813 & TRN \\
\hline CHEMBL1374633 & 688687 & 4.5 & 4.7011 & TRN \\
\hline CHEMBL1564246 & 688687 & 4.6 & 4.6502 & TRN \\
\hline CHEMBL1538469 & 688687 & 4.9 & 4.809 & TRN \\
\hline CHEMBL261118 & 688687 & 4.4 & 4.6233 & TRN \\
\hline CHEMBL1429415 & 688687 & 4.6 & 4.7483 & TRN \\
\hline CHEMBL1484933 & 688687 & 6.4 & 5.0165 & TRN \\
\hline CHEMBL1348345 & 688687 & 5.2 & 5.0206 & TRN \\
\hline CHEMBL1600003 & 688687 & 5.6 & 4.9894 & TRN \\
\hline CHEMBL1340479 & 688687 & 8.2007 & 4.6468 & TST \\
\hline CHEMBL1531944 & 688687 & 5.7 & 5.3645 & TRN \\
\hline CHEMBL1420564 & 688687 & 4.4 & 4.6297 & TRN \\
\hline CHEMBL1555537 & 688687 & 5.6 & 5.1178 & TST \\
\hline CHEMBL1366940 & 688687 & 4.6 & 4.881 & TRN \\
\hline CHEMBL1612688 & 688687 & 5.4 & 4.7166 & TRN \\
\hline CHEMBL1320937 & 688687 & 4.4 & 4.8662 & TRN \\
\hline CHEMBL1588326 & 688687 & 4.5 & 4.8353 & TRN \\
\hline CHEMBL1725279 & 688687 & 4.4 & 5.1831 & TST \\
\hline CHEMBL1427447 & 688687 & 6.2 & 5.8056 & TRN \\
\hline CHEMBL1481974 & 688687 & 6.2 & 5.4829 & TRN \\
\hline CHEMBL1346222 & 688687 & 4.5 & 4.6391 & TRN \\
\hline CHEMBL1416040 & 688687 & 4.4 & 4.2288 & TRN \\
\hline CHEMBL1299532 & 688687 & 4.5 & 4.5281 & TRN \\
\hline CHEMBL1530431 & 688687 & 4.9 & 4.599 & TRN \\
\hline CHEMBL1464287 & 688687 & 4.6 & 4.9656 & TST \\
\hline CHEMBL1442992 & 688687 & 4.7 & 5.1126 & TST \\
\hline CHEMBL1445386 & 688687 & 5.5 & 4.8059 & TST \\
\hline CHEMBL399121 & 688687 & 6.0 & 5.1295 & TST \\
\hline CHEMBL1503459 & 688687 & 4.5 & 4.8431 & TRN \\
\hline CHEMBL1325589 & 688687 & 4.5 & 4.4716 & TRN \\
\hline CHEMBL1347450 & 688687 & 4.6 & 4.7212 & TRN \\
\hline CHEMBL405386 & 688687 & 4.5 & 4.7751 & TRN \\
\hline CHEMBL1482787 & 688687 & 5.5 & 5.0746 & TRN \\
\hline CHEMBL1531200 & 688687 & 5.6 & 5.092 & TRN \\
\hline CHEMBL1560220 & 688687 & 4.7 & 4.7645 & TRN \\
\hline
\end{tabular}




\begin{tabular}{|c|c|c|c|c|c|}
\hline \\
\hline CHEMBL1572780 & 688687 & 4.5 & 4.7071 & TRN & \\
\hline CHEMBL 244707 & 688687 & 6.5 & 5.2655 & TRN & \\
\hline CHEMBL1593926 & 688687 & 5.4 & 4.8652 & TRN & \\
\hline CHEMBL1329878 & 688687 & 4.5 & 4.5292 & TRN & \\
\hline CHEMBL1530090 & 688687 & 6.1 & 5.2242 & TRN & \\
\hline CHEMBL1525842 & 688687 & 4.6 & 4.8835 & TRN & \\
\hline CHEMBL1611574 & 688687 & 5.8 & 4.9543 & TRN & \\
\hline CHEMBL1341981 & 688687 & 5.6 & 5.4027 & TRN & \\
\hline CHEMBL1400273 & 688687 & 4.9 & 4.3007 & TST & \\
\hline CHEMBL1321498 & 688687 & 5.5 & 4.8237 & TRN & \\
\hline CHEMBL1403738 & 688687 & 4.5 & 4.6106 & TRN & \\
\hline CHEMBL1550331 & 688687 & 4.5 & 4.7539 & TST & \\
\hline CHEMBL1587803 & 688687 & 5.0 & 4.7258 & TRN & \\
\hline CHEMBL1573454 & 688687 & 4.5 & 4.5455 & TRN & \\
\hline CHEMBL1602775 & 688687 & 5.5 & 4.8787 & TST & \\
\hline CHEMBL1402106 & 688687 & 5.1 & 5.01699 & 99999999995 & TST \\
\hline CHEMBL1412993 & 688687 & 6.7001 & 4.8333 & TRN & \\
\hline CHEMBL1363854 & 688687 & 4.4 & 4.4064 & TRN & \\
\hline CHEMBL1405719 & 688687 & 4.7 & 4.8777 & TRN & \\
\hline CHEMBL1326366 & 688687 & 4.5 & 4.3608 & TRN & \\
\hline CHEMBL1331659 & 688687 & 4.4 & 4.9678 & TRN & \\
\hline CHEMBL1547314 & 688687 & 4.9 & 4.7277 & TRN & \\
\hline CHEMBL1542156 & 688687 & 4.5 & 4.7907 & TRN & \\
\hline CHEMBL1566701 & 688687 & 4.5 & 4.7143 & TRN & \\
\hline CHEMBL1546397 & 688687 & 4.5 & 4.5356 & TRN & \\
\hline CHEMBL1310222 & 688687 & 5.8 & 4.6677 & TRN & \\
\hline CHEMBL1377022 & 688687 & 4.4 & 4.8071 & TST & \\
\hline CHEMBL1461961 & 688687 & 5.4 & 4.5857 & TRN & \\
\hline CHEMBL1466656 & 688687 & 8.2007 & 5.0606 & TRN & \\
\hline CHEMBL1348428 & 688687 & 4.5 & 4.7137 & TRN & \\
\hline CHEMBL1553694 & 688687 & 5.1 & 4.7882 & TRN & \\
\hline CHEMBL1330520 & 688687 & 6.3 & 5.0519 & TRN & \\
\hline CHEMBL1529341 & 688687 & 4.4 & 4.7457 & TRN & \\
\hline CHEMBL1448000 & 688687 & 4.6 & 4.6969 & TRN & \\
\hline CHEMBL1451978 & 688687 & 4.6 & 4.7938 & TRN & \\
\hline CHEMBL1385435 & 688687 & 4.4 & 4.8225 & TRN & \\
\hline CHEMBL1506325 & 688687 & 5.1 & 4.8568 & TRN & \\
\hline CHEMBL1479899 & 688687 & 4.9 & 4.9409 & TRN & \\
\hline CHEMBL1512870 & 688687 & 4.9 & 4.7343 & TRN & \\
\hline CHEMBL1559940 & 688687 & 4.4 & 5.1353 & TRN & \\
\hline CHEMBL1370834 & 688687 & 4.5 & 4.7834 & TRN & \\
\hline CHEMBL238624 & 688687 & 5.3 & 5.0406 & TRN & \\
\hline CHEMBL1256283 & 688687 & 5.3 & 5.1789 & TST & \\
\hline CHEMBL1457765 & 688687 & 4.6 & 4.9298 & TRN & \\
\hline CHEMBL1555980 & 688687 & 5.4 & 5.233 & TRN & \\
\hline CHEMBL1304004 & 688687 & 4.4 & 4.8118 & TRN & \\
\hline CHEMBL1550059 & 688687 & 5.4 & 5.2748 & TRN & \\
\hline CHEMBL1565576 & 688687 & 6.1 & 4.8049 & TRN & \\
\hline
\end{tabular}




\begin{tabular}{|c|c|c|c|c|}
\hline & & & pplement & al $\mathrm{Ta}$ \\
\hline CHEMBL1736254 & 688687 & 6.2 & 5.2724 & TST \\
\hline CHEMBL1364715 & 688687 & 4.5 & 4.5119 & TST \\
\hline CHEMBL1606004 & 688687 & 4.5 & 4.7415 & TRN \\
\hline CHEMBL1576666 & 688687 & 4.7 & 4.699 & TRN \\
\hline CHEMBL1468601 & 688687 & 4.9 & 4.5867 & TRN \\
\hline CHEMBL1501094 & 688687 & 5.0 & 4.8817 & TRN \\
\hline CHEMBL1505105 & 688687 & 4.9 & 4.7331 & TRN \\
\hline CHEMBL1422696 & 688687 & 5.5 & 4.8455 & TRN \\
\hline CHEMBL39947 & 688687 & 6.0 & 4.8646 & TST \\
\hline CHEMBL1411761 & 688687 & 4.6 & 4.9139 & TRN \\
\hline CHEMBL1603886 & 688687 & 4.8 & 4.9043 & TRN \\
\hline CHEMBL1587744 & 688687 & 6.3 & 4.5825 & TRN \\
\hline CHEMBL1387029 & 688687 & 5.9 & 4.8863 & TRN \\
\hline CHEMBL1540711 & 688687 & 5.7 & 4.5466 & TRN \\
\hline CHEMBL1412169 & 688687 & 4.6 & 5.1824 & TRN \\
\hline CHEMBL443831 & 688687 & 4.4 & 4.6868 & TRN \\
\hline CHEMBL1584561 & 688687 & 4.4 & 4.6557 & TST \\
\hline CHEMBL1346070 & 688687 & 4.5 & 4.7978 & TRN \\
\hline CHEMBL1550243 & 688687 & 5.0 & 5.1834 & TRN \\
\hline CHEMBL1578422 & 688687 & 4.4 & 4.9288 & TST \\
\hline CHEMBL24057 & 688687 & 5.2 & 4.78 & TST \\
\hline CHEMBL3207664 & 688687 & 4.5 & 4.9352 & TST \\
\hline CHEMBL1491570 & 688687 & 4.5 & 4.7276 & TRN \\
\hline CHEMBL1456850 & 688687 & 4.6 & 4.7241 & TRN \\
\hline CHEMBL288096 & 688687 & 5.5 & 5.2869 & TST \\
\hline CHEMBL1489681 & 688687 & 4.4 & 4.7921 & TRN \\
\hline CHEMBL1371569 & 688687 & 5.2 & 4.8341 & TRN \\
\hline CHEMBL1338448 & 688687 & 4.7 & 4.5809 & TRN \\
\hline CHEMBL3208547 & 688687 & 4.5 & 4.8561 & TST \\
\hline CHEMBL1498596 & 688687 & 5.3 & 5.2814 & TRN \\
\hline CHEMBL1426183 & 688687 & 4.6 & 4.6537 & TRN \\
\hline CHEMBL1319017 & 688687 & 4.4 & 4.9123 & TRN \\
\hline CHEMBL1377065 & 688687 & 4.4 & 4.5578 & TRN \\
\hline CHEMBL1341329 & 688687 & 5.2 & 4.9898 & TST \\
\hline CHEMBL1342666 & 688687 & 4.7 & 5.0782 & TRN \\
\hline CHEMBL258465 & 688687 & 4.4 & 5.0932 & TST \\
\hline CHEMBL1355896 & 688687 & 4.4 & 4.8747 & TRN \\
\hline CHEMBL1384311 & 688687 & 5.4 & 4.6067 & TRN \\
\hline CHEMBL1468124 & 688687 & 4.5 & 4.6448 & TRN \\
\hline CHEMBL1526767 & 688687 & 4.7 & 4.7546 & TRN \\
\hline CHEMBL1367648 & 688687 & 4.4 & 5.1116 & TST \\
\hline CHEMBL1548353 & 688687 & 5.5 & 4.801 & TRN \\
\hline CHEMBL545523 & 688687 & 4.7 & 4.8562 & TRN \\
\hline CHEMBL1497696 & 688687 & 4.4 & 4.8146 & TST \\
\hline CHEMBL1607024 & 688687 & 5.5 & 5.0693 & TRN \\
\hline CHEMBL1511972 & 688687 & 4.8 & 4.7012 & TRN \\
\hline CHEMBL1374273 & 688687 & 4.7 & 5.1693 & TST \\
\hline CHEMBL1447542 & 688687 & 4.6 & 4.522 & TRN \\
\hline
\end{tabular}




\begin{tabular}{|c|c|c|c|c|c|}
\hline \multirow{2}{*}{ CHEMBL1418567 } & \multirow[b]{2}{*}{688687} & \\
\hline & & 4.4 & 4.7467 & TRN & \\
\hline CHEMBL1377576 & 688687 & 4.4 & 4.8045 & TRN & \\
\hline CHEMBL1463711 & 688687 & 4.5 & 4.5838 & TRN & \\
\hline CHEMBL1451258 & 688687 & 4.6 & 5.1283 & TRN & \\
\hline CHEMBL1561796 & 688687 & 4.5 & 4.442 & TRN & \\
\hline CHEMBL1514280 & 688687 & 5.5 & 5.1309 & TRN & \\
\hline CHEMBL1525616 & 688687 & 4.7 & 4.6777 & TRN & \\
\hline CHEMBL1312478 & 688687 & 4.6 & 4.8263 & TRN & \\
\hline CHEMBL1348553 & 688687 & 4.6 & 4.8983 & TRN & \\
\hline CHEMBL1331486 & 688687 & 4.5 & 4.8339 & TRN & \\
\hline CHEMBL1408114 & 688687 & 5.4 & 5.1624 & TST & \\
\hline CHEMBL1429355 & 688687 & 4.5 & 4.8594 & TST & \\
\hline CHEMBL1526107 & 688687 & 5.2 & 4.9906 & TRN & \\
\hline CHEMBL1451794 & 688687 & 5.2 & 5.2112 & TRN & \\
\hline CHEMBL1351266 & 688687 & 4.6 & 4.7698 & TRN & \\
\hline CHEMBL1585739 & 688687 & 4.7 & 4.6592 & TRN & \\
\hline CHEMBL1471814 & 688687 & 5.9 & 5.05 & TST & \\
\hline CHEMBL1474468 & 688687 & 4.6 & 4.8147 & TRN & \\
\hline CHEMBL1493381 & 688687 & 4.4 & 4.7985 & TRN & \\
\hline CHEMBL1494607 & 688687 & 4.4 & 4.8001 & TRN & \\
\hline CHEMBL1386945 & 688687 & 4.5 & 4.6336 & TRN & \\
\hline CHEMBL1371155 & 688687 & 4.7 & 4.8884 & TRN & \\
\hline CHEMBL1462948 & 688687 & 4.6 & 5.13899 & 9999999999 & TRN \\
\hline CHEMBL560073 & 688687 & 5.5 & 4.8045 & TRN & \\
\hline CHEMBL1417863 & 688687 & 4.7 & 4.75899 & 99999999995 & TRN \\
\hline CHEMBL1566536 & 688687 & 6.6 & 4.9093 & TRN & \\
\hline CHEMBL1603046 & 688687 & 4.6 & 4.8353 & TRN & \\
\hline CHEMBL1613215 & 688687 & 5.5 & 4.7446 & TRN & \\
\hline CHEMBL1422470 & 688687 & 4.4 & 5.3168 & TRN & \\
\hline CHEMBL1453715 & 688687 & 5.7 & 5.1741 & TST & \\
\hline CHEMBL1399361 & 688687 & 5.4 & 4.9954 & TRN & \\
\hline CHEMBL1570212 & 688687 & 5.3 & 4.8091 & TRN & \\
\hline CHEMBL1363631 & 688687 & 4.6 & 4.7427 & TRN & \\
\hline CHEMBL1337634 & 688687 & 4.4 & 4.9111 & TRN & \\
\hline CHEMBL1407574 & 688687 & 4.4 & 4.7737 & TRN & \\
\hline CHEMBL1546073 & 688687 & 4.4 & 4.6005 & TRN & \\
\hline CHEMBL1603540 & 688687 & 4.6 & 4.8379 & TRN & \\
\hline CHEMBL265686 & 688687 & 4.4 & 4.7467 & TRN & \\
\hline CHEMBL1331234 & 688687 & 5.6 & 5.2755 & TST & \\
\hline CHEMBL1395792 & 688687 & 4.7 & 4.5858 & TRN & \\
\hline CHEMBL1568666 & 688687 & 4.4 & 4.7022 & TRN & \\
\hline CHEMBL1559909 & 688687 & 4.5 & 4.8714 & TRN & \\
\hline CHEMBL1507086 & 688687 & 7.5003 & 5.1462 & TRN & \\
\hline CHEMBL1579942 & 688687 & 4.7 & 5.0421 & TRN & \\
\hline CHEMBL1403976 & 688687 & 4.6 & 4.9509 & TRN & \\
\hline CHEMBL1469488 & 688687 & 5.5 & 4.8938 & TRN & \\
\hline CHEMBL1398713 & 688687 & 5.5 & 4.9749 & TST & \\
\hline CHEMBL1384454 & 688687 & 4.4 & 4.7282 & TRN & \\
\hline & & & & 6218 & \\
\hline
\end{tabular}




\begin{tabular}{|c|c|c|c|c|}
\hline & & & & $a \perp 1 a$ \\
\hline CHEMBL1515565 & 688687 & 4.6 & 4.8801 & TRN \\
\hline CHEMBL1545696 & 688687 & 4.5 & 4.9376 & TRN \\
\hline CHEMBL1315779 & 688687 & 5.1 & 5.335 & TST \\
\hline CHEMBL1452752 & 688687 & 5.2 & 5.0556 & TRN \\
\hline CHEMBL1612606 & 688687 & 4.8 & 4.9985 & TRN \\
\hline CHEMBL1380834 & 688687 & 5.8 & 4.8358 & TRN \\
\hline CHEMBL1385469 & 688687 & 5.2 & 4.7778 & TRN \\
\hline CHEMBL1453231 & 688687 & 4.5 & 5.0314 & TST \\
\hline CHEMBL1587985 & 688687 & 4.4 & 4.9514 & TRN \\
\hline CHEMBL1442663 & 688687 & 4.9 & 4.9911 & TRN \\
\hline CHEMBL 277120 & 688687 & 4.5 & 4.8729 & TRN \\
\hline CHEMBL1596144 & 688687 & 5.3 & 4.7281 & TRN \\
\hline CHEMBL1457571 & 688687 & 4.5 & 4.6823 & TRN \\
\hline CHEMBL1505849 & 688687 & 6.3 & 5.0531 & TRN \\
\hline CHEMBL 3207470 & 688687 & 5.5 & 4.9558 & TRN \\
\hline CHEMBL1331433 & 688687 & 4.5 & 4.6217 & TRN \\
\hline CHEMBL1537580 & 688687 & 5.8 & 4.8855 & TRN \\
\hline CHEMBL1348666 & 688687 & 5.3 & 4.8579 & TRN \\
\hline CHEMBL1458028 & 688687 & 4.8 & 4.8361 & TRN \\
\hline CHEMBL1486074 & 688687 & 4.5 & 4.7393 & TRN \\
\hline CHEMBL66 & 688687 & 5.3 & 5.7769 & TST \\
\hline CHEMBL1479852 & 688687 & 5.3 & 5.2748 & TRN \\
\hline CHEMBL1344206 & 688687 & 4.4 & 4.9496 & TRN \\
\hline CHEMBL1589458 & 688687 & 5.5 & 5.3494 & TRN \\
\hline CHEMBL1442502 & 688687 & 4.6 & 4.985 & TRN \\
\hline CHEMBL446315 & 688687 & 4.4 & 4.9508 & TST \\
\hline CHEMBL1222385 & 688687 & 5.0 & 4.7551 & TRN \\
\hline CHEMBL1567601 & 688687 & 4.5 & 4.9132 & TRN \\
\hline CHEMBL1301957 & 688687 & 4.5 & 5.0661 & TST \\
\hline CHEMBL1436715 & 688687 & 4.5 & 4.7399 & TRN \\
\hline CHEMBL1386674 & 688687 & 4.6 & 4.856 & TST \\
\hline CHEMBL3190151 & 688687 & 4.9 & 4.9882 & TRN \\
\hline CHEMBL1559654 & 688687 & 5.1 & 4.7826 & TRN \\
\hline CHEMBL1540512 & 688687 & 4.5 & 4.7001 & TRN \\
\hline CHEMBL1319794 & 688687 & 4.6 & 4.6132 & TRN \\
\hline CHEMBL1969353 & 688687 & 4.5 & 4.7758 & TRN \\
\hline CHEMBL1592804 & 688687 & 4.8 & 5.2193 & TRN \\
\hline CHEMBL1346595 & 688687 & 4.4 & 4.5084 & TRN \\
\hline CHEMBL1549385 & 688687 & 4.5 & 4.8434 & TRN \\
\hline CHEMBL1563996 & 688687 & 4.5 & 4.7039 & TRN \\
\hline CHEMBL1433343 & 688687 & 4.4 & 4.7361 & TRN \\
\hline CHEMBL1564508 & 688687 & 5.5 & 5.1157 & TST \\
\hline CHEMBL1450159 & 688687 & 4.9 & 4.8192 & TRN \\
\hline CHEMBL1592819 & 688687 & 4.6 & 4.2728 & TRN \\
\hline CHEMBL1474989 & 688687 & 4.6 & 4.6704 & TRN \\
\hline CHEMBL1393593 & 688687 & 4.6 & 5.1945 & TRN \\
\hline CHEMBL1583205 & 688687 & 4.5 & 4.6801 & TRN \\
\hline CHEMBL1504418 & 688687 & 4.6 & 4.7898 & TRN \\
\hline
\end{tabular}




\begin{tabular}{|c|c|c|c|c|}
\hline \multicolumn{5}{|c|}{ Supplemental Table S2.tx } \\
\hline CHEMBL1551915 & 688687 & 4.7 & 5.0376 & TST \\
\hline CHEMBL3209672 & 688687 & 4.5 & 4.6266 & TST \\
\hline CHEMBL1587654 & 688687 & 4.4 & 4.6396 & TRN \\
\hline CHEMBL1576376 & 688687 & 4.7 & 4.6591 & TST \\
\hline CHEMBL1328320 & 688687 & 7.6003 & 5.0758 & TRN \\
\hline CHEMBL1326539 & 688687 & 4.9 & 4.6093 & TRN \\
\hline CHEMBL1334396 & 688687 & 4.4 & 4.6069 & TRN \\
\hline CHEMBL1440269 & 688687 & 4.6 & 4.7006 & TRN \\
\hline CHEMBL1518116 & 688687 & 4.6 & 4.6317 & TRN \\
\hline CHEMBL1501852 & 688687 & 4.5 & 5.0913 & TRN \\
\hline CHEMBL1543632 & 688687 & 4.4 & 5.0183 & TRN \\
\hline CHEMBL1370800 & 688687 & 4.6 & 5.4595 & TRN \\
\hline CHEMBL1360784 & 688687 & 4.5 & 4.8401 & TRN \\
\hline CHEMBL1534248 & 688687 & 5.7 & 4.9913 & TST \\
\hline CHEMBL1351093 & 688687 & 4.4 & 4.9407 & TRN \\
\hline CHEMBL1320751 & 688687 & 5.1 & 4.8613 & TRN \\
\hline CHEMBL1416556 & 688687 & 5.3 & 4.6134 & TST \\
\hline CHEMBL1567698 & 688687 & 4.6 & 5.0504 & TST \\
\hline CHEMBL292368 & 688687 & 4.6 & 4.934 & TRN \\
\hline CHEMBL1472392 & 688687 & 4.5 & 4.7006 & TRN \\
\hline CHEMBL1478464 & 688687 & 4.5 & 4.8197 & TRN \\
\hline CHEMBL1512027 & 688687 & 5.2 & 5.1421 & TRN \\
\hline CHEMBL1456945 & 688687 & 4.6 & 4.7201 & TRN \\
\hline CHEMBL1534082 & 688687 & 4.4 & 4.7773 & TRN \\
\hline CHEMBL1338518 & 688687 & 4.4 & 4.5538 & TRN \\
\hline CHEMBL460366 & 688687 & 5.6 & 5.2114 & TRN \\
\hline CHEMBL1345124 & 688687 & 5.4 & 4.6972 & TRN \\
\hline CHEMBL1477531 & 688687 & 5.4 & 4.8238 & TRN \\
\hline CHEMBL1373244 & 688687 & 4.4 & 4.3974 & TRN \\
\hline CHEMBL1324178 & 688687 & 6.1 & 4.9662 & TST \\
\hline CHEMBL1437095 & 688687 & 4.5 & 4.8821 & TRN \\
\hline CHEMBL1470100 & 688687 & 4.4 & 4.8966 & TST \\
\hline CHEMBL1331809 & 688687 & 6.3 & 4.9858 & TST \\
\hline CHEMBL1448387 & 688687 & 7.2 & 5.6949 & TST \\
\hline CHEMBL1370647 & 688687 & 4.7 & 4.7374 & TST \\
\hline CHEMBL1414641 & 688687 & 5.2 & 4.8624 & TRN \\
\hline CHEMBL1445136 & 688687 & 5.0 & 4.8748 & TRN \\
\hline CHEMBL1511167 & 688687 & 6.8 & 4.8164 & TRN \\
\hline CHEMBL1361461 & 688687 & 6.8 & 4.9884 & TRN \\
\hline CHEMBL1310295 & 688687 & 4.5 & 4.7449 & TRN \\
\hline CHEMBL1400740 & 688687 & 5.1 & 4.6551 & TST \\
\hline CHEMBL1447714 & 688687 & 5.2 & 4.8735 & TRN \\
\hline CHEMBL1457486 & 688687 & 4.4 & 5.0273 & TRN \\
\hline CHEMBL1307459 & 688687 & 5.0 & 4.7346 & TRN \\
\hline CHEMBL1511184 & 688687 & 4.4 & 4.8881 & TRN \\
\hline CHEMBL3209536 & 688687 & 5.4 & 4.7649 & TRN \\
\hline CHEMBL 34241 & 688687 & 6.0 & 4.9223 & TST \\
\hline CHEMBL1444859 & 688687 & 5.0 & 4.8991 & TRN \\
\hline
\end{tabular}




\begin{tabular}{|c|c|c|c|c|c|}
\hline & & & & & \\
\hline CHEMBL1367453 & 688687 & 4.5 & 4.7274 & TRN & \\
\hline CHEMBL1582406 & 688687 & 5.0 & 4.7579 & TRN & \\
\hline CHEMBL1403882 & 688687 & 5.0 & 4.9385 & TRN & \\
\hline CHEMBL1412637 & 688687 & 5.1 & 5.047 & TRN & \\
\hline CHEMBL1309869 & 688687 & 5.5 & 4.6752 & TRN & \\
\hline CHEMBL1587583 & 688687 & 4.6 & 4.4513 & TRN & \\
\hline CHEMBL1373777 & 688687 & 4.5 & 5.07600 & 00000000005 & TRN \\
\hline CHEMBL1530946 & 688687 & 5.4 & 4.8025 & TRN & \\
\hline CHEMBL1425498 & 688687 & 4.4 & 4.7158 & TRN & \\
\hline CHEMBL1447852 & 688687 & 5.3 & 5.0684 & TRN & \\
\hline CHEMBL1568060 & 688687 & 4.5 & 4.8346 & TRN & \\
\hline CHEMBL1608093 & 688687 & 4.4 & 4.811 & TRN & \\
\hline CHEMBL1596090 & 688687 & 4.5 & 4.84399 & 9999999999 & TRN \\
\hline CHEMBL1491688 & 688687 & 5.1 & 4.99100 & 00000000005 & TRN \\
\hline CHEMBL1417556 & 688687 & 6.1 & 5.9431 & TRN & \\
\hline CHEMBL1597583 & 688687 & 4.4 & 4.8483 & TRN & \\
\hline CHEMBL1530439 & 688687 & 6.4 & 6.0789 & TRN & \\
\hline CHEMBL1319012 & 688687 & 4.8 & 4.7277 & TRN & \\
\hline CHEMBL1546083 & 688687 & 4.5 & 4.7125 & TST & \\
\hline CHEMBL1304015 & 688687 & 4.5 & 5.015 & TRN & \\
\hline CHEMBL1556356 & 688687 & 4.5 & 4.6928 & TRN & \\
\hline CHEMBL1443871 & 688687 & 4.5 & 4.9741 & TRN & \\
\hline CHEMBL1419492 & 688687 & 4.6 & 4.5944 & TRN & \\
\hline CHEMBL1465613 & 688687 & 4.4 & 4.6651 & TRN & \\
\hline CHEMBL1510798 & 688687 & 4.5 & 4.5387 & TRN & \\
\hline CHEMBL1342119 & 688687 & 4.6 & 4.8802 & TRN & \\
\hline CHEMBL1414008 & 688687 & 4.8 & 5.0006 & TRN & \\
\hline CHEMBL3391890 & 688687 & 4.4 & 4.6866 & TRN & \\
\hline CHEMBL1560296 & 688687 & 4.8 & 4.8367 & TRN & \\
\hline CHEMBL1498088 & 688687 & 4.4 & 4.7406 & TRN & \\
\hline CHEMBL1488671 & 688687 & 4.6 & 4.43199 & 99999999995 & TRN \\
\hline CHEMBL1555058 & 688687 & 5.4 & 4.9899 & TST & \\
\hline CHEMBL3192255 & 688687 & 5.3 & 5.2161 & TRN & \\
\hline CHEMBL1530697 & 688687 & 5.8 & 5.0685 & TRN & \\
\hline CHEMBL1417390 & 688687 & 4.6 & 4.6731 & TRN & \\
\hline CHEMBL261919 & 688687 & 6.0 & 5.2747 & TRN & \\
\hline CHEMBL1501053 & 688687 & 4.6 & 4.4212 & TRN & \\
\hline CHEMBL1608959 & 688687 & 5.7 & 5.109 & TRN & \\
\hline CHEMBL1299672 & 688687 & 4.4 & 4.5736 & TRN & \\
\hline CHEMBL1533335 & 688687 & 4.7 & 4.9171 & TRN & \\
\hline CHEMBL1440943 & 688687 & 4.4 & 4.4666 & TRN & \\
\hline CHEMBL1524370 & 688687 & 4.4 & 5.8125 & TRN & \\
\hline CHEMBL1562805 & 688687 & 4.9 & 4.6104 & TRN & \\
\hline CHEMBL1353227 & 688687 & 5.1 & 4.4985 & TRN & \\
\hline CHEMBL1586577 & 688687 & 4.4 & 5.591 & TST & \\
\hline CHEMBL1304193 & 688687 & 6.7001 & 5.5663 & TRN & \\
\hline CHEMBL1468740 & 688687 & 4.8 & 4.7828 & TRN & \\
\hline CHEMBL1496089 & 688687 & 5.5 & 5.0219 & TRN & \\
\hline & & & & 6221 & \\
\hline
\end{tabular}




\begin{tabular}{|c|c|c|c|c|c|}
\hline CHEMBL1572284 & 688687 & 4.6 & 4.6371 & TRN & \\
\hline CHEMBL1579513 & 688687 & 4.5 & 4.661006 & 00000000005 & TRN \\
\hline CHEMBL1399685 & 688687 & 4.5 & 4.9426 & TRN & \\
\hline CHEMBL1392113 & 688687 & 4.6 & 4.5832 & TRN & \\
\hline CHEMBL1515874 & 688687 & 5.5 & 4.8935 & TRN & \\
\hline CHEMBL1587717 & 688687 & 4.6 & 4.7221 & TRN & \\
\hline CHEMBL1386936 & 688687 & 4.4 & 4.6775 & TRN & \\
\hline CHEMBL418971 & 688687 & 4.5 & 5.099 & TRN & \\
\hline CHEMBL1483226 & 688687 & 4.7 & 5.0608 & TRN & \\
\hline CHEMBL1303974 & 688687 & 7.6003 & 5.3802 & TRN & \\
\hline CHEMBL1355909 & 688687 & 4.9 & 4.8526 & TRN & \\
\hline CHEMBL1358072 & 688687 & 5.4 & 4.9988 & TST & \\
\hline CHEMBL1566509 & 688687 & 5.4 & 4.9534 & TRN & \\
\hline CHEMBL1561885 & 688687 & 4.9 & 4.8326 & TRN & \\
\hline CHEMBL1315316 & 688687 & 5.7 & 5.2231 & TST & \\
\hline CHEMBL1445916 & 688687 & 5.4 & 4.8899 & TRN & \\
\hline CHEMBL1585723 & 688687 & 4.6 & 4.62 & TRN & \\
\hline CHEMBL1596597 & 688687 & 4.4 & 4.7505 & TRN & \\
\hline CHEMBL1404438 & 688687 & 4.8 & 5.0068 & TRN & \\
\hline CHEMBL1344769 & 688687 & 5.7 & 4.6255 & TST & \\
\hline CHEMBL1345328 & 688687 & 4.5 & 4.6555 & TRN & \\
\hline CHEMBL1381305 & 688687 & 4.5 & 4.5473 & TRN & \\
\hline CHEMBL1399958 & 688687 & 5.9 & 5.3108 & TRN & \\
\hline CHEMBL1471326 & 688687 & 4.5 & 4.8323 & TRN & \\
\hline CHEMBL1569640 & 688687 & 4.4 & 4.598 & TRN & \\
\hline CHEMBL1377382 & 688687 & 5.1 & 4.6233 & TRN & \\
\hline CHEMBL1309727 & 688687 & 4.6 & 4.608006 & 00000000005 & TRN \\
\hline CHEMBL491748 & 688687 & 4.4 & 4.4103 & TRN & \\
\hline CHEMBL1326516 & 688687 & 4.6 & 4.588 & TST & \\
\hline CHEMBL1377140 & 688687 & 5.5 & 4.7618 & TST & \\
\hline CHEMBL3196850 & 688687 & 4.5 & 4.9942 & TRN & \\
\hline CHEMBL1481944 & 688687 & 4.4 & 4.6358 & TRN & \\
\hline CHEMBL1330311 & 688687 & 4.8 & 4.8972 & TRN & \\
\hline CHEMBL1551503 & 688687 & 4.4 & 4.6887 & TRN & \\
\hline CHEMBL1311571 & 688687 & 4.6 & 4.7073 & TRN & \\
\hline CHEMBL1415933 & 688687 & 5.2 & 4.8682 & TRN & \\
\hline CHEMBL1305695 & 688687 & 4.6 & 4.792 & TRN & \\
\hline CHEMBL1328316 & 688687 & 4.5 & 5.1755 & TRN & \\
\hline CHEMBL1420862 & 688687 & 4.9 & 4.6528 & TRN & \\
\hline CHEMBL1339246 & 688687 & 4.5 & 4.8337 & TRN & \\
\hline CHEMBL1350508 & 688687 & 4.5 & 4.6355 & TRN & \\
\hline CHEMBL1331282 & 688687 & 4.6 & 4.6688 & TST & \\
\hline CHEMBL1343354 & 688687 & 4.5 & 4.8152 & TRN & \\
\hline CHEMBL1596559 & 688687 & 5.8 & 5.2798 & TRN & \\
\hline CHEMBL1540856 & 688687 & 4.4 & 5.0389 & TST & \\
\hline CHEMBL1467999 & 688687 & 4.4 & 5.0063 & TRN & \\
\hline CHEMBL1581648 & 688687 & 4.7 & 4.7859 & TRN & \\
\hline CHEMBL1447516 & 688687 & 5.1 & 4.6007 & TST & \\
\hline
\end{tabular}




\begin{tabular}{|c|c|c|c|c|}
\hline & & & ient & $a \perp 1 a$ \\
\hline CHEMBL1594612 & 688687 & 4.5 & 4.4572 & TRN \\
\hline CHEMBL1541487 & 688687 & 4.6 & 4.7459 & TRN \\
\hline CHEMBL1446563 & 688687 & 4.6 & 5.1076 & TRN \\
\hline CHEMBL1302294 & 688687 & 4.5 & 4.6368 & TRN \\
\hline CHEMBL1560284 & 688687 & 4.6 & 4.9231 & TRN \\
\hline CHEMBL1589205 & 688687 & 4.4 & 4.7635 & TRN \\
\hline CHEMBL1518745 & 688687 & 4.6 & 4.7757 & TRN \\
\hline CHEMBL1361413 & 688687 & 4.9 & 5.1971 & TST \\
\hline CHEMBL1431920 & 688687 & 4.4 & 4.7919 & TRN \\
\hline CHEMBL 70141 & 688687 & 4.4 & 5.0465 & TRN \\
\hline CHEMBL1586877 & 688687 & 5.4 & 5.0171 & TRN \\
\hline CHEMBL1500106 & 688687 & 4.4 & 4.535 & TRN \\
\hline CHEMBL1349178 & 688687 & 4.8 & 4.6886 & TRN \\
\hline CHEMBL1602710 & 688687 & 5.0 & 4.6659 & TRN \\
\hline CHEMBL1346194 & 688687 & 4.9 & 5.0057 & TST \\
\hline CHEMBL1319030 & 688687 & 4.6 & 4.8748 & TRN \\
\hline CHEMBL1371868 & 688687 & 5.7 & 4.8231 & TRN \\
\hline CHEMBL1540332 & 688687 & 5.0 & 5.1238 & TRN \\
\hline CHEMBL3210018 & 688687 & 5.8 & 5.0321 & TRN \\
\hline CHEMBL1402577 & 688687 & 4.4 & 4.685 & TRN \\
\hline CHEMBL1366338 & 688687 & 4.4 & 4.8124 & TRN \\
\hline CHEMBL1600502 & 688687 & 5.2 & 4.7931 & TRN \\
\hline CHEMBL1559596 & 688687 & 4.6 & 4.8884 & TRN \\
\hline CHEMBL1410245 & 688687 & 5.1 & 4.9697 & TRN \\
\hline CHEMBL1423359 & 688687 & 4.7 & 4.5327 & TRN \\
\hline CHEMBL1535801 & 688687 & 4.4 & 4.6615 & TRN \\
\hline CHEMBL1413858 & 688687 & 4.8 & 5.1265 & TRN \\
\hline CHEMBL1520708 & 688687 & 4.6 & 4.8315 & TRN \\
\hline CHEMBL1574378 & 688687 & 4.6 & 4.692 & TRN \\
\hline CHEMBL1584284 & 688687 & 4.5 & 4.6476 & TRN \\
\hline CHEMBL1482751 & 688687 & 4.4 & 4.6575 & TRN \\
\hline CHEMBL1490765 & 688687 & 4.6 & 4.9805 & TRN \\
\hline CHEMBL1429245 & 688687 & 4.7 & 4.6695 & TRN \\
\hline CHEMBL1575451 & 688687 & 4.6 & 4.7763 & TRN \\
\hline CHEMBL1325037 & 688687 & 5.8 & 4.7036 & TRN \\
\hline CHEMBL1485262 & 688687 & 4.6 & 4.6621 & TST \\
\hline CHEMBL1352161 & 688687 & 5.5 & 4.8607 & TST \\
\hline CHEMBL1501898 & 688687 & 4.9 & 4.8334 & TST \\
\hline CHEMBL1319037 & 688687 & 4.6 & 4.8548 & TRN \\
\hline CHEMBL1490451 & 688687 & 5.5 & 4.9679 & TRN \\
\hline CHEMBL1422535 & 688687 & 6.1 & 5.4293 & TRN \\
\hline CHEMBL1307558 & 688687 & 4.6 & 4.6455 & TRN \\
\hline CHEMBL1345225 & 688687 & 4.7 & 4.5367 & TRN \\
\hline CHEMBL1497983 & 688687 & 4.7 & 4.7365 & TRN \\
\hline CHEMBL1334728 & 688687 & 5.3 & 4.8644 & TRN \\
\hline CHEMBL1529810 & 688687 & 4.6 & 4.7539 & TRN \\
\hline CHEMBL1338645 & 688687 & 4.4 & 4.8527 & TRN \\
\hline CHEMBL1581345 & 688687 & 4.5 & 4.7087 & TRN \\
\hline
\end{tabular}




\begin{tabular}{|c|c|c|c|c|c|}
\hline \multicolumn{6}{|c|}{ Supplemental Table S2.txt } \\
\hline CHEMBL 8320 & 688687 & 5.0 & 4.9203 & TST & \\
\hline CHEMBL1362431 & 688687 & 5.5 & 4.7655 & TST & \\
\hline CHEMBL1504536 & 688687 & 5.4 & 4.5718 & TRN & \\
\hline CHEMBL1569696 & 688687 & 5.2 & 4.694 & TRN & \\
\hline CHEMBL3209543 & 688687 & 4.4 & 4.4935 & TST & \\
\hline CHEMBL476135 & 688687 & 5.1 & 5.0694 & TRN & \\
\hline CHEMBL1302722 & 688687 & 4.9 & 4.89199 & 99999999995 & TRN \\
\hline CHEMBL1498575 & 688687 & 4.5 & 4.761 & TRN & \\
\hline CHEMBL1458786 & 688687 & 4.4 & 5.2669 & TST & \\
\hline CHEMBL1309562 & 688687 & 4.6 & 4.8734 & TRN & \\
\hline CHEMBL1489289 & 688687 & 6.5 & 5.1059 & TRN & \\
\hline CHEMBL3194038 & 688687 & 4.6 & 4.5309 & TRN & \\
\hline CHEMBL1346802 & 688687 & 4.4 & 4.8459 & TRN & \\
\hline CHEMBL1516845 & 688687 & 4.6 & 4.8733 & TRN & \\
\hline CHEMBL1566105 & 688687 & 6.4 & 5.1598 & TST & \\
\hline CHEMBL1365489 & 688687 & 5.4 & 4.9035 & TST & \\
\hline CHEMBL1481275 & 688687 & 4.6 & 5.0809 & TST & \\
\hline CHEMBL447347 & 688687 & 5.5 & 5.3545 & TRN & \\
\hline CHEMBL1573738 & 688687 & 4.8 & 4.5533 & TRN & \\
\hline CHEMBL1345361 & 688687 & 4.4 & 4.8498 & TST & \\
\hline CHEMBL1368773 & 688687 & 5.4 & 5.0156 & TRN & \\
\hline CHEMBL1611130 & 688687 & 4.5 & 4.713 & TRN & \\
\hline CHEMBL1361953 & 688687 & 4.6 & 4.6541 & TRN & \\
\hline CHEMBL1478570 & 688687 & 4.8 & 4.8149 & TRN & \\
\hline CHEMBL1467572 & 688687 & 4.6 & 4.7491 & TRN & \\
\hline CHEMBL1324524 & 688687 & 4.4 & 4.1862 & TRN & \\
\hline CHEMBL1598910 & 688687 & 4.6 & 4.7099 & TRN & \\
\hline CHEMBL1539023 & 688687 & 4.5 & 5.2543 & TRN & \\
\hline CHEMBL1407042 & 688687 & 4.8 & 4.6628 & TRN & \\
\hline CHEMBL1589140 & 688687 & 4.7 & 5.0634 & TRN & \\
\hline CHEMBL1408812 & 688687 & 4.8 & 4.5832 & TST & \\
\hline CHEMBL1457981 & 688687 & 6.7001 & 4.8343 & TRN & \\
\hline CHEMBL1488889 & 688687 & 4.5 & 4.72199 & 99999999995 & TST \\
\hline CHEMBL1460570 & 688687 & 4.9 & 4.647 & TRN & \\
\hline CHEMBL1501276 & 688687 & 4.5 & 5.2403 & TRN & \\
\hline CHEMBL1516464 & 688687 & 5.0 & 4.9227 & TRN & \\
\hline CHEMBL1537386 & 688687 & 4.5 & 5.1587 & TST & \\
\hline CHEMBL1427992 & 688687 & 4.4 & 4.7944 & TRN & \\
\hline CHEMBL1560508 & 688687 & 4.4 & 4.7136 & TRN & \\
\hline CHEMBL1484566 & 688687 & 4.8 & 4.652 & TRN & \\
\hline CHEMBL1597235 & 688687 & 4.6 & 4.9395 & TRN & \\
\hline CHEMBL1606419 & 688687 & 4.6 & 4.2327 & TRN & \\
\hline CHEMBL1336503 & 688687 & 4.4 & 4.4743 & TRN & \\
\hline CHEMBL1519908 & 688687 & 4.4 & 4.6438 & TST & \\
\hline CHEMBL1367224 & 688687 & 5.5 & 4.8788 & TRN & \\
\hline CHEMBL1517304 & 688687 & 4.6 & 4.8288 & TRN & \\
\hline CHEMBL1447073 & 688687 & 4.5 & 4.6833 & TRN & \\
\hline CHEMBL1305742 & 688687 & 5.1 & 5.002 & TRN & \\
\hline
\end{tabular}




\begin{tabular}{|c|c|c|c|c|}
\hline & & & 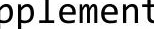 & \\
\hline CHEMBL1497727 & 688687 & 6.2 & 4.6623 & TST \\
\hline CHEMBL1328876 & 688687 & 4.4 & 4.9096 & TRN \\
\hline CHEMBL1464645 & 688687 & 4.6 & 4.6745 & TRN \\
\hline CHEMBL1437258 & 688687 & 4.6 & 4.6832 & TRN \\
\hline CHEMBL1887938 & 688687 & 4.4 & 4.7892 & TST \\
\hline CHEMBL1598394 & 688687 & 4.5 & 4.6913 & TRN \\
\hline CHEMBL1553766 & 688687 & 4.6 & 5.0984 & TRN \\
\hline CHEMBL1489610 & 688687 & 4.7 & 4.7846 & TRN \\
\hline CHEMBL1381820 & 688687 & 4.6 & 5.015 & TST \\
\hline CHEMBL1595377 & 688687 & 5.7 & 4.9301 & TRN \\
\hline CHEMBL1508671 & 688687 & 4.5 & 4.6281 & TRN \\
\hline CHEMBL1518540 & 688687 & 4.6 & 4.9143 & TRN \\
\hline CHEMBL1407030 & 688687 & 4.6 & 4.9257 & TRN \\
\hline CHEMBL1529210 & 688687 & 4.5 & 4.7357 & TRN \\
\hline CHEMBL1567113 & 688687 & 4.5 & 4.8661 & TRN \\
\hline CHEMBL1602499 & 688687 & 4.5 & 4.9858 & TRN \\
\hline CHEMBL1517350 & 688687 & 6.6 & 5.1857 & TRN \\
\hline CHEMBL1574871 & 688687 & 4.5 & 5.0949 & TRN \\
\hline CHEMBL1523561 & 688687 & 7.4001 & 4.9787 & TRN \\
\hline CHEMBL1507983 & 688687 & 4.6 & 4.555 & TRN \\
\hline CHEMBL1590077 & 688687 & 5.5 & 4.9425 & TRN \\
\hline CHEMBL1462139 & 688687 & 4.4 & 4.6246 & TRN \\
\hline CHEMBL1496968 & 688687 & 4.8 & 4.7064 & TRN \\
\hline CHEMBL1304412 & 688687 & 5.5 & 5.0543 & TRN \\
\hline CHEMBL1547533 & 688687 & 4.9 & 4.5944 & TRN \\
\hline CHEMBL598663 & 688687 & 4.5 & 5.2022 & TRN \\
\hline CHEMBL1506843 & 688687 & 4.6 & 4.5498 & TRN \\
\hline CHEMBL1353546 & 688687 & 4.6 & 4.9155 & TRN \\
\hline CHEMBL1351433 & 688687 & 4.6 & 4.8359 & TRN \\
\hline CHEMBL1304445 & 688687 & 4.8 & 5.6727 & TRN \\
\hline CHEMBL1590831 & 688687 & 4.4 & 4.8796 & TRN \\
\hline CHEMBL1323529 & 688687 & 4.4 & 4.7376 & TRN \\
\hline CHEMBL1326664 & 688687 & 4.4 & 5.0214 & TRN \\
\hline CHEMBL1417970 & 688687 & 4.7 & 4.9264 & TRN \\
\hline CHEMBL1457637 & 688687 & 5.1 & 4.7393 & TST \\
\hline CHEMBL1612961 & 688687 & 4.5 & 4.9064 & TRN \\
\hline CHEMBL1438691 & 688687 & 4.6 & 4.5861 & TRN \\
\hline CHEMBL1490004 & 688687 & 5.1 & 5.0666 & TRN \\
\hline CHEMBL1413519 & 688687 & 4.7 & 4.735 & TRN \\
\hline CHEMBL1344136 & 688687 & 4.6 & 4.5544 & TRN \\
\hline CHEMBL1304043 & 688687 & 4.4 & 4.7568 & TRN \\
\hline CHEMBL1612657 & 688687 & 4.8 & 4.5768 & TRN \\
\hline CHEMBL1580035 & 688687 & 5.1 & 5.0315 & TRN \\
\hline CHEMBL1505266 & 688687 & 5.1 & 4.7868 & TRN \\
\hline CHEMBL1414452 & 688687 & 5.6 & 5.1067 & TST \\
\hline CHEMBL1601590 & 688687 & 4.5 & 4.507 & TRN \\
\hline CHEMBL1546537 & 688687 & 5.0 & 5.0122 & TRN \\
\hline CHEMBL1399355 & 688687 & 4.6 & 4.8574 & TRN \\
\hline
\end{tabular}




\begin{tabular}{|c|c|c|c|c|}
\hline & & & ient & $a \perp 1 a$ \\
\hline CHEMBL1428027 & 688687 & 4.4 & 4.6876 & TRN \\
\hline CHEMBL1441938 & 688687 & 6.3 & 4.7154 & TRN \\
\hline CHEMBL1524892 & 688687 & 4.8 & 4.832 & TRN \\
\hline CHEMBL1387335 & 688687 & 4.6 & 4.8236 & TRN \\
\hline CHEMBL1442642 & 688687 & 5.1 & 4.8119 & TRN \\
\hline CHEMBL1389767 & 688687 & 4.4 & 4.8249 & TRN \\
\hline CHEMBL1605218 & 688687 & 4.6 & 4.914 & TRN \\
\hline CHEMBL1611536 & 688687 & 4.8 & 4.6161 & TRN \\
\hline CHEMBL475375 & 688687 & 4.7 & 4.3515 & TRN \\
\hline CHEMBL516075 & 688687 & 4.4 & 4.3965 & TRN \\
\hline CHEMBL1577858 & 688687 & 4.4 & 4.698 & TRN \\
\hline CHEMBL2374058 & 688687 & 4.4 & 4.8179 & TST \\
\hline CHEMBL1603602 & 688687 & 4.5 & 4.721 & TRN \\
\hline CHEMBL1556136 & 688687 & 4.9 & 5.2064 & TRN \\
\hline CHEMBL1561245 & 688687 & 4.5 & 4.8601 & TRN \\
\hline CHEMBL1479273 & 688687 & 4.5 & 4.5998 & TRN \\
\hline CHEMBL1448615 & 688687 & 4.5 & 4.7601 & TRN \\
\hline CHEMBL451722 & 688687 & 4.5 & 5.0443 & TST \\
\hline CHEMBL1350654 & 688687 & 4.4 & 4.4943 & TRN \\
\hline CHEMBL1584299 & 688687 & 4.5 & 4.9263 & TRN \\
\hline CHEMBL1598354 & 688687 & 4.5 & 4.6028 & TRN \\
\hline CHEMBL1590598 & 688687 & 4.6 & 4.788 & TRN \\
\hline CHEMBL1491677 & 688687 & 4.9 & 4.7962 & TST \\
\hline CHEMBL1524313 & 688687 & 4.4 & 4.7202 & TRN \\
\hline CHEMBL1438539 & 688687 & 4.6 & 4.5217 & TRN \\
\hline CHEMBL1373335 & 688687 & 4.8 & 5.0092 & TST \\
\hline CHEMBL1448182 & 688687 & 4.5 & 4.7681 & TRN \\
\hline CHEMBL393296 & 688687 & 4.6 & 4.9219 & TRN \\
\hline CHEMBL1425376 & 688687 & 4.5 & 4.6827 & TRN \\
\hline CHEMBL1410797 & 688687 & 4.7 & 4.6819 & TRN \\
\hline CHEMBL1390940 & 688687 & 4.4 & 4.9579 & TRN \\
\hline CHEMBL1441215 & 688687 & 4.4 & 4.5263 & TRN \\
\hline CHEMBL457665 & 688687 & 6.8 & 5.2533 & TST \\
\hline CHEMBL1569154 & 688687 & 4.6 & 5.0556 & TRN \\
\hline CHEMBL1491228 & 688687 & 4.6 & 4.6708 & TRN \\
\hline CHEMBL1385412 & 688687 & 5.7 & 5.6926 & TRN \\
\hline CHEMBL1340515 & 688687 & 4.6 & 4.6633 & TST \\
\hline CHEMBL1373168 & 688687 & 4.4 & 4.6445 & TRN \\
\hline CHEMBL1366350 & 688687 & 4.6 & 4.5939 & TRN \\
\hline CHEMBL1386896 & 688687 & 4.4 & 4.6012 & TRN \\
\hline CHEMBL1321452 & 688687 & 4.8 & 5.1231 & TST \\
\hline CHEMBL1405969 & 688687 & 4.5 & 4.6189 & TRN \\
\hline CHEMBL1520196 & 688687 & 4.8 & 4.8101 & TRN \\
\hline CHEMBL1590048 & 688687 & 4.4 & 4.7966 & TRN \\
\hline CHEMBL1393735 & 688687 & 4.4 & 4.3839 & TRN \\
\hline CHEMBL1327815 & 688687 & 6.2 & 4.971 & TRN \\
\hline CHEMBL1426589 & 688687 & 4.4 & 5.0024 & TRN \\
\hline CHEMBL192509 & 688687 & 4.6 & 4.4979 & TRN \\
\hline
\end{tabular}




\begin{tabular}{|c|c|c|c|c|}
\hline \multicolumn{5}{|c|}{ Supplemental Table S2.txt } \\
\hline CHEMBL1307695 & 688687 & 5.2 & 5.0556 & TST \\
\hline CHEMBL1613095 & 688687 & 5.2 & 4.5331 & TRN \\
\hline CHEMBL1307420 & 688687 & 5.5 & 5.4661 & TRN \\
\hline CHEMBL1540864 & 688687 & 4.5 & 4.6478 & TRN \\
\hline CHEMBL1459071 & 688687 & 4.8 & 4.8717 & TRN \\
\hline CHEMBL1557417 & 688687 & 4.4 & 4.4916 & TST \\
\hline CHEMBL1507052 & 688687 & 4.4 & 4.7009 & TRN \\
\hline CHEMBL189438 & 688687 & 6.0 & 4.8996 & TST \\
\hline CHEMBL1566730 & 688687 & 5.0 & 4.9164 & TRN \\
\hline CHEMBL1522253 & 688687 & 4.4 & 4.7965 & TRN \\
\hline CHEMBL1477586 & 688687 & 7.4001 & 5.3448 & TRN \\
\hline CHEMBL1499545 & 688687 & 4.6 & 4.8679 & TST \\
\hline CHEMBL473106 & 688687 & 4.8 & 5.2138 & TRN \\
\hline CHEMBL1426401 & 688687 & 4.4 & 5.0243 & TRN \\
\hline CHEMBL1517390 & 688687 & 5.6 & 4.9854 & TRN \\
\hline CHEMBL1545554 & 688687 & 4.5 & 5.0533 & TRN \\
\hline CHEMBL1586297 & 688687 & 4.4 & 4.9136 & TST \\
\hline CHEMBL1366408 & 688687 & 7.1002 & 5.3231 & TST \\
\hline CHEMBL489738 & 688687 & 4.6 & 4.8311 & TRN \\
\hline CHEMBL1383978 & 688687 & 4.4 & 4.6338 & TRN \\
\hline CHEMBL1308799 & 688687 & 5.4 & 5.0504 & TRN \\
\hline CHEMBL1526699 & 688687 & 5.3 & 4.8596 & TRN \\
\hline CHEMBL1541075 & 688687 & 4.9 & 5.1159 & TST \\
\hline CHEMBL1539718 & 688687 & 4.5 & 4.8244 & TST \\
\hline CHEMBL1490561 & 688687 & 4.5 & 5.025 & TRN \\
\hline CHEMBL1471008 & 688687 & 5.2 & 4.7416 & TRN \\
\hline CHEMBL1613087 & 688687 & 7.5003 & 4.6829 & TRN \\
\hline CHEMBL1590266 & 688687 & 4.5 & 4.643 & TRN \\
\hline CHEMBL1390394 & 688687 & 4.4 & 4.5266 & TRN \\
\hline CHEMBL460515 & 688687 & 5.9 & 5.0986 & TRN \\
\hline CHEMBL1387598 & 688687 & 4.7 & 4.6782 & TRN \\
\hline CHEMBL1336927 & 688687 & 4.5 & 4.7828 & TRN \\
\hline CHEMBL1372824 & 688687 & 4.5 & 4.5585 & TRN \\
\hline CHEMBL1566341 & 688687 & 6.7001 & 5.1107 & TST \\
\hline CHEMBL1564461 & 688687 & 4.8 & 4.739 & TRN \\
\hline CHEMBL1529788 & 688687 & 5.7 & 4.7767 & TST \\
\hline CHEMBL1559341 & 688687 & 5.9 & 5.1439 & TST \\
\hline CHEMBL1407862 & 688687 & 5.5 & 4.7553 & TRN \\
\hline CHEMBL1458873 & 688687 & 4.9 & 4.7463 & TRN \\
\hline CHEMBL1430058 & 688687 & 5.1 & 4.6035 & TRN \\
\hline CHEMBL1422708 & 688687 & 4.5 & 4.7381 & TRN \\
\hline CHEMBL1513511 & 688687 & 4.6 & 4.5854 & TRN \\
\hline CHEMBL1456810 & 688687 & 4.7 & 4.6412 & TRN \\
\hline CHEMBL1372348 & 688687 & 4.4 & 4.4382 & TRN \\
\hline CHEMBL1506364 & 688687 & 4.4 & 4.8229 & TST \\
\hline CHEMBL1327355 & 688687 & 4.4 & 4.5749 & TRN \\
\hline CHEMBL1607954 & 688687 & 4.4 & 4.9805 & TRN \\
\hline CHEMBL1545617 & 688687 & 4.9 & 4.6626 & TRN \\
\hline
\end{tabular}




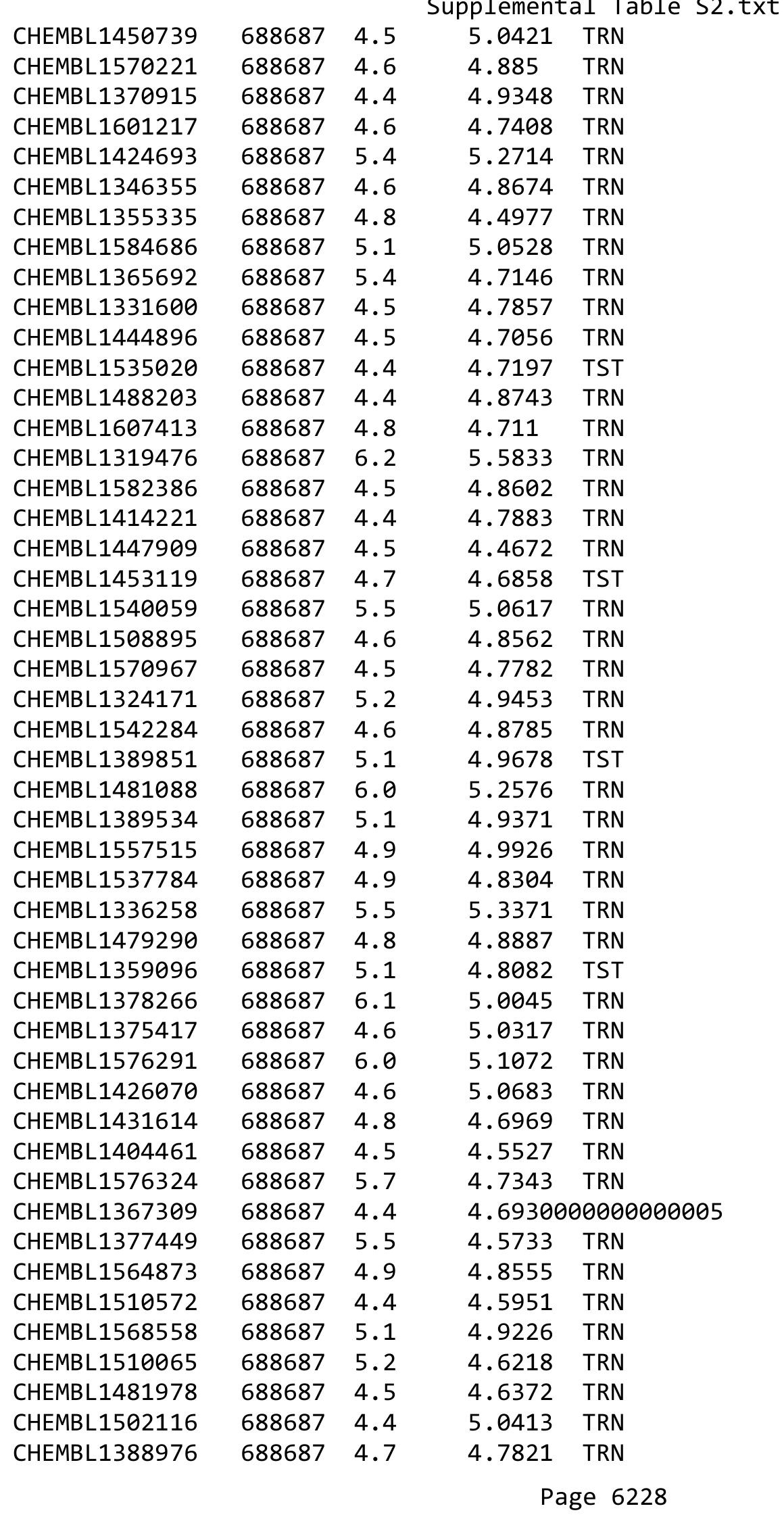




\begin{tabular}{|c|c|c|c|c|}
\hline \multicolumn{5}{|c|}{ plement } \\
\hline CHEMBL1391574 & 688687 & 4.6 & 4.5026 & TRN \\
\hline CHEMBL1566602 & 688687 & 4.4 & 5.0842 & TRN \\
\hline CHEMBL1541803 & 688687 & 5.3 & 5.1475 & TRN \\
\hline CHEMBL1608782 & 688687 & 4.6 & 4.7982 & TRN \\
\hline CHEMBL1380864 & 688687 & 5.8 & 4.6166 & TRN \\
\hline CHEMBL1549184 & 688687 & 4.6 & 4.7647 & TRN \\
\hline CHEMBL1335059 & 688687 & 5.1 & 4.6843 & TRN \\
\hline CHEMBL1524845 & 688687 & 5.1 & 4.6542 & TRN \\
\hline CHEMBL1525894 & 688687 & 4.5 & 4.8508 & TRN \\
\hline CHEMBL1332434 & 688687 & 4.7 & 5.1581 & TST \\
\hline CHEMBL1420950 & 688687 & 4.9 & 5.2136 & TRN \\
\hline CHEMBL1610040 & 688687 & 4.6 & 5.0467 & TRN \\
\hline CHEMBL1422101 & 688687 & 4.5 & 4.3434 & TRN \\
\hline CHEMBL1464602 & 688687 & 4.4 & 4.7329 & TRN \\
\hline CHEMBL1539103 & 688687 & 4.6 & 5.0215 & TST \\
\hline CHEMBL1309212 & 688687 & 6.1 & 4.9251 & TRN \\
\hline CHEMBL1322201 & 688687 & 4.4 & 5.0168 & TRN \\
\hline CHEMBL1572506 & 688687 & 4.5 & 4.7748 & TRN \\
\hline CHEMBL1336386 & 688687 & 5.5 & 5.1487 & TRN \\
\hline CHEMBL1549452 & 688687 & 6.1 & 5.5454 & TRN \\
\hline CHEMBL1332290 & 688687 & 4.6 & 4.6795 & TRN \\
\hline CHEMBL1475657 & 688687 & 5.4 & 4.8874 & TRN \\
\hline CHEMBL1356902 & 688687 & 5.9 & 5.244 & TRN \\
\hline CHEMBL1347460 & 688687 & 5.8 & 4.8164 & TRN \\
\hline CHEMBL1495515 & 688687 & 4.4 & 4.6415 & TRN \\
\hline CHEMBL1453313 & 688687 & 5.4 & 4.9579 & TRN \\
\hline CHEMBL1469101 & 688687 & 4.7 & 4.7888 & TRN \\
\hline CHEMBL1449018 & 688687 & 6.3 & 5.1596 & TRN \\
\hline CHEMBL1484383 & 688687 & 4.5 & 4.6917 & TRN \\
\hline CHEMBL1342544 & 688687 & 4.6 & 4.8177 & TRN \\
\hline CHEMBL1302885 & 688687 & 4.4 & 4.8932 & TRN \\
\hline CHEMBL195008 & 688687 & 4.6 & 5.1957 & TST \\
\hline CHEMBL1409330 & 688687 & 4.6 & 4.9489 & TST \\
\hline CHEMBL1310134 & 688687 & 4.5 & 4.655 & TRN \\
\hline CHEMBL1350241 & 688687 & 4.4 & 4.8458 & TRN \\
\hline CHEMBL1539419 & 688687 & 5.8 & 5.4517 & TRN \\
\hline CHEMBL1587883 & 688687 & 4.4 & 4.7601 & TRN \\
\hline CHEMBL1389917 & 688687 & 4.5 & 4.9089 & TRN \\
\hline CHEMBL1425091 & 688687 & 4.7 & 4.9842 & TRN \\
\hline CHEMBL1361642 & 688687 & 4.5 & 4.9418 & TRN \\
\hline CHEMBL1570165 & 688687 & 5.4 & 4.812 & TRN \\
\hline CHEMBL1369010 & 688687 & 5.7 & 5.2685 & TRN \\
\hline CHEMBL236899 & 688687 & 4.6 & 5.1597 & TRN \\
\hline CHEMBL1368166 & 688687 & 5.0 & 5.2191 & TST \\
\hline CHEMBL1538398 & 688687 & 5.5 & 4.8841 & TRN \\
\hline CHEMBL1359146 & 688687 & 6.6 & 4.9405 & TST \\
\hline CHEMBL1593370 & 688687 & 4.6 & 4.5279 & TRN \\
\hline CHEMBL1983700 & 688687 & 4.4 & 4.5744 & TRN \\
\hline
\end{tabular}




\begin{tabular}{|c|c|c|c|c|}
\hline & & & ient & $a \perp 1 a$ \\
\hline CHEMBL1491318 & 688687 & 4.6 & 4.6226 & TRN \\
\hline CHEMBL1600876 & 688687 & 4.7 & 4.815 & TRN \\
\hline CHEMBL1318083 & 688687 & 4.8 & 5.1924 & TRN \\
\hline CHEMBL1400900 & 688687 & 4.4 & 4.7295 & TRN \\
\hline CHEMBL1327833 & 688687 & 4.5 & 4.5276 & TRN \\
\hline CHEMBL1586442 & 688687 & 5.8 & 4.9267 & TRN \\
\hline CHEMBL1433174 & 688687 & 4.5 & 4.9764 & TRN \\
\hline CHEMBL1345514 & 688687 & 4.4 & 4.7151 & TST \\
\hline CHEMBL 3190370 & 688687 & 5.1 & 4.7954 & TRN \\
\hline CHEMBL1437064 & 688687 & 4.6 & 4.6515 & TRN \\
\hline CHEMBL1527049 & 688687 & 4.6 & 4.5874 & TRN \\
\hline CHEMBL1416201 & 688687 & 5.4 & 4.8008 & TRN \\
\hline CHEMBL1569057 & 688687 & 4.6 & 4.9173 & TRN \\
\hline CHEMBL1497318 & 688687 & 4.5 & 5.1413 & TST \\
\hline CHEMBL1526981 & 688687 & 4.6 & 4.8506 & TRN \\
\hline CHEMBL1565048 & 688687 & 4.6 & 4.8226 & TRN \\
\hline CHEMBL1457199 & 688687 & 4.5 & 4.4083 & TRN \\
\hline CHEMBL1501793 & 688687 & 4.6 & 4.768 & TRN \\
\hline CHEMBL1318744 & 688687 & 5.2 & 5.0102 & TRN \\
\hline CHEMBL1357674 & 688687 & 4.9 & 4.8929 & TST \\
\hline CHEMBL1545464 & 688687 & 4.5 & 4.6589 & TRN \\
\hline CHEMBL1531742 & 688687 & 4.5 & 4.7857 & TRN \\
\hline CHEMBL1371492 & 688687 & 4.5 & 5.0287 & TST \\
\hline CHEMBL1538644 & 688687 & 4.9 & 4.7612 & TST \\
\hline CHEMBL1583101 & 688687 & 4.8 & 4.8586 & TRN \\
\hline CHEMBL577546 & 688687 & 6.0 & 5.0354 & TRN \\
\hline CHEMBL1544846 & 688687 & 4.7 & 4.7165 & TRN \\
\hline CHEMBL1366537 & 688687 & 4.4 & 4.623 & TRN \\
\hline CHEMBL1459571 & 688687 & 4.5 & 4.6627 & TRN \\
\hline CHEMBL1493613 & 688687 & 4.9 & 4.7442 & TRN \\
\hline CHEMBL1450635 & 688687 & 4.4 & 4.9226 & TRN \\
\hline CHEMBL 242341 & 688687 & 4.4 & 4.9088 & TRN \\
\hline CHEMBL1585018 & 688687 & 5.4 & 4.8803 & TRN \\
\hline CHEMBL1490798 & 688687 & 4.6 & 4.8472 & TRN \\
\hline CHEMBL1526750 & 688687 & 4.5 & 4.8583 & TRN \\
\hline CHEMBL1334357 & 688687 & 5.7 & 5.0626 & TST \\
\hline CHEMBL1328096 & 688687 & 4.5 & 4.4883 & TRN \\
\hline CHEMBL3211701 & 688687 & 4.4 & 4.6872 & TRN \\
\hline CHEMBL1530485 & 688687 & 5.2 & 4.7968 & TRN \\
\hline CHEMBL1995218 & 688687 & 4.5 & 4.7151 & TRN \\
\hline CHEMBL1402827 & 688687 & 4.6 & 4.684 & TRN \\
\hline CHEMBL1491370 & 688687 & 4.6 & 4.9223 & TRN \\
\hline CHEMBL1587071 & 688687 & 4.9 & 4.6891 & TRN \\
\hline CHEMBL1257003 & 688687 & 5.6 & 5.4783 & TRN \\
\hline CHEMBL1343774 & 688687 & 4.4 & 4.8492 & TRN \\
\hline CHEMBL1364003 & 688687 & 4.4 & 4.763 & TRN \\
\hline CHEMBL1580372 & 688687 & 4.6 & 4.374 & TRN \\
\hline CHEMBL491940 & 688687 & 4.9 & 4.3873 & TRN \\
\hline
\end{tabular}




\begin{tabular}{|c|c|c|c|c|}
\hline \\
\hline CHEMBL1607842 & 688687 & 5.2 & 4.6513 & TRN \\
\hline CHEMBL1368339 & 688687 & 4.9 & 5.1232 & TRN \\
\hline CHEMBL1580791 & 688687 & 4.5 & 4.7042 & TRN \\
\hline CHEMBL1607135 & 688687 & 4.5 & 4.4111 & TRN \\
\hline CHEMBL222993 & 688687 & 6.0 & 5.4884 & TST \\
\hline CHEMBL1449506 & 688687 & 4.5 & 5.061 & TRN \\
\hline CHEMBL1424664 & 688687 & 4.7 & 4.7813 & TRN \\
\hline CHEMBL1531138 & 688687 & 4.8 & 4.8181 & TST \\
\hline CHEMBL1368802 & 688687 & 4.5 & 5.0781 & TRN \\
\hline CHEMBL1708832 & 688687 & 6.0 & 5.0774 & TST \\
\hline CHEMBL1496517 & 688687 & 4.5 & 4.8575 & TRN \\
\hline CHEMBL3190534 & 688687 & 5.6 & 4.8521 & TRN \\
\hline CHEMBL1448090 & 688687 & 4.6 & 4.5359 & TRN \\
\hline CHEMBL1329915 & 688687 & 4.4 & 5.0272 & TST \\
\hline CHEMBL1399959 & 688687 & 4.6 & 4.9392 & TST \\
\hline CHEMBL3189971 & 688687 & 4.8 & 4.9679 & TST \\
\hline CHEMBL1585396 & 688687 & 4.5 & 4.9385 & TST \\
\hline CHEMBL1307400 & 688687 & 5.4 & 4.9131 & TRN \\
\hline CHEMBL1417379 & 688687 & 4.6 & 4.5493 & TRN \\
\hline CHEMBL1481642 & 688687 & 5.4 & 4.8308 & TRN \\
\hline CHEMBL1365081 & 688687 & 4.5 & 4.6885 & TRN \\
\hline CHEMBL1415504 & 688687 & 7.6003 & 4.8453 & TRN \\
\hline CHEMBL1301758 & 688687 & 4.6 & 4.6762 & TRN \\
\hline CHEMBL1371554 & 688687 & 4.4 & 4.8137 & TRN \\
\hline CHEMBL1449853 & 688687 & 4.6 & 4.6722 & TRN \\
\hline CHEMBL 3208768 & 688687 & 4.8 & 4.9029 & TST \\
\hline CHEMBL1467171 & 688687 & 4.6 & 5.2574 & TST \\
\hline CHEMBL1302268 & 688687 & 4.4 & 4.64 & TRN \\
\hline CHEMBL1569565 & 688687 & 4.4 & 4.7181 & TRN \\
\hline CHEMBL1256191 & 688687 & 6.5 & 5.9551 & TST \\
\hline CHEMBL1440880 & 688687 & 4.5 & 4.823 & TRN \\
\hline CHEMBL1485983 & 688687 & 4.5 & 4.8848 & TST \\
\hline CHEMBL1582040 & 688687 & 6.1 & 5.2618 & TRN \\
\hline CHEMBL1397344 & 688687 & 4.8 & 5.0459 & TST \\
\hline CHEMBL1492641 & 688687 & 4.6 & 4.5894 & TRN \\
\hline CHEMBL1464555 & 688687 & 4.6 & 4.4135 & TRN \\
\hline CHEMBL3192042 & 688687 & 5.5 & 4.8149 & TST \\
\hline CHEMBL1544969 & 688687 & 5.2 & 4.8482 & TRN \\
\hline CHEMBL1364412 & 688687 & 4.4 & 4.8578 & TST \\
\hline CHEMBL1494481 & 688687 & 4.9 & 5.0636 & TRN \\
\hline CHEMBL1325911 & 688687 & 4.5 & 4.7276 & TRN \\
\hline CHEMBL1329084 & 688687 & 4.5 & 4.6279 & TRN \\
\hline CHEMBL1607818 & 688687 & 4.4 & 4.704 & TRN \\
\hline CHEMBL1449458 & 688687 & 4.4 & 4.8698 & TRN \\
\hline CHEMBL1337641 & 688687 & 4.6 & 4.8953 & TRN \\
\hline CHEMBL1365652 & 688687 & 4.5 & 4.7629 & TRN \\
\hline CHEMBL1468840 & 688687 & 4.4 & 5.1138 & TRN \\
\hline CHEMBL1364021 & 688687 & 4.7 & 4.7274 & TRN \\
\hline
\end{tabular}




\begin{tabular}{|c|c|c|c|c|c|}
\hline CHEMBL1509433 & 688687 & 4.5 & 4.8581 & TRN & \\
\hline CHEMBL1392905 & 688687 & 4.5 & 5.0475 & TRN & \\
\hline CHEMBL1534503 & 688687 & 4.4 & 4.9271 & TRN & \\
\hline CHEMBL1442106 & 688687 & 4.6 & 4.8728 & TRN & \\
\hline CHEMBL1327256 & 688687 & 6.0 & 5.1107 & TRN & \\
\hline CHEMBL1483214 & 688687 & 4.5 & 4.94300 & 00000000005 & TST \\
\hline CHEMBL1497949 & 688687 & 5.8 & 4.9729 & TRN & \\
\hline CHEMBL1532794 & 688687 & 5.7 & 4.75899 & 99999999995 & TRN \\
\hline CHEMBL1369614 & 688687 & 5.5 & 5.2365 & TRN & \\
\hline CHEMBL1256360 & 688687 & 6.0 & 6.0108 & TRN & \\
\hline CHEMBL1568805 & 688687 & 4.4 & 5.4423 & TRN & \\
\hline CHEMBL1561067 & 688687 & 4.6 & 5.0965 & TRN & \\
\hline CHEMBL1341971 & 688687 & 4.5 & 4.7723 & TRN & \\
\hline CHEMBL1361264 & 688687 & 4.6 & 4.5854 & TRN & \\
\hline CHEMBL1565125 & 688687 & 4.5 & 4.9057 & TST & \\
\hline CHEMBL1414524 & 688687 & 4.5 & 4.7686 & TRN & \\
\hline CHEMBL1493972 & 688687 & 4.5 & 5.1393 & TRN & \\
\hline CHEMBL1541122 & 688687 & 4.9 & 4.4869 & TRN & \\
\hline CHEMBL475198 & 688687 & 4.4 & 4.3856 & TRN & \\
\hline CHEMBL1454799 & 688687 & 4.5 & 4.8092 & TRN & \\
\hline CHEMBL1566670 & 688687 & 4.7 & 5.0086 & TRN & \\
\hline CHEMBL1406478 & 688687 & 4.5 & 4.7605 & TRN & \\
\hline CHEMBL1469096 & 688687 & 4.4 & 4.4868 & TRN & \\
\hline CHEMBL1550509 & 688687 & 5.7 & 5.5769 & TRN & \\
\hline CHEMBL1456436 & 688687 & 4.7 & 4.7516 & TRN & \\
\hline CHEMBL1488714 & 688687 & 5.0 & 4.905 & TRN & \\
\hline CHEMBL578112 & 688687 & 4.4 & 4.817 & TST & \\
\hline CHEMBL1605650 & 688687 & 4.7 & 5.1227 & TST & \\
\hline CHEMBL1559982 & 688687 & 4.6 & 4.8342 & TRN & \\
\hline CHEMBL1351070 & 688687 & 4.6 & 4.6348 & TRN & \\
\hline CHEMBL1433119 & 688687 & 4.4 & 4.8899 & TST & \\
\hline CHEMBL1483191 & 688687 & 4.6 & 4.9221 & TRN & \\
\hline CHEMBL 244090 & 688687 & 5.6 & 4.9766 & TST & \\
\hline CHEMBL1379045 & 688687 & 4.6 & 4.738 & TST & \\
\hline CHEMBL1489425 & 688687 & 4.6 & 4.6651 & TRN & \\
\hline CHEMBL486817 & 688687 & 4.5 & 5.1831 & TST & \\
\hline CHEMBL1393762 & 688687 & 4.5 & 4.709 & TRN & \\
\hline CHEMBL1477886 & 688687 & 4.4 & 4.5259 & TRN & \\
\hline CHEMBL1344260 & 688687 & 4.4 & 4.6265 & TRN & \\
\hline CHEMBL1566006 & 688687 & 5.2 & 4.921 & TRN & \\
\hline CHEMBL1442247 & 688687 & 5.3 & 4.8338 & TRN & \\
\hline CHEMBL1410260 & 688687 & 5.4 & 4.9305 & TRN & \\
\hline CHEMBL1369497 & 688687 & 4.4 & 4.6365 & TST & \\
\hline CHEMBL1609726 & 688687 & 4.5 & 4.6291 & TRN & \\
\hline CHEMBL1341626 & 688687 & 4.4 & 4.8671 & TST & \\
\hline CHEMBL1562735 & 688687 & 4.4 & 4.6407 & TRN & \\
\hline CHEMBL1415272 & 688687 & 4.4 & 4.5584 & TRN & \\
\hline CHEMBL1376286 & 688687 & 4.4 & 4.7671 & TRN & \\
\hline
\end{tabular}




\begin{tabular}{|c|c|c|c|c|}
\hline & & & pplement & $d \perp 1$ \\
\hline CHEMBL1608557 & 688687 & 5.4 & 4.676 & TRN \\
\hline CHEMBL1321642 & 688687 & 4.4 & 4.9494 & TST \\
\hline CHEMBL1571004 & 688687 & 4.4 & 4.7975 & TRN \\
\hline CHEMBL1360170 & 688687 & 4.5 & 4.769 & TRN \\
\hline CHEMBL1526856 & 688687 & 5.3 & 4.85 & TRN \\
\hline CHEMBL1402928 & 688687 & 4.5 & 4.881 & TRN \\
\hline CHEMBL1385925 & 688687 & 4.4 & 4.9127 & TRN \\
\hline CHEMBL1485366 & 688687 & 4.7 & 4.5199 & TRN \\
\hline CHEMBL1505545 & 688687 & 4.6 & 4.99 & TRN \\
\hline CHEMBL1385389 & 688687 & 5.2 & 5.2673 & TST \\
\hline CHEMBL1573135 & 688687 & 4.5 & 4.6167 & TRN \\
\hline CHEMBL1499314 & 688687 & 4.5 & 4.7569 & TST \\
\hline CHEMBL1381970 & 688687 & 4.9 & 5.0763 & TRN \\
\hline CHEMBL1325877 & 688687 & 5.8 & 5.0145 & TRN \\
\hline CHEMBL1417108 & 688687 & 4.5 & 4.7478 & TRN \\
\hline CHEMBL1382401 & 688687 & 5.5 & 5.1066 & TRN \\
\hline CHEMBL1497025 & 688687 & 4.4 & 4.5369 & TRN \\
\hline CHEMBL1522155 & 688687 & 5.4 & 5.0273 & TST \\
\hline CHEMBL1467815 & 688687 & 5.8 & 4.7374 & TRN \\
\hline CHEMBL1479123 & 688687 & 4.6 & 4.8405 & TRN \\
\hline CHEMBL1410314 & 688687 & 4.6 & 4.6323 & TST \\
\hline CHEMBL1578082 & 688687 & 4.9 & 4.8716 & TST \\
\hline CHEMBL1442558 & 688687 & 4.7 & 4.7307 & TST \\
\hline CHEMBL1380292 & 688687 & 4.4 & 4.8373 & TRN \\
\hline CHEMBL1353493 & 688687 & 5.5 & 4.9939 & TST \\
\hline CHEMBL1395226 & 688687 & 4.8 & 4.8952 & TRN \\
\hline CHEMBL167468 & 688687 & 4.5 & 4.8657 & TRN \\
\hline CHEMBL 2000175 & 688687 & 4.9 & 4.9188 & TST \\
\hline CHEMBL1566938 & 688687 & 4.4 & 4.5628 & TRN \\
\hline CHEMBL1534369 & 688687 & 7.5003 & 5.0533 & TRN \\
\hline CHEMBL1548659 & 688687 & 4.6 & 4.7223 & TRN \\
\hline CHEMBL1531552 & 688687 & 4.9 & 4.9229 & TRN \\
\hline CHEMBL1602620 & 688687 & 4.4 & 4.7767 & TRN \\
\hline CHEMBL1398315 & 688687 & 4.9 & 4.881 & TST \\
\hline CHEMBL1351020 & 688687 & 4.4 & 4.4676 & TRN \\
\hline CHEMBL1522834 & 688687 & 4.5 & 4.8568 & TRN \\
\hline CHEMBL 1371638 & 688687 & 4.5 & 4.6271 & TRN \\
\hline CHEMBL542700 & 688687 & 6.0 & 5.206 & TST \\
\hline CHEMBL140 & 688687 & 6.0 & 5.3157 & TRN \\
\hline CHEMBL1346112 & 688687 & 4.5 & 4.6396 & TRN \\
\hline CHEMBL1532234 & 688687 & 4.6 & 5.2613 & TRN \\
\hline CHEMBL32579 & 688687 & 4.5 & 5.6283 & TRN \\
\hline CHEMBL1574708 & 688687 & 5.1 & 4.5638 & TRN \\
\hline CHEMBL1320605 & 688687 & 4.9 & 4.7232 & TRN \\
\hline CHEMBL1510889 & 688687 & 4.6 & 4.984 & TRN \\
\hline CHEMBL1492804 & 688687 & 4.5 & 4.6634 & TRN \\
\hline CHEMBL 1455667 & 688687 & 4.4 & 4.7378 & TRN \\
\hline CHEMBL1372813 & 688687 & 5.0 & 4.7468 & TRN \\
\hline
\end{tabular}




\begin{tabular}{|c|c|c|c|c|}
\hline & & & $\begin{array}{c}5 \\
\end{array}$ & \\
\hline CHEMBL1501377 & 688687 & 4.5 & 4.7064 & TRN \\
\hline CHEMBL1339595 & 688687 & 4.6 & 4.9724 & TRN \\
\hline CHEMBL1445199 & 688687 & 5.4 & 5.0047 & TRN \\
\hline CHEMBL1599059 & 688687 & 4.9 & 4.7461 & TRN \\
\hline CHEMBL1346258 & 688687 & 4.4 & 4.7645 & TRN \\
\hline CHEMBL1549591 & 688687 & 4.4 & 4.4921 & TRN \\
\hline CHEMBL1582162 & 688687 & 5.5 & 4.8432 & TRN \\
\hline CHEMBL1406161 & 688687 & 5.1 & 4.5876 & TRN \\
\hline CHEMBL1399504 & 688687 & 5.2 & 4.9697 & TRN \\
\hline CHEMBL1445332 & 688687 & 4.6 & 4.2615 & TRN \\
\hline CHEMBL1459360 & 688687 & 5.8 & 5.4579 & TRN \\
\hline CHEMBL1391825 & 688687 & 4.5 & 4.5551 & TRN \\
\hline CHEMBL1499726 & 688687 & 4.6 & 4.8226 & TST \\
\hline CHEMBL1371312 & 688687 & 5.2 & 4.9839 & TRN \\
\hline CHEMBL1596296 & 688687 & 4.5 & 4.4673 & TRN \\
\hline CHEMBL1555505 & 688687 & 4.4 & 4.7356 & TRN \\
\hline CHEMBL1405278 & 688687 & 4.4 & 4.7425 & TRN \\
\hline CHEMBL1587657 & 688687 & 4.6 & 4.4526 & TRN \\
\hline CHEMBL1497932 & 688687 & 4.4 & 4.502 & TRN \\
\hline CHEMBL1346338 & 688687 & 4.6 & 5.1222 & TRN \\
\hline CHEMBL3197622 & 688687 & 5.3 & 4.9261 & TST \\
\hline CHEMBL1546292 & 688687 & 4.4 & 4.7746 & TRN \\
\hline CHEMBL1374054 & 688687 & 4.7 & 4.8667 & TRN \\
\hline CHEMBL1376341 & 688687 & 4.6 & 4.6082 & TRN \\
\hline CHEMBL1362994 & 688687 & 4.5 & 5.018 & TRN \\
\hline CHEMBL1441423 & 688687 & 4.4 & 4.9025 & TRN \\
\hline CHEMBL1316491 & 688687 & 5.4 & 5.1393 & TRN \\
\hline CHEMBL1577795 & 688687 & 4.4 & 4.7572 & TRN \\
\hline CHEMBL1490139 & 688687 & 4.9 & 4.8603 & TRN \\
\hline CHEMBL3191098 & 688687 & 5.7 & 4.9778 & TRN \\
\hline CHEMBL3197297 & 688687 & 4.4 & 4.7123 & TRN \\
\hline CHEMBL1321786 & 688687 & 4.4 & 4.9214 & TRN \\
\hline CHEMBL1373061 & 688687 & 5.3 & 4.7752 & TRN \\
\hline CHEMBL1384172 & 688687 & 5.3 & 5.2554 & TRN \\
\hline CHEMBL1463793 & 688687 & 4.8 & 4.6089 & TRN \\
\hline CHEMBL1395107 & 688687 & 6.1 & 4.7463 & TRN \\
\hline CHEMBL1461238 & 688687 & 4.4 & 4.5988 & TRN \\
\hline CHEMBL1419151 & 688687 & 4.6 & 5.1143 & TST \\
\hline CHEMBL1466749 & 688687 & 4.7 & 4.629 & TRN \\
\hline CHEMBL1500069 & 688687 & 4.4 & 4.6562 & TRN \\
\hline CHEMBL1534466 & 688687 & 4.5 & 4.6094 & TRN \\
\hline CHEMBL1367434 & 688687 & 4.6 & 4.9288 & TRN \\
\hline CHEMBL1549910 & 688687 & 4.8 & 5.0843 & TRN \\
\hline CHEMBL1525426 & 688687 & 5.8 & 4.7856 & TST \\
\hline CHEMBL1569702 & 688687 & 4.5 & 4.8013 & TRN \\
\hline CHEMBL1483679 & 688687 & 4.6 & 4.8099 & TRN \\
\hline CHEMBL1527946 & 688687 & 8.2007 & 5.3566 & TRN \\
\hline CHEMBL68423 & 688687 & 4.5 & 4.8666 & TST \\
\hline
\end{tabular}




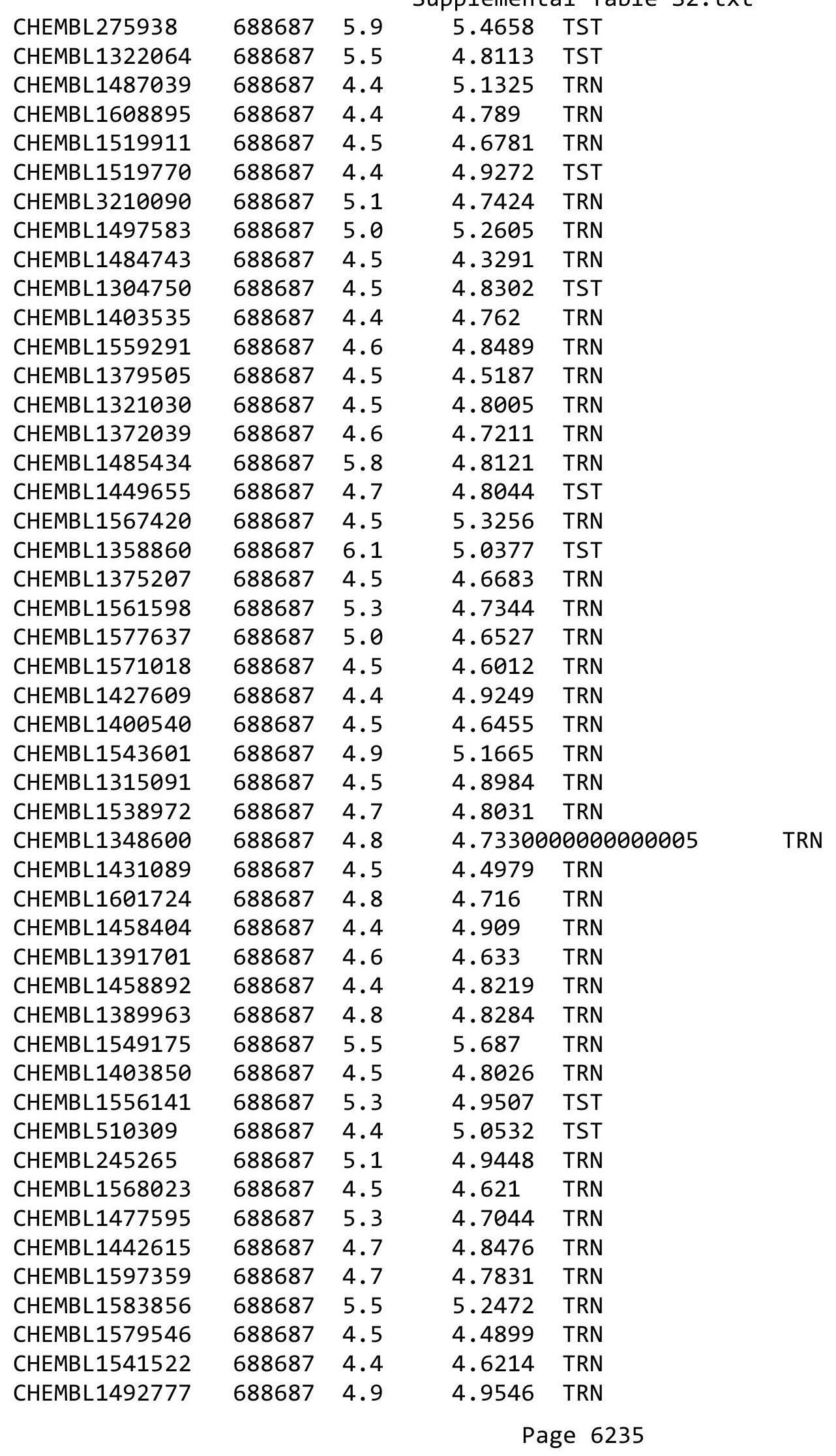




\begin{tabular}{|c|c|c|c|c|}
\hline \multicolumn{5}{|c|}{ Supplemental Table S2.txt } \\
\hline CHEMBL1429769 & 688687 & 4.6 & 4.7191 & TRN \\
\hline CHEMBL1449024 & 688687 & 4.5 & 4.5207 & TRN \\
\hline CHEMBL3190150 & 688687 & 4.6 & 4.8745 & TRN \\
\hline CHEMBL1443043 & 688687 & 4.5 & 4.785 & TRN \\
\hline CHEMBL1394499 & 688687 & 4.4 & 4.7461 & TRN \\
\hline CHEMBL1327563 & 688687 & 4.6 & 4.6145 & TRN \\
\hline CHEMBL1564351 & 688687 & 5.1 & 5.0123 & TRN \\
\hline CHEMBL1603853 & 688687 & 4.6 & 4.7655 & TRN \\
\hline CHEMBL1317166 & 688687 & 5.0 & 5.6339 & TRN \\
\hline CHEMBL1332314 & 688687 & 4.4 & 5.3966 & TST \\
\hline CHEMBL1449129 & 688687 & 4.5 & 4.999 & TRN \\
\hline CHEMBL1328248 & 688687 & 4.4 & 4.7688 & TRN \\
\hline CHEMBL1369293 & 688687 & 4.6 & 4.7487 & TRN \\
\hline CHEMBL1345813 & 688687 & 4.5 & 4.8359 & TRN \\
\hline CHEMBL1359269 & 688687 & 4.5 & 4.5899 & TRN \\
\hline CHEMBL1495693 & 688687 & 5.3 & 4.5869 & TRN \\
\hline CHEMBL1480742 & 688687 & 4.8 & 4.4704 & TRN \\
\hline CHEMBL1437747 & 688687 & 5.0 & 5.2075 & TRN \\
\hline CHEMBL370761 & 688687 & 4.6 & 5.1211 & TST \\
\hline CHEMBL1424575 & 688687 & 5.9 & 5.1039 & TRN \\
\hline CHEMBL1610274 & 688687 & 4.5 & 4.8876 & TRN \\
\hline CHEMBL1459530 & 688687 & 7.5003 & 4.8805 & TRN \\
\hline CHEMBL1443125 & 688687 & 5.1 & 5.2425 & TST \\
\hline CHEMBL1305201 & 688687 & 4.9 & 5.1984 & TRN \\
\hline CHEMBL1435916 & 688687 & 4.6 & 4.521 & TRN \\
\hline CHEMBL1479279 & 688687 & 4.6 & 4.8371 & TRN \\
\hline CHEMBL1522354 & 688687 & 4.6 & 4.7209 & TRN \\
\hline CHEMBL338479 & 688687 & 4.9 & 5.0894 & TRN \\
\hline CHEMBL1560015 & 688687 & 4.5 & 4.8849 & TRN \\
\hline CHEMBL 3210296 & 688687 & 4.5 & 4.8606 & TST \\
\hline CHEMBL1382551 & 688687 & 4.9 & 4.7735 & TRN \\
\hline CHEMBL1365337 & 688687 & 4.5 & 5.1157 & TST \\
\hline CHEMBL1511698 & 688687 & 4.5 & 4.8991 & TST \\
\hline CHEMBL1397724 & 688687 & 4.6 & 5.1423 & TRN \\
\hline CHEMBL1521213 & 688687 & 4.5 & 4.9987 & TRN \\
\hline CHEMBL1482558 & 688687 & 5.2 & 4.5975 & TRN \\
\hline CHEMBL1330296 & 688687 & 4.7 & 4.8262 & TRN \\
\hline CHEMBL1438992 & 688687 & 5.4 & 4.6438 & TRN \\
\hline CHEMBL1457951 & 688687 & 5.1 & 5.1315 & TRN \\
\hline CHEMBL1339702 & 688687 & 4.5 & 4.6195 & TRN \\
\hline CHEMBL1301525 & 688687 & 4.6 & 5.0099 & TRN \\
\hline CHEMBL1339467 & 688687 & 4.6 & 4.6277 & TRN \\
\hline CHEMBL1365331 & 688687 & 4.4 & 4.5622 & TRN \\
\hline CHEMBL1335959 & 688687 & 4.4 & 5.0951 & TST \\
\hline CHEMBL1410875 & 688687 & 4.5 & 4.805 & TRN \\
\hline CHEMBL1495360 & 688687 & 5.1 & 4.5727 & TRN \\
\hline CHEMBL1582184 & 688687 & 4.9 & 4.71 & TRN \\
\hline CHEMBL1400258 & 688687 & 4.5 & 4.7989 & TRN \\
\hline
\end{tabular}




\begin{tabular}{|c|c|c|c|c|}
\hline & & & Lement & al Ta \\
\hline CHEMBL1542060 & 688687 & 4.5 & 4.5458 & TRN \\
\hline CHEMBL1550841 & 688687 & 5.4 & 4.8484 & TRN \\
\hline CHEMBL1342521 & 688687 & 4.4 & 4.3406 & TRN \\
\hline CHEMBL1330543 & 688687 & 4.4 & 4.4495 & TRN \\
\hline CHEMBL1333384 & 688687 & 5.4 & 5.1976 & TST \\
\hline CHEMBL1447949 & 688687 & 4.5 & 4.6769 & TRN \\
\hline CHEMBL1457291 & 688687 & 4.5 & 4.8213 & TST \\
\hline CHEMBL1475990 & 688687 & 4.4 & 4.7241 & TRN \\
\hline CHEMBL1407696 & 688687 & 5.4 & 5.1223 & TRN \\
\hline CHEMBL1491602 & 688687 & 6.5 & 5.1197 & TRN \\
\hline CHEMBL1386337 & 688687 & 4.4 & 5.1975 & TRN \\
\hline CHEMBL1385800 & 688687 & 5.6 & 5.1918 & TRN \\
\hline CHEMBL1568242 & 688687 & 4.5 & 4.9501 & TST \\
\hline CHEMBL1528923 & 688687 & 4.8 & 5.0152 & TRN \\
\hline CHEMBL1566453 & 688687 & 4.9 & 4.957 & TRN \\
\hline CHEMBL1317275 & 688687 & 4.4 & 4.5404 & TRN \\
\hline CHEMBL1312858 & 688687 & 4.4 & 4.534 & TRN \\
\hline CHEMBL1547588 & 688687 & 4.6 & 4.7968 & TRN \\
\hline CHEMBL1364078 & 688687 & 4.4 & 4.8292 & TRN \\
\hline CHEMBL1406054 & 688687 & 4.7 & 4.7527 & TRN \\
\hline CHEMBL1612647 & 688687 & 4.5 & 4.7091 & TRN \\
\hline CHEMBL47047 & 688687 & 4.5 & 5.0285 & TRN \\
\hline CHEMBL1579582 & 688687 & 4.4 & 4.7021 & TRN \\
\hline CHEMBL1328626 & 688687 & 4.6 & 5.1777 & TST \\
\hline CHEMBL 285480 & 688687 & 5.5 & 5.151 & TST \\
\hline CHEMBL 3189685 & 688687 & 5.8 & 4.5897 & TRN \\
\hline CHEMBL1450654 & 688687 & 5.5 & 4.8002 & TRN \\
\hline CHEMBL1612686 & 688687 & 4.4 & 4.7042 & TRN \\
\hline CHEMBL1318718 & 688687 & 5.6 & 4.7422 & TRN \\
\hline CHEMBL1512413 & 688687 & 5.2 & 4.7463 & TRN \\
\hline CHEMBL1468811 & 688687 & 6.1 & 5.1195 & TST \\
\hline CHEMBL1530147 & 688687 & 5.1 & 4.504 & TRN \\
\hline CHEMBL1472077 & 688687 & 4.5 & 4.9509 & TRN \\
\hline CHEMBL1444573 & 688687 & 4.4 & 4.7795 & TRN \\
\hline CHEMBL1415565 & 688687 & 5.1 & 4.7695 & TRN \\
\hline CHEMBL1299346 & 688687 & 4.6 & 4.82 & TRN \\
\hline CHEMBL1524822 & 688687 & 4.5 & 4.7034 & TRN \\
\hline CHEMBL1490429 & 688687 & 4.4 & 4.8584 & TRN \\
\hline CHEMBL1462520 & 688687 & 4.5 & 4.6773 & TRN \\
\hline CHEMBL1539145 & 688687 & 4.7 & 4.9732 & TRN \\
\hline CHEMBL1556511 & 688687 & 4.5 & 4.5751 & TRN \\
\hline CHEMBL1434646 & 688687 & 4.4 & 4.7067 & TRN \\
\hline CHEMBL1376140 & 688687 & 4.7 & 5.0183 & TST \\
\hline CHEMBL1485192 & 688687 & 4.7 & 4.7412 & TST \\
\hline CHEMBL598773 & 688687 & 5.1 & 4.8831 & TST \\
\hline CHEMBL1330293 & 688687 & 4.5 & 4.775 & TRN \\
\hline CHEMBL1269845 & 688687 & 5.5 & 5.3451 & TRN \\
\hline CHEMBL1494206 & 688687 & 5.7 & 4.904 & TRN \\
\hline
\end{tabular}




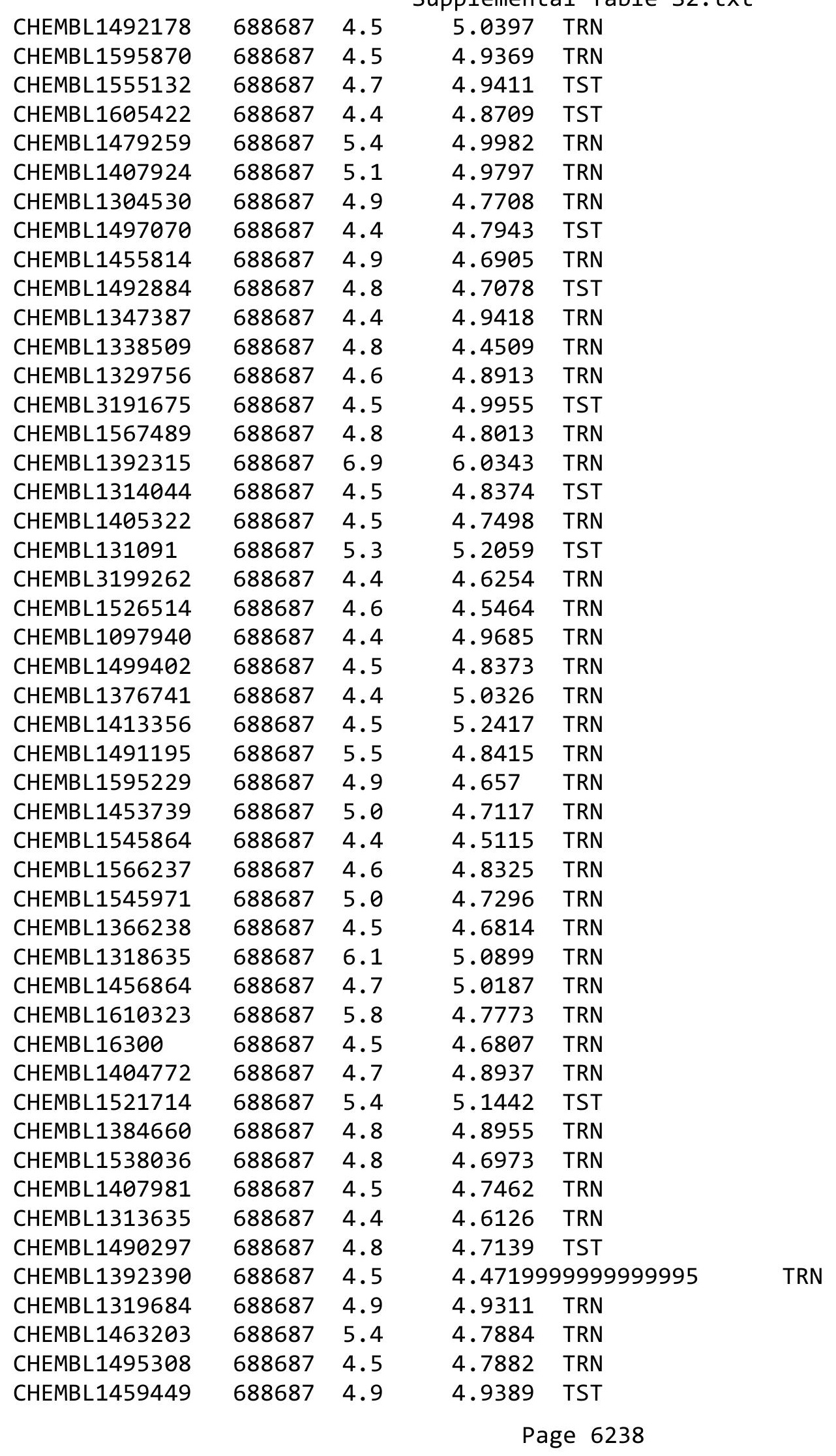




\begin{tabular}{|c|c|c|c|c|c|}
\hline \\
\hline CHEMBL1450791 & 688687 & 5.1 & 4.8733 & TRN & \\
\hline CHEMBL1369079 & 688687 & 4.5 & 5.0457 & TRN & \\
\hline CHEMBL1524252 & 688687 & 4.8 & 5.065 & TRN & \\
\hline CHEMBL1479058 & 688687 & 4.9 & 4.8046 & TRN & \\
\hline CHEMBL1506602 & 688687 & 4.5 & 4.7898 & TRN & \\
\hline CHEMBL1417308 & 688687 & 7.6003 & 5.2408 & TRN & \\
\hline CHEMBL1578068 & 688687 & 4.6 & 4.5812 & TRN & \\
\hline CHEMBL1478435 & 688687 & 4.6 & 4.8655 & TRN & \\
\hline CHEMBL1453259 & 688687 & 4.4 & 5.0274 & TST & \\
\hline CHEMBL1450394 & 688687 & 5.0 & 4.672 & TST & \\
\hline CHEMBL1570042 & 688687 & 5.2 & 5.1209 & TRN & \\
\hline CHEMBL1320836 & 688687 & 4.7 & 4.8156 & TRN & \\
\hline CHEMBL1972052 & 688687 & 6.1 & 5.0428 & TST & \\
\hline CHEMBL1538490 & 688687 & 4.4 & 5.0337 & TST & \\
\hline CHEMBL1348210 & 688687 & 4.6 & 4.9859 & TRN & \\
\hline CHEMBL468590 & 688687 & 4.9 & 5.081 & TRN & \\
\hline CHEMBL1607274 & 688687 & 4.4 & 5.14 & TRN & \\
\hline CHEMBL1559159 & 688687 & 4.9 & 4.7579 & TRN & \\
\hline CHEMBL1455030 & 688687 & 4.5 & 4.4872 & TRN & \\
\hline CHEMBL1541552 & 688687 & 4.4 & 4.8116 & TRN & \\
\hline CHEMBL1389142 & 688687 & 4.6 & 4.7453 & TRN & \\
\hline CHEMBL1473430 & 688687 & 4.4 & 4.7535 & TRN & \\
\hline CHEMBL1428682 & 688687 & 4.7 & 5.1954 & TRN & \\
\hline CHEMBL1596589 & 688687 & 4.6 & 4.7183 & TRN & \\
\hline CHEMBL1435919 & 688687 & 5.4 & 4.7559 & TRN & \\
\hline CHEMBL1417652 & 688687 & 4.4 & 4.8332 & TRN & \\
\hline CHEMBL1467282 & 688687 & 4.4 & 4.3977 & TRN & \\
\hline CHEMBL1583702 & 688687 & 4.6 & 4.7244 & TRN & \\
\hline CHEMBL1559997 & 688687 & 4.5 & 4.9277 & TST & \\
\hline CHEMBL1373384 & 688687 & 5.6 & 4.8066 & TRN & \\
\hline CHEMBL47940 & 688687 & 4.4 & 4.9682 & TST & \\
\hline CHEMBL468018 & 688687 & 4.6 & 4.7396 & TRN & \\
\hline CHEMBL1419934 & 688687 & 4.6 & 4.7825 & TRN & \\
\hline CHEMBL1350685 & 688687 & 4.5 & 4.70100 & 00000000005 & TRN \\
\hline CHEMBL1564877 & 688687 & 5.3 & 4.7031 & TRN & \\
\hline CHEMBL1587097 & 688687 & 5.1 & 4.7583 & TRN & \\
\hline CHEMBL1574278 & 688687 & 5.8 & 5.1892 & TRN & \\
\hline CHEMBL1530645 & 688687 & 4.7 & 4.698 & TRN & \\
\hline CHEMBL1604229 & 688687 & 4.4 & 4.4249 & TRN & \\
\hline CHEMBL1337266 & 688687 & 5.5 & 4.6736 & TST & \\
\hline CHEMBL1400643 & 688687 & 4.6 & 4.7495 & TRN & \\
\hline CHEMBL1970554 & 688687 & 4.6 & 4.7098 & TRN & \\
\hline CHEMBL1385297 & 688687 & 4.5 & 4.9331 & TRN & \\
\hline CHEMBL1523314 & 688687 & 4.8 & 5.1458 & TRN & \\
\hline CHEMBL1526475 & 688687 & 4.4 & 4.7865 & TRN & \\
\hline CHEMBL1604589 & 688687 & 4.7 & 4.9154 & TRN & \\
\hline CHEMBL1318419 & 688687 & 4.4 & 4.3152 & TRN & \\
\hline CHEMBL1314288 & 688687 & 4.9 & 4.7057 & TRN & \\
\hline
\end{tabular}




\begin{tabular}{|c|c|c|c|c|}
\hline & & & & \\
\hline CHEMBL1374247 & 688687 & 4.5 & 4.6425 & TRN \\
\hline CHEMBL1604943 & 688687 & 4.4 & 4.8338 & TRN \\
\hline CHEMBL1450838 & 688687 & 5.4 & 4.9945 & TRN \\
\hline CHEMBL1537871 & 688687 & 4.4 & 4.9037 & TRN \\
\hline CHEMBL1423813 & 688687 & 4.5 & 4.8378 & TRN \\
\hline CHEMBL1523556 & 688687 & 5.3 & 4.8028 & TRN \\
\hline CHEMBL1490459 & 688687 & 4.7 & 4.5469 & TRN \\
\hline CHEMBL1520379 & 688687 & 4.5 & 4.8245 & TRN \\
\hline CHEMBL1548976 & 688687 & 4.7 & 4.7372 & TRN \\
\hline CHEMBL1425497 & 688687 & 5.8 & 5.8378 & TRN \\
\hline CHEMBL1481867 & 688687 & 4.4 & 5.1038 & TRN \\
\hline CHEMBL1350544 & 688687 & 5.5 & 4.7941 & TRN \\
\hline CHEMBL1492100 & 688687 & 4.5 & 4.6813 & TRN \\
\hline CHEMBL1543191 & 688687 & 4.6 & 5.1336 & TST \\
\hline CHEMBL1564927 & 688687 & 5.5 & 5.1277 & TST \\
\hline CHEMBL1518439 & 688687 & 5.0 & 5.1639 & TST \\
\hline CHEMBL1537596 & 688687 & 4.5 & 4.8617 & TRN \\
\hline CHEMBL1525418 & 688687 & 4.5 & 4.8805 & TRN \\
\hline CHEMBL1270217 & 688687 & 4.5 & 4.8651 & TRN \\
\hline CHEMBL1506076 & 688687 & 4.9 & 4.9938 & TRN \\
\hline CHEMBL1457994 & 688687 & 4.9 & 4.9352 & TRN \\
\hline CHEMBL1444559 & 688687 & 4.5 & 4.7529 & TRN \\
\hline CHEMBL1454686 & 688687 & 4.4 & 4.7764 & TRN \\
\hline CHEMBL1478742 & 688687 & 5.5 & 4.9738 & TRN \\
\hline CHEMBL1484859 & 688687 & 4.6 & 4.9511 & TRN \\
\hline CHEMBL1587605 & 688687 & 4.6 & 4.6954 & TRN \\
\hline CHEMBL1480329 & 688687 & 5.4 & 4.6038 & TRN \\
\hline CHEMBL1413592 & 688687 & 4.5 & 4.8332 & TRN \\
\hline CHEMBL1303898 & 688687 & 4.5 & 4.7386 & TRN \\
\hline CHEMBL 1404782 & 688687 & 4.6 & 4.6859 & TRN \\
\hline CHEMBL1457311 & 688687 & 4.7 & 4.7611 & TRN \\
\hline CHEMBL1394520 & 688687 & 4.6 & 4.9193 & TRN \\
\hline CHEMBL1527671 & 688687 & 4.4 & 4.5382 & TST \\
\hline CHEMBL1577226 & 688687 & 4.5 & 4.6172 & TRN \\
\hline CHEMBL1517670 & 688687 & 5.3 & 4.7013 & TRN \\
\hline CHEMBL1451032 & 688687 & 4.9 & 4.8887 & TRN \\
\hline CHEMBL1526578 & 688687 & 5.6 & 5.2655 & TST \\
\hline CHEMBL1441874 & 688687 & 5.8 & 5.6416 & TRN \\
\hline CHEMBL1363535 & 688687 & 5.5 & 4.7396 & TRN \\
\hline CHEMBL1454264 & 688687 & 4.5 & 4.5935 & TRN \\
\hline CHEMBL1320919 & 688687 & 5.9 & 4.9208 & TRN \\
\hline CHEMBL1582949 & 688687 & 4.6 & 4.9257 & TRN \\
\hline CHEMBL1558431 & 688687 & 4.7 & 4.5019 & TRN \\
\hline CHEMBL507756 & 688687 & 4.6 & 5.0113 & TRN \\
\hline CHEMBL1426818 & 688687 & 4.5 & 4.9237 & TRN \\
\hline CHEMBL1365623 & 688687 & 5.1 & 4.8519 & TRN \\
\hline CHEMBL3199301 & 688687 & 4.5 & 4.788 & TST \\
\hline CHEMBL1510413 & 688687 & 4.4 & 5.0919 & TRN \\
\hline
\end{tabular}




\begin{tabular}{|c|c|c|c|c|}
\hline & & & PमEment & \\
\hline CHEMBL1526497 & 688687 & 6.0 & 4.9946 & TRN \\
\hline CHEMBL1461412 & 688687 & 5.1 & 4.52 & TRN \\
\hline CHEMBL1447629 & 688687 & 5.0 & 4.7047 & TRN \\
\hline CHEMBL1542863 & 688687 & 4.8 & 5.1265 & TRN \\
\hline CHEMBL1529638 & 688687 & 5.4 & 5.1564 & TRN \\
\hline CHEMBL580819 & 688687 & 4.5 & 4.4974 & TRN \\
\hline CHEMBL1560900 & 688687 & 4.5 & 4.7194 & TRN \\
\hline CHEMBL1307312 & 688687 & 5.0 & 4.6901 & TST \\
\hline CHEMBL1489365 & 688687 & 4.6 & 4.4918 & TRN \\
\hline CHEMBL1338900 & 688687 & 6.2 & 4.9336 & TST \\
\hline CHEMBL1602194 & 688687 & 5.0 & 4.9092 & TRN \\
\hline CHEMBL1606110 & 688687 & 4.5 & 4.8075 & TRN \\
\hline CHEMBL1323315 & 688687 & 4.5 & 4.6174 & TRN \\
\hline CHEMBL494081 & 688687 & 4.5 & 4.6032 & TRN \\
\hline CHEMBL1355840 & 688687 & 4.8 & 4.7031 & TRN \\
\hline CHEMBL1376870 & 688687 & 4.9 & 5.15 & TST \\
\hline CHEMBL1445467 & 688687 & 4.6 & 5.1272 & TRN \\
\hline CHEMBL1417371 & 688687 & 4.4 & 4.8551 & TRN \\
\hline CHEMBL1343808 & 688687 & 4.4 & 4.7163 & TRN \\
\hline CHEMBL282489 & 688687 & 4.6 & 4.9116 & TST \\
\hline CHEMBL1441683 & 688687 & 4.7 & 4.4372 & TRN \\
\hline CHEMBL1541430 & 688687 & 4.5 & 4.47 & TRN \\
\hline CHEMBL 28626 & 688687 & 6.0 & 5.3442 & TRN \\
\hline CHEMBL598952 & 688687 & 6.0 & 4.6358 & TRN \\
\hline CHEMBL1363372 & 688687 & 4.4 & 4.6994 & TRN \\
\hline CHEMBL1379246 & 688687 & 4.7 & 4.9169 & TST \\
\hline CHEMBL1347369 & 688687 & 4.9 & 4.9729 & TRN \\
\hline CHEMBL1496957 & 688687 & 4.5 & 5.3713 & TST \\
\hline CHEMBL1332437 & 688687 & 4.6 & 4.8317 & TST \\
\hline CHEMBL1576461 & 688687 & 4.5 & 4.9199 & TRN \\
\hline CHEMBL1459182 & 688687 & 4.6 & 5.3553 & TRN \\
\hline CHEMBL1613546 & 688687 & 4.5 & 4.9665 & TRN \\
\hline CHEMBL1573101 & 688687 & 4.6 & 4.8173 & TST \\
\hline CHEMBL1386092 & 688687 & 4.8 & 4.9782 & TRN \\
\hline CHEMBL1301692 & 688687 & 4.4 & 4.7073 & TRN \\
\hline CHEMBL1410496 & 688687 & 4.4 & 4.5202 & TRN \\
\hline CHEMBL1472364 & 688687 & 4.5 & 4.6913 & TRN \\
\hline CHEMBL1608679 & 688687 & 4.4 & 4.7879 & TRN \\
\hline CHEMBL1458486 & 688687 & 4.5 & 5.0163 & TRN \\
\hline CHEMBL1509691 & 688687 & 4.9 & 4.9787 & TRN \\
\hline CHEMBL1602329 & 688687 & 5.1 & 4.8951 & TST \\
\hline CHEMBL1506015 & 688687 & 5.0 & 4.7807 & TRN \\
\hline CHEMBL1487098 & 688687 & 4.6 & 4.3008 & TRN \\
\hline CHEMBL1428196 & 688687 & 4.5 & 4.9338 & TRN \\
\hline CHEMBL1307397 & 688687 & 4.6 & 4.8831 & TRN \\
\hline CHEMBL1972573 & 688687 & 5.4 & 4.7718 & TRN \\
\hline CHEMBL1413846 & 688687 & 4.6 & 4.7873 & TRN \\
\hline CHEMBL1613327 & 688687 & 4.4 & 4.6355 & TRN \\
\hline
\end{tabular}




\begin{tabular}{|c|c|c|c|c|c|}
\hline \multicolumn{6}{|c|}{ Supplemental Table S2.txt } \\
\hline CHEMBL1455705 & 688687 & 4.4 & 4.6926 & TRN & \\
\hline CHEMBL1528726 & 688687 & 6.0 & 4.699 & TRN & \\
\hline CHEMBL1576577 & 688687 & 6.7001 & 5.0881 & TRN & \\
\hline CHEMBL1580481 & 688687 & 4.7 & 5.5725 & TST & \\
\hline CHEMBL267160 & 688687 & 5.5 & 4.7108 & TRN & \\
\hline CHEMBL1364404 & 688687 & 4.8 & 4.7732 & TST & \\
\hline CHEMBL1412344 & 688687 & 4.4 & 4.6801 & TRN & \\
\hline CHEMBL1352976 & 688687 & 4.4 & 4.8382 & TRN & \\
\hline CHEMBL1564071 & 688687 & 4.5 & 4.8558 & TRN & \\
\hline CHEMBL1374476 & 688687 & 5.3 & 4.4432 & TRN & \\
\hline CHEMBL290426 & 688687 & 5.3 & 4.9726 & TRN & \\
\hline CHEMBL1328353 & 688687 & 4.7 & 4.9652 & TRN & \\
\hline CHEMBL1427175 & 688687 & 6.3 & 4.82600 & 00000000005 & TRN \\
\hline CHEMBL1323935 & 688687 & 4.5 & 4.938 & TRN & \\
\hline CHEMBL1598539 & 688687 & 5.1 & 4.7741 & TRN & \\
\hline CHEMBL1331648 & 688687 & 4.5 & 4.7893 & TRN & \\
\hline CHEMBL1600340 & 688687 & 4.6 & 4.6779 & TRN & \\
\hline CHEMBL1425003 & 688687 & 5.5 & 5.6726 & TRN & \\
\hline CHEMBL1546594 & 688687 & 4.5 & 5.1471 & TRN & \\
\hline CHEMBL1305311 & 688687 & 4.5 & 4.4938 & TRN & \\
\hline CHEMBL1501643 & 688687 & 4.5 & 4.6393 & TRN & \\
\hline CHEMBL1335023 & 688687 & 4.7 & 4.9691 & TRN & \\
\hline CHEMBL1359978 & 688687 & 4.5 & 4.8107 & TRN & \\
\hline CHEMBL1515777 & 688687 & 4.4 & 4.5546 & TRN & \\
\hline CHEMBL1455356 & 688687 & 4.5 & 4.9098 & TRN & \\
\hline CHEMBL 279564 & 688687 & 4.5 & 4.7736 & TRN & \\
\hline CHEMBL1373478 & 688687 & 4.4 & 4.704 & TRN & \\
\hline CHEMBL1609226 & 688687 & 4.8 & 4.7982 & TRN & \\
\hline CHEMBL1587655 & 688687 & 4.4 & 4.6856 & TRN & \\
\hline CHEMBL1365833 & 688687 & 4.6 & 4.7475 & TRN & \\
\hline CHEMBL1484049 & 688687 & 4.4 & 4.6485 & TRN & \\
\hline CHEMBL1539925 & 688687 & 4.8 & 4.8414 & TRN & \\
\hline CHEMBL 76904 & 688687 & 6.0 & 5.9156 & TRN & \\
\hline CHEMBL1494334 & 688687 & 5.8 & 4.6711 & TRN & \\
\hline CHEMBL606166 & 688687 & 4.6 & 4.8654 & TST & \\
\hline CHEMBL3214224 & 688687 & 4.6 & 5.0755 & TST & \\
\hline CHEMBL1368452 & 688687 & 4.6 & 4.7817 & TRN & \\
\hline CHEMBL1520411 & 688687 & 4.4 & 4.3565 & TRN & \\
\hline CHEMBL1491159 & 688687 & 5.2 & 4.6165 & TRN & \\
\hline CHEMBL1477506 & 688687 & 5.3 & 4.8975 & TST & \\
\hline CHEMBL1428002 & 688687 & 4.7 & 4.8775 & TRN & \\
\hline CHEMBL1302390 & 688687 & 4.6 & 4.9013 & TRN & \\
\hline CHEMBL1416829 & 688687 & 5.1 & 4.9432 & TRN & \\
\hline CHEMBL429711 & 688687 & 4.4 & 5.0357 & TST & \\
\hline CHEMBL137743 & 688687 & 6.3 & 5.6449 & TRN & \\
\hline CHEMBL1324935 & 688687 & 5.9 & 5.6344 & TRN & \\
\hline CHEMBL1517599 & 688687 & 5.2 & 4.6548 & TRN & \\
\hline CHEMBL1574523 & 688687 & 4.5 & 4.8579 & TRN & \\
\hline
\end{tabular}




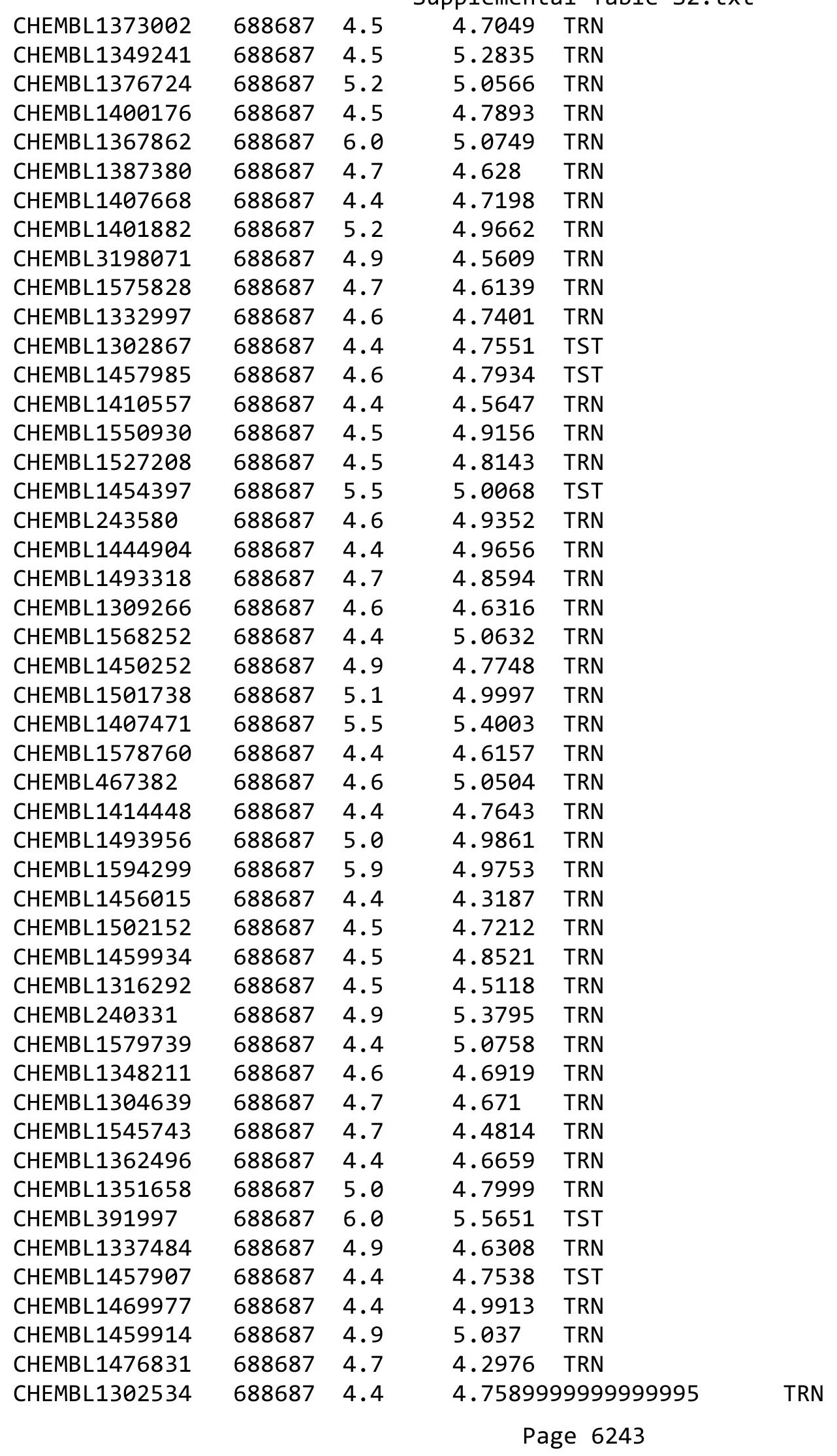




\begin{tabular}{|c|c|c|c|c|c|}
\hline \\
\hline CHEMBL1365284 & 688687 & 5.4 & 4.8163 & TRN & \\
\hline CHEMBL1432620 & 688687 & 4.9 & 5.0743 & TRN & \\
\hline CHEMBL1466843 & 688687 & 5.5 & 4.5424 & TRN & \\
\hline CHEMBL1497871 & 688687 & 4.5 & 4.7309 & TRN & \\
\hline CHEMBL1391491 & 688687 & 4.8 & 4.9622 & TRN & \\
\hline CHEMBL1577459 & 688687 & 4.5 & 4.6913 & TRN & \\
\hline CHEMBL1429644 & 688687 & 5.7 & 4.6911 & TRN & \\
\hline CHEMBL1453214 & 688687 & 4.4 & 4.7361 & TRN & \\
\hline CHEMBL1547738 & 688687 & 4.6 & 4.8754 & TRN & \\
\hline CHEMBL1514090 & 688687 & 6.0 & 5.0798 & TST & \\
\hline CHEMBL1353096 & 688687 & 4.6 & 4.8211 & TRN & \\
\hline CHEMBL1535173 & 688687 & 4.4 & 4.9183 & TRN & \\
\hline CHEMBL1329734 & 688687 & 4.5 & 4.8897 & TRN & \\
\hline CHEMBL1524101 & 688687 & 5.5 & 4.9899 & TRN & \\
\hline CHEMBL3195986 & 688687 & 4.7 & 4.8994 & TRN & \\
\hline CHEMBL1382840 & 688687 & 4.8 & 4.5504 & TRN & \\
\hline CHEMBL1544407 & 688687 & 4.5 & 4.5533 & TRN & \\
\hline CHEMBL1461042 & 688687 & 5.3 & 4.9036 & TRN & \\
\hline CHEMBL1611741 & 688687 & 5.4 & 4.8815 & TST & \\
\hline CHEMBL1346524 & 688687 & 5.1 & 4.8714 & TRN & \\
\hline CHEMBL1545383 & 688687 & 4.7 & 4.749 & TRN & \\
\hline CHEMBL1332080 & 688687 & 4.6 & 4.8024 & TRN & \\
\hline CHEMBL1471352 & 688687 & 5.8 & 5.33200 & 2000000001 & TRN \\
\hline CHEMBL1305080 & 688687 & 5.4 & 4.8294 & TRN & \\
\hline CHEMBL1310576 & 688687 & 4.4 & 4.4019 & TRN & \\
\hline CHEMBL3192719 & 688687 & 4.6 & 4.4733 & TRN & \\
\hline CHEMBL1331651 & 688687 & 4.5 & 4.6334 & TRN & \\
\hline CHEMBL1257078 & 688687 & 5.5 & 5.2502 & TST & \\
\hline CHEMBL1606283 & 688687 & 7.699 & 5.4443 & TRN & \\
\hline CHEMBL1432565 & 688687 & 4.8 & 4.7871 & TRN & \\
\hline CHEMBL1602873 & 688687 & 4.4 & 4.7109 & TRN & \\
\hline CHEMBL1306124 & 688687 & 4.5 & 5.0275 & TRN & \\
\hline CHEMBL1513643 & 688687 & 5.6 & 5.2777 & TST & \\
\hline CHEMBL1541291 & 688687 & 4.8 & 4.984 & TRN & \\
\hline CHEMBL3212593 & 688687 & 5.6 & 5.0423 & TST & \\
\hline CHEMBL1488376 & 688687 & 4.8 & 4.7076 & TRN & \\
\hline CHEMBL1524411 & 688687 & 4.4 & 4.7922 & TRN & \\
\hline CHEMBL1457028 & 688687 & 5.0 & 5.2375 & TRN & \\
\hline CHEMBL1566010 & 688687 & 4.9 & 4.9599 & TRN & \\
\hline CHEMBL1418235 & 688687 & 4.4 & 4.6955 & TRN & \\
\hline CHEMBL1366671 & 688687 & 4.5 & 4.8529 & TRN & \\
\hline CHEMBL1587791 & 688687 & 4.7 & 5.002 & TRN & \\
\hline CHEMBL3211325 & 688687 & 4.6 & 4.92899 & 9999999999 & TRN \\
\hline CHEMBL1586294 & 688687 & 4.9 & 4.9149 & TRN & \\
\hline CHEMBL277127 & 688687 & 7.5003 & 5.3335 & TRN & \\
\hline CHEMBL1387911 & 688687 & 4.4 & 4.6859 & TRN & \\
\hline CHEMBL1609748 & 688687 & 5.7 & 4.7132 & TRN & \\
\hline CHEMBL1306028 & 688687 & 4.4 & 4.8997 & TRN & \\
\hline
\end{tabular}




\begin{tabular}{|c|c|c|c|c|}
\hline & & & pplemen & \\
\hline CHEMBL56393 & 688687 & 5.8 & 5.899 & TRN \\
\hline CHEMBL1589718 & 688687 & 4.8 & 4.9731 & TRN \\
\hline CHEMBL1330487 & 688687 & 4.4 & 4.8717 & TRN \\
\hline CHEMBL3189947 & 688687 & 4.5 & 5.0666 & TST \\
\hline CHEMBL1558613 & 688687 & 4.6 & 4.9288 & TRN \\
\hline CHEMBL1306004 & 688687 & 4.4 & 4.5566 & TRN \\
\hline CHEMBL1537537 & 688687 & 4.9 & 4.6919 & TRN \\
\hline CHEMBL1318943 & 688687 & 4.9 & 5.1302 & TST \\
\hline CHEMBL1487668 & 688687 & 4.4 & 4.8903 & TRN \\
\hline CHEMBL1383919 & 688687 & 5.7 & 4.8475 & TRN \\
\hline CHEMBL1344834 & 688687 & 4.6 & 5.0223 & TRN \\
\hline CHEMBL1461491 & 688687 & 6.0 & 5.2449 & TST \\
\hline CHEMBL1388022 & 688687 & 4.6 & 4.6764 & TRN \\
\hline CHEMBL1571803 & 688687 & 4.8 & 4.8189 & TRN \\
\hline CHEMBL1488517 & 688687 & 4.6 & 4.6909 & TRN \\
\hline CHEMBL1523660 & 688687 & 4.5 & 4.7339 & TRN \\
\hline CHEMBL1312502 & 688687 & 4.5 & 4.4642 & TRN \\
\hline CHEMBL1412940 & 688687 & 4.5 & 4.6105 & TRN \\
\hline CHEMBL1391390 & 688687 & 4.7 & 4.699 & TRN \\
\hline CHEMBL1494683 & 688687 & 4.5 & 4.6468 & TRN \\
\hline CHEMBL583378 & 688687 & 5.6 & 5.0763 & TRN \\
\hline CHEMBL1487479 & 688687 & 4.5 & 5.0068 & TRN \\
\hline CHEMBL1508728 & 688687 & 6.0 & 5.0727 & TRN \\
\hline CHEMBL1453164 & 688687 & 4.5 & 4.9272 & TRN \\
\hline CHEMBL1555810 & 688687 & 4.5 & 5.1954 & TST \\
\hline CHEMBL1410058 & 688687 & 4.6 & 4.3802 & TST \\
\hline CHEMBL1502512 & 688687 & 4.4 & 4.8353 & TST \\
\hline CHEMBL1558008 & 688687 & 5.5 & 4.8215 & TRN \\
\hline CHEMBL1307971 & 688687 & 4.5 & 4.7853 & TST \\
\hline CHEMBL1412240 & 688687 & 4.4 & 4.8905 & TRN \\
\hline CHEMBL1968355 & 688687 & 6.9 & 5.2036 & TST \\
\hline CHEMBL1587750 & 688687 & 4.6 & 4.8995 & TRN \\
\hline CHEMBL1341360 & 688687 & 4.4 & 4.5432 & TST \\
\hline CHEMBL1523900 & 688687 & 5.8 & 5.2226 & TRN \\
\hline CHEMBL1327864 & 688687 & 5.5 & 4.7453 & TRN \\
\hline CHEMBL1393021 & 688687 & 6.0 & 4.7585 & TST \\
\hline CHEMBL1571456 & 688687 & 5.4 & 5.0091 & TRN \\
\hline CHEMBL1431174 & 688687 & 6.2 & 6.0274 & TRN \\
\hline CHEMBL1504653 & 688687 & 4.4 & 4.7745 & TRN \\
\hline CHEMBL1542165 & 688687 & 5.4 & 5.165 & TRN \\
\hline CHEMBL1554579 & 688687 & 4.6 & 4.5704 & TRN \\
\hline CHEMBL1347962 & 688687 & 5.4 & 5.1505 & TRN \\
\hline CHEMBL37400 & 688687 & 4.9 & 4.8219 & TRN \\
\hline CHEMBL1583209 & 688687 & 5.5 & 5.1691 & TRN \\
\hline CHEMBL1495155 & 688687 & 4.6 & 5.0015 & TRN \\
\hline CHEMBL3192808 & 688687 & 4.5 & 4.5437 & TRN \\
\hline CHEMBL1376094 & 688687 & 5.1 & 4.6153 & TRN \\
\hline CHEMBL1537267 & 688687 & 6.1 & 5.0002 & TRN \\
\hline
\end{tabular}




\begin{tabular}{|c|c|c|c|c|}
\hline \multicolumn{5}{|c|}{ Supplemental Table S2.txt } \\
\hline CHEMBL1443626 & 688687 & 4.7 & 4.7425 & TRN \\
\hline CHEMBL1530163 & 688687 & 4.6 & 4.683 & TRN \\
\hline CHEMBL1539125 & 688687 & 5.0 & 4.8087 & TRN \\
\hline CHEMBL1309987 & 688687 & 5.4 & 4.8272 & TST \\
\hline CHEMBL1306907 & 688687 & 5.4 & 5.3337 & TRN \\
\hline CHEMBL1557696 & 688687 & 4.8 & 4.8383 & TRN \\
\hline CHEMBL1334484 & 688687 & 5.3 & 4.9239 & TRN \\
\hline CHEMBL1444973 & 688687 & 4.6 & 4.6214 & TRN \\
\hline CHEMBL327035 & 688687 & 4.5 & 4.6853 & TRN \\
\hline CHEMBL109095 & 688687 & 4.5 & 5.0523 & TRN \\
\hline CHEMBL1516868 & 688687 & 4.5 & 5.1212 & TST \\
\hline CHEMBL1477778 & 688687 & 7.4001 & 4.9013 & TRN \\
\hline CHEMBL 3214237 & 688687 & 4.6 & 5.1327 & TST \\
\hline CHEMBL1309478 & 688687 & 5.4 & 4.8064 & TRN \\
\hline CHEMBL1597827 & 688687 & 5.5 & 4.8349 & TRN \\
\hline CHEMBL1588802 & 688687 & 4.4 & 4.8572 & TRN \\
\hline CHEMBL1489666 & 688687 & 5.1 & 4.5085 & TRN \\
\hline CHEMBL1361704 & 688687 & 4.6 & 4.6584 & TRN \\
\hline CHEMBL1552095 & 688687 & 5.2 & 4.9088 & TST \\
\hline CHEMBL1401452 & 688687 & 4.6 & 4.5181 & TRN \\
\hline CHEMBL1429988 & 688687 & 4.6 & 4.6313 & TRN \\
\hline CHEMBL1363347 & 688687 & 6.6 & 4.8459 & TST \\
\hline CHEMBL1369354 & 688687 & 5.1 & 4.5761 & TRN \\
\hline CHEMBL1486734 & 688687 & 4.6 & 4.6985 & TRN \\
\hline CHEMBL1586416 & 688687 & 4.4 & 4.8111 & TST \\
\hline CHEMBL1315922 & 688687 & 4.4 & 4.998 & TST \\
\hline CHEMBL1410746 & 688687 & 4.6 & 4.8786 & TRN \\
\hline CHEMBL546257 & 688687 & 4.8 & 4.3869 & TST \\
\hline CHEMBL1450965 & 688687 & 4.4 & 4.7307 & TRN \\
\hline CHEMBL1529434 & 688687 & 4.4 & 4.5204 & TRN \\
\hline CHEMBL1393118 & 688687 & 4.8 & 4.8619 & TRN \\
\hline CHEMBL1430871 & 688687 & 4.4 & 4.8756 & TRN \\
\hline CHEMBL1571968 & 688687 & 4.4 & 4.6337 & TRN \\
\hline CHEMBL1468746 & 688687 & 4.5 & 4.8496 & TRN \\
\hline CHEMBL1369583 & 688687 & 4.5 & 4.6131 & TRN \\
\hline CHEMBL1538772 & 688687 & 4.9 & 4.6814 & TRN \\
\hline CHEMBL1491966 & 688687 & 4.7 & 4.8809 & TRN \\
\hline CHEMBL1384855 & 688687 & 4.6 & 4.5778 & TRN \\
\hline CHEMBL1421410 & 688687 & 4.4 & 4.874 & TRN \\
\hline CHEMBL1407269 & 688687 & 6.0 & 5.1127 & TST \\
\hline CHEMBL1430776 & 688687 & 4.8 & 4.6389 & TRN \\
\hline CHEMBL1315457 & 688687 & 4.5 & 4.9856 & TST \\
\hline CHEMBL1453935 & 688687 & 4.6 & 4.7343 & TRN \\
\hline CHEMBL1363686 & 688687 & 4.7 & 4.8153 & TRN \\
\hline CHEMBL1447063 & 688687 & 4.4 & 4.3953 & TRN \\
\hline CHEMBL3193423 & 688687 & 4.4 & 4.6358 & TRN \\
\hline CHEMBL1593850 & 688687 & 4.6 & 4.5147 & TST \\
\hline CHEMBL1373711 & 688687 & 4.6 & 4.4949 & TRN \\
\hline
\end{tabular}




\begin{tabular}{|c|c|c|c|c|}
\hline & & & 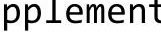 & \\
\hline CHEMBL1609199 & 688687 & 5.2 & 4.7857 & TRN \\
\hline CHEMBL1304994 & 688687 & 5.1 & 4.9976 & TRN \\
\hline CHEMBL1329956 & 688687 & 5.4 & 4.9774 & TST \\
\hline CHEMBL315348 & 688687 & 4.5 & 4.6665 & TRN \\
\hline CHEMBL1305922 & 688687 & 4.4 & 4.8903 & TRN \\
\hline CHEMBL1538696 & 688687 & 4.6 & 5.1691 & TST \\
\hline CHEMBL1477172 & 688687 & 4.6 & 4.9349 & TRN \\
\hline CHEMBL1440120 & 688687 & 4.4 & 4.8382 & TRN \\
\hline CHEMBL1526410 & 688687 & 5.4 & 5.1583 & TST \\
\hline CHEMBL3207432 & 688687 & 5.9 & 4.5842 & TRN \\
\hline CHEMBL1538363 & 688687 & 5.7 & 5.3302 & TRN \\
\hline CHEMBL1560551 & 688687 & 4.9 & 4.9216 & TST \\
\hline CHEMBL1325556 & 688687 & 4.4 & 4.8746 & TRN \\
\hline CHEMBL1480138 & 688687 & 5.0 & 4.625 & TRN \\
\hline CHEMBL1604705 & 688687 & 4.7 & 4.6845 & TRN \\
\hline CHEMBL1447960 & 688687 & 4.9 & 4.9771 & TRN \\
\hline CHEMBL1608407 & 688687 & 4.7 & 4.6351 & TRN \\
\hline CHEMBL1431603 & 688687 & 5.1 & 4.9712 & TRN \\
\hline CHEMBL1478430 & 688687 & 4.8 & 4.7706 & TRN \\
\hline CHEMBL1440908 & 688687 & 4.5 & 4.7202 & TRN \\
\hline CHEMBL1328667 & 688687 & 4.8 & 4.8931 & TST \\
\hline CHEMBL370458 & 688687 & 5.8 & 5.0905 & TRN \\
\hline CHEMBL1427073 & 688687 & 4.6 & 4.7597 & TRN \\
\hline CHEMBL1418081 & 688687 & 5.5 & 4.8915 & TRN \\
\hline CHEMBL1393232 & 688687 & 4.6 & 4.6119 & TRN \\
\hline CHEMBL1518674 & 688687 & 5.1 & 4.8543 & TRN \\
\hline CHEMBL1476687 & 688687 & 5.3 & 5.1873 & TRN \\
\hline CHEMBL1437929 & 688687 & 4.4 & 4.7616 & TRN \\
\hline CHEMBL1529652 & 688687 & 4.6 & 4.6223 & TRN \\
\hline CHEMBL1565456 & 688687 & 4.6 & 4.9309 & TRN \\
\hline CHEMBL1540011 & 688687 & 5.3 & 5.0106 & TRN \\
\hline CHEMBL1304190 & 688687 & 4.5 & 4.9042 & TRN \\
\hline CHEMBL1302106 & 688687 & 4.6 & 4.8208 & TRN \\
\hline CHEMBL1502084 & 688687 & 4.6 & 4.8255 & TRN \\
\hline CHEMBL1408170 & 688687 & 5.6 & 5.1763 & TRN \\
\hline CHEMBL1379571 & 688687 & 4.4 & 4.5783 & TRN \\
\hline CHEMBL1389037 & 688687 & 4.4 & 4.5092 & TRN \\
\hline CHEMBL1345212 & 688687 & 5.4 & 4.9306 & TRN \\
\hline CHEMBL1459152 & 688687 & 4.4 & 4.6157 & TRN \\
\hline CHEMBL1509238 & 688687 & 4.9 & 4.702 & TRN \\
\hline CHEMBL1493878 & 688687 & 4.6 & 4.5947 & TRN \\
\hline CHEMBL1560731 & 688687 & 4.5 & 4.6323 & TRN \\
\hline CHEMBL1543703 & 688687 & 4.5 & 4.7345 & TRN \\
\hline CHEMBL1578948 & 688687 & 4.5 & 4.665 & TRN \\
\hline CHEMBL1372695 & 688687 & 4.5 & 4.7651 & TRN \\
\hline CHEMBL1336039 & 688687 & 4.4 & 4.9612 & TRN \\
\hline CHEMBL1562835 & 688687 & 4.4 & 4.8917 & TRN \\
\hline CHEMBL1452948 & 688687 & 4.4 & 4.6948 & TRN \\
\hline
\end{tabular}




\begin{tabular}{|c|c|c|c|c|c|}
\hline \multicolumn{6}{|c|}{ Supplemental Table S2.txt } \\
\hline CHEMBL8867 & 688687 & 6.0 & 4.9082 & TST & \\
\hline CHEMBL1327713 & 688687 & 5.8 & 5.0919 & TST & \\
\hline CHEMBL1438907 & 688687 & 4.6 & 5.1061 & TRN & \\
\hline CHEMBL1347734 & 688687 & 4.5 & 5.0279 & TRN & \\
\hline CHEMBL1353183 & 688687 & 5.1 & 4.8537 & TRN & \\
\hline CHEMBL1382787 & 688687 & 5.1 & 5.1388 & TRN & \\
\hline CHEMBL1352540 & 688687 & 4.8 & 5.1854 & TRN & \\
\hline CHEMBL151797 & 688687 & 5.2 & 5.0351 & TST & \\
\hline CHEMBL244694 & 688687 & 6.0 & 4.769 & TRN & \\
\hline CHEMBL1440157 & 688687 & 4.5 & 4.6989 & TRN & \\
\hline CHEMBL259355 & 688687 & 4.5 & 4.9849 & TST & \\
\hline CHEMBL1560511 & 688687 & 4.5 & 5.1967 & TST & \\
\hline CHEMBL170408 & 688687 & 4.5 & 4.81800 & 00000000005 & TRN \\
\hline CHEMBL1378720 & 688687 & 4.4 & 4.6629 & TRN & \\
\hline CHEMBL 1255747 & 688687 & 4.5 & 5.4135 & TRN & \\
\hline CHEMBL1611022 & 688687 & 4.8 & 4.9878 & TST & \\
\hline CHEMBL581194 & 688687 & 5.1 & 4.6811 & TRN & \\
\hline CHEMBL1584646 & 688687 & 4.6 & 4.9407 & TRN & \\
\hline CHEMBL1365079 & 688687 & 4.7 & 4.7788 & TRN & \\
\hline CHEMBL1356808 & 688687 & 4.6 & 4.6778 & TRN & \\
\hline CHEMBL3207378 & 688687 & 4.5 & 4.9347 & TST & \\
\hline CHEMBL1561581 & 688687 & 4.4 & 4.5627 & TRN & \\
\hline CHEMBL3194879 & 688687 & 4.5 & 4.6581 & TST & \\
\hline CHEMBL1540153 & 688687 & 4.8 & 4.5215 & TRN & \\
\hline CHEMBL1341124 & 688687 & 5.6 & 4.9182 & TRN & \\
\hline CHEMBL1432336 & 688687 & 5.7 & 5.2839 & TRN & \\
\hline CHEMBL1575456 & 688687 & 4.8 & 4.7658 & TRN & \\
\hline CHEMBL1327420 & 688687 & 6.2 & 4.8764 & TRN & \\
\hline CHEMBL1519135 & 688687 & 4.6 & 4.7843 & TRN & \\
\hline CHEMBL1594363 & 688687 & 5.6 & 4.8842 & TRN & \\
\hline CHEMBL1335881 & 688687 & 5.1 & 5.063 & TST & \\
\hline CHEMBL1485646 & 688687 & 5.0 & 4.7374 & TRN & \\
\hline CHEMBL1565721 & 688687 & 5.2 & 5.0419 & TRN & \\
\hline CHEMBL1478008 & 688687 & 4.5 & 5.0048 & TRN & \\
\hline CHEMBL1496897 & 688687 & 4.9 & 4.9359 & TRN & \\
\hline CHEMBL1464142 & 688687 & 4.7 & 4.7901 & TRN & \\
\hline CHEMBL1488169 & 688687 & 4.5 & 4.3735 & TRN & \\
\hline CHEMBL1382779 & 688687 & 7.4001 & 5.3399 & TRN & \\
\hline CHEMBL1532371 & 688687 & 4.4 & 4.5205 & TRN & \\
\hline CHEMBL1549739 & 688687 & 4.5 & 4.6764 & TRN & \\
\hline CHEMBL1608788 & 688687 & 4.8 & 4.5349 & TRN & \\
\hline CHEMBL1392762 & 688687 & 4.4 & 5.1034 & TRN & \\
\hline CHEMBL1411473 & 688687 & 4.6 & 4.7659 & TRN & \\
\hline CHEMBL1302701 & 688687 & 4.6 & 4.5659 & TRN & \\
\hline CHEMBL1314545 & 688687 & 6.0 & 5.2554 & TST & \\
\hline CHEMBL1382103 & 688687 & 4.6 & 4.5448 & TRN & \\
\hline CHEMBL1371445 & 688687 & 5.4 & 4.8189 & TRN & \\
\hline CHEMBL1576068 & 688687 & 4.5 & 4.8321 & TRN & \\
\hline
\end{tabular}




\begin{tabular}{|c|c|c|c|c|}
\hline & & & & $a \perp 1 a$ \\
\hline CHEMBL1505787 & 688687 & 4.4 & 4.691 & TRN \\
\hline CHEMBL1452239 & 688687 & 5.5 & 4.7925 & TRN \\
\hline CHEMBL1608321 & 688687 & 4.9 & 4.9803 & TRN \\
\hline CHEMBL1460920 & 688687 & 4.8 & 5.0167 & TST \\
\hline CHEMBL1316453 & 688687 & 4.6 & 4.7921 & TRN \\
\hline CHEMBL1547853 & 688687 & 4.6 & 4.6966 & TRN \\
\hline CHEMBL1413566 & 688687 & 4.4 & 4.5568 & TRN \\
\hline CHEMBL1526135 & 688687 & 4.5 & 4.8196 & TRN \\
\hline CHEMBL1536935 & 688687 & 4.5 & 5.1353 & TST \\
\hline CHEMBL3392052 & 688687 & 5.5 & 5.379 & TRN \\
\hline CHEMBL1561532 & 688687 & 4.5 & 4.5761 & TRN \\
\hline CHEMBL1526433 & 688687 & 5.1 & 4.7281 & TRN \\
\hline CHEMBL1612145 & 688687 & 4.5 & 4.6036 & TRN \\
\hline CHEMBL1576724 & 688687 & 4.8 & 4.6249 & TRN \\
\hline CHEMBL1564995 & 688687 & 4.5 & 4.7951 & TRN \\
\hline CHEMBL1397636 & 688687 & 4.4 & 4.5202 & TRN \\
\hline CHEMBL1347567 & 688687 & 5.9 & 4.9182 & TST \\
\hline CHEMBL1458961 & 688687 & 4.4 & 4.8576 & TRN \\
\hline CHEMBL1332879 & 688687 & 5.1 & 4.6462 & TST \\
\hline CHEMBL1383666 & 688687 & 4.6 & 4.6504 & TRN \\
\hline CHEMBL1610146 & 688687 & 4.8 & 4.9755 & TRN \\
\hline CHEMBL1573278 & 688687 & 4.8 & 4.697 & TRN \\
\hline CHEMBL1423577 & 688687 & 4.7 & 4.7266 & TRN \\
\hline CHEMBL1523920 & 688687 & 4.9 & 4.8141 & TRN \\
\hline CHEMBL1368995 & 688687 & 4.7 & 4.641 & TRN \\
\hline CHEMBL1331196 & 688687 & 4.6 & 4.637 & TRN \\
\hline CHEMBL1382260 & 688687 & 4.4 & 5.0108 & TRN \\
\hline CHEMBL1525987 & 688687 & 4.4 & 4.7052 & TRN \\
\hline CHEMBL11348 & 688687 & 4.5 & 4.8097 & TRN \\
\hline CHEMBL6634 & 688687 & 6.0 & 4.9999 & TST \\
\hline CHEMBL1521042 & 688687 & 4.6 & 4.7302 & TRN \\
\hline CHEMBL1587680 & 688687 & 4.4 & 4.6271 & TRN \\
\hline CHEMBL1308990 & 688687 & 4.8 & 5.232 & TRN \\
\hline CHEMBL3207448 & 688687 & 4.8 & 4.921 & TRN \\
\hline CHEMBL1456967 & 688687 & 5.5 & 4.7867 & TRN \\
\hline CHEMBL1563569 & 688687 & 4.4 & 4.9856 & TRN \\
\hline CHEMBL1878162 & 688687 & 4.4 & 4.9823 & TRN \\
\hline CHEMBL515248 & 688687 & 4.5 & 4.488 & TRN \\
\hline CHEMBL1310912 & 688687 & 4.6 & 4.748 & TRN \\
\hline CHEMBL1506716 & 688687 & 4.5 & 4.7401 & TRN \\
\hline CHEMBL1442577 & 688687 & 4.4 & 4.6581 & TST \\
\hline CHEMBL1426492 & 688687 & 4.6 & 5.1941 & TRN \\
\hline CHEMBL1313122 & 688687 & 4.4 & 4.6268 & TRN \\
\hline CHEMBL1489385 & 688687 & 4.5 & 4.8802 & TRN \\
\hline CHEMBL1378612 & 688687 & 4.7 & 4.8609 & TRN \\
\hline CHEMBL1304669 & 688687 & 5.3 & 5.0663 & TRN \\
\hline CHEMBL1360136 & 688687 & 4.8 & 4.9147 & TRN \\
\hline CHEMBL1325339 & 688687 & 4.9 & 4.865 & TRN \\
\hline
\end{tabular}




\begin{tabular}{|c|c|c|c|c|}
\hline \multicolumn{5}{|c|}{ splemental T } \\
\hline CHEMBL1489634 & 688687 & 7.2 & 5.0094 & TRN \\
\hline CHEMBL1547220 & 688687 & 4.6 & 4.9114 & TST \\
\hline CHEMBL1572106 & 688687 & 4.5 & 4.7963 & TRN \\
\hline CHEMBL1584295 & 688687 & 4.4 & 4.5417 & TST \\
\hline CHEMBL1605406 & 688687 & 4.4 & 4.7942 & TRN \\
\hline CHEMBL1328941 & 688687 & 5.5 & 4.9243 & TRN \\
\hline CHEMBL1540685 & 688687 & 5.7 & 4.9343 & TRN \\
\hline CHEMBL1317928 & 688687 & 6.0 & 5.2268 & TST \\
\hline CHEMBL1326534 & 688687 & 4.7 & 4.7209 & TRN \\
\hline CHEMBL541231 & 688687 & 5.5 & 5.0605 & TST \\
\hline CHEMBL1608871 & 688687 & 4.8 & 4.3952 & TRN \\
\hline CHEMBL1365696 & 688687 & 5.6 & 5.5465 & TRN \\
\hline CHEMBL1550715 & 688687 & 4.6 & 4.8554 & TRN \\
\hline CHEMBL1393097 & 688687 & 4.8 & 4.9354 & TST \\
\hline CHEMBL1530855 & 688687 & 5.5 & 4.4441 & TST \\
\hline CHEMBL1301108 & 688687 & 6.0 & 5.9171 & TRN \\
\hline CHEMBL1393861 & 688687 & 4.5 & 4.4895 & TRN \\
\hline CHEMBL 2006039 & 688687 & 5.6 & 5.0008 & TST \\
\hline CHEMBL1439000 & 688687 & 4.4 & 4.6563 & TST \\
\hline CHEMBL1369533 & 688687 & 4.5 & 4.586 & TRN \\
\hline CHEMBL1459912 & 688687 & 4.5 & 4.5294 & TRN \\
\hline CHEMBL1573083 & 688687 & 4.5 & 4.9563 & TRN \\
\hline CHEMBL1401138 & 688687 & 4.5 & 4.9657 & TRN \\
\hline CHEMBL21396 & 688687 & 5.3 & 4.9029 & TRN \\
\hline CHEMBL1539954 & 688687 & 4.4 & 4.5548 & TRN \\
\hline CHEMBL1558607 & 688687 & 4.7 & 4.8141 & TRN \\
\hline CHEMBL1596444 & 688687 & 4.5 & 4.6412 & TRN \\
\hline CHEMBL1343723 & 688687 & 4.6 & 4.7907 & TRN \\
\hline CHEMBL1538814 & 688687 & 5.5 & 4.8049 & TRN \\
\hline CHEMBL1422370 & 688687 & 7.5003 & 4.8084 & TST \\
\hline CHEMBL1477509 & 688687 & 4.7 & 4.833 & TRN \\
\hline CHEMBL1533166 & 688687 & 4.8 & 4.5269 & TRN \\
\hline CHEMBL1561218 & 688687 & 4.5 & 4.9912 & TRN \\
\hline CHEMBL1530626 & 688687 & 4.4 & 4.595 & TRN \\
\hline CHEMBL1519768 & 688687 & 4.5 & 4.8699 & TST \\
\hline CHEMBL3196373 & 688687 & 4.6 & 4.8233 & TST \\
\hline CHEMBL1362829 & 688687 & 5.5 & 4.7991 & TRN \\
\hline CHEMBL1470359 & 688687 & 5.2 & 4.8861 & TRN \\
\hline CHEMBL1444968 & 688687 & 4.6 & 4.723 & TRN \\
\hline CHEMBL1350257 & 688687 & 5.8 & 4.8658 & TRN \\
\hline CHEMBL1540509 & 688687 & 4.5 & 4.8775 & TRN \\
\hline CHEMBL 260676 & 688687 & 4.5 & 4.824 & TRN \\
\hline CHEMBL1412163 & 688687 & 4.5 & 4.7502 & TST \\
\hline CHEMBL1337448 & 688687 & 5.4 & 5.2233 & TST \\
\hline CHEMBL1522070 & 688687 & 4.5 & 4.941 & TRN \\
\hline CHEMBL1377434 & 688687 & 4.4 & 4.5876 & TRN \\
\hline CHEMBL1568129 & 688687 & 4.6 & 4.9038 & TRN \\
\hline CHEMBL1534977 & 688687 & 5.2 & 4.7732 & TST \\
\hline
\end{tabular}




\begin{tabular}{|c|c|c|c|c|}
\hline & & & ient & al Ta \\
\hline CHEMBL1453299 & 688687 & 6.1 & 4.9898 & TRN \\
\hline CHEMBL1414830 & 688687 & 4.9 & 4.7925 & TRN \\
\hline CHEMBL1544244 & 688687 & 4.6 & 4.83 & TRN \\
\hline CHEMBL1417071 & 688687 & 5.6 & 4.6151 & TRN \\
\hline CHEMBL1387995 & 688687 & 4.5 & 4.9644 & TST \\
\hline CHEMBL1462694 & 688687 & 4.4 & 4.6096 & TRN \\
\hline CHEMBL1366373 & 688687 & 6.0 & 5.244 & TRN \\
\hline CHEMBL1373691 & 688687 & 5.5 & 5.2176 & TRN \\
\hline CHEMBL1376740 & 688687 & 4.4 & 4.5126 & TRN \\
\hline CHEMBL1578546 & 688687 & 5.0 & 4.6913 & TRN \\
\hline CHEMBL1584441 & 688687 & 4.6 & 4.7273 & TRN \\
\hline CHEMBL1373177 & 688687 & 6.0 & 5.2852 & TRN \\
\hline CHEMBL1359774 & 688687 & 4.8 & 4.7723 & TRN \\
\hline CHEMBL 3902037 & 688687 & 5.4 & 4.8293 & TRN \\
\hline CHEMBL1439266 & 688687 & 4.5 & 4.6727 & TRN \\
\hline CHEMBL1450386 & 688687 & 4.6 & 4.4425 & TRN \\
\hline CHEMBL1527971 & 688687 & 5.5 & 4.9564 & TRN \\
\hline CHEMBL1321146 & 688687 & 5.2 & 4.9892 & TST \\
\hline CHEMBL1434149 & 688687 & 4.7 & 5.1964 & TRN \\
\hline CHEMBL1429838 & 688687 & 6.0 & 4.8661 & TRN \\
\hline CHEMBL 1350590 & 688687 & 5.5 & 4.9154 & TST \\
\hline CHEMBL1604265 & 688687 & 4.4 & 4.7226 & TRN \\
\hline CHEMBL1502679 & 688687 & 4.4 & 4.8785 & TRN \\
\hline CHEMBL1514129 & 688687 & 4.5 & 4.3233 & TRN \\
\hline CHEMBL1559560 & 688687 & 5.5 & 5.0049 & TST \\
\hline CHEMBL1364384 & 688687 & 5.4 & 4.7347 & TRN \\
\hline CHEMBL1530363 & 688687 & 4.5 & 4.5002 & TRN \\
\hline CHEMBL1384241 & 688687 & 4.4 & 4.7723 & TRN \\
\hline CHEMBL1562090 & 688687 & 4.4 & 4.3742 & TRN \\
\hline CHEMBL1451373 & 688687 & 4.6 & 4.8108 & TRN \\
\hline CHEMBL1348916 & 688687 & 4.4 & 4.6608 & TRN \\
\hline CHEMBL1332066 & 688687 & 5.5 & 4.7511 & TRN \\
\hline CHEMBL541585 & 688687 & 6.0 & 4.9304 & TST \\
\hline CHEMBL1570882 & 688687 & 4.4 & 4.6727 & TRN \\
\hline CHEMBL1393129 & 688687 & 4.8 & 5.0313 & TRN \\
\hline CHEMBL1993627 & 688687 & 4.5 & 4.7942 & TRN \\
\hline CHEMBL1466625 & 688687 & 5.1 & 4.7492 & TRN \\
\hline CHEMBL3192812 & 688687 & 4.6 & 4.4581 & TRN \\
\hline CHEMBL1504651 & 688687 & 4.4 & 4.8611 & TRN \\
\hline CHEMBL1561927 & 688687 & 5.9 & 5.0846 & TRN \\
\hline CHEMBL1600882 & 688687 & 5.4 & 4.8333 & TRN \\
\hline CHEMBL1363522 & 688687 & 4.5 & 4.9946 & TRN \\
\hline CHEMBL1409689 & 688687 & 4.6 & 5.0013 & TRN \\
\hline CHEMBL1511352 & 688687 & 5.3 & 4.8035 & TST \\
\hline CHEMBL1464608 & 688687 & 4.6 & 4.7401 & TRN \\
\hline CHEMBL1385331 & 688687 & 4.5 & 4.6847 & TRN \\
\hline CHEMBL1482369 & 688687 & 4.6 & 4.5436 & TRN \\
\hline CHEMBL1539894 & 688687 & 4.6 & 4.9551 & TRN \\
\hline
\end{tabular}




\begin{tabular}{|c|c|c|c|c|}
\hline & & & Premcim & \\
\hline CHEMBL1603676 & 688687 & 5.5 & 4.6607 & TRN \\
\hline CHEMBL490718 & 688687 & 4.8 & 4.7897 & TRN \\
\hline CHEMBL1390589 & 688687 & 4.6 & 4.8264 & TST \\
\hline CHEMBL1392171 & 688687 & 5.2 & 4.9815 & TRN \\
\hline CHEMBL1589300 & 688687 & 5.3 & 5.0129 & TRN \\
\hline CHEMBL1526086 & 688687 & 4.5 & 4.7361 & TRN \\
\hline CHEMBL1452952 & 688687 & 4.5 & 4.7056 & TRN \\
\hline CHEMBL1380145 & 688687 & 4.5 & 4.5924 & TRN \\
\hline CHEMBL1349603 & 688687 & 5.0 & 4.783 & TRN \\
\hline CHEMBL1349134 & 688687 & 4.6 & 5.2099 & TRN \\
\hline CHEMBL1585481 & 688687 & 4.9 & 4.7798 & TRN \\
\hline CHEMBL1479154 & 688687 & 4.5 & 4.7303 & TRN \\
\hline CHEMBL1502644 & 688687 & 4.4 & 4.756 & TRN \\
\hline CHEMBL1608280 & 688687 & 5.1 & 4.6469 & TRN \\
\hline CHEMBL1441776 & 688687 & 4.6 & 4.7144 & TRN \\
\hline CHEMBL1435520 & 688687 & 5.3 & 4.8557 & TRN \\
\hline CHEMBL1456204 & 688687 & 5.1 & 4.7839 & TRN \\
\hline CHEMBL1475951 & 688687 & 4.8 & 4.7778 & TRN \\
\hline CHEMBL1569460 & 688687 & 5.4 & 4.6694 & TRN \\
\hline CHEMBL1574852 & 688687 & 4.5 & 4.9011 & TRN \\
\hline CHEMBL1403183 & 688687 & 4.6 & 5.0685 & TRN \\
\hline CHEMBL1389115 & 688687 & 4.7 & 4.5633 & TRN \\
\hline CHEMBL1420596 & 688687 & 5.0 & 4.6069 & TRN \\
\hline CHEMBL1384456 & 688687 & 4.4 & 4.7606 & TRN \\
\hline CHEMBL1561487 & 688687 & 4.4 & 5.1408 & TRN \\
\hline CHEMBL1365553 & 688687 & 6.0 & 4.9858 & TST \\
\hline CHEMBL1506771 & 688687 & 4.4 & 4.6555 & TRN \\
\hline CHEMBL492122 & 688687 & 4.4 & 4.2444 & TRN \\
\hline CHEMBL299155 & 688687 & 6.0 & 4.9773 & TRN \\
\hline CHEMBL1518190 & 688687 & 4.6 & 4.6419 & TST \\
\hline CHEMBL 274619 & 688687 & 4.9 & 5.1478 & TST \\
\hline CHEMBL1391201 & 688687 & 4.5 & 4.7324 & TRN \\
\hline CHEMBL1549316 & 688687 & 4.5 & 4.6628 & TRN \\
\hline CHEMBL1398854 & 688687 & 4.5 & 4.7367 & TRN \\
\hline CHEMBL1594793 & 688687 & 4.4 & 4.5544 & TRN \\
\hline CHEMBL1597612 & 688687 & 4.6 & 5.1334 & TST \\
\hline CHEMBL1375781 & 688687 & 5.1 & 4.8601 & TRN \\
\hline CHEMBL1328725 & 688687 & 4.4 & 4.9521 & TST \\
\hline CHEMBL1363536 & 688687 & 4.7 & 4.6278 & TRN \\
\hline CHEMBL1411204 & 688687 & 4.6 & 5.042 & TST \\
\hline CHEMBL3208767 & 688687 & 5.4 & 4.6346 & TST \\
\hline CHEMBL1445582 & 688687 & 4.4 & 4.8848 & TST \\
\hline CHEMBL1301320 & 688687 & 4.6 & 4.9297 & TRN \\
\hline CHEMBL1400300 & 688687 & 4.7 & 5.084 & TRN \\
\hline CHEMBL1507270 & 688687 & 4.9 & 4.75 & TRN \\
\hline CHEMBL1606624 & 688687 & 4.4 & 4.8459 & TRN \\
\hline CHEMBL1602157 & 688687 & 4.8 & 4.7173 & TRN \\
\hline CHEMBL1588628 & 688687 & 4.5 & 4.7937 & TRN \\
\hline
\end{tabular}




\begin{tabular}{|c|c|c|c|c|c|}
\hline CHEMBL1576658 & 688687 & 5.1 & 4.922 & TRN & \\
\hline CHEMBL1438625 & 688687 & 5.4 & 4.89199 & 99999999995 & TRN \\
\hline CHEMBL1573958 & 688687 & 5.2 & 4.9229 & TRN & \\
\hline CHEMBL275260 & 688687 & 4.7 & 5.0987 & TRN & \\
\hline CHEMBL1407495 & 688687 & 4.4 & 5.0352 & TRN & \\
\hline CHEMBL1524421 & 688687 & 4.4 & 4.237 & TRN & \\
\hline CHEMBL1495802 & 688687 & 4.6 & 5.0285 & TRN & \\
\hline CHEMBL1409275 & 688687 & 4.4 & 5.0919 & TRN & \\
\hline CHEMBL3195505 & 688687 & 4.6 & 4.6861 & TST & \\
\hline CHEMBL1536252 & 688687 & 5.7 & 5.1061 & TRN & \\
\hline CHEMBL1594989 & 688687 & 5.4 & 5.0304 & TRN & \\
\hline CHEMBL1330260 & 688687 & 4.4 & 5.1544 & TRN & \\
\hline CHEMBL1463052 & 688687 & 5.1 & 5.3153 & TRN & \\
\hline CHEMBL1493843 & 688687 & 5.1 & 4.6967 & TRN & \\
\hline CHEMBL1604435 & 688687 & 4.6 & 4.7468 & TRN & \\
\hline CHEMBL1403639 & 688687 & 5.3 & 4.5101 & TRN & \\
\hline CHEMBL1501836 & 688687 & 4.5 & 4.8664 & TST & \\
\hline CHEMBL1334713 & 688687 & 4.4 & 4.7797 & TRN & \\
\hline CHEMBL1468806 & 688687 & 4.4 & 4.6135 & TRN & \\
\hline CHEMBL1363889 & 688687 & 4.4 & 4.6717 & TRN & \\
\hline CHEMBL1528456 & 688687 & 6.1 & 4.8604 & TRN & \\
\hline CHEMBL1411703 & 688687 & 4.4 & 5.0406 & TRN & \\
\hline CHEMBL3198293 & 688687 & 4.6 & 5.0645 & TRN & \\
\hline CHEMBL1571106 & 688687 & 4.4 & 4.9985 & TST & \\
\hline CHEMBL1511212 & 688687 & 4.5 & 4.6272 & TRN & \\
\hline CHEMBL1531298 & 688687 & 5.3 & 5.0101 & TST & \\
\hline CHEMBL1533705 & 688687 & 6.4 & 6.0688 & TRN & \\
\hline CHEMBL1534667 & 688687 & 4.5 & 4.7257 & TRN & \\
\hline CHEMBL1584751 & 688687 & 4.5 & 4.8622 & TRN & \\
\hline CHEMBL1521086 & 688687 & 4.5 & 4.7863 & TRN & \\
\hline CHEMBL1565364 & 688687 & 4.4 & 4.755 & TRN & \\
\hline CHEMBL1362079 & 688687 & 4.5 & 4.6182 & TRN & \\
\hline CHEMBL1423358 & 688687 & 4.8 & 5.0101 & TRN & \\
\hline CHEMBL1537893 & 688687 & 4.6 & 4.5705 & TRN & \\
\hline CHEMBL1442154 & 688687 & 4.5 & 4.6281 & TRN & \\
\hline CHEMBL1529823 & 688687 & 5.5 & 4.7582 & TST & \\
\hline CHEMBL1311651 & 688687 & 4.6 & 4.5851 & TRN & \\
\hline CHEMBL1562605 & 688687 & 5.7 & 4.9691 & TRN & \\
\hline CHEMBL1349592 & 688687 & 6.9 & 4.9421 & TRN & \\
\hline CHEMBL1573961 & 688687 & 4.5 & 4.8834 & TRN & \\
\hline CHEMBL1504992 & 688687 & 6.1 & 5.1464 & TRN & \\
\hline CHEMBL1456230 & 688687 & 4.6 & 4.9227 & TRN & \\
\hline CHEMBL1323605 & 688687 & 4.4 & 4.3959 & TRN & \\
\hline CHEMBL1401431 & 688687 & 5.0 & 4.9909 & TRN & \\
\hline CHEMBL1369119 & 688687 & 4.5 & 4.7128 & TRN & \\
\hline CHEMBL491943 & 688687 & 4.7 & 4.8262 & TRN & \\
\hline CHEMBL1516388 & 688687 & 6.0 & 5.1528 & TST & \\
\hline CHEMBL1481175 & 688687 & 4.5 & 5.0829 & TRN & \\
\hline
\end{tabular}




\begin{tabular}{|c|c|c|c|c|c|}
\hline \\
\hline CHEMBL1209196 & 688687 & 4.4 & 4.6649 & TRN & \\
\hline CHEMBL1430895 & 688687 & 4.9 & 5.0528 & TRN & \\
\hline CHEMBL1508508 & 688687 & 5.6 & 5.0653 & TRN & \\
\hline CHEMBL1334873 & 688687 & 6.8 & 4.7917 & TRN & \\
\hline CHEMBL1529780 & 688687 & 4.7 & 4.6862 & TRN & \\
\hline CHEMBL1509053 & 688687 & 4.8 & 4.8138 & TRN & \\
\hline CHEMBL1451074 & 688687 & 4.6 & 4.8761 & TRN & \\
\hline CHEMBL1312282 & 688687 & 5.1 & 4.6561 & TRN & \\
\hline CHEMBL1474906 & 688687 & 6.0 & 4.7575 & TST & \\
\hline CHEMBL1606939 & 688687 & 4.5 & 4.6388 & TRN & \\
\hline CHEMBL1410947 & 688687 & 5.1 & 4.8418 & TRN & \\
\hline CHEMBL1499043 & 688687 & 4.6 & 4.819 & TRN & \\
\hline CHEMBL1324563 & 688687 & 5.2 & 5.3901 & TRN & \\
\hline CHEMBL1459617 & 688687 & 4.4 & 4.7854 & TRN & \\
\hline CHEMBL39372 & 688687 & 6.0 & 5.2586 & TRN & \\
\hline CHEMBL1340230 & 688687 & 4.5 & 4.702 & TRN & \\
\hline CHEMBL1376529 & 688687 & 4.5 & 4.5835 & TRN & \\
\hline CHEMBL1424364 & 688687 & 5.0 & 4.8821 & TRN & \\
\hline CHEMBL 380370 & 688687 & 5.0 & 5.0764 & TRN & \\
\hline CHEMBL1311351 & 688687 & 4.6 & 4.8093 & TST & \\
\hline CHEMBL1547321 & 688687 & 6.3 & 5.0953 & TRN & \\
\hline CHEMBL1524600 & 688687 & 4.5 & 4.9576 & TRN & \\
\hline CHEMBL1362008 & 688687 & 4.5 & 5.0092 & TRN & \\
\hline CHEMBL1434235 & 688687 & 5.1 & 5.4524 & TST & \\
\hline CHEMBL1402893 & 688687 & 4.4 & 4.8318 & TRN & \\
\hline CHEMBL1609459 & 688687 & 4.8 & 4.9796 & TST & \\
\hline CHEMBL1426219 & 688687 & 4.5 & 5.0709 & TRN & \\
\hline CHEMBL1334672 & 688687 & 4.5 & 5.2305 & TRN & \\
\hline CHEMBL1333512 & 688687 & 5.0 & 4.9856 & TRN & \\
\hline CHEMBL1351965 & 688687 & 4.4 & 4.6679 & TRN & \\
\hline CHEMBL1456564 & 688687 & 4.8 & 5.2044 & TST & \\
\hline CHEMBL1454903 & 688687 & 6.0 & 4.9132 & TST & \\
\hline CHEMBL1498427 & 688687 & 4.4 & 4.7394 & TRN & \\
\hline CHEMBL1337069 & 688687 & 4.6 & 4.8755 & TRN & \\
\hline CHEMBL1299478 & 688687 & 5.6 & 4.6881 & TRN & \\
\hline CHEMBL1256364 & 688687 & 4.8 & 5.28 & TRN & \\
\hline CHEMBL3208943 & 688687 & 5.3 & 4.63399 & 99999999995 & TRN \\
\hline CHEMBL574583 & 688687 & 4.9 & 5.0179 & TRN & \\
\hline CHEMBL259018 & 688687 & 6.1 & 5.4474 & TRN & \\
\hline CHEMBL1516573 & 688687 & 4.4 & 4.7091 & TRN & \\
\hline CHEMBL1471340 & 688687 & 5.2 & 5.1479 & TST & \\
\hline CHEMBL1500365 & 688687 & 4.5 & 4.9789 & TRN & \\
\hline CHEMBL1603515 & 688687 & 4.5 & 4.732 & TRN & \\
\hline CHEMBL1548546 & 688687 & 4.4 & 4.6513 & TST & \\
\hline CHEMBL1461340 & 688687 & 5.2 & 4.8615 & TRN & \\
\hline CHEMBL 8260 & 688687 & 6.0 & 5.2765 & TRN & \\
\hline CHEMBL1308140 & 688687 & 4.6 & 4.7112 & TRN & \\
\hline CHEMBL1360345 & 688687 & 7.0 & 5.3461 & TRN & \\
\hline
\end{tabular}




\begin{tabular}{|c|c|c|c|c|c|}
\hline \\
\hline CHEMBL1535237 & 688687 & 6.0 & 4.6897 & TST & \\
\hline CHEMBL1358885 & 688687 & 5.9 & 5.6551 & TST & \\
\hline CHEMBL333985 & 688687 & 4.4 & 4.8895 & TST & \\
\hline CHEMBL1440062 & 688687 & 4.7 & 4.6918 & TRN & \\
\hline CHEMBL1488661 & 688687 & 4.7 & 4.8961 & TRN & \\
\hline CHEMBL1597847 & 688687 & 4.4 & 4.8894 & TRN & \\
\hline CHEMBL1367638 & 688687 & 5.2 & 5.0064 & TST & \\
\hline CHEMBL1303037 & 688687 & 5.1 & 4.8438 & TRN & \\
\hline CHEMBL1511211 & 688687 & 5.0 & 4.7686 & TRN & \\
\hline CHEMBL1597692 & 688687 & 6.0 & 4.9609 & TST & \\
\hline CHEMBL1409783 & 688687 & 5.5 & 5.2532 & TRN & \\
\hline CHEMBL1380139 & 688687 & 5.4 & 4.6884 & TRN & \\
\hline CHEMBL1568320 & 688687 & 5.8 & 5.062 & TST & \\
\hline CHEMBL3198838 & 688687 & 4.9 & 5.1857 & TRN & \\
\hline CHEMBL1332395 & 688687 & 5.3 & 5.0814 & TST & \\
\hline CHEMBL1522678 & 688687 & 4.5 & 4.6947 & TRN & \\
\hline CHEMBL1372607 & 688687 & 4.4 & 4.6999 & TRN & \\
\hline CHEMBL1601790 & 688687 & 4.4 & 4.4851 & TRN & \\
\hline CHEMBL1454114 & 688687 & 4.7 & 4.771 & TRN & \\
\hline CHEMBL1526223 & 688687 & 5.9 & 5.3103 & TRN & \\
\hline CHEMBL3190705 & 688687 & 4.7 & 4.8429 & TRN & \\
\hline CHEMBL1367793 & 688687 & 4.7 & 4.94600 & 0000000001 & TRN \\
\hline CHEMBL1581518 & 688687 & 6.6 & 5.1186 & TRN & \\
\hline CHEMBL1350960 & 688687 & 4.5 & 4.7557 & TRN & \\
\hline CHEMBL1386074 & 688687 & 6.1 & 4.8478 & TRN & \\
\hline CHEMBL1312116 & 688687 & 4.5 & 4.8512 & TRN & \\
\hline CHEMBL1468635 & 688687 & 4.5 & 4.8052 & TRN & \\
\hline CHEMBL1576354 & 688687 & 4.8 & 4.6954 & TRN & \\
\hline CHEMBL1380282 & 688687 & 4.6 & 5.1406 & TRN & \\
\hline CHEMBL1387022 & 688687 & 4.6 & 4.6811 & TRN & \\
\hline CHEMBL164 & 688687 & 6.0 & 5.6301 & TRN & \\
\hline CHEMBL1568448 & 688687 & 4.6 & 4.5255 & TRN & \\
\hline CHEMBL1580701 & 688687 & 4.4 & 4.7232 & TRN & \\
\hline CHEMBL1346033 & 688687 & 4.8 & 4.6202 & TRN & \\
\hline CHEMBL3191996 & 688687 & 4.5 & 4.5735 & TRN & \\
\hline CHEMBL1319142 & 688687 & 4.5 & 4.6779 & TRN & \\
\hline CHEMBL1459762 & 688687 & 4.6 & 4.6599 & TRN & \\
\hline CHEMBL273094 & 688687 & 4.8 & 5.0231 & TRN & \\
\hline CHEMBL1364458 & 688687 & 5.8 & 5.0924 & TRN & \\
\hline CHEMBL3191519 & 688687 & 4.6 & 4.7548 & TRN & \\
\hline CHEMBL1348181 & 688687 & 4.4 & 4.9213 & TRN & \\
\hline CHEMBL1528957 & 688687 & 5.4 & 4.9011 & TRN & \\
\hline CHEMBL1548014 & 688687 & 4.9 & 4.7422 & TRN & \\
\hline CHEMBL1342974 & 688687 & 4.9 & 4.8189 & TRN & \\
\hline CHEMBL1557076 & 688687 & 4.7 & 5.0487 & TRN & \\
\hline CHEMBL1256878 & 688687 & 6.0 & 5.0503 & TST & \\
\hline CHEMBL1321147 & 688687 & 4.6 & 4.6831 & TRN & \\
\hline CHEMBL1610557 & 688687 & 5.4 & 5.0582 & TRN & \\
\hline
\end{tabular}




\begin{tabular}{|c|c|c|c|c|c|}
\hline & & & & & \\
\hline CHEMBL1518154 & 688687 & 5.4 & 4.7322 & TST & \\
\hline CHEMBL1299291 & 688687 & 4.6 & 4.7883 & TRN & \\
\hline CHEMBL1366296 & 688687 & 4.4 & 4.6599 & TRN & \\
\hline CHEMBL1598001 & 688687 & 4.5 & 4.4983 & TRN & \\
\hline CHEMBL1389752 & 688687 & 4.4 & 5.1232 & TRN & \\
\hline CHEMBL1399353 & 688687 & 5.9 & 5.1098 & TRN & \\
\hline CHEMBL1319810 & 688687 & 6.9 & 5.0626 & TRN & \\
\hline CHEMBL1572675 & 688687 & 4.7 & 4.9879 & TRN & \\
\hline CHEMBL1587831 & 688687 & 4.9 & 4.8656 & TST & \\
\hline CHEMBL1335466 & 688687 & 5.4 & 5.2049 & TST & \\
\hline CHEMBL1331443 & 688687 & 4.4 & 5.1588 & TRN & \\
\hline CHEMBL1605648 & 688687 & 4.8 & 4.7844 & TRN & \\
\hline CHEMBL1592741 & 688687 & 5.5 & 4.9162 & TST & \\
\hline CHEMBL1419926 & 688687 & 4.4 & 4.6132 & TRN & \\
\hline CHEMBL1500890 & 688687 & 5.1 & 4.872 & TRN & \\
\hline CHEMBL1310611 & 688687 & 4.5 & 4.5617 & TRN & \\
\hline CHEMBL1336655 & 688687 & 4.7 & 4.7145 & TRN & \\
\hline CHEMBL1348384 & 688687 & 4.6 & 4.6758 & TRN & \\
\hline CHEMBL1404747 & 688687 & 5.1 & 4.8733 & TRN & \\
\hline CHEMBL1302497 & 688687 & 4.8 & 4.7834 & TRN & \\
\hline CHEMBL1400826 & 688687 & 4.6 & 4.4644 & TRN & \\
\hline CHEMBL1359883 & 688687 & 4.5 & 4.9884 & TRN & \\
\hline CHEMBL1566148 & 688687 & 4.5 & 4.8635 & TRN & \\
\hline CHEMBL1359371 & 688687 & 4.6 & 4.6204 & TRN & \\
\hline CHEMBL1596996 & 688687 & 5.0 & 4.9256 & TRN & \\
\hline CHEMBL1329556 & 688687 & 4.9 & 4.5148 & TST & \\
\hline CHEMBL1516863 & 688687 & 4.6 & 4.6489 & TRN & \\
\hline CHEMBL1500116 & 688687 & 4.5 & 4.4142 & TRN & \\
\hline CHEMBL1317986 & 688687 & 5.5 & 5.2056 & TST & \\
\hline CHEMBL1491340 & 688687 & 4.9 & 5.2954 & TST & \\
\hline CHEMBL1413932 & 688687 & 5.4 & 4.65 & TRN & \\
\hline CHEMBL1314165 & 688687 & 4.4 & 4.6105 & TRN & \\
\hline CHEMBL1595221 & 688687 & 4.8 & 4.947 & TST & \\
\hline CHEMBL1506815 & 688687 & 4.4 & 4.7224 & TRN & \\
\hline CHEMBL1412133 & 688687 & 4.5 & 4.65300 & 00000000005 & TRN \\
\hline CHEMBL1461196 & 688687 & 4.5 & 4.5953 & TRN & \\
\hline CHEMBL1320004 & 688687 & 5.3 & 5.0109 & TST & \\
\hline CHEMBL1429872 & 688687 & 4.5 & 4.7529 & TRN & \\
\hline CHEMBL1612347 & 688687 & 4.6 & 4.4804 & TRN & \\
\hline CHEMBL1491600 & 688687 & 4.5 & 4.77800 & 00000000005 & TRN \\
\hline CHEMBL1430897 & 688687 & 4.6 & 4.5833 & TRN & \\
\hline CHEMBL1305249 & 688687 & 5.2 & 4.9056 & TRN & \\
\hline CHEMBL1482983 & 688687 & 4.7 & 5.169 & TST & \\
\hline CHEMBL1346312 & 688687 & 4.7 & 4.7572 & TRN & \\
\hline CHEMBL1354961 & 688687 & 5.4 & 5.0363 & TST & \\
\hline CHEMBL1416434 & 688687 & 4.6 & 4.879 & TRN & \\
\hline CHEMBL1362013 & 688687 & 4.6 & 4.743 & TRN & \\
\hline CHEMBL1568086 & 688687 & 4.9 & 4.7704 & TRN & \\
\hline & & & & 6256 & \\
\hline
\end{tabular}




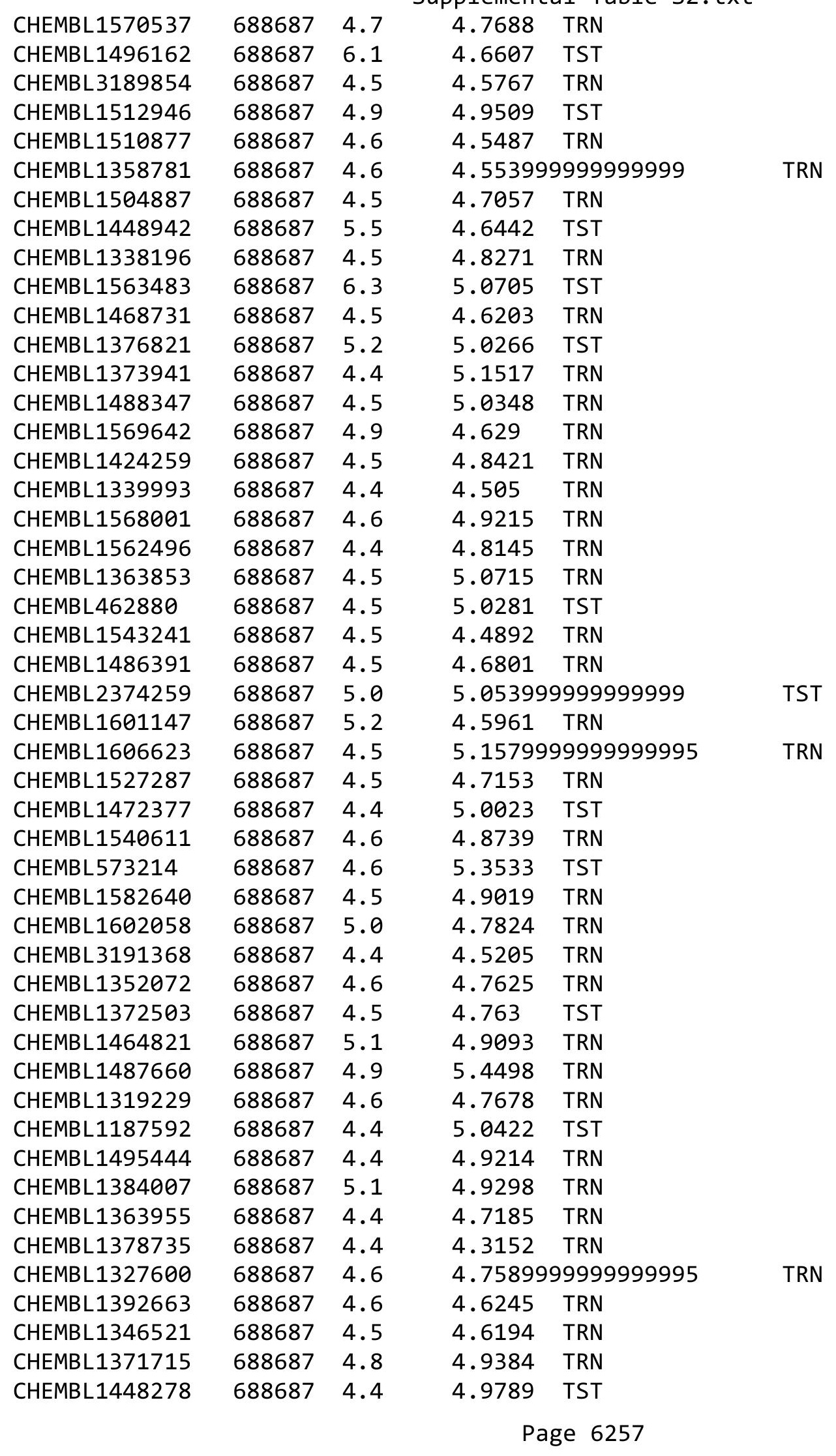




\begin{tabular}{|c|c|c|c|c|}
\hline & & & pplement & 0 \\
\hline CHEMBL453376 & 688687 & 5.2 & 4.8901 & TST \\
\hline CHEMBL1468353 & 688687 & 4.5 & 4.6905 & TRN \\
\hline CHEMBL1540421 & 688687 & 4.4 & 4.8126 & TRN \\
\hline CHEMBL1326844 & 688687 & 4.6 & 4.9858 & TRN \\
\hline CHEMBL1360146 & 688687 & 6.3 & 5.2095 & TRN \\
\hline CHEMBL1490504 & 688687 & 4.7 & 4.8883 & TRN \\
\hline CHEMBL570345 & 688687 & 6.2 & 5.154 & TRN \\
\hline CHEMBL1333061 & 688687 & 4.5 & 4.9229 & TRN \\
\hline CHEMBL1532604 & 688687 & 4.7 & 4.7664 & TRN \\
\hline CHEMBL1505320 & 688687 & 4.5 & 5.0594 & TRN \\
\hline CHEMBL1300479 & 688687 & 5.7 & 4.8532 & TST \\
\hline CHEMBL157093 & 688687 & 4.5 & 5.0109 & TST \\
\hline CHEMBL1340072 & 688687 & 4.5 & 4.6172 & TST \\
\hline CHEMBL1437226 & 688687 & 4.5 & 4.8254 & TRN \\
\hline CHEMBL1368572 & 688687 & 6.1 & 5.2225 & TST \\
\hline CHEMBL1467705 & 688687 & 5.1 & 5.0898 & TRN \\
\hline CHEMBL1508826 & 688687 & 5.5 & 4.9227 & TRN \\
\hline CHEMBL1586156 & 688687 & 4.7 & 4.7583 & TRN \\
\hline CHEMBL1474479 & 688687 & 4.9 & 4.8986 & TRN \\
\hline CHEMBL1544223 & 688687 & 5.7 & 4.8621 & TRN \\
\hline CHEMBL1470492 & 688687 & 7.2 & 5.1133 & TRN \\
\hline CHEMBL1416009 & 688687 & 6.1 & 4.9953 & TST \\
\hline CHEMBL1469830 & 688687 & 4.6 & 4.7271 & TRN \\
\hline CHEMBL1576312 & 688687 & 4.5 & 4.6096 & TRN \\
\hline CHEMBL1432436 & 688687 & 5.8 & 5.001 & TRN \\
\hline CHEMBL1422602 & 688687 & 4.5 & 4.6874 & TRN \\
\hline CHEMBL1574979 & 688687 & 4.6 & 4.5563 & TRN \\
\hline CHEMBL1346720 & 688687 & 4.4 & 4.89 & TRN \\
\hline CHEMBL1478622 & 688687 & 4.4 & 4.5581 & TRN \\
\hline CHEMBL1327720 & 688687 & 4.5 & 4.5922 & TRN \\
\hline CHEMBL1523545 & 688687 & 4.9 & 5.0031 & TST \\
\hline CHEMBL1528124 & 688687 & 4.4 & 4.5654 & TRN \\
\hline CHEMBL1588672 & 688687 & 4.5 & 4.9827 & TRN \\
\hline CHEMBL1459318 & 688687 & 4.5 & 4.7554 & TRN \\
\hline CHEMBL1455260 & 688687 & 5.2 & 5.5034 & TRN \\
\hline CHEMBL1448520 & 688687 & 5.8 & 4.9784 & TRN \\
\hline CHEMBL1519576 & 688687 & 4.5 & 4.7535 & TRN \\
\hline CHEMBL582081 & 688687 & 4.5 & 4.8842 & TRN \\
\hline CHEMBL1560689 & 688687 & 4.5 & 4.8513 & TST \\
\hline CHEMBL1372903 & 688687 & 4.4 & 4.8777 & TRN \\
\hline CHEMBL1350461 & 688687 & 5.1 & 4.9352 & TST \\
\hline CHEMBL1460342 & 688687 & 5.2 & 4.8169 & TST \\
\hline CHEMBL1393339 & 688687 & 4.4 & 4.7297 & TRN \\
\hline CHEMBL1506668 & 688687 & 5.5 & 5.1198 & TRN \\
\hline CHEMBL1563647 & 688687 & 5.2 & 4.6959 & TRN \\
\hline CHEMBL1385434 & 688687 & 5.2 & 5.0612 & TRN \\
\hline CHEMBL1450534 & 688687 & 4.6 & 4.7942 & TRN \\
\hline CHEMBL1498173 & 688687 & 4.5 & 4.4156 & TRN \\
\hline
\end{tabular}




\begin{tabular}{|c|c|c|c|c|}
\hline & & & & $a \perp$ la \\
\hline CHEMBL1333952 & 688687 & 4.4 & 4.8805 & TRN \\
\hline CHEMBL1471674 & 688687 & 4.4 & 4.6468 & TRN \\
\hline CHEMBL1414356 & 688687 & 4.4 & 4.92899 & 9999999999 \\
\hline CHEMBL1425808 & 688687 & 4.6 & 4.6715 & TRN \\
\hline CHEMBL1544647 & 688687 & 4.6 & 4.6898 & TRN \\
\hline CHEMBL1345948 & 688687 & 4.4 & 4.7603 & TRN \\
\hline CHEMBL1499110 & 688687 & 4.6 & 5.155 & TRN \\
\hline CHEMBL1437013 & 688687 & 4.6 & 4.7135 & TRN \\
\hline CHEMBL1329526 & 688687 & 4.5 & 4.6156 & TRN \\
\hline CHEMBL1480968 & 688687 & 4.8 & 4.6147 & TRN \\
\hline CHEMBL1519685 & 688687 & 4.6 & 4.9781 & TRN \\
\hline CHEMBL1378090 & 688687 & 4.6 & 5.0985 & TST \\
\hline CHEMBL3213918 & 688687 & 5.5 & 4.8147 & TRN \\
\hline CHEMBL1585417 & 688687 & 4.5 & 4.9576 & TRN \\
\hline CHEMBL1566780 & 688687 & 5.3 & 4.8837 & TRN \\
\hline CHEMBL1538037 & 688687 & 4.7 & 4.8454 & TRN \\
\hline CHEMBL1323973 & 688687 & 4.5 & 5.1761 & TST \\
\hline CHEMBL1500773 & 688687 & 4.6 & 4.7437 & TRN \\
\hline CHEMBL1428889 & 688687 & 4.6 & 4.5979 & TRN \\
\hline CHEMBL56731 & 688687 & 6.0 & 5.8627 & TRN \\
\hline CHEMBL1496523 & 688687 & 4.6 & 4.6998 & TRN \\
\hline CHEMBL1546697 & 688687 & 6.0 & 5.1114 & TRN \\
\hline CHEMBL587714 & 688687 & 4.4 & 4.989 & TST \\
\hline CHEMBL1308610 & 688687 & 4.5 & 4.2968 & TRN \\
\hline CHEMBL1322486 & 688687 & 4.6 & 4.7783 & TRN \\
\hline CHEMBL1449702 & 688687 & 4.4 & 4.7263 & TRN \\
\hline CHEMBL1563085 & 688687 & 4.4 & 4.3396 & TRN \\
\hline CHEMBL1528573 & 688687 & 4.6 & 4.9247 & TRN \\
\hline CHEMBL1367929 & 688687 & 4.8 & 4.8575 & TRN \\
\hline CHEMBL1418494 & 688687 & 4.4 & 4.5065 & TRN \\
\hline CHEMBL72365 & 688687 & 4.9 & 4.9025 & TST \\
\hline CHEMBL 221733 & 688687 & 5.8 & 5.0026 & TRN \\
\hline CHEMBL3198017 & 688687 & 4.5 & 4.5991 & TRN \\
\hline CHEMBL1607110 & 688687 & 4.7 & 4.7293 & TRN \\
\hline CHEMBL1331647 & 688687 & 4.6 & 5.1679 & TRN \\
\hline CHEMBL1412282 & 688687 & 4.8 & 4.723 & TRN \\
\hline CHEMBL1336949 & 688687 & 4.6 & 4.8879 & TST \\
\hline CHEMBL1410635 & 688687 & 4.8 & 5.0556 & TST \\
\hline CHEMBL1552172 & 688687 & 4.5 & 4.488 & TRN \\
\hline CHEMBL1462934 & 688687 & 4.9 & 4.5779 & TRN \\
\hline CHEMBL1488782 & 688687 & 4.5 & 4.7669 & TRN \\
\hline CHEMBL406555 & 688687 & 4.7 & 4.875 & TRN \\
\hline CHEMBL1599015 & 688687 & 4.4 & 4.5516 & TRN \\
\hline CHEMBL1603560 & 688687 & 4.4 & 4.391 & TRN \\
\hline CHEMBL1588325 & 688687 & 4.4 & 4.8093 & TRN \\
\hline CHEMBL1386431 & 688687 & 4.4 & 4.2891 & TRN \\
\hline CHEMBL1445109 & 688687 & 4.6 & 5.0787 & TST \\
\hline CHEMBL1340070 & 688687 & 5.1 & 4.9029 & TST \\
\hline
\end{tabular}

TRN 


\begin{tabular}{|c|c|c|c|c|}
\hline \\
\hline CHEMBL1423400 & 688687 & 4.4 & 4.8633 & TRN \\
\hline CHEMBL1576098 & 688687 & 4.8 & 4.9689 & TRN \\
\hline CHEMBL1543114 & 688687 & 4.5 & 4.9019 & TRN \\
\hline CHEMBL1581800 & 688687 & 4.5 & 4.8835 & TRN \\
\hline CHEMBL1571268 & 688687 & 4.6 & 4.7534 & TRN \\
\hline CHEMBL1393020 & 688687 & 4.6 & 4.8624 & TRN \\
\hline CHEMBL1504368 & 688687 & 5.8 & 5.0917 & TRN \\
\hline CHEMBL1468097 & 688687 & 4.5 & 4.5645 & TRN \\
\hline CHEMBL1526290 & 688687 & 4.6 & 4.7981 & TRN \\
\hline CHEMBL1732424 & 688687 & 4.5 & 4.8685 & TST \\
\hline CHEMBL1528298 & 688687 & 4.5 & 4.5554 & TRN \\
\hline CHEMBL1337035 & 688687 & 4.5 & 4.5099 & TRN \\
\hline CHEMBL1340739 & 688687 & 5.2 & 4.9297 & TRN \\
\hline CHEMBL3196261 & 688687 & 7.4001 & 4.8254 & TST \\
\hline CHEMBL1438117 & 688687 & 4.4 & 4.6228 & TRN \\
\hline CHEMBL1429947 & 688687 & 4.8 & 4.9097 & TRN \\
\hline CHEMBL1444351 & 688687 & 5.9 & 5.5613 & TRN \\
\hline CHEMBL1313755 & 688687 & 4.4 & 4.5658 & TRN \\
\hline CHEMBL1471738 & 688687 & 4.5 & 4.7586 & TRN \\
\hline CHEMBL1586091 & 688687 & 4.5 & 4.5579 & TRN \\
\hline CHEMBL1506086 & 688687 & 6.7001 & 4.9489 & TRN \\
\hline CHEMBL1339178 & 688687 & 4.4 & 4.7372 & TST \\
\hline CHEMBL1327424 & 688687 & 4.5 & 4.5699 & TRN \\
\hline CHEMBL1412661 & 688687 & 4.5 & 4.9647 & TRN \\
\hline CHEMBL1391298 & 688687 & 4.6 & 5.0681 & TRN \\
\hline CHEMBL263376 & 688687 & 4.6 & 4.9551 & TRN \\
\hline CHEMBL1435077 & 688687 & 4.5 & 4.7295 & TRN \\
\hline CHEMBL3191286 & 688687 & 6.3 & 5.4146 & TRN \\
\hline CHEMBL1487249 & 688687 & 4.4 & 4.9873 & TRN \\
\hline CHEMBL1568090 & 688687 & 4.6 & 5.0075 & TRN \\
\hline CHEMBL1535057 & 688687 & 6.3 & 5.5065 & TST \\
\hline CHEMBL1518206 & 688687 & 4.5 & 4.7915 & TRN \\
\hline CHEMBL1504149 & 688687 & 4.6 & 4.7054 & TRN \\
\hline CHEMBL1586973 & 688687 & 5.2 & 5.0649 & TRN \\
\hline CHEMBL165 & 688687 & 6.0 & 5.5082 & TRN \\
\hline CHEMBL1552839 & 688687 & 6.0 & 5.1624 & TRN \\
\hline CHEMBL1388324 & 688687 & 5.5 & 4.7491 & TRN \\
\hline CHEMBL1499961 & 688687 & 4.9 & 4.944 & TRN \\
\hline CHEMBL572994 & 688687 & 6.8 & 5.358 & TST \\
\hline CHEMBL1367968 & 688687 & 4.4 & 4.9512 & TST \\
\hline CHEMBL1513928 & 688687 & 4.4 & 4.8593 & TRN \\
\hline CHEMBL1362288 & 688687 & 4.4 & 4.7003 & TRN \\
\hline CHEMBL1334820 & 688687 & 5.4 & 4.9929 & TRN \\
\hline CHEMBL544115 & 688687 & 5.9 & 5.0005 & TST \\
\hline CHEMBL1509778 & 688687 & 4.8 & 4.5776 & TRN \\
\hline CHEMBL1454876 & 688687 & 4.5 & 4.5637 & TRN \\
\hline CHEMBL1473270 & 688687 & 4.5 & 5.0463 & TST \\
\hline CHEMBL1500317 & 688687 & 4.6 & 4.5377 & TRN \\
\hline
\end{tabular}




\begin{tabular}{|c|c|c|c|c|c|}
\hline \multicolumn{6}{|c|}{ Supplemental Table S2.txt } \\
\hline CHEMBL2358182 & 688687 & 4.6 & 4.4848 & TRN & \\
\hline CHEMBL1431888 & 688687 & 5.1 & 4.8352 & TRN & \\
\hline CHEMBL1311827 & 688687 & 4.8 & 4.8616 & TRN & \\
\hline CHEMBL1388051 & 688687 & 4.9 & 4.8814 & TRN & \\
\hline CHEMBL1519586 & 688687 & 4.8 & 5.1749 & TRN & \\
\hline CHEMBL1466373 & 688687 & 4.9 & 4.6347 & TRN & \\
\hline CHEMBL1531157 & 688687 & 4.6 & 4.627 & TRN & \\
\hline CHEMBL1460295 & 688687 & 4.6 & 4.5348 & TRN & \\
\hline CHEMBL1479675 & 688687 & 4.6 & 4.9817 & TRN & \\
\hline CHEMBL1474 & 688687 & 4.4 & 4.7987 & TST & \\
\hline CHEMBL1497581 & 688687 & 4.4 & 4.7588 & TRN & \\
\hline CHEMBL1464502 & 688687 & 4.9 & 4.5691 & TRN & \\
\hline CHEMBL1577104 & 688687 & 4.6 & 4.7576 & TRN & \\
\hline CHEMBL1364723 & 688687 & 7.6003 & 5.1801 & TST & \\
\hline CHEMBL1478660 & 688687 & 5.0 & 4.6961 & TRN & \\
\hline CHEMBL1557576 & 688687 & 5.3 & 5.0338 & TRN & \\
\hline CHEMBL1596024 & 688687 & 4.5 & 4.6894 & TRN & \\
\hline CHEMBL1347981 & 688687 & 4.4 & 5.0516 & TRN & \\
\hline CHEMBL1567402 & 688687 & 5.6 & 4.9207 & TRN & \\
\hline CHEMBL1306790 & 688687 & 4.4 & 4.8372 & TRN & \\
\hline CHEMBL1351716 & 688687 & 4.5 & 4.6847 & TRN & \\
\hline CHEMBL1467245 & 688687 & 4.4 & 4.8246 & TRN & \\
\hline CHEMBL1608748 & 688687 & 4.5 & 4.5034 & TRN & \\
\hline CHEMBL1598960 & 688687 & 5.0 & 5.0308 & TST & \\
\hline CHEMBL1502059 & 688687 & 4.5 & 4.85800 & 00000000005 & TRN \\
\hline CHEMBL1311173 & 688687 & 4.5 & 4.598 & TRN & \\
\hline CHEMBL1445850 & 688687 & 4.6 & 4.6259 & TRN & \\
\hline CHEMBL1464386 & 688687 & 4.6 & 4.5607 & TRN & \\
\hline CHEMBL1331245 & 688687 & 5.9 & 5.5947 & TRN & \\
\hline CHEMBL1540596 & 688687 & 4.6 & 5.0614 & TRN & \\
\hline CHEMBL184074 & 688687 & 4.4 & 4.7634 & TST & \\
\hline CHEMBL1588642 & 688687 & 5.2 & 4.8567 & TRN & \\
\hline CHEMBL1549435 & 688687 & 4.9 & 5.0048 & TST & \\
\hline CHEMBL1477057 & 688687 & 4.6 & 4.7485 & TRN & \\
\hline CHEMBL1450564 & 688687 & 4.5 & 4.7609 & TRN & \\
\hline CHEMBL1339794 & 688687 & 5.3 & 5.0119 & TRN & \\
\hline CHEMBL1541876 & 688687 & 5.5 & 4.8089 & TRN & \\
\hline CHEMBL1415927 & 688687 & 6.2 & 4.7477 & TST & \\
\hline CHEMBL380071 & 688687 & 4.4 & 5.0496 & TRN & \\
\hline CHEMBL1568767 & 688687 & 4.4 & 4.3618 & TRN & \\
\hline CHEMBL1606699 & 688687 & 4.7 & 4.7781 & TRN & \\
\hline CHEMBL172064 & 688687 & 6.0 & 5.0773 & TST & \\
\hline CHEMBL1300255 & 688687 & 4.4 & 4.6304 & TRN & \\
\hline CHEMBL1521830 & 688687 & 4.7 & 4.756 & TRN & \\
\hline CHEMBL1370926 & 688687 & 6.0 & 5.1872 & TST & \\
\hline CHEMBL1430935 & 688687 & 5.1 & 4.7818 & TST & \\
\hline CHEMBL1392532 & 688687 & 4.7 & 4.9298 & TRN & \\
\hline CHEMBL38508 & 688687 & 5.3 & 4.6939 & TST & \\
\hline
\end{tabular}




\begin{tabular}{|c|c|c|c|c|}
\hline & & & & $a \perp 1 a$ \\
\hline CHEMBL1558796 & 688687 & 4.8 & 5.0961 & TRN \\
\hline CHEMBL1462474 & 688687 & 5.6 & 5.2769 & TRN \\
\hline CHEMBL1337016 & 688687 & 4.4 & 4.2679 & TRN \\
\hline CHEMBL 3214278 & 688687 & 4.9 & 4.8237 & TST \\
\hline CHEMBL1564253 & 688687 & 5.6 & 4.9153 & TRN \\
\hline CHEMBL1494345 & 688687 & 4.5 & 5.2798 & TRN \\
\hline CHEMBL1336259 & 688687 & 4.5 & 4.7267 & TST \\
\hline CHEMBL1332930 & 688687 & 4.5 & 4.8846 & TST \\
\hline CHEMBL1362838 & 688687 & 4.7 & 4.5248 & TRN \\
\hline CHEMBL1426384 & 688687 & 4.4 & 4.7157 & TRN \\
\hline CHEMBL1545566 & 688687 & 5.5 & 4.7949 & TRN \\
\hline CHEMBL1438854 & 688687 & 4.5 & 4.9764 & TRN \\
\hline CHEMBL1374755 & 688687 & 4.8 & 4.7492 & TRN \\
\hline CHEMBL1386204 & 688687 & 4.4 & 4.5953 & TRN \\
\hline CHEMBL1484692 & 688687 & 5.5 & 4.8272 & TRN \\
\hline CHEMBL1511786 & 688687 & 5.0 & 4.5155 & TRN \\
\hline CHEMBL2373666 & 688687 & 4.4 & 4.8675 & TST \\
\hline CHEMBL1460017 & 688687 & 4.4 & 4.6425 & TRN \\
\hline CHEMBL1405193 & 688687 & 4.5 & 4.8183 & TRN \\
\hline CHEMBL1422438 & 688687 & 4.4 & 4.7338 & TRN \\
\hline CHEMBL1468507 & 688687 & 4.5 & 4.6041 & TRN \\
\hline CHEMBL1544635 & 688687 & 4.4 & 4.6187 & TRN \\
\hline CHEMBL1304385 & 688687 & 4.4 & 4.9053 & TRN \\
\hline CHEMBL1576166 & 688687 & 5.4 & 4.777 & TRN \\
\hline CHEMBL1489826 & 688687 & 4.5 & 4.5989 & TRN \\
\hline CHEMBL1481440 & 688687 & 4.5 & 4.5857 & TRN \\
\hline CHEMBL1321132 & 688687 & 5.9 & 5.1589 & TRN \\
\hline CHEMBL1602645 & 688687 & 5.5 & 4.6667 & TRN \\
\hline CHEMBL 224214 & 688687 & 4.5 & 4.82 & TRN \\
\hline CHEMBL1542068 & 688687 & 4.8 & 4.8793 & TRN \\
\hline CHEMBL1489346 & 688687 & 4.7 & 4.9547 & TST \\
\hline CHEMBL1521509 & 688687 & 5.7 & 4.8467 & TRN \\
\hline CHEMBL3198962 & 688687 & 5.0 & 5.0469 & TRN \\
\hline CHEMBL514432 & 688687 & 4.6 & 5.1526 & TST \\
\hline CHEMBL1487532 & 688687 & 5.1 & 5.2234 & TST \\
\hline CHEMBL259421 & 688687 & 5.5 & 4.8308 & TRN \\
\hline CHEMBL1728023 & 688687 & 6.0 & 5.5776 & TRN \\
\hline CHEMBL1607753 & 688687 & 4.6 & 4.8905 & TST \\
\hline CHEMBL1320821 & 688687 & 4.5 & 4.9808 & TRN \\
\hline CHEMBL1410824 & 688687 & 4.6 & 4.5341 & TRN \\
\hline CHEMBL1308260 & 688687 & 4.8 & 4.6262 & TRN \\
\hline CHEMBL1374536 & 688687 & 5.1 & 5.2705 & TRN \\
\hline CHEMBL1320506 & 688687 & 4.4 & 4.4286 & TRN \\
\hline CHEMBL1379646 & 688687 & 4.5 & 4.5116 & TRN \\
\hline CHEMBL1359565 & 688687 & 4.5 & 4.7825 & TRN \\
\hline CHEMBL1388160 & 688687 & 4.5 & 5.2472 & TST \\
\hline CHEMBL1590886 & 688687 & 5.6 & 4.845 & TRN \\
\hline CHEMBL1371007 & 688687 & 5.4 & 5.0573 & TRN \\
\hline
\end{tabular}




\begin{tabular}{|c|c|c|c|c|c|}
\hline \multicolumn{6}{|c|}{ Supplemental Table S2.txt } \\
\hline CHEMBL220845 & 688687 & 6.6 & 5.7347 & TRN & \\
\hline CHEMBL1422252 & 688687 & 4.5 & 5.0716 & TST & \\
\hline CHEMBL1405909 & 688687 & 4.5 & 4.8583 & TRN & \\
\hline CHEMBL1394764 & 688687 & 4.9 & 4.8754 & TST & \\
\hline CHEMBL1581520 & 688687 & 4.4 & 4.4949 & TRN & \\
\hline CHEMBL3197415 & 688687 & 4.6 & 4.5508 & TRN & \\
\hline CHEMBL1557155 & 688687 & 4.4 & $4.9910 e$ & 00000000005 & TRN \\
\hline CHEMBL1473366 & 688687 & 4.4 & 4.5678 & TRN & \\
\hline CHEMBL1573711 & 688687 & 4.8 & 4.9576 & TST & \\
\hline CHEMBL1508424 & 688687 & 4.7 & 4.6426 & TRN & \\
\hline CHEMBL1555682 & 688687 & 4.6 & $4.6160 €$ & 00000000005 & TST \\
\hline CHEMBL469309 & 688687 & 5.6 & 5.3344 & TRN & \\
\hline CHEMBL1470899 & 688687 & 4.7 & 4.6586 & TST & \\
\hline CHEMBL1488952 & 688687 & 5.0 & 4.8826 & TRN & \\
\hline CHEMBL1360942 & 688687 & 5.4 & 5.2392 & TST & \\
\hline CHEMBL1362964 & 688687 & 4.8 & 4.6073 & TRN & \\
\hline CHEMBL1363241 & 688687 & 4.5 & 4.8277 & TRN & \\
\hline CHEMBL1445799 & 688687 & 4.4 & 4.9826 & TRN & \\
\hline CHEMBL1349514 & 688687 & 4.5 & 4.5147 & TRN & \\
\hline CHEMBL1526428 & 688687 & 5.4 & 4.6173 & TST & \\
\hline CHEMBL1419183 & 688687 & 4.4 & 4.8389 & TRN & \\
\hline CHEMBL296407 & 688687 & 4.5 & 6.0224 & TRN & \\
\hline CHEMBL1389724 & 688687 & 4.4 & 4.6997 & TRN & \\
\hline CHEMBL1471969 & 688687 & 4.5 & 4.9148 & TRN & \\
\hline CHEMBL1488433 & 688687 & 5.4 & 4.523 & TRN & \\
\hline CHEMBL85139 & 688687 & 4.6 & 4.8776 & TRN & \\
\hline CHEMBL1530084 & 688687 & 5.6 & 4.8859 & TRN & \\
\hline CHEMBL1480939 & 688687 & 4.5 & 4.6738 & TRN & \\
\hline CHEMBL1439019 & 688687 & 6.7001 & 5.1076 & TRN & \\
\hline CHEMBL1386207 & 688687 & 4.6 & 4.68199 & 99999999995 & TST \\
\hline CHEMBL1340697 & 688687 & 4.8 & 4.6126 & TRN & \\
\hline CHEMBL1572777 & 688687 & 5.4 & 4.8772 & TRN & \\
\hline CHEMBL1300912 & 688687 & 4.6 & 4.827 & TRN & \\
\hline CHEMBL586058 & 688687 & 4.4 & 4.7436 & TST & \\
\hline CHEMBL1440808 & 688687 & 4.6 & 4.4635 & TRN & \\
\hline CHEMBL1595761 & 688687 & 4.4 & 4.3884 & TRN & \\
\hline CHEMBL 1450470 & 688687 & 4.5 & 4.5739 & TRN & \\
\hline CHEMBL1312447 & 688687 & 5.4 & 4.9658 & TRN & \\
\hline CHEMBL1439893 & 688687 & 5.5 & 4.7934 & TRN & \\
\hline CHEMBL1331857 & 688687 & 4.6 & 4.9557 & TRN & \\
\hline CHEMBL1458941 & 688687 & 4.4 & 4.8757 & TST & \\
\hline CHEMBL1574021 & 688687 & 4.7 & 5.2089 & TRN & \\
\hline CHEMBL1492434 & 688687 & 5.5 & 4.8797 & TST & \\
\hline CHEMBL1447527 & 688687 & 5.5 & 5.1941 & TST & \\
\hline CHEMBL1543554 & 688687 & 4.4 & 4.6762 & TRN & \\
\hline CHEMBL1386385 & 688687 & 4.8 & 4.9336 & TRN & \\
\hline CHEMBL1349978 & 688687 & 4.5 & 4.7532 & TRN & \\
\hline CHEMBL1367030 & 688687 & 5.4 & 5.4683 & TRN & \\
\hline
\end{tabular}




\begin{tabular}{|c|c|c|c|c|}
\hline & & & & al lable \\
\hline CHEMBL1421372 & 688687 & 4.5 & 4.8205 & TRN \\
\hline CHEMBL1534227 & 688687 & 4.6 & 4.5275 & TRN \\
\hline CHEMBL1378485 & 688687 & 4.6 & 4.7937 & TRN \\
\hline CHEMBL1592470 & 688687 & 4.6 & 4.756 & TRN \\
\hline CHEMBL1527742 & 688687 & 5.4 & 5.2094 & TRN \\
\hline CHEMBL1491288 & 688687 & 5.9 & 5.3168 & TRN \\
\hline CHEMBL1345866 & 688687 & 6.2 & 4.8792 & TST \\
\hline CHEMBL1385419 & 688687 & 4.4 & 4.4248 & TRN \\
\hline CHEMBL1431853 & 688687 & 5.5 & 5.3805 & TRN \\
\hline CHEMBL1300106 & 688687 & 5.4 & 5.0825 & TRN \\
\hline CHEMBL1537700 & 688687 & 4.6 & 4.5675 & TRN \\
\hline CHEMBL1468708 & 688687 & 4.6 & 4.7976 & TRN \\
\hline CHEMBL1395027 & 688687 & 4.8 & 5.0001 & TRN \\
\hline CHEMBL1438751 & 688687 & 4.4 & 4.3881 & TST \\
\hline CHEMBL1486790 & 688687 & 4.4 & 4.8784 & TRN \\
\hline CHEMBL1572127 & 688687 & 4.4 & 4.5596 & TRN \\
\hline CHEMBL1257041 & 688687 & 5.8 & 5.2682 & TST \\
\hline CHEMBL1522688 & 688687 & 4.6 & 4.6386 & TRN \\
\hline CHEMBL88584 & 688687 & 4.6 & 4.905 & TRN \\
\hline CHEMBL1312768 & 688687 & 4.6 & 4.6652 & TRN \\
\hline CHEMBL1383829 & 688687 & 5.4 & 4.8252 & TRN \\
\hline CHEMBL1348518 & 688687 & 4.4 & 4.6703 & TRN \\
\hline CHEMBL1999648 & 688687 & 4.4 & 4.7725 & TST \\
\hline CHEMBL3190863 & 688687 & 4.4 & 4.7571 & TRN \\
\hline CHEMBL1534814 & 688687 & 4.5 & 4.7246 & TRN \\
\hline CHEMBL1609172 & 688687 & 4.4 & 4.69600 & 0000000001 \\
\hline CHEMBL1339527 & 688687 & 4.9 & 4.8704 & TRN \\
\hline CHEMBL1600491 & 688687 & 4.4 & 4.6788 & TRN \\
\hline CHEMBL1471912 & 688687 & 4.4 & 4.6493 & TRN \\
\hline CHEMBL1518911 & 688687 & 4.4 & 4.8207 & TRN \\
\hline CHEMBL1485713 & 688687 & 4.6 & 4.575 & TRN \\
\hline CHEMBL1603509 & 688687 & 4.6 & 4.8799 & TRN \\
\hline CHEMBL1336664 & 688687 & 4.6 & 5.2997 & TRN \\
\hline CHEMBL1416373 & 688687 & 4.5 & 4.7923 & TRN \\
\hline CHEMBL1528903 & 688687 & 4.5 & 4.6062 & TRN \\
\hline CHEMBL1505672 & 688687 & 4.5 & 4.7667 & TRN \\
\hline CHEMBL1430604 & 688687 & 4.7 & 4.7959 & TRN \\
\hline CHEMBL1520555 & 688687 & 4.7 & 4.3322 & TRN \\
\hline CHEMBL1609927 & 688687 & 4.8 & 4.9768 & TRN \\
\hline CHEMBL1314291 & 688687 & 4.4 & 4.7457 & TRN \\
\hline CHEMBL1420687 & 688687 & 4.8 & 4.7093 & TRN \\
\hline CHEMBL1482809 & 688687 & 4.5 & 4.2703 & TRN \\
\hline CHEMBL1345037 & 688687 & 4.9 & 5.1288 & TRN \\
\hline CHEMBL1491586 & 688687 & 4.5 & 5.1467 & TST \\
\hline CHEMBL1325128 & 688687 & 4.4 & 4.7896 & TRN \\
\hline CHEMBL1601692 & 688687 & 4.4 & 4.5317 & TRN \\
\hline CHEMBL1372512 & 688687 & 4.6 & 4.9038 & TST \\
\hline CHEMBL1478628 & 688687 & 4.4 & 4.8861 & TRN \\
\hline
\end{tabular}




\begin{tabular}{|c|c|c|c|c|}
\hline & & & ient & $a \perp 1 a$ \\
\hline CHEMBL1363128 & 688687 & 5.9 & 5.0338 & TRN \\
\hline CHEMBL1418519 & 688687 & 4.4 & 4.7515 & TRN \\
\hline CHEMBL1525222 & 688687 & 4.5 & 4.6777 & TRN \\
\hline CHEMBL1446539 & 688687 & 4.5 & 4.4831 & TRN \\
\hline CHEMBL1328607 & 688687 & 5.3 & 5.3693 & TST \\
\hline CHEMBL1334148 & 688687 & 4.6 & 4.6712 & TRN \\
\hline CHEMBL1408465 & 688687 & 4.6 & 4.4878 & TRN \\
\hline CHEMBL1541811 & 688687 & 4.4 & 4.9463 & TRN \\
\hline CHEMBL1333708 & 688687 & 4.4 & 4.7331 & TRN \\
\hline CHEMBL1423146 & 688687 & 5.1 & 4.8553 & TRN \\
\hline CHEMBL1496575 & 688687 & 4.8 & 5.2973 & TST \\
\hline CHEMBL1568866 & 688687 & 4.4 & 5.0794 & TRN \\
\hline CHEMBL1504657 & 688687 & 4.4 & 4.6959 & TRN \\
\hline CHEMBL1472229 & 688687 & 4.5 & 4.8248 & TRN \\
\hline CHEMBL1403748 & 688687 & 4.8 & 4.8622 & TRN \\
\hline CHEMBL1562990 & 688687 & 4.6 & 4.8432 & TRN \\
\hline CHEMBL1515858 & 688687 & 5.3 & 4.9093 & TRN \\
\hline CHEMBL1362221 & 688687 & 5.7 & 5.7104 & TRN \\
\hline CHEMBL1416566 & 688687 & 4.8 & 4.7529 & TRN \\
\hline CHEMBL1504708 & 688687 & 4.4 & 4.8101 & TRN \\
\hline CHEMBL 3208751 & 688687 & 4.4 & 4.5356 & TRN \\
\hline CHEMBL1488131 & 688687 & 6.0 & 4.8366 & TST \\
\hline CHEMBL1444485 & 688687 & 4.8 & 5.0301 & TRN \\
\hline CHEMBL1480110 & 688687 & 4.5 & 4.8192 & TRN \\
\hline CHEMBL1597558 & 688687 & 4.5 & 4.9111 & TST \\
\hline CHEMBL1324889 & 688687 & 4.4 & 4.8341 & TRN \\
\hline CHEMBL1527727 & 688687 & 4.4 & 4.79 & TRN \\
\hline CHEMBL1528768 & 688687 & 4.8 & 4.7564 & TRN \\
\hline CHEMBL1575442 & 688687 & 4.6 & 4.7541 & TRN \\
\hline CHEMBL1343376 & 688687 & 4.5 & 4.8329 & TRN \\
\hline CHEMBL1449373 & 688687 & 6.5 & 5.2093 & TRN \\
\hline CHEMBL3195336 & 688687 & 4.4 & 5.0975 & TST \\
\hline CHEMBL1527942 & 688687 & 4.4 & 4.551 & TST \\
\hline CHEMBL1443946 & 688687 & 5.8 & 5.4278 & TST \\
\hline CHEMBL1467954 & 688687 & 4.6 & 5.3385 & TRN \\
\hline CHEMBL1382722 & 688687 & 4.7 & 4.74 & TRN \\
\hline CHEMBL1528688 & 688687 & 6.3 & 5.2043 & TRN \\
\hline CHEMBL1572848 & 688687 & 4.7 & 4.6524 & TRN \\
\hline CHEMBL1470991 & 688687 & 5.1 & 5.0787 & TRN \\
\hline CHEMBL1402426 & 688687 & 4.4 & 4.9357 & TRN \\
\hline CHEMBL1560598 & 688687 & 4.5 & 4.9438 & TRN \\
\hline CHEMBL1422046 & 688687 & 4.5 & 5.0942 & TRN \\
\hline CHEMBL1518099 & 688687 & 4.4 & 4.7817 & TRN \\
\hline CHEMBL1320489 & 688687 & 4.4 & 5.186 & TST \\
\hline CHEMBL1514740 & 688687 & 4.8 & 4.7298 & TRN \\
\hline CHEMBL1361853 & 688687 & 4.7 & 4.7956 & TRN \\
\hline CHEMBL1330867 & 688687 & 4.4 & 4.5983 & TRN \\
\hline CHEMBL1560155 & 688687 & 4.4 & 4.4068 & TRN \\
\hline
\end{tabular}




\begin{tabular}{|c|c|c|c|c|c|}
\hline & & & & & \\
\hline CHEMBL113142 & 688687 & 4.5 & 4.9504 & TRN & \\
\hline CHEMBL1487036 & 688687 & 5.1 & 4.6836 & TRN & \\
\hline CHEMBL1431445 & 688687 & 5.4 & 4.9669 & TST & \\
\hline CHEMBL1455200 & 688687 & 4.7 & 4.796 & TRN & \\
\hline CHEMBL1437918 & 688687 & 4.8 & 4.7594 & TST & \\
\hline CHEMBL1605469 & 688687 & 4.8 & 4.7749 & TRN & \\
\hline CHEMBL1347247 & 688687 & 4.5 & 4.9254 & TST & \\
\hline CHEMBL1444437 & 688687 & 4.7 & 4.8773 & TRN & \\
\hline CHEMBL1577029 & 688687 & 5.3 & 4.6347 & TRN & \\
\hline CHEMBL1325938 & 688687 & 4.9 & 4.6283 & TRN & \\
\hline CHEMBL1413795 & 688687 & 4.9 & 5.5811 & TRN & \\
\hline CHEMBL1352045 & 688687 & 5.3 & 4.8562 & TRN & \\
\hline CHEMBL1376178 & 688687 & 7.0 & 5.0881 & TRN & \\
\hline CHEMBL1509063 & 688687 & 4.8 & 4.5032 & TRN & \\
\hline CHEMBL1560374 & 688687 & 4.9 & 4.7346 & TRN & \\
\hline CHEMBL1363639 & 688687 & 4.5 & 4.8535 & TRN & \\
\hline CHEMBL1333482 & 688687 & 4.5 & 4.5844 & TRN & \\
\hline CHEMBL1441028 & 688687 & 4.6 & 4.9421 & TRN & \\
\hline CHEMBL1602299 & 688687 & 4.4 & 4.6873 & TRN & \\
\hline CHEMBL1466840 & 688687 & 4.8 & 4.8768 & TRN & \\
\hline CHEMBL1485869 & 688687 & 4.9 & 4.8028 & TRN & \\
\hline CHEMBL1308200 & 688687 & 4.5 & 4.9457 & TRN & \\
\hline CHEMBL1363732 & 688687 & 4.6 & 4.7081 & TRN & \\
\hline CHEMBL1486025 & 688687 & 5.1 & 4.8388 & TRN & \\
\hline CHEMBL1547423 & 688687 & 4.5 & 4.6037 & TRN & \\
\hline CHEMBL1341032 & 688687 & 5.4 & 4.98600 & 0000000001 & TRN \\
\hline CHEMBL448966 & 688687 & 4.5 & 4.6203 & TRN & \\
\hline CHEMBL1588601 & 688687 & 5.3 & 4.8398 & TST & \\
\hline CHEMBL1376723 & 688687 & 6.8 & 5.4593 & TRN & \\
\hline CHEMBL1304661 & 688687 & 5.4 & 4.6996 & TRN & \\
\hline CHEMBL1370691 & 688687 & 4.4 & 4.6876 & TRN & \\
\hline CHEMBL1450165 & 688687 & 5.1 & 4.9362 & TRN & \\
\hline CHEMBL1420031 & 688687 & 4.4 & 4.6762 & TRN & \\
\hline CHEMBL1483638 & 688687 & 4.5 & 4.9954 & TRN & \\
\hline CHEMBL1540492 & 688687 & 4.8 & 4.8462 & TRN & \\
\hline CHEMBL1417638 & 688687 & 5.4 & 4.8106 & TRN & \\
\hline CHEMBL1579658 & 688687 & 4.6 & 4.5757 & TRN & \\
\hline CHEMBL1369318 & 688687 & 4.4 & 4.7104 & TRN & \\
\hline CHEMBL1582838 & 688687 & 5.6 & 4.8139 & TRN & \\
\hline CHEMBL1415575 & 688687 & 4.9 & 4.8295 & TRN & \\
\hline CHEMBL1457595 & 688687 & 5.0 & 5.2806 & TRN & \\
\hline CHEMBL1468837 & 688687 & 4.6 & 5.1231 & TRN & \\
\hline CHEMBL1592095 & 688687 & 4.9 & 5.1964 & TST & \\
\hline CHEMBL1471093 & 688687 & 5.0 & 4.8619 & TRN & \\
\hline CHEMBL1504284 & 688687 & 5.9 & 5.6056 & TRN & \\
\hline CHEMBL1565651 & 688687 & 4.5 & 4.9603 & TRN & \\
\hline CHEMBL429335 & 688687 & 4.6 & 4.7973 & TRN & \\
\hline CHEMBL1580103 & 688687 & 4.5 & 4.7573 & TRN & \\
\hline & & & & 6266 & \\
\hline
\end{tabular}




\begin{tabular}{|c|c|c|c|c|c|}
\hline \multicolumn{6}{|c|}{ Supplemental Table S2.txt } \\
\hline CHEMBL1605701 & 688687 & 5.1 & 5.1963 & TRN & \\
\hline CHEMBL1321112 & 688687 & 4.7 & 4.7625 & TRN & \\
\hline CHEMBL1301372 & 688687 & 4.4 & 4.7627 & TRN & \\
\hline CHEMBL1447588 & 688687 & 5.9 & 4.9522 & TST & \\
\hline CHEMBL1520949 & 688687 & 4.6 & 4.6313 & TST & \\
\hline CHEMBL1309107 & 688687 & 4.6 & 4.7884 & TRN & \\
\hline CHEMBL1502773 & 688687 & 4.6 & 5.2608 & TST & \\
\hline CHEMBL1312849 & 688687 & 4.6 & 5.1028 & TST & \\
\hline CHEMBL1581308 & 688687 & 4.6 & 4.8048 & TRN & \\
\hline CHEMBL1357429 & 688687 & 4.6 & 4.7053 & TRN & \\
\hline CHEMBL1428621 & 688687 & 4.9 & 4.8988 & TRN & \\
\hline CHEMBL1491933 & 688687 & 6.0 & 5.013 & TRN & \\
\hline CHEMBL1482759 & 688687 & 6.0 & 5.1871 & TRN & \\
\hline CHEMBL1522300 & 688687 & 4.4 & 4.6329 & TRN & \\
\hline CHEMBL1422053 & 688687 & 5.4 & 5.0535 & TRN & \\
\hline CHEMBL1470485 & 688687 & 7.5003 & 5.4662 & TST & \\
\hline CHEMBL565856 & 688687 & 4.5 & 4.3357 & TRN & \\
\hline CHEMBL1309430 & 688687 & 4.8 & 5.4883 & TST & \\
\hline CHEMBL1321179 & 688687 & 5.4 & 4.8773 & TRN & \\
\hline CHEMBL1430601 & 688687 & 4.8 & 5.0459 & TRN & \\
\hline CHEMBL1604212 & 688687 & 4.4 & 4.6256 & TRN & \\
\hline CHEMBL1339860 & 688687 & 5.5 & 4.5496 & TRN & \\
\hline CHEMBL1392486 & 688687 & 4.6 & 4.8449 & TRN & \\
\hline CHEMBL1550552 & 688687 & 4.4 & 5.0368 & TST & \\
\hline CHEMBL3195801 & 688687 & 4.6 & 4.9367 & TST & \\
\hline CHEMBL1330661 & 688687 & 5.4 & 4.9083 & TRN & \\
\hline CHEMBL1396561 & 688687 & 4.6 & 4.777 & TRN & \\
\hline CHEMBL1441745 & 688687 & 5.8 & 4.7418 & TRN & \\
\hline CHEMBL1541009 & 688687 & 4.4 & 4.7768 & TRN & \\
\hline CHEMBL1592211 & 688687 & 4.4 & 4.5555 & TRN & \\
\hline CHEMBL1375958 & 688687 & 5.2 & 4.7704 & TRN & \\
\hline CHEMBL1255659 & 688687 & 6.2 & 5.0579 & TRN & \\
\hline CHEMBL1548181 & 688687 & 4.7 & $4.6110 e$ & $\partial 000000001$ & TRN \\
\hline CHEMBL1548533 & 688687 & 4.8 & 4.836 & TRN & \\
\hline CHEMBL1416511 & 688687 & 5.1 & 4.555 & TRN & \\
\hline CHEMBL1601153 & 688687 & 4.4 & 4.4191 & TRN & \\
\hline CHEMBL1379905 & 688687 & 5.2 & 5.2985 & TRN & \\
\hline CHEMBL1532225 & 688687 & 4.4 & 4.813 & TRN & \\
\hline CHEMBL1538327 & 688687 & 4.5 & 4.5139 & TRN & \\
\hline CHEMBL1532615 & 688687 & 4.4 & 5.1464 & TST & \\
\hline CHEMBL1466792 & 688687 & 4.6 & 4.6235 & TRN & \\
\hline CHEMBL3199366 & 688687 & 5.4 & 4.9366 & TST & \\
\hline CHEMBL1538886 & 688687 & 5.2 & 4.6219 & TRN & \\
\hline CHEMBL1509049 & 688687 & 4.6 & 4.5255 & TST & \\
\hline CHEMBL3207696 & 688687 & 4.6 & 4.2115 & TRN & \\
\hline CHEMBL1467020 & 688687 & 4.4 & 4.6206 & TRN & \\
\hline CHEMBL1425257 & 688687 & 4.5 & 4.8639 & TRN & \\
\hline CHEMBL1597766 & 688687 & 4.5 & 4.7663 & TRN & \\
\hline
\end{tabular}




\begin{tabular}{|c|c|c|c|c|c|}
\hline & & & & & \\
\hline CHEMBL1362245 & 688687 & 4.6 & 4.9851 & TRN & \\
\hline CHEMBL1487817 & 688687 & 4.5 & 5.0672 & TST & \\
\hline CHEMBL1491026 & 688687 & 4.5 & 4.7557 & TRN & \\
\hline CHEMBL1555657 & 688687 & 4.5 & 4.8367 & TRN & \\
\hline CHEMBL1563220 & 688687 & 4.6 & 4.8007 & TRN & \\
\hline CHEMBL1309506 & 688687 & 4.4 & 4.7565 & TRN & \\
\hline CHEMBL1310191 & 688687 & 4.6 & 4.5673 & TRN & \\
\hline CHEMBL1334041 & 688687 & 4.5 & 4.6045 & TRN & \\
\hline CHEMBL1587932 & 688687 & 4.8 & 4.8501 & TRN & \\
\hline CHEMBL1388742 & 688687 & 4.4 & 4.6064 & TRN & \\
\hline CHEMBL1396301 & 688687 & 4.5 & 4.2872 & TRN & \\
\hline CHEMBL1601181 & 688687 & 4.5 & 4.8605 & TRN & \\
\hline CHEMBL1317235 & 688687 & 4.4 & 4.9459 & TST & \\
\hline CHEMBL1400116 & 688687 & 4.4 & 4.4429 & TRN & \\
\hline CHEMBL1371167 & 688687 & 4.6 & 4.5251 & TRN & \\
\hline CHEMBL1440397 & 688687 & 5.0 & 4.6534 & TST & \\
\hline CHEMBL1350376 & 688687 & 4.4 & 4.7211 & TST & \\
\hline CHEMBL1385344 & 688687 & 4.6 & 4.6884 & TRN & \\
\hline CHEMBL1565171 & 688687 & 4.9 & 4.7704 & TRN & \\
\hline CHEMBL1436222 & 688687 & 5.2 & 4.6409 & TRN & \\
\hline CHEMBL1315129 & 688687 & 4.8 & 5.2339 & TRN & \\
\hline CHEMBL280998 & 688687 & 6.0 & 5.1085 & TRN & \\
\hline CHEMBL1515795 & 688687 & 5.1 & 4.9045 & TST & \\
\hline CHEMBL1530272 & 688687 & 4.6 & 4.5782 & TRN & \\
\hline CHEMBL1583489 & 688687 & 4.5 & 4.6064 & TRN & \\
\hline CHEMBL1299830 & 688687 & 4.6 & 4.6168 & TRN & \\
\hline CHEMBL1332660 & 688687 & 4.6 & 4.945 & TRN & \\
\hline CHEMBL3192897 & 688687 & 4.6 & 4.7501 & TST & \\
\hline CHEMBL1408138 & 688687 & 5.8 & 4.9269 & TRN & \\
\hline CHEMBL1314625 & 688687 & 4.7 & 4.72199 & 99999999995 & TRN \\
\hline CHEMBL1325572 & 688687 & 5.1 & 4.7408 & TRN & \\
\hline CHEMBL1442925 & 688687 & 5.3 & 4.7224 & TRN & \\
\hline CHEMBL1611630 & 688687 & 5.5 & 4.7099 & TRN & \\
\hline CHEMBL37081 & 688687 & 4.9 & 6.0596 & TRN & \\
\hline CHEMBL1429504 & 688687 & 5.5 & 5.0889 & TRN & \\
\hline CHEMBL1448272 & 688687 & 4.6 & 4.6015 & TRN & \\
\hline CHEMBL 540848 & 688687 & 6.0 & 5.0243 & TST & \\
\hline CHEMBL1368232 & 688687 & 5.0 & 4.9041 & TRN & \\
\hline CHEMBL1534514 & 688687 & 4.5 & 4.9185 & TRN & \\
\hline CHEMBL1446866 & 688687 & 4.5 & 4.6818 & TRN & \\
\hline CHEMBL1332922 & 688687 & 4.4 & 4.7525 & TRN & \\
\hline CHEMBL1526488 & 688687 & 4.5 & 4.5867 & TRN & \\
\hline CHEMBL1200766 & 688687 & 5.8 & 5.0516 & TRN & \\
\hline CHEMBL1541000 & 688687 & 4.4 & 4.6118 & TRN & \\
\hline CHEMBL1374573 & 688687 & 4.6 & 5.0743 & TRN & \\
\hline CHEMBL1308590 & 688687 & 4.6 & 4.9189 & TRN & \\
\hline CHEMBL1325367 & 688687 & 4.6 & 5.1489 & TRN & \\
\hline CHEMBL1589489 & 688687 & 4.4 & 4.6159 & TRN & \\
\hline & & & & e 6268 & \\
\hline
\end{tabular}




\begin{tabular}{|c|c|c|c|c|}
\hline & & & & $a \perp 1 a$ \\
\hline CHEMBL1553173 & 688687 & 5.0 & 4.8517 & TRN \\
\hline CHEMBL1380417 & 688687 & 4.6 & 4.8988 & TRN \\
\hline CHEMBL1534573 & 688687 & 4.6 & 4.8375 & TRN \\
\hline CHEMBL1529086 & 688687 & 4.9 & 4.8048 & TRN \\
\hline CHEMBL1543818 & 688687 & 4.5 & 4.6929 & TRN \\
\hline CHEMBL1317208 & 688687 & 5.4 & 4.9228 & TRN \\
\hline CHEMBL1348608 & 688687 & 5.2 & 4.6882 & TRN \\
\hline CHEMBL1450133 & 688687 & 4.4 & 4.6605 & TRN \\
\hline CHEMBL1439504 & 688687 & 4.5 & 4.6602 & TRN \\
\hline CHEMBL418333 & 688687 & 5.5 & 5.01 & TRN \\
\hline CHEMBL1570620 & 688687 & 4.6 & 4.8023 & TRN \\
\hline CHEMBL1485984 & 688687 & 5.5 & 5.0609 & TST \\
\hline CHEMBL1586975 & 688687 & 4.8 & 4.586 & TST \\
\hline CHEMBL1344937 & 688687 & 4.6 & 4.749 & TRN \\
\hline CHEMBL1577622 & 688687 & 4.5 & 4.4895 & TRN \\
\hline CHEMBL1586796 & 688687 & 5.0 & 4.4068 & TRN \\
\hline CHEMBL1532378 & 688687 & 4.5 & 4.8705 & TRN \\
\hline CHEMBL3392062 & 688687 & 4.6 & 4.6362 & TST \\
\hline CHEMBL1362624 & 688687 & 5.1 & 4.8644 & TRN \\
\hline CHEMBL466 & 688687 & 4.9 & 4.7893 & TST \\
\hline CHEMBL26320 & 688687 & 4.4 & 5.1992 & TST \\
\hline CHEMBL1598425 & 688687 & 4.5 & 4.7686 & TRN \\
\hline CHEMBL1305452 & 688687 & 4.8 & 4.8733 & TRN \\
\hline CHEMBL1370010 & 688687 & 6.6 & 5.1644 & TRN \\
\hline CHEMBL1526851 & 688687 & 6.0 & 5.6412 & TRN \\
\hline CHEMBL1566658 & 688687 & 4.4 & 4.7428 & TRN \\
\hline CHEMBL1321749 & 688687 & 4.7 & 4.7875 & TRN \\
\hline CHEMBL1601417 & 688687 & 4.5 & 4.8773 & TRN \\
\hline CHEMBL1380347 & 688687 & 4.4 & 4.4357 & TRN \\
\hline CHEMBL1565799 & 688687 & 5.4 & 4.9108 & TRN \\
\hline CHEMBL1490680 & 688687 & 4.5 & 4.8587 & TST \\
\hline CHEMBL1487307 & 688687 & 4.6 & 4.5875 & TRN \\
\hline CHEMBL1391214 & 688687 & 4.5 & 4.9949 & TRN \\
\hline CHEMBL1445618 & 688687 & 4.5 & 4.7249 & TRN \\
\hline CHEMBL3193298 & 688687 & 4.9 & 4.9929 & TRN \\
\hline CHEMBL1537787 & 688687 & 4.7 & 4.9629 & TRN \\
\hline CHEMBL1421453 & 688687 & 4.4 & 4.9616 & TRN \\
\hline CHEMBL1613477 & 688687 & 4.6 & 4.885 & TST \\
\hline CHEMBL1368115 & 688687 & 4.6 & 4.8065 & TST \\
\hline CHEMBL1532447 & 688687 & 4.5 & 4.8908 & TRN \\
\hline CHEMBL1471361 & 688687 & 5.3 & 4.8137 & TRN \\
\hline CHEMBL3195623 & 688687 & 4.5 & 5.1004 & TRN \\
\hline CHEMBL1431996 & 688687 & 4.5 & 4.5596 & TRN \\
\hline CHEMBL1575796 & 688687 & 4.6 & 4.8371 & TRN \\
\hline CHEMBL1345847 & 688687 & 4.8 & 4.6205 & TRN \\
\hline CHEMBL1443217 & 688687 & 4.7 & 4.8369 & TST \\
\hline CHEMBL1593743 & 688687 & 5.1 & 5.1749 & TST \\
\hline CHEMBL1331095 & 688687 & 4.7 & 4.8358 & TST \\
\hline
\end{tabular}




\begin{tabular}{|c|c|c|c|c|c|}
\hline \\
\hline CHEMBL3212526 & 688687 & 4.4 & 4.725 & TRN & \\
\hline CHEMBL1584897 & 688687 & 4.6 & 4.816 & TRN & \\
\hline CHEMBL1376974 & 688687 & 4.5 & 5.0314 & TST & \\
\hline CHEMBL1406018 & 688687 & 4.5 & 4.6797 & TRN & \\
\hline CHEMBL1353776 & 688687 & 4.7 & 4.6596 & TST & \\
\hline CHEMBL1518723 & 688687 & 5.5 & 4.9956 & TRN & \\
\hline CHEMBL1370718 & 688687 & 5.9 & 5.2465 & TRN & \\
\hline CHEMBL1517068 & 688687 & 4.5 & 4.7794 & TRN & \\
\hline CHEMBL1365170 & 688687 & 5.5 & 4.9736 & TRN & \\
\hline CHEMBL1392298 & 688687 & 4.6 & 4.7358 & TRN & \\
\hline CHEMBL1569470 & 688687 & 4.5 & 4.7764 & TRN & \\
\hline CHEMBL1576840 & 688687 & 4.5 & 4.8279 & TRN & \\
\hline CHEMBL1343053 & 688687 & 5.2 & 4.6174 & TRN & \\
\hline CHEMBL1501048 & 688687 & 4.7 & 4.8594 & TRN & \\
\hline CHEMBL1409828 & 688687 & 4.6 & 4.8884 & TRN & \\
\hline CHEMBL1905194 & 688687 & 4.5 & 4.7645 & TRN & \\
\hline CHEMBL1450136 & 688687 & 4.6 & 4.8078 & TRN & \\
\hline CHEMBL1554018 & 688687 & 4.8 & 4.5735 & TRN & \\
\hline CHEMBL1584629 & 688687 & 4.6 & 4.8868 & TST & \\
\hline CHEMBL1576033 & 688687 & 4.4 & 5.0499 & TST & \\
\hline CHEMBL1588401 & 688687 & 4.5 & 4.7765 & TRN & \\
\hline CHEMBL1489349 & 688687 & 4.6 & 5.047 & TRN & \\
\hline CHEMBL1555713 & 688687 & 4.4 & 4.723 & TRN & \\
\hline CHEMBL1536909 & 688687 & 4.5 & 4.96399 & 99999999995 & TRN \\
\hline CHEMBL1444198 & 688687 & 5.1 & 5.1019 & TRN & \\
\hline CHEMBL1464902 & 688687 & 5.9 & 4.9433 & TRN & \\
\hline CHEMBL1383694 & 688687 & 5.3 & 5.0399 & TRN & \\
\hline CHEMBL1142 & 688687 & 5.5 & 4.9013 & TRN & \\
\hline CHEMBL1556815 & 688687 & 4.4 & 5.0416 & TRN & \\
\hline CHEMBL1494832 & 688687 & 4.7 & 4.8413 & TRN & \\
\hline CHEMBL1607784 & 688687 & 4.7 & 4.8563 & TRN & \\
\hline CHEMBL1330947 & 688687 & 4.4 & 5.0017 & TRN & \\
\hline CHEMBL1605685 & 688687 & 4.5 & 4.7943 & TRN & \\
\hline CHEMBL1543536 & 688687 & 4.4 & 4.7722 & TRN & \\
\hline CHEMBL1503751 & 688687 & 5.3 & 4.672 & TST & \\
\hline CHEMBL1420531 & 688687 & 4.6 & 4.7088 & TRN & \\
\hline CHEMBL1594753 & 688687 & 5.1 & 4.9384 & TRN & \\
\hline CHEMBL1475999 & 688687 & 5.2 & 5.0745 & TST & \\
\hline CHEMBL77387 & 688687 & 6.8 & 5.4896 & TRN & \\
\hline CHEMBL1521036 & 688687 & 4.7 & 4.3844 & TRN & \\
\hline CHEMBL1485067 & 688687 & 4.4 & 4.7587 & TRN & \\
\hline CHEMBL1542541 & 688687 & 4.5 & 4.59 & TRN & \\
\hline CHEMBL1439929 & 688687 & 4.5 & 5.0416 & TRN & \\
\hline CHEMBL1349651 & 688687 & 4.5 & 4.8767 & TRN & \\
\hline CHEMBL1477634 & 688687 & 4.7 & 4.9284 & TRN & \\
\hline CHEMBL1513041 & 688687 & 4.7 & 4.7514 & TRN & \\
\hline CHEMBL1527737 & 688687 & 5.4 & 4.9205 & TRN & \\
\hline CHEMBL1358614 & 688687 & 4.4 & 4.6418 & TRN & \\
\hline
\end{tabular}




\begin{tabular}{|c|c|c|c|c|c|}
\hline & & & & & \\
\hline CHEMBL1450348 & 688687 & 4.5 & 4.734 & TRN & \\
\hline CHEMBL1574451 & 688687 & 5.2 & 4.977 & TRN & \\
\hline CHEMBL1340173 & 688687 & 4.6 & 4.9113 & TST & \\
\hline CHEMBL1424468 & 688687 & 4.4 & 4.5318 & TRN & \\
\hline CHEMBL1361869 & 688687 & 4.4 & 4.6243 & TRN & \\
\hline CHEMBL1352632 & 688687 & 4.4 & 4.98 & TRN & \\
\hline CHEMBL1443465 & 688687 & 4.7 & 4.6423 & TRN & \\
\hline CHEMBL1529141 & 688687 & 4.5 & 5.3794 & TRN & \\
\hline CHEMBL1489906 & 688687 & 5.4 & $5.2620 e$ & 30000000005 & TRN \\
\hline CHEMBL1374097 & 688687 & 4.4 & 4.5359 & TRN & \\
\hline CHEMBL489941 & 688687 & 5.1 & 4.7344 & TRN & \\
\hline CHEMBL1482537 & 688687 & 4.7 & 4.7559 & TRN & \\
\hline CHEMBL1588416 & 688687 & 4.6 & 4.7316 & TRN & \\
\hline CHEMBL1554745 & 688687 & 4.4 & 4.6304 & TRN & \\
\hline CHEMBL1346458 & 688687 & 4.6 & 4.6633 & TRN & \\
\hline CHEMBL3214039 & 688687 & 4.5 & 5.0589 & TRN & \\
\hline CHEMBL1385123 & 688687 & 4.4 & 4.6124 & TRN & \\
\hline CHEMBL1448827 & 688687 & 4.4 & 4.691 & TRN & \\
\hline CHEMBL1410359 & 688687 & 5.3 & 5.0298 & TRN & \\
\hline CHEMBL1590095 & 688687 & 4.5 & 4.4653 & TRN & \\
\hline CHEMBL1319093 & 688687 & 5.1 & 4.7159 & TRN & \\
\hline CHEMBL1493463 & 688687 & 4.7 & 4.9601 & TRN & \\
\hline CHEMBL1532640 & 688687 & 4.4 & 4.5903 & TRN & \\
\hline CHEMBL1507626 & 688687 & 4.5 & 4.6581 & TRN & \\
\hline CHEMBL1324546 & 688687 & 4.5 & 4.6957 & TRN & \\
\hline CHEMBL1530122 & 688687 & 6.8 & 4.8919 & TRN & \\
\hline CHEMBL1412945 & 688687 & 5.3 & 4.8201 & TRN & \\
\hline CHEMBL1419709 & 688687 & 5.6 & 5.9703 & TRN & \\
\hline CHEMBL3195135 & 688687 & 4.5 & 4.7577 & TRN & \\
\hline CHEMBL1235157 & 688687 & 4.5 & 5.0512 & TST & \\
\hline CHEMBL1389289 & 688687 & 4.4 & 4.6516 & TRN & \\
\hline CHEMBL1425881 & 688687 & 4.5 & 4.5625 & TST & \\
\hline CHEMBL68534 & 688687 & 4.8 & 5.5869 & TRN & \\
\hline CHEMBL1519116 & 688687 & 4.4 & 4.8963 & TRN & \\
\hline CHEMBL1604690 & 688687 & 4.4 & 4.6433 & TRN & \\
\hline CHEMBL1420748 & 688687 & 4.4 & 4.9439 & TRN & \\
\hline CHEMBL1561293 & 688687 & 4.4 & 4.6748 & TRN & \\
\hline CHEMBL1372752 & 688687 & 4.5 & 4.5116 & TRN & \\
\hline CHEMBL1516054 & 688687 & 4.6 & 4.3798 & TRN & \\
\hline CHEMBL1304359 & 688687 & 6.8 & 5.0536 & TRN & \\
\hline CHEMBL1557836 & 688687 & 5.1 & 4.8313 & TRN & \\
\hline CHEMBL1457915 & 688687 & 4.6 & 4.8062 & TST & \\
\hline CHEMBL1313547 & 688687 & 4.5 & 4.9916 & TRN & \\
\hline CHEMBL1417144 & 688687 & 4.4 & 4.6243 & TRN & \\
\hline CHEMBL1311847 & 688687 & 5.2 & 5.0023 & TRN & \\
\hline CHEMBL1574591 & 688687 & 5.1 & 4.9687 & TRN & \\
\hline CHEMBL1337502 & 688687 & 5.5 & 4.8475 & TRN & \\
\hline CHEMBL1379456 & 688687 & 4.6 & 4.7065 & TRN & \\
\hline
\end{tabular}




\begin{tabular}{|c|c|c|c|c|}
\hline \\
\hline CHEMBL1372404 & 688687 & 4.6 & 4.7779 & TRN \\
\hline CHEMBL1487352 & 688687 & 5.0 & 5.0266 & TRN \\
\hline CHEMBL8145 & 688687 & 6.0 & 5.1147 & TRN \\
\hline CHEMBL408702 & 688687 & 4.5 & 4.7024 & TRN \\
\hline CHEMBL1539114 & 688687 & 4.5 & 4.5359 & TRN \\
\hline CHEMBL161343 & 688687 & 4.7 & 4.9865 & TRN \\
\hline CHEMBL 2374063 & 688687 & 4.5 & 4.9857 & TST \\
\hline CHEMBL3392040 & 688687 & 6.3 & 5.2474 & TRN \\
\hline CHEMBL1485048 & 688687 & 5.0 & 5.001 & TST \\
\hline CHEMBL1310898 & 688687 & 4.4 & 5.0296 & TRN \\
\hline CHEMBL 1467839 & 688687 & 4.5 & 5.0615 & TRN \\
\hline CHEMBL1571461 & 688687 & 4.5 & 4.9203 & TRN \\
\hline CHEMBL1353727 & 688687 & 5.4 & 4.7431 & TRN \\
\hline CHEMBL1524964 & 688687 & 5.1 & 5.0485 & TRN \\
\hline CHEMBL1319851 & 688687 & 4.4 & 4.7864 & TRN \\
\hline CHEMBL 1608857 & 688687 & 4.4 & 4.5877 & TRN \\
\hline CHEMBL1529860 & 688687 & 4.5 & 4.8055 & TRN \\
\hline CHEMBL1512250 & 688687 & 4.5 & 4.6041 & TRN \\
\hline CHEMBL1605768 & 688687 & 4.5 & 4.6687 & TRN \\
\hline CHEMBL1581714 & 688687 & 4.5 & 4.6794 & TRN \\
\hline CHEMBL1588404 & 688687 & 5.1 & 4.8454 & TRN \\
\hline CHEMBL1583977 & 688687 & 4.4 & 4.5946 & TRN \\
\hline CHEMBL1478970 & 688687 & 4.6 & 4.3517 & TRN \\
\hline CHEMBL1505677 & 688687 & 7.8996 & 5.1258 & TRN \\
\hline CHEMBL1311995 & 688687 & 4.5 & 4.6815 & TRN \\
\hline CHEMBL1398727 & 688687 & 4.5 & 4.8068 & TRN \\
\hline CHEMBL1543477 & 688687 & 4.4 & 4.6815 & TRN \\
\hline CHEMBL1580510 & 688687 & 5.2 & 5.2035 & TRN \\
\hline CHEMBL587826 & 688687 & 4.5 & 5.2038 & TRN \\
\hline CHEMBL1399873 & 688687 & 5.4 & 5.2236 & TRN \\
\hline CHEMBL1326646 & 688687 & 5.5 & 5.1167 & TRN \\
\hline CHEMBL1612694 & 688687 & 5.4 & 4.9635 & TRN \\
\hline CHEMBL1409850 & 688687 & 4.5 & 4.6371 & TRN \\
\hline CHEMBL1507719 & 688687 & 4.5 & 4.697 & TRN \\
\hline CHEMBL1368663 & 688687 & 4.6 & 5.2095 & TST \\
\hline CHEMBL1400275 & 688687 & 4.4 & 4.8243 & TST \\
\hline CHEMBL1464928 & 688687 & 4.5 & 5.0676 & TRN \\
\hline CHEMBL1563201 & 688687 & 5.6 & 4.8432 & TRN \\
\hline CHEMBL538965 & 688687 & 4.5 & 4.9511 & TRN \\
\hline CHEMBL1416853 & 688687 & 4.4 & 4.8704 & TST \\
\hline CHEMBL1507299 & 688687 & 4.6 & 4.6398 & TRN \\
\hline CHEMBL1528822 & 688687 & 4.7 & 4.9142 & TRN \\
\hline CHEMBL441282 & 688687 & 6.0 & 5.0696 & TRN \\
\hline CHEMBL3192047 & 688687 & 4.7 & 4.7134 & TRN \\
\hline CHEMBL1306170 & 688687 & 4.6 & 4.8597 & TRN \\
\hline CHEMBL1344576 & 688687 & 6.0 & 4.8648 & TRN \\
\hline CHEMBL1527565 & 688687 & 6.4 & 5.3206 & TST \\
\hline CHEMBL1509119 & 688687 & 4.6 & 4.7111 & TRN \\
\hline
\end{tabular}




\begin{tabular}{|c|c|c|c|c|}
\hline \\
\hline CHEMBL1576290 & 688687 & 5.4 & 4.5913 & TRN \\
\hline CHEMBL1389728 & 688687 & 4.7 & 4.6255 & TRN \\
\hline CHEMBL1316357 & 688687 & 4.4 & 4.5061 & TRN \\
\hline CHEMBL1522275 & 688687 & 5.7 & 5.3964 & TRN \\
\hline CHEMBL1583199 & 688687 & 4.5 & 4.8295 & TRN \\
\hline CHEMBL1484727 & 688687 & 4.5 & 4.7978 & TRN \\
\hline CHEMBL 2003973 & 688687 & 5.9 & 4.7178 & TST \\
\hline CHEMBL402063 & 688687 & 6.5 & 5.0469 & TST \\
\hline CHEMBL1334246 & 688687 & 5.6 & 4.8658 & TRN \\
\hline CHEMBL1407417 & 688687 & 5.6 & 5.2667 & TST \\
\hline CHEMBL1372751 & 688687 & 4.8 & 4.9488 & TRN \\
\hline CHEMBL1424802 & 688687 & 4.5 & 4.7043 & TRN \\
\hline CHEMBL1496131 & 688687 & 5.8 & 4.9558 & TST \\
\hline CHEMBL1531826 & 688687 & 4.6 & 4.72 & TRN \\
\hline CHEMBL1441479 & 688687 & 4.5 & 4.6392 & TRN \\
\hline CHEMBL 1490814 & 688687 & 4.5 & 5.11 & TRN \\
\hline CHEMBL1518383 & 688687 & 4.4 & 4.5658 & TRN \\
\hline CHEMBL1440251 & 688687 & 4.6 & 4.5785 & TRN \\
\hline CHEMBL251904 & 688687 & 4.8 & 5.1291 & TST \\
\hline CHEMBL1373659 & 688687 & 4.5 & 4.6766 & TRN \\
\hline CHEMBL 1438122 & 688687 & 4.5 & 4.6184 & TRN \\
\hline CHEMBL1520402 & 688687 & 4.4 & 4.7566 & TRN \\
\hline CHEMBL1586914 & 688687 & 4.5 & 4.6472 & TRN \\
\hline CHEMBL1441101 & 688687 & 4.5 & 4.5953 & TRN \\
\hline CHEMBL1382095 & 688687 & 4.7 & 4.6117 & TRN \\
\hline CHEMBL1399107 & 688687 & 4.5 & 4.6326 & TRN \\
\hline CHEMBL1406513 & 688687 & 4.6 & 5.1808 & TST \\
\hline CHEMBL1504498 & 688687 & 4.5 & 4.374 & TRN \\
\hline CHEMBL1319597 & 688687 & 4.6 & 4.6095 & TRN \\
\hline CHEMBL3199720 & 688687 & 4.9 & 4.5348 & TRN \\
\hline CHEMBL1406865 & 688687 & 4.4 & 4.4187 & TRN \\
\hline CHEMBL1571126 & 688687 & 5.2 & 4.4685 & TST \\
\hline CHEMBL1408041 & 688687 & 4.4 & 4.7581 & TRN \\
\hline CHEMBL120806 & 688687 & 6.4 & 5.4111 & TRN \\
\hline CHEMBL1520065 & 688687 & 5.3 & 4.7505 & TRN \\
\hline CHEMBL1558744 & 688687 & 4.8 & 4.8998 & TRN \\
\hline CHEMBL1492631 & 688687 & 6.2 & 5.4556 & TRN \\
\hline CHEMBL1572302 & 688687 & 4.6 & 4.5116 & TRN \\
\hline CHEMBL1326920 & 688687 & 4.5 & 4.7854 & TRN \\
\hline CHEMBL1544772 & 688687 & 4.5 & 4.6741 & TRN \\
\hline CHEMBL1371147 & 688687 & 4.5 & 4.919 & TRN \\
\hline CHEMBL1613672 & 688687 & 4.6 & 4.5819 & TRN \\
\hline CHEMBL1367163 & 688687 & 6.7001 & 5.8323 & TRN \\
\hline CHEMBL1440392 & 688687 & 4.5 & 4.8054 & TRN \\
\hline CHEMBL1607229 & 688687 & 4.5 & 5.1237 & TRN \\
\hline CHEMBL1336329 & 688687 & 5.5 & 4.9605 & TRN \\
\hline CHEMBL1466443 & 688687 & 4.6 & 4.6163 & TRN \\
\hline CHEMBL1352687 & 688687 & 7.5003 & 4.8875 & TRN \\
\hline
\end{tabular}




\begin{tabular}{|c|c|c|c|c|}
\hline & & & & $a+1$ \\
\hline CHEMBL1334497 & 688687 & 4.5 & 4.76 & TRN \\
\hline CHEMBL1585842 & 688687 & 4.5 & 4.676 & TRN \\
\hline CHEMBL1571846 & 688687 & 4.5 & 4.8413 & TRN \\
\hline CHEMBL1527680 & 688687 & 4.4 & 4.3587 & TRN \\
\hline CHEMBL1410981 & 688687 & 4.5 & 5.0294 & TRN \\
\hline CHEMBL1449204 & 688687 & 4.7 & 5.0254 & TRN \\
\hline CHEMBL1330519 & 688687 & 5.4 & 4.7127 & TRN \\
\hline CHEMBL1300534 & 688687 & 5.1 & 4.4862 & TRN \\
\hline CHEMBL1419836 & 688687 & 4.4 & 4.8794 & TRN \\
\hline CHEMBL1577026 & 688687 & 5.9 & 4.9033 & TST \\
\hline CHEMBL1381098 & 688687 & 4.6 & 4.9656 & TRN \\
\hline CHEMBL1565463 & 688687 & 5.0 & 4.7717 & TRN \\
\hline CHEMBL1358819 & 688687 & 4.8 & 4.8643 & TRN \\
\hline CHEMBL1534085 & 688687 & 4.6 & 4.8866 & TST \\
\hline CHEMBL1428267 & 688687 & 5.9 & 5.1139 & TRN \\
\hline CHEMBL1469112 & 688687 & 4.5 & 4.7875 & TST \\
\hline CHEMBL1504991 & 688687 & 5.2 & 4.9827 & TRN \\
\hline CHEMBL567508 & 688687 & 5.5 & 5.1129 & TRN \\
\hline CHEMBL1479425 & 688687 & 4.4 & 4.989 & TST \\
\hline CHEMBL1519060 & 688687 & 4.4 & 5.0461 & TST \\
\hline CHEMBL1547416 & 688687 & 4.8 & 4.5918 & TRN \\
\hline CHEMBL1597765 & 688687 & 4.6 & 4.8326 & TRN \\
\hline CHEMBL1400670 & 688687 & 4.9 & 5.0376 & TRN \\
\hline CHEMBL1597805 & 688687 & 5.0 & 4.9098 & TST \\
\hline CHEMBL1413683 & 688687 & 4.4 & 4.7122 & TRN \\
\hline CHEMBL1330344 & 688687 & 4.6 & 4.4779 & TRN \\
\hline CHEMBL1582538 & 688687 & 4.4 & 4.7334 & TRN \\
\hline CHEMBL1527022 & 688687 & 5.2 & 5.078 & TST \\
\hline CHEMBL1377151 & 688687 & 4.5 & 4.6475 & TRN \\
\hline CHEMBL1574468 & 688687 & 4.5 & 4.3675 & TRN \\
\hline CHEMBL1429614 & 688687 & 4.5 & 4.5879 & TRN \\
\hline CHEMBL1469056 & 688687 & 4.8 & 4.581 & TRN \\
\hline CHEMBL1551064 & 688687 & 4.6 & 4.546 & TRN \\
\hline CHEMBL1346068 & 688687 & 5.0 & 4.7698 & TRN \\
\hline CHEMBL1425417 & 688687 & 4.8 & 4.8511 & TRN \\
\hline CHEMBL1566540 & 688687 & 6.4 & 4.6943 & TST \\
\hline CHEMBL1408430 & 688687 & 4.7 & 4.7259 & TRN \\
\hline CHEMBL1390710 & 688687 & 5.8 & 5.9137 & TRN \\
\hline CHEMBL1530805 & 688687 & 4.4 & 4.6095 & TRN \\
\hline CHEMBL1498604 & 688687 & 4.4 & 4.8382 & TRN \\
\hline CHEMBL1573365 & 688687 & 5.5 & 4.9261 & TST \\
\hline CHEMBL1381236 & 688687 & 5.1 & 4.8419 & TST \\
\hline CHEMBL1393325 & 688687 & 5.5 & 4.8563 & TRN \\
\hline CHEMBL1594305 & 688687 & 5.3 & 4.7543 & TRN \\
\hline CHEMBL1552540 & 688687 & 5.1 & 4.7336 & TRN \\
\hline CHEMBL1371627 & 688687 & 4.8 & 4.6693 & TRN \\
\hline CHEMBL1578330 & 688687 & 4.4 & 4.8561 & TRN \\
\hline CHEMBL1332289 & 688687 & 5.2 & 4.8359 & TRN \\
\hline
\end{tabular}




\begin{tabular}{|c|c|c|c|c|c|}
\hline & & & & & \\
\hline CHEMBL1588086 & 688687 & 4.6 & 4.6998 & TRN & \\
\hline CHEMBL1309077 & 688687 & 5.4 & 4.9606 & TRN & \\
\hline CHEMBL1390198 & 688687 & 4.8 & 5.0746 & TRN & \\
\hline CHEMBL1563743 & 688687 & 4.5 & 4.9145 & TRN & \\
\hline CHEMBL225513 & 688687 & 5.3 & 5.1579 & TRN & \\
\hline CHEMBL1459896 & 688687 & 5.4 & 5.3356 & TRN & \\
\hline CHEMBL1581158 & 688687 & 4.7 & 4.9678 & TST & \\
\hline CHEMBL1462928 & 688687 & 4.4 & 4.4351 & TRN & \\
\hline CHEMBL1524475 & 688687 & 4.5 & 4.97199 & 99999999995 & TRN \\
\hline CHEMBL 1447866 & 688687 & 4.5 & 4.619 & TRN & \\
\hline CHEMBL1600090 & 688687 & 4.4 & 4.9531 & TRN & \\
\hline CHEMBL1489771 & 688687 & 5.9 & 5.6108 & TRN & \\
\hline CHEMBL1493416 & 688687 & 4.4 & 5.0166 & TST & \\
\hline CHEMBL1558206 & 688687 & 4.5 & 5.0339 & TRN & \\
\hline CHEMBL1329419 & 688687 & 5.5 & 5.2732 & TRN & \\
\hline CHEMBL1458566 & 688687 & 5.3 & 4.703 & TRN & \\
\hline CHEMBL1409480 & 688687 & 4.5 & 4.5902 & TRN & \\
\hline CHEMBL1381518 & 688687 & 5.4 & 4.6172 & TRN & \\
\hline CHEMBL1411476 & 688687 & 4.7 & 4.8331 & TRN & \\
\hline CHEMBL1371305 & 688687 & 4.6 & 5.0046 & TRN & \\
\hline CHEMBL1598870 & 688687 & 4.6 & 4.7588 & TRN & \\
\hline CHEMBL1388012 & 688687 & 4.4 & 4.9204 & TRN & \\
\hline CHEMBL1568268 & 688687 & 4.6 & 4.8819 & TRN & \\
\hline CHEMBL1357850 & 688687 & 4.4 & 4.6269 & TRN & \\
\hline CHEMBL1455763 & 688687 & 4.4 & 4.9484 & TRN & \\
\hline CHEMBL1570154 & 688687 & 5.1 & 4.7788 & TRN & \\
\hline CHEMBL1417268 & 688687 & 4.8 & 5.0061 & TST & \\
\hline CHEMBL1372378 & 688687 & 4.7 & 4.7881 & TRN & \\
\hline CHEMBL1387501 & 688687 & 4.8 & 4.9294 & TST & \\
\hline CHEMBL1305538 & 688687 & 4.6 & 4.90300 & 00000000005 & TST \\
\hline CHEMBL 2373651 & 688687 & 5.3 & 5.0624 & TST & \\
\hline CHEMBL1526104 & 688687 & 4.4 & 4.7059 & TRN & \\
\hline CHEMBL1451481 & 688687 & 7.5003 & 5.4735 & TRN & \\
\hline CHEMBL1512122 & 688687 & 5.5 & 5.3272 & TST & \\
\hline CHEMBL1496640 & 688687 & 4.5 & 4.9997 & TRN & \\
\hline CHEMBL1403412 & 688687 & 4.6 & 4.5965 & TRN & \\
\hline CHEMBL1336114 & 688687 & 4.7 & 4.477 & TRN & \\
\hline CHEMBL1525320 & 688687 & 4.6 & 4.72 & TRN & \\
\hline CHEMBL1497435 & 688687 & 4.5 & 4.9441 & TRN & \\
\hline CHEMBL1454730 & 688687 & 5.4 & 4.8744 & TST & \\
\hline CHEMBL1438166 & 688687 & 5.3 & 4.7556 & TRN & \\
\hline CHEMBL1585651 & 688687 & 4.4 & 4.5944 & TRN & \\
\hline CHEMBL1386312 & 688687 & 5.2 & 5.1272 & TST & \\
\hline CHEMBL1442635 & 688687 & 4.5 & 4.5985 & TRN & \\
\hline CHEMBL516616 & 688687 & 5.8 & 5.2772 & TRN & \\
\hline CHEMBL1380868 & 688687 & 5.9 & 5.0894 & TRN & \\
\hline CHEMBL1518293 & 688687 & 4.6 & 4.718 & TRN & \\
\hline CHEMBL1509639 & 688687 & 4.8 & 4.8968 & TRN & \\
\hline & & & & 6275 & \\
\hline
\end{tabular}




\begin{tabular}{|c|c|c|c|c|}
\hline & & & & $a \perp 1$ \\
\hline CHEMBL1566696 & 688687 & 5.6 & 4.5636 & TRN \\
\hline CHEMBL1568982 & 688687 & 4.4 & 4.7329 & TRN \\
\hline CHEMBL1370480 & 688687 & 5.4 & 5.0497 & TRN \\
\hline CHEMBL1499248 & 688687 & 6.2 & 4.9294 & TRN \\
\hline CHEMBL1424823 & 688687 & 5.4 & 4.90300 & 00000000005 \\
\hline CHEMBL12252 & 688687 & 4.5 & 5.1109 & TRN \\
\hline CHEMBL1308694 & 688687 & 5.0 & 4.7712 & TRN \\
\hline CHEMBL1612870 & 688687 & 4.5 & 4.7998 & TRN \\
\hline CHEMBL1465615 & 688687 & 5.5 & 4.961 & TRN \\
\hline CHEMBL1438626 & 688687 & 4.7 & 4.7928 & TRN \\
\hline CHEMBL1543686 & 688687 & 4.4 & 4.9833 & TRN \\
\hline CHEMBL1386757 & 688687 & 4.4 & 4.5705 & TRN \\
\hline CHEMBL1489461 & 688687 & 4.4 & 4.5653 & TRN \\
\hline CHEMBL1333052 & 688687 & 4.4 & 5.0735 & TRN \\
\hline CHEMBL1400666 & 688687 & 4.5 & 4.8282 & TRN \\
\hline CHEMBL1598907 & 688687 & 5.6 & 4.8949 & TST \\
\hline CHEMBL1543597 & 688687 & 4.5 & 4.8074 & TRN \\
\hline CHEMBL1441140 & 688687 & 4.4 & 5.0101 & TST \\
\hline CHEMBL1351257 & 688687 & 4.7 & 4.6967 & TRN \\
\hline CHEMBL1565207 & 688687 & 4.5 & 4.7596 & TRN \\
\hline CHEMBL1605613 & 688687 & 4.4 & 4.6627 & TRN \\
\hline CHEMBL1579661 & 688687 & 4.9 & 4.7061 & TRN \\
\hline CHEMBL1461980 & 688687 & 5.1 & 5.1631 & TRN \\
\hline CHEMBL1487583 & 688687 & 4.4 & 4.6617 & TRN \\
\hline CHEMBL1444756 & 688687 & 4.9 & 4.9231 & TRN \\
\hline CHEMBL1322960 & 688687 & 4.5 & 4.7848 & TRN \\
\hline CHEMBL1321365 & 688687 & 5.1 & 4.9397 & TRN \\
\hline CHEMBL1454006 & 688687 & 4.4 & 4.7983 & TRN \\
\hline CHEMBL1416584 & 688687 & 4.7 & 4.7191 & TRN \\
\hline CHEMBL1308032 & 688687 & 4.5 & 4.6076 & TRN \\
\hline CHEMBL1476362 & 688687 & 5.6 & 5.1162 & TST \\
\hline CHEMBL1362096 & 688687 & 4.6 & 5.2066 & TST \\
\hline CHEMBL1429956 & 688687 & 4.8 & 5.2659 & TRN \\
\hline CHEMBL1388793 & 688687 & 4.5 & 4.7658 & TRN \\
\hline CHEMBL1555813 & 688687 & 5.4 & 5.1503 & TST \\
\hline CHEMBL1363492 & 688687 & 4.6 & 4.7362 & TRN \\
\hline CHEMBL1407826 & 688687 & 5.0 & 5.395 & TST \\
\hline CHEMBL1487527 & 688687 & 5.4 & 4.8773 & TRN \\
\hline CHEMBL1370634 & 688687 & 4.4 & 4.667 & TRN \\
\hline CHEMBL1578893 & 688687 & 6.2 & 4.8546 & TRN \\
\hline CHEMBL1453521 & 688687 & 4.4 & 4.5569 & TRN \\
\hline CHEMBL1412223 & 688687 & 4.6 & 4.7628 & TRN \\
\hline CHEMBL1509699 & 688687 & 5.3 & 4.9369 & TST \\
\hline CHEMBL1511205 & 688687 & 4.7 & 5.1686 & TST \\
\hline CHEMBL1377009 & 688687 & 4.5 & 5.0369 & TRN \\
\hline CHEMBL1445094 & 688687 & 4.7 & 4.8803 & TRN \\
\hline CHEMBL1497567 & 688687 & 4.8 & 5.0702 & TRN \\
\hline CHEMBL1368261 & 688687 & 5.0 & 5.1277 & TRN \\
\hline
\end{tabular}




\begin{tabular}{|c|c|c|c|c|}
\hline \multicolumn{5}{|c|}{ plement } \\
\hline CHEMBL1385245 & 688687 & 4.6 & 4.6581 & TRN \\
\hline CHEMBL1361764 & 688687 & 5.2 & 4.8567 & TST \\
\hline CHEMBL1317982 & 688687 & 4.5 & 4.6166 & TRN \\
\hline CHEMBL1592464 & 688687 & 4.6 & 4.7678 & TRN \\
\hline CHEMBL1550217 & 688687 & 5.5 & 5.1134 & TRN \\
\hline CHEMBL309917 & 688687 & 4.5 & 4.9837 & TRN \\
\hline CHEMBL1544075 & 688687 & 4.6 & 4.7026 & TRN \\
\hline CHEMBL1571314 & 688687 & 4.4 & 4.9944 & TRN \\
\hline CHEMBL1329458 & 688687 & 4.9 & 5.2646 & TRN \\
\hline CHEMBL1385705 & 688687 & 4.5 & 4.7388 & TRN \\
\hline CHEMBL3193719 & 688687 & 5.5 & 4.7873 & TRN \\
\hline CHEMBL14173 & 688687 & 4.4 & 5.0426 & TRN \\
\hline CHEMBL1545039 & 688687 & 6.0 & 4.9311 & TST \\
\hline CHEMBL1510186 & 688687 & 4.9 & 4.9697 & TRN \\
\hline CHEMBL1571560 & 688687 & 5.5 & 5.1879 & TRN \\
\hline CHEMBL 270672 & 688687 & 5.5 & 4.7796 & TRN \\
\hline CHEMBL244645 & 688687 & 5.5 & 4.8908 & TST \\
\hline CHEMBL1550045 & 688687 & 5.5 & 4.8175 & TRN \\
\hline CHEMBL1503704 & 688687 & 4.4 & 4.8133 & TRN \\
\hline CHEMBL1383304 & 688687 & 4.6 & 4.7065 & TRN \\
\hline CHEMBL1591963 & 688687 & 5.1 & 5.3856 & TST \\
\hline CHEMBL1569856 & 688687 & 4.4 & 4.9644 & TRN \\
\hline CHEMBL1507699 & 688687 & 4.4 & 4.6789 & TRN \\
\hline CHEMBL1299367 & 688687 & 4.5 & 4.5781 & TRN \\
\hline CHEMBL490706 & 688687 & 4.6 & 4.4394 & TRN \\
\hline CHEMBL1454183 & 688687 & 5.7 & 5.474 & TST \\
\hline CHEMBL1444884 & 688687 & 4.5 & 4.7564 & TRN \\
\hline CHEMBL1566340 & 688687 & 4.4 & 4.4499 & TRN \\
\hline CHEMBL3190658 & 688687 & 4.4 & 4.737 & TRN \\
\hline CHEMBL1304812 & 688687 & 5.1 & 5.0918 & TRN \\
\hline CHEMBL1528670 & 688687 & 5.3 & 5.072 & TST \\
\hline CHEMBL1497493 & 688687 & 4.5 & 4.578 & TRN \\
\hline CHEMBL1573328 & 688687 & 4.6 & 4.7229 & TRN \\
\hline CHEMBL1409625 & 688687 & 4.9 & 4.7951 & TRN \\
\hline CHEMBL1577977 & 688687 & 4.8 & 4.9441 & TRN \\
\hline CHEMBL1412731 & 688687 & 6.6 & 5.6788 & TRN \\
\hline CHEMBL1465876 & 688687 & 6.2 & 4.3201 & TST \\
\hline CHEMBL1578533 & 688687 & 4.7 & 4.5956 & TRN \\
\hline CHEMBL408850 & 688687 & 4.6 & 4.5915 & TRN \\
\hline CHEMBL1383517 & 688687 & 4.4 & 5.0151 & TRN \\
\hline CHEMBL1381323 & 688687 & 5.8 & 6.055 & TRN \\
\hline CHEMBL1161461 & 688687 & 5.1 & 5.0384 & TST \\
\hline CHEMBL1580418 & 688687 & 4.5 & 4.5584 & TRN \\
\hline CHEMBL1301505 & 688687 & 4.6 & 4.5813 & TRN \\
\hline CHEMBL1526171 & 688687 & 5.2 & 5.5131 & TRN \\
\hline CHEMBL1371504 & 688687 & 5.5 & 4.9909 & TRN \\
\hline CHEMBL1306258 & 688687 & 4.5 & 4.7837 & TRN \\
\hline CHEMBL1415573 & 688687 & 4.9 & 4.6097 & TRN \\
\hline
\end{tabular}




\begin{tabular}{|c|c|c|c|c|}
\hline & & & & \\
\hline CHEMBL1566138 & 688687 & 4.4 & 4.9545 & TRN \\
\hline CHEMBL1399595 & 688687 & 4.7 & 4.8425 & TRN \\
\hline CHEMBL1452664 & 688687 & 4.5 & 5.0577 & TST \\
\hline CHEMBL487187 & 688687 & 5.8 & 4.9894 & TST \\
\hline CHEMBL1256735 & 688687 & 4.7 & 4.978 & TST \\
\hline CHEMBL1445774 & 688687 & 5.4 & 5.0204 & TRN \\
\hline CHEMBL1461478 & 688687 & 5.1 & 4.8748 & TRN \\
\hline CHEMBL1416762 & 688687 & 4.4 & 4.4283 & TRN \\
\hline CHEMBL1488465 & 688687 & 5.0 & 4.8033 & TRN \\
\hline CHEMBL1569001 & 688687 & 4.6 & 4.6356 & TRN \\
\hline CHEMBL1583467 & 688687 & 4.5 & 4.8728 & TRN \\
\hline CHEMBL1497427 & 688687 & 4.4 & 4.8115 & TRN \\
\hline CHEMBL1416815 & 688687 & 4.6 & 4.8941 & TRN \\
\hline CHEMBL1604062 & 688687 & 4.5 & 4.7206 & TRN \\
\hline CHEMBL1380986 & 688687 & 4.6 & 4.6135 & TRN \\
\hline CHEMBL1369374 & 688687 & 5.5 & 5.1288 & TST \\
\hline CHEMBL1333614 & 688687 & 4.5 & 4.9463 & TST \\
\hline CHEMBL1380958 & 688687 & 6.6 & 5.0637 & TRN \\
\hline CHEMBL1382947 & 688687 & 5.0 & 4.8076 & TRN \\
\hline CHEMBL1450992 & 688687 & 4.4 & 4.8287 & TRN \\
\hline CHEMBL1561171 & 688687 & 5.4 & 4.7911 & TRN \\
\hline CHEMBL1585780 & 688687 & 4.9 & 4.9347 & TRN \\
\hline CHEMBL1598807 & 688687 & 4.9 & 4.7901 & TRN \\
\hline CHEMBL1549766 & 688687 & 4.6 & 4.756 & TRN \\
\hline CHEMBL1568860 & 688687 & 5.0 & 4.5434 & TST \\
\hline CHEMBL1522523 & 688687 & 5.2 & 4.8683 & TRN \\
\hline CHEMBL1405153 & 688687 & 4.6 & 4.5497 & TRN \\
\hline CHEMBL3189536 & 688687 & 4.4 & 5.0521 & TST \\
\hline CHEMBL1471289 & 688687 & 5.7 & 5.0507 & TRN \\
\hline CHEMBL1256718 & 688687 & 4.9 & 4.9286 & TST \\
\hline CHEMBL1607786 & 688687 & 4.6 & 4.7426 & TRN \\
\hline CHEMBL1584903 & 688687 & 4.4 & 4.8129 & TRN \\
\hline CHEMBL 229012 & 688687 & 4.5 & 4.7396 & TRN \\
\hline CHEMBL1390669 & 688687 & 4.9 & 5.0084 & TRN \\
\hline CHEMBL1492547 & 688687 & 4.4 & 4.6217 & TRN \\
\hline CHEMBL1424937 & 688687 & 4.6 & 4.7089 & TRN \\
\hline CHEMBL1500377 & 688687 & 4.4 & 4.8209 & TST \\
\hline CHEMBL1408673 & 688687 & 4.6 & 4.6501 & TRN \\
\hline CHEMBL1598471 & 688687 & 4.6 & 4.6703 & TRN \\
\hline CHEMBL1361692 & 688687 & 4.7 & 4.9245 & TRN \\
\hline CHEMBL1523474 & 688687 & 4.9 & 4.9305 & TRN \\
\hline CHEMBL1550891 & 688687 & 4.6 & 4.6447 & TRN \\
\hline CHEMBL1592585 & 688687 & 4.5 & 4.5693 & TRN \\
\hline CHEMBL3145017 & 688687 & 5.4 & $5.3270 e$ & 0000000001 \\
\hline CHEMBL1309910 & 688687 & 4.6 & 4.7615 & TRN \\
\hline CHEMBL1402681 & 688687 & 4.6 & 4.9274 & TRN \\
\hline CHEMBL1572142 & 688687 & 5.1 & 5.0165 & TRN \\
\hline CHEMBL1353809 & 688687 & 4.4 & 4.6525 & TRN \\
\hline
\end{tabular}




\begin{tabular}{|c|c|c|c|c|}
\hline & & & & \\
\hline CHEMBL1427979 & 688687 & 5.5 & 4.7167 & TST \\
\hline CHEMBL3214013 & 688687 & 4.5 & 4.8227 & TRN \\
\hline CHEMBL1311028 & 688687 & 4.4 & 4.8232 & TRN \\
\hline CHEMBL332122 & 688687 & 5.4 & 5.0942 & TRN \\
\hline CHEMBL1542101 & 688687 & 4.5 & 4.6319 & TRN \\
\hline CHEMBL490577 & 688687 & 4.5 & 5.8233 & TRN \\
\hline CHEMBL1303754 & 688687 & 4.8 & 4.9167 & TRN \\
\hline CHEMBL1542189 & 688687 & 4.4 & 4.921 & TRN \\
\hline CHEMBL1437244 & 688687 & 6.0 & 5.0408 & TST \\
\hline CHEMBL1583898 & 688687 & 4.6 & 4.3694 & TRN \\
\hline CHEMBL1470441 & 688687 & 4.5 & 5.1062 & TRN \\
\hline CHEMBL1435227 & 688687 & 4.6 & 4.8726 & TRN \\
\hline CHEMBL1331618 & 688687 & 7.0 & 5.2924 & TRN \\
\hline CHEMBL1431175 & 688687 & 4.6 & 4.8419 & TRN \\
\hline CHEMBL1381836 & 688687 & 4.4 & 4.9588 & TRN \\
\hline CHEMBL1459258 & 688687 & 5.7 & 5.6565 & TRN \\
\hline CHEMBL1585164 & 688687 & 4.7 & 4.813 & TRN \\
\hline CHEMBL1339133 & 688687 & 4.9 & 4.718 & TRN \\
\hline CHEMBL 259840 & 688687 & 5.5 & 5.1213 & TRN \\
\hline CHEMBL1351379 & 688687 & 4.5 & 4.7589 & TRN \\
\hline CHEMBL1513990 & 688687 & 4.5 & 4.6407 & TRN \\
\hline CHEMBL1343750 & 688687 & 4.4 & 4.4889 & TRN \\
\hline CHEMBL1609081 & 688687 & 5.0 & 4.5288 & TRN \\
\hline CHEMBL423081 & 688687 & 4.7 & 5.0273 & TST \\
\hline CHEMBL1409133 & 688687 & 4.5 & 4.5835 & TRN \\
\hline CHEMBL 267548 & 688687 & 4.9 & 5.3236 & TST \\
\hline CHEMBL1502296 & 688687 & 4.4 & 4.7394 & TST \\
\hline CHEMBL1421675 & 688687 & 4.4 & 4.8902 & TRN \\
\hline CHEMBL1371614 & 688687 & 4.7 & 4.6438 & TRN \\
\hline CHEMBL1389322 & 688687 & 4.5 & 4.7112 & TRN \\
\hline CHEMBL1608129 & 688687 & 5.2 & 5.1611 & TRN \\
\hline CHEMBL3209422 & 688687 & 4.6 & 4.831 & TST \\
\hline CHEMBL1332646 & 688687 & 4.8 & 4.7802 & TRN \\
\hline CHEMBL1348159 & 688687 & 5.9 & 4.776 & TST \\
\hline CHEMBL1479059 & 688687 & 6.2 & 5.0145 & TRN \\
\hline CHEMBL1351610 & 688687 & 4.7 & 4.7701 & TST \\
\hline CHEMBL1594149 & 688687 & 5.5 & 4.9 & TST \\
\hline CHEMBL3214556 & 688687 & 5.8 & 4.8317 & TRN \\
\hline CHEMBL1590123 & 688687 & 4.4 & 4.3656 & TRN \\
\hline CHEMBL1327398 & 688687 & 4.5 & 4.7933 & TRN \\
\hline CHEMBL1366916 & 688687 & 4.5 & 4.8727 & TRN \\
\hline CHEMBL1344285 & 688687 & 4.4 & 4.618 & TRN \\
\hline CHEMBL1488868 & 688687 & 5.7 & 4.7374 & TRN \\
\hline CHEMBL1321812 & 688687 & 4.7 & 4.6482 & TRN \\
\hline CHEMBL1568018 & 688687 & 5.0 & 4.7859 & TRN \\
\hline CHEMBL1548858 & 688687 & 4.6 & 4.9731 & TST \\
\hline CHEMBL1557823 & 688687 & 4.5 & 4.8095 & TRN \\
\hline CHEMBL34704 & 688687 & 6.0 & 5.3019 & TST \\
\hline
\end{tabular}




\begin{tabular}{|c|c|c|c|c|c|}
\hline \\
\hline CHEMBL1605285 & 688687 & 4.4 & 4.5001 & TRN & \\
\hline CHEMBL1433062 & 688687 & 4.5 & 4.8461 & TRN & \\
\hline CHEMBL1487406 & 688687 & 5.1 & 4.8401 & TRN & \\
\hline CHEMBL1568234 & 688687 & 4.7 & 4.6979 & TRN & \\
\hline CHEMBL1601765 & 688687 & 4.5 & 4.715 & TRN & \\
\hline CHEMBL1486271 & 688687 & 4.7 & 4.6516 & TRN & \\
\hline CHEMBL1527008 & 688687 & 5.5 & 4.9173 & TST & \\
\hline CHEMBL1589376 & 688687 & 4.5 & 4.8982 & TRN & \\
\hline CHEMBL1341463 & 688687 & 4.6 & 4.6661 & TRN & \\
\hline CHEMBL1367239 & 688687 & 5.2 & 4.7995 & TRN & \\
\hline CHEMBL1543662 & 688687 & 4.5 & 4.9511 & TRN & \\
\hline CHEMBL1613067 & 688687 & 4.4 & 4.7553 & TRN & \\
\hline CHEMBL1489478 & 688687 & 4.4 & 4.6113 & TST & \\
\hline CHEMBL1304697 & 688687 & 4.4 & 4.6643 & TRN & \\
\hline CHEMBL1361615 & 688687 & 4.6 & 4.5998 & TRN & \\
\hline CHEMBL1446116 & 688687 & 4.6 & 4.8415 & TRN & \\
\hline CHEMBL1571108 & 688687 & 4.5 & 4.8707 & TRN & \\
\hline CHEMBL1528907 & 688687 & 4.5 & 5.0377 & TRN & \\
\hline CHEMBL1545021 & 688687 & 4.6 & 4.7908 & TRN & \\
\hline CHEMBL388342 & 688687 & 6.0 & 5.1533 & TST & \\
\hline CHEMBL1418655 & 688687 & 5.9 & 5.2491 & TST & \\
\hline CHEMBL1491818 & 688687 & 4.6 & 4.882 & TRN & \\
\hline CHEMBL1338400 & 688687 & 4.6 & 4.955 & TRN & \\
\hline CHEMBL1364873 & 688687 & 4.5 & 4.4685 & TRN & \\
\hline CHEMBL1407550 & 688687 & 4.5 & 4.5563 & TRN & \\
\hline CHEMBL1393347 & 688687 & 4.6 & 4.7761 & TRN & \\
\hline CHEMBL1371405 & 688687 & 4.5 & 4.7683 & TRN & \\
\hline CHEMBL24983 & 688687 & 5.5 & 4.9817 & TST & \\
\hline CHEMBL1410585 & 688687 & 4.5 & 4.6303 & TRN & \\
\hline CHEMBL1508235 & 688687 & 4.4 & 4.6457 & TST & \\
\hline CHEMBL1256984 & 688687 & 4.6 & 4.7757 & TST & \\
\hline CHEMBL1970272 & 688687 & 5.0 & 4.8191 & TST & \\
\hline CHEMBL1523206 & 688687 & 4.5 & 4.787 & TRN & \\
\hline CHEMBL1470675 & 688687 & 4.4 & 4.9685 & TRN & \\
\hline CHEMBL1492865 & 688687 & 5.1 & 4.9482 & TRN & \\
\hline CHEMBL587884 & 688687 & 4.6 & 4.9572 & TST & \\
\hline CHEMBL1365922 & 688687 & 5.1 & 4.4057 & TRN & \\
\hline CHEMBL1347221 & 688687 & 5.2 & 4.9862 & TRN & \\
\hline CHEMBL1468756 & 688687 & 4.5 & 4.8531 & TRN & \\
\hline CHEMBL1310188 & 688687 & 4.4 & 4.7347 & TRN & \\
\hline CHEMBL1208858 & 688687 & 6.9 & 5.131 & TST & \\
\hline CHEMBL1547522 & 688687 & 5.2 & 4.8178 & TRN & \\
\hline CHEMBL1497555 & 688687 & 4.8 & 4.6625 & TRN & \\
\hline CHEMBL1335866 & 688687 & 4.6 & 4.7772 & TRN & \\
\hline CHEMBL1353364 & 688687 & 4.6 & 4.7726 & TRN & \\
\hline CHEMBL1558088 & 688687 & 5.5 & 4.9718 & TRN & \\
\hline CHEMBL1561945 & 688687 & 4.6 & 4.8371 & TRN & \\
\hline CHEMBL28 & 688687 & 6.0 & 5.36100 & 0000000001 & TRN \\
\hline & & & & 6280 & \\
\hline
\end{tabular}




\begin{tabular}{|c|c|c|c|c|c|}
\hline & & & & & \\
\hline CHEMBL1453787 & 688687 & 4.7 & 4.9973 & TRN & \\
\hline CHEMBL1313163 & 688687 & 4.5 & 4.8251 & TRN & \\
\hline CHEMBL1486142 & 688687 & 5.4 & 4.8782 & TRN & \\
\hline CHEMBL1480935 & 688687 & 4.6 & 4.9864 & TST & \\
\hline CHEMBL 225230 & 688687 & 6.3 & 5.4394 & TST & \\
\hline CHEMBL1604100 & 688687 & 5.2 & 5.1495 & TRN & \\
\hline CHEMBL1385074 & 688687 & 5.4 & 4.3804 & TRN & \\
\hline CHEMBL1336348 & 688687 & 6.7001 & 5.2511 & TRN & \\
\hline CHEMBL1406449 & 688687 & 4.4 & 4.5962 & TRN & \\
\hline CHEMBL1334254 & 688687 & 5.4 & 5.2234 & TST & \\
\hline CHEMBL1306960 & 688687 & 4.4 & 4.8221 & TRN & \\
\hline CHEMBL1518331 & 688687 & 4.4 & 4.6537 & TRN & \\
\hline CHEMBL1368138 & 688687 & 5.5 & 4.71399 & 99999999995 & TRN \\
\hline CHEMBL1474817 & 688687 & 4.4 & 4.4047 & TRN & \\
\hline CHEMBL1454997 & 688687 & 5.4 & 4.9787 & TRN & \\
\hline CHEMBL1502878 & 688687 & 4.4 & 5.0685 & TRN & \\
\hline CHEMBL1352859 & 688687 & 4.9 & 4.7631 & TRN & \\
\hline CHEMBL1501742 & 688687 & 4.8 & 4.5988 & TRN & \\
\hline CHEMBL1507844 & 688687 & 4.7 & 4.891 & TST & \\
\hline CHEMBL1507183 & 688687 & 6.4 & 4.905 & TRN & \\
\hline CHEMBL1368099 & 688687 & 4.4 & 4.6444 & TRN & \\
\hline CHEMBL1552732 & 688687 & 4.4 & 4.5953 & TRN & \\
\hline CHEMBL1548487 & 688687 & 4.6 & 4.66 & TRN & \\
\hline CHEMBL1411897 & 688687 & 6.3 & 5.2929 & TST & \\
\hline CHEMBL1256291 & 688687 & 5.4 & 5.1081 & TST & \\
\hline CHEMBL1560057 & 688687 & 4.6 & 4.7181 & TRN & \\
\hline CHEMBL1598064 & 688687 & 4.4 & 4.6944 & TRN & \\
\hline CHEMBL1424125 & 688687 & 4.6 & 4.9509 & TRN & \\
\hline CHEMBL1508257 & 688687 & 4.7 & 4.9796 & TRN & \\
\hline CHEMBL1322702 & 688687 & 4.6 & 4.9272 & TRN & \\
\hline CHEMBL1340294 & 688687 & 4.9 & 4.6745 & TST & \\
\hline CHEMBL1547267 & 688687 & 4.7 & 4.7517 & TRN & \\
\hline CHEMBL1606247 & 688687 & 4.4 & 4.7638 & TRN & \\
\hline CHEMBL1382621 & 688687 & 4.4 & 4.6547 & TRN & \\
\hline CHEMBL1463466 & 688687 & 5.4 & 4.5523 & TRN & \\
\hline CHEMBL338314 & 688687 & 4.5 & 5.0265 & TRN & \\
\hline CHEMBL1451125 & 688687 & 4.7 & 5.0866 & TRN & \\
\hline CHEMBL1307406 & 688687 & 4.5 & 4.7327 & TRN & \\
\hline CHEMBL1384184 & 688687 & 4.5 & 4.6901 & TRN & \\
\hline CHEMBL1579456 & 688687 & 4.4 & 4.4979 & TRN & \\
\hline CHEMBL1442918 & 688687 & 5.0 & 4.6618 & TRN & \\
\hline CHEMBL1365320 & 688687 & 4.7 & 4.7276 & TRN & \\
\hline CHEMBL1528901 & 688687 & 6.1 & 4.9454 & TRN & \\
\hline CHEMBL1348062 & 688687 & 4.5 & 4.6592 & TRN & \\
\hline CHEMBL399043 & 688687 & 4.7 & 5.2064 & TST & \\
\hline CHEMBL1458367 & 688687 & 4.4 & 5.0351 & TRN & \\
\hline CHEMBL1411449 & 688687 & 4.8 & 4.9905 & TST & \\
\hline CHEMBL1459368 & 688687 & 4.9 & 4.918 & TRN & \\
\hline
\end{tabular}




\begin{tabular}{|c|c|c|c|c|c|}
\hline & & & & & \\
\hline CHEMBL1408529 & 688687 & 5.5 & 4.9146 & TST & \\
\hline CHEMBL1538259 & 688687 & 4.4 & 4.4701 & TRN & \\
\hline CHEMBL1496112 & 688687 & 4.6 & 5.0384 & TRN & \\
\hline CHEMBL1358570 & 688687 & 5.5 & 5.3214 & TST & \\
\hline CHEMBL1399358 & 688687 & 4.5 & 4.7797 & TRN & \\
\hline CHEMBL1469929 & 688687 & 5.5 & 4.7783 & TRN & \\
\hline CHEMBL3192698 & 688687 & 4.6 & 4.8843 & TST & \\
\hline CHEMBL1552150 & 688687 & 4.5 & 4.9151 & TRN & \\
\hline CHEMBL1501839 & 688687 & 6.3 & 5.0746 & TRN & \\
\hline CHEMBL1358266 & 688687 & 4.5 & 4.7892 & TST & \\
\hline CHEMBL1364647 & 688687 & 4.5 & 4.5756 & TST & \\
\hline CHEMBL1553768 & 688687 & 5.6 & 4.9206 & TST & \\
\hline CHEMBL1409173 & 688687 & 4.6 & 4.926 & TRN & \\
\hline CHEMBL1454855 & 688687 & 4.4 & 4.4633 & TRN & \\
\hline CHEMBL1373952 & 688687 & 4.4 & 4.6574 & TRN & \\
\hline CHEMBL1447133 & 688687 & 4.5 & 4.5038 & TRN & \\
\hline CHEMBL1393628 & 688687 & 4.5 & 4.5929 & TRN & \\
\hline CHEMBL1449800 & 688687 & 4.4 & 5.0574 & TRN & \\
\hline CHEMBL289277 & 688687 & 6.4 & 5.3747 & TST & \\
\hline CHEMBL221137 & 688687 & 4.4 & 4.8913 & TST & \\
\hline CHEMBL1427056 & 688687 & 4.4 & 4.9353 & TRN & \\
\hline CHEMBL1353082 & 688687 & 5.1 & 5.1345 & TST & \\
\hline CHEMBL1470281 & 688687 & 5.5 & 4.9147 & TST & \\
\hline CHEMBL1593422 & 688687 & 5.1 & 4.8692 & TST & \\
\hline CHEMBL1452137 & 688687 & 5.3 & 5.2119 & TRN & \\
\hline CHEMBL1481414 & 688687 & 4.4 & 4.9347 & TRN & \\
\hline CHEMBL507900 & 688687 & 5.3 & 5.2492 & TST & \\
\hline CHEMBL1392188 & 688687 & 4.4 & 4.8267 & TRN & \\
\hline CHEMBL1470748 & 688687 & 4.4 & 4.7259 & TRN & \\
\hline CHEMBL1507611 & 688687 & 4.5 & 4.6617 & TRN & \\
\hline CHEMBL1532281 & 688687 & 4.5 & 4.9545 & TRN & \\
\hline CHEMBL1407137 & 688687 & 4.6 & 4.7787 & TRN & \\
\hline CHEMBL1554659 & 688687 & 4.7 & 5.0291 & TRN & \\
\hline CHEMBL261237 & 688687 & 4.4 & 4.8156 & TST & \\
\hline CHEMBL1433083 & 688687 & 5.5 & 4.6998 & TRN & \\
\hline CHEMBL1490260 & 688687 & 4.5 & 4.7654 & TRN & \\
\hline CHEMBL1341713 & 688687 & 5.2 & 5.0088 & TST & \\
\hline CHEMBL1388273 & 688687 & 4.5 & 4.7191 & TRN & \\
\hline CHEMBL1451984 & 688687 & 4.5 & 5.0027 & TRN & \\
\hline CHEMBL1450655 & 688687 & 4.8 & 4.6012 & TRN & \\
\hline CHEMBL1562791 & 688687 & 4.4 & 4.6285 & TRN & \\
\hline CHEMBL1531663 & 688687 & 8.2007 & 5.1878 & TRN & \\
\hline CHEMBL1599593 & 688687 & 5.8 & 5.7333 & TRN & \\
\hline CHEMBL1518110 & 688687 & 4.4 & 4.9445 & TRN & \\
\hline CHEMBL1421238 & 688687 & 5.2 & 5.0258 & TRN & \\
\hline CHEMBL1576128 & 688687 & 4.5 & 4.9306 & TST & \\
\hline CHEMBL1375226 & 688687 & 4.8 & 4.79899 & 99999999995 & TRN \\
\hline CHEMBL1511587 & 688687 & 5.9 & 4.9325 & TRN & \\
\hline
\end{tabular}




\begin{tabular}{|c|c|c|c|c|c|}
\hline \multicolumn{6}{|c|}{ Supplemental Table s2.txt } \\
\hline CHEMBL1525521 & 688687 & 5.3 & 4.6047 & TST & \\
\hline CHEMBL1578022 & 688687 & 4.7 & 4.7984 & TRN & \\
\hline CHEMBL1530009 & 688687 & 5.7 & 4.9745 & TST & \\
\hline CHEMBL1541466 & 688687 & 4.8 & 4.8027 & TRN & \\
\hline CHEMBL1331525 & 688687 & 5.0 & 4.7219 & TRN & \\
\hline CHEMBL1330411 & 688687 & 4.5 & 4.7239 & TRN & \\
\hline CHEMBL1340820 & 688687 & 5.1 & 4.9075 & TRN & \\
\hline CHEMBL1385512 & 688687 & 5.0 & 4.9116 & TST & \\
\hline CHEMBL1375883 & 688687 & 5.6 & 4.9565 & TRN & \\
\hline CHEMBL1537868 & 688687 & 4.4 & 4.6936 & TRN & \\
\hline CHEMBL1579056 & 688687 & 4.4 & 4.5863 & TRN & \\
\hline CHEMBL1446954 & 688687 & 4.7 & 4.5884 & TRN & \\
\hline CHEMBL1399316 & 688687 & 4.4 & 4.479 & TRN & \\
\hline CHEMBL522990 & 688687 & 4.4 & 4.6135 & TRN & \\
\hline CHEMBL1510394 & 688687 & 6.6 & 5.8753 & TRN & \\
\hline CHEMBL 1374386 & 688687 & 5.2 & 4.5952 & TRN & \\
\hline CHEMBL1523930 & 688687 & 4.6 & 4.6919 & TRN & \\
\hline CHEMBL1395344 & 688687 & 5.0 & 5.2561 & TRN & \\
\hline CHEMBL1396791 & 688687 & 6.1 & 5.2167 & TRN & \\
\hline CHEMBL1307405 & 688687 & 4.4 & 4.8078 & TRN & \\
\hline CHEMBL1605749 & 688687 & 4.6 & 4.8118 & TRN & \\
\hline CHEMBL1411257 & 688687 & 5.4 & 4.9818 & TRN & \\
\hline CHEMBL1583248 & 688687 & 4.7 & 4.9816 & TRN & \\
\hline CHEMBL1515526 & 688687 & 5.2 & 4.7844 & TRN & \\
\hline CHEMBL1520286 & 688687 & 4.4 & 4.8004 & TRN & \\
\hline CHEMBL1347477 & 688687 & 4.4 & 4.7287 & TRN & \\
\hline CHEMBL1360805 & 688687 & 4.6 & 4.8104 & TRN & \\
\hline CHEMBL1391256 & 688687 & 4.5 & 4.6831 & TRN & \\
\hline CHEMBL1336469 & 688687 & 5.3 & 5.1014 & TRN & \\
\hline CHEMBL1575770 & 688687 & 7.0 & 4.8238 & TRN & \\
\hline CHEMBL1446459 & 688687 & 4.5 & 4.7586 & TST & \\
\hline CHEMBL1376261 & 688687 & 4.4 & 4.8486 & TRN & \\
\hline CHEMBL1420151 & 688687 & 5.3 & 4.8118 & TRN & \\
\hline CHEMBL3199900 & 688687 & 4.5 & 4.6233 & TRN & \\
\hline CHEMBL1526828 & 688687 & 6.1 & 5.1593 & TST & \\
\hline CHEMBL1440703 & 688687 & 4.8 & 4.9229 & TST & \\
\hline CHEMBL1606597 & 688687 & 4.5 & 4.7946 & TRN & \\
\hline CHEMBL 2028178 & 688687 & 5.4 & 4.8707 & TST & \\
\hline CHEMBL1385193 & 688687 & 4.9 & 5.1189 & TRN & \\
\hline CHEMBL1609665 & 688687 & 4.4 & 4.7458 & TRN & \\
\hline CHEMBL1558140 & 688687 & 4.5 & 4.5428 & TRN & \\
\hline CHEMBL1417197 & 688687 & 5.4 & 4.7438 & TRN & \\
\hline CHEMBL549321 & 688687 & 4.9 & $5.1320 e$ & 0000000001 & TRN \\
\hline CHEMBL1395862 & 688687 & 4.8 & 5.0462 & TRN & \\
\hline CHEMBL1489064 & 688687 & 7.4001 & 5.2933 & TST & \\
\hline CHEMBL62350 & 688687 & 5.5 & 4.7479 & TRN & \\
\hline CHEMBL1409473 & 688687 & 5.1 & 5.3013 & TRN & \\
\hline CHEMBL1427890 & 688687 & 5.7 & 4.8809 & TRN & \\
\hline
\end{tabular}




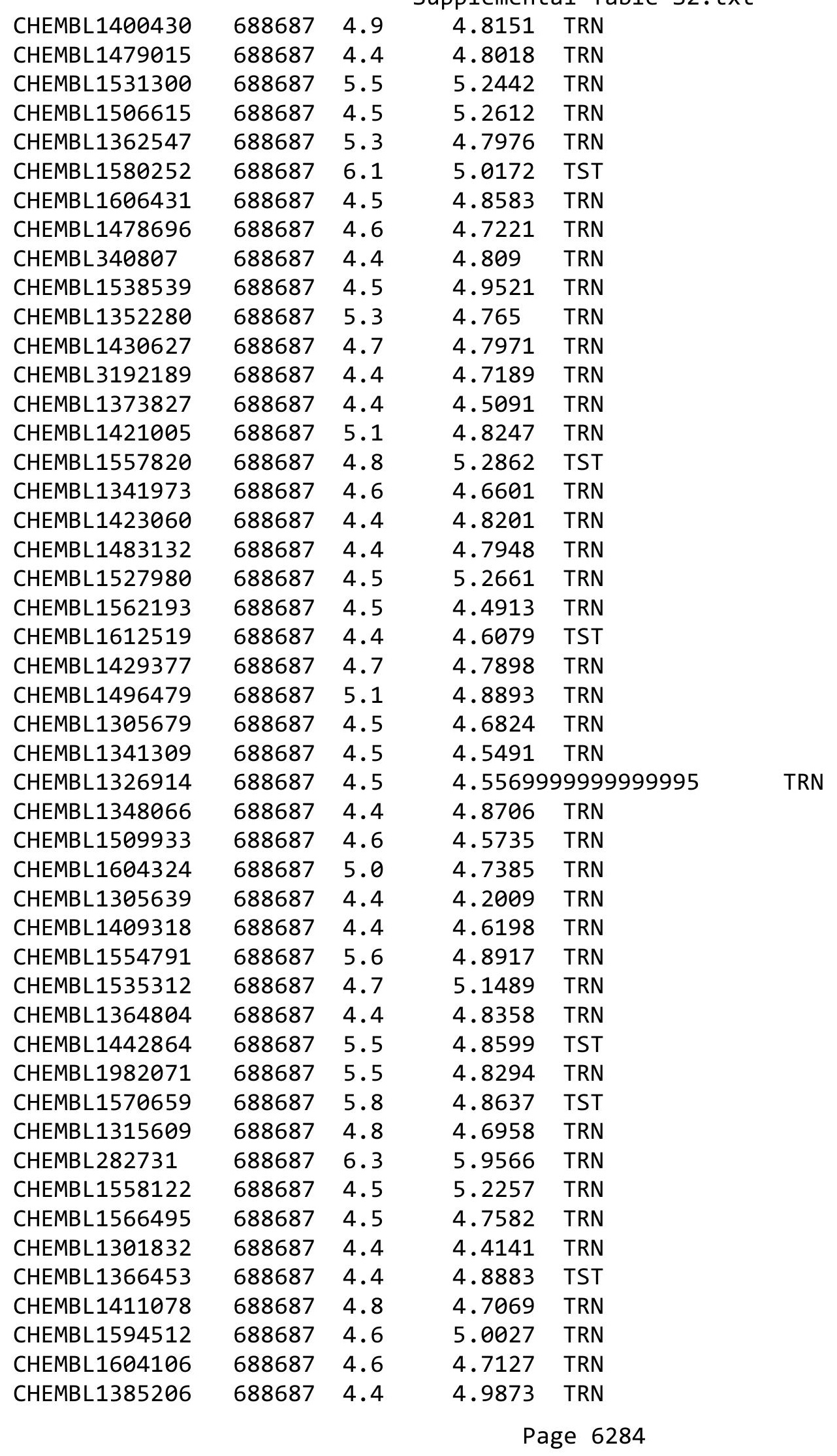




\begin{tabular}{|c|c|c|c|c|c|}
\hline \multirow{3}{*}{ CHEMBL1576679 } & \multirow{2}{*}{688687} & \multirow{2}{*}{4.8} & \\
\hline & & & & & \\
\hline & 688687 & 4.4 & 4.8151 & TRN & \\
\hline CHEMBL1359534 & 688687 & 4.5 & 4.7789 & TRN & \\
\hline CHEMBL1467711 & 688687 & 4.8 & 4.5681 & TRN & \\
\hline CHEMBL3212848 & 688687 & 4.4 & 5.1142 & TST & \\
\hline CHEMBL1550083 & 688687 & 4.4 & 4.6586 & TRN & \\
\hline CHEMBL1412288 & 688687 & 4.8 & 4.9342 & TRN & \\
\hline CHEMBL1452874 & 688687 & 4.4 & 5.0688 & TRN & \\
\hline CHEMBL1330080 & 688687 & 4.5 & 4.319 & TRN & \\
\hline CHEMBL1355701 & 688687 & 4.8 & 4.7884 & TRN & \\
\hline CHEMBL1349627 & 688687 & 4.6 & 5.0038 & TRN & \\
\hline CHEMBL1306804 & 688687 & 5.4 & 4.8239 & TRN & \\
\hline CHEMBL1579158 & 688687 & 4.5 & 4.5322 & TRN & \\
\hline CHEMBL1561174 & 688687 & 4.8 & 5.2271 & TRN & \\
\hline CHEMBL1498218 & 688687 & 4.6 & 4.9267 & TRN & \\
\hline CHEMBL1463525 & 688687 & 4.5 & \multicolumn{2}{|c|}{4.7860000000000005} & TRN \\
\hline CHEMBL1240755 & 688687 & 4.5 & 4.7163 & TRN & \\
\hline CHEMBL1470177 & 688687 & 4.6 & 4.8626 & TRN & \\
\hline CHEMBL1370320 & 688687 & 5.5 & 4.9781 & TRN & \\
\hline CHEMBL1348377 & 688687 & 4.8 & 4.9158 & TRN & \\
\hline CHEMBL1565914 & 688687 & 5.2 & 5.1872 & TST & \\
\hline CHEMBL1325715 & 688687 & 4.5 & 4.6213 & TRN & \\
\hline CHEMBL1366168 & 688687 & 4.5 & 4.6934 & TRN & \\
\hline CHEMBL1315920 & 688687 & 4.9 & 4.7698 & TRN & \\
\hline CHEMBL1608662 & 688687 & 4.6 & 4.4403 & TRN & \\
\hline CHEMBL1420077 & 688687 & 4.5 & 4.6831 & TRN & \\
\hline CHEMBL1448556 & 688687 & 4.4 & 4.7017 & TST & \\
\hline CHEMBL1387003 & 688687 & 5.7 & 4.8075 & TRN & \\
\hline CHEMBL3213883 & 688687 & 5.4 & 5.3465 & TST & \\
\hline CHEMBL1372694 & 688687 & 4.4 & \multicolumn{2}{|c|}{4.8580000000000005} & TRN \\
\hline CHEMBL1382491 & 688687 & 4.4 & 4.8395 & TRN & \\
\hline CHEMBL1357151 & 688687 & 4.4 & 5.3265 & TST & \\
\hline CHEMBL1383659 & 688687 & 4.6 & 4.8759 & TST & \\
\hline CHEMBL1559207 & 688687 & 4.6 & \multicolumn{2}{|c|}{4.656000000000001} & TRN \\
\hline CHEMBL1396377 & 688687 & 4.5 & 4.402 & TRN & \\
\hline CHEMBL1325756 & 688687 & 5.5 & 5.4319 & TRN & \\
\hline CHEMBL1313365 & 688687 & 4.4 & 4.6937 & TRN & \\
\hline CHEMBL1429215 & 688687 & 5.2 & 4.5486 & TRN & \\
\hline CHEMBL490744 & 688687 & 4.5 & 4.6255 & TRN & \\
\hline CHEMBL1333924 & 688687 & 4.4 & 4.9277 & TRN & \\
\hline CHEMBL1446151 & 688687 & 4.8 & 4.9358 & TST & \\
\hline CHEMBL1596661 & 688687 & 4.7 & 4.7368 & TRN & \\
\hline CHEMBL491578 & 688687 & 5.4 & 4.8222 & TRN & \\
\hline CHEMBL1504602 & 688687 & 4.9 & 5.0865 & TST & \\
\hline CHEMBL566706 & 688687 & 4.5 & 4.8351 & TRN & \\
\hline CHEMBL1342209 & 688687 & 4.6 & 4.7389 & TRN & \\
\hline CHEMBL1417749 & 688687 & 4.7 & 4.9518 & TRN & \\
\hline \multirow[t]{2}{*}{ CHEMBL1467378 } & 688687 & 4.7 & \multirow{2}{*}{\multicolumn{2}{|c|}{ Page 6285}} & TRN \\
\hline & & & & & \\
\hline
\end{tabular}




\begin{tabular}{|c|c|c|c|c|}
\hline \multicolumn{5}{|c|}{ plemental T } \\
\hline CHEMBL1507418 & 688687 & 4.6 & 4.5803 & TRN \\
\hline CHEMBL1321559 & 688687 & 4.6 & 4.7076 & TRN \\
\hline CHEMBL1441414 & 688687 & 4.4 & 5.075 & TRN \\
\hline CHEMBL1372207 & 688687 & 4.6 & 4.8467 & TST \\
\hline CHEMBL1531716 & 688687 & 5.8 & 5.3513 & TRN \\
\hline CHEMBL1383591 & 688687 & 5.1 & 5.0067 & TRN \\
\hline CHEMBL1497287 & 688687 & 4.8 & 5.0049 & TST \\
\hline CHEMBL1561663 & 688687 & 4.6 & 4.6797 & TRN \\
\hline CHEMBL1707818 & 688687 & 5.4 & 4.7487 & TRN \\
\hline CHEMBL1536856 & 688687 & 5.3 & 4.8494 & TRN \\
\hline CHEMBL1431654 & 688687 & 4.4 & 4.8629 & TRN \\
\hline CHEMBL1586893 & 688687 & 4.6 & 4.7154 & TRN \\
\hline CHEMBL1256851 & 688687 & 5.1 & 5.2027 & TST \\
\hline CHEMBL1577354 & 688687 & 5.2 & 5.0782 & TST \\
\hline CHEMBL1554721 & 688687 & 4.4 & 4.6967 & TRN \\
\hline CHEMBL1503644 & 688687 & 5.1 & 4.9243 & TRN \\
\hline CHEMBL1507262 & 688687 & 4.8 & 4.8897 & TRN \\
\hline CHEMBL1458630 & 688687 & 4.6 & 4.6413 & TRN \\
\hline CHEMBL1497451 & 688687 & 4.5 & 5.3572 & TRN \\
\hline CHEMBL1540213 & 688687 & 5.2 & 4.8784 & TST \\
\hline CHEMBL1565617 & 688687 & 4.4 & 4.8023 & TRN \\
\hline CHEMBL491939 & 688687 & 4.4 & 4.4405 & TRN \\
\hline CHEMBL1553825 & 688687 & 5.4 & 5.1205 & TRN \\
\hline CHEMBL1530229 & 688687 & 5.5 & 4.8702 & TRN \\
\hline CHEMBL1563874 & 688687 & 4.4 & 4.4492 & TRN \\
\hline CHEMBL1307720 & 688687 & 4.5 & 4.4558 & TRN \\
\hline CHEMBL1343536 & 688687 & 4.6 & 4.9881 & TRN \\
\hline CHEMBL1563212 & 688687 & 4.5 & 4.7137 & TRN \\
\hline CHEMBL1322113 & 688687 & 5.0 & 4.7984 & TRN \\
\hline CHEMBL1300832 & 688687 & 4.7 & 5.0344 & TRN \\
\hline CHEMBL1403681 & 688687 & 4.5 & 4.7055 & TRN \\
\hline CHEMBL1369532 & 688687 & 7.4001 & 5.2656 & TST \\
\hline CHEMBL1487152 & 688687 & 5.4 & 4.8733 & TRN \\
\hline CHEMBL1501292 & 688687 & 4.4 & 4.5903 & TRN \\
\hline CHEMBL1336155 & 688687 & 5.5 & 5.0324 & TST \\
\hline CHEMBL399249 & 688687 & 4.6 & 5.0865 & TST \\
\hline CHEMBL1336284 & 688687 & 4.8 & 5.5323 & TRN \\
\hline CHEMBL1334633 & 688687 & 5.4 & 5.022 & TST \\
\hline CHEMBL1495004 & 688687 & 4.4 & 4.5965 & TRN \\
\hline CHEMBL1428143 & 688687 & 4.6 & 4.727 & TRN \\
\hline CHEMBL1359511 & 688687 & 5.2 & 4.5237 & TRN \\
\hline CHEMBL1494136 & 688687 & 4.7 & 4.7482 & TRN \\
\hline CHEMBL1596068 & 688687 & 4.6 & 4.8623 & TRN \\
\hline CHEMBL1607913 & 688687 & 4.4 & 4.7729 & TRN \\
\hline CHEMBL1441856 & 688687 & 4.5 & 4.5544 & TRN \\
\hline CHEMBL1608276 & 688687 & 5.2 & 4.5796 & TRN \\
\hline CHEMBL1429363 & 688687 & 4.4 & 4.5098 & TRN \\
\hline CHEMBL1498297 & 688687 & 7.8996 & 4.6886 & TRN \\
\hline
\end{tabular}




\begin{tabular}{|c|c|c|c|c|c|}
\hline \\
\hline CHEMBL1400475 & 688687 & 4.5 & 4.7849 & TRN & \\
\hline CHEMBL1408061 & 688687 & 4.8 & 4.681 & TRN & \\
\hline CHEMBL1327906 & 688687 & 4.4 & 4.5794 & TRN & \\
\hline CHEMBL1336008 & 688687 & 5.7 & 4.9981 & TST & \\
\hline CHEMBL1352498 & 688687 & 5.4 & 4.9024 & TRN & \\
\hline CHEMBL1537230 & 688687 & 4.9 & 4.6006 & TRN & \\
\hline CHEMBL1510870 & 688687 & 4.4 & 4.525 & TRN & \\
\hline CHEMBL1514782 & 688687 & 5.2 & 5.2843 & TST & \\
\hline CHEMBL1609089 & 688687 & 4.5 & 4.862 & TRN & \\
\hline CHEMBL1498324 & 688687 & 5.2 & 5.1029 & TRN & \\
\hline CHEMBL1503105 & 688687 & 4.9 & 4.8357 & TRN & \\
\hline CHEMBL1444847 & 688687 & 4.6 & 5.0332 & TRN & \\
\hline CHEMBL1325503 & 688687 & 4.8 & 4.904 & TRN & \\
\hline CHEMBL1455957 & 688687 & 4.4 & 4.8235 & TST & \\
\hline CHEMBL1461487 & 688687 & 5.1 & 4.8287 & TRN & \\
\hline CHEMBL1481546 & 688687 & 6.9 & 5.896 & TRN & \\
\hline CHEMBL1604166 & 688687 & 4.9 & 4.6129 & TRN & \\
\hline CHEMBL1255653 & 688687 & 4.6 & 5.0358 & TST & \\
\hline CHEMBL1311916 & 688687 & 4.6 & 4.3925 & TRN & \\
\hline CHEMBL1417130 & 688687 & 4.8 & 5.1248 & TRN & \\
\hline CHEMBL1489178 & 688687 & 4.5 & 4.9129 & TRN & \\
\hline CHEMBL428814 & 688687 & 4.4 & 4.4186 & TRN & \\
\hline CHEMBL1373443 & 688687 & 4.6 & 4.6884 & TRN & \\
\hline CHEMBL1307310 & 688687 & 4.6 & 4.7292 & TRN & \\
\hline CHEMBL1577953 & 688687 & 4.5 & 5.005 & TRN & \\
\hline CHEMBL1596384 & 688687 & 5.5 & 4.7773 & TRN & \\
\hline CHEMBL1573153 & 688687 & 4.4 & 4.7472 & TRN & \\
\hline CHEMBL1465067 & 688687 & 4.8 & 4.7025 & TST & \\
\hline CHEMBL1522524 & 688687 & 4.5 & 5.1217 & TRN & \\
\hline CHEMBL1586886 & 688687 & 5.0 & 5.4035 & TST & \\
\hline CHEMBL1481474 & 688687 & 4.5 & 4.6003 & TRN & \\
\hline CHEMBL1526600 & 688687 & 4.5 & 4.9925 & TRN & \\
\hline CHEMBL1315528 & 688687 & 4.5 & 4.30699 & 99999999995 & TRN \\
\hline CHEMBL1423947 & 688687 & 4.5 & 5.0218 & TRN & \\
\hline CHEMBL1326188 & 688687 & 5.3 & 4.8115 & TRN & \\
\hline CHEMBL1374609 & 688687 & 4.4 & 4.6831 & TRN & \\
\hline CHEMBL1383379 & 688687 & 4.6 & 4.7843 & TRN & \\
\hline CHEMBL1497527 & 688687 & 4.4 & 4.4681 & TRN & \\
\hline CHEMBL1445897 & 688687 & 4.6 & 4.813 & TRN & \\
\hline CHEMBL1492620 & 688687 & 4.5 & 4.8185 & TRN & \\
\hline CHEMBL1475284 & 688687 & 4.4 & 4.8446 & TRN & \\
\hline CHEMBL1581571 & 688687 & 5.2 & 4.8507 & TST & \\
\hline CHEMBL1468677 & 688687 & 4.5 & 4.7997 & TRN & \\
\hline CHEMBL1392282 & 688687 & 5.5 & 4.62 & TST & \\
\hline CHEMBL1389117 & 688687 & 4.5 & 4.9307 & TRN & \\
\hline CHEMBL1255650 & 688687 & 5.2 & 4.7243 & TST & \\
\hline CHEMBL1556608 & 688687 & 4.4 & 4.5606 & TRN & \\
\hline CHEMBL1544333 & 688687 & 4.7 & 4.7252 & TRN & \\
\hline
\end{tabular}




\begin{tabular}{|c|c|c|c|c|}
\hline & & & & $a \perp 1 a$ \\
\hline CHEMBL1425267 & 688687 & 4.8 & 4.8688 & TRN \\
\hline CHEMBL1451792 & 688687 & 4.5 & 4.6021 & TRN \\
\hline CHEMBL1561653 & 688687 & 5.4 & 4.8755 & TRN \\
\hline CHEMBL1324196 & 688687 & 5.3 & 4.9648 & TRN \\
\hline CHEMBL263116 & 688687 & 4.5 & 5.003 & TRN \\
\hline CHEMBL1403497 & 688687 & 4.8 & 5.0937 & TRN \\
\hline CHEMBL1503334 & 688687 & 4.5 & 4.9482 & TST \\
\hline CHEMBL1429428 & 688687 & 4.6 & 5.1041 & TRN \\
\hline CHEMBL1306078 & 688687 & 4.6 & 4.6827 & TRN \\
\hline CHEMBL3190739 & 688687 & 4.4 & 4.7001 & TRN \\
\hline CHEMBL1498329 & 688687 & 4.6 & 5.1651 & TRN \\
\hline CHEMBL1544110 & 688687 & 4.4 & 4.5704 & TRN \\
\hline CHEMBL1432570 & 688687 & 4.5 & 4.9415 & TRN \\
\hline CHEMBL1338503 & 688687 & 4.4 & 4.5779 & TST \\
\hline CHEMBL1571020 & 688687 & 4.9 & 4.8792 & TRN \\
\hline CHEMBL1566731 & 688687 & 4.4 & 4.515 & TRN \\
\hline CHEMBL1508109 & 688687 & 4.7 & 4.6124 & TRN \\
\hline CHEMBL1569358 & 688687 & 4.5 & 4.9559 & TRN \\
\hline CHEMBL1556666 & 688687 & 4.6 & 4.8638 & TRN \\
\hline CHEMBL1573401 & 688687 & 4.8 & 4.6238 & TRN \\
\hline CHEMBL1495846 & 688687 & 5.4 & 4.8615 & TRN \\
\hline CHEMBL1332471 & 688687 & 4.8 & 5.0238 & TST \\
\hline CHEMBL1468887 & 688687 & 4.4 & 4.9035 & TRN \\
\hline CHEMBL1562041 & 688687 & 4.4 & 4.5113 & TRN \\
\hline CHEMBL1602522 & 688687 & 6.8 & 5.0781 & TRN \\
\hline CHEMBL1469091 & 688687 & 4.6 & 4.98 & TST \\
\hline CHEMBL1349305 & 688687 & 4.7 & 4.6781 & TRN \\
\hline CHEMBL1548434 & 688687 & 4.6 & 5.1985 & TRN \\
\hline CHEMBL1595336 & 688687 & 5.4 & 5.0845 & TRN \\
\hline CHEMBL1569671 & 688687 & 4.4 & 4.8649 & TRN \\
\hline CHEMBL1302259 & 688687 & 4.7 & 4.6171 & TRN \\
\hline CHEMBL1470371 & 688687 & 4.5 & 4.882 & TST \\
\hline CHEMBL1513845 & 688687 & 6.0 & 5.5254 & TRN \\
\hline CHEMBL1550099 & 688687 & 4.5 & 4.5112 & TRN \\
\hline CHEMBL1457517 & 688687 & 4.5 & 5.0024 & TRN \\
\hline CHEMBL1561641 & 688687 & 4.6 & 4.7962 & TRN \\
\hline CHEMBL1567951 & 688687 & 4.4 & 4.7165 & TRN \\
\hline CHEMBL1555014 & 688687 & 4.6 & 4.7136 & TRN \\
\hline CHEMBL1380964 & 688687 & 4.6 & 4.6928 & TRN \\
\hline CHEMBL1610810 & 688687 & 5.1 & 4.8342 & TRN \\
\hline CHEMBL1510729 & 688687 & 4.4 & 4.9218 & TRN \\
\hline CHEMBL1526615 & 688687 & 4.4 & 4.5533 & TRN \\
\hline CHEMBL1365371 & 688687 & 4.8 & 4.9322 & TRN \\
\hline CHEMBL1352126 & 688687 & 5.6 & 4.7052 & TRN \\
\hline CHEMBL1494574 & 688687 & 4.6 & 4.4237 & TRN \\
\hline CHEMBL1353698 & 688687 & 5.5 & 4.7112 & TRN \\
\hline CHEMBL1401424 & 688687 & 5.4 & 4.8684 & TRN \\
\hline CHEMBL1486606 & 688687 & 4.4 & 4.7589 & TRN \\
\hline
\end{tabular}




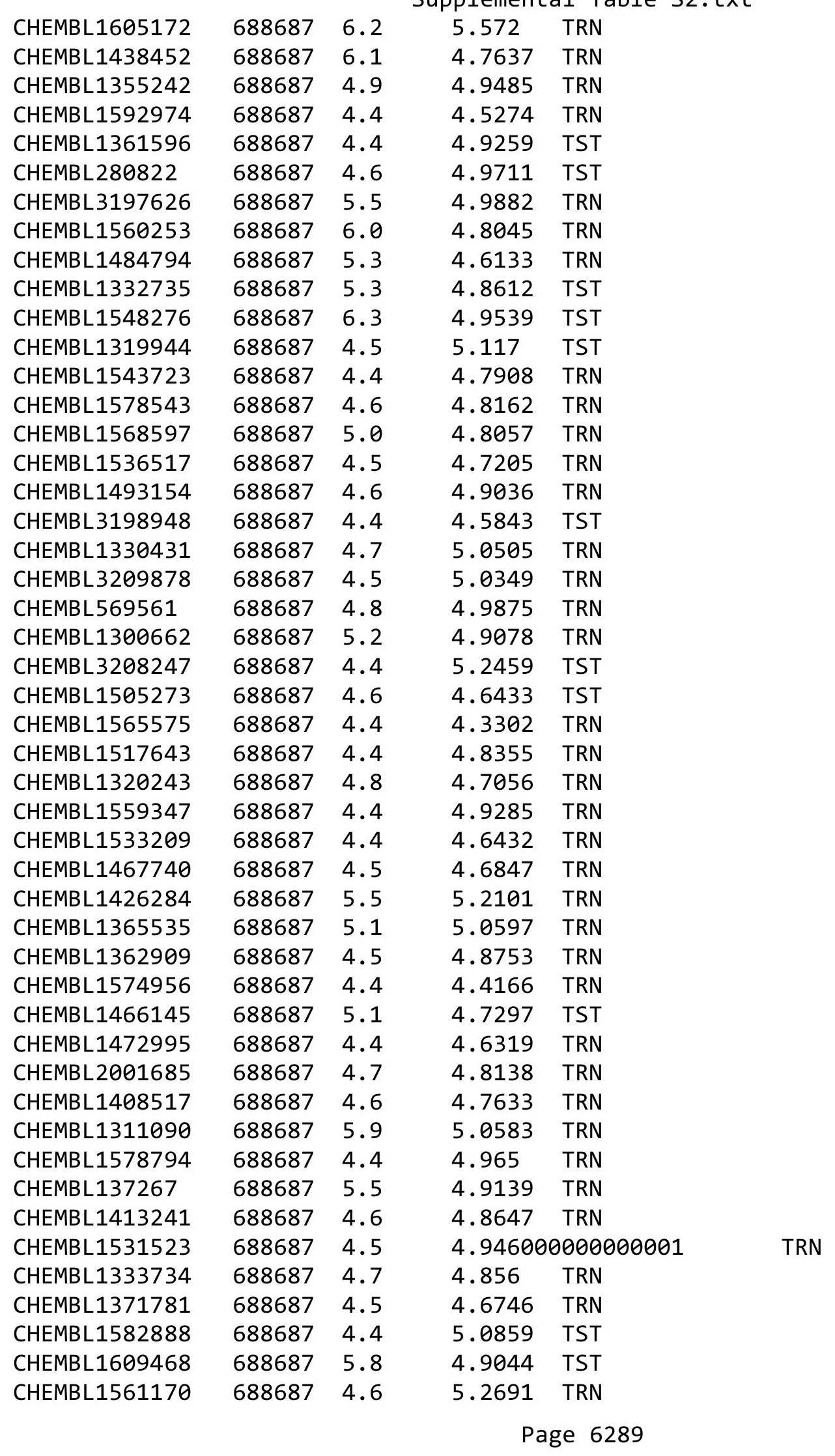




\begin{tabular}{|c|c|c|c|c|}
\hline & & & ement & al Ta \\
\hline CHEMBL1579098 & 688687 & 5.0 & 4.6236 & TRN \\
\hline CHEMBL1342900 & 688687 & 5.5 & 5.0005 & TRN \\
\hline CHEMBL1421684 & 688687 & 4.8 & 4.8466 & TRN \\
\hline CHEMBL1420557 & 688687 & 4.4 & 4.88 & TRN \\
\hline CHEMBL1536660 & 688687 & 4.4 & 5.079 & TST \\
\hline CHEMBL1527520 & 688687 & 4.9 & 5.3469 & TST \\
\hline CHEMBL1556742 & 688687 & 5.9 & 5.1829 & TST \\
\hline CHEMBL1559267 & 688687 & 4.5 & 4.9577 & TRN \\
\hline CHEMBL1390640 & 688687 & 4.7 & 4.5331 & TRN \\
\hline CHEMBL1429456 & 688687 & 4.4 & 5.1673 & TRN \\
\hline CHEMBL1341777 & 688687 & 4.5 & 4.6418 & TRN \\
\hline CHEMBL1541800 & 688687 & 4.4 & 4.6055 & TRN \\
\hline CHEMBL1349236 & 688687 & 4.4 & 4.5931 & TRN \\
\hline CHEMBL1585799 & 688687 & 4.5 & 4.6783 & TRN \\
\hline CHEMBL1448974 & 688687 & 5.2 & 5.3157 & TRN \\
\hline CHEMBL1548700 & 688687 & 4.7 & 4.261 & TRN \\
\hline CHEMBL1612321 & 688687 & 4.6 & 4.6704 & TST \\
\hline CHEMBL1527393 & 688687 & 5.4 & 4.8086 & TRN \\
\hline CHEMBL1359102 & 688687 & 4.6 & 4.6587 & TRN \\
\hline CHEMBL1559311 & 688687 & 4.8 & 4.7687 & TRN \\
\hline CHEMBL1323714 & 688687 & 4.4 & 4.5573 & TST \\
\hline CHEMBL1407953 & 688687 & 4.6 & 4.9785 & TRN \\
\hline CHEMBL1399711 & 688687 & 5.5 & 4.6719 & TRN \\
\hline CHEMBL1337605 & 688687 & 5.0 & 4.6425 & TRN \\
\hline CHEMBL1604546 & 688687 & 5.4 & 5.03 & TST \\
\hline CHEMBL1544342 & 688687 & 4.4 & 4.6296 & TRN \\
\hline CHEMBL1433360 & 688687 & 4.5 & 4.9123 & TST \\
\hline CHEMBL1534131 & 688687 & 5.7 & 4.8271 & TST \\
\hline CHEMBL1377177 & 688687 & 5.3 & 5.0069 & TRN \\
\hline CHEMBL1606278 & 688687 & 4.5 & 4.7108 & TRN \\
\hline CHEMBL1573333 & 688687 & 4.8 & 4.9002 & TRN \\
\hline CHEMBL1427430 & 688687 & 4.5 & 4.4722 & TRN \\
\hline CHEMBL1458405 & 688687 & 4.5 & 4.7164 & TRN \\
\hline CHEMBL1475541 & 688687 & 4.6 & 4.5645 & TRN \\
\hline CHEMBL1432058 & 688687 & 5.0 & 4.7483 & TRN \\
\hline CHEMBL118109 & 688687 & 4.9 & 4.8685 & TST \\
\hline CHEMBL1541587 & 688687 & 5.4 & 4.9923 & TRN \\
\hline CHEMBL1430321 & 688687 & 4.6 & 4.8769 & TRN \\
\hline CHEMBL1370669 & 688687 & 4.6 & 5.0184 & TRN \\
\hline CHEMBL1307948 & 688687 & 5.4 & 4.7602 & TRN \\
\hline CHEMBL1580511 & 688687 & 4.4 & 5.1392 & TRN \\
\hline CHEMBL1518035 & 688687 & 4.7 & 4.6438 & TRN \\
\hline CHEMBL1490740 & 688687 & 4.6 & 4.7044 & TRN \\
\hline CHEMBL1526528 & 688687 & 4.4 & 4.9716 & TRN \\
\hline CHEMBL1548265 & 688687 & 5.2 & 4.7424 & TRN \\
\hline CHEMBL1368742 & 688687 & 4.8 & 4.817 & TRN \\
\hline CHEMBL1524874 & 688687 & 4.9 & 4.9143 & TRN \\
\hline CHEMBL1534231 & 688687 & 4.5 & 4.6935 & TRN \\
\hline
\end{tabular}




\begin{tabular}{|c|c|c|c|c|}
\hline & & & eris & $a \perp 1 a$ \\
\hline CHEMBL1539677 & 688687 & 5.6 & 4.68 & TRN \\
\hline CHEMBL1438704 & 688687 & 5.2 & 5.2382 & TRN \\
\hline CHEMBL1466997 & 688687 & 6.1 & 4.8524 & TRN \\
\hline CHEMBL1415442 & 688687 & 4.6 & 4.8109 & TRN \\
\hline CHEMBL1488080 & 688687 & 4.6 & 4.8418 & TST \\
\hline CHEMBL1585485 & 688687 & 4.9 & 4.8351 & TRN \\
\hline CHEMBL1470911 & 688687 & 4.6 & 4.8098 & TRN \\
\hline CHEMBL1404490 & 688687 & 4.5 & 5.0996 & TST \\
\hline CHEMBL1317133 & 688687 & 7.2 & 5.2062 & TRN \\
\hline CHEMBL1448248 & 688687 & 4.8 & 4.989 & TST \\
\hline CHEMBL1489175 & 688687 & 4.5 & 4.6938 & TRN \\
\hline CHEMBL1430893 & 688687 & 4.5 & 4.8765 & TRN \\
\hline CHEMBL2373676 & 688687 & 5.1 & 4.9546 & TST \\
\hline CHEMBL1469169 & 688687 & 5.4 & 5.0261 & TRN \\
\hline CHEMBL405317 & 688687 & 4.5 & 4.704 & TRN \\
\hline CHEMBL1368759 & 688687 & 4.9 & 5.2642 & TRN \\
\hline CHEMBL1450614 & 688687 & 4.6 & 4.6665 & TRN \\
\hline CHEMBL1561366 & 688687 & 4.4 & 4.6294 & TRN \\
\hline CHEMBL1353987 & 688687 & 4.4 & 4.8611 & TRN \\
\hline CHEMBL1300611 & 688687 & 5.5 & 4.8721 & TRN \\
\hline CHEMBL1499754 & 688687 & 4.5 & 4.8087 & TRN \\
\hline CHEMBL563294 & 688687 & 5.1 & 5.006 & TRN \\
\hline CHEMBL1331286 & 688687 & 4.6 & 4.6747 & TRN \\
\hline CHEMBL1491831 & 688687 & 4.4 & 4.8149 & TST \\
\hline CHEMBL1580990 & 688687 & 5.4 & 5.1723 & TRN \\
\hline CHEMBL1540464 & 688687 & 5.5 & 4.9987 & TST \\
\hline CHEMBL1383746 & 688687 & 5.4 & 5.1331 & TRN \\
\hline CHEMBL1306250 & 688687 & 4.6 & 4.6598 & TRN \\
\hline CHEMBL1479449 & 688687 & 4.8 & 5.1624 & TRN \\
\hline CHEMBL1377868 & 688687 & 4.5 & 4.7238 & TRN \\
\hline CHEMBL1375570 & 688687 & 4.6 & 4.6215 & TRN \\
\hline CHEMBL453066 & 688687 & 4.5 & 4.8622 & TRN \\
\hline CHEMBL1536285 & 688687 & 4.6 & 4.6676 & TRN \\
\hline CHEMBL1607198 & 688687 & 4.5 & 4.8035 & TRN \\
\hline CHEMBL1383936 & 688687 & 4.5 & 5.0249 & TRN \\
\hline CHEMBL1415790 & 688687 & 4.7 & 4.6407 & TRN \\
\hline CHEMBL1585051 & 688687 & 5.8 & 4.7464 & TRN \\
\hline CHEMBL1551534 & 688687 & 4.4 & 4.3251 & TRN \\
\hline CHEMBL1485295 & 688687 & 5.1 & 4.8324 & TRN \\
\hline CHEMBL1431627 & 688687 & 4.4 & 4.6849 & TRN \\
\hline CHEMBL1477642 & 688687 & 4.4 & 4.8516 & TRN \\
\hline CHEMBL1346315 & 688687 & 4.6 & 4.6917 & TRN \\
\hline CHEMBL1500854 & 688687 & 4.4 & 4.6453 & TST \\
\hline CHEMBL1518102 & 688687 & 5.6 & 4.7858 & TRN \\
\hline CHEMBL1413178 & 688687 & 4.5 & 4.6688 & TST \\
\hline CHEMBL1347871 & 688687 & 4.7 & 4.5135 & TRN \\
\hline CHEMBL1329427 & 688687 & 5.5 & 4.9636 & TRN \\
\hline CHEMBL1404107 & 688687 & 4.7 & 4.9034 & TRN \\
\hline
\end{tabular}




\begin{tabular}{|c|c|c|c|c|}
\hline & & & ient & al Ta \\
\hline CHEMBL1536259 & 688687 & 4.6 & 4.7448 & TRN \\
\hline CHEMBL399760 & 688687 & 5.1 & 4.916 & TRN \\
\hline CHEMBL1579840 & 688687 & 4.5 & 4.9749 & TST \\
\hline CHEMBL1576338 & 688687 & 4.5 & 4.5705 & TRN \\
\hline CHEMBL1347985 & 688687 & 6.1 & 6.0564 & TRN \\
\hline CHEMBL1356134 & 688687 & 5.0 & 4.8146 & TRN \\
\hline CHEMBL1381967 & 688687 & 5.4 & 4.763 & TRN \\
\hline CHEMBL1480886 & 688687 & 4.4 & 5.0112 & TST \\
\hline CHEMBL1339240 & 688687 & 4.5 & 4.4736 & TRN \\
\hline CHEMBL1603351 & 688687 & 4.9 & 4.6892 & TRN \\
\hline CHEMBL1576326 & 688687 & 4.6 & 4.8551 & TRN \\
\hline CHEMBL1595467 & 688687 & 4.5 & 4.7784 & TRN \\
\hline CHEMBL1343906 & 688687 & 4.5 & 4.563 & TRN \\
\hline CHEMBL1325735 & 688687 & 4.6 & 4.7002 & TRN \\
\hline CHEMBL1459444 & 688687 & 4.5 & 4.9108 & TRN \\
\hline CHEMBL1338712 & 688687 & 4.6 & 4.5652 & TRN \\
\hline CHEMBL1590270 & 688687 & 5.2 & 5.1223 & TRN \\
\hline CHEMBL1609875 & 688687 & 5.5 & 4.6509 & TST \\
\hline CHEMBL1479488 & 688687 & 5.9 & 4.7851 & TRN \\
\hline CHEMBL1341438 & 688687 & 4.6 & 4.8543 & TRN \\
\hline CHEMBL1604561 & 688687 & 4.4 & 4.8787 & TRN \\
\hline CHEMBL1510509 & 688687 & 5.4 & 4.6589 & TRN \\
\hline CHEMBL1402807 & 688687 & 4.9 & 4.4433 & TRN \\
\hline CHEMBL1546815 & 688687 & 4.4 & 4.9351 & TRN \\
\hline CHEMBL1969704 & 688687 & 4.4 & 4.5082 & TRN \\
\hline CHEMBL1347594 & 688687 & 4.6 & 4.7468 & TRN \\
\hline CHEMBL1408872 & 688687 & 5.7 & 5.1935 & TRN \\
\hline CHEMBL1519100 & 688687 & 4.5 & 4.604 & TRN \\
\hline CHEMBL1407866 & 688687 & 4.4 & 4.8679 & TRN \\
\hline CHEMBL1405295 & 688687 & 5.1 & 4.99 & TRN \\
\hline CHEMBL1455993 & 688687 & 5.4 & 5.0484 & TRN \\
\hline CHEMBL1374854 & 688687 & 4.5 & 4.7659 & TRN \\
\hline CHEMBL1444429 & 688687 & 5.2 & 4.9635 & TST \\
\hline CHEMBL1401075 & 688687 & 4.5 & 4.7681 & TRN \\
\hline CHEMBL1344546 & 688687 & 4.4 & 4.9039 & TRN \\
\hline CHEMBL1373914 & 688687 & 5.0 & 4.7349 & TRN \\
\hline CHEMBL1324772 & 688687 & 5.1 & 5.0274 & TRN \\
\hline CHEMBL1479195 & 688687 & 4.6 & 4.7119 & TRN \\
\hline CHEMBL1488374 & 688687 & 4.4 & 4.8852 & TRN \\
\hline CHEMBL1587578 & 688687 & 4.8 & 5.1284 & TRN \\
\hline CHEMBL1503252 & 688687 & 4.8 & 4.5966 & TRN \\
\hline CHEMBL1562158 & 688687 & 4.7 & 4.7757 & TRN \\
\hline CHEMBL1584571 & 688687 & 4.5 & 4.6144 & TRN \\
\hline CHEMBL1479579 & 688687 & 4.6 & 4.8613 & TRN \\
\hline CHEMBL1322220 & 688687 & 4.5 & 4.7022 & TRN \\
\hline CHEMBL2369215 & 688687 & 4.6 & 5.0422 & TST \\
\hline CHEMBL1364764 & 688687 & 4.6 & 4.5689 & TRN \\
\hline CHEMBL1409899 & 688687 & 4.4 & 5.0148 & TRN \\
\hline
\end{tabular}




\begin{tabular}{|c|c|c|c|c|c|}
\hline \\
\hline CHEMBL1544013 & 688687 & 6.8 & 5.0362 & TST & \\
\hline CHEMBL1209369 & 688687 & 5.5 & 4.7796 & TRN & \\
\hline CHEMBL1575830 & 688687 & 4.7 & 4.9176 & TRN & \\
\hline CHEMBL1323754 & 688687 & 4.6 & 4.7917 & TRN & \\
\hline CHEMBL1371696 & 688687 & 5.6 & 4.9188 & TST & \\
\hline CHEMBL1608331 & 688687 & 4.5 & 4.6853 & TRN & \\
\hline CHEMBL1589646 & 688687 & 4.7 & 4.6979 & TRN & \\
\hline CHEMBL1378666 & 688687 & 4.6 & 5.0337 & TST & \\
\hline CHEMBL1349749 & 688687 & 4.7 & 4.6948 & TST & \\
\hline CHEMBL1361207 & 688687 & 4.5 & 4.5888 & TRN & \\
\hline CHEMBL1489146 & 688687 & 4.7 & 4.5954 & TST & \\
\hline CHEMBL 3212480 & 688687 & 4.4 & 5.0265 & TRN & \\
\hline CHEMBL1463090 & 688687 & 4.6 & 4.9754 & TRN & \\
\hline CHEMBL1493396 & 688687 & 6.1 & 5.0121 & TST & \\
\hline CHEMBL1533496 & 688687 & 4.5 & 5.3373 & TRN & \\
\hline CHEMBL1382563 & 688687 & 5.4 & 4.688 & TRN & \\
\hline CHEMBL1345845 & 688687 & 4.4 & 4.8586 & TRN & \\
\hline CHEMBL1565192 & 688687 & 4.5 & 5.0162 & TRN & \\
\hline CHEMBL1438371 & 688687 & 4.8 & 4.8724 & TRN & \\
\hline CHEMBL1299542 & 688687 & 5.2 & 4.8237 & TRN & \\
\hline CHEMBL1305672 & 688687 & 4.4 & 5.1215 & TRN & \\
\hline CHEMBL1574261 & 688687 & 5.2 & 4.9238 & TRN & \\
\hline CHEMBL1422056 & 688687 & 4.9 & 4.8921 & TST & \\
\hline CHEMBL1970265 & 688687 & 5.0 & 4.9806 & TRN & \\
\hline CHEMBL1311625 & 688687 & 4.9 & 4.9422 & TRN & \\
\hline CHEMBL1231667 & 688687 & 5.4 & 4.8906 & TST & \\
\hline CHEMBL1352443 & 688687 & 4.5 & 4.7648 & TRN & \\
\hline CHEMBL1410321 & 688687 & 5.7 & 4.7577 & TRN & \\
\hline CHEMBL1377994 & 688687 & 4.4 & 4.7929 & TRN & \\
\hline CHEMBL1370073 & 688687 & 4.7 & 4.7903 & TRN & \\
\hline CHEMBL1494977 & 688687 & 5.0 & 4.9041 & TRN & \\
\hline CHEMBL1559715 & 688687 & 4.6 & 4.7451 & TRN & \\
\hline CHEMBL1716742 & 688687 & 5.6 & 4.8265 & TST & \\
\hline CHEMBL1331227 & 688687 & 5.5 & 5.1719 & TRN & \\
\hline CHEMBL1421580 & 688687 & 4.8 & 4.8318 & TRN & \\
\hline CHEMBL1380494 & 688687 & 4.6 & 4.6109 & TRN & \\
\hline CHEMBL1453291 & 688687 & 4.4 & 5.02800 & 00000000005 & TST \\
\hline CHEMBL1406280 & 688687 & 4.5 & 4.7139 & TRN & \\
\hline CHEMBL1447721 & 688687 & 5.2 & 5.2018 & TST & \\
\hline CHEMBL1381991 & 688687 & 4.6 & 5.2324 & TRN & \\
\hline CHEMBL1407909 & 688687 & 5.4 & 5.14 & TST & \\
\hline CHEMBL1329708 & 688687 & 4.8 & 4.6856 & TRN & \\
\hline CHEMBL80941 & 688687 & 6.0 & 5.6829 & TST & \\
\hline CHEMBL3192945 & 688687 & 5.5 & 4.894 & TRN & \\
\hline CHEMBL1571236 & 688687 & 4.6 & 4.627 & TRN & \\
\hline CHEMBL1385458 & 688687 & 5.2 & 4.6315 & TRN & \\
\hline CHEMBL592712 & 688687 & 4.4 & 4.4624 & TST & \\
\hline CHEMBL1338958 & 688687 & 5.6 & 5.5409 & TRN & \\
\hline
\end{tabular}




\begin{tabular}{|c|c|c|c|c|c|}
\hline \\
\hline CHEMBL1593547 & 688687 & 4.5 & 4.9678 & TRN & \\
\hline CHEMBL1545253 & 688687 & 5.1 & 4.9254 & TRN & \\
\hline CHEMBL1331426 & 688687 & 5.4 & 4.7807 & TST & \\
\hline CHEMBL1366544 & 688687 & 4.5 & 4.7072 & TRN & \\
\hline CHEMBL1365873 & 688687 & 4.6 & 4.7023 & TRN & \\
\hline CHEMBL1592542 & 688687 & 6.0 & 5.3362 & TST & \\
\hline CHEMBL1438231 & 688687 & 4.6 & 4.7532 & TRN & \\
\hline CHEMBL1456110 & 688687 & 4.6 & 4.9923 & TRN & \\
\hline CHEMBL1366889 & 688687 & 4.4 & 4.4588 & TST & \\
\hline CHEMBL1304640 & 688687 & 4.4 & 4.5003 & TRN & \\
\hline CHEMBL504791 & 688687 & 5.6 & 5.0835 & TRN & \\
\hline CHEMBL1347831 & 688687 & 4.7 & 4.4612 & TRN & \\
\hline CHEMBL1346741 & 688687 & 4.4 & 4.716 & TRN & \\
\hline CHEMBL1383055 & 688687 & 5.0 & 5.306 & TRN & \\
\hline CHEMBL1571784 & 688687 & 4.5 & 4.7319 & TRN & \\
\hline CHEMBL1562110 & 688687 & 4.8 & 4.8637 & TRN & \\
\hline CHEMBL1529812 & 688687 & 4.5 & 4.6174 & TRN & \\
\hline CHEMBL1530690 & 688687 & 4.4 & 4.9954 & TRN & \\
\hline CHEMBL1503390 & 688687 & 4.4 & 5.0406 & TRN & \\
\hline CHEMBL1605716 & 688687 & 4.6 & 4.6035 & TRN & \\
\hline CHEMBL1474561 & 688687 & 4.4 & 4.35 & TRN & \\
\hline CHEMBL1598952 & 688687 & 6.2 & 5.041 & TRN & \\
\hline CHEMBL1481813 & 688687 & 5.8 & 5.5735 & TRN & \\
\hline CHEMBL1318616 & 688687 & 4.7 & 4.8923 & TRN & \\
\hline CHEMBL1573700 & 688687 & 5.7 & 5.1368 & TRN & \\
\hline CHEMBL1487806 & 688687 & 4.6 & 4.8606 & TRN & \\
\hline CHEMBL1448687 & 688687 & 4.5 & 4.55399 & 9999999999 & TRN \\
\hline CHEMBL1377708 & 688687 & 5.0 & 5.1854 & TRN & \\
\hline CHEMBL 28140 & 688687 & 6.0 & 5.322 & TRN & \\
\hline CHEMBL1411358 & 688687 & 5.2 & 4.673 & TST & \\
\hline CHEMBL1304011 & 688687 & 4.5 & 4.5514 & TRN & \\
\hline CHEMBL125569 & 688687 & 5.6 & 4.8285 & TST & \\
\hline CHEMBL1566333 & 688687 & 4.4 & 4.7752 & TRN & \\
\hline CHEMBL1200938 & 688687 & 6.0 & 4.8938 & TST & \\
\hline CHEMBL1360310 & 688687 & 4.6 & 4.3737 & TRN & \\
\hline CHEMBL1512023 & 688687 & 4.5 & 4.9743 & TRN & \\
\hline CHEMBL1527011 & 688687 & 5.5 & 4.7673 & TST & \\
\hline CHEMBL1454092 & 688687 & 4.9 & 4.9678 & TRN & \\
\hline CHEMBL1412821 & 688687 & 5.7 & 4.9346 & TST & \\
\hline CHEMBL1413156 & 688687 & 4.5 & 4.8036 & TRN & \\
\hline CHEMBL1529807 & 688687 & 4.7 & 5.0243 & TRN & \\
\hline CHEMBL1541193 & 688687 & 5.8 & 5.0607 & TRN & \\
\hline CHEMBL1470714 & 688687 & 4.6 & 4.941 & TRN & \\
\hline CHEMBL1329833 & 688687 & 4.4 & 5.0802 & TRN & \\
\hline CHEMBL1508279 & 688687 & 4.4 & 4.958 & TRN & \\
\hline CHEMBL1333895 & 688687 & 5.0 & 5.1572 & TRN & \\
\hline CHEMBL1363883 & 688687 & 5.4 & 5.2156 & TST & \\
\hline CHEMBL1493436 & 688687 & 4.4 & 5.3132 & TST & \\
\hline
\end{tabular}




\begin{tabular}{|c|c|c|c|c|c|}
\hline & & & & & \\
\hline CHEMBL1560839 & 688687 & 4.5 & 4.7503 & TRN & \\
\hline CHEMBL489737 & 688687 & 4.4 & 4.8437 & TRN & \\
\hline CHEMBL1570711 & 688687 & 4.5 & 4.7778 & TRN & \\
\hline CHEMBL10247 & 688687 & 4.7 & 4.9355 & TST & \\
\hline CHEMBL1534710 & 688687 & 4.5 & 4.7148 & TRN & \\
\hline CHEMBL1478942 & 688687 & 4.9 & 4.6593 & TST & \\
\hline CHEMBL1591487 & 688687 & 4.9 & 4.8513 & TRN & \\
\hline CHEMBL1510179 & 688687 & 4.7 & 4.5221 & TRN & \\
\hline CHEMBL1608758 & 688687 & 5.1 & 4.8803 & TRN & \\
\hline CHEMBL1544839 & 688687 & 4.5 & 4.8191 & TRN & \\
\hline CHEMBL1508323 & 688687 & 6.1 & 4.683 & TRN & \\
\hline CHEMBL1388937 & 688687 & 4.5 & 4.7424 & TRN & \\
\hline CHEMBL1315690 & 688687 & 4.6 & 4.6431 & TRN & \\
\hline CHEMBL1405259 & 688687 & 5.3 & 4.9212 & TRN & \\
\hline CHEMBL1428589 & 688687 & 5.2 & 5.0291 & TRN & \\
\hline CHEMBL1612525 & 688687 & 5.2 & 4.9928 & TST & \\
\hline CHEMBL1443892 & 688687 & 4.6 & 4.9256 & TRN & \\
\hline CHEMBL1480102 & 688687 & 5.6 & 5.2204 & TRN & \\
\hline CHEMBL1473099 & 688687 & 5.0 & 4.8416 & TRN & \\
\hline CHEMBL1309538 & 688687 & 4.4 & 4.6125 & TRN & \\
\hline CHEMBL1364849 & 688687 & 4.6 & 4.9431 & TST & \\
\hline CHEMBL1489916 & 688687 & 5.4 & 4.8232 & TRN & \\
\hline CHEMBL1504575 & 688687 & 4.4 & 4.6079 & TRN & \\
\hline CHEMBL1584529 & 688687 & 4.6 & 4.7617 & TRN & \\
\hline CHEMBL1583937 & 688687 & 4.7 & 5.19600 & 0000000001 & TST \\
\hline CHEMBL1367634 & 688687 & 4.5 & 4.64199 & 99999999995 & TRN \\
\hline CHEMBL86537 & 688687 & 4.4 & 4.9298 & TST & \\
\hline CHEMBL1407145 & 688687 & 7.6003 & 5.3949 & TRN & \\
\hline CHEMBL1505224 & 688687 & 5.1 & 4.7647 & TST & \\
\hline CHEMBL1528142 & 688687 & 4.9 & 4.6319 & TRN & \\
\hline CHEMBL1558419 & 688687 & 5.3 & 4.9038 & TRN & \\
\hline CHEMBL1349063 & 688687 & 5.2 & 5.4173 & TRN & \\
\hline CHEMBL1414872 & 688687 & 4.4 & 4.5933 & TRN & \\
\hline CHEMBL1340121 & 688687 & 4.9 & 4.8293 & TRN & \\
\hline CHEMBL1564313 & 688687 & 4.4 & 4.8652 & TRN & \\
\hline CHEMBL1409985 & 688687 & 5.7 & 4.9473 & TRN & \\
\hline CHEMBL1576244 & 688687 & 4.6 & 4.3946 & TRN & \\
\hline CHEMBL1288936 & 688687 & 4.5 & 5.1648 & TRN & \\
\hline CHEMBL1550861 & 688687 & 4.5 & 4.8826 & TRN & \\
\hline CHEMBL1393477 & 688687 & 5.2 & 4.769 & TRN & \\
\hline CHEMBL1419272 & 688687 & 4.8 & 4.8828 & TRN & \\
\hline CHEMBL1421985 & 688687 & 7.2 & 4.7488 & TRN & \\
\hline CHEMBL154580 & 688687 & 4.7 & 5.0539 & TRN & \\
\hline CHEMBL1450686 & 688687 & 4.5 & 4.6348 & TRN & \\
\hline CHEMBL3211445 & 688687 & 4.4 & 4.4459 & TRN & \\
\hline CHEMBL1485781 & 688687 & 4.5 & 4.5291 & TRN & \\
\hline CHEMBL1345088 & 688687 & 5.5 & 5.4243 & TRN & \\
\hline CHEMBL1467951 & 688687 & 4.7 & 4.7181 & TRN & \\
\hline
\end{tabular}




\begin{tabular}{|c|c|c|c|c|}
\hline & & & & \\
\hline CHEMBL1516850 & 688687 & 5.5 & 4.9083 & TRN \\
\hline CHEMBL1395196 & 688687 & 4.5 & 5.0988 & TST \\
\hline CHEMBL1457174 & 688687 & 5.8 & 5.8714 & TRN \\
\hline CHEMBL1314107 & 688687 & 4.5 & 4.7409 & TRN \\
\hline CHEMBL1532831 & 688687 & 4.6 & 4.8062 & TRN \\
\hline CHEMBL566064 & 688687 & 4.4 & 4.9531 & TRN \\
\hline CHEMBL1388790 & 688687 & 5.0 & 4.617 & TRN \\
\hline CHEMBL1596266 & 688687 & 5.0 & 4.6046 & TRN \\
\hline CHEMBL1506225 & 688687 & 5.3 & 5.0693 & TST \\
\hline CHEMBL1356771 & 688687 & 4.5 & 4.7838 & TRN \\
\hline CHEMBL1431301 & 688687 & 4.5 & 4.8738 & TRN \\
\hline CHEMBL1430213 & 688687 & 4.4 & 4.5605 & TRN \\
\hline CHEMBL1560385 & 688687 & 4.8 & 4.6862 & TRN \\
\hline CHEMBL1475325 & 688687 & 5.1 & 5.143 & TST \\
\hline CHEMBL1601235 & 688687 & 4.4 & 4.9765 & TRN \\
\hline CHEMBL1307748 & 688687 & 4.5 & 4.824 & TRN \\
\hline CHEMBL1523983 & 688687 & 4.8 & 4.9281 & TST \\
\hline CHEMBL1481059 & 688687 & 5.1 & 5.1152 & TRN \\
\hline CHEMBL1491545 & 688687 & 4.7 & 4.7526 & TRN \\
\hline CHEMBL1388407 & 688687 & 5.9 & 5.2911 & TRN \\
\hline CHEMBL1337364 & 688687 & 6.3 & 5.2921 & TRN \\
\hline CHEMBL1487565 & 688687 & 4.8 & 4.7109 & TRN \\
\hline CHEMBL1525659 & 688687 & 5.9 & 4.9986 & TRN \\
\hline CHEMBL1343484 & 688687 & 4.4 & 4.4005 & TRN \\
\hline CHEMBL1411698 & 688687 & 4.6 & 4.6403 & TRN \\
\hline CHEMBL1538120 & 688687 & 5.5 & 4.6659 & TRN \\
\hline CHEMBL1332182 & 688687 & 5.5 & 4.72 & TST \\
\hline CHEMBL1327466 & 688687 & 6.0 & 5.0324 & TST \\
\hline CHEMBL75967 & 688687 & 4.5 & 4.9998 & TRN \\
\hline CHEMBL1306711 & 688687 & 4.6 & 4.6883 & TST \\
\hline CHEMBL1443574 & 688687 & 4.4 & 4.712 & TST \\
\hline CHEMBL1532263 & 688687 & 4.7 & 4.7804 & TRN \\
\hline CHEMBL1449004 & 688687 & 4.5 & 4.9101 & TRN \\
\hline CHEMBL1388470 & 688687 & 4.4 & 4.703 & TST \\
\hline CHEMBL1519432 & 688687 & 4.9 & 4.5616 & TRN \\
\hline CHEMBL1490528 & 688687 & 4.9 & 4.6811 & TRN \\
\hline CHEMBL1462728 & 688687 & 5.0 & 4.8446 & TRN \\
\hline CHEMBL1608901 & 688687 & 5.7 & 4.894 & TRN \\
\hline CHEMBL1467730 & 688687 & 4.9 & 4.5195 & TRN \\
\hline CHEMBL1609405 & 688687 & 4.4 & 4.9818 & TRN \\
\hline CHEMBL1424982 & 688687 & 4.4 & 4.6776 & TRN \\
\hline CHEMBL1426027 & 688687 & 4.8 & 4.8732 & TST \\
\hline CHEMBL1511405 & 688687 & 5.2 & 4.8191 & TRN \\
\hline CHEMBL1491420 & 688687 & 4.4 & 4.7977 & TRN \\
\hline CHEMBL1599466 & 688687 & 4.4 & 5.035 & TRN \\
\hline CHEMBL1598547 & 688687 & 4.9 & 4.7005 & TRN \\
\hline CHEMBL1456245 & 688687 & 4.4 & 4.7623 & TST \\
\hline CHEMBL1375673 & 688687 & 4.4 & 5.0211 & TRN \\
\hline
\end{tabular}




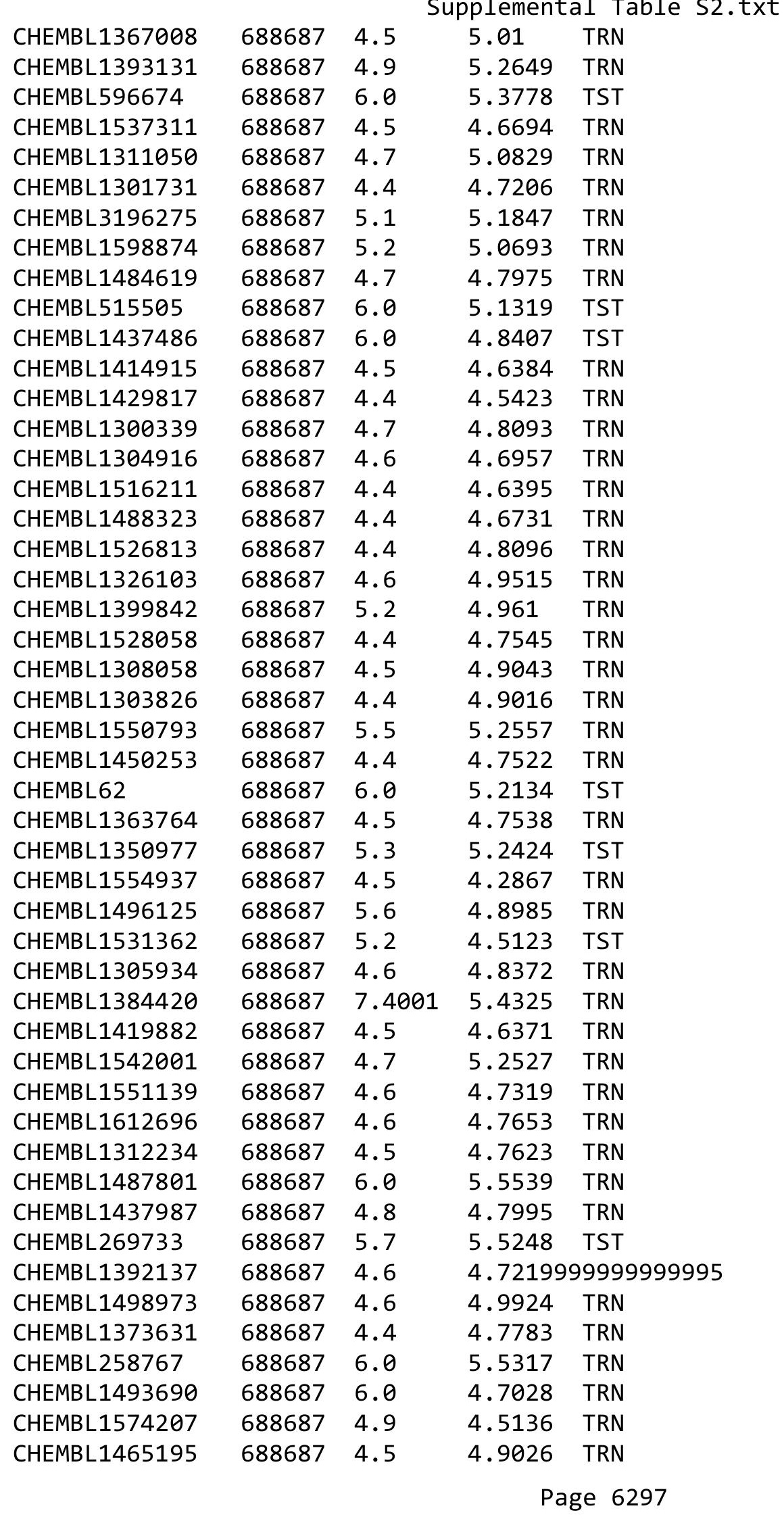




\begin{tabular}{|c|c|c|c|c|}
\hline & & & pplement & al Ta \\
\hline CHEMBL1410237 & 688687 & 4.7 & 4.7182 & TRN \\
\hline CHEMBL1488104 & 688687 & 4.6 & 4.9175 & TRN \\
\hline CHEMBL1379896 & 688687 & 4.6 & 4.8721 & TRN \\
\hline CHEMBL1269022 & 688687 & 5.8 & 4.9689 & TST \\
\hline CHEMBL1580759 & 688687 & 4.8 & 4.811 & TST \\
\hline CHEMBL1559126 & 688687 & 4.4 & 4.6739 & TRN \\
\hline CHEMBL1559411 & 688687 & 4.4 & 4.484 & TRN \\
\hline CHEMBL1497876 & 688687 & 4.6 & 4.6569 & TRN \\
\hline CHEMBL1370698 & 688687 & 5.5 & 5.0102 & TST \\
\hline CHEMBL540851 & 688687 & 4.5 & 4.9292 & TST \\
\hline CHEMBL1386214 & 688687 & 6.0 & 4.8975 & TRN \\
\hline CHEMBL1450025 & 688687 & 4.5 & 4.5666 & TRN \\
\hline CHEMBL1419900 & 688687 & 4.5 & 4.7972 & TRN \\
\hline CHEMBL1370970 & 688687 & 4.5 & 4.5672 & TRN \\
\hline CHEMBL1352302 & 688687 & 5.2 & 4.9027 & TST \\
\hline CHEMBL1425208 & 688687 & 5.2 & 5.274 & TRN \\
\hline CHEMBL1578446 & 688687 & 4.5 & 4.8844 & TRN \\
\hline CHEMBL1581389 & 688687 & 4.5 & 4.6787 & TRN \\
\hline CHEMBL1414269 & 688687 & 4.9 & 4.6874 & TRN \\
\hline CHEMBL1380189 & 688687 & 4.5 & 5.1068 & TRN \\
\hline CHEMBL1434460 & 688687 & 4.4 & 4.5389 & TRN \\
\hline CHEMBL1502021 & 688687 & 4.9 & 4.8764 & TRN \\
\hline CHEMBL1581069 & 688687 & 4.4 & 4.9619 & TRN \\
\hline CHEMBL530149 & 688687 & 4.4 & 4.6076 & TRN \\
\hline CHEMBL1488036 & 688687 & 5.6 & 4.9764 & TRN \\
\hline CHEMBL1482554 & 688687 & 4.8 & 4.9193 & TRN \\
\hline CHEMBL 254348 & 688687 & 4.5 & 5.1475 & TST \\
\hline CHEMBL1419676 & 688687 & 4.6 & 4.9076 & TRN \\
\hline CHEMBL1575759 & 688687 & 4.5 & 4.5474 & TRN \\
\hline CHEMBL1486992 & 688687 & 5.5 & 4.9025 & TRN \\
\hline CHEMBL1396230 & 688687 & 4.5 & 4.5624 & TRN \\
\hline CHEMBL1428805 & 688687 & 4.4 & 4.6499 & TRN \\
\hline CHEMBL1415491 & 688687 & 4.7 & 4.9521 & TST \\
\hline CHEMBL1316402 & 688687 & 5.3 & 4.8084 & TRN \\
\hline CHEMBL1369249 & 688687 & 6.0 & 5.1371 & TRN \\
\hline CHEMBL1524981 & 688687 & 5.3 & 5.021 & TRN \\
\hline CHEMBL1511489 & 688687 & 5.9 & 5.0713 & TRN \\
\hline CHEMBL1433596 & 688687 & 4.4 & 4.7548 & TRN \\
\hline CHEMBL1489712 & 688687 & 4.5 & 4.375 & TRN \\
\hline CHEMBL1500570 & 688687 & 4.6 & 5.1557 & TRN \\
\hline CHEMBL1334978 & 688687 & 5.4 & 5.2138 & TST \\
\hline CHEMBL1308471 & 688687 & 4.6 & 4.8148 & TRN \\
\hline CHEMBL1578827 & 688687 & 5.1 & 4.8546 & TRN \\
\hline CHEMBL1560995 & 688687 & 4.5 & 4.5663 & TRN \\
\hline CHEMBL1399833 & 688687 & 5.0 & 4.8376 & TRN \\
\hline CHEMBL 3214002 & 688687 & 4.5 & 4.9633 & TST \\
\hline CHEMBL1307389 & 688687 & 4.9 & 4.784 & TRN \\
\hline CHEMBL1479386 & 688687 & 5.9 & 5.084 & TST \\
\hline
\end{tabular}




\begin{tabular}{|c|c|c|c|c|}
\hline \multicolumn{5}{|c|}{ Supplemental Table S2.txt } \\
\hline CHEMBL1581638 & 688687 & 5.6 & 5.064 & TRN \\
\hline CHEMBL1349014 & 688687 & 4.7 & 4.9262 & TRN \\
\hline CHEMBL1417914 & 688687 & 6.3 & 4.8364 & TRN \\
\hline CHEMBL1443235 & 688687 & 4.5 & 4.7985 & TRN \\
\hline CHEMBL1497422 & 688687 & 4.5 & 4.6608 & TRN \\
\hline CHEMBL1469984 & 688687 & 4.4 & 4.9249 & TRN \\
\hline CHEMBL1488663 & 688687 & 4.5 & 4.6691 & TRN \\
\hline CHEMBL1438123 & 688687 & 5.7 & 5.0732 & TRN \\
\hline CHEMBL1600434 & 688687 & 4.5 & 4.7999 & TRN \\
\hline CHEMBL 3212537 & 688687 & 4.6 & 4.9133 & TRN \\
\hline CHEMBL1495694 & 688687 & 6.1 & 5.0843 & TRN \\
\hline CHEMBL1372646 & 688687 & 4.4 & 4.6474 & TRN \\
\hline CHEMBL1533514 & 688687 & 4.4 & 4.8395 & TRN \\
\hline CHEMBL1439563 & 688687 & 5.0 & 4.6702 & TRN \\
\hline CHEMBL1346098 & 688687 & 4.8 & 4.9021 & TRN \\
\hline CHEMBL1464298 & 688687 & 4.4 & 5.045 & TRN \\
\hline CHEMBL1328953 & 688687 & 4.9 & 4.6132 & TST \\
\hline CHEMBL1610257 & 688687 & 5.5 & 4.8495 & TRN \\
\hline CHEMBL1406016 & 688687 & 5.3 & 5.0627 & TRN \\
\hline CHEMBL1360572 & 688687 & 4.4 & 4.6746 & TRN \\
\hline CHEMBL1368329 & 688687 & 7.4001 & 4.7043 & TRN \\
\hline CHEMBL76897 & 688687 & 5.1 & 4.857 & TST \\
\hline CHEMBL1501151 & 688687 & 5.8 & 5.8534 & TRN \\
\hline CHEMBL1507993 & 688687 & 4.5 & 4.8271 & TRN \\
\hline CHEMBL1528128 & 688687 & 4.5 & 4.9849 & TST \\
\hline CHEMBL1305681 & 688687 & 4.5 & 4.6916 & TRN \\
\hline CHEMBL1548237 & 688687 & 4.5 & 4.9146 & TRN \\
\hline CHEMBL1563767 & 688687 & 5.5 & 4.7009 & TRN \\
\hline CHEMBL1561667 & 688687 & 4.4 & 4.6638 & TRN \\
\hline CHEMBL1300686 & 688687 & 6.2 & 4.9711 & TRN \\
\hline CHEMBL1441603 & 688687 & 4.5 & 4.8669 & TRN \\
\hline CHEMBL1613623 & 688687 & 4.4 & 5.4021 & TST \\
\hline CHEMBL1442228 & 688687 & 4.4 & 4.8688 & TRN \\
\hline CHEMBL1433027 & 688687 & 6.2 & 5.1419 & TRN \\
\hline CHEMBL1341507 & 688687 & 5.5 & 5.1789 & TRN \\
\hline CHEMBL1469705 & 688687 & 4.6 & $4.8610 e$ & 0000000001 \\
\hline CHEMBL1305666 & 688687 & 4.4 & 4.6754 & TRN \\
\hline CHEMBL1417287 & 688687 & 4.5 & 4.7962 & TRN \\
\hline CHEMBL1443045 & 688687 & 4.4 & 4.7765 & TRN \\
\hline CHEMBL3194157 & 688687 & 5.6 & 4.9414 & TRN \\
\hline CHEMBL 1470012 & 688687 & 4.6 & 4.9124 & TRN \\
\hline CHEMBL1594934 & 688687 & 4.9 & 4.8181 & TRN \\
\hline CHEMBL1416214 & 688687 & 4.4 & 4.551 & TRN \\
\hline CHEMBL1345495 & 688687 & 4.4 & 4.5139 & TRN \\
\hline CHEMBL1356497 & 688687 & 4.7 & 4.8517 & TRN \\
\hline CHEMBL1359354 & 688687 & 4.7 & 4.9674 & TRN \\
\hline CHEMBL1302742 & 688687 & 4.5 & 4.3703 & TRN \\
\hline CHEMBL1329054 & 688687 & 4.5 & 4.431 & TRN \\
\hline
\end{tabular}




\begin{tabular}{|c|c|c|c|c|c|}
\hline \multicolumn{6}{|c|}{ Supplemental Table S2.txt } \\
\hline CHEMBL52722 & 688687 & 4.5 & 4.7972 & TRN & \\
\hline CHEMBL1429119 & 688687 & 4.4 & 4.7628 & TRN & \\
\hline CHEMBL3207567 & 688687 & 4.4 & 4.9589 & TST & \\
\hline CHEMBL1543101 & 688687 & 4.6 & 4.68199 & 99999999995 & TRN \\
\hline CHEMBL543557 & 688687 & 5.3 & 5.19600 & 0000000001 & TRN \\
\hline CHEMBL1363989 & 688687 & 5.4 & 4.7815 & TST & \\
\hline CHEMBL1361718 & 688687 & 4.4 & 4.7885 & TRN & \\
\hline CHEMBL1508674 & 688687 & 4.6 & 4.3881 & TRN & \\
\hline CHEMBL1368286 & 688687 & 5.8 & 5.0313 & TRN & \\
\hline CHEMBL1302980 & 688687 & 6.1 & 5.1525 & TRN & \\
\hline CHEMBL1558816 & 688687 & 4.8 & 5.2426 & TRN & \\
\hline CHEMBL1596477 & 688687 & 4.4 & 4.5539 & TRN & \\
\hline CHEMBL1543781 & 688687 & 4.8 & 4.9176 & TRN & \\
\hline CHEMBL1350417 & 688687 & 4.4 & 4.849 & TRN & \\
\hline CHEMBL1459417 & 688687 & 5.3 & 4.8893 & TRN & \\
\hline CHEMBL1349666 & 688687 & 4.6 & 4.6843 & TRN & \\
\hline CHEMBL1455689 & 688687 & 4.6 & 4.4765 & TRN & \\
\hline CHEMBL1427266 & 688687 & 4.8 & 4.664 & TRN & \\
\hline CHEMBL1484137 & 688687 & 4.4 & 4.9368 & TRN & \\
\hline CHEMBL1509253 & 688687 & 4.4 & 4.6672 & TRN & \\
\hline CHEMBL1426994 & 688687 & 4.6 & 4.8168 & TRN & \\
\hline CHEMBL611207 & 688687 & 5.4 & 5.2423 & TST & \\
\hline CHEMBL1370286 & 688687 & 5.1 & 4.7102 & TRN & \\
\hline CHEMBL1588408 & 688687 & 4.9 & 5.1667 & TST & \\
\hline CHEMBL1430855 & 688687 & 4.6 & 4.8186 & TRN & \\
\hline CHEMBL1497248 & 688687 & 4.6 & 4.8711 & TRN & \\
\hline CHEMBL1480179 & 688687 & 4.5 & 4.8814 & TRN & \\
\hline CHEMBL1406806 & 688687 & 4.7 & 4.7225 & TRN & \\
\hline CHEMBL1332117 & 688687 & 5.4 & 4.9569 & TRN & \\
\hline CHEMBL66966 & 688687 & 7.6003 & 6.3024 & TRN & \\
\hline CHEMBL1414236 & 688687 & 4.9 & 4.8552 & TST & \\
\hline CHEMBL1429451 & 688687 & 4.9 & 4.5468 & TRN & \\
\hline CHEMBL1500636 & 688687 & 4.6 & 4.6369 & TRN & \\
\hline CHEMBL1303477 & 688687 & 4.4 & 4.6443 & TRN & \\
\hline CHEMBL164660 & 688687 & 4.5 & 5.0148 & TRN & \\
\hline CHEMBL1310493 & 688687 & 4.6 & 4.8521 & TRN & \\
\hline CHEMBL143399 & 688687 & 4.6 & 4.8727 & TST & \\
\hline CHEMBL1328519 & 688687 & 5.7 & 5.7665 & TRN & \\
\hline CHEMBL1400985 & 688687 & 4.4 & 4.9482 & TRN & \\
\hline CHEMBL1400061 & 688687 & 4.4 & 4.5569 & TRN & \\
\hline CHEMBL1495167 & 688687 & 4.6 & 4.841 & TRN & \\
\hline CHEMBL1383873 & 688687 & 4.4 & 5.0246 & TRN & \\
\hline CHEMBL1536391 & 688687 & 4.5 & 4.8019 & TRN & \\
\hline CHEMBL1454284 & 688687 & 4.5 & 5.0557 & TST & \\
\hline CHEMBL1410677 & 688687 & 4.4 & 4.7752 & TRN & \\
\hline CHEMBL 242383 & 688687 & 4.6 & 5.0252 & TRN & \\
\hline CHEMBL 1484480 & 688687 & 4.4 & 4.9072 & TRN & \\
\hline CHEMBL579045 & 688687 & 4.5 & 5.0803 & TRN & \\
\hline
\end{tabular}




\begin{tabular}{|c|c|c|c|c|c|}
\hline & & & & & \\
\hline CHEMBL1482317 & 688687 & 4.5 & 4.5358 & TRN & \\
\hline CHEMBL1579536 & 688687 & 4.6 & 4.8249 & TRN & \\
\hline CHEMBL1472198 & 688687 & 4.5 & 4.57600 & 00000000005 & TRN \\
\hline CHEMBL1390468 & 688687 & 4.4 & 4.4962 & TRN & \\
\hline CHEMBL1494320 & 688687 & 4.4 & 4.7941 & TRN & \\
\hline CHEMBL1597177 & 688687 & 5.0 & 5.1444 & TRN & \\
\hline CHEMBL1330698 & 688687 & 6.0 & 4.7968 & TRN & \\
\hline CHEMBL1521064 & 688687 & 4.5 & 4.7242 & TRN & \\
\hline CHEMBL1331313 & 688687 & 4.5 & 5.0683 & TRN & \\
\hline CHEMBL1519676 & 688687 & 5.4 & 4.8306 & TRN & \\
\hline CHEMBL1518903 & 688687 & 4.5 & 4.7351 & TRN & \\
\hline CHEMBL1495381 & 688687 & 4.8 & 5.0199 & TST & \\
\hline CHEMBL1533940 & 688687 & 5.7 & 5.4019 & TRN & \\
\hline CHEMBL1515355 & 688687 & 4.6 & 4.7376 & TRN & \\
\hline CHEMBL1521065 & 688687 & 4.5 & 4.9192 & TRN & \\
\hline CHEMBL1367073 & 688687 & 4.5 & 4.9306 & TRN & \\
\hline CHEMBL1363762 & 688687 & 4.9 & 5.0764 & TRN & \\
\hline CHEMBL1339542 & 688687 & 4.5 & 4.7525 & TRN & \\
\hline CHEMBL 3197293 & 688687 & 5.5 & 4.8597 & TRN & \\
\hline CHEMBL1314247 & 688687 & 4.4 & 4.8354 & TRN & \\
\hline CHEMBL1552270 & 688687 & 4.4 & 4.3634 & TRN & \\
\hline CHEMBL1487318 & 688687 & 5.1 & 5.0919 & TST & \\
\hline CHEMBL1457908 & 688687 & 4.5 & 4.34699 & 99999999995 & TRN \\
\hline CHEMBL1580954 & 688687 & 4.6 & 4.7195 & TRN & \\
\hline CHEMBL1439291 & 688687 & 4.9 & 5.1389 & TRN & \\
\hline CHEMBL1490535 & 688687 & 4.4 & 5.1242 & TST & \\
\hline CHEMBL1391411 & 688687 & 4.6 & 4.7977 & TRN & \\
\hline CHEMBL1527367 & 688687 & 4.6 & 4.7863 & TRN & \\
\hline CHEMBL1471811 & 688687 & 4.7 & 5.1336 & TRN & \\
\hline CHEMBL1444887 & 688687 & 4.5 & 4.5981 & TST & \\
\hline CHEMBL1448381 & 688687 & 5.7 & 5.7382 & TRN & \\
\hline CHEMBL1565987 & 688687 & 5.5 & 5.0846 & TST & \\
\hline CHEMBL1467125 & 688687 & 5.4 & 4.9208 & TRN & \\
\hline CHEMBL 2002792 & 688687 & 4.6 & 4.8556 & TST & \\
\hline CHEMBL1375005 & 688687 & 4.5 & 4.7077 & TRN & \\
\hline CHEMBL1442627 & 688687 & 4.5 & 4.7436 & TRN & \\
\hline CHEMBL1503576 & 688687 & 4.7 & 5.0892 & TST & \\
\hline CHEMBL1318041 & 688687 & 4.9 & 4.6451 & TRN & \\
\hline CHEMBL1498919 & 688687 & 4.6 & 4.73300 & 30000000005 & TRN \\
\hline CHEMBL1599268 & 688687 & 5.0 & 4.8961 & TRN & \\
\hline CHEMBL1531456 & 688687 & 5.1 & 4.6805 & TRN & \\
\hline CHEMBL1379834 & 688687 & 4.5 & 4.5849 & TRN & \\
\hline CHEMBL1462429 & 688687 & 4.4 & 4.6562 & TRN & \\
\hline CHEMBL1566507 & 688687 & 4.4 & 4.8211 & TRN & \\
\hline CHEMBL1577978 & 688687 & 6.0 & 4.9252 & TST & \\
\hline CHEMBL1329234 & 688687 & 4.7 & 4.824 & TRN & \\
\hline CHEMBL1408427 & 688687 & 5.1 & 4.7849 & TRN & \\
\hline CHEMBL1511160 & 688687 & 4.8 & 4.7543 & TRN & \\
\hline & & & & 6301 & \\
\hline
\end{tabular}




\begin{tabular}{|c|c|c|c|c|c|}
\hline & & & & & \\
\hline CHEMBL1406880 & 688687 & 4.6 & 4.4384 & TRN & \\
\hline CHEMBL1467553 & 688687 & 4.6 & 4.9324 & TRN & \\
\hline CHEMBL1464256 & 688687 & 4.9 & 4.5968 & TRN & \\
\hline CHEMBL1427879 & 688687 & 4.6 & 5.126 & TRN & \\
\hline CHEMBL1547143 & 688687 & 4.8 & 4.8565 & TRN & \\
\hline CHEMBL3207510 & 688687 & 4.5 & 4.646 & TRN & \\
\hline CHEMBL1483285 & 688687 & 4.5 & 4.8509 & TRN & \\
\hline CHEMBL502044 & 688687 & 4.8 & 5.2069 & TST & \\
\hline CHEMBL1383780 & 688687 & 4.5 & 4.7978 & TRN & \\
\hline CHEMBL65 & 688687 & 6.0 & 4.4844 & TST & \\
\hline CHEMBL1373741 & 688687 & 4.6 & 5.07600 & 00000000005 & TRN \\
\hline CHEMBL1564414 & 688687 & 4.6 & 5.0187 & TRN & \\
\hline CHEMBL1501864 & 688687 & 4.8 & 4.4755 & TRN & \\
\hline CHEMBL1421468 & 688687 & 4.6 & 4.78100 & 0000000001 & TRN \\
\hline CHEMBL1518120 & 688687 & 8.0 & 4.6132 & TST & \\
\hline CHEMBL1313955 & 688687 & 4.5 & 4.5136 & TRN & \\
\hline CHEMBL1302680 & 688687 & 5.5 & 4.9402 & TRN & \\
\hline CHEMBL1536206 & 688687 & 4.5 & 4.8517 & TRN & \\
\hline CHEMBL3209285 & 688687 & 4.9 & 4.8546 & TRN & \\
\hline CHEMBL1490439 & 688687 & 4.4 & 4.5988 & TRN & \\
\hline CHEMBL 243677 & 688687 & 4.4 & 5.5097 & TRN & \\
\hline CHEMBL1452282 & 688687 & 4.5 & 4.8498 & TRN & \\
\hline CHEMBL3199108 & 688687 & 5.7 & 5.4081 & TRN & \\
\hline CHEMBL1337478 & 688687 & 4.4 & 4.5858 & TRN & \\
\hline CHEMBL1587888 & 688687 & 7.1002 & 4.9838 & TST & \\
\hline CHEMBL1595853 & 688687 & 5.4 & 4.9046 & TST & \\
\hline CHEMBL1409604 & 688687 & 4.5 & 4.4349 & TRN & \\
\hline CHEMBL1540103 & 688687 & 4.6 & 4.5753 & TRN & \\
\hline CHEMBL1378164 & 688687 & 5.6 & 4.8886 & TST & \\
\hline CHEMBL1497544 & 688687 & 4.7 & 4.7209 & TST & \\
\hline CHEMBL187734 & 688687 & 5.3 & 4.8925 & TRN & \\
\hline CHEMBL1478472 & 688687 & 4.7 & 4.7828 & TRN & \\
\hline CHEMBL1595235 & 688687 & 5.1 & 4.9357 & TRN & \\
\hline CHEMBL1511543 & 688687 & 4.6 & 5.21200 & 0000000001 & TRN \\
\hline CHEMBL1407590 & 688687 & 4.6 & 4.6942 & TRN & \\
\hline CHEMBL1566549 & 688687 & 4.6 & 4.6862 & TRN & \\
\hline CHEMBL1595835 & 688687 & 4.6 & 5.0884 & TST & \\
\hline CHEMBL1486886 & 688687 & 4.7 & 4.8153 & TRN & \\
\hline CHEMBL1345861 & 688687 & 4.5 & 4.7027 & TRN & \\
\hline CHEMBL1447333 & 688687 & 5.5 & 4.8309 & TST & \\
\hline CHEMBL1546601 & 688687 & 4.4 & 4.5479 & TRN & \\
\hline CHEMBL1345487 & 688687 & 4.4 & 4.7603 & TRN & \\
\hline CHEMBL1592754 & 688687 & 5.0 & 4.7369 & TRN & \\
\hline CHEMBL1868098 & 688687 & 4.5 & 4.6276 & TRN & \\
\hline CHEMBL1391676 & 688687 & 5.8 & 5.4629 & TRN & \\
\hline CHEMBL1606229 & 688687 & 4.6 & 4.8446 & TRN & \\
\hline CHEMBL577758 & 688687 & 4.7 & 4.9104 & TRN & \\
\hline CHEMBL1374411 & 688687 & 4.6 & 4.8041 & TRN & \\
\hline & & & & 6302 & \\
\hline
\end{tabular}




\begin{tabular}{|c|c|c|c|c|}
\hline & & & CIIC & al Table \\
\hline CHEMBL1481715 & 688687 & 4.4 & 4.378 & TRN \\
\hline CHEMBL1398665 & 688687 & 5.2 & 4.6732 & TRN \\
\hline CHEMBL1349712 & 688687 & 4.6 & 4.9461 & TRN \\
\hline CHEMBL1498662 & 688687 & 4.5 & $4.6960 e$ & 0000000001 \\
\hline CHEMBL1321876 & 688687 & 4.5 & 4.6861 & TRN \\
\hline CHEMBL1366497 & 688687 & 4.5 & 4.8483 & TRN \\
\hline CHEMBL1517297 & 688687 & 4.4 & 5.3854 & TST \\
\hline CHEMBL1555314 & 688687 & 4.6 & 4.6845 & TRN \\
\hline CHEMBL1490807 & 688687 & 5.2 & 4.9077 & TRN \\
\hline CHEMBL1561040 & 688687 & 5.8 & 4.9028 & TST \\
\hline CHEMBL1491601 & 688687 & 4.4 & 4.6189 & TRN \\
\hline CHEMBL1336496 & 688687 & 4.5 & 4.6669 & TRN \\
\hline CHEMBL1549590 & 688687 & 4.5 & 4.3745 & TRN \\
\hline CHEMBL1308582 & 688687 & 4.6 & 4.878 & TRN \\
\hline CHEMBL1343531 & 688687 & 6.0 & 5.0262 & TST \\
\hline CHEMBL1601163 & 688687 & 5.0 & 4.6849 & TRN \\
\hline CHEMBL1409735 & 688687 & 4.9 & 4.7813 & TRN \\
\hline CHEMBL1344784 & 688687 & 4.8 & 4.856 & TRN \\
\hline CHEMBL1319667 & 688687 & 4.6 & 4.5025 & TRN \\
\hline CHEMBL1595951 & 688687 & 4.6 & 4.9188 & TST \\
\hline CHEMBL 387812 & 688687 & 4.7 & 4.8823 & TRN \\
\hline CHEMBL1411788 & 688687 & 5.8 & 4.888 & TST \\
\hline CHEMBL1387667 & 688687 & 4.7 & 4.6886 & TRN \\
\hline CHEMBL1335482 & 688687 & 4.6 & 4.6343 & TRN \\
\hline CHEMBL1585236 & 688687 & 5.1 & 4.8875 & TST \\
\hline CHEMBL1555893 & 688687 & 4.6 & 4.6405 & TRN \\
\hline CHEMBL1613725 & 688687 & 4.9 & 4.6561 & TRN \\
\hline CHEMBL1592041 & 688687 & 4.4 & 4.2526 & TRN \\
\hline CHEMBL1431881 & 688687 & 5.5 & 4.6846 & TRN \\
\hline CHEMBL164269 & 688687 & 5.5 & 4.9061 & TST \\
\hline CHEMBL1451251 & 688687 & 5.1 & 4.5943 & TRN \\
\hline CHEMBL1547905 & 688687 & 4.7 & 4.3077 & TRN \\
\hline CHEMBL1427829 & 688687 & 5.1 & 4.5566 & TRN \\
\hline CHEMBL1410702 & 688687 & 4.5 & 4.8439 & TST \\
\hline CHEMBL1340456 & 688687 & 5.7 & 4.8941 & TRN \\
\hline CHEMBL1423690 & 688687 & 6.5 & 6.1115 & TRN \\
\hline CHEMBL1379766 & 688687 & 5.1 & 4.9434 & TRN \\
\hline CHEMBL1569742 & 688687 & 4.6 & 5.2431 & TRN \\
\hline CHEMBL1469840 & 688687 & 6.5 & 5.4746 & TRN \\
\hline CHEMBL1531620 & 688687 & 4.8 & 4.8479 & TST \\
\hline CHEMBL1567730 & 688687 & 4.4 & 4.9642 & TRN \\
\hline CHEMBL1571786 & 688687 & 5.1 & 5.0355 & TRN \\
\hline CHEMBL1402925 & 688687 & 4.4 & 4.5453 & TST \\
\hline CHEMBL1456820 & 688687 & 5.2 & 4.9455 & TRN \\
\hline CHEMBL1540088 & 688687 & 5.3 & 4.8137 & TRN \\
\hline CHEMBL1581820 & 688687 & 4.4 & 4.7105 & TRN \\
\hline CHEMBL1337068 & 688687 & 5.6 & 4.754 & TRN \\
\hline CHEMBL1397367 & 688687 & 6.1 & 5.445 & TRN \\
\hline
\end{tabular}




\begin{tabular}{|c|c|c|c|c|c|}
\hline \\
\hline CHEMBL1521398 & 688687 & 4.4 & 4.7589 & TRN & \\
\hline CHEMBL1468027 & 688687 & 4.6 & 4.7239 & TRN & \\
\hline CHEMBL1607766 & 688687 & 5.1 & 4.9958 & TRN & \\
\hline CHEMBL1982713 & 688687 & 4.9 & 4.555 & TRN & \\
\hline CHEMBL1307319 & 688687 & 5.5 & 4.9289 & TST & \\
\hline CHEMBL1547250 & 688687 & 4.5 & 4.6191 & TRN & \\
\hline CHEMBL1423477 & 688687 & 5.0 & 4.7295 & TRN & \\
\hline CHEMBL3199764 & 688687 & 4.5 & 4.6982 & TRN & \\
\hline CHEMBL3211336 & 688687 & 4.6 & 4.7962 & TRN & \\
\hline CHEMBL1457879 & 688687 & 4.4 & 4.7573 & TRN & \\
\hline CHEMBL1546690 & 688687 & 4.6 & 5.3481 & TRN & \\
\hline CHEMBL1505934 & 688687 & 4.5 & 4.6447 & TRN & \\
\hline CHEMBL1403608 & 688687 & 4.4 & 4.5002 & TRN & \\
\hline CHEMBL1573862 & 688687 & 4.4 & 4.849 & TRN & \\
\hline CHEMBL1336174 & 688687 & 4.4 & 5.1736 & TST & \\
\hline CHEMBL1508899 & 688687 & 4.6 & 4.8385 & TRN & \\
\hline CHEMBL1604374 & 688687 & 7.6003 & 5.16299 & 9999999999 & TRN \\
\hline CHEMBL1348974 & 688687 & 4.8 & 5.1209 & TRN & \\
\hline CHEMBL1519327 & 688687 & 5.5 & 5.3308 & TST & \\
\hline CHEMBL 3210051 & 688687 & 4.6 & 5.1439 & TRN & \\
\hline CHEMBL1458953 & 688687 & 4.4 & 4.5024 & TRN & \\
\hline CHEMBL1501332 & 688687 & 4.6 & 4.975 & TRN & \\
\hline CHEMBL1978564 & 688687 & 5.7 & 4.9267 & TRN & \\
\hline CHEMBL1456185 & 688687 & 4.6 & 4.6212 & TRN & \\
\hline CHEMBL1372550 & 688687 & 4.5 & 4.797 & TRN & \\
\hline CHEMBL1493103 & 688687 & 5.0 & 5.0973 & TST & \\
\hline CHEMBL3189194 & 688687 & 4.5 & 4.8999 & TRN & \\
\hline CHEMBL1455056 & 688687 & 4.7 & 5.3018 & TRN & \\
\hline CHEMBL1578233 & 688687 & 4.4 & 4.4488 & TRN & \\
\hline CHEMBL1500830 & 688687 & 4.4 & 4.5874 & TRN & \\
\hline CHEMBL1510903 & 688687 & 4.4 & 4.7937 & TRN & \\
\hline CHEMBL1332098 & 688687 & 4.4 & 4.7863 & TRN & \\
\hline CHEMBL1530193 & 688687 & 5.0 & 4.7953 & TRN & \\
\hline CHEMBL1319806 & 688687 & 4.8 & 5.1962 & TRN & \\
\hline CHEMBL1581095 & 688687 & 4.4 & 4.7472 & TRN & \\
\hline CHEMBL1348895 & 688687 & 4.6 & 4.8375 & TRN & \\
\hline CHEMBL1334684 & 688687 & 5.2 & 5.0936 & TST & \\
\hline CHEMBL1483095 & 688687 & 5.4 & 4.5566 & TRN & \\
\hline CHEMBL1498952 & 688687 & 5.1 & 4.7654 & TRN & \\
\hline CHEMBL1565537 & 688687 & 5.1 & 4.9211 & TRN & \\
\hline CHEMBL1574540 & 688687 & 6.1 & 5.0322 & TRN & \\
\hline CHEMBL1405002 & 688687 & 4.4 & 4.7472 & TRN & \\
\hline CHEMBL1405892 & 688687 & 4.4 & 4.5969 & TRN & \\
\hline CHEMBL1494526 & 688687 & 4.5 & 4.6226 & TRN & \\
\hline CHEMBL1352543 & 688687 & 4.5 & 4.5693 & TRN & \\
\hline CHEMBL1410720 & 688687 & 4.6 & 5.088 & TRN & \\
\hline CHEMBL1525989 & 688687 & 5.6 & 5.1132 & TST & \\
\hline CHEMBL1602145 & 688687 & 4.4 & 4.5679 & TRN & \\
\hline
\end{tabular}




\begin{tabular}{|c|c|c|c|c|}
\hline & & & & $a \perp 1 a$ \\
\hline CHEMBL1370759 & 688687 & 4.4 & 4.5947 & TRN \\
\hline CHEMBL1383507 & 688687 & 5.4 & 5.0057 & TRN \\
\hline CHEMBL322970 & 688687 & 6.0 & 4.783 & TST \\
\hline CHEMBL1524617 & 688687 & 6.3 & 5.1108 & TST \\
\hline CHEMBL1736785 & 688687 & 4.5 & 4.7084 & TRN \\
\hline CHEMBL1594961 & 688687 & 4.5 & 4.7943 & TRN \\
\hline CHEMBL1560706 & 688687 & 4.8 & 4.7803 & TRN \\
\hline CHEMBL1606991 & 688687 & 5.3 & 4.7551 & TST \\
\hline CHEMBL1505000 & 688687 & 4.4 & 4.7132 & TRN \\
\hline CHEMBL1600039 & 688687 & 4.5 & 4.9212 & TRN \\
\hline CHEMBL1370291 & 688687 & 4.6 & 4.3886 & TRN \\
\hline CHEMBL1604999 & 688687 & 5.1 & 4.7029 & TRN \\
\hline CHEMBL1421864 & 688687 & 4.4 & 5.105 & TST \\
\hline CHEMBL3212046 & 688687 & 4.6 & 4.7593 & TRN \\
\hline CHEMBL1569863 & 688687 & 4.6 & 4.6315 & TST \\
\hline CHEMBL1301670 & 688687 & 4.8 & 4.5102 & TRN \\
\hline CHEMBL1326202 & 688687 & 4.5 & 4.8967 & TRN \\
\hline CHEMBL1558400 & 688687 & 4.5 & 5.1652 & TST \\
\hline CHEMBL1371801 & 688687 & 5.0 & 4.6858 & TRN \\
\hline CHEMBL 3212751 & 688687 & 4.5 & 5.0644 & TRN \\
\hline CHEMBL1457259 & 688687 & 4.4 & 4.7679 & TRN \\
\hline CHEMBL1565196 & 688687 & 4.5 & 4.7789 & TRN \\
\hline CHEMBL1416919 & 688687 & 4.4 & 5.0266 & TST \\
\hline CHEMBL3190248 & 688687 & 4.9 & 4.7049 & TST \\
\hline CHEMBL1371797 & 688687 & 4.9 & 4.6529 & TRN \\
\hline CHEMBL1452152 & 688687 & 4.5 & 4.8512 & TRN \\
\hline CHEMBL1320946 & 688687 & 4.4 & 4.8495 & TRN \\
\hline CHEMBL1424290 & 688687 & 4.9 & 4.795 & TRN \\
\hline CHEMBL1406306 & 688687 & 4.6 & 4.59 & TRN \\
\hline CHEMBL1567913 & 688687 & 5.5 & 4.8446 & TST \\
\hline CHEMBL1459161 & 688687 & 4.7 & 4.9787 & TRN \\
\hline CHEMBL1520120 & 688687 & 4.5 & 4.4192 & TRN \\
\hline CHEMBL1472514 & 688687 & 4.8 & 4.831 & TRN \\
\hline CHEMBL1518987 & 688687 & 4.5 & 5.001 & TRN \\
\hline CHEMBL1505809 & 688687 & 4.8 & 4.8128 & TRN \\
\hline CHEMBL1535413 & 688687 & 4.6 & 4.9287 & TRN \\
\hline CHEMBL1384727 & 688687 & 5.4 & 4.9651 & TST \\
\hline CHEMBL1592966 & 688687 & 5.1 & 5.1602 & TRN \\
\hline CHEMBL1562028 & 688687 & 4.6 & 4.7133 & TST \\
\hline CHEMBL1525277 & 688687 & 4.4 & 4.9732 & TRN \\
\hline CHEMBL1469105 & 688687 & 4.7 & 4.9389 & TRN \\
\hline CHEMBL1424768 & 688687 & 4.5 & 4.7973 & TRN \\
\hline CHEMBL1431172 & 688687 & 4.4 & 4.5442 & TRN \\
\hline CHEMBL1342481 & 688687 & 4.5 & 4.5584 & TRN \\
\hline CHEMBL1462076 & 688687 & 4.8 & 5.1236 & TST \\
\hline CHEMBL129795 & 688687 & 5.0 & 5.1746 & TRN \\
\hline CHEMBL1393484 & 688687 & 4.7 & 4.9393 & TRN \\
\hline CHEMBL1508675 & 688687 & 4.7 & 4.8932 & TRN \\
\hline
\end{tabular}




\begin{tabular}{|c|c|c|c|c|}
\hline & & & ient & $a \perp 1 a$ \\
\hline CHEMBL1373485 & 688687 & 5.6 & 5.2987 & TRN \\
\hline CHEMBL1399821 & 688687 & 4.6 & 4.8465 & TRN \\
\hline CHEMBL1984703 & 688687 & 4.6 & 4.6039 & TRN \\
\hline CHEMBL1606815 & 688687 & 5.2 & 4.6594 & TST \\
\hline CHEMBL1429267 & 688687 & 4.4 & 4.6623 & TRN \\
\hline CHEMBL1421531 & 688687 & 4.5 & 5.0122 & TST \\
\hline CHEMBL1571750 & 688687 & 4.5 & 4.6193 & TRN \\
\hline CHEMBL1478676 & 688687 & 4.4 & 5.0658 & TRN \\
\hline CHEMBL1368619 & 688687 & 4.5 & 4.8999 & TRN \\
\hline CHEMBL1433199 & 688687 & 4.4 & 4.9412 & TRN \\
\hline CHEMBL1324680 & 688687 & 5.5 & 5.3687 & TRN \\
\hline CHEMBL1383927 & 688687 & 7.0 & 5.1579 & TRN \\
\hline CHEMBL1324916 & 688687 & 5.1 & 4.7745 & TRN \\
\hline CHEMBL1499925 & 688687 & 4.5 & 4.8509 & TRN \\
\hline CHEMBL1438003 & 688687 & 4.5 & 5.0779 & TST \\
\hline CHEMBL1604486 & 688687 & 4.6 & 5.0168 & TRN \\
\hline CHEMBL462861 & 688687 & 5.8 & 5.0748 & TRN \\
\hline CHEMBL3196169 & 688687 & 4.8 & 4.7575 & TRN \\
\hline CHEMBL1407333 & 688687 & 4.5 & 4.9279 & TRN \\
\hline CHEMBL1501390 & 688687 & 4.4 & 4.8333 & TRN \\
\hline CHEMBL1371693 & 688687 & 4.5 & 4.7338 & TRN \\
\hline CHEMBL1371315 & 688687 & 5.5 & 5.2862 & TRN \\
\hline CHEMBL1552677 & 688687 & 4.4 & 4.5234 & TRN \\
\hline CHEMBL1549341 & 688687 & 5.1 & 4.8052 & TRN \\
\hline CHEMBL1515372 & 688687 & 4.5 & 4.2892 & TRN \\
\hline CHEMBL1459668 & 688687 & 4.4 & 4.6972 & TRN \\
\hline CHEMBL1402517 & 688687 & 5.3 & 4.8744 & TRN \\
\hline CHEMBL1450032 & 688687 & 5.5 & 5.0107 & TRN \\
\hline CHEMBL1466141 & 688687 & 4.5 & 4.9426 & TRN \\
\hline CHEMBL1568579 & 688687 & 4.6 & 4.5911 & TRN \\
\hline CHEMBL1508361 & 688687 & 4.9 & 4.5019 & TRN \\
\hline CHEMBL1586096 & 688687 & 5.8 & 4.9352 & TRN \\
\hline CHEMBL1505577 & 688687 & 4.6 & 4.9446 & TRN \\
\hline CHEMBL1485381 & 688687 & 4.9 & 5.0664 & TRN \\
\hline CHEMBL1328241 & 688687 & 5.1 & 4.8534 & TRN \\
\hline CHEMBL1421316 & 688687 & 4.8 & 4.842 & TRN \\
\hline CHEMBL52347 & 688687 & 5.4 & 4.9621 & TST \\
\hline CHEMBL1434482 & 688687 & 4.6 & 4.5517 & TRN \\
\hline CHEMBL1362023 & 688687 & 5.3 & 5.0308 & TST \\
\hline CHEMBL1452917 & 688687 & 5.6 & 4.7269 & TRN \\
\hline CHEMBL1558065 & 688687 & 4.6 & 5.0055 & TRN \\
\hline CHEMBL1422960 & 688687 & 4.5 & 4.4021 & TRN \\
\hline CHEMBL1375760 & 688687 & 4.6 & 4.815 & TRN \\
\hline CHEMBL1561704 & 688687 & 5.3 & 5.1858 & TST \\
\hline CHEMBL1311854 & 688687 & 5.1 & 5.0555 & TRN \\
\hline CHEMBL1607736 & 688687 & 4.7 & 4.7114 & TST \\
\hline CHEMBL1531249 & 688687 & 4.4 & 4.7914 & TRN \\
\hline CHEMBL1487908 & 688687 & 4.4 & 4.8438 & TRN \\
\hline
\end{tabular}




\begin{tabular}{|c|c|c|c|c|}
\hline \\
\hline CHEMBL1388744 & 688687 & 4.8 & 5.1338 & TRN \\
\hline CHEMBL1467102 & 688687 & 4.5 & 4.6646 & TRN \\
\hline CHEMBL1311735 & 688687 & 6.1 & 5.033 & TRN \\
\hline CHEMBL1501066 & 688687 & 4.5 & 4.4196 & TRN \\
\hline CHEMBL1367765 & 688687 & 4.4 & 4.5049 & TRN \\
\hline CHEMBL1595527 & 688687 & 4.4 & 4.841 & TRN \\
\hline CHEMBL1540684 & 688687 & 4.6 & 5.0339 & TRN \\
\hline CHEMBL1412664 & 688687 & 4.7 & 4.6512 & TST \\
\hline CHEMBL520992 & 688687 & 6.0 & 4.9995 & TST \\
\hline CHEMBL1492954 & 688687 & 5.1 & 5.2778 & TRN \\
\hline CHEMBL1481770 & 688687 & 5.1 & 5.4292 & TRN \\
\hline CHEMBL1545411 & 688687 & 4.6 & 4.8925 & TRN \\
\hline CHEMBL1588183 & 688687 & 4.4 & 4.8662 & TRN \\
\hline CHEMBL1360632 & 688687 & 4.4 & 4.9289 & TRN \\
\hline CHEMBL1609547 & 688687 & 4.6 & 4.6479 & TRN \\
\hline CHEMBL1424548 & 688687 & 4.5 & 4.74 & TRN \\
\hline CHEMBL1448741 & 688687 & 4.7 & 4.3783 & TRN \\
\hline CHEMBL1465366 & 688687 & 4.6 & 5.088 & TRN \\
\hline CHEMBL1363166 & 688687 & 4.6 & 4.8806 & TRN \\
\hline CHEMBL1584169 & 688687 & 4.6 & 5.0297 & TST \\
\hline CHEMBL1314768 & 688687 & 5.3 & 5.1775 & TST \\
\hline CHEMBL1483602 & 688687 & 5.7 & 4.926 & TRN \\
\hline CHEMBL1431763 & 688687 & 5.2 & 5.2935 & TRN \\
\hline CHEMBL1592388 & 688687 & 4.7 & 4.7327 & TRN \\
\hline CHEMBL358326 & 688687 & 4.7 & 4.9741 & TST \\
\hline CHEMBL1523821 & 688687 & 4.8 & 4.619 & TRN \\
\hline CHEMBL1548437 & 688687 & 5.4 & 4.7083 & TRN \\
\hline CHEMBL1373173 & 688687 & 4.5 & 4.773 & TRN \\
\hline CHEMBL283196 & 688687 & 4.4 & 4.836 & TRN \\
\hline CHEMBL1489430 & 688687 & 4.6 & 4.8846 & TST \\
\hline CHEMBL1378972 & 688687 & 4.5 & 4.7525 & TRN \\
\hline CHEMBL1385710 & 688687 & 4.4 & 4.9104 & TRN \\
\hline CHEMBL1571828 & 688687 & 4.4 & 4.5505 & TRN \\
\hline CHEMBL1557901 & 688687 & 5.8 & 4.8398 & TRN \\
\hline CHEMBL1603717 & 688687 & 4.5 & 4.7855 & TRN \\
\hline CHEMBL1426535 & 688687 & 4.6 & 4.4872 & TST \\
\hline CHEMBL1506836 & 688687 & 5.1 & 4.8203 & TRN \\
\hline CHEMBL1603030 & 688687 & 5.2 & 4.8252 & TRN \\
\hline CHEMBL1305312 & 688687 & 4.4 & 4.8383 & TST \\
\hline CHEMBL526673 & 688687 & 5.0 & 4.96 & TRN \\
\hline CHEMBL1388106 & 688687 & 4.4 & 4.5653 & TRN \\
\hline CHEMBL1465933 & 688687 & 4.5 & 4.6147 & TRN \\
\hline CHEMBL1540272 & 688687 & 4.7 & 4.7544 & TRN \\
\hline CHEMBL1393472 & 688687 & 4.6 & 5.02800 & 00000000005 \\
\hline CHEMBL1518947 & 688687 & 5.3 & 4.9832 & TRN \\
\hline CHEMBL97760 & 688687 & 4.6 & 5.0453 & TRN \\
\hline CHEMBL1393931 & 688687 & 4.4 & 4.6444 & TRN \\
\hline CHEMBL1474016 & 688687 & 5.0 & 4.8748 & TRN \\
\hline
\end{tabular}

TRN 


\begin{tabular}{|c|c|c|c|c|}
\hline & & & ient & $a \perp 1 a$ \\
\hline CHEMBL1332758 & 688687 & 5.2 & 4.7028 & TRN \\
\hline CHEMBL1396374 & 688687 & 4.4 & 4.5719 & TRN \\
\hline CHEMBL1347266 & 688687 & 4.6 & 4.6101 & TRN \\
\hline CHEMBL1308361 & 688687 & 4.5 & 4.8343 & TRN \\
\hline CHEMBL1599095 & 688687 & 5.2 & 5.0262 & TRN \\
\hline CHEMBL1301956 & 688687 & 4.4 & 4.7313 & TRN \\
\hline CHEMBL1303226 & 688687 & 5.9 & 4.8277 & TRN \\
\hline CHEMBL1424407 & 688687 & 4.5 & 4.7546 & TRN \\
\hline CHEMBL1412354 & 688687 & 5.6 & 4.5831 & TST \\
\hline CHEMBL1344791 & 688687 & 4.6 & 4.5814 & TRN \\
\hline CHEMBL 213432 & 688687 & 4.6 & 4.8725 & TRN \\
\hline CHEMBL1540610 & 688687 & 5.6 & 5.078 & TRN \\
\hline CHEMBL1383872 & 688687 & 4.5 & 4.5554 & TRN \\
\hline CHEMBL1608455 & 688687 & 4.4 & 4.5192 & TRN \\
\hline CHEMBL1487747 & 688687 & 4.6 & 4.8305 & TRN \\
\hline CHEMBL1396203 & 688687 & 4.9 & 4.7255 & TRN \\
\hline CHEMBL1569140 & 688687 & 4.4 & 4.4895 & TRN \\
\hline CHEMBL1463132 & 688687 & 5.6 & 5.6811 & TRN \\
\hline CHEMBL1401072 & 688687 & 5.0 & 4.5499 & TST \\
\hline CHEMBL1415894 & 688687 & 4.4 & 4.8021 & TRN \\
\hline CHEMBL1510325 & 688687 & 4.6 & 4.9369 & TRN \\
\hline CHEMBL1361652 & 688687 & 4.5 & 4.6372 & TRN \\
\hline CHEMBL1401044 & 688687 & 4.8 & 4.7074 & TRN \\
\hline CHEMBL1578380 & 688687 & 4.4 & 4.6579 & TRN \\
\hline CHEMBL1545206 & 688687 & 5.0 & 4.877 & TRN \\
\hline CHEMBL 3207801 & 688687 & 4.9 & 4.8544 & TRN \\
\hline CHEMBL1369785 & 688687 & 4.6 & 4.672 & TRN \\
\hline CHEMBL1506343 & 688687 & 4.5 & 4.6573 & TRN \\
\hline CHEMBL1583788 & 688687 & 5.1 & 5.3648 & TRN \\
\hline CHEMBL1556465 & 688687 & 4.6 & 5.5139 & TRN \\
\hline CHEMBL1585030 & 688687 & 4.4 & 4.5964 & TST \\
\hline CHEMBL1523830 & 688687 & 4.5 & 4.9847 & TRN \\
\hline CHEMBL1599004 & 688687 & 4.7 & 4.9706 & TRN \\
\hline CHEMBL1575849 & 688687 & 4.8 & 4.8761 & TRN \\
\hline CHEMBL3189530 & 688687 & 4.5 & 4.4139 & TRN \\
\hline CHEMBL1531521 & 688687 & 5.4 & 5.2095 & TRN \\
\hline CHEMBL1571407 & 688687 & 5.0 & 4.7202 & TRN \\
\hline CHEMBL1351386 & 688687 & 4.6 & 4.8971 & TST \\
\hline CHEMBL1381606 & 688687 & 4.5 & 4.7742 & TRN \\
\hline CHEMBL1418682 & 688687 & 4.4 & 4.9504 & TRN \\
\hline CHEMBL1600520 & 688687 & 4.5 & 4.9171 & TRN \\
\hline CHEMBL1304093 & 688687 & 4.4 & 4.8332 & TRN \\
\hline CHEMBL1555665 & 688687 & 5.2 & 4.6563 & TRN \\
\hline CHEMBL1464979 & 688687 & 4.4 & 4.8084 & TRN \\
\hline CHEMBL1256661 & 688687 & 4.4 & 5.0363 & TST \\
\hline CHEMBL 372832 & 688687 & 4.6 & 4.7975 & TRN \\
\hline CHEMBL1457738 & 688687 & 4.5 & 4.8717 & TRN \\
\hline CHEMBL1503542 & 688687 & 4.4 & 4.4738 & TRN \\
\hline
\end{tabular}




\begin{tabular}{|c|c|c|c|c|}
\hline & & & & $a+1 a$ \\
\hline CHEMBL1469209 & 688687 & 4.4 & 4.5855 & TRN \\
\hline CHEMBL3199404 & 688687 & 4.4 & 4.6699 & TRN \\
\hline CHEMBL1521269 & 688687 & 4.4 & 4.9659 & TRN \\
\hline CHEMBL1333783 & 688687 & 5.0 & 4.8036 & TRN \\
\hline CHEMBL1464614 & 688687 & 4.5 & 4.64199 & 99999999995 \\
\hline CHEMBL1472003 & 688687 & 4.9 & 5.0182 & TST \\
\hline CHEMBL1545979 & 688687 & 4.4 & 4.9563 & TRN \\
\hline CHEMBL1452441 & 688687 & 5.4 & 4.6485 & TRN \\
\hline CHEMBL1349610 & 688687 & 4.6 & 4.5682 & TRN \\
\hline CHEMBL1450376 & 688687 & 4.6 & 4.7825 & TRN \\
\hline CHEMBL1511785 & 688687 & 4.7 & 4.8408 & TRN \\
\hline CHEMBL1414129 & 688687 & 4.5 & 4.7418 & TRN \\
\hline CHEMBL1472380 & 688687 & 4.5 & 4.7768 & TRN \\
\hline CHEMBL1490602 & 688687 & 4.6 & 4.7231 & TRN \\
\hline CHEMBL1596230 & 688687 & 4.5 & 4.6997 & TRN \\
\hline CHEMBL1344571 & 688687 & 4.5 & 4.5139 & TRN \\
\hline CHEMBL1378685 & 688687 & 4.6 & 4.7425 & TRN \\
\hline CHEMBL1317748 & 688687 & 5.1 & 5.3135 & TRN \\
\hline CHEMBL1351418 & 688687 & 5.0 & 4.8465 & TRN \\
\hline CHEMBL1389165 & 688687 & 5.3 & 5.1078 & TRN \\
\hline CHEMBL1391746 & 688687 & 4.8 & 4.7049 & TRN \\
\hline CHEMBL1349788 & 688687 & 4.6 & 4.8936 & TRN \\
\hline CHEMBL1978364 & 688687 & 4.7 & 4.6145 & TRN \\
\hline CHEMBL1581261 & 688687 & 5.4 & 5.3979 & TRN \\
\hline CHEMBL1380020 & 688687 & 4.4 & 4.8776 & TRN \\
\hline CHEMBL1580837 & 688687 & 4.6 & 4.7643 & TRN \\
\hline CHEMBL1506095 & 688687 & 4.5 & 4.926 & TRN \\
\hline CHEMBL1496083 & 688687 & 5.0 & 5.0879 & TRN \\
\hline CHEMBL1610903 & 688687 & 5.0 & 5.1964 & TRN \\
\hline CHEMBL1410002 & 688687 & 5.4 & 4.8321 & TST \\
\hline CHEMBL1541656 & 688687 & 4.5 & 4.5457 & TRN \\
\hline CHEMBL1406459 & 688687 & 5.3 & 4.7126 & TRN \\
\hline CHEMBL1320044 & 688687 & 4.4 & 5.0622 & TRN \\
\hline CHEMBL1306807 & 688687 & 4.7 & 4.9873 & TST \\
\hline CHEMBL1349037 & 688687 & 4.6 & 4.9197 & TRN \\
\hline CHEMBL1328274 & 688687 & 4.7 & 4.6009 & TRN \\
\hline CHEMBL1520681 & 688687 & 4.7 & 4.8651 & TRN \\
\hline CHEMBL1478630 & 688687 & 4.5 & 4.2629 & TRN \\
\hline CHEMBL1333836 & 688687 & 4.5 & 4.8935 & TRN \\
\hline CHEMBL1610945 & 688687 & 5.9 & 4.9744 & TST \\
\hline CHEMBL1389996 & 688687 & 5.4 & 4.8648 & TRN \\
\hline CHEMBL1503345 & 688687 & 4.4 & 4.87 & TRN \\
\hline CHEMBL1290657 & 688687 & 4.6 & 4.5766 & TRN \\
\hline CHEMBL1351318 & 688687 & 6.0 & 4.7341 & TRN \\
\hline CHEMBL1584508 & 688687 & 4.5 & 5.0105 & TRN \\
\hline CHEMBL1376874 & 688687 & 4.8 & 4.7654 & TRN \\
\hline CHEMBL1359118 & 688687 & 4.6 & 4.9242 & TRN \\
\hline CHEMBL1522808 & 688687 & 4.6 & 4.7908 & TRN \\
\hline
\end{tabular}




\begin{tabular}{|c|c|c|c|c|}
\hline & & & & $a \perp 1 a$ \\
\hline CHEMBL1315336 & 688687 & 4.8 & 4.7648 & TRN \\
\hline CHEMBL1578019 & 688687 & 5.1 & 4.7834 & TRN \\
\hline CHEMBL2003798 & 688687 & 5.5 & 4.5897 & TRN \\
\hline CHEMBL1477914 & 688687 & 4.9 & 4.6817 & TRN \\
\hline CHEMBL1494484 & 688687 & 4.4 & 4.5451 & TRN \\
\hline CHEMBL1319525 & 688687 & 4.5 & 4.916 & TRN \\
\hline CHEMBL1422605 & 688687 & 4.4 & 4.4616 & TRN \\
\hline CHEMBL1569074 & 688687 & 5.6 & 4.7356 & TRN \\
\hline CHEMBL1606800 & 688687 & 6.2 & 5.0189 & TRN \\
\hline CHEMBL1528453 & 688687 & 4.5 & 4.8919 & TRN \\
\hline CHEMBL1610852 & 688687 & 4.5 & 4.6742 & TRN \\
\hline CHEMBL1399825 & 688687 & 4.8 & 4.9035 & TRN \\
\hline CHEMBL3192946 & 688687 & 4.4 & 4.6329 & TRN \\
\hline CHEMBL1313979 & 688687 & 4.9 & 4.4968 & TRN \\
\hline CHEMBL1607991 & 688687 & 5.7 & 5.6974 & TRN \\
\hline CHEMBL1522344 & 688687 & 4.5 & 4.6152 & TRN \\
\hline CHEMBL1467168 & 688687 & 4.5 & 4.6742 & TRN \\
\hline CHEMBL 267373 & 688687 & 4.4 & 4.9998 & TRN \\
\hline CHEMBL1559515 & 688687 & 4.4 & 4.6525 & TRN \\
\hline CHEMBL1432672 & 688687 & 4.4 & 4.8021 & TRN \\
\hline CHEMBL1537146 & 688687 & 4.4 & 5.0671 & TRN \\
\hline CHEMBL1365708 & 688687 & 4.4 & 4.4423 & TRN \\
\hline CHEMBL1385353 & 688687 & 4.5 & 4.5844 & TRN \\
\hline CHEMBL1599163 & 688687 & 4.6 & 4.5776 & TRN \\
\hline CHEMBL363506 & 688687 & 4.8 & 4.8647 & TST \\
\hline CHEMBL1305254 & 688687 & 4.5 & 5.0226 & TST \\
\hline CHEMBL1323351 & 688687 & 4.8 & 5.0735 & TRN \\
\hline CHEMBL1301214 & 688687 & 4.8 & 4.863 & TRN \\
\hline CHEMBL1502851 & 688687 & 5.5 & 5.021 & TRN \\
\hline CHEMBL1457400 & 688687 & 5.4 & 4.9339 & TRN \\
\hline CHEMBL1595253 & 688687 & 4.5 & 4.6381 & TRN \\
\hline CHEMBL1390021 & 688687 & 4.8 & 4.641 & TRN \\
\hline CHEMBL1533620 & 688687 & 4.4 & 4.7842 & TRN \\
\hline CHEMBL1366859 & 688687 & 4.4 & 4.837 & TRN \\
\hline CHEMBL1335945 & 688687 & 5.9 & 5.0253 & TST \\
\hline CHEMBL1339652 & 688687 & 4.6 & 4.6228 & TRN \\
\hline CHEMBL3392050 & 688687 & 5.4 & 4.7444 & TST \\
\hline CHEMBL1516905 & 688687 & 4.6 & 4.4715 & TRN \\
\hline CHEMBL1301573 & 688687 & 4.5 & 4.6698 & TRN \\
\hline CHEMBL1583911 & 688687 & 4.9 & 4.8406 & TST \\
\hline CHEMBL1405306 & 688687 & 4.6 & 4.7921 & TRN \\
\hline CHEMBL1571238 & 688687 & 5.5 & 4.9306 & TRN \\
\hline CHEMBL1473760 & 688687 & 4.7 & 4.8521 & TRN \\
\hline CHEMBL1604803 & 688687 & 4.8 & 4.7855 & TRN \\
\hline CHEMBL1425365 & 688687 & 4.6 & 4.942 & TRN \\
\hline CHEMBL1546263 & 688687 & 4.4 & 4.8312 & TRN \\
\hline CHEMBL1455898 & 688687 & 4.6 & 4.9394 & TRN \\
\hline CHEMBL1307119 & 688687 & 4.6 & 5.2022 & TST \\
\hline
\end{tabular}




\begin{tabular}{|c|c|c|c|c|}
\hline & & & & -10 \\
\hline CHEMBL3190817 & 688687 & 4.6 & 4.7133 & TRN \\
\hline CHEMBL1394833 & 688687 & 4.4 & 5.1602 & TRN \\
\hline CHEMBL490743 & 688687 & 4.7 & 4.716 & TRN \\
\hline CHEMBL1512312 & 688687 & 4.5 & 4.6966 & TRN \\
\hline CHEMBL1539704 & 688687 & 4.5 & 4.84399 & 9999999999 \\
\hline CHEMBL1527615 & 688687 & 4.4 & 4.6416 & TRN \\
\hline CHEMBL1532550 & 688687 & 5.4 & 4.7675 & TRN \\
\hline CHEMBL1484826 & 688687 & 4.4 & 4.8904 & TRN \\
\hline CHEMBL1313852 & 688687 & 4.4 & 4.5551 & TRN \\
\hline CHEMBL1405767 & 688687 & 4.6 & 4.7678 & TRN \\
\hline CHEMBL1392164 & 688687 & 4.5 & 4.421 & TRN \\
\hline CHEMBL1476049 & 688687 & 4.5 & 5.0345 & TRN \\
\hline CHEMBL1528112 & 688687 & 4.6 & 4.9543 & TRN \\
\hline CHEMBL3190231 & 688687 & 4.8 & 5.079 & TRN \\
\hline CHEMBL1332953 & 688687 & 4.5 & 4.8207 & TRN \\
\hline CHEMBL1551068 & 688687 & 4.4 & 4.5537 & TRN \\
\hline CHEMBL1496183 & 688687 & 4.4 & 4.7404 & TST \\
\hline CHEMBL1516854 & 688687 & 4.6 & 4.6784 & TRN \\
\hline CHEMBL1417558 & 688687 & 4.4 & 4.8071 & TRN \\
\hline CHEMBL1587620 & 688687 & 4.4 & 4.7164 & TRN \\
\hline CHEMBL1391969 & 688687 & 4.5 & 4.6805 & TRN \\
\hline CHEMBL1426847 & 688687 & 4.6 & 4.3658 & TRN \\
\hline CHEMBL1438121 & 688687 & 4.4 & 4.8952 & TRN \\
\hline CHEMBL1340168 & 688687 & 4.6 & 5.1238 & TST \\
\hline CHEMBL1460401 & 688687 & 5.5 & 5.4413 & TRN \\
\hline CHEMBL1411764 & 688687 & 4.6 & 4.8301 & TRN \\
\hline CHEMBL1540836 & 688687 & 5.4 & 4.7483 & TRN \\
\hline CHEMBL1399136 & 688687 & 4.7 & 4.558 & TRN \\
\hline CHEMBL1402982 & 688687 & 4.5 & 4.7932 & TST \\
\hline CHEMBL1405813 & 688687 & 4.6 & 4.9246 & TST \\
\hline CHEMBL566531 & 688687 & 5.7 & 5.1875 & TRN \\
\hline CHEMBL1391415 & 688687 & 4.5 & 4.562 & TRN \\
\hline CHEMBL3190510 & 688687 & 5.3 & 4.5363 & TRN \\
\hline CHEMBL536950 & 688687 & 6.6 & 5.0849 & TST \\
\hline CHEMBL1716991 & 688687 & 5.5 & 4.9635 & TRN \\
\hline CHEMBL1547457 & 688687 & 4.7 & 4.5827 & TRN \\
\hline CHEMBL1538411 & 688687 & 4.7 & 4.9439 & TRN \\
\hline CHEMBL1256395 & 688687 & 4.4 & 5.2287 & TST \\
\hline CHEMBL1437986 & 688687 & 4.6 & 4.6715 & TRN \\
\hline CHEMBL1325350 & 688687 & 4.4 & 4.7373 & TST \\
\hline CHEMBL 375126 & 688687 & 4.9 & 5.0282 & TST \\
\hline CHEMBL53898 & 688687 & 5.0 & 5.8195 & TRN \\
\hline CHEMBL1420337 & 688687 & 5.4 & 5.0164 & TST \\
\hline CHEMBL1607712 & 688687 & 6.7001 & 4.9459 & TRN \\
\hline CHEMBL1594871 & 688687 & 4.5 & 4.7557 & TRN \\
\hline CHEMBL1330514 & 688687 & 4.8 & 4.9558 & TRN \\
\hline CHEMBL1349239 & 688687 & 4.5 & 4.8827 & TRN \\
\hline CHEMBL1533131 & 688687 & 4.5 & 4.8703 & TRN \\
\hline
\end{tabular}




\begin{tabular}{|c|c|c|c|c|c|}
\hline \\
\hline CHEMBL1482499 & 688687 & 4.4 & 4.8093 & TRN & \\
\hline CHEMBL1463376 & 688687 & 4.5 & 5.1998 & TRN & \\
\hline CHEMBL1569778 & 688687 & 4.6 & 4.4449 & TRN & \\
\hline CHEMBL1547055 & 688687 & 4.5 & 4.5695 & TRN & \\
\hline CHEMBL1523769 & 688687 & 4.4 & 4.8422 & TRN & \\
\hline CHEMBL1498183 & 688687 & 5.5 & 5.1707 & TRN & \\
\hline CHEMBL1312358 & 688687 & 4.4 & 4.4492 & TRN & \\
\hline CHEMBL51085 & 688687 & 6.0 & 5.4304 & TST & \\
\hline CHEMBL1320652 & 688687 & 4.4 & 4.5571 & TRN & \\
\hline CHEMBL1389022 & 688687 & 4.7 & 4.7822 & TRN & \\
\hline CHEMBL1569769 & 688687 & 4.6 & 4.7232 & TRN & \\
\hline CHEMBL1332547 & 688687 & 4.7 & 4.8873 & TRN & \\
\hline CHEMBL1481663 & 688687 & 5.3 & 4.7961 & TRN & \\
\hline CHEMBL1428762 & 688687 & 4.8 & 4.7476 & TRN & \\
\hline CHEMBL1350093 & 688687 & 4.5 & 4.8923 & TRN & \\
\hline CHEMBL1394579 & 688687 & 5.1 & 4.8664 & TRN & \\
\hline CHEMBL1383723 & 688687 & 5.5 & 5.20100 & j0000000005 & TRN \\
\hline CHEMBL1454350 & 688687 & 4.4 & 5.1753 & TRN & \\
\hline CHEMBL1479990 & 688687 & 4.5 & 4.8361 & TRN & \\
\hline CHEMBL1504352 & 688687 & 5.1 & 5.1456 & TRN & \\
\hline CHEMBL1342873 & 688687 & 4.5 & 4.8893 & TRN & \\
\hline CHEMBL1384473 & 688687 & 5.4 & 4.8558 & TRN & \\
\hline CHEMBL3212752 & 688687 & 4.4 & 4.8829 & TRN & \\
\hline CHEMBL1999149 & 688687 & 4.4 & 4.8905 & TRN & \\
\hline CHEMBL1389272 & 688687 & 5.1 & 4.593 & TRN & \\
\hline CHEMBL1567878 & 688687 & 4.5 & 4.3171 & TRN & \\
\hline CHEMBL 20562 & 688687 & 5.3 & 5.2389 & TST & \\
\hline CHEMBL1605454 & 688687 & 4.4 & 4.6913 & TRN & \\
\hline CHEMBL1595747 & 688687 & 4.4 & 4.7128 & TRN & \\
\hline CHEMBL1975746 & 688687 & 4.6 & 4.7003 & TRN & \\
\hline CHEMBL1438786 & 688687 & 5.1 & 5.1872 & TST & \\
\hline CHEMBL1531635 & 688687 & 4.6 & 4.3823 & TRN & \\
\hline CHEMBL1433939 & 688687 & 5.3 & 5.147 & TST & \\
\hline CHEMBL1412272 & 688687 & 4.4 & 4.8412 & TRN & \\
\hline CHEMBL3190407 & 688687 & 4.8 & 5.0864 & TRN & \\
\hline CHEMBL1606436 & 688687 & 4.6 & 4.4507 & TRN & \\
\hline CHEMBL1541462 & 688687 & 4.6 & 4.6474 & TRN & \\
\hline CHEMBL1544093 & 688687 & 4.6 & 5.1553 & TST & \\
\hline CHEMBL1364183 & 688687 & 4.6 & 4.9878 & TRN & \\
\hline CHEMBL8682 & 688687 & 4.4 & 4.7936 & TRN & \\
\hline CHEMBL1531466 & 688687 & 4.5 & 4.9437 & TST & \\
\hline CHEMBL1504088 & 688687 & 4.6 & 4.7641 & TRN & \\
\hline CHEMBL1343646 & 688687 & 4.4 & 4.6267 & TRN & \\
\hline CHEMBL1407962 & 688687 & 5.9 & 5.0316 & TST & \\
\hline CHEMBL1531594 & 688687 & 4.6 & 5.0454 & TST & \\
\hline CHEMBL1369589 & 688687 & 5.2 & 4.8782 & TRN & \\
\hline CHEMBL1466582 & 688687 & 4.4 & 4.8387 & TST & \\
\hline CHEMBL1345970 & 688687 & 5.1 & 4.8436 & TRN & \\
\hline
\end{tabular}




\begin{tabular}{|c|c|c|c|c|c|}
\hline & & & & & \\
\hline CHEMBL1529179 & 688687 & 4.9 & 5.0012 & TST & \\
\hline CHEMBL1390690 & 688687 & 4.8 & 4.7984 & TRN & \\
\hline CHEMBL1498011 & 688687 & 5.5 & 5.1019 & TRN & \\
\hline CHEMBL1484908 & 688687 & 5.0 & 4.8375 & TRN & \\
\hline CHEMBL1575246 & 688687 & 4.5 & 4.413 & TRN & \\
\hline CHEMBL1534839 & 688687 & 4.5 & 4.7251 & TRN & \\
\hline CHEMBL1406978 & 688687 & 5.0 & 4.8157 & TRN & \\
\hline CHEMBL1452199 & 688687 & 4.4 & 4.8613 & TRN & \\
\hline CHEMBL1413733 & 688687 & 4.6 & 4.3678 & TRN & \\
\hline CHEMBL1599981 & 688687 & 5.0 & 5.037 & TRN & \\
\hline CHEMBL1375255 & 688687 & 4.5 & 4.827 & TRN & \\
\hline CHEMBL1303632 & 688687 & 4.4 & 4.9105 & TRN & \\
\hline CHEMBL1408956 & 688687 & 4.4 & 4.9296 & TRN & \\
\hline CHEMBL1570640 & 688687 & 4.6 & 4.5465 & TRN & \\
\hline CHEMBL1383118 & 688687 & 4.5 & 4.953 & TST & \\
\hline CHEMBL1449821 & 688687 & 4.5 & 4.9822 & TST & \\
\hline CHEMBL1375471 & 688687 & 5.2 & 4.5204 & TST & \\
\hline CHEMBL1868202 & 688687 & 5.5 & 4.9881 & TRN & \\
\hline CHEMBL1335123 & 688687 & 4.6 & 4.7361 & TRN & \\
\hline CHEMBL1341879 & 688687 & 4.5 & 4.9057 & TRN & \\
\hline CHEMBL1434882 & 688687 & 4.5 & 4.7187 & TRN & \\
\hline CHEMBL1603812 & 688687 & 4.5 & 4.7814 & TRN & \\
\hline CHEMBL1091971 & 688687 & 5.2 & 5.2513 & TST & \\
\hline CHEMBL3392041 & 688687 & 4.8 & 5.3257 & TRN & \\
\hline CHEMBL1370817 & 688687 & 4.6 & 4.7671 & TRN & \\
\hline CHEMBL1555838 & 688687 & 5.4 & 4.7672 & TRN & \\
\hline CHEMBL1440727 & 688687 & 4.5 & $4.7410 e$ & 00000000005 & TRN \\
\hline CHEMBL168276 & 688687 & 6.0 & 5.2248 & TST & \\
\hline CHEMBL1500158 & 688687 & 5.2 & 5.0688 & TRN & \\
\hline CHEMBL1488380 & 688687 & 4.7 & 4.5296 & TRN & \\
\hline CHEMBL15060 & 688687 & 4.5 & 4.7598 & TRN & \\
\hline CHEMBL1404530 & 688687 & 4.6 & 5.0276 & TRN & \\
\hline CHEMBL1384969 & 688687 & 4.7 & 4.8403 & TRN & \\
\hline CHEMBL1492324 & 688687 & 4.7 & 4.8947 & TRN & \\
\hline CHEMBL1485230 & 688687 & 4.4 & 5.0243 & TRN & \\
\hline CHEMBL1382734 & 688687 & 5.4 & 4.7473 & TRN & \\
\hline CHEMBL1361586 & 688687 & 4.9 & 4.8636 & TRN & \\
\hline CHEMBL1532515 & 688687 & 4.6 & 4.7024 & TRN & \\
\hline CHEMBL1595390 & 688687 & 4.5 & 4.5252 & TRN & \\
\hline CHEMBL1472002 & 688687 & 4.6 & 4.9058 & TRN & \\
\hline CHEMBL1340705 & 688687 & 4.6 & 4.747 & TRN & \\
\hline CHEMBL1410374 & 688687 & 4.5 & 4.5063 & TRN & \\
\hline CHEMBL1604068 & 688687 & 4.5 & 4.5957 & TRN & \\
\hline CHEMBL1528209 & 688687 & 4.5 & 4.7254 & TRN & \\
\hline CHEMBL1378543 & 688687 & 4.8 & 4.9888 & TRN & \\
\hline CHEMBL1468490 & 688687 & 4.5 & 5.0043 & TRN & \\
\hline CHEMBL149322 & 688687 & 4.8 & 4.7404 & TRN & \\
\hline CHEMBL1422065 & 688687 & 4.5 & 5.0496 & TRN & \\
\hline & & & & 6313 & \\
\hline
\end{tabular}




\begin{tabular}{|c|c|c|c|c|}
\hline & & & ent & al \\
\hline CHEMBL1578790 & 688687 & 5.5 & 4.6463 & TST \\
\hline CHEMBL1549176 & 688687 & 4.4 & 4.6214 & TRN \\
\hline CHEMBL1332712 & 688687 & 6.1 & 4.8889 & TRN \\
\hline CHEMBL1514307 & 688687 & 4.9 & 4.7592 & TRN \\
\hline CHEMBL1579938 & 688687 & 4.6 & 4.4171 & TST \\
\hline CHEMBL1533848 & 688687 & 4.6 & 4.6776 & TRN \\
\hline CHEMBL1370790 & 688687 & 5.9 & 4.753 & TST \\
\hline CHEMBL1308667 & 688687 & 4.6 & 4.9868 & TRN \\
\hline CHEMBL1540519 & 688687 & 4.6 & 4.6897 & TRN \\
\hline CHEMBL1549790 & 688687 & 5.2 & 4.6501 & TRN \\
\hline CHEMBL1459230 & 688687 & 4.5 & 4.5717 & TRN \\
\hline CHEMBL1560367 & 688687 & 4.5 & 5.1335 & TRN \\
\hline CHEMBL1577929 & 688687 & 4.5 & 4.7668 & TRN \\
\hline CHEMBL1489528 & 688687 & 4.8 & 4.6235 & TRN \\
\hline CHEMBL1406566 & 688687 & 5.5 & 4.9979 & TST \\
\hline CHEMBL1590261 & 688687 & 4.9 & 4.2472 & TRN \\
\hline CHEMBL1485196 & 688687 & 4.8 & 4.7772 & TRN \\
\hline CHEMBL1585534 & 688687 & 4.5 & 4.7716 & TRN \\
\hline CHEMBL1568102 & 688687 & 4.5 & 4.8058 & TRN \\
\hline CHEMBL1575586 & 688687 & 4.6 & 4.6955 & TRN \\
\hline CHEMBL1366321 & 688687 & 4.5 & 4.5605 & TRN \\
\hline CHEMBL1416218 & 688687 & 5.4 & 5.2724 & TST \\
\hline CHEMBL1534626 & 688687 & 4.5 & 4.8514 & TRN \\
\hline CHEMBL1535183 & 688687 & 4.8 & 4.8829 & TST \\
\hline CHEMBL1570175 & 688687 & 4.7 & 5.0587 & TRN \\
\hline CHEMBL182786 & 688687 & 4.5 & 4.7206 & TRN \\
\hline CHEMBL1362987 & 688687 & 4.6 & 4.9281 & TRN \\
\hline CHEMBL1524061 & 688687 & 5.5 & 4.9263 & TST \\
\hline CHEMBL1328592 & 688687 & 5.2 & 4.5478 & TRN \\
\hline CHEMBL1544633 & 688687 & 4.5 & 4.6665 & TRN \\
\hline CHEMBL1327271 & 688687 & 4.4 & 4.928 & TRN \\
\hline CHEMBL1412548 & 688687 & 4.8 & 4.8603 & TRN \\
\hline CHEMBL1508182 & 688687 & 5.9 & 5.6543 & TRN \\
\hline CHEMBL1356777 & 688687 & 6.0 & 4.5417 & TST \\
\hline CHEMBL1451509 & 688687 & 4.4 & 4.6156 & TRN \\
\hline CHEMBL1507083 & 688687 & 4.4 & 4.6436 & TST \\
\hline CHEMBL1381127 & 688687 & 4.6 & 4.5579 & TRN \\
\hline CHEMBL1420867 & 688687 & 4.6 & 4.5904 & TRN \\
\hline CHEMBL1543115 & 688687 & 5.3 & 4.5241 & TST \\
\hline CHEMBL1530625 & 688687 & 4.6 & 5.0158 & TRN \\
\hline CHEMBL1482668 & 688687 & 5.0 & 4.706 & TRN \\
\hline CHEMBL1306011 & 688687 & 4.6 & 4.7725 & TRN \\
\hline CHEMBL1464836 & 688687 & 5.1 & 5.0456 & TRN \\
\hline CHEMBL1305414 & 688687 & 4.7 & 4.7128 & TST \\
\hline CHEMBL1307565 & 688687 & 5.0 & 5.3221 & TST \\
\hline CHEMBL1497732 & 688687 & 5.3 & 4.6839 & TRN \\
\hline CHEMBL1587522 & 688687 & 4.5 & 5.0659 & TRN \\
\hline CHEMBL1606995 & 688687 & 4.5 & 5.1167 & TRN \\
\hline
\end{tabular}




\begin{tabular}{|c|c|c|c|c|c|}
\hline & & & & & \\
\hline CHEMBL1454153 & 688687 & 4.5 & 4.8854 & TRN & \\
\hline CHEMBL1514604 & 688687 & 5.7 & 4.882 & TST & \\
\hline CHEMBL1360999 & 688687 & 4.4 & 5.135 & TRN & \\
\hline CHEMBL1414425 & 688687 & 5.3 & 4.9341 & TRN & \\
\hline CHEMBL1429998 & 688687 & 5.2 & 4.7097 & TST & \\
\hline CHEMBL1335472 & 688687 & 5.0 & 4.739 & TRN & \\
\hline CHEMBL1454656 & 688687 & 4.6 & 4.651 & TRN & \\
\hline CHEMBL1374582 & 688687 & 4.5 & 4.7458 & TRN & \\
\hline CHEMBL1308495 & 688687 & 4.5 & 4.6852 & TRN & \\
\hline CHEMBL1426869 & 688687 & 4.4 & 4.4245 & TRN & \\
\hline CHEMBL1598711 & 688687 & 4.5 & 5.2445 & TRN & \\
\hline CHEMBL1366926 & 688687 & 4.5 & 4.7711 & TRN & \\
\hline CHEMBL1507092 & 688687 & 4.4 & 4.8367 & TRN & \\
\hline CHEMBL1335668 & 688687 & 5.5 & 4.95 & TST & \\
\hline CHEMBL1392723 & 688687 & 4.5 & 4.6362 & TRN & \\
\hline CHEMBL1417052 & 688687 & 4.6 & 4.7366 & TRN & \\
\hline CHEMBL1352844 & 688687 & 4.4 & 4.3957 & TRN & \\
\hline CHEMBL1368505 & 688687 & 5.1 & 4.6682 & TRN & \\
\hline CHEMBL1605692 & 688687 & 4.4 & 5.0244 & TRN & \\
\hline CHEMBL1563624 & 688687 & 4.7 & $4.7010 €$ & 00000000005 & TRN \\
\hline CHEMBL1440675 & 688687 & 4.4 & 5.035 & TRN & \\
\hline CHEMBL1566512 & 688687 & 5.9 & 5.6829 & TRN & \\
\hline CHEMBL1463642 & 688687 & 4.6 & 4.8289 & TRN & \\
\hline CHEMBL1373679 & 688687 & 4.7 & 5.0463 & TRN & \\
\hline CHEMBL1353706 & 688687 & 4.7 & 4.8131 & TRN & \\
\hline CHEMBL1574133 & 688687 & 4.4 & 4.5827 & TRN & \\
\hline CHEMBL1432151 & 688687 & 4.5 & 4.9802 & TRN & \\
\hline CHEMBL1546956 & 688687 & 4.9 & 4.7113 & TRN & \\
\hline CHEMBL1519384 & 688687 & 4.9 & 4.9036 & TRN & \\
\hline CHEMBL1568981 & 688687 & 4.5 & 4.6436 & TRN & \\
\hline CHEMBL1549257 & 688687 & 4.5 & 4.5506 & TRN & \\
\hline CHEMBL1349340 & 688687 & 5.0 & 4.85 & TRN & \\
\hline CHEMBL1370307 & 688687 & 4.5 & 4.732 & TRN & \\
\hline CHEMBL1582814 & 688687 & 7.3002 & 4.7125 & TRN & \\
\hline CHEMBL1535202 & 688687 & 4.9 & 4.7066 & TRN & \\
\hline CHEMBL1399111 & 688687 & 5.1 & 4.9445 & TST & \\
\hline CHEMBL1333773 & 688687 & 5.4 & 5.1118 & TRN & \\
\hline CHEMBL1332169 & 688687 & 4.5 & 4.573 & TRN & \\
\hline CHEMBL1414195 & 688687 & 4.5 & 4.8019 & TRN & \\
\hline CHEMBL1450949 & 688687 & 4.4 & 4.5588 & TRN & \\
\hline CHEMBL1382198 & 688687 & 4.5 & 5.027 & TRN & \\
\hline CHEMBL 66874 & 688687 & 4.6 & 4.8363 & TRN & \\
\hline CHEMBL1466662 & 688687 & 4.6 & 5.0434 & TRN & \\
\hline CHEMBL1307154 & 688687 & 4.8 & 4.4697 & TRN & \\
\hline CHEMBL1516601 & 688687 & 4.6 & 4.4941 & TRN & \\
\hline CHEMBL1489867 & 688687 & 4.4 & 4.9094 & TRN & \\
\hline CHEMBL1492818 & 688687 & 4.7 & 4.7405 & TRN & \\
\hline CHEMBL1483527 & 688687 & 4.4 & 4.7333 & TRN & \\
\hline & & & & 6315 & \\
\hline
\end{tabular}




\begin{tabular}{|c|c|c|c|c|c|}
\hline \multicolumn{6}{|c|}{ Supplemental Table S2.txt } \\
\hline CHEMBL1349960 & 688687 & 4.7 & 4.9056 & TRN & \\
\hline CHEMBL1492811 & 688687 & 4.5 & 4.7207 & TRN & \\
\hline CHEMBL1339524 & 688687 & 4.8 & 5.1953 & TST & \\
\hline CHEMBL1415499 & 688687 & 8.2007 & 4.9172 & TST & \\
\hline CHEMBL1479267 & 688687 & 4.9 & 4.7725 & TRN & \\
\hline CHEMBL1518801 & 688687 & 4.6 & 4.7569 & TRN & \\
\hline CHEMBL1445186 & 688687 & 4.7 & 5.0477 & TST & \\
\hline CHEMBL1987511 & 688687 & 4.5 & 4.6292 & TRN & \\
\hline CHEMBL1399650 & 688687 & 4.4 & 4.4442 & TRN & \\
\hline CHEMBL1604054 & 688687 & 4.6 & 4.8361 & TRN & \\
\hline CHEMBL1457918 & 688687 & 4.6 & 4.546 & TRN & \\
\hline CHEMBL1344503 & 688687 & 5.0 & 5.1798 & TST & \\
\hline CHEMBL1392956 & 688687 & 5.0 & 4.8374 & TRN & \\
\hline CHEMBL1571182 & 688687 & 4.5 & 4.6209 & TRN & \\
\hline CHEMBL1312001 & 688687 & 4.4 & 4.9458 & TRN & \\
\hline CHEMBL1529307 & 688687 & 4.6 & 4.7574 & TRN & \\
\hline CHEMBL1491063 & 688687 & 4.5 & 4.7777 & TST & \\
\hline CHEMBL1585214 & 688687 & 4.7 & 4.8563 & TRN & \\
\hline CHEMBL299613 & 688687 & 4.5 & 5.3215 & TST & \\
\hline CHEMBL1562408 & 688687 & 4.8 & 4.7692 & TRN & \\
\hline CHEMBL1456454 & 688687 & 4.4 & 4.7996 & TRN & \\
\hline CHEMBL1472228 & 688687 & 4.6 & 4.4822 & TRN & \\
\hline CHEMBL1347208 & 688687 & 5.3 & 4.8069 & TST & \\
\hline CHEMBL1429114 & 688687 & 4.4 & 4.5911 & TRN & \\
\hline CHEMBL1359852 & 688687 & 6.7001 & 5.1396 & TST & \\
\hline CHEMBL1560229 & 688687 & 4.4 & 4.703 & TRN & \\
\hline CHEMBL1344123 & 688687 & 5.4 & 4.9336 & TRN & \\
\hline CHEMBL1324487 & 688687 & 4.6 & 4.7687 & TRN & \\
\hline CHEMBL1416862 & 688687 & 4.5 & 4.9523 & TRN & \\
\hline CHEMBL1307165 & 688687 & 5.0 & 4.6502 & TRN & \\
\hline CHEMBL1586711 & 688687 & 4.5 & 4.601 & TRN & \\
\hline CHEMBL3195020 & 688687 & 4.5 & 4.5068 & TRN & \\
\hline CHEMBL1350196 & 688687 & 5.6 & 5.06800 & 00000000005 & TRN \\
\hline CHEMBL80155 & 688687 & 4.7 & 4.8823 & TRN & \\
\hline CHEMBL1327215 & 688687 & 4.6 & 4.649 & TRN & \\
\hline CHEMBL1402315 & 688687 & 4.6 & 4.6488 & TRN & \\
\hline CHEMBL1362849 & 688687 & 4.6 & 4.6423 & TRN & \\
\hline CHEMBL1574297 & 688687 & 7.5003 & 5.0497 & TST & \\
\hline CHEMBL1578769 & 688687 & 4.6 & 4.8951 & TRN & \\
\hline CHEMBL1299992 & 688687 & 4.5 & 4.9073 & TRN & \\
\hline CHEMBL1612476 & 688687 & 4.9 & 5.043 & TRN & \\
\hline CHEMBL1323790 & 688687 & 4.5 & 4.6547 & TRN & \\
\hline CHEMBL1451433 & 688687 & 4.9 & 4.8366 & TRN & \\
\hline CHEMBL1403855 & 688687 & 4.6 & 4.6559 & TRN & \\
\hline CHEMBL153062 & 688687 & 4.6 & 4.9429 & TRN & \\
\hline CHEMBL1478406 & 688687 & 4.5 & 4.7579 & TRN & \\
\hline CHEMBL1464418 & 688687 & 5.0 & 5.0085 & TRN & \\
\hline CHEMBL1584272 & 688687 & 5.1 & 4.67899 & 9999999999 & TST \\
\hline & & & & 6316 & \\
\hline
\end{tabular}




\begin{tabular}{|c|c|c|c|c|}
\hline & & & & \\
\hline CHEMBL 2373648 & 688687 & 5.4 & 5.1557 & TST \\
\hline CHEMBL263972 & 688687 & 4.4 & 4.5997 & TRN \\
\hline CHEMBL1474114 & 688687 & 4.7 & 4.9354 & TRN \\
\hline CHEMBL1496272 & 688687 & 4.6 & 4.2773 & TRN \\
\hline CHEMBL1441139 & 688687 & 4.4 & 4.7295 & TRN \\
\hline CHEMBL1562333 & 688687 & 4.8 & 4.4394 & TRN \\
\hline CHEMBL1428466 & 688687 & 5.3 & 4.822 & TRN \\
\hline CHEMBL1509860 & 688687 & 4.5 & 4.5645 & TRN \\
\hline CHEMBL1491540 & 688687 & 4.4 & 4.7511 & TRN \\
\hline CHEMBL1328369 & 688687 & 5.8 & 5.0924 & TST \\
\hline CHEMBL1531244 & 688687 & 5.2 & 4.8546 & TRN \\
\hline CHEMBL1541229 & 688687 & 4.5 & 4.6489 & TRN \\
\hline CHEMBL1483338 & 688687 & 4.7 & 4.6954 & TST \\
\hline CHEMBL1349111 & 688687 & 4.9 & 4.8279 & TRN \\
\hline CHEMBL1613706 & 688687 & 5.1 & 4.6734 & TRN \\
\hline CHEMBL1541567 & 688687 & 4.5 & 4.8543 & TRN \\
\hline CHEMBL184450 & 688687 & 6.0 & 5.0901 & TRN \\
\hline CHEMBL1361174 & 688687 & 4.5 & 4.9808 & TRN \\
\hline CHEMBL1590688 & 688687 & 5.1 & 4.8094 & TRN \\
\hline CHEMBL1579654 & 688687 & 4.5 & 4.8869 & TST \\
\hline CHEMBL 1386875 & 688687 & 4.6 & 4.8483 & TRN \\
\hline CHEMBL1257130 & 688687 & 4.7 & 5.2529 & TST \\
\hline CHEMBL1324780 & 688687 & 5.3 & 4.4867 & TRN \\
\hline CHEMBL1560043 & 688687 & 4.4 & 4.6867 & TRN \\
\hline CHEMBL1499367 & 688687 & 5.6 & 4.9568 & TST \\
\hline CHEMBL1501051 & 688687 & 4.7 & 4.629 & TRN \\
\hline CHEMBL1319506 & 688687 & 4.5 & 4.881 & TRN \\
\hline CHEMBL1410399 & 688687 & 6.3 & 5.5388 & TST \\
\hline CHEMBL1337529 & 688687 & 4.5 & 4.9794 & TRN \\
\hline CHEMBL1369907 & 688687 & 4.6 & 4.7383 & TRN \\
\hline CHEMBL1601573 & 688687 & 4.4 & 4.8063 & TRN \\
\hline CHEMBL1496487 & 688687 & 4.5 & 4.6573 & TRN \\
\hline CHEMBL1547376 & 688687 & 4.5 & 4.898 & TST \\
\hline CHEMBL52 & 688687 & 6.0 & 5.7903 & TRN \\
\hline CHEMBL1607067 & 688687 & 4.5 & 4.7795 & TRN \\
\hline CHEMBL1508382 & 688687 & 4.9 & 4.5602 & TST \\
\hline CHEMBL1442603 & 688687 & 5.5 & 5.2287 & TST \\
\hline CHEMBL1577743 & 688687 & 4.9 & 4.9669 & TRN \\
\hline CHEMBL 304008 & 688687 & 4.5 & 4.8935 & TST \\
\hline CHEMBL1544605 & 688687 & 4.7 & 4.7886 & TRN \\
\hline CHEMBL1448530 & 688687 & 4.5 & 4.8064 & TRN \\
\hline CHEMBL1311424 & 688687 & 4.4 & 5.0214 & TRN \\
\hline CHEMBL1504738 & 688687 & 4.9 & 4.5538 & TRN \\
\hline CHEMBL1454813 & 688687 & 4.6 & 5.0963 & TRN \\
\hline CHEMBL3194523 & 688687 & 4.8 & 4.699 & TRN \\
\hline CHEMBL1409700 & 688687 & 4.9 & 5.088 & TRN \\
\hline CHEMBL1375938 & 688687 & 7.1002 & 5.1399 & TRN \\
\hline CHEMBL1321713 & 688687 & 4.4 & 4.5777 & TRN \\
\hline
\end{tabular}




\begin{tabular}{|c|c|c|c|c|}
\hline & & & & \\
\hline CHEMBL1558677 & 688687 & 4.5 & 4.9162 & TRN \\
\hline CHEMBL1373599 & 688687 & 4.5 & 4.5245 & TRN \\
\hline CHEMBL1540890 & 688687 & 4.6 & 4.6643 & TRN \\
\hline CHEMBL1460084 & 688687 & 4.5 & 4.8199 & TRN \\
\hline CHEMBL1438401 & 688687 & 4.7 & 5.0869 & TRN \\
\hline CHEMBL12329 & 688687 & 4.6 & 4.9418 & TRN \\
\hline CHEMBL1424925 & 688687 & 4.4 & 4.902 & TRN \\
\hline CHEMBL1542752 & 688687 & 5.5 & 4.7275 & TRN \\
\hline CHEMBL1490659 & 688687 & 4.5 & 4.7023 & TRN \\
\hline CHEMBL1422481 & 688687 & 5.5 & 4.947 & TST \\
\hline CHEMBL1536953 & 688687 & 4.4 & 4.6807 & TRN \\
\hline CHEMBL1588727 & 688687 & 4.4 & 4.8401 & TRN \\
\hline CHEMBL1415429 & 688687 & 5.3 & 4.8052 & TRN \\
\hline CHEMBL1407847 & 688687 & 5.7 & 5.1333 & TRN \\
\hline CHEMBL1466028 & 688687 & 4.6 & 4.7219 & TRN \\
\hline CHEMBL1519308 & 688687 & 4.6 & 4.6527 & TRN \\
\hline CHEMBL1449432 & 688687 & 4.5 & 4.6864 & TRN \\
\hline CHEMBL1408864 & 688687 & 5.9 & 4.8287 & TRN \\
\hline CHEMBL1424255 & 688687 & 5.4 & 4.7475 & TRN \\
\hline CHEMBL1380830 & 688687 & 4.5 & 4.7785 & TST \\
\hline CHEMBL1316353 & 688687 & 5.5 & 4.8721 & TRN \\
\hline CHEMBL1373293 & 688687 & 4.6 & 4.7568 & TRN \\
\hline CHEMBL1356083 & 688687 & 4.4 & 4.44 & TRN \\
\hline CHEMBL1424816 & 688687 & 4.9 & 4.6824 & TRN \\
\hline CHEMBL1481914 & 688687 & 5.4 & 5.1484 & TRN \\
\hline CHEMBL1404380 & 688687 & 5.3 & 4.725 & TRN \\
\hline CHEMBL1404372 & 688687 & 4.5 & 5.1469 & TRN \\
\hline CHEMBL1566614 & 688687 & 4.5 & 4.7133 & TRN \\
\hline CHEMBL1468719 & 688687 & 4.4 & 4.7654 & TST \\
\hline CHEMBL1593592 & 688687 & 4.4 & 4.6604 & TRN \\
\hline CHEMBL1331925 & 688687 & 4.6 & 4.8276 & TRN \\
\hline CHEMBL1572363 & 688687 & 4.6 & 4.6701 & TRN \\
\hline CHEMBL1329994 & 688687 & 4.8 & 4.7663 & TRN \\
\hline CHEMBL1335350 & 688687 & 5.5 & 4.6167 & TRN \\
\hline CHEMBL1498409 & 688687 & 4.6 & 4.8929 & TRN \\
\hline CHEMBL1589324 & 688687 & 4.5 & 4.8023 & TRN \\
\hline CHEMBL1531761 & 688687 & 4.7 & 5.0546 & TRN \\
\hline CHEMBL1537575 & 688687 & 5.3 & 4.8642 & TRN \\
\hline CHEMBL1527578 & 688687 & 5.2 & 5.1293 & TRN \\
\hline CHEMBL111951 & 688687 & 4.5 & 4.7313 & TRN \\
\hline CHEMBL1404810 & 688687 & 4.6 & 5.045 & TRN \\
\hline CHEMBL 1486574 & 688687 & 5.3 & 4.6409 & TRN \\
\hline CHEMBL1468934 & 688687 & 4.4 & 5.28700 & 0000000001 \\
\hline CHEMBL1599624 & 688687 & 4.6 & 4.7277 & TRN \\
\hline CHEMBL1391326 & 688687 & 5.6 & 5.034 & TST \\
\hline CHEMBL1564889 & 688687 & 4.6 & 4.869 & TRN \\
\hline CHEMBL1429192 & 688687 & 4.5 & 4.9514 & TRN \\
\hline CHEMBL1405348 & 688687 & 4.4 & 4.6053 & TRN \\
\hline
\end{tabular}

TRN 


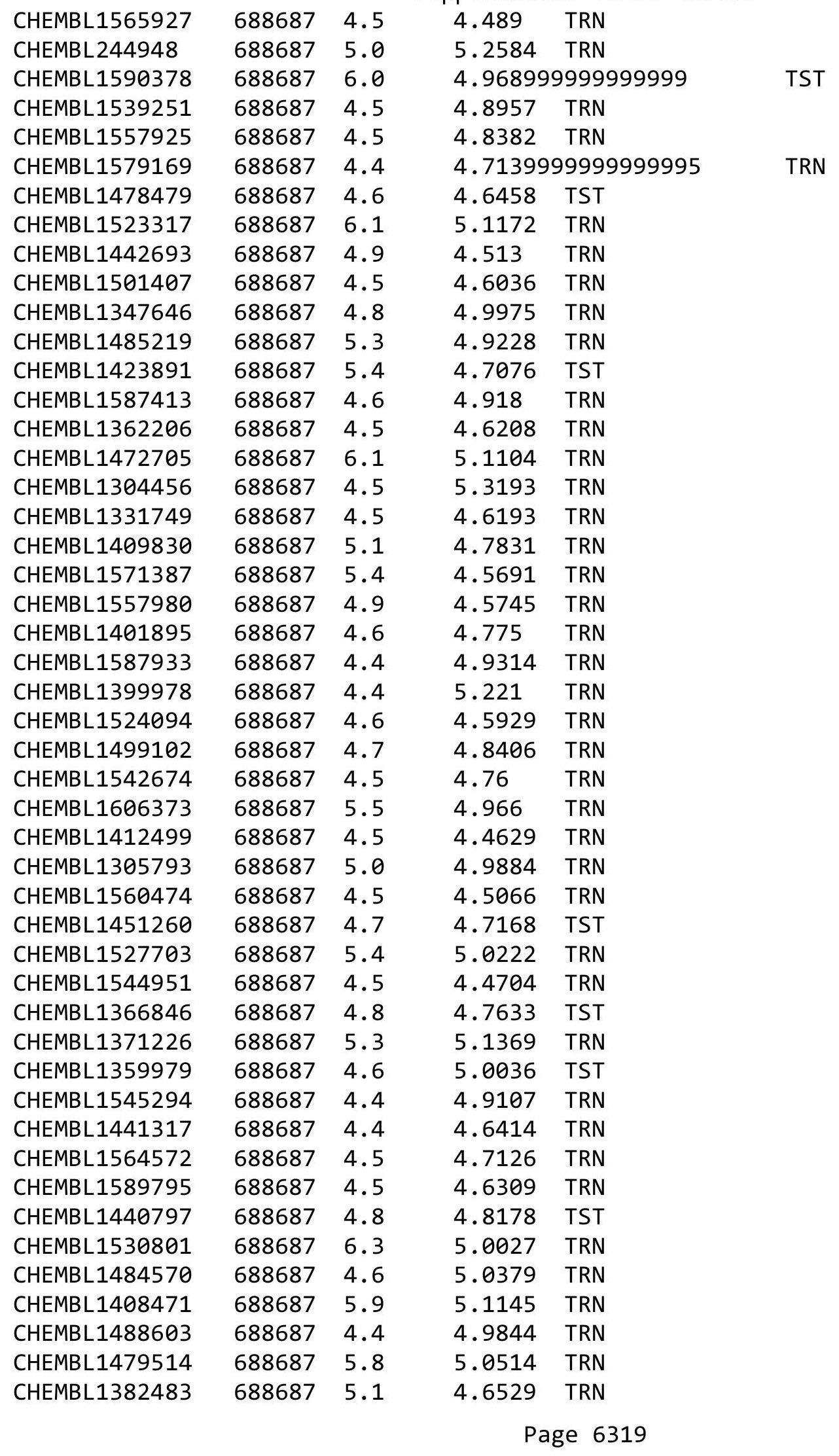




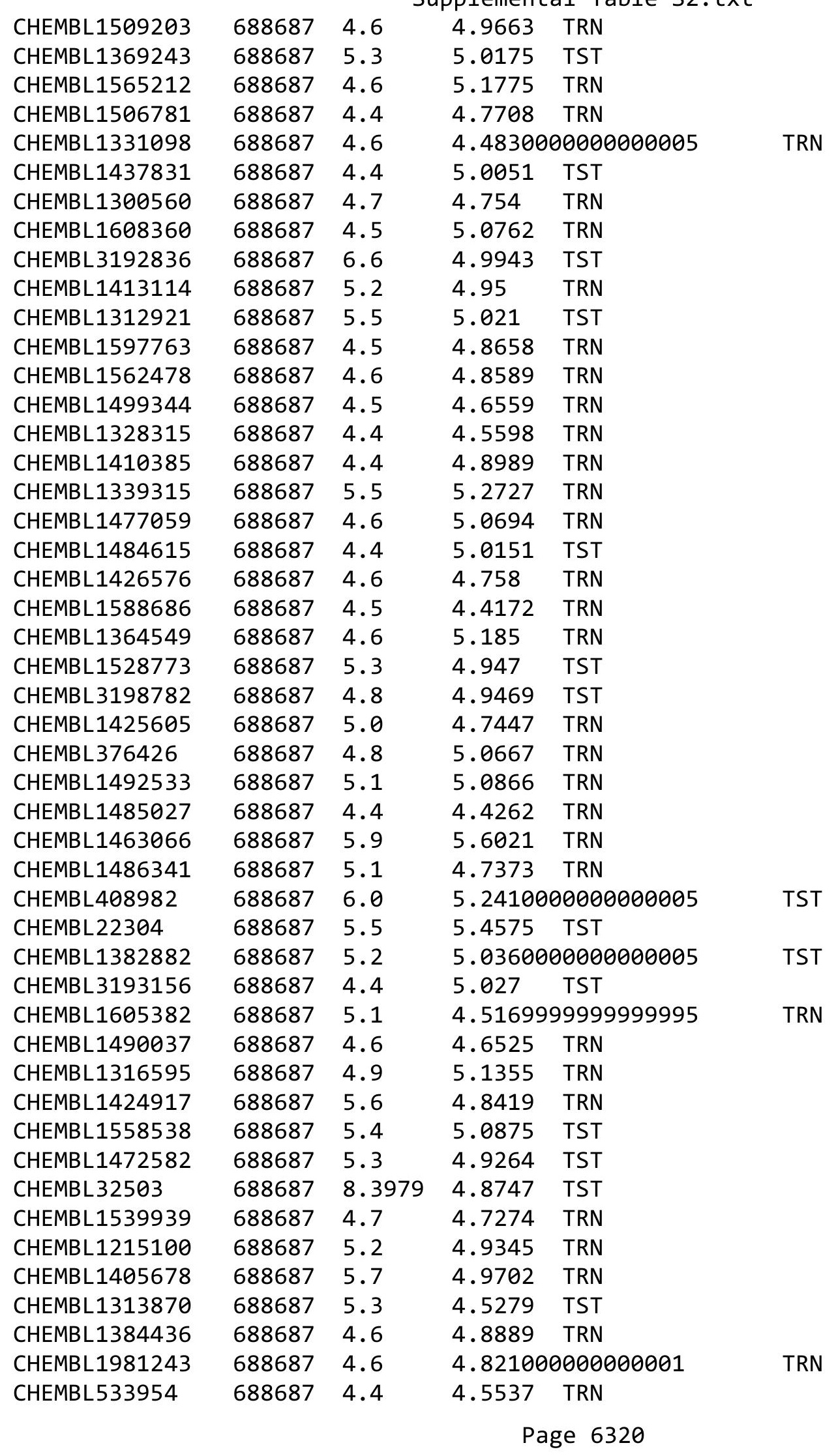




\begin{tabular}{|c|c|c|c|c|c|}
\hline \multirow[b]{2}{*}{ CHEMBL1380385 } & \multirow[b]{2}{*}{688687} & \\
\hline & & 4.6 & 4.8832 & TRN & \\
\hline CHEMBL1439783 & 688687 & 5.8 & 4.9771 & TRN & \\
\hline CHEMBL1372964 & 688687 & 4.9 & 4.8638 & TST & \\
\hline CHEMBL1457512 & 688687 & 4.6 & 4.5624 & TRN & \\
\hline CHEMBL1504336 & 688687 & 5.5 & 5.1347 & TRN & \\
\hline CHEMBL1345130 & 688687 & 4.4 & 4.7574 & TRN & \\
\hline CHEMBL1577510 & 688687 & 4.5 & 5.0123 & TRN & \\
\hline CHEMBL1346066 & 688687 & 4.5 & 4.7153 & TRN & \\
\hline CHEMBL1402174 & 688687 & 4.5 & 4.647 & TRN & \\
\hline CHEMBL1471583 & 688687 & 4.6 & 4.9425 & TRN & \\
\hline CHEMBL1375846 & 688687 & 4.7 & 5.0226 & TST & \\
\hline CHEMBL1335981 & 688687 & 4.5 & 4.7992 & TRN & \\
\hline CHEMBL1331629 & 688687 & 4.5 & 4.8562 & TRN & \\
\hline CHEMBL1428482 & 688687 & 5.0 & 4.6991 & TRN & \\
\hline CHEMBL1495282 & 688687 & 4.5 & 4.4906 & TRN & \\
\hline CHEMBL1398916 & 688687 & 5.2 & 4.9158 & TRN & \\
\hline CHEMBL1448275 & 688687 & 4.8 & 4.6099 & TRN & \\
\hline CHEMBL1393912 & 688687 & 5.5 & 4.9842 & TRN & \\
\hline CHEMBL1365611 & 688687 & 4.5 & 4.6928 & TRN & \\
\hline CHEMBL1338442 & 688687 & 4.4 & 4.6092 & TRN & \\
\hline CHEMBL1611655 & 688687 & 4.6 & 4.6383 & TRN & \\
\hline CHEMBL3189877 & 688687 & 4.4 & 4.4034 & TRN & \\
\hline CHEMBL1333454 & 688687 & 5.3 & 5.0059 & TST & \\
\hline CHEMBL1520857 & 688687 & 4.6 & 4.6142 & TRN & \\
\hline CHEMBL1342664 & 688687 & 4.4 & 4.7913 & TRN & \\
\hline CHEMBL1376771 & 688687 & 4.5 & 4.8069 & TRN & \\
\hline CHEMBL1397293 & 688687 & 4.5 & 4.6698 & TRN & \\
\hline CHEMBL1415616 & 688687 & 5.8 & 4.98300 & 00000000005 & TST \\
\hline CHEMBL1513241 & 688687 & 4.6 & 4.67899 & 9999999999 & TRN \\
\hline CHEMBL1500828 & 688687 & 4.5 & 4.7294 & TST & \\
\hline CHEMBL1307905 & 688687 & 4.4 & 5.0713 & TRN & \\
\hline CHEMBL1326021 & 688687 & 4.5 & 4.4757 & TRN & \\
\hline CHEMBL1525273 & 688687 & 7.5003 & 5.0725 & TRN & \\
\hline CHEMBL1362550 & 688687 & 4.6 & 4.7522 & TRN & \\
\hline CHEMBL1563307 & 688687 & 4.6 & 5.0549 & TST & \\
\hline CHEMBL1331615 & 688687 & 4.6 & 4.5109 & TRN & \\
\hline CHEMBL1570813 & 688687 & 4.6 & 4.7704 & TRN & \\
\hline CHEMBL1417815 & 688687 & 4.5 & 4.6646 & TRN & \\
\hline CHEMBL1558498 & 688687 & 4.7 & 4.6089 & TRN & \\
\hline CHEMBL1579777 & 688687 & 4.9 & 4.6394 & TRN & \\
\hline CHEMBL1498547 & 688687 & 5.5 & 4.8484 & TRN & \\
\hline CHEMBL99344 & 688687 & 4.4 & 4.8236 & TRN & \\
\hline CHEMBL1575869 & 688687 & 4.4 & 4.3734 & TRN & \\
\hline CHEMBL1567983 & 688687 & 4.6 & 4.9 & TRN & \\
\hline CHEMBL388676 & 688687 & 7.1002 & 5.3542 & TST & \\
\hline CHEMBL1542007 & 688687 & 5.3 & 4.8085 & TST & \\
\hline CHEMBL1359833 & 688687 & 4.9 & 4.8411 & TRN & \\
\hline CHEMBL1407524 & 688687 & 4.5 & 4.7471 & TRN & \\
\hline & & & & 6321 & \\
\hline
\end{tabular}




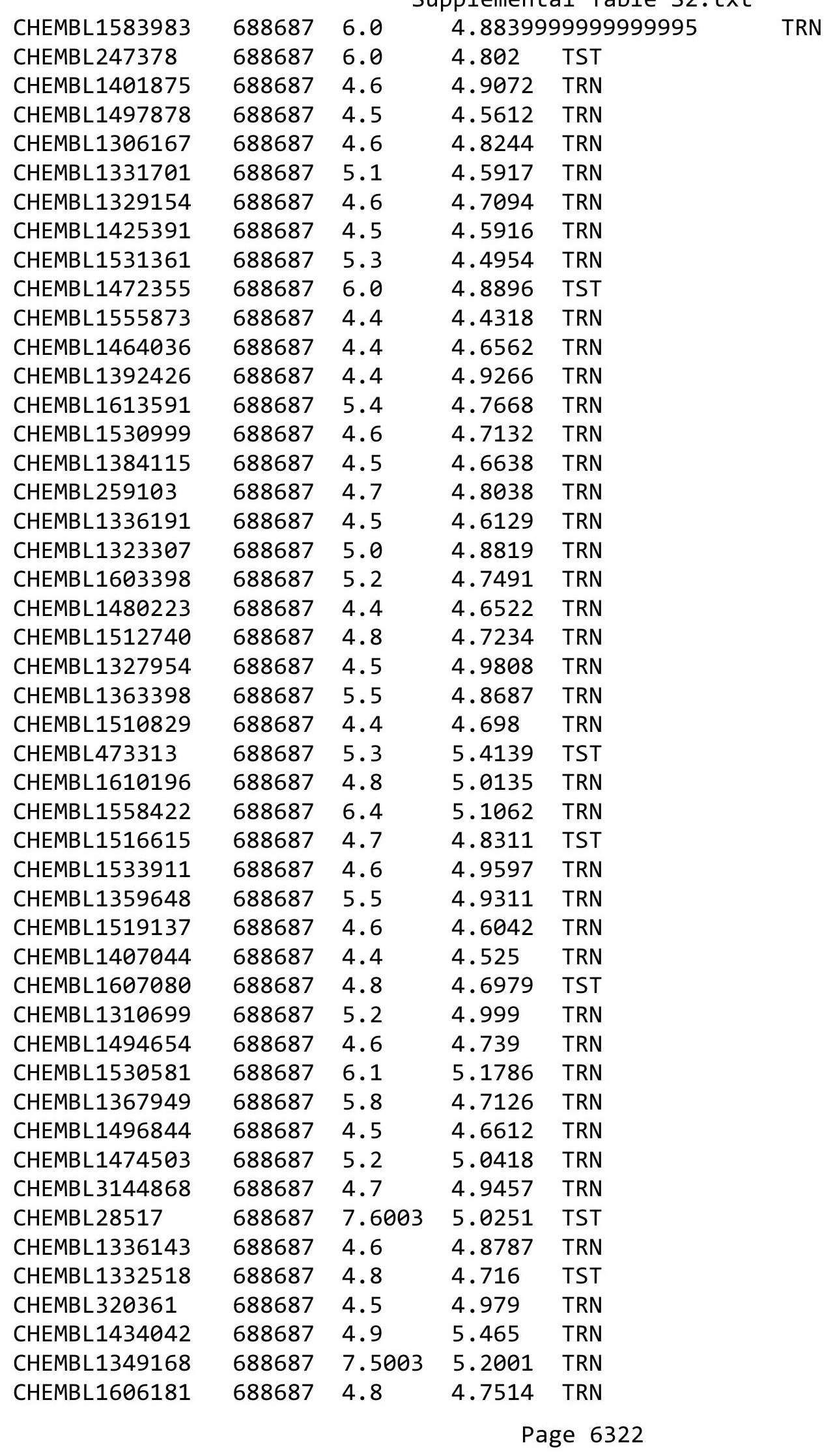




\begin{tabular}{|c|c|c|c|c|c|}
\hline \multirow{3}{*}{ CHEMBL 1416187} & \multirow{2}{*}{688687} & \multirow{2}{*}{5.4} & \multirow{2}{*}{\multicolumn{3}{|c|}{4.6201 TRN }} \\
\hline & & & & & \\
\hline & 688687 & 5.1 & 4.675 & TRN & \\
\hline CHEMBL562192 & 688687 & 4.5 & 4.5805 & TRN & \\
\hline CHEMBL1556988 & 688687 & 4.4 & 4.48 & TRN & \\
\hline CHEMBL490745 & 688687 & 4.5 & 4.5501 & TRN & \\
\hline CHEMBL1555967 & 688687 & 6.8 & \multicolumn{2}{|c|}{ 4.96399999999999995 } & TRN \\
\hline CHEMBL1378682 & 688687 & 4.6 & 4.5123 & TRN & \\
\hline CHEMBL3207531 & 688687 & 4.5 & 4.6863 & TRN & \\
\hline CHEMBL1587008 & 688687 & 4.6 & 4.7958 & TRN & \\
\hline CHEMBL1549860 & 688687 & 4.6 & 4.3363 & TRN & \\
\hline CHEMBL1359214 & 688687 & 4.6 & 4.9318 & TRN & \\
\hline CHEMBL1337575 & 688687 & 4.8 & 4.5562 & TRN & \\
\hline CHEMBL1594170 & 688687 & 5.4 & 5.0381 & TRN & \\
\hline CHEMBL1391342 & 688687 & 5.5 & \multicolumn{2}{|c|}{5.0760000000000005} & TST \\
\hline CHEMBL1383046 & 688687 & 4.5 & 4.8882 & TRN & \\
\hline CHEMBL1572870 & 688687 & 4.5 & 4.8402 & TRN & \\
\hline CHEMBL1422663 & 688687 & 4.4 & 5.0065 & TRN & \\
\hline CHEMBL1558533 & 688687 & 4.5 & 4.4969 & TRN & \\
\hline CHEMBL1434072 & 688687 & 4.8 & 4.909 & TRN & \\
\hline CHEMBL1487727 & 688687 & 4.5 & 5.2318 & TST & \\
\hline CHEMBL86931 & 688687 & 7.0 & 5.0451 & TST & \\
\hline CHEMBL1480219 & 688687 & 4.4 & 4.4785 & TRN & \\
\hline CHEMBL1525610 & 688687 & 4.5 & 4.6582 & TRN & \\
\hline CHEMBL1412062 & 688687 & 4.4 & 4.9966 & TRN & \\
\hline CHEMBL1568892 & 688687 & 4.8 & 4.5586 & TRN & \\
\hline CHEMBL1256659 & 688687 & 6.1 & 5.0524 & TST & \\
\hline CHEMBL1336394 & 688687 & 4.4 & 4.9406 & TST & \\
\hline CHEMBL 8565 & 688687 & 6.4 & 4.9589 & TRN & \\
\hline CHEMBL1542283 & 688687 & 4.4 & 4.7016 & TRN & \\
\hline CHEMBL1433084 & 688687 & 4.5 & 4.8418 & TRN & \\
\hline CHEMBL1446593 & 688687 & 4.4 & 4.7539 & TRN & \\
\hline CHEMBL1343420 & 688687 & 5.1 & 4.9442 & TRN & \\
\hline CHEMBL1581108 & 688687 & 4.8 & 4.6988 & TRN & \\
\hline CHEMBL1318042 & 688687 & 4.4 & 4.7322 & TRN & \\
\hline CHEMBL1328202 & 688687 & 4.4 & 4.8089 & TRN & \\
\hline CHEMBL1421754 & 688687 & 4.5 & 4.4138 & TRN & \\
\hline CHEMBL1369231 & 688687 & 4.5 & 4.8742 & TRN & \\
\hline CHEMBL1415517 & 688687 & 4.4 & 4.74100 & 00000000005 & TRN \\
\hline CHEMBL1585453 & 688687 & 4.6 & 4.9241 & TRN & \\
\hline CHEMBL1498591 & 688687 & 6.5 & 4.9285 & TRN & \\
\hline CHEMBL1496007 & 688687 & 4.5 & 4.4883 & TST & \\
\hline CHEMBL1453769 & 688687 & 4.6 & 4.8212 & TRN & \\
\hline CHEMBL1573297 & 688687 & 6.0 & 4.7097 & TST & \\
\hline CHEMBL3192376 & 688687 & 4.5 & 4.8592 & TRN & \\
\hline CHEMBL1302850 & 688687 & 4.5 & 4.876 & TRN & \\
\hline CHEMBL1363514 & 688687 & 5.4 & 4.6918 & TRN & \\
\hline CHEMBL1427319 & 688687 & 4.4 & 4.8576 & TRN & \\
\hline \multirow[t]{2}{*}{ CHEMBL1422629 } & 688687 & 5.1 & 4.6396 & TRN & \\
\hline & & \multicolumn{4}{|c|}{ Page 6323} \\
\hline
\end{tabular}




\begin{tabular}{|c|c|c|c|c|}
\hline & & & LEIILTL & al Ta \\
\hline CHEMBL1256390 & 688687 & 4.5 & 4.9424 & TRN \\
\hline CHEMBL1478141 & 688687 & 4.7 & 4.7416 & TRN \\
\hline CHEMBL1543469 & 688687 & 4.6 & 4.5541 & TRN \\
\hline CHEMBL1486644 & 688687 & 4.8 & 4.9265 & TRN \\
\hline CHEMBL1595194 & 688687 & 4.6 & 4.6231 & TRN \\
\hline CHEMBL 1458374 & 688687 & 5.0 & 4.9402 & TRN \\
\hline CHEMBL1374063 & 688687 & 4.9 & 4.817 & TRN \\
\hline CHEMBL1528814 & 688687 & 5.5 & 5.1771 & TST \\
\hline CHEMBL1477847 & 688687 & 4.5 & 4.7063 & TRN \\
\hline CHEMBL1414780 & 688687 & 4.4 & 4.8582 & TRN \\
\hline CHEMBL1468622 & 688687 & 4.6 & 4.8055 & TRN \\
\hline CHEMBL1521414 & 688687 & 4.4 & 4.5 & TRN \\
\hline CHEMBL1383035 & 688687 & 4.4 & 5.1023 & TRN \\
\hline CHEMBL1548693 & 688687 & 4.5 & 4.9944 & TRN \\
\hline CHEMBL319244 & 688687 & 4.9 & 5.9466 & TRN \\
\hline CHEMBL1500438 & 688687 & 4.5 & 4.672 & TRN \\
\hline CHEMBL1447551 & 688687 & 4.4 & 4.8098 & TRN \\
\hline CHEMBL1399208 & 688687 & 4.4 & 4.704 & TRN \\
\hline CHEMBL1360927 & 688687 & 4.5 & 4.5598 & TRN \\
\hline CHEMBL1353190 & 688687 & 4.8 & 4.962 & TRN \\
\hline CHEMBL1484356 & 688687 & 4.4 & 4.805 & TRN \\
\hline CHEMBL1566553 & 688687 & 5.4 & 4.7899 & TRN \\
\hline CHEMBL1439640 & 688687 & 4.5 & 4.6117 & TRN \\
\hline CHEMBL1312719 & 688687 & 4.5 & 4.904 & TRN \\
\hline CHEMBL1611439 & 688687 & 4.5 & 4.7497 & TRN \\
\hline CHEMBL1301069 & 688687 & 4.8 & 4.7898 & TRN \\
\hline CHEMBL1343178 & 688687 & 4.5 & 4.5821 & TRN \\
\hline CHEMBL1608393 & 688687 & 5.0 & 4.8761 & TRN \\
\hline CHEMBL1415281 & 688687 & 4.4 & 4.9614 & TRN \\
\hline CHEMBL3199408 & 688687 & 4.6 & 5.0428 & TRN \\
\hline CHEMBL1412326 & 688687 & 4.6 & 4.4268 & TRN \\
\hline CHEMBL1472732 & 688687 & 4.4 & 4.6748 & TRN \\
\hline CHEMBL 3193762 & 688687 & 4.5 & 5.0268 & TST \\
\hline CHEMBL259853 & 688687 & 4.4 & 4.4358 & TRN \\
\hline CHEMBL1327373 & 688687 & 4.5 & 4.902 & TRN \\
\hline CHEMBL1438788 & 688687 & 4.6 & 4.518 & TRN \\
\hline CHEMBL1610636 & 688687 & 4.4 & 4.5526 & TRN \\
\hline CHEMBL1562688 & 688687 & 4.6 & 4.6598 & TRN \\
\hline CHEMBL1332016 & 688687 & 5.5 & 5.3938 & TRN \\
\hline CHEMBL1474701 & 688687 & 7.0 & 4.9663 & TST \\
\hline CHEMBL1543940 & 688687 & 4.6 & 4.8577 & TST \\
\hline CHEMBL 224282 & 688687 & 5.5 & 5.2242 & TRN \\
\hline CHEMBL1359891 & 688687 & 4.5 & 4.6227 & TRN \\
\hline CHEMBL1466923 & 688687 & 4.5 & 4.6407 & TRN \\
\hline CHEMBL1350547 & 688687 & 4.5 & 4.7181 & TRN \\
\hline CHEMBL1397914 & 688687 & 4.4 & 4.7249 & TRN \\
\hline CHEMBL1450169 & 688687 & 5.8 & 5.1999 & TST \\
\hline CHEMBL1459601 & 688687 & 4.4 & 4.6002 & TRN \\
\hline
\end{tabular}




\begin{tabular}{|c|c|c|c|c|c|}
\hline \\
\hline CHEMBL1382202 & 688687 & 6.1 & 5.2299 & TRN & \\
\hline CHEMBL1476267 & 688687 & 5.2 & 5.1056 & TST & \\
\hline CHEMBL543 & 688687 & 4.4 & 4.9382 & TST & \\
\hline CHEMBL1390384 & 688687 & 4.9 & 4.7844 & TRN & \\
\hline CHEMBL1333281 & 688687 & 5.0 & 5.0563 & TRN & \\
\hline CHEMBL1309350 & 688687 & 4.4 & 5.1953 & TST & \\
\hline CHEMBL512908 & 688687 & 6.1 & 5.1336 & TRN & \\
\hline CHEMBL1402835 & 688687 & 5.4 & 4.9676 & TST & \\
\hline CHEMBL1455546 & 688687 & 4.5 & 4.4278 & TRN & \\
\hline CHEMBL1342004 & 688687 & 4.4 & 4.7506 & TST & \\
\hline CHEMBL1311322 & 688687 & 5.5 & 4.5941 & TRN & \\
\hline CHEMBL1312829 & 688687 & 4.9 & 4.8157 & TRN & \\
\hline CHEMBL1399368 & 688687 & 4.4 & 4.7055 & TRN & \\
\hline CHEMBL1329237 & 688687 & 4.7 & 4.3922 & TRN & \\
\hline CHEMBL1548242 & 688687 & 5.0 & 4.94300 & 00000000005 & TST \\
\hline CHEMBL1575793 & 688687 & 6.5 & 4.965 & TST & \\
\hline CHEMBL1404255 & 688687 & 4.6 & 4.6144 & TRN & \\
\hline CHEMBL1489875 & 688687 & 4.8 & 4.947 & TRN & \\
\hline CHEMBL1414235 & 688687 & 5.0 & 4.7675 & TRN & \\
\hline CHEMBL1506252 & 688687 & 5.7 & 5.2451 & TST & \\
\hline CHEMBL1573693 & 688687 & 5.5 & 5.0976 & TRN & \\
\hline CHEMBL1301955 & 688687 & 6.0 & 4.9147 & TRN & \\
\hline CHEMBL1302494 & 688687 & 5.3 & 5.1361 & TRN & \\
\hline CHEMBL71851 & 688687 & 5.3 & 5.0793 & TRN & \\
\hline CHEMBL1564374 & 688687 & 4.6 & 4.5741 & TRN & \\
\hline CHEMBL1445449 & 688687 & 5.6 & 4.7523 & TRN & \\
\hline CHEMBL1454049 & 688687 & 4.4 & 4.8734 & TRN & \\
\hline CHEMBL1437011 & 688687 & 5.6 & 4.8826 & TRN & \\
\hline CHEMBL1332277 & 688687 & 4.5 & 4.6268 & TRN & \\
\hline CHEMBL1391230 & 688687 & 4.4 & 4.8752 & TRN & \\
\hline CHEMBL1447582 & 688687 & 4.9 & 5.0703 & TRN & \\
\hline CHEMBL1369275 & 688687 & 4.6 & 4.8277 & TRN & \\
\hline CHEMBL1592213 & 688687 & 4.8 & 4.6116 & TRN & \\
\hline CHEMBL1397782 & 688687 & 4.4 & 4.8977 & TST & \\
\hline CHEMBL1527794 & 688687 & 4.5 & 4.7612 & TRN & \\
\hline CHEMBL1608171 & 688687 & 4.6 & 4.7273 & TRN & \\
\hline CHEMBL1512878 & 688687 & 4.8 & 4.8509 & TRN & \\
\hline CHEMBL52030 & 688687 & 5.2 & 4.7874 & TST & \\
\hline CHEMBL1491326 & 688687 & 4.6 & 4.8039 & TRN & \\
\hline CHEMBL47814 & 688687 & 4.4 & 4.7854 & TRN & \\
\hline CHEMBL1447593 & 688687 & 4.5 & 4.5005 & TRN & \\
\hline CHEMBL1441612 & 688687 & 6.1 & 4.7383 & TRN & \\
\hline CHEMBL1447084 & 688687 & 6.8 & 5.0126 & TRN & \\
\hline CHEMBL1454758 & 688687 & 4.9 & 5.2426 & TRN & \\
\hline CHEMBL1578334 & 688687 & 4.4 & 4.6616 & TRN & \\
\hline CHEMBL510515 & 688687 & 6.0 & 5.3636 & TRN & \\
\hline CHEMBL1464313 & 688687 & 4.6 & 4.6736 & TRN & \\
\hline CHEMBL1451986 & 688687 & 6.1 & 5.1104 & TST & \\
\hline
\end{tabular}




\begin{tabular}{|c|c|c|c|c|}
\hline & & & & \\
\hline CHEMBL1368562 & 688687 & 4.9 & 5.0464 & TST \\
\hline CHEMBL1440708 & 688687 & 4.9 & 4.8927 & TRN \\
\hline CHEMBL1431512 & 688687 & 4.6 & 4.9113 & TRN \\
\hline CHEMBL1534239 & 688687 & 4.9 & 4.5387 & TRN \\
\hline CHEMBL1456676 & 688687 & 6.3 & 4.6882 & TRN \\
\hline CHEMBL1577295 & 688687 & 4.5 & 4.5764 & TRN \\
\hline CHEMBL3194665 & 688687 & 4.4 & 4.8661 & TST \\
\hline CHEMBL1495239 & 688687 & 4.4 & 4.9276 & TRN \\
\hline CHEMBL1450925 & 688687 & 4.6 & 4.7536 & TRN \\
\hline CHEMBL1447473 & 688687 & 4.8 & 4.882 & TRN \\
\hline CHEMBL1339718 & 688687 & 4.8 & 4.8875 & TRN \\
\hline CHEMBL1305485 & 688687 & 4.6 & 4.8598 & TRN \\
\hline CHEMBL1420831 & 688687 & 5.2 & 4.7068 & TRN \\
\hline CHEMBL1332964 & 688687 & 5.1 & 4.8584 & TST \\
\hline CHEMBL3192682 & 688687 & 5.4 & 4.6074 & TRN \\
\hline CHEMBL1512562 & 688687 & 4.6 & 4.963 & TRN \\
\hline CHEMBL1381308 & 688687 & 5.8 & 4.624 & TRN \\
\hline CHEMBL 274438 & 688687 & 4.5 & 4.9139 & TRN \\
\hline CHEMBL1363731 & 688687 & 4.4 & 4.588 & TRN \\
\hline CHEMBL1517430 & 688687 & 4.5 & 4.6118 & TRN \\
\hline CHEMBL1519790 & 688687 & 4.6 & 4.785 & TRN \\
\hline CHEMBL1431783 & 688687 & 4.5 & 4.5768 & TRN \\
\hline CHEMBL1390871 & 688687 & 4.5 & 5.1137 & TRN \\
\hline CHEMBL1573462 & 688687 & 5.3 & 5.0807 & TRN \\
\hline CHEMBL1581560 & 688687 & 4.5 & 5.1298 & TST \\
\hline CHEMBL1572146 & 688687 & 4.6 & 4.9854 & TRN \\
\hline CHEMBL1446921 & 688687 & 4.4 & 4.7115 & TRN \\
\hline CHEMBL1505063 & 688687 & 4.5 & 5.051 & TRN \\
\hline CHEMBL1525129 & 688687 & 4.9 & 4.6359 & TRN \\
\hline CHEMBL1529531 & 688687 & 4.4 & 4.7368 & TRN \\
\hline CHEMBL1495491 & 688687 & 5.0 & 4.4856 & TRN \\
\hline CHEMBL1345810 & 688687 & 4.7 & 4.4884 & TRN \\
\hline CHEMBL1356794 & 688687 & 4.6 & 4.7689 & TRN \\
\hline CHEMBL1482449 & 688687 & 5.5 & 4.9092 & TRN \\
\hline CHEMBL1612693 & 688687 & 4.8 & 4.7919 & TRN \\
\hline CHEMBL1502944 & 688687 & 4.5 & 4.7088 & TRN \\
\hline CHEMBL67535 & 688687 & 4.8 & 5.9704 & TRN \\
\hline CHEMBL1332486 & 688687 & 4.4 & 5.1748 & TRN \\
\hline CHEMBL1535271 & 688687 & 4.4 & 4.8268 & TRN \\
\hline CHEMBL1580636 & 688687 & 4.4 & 4.5588 & TRN \\
\hline CHEMBL1595181 & 688687 & 5.0 & 4.8435 & TRN \\
\hline CHEMBL1482207 & 688687 & 4.5 & 4.6761 & TRN \\
\hline CHEMBL1560885 & 688687 & 5.0 & 4.8344 & TRN \\
\hline CHEMBL1445003 & 688687 & 4.4 & 4.8089 & TRN \\
\hline CHEMBL1418734 & 688687 & 4.5 & 4.6035 & TST \\
\hline CHEMBL1462106 & 688687 & 4.5 & 4.8141 & TRN \\
\hline CHEMBL1330937 & 688687 & 4.6 & 4.4423 & TRN \\
\hline CHEMBL1508973 & 688687 & 4.6 & 4.4909 & TST \\
\hline
\end{tabular}




\begin{tabular}{|c|c|c|c|c|c|}
\hline CHEMBL1418094 & 688687 & 5.5 & 5.0566 & TST & \\
\hline CHEMBL1399528 & 688687 & 4.4 & 4.5237 & TRN & \\
\hline CHEMBL1609807 & 688687 & 5.0 & 4.7207 & TST & \\
\hline CHEMBL1309148 & 688687 & 4.5 & 4.8949 & TRN & \\
\hline CHEMBL1588787 & 688687 & 4.5 & 4.8609 & TRN & \\
\hline CHEMBL1311974 & 688687 & 5.5 & 4.9192 & TRN & \\
\hline CHEMBL1495619 & 688687 & 5.0 & 4.6098 & TRN & \\
\hline CHEMBL1302787 & 688687 & 4.4 & 4.7367 & TRN & \\
\hline CHEMBL1548716 & 688687 & 4.4 & 4.8271 & TRN & \\
\hline CHEMBL1435477 & 688687 & 6.0 & 5.0651 & TST & \\
\hline CHEMBL3194422 & 688687 & 4.6 & 4.8234 & TST & \\
\hline CHEMBL1352304 & 688687 & 4.4 & 4.6105 & TRN & \\
\hline CHEMBL1383429 & 688687 & 5.2 & 4.9982 & TST & \\
\hline CHEMBL1401280 & 688687 & 4.5 & 4.6248 & TRN & \\
\hline CHEMBL1535126 & 688687 & 5.4 & 4.62 & TRN & \\
\hline CHEMBL1440883 & 688687 & 4.9 & 4.5507 & TRN & \\
\hline CHEMBL1403312 & 688687 & 5.5 & 4.7006 & TRN & \\
\hline CHEMBL1492666 & 688687 & 4.6 & 4.8906 & TRN & \\
\hline CHEMBL1330414 & 688687 & 4.9 & 5.306 & TRN & \\
\hline CHEMBL1398294 & 688687 & 5.5 & 5.184 & TRN & \\
\hline CHEMBL1479591 & 688687 & 5.2 & 5.1017 & TRN & \\
\hline CHEMBL1402138 & 688687 & 4.4 & 5.155 & TRN & \\
\hline CHEMBL1429654 & 688687 & 4.5 & 4.6846 & TRN & \\
\hline CHEMBL1400764 & 688687 & 4.9 & 4.6122 & TRN & \\
\hline CHEMBL1544440 & 688687 & 4.4 & 4.7501 & TRN & \\
\hline CHEMBL1446523 & 688687 & 4.4 & 4.5376 & TRN & \\
\hline CHEMBL1590181 & 688687 & 6.0 & 5.94799 & 99999999995 & TRN \\
\hline CHEMBL1448844 & 688687 & 4.7 & 4.6049 & TRN & \\
\hline CHEMBL 1457257 & 688687 & 4.4 & 4.6726 & TRN & \\
\hline CHEMBL1590550 & 688687 & 4.6 & 4.5149 & TRN & \\
\hline CHEMBL1560982 & 688687 & 4.6 & 4.94600 & 3000000001 & TRN \\
\hline CHEMBL1343858 & 688687 & 4.6 & 4.8442 & TRN & \\
\hline CHEMBL1446466 & 688687 & 4.6 & 4.8684 & TRN & \\
\hline CHEMBL1308234 & 688687 & 4.4 & 4.6314 & TRN & \\
\hline CHEMBL167869 & 688687 & 4.6 & 5.1184 & TRN & \\
\hline CHEMBL1581681 & 688687 & 4.4 & 4.808 & TRN & \\
\hline CHEMBL1324328 & 688687 & 4.5 & 4.753 & TRN & \\
\hline CHEMBL1374982 & 688687 & 5.3 & 5.0345 & TRN & \\
\hline CHEMBL1452992 & 688687 & 4.8 & 4.961 & TST & \\
\hline CHEMBL1560612 & 688687 & 4.9 & 4.6329 & TRN & \\
\hline CHEMBL1506434 & 688687 & 4.5 & 4.9837 & TRN & \\
\hline CHEMBL1333084 & 688687 & 4.7 & 4.7391 & TST & \\
\hline CHEMBL1385563 & 688687 & 4.5 & 4.4935 & TRN & \\
\hline CHEMBL1605399 & 688687 & 4.4 & 4.5044 & TRN & \\
\hline CHEMBL3210339 & 688687 & 4.6 & 4.5482 & TRN & \\
\hline CHEMBL1371458 & 688687 & 5.5 & 4.5434 & TRN & \\
\hline CHEMBL1494788 & 688687 & 4.5 & 4.8195 & TRN & \\
\hline \multirow[t]{2}{*}{ CHEMBL1533452 } & 688687 & 4.4 & 4.4706 & TRN & \\
\hline & & \multicolumn{4}{|c|}{ Page 6327} \\
\hline
\end{tabular}




\begin{tabular}{|c|c|c|c|c|}
\hline & & & pplement & 0 \\
\hline CHEMBL3210001 & 688687 & 4.9 & 4.7787 & TRN \\
\hline CHEMBL1600727 & 688687 & 5.4 & 4.9669 & TRN \\
\hline CHEMBL1410575 & 688687 & 4.4 & 4.4866 & TRN \\
\hline CHEMBL1387211 & 688687 & 5.4 & 5.124 & TRN \\
\hline CHEMBL1541027 & 688687 & 4.5 & 4.613 & TRN \\
\hline CHEMBL1447590 & 688687 & 6.0 & 4.9416 & TST \\
\hline CHEMBL1466140 & 688687 & 5.2 & 4.8369 & TRN \\
\hline CHEMBL1475787 & 688687 & 4.4 & 4.1714 & TRN \\
\hline CHEMBL1416101 & 688687 & 4.5 & 4.9099 & TRN \\
\hline CHEMBL1447406 & 688687 & 4.6 & 4.6895 & TST \\
\hline CHEMBL1423913 & 688687 & 4.5 & 4.6826 & TRN \\
\hline CHEMBL1585343 & 688687 & 5.5 & 4.7862 & TRN \\
\hline CHEMBL1319407 & 688687 & 5.0 & 5.0514 & TRN \\
\hline CHEMBL1346446 & 688687 & 5.0 & 5.0906 & TRN \\
\hline CHEMBL1306736 & 688687 & 4.5 & 4.6876 & TRN \\
\hline CHEMBL1595989 & 688687 & 4.7 & 4.6644 & TRN \\
\hline CHEMBL1324495 & 688687 & 4.5 & 4.81 & TRN \\
\hline CHEMBL1558655 & 688687 & 4.9 & 4.4167 & TRN \\
\hline CHEMBL1303139 & 688687 & 7.2 & 5.1447 & TRN \\
\hline CHEMBL1972346 & 688687 & 5.7 & 6.2117 & TRN \\
\hline CHEMBL1478045 & 688687 & 4.5 & 5.0282 & TST \\
\hline CHEMBL1581991 & 688687 & 4.7 & 4.6358 & TRN \\
\hline CHEMBL1305936 & 688687 & 4.4 & 4.6741 & TRN \\
\hline CHEMBL1456557 & 688687 & 5.1 & 5.073 & TST \\
\hline CHEMBL1517449 & 688687 & 4.6 & 4.6321 & TST \\
\hline CHEMBL1343759 & 688687 & 4.4 & 5.0828 & TRN \\
\hline CHEMBL1322627 & 688687 & 4.8 & 4.7621 & TRN \\
\hline CHEMBL1544354 & 688687 & 5.2 & 5.3489 & TST \\
\hline CHEMBL1299274 & 688687 & 4.5 & 4.6831 & TST \\
\hline CHEMBL1595820 & 688687 & 4.7 & 4.8515 & TRN \\
\hline CHEMBL1463826 & 688687 & 4.4 & 4.5214 & TRN \\
\hline CHEMBL1493896 & 688687 & 4.6 & 4.7542 & TRN \\
\hline CHEMBL1452894 & 688687 & 5.2 & 4.9927 & TST \\
\hline CHEMBL1480832 & 688687 & 5.1 & 4.9298 & TST \\
\hline CHEMBL1214274 & 688687 & 5.6 & 5.2229 & TST \\
\hline CHEMBL3197322 & 688687 & 4.8 & 4.6826 & TRN \\
\hline CHEMBL1330386 & 688687 & 4.6 & 4.7294 & TRN \\
\hline CHEMBL1515310 & 688687 & 4.4 & 5.1602 & TST \\
\hline CHEMBL1509822 & 688687 & 4.7 & 5.0275 & TRN \\
\hline CHEMBL1978101 & 688687 & 5.5 & 4.5077 & TRN \\
\hline CHEMBL1326336 & 688687 & 4.7 & 4.7227 & TST \\
\hline CHEMBL1359848 & 688687 & 4.6 & 4.9645 & TRN \\
\hline CHEMBL1533288 & 688687 & 4.5 & 5.058 & TST \\
\hline CHEMBL1333915 & 688687 & 4.4 & 4.7005 & TST \\
\hline CHEMBL1466087 & 688687 & 4.4 & 4.9992 & TRN \\
\hline CHEMBL1594030 & 688687 & 4.5 & 4.7121 & TRN \\
\hline CHEMBL1442580 & 688687 & 4.8 & 4.9877 & TRN \\
\hline CHEMBL1391460 & 688687 & 6.0 & 5.1472 & TRN \\
\hline
\end{tabular}




\begin{tabular}{|c|c|c|c|c|}
\hline \multicolumn{5}{|c|}{ lementa } \\
\hline CHEMBL1353205 & 688687 & 4.5 & 4.5383 & TRN \\
\hline CHEMBL1367484 & 688687 & 5.9 & 5.0101 & TRN \\
\hline CHEMBL1485541 & 688687 & 4.4 & 4.2386 & TRN \\
\hline CHEMBL1347687 & 688687 & 5.4 & 4.7442 & TRN \\
\hline CHEMBL1382536 & 688687 & 5.0 & 4.9561 & TRN \\
\hline CHEMBL1352752 & 688687 & 4.5 & 4.9782 & TRN \\
\hline CHEMBL1372624 & 688687 & 5.4 & 5.0659 & TRN \\
\hline CHEMBL1463304 & 688687 & 4.4 & 4.655 & TRN \\
\hline CHEMBL1325274 & 688687 & 4.6 & 5.0074 & TRN \\
\hline CHEMBL1390762 & 688687 & 4.4 & 4.6899 & TRN \\
\hline CHEMBL 3210485 & 688687 & 5.4 & 4.6168 & TRN \\
\hline CHEMBL1499016 & 688687 & 4.4 & 4.734 & TRN \\
\hline CHEMBL1340393 & 688687 & 4.5 & 4.7719 & TRN \\
\hline CHEMBL1544909 & 688687 & 4.6 & 4.7363 & TST \\
\hline CHEMBL1370582 & 688687 & 4.4 & 4.5595 & TRN \\
\hline CHEMBL265715 & 688687 & 4.4 & 4.7387 & TRN \\
\hline CHEMBL151 & 688687 & 6.0 & 5.773 & TRN \\
\hline CHEMBL1576399 & 688687 & 5.4 & 4.752 & TRN \\
\hline CHEMBL1534795 & 688687 & 6.0 & 5.0387 & TRN \\
\hline CHEMBL1562384 & 688687 & 5.2 & 4.9003 & TRN \\
\hline CHEMBL1571328 & 688687 & 4.6 & 4.9379 & TRN \\
\hline CHEMBL260148 & 688687 & 5.8 & 5.401 & TRN \\
\hline CHEMBL1558784 & 688687 & 5.1 & 4.8075 & TRN \\
\hline CHEMBL1403488 & 688687 & 5.0 & 4.8071 & TRN \\
\hline CHEMBL1334687 & 688687 & 5.8 & 4.9034 & TRN \\
\hline CHEMBL1162107 & 688687 & 5.4 & 5.0814 & TST \\
\hline CHEMBL 2373683 & 688687 & 5.5 & 5.23600 & 0000000001 \\
\hline CHEMBL1376616 & 688687 & 4.7 & 4.7117 & TRN \\
\hline CHEMBL1484912 & 688687 & 4.5 & 4.7393 & TRN \\
\hline CHEMBL109037 & 688687 & 5.9 & 5.6806 & TST \\
\hline CHEMBL1474625 & 688687 & 5.0 & 4.8326 & TRN \\
\hline CHEMBL150924 & 688687 & 4.6 & 5.2505 & TRN \\
\hline CHEMBL1569844 & 688687 & 4.5 & 4.6827 & TRN \\
\hline CHEMBL1308910 & 688687 & 5.5 & 4.6051 & TRN \\
\hline CHEMBL1500078 & 688687 & 4.5 & 4.6886 & TRN \\
\hline CHEMBL1528252 & 688687 & 4.5 & 4.7234 & TST \\
\hline CHEMBL1367129 & 688687 & 4.6 & 4.7729 & TRN \\
\hline CHEMBL1489252 & 688687 & 4.4 & 4.7757 & TRN \\
\hline CHEMBL1553700 & 688687 & 5.4 & 5.0326 & TRN \\
\hline CHEMBL1482665 & 688687 & 4.5 & 4.6806 & TRN \\
\hline CHEMBL1502415 & 688687 & 4.4 & 4.9821 & TST \\
\hline CHEMBL510539 & 688687 & 7.0 & 6.1809 & TRN \\
\hline CHEMBL1382604 & 688687 & 4.9 & 4.8145 & TRN \\
\hline CHEMBL1526582 & 688687 & 4.5 & 4.6317 & TRN \\
\hline CHEMBL1458900 & 688687 & 5.1 & 4.83 & TRN \\
\hline CHEMBL1592963 & 688687 & 4.9 & 4.8174 & TRN \\
\hline CHEMBL1498363 & 688687 & 4.6 & 4.8084 & TRN \\
\hline CHEMBL1417646 & 688687 & 4.8 & 4.5307 & TRN \\
\hline
\end{tabular}




\begin{tabular}{|c|c|c|c|c|c|}
\hline & & & & & \\
\hline CHEMBL 3211670 & 688687 & 4.4 & 4.4728 & TST & \\
\hline CHEMBL1365172 & 688687 & 5.2 & 4.748 & TRN & \\
\hline CHEMBL1340600 & 688687 & 5.1 & 4.8597 & TST & \\
\hline CHEMBL1402656 & 688687 & 4.5 & 4.8814 & TST & \\
\hline CHEMBL1433898 & 688687 & 4.6 & 4.7699 & TRN & \\
\hline CHEMBL1559310 & 688687 & 4.6 & 4.9442 & TRN & \\
\hline CHEMBL1434484 & 688687 & 4.4 & 4.3445 & TRN & \\
\hline CHEMBL1432964 & 688687 & 5.4 & 5.1653 & TRN & \\
\hline CHEMBL1518415 & 688687 & 4.5 & 4.7348 & TRN & \\
\hline CHEMBL1401186 & 688687 & 4.5 & 4.7766 & TRN & \\
\hline CHEMBL1510883 & 688687 & 4.9 & 4.7328 & TRN & \\
\hline CHEMBL1442986 & 688687 & 4.6 & 4.7157 & TRN & \\
\hline CHEMBL1354678 & 688687 & 4.6 & 4.9366 & TRN & \\
\hline CHEMBL1550496 & 688687 & 4.4 & 5.0765 & TST & \\
\hline CHEMBL1322362 & 688687 & 4.6 & 4.5661 & TRN & \\
\hline CHEMBL1532637 & 688687 & 4.5 & 5.1763 & TRN & \\
\hline CHEMBL1415053 & 688687 & 6.1 & 5.3427 & TST & \\
\hline CHEMBL1504117 & 688687 & 4.6 & 4.5631 & TRN & \\
\hline CHEMBL1337702 & 688687 & 4.9 & 4.6435 & TRN & \\
\hline CHEMBL1516005 & 688687 & 4.8 & 4.7623 & TRN & \\
\hline CHEMBL1313927 & 688687 & 5.4 & 4.9001 & TRN & \\
\hline CHEMBL1454881 & 688687 & 4.4 & 4.9053 & TRN & \\
\hline CHEMBL3196407 & 688687 & 5.4 & 5.0994 & TRN & \\
\hline CHEMBL1509003 & 688687 & 4.6 & 4.9219 & TRN & \\
\hline CHEMBL1346584 & 688687 & 4.4 & 4.5255 & TRN & \\
\hline CHEMBL1531750 & 688687 & 4.6 & 5.0659 & TRN & \\
\hline CHEMBL1529130 & 688687 & 5.0 & 5.0542 & TRN & \\
\hline CHEMBL1567295 & 688687 & 4.8 & 4.5169 & TRN & \\
\hline CHEMBL3196842 & 688687 & 5.3 & 4.7757 & TRN & \\
\hline CHEMBL1461896 & 688687 & 4.5 & 4.9364 & TRN & \\
\hline CHEMBL1431188 & 688687 & 4.4 & 4.4634 & TRN & \\
\hline CHEMBL3197983 & 688687 & 5.4 & 4.7444 & TRN & \\
\hline CHEMBL1335437 & 688687 & 4.6 & 4.8931 & TRN & \\
\hline CHEMBL1608228 & 688687 & 4.9 & 4.9004 & TRN & \\
\hline CHEMBL1368134 & 688687 & 4.4 & 4.8882 & TST & \\
\hline CHEMBL1519798 & 688687 & 4.5 & 4.4659 & TRN & \\
\hline CHEMBL1503638 & 688687 & 4.4 & 4.8394 & TRN & \\
\hline CHEMBL1447501 & 688687 & 4.7 & 5.0043 & TRN & \\
\hline CHEMBL1608527 & 688687 & 4.5 & 4.8347 & TRN & \\
\hline CHEMBL1525416 & 688687 & 5.1 & 5.4288 & TRN & \\
\hline CHEMBL1344611 & 688687 & 4.8 & 4.502 & TRN & \\
\hline CHEMBL1408884 & 688687 & 4.7 & 4.6774 & TRN & \\
\hline CHEMBL1432233 & 688687 & 4.6 & $4.8180 e$ & 20000000005 & TRN \\
\hline CHEMBL3209182 & 688687 & 4.9 & 4.7721 & TST & \\
\hline CHEMBL1345055 & 688687 & 4.4 & 4.7347 & TRN & \\
\hline CHEMBL1332833 & 688687 & 4.4 & 4.8163 & TRN & \\
\hline CHEMBL1604468 & 688687 & 5.1 & 4.8349 & TRN & \\
\hline CHEMBL1336838 & 688687 & 6.1 & 4.6439 & TRN & \\
\hline & & & & 6330 & \\
\hline
\end{tabular}




\begin{tabular}{|c|c|c|c|c|}
\hline \multicolumn{5}{|c|}{ Supplemental T } \\
\hline CHEMBL1427148 & 688687 & 5.1 & 5.0132 & TST \\
\hline CHEMBL1511071 & 688687 & 4.4 & 4.6889 & TRN \\
\hline CHEMBL1444511 & 688687 & 6.0 & 5.34 & TRN \\
\hline CHEMBL1574115 & 688687 & 4.5 & 4.9035 & TRN \\
\hline CHEMBL1327936 & 688687 & 5.0 & 5.1237 & TRN \\
\hline CHEMBL1520541 & 688687 & 4.6 & 4.8069 & TRN \\
\hline CHEMBL1410737 & 688687 & 4.6 & 4.7261 & TRN \\
\hline CHEMBL1482872 & 688687 & 4.4 & 4.8747 & TRN \\
\hline CHEMBL1492090 & 688687 & 5.3 & 4.9689 & TRN \\
\hline CHEMBL1420781 & 688687 & 5.5 & 4.8042 & TRN \\
\hline CHEMBL1537574 & 688687 & 5.1 & 5.4745 & TRN \\
\hline CHEMBL1531073 & 688687 & 5.9 & 5.1362 & TRN \\
\hline CHEMBL1460824 & 688687 & 5.1 & 4.8351 & TRN \\
\hline CHEMBL1341097 & 688687 & 4.5 & 4.7767 & TST \\
\hline CHEMBL428909 & 688687 & 4.4 & 4.89 & TST \\
\hline CHEMBL1398260 & 688687 & 7.8013 & 5.1159 & TST \\
\hline CHEMBL1408676 & 688687 & 4.8 & 4.7206 & TRN \\
\hline CHEMBL1366732 & 688687 & 4.7 & 4.5933 & TRN \\
\hline CHEMBL1501110 & 688687 & 4.4 & 4.7209 & TRN \\
\hline CHEMBL1329017 & 688687 & 4.8 & 4.9675 & TST \\
\hline CHEMBL1580009 & 688687 & 4.6 & 4.5449 & TST \\
\hline CHEMBL1529962 & 688687 & 4.5 & 4.553 & TRN \\
\hline CHEMBL1576251 & 688687 & 4.5 & 4.4256 & TRN \\
\hline CHEMBL1526738 & 688687 & 4.5 & 4.7371 & TRN \\
\hline CHEMBL1508575 & 688687 & 5.3 & 4.8492 & TRN \\
\hline CHEMBL1604836 & 688687 & 4.6 & 4.7236 & TST \\
\hline CHEMBL1396384 & 688687 & 4.4 & 4.5914 & TRN \\
\hline CHEMBL456881 & 688687 & 4.5 & 5.029 & TRN \\
\hline CHEMBL1408789 & 688687 & 4.9 & 4.7339 & TRN \\
\hline CHEMBL1587424 & 688687 & 5.7 & 4.8651 & TRN \\
\hline CHEMBL1377448 & 688687 & 4.9 & 5.0363 & TRN \\
\hline CHEMBL1542518 & 688687 & 4.6 & 4.998 & TRN \\
\hline CHEMBL1563478 & 688687 & 4.5 & 4.6365 & TRN \\
\hline CHEMBL1546492 & 688687 & 4.4 & 4.9256 & TRN \\
\hline CHEMBL1523485 & 688687 & 4.4 & 4.7247 & TRN \\
\hline CHEMBL1302139 & 688687 & 6.5 & 5.794 & TRN \\
\hline CHEMBL1304955 & 688687 & 4.5 & 4.8603 & TRN \\
\hline CHEMBL1537335 & 688687 & 4.4 & 5.1617 & TST \\
\hline CHEMBL1594740 & 688687 & 4.4 & 4.8262 & TRN \\
\hline CHEMBL1534731 & 688687 & 5.2 & 5.2963 & TRN \\
\hline CHEMBL1551899 & 688687 & 5.4 & 4.9651 & TST \\
\hline CHEMBL1437997 & 688687 & 4.4 & 4.7955 & TST \\
\hline CHEMBL1354319 & 688687 & 4.4 & 5.0856 & TRN \\
\hline CHEMBL1394045 & 688687 & 4.4 & 4.7147 & TRN \\
\hline CHEMBL1504903 & 688687 & 4.5 & 4.9162 & TST \\
\hline CHEMBL1441675 & 688687 & 4.6 & 5.0083 & TST \\
\hline CHEMBL1481510 & 688687 & 4.5 & 4.6822 & TRN \\
\hline CHEMBL1494764 & 688687 & 5.3 & 5.0037 & TRN \\
\hline
\end{tabular}




\begin{tabular}{|c|c|c|c|c|}
\hline \multicolumn{5}{|c|}{ Supplemental Table S2.txt } \\
\hline CHEMBL1341665 & 688687 & 5.5 & 5.2003 & TST \\
\hline CHEMBL1533632 & 688687 & 4.8 & 4.9442 & TRN \\
\hline CHEMBL1327408 & 688687 & 4.5 & 4.9751 & TRN \\
\hline CHEMBL1342311 & 688687 & 4.7 & 4.4235 & TRN \\
\hline CHEMBL1533246 & 688687 & 4.6 & 4.7965 & TRN \\
\hline CHEMBL1402614 & 688687 & 4.4 & 4.8266 & TST \\
\hline CHEMBL85811 & 688687 & 5.7 & 5.1078 & TRN \\
\hline CHEMBL 242171 & 688687 & 6.7001 & 5.2332 & TRN \\
\hline CHEMBL1302750 & 688687 & 5.2 & 4.6891 & TST \\
\hline CHEMBL1378621 & 688687 & 4.6 & 4.9816 & TRN \\
\hline CHEMBL1466572 & 688687 & 5.9 & 4.579 & TRN \\
\hline CHEMBL1383874 & 688687 & 4.6 & 4.8741 & TRN \\
\hline CHEMBL1255778 & 688687 & 6.0 & 5.6629 & TST \\
\hline CHEMBL1332633 & 688687 & 5.7 & 4.525 & TRN \\
\hline CHEMBL1598356 & 688687 & 4.6 & 4.6635 & TST \\
\hline CHEMBL1445711 & 688687 & 4.4 & 4.8924 & TRN \\
\hline CHEMBL1313167 & 688687 & 4.5 & 4.785 & TRN \\
\hline CHEMBL1538344 & 688687 & 4.6 & 4.6614 & TRN \\
\hline CHEMBL1378536 & 688687 & 4.4 & 4.7813 & TRN \\
\hline CHEMBL1547766 & 688687 & 5.1 & 4.8949 & TRN \\
\hline CHEMBL1611646 & 688687 & 5.5 & 5.1662 & TRN \\
\hline CHEMBL1447375 & 688687 & 4.4 & 5.1672 & TRN \\
\hline CHEMBL1372967 & 688687 & 4.6 & 4.6033 & TRN \\
\hline CHEMBL1601545 & 688687 & 4.5 & 4.5521 & TRN \\
\hline CHEMBL1577366 & 688687 & 5.4 & 4.6761 & TRN \\
\hline CHEMBL1306926 & 688687 & 4.6 & 4.9835 & TRN \\
\hline CHEMBL1300796 & 688687 & 4.4 & 4.6212 & TRN \\
\hline CHEMBL1518320 & 688687 & 5.4 & 4.9294 & TRN \\
\hline CHEMBL1549946 & 688687 & 4.4 & 4.8398 & TRN \\
\hline CHEMBL1462978 & 688687 & 4.7 & 4.7531 & TRN \\
\hline CHEMBL1414749 & 688687 & 4.5 & 4.9951 & TRN \\
\hline CHEMBL3196620 & 688687 & 5.3 & 4.6966 & TRN \\
\hline CHEMBL1463808 & 688687 & 4.5 & 4.98 & TRN \\
\hline CHEMBL1458559 & 688687 & 5.2 & 4.6712 & TRN \\
\hline CHEMBL1374915 & 688687 & 5.2 & 4.6829 & TRN \\
\hline CHEMBL1362168 & 688687 & 4.8 & 4.8928 & TRN \\
\hline CHEMBL26138 & 688687 & 5.4 & 4.6648 & TRN \\
\hline CHEMBL1346172 & 688687 & 5.3 & 5.2863 & TRN \\
\hline CHEMBL1337451 & 688687 & 4.4 & 4.5804 & TRN \\
\hline CHEMBL1566846 & 688687 & 4.5 & 4.9783 & TRN \\
\hline CHEMBL1302992 & 688687 & 4.4 & 4.6709 & TRN \\
\hline CHEMBL567130 & 688687 & 4.5 & 4.6246 & TRN \\
\hline CHEMBL1604896 & 688687 & 5.1 & 4.9527 & TRN \\
\hline CHEMBL1605497 & 688687 & 4.5 & 5.006 & TRN \\
\hline CHEMBL1573712 & 688687 & 4.4 & 4.4298 & TRN \\
\hline CHEMBL1305887 & 688687 & 4.5 & 4.7566 & TRN \\
\hline CHEMBL1561388 & 688687 & 5.2 & 4.8909 & TRN \\
\hline CHEMBL1457298 & 688687 & 5.1 & 4.7626 & TRN \\
\hline
\end{tabular}




\begin{tabular}{|c|c|c|c|c|}
\hline \\
\hline CHEMBL1570737 & 688687 & 4.4 & 4.7316 & TRN \\
\hline CHEMBL1431887 & 688687 & 4.7 & 5.1073 & TRN \\
\hline CHEMBL1463402 & 688687 & 4.5 & 4.6451 & TRN \\
\hline CHEMBL191750 & 688687 & 4.7 & 5.1664 & TRN \\
\hline CHEMBL1306623 & 688687 & 4.5 & 5.0044 & TRN \\
\hline CHEMBL1336339 & 688687 & 4.6 & 4.9568 & TRN \\
\hline CHEMBL1499996 & 688687 & 6.8 & 5.8683 & TRN \\
\hline CHEMBL1359611 & 688687 & 4.4 & 4.6068 & TRN \\
\hline CHEMBL1463027 & 688687 & 4.4 & 4.7695 & TRN \\
\hline CHEMBL1981464 & 688687 & 5.6 & 5.2236 & TRN \\
\hline CHEMBL1556587 & 688687 & 4.5 & 4.6669 & TRN \\
\hline CHEMBL1465517 & 688687 & 4.4 & 4.6749 & TRN \\
\hline CHEMBL1388788 & 688687 & 4.5 & 4.6975 & TRN \\
\hline CHEMBL1353220 & 688687 & 4.6 & 4.53 & TRN \\
\hline CHEMBL1565727 & 688687 & 4.6 & 4.9261 & TRN \\
\hline CHEMBL3193519 & 688687 & 4.7 & 4.6169 & TST \\
\hline CHEMBL1514547 & 688687 & 6.7001 & 5.769 & TRN \\
\hline CHEMBL1334796 & 688687 & 5.1 & 5.2612 & TRN \\
\hline CHEMBL1450148 & 688687 & 4.4 & 4.7498 & TRN \\
\hline CHEMBL1378470 & 688687 & 4.7 & 4.8305 & TRN \\
\hline CHEMBL1451838 & 688687 & 4.5 & 4.9107 & TST \\
\hline CHEMBL1424915 & 688687 & 4.7 & 4.75 & TRN \\
\hline CHEMBL1481416 & 688687 & 4.7 & 4.59 & TRN \\
\hline CHEMBL1424952 & 688687 & 4.4 & 4.6073 & TRN \\
\hline CHEMBL1441834 & 688687 & 5.0 & 4.5161 & TRN \\
\hline CHEMBL1327707 & 688687 & 4.6 & 4.8288 & TRN \\
\hline CHEMBL1348771 & 688687 & 4.7 & 5.001 & TRN \\
\hline CHEMBL1381418 & 688687 & 4.6 & 4.9227 & TRN \\
\hline CHEMBL1491275 & 688687 & 5.5 & 4.8283 & TRN \\
\hline CHEMBL1378656 & 688687 & 5.2 & 4.934 & TRN \\
\hline CHEMBL1308088 & 688687 & 5.1 & 5.0698 & TRN \\
\hline CHEMBL1581280 & 688687 & 4.7 & 4.8002 & TRN \\
\hline CHEMBL1544475 & 688687 & 6.9 & 4.8346 & TST \\
\hline CHEMBL1535537 & 688687 & 5.2 & 4.9223 & TRN \\
\hline CHEMBL1431145 & 688687 & 5.7 & 5.0421 & TRN \\
\hline CHEMBL1593288 & 688687 & 5.2 & 4.2956 & TRN \\
\hline CHEMBL 3210730 & 688687 & 5.1 & 4.5439 & TRN \\
\hline CHEMBL1540891 & 688687 & 4.9 & 5.1404 & TST \\
\hline CHEMBL1422096 & 688687 & 4.4 & 4.5919 & TRN \\
\hline CHEMBL1579670 & 688687 & 4.5 & 4.6942 & TRN \\
\hline CHEMBL1344566 & 688687 & 4.6 & 5.1944 & TRN \\
\hline CHEMBL1450174 & 688687 & 5.6 & 4.8612 & TRN \\
\hline CHEMBL1489606 & 688687 & 4.5 & 4.8506 & TRN \\
\hline CHEMBL1317300 & 688687 & 6.0 & 5.1649 & TRN \\
\hline CHEMBL1380365 & 688687 & 4.6 & 4.7232 & TRN \\
\hline CHEMBL3197036 & 688687 & 5.5 & 4.9792 & TST \\
\hline CHEMBL1525367 & 688687 & 5.2 & 4.9862 & TRN \\
\hline CHEMBL1582155 & 688687 & 5.5 & 4.7554 & TRN \\
\hline
\end{tabular}




\begin{tabular}{|c|c|c|c|c|}
\hline \multicolumn{5}{|c|}{ oplemental Ta } \\
\hline CHEMBL531269 & 688687 & 4.6 & 4.8335 & TRN \\
\hline CHEMBL1396936 & 688687 & 4.4 & 4.8292 & TRN \\
\hline CHEMBL1344289 & 688687 & 4.5 & 4.6632 & TRN \\
\hline CHEMBL1603051 & 688687 & 4.8 & 4.7705 & TRN \\
\hline CHEMBL1422030 & 688687 & 4.6 & 4.8858 & TRN \\
\hline CHEMBL1436242 & 688687 & 4.8 & 4.7299 & TRN \\
\hline CHEMBL1599915 & 688687 & 4.4 & 4.6326 & TRN \\
\hline CHEMBL1506147 & 688687 & 5.0 & 4.7033 & TRN \\
\hline CHEMBL1410147 & 688687 & 5.7 & 5.3955 & TRN \\
\hline CHEMBL1370610 & 688687 & 6.0 & 4.9527 & TST \\
\hline CHEMBL1563871 & 688687 & 4.7 & 4.6156 & TRN \\
\hline CHEMBL1392242 & 688687 & 4.6 & 4.7987 & TRN \\
\hline CHEMBL1981008 & 688687 & 5.4 & 4.7974 & TST \\
\hline CHEMBL1487795 & 688687 & 5.4 & 4.9225 & TRN \\
\hline CHEMBL54909 & 688687 & 6.1 & 4.9619 & TRN \\
\hline CHEMBL1423568 & 688687 & 4.4 & 4.9573 & TRN \\
\hline CHEMBL393287 & 688687 & 4.4 & 4.8098 & TRN \\
\hline CHEMBL1507997 & 688687 & 4.6 & 4.6328 & TRN \\
\hline CHEMBL1375429 & 688687 & 7.8013 & 5.2367 & TRN \\
\hline CHEMBL1322317 & 688687 & 4.6 & 4.4662 & TRN \\
\hline CHEMBL1308557 & 688687 & 4.6 & 5.2182 & TRN \\
\hline CHEMBL1513870 & 688687 & 5.5 & 5.3502 & TST \\
\hline CHEMBL1513633 & 688687 & 4.7 & 4.6675 & TRN \\
\hline CHEMBL1390473 & 688687 & 4.5 & 4.9786 & TRN \\
\hline CHEMBL1458190 & 688687 & 4.4 & 4.6811 & TRN \\
\hline CHEMBL1302381 & 688687 & 5.1 & 4.9964 & TRN \\
\hline CHEMBL1444840 & 688687 & 4.9 & 4.698 & TRN \\
\hline CHEMBL1540900 & 688687 & 4.4 & 4.8195 & TRN \\
\hline CHEMBL1468793 & 688687 & 4.4 & 4.7958 & TRN \\
\hline CHEMBL 221721 & 688687 & 5.6 & 4.6068 & TST \\
\hline CHEMBL1384854 & 688687 & 4.5 & 5.0967 & TRN \\
\hline CHEMBL1420499 & 688687 & 5.4 & 5.1054 & TRN \\
\hline CHEMBL1565329 & 688687 & 6.4 & 5.1005 & TRN \\
\hline CHEMBL1330103 & 688687 & 4.5 & 4.7576 & TRN \\
\hline CHEMBL1419223 & 688687 & 4.4 & 4.9115 & TRN \\
\hline CHEMBL1542929 & 688687 & 7.5003 & 4.5264 & TST \\
\hline CHEMBL1303992 & 688687 & 5.5 & 5.7789 & TRN \\
\hline CHEMBL1420830 & 688687 & 4.8 & 4.9638 & TRN \\
\hline CHEMBL1582677 & 688687 & 5.5 & 5.2857 & TRN \\
\hline CHEMBL1978817 & 688687 & 5.4 & 5.0559 & TRN \\
\hline CHEMBL1422889 & 688687 & 4.5 & 4.7847 & TRN \\
\hline CHEMBL1579020 & 688687 & 5.3 & 4.9301 & TST \\
\hline CHEMBL1485559 & 688687 & 4.4 & 5.0822 & TRN \\
\hline CHEMBL1500092 & 688687 & 4.6 & 4.8354 & TRN \\
\hline CHEMBL1387615 & 688687 & 4.9 & 4.9367 & TRN \\
\hline CHEMBL1544104 & 688687 & 4.6 & 5.2593 & TST \\
\hline CHEMBL1403709 & 688687 & 4.6 & 4.6642 & TRN \\
\hline CHEMBL1412195 & 688687 & 5.0 & 4.6725 & TST \\
\hline
\end{tabular}




\begin{tabular}{|c|c|c|c|c|}
\hline & & & $p p+e m e$ & \\
\hline CHEMBL1350199 & 688687 & 4.4 & 4.8203 & TRN \\
\hline CHEMBL1609588 & 688687 & 4.4 & 4.5665 & TRN \\
\hline CHEMBL1501543 & 688687 & 5.1 & 5.1394 & TST \\
\hline CHEMBL1385846 & 688687 & 4.4 & 4.6455 & TRN \\
\hline CHEMBL1357018 & 688687 & 4.6 & 4.6821 & TRN \\
\hline CHEMBL1358771 & 688687 & 4.6 & 4.7412 & TRN \\
\hline CHEMBL1569012 & 688687 & 5.5 & 4.9056 & TRN \\
\hline CHEMBL1455971 & 688687 & 5.6 & 5.6515 & TRN \\
\hline CHEMBL1491845 & 688687 & 4.9 & 4.6717 & TRN \\
\hline CHEMBL1304351 & 688687 & 6.1 & 5.9829 & TRN \\
\hline CHEMBL1507075 & 688687 & 4.4 & 5.0478 & TRN \\
\hline CHEMBL3213581 & 688687 & 5.5 & 5.1052 & TST \\
\hline CHEMBL1331614 & 688687 & 5.2 & 5.0308 & TRN \\
\hline CHEMBL1301960 & 688687 & 4.4 & 4.5262 & TRN \\
\hline CHEMBL1532407 & 688687 & 5.1 & 5.011 & TRN \\
\hline CHEMBL1558303 & 688687 & 5.1 & 5.2842 & TRN \\
\hline CHEMBL 8488 & 688687 & 6.0 & 4.9485 & TRN \\
\hline CHEMBL1464123 & 688687 & 4.4 & 4.5205 & TRN \\
\hline CHEMBL1093246 & 688687 & 5.5 & 5.7837 & TRN \\
\hline CHEMBL1320708 & 688687 & 4.8 & 4.9448 & TRN \\
\hline CHEMBL1455135 & 688687 & 4.4 & 4.6582 & TRN \\
\hline CHEMBL1388832 & 688687 & 5.4 & 4.5857 & TRN \\
\hline CHEMBL1601694 & 688687 & 5.2 & 4.9595 & TRN \\
\hline CHEMBL1307274 & 688687 & 4.9 & 5.1574 & TST \\
\hline CHEMBL1318259 & 688687 & 4.4 & 4.8108 & TST \\
\hline CHEMBL1579811 & 688687 & 5.9 & 4.97 & TRN \\
\hline CHEMBL1378110 & 688687 & 4.8 & 4.7156 & TRN \\
\hline CHEMBL1329033 & 688687 & 4.8 & 5.9319 & TST \\
\hline CHEMBL1533998 & 688687 & 4.8 & 4.7919 & TRN \\
\hline CHEMBL1545534 & 688687 & 4.4 & 4.4516 & TRN \\
\hline CHEMBL1534126 & 688687 & 5.3 & 4.8486 & TRN \\
\hline CHEMBL3192077 & 688687 & 5.1 & 4.6892 & TRN \\
\hline CHEMBL1303786 & 688687 & 7.4001 & 5.0646 & TRN \\
\hline CHEMBL1564004 & 688687 & 6.2 & 5.0056 & TRN \\
\hline CHEMBL1432840 & 688687 & 4.4 & 5.0741 & TST \\
\hline CHEMBL1409586 & 688687 & 6.0 & 5.7997 & TRN \\
\hline CHEMBL1340346 & 688687 & 4.5 & 4.7007 & TRN \\
\hline CHEMBL1389239 & 688687 & 4.6 & 5.0639 & TRN \\
\hline CHEMBL 3194890 & 688687 & 4.4 & 4.6871 & TRN \\
\hline CHEMBL1542047 & 688687 & 4.6 & 5.2472 & TRN \\
\hline CHEMBL1340559 & 688687 & 5.1 & 4.6312 & TST \\
\hline CHEMBL1991885 & 688687 & 4.8 & 5.1472 & TST \\
\hline CHEMBL1528516 & 688687 & 4.6 & 4.7804 & TRN \\
\hline CHEMBL1444006 & 688687 & 4.9 & 4.7842 & TRN \\
\hline CHEMBL1547315 & 688687 & 4.6 & 4.5368 & TRN \\
\hline CHEMBL1417290 & 688687 & 5.4 & 4.6109 & TRN \\
\hline CHEMBL1406627 & 688687 & 4.4 & 4.5625 & TRN \\
\hline CHEMBL3197685 & 688687 & 4.5 & 4.5501 & TRN \\
\hline
\end{tabular}




\begin{tabular}{|c|c|c|c|c|}
\hline & & & & \\
\hline CHEMBL1429236 & 688687 & 4.4 & 4.6839 & TRN \\
\hline CHEMBL1406204 & 688687 & 4.6 & 4.8173 & TRN \\
\hline CHEMBL1599099 & 688687 & 4.6 & 4.8058 & TRN \\
\hline CHEMBL1321846 & 688687 & 4.5 & 4.7184 & TRN \\
\hline CHEMBL1563092 & 688687 & 4.5 & 4.4527 & TRN \\
\hline CHEMBL1712181 & 688687 & 6.1 & 4.775 & TST \\
\hline CHEMBL1337075 & 688687 & 4.5 & 4.6056 & TRN \\
\hline CHEMBL1563812 & 688687 & 4.4 & 4.6563 & TRN \\
\hline CHEMBL1568468 & 688687 & 4.4 & 4.7936 & TRN \\
\hline CHEMBL3189821 & 688687 & 4.7 & 4.6085 & TST \\
\hline CHEMBL1414251 & 688687 & 4.8 & 5.0409 & TRN \\
\hline CHEMBL1563327 & 688687 & 4.5 & 5.0069 & TST \\
\hline CHEMBL1610343 & 688687 & 4.4 & 5.099 & TRN \\
\hline CHEMBL1455190 & 688687 & 4.4 & 4.9737 & TRN \\
\hline CHEMBL1584452 & 688687 & 4.4 & 4.8414 & TST \\
\hline CHEMBL1448750 & 688687 & 5.2 & 4.6999 & TRN \\
\hline CHEMBL222808 & 688687 & 5.5 & 5.2544 & TRN \\
\hline CHEMBL3198706 & 688687 & 4.5 & 4.6855 & TRN \\
\hline CHEMBL1568684 & 688687 & 4.5 & 4.8853 & TRN \\
\hline CHEMBL1402362 & 688687 & 4.5 & 4.8566 & TRN \\
\hline CHEMBL1349451 & 688687 & 4.5 & 4.7069 & TRN \\
\hline CHEMBL1410449 & 688687 & 4.6 & 4.7997 & TRN \\
\hline CHEMBL1369657 & 688687 & 4.6 & 4.7412 & TRN \\
\hline CHEMBL1428984 & 688687 & 4.5 & 4.8063 & TRN \\
\hline CHEMBL1415503 & 688687 & 4.6 & 4.6102 & TRN \\
\hline CHEMBL1604932 & 688687 & 4.7 & 4.7636 & TRN \\
\hline CHEMBL1441714 & 688687 & 4.9 & 4.7666 & TRN \\
\hline CHEMBL1213073 & 688687 & 4.6 & 5.0331 & TRN \\
\hline CHEMBL1420158 & 688687 & 4.4 & 4.9501 & TRN \\
\hline CHEMBL1539313 & 688687 & 4.5 & 4.7335 & TRN \\
\hline CHEMBL1388275 & 688687 & 4.5 & 4.9444 & TRN \\
\hline CHEMBL1412990 & 688687 & 5.2 & 4.8804 & TRN \\
\hline CHEMBL1341830 & 688687 & 5.1 & 4.7153 & TRN \\
\hline CHEMBL1501236 & 688687 & 4.9 & 4.4604 & TST \\
\hline CHEMBL1430584 & 688687 & 5.9 & 5.6512 & TRN \\
\hline CHEMBL3208935 & 688687 & 4.8 & 5.1539 & TST \\
\hline CHEMBL1522053 & 688687 & 4.5 & 4.5663 & TRN \\
\hline CHEMBL1375808 & 688687 & 4.9 & 4.5952 & TRN \\
\hline CHEMBL1468759 & 688687 & 4.8 & 4.7858 & TRN \\
\hline CHEMBL 1357445 & 688687 & 4.8 & 4.8644 & TRN \\
\hline CHEMBL1385973 & 688687 & 4.6 & 4.6873 & TRN \\
\hline CHEMBL1388598 & 688687 & 5.1 & 4.7549 & TRN \\
\hline CHEMBL1580490 & 688687 & 5.2 & 5.1441 & TRN \\
\hline CHEMBL1496718 & 688687 & 4.4 & 5.0628 & TRN \\
\hline CHEMBL1432238 & 688687 & 4.6 & 4.7607 & TRN \\
\hline CHEMBL 1505878 & 688687 & 5.0 & 4.7794 & TRN \\
\hline CHEMBL1349447 & 688687 & 4.6 & 4.74 & TRN \\
\hline CHEMBL1352829 & 688687 & 4.6 & 4.8853 & TRN \\
\hline
\end{tabular}




\begin{tabular}{|c|c|c|c|c|}
\hline & & & & \\
\hline CHEMBL1352634 & 688687 & 5.6 & 4.8589 & TRN \\
\hline CHEMBL1359483 & 688687 & 4.9 & 4.7293 & TRN \\
\hline CHEMBL1562372 & 688687 & 4.6 & 4.6476 & TRN \\
\hline CHEMBL1487874 & 688687 & 5.1 & 4.9365 & TRN \\
\hline CHEMBL1470934 & 688687 & 4.7 & 4.8387 & TRN \\
\hline CHEMBL1536550 & 688687 & 4.5 & 4.71 & TRN \\
\hline CHEMBL1572265 & 688687 & 4.9 & 4.7326 & TRN \\
\hline CHEMBL1519311 & 688687 & 5.8 & 4.8451 & TRN \\
\hline CHEMBL1349056 & 688687 & 4.5 & 4.8664 & TRN \\
\hline CHEMBL1598223 & 688687 & 4.6 & 4.8335 & TST \\
\hline CHEMBL1311793 & 688687 & 4.6 & 4.9283 & TRN \\
\hline CHEMBL3193484 & 688687 & 4.4 & 4.9029 & TST \\
\hline CHEMBL1449737 & 688687 & 5.8 & 5.4342 & TST \\
\hline CHEMBL1501764 & 688687 & 4.5 & 4.677 & TRN \\
\hline CHEMBL1504377 & 688687 & 4.6 & 4.9261 & TRN \\
\hline CHEMBL1386079 & 688687 & 4.7 & 5.1029 & TRN \\
\hline CHEMBL1460155 & 688687 & 5.5 & 5.2973 & TST \\
\hline CHEMBL1347168 & 688687 & 5.2 & 4.9931 & TRN \\
\hline CHEMBL1341395 & 688687 & 4.5 & 4.6213 & TRN \\
\hline CHEMBL1361600 & 688687 & 4.9 & 4.8326 & TRN \\
\hline CHEMBL1340532 & 688687 & 4.6 & 4.4292 & TST \\
\hline CHEMBL1573960 & 688687 & 4.6 & 4.8619 & TRN \\
\hline CHEMBL1522830 & 688687 & 4.5 & 4.6453 & TRN \\
\hline CHEMBL1310265 & 688687 & 4.7 & 4.6491 & TRN \\
\hline CHEMBL1602759 & 688687 & 6.8 & 5.3597 & TRN \\
\hline CHEMBL1609849 & 688687 & 4.6 & 4.7426 & TRN \\
\hline CHEMBL1401211 & 688687 & 6.3 & 5.3361 & TRN \\
\hline CHEMBL1455517 & 688687 & 4.5 & 4.9857 & TRN \\
\hline CHEMBL1514898 & 688687 & 4.9 & 5.0965 & TRN \\
\hline CHEMBL542493 & 688687 & 6.5 & 5.4189 & TST \\
\hline CHEMBL1391798 & 688687 & 6.4 & 5.3338 & TRN \\
\hline CHEMBL1348985 & 688687 & 4.4 & 4.8168 & TRN \\
\hline CHEMBL1467112 & 688687 & 4.4 & 4.8147 & TRN \\
\hline CHEMBL1328727 & 688687 & 4.5 & 4.9465 & TRN \\
\hline CHEMBL1606272 & 688687 & 5.5 & 5.1522 & TST \\
\hline CHEMBL1504804 & 688687 & 4.4 & 4.7715 & TRN \\
\hline CHEMBL1412185 & 688687 & 4.4 & 4.678 & TRN \\
\hline CHEMBL1439954 & 688687 & 5.1 & 4.8393 & TRN \\
\hline CHEMBL196228 & 688687 & 4.6 & 5.0458 & TST \\
\hline CHEMBL1310309 & 688687 & 4.5 & 4.9233 & TRN \\
\hline CHEMBL1565842 & 688687 & 5.4 & 4.7204 & TST \\
\hline CHEMBL1312600 & 688687 & 4.6 & 4.7507 & TRN \\
\hline CHEMBL1449715 & 688687 & 4.5 & 4.897 & TRN \\
\hline CHEMBL1586107 & 688687 & 4.5 & 5.1132 & TRN \\
\hline CHEMBL1418757 & 688687 & 4.4 & 4.4148 & TRN \\
\hline CHEMBL1317237 & 688687 & 5.4 & 4.8366 & TST \\
\hline CHEMBL437061 & 688687 & 4.7 & 4.8904 & TRN \\
\hline CHEMBL1600985 & 688687 & 4.4 & 4.5558 & TRN \\
\hline
\end{tabular}




\begin{tabular}{|c|c|c|c|c|}
\hline \multicolumn{5}{|c|}{ Supplemental Table S2.txt } \\
\hline CHEMBL1365545 & 688687 & 5.2 & 4.6646 & TRN \\
\hline CHEMBL1172995 & 688687 & 5.9 & 5.3109 & TRN \\
\hline CHEMBL1584677 & 688687 & 6.7001 & 4.7893 & TRN \\
\hline CHEMBL1479618 & 688687 & 4.7 & 4.6822 & TST \\
\hline CHEMBL1490257 & 688687 & 4.4 & 4.6197 & TRN \\
\hline CHEMBL1505904 & 688687 & 4.4 & 5.0955 & TST \\
\hline CHEMBL1571705 & 688687 & 5.1 & 4.8259 & TRN \\
\hline CHEMBL1531042 & 688687 & 5.0 & 4.9727 & TRN \\
\hline CHEMBL1427987 & 688687 & 5.4 & 4.88 & TRN \\
\hline CHEMBL346516 & 688687 & 4.7 & 5.289 & TRN \\
\hline CHEMBL1611984 & 688687 & 4.6 & 4.9826 & TRN \\
\hline CHEMBL1300824 & 688687 & 4.6 & 4.8509 & TRN \\
\hline CHEMBL1602678 & 688687 & 4.5 & 4.9471 & TST \\
\hline CHEMBL1576369 & 688687 & 4.8 & 4.4384 & TRN \\
\hline CHEMBL1465117 & 688687 & 6.2 & 5.0754 & TRN \\
\hline CHEMBL1457696 & 688687 & 4.7 & 4.7888 & TRN \\
\hline CHEMBL1438928 & 688687 & 4.6 & 4.8366 & TRN \\
\hline CHEMBL1523877 & 688687 & 4.4 & 4.7502 & TRN \\
\hline CHEMBL1319279 & 688687 & 5.9 & 4.6211 & TRN \\
\hline CHEMBL1371125 & 688687 & 4.5 & 4.883 & TRN \\
\hline CHEMBL1524069 & 688687 & 5.4 & 4.7126 & TRN \\
\hline CHEMBL1318708 & 688687 & 4.9 & 4.9449 & TST \\
\hline CHEMBL1374656 & 688687 & 4.5 & 4.8277 & TST \\
\hline CHEMBL1527239 & 688687 & 4.4 & 4.4989 & TST \\
\hline CHEMBL1357293 & 688687 & 4.4 & 4.59699 & 99999999995 \\
\hline CHEMBL1538503 & 688687 & 4.6 & 4.926 & TST \\
\hline CHEMBL1355176 & 688687 & 4.4 & 4.56800 & 00000000005 \\
\hline CHEMBL1488522 & 688687 & 4.7 & 5.1746 & TST \\
\hline CHEMBL1304259 & 688687 & 4.5 & 4.6125 & TST \\
\hline CHEMBL1550241 & 688687 & 5.1 & 4.6365 & TST \\
\hline CHEMBL1300006 & 688687 & 4.4 & 4.5928 & TST \\
\hline CHEMBL1569694 & 688687 & 4.9 & 4.5095 & TST \\
\hline CHEMBL1411975 & 688687 & 5.2 & 4.6559 & TST \\
\hline CHEMBL1463829 & 688687 & 4.5 & 4.4736 & TST \\
\hline CHEMBL1504444 & 688687 & 4.5 & 4.8261 & TST \\
\hline CHEMBL1528384 & 688687 & 4.5 & 5.0667 & TST \\
\hline CHEMBL1452857 & 688687 & 5.2 & 4.9964 & TST \\
\hline CHEMBL1600302 & 688687 & 4.5 & 4.7734 & TST \\
\hline CHEMBL1532337 & 688687 & 4.8 & 5.0554 & TST \\
\hline CHEMBL1513568 & 688687 & 6.1 & 4.7314 & TST \\
\hline CHEMBL1535147 & 688687 & 4.4 & 4.7548 & TST \\
\hline CHEMBL1392167 & 688687 & 5.5 & 5.3766 & TST \\
\hline CHEMBL1373474 & 688687 & 5.0 & 4.7141 & TST \\
\hline CHEMBL1508906 & 688687 & 4.4 & 4.9892 & TST \\
\hline CHEMBL1326644 & 688687 & 4.5 & 4.702 & TST \\
\hline CHEMBL192627 & 688687 & 6.9 & 5.4384 & TST \\
\hline CHEMBL3208367 & 688687 & 4.4 & 4.5701 & TST \\
\hline CHEMBL1352133 & 688687 & 4.4 & 4.752 & TST \\
\hline
\end{tabular}




\begin{tabular}{|c|c|c|c|c|c|}
\hline \\
\hline CHEMBL1311338 & 688687 & 4.6 & 4.7377 & TST & \\
\hline CHEMBL1585897 & 688687 & 4.5 & 5.0136 & TST & \\
\hline CHEMBL1411866 & 688687 & 4.8 & 4.6085 & TST & \\
\hline CHEMBL1602170 & 688687 & 4.5 & 4.8275 & TST & \\
\hline CHEMBL1495812 & 688687 & 4.4 & 5.1643 & TST & \\
\hline CHEMBL1451814 & 688687 & 4.5 & 4.6726 & TST & \\
\hline CHEMBL1456266 & 688687 & 4.9 & 4.6953 & TST & \\
\hline CHEMBL1521483 & 688687 & 7.5003 & 4.8738 & TST & \\
\hline CHEMBL1509422 & 688687 & 5.1 & 4.8708 & TST & \\
\hline CHEMBL1483770 & 688687 & 4.4 & 4.8529 & TST & \\
\hline CHEMBL1341106 & 688687 & 4.7 & 4.5584 & TST & \\
\hline CHEMBL1471436 & 688687 & 4.7 & 4.539 & TST & \\
\hline CHEMBL1406680 & 688687 & 5.3 & 4.5829 & TST & \\
\hline CHEMBL1553740 & 688687 & 5.1 & 4.8128 & TST & \\
\hline CHEMBL1354914 & 688687 & 4.5 & 4.8478 & TST & \\
\hline CHEMBL1482852 & 688687 & 4.7 & 4.6455 & TST & \\
\hline CHEMBL1402019 & 688687 & 4.4 & 4.7757 & TST & \\
\hline CHEMBL1562802 & 688687 & 4.6 & 4.9169 & TST & \\
\hline CHEMBL1595706 & 688687 & 5.3 & 4.6053 & TST & \\
\hline CHEMBL1400175 & 688687 & 5.5 & 4.9211 & TST & \\
\hline CHEMBL1554236 & 688687 & 4.9 & 4.6971 & TST & \\
\hline CHEMBL1559717 & 688687 & 4.4 & 4.9349 & TST & \\
\hline CHEMBL1608006 & 688687 & 7.2 & 4.6834 & TST & \\
\hline CHEMBL1522881 & 688687 & 4.8 & 4.6404 & TST & \\
\hline CHEMBL1363662 & 688687 & 4.4 & 4.8036 & TST & \\
\hline CHEMBL1613140 & 688687 & 5.4 & 4.8531 & TST & \\
\hline CHEMBL3193151 & 688687 & 4.5 & 4.4985 & TST & \\
\hline CHEMBL 8618 & 688687 & 4.5 & 4.6239 & TST & \\
\hline CHEMBL491952 & 688687 & 4.4 & 4.2701 & TST & \\
\hline CHEMBL1367656 & 688687 & 5.4 & 5.1147 & TST & \\
\hline CHEMBL1363449 & 688687 & 4.4 & 4.8044 & TST & \\
\hline CHEMBL1561288 & 688687 & 4.9 & 4.7446 & TST & \\
\hline CHEMBL163316 & 688687 & 5.0 & 5.4651 & TST & \\
\hline CHEMBL1534097 & 688687 & 4.5 & 4.6793 & TST & \\
\hline CHEMBL1433354 & 688687 & 4.4 & 4.65600 & 0000000001 & TST \\
\hline CHEMBL1493178 & 688687 & 4.4 & 4.6251 & TST & \\
\hline CHEMBL1344731 & 688687 & 4.6 & 4.7918 & TST & \\
\hline CHEMBL1374550 & 688687 & 5.4 & 4.73600 & 2000000001 & TST \\
\hline CHEMBL1426146 & 688687 & 4.4 & 4.7457 & TST & \\
\hline CHEMBL1521607 & 688687 & 5.4 & 4.7229 & TST & \\
\hline CHEMBL1500466 & 688687 & 4.5 & 5.1128 & TST & \\
\hline CHEMBL1386323 & 688687 & 4.4 & 5.0026 & TST & \\
\hline CHEMBL1542061 & 688687 & 6.2 & 5.7894 & TST & \\
\hline CHEMBL1367018 & 688687 & 4.6 & 4.8145 & TST & \\
\hline CHEMBL1434848 & 688687 & 5.1 & 4.8344 & TST & \\
\hline CHEMBL1403304 & 688687 & 4.5 & 4.7849 & TST & \\
\hline CHEMBL245121 & 688687 & 4.5 & 5.2048 & TST & \\
\hline CHEMBL1480310 & 688687 & 5.4 & 4.9667 & TST & \\
\hline
\end{tabular}




\begin{tabular}{|c|c|c|c|c|c|}
\hline & & & & & \\
\hline CHEMBL1301020 & 688687 & 5.9 & 5.4384 & TST & \\
\hline CHEMBL1410679 & 688687 & 4.4 & 5.0933 & TST & \\
\hline CHEMBL1301540 & 688687 & 5.9 & 4.6604 & TST & \\
\hline CHEMBL1601040 & 688687 & 4.5 & 5.1927 & TST & \\
\hline CHEMBL1422858 & 688687 & 5.4 & 4.7887 & TST & \\
\hline CHEMBL512649 & 688687 & 5.0 & 4.8614 & TST & \\
\hline CHEMBL1413692 & 688687 & 4.6 & 4.9649 & TST & \\
\hline CHEMBL3193472 & 688687 & 5.3 & 4.9609 & TST & \\
\hline CHEMBL1473996 & 688687 & 4.6 & 4.7976 & TST & \\
\hline CHEMBL1398518 & 688687 & 5.1 & 5.2308 & TST & \\
\hline CHEMBL1341711 & 688687 & 4.4 & 4.9069 & TST & \\
\hline CHEMBL1463919 & 688687 & 5.5 & 4.6444 & TST & \\
\hline CHEMBL1325171 & 688687 & 4.8 & 4.7831 & TST & \\
\hline CHEMBL1577372 & 688687 & 4.4 & 4.7463 & TST & \\
\hline CHEMBL1341130 & 688687 & 4.5 & 4.6994 & TST & \\
\hline CHEMBL1593545 & 688687 & 4.6 & 5.1228 & TST & \\
\hline CHEMBL1301837 & 688687 & 5.0 & 4.9762 & TST & \\
\hline CHEMBL1402090 & 688687 & 4.4 & 4.7515 & TST & \\
\hline CHEMBL1407764 & 688687 & 4.8 & 5.0634 & TST & \\
\hline CHEMBL1537005 & 688687 & 6.8 & 5.2157 & TST & \\
\hline CHEMBL1559351 & 688687 & 7.699 & 5.0447 & TST & \\
\hline CHEMBL1422672 & 688687 & 4.5 & 4.8718 & TST & \\
\hline CHEMBL1330936 & 688687 & 4.4 & 4.6106 & TST & \\
\hline CHEMBL1532258 & 688687 & 4.7 & 5.1733 & TST & \\
\hline CHEMBL1496529 & 688687 & 4.8 & 4.7746 & TST & \\
\hline CHEMBL1418145 & 688687 & 4.6 & 4.5137 & TST & \\
\hline CHEMBL1448251 & 688687 & 4.4 & 4.9395 & TST & \\
\hline CHEMBL3198433 & 688687 & 5.1 & 4.9317 & TST & \\
\hline CHEMBL1510672 & 688687 & 4.5 & 4.6741 & TST & \\
\hline CHEMBL1565375 & 688687 & 5.3 & 4.54 & TST & \\
\hline CHEMBL1473492 & 688687 & 5.0 & 4.7963 & TST & \\
\hline CHEMBL1603924 & 688687 & 4.4 & 4.7789 & TST & \\
\hline CHEMBL1429901 & 688687 & 4.6 & 4.9999 & TST & \\
\hline CHEMBL261011 & 688687 & 5.1 & 4.5712 & TST & \\
\hline CHEMBL1565991 & 688687 & 4.4 & 4.8438 & TST & \\
\hline CHEMBL1200567 & 688687 & 4.9 & 4.9073 & TST & \\
\hline CHEMBL1469341 & 688687 & 4.5 & 4.7558 & TST & \\
\hline CHEMBL1552519 & 688687 & 4.5 & 4.4922 & TST & \\
\hline CHEMBL1487744 & 688687 & 6.2 & 5.0138 & TST & \\
\hline CHEMBL1542323 & 688687 & 4.9 & 4.8429 & TST & \\
\hline CHEMBL1521198 & 688687 & 4.9 & 5.0021 & TST & \\
\hline CHEMBL1305957 & 688687 & 5.1 & 4.5016 & TST & \\
\hline CHEMBL1611096 & 688687 & 4.8 & 5.0903 & TST & \\
\hline CHEMBL1606550 & 688687 & 4.5 & 4.9474 & TST & \\
\hline CHEMBL1484454 & 688687 & 4.6 & 4.8006 & TST & \\
\hline CHEMBL1300249 & 688687 & 4.5 & 4.7245 & TST & \\
\hline CHEMBL1308627 & 688687 & 5.5 & 4.9481 & TST & \\
\hline CHEMBL1255936 & 688687 & 6.1 & 5.03100 & 2000000001 & TST \\
\hline & & & & e 6340 & \\
\hline
\end{tabular}




\begin{tabular}{|c|c|c|c|c|}
\hline & & & pplement & al $\mathrm{Ta}$ \\
\hline CHEMBL1315913 & 688687 & 4.4 & 4.5951 & TST \\
\hline CHEMBL1371855 & 688687 & 5.8 & 4.8712 & TST \\
\hline CHEMBL1612994 & 688687 & 5.5 & 4.6325 & TST \\
\hline CHEMBL1350782 & 688687 & 4.5 & 4.585 & TST \\
\hline CHEMBL1492945 & 688687 & 4.4 & 4.9053 & TST \\
\hline CHEMBL1318870 & 688687 & 4.5 & 5.0576 & TST \\
\hline CHEMBL1563529 & 688687 & 5.3 & 4.7706 & TST \\
\hline CHEMBL1486922 & 688687 & 4.6 & 4.66 & TST \\
\hline CHEMBL1454721 & 688687 & 4.5 & 4.6691 & TST \\
\hline CHEMBL1407940 & 688687 & 4.7 & 4.6991 & TST \\
\hline CHEMBL1448755 & 688687 & 5.5 & 5.1034 & TST \\
\hline CHEMBL3194566 & 688687 & 4.4 & 4.987 & TST \\
\hline CHEMBL1342589 & 688687 & 4.7 & 4.7283 & TST \\
\hline CHEMBL1440030 & 688687 & 5.0 & 4.6042 & TST \\
\hline CHEMBL577938 & 688687 & 4.6 & 5.0523 & TST \\
\hline CHEMBL1396236 & 688687 & 5.5 & 5.1515 & TST \\
\hline CHEMBL1389981 & 688687 & 4.5 & 4.7308 & TST \\
\hline CHEMBL1339192 & 688687 & 4.6 & 4.7691 & TST \\
\hline CHEMBL1546597 & 688687 & 4.6 & 4.6671 & TST \\
\hline CHEMBL1326603 & 688687 & 4.7 & 5.2011 & TST \\
\hline CHEMBL1339209 & 688687 & 4.6 & 4.7926 & TST \\
\hline CHEMBL1424068 & 688687 & 4.5 & 4.8064 & TST \\
\hline CHEMBL1358796 & 688687 & 4.5 & 4.4123 & TST \\
\hline CHEMBL1506963 & 688687 & 4.7 & 4.8528 & TST \\
\hline CHEMBL1603890 & 688687 & 4.5 & 4.8799 & TST \\
\hline CHEMBL1466514 & 688687 & 4.6 & 5.0351 & TST \\
\hline CHEMBL1533110 & 688687 & 4.5 & 4.7397 & TST \\
\hline CHEMBL1440291 & 688687 & 4.5 & 4.8748 & TST \\
\hline CHEMBL1439449 & 688687 & 4.6 & 4.6551 & TST \\
\hline CHEMBL1557619 & 688687 & 4.8 & 5.0545 & TST \\
\hline CHEMBL1347117 & 688687 & 5.5 & 4.5531 & TST \\
\hline CHEMBL1468138 & 688687 & 4.5 & 4.8263 & TST \\
\hline CHEMBL1511442 & 688687 & 5.1 & 4.7593 & TST \\
\hline CHEMBL1502211 & 688687 & 4.6 & 5.051 & TST \\
\hline CHEMBL1574830 & 688687 & 5.0 & 5.3583 & TST \\
\hline CHEMBL201221 & 688687 & 4.6 & 5.0458 & TST \\
\hline CHEMBL1485902 & 688687 & 4.6 & 4.9459 & TST \\
\hline CHEMBL1438676 & 688687 & 5.1 & 4.7591 & TST \\
\hline CHEMBL1432130 & 688687 & 4.5 & 4.7871 & TST \\
\hline CHEMBL1514910 & 688687 & 4.4 & 4.7543 & TST \\
\hline CHEMBL1596379 & 688687 & 4.6 & 4.7038 & TST \\
\hline CHEMBL1348342 & 688687 & 5.6 & 5.1503 & TST \\
\hline CHEMBL1439202 & 688687 & 4.6 & 4.9549 & TST \\
\hline CHEMBL1475358 & 688687 & 5.4 & 4.7262 & TST \\
\hline CHEMBL1466728 & 688687 & 4.6 & 4.4427 & TST \\
\hline CHEMBL1385176 & 688687 & 4.4 & 4.6544 & TST \\
\hline CHEMBL1309891 & 688687 & 4.5 & 4.8803 & TST \\
\hline CHEMBL1550849 & 688687 & 4.5 & 4.9017 & TST \\
\hline
\end{tabular}




\begin{tabular}{|c|c|c|c|c|}
\hline & & & & al lable s \\
\hline CHEMBL1319971 & 688687 & 4.5 & 4.7803 & TST \\
\hline CHEMBL1301842 & 688687 & 5.8 & 5.7132 & TST \\
\hline CHEMBL1568118 & 688687 & 4.5 & 4.5549 & TST \\
\hline CHEMBL578585 & 688687 & 4.6 & 4.725 & TST \\
\hline CHEMBL1491841 & 688687 & 5.5 & 5.0601 & TST \\
\hline CHEMBL1517331 & 688687 & 4.6 & 5.0087 & TST \\
\hline CHEMBL1586610 & 688687 & 4.4 & 4.7686 & TST \\
\hline CHEMBL309711 & 688687 & 6.5 & 4.9885 & TST \\
\hline CHEMBL1367155 & 688687 & 5.0 & 4.4835 & TST \\
\hline CHEMBL477139 & 688687 & 4.5 & 4.5495 & TST \\
\hline CHEMBL3191280 & 688687 & 4.4 & 4.783 & TST \\
\hline CHEMBL1461877 & 688687 & 5.4 & 5.2511 & TST \\
\hline CHEMBL1422353 & 688687 & 4.5 & 4.5748 & TST \\
\hline CHEMBL1594328 & 688687 & 4.6 & 4.8875 & TST \\
\hline CHEMBL1453801 & 688687 & 4.5 & 4.6908 & TST \\
\hline CHEMBL2004794 & 688687 & 4.5 & 4.7624 & TST \\
\hline CHEMBL1494645 & 688687 & 4.6 & 4.7065 & TST \\
\hline CHEMBL1256885 & 688687 & 6.0 & 5.2806 & TST \\
\hline CHEMBL1570808 & 688687 & 4.7 & 5.1426 & TST \\
\hline CHEMBL595227 & 688687 & 6.1 & 5.5084 & TST \\
\hline CHEMBL1329411 & 688687 & 4.7 & 4.6738 & TST \\
\hline CHEMBL1517382 & 688687 & 8.0 & 5.2104 & TST \\
\hline CHEMBL1344453 & 688687 & 4.5 & 4.9243 & TST \\
\hline CHEMBL1410458 & 688687 & 4.5 & 5.0634 & TST \\
\hline CHEMBL1355970 & 688687 & 4.6 & 4.7902 & TST \\
\hline CHEMBL1369506 & 688687 & 4.9 & 4.8619 & TST \\
\hline CHEMBL1455209 & 688687 & 4.4 & 4.6385 & TST \\
\hline CHEMBL1569972 & 688687 & 4.4 & 4.6747 & TST \\
\hline CHEMBL1431650 & 688687 & 4.6 & 4.7705 & TST \\
\hline CHEMBL1459153 & 688687 & 4.9 & 4.5831 & TST \\
\hline CHEMBL1457845 & 688687 & 4.5 & 4.9187 & TST \\
\hline CHEMBL1302172 & 688687 & 4.6 & 4.9306 & TST \\
\hline CHEMBL1575530 & 688687 & 4.4 & 4.5788 & TST \\
\hline CHEMBL1406114 & 688687 & 4.5 & 5.0794 & TST \\
\hline CHEMBL1513665 & 688687 & 5.1 & 4.7973 & TST \\
\hline CHEMBL1533548 & 688687 & 4.5 & 4.8753 & TST \\
\hline CHEMBL1576299 & 688687 & 4.5 & 4.8258 & TST \\
\hline CHEMBL1391571 & 688687 & 4.4 & 4.8569 & TST \\
\hline CHEMBL1304922 & 688687 & 5.5 & 4.67399 & 99999999995 \\
\hline CHEMBL1300329 & 688687 & 4.6 & 4.6929 & TST \\
\hline CHEMBL1490014 & 688687 & 4.4 & 4.5132 & TST \\
\hline CHEMBL1544857 & 688687 & 4.4 & 4.7087 & TST \\
\hline CHEMBL1540227 & 688687 & 4.4 & 4.8202 & TST \\
\hline CHEMBL1605147 & 688687 & 4.6 & 4.5167 & TST \\
\hline CHEMBL1547101 & 688687 & 4.7 & 5.0273 & TST \\
\hline CHEMBL1469433 & 688687 & 4.4 & 5.0913 & TST \\
\hline CHEMBL1414191 & 688687 & 5.4 & 4.9064 & TST \\
\hline CHEMBL1590230 & 688687 & 4.5 & 4.8932 & TST \\
\hline
\end{tabular}




\begin{tabular}{|c|c|c|c|c|}
\hline & & & & \\
\hline CHEMBL1338389 & 688687 & 6.7001 & 4.9581 & TST \\
\hline CHEMBL1328429 & 688687 & 6.1 & 4.8045 & TST \\
\hline CHEMBL1488892 & 688687 & 4.5 & 5.0159 & TST \\
\hline CHEMBL1389510 & 688687 & 4.5 & 4.7846 & TST \\
\hline CHEMBL1407760 & 688687 & 4.5 & 4.9694 & TST \\
\hline CHEMBL1545257 & 688687 & 4.4 & 4.6354 & TST \\
\hline CHEMBL1525019 & 688687 & 4.4 & 4.9291 & TST \\
\hline CHEMBL1412010 & 688687 & 4.6 & 5.0522 & TST \\
\hline CHEMBL1531052 & 688687 & 4.5 & 4.7012 & TST \\
\hline CHEMBL1528455 & 688687 & 4.4 & 4.9037 & TST \\
\hline CHEMBL3189499 & 688687 & 4.4 & 5.1597 & TST \\
\hline CHEMBL1592803 & 688687 & 4.4 & 4.4366 & TST \\
\hline CHEMBL150 & 688687 & 4.8 & 5.5461 & TST \\
\hline CHEMBL1456054 & 688687 & 4.4 & 4.8581 & TST \\
\hline CHEMBL331372 & 688687 & 5.1 & 5.4058 & TST \\
\hline CHEMBL1460015 & 688687 & 4.6 & 4.5903 & TST \\
\hline CHEMBL1550451 & 688687 & 4.5 & 4.968 & TST \\
\hline CHEMBL1463544 & 688687 & 5.0 & 4.7863 & TST \\
\hline CHEMBL1449856 & 688687 & 4.4 & 4.6599 & TST \\
\hline CHEMBL1377624 & 688687 & 4.5 & 4.8753 & TST \\
\hline CHEMBL1418894 & 688687 & 4.4 & 4.9864 & TST \\
\hline CHEMBL1598549 & 688687 & 4.9 & 4.9921 & TST \\
\hline CHEMBL1534181 & 688687 & 4.4 & 4.6655 & TST \\
\hline CHEMBL1390160 & 688687 & 4.6 & 4.69 & TST \\
\hline CHEMBL1588574 & 688687 & 4.5 & 4.8635 & TST \\
\hline CHEMBL1393372 & 688687 & 6.0 & 4.9958 & TST \\
\hline CHEMBL1317461 & 688687 & 4.5 & 4.8113 & TST \\
\hline CHEMBL1452956 & 688687 & 4.4 & 4.8254 & TST \\
\hline CHEMBL1585211 & 688687 & 4.6 & 5.1949 & TST \\
\hline CHEMBL1365983 & 688687 & 4.8 & 4.7729 & TST \\
\hline CHEMBL1515867 & 688687 & 4.8 & 4.867 & TST \\
\hline CHEMBL1303063 & 688687 & 5.1 & 5.018 & TST \\
\hline CHEMBL3197060 & 688687 & 5.4 & 4.788 & TST \\
\hline CHEMBL1456900 & 688687 & 4.7 & 5.2567 & TST \\
\hline CHEMBL608699 & 688687 & 6.4 & 5.4225 & TST \\
\hline CHEMBL1357796 & 688687 & 4.7 & 4.7063 & TST \\
\hline CHEMBL1395241 & 688687 & 4.8 & 4.7088 & TST \\
\hline CHEMBL1358092 & 688687 & 4.5 & 4.6904 & TST \\
\hline CHEMBL1607905 & 688687 & 5.0 & 5.2441 & TST \\
\hline CHEMBL1371785 & 688687 & 4.5 & 4.6654 & TST \\
\hline CHEMBL1565777 & 688687 & 5.1 & 4.494 & TST \\
\hline CHEMBL478324 & 688687 & 4.9 & 5.0064 & TST \\
\hline CHEMBL1486813 & 688687 & 4.7 & 4.8998 & TST \\
\hline CHEMBL1529702 & 688687 & 5.9 & 4.5971 & TST \\
\hline CHEMBL239439 & 688687 & 6.9 & 4.9817 & TST \\
\hline CHEMBL1395026 & 688687 & 6.2 & 4.9634 & TST \\
\hline CHEMBL1491278 & 688687 & 4.4 & 4.5954 & TST \\
\hline CHEMBL1318977 & 688687 & 4.8 & 4.8436 & TST \\
\hline & & & & \\
\hline
\end{tabular}




\begin{tabular}{|c|c|c|c|c|c|}
\hline & & & & & \\
\hline CHEMBL1256813 & 688687 & 4.5 & 5.2659 & TST & \\
\hline CHEMBL121915 & 688687 & 4.4 & 4.9744 & TST & \\
\hline CHEMBL1343161 & 688687 & 4.5 & 4.7934 & TST & \\
\hline CHEMBL1454479 & 688687 & 4.4 & 4.6978 & TST & \\
\hline CHEMBL1450971 & 688687 & 4.4 & 5.215 & TST & \\
\hline CHEMBL1597970 & 688687 & 5.1 & 4.8169 & TST & \\
\hline CHEMBL483137 & 688687 & 4.6 & 4.5383 & TST & \\
\hline CHEMBL1587441 & 688687 & 4.5 & 5.0679 & TST & \\
\hline CHEMBL1308853 & 688687 & 5.7 & 5.46899 & 9999999999 & TST \\
\hline CHEMBL1610589 & 688687 & 4.5 & 4.9778 & TST & \\
\hline CHEMBL1561754 & 688687 & 4.5 & 4.654 & TST & \\
\hline CHEMBL1453954 & 688687 & 5.6 & 5.4266 & TST & \\
\hline CHEMBL1597666 & 688687 & 4.5 & 4.907 & TST & \\
\hline CHEMBL278332 & 688687 & 5.1 & 4.6281 & TST & \\
\hline CHEMBL1560588 & 688687 & 5.7 & 4.8885 & TST & \\
\hline CHEMBL1304965 & 688687 & 4.4 & 4.7285 & TST & \\
\hline CHEMBL1305016 & 688687 & 5.8 & 4.7681 & TST & \\
\hline CHEMBL1335502 & 688687 & 4.4 & 4.5264 & TST & \\
\hline CHEMBL1523390 & 688687 & 5.9 & 4.6105 & TST & \\
\hline CHEMBL1374416 & 688687 & 5.0 & 4.8367 & TST & \\
\hline CHEMBL1440150 & 688687 & 4.5 & 5.0455 & TST & \\
\hline CHEMBL1450795 & 688687 & 4.7 & 4.7424 & TST & \\
\hline CHEMBL1430353 & 688687 & 4.4 & 4.9996 & TST & \\
\hline CHEMBL1571862 & 688687 & 4.6 & 4.7698 & TST & \\
\hline CHEMBL 3214044 & 688687 & 4.7 & 4.7896 & TST & \\
\hline CHEMBL1359819 & 688687 & 4.6 & 4.6884 & TST & \\
\hline CHEMBL1401043 & 688687 & 5.3 & 4.4936 & TST & \\
\hline CHEMBL1475131 & 688687 & 4.8 & 4.6959 & TST & \\
\hline CHEMBL1359893 & 688687 & 4.6 & 4.5511 & TST & \\
\hline CHEMBL1325231 & 688687 & 4.4 & 4.8977 & TST & \\
\hline CHEMBL1530101 & 688687 & 4.6 & 4.7783 & TST & \\
\hline CHEMBL1546000 & 688687 & 4.4 & 4.8674 & TST & \\
\hline CHEMBL1344962 & 688687 & 4.4 & 4.8723 & TST & \\
\hline CHEMBL1384403 & 688687 & 4.5 & 4.6836 & TST & \\
\hline CHEMBL1976499 & 688687 & 4.8 & 4.6218 & TST & \\
\hline CHEMBL1509950 & 688687 & 4.6 & 4.9787 & TST & \\
\hline CHEMBL1423479 & 688687 & 5.1 & 5.3616 & TST & \\
\hline CHEMBL1594521 & 688687 & 4.4 & 4.69600 & 2000000001 & TST \\
\hline CHEMBL76589 & 688687 & 4.6 & 5.1473 & TST & \\
\hline CHEMBL1449517 & 688687 & 5.7 & 5.0067 & TST & \\
\hline CHEMBL1365318 & 688687 & 4.4 & 5.1069 & TST & \\
\hline CHEMBL1472466 & 688687 & 5.1 & 5.2425 & TST & \\
\hline CHEMBL1361955 & 688687 & 4.5 & 4.6825 & TST & \\
\hline CHEMBL1507162 & 688687 & 6.0 & 5.2405 & TST & \\
\hline CHEMBL1397604 & 688687 & 4.5 & 4.7787 & TST & \\
\hline CHEMBL1525484 & 688687 & 4.5 & 4.6645 & TST & \\
\hline CHEMBL1490320 & 688687 & 4.8 & 4.8007 & TST & \\
\hline CHEMBL1461732 & 688687 & 4.5 & 4.6824 & TST & \\
\hline
\end{tabular}




\begin{tabular}{|c|c|c|c|c|c|}
\hline \\
\hline CHEMBL1525939 & 688687 & 4.4 & 4.5585 & TST & \\
\hline CHEMBL1564845 & 688687 & 4.5 & 4.489 & TST & \\
\hline CHEMBL1234071 & 688687 & 4.9 & 5.0226 & TST & \\
\hline CHEMBL1502922 & 688687 & 4.5 & 4.825 & TST & \\
\hline CHEMBL1594666 & 688687 & 4.6 & 4.9811 & TST & \\
\hline CHEMBL1484902 & 688687 & 4.6 & 4.5794 & TST & \\
\hline CHEMBL1442492 & 688687 & 4.8 & 4.6833 & TST & \\
\hline CHEMBL1309446 & 688687 & 4.8 & 4.9271 & TST & \\
\hline CHEMBL1520292 & 688687 & 4.9 & 4.5957 & TST & \\
\hline CHEMBL1481853 & 688687 & 4.5 & 4.6079 & TST & \\
\hline CHEMBL1340376 & 688687 & 4.5 & 4.7071 & TST & \\
\hline CHEMBL1390729 & 688687 & 4.9 & 4.8662 & TST & \\
\hline CHEMBL1546620 & 688687 & 4.5 & 4.5637 & TST & \\
\hline CHEMBL1323772 & 688687 & 4.9 & 4.7059 & TST & \\
\hline CHEMBL1365345 & 688687 & 4.5 & 4.7863 & TST & \\
\hline CHEMBL1550503 & 688687 & 4.4 & 4.7718 & TST & \\
\hline CHEMBL1600998 & 688687 & 5.5 & 5.0682 & TST & \\
\hline CHEMBL1377446 & 688687 & 4.9 & 4.6885 & TST & \\
\hline CHEMBL1464646 & 688687 & 4.5 & 4.636 & TST & \\
\hline CHEMBL1492194 & 688687 & 4.8 & 4.6496 & TST & \\
\hline CHEMBL1570788 & 688687 & 5.2 & 4.8234 & TST & \\
\hline CHEMBL1423863 & 688687 & 4.5 & 4.4548 & TST & \\
\hline CHEMBL1507312 & 688687 & 5.0 & 5.0121 & TST & \\
\hline CHEMBL1431368 & 688687 & 4.6 & 4.7227 & TST & \\
\hline CHEMBL1469333 & 688687 & 4.8 & 4.5745 & TST & \\
\hline CHEMBL1487028 & 688687 & 4.5 & 5.0531 & TST & \\
\hline CHEMBL1430852 & 688687 & 4.4 & 4.5971 & TST & \\
\hline CHEMBL1400637 & 688687 & 5.0 & 4.79899 & 99999999995 & TST \\
\hline CHEMBL1462786 & 688687 & 4.6 & 4.7326 & TST & \\
\hline CHEMBL1432735 & 688687 & 4.8 & 5.1398 & TST & \\
\hline CHEMBL1587001 & 688687 & 4.5 & 5.29799 & 9999999999 & TST \\
\hline CHEMBL1401584 & 688687 & 4.7 & 4.8533 & TST & \\
\hline CHEMBL1597856 & 688687 & 6.1 & 4.9866 & TST & \\
\hline CHEMBL1587359 & 688687 & 4.4 & 5.0848 & TST & \\
\hline CHEMBL1579564 & 688687 & 5.9 & 5.92299 & 9999999999 & TST \\
\hline CHEMBL1478458 & 688687 & 5.1 & 4.9261 & TST & \\
\hline CHEMBL1537196 & 688687 & 5.0 & 4.9944 & TST & \\
\hline CHEMBL1608043 & 688687 & 4.6 & 4.7373 & TST & \\
\hline CHEMBL1510117 & 688687 & 4.7 & 4.7973 & TST & \\
\hline CHEMBL1613188 & 688687 & 4.5 & 4.761 & TST & \\
\hline CHEMBL1406655 & 688687 & 4.5 & 4.7056 & TST & \\
\hline CHEMBL1355677 & 688687 & 4.6 & 4.5197 & TST & \\
\hline CHEMBL1387705 & 688687 & 4.6 & 4.7273 & TST & \\
\hline CHEMBL521970 & 688687 & 5.0 & 4.3614 & TST & \\
\hline CHEMBL1521986 & 688687 & 5.9 & 4.7564 & TST & \\
\hline CHEMBL1350806 & 688687 & 4.4 & 4.8798 & TST & \\
\hline CHEMBL1559117 & 688687 & 4.5 & 4.9013 & TST & \\
\hline CHEMBL1413318 & 688687 & 5.4 & 4.6994 & TST & \\
\hline
\end{tabular}




\begin{tabular}{|c|c|c|c|c|}
\hline \multicolumn{5}{|c|}{ oplemental T } \\
\hline CHEMBL1464435 & 688687 & 5.2 & 4.588 & TST \\
\hline CHEMBL1517570 & 688687 & 4.4 & 4.7723 & TST \\
\hline CHEMBL1459500 & 688687 & 5.7 & 5.0029 & TST \\
\hline CHEMBL1581071 & 688687 & 4.7 & 4.9883 & TST \\
\hline CHEMBL1353215 & 688687 & 5.8 & 4.8709 & TST \\
\hline CHEMBL1479934 & 688687 & 4.5 & 4.793 & TST \\
\hline CHEMBL1449334 & 688687 & 6.0 & 5.2708 & TST \\
\hline CHEMBL1534488 & 688687 & 5.5 & 4.8853 & TST \\
\hline CHEMBL1440330 & 688687 & 4.4 & 4.6522 & TST \\
\hline CHEMBL1428630 & 688687 & 4.6 & 4.6017 & TST \\
\hline CHEMBL 1407552 & 688687 & 4.9 & 4.6838 & TST \\
\hline CHEMBL1587965 & 688687 & 5.3 & 5.0141 & TST \\
\hline CHEMBL1418834 & 688687 & 5.4 & 4.9589 & TST \\
\hline CHEMBL1588811 & 688687 & 4.6 & 4.8083 & TST \\
\hline CHEMBL1541411 & 688687 & 4.8 & 4.6301 & TST \\
\hline CHEMBL1521672 & 688687 & 4.5 & 4.7085 & TST \\
\hline CHEMBL1341920 & 688687 & 5.5 & 4.6189 & TST \\
\hline CHEMBL1444534 & 688687 & 4.6 & 4.3955 & TST \\
\hline CHEMBL1503135 & 688687 & 4.4 & 4.8691 & TST \\
\hline CHEMBL1455912 & 688687 & 7.5003 & 4.5773 & TST \\
\hline CHEMBL1361000 & 688687 & 6.1 & 5.3109 & TST \\
\hline CHEMBL1563858 & 688687 & 4.5 & 4.4797 & TST \\
\hline CHEMBL1417231 & 688687 & 4.8 & 4.7406 & TST \\
\hline CHEMBL1595860 & 688687 & 4.4 & 4.965 & TST \\
\hline CHEMBL 258881 & 688687 & 4.6 & 4.8619 & TST \\
\hline CHEMBL10009 & 688687 & 4.6 & 4.7615 & TST \\
\hline CHEMBL1452934 & 688687 & 4.4 & 4.9314 & TST \\
\hline CHEMBL1607562 & 688687 & 4.4 & 4.9056 & TST \\
\hline CHEMBL1606698 & 688687 & 4.4 & 4.8423 & TST \\
\hline CHEMBL1377112 & 688687 & 4.6 & 4.74 & TST \\
\hline CHEMBL1554479 & 688687 & 5.1 & 5.4029 & TST \\
\hline CHEMBL1612609 & 688687 & 4.4 & 4.5382 & TST \\
\hline CHEMBL1705631 & 688687 & 4.7 & 4.825 & TST \\
\hline CHEMBL1461626 & 688687 & 4.4 & 4.803 & TST \\
\hline CHEMBL 3199579 & 688687 & 4.5 & 4.9354 & TST \\
\hline CHEMBL1364572 & 688687 & 5.0 & 5.1145 & TST \\
\hline CHEMBL1346978 & 688687 & 4.5 & 4.9129 & TST \\
\hline CHEMBL1443986 & 688687 & 6.3 & 4.9319 & TST \\
\hline CHEMBL1414295 & 688687 & 4.6 & 4.7854 & TST \\
\hline CHEMBL1522852 & 688687 & 5.4 & 4.8393 & TST \\
\hline CHEMBL1430602 & 688687 & 5.2 & 4.7235 & TST \\
\hline CHEMBL1493974 & 688687 & 5.8 & 4.9337 & TST \\
\hline CHEMBL1399653 & 688687 & 5.4 & 4.771 & TST \\
\hline CHEMBL1304906 & 688687 & 6.1 & 4.9488 & TST \\
\hline CHEMBL1323839 & 688687 & 5.3 & 4.9454 & TST \\
\hline CHEMBL1467490 & 688687 & 4.5 & 4.7501 & TST \\
\hline CHEMBL1414263 & 688687 & 6.0 & 5.8453 & TST \\
\hline CHEMBL1333655 & 688687 & 5.8 & 5.0666 & TST \\
\hline
\end{tabular}




\begin{tabular}{|c|c|c|c|c|}
\hline & & & & \\
\hline CHEMBL1466939 & 688687 & 4.9 & 4.6877 & TST \\
\hline CHEMBL1517353 & 688687 & 4.9 & 4.6136 & TST \\
\hline CHEMBL1608732 & 688687 & 6.0 & 4.8549 & TST \\
\hline CHEMBL1388126 & 688687 & 5.4 & 5.1871 & TST \\
\hline CHEMBL1556351 & 688687 & 5.7 & 4.9312 & TST \\
\hline CHEMBL1426830 & 688687 & 6.0 & 4.6407 & TST \\
\hline CHEMBL1476741 & 688687 & 5.7 & 5.3765 & TST \\
\hline CHEMBL1520942 & 688687 & 4.5 & 4.6435 & TST \\
\hline CHEMBL1309655 & 688687 & 5.4 & 4.9233 & TST \\
\hline CHEMBL1586056 & 688687 & 4.5 & 4.7215 & TST \\
\hline CHEMBL1346588 & 688687 & 4.5 & 4.7625 & TST \\
\hline CHEMBL1328086 & 688687 & 4.7 & 4.9624 & TST \\
\hline CHEMBL1483764 & 688687 & 4.4 & 4.688 & TST \\
\hline CHEMBL1352800 & 688687 & 4.8 & 4.9308 & TST \\
\hline CHEMBL1489758 & 688687 & 6.5 & 4.6171 & TST \\
\hline CHEMBL1312986 & 688687 & 5.0 & 5.1093 & TST \\
\hline CHEMBL1501640 & 688687 & 4.4 & 4.8727 & TST \\
\hline CHEMBL1566165 & 688687 & 5.6 & 5.654 & TST \\
\hline CHEMBL1502203 & 688687 & 5.6 & 5.1545 & TST \\
\hline CHEMBL1482799 & 688687 & 4.8 & 4.7897 & TST \\
\hline CHEMBL1608118 & 688687 & 4.9 & 4.7345 & TST \\
\hline CHEMBL1451329 & 688687 & 4.4 & 4.7376 & TST \\
\hline CHEMBL1427756 & 688687 & 4.4 & 4.9761 & TST \\
\hline CHEMBL1386440 & 688687 & 5.4 & 5.0502 & TST \\
\hline CHEMBL1492738 & 688687 & 4.6 & 4.9235 & TST \\
\hline CHEMBL1307361 & 688687 & 4.6 & 4.8972 & TST \\
\hline CHEMBL1323236 & 688687 & 4.4 & 4.9778 & TST \\
\hline CHEMBL3199055 & 688687 & 4.5 & 4.5648 & TST \\
\hline CHEMBL1400868 & 688687 & 4.4 & 4.5846 & TST \\
\hline CHEMBL 3145170 & 688687 & 5.1 & 5.2413 & TST \\
\hline CHEMBL1436682 & 688687 & 4.6 & 4.6063 & TST \\
\hline CHEMBL1577496 & 688687 & 5.4 & 5.8661 & TST \\
\hline CHEMBL1546455 & 688687 & 5.0 & 4.7939 & TST \\
\hline CHEMBL1538612 & 688687 & 5.3 & 4.4499 & TST \\
\hline CHEMBL1550202 & 688687 & 4.5 & 5.1132 & TST \\
\hline CHEMBL1421461 & 688687 & 4.6 & 5.2618 & TST \\
\hline CHEMBL1335367 & 688687 & 5.5 & 4.9779 & TST \\
\hline CHEMBL1581244 & 688687 & 4.5 & 4.3709 & TST \\
\hline CHEMBL3214589 & 688687 & 4.5 & 4.4272 & TST \\
\hline CHEMBL1491660 & 688687 & 5.5 & 4.9852 & TST \\
\hline CHEMBL137246 & 688687 & 5.5 & 5.0102 & TST \\
\hline CHEMBL1378830 & 688687 & 4.8 & 4.8698 & TST \\
\hline CHEMBL1407387 & 688687 & 4.5 & 4.4609 & TST \\
\hline CHEMBL1443393 & 688687 & 4.5 & 4.8671 & TST \\
\hline CHEMBL1415738 & 688687 & 4.4 & 5.092 & TST \\
\hline CHEMBL1562945 & 688687 & 4.5 & 4.60800 & 00000000005 \\
\hline CHEMBL1230270 & 688687 & 5.2 & 5.0612 & TST \\
\hline CHEMBL1377687 & 688687 & 4.5 & 4.8325 & TST \\
\hline
\end{tabular}




\begin{tabular}{|c|c|c|c|c|}
\hline \\
\hline CHEMBL1577232 & 688687 & 4.8 & 4.4196 & TST \\
\hline CHEMBL1589925 & 688687 & 4.6 & 4.4699 & TST \\
\hline CHEMBL1439788 & 688687 & 4.6 & 4.5685 & TST \\
\hline CHEMBL1541840 & 688687 & 4.5 & 4.6575 & TST \\
\hline CHEMBL1348371 & 688687 & 4.6 & 4.6337 & TST \\
\hline CHEMBL1529766 & 688687 & 5.3 & 4.9099 & TST \\
\hline CHEMBL1467819 & 688687 & 4.6 & 4.6551 & TST \\
\hline CHEMBL1400315 & 688687 & 4.5 & 4.6592 & TST \\
\hline CHEMBL1563166 & 688687 & 4.5 & 5.0297 & TST \\
\hline CHEMBL1531153 & 688687 & 4.5 & 5.0291 & TST \\
\hline CHEMBL1373003 & 688687 & 4.6 & 4.8194 & TST \\
\hline CHEMBL1336316 & 688687 & 4.5 & 5.005 & TST \\
\hline CHEMBL420937 & 688687 & 4.6 & 4.8403 & TST \\
\hline CHEMBL1399612 & 688687 & 4.5 & 4.6104 & TST \\
\hline CHEMBL1315138 & 688687 & 4.4 & 4.7435 & TST \\
\hline CHEMBL1452561 & 688687 & 6.0 & 5.8544 & TST \\
\hline CHEMBL1570543 & 688687 & 4.6 & 5.1995 & TST \\
\hline CHEMBL1331907 & 688687 & 4.6 & 4.7679 & TST \\
\hline CHEMBL1340725 & 688687 & 4.4 & 4.5771 & TST \\
\hline CHEMBL1371869 & 688687 & 5.5 & 4.70100 & 00000000005 \\
\hline CHEMBL1580966 & 688687 & 4.6 & 5.1674 & TST \\
\hline CHEMBL1462377 & 688687 & 4.5 & 4.974 & TST \\
\hline CHEMBL1308793 & 688687 & 4.5 & 4.6724 & TST \\
\hline CHEMBL1542745 & 688687 & 5.5 & 4.8626 & TST \\
\hline CHEMBL1488167 & 688687 & 5.4 & 5.4582 & TST \\
\hline CHEMBL1448249 & 688687 & 4.7 & 4.8604 & TST \\
\hline CHEMBL3211878 & 688687 & 4.8 & 4.7109 & TST \\
\hline CHEMBL1543261 & 688687 & 4.5 & 5.1215 & TST \\
\hline CHEMBL1462693 & 688687 & 4.5 & 4.9971 & TST \\
\hline CHEMBL1489806 & 688687 & 4.4 & 4.7544 & TST \\
\hline CHEMBL1372111 & 688687 & 4.4 & 4.8231 & TST \\
\hline CHEMBL1440857 & 688687 & 5.1 & 4.8486 & TST \\
\hline CHEMBL1547827 & 688687 & 4.5 & 4.5138 & TST \\
\hline CHEMBL1417994 & 688687 & 4.4 & 4.6407 & TST \\
\hline CHEMBL1319873 & 688687 & 4.4 & 4.6888 & TST \\
\hline CHEMBL1378043 & 688687 & 5.5 & 4.7803 & TST \\
\hline CHEMBL1383901 & 688687 & 4.4 & 4.7488 & TST \\
\hline CHEMBL1449457 & 688687 & 4.7 & 4.6537 & TST \\
\hline CHEMBL1373974 & 688687 & 4.6 & 4.7534 & TST \\
\hline CHEMBL1608244 & 688687 & 5.4 & 4.8525 & TST \\
\hline CHEMBL1528589 & 688687 & 4.6 & 4.5035 & TST \\
\hline CHEMBL1401577 & 688687 & 4.6 & 4.4487 & TST \\
\hline CHEMBL1529534 & 688687 & 4.4 & 5.1875 & TST \\
\hline CHEMBL410484 & 688687 & 4.4 & 4.9263 & TST \\
\hline CHEMBL1599408 & 688687 & 4.4 & 4.3595 & TST \\
\hline CHEMBL1565591 & 688687 & 5.5 & 4.9946 & TST \\
\hline CHEMBL1570196 & 688687 & 4.4 & 4.8047 & TST \\
\hline CHEMBL1533322 & 688687 & 5.5 & 5.1168 & TST \\
\hline
\end{tabular}




\begin{tabular}{|c|c|c|c|c|c|}
\hline \\
\hline CHEMBL1511778 & 688687 & 5.0 & 4.8185 & TST & \\
\hline CHEMBL1545551 & 688687 & 5.1 & 5.0197 & TST & \\
\hline CHEMBL 305978 & 688687 & 5.1 & 5.2067 & TST & \\
\hline CHEMBL1410899 & 688687 & 4.6 & 4.9779 & TST & \\
\hline CHEMBL1601948 & 688687 & 4.6 & 4.687 & TST & \\
\hline CHEMBL1496206 & 688687 & 5.4 & 4.7765 & TST & \\
\hline CHEMBL1462735 & 688687 & 4.9 & 4.8752 & TST & \\
\hline CHEMBL3187257 & 688687 & 4.6 & 4.7014 & TST & \\
\hline CHEMBL1578129 & 688687 & 4.4 & 4.9104 & TST & \\
\hline CHEMBL1384151 & 688687 & 4.4 & 4.7 & TST & \\
\hline CHEMBL1343834 & 688687 & 5.5 & 4.683 & TST & \\
\hline CHEMBL1414032 & 688687 & 4.5 & 4.5023 & TST & \\
\hline CHEMBL1487346 & 688687 & 4.4 & 4.8697 & TST & \\
\hline CHEMBL1599021 & 688687 & 4.5 & 4.8535 & TST & \\
\hline CHEMBL1420962 & 688687 & 5.2 & 4.6948 & TST & \\
\hline CHEMBL1433093 & 688687 & 4.4 & 4.691 & TST & \\
\hline CHEMBL1413032 & 688687 & 4.8 & 4.5674 & TST & \\
\hline CHEMBL1369406 & 688687 & 5.1 & 4.92399 & 99999999995 & TST \\
\hline CHEMBL1502419 & 688687 & 4.9 & 5.2948 & TST & \\
\hline CHEMBL556024 & 688687 & 6.6 & 4.9526 & TST & \\
\hline CHEMBL1563581 & 688687 & 4.4 & 4.5062 & TST & \\
\hline CHEMBL1558283 & 688687 & 5.5 & 4.8525 & TST & \\
\hline CHEMBL1343460 & 688687 & 5.8 & 4.4793 & TST & \\
\hline CHEMBL1523035 & 688687 & 5.5 & 4.6074 & TST & \\
\hline CHEMBL1309683 & 688687 & 4.5 & 4.827 & TST & \\
\hline CHEMBL1480769 & 688687 & 4.4 & 5.0514 & TST & \\
\hline CHEMBL490913 & 688687 & 4.5 & 4.7954 & TST & \\
\hline CHEMBL1454958 & 688687 & 4.5 & 4.6071 & TST & \\
\hline CHEMBL1414097 & 688687 & 4.6 & 5.1679 & TST & \\
\hline CHEMBL1525860 & 688687 & 5.6 & 4.8152 & TST & \\
\hline CHEMBL1344156 & 688687 & 5.6 & 4.6354 & TST & \\
\hline CHEMBL1316979 & 688687 & 4.6 & 4.6566 & TST & \\
\hline CHEMBL1593412 & 688687 & 6.0 & 5.7353 & TST & \\
\hline CHEMBL1523322 & 688687 & 4.6 & 4.9575 & TST & \\
\hline CHEMBL1372422 & 688687 & 4.7 & 4.7339 & TST & \\
\hline CHEMBL1442150 & 688687 & 4.5 & 4.8777 & TST & \\
\hline CHEMBL1376541 & 688687 & 4.7 & 5.0453 & TST & \\
\hline CHEMBL1424149 & 688687 & 4.6 & 4.6533 & TST & \\
\hline CHEMBL1299521 & 688687 & 5.3 & 4.5941 & TST & \\
\hline CHEMBL1334768 & 688687 & 4.8 & 4.8134 & TST & \\
\hline CHEMBL1331734 & 688687 & 6.6 & 5.2268 & TST & \\
\hline CHEMBL1449460 & 688687 & 4.5 & 5.5227 & TST & \\
\hline CHEMBL1999166 & 688687 & 4.8 & 4.3967 & TST & \\
\hline CHEMBL1331550 & 688687 & 5.4 & 5.091 & TST & \\
\hline CHEMBL 3194220 & 688687 & 5.5 & 4.6917 & TST & \\
\hline CHEMBL1512222 & 688687 & 5.1 & 4.9425 & TST & \\
\hline CHEMBL1547680 & 688687 & 4.6 & 4.7163 & TST & \\
\hline CHEMBL1366150 & 688687 & 4.7 & 5.1134 & TST & \\
\hline
\end{tabular}




\begin{tabular}{|c|c|c|c|c|}
\hline \\
\hline CHEMBL1540142 & 688687 & 4.4 & 4.8072 & TST \\
\hline CHEMBL1547130 & 688687 & 5.0 & 5.2264 & TST \\
\hline CHEMBL1368420 & 688687 & 4.6 & 4.8709 & TST \\
\hline CHEMBL1447738 & 688687 & 6.4 & 5.5783 & TST \\
\hline CHEMBL1442750 & 688687 & 4.5 & 4.7098 & TST \\
\hline CHEMBL1359455 & 688687 & 4.4 & 4.5777 & TST \\
\hline CHEMBL1481035 & 688687 & 4.7 & 4.4849 & TST \\
\hline CHEMBL1448392 & 688687 & 4.5 & 4.85 & TST \\
\hline CHEMBL1313554 & 688687 & 4.5 & 4.849 & TST \\
\hline CHEMBL1547861 & 688687 & 4.5 & 4.9032 & TST \\
\hline CHEMBL1504563 & 688687 & 5.0 & 4.7403 & TST \\
\hline CHEMBL1591294 & 688687 & 8.301 & 5.0332 & TST \\
\hline CHEMBL1538493 & 688687 & 4.5 & 4.6647 & TST \\
\hline CHEMBL389390 & 688687 & 4.9 & 5.1092 & TST \\
\hline CHEMBL1334370 & 688687 & 4.4 & 4.7853 & TST \\
\hline CHEMBL1598346 & 688687 & 4.6 & 4.5307 & TST \\
\hline CHEMBL1380028 & 688687 & 6.1 & 4.9421 & TST \\
\hline CHEMBL1328778 & 688687 & 5.7 & 5.2948 & TST \\
\hline CHEMBL1560884 & 688687 & 5.7 & 5.0302 & TST \\
\hline CHEMBL3192201 & 688687 & 4.4 & 4.9055 & TST \\
\hline CHEMBL1376964 & 688687 & 4.5 & 4.9852 & TST \\
\hline CHEMBL1547156 & 688687 & 4.4 & 4.5931 & TST \\
\hline CHEMBL1333361 & 688687 & 4.5 & 4.926 & TST \\
\hline CHEMBL1554717 & 688687 & 4.5 & 4.7691 & TST \\
\hline CHEMBL1505379 & 688687 & 4.6 & 4.8906 & TST \\
\hline CHEMBL1432515 & 688687 & 4.5 & 4.9855 & TST \\
\hline CHEMBL1588463 & 688687 & 4.4 & 4.5138 & TST \\
\hline CHEMBL12014 & 688687 & 6.0 & 4.7362 & TST \\
\hline CHEMBL 2007077 & 688687 & 5.8 & 5.2796 & TST \\
\hline CHEMBL1451206 & 688687 & 4.5 & 4.9851 & TST \\
\hline CHEMBL1457355 & 688687 & 4.6 & 4.7124 & TST \\
\hline CHEMBL1351487 & 688687 & 5.7 & 5.1662 & TST \\
\hline CHEMBL6291 & 688687 & 4.4 & 4.5155 & TST \\
\hline CHEMBL1529527 & 688687 & 4.4 & 4.6968 & TST \\
\hline CHEMBL1568835 & 688687 & 4.5 & 4.8681 & TST \\
\hline CHEMBL1452690 & 688687 & 4.5 & 4.9076 & TST \\
\hline CHEMBL1486741 & 688687 & 4.5 & 5.13299 & 9999999999 \\
\hline CHEMBL1473133 & 688687 & 4.6 & 4.8035 & TST \\
\hline CHEMBL3196190 & 688687 & 4.8 & 4.7432 & TST \\
\hline CHEMBL 1466310 & 688687 & 4.4 & 4.4349 & TST \\
\hline CHEMBL1423397 & 688687 & 5.4 & 4.706 & TST \\
\hline CHEMBL1331518 & 688687 & 4.4 & 5.033 & TST \\
\hline CHEMBL1488186 & 688687 & 4.7 & 5.0072 & TST \\
\hline CHEMBL1575258 & 688687 & 4.5 & 5.0117 & TST \\
\hline CHEMBL1320841 & 688687 & 4.6 & 4.8 & TST \\
\hline CHEMBL1505491 & 688687 & 4.9 & 5.0182 & TST \\
\hline CHEMBL1369517 & 688687 & 4.5 & 5.0398 & TST \\
\hline CHEMBL1507750 & 688687 & 4.9 & 4.4548 & TST \\
\hline
\end{tabular}




\begin{tabular}{|c|c|c|c|c|}
\hline & & & pplement & al $\mathrm{T}$ \\
\hline CHEMBL1529696 & 688687 & 4.9 & 4.7874 & TST \\
\hline CHEMBL1496062 & 688687 & 5.9 & 5.2185 & TST \\
\hline CHEMBL1386855 & 688687 & 4.9 & 4.8059 & TST \\
\hline CHEMBL1484285 & 688687 & 4.9 & 4.7887 & TST \\
\hline CHEMBL367971 & 688687 & 4.8 & 5.0122 & TST \\
\hline CHEMBL1487256 & 688687 & 5.1 & 5.0228 & TST \\
\hline CHEMBL1369089 & 688687 & 4.5 & 4.9606 & TST \\
\hline CHEMBL1420459 & 688687 & 4.4 & 4.7114 & TST \\
\hline CHEMBL1347617 & 688687 & 5.5 & 4.931 & TST \\
\hline CHEMBL1351558 & 688687 & 4.6 & 4.7281 & TST \\
\hline CHEMBL1568187 & 688687 & 4.7 & 4.9219 & TST \\
\hline CHEMBL1305409 & 688687 & 4.6 & 4.5952 & TST \\
\hline CHEMBL1459655 & 688687 & 4.5 & 4.6384 & TST \\
\hline CHEMBL122701 & 688687 & 6.9 & 5.4951 & TST \\
\hline CHEMBL1374644 & 688687 & 4.5 & 4.5102 & TST \\
\hline CHEMBL1520216 & 688687 & 4.6 & 4.7395 & TST \\
\hline CHEMBL1485078 & 688687 & 4.7 & 4.825 & TST \\
\hline CHEMBL1507324 & 688687 & 4.5 & 4.4017 & TST \\
\hline CHEMBL1313648 & 688687 & 4.6 & 4.7512 & TST \\
\hline CHEMBL1557778 & 688687 & 4.9 & 4.6884 & TST \\
\hline CHEMBL1331465 & 688687 & 4.8 & 5.0544 & TST \\
\hline CHEMBL1505052 & 688687 & 5.2 & 4.7076 & TST \\
\hline CHEMBL1371633 & 688687 & 4.8 & 4.7648 & TST \\
\hline CHEMBL1339156 & 688687 & 4.4 & 4.5573 & TST \\
\hline CHEMBL1320424 & 688687 & 4.8 & 4.7515 & TST \\
\hline CHEMBL1438392 & 688687 & 4.5 & 4.952 & TST \\
\hline CHEMBL1542583 & 688687 & 5.2 & 4.8309 & TST \\
\hline CHEMBL1434308 & 688687 & 4.4 & 5.1039 & TST \\
\hline CHEMBL1490919 & 688687 & 5.1 & 4.9682 & TST \\
\hline CHEMBL1489756 & 688687 & 4.8 & 4.7168 & TST \\
\hline CHEMBL1363830 & 688687 & 5.0 & 4.9613 & TST \\
\hline CHEMBL1327884 & 688687 & 4.5 & 4.9127 & TST \\
\hline CHEMBL1583703 & 688687 & 5.0 & 4.5677 & TST \\
\hline CHEMBL1366133 & 688687 & 5.5 & 5.0318 & TST \\
\hline CHEMBL1496009 & 688687 & 4.6 & 4.697 & TST \\
\hline CHEMBL1468321 & 688687 & 4.6 & 4.9665 & TST \\
\hline CHEMBL1492652 & 688687 & 4.5 & 4.4236 & TST \\
\hline CHEMBL1507540 & 688687 & 4.7 & 4.9391 & TST \\
\hline CHEMBL1442173 & 688687 & 4.8 & 4.703 & TST \\
\hline CHEMBL437450 & 688687 & 4.8 & 4.4419 & TST \\
\hline CHEMBL1460491 & 688687 & 5.1 & 4.8531 & TST \\
\hline CHEMBL1334939 & 688687 & 4.6 & 4.8649 & TST \\
\hline CHEMBL3196541 & 688687 & 4.5 & 4.6807 & TST \\
\hline CHEMBL602807 & 688687 & 5.9 & 5.6802 & TST \\
\hline CHEMBL1370156 & 688687 & 4.4 & 4.7308 & TST \\
\hline CHEMBL1557224 & 688687 & 4.5 & 4.905 & TST \\
\hline CHEMBL1529114 & 688687 & 4.4 & 4.6603 & TST \\
\hline CHEMBL1444438 & 688687 & 4.6 & 4.6267 & TST \\
\hline
\end{tabular}




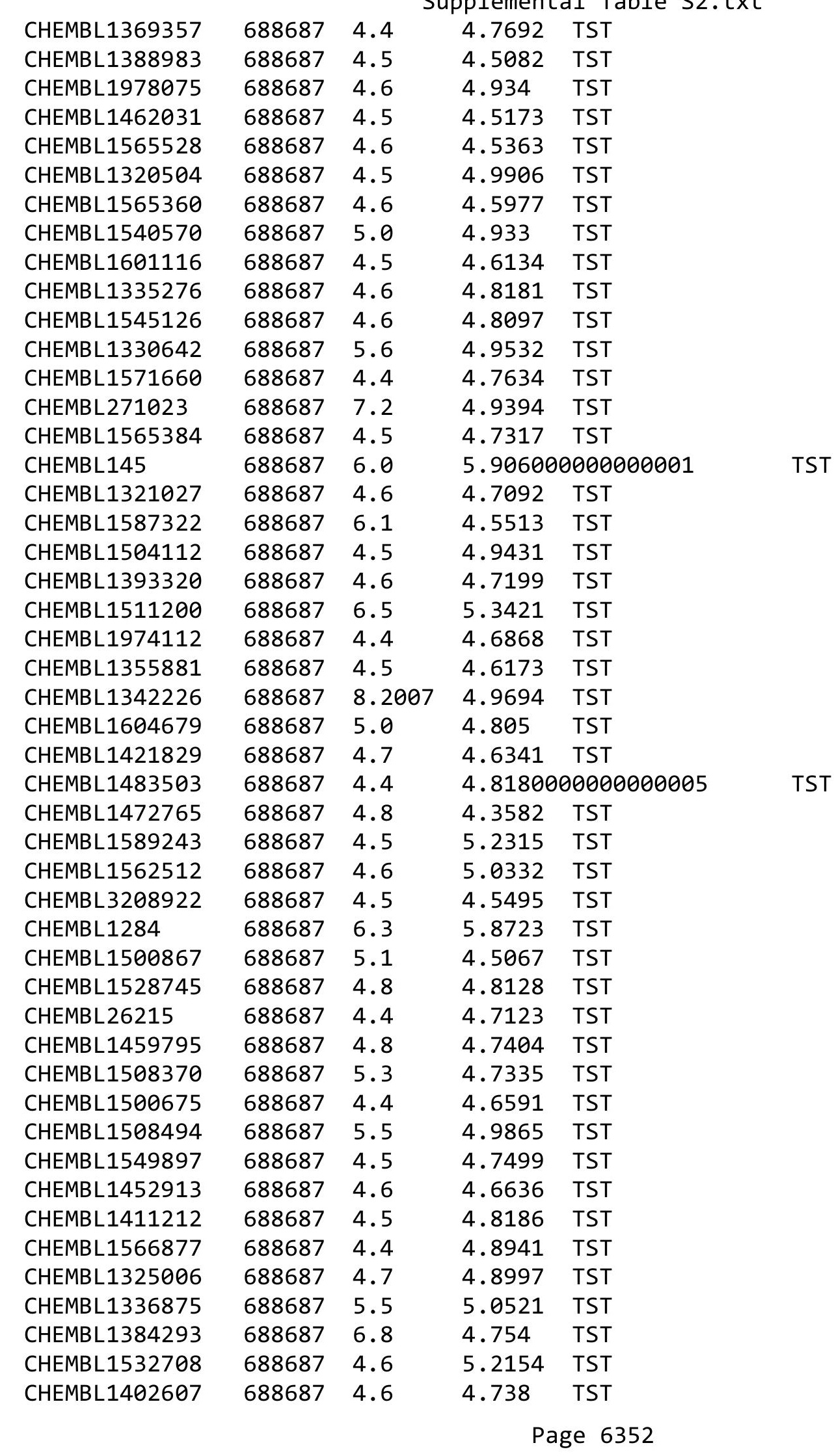




\begin{tabular}{|c|c|c|c|c|c|}
\hline & & & & & \\
\hline CHEMBL1354262 & 688687 & 4.4 & 4.8685 & TST & \\
\hline CHEMBL1524597 & 688687 & 4.4 & 5.0519 & TST & \\
\hline CHEMBL1425549 & 688687 & 5.2 & 4.8595 & TST & \\
\hline CHEMBL1546213 & 688687 & 4.6 & 4.8366 & TST & \\
\hline CHEMBL1496401 & 688687 & 4.6 & 4.8569 & TST & \\
\hline CHEMBL1490268 & 688687 & 4.4 & 4.8261 & TST & \\
\hline CHEMBL1450271 & 688687 & 4.6 & 4.6052 & TST & \\
\hline CHEMBL1466238 & 688687 & 5.0 & 4.8751 & TST & \\
\hline CHEMBL1478232 & 688687 & 4.5 & 4.7523 & TST & \\
\hline CHEMBL1343022 & 688687 & 4.6 & 4.8955 & TST & \\
\hline CHEMBL1359550 & 688687 & 4.5 & 4.6284 & TST & \\
\hline CHEMBL1352121 & 688687 & 5.2 & 4.6195 & TST & \\
\hline CHEMBL1411681 & 688687 & 6.6 & 4.9625 & TST & \\
\hline CHEMBL1411246 & 688687 & 5.4 & 5.1756 & TST & \\
\hline CHEMBL1489359 & 688687 & 5.5 & 4.8528 & TST & \\
\hline CHEMBL1446608 & 688687 & 4.7 & 5.37799 & 9999999999 & TST \\
\hline CHEMBL244857 & 688687 & 5.4 & 4.8887 & TST & \\
\hline CHEMBL1465175 & 688687 & 5.3 & 4.7696 & TST & \\
\hline CHEMBL236685 & 688687 & 6.1 & 4.9299 & TST & \\
\hline CHEMBL1398902 & 688687 & 4.5 & 4.59699 & 99999999995 & TST \\
\hline CHEMBL1372504 & 688687 & 4.6 & 4.7083 & TST & \\
\hline CHEMBL1393879 & 688687 & 4.5 & 4.8574 & TST & \\
\hline CHEMBL1342039 & 688687 & 4.4 & 4.5796 & TST & \\
\hline CHEMBL1495320 & 688687 & 4.5 & 4.7583 & TST & \\
\hline CHEMBL1342772 & 688687 & 4.4 & 4.6212 & TST & \\
\hline CHEMBL3392065 & 688687 & 4.4 & 5.0208 & TST & \\
\hline CHEMBL1525103 & 688687 & 4.5 & 4.496 & TST & \\
\hline CHEMBL1328040 & 688687 & 4.5 & 4.9953 & TST & \\
\hline CHEMBL1347892 & 688687 & 4.6 & 5.1028 & TST & \\
\hline CHEMBL1579398 & 688687 & 4.5 & 4.9909 & TST & \\
\hline CHEMBL1531067 & 688687 & 4.7 & 4.9804 & TST & \\
\hline CHEMBL1582569 & 688687 & 4.5 & 5.0535 & TST & \\
\hline CHEMBL1612434 & 688687 & 4.5 & 4.6643 & TST & \\
\hline CHEMBL1448444 & 688687 & 4.4 & 4.7636 & TST & \\
\hline CHEMBL1522129 & 688687 & 5.7 & 5.7591 & TST & \\
\hline CHEMBL1308898 & 688687 & 4.9 & 4.7627 & TST & \\
\hline CHEMBL1400407 & 688687 & 4.5 & 4.9137 & TST & \\
\hline CHEMBL1606322 & 688687 & 4.6 & 4.917 & TST & \\
\hline CHEMBL491976 & 688687 & 4.6 & 4.7636 & TST & \\
\hline CHEMBL1587055 & 688687 & 4.6 & 4.8695 & TST & \\
\hline CHEMBL1371792 & 688687 & 6.5 & 5.4129 & TST & \\
\hline CHEMBL580851 & 688687 & 4.8 & 5.0978 & TST & \\
\hline CHEMBL1537279 & 688687 & 5.4 & 4.6351 & TST & \\
\hline CHEMBL1466287 & 688687 & 4.5 & 4.814 & TST & \\
\hline CHEMBL1478772 & 688687 & 4.6 & 4.9382 & TST & \\
\hline CHEMBL1256019 & 688687 & 4.6 & 5.2061 & TST & \\
\hline CHEMBL 1353216 & 688687 & 4.6 & 4.873 & TST & \\
\hline CHEMBL1474681 & 688687 & 4.9 & 4.6454 & TST & \\
\hline & & & & e 6353 & \\
\hline
\end{tabular}




\begin{tabular}{|c|c|c|c|c|c|}
\hline & & & & & \\
\hline CHEMBL1537917 & 688687 & 4.5 & 4.6686 & TST & \\
\hline CHEMBL1448264 & 688687 & 4.6 & 5.0254 & TST & \\
\hline CHEMBL1605480 & 688687 & 4.6 & 4.709 & TST & \\
\hline CHEMBL1488865 & 688687 & 4.5 & 4.6503 & TST & \\
\hline CHEMBL1405511 & 688687 & 4.5 & 4.7998 & TST & \\
\hline CHEMBL1354249 & 688687 & 6.3 & $5.1960 e$ & 2000000001 & TST \\
\hline CHEMBL1565635 & 688687 & 5.0 & 4.8055 & TST & \\
\hline CHEMBL1329426 & 688687 & 4.8 & 4.9339 & TST & \\
\hline CHEMBL1492524 & 688687 & 5.5 & 4.6922 & TST & \\
\hline CHEMBL201325 & 688687 & 4.4 & 4.7846 & TST & \\
\hline CHEMBL1501318 & 688687 & 4.5 & 4.7147 & TST & \\
\hline CHEMBL1451698 & 688687 & 5.7 & 5.0902 & TST & \\
\hline CHEMBL1480554 & 688687 & 5.4 & 5.0019 & TST & \\
\hline CHEMBL1605162 & 688687 & 4.4 & 4.8583 & TST & \\
\hline CHEMBL1473849 & 688687 & 4.4 & 5.1776 & TST & \\
\hline CHEMBL1346737 & 688687 & 5.3 & 4.7836 & TST & \\
\hline CHEMBL1317009 & 688687 & 4.5 & 4.9203 & TST & \\
\hline CHEMBL1432842 & 688687 & 4.4 & 4.8878 & TST & \\
\hline CHEMBL1408476 & 688687 & 4.6 & 4.7999 & TST & \\
\hline CHEMBL1566869 & 688687 & 4.8 & 4.7986 & TST & \\
\hline CHEMBL1339717 & 688687 & 4.6 & 4.8641 & TST & \\
\hline CHEMBL1419169 & 688687 & 4.9 & 5.0777 & TST & \\
\hline CHEMBL1367737 & 688687 & 5.3 & 5.1712 & TST & \\
\hline CHEMBL18132 & 688687 & 4.4 & 5.1246 & TST & \\
\hline CHEMBL1374388 & 688687 & 4.5 & 4.7557 & TST & \\
\hline CHEMBL1575533 & 688687 & 4.8 & $4.5760 e$ & 00000000005 & TST \\
\hline CHEMBL1559303 & 688687 & 4.9 & 5.1328 & TST & \\
\hline CHEMBL1975289 & 688687 & 6.4 & 4.9269 & TST & \\
\hline CHEMBL1543497 & 688687 & 4.5 & 4.8151 & TST & \\
\hline CHEMBL1256698 & 688687 & 6.1 & 5.2833 & TST & \\
\hline CHEMBL1527601 & 688687 & 5.0 & 4.8766 & TST & \\
\hline CHEMBL1608349 & 688687 & 4.7 & 4.9555 & TST & \\
\hline CHEMBL3193785 & 688687 & 5.4 & 4.9025 & TST & \\
\hline CHEMBL1501739 & 688687 & 4.4 & 4.864 & TST & \\
\hline CHEMBL1437408 & 688687 & 4.7 & 4.6606 & TST & \\
\hline CHEMBL1382640 & 688687 & 4.5 & 4.6406 & TST & \\
\hline CHEMBL1542241 & 688687 & 4.8 & 4.8461 & TST & \\
\hline CHEMBL1303411 & 688687 & 5.5 & 5.0377 & TST & \\
\hline CHEMBL1538890 & 688687 & 4.6 & 4.638 & TST & \\
\hline CHEMBL1368877 & 688687 & 4.5 & 4.9798 & TST & \\
\hline CHEMBL1509585 & 688687 & 5.5 & 5.6683 & TST & \\
\hline CHEMBL1391901 & 688687 & 4.5 & 4.5616 & TST & \\
\hline CHEMBL1600740 & 688687 & 4.5 & 4.871 & TST & \\
\hline CHEMBL1563238 & 688687 & 4.5 & 4.8932 & TST & \\
\hline CHEMBL1256623 & 688687 & 5.8 & 5.7691 & TST & \\
\hline CHEMBL1485029 & 688687 & 4.9 & 4.6285 & TST & \\
\hline CHEMBL1439981 & 688687 & 4.5 & 4.599 & TST & \\
\hline CHEMBL1432222 & 688687 & 4.6 & 4.77 & TST & \\
\hline & & & & e 6354 & \\
\hline
\end{tabular}




\begin{tabular}{|c|c|c|c|c|}
\hline & & & pplement & al $\mathrm{Ta}$ \\
\hline CHEMBL1538676 & 688687 & 4.4 & 4.7472 & TST \\
\hline CHEMBL1559235 & 688687 & 4.6 & 4.5786 & TST \\
\hline CHEMBL1534533 & 688687 & 4.4 & 4.7248 & TST \\
\hline CHEMBL1363255 & 688687 & 4.5 & 4.6082 & TST \\
\hline CHEMBL1611308 & 688687 & 6.5 & 5.1297 & TST \\
\hline CHEMBL1584781 & 688687 & 5.1 & 4.7996 & TST \\
\hline CHEMBL1371148 & 688687 & 4.6 & 4.5088 & TST \\
\hline CHEMBL1524586 & 688687 & 4.5 & 4.5917 & TST \\
\hline CHEMBL1352679 & 688687 & 4.6 & 4.5862 & TST \\
\hline CHEMBL1566336 & 688687 & 4.6 & 4.8284 & TST \\
\hline CHEMBL1546734 & 688687 & 5.7 & 4.64 & TST \\
\hline CHEMBL1501471 & 688687 & 4.5 & 5.0497 & TST \\
\hline CHEMBL1603324 & 688687 & 4.4 & 4.9057 & TST \\
\hline CHEMBL1510397 & 688687 & 5.2 & 5.096 & TST \\
\hline CHEMBL1528757 & 688687 & 5.6 & 5.3346 & TST \\
\hline CHEMBL3338010 & 1435308 & 8.3979 & 8.2952 & TRN \\
\hline CHEMBL3338038 & 1435308 & 5.983 & 5.9497 & TRN \\
\hline CHEMBL3338046 & 1435308 & 5.7167 & 5.7695 & TRN \\
\hline CHEMBL3338013 & 1435308 & 8.0969 & 8.1422 & TRN \\
\hline CHEMBL3338026 & 1435308 & 8.1549 & 8.1664 & TRN \\
\hline CHEMBL3338041 & 1435308 & 5.6696 & 5.6384 & TRN \\
\hline CHEMBL3338009 & 1435308 & 8.0 & 8.1213 & TRN \\
\hline CHEMBL3338012 & 1435308 & 8.0969 & 8.0385 & TRN \\
\hline CHEMBL3338054 & 1435308 & 7.0088 & 7.0004 & TRN \\
\hline CHEMBL3338044 & 1435308 & 5.5702 & 5.5233 & TRN \\
\hline CHEMBL72529 & 1435308 & 8.5229 & 8.4655 & TRN \\
\hline CHEMBL3338050 & 1435308 & 8.699 & 8.7089 & TRN \\
\hline CHEMBL3338011 & 1435308 & 6.3098 & 6.3177 & TRN \\
\hline CHEMBL3338051 & 1435308 & 7.9208 & 7.9559 & TRN \\
\hline CHEMBL3338031 & 1435308 & 7.9586 & 7.9434 & TRN \\
\hline CHEMBL3338014 & 1435308 & 6.7959 & 6.8086 & TRN \\
\hline CHEMBL3338005 & 1435308 & 9.0 & 4.7811 & TST \\
\hline CHEMBL 71521 & 1435308 & 8.699 & 8.7505 & TRN \\
\hline CHEMBL3338029 & 1435308 & 7.4437 & 7.4627 & TRN \\
\hline CHEMBL3338045 & 1435308 & 5.2832 & 5.2626 & TRN \\
\hline CHEMBL3338023 & 1435308 & 8.5229 & 8.4952 & TRN \\
\hline CHEMBL3338037 & 1435308 & 7.2218 & 7.2219 & TRN \\
\hline CHEMBL3338032 & 1435308 & 6.8239 & 6.8038 & TRN \\
\hline CHEMBL3337461 & 1435308 & 4.0 & 4.0116 & TRN \\
\hline CHEMBL3338001 & 1435308 & 4.0 & 4.0188 & TRN \\
\hline CHEMBL3338007 & 1435308 & 5.1068 & 5.0477 & TRN \\
\hline CHEMBL3338016 & 1435308 & 8.0969 & 8.036 & TRN \\
\hline CHEMBL3338033 & 1435308 & 6.9208 & 6.9083 & TRN \\
\hline CHEMBL3338030 & 1435308 & 7.9586 & 7.9617 & TRN \\
\hline CHEMBL3338015 & 1435308 & 7.1871 & 7.1467 & TRN \\
\hline CHEMBL578061 & 1435308 & 4.0 & 5.5388 & TST \\
\hline CHEMBL3338002 & 1435308 & 4.0 & 4.0082 & TRN \\
\hline CHEMBL54893 & 1435308 & 8.5229 & 5.9955 & TST \\
\hline
\end{tabular}


Supplemental Table S2.txt

\begin{tabular}{|c|c|c|c|c|c|}
\hline CHEMBL3338004 & 1435308 & 4.0 & 3.9702 & TRN & \\
\hline CHEMBL3338049 & 1435308 & 8.699 & 8.7094 & TRN & \\
\hline CHEMBL 302791 & 1435308 & 8.699 & 8.6832 & TRN & \\
\hline CHEMBL 71728 & 1435308 & 8.699 & 8.7411 & TRN & \\
\hline CHEMBL470025 & 1435308 & 8.699 & 8.6933 & TRN & \\
\hline CHEMBL69503 & 1435308 & 8.699 & 8.6789 & TRN & \\
\hline CHEMBL 3338000 & 1435308 & 5.3468 & 6.1664 & TST & \\
\hline CHEMBL3338042 & 1435308 & 5.2708 & 5.3246 & TRN & \\
\hline CHEMBL3338017 & 1435308 & 8.0458 & 8.1356 & TRN & \\
\hline CHEMBL3338027 & 1435308 & 8.699 & 8.7014 & TRN & \\
\hline CHEMBL 3338043 & 1435308 & 5.5901 & 5.5933 & TRN & \\
\hline CHEMBL3338036 & 1435308 & 6.3872 & 6.3455 & TRN & \\
\hline CHEMBL 3338034 & 1435308 & 7.9586 & 7.967006 & 00000000005 & TRN \\
\hline CHEMBL3338035 & 1435308 & 5.8477 & 5.8926 & TRN & \\
\hline CHEMBL3338053 & 1435308 & 6.8013 & 6.81 & TRN & \\
\hline CHEMBL3338003 & 1435308 & 4.0 & 4.0392 & TRN & \\
\hline CHEMBL3337999 & 1435308 & 4.0 & 6.6015 & TST & \\
\hline CHEMBL3338055 & 1435308 & 9.0 & 3.7213 & TST & \\
\hline CHEMBL 74174 & 1435308 & 8.3979 & 8.3832 & TRN & \\
\hline CHEMBL3338025 & 1435308 & 7.4815 & 7.5383 & TRN & \\
\hline CHEMBL421114 & 1435308 & 8.0969 & 8.0684 & TRN & \\
\hline CHEMBL3338018 & 1435308 & 8.5229 & 8.5059 & TRN & \\
\hline CHEMBL 3338022 & 1435308 & 8.0458 & 8.0697 & TRN & \\
\hline CHEMBL3338052 & 1435308 & 8.5229 & 8.4985 & TRN & \\
\hline CHEMBL3338021 & 1435308 & 8.3979 & 7.2815 & TST & \\
\hline CHEMBL3338024 & 1435308 & 6.8861 & 6.9505 & TST & \\
\hline CHEMBL3338006 & 1435308 & 5.3615 & 5.1661 & TST & \\
\hline CHEMBL 3338020 & 1435308 & 9.0 & 8.5645 & TST & \\
\hline CHEMBL3338040 & 1435308 & 5.4179 & 5.9626 & TST & \\
\hline CHEMBL71659 & 1435308 & 8.5229 & 8.247 & TST & \\
\hline CHEMBL3338039 & 1435308 & 5.6946 & 6.0955 & TST & \\
\hline CHEMBL3338028 & 1435308 & 8.301 & 8.5266 & TST & \\
\hline CHEMBL 3338008 & 1435308 & 8.699 & 8.3347 & TST & \\
\hline CHEMBL3337998 & 1435308 & 4.0 & 7.8453 & TST & \\
\hline CHEMBL3338019 & 1435308 & 8.699 & 8.3861 & TST & \\
\hline CHEMBL3650500 & 1641572 & 8.5173 & 8.7468 & TRN & \\
\hline CHEMBL 3650494 & 1641572 & 9.1226 & 8.7684 & TRN & \\
\hline CHEMBL 3650503 & 1641572 & 8.4018 & 8.2671 & TRN & \\
\hline CHEMBL3650631 & 1641572 & 7.7307 & 7.9829 & TRN & \\
\hline CHEMBL 3654121 & 1641572 & 12.0 & 11.9676 & TRN & \\
\hline CHEMBL3654136 & 1641572 & 12.0 & 11.9756 & TRN & \\
\hline CHEMBL3650601 & 1641572 & 10.0915 & 10.0947 & TRN & \\
\hline CHEMBL3654117 & 1641572 & 9.9586 & 9.9377 & TST & \\
\hline CHEMBL 3654051 & 1641572 & 9.6003 & 9.6186 & TRN & \\
\hline CHEMBL 3654027 & 1641572 & 9.0915 & 9.1967 & TRN & \\
\hline CHEMBL 3654078 & 1641572 & 10.5528 & 10.7988 & TRN & \\
\hline CHEMBL3650565 & 1641572 & 4.9226 & 5.4119 & TRN & \\
\hline CHEMBL3650632 & 1641572 & 10.9208 & 10.669 & TRN & \\
\hline
\end{tabular}

Page 6356 
Supplemental Table S2.txt

\begin{tabular}{|c|c|c|c|c|c|c|}
\hline CHEMBL 3650663 & 1641572 & 10.2676 & \multicolumn{2}{|c|}{10.27900000000000} & TRN & \\
\hline CHEMBL 3650621 & 1641572 & 9.317 & 9.5118 & TRN & & \\
\hline CHEMBL 3654023 & 1641572 & 9.5591 & 9.8062 & TRN & & \\
\hline CHEMBL 3650660 & 1641572 & 9.8097 & 9.5155 & TRN & & \\
\hline CHEMBL 3650614 & 1641572 & 9.7423 & 10.1216 & TRN & & \\
\hline CHEMBL3654072 & 1641572 & 8.5095 & 8.6349 & TST & & \\
\hline CHEMBL 3984634 & 1641572 & 9.0851 & 9.5346 & TST & & \\
\hline CHEMBL 3650582 & 1641572 & 6.947 & 6.8816 & TRN & & \\
\hline CHEMBL3650639 & 1641572 & 10.3188 & 10.3228 & TRN & & \\
\hline CHEMBL 3650578 & 1641572 & 4.9226 & 5.0249 & TRN & & \\
\hline CHEMBL3650658 & 1641572 & 9.7645 & 9.8486 & TRN & & \\
\hline CHEMBL 3654163 & 1641572 & 9.451 & 9.669 & TST & & \\
\hline CHEMBL 3650537 & 1641572 & 10.0458 & 9.9155 & TRN & & \\
\hline CHEMBL 3650580 & 1641572 & 9.0182 & 8.5879 & TRN & & \\
\hline CHEMBL 3654001 & 1641572 & 9.9788 & 10.0544 & TRN & & \\
\hline CHEMBL 3654004 & 1641572 & 10.0362 & 9.9502 & TRN & & \\
\hline CHEMBL3650661 & 1641572 & 10.0809 & 10.1246 & TRN & & \\
\hline CHEMBL 3654118 & 1641572 & 10.30099 & 999999999 & 998 & 10.5925 TRN & \\
\hline CHEMBL 3654029 & 1641572 & 10.3768 & 10.3352 & TRN & & \\
\hline CHEMBL 3650668 & 1641572 & 10.6198 & 10.5843 & TRN & & \\
\hline CHEMBL 3650651 & 1641572 & 10.3372 & 10.4357 & TRN & & \\
\hline CHEMBL 3654064 & 1641572 & 9.8356 & 9.3742 & TST & & \\
\hline CHEMBL 3654100 & 1641572 & 8.4763 & 8.724 & TST & & \\
\hline CHEMBL 3650546 & 1641572 & 9.3391 & 9.4085 & TRN & & \\
\hline CHEMBL 3650603 & 1641572 & 9.9586 & 10.2882 & TRN & & \\
\hline CHEMBL 3650529 & 1641572 & 10.30099 & 999999999 & 998 & 10.0472 TRN & \\
\hline CHEMBL 3650486 & 1641572 & 8.0781 & 7.8742 & TRN & & \\
\hline CHEMBL3653989 & 1641572 & 8.12 & 8.2602 & TRN & & \\
\hline CHEMBL 3938580 & 1641572 & 7.5476 & 9.0099 & TST & & \\
\hline CHEMBL 3639530 & 1641572 & 9.7799 & 9.5009 & TST & & \\
\hline CHEMBL 3654129 & 1641572 & 12.0 & 11.8209 & TRN & & \\
\hline CHEMBL 3650655 & 1641572 & 10.4437 & 10.5965 & TRN & & \\
\hline CHEMBL 3654145 & 1641572 & 12.0 & 12.1305 & TRN & & \\
\hline CHEMBL 3654146 & 1641572 & 10.69906 & 000000000 & 002 & 10.584000000000001 & TST \\
\hline CHEMBL 3650589 & 1641572 & 9.4802 & 9.4404 & TRN & & \\
\hline CHEMBL3654161 & 1641572 & 8.6704 & 8.6981 & TRN & & \\
\hline CHEMBL 3650509 & 1641572 & 9.2916 & 9.0586 & TRN & & \\
\hline CHEMBL 3654028 & 1641572 & 7.5462 & 8.0258 & TRN & & \\
\hline CHEMBL 3654159 & 1641572 & 10.4559 & 10.8924 & TRN & & \\
\hline CHEMBL3653993 & 1641572 & 7.4324 & 7.9244 & TST & & \\
\hline CHEMBL 3654083 & 1641572 & 9.7375 & 9.4263 & TST & & \\
\hline CHEMBL 3654156 & 1641572 & 9.757 & 10.0127 & TST & & \\
\hline CHEMBL3653974 & 1641572 & 12.0 & 11.5382 & TRN & & \\
\hline CHEMBL 3654059 & 1641572 & 7.2866 & 7.7177 & TRN & & \\
\hline CHEMBL 3650605 & 1641572 & 10.1249 & 10.4193 & TRN & & \\
\hline CHEMBL 3650579 & 1641572 & 6.8339 & 6.5684 & TRN & & \\
\hline CHEMBL 3650570 & 1641572 & 4.9226 & 5.0682 & TRN & & \\
\hline CHEMBL 3654063 & 1641572 & 10.0362 & 9.5706 & TST & & \\
\hline
\end{tabular}




\begin{tabular}{|c|c|c|c|c|c|c|}
\hline \multirow[b]{2}{*}{ CHEMBL 3654090} & \multicolumn{6}{|c|}{ Supplemental Table S2.txt } \\
\hline & 1641572 & 10.4685 & 10.43 & TRN & & \\
\hline CHEMBL3654052 & 1641572 & 9.5638 & 9.6455 & TRN & & \\
\hline CHEMBL 3650495 & 1641572 & 9.767006 & 000000000 & $\partial 1$ & 9.7941 & TRN \\
\hline CHEMBL 3650551 & 1641572 & 8.0838 & 8.1366 & TRN & & \\
\hline CHEMBL3654095 & 1641572 & 10.3098 & 10.2889 & TRN & & \\
\hline CHEMBL 3650640 & 1641572 & 9.1637 & 9.2765 & TRN & & \\
\hline CHEMBL3650644 & 1641572 & 8.8713 & 9.1384 & TRN & & \\
\hline CHEMBL 3654125 & 1641572 & 10.9208 & 10.8725 & TRN & & \\
\hline CHEMBL3639494 & 1641572 & 9.8069 & 9.9991 & TRN & & \\
\hline CHEMBL3650590 & 1641572 & 9.6253 & 9.7066 & TRN & & \\
\hline CHEMBL3654162 & 1641572 & 10.1612 & 10.0486 & TRN & & \\
\hline CHEMBL3650629 & 1641572 & 9.1198 & 9.4268 & TRN & & \\
\hline CHEMBL3653998 & 1641572 & 10.1487 & 10.1165 & TRN & & \\
\hline CHEMBL 3650581 & 1641572 & 7.1465 & 7.2756 & TRN & & \\
\hline CHEMBL3650602 & 1641572 & 13.0 & 12.532 & TRN & & \\
\hline CHEMBL 3650574 & 1641572 & 8.5902 & 8.5568 & TRN & & \\
\hline CHEMBL 3650588 & 1641572 & 6.6685 & 6.7704 & TRN & & \\
\hline CHEMBL 3653964 & 1641572 & 12.0 & 11.7457 & TRN & & \\
\hline CHEMBL 3654010 & 1641572 & 10.2924 & 10.1478 & TRN & & \\
\hline CHEMBL 3654013 & 1641572 & 9.3615 & 9.6369 & TRN & & \\
\hline CHEMBL3654152 & 1641572 & 10.7447 & 10.9098 & TST & & \\
\hline CHEMBL3654094 & 1641572 & 12.0 & 11.6424 & TRN & & \\
\hline CHEMBL 3654109 & 1641572 & 8.5462 & 9.0967 & TRN & & \\
\hline CHEMBL 3654111 & 1641572 & 10.7959 & 10.7563 & TST & & \\
\hline CHEMBL 3654133 & 1641572 & 6.4844 & 6.737999 & 999999999 & 995 & TRN \\
\hline CHEMBL 3650592 & 1641572 & 7.7585 & 8.1383 & TST & & \\
\hline CHEMBL3654113 & 1641572 & 8.0192 & 7.7061 & TRN & & \\
\hline CHEMBL 3654038 & 1641572 & 10.7696 & 10.7664 & TRN & & \\
\hline CHEMBL3654116 & 1641572 & 10.2076 & 10.659 & TST & & \\
\hline CHEMBL 3654055 & 1641572 & 9.8962 & 9.9469 & TRN & & \\
\hline CHEMBL 3650672 & 1641572 & 9.6576 & 9.712 & TRN & & \\
\hline CHEMBL 3650525 & 1641572 & 10.4685 & 10.3084 & TRN & & \\
\hline CHEMBL 3650508 & 1641572 & 8.8236 & 8.836 & TRN & & \\
\hline CHEMBL3653975 & 1641572 & 10.6990 & 000000000 & 002 & 10.8558 & TRN \\
\hline CHEMBL 3654115 & 1641572 & 9.752 & 9.7098 & TRN & & \\
\hline CHEMBL 3650498 & 1641572 & 10.1024 & 10.014 & TRN & & \\
\hline CHEMBL3650521 & 1641572 & 10.7212 & 9.957 & TRN & & \\
\hline CHEMBL 3654093 & 1641572 & 12.0 & 11.5237 & TRN & & \\
\hline CHEMBL3892359 & 1641572 & 7.92700 & 000000000 & 205 & 8.4069 & TST \\
\hline CHEMBL 3968773 & 1641572 & 10.7959 & 10.2408 & TST & & \\
\hline CHEMBL 3654024 & 1641572 & 9.9586 & 9.9062 & TRN & & \\
\hline CHEMBL3654149 & 1641572 & 12.0 & 12.2438 & TST & & \\
\hline CHEMBL 3654140 & 1641572 & 9.9431 & 10.3022 & TST & & \\
\hline CHEMBL3650512 & 1641572 & 9.0443 & 9.073 & TRN & & \\
\hline CHEMBL 3650505 & 1641572 & 8.2632 & 7.9479 & TRN & & \\
\hline CHEMBL 3654026 & 1641572 & 9.4401 & 9.29 & TRN & & \\
\hline CHEMBL3650649 & 1641572 & 10.7212 & 10.6983 & TRN & & \\
\hline CHEMBL3654092 & 1641572 & 9.7055 & 9.8748 & TRN & & \\
\hline
\end{tabular}




$$
\text { Supplemental Table S2.txt }
$$

\begin{tabular}{|c|c|c|c|c|}
\hline CHEMBL 3650568 & 1641572 & 8.2788 & 8.2135 & TRN \\
\hline CHEMBL 3650543 & 1641572 & 9.6576 & 9.6102 & TRN \\
\hline CHEMBL3650666 & 1641572 & 10.1135 & 10.1807 & TRN \\
\hline CHEMBL 3650550 & 1641572 & 8.2267 & 8.2918 & TRN \\
\hline CHEMBL3650522 & 1641572 & 10.7212 & 10.51799 & 99999999999 \\
\hline CHEMBL3654137 & 1641572 & 7.7459 & 7.7777 & TRN \\
\hline CHEMBL3654123 & 1641572 & 8.3419 & 8.7153 & TRN \\
\hline CHEMBL3923860 & 1641572 & 9.7595 & 8.3142 & TST \\
\hline CHEMBL3650560 & 1641572 & 4.9226 & 5.3498 & TRN \\
\hline CHEMBL3654124 & 1641572 & 8.2181 & 8.7705 & TRN \\
\hline CHEMBL3650652 & 1641572 & 9.6198 & 9.7986 & TRN \\
\hline CHEMBL3654080 & 1641572 & 8.3439 & 8.3044 & TST \\
\hline CHEMBL3654135 & 1641572 & 8.634 & 8.6837 & TRN \\
\hline CHEMBL3654102 & 1641572 & 10.3768 & 10.6519 & TRN \\
\hline CHEMBL3650506 & 1641572 & 8.0825 & 7.8779 & TRN \\
\hline CHEMBL3654130 & 1641572 & 7.8245 & 7.4071 & TRN \\
\hline CHEMBL3654039 & 1641572 & 7.3983 & 7.3658 & TRN \\
\hline CHEMBL3650538 & 1641572 & 9.9747 & 10.1209 & TRN \\
\hline CHEMBL3653977 & 1641572 & 9.426 & 9.7705 & TST \\
\hline CHEMBL3653994 & 1641572 & 8.9801 & 8.9204 & TST \\
\hline CHEMBL3654017 & 1641572 & 8.1541 & 8.1896 & TRN \\
\hline CHEMBL3650517 & 1641572 & 10.6576 & 10.5833 & TRN \\
\hline CHEMBL3654040 & 1641572 & 8.7688 & 8.8046 & TRN \\
\hline CHEMBL3654132 & 1641572 & 8.2727 & 8.0335 & TRN \\
\hline CHEMBL3654018 & 1641572 & 9.9788 & 9.9323 & TST \\
\hline CHEMBL3650499 & 1641572 & 9.2321 & 9.2109 & TRN \\
\hline CHEMBL3654167 & 1641572 & 12.0 & 11.405 & TST \\
\hline CHEMBL3650659 & 1641572 & 8.5969 & 9.1134 & TST \\
\hline CHEMBL 3654171 & 1641572 & 9.279 & 9.3383 & TRN \\
\hline CHEMBL3650513 & 1641572 & 10.1487 & 10.0314 & TRN \\
\hline CHEMBL3654169 & 1641572 & 9.1427 & 9.0592 & TRN \\
\hline CHEMBL3650596 & 1641572 & 10.3768 & 10.3767 & TRN \\
\hline CHEMBL3654067 & 1641572 & 9.1612 & 9.1563 & TRN \\
\hline CHEMBL3654009 & 1641572 & 10.4089 & 10.1134 & TRN \\
\hline CHEMBL3650638 & 1641572 & 10.5086 & 10.6481 & TRN \\
\hline CHEMBL3650557 & 1641572 & 7.1145 & 6.7972 & TRN \\
\hline CHEMBL3650567 & 1641572 & 8.2498 & 7.7777 & TRN \\
\hline CHEMBL3650656 & 1641572 & 9.9508 & 9.9018 & TRN \\
\hline CHEMBL 3650573 & 1641572 & 4.9226 & 5.5676 & TRN \\
\hline CHEMBL3653973 & 1641572 & 9.5834 & 9.4676 & TRN \\
\hline CHEMBL3654034 & 1641572 & 9.2874 & 9.2866 & TRN \\
\hline CHEMBL3653967 & 1641572 & 7.6981 & 7.9927 & TST \\
\hline CHEMBL3653986 & 1641572 & 7.9622 & 7.6077 & TST \\
\hline CHEMBL3650635 & 1641572 & 9.1427 & 9.3404 & TRN \\
\hline CHEMBL 3654054 & 1641572 & 9.6326 & 9.6673 & TRN \\
\hline CHEMBL3653999 & 1641572 & 9.7055 & 9.842 & TRN \\
\hline CHEMBL3650650 & 1641572 & 10.4318 & 10.4609 & TRN \\
\hline CHEMBL3650667 & 1641572 & 9.2581 & 9.538 & TRN \\
\hline
\end{tabular}


Supplemental Table S2.txt

CHEMBL 3650535

CHEMBL 3650562

CHEMBL3654011

CHEMBL 3650625

CHEMBL 3654079

CHEMBL 3654108

CHEMBL 3650585

CHEMBL 3654068

CHEMBL 3650488

CHEMBL3650515

CHEMBL 3650533

CHEMBL3654070

CHEMBL 3654048

CHEMBL3650586

CHEMBL3654127

CHEMBL 3650518

CHEMBL3653978

CHEMBL3650612

CHEMBL 3650536

CHEMBL 3654060

CHEMBL 3650608

CHEMBL 3653972

CHEMBL 3654058

CHEMBL 3650534

CHEMBL 3650520

CHEMBL3650507

CHEMBL 3650634

CHEMBL3654089

CHEMBL 3654006

CHEMBL3653997

CHEMBL3650584

CHEMBL3654097

CHEMBL 3654035

CHEMBL3650524

CHEMBL3654114

CHEMBL3654139

CHEMBL 3653992

CHEMBL 3650617

CHEMBL 3653966

CHEMBL 3650597

CHEMBL 3654166

CHEMBL 3654053

CHEMBL3650541

CHEMBL3654056

CHEMBL3654104

CHEMBL 3654134

CHEMBL 3650577

CHEMBL 3654170 $\begin{array}{lll}1641572 & 10.1135 & 10.0378\end{array}$

$\begin{array}{llll}1641572 & 6.8276 & 6.7867 & \text { TRN }\end{array}$

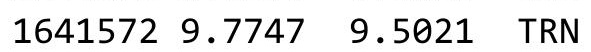

$\begin{array}{lll}1641572 & 10.2441 & 10.4664 \text { TRN }\end{array}$

$\begin{array}{lll}1641572 & 10.5376 & 10.6793\end{array}$

$\begin{array}{lll}1641572 & 12.0 \quad 11.6221 \text { TRN }\end{array}$

$\begin{array}{llll}1641572 & 8.1704 & 8.0675 & \text { TRN }\end{array}$

$\begin{array}{llll}1641572 & 9.8097 & 9.413 & \text { TST }\end{array}$

$\begin{array}{llll}1641572 & 9.0825 & 9.177 & \text { TRN }\end{array}$

$\begin{array}{llll}1641572 & 8.8002 & 8.7448 & \text { TRN }\end{array}$

$\begin{array}{lll}1641572 & 10.1805 & 10.1925 \text { TRN }\end{array}$

$\begin{array}{lll}1641572 & 9.2749 & 9.0092\end{array}$

$\begin{array}{lll}1641572 & 9.8827 & 10.0434\end{array}$

$\begin{array}{llll}1641572 & 8.6343 & 8.8637 & \text { TRN }\end{array}$

$\begin{array}{lll}1641572 & 10.8539 & 11.2493 \text { TRN }\end{array}$

$\begin{array}{lll}1641572 & 10.1549 & 10.2764 \text { TRN }\end{array}$

$\begin{array}{lll}1641572 & 10.5086 & 10.3173 \text { TRN }\end{array}$

$\begin{array}{llll}1641572 & 9.6757 & 9.7757 & \text { TRN }\end{array}$

$\begin{array}{lll}1641572 & 10.0862 & 9.5368\end{array}$

$\begin{array}{llll}1641572 & 7.8645 & 7.8667 & \text { TST }\end{array}$

$\begin{array}{lll}1641572 & 10.1938 & 10.1327 \\ \text { TRN }\end{array}$

$\begin{array}{lll}1641572 & 10.1308 & 10.0623\end{array}$

$\begin{array}{lll}1641572 & 10.2676 & 9.9662\end{array}$

$\begin{array}{lll}1641572 & 10.1427 & 10.0958 \text { TRN }\end{array}$

$\begin{array}{lll}1641572 & 10.8861 & 10.7305\end{array}$

$\begin{array}{llll}1641572 & 7.8245 & 7.647 & \text { TRN }\end{array}$

$\begin{array}{lll}1641572 & 10.4559 & 10.4947 \text { TRN }\end{array}$

$\begin{array}{llll}1641572 & 9.6234 & 9.4433 & \text { TRN }\end{array}$

16415728.761000000000001

$\begin{array}{lll}1641572 & 10.4089 & 10.3723 \text { TRN }\end{array}$

$\begin{array}{llll}1641572 & 7.3613 & 7.224 & \text { TRN }\end{array}$

$\begin{array}{lll}1641572 & 10.2441 & 10.1553 \text { TRN }\end{array}$

$\begin{array}{llll}1641572 & 9.0287 & 8.8269 & \text { TRN }\end{array}$

$\begin{array}{lll}1641572 & 10.5229 & 10.3692 \text { TRN }\end{array}$

$\begin{array}{llll}1641572 & 8.5494 & 8.2079 & \text { TRN }\end{array}$

164157210.699000000000002

$\begin{array}{llll}1641572 & 8.5478 & 8.4153 & \text { TRN }\end{array}$

$\begin{array}{lll}1641572 & 10.6778 & 10.9911 \text { TRN }\end{array}$

$\begin{array}{lll}1641572 & 11.0 & 10.7689\end{array}$

$\begin{array}{lll}1641572 & 9.9101 & 10.0627\end{array}$

$\begin{array}{llll}1641572 & 9.1637 & 9.4674 & \text { TST }\end{array}$

$\begin{array}{llll}1641572 & 9.719 & 9.9314 & \text { TRN }\end{array}$

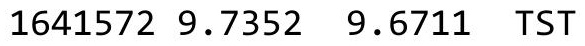

$\begin{array}{lll}1641572 & 10.113510 .1603 \text { TRN }\end{array}$

$\begin{array}{lll}1641572 & 12.0 & 11.9409 \\ 12.0\end{array}$

$\begin{array}{llll}1641572 & 7.2388 & 6.9513 & \text { TRN }\end{array}$

$\begin{array}{llll}1641572 & 9.3686 & 9.2262 & \text { TST }\end{array}$

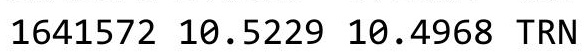

8.836 TRN

10.7868 TRN

Page 6360 
Supplemental Table S2.txt

$\begin{array}{lllll}\text { CHEMBL3653983 } & 1641572 & 9.8962 & 9.6149 & \text { TRN } \\ \text { CHEMBL3654045 } & 1641572 & 7.1005 & 7.2012 & \text { TRN } \\ \text { CHEMBL3654168 } & 1641572 & 7.6718 & 8.421 & \text { TRN } \\ \text { CHEMBL3653991 } & 1641572 & 8.9646 & 9.0127 & \text { TST } \\ \text { CHEMBL3650566 } & 1641572 & 7.8649 & 8.1182 & \text { TRN } \\ \text { CHEMBL3650572 } & 1641572 & 7.9735 & 7.7929 & \text { TRN } \\ \text { CHEMBL3654165 } & 1641572 & 8.9355 & 9.1504 & \text { TST } \\ \text { CHEMBL3650559 } & 1641572 & 6.3463 & 6.7289 & \text { TRN } \\ \text { CHEMBL3654065 } & 1641572 & 9.2807 & 8.9407 & \text { TST } \\ \text { CHEMBL3650576 } & 1641572 & 6.2509 & 6.2885 & \text { TRN } \\ \text { CHEMBL3654173 } & 1641572 & 9.757 & 7.2211 & \text { TRN } \\ \text { CHEMBL3650669 } & 1641572 & 10.1938 & 10.2183 & \text { TRN } \\ \text { CHEMBL3650642 } & 1641572 & 9.9208 & 10.0595 & \text { TRN } \\ \text { CHEMBL3650627 } & 1641572 & 9.8962 & 9.7815 & \text { TRN } \\ \text { CHEMBL3650563 } & 1641572 & 7.5079 & 7.4474 & \text { TRN } \\ \text { CHEMBL3650600 } & 1641572 & 9.6696 & 9.8445 & \text { TRN } \\ \text { CHEMBL3654164 } & 1641572 & 9.0241 & 9.1522 & \text { TST } \\ \text { CHEMBL3650504 } & 1641572 & 7.8523 & 7.8303 & \text { TRN } \\ \text { CHEMBL3650637 } & 1641572 & 10.5528 & 10.6357 & \text { TRN } \\ \text { CHEMBL3654012 } & 1641572 & 9.1726 & 9.5181 & \text { TRN } \\ \text { CHEMBL3654032 } & 1641572 & 8.7194 & 8.465 & \text { TRN } \\ \text { CHEMBL3654150 } & 1641572 & 12.0 & 12.3283 & \text { TST } \\ \text { CHEMBL3653984 } & 1641572 & 9.644 & 9.3861 & \text { TRN } \\ \text { CHEMBL3650502 } & 1641572 & 8.7749 & 8.5282 & \text { TST } \\ \text { CHEMBL3650591 } & 1641572 & 10.4089 & 10.5878 & \text { TST } \\ \text { CHEMBL3654157 } & 1641572 & 12.0 & 11.1917 & \text { TST } \\ \text { CHEMBL3654050 } & 1641572 & 12.0 & 11.6779 & \text { TRN } \\ \text { CHEMBL3654106 } & 1641572 & 8.4226 & 8.9018 & \text { TRN } \\ \text { CHEMBL3654041 } & 1641572 & 8.1221 & 7.695 & \text { TRN } \\ \text { CHEMBL3650527 } & 1641572 & 10.3279 & 10.3942 & \text { TRN } \\ \text { CHEMBL3654005 } & 1641572 & 10.1612 & 10.1911 & \text { TRN } \\ \text { CHEMBL3654044 } & 1641572 & 7.7642 & 7.7648 & \text { TRN } \\ \text { CHEMBL3650624 } & 1641572 & 10.5528 & 10.6888 & \text { TRN } \\ \text { CHEMBEL3650 } 3654014 & 1641572 & 8.9404 & 8.9812 & \text { TRN } \\ \text { CHEM } & 1641572 & 10.1487 & 10.3294 & \text { TRN }\end{array}$

Page 6361 
Supplemental Table S2.txt

\begin{tabular}{|c|c|c|c|c|c|c|}
\hline CHEMBL3654019 & 1641572 & 10.0132 & 10.1331 & TRN & & \\
\hline CHEMBL3654147 & 1641572 & 12.0 & 12.198 & TRN & & \\
\hline CHEMBL3653968 & 1641572 & 10.0757 & 10.3014 & TRN & & \\
\hline CHEMBL3654112 & 1641572 & 9.9431 & 9.7897 & TST & & \\
\hline CHEMBL3650628 & 1641572 & 9.9747 & 9.998 & TRN & & \\
\hline CHEMBL3650569 & 1641572 & 6.577999 & 99999999؛ & 99 & 6.8647 & TST \\
\hline CHEMBL3654160 & 1641572 & 10.4089 & 10.0924 & TRN & & \\
\hline CHEMBL 3654110 & 1641572 & 10.1024 & 10.0195 & TRN & & \\
\hline CHEMBL 3650613 & 1641572 & 10.2596 & 10.2093 & TRN & & \\
\hline CHEMBL3654049 & 1641572 & 10.7696 & 10.8348 & TRN & & \\
\hline CHEMBL3654069 & 1641572 & 9.7328 & 9.7081 & TRN & & \\
\hline CHEMBL3654103 & 1641572 & 11.30099 & 999999999 & 998 & 11.4864 & TRN \\
\hline CHEMBL3653990 & 1641572 & 9.7595 & 9.835 & TRN & & \\
\hline CHEMBL3650501 & 1641572 & 8.6043 & 8.4154 & TST & & \\
\hline CHEMBL 3650657 & 1641572 & 9.9245 & 9.8781 & TRN & & \\
\hline CHEMBL 3654148 & 1641572 & 12.0 & 11.5345 & TRN & & \\
\hline CHEMBL3650636 & 1641572 & 9.2083 & 9.2782 & TRN & & \\
\hline CHEMBL3650593 & 1641572 & 10.3768 & 10.3641 & TRN & & \\
\hline CHEMBL3653995 & 1641572 & 10.4318 & 10.3356 & TRN & & \\
\hline CHEMBL 3650552 & 1641572 & 7.6899 & 7.6036 & TST & & \\
\hline CHEMBL3639529 & 1641572 & 9.1733 & 8.9693 & TST & & \\
\hline CHEMBL 3650540 & 1641572 & 9.8097 & 9.7315 & TST & & \\
\hline CHEMBL 3650542 & 1641572 & 9.7282 & 9.4927 & TRN & & \\
\hline CHEMBL3650553 & 1641572 & 7.5003 & 7.2152 & TST & & \\
\hline CHEMBL 3650620 & 1641572 & 9.6517 & 9.8117 & TRN & & \\
\hline CHEMBL3654016 & 1641572 & 9.9245 & 10.0705 & TRN & & \\
\hline CHEMBL 3654081 & 1641572 & 8.4579 & 8.8326 & TST & & \\
\hline CHEMBL3654075 & 1641572 & 9.6882 & 9.6434 & TRN & & \\
\hline CHEMBL 3654077 & 1641572 & 9.7033 & 9.7262 & TRN & & \\
\hline CHEMBL 3653987 & 1641572 & 8.2516 & 8.4809 & TRN & & \\
\hline CHEMBL3650561 & 1641572 & 7.0007 & 6.6819 & TST & & \\
\hline CHEMBL3654015 & 1641572 & 10.30099 & 999999999 & 998 & 10.0957 & TRN \\
\hline CHEMBL 3654031 & 1641572 & 4.9226 & 5.4971 & TRN & & \\
\hline CHEMBL 3650653 & 1641572 & 10.4318 & 10.36900 & 0000000006 & 02 & TRN \\
\hline CHEMBL 3650575 & 1641572 & 7.7739 & 7.4274 & TST & & \\
\hline CHEMBL3653985 & 1641572 & 4.9226 & 5.5701 & TST & & \\
\hline CHEMBL3654061 & 1641572 & 9.9469 & 9.374 & TST & & \\
\hline CHEMBL 3654141 & 1641572 & 6.3691 & 6.4951 & TRN & & \\
\hline CHEMBL3650606 & 1641572 & 10.1675 & 10.3669 & TRN & & \\
\hline CHEMBL3653969 & 1641572 & 10.1249 & 10.2553 & TRN & & \\
\hline CHEMBL3650633 & 1641572 & 10.2076 & 10.1616 & TRN & & \\
\hline CHEMBL 3650662 & 1641572 & 10.4559 & 10.3115 & TRN & & \\
\hline CHEMBL3650496 & 1641572 & 9.4802 & 9.1365 & TST & & \\
\hline CHEMBL 3650491 & 1641572 & 9.104 & 9.0421 & TST & & \\
\hline CHEMBL3650630 & 1641572 & 8.158999 & 999999999 & & 8.1129 & TRN \\
\hline CHEMBL 3650641 & 1641572 & 10.2518 & 10.1601 & TRN & & \\
\hline CHEMBL 3650497 & 1641572 & 8.7902 & 8.1439 & TST & & \\
\hline CHEMBL 3654087 & 1641572 & 9.9666 & 9.9702 & TRN & & \\
\hline
\end{tabular}


Supplemental Table S2.txt

\begin{tabular}{|c|c|c|c|c|c|c|}
\hline CHEMBL3654099 & 1641572 & 10.7696 & 10.6797 & TRN & & \\
\hline CHEMBL3650549 & 1641572 & 9.0931 & 9.401 & TRN & & \\
\hline CHEMBL3650514 & 1641572 & 8.6975 & 8.8088 & TST & & \\
\hline CHEMBL 3650545 & 1641572 & 9.3585 & 9.4284 & TRN & & \\
\hline CHEMBL3653996 & 1641572 & 10.0044 & 10.2035 & TRN & & \\
\hline CHEMBL3650564 & 1641572 & 6.2911 & 6.1973 & TST & & \\
\hline CHEMBL3650487 & 1641572 & 7.5021 & 7.5467 & TST & & \\
\hline CHEMBL3650654 & 1641572 & 9.757 & 9.9088 & TRN & & \\
\hline CHEMBL 3654084 & 1641572 & 10.4318 & 10.2255 & TST & & \\
\hline CHEMBL3654025 & 1641572 & 10.1675 & 9.9821 & TRN & & \\
\hline CHEMBL3914833 & 1641572 & 12.0 & 10.9389 & TST & & \\
\hline CHEMBL3654098 & 1641572 & 9.4145 & 9.2866 & TRN & & \\
\hline CHEMBL3650647 & 1641572 & 10.1805 & 10.0539 & TRN & & \\
\hline CHEMBL 3654085 & 1641572 & 9.6737 & 9.6842 & TRN & & \\
\hline CHEMBL3654091 & 1641572 & 9.9706 & 9.387 & TST & & \\
\hline CHEMBL3650599 & 1641572 & 9.821 & 9.9219 & TRN & & \\
\hline CHEMBL3654151 & 1641572 & 12.0 & 11.1157 & TRN & & \\
\hline CHEMBL3650516 & 1641572 & 8.1443 & 7.9722 & TST & & \\
\hline CHEMBL3654142 & 1641572 & 8.2053 & 8.3433 & TST & & \\
\hline CHEMBL3650615 & 1641572 & 10.1675 & 10.0821 & TRN & & \\
\hline CHEMBL3650611 & 1641572 & 10.1805 & 10.261 & TST & & \\
\hline CHEMBL3654153 & 1641572 & 10.1135 & 9.6178 & TRN & & \\
\hline CHEMBL 3654120 & 1641572 & 10.4815 & 10.5641 & TRN & & \\
\hline CHEMBL3650610 & 1641572 & 10.1739 & 10.1901 & TRN & & \\
\hline CHEMBL3654074 & 1641572 & 10.2366 & 10.1007 & TRN & & \\
\hline CHEMBL3654155 & 1641572 & 9.8633 & 9.8668 & TST & & \\
\hline CHEMBL3654105 & 1641572 & 9.4237 & 9.526 & TST & & \\
\hline CHEMBL 3650547 & 1641572 & 9.28399 & 999999999 & 99 & 9.5111 & TRN \\
\hline CHEMBL3654071 & 1641572 & 12.0 & 11.8948 & TST & & \\
\hline CHEMBL3650595 & 1641572 & 10.4437 & 10.4175 & TRN & & \\
\hline CHEMBL3653981 & 1641572 & 10.5686 & 10.5696 & TRN & & \\
\hline CHEMBL3650492 & 1641572 & 8.5864 & 8.0785 & TST & & \\
\hline CHEMBL3650511 & 1641572 & 8.8775 & 8.9035 & TST & & \\
\hline CHEMBL3654046 & 1641572 & 10.4318 & 10.1524 & TRN & & \\
\hline CHEMBL3654128 & 1641572 & 12.0 & 11.6496 & TST & & \\
\hline CHEMBL3654076 & 1641572 & 12.0 & 12.0551 & TRN & & \\
\hline CHEMBL3650643 & 1641572 & 10.0862 & 10.1477 & TRN & & \\
\hline CHEMBL3654131 & 1641572 & 5.9226 & 6.2725 & TRN & & \\
\hline CHEMBL3650645 & 1641572 & 6.0 & 9.3605 & TRN & & \\
\hline CHEMBL3650648 & 1641572 & 9.2604 & 9.3088 & TRN & & \\
\hline CHEMBL3654042 & 1641572 & 9.9547 & 9.8179 & TRN & & \\
\hline CHEMBL3653971 & 1641572 & 10.4318 & 10.5417 & TST & & \\
\hline CHEMBL3654066 & 1641572 & 10.3979 & 10.0946 & TST & & \\
\hline CHEMBL3650556 & 1641572 & 6.7226 & 6.5798 & TST & & \\
\hline CHEMBL3653979 & 1641572 & 9.6556 & 9.7809 & TRN & & \\
\hline CHEMBL3650587 & 1641572 & 8.4477 & 8.2154 & TST & & \\
\hline CHEMBL3650598 & 1641572 & 10.1427 & 9.9734 & TRN & & \\
\hline CHEMBL3650594 & 1641572 & 10.4949 & 10.4121 & TRN & & \\
\hline
\end{tabular}

Page 6363 
Supplemental Table S2.txt

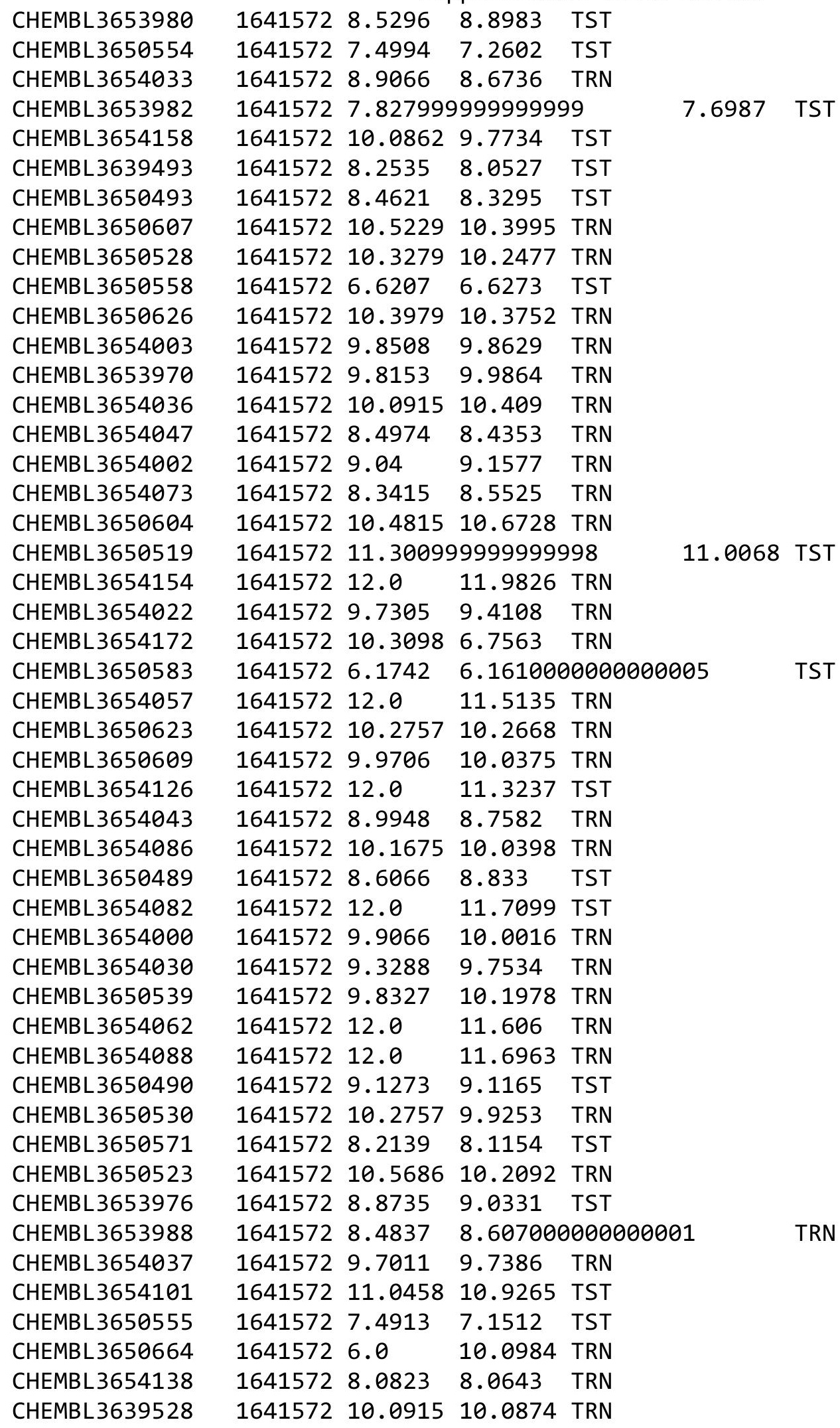


Supplemental Table S2.txt

\begin{tabular}{|c|c|c|c|c|c|}
\hline CHEMBL3650526 & 1641572 & 10.4437 & 10.242 & TRN & \\
\hline CHEMBL3650544 & 1641572 & 9.644 & 9.456 & TRN & \\
\hline CHEMBL3986031 & 1638333 & 6.5 & 6.8446 & TRN & \\
\hline CHEMBL3950244 & 1638333 & 7.4 & 7.4116 & TST & \\
\hline CHEMBL3936313 & 1638333 & 6.8 & 7.5527 & TRN & \\
\hline CHEMBL3975361 & 1638333 & 7.85 & 7.9515 & TRN & \\
\hline CHEMBL3972891 & 1638333 & 8.3 & 7.7056 & TRN & \\
\hline CHEMBL3936030 & 1638333 & 7.2 & 6.9364 & TST & \\
\hline CHEMBL3926339 & 1638333 & 6.4 & 6.8163 & TST & \\
\hline CHEMBL3981280 & 1638333 & 7.1 & 7.6096 & TRN & \\
\hline CHEMBL3978906 & 1638333 & 7.5 & 6.7555 & TST & \\
\hline CHEMBL3936387 & 1638333 & 6.8 & 6.4368 & TST & \\
\hline CHEMBL3939149 & 1638333 & 7.0 & 6.9364 & TST & \\
\hline CHEMBL3975672 & 1638333 & 7.4 & 7.0617 & TRN & \\
\hline CHEMBL3978163 & 1638333 & 7.6 & 7.59399 & 9999999999 & TRN \\
\hline CHEMBL3914902 & 1638333 & 7.9 & 7.6381 & TRN & \\
\hline CHEMBL3924729 & 1638333 & 7.8 & 6.7291 & TST & \\
\hline CHEMBL3922595 & 1638333 & 6.6 & 7.0083 & TRN & \\
\hline CHEMBL3962216 & 1638333 & 6.9 & 6.5351 & TST & \\
\hline CHEMBL3900518 & 1638333 & 7.4 & 6.5351 & TST & \\
\hline CHEMBL3903238 & 1638333 & 7.2 & 6.7997 & TST & \\
\hline CHEMBL3913118 & 1638333 & 7.0 & 6.6788 & TST & \\
\hline CHEMBL3964255 & 1638333 & 6.95 & 6.897 & TRN & \\
\hline CHEMBL3950900 & 1638333 & 8.55 & 7.0309 & TST & \\
\hline CHEMBL3948263 & 1638333 & 8.58 & 6.8703 & TST & \\
\hline CHEMBL3955287 & 1638333 & 6.6 & 7.108 & TST & \\
\hline CHEMBL3952672 & 1638333 & 7.7 & 7.7753 & TRN & \\
\hline CHEMBL3967281 & 1638333 & 8.4 & 8.0796 & TRN & \\
\hline CHEMBL 3962344 & 1638333 & 8.1 & 7.0597 & TST & \\
\hline CHEMBL3978115 & 1638333 & 8.1 & 7.6966 & TRN & \\
\hline CHEMBL3968950 & 1638333 & 8.4 & 8.0501 & TRN & \\
\hline CHEMBL3920558 & 1638333 & 7.7 & 7.6687 & TRN & \\
\hline CHEMBL3923266 & 1638333 & 8.4 & 7.0309 & TST & \\
\hline CHEMBL3910676 & 1638333 & 7.9 & 7.2714 & TST & \\
\hline CHEMBL3913347 & 1638333 & 8.2 & 7.0085 & TST & \\
\hline CHEMBL3906068 & 1638333 & 8.3 & 7.2336 & TST & \\
\hline CHEMBL3908892 & 1638333 & 8.0 & 6.8594 & TST & \\
\hline CHEMBL3958090 & 1638333 & 7.5 & 6.6412 & TST & \\
\hline CHEMBL3969947 & 1638333 & 5.6 & 6.9146 & TST & \\
\hline CHEMBL3889736 & 1638333 & 4.0 & 6.9646 & TRN & \\
\hline CHEMBL3946862 & 1638333 & 8.2 & 7.4754 & TST & \\
\hline CHEMBL3949556 & 1638333 & 8.2 & 7.2714 & TST & \\
\hline CHEMBL3909026 & 1638333 & 7.7 & 7.366006 & 00000000005 & TST \\
\hline CHEMBL3911750 & 1638333 & 7.9 & 7.5645 & TST & \\
\hline CHEMBL3932568 & 1638333 & 7.9 & 6.8961 & TST & \\
\hline CHEMBL3935259 & 1638333 & 7.9 & 7.1631 & TST & \\
\hline CHEMBL3976345 & 1638333 & 7.8 & 7.567 & TRN & \\
\hline CHEMBL3897251 & 1638333 & 7.1 & 7.9688 & TRN & \\
\hline
\end{tabular}




\begin{tabular}{|c|c|c|c|c|}
\hline & & & & \\
\hline CHEMBL 3908412 & 1638333 & 7.4 & 7.9688 & TRN \\
\hline CHEMBL3957021 & 1638333 & 7.6 & 7.7248 & TRN \\
\hline CHEMBL3965836 & 1638333 & 7.9 & 7.567 & TRN \\
\hline CHEMBL 3953888 & 1638333 & 7.4 & 7.7248 & TRN \\
\hline CHEMBL3904443 & 1638333 & 7.4 & 7.6015 & TRN \\
\hline CHEMBL3901739 & 1638333 & 7.5 & 7.6015 & TRN \\
\hline CHEMBL3979206 & 1638333 & 7.9 & 8.1315 & TRN \\
\hline CHEMBL3969300 & 1638333 & 7.0 & 6.8964 & TRN \\
\hline CHEMBL3918931 & 1638333 & 7.5 & 7.0748 & TRN \\
\hline CHEMBL3916168 & 1638333 & 7.3 & 6.4094 & TRN \\
\hline CHEMBL3973218 & 1638333 & 7.3 & 6.9081 & TRN \\
\hline CHEMBL3907955 & 1638333 & 7.1 & 7.0684 & TRN \\
\hline CHEMBL3906665 & 1638333 & 7.8 & 6.9875 & TRN \\
\hline CHEMBL3986076 & 1638333 & 7.25 & 6.6336 & TST \\
\hline CHEMBL3964147 & 1638333 & 8.0 & 7.1542 & TRN \\
\hline CHEMBL3954142 & 1638333 & 8.2 & 7.2417 & TRN \\
\hline CHEMBL3987020 & 1638333 & 8.7 & 7.7599 & TRN \\
\hline CHEMBL3940806 & 1638333 & 4.0 & 6.7919 & TST \\
\hline CHEMBL3969936 & 1638333 & 6.7 & 6.3621 & TRN \\
\hline CHEMBL3978946 & 1638333 & 7.2 & 6.7866 & TRN \\
\hline CHEMBL 3986344 & 1638333 & 7.0 & 6.9559 & TST \\
\hline CHEMBL 3902724 & 1638333 & 6.3 & 6.6526 & TST \\
\hline CHEMBL3920001 & 1638333 & 6.8 & 7.0748 & TRN \\
\hline CHEMBL3938343 & 1638333 & 6.9 & 7.119 & TRN \\
\hline CHEMBL3973838 & 1638333 & 6.4 & 6.9081 & TRN \\
\hline CHEMBL3921165 & 1638333 & 7.35 & 7.2417 & TRN \\
\hline CHEMBL3934345 & 1638333 & 6.5 & 6.9875 & TRN \\
\hline CHEMBL3931639 & 1638333 & 7.2 & 6.9457 & TRN \\
\hline CHEMBL3950017 & 1638333 & 6.93 & 6.9457 & TRN \\
\hline CHEMBL3947345 & 1638333 & 7.9 & 7.7599 & TRN \\
\hline CHEMBL 3940623 & 1638333 & 7.1 & 6.9216 & TRN \\
\hline CHEMBL3943265 & 1638333 & 4.0 & 6.135 & TRN \\
\hline CHEMBL3895518 & 1638333 & 7.7 & 7.3622 & TRN \\
\hline CHEMBL3905218 & 1638333 & 6.1 & 7.1542 & TRN \\
\hline CHEMBL3954659 & 1638333 & 5.9 & 6.6542 & TRN \\
\hline CHEMBL3908976 & 1638333 & 8.2 & 6.5787 & TST \\
\hline CHEMBL3986598 & 1638333 & 7.93 & 7.2392 & TRN \\
\hline CHEMBL3891538 & 1638333 & 7.9 & 7.1231 & TRN \\
\hline CHEMBL 3929745 & 1638333 & 7.85 & 7.2392 & TRN \\
\hline CHEMBL3950815 & 1638333 & 4.0 & 5.444 & TRN \\
\hline CHEMBL3896696 & 1638333 & 5.6 & 6.0194 & TRN \\
\hline CHEMBL3964543 & 1638333 & 7.0 & 6.9216 & TRN \\
\hline CHEMBL3903230 & 1638333 & 8.3 & 7.5451 & TST \\
\hline CHEMBL 3921641 & 1638333 & 8.5 & 7.5697 & TST \\
\hline CHEMBL3970997 & 1638333 & 8.1 & 8.1315 & TRN \\
\hline CHEMBL 3968241 & 1638333 & 5.0 & 7.8111 & TRN \\
\hline CHEMBL3909990 & 1638333 & 8.3 & 7.6209 & TRN \\
\hline CHEMBL3951502 & 1638333 & 8.1 & 7.169 & TRN \\
\hline
\end{tabular}




\begin{tabular}{|c|c|c|c|c|c|}
\hline \multicolumn{6}{|c|}{ Supplemental Table S2.txt } \\
\hline CHEMBL3985316 & 1638333 & 7.9 & 7.5943 & TST & \\
\hline CHEMBL3897301 & 1638333 & 8.1 & 7.3924 & TRN & \\
\hline CHEMBL3935315 & 1638333 & 8.1 & 7.1962 & TRN & \\
\hline CHEMBL3923362 & 1638333 & 4.0 & 4.728 & TRN & \\
\hline CHEMBL3956990 & 1638333 & 4.0 & 4.728 & TRN & \\
\hline CHEMBL3954388 & 1638333 & 8.55 & 7.0605 & TRN & \\
\hline CHEMBL3911722 & 1638333 & 8.3 & 7.041 & TRN & \\
\hline CHEMBL3908997 & 1638333 & 8.2 & 7.6209 & TRN & \\
\hline CHEMBL3972691 & 1638333 & 8.1 & 7.169 & TRN & \\
\hline CHEMBL3960838 & 1638333 & 7.8 & 8.0384 & TRN & \\
\hline CHEMBL3903052 & 1638333 & 6.8 & 6.9821 & TRN & \\
\hline CHEMBL3905716 & 1638333 & 7.8 & 7.5146 & TRN & \\
\hline CHEMBL3962012 & 1638333 & 7.5 & 7.2741 & TRN & \\
\hline CHEMBL3986393 & 1638333 & 6.55 & 6.641 & TST & \\
\hline CHEMBL3891308 & 1638333 & 8.3 & 8.2006 & TRN & \\
\hline CHEMBL3941108 & 1638333 & 8.0 & 7.2688 & TRN & \\
\hline CHEMBL3950597 & 1638333 & 6.9 & 6.941 & TRN & \\
\hline CHEMBL3895308 & 1638333 & 7.2 & 6.846 & TRN & \\
\hline CHEMBL3897976 & 1638333 & 7.2 & 7.4239 & TRN & \\
\hline CHEMBL3935894 & 1638333 & 7.7 & 7.2678 & TRN & \\
\hline CHEMBL3926192 & 1638333 & 7.3 & 7.1018 & TRN & \\
\hline CHEMBL3908728 & 1638333 & 6.5 & 7.2663 & TRN & \\
\hline CHEMBL3972753 & 1638333 & 8.45 & 7.2069 & TST & \\
\hline CHEMBL3950116 & 1638333 & 7.7 & 7.2375 & TRN & \\
\hline CHEMBL3926955 & 1638333 & 7.3 & 7.3797 & TRN & \\
\hline CHEMBL3890799 & 1638333 & 7.3 & 7.5256 & TRN & \\
\hline CHEMBL3985868 & 1638333 & 7.8 & 7.5157 & TRN & \\
\hline CHEMBL3926527 & 1638333 & 7.7 & 7.9944 & TRN & \\
\hline CHEMBL3918424 & 1638333 & 7.4 & 7.2933 & TRN & \\
\hline CHEMBL3895338 & 1638333 & 7.1 & 7.9274 & TRN & \\
\hline CHEMBL3892607 & 1638333 & 7.27 & 7.6638 & TRN & \\
\hline CHEMBL3954472 & 1638333 & 7.77 & 7.2957 & TRN & \\
\hline CHEMBL3951816 & 1638333 & 7.7 & 7.58700 & 0000000001 & TRN \\
\hline CHEMBL3979252 & 1638333 & 8.35 & 7.6664 & TRN & \\
\hline CHEMBL3940439 & 1638333 & 7.8 & 8.5827 & TRN & \\
\hline CHEMBL3930643 & 1638333 & 8.0 & 8.4854 & TRN & \\
\hline CHEMBL3976660 & 1638333 & 8.0 & 8.9036 & TRN & \\
\hline CHEMBL3982724 & 1638333 & 7.5 & 8.6526 & TRN & \\
\hline CHEMBL3942614 & 1638333 & 8.7 & 7.4509 & TRN & \\
\hline CHEMBL3932191 & 1638333 & 7.5 & 7.1775 & TRN & \\
\hline CHEMBL3981204 & 1638333 & 6.8 & 7.0585 & TRN & \\
\hline CHEMBL3983692 & 1638333 & 7.9 & 7.7067 & TRN & \\
\hline CHEMBL3921195 & 1638333 & 7.2 & 7.0323 & TRN & \\
\hline CHEMBL3943152 & 1638333 & 7.77 & 7.3557 & TRN & \\
\hline CHEMBL3965393 & 1638333 & 6.9 & 6.5985 & TRN & \\
\hline CHEMBL3970565 & 1638333 & 7.3 & 7.6046 & TRN & \\
\hline CHEMBL3906749 & 1638333 & 7.7 & 6.5785 & TST & \\
\hline CHEMBL3965282 & 1638333 & 7.6 & 7.9379 & TRN & \\
\hline
\end{tabular}




\begin{tabular}{|c|c|c|c|c|c|c|}
\hline \multicolumn{7}{|c|}{ pplemental Ta } \\
\hline CHEMBL3943229 & 1638333 & 6.6 & 7.0248 & TRN & & \\
\hline CHEMBL3940580 & 1638333 & 7.6 & 7.607 & TRN & & \\
\hline CHEMBL3911951 & 1638333 & 8.13 & 7.4746 & TRN & & \\
\hline CHEMBL 3909231 & 1638333 & 8.2 & 6.3697 & TST & & \\
\hline CHEMBL 3956501 & 1638333 & 8.4 & 7.2389 & TRN & & \\
\hline CHEMBL 3947060 & 1638333 & 8.37 & 7.4433 & TRN & & \\
\hline CHEMBL3928899 & 1638333 & 6.2 & 6.9388 & TRN & & \\
\hline CHEMBL 3979858 & 1638333 & 7.2 & 7.235 & TRN & & \\
\hline CHEMBL 3977506 & 1638333 & 8.2 & 8.1436 & TRN & & \\
\hline CHEMBL 3983258 & 1638333 & 7.1 & 7.626 & TRN & & \\
\hline CHEMBL3985915 & 1638333 & 8.1 & 7.6197 & TRN & & \\
\hline CHEMBL3937928 & 1638333 & 8.53 & 8.5961 & TRN & & \\
\hline CHEMBL 3945874 & 1638333 & 7.4 & 7.7033 & TRN & & \\
\hline CHEMBL3960033 & 1638333 & 7.4 & 7.5875 & TRN & & \\
\hline CHEMBL 3902600 & 1638333 & 7.8 & 7.8198 & TRN & & \\
\hline CHEMBL 3958849 & 1638333 & 7.33 & 7.3532 & TRN & & \\
\hline CHEMBL3961536 & 1638333 & 7.77 & 8.8619 & TRN & & \\
\hline CHEMBL212911 & 822294 & 7.921 & 7.9428 & TRN & & \\
\hline CHEMBL 213315 & 822294 & 8.2220 & 00000000 & & 7.7073 & TRN \\
\hline CHEMBL 214921 & 822294 & 8.2220 & 00000000 & & 7.8106 & TRN \\
\hline CHEMBL 213314 & 822294 & 7.42 & 7.4254 & TRN & & \\
\hline CHEMBL 2037003 & 822294 & 8.2220 & 00000000 & & 7.9523 & TRN \\
\hline CHEMBL 2036997 & 822294 & 7.229 & 7.2843 & TRN & & \\
\hline CHEMBL237519 & 822294 & 7.77 & 8.2188 & TRN & & \\
\hline CHEMBL 237307 & 822294 & 8.301 & 8.2612 & TRN & & \\
\hline CHEMBL 215245 & 822294 & 7.2010 & 30000000 & 005 & 7.5617 & TRN \\
\hline CHEMBL 2037004 & 822294 & 7.745 & 8.0378 & TRN & & \\
\hline CHEMBL344282 & 822294 & 5.77 & 5.7329 & TRN & & \\
\hline CHEMBL149438 & 822294 & 5.77 & 5.522 & TRN & & \\
\hline CHEMBL 237520 & 822294 & 8.0970 & 30000000 & & 8.2309 & TRN \\
\hline CHEMBL 237305 & 822294 & 7.3279 & 99999999 & & 7.689 & TRN \\
\hline CHEMBL149676 & 822294 & 5.31 & 5.4405 & TRN & & \\
\hline CHEMBL148639 & 822294 & 6.284 & 5.9448 & TRN & & \\
\hline CHEMBL 215701 & 822294 & 7.721 & 7.7386 & TRN & & \\
\hline CHEMBL 377660 & 822294 & 8.2220 & 00000000 & & 7.5417 & TRN \\
\hline CHEMBL213361 & 822294 & 7.215 & 7.7067 & TRN & & \\
\hline CHEMBL 214026 & 822294 & 7.824 & 7.7181 & TRN & & \\
\hline CHEMBL237306 & 822294 & 8.0970 & 00000000 & & 7.5231 & TRN \\
\hline CHEMBL 237277 & 822294 & 7.886 & 7.8067 & TST & & \\
\hline CHEMBL 236877 & 822294 & 7.921 & 7.6268 & TRN & & \\
\hline CHEMBL 237485 & 822294 & 8.0970 & 00000000 & & 7.5528 & TST \\
\hline CHEMBL392058 & 822294 & 7.745 & 7.78 & TRN & & \\
\hline CHEMBL236875 & 822294 & 8.0 & 7.7327 & TRN & & \\
\hline CHEMBL 236664 & 822294 & 8.046 & 7.6868 & TRN & & \\
\hline CHEMBL232396 & 822294 & 4.666 & 6.5579 & TST & & \\
\hline CHEMBL234659 & 822294 & 4.627 & 6.7111 & TST & & \\
\hline CHEMBL 234662 & 822294 & 4.86 & 6.2088 & TST & & \\
\hline CHEMBL 2037005 & 822294 & 5.65 & 6.6043 & TST & & \\
\hline
\end{tabular}




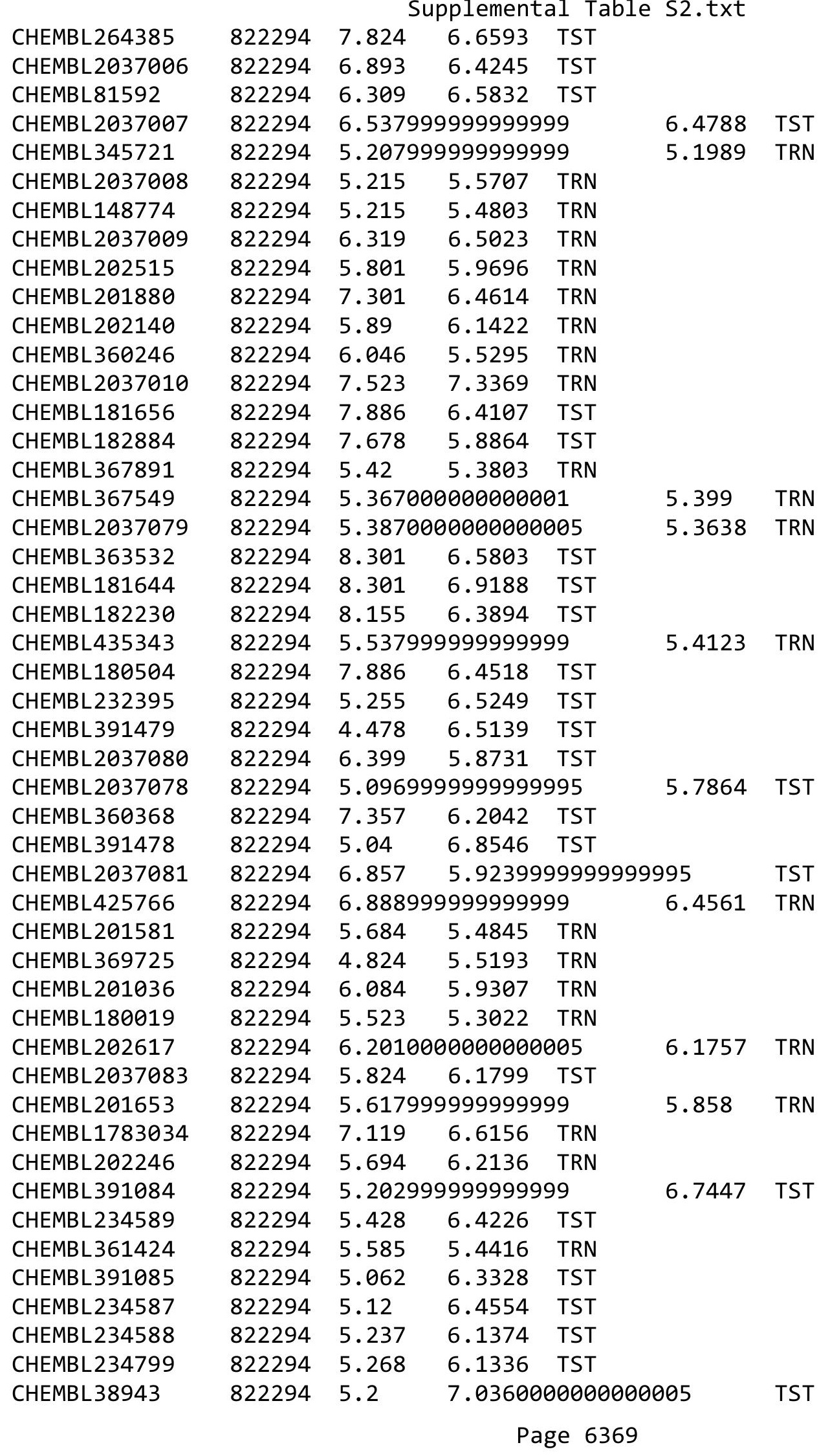




\begin{tabular}{|c|c|c|c|c|c|c|}
\hline \multirow[b]{2}{*}{ CHEMBL 278994} & \multirow[b]{2}{*}{822294} & \multicolumn{5}{|c|}{ Supplemental Table S2.txt } \\
\hline & & \multicolumn{5}{|c|}{$\begin{array}{lll}7.027 & 6.6644 & \text { TRN }\end{array}$} \\
\hline CHEMBL 207103 & 822294 & \multicolumn{3}{|c|}{6.9910000000000005} & 7.1703 & TRN \\
\hline CHEMBL427040 & 822294 & \multicolumn{3}{|c|}{5.337000000000001} & 5.8143 & TRN \\
\hline CHEMBL 383728 & 822294 & 5.721 & 5.9359 & TRN & & \\
\hline CHEMBL 209563 & 822294 & \multicolumn{3}{|c|}{6.337000000000001} & 5.91 & TRN \\
\hline CHEMBL 210768 & 822294 & 6.553 & 6.6447 & TRN & & \\
\hline CHEMBL 210973 & 822294 & 6.569 & 6.5793 & TRN & & \\
\hline CHEMBL207907 & 822294 & 5.921 & 5.955 & TRN & & \\
\hline CHEMBL 207442 & 822294 & 5.523 & 5.455 & TRN & & \\
\hline CHEMBL207019 & 822294 & \multicolumn{3}{|c|}{5.537999999999999} & 5.6956 & TRN \\
\hline CHEMBL 241286 & 822294 & 6.461 & 6.4965 & TRN & & \\
\hline CHEMBL241471 & 822294 & \multicolumn{3}{|c|}{7.337000000000001} & 7.445 & TRN \\
\hline CHEMBL 241479 & 822294 & 7.456 & 7.5061 & TRN & & \\
\hline CHEMBL 241478 & 822294 & 7.699 & 7.8228 & TRN & & \\
\hline CHEMBL391470 & 822294 & 6.316 & 6.307 & TRN & & \\
\hline CHEMBL 238970 & 822294 & 7.796 & 7.9049 & TRN & & \\
\hline CHEMBL391264 & 822294 & 6.027 & 6.2333 & TRN & & \\
\hline CHEMBL 241298 & 822294 & \multicolumn{3}{|c|}{6.0089999999999995} & 6.0857 & TRN \\
\hline CHEMBL 2037082 & 822294 & 6.347 & 6.2135 & TRN & & \\
\hline CHEMBL 206794 & 822294 & \multicolumn{3}{|c|}{6.007999999999999} & 6.5214 & TRN \\
\hline CHEMBL23296 & 822294 & 6.71 & 7.0551 & TRN & & \\
\hline CHEMBL23670 & 822294 & \multicolumn{3}{|c|}{6.252000000000001} & 6.2986 & TRN \\
\hline CHEMBL 241078 & 822294 & \multicolumn{3}{|c|}{5.962999999999999} & 6.1661 & TRN \\
\hline CHEMBL 392063 & 822294 & 6.246 & 6.2991 & TRN & & \\
\hline CHEMBL1783033 & 822294 & 7.319 & 6.7893 & TRN & & \\
\hline CHEMBL 279053 & 822294 & 6.959 & 7.1027 & TRN & & \\
\hline CHEMBL 200495 & 822294 & 6.818 & 6.2358 & TRN & & \\
\hline CHEMBL 2037181 & 822294 & \multicolumn{3}{|c|}{7.2010000000000005} & 6.9764 & TRN \\
\hline CHEMBL 2037182 & 822294 & 7.523 & 7.5888 & TRN & & \\
\hline CHEMBL 2037183 & 822294 & 7.721 & 7.6158 & TRN & & \\
\hline CHEMBL 2037184 & 822294 & 5.975 & 6.0467 & TRN & & \\
\hline CHEMBL 205665 & 822294 & 6.07 & 6.3815 & TST & & \\
\hline CHEMBL 23881 & 822294 & 6.237 & 6.7421 & TRN & & \\
\hline CHEMBL 25710 & 822294 & 6.523 & 6.7472 & TRN & & \\
\hline CHEMBL491039 & 822294 & 4.398 & 5.9159 & TST & & \\
\hline CHEMBL491237 & 822294 & 4.699 & 5.6546 & TST & & \\
\hline CHEMBL 235143 & 822294 & 7.569 & 7.785 & TST & & \\
\hline CHEMBL393939 & 822294 & 8.155 & 7.7286 & TRN & & \\
\hline CHEMBL 238357 & 822294 & 7.409 & \multicolumn{3}{|c|}{6.928999999999999} & TST \\
\hline CHEMBL237518 & 822294 & 7.921 & 8.3342 & TRN & & \\
\hline CHEMBL392717 & 822294 & \multicolumn{3}{|c|}{8.097000000000001} & 8.0991 & TRN \\
\hline CHEMBL237086 & 822294 & 8.046 & 7.9062 & TRN & & \\
\hline CHEMBL 237710 & 822294 & 6.943 & 7.7183 & TRN & & \\
\hline CHEMBL 236876 & 822294 & 7.921 & 7.8421 & TRN & & \\
\hline CHEMBL 237484 & 822294 & \multicolumn{3}{|c|}{6.632999999999999} & 7.7035 & TST \\
\hline CHEMBL393938 & 822294 & 7.824 & 7.8118 & TRN & & \\
\hline CHEMBL 237084 & 822294 & 6.693 & 7.4037 & TRN & & \\
\hline \multirow[t]{2}{*}{ CHEMBL401236 } & 822294 & 7.301 & 7.2901 & TST & & \\
\hline & & \multicolumn{5}{|c|}{ Page 6370} \\
\hline
\end{tabular}




\begin{tabular}{|c|c|c|c|c|c|}
\hline & & & & & \\
\hline CHEMBL236218 & 822294 & 7.432 & 7.4234 & TST & \\
\hline CHEMBL399217 & 822294 & 7.022 & 7.6221 & TST & \\
\hline CHEMBL237085 & 822294 & 8.155 & 7.5876 & TRN & \\
\hline CHEMBL485087 & 822294 & 5.3 & 5.3493 & TRN & \\
\hline CHEMBL495904 & 822294 & 5.7 & 5.8003 & TRN & \\
\hline CHEMBL495905 & 822294 & 5.9 & 5.8359 & TRN & \\
\hline CHEMBL498172 & 822294 & 5.8 & 5.8858 & TRN & \\
\hline CHEMBL525552 & 822294 & 5.0 & 5.5266 & TRN & \\
\hline CHEMBL525366 & 822294 & 5.8 & 5.5288 & TRN & \\
\hline CHEMBL498171 & 822294 & 5.6 & 5.5014 & TRN & \\
\hline CHEMBL496733 & 822294 & 5.7 & 5.8859 & TRN & \\
\hline CHEMBL522575 & 822294 & 5.6 & 5.4995 & TRN & \\
\hline CHEMBL519345 & 822294 & 5.2 & 5.2187 & TRN & \\
\hline CHEMBL522619 & 822294 & 5.5 & 5.3385 & TRN & \\
\hline CHEMBL485088 & 822294 & 5.4 & 5.3834 & TRN & \\
\hline CHEMBL484266 & 822294 & 5.6 & 5.45200 & $\partial 000000001$ & TRN \\
\hline CHEMBL496116 & 822294 & 5.1 & 5.36799 & 9999999999 & TRN \\
\hline CHEMBL496744 & 822294 & 5.7 & 5.4709 & TRN & \\
\hline CHEMBL484467 & 822294 & 5.4 & 5.3978 & TRN & \\
\hline CHEMBL497789 & 822294 & 5.4 & 5.5612 & TRN & \\
\hline CHEMBL497991 & 822294 & 5.6 & 5.4103 & TRN & \\
\hline CHEMBL520827 & 822294 & 5.3 & 5.0736 & TRN & \\
\hline CHEMBL522577 & 822294 & 5.5 & 5.72 & TRN & \\
\hline CHEMBL522224 & 822294 & 6.0 & 5.8324 & TRN & \\
\hline CHEMBL496136 & 822294 & 5.1 & 5.3412 & TRN & \\
\hline CHEMBL496534 & 822294 & 6.1 & 6.0642 & TRN & \\
\hline CHEMBL498401 & 822294 & 5.1 & 5.2321 & TRN & \\
\hline CHEMBL496743 & 822294 & 5.5 & 5.7152 & TRN & \\
\hline CHEMBL524829 & 822294 & 5.2 & 5.2115 & TRN & \\
\hline CHEMBL496726 & 822294 & 5.4 & 5.29899 & 99999999995 & TRN \\
\hline CHEMBL498608 & 822294 & 5.5 & 5.2936 & TRN & \\
\hline CHEMBL496933 & 822294 & 5.3 & 5.3149 & TRN & \\
\hline CHEMBL1412900 & 737826 & 4.9 & 4.9227 & TRN & \\
\hline CHEMBL1445999 & 737826 & 4.85 & 5.1163 & TST & \\
\hline CHEMBL1522755 & 737826 & 6.15 & 5.4301 & TRN & \\
\hline CHEMBL1353351 & 737826 & 5.7 & 5.4172 & TRN & \\
\hline CHEMBL1384001 & 737826 & 5.55 & 5.2199 & TST & \\
\hline CHEMBL1602560 & 737826 & 8.15 & 5.1763 & TRN & \\
\hline CHEMBL576349 & 737826 & 4.6 & 4.7427 & TRN & \\
\hline CHEMBL1412519 & 737826 & 5.4 & 5.3908 & TST & \\
\hline CHEMBL1423250 & 737826 & 5.6 & 5.2618 & TRN & \\
\hline CHEMBL1460984 & 737826 & 5.05 & 5.4556 & TRN & \\
\hline CHEMBL1598994 & 737826 & 4.9 & 4.7922 & TRN & \\
\hline CHEMBL1529948 & 737826 & 5.3 & 5.4081 & TRN & \\
\hline CHEMBL 1457317 & 737826 & 4.7 & 4.7582 & TRN & \\
\hline CHEMBL 3210478 & 737826 & 5.15 & 5.3469 & TRN & \\
\hline CHEMBL1602002 & 737826 & 5.0 & 5.3412 & TRN & \\
\hline CHEMBL1466869 & 737826 & 5.05 & 5.3442 & TRN & \\
\hline
\end{tabular}




\begin{tabular}{|c|c|c|c|c|c|}
\hline & & & & & \\
\hline CHEMBL3195378 & 737826 & 4.55 & 5.3268 & TST & \\
\hline CHEMBL1372941 & 737826 & 5.15 & 5.3325 & TST & \\
\hline CHEMBL1582197 & 737826 & 5.55 & 5.239 & TST & \\
\hline CHEMBL1317805 & 737826 & 5.6 & 5.3035 & TRN & \\
\hline CHEMBL 3197283 & 737826 & 5.3 & 5.2619 & TRN & \\
\hline CHEMBL1602211 & 737826 & 4.8 & 5.2467 & TRN & \\
\hline CHEMBL1592982 & 737826 & 6.9 & 6.6621 & TRN & \\
\hline CHEMBL1338311 & 737826 & 5.0 & 4.6822 & TRN & \\
\hline CHEMBL1358092 & 737826 & 6.2 & 6.07700 & 0000000001 & TRN \\
\hline CHEMBL452153 & 737826 & 5.3 & 5.4949 & TST & \\
\hline CHEMBL15060 & 737826 & 4.8 & 4.7618 & TRN & \\
\hline CHEMBL1964464 & 737826 & 4.85 & 5.2944 & TRN & \\
\hline CHEMBL1704851 & 737826 & 5.0 & 5.2303 & TRN & \\
\hline CHEMBL3194986 & 737826 & 5.65 & 5.3199 & TST & \\
\hline CHEMBL1418074 & 737826 & 5.45 & 5.3155 & TRN & \\
\hline CHEMBL3211592 & 737826 & 5.6 & 5.1207 & TRN & \\
\hline CHEMBL1429370 & 737826 & 5.0 & 5.4274 & TRN & \\
\hline CHEMBL3197073 & 737826 & 4.9 & 5.3406 & TST & \\
\hline CHEMBL1303855 & 737826 & 4.95 & 5.0436 & TRN & \\
\hline CHEMBL476513 & 737826 & 5.05 & 5.266 & TRN & \\
\hline CHEMBL1569326 & 737826 & 5.1 & 5.2273 & TRN & \\
\hline CHEMBL1376755 & 737826 & 5.35 & 5.3474 & TRN & \\
\hline CHEMBL1306015 & 737826 & 6.35 & 5.349 & TRN & \\
\hline CHEMBL1313693 & 737826 & 4.9 & 5.2177 & TST & \\
\hline CHEMBL 3214238 & 737826 & 5.4 & 5.1986 & TRN & \\
\hline CHEMBL1436521 & 737826 & 5.5 & 5.274 & TRN & \\
\hline CHEMBL1486399 & 737826 & 4.8 & 4.9085 & TRN & \\
\hline CHEMBL1499214 & 737826 & 6.45 & 5.2527 & TRN & \\
\hline CHEMBL1528578 & 737826 & 4.85 & 5.4043 & TRN & \\
\hline CHEMBL1208858 & 737826 & 4.5 & 4.947 & TST & \\
\hline CHEMBL1433898 & 737826 & 5.4 & 5.3442 & TRN & \\
\hline CHEMBL1570769 & 737826 & 6.25 & 5.1889 & TRN & \\
\hline CHEMBL3213672 & 737826 & 5.45 & 5.5121 & TRN & \\
\hline CHEMBL1606727 & 737826 & 7.2 & 6.9353 & TRN & \\
\hline CHEMBL1351200 & 737826 & 5.65 & 5.2496 & TST & \\
\hline CHEMBL1539070 & 737826 & 4.85 & 5.3371 & TRN & \\
\hline CHEMBL1338163 & 737826 & 5.0 & 5.0291 & TRN & \\
\hline CHEMBL1394137 & 737826 & 5.2 & 5.0102 & TRN & \\
\hline CHEMBL1480788 & 737826 & 7.25 & 5.1384 & TRN & \\
\hline CHEMBL1594227 & 737826 & 5.2 & 5.1228 & TST & \\
\hline CHEMBL1494408 & 737826 & 4.9 & 4.7343 & TRN & \\
\hline CHEMBL1598462 & 737826 & 5.0 & 5.2499 & TRN & \\
\hline CHEMBL1546319 & 737826 & 5.0 & 5.1223 & TST & \\
\hline CHEMBL1362959 & 737826 & 4.8 & 5.466 & TST & \\
\hline CHEMBL1240673 & 737826 & 5.1 & 5.2322 & TRN & \\
\hline CHEMBL1498977 & 737826 & 5.3 & 5.1969 & TRN & \\
\hline CHEMBL1331148 & 737826 & 7.3 & 6.54899 & 99999999995 & TRN \\
\hline CHEMBL3211758 & 737826 & 4.95 & 5.4327 & TRN & \\
\hline & & & & 6372 & \\
\hline
\end{tabular}




\begin{tabular}{|c|c|c|c|c|c|}
\hline \\
\hline CHEMBL1522372 & 737826 & 5.7 & 5.3566 & TRN & \\
\hline CHEMBL1503769 & 737826 & 4.75 & 5.1767 & TRN & \\
\hline CHEMBL1517752 & 737826 & 6.0 & 5.3464 & TRN & \\
\hline CHEMBL 3194463 & 737826 & 5.65 & 5.3035 & TST & \\
\hline CHEMBL1492687 & 737826 & 5.35 & 5.1596 & TRN & \\
\hline CHEMBL1556431 & 737826 & 4.9 & 4.7498 & TRN & \\
\hline CHEMBL1595037 & 737826 & 4.6 & 5.362 & TRN & \\
\hline CHEMBL1993788 & 737826 & 5.75 & 5.4476 & TRN & \\
\hline CHEMBL1554564 & 737826 & 4.9 & 4.7269 & TRN & \\
\hline CHEMBL1573735 & 737826 & 5.2 & 5.3243 & TST & \\
\hline CHEMBL1892270 & 737826 & 5.1 & 5.1222 & TRN & \\
\hline CHEMBL1317231 & 737826 & 6.2 & 5.8949 & TRN & \\
\hline CHEMBL1601536 & 737826 & 4.5 & 5.0474 & TRN & \\
\hline CHEMBL1366393 & 737826 & 5.9 & 5.909 & TRN & \\
\hline CHEMBL1598049 & 737826 & 4.5 & 5.0773 & TRN & \\
\hline CHEMBL1442612 & 737826 & 6.55 & 5.5617 & TRN & \\
\hline CHEMBL1453992 & 737826 & 5.6 & 5.5098 & TRN & \\
\hline CHEMBL1414185 & 737826 & 5.5 & 5.4251 & TST & \\
\hline CHEMBL1316557 & 737826 & 4.4 & 4.3543 & TRN & \\
\hline CHEMBL1415616 & 737826 & 5.2 & 5.16299 & 9999999999 & TST \\
\hline CHEMBL1578122 & 737826 & 4.7 & 5.2349 & TRN & \\
\hline CHEMBL1562337 & 737826 & 5.4 & 5.1598 & TRN & \\
\hline CHEMBL1584452 & 737826 & 5.65 & 5.2268 & TRN & \\
\hline CHEMBL1559248 & 737826 & 5.15 & 5.4886 & TRN & \\
\hline CHEMBL123433 & 737826 & 4.5 & 4.7346 & TST & \\
\hline CHEMBL1235001 & 737826 & 4.9 & 4.8672 & TRN & \\
\hline CHEMBL1554170 & 737826 & 5.2 & 4.9577 & TRN & \\
\hline CHEMBL1368866 & 737826 & 5.3 & 5.4754 & TRN & \\
\hline CHEMBL1450942 & 737826 & 4.85 & 5.1217 & TRN & \\
\hline CHEMBL1320141 & 737826 & 5.7 & 5.5341 & TRN & \\
\hline CHEMBL1474468 & 737826 & 5.8 & 5.8322 & TRN & \\
\hline CHEMBL1596110 & 737826 & 5.05 & 5.3175 & TRN & \\
\hline CHEMBL1514307 & 737826 & 6.2 & 5.8594 & TRN & \\
\hline CHEMBL574181 & 737826 & 4.7 & 4.8662 & TST & \\
\hline CHEMBL1345025 & 737826 & 5.0 & 5.4287 & TRN & \\
\hline CHEMBL1361742 & 737826 & 5.15 & 5.4462 & TRN & \\
\hline CHEMBL1431337 & 737826 & 4.75 & 5.3464 & TRN & \\
\hline CHEMBL1612920 & 737826 & 5.1 & 5.1946 & TRN & \\
\hline CHEMBL1528124 & 737826 & 7.0 & 5.2472 & TRN & \\
\hline CHEMBL1339380 & 737826 & 4.95 & 5.1979 & TRN & \\
\hline CHEMBL1443643 & 737826 & 5.0 & 5.2398 & TRN & \\
\hline CHEMBL1524211 & 737826 & 5.6 & 5.525 & TRN & \\
\hline CHEMBL1525058 & 737826 & 5.1 & 5.6383 & TRN & \\
\hline CHEMBL1734683 & 737826 & 4.4 & 5.1492 & TST & \\
\hline CHEMBL1437138 & 737826 & 6.0 & 5.7157 & TRN & \\
\hline CHEMBL1396989 & 737826 & 4.8 & 4.6818 & TRN & \\
\hline CHEMBL1407530 & 737826 & 4.4 & 5.1415 & TRN & \\
\hline CHEMBL1519953 & 737826 & 5.05 & 5.4698 & TRN & \\
\hline
\end{tabular}




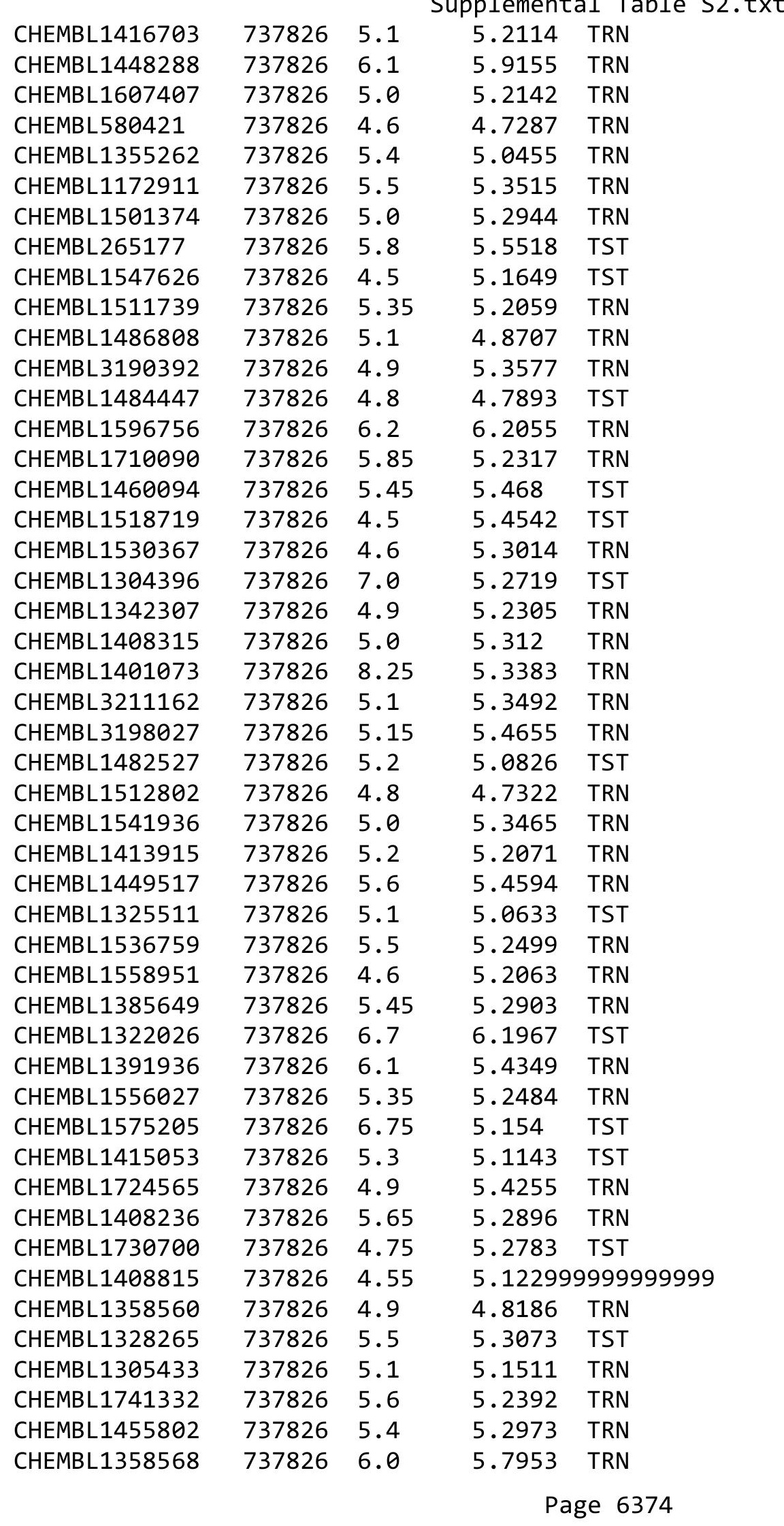

TRN 


\begin{tabular}{|c|c|c|c|c|c|}
\hline \multicolumn{6}{|c|}{ Supplemental Table S2.txt } \\
\hline CHEMBL1733680 & 737826 & 4.75 & 5.1838 & TRN & \\
\hline CHEMBL1598492 & 737826 & 5.05 & 5.2653 & TRN & \\
\hline CHEMBL1465428 & 737826 & 4.7 & 5.3745 & TRN & \\
\hline CHEMBL1433752 & 737826 & 6.4 & 6.3161 & TRN & \\
\hline CHEMBL1371698 & 737826 & 5.4 & 5.3538 & TRN & \\
\hline CHEMBL1547788 & 737826 & 6.75 & 5.5105 & TRN & \\
\hline CHEMBL1343620 & 737826 & 4.6 & 5.2106 & TRN & \\
\hline CHEMBL1598704 & 737826 & 5.35 & 5.2865 & TRN & \\
\hline CHEMBL1606201 & 737826 & 5.85 & 5.2653 & TRN & \\
\hline CHEMBL1587843 & 737826 & 5.45 & 5.1604 & TRN & \\
\hline CHEMBL1505382 & 737826 & 5.15 & 5.0766 & TST & \\
\hline CHEMBL1311780 & 737826 & 4.75 & 5.2278 & TRN & \\
\hline CHEMBL1502327 & 737826 & 5.4 & 5.2869 & TRN & \\
\hline CHEMBL1379744 & 737826 & 6.15 & 5.1283 & TRN & \\
\hline CHEMBL1741919 & 737826 & 4.55 & 5.267 & TRN & \\
\hline CHEMBL1303042 & 737826 & 4.8 & 5.3684 & TRN & \\
\hline CHEMBL1491709 & 737826 & 4.9 & 5.48799 & 99999999995 & TRN \\
\hline CHEMBL1540345 & 737826 & 5.0 & 5.3716 & TRN & \\
\hline CHEMBL1308726 & 737826 & 4.85 & 5.3175 & TRN & \\
\hline CHEMBL1381005 & 737826 & 5.05 & 5.3876 & TRN & \\
\hline CHEMBL1442392 & 737826 & 5.6 & 5.3015 & TRN & \\
\hline CHEMBL3197456 & 737826 & 5.05 & 5.1939 & TRN & \\
\hline CHEMBL1523126 & 737826 & 5.45 & 5.3256 & TRN & \\
\hline CHEMBL1604492 & 737826 & 4.95 & 5.2504 & TRN & \\
\hline CHEMBL1396615 & 737826 & 4.4 & 4.5224 & TRN & \\
\hline CHEMBL 2000120 & 737826 & 5.55 & 5.4617 & TST & \\
\hline CHEMBL1401672 & 737826 & 4.7 & 4.6893 & TRN & \\
\hline CHEMBL1430749 & 737826 & 5.45 & 5.4038 & TRN & \\
\hline CHEMBL1471091 & 737826 & 4.9 & 5.6324 & TRN & \\
\hline CHEMBL1489659 & 737826 & 5.1 & 4.9711 & TRN & \\
\hline CHEMBL3191557 & 737826 & 7.2 & 5.6273 & TRN & \\
\hline CHEMBL1594421 & 737826 & 5.4 & 5.1054 & TRN & \\
\hline CHEMBL1379079 & 737826 & 5.05 & 5.2903 & TST & \\
\hline CHEMBL1568555 & 737826 & 4.95 & 5.1752 & TST & \\
\hline CHEMBL1493411 & 737826 & 5.35 & 5.3406 & TST & \\
\hline CHEMBL1723292 & 737826 & 7.5501 & 5.1411 & TRN & \\
\hline CHEMBL1363474 & 737826 & 4.4 & 5.3035 & TRN & \\
\hline CHEMBL3195554 & 737826 & 4.6 & 5.3632 & TRN & \\
\hline CHEMBL1595826 & 737826 & 4.75 & 5.3578 & TRN & \\
\hline CHEMBL1587080 & 737826 & 4.8 & 5.0536 & TST & \\
\hline CHEMBL1364185 & 737826 & 4.4 & 5.4237 & TRN & \\
\hline CHEMBL1600294 & 737826 & 4.8 & 5.3202 & TRN & \\
\hline CHEMBL1510699 & 737826 & 5.45 & 5.3046 & TRN & \\
\hline CHEMBL1474890 & 737826 & 6.1 & 5.9929 & TRN & \\
\hline CHEMBL1400385 & 737826 & 6.7 & 5.1704 & TRN & \\
\hline CHEMBL1433704 & 737826 & 5.0 & 4.8824 & TRN & \\
\hline CHEMBL429711 & 737826 & 4.5 & 4.6618 & TRN & \\
\hline CHEMBL1370053 & 737826 & 4.9 & 5.1737 & TRN & \\
\hline
\end{tabular}




\begin{tabular}{|c|c|c|c|c|c|}
\hline & & & & & \\
\hline CHEMBL1530613 & 737826 & 7.0 & 6.4455 & TST & \\
\hline CHEMBL1742383 & 737826 & 4.95 & 5.2949 & TRN & \\
\hline CHEMBL1371975 & 737826 & 4.5 & 5.1003 & TST & \\
\hline CHEMBL1329939 & 737826 & 5.5 & 5.6919 & TST & \\
\hline CHEMBL1378322 & 737826 & 5.1 & 5.3173 & TRN & \\
\hline CHEMBL1472233 & 737826 & 5.05 & 5.2949 & TRN & \\
\hline CHEMBL1397596 & 737826 & 4.4 & 4.3099 & TRN & \\
\hline CHEMBL1503919 & 737826 & 5.1 & 5.2118 & TRN & \\
\hline CHEMBL1337787 & 737826 & 5.05 & 5.1174 & TRN & \\
\hline CHEMBL1404945 & 737826 & 5.4 & 5.1403 & TST & \\
\hline CHEMBL1526390 & 737826 & 5.15 & 5.2038 & TRN & \\
\hline CHEMBL1356744 & 737826 & 6.2 & 6.0262 & TRN & \\
\hline CHEMBL1518558 & 737826 & 5.75 & 5.1925 & TRN & \\
\hline CHEMBL1466128 & 737826 & 5.6 & 5.2127 & TRN & \\
\hline CHEMBL1530805 & 737826 & 5.5 & 5.36100 & 0000000001 & TRN \\
\hline CHEMBL1461873 & 737826 & 5.55 & 5.1948 & TRN & \\
\hline CHEMBL1376178 & 737826 & 5.7 & 5.5319 & TRN & \\
\hline CHEMBL1379469 & 737826 & 4.75 & 5.189 & TRN & \\
\hline CHEMBL1611508 & 737826 & 5.65 & 5.5512 & TRN & \\
\hline CHEMBL1379350 & 737826 & 5.0 & 5.2505 & TST & \\
\hline CHEMBL1437990 & 737826 & 5.4 & 5.2045 & TRN & \\
\hline CHEMBL1731530 & 737826 & 5.15 & 5.245 & TRN & \\
\hline CHEMBL1724190 & 737826 & 4.95 & 5.2067 & TRN & \\
\hline CHEMBL1413367 & 737826 & 8.25 & 5.3389 & TRN & \\
\hline CHEMBL1611062 & 737826 & 4.5 & 4.4986 & TRN & \\
\hline CHEMBL1714628 & 737826 & 4.4 & 5.0851 & TRN & \\
\hline CHEMBL1594284 & 737826 & 4.95 & 5.1697 & TRN & \\
\hline CHEMBL1373610 & 737826 & 5.6 & 5.3608 & TRN & \\
\hline CHEMBL1551834 & 737826 & 5.0 & 4.8857 & TRN & \\
\hline CHEMBL1569352 & 737826 & 4.65 & 5.4718 & TRN & \\
\hline CHEMBL1377580 & 737826 & 6.45 & 5.3341 & TRN & \\
\hline CHEMBL1424384 & 737826 & 5.4 & 5.2445 & TRN & \\
\hline CHEMBL3189338 & 737826 & 5.7 & 5.2326 & TRN & \\
\hline CHEMBL1451119 & 737826 & 5.5 & 5.1773 & TRN & \\
\hline CHEMBL1609178 & 737826 & 5.1 & 5.1068 & TRN & \\
\hline CHEMBL1742147 & 737826 & 5.2 & 5.3682 & TRN & \\
\hline CHEMBL1358525 & 737826 & 4.4 & 4.6116 & TRN & \\
\hline CHEMBL3209087 & 737826 & 4.4 & 5.7689 & TRN & \\
\hline CHEMBL1502064 & 737826 & 8.25 & 5.3367 & TST & \\
\hline CHEMBL1335401 & 737826 & 5.65 & 5.4273 & TST & \\
\hline CHEMBL3213461 & 737826 & 5.1 & 5.1587 & TST & \\
\hline CHEMBL1591876 & 737826 & 6.4 & 5.808 & TRN & \\
\hline CHEMBL1466015 & 737826 & 5.5 & 5.2817 & TRN & \\
\hline CHEMBL1350860 & 737826 & 5.4 & 5.1035 & TRN & \\
\hline CHEMBL287689 & 737826 & 5.5 & 5.3827 & TRN & \\
\hline CHEMBL1584831 & 737826 & 4.6 & 5.32700 & 0000000001 & TST \\
\hline CHEMBL1497898 & 737826 & 5.7 & 5.3801 & TRN & \\
\hline CHEMBL1597580 & 737826 & 5.5 & 5.1561 & TRN & \\
\hline & & & & 6376 & \\
\hline
\end{tabular}




\begin{tabular}{|c|c|c|c|c|}
\hline \\
\hline CHEMBL1606259 & 737826 & 5.9 & 5.2004 & TRN \\
\hline CHEMBL1343075 & 737826 & 5.3 & 5.3843 & TRN \\
\hline CHEMBL1413831 & 737826 & 5.1 & 5.2222 & TRN \\
\hline CHEMBL1461021 & 737826 & 5.3 & 5.2354 & TRN \\
\hline CHEMBL1309305 & 737826 & 5.0 & 5.2997 & TRN \\
\hline CHEMBL1432007 & 737826 & 4.65 & 5.2586 & TRN \\
\hline CHEMBL1538161 & 737826 & 4.9 & 5.5129 & TRN \\
\hline CHEMBL1459103 & 737826 & 6.15 & 5.3382 & TRN \\
\hline CHEMBL1316979 & 737826 & 5.9 & 5.926 & TRN \\
\hline CHEMBL1364980 & 737826 & 4.7 & 4.7098 & TRN \\
\hline CHEMBL1501536 & 737826 & 5.3 & 5.2885 & TRN \\
\hline CHEMBL1560697 & 737826 & 7.6 & 5.322 & TRN \\
\hline CHEMBL1547352 & 737826 & 4.8 & 5.0911 & TRN \\
\hline CHEMBL1498833 & 737826 & 4.45 & 5.2007 & TRN \\
\hline CHEMBL1524591 & 737826 & 4.75 & 5.394 & TRN \\
\hline CHEMBL 1341070 & 737826 & 4.5 & 5.3276 & TRN \\
\hline CHEMBL1378800 & 737826 & 5.2 & 5.1379 & TST \\
\hline CHEMBL1568061 & 737826 & 5.35 & 5.2667 & TRN \\
\hline CHEMBL1415305 & 737826 & 5.55 & 5.5267 & TST \\
\hline CHEMBL1408424 & 737826 & 4.55 & 5.2832 & TRN \\
\hline CHEMBL1416389 & 737826 & 6.0 & 5.7663 & TST \\
\hline CHEMBL3198037 & 737826 & 6.05 & 5.2704 & TRN \\
\hline CHEMBL3214530 & 737826 & 6.05 & 5.2254 & TST \\
\hline CHEMBL1304993 & 737826 & 5.6 & 5.2975 & TRN \\
\hline CHEMBL1532604 & 737826 & 4.95 & 5.4188 & TRN \\
\hline CHEMBL 1741745 & 737826 & 5.1 & 5.4316 & TRN \\
\hline CHEMBL1551122 & 737826 & 5.1 & 5.0276 & TRN \\
\hline CHEMBL1500692 & 737826 & 5.4 & 5.2636 & TRN \\
\hline CHEMBL1591107 & 737826 & 6.1 & 5.9517 & TRN \\
\hline CHEMBL1523876 & 737826 & 5.75 & 5.2116 & TRN \\
\hline CHEMBL 1450689 & 737826 & 5.1 & 5.3442 & TRN \\
\hline CHEMBL1517817 & 737826 & 4.8 & 5.2866 & TRN \\
\hline CHEMBL410873 & 737826 & 4.6 & 4.6346 & TST \\
\hline CHEMBL1522087 & 737826 & 5.6 & 5.1886 & TST \\
\hline CHEMBL1406457 & 737826 & 5.0 & 5.2918 & TRN \\
\hline CHEMBL1500582 & 737826 & 4.85 & 5.441 & TST \\
\hline CHEMBL3193489 & 737826 & 5.65 & 5.2616 & TRN \\
\hline CHEMBL1331253 & 737826 & 4.85 & 5.2503 & TRN \\
\hline CHEMBL1491137 & 737826 & 5.5 & 5.2488 & TRN \\
\hline CHEMBL1588389 & 737826 & 5.85 & 5.3963 & TRN \\
\hline CHEMBL1600653 & 737826 & 4.8 & 5.4826 & TST \\
\hline CHEMBL1741648 & 737826 & 4.55 & 5.2131 & TRN \\
\hline CHEMBL1538297 & 737826 & 5.0 & 5.3272 & TRN \\
\hline CHEMBL1607133 & 737826 & 5.3 & 5.2342 & TRN \\
\hline CHEMBL1450115 & 737826 & 6.0 & 5.2856 & TRN \\
\hline CHEMBL1611895 & 737826 & 4.85 & 5.433 & TRN \\
\hline CHEMBL1562974 & 737826 & 4.9 & 5.3494 & TRN \\
\hline CHEMBL1436037 & 737826 & 6.0 & 5.7448 & TRN \\
\hline
\end{tabular}




\begin{tabular}{|c|c|c|c|c|c|}
\hline \multicolumn{6}{|c|}{ Supplemental Table S2.txt } \\
\hline CHEMBL1499314 & 737826 & 4.75 & 5.4236 & TST & \\
\hline CHEMBL1521067 & 737826 & 6.05 & 5.3335 & TRN & \\
\hline CHEMBL1559990 & 737826 & 6.45 & 5.4043 & TRN & \\
\hline CHEMBL1518559 & 737826 & 5.35 & 5.282 & TRN & \\
\hline CHEMBL1420088 & 737826 & 5.4 & 5.2271 & TRN & \\
\hline CHEMBL1559362 & 737826 & 4.75 & 5.2035 & TRN & \\
\hline CHEMBL1494979 & 737826 & 4.8 & 5.4708 & TRN & \\
\hline CHEMBL1466628 & 737826 & 5.0 & 5.4365 & TRN & \\
\hline CHEMBL478 & 737826 & 5.0 & 4.9097 & TRN & \\
\hline CHEMBL1581163 & 737826 & 4.75 & 5.3705 & TRN & \\
\hline CHEMBL1474695 & 737826 & 5.1 & 4.8874 & TRN & \\
\hline CHEMBL1363413 & 737826 & 6.0 & 5.8807 & TRN & \\
\hline CHEMBL1173475 & 737826 & 6.0 & 5.7019 & TRN & \\
\hline CHEMBL1526515 & 737826 & 5.0 & 5.3951 & TRN & \\
\hline CHEMBL1587410 & 737826 & 4.9 & 5.4062 & TRN & \\
\hline CHEMBL1571716 & 737826 & 5.6 & 5.2132 & TRN & \\
\hline CHEMBL1448291 & 737826 & 5.35 & 5.1196 & TRN & \\
\hline CHEMBL1525916 & 737826 & 6.3 & 5.2765 & TRN & \\
\hline CHEMBL1507167 & 737826 & 5.3 & 5.3234 & TRN & \\
\hline CHEMBL1600247 & 737826 & 4.45 & 5.3978 & TRN & \\
\hline CHEMBL1361149 & 737826 & 4.5 & 4.4249 & TRN & \\
\hline CHEMBL1416438 & 737826 & 5.05 & 5.4383 & TRN & \\
\hline CHEMBL3193076 & 737826 & 5.4 & 5.1642 & TRN & \\
\hline CHEMBL1342397 & 737826 & 4.85 & 5.3212 & TRN & \\
\hline CHEMBL1741334 & 737826 & 4.9 & 5.234 & TRN & \\
\hline CHEMBL1547205 & 737826 & 5.75 & 5.1823 & TRN & \\
\hline CHEMBL1444406 & 737826 & 5.85 & 5.185 & TRN & \\
\hline CHEMBL1603700 & 737826 & 4.85 & 5.3073 & TRN & \\
\hline CHEMBL1333615 & 737826 & 4.65 & 5.1478 & TRN & \\
\hline CHEMBL1407380 & 737826 & 4.8 & 5.3292 & TRN & \\
\hline CHEMBL1572530 & 737826 & 5.8 & 5.3592 & TST & \\
\hline CHEMBL1365367 & 737826 & 5.7 & 5.6546 & TRN & \\
\hline CHEMBL1553941 & 737826 & 4.6 & 4.5875 & TRN & \\
\hline CHEMBL1425899 & 737826 & 4.95 & 5.3345 & TRN & \\
\hline CHEMBL492127 & 737826 & 6.1 & 6.07799 & 9999999999 & TRN \\
\hline CHEMBL1529694 & 737826 & 4.85 & 5.4992 & TRN & \\
\hline CHEMBL1597539 & 737826 & 6.45 & 5.3406 & TRN & \\
\hline CHEMBL1417980 & 737826 & 5.45 & 5.4129 & TRN & \\
\hline CHEMBL577455 & 737826 & 4.5 & 4.6939 & TST & \\
\hline CHEMBL1354355 & 737826 & 5.1 & 4.9294 & TRN & \\
\hline CHEMBL1600985 & 737826 & 5.35 & 5.4447 & TST & \\
\hline CHEMBL1583279 & 737826 & 5.15 & 5.2277 & TRN & \\
\hline CHEMBL1968402 & 737826 & 5.2 & 5.2295 & TRN & \\
\hline CHEMBL1708371 & 737826 & 4.5 & 5.2944 & TRN & \\
\hline CHEMBL1331881 & 737826 & 4.95 & 5.4399 & TRN & \\
\hline CHEMBL1479862 & 737826 & 5.05 & 5.2722 & TRN & \\
\hline CHEMBL1558802 & 737826 & 4.85 & 5.4424 & TST & \\
\hline CHEMBL1546475 & 737826 & 4.85 & 5.1288 & TRN & \\
\hline
\end{tabular}




\begin{tabular}{|c|c|c|c|c|c|}
\hline \\
\hline CHEMBL1741761 & 737826 & 5.0 & 5.2356 & TRN & \\
\hline CHEMBL1257014 & 737826 & 4.6 & 4.5848 & TRN & \\
\hline CHEMBL1524242 & 737826 & 4.85 & 5.3289 & TRN & \\
\hline CHEMBL1509804 & 737826 & 5.15 & 5.1757 & TRN & \\
\hline CHEMBL1453970 & 737826 & 4.85 & 5.2719 & TRN & \\
\hline CHEMBL1336082 & 737826 & 5.8 & 5.4189 & TRN & \\
\hline CHEMBL1522222 & 737826 & 5.5 & 5.2992 & TRN & \\
\hline CHEMBL286721 & 737826 & 4.7 & 4.9893 & TRN & \\
\hline CHEMBL1413685 & 737826 & 4.7 & 5.3303 & TRN & \\
\hline CHEMBL1529571 & 737826 & 5.1 & 5.4345 & TRN & \\
\hline CHEMBL3191906 & 737826 & 4.9 & 5.5437 & TRN & \\
\hline CHEMBL1304670 & 737826 & 4.85 & 5.3014 & TRN & \\
\hline CHEMBL1438771 & 737826 & 4.9 & 5.49799 & 9999999999 & TRN \\
\hline CHEMBL1587518 & 737826 & 4.6 & 5.4751 & TST & \\
\hline CHEMBL1570763 & 737826 & 6.15 & 5.3964 & TRN & \\
\hline CHEMBL3196775 & 737826 & 4.95 & 5.3732 & TRN & \\
\hline CHEMBL1400050 & 737826 & 6.0 & 5.8158 & TRN & \\
\hline CHEMBL1374050 & 737826 & 4.85 & 5.2129 & TRN & \\
\hline CHEMBL1563546 & 737826 & 5.75 & 5.4909 & TRN & \\
\hline CHEMBL1348374 & 737826 & 4.4 & 5.3564 & TRN & \\
\hline CHEMBL1499610 & 737826 & 5.35 & 5.2819 & TST & \\
\hline CHEMBL1602966 & 737826 & 4.65 & 5.2415 & TST & \\
\hline CHEMBL1333030 & 737826 & 5.85 & 5.1872 & TRN & \\
\hline CHEMBL1488918 & 737826 & 5.5 & 5.2842 & TRN & \\
\hline CHEMBL1470386 & 737826 & 5.3 & 5.4463 & TRN & \\
\hline CHEMBL1350810 & 737826 & 6.45 & 5.3949 & TRN & \\
\hline CHEMBL1518338 & 737826 & 5.5 & 5.2432 & TRN & \\
\hline CHEMBL1384797 & 737826 & 4.7 & 5.2635 & TST & \\
\hline CHEMBL1594054 & 737826 & 5.5 & 5.3336 & TRN & \\
\hline CHEMBL1410009 & 737826 & 5.7 & 5.5603 & TRN & \\
\hline CHEMBL384903 & 737826 & 6.1 & 5.7368 & TST & \\
\hline CHEMBL1453620 & 737826 & 5.25 & 5.4663 & TRN & \\
\hline CHEMBL1349783 & 737826 & 7.3 & 5.3007 & TRN & \\
\hline CHEMBL1307390 & 737826 & 5.85 & 5.3406 & TRN & \\
\hline CHEMBL1510205 & 737826 & 5.4 & 5.2494 & TRN & \\
\hline CHEMBL1557089 & 737826 & 5.05 & 5.4284 & TRN & \\
\hline CHEMBL1393189 & 737826 & 5.5 & 5.2392 & TRN & \\
\hline CHEMBL1334985 & 737826 & 5.0 & 5.3596 & TRN & \\
\hline CHEMBL1548739 & 737826 & 5.1 & 5.3041 & TRN & \\
\hline CHEMBL1483672 & 737826 & 5.3 & 5.2585 & TST & \\
\hline CHEMBL1388665 & 737826 & 5.4 & 5.2939 & TRN & \\
\hline CHEMBL3209319 & 737826 & 5.05 & 5.5693 & TRN & \\
\hline CHEMBL1607968 & 737826 & 4.4 & 5.437 & TRN & \\
\hline CHEMBL1465378 & 737826 & 4.95 & 5.3854 & TRN & \\
\hline CHEMBL1490786 & 737826 & 5.0 & 4.9136 & TRN & \\
\hline CHEMBL1376879 & 737826 & 4.9 & 5.237 & TRN & \\
\hline CHEMBL1573739 & 737826 & 5.65 & 5.4146 & TRN & \\
\hline CHEMBL3198645 & 737826 & 4.85 & 5.1121 & TRN & \\
\hline
\end{tabular}




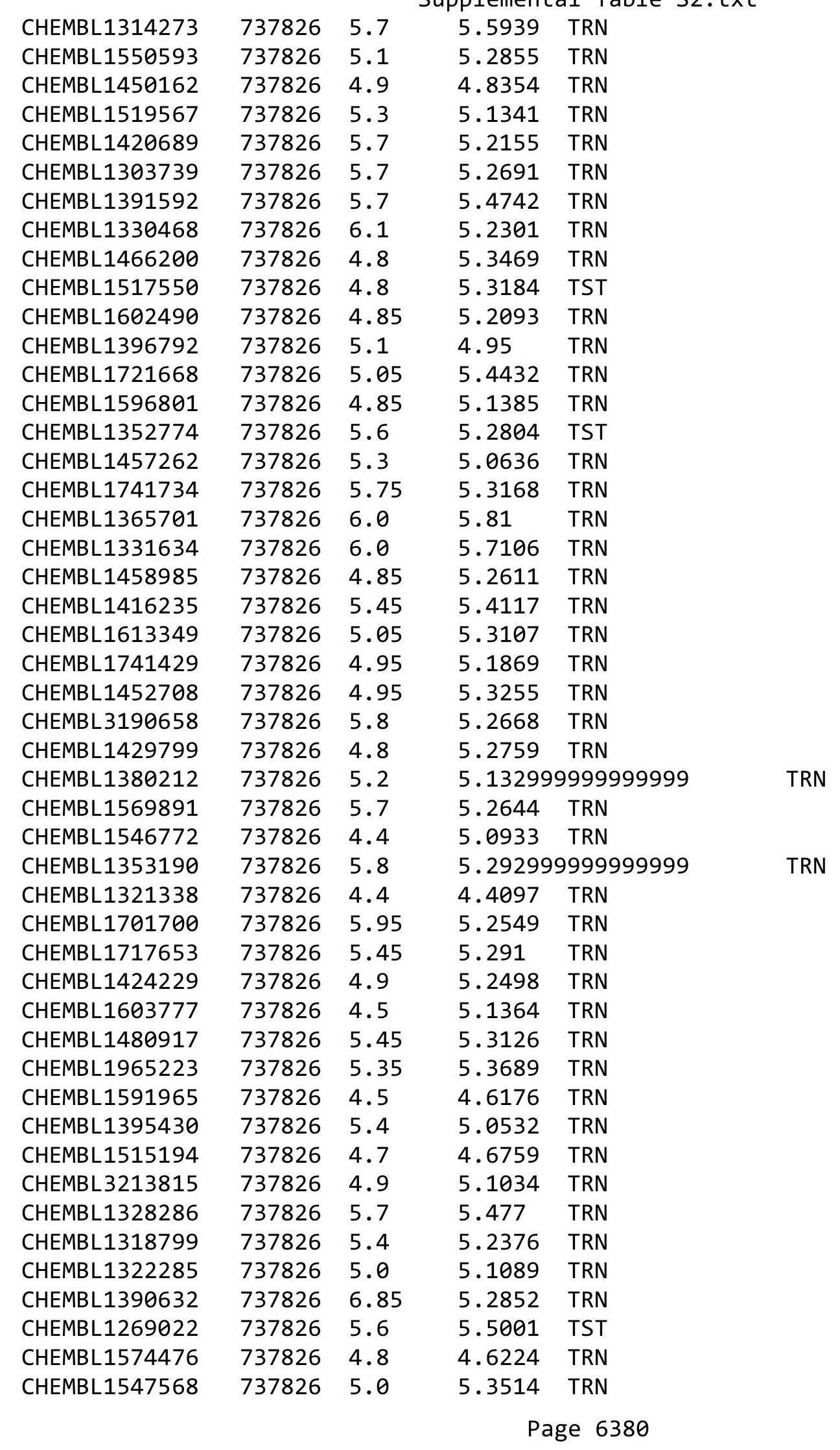




\begin{tabular}{|c|c|c|c|c|c|}
\hline \multicolumn{6}{|c|}{ plemental } \\
\hline CHEMBL1445795 & 737826 & 5.3 & 5.3995 & TRN & \\
\hline CHEMBL1348181 & 737826 & 5.05 & 5.2088 & TRN & \\
\hline CHEMBL1367355 & 737826 & 5.2 & 5.1288 & TRN & \\
\hline CHEMBL1415180 & 737826 & 4.8 & 4.6709 & TRN & \\
\hline CHEMBL1453758 & 737826 & 5.1 & 5.4657 & TRN & \\
\hline CHEMBL1337713 & 737826 & 4.7 & 4.7778 & TRN & \\
\hline CHEMBL1487641 & 737826 & 4.45 & 5.3584 & TRN & \\
\hline CHEMBL1458664 & 737826 & 5.4 & 5.2788 & TRN & \\
\hline CHEMBL350343 & 737826 & 4.8 & 4.8875 & TRN & \\
\hline CHEMBL1365785 & 737826 & 5.35 & 5.295 & TRN & \\
\hline CHEMBL1487735 & 737826 & 6.4 & 6.0343 & TRN & \\
\hline CHEMBL1488395 & 737826 & 5.8 & 5.4729 & TST & \\
\hline CHEMBL1446448 & 737826 & 5.45 & 5.3018 & TRN & \\
\hline CHEMBL1419723 & 737826 & 4.95 & 5.2289 & TRN & \\
\hline CHEMBL1496101 & 737826 & 5.6 & 5.221 & TRN & \\
\hline CHEMBL574985 & 737826 & 5.4 & 5.3382 & TST & \\
\hline CHEMBL1566984 & 737826 & 4.9 & 5.1342 & TRN & \\
\hline CHEMBL1542159 & 737826 & 6.35 & 5.4162 & TRN & \\
\hline CHEMBL1581575 & 737826 & 4.75 & 5.3987 & TRN & \\
\hline CHEMBL1553399 & 737826 & 4.6 & 4.6779 & TST & \\
\hline CHEMBL600287 & 737826 & 4.8 & 5.2033 & TRN & \\
\hline CHEMBL1741783 & 737826 & 5.45 & 5.1143 & TRN & \\
\hline CHEMBL1551308 & 737826 & 4.9 & 4.6928 & TRN & \\
\hline CHEMBL1601285 & 737826 & 5.0 & 5.2452 & TRN & \\
\hline CHEMBL1742217 & 737826 & 4.85 & 5.347 & TRN & \\
\hline CHEMBL1464417 & 737826 & 6.65 & 5.3308 & TRN & \\
\hline CHEMBL1367845 & 737826 & 5.75 & 5.2204 & TRN & \\
\hline CHEMBL1301444 & 737826 & 4.85 & 5.3679 & TRN & \\
\hline CHEMBL1474875 & 737826 & 4.8 & 4.6588 & TRN & \\
\hline CHEMBL1396791 & 737826 & 5.5 & 5.4305 & TST & \\
\hline CHEMBL1409547 & 737826 & 4.9 & 4.8853 & TRN & \\
\hline CHEMBL1408323 & 737826 & 5.15 & 5.3242 & TRN & \\
\hline CHEMBL1366446 & 737826 & 5.55 & 5.29299 & 9999999999 & TRN \\
\hline CHEMBL1427243 & 737826 & 5.45 & 5.3485 & TRN & \\
\hline CHEMBL1463617 & 737826 & 5.35 & 5.3398 & TRN & \\
\hline CHEMBL1554723 & 737826 & 6.2 & 5.7545 & TRN & \\
\hline CHEMBL3199688 & 737826 & 4.9 & 5.28100 & 0000000001 & TST \\
\hline CHEMBL1424121 & 737826 & 5.4 & 5.1882 & TRN & \\
\hline CHEMBL3214362 & 737826 & 6.55 & 5.3624 & TRN & \\
\hline CHEMBL1416055 & 737826 & 5.0 & 5.1383 & TRN & \\
\hline CHEMBL1591757 & 737826 & 5.5 & 5.1719 & TRN & \\
\hline CHEMBL1380712 & 737826 & 5.05 & 5.2471 & TST & \\
\hline CHEMBL168276 & 737826 & 6.1 & 5.772 & TRN & \\
\hline CHEMBL3211406 & 737826 & 5.05 & 5.2066 & TRN & \\
\hline CHEMBL1356628 & 737826 & 5.7 & 5.3062 & TST & \\
\hline CHEMBL1528670 & 737826 & -0.0 & 5.2719 & TRN & \\
\hline CHEMBL1568370 & 737826 & 5.5 & 5.2965 & TRN & \\
\hline CHEMBL1393272 & 737826 & 7.1 & 5.2177 & TRN & \\
\hline
\end{tabular}




\begin{tabular}{|c|c|c|c|c|c|}
\hline \multicolumn{6}{|c|}{ plemental } \\
\hline CHEMBL1506203 & 737826 & 4.9 & 5.3748 & TRN & \\
\hline CHEMBL1423078 & 737826 & 7.35 & 5.5119 & TST & \\
\hline CHEMBL1350723 & 737826 & 4.6 & 5.4375 & TRN & \\
\hline CHEMBL1479088 & 737826 & 5.2 & 5.0569 & TRN & \\
\hline CHEMBL1301027 & 737826 & 7.2 & 5.20700 & $\partial 000000001$ & TRN \\
\hline CHEMBL3208106 & 737826 & 5.1 & 5.6326 & TRN & \\
\hline CHEMBL1340676 & 737826 & 4.4 & 5.4372 & TST & \\
\hline CHEMBL3199224 & 737826 & 5.35 & 5.4199 & TRN & \\
\hline CHEMBL1456872 & 737826 & 6.9 & 6.6239 & TRN & \\
\hline CHEMBL1334179 & 737826 & 5.55 & 5.1614 & TRN & \\
\hline CHEMBL1475487 & 737826 & 5.9 & 5.8414 & TRN & \\
\hline CHEMBL1404831 & 737826 & 4.4 & 5.3646 & TRN & \\
\hline CHEMBL1338276 & 737826 & 6.05 & 5.2262 & TRN & \\
\hline CHEMBL1366428 & 737826 & 6.2 & 5.3826 & TRN & \\
\hline CHEMBL1741947 & 737826 & 4.4 & 5.3975 & TRN & \\
\hline CHEMBL334378 & 737826 & 4.9 & 4.8868 & TRN & \\
\hline CHEMBL1567584 & 737826 & 5.3 & 5.2278 & TRN & \\
\hline CHEMBL1354287 & 737826 & 6.6 & 6.237 & TRN & \\
\hline CHEMBL1473191 & 737826 & 6.0 & 5.659 & TST & \\
\hline CHEMBL1406851 & 737826 & 6.4 & 6.4316 & TRN & \\
\hline CHEMBL1497925 & 737826 & 5.5 & 5.3866 & TRN & \\
\hline CHEMBL1451950 & 737826 & 5.95 & 5.155 & TRN & \\
\hline CHEMBL1726083 & 737826 & 5.2 & 5.1958 & TRN & \\
\hline CHEMBL1571005 & 737826 & 5.0 & 5.2858 & TRN & \\
\hline CHEMBL1329927 & 737826 & 4.8 & 4.86600 & 00000000005 & TST \\
\hline CHEMBL1382823 & 737826 & 4.55 & 5.4766 & TRN & \\
\hline CHEMBL1416009 & 737826 & 5.9 & 5.5518 & TST & \\
\hline CHEMBL1359094 & 737826 & 4.9 & 5.3024 & TRN & \\
\hline CHEMBL16671 & 737826 & 5.6 & 5.4682 & TRN & \\
\hline CHEMBL3195528 & 737826 & 6.0 & 5.3855 & TRN & \\
\hline CHEMBL1337895 & 737826 & 4.4 & 5.5222 & TRN & \\
\hline CHEMBL1369940 & 737826 & 5.5 & 5.4204 & TRN & \\
\hline CHEMBL1589340 & 737826 & 4.7 & 5.3821 & TRN & \\
\hline CHEMBL1574576 & 737826 & 5.75 & 5.5346 & TRN & \\
\hline CHEMBL1450241 & 737826 & 5.6 & 5.4637 & TRN & \\
\hline CHEMBL1477307 & 737826 & 5.4 & 5.255 & TRN & \\
\hline CHEMBL1596260 & 737826 & 6.3 & 5.1544 & TRN & \\
\hline CHEMBL1567251 & 737826 & 5.1 & 4.9861 & TRN & \\
\hline CHEMBL1405581 & 737826 & 5.0 & 5.178 & TRN & \\
\hline CHEMBL1450617 & 737826 & 4.85 & 5.2915 & TRN & \\
\hline CHEMBL1590909 & 737826 & 6.0 & 5.9947 & TRN & \\
\hline CHEMBL1410016 & 737826 & 5.7 & 5.5476 & TRN & \\
\hline CHEMBL1565125 & 737826 & 4.8 & 4.6937 & TST & \\
\hline CHEMBL3212051 & 737826 & 5.0 & 5.2724 & TST & \\
\hline CHEMBL69367 & 737826 & 4.8 & 4.8338 & TRN & \\
\hline CHEMBL 274438 & 737826 & 5.4 & 5.3625 & TRN & \\
\hline CHEMBL1488477 & 737826 & 4.8 & 4.7431 & TRN & \\
\hline CHEMBL1335579 & 737826 & 4.8 & 5.3389 & TRN & \\
\hline
\end{tabular}




\begin{tabular}{|c|c|c|c|c|c|}
\hline \\
\hline CHEMBL1470395 & 737826 & 4.4 & 5.2944 & TRN & \\
\hline CHEMBL1558388 & 737826 & 4.4 & 5.2965 & TRN & \\
\hline CHEMBL1468227 & 737826 & 4.4 & 5.3163 & TRN & \\
\hline CHEMBL1516054 & 737826 & 6.4 & 6.2513 & TRN & \\
\hline CHEMBL1518532 & 737826 & 5.05 & 5.3367 & TRN & \\
\hline CHEMBL1326616 & 737826 & 5.6 & 5.2582 & TRN & \\
\hline CHEMBL1313862 & 737826 & 4.6 & 5.3692 & TRN & \\
\hline CHEMBL1590982 & 737826 & 5.0 & 5.0488 & TRN & \\
\hline CHEMBL1551036 & 737826 & 4.8 & 4.6267 & TRN & \\
\hline CHEMBL490718 & 737826 & 6.4 & 6.2937 & TRN & \\
\hline CHEMBL1329026 & 737826 & 5.3 & 5.2713 & TST & \\
\hline CHEMBL1530695 & 737826 & 4.9 & 5.2971 & TRN & \\
\hline CHEMBL269521 & 737826 & 5.7 & 5.4112 & TRN & \\
\hline CHEMBL1378208 & 737826 & 5.0 & 4.8916 & TRN & \\
\hline CHEMBL1576980 & 737826 & 5.5 & 5.2864 & TRN & \\
\hline CHEMBL1524187 & 737826 & 5.85 & 5.3039 & TRN & \\
\hline CHEMBL1581616 & 737826 & 5.75 & 5.1874 & TRN & \\
\hline CHEMBL1340013 & 737826 & 6.95 & 5.5137 & TRN & \\
\hline CHEMBL1380975 & 737826 & 4.85 & 5.2968 & TRN & \\
\hline CHEMBL1381863 & 737826 & 5.1 & 5.4511 & TRN & \\
\hline CHEMBL1505390 & 737826 & 5.05 & 5.3399 & TRN & \\
\hline CHEMBL3210945 & 737826 & 5.05 & 5.4184 & TRN & \\
\hline CHEMBL1576777 & 737826 & 5.7 & 5.5073 & TRN & \\
\hline CHEMBL1407962 & 737826 & 5.6 & 5.3818 & TST & \\
\hline CHEMBL1414662 & 737826 & 4.65 & 5.2349 & TRN & \\
\hline CHEMBL1522566 & 737826 & 4.9 & 5.4692 & TRN & \\
\hline CHEMBL3207645 & 737826 & 5.7 & 5.07100 & 0000000001 & TRN \\
\hline CHEMBL1552181 & 737826 & 5.4 & 5.2361 & TRN & \\
\hline CHEMBL1350756 & 737826 & 5.6 & 5.3308 & TRN & \\
\hline CHEMBL1479112 & 737826 & 5.3 & 5.4602 & TRN & \\
\hline CHEMBL3208933 & 737826 & 5.0 & 5.1912 & TST & \\
\hline CHEMBL1463824 & 737826 & 5.7 & 5.2749 & TRN & \\
\hline CHEMBL1586621 & 737826 & 5.35 & 5.2649 & TRN & \\
\hline CHEMBL1327351 & 737826 & 5.05 & 5.4335 & TRN & \\
\hline CHEMBL1699997 & 737826 & 6.45 & 5.2804 & TRN & \\
\hline CHEMBL1388224 & 737826 & 4.95 & 5.5589 & TRN & \\
\hline CHEMBL1519291 & 737826 & 6.2 & 5.268 & TRN & \\
\hline CHEMBL1576730 & 737826 & 5.05 & 5.1974 & TRN & \\
\hline CHEMBL1481029 & 737826 & 5.5 & 5.386 & TRN & \\
\hline CHEMBL1555677 & 737826 & 5.7 & 5.1852 & TRN & \\
\hline CHEMBL1595521 & 737826 & 5.15 & 5.1318 & TRN & \\
\hline CHEMBL1606415 & 737826 & 6.1 & 5.187 & TRN & \\
\hline CHEMBL1500686 & 737826 & 4.65 & 5.3175 & TRN & \\
\hline CHEMBL3213029 & 737826 & 4.6 & 5.2879 & TRN & \\
\hline CHEMBL1453216 & 737826 & 5.5 & 5.2461 & TRN & \\
\hline CHEMBL1337096 & 737826 & 5.25 & 5.1611 & TRN & \\
\hline CHEMBL1311035 & 737826 & 4.8 & 5.1414 & TRN & \\
\hline CHEMBL1306308 & 737826 & 4.65 & 5.3676 & TST & \\
\hline
\end{tabular}




\begin{tabular}{|c|c|c|c|c|c|}
\hline \\
\hline CHEMBL1550052 & 737826 & 4.8 & 5.4043 & TRN & \\
\hline CHEMBL1367474 & 737826 & 4.55 & 5.1557 & TRN & \\
\hline CHEMBL1504920 & 737826 & 4.6 & 5.3945 & TRN & \\
\hline CHEMBL1443859 & 737826 & 6.05 & 5.2429 & TRN & \\
\hline CHEMBL1400520 & 737826 & 4.4 & 5.3346 & TRN & \\
\hline CHEMBL1500398 & 737826 & 5.3 & 5.5132 & TRN & \\
\hline CHEMBL1524001 & 737826 & 5.0 & 4.7843 & TRN & \\
\hline CHEMBL165 & 737826 & 5.0 & 5.6658 & TRN & \\
\hline CHEMBL1446112 & 737826 & 5.6 & 5.3129 & TRN & \\
\hline CHEMBL1325093 & 737826 & 4.8 & 5.2648 & TST & \\
\hline CHEMBL1509337 & 737826 & 5.7 & 5.2784 & TRN & \\
\hline CHEMBL1331726 & 737826 & 5.3 & 5.4568 & TRN & \\
\hline CHEMBL1364931 & 737826 & 5.35 & 5.484 & TRN & \\
\hline CHEMBL1589942 & 737826 & 5.4 & 5.25899 & 99999999995 & TST \\
\hline CHEMBL1476981 & 737826 & 4.9 & 4.6279 & TRN & \\
\hline CHEMBL1461188 & 737826 & 5.45 & 5.1593 & TRN & \\
\hline CHEMBL1710203 & 737826 & 8.25 & 5.2186 & TRN & \\
\hline CHEMBL1397902 & 737826 & 5.5 & 5.4541 & TRN & \\
\hline CHEMBL1438458 & 737826 & 5.45 & 5.2623 & TRN & \\
\hline CHEMBL1370377 & 737826 & 4.4 & 5.3473 & TRN & \\
\hline CHEMBL1524323 & 737826 & 4.6 & 5.2949 & TRN & \\
\hline CHEMBL1732053 & 737826 & 4.7 & 5.2997 & TRN & \\
\hline CHEMBL1366030 & 737826 & 5.45 & 5.3258 & TRN & \\
\hline CHEMBL1541179 & 737826 & 4.9 & 5.2842 & TST & \\
\hline CHEMBL402063 & 737826 & 4.4 & 4.6027 & TST & \\
\hline CHEMBL1325554 & 737826 & 4.95 & 5.3978 & TRN & \\
\hline CHEMBL1397192 & 737826 & 5.8 & 5.5407 & TRN & \\
\hline CHEMBL1343566 & 737826 & 4.6 & 5.3038 & TRN & \\
\hline CHEMBL1523594 & 737826 & 4.8 & 4.7381 & TRN & \\
\hline CHEMBL1578522 & 737826 & 7.5501 & 5.3187 & TRN & \\
\hline CHEMBL1432433 & 737826 & 4.65 & 5.3761 & TRN & \\
\hline CHEMBL1537099 & 737826 & 6.0 & 5.5377 & TST & \\
\hline CHEMBL1560706 & 737826 & 4.75 & 5.1439 & TRN & \\
\hline CHEMBL1537215 & 737826 & 4.85 & 5.3995 & TRN & \\
\hline CHEMBL1310701 & 737826 & 4.75 & 5.2284 & TRN & \\
\hline CHEMBL1317172 & 737826 & 4.7 & 4.7074 & TRN & \\
\hline CHEMBL1532708 & 737826 & 4.8 & 5.2689 & TRN & \\
\hline CHEMBL1413982 & 737826 & 5.6 & 5.2979 & TRN & \\
\hline CHEMBL1488504 & 737826 & 5.0 & 5.3075 & TRN & \\
\hline CHEMBL261011 & 737826 & 4.8 & 4.7304 & TRN & \\
\hline CHEMBL3194238 & 737826 & 5.55 & 5.3649 & TRN & \\
\hline CHEMBL1317823 & 737826 & 4.5 & 4.6645 & TRN & \\
\hline CHEMBL1360327 & 737826 & 6.05 & 5.2689 & TRN & \\
\hline CHEMBL1416476 & 737826 & 6.0 & 6.0687 & TRN & \\
\hline CHEMBL1579981 & 737826 & 4.9 & 5.2606 & TRN & \\
\hline CHEMBL876 & 737826 & 5.1 & 5.0274 & TST & \\
\hline CHEMBL1584775 & 737826 & 4.85 & 5.2991 & TRN & \\
\hline CHEMBL47940 & 737826 & 4.5 & 4.6624 & TST & \\
\hline
\end{tabular}




\begin{tabular}{|c|c|c|c|c|c|}
\hline \\
\hline CHEMBL1514458 & 737826 & 4.4 & 4.3963 & TRN & \\
\hline CHEMBL1362441 & 737826 & 5.15 & 5.3234 & TRN & \\
\hline CHEMBL1582293 & 737826 & 5.7 & 5.3362 & TRN & \\
\hline CHEMBL1551065 & 737826 & 4.8 & 4.6339 & TRN & \\
\hline CHEMBL1594058 & 737826 & 4.8 & 4.7884 & TRN & \\
\hline CHEMBL 3208377 & 737826 & 5.2 & 5.2901 & TST & \\
\hline CHEMBL1539972 & 737826 & 5.0 & 5.4631 & TRN & \\
\hline CHEMBL1505006 & 737826 & 4.95 & 5.2616 & TRN & \\
\hline CHEMBL1971420 & 737826 & 5.25 & 5.2089 & TRN & \\
\hline CHEMBL1492898 & 737826 & 4.85 & 5.325 & TST & \\
\hline CHEMBL1302827 & 737826 & 6.35 & 5.4241 & TST & \\
\hline CHEMBL1578254 & 737826 & 5.5 & 5.1544 & TRN & \\
\hline CHEMBL1379007 & 737826 & 5.45 & 5.3143 & TRN & \\
\hline CHEMBL1610961 & 737826 & 4.95 & 5.101 & TRN & \\
\hline CHEMBL1437436 & 737826 & 5.5 & 5.3158 & TST & \\
\hline CHEMBL1376134 & 737826 & 4.95 & 5.2996 & TRN & \\
\hline CHEMBL1256359 & 737826 & 4.4 & 4.5029 & TRN & \\
\hline CHEMBL1460996 & 737826 & 4.85 & 5.2188 & TRN & \\
\hline CHEMBL 3192271 & 737826 & 5.3 & 5.2204 & TRN & \\
\hline CHEMBL1463649 & 737826 & 6.1 & 5.2494 & TRN & \\
\hline CHEMBL1342890 & 737826 & 5.2 & 5.4494 & TRN & \\
\hline CHEMBL1400921 & 737826 & 5.3 & 5.5917 & TRN & \\
\hline CHEMBL1389687 & 737826 & 4.55 & 5.4879 & TST & \\
\hline CHEMBL1612234 & 737826 & 5.45 & 5.3006 & TRN & \\
\hline CHEMBL1334145 & 737826 & 4.8 & 5.2756 & TRN & \\
\hline CHEMBL1598705 & 737826 & 5.15 & 5.4097 & TRN & \\
\hline CHEMBL1447964 & 737826 & 5.95 & 5.3185 & TRN & \\
\hline CHEMBL3212912 & 737826 & 5.7 & 5.1372 & TST & \\
\hline CHEMBL3196233 & 737826 & 5.2 & 5.303 & TRN & \\
\hline CHEMBL 3190214 & 737826 & 6.4 & 5.3153 & TRN & \\
\hline CHEMBL1467940 & 737826 & 5.7 & 5.3111 & TST & \\
\hline CHEMBL1453311 & 737826 & 5.0 & 5.3095 & TRN & \\
\hline CHEMBL1608425 & 737826 & 4.6 & 5.2983 & TRN & \\
\hline CHEMBL1391723 & 737826 & 4.6 & 5.3758 & TRN & \\
\hline CHEMBL1601898 & 737826 & 6.05 & 5.3795 & TRN & \\
\hline CHEMBL1408760 & 737826 & 4.7 & 4.6974 & TRN & \\
\hline CHEMBL1597203 & 737826 & 4.75 & 5.3670 & 0000000001 & TRN \\
\hline CHEMBL1364517 & 737826 & 5.3 & 5.194 & TRN & \\
\hline CHEMBL1437650 & 737826 & 5.1 & 4.9502 & TRN & \\
\hline CHEMBL60718 & 737826 & 4.7 & 4.7495 & TRN & \\
\hline CHEMBL1527279 & 737826 & 5.55 & 5.1394 & TRN & \\
\hline CHEMBL3193407 & 737826 & 4.8 & 5.3158 & TRN & \\
\hline CHEMBL1482575 & 737826 & 4.6 & 4.6185 & TRN & \\
\hline CHEMBL1489705 & 737826 & 5.5 & 5.3282 & TRN & \\
\hline CHEMBL1400535 & 737826 & 5.15 & 5.4129 & TRN & \\
\hline CHEMBL1501526 & 737826 & 5.4 & 5.3743 & TRN & \\
\hline CHEMBL1414071 & 737826 & 8.25 & 5.3421 & TRN & \\
\hline CHEMBL1471206 & 737826 & 5.55 & 5.3155 & TRN & \\
\hline
\end{tabular}




\begin{tabular}{|c|c|c|c|c|c|}
\hline \\
\hline CHEMBL1414754 & 737826 & 5.3 & 5.3243 & TRN & \\
\hline CHEMBL1599585 & 737826 & 5.45 & 5.2933 & TRN & \\
\hline CHEMBL1483257 & 737826 & 5.05 & 5.3442 & TRN & \\
\hline CHEMBL1407398 & 737826 & 4.75 & 5.36299 & 99999999995 & TRN \\
\hline CHEMBL1471064 & 737826 & 5.05 & 5.32600 & 00000000005 & TRN \\
\hline CHEMBL1361675 & 737826 & 5.1 & 5.2689 & TRN & \\
\hline CHEMBL1730298 & 737826 & 5.05 & 5.1813 & TRN & \\
\hline CHEMBL1474475 & 737826 & 4.7 & 4.6985 & TRN & \\
\hline CHEMBL1308013 & 737826 & 5.55 & 5.3324 & TRN & \\
\hline CHEMBL1528654 & 737826 & 5.2 & 5.0947 & TRN & \\
\hline CHEMBL1562643 & 737826 & 5.35 & 5.3892 & TRN & \\
\hline CHEMBL1742093 & 737826 & 4.5 & 5.2714 & TRN & \\
\hline CHEMBL1354864 & 737826 & 4.6 & 4.5809 & TRN & \\
\hline CHEMBL1359379 & 737826 & 5.8 & 5.4832 & TRN & \\
\hline CHEMBL1569337 & 737826 & 5.15 & 5.1516 & TRN & \\
\hline CHEMBL1735134 & 737826 & 5.95 & 5.5998 & TRN & \\
\hline CHEMBL1537907 & 737826 & 4.9 & 5.1752 & TST & \\
\hline CHEMBL1592557 & 737826 & 6.2 & 5.8881 & TRN & \\
\hline CHEMBL1433950 & 737826 & 4.4 & 4.4175 & TRN & \\
\hline CHEMBL1403905 & 737826 & 4.9 & 4.7651 & TRN & \\
\hline CHEMBL1418947 & 737826 & 5.05 & 5.1421 & TRN & \\
\hline CHEMBL1306197 & 737826 & 4.4 & 5.33299 & 9999999999 & TRN \\
\hline CHEMBL1443628 & 737826 & 5.7 & 5.5077 & TRN & \\
\hline CHEMBL1508024 & 737826 & 5.3 & 5.2727 & TRN & \\
\hline CHEMBL1505285 & 737826 & 5.15 & 5.1863 & TRN & \\
\hline CHEMBL1417789 & 737826 & 5.8 & 5.6361 & TRN & \\
\hline CHEMBL1331618 & 737826 & 5.5 & 5.3774 & TRN & \\
\hline CHEMBL1532441 & 737826 & 5.35 & 5.3888 & TRN & \\
\hline CHEMBL1487092 & 737826 & 5.15 & 5.3478 & TRN & \\
\hline CHEMBL1336008 & 737826 & 5.6 & 5.3578 & TST & \\
\hline CHEMBL1558029 & 737826 & 5.0 & 5.2318 & TRN & \\
\hline CHEMBL1309272 & 737826 & 5.0 & 5.2808 & TRN & \\
\hline CHEMBL1547055 & 737826 & 5.35 & 5.2207 & TRN & \\
\hline CHEMBL1447637 & 737826 & 5.65 & 5.1042 & TRN & \\
\hline CHEMBL1350243 & 737826 & 4.85 & 5.472 & TRN & \\
\hline CHEMBL1573692 & 737826 & 5.1 & 5.2441 & TRN & \\
\hline CHEMBL1323273 & 737826 & 5.3 & 5.2812 & TRN & \\
\hline CHEMBL3193309 & 737826 & 4.9 & 5.4557 & TRN & \\
\hline CHEMBL1464437 & 737826 & 4.95 & 5.2784 & TST & \\
\hline CHEMBL1503047 & 737826 & 7.35 & 5.4902 & TRN & \\
\hline CHEMBL1501924 & 737826 & 5.5 & 5.2381 & TRN & \\
\hline CHEMBL1522232 & 737826 & 5.15 & 5.4564 & TRN & \\
\hline CHEMBL1487003 & 737826 & 5.2 & 5.2563 & TRN & \\
\hline CHEMBL1301014 & 737826 & 5.45 & 5.2311 & TST & \\
\hline CHEMBL3214241 & 737826 & 5.45 & 5.2353 & TRN & \\
\hline CHEMBL1461321 & 737826 & 5.85 & 5.2397 & TRN & \\
\hline CHEMBL1390454 & 737826 & 5.65 & 5.5883 & TRN & \\
\hline CHEMBL1485152 & 737826 & 4.8 & 5.3836 & TRN & \\
\hline
\end{tabular}




\begin{tabular}{|c|c|c|c|c|}
\hline \multicolumn{5}{|r|}{$a \perp 1$} \\
\hline CHEMBL1514090 & 737826 & 4.8 & 4.8106 & TST \\
\hline CHEMBL1492346 & 737826 & 5.3 & 5.1963 & TRN \\
\hline CHEMBL1584442 & 737826 & 4.4 & 5.3614 & TRN \\
\hline CHEMBL1592556 & 737826 & 6.5 & 6.0746 & TRN \\
\hline CHEMBL1307309 & 737826 & 4.75 & 5.0611 & TRN \\
\hline CHEMBL1533962 & 737826 & 4.8 & 5.3988 & TRN \\
\hline CHEMBL1565437 & 737826 & 5.55 & 5.3853 & TRN \\
\hline CHEMBL1323166 & 737826 & 4.75 & 5.551 & TRN \\
\hline CHEMBL1605356 & 737826 & 5.0 & 4.8515 & TRN \\
\hline CHEMBL601123 & 737826 & 5.15 & 5.194 & TRN \\
\hline CHEMBL1356395 & 737826 & 6.0 & 5.7415 & TRN \\
\hline CHEMBL1589335 & 737826 & 4.8 & 5.1791 & TST \\
\hline CHEMBL1335059 & 737826 & 5.1 & 5.3184 & TRN \\
\hline CHEMBL1430842 & 737826 & 7.5501 & 5.0939 & TRN \\
\hline CHEMBL192566 & 737826 & 4.5 & 4.6264 & TST \\
\hline CHEMBL1742156 & 737826 & 5.0 & 5.0136 & TRN \\
\hline CHEMBL80155 & 737826 & 5.6 & 5.4182 & TRN \\
\hline CHEMBL1354272 & 737826 & 4.7 & 4.4975 & TRN \\
\hline CHEMBL1487316 & 737826 & 8.25 & 5.0513 & TST \\
\hline CHEMBL1719945 & 737826 & 4.7 & 5.2951 & TRN \\
\hline CHEMBL1592533 & 737826 & 4.4 & 4.3423 & TRN \\
\hline CHEMBL1557657 & 737826 & 5.3 & 5.2735 & TRN \\
\hline CHEMBL1541719 & 737826 & 5.15 & 5.3094 & TRN \\
\hline CHEMBL1409109 & 737826 & 4.6 & 4.5294 & TST \\
\hline CHEMBL1511085 & 737826 & 4.65 & 5.3666 & TRN \\
\hline CHEMBL1501148 & 737826 & 5.2 & 5.4553 & TRN \\
\hline CHEMBL1410759 & 737826 & 5.5 & 5.391 & TST \\
\hline CHEMBL1329806 & 737826 & 5.6 & 5.3791 & TRN \\
\hline CHEMBL1339377 & 737826 & 4.6 & 5.1616 & TRN \\
\hline CHEMBL1430379 & 737826 & 5.05 & 5.3682 & TRN \\
\hline CHEMBL1433093 & 737826 & 6.1 & 5.42 & TST \\
\hline CHEMBL1542131 & 737826 & 5.3 & 5.4241 & TRN \\
\hline CHEMBL1308605 & 737826 & 4.6 & 5.255 & TRN \\
\hline CHEMBL1358012 & 737826 & 4.8 & 5.5373 & TRN \\
\hline CHEMBL1742056 & 737826 & 5.05 & 5.3329 & TST \\
\hline CHEMBL1330385 & 737826 & 6.0 & 5.7774 & TRN \\
\hline CHEMBL1488115 & 737826 & 4.65 & 5.1765 & TRN \\
\hline CHEMBL1539794 & 737826 & 4.85 & 5.3143 & TRN \\
\hline CHEMBL1611022 & 737826 & 5.1 & 5.3564 & TST \\
\hline CHEMBL3194935 & 737826 & 4.5 & 5.3057 & TRN \\
\hline CHEMBL1533335 & 737826 & 6.0 & 6.00200 & 0000000001 \\
\hline CHEMBL1464306 & 737826 & 5.35 & 5.3728 & TRN \\
\hline CHEMBL1608175 & 737826 & 5.0 & 5.3614 & TST \\
\hline CHEMBL1392169 & 737826 & 4.85 & 5.4327 & TRN \\
\hline CHEMBL1516856 & 737826 & 4.6 & 5.3428 & TRN \\
\hline CHEMBL1530280 & 737826 & 6.3 & 5.3105 & TRN \\
\hline CHEMBL1575261 & 737826 & 6.4 & 5.2097 & TRN \\
\hline CHEMBL3198450 & 737826 & 4.85 & 5.5251 & TST \\
\hline
\end{tabular}




\begin{tabular}{|c|c|c|c|c|}
\hline \multicolumn{5}{|c|}{ nental Ta } \\
\hline CHEMBL1527209 & 737826 & 4.6 & 4.678 & TRN \\
\hline CHEMBL1333658 & 737826 & 6.05 & 5.2378 & TST \\
\hline CHEMBL1485384 & 737826 & 4.8 & 5.3486 & TRN \\
\hline CHEMBL1593601 & 737826 & 4.6 & 4.6243 & TRN \\
\hline CHEMBL1422234 & 737826 & 4.9 & 5.2397 & TRN \\
\hline CHEMBL1462730 & 737826 & 5.4 & 5.5345 & TST \\
\hline CHEMBL1411578 & 737826 & 4.4 & 4.3878 & TST \\
\hline CHEMBL1588028 & 737826 & 4.6 & 5.0611 & TRN \\
\hline CHEMBL1397782 & 737826 & 5.1 & 4.8906 & TST \\
\hline CHEMBL1393830 & 737826 & 5.45 & 5.4028 & TST \\
\hline CHEMBL1741327 & 737826 & 5.55 & 5.2462 & TRN \\
\hline CHEMBL1523959 & 737826 & 5.2 & 5.0074 & TRN \\
\hline CHEMBL1445685 & 737826 & 5.3 & 5.5495 & TRN \\
\hline CHEMBL1545862 & 737826 & 5.4 & 5.1641 & TST \\
\hline CHEMBL1396236 & 737826 & 5.8 & 5.5694 & TST \\
\hline CHEMBL1499485 & 737826 & 5.0 & 5.4116 & TRN \\
\hline CHEMBL1418866 & 737826 & 7.1 & 5.2884 & TST \\
\hline CHEMBL 77387 & 737826 & 4.5 & 4.7652 & TRN \\
\hline CHEMBL1432676 & 737826 & 4.8 & 5.4653 & TST \\
\hline CHEMBL1472011 & 737826 & 6.1 & 5.2685 & TRN \\
\hline CHEMBL1604421 & 737826 & 5.0 & 4.856 & TRN \\
\hline CHEMBL1454224 & 737826 & 5.5 & 5.2744 & TRN \\
\hline CHEMBL1437226 & 737826 & 6.0 & 5.9688 & TRN \\
\hline CHEMBL1436272 & 737826 & 6.2 & 6.2106 & TRN \\
\hline CHEMBL1419618 & 737826 & 4.55 & 5.1019 & TST \\
\hline CHEMBL1534919 & 737826 & 6.2 & 5.4113 & TRN \\
\hline CHEMBL1516005 & 737826 & 6.3 & 6.1811 & TRN \\
\hline CHEMBL1439336 & 737826 & 4.65 & 5.3185 & TST \\
\hline CHEMBL1609497 & 737826 & 4.8 & 5.3537 & TST \\
\hline CHEMBL1483625 & 737826 & 4.8 & 4.7159 & TRN \\
\hline CHEMBL1384399 & 737826 & 5.4 & 5.0941 & TRN \\
\hline CHEMBL1409782 & 737826 & 4.85 & 5.3421 & TRN \\
\hline CHEMBL1592506 & 737826 & 5.0 & 4.8491 & TRN \\
\hline CHEMBL1335595 & 737826 & -0.0 & 5.3213 & TRN \\
\hline CHEMBL1310213 & 737826 & 7.0 & 5.4354 & TRN \\
\hline CHEMBL140220 & 737826 & 4.4 & 4.5577 & TRN \\
\hline CHEMBL1544265 & 737826 & 5.2 & 5.1912 & TRN \\
\hline CHEMBL1424946 & 737826 & 5.05 & 5.0898 & TRN \\
\hline CHEMBL1561506 & 737826 & 5.05 & 5.2616 & TRN \\
\hline CHEMBL1495160 & 737826 & 4.85 & 5.285 & TRN \\
\hline CHEMBL1729654 & 737826 & 6.1 & 5.4236 & TRN \\
\hline CHEMBL1436042 & 737826 & 5.1 & 4.8654 & TRN \\
\hline CHEMBL1393461 & 737826 & 4.85 & 5.3797 & TRN \\
\hline CHEMBL3214477 & 737826 & 4.95 & 5.316 & TRN \\
\hline CHEMBL1458660 & 737826 & 6.7 & 5.4058 & TRN \\
\hline CHEMBL1508867 & 737826 & 5.05 & 4.9776 & TRN \\
\hline CHEMBL 281622 & 737826 & 6.5 & 6.1024 & TST \\
\hline CHEMBL1519373 & 737826 & 5.15 & 5.2872 & TRN \\
\hline
\end{tabular}




\begin{tabular}{|c|c|c|c|c|}
\hline & & & pplement & al $\mathrm{Ta}$ \\
\hline CHEMBL1425640 & 737826 & 4.4 & 5.275 & TRN \\
\hline CHEMBL434119 & 737826 & 4.4 & 4.4887 & TRN \\
\hline CHEMBL1539764 & 737826 & 4.95 & 5.2601 & TRN \\
\hline CHEMBL1447946 & 737826 & 5.0 & 4.8011 & TRN \\
\hline CHEMBL1345927 & 737826 & 4.55 & 5.2301 & TST \\
\hline CHEMBL1333742 & 737826 & 5.8 & 5.2778 & TRN \\
\hline CHEMBL 1255940 & 737826 & 5.0 & 4.9792 & TRN \\
\hline CHEMBL 3193508 & 737826 & 4.8 & 5.2752 & TRN \\
\hline CHEMBL1381739 & 737826 & 5.45 & 5.607 & TRN \\
\hline CHEMBL1358756 & 737826 & 5.1 & 4.9466 & TRN \\
\hline CHEMBL1465834 & 737826 & 4.85 & 5.3231 & TRN \\
\hline CHEMBL1607752 & 737826 & 4.8 & 5.3458 & TST \\
\hline CHEMBL1558384 & 737826 & 4.9 & 4.9006 & TRN \\
\hline CHEMBL1515287 & 737826 & 4.6 & 4.52 & TRN \\
\hline CHEMBL1409866 & 737826 & 5.3 & 5.2388 & TRN \\
\hline CHEMBL1552028 & 737826 & 4.4 & 4.4121 & TRN \\
\hline CHEMBL1318411 & 737826 & 4.9 & 4.7543 & TRN \\
\hline CHEMBL1355351 & 737826 & 4.9 & 4.8762 & TRN \\
\hline CHEMBL1527872 & 737826 & 6.25 & 5.5686 & TRN \\
\hline CHEMBL 1403448 & 737826 & 5.55 & 5.2479 & TRN \\
\hline CHEMBL1309281 & 737826 & 5.4 & 5.3748 & TRN \\
\hline CHEMBL1329174 & 737826 & 4.6 & 5.42 & TRN \\
\hline CHEMBL1473715 & 737826 & 4.4 & 4.3721 & TRN \\
\hline CHEMBL1584911 & 737826 & 4.65 & 5.244 & TRN \\
\hline CHEMBL1497621 & 737826 & 6.9 & 5.2488 & TST \\
\hline CHEMBL1331118 & 737826 & 4.8 & 4.6867 & TRN \\
\hline CHEMBL1358538 & 737826 & 5.4 & 5.3229 & TST \\
\hline CHEMBL1562333 & 737826 & 5.55 & 5.2912 & TRN \\
\hline CHEMBL 67212 & 737826 & 6.05 & 5.4122 & TRN \\
\hline CHEMBL1362108 & 737826 & 5.05 & 5.5116 & TRN \\
\hline CHEMBL1331952 & 737826 & 5.95 & 5.3282 & TRN \\
\hline CHEMBL1374614 & 737826 & 5.6 & 5.237 & TRN \\
\hline CHEMBL 3210947 & 737826 & 5.4 & 5.3463 & TRN \\
\hline CHEMBL1517652 & 737826 & 5.45 & 5.1246 & TRN \\
\hline CHEMBL1568086 & 737826 & 6.1 & 6.0322 & TRN \\
\hline CHEMBL1372330 & 737826 & 6.0 & 5.8849 & TRN \\
\hline CHEMBL1511621 & 737826 & 5.1 & 5.3212 & TRN \\
\hline CHEMBL1611691 & 737826 & 4.95 & 5.4923 & TRN \\
\hline CHEMBL1497639 & 737826 & 5.65 & 5.3205 & TRN \\
\hline CHEMBL1393348 & 737826 & 5.5 & 5.4312 & TRN \\
\hline CHEMBL222334 & 737826 & 5.7 & 5.5099 & TRN \\
\hline CHEMBL1363193 & 737826 & 5.2 & 5.2521 & TST \\
\hline CHEMBL3196166 & 737826 & 4.9 & 5.3898 & TRN \\
\hline CHEMBL1454931 & 737826 & 5.1 & 5.1021 & TRN \\
\hline CHEMBL1424953 & 737826 & 5.4 & 5.6954 & TRN \\
\hline CHEMBL1603926 & 737826 & 4.7 & 5.4807 & TRN \\
\hline CHEMBL1422860 & 737826 & 4.95 & 5.0611 & TST \\
\hline CHEMBL1490024 & 737826 & 5.3 & 5.129 & TRN \\
\hline
\end{tabular}




\begin{tabular}{|c|c|c|c|c|c|}
\hline \\
\hline CHEMBL26915 & 737826 & 4.6 & 4.7518 & TRN & \\
\hline CHEMBL3191729 & 737826 & 4.6 & 5.2892 & TRN & \\
\hline CHEMBL1699708 & 737826 & 4.9 & 5.3936 & TRN & \\
\hline CHEMBL1569985 & 737826 & 5.9 & 5.6394 & TRN & \\
\hline CHEMBL1604519 & 737826 & 5.45 & 5.3265 & TRN & \\
\hline CHEMBL3198587 & 737826 & 5.5 & 5.2023 & TST & \\
\hline CHEMBL1340051 & 737826 & 4.95 & 5.21 & TRN & \\
\hline CHEMBL1364168 & 737826 & 4.8 & 4.7416 & TRN & \\
\hline CHEMBL1383146 & 737826 & 4.75 & 5.5076 & TRN & \\
\hline CHEMBL1997370 & 737826 & 4.8 & 5.4011 & TRN & \\
\hline CHEMBL1474795 & 737826 & 4.6 & 4.5004 & TRN & \\
\hline CHEMBL1488845 & 737826 & 5.3 & 5.0623 & TST & \\
\hline CHEMBL1309304 & 737826 & 4.9 & 5.3605 & TRN & \\
\hline CHEMBL 279841 & 737826 & 5.4 & 5.2763 & TRN & \\
\hline CHEMBL10009 & 737826 & 5.9 & 5.7019 & TRN & \\
\hline CHEMBL1510192 & 737826 & 5.8 & 5.3356 & TRN & \\
\hline CHEMBL1438456 & 737826 & 4.5 & 5.13299 & 9999999999 & TRN \\
\hline CHEMBL1527955 & 737826 & 5.2 & 5.5308 & TST & \\
\hline CHEMBL1448655 & 737826 & 5.1 & 5.2244 & TRN & \\
\hline CHEMBL1573813 & 737826 & 4.8 & 5.3355 & TRN & \\
\hline CHEMBL1565366 & 737826 & 4.8 & 5.391 & TRN & \\
\hline CHEMBL1522767 & 737826 & 5.0 & 5.2074 & TRN & \\
\hline CHEMBL1741640 & 737826 & 4.85 & 5.3688 & TRN & \\
\hline CHEMBL1724748 & 737826 & 5.65 & 5.2764 & TRN & \\
\hline CHEMBL1467631 & 737826 & 4.85 & 5.3463 & TRN & \\
\hline CHEMBL1348021 & 737826 & 4.95 & 5.0461 & TRN & \\
\hline CHEMBL1350570 & 737826 & 4.75 & 5.0904 & TRN & \\
\hline CHEMBL1527324 & 737826 & 5.0 & 4.984 & TST & \\
\hline CHEMBL1607115 & 737826 & 5.2 & 5.2232 & TRN & \\
\hline CHEMBL1402965 & 737826 & 5.5 & 5.2993 & TRN & \\
\hline CHEMBL 286722 & 737826 & 4.4 & 4.6188 & TRN & \\
\hline CHEMBL1426363 & 737826 & 4.55 & 5.1714 & TRN & \\
\hline CHEMBL1515417 & 737826 & 5.9 & 5.6178 & TRN & \\
\hline CHEMBL1313459 & 737826 & 4.9 & 5.28799 & 9999999999 & TRN \\
\hline CHEMBL1397406 & 737826 & 4.6 & 4.6264 & TRN & \\
\hline CHEMBL1363364 & 737826 & 5.0 & 5.0675 & TST & \\
\hline CHEMBL1304201 & 737826 & 5.65 & 5.2473 & TRN & \\
\hline CHEMBL1403311 & 737826 & 6.05 & 5.1091 & TST & \\
\hline CHEMBL1443979 & 737826 & 5.45 & 5.5589 & TRN & \\
\hline CHEMBL1324697 & 737826 & 4.5 & 4.5604 & TST & \\
\hline CHEMBL1312235 & 737826 & 4.45 & 5.2773 & TRN & \\
\hline CHEMBL1309075 & 737826 & 4.6 & 5.36299 & 99999999995 & TRN \\
\hline CHEMBL1602892 & 737826 & 4.95 & 5.0939 & TRN & \\
\hline CHEMBL1481465 & 737826 & 5.0 & 5.0306 & TRN & \\
\hline CHEMBL1543685 & 737826 & 5.0 & 5.0248 & TST & \\
\hline CHEMBL1544377 & 737826 & 5.0 & 5.2952 & TRN & \\
\hline CHEMBL1530995 & 737826 & 5.55 & 5.1832 & TST & \\
\hline CHEMBL1397595 & 737826 & 6.3 & 5.7556 & TRN & \\
\hline
\end{tabular}




\begin{tabular}{|c|c|c|c|c|c|}
\hline \\
\hline CHEMBL1379160 & 737826 & 4.8 & 5.3269 & TRN & \\
\hline CHEMBL1539830 & 737826 & 5.75 & 5.4184 & TST & \\
\hline CHEMBL1308948 & 737826 & 5.85 & 5.5979 & TST & \\
\hline CHEMBL1544379 & 737826 & 5.5 & 5.2231 & TST & \\
\hline CHEMBL1413611 & 737826 & 5.3 & 5.2912 & TRN & \\
\hline CHEMBL1468272 & 737826 & 4.75 & 5.3115 & TRN & \\
\hline CHEMBL1473755 & 737826 & 6.1 & 6.0153 & TRN & \\
\hline CHEMBL1478530 & 737826 & 4.9 & 5.0199 & TST & \\
\hline CHEMBL1422796 & 737826 & 5.15 & 5.1314 & TRN & \\
\hline CHEMBL1301957 & 737826 & 4.9 & 5.2462 & TST & \\
\hline CHEMBL1520907 & 737826 & 5.5 & 5.2772 & TRN & \\
\hline CHEMBL1453899 & 737826 & 5.05 & 5.2875 & TRN & \\
\hline CHEMBL1553804 & 737826 & 4.4 & 4.3903 & TRN & \\
\hline CHEMBL1565060 & 737826 & 5.3 & 5.027 & TRN & \\
\hline CHEMBL1382075 & 737826 & 5.8 & 4.9769 & TRN & \\
\hline CHEMBL1335290 & 737826 & 4.95 & 5.52 & TRN & \\
\hline CHEMBL1340592 & 737826 & 4.85 & 5.2022 & TRN & \\
\hline CHEMBL1521167 & 737826 & 5.3 & 5.1154 & TST & \\
\hline CHEMBL1484214 & 737826 & 5.1 & 5.4305 & TRN & \\
\hline CHEMBL1233960 & 737826 & 5.3 & 5.1671 & TRN & \\
\hline CHEMBL 238624 & 737826 & 7.0 & 6.575 & TST & \\
\hline CHEMBL 3213228 & 737826 & 4.5 & 5.324 & TST & \\
\hline CHEMBL1404031 & 737826 & 6.15 & 5.3989 & TRN & \\
\hline CHEMBL3207571 & 737826 & 5.45 & 5.5234 & TRN & \\
\hline CHEMBL1518057 & 737826 & 5.25 & 5.4451 & TRN & \\
\hline CHEMBL1544721 & 737826 & 4.8 & 5.356 & TRN & \\
\hline CHEMBL3212240 & 737826 & 4.65 & 5.3982 & TRN & \\
\hline CHEMBL1524388 & 737826 & 4.8 & 5.4108 & TRN & \\
\hline CHEMBL1448803 & 737826 & 4.4 & 5.33700 & 0000000001 & TRN \\
\hline CHEMBL1369438 & 737826 & 4.6 & 5.2266 & TRN & \\
\hline CHEMBL1374226 & 737826 & 5.05 & 5.3935 & TRN & \\
\hline CHEMBL1965559 & 737826 & 5.65 & 5.2622 & TRN & \\
\hline CHEMBL3191740 & 737826 & 5.3 & 5.4542 & TRN & \\
\hline CHEMBL1497410 & 737826 & 6.0 & 5.3797 & TRN & \\
\hline CHEMBL1470219 & 737826 & 5.75 & 5.3866 & TRN & \\
\hline CHEMBL1386150 & 737826 & 4.7 & 5.2103 & TRN & \\
\hline CHEMBL1411201 & 737826 & 4.7 & 4.7106 & TRN & \\
\hline CHEMBL1478848 & 737826 & 4.95 & 5.3855 & TRN & \\
\hline CHEMBL1597346 & 737826 & 5.05 & 5.1546 & TRN & \\
\hline CHEMBL1492504 & 737826 & 5.0 & 5.1073 & TRN & \\
\hline CHEMBL1484108 & 737826 & 4.6 & 5.266 & TRN & \\
\hline CHEMBL1579818 & 737826 & 5.6 & 5.2913 & TRN & \\
\hline CHEMBL1362365 & 737826 & 6.05 & 5.1955 & TRN & \\
\hline CHEMBL1591272 & 737826 & 5.5 & 5.3559 & TRN & \\
\hline CHEMBL1441222 & 737826 & 5.4 & 5.2598 & TRN & \\
\hline CHEMBL1397860 & 737826 & 5.1 & 5.0137 & TRN & \\
\hline CHEMBL1392213 & 737826 & 4.85 & 5.3121 & TRN & \\
\hline CHEMBL1362249 & 737826 & 5.15 & 5.4633 & TRN & \\
\hline
\end{tabular}




\begin{tabular}{|c|c|c|c|c|}
\hline & & & pplement & al $\mathrm{Ta}$ \\
\hline CHEMBL1450860 & 737826 & 7.2 & 5.3939 & TRN \\
\hline CHEMBL1605341 & 737826 & 5.4 & 5.2422 & TRN \\
\hline CHEMBL1524127 & 737826 & 4.4 & 5.4162 & TRN \\
\hline CHEMBL3195193 & 737826 & 5.7 & 5.5031 & TRN \\
\hline CHEMBL1394640 & 737826 & 6.0 & 5.8095 & TRN \\
\hline CHEMBL1321758 & 737826 & 5.5 & 5.3917 & TRN \\
\hline CHEMBL1302877 & 737826 & 5.25 & 5.2628 & TRN \\
\hline CHEMBL1331105 & 737826 & 5.0 & 4.8961 & TRN \\
\hline CHEMBL1583920 & 737826 & 6.35 & 5.2543 & TRN \\
\hline CHEMBL1594020 & 737826 & 5.0 & 4.8342 & TRN \\
\hline CHEMBL1506687 & 737826 & 5.4 & 5.1803 & TRN \\
\hline CHEMBL1352042 & 737826 & 4.8 & 5.0249 & TRN \\
\hline CHEMBL1443508 & 737826 & 5.6 & 5.3508 & TRN \\
\hline CHEMBL 3208454 & 737826 & 4.65 & 5.1856 & TRN \\
\hline CHEMBL1319303 & 737826 & 5.4 & 5.2206 & TRN \\
\hline CHEMBL1484400 & 737826 & 5.1 & 5.2741 & TST \\
\hline CHEMBL1328247 & 737826 & 7.15 & 5.2009 & TRN \\
\hline CHEMBL1331780 & 737826 & 4.5 & 5.4891 & TRN \\
\hline CHEMBL1719582 & 737826 & 4.95 & 5.2842 & TRN \\
\hline CHEMBL1435080 & 737826 & 5.1 & 4.8676 & TRN \\
\hline CHEMBL1384608 & 737826 & 4.85 & 5.2138 & TST \\
\hline CHEMBL1445137 & 737826 & 5.55 & 5.2183 & TRN \\
\hline CHEMBL98350 & 737826 & 4.4 & 4.6563 & TST \\
\hline CHEMBL1972824 & 737826 & 5.6 & 5.3534 & TRN \\
\hline CHEMBL1741592 & 737826 & 4.7 & 5.4311 & TRN \\
\hline CHEMBL1319325 & 737826 & 4.8 & 5.2961 & TRN \\
\hline CHEMBL1376952 & 737826 & 5.4 & 5.3988 & TRN \\
\hline CHEMBL1469460 & 737826 & 5.45 & 5.2568 & TRN \\
\hline CHEMBL1561927 & 737826 & 5.1 & 5.0539 & TRN \\
\hline CHEMBL1423586 & 737826 & 5.3 & 5.2026 & TRN \\
\hline CHEMBL1530194 & 737826 & 5.2 & 5.2776 & TRN \\
\hline CHEMBL1477644 & 737826 & 4.85 & 5.2549 & TRN \\
\hline CHEMBL1406410 & 737826 & 4.7 & 4.7676 & TRN \\
\hline CHEMBL1453751 & 737826 & 4.85 & 5.3668 & TRN \\
\hline CHEMBL1316775 & 737826 & 4.4 & 4.521 & TRN \\
\hline CHEMBL1741481 & 737826 & 4.7 & 5.5057 & TRN \\
\hline CHEMBL1711464 & 737826 & 5.55 & 5.3455 & TRN \\
\hline CHEMBL1559333 & 737826 & 4.85 & 5.5379 & TRN \\
\hline CHEMBL1339651 & 737826 & 5.5 & 5.4302 & TRN \\
\hline CHEMBL3210074 & 737826 & 5.1 & 5.3337 & TST \\
\hline CHEMBL1456688 & 737826 & 5.1 & 4.9261 & TRN \\
\hline CHEMBL512832 & 737826 & 5.5 & 5.4128 & TRN \\
\hline CHEMBL1425061 & 737826 & 5.2 & 5.1033 & TRN \\
\hline CHEMBL1564813 & 737826 & 4.9 & 4.7641 & TRN \\
\hline CHEMBL1334357 & 737826 & 5.5 & 5.4054 & TST \\
\hline CHEMBL1365979 & 737826 & 4.4 & 4.3654 & TRN \\
\hline CHEMBL1564361 & 737826 & 4.65 & 5.1486 & TRN \\
\hline CHEMBL1333810 & 737826 & 5.0 & 5.2564 & TRN \\
\hline
\end{tabular}




\begin{tabular}{|c|c|c|c|c|c|}
\hline \multicolumn{6}{|c|}{ Supplemental Table S2.txt } \\
\hline CHEMBL1362189 & 737826 & 6.55 & 5.254 & TRN & \\
\hline CHEMBL1530692 & 737826 & 5.05 & 5.1899 & TRN & \\
\hline CHEMBL1426283 & 737826 & 5.0 & 5.4263 & TRN & \\
\hline CHEMBL1742029 & 737826 & 5.6 & 5.3866 & TRN & \\
\hline CHEMBL1584624 & 737826 & 7.95 & 5.1459 & TRN & \\
\hline CHEMBL1343900 & 737826 & 5.05 & 5.2134 & TRN & \\
\hline CHEMBL1542047 & 737826 & 5.1 & 5.2322 & TRN & \\
\hline CHEMBL 282489 & 737826 & 5.5 & 5.27 & TST & \\
\hline CHEMBL1709586 & 737826 & 5.1 & 5.4285 & TRN & \\
\hline CHEMBL1475788 & 737826 & 4.9 & 4.7846 & TRN & \\
\hline CHEMBL475376 & 737826 & 6.1 & 6.1149 & TRN & \\
\hline CHEMBL1421648 & 737826 & 5.4 & 5.1873 & TRN & \\
\hline CHEMBL1340893 & 737826 & 5.1 & 5.21299 & э999999999 & TRN \\
\hline CHEMBL1569843 & 737826 & 7.2 & 5.3003 & TRN & \\
\hline CHEMBL1523363 & 737826 & 5.15 & 5.5382 & TRN & \\
\hline CHEMBL1728383 & 737826 & 5.05 & 5.2612 & TRN & \\
\hline CHEMBL1379706 & 737826 & 5.35 & 5.2837 & TRN & \\
\hline CHEMBL1510646 & 737826 & 5.3 & 5.2462 & TRN & \\
\hline CHEMBL 3212172 & 737826 & 4.65 & 5.4494 & TRN & \\
\hline CHEMBL1450507 & 737826 & 4.85 & 5.3838 & TRN & \\
\hline CHEMBL1413489 & 737826 & 6.0 & 5.8295 & TRN & \\
\hline CHEMBL1578463 & 737826 & 5.55 & 5.0982 & TRN & \\
\hline CHEMBL1403831 & 737826 & 5.05 & 5.0999 & TRN & \\
\hline CHEMBL1444331 & 737826 & 5.2 & 5.1429 & TRN & \\
\hline CHEMBL1707407 & 737826 & 5.3 & 5.8644 & TRN & \\
\hline CHEMBL3191786 & 737826 & 5.55 & 5.4612 & TST & \\
\hline CHEMBL1971875 & 737826 & 5.55 & 5.3578 & TRN & \\
\hline CHEMBL1516629 & 737826 & 5.6 & 5.2686 & TRN & \\
\hline CHEMBL1389497 & 737826 & 5.7 & 5.1727 & TRN & \\
\hline CHEMBL1454178 & 737826 & 6.2 & 5.3352 & TRN & \\
\hline CHEMBL1528688 & 737826 & 5.2 & 5.1082 & TST & \\
\hline CHEMBL1515874 & 737826 & 4.5 & 4.6239 & TRN & \\
\hline CHEMBL1505786 & 737826 & 4.4 & 5.40600 & 0000000001 & TRN \\
\hline CHEMBL1531299 & 737826 & 5.3 & 5.3093 & TRN & \\
\hline CHEMBL1449042 & 737826 & 6.7 & 5.2134 & TRN & \\
\hline CHEMBL1445840 & 737826 & 5.3 & 5.4088 & TRN & \\
\hline CHEMBL1540051 & 737826 & 6.15 & 5.4058 & TRN & \\
\hline CHEMBL1446286 & 737826 & 5.4 & 5.2399 & TRN & \\
\hline CHEMBL1447438 & 737826 & 4.5 & 4.4974 & TRN & \\
\hline CHEMBL1607512 & 737826 & 5.5 & 5.2239 & TRN & \\
\hline CHEMBL1464912 & 737826 & 4.95 & 5.3338 & TRN & \\
\hline CHEMBL1429762 & 737826 & 5.35 & 5.2896 & TRN & \\
\hline CHEMBL1741926 & 737826 & 4.55 & 5.0642 & TST & \\
\hline CHEMBL1558771 & 737826 & 5.6 & 5.3297 & TRN & \\
\hline CHEMBL1528993 & 737826 & 4.5 & 5.3116 & TRN & \\
\hline CHEMBL1575899 & 737826 & 5.0 & 5.2373 & TRN & \\
\hline CHEMBL1474471 & 737826 & 5.9 & 5.5229 & TRN & \\
\hline CHEMBL1349786 & 737826 & 4.95 & 5.239 & TRN & \\
\hline
\end{tabular}




\begin{tabular}{|c|c|c|c|c|c|}
\hline \\
\hline CHEMBL1310796 & 737826 & 4.5 & 5.5045 & TRN & \\
\hline CHEMBL323356 & 737826 & 5.6 & 5.437 & TST & \\
\hline CHEMBL1394638 & 737826 & 4.6 & 4.5201 & TRN & \\
\hline CHEMBL1582625 & 737826 & 5.45 & 5.2081 & TRN & \\
\hline CHEMBL1383447 & 737826 & 5.45 & 5.1282 & TRN & \\
\hline CHEMBL1400043 & 737826 & 4.8 & 4.8144 & TRN & \\
\hline CHEMBL1255867 & 737826 & 4.6 & 4.8271 & TRN & \\
\hline CHEMBL1582750 & 737826 & 4.85 & 5.2097 & TRN & \\
\hline CHEMBL1518484 & 737826 & 4.8 & 5.3431 & TRN & \\
\hline CHEMBL1491965 & 737826 & 4.9 & 4.9514 & TRN & \\
\hline CHEMBL1567589 & 737826 & 4.9 & 5.2296 & TRN & \\
\hline CHEMBL1462816 & 737826 & 5.9 & 5.443 & TRN & \\
\hline CHEMBL1401324 & 737826 & 4.9 & 4.8798 & TRN & \\
\hline CHEMBL1521352 & 737826 & 5.65 & 5.2708 & TRN & \\
\hline CHEMBL1331154 & 737826 & 4.85 & 5.2 & TRN & \\
\hline CHEMBL1489512 & 737826 & 5.3 & 5.3909 & TRN & \\
\hline CHEMBL1525292 & 737826 & 8.0 & 4.9775 & TST & \\
\hline CHEMBL1607837 & 737826 & 5.8 & 5.401 & TRN & \\
\hline CHEMBL1503135 & 737826 & 4.8 & 5.3545 & TRN & \\
\hline CHEMBL1544037 & 737826 & 4.8 & 5.3296 & TRN & \\
\hline CHEMBL1407572 & 737826 & 5.8 & 5.3858 & TRN & \\
\hline CHEMBL1172977 & 737826 & 5.5 & 5.3837 & TRN & \\
\hline CHEMBL1347469 & 737826 & 5.65 & 5.1961 & TRN & \\
\hline CHEMBL1453354 & 737826 & 5.45 & 5.2335 & TRN & \\
\hline CHEMBL 328710 & 737826 & 4.4 & 5.6574 & TRN & \\
\hline CHEMBL1356941 & 737826 & 4.8 & 4.8138 & TRN & \\
\hline CHEMBL1511690 & 737826 & 4.8 & 5.3823 & TST & \\
\hline CHEMBL1992166 & 737826 & 5.0 & 5.3229 & TRN & \\
\hline CHEMBL1428733 & 737826 & 4.4 & 5.2657 & TRN & \\
\hline CHEMBL1532774 & 737826 & 4.75 & 5.526 & TRN & \\
\hline CHEMBL1352887 & 737826 & 4.7 & 5.3123 & TST & \\
\hline CHEMBL1567373 & 737826 & 5.5 & 5.2783 & TRN & \\
\hline CHEMBL527271 & 737826 & 5.15 & 5.1087 & TRN & \\
\hline CHEMBL1400546 & 737826 & 5.25 & 5.0929 & TST & \\
\hline CHEMBL1531213 & 737826 & 8.25 & 5.0918 & TRN & \\
\hline CHEMBL1300567 & 737826 & 5.2 & 5.5024 & TST & \\
\hline CHEMBL1459217 & 737826 & 6.05 & 5.1481 & TRN & \\
\hline CHEMBL1590886 & 737826 & 5.0 & 5.0544 & TRN & \\
\hline CHEMBL1426303 & 737826 & 5.05 & 5.2513 & TRN & \\
\hline CHEMBL1332964 & 737826 & 4.9 & 4.7223 & TRN & \\
\hline CHEMBL1386135 & 737826 & 4.9 & 5.2815 & TST & \\
\hline CHEMBL1539325 & 737826 & 4.55 & 5.0044 & TST & \\
\hline CHEMBL1409830 & 737826 & 6.3 & 6.16299 & 9999999999 & TRN \\
\hline CHEMBL1312033 & 737826 & 4.9 & 5.4038 & TRN & \\
\hline CHEMBL1323124 & 737826 & 4.6 & 4.4998 & TRN & \\
\hline CHEMBL1357770 & 737826 & 8.3 & 6.9854 & TST & \\
\hline CHEMBL1463543 & 737826 & 5.45 & 5.1963 & TRN & \\
\hline CHEMBL1453591 & 737826 & 4.85 & 5.3502 & TRN & \\
\hline
\end{tabular}




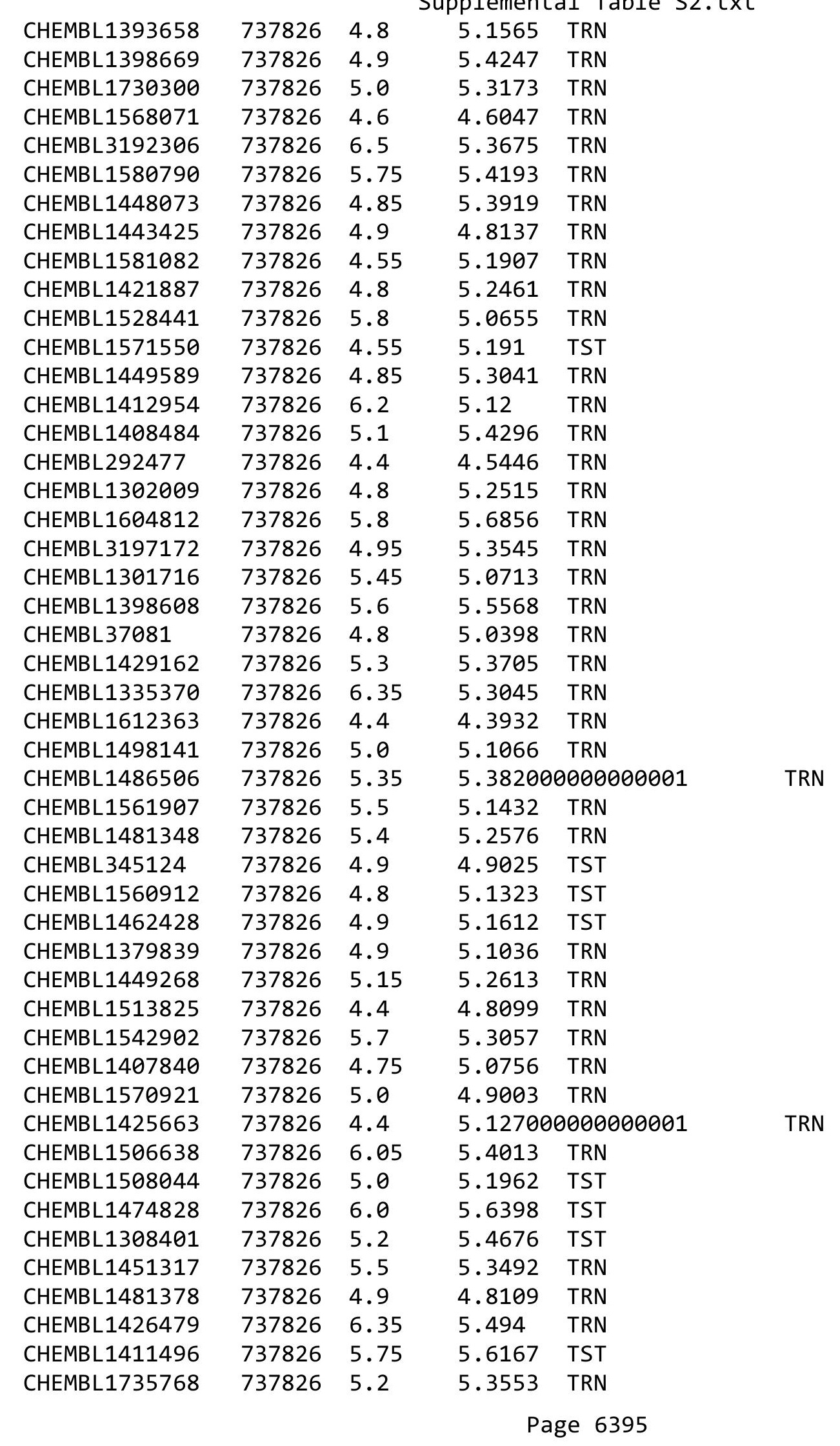




\begin{tabular}{|c|c|c|c|c|c|}
\hline & & & & & \\
\hline CHEMBL1541902 & 737826 & 5.0 & 5.1539 & TRN & \\
\hline CHEMBL1598771 & 737826 & 4.5 & 5.224 & TST & \\
\hline CHEMBL1476266 & 737826 & 4.8 & 4.7576 & TRN & \\
\hline CHEMBL3192068 & 737826 & 4.45 & 5.4537 & TRN & \\
\hline CHEMBL3207696 & 737826 & 5.65 & 5.1476 & TRN & \\
\hline CHEMBL1469660 & 737826 & 5.2 & 5.2038 & TRN & \\
\hline CHEMBL1357956 & 737826 & 4.9 & 4.762 & TRN & \\
\hline CHEMBL1360622 & 737826 & 5.65 & 5.3711 & TRN & \\
\hline CHEMBL1374713 & 737826 & 5.55 & 5.2991 & TRN & \\
\hline CHEMBL1553173 & 737826 & 6.0 & 6.0192 & TRN & \\
\hline CHEMBL582444 & 737826 & 8.3 & 7.0912 & TST & \\
\hline CHEMBL1541487 & 737826 & 4.9 & 5.3483 & TRN & \\
\hline CHEMBL 3212628 & 737826 & 5.0 & 5.3752 & TST & \\
\hline CHEMBL3208065 & 737826 & 5.5 & 5.3663 & TRN & \\
\hline CHEMBL1507862 & 737826 & 5.3 & 5.1293 & TST & \\
\hline CHEMBL1412477 & 737826 & 6.5 & 6.0284 & TST & \\
\hline CHEMBL1471244 & 737826 & 6.0 & 5.2842 & TRN & \\
\hline CHEMBL1299810 & 737826 & 5.4 & 5.4995 & TRN & \\
\hline CHEMBL1331410 & 737826 & 5.0 & 4.9518 & TRN & \\
\hline CHEMBL1483307 & 737826 & 5.85 & 5.3742 & TRN & \\
\hline CHEMBL1388203 & 737826 & 5.8 & 5.21299 & 9999999999 & TST \\
\hline CHEMBL1329761 & 737826 & 4.5 & 5.3899 & TRN & \\
\hline CHEMBL1584932 & 737826 & 5.05 & 5.3501 & TRN & \\
\hline CHEMBL1564746 & 737826 & 5.35 & 5.2769 & TRN & \\
\hline CHEMBL1596066 & 737826 & 4.8 & 5.3632 & TRN & \\
\hline CHEMBL1532878 & 737826 & 5.45 & 5.2821 & TRN & \\
\hline CHEMBL1973886 & 737826 & 4.95 & 5.5278 & TRN & \\
\hline CHEMBL1723585 & 737826 & 8.25 & 5.2744 & TRN & \\
\hline CHEMBL1722621 & 737826 & 6.0 & 5.2703 & TRN & \\
\hline CHEMBL1572383 & 737826 & 4.7 & 5.2414 & TRN & \\
\hline CHEMBL1544437 & 737826 & 5.2 & 5.1558 & TRN & \\
\hline CHEMBL1362616 & 737826 & 5.3 & 5.1319 & TRN & \\
\hline CHEMBL1333755 & 737826 & 5.0 & 5.2831 & TST & \\
\hline CHEMBL 3214622 & 737826 & 5.55 & 5.4825 & TRN & \\
\hline CHEMBL1416795 & 737826 & 5.7 & 5.4542 & TRN & \\
\hline CHEMBL1374696 & 737826 & 5.1 & 5.0027 & TRN & \\
\hline CHEMBL1432368 & 737826 & 5.45 & 5.4965 & TRN & \\
\hline CHEMBL1553498 & 737826 & 7.0 & 6.4256 & TST & \\
\hline CHEMBL1491976 & 737826 & 5.6 & 5.7737 & TRN & \\
\hline CHEMBL1306897 & 737826 & 5.4 & 5.2977 & TRN & \\
\hline CHEMBL1344162 & 737826 & 5.0 & 5.046 & TRN & \\
\hline CHEMBL1392868 & 737826 & 6.1 & 5.1492 & TRN & \\
\hline CHEMBL1304072 & 737826 & 4.95 & 5.4569 & TRN & \\
\hline CHEMBL1590980 & 737826 & 7.1 & 6.5523 & TRN & \\
\hline CHEMBL1508636 & 737826 & 4.75 & 5.2614 & TST & \\
\hline CHEMBL1324981 & 737826 & 5.05 & 5.2241 & TRN & \\
\hline CHEMBL1563094 & 737826 & 4.9 & 5.10800 & 00000000005 & TST \\
\hline CHEMBL 39372 & 737826 & 4.8 & 4.7727 & TST & \\
\hline
\end{tabular}




\begin{tabular}{|c|c|c|c|c|}
\hline \multicolumn{5}{|c|}{ plemental } \\
\hline CHEMBL1612675 & 737826 & 4.8 & 4.8301 & TRN \\
\hline CHEMBL1306540 & 737826 & 5.35 & 5.294 & TRN \\
\hline CHEMBL1543433 & 737826 & 4.75 & 5.2594 & TRN \\
\hline CHEMBL1436882 & 737826 & 6.1 & 5.7264 & TST \\
\hline CHEMBL1741907 & 737826 & 4.8 & 5.1555 & TRN \\
\hline CHEMBL1333449 & 737826 & 5.6 & 5.3899 & TRN \\
\hline CHEMBL1438358 & 737826 & 6.25 & \multicolumn{2}{|c|}{5.462000000000001} \\
\hline CHEMBL1727976 & 737826 & 4.95 & 5.3523 & TRN \\
\hline CHEMBL1568019 & 737826 & 6.7 & 6.1826 & TRN \\
\hline CHEMBL1519856 & 737826 & 4.65 & 5.1512 & TRN \\
\hline CHEMBL 3213165 & 737826 & 5.8 & 5.2972 & TRN \\
\hline CHEMBL1456743 & 737826 & 5.8 & 5.3993 & TRN \\
\hline CHEMBL1494332 & 737826 & 5.2 & 5.1401 & TRN \\
\hline CHEMBL1496891 & 737826 & 6.45 & 5.3233 & TRN \\
\hline CHEMBL1582074 & 737826 & 5.8 & 5.1372 & TRN \\
\hline CHEMBL1525975 & 737826 & 4.7 & 5.1579 & TRN \\
\hline CHEMBL1403270 & 737826 & 5.3 & 5.0691 & TST \\
\hline CHEMBL1312169 & 737826 & 4.9 & 5.4488 & TRN \\
\hline CHEMBL1161936 & 737826 & 5.8 & 5.5357 & TRN \\
\hline CHEMBL1383867 & 737826 & 5.1 & 5.051 & TRN \\
\hline CHEMBL1424097 & 737826 & 5.35 & 5.2404 & TST \\
\hline CHEMBL1396108 & 737826 & 5.0 & 4.8488 & TRN \\
\hline CHEMBL1372106 & 737826 & 5.4 & 5.5243 & TRN \\
\hline CHEMBL1481573 & 737826 & 7.45 & 5.3796 & TST \\
\hline CHEMBL1611446 & 737826 & 5.4 & 5.2559 & TRN \\
\hline CHEMBL1594320 & 737826 & 4.85 & 5.3448 & TRN \\
\hline CHEMBL1481747 & 737826 & 5.7 & 5.5425 & TRN \\
\hline CHEMBL1470016 & 737826 & 5.5 & 5.4939 & TRN \\
\hline CHEMBL1450936 & 737826 & 6.1 & 5.7864 & TRN \\
\hline CHEMBL1303518 & 737826 & 4.4 & 5.273 & TRN \\
\hline CHEMBL1430661 & 737826 & 5.2 & 5.2931 & TRN \\
\hline CHEMBL1742008 & 737826 & 5.15 & 5.4351 & TRN \\
\hline CHEMBL1529795 & 737826 & 4.6 & 5.4526 & TRN \\
\hline CHEMBL1734844 & 737826 & 4.9 & 5.3654 & TRN \\
\hline CHEMBL1551090 & 737826 & 4.7 & 4.651 & TRN \\
\hline CHEMBL1318958 & 737826 & 5.6 & 5.2062 & TRN \\
\hline CHEMBL1436361 & 737826 & 4.6 & 4.7308 & TRN \\
\hline CHEMBL1536326 & 737826 & 5.5 & 5.3215 & TRN \\
\hline CHEMBL3198738 & 737826 & 8.0 & 5.1228 & TRN \\
\hline CHEMBL1404451 & 737826 & 6.1 & 6.0804 & TRN \\
\hline CHEMBL1453369 & 737826 & 6.5 & 5.3666 & TRN \\
\hline CHEMBL1529330 & 737826 & 4.7 & 4.5685 & TRN \\
\hline CHEMBL1545653 & 737826 & 6.55 & 5.1788 & TRN \\
\hline CHEMBL3209584 & 737826 & 6.45 & 5.3688 & TRN \\
\hline CHEMBL1361050 & 737826 & 4.75 & 5.3589 & TRN \\
\hline CHEMBL1444632 & 737826 & 5.4 & 5.1065 & TST \\
\hline CHEMBL1361837 & 737826 & 5.9 & 5.5528 & TRN \\
\hline CHEMBL1548480 & 737826 & 5.0 & 5.1952 & TRN \\
\hline
\end{tabular}




\begin{tabular}{|c|c|c|c|c|c|}
\hline \\
\hline CHEMBL1484944 & 737826 & 4.7 & 4.7317 & TRN & \\
\hline CHEMBL1566015 & 737826 & 5.4 & 5.83 & TRN & \\
\hline CHEMBL1374204 & 737826 & 4.95 & 5.5014 & TRN & \\
\hline CHEMBL1415854 & 737826 & 4.55 & 5.371 & TST & \\
\hline CHEMBL1385440 & 737826 & 4.9 & 5.2381 & TRN & \\
\hline CHEMBL1443975 & 737826 & 4.95 & 5.1275 & TST & \\
\hline CHEMBL234978 & 737826 & 4.95 & 5.2375 & TRN & \\
\hline CHEMBL1321686 & 737826 & 5.45 & 5.2233 & TRN & \\
\hline CHEMBL1319691 & 737826 & 4.8 & 5.3127 & TRN & \\
\hline CHEMBL 2369288 & 737826 & 5.0 & 5.3531 & TRN & \\
\hline CHEMBL1588356 & 737826 & 4.5 & 5.396 & TRN & \\
\hline CHEMBL1741649 & 737826 & 6.95 & 5.4343 & TRN & \\
\hline CHEMBL1477506 & 737826 & 5.2 & 5.1974 & TST & \\
\hline CHEMBL1411164 & 737826 & 5.5 & 5.38700 & 00000000005 & TRN \\
\hline CHEMBL1438058 & 737826 & 4.4 & 5.3496 & TRN & \\
\hline CHEMBL1469165 & 737826 & 4.8 & 5.2114 & TRN & \\
\hline CHEMBL1343385 & 737826 & 5.1 & 5.2286 & TRN & \\
\hline CHEMBL1538975 & 737826 & 5.2 & 5.55200 & 00000000005 & TRN \\
\hline CHEMBL1397634 & 737826 & 5.5 & 5.4384 & TRN & \\
\hline CHEMBL1383537 & 737826 & 5.45 & 5.2144 & TRN & \\
\hline CHEMBL1512222 & 737826 & 4.6 & 4.7109 & TRN & \\
\hline CHEMBL1490656 & 737826 & 5.35 & 5.2547 & TRN & \\
\hline CHEMBL1542526 & 737826 & 4.5 & 5.33700 & 0000000001 & TRN \\
\hline CHEMBL3209598 & 737826 & 6.1 & 5.3714 & TST & \\
\hline CHEMBL1482542 & 737826 & 5.45 & 5.2855 & TRN & \\
\hline CHEMBL1365504 & 737826 & 5.0 & 5.4602 & TRN & \\
\hline CHEMBL1358297 & 737826 & 4.5 & 4.5604 & TST & \\
\hline CHEMBL1490268 & 737826 & 4.7 & 4.695 & TST & \\
\hline CHEMBL3209385 & 737826 & 4.9 & 5.2554 & TRN & \\
\hline CHEMBL1568277 & 737826 & 5.55 & 5.2762 & TRN & \\
\hline CHEMBL3190830 & 737826 & 5.35 & 5.4226 & TRN & \\
\hline CHEMBL1536459 & 737826 & 5.1 & 5.4653 & TRN & \\
\hline CHEMBL1564094 & 737826 & 5.4 & 5.3099 & TRN & \\
\hline CHEMBL1484231 & 737826 & 5.55 & 5.0998 & TRN & \\
\hline CHEMBL1331980 & 737826 & 5.1 & 5.0713 & TST & \\
\hline CHEMBL 277127 & 737826 & 5.1 & 5.1035 & TRN & \\
\hline CHEMBL1500199 & 737826 & 5.4 & 5.3373 & TRN & \\
\hline CHEMBL1410101 & 737826 & 6.15 & 5.34200 & 00000000005 & TRN \\
\hline CHEMBL523167 & 737826 & 5.6 & 5.4499 & TRN & \\
\hline CHEMBL3209589 & 737826 & 4.8 & 5.4826 & TRN & \\
\hline CHEMBL8867 & 737826 & 6.0 & 5.5715 & TST & \\
\hline CHEMBL1418094 & 737826 & 5.5 & 5.3421 & TST & \\
\hline CHEMBL1407304 & 737826 & 4.65 & 5.3507 & TRN & \\
\hline CHEMBL1487801 & 737826 & 5.1 & 5.0258 & TST & \\
\hline CHEMBL1484398 & 737826 & 6.9 & 5.3874 & TRN & \\
\hline CHEMBL1528565 & 737826 & -0.0 & 5.2579 & TRN & \\
\hline CHEMBL1314971 & 737826 & 5.0 & 4.6639 & TRN & \\
\hline CHEMBL1600150 & 737826 & 5.85 & 5.3772 & TRN & \\
\hline
\end{tabular}




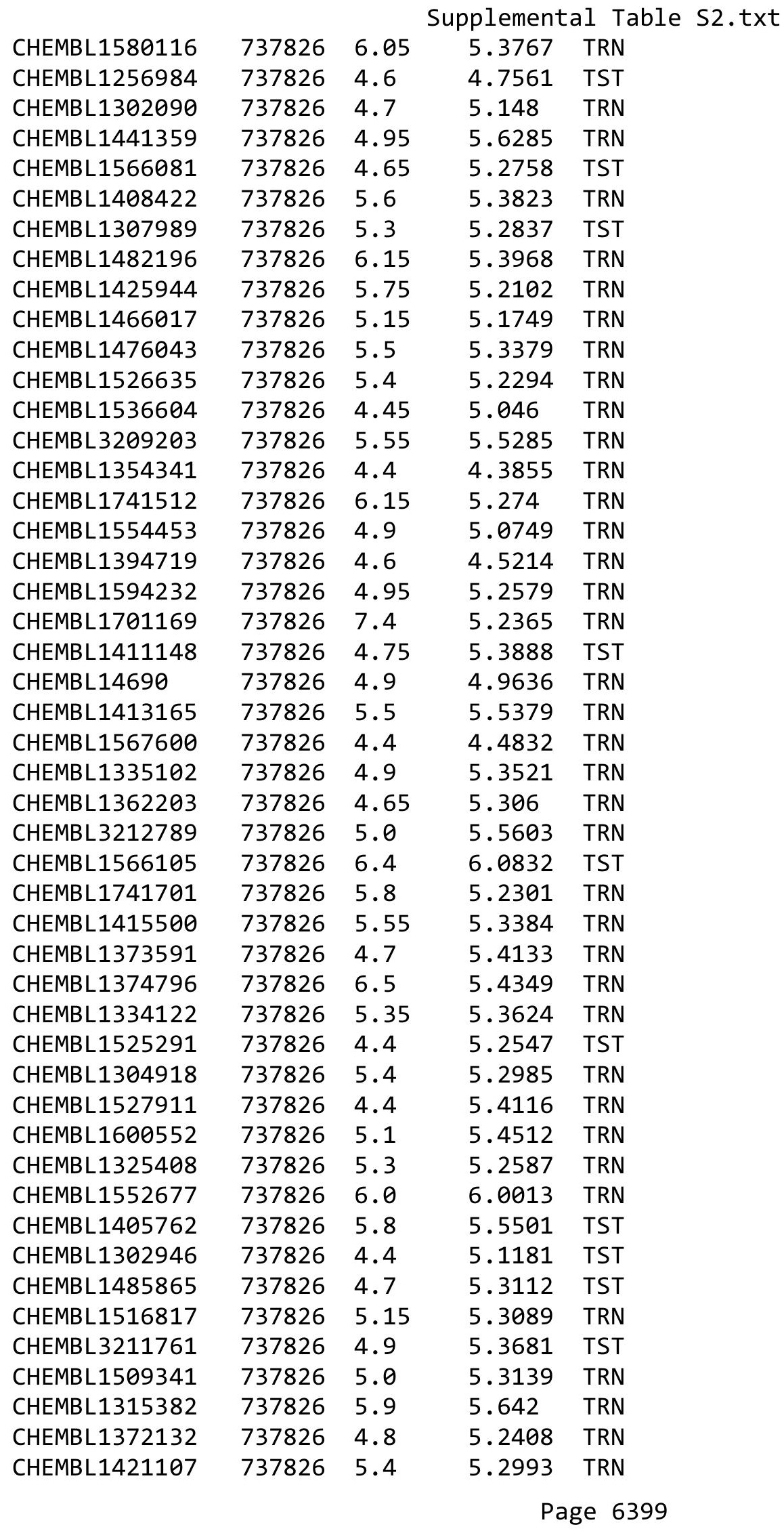




\begin{tabular}{|c|c|c|c|c|c|}
\hline \\
\hline CHEMBL1487159 & 737826 & 5.6 & 5.3132 & TST & \\
\hline CHEMBL1408128 & 737826 & 4.75 & 5.2505 & TRN & \\
\hline CHEMBL1538506 & 737826 & 5.1 & 5.6648 & TRN & \\
\hline CHEMBL1514161 & 737826 & 5.0 & 4.7267 & TRN & \\
\hline CHEMBL1492493 & 737826 & 5.95 & 5.2644 & TRN & \\
\hline CHEMBL1577056 & 737826 & 5.45 & 5.2747 & TRN & \\
\hline CHEMBL1342006 & 737826 & 6.7 & 5.2879 & TRN & \\
\hline CHEMBL1314388 & 737826 & 5.8 & 5.7938 & TRN & \\
\hline CHEMBL1578021 & 737826 & 6.0 & 5.0848 & TRN & \\
\hline CHEMBL1465393 & 737826 & 6.0 & 5.4295 & TRN & \\
\hline CHEMBL1549510 & 737826 & 5.6 & 5.5882 & TRN & \\
\hline CHEMBL1610056 & 737826 & 5.85 & 5.1433 & TST & \\
\hline CHEMBL1325530 & 737826 & 5.25 & 5.7695 & TRN & \\
\hline CHEMBL1470330 & 737826 & 5.55 & 5.2183 & TRN & \\
\hline CHEMBL1598717 & 737826 & 5.2 & 5.1079 & TRN & \\
\hline CHEMBL1533516 & 737826 & 5.1 & 5.0539 & TRN & \\
\hline CHEMBL3191056 & 737826 & 5.05 & 5.3371 & TST & \\
\hline CHEMBL1471920 & 737826 & 5.6 & 5.25899 & 99999999995 & TRN \\
\hline CHEMBL1256814 & 737826 & 4.9 & 4.71399 & 99999999995 & TRN \\
\hline CHEMBL1741657 & 737826 & 7.6 & 5.2296 & TST & \\
\hline CHEMBL1464371 & 737826 & 5.45 & 5.3848 & TRN & \\
\hline CHEMBL3196226 & 737826 & 4.8 & 5.3907 & TRN & \\
\hline CHEMBL1451176 & 737826 & 5.6 & 5.3769 & TST & \\
\hline CHEMBL1351579 & 737826 & 4.7 & 5.2383 & TRN & \\
\hline CHEMBL1432466 & 737826 & 5.5 & 5.2174 & TST & \\
\hline CHEMBL1200766 & 737826 & 5.9 & 5.6121 & TRN & \\
\hline CHEMBL1583880 & 737826 & 4.75 & 5.4894 & TRN & \\
\hline CHEMBL1611188 & 737826 & 5.95 & 5.2858 & TRN & \\
\hline CHEMBL3208441 & 737826 & 4.7 & 5.4125 & TRN & \\
\hline CHEMBL3198813 & 737826 & 5.15 & 5.5099 & TRN & \\
\hline CHEMBL1435384 & 737826 & 4.9 & 4.7344 & TRN & \\
\hline CHEMBL1397177 & 737826 & 5.0 & 4.8236 & TRN & \\
\hline CHEMBL1319109 & 737826 & 4.6 & 5.086 & TRN & \\
\hline CHEMBL24850 & 737826 & 4.6 & 4.9703 & TRN & \\
\hline CHEMBL1493227 & 737826 & 4.7 & 5.4327 & TRN & \\
\hline CHEMBL1460159 & 737826 & 4.85 & 5.1976 & TRN & \\
\hline CHEMBL1411115 & 737826 & 6.05 & 5.5931 & TRN & \\
\hline CHEMBL1609103 & 737826 & 4.85 & 5.2245 & TRN & \\
\hline CHEMBL1520582 & 737826 & 4.85 & 5.2451 & TRN & \\
\hline CHEMBL3189455 & 737826 & 5.45 & 5.3228 & TST & \\
\hline CHEMBL1319093 & 737826 & 6.1 & $5.9670 e$ & 20000000005 & TRN \\
\hline CHEMBL1600489 & 737826 & 6.2 & 5.876 & TRN & \\
\hline CHEMBL1415310 & 737826 & 4.9 & 5.3813 & TRN & \\
\hline CHEMBL1502885 & 737826 & 4.6 & 5.3331 & TRN & \\
\hline CHEMBL1557821 & 737826 & 6.6 & 5.9978 & TRN & \\
\hline CHEMBL566899 & 737826 & 5.8 & 5.8952 & TRN & \\
\hline CHEMBL1540708 & 737826 & 4.45 & 5.5815 & TRN & \\
\hline CHEMBL1579133 & 737826 & 4.75 & 5.2212 & TRN & \\
\hline
\end{tabular}




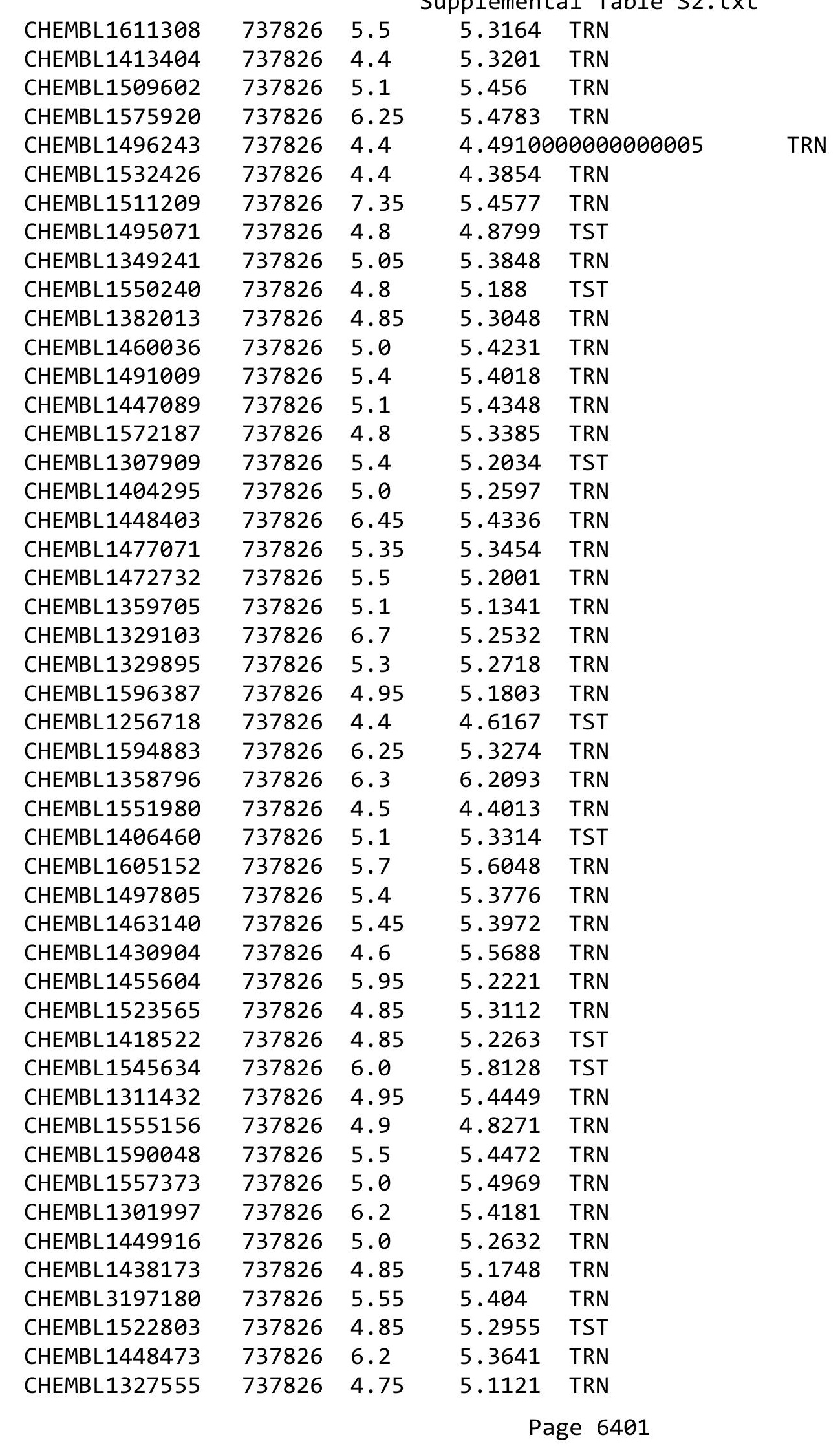




\begin{tabular}{|c|c|c|c|c|c|}
\hline \\
\hline CHEMBL1413340 & 737826 & 4.7 & 4.6793 & TRN & \\
\hline CHEMBL1443340 & 737826 & 4.7 & 5.4349 & TRN & \\
\hline CHEMBL1404858 & 737826 & 4.9 & 5.0966 & TRN & \\
\hline CHEMBL1576031 & 737826 & 5.3 & 5.3089 & TST & \\
\hline CHEMBL1499501 & 737826 & 5.05 & 5.4132 & TRN & \\
\hline CHEMBL1438566 & 737826 & 4.4 & 5.7695 & TRN & \\
\hline CHEMBL1541518 & 737826 & 6.05 & 5.4887 & TRN & \\
\hline CHEMBL1555810 & 737826 & 4.4 & 4.6798 & TST & \\
\hline CHEMBL3193547 & 737826 & 5.15 & 5.438 & TRN & \\
\hline CHEMBL1455570 & 737826 & 4.9 & 4.7855 & TRN & \\
\hline CHEMBL1329516 & 737826 & 6.05 & 5.1949 & TRN & \\
\hline CHEMBL1439808 & 737826 & 4.95 & 5.3886 & TST & \\
\hline CHEMBL1464044 & 737826 & 4.75 & 5.2483 & TRN & \\
\hline CHEMBL1366479 & 737826 & 5.1 & 5.1202 & TRN & \\
\hline CHEMBL1407857 & 737826 & 5.05 & 5.3663 & TRN & \\
\hline CHEMBL1326406 & 737826 & 5.8 & 5.3197 & TRN & \\
\hline CHEMBL1334334 & 737826 & 4.85 & 5.2861 & TRN & \\
\hline CHEMBL1574115 & 737826 & 4.9 & 4.7422 & TRN & \\
\hline CHEMBL1564261 & 737826 & 5.5 & 5.0376 & TRN & \\
\hline CHEMBL1500574 & 737826 & 6.1 & 5.2686 & TRN & \\
\hline CHEMBL1363933 & 737826 & 5.1 & 5.2591 & TST & \\
\hline CHEMBL1499066 & 737826 & 4.7 & 5.0695 & TRN & \\
\hline CHEMBL1508837 & 737826 & 5.1 & 5.1255 & TRN & \\
\hline CHEMBL1410452 & 737826 & 5.1 & 5.3397 & TRN & \\
\hline CHEMBL1544757 & 737826 & 4.6 & 5.0864 & TRN & \\
\hline CHEMBL1556569 & 737826 & 4.45 & 5.29700 & $\partial 000000001$ & TST \\
\hline CHEMBL1742259 & 737826 & 4.9 & 4.9584 & TRN & \\
\hline CHEMBL1543109 & 737826 & 5.8 & 5.5433 & TRN & \\
\hline CHEMBL1360650 & 737826 & 5.3 & 5.3896 & TRN & \\
\hline CHEMBL1476206 & 737826 & 4.9 & 4.8207 & TRN & \\
\hline CHEMBL3192906 & 737826 & 5.15 & 5.3367 & TRN & \\
\hline CHEMBL1331969 & 737826 & 5.5 & 5.4697 & TRN & \\
\hline CHEMBL1365616 & 737826 & 4.6 & 4.5668 & TRN & \\
\hline CHEMBL1580660 & 737826 & 6.2 & 5.312 & TST & \\
\hline CHEMBL1337873 & 737826 & 6.7 & 5.2262 & TRN & \\
\hline CHEMBL1602849 & 737826 & 6.3 & 5.4077 & TRN & \\
\hline CHEMBL1393481 & 737826 & 5.35 & 5.2557 & TRN & \\
\hline CHEMBL1579870 & 737826 & 4.85 & 5.2513 & TRN & \\
\hline CHEMBL1504955 & 737826 & 4.95 & 5.3928 & TRN & \\
\hline CHEMBL 270299 & 737826 & 5.1 & 5.6169 & TRN & \\
\hline CHEMBL1400744 & 737826 & 5.4 & 5.28 & TRN & \\
\hline CHEMBL1224512 & 737826 & 4.6 & 4.7052 & TRN & \\
\hline CHEMBL1311305 & 737826 & 4.95 & 5.23600 & 0000000001 & TRN \\
\hline CHEMBL1393270 & 737826 & 5.75 & 5.1236 & TRN & \\
\hline CHEMBL1508952 & 737826 & 5.8 & 5.386 & TRN & \\
\hline CHEMBL1452398 & 737826 & 5.0 & 5.4188 & TRN & \\
\hline CHEMBL1331122 & 737826 & 5.4 & 5.3046 & TST & \\
\hline CHEMBL1605148 & 737826 & 4.9 & 5.2819 & TRN & \\
\hline
\end{tabular}




\begin{tabular}{|c|c|c|c|c|c|}
\hline & & & & & \\
\hline CHEMBL1577237 & 737826 & 5.1 & 5.3957 & TRN & \\
\hline CHEMBL1742050 & 737826 & 4.8 & 5.1566 & TRN & \\
\hline CHEMBL1361133 & 737826 & 5.1 & 5.0156 & TST & \\
\hline CHEMBL1554577 & 737826 & 6.9 & 6.7503 & TRN & \\
\hline CHEMBL1709275 & 737826 & 5.95 & 5.3647 & TRN & \\
\hline CHEMBL1426036 & 737826 & 4.55 & 5.5003 & TRN & \\
\hline CHEMBL1378878 & 737826 & 5.4 & 5.2639 & TRN & \\
\hline CHEMBL1330299 & 737826 & 7.7001 & 5.319 & TRN & \\
\hline CHEMBL1553926 & 737826 & 5.3 & 4.9954 & TRN & \\
\hline CHEMBL1524497 & 737826 & 4.85 & 5.25299 & 9999999999 & TRN \\
\hline CHEMBL1390245 & 737826 & 6.55 & 5.1519 & TST & \\
\hline CHEMBL1455767 & 737826 & 5.0 & 5.0888 & TRN & \\
\hline CHEMBL1720191 & 737826 & 7.5501 & 5.3625 & TRN & \\
\hline CHEMBL1456686 & 737826 & 5.5 & 5.265 & TRN & \\
\hline CHEMBL259389 & 737826 & 5.7 & 5.4359 & TST & \\
\hline CHEMBL1322414 & 737826 & 5.8 & 5.5637 & TRN & \\
\hline CHEMBL1333759 & 737826 & 5.4 & 5.4215 & TRN & \\
\hline CHEMBL1393076 & 737826 & 4.75 & 5.2813 & TST & \\
\hline CHEMBL1171206 & 737826 & 6.6 & 5.2756 & TRN & \\
\hline CHEMBL3193871 & 737826 & 5.9 & 5.54 & TRN & \\
\hline CHEMBL1331064 & 737826 & 5.3 & 5.2166 & TRN & \\
\hline CHEMBL1518419 & 737826 & 4.75 & 5.2493 & TRN & \\
\hline CHEMBL1386207 & 737826 & 4.8 & 5.289 & TRN & \\
\hline CHEMBL1553056 & 737826 & 7.1 & 6.3199 & TRN & \\
\hline CHEMBL1565302 & 737826 & 4.4 & 4.4518 & TRN & \\
\hline CHEMBL1326546 & 737826 & 4.75 & 5.4643 & TRN & \\
\hline CHEMBL1515131 & 737826 & 5.2 & 5.1341 & TRN & \\
\hline CHEMBL1331525 & 737826 & 6.1 & 6.1543 & TRN & \\
\hline CHEMBL1313701 & 737826 & 4.85 & 5.3813 & TRN & \\
\hline CHEMBL1525073 & 737826 & 4.9 & 5.3372 & TRN & \\
\hline CHEMBL1334589 & 737826 & 5.3 & 5.45 & TRN & \\
\hline CHEMBL1367030 & 737826 & 5.1 & 5.0542 & TRN & \\
\hline CHEMBL1421764 & 737826 & 5.4 & 5.4772 & TRN & \\
\hline CHEMBL1361797 & 737826 & 5.15 & 5.2258 & TRN & \\
\hline CHEMBL1539333 & 737826 & 5.8 & 5.1716 & TST & \\
\hline CHEMBL1490181 & 737826 & 5.75 & 5.23799 & 99999999995 & TRN \\
\hline CHEMBL1515858 & 737826 & 4.8 & 4.9563 & TRN & \\
\hline CHEMBL1392455 & 737826 & 4.95 & 5.4199 & TST & \\
\hline CHEMBL1324178 & 737826 & 5.4 & 5.2117 & TRN & \\
\hline CHEMBL1522517 & 737826 & 4.85 & 5.3658 & TRN & \\
\hline CHEMBL1443898 & 737826 & 5.1 & 5.0565 & TRN & \\
\hline CHEMBL1299899 & 737826 & 5.15 & 5.2644 & TRN & \\
\hline CHEMBL1460951 & 737826 & 4.8 & 5.4166 & TRN & \\
\hline CHEMBL1438434 & 737826 & 5.55 & 5.2318 & TST & \\
\hline CHEMBL1348252 & 737826 & 5.1 & 5.3593 & TRN & \\
\hline CHEMBL1341772 & 737826 & 5.7 & 5.3559 & TRN & \\
\hline CHEMBL1508020 & 737826 & 4.95 & 5.2271 & TRN & \\
\hline CHEMBL1493592 & 737826 & 5.85 & 5.3079 & TRN & \\
\hline & & & & 6403 & \\
\hline
\end{tabular}




\begin{tabular}{|c|c|c|c|c|c|}
\hline \multicolumn{6}{|c|}{ Supplemental Table S2.txt } \\
\hline CHEMBL1428282 & 737826 & 4.75 & 5.2297 & TRN & \\
\hline CHEMBL1521468 & 737826 & 5.15 & 5.2704 & TRN & \\
\hline CHEMBL1372282 & 737826 & 7.3 & 6.4976 & TST & \\
\hline CHEMBL606167 & 737826 & 7.05 & 5.282 & TST & \\
\hline CHEMBL1600564 & 737826 & 6.4 & 6.0332 & TST & \\
\hline CHEMBL1527622 & 737826 & 5.5 & 5.3383 & TRN & \\
\hline CHEMBL1354426 & 737826 & 5.6 & 5.4849 & TRN & \\
\hline CHEMBL1538039 & 737826 & 5.25 & 5.2201 & TRN & \\
\hline CHEMBL1483545 & 737826 & 5.8 & 5.3029 & TRN & \\
\hline CHEMBL1567365 & 737826 & 5.5 & 5.4609 & TRN & \\
\hline CHEMBL1537646 & 737826 & 4.95 & 5.1097 & TST & \\
\hline CHEMBL1588525 & 737826 & 5.4 & 5.2022 & TRN & \\
\hline CHEMBL1561402 & 737826 & 4.6 & 4.5958 & TRN & \\
\hline CHEMBL1457730 & 737826 & 4.65 & 5.4396 & TRN & \\
\hline CHEMBL1561190 & 737826 & 5.15 & 5.3394 & TRN & \\
\hline CHEMBL1322901 & 737826 & 5.45 & 5.1886 & TST & \\
\hline CHEMBL1426826 & 737826 & 6.55 & 5.3522 & TRN & \\
\hline CHEMBL1487219 & 737826 & 5.0 & 4.8681 & TST & \\
\hline CHEMBL1432632 & 737826 & 5.85 & 5.4061 & TRN & \\
\hline CHEMBL1571395 & 737826 & 5.7 & 5.2725 & TRN & \\
\hline CHEMBL1422112 & 737826 & 5.45 & 5.3142 & TRN & \\
\hline CHEMBL1567447 & 737826 & 5.8 & 5.3907 & TRN & \\
\hline CHEMBL1454212 & 737826 & 5.7 & 5.0532 & TRN & \\
\hline CHEMBL1547349 & 737826 & 4.85 & 5.4269 & TRN & \\
\hline CHEMBL1474483 & 737826 & 5.2 & 5.01 & TRN & \\
\hline CHEMBL1419356 & 737826 & 7.05 & 5.0577 & TRN & \\
\hline CHEMBL1317932 & 737826 & 5.4 & 5.14 & TRN & \\
\hline CHEMBL1525963 & 737826 & 4.85 & 5.3105 & TRN & \\
\hline CHEMBL1603627 & 737826 & 4.9 & 4.8343 & TRN & \\
\hline CHEMBL1469167 & 737826 & 5.85 & 5.3026 & TRN & \\
\hline CHEMBL1412842 & 737826 & 6.0 & 5.7882 & TRN & \\
\hline CHEMBL1491776 & 737826 & 7.1 & 6.5735 & TRN & \\
\hline CHEMBL1311531 & 737826 & 5.05 & 5.3417 & TRN & \\
\hline CHEMBL3199708 & 737826 & 5.0 & 5.5239 & TRN & \\
\hline CHEMBL416657 & 737826 & 5.2 & 5.066 & TRN & \\
\hline CHEMBL1472456 & 737826 & 5.5 & 5.4004 & TRN & \\
\hline CHEMBL1448726 & 737826 & 4.7 & 4.6395 & TRN & \\
\hline CHEMBL1359713 & 737826 & 7.0 & 6.7967 & TST & \\
\hline CHEMBL1498803 & 737826 & 4.85 & 5.1854 & TRN & \\
\hline CHEMBL1340458 & 737826 & 6.25 & 5.1721 & TRN & \\
\hline CHEMBL1560502 & 737826 & 5.0 & 4.9072 & TRN & \\
\hline CHEMBL1557947 & 737826 & 5.9 & 5.51200 & 00000000005 & TRN \\
\hline CHEMBL1523175 & 737826 & 5.55 & 5.4413 & TRN & \\
\hline CHEMBL1397671 & 737826 & 4.7 & 4.7507 & TRN & \\
\hline CHEMBL1437263 & 737826 & 5.9 & 5.6523 & TRN & \\
\hline CHEMBL1568012 & 737826 & 4.9 & 5.1988 & TRN & \\
\hline CHEMBL1369886 & 737826 & 4.8 & 5.5255 & TRN & \\
\hline CHEMBL1305452 & 737826 & 5.35 & 5.11 & TRN & \\
\hline
\end{tabular}




\begin{tabular}{|c|c|c|c|c|c|}
\hline \\
\hline CHEMBL1339670 & 737826 & 5.3 & 5.2838 & TRN & \\
\hline CHEMBL1311840 & 737826 & 5.65 & 5.0832 & TRN & \\
\hline CHEMBL1371947 & 737826 & 5.2 & 5.2644 & TST & \\
\hline CHEMBL572203 & 737826 & 5.05 & 5.185 & TRN & \\
\hline CHEMBL1304990 & 737826 & 4.95 & 5.0199 & TST & \\
\hline CHEMBL1467364 & 737826 & 4.85 & 5.2573 & TRN & \\
\hline CHEMBL1324866 & 737826 & 5.15 & 5.2497 & TST & \\
\hline CHEMBL1409292 & 737826 & 4.8 & 5.2801 & TRN & \\
\hline CHEMBL1534897 & 737826 & 5.2 & 5.4579 & TRN & \\
\hline CHEMBL1369939 & 737826 & 4.85 & 5.2423 & TST & \\
\hline CHEMBL1463991 & 737826 & 4.7 & 5.1526 & TRN & \\
\hline CHEMBL1510054 & 737826 & 4.8 & 5.26 & TRN & \\
\hline CHEMBL1473753 & 737826 & 5.4 & 5.4359 & TRN & \\
\hline CHEMBL1396374 & 737826 & 6.0 & 5.9648 & TRN & \\
\hline CHEMBL1451330 & 737826 & 4.65 & 5.2193 & TRN & \\
\hline CHEMBL1420830 & 737826 & 7.05 & 5.5083 & TRN & \\
\hline CHEMBL1568009 & 737826 & 5.35 & 5.2193 & TRN & \\
\hline CHEMBL1367656 & 737826 & 6.1 & 5.8516 & TRN & \\
\hline CHEMBL1342714 & 737826 & 5.45 & 5.3692 & TRN & \\
\hline CHEMBL1374863 & 737826 & 5.0 & 4.9721 & TRN & \\
\hline CHEMBL1996902 & 737826 & 5.05 & 5.20700 & 0000000001 & TRN \\
\hline CHEMBL1538954 & 737826 & 4.8 & 5.365 & TRN & \\
\hline CHEMBL1741546 & 737826 & 4.9 & 5.2703 & TRN & \\
\hline CHEMBL1351886 & 737826 & 5.7 & 5.1529 & TRN & \\
\hline CHEMBL1574390 & 737826 & 5.1 & 5.0881 & TRN & \\
\hline CHEMBL1716715 & 737826 & 5.05 & 5.21 & TRN & \\
\hline CHEMBL1601997 & 737826 & 5.85 & 5.1989 & TST & \\
\hline CHEMBL1358266 & 737826 & 4.9 & 4.8503 & TRN & \\
\hline CHEMBL1511286 & 737826 & 4.4 & 5.2215 & TRN & \\
\hline CHEMBL1567236 & 737826 & 5.3 & 5.1917 & TRN & \\
\hline CHEMBL1323385 & 737826 & 5.5 & 5.36299 & 79999999995 & TRN \\
\hline CHEMBL1407646 & 737826 & 5.5 & 5.1568 & TRN & \\
\hline CHEMBL1256737 & 737826 & 4.4 & 4.6649 & TST & \\
\hline CHEMBL23731 & 737826 & 4.9 & 4.9109 & TRN & \\
\hline CHEMBL 288174 & 737826 & 4.9 & 4.8965 & TST & \\
\hline CHEMBL1601506 & 737826 & 5.4 & 5.5127 & TRN & \\
\hline CHEMBL1425423 & 737826 & 4.55 & 5.2238 & TRN & \\
\hline CHEMBL 3189280 & 737826 & 6.4 & 5.3969 & TRN & \\
\hline CHEMBL3197330 & 737826 & 5.45 & 5.2659 & TST & \\
\hline CHEMBL3195867 & 737826 & 6.25 & 5.3676 & TRN & \\
\hline CHEMBL1387098 & 737826 & 5.1 & 5.119 & TRN & \\
\hline CHEMBL1586050 & 737826 & 4.5 & 5.1003 & TRN & \\
\hline CHEMBL1741918 & 737826 & 4.8 & 5.169 & TRN & \\
\hline CHEMBL1478660 & 737826 & 5.15 & 5.3091 & TRN & \\
\hline CHEMBL1611902 & 737826 & 5.9 & 5.2506 & TST & \\
\hline CHEMBL39317 & 737826 & 4.5 & 4.7422 & TRN & \\
\hline CHEMBL1512708 & 737826 & 6.0 & 6.041 & TRN & \\
\hline CHEMBL1403781 & 737826 & 5.45 & 5.3207 & TRN & \\
\hline
\end{tabular}




\begin{tabular}{|c|c|c|c|c|c|}
\hline \multicolumn{6}{|c|}{ Supplemental Table S2.txt } \\
\hline CHEMBL107528 & 737826 & 5.4 & 5.2252 & TST & \\
\hline CHEMBL1473990 & 737826 & 4.4 & 4.4035 & TRN & \\
\hline CHEMBL1385673 & 737826 & 5.35 & 5.3341 & TRN & \\
\hline CHEMBL1330323 & 737826 & 5.2 & 5.244 & TRN & \\
\hline CHEMBL1390934 & 737826 & 4.9 & 5.2803 & TRN & \\
\hline CHEMBL1562612 & 737826 & 5.4 & 5.3111 & TRN & \\
\hline CHEMBL3194535 & 737826 & 5.3 & 5.3122 & TRN & \\
\hline CHEMBL1322078 & 737826 & 4.75 & 5.3572 & TRN & \\
\hline CHEMBL1546480 & 737826 & 4.5 & 5.1779 & TRN & \\
\hline CHEMBL3195990 & 737826 & 4.75 & 5.2646 & TRN & \\
\hline CHEMBL399121 & 737826 & 5.0 & 5.6102 & TST & \\
\hline CHEMBL1302492 & 737826 & 5.85 & 5.3756 & TRN & \\
\hline CHEMBL18132 & 737826 & 5.1 & 5.5807 & TRN & \\
\hline CHEMBL1707011 & 737826 & 4.9 & 5.1754 & TRN & \\
\hline CHEMBL 3214128 & 737826 & 5.75 & 5.4167 & TRN & \\
\hline CHEMBL1356132 & 737826 & 4.7 & 4.5139 & TRN & \\
\hline CHEMBL490913 & 737826 & 6.0 & 6.0793 & TRN & \\
\hline CHEMBL1520153 & 737826 & 5.6 & 5.284 & TRN & \\
\hline CHEMBL1511393 & 737826 & 5.9 & 5.2828 & TRN & \\
\hline CHEMBL1329408 & 737826 & 5.45 & 5.20700 & 0000000001 & TRN \\
\hline CHEMBL1466951 & 737826 & 6.15 & 5.23600 & 0000000001 & TRN \\
\hline CHEMBL1521273 & 737826 & 6.2 & 5.2999 & TRN & \\
\hline CHEMBL1346096 & 737826 & 5.75 & 5.2056 & TRN & \\
\hline CHEMBL1302253 & 737826 & 5.35 & 5.3868 & TRN & \\
\hline CHEMBL1363185 & 737826 & 4.8 & 5.5404 & TRN & \\
\hline CHEMBL1436488 & 737826 & 4.7 & 4.6083 & TRN & \\
\hline CHEMBL1376097 & 737826 & 4.85 & 5.4103 & TRN & \\
\hline CHEMBL1361698 & 737826 & 4.5 & 5.2256 & TST & \\
\hline CHEMBL1370805 & 737826 & 5.6 & 5.4544 & TRN & \\
\hline CHEMBL1582789 & 737826 & 4.55 & 5.3254 & TRN & \\
\hline CHEMBL1364637 & 737826 & 4.65 & 5.3806 & TRN & \\
\hline CHEMBL1550506 & 737826 & 4.55 & 5.3533 & TRN & \\
\hline CHEMBL1425498 & 737826 & 6.25 & 5.2691 & TRN & \\
\hline CHEMBL1547277 & 737826 & 5.4 & 5.265 & TRN & \\
\hline CHEMBL1597735 & 737826 & 4.8 & 5.0507 & TRN & \\
\hline CHEMBL1742187 & 737826 & 5.0 & 5.118 & TRN & \\
\hline CHEMBL598952 & 737826 & 4.4 & 4.5973 & TST & \\
\hline CHEMBL1510930 & 737826 & 5.0 & 5.3095 & TST & \\
\hline CHEMBL1474326 & 737826 & 4.9 & 4.8558 & TRN & \\
\hline CHEMBL1383401 & 737826 & 4.6 & 5.3968 & TRN & \\
\hline CHEMBL1306964 & 737826 & 4.95 & 5.3741 & TRN & \\
\hline CHEMBL1519490 & 737826 & 6.0 & 5.7858 & TST & \\
\hline CHEMBL1729271 & 737826 & 4.85 & 5.303 & TRN & \\
\hline CHEMBL3199510 & 737826 & 4.85 & 5.2068 & TST & \\
\hline CHEMBL 2001481 & 737826 & 5.15 & 5.4666 & TRN & \\
\hline CHEMBL1552314 & 737826 & 4.8 & 4.6176 & TRN & \\
\hline CHEMBL1369062 & 737826 & 4.4 & 4.511 & TRN & \\
\hline CHEMBL3208837 & 737826 & 4.65 & 4.9747 & TST & \\
\hline
\end{tabular}




\begin{tabular}{|c|c|c|c|c|c|}
\hline \\
\hline CHEMBL1544733 & 737826 & 6.05 & 5.409 & TRN & \\
\hline CHEMBL3145176 & 737826 & 5.35 & 5.2169 & TST & \\
\hline CHEMBL1323854 & 737826 & 6.0 & 5.3443 & TRN & \\
\hline CHEMBL1415547 & 737826 & 4.9 & 5.3581 & TST & \\
\hline CHEMBL1330272 & 737826 & 5.3 & 5.1854 & TRN & \\
\hline CHEMBL1323317 & 737826 & 7.6499 & 5.3046 & TRN & \\
\hline CHEMBL1484866 & 737826 & 7.1 & 5.6072 & TST & \\
\hline CHEMBL1431724 & 737826 & 5.45 & 5.3914 & TRN & \\
\hline CHEMBL1403937 & 737826 & 5.45 & 5.3414 & TRN & \\
\hline CHEMBL1357498 & 737826 & 4.7 & 4.6006 & TRN & \\
\hline CHEMBL1702111 & 737826 & 4.85 & 5.5132 & TRN & \\
\hline CHEMBL1742306 & 737826 & 5.5 & 5.3561 & TRN & \\
\hline CHEMBL1256760 & 737826 & 4.6 & 4.7694 & TST & \\
\hline CHEMBL1708264 & 737826 & 4.9 & 5.0509 & TRN & \\
\hline CHEMBL1607962 & 737826 & 5.15 & 5.1641 & TRN & \\
\hline CHEMBL1569400 & 737826 & 4.5 & 4.4559 & TRN & \\
\hline CHEMBL1601955 & 737826 & 4.6 & 5.0295 & TRN & \\
\hline CHEMBL1394031 & 737826 & 5.05 & 5.3791 & TRN & \\
\hline CHEMBL398673 & 737826 & 5.1 & 5.0122 & TRN & \\
\hline CHEMBL1371337 & 737826 & 5.45 & 5.407 & TST & \\
\hline CHEMBL1305576 & 737826 & 5.7 & 5.1351 & TRN & \\
\hline CHEMBL3211462 & 737826 & 4.7 & 5.5383 & TST & \\
\hline CHEMBL1427884 & 737826 & 5.55 & 5.2975 & TST & \\
\hline CHEMBL1417341 & 737826 & 4.85 & 5.2461 & TRN & \\
\hline CHEMBL1427101 & 737826 & 5.1 & 5.296 & TRN & \\
\hline CHEMBL1350293 & 737826 & 5.85 & 5.2574 & TRN & \\
\hline CHEMBL1303868 & 737826 & 5.15 & 5.4407 & TRN & \\
\hline CHEMBL1401981 & 737826 & 4.7 & 4.9306 & TRN & \\
\hline CHEMBL1321655 & 737826 & 4.9 & 5.0646 & TRN & \\
\hline CHEMBL1372421 & 737826 & 5.05 & 5.4697 & TRN & \\
\hline CHEMBL1350835 & 737826 & 4.95 & 5.3845 & TRN & \\
\hline CHEMBL1526170 & 737826 & 4.8 & 4.7182 & TRN & \\
\hline CHEMBL1499404 & 737826 & 4.7 & 5.221 & TST & \\
\hline CHEMBL481537 & 737826 & 4.5 & 5.6904 & TST & \\
\hline CHEMBL1514221 & 737826 & 5.5 & 5.3657 & TST & \\
\hline CHEMBL1604914 & 737826 & 5.5 & 5.2998 & TST & \\
\hline CHEMBL1533923 & 737826 & 6.0 & 5.7818 & TRN & \\
\hline CHEMBL1256865 & 737826 & 4.9 & 4.94 & TST & \\
\hline CHEMBL1549097 & 737826 & 6.0 & 5.4781 & TRN & \\
\hline CHEMBL1356113 & 737826 & 5.7 & 5.4806 & TRN & \\
\hline CHEMBL1411743 & 737826 & 5.0 & 4.9572 & TRN & \\
\hline CHEMBL1315380 & 737826 & 5.4 & 5.24799 & 9999999999 & TRN \\
\hline CHEMBL1491874 & 737826 & 7.0 & 5.5877 & TRN & \\
\hline CHEMBL1496246 & 737826 & 5.1 & 5.0105 & TRN & \\
\hline CHEMBL1514390 & 737826 & 5.6 & 5.2589 & TRN & \\
\hline CHEMBL1522654 & 737826 & 4.5 & 5.3338 & TRN & \\
\hline CHEMBL1453244 & 737826 & 5.3 & 5.1856 & TRN & \\
\hline CHEMBL1490386 & 737826 & 5.0 & 4.8256 & TRN & \\
\hline
\end{tabular}




\begin{tabular}{|c|c|c|c|c|c|}
\hline \multicolumn{6}{|c|}{ Supplemental Table S2.txt } \\
\hline CHEMBL1413668 & 737826 & 5.05 & 5.11 & TST & \\
\hline CHEMBL1256659 & 737826 & 4.5 & 4.5278 & TST & \\
\hline CHEMBL1558574 & 737826 & 4.95 & 5.3575 & TRN & \\
\hline CHEMBL 3213877 & 737826 & 5.0 & 5.2237 & TRN & \\
\hline CHEMBL1371329 & 737826 & 4.5 & 5.1838 & TRN & \\
\hline CHEMBL1594372 & 737826 & 5.8 & 5.8681 & TRN & \\
\hline CHEMBL1608975 & 737826 & 4.7 & 4.725 & TRN & \\
\hline CHEMBL1411123 & 737826 & 5.35 & 5.1618 & TRN & \\
\hline CHEMBL1358588 & 737826 & 4.8 & 4.9524 & TRN & \\
\hline CHEMBL1304718 & 737826 & 4.85 & 5.2669 & TST & \\
\hline CHEMBL1973500 & 737826 & 4.55 & 5.4637 & TST & \\
\hline CHEMBL1340864 & 737826 & 5.9 & 5.1437 & TRN & \\
\hline CHEMBL1328536 & 737826 & 5.4 & 5.2982 & TRN & \\
\hline CHEMBL1591380 & 737826 & 4.8 & 4.9019 & TRN & \\
\hline CHEMBL3194665 & 737826 & 4.8 & 5.4993 & TST & \\
\hline CHEMBL1367387 & 737826 & 5.3 & 5.1738 & TRN & \\
\hline CHEMBL584860 & 737826 & 4.95 & 5.1826 & TRN & \\
\hline CHEMBL1429297 & 737826 & 5.15 & 5.3603 & TRN & \\
\hline CHEMBL1568767 & 737826 & 6.1 & 6.1643 & TRN & \\
\hline CHEMBL1303328 & 737826 & 5.2 & 5.2762 & TRN & \\
\hline CHEMBL1601015 & 737826 & 4.85 & 5.2503 & TRN & \\
\hline CHEMBL1789998 & 737826 & 4.4 & 4.5068 & TST & \\
\hline CHEMBL1409074 & 737826 & 5.5 & 5.3008 & TRN & \\
\hline CHEMBL1574886 & 737826 & 4.4 & 5.1226 & TRN & \\
\hline CHEMBL1741989 & 737826 & 5.15 & 5.1574 & TRN & \\
\hline CHEMBL1307158 & 737826 & 4.75 & 5.2707 & TRN & \\
\hline CHEMBL1413306 & 737826 & 5.0 & 5.1726 & TRN & \\
\hline CHEMBL1457419 & 737826 & 5.4 & 5.3335 & TST & \\
\hline CHEMBL1309131 & 737826 & 5.25 & 5.4011 & TRN & \\
\hline CHEMBL1517418 & 737826 & 4.7 & 5.13899 & 9999999999 & TRN \\
\hline CHEMBL1525560 & 737826 & 4.5 & 5.234 & TRN & \\
\hline CHEMBL1362669 & 737826 & 5.65 & 5.5031 & TRN & \\
\hline CHEMBL1428357 & 737826 & 4.95 & 5.1805 & TRN & \\
\hline CHEMBL1555132 & 737826 & 5.0 & 4.9797 & TRN & \\
\hline CHEMBL1742034 & 737826 & 7.2 & 5.2413 & TRN & \\
\hline CHEMBL1372406 & 737826 & 5.05 & 5.2998 & TRN & \\
\hline CHEMBL1442542 & 737826 & 4.7 & 5.6547 & TST & \\
\hline CHEMBL1349240 & 737826 & 5.0 & 5.1683 & TRN & \\
\hline CHEMBL1381224 & 737826 & 6.05 & 5.199 & TRN & \\
\hline CHEMBL 3197094 & 737826 & 5.1 & 5.2961 & TRN & \\
\hline CHEMBL1529232 & 737826 & 6.9 & 5.3695 & TRN & \\
\hline CHEMBL1374913 & 737826 & 4.5 & 4.5287 & TRN & \\
\hline CHEMBL1435293 & 737826 & 6.0 & 5.8719 & TRN & \\
\hline CHEMBL1426500 & 737826 & 4.85 & 5.2411 & TRN & \\
\hline CHEMBL1538481 & 737826 & 4.85 & 5.1287 & TRN & \\
\hline CHEMBL1396583 & 737826 & 4.4 & 4.3786 & TRN & \\
\hline CHEMBL1417135 & 737826 & 5.0 & 4.8907 & TRN & \\
\hline CHEMBL1529265 & 737826 & 5.5 & 5.3941 & TRN & \\
\hline
\end{tabular}




\begin{tabular}{|c|c|c|c|c|}
\hline \multicolumn{5}{|c|}{ plemental T } \\
\hline CHEMBL1558420 & 737826 & 4.6 & 4.5439 & TRN \\
\hline CHEMBL1356106 & 737826 & 5.0 & 5.0235 & TST \\
\hline CHEMBL1370632 & 737826 & 5.25 & 5.2523 & TRN \\
\hline CHEMBL1551051 & 737826 & 4.8 & 4.7653 & TRN \\
\hline CHEMBL1346226 & 737826 & 5.7 & 5.2987 & TRN \\
\hline CHEMBL1371838 & 737826 & 6.4 & 5.8893 & TST \\
\hline CHEMBL1490894 & 737826 & 5.0 & 5.1517 & TRN \\
\hline CHEMBL1416351 & 737826 & 6.05 & 5.6906 & TRN \\
\hline CHEMBL1595145 & 737826 & 4.9 & 5.0975 & TST \\
\hline CHEMBL1388315 & 737826 & 6.3 & 5.3501 & TRN \\
\hline CHEMBL1457798 & 737826 & 5.35 & 5.4684 & TRN \\
\hline CHEMBL1329928 & 737826 & 4.5 & 5.2681 & TST \\
\hline CHEMBL1559877 & 737826 & 5.5 & 5.2831 & TRN \\
\hline CHEMBL1354626 & 737826 & 5.5 & 5.3849 & TRN \\
\hline CHEMBL1460907 & 737826 & 5.1 & 5.2742 & TRN \\
\hline CHEMBL145725 & 737826 & 6.4 & 5.8783 & TST \\
\hline CHEMBL3192769 & 737826 & 4.85 & 5.3727 & TRN \\
\hline CHEMBL103469 & 737826 & 5.1 & 5.075 & TRN \\
\hline CHEMBL1319717 & 737826 & 6.3 & 5.4218 & TRN \\
\hline CHEMBL1427581 & 737826 & 5.05 & 5.1787 & TRN \\
\hline CHEMBL1611170 & 737826 & 5.1 & 5.3491 & TRN \\
\hline CHEMBL1500134 & 737826 & 4.85 & 5.2359 & TRN \\
\hline CHEMBL1335865 & 737826 & 7.4 & 5.4374 & TRN \\
\hline CHEMBL1378758 & 737826 & 5.4 & 5.3529 & TRN \\
\hline CHEMBL1404955 & 737826 & 7.45 & 5.3836 & TRN \\
\hline CHEMBL1552680 & 737826 & 4.6 & 4.4778 & TRN \\
\hline CHEMBL1356041 & 737826 & 6.6 & 6.4635 & TRN \\
\hline CHEMBL3191636 & 737826 & 4.95 & 5.3036 & TST \\
\hline CHEMBL3199876 & 737826 & 5.55 & 5.3854 & TRN \\
\hline CHEMBL 2369218 & 737826 & 5.9 & 5.4243 & TST \\
\hline CHEMBL1545870 & 737826 & 4.75 & 5.2928 & TRN \\
\hline CHEMBL275809 & 737826 & 4.7 & 4.7678 & TRN \\
\hline CHEMBL3214412 & 737826 & 5.45 & 5.3749 & TRN \\
\hline CHEMBL1310018 & 737826 & 4.85 & 5.2686 & TRN \\
\hline CHEMBL1433013 & 737826 & 4.95 & 5.2193 & TRN \\
\hline CHEMBL1454734 & 737826 & 5.45 & 5.051 & TST \\
\hline CHEMBL1489541 & 737826 & 5.5 & 5.3603 & TRN \\
\hline CHEMBL1495801 & 737826 & 4.4 & 5.2118 & TRN \\
\hline CHEMBL1380474 & 737826 & 5.2 & 5.5121 & TST \\
\hline CHEMBL1474056 & 737826 & 5.5 & 5.1796 & TRN \\
\hline CHEMBL1322914 & 737826 & 4.6 & 5.2236 & TST \\
\hline CHEMBL1714794 & 737826 & 4.85 & 5.2208 & TST \\
\hline CHEMBL1339353 & 737826 & 4.4 & 5.3504 & TST \\
\hline CHEMBL1369414 & 737826 & 6.2 & 5.779 & TST \\
\hline CHEMBL1310646 & 737826 & 4.4 & 5.3146 & TRN \\
\hline CHEMBL1301464 & 737826 & 5.75 & 5.3088 & TST \\
\hline CHEMBL1612407 & 737826 & 4.5 & 5.2674 & TRN \\
\hline CHEMBL1532386 & 737826 & 5.7 & 5.2943 & TRN \\
\hline
\end{tabular}




\begin{tabular}{|c|c|c|c|c|c|}
\hline \\
\hline CHEMBL1605309 & 737826 & 4.9 & 5.4831 & TRN & \\
\hline CHEMBL3192865 & 737826 & 5.4 & 5.4145 & TRN & \\
\hline CHEMBL1421520 & 737826 & 5.5 & 5.3164 & TRN & \\
\hline CHEMBL1970527 & 737826 & 5.65 & 5.4033 & TRN & \\
\hline CHEMBL1326533 & 737826 & 4.65 & 5.2422 & TRN & \\
\hline CHEMBL1458191 & 737826 & 5.7 & 5.2037 & TRN & \\
\hline CHEMBL1347770 & 737826 & 4.6 & 5.2259 & TRN & \\
\hline CHEMBL3196221 & 737826 & 5.2 & 5.3786 & TST & \\
\hline CHEMBL1502739 & 737826 & 4.95 & 5.2004 & TRN & \\
\hline CHEMBL1365833 & 737826 & 5.1 & 5.4344 & TST & \\
\hline CHEMBL1595644 & 737826 & 5.3 & 5.2536 & TST & \\
\hline CHEMBL1387287 & 737826 & 5.15 & 5.3914 & TRN & \\
\hline CHEMBL180966 & 737826 & 5.6 & 5.4253 & TRN & \\
\hline CHEMBL1378110 & 737826 & 5.15 & 5.4481 & TRN & \\
\hline CHEMBL1509024 & 737826 & 5.55 & 5.3188 & TRN & \\
\hline CHEMBL1301765 & 737826 & 4.7 & 5.3496 & TRN & \\
\hline CHEMBL1741340 & 737826 & 5.35 & 5.2789 & TST & \\
\hline CHEMBL1724716 & 737826 & 4.95 & 5.3781 & TRN & \\
\hline CHEMBL1504999 & 737826 & 5.25 & 5.1804 & TST & \\
\hline CHEMBL1529652 & 737826 & 5.45 & 5.1743 & TRN & \\
\hline CHEMBL1524305 & 737826 & 4.5 & 4.5396 & TRN & \\
\hline CHEMBL1352808 & 737826 & 6.75 & 5.2403 & TRN & \\
\hline CHEMBL1488466 & 737826 & 6.0 & 5.3371 & TRN & \\
\hline CHEMBL1590974 & 737826 & 5.3 & 5.1384 & TRN & \\
\hline CHEMBL1705804 & 737826 & 4.9 & 5.1836 & TRN & \\
\hline CHEMBL1598112 & 737826 & 4.65 & 5.1752 & TRN & \\
\hline CHEMBL1389433 & 737826 & 4.6 & 5.3818 & TRN & \\
\hline CHEMBL1409167 & 737826 & 4.65 & 5.20799 & 9999999999 & TRN \\
\hline CHEMBL39 & 737826 & 4.8 & 4.6832 & TRN & \\
\hline CHEMBL1558201 & 737826 & 5.55 & 5.3984 & TRN & \\
\hline CHEMBL1447333 & 737826 & 6.3 & 5.8225 & TST & \\
\hline CHEMBL1329108 & 737826 & 4.9 & 4.7738 & TRN & \\
\hline CHEMBL1537183 & 737826 & 5.5 & 5.3211 & TRN & \\
\hline CHEMBL1412564 & 737826 & 4.7 & 5.2294 & TRN & \\
\hline CHEMBL1487532 & 737826 & 5.1 & 5.0508 & TST & \\
\hline CHEMBL1547490 & 737826 & 4.95 & 5.2456 & TRN & \\
\hline CHEMBL3195211 & 737826 & 5.0 & 5.4153 & TRN & \\
\hline CHEMBL1521453 & 737826 & 5.4 & 5.6756 & TST & \\
\hline CHEMBL1446716 & 737826 & 7.7001 & 7.2389 & TST & \\
\hline CHEMBL1593707 & 737826 & 5.4 & 5.3181 & TRN & \\
\hline CHEMBL1453519 & 737826 & 5.85 & 5.4735 & TRN & \\
\hline CHEMBL1554291 & 737826 & 5.9 & 5.4987 & TST & \\
\hline CHEMBL 256835 & 737826 & 5.1 & 5.1241 & TRN & \\
\hline CHEMBL1302300 & 737826 & 5.0 & 5.1676 & TST & \\
\hline CHEMBL1411008 & 737826 & 4.55 & 5.2928 & TRN & \\
\hline CHEMBL1568990 & 737826 & 4.5 & 5.1665 & TRN & \\
\hline CHEMBL1470566 & 737826 & 6.0 & 5.4199 & TRN & \\
\hline CHEMBL1256291 & 737826 & 5.9 & 5.7297 & TRN & \\
\hline
\end{tabular}




\begin{tabular}{|c|c|c|c|c|}
\hline \multicolumn{5}{|c|}{ Supplemental Table S2.txt } \\
\hline CHEMBL1407215 & 737826 & 4.9 & 5.3543 & TRN \\
\hline CHEMBL1511199 & 737826 & 4.75 & 5.2491 & TRN \\
\hline CHEMBL1329846 & 737826 & 5.15 & 5.2537 & TRN \\
\hline CHEMBL1425367 & 737826 & 4.8 & 5.2176 & TRN \\
\hline CHEMBL1497183 & 737826 & 4.8 & 5.319 & TRN \\
\hline CHEMBL1502348 & 737826 & 4.85 & 5.394 & TRN \\
\hline CHEMBL1569979 & 737826 & 4.65 & 5.3482 & TST \\
\hline CHEMBL1480087 & 737826 & 5.7 & 5.1812 & TRN \\
\hline CHEMBL1329418 & 737826 & 5.55 & 5.2126 & TRN \\
\hline CHEMBL1534054 & 737826 & 5.05 & 5.4696 & TRN \\
\hline CHEMBL1405203 & 737826 & 4.8 & 5.2946 & TRN \\
\hline CHEMBL1610409 & 737826 & 5.1 & 5.3246 & TRN \\
\hline CHEMBL1306491 & 737826 & 5.65 & 5.2202 & TRN \\
\hline CHEMBL1366766 & 737826 & 5.2 & 5.2308 & TRN \\
\hline CHEMBL1485397 & 737826 & 5.35 & 5.4193 & TRN \\
\hline CHEMBL1524598 & 737826 & 5.25 & 5.1745 & TST \\
\hline CHEMBL1396577 & 737826 & 5.2 & 5.1222 & TRN \\
\hline CHEMBL1573418 & 737826 & 4.8 & 5.2632 & TRN \\
\hline CHEMBL1406495 & 737826 & 4.55 & 5.1424 & TRN \\
\hline CHEMBL1429119 & 737826 & 4.75 & 5.2763 & TRN \\
\hline CHEMBL1425746 & 737826 & 5.35 & 5.2791 & TRN \\
\hline CHEMBL1590259 & 737826 & 4.6 & 4.5985 & TRN \\
\hline CHEMBL1376005 & 737826 & 5.5 & 5.3218 & TST \\
\hline CHEMBL1403626 & 737826 & 6.0 & 5.7871 & TRN \\
\hline CHEMBL1609472 & 737826 & 6.45 & 5.0996 & TST \\
\hline CHEMBL1312586 & 737826 & 5.6 & 5.4573 & TRN \\
\hline CHEMBL1547530 & 737826 & 4.75 & 5.3722 & TRN \\
\hline CHEMBL1444936 & 737826 & 4.55 & 5.4017 & TRN \\
\hline CHEMBL1408334 & 737826 & 6.0 & 5.716 & TRN \\
\hline CHEMBL1420005 & 737826 & 5.85 & 5.318 & TRN \\
\hline CHEMBL1328375 & 737826 & 5.0 & 5.0848 & TRN \\
\hline CHEMBL1362034 & 737826 & 5.1 & 5.2173 & TRN \\
\hline CHEMBL1361984 & 737826 & 5.5 & 5.2185 & TRN \\
\hline CHEMBL1478772 & 737826 & 4.8 & 4.6285 & TRN \\
\hline CHEMBL1516851 & 737826 & 5.75 & 5.3312 & TRN \\
\hline CHEMBL1381829 & 737826 & 6.0 & 5.3454 & TRN \\
\hline CHEMBL1435886 & 737826 & 4.5 & 4.4153 & TRN \\
\hline CHEMBL1544821 & 737826 & 5.45 & 5.3727 & TRN \\
\hline CHEMBL553751 & 737826 & 4.8 & 4.7081 & TST \\
\hline CHEMBL1531701 & 737826 & 6.0 & 5.4488 & TRN \\
\hline CHEMBL1363697 & 737826 & 6.1 & 5.3362 & TRN \\
\hline CHEMBL3192117 & 737826 & 4.9 & 5.3293 & TRN \\
\hline CHEMBL1366112 & 737826 & 5.7 & 5.3217 & TRN \\
\hline CHEMBL1484692 & 737826 & 5.7 & 5.1432 & TST \\
\hline CHEMBL1332143 & 737826 & 5.15 & 5.0893 & TST \\
\hline CHEMBL1591635 & 737826 & 5.4 & 5.1165 & TRN \\
\hline CHEMBL1599391 & 737826 & 5.55 & 5.3679 & TRN \\
\hline CHEMBL1315083 & 737826 & 6.3 & 6.2401 & TRN \\
\hline
\end{tabular}




\begin{tabular}{|c|c|c|c|c|c|}
\hline \\
\hline CHEMBL1564545 & 737826 & 4.7 & 4.7124 & TRN & \\
\hline CHEMBL1450677 & 737826 & 5.05 & 5.1652 & TRN & \\
\hline CHEMBL1469742 & 737826 & 6.45 & 5.2665 & TRN & \\
\hline CHEMBL1396261 & 737826 & 6.3 & 6.2124 & TRN & \\
\hline CHEMBL1397218 & 737826 & 6.5 & 6.0445 & TST & \\
\hline CHEMBL1408303 & 737826 & 5.0 & 5.4939 & TRN & \\
\hline CHEMBL1351663 & 737826 & 5.6 & 4.9797 & TRN & \\
\hline CHEMBL1605237 & 737826 & 5.15 & 5.3668 & TRN & \\
\hline CHEMBL1584828 & 737826 & 6.65 & 5.0995 & TRN & \\
\hline CHEMBL1392767 & 737826 & 5.45 & 5.2885 & TRN & \\
\hline CHEMBL1987784 & 737826 & 5.3 & 5.1521 & TRN & \\
\hline CHEMBL1405744 & 737826 & 5.1 & 5.1342 & TRN & \\
\hline CHEMBL1353037 & 737826 & 5.4 & 5.2472 & TRN & \\
\hline CHEMBL1310057 & 737826 & 4.6 & 5.1495 & TRN & \\
\hline CHEMBL1320225 & 737826 & 4.95 & 5.0842 & TRN & \\
\hline CHEMBL 7634 & 737826 & 5.7 & 5.6708 & TST & \\
\hline CHEMBL1538337 & 737826 & 5.15 & 5.4332 & TRN & \\
\hline CHEMBL1443019 & 737826 & 6.45 & 5.3027 & TRN & \\
\hline CHEMBL1451471 & 737826 & 6.75 & 5.5533 & TRN & \\
\hline CHEMBL1343101 & 737826 & 4.95 & 5.1169 & TST & \\
\hline CHEMBL592561 & 737826 & 5.1 & 5.4089 & TRN & \\
\hline CHEMBL1711658 & 737826 & 4.9 & 5.0777 & TST & \\
\hline CHEMBL1512702 & 737826 & 5.2 & 4.9265 & TRN & \\
\hline CHEMBL1470727 & 737826 & 6.05 & 5.221 & TRN & \\
\hline CHEMBL1527392 & 737826 & 4.4 & 5.2443 & TRN & \\
\hline CHEMBL1500523 & 737826 & 5.1 & 5.1896 & TRN & \\
\hline CHEMBL1363513 & 737826 & 4.4 & 4.3869 & TRN & \\
\hline CHEMBL1580242 & 737826 & 4.6 & 5.3598 & TRN & \\
\hline CHEMBL1341400 & 737826 & 5.45 & 5.1321 & TRN & \\
\hline CHEMBL1329240 & 737826 & 6.0 & 5.3084 & TRN & \\
\hline CHEMBL1507704 & 737826 & 4.7 & 5.0533 & TRN & \\
\hline CHEMBL1418437 & 737826 & 4.95 & 5.4469 & TRN & \\
\hline CHEMBL1461239 & 737826 & 6.3 & 5.2681 & TRN & \\
\hline CHEMBL1720268 & 737826 & 5.0 & 5.347 & TRN & \\
\hline CHEMBL567175 & 737826 & 6.0 & 5.4854 & TST & \\
\hline CHEMBL1400899 & 737826 & 4.4 & 5.2172 & TRN & \\
\hline CHEMBL1370229 & 737826 & 5.5 & 5.45200 & 0000000001 & TRN \\
\hline CHEMBL1582272 & 737826 & 5.0 & 5.5019 & TRN & \\
\hline CHEMBL1435200 & 737826 & 4.8 & 4.7818 & TST & \\
\hline CHEMBL1529625 & 737826 & 4.7 & 4.532 & TST & \\
\hline CHEMBL1516249 & 737826 & 4.9 & 4.7164 & TRN & \\
\hline CHEMBL1331579 & 737826 & 5.7 & 5.5249 & TRN & \\
\hline CHEMBL1319626 & 737826 & 5.5 & 5.3373 & TRN & \\
\hline CHEMBL1335037 & 737826 & 5.4 & 5.3223 & TRN & \\
\hline CHEMBL1389097 & 737826 & 5.1 & 5.1401 & TRN & \\
\hline CHEMBL1310248 & 737826 & 5.65 & 5.2793 & TRN & \\
\hline CHEMBL2373630 & 737826 & 5.6 & 5.4022 & TST & \\
\hline CHEMBL1352502 & 737826 & 4.65 & 5.2863 & TRN & \\
\hline
\end{tabular}




\begin{tabular}{|c|c|c|c|c|c|}
\hline \\
\hline CHEMBL1452722 & 737826 & 6.2 & 5.875 & TRN & \\
\hline CHEMBL1399291 & 737826 & 4.75 & 5.4523 & TRN & \\
\hline CHEMBL1398691 & 737826 & 5.5 & 5.2645 & TRN & \\
\hline CHEMBL1559127 & 737826 & 5.0 & 4.8664 & TRN & \\
\hline CHEMBL1612048 & 737826 & 4.95 & 5.4111 & TST & \\
\hline CHEMBL42485 & 737826 & 6.1 & 5.8894 & TST & \\
\hline CHEMBL1507424 & 737826 & 4.95 & 5.1021 & TRN & \\
\hline CHEMBL1324352 & 737826 & 4.9 & 5.5183 & TRN & \\
\hline CHEMBL1585320 & 737826 & 5.1 & 5.2945 & TRN & \\
\hline CHEMBL75967 & 737826 & 6.0 & 5.6982 & TST & \\
\hline CHEMBL1255837 & 737826 & 6.0 & 5.7722 & TST & \\
\hline CHEMBL1475620 & 737826 & 4.9 & 4.6832 & TRN & \\
\hline CHEMBL3213158 & 737826 & 5.55 & 5.2136 & TRN & \\
\hline CHEMBL1507419 & 737826 & 4.8 & 5.1412 & TST & \\
\hline CHEMBL3207903 & 737826 & 5.8 & 5.6169 & TRN & \\
\hline CHEMBL1514143 & 737826 & 5.5 & 5.1906 & TRN & \\
\hline CHEMBL1304054 & 737826 & 5.35 & 5.4118 & TRN & \\
\hline CHEMBL1318597 & 737826 & 4.5 & 4.4216 & TRN & \\
\hline CHEMBL1409262 & 737826 & 5.15 & 5.1765 & TRN & \\
\hline CHEMBL1383364 & 737826 & 4.85 & 5.2423 & TRN & \\
\hline CHEMBL1344123 & 737826 & 5.2 & 5.4231 & TRN & \\
\hline CHEMBL 3207490 & 737826 & 5.1 & 5.3606 & TRN & \\
\hline CHEMBL1573688 & 737826 & 5.3 & 5.34399 & 9999999999 & TRN \\
\hline CHEMBL1490414 & 737826 & 4.9 & 5.1385 & TRN & \\
\hline CHEMBL1564665 & 737826 & 4.6 & 5.3337 & TST & \\
\hline CHEMBL1597695 & 737826 & 4.95 & 5.2857 & TST & \\
\hline CHEMBL1478351 & 737826 & 5.05 & 5.2844 & TRN & \\
\hline CHEMBL3195098 & 737826 & 5.05 & 5.4381 & TRN & \\
\hline CHEMBL1479131 & 737826 & 5.45 & 5.211 & TRN & \\
\hline CHEMBL1419672 & 737826 & 4.9 & 5.4446 & TST & \\
\hline CHEMBL1463329 & 737826 & 6.35 & 5.2166 & TST & \\
\hline CHEMBL1530213 & 737826 & 5.2 & 5.1511 & TRN & \\
\hline CHEMBL1451128 & 737826 & 4.95 & 5.32299 & 99999999995 & TST \\
\hline CHEMBL1337320 & 737826 & 5.3 & 5.1898 & TRN & \\
\hline CHEMBL3198312 & 737826 & 5.25 & 5.5127 & TRN & \\
\hline CHEMBL1447245 & 737826 & 5.05 & 5.206 & TRN & \\
\hline CHEMBL1476139 & 737826 & 4.7 & 4.6166 & TRN & \\
\hline CHEMBL1415777 & 737826 & 5.7 & 5.4509 & TST & \\
\hline CHEMBL1538008 & 737826 & 4.55 & 5.2834 & TRN & \\
\hline CHEMBL1612691 & 737826 & 4.9 & 5.1447 & TRN & \\
\hline CHEMBL1488098 & 737826 & 4.55 & 5.1577 & TST & \\
\hline CHEMBL1501275 & 737826 & 6.8 & 5.2832 & TRN & \\
\hline CHEMBL1314100 & 737826 & 4.6 & 5.5218 & TST & \\
\hline CHEMBL1422591 & 737826 & 5.4 & 5.2602 & TRN & \\
\hline CHEMBL1579455 & 737826 & 4.8 & 5.3021 & TST & \\
\hline CHEMBL1408908 & 737826 & 6.85 & 5.274 & TST & \\
\hline CHEMBL1505191 & 737826 & 7.35 & 5.267 & TRN & \\
\hline CHEMBL1334465 & 737826 & 5.2 & 5.1662 & TRN & \\
\hline
\end{tabular}




\begin{tabular}{|c|c|c|c|c|}
\hline \multicolumn{5}{|c|}{ Supplemental } \\
\hline CHEMBL1562715 & 737826 & 5.0 & 5.2931 & TRN \\
\hline CHEMBL1503270 & 737826 & 4.85 & 5.0762 & TRN \\
\hline CHEMBL1741944 & 737826 & 4.5 & 5.3336 & TRN \\
\hline CHEMBL1699754 & 737826 & 5.45 & 5.2397 & TST \\
\hline CHEMBL1381655 & 737826 & 5.2 & 5.0982 & TRN \\
\hline CHEMBL1565724 & 737826 & 5.6 & 5.6164 & TRN \\
\hline CHEMBL3192772 & 737826 & 4.85 & 5.279 & TRN \\
\hline CHEMBL1457381 & 737826 & 4.4 & 5.3892 & TRN \\
\hline CHEMBL1307437 & 737826 & 5.7 & 5.3187 & TRN \\
\hline CHEMBL1325701 & 737826 & 5.2 & 5.0842 & TRN \\
\hline CHEMBL1307320 & 737826 & 5.4 & 5.3722 & TRN \\
\hline CHEMBL1380424 & 737826 & 5.0 & 5.2984 & TRN \\
\hline CHEMBL1393997 & 737826 & 4.55 & 5.2612 & TRN \\
\hline CHEMBL1476687 & 737826 & 5.3 & 5.2147 & TRN \\
\hline CHEMBL1440329 & 737826 & 4.9 & 5.3945 & TRN \\
\hline CHEMBL1352082 & 737826 & 5.6 & 5.2449 & TRN \\
\hline CHEMBL1317451 & 737826 & 4.6 & 4.5839 & TRN \\
\hline CHEMBL1496576 & 737826 & 5.0 & 4.9071 & TRN \\
\hline CHEMBL1526262 & 737826 & 5.45 & 5.5014 & TRN \\
\hline CHEMBL1569592 & 737826 & 5.1 & 5.0779 & TRN \\
\hline CHEMBL1414438 & 737826 & 5.3 & 5.5505 & TRN \\
\hline CHEMBL1554411 & 737826 & 6.2 & 5.9334 & TRN \\
\hline CHEMBL1301326 & 737826 & 6.2 & 5.3193 & TRN \\
\hline CHEMBL1415465 & 737826 & 4.9 & 4.7264 & TRN \\
\hline CHEMBL1375115 & 737826 & 4.8 & 5.4435 & TST \\
\hline CHEMBL1582527 & 737826 & 5.0 & 5.2846 & TRN \\
\hline CHEMBL24909 & 737826 & 5.1 & 5.0848 & TRN \\
\hline CHEMBL1448646 & 737826 & 6.1 & 5.4232 & TRN \\
\hline CHEMBL1473331 & 737826 & 6.0 & 5.9262 & TRN \\
\hline CHEMBL1584983 & 737826 & 6.05 & 5.2979 & TST \\
\hline CHEMBL1464487 & 737826 & 6.4 & 5.2859 & TST \\
\hline CHEMBL3198972 & 737826 & 4.9 & 5.2504 & TRN \\
\hline CHEMBL1551515 & 737826 & 5.9 & 5.8303 & TRN \\
\hline CHEMBL1531174 & 737826 & 5.1 & 5.131 & TRN \\
\hline CHEMBL1401483 & 737826 & 4.4 & 4.5128 & TRN \\
\hline CHEMBL1442087 & 737826 & 5.5 & 5.3612 & TRN \\
\hline CHEMBL1316562 & 737826 & 6.9 & 6.3001 & TRN \\
\hline CHEMBL 1741910 & 737826 & 5.1 & 5.2851 & TRN \\
\hline CHEMBL1393866 & 737826 & 5.4 & 5.215 & TRN \\
\hline CHEMBL1478806 & 737826 & 5.0 & 5.3385 & TRN \\
\hline CHEMBL1392330 & 737826 & 5.0 & 5.3003 & TRN \\
\hline CHEMBL1351344 & 737826 & 5.4 & 5.1629 & TRN \\
\hline CHEMBL1458392 & 737826 & 5.3 & 5.3945 & TRN \\
\hline CHEMBL1602394 & 737826 & 5.2 & 5.2236 & TRN \\
\hline CHEMBL1571146 & 737826 & 4.7 & 5.3642 & TRN \\
\hline CHEMBL1462862 & 737826 & 5.2 & 5.3941 & TST \\
\hline CHEMBL1501021 & 737826 & 5.0 & 5.2035 & TST \\
\hline CHEMBL1372018 & 737826 & 4.75 & 4.9961 & TRN \\
\hline
\end{tabular}




\begin{tabular}{|c|c|c|c|c|c|}
\hline \\
\hline CHEMBL1329855 & 737826 & 5.0 & 5.2229 & TRN & \\
\hline CHEMBL1358197 & 737826 & 5.0 & 4.8621 & TRN & \\
\hline CHEMBL1303031 & 737826 & 5.95 & 5.2713 & TRN & \\
\hline CHEMBL1540172 & 737826 & 5.55 & 5.0706 & TRN & \\
\hline CHEMBL1342730 & 737826 & 5.45 & 5.3986 & TST & \\
\hline CHEMBL1707752 & 737826 & 6.15 & 5.2581 & TRN & \\
\hline CHEMBL1566647 & 737826 & 4.8 & 5.3926 & TRN & \\
\hline CHEMBL1382247 & 737826 & 5.05 & 5.3775 & TRN & \\
\hline CHEMBL1525169 & 737826 & 5.45 & 5.2279 & TRN & \\
\hline CHEMBL1542385 & 737826 & 4.9 & 5.2532 & TRN & \\
\hline CHEMBL1382292 & 737826 & 4.55 & 5.2366 & TRN & \\
\hline CHEMBL1351838 & 737826 & 4.4 & 5.4901 & TST & \\
\hline CHEMBL1385130 & 737826 & 5.9 & 5.2589 & TRN & \\
\hline CHEMBL1568080 & 737826 & 5.3 & 5.13399 & 99999999995 & TRN \\
\hline CHEMBL1542169 & 737826 & 5.35 & 5.1281 & TST & \\
\hline CHEMBL1363272 & 737826 & 4.95 & 5.1944 & TRN & \\
\hline CHEMBL1562221 & 737826 & 5.3 & 5.1824 & TRN & \\
\hline CHEMBL1566780 & 737826 & 5.8 & 5.8219 & TRN & \\
\hline CHEMBL1407011 & 737826 & 4.8 & 4.7969 & TST & \\
\hline CHEMBL1486496 & 737826 & 5.2 & 5.3994 & TRN & \\
\hline CHEMBL1412594 & 737826 & 5.0 & 5.3095 & TRN & \\
\hline CHEMBL1338333 & 737826 & 4.4 & 5.3931 & TRN & \\
\hline CHEMBL1495763 & 737826 & 5.2 & 5.3561 & TRN & \\
\hline CHEMBL1506462 & 737826 & 4.4 & 5.4147 & TRN & \\
\hline CHEMBL1470129 & 737826 & 4.9 & 5.1738 & TRN & \\
\hline CHEMBL1483874 & 737826 & 4.8 & 5.3206 & TRN & \\
\hline CHEMBL1440867 & 737826 & 4.6 & 5.3001 & TRN & \\
\hline CHEMBL1411808 & 737826 & 5.4 & 5.2864 & TRN & \\
\hline CHEMBL1439631 & 737826 & 5.5 & 5.263 & TRN & \\
\hline CHEMBL1397623 & 737826 & 5.5 & 5.3941 & TRN & \\
\hline CHEMBL1340374 & 737826 & 4.7 & 5.3504 & TRN & \\
\hline CHEMBL1409605 & 737826 & 5.6 & 5.3587 & TRN & \\
\hline CHEMBL1484196 & 737826 & 5.4 & 5.2157 & TRN & \\
\hline CHEMBL1417025 & 737826 & 5.5 & 5.2859 & TRN & \\
\hline CHEMBL1597865 & 737826 & 4.45 & 5.2482 & TRN & \\
\hline CHEMBL1487063 & 737826 & 7.2 & 5.5331 & TRN & \\
\hline CHEMBL1478703 & 737826 & 4.85 & 5.33299 & 9999999999 & TRN \\
\hline CHEMBL1545539 & 737826 & 5.3 & 4.8696 & TST & \\
\hline CHEMBL1699751 & 737826 & 5.1 & 5.192 & TRN & \\
\hline CHEMBL1422344 & 737826 & 4.6 & 5.2903 & TRN & \\
\hline CHEMBL1533537 & 737826 & 4.9 & 4.8122 & TRN & \\
\hline CHEMBL1580701 & 737826 & 4.6 & 5.1876 & TRN & \\
\hline CHEMBL1577436 & 737826 & 5.15 & 5.4731 & TST & \\
\hline CHEMBL1568735 & 737826 & 5.9 & 5.9752 & TRN & \\
\hline CHEMBL3192875 & 737826 & 5.45 & 5.3168 & TRN & \\
\hline CHEMBL1444394 & 737826 & 6.3 & 5.9522 & TRN & \\
\hline CHEMBL1741567 & 737826 & 5.65 & 5.1147 & TRN & \\
\hline CHEMBL1454052 & 737826 & 4.8 & 4.8182 & TRN & \\
\hline
\end{tabular}




\begin{tabular}{|c|c|c|c|c|c|}
\hline \multicolumn{6}{|c|}{ Supplemental Table S2.txt } \\
\hline CHEMBL1450096 & 737826 & 6.45 & 5.5358 & TRN & \\
\hline CHEMBL1382227 & 737826 & 4.85 & 5.4451 & TRN & \\
\hline CHEMBL1588059 & 737826 & 5.85 & 5.1165 & TRN & \\
\hline CHEMBL1353815 & 737826 & 5.6 & 5.2236 & TRN & \\
\hline CHEMBL1452391 & 737826 & 5.5 & 5.4679 & TRN & \\
\hline CHEMBL1595929 & 737826 & 4.8 & 5.2509 & TST & \\
\hline CHEMBL1539317 & 737826 & 5.35 & 5.2983 & TRN & \\
\hline CHEMBL1566556 & 737826 & 5.0 & 4.9625 & TRN & \\
\hline CHEMBL1595377 & 737826 & 4.4 & 4.5327 & TRN & \\
\hline CHEMBL1575911 & 737826 & 5.6 & 5.3622 & TRN & \\
\hline CHEMBL491547 & 737826 & 6.3 & 6.3058 & TRN & \\
\hline CHEMBL1447745 & 737826 & 5.1 & 4.9681 & TRN & \\
\hline CHEMBL1539526 & 737826 & 5.5 & 5.4618 & TST & \\
\hline CHEMBL1391308 & 737826 & 5.0 & 5.351 & TRN & \\
\hline CHEMBL1334959 & 737826 & 6.0 & 5.6831 & TRN & \\
\hline CHEMBL1570894 & 737826 & 6.6 & 6.1736 & TRN & \\
\hline CHEMBL1581055 & 737826 & 5.55 & 5.2219 & TRN & \\
\hline CHEMBL1485450 & 737826 & 4.65 & 5.25299 & 9999999999 & TRN \\
\hline CHEMBL1448533 & 737826 & 4.85 & 5.2462 & TRN & \\
\hline CHEMBL1523894 & 737826 & -0.0 & 5.2872 & TST & \\
\hline CHEMBL1576072 & 737826 & 4.9 & 5.3422 & TRN & \\
\hline CHEMBL1413296 & 737826 & 4.65 & 5.188 & TRN & \\
\hline CHEMBL1612774 & 737826 & 4.45 & 5.2799 & TRN & \\
\hline CHEMBL3192219 & 737826 & 5.05 & 5.4368 & TRN & \\
\hline CHEMBL1610320 & 737826 & 5.15 & 5.1743 & TRN & \\
\hline CHEMBL1479106 & 737826 & 5.35 & 5.2515 & TRN & \\
\hline CHEMBL1326159 & 737826 & 4.55 & 5.347 & TRN & \\
\hline CHEMBL1411396 & 737826 & 5.1 & 5.4113 & TRN & \\
\hline CHEMBL1311139 & 737826 & 5.0 & 5.336 & TRN & \\
\hline CHEMBL1703723 & 737826 & 7.7501 & 5.6263 & TRN & \\
\hline CHEMBL1470690 & 737826 & 5.05 & 5.3577 & TRN & \\
\hline CHEMBL1592803 & 737826 & 6.3 & 6.2765 & TRN & \\
\hline CHEMBL242363 & 737826 & 4.5 & 5.3231 & TRN & \\
\hline CHEMBL1318495 & 737826 & 6.3 & 6.2368 & TRN & \\
\hline CHEMBL1498884 & 737826 & 5.75 & 5.2146 & TRN & \\
\hline CHEMBL1411555 & 737826 & 5.75 & 5.4724 & TRN & \\
\hline CHEMBL1467087 & 737826 & 5.4 & 5.3292 & TRN & \\
\hline CHEMBL1340104 & 737826 & 4.8 & 5.2393 & TST & \\
\hline CHEMBL1330057 & 737826 & 5.5 & 5.3917 & TRN & \\
\hline CHEMBL1573171 & 737826 & 6.75 & 5.4692 & TRN & \\
\hline CHEMBL1496811 & 737826 & 4.85 & 5.2669 & TRN & \\
\hline CHEMBL1433232 & 737826 & 5.55 & 5.3903 & TRN & \\
\hline CHEMBL1417771 & 737826 & 6.3 & 6.3011 & TRN & \\
\hline CHEMBL1300602 & 737826 & 4.8 & 5.3403 & TRN & \\
\hline CHEMBL1370314 & 737826 & 5.0 & 5.2821 & TRN & \\
\hline CHEMBL1485850 & 737826 & 4.8 & 4.7143 & TRN & \\
\hline CHEMBL1429193 & 737826 & 4.6 & 5.1786 & TRN & \\
\hline CHEMBL3192647 & 737826 & 5.0 & 5.3401 & TRN & \\
\hline
\end{tabular}




\begin{tabular}{|c|c|c|c|c|c|}
\hline \multicolumn{6}{|c|}{ Supplemental Table S2.txt } \\
\hline CHEMBL1351689 & 737826 & 5.25 & 5.2606 & TRN & \\
\hline CHEMBL1376629 & 737826 & 5.05 & 5.3567 & TRN & \\
\hline CHEMBL1428339 & 737826 & 5.2 & 5.291 & TRN & \\
\hline CHEMBL1742361 & 737826 & 4.85 & 5.2307 & TST & \\
\hline CHEMBL1578807 & 737826 & 5.0 & 5.2713 & TRN & \\
\hline CHEMBL1256687 & 737826 & 7.5 & 6.4698 & TST & \\
\hline CHEMBL1310531 & 737826 & 5.2 & 5.475 & TRN & \\
\hline CHEMBL1611048 & 737826 & 6.0 & 5.2522 & TRN & \\
\hline CHEMBL1363142 & 737826 & 5.9 & 5.7665 & TRN & \\
\hline CHEMBL77287 & 737826 & 5.6 & 5.3974 & TRN & \\
\hline CHEMBL1570922 & 737826 & 6.05 & 5.1837 & TRN & \\
\hline CHEMBL1606076 & 737826 & 5.4 & 5.426 & TRN & \\
\hline CHEMBL1362305 & 737826 & 5.35 & 5.1929 & TRN & \\
\hline CHEMBL1904453 & 737826 & 5.5 & 5.3749 & TRN & \\
\hline CHEMBL3208761 & 737826 & 4.9 & 5.32600 & 00000000005 & TRN \\
\hline CHEMBL1595827 & 737826 & 4.6 & 5.2526 & TRN & \\
\hline CHEMBL1332301 & 737826 & 4.6 & 5.2558 & TRN & \\
\hline CHEMBL 3192650 & 737826 & 5.4 & 5.4308 & TRN & \\
\hline CHEMBL1395281 & 737826 & 5.3 & 5.0361 & TRN & \\
\hline CHEMBL1566217 & 737826 & 4.4 & 5.2215 & TRN & \\
\hline CHEMBL1482677 & 737826 & 4.6 & 5.3238 & TRN & \\
\hline CHEMBL1566209 & 737826 & 4.4 & 5.1922 & TRN & \\
\hline CHEMBL50112 & 737826 & 4.4 & 4.5582 & TRN & \\
\hline CHEMBL1313335 & 737826 & 6.6 & 5.3502 & TRN & \\
\hline CHEMBL1485818 & 737826 & 5.6 & 5.3135 & TRN & \\
\hline CHEMBL 3212563 & 737826 & 5.9 & 5.6356 & TST & \\
\hline CHEMBL1554659 & 737826 & 4.8 & 4.7209 & TRN & \\
\hline CHEMBL1742326 & 737826 & 4.95 & 5.2724 & TRN & \\
\hline CHEMBL1512385 & 737826 & 4.9 & 4.7527 & TRN & \\
\hline CHEMBL1538177 & 737826 & 4.9 & 5.1269 & TRN & \\
\hline CHEMBL1350039 & 737826 & 5.6 & 5.3126 & TRN & \\
\hline CHEMBL1509009 & 737826 & 6.25 & 5.3051 & TRN & \\
\hline CHEMBL1321118 & 737826 & 4.8 & 4.7178 & TRN & \\
\hline CHEMBL1579705 & 737826 & 5.1 & 5.3363 & TRN & \\
\hline CHEMBL1972348 & 737826 & 5.4 & 5.2118 & TRN & \\
\hline CHEMBL1491258 & 737826 & 4.4 & 4.5087 & TRN & \\
\hline CHEMBL1447162 & 737826 & 6.4 & 5.1706 & TRN & \\
\hline CHEMBL1589879 & 737826 & 5.2 & 5.1776 & TRN & \\
\hline CHEMBL1370480 & 737826 & 4.9 & 4.7758 & TRN & \\
\hline CHEMBL1384711 & 737826 & 5.35 & 5.3002 & TRN & \\
\hline CHEMBL1591275 & 737826 & 4.5 & 4.4063 & TRN & \\
\hline CHEMBL1368186 & 737826 & 4.85 & 5.3931 & TRN & \\
\hline CHEMBL1533661 & 737826 & 5.05 & 5.2024 & TRN & \\
\hline CHEMBL1484261 & 737826 & 7.0 & 6.7361 & TRN & \\
\hline CHEMBL546597 & 737826 & 5.55 & 5.4063 & TRN & \\
\hline CHEMBL1383786 & 737826 & 8.0 & 4.9593 & TRN & \\
\hline CHEMBL1479771 & 737826 & 5.4 & 5.1903 & TRN & \\
\hline CHEMBL 266500 & 737826 & 5.95 & 5.2263 & TRN & \\
\hline
\end{tabular}




\begin{tabular}{|c|c|c|c|c|}
\hline \multicolumn{5}{|c|}{ Supplemental Table S2.txt } \\
\hline CHEMBL1973729 & 737826 & 5.65 & 5.5122 & TRN \\
\hline CHEMBL1466220 & 737826 & 4.4 & 5.4084 & TRN \\
\hline CHEMBL1599334 & 737826 & 4.85 & 5.3084 & TRN \\
\hline CHEMBL1416685 & 737826 & 4.95 & 5.1267 & TRN \\
\hline CHEMBL1447719 & 737826 & 6.4 & 5.7196 & TRN \\
\hline CHEMBL1485581 & 737826 & 5.0 & 5.2871 & TRN \\
\hline CHEMBL1410629 & 737826 & 5.0 & 5.4596 & TST \\
\hline CHEMBL1371959 & 737826 & 6.5 & 5.2215 & TRN \\
\hline CHEMBL1369874 & 737826 & 5.5 & 5.651 & TST \\
\hline CHEMBL1718203 & 737826 & 4.85 & 5.1922 & TRN \\
\hline CHEMBL1380031 & 737826 & 4.65 & 5.4047 & TST \\
\hline CHEMBL1510212 & 737826 & 4.7 & 5.5868 & TRN \\
\hline CHEMBL3210667 & 737826 & 4.75 & 5.4557 & TRN \\
\hline CHEMBL1558371 & 737826 & 4.9 & 5.2858 & TRN \\
\hline CHEMBL1352931 & 737826 & 5.05 & 5.3056 & TRN \\
\hline CHEMBL409024 & 737826 & 4.7 & 4.7476 & TST \\
\hline CHEMBL1351562 & 737826 & 5.05 & 5.31 & TRN \\
\hline CHEMBL2028085 & 737826 & 4.4 & 4.5491 & TST \\
\hline CHEMBL1562088 & 737826 & 5.1 & 4.9652 & TST \\
\hline CHEMBL1995904 & 737826 & 5.5 & 5.3604 & TRN \\
\hline CHEMBL1438323 & 737826 & 6.0 & 6.1165 & TRN \\
\hline CHEMBL1517172 & 737826 & 5.1 & 5.1135 & TRN \\
\hline CHEMBL1450977 & 737826 & 6.65 & 5.4095 & TRN \\
\hline CHEMBL1516477 & 737826 & 4.6 & 4.8242 & TST \\
\hline CHEMBL1481724 & 737826 & 4.75 & 5.1239 & TRN \\
\hline CHEMBL1432275 & 737826 & 4.55 & 5.1962 & TRN \\
\hline CHEMBL38576 & 737826 & 7.0 & 6.4632 & TST \\
\hline CHEMBL1410676 & 737826 & 6.0 & 6.0354 & TRN \\
\hline CHEMBL1332636 & 737826 & 5.2 & 5.192 & TRN \\
\hline CHEMBL1370255 & 737826 & 4.8 & 5.2622 & TRN \\
\hline CHEMBL1409148 & 737826 & 6.0 & 5.7507 & TRN \\
\hline CHEMBL1447487 & 737826 & 5.3 & 5.275 & TRN \\
\hline CHEMBL1578193 & 737826 & 4.75 & 5.2698 & TRN \\
\hline CHEMBL1400398 & 737826 & 4.6 & 5.375 & TRN \\
\hline CHEMBL1380396 & 737826 & 6.1 & 5.7504 & TRN \\
\hline CHEMBL1383753 & 737826 & 6.5 & 5.1067 & TRN \\
\hline CHEMBL1380899 & 737826 & 5.3 & 5.4128 & TRN \\
\hline CHEMBL1434022 & 737826 & 4.7 & 4.6205 & TRN \\
\hline CHEMBL1490857 & 737826 & 4.65 & 5.5373 & TRN \\
\hline CHEMBL1427154 & 737826 & 6.1 & 5.3705 & TRN \\
\hline CHEMBL1371547 & 737826 & 5.2 & 5.1116 & TRN \\
\hline CHEMBL1512434 & 737826 & 6.0 & 5.9244 & TRN \\
\hline CHEMBL1554854 & 737826 & 5.5 & 5.4526 & TRN \\
\hline CHEMBL1478226 & 737826 & 5.0 & 4.8557 & TRN \\
\hline CHEMBL1506550 & 737826 & 5.05 & 5.5387 & TRN \\
\hline CHEMBL1491801 & 737826 & 5.15 & 5.2972 & TRN \\
\hline CHEMBL1430016 & 737826 & 5.95 & 5.3145 & TRN \\
\hline CHEMBL1540834 & 737826 & 4.95 & 5.2933 & TST \\
\hline
\end{tabular}




\begin{tabular}{|c|c|c|c|c|c|}
\hline \\
\hline CHEMBL1317950 & 737826 & 7.9 & 7.1331 & TST & \\
\hline CHEMBL1549000 & 737826 & 5.4 & 5.4274 & TRN & \\
\hline CHEMBL1331443 & 737826 & 6.0 & 5.4268 & TST & \\
\hline CHEMBL1534214 & 737826 & 5.65 & 5.5291 & TRN & \\
\hline CHEMBL1342336 & 737826 & 4.85 & 5.4763 & TRN & \\
\hline CHEMBL1732228 & 737826 & 5.6 & 5.4128 & TRN & \\
\hline CHEMBL1349535 & 737826 & 5.55 & 5.204 & TRN & \\
\hline CHEMBL1546816 & 737826 & 4.55 & 5.5995 & TRN & \\
\hline CHEMBL1402493 & 737826 & 5.8 & 5.1964 & TRN & \\
\hline CHEMBL1445799 & 737826 & 4.7 & 4.7408 & TRN & \\
\hline CHEMBL1301709 & 737826 & 5.3 & 5.3159 & TRN & \\
\hline CHEMBL1577470 & 737826 & 4.85 & 5.465 & TST & \\
\hline CHEMBL1742342 & 737826 & 4.8 & 5.3333 & TRN & \\
\hline CHEMBL1348996 & 737826 & 5.25 & 5.3637 & TRN & \\
\hline CHEMBL1389765 & 737826 & 5.6 & 5.2634 & TRN & \\
\hline CHEMBL1331004 & 737826 & 4.7 & 4.699 & TRN & \\
\hline CHEMBL1519798 & 737826 & 5.3 & 5.3276 & TRN & \\
\hline CHEMBL1472955 & 737826 & 6.2 & 6.0778 & TRN & \\
\hline CHEMBL1232596 & 737826 & 4.4 & 5.0817 & TRN & \\
\hline CHEMBL1344743 & 737826 & 5.15 & 5.1341 & TRN & \\
\hline CHEMBL1483214 & 737826 & 5.0 & 5.1286 & TRN & \\
\hline CHEMBL1409261 & 737826 & 5.5 & 5.3983 & TRN & \\
\hline CHEMBL1500641 & 737826 & 5.0 & 5.2338 & TRN & \\
\hline CHEMBL321820 & 737826 & 4.9 & 4.934 & TST & \\
\hline CHEMBL1224553 & 737826 & 7.3 & 5.3718 & TRN & \\
\hline CHEMBL1398834 & 737826 & 5.0 & 4.7491 & TRN & \\
\hline CHEMBL1333056 & 737826 & 6.0 & 5.5871 & TST & \\
\hline CHEMBL1526543 & 737826 & 5.9 & $5.5870 e$ & 0000000001 & TST \\
\hline CHEMBL 3212090 & 737826 & 4.4 & 5.1979 & TRN & \\
\hline CHEMBL1365092 & 737826 & 4.4 & 5.4261 & TRN & \\
\hline CHEMBL1549333 & 737826 & 5.95 & 5.2913 & TRN & \\
\hline CHEMBL1463367 & 737826 & 4.9 & 5.2928 & TRN & \\
\hline CHEMBL222808 & 737826 & 6.5 & 6.0491 & TRN & \\
\hline CHEMBL1446009 & 737826 & 7.8 & 7.1849 & TRN & \\
\hline CHEMBL1312725 & 737826 & 5.3 & 5.4232 & TRN & \\
\hline CHEMBL1605713 & 737826 & 4.85 & 5.0092 & TRN & \\
\hline CHEMBL1493838 & 737826 & 5.4 & $5.5020 e$ & 0000000001 & TRN \\
\hline CHEMBL1700705 & 737826 & 4.45 & $5.2070 e$ & 0000000001 & TRN \\
\hline CHEMBL1534573 & 737826 & 4.7 & 4.5495 & TRN & \\
\hline CHEMBL315268 & 737826 & 5.0 & 4.8741 & TST & \\
\hline CHEMBL1587412 & 737826 & 6.6 & 5.1408 & TST & \\
\hline CHEMBL1587524 & 737826 & 5.65 & 5.2367 & TRN & \\
\hline CHEMBL56331 & 737826 & 4.5 & 4.6231 & TRN & \\
\hline CHEMBL1733967 & 737826 & 4.9 & 5.2151 & TRN & \\
\hline CHEMBL 3197815 & 737826 & 5.8 & 5.3846 & TRN & \\
\hline CHEMBL1348303 & 737826 & 6.35 & 5.3103 & TRN & \\
\hline CHEMBL1420531 & 737826 & 5.65 & 5.211 & TRN & \\
\hline CHEMBL1399438 & 737826 & 5.0 & 5.147 & TRN & \\
\hline
\end{tabular}




\begin{tabular}{|c|c|c|c|c|}
\hline & & & IETC & al lable s \\
\hline CHEMBL1523557 & 737826 & 5.5 & 5.4895 & TRN \\
\hline CHEMBL1332726 & 737826 & 4.9 & 4.8409 & TRN \\
\hline CHEMBL1969457 & 737826 & 5.15 & 5.4729 & TRN \\
\hline CHEMBL1533967 & 737826 & 5.75 & 5.3062 & TST \\
\hline CHEMBL1741695 & 737826 & 4.65 & 5.3058 & TRN \\
\hline CHEMBL1357381 & 737826 & 5.5 & 5.5641 & TRN \\
\hline CHEMBL1556561 & 737826 & 5.05 & 5.4397 & TRN \\
\hline CHEMBL120806 & 737826 & 6.1 & 5.8596 & TST \\
\hline CHEMBL1543038 & 737826 & 6.15 & 5.4082 & TRN \\
\hline CHEMBL1596743 & 737826 & 4.9 & 4.7184 & TRN \\
\hline CHEMBL1602112 & 737826 & 4.7 & 4.6913 & TRN \\
\hline CHEMBL1401933 & 737826 & 5.8 & 5.4012 & TRN \\
\hline CHEMBL1399066 & 737826 & 5.2 & 5.0932 & TST \\
\hline CHEMBL1592465 & 737826 & 4.5 & 4.5003 & TRN \\
\hline CHEMBL1423348 & 737826 & 4.85 & 5.0972 & TRN \\
\hline CHEMBL1516500 & 737826 & 5.3 & 5.1877 & TRN \\
\hline CHEMBL1554088 & 737826 & 4.5 & 4.6031 & TRN \\
\hline CHEMBL1488679 & 737826 & 5.6 & 5.4151 & TST \\
\hline CHEMBL1338077 & 737826 & 5.0 & 5.4223 & TRN \\
\hline CHEMBL1518285 & 737826 & 6.5 & 5.3158 & TST \\
\hline CHEMBL1431551 & 737826 & 4.75 & 5.386 & TRN \\
\hline CHEMBL491578 & 737826 & 6.1 & 6.0841 & TRN \\
\hline CHEMBL1581951 & 737826 & 6.4 & 5.4907 & TRN \\
\hline CHEMBL1393431 & 737826 & 5.6 & 5.2862 & TRN \\
\hline CHEMBL1355216 & 737826 & 4.6 & 4.926 & TRN \\
\hline CHEMBL1451957 & 737826 & 4.4 & 5.2357 & TRN \\
\hline CHEMBL1399677 & 737826 & 5.6 & 5.1269 & TST \\
\hline CHEMBL1529089 & 737826 & 5.5 & 5.3708 & TST \\
\hline CHEMBL3213699 & 737826 & 5.4 & 5.4247 & TRN \\
\hline CHEMBL1303741 & 737826 & 4.4 & 5.4993 & TRN \\
\hline CHEMBL1612434 & 737826 & 6.35 & 5.2166 & TST \\
\hline CHEMBL1319038 & 737826 & 5.1 & 5.4922 & TRN \\
\hline CHEMBL469309 & 737826 & 5.5 & 5.3667 & TRN \\
\hline CHEMBL1358570 & 737826 & 5.1 & 5.0343 & TST \\
\hline CHEMBL1580216 & 737826 & 4.85 & 5.2423 & TRN \\
\hline CHEMBL1485948 & 737826 & 5.95 & 5.1877 & TRN \\
\hline CHEMBL1571734 & 737826 & 5.2 & 5.1801 & TRN \\
\hline CHEMBL1972346 & 737826 & 4.5 & 4.6834 & TRN \\
\hline CHEMBL1461327 & 737826 & 5.4 & 5.0608 & TRN \\
\hline CHEMBL1354941 & 737826 & 4.9 & 4.8403 & TRN \\
\hline CHEMBL1312952 & 737826 & 5.05 & 5.4205 & TRN \\
\hline CHEMBL1469541 & 737826 & 5.05 & $5.2520 e$ & 0000000001 \\
\hline CHEMBL1519709 & 737826 & 5.2 & 5.1967 & TRN \\
\hline CHEMBL1501400 & 737826 & 5.35 & 5.7227 & TRN \\
\hline CHEMBL1559279 & 737826 & 6.1 & 5.6902 & TRN \\
\hline CHEMBL1380717 & 737826 & 5.4 & 5.3896 & TRN \\
\hline CHEMBL1602083 & 737826 & 4.75 & 5.0672 & TRN \\
\hline CHEMBL1434643 & 737826 & 4.6 & 4.6491 & TRN \\
\hline
\end{tabular}

TRN 


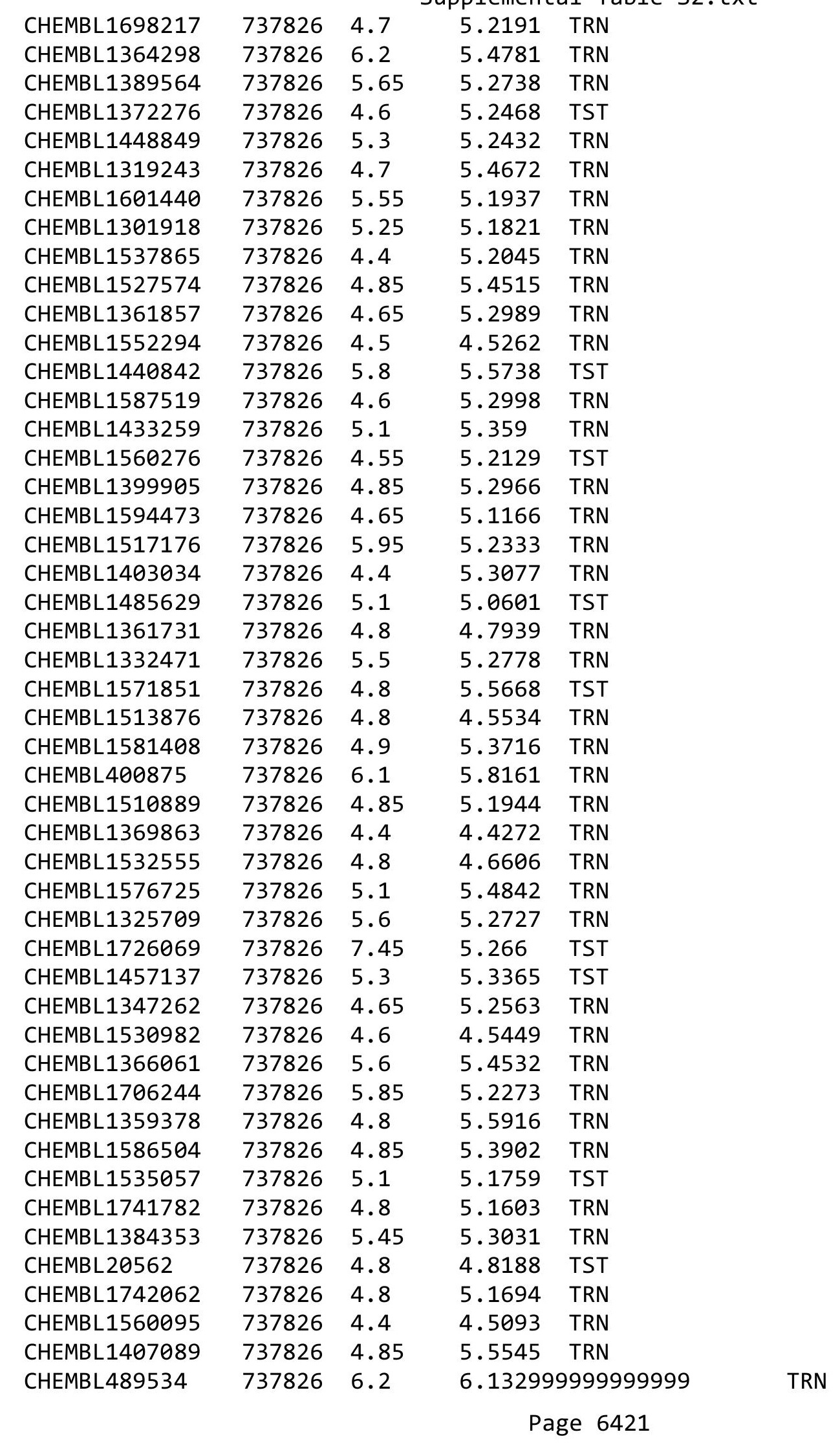




\begin{tabular}{|c|c|c|c|c|}
\hline \multirow[b]{2}{*}{ CHEMBL1593827 } & \multicolumn{4}{|c|}{ Supplemental Table S2.tx } \\
\hline & 737826 & 5.8 & 5.8464 & TRN \\
\hline CHEMBL1502413 & 737826 & 5.95 & 5.2679 & TRN \\
\hline CHEMBL1330569 & 737826 & 4.8 & 5.4201 & TST \\
\hline CHEMBL1410367 & 737826 & 5.6 & 5.3115 & TRN \\
\hline CHEMBL1447970 & 737826 & 7.7001 & 5.1762 & TRN \\
\hline CHEMBL1612133 & 737826 & 5.35 & 5.4349 & TRN \\
\hline CHEMBL1317010 & 737826 & 7.9 & 7.2267 & TRN \\
\hline CHEMBL1579887 & 737826 & 5.65 & 5.2199 & TRN \\
\hline CHEMBL1551548 & 737826 & 4.8 & 4.6264 & TRN \\
\hline CHEMBL1456330 & 737826 & 4.4 & 5.233 & TST \\
\hline CHEMBL1470904 & 737826 & 5.55 & 5.1671 & TRN \\
\hline CHEMBL1366573 & 737826 & 5.0 & 5.3555 & TRN \\
\hline CHEMBL1552922 & 737826 & 4.5 & 4.5537 & TRN \\
\hline CHEMBL1515449 & 737826 & 6.6 & 6.4453 & TRN \\
\hline CHEMBL1338825 & 737826 & 5.45 & 5.1743 & TRN \\
\hline CHEMBL86537 & 737826 & 5.1 & 5.0796 & TST \\
\hline CHEMBL1553766 & 737826 & 4.5 & 4.532 & TRN \\
\hline CHEMBL1594947 & 737826 & 5.5 & 5.4783 & TRN \\
\hline CHEMBL1330317 & 737826 & 5.8 & 5.7903 & TRN \\
\hline CHEMBL1493851 & 737826 & 5.8 & 5.6172 & TRN \\
\hline CHEMBL3145119 & 737826 & 6.35 & 5.3491 & TST \\
\hline CHEMBL1309244 & 737826 & 4.95 & 5.3335 & TRN \\
\hline CHEMBL1494353 & 737826 & 5.15 & 5.3882 & TRN \\
\hline CHEMBL3196379 & 737826 & 5.4 & 5.4496 & TRN \\
\hline CHEMBL1441408 & 737826 & 4.85 & 5.4004 & TST \\
\hline CHEMBL1595190 & 737826 & 5.25 & 5.1587 & TRN \\
\hline CHEMBL1439893 & 737826 & 5.8 & 5.879 & TRN \\
\hline CHEMBL1439144 & 737826 & 4.55 & 5.4923 & TST \\
\hline CHEMBL1502235 & 737826 & 4.75 & 5.5046 & TRN \\
\hline CHEMBL1466883 & 737826 & 5.2 & 5.2681 & TRN \\
\hline CHEMBL406845 & 737826 & 5.15 & 5.2517 & TST \\
\hline CHEMBL1369515 & 737826 & 6.3 & 5.9237 & TRN \\
\hline CHEMBL1527443 & 737826 & 5.5 & 5.2329 & TRN \\
\hline CHEMBL1724983 & 737826 & 4.65 & 5.3062 & TRN \\
\hline CHEMBL 3191893 & 737826 & 5.35 & 5.4203 & TRN \\
\hline CHEMBL1430823 & 737826 & 5.5 & 5.6075 & TRN \\
\hline CHEMBL1537609 & 737826 & 4.45 & 5.1571 & TRN \\
\hline CHEMBL1705301 & 737826 & 4.9 & 5.4793 & TRN \\
\hline CHEMBL1393011 & 737826 & 4.7 & 5.4965 & TRN \\
\hline CHEMBL1344080 & 737826 & 5.55 & 5.3624 & TRN \\
\hline CHEMBL1311749 & 737826 & 5.25 & 5.4033 & TST \\
\hline CHEMBL1425971 & 737826 & 5.1 & 5.0965 & TRN \\
\hline CHEMBL3213210 & 737826 & 5.4 & 5.3201 & TRN \\
\hline CHEMBL1356060 & 737826 & 6.1 & 6.0982 & TRN \\
\hline CHEMBL1450153 & 737826 & 4.9 & 5.34 & TRN \\
\hline CHEMBL1299856 & 737826 & 5.55 & 5.2436 & TRN \\
\hline CHEMBL3212828 & 737826 & 4.85 & 5.3427 & TRN \\
\hline CHEMBL1436761 & 737826 & 4.8 & 4.6021 & TRN \\
\hline
\end{tabular}




\begin{tabular}{|c|c|c|c|c|c|}
\hline \multicolumn{6}{|c|}{ oplemental Table S2 } \\
\hline CHEMBL 2094549 & 737826 & 5.1 & 5.3872 & TRN & \\
\hline CHEMBL1482806 & 737826 & 4.7 & 5.3861 & TRN & \\
\hline CHEMBL1357338 & 737826 & 4.7 & 4.6518 & TRN & \\
\hline CHEMBL1612492 & 737826 & 5.05 & 5.3408 & TRN & \\
\hline CHEMBL1411912 & 737826 & 5.05 & 5.1618 & TRN & \\
\hline CHEMBL1450395 & 737826 & 5.2 & 5.0997 & TST & \\
\hline CHEMBL1559062 & 737826 & 5.1 & 5.0998 & TRN & \\
\hline CHEMBL1459145 & 737826 & 5.95 & 5.2408 & TRN & \\
\hline CHEMBL1521909 & 737826 & 5.15 & 5.5326 & TST & \\
\hline CHEMBL475375 & 737826 & 6.4 & 6.3277 & TRN & \\
\hline CHEMBL1579482 & 737826 & 5.6 & 5.2885 & TRN & \\
\hline CHEMBL1320000 & 737826 & 4.95 & 5.2762 & TRN & \\
\hline CHEMBL313163 & 737826 & 6.2 & 5.5883 & TRN & \\
\hline CHEMBL1742139 & 737826 & 4.5 & 5.2939 & TRN & \\
\hline CHEMBL1592547 & 737826 & 6.2 & 5.6969 & TRN & \\
\hline CHEMBL1440145 & 737826 & 5.6 & 5.4573 & TRN & \\
\hline CHEMBL1587070 & 737826 & 4.6 & 5.2445 & TRN & \\
\hline CHEMBL1509858 & 737826 & 4.65 & 5.1089 & TRN & \\
\hline CHEMBL1379690 & 737826 & 4.9 & 5.1984 & TST & \\
\hline CHEMBL1490884 & 737826 & 4.95 & 5.3542 & TRN & \\
\hline CHEMBL1423713 & 737826 & 4.95 & 5.2877 & TRN & \\
\hline CHEMBL1524183 & 737826 & 4.4 & 5.416 & TRN & \\
\hline CHEMBL1300301 & 737826 & 4.4 & 5.3731 & TST & \\
\hline CHEMBL421215 & 737826 & 5.9 & 5.6756 & TST & \\
\hline CHEMBL1493369 & 737826 & 6.3 & 5.91299 & 9999999999 & TRN \\
\hline CHEMBL1315457 & 737826 & 4.4 & 4.5797 & TST & \\
\hline CHEMBL1256797 & 737826 & 4.5 & 4.598 & TRN & \\
\hline CHEMBL1436817 & 737826 & 4.5 & 4.4585 & TRN & \\
\hline CHEMBL1441415 & 737826 & 6.1 & 6.0113 & TRN & \\
\hline CHEMBL1573944 & 737826 & 5.15 & $5.1080 e$ & 00000000005 & TST \\
\hline CHEMBL1467227 & 737826 & 5.5 & 5.1393 & TRN & \\
\hline CHEMBL1320272 & 737826 & 5.05 & 5.4483 & TRN & \\
\hline CHEMBL1568026 & 737826 & 4.75 & 5.3692 & TST & \\
\hline CHEMBL1458145 & 737826 & 5.6 & 5.4427 & TRN & \\
\hline CHEMBL1299778 & 737826 & 5.5 & 5.3958 & TRN & \\
\hline CHEMBL1529327 & 737826 & 7.0 & 5.3299 & TRN & \\
\hline CHEMBL1440108 & 737826 & 5.8 & 5.3272 & TRN & \\
\hline CHEMBL1540244 & 737826 & 5.6 & 5.2799 & TRN & \\
\hline CHEMBL1399844 & 737826 & 5.3 & 5.2367 & TRN & \\
\hline CHEMBL1438677 & 737826 & 5.3 & 5.3467 & TRN & \\
\hline CHEMBL1596030 & 737826 & 4.5 & 5.3449 & TRN & \\
\hline CHEMBL1458583 & 737826 & 4.9 & 5.29 & TRN & \\
\hline CHEMBL1572430 & 737826 & 4.85 & 5.303 & TST & \\
\hline CHEMBL1459535 & 737826 & 5.7 & 5.2183 & TRN & \\
\hline CHEMBL1326282 & 737826 & 5.4 & 5.5187 & TRN & \\
\hline CHEMBL1327912 & 737826 & 6.05 & 5.3158 & TRN & \\
\hline CHEMBL1477492 & 737826 & 5.3 & 4.9507 & TRN & \\
\hline CHEMBL1387238 & 737826 & 5.65 & 5.4386 & TRN & \\
\hline
\end{tabular}




\begin{tabular}{|c|c|c|c|c|c|}
\hline \multicolumn{6}{|c|}{ Supplemental Table S2.txt } \\
\hline CHEMBL1567229 & 737826 & 5.65 & 5.296 & TRN & \\
\hline CHEMBL123904 & 737826 & 5.4 & 5.265 & TST & \\
\hline CHEMBL1576446 & 737826 & 5.45 & 5.1523 & TRN & \\
\hline CHEMBL1562786 & 737826 & 4.9 & 4.7009 & TRN & \\
\hline CHEMBL1720716 & 737826 & 4.4 & 5.1355 & TRN & \\
\hline CHEMBL491960 & 737826 & 5.1 & 5.0537 & TRN & \\
\hline CHEMBL1349372 & 737826 & 4.85 & 5.2915 & TRN & \\
\hline CHEMBL1560803 & 737826 & 4.85 & 5.0917 & TRN & \\
\hline CHEMBL536950 & 737826 & 5.7 & 5.4617 & TST & \\
\hline CHEMBL1520374 & 737826 & 4.4 & 5.4616 & TRN & \\
\hline CHEMBL1467491 & 737826 & 4.85 & 5.6032 & TRN & \\
\hline CHEMBL1431981 & 737826 & 5.0 & 5.2528 & TRN & \\
\hline CHEMBL 3192578 & 737826 & 4.5 & 5.3737 & TST & \\
\hline CHEMBL1353502 & 737826 & 4.9 & 5.3601 & TRN & \\
\hline CHEMBL1386058 & 737826 & 4.65 & 5.391 & TRN & \\
\hline CHEMBL1486593 & 737826 & 4.4 & 5.4168 & TRN & \\
\hline CHEMBL1382870 & 737826 & 4.75 & 5.3137 & TRN & \\
\hline CHEMBL1395634 & 737826 & 6.0 & 5.7438 & TRN & \\
\hline CHEMBL1160544 & 737826 & 6.2 & 5.7693 & TST & \\
\hline CHEMBL1588818 & 737826 & 6.05 & 5.2248 & TRN & \\
\hline CHEMBL1567435 & 737826 & 5.2 & 5.2532 & TRN & \\
\hline CHEMBL1314286 & 737826 & 6.0 & 5.6729 & TST & \\
\hline CHEMBL1356336 & 737826 & 6.0 & 5.9715 & TRN & \\
\hline CHEMBL1722610 & 737826 & 5.4 & 5.306 & TRN & \\
\hline CHEMBL542493 & 737826 & 4.5 & 4.6916 & TST & \\
\hline CHEMBL1540313 & 737826 & 5.4 & 5.5926 & TST & \\
\hline CHEMBL1610758 & 737826 & 4.85 & 5.1412 & TST & \\
\hline CHEMBL1611856 & 737826 & 4.8 & 4.7388 & TRN & \\
\hline CHEMBL3212631 & 737826 & 5.15 & 5.2006 & TRN & \\
\hline CHEMBL1507984 & 737826 & 5.3 & 5.2027 & TST & \\
\hline CHEMBL1419019 & 737826 & 5.05 & 5.2338 & TRN & \\
\hline CHEMBL1334293 & 737826 & 4.8 & 5.3764 & TRN & \\
\hline CHEMBL1534263 & 737826 & 5.85 & 5.2236 & TST & \\
\hline CHEMBL1461253 & 737826 & 5.0 & 5.3653 & TRN & \\
\hline CHEMBL1402633 & 737826 & 6.35 & 5.8293 & TRN & \\
\hline CHEMBL1719646 & 737826 & 4.9 & 5.2997 & TST & \\
\hline CHEMBL1476009 & 737826 & 4.8 & 4.7073 & TRN & \\
\hline CHEMBL1571483 & 737826 & 5.45 & 5.4193 & TRN & \\
\hline CHEMBL 3193223 & 737826 & 4.85 & 5.4611 & TRN & \\
\hline CHEMBL1518270 & 737826 & 5.15 & 5.1746 & TRN & \\
\hline CHEMBL1440067 & 737826 & 5.4 & 5.1541 & TRN & \\
\hline CHEMBL1458143 & 737826 & 5.5 & 5.2552 & TRN & \\
\hline CHEMBL1327171 & 737826 & 6.0 & 5.2901 & TRN & \\
\hline CHEMBL1309259 & 737826 & 4.6 & 5.37799 & 9999999999 & TRN \\
\hline CHEMBL1542296 & 737826 & 5.95 & 5.0478 & TRN & \\
\hline CHEMBL1458881 & 737826 & 5.45 & 5.3555 & TRN & \\
\hline CHEMBL1491674 & 737826 & 5.35 & 5.2212 & TRN & \\
\hline CHEMBL1355135 & 737826 & 4.8 & 4.7395 & TRN & \\
\hline
\end{tabular}




\begin{tabular}{|c|c|c|c|c|}
\hline & & & ient & al Ts \\
\hline CHEMBL1543028 & 737826 & 4.8 & 5.4274 & TRN \\
\hline CHEMBL3211009 & 737826 & 6.05 & 5.2983 & TRN \\
\hline CHEMBL1587575 & 737826 & 4.8 & 5.3598 & TRN \\
\hline CHEMBL1593547 & 737826 & 5.4 & 5.2284 & TRN \\
\hline CHEMBL1520405 & 737826 & 5.25 & 5.3942 & TRN \\
\hline CHEMBL1741555 & 737826 & 4.8 & 5.1933 & TRN \\
\hline CHEMBL1366453 & 737826 & 5.1 & 5.221 & TRN \\
\hline CHEMBL1612722 & 737826 & 4.95 & 5.3428 & TRN \\
\hline CHEMBL1410491 & 737826 & 4.6 & 4.5335 & TRN \\
\hline CHEMBL3197177 & 737826 & 4.75 & 5.2852 & TRN \\
\hline CHEMBL1531681 & 737826 & 4.6 & 5.3314 & TRN \\
\hline CHEMBL1358449 & 737826 & 5.5 & 5.3658 & TST \\
\hline CHEMBL1476511 & 737826 & 4.7 & 4.7183 & TRN \\
\hline CHEMBL1478965 & 737826 & 8.05 & 5.3219 & TRN \\
\hline CHEMBL1742340 & 737826 & 4.6 & 5.2162 & TST \\
\hline CHEMBL 1580710 & 737826 & 5.0 & 5.3432 & TRN \\
\hline CHEMBL1461732 & 737826 & 6.25 & 5.2865 & TRN \\
\hline CHEMBL1509171 & 737826 & 5.45 & 5.2794 & TRN \\
\hline CHEMBL1409446 & 737826 & 4.95 & 5.3641 & TRN \\
\hline CHEMBL1481185 & 737826 & 4.45 & 5.1319 & TRN \\
\hline CHEMBL1451824 & 737826 & 5.0 & 5.303 & TRN \\
\hline CHEMBL1509238 & 737826 & 4.9 & 5.2569 & TRN \\
\hline CHEMBL1477727 & 737826 & 4.5 & 4.6002 & TRN \\
\hline CHEMBL1414073 & 737826 & 4.9 & 4.7842 & TRN \\
\hline CHEMBL1432973 & 737826 & 5.45 & 5.1963 & TRN \\
\hline CHEMBL 1473448 & 737826 & 4.8 & 4.746 & TRN \\
\hline CHEMBL1528076 & 737826 & 5.55 & 5.3353 & TRN \\
\hline CHEMBL1299214 & 737826 & 4.85 & 5.0402 & TST \\
\hline CHEMBL3211204 & 737826 & 5.3 & 5.2746 & TRN \\
\hline CHEMBL1338245 & 737826 & 4.75 & 5.3877 & TRN \\
\hline CHEMBL601110 & 737826 & 6.2 & 5.2706 & TRN \\
\hline CHEMBL1741515 & 737826 & 4.6 & 5.2046 & TRN \\
\hline CHEMBL1523188 & 737826 & 4.4 & 5.1027 & TRN \\
\hline CHEMBL1374288 & 737826 & 5.0 & 5.1013 & TRN \\
\hline CHEMBL1415569 & 737826 & 5.2 & 5.0473 & TRN \\
\hline CHEMBL 1480063 & 737826 & 5.1 & 5.1844 & TRN \\
\hline CHEMBL1427330 & 737826 & 5.9 & 5.1192 & TST \\
\hline CHEMBL342375 & 737826 & 4.7 & 4.8724 & TST \\
\hline CHEMBL1403333 & 737826 & 6.1 & 6.0156 & TRN \\
\hline CHEMBL1350587 & 737826 & 5.15 & 5.2586 & TRN \\
\hline CHEMBL1544498 & 737826 & 4.5 & 5.4354 & TRN \\
\hline CHEMBL1391091 & 737826 & 4.9 & 5.0981 & TRN \\
\hline CHEMBL1391435 & 737826 & 4.9 & 5.2596 & TRN \\
\hline CHEMBL1440293 & 737826 & 5.05 & 5.3645 & TRN \\
\hline CHEMBL1491098 & 737826 & 4.85 & 5.2928 & TRN \\
\hline CHEMBL1572174 & 737826 & 4.95 & 5.3169 & TRN \\
\hline CHEMBL1596762 & 737826 & 5.3 & 5.4725 & TRN \\
\hline CHEMBL1347205 & 737826 & 5.65 & 5.3454 & TRN \\
\hline
\end{tabular}




\begin{tabular}{|c|c|c|c|c|c|}
\hline \multirow[b]{2}{*}{ CHEMBL523283 } & \multicolumn{5}{|c|}{ Supplemental Table s2.txt } \\
\hline & 737826 & 5.9 & 5.9146 & TRN & \\
\hline CHEMBL1492641 & 737826 & 4.6 & 5.0757 & TRN & \\
\hline CHEMBL1604087 & 737826 & 5.45 & 5.29200 & 0000000001 & TRN \\
\hline CHEMBL1333556 & 737826 & 4.9 & 4.9124 & TST & \\
\hline CHEMBL1424596 & 737826 & 4.65 & 5.5153 & TST & \\
\hline CHEMBL1561206 & 737826 & 6.0 & 5.2808 & TRN & \\
\hline CHEMBL1329312 & 737826 & 5.1 & 5.4751 & TRN & \\
\hline CHEMBL1575432 & 737826 & 6.85 & 5.1459 & TRN & \\
\hline CHEMBL1445772 & 737826 & 5.0 & 4.8029 & TRN & \\
\hline CHEMBL1581282 & 737826 & 4.75 & 5.2494 & TRN & \\
\hline CHEMBL1604063 & 737826 & 5.2 & 5.1282 & TST & \\
\hline CHEMBL1536129 & 737826 & 4.75 & 5.1967 & TRN & \\
\hline CHEMBL1372708 & 737826 & 6.0 & 5.221 & TRN & \\
\hline CHEMBL1440032 & 737826 & 4.7 & 5.1486 & TST & \\
\hline CHEMBL29197 & 737826 & 6.4 & 6.0278 & TRN & \\
\hline CHEMBL3195443 & 737826 & 5.05 & 5.40799 & 99999999995 & TRN \\
\hline CHEMBL1321535 & 737826 & 5.75 & 5.2858 & TRN & \\
\hline CHEMBL1420257 & 737826 & 6.0 & 5.5758 & TRN & \\
\hline CHEMBL1611999 & 737826 & 4.4 & 4.3315 & TRN & \\
\hline CHEMBL1563513 & 737826 & 5.35 & 5.1513 & TRN & \\
\hline CHEMBL 2369261 & 737826 & 5.1 & 5.3948 & TST & \\
\hline CHEMBL1982520 & 737826 & 5.45 & 5.3711 & TST & \\
\hline CHEMBL1538593 & 737826 & 4.85 & 5.2572 & TRN & \\
\hline CHEMBL1560435 & 737826 & 5.75 & 5.2665 & TRN & \\
\hline CHEMBL 3210878 & 737826 & 4.55 & 5.3668 & TRN & \\
\hline CHEMBL1562477 & 737826 & 4.6 & 4.6255 & TRN & \\
\hline CHEMBL236789 & 737826 & 4.7 & 4.7792 & TRN & \\
\hline CHEMBL1548325 & 737826 & 4.8 & 5.3264 & TRN & \\
\hline CHEMBL1459170 & 737826 & 5.0 & 5.2062 & TRN & \\
\hline CHEMBL1742292 & 737826 & 5.95 & 5.25899 & 99999999995 & TRN \\
\hline CHEMBL1368887 & 737826 & 6.0 & 5.737 & TRN & \\
\hline CHEMBL448602 & 737826 & 5.7 & 5.5324 & TRN & \\
\hline CHEMBL1572893 & 737826 & 4.95 & 5.3434 & TRN & \\
\hline CHEMBL1496744 & 737826 & 5.5 & 5.2794 & TRN & \\
\hline CHEMBL1717461 & 737826 & 8.25 & 5.4651 & TST & \\
\hline CHEMBL1439063 & 737826 & 5.6 & 5.2368 & TRN & \\
\hline CHEMBL1592220 & 737826 & 5.4 & 4.9688 & TRN & \\
\hline CHEMBL1462380 & 737826 & 4.8 & 5.0231 & TRN & \\
\hline CHEMBL1373523 & 737826 & 5.5 & 5.3618 & TRN & \\
\hline CHEMBL1520792 & 737826 & 4.8 & 5.271 & TRN & \\
\hline CHEMBL1577854 & 737826 & 4.85 & 5.2805 & TRN & \\
\hline CHEMBL1530272 & 737826 & 6.95 & 5.2385 & TST & \\
\hline CHEMBL1318316 & 737826 & 5.5 & 5.4389 & TRN & \\
\hline CHEMBL1416634 & 737826 & 4.9 & 5.234 & TRN & \\
\hline CHEMBL3210104 & 737826 & 5.5 & 5.5057 & TRN & \\
\hline CHEMBL1602476 & 737826 & 4.4 & 4.4719 & TRN & \\
\hline CHEMBL1336532 & 737826 & 5.1 & 5.1528 & TST & \\
\hline CHEMBL1443713 & 737826 & 4.6 & 4.6369 & TRN & \\
\hline & & & & 6426 & \\
\hline
\end{tabular}




\begin{tabular}{|c|c|c|c|c|}
\hline \multicolumn{5}{|c|}{ Supplemental Table S2.txt } \\
\hline CHEMBL1502072 & 737826 & 6.05 & 5.4386 & TRN \\
\hline CHEMBL1378710 & 737826 & 4.9 & 5.3483 & TRN \\
\hline CHEMBL1352225 & 737826 & 7.25 & 5.4189 & TRN \\
\hline CHEMBL1214274 & 737826 & 5.7 & 5.5409 & TRN \\
\hline CHEMBL1576355 & 737826 & 5.7 & 5.4009 & TST \\
\hline CHEMBL1499071 & 737826 & 5.05 & 5.3592 & TST \\
\hline CHEMBL1445233 & 737826 & 5.2 & 5.2789 & TRN \\
\hline CHEMBL1408904 & 737826 & 5.0 & 5.1759 & TRN \\
\hline CHEMBL1337408 & 737826 & 5.05 & 5.1942 & TRN \\
\hline CHEMBL78150 & 737826 & 7.5 & 6.8157 & TRN \\
\hline CHEMBL1333156 & 737826 & 5.7 & 5.5104 & TRN \\
\hline CHEMBL1301015 & 737826 & 4.5 & 5.3542 & TRN \\
\hline CHEMBL3211668 & 737826 & 4.95 & 5.0991 & TST \\
\hline CHEMBL1465534 & 737826 & 5.1 & 5.2075 & TST \\
\hline CHEMBL1487819 & 737826 & 4.85 & 5.222 & TRN \\
\hline CHEMBL1979849 & 737826 & 4.9 & 5.3207 & TRN \\
\hline CHEMBL1565409 & 737826 & 6.15 & 5.2547 & TRN \\
\hline CHEMBL1579521 & 737826 & 5.95 & 5.2927 & TRN \\
\hline CHEMBL1490045 & 737826 & 5.2 & 5.425 & TST \\
\hline CHEMBL1545958 & 737826 & 4.75 & 5.4144 & TRN \\
\hline CHEMBL1606137 & 737826 & 7.6 & 5.1569 & TRN \\
\hline CHEMBL1369693 & 737826 & 5.9 & 5.3642 & TRN \\
\hline CHEMBL1515867 & 737826 & 4.4 & 4.6189 & TRN \\
\hline CHEMBL1569497 & 737826 & 4.9 & 4.7725 & TRN \\
\hline CHEMBL1357551 & 737826 & 4.5 & 4.4711 & TRN \\
\hline CHEMBL1486647 & 737826 & 5.35 & 5.1884 & TRN \\
\hline CHEMBL1509992 & 737826 & 4.75 & 5.18 & TRN \\
\hline CHEMBL1578958 & 737826 & 4.85 & 5.4568 & TRN \\
\hline CHEMBL1363376 & 737826 & 6.05 & 5.2499 & TRN \\
\hline CHEMBL1353322 & 737826 & 5.7 & 5.2727 & TRN \\
\hline CHEMBL1314182 & 737826 & 5.0 & 5.0972 & TRN \\
\hline CHEMBL1437176 & 737826 & 4.4 & 4.4356 & TRN \\
\hline CHEMBL1519435 & 737826 & 6.3 & 6.1695 & TRN \\
\hline CHEMBL1431523 & 737826 & 4.85 & 5.2297 & TRN \\
\hline CHEMBL1314011 & 737826 & 4.9 & 5.4282 & TRN \\
\hline CHEMBL1554236 & 737826 & 5.9 & 5.4918 & TRN \\
\hline CHEMBL1399842 & 737826 & 4.4 & 5.4402 & TST \\
\hline CHEMBL1594862 & 737826 & 4.85 & 5.3307 & TRN \\
\hline CHEMBL7463 & 737826 & 4.8 & 4.8665 & TST \\
\hline CHEMBL1314172 & 737826 & 4.9 & 4.6897 & TRN \\
\hline CHEMBL1331974 & 737826 & 5.85 & 5.2773 & TRN \\
\hline CHEMBL1483608 & 737826 & 5.45 & 5.2279 & TRN \\
\hline CHEMBL1388530 & 737826 & 5.55 & 5.2762 & TRN \\
\hline CHEMBL1566428 & 737826 & 6.3 & 6.079 & TRN \\
\hline CHEMBL1449707 & 737826 & 5.05 & 5.3786 & TRN \\
\hline CHEMBL1402908 & 737826 & 5.65 & 5.3357 & TRN \\
\hline CHEMBL1552303 & 737826 & 5.5 & 5.4477 & TRN \\
\hline CHEMBL305881 & 737826 & 6.0 & 5.5754 & TRN \\
\hline
\end{tabular}




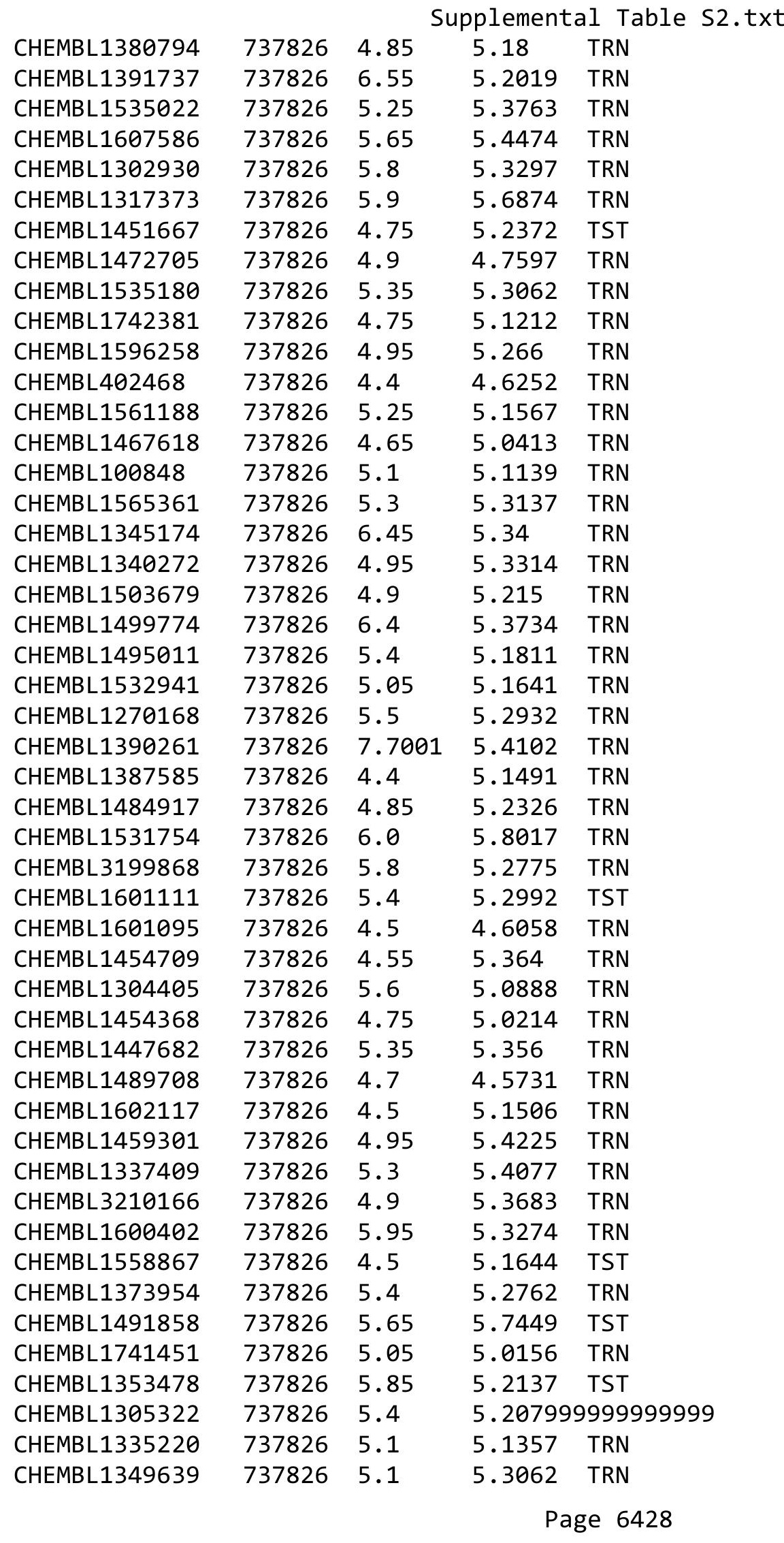

TRN 


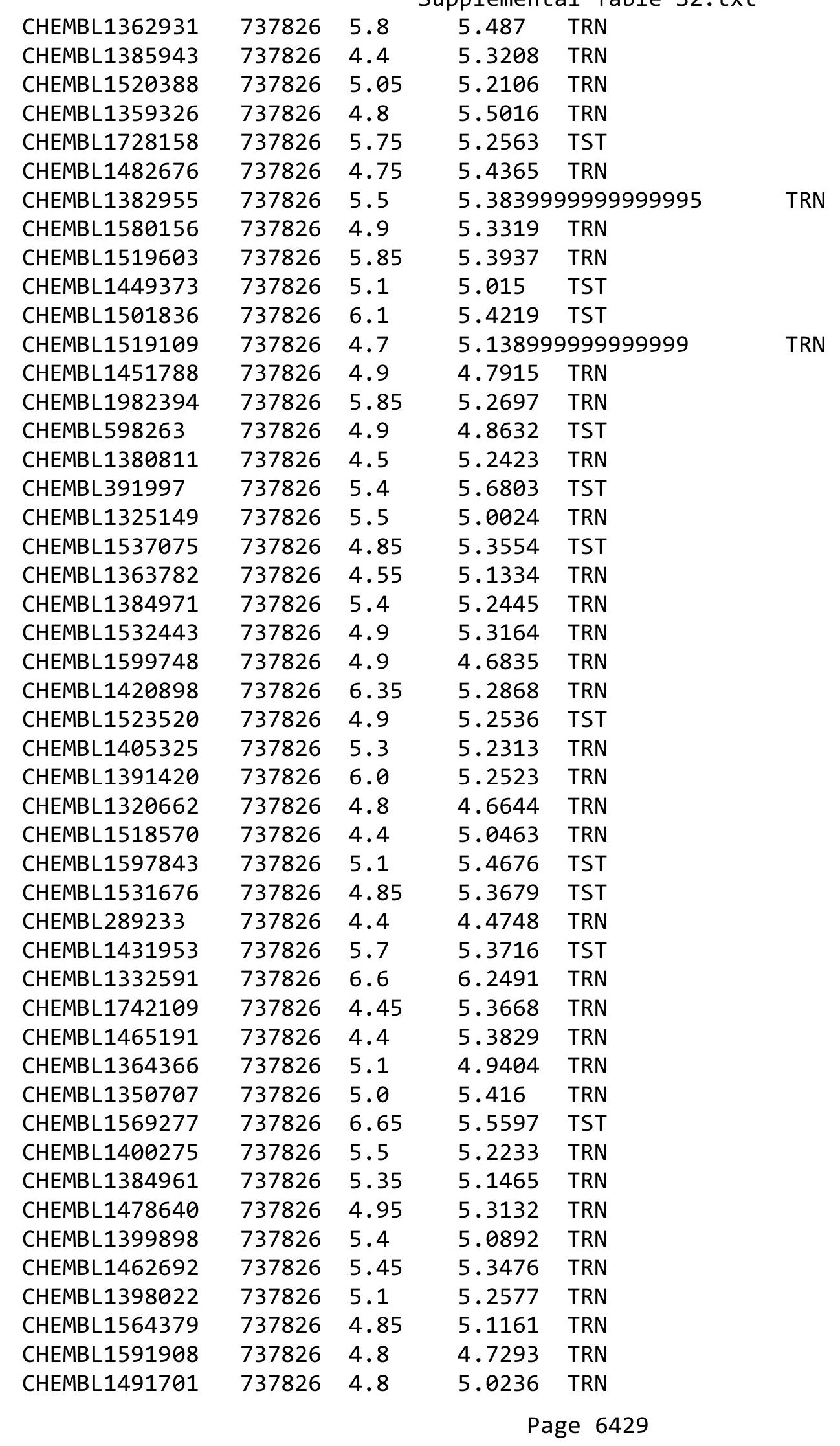




\begin{tabular}{|c|c|c|c|c|}
\hline \multicolumn{5}{|c|}{ Supplemental Table S2.txt } \\
\hline CHEMBL1514640 & 737826 & 4.9 & 4.7885 & TRN \\
\hline CHEMBL1347492 & 737826 & 5.25 & 5.4552 & TRN \\
\hline CHEMBL1371423 & 737826 & 5.9 & 5.0211 & TRN \\
\hline CHEMBL1334512 & 737826 & 4.65 & 5.0837 & TST \\
\hline CHEMBL1536220 & 737826 & 4.6 & 5.1925 & TRN \\
\hline CHEMBL1453240 & 737826 & 4.7 & 4.6594 & TST \\
\hline CHEMBL1574720 & 737826 & 4.6 & 5.2637 & TRN \\
\hline CHEMBL1445578 & 737826 & 5.1 & 4.8492 & TRN \\
\hline CHEMBL1374205 & 737826 & 5.35 & 5.2678 & TRN \\
\hline CHEMBL1305298 & 737826 & 5.05 & 5.3072 & TRN \\
\hline CHEMBL1474294 & 737826 & 5.4 & 5.2654 & TST \\
\hline CHEMBL1371689 & 737826 & 4.75 & 5.3501 & TRN \\
\hline CHEMBL1338596 & 737826 & 5.5 & 5.3191 & TRN \\
\hline CHEMBL1594761 & 737826 & 4.4 & 4.3598 & TRN \\
\hline CHEMBL1413637 & 737826 & 4.8 & 4.8049 & TRN \\
\hline CHEMBL3214365 & 737826 & 5.75 & 5.1255 & TRN \\
\hline CHEMBL1461496 & 737826 & 4.8 & 5.2379 & TRN \\
\hline CHEMBL1545790 & 737826 & 6.4 & 5.2332 & TRN \\
\hline CHEMBL1372363 & 737826 & 4.6 & 4.5509 & TRN \\
\hline CHEMBL1439882 & 737826 & 5.3 & 5.1882 & TRN \\
\hline CHEMBL1611012 & 737826 & 5.1 & 5.067 & TRN \\
\hline CHEMBL1742018 & 737826 & 5.4 & 5.24299 & 9999999999 \\
\hline CHEMBL1345354 & 737826 & 4.75 & 5.2337 & TRN \\
\hline CHEMBL1328386 & 737826 & 4.85 & 5.2434 & TRN \\
\hline CHEMBL1412209 & 737826 & 5.45 & 5.2681 & TRN \\
\hline CHEMBL1353336 & 737826 & 5.5 & 5.37 & TRN \\
\hline CHEMBL1439126 & 737826 & 5.8 & 5.5449 & TRN \\
\hline CHEMBL1500797 & 737826 & 4.85 & 5.1718 & TRN \\
\hline CHEMBL1299593 & 737826 & 5.95 & 5.2386 & TRN \\
\hline CHEMBL1407677 & 737826 & 4.85 & 5.4307 & TRN \\
\hline CHEMBL1742285 & 737826 & 4.9 & 5.2344 & TRN \\
\hline CHEMBL3194920 & 737826 & 6.7 & 5.2463 & TRN \\
\hline CHEMBL1375127 & 737826 & 7.7001 & 6.8041 & TRN \\
\hline CHEMBL1534734 & 737826 & 4.4 & 4.2774 & TRN \\
\hline CHEMBL1742164 & 737826 & 6.4 & 5.1897 & TRN \\
\hline CHEMBL1334255 & 737826 & 5.3 & 5.3356 & TRN \\
\hline CHEMBL1341313 & 737826 & 5.4 & 5.2696 & TRN \\
\hline CHEMBL259515 & 737826 & 4.85 & 5.1271 & TRN \\
\hline CHEMBL3192331 & 737826 & 5.3 & 5.3945 & TRN \\
\hline CHEMBL166161 & 737826 & 4.6 & 4.6132 & TST \\
\hline CHEMBL1457224 & 737826 & 4.75 & 5.5306 & TRN \\
\hline CHEMBL1741905 & 737826 & 5.15 & 5.2065 & TRN \\
\hline CHEMBL1493910 & 737826 & 5.5 & 5.4397 & TRN \\
\hline CHEMBL1475375 & 737826 & 5.6 & 5.4616 & TST \\
\hline CHEMBL1470084 & 737826 & 4.85 & 5.3266 & TRN \\
\hline CHEMBL1578496 & 737826 & 4.85 & 5.2717 & TRN \\
\hline CHEMBL1370601 & 737826 & 5.4 & 5.3485 & TRN \\
\hline CHEMBL1468521 & 737826 & 4.65 & 5.4727 & TRN \\
\hline
\end{tabular}




\begin{tabular}{|c|c|c|c|c|c|}
\hline \\
\hline CHEMBL1513511 & 737826 & 5.9 & 5.8197 & TRN & \\
\hline CHEMBL1364717 & 737826 & 4.5 & 4.5207 & TRN & \\
\hline CHEMBL1493054 & 737826 & 6.9 & 5.4173 & TRN & \\
\hline CHEMBL1323894 & 737826 & 4.55 & 5.3726 & TST & \\
\hline CHEMBL1367377 & 737826 & 4.6 & 5.2919 & TRN & \\
\hline CHEMBL1310513 & 737826 & 5.95 & 5.3277 & TRN & \\
\hline CHEMBL1450903 & 737826 & 4.8 & 4.7734 & TRN & \\
\hline CHEMBL1316285 & 737826 & 5.5 & 5.3494 & TRN & \\
\hline CHEMBL1301521 & 737826 & 4.75 & 5.3003 & TRN & \\
\hline CHEMBL3189630 & 737826 & 6.5 & 5.1539 & TST & \\
\hline CHEMBL1516787 & 737826 & 5.3 & 5.2273 & TRN & \\
\hline CHEMBL1312648 & 737826 & 5.85 & 5.3243 & TRN & \\
\hline CHEMBL1434149 & 737826 & 5.4 & 5.164 & TRN & \\
\hline CHEMBL1348606 & 737826 & 4.65 & 5.1665 & TRN & \\
\hline CHEMBL1506208 & 737826 & 4.55 & 5.1452 & TRN & \\
\hline CHEMBL1522673 & 737826 & 7.1 & 5.4302 & TRN & \\
\hline CHEMBL 260374 & 737826 & 6.0 & 5.6395 & TST & \\
\hline CHEMBL1496370 & 737826 & 6.65 & 5.206 & TST & \\
\hline CHEMBL1425311 & 737826 & 4.95 & 5.348 & TRN & \\
\hline CHEMBL1582419 & 737826 & 5.6 & 5.2435 & TRN & \\
\hline CHEMBL365739 & 737826 & 6.0 & 5.7056 & TST & \\
\hline CHEMBL1349709 & 737826 & 5.9 & 4.9642 & TRN & \\
\hline CHEMBL1595205 & 737826 & 4.5 & 4.4312 & TRN & \\
\hline CHEMBL3196035 & 737826 & 4.9 & 5.3685 & TRN & \\
\hline CHEMBL1362464 & 737826 & 4.9 & 5.1104 & TRN & \\
\hline CHEMBL1554654 & 737826 & 5.5 & 5.2532 & TST & \\
\hline CHEMBL105739 & 737826 & 5.6 & 5.3822 & TRN & \\
\hline CHEMBL1688558 & 737826 & 5.2 & 5.2161 & TRN & \\
\hline CHEMBL1456341 & 737826 & 4.8 & 5.3245 & TRN & \\
\hline CHEMBL1575136 & 737826 & 4.85 & 5.1312 & TRN & \\
\hline CHEMBL1534816 & 737826 & 4.95 & 5.3293 & TRN & \\
\hline CHEMBL1359877 & 737826 & 4.9 & 5.2685 & TRN & \\
\hline CHEMBL1439231 & 737826 & 5.35 & 5.505 & TRN & \\
\hline CHEMBL1375098 & 737826 & 5.4 & 5.2038 & TRN & \\
\hline CHEMBL1396936 & 737826 & 6.0 & 5.9741 & TRN & \\
\hline CHEMBL1609748 & 737826 & 4.4 & 4.9764 & TRN & \\
\hline CHEMBL1492087 & 737826 & 5.75 & 5.1689 & TRN & \\
\hline CHEMBL1523892 & 737826 & 5.45 & 5.268 & TRN & \\
\hline CHEMBL1412450 & 737826 & 5.35 & 5.3399 & TRN & \\
\hline CHEMBL1363367 & 737826 & 5.1 & 4.9877 & TST & \\
\hline CHEMBL1570869 & 737826 & 5.3 & 5.3614 & TRN & \\
\hline CHEMBL1406944 & 737826 & 5.6 & $5.2070 e$ & $\partial 000000001$ & TRN \\
\hline CHEMBL1447809 & 737826 & 5.15 & 5.6002 & TRN & \\
\hline CHEMBL1520928 & 737826 & 5.3 & 5.4538 & TST & \\
\hline CHEMBL1612335 & 737826 & 4.85 & 5.1432 & TRN & \\
\hline CHEMBL86931 & 737826 & 5.2 & 5.0811 & TST & \\
\hline CHEMBL1256727 & 737826 & 5.7 & 5.4215 & TRN & \\
\hline CHEMBL3213624 & 737826 & 4.75 & 5.2557 & TRN & \\
\hline
\end{tabular}




\begin{tabular}{|c|c|c|c|c|c|}
\hline & & & & & \\
\hline CHEMBL1597366 & 737826 & 4.6 & 4.4318 & TRN & \\
\hline CHEMBL1256759 & 737826 & 6.3 & 5.6653 & TRN & \\
\hline CHEMBL1506736 & 737826 & 5.4 & 5.20200 & 0000000001 & TRN \\
\hline CHEMBL1421334 & 737826 & 5.5 & 5.3239 & TST & \\
\hline CHEMBL1606094 & 737826 & 5.5 & 5.4177 & TST & \\
\hline CHEMBL1306988 & 737826 & 5.1 & 5.3298 & TRN & \\
\hline CHEMBL1714369 & 737826 & 5.7 & 5.2942 & TST & \\
\hline CHEMBL1547741 & 737826 & 5.05 & 5.23799 & 99999999995 & TRN \\
\hline CHEMBL1443926 & 737826 & 5.75 & 5.4699 & TRN & \\
\hline CHEMBL 29097 & 737826 & 4.9 & 4.9555 & TRN & \\
\hline CHEMBL1575273 & 737826 & 4.55 & 5.3581 & TRN & \\
\hline CHEMBL1417583 & 737826 & 4.85 & 5.2504 & TRN & \\
\hline CHEMBL1524904 & 737826 & 5.05 & 5.3334 & TRN & \\
\hline CHEMBL1512701 & 737826 & 6.8 & 6.6029 & TRN & \\
\hline CHEMBL1345861 & 737826 & 4.55 & 4.9504 & TRN & \\
\hline CHEMBL1304386 & 737826 & 5.1 & 5.271 & TRN & \\
\hline CHEMBL3193687 & 737826 & 4.5 & 5.2193 & TRN & \\
\hline CHEMBL1595282 & 737826 & 4.5 & 4.4866 & TRN & \\
\hline CHEMBL1326341 & 737826 & 4.4 & 4.428 & TRN & \\
\hline CHEMBL1741518 & 737826 & 4.9 & 5.2347 & TRN & \\
\hline CHEMBL1717253 & 737826 & 5.0 & 5.3008 & TRN & \\
\hline CHEMBL1374501 & 737826 & 5.4 & 5.3042 & TRN & \\
\hline CHEMBL1356463 & 737826 & 5.4 & 5.4027 & TST & \\
\hline CHEMBL1523995 & 737826 & 4.9 & 5.2515 & TST & \\
\hline CHEMBL1611549 & 737826 & 5.65 & 5.1904 & TRN & \\
\hline CHEMBL1459487 & 737826 & 4.95 & 5.2839 & TRN & \\
\hline CHEMBL1412756 & 737826 & 5.3 & 5.349 & TRN & \\
\hline CHEMBL1472152 & 737826 & 4.65 & 5.2987 & TRN & \\
\hline CHEMBL1519261 & 737826 & 6.0 & 6.0424 & TRN & \\
\hline CHEMBL1344533 & 737826 & 5.7 & 5.3985 & TRN & \\
\hline CHEMBL1551503 & 737826 & 6.2 & 6.1168 & TRN & \\
\hline CHEMBL1401813 & 737826 & 5.0 & 5.3484 & TRN & \\
\hline CHEMBL 3194740 & 737826 & 5.05 & 5.3875 & TRN & \\
\hline CHEMBL1540956 & 737826 & 5.7 & 5.2665 & TRN & \\
\hline CHEMBL1549003 & 737826 & 5.05 & 5.3712 & TRN & \\
\hline CHEMBL1725383 & 737826 & 5.3 & 5.5153 & TRN & \\
\hline CHEMBL1579424 & 737826 & 5.7 & 5.1927 & TRN & \\
\hline CHEMBL1344002 & 737826 & 5.0 & 5.2772 & TST & \\
\hline CHEMBL1437825 & 737826 & 4.4 & 5.6553 & TRN & \\
\hline CHEMBL1548199 & 737826 & 4.9 & 5.2544 & TRN & \\
\hline CHEMBL1301415 & 737826 & 5.15 & 5.1255 & TRN & \\
\hline CHEMBL1335382 & 737826 & 5.65 & 5.2409 & TRN & \\
\hline CHEMBL1346774 & 737826 & 7.0 & 5.3653 & TST & \\
\hline CHEMBL1397704 & 737826 & -0.0 & 4.9974 & TRN & \\
\hline CHEMBL1318400 & 737826 & 6.0 & 5.8672 & TRN & \\
\hline CHEMBL1713713 & 737826 & 5.65 & 5.318 & TRN & \\
\hline CHEMBL1458916 & 737826 & 5.6 & 5.2881 & TRN & \\
\hline CHEMBL1596246 & 737826 & 4.9 & 4.7529 & TRN & \\
\hline & & & & e 6432 & \\
\hline
\end{tabular}




\begin{tabular}{|c|c|c|c|c|c|}
\hline & & \multicolumn{4}{|c|}{ Supplemental Table s2.txt } \\
\hline CHEMBL1506666 & 737826 & 5.25 & 5.4783 & TRN & \\
\hline CHEMBL1741622 & 737826 & 5.6 & 5.438 & TRN & \\
\hline CHEMBL1489178 & 737826 & 6.05 & 5.0313 & TRN & \\
\hline CHEMBL1411662 & 737826 & 5.35 & 5.4082 & TST & \\
\hline CHEMBL 278041 & 737826 & 4.8 & 5.7158 & TRN & \\
\hline CHEMBL1714323 & 737826 & 6.45 & 5.3185 & TRN & \\
\hline CHEMBL3213443 & 737826 & 4.4 & 5.1781 & TRN & \\
\hline CHEMBL1506130 & 737826 & 5.05 & 5.0671 & TRN & \\
\hline CHEMBL1364946 & 737826 & 6.4 & 5.1603 & TRN & \\
\hline CHEMBL1982071 & 737826 & 4.55 & 5.28 & TRN & \\
\hline CHEMBL1519173 & 737826 & 6.0 & 5.2959 & TRN & \\
\hline CHEMBL1521744 & 737826 & 5.0 & 5.2824 & TRN & \\
\hline CHEMBL1567101 & 737826 & 4.4 & 4.6952 & TRN & \\
\hline CHEMBL 235453 & 737826 & 5.65 & 5.0891 & TRN & \\
\hline CHEMBL1407848 & 737826 & 6.9 & 5.3411 & TRN & \\
\hline CHEMBL1366754 & 737826 & 5.4 & 5.1674 & TRN & \\
\hline CHEMBL1302141 & 737826 & 5.35 & 5.2381 & TRN & \\
\hline CHEMBL1337691 & 737826 & 5.6 & 5.4676 & TRN & \\
\hline CHEMBL1447149 & 737826 & 5.9 & 5.5901 & TRN & \\
\hline CHEMBL1964690 & 737826 & 5.4 & 5.4285 & TRN & \\
\hline CHEMBL1383851 & 737826 & 4.8 & 5.2989 & TRN & \\
\hline CHEMBL1351231 & 737826 & 5.35 & 5.1261 & TST & \\
\hline CHEMBL1492293 & 737826 & 5.35 & 5.1135 & TRN & \\
\hline CHEMBL1331782 & 737826 & 5.4 & 5.4618 & TRN & \\
\hline CHEMBL3196069 & 737826 & 5.5 & 5.3954 & TRN & \\
\hline CHEMBL1403294 & 737826 & 4.9 & 5.3239 & TRN & \\
\hline CHEMBL1334652 & 737826 & 5.5 & 5.2683 & TRN & \\
\hline CHEMBL3199738 & 737826 & 5.05 & 5.5172 & TRN & \\
\hline CHEMBL1525931 & 737826 & 5.45 & 5.49200 & 000000001 & TRN \\
\hline CHEMBL1420945 & 737826 & 5.0 & 5.3185 & TRN & \\
\hline CHEMBL1335806 & 737826 & 5.3 & 5.2531 & TRN & \\
\hline CHEMBL1299867 & 737826 & 5.85 & 5.2756 & TRN & \\
\hline CHEMBL1585681 & 737826 & 5.1 & 5.3258 & TRN & \\
\hline CHEMBL1351222 & 737826 & 5.1 & 5.5014 & TRN & \\
\hline CHEMBL3189154 & 737826 & 5.15 & 5.5089 & TRN & \\
\hline CHEMBL1369642 & 737826 & 4.8 & 5.3035 & TRN & \\
\hline CHEMBL1560365 & 737826 & 5.0 & 5.3683 & TRN & \\
\hline CHEMBL1389184 & 737826 & 5.3 & 5.2544 & TRN & \\
\hline CHEMBL1391282 & 737826 & 4.4 & 5.3083 & TRN & \\
\hline CHEMBL1600209 & 737826 & 5.5 & 5.2688 & TST & \\
\hline CHEMBL1418178 & 737826 & 4.4 & 5.4871 & TRN & \\
\hline CHEMBL1601019 & 737826 & 4.9 & 4.8957 & TRN & \\
\hline CHEMBL3209279 & 737826 & 4.85 & 5.3513 & TRN & \\
\hline CHEMBL1562915 & 737826 & 6.35 & 5.3657 & TRN & \\
\hline CHEMBL1367149 & 737826 & 4.4 & 5.2684 & TRN & \\
\hline CHEMBL1304570 & 737826 & 6.0 & 5.2932 & TRN & \\
\hline CHEMBL1357676 & 737826 & 4.7 & 4.7138 & TRN & \\
\hline CHEMBL32503 & 737826 & 5.5 & 5.2782 & TST & \\
\hline
\end{tabular}




\begin{tabular}{|c|c|c|c|c|}
\hline \multicolumn{5}{|c|}{ Supplemental Table S2.txt } \\
\hline CHEMBL1392699 & 737826 & 5.2 & 5.5116 & TRN \\
\hline CHEMBL1408647 & 737826 & 4.75 & 5.3981 & TST \\
\hline CHEMBL1580108 & 737826 & 4.85 & 5.3058 & TRN \\
\hline CHEMBL129795 & 737826 & 4.7 & 5.7362 & TRN \\
\hline CHEMBL1574158 & 737826 & 4.9 & 5.3378 & TRN \\
\hline CHEMBL1328880 & 737826 & 6.15 & 5.4188 & TRN \\
\hline CHEMBL1314367 & 737826 & 6.0 & 6.0518 & TRN \\
\hline CHEMBL1554976 & 737826 & 6.1 & 5.9721 & TRN \\
\hline CHEMBL1539637 & 737826 & 4.4 & 5.1692 & TST \\
\hline CHEMBL1444269 & 737826 & 5.0 & 5.6052 & TRN \\
\hline CHEMBL1522198 & 737826 & 4.8 & 5.2461 & TST \\
\hline CHEMBL2369256 & 737826 & 5.35 & 5.1837 & TRN \\
\hline CHEMBL1576119 & 737826 & 4.6 & 5.2993 & TST \\
\hline CHEMBL1346850 & 737826 & 4.9 & 5.2445 & TRN \\
\hline CHEMBL 275938 & 737826 & 4.8 & 4.9984 & TRN \\
\hline CHEMBL1493118 & 737826 & 5.3 & 5.4247 & TRN \\
\hline CHEMBL1706260 & 737826 & 4.95 & 5.2232 & TRN \\
\hline CHEMBL1608125 & 737826 & 6.0 & 5.9898 & TRN \\
\hline CHEMBL1542112 & 737826 & 5.95 & 5.3486 & TRN \\
\hline CHEMBL1516521 & 737826 & 4.8 & 5.2852 & TRN \\
\hline CHEMBL1605130 & 737826 & 4.4 & 4.379 & TRN \\
\hline CHEMBL1610942 & 737826 & 8.05 & 5.1131 & TST \\
\hline CHEMBL1382355 & 737826 & 5.0 & 5.4341 & TRN \\
\hline CHEMBL1989625 & 737826 & 5.4 & 5.5065 & TST \\
\hline CHEMBL3208773 & 737826 & 5.1 & 5.4225 & TST \\
\hline CHEMBL1362630 & 737826 & 4.8 & 4.8962 & TRN \\
\hline CHEMBL1585369 & 737826 & 4.75 & 5.1831 & TST \\
\hline CHEMBL1577187 & 737826 & 4.9 & 5.6338 & TRN \\
\hline CHEMBL3145059 & 737826 & 5.6 & 5.4124 & TRN \\
\hline CHEMBL1607455 & 737826 & 5.6 & 5.2751 & TRN \\
\hline CHEMBL1509124 & 737826 & 4.95 & 5.0377 & TRN \\
\hline CHEMBL111545 & 737826 & 5.1 & 5.0526 & TST \\
\hline CHEMBL1501938 & 737826 & 5.9 & 5.4333 & TRN \\
\hline CHEMBL1710092 & 737826 & 4.95 & 5.4 & TRN \\
\hline CHEMBL1444213 & 737826 & 5.95 & 5.1265 & TRN \\
\hline CHEMBL3207422 & 737826 & 5.7 & 5.3294 & TRN \\
\hline CHEMBL1331734 & 737826 & 5.1 & 5.0531 & TST \\
\hline CHEMBL3195954 & 737826 & 4.9 & 5.356 & TRN \\
\hline CHEMBL1588849 & 737826 & 4.9 & 5.3939 & TST \\
\hline CHEMBL1359473 & 737826 & 4.95 & 5.3752 & TRN \\
\hline CHEMBL1366390 & 737826 & 5.2 & 5.3073 & TRN \\
\hline CHEMBL3209548 & 737826 & 5.05 & 5.4416 & TRN \\
\hline CHEMBL1461359 & 737826 & 4.9 & 5.4936 & TRN \\
\hline CHEMBL1301385 & 737826 & 4.95 & 5.3689 & TRN \\
\hline CHEMBL19980 & 737826 & 4.8 & 4.8382 & TST \\
\hline CHEMBL3210631 & 737826 & 4.85 & 5.4239 & TRN \\
\hline CHEMBL1607605 & 737826 & 5.4 & 5.5132 & TRN \\
\hline CHEMBL1415331 & 737826 & 5.9 & 5.3905 & TRN \\
\hline
\end{tabular}




\begin{tabular}{|c|c|c|c|c|}
\hline \\
\hline CHEMBL1558480 & 737826 & 5.0 & 4.8711 & TRN \\
\hline CHEMBL1546073 & 737826 & 5.0 & 5.4189 & TRN \\
\hline CHEMBL1524331 & 737826 & 5.5 & 5.234 & TRN \\
\hline CHEMBL1518689 & 737826 & 5.5 & 5.3094 & TRN \\
\hline CHEMBL1382389 & 737826 & 5.7 & 5.4257 & TRN \\
\hline CHEMBL1557015 & 737826 & 4.95 & 5.3708 & TRN \\
\hline CHEMBL1465985 & 737826 & 6.2 & 5.454 & TRN \\
\hline CHEMBL1482789 & 737826 & 4.55 & 5.2456 & TRN \\
\hline CHEMBL3211303 & 737826 & 8.1 & 4.9499 & TST \\
\hline CHEMBL1450537 & 737826 & 6.3 & 5.1561 & TST \\
\hline CHEMBL1407064 & 737826 & 5.1 & 5.3315 & TRN \\
\hline CHEMBL1343084 & 737826 & 5.8 & 5.2723 & TRN \\
\hline CHEMBL1450026 & 737826 & 4.7 & 4.6619 & TRN \\
\hline CHEMBL1604670 & 737826 & 5.6 & 5.2633 & TRN \\
\hline CHEMBL1514027 & 737826 & 5.8 & 5.856 & TRN \\
\hline CHEMBL1479959 & 737826 & 5.6 & 5.3516 & TRN \\
\hline CHEMBL1486304 & 737826 & 5.4 & 5.2786 & TST \\
\hline CHEMBL1335409 & 737826 & 5.1 & 5.0475 & TRN \\
\hline CHEMBL1416639 & 737826 & 4.5 & 4.5989 & TRN \\
\hline CHEMBL3199291 & 737826 & 4.9 & 5.2011 & TRN \\
\hline CHEMBL428768 & 737826 & 6.0 & 5.7533 & TRN \\
\hline CHEMBL1300933 & 737826 & 6.1 & 5.4006 & TRN \\
\hline CHEMBL1368786 & 737826 & 4.8 & 5.4534 & TRN \\
\hline CHEMBL1330692 & 737826 & 5.4 & 5.3018 & TRN \\
\hline CHEMBL1492616 & 737826 & 5.4 & 5.2613 & TRN \\
\hline CHEMBL1435647 & 737826 & 5.0 & 4.9218 & TST \\
\hline CHEMBL1409320 & 737826 & 5.4 & 5.1318 & TRN \\
\hline CHEMBL1480012 & 737826 & 6.0 & 5.1965 & TRN \\
\hline CHEMBL1499297 & 737826 & 4.65 & 5.0639 & TST \\
\hline CHEMBL1416727 & 737826 & 4.5 & 5.2563 & TRN \\
\hline CHEMBL 1405262 & 737826 & 4.9 & 5.4399 & TRN \\
\hline CHEMBL1419070 & 737826 & 5.4 & 5.1124 & TRN \\
\hline CHEMBL1742180 & 737826 & 4.85 & 5.4048 & TRN \\
\hline CHEMBL1587467 & 737826 & 7.25 & 5.1239 & TRN \\
\hline CHEMBL1742325 & 737826 & 4.75 & 5.3872 & TRN \\
\hline CHEMBL 1337740 & 737826 & 6.0 & 5.7802 & TRN \\
\hline CHEMBL1335680 & 737826 & 5.45 & 5.2548 & TRN \\
\hline CHEMBL1366197 & 737826 & 4.55 & 5.2755 & TRN \\
\hline CHEMBL1457785 & 737826 & 5.5 & 5.2451 & TST \\
\hline CHEMBL1525716 & 737826 & 5.3 & 5.1986 & TRN \\
\hline CHEMBL63154 & 737826 & 5.3 & 5.2115 & TST \\
\hline CHEMBL1528626 & 737826 & 5.45 & 5.2997 & TRN \\
\hline CHEMBL1399815 & 737826 & 5.45 & 5.2143 & TRN \\
\hline CHEMBL1444367 & 737826 & 4.4 & 4.3932 & TRN \\
\hline CHEMBL1606541 & 737826 & 5.55 & 5.1935 & TST \\
\hline CHEMBL1492541 & 737826 & 5.8 & 5.2856 & TST \\
\hline CHEMBL 2374058 & 737826 & 5.0 & 4.9425 & TST \\
\hline CHEMBL1315521 & 737826 & 4.4 & 4.3291 & TRN \\
\hline
\end{tabular}




\begin{tabular}{|c|c|c|c|c|c|}
\hline \\
\hline CHEMBL1555537 & 737826 & 5.2 & 5.2037 & TST & \\
\hline CHEMBL1557752 & 737826 & 5.25 & 5.1191 & TRN & \\
\hline CHEMBL216973 & 737826 & 4.55 & 5.1881 & TST & \\
\hline CHEMBL1741932 & 737826 & 4.4 & 5.3418 & TRN & \\
\hline CHEMBL1425091 & 737826 & 6.45 & 5.3814 & TRN & \\
\hline CHEMBL1491104 & 737826 & 5.4 & 5.2794 & TRN & \\
\hline CHEMBL1405129 & 737826 & 6.25 & 5.4545 & TRN & \\
\hline CHEMBL1489359 & 737826 & 5.6 & 5.4375 & TRN & \\
\hline CHEMBL1495116 & 737826 & 5.0 & 5.3982 & TST & \\
\hline CHEMBL1493496 & 737826 & 5.4 & 5.318 & TRN & \\
\hline CHEMBL1365347 & 737826 & 5.8 & 5.1889 & TRN & \\
\hline CHEMBL1555567 & 737826 & 5.0 & 4.867 & TRN & \\
\hline CHEMBL1466281 & 737826 & 5.65 & 5.1722 & TRN & \\
\hline CHEMBL1575087 & 737826 & 4.95 & 5.3952 & TRN & \\
\hline CHEMBL1489535 & 737826 & 4.5 & 5.4171 & TST & \\
\hline CHEMBL1542230 & 737826 & 5.2 & 5.3175 & TRN & \\
\hline CHEMBL1566936 & 737826 & 5.5 & 5.3355 & TRN & \\
\hline CHEMBL1440157 & 737826 & 6.4 & 6.2321 & TRN & \\
\hline CHEMBL1361505 & 737826 & 5.35 & 5.4334 & TRN & \\
\hline CHEMBL1424582 & 737826 & 5.1 & 5.2412 & TRN & \\
\hline CHEMBL1433021 & 737826 & 5.3 & 5.4172 & TRN & \\
\hline CHEMBL1964667 & 737826 & 5.2 & 5.5152 & TRN & \\
\hline CHEMBL1456047 & 737826 & 4.85 & 5.1145 & TRN & \\
\hline CHEMBL1465060 & 737826 & 4.5 & 5.1365 & TST & \\
\hline CHEMBL1582125 & 737826 & 6.35 & 5.4789 & TRN & \\
\hline CHEMBL3208450 & 737826 & 5.4 & 5.5759 & TRN & \\
\hline CHEMBL1488236 & 737826 & 4.85 & 5.3841 & TRN & \\
\hline CHEMBL1561151 & 737826 & 4.9 & 5.2183 & TRN & \\
\hline CHEMBL1592470 & 737826 & 4.7 & 4.6817 & TRN & \\
\hline CHEMBL1354751 & 737826 & 5.4 & 5.1063 & TRN & \\
\hline CHEMBL1381161 & 737826 & 5.8 & 5.2398 & TRN & \\
\hline CHEMBL76904 & 737826 & 5.1 & 5.5936 & TRN & \\
\hline CHEMBL1742168 & 737826 & 5.1 & 5.2944 & TRN & \\
\hline CHEMBL1551841 & 737826 & 6.0 & 5.6005 & TRN & \\
\hline CHEMBL1320722 & 737826 & 5.0 & 5.06800 & 00000000005 & TRN \\
\hline CHEMBL1377767 & 737826 & 4.8 & 5.3668 & TRN & \\
\hline CHEMBL1585542 & 737826 & 5.15 & 5.3962 & TRN & \\
\hline CHEMBL1384678 & 737826 & 5.0 & 5.296 & TRN & \\
\hline CHEMBL1415728 & 737826 & 5.3 & 5.0575 & TRN & \\
\hline CHEMBL3212534 & 737826 & 5.25 & 5.2854 & TRN & \\
\hline CHEMBL1302442 & 737826 & 5.65 & 5.4719 & TRN & \\
\hline CHEMBL1985310 & 737826 & 7.1 & 5.4875 & TST & \\
\hline CHEMBL1452159 & 737826 & 5.3 & 5.2655 & TRN & \\
\hline CHEMBL1521039 & 737826 & 5.15 & 5.1636 & TRN & \\
\hline CHEMBL76897 & 737826 & 4.4 & 4.5716 & TST & \\
\hline CHEMBL1517935 & 737826 & 5.2 & 4.9948 & TRN & \\
\hline CHEMBL1455565 & 737826 & 4.8 & 4.9381 & TRN & \\
\hline CHEMBL1513241 & 737826 & 6.2 & 6.0286 & TRN & \\
\hline
\end{tabular}




\begin{tabular}{|c|c|c|c|c|c|}
\hline \\
\hline CHEMBL1548829 & 737826 & 4.8 & 5.3735 & TST & \\
\hline CHEMBL1481361 & 737826 & 5.0 & 4.7947 & TRN & \\
\hline CHEMBL3192255 & 737826 & 6.5 & 5.2675 & TRN & \\
\hline CHEMBL1586835 & 737826 & 4.85 & 5.3394 & TRN & \\
\hline CHEMBL1341809 & 737826 & 5.6 & 5.4375 & TST & \\
\hline CHEMBL1470136 & 737826 & 5.85 & 5.2933 & TRN & \\
\hline CHEMBL1325662 & 737826 & 6.85 & 5.303 & TRN & \\
\hline CHEMBL1356256 & 737826 & 4.7 & 4.5013 & TRN & \\
\hline CHEMBL1603186 & 737826 & 5.7 & 5.4722 & TRN & \\
\hline CHEMBL1382206 & 737826 & 4.7 & 5.3128 & TRN & \\
\hline CHEMBL1538763 & 737826 & 4.75 & 5.4131 & TRN & \\
\hline CHEMBL1385137 & 737826 & 5.45 & 5.3608 & TST & \\
\hline CHEMBL1546114 & 737826 & 5.2 & 5.1282 & TRN & \\
\hline CHEMBL1408386 & 737826 & 5.9 & 5.2515 & TRN & \\
\hline CHEMBL1465487 & 737826 & 4.4 & 5.3193 & TRN & \\
\hline CHEMBL1376830 & 737826 & 7.05 & 5.3181 & TRN & \\
\hline CHEMBL1562832 & 737826 & 6.2 & 5.2052 & TRN & \\
\hline CHEMBL1742382 & 737826 & 4.95 & 5.1646 & TRN & \\
\hline CHEMBL1375812 & 737826 & 5.55 & 5.2074 & TRN & \\
\hline CHEMBL1549419 & 737826 & 6.55 & 5.6253 & TRN & \\
\hline CHEMBL1348385 & 737826 & 5.85 & 5.244 & TRN & \\
\hline CHEMBL1340482 & 737826 & 6.05 & 5.4024 & TRN & \\
\hline CHEMBL3212934 & 737826 & 6.3 & 5.37299 & 9999999999 & TRN \\
\hline CHEMBL1490809 & 737826 & 4.95 & 5.3545 & TRN & \\
\hline CHEMBL1721518 & 737826 & 4.8 & 5.348 & TRN & \\
\hline CHEMBL1309312 & 737826 & 6.6 & 5.4101 & TRN & \\
\hline CHEMBL1456646 & 737826 & 4.8 & 5.3021 & TRN & \\
\hline CHEMBL1316317 & 737826 & 5.0 & 4.9004 & TRN & \\
\hline CHEMBL1452742 & 737826 & 5.05 & 5.0976 & TRN & \\
\hline CHEMBL1391286 & 737826 & 4.55 & 5.3115 & TRN & \\
\hline CHEMBL1501953 & 737826 & 4.9 & 5.3727 & TST & \\
\hline CHEMBL1484006 & 737826 & 6.0 & 5.9004 & TRN & \\
\hline CHEMBL1359843 & 737826 & 5.0 & 4.88399 & 99999999995 & TRN \\
\hline CHEMBL1532921 & 737826 & 5.5 & 5.3848 & TRN & \\
\hline CHEMBL1492095 & 737826 & 4.7 & 5.1728 & TRN & \\
\hline CHEMBL1414668 & 737826 & 4.55 & 5.3097 & TRN & \\
\hline CHEMBL1329119 & 737826 & 5.0 & 5.3052 & TRN & \\
\hline CHEMBL1381787 & 737826 & 5.05 & 5.185 & TRN & \\
\hline CHEMBL1489981 & 737826 & 4.85 & 5.3191 & TRN & \\
\hline CHEMBL1348445 & 737826 & 4.9 & 5.4326 & TRN & \\
\hline CHEMBL3212851 & 737826 & 4.8 & 5.4131 & TST & \\
\hline CHEMBL1481746 & 737826 & 5.35 & 5.1539 & TST & \\
\hline CHEMBL1441218 & 737826 & 5.7 & 5.308 & TRN & \\
\hline CHEMBL1400890 & 737826 & 5.45 & 5.1503 & TRN & \\
\hline CHEMBL1472356 & 737826 & 5.0 & 5.3003 & TRN & \\
\hline CHEMBL1553694 & 737826 & 6.2 & 6.1357 & TRN & \\
\hline CHEMBL1359613 & 737826 & 5.0 & 4.9614 & TRN & \\
\hline CHEMBL1421758 & 737826 & 5.4 & 5.2562 & TRN & \\
\hline
\end{tabular}




\begin{tabular}{|c|c|c|c|c|}
\hline \multicolumn{5}{|c|}{ Supplemental Table S2.txt } \\
\hline CHEMBL3212521 & 737826 & 5.65 & 5.3547 & TRN \\
\hline CHEMBL1722471 & 737826 & 4.4 & 5.1951 & TRN \\
\hline CHEMBL1435809 & 737826 & 4.8 & 4.6901 & TRN \\
\hline CHEMBL1253351 & 737826 & 5.1 & 5.1652 & TST \\
\hline CHEMBL1723390 & 737826 & 4.9 & 5.1947 & TRN \\
\hline CHEMBL1505574 & 737826 & 4.65 & 5.355 & TRN \\
\hline CHEMBL1515401 & 737826 & 5.6 & 5.3875 & TRN \\
\hline CHEMBL1513643 & 737826 & 5.5 & 5.4537 & TRN \\
\hline CHEMBL1511129 & 737826 & 6.6 & 5.5799 & TRN \\
\hline CHEMBL1389235 & 737826 & 4.85 & 5.2644 & TRN \\
\hline CHEMBL1382385 & 737826 & 5.0 & 5.4951 & TRN \\
\hline CHEMBL3211853 & 737826 & 4.6 & 5.322 & TRN \\
\hline CHEMBL1436228 & 737826 & 4.6 & 4.4521 & TRN \\
\hline CHEMBL1470888 & 737826 & 7.6499 & 5.1473 & TRN \\
\hline CHEMBL1323732 & 737826 & 5.1 & 5.3825 & TRN \\
\hline CHEMBL3190560 & 737826 & 5.65 & 5.371 & TRN \\
\hline CHEMBL1557234 & 737826 & 4.7 & 4.596 & TRN \\
\hline CHEMBL1333783 & 737826 & 6.3 & 6.1658 & TRN \\
\hline CHEMBL1521460 & 737826 & 4.9 & 5.5007 & TRN \\
\hline CHEMBL1531038 & 737826 & 4.85 & 5.3649 & TRN \\
\hline CHEMBL1372577 & 737826 & 5.7 & 5.256 & TRN \\
\hline CHEMBL1401539 & 737826 & 4.85 & 5.2549 & TRN \\
\hline CHEMBL1330422 & 737826 & 5.2 & 4.9929 & TRN \\
\hline CHEMBL1424424 & 737826 & 4.85 & 4.9417 & TRN \\
\hline CHEMBL1441254 & 737826 & 4.95 & 5.1658 & TRN \\
\hline CHEMBL1339319 & 737826 & 5.35 & 5.2611 & TRN \\
\hline CHEMBL1387889 & 737826 & 5.05 & 5.169 & TRN \\
\hline CHEMBL1444408 & 737826 & 4.8 & 5.1463 & TST \\
\hline CHEMBL 3211776 & 737826 & 5.65 & 5.4494 & TRN \\
\hline CHEMBL1395226 & 737826 & 4.5 & 4.5335 & TRN \\
\hline CHEMBL1600504 & 737826 & 4.8 & 5.2838 & TST \\
\hline CHEMBL1437007 & 737826 & 4.9 & 4.9116 & TRN \\
\hline CHEMBL1448839 & 737826 & 4.5 & 4.4258 & TRN \\
\hline CHEMBL1741781 & 737826 & 4.9 & 5.4042 & TRN \\
\hline CHEMBL1583365 & 737826 & 5.55 & 5.1101 & TRN \\
\hline CHEMBL1704176 & 737826 & 4.7 & 5.237 & TRN \\
\hline CHEMBL1741665 & 737826 & 7.9 & 5.1592 & TST \\
\hline CHEMBL1526761 & 737826 & 4.6 & 5.0805 & TST \\
\hline CHEMBL1303941 & 737826 & 4.4 & 5.1974 & TRN \\
\hline CHEMBL 3207783 & 737826 & 5.6 & 5.5462 & TRN \\
\hline CHEMBL1504577 & 737826 & 5.4 & 5.3277 & TRN \\
\hline CHEMBL1546249 & 737826 & 5.6 & 5.3824 & TST \\
\hline CHEMBL1464331 & 737826 & 4.4 & 5.2573 & TRN \\
\hline CHEMBL1987514 & 737826 & 6.05 & 5.3169 & TRN \\
\hline CHEMBL1447127 & 737826 & 5.35 & 5.0391 & TRN \\
\hline CHEMBL1741914 & 737826 & 4.55 & 5.3647 & TRN \\
\hline CHEMBL1437128 & 737826 & 5.1 & 5.0497 & TRN \\
\hline CHEMBL1589098 & 737826 & 4.9 & 5.0469 & TRN \\
\hline
\end{tabular}




\begin{tabular}{|c|c|c|c|c|c|}
\hline \multicolumn{6}{|c|}{ Supplemental Table S2.txt } \\
\hline CHEMBL1330781 & 737826 & 5.45 & 5.3685 & TST & \\
\hline CHEMBL1604088 & 737826 & 4.7 & 5.1924 & TRN & \\
\hline CHEMBL1609528 & 737826 & 5.0 & 4.8148 & TRN & \\
\hline CHEMBL1569972 & 737826 & 4.9 & 4.9329 & TRN & \\
\hline CHEMBL1331419 & 737826 & 5.3 & 5.3336 & TST & \\
\hline CHEMBL604119 & 737826 & 4.6 & 4.6629 & TST & \\
\hline CHEMBL1604631 & 737826 & 4.95 & 5.3141 & TRN & \\
\hline CHEMBL1542520 & 737826 & 5.4 & 5.16200 & 0000000001 & TRN \\
\hline CHEMBL1320315 & 737826 & 5.5 & 5.3164 & TST & \\
\hline CHEMBL1351404 & 737826 & 4.4 & 5.3533 & TST & \\
\hline CHEMBL1602940 & 737826 & 4.85 & 5.1303 & TRN & \\
\hline CHEMBL1517765 & 737826 & 4.9 & 5.03600 & 00000000005 & TRN \\
\hline CHEMBL1256364 & 737826 & 4.7 & 4.8433 & TRN & \\
\hline CHEMBL3145019 & 737826 & 4.9 & 5.3058 & TST & \\
\hline CHEMBL1449111 & 737826 & 6.05 & 5.1817 & TRN & \\
\hline CHEMBL1299690 & 737826 & 5.8 & 5.2939 & TRN & \\
\hline CHEMBL1445850 & 737826 & 6.15 & 5.2499 & TRN & \\
\hline CHEMBL1393776 & 737826 & 5.4 & 5.3031 & TRN & \\
\hline CHEMBL1386397 & 737826 & 5.3 & 5.4115 & TRN & \\
\hline CHEMBL1584418 & 737826 & 4.45 & 5.3518 & TRN & \\
\hline CHEMBL1397079 & 737826 & 5.0 & 4.8612 & TRN & \\
\hline CHEMBL1524985 & 737826 & 5.3 & 5.4585 & TRN & \\
\hline CHEMBL1460135 & 737826 & 6.95 & 5.1657 & TRN & \\
\hline CHEMBL429023 & 737826 & 4.5 & 5.7742 & TST & \\
\hline CHEMBL1532736 & 737826 & 5.3 & 5.436 & TRN & \\
\hline CHEMBL1454748 & 737826 & 5.3 & 5.2836 & TRN & \\
\hline CHEMBL1310284 & 737826 & 5.05 & 5.4376 & TRN & \\
\hline CHEMBL1428398 & 737826 & 4.85 & 5.1317 & TRN & \\
\hline CHEMBL1362562 & 737826 & 5.8 & 5.6748 & TRN & \\
\hline CHEMBL1548902 & 737826 & 4.55 & 5.2083 & TRN & \\
\hline CHEMBL1557790 & 737826 & 5.15 & 5.3344 & TRN & \\
\hline CHEMBL3196659 & 737826 & 5.05 & 5.5369 & TRN & \\
\hline CHEMBL1301598 & 737826 & 4.7 & 5.6908 & TRN & \\
\hline CHEMBL1569058 & 737826 & 5.55 & 5.4674 & TRN & \\
\hline CHEMBL1162521 & 737826 & 5.2 & 5.2029 & TRN & \\
\hline CHEMBL17002 & 737826 & 4.4 & 4.6165 & TRN & \\
\hline CHEMBL1574393 & 737826 & 4.75 & 5.3544 & TRN & \\
\hline CHEMBL1334847 & 737826 & 4.7 & 4.5718 & TRN & \\
\hline CHEMBL1414213 & 737826 & 5.5 & 5.1677 & TRN & \\
\hline CHEMBL1403482 & 737826 & 5.75 & 5.4365 & TRN & \\
\hline CHEMBL1563507 & 737826 & 5.2 & 5.2775 & TRN & \\
\hline CHEMBL1327697 & 737826 & 4.9 & 4.7533 & TRN & \\
\hline CHEMBL110739 & 737826 & 4.8 & 4.8156 & TST & \\
\hline CHEMBL1451274 & 737826 & 5.55 & 5.3723 & TRN & \\
\hline CHEMBL3192006 & 737826 & 4.85 & 5.6602 & TST & \\
\hline CHEMBL1981657 & 737826 & 5.1 & 5.3789 & TRN & \\
\hline CHEMBL1306989 & 737826 & 5.45 & 5.3336 & TRN & \\
\hline CHEMBL1540570 & 737826 & 5.0 & 5.2325 & TST & \\
\hline
\end{tabular}




\begin{tabular}{|c|c|c|c|c|}
\hline & & & upplement & d 1 \\
\hline CHEMBL1322740 & 737826 & 6.5 & 5.6189 & TRN \\
\hline CHEMBL1481608 & 737826 & 4.9 & 4.8976 & TRN \\
\hline CHEMBL1420598 & 737826 & 5.0 & 5.2654 & TRN \\
\hline CHEMBL1506693 & 737826 & 5.5 & 5.4657 & TRN \\
\hline CHEMBL1256656 & 737826 & 5.1 & 5.1035 & TRN \\
\hline CHEMBL1392042 & 737826 & 5.9 & 5.2939 & TRN \\
\hline CHEMBL1369444 & 737826 & 4.9 & 5.3122 & TRN \\
\hline CHEMBL1599059 & 737826 & 4.9 & 5.1984 & TRN \\
\hline CHEMBL1337629 & 737826 & 5.5 & 5.4085 & TST \\
\hline CHEMBL1455438 & 737826 & 5.1 & 5.0533 & TRN \\
\hline CHEMBL1404071 & 737826 & 4.8 & 5.5174 & TRN \\
\hline CHEMBL1613049 & 737826 & 4.9 & 5.2746 & TRN \\
\hline CHEMBL1558093 & 737826 & 4.6 & 5.1192 & TRN \\
\hline CHEMBL1532015 & 737826 & 5.55 & 5.3159 & TRN \\
\hline CHEMBL1356085 & 737826 & 4.7 & 4.6467 & TRN \\
\hline CHEMBL1319346 & 737826 & 4.85 & 5.0762 & TRN \\
\hline CHEMBL1441039 & 737826 & 4.95 & 5.1561 & TRN \\
\hline CHEMBL1366777 & 737826 & 4.9 & 5.3045 & TRN \\
\hline CHEMBL1607620 & 737826 & 6.4 & 5.1545 & TRN \\
\hline CHEMBL1526613 & 737826 & 5.65 & 5.4548 & TRN \\
\hline CHEMBL1460769 & 737826 & 5.9 & 5.2848 & TRN \\
\hline CHEMBL1490497 & 737826 & 5.3 & 5.2433 & TRN \\
\hline CHEMBL1603542 & 737826 & 4.6 & 5.0896 & TRN \\
\hline CHEMBL1521414 & 737826 & 6.0 & 5.1525 & TRN \\
\hline CHEMBL1487790 & 737826 & 4.5 & 5.3397 & TRN \\
\hline CHEMBL1399879 & 737826 & 6.35 & 5.3936 & TRN \\
\hline CHEMBL1511006 & 737826 & 5.55 & 5.1587 & TRN \\
\hline CHEMBL1557807 & 737826 & 4.9 & 5.2764 & TST \\
\hline CHEMBL1435912 & 737826 & 4.7 & 4.6888 & TRN \\
\hline CHEMBL1495091 & 737826 & 5.95 & 5.2943 & TRN \\
\hline CHEMBL1415406 & 737826 & 4.9 & 4.8685 & TRN \\
\hline CHEMBL1487894 & 737826 & 4.9 & 5.3636 & TRN \\
\hline CHEMBL1591731 & 737826 & 6.9 & 6.3308 & TST \\
\hline CHEMBL1410602 & 737826 & 5.1 & 5.1676 & TRN \\
\hline CHEMBL 1742242 & 737826 & 4.55 & 5.3406 & TRN \\
\hline CHEMBL1352270 & 737826 & 4.85 & 5.3963 & TRN \\
\hline CHEMBL1416252 & 737826 & 5.0 & 5.6028 & TRN \\
\hline CHEMBL279218 & 737826 & 4.4 & 4.5371 & TST \\
\hline CHEMBL1507026 & 737826 & 5.4 & 5.2612 & TRN \\
\hline CHEMBL1520238 & 737826 & 4.85 & 5.5562 & TRN \\
\hline CHEMBL1308621 & 737826 & 5.0 & 5.2226 & TST \\
\hline CHEMBL1310810 & 737826 & 5.35 & 5.4826 & TRN \\
\hline CHEMBL1713947 & 737826 & 4.55 & 5.0435 & TRN \\
\hline CHEMBL1537500 & 737826 & 5.0 & 5.3442 & TRN \\
\hline CHEMBL1406491 & 737826 & 4.6 & 5.3036 & TST \\
\hline CHEMBL1605255 & 737826 & 4.9 & 4.7778 & TRN \\
\hline CHEMBL1483077 & 737826 & 7.15 & 5.2327 & TST \\
\hline CHEMBL1610581 & 737826 & 5.15 & 5.2389 & TRN \\
\hline
\end{tabular}




\begin{tabular}{|c|c|c|c|c|c|}
\hline & & \multicolumn{4}{|c|}{ Supplemental Table S2.txt } \\
\hline CHEMBL1725515 & 737826 & 5.45 & 5.2829 & TRN & \\
\hline CHEMBL1486638 & 737826 & 4.8 & 4.7489 & TRN & \\
\hline CHEMBL1472029 & 737826 & 5.05 & 5.3786 & TRN & \\
\hline CHEMBL1450275 & 737826 & 4.85 & 5.229 & TRN & \\
\hline CHEMBL1554569 & 737826 & 4.8 & 4.86100 & 0000000001 & TRN \\
\hline CHEMBL1432283 & 737826 & 4.9 & 5.2525 & TRN & \\
\hline CHEMBL3193830 & 737826 & 5.8 & 5.3014 & TRN & \\
\hline CHEMBL1533680 & 737826 & 5.4 & 5.3179 & TRN & \\
\hline CHEMBL1334292 & 737826 & 4.85 & 5.3309 & TRN & \\
\hline CHEMBL1478808 & 737826 & 4.8 & 5.2572 & TRN & \\
\hline CHEMBL1496619 & 737826 & 5.15 & 5.2024 & TRN & \\
\hline CHEMBL1318544 & 737826 & 4.9 & 4.9042 & TRN & \\
\hline CHEMBL1332937 & 737826 & 6.1 & 5.9778 & TRN & \\
\hline CHEMBL1448819 & 737826 & 6.55 & 5.4175 & TRN & \\
\hline CHEMBL1442250 & 737826 & 4.9 & 4.7623 & TRN & \\
\hline CHEMBL1395974 & 737826 & 4.7 & 4.6954 & TRN & \\
\hline CHEMBL1453749 & 737826 & 4.6 & 4.7416 & TRN & \\
\hline CHEMBL1326204 & 737826 & 5.5 & 5.3823 & TST & \\
\hline CHEMBL1328527 & 737826 & 4.95 & 5.4974 & TRN & \\
\hline CHEMBL1422001 & 737826 & 5.4 & 5.3012 & TRN & \\
\hline CHEMBL1741681 & 737826 & 4.8 & 5.3116 & TRN & \\
\hline CHEMBL1541286 & 737826 & 6.4 & 5.318 & TRN & \\
\hline CHEMBL1453327 & 737826 & 4.5 & 5.3474 & TRN & \\
\hline CHEMBL1588349 & 737826 & 5.8 & 5.2998 & TRN & \\
\hline CHEMBL1324882 & 737826 & 5.6 & 5.3719 & TRN & \\
\hline CHEMBL1477545 & 737826 & 5.05 & 5.3063 & TRN & \\
\hline CHEMBL1562101 & 737826 & 4.55 & 5.2499 & TRN & \\
\hline CHEMBL1363467 & 737826 & 4.6 & 4.5062 & TRN & \\
\hline CHEMBL1428217 & 737826 & 5.3 & 5.4079 & TRN & \\
\hline CHEMBL1558135 & 737826 & 4.5 & 4.7552 & TRN & \\
\hline CHEMBL1577673 & 737826 & 5.45 & 5.1366 & TRN & \\
\hline CHEMBL1307249 & 737826 & 4.9 & 5.24799 & 9999999999 & TRN \\
\hline CHEMBL1425715 & 737826 & 5.3 & 5.2139 & TRN & \\
\hline CHEMBL1311520 & 737826 & 4.7 & 5.2913 & TRN & \\
\hline CHEMBL1591573 & 737826 & 4.7 & 4.5357 & TRN & \\
\hline CHEMBL1429809 & 737826 & 7.45 & 5.1218 & TRN & \\
\hline CHEMBL1416184 & 737826 & 6.2 & 5.5827 & TRN & \\
\hline CHEMBL1422932 & 737826 & 4.95 & 5.1171 & TRN & \\
\hline CHEMBL1416194 & 737826 & 4.5 & 5.1438 & TRN & \\
\hline CHEMBL1741636 & 737826 & 4.5 & 5.1662 & TRN & \\
\hline CHEMBL1407688 & 737826 & 4.4 & 5.4241 & TRN & \\
\hline CHEMBL1489162 & 737826 & 5.2 & 5.0956 & TRN & \\
\hline CHEMBL1502745 & 737826 & 5.8 & 5.0634 & TRN & \\
\hline CHEMBL1454660 & 737826 & 4.8 & 5.3174 & TRN & \\
\hline CHEMBL1523570 & 737826 & 5.45 & 5.3735 & TRN & \\
\hline CHEMBL1437448 & 737826 & 4.9 & 4.8037 & TST & \\
\hline CHEMBL1492429 & 737826 & 4.4 & 5.2016 & TRN & \\
\hline CHEMBL1407035 & 737826 & 6.1 & 5.852 & TRN & \\
\hline
\end{tabular}




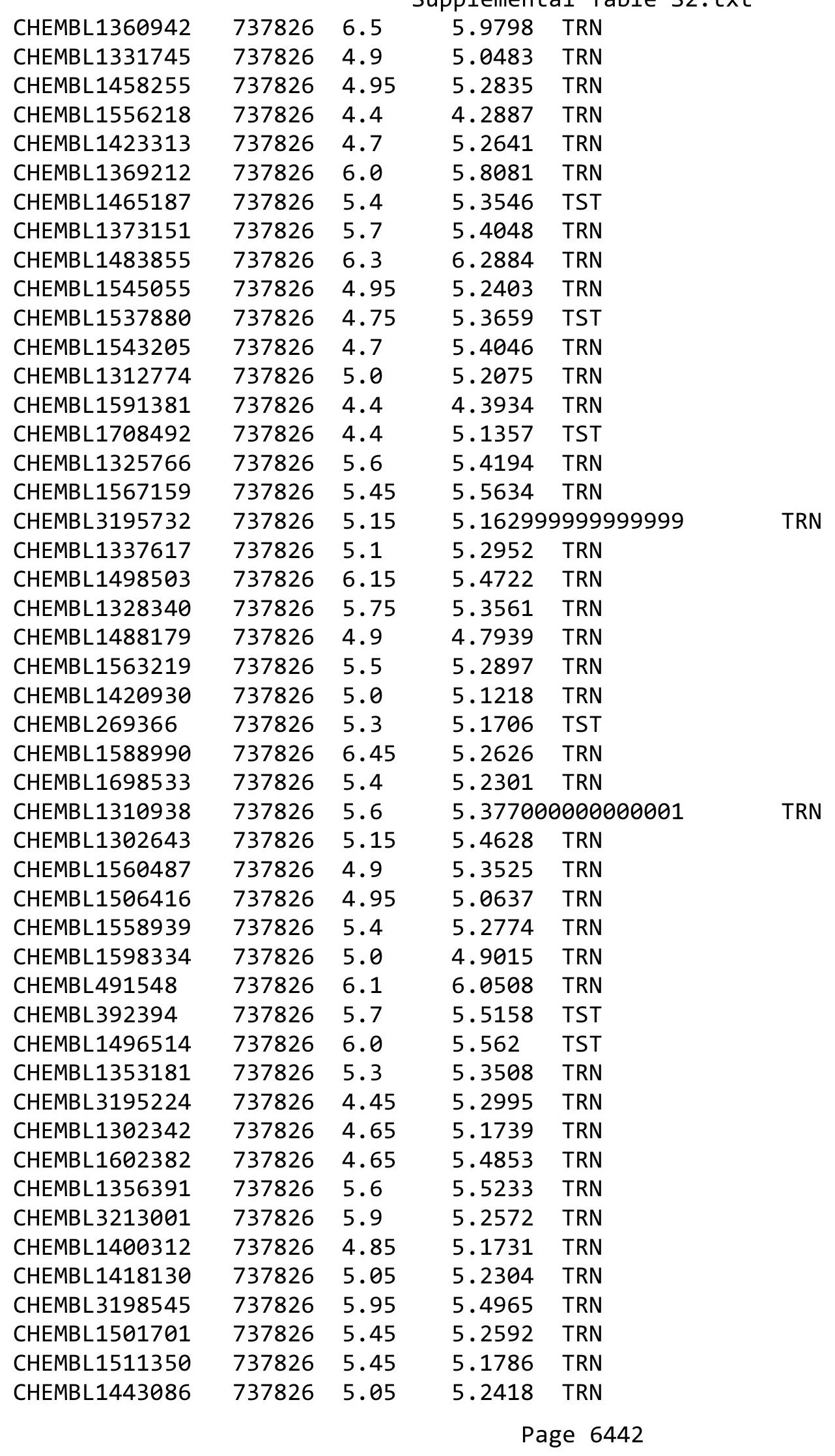




\begin{tabular}{|c|c|c|c|c|c|}
\hline \multicolumn{6}{|c|}{ Supplemental Table S2.txt } \\
\hline CHEMBL1463219 & 737826 & 5.45 & 5.2584 & TRN & \\
\hline CHEMBL1567450 & 737826 & 5.25 & 5.2192 & TRN & \\
\hline CHEMBL1559538 & 737826 & 5.1 & 5.2367 & TRN & \\
\hline CHEMBL1741956 & 737826 & 4.4 & 5.0708 & TRN & \\
\hline CHEMBL1386361 & 737826 & 4.4 & 5.61700 & 0000000001 & TST \\
\hline CHEMBL1346239 & 737826 & 5.35 & 5.3273 & TRN & \\
\hline CHEMBL1332887 & 737826 & 4.7 & 5.2568 & TRN & \\
\hline CHEMBL1471931 & 737826 & 5.15 & 5.3017 & TRN & \\
\hline CHEMBL1426716 & 737826 & 5.45 & 5.2433 & TRN & \\
\hline CHEMBL1392464 & 737826 & 5.35 & 5.5738 & TRN & \\
\hline CHEMBL 1457550 & 737826 & 6.0 & 5.7353 & TRN & \\
\hline CHEMBL1318020 & 737826 & 4.9 & 5.74100 & 00000000005 & TST \\
\hline CHEMBL1355708 & 737826 & 4.8 & 4.886 & TRN & \\
\hline CHEMBL1391756 & 737826 & 5.35 & 5.3027 & TRN & \\
\hline CHEMBL1463191 & 737826 & 5.7 & 5.1549 & TRN & \\
\hline CHEMBL1552542 & 737826 & 4.4 & 4.5594 & TRN & \\
\hline CHEMBL1330449 & 737826 & 5.4 & 5.32299 & 99999999995 & TRN \\
\hline CHEMBL1454049 & 737826 & 6.3 & 6.2053 & TRN & \\
\hline CHEMBL1361226 & 737826 & 5.8 & 5.6013 & TRN & \\
\hline CHEMBL1331031 & 737826 & 5.8 & 5.6796 & TRN & \\
\hline CHEMBL1567265 & 737826 & 6.0 & 5.2662 & TRN & \\
\hline CHEMBL3193279 & 737826 & 6.7 & 5.1761 & TRN & \\
\hline CHEMBL1432644 & 737826 & 5.65 & 5.2724 & TRN & \\
\hline CHEMBL1440487 & 737826 & 5.9 & 5.9747 & TRN & \\
\hline CHEMBL1359291 & 737826 & 4.5 & 4.3958 & TRN & \\
\hline CHEMBL1445702 & 737826 & 5.85 & 5.1058 & TRN & \\
\hline CHEMBL1511553 & 737826 & 4.95 & 5.3743 & TRN & \\
\hline CHEMBL1500365 & 737826 & 5.9 & 5.3776 & TRN & \\
\hline CHEMBL471225 & 737826 & 5.5 & 5.2873 & TST & \\
\hline CHEMBL1424256 & 737826 & 5.25 & 5.2081 & TST & \\
\hline CHEMBL3198835 & 737826 & 5.4 & 5.2911 & TRN & \\
\hline CHEMBL1478762 & 737826 & 5.55 & 5.3334 & TRN & \\
\hline CHEMBL1407287 & 737826 & 5.7 & 5.1297 & TRN & \\
\hline CHEMBL1393740 & 737826 & 5.7 & 5.3899 & TRN & \\
\hline CHEMBL1429416 & 737826 & 4.5 & 5.1089 & TRN & \\
\hline CHEMBL1419233 & 737826 & 4.7 & 5.1423 & TRN & \\
\hline CHEMBL1378443 & 737826 & 6.2 & 5.2208 & TRN & \\
\hline CHEMBL1394956 & 737826 & 4.5 & 4.4464 & TRN & \\
\hline CHEMBL1487502 & 737826 & 5.45 & 5.5599 & TRN & \\
\hline CHEMBL1434801 & 737826 & 5.0 & 4.9572 & TRN & \\
\hline CHEMBL1368895 & 737826 & 5.5 & 5.1646 & TST & \\
\hline CHEMBL473136 & 737826 & 4.5 & 4.5695 & TST & \\
\hline CHEMBL1303217 & 737826 & 5.4 & 5.185 & TRN & \\
\hline CHEMBL1451794 & 737826 & 5.6 & 5.4456 & TRN & \\
\hline CHEMBL1376318 & 737826 & 4.9 & 5.2124 & TRN & \\
\hline CHEMBL544115 & 737826 & 4.5 & 4.4801 & TST & \\
\hline CHEMBL1706520 & 737826 & 4.4 & 5.2746 & TRN & \\
\hline CHEMBL3212989 & 737826 & 5.1 & 5.4028 & TRN & \\
\hline
\end{tabular}




\begin{tabular}{|c|c|c|c|c|}
\hline \multicolumn{5}{|c|}{ Supplemental Table S2.txt } \\
\hline CHEMBL1699614 & 737826 & 5.25 & 5.2444 & TRN \\
\hline CHEMBL1384330 & 737826 & 5.95 & 5.1431 & TRN \\
\hline CHEMBL1613160 & 737826 & 5.05 & 5.4907 & TST \\
\hline CHEMBL1531620 & 737826 & 5.45 & 5.2145 & TST \\
\hline CHEMBL1507654 & 737826 & 6.85 & 5.3084 & TST \\
\hline CHEMBL1571457 & 737826 & 4.85 & 5.2219 & TRN \\
\hline CHEMBL1435654 & 737826 & 5.6 & 5.2171 & TRN \\
\hline CHEMBL1319393 & 737826 & 4.75 & 5.3027 & TRN \\
\hline CHEMBL1322189 & 737826 & 5.1 & 5.1697 & TRN \\
\hline CHEMBL1319286 & 737826 & 4.6 & 4.6046 & TRN \\
\hline CHEMBL1604462 & 737826 & 6.75 & 5.3135 & TST \\
\hline CHEMBL1332346 & 737826 & 5.0 & 4.8781 & TRN \\
\hline CHEMBL1458309 & 737826 & 5.4 & 5.3767 & TST \\
\hline CHEMBL1324891 & 737826 & 4.75 & 5.1675 & TRN \\
\hline CHEMBL1309860 & 737826 & 5.1 & 5.4032 & TST \\
\hline CHEMBL1567437 & 737826 & 5.15 & 5.2082 & TRN \\
\hline CHEMBL1443798 & 737826 & 5.25 & 5.5432 & TST \\
\hline CHEMBL1398467 & 737826 & 5.4 & 5.1856 & TRN \\
\hline CHEMBL1348281 & 737826 & 5.7 & 5.3428 & TRN \\
\hline CHEMBL1505844 & 737826 & 5.1 & 5.2177 & TRN \\
\hline CHEMBL3198273 & 737826 & 5.8 & 5.6166 & TRN \\
\hline CHEMBL1355909 & 737826 & 4.7 & 4.753 & TRN \\
\hline CHEMBL1490012 & 737826 & 5.05 & 5.2829 & TRN \\
\hline CHEMBL1517335 & 737826 & 5.55 & 5.1705 & TRN \\
\hline CHEMBL 333985 & 737826 & 4.5 & 4.6883 & TRN \\
\hline CHEMBL1575591 & 737826 & 6.7 & 5.4643 & TRN \\
\hline CHEMBL1508362 & 737826 & 6.1 & 5.2279 & TRN \\
\hline CHEMBL1333382 & 737826 & 5.8 & 5.3228 & TRN \\
\hline CHEMBL1722019 & 737826 & 5.0 & 5.1968 & TRN \\
\hline CHEMBL1329218 & 737826 & 4.7 & 4.6327 & TST \\
\hline CHEMBL1328460 & 737826 & 5.35 & 5.1046 & TRN \\
\hline CHEMBL1554936 & 737826 & 5.6 & 5.407 & TRN \\
\hline CHEMBL1501211 & 737826 & 4.8 & 4.8395 & TRN \\
\hline CHEMBL1508832 & 737826 & 4.95 & 5.3662 & TRN \\
\hline CHEMBL1472880 & 737826 & 5.7 & 5.3157 & TRN \\
\hline CHEMBL3214111 & 737826 & 7.5501 & 5.3636 & TRN \\
\hline CHEMBL1452192 & 737826 & 5.4 & 5.0566 & TRN \\
\hline CHEMBL1525957 & 737826 & 5.0 & 5.2702 & TRN \\
\hline CHEMBL1349401 & 737826 & 4.8 & 5.3466 & TRN \\
\hline CHEMBL1482482 & 737826 & 6.1 & 5.3855 & TRN \\
\hline CHEMBL1595944 & 737826 & 5.9 & 5.285 & TRN \\
\hline CHEMBL1317232 & 737826 & 5.5 & 5.3289 & TRN \\
\hline CHEMBL1345410 & 737826 & 5.1 & 5.5612 & TRN \\
\hline CHEMBL1395605 & 737826 & 4.5 & 4.4613 & TRN \\
\hline CHEMBL1412769 & 737826 & 4.8 & 5.1642 & TRN \\
\hline CHEMBL1323118 & 737826 & 4.7 & 5.1408 & TRN \\
\hline CHEMBL1314416 & 737826 & 5.7 & 5.3805 & TRN \\
\hline CHEMBL3191489 & 737826 & 4.75 & 5.46299 & 9999999999 \\
\hline
\end{tabular}




\begin{tabular}{|c|c|c|c|c|c|}
\hline \\
\hline CHEMBL1379481 & 737826 & 5.6 & 5.4472 & TRN & \\
\hline CHEMBL1421029 & 737826 & 4.9 & 5.3394 & TRN & \\
\hline CHEMBL1404595 & 737826 & 5.05 & 5.1943 & TRN & \\
\hline CHEMBL1481347 & 737826 & 4.7 & 4.9722 & TST & \\
\hline CHEMBL1605992 & 737826 & 4.75 & 5.3985 & TST & \\
\hline CHEMBL1555118 & 737826 & 5.1 & 5.0258 & TRN & \\
\hline CHEMBL1301792 & 737826 & 4.6 & 5.399 & TST & \\
\hline CHEMBL1383601 & 737826 & 6.1 & 5.4649 & TRN & \\
\hline CHEMBL1718851 & 737826 & 6.05 & 5.2206 & TST & \\
\hline CHEMBL1398216 & 737826 & 5.5 & 5.3893 & TRN & \\
\hline CHEMBL1422116 & 737826 & 5.0 & 5.3357 & TRN & \\
\hline CHEMBL1344032 & 737826 & 5.65 & 5.2777 & TRN & \\
\hline CHEMBL1354262 & 737826 & 4.6 & 4.565 & TRN & \\
\hline CHEMBL1338884 & 737826 & 4.7 & 5.2103 & TRN & \\
\hline CHEMBL362863 & 737826 & 6.2 & 5.8386 & TST & \\
\hline CHEMBL1399008 & 737826 & 4.95 & 5.2945 & TRN & \\
\hline CHEMBL1421737 & 737826 & 5.0 & 5.3131 & TRN & \\
\hline CHEMBL1418864 & 737826 & 7.9 & 5.585 & TRN & \\
\hline CHEMBL1353404 & 737826 & 6.15 & 5.3062 & TRN & \\
\hline CHEMBL1393667 & 737826 & 4.85 & 5.3976 & TRN & \\
\hline CHEMBL1420741 & 737826 & 5.9 & 5.1988 & TRN & \\
\hline CHEMBL375270 & 737826 & 5.2 & 5.1716 & TRN & \\
\hline CHEMBL1353611 & 737826 & 5.0 & 5.1467 & TRN & \\
\hline CHEMBL1485568 & 737826 & 5.8 & 5.3287 & TRN & \\
\hline CHEMBL1320206 & 737826 & 5.1 & 4.9754 & TRN & \\
\hline CHEMBL1587783 & 737826 & 4.85 & 5.3529 & TRN & \\
\hline CHEMBL1256186 & 737826 & 4.9 & 4.9496 & TST & \\
\hline CHEMBL1509359 & 737826 & 5.35 & 5.23 & TRN & \\
\hline CHEMBL1349528 & 737826 & 4.8 & 5.1623 & TRN & \\
\hline CHEMBL1501724 & 737826 & 5.65 & 5.2494 & TRN & \\
\hline CHEMBL1502534 & 737826 & 4.9 & 5.2767 & TRN & \\
\hline CHEMBL1741821 & 737826 & 4.4 & 5.0466 & TRN & \\
\hline CHEMBL3196220 & 737826 & 5.2 & 5.4794 & TRN & \\
\hline CHEMBL60859 & 737826 & 4.9 & 4.8735 & TST & \\
\hline CHEMBL3198385 & 737826 & 4.6 & 5.45100 & 00000000005 & TRN \\
\hline CHEMBL1571526 & 737826 & 4.85 & 5.1496 & TRN & \\
\hline CHEMBL1549020 & 737826 & 4.5 & 5.3743 & TRN & \\
\hline CHEMBL1407160 & 737826 & 4.55 & 5.434 & TRN & \\
\hline CHEMBL1486554 & 737826 & 4.95 & 5.4027 & TRN & \\
\hline CHEMBL1473754 & 737826 & 5.4 & 5.1924 & TRN & \\
\hline CHEMBL3213530 & 737826 & 5.45 & 5.4091 & TRN & \\
\hline CHEMBL1389291 & 737826 & 5.45 & 5.2016 & TRN & \\
\hline CHEMBL1548218 & 737826 & 4.75 & 5.2164 & TRN & \\
\hline CHEMBL3193274 & 737826 & 6.1 & 5.4182 & TRN & \\
\hline CHEMBL1345104 & 737826 & 5.35 & 5.1961 & TRN & \\
\hline CHEMBL1335777 & 737826 & 4.8 & 5.1667 & TRN & \\
\hline CHEMBL1531376 & 737826 & 5.15 & 5.3347 & TRN & \\
\hline CHEMBL1511181 & 737826 & 6.7 & 5.2884 & TRN & \\
\hline & & & & 6445 & \\
\hline
\end{tabular}




\begin{tabular}{|c|c|c|c|c|c|}
\hline & & \\
\hline CHEMBL1374947 & 737826 & 6.2 & 5.1292 & TRN & \\
\hline CHEMBL1322349 & 737826 & 5.75 & 5.2063 & TRN & \\
\hline CHEMBL1523108 & 737826 & 5.4 & 5.0811 & TRN & \\
\hline CHEMBL1353317 & 737826 & 4.8 & 5.375 & TRN & \\
\hline CHEMBL1601508 & 737826 & 4.75 & 5.3458 & TRN & \\
\hline CHEMBL1582760 & 737826 & 5.1 & 5.4698 & TRN & \\
\hline CHEMBL1474523 & 737826 & 5.2 & 5.1352 & TST & \\
\hline CHEMBL1584758 & 737826 & 5.0 & 5.4016 & TRN & \\
\hline CHEMBL1548624 & 737826 & 4.65 & 5.1295 & TRN & \\
\hline CHEMBL1323529 & 737826 & 4.8 & 4.6846 & TRN & \\
\hline CHEMBL1308139 & 737826 & 4.75 & 5.1824 & TRN & \\
\hline CHEMBL1375285 & 737826 & 6.0 & 5.6776 & TRN & \\
\hline CHEMBL1451899 & 737826 & 5.05 & 5.1152 & TRN & \\
\hline CHEMBL3189991 & 737826 & 5.0 & 5.45799 & 9999999999 & TRN \\
\hline CHEMBL3189663 & 737826 & 5.55 & 5.45299 & 9999999999 & TRN \\
\hline CHEMBL1558820 & 737826 & 4.6 & 5.1496 & TRN & \\
\hline CHEMBL1411094 & 737826 & 5.1 & 4.9492 & TRN & \\
\hline CHEMBL1703998 & 737826 & 8.25 & 5.12700 & 0000000001 & TRN \\
\hline CHEMBL1554888 & 737826 & 6.9 & 6.6551 & TRN & \\
\hline CHEMBL1465094 & 737826 & 4.55 & 5.2794 & TRN & \\
\hline CHEMBL1405510 & 737826 & 5.25 & 5.3367 & TRN & \\
\hline CHEMBL1594359 & 737826 & 6.5 & 5.6412 & TRN & \\
\hline CHEMBL1543676 & 737826 & 4.9 & 5.1883 & TRN & \\
\hline CHEMBL1372883 & 737826 & 5.55 & 5.3662 & TRN & \\
\hline CHEMBL1558223 & 737826 & 4.6 & 5.1813 & TRN & \\
\hline CHEMBL1533024 & 737826 & 5.1 & 5.3341 & TRN & \\
\hline CHEMBL1541112 & 737826 & 5.55 & 5.4499 & TRN & \\
\hline CHEMBL1564353 & 737826 & 6.5 & 5.2765 & TST & \\
\hline CHEMBL1328490 & 737826 & 5.5 & 5.5024 & TRN & \\
\hline CHEMBL1704202 & 737826 & 4.6 & 5.1882 & TRN & \\
\hline CHEMBL1305215 & 737826 & 5.3 & 5.2273 & TRN & \\
\hline CHEMBL1736563 & 737826 & 4.75 & 5.3845 & TRN & \\
\hline CHEMBL1600753 & 737826 & 5.4 & 5.3364 & TRN & \\
\hline CHEMBL1331112 & 737826 & 5.0 & 4.8447 & TST & \\
\hline CHEMBL1452961 & 737826 & 5.45 & 5.4322 & TRN & \\
\hline CHEMBL1391059 & 737826 & 5.2 & 5.2567 & TST & \\
\hline CHEMBL1333061 & 737826 & 4.8 & 4.6703 & TRN & \\
\hline CHEMBL1390122 & 737826 & 5.95 & 5.2643 & TRN & \\
\hline CHEMBL1607611 & 737826 & 5.5 & 5.2905 & TRN & \\
\hline CHEMBL1497504 & 737826 & 6.4 & 5.5145 & TRN & \\
\hline CHEMBL3196253 & 737826 & 5.65 & 5.2071 & TST & \\
\hline CHEMBL3210605 & 737826 & 4.9 & 5.5055 & TRN & \\
\hline CHEMBL541585 & 737826 & -0.0 & 4.8916 & TST & \\
\hline CHEMBL1513966 & 737826 & 5.4 & 5.4129 & TRN & \\
\hline CHEMBL75913 & 737826 & 5.2 & 5.2471 & TST & \\
\hline CHEMBL1704069 & 737826 & 5.3 & 4.984 & TRN & \\
\hline CHEMBL1565139 & 737826 & 4.75 & 5.2299 & TRN & \\
\hline CHEMBL522121 & 737826 & 6.1 & 6.2448 & TRN & \\
\hline
\end{tabular}




\begin{tabular}{|c|c|c|c|c|}
\hline \multicolumn{5}{|c|}{ Supplemental Table S2.txt } \\
\hline CHEMBL1548943 & 737826 & 4.55 & 5.1608 & TRN \\
\hline CHEMBL1410420 & 737826 & 5.4 & 5.4671 & TRN \\
\hline CHEMBL1568109 & 737826 & 4.8 & 5.4318 & TST \\
\hline CHEMBL1992293 & 737826 & 4.85 & 5.3464 & TST \\
\hline CHEMBL1255936 & 737826 & 4.9 & 4.873 & TRN \\
\hline CHEMBL239439 & 737826 & 5.8 & 5.5986 & TST \\
\hline CHEMBL1455043 & 737826 & 4.55 & 5.0577 & TRN \\
\hline CHEMBL1574026 & 737826 & 4.9 & 5.2824 & TRN \\
\hline CHEMBL1565577 & 737826 & 5.4 & 5.2479 & TST \\
\hline CHEMBL52387 & 737826 & 6.5 & 6.1469 & TRN \\
\hline CHEMBL1324806 & 737826 & 5.3 & 5.3366 & TRN \\
\hline CHEMBL1471318 & 737826 & 5.5 & 5.3283 & TRN \\
\hline CHEMBL1326688 & 737826 & 4.4 & 5.3576 & TRN \\
\hline CHEMBL1324667 & 737826 & 5.6 & 5.3723 & TRN \\
\hline CHEMBL3210053 & 737826 & 5.9 & 5.3376 & TRN \\
\hline CHEMBL1536668 & 737826 & 7.15 & 5.3663 & TRN \\
\hline CHEMBL1331301 & 737826 & 5.5 & 5.4011 & TRN \\
\hline CHEMBL1607419 & 737826 & 5.8 & 5.3374 & TRN \\
\hline CHEMBL1402138 & 737826 & 5.1 & 5.2478 & TRN \\
\hline CHEMBL1346685 & 737826 & 5.65 & 5.1781 & TRN \\
\hline CHEMBL1389815 & 737826 & 5.65 & 5.0906 & TRN \\
\hline CHEMBL1523773 & 737826 & 4.8 & 5.5004 & TRN \\
\hline CHEMBL1302645 & 737826 & 6.0 & 5.1417 & TRN \\
\hline CHEMBL1498144 & 737826 & 4.9 & 5.1644 & TRN \\
\hline CHEMBL1364880 & 737826 & 4.8 & 5.2373 & TRN \\
\hline CHEMBL1396142 & 737826 & 4.4 & 4.4225 & TRN \\
\hline CHEMBL1557762 & 737826 & 4.8 & 5.2847 & TRN \\
\hline CHEMBL1593001 & 737826 & 4.8 & 4.8131 & TRN \\
\hline CHEMBL1329094 & 737826 & 5.1 & 5.2433 & TST \\
\hline CHEMBL1576264 & 737826 & 4.8 & 5.4946 & TRN \\
\hline CHEMBL3213969 & 737826 & 4.85 & 5.2704 & TRN \\
\hline CHEMBL3190499 & 737826 & 4.6 & 5.3123 & TST \\
\hline CHEMBL1475860 & 737826 & 5.0 & 4.7813 & TRN \\
\hline CHEMBL1419997 & 737826 & 4.8 & 5.4841 & TRN \\
\hline CHEMBL1419479 & 737826 & 4.9 & 5.1745 & TST \\
\hline CHEMBL1441066 & 737826 & 5.45 & 5.2656 & TST \\
\hline CHEMBL1328319 & 737826 & 4.5 & 4.5179 & TRN \\
\hline CHEMBL250711 & 737826 & 5.8 & 5.391 & TRN \\
\hline CHEMBL1325869 & 737826 & 5.9 & 5.3415 & TRN \\
\hline CHEMBL1611463 & 737826 & 5.6 & 5.2587 & TRN \\
\hline CHEMBL1327466 & 737826 & 5.8 & 5.6644 & TRN \\
\hline CHEMBL1564977 & 737826 & 5.15 & 5.3067 & TRN \\
\hline CHEMBL1406121 & 737826 & 4.85 & 5.1319 & TST \\
\hline CHEMBL1371022 & 737826 & 4.8 & 5.4193 & TRN \\
\hline CHEMBL1331444 & 737826 & 4.4 & 4.365 & TRN \\
\hline CHEMBL1366297 & 737826 & 4.9 & 4.8521 & TRN \\
\hline CHEMBL1326753 & 737826 & 4.85 & 5.1442 & TRN \\
\hline CHEMBL1446260 & 737826 & 4.95 & 5.2502 & TRN \\
\hline
\end{tabular}




\begin{tabular}{|c|c|c|c|c|}
\hline \multicolumn{5}{|c|}{ Lemental } \\
\hline CHEMBL1332670 & 737826 & 5.8 & 5.2211 & TRN \\
\hline CHEMBL1501874 & 737826 & 5.65 & 5.2568 & TRN \\
\hline CHEMBL1599025 & 737826 & 5.0 & 5.3062 & TRN \\
\hline CHEMBL3209485 & 737826 & 5.0 & 5.3538 & TRN \\
\hline CHEMBL1592760 & 737826 & 4.6 & 4.6151 & TRN \\
\hline CHEMBL3208819 & 737826 & 5.0 & 5.3201 & TRN \\
\hline CHEMBL1574196 & 737826 & 5.0 & 4.9434 & TRN \\
\hline CHEMBL1536509 & 737826 & 5.75 & 5.32 & TRN \\
\hline CHEMBL1569923 & 737826 & 5.7 & 5.2623 & TRN \\
\hline CHEMBL1368965 & 737826 & 4.9 & 4.7468 & TRN \\
\hline CHEMBL3212645 & 737826 & 5.4 & 5.275 & TRN \\
\hline CHEMBL1604077 & 737826 & 4.95 & 5.1921 & TST \\
\hline CHEMBL3197893 & 737826 & 4.65 & 5.4278 & TRN \\
\hline CHEMBL 3199347 & 737826 & 4.95 & 5.1516 & TRN \\
\hline CHEMBL1431831 & 737826 & 5.55 & 5.4385 & TRN \\
\hline CHEMBL1372627 & 737826 & 4.8 & 4.7014 & TRN \\
\hline CHEMBL1530895 & 737826 & 4.8 & 5.1797 & TRN \\
\hline CHEMBL14276 & 737826 & 6.1 & 6.0211 & TRN \\
\hline CHEMBL1609333 & 737826 & 6.15 & 5.4881 & TST \\
\hline CHEMBL1402960 & 737826 & 5.5 & 5.3733 & TRN \\
\hline CHEMBL1442770 & 737826 & 4.7 & 4.5725 & TST \\
\hline CHEMBL1565342 & 737826 & 6.0 & 5.8019 & TRN \\
\hline CHEMBL1308538 & 737826 & 5.15 & 5.3421 & TRN \\
\hline CHEMBL1328533 & 737826 & 5.4 & 5.2551 & TRN \\
\hline CHEMBL329872 & 737826 & 4.65 & 5.2053 & TRN \\
\hline CHEMBL1481014 & 737826 & 4.85 & 5.3033 & TRN \\
\hline CHEMBL1512683 & 737826 & 4.5 & 4.6092 & TST \\
\hline CHEMBL1488264 & 737826 & 5.35 & 5.3732 & TRN \\
\hline CHEMBL1330114 & 737826 & 5.5 & 5.3656 & TRN \\
\hline CHEMBL1337622 & 737826 & 5.9 & 5.3091 & TRN \\
\hline CHEMBL1474681 & 737826 & 6.1 & 6.0968 & TRN \\
\hline CHEMBL1352779 & 737826 & 5.1 & 5.3685 & TRN \\
\hline CHEMBL520107 & 737826 & 4.9 & 4.9035 & TST \\
\hline CHEMBL1570950 & 737826 & 5.95 & 5.3796 & TST \\
\hline CHEMBL1483152 & 737826 & 5.1 & 4.8788 & TRN \\
\hline CHEMBL3214392 & 737826 & 4.95 & 5.2866 & TRN \\
\hline CHEMBL1324022 & 737826 & 4.5 & 4.6821 & TST \\
\hline CHEMBL1307282 & 737826 & 5.0 & 5.3561 & TRN \\
\hline CHEMBL1376736 & 737826 & 4.4 & 4.3568 & TRN \\
\hline CHEMBL1394855 & 737826 & 5.5 & 5.3928 & TRN \\
\hline CHEMBL1446687 & 737826 & 4.95 & 5.438 & TRN \\
\hline CHEMBL1536670 & 737826 & 6.55 & 5.1314 & TRN \\
\hline CHEMBL1384675 & 737826 & 6.05 & 5.5365 & TRN \\
\hline CHEMBL1548012 & 737826 & 6.3 & 5.8214 & TRN \\
\hline CHEMBL1520743 & 737826 & 6.05 & 5.2542 & TRN \\
\hline CHEMBL1480575 & 737826 & 5.4 & 5.4638 & TRN \\
\hline CHEMBL1559650 & 737826 & 5.0 & 5.3257 & TRN \\
\hline CHEMBL1307306 & 737826 & 5.4 & 5.2466 & TST \\
\hline
\end{tabular}




\begin{tabular}{|c|c|c|c|c|c|}
\hline \\
\hline CHEMBL1600620 & 737826 & 4.9 & 4.7309 & TRN & \\
\hline CHEMBL1519083 & 737826 & 5.5 & 5.2401 & TRN & \\
\hline CHEMBL1304114 & 737826 & 5.15 & 5.2429 & TRN & \\
\hline CHEMBL1522524 & 737826 & 4.9 & 5.1478 & TRN & \\
\hline CHEMBL1495213 & 737826 & 5.0 & 4.90300 & 00000000005 & TRN \\
\hline CHEMBL1255578 & 737826 & 4.5 & 5.6822 & TST & \\
\hline CHEMBL1399621 & 737826 & 5.55 & 5.4209 & TRN & \\
\hline CHEMBL1326360 & 737826 & 4.8 & 4.7207 & TRN & \\
\hline CHEMBL1501061 & 737826 & 6.1 & 5.54 & TRN & \\
\hline CHEMBL1379149 & 737826 & 4.75 & 5.2435 & TRN & \\
\hline CHEMBL1308151 & 737826 & 4.7 & 5.2816 & TRN & \\
\hline CHEMBL1395882 & 737826 & 4.9 & 4.8379 & TRN & \\
\hline CHEMBL1496315 & 737826 & 5.8 & 5.5619 & TRN & \\
\hline CHEMBL1309646 & 737826 & 4.95 & 5.3411 & TRN & \\
\hline CHEMBL1350410 & 737826 & 5.65 & 5.3947 & TRN & \\
\hline CHEMBL1402552 & 737826 & 5.55 & 5.4912 & TRN & \\
\hline CHEMBL1370770 & 737826 & 5.0 & 4.8565 & TRN & \\
\hline CHEMBL1590270 & 737826 & 5.2 & 4.9856 & TRN & \\
\hline CHEMBL1572935 & 737826 & 6.0 & 5.2832 & TRN & \\
\hline CHEMBL1474876 & 737826 & 4.7 & 4.6952 & TRN & \\
\hline CHEMBL1376224 & 737826 & 5.05 & 5.4002 & TRN & \\
\hline CHEMBL1537212 & 737826 & 4.75 & 4.9023 & TST & \\
\hline CHEMBL77030 & 737826 & 4.6 & 4.8747 & TRN & \\
\hline CHEMBL1403554 & 737826 & 5.2 & 5.1794 & TRN & \\
\hline CHEMBL1527565 & 737826 & 5.9 & 5.6644 & TST & \\
\hline CHEMBL1388783 & 737826 & 5.45 & 5.1964 & TRN & \\
\hline CHEMBL3209702 & 737826 & 5.5 & 5.4314 & TRN & \\
\hline CHEMBL3198484 & 737826 & 8.25 & 5.4713 & TRN & \\
\hline CHEMBL1437088 & 737826 & 4.6 & 4.5629 & TRN & \\
\hline CHEMBL1464821 & 737826 & 4.85 & 5.3319 & TRN & \\
\hline CHEMBL1555164 & 737826 & 5.8 & 5.6225 & TRN & \\
\hline CHEMBL1437447 & 737826 & 5.7 & 5.3168 & TRN & \\
\hline CHEMBL1530789 & 737826 & 5.2 & 5.2392 & TRN & \\
\hline CHEMBL1612486 & 737826 & 5.6 & 5.3453 & TRN & \\
\hline CHEMBL1461461 & 737826 & 6.0 & 5.2844 & TRN & \\
\hline CHEMBL1522582 & 737826 & 5.45 & 5.17399 & 99999999995 & TRN \\
\hline CHEMBL1448138 & 737826 & 5.4 & 5.2196 & TRN & \\
\hline CHEMBL1605632 & 737826 & 5.4 & 5.2918 & TRN & \\
\hline CHEMBL1425687 & 737826 & 5.05 & 5.21200 & 0000000001 & TRN \\
\hline CHEMBL1363345 & 737826 & 4.65 & 5.2805 & TRN & \\
\hline CHEMBL1306942 & 737826 & 5.1 & 5.2714 & TRN & \\
\hline CHEMBL1517886 & 737826 & 4.9 & 5.6102 & TRN & \\
\hline CHEMBL1503340 & 737826 & 5.15 & 5.2655 & TST & \\
\hline CHEMBL1331120 & 737826 & 5.45 & 5.1122 & TRN & \\
\hline CHEMBL1527745 & 737826 & 5.2 & 5.1365 & TRN & \\
\hline CHEMBL1381498 & 737826 & 5.55 & 5.0569 & TST & \\
\hline CHEMBL1357724 & 737826 & 6.0 & 5.9746 & TRN & \\
\hline CHEMBL1583979 & 737826 & 5.45 & 5.3749 & TRN & \\
\hline
\end{tabular}




\begin{tabular}{|c|c|c|c|c|}
\hline \multicolumn{5}{|c|}{ plemental T } \\
\hline CHEMBL1553185 & 737826 & 6.6 & 6.4787 & TRN \\
\hline CHEMBL1433726 & 737826 & 4.6 & 4.6667 & TST \\
\hline CHEMBL1374962 & 737826 & 7.35 & 5.5061 & TRN \\
\hline CHEMBL1407670 & 737826 & 4.8 & 4.7625 & TRN \\
\hline CHEMBL1344685 & 737826 & 4.9 & 5.3148 & TRN \\
\hline CHEMBL1593128 & 737826 & 4.8 & 4.6422 & TRN \\
\hline CHEMBL1350898 & 737826 & 5.0 & 5.1689 & TRN \\
\hline CHEMBL1333410 & 737826 & 4.6 & 5.3304 & TRN \\
\hline CHEMBL1416414 & 737826 & 5.1 & 5.2953 & TRN \\
\hline CHEMBL1361839 & 737826 & 4.8 & 4.6453 & TRN \\
\hline CHEMBL1424275 & 737826 & 5.6 & 5.3206 & TST \\
\hline CHEMBL1574160 & 737826 & 4.9 & 4.64 & TRN \\
\hline CHEMBL1322527 & 737826 & 5.3 & 5.3951 & TST \\
\hline CHEMBL1531294 & 737826 & 5.5 & 5.231 & TRN \\
\hline CHEMBL1605586 & 737826 & 7.35 & 5.2716 & TRN \\
\hline CHEMBL1385992 & 737826 & 5.75 & 4.9542 & TST \\
\hline CHEMBL1565527 & 737826 & 5.0 & 5.2934 & TRN \\
\hline CHEMBL1304215 & 737826 & 4.65 & 5.3158 & TRN \\
\hline CHEMBL1399922 & 737826 & 4.4 & 4.6853 & TST \\
\hline CHEMBL1363569 & 737826 & 5.5 & 5.4226 & TRN \\
\hline CHEMBL1445399 & 737826 & 4.7 & 4.757 & TST \\
\hline CHEMBL1344709 & 737826 & 6.0 & 5.1858 & TST \\
\hline CHEMBL1523038 & 737826 & 5.65 & 5.2213 & TRN \\
\hline CHEMBL1446628 & 737826 & 4.8 & 5.4018 & TRN \\
\hline CHEMBL1448974 & 737826 & -0.0 & 5.3944 & TST \\
\hline CHEMBL1338060 & 737826 & 5.1 & 5.3916 & TRN \\
\hline CHEMBL3208765 & 737826 & 8.25 & 5.4015 & TRN \\
\hline CHEMBL1495971 & 737826 & 4.95 & 5.5223 & TRN \\
\hline CHEMBL1514416 & 737826 & 5.7 & 5.4396 & TRN \\
\hline CHEMBL1567410 & 737826 & 5.7 & 5.7662 & TRN \\
\hline CHEMBL 3145078 & 737826 & 5.15 & 5.3165 & TST \\
\hline CHEMBL1498880 & 737826 & 4.6 & 5.1713 & TRN \\
\hline CHEMBL1507467 & 737826 & 7.1 & 5.1175 & TRN \\
\hline CHEMBL1329446 & 737826 & 4.5 & 5.0638 & TRN \\
\hline CHEMBL1421016 & 737826 & 4.9 & 4.8714 & TRN \\
\hline CHEMBL1371821 & 737826 & 6.1 & 5.2515 & TRN \\
\hline CHEMBL1447392 & 737826 & 5.0 & 4.9094 & TRN \\
\hline CHEMBL1581350 & 737826 & 5.5 & 5.4638 & TRN \\
\hline CHEMBL1373818 & 737826 & 5.0 & 4.9265 & TST \\
\hline CHEMBL1453715 & 737826 & 5.1 & 5.0525 & TST \\
\hline CHEMBL3212657 & 737826 & 6.9 & 5.4064 & TRN \\
\hline CHEMBL1311806 & 737826 & 4.6 & 5.2944 & TRN \\
\hline CHEMBL1580159 & 737826 & 5.0 & 5.2199 & TRN \\
\hline CHEMBL611494 & 737826 & 6.0 & 5.6209 & TST \\
\hline CHEMBL1561667 & 737826 & 5.9 & 5.1968 & TRN \\
\hline CHEMBL1396546 & 737826 & 4.9 & 4.8783 & TST \\
\hline CHEMBL 267458 & 737826 & 6.2 & 5.8405 & TRN \\
\hline CHEMBL1579698 & 737826 & 4.75 & 5.3234 & TRN \\
\hline
\end{tabular}




\begin{tabular}{|c|c|c|c|c|c|}
\hline \\
\hline CHEMBL1602926 & 737826 & 5.5 & 5.3969 & TRN & \\
\hline CHEMBL1716960 & 737826 & 4.55 & 5.1198 & TRN & \\
\hline CHEMBL1531672 & 737826 & 6.1 & 5.4364 & TRN & \\
\hline CHEMBL1483972 & 737826 & 6.15 & 5.2763 & TRN & \\
\hline CHEMBL1256851 & 737826 & 7.0 & 6.4729 & TST & \\
\hline CHEMBL1395088 & 737826 & 4.8 & 4.8782 & TRN & \\
\hline CHEMBL1351101 & 737826 & 4.55 & 5.0624 & TRN & \\
\hline CHEMBL1509210 & 737826 & 5.35 & 5.1507 & TRN & \\
\hline CHEMBL1741496 & 737826 & 5.6 & 5.3051 & TRN & \\
\hline CHEMBL1742327 & 737826 & 4.6 & 5.2792 & TST & \\
\hline CHEMBL1388158 & 737826 & 5.7 & 5.2672 & TST & \\
\hline CHEMBL1362872 & 737826 & 5.25 & 5.2644 & TRN & \\
\hline CHEMBL1327059 & 737826 & 5.0 & 4.8245 & TRN & \\
\hline CHEMBL1608397 & 737826 & 5.6 & 5.3448 & TRN & \\
\hline CHEMBL1421523 & 737826 & 4.85 & 5.189 & TST & \\
\hline CHEMBL1599014 & 737826 & 4.7 & 4.5665 & TRN & \\
\hline CHEMBL1404209 & 737826 & 6.3 & 5.2503 & TRN & \\
\hline CHEMBL1484861 & 737826 & 6.1 & 5.96299 & 9999999999 & TRN \\
\hline CHEMBL1482582 & 737826 & 6.0 & 5.9249 & TRN & \\
\hline CHEMBL1451099 & 737826 & 5.5 & 5.3627 & TST & \\
\hline CHEMBL1513030 & 737826 & 4.4 & 4.5051 & TRN & \\
\hline CHEMBL1396949 & 737826 & 5.5 & 5.44 & TRN & \\
\hline CHEMBL1373773 & 737826 & 4.9 & 4.8107 & TRN & \\
\hline CHEMBL3194842 & 737826 & 5.55 & 5.2435 & TRN & \\
\hline CHEMBL1368357 & 737826 & 5.0 & 5.5368 & TRN & \\
\hline CHEMBL1527195 & 737826 & 4.95 & 5.2727 & TRN & \\
\hline CHEMBL3195855 & 737826 & 5.45 & 5.4829 & TRN & \\
\hline CHEMBL1610945 & 737826 & 5.2 & 5.1572 & TST & \\
\hline CHEMBL1328324 & 737826 & 4.9 & 4.8672 & TST & \\
\hline CHEMBL1417581 & 737826 & 4.4 & 5.2145 & TRN & \\
\hline CHEMBL1361455 & 737826 & 5.65 & 5.29799 & 9999999999 & TRN \\
\hline CHEMBL1507109 & 737826 & 4.8 & 5.0844 & TST & \\
\hline CHEMBL1302204 & 737826 & 4.65 & 5.1488 & TRN & \\
\hline CHEMBL1406712 & 737826 & 4.95 & 5.4295 & TST & \\
\hline CHEMBL1485587 & 737826 & 5.6 & 5.3278 & TRN & \\
\hline CHEMBL1302086 & 737826 & 5.25 & 5.2594 & TST & \\
\hline CHEMBL1495867 & 737826 & 5.45 & 5.1755 & TRN & \\
\hline CHEMBL1355139 & 737826 & 6.5 & 6.3694 & TRN & \\
\hline CHEMBL1341978 & 737826 & 5.1 & 5.3282 & TRN & \\
\hline CHEMBL1599388 & 737826 & 5.0 & 5.2365 & TST & \\
\hline CHEMBL1472036 & 737826 & 4.85 & 5.3552 & TRN & \\
\hline CHEMBL1342226 & 737826 & 4.95 & 5.2847 & TRN & \\
\hline CHEMBL1348609 & 737826 & 5.95 & 5.2395 & TRN & \\
\hline CHEMBL1425402 & 737826 & 4.85 & 5.3437 & TRN & \\
\hline CHEMBL1565333 & 737826 & 5.2 & 5.1946 & TST & \\
\hline CHEMBL1330954 & 737826 & 5.05 & 5.3648 & TRN & \\
\hline CHEMBL1570405 & 737826 & 5.0 & 5.1626 & TST & \\
\hline CHEMBL1079374 & 737826 & 4.85 & 5.8422 & TRN & \\
\hline
\end{tabular}




\begin{tabular}{|c|c|c|c|c|c|}
\hline \\
\hline CHEMBL1533672 & 737826 & 5.5 & 5.4479 & TRN & \\
\hline CHEMBL164 & 737826 & 6.0 & 5.7416 & TRN & \\
\hline CHEMBL1446600 & 737826 & 4.85 & 5.1896 & TRN & \\
\hline CHEMBL1331489 & 737826 & 6.5 & 5.8434 & TRN & \\
\hline CHEMBL1422487 & 737826 & 4.9 & 5.49200 & 0000000001 & TRN \\
\hline CHEMBL472994 & 737826 & 5.7 & 5.518 & TST & \\
\hline CHEMBL1431432 & 737826 & 5.6 & 5.2714 & TST & \\
\hline CHEMBL1541004 & 737826 & 5.0 & 5.394 & TRN & \\
\hline CHEMBL1587759 & 737826 & 4.95 & 5.2315 & TST & \\
\hline CHEMBL1484079 & 737826 & 4.9 & 5.3981 & TRN & \\
\hline CHEMBL1325353 & 737826 & 4.6 & 5.2975 & TRN & \\
\hline CHEMBL3194024 & 737826 & 5.05 & 5.037 & TST & \\
\hline CHEMBL1576205 & 737826 & 5.6 & 5.3052 & TRN & \\
\hline CHEMBL1307581 & 737826 & 4.8 & 5.3599 & TRN & \\
\hline CHEMBL1425720 & 737826 & 5.45 & 5.4689 & TRN & \\
\hline CHEMBL1403280 & 737826 & 5.1 & 4.8778 & TRN & \\
\hline CHEMBL1475698 & 737826 & 4.9 & 4.9282 & TST & \\
\hline CHEMBL1574106 & 737826 & 5.2 & 5.0711 & TRN & \\
\hline CHEMBL1321892 & 737826 & 5.45 & 5.2183 & TRN & \\
\hline CHEMBL1573063 & 737826 & 6.3 & 6.2541 & TRN & \\
\hline CHEMBL1729658 & 737826 & 4.4 & 5.3369 & TRN & \\
\hline CHEMBL1364808 & 737826 & 4.5 & 4.6864 & TST & \\
\hline CHEMBL1345940 & 737826 & 4.95 & 5.5287 & TRN & \\
\hline CHEMBL1716417 & 737826 & 4.6 & 5.1615 & TRN & \\
\hline CHEMBL1502711 & 737826 & 6.6 & 5.3387 & TRN & \\
\hline CHEMBL1526421 & 737826 & 5.45 & 5.2246 & TRN & \\
\hline CHEMBL1424249 & 737826 & 5.75 & 5.1686 & TST & \\
\hline CHEMBL1414317 & 737826 & 4.9 & 5.1096 & TST & \\
\hline CHEMBL1362880 & 737826 & 4.8 & 4.587 & TRN & \\
\hline CHEMBL3209936 & 737826 & 4.65 & 5.3101 & TRN & \\
\hline CHEMBL1521391 & 737826 & 5.7 & 5.5041 & TRN & \\
\hline CHEMBL1493183 & 737826 & 5.45 & 5.3321 & TRN & \\
\hline CHEMBL1557809 & 737826 & 5.8 & 5.4225 & TST & \\
\hline CHEMBL1365848 & 737826 & 4.65 & 5.1848 & TRN & \\
\hline CHEMBL1592327 & 737826 & 6.4 & 6.0793 & TRN & \\
\hline CHEMBL1501668 & 737826 & 5.65 & 5.2201 & TRN & \\
\hline CHEMBL1605449 & 737826 & 5.05 & 5.4301 & TRN & \\
\hline CHEMBL1578418 & 737826 & 5.55 & 5.4291 & TRN & \\
\hline CHEMBL145 & 737826 & 4.8 & 4.80699 & 99999999995 & TRN \\
\hline CHEMBL3208021 & 737826 & 5.6 & 5.4455 & TRN & \\
\hline CHEMBL1454730 & 737826 & 5.4 & 5.2626 & TRN & \\
\hline CHEMBL1422181 & 737826 & 5.0 & 5.185 & TRN & \\
\hline CHEMBL1450934 & 737826 & 4.85 & 5.0045 & TRN & \\
\hline CHEMBL1583076 & 737826 & 4.9 & 5.3193 & TST & \\
\hline CHEMBL434063 & 737826 & 4.5 & 5.6783 & TST & \\
\hline CHEMBL1491193 & 737826 & 5.1 & 5.2059 & TRN & \\
\hline CHEMBL1570716 & 737826 & 6.0 & 5.7077 & TRN & \\
\hline CHEMBL1482153 & 737826 & 5.45 & 5.2044 & TRN & \\
\hline
\end{tabular}




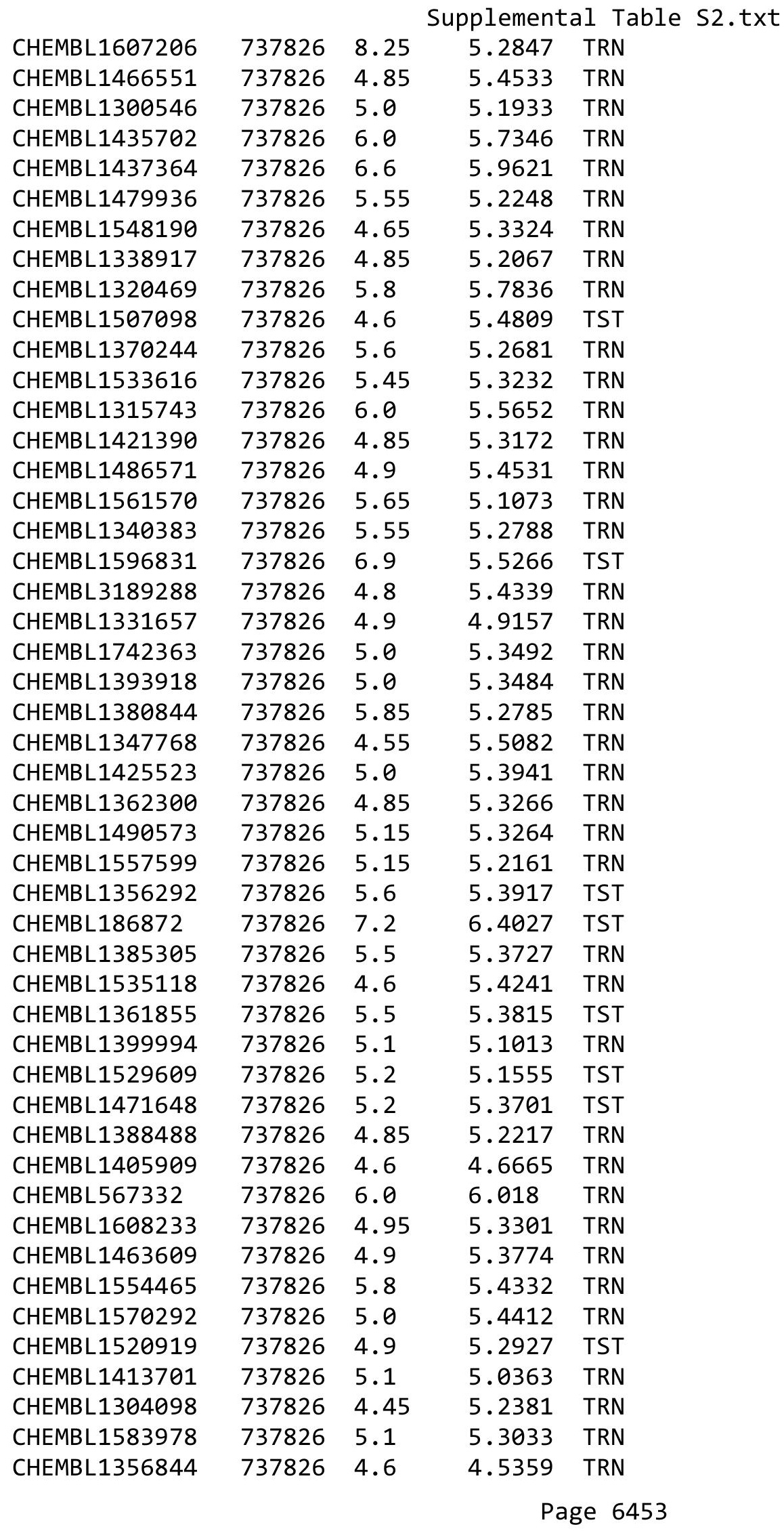




\begin{tabular}{|c|c|c|c|c|c|}
\hline & & & & & \\
\hline CHEMBL1370100 & 737826 & 5.3 & 5.3368 & TRN & \\
\hline CHEMBL1414083 & 737826 & 4.7 & 4.9976 & TRN & \\
\hline CHEMBL1558444 & 737826 & 5.15 & 5.6861 & TRN & \\
\hline CHEMBL1519978 & 737826 & 5.1 & 4.9307 & TRN & \\
\hline CHEMBL1549240 & 737826 & 5.05 & 5.3552 & TRN & \\
\hline CHEMBL1465250 & 737826 & 5.45 & 5.3555 & TRN & \\
\hline CHEMBL1533643 & 737826 & 7.15 & 5.0188 & TRN & \\
\hline CHEMBL1557212 & 737826 & 5.0 & 5.6156 & TST & \\
\hline CHEMBL1586326 & 737826 & 5.55 & 5.311 & TRN & \\
\hline CHEMBL1517040 & 737826 & 5.05 & 5.385 & TRN & \\
\hline CHEMBL1299525 & 737826 & 7.8499 & 5.4787 & TRN & \\
\hline CHEMBL3199536 & 737826 & 5.0 & 5.532 & TRN & \\
\hline CHEMBL1498258 & 737826 & 4.85 & 5.2182 & TRN & \\
\hline CHEMBL1500786 & 737826 & 6.55 & 5.1899 & TRN & \\
\hline CHEMBL1597874 & 737826 & 5.45 & 5.3196 & TRN & \\
\hline CHEMBL1601398 & 737826 & 6.3 & 5.2189 & TRN & \\
\hline CHEMBL1371710 & 737826 & 5.3 & 5.1491 & TRN & \\
\hline CHEMBL1480806 & 737826 & 6.1 & 6.022 & TRN & \\
\hline CHEMBL1353756 & 737826 & 5.0 & 5.3615 & TRN & \\
\hline CHEMBL1554246 & 737826 & 4.8 & 4.8177 & TST & \\
\hline CHEMBL1568588 & 737826 & 6.4 & 5.3437 & TRN & \\
\hline CHEMBL1484689 & 737826 & 4.5 & 4.5087 & TRN & \\
\hline CHEMBL1384414 & 737826 & 5.4 & 5.2891 & TRN & \\
\hline CHEMBL3192627 & 737826 & 5.1 & 5.2934 & TRN & \\
\hline CHEMBL1320019 & 737826 & 6.0 & 5.3735 & TRN & \\
\hline CHEMBL1421353 & 737826 & 5.0 & 5.244 & TRN & \\
\hline CHEMBL1398488 & 737826 & 4.6 & 4.5365 & TRN & \\
\hline CHEMBL1533658 & 737826 & 5.5 & 5.50299 & 9999999999 & TRN \\
\hline CHEMBL3189742 & 737826 & 4.6 & 5.3882 & TRN & \\
\hline CHEMBL1367220 & 737826 & 5.9 & 5.32600 & 30000000005 & TRN \\
\hline CHEMBL1442091 & 737826 & 4.95 & 5.2586 & TRN & \\
\hline CHEMBL1489354 & 737826 & 5.3 & 5.2082 & TRN & \\
\hline CHEMBL1412557 & 737826 & 4.4 & 5.0972 & TST & \\
\hline CHEMBL1389327 & 737826 & 4.8 & 5.4723 & TRN & \\
\hline CHEMBL3208477 & 737826 & 4.55 & 5.1351 & TRN & \\
\hline CHEMBL3190451 & 737826 & 4.85 & 5.385 & TRN & \\
\hline CHEMBL1368572 & 737826 & 5.2 & 5.1319 & TRN & \\
\hline CHEMBL221733 & 737826 & 5.1 & 5.0477 & TRN & \\
\hline CHEMBL1462374 & 737826 & 4.7 & 5.1593 & TRN & \\
\hline CHEMBL1586937 & 737826 & 6.25 & 5.3215 & TRN & \\
\hline CHEMBL1398543 & 737826 & 4.6 & 4.5325 & TRN & \\
\hline CHEMBL1512413 & 737826 & 5.6 & 5.5358 & TRN & \\
\hline CHEMBL1419702 & 737826 & 4.85 & 5.3508 & TRN & \\
\hline CHEMBL1544357 & 737826 & 4.6 & 5.3508 & TST & \\
\hline CHEMBL1741612 & 737826 & 4.6 & 5.3596 & TRN & \\
\hline CHEMBL3194051 & 737826 & 5.45 & 5.4107 & TST & \\
\hline CHEMBL1604261 & 737826 & 4.9 & 5.5124 & TST & \\
\hline CHEMBL1564800 & 737826 & 5.0 & 5.0751 & TRN & \\
\hline
\end{tabular}




\begin{tabular}{|c|c|c|c|c|}
\hline \multicolumn{5}{|c|}{ lemental T } \\
\hline CHEMBL1320913 & 737826 & 5.6 & 5.3233 & TST \\
\hline CHEMBL1607228 & 737826 & 6.0 & 5.7737 & TRN \\
\hline CHEMBL1409938 & 737826 & 4.7 & 5.1722 & TRN \\
\hline CHEMBL1305256 & 737826 & 5.15 & 5.2761 & TRN \\
\hline CHEMBL1436536 & 737826 & 4.8 & 5.704 & TRN \\
\hline CHEMBL1352528 & 737826 & 5.8 & 5.415 & TRN \\
\hline CHEMBL1345018 & 737826 & 4.85 & 5.2874 & TRN \\
\hline CHEMBL1540150 & 737826 & 4.75 & 5.2441 & TRN \\
\hline CHEMBL1458036 & 737826 & 4.9 & 5.255 & TRN \\
\hline CHEMBL1462462 & 737826 & 5.35 & 5.4412 & TST \\
\hline CHEMBL1452049 & 737826 & 4.9 & 4.6776 & TRN \\
\hline CHEMBL1499837 & 737826 & 4.95 & 5.3234 & TRN \\
\hline CHEMBL1515717 & 737826 & 6.0 & 6.0091 & TRN \\
\hline CHEMBL1514639 & 737826 & 4.6 & 4.8135 & TST \\
\hline CHEMBL1408222 & 737826 & 5.5 & 5.0364 & TST \\
\hline CHEMBL1605000 & 737826 & 5.65 & 5.3979 & TRN \\
\hline CHEMBL1412520 & 737826 & 6.4 & 5.5396 & TRN \\
\hline CHEMBL1444972 & 737826 & 4.9 & 5.1669 & TRN \\
\hline CHEMBL1420885 & 737826 & 4.9 & 5.3917 & TST \\
\hline CHEMBL1460922 & 737826 & 5.8 & 5.2539 & TRN \\
\hline CHEMBL1491340 & 737826 & 6.0 & 5.7469 & TST \\
\hline CHEMBL1439866 & 737826 & 5.3 & 5.1593 & TST \\
\hline CHEMBL1520998 & 737826 & 5.95 & 5.2204 & TRN \\
\hline CHEMBL1332225 & 737826 & 6.75 & 5.3212 & TRN \\
\hline CHEMBL1381972 & 737826 & 6.2 & 5.5602 & TRN \\
\hline CHEMBL1449777 & 737826 & 5.5 & 5.4483 & TST \\
\hline CHEMBL1371869 & 737826 & 4.7 & 5.335 & TST \\
\hline CHEMBL1306134 & 737826 & 5.55 & 5.2637 & TRN \\
\hline CHEMBL1420370 & 737826 & 5.3 & 5.6278 & TRN \\
\hline CHEMBL1451562 & 737826 & 4.5 & 4.5282 & TRN \\
\hline CHEMBL1091971 & 737826 & 5.1 & 5.1166 & TST \\
\hline CHEMBL1447544 & 737826 & 4.55 & 5.2471 & TRN \\
\hline CHEMBL1369966 & 737826 & 5.5 & 5.3214 & TRN \\
\hline CHEMBL1509370 & 737826 & 5.4 & 5.3785 & TRN \\
\hline CHEMBL1527775 & 737826 & 5.7 & 5.3471 & TRN \\
\hline CHEMBL1993145 & 737826 & 4.95 & 5.1743 & TRN \\
\hline CHEMBL1433336 & 737826 & 4.85 & 5.3939 & TRN \\
\hline CHEMBL 3197876 & 737826 & 5.6 & 5.3787 & TRN \\
\hline CHEMBL1600813 & 737826 & 5.65 & 5.4668 & TRN \\
\hline CHEMBL1521520 & 737826 & 5.8 & 5.459 & TRN \\
\hline CHEMBL1568465 & 737826 & 4.9 & 5.4488 & TRN \\
\hline CHEMBL1535980 & 737826 & 4.9 & 5.1834 & TRN \\
\hline CHEMBL1516187 & 737826 & 6.0 & 5.6816 & TRN \\
\hline CHEMBL1424743 & 737826 & 4.55 & 5.1151 & TRN \\
\hline CHEMBL1337584 & 737826 & 4.7 & 5.1345 & TRN \\
\hline CHEMBL1499209 & 737826 & 4.55 & 5.309 & TRN \\
\hline CHEMBL1256873 & 737826 & 4.5 & 4.6826 & TRN \\
\hline CHEMBL1487396 & 737826 & 5.7 & 5.4102 & TRN \\
\hline
\end{tabular}




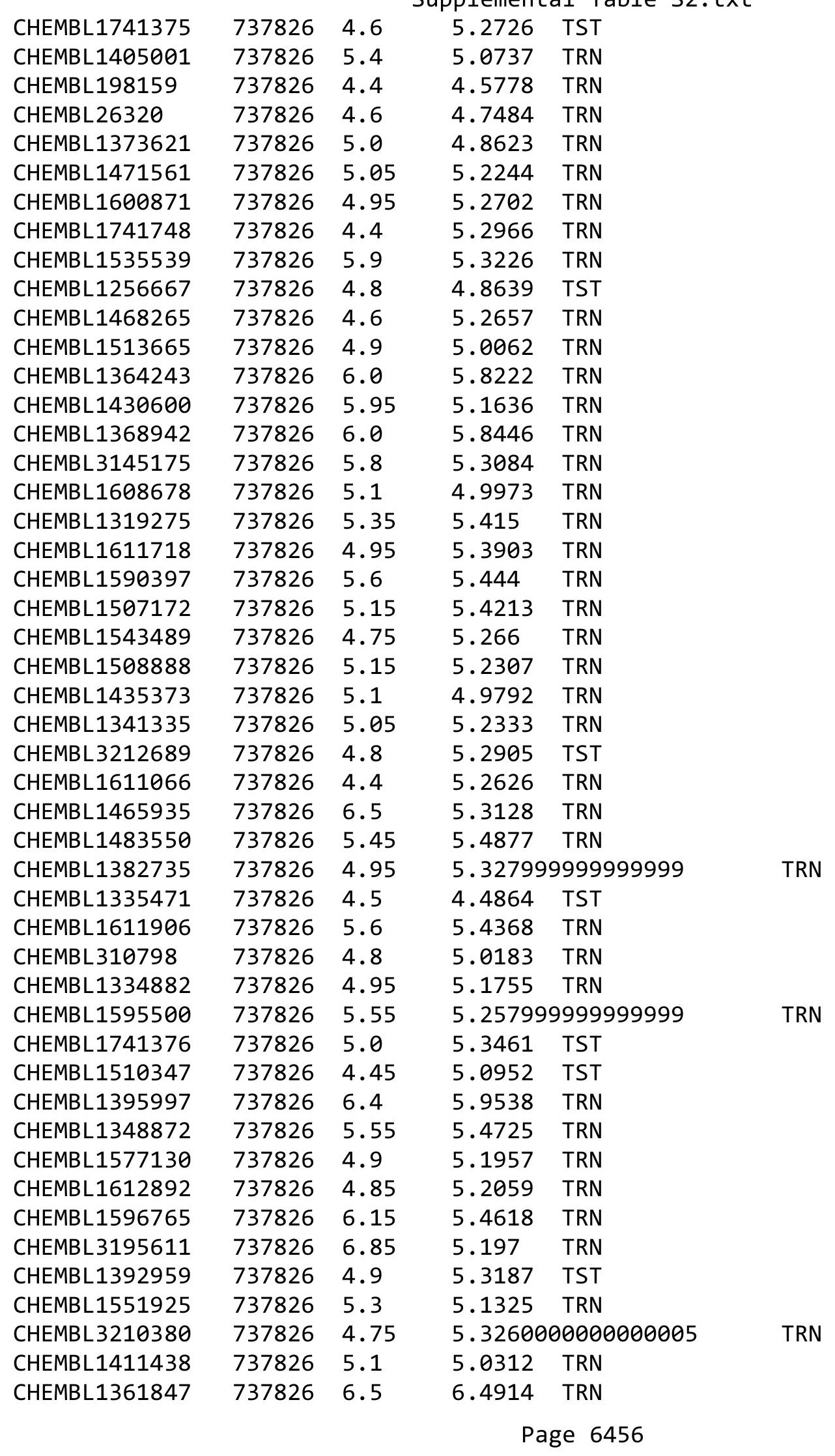




\begin{tabular}{|c|c|c|c|c|c|}
\hline \multicolumn{6}{|c|}{ Supplemental Table S2.txt } \\
\hline CHEMBL1528428 & 737826 & 4.45 & 5.2573 & TST & \\
\hline CHEMBL1343240 & 737826 & 4.4 & 5.3142 & TRN & \\
\hline CHEMBL1329104 & 737826 & 5.75 & 5.3586 & TRN & \\
\hline CHEMBL1569147 & 737826 & 4.9 & 5.3012 & TRN & \\
\hline CHEMBL149223 & 737826 & 6.5 & 6.0354 & TST & \\
\hline CHEMBL313833 & 737826 & 6.0 & 5.6333 & TST & \\
\hline CHEMBL1398600 & 737826 & 5.5 & 5.3176 & TRN & \\
\hline CHEMBL1405464 & 737826 & 5.6 & 5.393 & TRN & \\
\hline CHEMBL 30432 & 737826 & 4.9 & 5.0799 & TST & \\
\hline CHEMBL1375967 & 737826 & 5.4 & 5.3162 & TRN & \\
\hline CHEMBL 3210188 & 737826 & 5.2 & 5.4723 & TRN & \\
\hline CHEMBL1526824 & 737826 & 5.05 & 5.1686 & TRN & \\
\hline CHEMBL1322743 & 737826 & 5.0 & 4.8493 & TRN & \\
\hline CHEMBL1374373 & 737826 & 5.25 & 5.3925 & TST & \\
\hline CHEMBL1452116 & 737826 & 5.35 & 5.3984 & TRN & \\
\hline CHEMBL1411832 & 737826 & 5.35 & 5.2293 & TRN & \\
\hline CHEMBL1453208 & 737826 & 4.4 & 4.5797 & TRN & \\
\hline CHEMBL1433052 & 737826 & 5.3 & 5.2268 & TST & \\
\hline CHEMBL 2374062 & 737826 & 4.6 & 4.7052 & TST & \\
\hline CHEMBL1590378 & 737826 & 6.0 & 5.5716 & TST & \\
\hline CHEMBL1378505 & 737826 & 6.6 & 5.2162 & TST & \\
\hline CHEMBL1394579 & 737826 & 5.4 & 5.1119 & TRN & \\
\hline CHEMBL1595404 & 737826 & 5.0 & 4.8713 & TRN & \\
\hline CHEMBL1570515 & 737826 & 4.75 & 5.147 & TRN & \\
\hline CHEMBL1490139 & 737826 & 5.0 & 4.8388 & TRN & \\
\hline CHEMBL1483182 & 737826 & 4.5 & 5.1829 & TRN & \\
\hline CHEMBL1468225 & 737826 & 5.15 & 5.3849 & TRN & \\
\hline CHEMBL1538879 & 737826 & 4.65 & 5.4011 & TST & \\
\hline CHEMBL1602812 & 737826 & 5.3 & 5.1187 & TRN & \\
\hline CHEMBL1447768 & 737826 & 5.0 & 5.3093 & TRN & \\
\hline CHEMBL1593269 & 737826 & 5.3 & 5.0611 & TRN & \\
\hline CHEMBL1710363 & 737826 & 4.85 & 5.2613 & TRN & \\
\hline CHEMBL1513392 & 737826 & 5.9 & 5.63700 & 00000000005 & TRN \\
\hline CHEMBL1360821 & 737826 & 4.65 & 5.1973 & TRN & \\
\hline CHEMBL1429896 & 737826 & 4.95 & 5.1604 & TRN & \\
\hline CHEMBL1407667 & 737826 & 6.2 & 5.2791 & TRN & \\
\hline CHEMBL1368168 & 737826 & 6.05 & 5.2135 & TRN & \\
\hline CHEMBL1319789 & 737826 & 6.0 & 5.4953 & TRN & \\
\hline CHEMBL1478504 & 737826 & 5.3 & 5.2224 & TRN & \\
\hline CHEMBL1306881 & 737826 & 4.9 & 5.4049 & TRN & \\
\hline CHEMBL1485494 & 737826 & 5.35 & 5.8869 & TRN & \\
\hline CHEMBL 2004183 & 737826 & 4.9 & 5.5062 & TRN & \\
\hline CHEMBL1372199 & 737826 & 4.55 & 5.303 & TRN & \\
\hline CHEMBL1527221 & 737826 & 6.1 & 6.0838 & TRN & \\
\hline CHEMBL1600421 & 737826 & 4.8 & 5.1783 & TST & \\
\hline CHEMBL1571514 & 737826 & 4.95 & 5.1185 & TST & \\
\hline CHEMBL1409046 & 737826 & 5.2 & 5.1501 & TST & \\
\hline CHEMBL1568519 & 737826 & 4.95 & 5.1525 & TST & \\
\hline
\end{tabular}




\begin{tabular}{|c|c|c|c|c|}
\hline \multicolumn{5}{|c|}{ oplemental Iable S2. } \\
\hline CHEMBL1528708 & 737826 & 5.0 & 4.7282 & TRN \\
\hline CHEMBL1328369 & 737826 & 5.2 & 5.0923 & TRN \\
\hline CHEMBL1538999 & 737826 & 4.85 & 5.1102 & TRN \\
\hline CHEMBL608109 & 737826 & 5.8 & 5.5966 & TRN \\
\hline CHEMBL1452436 & 737826 & 5.8 & 5.3957 & TRN \\
\hline CHEMBL1571840 & 737826 & 5.55 & 5.1882 & TRN \\
\hline CHEMBL1741760 & 737826 & 4.85 & 5.1722 & TST \\
\hline CHEMBL1599438 & 737826 & 5.65 & 5.3065 & TRN \\
\hline CHEMBL1442987 & 737826 & 6.0 & 5.8859 & TRN \\
\hline CHEMBL1354693 & 737826 & 5.4 & 5.2254 & TRN \\
\hline CHEMBL1592464 & 737826 & 6.7 & 6.6201 & TRN \\
\hline CHEMBL1539911 & 737826 & 5.0 & 5.13200 & 0000000001 \\
\hline CHEMBL1549831 & 737826 & 5.6 & 5.4038 & TRN \\
\hline CHEMBL1498873 & 737826 & 5.0 & 5.3444 & TRN \\
\hline CHEMBL1500145 & 737826 & 5.45 & 5.2277 & TRN \\
\hline CHEMBL1600239 & 737826 & 5.4 & 5.3097 & TRN \\
\hline CHEMBL1424761 & 737826 & 5.65 & 5.4241 & TRN \\
\hline CHEMBL1332504 & 737826 & 5.8 & 5.5881 & TRN \\
\hline CHEMBL1317916 & 737826 & 5.4 & 5.2963 & TRN \\
\hline CHEMBL1741831 & 737826 & 6.5 & 5.5192 & TRN \\
\hline CHEMBL1331642 & 737826 & 4.6 & 5.2859 & TRN \\
\hline CHEMBL1371696 & 737826 & 5.5 & 5.4086 & TRN \\
\hline CHEMBL1363953 & 737826 & 4.55 & 5.029 & TST \\
\hline CHEMBL1601844 & 737826 & 4.9 & 5.147 & TRN \\
\hline CHEMBL1312003 & 737826 & 4.7 & 5.1493 & TST \\
\hline CHEMBL1317148 & 737826 & 4.6 & 4.9218 & TST \\
\hline CHEMBL1335890 & 737826 & 5.8 & 5.725 & TRN \\
\hline CHEMBL1487561 & 737826 & 4.6 & 4.7471 & TRN \\
\hline CHEMBL1571995 & 737826 & 5.4 & 5.3512 & TRN \\
\hline CHEMBL1742103 & 737826 & 4.75 & 5.2505 & TST \\
\hline CHEMBL476833 & 737826 & 5.2 & 5.2132 & TRN \\
\hline CHEMBL1542467 & 737826 & 5.0 & 5.1717 & TRN \\
\hline CHEMBL1463376 & 737826 & 5.3 & 5.2376 & TRN \\
\hline CHEMBL1487537 & 737826 & 8.25 & 5.2111 & TRN \\
\hline CHEMBL1554243 & 737826 & 4.9 & 4.8234 & TRN \\
\hline CHEMBL1532949 & 737826 & 5.0 & 5.3422 & TRN \\
\hline CHEMBL1358708 & 737826 & 6.3 & 5.8866 & TST \\
\hline CHEMBL1455699 & 737826 & 5.4 & 5.2602 & TRN \\
\hline CHEMBL1494046 & 737826 & 4.95 & 5.3217 & TRN \\
\hline CHEMBL1990383 & 737826 & 5.1 & 5.4028 & TRN \\
\hline CHEMBL1448350 & 737826 & 4.9 & 5.144 & TST \\
\hline CHEMBL1346358 & 737826 & 4.8 & 5.3226 & TRN \\
\hline CHEMBL1318045 & 737826 & 6.0 & 5.9255 & TRN \\
\hline CHEMBL1577515 & 737826 & 5.55 & 5.0865 & TRN \\
\hline CHEMBL1371014 & 737826 & 5.3 & 5.21200 & 0000000001 \\
\hline CHEMBL1580880 & 737826 & 5.0 & 5.1046 & TRN \\
\hline CHEMBL1331572 & 737826 & 8.25 & 5.478 & TRN \\
\hline CHEMBL1441290 & 737826 & 4.4 & 5.3047 & TRN \\
\hline
\end{tabular}




\begin{tabular}{|c|c|c|c|c|}
\hline \multicolumn{5}{|c|}{ Supplemental Table S2.txt } \\
\hline CHEMBL1556619 & 737826 & 5.25 & 5.3186 & TST \\
\hline CHEMBL1568723 & 737826 & 5.6 & 5.296 & TRN \\
\hline CHEMBL1327793 & 737826 & 5.5 & 5.3647 & TST \\
\hline CHEMBL1352745 & 737826 & 4.55 & 5.20299 & 9999999999 \\
\hline CHEMBL3196138 & 737826 & 4.8 & 5.2421 & TST \\
\hline CHEMBL1376927 & 737826 & 6.45 & 5.3813 & TRN \\
\hline CHEMBL1502952 & 737826 & 4.55 & 5.4589 & TRN \\
\hline CHEMBL1724774 & 737826 & 4.65 & 5.2563 & TRN \\
\hline CHEMBL1529730 & 737826 & 5.3 & 5.0669 & TRN \\
\hline CHEMBL1417604 & 737826 & 5.85 & 5.3017 & TST \\
\hline CHEMBL1361909 & 737826 & 5.05 & 5.0228 & TRN \\
\hline CHEMBL1512023 & 737826 & 4.7 & 4.8454 & TRN \\
\hline CHEMBL1539239 & 737826 & 4.95 & 5.1792 & TRN \\
\hline CHEMBL 388054 & 737826 & 4.4 & 4.45 & TRN \\
\hline CHEMBL1519225 & 737826 & 4.5 & 4.6934 & TRN \\
\hline CHEMBL1514779 & 737826 & 4.4 & 4.37 & TRN \\
\hline CHEMBL1609324 & 737826 & 6.0 & 6.0531 & TRN \\
\hline CHEMBL1322959 & 737826 & 6.0 & 5.7252 & TST \\
\hline CHEMBL1548181 & 737826 & 5.15 & 5.1148 & TRN \\
\hline CHEMBL1530525 & 737826 & 5.1 & 5.2328 & TST \\
\hline CHEMBL1601104 & 737826 & 5.45 & 5.0095 & TST \\
\hline CHEMBL1604398 & 737826 & 5.15 & 5.3116 & TRN \\
\hline CHEMBL1330032 & 737826 & 5.85 & 5.3147 & TRN \\
\hline CHEMBL1318480 & 737826 & 5.6 & 5.3747 & TRN \\
\hline CHEMBL1387342 & 737826 & 5.0 & 5.2986 & TRN \\
\hline CHEMBL1534710 & 737826 & 5.1 & 5.1409 & TRN \\
\hline CHEMBL3198365 & 737826 & 5.85 & 5.3721 & TRN \\
\hline CHEMBL1527363 & 737826 & 4.95 & 5.3157 & TRN \\
\hline CHEMBL1469535 & 737826 & 5.2 & 5.3565 & TRN \\
\hline CHEMBL1397283 & 737826 & 5.7 & 5.4461 & TRN \\
\hline CHEMBL1324982 & 737826 & 5.85 & 5.3774 & TRN \\
\hline CHEMBL1311630 & 737826 & 5.9 & 5.4385 & TRN \\
\hline CHEMBL1598666 & 737826 & 5.3 & 5.5436 & TRN \\
\hline CHEMBL1367222 & 737826 & 5.3 & 5.0925 & TRN \\
\hline CHEMBL1374456 & 737826 & 5.5 & 5.2788 & TRN \\
\hline CHEMBL1437325 & 737826 & 4.9 & 4.7623 & TRN \\
\hline CHEMBL1412815 & 737826 & 4.9 & 5.3419 & TRN \\
\hline CHEMBL1332453 & 737826 & 5.4 & 5.2906 & TRN \\
\hline CHEMBL1399481 & 737826 & 5.4 & 5.2473 & TRN \\
\hline CHEMBL6215 & 737826 & 4.55 & 5.3449 & TRN \\
\hline CHEMBL1460432 & 737826 & 4.9 & 5.3963 & TRN \\
\hline CHEMBL1454711 & 737826 & 6.55 & 5.3162 & TST \\
\hline CHEMBL1366979 & 737826 & 5.9 & 5.356 & TRN \\
\hline CHEMBL1361022 & 737826 & 4.45 & 5.2982 & TRN \\
\hline CHEMBL1420680 & 737826 & 5.5 & 5.3114 & TST \\
\hline CHEMBL1392952 & 737826 & 5.55 & 5.3014 & TRN \\
\hline CHEMBL1410008 & 737826 & 5.4 & 5.2032 & TRN \\
\hline CHEMBL1600497 & 737826 & 5.1 & 5.0724 & TST \\
\hline
\end{tabular}

TRN 


\begin{tabular}{|c|c|c|c|c|}
\hline \multicolumn{5}{|c|}{ Supplemental Table S2.txt } \\
\hline CHEMBL1603120 & 737826 & 5.7 & 5.1996 & TRN \\
\hline CHEMBL1340514 & 737826 & 4.95 & 5.551 & TRN \\
\hline CHEMBL1486217 & 737826 & 5.0 & 5.3881 & TRN \\
\hline CHEMBL1339209 & 737826 & 6.1 & 6.005 & TRN \\
\hline CHEMBL1489549 & 737826 & 4.85 & 5.476 & TRN \\
\hline CHEMBL1509598 & 737826 & 5.0 & 5.2958 & TRN \\
\hline CHEMBL1432284 & 737826 & 5.05 & 5.3785 & TRN \\
\hline CHEMBL1304478 & 737826 & 5.0 & 5.3367 & TRN \\
\hline CHEMBL1371243 & 737826 & 5.95 & 5.2311 & TRN \\
\hline CHEMBL1452079 & 737826 & 5.15 & 5.0822 & TRN \\
\hline CHEMBL1381586 & 737826 & 5.25 & 5.0965 & TRN \\
\hline CHEMBL1562730 & 737826 & 5.2 & 5.1775 & TRN \\
\hline CHEMBL1511012 & 737826 & 4.75 & 5.3351 & TRN \\
\hline CHEMBL1538191 & 737826 & 6.9 & 5.2776 & TST \\
\hline CHEMBL1580257 & 737826 & 4.8 & 5.1581 & TRN \\
\hline CHEMBL1335329 & 737826 & 6.65 & 5.4691 & TRN \\
\hline CHEMBL1374274 & 737826 & 4.6 & 5.1362 & TRN \\
\hline CHEMBL1466372 & 737826 & 4.95 & 5.3384 & TST \\
\hline CHEMBL 3213457 & 737826 & 4.95 & 5.5986 & TST \\
\hline CHEMBL1315316 & 737826 & 5.5 & 5.4283 & TRN \\
\hline CHEMBL1603582 & 737826 & 4.8 & 4.8182 & TST \\
\hline CHEMBL3198104 & 737826 & 4.6 & 5.2569 & TRN \\
\hline CHEMBL1348806 & 737826 & 4.75 & 5.3802 & TST \\
\hline CHEMBL1531871 & 737826 & 4.7 & 5.1839 & TRN \\
\hline CHEMBL1469402 & 737826 & 4.85 & 5.2519 & TRN \\
\hline CHEMBL1320453 & 737826 & 4.5 & 5.1496 & TST \\
\hline CHEMBL1364466 & 737826 & 4.95 & 5.3481 & TRN \\
\hline CHEMBL1526199 & 737826 & 6.4 & 5.2278 & TRN \\
\hline CHEMBL1498886 & 737826 & 5.05 & 5.3978 & TRN \\
\hline CHEMBL1565236 & 737826 & 6.45 & 5.3389 & TRN \\
\hline CHEMBL1335760 & 737826 & 5.55 & 5.5196 & TRN \\
\hline CHEMBL1602161 & 737826 & 5.15 & 5.5199 & TRN \\
\hline CHEMBL1570285 & 737826 & 5.4 & 5.2375 & TRN \\
\hline CHEMBL1355010 & 737826 & 4.4 & 4.4103 & TRN \\
\hline CHEMBL1395165 & 737826 & 4.6 & 4.8456 & TRN \\
\hline CHEMBL1386703 & 737826 & 4.5 & 5.3196 & TRN \\
\hline CHEMBL1423903 & 737826 & 4.8 & 5.3872 & TRN \\
\hline CHEMBL1376723 & 737826 & 4.5 & 4.7161 & TRN \\
\hline CHEMBL1588523 & 737826 & 5.3 & 5.4311 & TRN \\
\hline CHEMBL1357520 & 737826 & 6.2 & 5.8676 & TRN \\
\hline CHEMBL1735424 & 737826 & 5.35 & 5.3431 & TRN \\
\hline CHEMBL1403488 & 737826 & 4.9 & 4.8889 & TRN \\
\hline CHEMBL1318104 & 737826 & 5.4 & 5.2274 & TRN \\
\hline CHEMBL1526113 & 737826 & 6.5 & 5.2709 & TRN \\
\hline CHEMBL1374763 & 737826 & -0.0 & 5.2672 & TRN \\
\hline CHEMBL81977 & 737826 & 4.9 & 4.8829 & TRN \\
\hline CHEMBL1574278 & 737826 & 5.4 & 5.3518 & TRN \\
\hline CHEMBL3197786 & 737826 & 5.65 & 5.6101 & TRN \\
\hline
\end{tabular}




\begin{tabular}{|c|c|c|c|c|c|}
\hline \multicolumn{6}{|c|}{ plemental labıe S2. } \\
\hline CHEMBL1441148 & 737826 & 4.55 & 5.4686 & TRN & \\
\hline CHEMBL1429565 & 737826 & 5.05 & 5.1593 & TRN & \\
\hline CHEMBL1572789 & 737826 & 4.9 & 5.4216 & TRN & \\
\hline CHEMBL1570851 & 737826 & 5.1 & 5.1346 & TRN & \\
\hline CHEMBL1567704 & 737826 & 5.0 & 5.36299 & 99999999995 & TRN \\
\hline CHEMBL1330587 & 737826 & 5.9 & 5.5898 & TRN & \\
\hline CHEMBL1435834 & 737826 & 4.4 & 4.6683 & TRN & \\
\hline CHEMBL1531607 & 737826 & 5.3 & 5.3154 & TRN & \\
\hline CHEMBL1561905 & 737826 & 5.45 & 5.3102 & TRN & \\
\hline CHEMBL1386594 & 737826 & 4.6 & 5.2803 & TRN & \\
\hline CHEMBL1422980 & 737826 & 4.9 & 5.1481 & TRN & \\
\hline CHEMBL3207937 & 737826 & 5.15 & 5.2477 & TRN & \\
\hline CHEMBL1513740 & 737826 & 5.1 & 4.8368 & TRN & \\
\hline CHEMBL1522815 & 737826 & 4.8 & 5.3096 & TRN & \\
\hline CHEMBL1430286 & 737826 & 6.55 & 5.3161 & TST & \\
\hline CHEMBL489934 & 737826 & 6.8 & 6.5498 & TRN & \\
\hline CHEMBL1309557 & 737826 & 5.35 & 5.2851 & TRN & \\
\hline CHEMBL1552562 & 737826 & 4.5 & 4.4481 & TRN & \\
\hline CHEMBL1333637 & 737826 & 5.0 & 5.5002 & TRN & \\
\hline CHEMBL1529093 & 737826 & 5.1 & 5.0269 & TST & \\
\hline CHEMBL1491288 & 737826 & 5.1 & 4.9846 & TRN & \\
\hline CHEMBL1741737 & 737826 & 4.45 & 5.3613 & TRN & \\
\hline CHEMBL1476791 & 737826 & 4.9 & 4.8733 & TRN & \\
\hline CHEMBL1481510 & 737826 & 6.8 & 6.3052 & TRN & \\
\hline CHEMBL1877767 & 737826 & 5.6 & 5.428 & TST & \\
\hline CHEMBL1355263 & 737826 & 4.4 & 4.3459 & TRN & \\
\hline CHEMBL1358122 & 737826 & 5.4 & 5.3017 & TRN & \\
\hline CHEMBL1528942 & 737826 & 4.5 & 5.3634 & TST & \\
\hline CHEMBL1507021 & 737826 & 4.9 & 5.2815 & TRN & \\
\hline CHEMBL1733899 & 737826 & 5.4 & 5.4247 & TRN & \\
\hline CHEMBL1369376 & 737826 & 5.2 & 5.2789 & TRN & \\
\hline CHEMBL1388668 & 737826 & 5.1 & 5.4648 & TRN & \\
\hline CHEMBL1560716 & 737826 & 6.45 & 5.126 & TRN & \\
\hline CHEMBL1393064 & 737826 & 5.45 & 5.4206 & TRN & \\
\hline CHEMBL1485598 & 737826 & 5.6 & 5.1984 & TRN & \\
\hline CHEMBL1496349 & 737826 & 4.8 & 5.4303 & TRN & \\
\hline CHEMBL1308408 & 737826 & 5.45 & 5.3552 & TRN & \\
\hline CHEMBL1447410 & 737826 & 4.4 & 5.2499 & TRN & \\
\hline CHEMBL1398762 & 737826 & 4.8 & 5.0477 & TRN & \\
\hline CHEMBL1413001 & 737826 & 4.7 & 5.0779 & TRN & \\
\hline CHEMBL3193903 & 737826 & 4.8 & 5.3737 & TRN & \\
\hline CHEMBL1730467 & 737826 & 4.4 & 5.3159 & TRN & \\
\hline CHEMBL1526486 & 737826 & 5.0 & 4.86600 & 00000000005 & TST \\
\hline CHEMBL1575560 & 737826 & 5.0 & 5.2954 & TRN & \\
\hline CHEMBL1584779 & 737826 & 4.7 & 5.3988 & TRN & \\
\hline CHEMBL1445889 & 737826 & 5.75 & 5.3463 & TRN & \\
\hline CHEMBL311226 & 737826 & 4.6 & 4.6741 & TST & \\
\hline CHEMBL1592452 & 737826 & 4.6 & 4.7832 & TRN & \\
\hline
\end{tabular}




\begin{tabular}{|c|c|c|c|c|c|}
\hline \multicolumn{6}{|c|}{ oplemental labıe s. } \\
\hline CHEMBL3193388 & 737826 & 4.05 & 5.4284 & TRN & \\
\hline CHEMBL1606292 & 737826 & 5.1 & 5.003 & TRN & \\
\hline CHEMBL1441667 & 737826 & 5.85 & 5.32 & TRN & \\
\hline CHEMBL1598818 & 737826 & 4.9 & 5.5464 & TST & \\
\hline CHEMBL1353889 & 737826 & 5.85 & 5.6156 & TRN & \\
\hline CHEMBL1513347 & 737826 & 4.9 & 4.8662 & TRN & \\
\hline CHEMBL 259073 & 737826 & 5.1 & 4.873 & TRN & \\
\hline CHEMBL1476711 & 737826 & 4.4 & 4.3384 & TRN & \\
\hline CHEMBL1344451 & 737826 & 4.8 & 5.2837 & TRN & \\
\hline CHEMBL1381238 & 737826 & 5.45 & 5.3564 & TST & \\
\hline CHEMBL1392762 & 737826 & 5.35 & 5.28 & TRN & \\
\hline CHEMBL1360980 & 737826 & 5.65 & 5.0372 & TST & \\
\hline CHEMBL 3214277 & 737826 & 5.45 & 5.3886 & TRN & \\
\hline CHEMBL1570083 & 737826 & 5.4 & 5.3103 & TRN & \\
\hline CHEMBL 3191520 & 737826 & 5.7 & 5.3824 & TRN & \\
\hline CHEMBL1585720 & 737826 & 5.0 & 5.1144 & TRN & \\
\hline CHEMBL1372413 & 737826 & 4.9 & 5.1101 & TRN & \\
\hline CHEMBL1357909 & 737826 & 6.0 & 5.6923 & TRN & \\
\hline CHEMBL1741917 & 737826 & 4.4 & 5.305 & TRN & \\
\hline CHEMBL1542592 & 737826 & 5.4 & 5.3275 & TST & \\
\hline CHEMBL1312265 & 737826 & 5.05 & 5.4188 & TRN & \\
\hline CHEMBL1586091 & 737826 & 4.4 & 5.3384 & TRN & \\
\hline CHEMBL1483978 & 737826 & 4.8 & 5.21399 & 99999999995 & TRN \\
\hline CHEMBL1462156 & 737826 & 4.85 & 5.272 & TRN & \\
\hline CHEMBL1544662 & 737826 & 5.45 & 5.3202 & TRN & \\
\hline CHEMBL 3199344 & 737826 & 4.9 & 5.5398 & TRN & \\
\hline CHEMBL327708 & 737826 & 5.5 & 5.2467 & TRN & \\
\hline CHEMBL1554141 & 737826 & 5.5 & 5.4122 & TRN & \\
\hline CHEMBL1329488 & 737826 & 5.5 & 5.33799 & 9999999999 & TRN \\
\hline CHEMBL1563936 & 737826 & 5.35 & 5.3301 & TRN & \\
\hline CHEMBL1579324 & 737826 & 5.6 & 5.3317 & TRN & \\
\hline CHEMBL1548111 & 737826 & 4.95 & 5.2381 & TRN & \\
\hline CHEMBL1097940 & 737826 & 4.5 & 4.7828 & TST & \\
\hline CHEMBL1367984 & 737826 & 5.2 & 5.1716 & TRN & \\
\hline CHEMBL1705167 & 737826 & 4.9 & 5.2714 & TRN & \\
\hline CHEMBL1484898 & 737826 & 4.4 & 5.2412 & TST & \\
\hline CHEMBL1368566 & 737826 & 4.6 & 4.5891 & TRN & \\
\hline CHEMBL1256835 & 737826 & 4.8 & 4.8422 & TST & \\
\hline CHEMBL1372773 & 737826 & 4.65 & 5.2762 & TRN & \\
\hline CHEMBL1489778 & 737826 & 4.85 & 5.1496 & TRN & \\
\hline CHEMBL1358272 & 737826 & 6.0 & 5.9484 & TRN & \\
\hline CHEMBL1464341 & 737826 & 4.75 & 5.0818 & TRN & \\
\hline CHEMBL1322137 & 737826 & 5.5 & 5.3121 & TRN & \\
\hline CHEMBL1496611 & 737826 & 4.9 & 5.1472 & TRN & \\
\hline CHEMBL1441453 & 737826 & 5.1 & 5.0776 & TRN & \\
\hline CHEMBL1403372 & 737826 & 5.3 & 5.2144 & TRN & \\
\hline CHEMBL1476741 & 737826 & 4.4 & 5.0604 & TRN & \\
\hline CHEMBL1356262 & 737826 & 5.0 & 4.9169 & TRN & \\
\hline
\end{tabular}




\begin{tabular}{|c|c|c|c|c|}
\hline \multicolumn{5}{|c|}{ lemental Table sa } \\
\hline CHEMBL1454735 & 737826 & 4.8 & 5.2471 & TRN \\
\hline CHEMBL1462826 & 737826 & 4.75 & 5.1824 & TST \\
\hline CHEMBL1364826 & 737826 & 4.5 & 5.244 & TRN \\
\hline CHEMBL3195972 & 737826 & 4.85 & 5.3477 & TRN \\
\hline CHEMBL1400132 & 737826 & 4.65 & 5.3663 & TRN \\
\hline CHEMBL1560141 & 737826 & 4.95 & 5.3249 & TST \\
\hline CHEMBL1398636 & 737826 & 5.5 & 5.3964 & TRN \\
\hline CHEMBL1741955 & 737826 & 5.45 & 5.4123 & TRN \\
\hline CHEMBL1586705 & 737826 & 7.2 & 5.8735 & TRN \\
\hline CHEMBL1741551 & 737826 & 5.0 & 5.2704 & TRN \\
\hline CHEMBL 441618 & 737826 & 5.0 & 4.9373 & TRN \\
\hline CHEMBL1515526 & 737826 & 5.8 & 5.5382 & TRN \\
\hline CHEMBL1606796 & 737826 & 4.9 & 4.6609 & TRN \\
\hline CHEMBL1605619 & 737826 & 4.65 & 5.5469 & TRN \\
\hline CHEMBL1388707 & 737826 & 5.15 & 5.4022 & TST \\
\hline CHEMBL1516388 & 737826 & 6.0 & 5.7051 & TST \\
\hline CHEMBL478501 & 737826 & 4.75 & 5.164 & TRN \\
\hline CHEMBL1315091 & 737826 & 4.7 & 4.7575 & TRN \\
\hline CHEMBL1371311 & 737826 & 5.4 & 5.1802 & TST \\
\hline CHEMBL1435788 & 737826 & 4.4 & 4.3604 & TRN \\
\hline CHEMBL 3196953 & 737826 & 6.5 & 5.2281 & TRN \\
\hline CHEMBL68230 & 737826 & 4.6 & 5.3706 & TRN \\
\hline CHEMBL1741698 & 737826 & 5.3 & 5.3507 & TRN \\
\hline CHEMBL1315257 & 737826 & 6.6 & 6.0211 & TRN \\
\hline CHEMBL1552405 & 737826 & 5.1 & 4.9391 & TRN \\
\hline CHEMBL1422219 & 737826 & 5.45 & 5.2946 & TRN \\
\hline CHEMBL1372210 & 737826 & 5.05 & 5.1603 & TRN \\
\hline CHEMBL1302224 & 737826 & 5.45 & 5.1368 & TRN \\
\hline CHEMBL3210860 & 737826 & 5.65 & 5.3672 & TRN \\
\hline CHEMBL1318708 & 737826 & 5.0 & 4.9856 & TST \\
\hline CHEMBL123 & 737826 & -0.0 & 4.6444 & TST \\
\hline CHEMBL1532939 & 737826 & 4.7 & 5.3385 & TST \\
\hline CHEMBL3210612 & 737826 & 5.05 & 5.4256 & TRN \\
\hline CHEMBL1316796 & 737826 & 5.0 & 4.7509 & TRN \\
\hline CHEMBL1308520 & 737826 & 5.05 & 5.3057 & TRN \\
\hline CHEMBL1319962 & 737826 & 4.75 & 5.2867 & TST \\
\hline CHEMBL1310444 & 737826 & 4.8 & 5.2059 & TRN \\
\hline CHEMBL1496004 & 737826 & 5.05 & 5.3703 & TRN \\
\hline CHEMBL1581696 & 737826 & 4.55 & 5.1582 & TRN \\
\hline CHEMBL1372404 & 737826 & 5.35 & 5.3639 & TRN \\
\hline CHEMBL1565848 & 737826 & 4.5 & 5.2274 & TRN \\
\hline CHEMBL1598317 & 737826 & 4.95 & 5.3644 & TST \\
\hline CHEMBL1542591 & 737826 & 4.8 & 5.0779 & TRN \\
\hline CHEMBL1455816 & 737826 & 4.75 & 5.21700 & 20000000005 \\
\hline CHEMBL1459758 & 737826 & 4.9 & 5.0154 & TRN \\
\hline CHEMBL1372401 & 737826 & 5.15 & 5.4349 & TRN \\
\hline CHEMBL113142 & 737826 & 4.4 & 4.6276 & TRN \\
\hline CHEMBL1537303 & 737826 & 4.65 & 5.2586 & TST \\
\hline
\end{tabular}




\begin{tabular}{|c|c|c|c|c|c|}
\hline \multicolumn{6}{|c|}{ oplemental Table S2 } \\
\hline CHEMBL1467355 & 737826 & 4.95 & 5.4965 & TST & \\
\hline CHEMBL1503678 & 737826 & 5.45 & 4.8445 & TRN & \\
\hline CHEMBL1539061 & 737826 & 4.9 & 5.2323 & TRN & \\
\hline CHEMBL1495875 & 737826 & 4.5 & 4.351 & TRN & \\
\hline CHEMBL1507563 & 737826 & 5.25 & 5.2655 & TST & \\
\hline CHEMBL1410635 & 737826 & 4.9 & 4.8143 & TRN & \\
\hline CHEMBL1481781 & 737826 & 5.0 & 4.9947 & TRN & \\
\hline CHEMBL1313827 & 737826 & 6.35 & 5.2782 & TST & \\
\hline CHEMBL1411982 & 737826 & 4.7 & 5.3956 & TRN & \\
\hline CHEMBL1552066 & 737826 & 5.4 & 5.2461 & TRN & \\
\hline CHEMBL1560839 & 737826 & 4.6 & 5.2596 & TRN & \\
\hline CHEMBL1340140 & 737826 & 5.55 & 5.1445 & TRN & \\
\hline CHEMBL1520681 & 737826 & 4.9 & 4.7086 & TRN & \\
\hline CHEMBL1311981 & 737826 & 5.45 & 5.2337 & TRN & \\
\hline CHEMBL552439 & 737826 & 5.9 & 5.7179 & TST & \\
\hline CHEMBL1469707 & 737826 & 4.5 & 5.3063 & TST & \\
\hline CHEMBL1461234 & 737826 & 4.75 & 5.1781 & TRN & \\
\hline CHEMBL10 & 737826 & 5.7 & 5.5404 & TRN & \\
\hline CHEMBL1308019 & 737826 & 4.65 & 5.3566 & TRN & \\
\hline CHEMBL1582663 & 737826 & 4.85 & 5.1612 & TRN & \\
\hline CHEMBL1417837 & 737826 & 5.8 & 5.6384 & TRN & \\
\hline CHEMBL1478614 & 737826 & -0.0 & 5.00899 & 99999999995 & TST \\
\hline CHEMBL1505752 & 737826 & 4.7 & 5.2751 & TRN & \\
\hline CHEMBL1565215 & 737826 & 4.95 & 5.3702 & TRN & \\
\hline CHEMBL1451815 & 737826 & 4.9 & 5.4033 & TRN & \\
\hline CHEMBL1498995 & 737826 & 5.1 & 5.2335 & TRN & \\
\hline CHEMBL1494817 & 737826 & 4.45 & 5.4998 & TRN & \\
\hline CHEMBL269733 & 737826 & 5.0 & 5.0345 & TST & \\
\hline CHEMBL3192684 & 737826 & 5.0 & 5.4134 & TRN & \\
\hline CHEMBL1392360 & 737826 & 4.95 & 5.3686 & TRN & \\
\hline CHEMBL1520025 & 737826 & 6.4 & 5.9137 & TST & \\
\hline CHEMBL1490198 & 737826 & 4.4 & 5.3579 & TRN & \\
\hline CHEMBL1476108 & 737826 & 4.7 & 4.6152 & TRN & \\
\hline CHEMBL1256646 & 737826 & 4.5 & 4.5985 & TST & \\
\hline CHEMBL1525473 & 737826 & 5.45 & 5.3957 & TST & \\
\hline CHEMBL1591209 & 737826 & 4.9 & 5.0618 & TRN & \\
\hline CHEMBL358326 & 737826 & 4.6 & 5.1131 & TRN & \\
\hline CHEMBL543557 & 737826 & 5.1 & 5.0521 & TRN & \\
\hline CHEMBL1569035 & 737826 & 5.0 & 5.3909 & TRN & \\
\hline CHEMBL1581533 & 737826 & 5.55 & 5.4035 & TRN & \\
\hline CHEMBL1525320 & 737826 & 5.3 & 5.1249 & TRN & \\
\hline CHEMBL1378440 & 737826 & 4.9 & 4.7781 & TRN & \\
\hline CHEMBL1736254 & 737826 & 5.8 & 5.5812 & TST & \\
\hline CHEMBL1404254 & 737826 & 5.55 & 5.2767 & TRN & \\
\hline CHEMBL1371160 & 737826 & 5.4 & 5.3346 & TRN & \\
\hline CHEMBL1574531 & 737826 & 5.0 & 5.2022 & TRN & \\
\hline CHEMBL1363867 & 737826 & 5.0 & 5.3324 & TRN & \\
\hline CHEMBL1303933 & 737826 & 4.85 & 5.2497 & TRN & \\
\hline
\end{tabular}




\begin{tabular}{|c|c|c|c|c|}
\hline \multicolumn{5}{|c|}{ Supplemental Table S2.t) } \\
\hline CHEMBL1513824 & 737826 & 5.6 & 5.771 & TST \\
\hline CHEMBL1336155 & 737826 & 5.5 & 5.2784 & TST \\
\hline CHEMBL1567887 & 737826 & 4.5 & 5.3503 & TRN \\
\hline CHEMBL1741922 & 737826 & 4.95 & 5.2917 & TST \\
\hline CHEMBL1989847 & 737826 & 5.1 & 5.3992 & TST \\
\hline CHEMBL 295212 & 737826 & 4.4 & 4.5969 & TST \\
\hline CHEMBL1476280 & 737826 & 4.6 & 4.9028 & TRN \\
\hline CHEMBL1450521 & 737826 & 7.0 & 6.8393 & TRN \\
\hline CHEMBL1595576 & 737826 & 5.9 & 5.9201 & TRN \\
\hline CHEMBL1365902 & 737826 & 6.1 & 5.341 & TRN \\
\hline CHEMBL1493402 & 737826 & 5.75 & 5.3303 & TRN \\
\hline CHEMBL 3198264 & 737826 & 4.85 & 5.2806 & TST \\
\hline CHEMBL1452850 & 737826 & 5.7 & 5.4584 & TRN \\
\hline CHEMBL1378944 & 737826 & 4.85 & 5.1891 & TRN \\
\hline CHEMBL1357167 & 737826 & 6.2 & 6.0715 & TRN \\
\hline CHEMBL1555483 & 737826 & 5.55 & 5.3309 & TRN \\
\hline CHEMBL1487648 & 737826 & 5.85 & 5.3844 & TRN \\
\hline CHEMBL1473420 & 737826 & 5.0 & 4.8345 & TRN \\
\hline CHEMBL1564756 & 737826 & 5.1 & 5.195 & TRN \\
\hline CHEMBL1516342 & 737826 & 5.1 & 5.0477 & TRN \\
\hline CHEMBL1605814 & 737826 & 4.75 & 5.2684 & TRN \\
\hline CHEMBL1419308 & 737826 & 8.25 & 5.1868 & TRN \\
\hline CHEMBL1487874 & 737826 & 5.15 & 5.2471 & TRN \\
\hline CHEMBL1359469 & 737826 & 5.25 & 5.4016 & TRN \\
\hline CHEMBL1558929 & 737826 & 4.85 & 5.1987 & TRN \\
\hline CHEMBL1347942 & 737826 & 4.8 & 5.3345 & TRN \\
\hline CHEMBL1306927 & 737826 & 5.3 & 5.3298 & TRN \\
\hline CHEMBL1417002 & 737826 & 5.05 & 5.1673 & TRN \\
\hline CHEMBL1600038 & 737826 & 4.8 & 5.0808 & TRN \\
\hline CHEMBL1578454 & 737826 & 4.8 & 5.271 & TRN \\
\hline CHEMBL1393508 & 737826 & 5.0 & 5.3376 & TRN \\
\hline CHEMBL1566900 & 737826 & 5.5 & 5.2391 & TRN \\
\hline CHEMBL1375321 & 737826 & 4.85 & 5.4687 & TRN \\
\hline CHEMBL1611388 & 737826 & 4.9 & 5.3893 & TRN \\
\hline CHEMBL1502591 & 737826 & 4.9 & 5.3222 & TRN \\
\hline CHEMBL3211338 & 737826 & 6.0 & 5.8222 & TRN \\
\hline CHEMBL541847 & 737826 & 6.0 & 5.9377 & TRN \\
\hline CHEMBL1741467 & 737826 & 4.45 & 5.0394 & TRN \\
\hline CHEMBL1581598 & 737826 & 5.5 & 5.6531 & TRN \\
\hline CHEMBL 3190254 & 737826 & 4.75 & 5.3343 & TRN \\
\hline CHEMBL1346159 & 737826 & 5.0 & 5.2476 & TST \\
\hline CHEMBL1555369 & 737826 & 5.5 & 5.4039 & TRN \\
\hline CHEMBL1319232 & 737826 & 4.55 & 5.1802 & TST \\
\hline CHEMBL1566407 & 737826 & 6.25 & 5.3443 & TRN \\
\hline CHEMBL1546137 & 737826 & 5.05 & 5.1678 & TST \\
\hline CHEMBL1529954 & 737826 & 4.4 & 5.125 & TRN \\
\hline CHEMBL1256869 & 737826 & 5.1 & 5.0746 & TRN \\
\hline CHEMBL 303579 & 737826 & 4.9 & 4.9203 & TRN \\
\hline
\end{tabular}




\begin{tabular}{|c|c|c|c|c|c|}
\hline \multicolumn{6}{|c|}{ Supplemental Table S2.txt } \\
\hline CHEMBL1612814 & 737826 & 5.05 & 5.3163 & TST & \\
\hline CHEMBL1518970 & 737826 & 5.55 & 5.3102 & TRN & \\
\hline CHEMBL1463503 & 737826 & 4.9 & 5.1946 & TRN & \\
\hline CHEMBL1383658 & 737826 & 5.35 & 5.2461 & TRN & \\
\hline CHEMBL1398931 & 737826 & 5.05 & 5.2196 & TRN & \\
\hline CHEMBL1512027 & 737826 & 4.5 & 4.4746 & TRN & \\
\hline CHEMBL1531070 & 737826 & 5.1 & 5.0209 & TRN & \\
\hline CHEMBL1343091 & 737826 & 4.65 & 5.1182 & TRN & \\
\hline CHEMBL1340538 & 737826 & 5.0 & 5.2797 & TRN & \\
\hline CHEMBL1383897 & 737826 & 4.95 & 5.1864 & TRN & \\
\hline CHEMBL 3208062 & 737826 & 4.5 & 5.4117 & TRN & \\
\hline CHEMBL1391209 & 737826 & 4.75 & 5.1983 & TRN & \\
\hline CHEMBL1399058 & 737826 & 5.3 & 5.2925 & TRN & \\
\hline CHEMBL1558076 & 737826 & 4.9 & 5.3069 & TST & \\
\hline CHEMBL153648 & 737826 & 4.5 & 4.673 & TST & \\
\hline CHEMBL1466675 & 737826 & 5.85 & 5.3164 & TRN & \\
\hline CHEMBL1563008 & 737826 & 6.95 & 5.277 & TRN & \\
\hline CHEMBL1596347 & 737826 & 6.2 & 5.8809 & TST & \\
\hline CHEMBL1369322 & 737826 & 5.3 & 5.475 & TRN & \\
\hline CHEMBL1563772 & 737826 & 5.3 & 5.42899 & 9999999999 & TRN \\
\hline CHEMBL1310543 & 737826 & 5.95 & 5.237 & TRN & \\
\hline CHEMBL1741912 & 737826 & 5.25 & 5.4168 & TRN & \\
\hline CHEMBL1510918 & 737826 & 5.95 & 5.0586 & TST & \\
\hline CHEMBL1310885 & 737826 & 5.0 & 5.3148 & TRN & \\
\hline CHEMBL1388353 & 737826 & 5.0 & 5.1507 & TRN & \\
\hline CHEMBL1335644 & 737826 & 5.35 & 5.4327 & TRN & \\
\hline CHEMBL1599905 & 737826 & 5.0 & 5.3035 & TST & \\
\hline CHEMBL1446244 & 737826 & 4.95 & 5.3078 & TRN & \\
\hline CHEMBL1563004 & 737826 & 5.35 & 5.2142 & TRN & \\
\hline CHEMBL1498179 & 737826 & 5.6 & 5.3652 & TRN & \\
\hline CHEMBL1455106 & 737826 & 4.85 & 5.2869 & TRN & \\
\hline CHEMBL1315820 & 737826 & 4.8 & 4.6699 & TRN & \\
\hline CHEMBL1603446 & 737826 & 5.8 & 5.7128 & TRN & \\
\hline CHEMBL1473055 & 737826 & 4.6 & 4.5875 & TRN & \\
\hline CHEMBL 288096 & 737826 & 4.4 & 4.5173 & TST & \\
\hline CHEMBL1444164 & 737826 & 5.2 & 5.2818 & TRN & \\
\hline CHEMBL1426718 & 737826 & 4.55 & 5.3851 & TRN & \\
\hline CHEMBL3209943 & 737826 & 5.4 & 5.45299 & & TRN \\
\hline CHEMBL1316749 & 737826 & 5.4 & 5.355 & TRN & \\
\hline CHEMBL1325634 & 737826 & 6.6 & 5.2045 & TRN & \\
\hline CHEMBL1999906 & 737826 & 5.3 & 5.4703 & TST & \\
\hline CHEMBL1423999 & 737826 & 4.8 & 5.2661 & TRN & \\
\hline CHEMBL1504481 & 737826 & 5.2 & 5.7282 & TRN & \\
\hline CHEMBL1351656 & 737826 & 4.65 & 5.3799 & TRN & \\
\hline CHEMBL1305982 & 737826 & 5.3 & 5.3672 & TRN & \\
\hline CHEMBL1324528 & 737826 & 6.15 & 5.5221 & TRN & \\
\hline CHEMBL1578679 & 737826 & 4.85 & 5.1367 & TRN & \\
\hline CHEMBL1436644 & 737826 & 4.9 & 4.9077 & TRN & \\
\hline
\end{tabular}




\begin{tabular}{|c|c|c|c|c|}
\hline \multicolumn{5}{|c|}{ lemental T } \\
\hline CHEMBL1512693 & 737826 & 5.5 & 5.3616 & TRN \\
\hline CHEMBL1502052 & 737826 & 6.1 & 5.4303 & TRN \\
\hline CHEMBL1726451 & 737826 & 4.6 & 5.0649 & TRN \\
\hline CHEMBL1459871 & 737826 & 4.8 & 5.1237 & TRN \\
\hline CHEMBL1318937 & 737826 & 5.1 & 5.4103 & TRN \\
\hline CHEMBL1515614 & 737826 & 4.4 & 4.3881 & TRN \\
\hline CHEMBL1449838 & 737826 & 5.5 & 5.4256 & TRN \\
\hline CHEMBL1371238 & 737826 & 5.3 & 5.3217 & TRN \\
\hline CHEMBL1345528 & 737826 & 5.1 & 5.4241 & TST \\
\hline CHEMBL159096 & 737826 & 4.6 & 4.6858 & TST \\
\hline CHEMBL1611644 & 737826 & 5.35 & 5.244 & TRN \\
\hline CHEMBL1572855 & 737826 & 6.2 & 5.7209 & TRN \\
\hline CHEMBL1541013 & 737826 & 4.65 & 5.3558 & TRN \\
\hline CHEMBL1543084 & 737826 & 6.0 & 5.3796 & TRN \\
\hline CHEMBL1343857 & 737826 & 4.9 & 5.319 & TRN \\
\hline CHEMBL1306142 & 737826 & 6.25 & 5.2746 & TRN \\
\hline CHEMBL1402608 & 737826 & 6.65 & 5.1595 & TST \\
\hline CHEMBL1318310 & 737826 & 5.8 & 5.8672 & TRN \\
\hline CHEMBL1497099 & 737826 & 4.95 & 5.3052 & TRN \\
\hline CHEMBL1602770 & 737826 & 4.4 & 5.3649 & TRN \\
\hline CHEMBL1596241 & 737826 & 6.1 & 6.0668 & TRN \\
\hline CHEMBL1603192 & 737826 & 6.35 & 5.4335 & TRN \\
\hline CHEMBL1380300 & 737826 & 6.25 & 5.3399 & TRN \\
\hline CHEMBL1319783 & 737826 & 5.8 & 5.3634 & TRN \\
\hline CHEMBL1522909 & 737826 & 4.75 & 5.2504 & TST \\
\hline CHEMBL1544856 & 737826 & 4.9 & 5.0821 & TRN \\
\hline CHEMBL1541405 & 737826 & 5.15 & 5.4167 & TRN \\
\hline CHEMBL393136 & 737826 & 5.5 & 5.4665 & TST \\
\hline CHEMBL1579683 & 737826 & 4.9 & 5.3917 & TRN \\
\hline CHEMBL1335414 & 737826 & 6.1 & 5.97 & TRN \\
\hline CHEMBL1324405 & 737826 & 6.0 & 5.6622 & TRN \\
\hline CHEMBL1568113 & 737826 & 5.6 & 5.3558 & TRN \\
\hline CHEMBL1449293 & 737826 & 7.3 & 5.1785 & TRN \\
\hline CHEMBL1501140 & 737826 & 7.1 & 5.2047 & TRN \\
\hline CHEMBL1476670 & 737826 & 6.1 & 5.7431 & TRN \\
\hline CHEMBL1494832 & 737826 & 4.5 & 4.5292 & TRN \\
\hline CHEMBL1306798 & 737826 & 4.8 & 5.1781 & TRN \\
\hline CHEMBL587849 & 737826 & 6.5 & 6.1764 & TRN \\
\hline CHEMBL1361757 & 737826 & 4.9 & 5.3515 & TRN \\
\hline CHEMBL1380641 & 737826 & 5.8 & 5.1137 & TRN \\
\hline CHEMBL11405 & 737826 & 4.9 & 5.2904 & TRN \\
\hline CHEMBL1333076 & 737826 & 4.85 & 5.5144 & TRN \\
\hline CHEMBL1415957 & 737826 & 4.4 & 4.3933 & TRN \\
\hline CHEMBL1443952 & 737826 & 5.5 & 5.3421 & TRN \\
\hline CHEMBL1460680 & 737826 & 4.65 & 5.2152 & TRN \\
\hline CHEMBL1547764 & 737826 & 5.3 & 5.3078 & TRN \\
\hline CHEMBL1499077 & 737826 & 6.5 & 6.2863 & TRN \\
\hline CHEMBL1586684 & 737826 & 5.7 & 5.4997 & TRN \\
\hline
\end{tabular}




\begin{tabular}{|c|c|c|c|c|c|}
\hline \\
\hline CHEMBL104554 & 737826 & 4.8 & 5.2407 & TRN & \\
\hline CHEMBL3195553 & 737826 & 5.5 & 5.5394 & TRN & \\
\hline CHEMBL1482289 & 737826 & 4.7 & 5.2164 & TRN & \\
\hline CHEMBL1547955 & 737826 & 4.75 & 5.2052 & TRN & \\
\hline CHEMBL1701329 & 737826 & 4.4 & 5.3084 & TRN & \\
\hline CHEMBL1477786 & 737826 & 5.65 & 5.2108 & TRN & \\
\hline CHEMBL1356331 & 737826 & 5.8 & 5.6139 & TRN & \\
\hline CHEMBL1417861 & 737826 & 6.25 & 5.495 & TST & \\
\hline CHEMBL1453364 & 737826 & 5.5 & 5.3792 & TRN & \\
\hline CHEMBL3208230 & 737826 & 4.9 & 5.2684 & TRN & \\
\hline CHEMBL2028181 & 737826 & 5.7 & 5.5068 & TST & \\
\hline CHEMBL1303356 & 737826 & 5.35 & 5.4916 & TST & \\
\hline CHEMBL1456911 & 737826 & 5.9 & 5.5019 & TRN & \\
\hline CHEMBL1604264 & 737826 & 5.0 & 5.5533 & TRN & \\
\hline CHEMBL1560551 & 737826 & 4.9 & 4.7382 & TST & \\
\hline CHEMBL1555510 & 737826 & 4.4 & 5.3866 & TRN & \\
\hline CHEMBL1342562 & 737826 & 4.8 & 5.4441 & TRN & \\
\hline CHEMBL1384802 & 737826 & 4.9 & 5.2972 & TRN & \\
\hline CHEMBL3193269 & 737826 & 5.35 & 5.2659 & TRN & \\
\hline CHEMBL1527466 & 737826 & 6.0 & 5.8837 & TRN & \\
\hline CHEMBL1556272 & 737826 & 6.9 & 5.5727 & TRN & \\
\hline CHEMBL1588603 & 737826 & 4.8 & 5.2817 & TRN & \\
\hline CHEMBL1502536 & 737826 & 5.35 & 5.268 & TRN & \\
\hline CHEMBL1549864 & 737826 & 5.45 & 5.2141 & TST & \\
\hline CHEMBL1572157 & 737826 & 5.2 & 5.3568 & TRN & \\
\hline CHEMBL1392564 & 737826 & 5.55 & 5.4332 & TRN & \\
\hline CHEMBL1487205 & 737826 & 5.5 & 5.3196 & TRN & \\
\hline CHEMBL 303516 & 737826 & 5.3 & 5.1399 & TST & \\
\hline CHEMBL1586390 & 737826 & 4.8 & 5.1898 & TST & \\
\hline CHEMBL1343368 & 737826 & 5.0 & 5.4572 & TRN & \\
\hline CHEMBL1422718 & 737826 & 6.2 & 5.18 & TRN & \\
\hline CHEMBL1444135 & 737826 & 4.95 & 5.185 & TRN & \\
\hline CHEMBL1458289 & 737826 & 4.95 & 5.5792 & TRN & \\
\hline CHEMBL1526524 & 737826 & 5.65 & 5.263 & TRN & \\
\hline CHEMBL1366361 & 737826 & 4.9 & 5.4139 & TRN & \\
\hline CHEMBL3213017 & 737826 & 6.05 & 5.5472 & TRN & \\
\hline CHEMBL1409996 & 737826 & 5.0 & 5.0187 & TRN & \\
\hline CHEMBL1463002 & 737826 & 5.95 & 5.402 & TRN & \\
\hline CHEMBL1565546 & 737826 & 4.45 & 5.17200 & 0000000001 & TRN \\
\hline CHEMBL1741479 & 737826 & 4.6 & 5.3738 & TST & \\
\hline CHEMBL1308361 & 737826 & 4.55 & 5.4676 & TRN & \\
\hline CHEMBL1430949 & 737826 & 6.75 & 5.2869 & TST & \\
\hline CHEMBL1500226 & 737826 & 5.0 & 5.2113 & TST & \\
\hline CHEMBL1988621 & 737826 & 4.9 & 5.3005 & TRN & \\
\hline CHEMBL1446341 & 737826 & 6.1 & 5.211 & TRN & \\
\hline CHEMBL1698063 & 737826 & 5.05 & 5.2435 & TRN & \\
\hline CHEMBL491771 & 737826 & 6.3 & 6.2033 & TRN & \\
\hline CHEMBL1433173 & 737826 & 4.55 & 5.3012 & TRN & \\
\hline
\end{tabular}




\begin{tabular}{|c|c|c|c|c|c|}
\hline & & & & & \\
\hline CHEMBL1509952 & 737826 & 4.8 & 5.3443 & TRN & \\
\hline CHEMBL1378545 & 737826 & 5.75 & 5.1168 & TST & \\
\hline CHEMBL1491744 & 737826 & 6.5 & 6.1893 & TRN & \\
\hline CHEMBL3191464 & 737826 & 5.0 & 5.1228 & TRN & \\
\hline CHEMBL1469597 & 737826 & 5.05 & 5.2388 & TRN & \\
\hline CHEMBL1304606 & 737826 & 5.0 & 5.4614 & TRN & \\
\hline CHEMBL1484032 & 737826 & 4.8 & 4.6193 & TST & \\
\hline CHEMBL3192412 & 737826 & 5.1 & 5.1716 & TRN & \\
\hline CHEMBL1585305 & 737826 & 4.65 & 5.0727 & TRN & \\
\hline CHEMBL1552095 & 737826 & 6.0 & 5.7432 & TST & \\
\hline CHEMBL1595166 & 737826 & 5.1 & 4.9436 & TRN & \\
\hline CHEMBL1505201 & 737826 & 5.25 & 5.0777 & TRN & \\
\hline CHEMBL1363622 & 737826 & 5.3 & 5.1939 & TRN & \\
\hline CHEMBL1980031 & 737826 & 5.25 & 5.2702 & TRN & \\
\hline CHEMBL1428264 & 737826 & 6.3 & 5.5777 & TRN & \\
\hline CHEMBL1573532 & 737826 & 5.7 & 5.5839 & TRN & \\
\hline CHEMBL1515324 & 737826 & 4.9 & 4.8404 & TRN & \\
\hline CHEMBL1528911 & 737826 & 8.05 & 5.2869 & TRN & \\
\hline CHEMBL1256740 & 737826 & 7.8 & 6.7404 & TST & \\
\hline CHEMBL1303348 & 737826 & 5.3 & 5.2719 & TST & \\
\hline CHEMBL1533276 & 737826 & 4.75 & 5.28799 & 9999999999 & TRN \\
\hline CHEMBL1443362 & 737826 & 5.25 & 5.416 & TRN & \\
\hline CHEMBL1600490 & 737826 & 5.1 & 5.4775 & TRN & \\
\hline CHEMBL1613529 & 737826 & 4.5 & 5.5174 & TRN & \\
\hline CHEMBL1257012 & 737826 & 4.4 & 4.5753 & TST & \\
\hline CHEMBL3197678 & 737826 & 5.45 & 5.2762 & TRN & \\
\hline CHEMBL1593068 & 737826 & 5.2 & 5.2234 & TRN & \\
\hline CHEMBL1435254 & 737826 & 5.7 & 5.5102 & TRN & \\
\hline CHEMBL1406631 & 737826 & 6.35 & 5.2557 & TRN & \\
\hline CHEMBL1333080 & 737826 & 5.3 & 5.2837 & TRN & \\
\hline CHEMBL106780 & 737826 & 4.6 & 5.318 & TRN & \\
\hline CHEMBL10347 & 737826 & 4.7 & 5.7815 & TRN & \\
\hline CHEMBL1460723 & 737826 & 5.55 & 5.2687 & TRN & \\
\hline CHEMBL1400667 & 737826 & 4.4 & 4.61 & TST & \\
\hline CHEMBL1375469 & 737826 & 6.0 & 5.8472 & TRN & \\
\hline CHEMBL1372099 & 737826 & 4.75 & 5.16299 & 9999999999 & TRN \\
\hline CHEMBL1409258 & 737826 & 5.35 & 5.3661 & TRN & \\
\hline CHEMBL1411081 & 737826 & 6.0 & 5.7319 & TRN & \\
\hline CHEMBL1587109 & 737826 & 5.5 & 5.375 & TRN & \\
\hline CHEMBL1469212 & 737826 & 7.6 & 5.07600 & j0000000005 & TRN \\
\hline CHEMBL1528262 & 737826 & 5.75 & 5.4105 & TRN & \\
\hline CHEMBL1458424 & 737826 & 4.4 & 5.0496 & TRN & \\
\hline CHEMBL1535905 & 737826 & 5.55 & 5.3146 & TRN & \\
\hline CHEMBL1741331 & 737826 & 7.6499 & 5.1018 & TRN & \\
\hline CHEMBL1406854 & 737826 & 5.05 & 5.18 & TST & \\
\hline CHEMBL1348276 & 737826 & 5.55 & 5.1164 & TRN & \\
\hline CHEMBL1424808 & 737826 & 4.4 & 5.2922 & TRN & \\
\hline CHEMBL1611715 & 737826 & 4.65 & 5.1416 & TRN & \\
\hline
\end{tabular}




\begin{tabular}{|c|c|c|c|c|c|}
\hline \\
\hline CHEMBL1344769 & 737826 & 4.9 & 5.3977 & TST & \\
\hline CHEMBL1561515 & 737826 & 4.65 & 5.3771 & TST & \\
\hline CHEMBL1541564 & 737826 & 5.25 & 5.2413 & TRN & \\
\hline CHEMBL1324334 & 737826 & 5.4 & 5.3251 & TRN & \\
\hline CHEMBL1325335 & 737826 & 4.4 & 4.4371 & TRN & \\
\hline CHEMBL1302767 & 737826 & 5.7 & 5.2041 & TST & \\
\hline CHEMBL1397825 & 737826 & 5.0 & 4.82100 & 0000000001 & TRN \\
\hline CHEMBL1404317 & 737826 & 4.9 & 4.8899 & TRN & \\
\hline CHEMBL1566244 & 737826 & 5.1 & 5.073 & TRN & \\
\hline CHEMBL1452221 & 737826 & 6.1 & 5.9008 & TRN & \\
\hline CHEMBL286615 & 737826 & 4.8 & 4.8423 & TRN & \\
\hline CHEMBL1341999 & 737826 & 4.95 & 5.4009 & TRN & \\
\hline CHEMBL1989683 & 737826 & 5.65 & 5.184 & TRN & \\
\hline CHEMBL1605233 & 737826 & 4.6 & 4.5588 & TST & \\
\hline CHEMBL1358137 & 737826 & 5.1 & 5.1132 & TRN & \\
\hline CHEMBL1439366 & 737826 & 5.25 & 5.289 & TRN & \\
\hline CHEMBL1572173 & 737826 & 4.8 & 4.7494 & TRN & \\
\hline CHEMBL1542262 & 737826 & 5.0 & 5.1594 & TRN & \\
\hline CHEMBL1544250 & 737826 & 5.25 & 5.2132 & TRN & \\
\hline CHEMBL1405696 & 737826 & 6.75 & 5.2571 & TRN & \\
\hline CHEMBL180162 & 737826 & 5.65 & 5.1679 & TRN & \\
\hline CHEMBL1313226 & 737826 & 5.9 & 5.42200 & 0000000001 & TRN \\
\hline CHEMBL1355935 & 737826 & 4.7 & 4.7176 & TRN & \\
\hline CHEMBL1317924 & 737826 & 4.6 & 4.8214 & TRN & \\
\hline CHEMBL1552249 & 737826 & 4.6 & 4.6854 & TST & \\
\hline CHEMBL1603445 & 737826 & 4.95 & 5.2641 & TRN & \\
\hline CHEMBL1536254 & 737826 & 4.95 & 5.4531 & TRN & \\
\hline CHEMBL1525465 & 737826 & 6.15 & 5.2735 & TRN & \\
\hline CHEMBL1591860 & 737826 & 4.4 & 4.4209 & TRN & \\
\hline CHEMBL1417599 & 737826 & 5.0 & 5.2888 & TRN & \\
\hline CHEMBL1742215 & 737826 & 4.9 & 5.1294 & TRN & \\
\hline CHEMBL1425874 & 737826 & 5.65 & 5.1088 & TRN & \\
\hline CHEMBL1603267 & 737826 & 5.0 & 5.2741 & TRN & \\
\hline CHEMBL428814 & 737826 & 6.3 & 6.3169 & TRN & \\
\hline CHEMBL1353281 & 737826 & 5.05 & 5.2477 & TRN & \\
\hline CHEMBL1422586 & 737826 & 4.8 & 5.1363 & TRN & \\
\hline CHEMBL1437991 & 737826 & 5.0 & 5.3635 & TRN & \\
\hline CHEMBL1332990 & 737826 & 5.5 & 5.187 & TRN & \\
\hline CHEMBL1500967 & 737826 & 4.45 & 5.2328 & TRN & \\
\hline CHEMBL1470796 & 737826 & 5.5 & 5.3512 & TST & \\
\hline CHEMBL1741329 & 737826 & 4.75 & 5.3689 & TRN & \\
\hline CHEMBL1391888 & 737826 & 4.95 & 5.1727 & TST & \\
\hline CHEMBL1371726 & 737826 & 6.0 & 5.6446 & TRN & \\
\hline CHEMBL1493869 & 737826 & 7.2 & 5.3054 & TRN & \\
\hline CHEMBL1356842 & 737826 & 7.1 & 6.1506 & TRN & \\
\hline CHEMBL1526369 & 737826 & 4.85 & 5.2156 & TRN & \\
\hline CHEMBL1346437 & 737826 & 4.9 & 5.3004 & TRN & \\
\hline CHEMBL1410399 & 737826 & 5.5 & 5.376 & TRN & \\
\hline
\end{tabular}




\begin{tabular}{|c|c|c|c|c|c|}
\hline \\
\hline CHEMBL1322634 & 737826 & 5.0 & 5.2649 & TST & \\
\hline CHEMBL1456034 & 737826 & 4.8 & 5.3355 & TST & \\
\hline CHEMBL3209838 & 737826 & 5.5 & 5.4625 & TRN & \\
\hline CHEMBL1597078 & 737826 & 5.55 & 5.1925 & TRN & \\
\hline CHEMBL1375424 & 737826 & 5.85 & 5.2886 & TRN & \\
\hline CHEMBL1323524 & 737826 & 5.8 & 5.2735 & TRN & \\
\hline CHEMBL1385847 & 737826 & 6.7 & 5.1679 & TRN & \\
\hline CHEMBL1299692 & 737826 & 5.4 & 5.1852 & TRN & \\
\hline CHEMBL608555 & 737826 & 5.0 & 4.8816 & TST & \\
\hline CHEMBL241657 & 737826 & 5.55 & 5.2201 & TRN & \\
\hline CHEMBL1568413 & 737826 & 6.15 & 5.1463 & TRN & \\
\hline CHEMBL1375723 & 737826 & 5.4 & 5.3555 & TRN & \\
\hline CHEMBL1572371 & 737826 & 5.1 & 5.3725 & TRN & \\
\hline CHEMBL1348987 & 737826 & 5.5 & 5.3082 & TRN & \\
\hline CHEMBL1478570 & 737826 & 4.65 & 5.3444 & TRN & \\
\hline CHEMBL539947 & 737826 & 7.0 & 6.4311 & TRN & \\
\hline CHEMBL1468024 & 737826 & 5.2 & 5.2528 & TRN & \\
\hline CHEMBL188 & 737826 & 5.9 & 5.4868 & TST & \\
\hline CHEMBL1380969 & 737826 & 6.05 & 5.4784 & TRN & \\
\hline CHEMBL1352020 & 737826 & 5.2 & 5.4746 & TRN & \\
\hline CHEMBL1511207 & 737826 & 5.45 & 5.3145 & TRN & \\
\hline CHEMBL1392763 & 737826 & 5.1 & 5.33200 & 2000000001 & TST \\
\hline CHEMBL1467331 & 737826 & 5.1 & 5.3834 & TRN & \\
\hline CHEMBL1559472 & 737826 & 5.75 & 5.23600 & 2000000001 & TRN \\
\hline CHEMBL 3189450 & 737826 & 4.4 & 5.3192 & TRN & \\
\hline CHEMBL1569846 & 737826 & 4.8 & 5.2743 & TRN & \\
\hline CHEMBL1334687 & 737826 & 5.1 & 5.0851 & TRN & \\
\hline CHEMBL3214373 & 737826 & 5.6 & 5.266 & TRN & \\
\hline CHEMBL1483441 & 737826 & 4.8 & 5.2025 & TRN & \\
\hline CHEMBL1328307 & 737826 & 4.85 & 5.2392 & TRN & \\
\hline CHEMBL475198 & 737826 & 6.2 & 6.1624 & TRN & \\
\hline CHEMBL3211898 & 737826 & 4.85 & 5.1796 & TRN & \\
\hline CHEMBL1408138 & 737826 & 5.4 & 5.438 & TST & \\
\hline CHEMBL1525907 & 737826 & 4.45 & 5.2012 & TRN & \\
\hline CHEMBL1526175 & 737826 & 5.35 & 5.0862 & TRN & \\
\hline CHEMBL3209269 & 737826 & 4.7 & 5.4068 & TRN & \\
\hline CHEMBL1470174 & 737826 & 6.05 & 5.3194 & TRN & \\
\hline CHEMBL1480293 & 737826 & 4.8 & 4.7587 & TRN & \\
\hline CHEMBL1429594 & 737826 & 5.75 & 5.2796 & TRN & \\
\hline CHEMBL1364097 & 737826 & 4.8 & 5.2854 & TST & \\
\hline CHEMBL1344097 & 737826 & 4.65 & 5.2142 & TST & \\
\hline CHEMBL1321459 & 737826 & 5.9 & 5.7944 & TRN & \\
\hline CHEMBL1364804 & 737826 & 5.4 & 5.2561 & TRN & \\
\hline CHEMBL1352043 & 737826 & 5.4 & 5.3748 & TRN & \\
\hline CHEMBL1326308 & 737826 & 5.4 & 5.23600 & 2000000001 & TRN \\
\hline CHEMBL1489737 & 737826 & 4.7 & 5.2945 & TRN & \\
\hline CHEMBL1565411 & 737826 & 4.6 & 5.0972 & TRN & \\
\hline CHEMBL1333282 & 737826 & 4.85 & 5.2675 & TRN & \\
\hline & & & & 6471 & \\
\hline
\end{tabular}




\begin{tabular}{|c|c|c|c|c|}
\hline \multicolumn{5}{|c|}{ Supplemental Table S2.txt } \\
\hline CHEMBL1732802 & 737826 & 5.35 & 5.5489 & TRN \\
\hline CHEMBL1552727 & 737826 & -0.0 & 4.6988 & TRN \\
\hline CHEMBL1474185 & 737826 & 4.4 & 4.4067 & TRN \\
\hline CHEMBL1438061 & 737826 & 6.2 & 5.254 & TRN \\
\hline CHEMBL1508431 & 737826 & 5.5 & 5.4992 & TST \\
\hline CHEMBL1437054 & 737826 & 8.0 & 7.1597 & TRN \\
\hline CHEMBL1604366 & 737826 & 5.5 & 5.2782 & TRN \\
\hline CHEMBL1612107 & 737826 & 4.95 & 5.0677 & TRN \\
\hline CHEMBL1417999 & 737826 & 5.05 & 5.3917 & TRN \\
\hline CHEMBL1587603 & 737826 & 4.4 & 5.1963 & TRN \\
\hline CHEMBL1470247 & 737826 & 4.75 & 5.2724 & TRN \\
\hline CHEMBL1395869 & 737826 & 5.4 & 5.4282 & TRN \\
\hline CHEMBL1389090 & 737826 & 5.15 & 5.3089 & TRN \\
\hline CHEMBL1490214 & 737826 & 4.45 & 5.2939 & TST \\
\hline CHEMBL1519293 & 737826 & 4.85 & 5.4237 & TRN \\
\hline CHEMBL1432603 & 737826 & 5.5 & 5.256 & TRN \\
\hline CHEMBL1332286 & 737826 & 4.4 & 5.2176 & TRN \\
\hline CHEMBL1307904 & 737826 & 5.05 & 5.2429 & TST \\
\hline CHEMBL1733672 & 737826 & 4.6 & 5.1841 & TRN \\
\hline CHEMBL1599607 & 737826 & 5.0 & 5.324 & TRN \\
\hline CHEMBL1383143 & 737826 & 5.75 & 5.3973 & TRN \\
\hline CHEMBL1403154 & 737826 & 5.4 & 5.2543 & TST \\
\hline CHEMBL1485231 & 737826 & 4.4 & 5.0423 & TST \\
\hline CHEMBL1408259 & 737826 & 6.0 & 5.8697 & TRN \\
\hline CHEMBL1343392 & 737826 & 5.1 & 5.2805 & TST \\
\hline CHEMBL1390555 & 737826 & 5.75 & 5.3357 & TRN \\
\hline CHEMBL1467341 & 737826 & 4.5 & 5.5919 & TRN \\
\hline CHEMBL1390586 & 737826 & 5.4 & 5.2964 & TRN \\
\hline CHEMBL1591190 & 737826 & 4.4 & 4.4127 & TRN \\
\hline CHEMBL1316463 & 737826 & 4.8 & 5.0096 & TRN \\
\hline CHEMBL1351212 & 737826 & 5.1 & 5.3059 & TRN \\
\hline CHEMBL 1602780 & 737826 & 4.9 & 5.3593 & TRN \\
\hline CHEMBL1404598 & 737826 & 6.0 & 6.0739 & TRN \\
\hline CHEMBL1489033 & 737826 & 5.45 & 5.2901 & TRN \\
\hline CHEMBL1525813 & 737826 & 5.4 & 5.3071 & TRN \\
\hline CHEMBL1414577 & 737826 & 4.95 & 5.3449 & TRN \\
\hline CHEMBL1491065 & 737826 & 4.8 & 4.6415 & TRN \\
\hline CHEMBL1309064 & 737826 & 4.9 & 5.4247 & TRN \\
\hline CHEMBL1313575 & 737826 & 4.95 & 5.2338 & TRN \\
\hline CHEMBL1309874 & 737826 & 5.95 & 5.3658 & TRN \\
\hline CHEMBL1574233 & 737826 & 4.4 & 5.2443 & TRN \\
\hline CHEMBL1378306 & 737826 & 5.1 & 5.2919 & TRN \\
\hline CHEMBL1441347 & 737826 & 4.5 & 5.1078 & TST \\
\hline CHEMBL1441394 & 737826 & 4.8 & 5.6948 & TRN \\
\hline CHEMBL3197859 & 737826 & 4.85 & 5.2917 & TST \\
\hline CHEMBL1980826 & 737826 & 6.1 & 5.3114 & TST \\
\hline CHEMBL3191804 & 737826 & 4.7 & 5.4949 & TRN \\
\hline CHEMBL1865547 & 737826 & 5.4 & 5.3812 & TRN \\
\hline
\end{tabular}




\begin{tabular}{|c|c|c|c|c|c|}
\hline & & & & & \\
\hline CHEMBL1443124 & 737826 & 5.2 & 5.1862 & TRN & \\
\hline CHEMBL1526260 & 737826 & 4.5 & 5.4754 & TRN & \\
\hline CHEMBL1337781 & 737826 & 6.7 & 6.2936 & TRN & \\
\hline CHEMBL1391390 & 737826 & 5.2 & 5.2344 & TRN & \\
\hline CHEMBL1701090 & 737826 & 4.8 & 5.3411 & TRN & \\
\hline CHEMBL587259 & 737826 & 5.2 & 5.2665 & TRN & \\
\hline CHEMBL1476632 & 737826 & 6.2 & 5.831 & TRN & \\
\hline CHEMBL1476383 & 737826 & 4.9 & 4.8296 & TST & \\
\hline CHEMBL1482233 & 737826 & 4.85 & 5.4724 & TRN & \\
\hline CHEMBL1415482 & 737826 & 4.45 & 5.352 & TRN & \\
\hline CHEMBL1588553 & 737826 & 4.8 & 5.7946 & TRN & \\
\hline CHEMBL1583320 & 737826 & 4.6 & 5.4579 & TRN & \\
\hline CHEMBL1325392 & 737826 & 5.0 & 5.471 & TRN & \\
\hline CHEMBL1505565 & 737826 & 5.45 & 5.5143 & TRN & \\
\hline CHEMBL1475146 & 737826 & 6.3 & 5.965 & TRN & \\
\hline CHEMBL1395992 & 737826 & 6.4 & 6.1056 & TRN & \\
\hline CHEMBL1368337 & 737826 & 5.25 & 5.4738 & TRN & \\
\hline CHEMBL1594988 & 737826 & 5.1 & 5.2279 & TRN & \\
\hline CHEMBL1583568 & 737826 & 4.55 & 5.2194 & TST & \\
\hline CHEMBL1309858 & 737826 & 5.45 & 5.1943 & TRN & \\
\hline CHEMBL1462421 & 737826 & 4.9 & 5.4083 & TRN & \\
\hline CHEMBL1356372 & 737826 & 4.8 & 4.7194 & TRN & \\
\hline CHEMBL1427178 & 737826 & 5.7 & 5.3807 & TRN & \\
\hline CHEMBL187734 & 737826 & 4.4 & 4.4382 & TRN & \\
\hline CHEMBL1440509 & 737826 & 5.2 & 5.1408 & TRN & \\
\hline CHEMBL1418881 & 737826 & 4.85 & 5.4488 & TST & \\
\hline CHEMBL 3210244 & 737826 & 5.5 & 5.3468 & TRN & \\
\hline CHEMBL3193125 & 737826 & 5.45 & 5.2786 & TRN & \\
\hline CHEMBL1364963 & 737826 & 5.25 & 5.1423 & TST & \\
\hline CHEMBL1365994 & 737826 & 5.3 & 5.2365 & TRN & \\
\hline CHEMBL1409809 & 737826 & 6.0 & 5.1535 & TRN & \\
\hline CHEMBL1531688 & 737826 & 4.75 & 5.2778 & TRN & \\
\hline CHEMBL1502523 & 737826 & 5.2 & 5.3437 & TRN & \\
\hline CHEMBL1583260 & 737826 & 5.35 & 5.124 & TST & \\
\hline CHEMBL1426357 & 737826 & 5.7 & 5.1597 & TRN & \\
\hline CHEMBL3189354 & 737826 & 5.6 & 5.4981 & TRN & \\
\hline CHEMBL1377215 & 737826 & 6.55 & 5.3431 & TRN & \\
\hline CHEMBL1530558 & 737826 & 4.95 & 5.2281 & TRN & \\
\hline CHEMBL1338432 & 737826 & 5.05 & 5.5024 & TRN & \\
\hline CHEMBL1602633 & 737826 & 5.3 & 5.2347 & TRN & \\
\hline CHEMBL1495077 & 737826 & 4.8 & 4.5544 & TRN & \\
\hline CHEMBL1471962 & 737826 & 4.85 & 5.2454 & TRN & \\
\hline CHEMBL1556705 & 737826 & 5.85 & 5.3475 & TRN & \\
\hline CHEMBL1376622 & 737826 & 5.15 & 5.3728 & TRN & \\
\hline CHEMBL1321476 & 737826 & 5.0 & 5.2234 & TRN & \\
\hline CHEMBL1360952 & 737826 & 5.0 & 5.1614 & TST & \\
\hline CHEMBL1544694 & 737826 & 5.3 & 5.1192 & TST & \\
\hline CHEMBL1372102 & 737826 & 5.55 & $5.3270 e$ & 2000000001 & TST \\
\hline & & & & e 6473 & \\
\hline
\end{tabular}




\begin{tabular}{|c|c|c|c|c|c|}
\hline \multicolumn{6}{|c|}{ 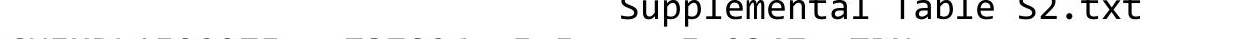 } \\
\hline CHEMBL1590975 & 737826 & 5.5 & 5.2347 & TRN & \\
\hline CHEMBL1461759 & 737826 & 5.25 & 5.1417 & TRN & \\
\hline CHEMBL1468283 & 737826 & 6.05 & 5.2632 & TRN & \\
\hline CHEMBL1433783 & 737826 & 4.7 & 4.6241 & TRN & \\
\hline CHEMBL1525558 & 737826 & 4.9 & 5.1762 & TRN & \\
\hline CHEMBL1519178 & 737826 & 4.7 & 5.5378 & TST & \\
\hline CHEMBL1527722 & 737826 & 6.0 & 5.6654 & TST & \\
\hline CHEMBL1741647 & 737826 & 4.7 & 5.3356 & TRN & \\
\hline CHEMBL1326272 & 737826 & 5.55 & 5.2224 & TRN & \\
\hline CHEMBL1388465 & 737826 & 5.3 & 5.2346 & TRN & \\
\hline CHEMBL1457723 & 737826 & 4.6 & 5.2066 & TRN & \\
\hline CHEMBL1488931 & 737826 & 5.4 & 5.3595 & TST & \\
\hline CHEMBL1256923 & 737826 & 4.7 & 4.7792 & TST & \\
\hline CHEMBL1613702 & 737826 & 4.85 & 5.3426 & TRN & \\
\hline CHEMBL1585809 & 737826 & 5.3 & 5.6272 & TRN & \\
\hline CHEMBL1329402 & 737826 & 5.55 & 5.3114 & TRN & \\
\hline CHEMBL1533932 & 737826 & 4.9 & 4.8534 & TRN & \\
\hline CHEMBL1307715 & 737826 & 5.0 & 5.3093 & TRN & \\
\hline CHEMBL1389204 & 737826 & 5.75 & 5.3977 & TRN & \\
\hline CHEMBL1346999 & 737826 & 5.6 & 5.1826 & TRN & \\
\hline CHEMBL1466162 & 737826 & 4.75 & 5.0097 & TRN & \\
\hline CHEMBL1409369 & 737826 & 5.5 & 5.4267 & TRN & \\
\hline CHEMBL1396773 & 737826 & 4.9 & 4.817 & TRN & \\
\hline CHEMBL1327836 & 737826 & 5.4 & 5.2076 & TRN & \\
\hline CHEMBL1338714 & 737826 & 4.9 & 5.2735 & TRN & \\
\hline CHEMBL1374931 & 737826 & 5.7 & 5.3238 & TRN & \\
\hline CHEMBL1493944 & 737826 & 6.2 & 5.2661 & TRN & \\
\hline CHEMBL1375428 & 737826 & 4.9 & 5.3335 & TRN & \\
\hline CHEMBL1494697 & 737826 & 6.5 & 6.0534 & TRN & \\
\hline CHEMBL1502684 & 737826 & 5.9 & 5.324 & TRN & \\
\hline CHEMBL3145111 & 737826 & 5.0 & 5.2963 & TRN & \\
\hline CHEMBL1368892 & 737826 & 5.6 & 5.42899 & 9999999999 & TRN \\
\hline CHEMBL1470199 & 737826 & 6.15 & 5.4755 & TRN & \\
\hline CHEMBL23832 & 737826 & 4.8 & 4.8396 & TRN & \\
\hline CHEMBL1726157 & 737826 & 5.5 & 5.1441 & TRN & \\
\hline CHEMBL1575476 & 737826 & 5.15 & 5.3979 & TST & \\
\hline CHEMBL1490528 & 737826 & 5.7 & 5.3893 & TRN & \\
\hline CHEMBL1561615 & 737826 & 4.65 & 5.2499 & TRN & \\
\hline CHEMBL1336932 & 737826 & 4.6 & 4.4814 & TRN & \\
\hline CHEMBL1442106 & 737826 & 4.5 & 4.3776 & TRN & \\
\hline CHEMBL 2002680 & 737826 & 4.85 & 5.4563 & TRN & \\
\hline CHEMBL3191940 & 737826 & 5.35 & 5.3161 & TST & \\
\hline CHEMBL1492374 & 737826 & 5.7 & 5.7409 & TRN & \\
\hline CHEMBL1570465 & 737826 & 5.6 & 5.525 & TRN & \\
\hline CHEMBL1380684 & 737826 & 6.0 & 5.4376 & TST & \\
\hline CHEMBL1530209 & 737826 & 4.6 & 5.2935 & TRN & \\
\hline CHEMBL1354841 & 737826 & 4.7 & 4.8803 & TRN & \\
\hline CHEMBL1409626 & 737826 & 5.55 & 5.3807 & TRN & \\
\hline
\end{tabular}




\begin{tabular}{|c|c|c|c|c|c|}
\hline & & \multicolumn{4}{|c|}{ Supplemental Table s2.txt } \\
\hline CHEMBL1519576 & 737826 & 5.55 & 5.2778 & TRN & \\
\hline CHEMBL1366635 & 737826 & 4.7 & 5.2038 & TRN & \\
\hline CHEMBL1392640 & 737826 & 6.45 & 5.7744 & TRN & \\
\hline CHEMBL1608337 & 737826 & 5.1 & 5.1169 & TRN & \\
\hline CHEMBL1609142 & 737826 & 5.0 & 4.8338 & TRN & \\
\hline CHEMBL516616 & 737826 & 5.1 & 5.0606 & TST & \\
\hline CHEMBL1311969 & 737826 & 4.95 & 5.1116 & TRN & \\
\hline CHEMBL1415219 & 737826 & 4.65 & 5.2991 & TRN & \\
\hline CHEMBL1483088 & 737826 & 4.8 & 5.1621 & TRN & \\
\hline CHEMBL1325971 & 737826 & 7.0 & 5.4342 & TRN & \\
\hline CHEMBL1310477 & 737826 & 5.9 & 5.2188 & TRN & \\
\hline CHEMBL1536844 & 737826 & 4.95 & 5.2411 & TST & \\
\hline CHEMBL1575193 & 737826 & 5.05 & 5.25700 & 3000000001 & TRN \\
\hline CHEMBL1517195 & 737826 & 5.65 & 5.1688 & TRN & \\
\hline CHEMBL317757 & 737826 & 5.3 & 5.2016 & TST & \\
\hline CHEMBL1606723 & 737826 & 4.55 & 5.4129 & TRN & \\
\hline CHEMBL3192742 & 737826 & 5.6 & 5.4343 & TRN & \\
\hline CHEMBL1424948 & 737826 & 4.9 & 5.2504 & TRN & \\
\hline CHEMBL1361182 & 737826 & 5.6 & 5.4895 & TRN & \\
\hline CHEMBL40004 & 737826 & 6.35 & 5.5223 & TRN & \\
\hline CHEMBL1403606 & 737826 & 5.0 & 5.3449 & TST & \\
\hline CHEMBL268609 & 737826 & 6.0 & 5.8542 & TRN & \\
\hline CHEMBL1343285 & 737826 & 5.45 & 5.3387 & TRN & \\
\hline CHEMBL1350415 & 737826 & 5.2 & 5.5008 & TRN & \\
\hline CHEMBL1452932 & 737826 & 4.5 & 5.0965 & TRN & \\
\hline CHEMBL1445094 & 737826 & 5.9 & 5.9357 & TRN & \\
\hline CHEMBL1320948 & 737826 & 5.4 & 5.2954 & TRN & \\
\hline CHEMBL1601482 & 737826 & 4.7 & 5.2047 & TRN & \\
\hline CHEMBL1324162 & 737826 & 4.85 & 5.29 & TRN & \\
\hline CHEMBL1336412 & 737826 & 5.15 & 5.2852 & TST & \\
\hline CHEMBL1390396 & 737826 & 5.45 & 5.21399 & 99999999995 & TRN \\
\hline CHEMBL1742104 & 737826 & 5.5 & 5.3624 & TRN & \\
\hline CHEMBL1557851 & 737826 & 5.45 & 5.4606 & TST & \\
\hline CHEMBL1414477 & 737826 & 5.8 & 5.6493 & TRN & \\
\hline CHEMBL1488362 & 737826 & 4.9 & 5.2121 & TRN & \\
\hline CHEMBL1388771 & 737826 & 5.45 & 5.1551 & TRN & \\
\hline CHEMBL1414993 & 737826 & 5.2 & 5.1959 & TRN & \\
\hline CHEMBL1584987 & 737826 & 4.55 & 5.2217 & TRN & \\
\hline CHEMBL1712617 & 737826 & 5.5 & 5.1668 & TST & \\
\hline CHEMBL 3197274 & 737826 & 4.6 & 5.0784 & TRN & \\
\hline CHEMBL1532380 & 737826 & 5.5 & 5.2708 & TRN & \\
\hline CHEMBL1580804 & 737826 & 5.1 & 5.2955 & TRN & \\
\hline CHEMBL1508610 & 737826 & 5.25 & 5.1159 & TRN & \\
\hline CHEMBL39878 & 737826 & 5.3 & 5.0703 & TRN & \\
\hline CHEMBL1357968 & 737826 & 4.7 & 4.5486 & TRN & \\
\hline CHEMBL1387271 & 737826 & 5.0 & 5.4648 & TRN & \\
\hline CHEMBL1523670 & 737826 & 5.1 & 5.2638 & TRN & \\
\hline CHEMBL1371944 & 737826 & 5.3 & 5.1764 & TRN & \\
\hline
\end{tabular}




\begin{tabular}{|c|c|c|c|c|c|}
\hline \\
\hline CHEMBL1545407 & 737826 & 6.2 & 5.4338 & TRN & \\
\hline CHEMBL1433668 & 737826 & 4.4 & 4.5803 & TRN & \\
\hline CHEMBL407874 & 737826 & 4.4 & 4.629 & TRN & \\
\hline CHEMBL1554459 & 737826 & 5.6 & 5.5008 & TRN & \\
\hline CHEMBL1705149 & 737826 & 4.6 & 5.1303 & TRN & \\
\hline CHEMBL1489765 & 737826 & 8.25 & 5.22 & TRN & \\
\hline CHEMBL1549118 & 737826 & 5.6 & 5.3215 & TRN & \\
\hline CHEMBL1519647 & 737826 & 4.85 & 5.1672 & TRN & \\
\hline CHEMBL1326093 & 737826 & 5.0 & 5.2664 & TRN & \\
\hline CHEMBL1703799 & 737826 & 5.65 & 5.2629 & TRN & \\
\hline CHEMBL1439839 & 737826 & 4.7 & 4.6711 & TRN & \\
\hline CHEMBL1318758 & 737826 & 4.75 & 5.1837 & TRN & \\
\hline CHEMBL1336102 & 737826 & 4.8 & 5.303 & TRN & \\
\hline CHEMBL1409815 & 737826 & 4.9 & 5.1032 & TRN & \\
\hline CHEMBL1414633 & 737826 & 5.45 & 5.29700 & 0000000001 & TRN \\
\hline CHEMBL1505211 & 737826 & 5.05 & 5.274 & TST & \\
\hline CHEMBL1501247 & 737826 & 4.9 & 5.2188 & TRN & \\
\hline CHEMBL1590663 & 737826 & 4.6 & 4.4114 & TRN & \\
\hline CHEMBL1496125 & 737826 & 5.1 & 5.16700 & 0000000001 & TRN \\
\hline CHEMBL1341789 & 737826 & 5.55 & 5.2174 & TRN & \\
\hline CHEMBL1374718 & 737826 & 5.45 & 5.1031 & TRN & \\
\hline CHEMBL1586264 & 737826 & 4.7 & 5.4283 & TRN & \\
\hline CHEMBL1335668 & 737826 & 6.2 & 5.8477 & TRN & \\
\hline CHEMBL464859 & 737826 & 4.6 & 4.5894 & TST & \\
\hline CHEMBL1386571 & 737826 & 5.1 & 5.0631 & TRN & \\
\hline CHEMBL1563190 & 737826 & 5.5 & 5.4496 & TRN & \\
\hline CHEMBL1537750 & 737826 & 5.35 & 5.1861 & TRN & \\
\hline CHEMBL1741337 & 737826 & 4.55 & 5.3353 & TRN & \\
\hline CHEMBL1389308 & 737826 & 4.85 & 5.1405 & TRN & \\
\hline CHEMBL1354190 & 737826 & 5.6 & 5.4923 & TST & \\
\hline CHEMBL1356630 & 737826 & 5.9 & 6.12299 & 9999999999 & TRN \\
\hline CHEMBL1396090 & 737826 & 4.6 & 4.5941 & TRN & \\
\hline CHEMBL3194069 & 737826 & 5.45 & 5.4115 & TRN & \\
\hline CHEMBL1741851 & 737826 & 5.45 & 5.2322 & TRN & \\
\hline CHEMBL1424426 & 737826 & 5.25 & 5.3693 & TRN & \\
\hline CHEMBL1566017 & 737826 & 4.7 & 4.7498 & TRN & \\
\hline CHEMBL1457332 & 737826 & 5.1 & 4.8887 & TRN & \\
\hline CHEMBL1330929 & 737826 & 6.15 & 5.2364 & TRN & \\
\hline CHEMBL1611075 & 737826 & 5.15 & 5.2728 & TRN & \\
\hline CHEMBL1984764 & 737826 & 6.45 & 5.4685 & TRN & \\
\hline CHEMBL1470037 & 737826 & 4.7 & 5.3971 & TST & \\
\hline CHEMBL1465386 & 737826 & 6.5 & 5.2741 & TRN & \\
\hline CHEMBL1563992 & 737826 & 5.2 & 5.2897 & TRN & \\
\hline CHEMBL490756 & 737826 & 6.3 & 6.1866 & TRN & \\
\hline CHEMBL1595376 & 737826 & 4.85 & 5.2112 & TST & \\
\hline CHEMBL1414240 & 737826 & 5.4 & 5.3509 & TST & \\
\hline CHEMBL1411467 & 737826 & 6.4 & 5.3662 & TRN & \\
\hline CHEMBL1546010 & 737826 & 5.0 & 5.1902 & TST & \\
\hline
\end{tabular}




\begin{tabular}{|c|c|c|c|c|c|}
\hline CHEMBL1543760 & 737826 & 6.1 & \multicolumn{2}{|c|}{5.3260000000000005} & TRN \\
\hline CHEMBL1461471 & 737826 & 4.85 & 5.1955 & TST & \\
\hline CHEMBL1741773 & 737826 & 4.55 & 5.0043 & TST & \\
\hline CHEMBL1390189 & 737826 & 4.6 & 5.2332 & TRN & \\
\hline CHEMBL3191155 & 737826 & 4.55 & 5.1792 & TST & \\
\hline CHEMBL1514149 & 737826 & 5.9 & 5.9186 & TRN & \\
\hline CHEMBL1428944 & 737826 & 4.85 & 5.1314 & TRN & \\
\hline CHEMBL332898 & 737826 & 5.4 & 5.3035 & TRN & \\
\hline CHEMBL1591460 & 737826 & 6.0 & 5.7653 & TRN & \\
\hline CHEMBL1401085 & 737826 & 5.75 & 5.3315 & TRN & \\
\hline CHEMBL1470528 & 737826 & 5.4 & 5.3194 & TST & \\
\hline CHEMBL1566442 & 737826 & 4.6 & 4.5911 & TRN & \\
\hline CHEMBL1256749 & 737826 & 4.8 & 4.8473 & TST & \\
\hline CHEMBL1372952 & 737826 & 4.8 & 5.1228 & TRN & \\
\hline CHEMBL1345906 & 737826 & 5.35 & 5.2918 & TRN & \\
\hline CHEMBL1360125 & 737826 & 5.1 & 5.2405 & TRN & \\
\hline CHEMBL1398707 & 737826 & 6.4 & 5.3242 & TRN & \\
\hline CHEMBL1373007 & 737826 & 5.0 & 5.0033 & TST & \\
\hline CHEMBL1514045 & 737826 & 4.7 & 4.6314 & TRN & \\
\hline CHEMBL1410933 & 737826 & 5.1 & 5.03600 & 00000000005 & TRN \\
\hline CHEMBL1603803 & 737826 & 5.2 & 5.1002 & TRN & \\
\hline CHEMBL 3212049 & 737826 & 5.6 & 5.4837 & TRN & \\
\hline CHEMBL1417540 & 737826 & 5.5 & 5.6275 & TRN & \\
\hline CHEMBL3350578 & 737826 & 5.2 & 5.2328 & TST & \\
\hline CHEMBL1311260 & 737826 & 4.9 & 5.4161 & TRN & \\
\hline CHEMBL1317802 & 737826 & 4.9 & 4.7086 & TRN & \\
\hline CHEMBL1605699 & 737826 & 4.85 & 5.3594 & TRN & \\
\hline CHEMBL1395297 & 737826 & 5.0 & 4.7898 & TRN & \\
\hline CHEMBL1479817 & 737826 & 5.3 & 5.0732 & TRN & \\
\hline CHEMBL1354093 & 737826 & 4.7 & 5.3556 & TRN & \\
\hline CHEMBL1605678 & 737826 & 5.1 & 5.1457 & TRN & \\
\hline CHEMBL1359917 & 737826 & 5.4 & 5.4959 & TRN & \\
\hline CHEMBL1361114 & 737826 & 5.2 & 5.4312 & TST & \\
\hline CHEMBL35482 & 737826 & 4.5 & 4.5411 & TRN & \\
\hline CHEMBL1602549 & 737826 & 5.05 & 5.2204 & TST & \\
\hline CHEMBL1600243 & 737826 & 5.15 & 5.273 & TRN & \\
\hline CHEMBL3214406 & 737826 & 6.0 & 5.3442 & TST & \\
\hline CHEMBL1426928 & 737826 & 4.75 & 5.1223 & TST & \\
\hline CHEMBL1579444 & 737826 & 5.6 & 5.4745 & TRN & \\
\hline CHEMBL1316647 & 737826 & 4.7 & 4.5994 & TRN & \\
\hline CHEMBL158507 & 737826 & 5.8 & 5.4146 & TRN & \\
\hline CHEMBL1490869 & 737826 & 4.9 & 4.775 & TRN & \\
\hline CHEMBL585045 & 737826 & 5.5 & 5.3155 & TRN & \\
\hline CHEMBL1387502 & 737826 & 4.95 & 5.3599 & TRN & \\
\hline CHEMBL1374334 & 737826 & 5.5 & 5.3237 & TST & \\
\hline CHEMBL16687 & 737826 & 4.5 & 4.6306 & TRN & \\
\hline CHEMBL540294 & 737826 & 6.0 & 5.6944 & TST & \\
\hline CHEMBL1540475 & 737826 & 4.8 & 5.3963 & TRN & \\
\hline
\end{tabular}




\begin{tabular}{|c|c|c|c|c|c|}
\hline & & & & & \\
\hline CHEMBL1371572 & 737826 & 5.5 & 5.364 & TRN & \\
\hline CHEMBL1544565 & 737826 & 4.85 & 5.4015 & TRN & \\
\hline CHEMBL1568744 & 737826 & 4.4 & 4.7067 & TRN & \\
\hline CHEMBL1361813 & 737826 & 4.9 & 5.1987 & TRN & \\
\hline CHEMBL1496722 & 737826 & 4.85 & 5.3271 & TRN & \\
\hline CHEMBL1432440 & 737826 & 5.0 & 5.1061 & TRN & \\
\hline CHEMBL565654 & 737826 & 6.2 & 6.143 & TRN & \\
\hline CHEMBL1539817 & 737826 & 5.55 & 5.28600 & 00000000005 & TRN \\
\hline CHEMBL1566928 & 737826 & 5.0 & 5.2225 & TST & \\
\hline CHEMBL90769 & 737826 & 4.7 & 4.6889 & TRN & \\
\hline CHEMBL1590081 & 737826 & 5.5 & 5.2994 & TRN & \\
\hline CHEMBL1611348 & 737826 & 5.1 & 5.1161 & TRN & \\
\hline CHEMBL1405364 & 737826 & 4.8 & 5.3446 & TRN & \\
\hline CHEMBL1331020 & 737826 & 8.25 & 5.37 & TRN & \\
\hline CHEMBL1567499 & 737826 & 5.1 & 5.4231 & TST & \\
\hline CHEMBL1972133 & 737826 & 5.65 & 5.733 & TRN & \\
\hline CHEMBL1552623 & 737826 & 6.3 & 6.3093 & TRN & \\
\hline CHEMBL1513490 & 737826 & 5.1 & 5.0649 & TST & \\
\hline CHEMBL1373767 & 737826 & 4.65 & 5.2986 & TRN & \\
\hline CHEMBL1534143 & 737826 & 5.0 & 5.2807 & TRN & \\
\hline CHEMBL1468198 & 737826 & 4.9 & 5.1445 & TRN & \\
\hline CHEMBL1565645 & 737826 & 5.4 & 5.4575 & TRN & \\
\hline CHEMBL1454463 & 737826 & 4.95 & 5.4257 & TRN & \\
\hline CHEMBL1478430 & 737826 & 7.9 & 6.5731 & TRN & \\
\hline CHEMBL1331288 & 737826 & 4.4 & 4.5958 & TRN & \\
\hline CHEMBL1450781 & 737826 & 5.85 & 5.1417 & TRN & \\
\hline CHEMBL1532597 & 737826 & 5.6 & 5.54 & TRN & \\
\hline CHEMBL1406703 & 737826 & 5.05 & 5.496 & TST & \\
\hline CHEMBL1520442 & 737826 & 4.9 & 4.8181 & TRN & \\
\hline CHEMBL1607650 & 737826 & 5.4 & 5.2815 & TST & \\
\hline CHEMBL1556742 & 737826 & 5.8 & 5.586 & TST & \\
\hline CHEMBL457665 & 737826 & 4.9 & 4.8687 & TST & \\
\hline CHEMBL1519649 & 737826 & 5.8 & 5.8563 & TRN & \\
\hline CHEMBL1710426 & 737826 & 5.1 & 5.2505 & TRN & \\
\hline CHEMBL2141452 & 737826 & 4.9 & 5.1442 & TRN & \\
\hline CHEMBL1333749 & 737826 & 6.5 & 5.3867 & TRN & \\
\hline CHEMBL1374043 & 737826 & 4.6 & 5.2024 & TRN & \\
\hline CHEMBL1378030 & 737826 & 4.85 & 5.3754 & TRN & \\
\hline CHEMBL1350038 & 737826 & 5.4 & 5.3228 & TRN & \\
\hline CHEMBL1573683 & 737826 & 4.75 & 5.1416 & TRN & \\
\hline CHEMBL1539506 & 737826 & 5.35 & 5.3282 & TRN & \\
\hline CHEMBL1317498 & 737826 & 4.8 & 4.8398 & TRN & \\
\hline CHEMBL1257002 & 737826 & 5.3 & 5.2467 & TRN & \\
\hline CHEMBL1733088 & 737826 & 5.45 & 5.4269 & TRN & \\
\hline CHEMBL1527251 & 737826 & 5.35 & 5.2361 & TRN & \\
\hline CHEMBL1364955 & 737826 & 5.4 & 5.4672 & TRN & \\
\hline CHEMBL1342850 & 737826 & 4.85 & 5.1893 & TRN & \\
\hline CHEMBL1386540 & 737826 & 5.4 & 5.14 & TRN & \\
\hline & & & & 6478 & \\
\hline
\end{tabular}




\begin{tabular}{|c|c|c|c|c|c|}
\hline & & & & & \\
\hline CHEMBL1472898 & 737826 & 5.2 & 5.1842 & TRN & \\
\hline CHEMBL1362390 & 737826 & 5.1 & 5.1299 & TRN & \\
\hline CHEMBL1552953 & 737826 & 5.6 & 5.4451 & TRN & \\
\hline CHEMBL1474241 & 737826 & 6.0 & 5.614 & TRN & \\
\hline CHEMBL1609754 & 737826 & 5.0 & 5.2098 & TRN & \\
\hline CHEMBL3190530 & 737826 & 5.15 & 5.4306 & TST & \\
\hline CHEMBL504911 & 737826 & 4.6 & 5.1828 & TRN & \\
\hline CHEMBL1597015 & 737826 & 5.1 & 5.2947 & TRN & \\
\hline CHEMBL1459860 & 737826 & 5.05 & 5.3028 & TRN & \\
\hline CHEMBL1301960 & 737826 & 5.3 & 5.3947 & TRN & \\
\hline CHEMBL1591459 & 737826 & 5.4 & 5.2975 & TRN & \\
\hline CHEMBL1741361 & 737826 & 5.55 & 5.6157 & TST & \\
\hline CHEMBL1574915 & 737826 & 5.6 & 5.3441 & TRN & \\
\hline CHEMBL1475255 & 737826 & 6.5 & 6.2273 & TRN & \\
\hline CHEMBL1705400 & 737826 & 5.0 & 5.2864 & TRN & \\
\hline CHEMBL1352445 & 737826 & 5.1 & 5.2762 & TST & \\
\hline CHEMBL1593981 & 737826 & 5.1 & 5.1533 & TRN & \\
\hline CHEMBL1529700 & 737826 & 5.7 & 5.3047 & TRN & \\
\hline CHEMBL1572029 & 737826 & 5.05 & 5.3025 & TRN & \\
\hline CHEMBL1340186 & 737826 & 5.15 & 5.4266 & TRN & \\
\hline CHEMBL 258465 & 737826 & 5.6 & 5.4445 & TST & \\
\hline CHEMBL1395421 & 737826 & 4.4 & 4.4769 & TST & \\
\hline CHEMBL1357085 & 737826 & 5.2 & 5.2043 & TRN & \\
\hline CHEMBL1504734 & 737826 & 4.55 & 5.0666 & TRN & \\
\hline CHEMBL1528491 & 737826 & 5.2 & 5.1647 & TRN & \\
\hline CHEMBL1442380 & 737826 & 5.7 & 5.2167 & TRN & \\
\hline CHEMBL1525226 & 737826 & 5.5 & 5.8992 & TRN & \\
\hline CHEMBL3199351 & 737826 & 5.1 & 5.3287 & TRN & \\
\hline CHEMBL1474169 & 737826 & 4.9 & 4.8167 & TRN & \\
\hline CHEMBL1725507 & 737826 & 5.25 & 5.273 & TRN & \\
\hline CHEMBL1488574 & 737826 & 6.5 & 6.0815 & TRN & \\
\hline CHEMBL1578011 & 737826 & 5.0 & 5.2816 & TRN & \\
\hline CHEMBL1337387 & 737826 & 4.9 & 5.3781 & TRN & \\
\hline CHEMBL1546411 & 737826 & 5.05 & 5.2289 & TRN & \\
\hline CHEMBL1391974 & 737826 & 5.6 & 5.4492 & TST & \\
\hline CHEMBL3193586 & 737826 & 4.4 & 5.3153 & TRN & \\
\hline CHEMBL1587637 & 737826 & 4.85 & 5.231 & TRN & \\
\hline CHEMBL1515209 & 737826 & 5.5 & 5.3684 & TST & \\
\hline CHEMBL1479144 & 737826 & 5.35 & 5.2386 & TRN & \\
\hline CHEMBL1529538 & 737826 & 4.4 & 4.4331 & TST & \\
\hline CHEMBL1435509 & 737826 & 5.9 & 5.5568 & TRN & \\
\hline CHEMBL1415013 & 737826 & 5.0 & $5.2810 e$ & 0000000001 & TRN \\
\hline CHEMBL1608193 & 737826 & 4.75 & 5.2014 & TRN & \\
\hline CHEMBL1742376 & 737826 & 5.7 & 5.2703 & TRN & \\
\hline CHEMBL1504000 & 737826 & 5.85 & 5.3931 & TRN & \\
\hline CHEMBL1437408 & 737826 & 4.8 & 4.9219 & TRN & \\
\hline CHEMBL1581512 & 737826 & 4.65 & 5.3741 & TRN & \\
\hline CHEMBL1321695 & 737826 & 4.95 & $5.3210 e$ & 2000000001 & TRN \\
\hline & & & & e 6479 & \\
\hline
\end{tabular}




\begin{tabular}{|c|c|c|c|c|c|}
\hline \multicolumn{6}{|c|}{ Supplemental Table S2.txt } \\
\hline CHEMBL3213904 & 737826 & 5.55 & 5.4236 & TST & \\
\hline CHEMBL3194967 & 737826 & 5.65 & 5.4892 & TRN & \\
\hline CHEMBL584854 & 737826 & 6.7 & 5.476 & TRN & \\
\hline CHEMBL1388994 & 737826 & 5.0 & 5.34 & TRN & \\
\hline CHEMBL1350935 & 737826 & 5.15 & 5.1121 & TRN & \\
\hline CHEMBL1706994 & 737826 & 5.6 & 5.7296 & TRN & \\
\hline CHEMBL1412847 & 737826 & 5.9 & 5.9879 & TRN & \\
\hline CHEMBL1583603 & 737826 & 5.05 & 5.3898 & TRN & \\
\hline CHEMBL1607244 & 737826 & 5.5 & 5.3501 & TRN & \\
\hline CHEMBL1512744 & 737826 & 5.7 & 5.4508 & TRN & \\
\hline CHEMBL1322091 & 737826 & 5.9 & 5.2409 & TRN & \\
\hline CHEMBL1469557 & 737826 & 4.65 & 5.2553 & TRN & \\
\hline CHEMBL1594149 & 737826 & 4.5 & 4.615 & TST & \\
\hline CHEMBL1392924 & 737826 & 4.9 & 5.3194 & TST & \\
\hline CHEMBL1544965 & 737826 & 4.9 & 5.4306 & TRN & \\
\hline CHEMBL1562420 & 737826 & 4.9 & 5.0888 & TRN & \\
\hline CHEMBL1550597 & 737826 & 4.5 & 5.4925 & TRN & \\
\hline CHEMBL1409686 & 737826 & 5.05 & 5.1105 & TRN & \\
\hline CHEMBL1465072 & 737826 & 5.75 & 5.2282 & TRN & \\
\hline CHEMBL1371824 & 737826 & 5.85 & 5.3641 & TRN & \\
\hline CHEMBL1742105 & 737826 & 5.2 & 5.4367 & TRN & \\
\hline CHEMBL1475924 & 737826 & 4.9 & 4.7906 & TRN & \\
\hline CHEMBL1306550 & 737826 & 5.8 & 5.303 & TRN & \\
\hline CHEMBL1603371 & 737826 & 5.7 & 5.5337 & TRN & \\
\hline CHEMBL1361977 & 737826 & 4.6 & 4.496 & TRN & \\
\hline CHEMBL1407576 & 737826 & 5.1 & 5.1019 & TST & \\
\hline CHEMBL1582268 & 737826 & 5.5 & 5.399 & TRN & \\
\hline CHEMBL1603692 & 737826 & 4.4 & 4.5402 & TRN & \\
\hline CHEMBL1569474 & 737826 & 4.65 & 5.2603 & TRN & \\
\hline CHEMBL1457564 & 737826 & 4.9 & 5.1048 & TRN & \\
\hline CHEMBL1587716 & 737826 & 4.65 & 5.4581 & TRN & \\
\hline CHEMBL1427738 & 737826 & 5.65 & 5.2432 & TRN & \\
\hline CHEMBL1412055 & 737826 & 4.9 & 5.1915 & TST & \\
\hline CHEMBL 3144985 & 737826 & 4.85 & 5.2622 & TST & \\
\hline CHEMBL1447425 & 737826 & 4.8 & 5.3464 & TRN & \\
\hline CHEMBL1741617 & 737826 & 4.85 & 5.2333 & TRN & \\
\hline CHEMBL1427932 & 737826 & 8.25 & 5.2938 & TST & \\
\hline CHEMBL1322376 & 737826 & 6.1 & 5.2273 & TRN & \\
\hline CHEMBL1396203 & 737826 & 6.1 & 6.00200 & 2000000001 & TRN \\
\hline CHEMBL1456942 & 737826 & 5.0 & 5.5255 & TRN & \\
\hline CHEMBL1346283 & 737826 & 6.0 & 5.2318 & TRN & \\
\hline CHEMBL1559387 & 737826 & 4.45 & 5.2162 & TST & \\
\hline CHEMBL1579467 & 737826 & 4.85 & 5.3035 & TST & \\
\hline CHEMBL1371202 & 737826 & 5.5 & 5.4814 & TRN & \\
\hline CHEMBL1316337 & 737826 & 4.9 & 4.7867 & TRN & \\
\hline CHEMBL1326132 & 737826 & 5.55 & 5.1529 & TRN & \\
\hline CHEMBL1366995 & 737826 & 4.75 & 5.4526 & TRN & \\
\hline CHEMBL1576710 & 737826 & 5.65 & 5.2606 & TRN & \\
\hline
\end{tabular}




\begin{tabular}{|c|c|c|c|c|c|}
\hline & & & & & \\
\hline CHEMBL1570658 & 737826 & 6.8 & 5.3367 & TRN & \\
\hline CHEMBL1318622 & 737826 & 6.3 & 5.9565 & TRN & \\
\hline CHEMBL1377201 & 737826 & 4.7 & 5.1718 & TRN & \\
\hline CHEMBL1438722 & 737826 & 5.25 & 5.2067 & TRN & \\
\hline CHEMBL1452827 & 737826 & 5.55 & $5.3270 e$ & 0000000001 & TRN \\
\hline CHEMBL1588011 & 737826 & 5.1 & 5.2099 & TRN & \\
\hline CHEMBL1495397 & 737826 & 4.95 & 5.3519 & TRN & \\
\hline CHEMBL1489212 & 737826 & 4.6 & 4.6296 & TRN & \\
\hline CHEMBL1741463 & 737826 & 5.85 & 5.5729 & TRN & \\
\hline CHEMBL1530352 & 737826 & 4.75 & 5.4392 & TST & \\
\hline CHEMBL1568982 & 737826 & 5.9 & 5.3205 & TRN & \\
\hline CHEMBL1388860 & 737826 & 5.2 & 5.5497 & TRN & \\
\hline CHEMBL1596063 & 737826 & 5.2 & 5.3235 & TST & \\
\hline CHEMBL1568684 & 737826 & 5.05 & $5.3420 e$ & 20000000005 & TST \\
\hline CHEMBL1484469 & 737826 & 5.45 & 5.3537 & TRN & \\
\hline CHEMBL1388234 & 737826 & 4.6 & 5.4614 & TRN & \\
\hline CHEMBL1379083 & 737826 & 4.7 & 5.0772 & TST & \\
\hline CHEMBL1400309 & 737826 & 5.3 & 5.1991 & TRN & \\
\hline CHEMBL1366323 & 737826 & 4.95 & 5.2921 & TRN & \\
\hline CHEMBL1505026 & 737826 & 5.25 & 5.3741 & TRN & \\
\hline CHEMBL86676 & 737826 & 4.5 & 5.6928 & TST & \\
\hline CHEMBL1741849 & 737826 & 4.9 & 5.154 & TRN & \\
\hline CHEMBL1380022 & 737826 & 4.85 & 5.1492 & TRN & \\
\hline CHEMBL19612 & 737826 & 4.9 & 4.9275 & TST & \\
\hline CHEMBL3197506 & 737826 & 4.4 & 5.5839 & TRN & \\
\hline CHEMBL136906 & 737826 & 5.1 & 4.9802 & TRN & \\
\hline CHEMBL1486864 & 737826 & 4.9 & 5.0848 & TST & \\
\hline CHEMBL1451548 & 737826 & 4.95 & 5.38899 & 9999999999 & TRN \\
\hline CHEMBL1460429 & 737826 & 4.65 & 5.3099 & TRN & \\
\hline CHEMBL1451363 & 737826 & 5.75 & 5.5492 & TRN & \\
\hline CHEMBL1612230 & 737826 & 5.75 & 5.5986 & TST & \\
\hline CHEMBL1499015 & 737826 & 5.35 & 5.3829 & TRN & \\
\hline CHEMBL1709113 & 737826 & 4.6 & 5.0976 & TRN & \\
\hline CHEMBL291536 & 737826 & -0.0 & 5.5587 & TRN & \\
\hline CHEMBL1413058 & 737826 & 5.35 & 5.2249 & TRN & \\
\hline CHEMBL1370467 & 737826 & 6.0 & 5.8565 & TRN & \\
\hline CHEMBL1612296 & 737826 & 4.5 & 5.284 & TRN & \\
\hline CHEMBL1385596 & 737826 & 5.45 & 5.1397 & TRN & \\
\hline CHEMBL1517248 & 737826 & 5.6 & 5.2718 & TRN & \\
\hline CHEMBL1304517 & 737826 & 4.75 & 5.1555 & TRN & \\
\hline CHEMBL1330718 & 737826 & 5.6 & 5.3477 & TRN & \\
\hline CHEMBL1476084 & 737826 & 6.5 & 6.0676 & TRN & \\
\hline CHEMBL1357294 & 737826 & 5.5 & 5.1882 & TRN & \\
\hline CHEMBL1486121 & 737826 & 6.1 & 5.2615 & TRN & \\
\hline CHEMBL1605363 & 737826 & 6.2 & 5.556 & TRN & \\
\hline CHEMBL1603393 & 737826 & 5.1 & 4.9013 & TRN & \\
\hline CHEMBL1545514 & 737826 & 4.7 & 5.3457 & TRN & \\
\hline CHEMBL1501395 & 737826 & 5.15 & $5.1670 e$ & j000000001 & TRN \\
\hline & & & & e 6481 & \\
\hline
\end{tabular}




\begin{tabular}{|c|c|c|c|c|}
\hline \multicolumn{5}{|c|}{ Supplemental Table S2.txt } \\
\hline CHEMBL1717521 & 737826 & 4.6 & 5.1278 & TRN \\
\hline CHEMBL1343568 & 737826 & 4.55 & 5.3383 & TST \\
\hline CHEMBL1479994 & 737826 & 4.4 & 5.4397 & TRN \\
\hline CHEMBL1559023 & 737826 & 4.9 & 4.6579 & TRN \\
\hline CHEMBL1331921 & 737826 & 5.3 & 5.2726 & TRN \\
\hline CHEMBL1467429 & 737826 & 4.7 & 5.1293 & TRN \\
\hline CHEMBL1436506 & 737826 & 5.2 & 5.2016 & TST \\
\hline CHEMBL1422703 & 737826 & 7.15 & 5.2038 & TRN \\
\hline CHEMBL1341152 & 737826 & 6.5 & 5.4445 & TRN \\
\hline CHEMBL1419743 & 737826 & 4.75 & 5.3112 & TST \\
\hline CHEMBL1432327 & 737826 & 5.65 & 5.2843 & TST \\
\hline CHEMBL1454544 & 737826 & 6.4 & 6.2571 & TRN \\
\hline CHEMBL1708288 & 737826 & 5.05 & 5.1938 & TRN \\
\hline CHEMBL1460553 & 737826 & 5.4 & 5.4045 & TRN \\
\hline CHEMBL1379991 & 737826 & 5.15 & 5.0505 & TST \\
\hline CHEMBL1441404 & 737826 & 5.0 & 5.4686 & TRN \\
\hline CHEMBL1524629 & 737826 & 5.55 & 5.1496 & TRN \\
\hline CHEMBL1370622 & 737826 & 6.0 & 5.9625 & TRN \\
\hline CHEMBL899 & 737826 & 4.95 & 5.3577 & TRN \\
\hline CHEMBL1599203 & 737826 & 5.1 & 5.2931 & TRN \\
\hline CHEMBL1453108 & 737826 & 5.8 & 5.3717 & TRN \\
\hline CHEMBL1329110 & 737826 & 6.1 & 5.6446 & TRN \\
\hline CHEMBL1518301 & 737826 & 5.1 & 5.0409 & TRN \\
\hline CHEMBL1430258 & 737826 & 5.5 & 5.06 & TRN \\
\hline CHEMBL1538866 & 737826 & 4.7 & 4.8206 & TRN \\
\hline CHEMBL1463577 & 737826 & 5.45 & 5.4356 & TRN \\
\hline CHEMBL545050 & 737826 & 4.5 & 5.6145 & TRN \\
\hline CHEMBL3213913 & 737826 & 5.8 & 5.3866 & TRN \\
\hline CHEMBL1378653 & 737826 & 5.35 & 5.3206 & TRN \\
\hline CHEMBL1705664 & 737826 & 4.45 & 5.3483 & TST \\
\hline CHEMBL1504465 & 737826 & 6.45 & 5.4392 & TRN \\
\hline CHEMBL1473554 & 737826 & 4.4 & 4.5398 & TRN \\
\hline CHEMBL1446743 & 737826 & 5.0 & 5.0306 & TST \\
\hline CHEMBL1307620 & 737826 & 4.85 & 5.3506 & TRN \\
\hline CHEMBL1390207 & 737826 & 4.95 & 5.3116 & TST \\
\hline CHEMBL1450157 & 737826 & 5.15 & 5.3662 & TRN \\
\hline CHEMBL1079460 & 737826 & 4.6 & 4.6731 & TST \\
\hline CHEMBL1532107 & 737826 & 4.85 & 5.1196 & TST \\
\hline CHEMBL1456755 & 737826 & 5.2 & 5.3061 & TRN \\
\hline CHEMBL1530832 & 737826 & 6.0 & 5.6531 & TRN \\
\hline CHEMBL1555668 & 737826 & 6.0 & 5.2199 & TRN \\
\hline CHEMBL1598281 & 737826 & 4.7 & 5.1722 & TRN \\
\hline CHEMBL 1308052 & 737826 & 5.4 & 5.2129 & TRN \\
\hline CHEMBL1359063 & 737826 & 4.55 & 5.2128 & TRN \\
\hline CHEMBL1443681 & 737826 & 4.85 & 5.2198 & TRN \\
\hline CHEMBL1742086 & 737826 & 4.5 & 5.2846 & TRN \\
\hline CHEMBL1431735 & 737826 & 6.1 & 5.244 & TRN \\
\hline CHEMBL3213185 & 737826 & 4.65 & 5.3674 & TRN \\
\hline
\end{tabular}




\begin{tabular}{|c|c|c|c|c|c|}
\hline \\
\hline CHEMBL1346800 & 737826 & 4.95 & 4.9467 & TRN & \\
\hline CHEMBL1405016 & 737826 & 4.9 & 5.1329 & TRN & \\
\hline CHEMBL1471546 & 737826 & 5.35 & 5.4267 & TST & \\
\hline CHEMBL1510139 & 737826 & 5.1 & 5.3325 & TRN & \\
\hline CHEMBL1608779 & 737826 & 5.5 & 5.2569 & TST & \\
\hline CHEMBL1408176 & 737826 & 5.5 & 5.4271 & TRN & \\
\hline CHEMBL1410496 & 737826 & 4.7 & 5.3379 & TRN & \\
\hline CHEMBL1533010 & 737826 & 4.55 & 5.17700 & 00000000005 & TRN \\
\hline CHEMBL1591508 & 737826 & 4.8 & 4.8311 & TST & \\
\hline CHEMBL1505568 & 737826 & 6.75 & 5.1997 & TRN & \\
\hline CHEMBL1711461 & 737826 & 5.45 & 5.3555 & TRN & \\
\hline CHEMBL1516622 & 737826 & 5.4 & 5.3319 & TRN & \\
\hline CHEMBL1330730 & 737826 & 4.8 & 5.3157 & TST & \\
\hline CHEMBL1397466 & 737826 & 4.9 & 4.8542 & TST & \\
\hline CHEMBL1555896 & 737826 & 4.9 & 5.3512 & TRN & \\
\hline CHEMBL 3213021 & 737826 & 4.9 & 5.3716 & TRN & \\
\hline CHEMBL1430479 & 737826 & 5.9 & 5.3062 & TRN & \\
\hline CHEMBL2068217 & 737826 & 5.5 & 5.3217 & TST & \\
\hline CHEMBL1380994 & 737826 & 6.4 & 5.3809 & TRN & \\
\hline CHEMBL1554983 & 737826 & 5.0 & 4.9601 & TRN & \\
\hline CHEMBL1347463 & 737826 & 5.35 & 5.2822 & TRN & \\
\hline CHEMBL476135 & 737826 & 5.3 & 5.2118 & TRN & \\
\hline CHEMBL1352069 & 737826 & 4.85 & 5.2557 & TST & \\
\hline CHEMBL1309472 & 737826 & 4.55 & 5.103 & TST & \\
\hline CHEMBL1529656 & 737826 & 4.45 & 5.4237 & TRN & \\
\hline CHEMBL1583992 & 737826 & 5.4 & 5.0671 & TRN & \\
\hline CHEMBL1489424 & 737826 & 5.5 & 5.449 & TRN & \\
\hline CHEMBL1698558 & 737826 & 4.95 & 5.1722 & TRN & \\
\hline CHEMBL1545061 & 737826 & 5.25 & 5.3041 & TRN & \\
\hline CHEMBL1370525 & 737826 & 4.85 & 5.1282 & TRN & \\
\hline CHEMBL1471858 & 737826 & 5.5 & 5.4775 & TRN & \\
\hline CHEMBL1411519 & 737826 & 4.7 & 4.9415 & TRN & \\
\hline CHEMBL1741802 & 737826 & 4.95 & 5.42299 & 9999999999 & TRN \\
\hline CHEMBL3192460 & 737826 & 5.1 & 5.2781 & TRN & \\
\hline CHEMBL1558413 & 737826 & 4.85 & 5.1866 & TST & \\
\hline CHEMBL1415100 & 737826 & 5.4 & 5.3062 & TST & \\
\hline CHEMBL1608942 & 737826 & 7.4 & 5.3813 & TRN & \\
\hline CHEMBL1604846 & 737826 & 4.8 & 5.1916 & TRN & \\
\hline CHEMBL1317769 & 737826 & 5.0 & 4.8105 & TRN & \\
\hline CHEMBL1396809 & 737826 & 4.9 & 4.8484 & TRN & \\
\hline CHEMBL1491888 & 737826 & 5.0 & 5.3139 & TST & \\
\hline CHEMBL1518920 & 737826 & 5.25 & 5.4291 & TRN & \\
\hline CHEMBL1742228 & 737826 & 5.6 & 5.25899 & 99999999995 & TRN \\
\hline CHEMBL1395219 & 737826 & 4.8 & 4.6938 & TRN & \\
\hline CHEMBL1561341 & 737826 & 5.3 & 5.3453 & TRN & \\
\hline CHEMBL1601300 & 737826 & 5.35 & 5.2992 & TRN & \\
\hline CHEMBL1345892 & 737826 & 5.05 & 5.2992 & TRN & \\
\hline CHEMBL1305585 & 737826 & 4.65 & 5.4157 & TRN & \\
\hline
\end{tabular}




\begin{tabular}{|c|c|c|c|c|c|}
\hline & & \multicolumn{4}{|c|}{ Supplemental Table S2.txt } \\
\hline CHEMBL1421734 & 737826 & 7.1 & 5.2423 & TRN & \\
\hline CHEMBL1720126 & 737826 & 5.55 & 5.504 & TRN & \\
\hline CHEMBL3213016 & 737826 & 5.0 & 5.2467 & TRN & \\
\hline CHEMBL1344112 & 737826 & 5.4 & 5.2011 & TRN & \\
\hline CHEMBL1604396 & 737826 & 5.9 & 5.1762 & TRN & \\
\hline CHEMBL1551749 & 737826 & 4.8 & 4.8387 & TRN & \\
\hline CHEMBL1510521 & 737826 & 4.75 & 5.5084 & TST & \\
\hline CHEMBL1353886 & 737826 & 5.6 & 5.4974 & TRN & \\
\hline CHEMBL1096400 & 737826 & 4.9 & 5.0069 & TST & \\
\hline CHEMBL1428554 & 737826 & 4.85 & 5.1089 & TRN & \\
\hline CHEMBL1352525 & 737826 & 4.9 & 5.2451 & TRN & \\
\hline CHEMBL1387144 & 737826 & 5.6 & 5.4371 & TRN & \\
\hline CHEMBL1435276 & 737826 & 4.5 & 4.5114 & TRN & \\
\hline CHEMBL372797 & 737826 & 5.2 & 5.1603 & TST & \\
\hline CHEMBL1589133 & 737826 & 5.0 & 5.2453 & TRN & \\
\hline CHEMBL150 & 737826 & 8.9 & 5.7391 & TRN & \\
\hline CHEMBL1435908 & 737826 & 5.4 & 5.3389 & TRN & \\
\hline CHEMBL1505628 & 737826 & 5.3 & 5.3546 & TST & \\
\hline CHEMBL1471369 & 737826 & 5.55 & 5.4501 & TRN & \\
\hline CHEMBL1314371 & 737826 & 5.1 & 4.9738 & TRN & \\
\hline CHEMBL1590123 & 737826 & 6.0 & 5.9957 & TRN & \\
\hline CHEMBL1420206 & 737826 & 6.05 & 5.3245 & TRN & \\
\hline CHEMBL 2002517 & 737826 & 5.35 & 5.5295 & TRN & \\
\hline CHEMBL1336793 & 737826 & 4.4 & 4.4112 & TRN & \\
\hline CHEMBL409902 & 737826 & 4.9 & 4.7288 & TRN & \\
\hline CHEMBL1508220 & 737826 & 6.3 & 5.3854 & TRN & \\
\hline CHEMBL1402049 & 737826 & 5.8 & 5.5721 & TRN & \\
\hline CHEMBL1448379 & 737826 & 4.45 & 5.1922 & TST & \\
\hline CHEMBL1470051 & 737826 & 5.4 & 5.42399 & 99999999995 & TRN \\
\hline CHEMBL1307425 & 737826 & 5.15 & 5.3055 & TRN & \\
\hline CHEMBL1395089 & 737826 & 6.4 & 6.3599 & TRN & \\
\hline CHEMBL1339516 & 737826 & 5.4 & 5.2173 & TRN & \\
\hline CHEMBL1528538 & 737826 & 6.1 & 5.3105 & TRN & \\
\hline CHEMBL1544132 & 737826 & 4.95 & 5.5185 & TRN & \\
\hline CHEMBL1476729 & 737826 & 4.9 & 4.6834 & TRN & \\
\hline CHEMBL153036 & 737826 & 6.0 & 4.7431 & TRN & \\
\hline CHEMBL1490108 & 737826 & 4.85 & 5.1167 & TRN & \\
\hline CHEMBL1468477 & 737826 & 4.8 & 5.1191 & TRN & \\
\hline CHEMBL1304655 & 737826 & 4.75 & 5.7883 & TRN & \\
\hline CHEMBL1532985 & 737826 & 5.25 & 5.1233 & TRN & \\
\hline CHEMBL1547276 & 737826 & 5.35 & 5.4474 & TRN & \\
\hline CHEMBL1578674 & 737826 & 4.85 & 5.2734 & TRN & \\
\hline CHEMBL1590334 & 737826 & 5.1 & 5.0853 & TRN & \\
\hline CHEMBL1475075 & 737826 & 5.6 & 5.5668 & TRN & \\
\hline CHEMBL1308386 & 737826 & 5.3 & 5.2339 & TRN & \\
\hline CHEMBL1730832 & 737826 & 4.6 & 4.9747 & TST & \\
\hline CHEMBL1569485 & 737826 & 5.5 & 5.2816 & TRN & \\
\hline CHEMBL489738 & 737826 & 5.8 & 5.8586 & TRN & \\
\hline
\end{tabular}




\begin{tabular}{|c|c|c|c|c|c|}
\hline \\
\hline CHEMBL1544180 & 737826 & 5.1 & 5.3115 & TRN & \\
\hline CHEMBL1371031 & 737826 & 4.4 & 5.2966 & TRN & \\
\hline CHEMBL1315690 & 737826 & 5.4 & 5.2102 & TRN & \\
\hline CHEMBL1352133 & 737826 & 4.9 & 5.0524 & TRN & \\
\hline CHEMBL1360767 & 737826 & 6.15 & 5.2306 & TRN & \\
\hline CHEMBL1470721 & 737826 & 4.85 & 5.8237 & TRN & \\
\hline CHEMBL1600340 & 737826 & 6.8 & 6.3733 & TRN & \\
\hline CHEMBL1438357 & 737826 & 4.7 & 5.4225 & TRN & \\
\hline CHEMBL1610350 & 737826 & 5.9 & 5.7062 & TRN & \\
\hline CHEMBL3196296 & 737826 & 6.05 & 5.3577 & TST & \\
\hline CHEMBL1712981 & 737826 & 5.3 & 5.4143 & TST & \\
\hline CHEMBL1599122 & 737826 & 4.8 & 5.1886 & TRN & \\
\hline CHEMBL1313790 & 737826 & 4.8 & 5.3084 & TRN & \\
\hline CHEMBL1510151 & 737826 & 5.25 & 5.2746 & TRN & \\
\hline CHEMBL1417375 & 737826 & 5.5 & 5.4025 & TRN & \\
\hline CHEMBL1742323 & 737826 & 5.3 & 5.4013 & TRN & \\
\hline CHEMBL1423034 & 737826 & 4.9 & 5.58799 & 9999999999 & TRN \\
\hline CHEMBL1511135 & 737826 & 4.7 & 5.3053 & TRN & \\
\hline CHEMBL1310995 & 737826 & 5.05 & 5.2664 & TRN & \\
\hline CHEMBL1711322 & 737826 & 5.55 & 5.1969 & TST & \\
\hline CHEMBL1309678 & 737826 & 5.6 & 5.1797 & TRN & \\
\hline CHEMBL1505071 & 737826 & 5.6 & 5.3218 & TST & \\
\hline CHEMBL1372491 & 737826 & 5.8 & 5.1747 & TRN & \\
\hline CHEMBL1397559 & 737826 & 4.6 & 4.6816 & TST & \\
\hline CHEMBL1527157 & 737826 & 5.1 & 5.0788 & TST & \\
\hline CHEMBL1497138 & 737826 & 5.4 & 5.0428 & TRN & \\
\hline CHEMBL429095 & 737826 & 5.3 & 5.7394 & TST & \\
\hline CHEMBL1478279 & 737826 & 4.5 & 4.44600 & 0000000001 & TRN \\
\hline CHEMBL1314222 & 737826 & 6.3 & 6.2098 & TRN & \\
\hline CHEMBL1462914 & 737826 & 6.05 & 5.4234 & TRN & \\
\hline CHEMBL113180 & 737826 & 4.5 & 4.6178 & TST & \\
\hline CHEMBL1373587 & 737826 & 5.5 & 5.4304 & TST & \\
\hline CHEMBL1552161 & 737826 & 5.2 & 5.21299 & 9999999999 & TRN \\
\hline CHEMBL1967772 & 737826 & 5.1 & 5.4834 & TRN & \\
\hline CHEMBL1591745 & 737826 & 5.5 & 5.415 & TST & \\
\hline CHEMBL1316408 & 737826 & 5.9 & 5.9191 & TRN & \\
\hline CHEMBL1590968 & 737826 & 5.0 & 4.8806 & TRN & \\
\hline CHEMBL1550134 & 737826 & 4.85 & 5.3191 & TRN & \\
\hline CHEMBL1353933 & 737826 & 6.1 & 5.36299 & 99999999995 & TRN \\
\hline CHEMBL 3210325 & 737826 & 5.65 & 5.1593 & TRN & \\
\hline CHEMBL1389304 & 737826 & 4.9 & 5.2606 & TRN & \\
\hline CHEMBL1403902 & 737826 & 5.45 & 5.3207 & TRN & \\
\hline CHEMBL32142 & 737826 & 5.2 & 4.9512 & TST & \\
\hline CHEMBL24983 & 737826 & 4.8 & 4.8721 & TST & \\
\hline CHEMBL3190643 & 737826 & 4.7 & 5.2349 & TST & \\
\hline CHEMBL1426147 & 737826 & 5.4 & 5.1772 & TRN & \\
\hline CHEMBL1474503 & 737826 & 4.6 & 4.5121 & TRN & \\
\hline CHEMBL1708951 & 737826 & 4.9 & 5.41 & TRN & \\
\hline & & & & 6485 & \\
\hline
\end{tabular}




\begin{tabular}{|c|c|c|c|c|c|}
\hline \multicolumn{6}{|c|}{ Supplemental Table S2.txt } \\
\hline CHEMBL1492815 & 737826 & 5.05 & 5.3303 & TRN & \\
\hline CHEMBL1257003 & 737826 & 6.3 & 5.8315 & TRN & \\
\hline CHEMBL1561791 & 737826 & 5.9 & 5.2619 & TRN & \\
\hline CHEMBL1388133 & 737826 & 5.1 & 5.1715 & TRN & \\
\hline CHEMBL1320109 & 737826 & 4.4 & 5.2705 & TRN & \\
\hline CHEMBL1488727 & 737826 & 6.55 & 5.2949 & TRN & \\
\hline CHEMBL1409713 & 737826 & 4.9 & 5.2602 & TST & \\
\hline CHEMBL3196906 & 737826 & 5.0 & 5.3432 & TRN & \\
\hline CHEMBL1447904 & 737826 & 5.0 & 5.1714 & TRN & \\
\hline CHEMBL1573473 & 737826 & 4.75 & 5.2376 & TRN & \\
\hline CHEMBL1365235 & 737826 & 4.9 & 5.1776 & TRN & \\
\hline CHEMBL1533882 & 737826 & 4.7 & 5.2188 & TRN & \\
\hline CHEMBL1565914 & 737826 & 5.2 & 5.2357 & TRN & \\
\hline CHEMBL1357982 & 737826 & 5.4 & 5.1623 & TRN & \\
\hline CHEMBL1565311 & 737826 & 7.1 & 6.5325 & TRN & \\
\hline CHEMBL3214385 & 737826 & 4.95 & 5.4666 & TRN & \\
\hline CHEMBL1700747 & 737826 & 4.85 & 5.51200 & 00000000005 & TRN \\
\hline CHEMBL1515802 & 737826 & 5.1 & 5.2077 & TST & \\
\hline CHEMBL1554791 & 737826 & 4.9 & 4.8199 & TRN & \\
\hline CHEMBL464433 & 737826 & 5.55 & 6.9609 & TRN & \\
\hline CHEMBL1313698 & 737826 & 5.0 & 5.2392 & TRN & \\
\hline CHEMBL1341727 & 737826 & 4.85 & 5.4017 & TRN & \\
\hline CHEMBL1320051 & 737826 & 5.5 & 5.1699 & TRN & \\
\hline CHEMBL1533607 & 737826 & 5.95 & 5.3601 & TRN & \\
\hline CHEMBL1434833 & 737826 & 5.9 & 5.5911 & TRN & \\
\hline CHEMBL1562937 & 737826 & 5.3 & 5.0502 & TRN & \\
\hline CHEMBL1365537 & 737826 & 5.4 & 5.315 & TRN & \\
\hline CHEMBL1476298 & 737826 & 4.7 & 4.6402 & TRN & \\
\hline CHEMBL1465287 & 737826 & 4.4 & 5.2906 & TRN & \\
\hline CHEMBL1393480 & 737826 & 4.8 & 5.4713 & TRN & \\
\hline CHEMBL1538256 & 737826 & 5.55 & 5.3303 & TRN & \\
\hline CHEMBL1374849 & 737826 & 4.9 & 4.8096 & TRN & \\
\hline CHEMBL1445737 & 737826 & 5.55 & 5.1566 & TST & \\
\hline CHEMBL1446649 & 737826 & 5.7 & 5.2801 & TRN & \\
\hline CHEMBL1446314 & 737826 & 4.85 & 5.4669 & TST & \\
\hline CHEMBL1727631 & 737826 & 5.05 & 5.2757 & TRN & \\
\hline CHEMBL1390028 & 737826 & 6.65 & 5.555 & TRN & \\
\hline CHEMBL1389326 & 737826 & 5.9 & 5.3914 & TRN & \\
\hline CHEMBL1613268 & 737826 & 6.85 & 5.3432 & TRN & \\
\hline CHEMBL1358939 & 737826 & 5.3 & 5.1228 & TRN & \\
\hline CHEMBL1476159 & 737826 & 5.5 & 5.3656 & TRN & \\
\hline CHEMBL1335889 & 737826 & 4.7 & 4.6817 & TRN & \\
\hline CHEMBL1400192 & 737826 & 4.95 & 5.6617 & TRN & \\
\hline CHEMBL25230 & 737826 & 5.4 & 5.1078 & TST & \\
\hline CHEMBL1454793 & 737826 & 5.0 & 4.9571 & TRN & \\
\hline CHEMBL1344974 & 737826 & 5.2 & 5.1708 & TRN & \\
\hline CHEMBL1392973 & 737826 & 4.75 & 5.1743 & TRN & \\
\hline CHEMBL1319720 & 737826 & 5.2 & 5.3051 & TST & \\
\hline
\end{tabular}




\begin{tabular}{|c|c|c|c|c|c|}
\hline \multicolumn{6}{|c|}{ Supplemental Table S2.txt } \\
\hline CHEMBL1598359 & 737826 & 5.05 & 5.1815 & TRN & \\
\hline CHEMBL1557564 & 737826 & 4.9 & 4.9436 & TRN & \\
\hline CHEMBL1397225 & 737826 & 5.0 & 4.9558 & TRN & \\
\hline CHEMBL1488197 & 737826 & 6.0 & 5.7641 & TRN & \\
\hline CHEMBL1389843 & 737826 & 5.3 & 5.4719 & TRN & \\
\hline CHEMBL1474479 & 737826 & 4.8 & 4.9083 & TRN & \\
\hline CHEMBL1517696 & 737826 & 5.5 & 5.2885 & TRN & \\
\hline CHEMBL1474302 & 737826 & 4.8 & 4.662 & TRN & \\
\hline CHEMBL1610199 & 737826 & 7.4 & 5.3087 & TRN & \\
\hline CHEMBL1320619 & 737826 & 4.6 & 4.462 & TRN & \\
\hline CHEMBL1406879 & 737826 & 4.6 & 4.5102 & TRN & \\
\hline CHEMBL1451057 & 737826 & 5.6 & 5.4928 & TRN & \\
\hline CHEMBL1418118 & 737826 & 4.45 & 5.3887 & TRN & \\
\hline CHEMBL1538146 & 737826 & 5.1 & 5.2938 & TRN & \\
\hline CHEMBL1496566 & 737826 & 4.55 & 5.3147 & TRN & \\
\hline CHEMBL1315794 & 737826 & 5.1 & 4.9314 & TRN & \\
\hline CHEMBL1596477 & 737826 & 4.95 & 5.3601 & TRN & \\
\hline CHEMBL1742378 & 737826 & 5.15 & 5.1535 & TRN & \\
\hline CHEMBL1477725 & 737826 & 5.9 & 5.3533 & TRN & \\
\hline CHEMBL1479727 & 737826 & 5.0 & 5.021 & TRN & \\
\hline CHEMBL1529777 & 737826 & 4.6 & 5.6053 & TRN & \\
\hline CHEMBL1475207 & 737826 & 4.9 & 4.8855 & TRN & \\
\hline CHEMBL1349496 & 737826 & 5.35 & 5.3051 & TRN & \\
\hline CHEMBL1422230 & 737826 & 5.65 & 5.4489 & TST & \\
\hline CHEMBL1432651 & 737826 & 4.75 & 5.1517 & TRN & \\
\hline CHEMBL1541180 & 737826 & 5.9 & 5.17 & TRN & \\
\hline CHEMBL1256943 & 737826 & 5.0 & 4.8917 & TRN & \\
\hline CHEMBL3191366 & 737826 & 5.3 & 5.4 & TRN & \\
\hline CHEMBL1970734 & 737826 & 5.4 & 5.3174 & TRN & \\
\hline CHEMBL1305370 & 737826 & 4.6 & 5.2317 & TST & \\
\hline CHEMBL1358033 & 737826 & 5.3 & 5.17899 & 9999999999 & TRN \\
\hline CHEMBL1352421 & 737826 & 4.9 & 5.1343 & TRN & \\
\hline CHEMBL1543168 & 737826 & 5.75 & 5.4339 & TRN & \\
\hline CHEMBL1380069 & 737826 & 7.45 & 5.4004 & TRN & \\
\hline CHEMBL1316219 & 737826 & 4.8 & 4.9512 & TST & \\
\hline CHEMBL1347641 & 737826 & 5.05 & 5.301 & TST & \\
\hline CHEMBL126077 & 737826 & 4.4 & 5.5957 & TST & \\
\hline CHEMBL1589049 & 737826 & 5.5 & 5.3253 & TRN & \\
\hline CHEMBL1531779 & 737826 & 5.9 & 5.4211 & TRN & \\
\hline CHEMBL1506066 & 737826 & 6.55 & 5.3054 & TRN & \\
\hline CHEMBL1603549 & 737826 & 5.3 & 5.4434 & TST & \\
\hline CHEMBL1555944 & 737826 & 4.55 & 5.3175 & TRN & \\
\hline CHEMBL1481127 & 737826 & 4.9 & 4.7482 & TRN & \\
\hline CHEMBL1337292 & 737826 & 5.1 & 5.2322 & TRN & \\
\hline CHEMBL1495099 & 737826 & 4.7 & 5.2831 & TRN & \\
\hline CHEMBL1505091 & 737826 & 5.15 & 5.3303 & TST & \\
\hline CHEMBL1381203 & 737826 & 6.05 & 5.2864 & TRN & \\
\hline CHEMBL596728 & 737826 & 5.7 & 5.0936 & TRN & \\
\hline
\end{tabular}




\begin{tabular}{|c|c|c|c|c|c|}
\hline \\
\hline CHEMBL1546843 & 737826 & 5.1 & 5.4064 & TRN & \\
\hline CHEMBL1598878 & 737826 & 4.75 & 5.2057 & TST & \\
\hline CHEMBL1479420 & 737826 & 4.85 & 5.1097 & TRN & \\
\hline CHEMBL1441795 & 737826 & 4.75 & 5.4768 & TRN & \\
\hline CHEMBL1317885 & 737826 & 4.6 & 4.5736 & TRN & \\
\hline CHEMBL1414996 & 737826 & 4.6 & 5.2477 & TST & \\
\hline CHEMBL1536842 & 737826 & 5.2 & 5.11600 & 00000000005 & TRN \\
\hline CHEMBL1532466 & 737826 & 4.6 & 5.5 & TRN & \\
\hline CHEMBL1256719 & 737826 & 5.6 & 5.2574 & TST & \\
\hline CHEMBL1337725 & 737826 & 4.85 & 5.4263 & TRN & \\
\hline CHEMBL1433039 & 737826 & 5.55 & 5.3245 & TST & \\
\hline CHEMBL1499289 & 737826 & 4.65 & 5.2145 & TRN & \\
\hline CHEMBL3212375 & 737826 & 4.85 & 5.1084 & TST & \\
\hline CHEMBL1303510 & 737826 & 4.65 & 5.2456 & TST & \\
\hline CHEMBL1488095 & 737826 & 4.95 & 5.2392 & TRN & \\
\hline CHEMBL1568392 & 737826 & 4.4 & 5.1128 & TRN & \\
\hline CHEMBL1589202 & 737826 & 6.0 & 5.3243 & TRN & \\
\hline CHEMBL1534566 & 737826 & 8.8 & 7.5065 & TRN & \\
\hline CHEMBL 3207894 & 737826 & 6.0 & 5.7672 & TRN & \\
\hline CHEMBL1509960 & 737826 & 4.85 & 5.2945 & TRN & \\
\hline CHEMBL1577593 & 737826 & 4.85 & 5.3828 & TRN & \\
\hline CHEMBL1482968 & 737826 & 4.4 & 4.5322 & TRN & \\
\hline CHEMBL1467911 & 737826 & 5.2 & 5.4873 & TRN & \\
\hline CHEMBL1589130 & 737826 & 5.5 & 5.2868 & TRN & \\
\hline CHEMBL3208355 & 737826 & 5.5 & 5.2992 & TRN & \\
\hline CHEMBL1438690 & 737826 & 6.3 & 6.392 & TRN & \\
\hline CHEMBL1363110 & 737826 & 5.05 & 5.4424 & TRN & \\
\hline CHEMBL1597288 & 737826 & 5.1 & 5.1081 & TRN & \\
\hline CHEMBL1360221 & 737826 & 5.6 & 5.2905 & TRN & \\
\hline CHEMBL1361000 & 737826 & 5.1 & 5.0451 & TST & \\
\hline CHEMBL1358807 & 737826 & 5.2 & 4.9454 & TRN & \\
\hline CHEMBL1538647 & 737826 & 4.75 & 5.4126 & TRN & \\
\hline CHEMBL1445255 & 737826 & 4.7 & 5.36 & TRN & \\
\hline CHEMBL102714 & 737826 & 4.5 & 5.6633 & TST & \\
\hline CHEMBL1316033 & 737826 & 4.6 & 4.4454 & TRN & \\
\hline CHEMBL471005 & 737826 & 5.1 & 5.1721 & TST & \\
\hline CHEMBL1481963 & 737826 & 6.55 & 5.3165 & TST & \\
\hline CHEMBL253765 & 737826 & 4.9 & 4.9025 & TRN & \\
\hline CHEMBL3190938 & 737826 & 5.6 & 5.36100 & 2000000001 & TRN \\
\hline CHEMBL1418280 & 737826 & 5.45 & 5.3271 & TRN & \\
\hline CHEMBL1602964 & 737826 & 4.4 & 5.2861 & TST & \\
\hline CHEMBL1327243 & 737826 & 5.6 & 5.4 & TST & \\
\hline CHEMBL1378064 & 737826 & 6.0 & 5.3297 & TRN & \\
\hline CHEMBL1435638 & 737826 & 6.1 & 6.1176 & TRN & \\
\hline CHEMBL1323342 & 737826 & 5.85 & 5.0965 & TRN & \\
\hline CHEMBL1394731 & 737826 & 5.7 & 5.4828 & TRN & \\
\hline CHEMBL1452894 & 737826 & 4.9 & 4.916 & TRN & \\
\hline CHEMBL1385802 & 737826 & 4.8 & 5.2611 & TRN & \\
\hline
\end{tabular}




\begin{tabular}{|c|c|c|c|c|c|}
\hline & & \multicolumn{4}{|c|}{ Supplemental Table S2.txt } \\
\hline CHEMBL1256392 & 737826 & 5.7 & 5.3237 & TRN & \\
\hline CHEMBL1365033 & 737826 & 5.35 & 5.2462 & TRN & \\
\hline CHEMBL1372798 & 737826 & 4.6 & 5.1491 & TST & \\
\hline CHEMBL491953 & 737826 & 6.3 & 6.2075 & TRN & \\
\hline CHEMBL1486831 & 737826 & 5.0 & 5.1932 & TRN & \\
\hline CHEMBL1596221 & 737826 & 5.25 & 5.4444 & TRN & \\
\hline CHEMBL1498572 & 737826 & 6.7 & 5.3148 & TRN & \\
\hline CHEMBL1383487 & 737826 & 6.65 & 5.5495 & TST & \\
\hline CHEMBL1514016 & 737826 & 4.9 & 4.7352 & TRN & \\
\hline CHEMBL1322864 & 737826 & 5.8 & 5.5623 & TRN & \\
\hline CHEMBL1449218 & 737826 & 4.9 & 4.7987 & TRN & \\
\hline CHEMBL1403168 & 737826 & 4.9 & 5.3746 & TRN & \\
\hline CHEMBL1398622 & 737826 & 4.75 & 5.20100 & 00000000005 & TRN \\
\hline CHEMBL1604074 & 737826 & 5.0 & 5.1062 & TRN & \\
\hline CHEMBL1515698 & 737826 & 5.8 & 5.7185 & TRN & \\
\hline CHEMBL1573858 & 737826 & 4.75 & 5.5421 & TRN & \\
\hline CHEMBL1501081 & 737826 & 4.4 & 5.1796 & TRN & \\
\hline CHEMBL1451307 & 737826 & 5.35 & 5.4304 & TRN & \\
\hline CHEMBL1386373 & 737826 & 5.45 & 5.2868 & TRN & \\
\hline CHEMBL411502 & 737826 & 4.6 & 4.555 & TRN & \\
\hline CHEMBL1727071 & 737826 & 6.15 & 5.2441 & TRN & \\
\hline CHEMBL1347390 & 737826 & 5.45 & 5.2316 & TRN & \\
\hline CHEMBL1733817 & 737826 & 4.8 & 4.992 & TRN & \\
\hline CHEMBL1594329 & 737826 & 6.7 & 6.3239 & TRN & \\
\hline CHEMBL1577148 & 737826 & 5.05 & 5.2295 & TRN & \\
\hline CHEMBL1306864 & 737826 & 4.8 & 5.5008 & TRN & \\
\hline CHEMBL1365427 & 737826 & 4.4 & 4.3437 & TRN & \\
\hline CHEMBL1559187 & 737826 & 4.85 & 5.3164 & TRN & \\
\hline CHEMBL1358628 & 737826 & 6.0 & 5.5158 & TST & \\
\hline CHEMBL420539 & 737826 & 5.45 & 5.8831 & TRN & \\
\hline CHEMBL1606258 & 737826 & 4.6 & 5.4215 & TRN & \\
\hline CHEMBL1409961 & 737826 & 5.1 & 5.1228 & TRN & \\
\hline CHEMBL1329940 & 737826 & 5.5 & 5.3688 & TST & \\
\hline CHEMBL1583562 & 737826 & 4.85 & 5.237 & TRN & \\
\hline CHEMBL1454035 & 737826 & 6.2 & 5.103 & TRN & \\
\hline CHEMBL3199177 & 737826 & 5.8 & 5.2295 & TRN & \\
\hline CHEMBL1517085 & 737826 & 5.35 & 5.2952 & TRN & \\
\hline CHEMBL1396559 & 737826 & 5.0 & 4.7291 & TRN & \\
\hline CHEMBL1537367 & 737826 & 5.5 & 5.2854 & TRN & \\
\hline CHEMBL1480847 & 737826 & 5.05 & 5.3024 & TRN & \\
\hline CHEMBL590670 & 737826 & 5.85 & 5.2697 & TRN & \\
\hline CHEMBL1505689 & 737826 & 5.3 & 5.0783 & TRN & \\
\hline CHEMBL3213435 & 737826 & 4.85 & 5.2314 & TRN & \\
\hline CHEMBL1408703 & 737826 & 4.5 & 4.479 & TRN & \\
\hline CHEMBL1354281 & 737826 & 5.0 & 4.8952 & TRN & \\
\hline CHEMBL1405257 & 737826 & 4.65 & 5.2777 & TRN & \\
\hline CHEMBL1741335 & 737826 & 4.75 & 5.0469 & TRN & \\
\hline CHEMBL1451875 & 737826 & 5.1 & 5.4797 & TRN & \\
\hline
\end{tabular}




\begin{tabular}{|c|c|c|c|c|c|}
\hline \multicolumn{6}{|c|}{ Supplemental Table S2.txt } \\
\hline CHEMBL 3191841 & 737826 & 5.35 & 5.2735 & TST & \\
\hline CHEMBL1526964 & 737826 & 5.6 & 5.3814 & TST & \\
\hline CHEMBL1584783 & 737826 & 6.25 & 5.2146 & TST & \\
\hline CHEMBL1329630 & 737826 & 4.75 & 5.1169 & TRN & \\
\hline CHEMBL1350113 & 737826 & 6.35 & 5.25700 & 0000000001 & TRN \\
\hline CHEMBL1559193 & 737826 & 4.8 & 5.3552 & TRN & \\
\hline CHEMBL1555368 & 737826 & 4.9 & 4.9069 & TRN & \\
\hline CHEMBL313339 & 737826 & 5.15 & 5.2879 & TST & \\
\hline CHEMBL1449598 & 737826 & 5.2 & 5.1679 & TRN & \\
\hline CHEMBL1468432 & 737826 & 5.0 & 5.2991 & TRN & \\
\hline CHEMBL 3197465 & 737826 & 5.1 & 5.3351 & TRN & \\
\hline CHEMBL1365404 & 737826 & 4.9 & 5.1893 & TRN & \\
\hline CHEMBL1515295 & 737826 & 4.4 & 4.3101 & TRN & \\
\hline CHEMBL1409078 & 737826 & 5.0 & 5.3801 & TRN & \\
\hline CHEMBL1336185 & 737826 & 5.5 & 5.3684 & TST & \\
\hline CHEMBL 2369279 & 737826 & 4.85 & 5.2378 & TRN & \\
\hline CHEMBL1536954 & 737826 & 4.9 & 5.5339 & TST & \\
\hline CHEMBL1487421 & 737826 & 5.0 & 5.2167 & TRN & \\
\hline CHEMBL1373797 & 737826 & 4.9 & 5.1851 & TRN & \\
\hline CHEMBL1719804 & 737826 & 5.65 & 5.3702 & TRN & \\
\hline CHEMBL1741492 & 737826 & 4.8 & 5.4703 & TRN & \\
\hline CHEMBL3195516 & 737826 & 4.45 & 5.239 & TRN & \\
\hline CHEMBL1400006 & 737826 & 6.6 & 5.5299 & TRN & \\
\hline CHEMBL1351832 & 737826 & 5.3 & 5.154 & TRN & \\
\hline CHEMBL433461 & 737826 & 5.7 & 5.5348 & TRN & \\
\hline CHEMBL1433115 & 737826 & 6.0 & 5.4129 & TRN & \\
\hline CHEMBL1565888 & 737826 & 5.0 & 5.2199 & TRN & \\
\hline CHEMBL1412499 & 737826 & 5.95 & 5.3652 & TRN & \\
\hline CHEMBL1411389 & 737826 & 4.7 & 4.5258 & TRN & \\
\hline CHEMBL1360641 & 737826 & 7.45 & 5.4506 & TST & \\
\hline CHEMBL1736619 & 737826 & 8.25 & 5.20700 & 0000000001 & TRN \\
\hline CHEMBL1456420 & 737826 & 5.0 & 4.85800 & 00000000005 & TRN \\
\hline CHEMBL1516262 & 737826 & 4.7 & 4.6397 & TRN & \\
\hline CHEMBL521970 & 737826 & 6.2 & 6.1419 & TRN & \\
\hline CHEMBL3207899 & 737826 & 5.8 & 5.6694 & TRN & \\
\hline CHEMBL1533232 & 737826 & 5.5 & 5.3283 & TRN & \\
\hline CHEMBL1544880 & 737826 & 4.65 & 5.1098 & TRN & \\
\hline CHEMBL1603394 & 737826 & 5.5 & 5.1855 & TRN & \\
\hline CHEMBL1548666 & 737826 & 4.4 & 5.0318 & TRN & \\
\hline CHEMBL1430702 & 737826 & 5.45 & 5.6315 & TRN & \\
\hline CHEMBL 3196704 & 737826 & 5.05 & 5.3616 & TRN & \\
\hline CHEMBL1572988 & 737826 & 4.4 & 4.4021 & TRN & \\
\hline CHEMBL1312757 & 737826 & 5.35 & 5.331 & TRN & \\
\hline CHEMBL1732963 & 737826 & 6.9 & 5.2193 & TRN & \\
\hline CHEMBL3189225 & 737826 & 4.85 & 5.5659 & TST & \\
\hline CHEMBL1532016 & 737826 & 5.1 & 5.1014 & TRN & \\
\hline CHEMBL1488305 & 737826 & 4.6 & 4.5848 & TRN & \\
\hline CHEMBL1469083 & 737826 & 5.25 & 5.3105 & TST & \\
\hline
\end{tabular}




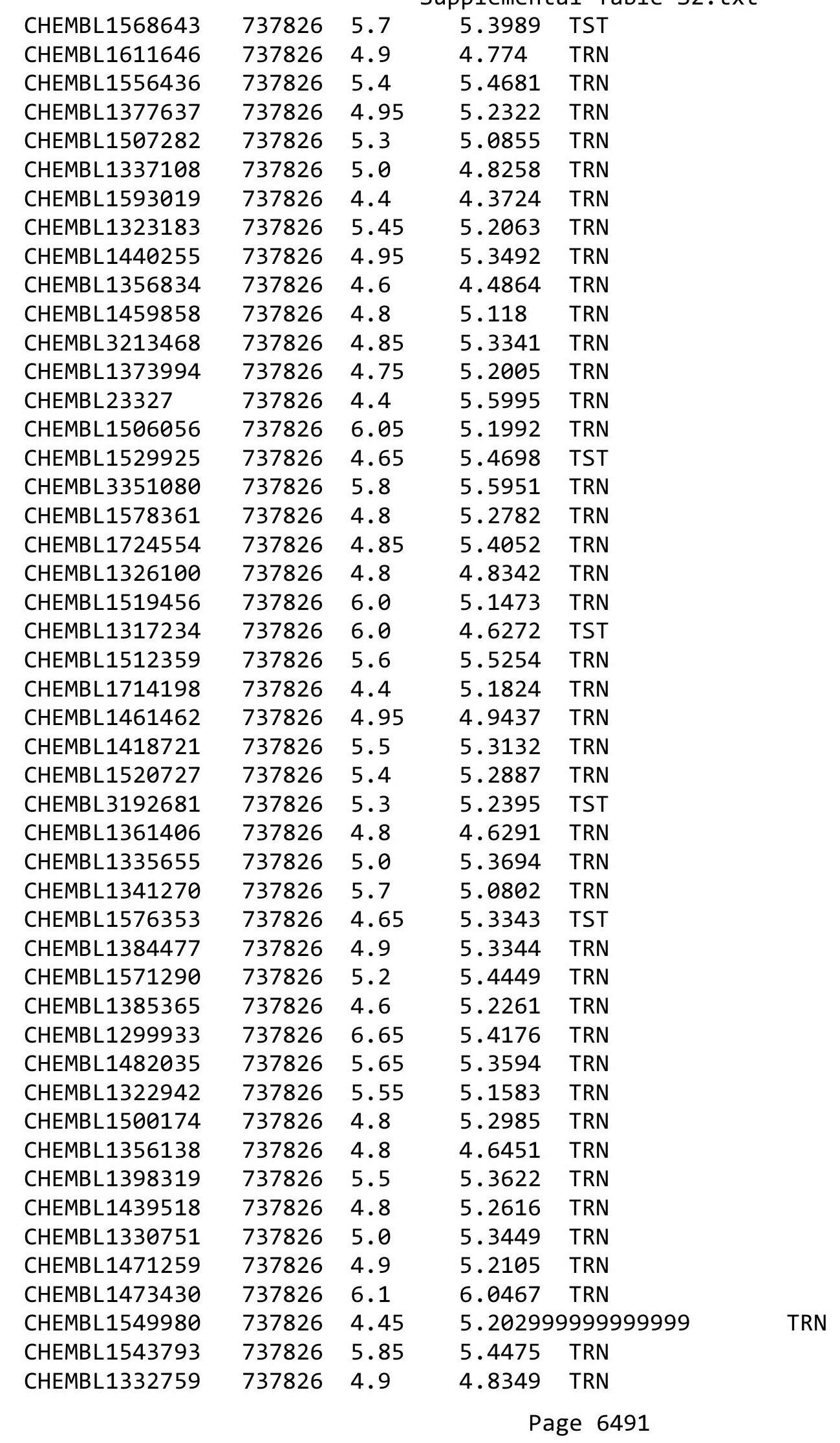




\begin{tabular}{|c|c|c|c|c|c|}
\hline \\
\hline CHEMBL1583174 & 737826 & 5.7 & 5.1795 & TRN & \\
\hline CHEMBL1483131 & 737826 & 7.0 & 5.2866 & TRN & \\
\hline CHEMBL3214056 & 737826 & 6.1 & 5.4949 & TRN & \\
\hline CHEMBL1566987 & 737826 & 6.4 & 5.9638 & TRN & \\
\hline CHEMBL1578181 & 737826 & 5.95 & 5.392 & TRN & \\
\hline CHEMBL1416402 & 737826 & 5.5 & 5.0874 & TST & \\
\hline CHEMBL1975888 & 737826 & 7.05 & 5.3773 & TRN & \\
\hline CHEMBL1567805 & 737826 & 4.6 & 5.3187 & TRN & \\
\hline CHEMBL1362504 & 737826 & 5.35 & 5.2493 & TRN & \\
\hline CHEMBL1347827 & 737826 & 4.85 & 5.1087 & TRN & \\
\hline CHEMBL1492205 & 737826 & 5.4 & 5.2941 & TRN & \\
\hline CHEMBL1330087 & 737826 & 6.0 & 5.8508 & TRN & \\
\hline CHEMBL1302993 & 737826 & 4.55 & 5.1243 & TRN & \\
\hline CHEMBL 3193784 & 737826 & 6.15 & 5.3858 & TRN & \\
\hline CHEMBL1353420 & 737826 & 5.35 & 5.4187 & TRN & \\
\hline CHEMBL1438916 & 737826 & 5.5 & 5.3454 & TST & \\
\hline CHEMBL1387625 & 737826 & 7.0 & 5.3411 & TST & \\
\hline CHEMBL1466277 & 737826 & 5.85 & 5.3169 & TST & \\
\hline CHEMBL1452250 & 737826 & 6.1 & 6.0168 & TRN & \\
\hline CHEMBL515505 & 737826 & 5.5 & 5.3095 & TRN & \\
\hline CHEMBL 3198125 & 737826 & 5.05 & 5.4859 & TRN & \\
\hline CHEMBL1565610 & 737826 & 4.9 & 5.2401 & TRN & \\
\hline CHEMBL1304739 & 737826 & 5.0 & 5.28299 & э9999999995 & TST \\
\hline CHEMBL1397752 & 737826 & 5.0 & 4.9749 & TRN & \\
\hline CHEMBL1557159 & 737826 & 5.35 & 5.1401 & TRN & \\
\hline CHEMBL1394187 & 737826 & 5.5 & 5.1578 & TRN & \\
\hline CHEMBL1716896 & 737826 & 4.55 & 5.2175 & TRN & \\
\hline CHEMBL1590156 & 737826 & 6.5 & 6.3541 & TRN & \\
\hline CHEMBL1728064 & 737826 & 7.5501 & 5.3636 & TST & \\
\hline CHEMBL1305253 & 737826 & 5.8 & 5.4718 & TRN & \\
\hline CHEMBL 3209650 & 737826 & 4.45 & 5.4021 & TST & \\
\hline CHEMBL1594242 & 737826 & 6.65 & 5.4289 & TRN & \\
\hline CHEMBL1729853 & 737826 & 4.4 & 5.3683 & TRN & \\
\hline CHEMBL1572595 & 737826 & 4.9 & 5.1432 & TRN & \\
\hline CHEMBL1471411 & 737826 & 5.05 & 5.5223 & TRN & \\
\hline CHEMBL1326152 & 737826 & 4.5 & 4.61600 & 00000000005 & TRN \\
\hline CHEMBL1471701 & 737826 & 4.4 & 5.1825 & TRN & \\
\hline CHEMBL1595731 & 737826 & 4.6 & 5.2058 & TRN & \\
\hline CHEMBL1375985 & 737826 & 5.15 & 5.3512 & TRN & \\
\hline CHEMBL148296 & 737826 & 5.1 & 4.9998 & TRN & \\
\hline CHEMBL1367733 & 737826 & 5.5 & 5.3062 & TRN & \\
\hline CHEMBL1563724 & 737826 & 5.3 & 5.24299 & э999999999 & TRN \\
\hline CHEMBL1331054 & 737826 & 4.95 & 5.3289 & TRN & \\
\hline CHEMBL1484990 & 737826 & 4.4 & 5.2128 & TST & \\
\hline CHEMBL1331363 & 737826 & 6.1 & 6.0352 & TRN & \\
\hline CHEMBL1361427 & 737826 & 5.05 & 5.3982 & TRN & \\
\hline CHEMBL1442761 & 737826 & 4.4 & 5.3449 & TRN & \\
\hline CHEMBL1606193 & 737826 & 5.5 & 5.3325 & TRN & \\
\hline
\end{tabular}




\begin{tabular}{|c|c|c|c|c|}
\hline & & & pplement & al $\mathrm{Ta}$ \\
\hline CHEMBL516075 & 737826 & 6.4 & 6.254 & TRN \\
\hline CHEMBL1564907 & 737826 & 5.65 & 5.2916 & TRN \\
\hline CHEMBL1429320 & 737826 & 5.05 & 5.3823 & TST \\
\hline CHEMBL1417412 & 737826 & 5.15 & 5.2667 & TST \\
\hline CHEMBL 3211113 & 737826 & 5.95 & 5.3895 & TRN \\
\hline CHEMBL1313121 & 737826 & 4.55 & 5.3762 & TRN \\
\hline CHEMBL1311526 & 737826 & 5.15 & 5.4361 & TRN \\
\hline CHEMBL1526213 & 737826 & 5.7 & 5.6628 & TRN \\
\hline CHEMBL1440921 & 737826 & 8.25 & 5.0803 & TRN \\
\hline CHEMBL1461936 & 737826 & 4.85 & 5.4391 & TRN \\
\hline CHEMBL1554851 & 737826 & 5.6 & 5.4691 & TRN \\
\hline CHEMBL1563254 & 737826 & 5.5 & 5.4038 & TST \\
\hline CHEMBL1490544 & 737826 & 4.9 & 5.3681 & TRN \\
\hline CHEMBL1368479 & 737826 & 5.15 & 5.3936 & TRN \\
\hline CHEMBL1308450 & 737826 & 4.75 & 5.1216 & TRN \\
\hline CHEMBL1418803 & 737826 & 4.8 & 5.3862 & TRN \\
\hline CHEMBL1338095 & 737826 & 6.0 & 5.9462 & TRN \\
\hline CHEMBL1494865 & 737826 & 4.8 & 5.1679 & TRN \\
\hline CHEMBL1464079 & 737826 & 4.75 & 5.3181 & TRN \\
\hline CHEMBL1518415 & 737826 & 6.4 & 6.1712 & TRN \\
\hline CHEMBL1520971 & 737826 & 5.55 & 5.3148 & TST \\
\hline CHEMBL1498778 & 737826 & 6.5 & 5.4344 & TRN \\
\hline CHEMBL1580697 & 737826 & 4.7 & 5.2618 & TRN \\
\hline CHEMBL1371060 & 737826 & 4.65 & 5.1089 & TRN \\
\hline CHEMBL1572635 & 737826 & 6.45 & 5.1636 & TRN \\
\hline CHEMBL1411049 & 737826 & 4.9 & 4.8688 & TRN \\
\hline CHEMBL1378959 & 737826 & 5.1 & 5.2601 & TRN \\
\hline CHEMBL1360848 & 737826 & 5.0 & 5.4094 & TRN \\
\hline CHEMBL1487692 & 737826 & 5.05 & 5.4937 & TRN \\
\hline CHEMBL1588072 & 737826 & 5.4 & 5.2021 & TRN \\
\hline CHEMBL1552150 & 737826 & 4.8 & 4.7093 & TRN \\
\hline CHEMBL1516905 & 737826 & 6.1 & 5.4387 & TRN \\
\hline CHEMBL1232474 & 737826 & 6.8 & 6.7618 & TST \\
\hline CHEMBL510009 & 737826 & 6.2 & 6.1367 & TRN \\
\hline CHEMBL1358462 & 737826 & 5.3 & 5.0295 & TST \\
\hline CHEMBL3213929 & 737826 & 5.95 & 5.3615 & TRN \\
\hline CHEMBL1465707 & 737826 & 5.45 & 5.1107 & TRN \\
\hline CHEMBL1547372 & 737826 & 5.05 & 5.1233 & TRN \\
\hline CHEMBL1700721 & 737826 & 6.45 & 5.2056 & TRN \\
\hline CHEMBL1419811 & 737826 & 4.95 & 5.3088 & TST \\
\hline CHEMBL3194323 & 737826 & 6.45 & 5.4 & TRN \\
\hline CHEMBL1435028 & 737826 & 4.7 & 4.5562 & TRN \\
\hline CHEMBL1521440 & 737826 & 5.5 & 5.3619 & TRN \\
\hline CHEMBL1360744 & 737826 & 5.7 & 5.1148 & TRN \\
\hline CHEMBL1439148 & 737826 & 5.55 & 5.4716 & TRN \\
\hline CHEMBL1372635 & 737826 & 5.2 & 4.916 & TRN \\
\hline CHEMBL1490799 & 737826 & 7.5 & 5.3421 & TST \\
\hline CHEMBL1613397 & 737826 & 4.55 & 5.4867 & TRN \\
\hline
\end{tabular}




\begin{tabular}{|c|c|c|c|c|c|}
\hline \\
\hline CHEMBL1393271 & 737826 & 4.8 & 5.1686 & TST & \\
\hline CHEMBL1544517 & 737826 & 6.05 & 5.5887 & TRN & \\
\hline CHEMBL1396862 & 737826 & 7.1 & 6.4607 & TRN & \\
\hline CHEMBL1339054 & 737826 & 5.45 & 5.1369 & TRN & \\
\hline CHEMBL1582278 & 737826 & 6.35 & 5.3282 & TRN & \\
\hline CHEMBL1320042 & 737826 & 4.95 & 5.2799 & TST & \\
\hline CHEMBL1423865 & 737826 & 5.0 & 5.0339 & TRN & \\
\hline CHEMBL1546034 & 737826 & 5.3 & 5.3209 & TRN & \\
\hline CHEMBL1594648 & 737826 & 7.1 & 6.2996 & TRN & \\
\hline CHEMBL1381111 & 737826 & 5.3 & 5.2553 & TRN & \\
\hline CHEMBL1577213 & 737826 & 4.7 & 5.1725 & TRN & \\
\hline CHEMBL1406920 & 737826 & 6.05 & 5.5384 & TRN & \\
\hline CHEMBL554041 & 737826 & 4.7 & 4.7746 & TST & \\
\hline CHEMBL1507561 & 737826 & 7.6 & 5.2857 & TRN & \\
\hline CHEMBL1437985 & 737826 & 4.45 & 5.2231 & TST & \\
\hline CHEMBL1591874 & 737826 & -0.0 & 4.8607 & TRN & \\
\hline CHEMBL1565164 & 737826 & 4.7 & 5.1392 & TST & \\
\hline CHEMBL3209355 & 737826 & 4.8 & 5.2798 & TRN & \\
\hline CHEMBL1486659 & 737826 & 5.2 & 5.0687 & TST & \\
\hline CHEMBL1560252 & 737826 & 5.3 & 5.3485 & TRN & \\
\hline CHEMBL1364972 & 737826 & 6.0 & 5.6398 & TRN & \\
\hline CHEMBL1333519 & 737826 & 6.4 & 5.1501 & TRN & \\
\hline CHEMBL 1475657 & 737826 & 5.1 & 4.99100 & 00000000005 & TRN \\
\hline CHEMBL1379187 & 737826 & 5.6 & 5.4721 & TRN & \\
\hline CHEMBL1593371 & 737826 & 5.5 & 5.3619 & TRN & \\
\hline CHEMBL1442996 & 737826 & 4.7 & 4.57600 & 20000000005 & TRN \\
\hline CHEMBL1598297 & 737826 & 6.4 & 5.0932 & TRN & \\
\hline CHEMBL1476958 & 737826 & 4.5 & 4.4076 & TRN & \\
\hline CHEMBL1435409 & 737826 & 6.1 & 5.9764 & TRN & \\
\hline CHEMBL1553404 & 737826 & 4.9 & 4.7231 & TRN & \\
\hline CHEMBL1561829 & 737826 & 7.1 & 6.3599 & TST & \\
\hline CHEMBL1606425 & 737826 & 5.8 & 5.3723 & TRN & \\
\hline CHEMBL1404703 & 737826 & 5.1 & 4.992 & TRN & \\
\hline CHEMBL1383348 & 737826 & 7.0 & 5.0905 & TRN & \\
\hline CHEMBL1410865 & 737826 & 6.0 & 5.78700 & 0000000001 & TRN \\
\hline CHEMBL1404660 & 737826 & 5.8 & 5.5058 & TRN & \\
\hline CHEMBL1604095 & 737826 & 5.5 & 5.1215 & TRN & \\
\hline CHEMBL1452910 & 737826 & 5.0 & 4.7644 & TST & \\
\hline CHEMBL1377868 & 737826 & 5.5 & 5.1231 & TRN & \\
\hline CHEMBL1542604 & 737826 & 5.0 & 5.3941 & TST & \\
\hline CHEMBL1554194 & 737826 & 6.5 & 6.3241 & TRN & \\
\hline CHEMBL1733552 & 737826 & 4.9 & 5.2902 & TRN & \\
\hline CHEMBL168461 & 737826 & 4.8 & 4.843 & TST & \\
\hline CHEMBL1364047 & 737826 & 7.6499 & 5.1969 & TRN & \\
\hline CHEMBL1428349 & 737826 & 5.2 & 5.4321 & TST & \\
\hline CHEMBL1352616 & 737826 & 5.85 & 5.2821 & TRN & \\
\hline CHEMBL1547832 & 737826 & 5.65 & 5.1156 & TRN & \\
\hline CHEMBL1330626 & 737826 & 4.8 & 5.2231 & TRN & \\
\hline
\end{tabular}




\begin{tabular}{|c|c|c|c|c|c|}
\hline \\
\hline CHEMBL8747 & 737826 & 4.5 & 4.6575 & TRN & \\
\hline CHEMBL1501500 & 737826 & 5.85 & 5.3105 & TRN & \\
\hline CHEMBL1331690 & 737826 & 4.7 & 5.1785 & TRN & \\
\hline CHEMBL1375478 & 737826 & 5.05 & 5.3845 & TRN & \\
\hline CHEMBL1593663 & 737826 & 4.8 & 4.6893 & TRN & \\
\hline CHEMBL1742280 & 737826 & 5.2 & 5.5079 & TRN & \\
\hline CHEMBL3213131 & 737826 & 4.85 & 5.4077 & TST & \\
\hline CHEMBL1396358 & 737826 & 4.8 & 4.8012 & TRN & \\
\hline CHEMBL1329562 & 737826 & 6.25 & 5.4676 & TRN & \\
\hline CHEMBL3195361 & 737826 & 5.35 & 5.3668 & TRN & \\
\hline CHEMBL1397548 & 737826 & -0.0 & 5.9082 & TRN & \\
\hline CHEMBL1591847 & 737826 & 4.4 & 4.396 & TRN & \\
\hline CHEMBL1425063 & 737826 & 4.9 & 5.3969 & TST & \\
\hline CHEMBL1557870 & 737826 & 5.7 & 5.25299 & 9999999999 & TRN \\
\hline CHEMBL1173453 & 737826 & 5.6 & 5.4909 & TRN & \\
\hline CHEMBL1567530 & 737826 & 5.5 & 5.3768 & TST & \\
\hline CHEMBL1580610 & 737826 & 5.2 & 5.2909 & TRN & \\
\hline CHEMBL3208389 & 737826 & 4.7 & 5.4454 & TRN & \\
\hline CHEMBL1469862 & 737826 & 5.2 & 5.3426 & TRN & \\
\hline CHEMBL1548380 & 737826 & 4.9 & 5.079 & TRN & \\
\hline CHEMBL1602661 & 737826 & 7.6 & 5.3142 & TRN & \\
\hline CHEMBL1445647 & 737826 & 4.7 & 5.2829 & TST & \\
\hline CHEMBL1490333 & 737826 & 5.0 & 5.3378 & TRN & \\
\hline CHEMBL1595363 & 737826 & 5.05 & 5.1291 & TRN & \\
\hline CHEMBL1312936 & 737826 & 6.5 & 5.4033 & TRN & \\
\hline CHEMBL1328979 & 737826 & 5.1 & 5.0112 & TRN & \\
\hline CHEMBL1524851 & 737826 & 4.7 & 4.7419 & TRN & \\
\hline CHEMBL1481588 & 737826 & 4.95 & 5.3427 & TRN & \\
\hline CHEMBL1554664 & 737826 & 5.9 & 5.9547 & TRN & \\
\hline CHEMBL1546037 & 737826 & 4.55 & 5.3328 & TRN & \\
\hline CHEMBL1741539 & 737826 & 4.8 & 5.2491 & TST & \\
\hline CHEMBL1367958 & 737826 & 4.8 & 5.1438 & TRN & \\
\hline CHEMBL3196667 & 737826 & 5.9 & 5.2881 & TRN & \\
\hline CHEMBL1742219 & 737826 & 5.3 & 5.3144 & TRN & \\
\hline CHEMBL1403388 & 737826 & 7.0 & 6.4815 & TST & \\
\hline CHEMBL1433153 & 737826 & 6.1 & 5.3514 & TRN & \\
\hline CHEMBL1399944 & 737826 & 5.5 & 5.3131 & TRN & \\
\hline CHEMBL1460935 & 737826 & 5.55 & 5.2843 & TRN & \\
\hline CHEMBL1433805 & 737826 & 5.3 & 5.1971 & TRN & \\
\hline CHEMBL1399273 & 737826 & 6.15 & 5.3453 & TRN & \\
\hline CHEMBL1307366 & 737826 & 5.4 & 5.3234 & TRN & \\
\hline CHEMBL3198825 & 737826 & 5.9 & 5.1798 & TST & \\
\hline CHEMBL1378237 & 737826 & 5.0 & 4.9657 & TRN & \\
\hline CHEMBL1527851 & 737826 & 5.5 & 5.221 & TRN & \\
\hline CHEMBL1311978 & 737826 & 5.45 & 5.3795 & TRN & \\
\hline CHEMBL1341642 & 737826 & 4.75 & 5.3907 & TRN & \\
\hline CHEMBL1315417 & 737826 & 4.6 & 4.6504 & TST & \\
\hline CHEMBL1256910 & 737826 & 5.9 & 5.6542 & TST & \\
\hline
\end{tabular}




\begin{tabular}{|c|c|c|c|c|c|}
\hline & & \multicolumn{4}{|c|}{ Supplemental Table s2.txt } \\
\hline CHEMBL1335690 & 737826 & 6.75 & 5.3948 & TRN & \\
\hline CHEMBL1312233 & 737826 & 4.8 & 5.24 & TST & \\
\hline CHEMBL596674 & 737826 & 4.9 & 4.9652 & TRN & \\
\hline CHEMBL1565536 & 737826 & 5.0 & 5.2481 & TRN & \\
\hline CHEMBL1525571 & 737826 & 4.95 & 5.3831 & TRN & \\
\hline CHEMBL1569975 & 737826 & 4.6 & 5.4009 & TRN & \\
\hline CHEMBL446774 & 737826 & 5.4 & 5.2446 & TRN & \\
\hline CHEMBL1584523 & 737826 & 5.5 & 5.3299 & TRN & \\
\hline CHEMBL1509145 & 737826 & 5.35 & 5.336 & TRN & \\
\hline CHEMBL1563032 & 737826 & 5.5 & 5.2966 & TRN & \\
\hline CHEMBL1562639 & 737826 & 4.8 & 5.2969 & TRN & \\
\hline CHEMBL512908 & 737826 & 5.8 & 5.5398 & TST & \\
\hline CHEMBL3212233 & 737826 & 5.0 & 5.0854 & TST & \\
\hline CHEMBL1323905 & 737826 & 4.9 & 4.8685 & TRN & \\
\hline CHEMBL1493707 & 737826 & 5.6 & 5.4569 & TRN & \\
\hline CHEMBL1495886 & 737826 & 4.75 & 5.24200 & 0000000001 & TST \\
\hline CHEMBL1393435 & 737826 & 4.8 & 5.5192 & TST & \\
\hline CHEMBL1566978 & 737826 & 5.4 & 5.2274 & TRN & \\
\hline CHEMBL1423337 & 737826 & 4.95 & 5.3116 & TRN & \\
\hline CHEMBL1326501 & 737826 & 5.1 & 5.309 & TRN & \\
\hline CHEMBL1311026 & 737826 & 5.35 & 5.3029 & TST & \\
\hline CHEMBL1547886 & 737826 & 4.7 & 5.3668 & TRN & \\
\hline CHEMBL1094842 & 737826 & 5.05 & 5.1191 & TRN & \\
\hline CHEMBL1494592 & 737826 & 4.4 & 4.5642 & TRN & \\
\hline CHEMBL1310193 & 737826 & 5.1 & 5.2546 & TRN & \\
\hline CHEMBL1459455 & 737826 & 5.6 & 5.4843 & TRN & \\
\hline CHEMBL1377321 & 737826 & 5.6 & 5.3177 & TRN & \\
\hline CHEMBL1551133 & 737826 & 5.3 & 5.2657 & TRN & \\
\hline CHEMBL1320326 & 737826 & 5.55 & 5.1732 & TRN & \\
\hline CHEMBL1395899 & 737826 & 5.4 & 5.1961 & TRN & \\
\hline CHEMBL1432402 & 737826 & 4.6 & 5.4484 & TST & \\
\hline CHEMBL1382729 & 737826 & 5.15 & 5.3378 & TRN & \\
\hline CHEMBL1557721 & 737826 & 5.45 & 5.3373 & TRN & \\
\hline CHEMBL1326359 & 737826 & 5.4 & 5.4188 & TRN & \\
\hline CHEMBL3214452 & 737826 & 5.25 & 5.0236 & TRN & \\
\hline CHEMBL1725604 & 737826 & 5.3 & 5.2729 & TRN & \\
\hline CHEMBL1367548 & 737826 & 4.8 & 5.3539 & TRN & \\
\hline CHEMBL1385746 & 737826 & 6.95 & 5.0331 & TRN & \\
\hline CHEMBL1316760 & 737826 & 4.6 & 4.5584 & TRN & \\
\hline CHEMBL1317344 & 737826 & 4.5 & 4.5714 & TRN & \\
\hline CHEMBL1299997 & 737826 & 4.5 & 5.3747 & TST & \\
\hline CHEMBL1550370 & 737826 & 4.95 & 5.2592 & TRN & \\
\hline CHEMBL1414061 & 737826 & 5.35 & 5.2466 & TRN & \\
\hline CHEMBL3212510 & 737826 & 4.4 & 5.4109 & TRN & \\
\hline CHEMBL1366732 & 737826 & 6.4 & 6.3658 & TRN & \\
\hline CHEMBL1476430 & 737826 & 6.3 & 6.1571 & TRN & \\
\hline CHEMBL1333616 & 737826 & 4.8 & 5.1867 & TRN & \\
\hline CHEMBL1459899 & 737826 & 5.6 & 5.0175 & TRN & \\
\hline
\end{tabular}




\begin{tabular}{|c|c|c|c|c|c|}
\hline \\
\hline CHEMBL1305989 & 737826 & 5.2 & 5.4729 & TST & \\
\hline CHEMBL1479340 & 737826 & 5.65 & 5.263 & TRN & \\
\hline CHEMBL3208361 & 737826 & 5.05 & 5.4284 & TST & \\
\hline CHEMBL1564734 & 737826 & 6.05 & 5.3284 & TRN & \\
\hline CHEMBL3195166 & 737826 & 5.45 & 5.4327 & TRN & \\
\hline CHEMBL1554693 & 737826 & 5.0 & 5.0883 & TRN & \\
\hline CHEMBL1342661 & 737826 & 4.6 & 5.2676 & TRN & \\
\hline CHEMBL1574626 & 737826 & 5.5 & 5.2342 & TRN & \\
\hline CHEMBL1490330 & 737826 & 4.75 & 5.3331 & TRN & \\
\hline CHEMBL1505175 & 737826 & 5.55 & 5.0219 & TRN & \\
\hline CHEMBL1741558 & 737826 & 5.0 & 5.3084 & TRN & \\
\hline CHEMBL1519172 & 737826 & 5.15 & 5.2113 & TRN & \\
\hline CHEMBL1506402 & 737826 & 4.4 & 5.3568 & TRN & \\
\hline CHEMBL1575145 & 737826 & 4.65 & 5.3959 & TRN & \\
\hline CHEMBL1434098 & 737826 & 4.7 & 4.6183 & TRN & \\
\hline CHEMBL1549843 & 737826 & 4.95 & 5.3383 & TST & \\
\hline CHEMBL1314516 & 737826 & 5.5 & 5.3758 & TRN & \\
\hline CHEMBL1322136 & 737826 & 5.4 & 5.4478 & TRN & \\
\hline CHEMBL3661417 & 737826 & 4.9 & 4.9616 & TST & \\
\hline CHEMBL1612410 & 737826 & 4.5 & 4.5727 & TRN & \\
\hline CHEMBL1587153 & 737826 & 5.0 & 5.255 & TRN & \\
\hline CHEMBL145346 & 737826 & 5.0 & 5.3445 & TRN & \\
\hline CHEMBL3214295 & 737826 & 5.45 & 5.4493 & TRN & \\
\hline CHEMBL1451986 & 737826 & 5.6 & 5.3985 & TST & \\
\hline CHEMBL1422472 & 737826 & 6.25 & 5.2076 & TRN & \\
\hline CHEMBL1562047 & 737826 & 4.9 & 5.2252 & TRN & \\
\hline CHEMBL1341328 & 737826 & 5.0 & 5.2625 & TRN & \\
\hline CHEMBL1387431 & 737826 & 5.0 & 5.3697 & TRN & \\
\hline CHEMBL1467857 & 737826 & 5.4 & 5.2973 & TRN & \\
\hline CHEMBL1560445 & 737826 & 4.8 & 4.6461 & TRN & \\
\hline CHEMBL1578591 & 737826 & 5.85 & 5.5355 & TRN & \\
\hline CHEMBL1503191 & 737826 & 4.55 & 5.1003 & TRN & \\
\hline CHEMBL1365082 & 737826 & 5.5 & 5.3608 & TST & \\
\hline CHEMBL1440290 & 737826 & 4.6 & 5.4315 & TRN & \\
\hline CHEMBL1389262 & 737826 & 4.5 & 5.0327 & TRN & \\
\hline CHEMBL1741388 & 737826 & 5.45 & 5.3019 & TRN & \\
\hline CHEMBL1330580 & 737826 & 6.4 & 5.3432 & TRN & \\
\hline CHEMBL1561738 & 737826 & 4.95 & 5.57700 & $\partial 000000001$ & TRN \\
\hline CHEMBL1481810 & 737826 & 5.8 & 5.1882 & TRN & \\
\hline CHEMBL1390135 & 737826 & 6.5 & 5.2402 & TRN & \\
\hline CHEMBL1453817 & 737826 & 5.85 & 5.7936 & TRN & \\
\hline CHEMBL1459485 & 737826 & 5.1 & 5.0213 & TRN & \\
\hline CHEMBL1393682 & 737826 & 5.05 & 5.2166 & TST & \\
\hline CHEMBL1318114 & 737826 & 6.3 & 6.1528 & TRN & \\
\hline CHEMBL1452111 & 737826 & 6.0 & 5.8316 & TRN & \\
\hline CHEMBL1406530 & 737826 & 4.6 & 5.1475 & TRN & \\
\hline CHEMBL34730 & 737826 & 5.0 & 5.6745 & TRN & \\
\hline CHEMBL1375286 & 737826 & 5.15 & 5.4971 & TRN & \\
\hline
\end{tabular}




\begin{tabular}{|c|c|c|c|c|}
\hline & & & ipplement & al Table S \\
\hline CHEMBL153057 & 737826 & 5.0 & 5.0167 & TST \\
\hline CHEMBL1398321 & 737826 & 5.3 & 5.2366 & TST \\
\hline CHEMBL1359661 & 737826 & 5.3 & 5.2922 & TRN \\
\hline CHEMBL1491168 & 737826 & 4.75 & 5.2751 & TRN \\
\hline CHEMBL269550 & 737826 & 5.4 & 5.2478 & TRN \\
\hline CHEMBL1423135 & 737826 & 5.3 & 5.42899 & 9999999999 \\
\hline CHEMBL1495604 & 737826 & 5.5 & 5.3469 & TRN \\
\hline CHEMBL1521564 & 737826 & 4.4 & 5.3221 & TRN \\
\hline CHEMBL1589124 & 737826 & 5.85 & 5.2656 & TST \\
\hline CHEMBL471226 & 737826 & 7.1 & 6.5373 & TST \\
\hline CHEMBL1391995 & 737826 & 5.1 & 5.2826 & TRN \\
\hline CHEMBL1256776 & 737826 & 6.5 & 6.0644 & TRN \\
\hline CHEMBL1347362 & 737826 & 4.85 & 5.1995 & TRN \\
\hline CHEMBL1343666 & 737826 & 5.5 & 5.1732 & TRN \\
\hline CHEMBL1571970 & 737826 & 8.25 & 5.4382 & TRN \\
\hline CHEMBL1524503 & 737826 & 4.4 & 5.1674 & TRN \\
\hline CHEMBL518923 & 737826 & 5.25 & 5.5683 & TRN \\
\hline CHEMBL1439338 & 737826 & 5.0 & 5.2638 & TRN \\
\hline CHEMBL1354408 & 737826 & 5.8 & 5.5448 & TRN \\
\hline CHEMBL1450169 & 737826 & 5.1 & 4.9803 & TST \\
\hline CHEMBL1307882 & 737826 & 5.1 & 5.4167 & TRN \\
\hline CHEMBL1522155 & 737826 & 5.2 & 5.1826 & TRN \\
\hline CHEMBL1312373 & 737826 & 6.2 & 5.2171 & TRN \\
\hline CHEMBL1307908 & 737826 & 6.1 & 5.2508 & TRN \\
\hline CHEMBL1390229 & 737826 & 4.85 & 5.2849 & TRN \\
\hline CHEMBL3211211 & 737826 & 5.35 & 5.4478 & TRN \\
\hline CHEMBL3196632 & 737826 & 6.55 & 5.4276 & TRN \\
\hline CHEMBL1539107 & 737826 & 5.2 & 5.4755 & TRN \\
\hline CHEMBL1376767 & 737826 & 5.0 & 5.3422 & TRN \\
\hline CHEMBL1362068 & 737826 & 4.6 & 4.5452 & TRN \\
\hline CHEMBL1313465 & 737826 & 5.25 & 5.3078 & TRN \\
\hline CHEMBL1611423 & 737826 & 5.0 & 5.3319 & TRN \\
\hline CHEMBL1588802 & 737826 & 4.85 & 5.1587 & TRN \\
\hline CHEMBL1566670 & 737826 & 4.4 & 4.6197 & TST \\
\hline CHEMBL1453834 & 737826 & 5.7 & 5.3914 & TRN \\
\hline CHEMBL1599861 & 737826 & 4.6 & 5.2345 & TRN \\
\hline CHEMBL1439936 & 737826 & 5.35 & 5.3219 & TST \\
\hline CHEMBL1742307 & 737826 & 4.7 & 5.3392 & TRN \\
\hline CHEMBL1350043 & 737826 & 4.8 & 5.5542 & TRN \\
\hline CHEMBL1327203 & 737826 & 6.4 & 6.4262 & TST \\
\hline CHEMBL1357157 & 737826 & 4.9 & 4.8186 & TRN \\
\hline CHEMBL1316055 & 737826 & 6.0 & 5.9537 & TRN \\
\hline CHEMBL1395620 & 737826 & 5.5 & 5.2944 & TRN \\
\hline CHEMBL1510548 & 737826 & 4.9 & 5.1223 & TST \\
\hline CHEMBL1399384 & 737826 & 5.45 & 5.2494 & TST \\
\hline CHEMBL1727680 & 737826 & 7.0 & 6.4005 & TRN \\
\hline CHEMBL1734974 & 737826 & 5.35 & 5.2092 & TRN \\
\hline CHEMBL1575531 & 737826 & 4.5 & 5.4042 & TRN \\
\hline
\end{tabular}




\begin{tabular}{|c|c|c|c|c|c|}
\hline \multicolumn{6}{|c|}{ Supplemental Table S2.txt } \\
\hline CHEMBL1547685 & 737826 & 5.65 & 5.2612 & TRN & \\
\hline CHEMBL1594799 & 737826 & 4.55 & 5.1226 & TRN & \\
\hline CHEMBL1719399 & 737826 & 5.0 & 5.1901 & TRN & \\
\hline CHEMBL1471467 & 737826 & 4.6 & 5.2949 & TRN & \\
\hline CHEMBL1373464 & 737826 & 4.4 & 4.6783 & TRN & \\
\hline CHEMBL1741419 & 737826 & 5.1 & 5.1063 & TST & \\
\hline CHEMBL1527813 & 737826 & 4.85 & 5.077 & TRN & \\
\hline CHEMBL491940 & 737826 & 6.2 & 6.1614 & TRN & \\
\hline CHEMBL1593589 & 737826 & 6.9 & 6.1696 & TRN & \\
\hline CHEMBL1449669 & 737826 & 4.7 & 5.3878 & TRN & \\
\hline CHEMBL1299891 & 737826 & 4.75 & 5.3717 & TRN & \\
\hline CHEMBL369142 & 737826 & 4.8 & 4.8751 & TST & \\
\hline CHEMBL1373723 & 737826 & 6.0 & 5.7628 & TRN & \\
\hline CHEMBL1469385 & 737826 & 5.6 & 5.3791 & TST & \\
\hline CHEMBL1382877 & 737826 & 5.0 & 5.3378 & TRN & \\
\hline CHEMBL1574385 & 737826 & 4.85 & 5.3702 & TRN & \\
\hline CHEMBL1449490 & 737826 & 5.7 & 5.44 & TST & \\
\hline CHEMBL1357759 & 737826 & 5.5 & 5.1511 & TRN & \\
\hline CHEMBL1388711 & 737826 & 4.85 & 5.2542 & TRN & \\
\hline CHEMBL1455919 & 737826 & 4.4 & 5.0501 & TRN & \\
\hline CHEMBL1507825 & 737826 & 5.35 & 5.553 & TRN & \\
\hline CHEMBL3208184 & 737826 & 6.6 & 5.4031 & TRN & \\
\hline CHEMBL1449528 & 737826 & 5.3 & 5.0816 & TRN & \\
\hline CHEMBL1593219 & 737826 & 5.1 & 5.1809 & TRN & \\
\hline CHEMBL1513431 & 737826 & 5.5 & 5.4875 & TRN & \\
\hline CHEMBL1303450 & 737826 & 5.0 & 5.1319 & TRN & \\
\hline CHEMBL1461511 & 737826 & 5.1 & 5.4715 & TRN & \\
\hline CHEMBL1413858 & 737826 & 4.8 & 4.8011 & TRN & \\
\hline CHEMBL1495395 & 737826 & 5.5 & 5.3929 & TRN & \\
\hline CHEMBL1336787 & 737826 & 5.0 & 4.9687 & TRN & \\
\hline CHEMBL1449103 & 737826 & 7.0 & 5.3813 & TRN & \\
\hline CHEMBL1323029 & 737826 & 4.95 & 5.45100 & 00000000005 & TRN \\
\hline CHEMBL1318454 & 737826 & 4.9 & 4.8061 & TRN & \\
\hline CHEMBL 3214400 & 737826 & 5.15 & 5.266 & TRN & \\
\hline CHEMBL 3210786 & 737826 & 7.6499 & 5.4507 & TST & \\
\hline CHEMBL1566684 & 737826 & 4.8 & 5.4404 & TST & \\
\hline CHEMBL1496418 & 737826 & 6.25 & 5.4885 & TRN & \\
\hline CHEMBL1380304 & 737826 & 4.45 & 5.3118 & TRN & \\
\hline CHEMBL1404647 & 737826 & 4.75 & 5.1967 & TRN & \\
\hline CHEMBL1470578 & 737826 & 5.1 & 5.305 & TRN & \\
\hline CHEMBL1613544 & 737826 & 4.9 & 4.888 & TST & \\
\hline CHEMBL1523323 & 737826 & 5.1 & 5.3548 & TRN & \\
\hline CHEMBL1466831 & 737826 & 4.85 & 5.1596 & TRN & \\
\hline CHEMBL1451411 & 737826 & 5.2 & 5.0567 & TRN & \\
\hline CHEMBL1415115 & 737826 & 4.95 & 5.369 & TST & \\
\hline CHEMBL1403214 & 737826 & 4.85 & 5.3248 & TRN & \\
\hline CHEMBL1538611 & 737826 & 4.95 & 5.29799 & 9999999999 & TRN \\
\hline CHEMBL1411424 & 737826 & 4.4 & 4.3272 & TRN & \\
\hline
\end{tabular}




\begin{tabular}{|c|c|c|c|c|}
\hline \multicolumn{5}{|c|}{ Supplemental Table S2.txt } \\
\hline CHEMBL1336865 & 737826 & 5.4 & 5.2083 & TRN \\
\hline CHEMBL1441650 & 737826 & 4.6 & 5.1807 & TRN \\
\hline CHEMBL1425093 & 737826 & 5.4 & 5.3566 & TRN \\
\hline CHEMBL1384157 & 737826 & 5.0 & 5.2589 & TRN \\
\hline CHEMBL 276727 & 737826 & 4.4 & 4.5403 & TST \\
\hline CHEMBL1471304 & 737826 & 5.3 & 5.2175 & TRN \\
\hline CHEMBL1477833 & 737826 & 4.8 & 5.0026 & TRN \\
\hline CHEMBL3195142 & 737826 & 5.4 & 5.4485 & TRN \\
\hline CHEMBL1317039 & 737826 & 5.8 & 5.6585 & TRN \\
\hline CHEMBL1347250 & 737826 & 5.45 & 5.4545 & TRN \\
\hline CHEMBL1600437 & 737826 & 5.55 & 5.1368 & TRN \\
\hline CHEMBL1525540 & 737826 & 5.45 & 5.2177 & TRN \\
\hline CHEMBL 2003072 & 737826 & 5.6 & 5.4386 & TRN \\
\hline CHEMBL1407910 & 737826 & 6.55 & 5.4037 & TST \\
\hline CHEMBL3191244 & 737826 & 4.95 & 5.3211 & TRN \\
\hline CHEMBL 87418 & 737826 & 4.9 & 5.0231 & TST \\
\hline CHEMBL1490567 & 737826 & 4.4 & 5.0991 & TRN \\
\hline CHEMBL1369125 & 737826 & 6.15 & 5.1964 & TRN \\
\hline CHEMBL1437776 & 737826 & 4.4 & 4.3412 & TRN \\
\hline CHEMBL1401960 & 737826 & 5.05 & 5.2654 & TRN \\
\hline CHEMBL1559828 & 737826 & 5.15 & 5.23 & TRN \\
\hline CHEMBL1255778 & 737826 & 4.9 & 4.9566 & TST \\
\hline CHEMBL 276140 & 737826 & 8.2 & 7.2694 & TRN \\
\hline CHEMBL1479218 & 737826 & 5.1 & 5.3446 & TRN \\
\hline CHEMBL1487435 & 737826 & 5.75 & 5.4358 & TRN \\
\hline CHEMBL1582127 & 737826 & 6.05 & 5.1789 & TRN \\
\hline CHEMBL1558087 & 737826 & 4.8 & 5.4713 & TRN \\
\hline CHEMBL1427186 & 737826 & 4.7 & 5.3195 & TRN \\
\hline CHEMBL1480192 & 737826 & 5.25 & 5.3749 & TRN \\
\hline CHEMBL1566184 & 737826 & 6.3 & 5.0898 & TRN \\
\hline CHEMBL3208532 & 737826 & 8.25 & 5.6032 & TRN \\
\hline CHEMBL1453185 & 737826 & 4.8 & 5.0956 & TRN \\
\hline CHEMBL1502107 & 737826 & 5.8 & 5.3138 & TRN \\
\hline CHEMBL1982203 & 737826 & 5.5 & 5.3513 & TRN \\
\hline CHEMBL1425173 & 737826 & 6.4 & 5.3873 & TRN \\
\hline CHEMBL1557355 & 737826 & 5.65 & 5.4039 & TRN \\
\hline CHEMBL1488167 & 737826 & 5.5 & 5.4524 & TRN \\
\hline CHEMBL1444141 & 737826 & 5.6 & 5.1019 & TRN \\
\hline CHEMBL1490998 & 737826 & 4.5 & 4.4284 & TRN \\
\hline CHEMBL1581244 & 737826 & 5.4 & 5.3308 & TRN \\
\hline CHEMBL1493861 & 737826 & 5.45 & 5.1907 & TRN \\
\hline CHEMBL1522556 & 737826 & 5.3 & 5.0778 & TRN \\
\hline CHEMBL1302626 & 737826 & 5.2 & 5.1642 & TRN \\
\hline CHEMBL21260 & 737826 & 6.0 & 5.7979 & TRN \\
\hline CHEMBL3193339 & 737826 & 4.9 & 5.5185 & TRN \\
\hline CHEMBL1492266 & 737826 & 4.85 & 5.3591 & TRN \\
\hline CHEMBL1367708 & 737826 & 5.15 & 5.2835 & TRN \\
\hline CHEMBL1425077 & 737826 & 4.85 & 5.2594 & TRN \\
\hline
\end{tabular}




\begin{tabular}{|c|c|c|c|c|c|}
\hline CHEMBL1437491 & 737826 & 4.5 & \multicolumn{2}{|c|}{4.4510000000000005} & \multirow[t]{2}{*}{ TRN } \\
\hline CHEMBL1421692 & 737826 & 6.55 & 5.1683 & TRN & \\
\hline CHEMBL1604377 & 737826 & 5.5 & 5.3288 & TST & \\
\hline CHEMBL3213793 & 737826 & 4.75 & 5.3094 & TRN & \\
\hline CHEMBL1456747 & 737826 & 5.4 & 5.2274 & TST & \\
\hline CHEMBL1449726 & 737826 & 5.4 & 5.2607 & TRN & \\
\hline CHEMBL1382502 & 737826 & 4.7 & 5.4315 & TRN & \\
\hline CHEMBL1595862 & 737826 & 4.9 & 5.2724 & TST & \\
\hline CHEMBL1434783 & 737826 & 4.9 & 4.7248 & TRN & \\
\hline CHEMBL1532175 & 737826 & 4.85 & 5.2778 & TST & \\
\hline CHEMBL73310 & 737826 & 4.9 & 4.962 & TRN & \\
\hline CHEMBL1381730 & 737826 & 5.95 & \multicolumn{2}{|c|}{5.2139999999999995} & TRN \\
\hline CHEMBL460571 & 737826 & 4.8 & 5.3861 & TRN & \\
\hline CHEMBL1416531 & 737826 & 5.95 & 5.2323 & TRN & \\
\hline CHEMBL1479372 & 737826 & 4.8 & 4.6823 & TRN & \\
\hline CHEMBL3190590 & 737826 & 5.05 & 5.5561 & TST & \\
\hline CHEMBL1606968 & 737826 & 5.0 & 5.2596 & TRN & \\
\hline CHEMBL1582198 & 737826 & 5.35 & 5.4235 & TRN & \\
\hline CHEMBL1500383 & 737826 & 4.85 & 5.3862 & TRN & \\
\hline CHEMBL1484337 & 737826 & 4.7 & 4.728 & TRN & \\
\hline CHEMBL1562987 & 737826 & 5.8 & 5.2858 & TRN & \\
\hline CHEMBL1399750 & 737826 & 4.5 & 5.5126 & TRN & \\
\hline CHEMBL1570792 & 737826 & 4.85 & 5.3593 & TRN & \\
\hline CHEMBL45068 & 737826 & 4.9 & 5.6884 & TST & \\
\hline CHEMBL1376554 & 737826 & 4.4 & 5.164 & TRN & \\
\hline CHEMBL1333445 & 737826 & 5.7 & 5.4383 & TRN & \\
\hline CHEMBL1323434 & 737826 & 5.55 & \multicolumn{2}{|c|}{5.178999999999999} & TRN \\
\hline CHEMBL1611857 & 737826 & 6.0 & 5.3179 & TRN & \\
\hline CHEMBL1368681 & 737826 & 6.45 & 5.2531 & TRN & \\
\hline CHEMBL1333773 & 737826 & 6.7 & 5.1748 & TRN & \\
\hline CHEMBL1363275 & 737826 & 5.9 & 5.1715 & TRN & \\
\hline CHEMBL1386277 & 737826 & 5.3 & 5.4242 & TRN & \\
\hline CHEMBL1511687 & 737826 & 5.6 & \multicolumn{2}{|c|}{5.297000000000001} & TRN \\
\hline CHEMBL1374544 & 737826 & 5.9 & 5.8078 & TRN & \\
\hline CHEMBL1580538 & 737826 & 4.4 & 5.4697 & TRN & \\
\hline CHEMBL1364135 & 737826 & 5.85 & 5.415 & TRN & \\
\hline CHEMBL1527436 & 737826 & 4.55 & 5.3294 & TST & \\
\hline CHEMBL1499919 & 737826 & 5.5 & 5.2424 & TRN & \\
\hline CHEMBL1392359 & 737826 & 4.7 & 5.38 & TRN & \\
\hline CHEMBL1315072 & 737826 & 5.0 & 4.8527 & TRN & \\
\hline CHEMBL1389233 & 737826 & 4.65 & 5.3684 & TRN & \\
\hline CHEMBL 285932 & 737826 & 5.7 & 5.4668 & TRN & \\
\hline CHEMBL1542248 & 737826 & 5.4 & 5.4896 & TRN & \\
\hline CHEMBL3211292 & 737826 & 4.9 & 5.5692 & TRN & \\
\hline CHEMBL1584461 & 737826 & 6.0 & 5.3559 & TRN & \\
\hline CHEMBL1379383 & 737826 & 5.9 & 5.2866 & TRN & \\
\hline CHEMBL1404456 & 737826 & 4.95 & 5.2585 & TRN & \\
\hline CHEMBL1475366 & 737826 & 6.4 & 6.4053 & TRN & \\
\hline & & & & 6501 & \\
\hline
\end{tabular}




\begin{tabular}{|c|c|c|c|c|c|}
\hline & & \\
\hline CHEMBL1485287 & 737826 & 5.6 & 5.2049 & TRN & \\
\hline CHEMBL1741986 & 737826 & 4.75 & \multicolumn{2}{|c|}{5.202000000000001} & TRN \\
\hline CHEMBL1451031 & 737826 & 5.0 & 5.3432 & TRN & \\
\hline CHEMBL1494802 & 737826 & 5.1 & 5.2158 & TRN & \\
\hline CHEMBL1454402 & 737826 & 5.05 & 5.3934 & TST & \\
\hline CHEMBL1512307 & 737826 & 5.5 & 5.4639 & TRN & \\
\hline CHEMBL1354913 & 737826 & 7.9 & 7.1835 & TST & \\
\hline CHEMBL1353342 & 737826 & 5.25 & 5.1837 & TRN & \\
\hline CHEMBL1553741 & 737826 & 4.8 & 4.8347 & TRN & \\
\hline CHEMBL1490820 & 737826 & 7.4 & 5.2241 & TRN & \\
\hline CHEMBL3193293 & 737826 & 5.2 & 5.1491 & TST & \\
\hline CHEMBL3192674 & 737826 & 5.9 & 5.7131 & TRN & \\
\hline CHEMBL1742229 & 737826 & 4.8 & 5.2403 & TRN & \\
\hline CHEMBL1562791 & 737826 & 6.0 & 6.0247 & TRN & \\
\hline CHEMBL1484573 & 737826 & 4.7 & 5.3218 & TST & \\
\hline CHEMBL533542 & 737826 & 6.6 & 5.5833 & TRN & \\
\hline CHEMBL294989 & 737826 & 5.1 & 5.0435 & TRN & \\
\hline CHEMBL1607885 & 737826 & 6.3 & 6.1767 & TRN & \\
\hline CHEMBL1480944 & 737826 & 4.8 & 5.2321 & TRN & \\
\hline CHEMBL1475338 & 737826 & 6.5 & \multicolumn{2}{|c|}{6.367999999999999} & TRN \\
\hline CHEMBL1574831 & 737826 & 5.55 & 5.3677 & TRN & \\
\hline CHEMBL1742195 & 737826 & 4.8 & 5.4363 & TRN & \\
\hline CHEMBL1354563 & 737826 & 6.3 & 6.2733 & TRN & \\
\hline CHEMBL1418358 & 737826 & 4.95 & 5.3553 & TRN & \\
\hline CHEMBL15192 & 737826 & 4.5 & 4.5556 & TST & \\
\hline CHEMBL3199680 & 737826 & 4.9 & 5.3992 & TRN & \\
\hline CHEMBL1368773 & 737826 & 5.7 & 5.6992 & TRN & \\
\hline CHEMBL1302425 & 737826 & 4.55 & 5.1378 & TST & \\
\hline CHEMBL1451037 & 737826 & 5.2 & 5.2848 & TST & \\
\hline CHEMBL1607106 & 737826 & 5.4 & 5.3512 & TRN & \\
\hline CHEMBL1717341 & 737826 & 4.85 & 5.2917 & TRN & \\
\hline CHEMBL1406556 & 737826 & 5.5 & 5.3593 & TRN & \\
\hline CHEMBL3210395 & 737826 & 5.9 & \multicolumn{2}{|c|}{5.3260000000000005} & TRN \\
\hline CHEMBL1335882 & 737826 & 4.6 & 5.2306 & TRN & \\
\hline CHEMBL1354231 & 737826 & 5.5 & 5.4087 & TRN & \\
\hline CHEMBL1305513 & 737826 & 4.9 & 5.1102 & TST & \\
\hline CHEMBL1560068 & 737826 & 4.4 & 5.3483 & TST & \\
\hline CHEMBL1706840 & 737826 & 4.7 & 5.2763 & TRN & \\
\hline CHEMBL1468814 & 737826 & 5.05 & 4.9632 & TRN & \\
\hline CHEMBL3213666 & 737826 & 4.95 & 5.414 & TRN & \\
\hline CHEMBL1450809 & 737826 & 4.95 & 5.2074 & TRN & \\
\hline CHEMBL1531727 & 737826 & 5.6 & 5.3762 & TST & \\
\hline CHEMBL1550234 & 737826 & 5.5 & 5.1936 & TRN & \\
\hline CHEMBL1504724 & 737826 & 5.75 & 5.5874 & TST & \\
\hline CHEMBL1392755 & 737826 & 4.9 & 5.1733 & TRN & \\
\hline CHEMBL1393933 & 737826 & 5.0 & 5.4424 & TRN & \\
\hline CHEMBL1559560 & 737826 & 4.95 & 5.2577 & TRN & \\
\hline \multirow[t]{2}{*}{ CHEMBL1600292 } & 737826 & 5.4 & $5.2410 e$ & 00000000005 & TRN \\
\hline & & & \multicolumn{2}{|c|}{ Page 6502} & \\
\hline
\end{tabular}




\begin{tabular}{|c|c|c|c|c|}
\hline \multicolumn{5}{|c|}{ Supplemental Table S2.txt } \\
\hline CHEMBL267548 & 737826 & 5.2 & 5.0226 & TST \\
\hline CHEMBL1498966 & 737826 & 4.8 & 5.1738 & TRN \\
\hline CHEMBL1399528 & 737826 & 5.9 & 5.8664 & TRN \\
\hline CHEMBL1305118 & 737826 & 4.7 & 5.1577 & TRN \\
\hline CHEMBL1307175 & 737826 & 5.45 & 5.3229 & TRN \\
\hline CHEMBL1336557 & 737826 & 5.65 & 5.2916 & TRN \\
\hline CHEMBL1351829 & 737826 & 4.95 & 5.3793 & TRN \\
\hline CHEMBL1464193 & 737826 & 5.45 & 5.1207 & TST \\
\hline CHEMBL1445747 & 737826 & 4.55 & 5.1845 & TRN \\
\hline CHEMBL1603471 & 737826 & 5.2 & 5.34 & TRN \\
\hline CHEMBL1390616 & 737826 & 5.2 & 5.2627 & TRN \\
\hline CHEMBL3199416 & 737826 & 5.15 & 5.3237 & TRN \\
\hline CHEMBL1384720 & 737826 & 5.4 & 5.4155 & TRN \\
\hline CHEMBL 257359 & 737826 & 5.2 & 5.3695 & TST \\
\hline CHEMBL1538764 & 737826 & 5.45 & 5.3603 & TRN \\
\hline CHEMBL1382161 & 737826 & 4.85 & 5.2347 & TST \\
\hline CHEMBL1565578 & 737826 & 6.0 & 5.0059 & TRN \\
\hline CHEMBL1347829 & 737826 & 5.65 & 5.1438 & TRN \\
\hline CHEMBL1331751 & 737826 & 4.8 & 5.2711 & TRN \\
\hline CHEMBL1608871 & 737826 & 5.3 & 5.5053 & TRN \\
\hline CHEMBL1481847 & 737826 & 5.6 & 5.3971 & TRN \\
\hline CHEMBL1352783 & 737826 & 4.85 & 5.5025 & TRN \\
\hline CHEMBL1389803 & 737826 & 5.05 & 5.3776 & TRN \\
\hline CHEMBL1571749 & 737826 & 5.1 & 5.3491 & TRN \\
\hline CHEMBL1353871 & 737826 & 4.9 & 5.379 & TRN \\
\hline CHEMBL1366680 & 737826 & 5.05 & 5.2161 & TST \\
\hline CHEMBL1320841 & 737826 & 5.45 & 5.2901 & TRN \\
\hline CHEMBL1323549 & 737826 & 5.9 & 5.5156 & TRN \\
\hline CHEMBL1389823 & 737826 & 5.0 & 5.0578 & TST \\
\hline CHEMBL1358583 & 737826 & 4.6 & 4.4897 & TRN \\
\hline CHEMBL1257123 & 737826 & 4.8 & 5.0175 & TRN \\
\hline CHEMBL518430 & 737826 & 4.95 & 5.3422 & TRN \\
\hline CHEMBL1526455 & 737826 & 4.9 & 5.4116 & TRN \\
\hline CHEMBL1182777 & 737826 & 6.8 & 6.1909 & TST \\
\hline CHEMBL1537227 & 737826 & 5.45 & 5.356 & TRN \\
\hline CHEMBL1498788 & 737826 & 5.4 & 5.6276 & TRN \\
\hline CHEMBL1518362 & 737826 & 5.15 & 5.096 & TRN \\
\hline CHEMBL1570196 & 737826 & 5.0 & 4.8644 & TST \\
\hline CHEMBL1343012 & 737826 & 4.5 & 5.3088 & TRN \\
\hline CHEMBL1313409 & 737826 & 5.4 & 5.1689 & TST \\
\hline CHEMBL83899 & 737826 & 6.6 & 5.9356 & TST \\
\hline CHEMBL1351254 & 737826 & 5.95 & 5.3217 & TRN \\
\hline CHEMBL1378037 & 737826 & 5.0 & 5.1297 & TST \\
\hline CHEMBL1404501 & 737826 & 4.4 & 4.3733 & TRN \\
\hline CHEMBL1574148 & 737826 & 4.4 & 5.5814 & TRN \\
\hline CHEMBL1400835 & 737826 & 5.3 & 5.2922 & TRN \\
\hline CHEMBL1465552 & 737826 & 5.5 & 5.2397 & TRN \\
\hline CHEMBL1440650 & 737826 & 4.8 & 4.7743 & TRN \\
\hline
\end{tabular}




\begin{tabular}{|c|c|c|c|c|c|}
\hline \multicolumn{6}{|c|}{ Supplemental Table S2.txt } \\
\hline CHEMBL1506343 & 737826 & 4.95 & 5.254 & TRN & \\
\hline CHEMBL1358313 & 737826 & 4.4 & 4.386 & TRN & \\
\hline CHEMBL1557048 & 737826 & 6.5 & 6.3568 & TRN & \\
\hline CHEMBL1484181 & 737826 & 4.85 & 5.2394 & TRN & \\
\hline CHEMBL1414493 & 737826 & 6.15 & 5.5158 & TRN & \\
\hline CHEMBL1446050 & 737826 & 5.0 & 5.31 & TRN & \\
\hline CHEMBL1742322 & 737826 & 4.6 & 5.2423 & TRN & \\
\hline CHEMBL1487748 & 737826 & 6.0 & 5.8762 & TRN & \\
\hline CHEMBL1425169 & 737826 & 4.7 & 5.3752 & TRN & \\
\hline CHEMBL1532991 & 737826 & 6.05 & 5.5445 & TRN & \\
\hline CHEMBL1328688 & 737826 & 4.95 & 5.2127 & TRN & \\
\hline CHEMBL1606423 & 737826 & 4.5 & 5.0391 & TST & \\
\hline CHEMBL1564477 & 737826 & 4.9 & 4.8009 & TRN & \\
\hline CHEMBL1318340 & 737826 & 6.3 & 6.1654 & TRN & \\
\hline CHEMBL1565585 & 737826 & 4.9 & 5.2965 & TST & \\
\hline CHEMBL1433785 & 737826 & 4.8 & 4.6854 & TRN & \\
\hline CHEMBL1571807 & 737826 & 5.8 & 5.2703 & TRN & \\
\hline CHEMBL1496986 & 737826 & 5.4 & 5.2391 & TRN & \\
\hline CHEMBL1545002 & 737826 & 4.95 & 5.11100 & 0000000001 & TRN \\
\hline CHEMBL3214519 & 737826 & 4.6 & 5.5174 & TST & \\
\hline CHEMBL1408735 & 737826 & 6.2 & 5.7373 & TRN & \\
\hline CHEMBL1463032 & 737826 & 5.6 & 5.2604 & TRN & \\
\hline CHEMBL1387472 & 737826 & 5.4 & 5.3819 & TST & \\
\hline CHEMBL1333338 & 737826 & 5.8 & 5.4193 & TST & \\
\hline CHEMBL1574548 & 737826 & 5.0 & 5.3919 & TST & \\
\hline CHEMBL311489 & 737826 & 5.5 & 5.3802 & TRN & \\
\hline CHEMBL1413443 & 737826 & 4.85 & 5.3839 & TRN & \\
\hline CHEMBL3192281 & 737826 & 5.45 & 5.5029 & TST & \\
\hline CHEMBL1188431 & 737826 & 6.7 & 6.3858 & TST & \\
\hline CHEMBL1422368 & 737826 & 5.45 & 5.2696 & TST & \\
\hline CHEMBL1457544 & 737826 & 4.4 & 4.3181 & TST & \\
\hline CHEMBL 3214169 & 737826 & 5.65 & 5.4381 & TST & \\
\hline CHEMBL1355431 & 737826 & 5.5 & 5.1328 & TST & \\
\hline CHEMBL1519165 & 737826 & 5.05 & 5.399 & TST & \\
\hline CHEMBL1503273 & 737826 & 4.7 & 5.2634 & TST & \\
\hline CHEMBL1577699 & 737826 & 5.45 & 5.3082 & TST & \\
\hline CHEMBL3190889 & 737826 & 5.8 & 5.5459 & TST & \\
\hline CHEMBL1470840 & 737826 & 5.4 & 5.16100 & 00000000005 & TST \\
\hline CHEMBL1578982 & 737826 & 5.0 & 5.4782 & TST & \\
\hline CHEMBL1427095 & 737826 & 5.25 & 5.2488 & TST & \\
\hline CHEMBL1609156 & 737826 & 4.95 & 5.4256 & TST & \\
\hline CHEMBL3210255 & 737826 & 5.9 & 5.3722 & TST & \\
\hline CHEMBL492193 & 737826 & 6.1 & 5.7223 & TST & \\
\hline CHEMBL1980198 & 737826 & 5.15 & 5.44 & TST & \\
\hline CHEMBL1406437 & 737826 & 4.85 & 5.3003 & TST & \\
\hline CHEMBL1348828 & 737826 & 5.0 & 5.4516 & TST & \\
\hline CHEMBL3211795 & 737826 & 5.05 & 5.3722 & TST & \\
\hline CHEMBL1410725 & 737826 & 4.9 & 5.2874 & TST & \\
\hline
\end{tabular}




\begin{tabular}{|c|c|c|c|c|c|}
\hline \multicolumn{6}{|c|}{ pplemental I } \\
\hline CHEMBL1461827 & 737826 & 4.85 & 5.2585 & TST & \\
\hline CHEMBL1317986 & 737826 & 5.4 & 5.2639 & TST & \\
\hline CHEMBL1435604 & 737826 & 5.0 & 4.7335 & TST & \\
\hline CHEMBL1314451 & 737826 & 6.4 & 6.0056 & TST & \\
\hline CHEMBL1605085 & 737826 & 5.95 & 5.4064 & TST & \\
\hline CHEMBL1316213 & 737826 & 5.4 & 5.3612 & TST & \\
\hline CHEMBL1458493 & 737826 & 5.8 & 5.1517 & TST & \\
\hline CHEMBL1362324 & 737826 & 5.75 & 5.1413 & TST & \\
\hline CHEMBL1403583 & 737826 & 5.0 & 5.1789 & TST & \\
\hline CHEMBL1366219 & 737826 & 4.7 & 5.385 & TST & \\
\hline CHEMBL1305873 & 737826 & 6.0 & 5.3742 & TST & \\
\hline CHEMBL1315268 & 737826 & 4.6 & 4.5074 & TST & \\
\hline CHEMBL1741399 & 737826 & 4.7 & 5.2691 & TST & \\
\hline CHEMBL1359108 & 737826 & 5.0 & 4.909 & TST & \\
\hline CHEMBL3193466 & 737826 & 4.85 & 5.3683 & TST & \\
\hline CHEMBL1302924 & 737826 & 4.85 & 5.0574 & TST & \\
\hline CHEMBL1603100 & 737826 & 5.3 & 5.2558 & TST & \\
\hline CHEMBL1546161 & 737826 & 5.15 & 5.4008 & TST & \\
\hline CHEMBL3192856 & 737826 & 4.55 & 5.1857 & TST & \\
\hline CHEMBL137246 & 737826 & 5.2 & 5.2155 & TST & \\
\hline CHEMBL1741578 & 737826 & 5.4 & 5.4744 & TST & \\
\hline CHEMBL2000196 & 737826 & 4.85 & 5.4423 & TST & \\
\hline CHEMBL1408022 & 737826 & 4.9 & 5.3563 & TST & \\
\hline CHEMBL1372850 & 737826 & 5.6 & 5.4874 & TST & \\
\hline CHEMBL1439483 & 737826 & 5.45 & 5.2063 & TST & \\
\hline CHEMBL1480116 & 737826 & 5.15 & 5.4354 & TST & \\
\hline CHEMBL 243664 & 737826 & 5.9 & 5.66299 & 9999999999 & TST \\
\hline CHEMBL3193196 & 737826 & 5.45 & 5.29200 & 0000000001 & TST \\
\hline CHEMBL1321719 & 737826 & 5.45 & 5.1742 & TST & \\
\hline CHEMBL1456464 & 737826 & 5.0 & 5.2576 & TST & \\
\hline CHEMBL1527611 & 737826 & 4.7 & 5.2659 & TST & \\
\hline CHEMBL1335634 & 737826 & 4.8 & 5.6712 & TST & \\
\hline CHEMBL1742020 & 737826 & 5.25 & 5.4216 & TST & \\
\hline CHEMBL1498627 & 737826 & 5.9 & 5.215 & TST & \\
\hline CHEMBL1558934 & 737826 & 5.45 & 5.2713 & TST & \\
\hline CHEMBL1571238 & 737826 & 6.65 & 5.1706 & TST & \\
\hline CHEMBL1973707 & 737826 & 5.2 & 5.3995 & TST & \\
\hline CHEMBL1446324 & 737826 & 4.7 & 4.5779 & TST & \\
\hline CHEMBL1337078 & 737826 & 4.75 & 5.1609 & TST & \\
\hline CHEMBL1312749 & 737826 & 6.8 & 5.3367 & TST & \\
\hline CHEMBL1356497 & 737826 & 5.5 & 5.3491 & TST & \\
\hline CHEMBL1517718 & 737826 & 5.5 & 5.2082 & TST & \\
\hline CHEMBL1389041 & 737826 & 4.9 & 5.3482 & TST & \\
\hline CHEMBL1421103 & 737826 & 5.7 & 5.1935 & TST & \\
\hline CHEMBL495068 & 737826 & 6.1 & 6.1006 & TST & \\
\hline CHEMBL1574567 & 737826 & 5.55 & 5.3883 & TST & \\
\hline CHEMBL1742255 & 737826 & 4.9 & 5.421 & TST & \\
\hline CHEMBL1409720 & 737826 & 5.6 & 5.4701 & TST & \\
\hline
\end{tabular}




\begin{tabular}{|c|c|c|c|c|c|}
\hline \multicolumn{6}{|c|}{ Supplemental Table S2.txt } \\
\hline CHEMBL1536139 & 737826 & 5.55 & 5.303 & TST & \\
\hline CHEMBL1724475 & 737826 & 4.4 & 5.3909 & TST & \\
\hline CHEMBL1718423 & 737826 & 5.15 & 5.2905 & TST & \\
\hline CHEMBL3210367 & 737826 & 5.95 & 5.395 & TST & \\
\hline CHEMBL1170522 & 737826 & 6.25 & 5.0901 & TST & \\
\hline CHEMBL1401126 & 737826 & 5.25 & 5.2526 & TST & \\
\hline CHEMBL1421344 & 737826 & 5.8 & 5.4355 & TST & \\
\hline CHEMBL1508906 & 737826 & 5.3 & 5.2775 & TST & \\
\hline CHEMBL1349604 & 737826 & 4.95 & 5.022 & TST & \\
\hline CHEMBL1439210 & 737826 & 4.7 & 5.2879 & TST & \\
\hline CHEMBL1551477 & 737826 & 5.2 & 5.0418 & TST & \\
\hline CHEMBL1391721 & 737826 & 4.85 & 5.2898 & TST & \\
\hline CHEMBL1546667 & 737826 & 5.9 & 5.1108 & TST & \\
\hline CHEMBL1607197 & 737826 & 5.25 & 5.2322 & TST & \\
\hline CHEMBL1612582 & 737826 & 5.9 & 5.9925 & TST & \\
\hline CHEMBL1531277 & 737826 & 5.15 & 5.2301 & TST & \\
\hline CHEMBL1741684 & 737826 & 5.0 & 5.2461 & TST & \\
\hline CHEMBL1395137 & 737826 & 5.0 & 5.1229 & TST & \\
\hline CHEMBL1315184 & 737826 & 5.8 & 5.8488 & TST & \\
\hline CHEMBL1303309 & 737826 & 5.1 & 5.3786 & TST & \\
\hline CHEMBL1396010 & 737826 & 4.6 & 4.4749 & TST & \\
\hline CHEMBL1390185 & 737826 & 4.85 & 5.322 & TST & \\
\hline CHEMBL1301725 & 737826 & 4.9 & 5.1741 & TST & \\
\hline CHEMBL1433002 & 737826 & 4.65 & 5.244 & TST & \\
\hline CHEMBL1472481 & 737826 & 5.45 & 5.2853 & TST & \\
\hline CHEMBL1320172 & 737826 & 5.4 & 5.2983 & TST & \\
\hline CHEMBL1507676 & 737826 & 4.85 & 5.2258 & TST & \\
\hline CHEMBL1487013 & 737826 & 5.5 & 5.2881 & TST & \\
\hline CHEMBL1729662 & 737826 & 5.4 & 5.5597 & TST & \\
\hline CHEMBL 2003798 & 737826 & 5.3 & 5.319 & TST & \\
\hline CHEMBL1360601 & 737826 & 5.8 & 5.28799 & 9999999999 & TST \\
\hline CHEMBL1514440 & 737826 & 6.0 & 5.7765 & TST & \\
\hline CHEMBL1493877 & 737826 & 4.8 & 5.3259 & TST & \\
\hline CHEMBL1573783 & 737826 & 4.65 & 5.2729 & TST & \\
\hline CHEMBL1550048 & 737826 & 6.35 & 5.2737 & TST & \\
\hline CHEMBL1443332 & 737826 & 4.85 & 5.3545 & TST & \\
\hline CHEMBL1606693 & 737826 & 4.7 & 5.16299 & 9999999999 & TST \\
\hline CHEMBL1329507 & 737826 & 5.3 & 5.0788 & TST & \\
\hline CHEMBL491555 & 737826 & 6.0 & 6.0748 & TST & \\
\hline CHEMBL1482804 & 737826 & 5.35 & 5.2885 & TST & \\
\hline CHEMBL1427403 & 737826 & 6.15 & 5.2424 & TST & \\
\hline CHEMBL1330020 & 737826 & 5.2 & 5.254 & TST & \\
\hline CHEMBL182310 & 737826 & 4.9 & 4.7577 & TST & \\
\hline CHEMBL1569088 & 737826 & 4.8 & 5.0916 & TST & \\
\hline CHEMBL1522433 & 737826 & 5.6 & 5.3287 & TST & \\
\hline CHEMBL28992 & 737826 & 4.9 & 5.0219 & TST & \\
\hline CHEMBL1455353 & 737826 & 5.7 & 5.3319 & TST & \\
\hline CHEMBL1306717 & 737826 & 5.9 & 5.2381 & TST & \\
\hline
\end{tabular}




\begin{tabular}{|c|c|c|c|c|}
\hline & & & $\begin{array}{ll} \\
\end{array}$ & al Table \\
\hline CHEMBL1428605 & 737826 & 4.8 & 5.278 & TST \\
\hline CHEMBL1741865 & 737826 & 6.5 & 5.3861 & TST \\
\hline CHEMBL311158 & 737826 & 5.6 & 5.6947 & TST \\
\hline CHEMBL1583067 & 737826 & 5.7 & 5.3045 & TST \\
\hline CHEMBL 3195544 & 737826 & 5.05 & 5.2367 & TST \\
\hline CHEMBL3213403 & 737826 & 6.05 & 5.4295 & TST \\
\hline CHEMBL1444270 & 737826 & 5.4 & 5.3447 & TST \\
\hline CHEMBL1436054 & 737826 & 6.0 & 5.6513 & TST \\
\hline CHEMBL1454533 & 737826 & 4.9 & 5.2064 & TST \\
\hline CHEMBL1451097 & 737826 & 4.7 & 4.6435 & TST \\
\hline CHEMBL1323204 & 737826 & 5.5 & 5.3856 & TST \\
\hline CHEMBL1483332 & 737826 & 4.8 & 5.1032 & TST \\
\hline CHEMBL1742231 & 737826 & 4.95 & 5.3865 & TST \\
\hline CHEMBL1342399 & 737826 & 4.85 & 5.1507 & TST \\
\hline CHEMBL1467157 & 737826 & 5.4 & 5.4321 & TST \\
\hline CHEMBL1424521 & 737826 & 4.4 & 5.1357 & TST \\
\hline CHEMBL1605333 & 737826 & 7.8 & 5.2006 & TST \\
\hline CHEMBL1965376 & 737826 & 5.1 & 5.4631 & TST \\
\hline CHEMBL1306504 & 737826 & 5.85 & 5.2351 & TST \\
\hline CHEMBL1412390 & 737826 & 5.9 & 5.9872 & TST \\
\hline CHEMBL1539897 & 737826 & 5.4 & $5.2120 e$ & 0000000001 \\
\hline CHEMBL1322311 & 737826 & 5.65 & 5.4609 & TST \\
\hline CHEMBL1385652 & 737826 & 5.7 & 5.2532 & TST \\
\hline CHEMBL1589282 & 737826 & 5.35 & 5.3933 & TST \\
\hline CHEMBL1355537 & 737826 & 4.8 & 4.8564 & TST \\
\hline CHEMBL 1558526 & 737826 & 5.0 & 4.8642 & TST \\
\hline CHEMBL1369728 & 737826 & 5.3 & 5.1957 & TST \\
\hline CHEMBL1256484 & 737826 & -0.0 & 5.2402 & TST \\
\hline CHEMBL3194627 & 737826 & 5.5 & 5.374 & TST \\
\hline CHEMBL1471612 & 737826 & 4.95 & 5.4461 & TST \\
\hline CHEMBL1535635 & 737826 & 4.7 & 4.689 & TST \\
\hline CHEMBL1312830 & 737826 & 5.7 & 5.3401 & TST \\
\hline CHEMBL1492946 & 737826 & 5.0 & 5.2397 & TST \\
\hline CHEMBL3196654 & 737826 & 5.8 & 5.3665 & TST \\
\hline CHEMBL1302114 & 737826 & 6.05 & 5.3304 & TST \\
\hline CHEMBL 304008 & 737826 & 5.1 & 5.0416 & TST \\
\hline CHEMBL1356485 & 737826 & 4.7 & 4.7252 & TST \\
\hline CHEMBL 251647 & 737826 & 5.3 & 5.8193 & TST \\
\hline CHEMBL1543213 & 737826 & 4.85 & 5.2691 & TST \\
\hline CHEMBL1485361 & 737826 & 4.4 & 4.5813 & TST \\
\hline CHEMBL1551639 & 737826 & 5.1 & 5.1583 & TST \\
\hline CHEMBL1595253 & 737826 & 5.45 & 5.2231 & TST \\
\hline CHEMBL1525376 & 737826 & 4.55 & 5.1658 & TST \\
\hline CHEMBL1370553 & 737826 & 4.5 & 4.4215 & TST \\
\hline CHEMBL1410910 & 737826 & 5.7 & 5.5272 & TST \\
\hline CHEMBL1582671 & 737826 & 4.45 & 5.1236 & TST \\
\hline CHEMBL1417610 & 737826 & 4.6 & 5.2287 & TST \\
\hline CHEMBL3208032 & 737826 & 5.35 & 5.3339 & TST \\
\hline
\end{tabular}




\begin{tabular}{|c|c|c|c|c|c|}
\hline \\
\hline CHEMBL602314 & 737826 & 4.9 & 5.2397 & TST & \\
\hline CHEMBL1511512 & 737826 & 4.8 & 5.2702 & TST & \\
\hline CHEMBL1398528 & 737826 & 4.8 & 4.7332 & TST & \\
\hline CHEMBL1393246 & 737826 & 5.05 & 5.3866 & TST & \\
\hline CHEMBL1505375 & 737826 & 5.55 & 5.225 & TST & \\
\hline CHEMBL1610687 & 737826 & 4.85 & 5.2459 & TST & \\
\hline CHEMBL1485060 & 737826 & 5.3 & 5.2666 & TST & \\
\hline CHEMBL1485338 & 737826 & 7.15 & 5.141 & TST & \\
\hline CHEMBL1349875 & 737826 & 4.6 & 5.3513 & TST & \\
\hline CHEMBL3197789 & 737826 & 5.8 & 5.3529 & TST & \\
\hline CHEMBL1565525 & 737826 & 6.3 & 6.1742 & TST & \\
\hline CHEMBL1312105 & 737826 & 4.4 & 5.2869 & TST & \\
\hline CHEMBL1411881 & 737826 & 7.9 & 5.2778 & TST & \\
\hline CHEMBL1375753 & 737826 & 5.6 & 5.3433 & TST & \\
\hline CHEMBL1378764 & 737826 & 5.2 & 4.9175 & TST & \\
\hline CHEMBL1592754 & 737826 & 5.0 & 5.0072 & TST & \\
\hline CHEMBL1707644 & 737826 & 4.85 & 5.1746 & TST & \\
\hline CHEMBL1447746 & 737826 & 5.2 & 5.1395 & TST & \\
\hline CHEMBL1475999 & 737826 & 5.3 & 5.20700 & 0000000001 & TST \\
\hline CHEMBL1604232 & 737826 & 5.65 & 5.1655 & TST & \\
\hline CHEMBL1429067 & 737826 & 5.15 & 5.3681 & TST & \\
\hline CHEMBL1423533 & 737826 & 5.5 & 5.3047 & TST & \\
\hline CHEMBL1593504 & 737826 & 4.9 & 4.6846 & TST & \\
\hline CHEMBL1556022 & 737826 & 5.9 & 5.2754 & TST & \\
\hline CHEMBL1518168 & 737826 & 4.55 & 5.20799 & 9999999999 & TST \\
\hline CHEMBL1303722 & 737826 & 4.6 & 5.3797 & TST & \\
\hline CHEMBL1335233 & 737826 & 5.25 & 5.1856 & TST & \\
\hline CHEMBL1543021 & 737826 & 5.15 & 5.0694 & TST & \\
\hline CHEMBL1464066 & 737826 & 4.85 & 5.4702 & TST & \\
\hline CHEMBL1520347 & 737826 & 4.5 & 4.4071 & TST & \\
\hline CHEMBL1578210 & 737826 & 4.8 & 5.5025 & TST & \\
\hline CHEMBL1416213 & 737826 & 6.25 & 5.3109 & TST & \\
\hline CHEMBL1448158 & 737826 & 8.15 & 5.3106 & TST & \\
\hline CHEMBL1359620 & 737826 & 5.3 & 5.0435 & TST & \\
\hline CHEMBL1354154 & 737826 & 6.1 & 6.0892 & TST & \\
\hline CHEMBL1315700 & 737826 & 5.0 & 4.8543 & TST & \\
\hline CHEMBL1307460 & 737826 & 4.85 & 5.1512 & TST & \\
\hline CHEMBL1448896 & 737826 & 5.9 & 5.6364 & TST & \\
\hline CHEMBL1544981 & 737826 & 4.5 & 5.3018 & TST & \\
\hline CHEMBL1475381 & 737826 & 4.8 & 4.6126 & TST & \\
\hline CHEMBL1454951 & 737826 & 5.9 & 5.1304 & TST & \\
\hline CHEMBL1529705 & 737826 & 5.6 & 5.36299 & 99999999995 & TST \\
\hline CHEMBL1320525 & 737826 & 4.6 & 4.5107 & TST & \\
\hline CHEMBL1710935 & 737826 & 4.9 & 5.1016 & TST & \\
\hline CHEMBL1487111 & 737826 & 5.5 & 5.3204 & TST & \\
\hline CHEMBL1408013 & 737826 & 6.0 & 5.8107 & TST & \\
\hline CHEMBL1486160 & 737826 & 4.9 & 5.3303 & TST & \\
\hline CHEMBL1414719 & 737826 & 6.25 & 5.3765 & TST & \\
\hline
\end{tabular}




\begin{tabular}{|c|c|c|c|c|c|}
\hline \multicolumn{6}{|c|}{ Supplemental Table S2.txt } \\
\hline CHEMBL1533852 & 737826 & 5.45 & 5.0827 & TST & \\
\hline CHEMBL1385038 & 737826 & 5.1 & 5.1988 & TST & \\
\hline CHEMBL1330251 & 737826 & 5.0 & 4.8026 & TST & \\
\hline CHEMBL1576560 & 737826 & 4.85 & 5.7403 & TST & \\
\hline CHEMBL1556106 & 737826 & 4.8 & 5.0198 & TST & \\
\hline CHEMBL3211454 & 737826 & 5.55 & 5.3683 & TST & \\
\hline CHEMBL1603595 & 737826 & 4.5 & 4.3994 & TST & \\
\hline CHEMBL1610944 & 737826 & 5.0 & 4.9968 & TST & \\
\hline CHEMBL1489605 & 737826 & 4.95 & 5.4395 & TST & \\
\hline CHEMBL1333833 & 737826 & 5.45 & 5.2151 & TST & \\
\hline CHEMBL1413843 & 737826 & 5.05 & 5.1797 & TST & \\
\hline CHEMBL1568802 & 737826 & 5.55 & 5.1966 & TST & \\
\hline CHEMBL1446731 & 737826 & 5.6 & 5.61600 & 00000000005 & TST \\
\hline CHEMBL1423810 & 737826 & 4.5 & 5.2676 & TST & \\
\hline CHEMBL1378339 & 737826 & 4.65 & 5.4611 & TST & \\
\hline CHEMBL1480903 & 737826 & 6.2 & 5.9142 & TST & \\
\hline CHEMBL1443307 & 737826 & 4.95 & 5.3094 & TST & \\
\hline CHEMBL1334323 & 737826 & 5.4 & 5.2526 & TST & \\
\hline CHEMBL1585050 & 737826 & 6.0 & 5.1513 & TST & \\
\hline CHEMBL1549796 & 737826 & 4.75 & 5.3498 & TST & \\
\hline CHEMBL1559404 & 737826 & 4.6 & 4.6038 & TST & \\
\hline CHEMBL1329460 & 737826 & 5.15 & 5.5124 & TST & \\
\hline CHEMBL472656 & 737826 & 5.9 & 5.71899 & 7999999999 & TST \\
\hline CHEMBL3197677 & 737826 & 6.1 & 5.5415 & TST & \\
\hline CHEMBL1313894 & 737826 & 4.85 & 5.182 & TST & \\
\hline CHEMBL1370855 & 737826 & 5.95 & 5.2161 & TST & \\
\hline CHEMBL1461491 & 737826 & 4.4 & 4.5448 & TST & \\
\hline CHEMBL1359919 & 737826 & 5.75 & 5.2643 & TST & \\
\hline CHEMBL3192957 & 737826 & 5.4 & 5.3915 & TST & \\
\hline CHEMBL1742090 & 737826 & 4.85 & 5.1838 & TST & \\
\hline CHEMBL1361876 & 737826 & 4.7 & 5.2569 & TST & \\
\hline CHEMBL1571756 & 737826 & 5.1 & 5.3627 & TST & \\
\hline CHEMBL1436507 & 737826 & 5.0 & 4.8747 & TST & \\
\hline CHEMBL1610132 & 737826 & 5.75 & 5.2341 & TST & \\
\hline CHEMBL1475036 & 737826 & 4.9 & 4.993 & TST & \\
\hline CHEMBL1548495 & 737826 & 5.25 & 5.2847 & TST & \\
\hline CHEMBL3197511 & 737826 & 6.2 & 5.3567 & TST & \\
\hline CHEMBL490706 & 737826 & 6.4 & 6.3293 & TST & \\
\hline CHEMBL1314211 & 737826 & 6.4 & 6.33899 & 99999999995 & TST \\
\hline CHEMBL1583276 & 737826 & 4.9 & 5.2199 & TST & \\
\hline CHEMBL258893 & 737826 & 4.4 & 4.622 & TST & \\
\hline CHEMBL1535305 & 737826 & 5.2 & 5.1684 & TST & \\
\hline CHEMBL1503381 & 737826 & 5.15 & 5.3747 & TST & \\
\hline CHEMBL1325833 & 737826 & 4.6 & 4.5308 & TST & \\
\hline CHEMBL1343750 & 737826 & 5.2 & 5.5467 & TST & \\
\hline CHEMBL1729999 & 737826 & 4.55 & 5.0462 & TST & \\
\hline CHEMBL1537973 & 737826 & 7.6 & 5.2977 & TST & \\
\hline CHEMBL1565965 & 737826 & 4.6 & 4.6037 & TST & \\
\hline
\end{tabular}




\begin{tabular}{|c|c|c|c|c|c|}
\hline \multicolumn{6}{|c|}{ Supplemental Table S2.txt } \\
\hline CHEMBL3207808 & 737826 & 5.25 & 5.416 & TST & \\
\hline CHEMBL1450125 & 737826 & 5.1 & 5.2164 & TST & \\
\hline CHEMBL1398538 & 737826 & 6.6 & 6.2133 & TST & \\
\hline CHEMBL1322537 & 737826 & 5.05 & 5.2199 & TST & \\
\hline CHEMBL1544155 & 737826 & 4.9 & 5.3251 & TST & \\
\hline CHEMBL1535457 & 737826 & 5.3 & 5.2825 & TST & \\
\hline CHEMBL1438615 & 737826 & 5.05 & 5.5857 & TST & \\
\hline CHEMBL1582666 & 737826 & 4.55 & 5.229 & TST & \\
\hline CHEMBL1357429 & 737826 & 6.5 & 6.3292 & TST & \\
\hline CHEMBL1613347 & 737826 & 4.9 & 4.8367 & TST & \\
\hline CHEMBL1480273 & 737826 & 5.55 & 5.2002 & TST & \\
\hline CHEMBL1565219 & 737826 & 4.8 & 5.1874 & TST & \\
\hline CHEMBL1415221 & 737826 & 4.95 & 5.3218 & TST & \\
\hline CHEMBL1567176 & 737826 & 4.5 & 4.4076 & TST & \\
\hline CHEMBL1320471 & 737826 & 4.65 & 5.25200 & 0000000001 & TST \\
\hline CHEMBL1742209 & 737826 & 6.0 & 5.3895 & TST & \\
\hline CHEMBL1554982 & 737826 & 4.8 & 4.7674 & TST & \\
\hline CHEMBL1307201 & 737826 & 4.85 & 5.4793 & TST & \\
\hline CHEMBL1382384 & 737826 & 4.8 & 5.2038 & TST & \\
\hline CHEMBL1349620 & 737826 & 5.4 & 5.2668 & TST & \\
\hline CHEMBL1448728 & 737826 & 4.9 & 4.9009 & TST & \\
\hline CHEMBL1532319 & 737826 & 6.1 & 5.7078 & TST & \\
\hline CHEMBL1590038 & 737826 & 4.8 & 4.5716 & TST & \\
\hline CHEMBL1466013 & 737826 & 4.45 & 5.1284 & TST & \\
\hline CHEMBL1301471 & 737826 & 4.85 & 5.3925 & TST & \\
\hline CHEMBL1453217 & 737826 & 5.05 & 5.6372 & TST & \\
\hline CHEMBL3197871 & 737826 & 5.5 & 5.3709 & TST & \\
\hline CHEMBL1598543 & 737826 & 4.9 & 5.1276 & TST & \\
\hline CHEMBL1968162 & 737826 & 6.2 & 5.5123 & TST & \\
\hline CHEMBL1496623 & 737826 & 5.45 & 5.2897 & TST & \\
\hline CHEMBL1733541 & 737826 & 4.95 & 5.3293 & TST & \\
\hline CHEMBL1477140 & 737826 & 6.0 & 5.6695 & TST & \\
\hline CHEMBL1544545 & 737826 & 5.65 & 5.1963 & TST & \\
\hline CHEMBL52 & 737826 & 4.9 & 5.6039 & TST & \\
\hline CHEMBL1484949 & 737826 & 4.9 & 5.1732 & TST & \\
\hline CHEMBL1451149 & 737826 & 5.6 & 5.2631 & TST & \\
\hline CHEMBL491939 & 737826 & 7.8 & 7.2495 & TST & \\
\hline CHEMBL1518546 & 737826 & 4.65 & 5.2525 & TST & \\
\hline CHEMBL3189813 & 737826 & 4.6 & 5.5496 & TST & \\
\hline CHEMBL605003 & 737826 & 5.0 & 4.9937 & TST & \\
\hline CHEMBL1408520 & 737826 & 5.4 & 5.3907 & TST & \\
\hline CHEMBL1288013 & 737826 & 5.1 & 5.178 & TST & \\
\hline CHEMBL1725270 & 737826 & 4.9 & 5.2412 & TST & \\
\hline CHEMBL1328830 & 737826 & 6.45 & 5.2717 & TST & \\
\hline CHEMBL1402562 & 737826 & 5.6 & 5.2721 & TST & \\
\hline CHEMBL1554721 & 737826 & 6.1 & 6.0999 & TST & \\
\hline CHEMBL1405921 & 737826 & 6.8 & 5.2114 & TST & \\
\hline CHEMBL1448161 & 737826 & 5.0 & 5.3447 & TST & \\
\hline
\end{tabular}




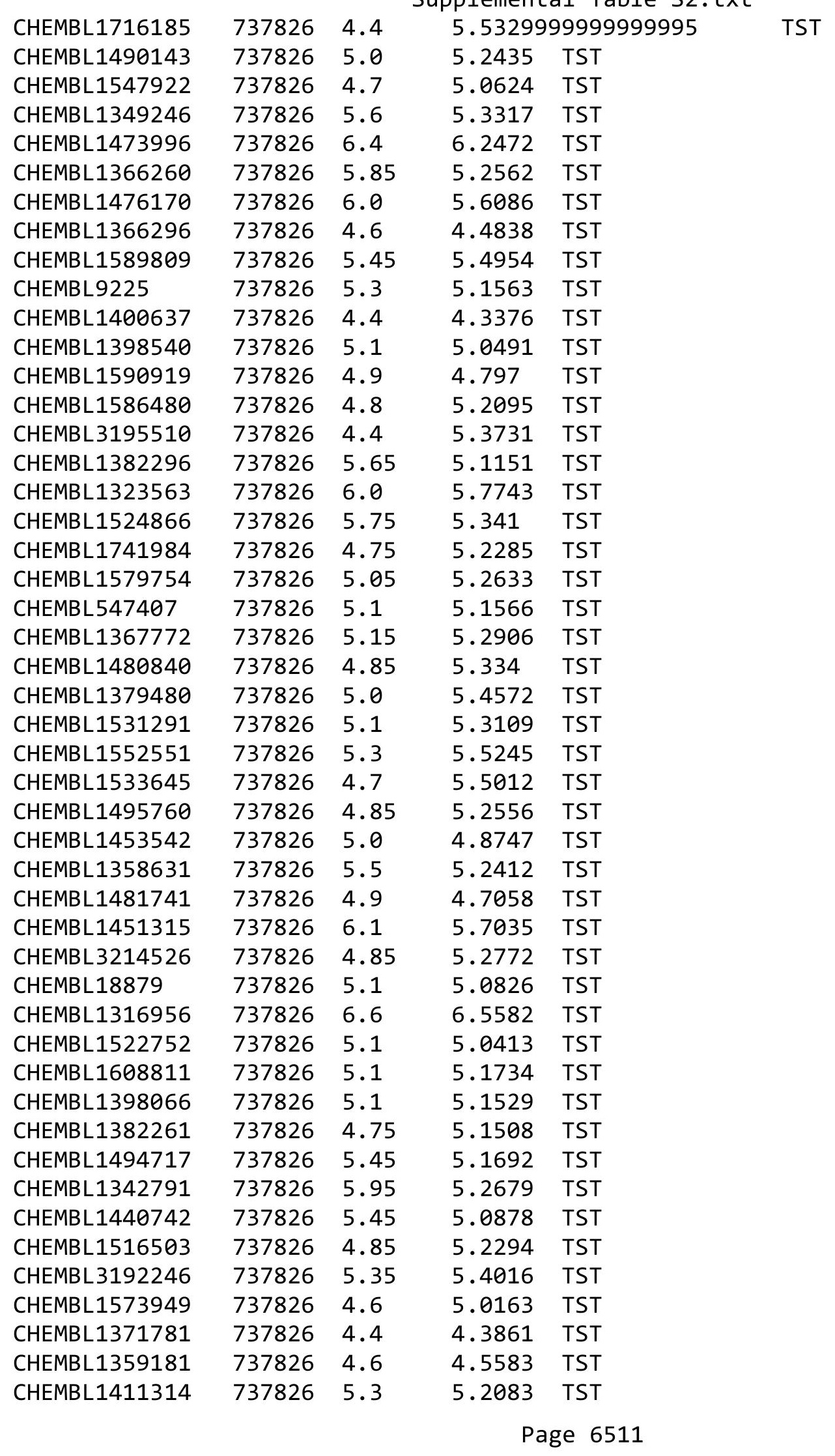




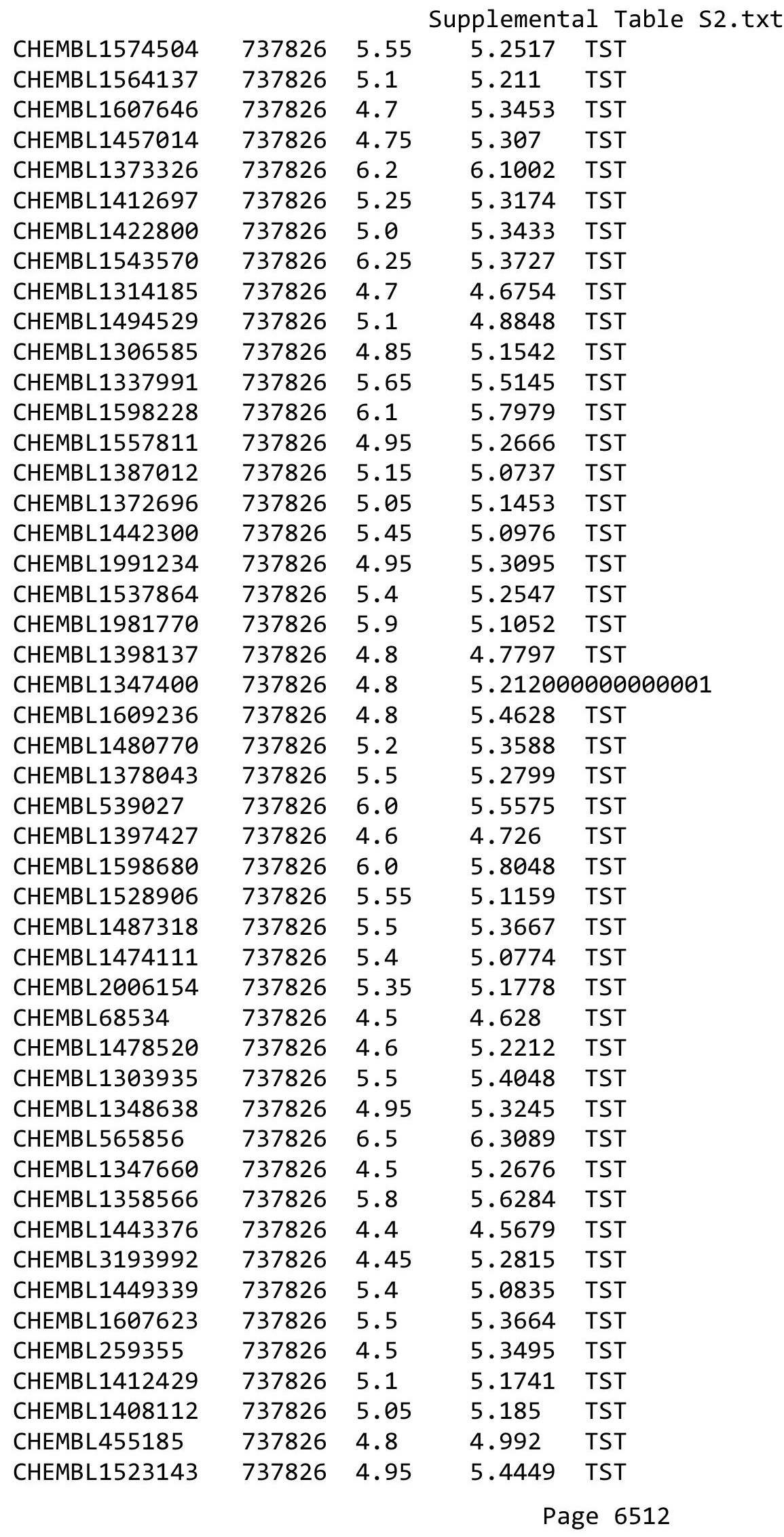




\begin{tabular}{|c|c|c|c|c|c|}
\hline & & \multicolumn{4}{|c|}{ Supplemental Table s2.txt } \\
\hline CHEMBL1430976 & 737826 & 5.05 & 5.1957 & TST & \\
\hline CHEMBL1528351 & 737826 & 5.25 & 5.5156 & TST & \\
\hline CHEMBL1490646 & 737826 & 4.75 & 5.2272 & TST & \\
\hline CHEMBL1402656 & 737826 & 4.4 & 4.4666 & TST & \\
\hline CHEMBL1543285 & 737826 & 5.15 & 5.2322 & TST & \\
\hline CHEMBL1545995 & 737826 & 5.05 & 5.3071 & TST & \\
\hline CHEMBL1313321 & 737826 & 5.05 & 5.6386 & TST & \\
\hline CHEMBL3208462 & 737826 & 4.9 & 5.2901 & TST & \\
\hline CHEMBL1595491 & 737826 & 8.3 & 5.2914 & TST & \\
\hline CHEMBL1319632 & 737826 & 5.45 & 5.2635 & TST & \\
\hline CHEMBL1501014 & 737826 & 4.9 & 5.2687 & TST & \\
\hline CHEMBL3207962 & 737826 & 5.45 & 5.45100 & 00000000005 & TST \\
\hline CHEMBL72365 & 737826 & 4.9 & 5.7383 & TST & \\
\hline CHEMBL1433939 & 737826 & 5.1 & 5.103 & TST & \\
\hline CHEMBL1555480 & 737826 & 4.4 & 4.4247 & TST & \\
\hline CHEMBL1455754 & 737826 & 4.85 & 5.3865 & TST & \\
\hline CHEMBL1526648 & 737826 & 4.9 & 5.3255 & TST & \\
\hline CHEMBL1351426 & 737826 & 4.85 & 5.3964 & TST & \\
\hline CHEMBL1490078 & 737826 & 6.0 & 5.4434 & TST & \\
\hline CHEMBL1401214 & 737826 & 5.7 & 5.4498 & TST & \\
\hline CHEMBL1551633 & 737826 & 5.1 & 4.881 & TST & \\
\hline CHEMBL588859 & 737826 & 5.75 & 5.1158 & TST & \\
\hline CHEMBL1416473 & 737826 & 5.85 & 5.2772 & TST & \\
\hline CHEMBL1316808 & 737826 & 5.8 & 5.6304 & TST & \\
\hline CHEMBL1581528 & 737826 & 4.75 & 5.3111 & TST & \\
\hline CHEMBL1552752 & 737826 & 6.1 & 6.0412 & TST & \\
\hline CHEMBL1487191 & 737826 & 5.3 & 5.112 & TST & \\
\hline CHEMBL1323499 & 737826 & 4.8 & 5.4009 & TST & \\
\hline CHEMBL1548421 & 737826 & 4.4 & 5.3736 & TST & \\
\hline CHEMBL1331913 & 737826 & 5.2 & 5.1121 & TST & \\
\hline CHEMBL1432016 & 737826 & 5.0 & 5.3459 & TST & \\
\hline CHEMBL1306752 & 737826 & 6.35 & 5.2798 & TST & \\
\hline CHEMBL1741414 & 737826 & 4.4 & 5.2336 & TST & \\
\hline CHEMBL1482566 & 737826 & 6.55 & 5.5957 & TST & \\
\hline CHEMBL1472322 & 737826 & 4.85 & 5.2387 & TST & \\
\hline CHEMBL1563819 & 737826 & 5.55 & 5.3957 & TST & \\
\hline CHEMBL1407527 & 737826 & 5.1 & 4.907 & TST & \\
\hline CHEMBL1596186 & 737826 & 5.5 & 5.3539 & TST & \\
\hline CHEMBL1546136 & 737826 & 5.75 & 5.1883 & TST & \\
\hline CHEMBL1305410 & 737826 & 6.0 & 5.2653 & TST & \\
\hline CHEMBL1437906 & 737826 & 5.0 & 4.9244 & TST & \\
\hline CHEMBL1741697 & 737826 & 5.05 & 5.2615 & TST & \\
\hline CHEMBL1607270 & 737826 & 4.45 & 5.3158 & TST & \\
\hline CHEMBL1420145 & 737826 & 6.75 & 5.1654 & TST & \\
\hline CHEMBL1419469 & 737826 & 5.0 & 5.263 & TST & \\
\hline CHEMBL1524366 & 737826 & 4.8 & 5.2808 & TST & \\
\hline CHEMBL1369822 & 737826 & 5.1 & 5.0285 & TST & \\
\hline CHEMBL1447538 & 737826 & 6.0 & 5.7914 & TST & \\
\hline
\end{tabular}




\begin{tabular}{|c|c|c|c|c|c|}
\hline \\
\hline CHEMBL1429733 & 737826 & 4.7 & 5.4972 & TST & \\
\hline CHEMBL1519453 & 737826 & 5.4 & 5.466 & TST & \\
\hline CHEMBL1389059 & 737826 & 6.2 & 5.3979 & TST & \\
\hline CHEMBL1302696 & 737826 & 5.1 & 5.3888 & TST & \\
\hline CHEMBL1441981 & 737826 & 5.3 & 5.0885 & TST & \\
\hline CHEMBL1507150 & 737826 & 5.55 & 5.1288 & TST & \\
\hline CHEMBL1612976 & 737826 & 4.9 & 5.1549 & TST & \\
\hline CHEMBL1527132 & 737826 & 5.0 & 4.8063 & TST & \\
\hline CHEMBL1359027 & 737826 & 5.4 & 5.3019 & TST & \\
\hline CHEMBL1302790 & 737826 & 5.95 & 5.227 & TST & \\
\hline CHEMBL1395429 & 737826 & 4.9 & 4.6905 & TST & \\
\hline CHEMBL1327850 & 737826 & 4.8 & 5.4481 & TST & \\
\hline CHEMBL1457902 & 737826 & 5.55 & 5.1471 & TST & \\
\hline CHEMBL1362547 & 737826 & 4.95 & 5.2091 & TST & \\
\hline CHEMBL1319049 & 737826 & 6.0 & 5.8114 & TST & \\
\hline CHEMBL1486231 & 737826 & 6.45 & 5.3293 & TST & \\
\hline CHEMBL 88147 & 737826 & 5.5 & 5.3385 & TST & \\
\hline CHEMBL1503387 & 737826 & 7.35 & 5.21899 & 9999999999 & TST \\
\hline CHEMBL1370296 & 737826 & 6.0 & 5.9488 & TST & \\
\hline CHEMBL 77971 & 737826 & 5.4 & 5.2753 & TST & \\
\hline CHEMBL1422725 & 737826 & 5.1 & 5.1777 & TST & \\
\hline CHEMBL1327566 & 737826 & 5.05 & 5.3941 & TST & \\
\hline CHEMBL3209784 & 737826 & 5.0 & 5.4279 & TST & \\
\hline CHEMBL1404882 & 737826 & 5.5 & 5.4427 & TST & \\
\hline CHEMBL1523400 & 737826 & 4.85 & 5.2693 & TST & \\
\hline CHEMBL3211920 & 737826 & 4.8 & 5.2276 & TST & \\
\hline CHEMBL1576499 & 737826 & 6.6 & 5.2301 & TST & \\
\hline CHEMBL1564927 & 737826 & 5.7 & 5.5788 & TST & \\
\hline CHEMBL1429056 & 737826 & 7.7001 & 5.2131 & TST & \\
\hline CHEMBL1500880 & 737826 & 5.05 & 5.3479 & TST & \\
\hline CHEMBL1430383 & 737826 & 5.15 & 5.1636 & TST & \\
\hline CHEMBL1345183 & 737826 & 5.7 & 5.1953 & TST & \\
\hline CHEMBL1409313 & 737826 & 5.65 & 5.4455 & TST & \\
\hline CHEMBL1413230 & 737826 & 5.0 & 5.3714 & TST & \\
\hline CHEMBL1568994 & 737826 & 5.15 & 5.3921 & TST & \\
\hline CHEMBL1533413 & 737826 & 5.5 & 5.3622 & TST & \\
\hline CHEMBL1569585 & 737826 & 5.4 & 5.1625 & TST & \\
\hline CHEMBL1487944 & 737826 & 4.9 & 4.8368 & TST & \\
\hline CHEMBL1329046 & 737826 & 5.95 & 5.4006 & TST & \\
\hline CHEMBL1456931 & 737826 & 6.0 & 5.1242 & TST & \\
\hline CHEMBL1301881 & 737826 & 5.1 & 5.5957 & TST & \\
\hline CHEMBL399491 & 737826 & 6.0 & 5.6464 & TST & \\
\hline CHEMBL543467 & 737826 & 4.5 & 4.6419 & TST & \\
\hline CHEMBL1342069 & 737826 & 6.1 & 5.3082 & TST & \\
\hline CHEMBL1988535 & 737826 & 4.8 & 5.1913 & TST & \\
\hline CHEMBL1354145 & 737826 & 4.4 & 4.4523 & TST & \\
\hline CHEMBL 222993 & 737826 & 5.1 & 5.1491 & TST & \\
\hline CHEMBL1557567 & 737826 & 5.7 & 5.2105 & TST & \\
\hline
\end{tabular}




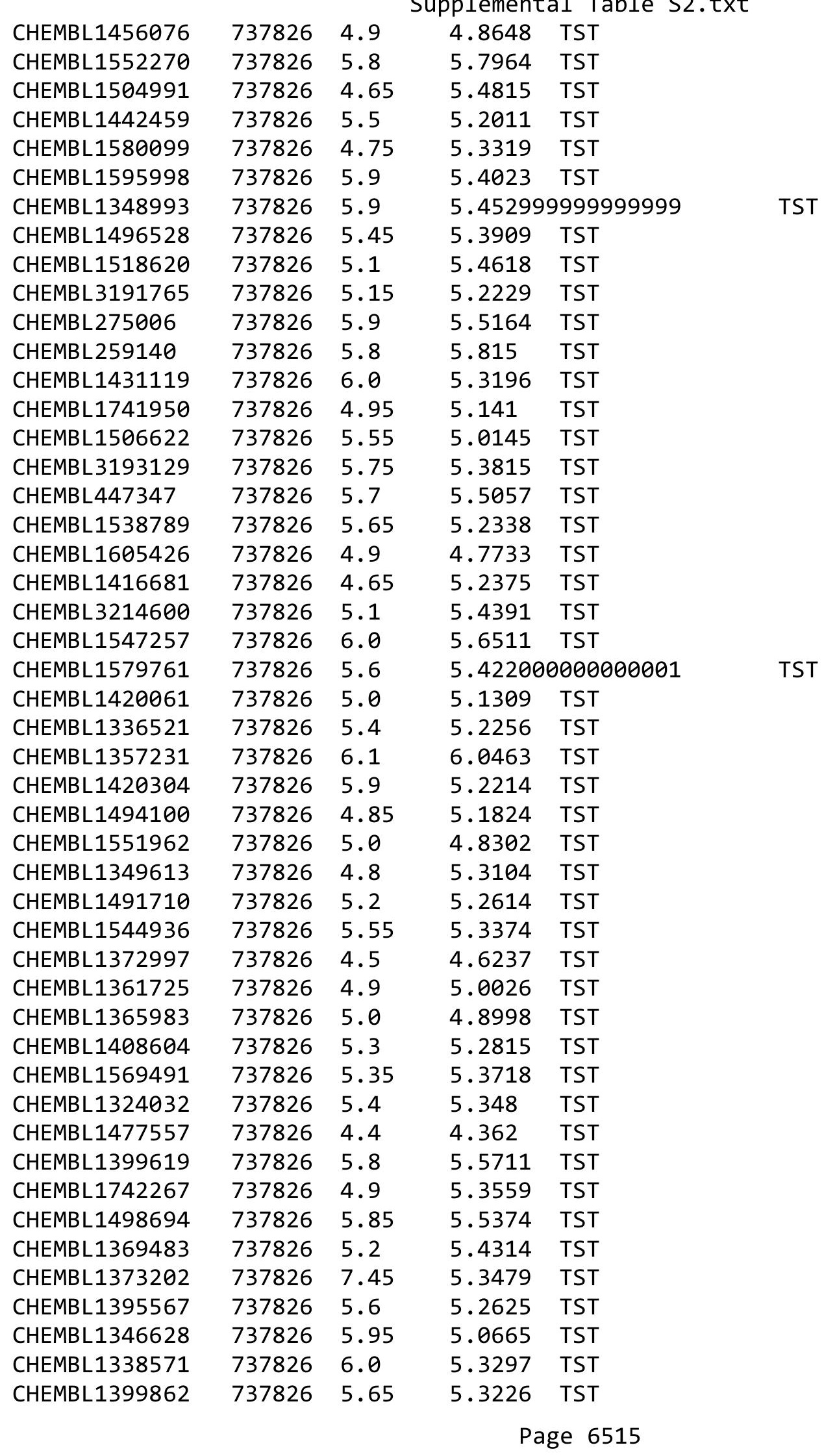




\begin{tabular}{|c|c|c|c|c|}
\hline & & & ipplement & al Table S \\
\hline CHEMBL3196162 & 737826 & 4.7 & 5.4656 & TST \\
\hline CHEMBL1360672 & 737826 & 5.2 & 5.4392 & TST \\
\hline CHEMBL1603906 & 737826 & 5.7 & 5.3388 & TST \\
\hline CHEMBL1526480 & 737826 & 5.3 & 5.4637 & TST \\
\hline CHEMBL1442986 & 737826 & 4.75 & 5.3653 & TST \\
\hline CHEMBL1374260 & 737826 & 4.8 & 5.2912 & TST \\
\hline CHEMBL1575849 & 737826 & 5.0 & 5.2858 & TST \\
\hline CHEMBL1436323 & 737826 & 5.6 & 5.1369 & TST \\
\hline CHEMBL1580037 & 737826 & 4.9 & 5.1327 & TST \\
\hline CHEMBL1372528 & 737826 & 5.05 & 5.2828 & TST \\
\hline CHEMBL1741547 & 737826 & 4.4 & 5.3114 & TST \\
\hline CHEMBL1467606 & 737826 & 4.8 & 5.2066 & TST \\
\hline CHEMBL1534630 & 737826 & 4.7 & 4.5487 & TST \\
\hline CHEMBL1349047 & 737826 & 5.25 & 5.2296 & TST \\
\hline CHEMBL1329197 & 737826 & 4.75 & 5.5268 & TST \\
\hline CHEMBL1545141 & 737826 & 5.3 & 5.2475 & TST \\
\hline CHEMBL1323320 & 737826 & 5.35 & 5.3208 & TST \\
\hline CHEMBL1353136 & 737826 & 4.9 & 5.2817 & TST \\
\hline CHEMBL3191564 & 737826 & 5.95 & 5.2862 & TST \\
\hline CHEMBL1508885 & 737826 & 4.8 & 5.13 & TST \\
\hline CHEMBL1538747 & 737826 & 4.85 & 5.33299 & 9999999999 \\
\hline CHEMBL1319426 & 737826 & 5.6 & 5.3709 & TST \\
\hline CHEMBL1550866 & 737826 & 4.4 & 5.3446 & TST \\
\hline CHEMBL1702153 & 737826 & 4.9 & 5.3343 & TST \\
\hline CHEMBL258405 & 737826 & 6.0 & 5.7201 & TST \\
\hline CHEMBL1741711 & 737826 & 4.8 & 5.2731 & TST \\
\hline CHEMBL1572006 & 737826 & 5.25 & 5.4043 & TST \\
\hline CHEMBL1312826 & 737826 & 4.95 & 5.1282 & TST \\
\hline CHEMBL1492339 & 737826 & 4.7 & 5.3173 & TST \\
\hline CHEMBL1314808 & 737826 & 4.4 & 4.7137 & TST \\
\hline CHEMBL1371661 & 737826 & 4.95 & 5.2097 & TST \\
\hline CHEMBL1416225 & 737826 & 6.6 & 5.379 & TST \\
\hline CHEMBL1511940 & 737826 & 5.75 & 5.273 & TST \\
\hline CHEMBL1583617 & 737826 & 4.4 & 5.1593 & TST \\
\hline CHEMBL1477299 & 737826 & 4.9 & 5.2159 & TST \\
\hline CHEMBL1483302 & 737826 & 7.4 & 5.1791 & TST \\
\hline CHEMBL1331231 & 737826 & 4.85 & 5.0945 & TST \\
\hline CHEMBL1538531 & 737826 & 5.65 & 5.3905 & TST \\
\hline CHEMBL1356843 & 737826 & 4.6 & 4.6153 & TST \\
\hline CHEMBL1597410 & 737826 & 5.0 & 4.8932 & TST \\
\hline CHEMBL1413631 & 737826 & 5.1 & 5.2627 & TST \\
\hline CHEMBL1326815 & 737826 & 5.5 & 5.4354 & TST \\
\hline CHEMBL1363773 & 737826 & 5.65 & 5.2751 & TST \\
\hline CHEMBL1524768 & 737826 & 5.35 & 5.3179 & TST \\
\hline CHEMBL1536942 & 737826 & 5.05 & 5.2861 & TST \\
\hline CHEMBL3197340 & 737826 & 5.4 & 5.4295 & TST \\
\hline CHEMBL1489353 & 737826 & 5.0 & 5.0456 & TST \\
\hline CHEMBL1432354 & 737826 & 5.35 & 5.4028 & TST \\
\hline
\end{tabular}




\begin{tabular}{|c|c|c|c|c|}
\hline \multicolumn{5}{|c|}{ Supplemental Table s2.txt } \\
\hline CHEMBL2369181 & 737826 & 5.4 & 5.1996 & TST \\
\hline CHEMBL1540663 & 737826 & 5.0 & 5.2408 & TST \\
\hline CHEMBL1550463 & 737826 & 4.95 & 5.3664 & TST \\
\hline CHEMBL352396 & 737826 & 5.2 & 5.1271 & TST \\
\hline CHEMBL 1453450 & 737826 & 4.4 & 5.2246 & TST \\
\hline CHEMBL1601527 & 737826 & 4.55 & 5.3302 & TST \\
\hline CHEMBL1479912 & 737826 & 4.9 & 4.7335 & TST \\
\hline CHEMBL1539127 & 737826 & 4.8 & 5.4526 & TST \\
\hline CHEMBL1318448 & 737826 & 4.4 & 4.4483 & TST \\
\hline CHEMBL1413605 & 737826 & 5.45 & 5.4886 & TST \\
\hline CHEMBL1563501 & 737826 & 4.4 & 4.5171 & TST \\
\hline CHEMBL1424441 & 737826 & 5.2 & 5.3115 & TST \\
\hline CHEMBL1351420 & 737826 & 4.95 & 5.112 & TST \\
\hline CHEMBL1451768 & 737826 & 4.8 & 4.7439 & TST \\
\hline CHEMBL1343639 & 737826 & 5.4 & 5.3106 & TST \\
\hline CHEMBL1523936 & 737826 & 4.7 & 5.2825 & TST \\
\hline CHEMBL1496056 & 737826 & 5.8 & 5.4751 & TST \\
\hline CHEMBL 3207650 & 737826 & 5.45 & 5.2918 & TST \\
\hline CHEMBL1508113 & 737826 & 5.0 & 5.4665 & TST \\
\hline CHEMBL1493037 & 737826 & 4.7 & 4.7923 & TST \\
\hline CHEMBL3192169 & 737826 & 5.0 & 5.4484 & TST \\
\hline CHEMBL1387681 & 737826 & 4.95 & 5.3563 & TST \\
\hline CHEMBL1391234 & 737826 & 4.85 & 5.3495 & TST \\
\hline CHEMBL1544520 & 737826 & 5.1 & 5.3518 & TST \\
\hline CHEMBL1442060 & 737826 & 4.85 & 4.9911 & TST \\
\hline CHEMBL1489204 & 737826 & 6.45 & 5.6913 & TST \\
\hline CHEMBL1609585 & 737826 & 5.0 & 5.303 & TST \\
\hline CHEMBL1386579 & 737826 & 5.1 & 5.2487 & TST \\
\hline CHEMBL3190824 & 737826 & 5.2 & 5.2278 & TST \\
\hline CHEMBL1478612 & 737826 & 5.6 & 5.0849 & TST \\
\hline CHEMBL1319381 & 737826 & 4.7 & 5.2053 & TST \\
\hline CHEMBL1508815 & 737826 & 4.75 & 5.2237 & TST \\
\hline CHEMBL 319244 & 737826 & 4.4 & 4.6124 & TST \\
\hline CHEMBL1706828 & 737826 & 4.9 & 5.2269 & TST \\
\hline CHEMBL1373998 & 737826 & 5.2 & 5.0756 & TST \\
\hline CHEMBL1534872 & 737826 & 4.5 & 4.4806 & TST \\
\hline CHEMBL1385123 & 737826 & 5.25 & 5.1642 & TST \\
\hline CHEMBL1582776 & 737826 & 4.55 & 5.1386 & TST \\
\hline CHEMBL1430082 & 737826 & 4.9 & 5.2225 & TST \\
\hline CHEMBL1519980 & 737826 & 4.85 & 5.1721 & TST \\
\hline CHEMBL1314906 & 737826 & 5.0 & 4.8154 & TST \\
\hline CHEMBL1335967 & 737826 & 7.9 & 6.8886 & TST \\
\hline CHEMBL1376572 & 737826 & 4.9 & 4.8539 & TST \\
\hline CHEMBL1401938 & 737826 & 5.25 & 5.399 & TST \\
\hline CHEMBL1403307 & 737826 & 4.7 & 5.5065 & TST \\
\hline CHEMBL1382819 & 737826 & 4.95 & 5.1374 & TST \\
\hline CHEMBL3196691 & 737826 & 4.65 & 5.29700 & 0000000001 \\
\hline CHEMBL1595551 & 737826 & 4.9 & 5.2751 & TST \\
\hline
\end{tabular}




\begin{tabular}{|c|c|c|c|c|}
\hline \multicolumn{5}{|c|}{ Supplemental 1} \\
\hline CHEMBL1529578 & 737826 & 5.7 & 5.4243 & TST \\
\hline CHEMBL1390056 & 737826 & 4.75 & 5.1502 & TST \\
\hline CHEMBL1701677 & 737826 & 4.6 & 5.2365 & TST \\
\hline CHEMBL1494615 & 737826 & 5.5 & 5.3273 & TST \\
\hline CHEMBL 275854 & 737826 & 5.0 & 4.8639 & TST \\
\hline CHEMBL117 & 737826 & 5.3 & 5.2558 & TST \\
\hline CHEMBL1491574 & 737826 & 4.9 & 4.7761 & TST \\
\hline CHEMBL1362642 & 737826 & 5.15 & 5.1873 & TST \\
\hline CHEMBL1607187 & 737826 & 5.5 & 5.2102 & TST \\
\hline CHEMBL1317056 & 737826 & 4.9 & 4.8732 & TST \\
\hline CHEMBL1324402 & 737826 & 5.6 & 5.6285 & TST \\
\hline CHEMBL1413962 & 737826 & 5.0 & 4.8468 & TST \\
\hline CHEMBL1515246 & 737826 & 5.7 & 5.5283 & TST \\
\hline CHEMBL 79140 & 737826 & 5.0 & 4.908 & TST \\
\hline CHEMBL1500518 & 737826 & 5.05 & 5.4105 & TST \\
\hline CHEMBL 8145 & 737826 & 5.2 & 5.5308 & TST \\
\hline CHEMBL1598896 & 737826 & 5.45 & 5.114 & TST \\
\hline CHEMBL1543533 & 737826 & 5.7 & 5.0584 & TST \\
\hline CHEMBL1342700 & 737826 & 4.5 & 5.3456 & TST \\
\hline CHEMBL1539263 & 737826 & 5.8 & 5.3062 & TST \\
\hline CHEMBL1412170 & 737826 & 5.3 & 5.2546 & TST \\
\hline CHEMBL1571361 & 737826 & 5.1 & 5.2049 & TST \\
\hline CHEMBL1502796 & 737826 & 5.0 & 5.2177 & TST \\
\hline CHEMBL1465342 & 737826 & 4.9 & 5.4569 & TST \\
\hline CHEMBL1463823 & 737826 & 5.25 & 5.2297 & TST \\
\hline CHEMBL1450373 & 737826 & 5.3 & 5.2755 & TST \\
\hline CHEMBL1383268 & 737826 & 4.6 & 5.1545 & TST \\
\hline CHEMBL1313588 & 737826 & 5.4 & 5.1976 & TST \\
\hline CHEMBL3208849 & 737826 & 4.95 & 5.5014 & TST \\
\hline CHEMBL1398580 & 737826 & 4.6 & 5.2078 & TST \\
\hline CHEMBL1334104 & 737826 & 5.5 & 5.2869 & TST \\
\hline CHEMBL3213479 & 737826 & 4.4 & 5.5786 & TST \\
\hline CHEMBL1451747 & 737826 & 4.8 & 5.4857 & TST \\
\hline CHEMBL3212613 & 737826 & 4.4 & 5.2837 & TST \\
\hline CHEMBL1308218 & 737826 & 4.85 & 5.285 & TST \\
\hline CHEMBL1742011 & 737826 & 6.4 & 5.3412 & TST \\
\hline CHEMBL1599663 & 737826 & 5.25 & 5.3542 & TST \\
\hline CHEMBL1300494 & 737826 & 5.0 & 5.2418 & TST \\
\hline CHEMBL172064 & 737826 & 5.7 & 5.6567 & TST \\
\hline CHEMBL1315833 & 737826 & 4.9 & 4.7743 & TST \\
\hline CHEMBL1330448 & 737826 & 4.8 & 5.2316 & TST \\
\hline CHEMBL1742296 & 737826 & 5.1 & 5.4093 & TST \\
\hline CHEMBL3209398 & 737826 & 4.95 & 5.5162 & TST \\
\hline CHEMBL1443967 & 737826 & 5.6 & 5.2316 & TST \\
\hline CHEMBL1509049 & 688673 & 7.2 & 5.6333 & TST \\
\hline CHEMBL1490928 & 688673 & 8.4949 & 5.3947 & TRN \\
\hline CHEMBL1532037 & 688673 & 5.6 & 5.3559 & TRN \\
\hline CHEMBL1564162 & 688673 & 6.1 & 5.8569 & TRN \\
\hline
\end{tabular}




\begin{tabular}{|c|c|c|c|c|c|}
\hline \multicolumn{6}{|c|}{ Supplemental Table S2.txt } \\
\hline CHEMBL1369392 & 688673 & 6.9 & 5.845 & TRN & \\
\hline CHEMBL1613112 & 688673 & 4.85 & 5.3753 & TRN & \\
\hline CHEMBL1491654 & 688673 & 4.45 & 5.5463 & TRN & \\
\hline CHEMBL1356116 & 688673 & 6.45 & 5.8408 & TRN & \\
\hline CHEMBL1582488 & 688673 & 4.8 & 5.7357 & TRN & \\
\hline CHEMBL1464031 & 688673 & 4.45 & 5.5013 & TRN & \\
\hline CHEMBL1573339 & 688673 & 6.9 & 5.7321 & TRN & \\
\hline CHEMBL1500566 & 688673 & 6.9 & 6.1063 & TRN & \\
\hline CHEMBL1450042 & 688673 & 4.5 & 5.7468 & TRN & \\
\hline CHEMBL1312530 & 688673 & 6.1 & 5.9267 & TRN & \\
\hline CHEMBL 3208852 & 688673 & 4.7 & 5.7115 & TRN & \\
\hline CHEMBL1479144 & 688673 & 4.9 & 4.994 & TRN & \\
\hline CHEMBL1388981 & 688673 & 6.4 & 5.92399 & 99999999995 & TRN \\
\hline CHEMBL1374395 & 688673 & 6.1 & 5.86299 & 99999999995 & TRN \\
\hline CHEMBL1500101 & 688673 & 5.5 & 5.7208 & TRN & \\
\hline CHEMBL1589632 & 688673 & 5.75 & 5.817 & TRN & \\
\hline CHEMBL1465337 & 688673 & 7.8013 & 5.7917 & TRN & \\
\hline CHEMBL1574488 & 688673 & 4.6 & 6.018 & TRN & \\
\hline CHEMBL1549896 & 688673 & 5.8 & 5.8221 & TRN & \\
\hline CHEMBL1425383 & 688673 & 4.45 & 5.9881 & TRN & \\
\hline CHEMBL1384065 & 688673 & 6.0 & 5.9323 & TRN & \\
\hline CHEMBL3198964 & 688673 & 6.6 & 5.5059 & TRN & \\
\hline CHEMBL1518609 & 688673 & 5.4 & 5.45100 & 00000000005 & TRN \\
\hline CHEMBL1434160 & 688673 & 5.45 & 5.8355 & TRN & \\
\hline CHEMBL1310775 & 688673 & 4.9 & 5.6356 & TRN & \\
\hline CHEMBL1446854 & 688673 & 4.5 & 5.9917 & TRN & \\
\hline CHEMBL3211510 & 688673 & 6.5 & 5.5156 & TRN & \\
\hline CHEMBL1308855 & 688673 & 4.75 & 5.4603 & TST & \\
\hline CHEMBL1530823 & 688673 & 4.5 & 5.5386 & TRN & \\
\hline CHEMBL1572399 & 688673 & 5.2 & 5.6956 & TRN & \\
\hline CHEMBL1477116 & 688673 & 4.5 & 6.018 & TRN & \\
\hline CHEMBL1464092 & 688673 & 4.6 & 5.7638 & TRN & \\
\hline CHEMBL1505268 & 688673 & 4.5 & 5.4386 & TRN & \\
\hline CHEMBL1976099 & 688673 & 5.3 & 5.3998 & TRN & \\
\hline CHEMBL1331234 & 688673 & 4.6 & 5.6927 & TST & \\
\hline CHEMBL1405934 & 688673 & 4.5 & 5.8948 & TRN & \\
\hline CHEMBL1408910 & 688673 & 4.5 & 6.1859 & TRN & \\
\hline CHEMBL1503234 & 688673 & 4.9 & 5.3008 & TRN & \\
\hline CHEMBL1311697 & 688673 & 4.45 & 5.8308 & TRN & \\
\hline CHEMBL1374204 & 688673 & 4.8 & 5.6096 & TRN & \\
\hline CHEMBL1401201 & 688673 & 5.3 & 5.7872 & TRN & \\
\hline CHEMBL1309987 & 688673 & 4.6 & 5.5663 & TST & \\
\hline CHEMBL1300534 & 688673 & 5.3 & 5.4985 & TRN & \\
\hline CHEMBL1566542 & 688673 & 5.2 & 6.2187 & TRN & \\
\hline CHEMBL1598617 & 688673 & 8.3979 & 5.49 & TRN & \\
\hline CHEMBL1385534 & 688673 & 4.85 & 5.8463 & TRN & \\
\hline CHEMBL1361956 & 688673 & 6.95 & 5.6953 & TRN & \\
\hline CHEMBL1537965 & 688673 & 7.8013 & 5.9849 & TRN & \\
\hline
\end{tabular}




\begin{tabular}{|c|c|c|c|c|c|}
\hline \\
\hline CHEMBL1392442 & 688673 & 5.4 & 5.5371 & TST & \\
\hline CHEMBL1383685 & 688673 & 6.6 & 5.2612 & TRN & \\
\hline CHEMBL1410261 & 688673 & 4.6 & 5.5292 & TRN & \\
\hline CHEMBL1307329 & 688673 & 5.2 & 5.7123 & TRN & \\
\hline CHEMBL1439937 & 688673 & 4.9 & 5.9679 & TRN & \\
\hline CHEMBL2373651 & 688673 & 5.0 & 5.6785 & TST & \\
\hline CHEMBL1324985 & 688673 & 4.9 & 5.9687 & TRN & \\
\hline CHEMBL1536091 & 688673 & 7.8996 & 5.8359 & TRN & \\
\hline CHEMBL1546779 & 688673 & 6.6 & 6.1765 & TRN & \\
\hline CHEMBL1599735 & 688673 & 6.2 & 5.6886 & TRN & \\
\hline CHEMBL1517358 & 688673 & 4.6 & 5.9265 & TRN & \\
\hline CHEMBL1368973 & 688673 & 5.5 & 5.806 & TRN & \\
\hline CHEMBL1571372 & 688673 & 5.3 & 5.7775 & TRN & \\
\hline CHEMBL1427227 & 688673 & 7.699 & 5.9881 & TRN & \\
\hline CHEMBL1400718 & 688673 & 4.5 & 5.8869 & TRN & \\
\hline CHEMBL1557458 & 688673 & 5.6 & 5.6699 & TRN & \\
\hline CHEMBL1419909 & 688673 & 4.5 & 5.3716 & TST & \\
\hline CHEMBL1426928 & 688673 & 7.0 & 5.7477 & TRN & \\
\hline CHEMBL1408036 & 688673 & 5.3 & 5.61100 & 0000000001 & TRN \\
\hline CHEMBL1492426 & 688673 & 6.8 & 6.0875 & TRN & \\
\hline CHEMBL1325866 & 688673 & 7.15 & 5.3386 & TRN & \\
\hline CHEMBL1354707 & 688673 & 4.65 & 5.4758 & TRN & \\
\hline CHEMBL1433015 & 688673 & 5.6 & 5.4132 & TRN & \\
\hline CHEMBL1608862 & 688673 & 5.0 & 5.5417 & TRN & \\
\hline CHEMBL1414449 & 688673 & 6.3 & 6.1878 & TRN & \\
\hline CHEMBL3191856 & 688673 & 5.4 & 5.7345 & TRN & \\
\hline CHEMBL1585255 & 688673 & 7.3002 & 5.9539 & TRN & \\
\hline CHEMBL1596380 & 688673 & 8.3979 & 5.4606 & TRN & \\
\hline CHEMBL1569840 & 688673 & 5.4 & 5.7035 & TRN & \\
\hline CHEMBL1444771 & 688673 & 7.2 & 5.4317 & TRN & \\
\hline CHEMBL1466504 & 688673 & 4.6 & 5.6916 & TRN & \\
\hline CHEMBL1571803 & 688673 & 4.9 & 5.61100 & 3000000001 & TRN \\
\hline CHEMBL1514690 & 688673 & 5.9 & 5.8073 & TRN & \\
\hline CHEMBL1479052 & 688673 & 4.5 & 5.6767 & TRN & \\
\hline CHEMBL1312189 & 688673 & 4.7 & 5.6789 & TRN & \\
\hline CHEMBL1321356 & 688673 & 4.8 & 5.276 & TRN & \\
\hline CHEMBL1509998 & 688673 & 6.0 & 5.6049 & TRN & \\
\hline CHEMBL1503975 & 688673 & 7.5003 & 5.8297 & TRN & \\
\hline CHEMBL1441350 & 688673 & 4.45 & 5.7183 & TRN & \\
\hline CHEMBL1595488 & 688673 & 6.1 & 5.485 & TRN & \\
\hline CHEMBL1494855 & 688673 & 6.7501 & 5.5253 & TRN & \\
\hline CHEMBL1521341 & 688673 & 4.9 & 6.0248 & TRN & \\
\hline CHEMBL1609214 & 688673 & 6.1 & 5.5952 & TRN & \\
\hline CHEMBL1359262 & 688673 & 7.7496 & 6.0788 & TRN & \\
\hline CHEMBL3210899 & 688673 & 7.6003 & 6.0018 & TST & \\
\hline CHEMBL1487974 & 688673 & 4.5 & 5.9452 & TRN & \\
\hline CHEMBL1320645 & 688673 & 5.5 & 5.6704 & TRN & \\
\hline CHEMBL1321728 & 688673 & 4.9 & 5.4202 & TRN & \\
\hline
\end{tabular}




\begin{tabular}{|c|c|c|c|c|c|}
\hline \multirow{3}{*}{$\begin{array}{l}\text { CHEMBL1320149 } \\
\text { CHEMBL1458897 }\end{array}$} & \multirow{3}{*}{$\begin{array}{l}688673 \\
688673\end{array}$} & \multicolumn{4}{|c|}{ Supplemental Table S2.txt } \\
\hline & & 7.0 & \multicolumn{2}{|c|}{5.587000000000001} & \multirow[t]{2}{*}{ TRA } \\
\hline & & 7.8996 & 5.6433 & TRN & \\
\hline CHEMBL1444172 & 688673 & 4.75 & 5.9081 & TRN & \\
\hline CHEMBL1311881 & 688673 & 4.5 & 5.7189 & TRN & \\
\hline CHEMBL1560048 & 688673 & 4.9 & 5.4702 & TRN & \\
\hline CHEMBL1558251 & 688673 & 5.0 & 5.5843 & TRN & \\
\hline CHEMBL1379877 & 688673 & 7.5003 & 5.6113 & TRN & \\
\hline CHEMBL1486389 & 688673 & 5.25 & 5.6485 & TRN & \\
\hline CHEMBL1419203 & 688673 & 5.2 & 5.7925 & TST & \\
\hline CHEMBL1561564 & 688673 & 5.2 & 5.6303 & TRN & \\
\hline CHEMBL1375768 & 688673 & 4.8 & 5.4896 & TST & \\
\hline CHEMBL1313038 & 688673 & 6.7501 & 5.7774 & TRN & \\
\hline CHEMBL1590015 & 688673 & 4.45 & 5.8556 & TRN & \\
\hline CHEMBL1393861 & 688673 & 8.3979 & 5.7717 & TRN & \\
\hline CHEMBL1364718 & 688673 & 5.3 & 5.92 & TRN & \\
\hline CHEMBL3198826 & 688673 & 7.0 & 5.473 & TRN & \\
\hline CHEMBL1335873 & 688673 & 4.6 & 5.6608 & TRN & \\
\hline CHEMBL1311879 & 688673 & 4.8 & 5.3157 & TST & \\
\hline CHEMBL1582791 & 688673 & 5.4 & 5.5903 & TRN & \\
\hline CHEMBL1549183 & 688673 & 4.95 & \multicolumn{2}{|c|}{5.593999999999999} & TRN \\
\hline CHEMBL 217920 & 688673 & 4.8 & 5.5564 & TRN & \\
\hline CHEMBL1496061 & 688673 & 5.45 & 6.0863 & TRN & \\
\hline CHEMBL1366217 & 688673 & 4.6 & 5.8138 & TRN & \\
\hline CHEMBL1599985 & 688673 & 4.8 & 5.9498 & TRN & \\
\hline CHEMBL3192843 & 688673 & 6.0 & 5.7575 & TRN & \\
\hline CHEMBL1492301 & 688673 & 5.5 & 5.9208 & TRN & \\
\hline CHEMBL1315620 & 688673 & 5.55 & 5.8759 & TRN & \\
\hline CHEMBL1318957 & 688673 & 4.9 & 5.6585 & TRN & \\
\hline CHEMBL1353354 & 688673 & 4.6 & 5.4908 & TRN & \\
\hline CHEMBL1344115 & 688673 & 4.95 & 5.8856 & TRN & \\
\hline CHEMBL1323590 & 688673 & 4.45 & 5.5538 & TRN & \\
\hline CHEMBL1426236 & 688673 & 4.6 & 5.5009 & TRN & \\
\hline CHEMBL1365784 & 688673 & 6.45 & 6.2193 & TRN & \\
\hline CHEMBL1348890 & 688673 & 5.5 & 5.7829 & TRN & \\
\hline CHEMBL1316079 & 688673 & 6.1 & 5.5038 & TRN & \\
\hline CHEMBL1328866 & 688673 & 6.7001 & 6.0848 & TRN & \\
\hline CHEMBL1442198 & 688673 & 5.9 & 5.8406 & TRN & \\
\hline CHEMBL1605481 & 688673 & 8.3979 & \multicolumn{2}{|c|}{6.087000000000001} & TRN \\
\hline CHEMBL1423381 & 688673 & 7.699 & 5.664 & TST & \\
\hline CHEMBL1389630 & 688673 & 6.3 & \multicolumn{2}{|c|}{5.787999999999999} & TRN \\
\hline CHEMBL1598911 & 688673 & 5.4 & 5.8102 & TRN & \\
\hline CHEMBL1497110 & 688673 & 6.1 & 5.8808 & TRN & \\
\hline CHEMBL1536665 & 688673 & 4.9 & \multicolumn{2}{|c|}{5.4879999999999995} & TRN \\
\hline CHEMBL1536963 & 688673 & 5.55 & 5.5991 & TRN & \\
\hline CHEMBL1607137 & 688673 & 5.4 & 5.9863 & TRN & \\
\hline CHEMBL1454087 & 688673 & 8.0 & 5.6994 & TRN & \\
\hline CHEMBL1320907 & 688673 & 4.7 & 5.8188 & TRN & \\
\hline CHEMBL600060 & 688673 & 5.5 & 5.6884 & TRN & \\
\hline
\end{tabular}




\begin{tabular}{|c|c|c|c|c|c|}
\hline \multirow[b]{2}{*}{ CHEMBL1613024 } & \multicolumn{5}{|c|}{ Supplemental Table S2.txt } \\
\hline & 688673 & 7.8508 & 5.7034 & TRN & \\
\hline CHEMBL1431883 & 688673 & 5.2 & 5.7947 & TST & \\
\hline CHEMBL1303624 & 688673 & 7.5498 & 5.6123 & TRN & \\
\hline CHEMBL1560721 & 688673 & 6.1 & 5.5338 & TST & \\
\hline CHEMBL1401890 & 688673 & 8.0 & 6.0204 & TRN & \\
\hline CHEMBL1333441 & 688673 & 4.5 & 5.5554 & TRN & \\
\hline CHEMBL442347 & 688673 & 7.8013 & 5.5353 & TRN & \\
\hline CHEMBL1496379 & 688673 & 5.1 & 5.6668 & TRN & \\
\hline CHEMBL1461568 & 688673 & 5.5 & 5.5006 & TRN & \\
\hline CHEMBL1312517 & 688673 & 4.9 & 5.7539 & TRN & \\
\hline CHEMBL1328473 & 688673 & 4.7 & 5.2005 & TRN & \\
\hline CHEMBL1351580 & 688673 & 4.95 & 5.4599 & TRN & \\
\hline CHEMBL1464426 & 688673 & 5.7 & 5.9904 & TRN & \\
\hline CHEMBL3191441 & 688673 & 6.0 & 5.7012 & TRN & \\
\hline CHEMBL1419053 & 688673 & 5.5 & 5.4883 & TRN & \\
\hline CHEMBL1464950 & 688673 & 4.5 & 6.0041 & TRN & \\
\hline CHEMBL1332663 & 688673 & 6.9 & 6.081 & TRN & \\
\hline CHEMBL1382032 & 688673 & 5.0 & 5.5667 & TRN & \\
\hline CHEMBL1494276 & 688673 & 4.5 & 5.7479 & TRN & \\
\hline CHEMBL1526492 & 688673 & 4.7 & 5.9339 & TRN & \\
\hline CHEMBL 1538772 & 688673 & 6.4 & 5.8649 & TRN & \\
\hline CHEMBL1359126 & 688673 & 7.3002 & 6.0884 & TRN & \\
\hline CHEMBL1509561 & 688673 & 5.3 & 6.0641 & TRN & \\
\hline CHEMBL1602180 & 688673 & 6.1 & 5.7478 & TRN & \\
\hline CHEMBL1320396 & 688673 & 4.85 & 5.9113 & TRN & \\
\hline CHEMBL1301525 & 688673 & 4.5 & 5.6154 & TRN & \\
\hline CHEMBL1302995 & 688673 & 4.9 & 5.7668 & TRN & \\
\hline CHEMBL1380232 & 688673 & 4.7 & 6.0773 & TRN & \\
\hline CHEMBL1588281 & 688673 & 7.3002 & 5.7545 & TRN & \\
\hline CHEMBL1416645 & 688673 & 5.6 & 5.6469 & TRN & \\
\hline CHEMBL1356521 & 688673 & 5.25 & 5.71399 & 99999999995 & TRN \\
\hline CHEMBL3195176 & 688673 & 4.9 & 5.7684 & TRN & \\
\hline CHEMBL55814 & 688673 & 4.8 & 5.4011 & TRN & \\
\hline CHEMBL1420434 & 688673 & 4.9 & 5.7792 & TRN & \\
\hline CHEMBL1390461 & 688673 & 6.7501 & 5.72 & TRN & \\
\hline CHEMBL1437695 & 688673 & 4.6 & 5.8554 & TRN & \\
\hline CHEMBL1613065 & 688673 & 5.25 & 6.0583 & TRN & \\
\hline CHEMBL1558363 & 688673 & 5.3 & 5.8563 & TRN & \\
\hline CHEMBL1568107 & 688673 & 7.4001 & 5.6453 & TST & \\
\hline CHEMBL1479965 & 688673 & 4.9 & 5.6883 & TRN & \\
\hline CHEMBL1460186 & 688673 & 4.8 & 5.7647 & TRN & \\
\hline CHEMBL1435903 & 688673 & 5.5 & 5.8663 & TRN & \\
\hline CHEMBL462880 & 688673 & 4.5 & 5.67200 & 0000000001 & TST \\
\hline CHEMBL1387205 & 688673 & 4.45 & 5.3059 & TRN & \\
\hline CHEMBL1534808 & 688673 & 7.6003 & 6.1149 & TRN & \\
\hline CHEMBL1309926 & 688673 & 4.45 & 5.7553 & TRN & \\
\hline CHEMBL1353508 & 688673 & 5.3 & 5.6032 & TRN & \\
\hline CHEMBL1595336 & 688673 & 4.5 & 5.6751 & TRN & \\
\hline
\end{tabular}




\begin{tabular}{|c|c|c|c|c|c|}
\hline \multicolumn{6}{|c|}{ Supplemental Table S2.txt } \\
\hline CHEMBL1536252 & 688673 & 4.9 & 5.5223 & TRN & \\
\hline CHEMBL1381330 & 688673 & 7.6003 & 5.79 & TRN & \\
\hline CHEMBL1564780 & 688673 & 5.4 & 5.8468 & TRN & \\
\hline CHEMBL1491326 & 688673 & 5.1 & 5.3729 & TRN & \\
\hline CHEMBL1531392 & 688673 & 5.4 & 5.8444 & TRN & \\
\hline CHEMBL1472443 & 688673 & 4.5 & 5.5964 & TRN & \\
\hline CHEMBL1450007 & 688673 & 6.7001 & 5.8933 & TRN & \\
\hline CHEMBL1432043 & 688673 & 5.15 & 6.0078 & TRN & \\
\hline CHEMBL1324176 & 688673 & 4.95 & 5.4129 & TRN & \\
\hline CHEMBL1539052 & 688673 & 4.5 & 5.9912 & TRN & \\
\hline CHEMBL1413027 & 688673 & 5.2 & 5.7386 & TRN & \\
\hline CHEMBL1377524 & 688673 & 7.699 & 5.8996 & TRN & \\
\hline CHEMBL1317868 & 688673 & 5.2 & 5.6705 & TRN & \\
\hline CHEMBL1607975 & 688673 & 4.45 & 6.04200 & 0000000001 & TRN \\
\hline CHEMBL1578180 & 688673 & 5.2 & 6.0581 & TRN & \\
\hline CHEMBL1372234 & 688673 & 8.301 & 6.0367 & TRN & \\
\hline CHEMBL1432394 & 688673 & 4.65 & 5.8131 & TRN & \\
\hline CHEMBL1447613 & 688673 & 6.2 & 5.74200 & 0000000001 & TRN \\
\hline CHEMBL1324134 & 688673 & 7.5498 & 5.7996 & TRN & \\
\hline CHEMBL1587826 & 688673 & 6.5 & 5.9809 & TRN & \\
\hline CHEMBL1400740 & 688673 & 7.5498 & 5.6074 & TST & \\
\hline CHEMBL1355993 & 688673 & 4.85 & 5.3389 & TRN & \\
\hline CHEMBL1340491 & 688673 & 4.5 & 5.7721 & TRN & \\
\hline CHEMBL1327168 & 688673 & 4.8 & 5.8232 & TST & \\
\hline CHEMBL1300433 & 688673 & 5.0 & 5.9855 & TRN & \\
\hline CHEMBL1312186 & 688673 & 6.1 & 5.6084 & TRN & \\
\hline CHEMBL1526172 & 688673 & 6.0 & 5.4474 & TRN & \\
\hline CHEMBL1492529 & 688673 & 4.9 & 5.7038 & TRN & \\
\hline CHEMBL1356755 & 688673 & 5.25 & 5.7873 & TRN & \\
\hline CHEMBL1443531 & 688673 & 5.25 & 5.4974 & TRN & \\
\hline CHEMBL 261122 & 688673 & 8.4949 & 5.75700 & 0000000001 & TST \\
\hline CHEMBL1310964 & 688673 & 4.9 & 5.7459 & TRN & \\
\hline CHEMBL1449209 & 688673 & 5.2 & 5.6381 & TRN & \\
\hline CHEMBL1414655 & 688673 & 5.4 & 5.2547 & TRN & \\
\hline CHEMBL1399507 & 688673 & 4.95 & 5.4294 & TRN & \\
\hline CHEMBL589507 & 688673 & 4.55 & 5.5078 & TRN & \\
\hline CHEMBL1504992 & 688673 & 4.6 & 5.7467 & TRN & \\
\hline CHEMBL1429739 & 688673 & 4.45 & 5.5546 & TRN & \\
\hline CHEMBL1611920 & 688673 & 4.6 & 5.7698 & TRN & \\
\hline CHEMBL1359086 & 688673 & 7.6003 & 6.0382 & TRN & \\
\hline CHEMBL1492905 & 688673 & 7.4001 & 5.6893 & TRN & \\
\hline CHEMBL1440461 & 688673 & 4.6 & 5.7684 & TRN & \\
\hline CHEMBL1601462 & 688673 & 5.4 & 6.1501 & TRN & \\
\hline CHEMBL1550542 & 688673 & 4.5 & 5.8347 & TRN & \\
\hline CHEMBL1504868 & 688673 & 4.45 & 5.8513 & TRN & \\
\hline CHEMBL1488367 & 688673 & 6.4 & 5.9365 & TRN & \\
\hline CHEMBL1424761 & 688673 & 5.7 & 5.7939 & TRN & \\
\hline CHEMBL1478495 & 688673 & 8.301 & 5.9964 & TRN & \\
\hline
\end{tabular}




\begin{tabular}{|c|c|c|c|c|c|}
\hline \multicolumn{6}{|c|}{ Supplemental Table S2.txt } \\
\hline CHEMBL1349376 & 688673 & 5.1 & 5.8591 & TRN & \\
\hline CHEMBL3184468 & 688673 & 4.9 & 5.746 & TST & \\
\hline CHEMBL1335500 & 688673 & 6.9 & 5.7043 & TRN & \\
\hline CHEMBL1577123 & 688673 & 5.3 & 5.8387 & TRN & \\
\hline CHEMBL1486318 & 688673 & 4.5 & 5.7497 & TRN & \\
\hline CHEMBL1388993 & 688673 & 7.6498 & 5.939 & TRN & \\
\hline CHEMBL1458130 & 688673 & 4.6 & 5.5893 & TRN & \\
\hline CHEMBL1542286 & 688673 & 4.9 & 5.801 & TRN & \\
\hline CHEMBL1370986 & 688673 & 5.5 & 5.4583 & TRN & \\
\hline CHEMBL1524640 & 688673 & 7.699 & 5.9111 & TRN & \\
\hline CHEMBL1585813 & 688673 & 4.5 & 5.6758 & TRN & \\
\hline CHEMBL1432425 & 688673 & 5.2 & 6.0562 & TRN & \\
\hline CHEMBL1439130 & 688673 & 6.3 & 5.9758 & TRN & \\
\hline CHEMBL1278182 & 688673 & 4.9 & 5.4661 & TRN & \\
\hline CHEMBL1534309 & 688673 & 4.5 & 5.5514 & TRN & \\
\hline CHEMBL3211594 & 688673 & 7.8013 & 5.8357 & TST & \\
\hline CHEMBL1576245 & 688673 & 4.65 & 5.7894 & TRN & \\
\hline CHEMBL1570680 & 688673 & 4.7 & 5.6106 & TRN & \\
\hline CHEMBL3197121 & 688673 & 7.0 & 5.6589 & TRN & \\
\hline CHEMBL1377282 & 688673 & 4.7 & 5.6037 & TST & \\
\hline CHEMBL1536363 & 688673 & 4.8 & 5.3613 & TRN & \\
\hline CHEMBL1463488 & 688673 & 6.3 & 5.55399 & 9999999999 & TRN \\
\hline CHEMBL1497075 & 688673 & 8.301 & 5.7893 & TRN & \\
\hline CHEMBL1555638 & 688673 & 6.0 & 5.8278 & TRN & \\
\hline CHEMBL1544613 & 688673 & 5.05 & 6.11600 & 00000000005 & TRN \\
\hline CHEMBL1606401 & 688673 & 4.9 & 5.2804 & TRN & \\
\hline CHEMBL1307319 & 688673 & 4.6 & 5.6704 & TST & \\
\hline CHEMBL1600625 & 688673 & 6.1 & 5.7877 & TRN & \\
\hline CHEMBL1572780 & 688673 & 5.2 & 5.7479 & TRN & \\
\hline CHEMBL1299855 & 688673 & 7.8013 & 5.642 & TST & \\
\hline CHEMBL1385798 & 688673 & 6.1 & 5.7269 & TRN & \\
\hline CHEMBL1383004 & 688673 & 4.9 & 5.6835 & TRN & \\
\hline CHEMBL1578303 & 688673 & 4.6 & 5.4138 & TRN & \\
\hline CHEMBL1347130 & 688673 & 4.7 & 5.41299 & 9999999999 & TRN \\
\hline CHEMBL1325700 & 688673 & 4.8 & 5.6239 & TST & \\
\hline CHEMBL592001 & 688673 & 4.9 & 5.5186 & TST & \\
\hline CHEMBL1464282 & 688673 & 5.3 & 5.86600 & 00000000005 & TST \\
\hline CHEMBL1347780 & 688673 & 6.7001 & 5.8751 & TRN & \\
\hline CHEMBL3397111 & 688673 & 5.2 & 5.7454 & TST & \\
\hline CHEMBL1356728 & 688673 & 6.3 & 5.675 & TRN & \\
\hline CHEMBL1549631 & 688673 & 4.5 & 5.8947 & TRN & \\
\hline CHEMBL1347958 & 688673 & 6.05 & 5.6957 & TRN & \\
\hline CHEMBL1311205 & 688673 & 5.5 & 5.8835 & TST & \\
\hline CHEMBL1384482 & 688673 & 6.9 & 5.9034 & TST & \\
\hline CHEMBL1581313 & 688673 & 5.5 & 5.5143 & TST & \\
\hline CHEMBL1310587 & 688673 & 4.7 & 6.0049 & TRN & \\
\hline CHEMBL1464267 & 688673 & 4.9 & 5.7514 & TRN & \\
\hline CHEMBL1436278 & 688673 & 4.6 & 5.7056 & TRN & \\
\hline
\end{tabular}




\begin{tabular}{|c|c|c|c|c|c|}
\hline & & \multicolumn{4}{|c|}{ Supplemental Table S2.txt } \\
\hline CHEMBL1484696 & 688673 & 7.8996 & 5.546 & TRN & \\
\hline CHEMBL1521385 & 688673 & 6.1 & 5.9447 & TRN & \\
\hline CHEMBL1331159 & 688673 & 7.8996 & 5.8145 & TRN & \\
\hline CHEMBL1499281 & 688673 & 6.9 & 5.7974 & TST & \\
\hline CHEMBL1391862 & 688673 & 6.5 & 5.5304 & TRN & \\
\hline CHEMBL1510509 & 688673 & 4.8 & 5.6237 & TRN & \\
\hline CHEMBL1376733 & 688673 & 5.7 & 5.7038 & TST & \\
\hline CHEMBL1331311 & 688673 & 4.9 & 5.5865 & TRN & \\
\hline CHEMBL1508468 & 688673 & 6.9 & 5.9251 & TRN & \\
\hline CHEMBL1457449 & 688673 & 4.5 & 5.5159 & TRN & \\
\hline CHEMBL1427380 & 688673 & 6.3 & 5.7124 & TRN & \\
\hline CHEMBL1504257 & 688673 & 4.45 & 6.0725 & TRN & \\
\hline CHEMBL81082 & 688673 & 5.3 & 5.8189 & TST & \\
\hline CHEMBL1365455 & 688673 & 8.7959 & 5.8438 & TST & \\
\hline CHEMBL1440652 & 688673 & 5.5 & 5.6882 & TRN & \\
\hline CHEMBL1497609 & 688673 & 6.9 & 5.8527 & TRN & \\
\hline CHEMBL1575027 & 688673 & 4.45 & 5.7648 & TRN & \\
\hline CHEMBL1311621 & 688673 & 6.5 & 5.9749 & TST & \\
\hline CHEMBL1376006 & 688673 & 6.2 & 5.3729 & TRN & \\
\hline CHEMBL1450036 & 688673 & 6.1 & 5.5729 & TRN & \\
\hline CHEMBL1458502 & 688673 & 4.5 & 5.9018 & TRN & \\
\hline CHEMBL1380485 & 688673 & 6.6499 & 5.8188 & TRN & \\
\hline CHEMBL1550012 & 688673 & 6.1 & 5.8269 & TRN & \\
\hline CHEMBL1599784 & 688673 & 6.1 & 5.7134 & TRN & \\
\hline CHEMBL1458940 & 688673 & 4.9 & 6.0378 & TRN & \\
\hline CHEMBL1460496 & 688673 & 5.9 & 5.8183 & TST & \\
\hline CHEMBL1605380 & 688673 & 6.4 & 6.0539 & TRN & \\
\hline CHEMBL1414552 & 688673 & 6.6 & 5.8525 & TRN & \\
\hline CHEMBL1505300 & 688673 & 4.5 & 5.3851 & TRN & \\
\hline CHEMBL1424953 & 688673 & 8.3979 & 5.3517 & TRN & \\
\hline CHEMBL1367765 & 688673 & 4.6 & 5.50799 & 9999999999 & TRN \\
\hline CHEMBL1479135 & 688673 & 4.45 & 5.9043 & TRN & \\
\hline CHEMBL1461424 & 688673 & 4.9 & 5.7763 & TRN & \\
\hline CHEMBL1449858 & 688673 & 8.301 & 5.7769 & TRN & \\
\hline CHEMBL1377652 & 688673 & 4.6 & 6.1035 & TRN & \\
\hline CHEMBL1336927 & 688673 & 4.7 & 5.4218 & TRN & \\
\hline CHEMBL1417322 & 688673 & 6.5 & 5.9871 & TRN & \\
\hline CHEMBL1406018 & 688673 & 5.7 & 5.76399 & 9999999999 & TRN \\
\hline CHEMBL1379419 & 688673 & 8.2007 & 5.65600 & 0000000001 & TRN \\
\hline CHEMBL1452198 & 688673 & 6.0 & 6.1144 & TRN & \\
\hline CHEMBL1986591 & 688673 & 4.5 & 5.5337 & TRN & \\
\hline CHEMBL1404336 & 688673 & 7.5003 & 5.8036 & TRN & \\
\hline CHEMBL3191474 & 688673 & 4.7 & 5.4797 & TRN & \\
\hline CHEMBL3189971 & 688673 & 4.9 & 5.3673 & TST & \\
\hline CHEMBL1477984 & 688673 & 5.6 & 5.6426 & TST & \\
\hline CHEMBL1381318 & 688673 & 4.9 & 5.3782 & TRN & \\
\hline CHEMBL1539484 & 688673 & 6.0 & 5.8623 & TRN & \\
\hline CHEMBL1352368 & 688673 & 6.8 & 5.8096 & TRN & \\
\hline
\end{tabular}




\begin{tabular}{|c|c|c|c|c|c|}
\hline & & \multicolumn{4}{|c|}{ Supplemental Table S2.txt } \\
\hline CHEMBL1557364 & 688673 & 7.1002 & 5.4129 & TRN & \\
\hline CHEMBL 2373588 & 688673 & 7.2 & 5.9801 & TRN & \\
\hline CHEMBL1375485 & 688673 & 6.1 & 5.5429 & TRN & \\
\hline CHEMBL1413699 & 688673 & 6.8 & 6.1272 & TRN & \\
\hline CHEMBL175266 & 688673 & 4.9 & 5.3963 & TRN & \\
\hline CHEMBL1507984 & 688673 & 6.7001 & 6.0136 & TRN & \\
\hline CHEMBL1553721 & 688673 & 4.8 & 5.3071 & TRN & \\
\hline CHEMBL1587642 & 688673 & 5.2 & 6.1052 & TST & \\
\hline CHEMBL1347102 & 688673 & 5.5 & 5.8782 & TRN & \\
\hline CHEMBL1324446 & 688673 & 7.6003 & 5.5486 & TRN & \\
\hline CHEMBL1320298 & 688673 & 6.3 & 6.0548 & TRN & \\
\hline CHEMBL1604588 & 688673 & 4.5 & 5.6445 & TRN & \\
\hline CHEMBL1559829 & 688673 & 5.0 & 5.4207 & TRN & \\
\hline CHEMBL1419718 & 688673 & 5.2 & 5.5508 & TRN & \\
\hline CHEMBL3207687 & 688673 & 5.0 & 5.7923 & TRN & \\
\hline CHEMBL1487939 & 688673 & 4.5 & 5.8181 & TRN & \\
\hline CHEMBL1409639 & 688673 & 5.4 & 5.7484 & TRN & \\
\hline CHEMBL1420954 & 688673 & 6.2 & 5.7704 & TRN & \\
\hline CHEMBL1975975 & 688673 & 5.1 & 5.5088 & TRN & \\
\hline CHEMBL1556856 & 688673 & 5.4 & 5.7754 & TRN & \\
\hline CHEMBL1516105 & 688673 & 4.5 & 5.5285 & TRN & \\
\hline CHEMBL1582833 & 688673 & 4.8 & 5.5487 & TRN & \\
\hline CHEMBL1377444 & 688673 & 7.8013 & 6.03600 & 00000000005 & TRN \\
\hline CHEMBL1414852 & 688673 & 8.301 & 5.777 & TRN & \\
\hline CHEMBL1588383 & 688673 & 8.0 & 5.85 & TRN & \\
\hline CHEMBL1562539 & 688673 & 4.9 & 5.5186 & TRN & \\
\hline CHEMBL1533777 & 688673 & 7.5003 & 5.5434 & TRN & \\
\hline CHEMBL1545286 & 688673 & 6.6 & 6.0099 & TRN & \\
\hline CHEMBL1465164 & 688673 & 6.3 & 5.3614 & TRN & \\
\hline CHEMBL 3208625 & 688673 & 5.4 & 5.8679 & TST & \\
\hline CHEMBL1333492 & 688673 & 7.6003 & 5.8124 & TRN & \\
\hline CHEMBL1606506 & 688673 & 5.8 & 6.0209 & TRN & \\
\hline CHEMBL1587639 & 688673 & 4.5 & 5.8016 & TRN & \\
\hline CHEMBL1533127 & 688673 & 5.9 & 5.9695 & TRN & \\
\hline CHEMBL1598791 & 688673 & 4.7 & 5.5843 & TST & \\
\hline CHEMBL1348666 & 688673 & 7.1002 & 5.8426 & TRN & \\
\hline CHEMBL1541382 & 688673 & 7.6003 & 5.7605 & TRN & \\
\hline CHEMBL1497376 & 688673 & 5.3 & 5.9452 & TST & \\
\hline CHEMBL1304227 & 688673 & 4.65 & 5.5321 & TRN & \\
\hline CHEMBL1498023 & 688673 & 4.85 & 5.9243 & TRN & \\
\hline CHEMBL1390086 & 688673 & 7.4001 & 5.9123 & TRN & \\
\hline CHEMBL1314719 & 688673 & 4.45 & 5.6263 & TRN & \\
\hline CHEMBL1546884 & 688673 & 4.6 & 5.6676 & TRN & \\
\hline CHEMBL1442858 & 688673 & 4.9 & 5.8215 & TRN & \\
\hline CHEMBL1589173 & 688673 & 5.2 & 5.8015 & TRN & \\
\hline CHEMBL1404881 & 688673 & 7.2 & 5.7827 & TRN & \\
\hline CHEMBL1404472 & 688673 & 4.6 & 5.5517 & TRN & \\
\hline CHEMBL1410045 & 688673 & 5.7 & 5.5456 & TST & \\
\hline
\end{tabular}




\begin{tabular}{|c|c|c|c|c|c|}
\hline \multicolumn{6}{|c|}{ Supplemental Table S2.txt } \\
\hline CHEMBL1465291 & 688673 & 5.2 & 5.7699 & TRN & \\
\hline CHEMBL1603383 & 688673 & 5.4 & 6.0622 & TRN & \\
\hline CHEMBL1158 & 688673 & 4.5 & 5.7447 & TST & \\
\hline CHEMBL1607893 & 688673 & 5.3 & 5.8289 & TRN & \\
\hline CHEMBL1432680 & 688673 & 7.3002 & 5.6532 & TRN & \\
\hline CHEMBL1444514 & 688673 & 5.7 & 5.6509 & TRN & \\
\hline CHEMBL1427954 & 688673 & 4.45 & 6.0065 & TRN & \\
\hline CHEMBL1508936 & 688673 & 6.4 & 5.7504 & TRN & \\
\hline CHEMBL1302829 & 688673 & 8.3979 & 5.8375 & TRN & \\
\hline CHEMBL1465767 & 688673 & 7.6003 & 5.8983 & TRN & \\
\hline CHEMBL1424340 & 688673 & 4.6 & 5.70799 & 9999999999 & TRN \\
\hline CHEMBL1548203 & 688673 & 5.3 & 5.5742 & TRN & \\
\hline CHEMBL1442529 & 688673 & 7.5003 & 5.7657 & TRN & \\
\hline CHEMBL1361207 & 688673 & 6.6 & 5.6267 & TRN & \\
\hline CHEMBL1401833 & 688673 & 4.45 & 6.1016 & TRN & \\
\hline CHEMBL1361419 & 688673 & 5.3 & 5.9627 & TRN & \\
\hline CHEMBL1304242 & 688673 & 4.95 & 5.90600 & 0000000001 & TRN \\
\hline CHEMBL1384687 & 688673 & 5.5 & 5.7643 & TRN & \\
\hline CHEMBL1585415 & 688673 & 5.3 & 5.6766 & TRN & \\
\hline CHEMBL1366846 & 688673 & 7.3002 & 5.6547 & TST & \\
\hline CHEMBL1427564 & 688673 & 5.6 & 5.6167 & TRN & \\
\hline CHEMBL1575702 & 688673 & 5.0 & 5.8634 & TRN & \\
\hline CHEMBL3209467 & 688673 & 6.7001 & 5.5465 & TRN & \\
\hline CHEMBL1587559 & 688673 & 7.8013 & 6.1357 & TRN & \\
\hline CHEMBL1571579 & 688673 & 6.8 & 5.7039 & TRN & \\
\hline CHEMBL1595094 & 688673 & 7.2 & 5.79799 & 9999999999 & TRN \\
\hline CHEMBL1346612 & 688673 & 5.25 & 5.6826 & TST & \\
\hline CHEMBL1599847 & 688673 & 4.8 & 5.8059 & TRN & \\
\hline CHEMBL1457743 & 688673 & 5.2 & 5.8168 & TRN & \\
\hline CHEMBL1382231 & 688673 & 4.45 & 5.7401 & TRN & \\
\hline CHEMBL1563677 & 688673 & 7.0 & 5.706 & TRN & \\
\hline CHEMBL1323269 & 688673 & 8.3979 & 5.6015 & TST & \\
\hline CHEMBL1381461 & 688673 & 7.3002 & 5.8008 & TRN & \\
\hline CHEMBL1606120 & 688673 & 8.301 & 5.3519 & TRN & \\
\hline CHEMBL1449353 & 688673 & 4.6 & 5.6999 & TRN & \\
\hline CHEMBL1362585 & 688673 & 5.7 & 5.8446 & TRN & \\
\hline CHEMBL1399076 & 688673 & 7.8996 & 6.0379 & TRN & \\
\hline CHEMBL1341298 & 688673 & 4.6 & 5.5157 & TRN & \\
\hline CHEMBL1455993 & 688673 & 4.45 & 5.3907 & TRN & \\
\hline CHEMBL 3212793 & 688673 & 6.0 & 5.8392 & TRN & \\
\hline CHEMBL1510854 & 688673 & 4.5 & 6.0371 & TRN & \\
\hline CHEMBL1344470 & 688673 & 4.85 & 5.398 & TST & \\
\hline CHEMBL1448914 & 688673 & 8.301 & 5.4897 & TRN & \\
\hline CHEMBL1344132 & 688673 & 5.4 & 5.9067 & TRN & \\
\hline CHEMBL1406816 & 688673 & 6.0 & 5.3138 & TRN & \\
\hline CHEMBL1334465 & 688673 & 4.5 & 5.6723 & TRN & \\
\hline CHEMBL1570127 & 688673 & 4.8 & 5.1803 & TRN & \\
\hline CHEMBL1304073 & 688673 & 4.9 & 5.5696 & TRN & \\
\hline
\end{tabular}




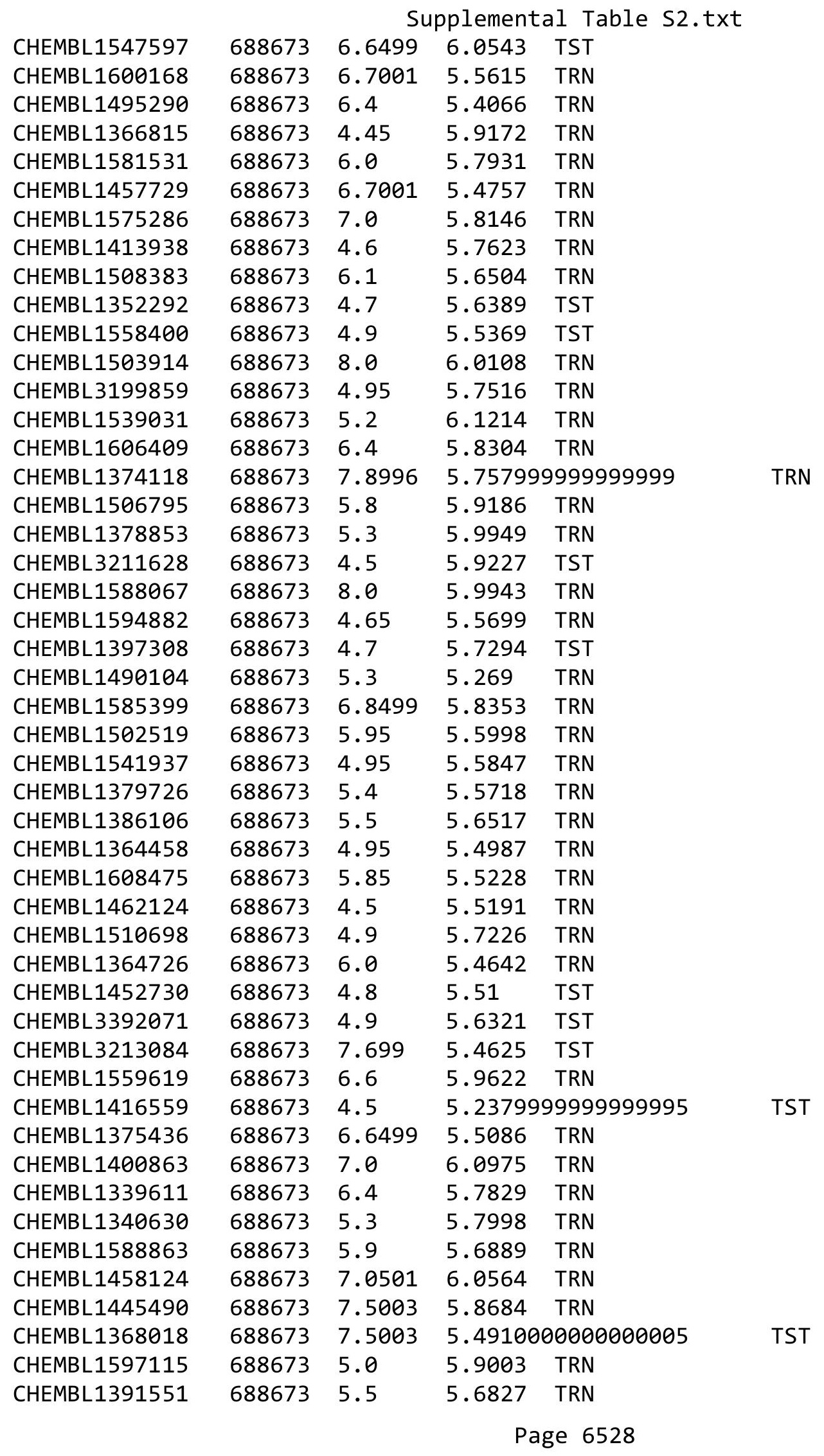




\begin{tabular}{|c|c|c|c|c|c|}
\hline \multicolumn{6}{|c|}{ Supplemental Table s2.txt } \\
\hline CHEMBL1477811 & 688673 & 4.45 & 6.2757 & TRN & \\
\hline CHEMBL1407094 & 688673 & 5.4 & 5.5792 & TRN & \\
\hline CHEMBL1318574 & 688673 & 4.9 & 5.3215 & TST & \\
\hline CHEMBL1489707 & 688673 & 4.5 & 5.6741 & TRN & \\
\hline CHEMBL1517746 & 688673 & 5.1 & 5.9032 & TRN & \\
\hline CHEMBL1328335 & 688673 & 6.1 & 5.853 & TST & \\
\hline CHEMBL1460763 & 688673 & 6.7001 & 5.8107 & TRN & \\
\hline CHEMBL1497679 & 688673 & 6.6 & 5.6684 & TRN & \\
\hline CHEMBL1451452 & 688673 & 6.6499 & 5.6924 & TRN & \\
\hline CHEMBL1416597 & 688673 & 8.0 & 5.8649 & TST & \\
\hline CHEMBL1521675 & 688673 & 5.35 & 5.3596 & TRN & \\
\hline CHEMBL1310927 & 688673 & 6.4 & 5.4864 & TRN & \\
\hline CHEMBL1340279 & 688673 & 7.8996 & 5.5769 & TST & \\
\hline CHEMBL1426347 & 688673 & 4.5 & 5.6983 & TRN & \\
\hline CHEMBL1558431 & 688673 & 4.5 & 5.4553 & TRN & \\
\hline CHEMBL1388190 & 688673 & 4.5 & 5.7624 & TRN & \\
\hline CHEMBL1550418 & 688673 & 4.45 & 6.1819 & TRN & \\
\hline CHEMBL1565486 & 688673 & 8.4949 & 5.7422 & TRN & \\
\hline CHEMBL1345411 & 688673 & 4.45 & 5.4882 & TRN & \\
\hline CHEMBL1337053 & 688673 & 5.3 & 5.7675 & TRN & \\
\hline CHEMBL1417038 & 688673 & 7.699 & 5.9791 & TRN & \\
\hline CHEMBL3194401 & 688673 & 6.5 & 5.7897 & TST & \\
\hline CHEMBL1574722 & 688673 & 7.0 & 5.6774 & TRN & \\
\hline CHEMBL1426682 & 688673 & 4.9 & 6.0977 & TRN & \\
\hline CHEMBL1438931 & 688673 & 5.75 & 5.5611 & TRN & \\
\hline CHEMBL1563635 & 688673 & 4.5 & 5.6071 & TRN & \\
\hline CHEMBL1607533 & 688673 & 7.6003 & 6.0306 & TST & \\
\hline CHEMBL1421906 & 688673 & 6.2 & 5.9207 & TRN & \\
\hline CHEMBL1568641 & 688673 & 5.9 & 5.3698 & TRN & \\
\hline CHEMBL1366056 & 688673 & 4.5 & 6.2584 & TRN & \\
\hline CHEMBL1441355 & 688673 & 4.5 & 5.5442 & TST & \\
\hline CHEMBL1318054 & 688673 & 4.95 & 5.62700 & 0000000001 & TRN \\
\hline CHEMBL1585809 & 688673 & 6.2 & 5.7915 & TRN & \\
\hline CHEMBL1533910 & 688673 & 4.5 & 5.8278 & TRN & \\
\hline CHEMBL1569682 & 688673 & 7.8013 & 5.8682 & TRN & \\
\hline CHEMBL1515305 & 688673 & 5.9 & 5.5854 & TST & \\
\hline CHEMBL1381495 & 688673 & 6.4 & 5.7245 & TST & \\
\hline CHEMBL1431483 & 688673 & 4.8 & 5.6305 & TRN & \\
\hline CHEMBL1403027 & 688673 & 4.45 & 5.7719 & TRN & \\
\hline CHEMBL1537860 & 688673 & 4.7 & 5.79700 & 0000000001 & TRN \\
\hline CHEMBL1323750 & 688673 & 7.6003 & 6.08200 & 0000000001 & TRN \\
\hline CHEMBL1450888 & 688673 & 4.8 & 5.5536 & TRN & \\
\hline CHEMBL1565052 & 688673 & 5.25 & 6.0228 & TRN & \\
\hline CHEMBL1529399 & 688673 & 5.4 & 5.7278 & TRN & \\
\hline CHEMBL1312846 & 688673 & 5.5 & 5.8549 & TRN & \\
\hline CHEMBL1571456 & 688673 & 4.75 & 5.4412 & TRN & \\
\hline CHEMBL1315066 & 688673 & 6.45 & 5.2841 & TRN & \\
\hline CHEMBL1369930 & 688673 & 8.3468 & 5.8517 & TRN & \\
\hline
\end{tabular}




\begin{tabular}{|c|c|c|c|c|c|}
\hline \multicolumn{6}{|c|}{ Supplemental Table S2.txt } \\
\hline CHEMBL1428717 & 688673 & 5.4 & 5.7529 & TRN & \\
\hline CHEMBL1576782 & 688673 & 5.3 & 5.9018 & TRN & \\
\hline CHEMBL1393118 & 688673 & 5.9 & 5.5854 & TST & \\
\hline CHEMBL1517796 & 688673 & 4.5 & 5.8579 & TRN & \\
\hline CHEMBL1510623 & 688673 & 4.5 & 5.5242 & TRN & \\
\hline CHEMBL1437976 & 688673 & 4.75 & 5.5171 & TST & \\
\hline CHEMBL1459175 & 688673 & 5.5 & 6.0016 & TRN & \\
\hline CHEMBL1580928 & 688673 & 5.2 & 6.0967 & TRN & \\
\hline CHEMBL1565907 & 688673 & 5.2 & 5.8556 & TRN & \\
\hline CHEMBL1409194 & 688673 & 8.3979 & 5.7182 & TRN & \\
\hline CHEMBL1369045 & 688673 & 5.3 & 5.6073 & TRN & \\
\hline CHEMBL 225513 & 688673 & 4.6 & 5.2288 & TST & \\
\hline CHEMBL1563349 & 688673 & 7.8013 & 5.6173 & TRN & \\
\hline CHEMBL1464093 & 688673 & 4.5 & 5.4742 & TRN & \\
\hline CHEMBL1488462 & 688673 & 8.301 & 5.7846 & TRN & \\
\hline CHEMBL1609664 & 688673 & 5.95 & 5.9791 & TRN & \\
\hline CHEMBL1503284 & 688673 & 5.3 & 6.0345 & TRN & \\
\hline CHEMBL1379517 & 688673 & 6.8 & 6.126 & TRN & \\
\hline CHEMBL1546947 & 688673 & 4.6 & 5.3701 & TRN & \\
\hline CHEMBL1509659 & 688673 & 4.5 & 5.3252 & TST & \\
\hline CHEMBL1539297 & 688673 & 4.9 & 5.4313 & TRN & \\
\hline CHEMBL1308190 & 688673 & 7.3002 & 6.1303 & TRN & \\
\hline CHEMBL1352214 & 688673 & 5.4 & 5.7473 & TRN & \\
\hline CHEMBL3210922 & 688673 & 6.0 & 5.5663 & TST & \\
\hline CHEMBL1611128 & 688673 & 6.95 & 5.6823 & TRN & \\
\hline CHEMBL1559537 & 688673 & 4.7 & 5.7081 & TRN & \\
\hline CHEMBL1557901 & 688673 & 6.5 & 5.5154 & TRN & \\
\hline CHEMBL1518113 & 688673 & 8.4949 & 6.1594 & TRN & \\
\hline CHEMBL1505639 & 688673 & 8.3979 & 5.9761 & TRN & \\
\hline CHEMBL3191780 & 688673 & 4.9 & 5.3115 & TST & \\
\hline CHEMBL407501 & 688673 & 6.3 & 5.96399 & 99999999995 & TRN \\
\hline CHEMBL1368926 & 688673 & 8.4949 & 5.9916 & TRN & \\
\hline CHEMBL1606229 & 688673 & 5.2 & 5.9839 & TRN & \\
\hline CHEMBL1405571 & 688673 & 5.3 & 5.3182 & TRN & \\
\hline CHEMBL365809 & 688673 & 8.0 & 5.916 & TST & \\
\hline CHEMBL1404747 & 688673 & 4.5 & 5.6139 & TRN & \\
\hline CHEMBL1473745 & 688673 & 7.4498 & 5.5884 & TRN & \\
\hline CHEMBL1346299 & 688673 & 5.5 & 5.909 & TRN & \\
\hline CHEMBL1335907 & 688673 & 7.699 & 5.4388 & TRN & \\
\hline CHEMBL3214109 & 688673 & 5.8 & 5.6189 & TRN & \\
\hline CHEMBL1552649 & 688673 & 5.45 & 5.8436 & TRN & \\
\hline CHEMBL1570517 & 688673 & 4.9 & 6.0232 & TST & \\
\hline CHEMBL1545698 & 688673 & 4.7 & 5.6558 & TRN & \\
\hline CHEMBL1338647 & 688673 & 6.7001 & 5.5058 & TRN & \\
\hline CHEMBL1407888 & 688673 & 4.6 & 5.5716 & TRN & \\
\hline CHEMBL1444310 & 688673 & 6.1 & 5.7654 & TRN & \\
\hline CHEMBL1334743 & 688673 & 4.45 & 5.5491 & TRN & \\
\hline CHEMBL1341677 & 688673 & 7.2 & 5.5447 & TRN & \\
\hline
\end{tabular}




\begin{tabular}{|c|c|c|c|c|c|}
\hline \multicolumn{6}{|c|}{ Supplemental Table S2.txt } \\
\hline CHEMBL588038 & 688673 & 4.9 & 5.3079 & TST & \\
\hline CHEMBL1487856 & 688673 & 7.5003 & 6.1454 & TRN & \\
\hline CHEMBL1579001 & 688673 & 5.95 & 5.8459 & TRN & \\
\hline CHEMBL1541028 & 688673 & 8.1024 & 5.8553 & TRN & \\
\hline CHEMBL1420514 & 688673 & 7.0 & 5.795 & TRN & \\
\hline CHEMBL1447164 & 688673 & 4.5 & 5.62200 & 0000000001 & TRN \\
\hline CHEMBL1536154 & 688673 & 5.35 & 5.9462 & TRN & \\
\hline CHEMBL1356452 & 688673 & 4.45 & 5.7526 & TRN & \\
\hline CHEMBL1530172 & 688673 & 5.6 & 5.5128 & TRN & \\
\hline CHEMBL1422620 & 688673 & 5.3 & 5.5645 & TRN & \\
\hline CHEMBL1302867 & 688673 & 6.7001 & 5.7251 & TST & \\
\hline CHEMBL1402900 & 688673 & 4.85 & 5.777 & TST & \\
\hline CHEMBL1465522 & 688673 & 5.45 & 5.4299 & TST & \\
\hline CHEMBL1376057 & 688673 & 5.8 & 5.7058 & TRN & \\
\hline CHEMBL1532708 & 688673 & 5.6 & 5.8553 & TRN & \\
\hline CHEMBL1521970 & 688673 & 5.6 & 5.9089 & TRN & \\
\hline CHEMBL1558023 & 688673 & 5.4 & 5.8342 & TRN & \\
\hline CHEMBL1416028 & 688673 & 6.0 & 5.8162 & TRN & \\
\hline CHEMBL1489045 & 688673 & 6.0 & 5.269 & TRN & \\
\hline CHEMBL1318873 & 688673 & 5.2 & 5.6625 & TRN & \\
\hline CHEMBL1500006 & 688673 & 7.699 & 5.7983 & TRN & \\
\hline CHEMBL1588457 & 688673 & 5.5 & 5.6405 & TRN & \\
\hline CHEMBL1338898 & 688673 & 4.5 & 6.1386 & TRN & \\
\hline CHEMBL1346932 & 688673 & 5.3 & 5.7289 & TRN & \\
\hline CHEMBL1378288 & 688673 & 4.5 & 5.5039 & TRN & \\
\hline CHEMBL1546827 & 688673 & 4.45 & 5.6032 & TST & \\
\hline CHEMBL1585190 & 688673 & 7.6003 & 5.6726 & TRN & \\
\hline CHEMBL1306528 & 688673 & 7.8013 & 5.7944 & TRN & \\
\hline CHEMBL1533483 & 688673 & 8.4949 & 5.5673 & TRN & \\
\hline CHEMBL1429345 & 688673 & 5.55 & 5.9049 & TRN & \\
\hline CHEMBL1466576 & 688673 & 5.6 & 5.8974 & TRN & \\
\hline CHEMBL1418329 & 688673 & 5.2 & 6.1094 & TRN & \\
\hline CHEMBL1327422 & 688673 & 5.35 & 5.7463 & TRN & \\
\hline CHEMBL1520732 & 688673 & 7.5003 & 5.8225 & TRN & \\
\hline CHEMBL1594705 & 688673 & 4.95 & 5.6685 & TRN & \\
\hline CHEMBL88147 & 688673 & 4.5 & 5.4989 & TRN & \\
\hline CHEMBL1365692 & 688673 & 7.2 & 5.4394 & TRN & \\
\hline CHEMBL1463091 & 688673 & 7.699 & 5.7954 & TRN & \\
\hline CHEMBL1335460 & 688673 & 7.8996 & 6.0581 & TRN & \\
\hline CHEMBL1449973 & 688673 & 7.5003 & 5.9673 & TRN & \\
\hline CHEMBL1421587 & 688673 & 5.0 & 5.447 & TRN & \\
\hline CHEMBL1407407 & 688673 & 4.8 & 5.6553 & TST & \\
\hline CHEMBL1469855 & 688673 & 5.8 & 5.5191 & TRN & \\
\hline CHEMBL1564409 & 688673 & 4.45 & 5.7225 & TRN & \\
\hline CHEMBL1331853 & 688673 & 6.7001 & 5.6093 & TRN & \\
\hline CHEMBL1492324 & 688673 & 5.5 & 5.3762 & TRN & \\
\hline CHEMBL1511162 & 688673 & 6.7001 & 5.5471 & TRN & \\
\hline CHEMBL1351180 & 688673 & 4.9 & 5.5332 & TRN & \\
\hline
\end{tabular}




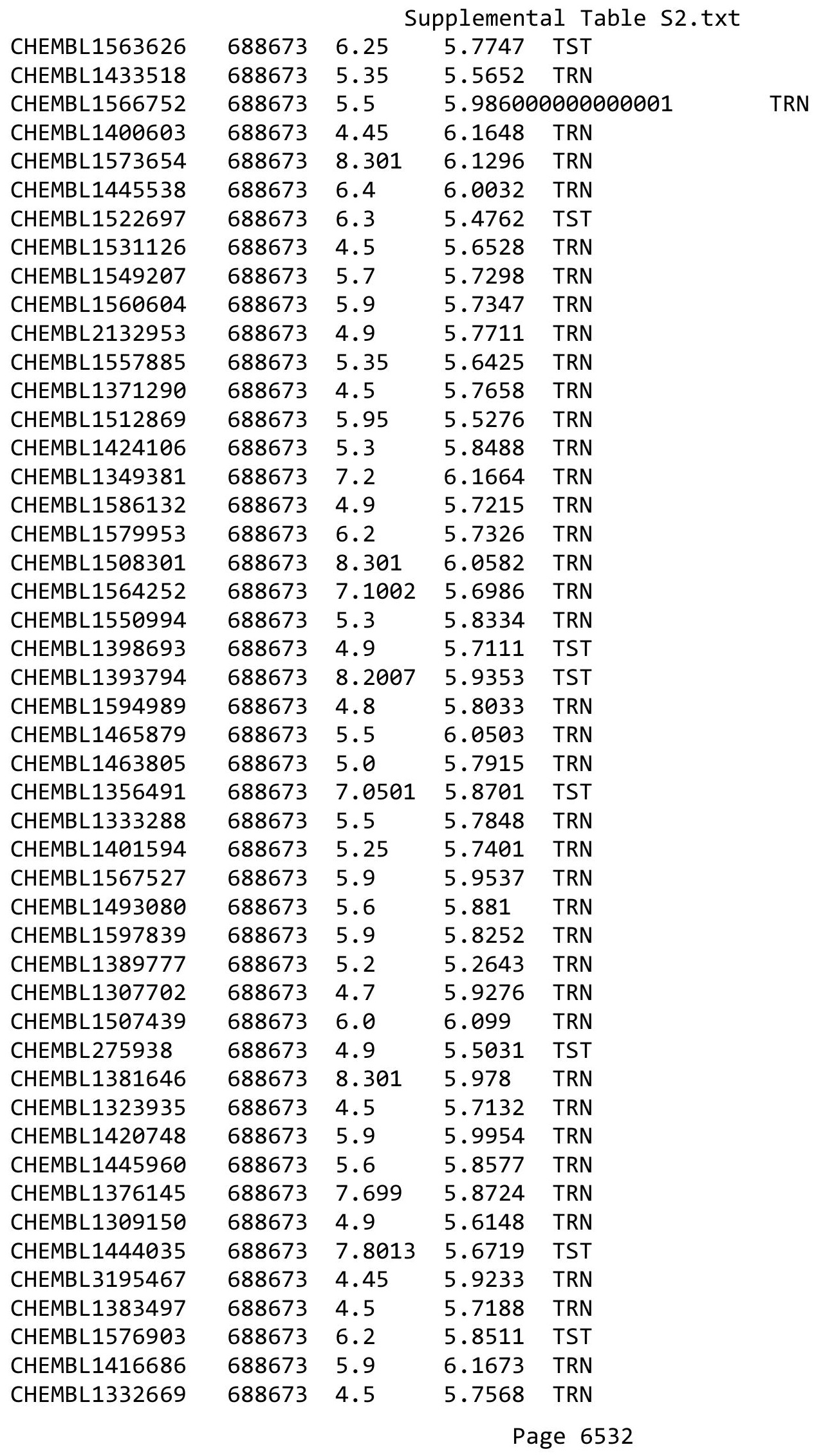




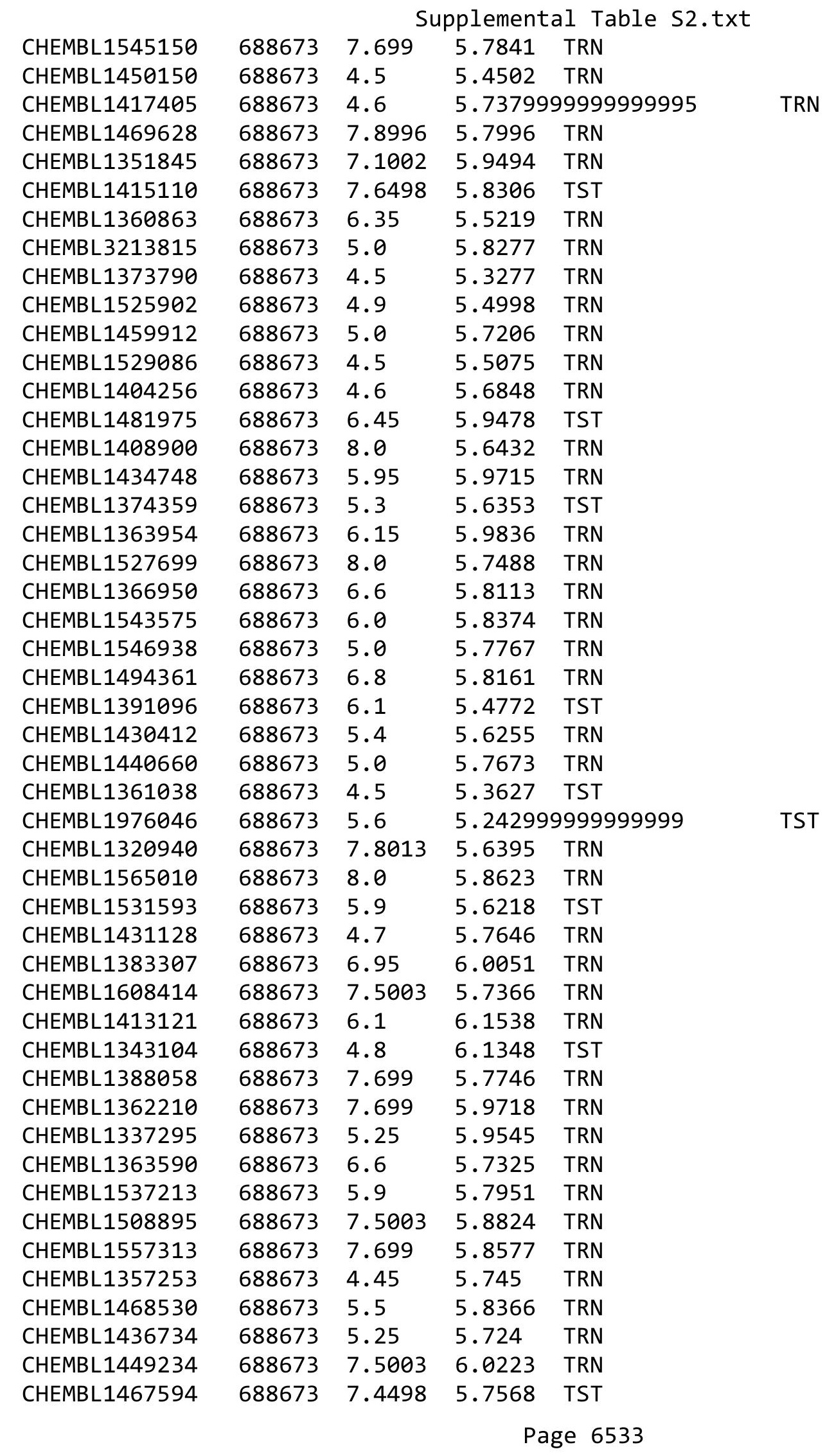




\begin{tabular}{|c|c|c|c|c|c|}
\hline CHEMBL1329230 & 688673 & 4.8 & \multicolumn{2}{|c|}{5.912000000000001} & TRN \\
\hline CHEMBL1468262 & 688673 & 4.9 & 5.6804 & TRN & \\
\hline CHEMBL1455784 & 688673 & 4.8 & 5.9722 & TRN & \\
\hline CHEMBL1427309 & 688673 & 4.5 & 5.5078 & TST & \\
\hline CHEMBL1359720 & 688673 & 7.8996 & 5.7376 & TRN & \\
\hline CHEMBL1360874 & 688673 & 6.2 & 5.8356 & TRN & \\
\hline CHEMBL1554789 & 688673 & 8.0 & 5.6433 & TRN & \\
\hline CHEMBL1337896 & 688673 & 5.9 & \multicolumn{2}{|c|}{5.7410000000000005} & TRN \\
\hline CHEMBL1493646 & 688673 & 4.45 & 5.4756 & TST & \\
\hline CHEMBL3212046 & 688673 & 6.5 & 5.5434 & TRN & \\
\hline CHEMBL1581459 & 688673 & 4.45 & 5.7931 & TRN & \\
\hline CHEMBL1573462 & 688673 & 6.0 & 5.9165 & TRN & \\
\hline CHEMBL1343936 & 688673 & 4.5 & 5.6528 & TRN & \\
\hline CHEMBL1459853 & 688673 & 6.0 & 5.5929 & TRN & \\
\hline CHEMBL1427251 & 688673 & 7.4001 & 5.6996 & TRN & \\
\hline CHEMBL1567680 & 688673 & 4.5 & 5.9557 & TST & \\
\hline CHEMBL 380071 & 688673 & 7.0 & 5.3561 & TRN & \\
\hline CHEMBL1313201 & 688673 & 5.25 & 6.1464 & TRN & \\
\hline CHEMBL1602170 & 688673 & 4.6 & 5.6376 & TRN & \\
\hline CHEMBL1528872 & 688673 & 8.3468 & 5.6711 & TRN & \\
\hline CHEMBL1380997 & 688673 & 6.3 & 6.1196 & TRN & \\
\hline CHEMBL1444644 & 688673 & 5.4 & 5.6831 & TRN & \\
\hline CHEMBL1521487 & 688673 & 6.1 & \multicolumn{2}{|c|}{5.7620000000000005} & TRN \\
\hline CHEMBL1594281 & 688673 & 7.3002 & 5.7461 & TRN & \\
\hline CHEMBL1499340 & 688673 & 6.6 & 5.6971 & TRN & \\
\hline CHEMBL1353299 & 688673 & 5.6 & 6.1494 & TRN & \\
\hline CHEMBL1532922 & 688673 & 7.6003 & 5.8234 & TST & \\
\hline CHEMBL1464821 & 688673 & 4.7 & 5.4595 & TRN & \\
\hline CHEMBL1324995 & 688673 & 4.6 & \multicolumn{2}{|c|}{5.327999999999999} & TRN \\
\hline CHEMBL1474259 & 688673 & 4.6 & 5.4231 & TRN & \\
\hline CHEMBL1427512 & 688673 & 5.65 & 5.9553 & TRN & \\
\hline CHEMBL1215100 & 688673 & 5.0 & 5.2893 & TRN & \\
\hline CHEMBL1374890 & 688673 & 6.7001 & 6.0562 & TRN & \\
\hline CHEMBL1476840 & 688673 & 5.0 & 5.4531 & TRN & \\
\hline CHEMBL1533990 & 688673 & 4.9 & 6.2515 & TRN & \\
\hline CHEMBL1438835 & 688673 & 7.8013 & 5.8207 & TRN & \\
\hline CHEMBL1987250 & 688673 & 5.5 & 5.7766 & TST & \\
\hline CHEMBL1474912 & 688673 & 5.95 & 5.9708 & TRN & \\
\hline CHEMBL1468023 & 688673 & 4.9 & 5.8737 & TRN & \\
\hline CHEMBL1342243 & 688673 & 4.75 & 5.6793 & TRN & \\
\hline CHEMBL1553909 & 688673 & 4.45 & 5.2979 & TRN & \\
\hline CHEMBL1350257 & 688673 & 6.0 & 5.8588 & TRN & \\
\hline CHEMBL1341770 & 688673 & 6.8 & 6.3358 & TRN & \\
\hline CHEMBL3208126 & 688673 & 5.5 & 5.6324 & TST & \\
\hline CHEMBL1577611 & 688673 & 6.3 & 5.9194 & TRN & \\
\hline CHEMBL1463387 & 688673 & 6.8 & 6.1701 & TRN & \\
\hline CHEMBL1548408 & 688673 & 4.55 & 5.3767 & TRN & \\
\hline CHEMBL1351062 & 688673 & 5.0 & 5.5493 & TRN & \\
\hline
\end{tabular}




\begin{tabular}{|c|c|c|c|c|c|}
\hline \\
\hline CHEMBL1381537 & 688673 & 4.5 & 5.7258 & TRN & \\
\hline CHEMBL1467831 & 688673 & 6.0 & 5.6987 & TRN & \\
\hline CHEMBL3211797 & 688673 & 5.3 & 5.7201 & TRN & \\
\hline CHEMBL1577389 & 688673 & 5.0 & 5.6731 & TRN & \\
\hline CHEMBL1531320 & 688673 & 5.3 & 5.4785 & TRN & \\
\hline CHEMBL1509135 & 688673 & 5.6 & 5.3029 & TRN & \\
\hline CHEMBL1553647 & 688673 & 6.5501 & 5.8721 & TRN & \\
\hline CHEMBL1359979 & 688673 & 4.8 & 5.6923 & TRN & \\
\hline CHEMBL1543481 & 688673 & 7.5003 & 5.70299 & 9999999999 & TRN \\
\hline CHEMBL3193388 & 688673 & 4.9 & 5.6406 & TRN & \\
\hline CHEMBL1598413 & 688673 & 4.6 & 5.4652 & TST & \\
\hline CHEMBL1397309 & 688673 & 5.35 & 5.8116 & TRN & \\
\hline CHEMBL1338490 & 688673 & 4.6 & 5.6284 & TRN & \\
\hline CHEMBL1544392 & 688673 & 6.5 & 5.7074 & TRN & \\
\hline CHEMBL1460332 & 688673 & 5.4 & 5.5272 & TST & \\
\hline CHEMBL1353116 & 688673 & 4.9 & 5.6932 & TRN & \\
\hline CHEMBL1356773 & 688673 & 7.6498 & 5.5997 & TRN & \\
\hline CHEMBL1513169 & 688673 & 5.25 & 5.4942 & TRN & \\
\hline CHEMBL1484219 & 688673 & 6.25 & 5.4009 & TRN & \\
\hline CHEMBL1326309 & 688673 & 5.6 & 5.692 & TRN & \\
\hline CHEMBL1257014 & 688673 & 8.3979 & 5.8314 & TRN & \\
\hline CHEMBL1523890 & 688673 & 4.45 & 5.7112 & TRN & \\
\hline CHEMBL3214529 & 688673 & 8.4559 & 5.6364 & TRN & \\
\hline CHEMBL1463876 & 688673 & 5.6 & 5.8692 & TRN & \\
\hline CHEMBL1522485 & 688673 & 4.7 & 5.5636 & TRN & \\
\hline CHEMBL1472833 & 688673 & 5.25 & 5.8104 & TRN & \\
\hline CHEMBL1416518 & 688673 & 7.2 & 5.9239 & TRN & \\
\hline CHEMBL1512094 & 688673 & 4.45 & 5.7882 & TRN & \\
\hline CHEMBL119247 & 688673 & 6.5501 & 6.1203 & TRN & \\
\hline CHEMBL1359566 & 688673 & 7.699 & 5.6797 & TRN & \\
\hline CHEMBL1314530 & 688673 & 8.6576 & 5.8548 & TRN & \\
\hline CHEMBL3196592 & 688673 & 4.6 & 5.5199 & TRN & \\
\hline CHEMBL1395717 & 688673 & 4.6 & 5.6576 & TRN & \\
\hline CHEMBL1372085 & 688673 & 6.8 & 5.5499 & TST & \\
\hline CHEMBL235928 & 688673 & 6.05 & 6.2064 & TRN & \\
\hline CHEMBL1559160 & 688673 & 5.4 & 5.62299 & 9999999999 & TRN \\
\hline CHEMBL1411132 & 688673 & 6.1 & 6.0124 & TRN & \\
\hline CHEMBL1526800 & 688673 & 4.45 & 5.8315 & TRN & \\
\hline CHEMBL1457517 & 688673 & 5.2 & 5.9303 & TRN & \\
\hline CHEMBL1380684 & 688673 & 7.1002 & 5.6431 & TST & \\
\hline CHEMBL1310766 & 688673 & 5.7 & 5.7117 & TST & \\
\hline CHEMBL1353782 & 688673 & 6.1 & 5.8236 & TRN & \\
\hline CHEMBL1393073 & 688673 & 6.5 & 5.9653 & TRN & \\
\hline CHEMBL1343458 & 688673 & 4.85 & 5.3256 & TRN & \\
\hline CHEMBL1312187 & 688673 & 5.05 & 5.8361 & TRN & \\
\hline CHEMBL1537185 & 688673 & 5.8 & 5.6505 & TST & \\
\hline CHEMBL1488734 & 688673 & 5.8 & 5.6193 & TRN & \\
\hline CHEMBL1494340 & 688673 & 6.2 & 6.0138 & TRN & \\
\hline
\end{tabular}




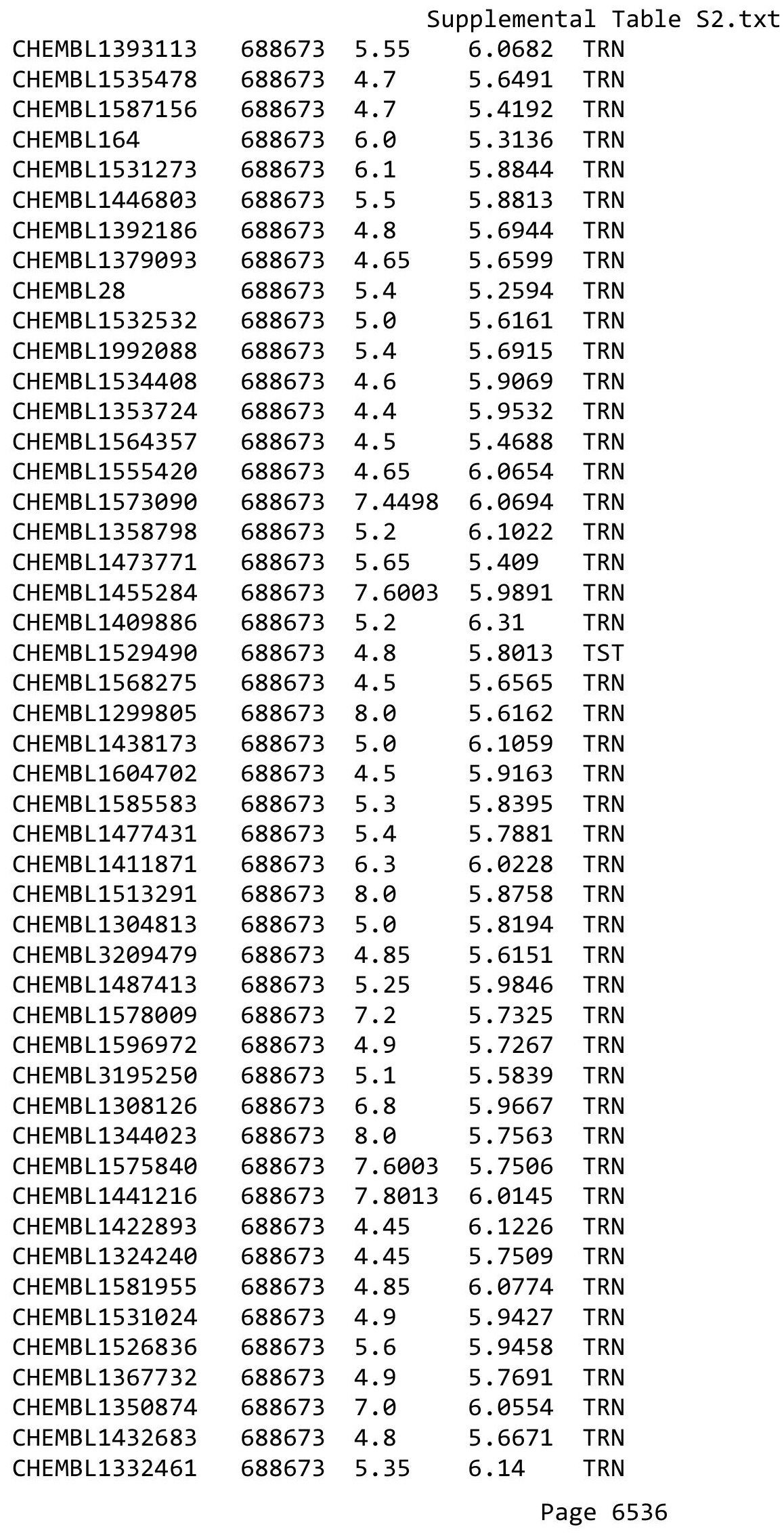




\begin{tabular}{|c|c|c|c|c|c|}
\hline \multicolumn{6}{|c|}{ Supplemental Table s2.txt } \\
\hline CHEMBL1329226 & 688673 & 4.9 & 6.2115 & TRN & \\
\hline CHEMBL557050 & 688673 & 4.7 & 5.9511 & TRN & \\
\hline CHEMBL1330662 & 688673 & 6.1 & 5.6921 & TRN & \\
\hline CHEMBL1492903 & 688673 & 5.5 & 5.9831 & TRN & \\
\hline CHEMBL1463451 & 688673 & 4.45 & 5.8097 & TRN & \\
\hline CHEMBL1486159 & 688673 & 6.0 & 5.9644 & TRN & \\
\hline CHEMBL1542457 & 688673 & 4.9 & 5.9442 & TRN & \\
\hline CHEMBL1490103 & 688673 & 4.85 & 5.4955 & TRN & \\
\hline CHEMBL1466625 & 688673 & 6.4 & 5.6298 & TRN & \\
\hline CHEMBL3208724 & 688673 & 7.6003 & 5.8746 & TRN & \\
\hline CHEMBL1381051 & 688673 & 7.6003 & 5.9296 & TRN & \\
\hline CHEMBL1329558 & 688673 & 4.45 & 5.6581 & TRN & \\
\hline CHEMBL1333942 & 688673 & 8.3979 & 6.0615 & TRN & \\
\hline CHEMBL1582104 & 688673 & 7.6003 & 6.0229 & TST & \\
\hline CHEMBL1422968 & 688673 & 6.8 & 5.955 & TRN & \\
\hline CHEMBL1610133 & 688673 & 4.5 & 6.03799 & 9999999999 & TRN \\
\hline CHEMBL1525634 & 688673 & 4.5 & 5.8444 & TRN & \\
\hline CHEMBL1427745 & 688673 & 4.95 & 5.8432 & TST & \\
\hline CHEMBL3195456 & 688673 & 5.95 & 5.8516 & TST & \\
\hline CHEMBL1381283 & 688673 & 5.6 & 5.9307 & TRN & \\
\hline CHEMBL1484084 & 688673 & 4.9 & 6.0726 & TRN & \\
\hline CHEMBL1344753 & 688673 & 5.0 & 5.7127 & TRN & \\
\hline CHEMBL1333958 & 688673 & 5.2 & 5.5899 & TST & \\
\hline CHEMBL1972106 & 688673 & 5.0 & 5.6159 & TST & \\
\hline CHEMBL1423683 & 688673 & 4.5 & 6.0672 & TRN & \\
\hline CHEMBL1400903 & 688673 & 6.6 & 5.6417 & TRN & \\
\hline CHEMBL1320505 & 688673 & 6.2 & 5.6649 & TRN & \\
\hline CHEMBL1446272 & 688673 & 7.0501 & 5.6209 & TRN & \\
\hline CHEMBL1522203 & 688673 & 4.5 & 5.6249 & TRN & \\
\hline CHEMBL1530938 & 688673 & 5.4 & 5.61299 & 99999999995 & TRN \\
\hline CHEMBL1572119 & 688673 & 7.2 & 5.2534 & TRN & \\
\hline CHEMBL1528934 & 688673 & 4.45 & 5.5354 & TRN & \\
\hline CHEMBL1561149 & 688673 & 8.0 & 5.6383 & TRN & \\
\hline CHEMBL1392697 & 688673 & 6.5 & 5.8788 & TRN & \\
\hline CHEMBL1468903 & 688673 & 6.5 & 5.4792 & TRN & \\
\hline CHEMBL1455448 & 688673 & 6.1 & 5.9042 & TRN & \\
\hline CHEMBL1445651 & 688673 & 4.45 & 6.2211 & TRN & \\
\hline CHEMBL1728993 & 688673 & 7.699 & 5.4061 & TST & \\
\hline CHEMBL1321769 & 688673 & 4.95 & 5.8988 & TRN & \\
\hline CHEMBL1529267 & 688673 & 6.3 & 5.9067 & TRN & \\
\hline CHEMBL1386214 & 688673 & 5.3 & 5.6593 & TRN & \\
\hline CHEMBL1374804 & 688673 & 4.45 & 5.6167 & TRN & \\
\hline CHEMBL1531038 & 688673 & 4.5 & 5.4768 & TRN & \\
\hline CHEMBL1578117 & 688673 & 4.5 & 5.7423 & TRN & \\
\hline CHEMBL1345174 & 688673 & 4.6 & 5.5062 & TRN & \\
\hline CHEMBL192009 & 688673 & 8.301 & 5.6241 & TRN & \\
\hline CHEMBL1323592 & 688673 & 4.5 & 6.0157 & TRN & \\
\hline CHEMBL1370686 & 688673 & 5.6 & 6.0372 & TRN & \\
\hline
\end{tabular}




\begin{tabular}{|c|c|c|c|c|c|}
\hline \multicolumn{6}{|c|}{ Supplemental Table S2.txt } \\
\hline CHEMBL1529732 & 688673 & 4.5 & 5.8704 & TRN & \\
\hline CHEMBL1457667 & 688673 & 6.0 & 5.5693 & TRN & \\
\hline CHEMBL1545310 & 688673 & 8.0 & 6.0993 & TRN & \\
\hline CHEMBL1569891 & 688673 & 6.8 & 5.468 & TRN & \\
\hline CHEMBL1391567 & 688673 & 4.8 & 5.6819 & TRN & \\
\hline CHEMBL1375332 & 688673 & 4.95 & 5.4959 & TST & \\
\hline CHEMBL1541810 & 688673 & 4.9 & 5.7052 & TRN & \\
\hline CHEMBL1500066 & 688673 & 5.5 & 5.4423 & TRN & \\
\hline CHEMBL1327056 & 688673 & 6.0 & 5.653 & TRN & \\
\hline CHEMBL1411034 & 688673 & 5.5 & 6.0781 & TRN & \\
\hline CHEMBL1537679 & 688673 & 4.45 & 5.8042 & TRN & \\
\hline CHEMBL1528826 & 688673 & 4.5 & 5.6972 & TST & \\
\hline CHEMBL1464977 & 688673 & 4.5 & 5.7903 & TRN & \\
\hline CHEMBL1569734 & 688673 & 6.1 & 5.7933 & TRN & \\
\hline CHEMBL590947 & 688673 & 5.3 & 5.4886 & TST & \\
\hline CHEMBL1602757 & 688673 & 5.35 & 5.6332 & TRN & \\
\hline CHEMBL1579570 & 688673 & 4.8 & 5.5544 & TRN & \\
\hline CHEMBL1313827 & 688673 & 5.4 & 5.7554 & TRN & \\
\hline CHEMBL1465187 & 688673 & 5.4 & 5.5567 & TRN & \\
\hline CHEMBL3196958 & 688673 & 6.9 & 5.5 & TRN & \\
\hline CHEMBL1586590 & 688673 & 5.4 & 5.7482 & TRN & \\
\hline CHEMBL1485301 & 688673 & 5.2 & 5.8753 & TRN & \\
\hline CHEMBL1393704 & 688673 & 7.4498 & 5.9969 & TRN & \\
\hline CHEMBL 3196403 & 688673 & 4.65 & 5.7894 & TST & \\
\hline CHEMBL1453454 & 688673 & 5.8 & 5.7208 & TRN & \\
\hline CHEMBL1511314 & 688673 & 7.8996 & 5.7825 & TRN & \\
\hline CHEMBL1452851 & 688673 & 7.15 & 5.4076 & TRN & \\
\hline CHEMBL1452699 & 688673 & 4.7 & 5.67700 & 00000000005 & TRN \\
\hline CHEMBL3196823 & 688673 & 6.5 & 5.7117 & TRN & \\
\hline CHEMBL1484912 & 688673 & 6.1 & 5.8754 & TRN & \\
\hline CHEMBL1404301 & 688673 & 4.9 & 5.5745 & TRN & \\
\hline CHEMBL1420547 & 688673 & 4.6 & 5.7482 & TRN & \\
\hline CHEMBL1299654 & 688673 & 6.3 & 5.9021 & TST & \\
\hline CHEMBL3199558 & 688673 & 5.5 & 5.6918 & TRN & \\
\hline CHEMBL3189365 & 688673 & 5.5 & 5.7929 & TRN & \\
\hline CHEMBL1453306 & 688673 & 4.6 & 5.6384 & TRN & \\
\hline CHEMBL1371958 & 688673 & 4.8 & 5.4412 & TRN & \\
\hline CHEMBL1423158 & 688673 & 5.45 & 5.7084 & TRN & \\
\hline CHEMBL3209976 & 688673 & 4.45 & 5.7274 & TRN & \\
\hline CHEMBL1604419 & 688673 & 5.8 & 5.8351 & TRN & \\
\hline CHEMBL1502490 & 688673 & 5.7 & 6.1013 & TRN & \\
\hline CHEMBL1428906 & 688673 & 4.9 & 6.03700 & 0000000001 & TRN \\
\hline CHEMBL1519439 & 688673 & 5.2 & 5.9515 & TRN & \\
\hline CHEMBL1452996 & 688673 & 4.8 & 5.8798 & TST & \\
\hline CHEMBL1519103 & 688673 & 4.45 & 5.5336 & TRN & \\
\hline CHEMBL1612031 & 688673 & 4.8 & 5.4298 & TST & \\
\hline CHEMBL1328322 & 688673 & 4.5 & 5.8037 & TRN & \\
\hline CHEMBL1508320 & 688673 & 4.7 & 5.7113 & TST & \\
\hline
\end{tabular}




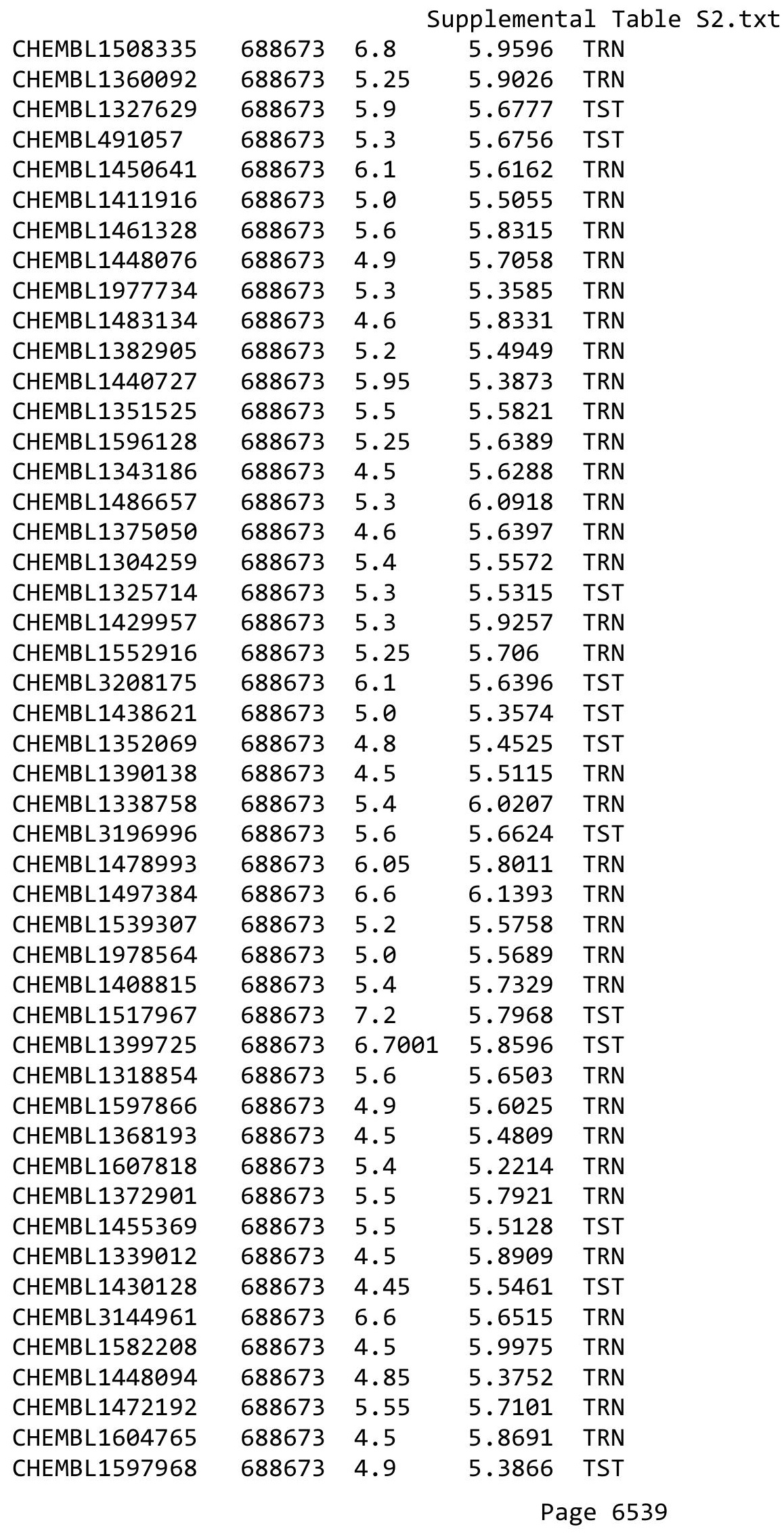




\begin{tabular}{|c|c|c|c|c|c|}
\hline \multicolumn{6}{|c|}{ Supplemental Table S2.txt } \\
\hline CHEMBL1534028 & 688673 & 6.8 & 5.7994 & TRN & \\
\hline CHEMBL1502290 & 688673 & 8.0 & 5.7 & TRN & \\
\hline CHEMBL1463671 & 688673 & 7.5003 & 5.6106 & TRN & \\
\hline CHEMBL1559832 & 688673 & 5.25 & 5.5827 & TRN & \\
\hline CHEMBL1598353 & 688673 & 4.45 & 5.9568 & TRN & \\
\hline CHEMBL1302058 & 688673 & 5.3 & 5.5152 & TRN & \\
\hline CHEMBL1344684 & 688673 & 4.9 & 5.3472 & TRN & \\
\hline CHEMBL1363243 & 688673 & 6.8 & 5.6907 & TRN & \\
\hline CHEMBL1495241 & 688673 & 4.55 & 5.5053 & TRN & \\
\hline CHEMBL1380975 & 688673 & 4.9 & 5.3717 & TRN & \\
\hline CHEMBL1574891 & 688673 & 5.6 & 5.5435 & TRN & \\
\hline CHEMBL1565249 & 688673 & 6.4 & 5.4641 & TST & \\
\hline CHEMBL1439562 & 688673 & 4.5 & 5.1715 & TRN & \\
\hline CHEMBL1529458 & 688673 & 5.25 & 5.4716 & TST & \\
\hline CHEMBL1574495 & 688673 & 5.5 & 5.5416 & TRN & \\
\hline CHEMBL1491533 & 688673 & 4.75 & 5.51399 & 9999999999 & TRN \\
\hline CHEMBL1436804 & 688673 & 5.95 & 5.6316 & TRN & \\
\hline CHEMBL1551265 & 688673 & 4.45 & 5.9639 & TRN & \\
\hline CHEMBL1354138 & 688673 & 5.9 & 5.9292 & TRN & \\
\hline CHEMBL1462233 & 688673 & 5.4 & 5.7751 & TST & \\
\hline CHEMBL1450152 & 688673 & 6.25 & 5.6476 & TRN & \\
\hline CHEMBL1427864 & 688673 & 4.5 & 5.6849 & TST & \\
\hline CHEMBL1486733 & 688673 & 6.8 & 5.7857 & TRN & \\
\hline CHEMBL1584696 & 688673 & 5.45 & 5.3215 & TRN & \\
\hline CHEMBL1561918 & 688673 & 7.5498 & 5.8793 & TRN & \\
\hline CHEMBL1356339 & 688673 & 5.0 & 5.9192 & TRN & \\
\hline CHEMBL1420094 & 688673 & 5.15 & 5.6166 & TRN & \\
\hline CHEMBL1319431 & 688673 & 5.3 & 5.7677 & TRN & \\
\hline CHEMBL1382767 & 688673 & 6.7001 & 5.6699 & TRN & \\
\hline CHEMBL1427677 & 688673 & 5.3 & 5.86799 & 9999999999 & TRN \\
\hline CHEMBL1471355 & 688673 & 7.6003 & 5.7182 & TRN & \\
\hline CHEMBL1586984 & 688673 & 4.5 & 5.8857 & TRN & \\
\hline CHEMBL3210108 & 688673 & 7.699 & 5.4563 & TRN & \\
\hline CHEMBL1530940 & 688673 & 8.2007 & 5.9649 & TRN & \\
\hline CHEMBL1446199 & 688673 & 4.65 & 5.6026 & TRN & \\
\hline CHEMBL1317090 & 688673 & 6.25 & 5.8268 & TRN & \\
\hline CHEMBL1565546 & 688673 & 6.9 & 6.1174 & TRN & \\
\hline CHEMBL1406961 & 688673 & 4.6 & 5.3108 & TST & \\
\hline CHEMBL1322959 & 688673 & 8.6021 & 5.6363 & TST & \\
\hline CHEMBL1343997 & 688673 & 4.7 & 5.9714 & TST & \\
\hline CHEMBL1465367 & 688673 & 5.9 & 5.6724 & TRN & \\
\hline CHEMBL1556512 & 688673 & 6.5 & 5.9251 & TRN & \\
\hline CHEMBL1352710 & 688673 & 5.1 & 5.697 & TRN & \\
\hline CHEMBL1493226 & 688673 & 7.2 & 5.7473 & TST & \\
\hline CHEMBL3199222 & 688673 & 8.0 & 5.5933 & TRN & \\
\hline CHEMBL1354307 & 688673 & 6.6 & 5.8247 & TRN & \\
\hline CHEMBL1521445 & 688673 & 5.4 & 6.0791 & TRN & \\
\hline CHEMBL1440137 & 688673 & 4.8 & 5.6562 & TRN & \\
\hline
\end{tabular}




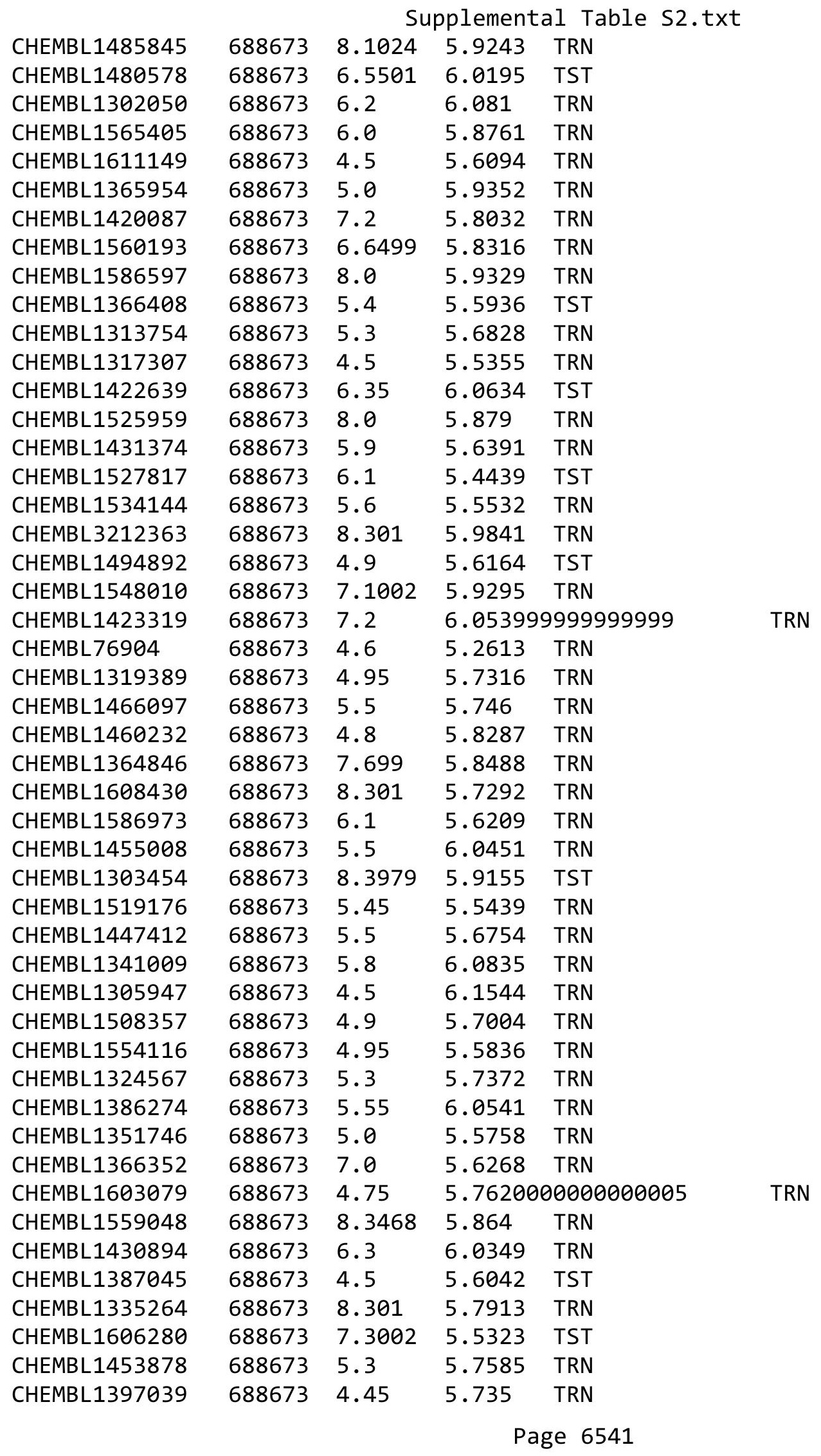




\begin{tabular}{|c|c|c|c|c|}
\hline \multicolumn{5}{|c|}{ Supplemental Table S2.txt } \\
\hline CHEMBL1473907 & 688673 & 7.3002 & 5.8765 & TRN \\
\hline CHEMBL1461041 & 688673 & 7.0 & 5.5297 & TRN \\
\hline CHEMBL1584754 & 688673 & 4.9 & 5.36799 & 9999999999 \\
\hline CHEMBL1382813 & 688673 & 4.9 & 5.6844 & TRN \\
\hline CHEMBL1580737 & 688673 & 4.9 & 5.7598 & TRN \\
\hline CHEMBL1377448 & 688673 & 4.7 & 5.6624 & TRN \\
\hline CHEMBL1375075 & 688673 & 5.4 & 6.0607 & TRN \\
\hline CHEMBL1414569 & 688673 & 5.5 & 5.7277 & TRN \\
\hline CHEMBL1423481 & 688673 & 6.6 & 6.237 & TRN \\
\hline CHEMBL1458730 & 688673 & 5.5 & 6.0626 & TRN \\
\hline CHEMBL1370334 & 688673 & 5.5 & 6.093 & TRN \\
\hline CHEMBL1510408 & 688673 & 4.9 & 5.7208 & TST \\
\hline CHEMBL1472812 & 688673 & 7.5498 & 5.7008 & TRN \\
\hline CHEMBL3208556 & 688673 & 4.9 & 5.4385 & TST \\
\hline CHEMBL1527080 & 688673 & 4.45 & 6.121 & TRN \\
\hline CHEMBL1609605 & 688673 & 8.0 & 5.8586 & TRN \\
\hline CHEMBL1460645 & 688673 & 6.6 & 5.6329 & TRN \\
\hline CHEMBL1395018 & 688673 & 4.9 & 5.6692 & TRN \\
\hline CHEMBL1464312 & 688673 & 4.8 & 5.6424 & TRN \\
\hline CHEMBL1349280 & 688673 & 7.5003 & 5.8775 & TRN \\
\hline CHEMBL1497193 & 688673 & 5.4 & 5.7204 & TRN \\
\hline CHEMBL1359092 & 688673 & 8.3468 & 5.7729 & TRN \\
\hline CHEMBL1525932 & 688673 & 7.699 & 5.7137 & TRN \\
\hline CHEMBL1449110 & 688673 & 4.5 & 5.5043 & TRN \\
\hline CHEMBL1519514 & 688673 & 4.45 & 5.7714 & TRN \\
\hline CHEMBL 1348747 & 688673 & 5.3 & 5.5912 & TRN \\
\hline CHEMBL1468768 & 688673 & 4.6 & 5.8811 & TRN \\
\hline CHEMBL1421889 & 688673 & 5.4 & 5.9145 & TRN \\
\hline CHEMBL1598587 & 688673 & 7.8013 & 5.8325 & TRN \\
\hline CHEMBL 3193247 & 688673 & 8.301 & 5.5921 & TRN \\
\hline CHEMBL 1452805 & 688673 & 4.45 & 5.5084 & TRN \\
\hline CHEMBL3193367 & 688673 & 7.8013 & 5.6566 & TRN \\
\hline CHEMBL1401654 & 688673 & 5.8 & 5.9007 & TST \\
\hline CHEMBL1523819 & 688673 & 5.2 & 5.7185 & TRN \\
\hline CHEMBL1299346 & 688673 & 5.3 & 5.4518 & TST \\
\hline CHEMBL1588102 & 688673 & 4.5 & 5.7164 & TST \\
\hline CHEMBL1527521 & 688673 & 6.1 & 5.9044 & TRN \\
\hline CHEMBL1559388 & 688673 & 6.3 & 5.6196 & TRN \\
\hline CHEMBL1563131 & 688673 & 4.5 & 5.4115 & TRN \\
\hline CHEMBL1319990 & 688673 & 4.6 & 5.5995 & TRN \\
\hline CHEMBL1452695 & 688673 & 5.5 & 5.8136 & TRN \\
\hline CHEMBL1410063 & 688673 & 4.5 & 5.2954 & TRN \\
\hline CHEMBL1368507 & 688673 & 6.15 & 5.6512 & TRN \\
\hline CHEMBL1567484 & 688673 & 8.1024 & 5.846 & TRN \\
\hline CHEMBL1528348 & 688673 & 6.2 & 6.0721 & TRN \\
\hline CHEMBL 1427520 & 688673 & 4.95 & 5.7936 & TRN \\
\hline CHEMBL1605444 & 688673 & 4.9 & 5.6448 & TRN \\
\hline CHEMBL1356590 & 688673 & 6.1 & 5.8106 & TRN \\
\hline
\end{tabular}




\begin{tabular}{|c|c|c|c|c|c|}
\hline \multicolumn{6}{|c|}{ Supplemental Table S2.txt } \\
\hline CHEMBL1605635 & 688673 & 4.9 & 5.5666 & TRN & \\
\hline CHEMBL1421509 & 688673 & 4.9 & 5.4927 & TRN & \\
\hline CHEMBL1467112 & 688673 & 7.8996 & 5.2641 & TST & \\
\hline CHEMBL1486010 & 688673 & 4.9 & 5.3322 & TRN & \\
\hline CHEMBL1509018 & 688673 & 4.8 & 5.5285 & TRN & \\
\hline CHEMBL1568234 & 688673 & 6.0 & 5.5344 & TRN & \\
\hline CHEMBL1408968 & 688673 & 5.65 & 5.6125 & TRN & \\
\hline CHEMBL1499384 & 688673 & 9.3979 & 5.8734 & TRN & \\
\hline CHEMBL1420400 & 688673 & 6.8 & 5.8737 & TRN & \\
\hline CHEMBL1393487 & 688673 & 5.2 & 6.37700 & 0000000001 & TRN \\
\hline CHEMBL1429112 & 688673 & 4.5 & 5.0507 & TST & \\
\hline CHEMBL1496459 & 688673 & 4.7 & 5.4873 & TRN & \\
\hline CHEMBL1299979 & 688673 & 7.2 & 5.5313 & TST & \\
\hline CHEMBL1413941 & 688673 & 4.5 & 5.4691 & TRN & \\
\hline CHEMBL1467848 & 688673 & 5.4 & 5.7247 & TRN & \\
\hline CHEMBL 3199425 & 688673 & 5.25 & 5.5157 & TRN & \\
\hline CHEMBL1363010 & 688673 & 4.5 & 5.9238 & TRN & \\
\hline CHEMBL 3195393 & 688673 & 5.4 & 5.7269 & TRN & \\
\hline CHEMBL1340209 & 688673 & 8.301 & 5.6109 & TST & \\
\hline CHEMBL1509738 & 688673 & 7.8996 & 5.7126 & TRN & \\
\hline CHEMBL1545684 & 688673 & 5.2 & 5.6529 & TRN & \\
\hline CHEMBL1374812 & 688673 & 5.55 & 5.7266 & TRN & \\
\hline CHEMBL1499298 & 688673 & 5.8 & 5.4034 & TST & \\
\hline CHEMBL1520058 & 688673 & 8.301 & 5.8061 & TRN & \\
\hline CHEMBL1553725 & 688673 & 5.25 & 5.564 & TRN & \\
\hline CHEMBL1322374 & 688673 & 4.5 & 5.7459 & TRN & \\
\hline CHEMBL1352232 & 688673 & 5.4 & 5.9864 & TRN & \\
\hline CHEMBL1574506 & 688673 & 4.95 & 5.8333 & TRN & \\
\hline CHEMBL1399612 & 688673 & 5.1 & 5.7276 & TRN & \\
\hline CHEMBL1424099 & 688673 & 6.1 & 5.7709 & TST & \\
\hline CHEMBL1468578 & 688673 & 6.2 & 5.8883 & TRN & \\
\hline CHEMBL1332679 & 688673 & 6.8 & 5.5527 & TRN & \\
\hline CHEMBL1385461 & 688673 & 7.2 & 6.1917 & TRN & \\
\hline CHEMBL1606424 & 688673 & 5.5 & 5.9591 & TRN & \\
\hline CHEMBL1321641 & 688673 & 6.0 & 5.8132 & TRN & \\
\hline CHEMBL3194750 & 688673 & 6.9 & 5.556 & TST & \\
\hline CHEMBL1424917 & 688673 & 8.3979 & 5.6979 & TRN & \\
\hline CHEMBL1467144 & 688673 & 6.1 & 5.8175 & TRN & \\
\hline CHEMBL1458629 & 688673 & 5.3 & 5.8032 & TRN & \\
\hline CHEMBL1504048 & 688673 & 5.2 & 5.4543 & TRN & \\
\hline CHEMBL3212813 & 688673 & 4.5 & 5.7381 & TRN & \\
\hline CHEMBL 3198842 & 688673 & 5.45 & 5.8022 & TRN & \\
\hline CHEMBL512216 & 688673 & 4.9 & 5.5862 & TRN & \\
\hline CHEMBL1397104 & 688673 & 4.45 & 5.6853 & TRN & \\
\hline CHEMBL1349626 & 688673 & 4.5 & 5.7407 & TRN & \\
\hline CHEMBL 1487550 & 688673 & 6.45 & 5.472 & TRN & \\
\hline CHEMBL1359588 & 688673 & 6.7501 & 5.6556 & TRN & \\
\hline CHEMBL1415374 & 688673 & 8.1024 & 5.475 & TRN & \\
\hline
\end{tabular}




\begin{tabular}{|c|c|c|c|c|}
\hline \multicolumn{5}{|c|}{ Supplemental Table S2.txt } \\
\hline CHEMBL1563388 & 688673 & 7.0 & 6.0138 & TRN \\
\hline CHEMBL1448201 & 688673 & 5.2 & 5.7252 & TRN \\
\hline CHEMBL1537726 & 688673 & 6.2 & 5.9754 & TRN \\
\hline CHEMBL1488072 & 688673 & 8.3979 & 5.816 & TRN \\
\hline CHEMBL1560067 & 688673 & 6.2 & 5.5336 & TRN \\
\hline CHEMBL1342861 & 688673 & 4.6 & 6.0804 & TRN \\
\hline CHEMBL1479377 & 688673 & 8.301 & 5.6574 & TRN \\
\hline CHEMBL 243379 & 688673 & 4.9 & 5.6166 & TRN \\
\hline CHEMBL1486312 & 688673 & 4.45 & 5.4946 & TRN \\
\hline CHEMBL1552829 & 688673 & 4.95 & 5.3754 & TST \\
\hline CHEMBL54909 & 688673 & 4.6 & 5.3673 & TRN \\
\hline CHEMBL1341999 & 688673 & 7.0 & 5.7658 & TRN \\
\hline CHEMBL1255647 & 688673 & 8.699 & 5.4434 & TST \\
\hline CHEMBL1447240 & 688673 & 8.3468 & 5.6632 & TRN \\
\hline CHEMBL1439429 & 688673 & 5.4 & 5.5235 & TRN \\
\hline CHEMBL1300711 & 688673 & 5.45 & 5.7989 & TRN \\
\hline CHEMBL1565446 & 688673 & 7.699 & 5.8816 & TRN \\
\hline CHEMBL1362805 & 688673 & 7.7496 & 5.9358 & TRN \\
\hline CHEMBL1440675 & 688673 & 4.8 & 5.5506 & TST \\
\hline CHEMBL1561316 & 688673 & 4.6 & 5.5269 & TRN \\
\hline CHEMBL1564940 & 688673 & 4.6 & 5.3618 & TRN \\
\hline CHEMBL1468109 & 688673 & 5.0 & 5.6575 & TRN \\
\hline CHEMBL1419343 & 688673 & 4.9 & 6.0561 & TRN \\
\hline CHEMBL1602145 & 688673 & 8.301 & 5.847 & TRN \\
\hline CHEMBL1424346 & 688673 & 4.5 & 5.3815 & TST \\
\hline CHEMBL1578794 & 688673 & 6.6 & 5.8857 & TRN \\
\hline CHEMBL1486837 & 688673 & 6.7001 & 6.0301 & TRN \\
\hline CHEMBL1461645 & 688673 & 4.6 & 5.6311 & TRN \\
\hline CHEMBL1450323 & 688673 & 8.301 & 6.0498 & TRN \\
\hline CHEMBL1306166 & 688673 & 4.5 & 5.6412 & TRN \\
\hline CHEMBL1385220 & 688673 & 4.45 & 5.7538 & TRN \\
\hline CHEMBL1526181 & 688673 & 4.65 & 5.8608 & TRN \\
\hline CHEMBL1510689 & 688673 & 5.0 & 5.6693 & TRN \\
\hline CHEMBL1581581 & 688673 & 6.35 & 5.4044 & TRN \\
\hline CHEMBL1368011 & 688673 & 6.95 & 5.9308 & TRN \\
\hline CHEMBL1341534 & 688673 & 7.6498 & 6.0592 & TRN \\
\hline CHEMBL334378 & 688673 & 8.6021 & 5.1877 & TST \\
\hline CHEMBL1500707 & 688673 & 5.0 & 5.5198 & TRN \\
\hline CHEMBL3189529 & 688673 & 6.8 & 5.5873 & TRN \\
\hline CHEMBL1469027 & 688673 & 4.5 & 6.1532 & TRN \\
\hline CHEMBL1577699 & 688673 & 5.2 & 5.3698 & TRN \\
\hline CHEMBL1489826 & 688673 & 4.5 & 5.9311 & TRN \\
\hline CHEMBL1312708 & 688673 & 8.301 & 5.9783 & TRN \\
\hline CHEMBL1425807 & 688673 & 7.2 & 5.8091 & TRN \\
\hline CHEMBL1416540 & 688673 & 5.5 & 6.0972 & TRN \\
\hline CHEMBL578741 & 688673 & 4.9 & 5.2681 & TRN \\
\hline CHEMBL1408373 & 688673 & 7.5003 & 5.6613 & TRN \\
\hline CHEMBL1324202 & 688673 & 4.9 & 5.7772 & TRN \\
\hline
\end{tabular}




\begin{tabular}{|c|c|c|c|c|c|}
\hline & & \multicolumn{4}{|c|}{ Supplemental Table S2.txt } \\
\hline CHEMBL1564698 & 688673 & 5.5 & 6.03299 & 99999999995 & TRN \\
\hline CHEMBL452894 & 688673 & 8.4949 & 5.8236 & TRN & \\
\hline CHEMBL1556225 & 688673 & 6.2 & 5.6864 & TRN & \\
\hline CHEMBL1557241 & 688673 & 8.7959 & 5.6277 & TRN & \\
\hline CHEMBL1393131 & 688673 & 4.8 & 5.3256 & TRN & \\
\hline CHEMBL1303750 & 688673 & 7.699 & 5.5652 & TRN & \\
\hline CHEMBL1365340 & 688673 & 6.6 & 6.0183 & TRN & \\
\hline CHEMBL1401754 & 688673 & 4.6 & 5.3752 & TST & \\
\hline CHEMBL1535139 & 688673 & 5.2 & 5.4605 & TST & \\
\hline CHEMBL1402783 & 688673 & 7.2 & 5.5176 & TRN & \\
\hline CHEMBL1432014 & 688673 & 6.5 & 5.7932 & TRN & \\
\hline CHEMBL1469295 & 688673 & 6.1 & 5.9873 & TRN & \\
\hline CHEMBL1308096 & 688673 & 6.6 & 5.766 & TRN & \\
\hline CHEMBL1472090 & 688673 & 4.5 & 5.6332 & TRN & \\
\hline CHEMBL1590070 & 688673 & 5.45 & 5.8834 & TRN & \\
\hline CHEMBL1483780 & 688673 & 4.9 & 5.6308 & TST & \\
\hline CHEMBL1354162 & 688673 & 6.3 & 5.79799 & 9999999999 & TRN \\
\hline CHEMBL1409951 & 688673 & 8.301 & 5.5368 & TRN & \\
\hline CHEMBL1468864 & 688673 & 4.5 & 5.5078 & TRN & \\
\hline CHEMBL1471857 & 688673 & 4.55 & 5.5522 & TRN & \\
\hline CHEMBL1426683 & 688673 & 8.301 & 6.0065 & TRN & \\
\hline CHEMBL566706 & 688673 & 5.5 & 5.8225 & TRN & \\
\hline CHEMBL1546820 & 688673 & 4.8 & 5.8347 & TRN & \\
\hline CHEMBL1333376 & 688673 & 8.0 & 5.7951 & TRN & \\
\hline CHEMBL1376724 & 688673 & 4.5 & 5.6714 & TRN & \\
\hline CHEMBL1557571 & 688673 & 8.4949 & 5.6477 & TRN & \\
\hline CHEMBL1377241 & 688673 & 7.0501 & 5.8302 & TRN & \\
\hline CHEMBL1509592 & 688673 & 5.4 & 6.1111 & TRN & \\
\hline CHEMBL1418675 & 688673 & 7.3002 & 5.97 & TRN & \\
\hline CHEMBL1312345 & 688673 & 7.8013 & 5.6426 & TRN & \\
\hline CHEMBL1313583 & 688673 & 5.0 & 5.6426 & TST & \\
\hline CHEMBL1439717 & 688673 & 4.8 & 5.6244 & TRN & \\
\hline CHEMBL3197057 & 688673 & 7.5003 & 5.7319 & TRN & \\
\hline CHEMBL1493519 & 688673 & 7.2 & 6.0722 & TRN & \\
\hline CHEMBL1563643 & 688673 & 7.5003 & 5.545 & TST & \\
\hline CHEMBL1487177 & 688673 & 5.7 & 5.7995 & TRN & \\
\hline CHEMBL1553249 & 688673 & 8.3979 & 5.6728 & TST & \\
\hline CHEMBL69003 & 688673 & 5.2 & 5.4906 & TRN & \\
\hline CHEMBL1359056 & 688673 & 5.5 & 5.9272 & TRN & \\
\hline CHEMBL1421084 & 688673 & 4.8 & 5.4105 & TST & \\
\hline CHEMBL1604887 & 688673 & 5.5 & 5.8095 & TRN & \\
\hline CHEMBL1535838 & 688673 & 8.301 & 5.4315 & TRN & \\
\hline CHEMBL1975523 & 688673 & 4.9 & 5.5014 & TRN & \\
\hline CHEMBL1526493 & 688673 & 7.0 & 5.694 & TRN & \\
\hline CHEMBL1484186 & 688673 & 4.9 & 5.4671 & TST & \\
\hline CHEMBL1597829 & 688673 & 4.9 & 5.4009 & TST & \\
\hline CHEMBL3194733 & 688673 & 6.9 & 5.7359 & TRN & \\
\hline CHEMBL1529362 & 688673 & 4.5 & 5.4363 & TRN & \\
\hline
\end{tabular}




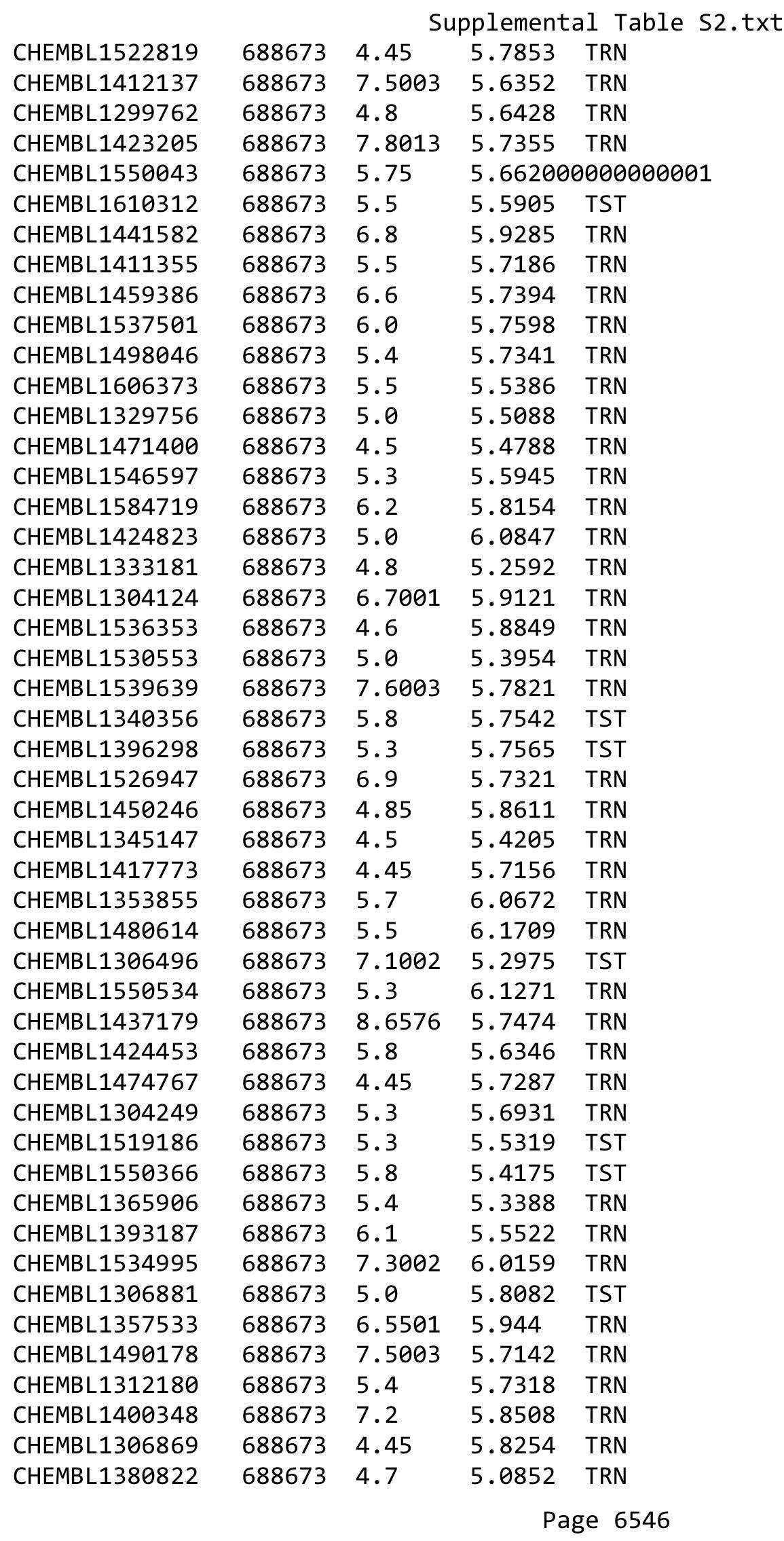




\begin{tabular}{|c|c|c|c|c|c|}
\hline \multirow{3}{*}{$\begin{array}{l}\text { CHEMBL1562667 } \\
\text { CHFMBI } 1452833\end{array}$} & & \multicolumn{4}{|c|}{ Supplemental Table S2.txt } \\
\hline & 688673 & 5.5 & \multicolumn{2}{|c|}{6.031000000000001} & TRN \\
\hline & 688673 & 7.6003 & 5.5083 & TST & \\
\hline CHEMBL1444437 & 688673 & 4.5 & 5.7101 & TRN & \\
\hline CHEMBL1595871 & 688673 & 5.5 & 5.1505 & TRN & \\
\hline CHEMBL1406024 & 688673 & 5.4 & 5.9038 & TRN & \\
\hline CHEMBL1497722 & 688673 & 5.55 & \multicolumn{2}{|c|}{5.8839999999999995} & TST \\
\hline CHEMBL1339467 & 688673 & 4.9 & 5.6791 & TRN & \\
\hline CHEMBL1451202 & 688673 & 4.8 & 5.5565 & TRN & \\
\hline CHEMBL1342388 & 688673 & 4.5 & \multicolumn{2}{|c|}{5.468999999999999} & TRN \\
\hline CHEMBL1537383 & 688673 & 5.2 & 5.7269 & TRN & \\
\hline CHEMBL1387945 & 688673 & 4.7 & 5.2911 & TRN & \\
\hline CHEMBL1358988 & 688673 & 4.45 & 6.0047 & TRN & \\
\hline CHEMBL1395301 & 688673 & 4.9 & 5.8171 & TRN & \\
\hline CHEMBL1464502 & 688673 & 6.1 & 5.5457 & TRN & \\
\hline CHEMBL1400709 & 688673 & 6.5 & 5.7966 & TRN & \\
\hline CHEMBL1325819 & 688673 & 4.8 & 5.4353 & TRN & \\
\hline CHEMBL1570156 & 688673 & 5.0 & 5.6751 & TRN & \\
\hline CHEMBL 3210914 & 688673 & 5.0 & 5.5339 & TST & \\
\hline CHEMBL1592686 & 688673 & 6.1 & 5.8023 & TRN & \\
\hline CHEMBL1440672 & 688673 & 4.65 & 5.813 & TRN & \\
\hline CHEMBL1382778 & 688673 & 6.9 & 5.9388 & TRN & \\
\hline CHEMBL1577889 & 688673 & 5.8 & 5.5595 & TRN & \\
\hline CHEMBL1576495 & 688673 & 6.3 & 5.7424 & TRN & \\
\hline CHEMBL1375601 & 688673 & 7.6498 & 6.0532 & TRN & \\
\hline CHEMBL1478454 & 688673 & 4.5 & 5.6285 & TRN & \\
\hline CHEMBL1532571 & 688673 & 4.8 & 5.3811 & TST & \\
\hline CHEMBL1360346 & 688673 & 4.8 & 5.4943 & TRN & \\
\hline CHEMBL1370669 & 688673 & 4.9 & 5.5621 & TRN & \\
\hline CHEMBL1561669 & 688673 & 5.2 & 5.8672 & TRN & \\
\hline CHEMBL1408059 & 688673 & 5.65 & 5.4184 & TRN & \\
\hline CHEMBL1327690 & 688673 & 5.5 & 5.7085 & TRN & \\
\hline CHEMBL1499086 & 688673 & 4.45 & 5.6379 & TRN & \\
\hline CHEMBL1372189 & 688673 & 8.0 & 5.5215 & TST & \\
\hline CHEMBL296407 & 688673 & 4.7 & 5.3482 & TRN & \\
\hline CHEMBL1457649 & 688673 & 4.5 & 6.0681 & TRN & \\
\hline CHEMBL1310490 & 688673 & 4.5 & 6.138 & TRN & \\
\hline CHEMBL1556423 & 688673 & 4.5 & 6.1764 & TRN & \\
\hline CHEMBL1567962 & 688673 & 6.0 & 5.5267 & TRN & \\
\hline CHEMBL1516775 & 688673 & 4.9 & 5.5671 & TRN & \\
\hline CHEMBL1505364 & 688673 & 4.9 & 5.4582 & TRN & \\
\hline CHEMBL1369115 & 688673 & 8.8861 & 6.0095 & TRN & \\
\hline CHEMBL1338049 & 688673 & 5.8 & 5.4519 & TRN & \\
\hline CHEMBL1340901 & 688673 & 5.3 & 6.0146 & TRN & \\
\hline CHEMBL1402788 & 688673 & 4.5 & 5.5349 & TRN & \\
\hline CHEMBL1333112 & 688673 & 5.25 & 5.6039 & TRN & \\
\hline CHEMBL1451616 & 688673 & 8.0 & 5.8876 & TRN & \\
\hline CHEMBL1304301 & 688673 & 6.1 & 5.8697 & TRN & \\
\hline CHEMBL1569012 & 688673 & 6.0 & 5.4205 & TRN & \\
\hline
\end{tabular}




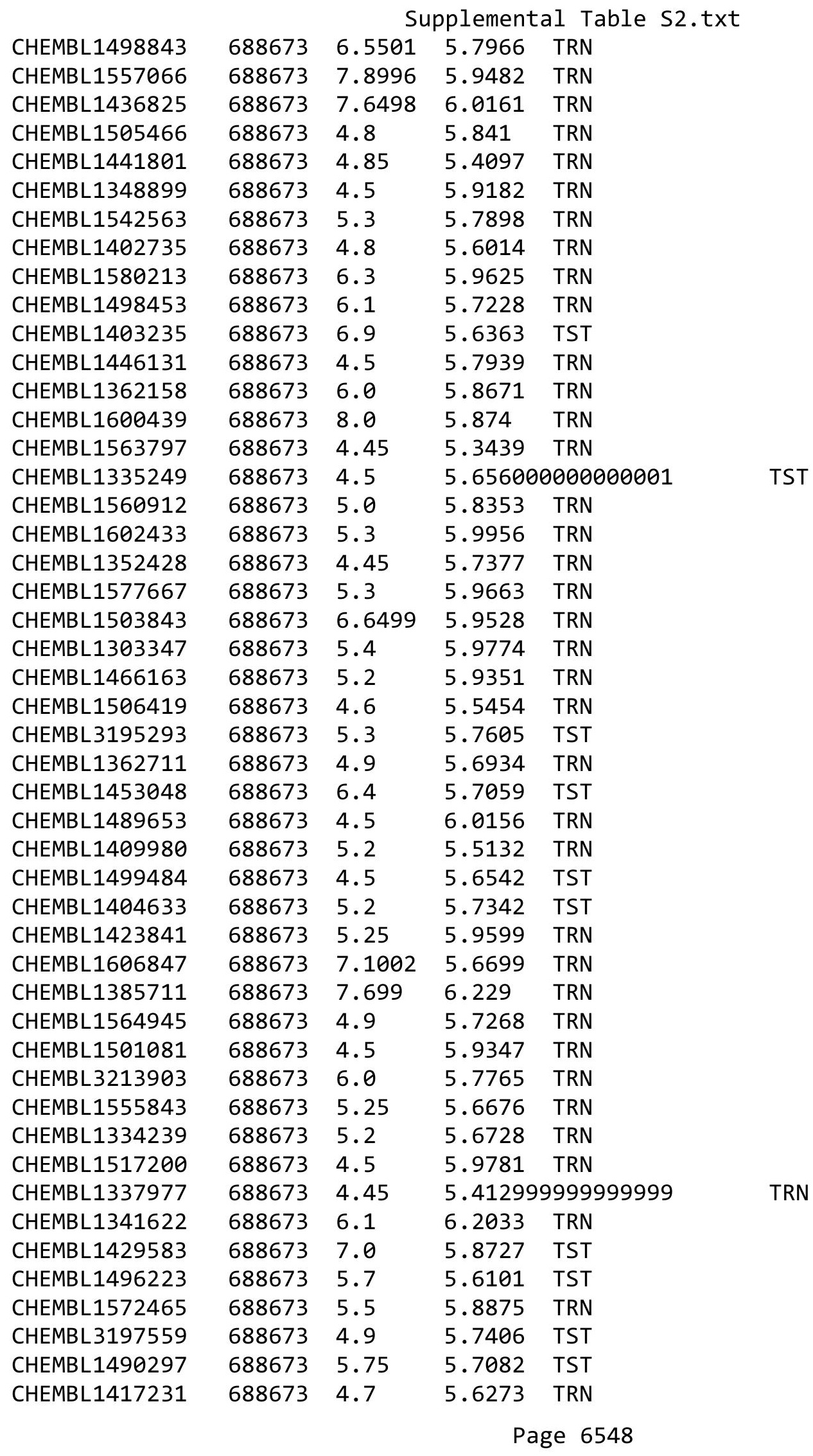




\begin{tabular}{|c|c|c|c|c|c|}
\hline \multicolumn{6}{|c|}{ Supplemental Table s2.txt } \\
\hline CHEMBL1556363 & 688673 & 8.0 & 5.8473 & TST & \\
\hline CHEMBL1460815 & 688673 & 6.1 & 5.8748 & TRN & \\
\hline CHEMBL1905194 & 688673 & 7.6003 & 5.6167 & TST & \\
\hline CHEMBL1342900 & 688673 & 5.6 & 5.7848 & TRN & \\
\hline CHEMBL3199111 & 688673 & 5.3 & 5.7493 & TST & \\
\hline CHEMBL1408640 & 688673 & 8.301 & 5.5315 & TRN & \\
\hline CHEMBL1462100 & 688673 & 4.5 & 6.0572 & TRN & \\
\hline CHEMBL1299227 & 688673 & 6.2 & 5.893 & TRN & \\
\hline CHEMBL1540380 & 688673 & 7.699 & 5.5748 & TST & \\
\hline CHEMBL1581814 & 688673 & 6.3 & 5.5449 & TRN & \\
\hline CHEMBL1390370 & 688673 & 7.4001 & 5.7262 & TRN & \\
\hline CHEMBL1328823 & 688673 & 5.55 & 6.2277 & TRN & \\
\hline CHEMBL1443333 & 688673 & 4.9 & 5.3073 & TRN & \\
\hline CHEMBL1587764 & 688673 & 4.9 & 5.6306 & TRN & \\
\hline CHEMBL1393035 & 688673 & 5.4 & 5.8543 & TRN & \\
\hline CHEMBL1472819 & 688673 & 4.45 & 5.4716 & TST & \\
\hline CHEMBL1371064 & 688673 & 6.6 & 6.2766 & TRN & \\
\hline CHEMBL1361827 & 688673 & 5.0 & 5.8507 & TRN & \\
\hline CHEMBL3195155 & 688673 & 4.9 & 5.4768 & TST & \\
\hline CHEMBL1493730 & 688673 & 6.1 & 5.83299 & 9999999999 & TST \\
\hline CHEMBL1400181 & 688673 & 5.3 & 5.6915 & TST & \\
\hline CHEMBL1307458 & 688673 & 8.0 & 5.517 & TRN & \\
\hline CHEMBL1521607 & 688673 & 6.3 & 5.6557 & TRN & \\
\hline CHEMBL1374559 & 688673 & 4.45 & 5.1858 & TRN & \\
\hline CHEMBL1528324 & 688673 & 6.1 & 5.9855 & TRN & \\
\hline CHEMBL1535480 & 688673 & 4.5 & 5.5448 & TRN & \\
\hline CHEMBL1300285 & 688673 & 7.3002 & 5.7023 & TRN & \\
\hline CHEMBL1495082 & 688673 & 6.9 & 5.2869 & TRN & \\
\hline CHEMBL1418113 & 688673 & 5.25 & 5.6816 & TST & \\
\hline CHEMBL1540114 & 688673 & 4.95 & 5.6199 & TRN & \\
\hline CHEMBL1506936 & 688673 & 5.0 & 5.9876 & TRN & \\
\hline CHEMBL1345744 & 688673 & 7.5003 & 5.8294 & TRN & \\
\hline CHEMBL1406674 & 688673 & 8.1024 & 5.5942 & TRN & \\
\hline CHEMBL3207858 & 688673 & 4.5 & 5.6865 & TRN & \\
\hline CHEMBL1431913 & 688673 & 7.5003 & 5.5522 & TRN & \\
\hline CHEMBL1449518 & 688673 & 4.6 & 5.6532 & TRN & \\
\hline CHEMBL1345711 & 688673 & 6.0 & 5.922006 & 0000000001 & TRN \\
\hline CHEMBL1575852 & 688673 & 5.25 & 5.5519 & TRN & \\
\hline CHEMBL1534337 & 688673 & 5.4 & 5.79200 & 0000000001 & TRN \\
\hline CHEMBL1335384 & 688673 & 5.15 & 5.4344 & TRN & \\
\hline CHEMBL1471756 & 688673 & 5.2 & 6.1779 & TRN & \\
\hline CHEMBL1495038 & 688673 & 5.25 & 5.4079 & TRN & \\
\hline CHEMBL1341969 & 688673 & 5.5 & 5.6565 & TRN & \\
\hline CHEMBL1449687 & 688673 & 4.45 & 5.9958 & TRN & \\
\hline CHEMBL1339696 & 688673 & 4.5 & 5.5908 & TRN & \\
\hline CHEMBL1565214 & 688673 & 4.45 & 5.7571 & TRN & \\
\hline CHEMBL1526581 & 688673 & 5.4 & 5.8267 & TRN & \\
\hline CHEMBL1456524 & 688673 & 6.95 & 6.0132 & TRN & \\
\hline
\end{tabular}




\begin{tabular}{|c|c|c|c|c|c|}
\hline \multicolumn{6}{|c|}{ Supplemental Table S2.txt } \\
\hline CHEMBL1458930 & 688673 & 6.2 & 5.6848 & TST & \\
\hline CHEMBL1345653 & 688673 & 8.0 & 5.5459 & TST & \\
\hline CHEMBL1609692 & 688673 & 8.3979 & 5.8173 & TRN & \\
\hline CHEMBL1578409 & 688673 & 6.1 & 5.465 & TRN & \\
\hline CHEMBL1495223 & 688673 & 4.5 & 5.4836 & TRN & \\
\hline CHEMBL1479188 & 688673 & 4.5 & 5.3846 & TRN & \\
\hline CHEMBL1536882 & 688673 & 6.1 & 6.1405 & TRN & \\
\hline CHEMBL1601297 & 688673 & 4.5 & 5.4682 & TRN & \\
\hline CHEMBL1371693 & 688673 & 5.4 & 5.7423 & TRN & \\
\hline CHEMBL1370701 & 688673 & 5.5 & 5.7564 & TRN & \\
\hline CHEMBL1488996 & 688673 & 7.6003 & 5.7991 & TRN & \\
\hline CHEMBL1425784 & 688673 & 7.699 & 5.9217 & TRN & \\
\hline CHEMBL1450517 & 688673 & 5.5 & 5.4715 & TRN & \\
\hline CHEMBL1379952 & 688673 & 5.25 & 5.7683 & TRN & \\
\hline CHEMBL1489869 & 688673 & 4.8 & 5.5519 & TRN & \\
\hline CHEMBL1447173 & 688673 & 6.6 & 5.7522 & TRN & \\
\hline CHEMBL3193019 & 688673 & 5.3 & 5.8256 & TRN & \\
\hline CHEMBL1599602 & 688673 & 4.7 & 5.4009 & TRN & \\
\hline CHEMBL1327138 & 688673 & 7.0501 & 5.7262 & TRN & \\
\hline CHEMBL1544327 & 688673 & 4.5 & 5.7209 & TST & \\
\hline CHEMBL1495975 & 688673 & 4.7 & 5.8669 & TRN & \\
\hline CHEMBL1495247 & 688673 & 5.5 & 5.8394 & TRN & \\
\hline CHEMBL1462773 & 688673 & 5.3 & 5.5173 & TST & \\
\hline CHEMBL1394384 & 688673 & 6.9 & 5.5183 & TRN & \\
\hline CHEMBL1470904 & 688673 & 4.5 & 5.3811 & TRN & \\
\hline CHEMBL1580511 & 688673 & 7.5003 & 5.6764 & TRN & \\
\hline CHEMBL1334297 & 688673 & 4.5 & 5.6067 & TRN & \\
\hline CHEMBL1506143 & 688673 & 5.3 & 6.0469 & TRN & \\
\hline CHEMBL1524634 & 688673 & 7.699 & 5.9288 & TRN & \\
\hline CHEMBL1346709 & 688673 & 4.8 & 6.0914 & TRN & \\
\hline CHEMBL1502390 & 688673 & 7.8013 & 6.0561 & TRN & \\
\hline CHEMBL1330988 & 688673 & 5.15 & 5.7676 & TRN & \\
\hline CHEMBL1419682 & 688673 & 5.5 & 5.5796 & TST & \\
\hline CHEMBL1567663 & 688673 & 4.95 & 5.1921 & TRN & \\
\hline CHEMBL1487445 & 688673 & 4.5 & 5.63299 & э999999999 & TRN \\
\hline CHEMBL 3214112 & 688673 & 4.45 & 5.5893 & TRN & \\
\hline CHEMBL1609156 & 688673 & 4.5 & 5.4416 & TRN & \\
\hline CHEMBL3189718 & 688673 & 6.1 & 5.4962 & TRN & \\
\hline CHEMBL1527073 & 688673 & 4.9 & 5.7333 & TST & \\
\hline CHEMBL1523473 & 688673 & 4.45 & 5.8115 & TRN & \\
\hline CHEMBL1335326 & 688673 & 5.2 & 5.65799 & 99999999995 & TRN \\
\hline CHEMBL1526978 & 688673 & 4.9 & 5.3706 & TRN & \\
\hline CHEMBL1506576 & 688673 & 6.3 & 5.9113 & TRN & \\
\hline CHEMBL1607905 & 688673 & 5.2 & 5.4106 & TST & \\
\hline CHEMBL1341833 & 688673 & 4.65 & 5.7128 & TRN & \\
\hline CHEMBL1486580 & 688673 & 6.9 & 5.66 & TRN & \\
\hline CHEMBL1382389 & 688673 & 5.4 & 5.6258 & TRN & \\
\hline CHEMBL1444494 & 688673 & 5.5 & 5.8558 & TRN & \\
\hline
\end{tabular}




\begin{tabular}{|c|c|c|c|c|c|}
\hline \multicolumn{6}{|c|}{ Supplemental Table s2.txt } \\
\hline CHEMBL1403102 & 688673 & 5.7 & 5.7517 & TRN & \\
\hline CHEMBL1402022 & 688673 & 5.3 & 5.8069 & TRN & \\
\hline CHEMBL1382351 & 688673 & 6.7001 & 5.8747 & TRN & \\
\hline CHEMBL1362985 & 688673 & 6.4 & 5.8739 & TRN & \\
\hline CHEMBL1446363 & 688673 & 4.5 & 5.6373 & TRN & \\
\hline CHEMBL1487287 & 688673 & 5.7 & 5.8107 & TRN & \\
\hline CHEMBL1440923 & 688673 & 5.45 & 5.8981 & TRN & \\
\hline CHEMBL1390617 & 688673 & 6.8 & 5.972 & TRN & \\
\hline CHEMBL1556348 & 688673 & 6.7001 & 5.5831 & TRN & \\
\hline CHEMBL3209140 & 688673 & 6.5 & 5.6293 & TRN & \\
\hline CHEMBL1507011 & 688673 & 8.301 & 5.8397 & TRN & \\
\hline CHEMBL1570874 & 688673 & 4.6 & 5.6064 & TRN & \\
\hline CHEMBL1370265 & 688673 & 4.45 & 5.3985 & TRN & \\
\hline CHEMBL1442776 & 688673 & 7.1002 & 5.7882 & TST & \\
\hline CHEMBL1538560 & 688673 & 4.5 & 5.5484 & TRN & \\
\hline CHEMBL1491184 & 688673 & 4.9 & 5.5783 & TRN & \\
\hline CHEMBL1421867 & 688673 & 4.95 & 5.7577 & TRN & \\
\hline CHEMBL1342856 & 688673 & 8.301 & 5.6707 & TRN & \\
\hline CHEMBL1337640 & 688673 & 5.5 & 5.7432 & TRN & \\
\hline CHEMBL1396086 & 688673 & 6.9 & 5.9133 & TRN & \\
\hline CHEMBL1366847 & 688673 & 4.7 & 5.8964 & TRN & \\
\hline CHEMBL 3210048 & 688673 & 5.0 & 5.6674 & TST & \\
\hline CHEMBL1368125 & 688673 & 4.7 & 6.0835 & TRN & \\
\hline CHEMBL1443938 & 688673 & 5.2 & 5.4292 & TRN & \\
\hline CHEMBL1497741 & 688673 & 6.4 & 6.1366 & TRN & \\
\hline CHEMBL3196976 & 688673 & 4.9 & 5.7047 & TRN & \\
\hline CHEMBL1345672 & 688673 & 6.5 & 5.5814 & TRN & \\
\hline CHEMBL1607026 & 688673 & 7.5003 & 5.9023 & TRN & \\
\hline CHEMBL1418122 & 688673 & 6.7001 & 5.8785 & TRN & \\
\hline CHEMBL1522774 & 688673 & 6.2 & 5.9245 & TRN & \\
\hline CHEMBL1551190 & 688673 & 7.2503 & 5.6621 & TRN & \\
\hline CHEMBL1467776 & 688673 & 4.8 & 5.74299 & 9999999999 & TST \\
\hline CHEMBL1399009 & 688673 & 8.4949 & 5.8044 & TRN & \\
\hline CHEMBL1444335 & 688673 & 4.5 & 5.8111 & TRN & \\
\hline CHEMBL1356104 & 688673 & 8.2518 & 5.8121 & TRN & \\
\hline CHEMBL1544559 & 688673 & 5.0 & 5.67200 & 0000000001 & TRN \\
\hline CHEMBL1375686 & 688673 & 4.45 & 5.9836 & TRN & \\
\hline CHEMBL1323697 & 688673 & 5.5 & 6.0069 & TRN & \\
\hline CHEMBL1422646 & 688673 & 7.3002 & 5.6412 & TRN & \\
\hline CHEMBL1440725 & 688673 & 5.3 & 5.5891 & TRN & \\
\hline CHEMBL1440165 & 688673 & 4.7 & 5.6418 & TRN & \\
\hline CHEMBL3190647 & 688673 & 4.9 & 5.5278 & TRN & \\
\hline CHEMBL1387110 & 688673 & 4.9 & 5.2027 & TRN & \\
\hline CHEMBL1517555 & 688673 & 8.0 & 5.6674 & TST & \\
\hline CHEMBL1578313 & 688673 & 7.8996 & 5.4436 & TST & \\
\hline CHEMBL1365175 & 688673 & 4.6 & 5.859 & TRN & \\
\hline CHEMBL1499911 & 688673 & 4.9 & 5.6389 & TRN & \\
\hline CHEMBL1482116 & 688673 & 6.0 & 5.8298 & TRN & \\
\hline
\end{tabular}




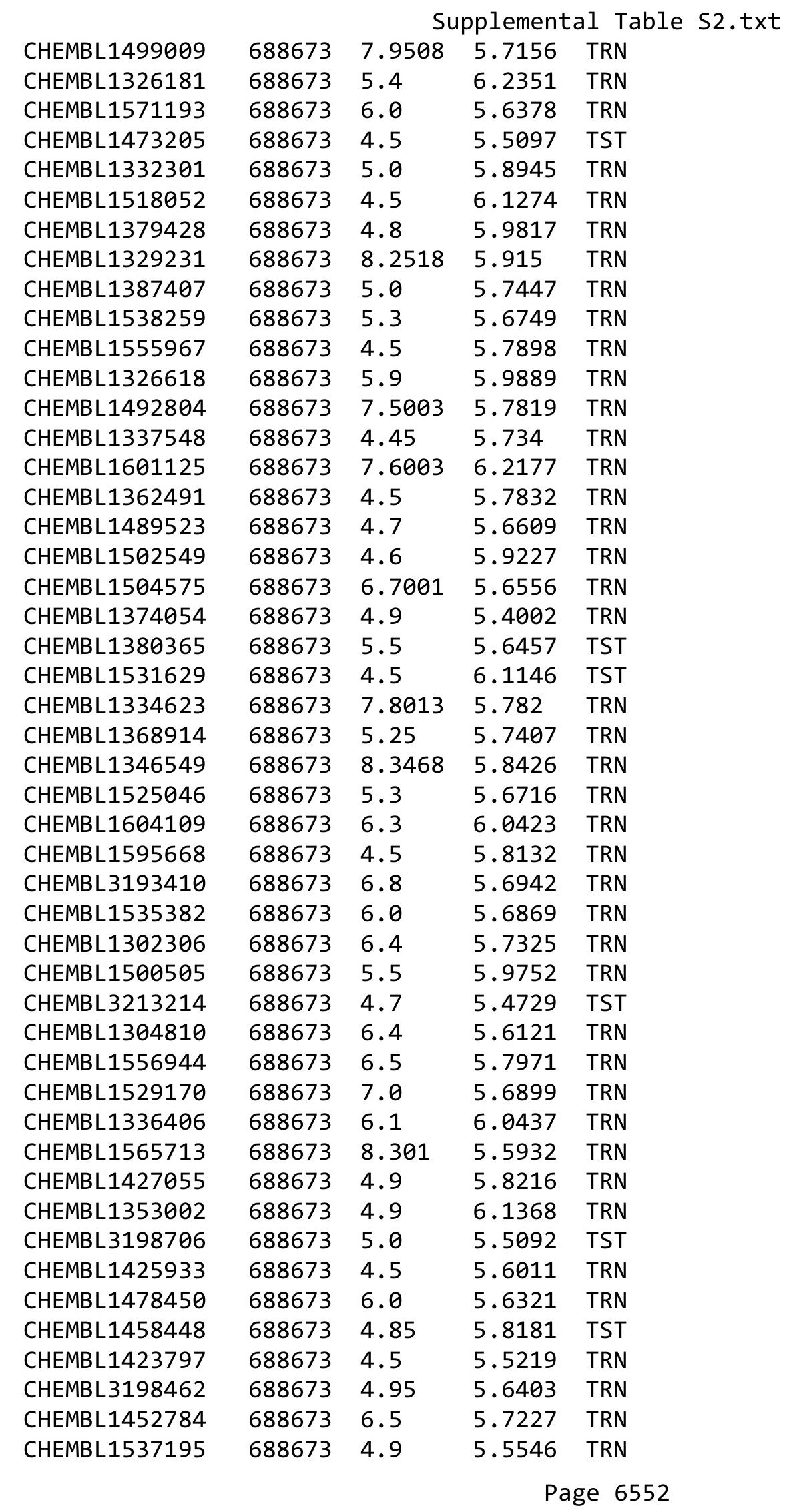




\begin{tabular}{|c|c|c|c|c|c|}
\hline \multicolumn{6}{|c|}{ Supplemental Table S2.txt } \\
\hline CHEMBL1491522 & 688673 & 5.2 & 5.8461 & TRN & \\
\hline CHEMBL1607059 & 688673 & 7.6003 & 5.7961 & TRN & \\
\hline CHEMBL1337427 & 688673 & 5.6 & 5.2037 & TST & \\
\hline CHEMBL1457879 & 688673 & 5.4 & 5.5459 & TRN & \\
\hline CHEMBL1579442 & 688673 & 5.2 & 6.0448 & TRN & \\
\hline CHEMBL1311532 & 688673 & 4.5 & 5.7158 & TRN & \\
\hline CHEMBL1443975 & 688673 & 6.5 & 5.6924 & TRN & \\
\hline CHEMBL1307189 & 688673 & 5.2 & 5.8975 & TRN & \\
\hline CHEMBL1607687 & 688673 & 5.5 & 5.4641 & TST & \\
\hline CHEMBL1536779 & 688673 & 5.5 & 5.5756 & TRN & \\
\hline CHEMBL1406994 & 688673 & 5.2 & 5.7885 & TST & \\
\hline CHEMBL1532247 & 688673 & 5.2 & 5.5616 & TRN & \\
\hline CHEMBL1523980 & 688673 & 7.2 & 5.8048 & TRN & \\
\hline CHEMBL1523705 & 688673 & 4.5 & 6.0118 & TRN & \\
\hline CHEMBL1306468 & 688673 & 6.2 & 5.9251 & TRN & \\
\hline CHEMBL1607110 & 688673 & 6.8499 & 6.1287 & TRN & \\
\hline CHEMBL1589538 & 688673 & 5.85 & 6.1788 & TRN & \\
\hline CHEMBL1558761 & 688673 & 4.9 & 5.8312 & TRN & \\
\hline CHEMBL1581265 & 688673 & 5.3 & 5.8665 & TRN & \\
\hline CHEMBL1339717 & 688673 & 4.65 & 5.6164 & TRN & \\
\hline CHEMBL1533684 & 688673 & 6.6 & 6.0269 & TRN & \\
\hline CHEMBL1453703 & 688673 & 5.3 & 5.9894 & TRN & \\
\hline CHEMBL1350082 & 688673 & 8.2007 & 6.1489 & TRN & \\
\hline CHEMBL1318493 & 688673 & 6.45 & 5.465 & TRN & \\
\hline CHEMBL1557484 & 688673 & 6.8 & 5.6738 & TRN & \\
\hline CHEMBL1599168 & 688673 & 4.45 & 5.6458 & TRN & \\
\hline CHEMBL1359366 & 688673 & 5.0 & 5.8308 & TRN & \\
\hline CHEMBL1314039 & 688673 & 4.5 & 5.7565 & TRN & \\
\hline CHEMBL1466772 & 688673 & 4.9 & 5.8698 & TRN & \\
\hline CHEMBL1366213 & 688673 & 5.25 & 5.6769 & TRN & \\
\hline CHEMBL1334528 & 688673 & 5.4 & 5.5024 & TRN & \\
\hline CHEMBL1588593 & 688673 & 7.699 & 5.8011 & TRN & \\
\hline CHEMBL1588098 & 688673 & 6.9 & 6.029 & TRN & \\
\hline CHEMBL1605540 & 688673 & 6.0 & 5.7397 & TRN & \\
\hline CHEMBL1486674 & 688673 & 6.8499 & 6.1567 & TRN & \\
\hline CHEMBL1383332 & 688673 & 7.5003 & 5.4264 & TRN & \\
\hline CHEMBL1335254 & 688673 & 5.0 & 5.7011 & TRN & \\
\hline CHEMBL1303714 & 688673 & 5.0 & 5.9276 & TRN & \\
\hline CHEMBL1505931 & 688673 & 4.6 & 5.2379 & TRN & \\
\hline CHEMBL1427100 & 688673 & 6.0 & 5.8612 & TRN & \\
\hline CHEMBL1465983 & 688673 & 7.6498 & 5.8719 & TRN & \\
\hline CHEMBL1530959 & 688673 & 4.9 & 5.5201 & TRN & \\
\hline CHEMBL1335568 & 688673 & 6.2 & 6.08700 & 0000000001 & TRN \\
\hline CHEMBL530291 & 688673 & 5.4 & 5.9359 & TST & \\
\hline CHEMBL 2006909 & 688673 & 8.0 & 5.3303 & TST & \\
\hline CHEMBL1572912 & 688673 & 6.1 & 5.83 & TRN & \\
\hline CHEMBL1401786 & 688673 & 5.2 & 5.7313 & TRN & \\
\hline CHEMBL1538753 & 688673 & 6.7001 & 5.4383 & TRN & \\
\hline
\end{tabular}




\begin{tabular}{|c|c|c|c|c|c|}
\hline \multirow{3}{*}{$\begin{array}{l}\text { CHEMBL1382978 } \\
\text { CHEMBL1521004 }\end{array}$} & \multirow{3}{*}{$\begin{array}{l}688673 \\
688673\end{array}$} & \multicolumn{4}{|c|}{ Supplemental Table S2.txt } \\
\hline & & 6.45 & \multicolumn{2}{|c|}{5.696000000000001} & TRN \\
\hline & & 4.9 & 5.6765 & TRN & \\
\hline CHEMBL1330443 & 688673 & 4.7 & 5.7971 & TRN & \\
\hline CHEMBL1607889 & 688673 & 7.2503 & 5.7573 & TRN & \\
\hline CHEMBL1607445 & 688673 & 4.5 & 5.6146 & TRN & \\
\hline CHEMBL1331145 & 688673 & 7.699 & 5.9232 & TRN & \\
\hline CHEMBL1400549 & 688673 & 5.0 & 5.7557 & TRN & \\
\hline CHEMBL1363989 & 688673 & 5.0 & 5.4554 & TRN & \\
\hline CHEMBL1528235 & 688673 & 5.7 & 5.6928 & TRN & \\
\hline CHEMBL1443559 & 688673 & 5.4 & 5.5144 & TST & \\
\hline CHEMBL1347013 & 688673 & 7.8013 & 5.9235 & TST & \\
\hline CHEMBL427449 & 688673 & 6.7001 & 5.8151 & TRN & \\
\hline CHEMBL1464890 & 688673 & 8.3468 & 5.9242 & TRN & \\
\hline CHEMBL1300256 & 688673 & 6.8 & 5.9442 & TRN & \\
\hline CHEMBL1435318 & 688673 & 4.9 & 5.4251 & TRN & \\
\hline CHEMBL1388715 & 688673 & 6.3 & 5.8199 & TRN & \\
\hline CHEMBL1414686 & 688673 & 5.45 & 5.3389 & TRN & \\
\hline CHEMBL394821 & 688673 & 6.7001 & 5.9096 & TRN & \\
\hline CHEMBL1359483 & 688673 & 8.0 & 6.0306 & TRN & \\
\hline CHEMBL1415759 & 688673 & 4.5 & 5.7046 & TRN & \\
\hline CHEMBL1323531 & 688673 & 6.1 & 5.5958 & TRN & \\
\hline CHEMBL1466580 & 688673 & 4.8 & 5.4191 & TRN & \\
\hline CHEMBL1344850 & 688673 & 7.5003 & 5.7799 & TST & \\
\hline CHEMBL1578543 & 688673 & 6.2 & 5.8225 & TRN & \\
\hline CHEMBL1494835 & 688673 & 5.25 & 5.75200 & 0000000001 & TRN \\
\hline CHEMBL1311728 & 688673 & 7.6003 & 5.8757 & TRN & \\
\hline CHEMBL1346978 & 688673 & 7.5003 & 5.9234 & TRN & \\
\hline CHEMBL1591093 & 688673 & 6.1 & 5.6953 & TRN & \\
\hline CHEMBL1558271 & 688673 & 6.7001 & 5.6957 & TRN & \\
\hline CHEMBL1371345 & 688673 & 4.5 & 5.3344 & TRN & \\
\hline CHEMBL1525421 & 688673 & 4.5 & 5.8446 & TRN & \\
\hline CHEMBL1383038 & 688673 & 5.0 & 5.6566 & TST & \\
\hline CHEMBL1531123 & 688673 & 8.0 & 5.5335 & TRN & \\
\hline CHEMBL1377425 & 688673 & 6.1 & 5.8353 & TRN & \\
\hline CHEMBL1605151 & 688673 & 8.301 & 5.8866 & TRN & \\
\hline CHEMBL1492008 & 688673 & 7.6003 & 5.9146 & TRN & \\
\hline CHEMBL1483885 & 688673 & 4.6 & 5.7155 & TRN & \\
\hline CHEMBL1478922 & 688673 & 4.9 & 5.8143 & TRN & \\
\hline CHEMBL1386516 & 688673 & 4.85 & 5.6908 & TRN & \\
\hline CHEMBL1468950 & 688673 & 5.9 & 5.7459 & TRN & \\
\hline CHEMBL1503124 & 688673 & 4.6 & 5.66200 & 2000000001 & TRN \\
\hline CHEMBL1572440 & 688673 & 7.0 & 5.9094 & TRN & \\
\hline CHEMBL1338478 & 688673 & 6.6 & 6.0506 & TRN & \\
\hline CHEMBL1543627 & 688673 & 4.7 & 5.6362 & TRN & \\
\hline CHEMBL1559233 & 688673 & 7.0 & 6.1189 & TRN & \\
\hline CHEMBL1310061 & 688673 & 7.0 & 5.9397 & TRN & \\
\hline CHEMBL1464517 & 688673 & 5.0 & 5.6805 & TRN & \\
\hline CHEMBL316992 & 688673 & 4.65 & 5.4429 & TRN & \\
\hline
\end{tabular}




\begin{tabular}{|c|c|c|c|c|c|}
\hline CHEMBL1587683 & 688673 & 4.9 & \multicolumn{2}{|c|}{5.4079999999999995} & TRN \\
\hline CHEMBL1564478 & 688673 & 4.8 & 5.6218 & TRN & \\
\hline CHEMBL1429456 & 688673 & 6.9 & 5.669 & TRN & \\
\hline CHEMBL1370060 & 688673 & 8.0 & 5.6089 & TRN & \\
\hline CHEMBL1374862 & 688673 & 8.1024 & 5.6252 & TST & \\
\hline CHEMBL1430274 & 688673 & 7.8013 & 5.48 & TST & \\
\hline CHEMBL1520893 & 688673 & 7.3002 & 5.987 & TRN & \\
\hline CHEMBL1468546 & 688673 & 6.9 & 5.9017 & TRN & \\
\hline CHEMBL1317796 & 688673 & 8.301 & 6.0417 & TRN & \\
\hline CHEMBL1378073 & 688673 & 4.6 & 5.7108 & TRN & \\
\hline CHEMBL1549400 & 688673 & 6.8 & 5.7198 & TST & \\
\hline CHEMBL1271075 & 688673 & 4.6 & 5.3654 & TRN & \\
\hline CHEMBL1306180 & 688673 & 4.5 & 5.8649 & TRN & \\
\hline CHEMBL1419499 & 688673 & 4.7 & \multicolumn{2}{|c|}{5.747999999999999} & TRN \\
\hline CHEMBL1612898 & 688673 & 4.5 & 5.6012 & TRN & \\
\hline CHEMBL1570597 & 688673 & 4.5 & 5.2325 & TRN & \\
\hline CHEMBL1324582 & 688673 & 4.9 & 5.8917 & TRN & \\
\hline CHEMBL1611886 & 688673 & 4.95 & 5.5016 & TRN & \\
\hline CHEMBL1330223 & 688673 & 6.7501 & 5.3162 & TRN & \\
\hline CHEMBL1537859 & 688673 & 5.2 & 6.0267 & TRN & \\
\hline CHEMBL1590011 & 688673 & 4.65 & 5.3959 & TRN & \\
\hline CHEMBL1348393 & 688673 & 4.9 & 5.8346 & TRN & \\
\hline CHEMBL1483773 & 688673 & 4.5 & 5.6573 & TRN & \\
\hline CHEMBL1487283 & 688673 & 4.5 & 6.0535 & TRN & \\
\hline CHEMBL1313351 & 688673 & 6.2 & 5.9423 & TRN & \\
\hline CHEMBL1577704 & 688673 & 6.1 & 5.5718 & TRN & \\
\hline CHEMBL1383589 & 688673 & 7.6003 & 5.864 & TRN & \\
\hline CHEMBL1300784 & 688673 & 7.5003 & 5.8854 & TRN & \\
\hline CHEMBL1452536 & 688673 & 4.55 & 5.5761 & TRN & \\
\hline CHEMBL1540912 & 688673 & 4.9 & 5.5134 & TRN & \\
\hline CHEMBL1571331 & 688673 & 4.5 & 5.7097 & TRN & \\
\hline CHEMBL1600075 & 688673 & 4.7 & 6.1665 & TRN & \\
\hline CHEMBL1310857 & 688673 & 4.75 & 5.3982 & TRN & \\
\hline CHEMBL1317317 & 688673 & 4.95 & 5.6224 & TRN & \\
\hline CHEMBL1448566 & 688673 & 6.1 & 5.5738 & TRN & \\
\hline CHEMBL1453935 & 688673 & 6.8 & 5.7249 & TRN & \\
\hline CHEMBL1463644 & 688673 & 4.7 & 6.0404 & TRN & \\
\hline CHEMBL1421058 & 688673 & 7.9508 & 5.5618 & TRN & \\
\hline CHEMBL1411680 & 688673 & 4.5 & 5.6561 & TRN & \\
\hline CHEMBL1511223 & 688673 & 5.5 & 5.5002 & TRN & \\
\hline CHEMBL1332037 & 688673 & 6.7001 & 5.8147 & TRN & \\
\hline CHEMBL1353162 & 688673 & 5.5 & 5.7059 & TST & \\
\hline CHEMBL1591017 & 688673 & 5.25 & 5.3092 & TRN & \\
\hline CHEMBL3210243 & 688673 & 6.7001 & 5.2498 & TST & \\
\hline CHEMBL555689 & 688673 & 4.7 & 5.461 & TRN & \\
\hline CHEMBL1607011 & 688673 & 4.9 & 5.9256 & TRN & \\
\hline CHEMBL1453602 & 688673 & 7.0501 & 5.6076 & TRN & \\
\hline CHEMBL1427637 & 688673 & 4.9 & 5.7235 & TST & \\
\hline
\end{tabular}




\begin{tabular}{|c|c|c|c|c|c|}
\hline \\
\hline CHEMBL1304148 & 688673 & 5.8 & 6.0398 & TST & \\
\hline CHEMBL1610836 & 688673 & 5.45 & 5.5495 & TRN & \\
\hline CHEMBL1557517 & 688673 & 5.6 & 5.5212 & TST & \\
\hline CHEMBL 3189880 & 688673 & 6.1 & 5.4323 & TRN & \\
\hline CHEMBL1394014 & 688673 & 4.45 & 5.50200 & 0000000001 & TRN \\
\hline CHEMBL1603304 & 688673 & 5.2 & 5.9165 & TRN & \\
\hline CHEMBL1485848 & 688673 & 5.0 & 5.8107 & TRN & \\
\hline CHEMBL1084955 & 688673 & 4.75 & 5.3173 & TRN & \\
\hline CHEMBL1472927 & 688673 & 8.3468 & 5.7438 & TRN & \\
\hline CHEMBL1419263 & 688673 & 6.4 & 5.9833 & TRN & \\
\hline CHEMBL1563270 & 688673 & 7.8996 & 6.0256 & TRN & \\
\hline CHEMBL1490735 & 688673 & 6.5 & 5.6317 & TST & \\
\hline CHEMBL1532156 & 688673 & 4.8 & 5.98 & TRN & \\
\hline CHEMBL1496828 & 688673 & 4.5 & 5.7953 & TRN & \\
\hline CHEMBL600523 & 688673 & 6.3 & 5.5655 & TRN & \\
\hline CHEMBL1324242 & 688673 & 4.9 & 5.6332 & TRN & \\
\hline CHEMBL1311090 & 688673 & 4.95 & 5.7415 & TRN & \\
\hline CHEMBL1498110 & 688673 & 4.9 & 5.5735 & TRN & \\
\hline CHEMBL1335713 & 688673 & 5.8 & 5.9068 & TRN & \\
\hline CHEMBL1450221 & 688673 & 6.8499 & 5.9555 & TRN & \\
\hline CHEMBL1566031 & 688673 & 4.9 & 5.6795 & TRN & \\
\hline CHEMBL1412352 & 688673 & 4.8 & 6.0481 & TRN & \\
\hline CHEMBL1543602 & 688673 & 7.0 & 5.9345 & TRN & \\
\hline CHEMBL1389323 & 688673 & 5.3 & 5.9525 & TRN & \\
\hline CHEMBL1545211 & 688673 & 6.5 & 5.7972 & TRN & \\
\hline CHEMBL1352674 & 688673 & 5.6 & 5.6548 & TRN & \\
\hline CHEMBL1212955 & 688673 & 6.3 & 5.7266 & TRN & \\
\hline CHEMBL1511400 & 688673 & 7.6003 & 5.9459 & TRN & \\
\hline CHEMBL1480232 & 688673 & 5.25 & 6.0347 & TRN & \\
\hline CHEMBL1525026 & 688673 & 4.5 & 5.5468 & TRN & \\
\hline CHEMBL1481586 & 688673 & 4.45 & 5.7663 & TRN & \\
\hline CHEMBL1441597 & 688673 & 6.8499 & 5.7284 & TRN & \\
\hline CHEMBL1550254 & 688673 & 8.0 & 5.7902 & TRN & \\
\hline CHEMBL1401209 & 688673 & 4.8 & 5.5869 & TRN & \\
\hline CHEMBL1452082 & 688673 & 4.5 & 5.9025 & TRN & \\
\hline CHEMBL1523520 & 688673 & 5.6 & 5.6252 & TRN & \\
\hline CHEMBL1455806 & 688673 & 6.7001 & 5.5131 & TST & \\
\hline CHEMBL1389468 & 688673 & 4.5 & 5.7404 & TST & \\
\hline CHEMBL1388860 & 688673 & 4.9 & 5.5601 & TRN & \\
\hline CHEMBL1359136 & 688673 & 6.4 & 5.5205 & TRN & \\
\hline CHEMBL1585650 & 688673 & 5.1 & 5.9054 & TRN & \\
\hline CHEMBL1348730 & 688673 & 4.9 & 5.6191 & TRN & \\
\hline CHEMBL1572057 & 688673 & 6.8 & 5.9687 & TRN & \\
\hline CHEMBL1441615 & 688673 & 6.1 & 6.2121 & TRN & \\
\hline CHEMBL1316566 & 688673 & 8.4949 & 5.5244 & TRN & \\
\hline CHEMBL1537203 & 688673 & 4.5 & 6.154 & TRN & \\
\hline CHEMBL1559674 & 688673 & 6.1 & 5.6396 & TRN & \\
\hline CHEMBL1456451 & 688673 & 7.6003 & 5.8981 & TST & \\
\hline
\end{tabular}




\begin{tabular}{|c|c|c|c|c|c|}
\hline \multicolumn{6}{|c|}{ Supplemental Table s2.txt } \\
\hline CHEMBL1494735 & 688673 & 8.0 & 5.7034 & TRN & \\
\hline CHEMBL1301641 & 688673 & 6.4 & 5.8484 & TRN & \\
\hline CHEMBL1574498 & 688673 & 5.9 & 5.9686 & TRN & \\
\hline CHEMBL1423390 & 688673 & 7.6003 & 5.7753 & TRN & \\
\hline CHEMBL1564034 & 688673 & 6.1 & 5.5466 & TRN & \\
\hline CHEMBL1995336 & 688673 & 4.7 & 5.6024 & TRN & \\
\hline CHEMBL1448977 & 688673 & 5.2 & 5.7207 & TRN & \\
\hline CHEMBL1333258 & 688673 & 5.4 & 5.8522 & TST & \\
\hline CHEMBL1500448 & 688673 & 6.25 & 6.0724 & TRN & \\
\hline CHEMBL1339942 & 688673 & 5.3 & 5.8886 & TRN & \\
\hline CHEMBL1554534 & 688673 & 8.0506 & 5.8259 & TRN & \\
\hline CHEMBL1463721 & 688673 & 6.1 & 5.8046 & TST & \\
\hline CHEMBL1448517 & 688673 & 6.1 & 5.6139 & TRN & \\
\hline CHEMBL1323069 & 688673 & 7.699 & 5.9483 & TRN & \\
\hline CHEMBL1560301 & 688673 & 6.6499 & 5.5587 & TRN & \\
\hline CHEMBL1454966 & 688673 & 4.5 & 5.6431 & TRN & \\
\hline CHEMBL1605826 & 688673 & 4.9 & 5.6921 & TRN & \\
\hline CHEMBL1423097 & 688673 & 5.45 & 5.4331 & TRN & \\
\hline CHEMBL1399226 & 688673 & 6.1 & 5.8604 & TST & \\
\hline CHEMBL1453890 & 688673 & 4.45 & 5.8107 & TRN & \\
\hline CHEMBL1324756 & 688673 & 4.8 & 5.8159 & TRN & \\
\hline CHEMBL1570524 & 688673 & 4.95 & 5.7706 & TRN & \\
\hline CHEMBL1381093 & 688673 & 4.5 & 5.7442 & TRN & \\
\hline CHEMBL1526135 & 688673 & 4.65 & 5.6487 & TRN & \\
\hline CHEMBL1398772 & 688673 & 7.8996 & 5.7066 & TRN & \\
\hline CHEMBL1507331 & 688673 & 4.45 & 5.8954 & TST & \\
\hline CHEMBL1423657 & 688673 & 4.9 & 5.3523 & TRN & \\
\hline CHEMBL565812 & 688673 & 8.3468 & 5.7924 & TRN & \\
\hline CHEMBL1520640 & 688673 & 8.301 & 5.8869 & TST & \\
\hline CHEMBL1496092 & 688673 & 6.15 & 5.7815 & TRN & \\
\hline CHEMBL1422058 & 688673 & 6.0 & 5.7325 & TRN & \\
\hline CHEMBL1449305 & 688673 & 5.0 & 5.4367 & TRN & \\
\hline CHEMBL1536272 & 688673 & 4.7 & 5.6232 & TRN & \\
\hline CHEMBL1401021 & 688673 & 7.8508 & 5.88299 & 9999999999 & TRN \\
\hline CHEMBL1568496 & 688673 & 7.1002 & 5.73600 & 0000000001 & TRN \\
\hline CHEMBL41794 & 688673 & 4.45 & 5.8857 & TST & \\
\hline CHEMBL3199657 & 688673 & 5.2 & 5.6243 & TST & \\
\hline CHEMBL1609159 & 688673 & 7.5003 & 5.6329 & TRN & \\
\hline CHEMBL1428934 & 688673 & 4.7 & 6.0036 & TRN & \\
\hline CHEMBL1527476 & 688673 & 6.25 & 5.6216 & TRN & \\
\hline CHEMBL1438709 & 688673 & 4.6 & 5.8168 & TRN & \\
\hline CHEMBL1505844 & 688673 & 4.6 & 5.6698 & TRN & \\
\hline CHEMBL1348199 & 688673 & 4.5 & 5.82 & TRN & \\
\hline CHEMBL1417283 & 688673 & 4.5 & 5.5069 & TST & \\
\hline CHEMBL1497527 & 688673 & 7.5003 & 5.9429 & TRN & \\
\hline CHEMBL1578359 & 688673 & 5.2 & 5.9205 & TRN & \\
\hline CHEMBL1322292 & 688673 & 6.45 & 5.5199 & TRN & \\
\hline CHEMBL1573098 & 688673 & 4.9 & 5.807 & TRN & \\
\hline
\end{tabular}




\begin{tabular}{|c|c|c|c|c|c|}
\hline \multicolumn{6}{|c|}{ Supplemental Table S2.txt } \\
\hline CHEMBL3198595 & 688673 & 4.5 & 5.4775 & TRN & \\
\hline CHEMBL1558944 & 688673 & 8.4949 & 5.7849 & TRN & \\
\hline CHEMBL1527442 & 688673 & 6.3 & 5.6715 & TST & \\
\hline CHEMBL1377113 & 688673 & 6.8 & 5.6045 & TRN & \\
\hline CHEMBL1462380 & 688673 & 5.0 & 5.699 & TRN & \\
\hline CHEMBL1452943 & 688673 & 5.3 & 5.729 & TST & \\
\hline CHEMBL1308743 & 688673 & 4.45 & 5.7461 & TRN & \\
\hline CHEMBL1427586 & 688673 & 5.25 & 5.8856 & TRN & \\
\hline CHEMBL1451472 & 688673 & 5.4 & 5.7588 & TRN & \\
\hline CHEMBL1605550 & 688673 & 6.4 & 6.0949 & TRN & \\
\hline CHEMBL1336564 & 688673 & 4.9 & 5.7714 & TRN & \\
\hline CHEMBL3193916 & 688673 & 4.45 & 5.4114 & TRN & \\
\hline CHEMBL1549809 & 688673 & 6.7001 & 5.7567 & TST & \\
\hline CHEMBL 3213045 & 688673 & 5.4 & 5.9324 & TST & \\
\hline CHEMBL1450332 & 688673 & 5.4 & 5.6221 & TRN & \\
\hline CHEMBL1412538 & 688673 & 5.2 & 5.5665 & TRN & \\
\hline CHEMBL1371878 & 688673 & 5.55 & 5.6672 & TRN & \\
\hline CHEMBL1339718 & 688673 & 6.3 & 5.7029 & TRN & \\
\hline CHEMBL1445507 & 688673 & 5.5 & 5.4957 & TRN & \\
\hline CHEMBL1576244 & 688673 & 6.5 & 5.9989 & TRN & \\
\hline CHEMBL1591234 & 688673 & 5.55 & 5.8282 & TRN & \\
\hline CHEMBL1477471 & 688673 & 4.4 & 5.7259 & TRN & \\
\hline CHEMBL1363974 & 688673 & 4.5 & 5.7362 & TRN & \\
\hline CHEMBL1322929 & 688673 & 4.7 & 5.4897 & TRN & \\
\hline CHEMBL1558727 & 688673 & 5.6 & 5.5532 & TRN & \\
\hline CHEMBL3195741 & 688673 & 4.65 & 5.7355 & TRN & \\
\hline CHEMBL1562486 & 688673 & 5.9 & 5.8199 & TRN & \\
\hline CHEMBL1350515 & 688673 & 7.4001 & 5.8418 & TRN & \\
\hline CHEMBL1495414 & 688673 & 5.05 & 5.7701 & TRN & \\
\hline CHEMBL1439809 & 688673 & 5.4 & 5.7521 & TRN & \\
\hline CHEMBL1559107 & 688673 & 4.6 & 5.3562 & TRN & \\
\hline CHEMBL1539012 & 688673 & 6.0 & 5.7204 & TRN & \\
\hline CHEMBL 1460310 & 688673 & 4.7 & 5.6106 & TRN & \\
\hline CHEMBL1308079 & 688673 & 4.8 & 5.9929 & TRN & \\
\hline CHEMBL1319122 & 688673 & 5.1 & 6.03700 & 0000000001 & TRN \\
\hline CHEMBL1369303 & 688673 & 7.0 & 5.6999 & TRN & \\
\hline CHEMBL1602761 & 688673 & 4.6 & 6.0735 & TRN & \\
\hline CHEMBL1478927 & 688673 & 5.5 & 5.8821 & TRN & \\
\hline CHEMBL1310345 & 688673 & 5.0 & 5.8392 & TRN & \\
\hline CHEMBL1387379 & 688673 & 4.8 & 5.8618 & TRN & \\
\hline CHEMBL1330651 & 688673 & 5.9 & 5.9967 & TRN & \\
\hline CHEMBL1546871 & 688673 & 5.5 & 5.8607 & TRN & \\
\hline CHEMBL1528418 & 688673 & 4.5 & 5.729 & TRN & \\
\hline CHEMBL1490919 & 688673 & 4.9 & 5.4505 & TST & \\
\hline CHEMBL1313510 & 688673 & 5.0 & 5.4651 & TRN & \\
\hline CHEMBL1456128 & 688673 & 4.9 & 5.8088 & TRN & \\
\hline CHEMBL1446912 & 688673 & 6.7001 & 5.9424 & TRN & \\
\hline CHEMBL1556666 & 688673 & 4.6 & 5.6565 & TRN & \\
\hline
\end{tabular}




\begin{tabular}{|c|c|c|c|c|c|}
\hline \multicolumn{6}{|c|}{ Supplemental Table S2.txt } \\
\hline CHEMBL1457309 & 688673 & 4.5 & 5.6033 & TRN & \\
\hline CHEMBL1356829 & 688673 & 4.5 & 5.7388 & TRN & \\
\hline CHEMBL1363952 & 688673 & 5.4 & 6.0755 & TRN & \\
\hline CHEMBL1391566 & 688673 & 4.95 & 5.7215 & TRN & \\
\hline CHEMBL1413025 & 688673 & 7.5003 & 5.7478 & TST & \\
\hline CHEMBL1597594 & 688673 & 6.15 & 5.62 & TRN & \\
\hline CHEMBL1359675 & 688673 & 5.9 & 5.4314 & TRN & \\
\hline CHEMBL1583724 & 688673 & 5.4 & 6.0208 & TRN & \\
\hline CHEMBL1331799 & 688673 & 5.25 & 5.5443 & TRN & \\
\hline CHEMBL1392973 & 688673 & 4.8 & 5.8833 & TRN & \\
\hline CHEMBL1532558 & 688673 & 5.5 & 5.6331 & TRN & \\
\hline CHEMBL1530386 & 688673 & 4.8 & 5.7825 & TRN & \\
\hline CHEMBL1305285 & 688673 & 4.9 & 5.33700 & 3000000001 & TRN \\
\hline CHEMBL1589556 & 688673 & 7.2 & 5.775 & TRN & \\
\hline CHEMBL1375899 & 688673 & 6.2 & 5.8079 & TRN & \\
\hline CHEMBL1303795 & 688673 & 7.1002 & 5.894 & TRN & \\
\hline CHEMBL1448568 & 688673 & 6.0 & 5.8901 & TST & \\
\hline CHEMBL1401079 & 688673 & 4.6 & 6.0203 & TRN & \\
\hline CHEMBL1409216 & 688673 & 4.45 & 5.5731 & TRN & \\
\hline CHEMBL1425046 & 688673 & 5.2 & 5.317 & TRN & \\
\hline CHEMBL3214217 & 688673 & 4.5 & 5.9969 & TRN & \\
\hline CHEMBL1359905 & 688673 & 5.25 & 5.6319 & TRN & \\
\hline CHEMBL1332745 & 688673 & 5.55 & 5.9713 & TRN & \\
\hline CHEMBL1324498 & 688673 & 4.5 & 5.6867 & TRN & \\
\hline CHEMBL1491984 & 688673 & 6.2 & 5.6698 & TRN & \\
\hline CHEMBL1546744 & 688673 & 5.5 & 5.9505 & TRN & \\
\hline CHEMBL1399698 & 688673 & 6.0 & 5.3765 & TST & \\
\hline CHEMBL1368428 & 688673 & 4.9 & 5.6004 & TRN & \\
\hline CHEMBL1377460 & 688673 & 6.6499 & 5.6747 & TRN & \\
\hline CHEMBL1458226 & 688673 & 5.1 & 5.6487 & TRN & \\
\hline CHEMBL1479296 & 688673 & 6.2 & 5.5002 & TRN & \\
\hline CHEMBL1378298 & 688673 & 7.3002 & 5.4711 & TRN & \\
\hline CHEMBL1530371 & 688673 & 4.5 & 5.7281 & TRN & \\
\hline CHEMBL1464874 & 688673 & 6.9 & 5.7366 & TRN & \\
\hline CHEMBL1416213 & 688673 & 4.9 & 5.455 & TRN & \\
\hline CHEMBL1341047 & 688673 & 8.0 & 6.09399 & 9999999999 & TRN \\
\hline CHEMBL1427155 & 688673 & 5.5 & 5.5829 & TRN & \\
\hline CHEMBL1402874 & 688673 & 4.8 & 5.4908 & TRN & \\
\hline CHEMBL1350998 & 688673 & 4.7 & 5.8418 & TST & \\
\hline CHEMBL1492024 & 688673 & 5.4 & 5.5321 & TRN & \\
\hline CHEMBL1307671 & 688673 & 7.3002 & 5.6099 & TRN & \\
\hline CHEMBL1384226 & 688673 & 7.0 & 5.8578 & TST & \\
\hline CHEMBL1571881 & 688673 & 4.6 & 5.5367 & TRN & \\
\hline CHEMBL1342111 & 688673 & 7.6003 & 5.8196 & TRN & \\
\hline CHEMBL1340874 & 688673 & 4.8 & 5.7915 & TST & \\
\hline CHEMBL1500994 & 688673 & 5.9 & 5.7686 & TRN & \\
\hline CHEMBL1420874 & 688673 & 4.8 & 5.8372 & TRN & \\
\hline CHEMBL1498790 & 688673 & 5.5 & 5.7053 & TRN & \\
\hline
\end{tabular}




\begin{tabular}{|c|c|c|c|c|c|}
\hline \\
\hline CHEMBL1301207 & 688673 & 4.5 & 5.9729 & TRN & \\
\hline CHEMBL1338375 & 688673 & 6.1 & 5.541 & TRN & \\
\hline CHEMBL1366024 & 688673 & 5.3 & 5.6492 & TRN & \\
\hline CHEMBL1355956 & 688673 & 5.5 & 5.6863 & TRN & \\
\hline CHEMBL1471182 & 688673 & 5.45 & 5.9916 & TRN & \\
\hline CHEMBL1507076 & 688673 & 5.3 & 5.4146 & TRN & \\
\hline CHEMBL1482973 & 688673 & 4.9 & 6.2182 & TRN & \\
\hline CHEMBL1353000 & 688673 & 5.25 & 5.972 & TRN & \\
\hline CHEMBL1583740 & 688673 & 6.5 & 5.8845 & TRN & \\
\hline CHEMBL1332221 & 688673 & 6.9 & 5.7941 & TRN & \\
\hline CHEMBL1485271 & 688673 & 6.6499 & 5.7312 & TRN & \\
\hline CHEMBL1486186 & 688673 & 4.6 & 5.6712 & TRN & \\
\hline CHEMBL1344853 & 688673 & 6.1 & 5.7163 & TRN & \\
\hline CHEMBL1606807 & 688673 & 5.65 & 6.0895 & TRN & \\
\hline CHEMBL1527258 & 688673 & 5.0 & 5.57299 & 99999999995 & TRN \\
\hline CHEMBL1339297 & 688673 & 6.0 & 5.5152 & TRN & \\
\hline CHEMBL1428221 & 688673 & 6.8 & 5.5215 & TST & \\
\hline CHEMBL1467863 & 688673 & 5.8 & 5.532 & TRN & \\
\hline CHEMBL1598249 & 688673 & 4.5 & 5.5364 & TRN & \\
\hline CHEMBL1507021 & 688673 & 5.5 & 5.6491 & TST & \\
\hline CHEMBL1528032 & 688673 & 4.6 & 5.6982 & TRN & \\
\hline CHEMBL1547415 & 688673 & 7.0 & 6.0669 & TRN & \\
\hline CHEMBL1399912 & 688673 & 4.5 & 5.6041 & TRN & \\
\hline CHEMBL1361124 & 688673 & 6.6 & 5.8211 & TRN & \\
\hline CHEMBL1486102 & 688673 & 4.95 & 5.4335 & TRN & \\
\hline CHEMBL1429643 & 688673 & 5.9 & 5.5564 & TST & \\
\hline CHEMBL1609398 & 688673 & 7.1002 & 6.0242 & TRN & \\
\hline CHEMBL1508830 & 688673 & 6.05 & 5.8196 & TRN & \\
\hline CHEMBL1417970 & 688673 & 4.7 & 5.6631 & TRN & \\
\hline CHEMBL1416968 & 688673 & 4.5 & 5.8184 & TRN & \\
\hline CHEMBL1469759 & 688673 & 7.2 & 6.0551 & TRN & \\
\hline CHEMBL1454587 & 688673 & 7.699 & 5.9061 & TRN & \\
\hline CHEMBL1384919 & 688673 & 5.3 & 5.4077 & TST & \\
\hline CHEMBL1480642 & 688673 & 6.1 & 5.5934 & TRN & \\
\hline CHEMBL1599625 & 688673 & 4.5 & 5.7036 & TRN & \\
\hline CHEMBL1357432 & 688673 & 7.8508 & 5.5459 & TRN & \\
\hline CHEMBL1303810 & 688673 & 4.6 & 5.6256 & TRN & \\
\hline CHEMBL1468599 & 688673 & 4.9 & 5.6062 & TRN & \\
\hline CHEMBL1609279 & 688673 & 4.9 & 5.8049 & TRN & \\
\hline CHEMBL1520704 & 688673 & 4.9 & 5.4804 & TRN & \\
\hline CHEMBL1584015 & 688673 & 6.2 & 5.598 & TRN & \\
\hline CHEMBL1581703 & 688673 & 5.0 & 5.6805 & TRN & \\
\hline CHEMBL1613407 & 688673 & 5.2 & 5.88899 & 9999999999 & TRN \\
\hline CHEMBL1314769 & 688673 & 6.05 & 5.8382 & TRN & \\
\hline CHEMBL1561641 & 688673 & 4.9 & 5.4846 & TRN & \\
\hline CHEMBL1430906 & 688673 & 4.5 & 5.7827 & TRN & \\
\hline CHEMBL1536625 & 688673 & 6.2 & 5.716 & TRN & \\
\hline CHEMBL1309230 & 688673 & 6.95 & 5.9694 & TRN & \\
\hline
\end{tabular}




\begin{tabular}{|c|c|c|c|c|c|}
\hline \multicolumn{6}{|c|}{ Supplemental Table S2.txt } \\
\hline CHEMBL3193785 & 688673 & 5.0 & 5.5626 & TST & \\
\hline CHEMBL1472055 & 688673 & 7.6003 & 5.869 & TRN & \\
\hline CHEMBL1553703 & 688673 & 5.25 & 5.3678 & TRN & \\
\hline CHEMBL1573419 & 688673 & 5.1 & 5.7823 & TRN & \\
\hline CHEMBL1468543 & 688673 & 7.699 & 5.6725 & TRN & \\
\hline CHEMBL1558141 & 688673 & 7.3002 & 5.8056 & TRN & \\
\hline CHEMBL1408165 & 688673 & 8.3468 & 6.2588 & TRN & \\
\hline CHEMBL1332426 & 688673 & 5.4 & 6.1845 & TRN & \\
\hline CHEMBL1449677 & 688673 & 7.8508 & 5.5905 & TST & \\
\hline CHEMBL1540658 & 688673 & 6.7001 & 5.7072 & TRN & \\
\hline CHEMBL1584468 & 688673 & 5.5 & 5.7763 & TRN & \\
\hline CHEMBL1500321 & 688673 & 4.6 & 5.7976 & TRN & \\
\hline CHEMBL1540708 & 688673 & 5.0 & 5.59200 & 00000000005 & TRN \\
\hline CHEMBL1343460 & 688673 & 7.2 & 5.574 & TST & \\
\hline CHEMBL1437710 & 688673 & 5.3 & 5.8869 & TRN & \\
\hline CHEMBL1361357 & 688673 & 5.9 & 5.7852 & TST & \\
\hline CHEMBL1608710 & 688673 & 4.65 & 5.4714 & TRN & \\
\hline CHEMBL1501453 & 688673 & 7.8996 & 5.7114 & TST & \\
\hline CHEMBL1344977 & 688673 & 7.5003 & 5.9406 & TST & \\
\hline CHEMBL1334332 & 688673 & 4.5 & 5.6356 & TRN & \\
\hline CHEMBL1573867 & 688673 & 4.9 & 5.4831 & TRN & \\
\hline CHEMBL1441304 & 688673 & 7.8013 & 5.1422 & TST & \\
\hline CHEMBL1530281 & 688673 & 5.5 & 5.6293 & TRN & \\
\hline CHEMBL1497117 & 688673 & 5.2 & 5.8856 & TRN & \\
\hline CHEMBL1500517 & 688673 & 5.5 & 5.9886 & TRN & \\
\hline CHEMBL1525398 & 688673 & 8.0 & 5.4162 & TRN & \\
\hline CHEMBL1609915 & 688673 & 4.45 & 5.7942 & TST & \\
\hline CHEMBL1364874 & 688673 & 4.45 & 6.0659 & TRN & \\
\hline CHEMBL1397215 & 688673 & 4.45 & 5.3983 & TRN & \\
\hline CHEMBL1516895 & 688673 & 7.0501 & 5.7833 & TRN & \\
\hline CHEMBL1578625 & 688673 & 5.5 & 5.8076 & TRN & \\
\hline CHEMBL1426223 & 688673 & 7.3002 & 5.5436 & TST & \\
\hline CHEMBL1374729 & 688673 & 5.5 & 5.5381 & TST & \\
\hline CHEMBL1504314 & 688673 & 6.0 & 5.7298 & TRN & \\
\hline CHEMBL1382052 & 688673 & 7.6003 & 5.7947 & TRN & \\
\hline CHEMBL1382991 & 688673 & 7.3002 & 5.6622 & TST & \\
\hline CHEMBL1407196 & 688673 & 5.5 & 5.9756 & TRN & \\
\hline CHEMBL1339928 & 688673 & 4.45 & 5.5065 & TRN & \\
\hline CHEMBL1601124 & 688673 & 4.45 & 5.9834 & TRN & \\
\hline CHEMBL1493472 & 688673 & 5.8 & 5.7964 & TRN & \\
\hline CHEMBL1446306 & 688673 & 5.0 & 5.7708 & TRN & \\
\hline CHEMBL1346037 & 688673 & 4.95 & 5.2461 & TRN & \\
\hline CHEMBL1489692 & 688673 & 8.2007 & 5.8378 & TRN & \\
\hline CHEMBL1355090 & 688673 & 4.5 & 5.686 & TST & \\
\hline CHEMBL1438608 & 688673 & 6.4 & 5.6763 & TRN & \\
\hline CHEMBL1500969 & 688673 & 7.8508 & 5.6992 & TRN & \\
\hline CHEMBL1437867 & 688673 & 7.3002 & 5.8973 & TRN & \\
\hline CHEMBL1337428 & 688673 & 4.5 & 5.7742 & TRN & \\
\hline
\end{tabular}




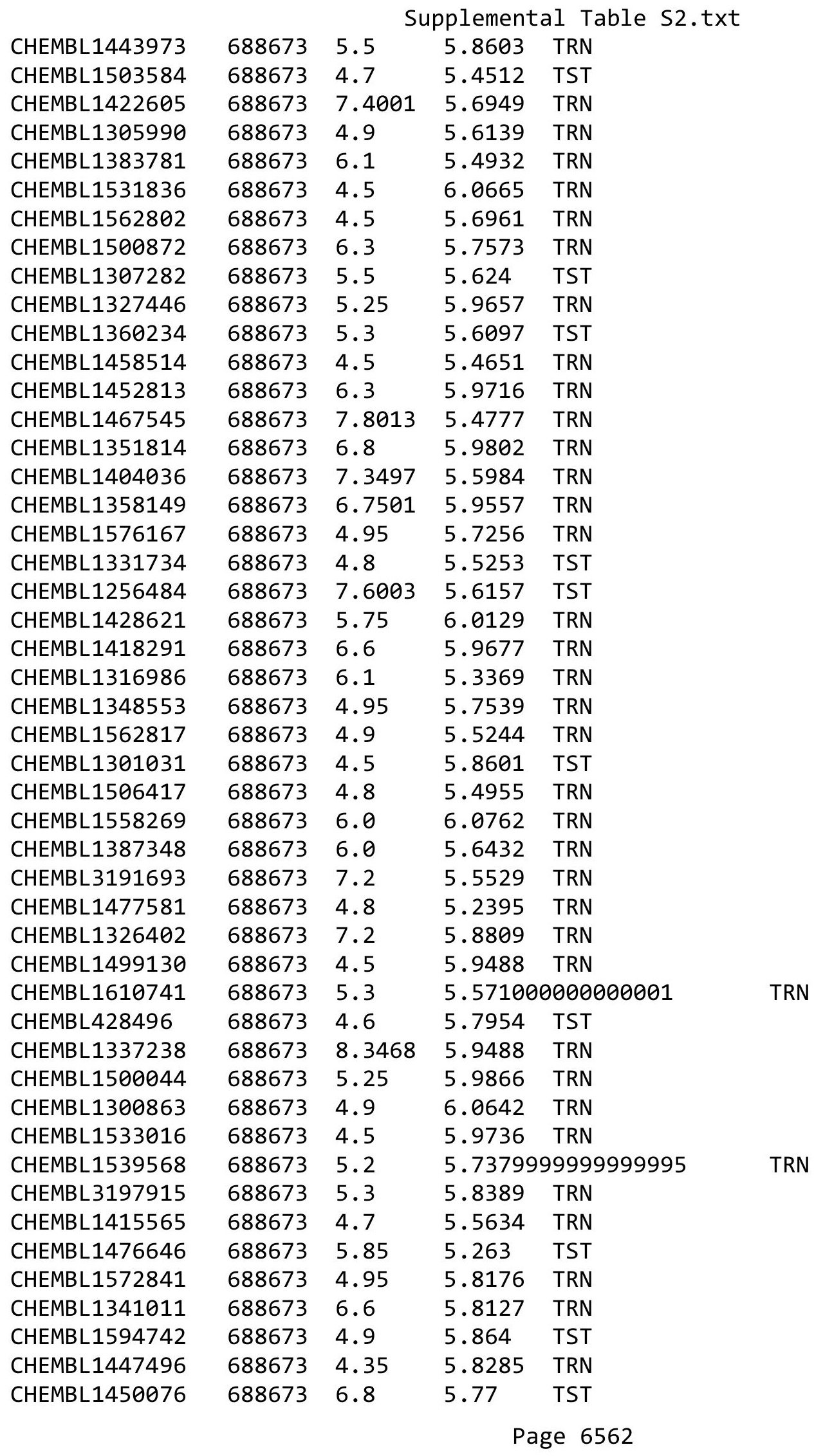




\begin{tabular}{|c|c|c|c|c|}
\hline \multicolumn{5}{|c|}{ Supplemental Table S2.txt } \\
\hline CHEMBL1494627 & 688673 & 4.6 & 5.7619 & TST \\
\hline CHEMBL1566928 & 688673 & 4.7 & 5.4793 & TST \\
\hline CHEMBL1461279 & 688673 & 6.2 & 5.4639 & TRN \\
\hline CHEMBL1562921 & 688673 & 6.7001 & 5.769 & TST \\
\hline CHEMBL1561617 & 688673 & 5.65 & 5.4444 & TRN \\
\hline CHEMBL1544039 & 688673 & 5.7 & 6.0043 & TRN \\
\hline CHEMBL1609146 & 688673 & 4.7 & 5.5485 & TRN \\
\hline CHEMBL1562262 & 688673 & 5.0 & 5.6444 & TRN \\
\hline CHEMBL1468601 & 688673 & 4.6 & 5.2388 & TRN \\
\hline CHEMBL1541014 & 688673 & 7.2503 & 5.9635 & TRN \\
\hline CHEMBL1464399 & 688673 & 4.7 & 5.4548 & TRN \\
\hline CHEMBL1255578 & 688673 & 4.7 & 5.8273 & TST \\
\hline CHEMBL 74913 & 688673 & 4.7 & 5.3628 & TRN \\
\hline CHEMBL1313891 & 688673 & 4.8 & 5.7379 & TRN \\
\hline CHEMBL1531595 & 688673 & 6.0 & 5.3553 & TRN \\
\hline CHEMBL1305182 & 688673 & 6.1 & 5.7857 & TRN \\
\hline CHEMBL1384261 & 688673 & 4.9 & 5.6277 & TRN \\
\hline CHEMBL1460367 & 688673 & 6.6 & 6.0095 & TRN \\
\hline CHEMBL1552003 & 688673 & 4.45 & 5.3944 & TRN \\
\hline CHEMBL1364278 & 688673 & 4.85 & 5.4351 & TRN \\
\hline CHEMBL1392695 & 688673 & 4.45 & 5.7654 & TRN \\
\hline CHEMBL1446116 & 688673 & 7.2 & 5.8445 & TRN \\
\hline CHEMBL1415295 & 688673 & 7.8013 & 5.7708 & TRN \\
\hline CHEMBL1321950 & 688673 & 4.45 & 5.2196 & TRN \\
\hline CHEMBL 267160 & 688673 & 4.55 & 5.3241 & TRN \\
\hline CHEMBL1471858 & 688673 & 6.4 & 5.5499 & TRN \\
\hline CHEMBL1489311 & 688673 & 5.4 & 5.7235 & TRN \\
\hline CHEMBL 8565 & 688673 & 4.5 & 5.8143 & TST \\
\hline CHEMBL1563062 & 688673 & 5.0 & 5.9897 & TRN \\
\hline CHEMBL1573670 & 688673 & 4.8 & 5.8126 & TRN \\
\hline CHEMBL1609533 & 688673 & 7.0 & 5.8194 & TRN \\
\hline CHEMBL1491150 & 688673 & 6.7001 & 5.5272 & TRN \\
\hline CHEMBL1587931 & 688673 & 6.0 & 5.9362 & TRN \\
\hline CHEMBL1412093 & 688673 & 5.2 & 5.3993 & TRN \\
\hline CHEMBL1431063 & 688673 & 4.5 & 5.5996 & TRN \\
\hline CHEMBL3191373 & 688673 & 7.699 & 5.7657 & TRN \\
\hline CHEMBL 1423320 & 688673 & 8.301 & 5.9673 & TRN \\
\hline CHEMBL1508235 & 688673 & 4.8 & 5.4616 & TRN \\
\hline CHEMBL1587769 & 688673 & 7.4001 & 5.6837 & TRN \\
\hline CHEMBL3213078 & 688673 & 6.7001 & 5.644 & TST \\
\hline CHEMBL1477814 & 688673 & 5.4 & 6.1683 & TRN \\
\hline CHEMBL1411729 & 688673 & 5.4 & 5.6548 & TRN \\
\hline CHEMBL1585275 & 688673 & 7.4498 & 5.3229 & TRN \\
\hline CHEMBL1301310 & 688673 & 4.45 & 5.9398 & TRN \\
\hline CHEMBL1439137 & 688673 & 5.4 & 5.6713 & TST \\
\hline CHEMBL1540603 & 688673 & 5.2 & 5.4313 & TST \\
\hline CHEMBL1588218 & 688673 & 5.3 & 5.7788 & TRN \\
\hline CHEMBL1420705 & 688673 & 7.4498 & 6.1287 & TRN \\
\hline
\end{tabular}




\begin{tabular}{|c|c|c|c|c|c|}
\hline \multicolumn{6}{|c|}{ Supplemental Table S2.txt } \\
\hline CHEMBL1417674 & 688673 & 5.05 & 5.7627 & TRN & \\
\hline CHEMBL1561483 & 688673 & 6.9 & 5.6943 & TRN & \\
\hline CHEMBL1446988 & 688673 & 4.9 & 6.0701 & TRN & \\
\hline CHEMBL1488810 & 688673 & 6.1 & 5.5891 & TRN & \\
\hline CHEMBL1469978 & 688673 & 6.5 & 5.7387 & TST & \\
\hline CHEMBL1527231 & 688673 & 5.2 & 5.2534 & TST & \\
\hline CHEMBL1534562 & 688673 & 5.25 & 5.8284 & TRN & \\
\hline CHEMBL1419581 & 688673 & 4.9 & 5.9863 & TRN & \\
\hline CHEMBL1452092 & 688673 & 4.65 & 5.4695 & TRN & \\
\hline CHEMBL1349036 & 688673 & 4.5 & 5.88200 & 0000000001 & TRN \\
\hline CHEMBL3212111 & 688673 & 4.9 & 5.70700 & 0000000001 & TRN \\
\hline CHEMBL1431585 & 688673 & 6.1 & 5.6801 & TRN & \\
\hline CHEMBL1523379 & 688673 & 5.7 & 5.9591 & TRN & \\
\hline CHEMBL1527072 & 688673 & 5.45 & 5.6805 & TRN & \\
\hline CHEMBL1531924 & 688673 & 6.6 & 5.6958 & TRN & \\
\hline CHEMBL3212448 & 688673 & 6.7001 & 5.4908 & TST & \\
\hline CHEMBL1604814 & 688673 & 5.3 & 6.4038 & TRN & \\
\hline CHEMBL1305048 & 688673 & 4.7 & 5.8059 & TRN & \\
\hline CHEMBL1335985 & 688673 & 5.2 & 5.6999 & TRN & \\
\hline CHEMBL1309189 & 688673 & 7.0 & 5.8781 & TRN & \\
\hline CHEMBL1491464 & 688673 & 4.45 & 6.0092 & TRN & \\
\hline CHEMBL1417549 & 688673 & 4.9 & 5.4846 & TRN & \\
\hline CHEMBL1545510 & 688673 & 4.7 & 5.7515 & TRN & \\
\hline CHEMBL1447245 & 688673 & 4.9 & 5.4544 & TRN & \\
\hline CHEMBL1337984 & 688673 & 4.95 & 5.0967 & TRN & \\
\hline CHEMBL1464918 & 688673 & 4.5 & 5.7101 & TRN & \\
\hline CHEMBL1505597 & 688673 & 4.8 & 5.6409 & TRN & \\
\hline CHEMBL1462667 & 688673 & 5.0 & 5.845 & TRN & \\
\hline CHEMBL1360209 & 688673 & 4.5 & 6.0576 & TRN & \\
\hline CHEMBL1538485 & 688673 & 5.5 & 5.9146 & TRN & \\
\hline CHEMBL1387942 & 688673 & 6.2 & 5.6041 & TRN & \\
\hline CHEMBL1455321 & 688673 & 4.5 & 5.6232 & TRN & \\
\hline CHEMBL1401358 & 688673 & 5.3 & 5.7401 & TRN & \\
\hline CHEMBL1489504 & 688673 & 6.6 & 5.8988 & TRN & \\
\hline CHEMBL1612034 & 688673 & 4.8 & 5.8422 & TRN & \\
\hline CHEMBL1589277 & 688673 & 7.5003 & 6.1111 & TRN & \\
\hline CHEMBL1541319 & 688673 & 7.4001 & 5.8972 & TRN & \\
\hline CHEMBL1303764 & 688673 & 5.5 & 5.7147 & TRN & \\
\hline CHEMBL1334197 & 688673 & 4.5 & 5.9983 & TRN & \\
\hline CHEMBL1338181 & 688673 & 8.3979 & 5.8153 & TRN & \\
\hline CHEMBL1385206 & 688673 & 4.8 & 5.8215 & TST & \\
\hline CHEMBL1466647 & 688673 & 5.3 & 5.8324 & TRN & \\
\hline CHEMBL1452091 & 688673 & 7.3002 & 6.0159 & TRN & \\
\hline CHEMBL1487207 & 688673 & 5.2 & 5.5571 & TRN & \\
\hline CHEMBL1463543 & 688673 & 5.9 & 5.2986 & TRN & \\
\hline CHEMBL1334930 & 688673 & 5.3 & 5.715 & TRN & \\
\hline CHEMBL1544051 & 688673 & 4.5 & 5.8895 & TRN & \\
\hline CHEMBL1504063 & 688673 & 6.1 & 5.8506 & TRN & \\
\hline
\end{tabular}




\begin{tabular}{|c|c|c|c|c|}
\hline & & & pplement & al $\mathrm{Ta}$ \\
\hline CHEMBL1319687 & 688673 & 6.6 & 5.183 & TRN \\
\hline CHEMBL1330942 & 688673 & 5.5 & 6.1263 & TRN \\
\hline CHEMBL1499352 & 688673 & 5.85 & 5.657 & TST \\
\hline CHEMBL1399498 & 688673 & 5.3 & 5.7442 & TRN \\
\hline CHEMBL1407524 & 688673 & 6.9 & 5.8978 & TRN \\
\hline CHEMBL1588424 & 688673 & 4.6 & 5.4101 & TRN \\
\hline CHEMBL1570433 & 688673 & 6.8 & 5.9431 & TRN \\
\hline CHEMBL1568594 & 688673 & 5.5 & 5.475 & TRN \\
\hline CHEMBL1570808 & 688673 & 5.8 & 6.2233 & TRN \\
\hline CHEMBL1565276 & 688673 & 4.95 & 5.7022 & TRN \\
\hline CHEMBL1376034 & 688673 & 7.0501 & 5.9845 & TRN \\
\hline CHEMBL1338128 & 688673 & 4.9 & 5.6272 & TRN \\
\hline CHEMBL1605608 & 688673 & 5.0 & 5.9994 & TRN \\
\hline CHEMBL1550292 & 688673 & 4.8 & 5.8576 & TRN \\
\hline CHEMBL1432472 & 688673 & 4.8 & 5.8101 & TRN \\
\hline CHEMBL1505171 & 688673 & 5.3 & 6.2826 & TRN \\
\hline CHEMBL1342247 & 688673 & 5.3 & 5.7744 & TRN \\
\hline CHEMBL1351517 & 688673 & 6.1 & 5.9579 & TRN \\
\hline CHEMBL1307144 & 688673 & 7.8996 & 5.9077 & TRN \\
\hline CHEMBL1341325 & 688673 & 4.7 & 5.5144 & TST \\
\hline CHEMBL1484601 & 688673 & 5.5 & 5.7618 & TRN \\
\hline CHEMBL1476969 & 688673 & 5.35 & 5.5426 & TRN \\
\hline CHEMBL1331960 & 688673 & 4.5 & 5.6864 & TST \\
\hline CHEMBL1422197 & 688673 & 6.3 & 5.841 & TRN \\
\hline CHEMBL1459459 & 688673 & 5.9 & 6.2165 & TRN \\
\hline CHEMBL1450308 & 688673 & 6.3 & 5.7938 & TRN \\
\hline CHEMBL1495083 & 688673 & 5.25 & 5.8414 & TRN \\
\hline CHEMBL1368316 & 688673 & 5.4 & 5.6705 & TST \\
\hline CHEMBL1471077 & 688673 & 4.9 & 5.9736 & TRN \\
\hline CHEMBL1299336 & 688673 & 6.1 & 5.8571 & TRN \\
\hline CHEMBL1352862 & 688673 & 4.9 & 5.3831 & TRN \\
\hline CHEMBL1558561 & 688673 & 6.6 & 5.5561 & TST \\
\hline CHEMBL1543927 & 688673 & 4.6 & 5.5792 & TRN \\
\hline CHEMBL447001 & 688673 & 8.699 & 5.7983 & TST \\
\hline CHEMBL1585526 & 688673 & 5.3 & 5.7598 & TRN \\
\hline CHEMBL1594890 & 688673 & 4.6 & 5.8485 & TRN \\
\hline CHEMBL1603973 & 688673 & 5.45 & 5.6654 & TRN \\
\hline CHEMBL1561443 & 688673 & 5.4 & 5.7947 & TRN \\
\hline CHEMBL1574478 & 688673 & 4.95 & 5.903 & TRN \\
\hline CHEMBL1393645 & 688673 & 5.5 & 5.7033 & TRN \\
\hline CHEMBL1503510 & 688673 & 7.6003 & 5.7483 & TRN \\
\hline CHEMBL1454096 & 688673 & 4.5 & 5.5914 & TRN \\
\hline CHEMBL1510142 & 688673 & 7.699 & 5.9932 & TRN \\
\hline CHEMBL1551915 & 688673 & 4.6 & 5.7872 & TST \\
\hline CHEMBL1412437 & 688673 & 5.3 & 5.5862 & TST \\
\hline CHEMBL1349745 & 688673 & 6.0 & 6.2092 & TRN \\
\hline CHEMBL1511327 & 688673 & 4.9 & 5.9557 & TRN \\
\hline CHEMBL1568973 & 688673 & 6.5501 & 5.7151 & TRN \\
\hline
\end{tabular}




\begin{tabular}{|c|c|c|c|c|}
\hline \multicolumn{5}{|c|}{ Supplemental Table S2.txt } \\
\hline CHEMBL1466770 & 688673 & 4.6 & 5.7645 & TRN \\
\hline CHEMBL1465270 & 688673 & 6.4 & 5.8391 & TRN \\
\hline CHEMBL1533997 & 688673 & 7.699 & 5.7153 & TRN \\
\hline CHEMBL1321710 & 688673 & 6.1 & 5.5169 & TRN \\
\hline CHEMBL1967566 & 688673 & 7.6003 & 5.3908 & TRN \\
\hline CHEMBL1388055 & 688673 & 5.9 & 5.8059 & TRN \\
\hline CHEMBL37514 & 688673 & 5.25 & 5.8285 & TRN \\
\hline CHEMBL1327864 & 688673 & 5.4 & 5.8388 & TST \\
\hline CHEMBL1451599 & 688673 & 4.6 & 5.8067 & TRN \\
\hline CHEMBL1577275 & 688673 & 6.0 & 5.8984 & TRN \\
\hline CHEMBL1453553 & 688673 & 6.6 & 5.7666 & TRN \\
\hline CHEMBL1511152 & 688673 & 6.4 & 6.0284 & TRN \\
\hline CHEMBL1335688 & 688673 & 5.6 & 5.249 & TRN \\
\hline CHEMBL1607608 & 688673 & 5.5 & 5.7274 & TRN \\
\hline CHEMBL1374358 & 688673 & 6.2 & 5.5417 & TRN \\
\hline CHEMBL1461982 & 688673 & 7.1002 & 5.4689 & TRN \\
\hline CHEMBL1532752 & 688673 & 8.301 & 5.7528 & TRN \\
\hline CHEMBL1330207 & 688673 & 7.8996 & 5.4642 & TRN \\
\hline CHEMBL1607932 & 688673 & 4.7 & 5.0616 & TRN \\
\hline CHEMBL1352797 & 688673 & 6.9 & 5.5814 & TRN \\
\hline CHEMBL1611420 & 688673 & 5.4 & 5.8416 & TRN \\
\hline CHEMBL1448420 & 688673 & 5.3 & 5.9743 & TRN \\
\hline CHEMBL1381447 & 688673 & 5.6 & 6.0475 & TRN \\
\hline CHEMBL1392093 & 688673 & 7.8996 & 5.6322 & TRN \\
\hline CHEMBL3199462 & 688673 & 6.8 & 5.3661 & TRN \\
\hline CHEMBL1517226 & 688673 & 4.65 & 5.8947 & TRN \\
\hline CHEMBL1596219 & 688673 & 4.45 & 5.4411 & TRN \\
\hline CHEMBL1481752 & 688673 & 5.2 & 5.9318 & TRN \\
\hline CHEMBL1602458 & 688673 & 6.8 & 5.6278 & TRN \\
\hline CHEMBL1427136 & 688673 & 5.3 & 5.5578 & TRN \\
\hline CHEMBL1548813 & 688673 & 7.8996 & 5.5189 & TRN \\
\hline CHEMBL1557721 & 688673 & 4.5 & 5.5781 & TRN \\
\hline CHEMBL1350581 & 688673 & 4.8 & 5.2455 & TRN \\
\hline CHEMBL1492850 & 688673 & 4.45 & 6.0113 & TRN \\
\hline CHEMBL1347362 & 688673 & 4.5 & 5.8403 & TRN \\
\hline CHEMBL1469024 & 688673 & 5.5 & 5.7307 & TRN \\
\hline CHEMBL1375429 & 688673 & 5.1 & 5.9818 & TRN \\
\hline CHEMBL1447051 & 688673 & 8.301 & 6.0149 & TRN \\
\hline CHEMBL1600661 & 688673 & 4.9 & 5.8401 & TRN \\
\hline CHEMBL1300901 & 688673 & 6.6499 & 5.9717 & TRN \\
\hline CHEMBL1521169 & 688673 & 7.6003 & 5.7778 & TRN \\
\hline CHEMBL1375001 & 688673 & 4.6 & 5.3752 & TRN \\
\hline CHEMBL1443904 & 688673 & 4.65 & 5.5905 & TRN \\
\hline CHEMBL1523537 & 688673 & 6.0 & 5.836 & TRN \\
\hline CHEMBL1581712 & 688673 & 7.6003 & 5.7387 & TRN \\
\hline CHEMBL1339151 & 688673 & 5.8 & 5.4327 & TRN \\
\hline CHEMBL1598795 & 688673 & 4.9 & 5.7818 & TRN \\
\hline CHEMBL1470324 & 688673 & 4.8 & 5.4993 & TRN \\
\hline
\end{tabular}




\begin{tabular}{|c|c|c|c|c|c|}
\hline & & \multicolumn{4}{|c|}{ Supplemental Table S2.txt } \\
\hline CHEMBL1571831 & 688673 & 8.1024 & 5.8731 & TST & \\
\hline CHEMBL1520614 & 688673 & 5.5 & 5.9652 & TRN & \\
\hline CHEMBL1522125 & 688673 & 5.95 & 5.8967 & TRN & \\
\hline CHEMBL1518384 & 688673 & 4.45 & 5.8868 & TRN & \\
\hline CHEMBL1583436 & 688673 & 6.3 & 5.8997 & TRN & \\
\hline CHEMBL1352448 & 688673 & 4.9 & 5.4956 & TRN & \\
\hline CHEMBL1462838 & 688673 & 4.5 & 5.7582 & TRN & \\
\hline CHEMBL1412828 & 688673 & 6.15 & 5.6439 & TRN & \\
\hline CHEMBL3197654 & 688673 & 5.5 & 5.599 & TST & \\
\hline CHEMBL1527721 & 688673 & 5.5 & 6.0366 & TRN & \\
\hline CHEMBL1500529 & 688673 & 6.4 & 6.1542 & TRN & \\
\hline CHEMBL1507583 & 688673 & 7.699 & 5.7583 & TRN & \\
\hline CHEMBL1471848 & 688673 & 5.4 & 5.8918 & TRN & \\
\hline CHEMBL1604999 & 688673 & 6.2 & 5.8019 & TRN & \\
\hline CHEMBL1583920 & 688673 & 5.4 & 5.954 & TRN & \\
\hline CHEMBL1609651 & 688673 & 6.9 & 5.5518 & TST & \\
\hline CHEMBL1325876 & 688673 & 6.9 & 5.4917 & TST & \\
\hline CHEMBL1458195 & 688673 & 8.1024 & 6.0539 & TST & \\
\hline CHEMBL1488522 & 688673 & 4.9 & 5.4817 & TRN & \\
\hline CHEMBL1412969 & 688673 & 4.6 & 6.2705 & TRN & \\
\hline CHEMBL1452945 & 688673 & 4.7 & 5.5142 & TRN & \\
\hline CHEMBL3198683 & 688673 & 6.3 & 5.593 & TRN & \\
\hline CHEMBL1419522 & 688673 & 6.6499 & 5.8165 & TRN & \\
\hline CHEMBL1414960 & 688673 & 8.0 & 5.4285 & TST & \\
\hline CHEMBL600713 & 688673 & 7.8013 & 5.7128 & TRN & \\
\hline CHEMBL1329997 & 688673 & 8.301 & 5.8043 & TRN & \\
\hline CHEMBL1397425 & 688673 & 6.6 & 5.818 & TRN & \\
\hline CHEMBL1452203 & 688673 & 5.5 & 5.2328 & TRN & \\
\hline CHEMBL1504312 & 688673 & 4.7 & 5.7919 & TRN & \\
\hline CHEMBL1433100 & 688673 & 5.4 & 5.6719 & TST & \\
\hline CHEMBL1477380 & 688673 & 7.3497 & 5.6804 & TRN & \\
\hline CHEMBL1427588 & 688673 & 5.9 & 5.9442 & TRN & \\
\hline CHEMBL1579689 & 688673 & 8.4559 & 5.5303 & TRN & \\
\hline CHEMBL1353972 & 688673 & 5.9 & 5.9238 & TST & \\
\hline CHEMBL1583181 & 688673 & 8.4949 & 5.9413 & TRN & \\
\hline CHEMBL1427042 & 688673 & 7.4001 & 6.001 & TRN & \\
\hline CHEMBL1303234 & 688673 & 7.2 & 5.8562 & TRN & \\
\hline CHEMBL1469977 & 688673 & 4.45 & 5.3681 & TRN & \\
\hline CHEMBL1730100 & 688673 & 4.9 & 5.5009 & TST & \\
\hline CHEMBL1562512 & 688673 & 5.15 & 5.944 & TRN & \\
\hline CHEMBL1503644 & 688673 & 6.9 & 5.41799 & 9999999999 & TRN \\
\hline CHEMBL1447524 & 688673 & 8.1487 & $5.53600 t$ & 00000000005 & TRN \\
\hline CHEMBL1535395 & 688673 & 4.9 & 5.7634 & TRN & \\
\hline CHEMBL66966 & 688673 & 4.7 & 5.4531 & TST & \\
\hline CHEMBL1372230 & 688673 & 4.65 & 5.7063 & TRN & \\
\hline CHEMBL1480089 & 688673 & 4.9 & 5.8264 & TRN & \\
\hline CHEMBL1612169 & 688673 & 5.55 & 5.7826 & TRN & \\
\hline CHEMBL1596375 & 688673 & 7.6003 & 5.9383 & TRN & \\
\hline
\end{tabular}




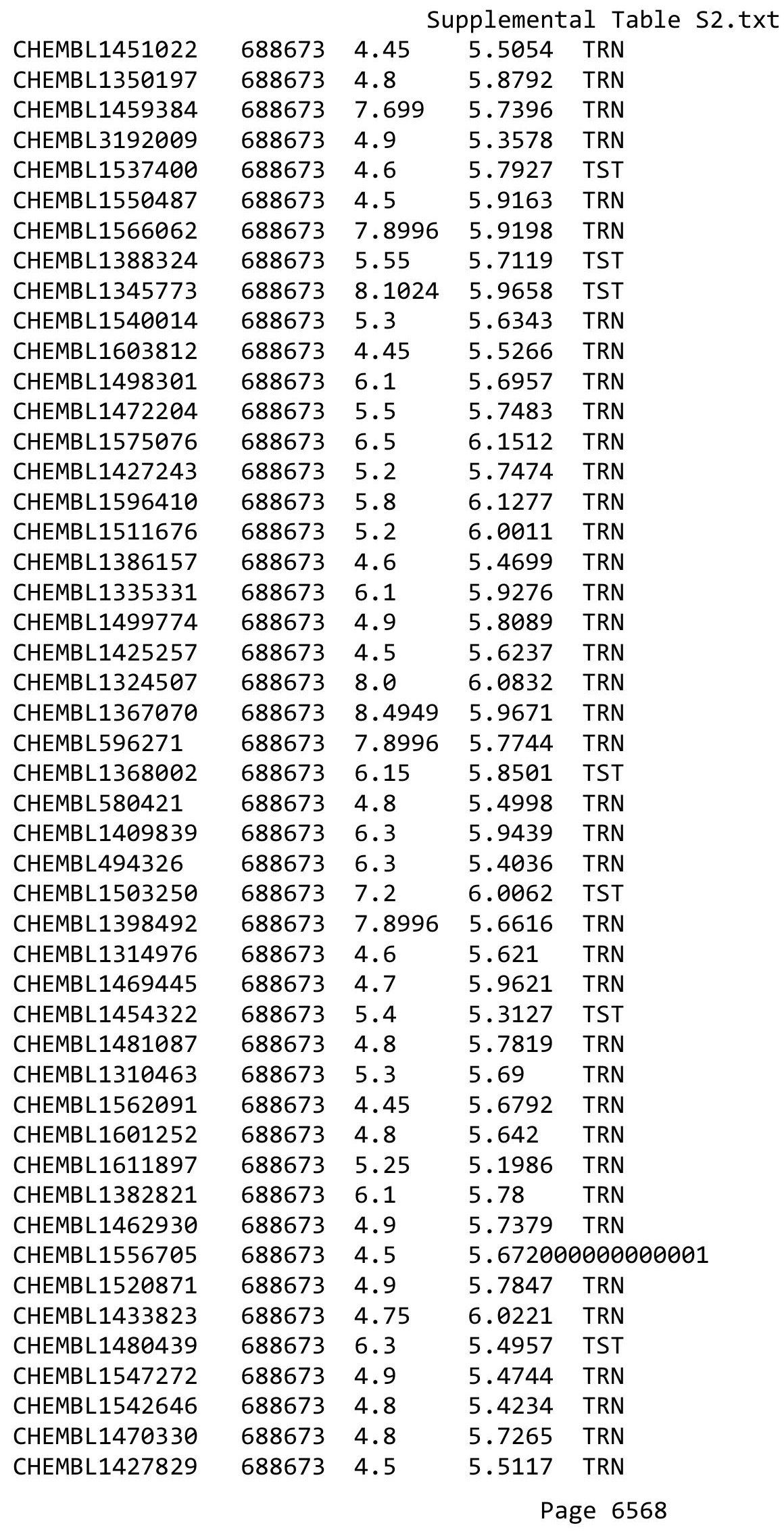




\begin{tabular}{|c|c|c|c|c|c|}
\hline \multicolumn{6}{|c|}{ Supplemental Table S2.txt } \\
\hline CHEMBL1579942 & 688673 & 4.5 & 5.7695 & TRN & \\
\hline CHEMBL1365843 & 688673 & 5.4 & 5.7699 & TST & \\
\hline CHEMBL1456663 & 688673 & 4.8 & 5.7781 & TST & \\
\hline CHEMBL1381789 & 688673 & 4.8 & 5.744 & TST & \\
\hline CHEMBL1588072 & 688673 & 4.7 & 5.7447 & TRN & \\
\hline CHEMBL1558294 & 688673 & 7.6003 & 5.6791 & TRN & \\
\hline CHEMBL1542929 & 688673 & 5.9 & 5.8732 & TRN & \\
\hline CHEMBL1520172 & 688673 & 7.8996 & 6.1098 & TRN & \\
\hline CHEMBL1416417 & 688673 & 5.4 & 5.7422 & TST & \\
\hline CHEMBL1507674 & 688673 & 7.2 & 5.7721 & TST & \\
\hline CHEMBL1358126 & 688673 & 4.45 & 5.33299 & 9999999999 & TRN \\
\hline CHEMBL1609893 & 688673 & 5.5 & 5.791 & TRN & \\
\hline CHEMBL1573015 & 688673 & 5.3 & 5.7993 & TRN & \\
\hline CHEMBL1421240 & 688673 & 4.9 & 5.7845 & TRN & \\
\hline CHEMBL1363084 & 688673 & 5.2 & 5.7914 & TRN & \\
\hline CHEMBL392515 & 688673 & 4.9 & 5.6087 & TRN & \\
\hline CHEMBL1497016 & 688673 & 4.9 & 5.4831 & TRN & \\
\hline CHEMBL1319357 & 688673 & 8.3979 & 6.0581 & TRN & \\
\hline CHEMBL1516178 & 688673 & 5.4 & 5.0347 & TRN & \\
\hline CHEMBL1518017 & 688673 & 5.2 & 5.8887 & TST & \\
\hline CHEMBL1399144 & 688673 & 7.6498 & 5.6254 & TRN & \\
\hline CHEMBL1990694 & 688673 & 4.8 & 5.5513 & TRN & \\
\hline CHEMBL3212475 & 688673 & 4.6 & 5.9715 & TRN & \\
\hline CHEMBL1602200 & 688673 & 6.0 & 5.7847 & TRN & \\
\hline CHEMBL1093507 & 688673 & 5.4 & 5.9199 & TRN & \\
\hline CHEMBL1596455 & 688673 & 5.2 & 5.6247 & TRN & \\
\hline CHEMBL1371302 & 688673 & 5.35 & 6.0143 & TRN & \\
\hline CHEMBL1503390 & 688673 & 4.7 & 5.4003 & TRN & \\
\hline CHEMBL1337387 & 688673 & 4.9 & 5.5986 & TRN & \\
\hline CHEMBL1321042 & 688673 & 7.699 & 5.8852 & TRN & \\
\hline CHEMBL1402176 & 688673 & 7.0501 & 5.8742 & TRN & \\
\hline CHEMBL1388510 & 688673 & 4.9 & 5.5848 & TRN & \\
\hline CHEMBL1547073 & 688673 & 5.25 & 5.6624 & TRN & \\
\hline CHEMBL1342360 & 688673 & 7.2 & 5.6672 & TRN & \\
\hline CHEMBL1425448 & 688673 & 7.3002 & 6.2873 & TRN & \\
\hline CHEMBL3194658 & 688673 & 4.9 & 5.3069 & TST & \\
\hline CHEMBL1583312 & 688673 & 4.9 & 5.6021 & TRN & \\
\hline CHEMBL1600647 & 688673 & 8.301 & 5.8133 & TST & \\
\hline CHEMBL1331930 & 688673 & 5.0 & 5.7164 & TST & \\
\hline CHEMBL1499563 & 688673 & 4.45 & 5.8376 & TRN & \\
\hline CHEMBL2002223 & 688673 & 8.4949 & 5.2664 & TRN & \\
\hline CHEMBL1319668 & 688673 & 4.4 & 5.7863 & TST & \\
\hline CHEMBL1359771 & 688673 & 6.4 & 5.6183 & TRN & \\
\hline CHEMBL1518913 & 688673 & 5.4 & 5.7377 & TRN & \\
\hline CHEMBL1456260 & 688673 & 7.1002 & 5.6924 & TRN & \\
\hline CHEMBL1456177 & 688673 & 4.5 & 5.9888 & TRN & \\
\hline CHEMBL1579044 & 688673 & 4.7 & 6.061 & TST & \\
\hline CHEMBL1607755 & 688673 & 5.8 & 5.8726 & TRN & \\
\hline
\end{tabular}




\begin{tabular}{|c|c|c|c|c|c|}
\hline \multicolumn{6}{|c|}{ Supplemental Table S2.txt } \\
\hline CHEMBL1576041 & 688673 & 5.0 & 5.3775 & TRN & \\
\hline CHEMBL1610279 & 688673 & 6.5 & 6.1598 & TRN & \\
\hline CHEMBL1459529 & 688673 & 4.9 & 5.825 & TRN & \\
\hline CHEMBL1470063 & 688673 & 4.9 & 5.6758 & TRN & \\
\hline CHEMBL1373663 & 688673 & 5.3 & 5.7705 & TRN & \\
\hline CHEMBL1370627 & 688673 & 8.4949 & 6.0232 & TRN & \\
\hline CHEMBL1597560 & 688673 & 7.699 & 5.5935 & TRN & \\
\hline CHEMBL1428273 & 688673 & 6.8 & 5.9046 & TRN & \\
\hline CHEMBL1503616 & 688673 & 6.9 & 5.5684 & TRN & \\
\hline CHEMBL1374523 & 688673 & 4.8 & 5.9216 & TRN & \\
\hline CHEMBL1546468 & 688673 & 5.35 & 5.5903 & TST & \\
\hline CHEMBL1578330 & 688673 & 8.0 & 5.7187 & TRN & \\
\hline CHEMBL1367068 & 688673 & 4.45 & 5.8256 & TRN & \\
\hline CHEMBL3213811 & 688673 & 4.8 & 5.4857 & TST & \\
\hline CHEMBL1331504 & 688673 & 4.65 & 5.8474 & TRN & \\
\hline CHEMBL 3211271 & 688673 & 7.2 & 5.5873 & TRN & \\
\hline CHEMBL1592912 & 688673 & 4.65 & 5.5601 & TRN & \\
\hline CHEMBL1311725 & 688673 & 5.3 & 5.8015 & TRN & \\
\hline CHEMBL1427902 & 688673 & 7.4001 & 5.818 & TRN & \\
\hline CHEMBL1487311 & 688673 & 7.8996 & 6.1339 & TRN & \\
\hline CHEMBL1433174 & 688673 & 6.6 & 6.0345 & TRN & \\
\hline CHEMBL1527737 & 688673 & 4.9 & 5.5768 & TRN & \\
\hline CHEMBL1470329 & 688673 & 4.8 & 5.7716 & TRN & \\
\hline CHEMBL1568124 & 688673 & 5.5 & 5.5955 & TRN & \\
\hline CHEMBL1563055 & 688673 & 5.45 & 5.6363 & TRN & \\
\hline CHEMBL1548571 & 688673 & 5.2 & 5.6504 & TRN & \\
\hline CHEMBL1325262 & 688673 & 6.2 & 5.61299 & 99999999995 & TRN \\
\hline CHEMBL1603319 & 688673 & 5.2 & 5.6244 & TST & \\
\hline CHEMBL1405789 & 688673 & 6.5 & 5.7974 & TRN & \\
\hline CHEMBL1557672 & 688673 & 4.8 & 6.0241 & TRN & \\
\hline CHEMBL1320239 & 688673 & 5.0 & 5.9302 & TRN & \\
\hline CHEMBL1470303 & 688673 & 6.9 & 5.5072 & TRN & \\
\hline CHEMBL1608860 & 688673 & 6.0 & 5.5852 & TRN & \\
\hline CHEMBL1445428 & 688673 & 4.45 & 5.6838 & TRN & \\
\hline CHEMBL1400941 & 688673 & 6.25 & 5.818 & TRN & \\
\hline CHEMBL1505409 & 688673 & 5.5 & 6.1315 & TRN & \\
\hline CHEMBL1385852 & 688673 & 4.6 & 5.5476 & TRN & \\
\hline CHEMBL1606031 & 688673 & 4.5 & 5.5127 & TRN & \\
\hline CHEMBL1364356 & 688673 & 5.3 & 5.9453 & TRN & \\
\hline CHEMBL1352807 & 688673 & 5.7 & 5.6339 & TST & \\
\hline CHEMBL1606275 & 688673 & 4.8 & 6.13899 & 9999999999 & TRN \\
\hline CHEMBL1477513 & 688673 & 5.4 & 5.9692 & TRN & \\
\hline CHEMBL1531214 & 688673 & 7.3002 & 6.0843 & TRN & \\
\hline CHEMBL1535411 & 688673 & 4.75 & 5.3968 & TRN & \\
\hline CHEMBL1390645 & 688673 & 4.95 & 5.8463 & TRN & \\
\hline CHEMBL1415480 & 688673 & 5.4 & 6.1175 & TRN & \\
\hline CHEMBL1410525 & 688673 & 5.8 & 6.0173 & TRN & \\
\hline CHEMBL1609943 & 688673 & 8.1024 & 5.7554 & TRN & \\
\hline
\end{tabular}




\begin{tabular}{|c|c|c|c|c|c|}
\hline & & & & & \\
\hline CHEMBL1452576 & 688673 & 6.9 & 5.9347 & TRN & \\
\hline CHEMBL1611036 & 688673 & 5.0 & 5.6849 & TRN & \\
\hline CHEMBL1498509 & 688673 & 6.0 & 5.4477 & TRN & \\
\hline CHEMBL1525857 & 688673 & 7.0 & 5.4941 & TST & \\
\hline CHEMBL1393336 & 688673 & 6.1 & 5.8619 & TRN & \\
\hline CHEMBL1590185 & 688673 & 7.6498 & 5.7507 & TRN & \\
\hline CHEMBL1591490 & 688673 & 5.5 & 5.4831 & TRN & \\
\hline CHEMBL1422212 & 688673 & 4.6 & 5.3869 & TRN & \\
\hline CHEMBL1490514 & 688673 & 5.5 & 5.9283 & TRN & \\
\hline CHEMBL1610826 & 688673 & 6.5 & 5.7871 & TST & \\
\hline CHEMBL1583614 & 688673 & 4.5 & 5.7308 & TRN & \\
\hline CHEMBL1391082 & 688673 & 5.2 & 6.1262 & TST & \\
\hline CHEMBL1580641 & 688673 & 5.5 & 5.78700 & 3000000001 & TRN \\
\hline CHEMBL1444301 & 688673 & 5.2 & 5.9267 & TRN & \\
\hline CHEMBL1426182 & 688673 & 7.2 & 5.6621 & TRN & \\
\hline CHEMBL1547450 & 688673 & 4.5 & 5.2851 & TRN & \\
\hline CHEMBL1487873 & 688673 & 4.45 & 5.6462 & TRN & \\
\hline CHEMBL1325519 & 688673 & 5.25 & 5.3922 & TRN & \\
\hline CHEMBL1526791 & 688673 & 6.9 & 5.8762 & TRN & \\
\hline CHEMBL1586494 & 688673 & 7.5003 & 5.8072 & TRN & \\
\hline CHEMBL1371614 & 688673 & 5.55 & 5.6054 & TRN & \\
\hline CHEMBL1304228 & 688673 & 7.0 & 5.7559 & TRN & \\
\hline CHEMBL1369815 & 688673 & 4.65 & 5.8278 & TRN & \\
\hline CHEMBL1588155 & 688673 & 7.3002 & 6.0292 & TRN & \\
\hline CHEMBL1380478 & 688673 & 5.5 & 5.5997 & TRN & \\
\hline CHEMBL1466792 & 688673 & 4.4 & 5.697 & TRN & \\
\hline CHEMBL3196665 & 688673 & 4.45 & 5.6904 & TST & \\
\hline CHEMBL1468319 & 688673 & 6.8 & 6.0281 & TRN & \\
\hline CHEMBL1507083 & 688673 & 7.2 & 5.5874 & TST & \\
\hline CHEMBL1438866 & 688673 & 5.7 & 5.6461 & TST & \\
\hline CHEMBL1394572 & 688673 & 5.4 & 5.5551 & TRN & \\
\hline CHEMBL1362858 & 688673 & 6.5 & 5.7998 & TRN & \\
\hline CHEMBL1572599 & 688673 & 7.6003 & 6.0863 & TRN & \\
\hline CHEMBL1545459 & 688673 & 4.5 & 5.9228 & TRN & \\
\hline CHEMBL1432476 & 688673 & 5.0 & 5.5946 & TST & \\
\hline CHEMBL1442873 & 688673 & 6.7001 & 5.5423 & TST & \\
\hline CHEMBL1610810 & 688673 & 4.85 & 5.2915 & TRN & \\
\hline CHEMBL1414877 & 688673 & 5.4 & 5.7884 & TRN & \\
\hline CHEMBL1579138 & 688673 & 6.25 & 6.21299 & 9999999999 & TRN \\
\hline CHEMBL1363944 & 688673 & 6.1 & 5.4901 & TRN & \\
\hline CHEMBL1503751 & 688673 & 6.1 & 5.6198 & TRN & \\
\hline CHEMBL1308905 & 688673 & 6.2 & 5.9527 & TRN & \\
\hline CHEMBL259389 & 688673 & 4.8 & 5.4279 & TST & \\
\hline CHEMBL1599746 & 688673 & 4.5 & 5.7087 & TRN & \\
\hline CHEMBL1549486 & 688673 & 5.4 & 5.7761 & TRN & \\
\hline CHEMBL1539699 & 688673 & 5.5 & 5.8833 & TST & \\
\hline CHEMBL1495460 & 688673 & 4.9 & 5.7205 & TST & \\
\hline CHEMBL1567205 & 688673 & 4.5 & 5.8659 & TRN & \\
\hline
\end{tabular}




\begin{tabular}{|c|c|c|c|c|c|}
\hline \multicolumn{6}{|c|}{ Supplemental Table s2.txt } \\
\hline CHEMBL1340942 & 688673 & 4.9 & 5.9281 & TRN & \\
\hline CHEMBL1346935 & 688673 & 6.2 & 5.535 & TST & \\
\hline CHEMBL3193432 & 688673 & 4.6 & 5.6134 & TRN & \\
\hline CHEMBL1497632 & 688673 & 5.0 & 5.9531 & TRN & \\
\hline CHEMBL1327365 & 688673 & 6.5 & 6.0659 & TRN & \\
\hline CHEMBL1380741 & 688673 & 4.7 & 5.6842 & TRN & \\
\hline CHEMBL 3212034 & 688673 & 5.35 & 5.3332 & TRN & \\
\hline CHEMBL1470500 & 688673 & 4.5 & 5.7436 & TRN & \\
\hline CHEMBL1578785 & 688673 & 6.3 & 5.4888 & TRN & \\
\hline CHEMBL1578624 & 688673 & 8.4949 & 6.0045 & TRN & \\
\hline CHEMBL1571563 & 688673 & 4.6 & 5.7012 & TRN & \\
\hline CHEMBL1528299 & 688673 & 4.9 & 5.5781 & TST & \\
\hline CHEMBL1419733 & 688673 & 4.45 & 5.1715 & TRN & \\
\hline CHEMBL1613150 & 688673 & 5.5 & 5.6149 & TRN & \\
\hline CHEMBL1385737 & 688673 & 6.1 & 5.6279 & TRN & \\
\hline CHEMBL1413946 & 688673 & 4.9 & 5.3009 & TRN & \\
\hline CHEMBL1471471 & 688673 & 6.2 & 6.0809 & TRN & \\
\hline CHEMBL1543826 & 688673 & 7.4498 & 5.6695 & TRN & \\
\hline CHEMBL1331813 & 688673 & 7.8996 & 5.7715 & TRN & \\
\hline CHEMBL1580105 & 688673 & 5.1 & 5.8557 & TRN & \\
\hline CHEMBL1399380 & 688673 & 5.0 & 5.2155 & TST & \\
\hline CHEMBL1378708 & 688673 & 5.3 & 5.8717 & TRN & \\
\hline CHEMBL1575368 & 688673 & 6.2 & 5.9253 & TRN & \\
\hline CHEMBL1320605 & 688673 & 4.45 & 5.6793 & TRN & \\
\hline CHEMBL1381039 & 688673 & 4.5 & 6.1364 & TRN & \\
\hline CHEMBL1376577 & 688673 & 7.6498 & 5.79899 & 99999999995 & TRN \\
\hline CHEMBL1322406 & 688673 & 5.3 & 5.347 & TST & \\
\hline CHEMBL1568404 & 688673 & 4.9 & 6.1489 & TRN & \\
\hline CHEMBL1566532 & 688673 & 7.6003 & 6.3343 & TRN & \\
\hline CHEMBL1549140 & 688673 & 7.5003 & 5.5266 & TRN & \\
\hline CHEMBL1375676 & 688673 & 5.45 & 5.9151 & TRN & \\
\hline CHEMBL1546372 & 688673 & 4.9 & 5.3493 & TRN & \\
\hline CHEMBL1344410 & 688673 & 7.4001 & 5.8419 & TRN & \\
\hline CHEMBL1603479 & 688673 & 4.45 & 4.9804 & TRN & \\
\hline CHEMBL1579482 & 688673 & 5.6 & 5.8663 & TRN & \\
\hline CHEMBL1581386 & 688673 & 5.25 & 6.0114 & TRN & \\
\hline CHEMBL1439588 & 688673 & 4.9 & 5.8846 & TST & \\
\hline CHEMBL1585126 & 688673 & 4.9 & 5.6098 & TRN & \\
\hline CHEMBL 32503 & 688673 & 5.2 & 5.689 & TRN & \\
\hline CHEMBL1328675 & 688673 & 6.1 & 6.1112 & TST & \\
\hline CHEMBL1377385 & 688673 & 4.8 & 5.8046 & TRN & \\
\hline CHEMBL1573262 & 688673 & 5.2 & 5.843 & TRN & \\
\hline CHEMBL1605198 & 688673 & 7.6003 & 5.9985 & TRN & \\
\hline CHEMBL1392143 & 688673 & 7.0501 & 5.99799 & 9999999999 & TST \\
\hline CHEMBL1372076 & 688673 & 4.6 & 5.3667 & TRN & \\
\hline CHEMBL1555719 & 688673 & 6.2 & 5.5445 & TRN & \\
\hline CHEMBL1556854 & 688673 & 7.0 & 6.193 & TRN & \\
\hline CHEMBL310798 & 688673 & 4.9 & 5.3571 & TRN & \\
\hline
\end{tabular}




\begin{tabular}{|c|c|c|c|c|c|}
\hline \multicolumn{6}{|c|}{ Supplemental Table S2.txt } \\
\hline CHEMBL1459728 & 688673 & 5.5 & 5.9684 & TRN & \\
\hline CHEMBL1518891 & 688673 & 4.9 & 5.6759 & TRN & \\
\hline CHEMBL1432603 & 688673 & 5.2 & 5.3465 & TRN & \\
\hline CHEMBL1548472 & 688673 & 4.9 & 5.6855 & TRN & \\
\hline CHEMBL1603954 & 688673 & 5.0 & 5.612 & TST & \\
\hline CHEMBL1376488 & 688673 & 4.7 & 5.3405 & TRN & \\
\hline CHEMBL1487684 & 688673 & 5.9 & 5.6296 & TRN & \\
\hline CHEMBL1450032 & 688673 & 5.5 & 5.5512 & TRN & \\
\hline CHEMBL1499821 & 688673 & 8.0 & 5.8813 & TRN & \\
\hline CHEMBL1599254 & 688673 & 4.5 & 5.7134 & TRN & \\
\hline CHEMBL1466952 & 688673 & 6.4 & 5.8786 & TRN & \\
\hline CHEMBL1559019 & 688673 & 5.4 & 5.9003 & TRN & \\
\hline CHEMBL1471554 & 688673 & 4.8 & 5.6223 & TRN & \\
\hline CHEMBL1350020 & 688673 & 4.6 & 5.6062 & TST & \\
\hline CHEMBL1534678 & 688673 & 5.4 & 5.9174 & TRN & \\
\hline CHEMBL 2006260 & 688673 & 5.9 & 5.6214 & TRN & \\
\hline CHEMBL1460306 & 688673 & 5.4 & 5.6028 & TRN & \\
\hline CHEMBL1530921 & 688673 & 4.95 & 6.0725 & TRN & \\
\hline CHEMBL1525960 & 688673 & 6.25 & 5.9589 & TRN & \\
\hline CHEMBL1464088 & 688673 & 4.9 & 5.9448 & TRN & \\
\hline CHEMBL1568609 & 688673 & 5.3 & 6.0242 & TST & \\
\hline CHEMBL1583670 & 688673 & 5.25 & 5.7764 & TRN & \\
\hline CHEMBL1339561 & 688673 & 4.95 & 5.6055 & TRN & \\
\hline CHEMBL1572445 & 688673 & 5.4 & 5.4949 & TST & \\
\hline CHEMBL1526516 & 688673 & 6.0 & 5.8867 & TRN & \\
\hline CHEMBL1443672 & 688673 & 5.9 & 5.9846 & TRN & \\
\hline CHEMBL1521604 & 688673 & 4.8 & 5.6147 & TRN & \\
\hline CHEMBL1604971 & 688673 & 5.8 & 5.559 & TRN & \\
\hline CHEMBL1606779 & 688673 & 7.6498 & 5.74100 & 00000000005 & TRN \\
\hline CHEMBL1445199 & 688673 & 4.5 & 5.782 & TRN & \\
\hline CHEMBL1403001 & 688673 & 4.95 & 5.6196 & TRN & \\
\hline CHEMBL1453453 & 688673 & 4.5 & 5.6018 & TRN & \\
\hline CHEMBL1378348 & 688673 & 6.2 & 6.0306 & TRN & \\
\hline CHEMBL1504117 & 688673 & 4.7 & 5.6116 & TRN & \\
\hline CHEMBL1586527 & 688673 & 4.9 & 5.6506 & TRN & \\
\hline CHEMBL1516293 & 688673 & 4.65 & 5.32700 & 0000000001 & TRN \\
\hline CHEMBL1450954 & 688673 & 7.4498 & 5.664 & TRN & \\
\hline CHEMBL1356247 & 688673 & 4.45 & 5.6882 & TST & \\
\hline CHEMBL1896260 & 688673 & 6.8 & 5.8768 & TRN & \\
\hline CHEMBL1566361 & 688673 & 6.9 & 5.7875 & TRN & \\
\hline CHEMBL1470991 & 688673 & 7.6003 & 6.125 & TRN & \\
\hline CHEMBL1307965 & 688673 & 8.1024 & 5.6882 & TRN & \\
\hline CHEMBL1497983 & 688673 & 6.1 & 5.5506 & TRN & \\
\hline CHEMBL1607033 & 688673 & 5.55 & 5.7309 & TRN & \\
\hline CHEMBL1511459 & 688673 & 4.5 & 5.3529 & TST & \\
\hline CHEMBL1461305 & 688673 & 8.0 & 6.0711 & TST & \\
\hline CHEMBL1413538 & 688673 & 8.0 & 5.7978 & TRN & \\
\hline CHEMBL1308605 & 688673 & 4.9 & 5.8847 & TRN & \\
\hline
\end{tabular}




\begin{tabular}{|c|c|c|c|c|c|}
\hline \multicolumn{6}{|c|}{ Supplemental Table S2.txt } \\
\hline CHEMBL3192362 & 688673 & 4.5 & 5.5101 & TRN & \\
\hline CHEMBL1311673 & 688673 & 6.3 & 5.8368 & TRN & \\
\hline CHEMBL1224553 & 688673 & 5.6 & 5.8265 & TRN & \\
\hline CHEMBL1576395 & 688673 & 5.4 & 5.6131 & TRN & \\
\hline CHEMBL1256667 & 688673 & 4.5 & 5.6979 & TST & \\
\hline CHEMBL1341387 & 688673 & 8.0 & 5.8926 & TRN & \\
\hline CHEMBL1406204 & 688673 & 4.8 & 5.2459 & TRN & \\
\hline CHEMBL1526738 & 688673 & 4.5 & 5.4673 & TRN & \\
\hline CHEMBL1457571 & 688673 & 6.0 & 5.8948 & TRN & \\
\hline CHEMBL1330273 & 688673 & 5.7 & 6.0769 & TRN & \\
\hline CHEMBL528712 & 688673 & 4.6 & 5.434 & TRN & \\
\hline CHEMBL1489749 & 688673 & 5.35 & 5.48799 & 99999999995 & TRN \\
\hline CHEMBL1556436 & 688673 & 6.7001 & 5.6167 & TST & \\
\hline CHEMBL1457521 & 688673 & 6.6 & 5.3757 & TRN & \\
\hline CHEMBL1417071 & 688673 & 7.8996 & 5.6536 & TRN & \\
\hline CHEMBL1545180 & 688673 & 5.55 & 6.0136 & TRN & \\
\hline CHEMBL1452315 & 688673 & 7.4001 & 5.4065 & TST & \\
\hline CHEMBL1576833 & 688673 & 7.3002 & 5.5879 & TRN & \\
\hline CHEMBL1340715 & 688673 & 7.2 & 5.96399 & 99999999995 & TRN \\
\hline CHEMBL1491128 & 688673 & 6.0 & 5.9634 & TRN & \\
\hline CHEMBL1478158 & 688673 & 6.9 & 5.4126 & TST & \\
\hline CHEMBL1543648 & 688673 & 4.45 & 5.6149 & TRN & \\
\hline CHEMBL1430042 & 688673 & 4.5 & 5.9813 & TRN & \\
\hline CHEMBL1491373 & 688673 & 5.1 & 6.03 & TRN & \\
\hline CHEMBL1310809 & 688673 & 6.2 & 5.8268 & TRN & \\
\hline CHEMBL1421751 & 688673 & 5.4 & 5.7545 & TRN & \\
\hline CHEMBL1569300 & 688673 & 5.4 & 5.6557 & TRN & \\
\hline CHEMBL3211878 & 688673 & 4.5 & 5.6261 & TRN & \\
\hline CHEMBL1589854 & 688673 & 5.5 & 5.7132 & TRN & \\
\hline CHEMBL1574143 & 688673 & 5.3 & 5.9211 & TRN & \\
\hline CHEMBL1399585 & 688673 & 4.5 & 5.4935 & TRN & \\
\hline CHEMBL1453667 & 688673 & 5.0 & 5.6866 & TRN & \\
\hline CHEMBL1469365 & 688673 & 7.2503 & 5.7721 & TRN & \\
\hline CHEMBL1324509 & 688673 & 6.5 & 5.6915 & TRN & \\
\hline CHEMBL1423905 & 688673 & 5.3 & 5.6236 & TRN & \\
\hline CHEMBL1518611 & 688673 & 4.9 & 5.6436 & TRN & \\
\hline CHEMBL1312839 & 688673 & 6.3 & 5.8434 & TRN & \\
\hline CHEMBL1367025 & 688673 & 4.9 & 5.7314 & TRN & \\
\hline CHEMBL1524169 & 688673 & 6.4 & 5.5956 & TRN & \\
\hline CHEMBL1580763 & 688673 & 5.5 & 5.8815 & TST & \\
\hline CHEMBL1341030 & 688673 & 4.5 & 6.0003 & TRN & \\
\hline CHEMBL1493425 & 688673 & 6.3 & 5.8777 & TRN & \\
\hline CHEMBL1333222 & 688673 & 6.35 & 5.4719 & TST & \\
\hline CHEMBL1334940 & 688673 & 8.0 & 5.6553 & TRN & \\
\hline CHEMBL411307 & 688673 & 7.0 & 5.4534 & TRN & \\
\hline CHEMBL1485796 & 688673 & 6.8499 & 5.626 & TRN & \\
\hline CHEMBL1536152 & 688673 & 7.699 & 5.9535 & TRN & \\
\hline CHEMBL1570187 & 688673 & 4.45 & 5.5627 & TRN & \\
\hline
\end{tabular}




\begin{tabular}{|c|c|c|c|c|}
\hline \multicolumn{5}{|c|}{ Supplemental Table S2.txt } \\
\hline CHEMBL1483464 & 688673 & 6.1 & 5.5932 & TRN \\
\hline CHEMBL1501863 & 688673 & 4.9 & 5.461 & TRN \\
\hline CHEMBL1600112 & 688673 & 5.4 & 5.9515 & TRN \\
\hline CHEMBL1465007 & 688673 & 4.7 & 5.6447 & TRN \\
\hline CHEMBL1383367 & 688673 & 7.3002 & 5.7921 & TRN \\
\hline CHEMBL1449721 & 688673 & 8.0 & 5.9422 & TRN \\
\hline CHEMBL1611527 & 688673 & 4.7 & 5.6132 & TRN \\
\hline CHEMBL1424352 & 688673 & 7.6003 & 5.835 & TRN \\
\hline CHEMBL1515319 & 688673 & 4.45 & 5.8345 & TRN \\
\hline CHEMBL1373577 & 688673 & 4.8 & 5.5585 & TST \\
\hline CHEMBL1364025 & 688673 & 6.3 & 5.6308 & TRN \\
\hline CHEMBL1369412 & 688673 & 7.699 & 5.5995 & TRN \\
\hline CHEMBL1470156 & 688673 & 4.9 & 5.7873 & TRN \\
\hline CHEMBL1574245 & 688673 & 8.3468 & 5.7782 & TRN \\
\hline CHEMBL1532782 & 688673 & 4.9 & 5.8987 & TRN \\
\hline CHEMBL1978995 & 688673 & 6.3 & 5.6633 & TRN \\
\hline CHEMBL1428263 & 688673 & 7.6498 & 6.0527 & TRN \\
\hline CHEMBL 3193763 & 688673 & 7.0 & 5.5618 & TRN \\
\hline CHEMBL1515520 & 688673 & 5.25 & 5.4527 & TRN \\
\hline CHEMBL1540811 & 688673 & 5.3 & 5.5692 & TRN \\
\hline CHEMBL1489527 & 688673 & 4.5 & 5.6794 & TRN \\
\hline CHEMBL1477304 & 688673 & 5.4 & 5.6031 & TRN \\
\hline CHEMBL1477052 & 688673 & 6.6 & 5.7539 & TRN \\
\hline CHEMBL1333278 & 688673 & 4.6 & 5.5441 & TRN \\
\hline CHEMBL1596965 & 688673 & 5.1 & 5.18 & TST \\
\hline CHEMBL1993447 & 688673 & 5.7 & 5.4502 & TRN \\
\hline CHEMBL1580143 & 688673 & 4.5 & 5.7563 & TRN \\
\hline CHEMBL1562028 & 688673 & 7.6003 & 5.7377 & TST \\
\hline CHEMBL503254 & 688673 & 8.0 & 5.7456 & TST \\
\hline CHEMBL1334484 & 688673 & 5.7 & 5.3475 & TST \\
\hline CHEMBL1420817 & 688673 & 6.7001 & 5.8773 & TRN \\
\hline CHEMBL1479211 & 688673 & 7.2 & 5.6827 & TRN \\
\hline CHEMBL1574014 & 688673 & 4.8 & 5.2706 & TRN \\
\hline CHEMBL1331857 & 688673 & 4.9 & 5.7606 & TRN \\
\hline CHEMBL1360045 & 688673 & 5.0 & 5.5708 & TRN \\
\hline CHEMBL1339358 & 688673 & 4.5 & 5.7086 & TRN \\
\hline CHEMBL1527163 & 688673 & 7.1002 & 5.5337 & TRN \\
\hline CHEMBL 3191888 & 688673 & 5.0 & 5.6407 & TRN \\
\hline CHEMBL1493687 & 688673 & 5.8 & 6.0599 & TRN \\
\hline CHEMBL1425985 & 688673 & 8.0 & 5.8077 & TRN \\
\hline CHEMBL1546412 & 688673 & 7.6003 & 5.7821 & TRN \\
\hline CHEMBL1255747 & 688673 & 7.5003 & 5.6053 & TST \\
\hline CHEMBL1455514 & 688673 & 6.0 & 5.8519 & TRN \\
\hline CHEMBL1307313 & 688673 & 4.5 & 5.5192 & TST \\
\hline CHEMBL1512788 & 688673 & 8.0 & 5.4177 & TRN \\
\hline CHEMBL1552865 & 688673 & 6.8499 & 5.4028 & TST \\
\hline CHEMBL 237816 & 688673 & 4.95 & 5.8806 & TRN \\
\hline CHEMBL1429883 & 688673 & 4.6 & 5.5823 & TST \\
\hline
\end{tabular}




\begin{tabular}{|c|c|c|c|c|c|}
\hline & & & & & \\
\hline CHEMBL1337578 & 688673 & 6.8 & 5.9003 & TRN & \\
\hline CHEMBL1601725 & 688673 & 6.6 & 5.7238 & TRN & \\
\hline CHEMBL1383967 & 688673 & 4.6 & 5.444 & TRN & \\
\hline CHEMBL1458736 & 688673 & 8.0 & 5.9106 & TRN & \\
\hline CHEMBL1597805 & 688673 & 4.7 & 5.4281 & TST & \\
\hline CHEMBL1300910 & 688673 & 6.7001 & 5.8459 & TRN & \\
\hline CHEMBL1399045 & 688673 & 5.2 & 5.9559 & TRN & \\
\hline CHEMBL1351354 & 688673 & 5.45 & 5.5865 & TRN & \\
\hline CHEMBL1397265 & 688673 & 4.45 & 5.6137 & TRN & \\
\hline CHEMBL1544785 & 688673 & 6.0 & 5.7244 & TST & \\
\hline CHEMBL1476934 & 688673 & 8.4949 & 5.6258 & TRN & \\
\hline CHEMBL1578896 & 688673 & 5.7 & 5.9183 & TRN & \\
\hline CHEMBL1307400 & 688673 & 6.8 & 5.9102 & TRN & \\
\hline CHEMBL1344665 & 688673 & 4.95 & 5.7218 & TRN & \\
\hline CHEMBL1464600 & 688673 & 7.1002 & 6.067 & TRN & \\
\hline CHEMBL3207314 & 688673 & 5.0 & 5.3685 & TRN & \\
\hline CHEMBL1319440 & 688673 & 4.6 & 5.477 & TRN & \\
\hline CHEMBL1540248 & 688673 & 4.55 & 5.8868 & TST & \\
\hline CHEMBL3199463 & 688673 & 4.9 & 5.99700 & 0000000001 & TRN \\
\hline CHEMBL1447056 & 688673 & 5.3 & 5.9416 & TST & \\
\hline CHEMBL1591781 & 688673 & 4.45 & 5.71700 & 00000000005 & TRN \\
\hline CHEMBL1329130 & 688673 & 4.5 & 5.7131 & TRN & \\
\hline CHEMBL 2000736 & 688673 & 5.3 & 5.9291 & TRN & \\
\hline CHEMBL1589782 & 688673 & 5.5 & 5.5487 & TRN & \\
\hline CHEMBL1543133 & 688673 & 6.8 & 5.6395 & TST & \\
\hline CHEMBL1538938 & 688673 & 4.5 & 5.6207 & TRN & \\
\hline CHEMBL1480964 & 688673 & 4.85 & 5.6614 & TRN & \\
\hline CHEMBL1472572 & 688673 & 4.7 & 5.5483 & TRN & \\
\hline CHEMBL1357880 & 688673 & 5.0 & 5.5463 & TRN & \\
\hline CHEMBL1583591 & 688673 & 6.1 & 5.7093 & TRN & \\
\hline CHEMBL1427340 & 688673 & 4.5 & 5.5954 & TRN & \\
\hline CHEMBL 3208343 & 688673 & 4.55 & 5.7364 & TST & \\
\hline CHEMBL1362773 & 688673 & 7.5003 & 5.8881 & TST & \\
\hline CHEMBL1420623 & 688673 & 4.5 & 5.7093 & TRN & \\
\hline CHEMBL1477837 & 688673 & 5.5 & 5.4571 & TRN & \\
\hline CHEMBL1373655 & 688673 & 6.1 & 5.5683 & TST & \\
\hline CHEMBL3190987 & 688673 & 4.45 & 5.6857 & TRN & \\
\hline CHEMBL1556915 & 688673 & 4.6 & 5.3881 & TST & \\
\hline CHEMBL1526245 & 688673 & 5.25 & 5.6349 & TRN & \\
\hline CHEMBL1411764 & 688673 & 4.8 & 5.5703 & TRN & \\
\hline CHEMBL1306211 & 688673 & 7.3002 & 5.8473 & TRN & \\
\hline CHEMBL1370336 & 688673 & 5.1 & 5.7322 & TRN & \\
\hline CHEMBL1461578 & 688673 & 5.3 & 5.5085 & TRN & \\
\hline CHEMBL1491657 & 688673 & 5.3 & 5.9751 & TRN & \\
\hline CHEMBL1385456 & 688673 & 4.45 & 5.6776 & TST & \\
\hline CHEMBL1526483 & 688673 & 5.2 & 5.8756 & TRN & \\
\hline CHEMBL1562008 & 688673 & 5.3 & 5.8187 & TRN & \\
\hline CHEMBL1416600 & 688673 & 5.95 & 5.8451 & TRN & \\
\hline
\end{tabular}




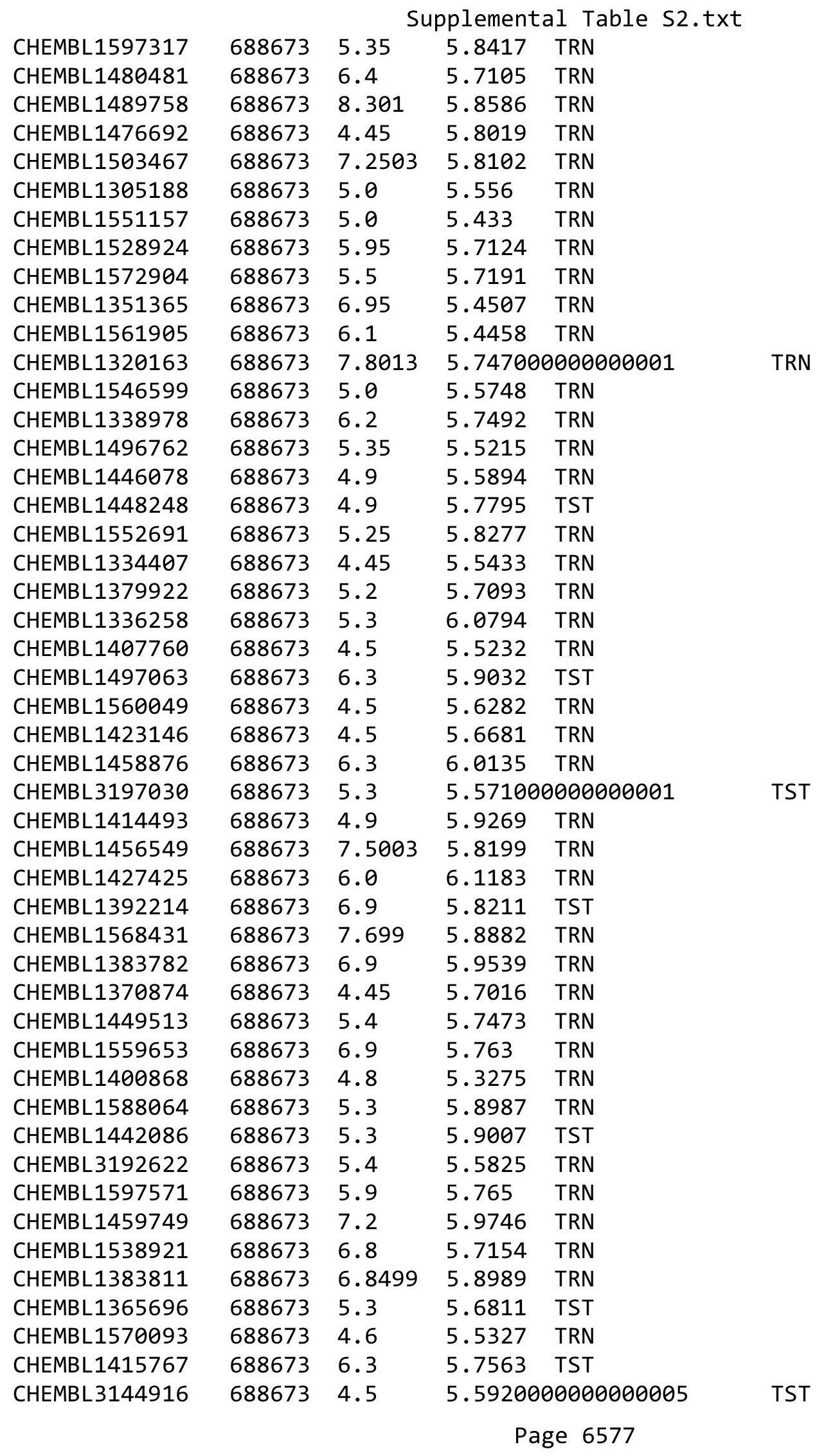




\begin{tabular}{|c|c|c|c|c|c|}
\hline \multicolumn{6}{|c|}{ Supplemental Table S2.txt } \\
\hline CHEMBL1451957 & 688673 & 4.9 & 5.6143 & TRN & \\
\hline CHEMBL3199227 & 688673 & 5.3 & 5.3031 & TRN & \\
\hline CHEMBL1320788 & 688673 & 4.5 & 5.5039 & TRN & \\
\hline CHEMBL1498919 & 688673 & 5.5 & 5.6357 & TRN & \\
\hline CHEMBL1316953 & 688673 & 5.6 & 5.7162 & TST & \\
\hline CHEMBL1561244 & 688673 & 5.4 & 5.5302 & TST & \\
\hline CHEMBL1409332 & 688673 & 4.95 & 5.7205 & TRN & \\
\hline CHEMBL1574127 & 688673 & 5.6 & 5.7472 & TRN & \\
\hline CHEMBL1499925 & 688673 & 4.6 & 5.3522 & TRN & \\
\hline CHEMBL1308675 & 688673 & 5.0 & 5.7125 & TRN & \\
\hline CHEMBL1331446 & 688673 & 8.4949 & 5.3108 & TST & \\
\hline CHEMBL1426843 & 688673 & 6.45 & 5.8478 & TST & \\
\hline CHEMBL1356602 & 688673 & 4.6 & 5.749 & TRN & \\
\hline CHEMBL1733957 & 688673 & 5.3 & 5.6064 & TST & \\
\hline CHEMBL1543800 & 688673 & 5.2 & 5.5471 & TRN & \\
\hline CHEMBL1595015 & 688673 & 4.9 & 5.4188 & TST & \\
\hline CHEMBL1500857 & 688673 & 4.9 & 6.011 & TRN & \\
\hline CHEMBL1482791 & 688673 & 7.5003 & 6.1363 & TRN & \\
\hline CHEMBL1375082 & 688673 & 7.8996 & 5.671 & TRN & \\
\hline CHEMBL3213003 & 688673 & 7.8996 & 5.5613 & TST & \\
\hline CHEMBL1319469 & 688673 & 8.0 & 5.9118 & TST & \\
\hline CHEMBL1381525 & 688673 & 4.8 & 5.7837 & TRN & \\
\hline CHEMBL1362129 & 688673 & 6.05 & 5.7626 & TST & \\
\hline CHEMBL1359220 & 688673 & 5.65 & 5.9518 & TRN & \\
\hline CHEMBL1363253 & 688673 & 6.8 & 6.0769 & TRN & \\
\hline CHEMBL1451482 & 688673 & 5.4 & 5.7446 & TRN & \\
\hline CHEMBL1548413 & 688673 & 7.6003 & 5.87299 & 9999999999 & TST \\
\hline CHEMBL1523317 & 688673 & 5.0 & 5.4192 & TRN & \\
\hline CHEMBL1546403 & 688673 & 5.9 & 5.5215 & TRN & \\
\hline CHEMBL1483225 & 688673 & 5.2 & 5.7207 & TRN & \\
\hline CHEMBL1465690 & 688673 & 7.5003 & 6.0063 & TRN & \\
\hline CHEMBL1588490 & 688673 & 8.3979 & 5.8014 & TRN & \\
\hline CHEMBL1351624 & 688673 & 5.25 & 6.0415 & TRN & \\
\hline CHEMBL1448092 & 688673 & 5.25 & 5.9203 & TRN & \\
\hline CHEMBL1479556 & 688673 & 5.7 & 5.9621 & TRN & \\
\hline CHEMBL1566796 & 688673 & 5.3 & 5.7045 & TRN & \\
\hline CHEMBL1391390 & 688673 & 4.5 & 5.3567 & TRN & \\
\hline CHEMBL1485010 & 688673 & 4.5 & 5.6707 & TRN & \\
\hline CHEMBL1385602 & 688673 & 7.2 & 5.6679 & TRN & \\
\hline CHEMBL1364689 & 688673 & 7.8996 & 5.7134 & TST & \\
\hline CHEMBL1489566 & 688673 & 4.45 & 5.7668 & TRN & \\
\hline CHEMBL1362137 & 688673 & 7.8013 & 6.0949 & TRN & \\
\hline CHEMBL1526481 & 688673 & 6.9 & 5.852 & TRN & \\
\hline CHEMBL1360423 & 688673 & 7.2 & 5.8183 & TRN & \\
\hline CHEMBL1428619 & 688673 & 7.6003 & 5.8906 & TRN & \\
\hline CHEMBL1427890 & 688673 & 5.9 & 5.6311 & TRN & \\
\hline CHEMBL1580279 & 688673 & 5.9 & 5.9519 & TRN & \\
\hline CHEMBL1442741 & 688673 & 5.4 & 5.66299 & 9999999999 & Niv \\
\hline & & & & 657 & \\
\hline
\end{tabular}




\begin{tabular}{|c|c|c|c|c|c|}
\hline \multicolumn{6}{|c|}{ Supplemental Table s2.txt } \\
\hline CHEMBL1410134 & 688673 & 5.0 & 5.6146 & TST & \\
\hline CHEMBL1328232 & 688673 & 4.7 & 5.5123 & TRN & \\
\hline CHEMBL1609982 & 688673 & 7.699 & 5.5315 & TRN & \\
\hline CHEMBL1491010 & 688673 & 4.8 & 5.4943 & TRN & \\
\hline CHEMBL1377654 & 688673 & 5.0 & 5.7427 & TST & \\
\hline CHEMBL1477524 & 688673 & 6.1 & 5.4668 & TRN & \\
\hline CHEMBL1470269 & 688673 & 4.5 & 5.6691 & TRN & \\
\hline CHEMBL1321726 & 688673 & 7.8996 & 6.0965 & TRN & \\
\hline CHEMBL1471924 & 688673 & 4.9 & 5.3582 & TST & \\
\hline CHEMBL1517495 & 688673 & 4.5 & 5.6079 & TRN & \\
\hline CHEMBL 3213138 & 688673 & 5.2 & 5.6718 & TST & \\
\hline CHEMBL1372594 & 688673 & 4.7 & 6.0054 & TRN & \\
\hline CHEMBL1554290 & 688673 & 6.8 & 5.7645 & TRN & \\
\hline CHEMBL 3211185 & 688673 & 6.5 & 5.6319 & TRN & \\
\hline CHEMBL1350285 & 688673 & 5.3 & 5.6743 & TRN & \\
\hline CHEMBL1353144 & 688673 & 4.5 & 5.5552 & TRN & \\
\hline CHEMBL1421602 & 688673 & 8.301 & 5.9097 & TRN & \\
\hline CHEMBL1311998 & 688673 & 6.1 & 5.7612 & TRN & \\
\hline CHEMBL1382936 & 688673 & 6.9 & 5.65799 & 99999999995 & TRN \\
\hline CHEMBL1499411 & 688673 & 4.9 & 5.7004 & TRN & \\
\hline CHEMBL1431542 & 688673 & 7.6498 & 5.975 & TRN & \\
\hline CHEMBL1480600 & 688673 & 7.8996 & 5.8391 & TRN & \\
\hline CHEMBL1487730 & 688673 & 8.0 & 5.7376 & TRN & \\
\hline CHEMBL1416465 & 688673 & 6.5 & 5.6884 & TRN & \\
\hline CHEMBL1309430 & 688673 & 4.7 & 5.7637 & TRN & \\
\hline CHEMBL1309181 & 688673 & 6.4 & 5.5518 & TST & \\
\hline CHEMBL1465693 & 688673 & 4.9 & 5.6798 & TRN & \\
\hline CHEMBL1325195 & 688673 & 5.2 & 5.8923 & TRN & \\
\hline CHEMBL1417249 & 688673 & 4.5 & 5.4318 & TRN & \\
\hline CHEMBL1577158 & 688673 & 4.5 & 5.5324 & TRN & \\
\hline CHEMBL1321751 & 688673 & 4.5 & 5.6863 & TRN & \\
\hline CHEMBL1363150 & 688673 & 4.8 & 5.8189 & TRN & \\
\hline CHEMBL1469723 & 688673 & 5.0 & 5.9156 & TRN & \\
\hline CHEMBL1381149 & 688673 & 6.95 & 5.5519 & TRN & \\
\hline CHEMBL1390263 & 688673 & 6.1 & 5.7291 & TRN & \\
\hline CHEMBL3207830 & 688673 & 5.3 & 5.8798 & TRN & \\
\hline CHEMBL1463289 & 688673 & 4.65 & 5.6723 & TRN & \\
\hline CHEMBL1597047 & 688673 & 6.2 & 6.0636 & TRN & \\
\hline CHEMBL1558154 & 688673 & 7.699 & 5.9368 & TRN & \\
\hline CHEMBL1571242 & 688673 & 5.2 & 5.5823 & TRN & \\
\hline CHEMBL1520845 & 688673 & 5.3 & 5.6309 & TST & \\
\hline CHEMBL1991885 & 688673 & 5.0 & 5.2871 & TRN & \\
\hline CHEMBL1470795 & 688673 & 5.0 & 5.5758 & TST & \\
\hline CHEMBL1565404 & 688673 & 4.6 & 5.6393 & TRN & \\
\hline CHEMBL1547362 & 688673 & 5.25 & 5.9152 & TRN & \\
\hline CHEMBL1377811 & 688673 & 8.301 & 5.6208 & TRN & \\
\hline CHEMBL1592844 & 688673 & 4.7 & 5.4983 & TRN & \\
\hline CHEMBL1454630 & 688673 & 5.9 & 5.7488 & TRN & \\
\hline
\end{tabular}




\begin{tabular}{|c|c|c|c|c|c|}
\hline \multirow[b]{2}{*}{ CHEMBL1376469 } & \multicolumn{5}{|c|}{ Supplemental Table S2.txt } \\
\hline & 688673 & 7.6498 & 6.0841 & TRN & \\
\hline CHEMBL1391097 & 688673 & 4.8 & 5.6844 & TRN & \\
\hline CHEMBL1370618 & 688673 & 5.9 & 5.8357 & TRN & \\
\hline CHEMBL1517771 & 688673 & 4.5 & 5.8868 & TRN & \\
\hline CHEMBL1474413 & 688673 & 4.75 & 5.6414 & TRN & \\
\hline CHEMBL1197556 & 688673 & 5.0 & 5.5121 & TST & \\
\hline CHEMBL1310926 & 688673 & 6.1 & 5.8553 & TST & \\
\hline CHEMBL1571034 & 688673 & 5.35 & 5.33200 & 0000000001 & TRN \\
\hline CHEMBL1421046 & 688673 & 6.7001 & 6.0791 & TRN & \\
\hline CHEMBL1303911 & 688673 & 5.9 & 5.6827 & TRN & \\
\hline CHEMBL1471859 & 688673 & 6.6 & 5.666 & TRN & \\
\hline CHEMBL1546004 & 688673 & 8.0 & 5.5394 & TST & \\
\hline CHEMBL1535773 & 688673 & 6.6 & 5.8358 & TRN & \\
\hline CHEMBL1536738 & 688673 & 4.8 & 5.7337 & TST & \\
\hline CHEMBL1356246 & 688673 & 5.5 & 5.6817 & TRN & \\
\hline CHEMBL1571642 & 688673 & 5.1 & 5.8062 & TRN & \\
\hline CHEMBL1351598 & 688673 & 4.9 & 5.3621 & TRN & \\
\hline CHEMBL1531156 & 688673 & 7.3002 & 5.7866 & TRN & \\
\hline CHEMBL1502811 & 688673 & 4.95 & 5.7407 & TRN & \\
\hline CHEMBL1405701 & 688673 & 4.45 & 5.8755 & TRN & \\
\hline CHEMBL1477690 & 688673 & 8.3468 & 5.2541 & TRN & \\
\hline CHEMBL1583266 & 688673 & 5.3 & 5.4412 & TRN & \\
\hline CHEMBL1612105 & 688673 & 6.0 & 6.104 & TRN & \\
\hline CHEMBL1508743 & 688673 & 4.8 & 5.7123 & TRN & \\
\hline CHEMBL1558193 & 688673 & 4.45 & 5.6973 & TRN & \\
\hline CHEMBL 1589112 & 688673 & 5.5 & 5.817 & TRN & \\
\hline CHEMBL492115 & 688673 & 5.3 & 5.7623 & TRN & \\
\hline CHEMBL1363596 & 688673 & 4.95 & 5.6927 & TRN & \\
\hline CHEMBL1613678 & 688673 & 4.85 & 5.7977 & TRN & \\
\hline CHEMBL1491485 & 688673 & 4.5 & 5.9775 & TRN & \\
\hline CHEMBL1481386 & 688673 & 6.7501 & 6.0352 & TRN & \\
\hline CHEMBL1389959 & 688673 & 4.9 & 5.5324 & TRN & \\
\hline CHEMBL1570348 & 688673 & 7.699 & 5.7479 & TRN & \\
\hline CHEMBL1352236 & 688673 & 5.1 & 5.6945 & TRN & \\
\hline CHEMBL1429090 & 688673 & 6.6 & 5.8477 & TRN & \\
\hline CHEMBL1448863 & 688673 & 5.6 & 5.6776 & TST & \\
\hline CHEMBL1383557 & 688673 & 4.6 & 5.7107 & TRN & \\
\hline CHEMBL1344408 & 688673 & 5.2 & 6.0048 & TRN & \\
\hline CHEMBL1324533 & 688673 & 5.3 & 6.0779 & TRN & \\
\hline CHEMBL1579511 & 688673 & 6.5501 & 5.7489 & TST & \\
\hline CHEMBL1419199 & 688673 & 6.1 & 5.4067 & TRN & \\
\hline CHEMBL1565076 & 688673 & 5.1 & 5.901 & TRN & \\
\hline CHEMBL1440258 & 688673 & 7.0501 & 5.7347 & TRN & \\
\hline CHEMBL 2003973 & 688673 & 7.3002 & 5.69799 & 99999999995 & TST \\
\hline CHEMBL1309378 & 688673 & 4.8 & 5.4751 & TRN & \\
\hline CHEMBL1561864 & 688673 & 7.5003 & 5.5987 & TRN & \\
\hline CHEMBL1537230 & 688673 & 5.0 & 5.6267 & TRN & \\
\hline CHEMBL1608072 & 688673 & 4.5 & 5.8881 & TRN & \\
\hline
\end{tabular}




\begin{tabular}{|c|c|c|c|c|c|}
\hline \\
\hline CHEMBL1465078 & 688673 & 5.2 & 5.7404 & TRN & \\
\hline CHEMBL1586880 & 688673 & 6.9 & 5.6896 & TRN & \\
\hline CHEMBL1570074 & 688673 & 5.5 & 6.0332 & TRN & \\
\hline CHEMBL1441242 & 688673 & 4.9 & 5.6695 & TRN & \\
\hline CHEMBL3191811 & 688673 & 5.3 & 5.441 & TRN & \\
\hline CHEMBL1321086 & 688673 & 6.1 & 5.78100 & 0000000001 & TRN \\
\hline CHEMBL1300035 & 688673 & 4.6 & 5.9089 & TRN & \\
\hline CHEMBL1432433 & 688673 & 5.8 & 6.0205 & TRN & \\
\hline CHEMBL1409389 & 688673 & 4.5 & 5.2778 & TRN & \\
\hline CHEMBL1421350 & 688673 & 4.55 & 6.1606 & TRN & \\
\hline CHEMBL1453831 & 688673 & 8.3979 & 5.5734 & TRN & \\
\hline CHEMBL1509747 & 688673 & 6.7001 & 5.5956 & TRN & \\
\hline CHEMBL1346875 & 688673 & 5.5 & 5.5218 & TRN & \\
\hline CHEMBL3193273 & 688673 & 7.1002 & 5.5934 & TRN & \\
\hline CHEMBL1429098 & 688673 & 4.7 & 5.4741 & TRN & \\
\hline CHEMBL1369105 & 688673 & 7.3002 & 5.9075 & TRN & \\
\hline CHEMBL1372414 & 688673 & 4.5 & 5.5254 & TRN & \\
\hline CHEMBL1338027 & 688673 & 4.5 & 5.3988 & TRN & \\
\hline CHEMBL1366750 & 688673 & 5.2 & 5.6115 & TRN & \\
\hline CHEMBL1309785 & 688673 & 4.5 & 5.3341 & TST & \\
\hline CHEMBL1532953 & 688673 & 4.65 & 5.6816 & TRN & \\
\hline CHEMBL1337413 & 688673 & 4.45 & 5.8194 & TRN & \\
\hline CHEMBL1548974 & 688673 & 7.5003 & 5.6769 & TRN & \\
\hline CHEMBL1345970 & 688673 & 4.6 & 5.7642 & TRN & \\
\hline CHEMBL1444261 & 688673 & 4.9 & 5.4056 & TRN & \\
\hline CHEMBL1462601 & 688673 & 7.8996 & 5.9136 & TRN & \\
\hline CHEMBL1967436 & 688673 & 4.6 & 5.5714 & TST & \\
\hline CHEMBL1497330 & 688673 & 5.5 & 5.8657 & TRN & \\
\hline CHEMBL1486570 & 688673 & 5.5 & 5.5502 & TRN & \\
\hline CHEMBL1582602 & 688673 & 4.8 & 5.6644 & TST & \\
\hline CHEMBL1608446 & 688673 & 5.95 & 5.6549 & TRN & \\
\hline CHEMBL1562550 & 688673 & 4.65 & 5.1566 & TRN & \\
\hline CHEMBL1333094 & 688673 & 6.0 & 5.7017 & TRN & \\
\hline CHEMBL1463383 & 688673 & 4.8 & 5.7117 & TST & \\
\hline CHEMBL1494683 & 688673 & 4.6 & 5.5394 & TRN & \\
\hline CHEMBL1569749 & 688673 & 7.5498 & 5.8203 & TRN & \\
\hline CHEMBL1601723 & 688673 & 5.3 & 5.6726 & TRN & \\
\hline CHEMBL1419253 & 688673 & 6.1 & 5.69799 & 99999999995 & TRN \\
\hline CHEMBL1486646 & 688673 & 4.45 & 5.4901 & TRN & \\
\hline CHEMBL1489833 & 688673 & 5.4 & 5.7134 & TST & \\
\hline CHEMBL1539208 & 688673 & 4.5 & 5.822 & TRN & \\
\hline CHEMBL1558672 & 688673 & 4.65 & 5.709 & TST & \\
\hline CHEMBL1405912 & 688673 & 7.0 & 5.7813 & TRN & \\
\hline CHEMBL1586726 & 688673 & 5.4 & 5.7407 & TRN & \\
\hline CHEMBL1510129 & 688673 & 4.8 & 5.3615 & TRN & \\
\hline CHEMBL1362872 & 688673 & 7.6003 & 5.3648 & TRN & \\
\hline CHEMBL1528496 & 688673 & 4.5 & 5.8429 & TRN & \\
\hline CHEMBL1611434 & 688673 & 7.1002 & 5.6112 & TRN & \\
\hline
\end{tabular}




\begin{tabular}{|c|c|c|c|c|c|}
\hline \multicolumn{6}{|c|}{ Supplemental Table S2.txt } \\
\hline CHEMBL1372544 & 688673 & 5.1 & 5.8801 & TRN & \\
\hline CHEMBL584849 & 688673 & 4.45 & 5.2858 & TRN & \\
\hline CHEMBL1332391 & 688673 & 6.1 & 5.6889 & TRN & \\
\hline CHEMBL1611989 & 688673 & 7.7496 & 5.8882 & TRN & \\
\hline CHEMBL1495019 & 688673 & 5.25 & 5.7441 & TRN & \\
\hline CHEMBL1427823 & 688673 & 4.9 & 5.5728 & TRN & \\
\hline CHEMBL1536419 & 688673 & 6.0 & 5.895 & TRN & \\
\hline CHEMBL1547588 & 688673 & 4.9 & 5.87700 & 0000000001 & TRN \\
\hline CHEMBL1595857 & 688673 & 6.5501 & 5.6684 & TRN & \\
\hline CHEMBL1602307 & 688673 & 4.5 & 5.7595 & TRN & \\
\hline CHEMBL1577110 & 688673 & 6.7501 & 5.4043 & TRN & \\
\hline CHEMBL1546716 & 688673 & 4.5 & 5.6369 & TRN & \\
\hline CHEMBL1534646 & 688673 & 5.55 & 5.5614 & TRN & \\
\hline CHEMBL1591741 & 688673 & 7.0 & 6.2777 & TRN & \\
\hline CHEMBL222840 & 688673 & 4.5 & 5.5388 & TRN & \\
\hline CHEMBL1519830 & 688673 & 5.3 & 6.0267 & TRN & \\
\hline CHEMBL1421246 & 688673 & 6.7001 & 5.4249 & TRN & \\
\hline CHEMBL1444276 & 688673 & 4.8 & 5.6583 & TRN & \\
\hline CHEMBL1608680 & 688673 & 4.5 & 5.9894 & TRN & \\
\hline CHEMBL1570605 & 688673 & 5.3 & 5.8798 & TRN & \\
\hline CHEMBL1331839 & 688673 & 4.9 & 5.504 & TRN & \\
\hline CHEMBL1539915 & 688673 & 6.3 & 5.4823 & TRN & \\
\hline CHEMBL1469528 & 688673 & 4.8 & 5.4858 & TRN & \\
\hline CHEMBL1606069 & 688673 & 4.7 & 5.5788 & TRN & \\
\hline CHEMBL1361904 & 688673 & 7.8996 & 5.8255 & TRN & \\
\hline CHEMBL1362209 & 688673 & 7.6003 & 5.9109 & TST & \\
\hline CHEMBL1309203 & 688673 & 4.45 & 5.5304 & TST & \\
\hline CHEMBL1535824 & 688673 & 5.55 & 5.6316 & TRN & \\
\hline CHEMBL1556185 & 688673 & 6.0 & 5.8739 & TRN & \\
\hline CHEMBL1509370 & 688673 & 7.0 & 5.5912 & TRN & \\
\hline CHEMBL1455111 & 688673 & 6.8 & 5.7142 & TRN & \\
\hline CHEMBL1333809 & 688673 & 7.699 & 5.6746 & TRN & \\
\hline CHEMBL1304738 & 688673 & 6.5 & 5.9314 & TRN & \\
\hline CHEMBL1421362 & 688673 & 7.3002 & 5.8682 & TRN & \\
\hline CHEMBL1501764 & 688673 & 7.4498 & 5.8507 & TST & \\
\hline CHEMBL1456523 & 688673 & 4.95 & 5.3922 & TRN & \\
\hline CHEMBL222418 & 688673 & 4.9 & 5.3851 & TST & \\
\hline CHEMBL1506653 & 688673 & 7.3002 & 5.5861 & TRN & \\
\hline CHEMBL1541741 & 688673 & 6.2 & 5.61 & TRN & \\
\hline CHEMBL1383122 & 688673 & 6.1 & 5.9329 & TRN & \\
\hline CHEMBL1382630 & 688673 & 5.5 & 5.5739 & TRN & \\
\hline CHEMBL1349062 & 688673 & 5.0 & 5.5299 & TRN & \\
\hline CHEMBL1533585 & 688673 & 6.9 & 5.6431 & TRN & \\
\hline CHEMBL1462774 & 688673 & 4.8 & 5.6232 & TRN & \\
\hline CHEMBL1512316 & 688673 & 4.45 & 5.7352 & TRN & \\
\hline CHEMBL1382724 & 688673 & 6.7001 & 5.8452 & TRN & \\
\hline CHEMBL1449215 & 688673 & 4.5 & 5.8687 & TRN & \\
\hline CHEMBL1404846 & 688673 & 4.7 & 5.6924 & TRN & \\
\hline
\end{tabular}




\begin{tabular}{|c|c|c|c|c|c|}
\hline & & \multicolumn{4}{|c|}{ Supplemental Table S2.txt } \\
\hline CHEMBL1566329 & 688673 & 7.8013 & 5.7652 & TRN & \\
\hline CHEMBL1352833 & 688673 & 4.5 & 6.1265 & TRN & \\
\hline CHEMBL1584054 & 688673 & 8.301 & 6.0561 & TRN & \\
\hline CHEMBL1370760 & 688673 & 5.2 & 5.7165 & TST & \\
\hline CHEMBL3196799 & 688673 & 6.0 & 5.6374 & TST & \\
\hline CHEMBL1541668 & 688673 & 5.9 & 5.8161 & TRN & \\
\hline CHEMBL1481268 & 688673 & 8.2007 & 5.5371 & TRN & \\
\hline CHEMBL1444148 & 688673 & 6.7001 & 5.9125 & TRN & \\
\hline CHEMBL1416552 & 688673 & 4.5 & 5.7944 & TRN & \\
\hline CHEMBL1427347 & 688673 & 4.5 & 5.9561 & TRN & \\
\hline CHEMBL1446315 & 688673 & 4.45 & 5.92299 & 9999999999 & TRN \\
\hline CHEMBL1546762 & 688673 & 4.6 & 5.5886 & TST & \\
\hline CHEMBL3212467 & 688673 & 7.8013 & 5.5996 & TST & \\
\hline CHEMBL1562252 & 688673 & 4.45 & 5.7243 & TRN & \\
\hline CHEMBL1611677 & 688673 & 4.6 & 6.1018 & TRN & \\
\hline CHEMBL1457257 & 688673 & 5.4 & 5.7931 & TRN & \\
\hline CHEMBL1524419 & 688673 & 4.9 & 6.1851 & TRN & \\
\hline CHEMBL1522719 & 688673 & 4.65 & 6.0731 & TRN & \\
\hline CHEMBL1350781 & 688673 & 5.6 & 5.9344 & TRN & \\
\hline CHEMBL1508961 & 688673 & 4.5 & 5.8139 & TRN & \\
\hline CHEMBL1422781 & 688673 & 5.5 & 5.5542 & TST & \\
\hline CHEMBL1480601 & 688673 & 5.4 & 6.2519 & TRN & \\
\hline CHEMBL1412471 & 688673 & 8.301 & 5.5389 & TRN & \\
\hline CHEMBL1302967 & 688673 & 4.5 & 5.8341 & TRN & \\
\hline CHEMBL3194605 & 688673 & 4.5 & 5.3854 & TRN & \\
\hline CHEMBL1421069 & 688673 & 7.8996 & 5.8798 & TST & \\
\hline CHEMBL1332112 & 688673 & 4.5 & 5.9955 & TRN & \\
\hline CHEMBL1439559 & 688673 & 6.0 & 5.9507 & TRN & \\
\hline CHEMBL1435516 & 688673 & 5.0 & 5.4385 & TRN & \\
\hline CHEMBL1496055 & 688673 & 5.2 & 5.5989 & TRN & \\
\hline CHEMBL1464878 & 688673 & 4.8 & 5.8718 & TRN & \\
\hline CHEMBL1484790 & 688673 & 6.7001 & 5.754 & TRN & \\
\hline CHEMBL1534294 & 688673 & 5.5 & 5.4208 & TRN & \\
\hline CHEMBL1173787 & 688673 & 4.9 & 5.6072 & TST & \\
\hline CHEMBL1557140 & 688673 & 5.0 & 5.8699 & TRN & \\
\hline CHEMBL1499667 & 688673 & 5.3 & 6.0041 & TRN & \\
\hline CHEMBL1508801 & 688673 & 6.1 & 5.8548 & TRN & \\
\hline CHEMBL1460876 & 688673 & 6.35 & 5.6643 & TST & \\
\hline CHEMBL1496519 & 688673 & 4.5 & 5.8856 & TRN & \\
\hline CHEMBL1384366 & 688673 & 4.65 & 5.7084 & TRN & \\
\hline CHEMBL1605423 & 688673 & 6.1 & 6.0377 & TRN & \\
\hline CHEMBL1432786 & 688673 & 8.301 & 5.9326 & TRN & \\
\hline CHEMBL1577056 & 688673 & 5.4 & 5.7514 & TRN & \\
\hline CHEMBL1452293 & 688673 & 7.5003 & 5.7585 & TRN & \\
\hline CHEMBL1430157 & 688673 & 4.5 & 5.7858 & TRN & \\
\hline CHEMBL1575774 & 688673 & 4.85 & 5.6087 & TRN & \\
\hline CHEMBL1330669 & 688673 & 4.75 & 5.9404 & TRN & \\
\hline CHEMBL1408319 & 688673 & 4.9 & 5.7988 & TST & \\
\hline
\end{tabular}




\begin{tabular}{|c|c|c|c|c|}
\hline \multicolumn{5}{|c|}{ Supplemental Table S2.txt } \\
\hline CHEMBL1425029 & 688673 & 5.5 & 6.1463 & TRN \\
\hline CHEMBL1460795 & 688673 & 5.4 & 5.6462 & TST \\
\hline CHEMBL1322916 & 688673 & 4.5 & 5.5711 & TST \\
\hline CHEMBL1305876 & 688673 & 4.45 & 5.824 & TRN \\
\hline CHEMBL1338766 & 688673 & 6.6 & 5.86 & TST \\
\hline CHEMBL1526027 & 688673 & 4.65 & 5.3768 & TRN \\
\hline CHEMBL1588159 & 688673 & 7.0 & 5.9802 & TRN \\
\hline CHEMBL3192969 & 688673 & 6.5 & 5.9468 & TRN \\
\hline CHEMBL1536158 & 688673 & 6.0 & 5.6289 & TRN \\
\hline CHEMBL1491357 & 688673 & 5.3 & 5.5747 & TRN \\
\hline CHEMBL1459902 & 688673 & 8.0 & 5.6632 & TRN \\
\hline CHEMBL1588225 & 688673 & 5.35 & 5.7939 & TRN \\
\hline CHEMBL1509514 & 688673 & 7.6498 & 5.9373 & TRN \\
\hline CHEMBL1544276 & 688673 & 7.4001 & 5.709 & TRN \\
\hline CHEMBL1452731 & 688673 & 6.1 & 6.0804 & TRN \\
\hline CHEMBL1429332 & 688673 & 4.7 & 5.881 & TRN \\
\hline CHEMBL1537884 & 688673 & 6.0 & 5.7109 & TRN \\
\hline CHEMBL1410307 & 688673 & 7.8508 & 5.7919 & TRN \\
\hline CHEMBL1447069 & 688673 & 7.6003 & 5.9786 & TRN \\
\hline CHEMBL1597625 & 688673 & 5.5 & 5.9043 & TRN \\
\hline CHEMBL1547354 & 688673 & 5.4 & 5.6605 & TRN \\
\hline CHEMBL1583328 & 688673 & 5.6 & 5.4982 & TRN \\
\hline CHEMBL1550248 & 688673 & 5.3 & 6.0682 & TRN \\
\hline CHEMBL1531596 & 688673 & 6.1 & 5.8946 & TRN \\
\hline CHEMBL1330791 & 688673 & 6.9 & 5.7429 & TRN \\
\hline CHEMBL1382889 & 688673 & 5.8 & 5.7024 & TRN \\
\hline CHEMBL1320001 & 688673 & 5.6 & 5.8894 & TRN \\
\hline CHEMBL1557817 & 688673 & 5.3 & 6.0851 & TRN \\
\hline CHEMBL1529405 & 688673 & 4.75 & 5.6727 & TRN \\
\hline CHEMBL1490532 & 688673 & 4.9 & 5.9967 & TRN \\
\hline CHEMBL1407628 & 688673 & 4.45 & 5.985 & TRN \\
\hline CHEMBL1494533 & 688673 & 4.6 & 5.4792 & TRN \\
\hline CHEMBL1979849 & 688673 & 5.0 & 5.4918 & TRN \\
\hline CHEMBL1605363 & 688673 & 4.7 & 5.4848 & TRN \\
\hline CHEMBL474589 & 688673 & 5.8 & 5.4717 & TRN \\
\hline CHEMBL1164316 & 688673 & 4.9 & 5.4533 & TRN \\
\hline CHEMBL1604873 & 688673 & 4.75 & 5.6752 & TRN \\
\hline CHEMBL1340363 & 688673 & 6.1 & 5.3378 & TRN \\
\hline CHEMBL1557859 & 688673 & 4.95 & 5.358 & TRN \\
\hline CHEMBL1520112 & 688673 & 5.7 & 6.0081 & TRN \\
\hline CHEMBL1413902 & 688673 & 4.6 & 5.9823 & TRN \\
\hline CHEMBL1529223 & 688673 & 5.3 & 5.4081 & TST \\
\hline CHEMBL1442901 & 688673 & 5.25 & 5.7334 & TRN \\
\hline CHEMBL1403145 & 688673 & 6.8 & 5.5727 & TRN \\
\hline CHEMBL1605126 & 688673 & 7.3497 & 5.4983 & TRN \\
\hline CHEMBL153336 & 688673 & 5.0 & 5.6627 & TRN \\
\hline CHEMBL1347511 & 688673 & 6.8 & 5.8111 & TRN \\
\hline CHEMBL1319111 & 688673 & 7.3002 & 5.8337 & TRN \\
\hline
\end{tabular}




\begin{tabular}{|c|c|c|c|c|c|}
\hline \multicolumn{6}{|c|}{ Supplemental Table s2.txt } \\
\hline CHEMBL1398596 & 688673 & 4.9 & 5.3495 & TRN & \\
\hline CHEMBL1440080 & 688673 & 5.5 & 6.1695 & TRN & \\
\hline CHEMBL1349712 & 688673 & 7.0 & 5.7943 & TRN & \\
\hline CHEMBL1413954 & 688673 & 5.7 & 5.9897 & TRN & \\
\hline CHEMBL1352734 & 688673 & 6.7001 & 5.8672 & TRN & \\
\hline CHEMBL1562900 & 688673 & 7.8996 & 5.8102 & TRN & \\
\hline CHEMBL1461362 & 688673 & 4.45 & 5.6614 & TRN & \\
\hline CHEMBL1487522 & 688673 & 5.2 & 5.5641 & TRN & \\
\hline CHEMBL1508238 & 688673 & 6.5 & 5.6901 & TRN & \\
\hline CHEMBL1610650 & 688673 & 4.6 & 5.8849 & TRN & \\
\hline CHEMBL1462621 & 688673 & 5.2 & 5.9815 & TRN & \\
\hline CHEMBL1300521 & 688673 & 4.7 & 5.816 & TRN & \\
\hline CHEMBL1461679 & 688673 & 7.8013 & 5.5983 & TRN & \\
\hline CHEMBL1539514 & 688673 & 5.4 & 6.0684 & TRN & \\
\hline CHEMBL1516412 & 688673 & 4.5 & 5.9609 & TST & \\
\hline CHEMBL1365927 & 688673 & 4.5 & 5.5045 & TRN & \\
\hline CHEMBL1507963 & 688673 & 5.7 & 5.5952 & TRN & \\
\hline CHEMBL1504010 & 688673 & 5.9 & 5.7968 & TRN & \\
\hline CHEMBL1405964 & 688673 & 4.55 & 5.6816 & TRN & \\
\hline CHEMBL1311178 & 688673 & 5.0 & 5.5906 & TST & \\
\hline CHEMBL1564838 & 688673 & 5.35 & 6.1421 & TRN & \\
\hline CHEMBL1319378 & 688673 & 5.9 & 5.6736 & TRN & \\
\hline CHEMBL1309335 & 688673 & 4.6 & 5.9323 & TRN & \\
\hline CHEMBL1528486 & 688673 & 8.1487 & 5.9199 & TRN & \\
\hline CHEMBL1327264 & 688673 & 4.9 & 5.7979 & TRN & \\
\hline CHEMBL1565541 & 688673 & 4.5 & 5.6722 & TRN & \\
\hline CHEMBL1580060 & 688673 & 7.6003 & 5.8284 & TRN & \\
\hline CHEMBL1568468 & 688673 & 6.7501 & 5.8857 & TRN & \\
\hline CHEMBL1401827 & 688673 & 5.3 & 5.82 & TRN & \\
\hline CHEMBL133576 & 688673 & 4.45 & 5.53799 & э999999999 & TRN \\
\hline CHEMBL1487516 & 688673 & 4.9 & 5.874 & TRN & \\
\hline CHEMBL1409452 & 688673 & 4.6 & 5.6867 & TRN & \\
\hline CHEMBL1576673 & 688673 & 4.7 & 5.4059 & TST & \\
\hline CHEMBL1604529 & 688673 & 6.0 & 5.8597 & TRN & \\
\hline CHEMBL1399873 & 688673 & 4.9 & 5.5156 & TRN & \\
\hline CHEMBL1451502 & 688673 & 4.5 & 5.5114 & TRN & \\
\hline CHEMBL1362418 & 688673 & 7.699 & 5.5816 & TST & \\
\hline CHEMBL1996376 & 688673 & 5.0 & 5.41200 & 0000000001 & TRN \\
\hline CHEMBL1569315 & 688673 & 4.7 & 5.7998 & TRN & \\
\hline CHEMBL1322365 & 688673 & 5.1 & 5.8726 & TRN & \\
\hline CHEMBL1358848 & 688673 & 5.3 & 6.0143 & TRN & \\
\hline CHEMBL1405736 & 688673 & 5.2 & 5.9011 & TRN & \\
\hline CHEMBL1394018 & 688673 & 7.0 & 5.8809 & TRN & \\
\hline CHEMBL1540789 & 688673 & 5.3 & 5.9743 & TRN & \\
\hline CHEMBL1603779 & 688673 & 5.3 & 5.6015 & TRN & \\
\hline CHEMBL1380995 & 688673 & 6.6 & 5.6621 & TST & \\
\hline CHEMBL1456530 & 688673 & 6.6 & 5.8157 & TST & \\
\hline CHEMBL1452913 & 688673 & 4.9 & 5.7101 & TRN & \\
\hline
\end{tabular}




\begin{tabular}{|c|c|c|c|c|c|}
\hline \multicolumn{6}{|c|}{ Supplemental Table S2.txt } \\
\hline CHEMBL1393143 & 688673 & 6.5 & 5.8536 & TRN & \\
\hline CHEMBL1497947 & 688673 & 6.2 & 5.8843 & TRN & \\
\hline CHEMBL1414360 & 688673 & 4.45 & 5.4546 & TRN & \\
\hline CHEMBL1368466 & 688673 & 6.1 & 5.9178 & TRN & \\
\hline CHEMBL1468011 & 688673 & 4.9 & 5.3282 & TRN & \\
\hline CHEMBL1597967 & 688673 & 6.15 & 6.0659 & TRN & \\
\hline CHEMBL1567062 & 688673 & 6.4 & 5.7674 & TRN & \\
\hline CHEMBL1359864 & 688673 & 7.2 & 6.1367 & TRN & \\
\hline CHEMBL1487977 & 688673 & 6.1 & 5.8147 & TRN & \\
\hline CHEMBL1606253 & 688673 & 5.3 & 5.9422 & TRN & \\
\hline CHEMBL1418982 & 688673 & 5.8 & 5.6573 & TRN & \\
\hline CHEMBL1311267 & 688673 & 5.6 & 6.0276 & TRN & \\
\hline CHEMBL1574132 & 688673 & 4.4 & 5.5352 & TRN & \\
\hline CHEMBL1315017 & 688673 & 7.2 & 5.6934 & TRN & \\
\hline CHEMBL1499616 & 688673 & 4.45 & 6.0256 & TRN & \\
\hline CHEMBL1382581 & 688673 & 7.5003 & 5.7297 & TRN & \\
\hline CHEMBL1320376 & 688673 & 5.25 & 5.6917 & TRN & \\
\hline CHEMBL1553602 & 688673 & 8.301 & 5.4684 & TRN & \\
\hline CHEMBL1469741 & 688673 & 7.8996 & 5.9349 & TRN & \\
\hline CHEMBL1488563 & 688673 & 6.2 & 5.7176 & TRN & \\
\hline CHEMBL1601494 & 688673 & 8.0 & 5.75700 & 0000000001 & TRN \\
\hline CHEMBL1349211 & 688673 & 6.1 & 5.9863 & TRN & \\
\hline CHEMBL1358909 & 688673 & 6.5 & 5.4822 & TRN & \\
\hline CHEMBL1418512 & 688673 & 4.5 & 5.6294 & TST & \\
\hline CHEMBL1481024 & 688673 & 4.8 & 5.9038 & TRN & \\
\hline CHEMBL1540311 & 688673 & 5.6 & 5.5189 & TRN & \\
\hline CHEMBL1442207 & 688673 & 5.9 & 5.4701 & TST & \\
\hline CHEMBL1586081 & 688673 & 6.5 & 5.7487 & TRN & \\
\hline CHEMBL1578982 & 688673 & 4.9 & 5.5388 & TRN & \\
\hline CHEMBL1511141 & 688673 & 4.9 & 5.4987 & TST & \\
\hline CHEMBL1451536 & 688673 & 6.3 & 5.8517 & TRN & \\
\hline CHEMBL1494296 & 688673 & 5.2 & 5.9476 & TRN & \\
\hline CHEMBL1421216 & 688673 & 4.9 & 5.8537 & TRN & \\
\hline CHEMBL1483346 & 688673 & 8.0 & 5.5569 & TST & \\
\hline CHEMBL1613154 & 688673 & 5.3 & 5.8456 & TST & \\
\hline CHEMBL1334167 & 688673 & 5.8 & 5.9572 & TST & \\
\hline CHEMBL1607161 & 688673 & 7.0 & 5.8658 & TST & \\
\hline CHEMBL1346315 & 688673 & 8.301 & 5.8815 & TRN & \\
\hline CHEMBL1562875 & 688673 & 5.5 & 5.6317 & TRN & \\
\hline CHEMBL1583438 & 688673 & 4.5 & 5.8495 & TRN & \\
\hline CHEMBL1458868 & 688673 & 5.9 & 5.9144 & TRN & \\
\hline CHEMBL1560888 & 688673 & 4.9 & 5.8122 & TRN & \\
\hline CHEMBL1337933 & 688673 & 4.9 & 5.6779 & TST & \\
\hline CHEMBL1350295 & 688673 & 5.25 & 5.8305 & TST & \\
\hline CHEMBL1394330 & 688673 & 5.15 & 5.301 & TRN & \\
\hline CHEMBL1397777 & 688673 & 4.45 & 5.6616 & TRN & \\
\hline CHEMBL1560619 & 688673 & 6.8 & 5.6681 & TRN & \\
\hline CHEMBL1610367 & 688673 & 7.6003 & 6.0641 & TRN & \\
\hline
\end{tabular}




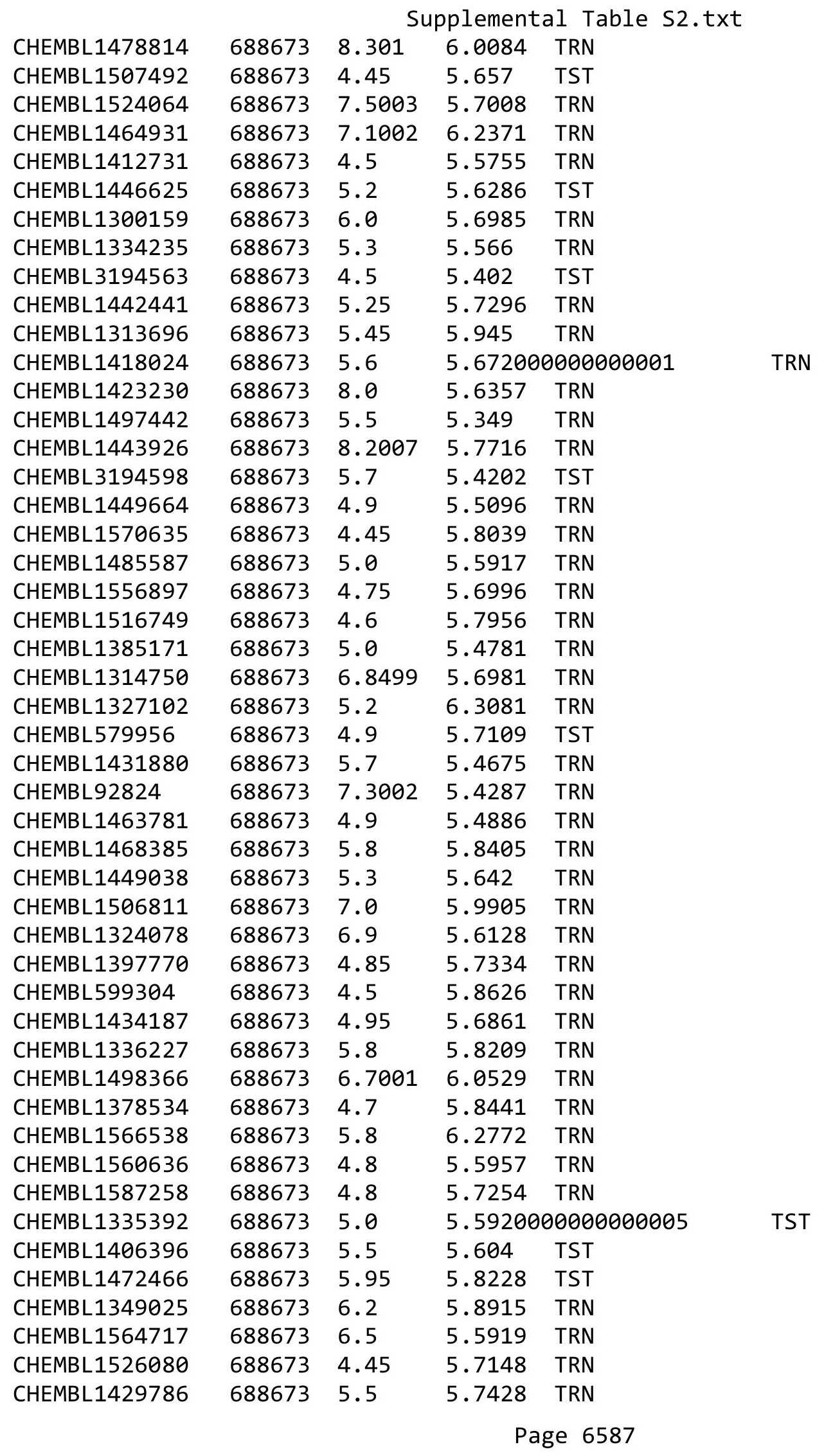




\begin{tabular}{|c|c|c|c|c|c|}
\hline \multicolumn{6}{|c|}{ Supplemental Table s2.txt } \\
\hline CHEMBL1348606 & 688673 & 4.5 & 5.7198 & TRN & \\
\hline CHEMBL1568077 & 688673 & 4.5 & 5.8851 & TRN & \\
\hline CHEMBL1565345 & 688673 & 6.6 & 5.9021 & TRN & \\
\hline CHEMBL1451617 & 688673 & 4.45 & 5.71200 & 0000000001 & TRN \\
\hline CHEMBL1331123 & 688673 & 5.85 & 5.5898 & TRN & \\
\hline CHEMBL1428882 & 688673 & 4.8 & 5.6255 & TRN & \\
\hline CHEMBL1407247 & 688673 & 4.9 & 5.704 & TRN & \\
\hline CHEMBL3190069 & 688673 & 4.9 & 5.5973 & TRN & \\
\hline CHEMBL1489584 & 688673 & 5.0 & 5.9759 & TRN & \\
\hline CHEMBL1301731 & 688673 & 4.5 & 5.437 & TRN & \\
\hline CHEMBL1507838 & 688673 & 8.3979 & 5.6247 & TST & \\
\hline CHEMBL1365553 & 688673 & 4.9 & 5.3626 & TRN & \\
\hline CHEMBL1306500 & 688673 & 4.5 & 6.1116 & TRN & \\
\hline CHEMBL3197622 & 688673 & 7.8996 & 5.4073 & TST & \\
\hline CHEMBL1538317 & 688673 & 5.2 & 5.6194 & TRN & \\
\hline CHEMBL1474002 & 688673 & 4.65 & 6.0402 & TRN & \\
\hline CHEMBL1474597 & 688673 & 5.4 & 5.2945 & TRN & \\
\hline CHEMBL1526689 & 688673 & 6.7001 & 5.6609 & TRN & \\
\hline CHEMBL1601634 & 688673 & 4.55 & 5.3789 & TRN & \\
\hline CHEMBL1461031 & 688673 & 6.2 & 5.6179 & TRN & \\
\hline CHEMBL1393405 & 688673 & 4.8 & 5.9481 & TRN & \\
\hline CHEMBL1588672 & 688673 & 4.7 & 5.3735 & TRN & \\
\hline CHEMBL1587608 & 688673 & 7.6003 & 5.7359 & TRN & \\
\hline CHEMBL1488834 & 688673 & 7.8013 & 6.0871 & TRN & \\
\hline CHEMBL1493481 & 688673 & 4.7 & 5.37299 & 9999999999 & TRN \\
\hline CHEMBL1414671 & 688673 & 4.9 & 5.5094 & TRN & \\
\hline CHEMBL1417596 & 688673 & 5.5 & 5.4381 & TRN & \\
\hline CHEMBL1433421 & 688673 & 4.8 & 5.476 & TRN & \\
\hline CHEMBL1570727 & 688673 & 5.3 & 5.7714 & TRN & \\
\hline CHEMBL1488909 & 688673 & 4.5 & 5.6994 & TRN & \\
\hline CHEMBL1976236 & 688673 & 6.6 & 5.6502 & TRN & \\
\hline CHEMBL1466654 & 688673 & 8.0 & 5.90600 & 0000000001 & TRN \\
\hline CHEMBL1360977 & 688673 & 5.1 & 5.6821 & TRN & \\
\hline CHEMBL1543803 & 688673 & 6.9 & 5.4142 & TST & \\
\hline CHEMBL1368045 & 688673 & 5.4 & 6.0345 & TRN & \\
\hline CHEMBL1561070 & 688673 & 5.9 & 5.8298 & TRN & \\
\hline CHEMBL1541408 & 688673 & 4.9 & 5.9572 & TRN & \\
\hline CHEMBL1583018 & 688673 & 7.0 & 5.9115 & TRN & \\
\hline CHEMBL533602 & 688673 & 4.7 & 5.2331 & TST & \\
\hline CHEMBL1469840 & 688673 & 4.9 & 5.5979 & TRN & \\
\hline CHEMBL1421997 & 688673 & 6.1 & 5.849 & TRN & \\
\hline CHEMBL1432274 & 688673 & 5.4 & 5.8422 & TRN & \\
\hline CHEMBL1965472 & 688673 & 4.5 & 5.5083 & TRN & \\
\hline CHEMBL1609031 & 688673 & 5.5 & 5.7856 & TRN & \\
\hline CHEMBL1571067 & 688673 & 4.85 & 5.67399 & 99999999995 & TRN \\
\hline CHEMBL1577713 & 688673 & 7.2 & 5.7677 & TRN & \\
\hline CHEMBL1536187 & 688673 & 6.15 & 5.6557 & TRN & \\
\hline CHEMBL1509267 & 688673 & 4.8 & 5.7727 & TRN & \\
\hline
\end{tabular}




\begin{tabular}{|c|c|c|c|c|c|}
\hline & & \multicolumn{4}{|c|}{ Supplemental Table S2.txt } \\
\hline CHEMBL1338952 & 688673 & 7.699 & 5.8591 & TRN & \\
\hline CHEMBL1359743 & 688673 & 7.2503 & 5.6924 & TRN & \\
\hline CHEMBL1390021 & 688673 & 5.35 & 5.5737 & TRN & \\
\hline CHEMBL1324726 & 688673 & 7.699 & 5.8955 & TRN & \\
\hline CHEMBL1468931 & 688673 & 6.1 & 5.7404 & TRN & \\
\hline CHEMBL1500471 & 688673 & 5.25 & 5.6722 & TRN & \\
\hline CHEMBL1517562 & 688673 & 5.4 & 5.9449 & TRN & \\
\hline CHEMBL1613736 & 688673 & 4.85 & 5.6228 & TRN & \\
\hline CHEMBL1533497 & 688673 & 6.4 & 5.5216 & TST & \\
\hline CHEMBL1336319 & 688673 & 5.9 & 5.9569 & TST & \\
\hline CHEMBL1386816 & 688673 & 6.2 & 6.1052 & TRN & \\
\hline CHEMBL1480948 & 688673 & 5.6 & 5.9338 & TRN & \\
\hline CHEMBL1519391 & 688673 & 4.5 & 5.4134 & TRN & \\
\hline CHEMBL1464294 & 688673 & 5.7 & 5.4956 & TRN & \\
\hline CHEMBL1459378 & 688673 & 7.2 & 5.5931 & TST & \\
\hline CHEMBL1438648 & 688673 & 4.5 & 5.9143 & TRN & \\
\hline CHEMBL3193840 & 688673 & 4.6 & 5.5647 & TRN & \\
\hline CHEMBL1400009 & 688673 & 5.9 & 5.63299 & 9999999999 & TRN \\
\hline CHEMBL1467582 & 688673 & 5.85 & 5.8334 & TRN & \\
\hline CHEMBL1490365 & 688673 & 5.5 & 6.1369 & TRN & \\
\hline CHEMBL1524055 & 688673 & 7.5498 & 5.8981 & TRN & \\
\hline CHEMBL1562027 & 688673 & 6.05 & 5.6881 & TRN & \\
\hline CHEMBL1533322 & 688673 & 5.0 & 5.5229 & TRN & \\
\hline CHEMBL1411437 & 688673 & 6.8 & 5.9498 & TRN & \\
\hline CHEMBL1349397 & 688673 & 4.5 & 5.9803 & TST & \\
\hline CHEMBL1304835 & 688673 & 5.0 & 5.9374 & TRN & \\
\hline CHEMBL1568257 & 688673 & 4.45 & 5.6319 & TRN & \\
\hline CHEMBL3190316 & 688673 & 4.8 & 5.7253 & TST & \\
\hline CHEMBL1344361 & 688673 & 5.5 & 5.7351 & TRN & \\
\hline CHEMBL1565484 & 688673 & 5.5 & 5.9782 & TRN & \\
\hline CHEMBL1345102 & 688673 & 4.5 & 5.7276 & TST & \\
\hline CHEMBL1340832 & 688673 & 4.65 & 5.5138 & TRN & \\
\hline CHEMBL1556797 & 688673 & 6.0 & 5.84200 & 00000000005 & TRN \\
\hline CHEMBL1426945 & 688673 & 4.8 & 5.5158 & TRN & \\
\hline CHEMBL1528442 & 688673 & 6.1 & 5.7366 & TRN & \\
\hline CHEMBL1485905 & 688673 & 5.5 & 5.6128 & TRN & \\
\hline CHEMBL1355119 & 688673 & 5.95 & 5.6275 & TRN & \\
\hline CHEMBL1417496 & 688673 & 4.9 & 5.7234 & TRN & \\
\hline CHEMBL1562342 & 688673 & 4.5 & 5.7708 & TRN & \\
\hline CHEMBL1305880 & 688673 & 5.2 & 5.63700 & 00000000005 & TRN \\
\hline CHEMBL1389922 & 688673 & 5.4 & 5.8205 & TRN & \\
\hline CHEMBL1577908 & 688673 & 5.0 & 5.6466 & TRN & \\
\hline CHEMBL1557987 & 688673 & 5.1 & 5.5663 & TRN & \\
\hline CHEMBL1602008 & 688673 & 4.45 & 5.8285 & TRN & \\
\hline CHEMBL1547434 & 688673 & 5.25 & 6.1261 & TRN & \\
\hline CHEMBL1397964 & 688673 & 5.7 & 5.6471 & TRN & \\
\hline CHEMBL1462005 & 688673 & 5.8 & 5.5664 & TRN & \\
\hline CHEMBL1574601 & 688673 & 4.5 & 5.9634 & TRN & \\
\hline
\end{tabular}




\begin{tabular}{|c|c|c|c|c|}
\hline \multicolumn{5}{|c|}{ Supplemental Table s2.txt } \\
\hline CHEMBL1338747 & 688673 & 4.8 & 5.5193 & TST \\
\hline CHEMBL1506102 & 688673 & 6.7001 & 5.89 & TST \\
\hline CHEMBL1303338 & 688673 & 5.4 & 5.9127 & TRN \\
\hline CHEMBL1312116 & 688673 & 7.699 & 5.8187 & TRN \\
\hline CHEMBL1344895 & 688673 & 5.8 & 5.8731 & TRN \\
\hline CHEMBL1346506 & 688673 & 7.3002 & 5.6306 & TRN \\
\hline CHEMBL1314951 & 688673 & 6.5501 & 5.49 & TRN \\
\hline CHEMBL1344796 & 688673 & 6.05 & 5.5458 & TRN \\
\hline CHEMBL1423165 & 688673 & 4.9 & 5.2862 & TRN \\
\hline CHEMBL1472505 & 688673 & 4.7 & 5.484 & TRN \\
\hline CHEMBL1374609 & 688673 & 5.25 & 5.7012 & TRN \\
\hline CHEMBL1599713 & 688673 & 4.45 & 5.5958 & TRN \\
\hline CHEMBL1418928 & 688673 & 4.5 & 5.6683 & TRN \\
\hline CHEMBL1547457 & 688673 & 5.2 & 5.5308 & TRN \\
\hline CHEMBL1497305 & 688673 & 5.3 & 6.0145 & TRN \\
\hline CHEMBL1530998 & 688673 & 5.0 & 5.6023 & TST \\
\hline CHEMBL1514289 & 688673 & 7.5003 & 5.3347 & TRN \\
\hline CHEMBL1444211 & 688673 & 6.2 & 6.0143 & TRN \\
\hline CHEMBL1311020 & 688673 & 8.4559 & 5.8791 & TRN \\
\hline CHEMBL1499261 & 688673 & 4.8 & 5.5861 & TRN \\
\hline CHEMBL1457580 & 688673 & 4.6 & 6.0875 & TRN \\
\hline CHEMBL58033 & 688673 & 8.6021 & 6.1031 & TST \\
\hline CHEMBL1306947 & 688673 & 7.699 & 5.7289 & TRN \\
\hline CHEMBL1461067 & 688673 & 5.4 & 5.7821 & TRN \\
\hline CHEMBL1480983 & 688673 & 7.3002 & 5.7634 & TRN \\
\hline CHEMBL1577894 & 688673 & 4.5 & 5.7043 & TRN \\
\hline CHEMBL1587766 & 688673 & 5.2 & 5.697 & TRN \\
\hline CHEMBL1586642 & 688673 & 5.9 & 5.7254 & TRN \\
\hline CHEMBL589439 & 688673 & 4.5 & 5.7658 & TRN \\
\hline CHEMBL1598768 & 688673 & 5.65 & 5.8041 & TRN \\
\hline CHEMBL1481335 & 688673 & 4.9 & 5.5675 & TRN \\
\hline CHEMBL1385074 & 688673 & 4.9 & 5.3651 & TRN \\
\hline CHEMBL1495406 & 688673 & 5.6 & 5.8012 & TRN \\
\hline CHEMBL1517143 & 688673 & 7.0 & 5.7283 & TRN \\
\hline CHEMBL1516845 & 688673 & 5.35 & 5.9554 & TRN \\
\hline CHEMBL1548484 & 688673 & 5.5 & 5.8657 & TRN \\
\hline CHEMBL1529358 & 688673 & 4.9 & 5.7748 & TRN \\
\hline CHEMBL1581452 & 688673 & 6.15 & 5.5023 & TST \\
\hline CHEMBL1425795 & 688673 & 4.45 & 5.3424 & TRN \\
\hline CHEMBL1330046 & 688673 & 6.3 & 5.4871 & TRN \\
\hline CHEMBL1405157 & 688673 & 6.8 & 5.9411 & TRN \\
\hline CHEMBL1344182 & 688673 & 5.5 & 6.2036 & TRN \\
\hline CHEMBL1333018 & 688673 & 5.7 & 5.8991 & TST \\
\hline CHEMBL1398690 & 688673 & 7.2 & 5.8218 & TRN \\
\hline CHEMBL1327392 & 688673 & 7.1002 & 6.0169 & TRN \\
\hline CHEMBL1611226 & 688673 & 4.45 & 5.7635 & TRN \\
\hline CHEMBL1545743 & 688673 & 7.5003 & 5.7079 & TRN \\
\hline CHEMBL1351724 & 688673 & 5.4 & 5.9379 & TRN \\
\hline
\end{tabular}




\begin{tabular}{|c|c|c|c|c|c|}
\hline \multirow{3}{*}{$\begin{array}{l}\text { CHEMBL1349386 } \\
\text { CHEMBL1525831 }\end{array}$} & \multirow{3}{*}{$\begin{array}{l}688673 \\
688673\end{array}$} & \multicolumn{4}{|c|}{ Supplemental Table S2.txt } \\
\hline & & 5.3 & \multicolumn{2}{|c|}{6.167000000000001} & \multirow[t]{2}{*}{ TRN } \\
\hline & & 4.55 & 5.8504 & TRN & \\
\hline CHEMBL1556010 & 688673 & 5.2 & 5.6454 & TRN & \\
\hline CHEMBL1449738 & 688673 & 4.45 & 6.1117 & TRN & \\
\hline CHEMBL1518120 & 688673 & 6.9 & 5.9501 & TRN & \\
\hline CHEMBL1587554 & 688673 & 6.1 & 5.9414 & TRN & \\
\hline CHEMBL1384937 & 688673 & 5.9 & 5.9467 & TRN & \\
\hline CHEMBL1392113 & 688673 & 5.4 & 5.4413 & TRN & \\
\hline CHEMBL1472074 & 688673 & 4.45 & 5.6649 & TST & \\
\hline CHEMBL1503060 & 688673 & 4.8 & 5.6116 & TRN & \\
\hline CHEMBL1498811 & 688673 & 5.2 & 5.5935 & TRN & \\
\hline CHEMBL3208658 & 688673 & 4.6 & 5.8275 & TRN & \\
\hline CHEMBL3198643 & 688673 & 4.5 & 5.3298 & TST & \\
\hline CHEMBL1400207 & 688673 & 5.3 & 6.0901 & TRN & \\
\hline CHEMBL1522577 & 688673 & 5.0 & 5.7766 & TRN & \\
\hline CHEMBL1556161 & 688673 & 4.9 & 5.6835 & TST & \\
\hline CHEMBL1304332 & 688673 & 4.85 & 5.3947 & TRN & \\
\hline CHEMBL1384333 & 688673 & 6.5 & 5.575 & TRN & \\
\hline CHEMBL1432799 & 688673 & 4.5 & 5.7801 & TRN & \\
\hline CHEMBL1410489 & 688673 & 4.5 & 5.6208 & TRN & \\
\hline CHEMBL1570119 & 688673 & 4.5 & 5.3162 & TRN & \\
\hline CHEMBL1412389 & 688673 & 5.3 & 5.9196 & TRN & \\
\hline CHEMBL1426284 & 688673 & 4.5 & 5.5515 & TRN & \\
\hline CHEMBL1313916 & 688673 & 4.45 & 5.6392 & TRN & \\
\hline CHEMBL1375824 & 688673 & 6.0 & 5.6062 & TRN & \\
\hline CHEMBL588338 & 688673 & 7.4001 & 5.9867 & TST & \\
\hline CHEMBL1431193 & 688673 & 7.0 & 5.5842 & TRN & \\
\hline CHEMBL1394089 & 688673 & 4.9 & 5.7978 & TST & \\
\hline CHEMBL1335361 & 688673 & 4.45 & 6.1302 & TST & \\
\hline CHEMBL1386585 & 688673 & 6.3 & 6.2287 & TRN & \\
\hline CHEMBL1420505 & 688673 & 6.45 & 6.05200 & 00000000005 & TRN \\
\hline CHEMBL1314667 & 688673 & 5.7 & 5.4749 & TST & \\
\hline CHEMBL1300237 & 688673 & 4.5 & 5.8414 & TRN & \\
\hline CHEMBL1364375 & 688673 & 7.8013 & 5.7278 & TRN & \\
\hline CHEMBL1426618 & 688673 & 6.7001 & 5.6292 & TRN & \\
\hline CHEMBL1345874 & 688673 & 7.6003 & 5.8382 & TRN & \\
\hline CHEMBL1347117 & 688673 & 4.9 & 5.6799 & TRN & \\
\hline CHEMBL1309910 & 688673 & 4.75 & 5.8131 & TRN & \\
\hline CHEMBL 3210008 & 688673 & 5.4 & 5.6054 & TRN & \\
\hline CHEMBL1561979 & 688673 & 4.5 & 5.7885 & TRN & \\
\hline CHEMBL1310341 & 688673 & 5.3 & 5.4346 & TRN & \\
\hline CHEMBL1544726 & 688673 & 5.6 & 5.9352 & TRN & \\
\hline CHEMBL1407847 & 688673 & 6.3 & 5.6222 & TRN & \\
\hline CHEMBL1472067 & 688673 & 4.9 & 5.61100 & 3000000001 & TRN \\
\hline CHEMBL1543331 & 688673 & 4.9 & 5.6594 & TRN & \\
\hline CHEMBL1557021 & 688673 & 4.45 & 5.8077 & TRN & \\
\hline CHEMBL1612359 & 688673 & 5.4 & 5.777 & TRN & \\
\hline CHEMBL1609373 & 688673 & 7.699 & 6.005 & TRN & \\
\hline
\end{tabular}




\begin{tabular}{|c|c|c|c|c|c|}
\hline & & & & & \\
\hline CHEMBL1521798 & 688673 & 5.3 & 5.454 & TRN & \\
\hline CHEMBL1397124 & 688673 & 5.75 & 5.8399 & TRN & \\
\hline CHEMBL1425897 & 688673 & 8.301 & 5.8252 & TRN & \\
\hline CHEMBL1335760 & 688673 & 5.4 & 5.6665 & TRN & \\
\hline CHEMBL1341644 & 688673 & 5.7 & 5.6967 & TRN & \\
\hline CHEMBL1303031 & 688673 & 4.5 & 5.5554 & TRN & \\
\hline CHEMBL1410937 & 688673 & 4.75 & 5.6402 & TRN & \\
\hline CHEMBL1387072 & 688673 & 4.7 & 5.4671 & TRN & \\
\hline CHEMBL1439226 & 688673 & 5.5 & 5.9731 & TRN & \\
\hline CHEMBL1578746 & 688673 & 7.6003 & 5.92 & TRN & \\
\hline CHEMBL1471162 & 688673 & 5.2 & 5.6095 & TRN & \\
\hline CHEMBL1612810 & 688673 & 4.9 & 5.5525 & TRN & \\
\hline CHEMBL1390929 & 688673 & 6.4 & 5.6894 & TRN & \\
\hline CHEMBL1444618 & 688673 & 6.0 & 5.7831 & TRN & \\
\hline CHEMBL1560494 & 688673 & 6.7001 & 5.7717 & TRN & \\
\hline CHEMBL1499339 & 688673 & 4.7 & 5.6059 & TRN & \\
\hline CHEMBL1338266 & 688673 & 4.7 & 5.4963 & TRN & \\
\hline CHEMBL1605350 & 688673 & 6.05 & 5.7511 & TRN & \\
\hline CHEMBL1455249 & 688673 & 4.45 & 5.7278 & TST & \\
\hline CHEMBL1320822 & 688673 & 5.25 & 5.9149 & TRN & \\
\hline CHEMBL1461340 & 688673 & 5.0 & 5.8315 & TRN & \\
\hline CHEMBL1348859 & 688673 & 5.7 & 5.6005 & TRN & \\
\hline CHEMBL1419046 & 688673 & 4.5 & 5.8137 & TRN & \\
\hline CHEMBL1563645 & 688673 & 8.2007 & 5.9489 & TRN & \\
\hline CHEMBL1550677 & 688673 & 5.0 & 6.1211 & TRN & \\
\hline CHEMBL1579331 & 688673 & 4.95 & 5.8044 & TST & \\
\hline CHEMBL1509989 & 688673 & 4.7 & 5.4879 & TRN & \\
\hline CHEMBL1412189 & 688673 & 4.45 & 5.7935 & TRN & \\
\hline CHEMBL 3196597 & 688673 & 5.25 & 5.7504 & TRN & \\
\hline CHEMBL1578932 & 688673 & 4.8 & 6.1393 & TRN & \\
\hline CHEMBL1331738 & 688673 & 5.1 & 5.4034 & TRN & \\
\hline CHEMBL1465659 & 688673 & 4.9 & 5.3932 & TST & \\
\hline CHEMBL1372815 & 688673 & 5.8 & 5.6472 & TRN & \\
\hline CHEMBL1377292 & 688673 & 5.25 & 5.3502 & TRN & \\
\hline CHEMBL 2374077 & 688673 & 4.5 & 5.9534 & TST & \\
\hline CHEMBL1586949 & 688673 & 5.0 & 5.6023 & TST & \\
\hline CHEMBL1550819 & 688673 & 5.5 & 5.8345 & TRN & \\
\hline CHEMBL1498973 & 688673 & 4.5 & 5.4645 & TRN & \\
\hline CHEMBL1482899 & 688673 & 5.4 & 5.8439 & TRN & \\
\hline CHEMBL1537498 & 688673 & 6.7001 & 5.858 & TRN & \\
\hline CHEMBL1576749 & 688673 & 4.5 & 5.3975 & TST & \\
\hline CHEMBL1575148 & 688673 & 4.45 & 5.7982 & TRN & \\
\hline CHEMBL1484649 & 688673 & 5.1 & 6.1002 & TRN & \\
\hline CHEMBL1460222 & 688673 & 7.4001 & 6.193 & TRN & \\
\hline CHEMBL1381564 & 688673 & 5.5 & 5.6276 & TRN & \\
\hline CHEMBL1605104 & 688673 & 5.3 & 5.67700 & 00000000005 & TRN \\
\hline CHEMBL1539853 & 688673 & 5.0 & 5.8905 & TRN & \\
\hline CHEMBL1477983 & 688673 & 4.6 & 5.8632 & TRN & \\
\hline
\end{tabular}




\begin{tabular}{|c|c|c|c|c|c|}
\hline \multicolumn{6}{|c|}{ Supplemental Table S2.txt } \\
\hline CHEMBL1494193 & 688673 & 6.95 & 5.7269 & TRN & \\
\hline CHEMBL1517409 & 688673 & 5.0 & 5.5646 & TRN & \\
\hline CHEMBL1591696 & 688673 & 6.5501 & 5.9008 & TRN & \\
\hline CHEMBL1485190 & 688673 & 7.8996 & 5.7527 & TRN & \\
\hline CHEMBL1489409 & 688673 & 4.5 & 5.4468 & TST & \\
\hline CHEMBL1486438 & 688673 & 5.3 & 5.5518 & TRN & \\
\hline CHEMBL1312612 & 688673 & 4.5 & 5.7602 & TRN & \\
\hline CHEMBL1345352 & 688673 & 6.8 & 5.9086 & TST & \\
\hline CHEMBL3213802 & 688673 & 7.8996 & 5.5609 & TST & \\
\hline CHEMBL1967609 & 688673 & 5.3 & 5.6023 & TRN & \\
\hline CHEMBL1583917 & 688673 & 5.2 & 5.3878 & TRN & \\
\hline CHEMBL1573586 & 688673 & 4.8 & 5.4657 & TST & \\
\hline CHEMBL3199909 & 688673 & 4.5 & 5.6805 & TRN & \\
\hline CHEMBL 1374156 & 688673 & 4.45 & 5.5313 & TRN & \\
\hline CHEMBL1510242 & 688673 & 5.7 & 5.9299 & TRN & \\
\hline CHEMBL1488137 & 688673 & 8.0506 & 5.5658 & TRN & \\
\hline CHEMBL1416138 & 688673 & 5.2 & 5.725 & TRN & \\
\hline CHEMBL1599491 & 688673 & 7.1002 & 5.7611 & TRN & \\
\hline CHEMBL1504112 & 688673 & 4.5 & 5.5698 & TRN & \\
\hline CHEMBL1390465 & 688673 & 4.5 & 5.2778 & TRN & \\
\hline CHEMBL1488584 & 688673 & 4.5 & 6.2097 & TRN & \\
\hline CHEMBL1522607 & 688673 & 5.25 & 5.9569 & TRN & \\
\hline CHEMBL1420667 & 688673 & 5.0 & 5.796 & TRN & \\
\hline CHEMBL1461238 & 688673 & 4.5 & 5.6014 & TRN & \\
\hline CHEMBL1428673 & 688673 & 7.699 & 5.8733 & TRN & \\
\hline CHEMBL1556190 & 688673 & 4.9 & 5.5117 & TRN & \\
\hline CHEMBL1422528 & 688673 & 5.0 & 5.9106 & TRN & \\
\hline CHEMBL1333386 & 688673 & 8.2007 & 5.228 & TRN & \\
\hline CHEMBL1392342 & 688673 & 5.5 & 6.2616 & TRN & \\
\hline CHEMBL1369691 & 688673 & 6.0 & 5.5137 & TRN & \\
\hline CHEMBL3208151 & 688673 & 6.6 & 5.5707 & TRN & \\
\hline CHEMBL1367738 & 688673 & 5.5 & 5.7624 & TRN & \\
\hline CHEMBL1306121 & 688673 & 4.65 & 5.57299 & 99999999995 & TRN \\
\hline CHEMBL1387184 & 688673 & 6.7001 & 6.0148 & TRN & \\
\hline CHEMBL1390779 & 688673 & 6.9 & 5.7779 & TRN & \\
\hline CHEMBL1567467 & 688673 & 4.45 & 6.1013 & TRN & \\
\hline CHEMBL1542030 & 688673 & 4.5 & 6.1501 & TRN & \\
\hline CHEMBL1430076 & 688673 & 6.3 & 5.8005 & TST & \\
\hline CHEMBL1530555 & 688673 & 4.6 & 5.3793 & TRN & \\
\hline CHEMBL577234 & 688673 & 5.8 & 6.2056 & TRN & \\
\hline CHEMBL3191701 & 688673 & 6.9 & 5.5216 & TRN & \\
\hline CHEMBL1400252 & 688673 & 8.0 & 5.8354 & TRN & \\
\hline CHEMBL1430358 & 688673 & 4.5 & 5.7182 & TRN & \\
\hline CHEMBL1565972 & 688673 & 6.3 & 5.8311 & TRN & \\
\hline CHEMBL1389190 & 688673 & 4.7 & 6.0124 & TRN & \\
\hline CHEMBL1370710 & 688673 & 6.1 & 5.6653 & TRN & \\
\hline CHEMBL1393833 & 688673 & 4.7 & 5.6495 & TRN & \\
\hline CHEMBL1427391 & 688673 & 6.0 & 5.45299 & 9999999999 & TRN \\
\hline & & & & 6593 & \\
\hline
\end{tabular}




\begin{tabular}{|c|c|c|c|c|c|}
\hline \\
\hline CHEMBL65 & 688673 & 6.5 & 5.4227 & TST & \\
\hline CHEMBL1356669 & 688673 & 4.75 & 5.4205 & TRN & \\
\hline CHEMBL1313374 & 688673 & 5.1 & 5.5794 & TRN & \\
\hline CHEMBL1495339 & 688673 & 4.6 & 5.8999 & TRN & \\
\hline CHEMBL1392102 & 688673 & 5.25 & 5.6169 & TRN & \\
\hline CHEMBL1577981 & 688673 & 6.6499 & 5.5283 & TRN & \\
\hline CHEMBL1555837 & 688673 & 5.9 & 5.9133 & TRN & \\
\hline CHEMBL1497431 & 688673 & 4.9 & 5.6485 & TRN & \\
\hline CHEMBL1561456 & 688673 & 4.45 & 5.9061 & TRN & \\
\hline CHEMBL1500535 & 688673 & 6.6 & 5.9025 & TRN & \\
\hline CHEMBL1602610 & 688673 & 7.699 & 5.8339 & TRN & \\
\hline CHEMBL1565290 & 688673 & 4.8 & 5.8139 & TRN & \\
\hline CHEMBL1567769 & 688673 & 4.55 & 5.9878 & TST & \\
\hline CHEMBL1412510 & 688673 & 5.2 & 5.4383 & TRN & \\
\hline CHEMBL1496488 & 688673 & 5.9 & 5.6187 & TST & \\
\hline CHEMBL1362160 & 688673 & 4.9 & 5.7695 & TRN & \\
\hline CHEMBL1397565 & 688673 & 6.5 & 5.83299 & 9999999999 & TRN \\
\hline CHEMBL1562391 & 688673 & 5.3 & 5.6727 & TRN & \\
\hline CHEMBL1578396 & 688673 & 6.35 & 5.8004 & TST & \\
\hline CHEMBL1538097 & 688673 & 5.8 & 5.5964 & TRN & \\
\hline CHEMBL1517642 & 688673 & 5.45 & 6.0064 & TRN & \\
\hline CHEMBL1333135 & 688673 & 4.8 & 5.9072 & TRN & \\
\hline CHEMBL1503809 & 688673 & 4.8 & 5.5918 & TRN & \\
\hline CHEMBL1518868 & 688673 & 4.9 & 5.6438 & TRN & \\
\hline CHEMBL1419003 & 688673 & 8.301 & 5.7541 & TRN & \\
\hline CHEMBL1986086 & 688673 & 6.8 & 5.7622 & TRN & \\
\hline CHEMBL1497880 & 688673 & 5.6 & 6.0563 & TRN & \\
\hline CHEMBL22870 & 688673 & 5.2 & 5.6714 & TRN & \\
\hline CHEMBL1397952 & 688673 & 5.6 & 5.3934 & TST & \\
\hline CHEMBL1325506 & 688673 & 5.0 & 5.4821 & TRN & \\
\hline CHEMBL1571741 & 688673 & 8.4949 & 5.8122 & TRN & \\
\hline CHEMBL1520804 & 688673 & 6.7001 & 5.7849 & TRN & \\
\hline CHEMBL1442231 & 688673 & 6.4 & 5.769 & TRN & \\
\hline CHEMBL1530431 & 688673 & 6.1 & 5.5823 & TRN & \\
\hline CHEMBL1483918 & 688673 & 4.7 & 5.3977 & TRN & \\
\hline CHEMBL1401947 & 688673 & 5.35 & 6.062 & TST & \\
\hline CHEMBL1535358 & 688673 & 5.0 & 5.7353 & TRN & \\
\hline CHEMBL1521878 & 688673 & 5.9 & 5.8198 & TRN & \\
\hline CHEMBL1242180 & 688673 & 4.8 & 5.4328 & TRN & \\
\hline CHEMBL1464608 & 688673 & 8.3979 & 5.6274 & TRN & \\
\hline CHEMBL1428299 & 688673 & 4.45 & 5.6508 & TRN & \\
\hline CHEMBL1364832 & 688673 & 4.4 & 5.9537 & TRN & \\
\hline CHEMBL1387281 & 688673 & 6.2 & 5.5457 & TST & \\
\hline CHEMBL3190248 & 688673 & 7.5003 & 5.6388 & TRN & \\
\hline CHEMBL1528741 & 688673 & 5.4 & 5.9852 & TST & \\
\hline CHEMBL1612982 & 688673 & 6.7501 & 5.70799 & 9999999999 & TRN \\
\hline CHEMBL1403058 & 688673 & 5.7 & 5.5245 & TRN & \\
\hline CHEMBL1323365 & 688673 & 6.8 & 5.7229 & TRN & \\
\hline
\end{tabular}




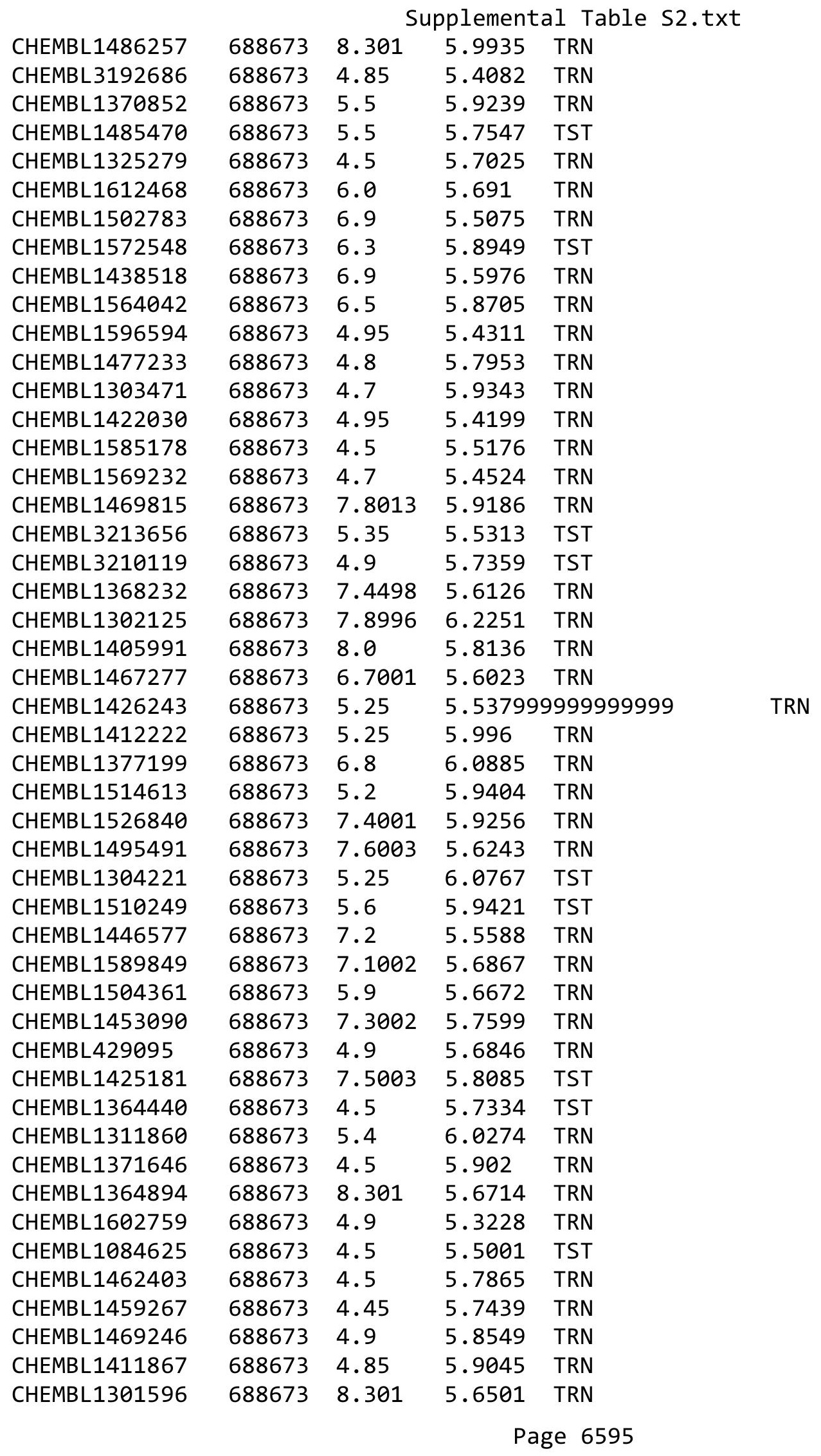




\begin{tabular}{|c|c|c|c|c|c|}
\hline \multicolumn{6}{|c|}{ Supplemental Table S2.txt } \\
\hline CHEMBL1537002 & 688673 & 5.25 & 5.6113 & TRN & \\
\hline CHEMBL1332664 & 688673 & 8.4949 & 6.0849 & TRN & \\
\hline CHEMBL1472142 & 688673 & 6.0 & 5.7493 & TRN & \\
\hline CHEMBL1520353 & 688673 & 5.3 & 5.984 & TRN & \\
\hline CHEMBL1384345 & 688673 & 4.45 & 6.0662 & TRN & \\
\hline CHEMBL1449212 & 688673 & 7.2503 & 5.4176 & TST & \\
\hline CHEMBL1508991 & 688673 & 4.9 & 5.8082 & TST & \\
\hline CHEMBL1475984 & 688673 & 5.25 & 5.7121 & TRN & \\
\hline CHEMBL1424919 & 688673 & 7.4001 & 6.0227 & TRN & \\
\hline CHEMBL1302425 & 688673 & 4.5 & 5.4368 & TST & \\
\hline CHEMBL1345547 & 688673 & 6.6 & 5.5775 & TRN & \\
\hline CHEMBL1611087 & 688673 & 5.0 & 5.7489 & TST & \\
\hline CHEMBL1300443 & 688673 & 7.699 & 5.7409 & TRN & \\
\hline CHEMBL1500964 & 688673 & 7.8996 & 5.5281 & TST & \\
\hline CHEMBL1407598 & 688673 & 4.5 & 5.7026 & TRN & \\
\hline CHEMBL1555629 & 688673 & 7.2 & 5.6817 & TRN & \\
\hline CHEMBL1432487 & 688673 & 7.8996 & 6.1222 & TRN & \\
\hline CHEMBL1567080 & 688673 & 5.3 & 5.5593 & TRN & \\
\hline CHEMBL1471801 & 688673 & 4.8 & 5.7309 & TRN & \\
\hline CHEMBL1360835 & 688673 & 6.6 & 5.5698 & TRN & \\
\hline CHEMBL1429536 & 688673 & 4.8 & 5.9055 & TRN & \\
\hline CHEMBL1464354 & 688673 & 6.4 & 5.4851 & TRN & \\
\hline CHEMBL1371934 & 688673 & 4.5 & 5.6087 & TRN & \\
\hline CHEMBL50267 & 688673 & 4.8 & 5.4477 & TST & \\
\hline CHEMBL1500591 & 688673 & 4.8 & 5.875 & TRN & \\
\hline CHEMBL1477217 & 688673 & 6.6 & 5.6658 & TRN & \\
\hline CHEMBL1421059 & 688673 & 5.3 & 5.7714 & TRN & \\
\hline CHEMBL1565569 & 688673 & 4.6 & 5.8475 & TST & \\
\hline CHEMBL1499296 & 688673 & 6.2 & 5.4879 & TRN & \\
\hline CHEMBL1490011 & 688673 & 7.5003 & 5.9454 & TRN & \\
\hline CHEMBL1445626 & 688673 & 4.7 & 5.2825 & TRN & \\
\hline CHEMBL1394490 & 688673 & 4.8 & 5.3064 & TRN & \\
\hline CHEMBL1597040 & 688673 & 4.5 & 5.7661 & TRN & \\
\hline CHEMBL1349968 & 688673 & 7.0501 & 5.53100 & 0000000001 & TRN \\
\hline CHEMBL1533464 & 688673 & 6.8 & 5.7505 & TST & \\
\hline CHEMBL1580742 & 688673 & 7.4001 & 5.6947 & TRN & \\
\hline CHEMBL1458517 & 688673 & 5.4 & 5.6334 & TRN & \\
\hline CHEMBL1446640 & 688673 & 7.3002 & 5.2908 & TRN & \\
\hline CHEMBL3213741 & 688673 & 4.45 & 5.6003 & TRN & \\
\hline CHEMBL1576985 & 688673 & 6.9 & 5.5315 & TRN & \\
\hline CHEMBL1448473 & 688673 & 4.9 & 5.4194 & TRN & \\
\hline CHEMBL1488501 & 688673 & 5.9 & 5.9487 & TRN & \\
\hline CHEMBL1408004 & 688673 & 4.5 & 5.7181 & TRN & \\
\hline CHEMBL1426674 & 688673 & 5.0 & 5.8163 & TRN & \\
\hline CHEMBL1541432 & 688673 & 5.2 & 5.8226 & TRN & \\
\hline CHEMBL1299304 & 688673 & 7.1002 & 5.9547 & TST & \\
\hline CHEMBL1536864 & 688673 & 4.6 & 5.5281 & TRN & \\
\hline CHEMBL1405690 & 688673 & 4.95 & 5.581 & TRN & \\
\hline
\end{tabular}




\begin{tabular}{|c|c|c|c|c|c|}
\hline \multirow[b]{2}{*}{ CHEMBL1609859 } & \multicolumn{5}{|c|}{ Supplemental Table S2.txt } \\
\hline & 688673 & 7.5498 & 5.7189 & TST & \\
\hline CHEMBL1502333 & 688673 & 5.25 & 5.7364 & TRN & \\
\hline CHEMBL1402426 & 688673 & 4.5 & 5.8381 & TRN & \\
\hline CHEMBL1431797 & 688673 & 4.9 & 5.725 & TRN & \\
\hline CHEMBL1356692 & 688673 & 6.15 & 5.5759 & TRN & \\
\hline CHEMBL1361939 & 688673 & 5.0 & 5.7345 & TRN & \\
\hline CHEMBL1450791 & 688673 & 4.9 & 5.5059 & TRN & \\
\hline CHEMBL1576604 & 688673 & 5.3 & 5.8794 & TST & \\
\hline CHEMBL1418038 & 688673 & 6.2 & 5.9506 & TRN & \\
\hline CHEMBL1411815 & 688673 & 8.4949 & 5.6712 & TRN & \\
\hline CHEMBL1392503 & 688673 & 8.0 & 5.8472 & TRN & \\
\hline CHEMBL1396110 & 688673 & 6.3 & 5.6374 & TRN & \\
\hline CHEMBL1501840 & 688673 & 5.6 & 5.6571 & TRN & \\
\hline CHEMBL1552586 & 688673 & 4.45 & 5.1937 & TRN & \\
\hline CHEMBL1326702 & 688673 & 5.1 & 6.0744 & TRN & \\
\hline CHEMBL1483564 & 688673 & 5.4 & 5.6121 & TRN & \\
\hline CHEMBL1587199 & 688673 & 4.7 & 5.7324 & TRN & \\
\hline CHEMBL1333865 & 688673 & 4.9 & 5.6393 & TRN & \\
\hline CHEMBL1569313 & 688673 & 5.25 & 5.6705 & TRN & \\
\hline CHEMBL1319980 & 688673 & 5.55 & 6.1335 & TRN & \\
\hline CHEMBL1544800 & 688673 & 5.5 & 5.8639 & TRN & \\
\hline CHEMBL1476113 & 688673 & 7.2 & 5.5678 & TRN & \\
\hline CHEMBL1311978 & 688673 & 5.2 & 5.8445 & TRN & \\
\hline CHEMBL1432773 & 688673 & 4.9 & 5.7059 & TRN & \\
\hline CHEMBL1392154 & 688673 & 6.8 & 5.7772 & TRN & \\
\hline CHEMBL1559234 & 688673 & 6.15 & 5.7352 & TRN & \\
\hline CHEMBL1368593 & 688673 & 5.5 & 5.5251 & TRN & \\
\hline CHEMBL1471084 & 688673 & 8.0 & 5.5939 & TRN & \\
\hline CHEMBL1451982 & 688673 & 4.7 & 5.5988 & TRN & \\
\hline CHEMBL 3211220 & 688673 & 4.7 & 5.7556 & TRN & \\
\hline CHEMBL3193930 & 688673 & 6.3 & 5.5386 & TST & \\
\hline CHEMBL1526928 & 688673 & 5.3 & 5.4174 & TRN & \\
\hline CHEMBL1302675 & 688673 & 6.8 & 5.86100 & 0000000001 & TRN \\
\hline CHEMBL1319661 & 688673 & 4.75 & 5.8577 & TRN & \\
\hline CHEMBL1531709 & 688673 & 7.8996 & 5.7442 & TRN & \\
\hline CHEMBL1365623 & 688673 & 4.5 & 5.7989 & TRN & \\
\hline CHEMBL1382462 & 688673 & 8.1024 & 5.5961 & TRN & \\
\hline CHEMBL3212815 & 688673 & 5.0 & 5.5519 & TST & \\
\hline CHEMBL 3212804 & 688673 & 6.6 & 5.7474 & TRN & \\
\hline CHEMBL581044 & 688673 & 4.8 & 5.7913 & TRN & \\
\hline CHEMBL1373953 & 688673 & 7.0 & 5.8841 & TRN & \\
\hline CHEMBL3189360 & 688673 & 4.95 & 5.6989 & TRN & \\
\hline CHEMBL417727 & 688673 & 4.9 & 5.465 & TRN & \\
\hline CHEMBL1380401 & 688673 & 5.6 & 6.1506 & TRN & \\
\hline CHEMBL1584016 & 688673 & 4.5 & 5.8758 & TRN & \\
\hline CHEMBL1385040 & 688673 & 4.45 & 5.7114 & TRN & \\
\hline CHEMBL1441897 & 688673 & 5.2 & 5.7008 & TRN & \\
\hline CHEMBL1388787 & 688673 & 6.8 & 5.8734 & TRN & \\
\hline
\end{tabular}




\begin{tabular}{|c|c|c|c|c|c|}
\hline \multicolumn{6}{|c|}{ Supplemental Table S2.txt } \\
\hline CHEMBL1502958 & 688673 & 5.2 & 5.5731 & TRN & \\
\hline CHEMBL1493501 & 688673 & 5.25 & 5.3001 & TRN & \\
\hline CHEMBL1586213 & 688673 & 6.4 & 5.7791 & TRN & \\
\hline CHEMBL1384222 & 688673 & 6.8 & 5.8048 & TRN & \\
\hline CHEMBL1380419 & 688673 & 5.8 & 6.1063 & TRN & \\
\hline CHEMBL575690 & 688673 & 5.3 & 5.5878 & TRN & \\
\hline CHEMBL1309144 & 688673 & 6.0 & 5.6579 & TRN & \\
\hline CHEMBL1559998 & 688673 & 5.95 & 5.7507 & TST & \\
\hline CHEMBL1410187 & 688673 & 5.4 & 5.4883 & TRN & \\
\hline CHEMBL1347358 & 688673 & 6.4 & 5.6476 & TRN & \\
\hline CHEMBL1533827 & 688673 & 6.3 & 5.91700 & 0000000001 & TRN \\
\hline CHEMBL1367203 & 688673 & 5.2 & 5.7683 & TRN & \\
\hline CHEMBL1567656 & 688673 & 8.0 & 5.857 & TST & \\
\hline CHEMBL1511729 & 688673 & 4.6 & 5.6998 & TST & \\
\hline CHEMBL1978424 & 688673 & 7.2 & 5.3851 & TST & \\
\hline CHEMBL1435860 & 688673 & 4.45 & 5.7022 & TRN & \\
\hline CHEMBL1494982 & 688673 & 5.0 & 6.0749 & TRN & \\
\hline CHEMBL1542797 & 688673 & 6.2 & 5.7432 & TRN & \\
\hline CHEMBL1426576 & 688673 & 5.2 & 5.6136 & TRN & \\
\hline CHEMBL1461558 & 688673 & 4.6 & 5.5519 & TRN & \\
\hline CHEMBL1432762 & 688673 & 4.9 & 5.2545 & TRN & \\
\hline CHEMBL1584272 & 688673 & 4.4 & 5.8324 & TRN & \\
\hline CHEMBL1390302 & 688673 & 4.75 & 5.5471 & TRN & \\
\hline CHEMBL1967256 & 688673 & 4.75 & 5.5052 & TRN & \\
\hline CHEMBL1429850 & 688673 & 4.45 & 5.3826 & TST & \\
\hline CHEMBL1452137 & 688673 & 5.0 & 5.4537 & TRN & \\
\hline CHEMBL1589069 & 688673 & 5.3 & 6.3214 & TRN & \\
\hline CHEMBL1338892 & 688673 & 6.1 & 5.938 & TRN & \\
\hline CHEMBL1306775 & 688673 & 4.5 & 5.9567 & TRN & \\
\hline CHEMBL1530135 & 688673 & 5.35 & 5.9453 & TRN & \\
\hline CHEMBL1573014 & 688673 & 5.5 & 5.6517 & TRN & \\
\hline CHEMBL1605678 & 688673 & 6.2 & 5.8948 & TRN & \\
\hline CHEMBL1562399 & 688673 & 6.9 & 5.9409 & TST & \\
\hline CHEMBL1557499 & 688673 & 5.0 & 5.5559 & TRN & \\
\hline CHEMBL1597010 & 688673 & 8.4949 & 5.9722 & TRN & \\
\hline CHEMBL1539438 & 688673 & 4.5 & 5.3801 & TRN & \\
\hline CHEMBL1380558 & 688673 & 7.3002 & 5.6022 & TRN & \\
\hline CHEMBL1602336 & 688673 & 5.3 & 5.8619 & TRN & \\
\hline CHEMBL1583473 & 688673 & 5.0 & 5.5786 & TRN & \\
\hline CHEMBL1438802 & 688673 & 8.0 & 5.9913 & TRN & \\
\hline CHEMBL1374095 & 688673 & 5.25 & 5.8971 & TRN & \\
\hline CHEMBL1543543 & 688673 & 4.6 & 5.65600 & 0000000001 & TRN \\
\hline CHEMBL1567253 & 688673 & 5.4 & 5.5527 & TRN & \\
\hline CHEMBL1560710 & 688673 & 4.95 & 5.8484 & TRN & \\
\hline CHEMBL3214103 & 688673 & 4.5 & 5.9213 & TRN & \\
\hline CHEMBL1553202 & 688673 & 4.65 & 5.5933 & TRN & \\
\hline CHEMBL1427857 & 688673 & 5.45 & 5.6969 & TRN & \\
\hline CHEMBL1450008 & 688673 & 4.5 & 5.3462 & TRN & \\
\hline
\end{tabular}




\begin{tabular}{|c|c|c|c|c|c|}
\hline \multicolumn{6}{|c|}{ Supplemental Table S2.txt } \\
\hline CHEMBL1395144 & 688673 & 5.35 & 5.4807 & TRN & \\
\hline CHEMBL1335681 & 688673 & 5.5 & 6.2074 & TRN & \\
\hline CHEMBL1581469 & 688673 & 4.9 & 5.5386 & TRN & \\
\hline CHEMBL1456485 & 688673 & 5.9 & 5.8343 & TRN & \\
\hline CHEMBL1486370 & 688673 & 7.4001 & 6.0239 & TRN & \\
\hline CHEMBL1337449 & 688673 & 4.6 & 5.7001 & TRN & \\
\hline CHEMBL1522487 & 688673 & 6.1 & 5.79299 & 9999999999 & TRN \\
\hline CHEMBL1448523 & 688673 & 8.1024 & 6.0536 & TRN & \\
\hline CHEMBL1304991 & 688673 & 6.3 & 5.4808 & TRN & \\
\hline CHEMBL1326967 & 688673 & 4.7 & 5.1929 & TRN & \\
\hline CHEMBL3211404 & 688673 & 7.3002 & 5.852 & TRN & \\
\hline CHEMBL1423490 & 688673 & 7.5003 & 5.3931 & TRN & \\
\hline CHEMBL1503822 & 688673 & 6.7001 & 5.92399 & 99999999995 & TRN \\
\hline CHEMBL1546719 & 688673 & 4.9 & 5.6372 & TRN & \\
\hline CHEMBL1472315 & 688673 & 5.3 & 5.6262 & TRN & \\
\hline CHEMBL1565471 & 688673 & 4.9 & 5.8198 & TRN & \\
\hline CHEMBL1411337 & 688673 & 5.6 & 5.6822 & TST & \\
\hline CHEMBL1519775 & 688673 & 6.6 & 5.5596 & TRN & \\
\hline CHEMBL1306212 & 688673 & 7.5498 & 5.6664 & TRN & \\
\hline CHEMBL1366918 & 688673 & 4.6 & 5.9814 & TRN & \\
\hline CHEMBL1455508 & 688673 & 6.2 & 5.8632 & TRN & \\
\hline CHEMBL1303423 & 688673 & 5.3 & 6.0487 & TRN & \\
\hline CHEMBL1569244 & 688673 & 5.0 & 5.91100 & 00000000005 & TRN \\
\hline CHEMBL1490115 & 688673 & 7.5003 & 5.9433 & TRN & \\
\hline CHEMBL1306952 & 688673 & 7.8013 & 5.6882 & TRN & \\
\hline CHEMBL1508485 & 688673 & 5.0 & 5.4391 & TRN & \\
\hline CHEMBL1558986 & 688673 & 5.25 & 5.8109 & TRN & \\
\hline CHEMBL1613454 & 688673 & 4.45 & 6.051 & TRN & \\
\hline CHEMBL1310914 & 688673 & 5.2 & 5.8565 & TRN & \\
\hline CHEMBL1373756 & 688673 & 6.15 & 5.9734 & TRN & \\
\hline CHEMBL1607842 & 688673 & 4.7 & 5.4394 & TRN & \\
\hline CHEMBL1432013 & 688673 & 5.2 & 5.9045 & TST & \\
\hline CHEMBL1427958 & 688673 & 5.9 & 5.815 & TRN & \\
\hline CHEMBL1580031 & 688673 & 6.5 & 5.4823 & TRN & \\
\hline CHEMBL1338701 & 688673 & 4.45 & 5.732 & TRN & \\
\hline CHEMBL1522528 & 688673 & 5.85 & 5.9625 & TRN & \\
\hline CHEMBL1320750 & 688673 & 5.3 & 5.88200 & 0000000001 & TRN \\
\hline CHEMBL1604776 & 688673 & 4.45 & 5.6499 & TRN & \\
\hline CHEMBL1405767 & 688673 & 4.65 & 5.6458 & TRN & \\
\hline CHEMBL1586964 & 688673 & 4.5 & 5.5071 & TRN & \\
\hline CHEMBL1588879 & 688673 & 4.5 & 5.7778 & TST & \\
\hline CHEMBL1561360 & 688673 & 4.75 & 5.4544 & TRN & \\
\hline CHEMBL1497052 & 688673 & 6.45 & 5.875 & TRN & \\
\hline CHEMBL1439453 & 688673 & 5.9 & 5.6973 & TRN & \\
\hline CHEMBL1303203 & 688673 & 7.5003 & 5.6575 & TRN & \\
\hline CHEMBL394657 & 688673 & 7.1002 & 5.7256 & TRN & \\
\hline CHEMBL1431877 & 688673 & 5.8 & 5.6503 & TRN & \\
\hline CHEMBL1403616 & 688673 & 6.0 & 5.6456 & TRN & \\
\hline
\end{tabular}




\begin{tabular}{|c|c|c|c|c|c|}
\hline \multicolumn{6}{|c|}{ Supplemental Table S2.txt } \\
\hline CHEMBL1448476 & 688673 & 4.8 & 5.5983 & TRN & \\
\hline CHEMBL1387832 & 688673 & 7.2 & 5.9147 & TRN & \\
\hline CHEMBL1331048 & 688673 & 5.3 & 5.7922 & TRN & \\
\hline CHEMBL1299983 & 688673 & 6.8 & 5.5178 & TRN & \\
\hline CHEMBL1603682 & 688673 & 6.35 & 5.7694 & TRN & \\
\hline CHEMBL3189877 & 688673 & 7.8013 & 5.3651 & TRN & \\
\hline CHEMBL1313678 & 688673 & 6.8 & 6.0105 & TRN & \\
\hline CHEMBL1556661 & 688673 & 4.65 & 5.5538 & TST & \\
\hline CHEMBL1586107 & 688673 & 4.6 & 5.4574 & TRN & \\
\hline CHEMBL603410 & 688673 & 6.0 & 5.9133 & TST & \\
\hline CHEMBL1560087 & 688673 & 7.3002 & 5.9432 & TRN & \\
\hline CHEMBL1613436 & 688673 & 5.5 & 5.8936 & TRN & \\
\hline CHEMBL1543691 & 688673 & 5.35 & 5.8613 & TRN & \\
\hline CHEMBL1337652 & 688673 & 4.8 & 5.6117 & TRN & \\
\hline CHEMBL3195177 & 688673 & 4.7 & 5.4193 & TST & \\
\hline CHEMBL1376641 & 688673 & 5.5 & 5.88700 & 00000000005 & TRN \\
\hline CHEMBL1544028 & 688673 & 5.3 & 5.8705 & TRN & \\
\hline CHEMBL1427541 & 688673 & 4.45 & 5.7253 & TRN & \\
\hline CHEMBL1574151 & 688673 & 6.0 & 5.8281 & TRN & \\
\hline CHEMBL1408219 & 688673 & 7.2 & 6.1499 & TRN & \\
\hline CHEMBL1448207 & 688673 & 7.4001 & 5.7065 & TRN & \\
\hline CHEMBL1581750 & 688673 & 5.5 & 6.1397 & TRN & \\
\hline CHEMBL1419692 & 688673 & 5.5 & 5.8256 & TST & \\
\hline CHEMBL1310248 & 688673 & 4.9 & 5.5959 & TRN & \\
\hline CHEMBL1599642 & 688673 & 4.9 & 5.6535 & TRN & \\
\hline CHEMBL1377687 & 688673 & 4.5 & 5.697 & TRN & \\
\hline CHEMBL1438247 & 688673 & 4.6 & 5.5651 & TRN & \\
\hline CHEMBL1339829 & 688673 & 4.45 & 5.8534 & TRN & \\
\hline CHEMBL1385079 & 688673 & 5.5 & 6.1768 & TRN & \\
\hline CHEMBL1305368 & 688673 & 5.4 & 5.6919 & TRN & \\
\hline CHEMBL1386595 & 688673 & 4.6 & 5.2177 & TRN & \\
\hline CHEMBL1596836 & 688673 & 4.5 & 5.2965 & TRN & \\
\hline CHEMBL1351192 & 688673 & 4.9 & 5.8123 & TRN & \\
\hline CHEMBL1589001 & 688673 & 6.6 & 5.8879 & TRN & \\
\hline CHEMBL1505026 & 688673 & 5.3 & 6.0044 & TRN & \\
\hline CHEMBL1377872 & 688673 & 5.0 & 5.585 & TRN & \\
\hline CHEMBL1559100 & 688673 & 7.0 & 5.6308 & TRN & \\
\hline CHEMBL1256024 & 688673 & 7.5003 & 5.8548 & TST & \\
\hline CHEMBL1414306 & 688673 & 5.0 & 5.5473 & TRN & \\
\hline CHEMBL1392327 & 688673 & 6.0 & 5.67200 & $\partial 000000001$ & TST \\
\hline CHEMBL1308118 & 688673 & 6.7001 & 5.67 & TST & \\
\hline CHEMBL1555084 & 688673 & 5.45 & 5.7986 & TRN & \\
\hline CHEMBL1303639 & 688673 & 7.8996 & 5.8111 & TST & \\
\hline CHEMBL1347618 & 688673 & 5.0 & 5.5944 & TRN & \\
\hline CHEMBL1319944 & 688673 & 6.5501 & 5.6992 & TST & \\
\hline CHEMBL1586524 & 688673 & 6.1 & 6.1534 & TRN & \\
\hline CHEMBL1533297 & 688673 & 8.3979 & 5.9315 & TRN & \\
\hline CHEMBL3189713 & 688673 & 4.9 & 5.6966 & TRN & \\
\hline
\end{tabular}




\begin{tabular}{|c|c|c|c|c|}
\hline \multicolumn{5}{|c|}{ Supplemental Table S2.txt } \\
\hline CHEMBL1426146 & 688673 & 5.4 & 5.8733 & TRN \\
\hline CHEMBL1565261 & 688673 & 4.9 & 5.4955 & TRN \\
\hline CHEMBL1439822 & 688673 & 4.5 & 5.8488 & TRN \\
\hline CHEMBL1507479 & 688673 & 5.6 & 5.7165 & TST \\
\hline CHEMBL1391564 & 688673 & 5.9 & 5.7186 & TRN \\
\hline CHEMBL1444571 & 688673 & 4.45 & 5.5147 & TRN \\
\hline CHEMBL1578464 & 688673 & 4.5 & 6.0599 & TRN \\
\hline CHEMBL1330788 & 688673 & 5.3 & 5.732 & TRN \\
\hline CHEMBL1364102 & 688673 & 5.5 & 5.6212 & TRN \\
\hline CHEMBL573938 & 688673 & 6.9 & 5.8313 & TRN \\
\hline CHEMBL1474849 & 688673 & 8.301 & 6.1164 & TRN \\
\hline CHEMBL1599304 & 688673 & 6.4 & 5.3553 & TRN \\
\hline CHEMBL 32142 & 688673 & 4.5 & 5.87 & TST \\
\hline CHEMBL1433256 & 688673 & 6.1 & 5.8727 & TRN \\
\hline CHEMBL1613004 & 688673 & 4.9 & 5.3074 & TST \\
\hline CHEMBL1434042 & 688673 & 4.8 & 5.4732 & TRN \\
\hline CHEMBL1451522 & 688673 & 7.0 & 5.7212 & TRN \\
\hline CHEMBL1585219 & 688673 & 4.5 & 5.5174 & TRN \\
\hline CHEMBL 3192980 & 688673 & 4.8 & 5.8227 & TST \\
\hline CHEMBL1418360 & 688673 & 4.8 & 5.7804 & TRN \\
\hline CHEMBL1331831 & 688673 & 4.6 & 6.0167 & TRN \\
\hline CHEMBL1416929 & 688673 & 7.1002 & 5.7771 & TRN \\
\hline CHEMBL1372314 & 688673 & 6.6 & 6.0052 & TRN \\
\hline CHEMBL1299381 & 688673 & 5.6 & 5.822 & TRN \\
\hline CHEMBL1504799 & 688673 & 5.3 & 5.5021 & TST \\
\hline CHEMBL1387843 & 688673 & 4.9 & 5.4567 & TST \\
\hline CHEMBL1429225 & 688673 & 7.8996 & 5.4975 & TRN \\
\hline CHEMBL1603576 & 688673 & 7.2 & 5.8348 & TRN \\
\hline CHEMBL1490181 & 688673 & 6.5 & 5.7793 & TRN \\
\hline CHEMBL1388195 & 688673 & 7.8996 & 5.6608 & TRN \\
\hline CHEMBL1523979 & 688673 & 7.3002 & 5.2759 & TRN \\
\hline CHEMBL1323778 & 688673 & 7.8013 & 6.1247 & TRN \\
\hline CHEMBL1368788 & 688673 & 4.5 & 5.8265 & TRN \\
\hline CHEMBL1470112 & 688673 & 4.9 & 5.5555 & TST \\
\hline CHEMBL107514 & 688673 & 6.8 & 5.8487 & TST \\
\hline CHEMBL1501734 & 688673 & 5.6 & 5.4791 & TRN \\
\hline CHEMBL1434866 & 688673 & 4.45 & 5.682 & TRN \\
\hline CHEMBL1376617 & 688673 & 7.1002 & 5.8007 & TRN \\
\hline CHEMBL1496961 & 688673 & 8.301 & 5.7779 & TRN \\
\hline CHEMBL1441931 & 688673 & 5.1 & 5.6222 & TRN \\
\hline CHEMBL1367922 & 688673 & 5.5 & 5.8579 & TRN \\
\hline CHEMBL1380657 & 688673 & 4.5 & $5.7620 e$ & 00000000005 \\
\hline CHEMBL1449431 & 688673 & 5.5 & 5.8437 & TST \\
\hline CHEMBL1377480 & 688673 & 5.2 & 5.858 & TRN \\
\hline CHEMBL1368490 & 688673 & 7.3002 & 5.7527 & TRN \\
\hline CHEMBL1390254 & 688673 & 4.5 & 5.4714 & TRN \\
\hline CHEMBL1320109 & 688673 & 4.9 & 5.6474 & TRN \\
\hline CHEMBL1500040 & 688673 & 5.1 & 5.8044 & TRN \\
\hline
\end{tabular}

TRN 


\begin{tabular}{|c|c|c|c|c|c|}
\hline \multicolumn{6}{|c|}{ Supplemental Table S2.txt } \\
\hline CHEMBL1568705 & 688673 & 5.4 & 5.9981 & TRN & \\
\hline CHEMBL1492815 & 688673 & 4.5 & 5.5103 & TRN & \\
\hline CHEMBL1427066 & 688673 & 5.2 & 5.6066 & TRN & \\
\hline CHEMBL1500267 & 688673 & 4.7 & 5.5075 & TRN & \\
\hline CHEMBL1378655 & 688673 & 5.3 & 5.9507 & TRN & \\
\hline CHEMBL3210456 & 688673 & 7.0 & 5.3824 & TST & \\
\hline CHEMBL1465482 & 688673 & 4.5 & 5.6747 & TRN & \\
\hline CHEMBL1356230 & 688673 & 4.5 & 5.3035 & TRN & \\
\hline CHEMBL1409655 & 688673 & 6.1 & 5.8628 & TRN & \\
\hline CHEMBL1322062 & 688673 & 6.5 & 5.9127 & TRN & \\
\hline CHEMBL1585248 & 688673 & 4.8 & 5.5044 & TST & \\
\hline CHEMBL1565915 & 688673 & 8.0 & 5.626 & TST & \\
\hline CHEMBL1583569 & 688673 & 8.301 & 5.7516 & TRN & \\
\hline CHEMBL1346787 & 688673 & 5.55 & 6.0855 & TRN & \\
\hline CHEMBL1390301 & 688673 & 6.0 & 5.63299 & 9999999999 & TRN \\
\hline CHEMBL1466835 & 688673 & 7.2 & 5.4029 & TRN & \\
\hline CHEMBL1563998 & 688673 & 5.2 & 5.99 & TRN & \\
\hline CHEMBL1511004 & 688673 & 6.0 & 5.7326 & TRN & \\
\hline CHEMBL1406538 & 688673 & 8.301 & 5.7585 & TRN & \\
\hline CHEMBL1333378 & 688673 & 5.5 & 6.0448 & TRN & \\
\hline CHEMBL1402038 & 688673 & 7.6003 & 5.6664 & TST & \\
\hline CHEMBL1534275 & 688673 & 6.6 & 5.5393 & TRN & \\
\hline CHEMBL1589743 & 688673 & 4.5 & 5.6173 & TRN & \\
\hline CHEMBL1400303 & 688673 & 4.45 & 5.8253 & TRN & \\
\hline CHEMBL1509201 & 688673 & 4.9 & 5.494 & TRN & \\
\hline CHEMBL1376788 & 688673 & 6.2 & 5.6236 & TRN & \\
\hline CHEMBL1430526 & 688673 & 4.8 & 5.9975 & TRN & \\
\hline CHEMBL1470920 & 688673 & 4.5 & 5.4776 & TRN & \\
\hline CHEMBL1373376 & 688673 & 4.45 & 5.6979 & TST & \\
\hline CHEMBL3208391 & 688673 & 5.4 & 5.7515 & TRN & \\
\hline CHEMBL564708 & 688673 & 4.45 & 5.7358 & TRN & \\
\hline CHEMBL1326409 & 688673 & 5.5 & 5.7829 & TRN & \\
\hline CHEMBL1495621 & 688673 & 5.5 & 5.6426 & TRN & \\
\hline CHEMBL1584462 & 688673 & 6.0 & 5.5306 & TRN & \\
\hline CHEMBL1376574 & 688673 & 5.5 & 5.4353 & TRN & \\
\hline CHEMBL1306024 & 688673 & 7.6003 & 5.6274 & TRN & \\
\hline CHEMBL211606 & 688673 & 6.5 & 5.9056 & TRN & \\
\hline CHEMBL1358640 & 688673 & 4.45 & 5.8544 & TRN & \\
\hline CHEMBL3198962 & 688673 & 5.1 & 5.6055 & TRN & \\
\hline CHEMBL1307479 & 688673 & 4.9 & 6.2046 & TRN & \\
\hline CHEMBL1574549 & 688673 & 6.1 & 5.5933 & TRN & \\
\hline CHEMBL1367980 & 688673 & 5.2 & 6.1632 & TRN & \\
\hline CHEMBL1551015 & 688673 & 4.9 & 5.7164 & TRN & \\
\hline CHEMBL1419089 & 688673 & 4.5 & 5.7878 & TRN & \\
\hline CHEMBL1532403 & 688673 & 4.6 & 5.7546 & TST & \\
\hline CHEMBL1517653 & 688673 & 6.0 & 6.0279 & TRN & \\
\hline CHEMBL1575850 & 688673 & 7.0 & 5.6719 & TRN & \\
\hline CHEMBL1555624 & 688673 & 5.4 & 5.9813 & TRN & \\
\hline
\end{tabular}




\begin{tabular}{|c|c|c|c|c|}
\hline \multicolumn{5}{|c|}{ Supplemental Table S2.txt } \\
\hline CHEMBL1321825 & 688673 & 5.25 & 5.6362 & TRN \\
\hline CHEMBL1321724 & 688673 & 6.3 & 5.8354 & TRN \\
\hline CHEMBL1333017 & 688673 & 5.0 & 5.7617 & TRN \\
\hline CHEMBL1334711 & 688673 & 4.7 & 5.3114 & TRN \\
\hline CHEMBL1493613 & 688673 & 8.0 & 5.6884 & TRN \\
\hline CHEMBL1611299 & 688673 & 4.7 & 5.7005 & TRN \\
\hline CHEMBL1389338 & 688673 & 4.9 & 5.5254 & TRN \\
\hline CHEMBL1457400 & 688673 & 5.4 & 5.7397 & TRN \\
\hline CHEMBL1386359 & 688673 & 6.3 & 5.9132 & TST \\
\hline CHEMBL1378607 & 688673 & 6.0 & 5.7194 & TRN \\
\hline CHEMBL1388883 & 688673 & 4.45 & 5.8573 & TRN \\
\hline CHEMBL1577593 & 688673 & 5.1 & 6.0387 & TRN \\
\hline CHEMBL1487925 & 688673 & 4.9 & 6.0746 & TRN \\
\hline CHEMBL1309478 & 688673 & 4.8 & 5.3436 & TRN \\
\hline CHEMBL1430550 & 688673 & 4.5 & 5.7329 & TST \\
\hline CHEMBL1595399 & 688673 & 5.3 & 5.6824 & TRN \\
\hline CHEMBL1484285 & 688673 & 5.3 & 5.3806 & TRN \\
\hline CHEMBL1400464 & 688673 & 6.1 & 5.6087 & TRN \\
\hline CHEMBL1328338 & 688673 & 5.55 & 5.8492 & TRN \\
\hline CHEMBL1347461 & 688673 & 7.0 & 6.1565 & TRN \\
\hline CHEMBL1605717 & 688673 & 5.2 & 5.4894 & TST \\
\hline CHEMBL1420271 & 688673 & 7.0 & 6.0533 & TRN \\
\hline CHEMBL1507190 & 688673 & 5.0 & 6.0387 & TRN \\
\hline CHEMBL597047 & 688673 & 5.1 & 5.5543 & TRN \\
\hline CHEMBL1505601 & 688673 & 4.45 & 5.6996 & TST \\
\hline CHEMBL 327035 & 688673 & 7.2 & 5.67 & TRN \\
\hline CHEMBL1558969 & 688673 & 5.45 & 5.5632 & TRN \\
\hline CHEMBL1397884 & 688673 & 4.45 & 5.9353 & TRN \\
\hline CHEMBL1491070 & 688673 & 7.2 & 5.3102 & TRN \\
\hline CHEMBL1374979 & 688673 & 6.8 & 5.6736 & TST \\
\hline CHEMBL1331817 & 688673 & 7.8996 & 6.0533 & TRN \\
\hline CHEMBL3191952 & 688673 & 4.5 & 5.558 & TST \\
\hline CHEMBL1475554 & 688673 & 4.65 & 5.9507 & TRN \\
\hline CHEMBL1573310 & 688673 & 6.5501 & 5.5905 & TRN \\
\hline CHEMBL1426539 & 688673 & 7.3497 & 5.5716 & TRN \\
\hline CHEMBL1386770 & 688673 & 7.2 & 5.8502 & TRN \\
\hline CHEMBL3210921 & 688673 & 6.15 & 5.5373 & TRN \\
\hline CHEMBL1368261 & 688673 & 4.8 & 5.391 & TST \\
\hline CHEMBL1507993 & 688673 & 4.9 & 5.6472 & TRN \\
\hline CHEMBL1543895 & 688673 & 5.65 & 5.8948 & TRN \\
\hline CHEMBL1299350 & 688673 & 6.0 & 5.8806 & TRN \\
\hline CHEMBL1480810 & 688673 & 4.45 & 5.8728 & TRN \\
\hline CHEMBL1526239 & 688673 & 4.45 & 5.6789 & TRN \\
\hline CHEMBL1457027 & 688673 & 4.5 & 5.8684 & TRN \\
\hline CHEMBL1588027 & 688673 & 5.0 & 5.7311 & TST \\
\hline CHEMBL1378612 & 688673 & 7.6003 & 5.7014 & TST \\
\hline CHEMBL1547006 & 688673 & 4.9 & 5.6197 & TRN \\
\hline CHEMBL1464246 & 688673 & 6.8 & 5.6684 & TST \\
\hline
\end{tabular}




\begin{tabular}{|c|c|c|c|c|}
\hline \multicolumn{5}{|c|}{ Supplemental Table S2.txt } \\
\hline CHEMBL1423466 & 688673 & 6.9 & 5.879 & TRN \\
\hline CHEMBL505863 & 688673 & 5.4 & 6.017 & TRN \\
\hline CHEMBL1313483 & 688673 & 4.8 & 5.5459 & TRN \\
\hline CHEMBL1336183 & 688673 & 5.4 & 5.6623 & TRN \\
\hline CHEMBL1350748 & 688673 & 4.5 & 5.7022 & TRN \\
\hline CHEMBL1375911 & 688673 & 6.5 & 5.7313 & TRN \\
\hline CHEMBL1529427 & 688673 & 5.55 & 5.7767 & TRN \\
\hline CHEMBL1361587 & 688673 & 5.8 & 6.0141 & TRN \\
\hline CHEMBL 1455455 & 688673 & 5.35 & 5.4195 & TRN \\
\hline CHEMBL1497338 & 688673 & 6.4 & 5.5956 & TRN \\
\hline CHEMBL1541069 & 688673 & 5.3 & 6.2413 & TRN \\
\hline CHEMBL1508815 & 688673 & 5.2 & 5.6745 & TRN \\
\hline CHEMBL1370066 & 688673 & 5.5 & 5.6576 & TRN \\
\hline CHEMBL1455948 & 688673 & 6.7001 & 5.928 & TRN \\
\hline CHEMBL1443739 & 688673 & 4.5 & 5.619 & TST \\
\hline CHEMBL1509610 & 688673 & 5.9 & 5.9007 & TST \\
\hline CHEMBL1514358 & 688673 & 5.3 & 5.6674 & TST \\
\hline CHEMBL1327388 & 688673 & 4.5 & 5.3731 & TST \\
\hline CHEMBL1452523 & 688673 & 5.5 & 5.4689 & TST \\
\hline CHEMBL1352818 & 688673 & 6.3 & 5.5687 & TST \\
\hline CHEMBL1383775 & 688673 & 5.3 & 5.8619 & TST \\
\hline CHEMBL1349660 & 688673 & 6.1 & 5.6302 & TST \\
\hline CHEMBL1355303 & 688673 & 8.2518 & 5.3593 & TST \\
\hline CHEMBL 372840 & 688673 & 4.5 & 5.6229 & TST \\
\hline CHEMBL1576261 & 688673 & 6.7501 & 6.20700 & 0000000001 \\
\hline CHEMBL1537948 & 688673 & 6.3 & 5.7775 & TST \\
\hline CHEMBL1093246 & 688673 & 4.95 & 5.2406 & TST \\
\hline CHEMBL1609098 & 688673 & 5.4 & 6.2929 & TST \\
\hline CHEMBL1484450 & 688673 & 4.5 & 5.5984 & TST \\
\hline CHEMBL 1346330 & 688673 & 5.0 & 6.0319 & TST \\
\hline CHEMBL1326828 & 688673 & 5.4 & 6.1737 & TST \\
\hline CHEMBL1389146 & 688673 & 7.4001 & 5.5524 & TST \\
\hline CHEMBL1600956 & 688673 & 5.3 & 5.5621 & TST \\
\hline CHEMBL1544714 & 688673 & 6.1 & 5.5613 & TST \\
\hline CHEMBL1359644 & 688673 & 6.0 & 5.6963 & TST \\
\hline CHEMBL1420026 & 688673 & 6.8 & 6.0682 & TST \\
\hline CHEMBL3214041 & 688673 & 4.5 & 6.0129 & TST \\
\hline CHEMBL1603167 & 688673 & 4.5 & 6.1449 & TST \\
\hline CHEMBL1537265 & 688673 & 8.1024 & 6.1069 & TST \\
\hline CHEMBL1563359 & 688673 & 5.6 & 5.7021 & TST \\
\hline CHEMBL1538195 & 688673 & 4.7 & 5.5772 & TST \\
\hline CHEMBL3211603 & 688673 & 5.25 & 5.7046 & TST \\
\hline CHEMBL1440693 & 688673 & 4.9 & 5.9221 & TST \\
\hline CHEMBL1329060 & 688673 & 4.75 & 5.6586 & TST \\
\hline CHEMBL1392693 & 688673 & 6.7501 & 5.3709 & TST \\
\hline CHEMBL1310917 & 688673 & 6.35 & 5.5541 & TST \\
\hline CHEMBL1571423 & 688673 & 7.5003 & 5.9439 & TST \\
\hline CHEMBL1447733 & 688673 & 6.0 & 5.5097 & TST \\
\hline
\end{tabular}




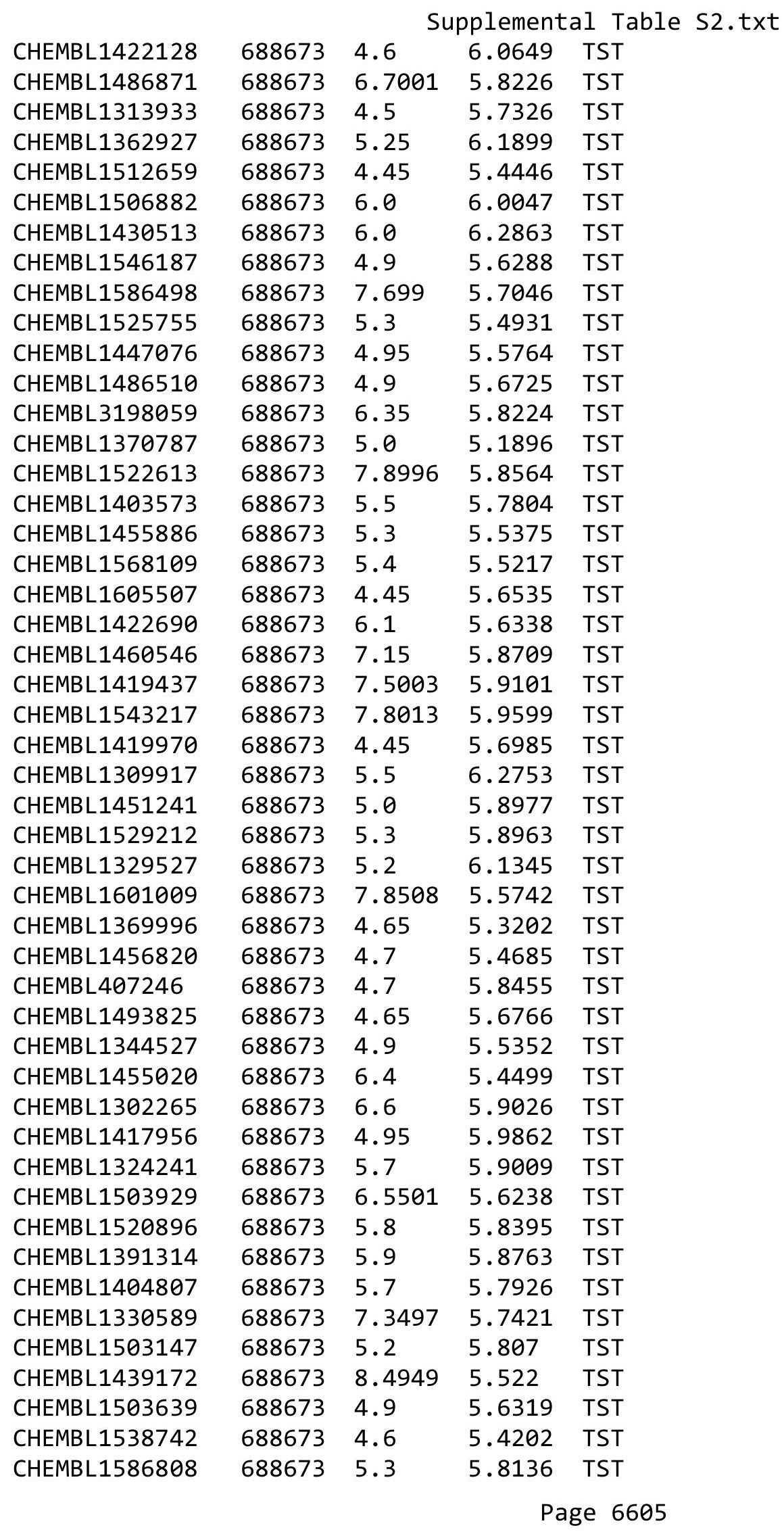




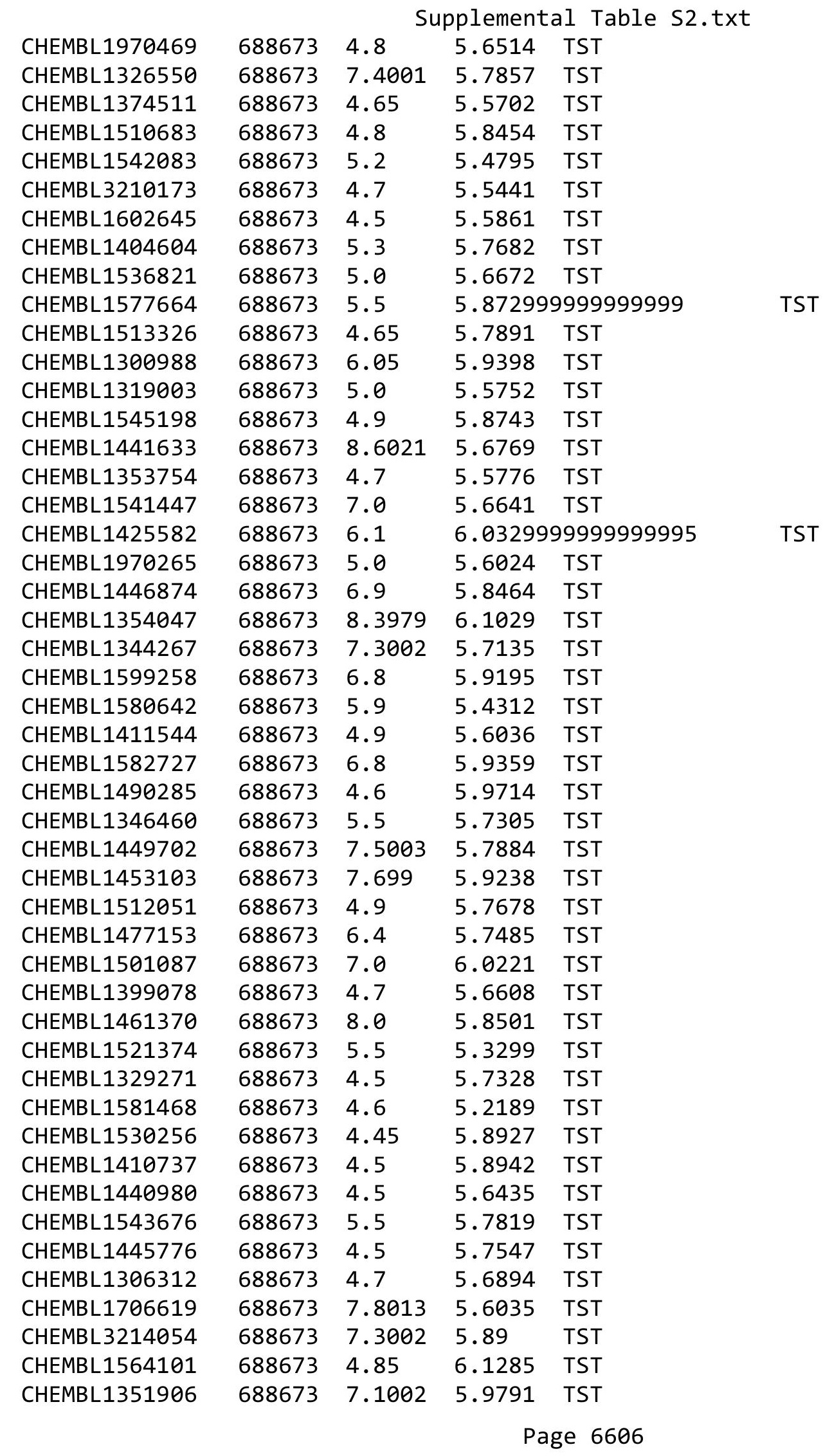




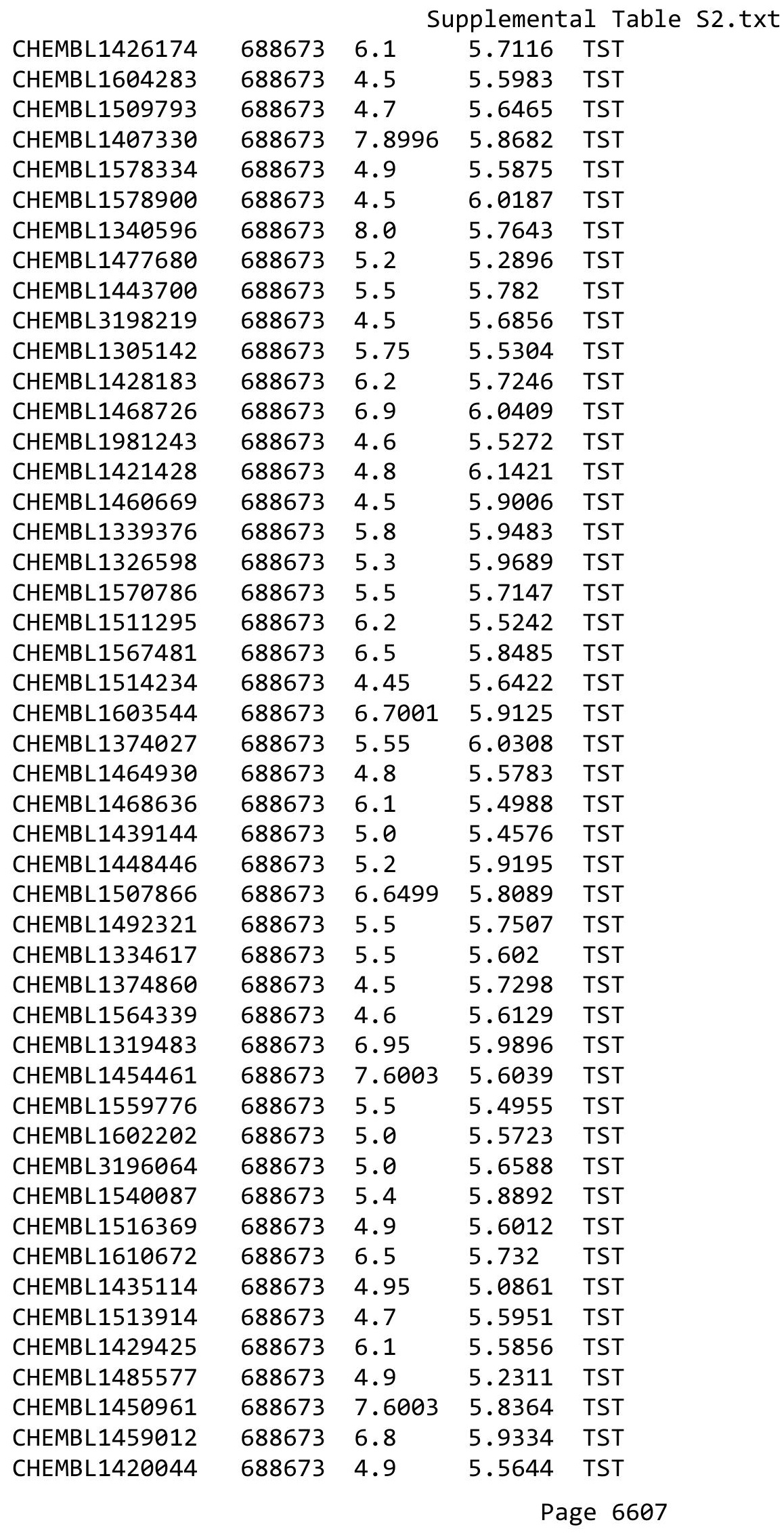




\begin{tabular}{|c|c|c|c|c|c|}
\hline \multicolumn{6}{|c|}{ Supplemental Table s2.txt } \\
\hline CHEMBL1609556 & 688673 & 4.5 & 5.6602 & TST & \\
\hline CHEMBL1485813 & 688673 & 4.45 & 5.7009 & TST & \\
\hline CHEMBL1487404 & 688673 & 6.4 & 5.7855 & TST & \\
\hline CHEMBL1546143 & 688673 & 4.9 & 5.7467 & TST & \\
\hline CHEMBL1456917 & 688673 & 5.7 & 5.7946 & TST & \\
\hline CHEMBL1560370 & 688673 & 6.8 & 5.6943 & TST & \\
\hline CHEMBL1339167 & 688673 & 5.5 & 6.112 & TST & \\
\hline CHEMBL1413764 & 688673 & 4.5 & 5.9702 & TST & \\
\hline CHEMBL1407926 & 688673 & 6.3 & 5.5011 & TST & \\
\hline CHEMBL1359987 & 688673 & 4.45 & 5.7981 & TST & \\
\hline CHEMBL1499052 & 688673 & 4.9 & 5.6686 & TST & \\
\hline CHEMBL1331497 & 688673 & 6.5 & 5.8149 & TST & \\
\hline CHEMBL1309716 & 688673 & 5.2 & 5.7235 & TST & \\
\hline CHEMBL1481191 & 688673 & 5.25 & 5.57600 & 00000000005 & TST \\
\hline CHEMBL1479268 & 688673 & 4.5 & 5.6759 & TST & \\
\hline CHEMBL1412461 & 688673 & 5.4 & 5.7069 & TST & \\
\hline CHEMBL1299987 & 688673 & 5.25 & 5.6723 & TST & \\
\hline CHEMBL530149 & 688673 & 8.1024 & 5.5714 & TST & \\
\hline CHEMBL1543396 & 688673 & 5.25 & 5.7114 & TST & \\
\hline CHEMBL1299539 & 688673 & 5.25 & 5.8463 & TST & \\
\hline CHEMBL1321734 & 688673 & 4.45 & 5.4197 & TST & \\
\hline CHEMBL1458630 & 688673 & 6.8499 & 5.4718 & TST & \\
\hline CHEMBL1411927 & 688673 & 5.5 & 5.5113 & TST & \\
\hline CHEMBL1451362 & 688673 & 8.301 & 5.6698 & TST & \\
\hline CHEMBL1524766 & 688673 & 4.5 & 5.5226 & TST & \\
\hline CHEMBL1530458 & 688673 & 4.5 & 6.3625 & TST & \\
\hline CHEMBL1569074 & 688673 & 4.5 & 5.4109 & TST & \\
\hline CHEMBL1581473 & 688673 & 5.2 & 5.6693 & TST & \\
\hline CHEMBL1464887 & 688673 & 7.0 & 6.0144 & TST & \\
\hline CHEMBL1578637 & 688673 & 4.8 & 5.9425 & TST & \\
\hline CHEMBL1405386 & 688673 & 4.5 & 5.8128 & TST & \\
\hline CHEMBL1453086 & 688673 & 4.65 & 5.6171 & TST & \\
\hline CHEMBL1426148 & 688673 & 4.8 & 5.78100 & 2000000001 & TST \\
\hline CHEMBL1363209 & 688673 & 7.8996 & 5.9319 & TST & \\
\hline CHEMBL1384241 & 688673 & 8.4559 & 5.965 & TST & \\
\hline CHEMBL1498205 & 688673 & 7.8996 & 5.6063 & TST & \\
\hline CHEMBL1338872 & 688673 & 7.699 & 5.7373 & TST & \\
\hline CHEMBL1370379 & 688673 & 7.3497 & 5.7171 & TST & \\
\hline CHEMBL3198234 & 688673 & 5.4 & 5.7184 & TST & \\
\hline CHEMBL1566391 & 688673 & 4.5 & 5.5914 & TST & \\
\hline CHEMBL1342940 & 688673 & 6.8 & 5.6566 & TST & \\
\hline CHEMBL1308362 & 688673 & 4.8 & 5.8243 & TST & \\
\hline CHEMBL1536730 & 688673 & 6.8 & 5.6086 & TST & \\
\hline CHEMBL1575330 & 688673 & 7.699 & 5.9156 & TST & \\
\hline CHEMBL1504091 & 688673 & 4.5 & 5.7753 & TST & \\
\hline CHEMBL56393 & 688673 & 4.5 & 5.3677 & TST & \\
\hline CHEMBL1488820 & 688673 & 4.6 & 5.5491 & TST & \\
\hline CHEMBL1585523 & 688673 & 6.3 & 6.1056 & TST & \\
\hline
\end{tabular}




\begin{tabular}{|c|c|c|c|c|}
\hline & & & oplement & al $\mathrm{Ta}$ \\
\hline CHEMBL1426800 & 688673 & 4.5 & 5.8545 & TST \\
\hline CHEMBL1364393 & 688673 & 5.5 & 5.6963 & TST \\
\hline CHEMBL1456655 & 688673 & 5.25 & 5.8895 & TST \\
\hline CHEMBL1313988 & 688673 & 4.9 & 5.6714 & TST \\
\hline CHEMBL1419413 & 688673 & 4.6 & 5.6046 & TST \\
\hline CHEMBL1377335 & 688673 & 4.5 & 5.6828 & TST \\
\hline CHEMBL1564290 & 688673 & 7.699 & 5.6695 & TST \\
\hline CHEMBL1312473 & 688673 & 5.4 & 5.5862 & TST \\
\hline CHEMBL1383567 & 688673 & 4.9 & 6.0553 & TST \\
\hline CHEMBL1383829 & 688673 & 7.3002 & 6.0626 & TST \\
\hline CHEMBL1545965 & 688673 & 7.8013 & 5.2099 & TST \\
\hline CHEMBL1465980 & 688673 & 5.3 & 5.6667 & TST \\
\hline CHEMBL1300960 & 688673 & 4.5 & 5.5645 & TST \\
\hline CHEMBL1593130 & 688673 & 4.5 & 5.7137 & TST \\
\hline CHEMBL1544760 & 688673 & 5.05 & 5.3469 & TST \\
\hline CHEMBL1538270 & 688673 & 6.1 & 6.0036 & TST \\
\hline CHEMBL1595644 & 688673 & 7.5003 & 5.5668 & TST \\
\hline CHEMBL1424847 & 688673 & 5.9 & 5.834 & TST \\
\hline CHEMBL1483737 & 688673 & 5.3 & 5.7177 & TST \\
\hline CHEMBL1519611 & 688673 & 5.0 & 5.5882 & TST \\
\hline CHEMBL1438679 & 688673 & 4.45 & 5.9949 & TST \\
\hline CHEMBL1610293 & 688673 & 4.45 & 6.0123 & TST \\
\hline CHEMBL1303597 & 688673 & 5.2 & 5.9533 & TST \\
\hline CHEMBL1373740 & 688673 & 5.3 & 5.5119 & TST \\
\hline CHEMBL1596920 & 688673 & 5.9 & 5.8563 & TST \\
\hline CHEMBL94990 & 688673 & 4.8 & 5.7471 & TST \\
\hline CHEMBL1439257 & 688673 & 8.1487 & 5.6696 & TST \\
\hline CHEMBL88621 & 688673 & 6.7001 & 5.8571 & TST \\
\hline CHEMBL1385312 & 688673 & 5.5 & 5.5749 & TST \\
\hline CHEMBL1444418 & 688673 & 7.8996 & 5.7239 & TST \\
\hline CHEMBL1460863 & 688673 & 4.45 & 5.7118 & TST \\
\hline CHEMBL1544372 & 688673 & 8.3979 & 5.773 & TST \\
\hline CHEMBL1419950 & 688673 & 7.699 & 5.8268 & TST \\
\hline CHEMBL1369339 & 688673 & 6.3 & 5.8597 & TST \\
\hline CHEMBL1523892 & 688673 & 5.4 & 5.8006 & TST \\
\hline CHEMBL1397367 & 688673 & 4.9 & 5.476 & TST \\
\hline CHEMBL1483396 & 688673 & 5.5 & 6.1054 & TST \\
\hline CHEMBL1465539 & 688673 & 5.35 & 5.7047 & TST \\
\hline CHEMBL1335134 & 688673 & 5.9 & 5.7728 & TST \\
\hline CHEMBL1521935 & 688673 & 5.2 & 5.5441 & TST \\
\hline CHEMBL1404296 & 688673 & 8.301 & 5.9158 & TST \\
\hline CHEMBL1508853 & 688673 & 6.8 & 5.9477 & TST \\
\hline CHEMBL1506748 & 688673 & 4.5 & 5.6849 & TST \\
\hline CHEMBL1364112 & 688673 & 8.0 & 6.1885 & TST \\
\hline CHEMBL1371567 & 688673 & 4.45 & 5.7012 & TST \\
\hline CHEMBL3196303 & 688673 & 6.2 & 5.6722 & TST \\
\hline CHEMBL1417253 & 688673 & 7.5003 & 5.9504 & TST \\
\hline CHEMBL1609494 & 688673 & 5.0 & 5.2754 & TST \\
\hline
\end{tabular}




\begin{tabular}{|c|c|c|c|c|c|}
\hline \multicolumn{6}{|c|}{ Supplemental Table S2.txt } \\
\hline CHEMBL1610009 & 688673 & 5.2 & 5.8216 & TST & \\
\hline CHEMBL1569931 & 688673 & 4.9 & 5.4951 & TST & \\
\hline CHEMBL1602742 & 688673 & 5.0 & 5.6109 & TST & \\
\hline CHEMBL1568287 & 688673 & 4.5 & 5.4016 & TST & \\
\hline CHEMBL1412641 & 688673 & 5.3 & 5.9791 & TST & \\
\hline CHEMBL1612476 & 688673 & 5.0 & 5.6215 & TST & \\
\hline CHEMBL1383475 & 688673 & 7.0501 & 5.704 & TST & \\
\hline CHEMBL1368847 & 688673 & 4.5 & 5.499 & TST & \\
\hline CHEMBL1420638 & 688673 & 7.0 & 5.6611 & TST & \\
\hline CHEMBL1348849 & 688673 & 4.5 & 5.739 & TST & \\
\hline CHEMBL1420570 & 688673 & 5.3 & 5.6652 & TST & \\
\hline CHEMBL3195885 & 688673 & 5.3 & 5.4399 & TST & \\
\hline CHEMBL1328648 & 688673 & 4.75 & 5.4167 & TST & \\
\hline CHEMBL1309026 & 688673 & 8.0 & 5.4667 & TST & \\
\hline CHEMBL1534097 & 688673 & 4.5 & 5.7951 & TST & \\
\hline CHEMBL1307918 & 688673 & 6.2 & 5.3421 & TST & \\
\hline CHEMBL1468522 & 688673 & 4.45 & 5.274 & TST & \\
\hline CHEMBL1442411 & 688673 & 4.9 & 5.3569 & TST & \\
\hline CHEMBL1977328 & 688673 & 4.95 & 5.76200 & 00000000005 & TST \\
\hline CHEMBL1606169 & 688673 & 7.8996 & 5.7417 & TST & \\
\hline CHEMBL1420498 & 688673 & 5.8 & 6.1131 & TST & \\
\hline CHEMBL1577888 & 688673 & 5.15 & 5.5066 & TST & \\
\hline CHEMBL1338177 & 688673 & 5.1 & 5.7688 & TST & \\
\hline CHEMBL1324137 & 688673 & 7.8013 & 5.6802 & TST & \\
\hline CHEMBL1480875 & 688673 & 5.7 & 6.0603 & TST & \\
\hline CHEMBL1611233 & 688673 & 6.45 & 5.9095 & TST & \\
\hline CHEMBL1407515 & 688673 & 4.7 & 5.6588 & TST & \\
\hline CHEMBL1321116 & 688673 & 5.0 & 5.7355 & TST & \\
\hline CHEMBL1365961 & 688673 & 5.0 & 5.5005 & TST & \\
\hline CHEMBL1452129 & 688673 & 5.3 & 5.7198 & TST & \\
\hline CHEMBL1312199 & 688673 & 5.6 & 5.4979 & TST & \\
\hline CHEMBL1509357 & 688673 & 6.1 & 5.4986 & TST & \\
\hline CHEMBL1483675 & 688673 & 5.4 & 5.7438 & TST & \\
\hline CHEMBL1585117 & 688673 & 4.9 & 5.9895 & TST & \\
\hline CHEMBL1423438 & 688673 & 4.5 & 5.9043 & TST & \\
\hline CHEMBL1431695 & 688673 & 5.3 & 5.6043 & TST & \\
\hline CHEMBL1485984 & 688673 & 4.7 & 5.5662 & TST & \\
\hline CHEMBL1569535 & 688673 & 4.9 & 5.6507 & TST & \\
\hline CHEMBL1506645 & 688673 & 7.0 & 5.8047 & TST & \\
\hline CHEMBL1400546 & 688673 & 5.8 & 5.5514 & TST & \\
\hline CHEMBL1502863 & 688673 & 5.5 & 5.5568 & TST & \\
\hline CHEMBL1567228 & 688673 & 6.0 & 5.6294 & TST & \\
\hline CHEMBL1376348 & 688673 & 8.0 & 5.9555 & TST & \\
\hline CHEMBL1501269 & 688673 & 4.9 & 5.729 & TST & \\
\hline CHEMBL1428491 & 688673 & 6.7001 & 5.9411 & TST & \\
\hline CHEMBL1562632 & 688673 & 5.0 & 5.6362 & TST & \\
\hline CHEMBL1341180 & 688673 & 5.25 & 6.0354 & TST & \\
\hline CHEMBL1611681 & 688673 & 5.5 & 5.5215 & TST & \\
\hline
\end{tabular}




\begin{tabular}{|c|c|c|c|c|}
\hline \multicolumn{5}{|c|}{ Supplemental Table S2.txt } \\
\hline CHEMBL1301702 & 688673 & 5.0 & 5.7974 & TST \\
\hline CHEMBL1393394 & 688673 & 5.3 & 5.7689 & TST \\
\hline CHEMBL1578014 & 688673 & 4.8 & 5.6608 & TST \\
\hline CHEMBL1411875 & 688673 & 4.5 & 5.5038 & TST \\
\hline CHEMBL1473272 & 688673 & 5.25 & 5.8928 & TST \\
\hline CHEMBL1338374 & 688673 & 5.2 & 5.6253 & TST \\
\hline CHEMBL1388589 & 688673 & 4.7 & 5.609 & TST \\
\hline CHEMBL1602372 & 688673 & 5.25 & 5.5764 & TST \\
\hline CHEMBL1379677 & 688673 & 4.9 & 5.5717 & TST \\
\hline CHEMBL1484773 & 688673 & 6.1 & 5.7972 & TST \\
\hline CHEMBL1369755 & 688673 & 4.8 & 5.57 & TST \\
\hline CHEMBL1331677 & 688673 & 6.9 & 5.6377 & TST \\
\hline CHEMBL1509533 & 688673 & 7.6003 & 5.9809 & TST \\
\hline CHEMBL1463034 & 688673 & 7.0 & 5.6562 & TST \\
\hline CHEMBL1313254 & 688673 & 4.7 & 5.4984 & TST \\
\hline CHEMBL1491944 & 688673 & 4.95 & 5.9084 & TST \\
\hline CHEMBL3208634 & 688673 & 4.8 & 5.6481 & TST \\
\hline CHEMBL1573328 & 688673 & 6.4 & 5.7793 & TST \\
\hline CHEMBL500351 & 688673 & 5.3 & 5.5348 & TST \\
\hline CHEMBL1534858 & 688673 & 4.7 & 6.0869 & TST \\
\hline CHEMBL1567248 & 688673 & 6.8 & 5.4639 & TST \\
\hline CHEMBL1535517 & 688673 & 4.5 & 5.7659 & TST \\
\hline CHEMBL1417852 & 688673 & 4.5 & 5.7618 & TST \\
\hline CHEMBL1470594 & 688673 & 8.301 & 5.8424 & TST \\
\hline CHEMBL1482167 & 688673 & 5.4 & 5.9203 & TST \\
\hline CHEMBL1721986 & 688673 & 4.55 & 5.3924 & TST \\
\hline CHEMBL1462936 & 688673 & 4.8 & 5.4445 & TST \\
\hline CHEMBL1471187 & 688673 & 6.5 & 5.7652 & TST \\
\hline CHEMBL3208579 & 688673 & 5.0 & 5.7748 & TST \\
\hline CHEMBL1443952 & 688673 & 8.0 & 5.8048 & TST \\
\hline CHEMBL1607414 & 688673 & 5.25 & 5.4393 & TST \\
\hline CHEMBL1377667 & 688673 & 4.45 & 5.8924 & TST \\
\hline CHEMBL1377741 & 688673 & 8.4949 & 5.8671 & TST \\
\hline CHEMBL1400482 & 688673 & 8.2007 & 6.0173 & TST \\
\hline CHEMBL601957 & 688673 & 7.5003 & 5.7589 & TST \\
\hline CHEMBL1568523 & 688673 & 4.95 & 5.7987 & TST \\
\hline CHEMBL1497639 & 688673 & 5.3 & 5.8378 & TST \\
\hline CHEMBL1527982 & 688673 & 6.1 & 5.7163 & TST \\
\hline CHEMBL1350422 & 688673 & 4.5 & 5.6598 & TST \\
\hline CHEMBL1401695 & 688673 & 5.5 & 5.7392 & TST \\
\hline CHEMBL1324305 & 688673 & 4.9 & 5.6608 & TST \\
\hline CHEMBL1485066 & 688673 & 7.0 & 5.8593 & TST \\
\hline CHEMBL1316470 & 688673 & 4.8 & 5.6688 & TST \\
\hline CHEMBL1537780 & 688673 & 5.3 & 5.8854 & TST \\
\hline CHEMBL1325774 & 688673 & 7.5003 & 5.8327 & TST \\
\hline CHEMBL1489641 & 688673 & 7.6003 & 5.624 & TST \\
\hline CHEMBL1341569 & 688673 & 5.2 & 5.5461 & TST \\
\hline CHEMBL1550700 & 688673 & 8.301 & 6.0273 & TST \\
\hline
\end{tabular}




\begin{tabular}{|c|c|c|c|c|c|}
\hline & & \multicolumn{4}{|c|}{ Supplemental Table S2.txt } \\
\hline CHEMBL1356552 & 688673 & 6.8499 & 5.7093 & TST & \\
\hline CHEMBL1550267 & 688673 & 4.7 & 5.8901 & TST & \\
\hline CHEMBL1479324 & 688673 & 6.3 & 5.8689 & TST & \\
\hline CHEMBL1463808 & 688673 & 5.5 & 5.5528 & TST & \\
\hline CHEMBL1535638 & 688673 & 5.3 & 5.9263 & TST & \\
\hline CHEMBL1576234 & 688673 & 6.9 & 5.5272 & TST & \\
\hline CHEMBL1335729 & 688673 & 4.5 & 5.6047 & TST & \\
\hline CHEMBL1461732 & 688673 & 4.5 & 5.6981 & TST & \\
\hline CHEMBL1325831 & 688673 & 4.7 & 5.2742 & TST & \\
\hline CHEMBL1325043 & 688673 & 6.4 & 5.4912 & TST & \\
\hline CHEMBL1300912 & 688673 & 4.9 & 5.5253 & TST & \\
\hline CHEMBL1499599 & 688673 & 5.0 & 5.8793 & TST & \\
\hline CHEMBL1501319 & 688673 & 7.8996 & 5.9408 & TST & \\
\hline CHEMBL1314460 & 688673 & 5.85 & 5.421 & TST & \\
\hline CHEMBL1506876 & 688673 & 5.3 & 6.0479 & TST & \\
\hline CHEMBL 2143754 & 688673 & 5.0 & 5.5323 & TST & \\
\hline CHEMBL1496010 & 688673 & 6.4 & 5.4702 & TST & \\
\hline CHEMBL1373575 & 688673 & 5.3 & 5.9363 & TST & \\
\hline CHEMBL1299490 & 688673 & 4.45 & 5.9764 & TST & \\
\hline CHEMBL1554440 & 688673 & 8.699 & 5.9132 & TST & \\
\hline CHEMBL1299830 & 688673 & 6.7001 & 5.6467 & TST & \\
\hline CHEMBL1530733 & 688673 & 4.7 & 5.5974 & TST & \\
\hline CHEMBL1580558 & 688673 & 5.4 & 5.82100 & 0000000001 & TST \\
\hline CHEMBL1469562 & 688673 & 5.6 & 5.7726 & TST & \\
\hline CHEMBL1493820 & 688673 & 6.2 & 5.9097 & TST & \\
\hline CHEMBL1460989 & 688673 & 5.0 & 5.8004 & TST & \\
\hline CHEMBL1426726 & 688673 & 5.0 & 5.78799 & 9999999999 & TST \\
\hline CHEMBL1324358 & 688673 & 4.85 & 5.1498 & TST & \\
\hline CHEMBL1509714 & 688673 & 8.0 & 5.9345 & TST & \\
\hline CHEMBL1309135 & 688673 & 5.3 & 5.6779 & TST & \\
\hline CHEMBL 3197060 & 688673 & 4.9 & 5.6318 & TST & \\
\hline CHEMBL1377086 & 688673 & 5.3 & 5.8176 & TST & \\
\hline CHEMBL1481275 & 688673 & 4.45 & 5.8155 & TST & \\
\hline CHEMBL1501980 & 688673 & 5.5 & 5.8074 & TST & \\
\hline CHEMBL1599196 & 688673 & 5.5 & 5.7906 & TST & \\
\hline CHEMBL1466285 & 688673 & 4.7 & 5.5346 & TST & \\
\hline CHEMBL1440386 & 688673 & 6.8 & 5.7534 & TST & \\
\hline CHEMBL1442547 & 688673 & 5.2 & 5.4916 & TST & \\
\hline CHEMBL1574683 & 688673 & 6.2 & 5.4762 & TST & \\
\hline CHEMBL1499271 & 688673 & 5.5 & 5.5617 & TST & \\
\hline CHEMBL1409514 & 688673 & 7.2 & 5.8817 & TST & \\
\hline CHEMBL1439904 & 688673 & 4.9 & 5.4103 & TST & \\
\hline CHEMBL1355998 & 688673 & 5.0 & 5.6406 & TST & \\
\hline CHEMBL1352936 & 688673 & 5.0 & 5.6898 & TST & \\
\hline CHEMBL1303325 & 688673 & 7.8013 & 5.5927 & TST & \\
\hline CHEMBL1510927 & 688673 & 5.4 & 5.955 & TST & \\
\hline CHEMBL1549101 & 688673 & 4.9 & 5.5117 & TST & \\
\hline CHEMBL1304140 & 688673 & 4.9 & 5.5143 & TST & \\
\hline
\end{tabular}




\begin{tabular}{|c|c|c|c|c|}
\hline \multicolumn{5}{|c|}{ Supplemental Table S2.txt } \\
\hline CHEMBL1492366 & 688673 & 6.9 & 5.8354 & TST \\
\hline CHEMBL1528822 & 688673 & 5.3 & 5.5136 & TST \\
\hline CHEMBL1592027 & 688673 & 6.35 & 6.0878 & TST \\
\hline CHEMBL1366555 & 688673 & 5.55 & 5.8385 & TST \\
\hline CHEMBL1445803 & 688673 & 5.3 & 5.825 & TST \\
\hline CHEMBL1596681 & 688673 & 4.65 & 5.9359 & TST \\
\hline CHEMBL1390377 & 688673 & 7.8996 & 6.044 & TST \\
\hline CHEMBL1442667 & 688673 & 4.5 & 5.6687 & TST \\
\hline CHEMBL1420467 & 688673 & 8.0 & 5.5069 & TST \\
\hline CHEMBL1450873 & 688673 & 5.3 & 5.5194 & TST \\
\hline CHEMBL1372926 & 688673 & 5.45 & 5.8095 & TST \\
\hline CHEMBL1385601 & 688673 & 4.9 & 5.6087 & TST \\
\hline CHEMBL1545639 & 688673 & 5.25 & 5.8442 & TST \\
\hline CHEMBL1330876 & 688673 & 5.2 & 6.0636 & TST \\
\hline CHEMBL1404845 & 688673 & 7.3002 & 5.6942 & TST \\
\hline CHEMBL1525549 & 688673 & 6.2 & 6.1658 & TST \\
\hline CHEMBL1536518 & 688673 & 6.0 & 5.6377 & TST \\
\hline CHEMBL1324971 & 688673 & 4.5 & 6.0703 & TST \\
\hline CHEMBL1576943 & 688673 & 6.6 & 6.0383 & TST \\
\hline CHEMBL1508747 & 688673 & 4.7 & 5.9533 & TST \\
\hline CHEMBL1419910 & 688673 & 5.8 & 5.7778 & TST \\
\hline CHEMBL1323891 & 688673 & 6.9 & 5.5238 & TST \\
\hline CHEMBL1584576 & 688673 & 6.4 & 5.87299 & 9999999999 \\
\hline CHEMBL1457130 & 688673 & 4.5 & 5.8827 & TST \\
\hline CHEMBL1335833 & 688673 & 5.0 & 5.7071 & TST \\
\hline CHEMBL1570936 & 688673 & 4.5 & 5.824 & TST \\
\hline CHEMBL1606746 & 688673 & 6.8 & 5.8418 & TST \\
\hline CHEMBL1311808 & 688673 & 4.9 & 5.5137 & TST \\
\hline CHEMBL1412651 & 688673 & 5.95 & 5.8585 & TST \\
\hline CHEMBL1327366 & 688673 & 8.301 & 5.5477 & TST \\
\hline CHEMBL1431956 & 688673 & 4.6 & 5.8794 & TST \\
\hline CHEMBL1381270 & 688673 & 4.45 & 5.6884 & TST \\
\hline CHEMBL3207802 & 688673 & 5.35 & 5.6856 & TST \\
\hline CHEMBL1353491 & 688673 & 5.4 & 5.8625 & TST \\
\hline CHEMBL1526805 & 688673 & 4.6 & 6.1708 & TST \\
\hline CHEMBL1522067 & 688673 & 4.8 & 5.8126 & TST \\
\hline CHEMBL1579193 & 688673 & 5.0 & 5.6782 & TST \\
\hline CHEMBL1315442 & 688673 & 4.45 & 5.7816 & TST \\
\hline CHEMBL1606046 & 688673 & 4.85 & 5.7806 & TST \\
\hline CHEMBL1335245 & 688673 & 5.6 & 5.8677 & TST \\
\hline CHEMBL1410470 & 688673 & 4.5 & 6.0657 & TST \\
\hline CHEMBL1355375 & 688673 & 7.8996 & 5.1955 & TST \\
\hline CHEMBL1359354 & 688673 & 6.8 & 5.7889 & TST \\
\hline CHEMBL1570931 & 688673 & 5.0 & 5.6172 & TST \\
\hline CHEMBL1457936 & 688673 & 4.9 & 5.4701 & TST \\
\hline CHEMBL1420005 & 688673 & 4.9 & 5.5274 & TST \\
\hline CHEMBL1419297 & 688673 & 5.2 & 5.8265 & TST \\
\hline CHEMBL1518140 & 688673 & 6.5 & 5.529 & TST \\
\hline
\end{tabular}




\begin{tabular}{|c|c|c|c|c|c|}
\hline \multicolumn{6}{|c|}{ Supplemental Table s2.txt } \\
\hline CHEMBL1345239 & 688673 & 5.55 & 5.8462 & TST & \\
\hline CHEMBL1407885 & 688673 & 6.8 & 5.7718 & TST & \\
\hline CHEMBL1521274 & 688673 & 4.9 & 5.4717 & TST & \\
\hline CHEMBL1372334 & 688673 & 4.5 & 5.6265 & TST & \\
\hline CHEMBL1610968 & 688673 & 4.9 & 5.4866 & TST & \\
\hline CHEMBL1381153 & 688673 & 4.45 & 5.364 & TST & \\
\hline CHEMBL1396077 & 688673 & 4.45 & 5.8262 & TST & \\
\hline CHEMBL1375303 & 688673 & 6.2 & 5.5028 & TST & \\
\hline CHEMBL55987 & 688673 & 4.5 & 5.7708 & TST & \\
\hline CHEMBL3199862 & 688673 & 5.6 & 5.4867 & TST & \\
\hline CHEMBL1545185 & 688673 & 5.0 & 5.4871 & TST & \\
\hline CHEMBL1408514 & 688673 & 4.8 & 5.5135 & TST & \\
\hline CHEMBL1567021 & 688673 & 6.0 & 5.7255 & TST & \\
\hline CHEMBL1224512 & 688673 & 4.9 & 5.2374 & TST & \\
\hline CHEMBL1304062 & 688673 & 4.8 & 5.4335 & TST & \\
\hline CHEMBL1461003 & 688673 & 4.6 & 5.8363 & TST & \\
\hline CHEMBL1163685 & 688673 & 5.6 & 6.028 & TST & \\
\hline CHEMBL1506835 & 688673 & 5.0 & 5.6701 & TST & \\
\hline CHEMBL1504624 & 688673 & 7.699 & 5.5019 & TST & \\
\hline CHEMBL1468018 & 688673 & 5.7 & 5.6723 & TST & \\
\hline CHEMBL1329708 & 688673 & 4.5 & 5.7955 & TST & \\
\hline CHEMBL1524445 & 688673 & 8.301 & 5.6016 & TST & \\
\hline CHEMBL1359931 & 688673 & 6.2 & 5.5572 & TST & \\
\hline CHEMBL1329401 & 688673 & 5.25 & 5.6005 & TST & \\
\hline CHEMBL1460977 & 688673 & 5.25 & 5.9972 & TST & \\
\hline CHEMBL3213950 & 688673 & 5.3 & 5.8556 & TST & \\
\hline CHEMBL259139 & 688673 & 5.1 & 5.5392 & TST & \\
\hline CHEMBL1380240 & 688673 & 7.3002 & 5.8865 & TST & \\
\hline CHEMBL1406894 & 688673 & 7.699 & 5.8241 & TST & \\
\hline CHEMBL1307642 & 688673 & 4.45 & 5.9646 & TST & \\
\hline CHEMBL3189469 & 688673 & 6.4 & 5.6669 & TST & \\
\hline CHEMBL1366168 & 688673 & 5.5 & 5.4468 & TST & \\
\hline CHEMBL1417331 & 688673 & 8.3979 & 5.44799 & 99999999995 & TST \\
\hline CHEMBL1450146 & 688673 & 6.6 & 5.9191 & TST & \\
\hline CHEMBL1470316 & 688673 & 4.7 & 5.38 & TST & \\
\hline CHEMBL1547626 & 688673 & 5.6 & 5.6 & TST & \\
\hline CHEMBL1343327 & 688673 & 7.2 & 5.6232 & TST & \\
\hline CHEMBL1338428 & 688673 & 6.0 & 5.9694 & TST & \\
\hline CHEMBL1458646 & 688673 & 7.8996 & 6.0826 & TST & \\
\hline CHEMBL1426671 & 688673 & 6.7001 & 5.7737 & TST & \\
\hline CHEMBL1447596 & 688673 & 7.5003 & 5.7943 & TST & \\
\hline CHEMBL1558026 & 688673 & 7.8996 & 5.4793 & TST & \\
\hline CHEMBL1543795 & 688673 & 6.7001 & 6.2272 & TST & \\
\hline CHEMBL1370691 & 688673 & 6.8 & 5.8876 & TST & \\
\hline CHEMBL1467749 & 688673 & 4.9 & 5.1709 & TST & \\
\hline CHEMBL1594349 & 688673 & 5.6 & 5.8609 & TST & \\
\hline CHEMBL1520236 & 688673 & 6.8 & 5.2 & TST & \\
\hline CHEMBL1532880 & 688673 & 7.5003 & 5.2351 & TST & \\
\hline
\end{tabular}




\begin{tabular}{|c|c|c|c|c|}
\hline \multicolumn{5}{|c|}{ Supplemental Table S2.txt } \\
\hline CHEMBL1547257 & 688673 & 4.8 & 5.3941 & TST \\
\hline CHEMBL1321979 & 688673 & 5.5 & 5.4908 & TST \\
\hline CHEMBL1350350 & 688673 & 4.85 & 5.7383 & TST \\
\hline CHEMBL1522667 & 688673 & 8.0 & 5.9295 & TST \\
\hline CHEMBL1345294 & 688673 & 6.1 & 5.6462 & TST \\
\hline CHEMBL1570957 & 688673 & 5.55 & 5.9942 & TST \\
\hline CHEMBL1404465 & 688673 & 4.5 & 5.2982 & TST \\
\hline CHEMBL1495418 & 688673 & 8.0 & 5.8362 & TST \\
\hline CHEMBL1406059 & 688673 & 4.7 & 5.4768 & TST \\
\hline CHEMBL1520954 & 688673 & 6.8 & 5.769 & TST \\
\hline CHEMBL1530394 & 688673 & 6.8 & 5.7182 & TST \\
\hline CHEMBL1406611 & 688673 & 6.3 & 6.2533 & TST \\
\hline CHEMBL1579414 & 688673 & 4.5 & 5.4644 & TST \\
\hline CHEMBL1464735 & 688673 & 4.45 & 5.8285 & TST \\
\hline CHEMBL1392955 & 688673 & 4.5 & 6.3713 & TST \\
\hline CHEMBL1368730 & 688673 & 6.9 & 6.0015 & TST \\
\hline CHEMBL1463349 & 688673 & 4.5 & 5.4472 & TST \\
\hline CHEMBL1328764 & 688673 & 8.4949 & 5.6839 & TST \\
\hline CHEMBL1595724 & 688673 & 4.9 & 5.8533 & TST \\
\hline CHEMBL1582356 & 688673 & 6.3 & 5.5609 & TST \\
\hline CHEMBL1310209 & 688673 & 5.2 & 5.4391 & TST \\
\hline CHEMBL1404330 & 688673 & 5.3 & 5.9954 & TST \\
\hline CHEMBL1531278 & 688673 & 5.1 & 5.6459 & TST \\
\hline CHEMBL1488504 & 688673 & 4.7 & 5.9396 & TST \\
\hline CHEMBL1364957 & 688673 & 4.8 & 5.7344 & TST \\
\hline CHEMBL1411542 & 688673 & 4.9 & 5.7452 & TST \\
\hline CHEMBL1606534 & 688673 & 7.5003 & 6.0397 & TST \\
\hline CHEMBL1449966 & 688673 & 4.9 & 5.1725 & TST \\
\hline CHEMBL1499176 & 688673 & 7.2 & 5.9405 & TST \\
\hline CHEMBL1388423 & 688673 & 4.5 & 5.3092 & TST \\
\hline CHEMBL1565778 & 688673 & 5.25 & 5.779 & TST \\
\hline CHEMBL1567746 & 688673 & 5.3 & 5.7389 & TST \\
\hline CHEMBL1301323 & 688673 & 4.85 & 5.9487 & TST \\
\hline CHEMBL1542639 & 688673 & 4.5 & 5.6522 & TST \\
\hline CHEMBL1449627 & 688673 & 6.7001 & 5.3458 & TST \\
\hline CHEMBL1421316 & 688673 & 5.5 & 5.4987 & TST \\
\hline CHEMBL1480392 & 688673 & 5.65 & 5.6125 & TST \\
\hline CHEMBL1378283 & 688673 & 8.301 & 6.0235 & TST \\
\hline CHEMBL1459223 & 688673 & 8.0 & 5.7749 & TST \\
\hline CHEMBL1496030 & 688673 & 6.1 & 5.9517 & TST \\
\hline CHEMBL1535422 & 688673 & 5.4 & 5.6332 & TST \\
\hline CHEMBL3195173 & 688673 & 5.7 & 5.5887 & TST \\
\hline CHEMBL1445632 & 688673 & 6.2 & 6.0119 & TST \\
\hline CHEMBL1438597 & 688673 & 7.2 & 5.6054 & TST \\
\hline CHEMBL1550507 & 688673 & 4.5 & 5.7796 & TST \\
\hline CHEMBL1445361 & 688673 & 7.699 & 5.5257 & TST \\
\hline CHEMBL1406379 & 688673 & 5.3 & 5.8356 & TST \\
\hline CHEMBL358644 & 688673 & 4.9 & 5.37 & TST \\
\hline
\end{tabular}




\begin{tabular}{|c|c|c|c|c|c|}
\hline \multicolumn{6}{|c|}{ Supplemental Table S2.txt } \\
\hline CHEMBL1398215 & 688673 & 5.4 & 5.8895 & TST & \\
\hline CHEMBL1566655 & 688673 & 4.75 & 5.7092 & TST & \\
\hline CHEMBL1543267 & 688673 & 4.6 & 5.8408 & TST & \\
\hline CHEMBL1358621 & 688673 & 4.55 & 5.5629 & TST & \\
\hline CHEMBL1388744 & 688673 & 5.0 & 5.6122 & TST & \\
\hline CHEMBL1369144 & 688673 & 7.699 & 5.612 & TST & \\
\hline CHEMBL3191778 & 688673 & 5.0 & 5.2672 & TST & \\
\hline CHEMBL1306396 & 688673 & 4.65 & 5.6095 & TST & \\
\hline CHEMBL1381243 & 688673 & 4.6 & 5.6987 & TST & \\
\hline CHEMBL1427801 & 688673 & 4.5 & 5.4175 & TST & \\
\hline CHEMBL1978236 & 688673 & 5.0 & 5.6254 & TST & \\
\hline CHEMBL1309227 & 688673 & 7.699 & 6.1381 & TST & \\
\hline CHEMBL1327014 & 688673 & 7.5003 & 6.181 & TST & \\
\hline CHEMBL1370586 & 688673 & 6.7001 & 5.8478 & TST & \\
\hline CHEMBL1589567 & 688673 & 4.8 & 5.1791 & TST & \\
\hline CHEMBL1492384 & 688673 & 6.1 & 5.6758 & TST & \\
\hline CHEMBL456678 & 688673 & 6.6 & 5.2394 & TST & \\
\hline CHEMBL1530791 & 688673 & 5.25 & 5.7133 & TST & \\
\hline CHEMBL1305600 & 688673 & 6.1 & 5.9707 & TST & \\
\hline CHEMBL1332535 & 688673 & 8.3468 & 5.6472 & TST & \\
\hline CHEMBL1454761 & 688673 & 4.9 & 5.6756 & TST & \\
\hline CHEMBL1391391 & 688673 & 7.2 & 5.9328 & TST & \\
\hline CHEMBL1386989 & 688673 & 4.9 & 5.6167 & TST & \\
\hline CHEMBL368602 & 88607 & 2.699 & 2.7265 & TRN & \\
\hline CHEMBL128740 & 88607 & 5.0862 & 4.8423 & TRN & \\
\hline CHEMBL1337620 & 88607 & 2.699 & 2.8662 & TRN & \\
\hline CHEMBL367939 & 88607 & 5.4685 & 5.4734 & TRN & \\
\hline CHEMBL413552 & 88607 & 6.0969 & 6.2478 & TRN & \\
\hline CHEMBL175107 & 88607 & 2.699 & 2.7095 & TRN & \\
\hline CHEMBL538398 & 88607 & 2.699 & 2.5743 & TRN & \\
\hline CHEMBL172888 & 88607 & 4.6198 & 4.8546 & TRN & \\
\hline CHEMBL609936 & 88607 & 2.699 & 3.698 & TST & \\
\hline CHEMBL340865 & 88607 & 3.9208 & 3.9975 & TRN & \\
\hline CHEMBL366634 & 88607 & 2.699 & 2.3842 & TRN & \\
\hline CHEMBL426583 & 88607 & 2.699 & 2.6773 & TRN & \\
\hline CHEMBL368453 & 88607 & 2.699 & 2.7715 & TRN & \\
\hline CHEMBL172993 & 88607 & 2.699 & 2.7726 & TRN & \\
\hline CHEMBL172958 & 88607 & 3.8539 & 3.8988 & TRN & \\
\hline CHEMBL440016 & 88607 & 4.5436 & 4.5074 & TRN & \\
\hline CHEMBL368451 & 88607 & 2.699 & 2.7238 & TRN & \\
\hline CHEMBL369213 & 88607 & 2.699 & 2.7493 & TST & \\
\hline CHEMBL369845 & 88607 & 2.699 & 2.8416 & TST & \\
\hline CHEMBL173574 & 88607 & 2.699 & 2.5708 & TRN & \\
\hline CHEMBL176555 & 88607 & 2.699 & 2.7465 & TRN & \\
\hline CHEMBL173548 & 88607 & 2.699 & 2.7437 & TRN & \\
\hline CHEMBL369592 & 88607 & 2.699 & 2.7716 & TRN & \\
\hline CHEMBL176619 & 88607 & 4. 3161 & 4.25899 & 99999999995 & TRN \\
\hline CHEMBL366739 & 88607 & 2.699 & 2.4856 & TRN & \\
\hline
\end{tabular}




\begin{tabular}{|c|c|c|c|c|c|}
\hline \multicolumn{6}{|c|}{ Supplemental Table S2.txt } \\
\hline CHEMBL174460 & 88607 & 3.9136 & 3.9857 & TRN & \\
\hline CHEMBL172148 & 88607 & 2.699 & 2.5666 & TRN & \\
\hline CHEMBL367706 & 88607 & 2.699 & 2.8175 & TRN & \\
\hline CHEMBL175003 & 88607 & 2.699 & 2.7376 & TRN & \\
\hline CHEMBL177200 & 88607 & 2.699 & 2.9304 & TRN & \\
\hline CHEMBL341067 & 88607 & 3.6126 & 3.6979 & TRN & \\
\hline CHEMBL367557 & 88607 & 2.699 & 2.6003 & TRN & \\
\hline CHEMBL176417 & 88607 & 2.699 & 2.7624 & TRN & \\
\hline CHEMBL144613 & 88607 & 6.3279 & 6.2236 & TRN & \\
\hline CHEMBL367419 & 88607 & 2.699 & 2.6766 & TRN & \\
\hline CHEMBL319244 & 88607 & 4.3768 & 4.3112 & TRN & \\
\hline CHEMBL 368800 & 88607 & 4.1487 & 3.9985 & TRN & \\
\hline CHEMBL173691 & 88607 & 2.699 & 2.9085 & TRN & \\
\hline CHEMBL129055 & 88607 & 3.7144 & 3.4497 & TRN & \\
\hline CHEMBL366481 & 88607 & 2.699 & 2.7417 & TRN & \\
\hline CHEMBL176890 & 88607 & 2.699 & 3.4733 & TST & \\
\hline CHEMBL173234 & 88607 & 4.1221 & 4.2229 & TRN & \\
\hline CHEMBL366434 & 88607 & 4.5544 & 4.6146 & TRN & \\
\hline CHEMBL608787 & 88607 & 2.699 & 3.3316 & TST & \\
\hline CHEMBL127388 & 88607 & 3.8729 & 3.55899 & 99999999997 & TRN \\
\hline CHEMBL173385 & 88607 & 2.699 & 3.1652 & TRN & \\
\hline CHEMBL338145 & 88607 & 4.3098 & 3.4654 & TRN & \\
\hline CHEMBL176775 & 88607 & 2.699 & 2.85600 & 00000000003 & TRN \\
\hline CHEMBL 281997 & 88607 & 2.699 & 3.1359 & TRN & \\
\hline CHEMBL173554 & 88607 & 2.699 & 3.7425 & TST & \\
\hline CHEMBL368650 & 88607 & 2.699 & 2.7142 & TST & \\
\hline CHEMBL173097 & 88607 & 2.699 & 4.1515 & TST & \\
\hline CHEMBL173696 & 88607 & 2.699 & 3.6374 & TST & \\
\hline CHEMBL435891 & 88607 & 2.699 & 2.5687 & TST & \\
\hline CHEMBL176639 & 88607 & 2.699 & 3.0884 & TST & \\
\hline CHEMBL367265 & 88607 & 2.699 & 2.8267 & TST & \\
\hline CHEMBL 172149 & 88607 & 2.699 & 3.33600 & 00000000003 & TST \\
\hline CHEMBL421450 & 88607 & 4.1549 & 3.3915 & TST & \\
\hline CHEMBL 366648 & 88607 & 2.699 & 2.9443 & TST & \\
\hline CHEMBL 3651010 & 1534934 & 4.8251 & 4.8247 & TRN & \\
\hline CHEMBL 3651001 & 1534934 & 4.8251 & 5.7545 & TST & \\
\hline CHEMBL 3651049 & 1534934 & 4.8251 & 4.942 & TRN & \\
\hline CHEMBL3651012 & 1534934 & 4.8251 & 4.7457 & TRN & \\
\hline CHEMBL 3650997 & 1534934 & 4.8251 & 4.7346 & TRN & \\
\hline CHEMBL3703494 & 1534934 & 6.6676 & 6.7969 & TRN & \\
\hline CHEMBL 3703504 & 1534934 & 7.1805 & 7.2282 & TRN & \\
\hline CHEMBL3651053 & 1534934 & 4.8251 & 4.8057 & TRN & \\
\hline CHEMBL3651041 & 1534934 & 4.8251 & 4.8586 & TRN & \\
\hline CHEMBL 3703498 & 1534934 & 6.7747 & 6.7635 & TRN & \\
\hline CHEMBL3651042 & 1534934 & 4.8251 & 4.9952 & TRN & \\
\hline CHEMBL 3651027 & 1534934 & 4.8251 & 4.92 & TRN & \\
\hline CHEMBL 3650990 & 1534934 & 4.8251 & 5.0498 & TRN & \\
\hline CHEMBL3703502 & 1534934 & 6.8447 & 6.8295 & TRN & \\
\hline
\end{tabular}


Supplemental Table S2.txt

\begin{tabular}{|c|c|c|c|c|}
\hline CHEMBL3703489 & 1534934 & 7.1079 & 6.9607 & TRN \\
\hline CHEMBL 3650982 & 1534934 & 6.9172 & 6.7992 & TRN \\
\hline CHEMBL3651065 & 1534934 & 4.8251 & 4.9194 & TRN \\
\hline CHEMBL 3651058 & 1534934 & 4.8251 & 6.3233 & TST \\
\hline CHEMBL 3651021 & 1534934 & 4.8251 & 5.079 & TRN \\
\hline CHEMBL 3650984 & 1534934 & 6.8153 & 6.7408 & TRN \\
\hline CHEMBL 3651044 & 1534934 & 4.8251 & 4.8179 & TRN \\
\hline CHEMBL 3651033 & 1534934 & 4.8251 & 4.8624 & TRN \\
\hline CHEMBL3650999 & 1534934 & 4.8251 & 4.9743 & TRN \\
\hline CHEMBL 3703503 & 1534934 & 7.0458 & 6.8029 & TRN \\
\hline CHEMBL 3703496 & 1534934 & 6.8386 & 6.7859 & TRN \\
\hline CHEMBL 3650993 & 1534934 & 4.8251 & 4.7491 & TRN \\
\hline CHEMBL 3651022 & 1534934 & 4.8251 & 5.183 & TRN \\
\hline CHEMBL 3651015 & 1534934 & 4.8251 & 4.9652 & TRN \\
\hline CHEMBL 3651059 & 1534934 & 7.1487 & 6.4696 & TST \\
\hline CHEMBL 3651051 & 1534934 & 4.8251 & 4.708 & TRN \\
\hline CHEMBL 3651008 & 1534934 & 4.8251 & 4.5924 & TRN \\
\hline CHEMBL 3651030 & 1534934 & 4.8251 & 4.7688 & TRN \\
\hline CHEMBL3651032 & 1534934 & 4.8251 & 4.7228 & TRN \\
\hline CHEMBL 3651047 & 1534934 & 4.8251 & 4.6902 & TRN \\
\hline CHEMBL 3650978 & 1534934 & 7.2147 & 7.0632 & TRN \\
\hline CHEMBL 3650987 & 1534934 & 4.8251 & 5.0044 & TRN \\
\hline CHEMBL 3650980 & 1534934 & 7.2757 & 7.2772 & TRN \\
\hline CHEMBL 3651024 & 1534934 & 4.8251 & 5.2725 & TRN \\
\hline CHEMBL 3650986 & 1534934 & 4.8251 & 4.9573 & TRN \\
\hline CHEMBL 3651037 & 1534934 & 4.8251 & 4.6936 & TRN \\
\hline CHEMBL 3703497 & 1534934 & 6.7305 & 7.0406 & TRN \\
\hline CHEMBL 3651040 & 1534934 & 4.8251 & 4.96899 & 999999999 \\
\hline CHEMBL3639498 & 1534934 & 4.8251 & 4.7264 & TRN \\
\hline CHEMBL 3650998 & 1534934 & 4.8251 & 4.9785 & TRN \\
\hline CHEMBL 3651055 & 1534934 & 5.301 & 5.11 & TRN \\
\hline CHEMBL 3651052 & 1534934 & 4.8251 & 4.8046 & TRN \\
\hline CHEMBL 3650981 & 1534934 & 6.8633 & 6.8795 & TRN \\
\hline CHEMBL 3651046 & 1534934 & 4.8251 & 4.8016 & TRN \\
\hline CHEMBL 3703493 & 1534934 & 7.041 & 6.6386 & TST \\
\hline CHEMBL3703501 & 1534934 & 6.8962 & 6.7537 & TRN \\
\hline CHEMBL 3651023 & 1534934 & 6.3449 & 5.9987 & TRN \\
\hline CHEMBL 3651006 & 1534934 & 4.8251 & 4.864 & TRN \\
\hline CHEMBL 3651016 & 1534934 & 4.8251 & 5.2032 & TRN \\
\hline CHEMBL 3651048 & 1534934 & 4.8251 & 4.6728 & TRN \\
\hline CHEMBL 3651061 & 1534934 & 4.8251 & 4.7683 & TRN \\
\hline CHEMBL 3651034 & 1534934 & 4.8251 & 4.90300 & 00000000005 \\
\hline CHEMBL 3703495 & 1534934 & 6.8729 & 7.1547 & TRN \\
\hline CHEMBL 3650995 & 1534934 & 4.8251 & 4.7964 & TRN \\
\hline CHEMBL 3651031 & 1534934 & 6.9626 & 6.0282 & TST \\
\hline CHEMBL 3650991 & 1534934 & 4.8251 & 4.6961 & TRN \\
\hline CHEMBL 3651003 & 1534934 & 4.8251 & 4.9265 & TRN \\
\hline CHEMBL 3651054 & 1534934 & 4.8251 & 4.9371 & TRN \\
\hline
\end{tabular}


Supplemental Table S2.txt

\begin{tabular}{|c|c|c|c|c|}
\hline HEN & & 251 & & \\
\hline & & 7.0315 & 6.1949 & \\
\hline & & & & \\
\hline AEMBL & & 251 & 8611 & \\
\hline AEMBL3 & & & 203 & \\
\hline HEMBL3651063 & 934 & 4.8251 & 8662 & \\
\hline HEMBL & & & 184 & \\
\hline IEMBL & & & 2023 & \\
\hline AEMBL3703485 & 34 & & 2204 & \\
\hline HEMBL3651002 & 34 & 4. & 1067 & \\
\hline AEMBL3651029 & 7 & 4. & 8362 & \\
\hline IEMBL36 & & 51 & 344 & \\
\hline AEMBL36 & & & & \\
\hline HEMBL 36 & & & 2129 & \\
\hline AEMBL3651014 & & & 16 & \\
\hline AEMBL3651004 & 44 & 4. & 7798 & \\
\hline HEMBL36 & & & 803 & \\
\hline HEMBL36 & & & 548 & \\
\hline HEMBL36 & & & 5633 & \\
\hline AEMBL37 & & & & \\
\hline HEMBL= & & & 15 & Niv \\
\hline AEMBL: & & & 53 & RIN \\
\hline HEMBL; & & & & \\
\hline 983 & & & & \\
\hline AEMBL3 & & & & I RIV \\
\hline HEMBL & & 7. & 85 & | \\
\hline HEMBL & & & 07 & RN \\
\hline HFMBI : & & 4. & & \\
\hline HEMBL36 & & & 754 & 15 \\
\hline HEMBL3651011 & & & 993 & $\mathrm{~K}$ \\
\hline HEMBL3 & & & 465 & RN \\
\hline HEMBL; & & & 06 & ST \\
\hline HEMBL & & & 18 & \\
\hline HEMBL3703490 & & & 07 & is \\
\hline HEMBL3650977 & & & 437 & TST \\
\hline HEMBL3 & & & 614 & TST \\
\hline HCMP - & & & 14 & ГST \\
\hline HEMBL3 & & & & TST \\
\hline HEMBL3651018 & 4 & 4. & 3458 & TST \\
\hline AEMBL3 & & & 427 & TST \\
\hline HEMBL36 & & & 957 & TST \\
\hline CHEMBL 3 & & & & ST \\
\hline HEMBL3651064 & & 4. & 7525 & TST \\
\hline HEMBL3651043 & 53 & 4.8251 & 7334 & TS \\
\hline $\mathrm{MPI}=$ & & & 734 & TS \\
\hline HEMBL3 & & & 5736 & \\
\hline HEMBL 37 & & .8729 & 7.1584 & \\
\hline CHEMBL3668937 & 1528125 & 7.4318 & 7.6176 & 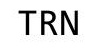 \\
\hline
\end{tabular}

Page 6619 
Supplemental Table S2.txt

\begin{tabular}{|c|c|c|c|c|c|}
\hline CHEMBL3668922 & 1528125 & 8.2441 & 7.9688 & TST & \\
\hline CHEMBL3668929 & 1528125 & 7.3279 & 6.6193 & TST & \\
\hline CHEMBL3668976 & 1528125 & 8.7696 & 8.5237 & TRN & \\
\hline CHEMBL 3668893 & 1528125 & 6.4685 & 7.1635 & TST & \\
\hline CHEMBL3668955 & 1528125 & 8.0555 & \multicolumn{2}{|c|}{ 7.218999999999999 } & TRN \\
\hline CHEMBL3668979 & 1528125 & 8.3979 & 8.4398 & TRN & \\
\hline CHEMBL3668986 & 1528125 & 8.0506 & 8.2899 & TRN & \\
\hline CHEMBL3668905 & 1528125 & 8.1024 & 7.8358 & TRN & \\
\hline CHEMBL3668971 & 1528125 & 7.6198 & 7.8636 & TRN & \\
\hline CHEMBL3668925 & 1528125 & 7.2076 & 7.1237 & TST & \\
\hline CHEMBL3668949 & 1528125 & 7.3372 & 7.227 & TRN & \\
\hline CHEMBL3668943 & 1528125 & 7.3279 & 7.4044 & TRN & \\
\hline CHEMBL3668988 & 1528125 & 7.4202 & 7.5767 & TST & \\
\hline CHEMBL 3668907 & 1528125 & 6.7959 & 7.0019 & TRN & \\
\hline CHEMBL 3668978 & 1528125 & 8.7696 & 8.9561 & TRN & \\
\hline CHEMBL3668895 & 1528125 & 6.7447 & 7.2807 & TST & \\
\hline CHEMBL3668980 & 1528125 & 8.1675 & 8.3224 & TRN & \\
\hline CHEMBL3668924 & 1528125 & 7.3468 & 8.0298 & TST & \\
\hline CHEMBL3668932 & 1528125 & 8.3768 & 8.2985 & TRN & \\
\hline CHEMBL 3668900 & 1528125 & 8.1192 & 7.7909 & TRN & \\
\hline CHEMBL3668985 & 1528125 & 8.2441 & 8.0882 & TRN & \\
\hline CHEMBL3668942 & 1528125 & 8.8239 & 8.842 & TRN & \\
\hline CHEMBL3668983 & 1528125 & 8.5686 & 8.3697 & TRN & \\
\hline CHEMBL3668951 & 1528125 & 7.2924 & 7.2259 & TRN & \\
\hline CHEMBL3668996 & 1528125 & 9.2596 & 9.4801 & TRN & \\
\hline CHEMBL3668899 & 1528125 & 8.0177 & 7.8041 & TRN & \\
\hline CHEMBL3668919 & 1528125 & 6.6778 & 6.8544 & TST & \\
\hline CHEMBL3668918 & 1528125 & 8.1249 & 8.1093 & TRN & \\
\hline CHEMBL3668981 & 1528125 & 9.4089 & 9.0468 & TRN & \\
\hline CHEMBL 3668908 & 1528125 & 7.3372 & 7.0403 & TRN & \\
\hline CHEMBL3668928 & 1528125 & 6.8539 & 6.3025 & TST & \\
\hline CHEMBL3668950 & 1528125 & 7.1135 & 7.4325 & TRN & \\
\hline CHEMBL3668991 & 1528125 & 8.1612 & 8.5362 & TRN & \\
\hline CHEMBL 3668961 & 1528125 & 7.5528 & 7.8843 & TRN & \\
\hline CHEMBL3668964 & 1528125 & 8.0362 & 7.8352 & TRN & \\
\hline CHEMBL3668944 & 1528125 & 7.0269 & 6.71899 & э999999999 & TRN \\
\hline CHEMBL3668982 & 1528125 & 8.6383 & 8.5988 & TRN & \\
\hline CHEMBL3668890 & 1528125 & 6.6576 & 6.2147 & TST & \\
\hline CHEMBL3668989 & 1528125 & 8.5376 & 8.7396 & TRN & \\
\hline CHEMBL3668959 & 1528125 & 7.2076 & 7.2615 & TRN & \\
\hline CHEMBL3668972 & 1528125 & 8.9586 & 8.9257 & TRN & \\
\hline CHEMBL3668970 & 1528125 & 8.0362 & 8.1923 & TRN & \\
\hline CHEMBL3668946 & 1528125 & 7.1549 & 7.2019 & TRN & \\
\hline CHEMBL3668953 & 1528125 & 5.0 & 6.0271 & TRN & \\
\hline CHEMBL3639677 & 1528125 & 8.2441 & 8.7174 & TRN & \\
\hline CHEMBL 3668994 & 1528125 & 9.3565 & 9.4354 & TRN & \\
\hline CHEMBL3668911 & 1528125 & 6.8861 & 7.1564 & TRN & \\
\hline CHEMBL3668990 & 1528125 & 7.699 & 8.0055 & TRN & \\
\hline
\end{tabular}


Supplemental Table S2.txt

\begin{tabular}{|c|c|c|c|c|c|}
\hline CHEMBL 3668941 & 1528125 & 6.284 & 6.0273 & TST & \\
\hline CHEMBL 3987159 & 1528125 & 7.1249 & 7.192 & TRN & \\
\hline CHEMBL 3668987 & 1528125 & 8.3768 & 8.3023 & TRN & \\
\hline CHEMBL3668954 & 1528125 & 7.8539 & 8.2199 & TRN & \\
\hline CHEMBL3668921 & 1528125 & 7.4685 & 7.2758 & TST & \\
\hline CHEMBL 3668948 & 1528125 & 7.7959 & 7.5116 & TRN & \\
\hline CHEMBL 3668935 & 1528125 & 7.4437 & 7.1292 & TRN & \\
\hline CHEMBL 3668934 & 1528125 & 7.7959 & 7.8173 & TRN & \\
\hline CHEMBL 3668927 & 1528125 & 7.0706 & 6.4649 & TST & \\
\hline CHEMBL3668931 & 1528125 & 8.5686 & 8.1403 & TST & \\
\hline CHEMBL3668904 & 1528125 & 8.0555 & 8.0424 & TRN & \\
\hline CHEMBL3668897 & 1528125 & 6.8539 & 6.6811 & TST & \\
\hline CHEMBL 3668915 & 1528125 & 9.2676 & 8.1084 & TST & \\
\hline CHEMBL3668939 & 1528125 & 8.5528 & 8.5574 & TRN & \\
\hline CHEMBL3668945 & 1528125 & 7.3279 & 7.4546 & TRN & \\
\hline CHEMBL3668995 & 1528125 & \multicolumn{3}{|c|}{9.283999999999999} & \multirow[t]{9}{*}{ TRN } \\
\hline CHEMBL 3668898 & 1528125 & 7.0915 & 7.2789 & \multirow{7}{*}{9.0534} & \\
\hline CHEMBL 3668914 & 1528125 & 7.2366 & 7.2754 & & \\
\hline CHEMBL3668993 & 1528125 & 9.3979 & 9.3629 & & \\
\hline CHEMBL3668902 & 1528125 & 7.4437 & 7.6247 & & \\
\hline CHEMBL3668909 & 1528125 & 8.1675 & 7.8781 & & \\
\hline CHEMBL3668916 & 1528125 & 9.0044 & 8.3663 & & \\
\hline CHEMBL 3668892 & 1528125 & 7.6021 & 6.5759 & & \\
\hline CHEMBL3668956 & 1528125 & 7.0132 & 6.9922 & TRN & \\
\hline CHEMBL3668952 & 1528125 & 7.5229 & \multicolumn{2}{|c|}{7.622999999999999} & \multirow[t]{18}{*}{ TRN } \\
\hline CHEMBL3917424 & 1528125 & 7.9208 & 7.7557 & TRN & \\
\hline CHEMBL3668965 & 1528125 & 7.8239 & 8.1216 & TRN & \\
\hline CHEMBL3668910 & 1528125 & 7.9208 & 8.0383 & TRN & \\
\hline CHEMBL3668963 & 1528125 & 8.0757 & 8.2925 & TRN & \\
\hline CHEMBL3668923 & 1528125 & 8.0177 & 6.9156 & TST & \\
\hline CHEMBL 3668920 & 1528125 & 7.3372 & 6.921 & TST & \\
\hline CHEMBL3668975 & 1528125 & 8.3872 & 8.3961 & TRN & \\
\hline CHEMBL3668974 & 1528125 & 8.9208 & 9.1571 & TRN & \\
\hline CHEMBL3668957 & 1528125 & 7.1938 & 7.0082 & TRN & \\
\hline CHEMBL3668969 & 1528125 & 7.4089 & 7.1981 & TRN & \\
\hline CHEMBL3668912 & 1528125 & 7.8539 & 7.7495 & TRN & \\
\hline CHEMBL3668958 & 1528125 & 7.3565 & 7.4408 & TST & \\
\hline CHEMBL3668940 & 1528125 & 7.0 & 6.716 & TST & \\
\hline CHEMBL3668938 & 1528125 & 6.5229 & 6.1213 & TST & \\
\hline CHEMBL3668936 & 1528125 & 7.2518 & 7.0006 & TRN & \\
\hline CHEMBL3668906 & 1528125 & 8.4685 & 7.9914 & TRN & \\
\hline CHEMBL3668889 & 1528125 & 7.4815 & 7.7443 & TRN & \\
\hline CHEMBL3668968 & 1528125 & 7.4437 & \multicolumn{2}{|c|}{ 7.412999999999999 } & TRN \\
\hline CHEMBL3668894 & 1528125 & 7.0132 & 6.5393 & TST & \\
\hline CHEMBL 3668977 & 1528125 & 9.4815 & 8.9716 & TRN & \\
\hline CHEMBL3668901 & 1528125 & 7.2076 & 7.2542 & TRN & \\
\hline CHEMBL3668896 & 1528125 & 7.2518 & \multicolumn{2}{|c|}{ 7.207999999999999 } & TST \\
\hline CHEMBL3668947 & 1528125 & 7.2366 & 7.7 & TST & \\
\hline & & & & 6621 & \\
\hline
\end{tabular}


Supplemental Table S2.txt

\begin{tabular}{|c|c|c|c|c|c|}
\hline CHEMBL 3668913 & 1528125 & 6.6778 & 6.5094 & TRN & \\
\hline CHEMBL 3668891 & 1528125 & 8.0555 & 7.0367 & TST & \\
\hline CHEMBL 3668903 & 1528125 & 7.3468 & 7.4884 & TRN & \\
\hline CHEMBL 3668930 & 1528125 & 7.2596 & 6.9067 & TST & \\
\hline CHEMBL3668967 & 1528125 & 7.1487 & 7.0692 & TRN & \\
\hline CHEMBL 3668926 & 1528125 & 7.284 & 7.1488 & TST & \\
\hline CHEMBL 3668984 & 1528125 & 8.5086 & 8.6484 & TRN & \\
\hline CHEMBL 3668917 & 1528125 & 8.1938 & 8.2972 & TRN & \\
\hline CHEMBL 3668960 & 1528125 & 6.5686 & 6.6418 & TRN & \\
\hline CHEMBL3668962 & 1528125 & 6.9208 & 7.0593 & TRN & \\
\hline CHEMBL 3668992 & 1528125 & 8.8894 & 9.0297 & TRN & \\
\hline CHEMBL 3668933 & 1528125 & 8.3468 & 7.7723 & TRN & \\
\hline CHEMBL 3668973 & 1528125 & 9.0 & 9.0149 & TRN & \\
\hline CHEMBL 3668966 & 1528125 & 7.3098 & 7.479 & TRN & \\
\hline CHEMBL180219 & 302499 & 6.6021 & 6.6589 & TRN & \\
\hline CHEMBL179004 & 302499 & 4.9208 & 5.2492 & TRN & \\
\hline CHEMBL177769 & 302499 & 8.2218 & 8.4113 & TRN & \\
\hline CHEMBL 360071 & 302499 & 8.7447 & 8.5906 & TRN & \\
\hline CHEMBL176491 & 302499 & 8.5686 & 8.2716 & TRN & \\
\hline CHEMBL369868 & 302499 & 6.0 & 6.0417 & TRN & \\
\hline CHEMBL 369008 & 302499 & 8.2757 & 8.5355 & TRN & \\
\hline CHEMBL 360751 & 302499 & 8.0315 & 8.1433 & TRN & \\
\hline CHEMBL179189 & 302499 & 4.9208 & 4.7704 & TRN & \\
\hline CHEMBL179210 & 302499 & 7.6576 & 8.2453 & TRN & \\
\hline CHEMBL 367237 & 302499 & 5.2218 & 5.5158 & TRN & \\
\hline CHEMBL 360684 & 302499 & 7.5229 & 6.9444 & TRN & \\
\hline CHEMBL176660 & 302499 & 8.4559 & 8.67 & TRN & \\
\hline CHEMBL361822 & 302499 & 8.7447 & 8.2775 & TRN & \\
\hline CHEMBL 176063 & 302499 & 8.8239 & 6.1838 & TST & \\
\hline CHEMBL367973 & 302499 & 7.0605 & 6.9805 & TRN & \\
\hline CHEMBL175612 & 302499 & 6.4815 & 6.2695 & TRN & \\
\hline CHEMBL 367890 & 302499 & 7.5086 & 7.8181 & TRN & \\
\hline CHEMBL 360542 & 302499 & 7.2441 & 6.2975 & TST & \\
\hline CHEMBL 180418 & 302499 & 6.0 & 6.1605 & TRN & \\
\hline CHEMBL 3084979 & 302499 & 6.0 & 5.9881 & TRN & \\
\hline CHEMBL179245 & 302499 & 9.5229 & 8.76799 & 9999999999 & TRN \\
\hline CHEMBL366882 & 302499 & 8.699 & 8.3171 & TRN & \\
\hline CHEMBL 361377 & 302499 & 7.8239 & 8.2247 & TRN & \\
\hline CHEMBL414655 & 302499 & 7.9208 & 8.0787 & TRN & \\
\hline CHEMBL361379 & 302499 & 8.5376 & 8.0599 & TST & \\
\hline CHEMBL404728 & 302499 & 7.1367 & 7.2204 & TST & \\
\hline CHEMBL368894 & 302499 & 7.6576 & 8.2801 & TRN & \\
\hline CHEMBL 272931 & 302499 & 5.2366 & 7.1701 & TST & \\
\hline CHEMBL 175620 & 302499 & 8.3565 & 8.3136 & TRN & \\
\hline CHEMBL401737 & 302499 & 8.5686 & 8.5049 & TRN & \\
\hline CHEMBL 366653 & 302499 & 8.6198 & 8.0895 & TRN & \\
\hline CHEMBL180112 & 302499 & 5.8861 & 6.39 & TRN & \\
\hline CHEMBL175497 & 302499 & 8.4318 & 8.5686 & TRN & \\
\hline
\end{tabular}




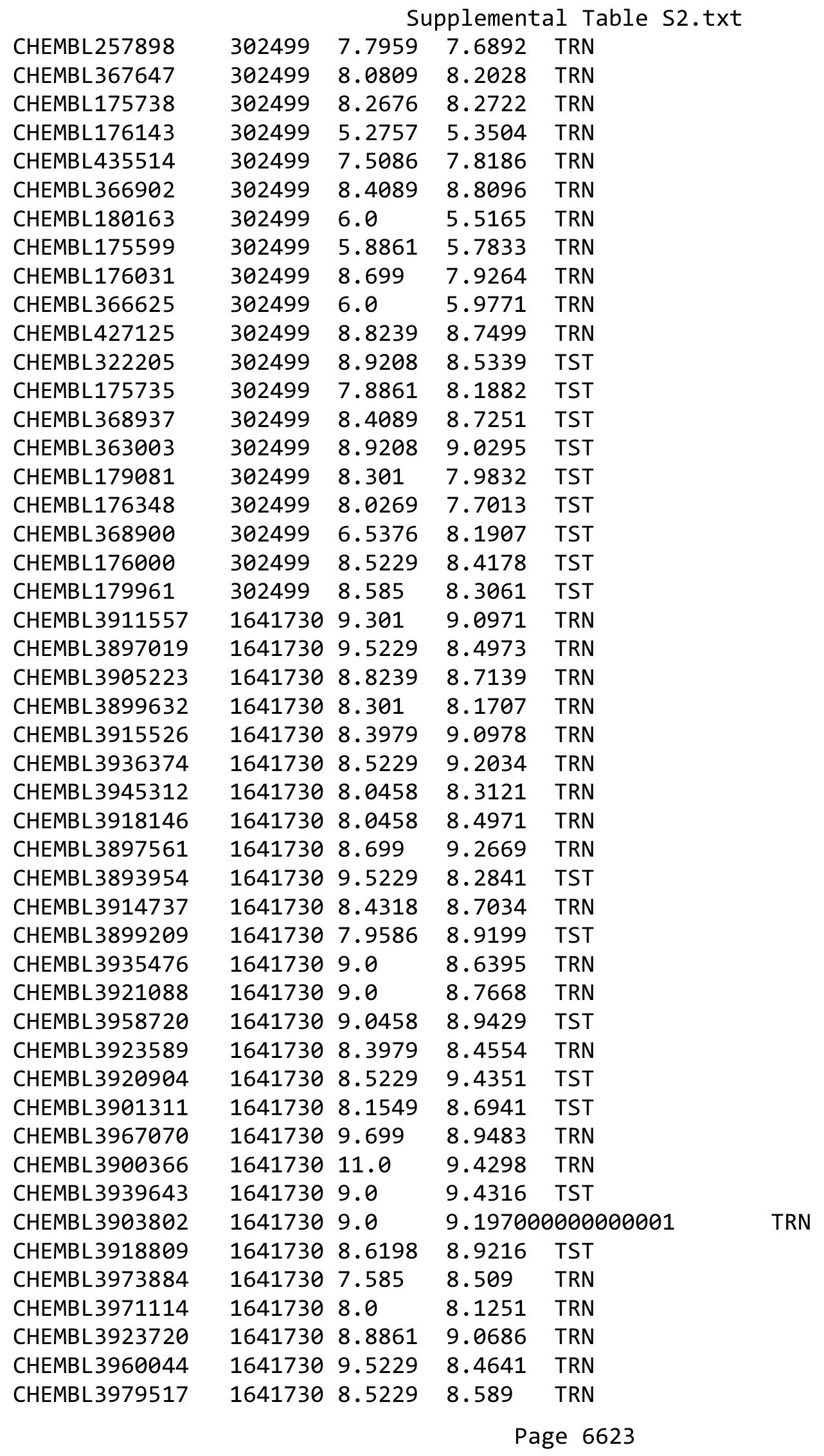




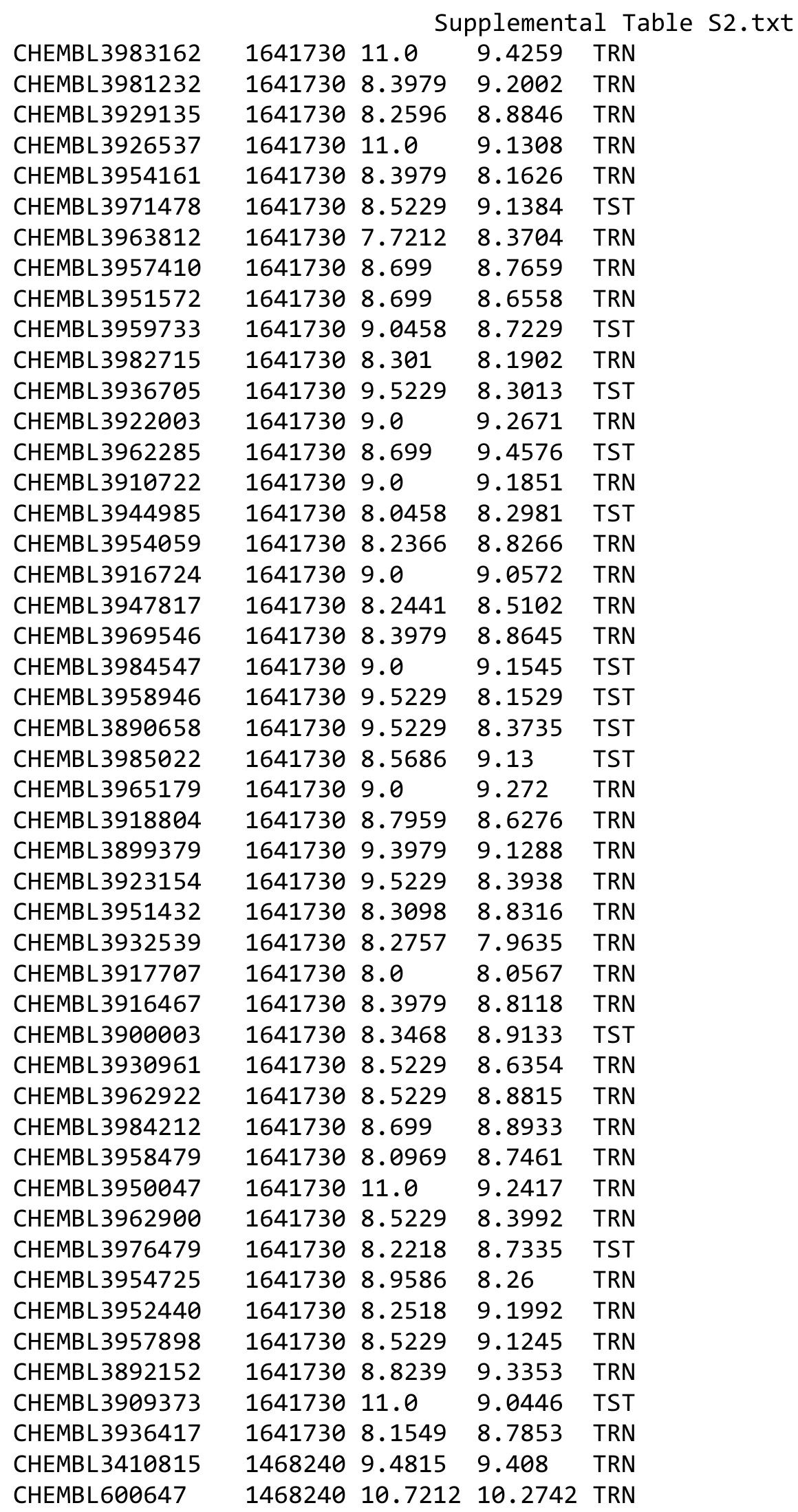

Page 6624 
Supplemental Table S2.txt

\begin{tabular}{|c|c|c|c|c|c|c|}
\hline CHEMBL 2023576 & 1468240 & 6.9208 & 6.6461 & TRN & & \\
\hline CHEMBL3410821 & 1468240 & 7.3565 & 7.1949 & TRN & & \\
\hline CHEMBL1822932 & 1468240 & 9.0969 & 9.1704 & TRN & & \\
\hline CHEMBL 2023575 & 1468240 & 7.3372 & 7.1651 & TRN & & \\
\hline CHEMBL1822943 & 1468240 & 10.0706 & 10.0429 & TRN & & \\
\hline CHEMBL3410818 & 1468240 & 10.2757 & 10.4088 & TRN & & \\
\hline CHEMBL3410822 & 1468240 & 8.4318 & 8.456 & TST & & \\
\hline CHEMBL3410816 & 1468240 & 9.0132 & 9.0688 & TRN & & \\
\hline CHEMBL3410819 & 1468240 & 9.6576 & 9.6439 & TRN & & \\
\hline CHEMBL 2023580 & 1468240 & 6.0531 & 6.1146 & TRN & & \\
\hline CHEMBL 3410811 & 1468240 & 9.3565 & 9.2137 & TRN & & \\
\hline CHEMBL3410832 & 1468240 & 10.6778 & 10.4867 & TRN & & \\
\hline CHEMBL204387 & 1468240 & 9.3188 & 9.5226 & TRN & & \\
\hline CHEMBL 2019081 & 1468240 & 8.1739 & 8.0008 & TRN & & \\
\hline CHEMBL 2019084 & 1468240 & 6.6073 & 6.6217 & TRN & & \\
\hline CHEMBL3410830 & 1468240 & 7.0 & 8.8843 & TST & & \\
\hline CHEMBL 2023574 & 1468240 & 6.9706 & 6.8031 & TRN & & \\
\hline CHEMBL1822930 & 1468240 & 8.6198 & 9.009 & TRN & & \\
\hline CHEMBL1822936 & 1468240 & 7.2366 & 7.0928 & TRN & & \\
\hline CHEMBL3410827 & 1468240 & 9.9586 & 8.5249 & TST & & \\
\hline CHEMBL3410826 & 1468240 & 10.0555 & 8.7818 & TST & & \\
\hline CHEMBL 2023049 & 1468240 & 6.2118 & 6.2562 & TRN & & \\
\hline CHEMBL 3410824 & 1468240 & 8.1367 & 8.911 & TST & & \\
\hline CHEMBL 3410820 & 1468240 & 8.9586 & 8.9661 & TRN & & \\
\hline CHEMBL3410834 & 1468240 & 7.9586 & 8.9987 & TST & & \\
\hline CHEMBL1822937 & 1468240 & 6.2076 & 6.2447 & TRN & & \\
\hline CHEMBL 2019085 & 1468240 & 5.6749 & 5.5907 & TRN & & \\
\hline CHEMBL 2019080 & 1468240 & 7.2518 & 8.0008 & TRN & & \\
\hline CHEMBL 3410810 & 1468240 & 7.1367 & 7.2916 & TRN & & \\
\hline CHEMBL1822944 & 1468240 & \multicolumn{3}{|c|}{10.699000000000002} & 10.4319 TRN & \\
\hline CHEMBL3410829 & 1468240 & 8.6021 & 8.06 & TST & & \\
\hline CHEMBL 2019078 & 1468240 & 8.2076 & 8.0008 & TRN & & \\
\hline CHEMBL 3410825 & 1468240 & 8.7447 & 8.526 & TST & & \\
\hline CHEMBL 2018656 & 1468240 & 6.4572 & 6.4347 & TRN & & \\
\hline CHEMBL 3410814 & 1468240 & \multicolumn{3}{|c|}{6.9270000000000005} & 8.402000000000001 & TST \\
\hline CHEMBL 2019086 & 1468240 & 7.7959 & 7.7878 & TRN & & \\
\hline CHEMBL3410812 & 1468240 & 8.7212 & 8.838 & TST & & \\
\hline CHEMBL 2023578 & 1468240 & 6.0348 & 6.1775 & TRN & & \\
\hline CHEMBL3410823 & 1468240 & 8.0757 & 7.8982 & TST & & \\
\hline CHEMBL 2023577 & 1468240 & 7.1308 & 7.2762 & TRN & & \\
\hline CHEMBL 2023582 & 1468240 & 8.3372 & 8.1986 & TRN & & \\
\hline CHEMBL3410828 & 1468240 & 7.8539 & 8.0721 & TST & & \\
\hline CHEMBL1822929 & 1468240 & 8.301 & 8.3192 & TRN & & \\
\hline CHEMBL3410730 & 1468240 & 7.7447 & 6.8163 & TST & & \\
\hline CHEMBL 2023048 & 1468240 & 6.7423 & 6.8263 & TRN & & \\
\hline CHEMBL3410817 & 1468240 & 10.0458 & 9.8971 & TRN & & \\
\hline CHEMBL3407534 & 1468240 & 9.1249 & 9.4482 & TRN & & \\
\hline CHEMBL3410833 & 1468240 & 8.3188 & 7.9407 & TST & & \\
\hline
\end{tabular}


Supplemental Table S2.txt

\begin{tabular}{|c|c|c|c|c|c|}
\hline CHEMBL3410813 & 1468240 & 10.585 & 10.9565 & TRN & \\
\hline CHEMBL 2023581 & 1468240 & 7.6576 & 7.6841 & TRN & \\
\hline CHEMBL3410831 & 1468240 & 9.7447 & 9.8771 & TRN & \\
\hline CHEMBL 3410729 & 1468240 & 10.0605 & 9.7964 & TRN & \\
\hline CHEMBL1822945 & 1468240 & 9.8861 & 9.847006 & 0000000001 & TRN \\
\hline CHEMBL1975935 & 1301619 & 4.9618 & 4.9628 & TRN & \\
\hline CHEMBL1581094 & 1301619 & 4.745 & 4.739 & TRN & \\
\hline CHEMBL1997132 & 1301619 & 5.0026 & 5.096999 & 99999999995 & TRN \\
\hline CHEMBL1478962 & 1301619 & 5.4271 & 5.4282 & TRN & \\
\hline CHEMBL261123 & 1301619 & 5.8996 & 5.641 & TRN & \\
\hline CHEMBL1387923 & 1301619 & 5.2161 & 5.2972 & TRN & \\
\hline CHEMBL1872364 & 1301619 & 5.1221 & 4.6483 & TRN & \\
\hline CHEMBL1301480 & 1301619 & 4.9087 & 4.9473 & TRN & \\
\hline CHEMBL1402010 & 1301619 & 6.6003 & 6.4654 & TRN & \\
\hline CHEMBL1380459 & 1301619 & 4.7194 & 4.7606 & TRN & \\
\hline CHEMBL3183439 & 1301619 & 4.6938 & 4.3892 & TRN & \\
\hline CHEMBL 2355520 & 1301619 & 5.1506 & 5.053 & TRN & \\
\hline CHEMBL1440317 & 1301619 & 5.5406 & 5.7477 & TRN & \\
\hline CHEMBL 3188410 & 1301619 & 5.757000 & 00000006 & 5.4657 & \\
\hline CHEMBL1332533 & 1301619 & 5.2366 & \multicolumn{3}{|c|}{$\begin{array}{ll}5.3389999999999995 & \text { TRN }\end{array}$} \\
\hline CHEMBL598885 & 1301619 & 6.6799 & 6.3761 & TRN & \\
\hline CHEMBL1468011 & 1301619 & 6.1878 & 6.04 & TRN & \\
\hline CHEMBL1705423 & 1301619 & 4.8976 & 4.9113 & TST & \\
\hline CHEMBL 2355370 & 1301619 & 5.7033 & 5.5449 & TRN & \\
\hline CHEMBL1483331 & 1301619 & 4.8536 & 4.723 & TST & \\
\hline CHEMBL1725682 & 1301619 & 5.5622 & 5.4569 & TRN & \\
\hline CHEMBL 2139358 & 1301619 & 4.6424 & 5.0576 & TRN & \\
\hline CHEMBL1372760 & 1301619 & 5.2226 & 5.2488 & TRN & \\
\hline CHEMBL1516047 & 1301619 & 5.6861 & 5.5142 & TRN & \\
\hline CHEMBL1369200 & 1301619 & 5.2211 & 4.5197 & TRN & \\
\hline CHEMBL535307 & 1301619 & 6.6799 & 6.4471 & TST & \\
\hline CHEMBL1613147 & 1301619 & 6.4962 & 6.3444 & TRN & \\
\hline CHEMBL1446067 & 1301619 & 5.3851 & 5.1993 & TRN & \\
\hline CHEMBL1594455 & 1301619 & 4.5342 & 4.8374 & TST & \\
\hline CHEMBL1422176 & 1301619 & 4.9698 & \multicolumn{2}{|c|}{5.1160000000000005} & TRN \\
\hline CHEMBL234378 & 1301619 & 5.4461 & 5.4225 & TRN & \\
\hline CHEMBL1904071 & 1301619 & 6.098 & 6.0208 & TRN & \\
\hline CHEMBL1549208 & 1301619 & 4.7151 & 5.2931 & TRN & \\
\hline CHEMBL 3187897 & 1301619 & 4.7359 & 4.652 & TRN & \\
\hline CHEMBL1396619 & 1301619 & 6.1002 & 5.8423 & TRN & \\
\hline CHEMBL1706877 & 1301619 & 4.4835 & 4.7492 & TRN & \\
\hline CHEMBL1455421 & 1301619 & 5.2118 & 5.2802 & TRN & \\
\hline CHEMBL1389748 & 1301619 & 5.466 & 5.3338 & TRN & \\
\hline CHEMBL1579902 & 1301619 & 5.5702 & 5.5029 & TST & \\
\hline CHEMBL1374258 & 1301619 & 5.1379 & 5.0767 & TRN & \\
\hline CHEMBL1412795 & 1301619 & 5.1818 & 5.0433 & TST & \\
\hline CHEMBL 3183001 & 1301619 & 6.0 & 5.6323 & TRN & \\
\hline CHEMBL1404547 & 1301619 & 5.1791 & 5.2458 & TRN & \\
\hline
\end{tabular}

Page 6626 
Supplemental Table S2.txt

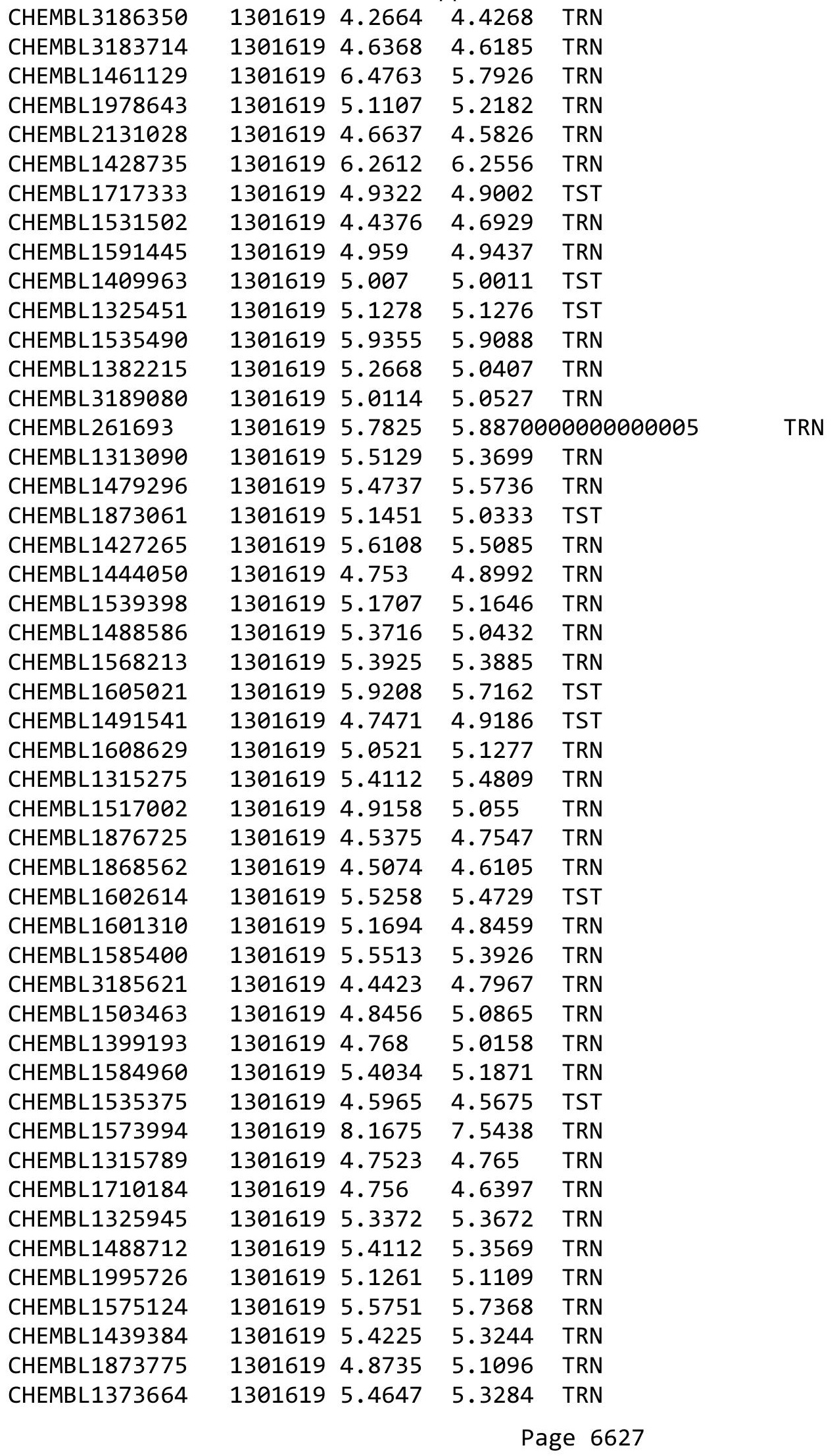


Supplemental Table S2.txt

\begin{tabular}{|c|c|c|c|c|c|}
\hline CHEMBL1600275 & 1301619 & 5.063 & 5.1941 & TRN & \\
\hline CHEMBL1344677 & 1301619 & 6.2381 & 6.7541 & TRN & \\
\hline CHEMBL1453565 & 1301619 & 5.4498 & 5.7789 & TRN & \\
\hline CHEMBL1299361 & 1301619 & 4.7115 & 4.7584 & TST & \\
\hline CHEMBL 267099 & 1301619 & 5.4001 & 5.625 & TST & \\
\hline CHEMBL1329974 & 1301619 & 4.3692 & 4.9372 & TST & \\
\hline CHEMBL 3184207 & 1301619 & 6.0 & 5.7156 & TRN & \\
\hline CHEMBL1866836 & 1301619 & 5.3625 & 5.2399 & TRN & \\
\hline CHEMBL1563176 & 1301619 & 4.5412 & 4.5776 & TST & \\
\hline CHEMBL1375966 & 1301619 & 5.0214 & 4.8698 & TRN & \\
\hline CHEMBL1488923 & 1301619 & 6.4535 & 6.451000 & 30000000005 & TRN \\
\hline CHEMBL 2144728 & 1301619 & 4.6946 & 4.5469 & TRN & \\
\hline CHEMBL1499127 & 1301619 & 5.2403 & 5.2531 & TRN & \\
\hline CHEMBL1714393 & 1301619 & 5.4486 & 5.4762 & TRN & \\
\hline CHEMBL1350432 & 1301619 & 4.6103 & 4.8577 & TST & \\
\hline CHEMBL1317322 & 1301619 & 5.4449 & 5.3364 & TRN & \\
\hline CHEMBL405317 & 1301619 & 6.5834 & 6.1728 & TRN & \\
\hline CHEMBL 2359034 & 1301619 & 4.7402 & 4.7095 & TRN & \\
\hline CHEMBL1594126 & 1301619 & 4.5317 & 4.8131 & TST & \\
\hline CHEMBL 1305566 & 1301619 & 5.1186 & 5.1931 & TRN & \\
\hline CHEMBL286593 & 1301619 & 5.4202 & 5.3045 & TRN & \\
\hline CHEMBL1444124 & 1301619 & 4.5926 & 4.9524 & TRN & \\
\hline CHEMBL1421287 & 1301619 & 5.083 & 5.0122 & TRN & \\
\hline CHEMBL1386622 & 1301619 & 5.2565 & 5.2226 & TST & \\
\hline CHEMBL1489148 & 1301619 & 4.4178 & 5.0562 & TRN & \\
\hline CHEMBL 3184527 & 1301619 & 5.1249 & 4.5976 & TRN & \\
\hline CHEMBL1331514 & 1301619 & 4.8333 & 5.1278 & TRN & \\
\hline CHEMBL1521187 & 1301619 & 5.52 & 5.7006 & TRN & \\
\hline CHEMBL1577174 & 1301619 & 5.5302 & 5.7893 & TRN & \\
\hline CHEMBL 2358899 & 1301619 & 6.0 & 5.6935 & TRN & \\
\hline CHEMBL1522279 & 1301619 & 5.2204 & 5.0719 & TRN & \\
\hline CHEMBL1589837 & 1301619 & 4.4751 & 4.5734 & TST & \\
\hline CHEMBL 1428850 & 1301619 & 5.5817 & 5.4596 & TRN & \\
\hline CHEMBL1866397 & 1301619 & 4.5889 & 4.6663 & TST & \\
\hline CHEMBL 1535021 & 1301619 & 5.15 & 5.3524 & TRN & \\
\hline CHEMBL1540513 & 1301619 & 4.5577 & 4.7494 & TRN & \\
\hline CHEMBL 1312318 & 1301619 & 5.7305 & 5.7428 & TRN & \\
\hline CHEMBL 3188484 & 1301619 & 5.5302 & 5.1094 & TRN & \\
\hline CHEMBL1420524 & 1301619 & 4.4519 & 5.1032 & TST & \\
\hline CHEMBL1337227 & 1301619 & 5.05699 & 999999999 & 4.7728 & TRN \\
\hline CHEMBL1486585 & 1301619 & 4.3555 & 5.6222 & TRN & \\
\hline CHEMBL 1475514 & 1301619 & 5.0825 & 5.1176 & TRN & \\
\hline CHEMBL1707441 & 1301619 & 4.5194 & 4.5927 & TST & \\
\hline CHEMBL1476017 & 1301619 & 5.3788 & 5.2088 & TRN & \\
\hline CHEMBL1611128 & 1301619 & 8.1675 & 7.4279 & TRN & \\
\hline CHEMBL1608430 & 1301619 & 5.1561 & 5.2073 & TRN & \\
\hline CHEMBL 3187715 & 1301619 & 4.3408 & 5.1131 & TRN & \\
\hline CHEMBL1506503 & 1301619 & 8.1675 & 6.6319 & TRN & \\
\hline
\end{tabular}




\begin{tabular}{|c|c|c|c|c|c|}
\hline \multicolumn{6}{|c|}{ Supplemental Table S2.txt } \\
\hline CHEMBL93109 & 1301619 & 5.8097 & 5.6671 & TRN & \\
\hline CHEMBL137586 & 1301619 & 5.1871 & 5.1178 & TRN & \\
\hline CHEMBL1876680 & 1301619 & 5.6253 & 5.5862 & TRN & \\
\hline CHEMBL1213608 & 1301619 & 5.8239 & 5.7256 & TRN & \\
\hline CHEMBL1441042 & 1301619 & 5.1726 & 5.4083 & TRN & \\
\hline CHEMBL1458038 & 1301619 & 5.1113 & 5.0391 & TRN & \\
\hline CHEMBL1734045 & 1301619 & 4.8013 & 5.0326 & TRN & \\
\hline CHEMBL1361072 & 1301619 & 4.6447 & 4.8152 & TST & \\
\hline CHEMBL1428452 & 1301619 & 5.0645 & 5.2834 & TRN & \\
\hline CHEMBL1437083 & 1301619 & 5.2147 & 5.2622 & TRN & \\
\hline CHEMBL1489637 & 1301619 & 4.8173 & 4.8979 & TRN & \\
\hline CHEMBL1339039 & 1301619 & 4.7455 & 5.0629 & TRN & \\
\hline CHEMBL1440781 & 1301619 & 4.8167 & 4.9501 & TRN & \\
\hline CHEMBL1594369 & 1301619 & 4.6108 & 4.9014 & TST & \\
\hline CHEMBL1450748 & 1301619 & 6.2782 & 6.3681 & TRN & \\
\hline CHEMBL3185466 & 1301619 & 4.8508 & 4.5116 & TRN & \\
\hline CHEMBL3186003 & 1301619 & 5.0159 & 4.6034 & TRN & \\
\hline CHEMBL1555066 & 1301619 & 5.5702 & 5.5245 & TRN & \\
\hline CHEMBL1733824 & 1301619 & 4.23600 & t00000006 & 5.0631 & TST \\
\hline CHEMBL1878940 & 1301619 & 5.6108 & 5.1676 & TST & \\
\hline CHEMBL1309463 & 1301619 & 4.8119 & 4.8403 & TST & \\
\hline CHEMBL1553553 & 1301619 & 4.8386 & 4.9408 & TRN & \\
\hline CHEMBL1454840 & 1301619 & 5.5421 & 5.619 & TRN & \\
\hline CHEMBL1878022 & 1301619 & 4.5056 & 4.6923 & TRN & \\
\hline CHEMBL1393635 & 1301619 & 4.6979 & 4.7528 & TRN & \\
\hline CHEMBL1421941 & 1301619 & 5.6904 & 5.6429 & TRN & \\
\hline CHEMBL1402439 & 1301619 & 5.2248 & 5.3644 & TRN & \\
\hline CHEMBL1878853 & 1301619 & 4.6059 & 4.6647 & TRN & \\
\hline CHEMBL1527400 & 1301619 & 5.6073 & 5.7499 & TRN & \\
\hline CHEMBL1500112 & 1301619 & 5.2441 & 5.1222 & TRN & \\
\hline CHEMBL3187662 & 1301619 & 4.4901 & 4.5552 & TRN & \\
\hline CHEMBL1385573 & 1301619 & 4.8748 & 4.9742 & TRN & \\
\hline CHEMBL1457961 & 1301619 & 5.011 & 5.01399 & 9999999999 & TRN \\
\hline CHEMBL1525789 & 1301619 & 6.1543 & 5.892 & TRN & \\
\hline CHEMBL 3187453 & 1301619 & 4.5947 & 5.0016 & TRN & \\
\hline CHEMBL3185534 & 1301619 & 4.2531 & 4.4885 & TRN & \\
\hline CHEMBL1366321 & 1301619 & 5.0762 & 5.0508 & TRN & \\
\hline CHEMBL1710219 & 1301619 & 4.475 & 4.8046 & TRN & \\
\hline CHEMBL1892565 & 1301619 & 4.4088 & 4.7302 & TRN & \\
\hline CHEMBL1488730 & 1301619 & 5.8239 & 5.9888 & TRN & \\
\hline CHEMBL3184516 & 1301619 & 5.1838 & 5.18 & TRN & \\
\hline CHEMBL3188477 & 1301619 & 4.4044 & 4.4468 & TRN & \\
\hline CHEMBL1375648 & 1301619 & 5.6289 & 5.7511 & TRN & \\
\hline CHEMBL1432977 & 1301619 & 5.1669 & 5.3499 & TST & \\
\hline CHEMBL1899921 & 1301619 & 4.4676 & 4.5927 & TST & \\
\hline CHEMBL1361936 & 1301619 & 5.1993 & 6.0944 & TRN & \\
\hline CHEMBL1427072 & 1301619 & 5.8386 & 5.8955 & TRN & \\
\hline CHEMBL1718952 & 1301619 & 5.1175 & 5.3496 & TST & \\
\hline
\end{tabular}


Supplemental Table S2.txt

\begin{tabular}{|c|c|c|c|c|c|}
\hline CHEMBL1463529 & 1301619 & 5.7447 & 5.6966 & TRN & \\
\hline CHEMBL1468323 & 1301619 & 6.4168 & 6.4549 & TRN & \\
\hline CHEMBL1349231 & 1301619 & 5.341 & 5.5005 & TRN & \\
\hline CHEMBL1494038 & 1301619 & 5.7447 & 5.4234 & TRN & \\
\hline CHEMBL512749 & 1301619 & 5.6882 & 5.6144 & TRN & \\
\hline CHEMBL1540839 & 1301619 & 5.2048 & 5.1741 & TRN & \\
\hline CHEMBL1373146 & 1301619 & 5.3696 & 5.3803 & TRN & \\
\hline CHEMBL1610938 & 1301619 & 5.7352 & 5.3755 & TRN & \\
\hline CHEMBL1373194 & 1301619 & 5.3215 & 5.3456 & TRN & \\
\hline CHEMBL1421255 & 1301619 & 5.6108 & 5.7095 & TST & \\
\hline CHEMBL1309142 & 1301619 & 5.3197 & 5.5625 & TRN & \\
\hline CHEMBL486569 & 1301619 & 5.1986 & 5.1488 & TRN & \\
\hline CHEMBL1483193 & 1301619 & 5.3747 & 5.2288 & TRN & \\
\hline CHEMBL1698291 & 1301619 & 4.3815 & 4.6961 & TST & \\
\hline CHEMBL1442326 & 1301619 & 5.6383 & 5.5433 & TRN & \\
\hline CHEMBL2132815 & 1301619 & 4.8887 & 4.6539 & TRN & \\
\hline CHEMBL1313954 & 1301619 & 4.9326 & 4.9925 & TRN & \\
\hline CHEMBL1479340 & 1301619 & 4.5728 & 4.5372 & TST & \\
\hline CHEMBL1386689 & 1301619 & 5.3335 & 5.1879 & TRN & \\
\hline CHEMBL1409883 & 1301619 & 5.6402 & 5.7891 & TRN & \\
\hline CHEMBL1309573 & 1301619 & 5.7932 & 5.9205 & TRN & \\
\hline CHEMBL1391313 & 1301619 & 5.52 & 5.5664 & TRN & \\
\hline CHEMBL2133586 & 1301619 & 5.1662 & 5.1204 & TST & \\
\hline CHEMBL490083 & 1301619 & 5.6289 & 5.4513 & TRN & \\
\hline CHEMBL2362612 & 1301619 & 5.5591 & 5.4793 & TRN & \\
\hline CHEMBL1348884 & 1301619 & 5.032 & 5.0618 & TRN & \\
\hline CHEMBL1899585 & 1301619 & 5.083 & 4.8574 & TRN & \\
\hline CHEMBL3186645 & 1301619 & 4.7972 & 4.5608 & TRN & \\
\hline CHEMBL2136235 & 1301619 & 4.9234 & 4.5862 & TRN & \\
\hline CHEMBL1597726 & 1301619 & 4.8557 & 5.3266 & TRN & \\
\hline CHEMBL1556786 & 1301619 & 4.9851 & 5.2365 & TRN & \\
\hline CHEMBL1345558 & 1301619 & 4.5574 & 4.7562 & TRN & \\
\hline CHEMBL2004141 & 1301619 & 6.6402 & 6.8485 & TRN & \\
\hline CHEMBL1409400 & 1301619 & 5.7077 & 5.5871 & TRN & \\
\hline CHEMBL1349442 & 1301619 & 4.8687 & 4.7404 & TRN & \\
\hline CHEMBL1308273 & 1301619 & 4.783 & 5.0271 & TRN & \\
\hline CHEMBL1472108 & 1301619 & 5.4045 & 5.2878 & TRN & \\
\hline CHEMBL1476877 & 1301619 & 5.556 & 5.5049 & TRN & \\
\hline CHEMBL1490537 & 1301619 & 5.7212 & 5.1441 & TST & \\
\hline CHEMBL1479234 & 1301619 & 4.9055 & 4.8939 & TRN & \\
\hline CHEMBL1488020 & 1301619 & 5.5272 & 5.285 & TRN & \\
\hline CHEMBL1384654 & 1301619 & 4.9187 & 5.0353 & TRN & \\
\hline CHEMBL3186447 & 1301619 & 5.3197 & 4.8788 & TRN & \\
\hline CHEMBL1562575 & 1301619 & 7.157999 & \multirow{2}{*}{\multicolumn{2}{|c|}{$\begin{array}{rr}99999999995 & 8 . \\
5.2860000000000005\end{array}$}} & TRN \\
\hline CHEMBL1582244 & 1301619 & 5.2941 & & & TRN \\
\hline CHEMBL3186317 & 1301619 & 5.5735 & 4.9778 & TRN & \\
\hline CHEMBL1485358 & 1301619 & 5.2924 & 5.37 & TST & \\
\hline CHEMBL1302266 & 1301619 & 5.2588 & 5.4668 & TRN & \\
\hline
\end{tabular}


Supplemental Table S2.txt

\begin{tabular}{|c|c|c|c|c|c|c|}
\hline CHEMBL2359997 & 1301619 & 4.9496 & 4.7913 & TRN & & \\
\hline CHEMBL1436393 & 1301619 & 5.6819 & 5.67899 & 999999999 & & TRN \\
\hline CHEMBL1995375 & 1301619 & 4.9523 & 4.9417 & TRN & & \\
\hline CHEMBL1321622 & 1301619 & 6.0942 & 6.0151 & TRN & & \\
\hline CHEMBL1488371 & 1301619 & 5.7595 & 5.3329 & TRN & & \\
\hline CHEMBL1416853 & 1301619 & 5.3915 & 5.2989 & TRN & & \\
\hline CHEMBL1380276 & 1301619 & 5.0872 & 5.2485 & TRN & & \\
\hline CHEMBL1456521 & 1301619 & 5.1373 & 5.2263 & TRN & & \\
\hline CHEMBL1587121 & 1301619 & 5.3233 & 5.2481 & TST & & \\
\hline CHEMBL 2136405 & 1301619 & 4.5789 & 4.3619 & TRN & & \\
\hline CHEMBL 2354532 & 1301619 & 5.24799 & 99999999 & 99 & 4.9502 & TRN \\
\hline CHEMBL1436748 & 1301619 & 5.5072 & 5.3845 & TRN & & \\
\hline CHEMBL 2356186 & 1301619 & 6.1649 & 5.6993 & TRN & & \\
\hline CHEMBL1597705 & 1301619 & 5.06 & 5.1642 & TRN & & \\
\hline CHEMBL1610597 & 1301619 & 6.3107 & 5.7026 & TST & & \\
\hline CHEMBL1545203 & 1301619 & 5.9101 & 5.7691 & TRN & & \\
\hline CHEMBL1383991 & 1301619 & 5.5622 & 5.6729 & TRN & & \\
\hline CHEMBL1597627 & 1301619 & 6.2351 & 6.1595 & TRN & & \\
\hline CHEMBL1726559 & 1301619 & 4.5214 & 4.6227 & TST & & \\
\hline CHEMBL1893675 & 1301619 & 5.2111 & 5.074 & TST & & \\
\hline CHEMBL1408542 & 1301619 & 5.5986 & 5.5019 & TRN & & \\
\hline CHEMBL1486874 & 1301619 & 6.8097 & 7.4715 & TRN & & \\
\hline CHEMBL1456271 & 1301619 & 4.7726 & 5.2792 & TRN & & \\
\hline CHEMBL 3186711 & 1301619 & 5.3054 & 5.0895 & TST & & \\
\hline CHEMBL1729737 & 1301619 & 6.7496 & 6.3639 & TRN & & \\
\hline CHEMBL1530216 & 1301619 & 4.8262 & 4.7091 & TRN & & \\
\hline CHEMBL1457060 & 1301619 & 5.4353 & 5.3322 & TRN & & \\
\hline CHEMBL1383534 & 1301619 & 6.2321 & 5.9331 & TRN & & \\
\hline CHEMBL1453723 & 1301619 & 6.3089 & 6.3179 & TRN & & \\
\hline CHEMBL1549599 & 1301619 & 5.1085 & 5.1249 & TRN & & \\
\hline CHEMBL1489293 & 1301619 & 5.3696 & 5.2807 & TRN & & \\
\hline CHEMBL1352521 & 1301619 & 6.5867 & 6.3026 & TRN & & \\
\hline CHEMBL1309162 & 1301619 & 5.5686 & 6.3466 & TRN & & \\
\hline CHEMBL1360295 & 1301619 & 5.4498 & 5.4068 & TRN & & \\
\hline CHEMBL1309228 & 1301619 & 4.6938 & 4.8973 & TST & & \\
\hline CHEMBL3188673 & 1301619 & 5.0872 & 4.8386 & TRN & & \\
\hline CHEMBL1551577 & 1301619 & 4.8365 & 4.8409 & TRN & & \\
\hline CHEMBL3185532 & 1301619 & 4.6291 & 4.6484 & TRN & & \\
\hline CHEMBL1595632 & 1301619 & 5.9318 & 6.1962 & TRN & & \\
\hline CHEMBL3197099 & 1301619 & 5.9172 & 5.8784 & TRN & & \\
\hline CHEMBL1877015 & 1301619 & 4.734 & 5.0907 & TST & & \\
\hline CHEMBL3181899 & 1301619 & 4.7326 & 4.6409 & TRN & & \\
\hline CHEMBL1484344 & 1301619 & 4.9918 & 4.8134 & TRN & & \\
\hline CHEMBL1528067 & 1301619 & 5.0742 & 5.1873 & TRN & & \\
\hline CHEMBL1363706 & 1301619 & 5.6271 & 5.2533 & TRN & & \\
\hline CHEMBL3187367 & 1301619 & 4.3755 & 5.1091 & TST & & \\
\hline CHEMBL1363219 & 1301619 & 5.6478 & 5.5444 & TRN & & \\
\hline CHEMBL1607801 & 1301619 & 6.6861 & 7.2997 & TRN & & \\
\hline
\end{tabular}

Page 6631 
Supplemental Table S2.txt

\begin{tabular}{|c|c|c|c|c|c|}
\hline CHEMBL1474280 & 1301619 & 5.2857 & 5.0867 & TRN & \\
\hline CHEMBL1607086 & 1301619 & 6.3354 & 6.2826 & TRN & \\
\hline CHEMBL1371507 & 1301619 & 5.9788 & 6.087999 & 9999999999 & TRN \\
\hline CHEMBL1454738 & 1301619 & 4.6988 & 4.6284 & TRN & \\
\hline CHEMBL1360928 & 1301619 & 5.8386 & 5.8521 & TRN & \\
\hline CHEMBL1542378 & 1301619 & 5.5867 & 5.6267 & TRN & \\
\hline CHEMBL1438614 & 1301619 & 5.0867 & 5.0865 & TST & \\
\hline CHEMBL1376288 & 1301619 & 5.9136 & 4.8946 & TRN & \\
\hline CHEMBL1572001 & 1301619 & 4.8419 & 4.8962 & TST & \\
\hline CHEMBL3185370 & 1301619 & 4.7075 & 4.5552 & TRN & \\
\hline CHEMBL1453108 & 1301619 & 5.2321 & 5.3768 & TST & \\
\hline CHEMBL1507537 & 1301619 & 4.5764 & 4.7761 & TRN & \\
\hline CHEMBL1438758 & 1301619 & 5.4157 & 5.6123 & TRN & \\
\hline CHEMBL1500923 & 1301619 & 5.475 & 5.4628 & TRN & \\
\hline CHEMBL1604245 & 1301619 & 5.5467 & 5.7868 & TRN & \\
\hline CHEMBL1595582 & 1301619 & 5.6091 & 5.8102 & TRN & \\
\hline CHEMBL1529404 & 1301619 & 5.8386 & 5.8488 & TRN & \\
\hline CHEMBL 2136434 & 1301619 & 4.9034 & 4.7118 & TST & \\
\hline CHEMBL607553 & 1301619 & 4.5608 & 4.5799 & TRN & \\
\hline CHEMBL1468355 & 1301619 & 5.7055 & 5.9459 & TRN & \\
\hline CHEMBL1378392 & 1301619 & 5.5498 & 5.2603 & TRN & \\
\hline CHEMBL1414808 & 1301619 & 4.9755 & 4.9551 & TST & \\
\hline CHEMBL1869875 & 1301619 & 5.6478 & 5.8884 & TRN & \\
\hline CHEMBL1450386 & 1301619 & 4.942 & 5.1124 & TRN & \\
\hline CHEMBL1881881 & 1301619 & 4.6411 & 4.7066 & TRN & \\
\hline CHEMBL1303280 & 1301619 & 5.6655 & 5.8088 & TRN & \\
\hline CHEMBL1304031 & 1301619 & 4.354 & 4.4417 & TRN & \\
\hline CHEMBL199194 & 1301619 & 5.3716 & 5.5076 & TST & \\
\hline CHEMBL1981570 & 1301619 & 6.0227 & 6.4862 & TRN & \\
\hline CHEMBL1442242 & 1301619 & \multicolumn{3}{|c|}{4.446000000000001} & TST \\
\hline CHEMBL3185075 & 1301619 & 4.3526 & 4.877 & TRN & \\
\hline CHEMBL1315401 & 1301619 & 6.1029 & 5.5899 & TST & \\
\hline CHEMBL1884029 & 1301619 & 4.6674 & 4.7001 & TRN & \\
\hline CHEMBL1303404 & 1301619 & 5.8041 & 5.5443 & TRN & \\
\hline CHEMBL3182522 & 1301619 & 4.5602 & 5.0287 & TRN & \\
\hline CHEMBL1902024 & 1301619 & 4.8447 & 4.871 & TRN & \\
\hline CHEMBL1425919 & 1301619 & 5.2351 & 5.3432 & TRN & \\
\hline CHEMBL1501859 & 1301619 & 4.7298 & 4.981 & TRN & \\
\hline CHEMBL1426107 & 1301619 & 5.2823 & 5.2177 & TRN & \\
\hline CHEMBL1365689 & 1301619 & 5.4248 & 5.2397 & TRN & \\
\hline CHEMBL1517072 & 1301619 & 5.5591 & 5.5611 & TRN & \\
\hline CHEMBL1374009 & 1301619 & 5.7447 & 5.6114 & TRN & \\
\hline CHEMBL1428752 & 1301619 & 4.2549 & 5.1253 & TST & \\
\hline CHEMBL1425034 & 1301619 & 5.5482 & 6.0354 & TRN & \\
\hline CHEMBL1712850 & 1301619 & 4.5819 & 4.5721 & TRN & \\
\hline CHEMBL1502544 & 1301619 & 5.1904 & 5.1486 & TRN & \\
\hline CHEMBL 2142817 & 1301619 & 6.0434 & 5.6102 & TRN & \\
\hline CHEMBL1578053 & 1301619 & 4.8821 & 5.1272 & TRN & \\
\hline
\end{tabular}


Supplemental Table S2.txt

\begin{tabular}{|c|c|c|c|c|}
\hline W & 301619 & & & \\
\hline & 301619 & & 5.3038 & \\
\hline 124 & & & & \\
\hline AEMBL15: & & & & \\
\hline AEMBL1495028 & 301619 & 0022 & 1375 & \\
\hline HEMBL1421199 & 301619 & 5.1694 & .22 & \\
\hline HEMBL3188377 & 619 & & 3732 & \\
\hline 99738 & & & & \\
\hline AEMBL1299526 & 301619 & 4.5372 & & \\
\hline HEMBL1549310 & 301619 & 5.3233 & 4023 & \\
\hline AEMBL1314602 & 619 & 5.2277 & 0922 & \\
\hline IEMBL3] & 19 & 976 & 974 & \\
\hline IEMBL1 & & & & \\
\hline HEMBL1585064 & 19 & 1898 & 4094 & \\
\hline AEMBL1315904 & 19 & 5. & & \\
\hline AEMBL1610 & 19 & 5 & 92 & \\
\hline HEMBL5C & 9 & & & \\
\hline HEMBL1: & & & & \\
\hline HEMBL1392228 & 19 & & & \\
\hline AEMBL151 & & & & \\
\hline HEMBI & 9 & 6 & & Niv \\
\hline AEMBL: & 9 & & & \\
\hline AEMBL1 & 19 & & & \\
\hline HEMBL2133510 & & & & \\
\hline AEMBL2362144 & & & & \\
\hline HEMBL1: & 9 & 5. & & RN \\
\hline HEMBL1 & 9 & & & RN \\
\hline HFMBI 1 & & 4. & & \\
\hline HEMBL1 & & & & TST \\
\hline HEMBL3181918 & & & & I RN \\
\hline HEMBL1C & 9 & & 784 & RIV \\
\hline HEMBL3 & 9 & & 56 & NIV \\
\hline HEMBL: & & 5. & & TRN \\
\hline HEMBL139 & & & & IR \\
\hline HEMBL 3198732 & 9 & & 877 & 「RN \\
\hline HEMBL1 & 19 & & 72 & RN \\
\hline - & & & & RN \\
\hline HEMBL3 & & & & $\Gamma \mathrm{RN}$ \\
\hline HEMBL1881477 & 19 & 4. & 5622 & TRI \\
\hline EMBL1 & 9 & & 074 & TST \\
\hline HEMBL1: & 19 & 21 & & \\
\hline CHEMBL15 & & & & \\
\hline HEMBL149 & 19 & & 5551 & TST \\
\hline HEMBL5958 & 19 & 5.4365 & & TR \\
\hline $\mathrm{MRI} 1$ & & 37 & & \\
\hline HEMBL31 & & 245 & & \\
\hline CHEMBL367376 & 5 & 5.7932 & .6449 & \\
\hline SHEMBL133251 & 1301619 & 5.857 & 5.9355 & ГRN \\
\hline
\end{tabular}

Page 6633 
Supplemental Table S2.txt

\begin{tabular}{|c|c|c|c|c|c|}
\hline CHEMBL1379493 & 1301619 & 4.5222 & 4.5923 & TRN & \\
\hline CHEMBL1429164 & 1301619 & 4.755 & 4.9969 & TRN & \\
\hline CHEMBL3188942 & 1301619 & 4.1987 & 4.5955 & TRN & \\
\hline CHEMBL1408307 & 1301619 & 5.9208 & 5.9693 & TRN & \\
\hline CHEMBL3188935 & 1301619 & 4.6953 & 4.4637 & TRN & \\
\hline CHEMBL1528342 & 1301619 & 5.2668 & 5.3795 & TRN & \\
\hline CHEMBL1361922 & 1301619 & 7.1203 & 7.0186 & TRN & \\
\hline CHEMBL3188008 & 1301619 & 6.0 & 5.0645 & TRN & \\
\hline CHEMBL1499752 & 1301619 & 5.2418 & 5.2336 & TRN & \\
\hline CHEMBL1334090 & 1301619 & 5.4815 & 5.3585 & TRN & \\
\hline CHEMBL1422160 & 1301619 & 4.588 & 4.7927 & TRN & \\
\hline CHEMBL1507515 & 1301619 & 4.6919 & 4.8633 & TRN & \\
\hline CHEMBL1898104 & 1301619 & 6.6021 & 6.239 & TRN & \\
\hline CHEMBL1430096 & 1301619 & 6.5498 & 6.8383 & TRN & \\
\hline CHEMBL1302164 & 1301619 & 5.3215 & 5.2751 & TRN & \\
\hline CHEMBL1377992 & 1301619 & 5.699 & 5.7471 & TRN & \\
\hline CHEMBL1902247 & 1301619 & 4.7361 & 4.6399 & TRN & \\
\hline CHEMBL1481616 & 1301619 & 5.5768 & \multicolumn{2}{|c|}{5.587000000000001} & TRN \\
\hline CHEMBL1506926 & 1301619 & 5.9706 & 5.9173 & TRN & \\
\hline CHEMBL1484208 & 1301619 & 5.4437 & 5.1505 & TRN & \\
\hline CHEMBL3182316 & 1301619 & 4.3258 & 4.3514 & TRN & \\
\hline CHEMBL1602085 & 1301619 & 5.3468 & 5.3592 & TRN & \\
\hline CHEMBL1472145 & 1301619 & 4.4829 & 4.8542 & TST & \\
\hline CHEMBL1415412 & 1301619 & 5.2741 & 5.08 & TRN & \\
\hline CHEMBL1724656 & 1301619 & 5.4622 & 5.5454 & TST & \\
\hline CHEMBL1544685 & 1301619 & 5.7167 & 5.5386 & TRN & \\
\hline CHEMBL1393189 & 1301619 & 4.95 & 4.9825 & TRN & \\
\hline CHEMBL3185444 & 1301619 & 4.8824 & 4.6997 & TRN & \\
\hline CHEMBL1410197 & 1301619 & 4.6737 & 4.8308 & TRN & \\
\hline CHEMBL2359304 & 1301619 & 4.5317 & 4.8384 & TRN & \\
\hline CHEMBL1612044 & 1301619 & 6.5406 & 6.4103 & TRN & \\
\hline CHEMBL1482964 & 1301619 & 5.1772 & 5.2882 & TRN & \\
\hline CHEMBL1891068 & 1301619 & 5.0472 & 4.8048 & TST & \\
\hline CHEMBL2359853 & 1301619 & 4.7525 & 4.6126 & TRN & \\
\hline CHEMBL251717 & 1301619 & 4.6513 & 4.7859 & TRN & \\
\hline CHEMBL1386466 & 1301619 & 4.8505 & 4.9451 & TRN & \\
\hline CHEMBL3184851 & 1301619 & 4.3695 & 4.9613 & TRN & \\
\hline CHEMBL1575720 & 1301619 & 5.6383 & 5.3674 & TST & \\
\hline CHEMBL1419031 & 1301619 & 5.8069 & 5.9042 & TRN & \\
\hline CHEMBL2355635 & 1301619 & 5.4449 & 5.2181 & TRN & \\
\hline CHEMBL1413841 & 1301619 & 5.3675 & 5.4969 & TRN & \\
\hline CHEMBL1487964 & 1301619 & 4.6981 & 4.4412 & TRN & \\
\hline CHEMBL1415374 & 1301619 & 6.1409 & 5.2225 & TRN & \\
\hline CHEMBL3189242 & 1301619 & 5.61799 & Э9999999 & 5.6679 & TRN \\
\hline CHEMBL 3187578 & 1301619 & 4.6276 & 4.6275 & TRN & \\
\hline CHEMBL1473464 & 1301619 & 5.6635 & 5.5215 & TRN & \\
\hline CHEMBL591598 & 1301619 & 5.301 & 5.4014 & TRN & \\
\hline CHEMBL1446234 & 1301619 & 4.475 & 4.4618 & TST & \\
\hline
\end{tabular}


Supplemental Table S2.txt

\begin{tabular}{|c|c|c|c|c|}
\hline CHEMBL1448943 & 1301619 & 5.1051 & 5.4378 & TRN \\
\hline CHEMBL1537106 & 1301619 & 5.2366 & 4.9767 & TRN \\
\hline CHEMBL460508 & 1301619 & 5.5607 & 5.6909 & TRN \\
\hline CHEMBL1573883 & 1301619 & 5.3645 & 5.3608 & TRN \\
\hline CHEMBL1485101 & 1301619 & 4.9759 & 5.1714 & TRN \\
\hline CHEMBL1720155 & 1301619 & 4.5346 & 4.6155 & TRN \\
\hline CHEMBL1343831 & 1301619 & 5.4034 & 5.4146 & TRN \\
\hline CHEMBL1549324 & 1301619 & 5.289 & 5.1738 & TRN \\
\hline CHEMBL1535919 & 1301619 & 4.7084 & 4.8406 & TRN \\
\hline CHEMBL1521051 & 1301619 & 5.2652 & 5.1816 & TRN \\
\hline CHEMBL3187793 & 1301619 & 4.7667 & 4.3108 & TRN \\
\hline CHEMBL1896073 & 1301619 & 4.8517 & 4.64199 & э9999999995 \\
\hline CHEMBL1316631 & 1301619 & 5.0429 & 5.2975 & TRN \\
\hline CHEMBL252403 & 1301619 & 5.5114 & 5.6214 & TRN \\
\hline CHEMBL1486726 & 1301619 & 5.5607 & 5.4305 & TRN \\
\hline CHEMBL1374200 & 1301619 & 4.8182 & 4.8156 & TST \\
\hline CHEMBL1493614 & 1301619 & 5.0259 & 4.9423 & TRN \\
\hline CHEMBL1448153 & 1301619 & 5.1555 & 5.0113 & TRN \\
\hline CHEMBL1307933 & 1301619 & 5.4342 & 5.3242 & TRN \\
\hline CHEMBL3182923 & 1301619 & 4.9694 & 4.3765 & TRN \\
\hline CHEMBL1871360 & 1301619 & 4.5725 & 4.6422 & TST \\
\hline CHEMBL1559529 & 1301619 & 5.8327 & 5.7597 & TRN \\
\hline CHEMBL 2133546 & 1301619 & 4.7582 & 4.7315 & TRN \\
\hline CHEMBL 2357924 & 1301619 & 5.3143 & 5.2377 & TRN \\
\hline CHEMBL1329650 & 1301619 & 5.2668 & 5.0511 & TRN \\
\hline CHEMBL1575970 & 1301619 & 5.4881 & 5.5911 & TRN \\
\hline CHEMBL1900154 & 1301619 & 4.4351 & 4.5819 & TRN \\
\hline CHEMBL1423377 & 1301619 & 5.3625 & 5.5169 & TRN \\
\hline CHEMBL3183033 & 1301619 & 4.3695 & 4.9574 & TRN \\
\hline CHEMBL1533657 & 1301619 & 4.5819 & 4.6729 & TST \\
\hline CHEMBL1419938 & 1301619 & 5.9245 & 5.7976 & TRN \\
\hline CHEMBL191015 & 1301619 & 4.6509 & 4.9876 & TRN \\
\hline CHEMBL1900256 & 1301619 & 5.098 & 5.1562 & TRN \\
\hline CHEMBL1481861 & 1301619 & 5.4157 & 5.2243 & TRN \\
\hline CHEMBL1346147 & 1301619 & 6.0964 & 5.5628 & TRN \\
\hline CHEMBL530609 & 1301619 & 5.6364 & 5.7114 & TRN \\
\hline CHEMBL1323174 & 1301619 & 5.4989 & 5.2195 & TRN \\
\hline CHEMBL1382538 & 1301619 & 5.0783 & 5.0555 & TRN \\
\hline CHEMBL3186236 & 1301619 & 4.6527 & 4.5479 & TRN \\
\hline CHEMBL1391158 & 1301619 & 5.2182 & \multicolumn{2}{|c|}{5.297000000000001} \\
\hline CHEMBL3187767 & 1301619 & 5.0726 & 4.7862 & TRN \\
\hline CHEMBL600572 & 1301619 & 4.6817 & 4.8908 & TRN \\
\hline CHEMBL1342147 & 1301619 & 5.032 & 5.5109 & TRN \\
\hline CHEMBL1546205 & 1301619 & 4.5103 & 4.5462 & TRN \\
\hline CHEMBL1470676 & 1301619 & 6.4935 & 6.1747 & TRN \\
\hline CHEMBL1423927 & 1301619 & 5.9547 & 5.7893 & TRN \\
\hline CHEMBL1390421 & 1301619 & 4.9914 & 5.0917 & TRN \\
\hline CHEMBL1277151 & 1301619 & 4.7469 & 4.8626 & TST \\
\hline
\end{tabular}


Supplemental Table S2.txt

\begin{tabular}{|c|c|c|c|c|}
\hline The & 1619 & 5662 & 7852 & \\
\hline & 301619 & 6.8729 & 6.602 & \\
\hline & & & 816 & \\
\hline AEMBL13 & & & & \\
\hline AEMBL1538625 & 301619 & 817 & 5354 & \\
\hline HEMBL1511219 & 301619 & 8.1675 & 8753 & \\
\hline HEMBL15 & 519 & & 699 & \\
\hline 948 & & & & \\
\hline AEMBL2360439 & 301619 & 5.2041 & 838 & \\
\hline HEMBL1877321 & 301619 & 19 & 8272 & \\
\hline AEMBL1435056 & 301619 & 5 . & L29 & \\
\hline IEMBL13 & 19 & & 754 & \\
\hline IEMBL13 & & & & \\
\hline HEMBL15 & 19 & & 0832 & \\
\hline IEMBL14 & 19 & & 341 & \\
\hline AEMBL 787 & 19 & 24 & 693 & \\
\hline HEMBL14 & 9 & & 982 & \\
\hline HEMBL23 & & & 327 & \\
\hline HEMBL13 & 19 & & 7886 & \\
\hline IEMBL13 & & & & \\
\hline$A=M B L 2$ & 9 & & 394 & \\
\hline AEMBL17 & 9 & & 315 & \\
\hline HEMBL1\& & 19 & & 184 & \\
\hline 539 & & & 147 & \\
\hline AEMBL13 & & & & 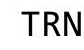 \\
\hline HEMBL1 & 9 & & 099 & RN \\
\hline HEMBL 2: & 9 & & 249 & 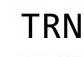 \\
\hline AFMB 1 & & & 226 & \\
\hline JEMBL14 & & & 652 & 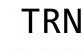 \\
\hline HEMBL13: & & & 162 & s \\
\hline HEMBL1S & 19 & & 531 & SI \\
\hline HEMBL1 & 9 & & 56 & RN \\
\hline AEMBL3 & & & 813 & RN \\
\hline HEMBL1336447 & & & 286 & IRN \\
\hline HEMBL1406361 & 9 & & 406 & ГRN \\
\hline HEMBL15 & 19 & & 1008 & RN \\
\hline HEMPI & & & 391 & RN \\
\hline HEMBL15 & & & 366 & RN \\
\hline HEMBL1995376 & 19 & & 079 & TRN \\
\hline IEMBL23 & מ & & 3832 & RN \\
\hline HEMBL17 & 9 & & 076 & \\
\hline HEMBL15 & & & 3299 & ST \\
\hline HEMBL14 & & & 2936 & RN \\
\hline AEMBL15 & 19 & 5 . & 102 & ГRN \\
\hline 04 & & & 997 & \\
\hline HEMBL14 & & & & \\
\hline HEMBL13L & & 5.9957 & 1677 & \\
\hline SHEMBL1328504 & 1301619 & 6.1314 & 5.8692 & \\
\hline
\end{tabular}

Page 6636 
Supplemental Table S2.txt

\begin{tabular}{|c|c|c|c|c|c|c|}
\hline CHEMBL1504453 & 1301619 & 4.5436 & 4.6525 & TRN & & \\
\hline CHEMBL610198 & 1301619 & 4.7875 & 4.5746 & TRN & & \\
\hline CHEMBL1606351 & 1301619 & 5.71899 & 79999999ऽ & 99 & 5.684 & TRN \\
\hline CHEMBL1521269 & 1301619 & 5.0894 & 5.1246 & TRN & & \\
\hline CHEMBL1385499 & 1301619 & 4.5781 & 4.787 & TST & & \\
\hline CHEMBL3185023 & 1301619 & 4.6807 & 4.3077 & TRN & & \\
\hline CHEMBL1329803 & 1301619 & 4.9961 & 5.0462 & TRN & & \\
\hline CHEMBL1974563 & 1301619 & 5.7773 & 6.0083 & TST & & \\
\hline CHEMBL1459468 & 1301619 & 6.5969 & 6.7743 & TRN & & \\
\hline CHEMBL523200 & 1301619 & 4.5411 & 4.7286 & TRN & & \\
\hline CHEMBL1404788 & 1301619 & 5.059 & 5.2377 & TRN & & \\
\hline CHEMBL1455756 & 1301619 & 5.5072 & 5.4543 & TRN & & \\
\hline CHEMBL2355407 & 1301619 & 5.5901 & 5.3863 & TRN & & \\
\hline CHEMBL2132222 & 1301619 & 4.4584 & 5.1039 & TRN & & \\
\hline CHEMBL1579644 & 1301619 & 4.5042 & 4.601 & TST & & \\
\hline CHEMBL1463659 & 1301619 & 5.5638 & 5.7034 & TRN & & \\
\hline CHEMBL1597669 & 1301619 & 5.7258 & 5.6613 & TRN & & \\
\hline CHEMBL1492399 & 1301619 & 6.0531 & 5.9049 & TRN & & \\
\hline CHEMBL1329798 & 1301619 & 6.5622 & 6.3137 & TRN & & \\
\hline CHEMBL3183027 & 1301619 & 6.0 & 5.3643 & TRN & & \\
\hline CHEMBL2357026 & 1301619 & 4.4453 & 4.4534 & TRN & & \\
\hline CHEMBL1895744 & 1301619 & 5.0255 & 4.8306 & TRN & & \\
\hline CHEMBL1464608 & 1301619 & 5.2549 & 5.3093 & TRN & & \\
\hline CHEMBL1584761 & 1301619 & 4.9566 & 4.9516 & TRN & & \\
\hline CHEMBL2361605 & 1301619 & 4.8438 & 4.8265 & TRN & & \\
\hline CHEMBL1595274 & 1301619 & 5.4949 & 5.5356 & TRN & & \\
\hline CHEMBL1490336 & 1301619 & 5.6162 & 5.8674 & TRN & & \\
\hline CHEMBL1864879 & 1301619 & 4.5471 & 4.5259 & TRN & & \\
\hline CHEMBL1427736 & 1301619 & 5.2449 & 5.4625 & TRN & & \\
\hline CHEMBL3183869 & 1301619 & 4.2797 & 5.1093 & TRN & & \\
\hline CHEMBL3183087 & 1301619 & 5.3391 & 5.1751 & TRN & & \\
\hline CHEMBL473735 & 1301619 & 5.9788 & 5.9166 & TRN & & \\
\hline CHEMBL1553183 & 1301619 & 4.8058 & 4.9842 & TRN & & \\
\hline CHEMBL1336848 & 1301619 & 5.0991 & 5.1662 & TRN & & \\
\hline CHEMBL1391972 & 1301619 & 5.2652 & 5.3425 & TRN & & \\
\hline CHEMBL1732740 & 1301619 & 5.2588 & 5.3785 & TRN & & \\
\hline CHEMBL1359120 & 1301619 & 5.8729 & 5.8332 & TRN & & \\
\hline CHEMBL1490041 & 1301619 & 4.9208 & 5.0939 & TRN & & \\
\hline CHEMBL3182659 & 1301619 & 4.8784 & 4.9512 & TRN & & \\
\hline CHEMBL1413454 & 1301619 & 4.6267 & 4.747 & TRN & & \\
\hline CHEMBL1384167 & 1301619 & 5.0259 & 5.0691 & TRN & & \\
\hline CHEMBL1352995 & 1301619 & 4.9382 & 5.2141 & TRN & & \\
\hline CHEMBL1486329 & 1301619 & 4.683 & 4.7892 & TRN & & \\
\hline CHEMBL1610783 & 1301619 & \multicolumn{3}{|c|}{5.0680000000000005} & 5.0846 & TRN \\
\hline CHEMBL2134655 & 1301619 & 4.4309 & 4.6431 & TST & & \\
\hline CHEMBL1548433 & 1301619 & 5.1163 & 5.1331 & TRN & & \\
\hline CHEMBL1519965 & 1301619 & 6.5391 & 6.4705 & TRN & & \\
\hline CHEMBL2357765 & 1301619 & 4.3701 & 4.9826 & TRN & & \\
\hline
\end{tabular}


Supplemental Table S2.txt

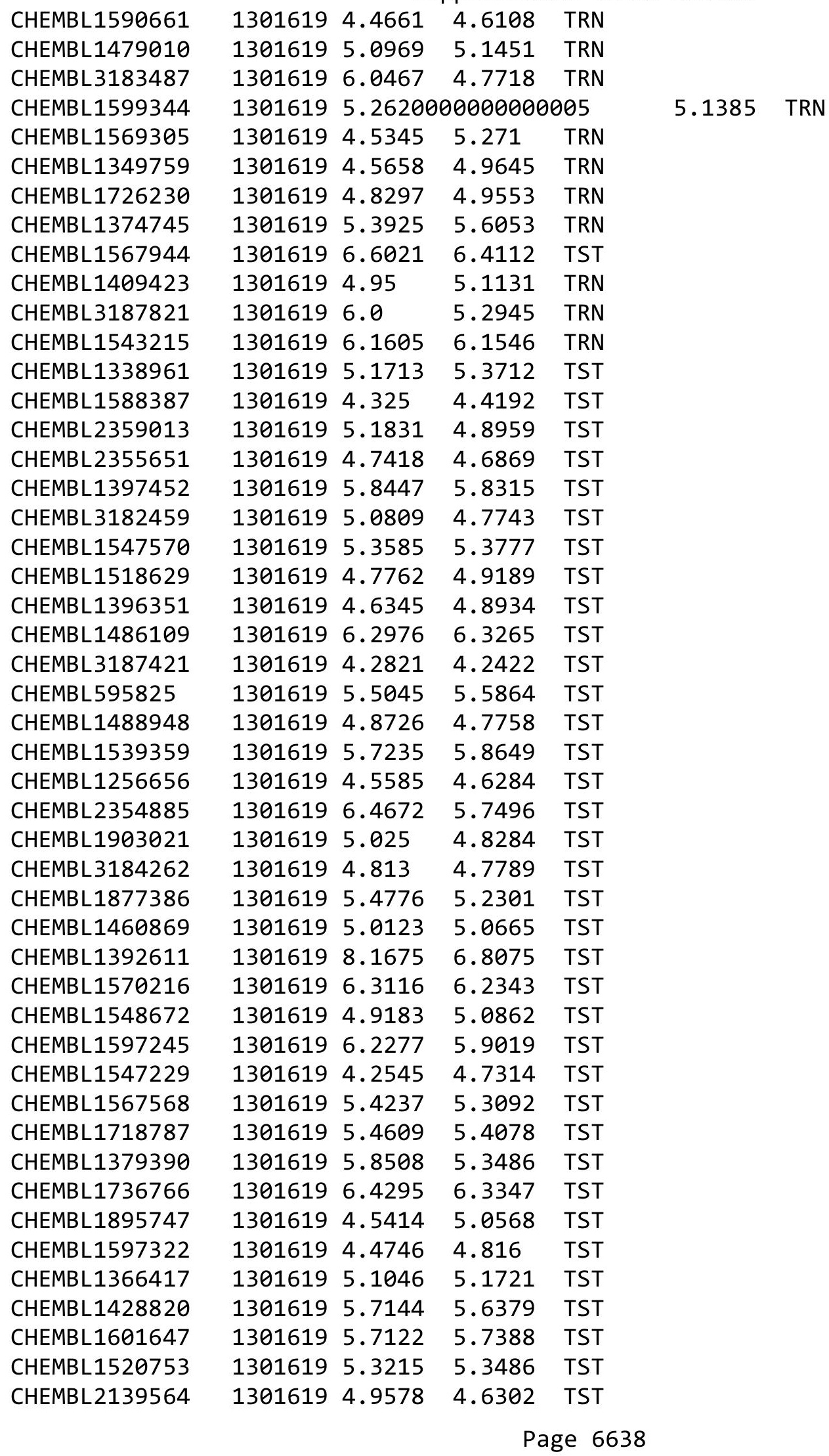


Supplemental Table S2.txt

\begin{tabular}{|c|c|c|c|c|}
\hline CHEMBL1467999 & 1301619 & 4.9796 & 4.9049 & TST \\
\hline CHEMBL1451293 & 1301619 & 5.6536 & 5.7884 & TST \\
\hline CHEMBL1311094 & 1301619 & 6.0106 & 6.0772 & TST \\
\hline CHEMBL1609784 & 1301619 & 4.4652 & 4.6369 & TST \\
\hline CHEMBL1486102 & 1301619 & 4.575 & 4.6727 & TST \\
\hline CHEMBL1734568 & 1301619 & 4.3935 & 4.8221 & TST \\
\hline CHEMBL1569984 & 1301619 & 5.3585 & 5.3177 & TST \\
\hline CHEMBL414890 & 1301619 & 4.5675 & 4.9694 & TST \\
\hline CHEMBL1310496 & 1301619 & 5.1612 & 5.3091 & TST \\
\hline CHEMBL1896333 & 1301619 & 5.6003 & 4.8924 & TST \\
\hline CHEMBL1496788 & 1301619 & 5.224 & 5.0298 & TST \\
\hline CHEMBL3185012 & 1301619 & 4.9374 & 4.5785 & TST \\
\hline CHEMBL1409101 & 1301619 & 5.3778 & 5.0924 & TST \\
\hline CHEMBL1582665 & 1301619 & 5.4828 & 5.5802 & TST \\
\hline CHEMBL1505044 & 1301619 & 5.1035 & 5.1146 & TST \\
\hline CHEMBL1448774 & 1301619 & 5.0297 & 5.0488 & TST \\
\hline CHEMBL1367759 & 1301619 & 5.6819 & 5.7741 & TST \\
\hline CHEMBL1904760 & 1301619 & 5.5436 & 4.8645 & TST \\
\hline CHEMBL1481849 & 1301619 & 4.648 & 4.7474 & TST \\
\hline CHEMBL1502487 & 1301619 & 4.6492 & 4.8172 & TST \\
\hline CHEMBL1408238 & 1301619 & 5.0329 & 5.3759 & TST \\
\hline CHEMBL1572605 & 1301619 & 5.4202 & 5.2375 & TST \\
\hline CHEMBL1456099 & 1301619 & 5.4365 & 5.4835 & TST \\
\hline CHEMBL3188022 & 1301619 & 5.1046 & 5.4096 & TST \\
\hline CHEMBL1493724 & 1301619 & 4.8306 & 4.9133 & TST \\
\hline CHEMBL1606999 & 1301619 & 5.4045 & 5.2589 & TST \\
\hline CHEMBL429335 & 1301619 & 5.4157 & 5.412999 & 9999999999 \\
\hline CHEMBL1542560 & 1301619 & 4.3647 & 5.0326 & TST \\
\hline CHEMBL2362844 & 1301619 & 5.0757 & 4.6434 & TST \\
\hline CHEMBL 3185003 & 1301619 & 4.4259 & 4.7759 & TST \\
\hline CHEMBL1502891 & 1301619 & 5.5918 & 5.5223 & TST \\
\hline CHEMBL1573261 & 1301619 & 5.1487 & 4.9883 & TST \\
\hline CHEMBL1590615 & 1301619 & 4.5745 & 4.7086 & TST \\
\hline CHEMBL1309466 & 1301619 & 5.4089 & 5.2356 & TST \\
\hline CHEMBL1351908 & 1301619 & 8.1675 & 6.7167 & TST \\
\hline CHEMBL1518734 & 1301619 & 4.4099 & 4.3767 & TST \\
\hline CHEMBL1317312 & 1301619 & 4.9974 & 5.1471 & TST \\
\hline CHEMBL3183209 & 1301619 & 6.0 & 4.8501 & TST \\
\hline CHEMBL1502192 & 1301619 & 5.1543 & 5.3789 & TST \\
\hline CHEMBL3194248 & 1301619 & 5.9431 & 5.727 & TST \\
\hline CHEMBL3662775 & 1528724 & 7.2941 & 7.2031 & TRN \\
\hline CHEMBL3913351 & 1528724 & 7.2984 & 7.1879 & TRN \\
\hline CHEMBL3662738 & 1528724 & 6.0 & 7.2225 & TRN \\
\hline CHEMBL3918822 & 1528724 & 7.0899 & 7.2656 & TST \\
\hline CHEMBL3662833 & 1528724 & 6.8729 & 6.9856 & TST \\
\hline CHEMBL3987088 & 1528724 & 7.6144 & 7.6167 & TST \\
\hline CHEMBL3662887 & 1528724 & 7.5045 & 7.1486 & TRN \\
\hline CHEMBL 3662881 & 1528724 & 7.1373 & 7.3846 & TRN \\
\hline
\end{tabular}


Supplemental Table S2.txt

\begin{tabular}{|c|c|c|c|c|c|}
\hline CHEMBL3911119 & 1528724 & 7.1778 & 6.9406 & TRN & \\
\hline CHEMBL3971979 & 1528724 & 7.857 & 7.3514 & TRN & \\
\hline CHEMBL3892774 & 1528724 & 9.0 & 8.8654 & TRN & \\
\hline CHEMBL3915837 & 1528724 & 6.2041 & 7.0265 & TRN & \\
\hline CHEMBL 3662763 & 1528724 & 7.0857 & 7.414 & TRN & \\
\hline CHEMBL3662782 & 1528724 & 7.3354 & 7.022 & TRN & \\
\hline CHEMBL 3662732 & 1528724 & 7.7932 & \multicolumn{2}{|c|}{7.638999999999999} & TRN \\
\hline CHEMBL3639616 & 1528724 & 7.7986 & 7.5085 & TRN & \\
\hline CHEMBL3662739 & 1528724 & 7.5406 & 7.4532 & TRN & \\
\hline CHEMBL3662786 & 1528724 & 7.983 & 7.2497 & TRN & \\
\hline CHEMBL 3662886 & 1528724 & 6.9281 & 7.1465 & TRN & \\
\hline CHEMBL3980006 & 1528724 & 7.8041 & 7.3754 & TRN & \\
\hline CHEMBL 3662791 & 1528724 & 7.0991 & 6.7547 & TST & \\
\hline CHEMBL3662742 & 1528724 & 7.0173 & 7.1341 & TRN & \\
\hline CHEMBL 3662795 & 1528724 & 6.0 & 6.7223 & TRN & \\
\hline CHEMBL3979086 & 1528724 & 7.0453 & 7.1295 & TST & \\
\hline CHEMBL3901971 & 1528724 & 6.7235 & 7.1042 & TST & \\
\hline CHEMBL 3662882 & 1528724 & 8.2588 & 7.7643 & TRN & \\
\hline CHEMBL3933469 & 1528724 & 9.0 & 7.7957 & TRN & \\
\hline CHEMBL 3662889 & 1528724 & 7.5391 & 7.228 & TRN & \\
\hline CHEMBL 3662783 & 1528724 & 7.3019 & 7.2172 & TRN & \\
\hline CHEMBL3969799 & 1528724 & 7.9245 & 8.0295 & TRN & \\
\hline CHEMBL3909087 & 1528724 & 7.3161 & 7.4941 & TRN & \\
\hline CHEMBL3980768 & 1528724 & 7.3862 & 7.6262 & TRN & \\
\hline CHEMBL 3662802 & 1528724 & 7.6925 & 7.5808 & TRN & \\
\hline CHEMBL 3662752 & 1528724 & 6.7423 & 7.1327 & TRN & \\
\hline CHEMBL3945458 & 1528724 & 6.0 & 7.0695 & TRN & \\
\hline CHEMBL3950724 & 1528724 & 7.699 & 7.4571 & TST & \\
\hline CHEMBL3662809 & 1528724 & 7.7011 & 6.8307 & TST & \\
\hline CHEMBL3903217 & 1528724 & 7.1965 & 7.0906 & TRN & \\
\hline CHEMBL3662748 & 1528724 & 6.0 & 7.1587 & TRN & \\
\hline CHEMBL3939506 & 1528724 & 7.3242 & 8.1574 & TST & \\
\hline CHEMBL3975219 & 1528724 & 7.3325 & 7.1531 & TRN & \\
\hline CHEMBL3967714 & 1528724 & 7.5918 & 7.9259 & TRN & \\
\hline CHEMBL3662754 & 1528724 & 7.4855 & 7.6684 & TRN & \\
\hline CHEMBL3929905 & 1528724 & 7.9508 & 7.6344 & TST & \\
\hline CHEMBL3662753 & 1528724 & 7.426 & 7.8002 & TRN & \\
\hline CHEMBL3982845 & 1528724 & 7.2832 & 7.4424 & TRN & \\
\hline CHEMBL3662813 & 1528724 & 7.8894 & 7.0648 & TST & \\
\hline CHEMBL3926605 & 1528724 & 7.6498 & 7.4763 & TRN & \\
\hline CHEMBL3662838 & 1528724 & 7.2083 & 7.13200 & 3000000001 & TRN \\
\hline CHEMBL3938864 & 1528724 & 8.0405 & 7.2608 & TRN & \\
\hline CHEMBL 3662890 & 1528724 & 7.2321 & 7.2134 & TRN & \\
\hline CHEMBL3662831 & 1528724 & 6.0 & 6.9178 & TST & \\
\hline CHEMBL3942264 & 1528724 & 7.6021 & 7.3375 & TRN & \\
\hline CHEMBL3975930 & 1528724 & 7.1733 & 6.7403 & TST & \\
\hline CHEMBL 3662781 & 1528724 & 7.1688 & 7.1445 & TRN & \\
\hline CHEMBL3658627 & 1528724 & 6.7282 & 6.6216 & TRN & \\
\hline
\end{tabular}


Supplemental Table S2.txt

\begin{tabular}{|c|c|c|c|c|}
\hline HEMBL & & 18 & 1 & \\
\hline HFMRI 3016795 & 528724 & 7.4318 & 7.5599 & \\
\hline HEMBL & & & & \\
\hline AEMBL3662814 & 528724 & 0773 & 1312 & \\
\hline HEMBL3940515 & 528724 & 6.8827 & 9317 & \\
\hline HEMBL & 3724 & 7.2262 & 1346 & \\
\hline AEMBL3 & 3724 & 7.8928 & & \\
\hline HEMBL36 & 8724 & 8.5157 & & \\
\hline HEMBL3890775 & 528724 & 36 & 2626 & \\
\hline HEMBL3943487 & 528724 & 7.5214 & 9853 & \\
\hline HEMBL39 & 528724 & 7.8761 & 35 & \\
\hline HEMBL3 & & & & \\
\hline HEMBL3S & 528724 & & & \\
\hline HEMBL 397 & 724 & & 5237 & \\
\hline HEMBL366 & 528724 & & 13 & \\
\hline AEMBL & 24 & & 52 & \\
\hline HEMBL; & & & & \\
\hline HEMBL3S & 724 & 6 . & 306 & \\
\hline HEMBL36 & & & & \\
\hline HEMBL396 & 24 & 6. & 58 & I RIV \\
\hline IEMBL3 & 24 & & & RN \\
\hline IEMBL & & & & NIV \\
\hline HEMBL & 24 & & & \\
\hline HEMBL & & & & \\
\hline AEMBL3S & 24 & 7. & 68 & RN \\
\hline AEMBL3 & & & & $\mathrm{RN}$ \\
\hline AEME & & & & ST \\
\hline 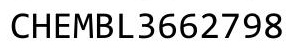 & & & & \\
\hline AEMBL & & & & 5 \\
\hline AEMBL36 & 24 & 6 . & 368 & $\mathrm{RN}$ \\
\hline FMBL & 24 & & 35 & ST \\
\hline 1 & & & & RN \\
\hline & & & & TST \\
\hline AEMBL36 & & & & RN \\
\hline HEMBL 366 & 724 & & 766 & RN \\
\hline AFMRI 3 & 4 & & 16 & ST \\
\hline & & & & RN \\
\hline HEMBL3 & & & & ГST \\
\hline HEMBL 391 & 528724 & & & 「RN \\
\hline EMBL: & 24 & & & RN \\
\hline HEMBL3 & 24 & & 953 & RIV \\
\hline HEMBL3 & & & & $\mathrm{RN}$ \\
\hline HEMBL36 & & & 937 & RN \\
\hline HEMBL 366 & 24 & 7. & & TR \\
\hline EBL3 & & & & \\
\hline HEMBL 398 & - & & 7.2307 & \\
\hline CHEMBL 366 & .528724 & & 7.4424 & \\
\hline CHEMBL3662755 & 1528724 & 7.3429 & 7.184 & rRN \\
\hline
\end{tabular}

Page 6641 
Supplemental Table S2.txt

\begin{tabular}{|c|c|c|c|c|c|}
\hline CHEMBL 3662767 & 1528724 & 7.3019 & 7.3985 & TRN & \\
\hline CHEMBL 3662729 & 1528724 & 6.0 & 7.2585 & TRN & \\
\hline CHEMBL 3662762 & 1528724 & 7.1624 & 7.4925 & TRN & \\
\hline CHEMBL 3935401 & 1528724 & 7.1057 & 6.9362 & TRN & \\
\hline CHEMBL3915428 & 1528724 & 9.0 & 8.0282 & TRN & \\
\hline CHEMBL 3662788 & 1528724 & 7.857 & 7.4302 & TRN & \\
\hline CHEMBL 3662756 & 1528724 & 7.1681 & 7.0508 & TRN & \\
\hline CHEMBL 3955466 & 1528724 & 7.4935 & 7.4238 & TST & \\
\hline CHEMBL3900638 & 1528724 & 7.6635 & 7.4022 & TRN & \\
\hline CHEMBL3662832 & 1528724 & 7.6536 & 7.1802 & TRN & \\
\hline CHEMBL 3662768 & 1528724 & $6.7520 e$ & 000000000 & 7.0335 & TRN \\
\hline CHEMBL3662815 & 1528724 & 6.9626 & 7.1388 & TRN & \\
\hline CHEMBL 3662780 & 1528724 & 7.6716 & 7.3912 & TRN & \\
\hline CHEMBL3924054 & 1528724 & 6.9666 & 7.0801 & TRN & \\
\hline CHEMBL 3658622 & 1528724 & 7.5346 & 7.3959 & TRN & \\
\hline CHEMBL 3945630 & 1528724 & 7.5421 & 7.4352 & TST & \\
\hline CHEMBL3662733 & 1528724 & 7.52 & 7.5374 & TRN & \\
\hline CHEMBL 3971887 & 1528724 & 7.3251 & 7.4664 & TRN & \\
\hline CHEMBL3662731 & 1528724 & 6.9469 & 7.2433 & TRN & \\
\hline CHEMBL 3923522 & 1528724 & 7.3625 & 7.124 & TRN & \\
\hline CHEMBL 3954242 & 1528724 & 6.0 & 7.4394 & TRN & \\
\hline CHEMBL 3899596 & 1528724 & 9.0 & 8.8881 & TRN & \\
\hline CHEMBL3911087 & 1528724 & 7.2782 & 7.8015 & TRN & \\
\hline CHEMBL3937787 & 1528724 & 7.0195 & 6.8693 & TRN & \\
\hline CHEMBL 3662796 & 1528724 & 7.1302 & 6.8422 & TST & \\
\hline CHEMBL 3980068 & 1528724 & 7.4547 & 7.093 & TST & \\
\hline CHEMBL3965116 & 1528724 & 7.8928 & 7.5506 & TRN & \\
\hline CHEMBL 3662737 & 1528724 & 7.5391 & 7.3129 & TRN & \\
\hline CHEMBL3904705 & 1528724 & 7.7545 & 7.763 & TRN & \\
\hline CHEMBL 3917094 & 1528724 & 6.0 & 7.0569 & TRN & \\
\hline CHEMBL 3662792 & 1528724 & 6.8894 & 6.8516 & TRN & \\
\hline CHEMBL 3658628 & 1528724 & 6.9066 & 6.883999 & & TRN \\
\hline CHEMBL 3662727 & 1528724 & 7.1314 & 7.2577 & TRN & \\
\hline CHEMBL3971796 & 1528724 & 7.4112 & 7.4617 & TRN & \\
\hline CHEMBL 3662793 & 1528724 & 6.0 & 7.0193 & TRN & \\
\hline CHEMBL 3662773 & 1528724 & 7.767 & 7.4579 & TRN & \\
\hline CHEMBL3941144 & 1528724 & $6.7520 e$ & 000000000 & 7.5168 & TRN \\
\hline CHEMBL 3662855 & 1528724 & 6.0 & 6.9562 & TST & \\
\hline CHEMBL3947241 & 1528724 & 7.8239 & 7.9198 & TRN & \\
\hline CHEMBL 3662746 & 1528724 & 7.0343 & 7.2084 & TRN & \\
\hline CHEMBL 3662789 & 1528724 & 7.109 & 7.3468 & TRN & \\
\hline CHEMBL 3662734 & 1528724 & 7.0391 & 7.1188 & TRN & \\
\hline CHEMBL3662891 & 1528724 & 6.8697 & 7.06 & TRN & \\
\hline CHEMBL3942662 & 1528724 & 9.0 & 8.3355 & TRN & \\
\hline CHEMBL 3662750 & 1528724 & 7.857 & 7.3188 & TRN & \\
\hline CHEMBL3941605 & 1528724 & 9.0 & 7.4284 & TST & \\
\hline CHEMBL3936881 & 1528724 & 9.0 & 7.8828 & TST & \\
\hline CHEMBL3658624 & 1528724 & 7.4342 & 7.5094 & TRN & \\
\hline
\end{tabular}


Supplemental Table S2.txt

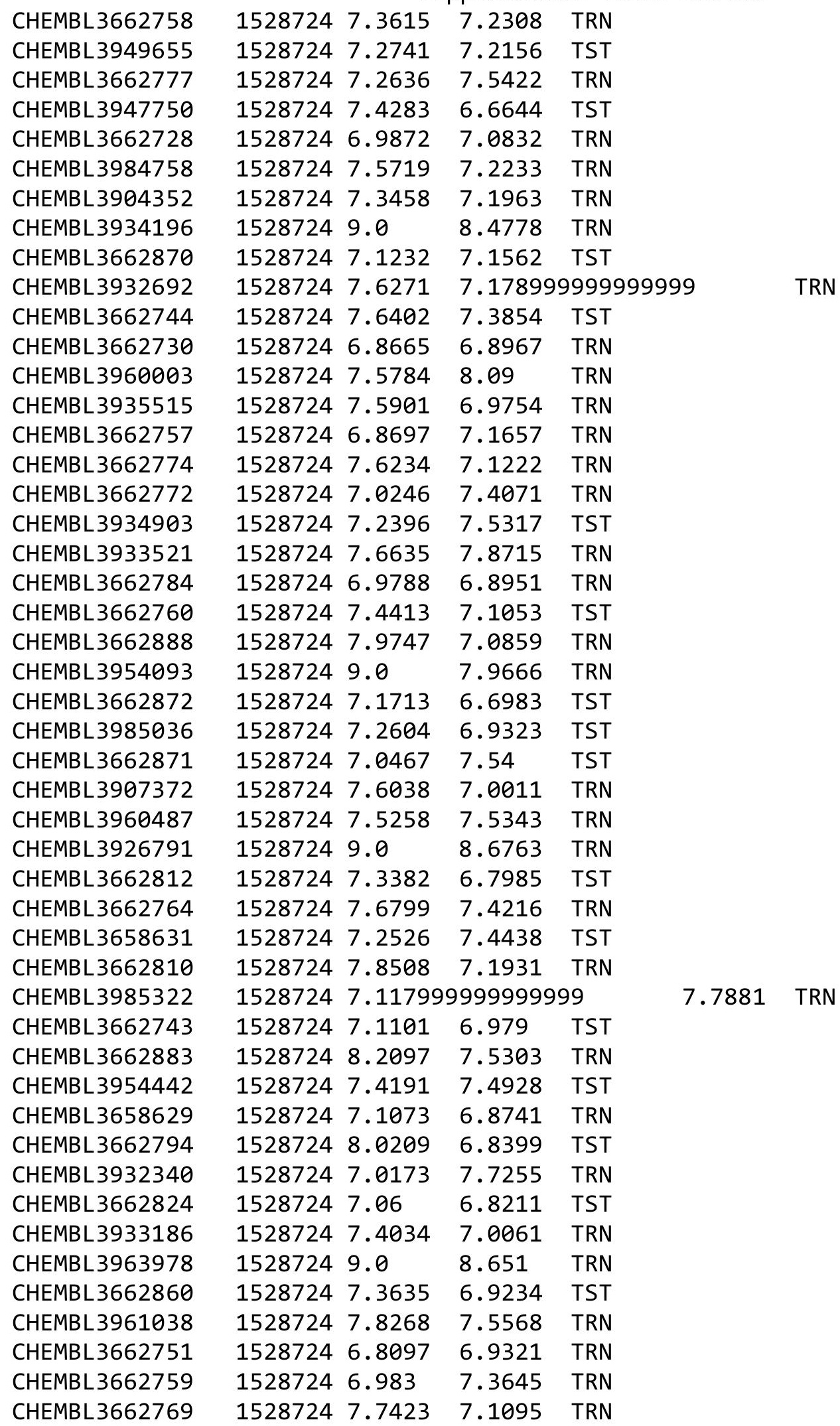

Page 6643 
Supplemental Table S2.txt

\begin{tabular}{|c|c|c|c|c|c|}
\hline CHEMBL 3662839 & 1528724 & 8.0665 & 6.9592 & TST & \\
\hline CHEMBL3936555 & 1528724 & 7.6459 & 7.6519 & TRN & \\
\hline CHEMBL3935627 & 1528724 & 7.699 & 7.4125 & TST & \\
\hline CHEMBL 3662811 & 1528724 & 6.8297 & 7.1455 & TST & \\
\hline CHEMBL3979969 & 1528724 & 7.7055 & 7.5842 & TRN & \\
\hline CHEMBL 3964124 & 1528724 & 7.6198 & 8.3533 & TRN & \\
\hline CHEMBL 3912065 & 1528724 & 7.5702 & 7.5343 & TRN & \\
\hline CHEMBL3968028 & 1528724 & 7.2907 & 7.4595 & TST & \\
\hline CHEMBL 3896223 & 1528724 & 7.1618 & 7.2502 & TST & \\
\hline CHEMBL3942286 & 1528724 & 7.5045 & 7.6129 & TRN & \\
\hline CHEMBL 3929842 & 1528724 & 7.1599 & 7.2575 & TRN & \\
\hline CHEMBL 3658630 & 1528724 & 6.7986 & 7.3007 & TST & \\
\hline CHEMBL 3967485 & 1528724 & 7.9136 & 8.7374 & TRN & \\
\hline CHEMBL3919962 & 1528724 & 7.1439 & 6.9193 & TST & \\
\hline CHEMBL 3662771 & 1528724 & 7.4522 & 7.2899 & TRN & \\
\hline CHEMBL 3951257 & 1528724 & 7.5884 & 7.6254 & TRN & \\
\hline CHEMBL 3662801 & 1528724 & 7.6925 & 7.6726 & TRN & \\
\hline CHEMBL 3658625 & 1528724 & 6.8356 & 6.9268 & TST & \\
\hline CHEMBL 3906555 & 1528724 & 6.9318 & 7.6554 & TRN & \\
\hline CHEMBL 3662800 & 1528724 & 6.9706 & 7.1913 & TRN & \\
\hline CHEMBL 3662761 & 1528724 & 7.1838 & 7.7941 & TRN & \\
\hline CHEMBL3957856 & 1528724 & 8.7696 & 8.4352 & TRN & \\
\hline CHEMBL 3662834 & 1528724 & 6.8069 & 6.8737 & TST & \\
\hline CHEMBL 3925633 & 1528724 & 7.4776 & 7.5297 & TRN & \\
\hline CHEMBL3662779 & 1528724 & 7.6144 & 7.5554 & TRN & \\
\hline CHEMBL3662776 & 1528724 & 7.1844 & 7.0682 & TRN & \\
\hline CHEMBL3914445 & 1528724 & 7.3307 & 7.9202 & TRN & \\
\hline CHEMBL 3662797 & 1528724 & 7.4908 & 7.4176 & TRN & \\
\hline CHEMBL3921008 & 1528724 & 7.8508 & 7.6148 & TST & \\
\hline CHEMBL3966622 & 1528724 & 8.3799 & 7.7136 & TST & \\
\hline CHEMBL3662749 & 1528724 & 6.7545 & 6.9907 & TRN & \\
\hline CHEMBL3960668 & 1528724 & 7.6108 & 7.2848 & TST & \\
\hline CHEMBL 3662885 & 1528724 & 7.9031 & 7.6211 & TRN & \\
\hline CHEMBL 3662765 & 1528724 & 6.8268 & 7.0932 & TRN & \\
\hline CHEMBL3985199 & 1528724 & 7.1733 & 7.8072 & TST & \\
\hline CHEMBL 212595 & 382037 & 6.0 & 6.0669 & TRN & \\
\hline CHEMBL 213828 & 382037 & 6.0 & 5.9385 & TRN & \\
\hline CHEMBL213398 & 382037 & 6.857 & 6.6067 & TRN & \\
\hline CHEMBL376639 & 382037 & 6.7852 & 6.4498 & TRN & \\
\hline CHEMBL 209759 & 382037 & 6.0 & \multicolumn{2}{|c|}{5.707000000000001} & TRN \\
\hline CHEMBL 212298 & 382037 & 8.6383 & 7.1339 & TRN & \\
\hline CHEMBL 212545 & 382037 & 7.3054 & 7.1268 & TRN & \\
\hline CHEMBL212188 & 382037 & 7.767 & 7.2643 & TRN & \\
\hline CHEMBL437493 & 382037 & 6.0 & 6.5582 & TRN & \\
\hline CHEMBL 214190 & 382037 & 8.0506 & 6.9663 & TRN & \\
\hline CHEMBL212831 & 382037 & 6.4949 & 6.4499 & TRN & \\
\hline CHEMBL 212073 & 382037 & 6.0 & 5.7537 & TRN & \\
\hline CHEMBL211972 & 382037 & 6.0 & 7.0164 & TRN & \\
\hline
\end{tabular}




\begin{tabular}{|c|c|c|c|c|c|}
\hline \multicolumn{6}{|c|}{ Supplemental Table S2.txt } \\
\hline CHEMBL211831 & 382037 & 6.2175 & 5.7656 & TST & \\
\hline CHEMBL 215704 & 382037 & 6.4597 & 5.9003 & TRN & \\
\hline CHEMBL385350 & 382037 & 6.0 & 7.0452 & TRN & \\
\hline CHEMBL384529 & 382037 & 6.3233 & 6.5223 & TRN & \\
\hline CHEMBL212236 & 382037 & 6.0 & 5.6728 & TRN & \\
\hline CHEMBL 212782 & 382037 & 6.0 & 6.3565 & TRN & \\
\hline CHEMBL 211985 & 382037 & 7.3391 & 6.966 & TRN & \\
\hline CHEMBL 378302 & 382037 & 6.9101 & 6.1697 & TST & \\
\hline CHEMBL 377794 & 382037 & 6.0 & 6.0984 & TRN & \\
\hline CHEMBL 213097 & 382037 & 6.0 & 5.5623 & TST & \\
\hline CHEMBL 211623 & 382037 & 6.0 & 6.49299 & 9999999999 & TST \\
\hline CHEMBL 377050 & 382037 & 6.0 & 6.0628 & TRN & \\
\hline CHEMBL 212902 & 382037 & 7.5086 & 6.9892 & TRN & \\
\hline CHEMBL 213004 & 382037 & 6.3382 & 5.7592 & TST & \\
\hline CHEMBL45244 & 382037 & 8.0809 & 7.1711 & TST & \\
\hline CHEMBL386867 & 382037 & 7.3125 & 6.5775 & TRN & \\
\hline CHEMBL211463 & 382037 & 6.0 & 6.9455 & TST & \\
\hline CHEMBL209447 & 382037 & 6.0 & 6.8815 & TRN & \\
\hline CHEMBL 215670 & 382037 & 6.0 & 7.2751 & TRN & \\
\hline CHEMBL 377023 & 382037 & 6.2111 & 6.3287 & TRN & \\
\hline CHEMBL 212969 & 382037 & 6.0 & 6.0344 & TRN & \\
\hline CHEMBL 2113243 & 382037 & 6.0 & 5.8672 & TST & \\
\hline CHEMBL213518 & 382037 & 6.0 & 7.0675 & TRN & \\
\hline CHEMBL 212847 & 382037 & 7.8827 & 7.512006 & 30000000005 & TRN \\
\hline CHEMBL426510 & 382037 & 6.0 & 6.3033 & TRN & \\
\hline CHEMBL 214247 & 382037 & 6.0 & 5.6877 & TST & \\
\hline CHEMBL 377388 & 382037 & 7.0872 & 6.4466 & TRN & \\
\hline CHEMBL411545 & 382037 & 5.5719 & 5.2905 & TRN & \\
\hline CHEMBL 214203 & 382037 & 4.0 & 4.9099 & TRN & \\
\hline CHEMBL215569 & 382037 & 6.0 & 5.7516 & TRN & \\
\hline CHEMBL376955 & 382037 & 7.4815 & 6.8851 & TRN & \\
\hline CHEMBL 213700 & 382037 & 6.4559 & 6.6374 & TRN & \\
\hline CHEMBL379597 & 382037 & 6.5969 & 6.3336 & TRN & \\
\hline CHEMBL 212444 & 382037 & 6.0 & 5.8474 & TRN & \\
\hline CHEMBL212292 & 382037 & 6.0 & 5.6272 & TRN & \\
\hline CHEMBL 211360 & 382037 & 5.4935 & 5.7453 & TST & \\
\hline CHEMBL437687 & 382037 & 6.0 & 5.8878 & TRN & \\
\hline CHEMBL 214954 & 382037 & 6.0 & 6.6465 & TRN & \\
\hline CHEMBL 378576 & 382037 & 6.0 & 5.8546 & TRN & \\
\hline CHEMBL215849 & 382037 & 6.0 & 6.6749 & TRN & \\
\hline CHEMBL 213246 & 382037 & 6.9626 & 6.0298 & TRN & \\
\hline CHEMBL 213106 & 382037 & 7.7167 & 6.9343 & TRN & \\
\hline CHEMBL 212861 & 382037 & 6.0 & 6.2766 & TRN & \\
\hline CHEMBL 212075 & 382037 & 4.0 & 6.1025 & TRN & \\
\hline CHEMBL 211732 & 382037 & 6.0 & 6.0974 & TRN & \\
\hline CHEMBL 377585 & 382037 & 6.0 & 5.9425 & TRN & \\
\hline CHEMBL212189 & 382037 & 7.9245 & 6.9097 & TST & \\
\hline CHEMBL 212288 & 382037 & 6.6861 & 5.7245 & TST & \\
\hline
\end{tabular}




\begin{tabular}{|c|c|c|c|c|c|}
\hline & & \multicolumn{4}{|c|}{ Supplemental Table s2.txt } \\
\hline CHEMBL212291 & 382037 & 7.4776 & 6.1729 & TST & \\
\hline CHEMBL 213208 & 382037 & 6.0 & 5.7525 & TST & \\
\hline CHEMBL261957 & 382037 & 6.4179 & 6.2138 & TST & \\
\hline CHEMBL 212607 & 382037 & 6.4711 & 5.631 & TST & \\
\hline CHEMBL212901 & 382037 & 5.3224 & 6.4521 & TST & \\
\hline CHEMBL 201084 & 465974 & 7.42 & 8.0585 & TST & \\
\hline CHEMBL270159 & 465974 & 5.21 & 5.2226 & TRN & \\
\hline CHEMBL 270158 & 465974 & 5.16 & 5.1479 & TRN & \\
\hline CHEMBL 272508 & 465974 & 4.38 & 4.3665 & TRN & \\
\hline CHEMBL403884 & 465974 & 4.7 & 4.6853 & TRN & \\
\hline CHEMBL 255773 & 465974 & 5.2 & 5.1947 & TRN & \\
\hline CHEMBL 255774 & 465974 & 4.89 & 4.9205 & TRN & \\
\hline CHEMBL 255156 & 465974 & 4.49 & 4.9405 & TST & \\
\hline CHEMBL401592 & 465974 & 5.52 & 5.5585 & TRN & \\
\hline CHEMBL 270389 & 465974 & 5.4 & 5.3819 & TRN & \\
\hline CHEMBL403538 & 465974 & 5.4 & 5.1806 & TST & \\
\hline CHEMBL 255364 & 465974 & 7.4 & 5.5727 & TST & \\
\hline CHEMBL 255363 & 465974 & 6.8 & 6.0396 & TST & \\
\hline CHEMBL402395 & 465974 & 5.4 & 4.5529 & TST & \\
\hline CHEMBL402394 & 465974 & 5.2 & 5.3456 & TST & \\
\hline CHEMBL 255562 & 465974 & 4.8 & 4.82 & TRN & \\
\hline CHEMBL 271893 & 465974 & 6.0 & 5.9903 & TRN & \\
\hline CHEMBL 273200 & 465974 & 4.5 & 4.5 & TRN & \\
\hline CHEMBL429753 & 465974 & 5.0 & 4.9739 & TRN & \\
\hline CHEMBL199409 & 465974 & 8.96 & 8.9144 & TRN & \\
\hline CHEMBL203420 & 465974 & 9.0 & 9.1255 & TRN & \\
\hline CHEMBL198347 & 465974 & 9.05 & 9.0123 & TRN & \\
\hline CHEMBL271451 & 465974 & 6.85 & 6.876 & TRN & \\
\hline CHEMBL201343 & 465974 & 8.44 & 8.4556 & TRN & \\
\hline CHEMBL203313 & 465974 & 8.21 & 8.1775 & TRN & \\
\hline CHEMBL382630 & 465974 & 7.03 & 7.0326 & TRN & \\
\hline CHEMBL201485 & 465974 & 8.48 & 8.4333 & TRN & \\
\hline CHEMBL427200 & 465974 & 6.43 & 6.4418 & TRN & \\
\hline CHEMBL199328 & 465974 & 8.82 & 8.8101 & TRN & \\
\hline CHEMBL382269 & 465974 & 7.36 & 7.3448 & TRN & \\
\hline CHEMBL427371 & 465974 & 8.3 & 8.3004 & TRN & \\
\hline CHEMBL383375 & 465974 & 6.81 & 6.7841 & TRN & \\
\hline CHEMBL 372818 & 465974 & 7.0 & 7.0337 & TRN & \\
\hline CHEMBL202822 & 465974 & 7.03 & 7.0369 & TRN & \\
\hline CHEMBL198398 & 465974 & 8.3 & 8.26100 & 0000000001 & TRN \\
\hline CHEMBL201527 & 465974 & 8.15 & 8.1517 & TRN & \\
\hline CHEMBL201793 & 465974 & 8.52 & 8.43 & TRN & \\
\hline CHEMBL426480 & 465974 & 8.22 & 8.2946 & TRN & \\
\hline CHEMBL201372 & 465974 & 7.14 & 6.3717 & TST & \\
\hline CHEMBL382644 & 465974 & 7.17 & 7.3142 & TST & \\
\hline CHEMBL199506 & 465974 & 8.22 & 8.1948 & TRN & \\
\hline CHEMBL199539 & 465974 & 8.7 & 8.7389 & TRN & \\
\hline CHEMBL275658 & 465974 & 8.7 & 8.6993 & TRN & \\
\hline
\end{tabular}




\begin{tabular}{|c|c|c|c|c|}
\hline \multirow[b]{2}{*}{ CHEMBL257667 } & \multicolumn{4}{|c|}{ Supplemental Table S2.tx } \\
\hline & 465974 & 7.8 & 7.8028 & TRN \\
\hline CHEMBL202929 & 465974 & 8.4 & 8.4165 & TRN \\
\hline CHEMBL202663 & 465974 & 8.4 & 8.4093 & TRN \\
\hline CHEMBL201526 & 465974 & 8.05 & 8.2642 & TST \\
\hline CHEMBL201352 & 465974 & 7.02 & 8.2856 & TST \\
\hline CHEMBL 200988 & 465974 & 6.96 & 8.3759 & TST \\
\hline CHEMBL203425 & 465974 & 6.8 & 7.0702 & TST \\
\hline CHEMBL3918857 & 1640745 & 6.4462 & 6.8002 & TST \\
\hline CHEMBL 3895049 & 1640745 & 7.9031 & 7.6453 & TRN \\
\hline CHEMBL3984929 & 1640745 & 8.0605 & 8.394 & TRN \\
\hline CHEMBL3931287 & 1640745 & 6.6383 & 7.0073 & TRN \\
\hline CHEMBL3909934 & 1640745 & 8.1871 & 7.8762 & TRN \\
\hline CHEMBL3701037 & 1640745 & 7.8386 & 7.6584 & TRN \\
\hline CHEMBL 3956266 & 1640745 & 7.9066 & 8.2574 & TRN \\
\hline CHEMBL3918450 & 1640745 & 7.9666 & 7.9757 & TRN \\
\hline CHEMBL3911120 & 1640745 & 7.7423 & 8.1435 & TRN \\
\hline CHEMBL3701036 & 1640745 & 4.0 & 4.8796 & TRN \\
\hline CHEMBL3946689 & 1640745 & 5.6242 & 6.3503 & TST \\
\hline CHEMBL 3971620 & 1640745 & 8.0269 & 7.8746 & TRN \\
\hline CHEMBL3945718 & 1640745 & 7.1824 & 7.3927 & TRN \\
\hline CHEMBL3910693 & 1640745 & 8.0269 & 8.1382 & TRN \\
\hline CHEMBL3701038 & 1640745 & 6.6126 & 5.8432 & TRN \\
\hline CHEMBL3979717 & 1640745 & 7.4157 & 7.6103 & TST \\
\hline CHEMBL3701033 & 1640745 & 8.1739 & 8.4316 & TRN \\
\hline CHEMBL3909279 & 1640745 & 8.4685 & 8.1499 & TRN \\
\hline CHEMBL3909511 & 1640745 & 7.4776 & 7.6983 & TST \\
\hline CHEMBL3937573 & 1640745 & 7.1163 & 7.519 & TRN \\
\hline CHEMBL3964569 & 1640745 & 7.5229 & 7.4044 & TRN \\
\hline CHEMBL3961483 & 1640745 & 6.0 & 5.5513 & TRN \\
\hline CHEMBL3701041 & 1640745 & 8.5376 & 8.407 & TRN \\
\hline CHEMBL3947443 & 1640745 & 6.4772 & 6.8938 & TRN \\
\hline CHEMBL3701034 & 1640745 & 7.9208 & 8.2444 & TRN \\
\hline CHEMBL3701032 & 1640745 & 7.8894 & 8.1863 & TRN \\
\hline CHEMBL 3908410 & 1640745 & 8.3665 & 8.4059 & TRN \\
\hline CHEMBL3893981 & 1640745 & 7.7721 & 7.9122 & TRN \\
\hline CHEMBL3941351 & 1640745 & 7.8447 & 7.6047 & TRN \\
\hline CHEMBL3933289 & 1640745 & 8.1367 & 7.7966 & TRN \\
\hline CHEMBL3940475 & 1640745 & 8.041 & 8.1615 & TRN \\
\hline CHEMBL3360855 & 1640745 & 7.0223 & 7.1849 & TST \\
\hline CHEMBL 3942268 & 1640745 & 7.8125 & 8.052 & TRN \\
\hline CHEMBL3971862 & 1640745 & 8.1024 & 8.0694 & TRN \\
\hline CHEMBL3916086 & 1640745 & 7.4584 & 7.4777 & TRN \\
\hline CHEMBL3701042 & 1640745 & 8.3279 & 8.1878 & TST \\
\hline CHEMBL3916617 & 1640745 & 8.6778 & 8.0762 & TRN \\
\hline CHEMBL3701043 & 1640745 & 9.0458 & 8.6491 & TST \\
\hline CHEMBL418052 & 1640745 & 5.1606 & 5.0122 & TST \\
\hline CHEMBL3925098 & 1640745 & 7.1457 & 7.3084 & TRN \\
\hline CHEMBL3949741 & 1640745 & 8.0 & 7.7388 & TRN \\
\hline
\end{tabular}


Supplemental Table S2.txt

\begin{tabular}{|c|c|c|c|c|}
\hline CHEMBL3769849 & 1640745 & 6.585 & 6.6783 & TST \\
\hline CHEMBL3963830 & 1640745 & 8.6021 & 7.8181 & TRN \\
\hline CHEMBL3939074 & 1640745 & 8.0555 & 7.8754 & TRN \\
\hline CHEMBL3701005 & 1640745 & 8.8539 & 8.4435 & TST \\
\hline CHEMBL3946376 & 1640745 & 6.8794 & 6.8639 & TST \\
\hline CHEMBL3701035 & 1640745 & 7.8729 & 7.3721 & TST \\
\hline CHEMBL 3942740 & 1640745 & 6.0 & 5.9415 & TRN \\
\hline CHEMBL 3770184 & 1640745 & 7.6517 & \multicolumn{2}{|c|}{7.8839999999999995} \\
\hline CHEMBL3938638 & 1640745 & 8.2147 & 8.3161 & TRN \\
\hline CHEMBL3960416 & 1641702 & 10.2596 & 10.4597 & TRN \\
\hline CHEMBL3962448 & 1641702 & 10.2596 & 9.8609 & TRN \\
\hline CHEMBL3932349 & 1641702 & 10.2596 & 9.5818 & TST \\
\hline CHEMBL3890208 & 1641702 & 10.2596 & 10.2837 & TST \\
\hline CHEMBL3906692 & 1641702 & 10.2596 & 9.2845 & TRN \\
\hline CHEMBL3928129 & 1641702 & 9.2596 & 10.0071 & TRN \\
\hline CHEMBL3952555 & 1641702 & 10.2596 & 9.6383 & TRN \\
\hline CHEMBL3902351 & 1641702 & 10.2596 & 9.686 & TRN \\
\hline CHEMBL3921320 & 1641702 & 10.2596 & 9.5763 & TRN \\
\hline CHEMBL3911346 & 1641702 & 10.2596 & 9.5011 & TST \\
\hline CHEMBL3965713 & 1641702 & 9.2596 & 9.7099 & TRN \\
\hline CHEMBL3958078 & 1641702 & 9.2596 & 9.0255 & TST \\
\hline CHEMBL3985350 & 1641702 & 9.2596 & 9.7708 & TRN \\
\hline CHEMBL3955948 & 1641702 & 10.2596 & 9.8044 & TRN \\
\hline CHEMBL3906885 & 1641702 & 10.2596 & 9.6357 & TRN \\
\hline CHEMBL3960213 & 1641702 & 9.2596 & 9.577 & TRN \\
\hline CHEMBL3930750 & 1641702 & 10.2596 & 9.7165 & TRN \\
\hline CHEMBL3955368 & 1641702 & 6.0 & 6.7354 & TRN \\
\hline CHEMBL3959421 & 1641702 & 7.2596 & 7.2125 & TRN \\
\hline CHEMBL3973113 & 1641702 & 9.2596 & 9.0817 & TRN \\
\hline CHEMBL 3893327 & 1641702 & 10.2596 & 10.4503 & TRN \\
\hline CHEMBL3913608 & 1641702 & 9.2596 & 9.8212 & TRN \\
\hline CHEMBL3937204 & 1641702 & 10.2596 & 10.0305 & TRN \\
\hline CHEMBL3896837 & 1641702 & 10.2596 & 9.6791 & TST \\
\hline CHEMBL3924625 & 1641702 & 9.2596 & 9.6142 & TRN \\
\hline CHEMBL 3891047 & 1641702 & 9.2596 & 9.9435 & TRN \\
\hline CHEMBL3942396 & 1641702 & 9.2596 & 9.4413 & TST \\
\hline CHEMBL3973848 & 1641702 & 10.2596 & 9.8067 & TRN \\
\hline CHEMBL3910166 & 1641702 & 9.2596 & 9.6972 & TST \\
\hline CHEMBL3948378 & 1641702 & 10.2596 & 9.7842 & TRN \\
\hline CHEMBL3920398 & 1641702 & 9.2596 & 9.5063 & TRN \\
\hline CHEMBL3983040 & 1641702 & 9.2596 & 9.5654 & TRN \\
\hline CHEMBL3934942 & 1641702 & 10.2596 & 9.8729 & TRN \\
\hline CHEMBL3903286 & 1641702 & 10.2596 & 9.4581 & TST \\
\hline CHEMBL3965889 & 1641702 & 9.2596 & 9.4272 & TST \\
\hline CHEMBL 3902542 & 1641702 & 10.2596 & 9.6223 & TRN \\
\hline CHEMBL3968579 & 1641702 & 9.2596 & 9.7149 & TRN \\
\hline CHEMBL3968478 & 1641702 & 9.2596 & 9.657 & TST \\
\hline CHEMBL3913220 & 1641702 & 10.2596 & 9.6765 & TST \\
\hline
\end{tabular}

TST 
Supplemental Table S2.txt

CHEMBL 3926930

CHEMBL 3930305

CHEMBL3982307

CHEMBL 3937835

CHEMBL 3945908

CHEMBL 3975430

CHEMBL3951623

CHEMBL 3890611

CHEMBL3949963

CHEMBL3926059

CHEMBL 3935988

CHEMBL3969009

CHEMBL3952191

CHEMBL3906422

CHEMBL3909435

CHEMBL3937439

CHEMBL3920484

CHEMBL 3925605

CHEMBL 3975440

CHEMBL 3980318

CHEMBL3925815

CHEMBL 3943618

CHEMBL 3933796

CHEMBL 3900044

CHEMBL 3974254

CHEMBL 3954558

CHEMBL3904624

CHEMBL3914739

CHEMBL 3955757

CHEMBL3940099

CHEMBL3959909

CHEMBL 3905754

CHEMBL 3951178

CHEMBL3909092

CHEMBL3911946

CHEMBL3942728

CHEMBL 3953590

CHEMBL 3959358

CHEMBL3933735

CHEMBL3979629

CHEMBL3949972

CHEMBL3981902

CHEMBL3899672

CHEMBL 3961850

CHEMBL3977452

CHEMBL 3961670

CHEMBL3946118

CHEMBL 3959770

$\begin{array}{lll}1641702 & 10.2596 & 9.9573 \\ \text { TRN }\end{array}$

$\begin{array}{lll}1641702 & 10.2596 & 9.9465 \\ \text { TRN }\end{array}$

$\begin{array}{lll}1641702 & 10.2596 & 9.6021 \\ \text { TRN }\end{array}$

$\begin{array}{lll}1641702 & 10.2596 & 10.3662 \text { TRN }\end{array}$

$\begin{array}{llll}1641702 & 10.2596 & 9.7334 & \text { TRN }\end{array}$

$\begin{array}{llll}1641702 & 9.2596 & 9.6834 & \text { TRN }\end{array}$

$\begin{array}{lll}1641702 & 10.2596 & 10.0837 \text { TST }\end{array}$

$\begin{array}{llll}1641702 & 9.2596 & 9.4023 & \text { TRN }\end{array}$

$\begin{array}{llll}1641702 & 9.2596 & 9.767000000000001 & \text { TRN }\end{array}$

164170210.25969 .7504 TRN

$\begin{array}{llll}1641702 & 9.2596 & 9.9062 & \text { TRN }\end{array}$

$\begin{array}{lll}1641702 & 9.2596 & 9.9158\end{array}$

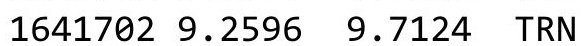

$\begin{array}{llll}1641702 & 9.2596 & 9.9499 & \text { TRN }\end{array}$

$\begin{array}{llll}1641702 & 9.2596 & 8.9791 & \text { TST }\end{array}$

$\begin{array}{llll}1641702 & 9.2596 & 9.6433 & \text { TRN }\end{array}$

$\begin{array}{lll}1641702 & 10.2596 & 10.3859\end{array}$

$\begin{array}{ll}164170210.2596 & 10.4348 \text { TRN }\end{array}$

$\begin{array}{llll}1641702 & 9.2596 & 9.1871 & \text { TST }\end{array}$

$\begin{array}{llll}1641702 & 9.2596 & 9.5535 & \text { TRN }\end{array}$

$\begin{array}{llll}1641702 & 9.2596 & 9.4826 & \text { TRN }\end{array}$

$\begin{array}{llll}1641702 & 9.2596 & 9.6098 & \text { TRN }\end{array}$

$\begin{array}{lll}1641702 & 10.2596 & 9.7631 \\ \text { TST }\end{array}$

$\begin{array}{llll}1641702 & 7.3862 & 8.3274 & \text { TRN }\end{array}$

$\begin{array}{llll}1641702 & 9.2596 & 9.6549 & \text { TST }\end{array}$

$\begin{array}{llll}1641702 & 10.2596 & 9.238 & \text { TST }\end{array}$

$\begin{array}{lll}1641702 & 9.2596 & 10.0985\end{array}$

$\begin{array}{lll}1641702 & 10.2596 & 9.8995\end{array}$

$\begin{array}{lll}1641702 & 10.2596 & 9.6037\end{array}$

$\begin{array}{lll}1641702 & 10.2596 & 10.1219\end{array}$

$\begin{array}{lll}1641702 & 10.2596 & 10.3778 \text { TRN }\end{array}$

$\begin{array}{llll}1641702 & 10.2596 & 9.7266 & \text { TRN }\end{array}$

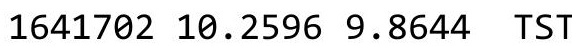

$\begin{array}{lll}1641702 & 10.2596 & 9.9742\end{array}$

$\begin{array}{llll}1641702 & 9.2596 & 9.7845 & \text { TRN }\end{array}$

$\begin{array}{lll}1641702 & 10.2596 & 10.3908\end{array}$

$\begin{array}{lll}1641702 & 6.0 & 8.9583 \\ \text { TST }\end{array}$

$\begin{array}{lll}1641702 & 10.2596 & 10.0691 \text { TRN }\end{array}$

$\begin{array}{llll}1641702 & 7.3125 & 7.9183 & \text { TRN }\end{array}$

$\begin{array}{llll}1641702 & 9.2596 & 9.4684 & \text { TST }\end{array}$

$\begin{array}{lll}1641702 & 10.2596 & 9.3671 \\ \text { TRN }\end{array}$

$\begin{array}{llll}1641702 & 9.2596 & 9.5867 & \text { TRN }\end{array}$

$\begin{array}{lll}1641702 & 10.2596 & 9.7127\end{array}$ TRN

$\begin{array}{llll}1641702 & 10.2596 & 9.9015 & \text { TRN }\end{array}$

$\begin{array}{llll}1641702 & 10.2596 & 9.7242 & \text { TST }\end{array}$

$\begin{array}{llll}1641702 & 9.2596 & 9.7929 & \text { TRN }\end{array}$

$\begin{array}{lll}1641702 & 7.1249 & 7.0275\end{array}$ TRN

$\begin{array}{lll}1641702 & 9.2596 \quad 10.0404 \text { TRN }\end{array}$ 
Supplemental Table S2.txt

CHEMBL 3956882

CHEMBL 3948936

CHEMBL3917906

CHEMBL 3956529

CHEMBL3929901

CHEMBL3930951

CHEMBL 3968548

CHEMBL 3902579

CHEMBL 3976708

CHEMBL3919105

CHEMBL3982255

CHEMBL3897417

CHEMBL3963715

CHEMBL3951700

CHEMBL3964318

CHEMBL 3943572

CHEMBL3973893

CHEMBL3919799

CHEMBL3944822

CHEMBL 3914438

CHEMBL3920581

CHEMBL3939379

CHEMBL 3925768

CHEMBL3915857

CHEMBL 3905748

CHEMBL 3930290

CHEMBL3964413

CHEMBL3890701

CHEMBL3941211

CHEMBL3984764

CHEMBL3685984

CHEMBL3685939

CHEMBL 3686058

CHEMBL 3685900

CHEMBL3685862

CHEMBL 3685990

CHEMBL 3685985

CHEMBL 3685851

CHEMBL 3685879

CHEMBL 3686025

CHEMBL3685963

CHEMBL 3685940

CHEMBL3685961

CHEMBL 3685956

CHEMBL 3686052

CHEMBL 3685918

CHEMBL 3685889

CHEMBL 3685913

$\begin{array}{lll}1641702 & 10.2596 & 10.4347\end{array}$

$\begin{array}{llll}1641702 & 9.2596 & 9.8257 & \text { TRN }\end{array}$

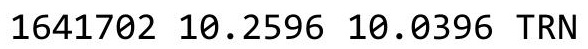

$\begin{array}{llll}1641702 & 10.2596 & 9.3442 & \text { TRN }\end{array}$

$\begin{array}{llll}1641702 & 9.2596 & 9.6872 & \text { TST }\end{array}$

$\begin{array}{llll}1641702 & 9.2596 & 9.6272 & \text { TRN }\end{array}$

$\begin{array}{lll}1641702 & 10.2596 & 9.4444\end{array}$

$\begin{array}{llll}1641702 & 9.2596 & 9.0087 & \text { TRN }\end{array}$

$\begin{array}{lll}1641702 & 10.2596 & 9.7921 \\ \text { TRN }\end{array}$

$\begin{array}{llll}1641702 & 9.2596 & 9.6658 & \text { TRN }\end{array}$

$\begin{array}{lll}1641702 & 10.2596 & 9.7181 \\ \text { TRN }\end{array}$

$\begin{array}{llll}1641702 & 10.2596 & 9.9139 & \text { TRN }\end{array}$

$\begin{array}{llll}1641702 & 9.2596 & 8.9298 & \text { TST }\end{array}$

$\begin{array}{lll}1641702 & 10.2596 & 10.3972 \text { TRN }\end{array}$

$\begin{array}{llll}1641702 & 9.2596 & 9.9825 & \text { TRN }\end{array}$

$\begin{array}{lll}1641702 & 10.2596 & 10.2217\end{array}$

$\begin{array}{llll}1641702 & 9.2596 & 9.2852 & \text { TRN }\end{array}$

$\begin{array}{lll}1641702 & 10.2596 & 8.8936\end{array}$

$\begin{array}{llll}1641702 & 10.2596 & 9.7613 & \text { TRN }\end{array}$

$\begin{array}{lll}1641702 & 10.2596 & 9.7639\end{array}$

$\begin{array}{llll}1641702 & 10.2596 & 9.7971 & \text { TRN }\end{array}$

$\begin{array}{llll}1641702 & 9.2596 & 9.6298 & \text { TRN }\end{array}$

$\begin{array}{llll}1641702 & 10.2596 & 9.8699 & \text { TRN }\end{array}$

$\begin{array}{lll}1641702 & 10.2596 & 9.7395 \\ \text { TRN }\end{array}$

164170210.259610 .0376 TRN

$\begin{array}{lll}1641702 & 10.2596 & 10.4186 \\ \text { TRN }\end{array}$

$\begin{array}{lll}1641702 & 9.2596 & 10.2529\end{array}$

$\begin{array}{llll}1641702 & 9.2596 & 9.5674 & \text { TRN }\end{array}$

$\begin{array}{lll}1641702 & 10.2596 & 10.4275 \text { TRN }\end{array}$

$\begin{array}{llll}1641702 & 10.2596 & 9.9531 & \text { TRN }\end{array}$

$\begin{array}{llll}1528488 & 5.7787 & 5.9948 & \text { TRN }\end{array}$

$\begin{array}{llll}1528488 & 7.7144 & 8.3091 & \text { TST }\end{array}$

$\begin{array}{llll}1528488 & 7.9136 & 7.7394 & \text { TST }\end{array}$

$\begin{array}{llll}1528488 & 8.2147 & 8.2368 & \text { TRN }\end{array}$

$\begin{array}{lllll}1528488 & 8.3979 & 8.1914 & \text { TST }\end{array}$

$\begin{array}{lllll}1528488 & 6.1748 & 6.144 & \text { TRN }\end{array}$

$\begin{array}{lllll}1528488 & 6.9041 & 6.7401 & \text { TRN }\end{array}$

$\begin{array}{llll}1528488 & 7.7878 & 8.0364 & \text { TRN }\end{array}$

$\begin{array}{llll}1528488 & 7.8356 & 7.7236 & \text { TRN }\end{array}$

$\begin{array}{lllll}1528488 & 6.8962 & 6.8579 & \text { TRN }\end{array}$

$\begin{array}{llll}1528488 & 6.3908 & 6.5016 & \text { TRN }\end{array}$

$\begin{array}{llll}1528488 & 7.7595 & 7.7662 & \text { TRN }\end{array}$

$\begin{array}{lllll}1528488 & 6.5067 & 6.6936 & \text { TRN }\end{array}$

$\begin{array}{llll}1528488 & 7.3575 & 7.3776 & \text { TRN }\end{array}$

$\begin{array}{llll}1528488 & 6.0691 & 6.1939 & \text { TRN }\end{array}$

$\begin{array}{llll}1528488 & 8.6383 & 8.6294 & \text { TRN }\end{array}$

$\begin{array}{llll}1528488 & 9.1249 & 9.2718 & \text { TRN }\end{array}$

$\begin{array}{llll}1528488 & 7.8894 & 8.0363 & \text { TRN }\end{array}$

Page 6650 
Supplemental Table S2.txt

\begin{tabular}{|c|c|c|c|c|}
\hline CHEMBL3685972 & 1528488 & 8.2596 & 8.0417 & TRN \\
\hline CHEMBL3685954 & 1528488 & 8.0506 & 8.0459 & TRN \\
\hline CHEMBL3685899 & 1528488 & 8.7212 & 8.7143 & TRN \\
\hline CHEMBL3686000 & 1528488 & 7.4078 & 6.9858 & TRN \\
\hline CHEMBL3685988 & 1528488 & 6.3695 & 6.2874 & TRN \\
\hline CHEMBL3685968 & 1528488 & 8.9208 & 8.6157 & TRN \\
\hline CHEMBL3685982 & 1528488 & 8.6576 & 8.6664 & TRN \\
\hline CHEMBL3685946 & 1528488 & 7.8268 & 7.6607 & TRN \\
\hline CHEMBL3686051 & 1528488 & 6.4881 & 6.9138 & TST \\
\hline CHEMBL3685888 & 1528488 & 8.8861 & 8.8416 & TRN \\
\hline CHEMBL3685893 & 1528488 & 7.6216 & 7.9514 & TST \\
\hline CHEMBL3685966 & 1528488 & 8.6576 & 7.9889 & TRN \\
\hline CHEMBL3685959 & 1528488 & 6.6379 & 6.8045 & TRN \\
\hline CHEMBL3685983 & 1528488 & 8.7212 & 8.1575 & TST \\
\hline CHEMBL3686056 & 1528488 & 7.3615 & 7.2037 & TST \\
\hline CHEMBL 3685878 & 1528488 & 8.6021 & 8.599 & TST \\
\hline CHEMBL3685864 & 1528488 & 9.699 & 9.6089 & TRN \\
\hline CHEMBL3686026 & 1528488 & 7.2495 & 7.2438 & TRN \\
\hline CHEMBL3685916 & 1528488 & 9.0969 & 8.9575 & TRN \\
\hline CHEMBL3685895 & 1528488 & 8.5528 & 7.5046 & TST \\
\hline CHEMBL 3686034 & 1528488 & 7.8097 & 7.7435 & TST \\
\hline CHEMBL3685905 & 1528488 & 7.767 & 7.7625 & TRN \\
\hline CHEMBL3685934 & 1528488 & 8.4559 & 8.3917 & TST \\
\hline CHEMBL3686011 & 1528488 & 8.1079 & 7.9511 & TST \\
\hline CHEMBL3685904 & 1528488 & 8.3665 & 8.2948 & TRN \\
\hline CHEMBL3685950 & 1528488 & 8.28399 & 999999999 & 8.4017 \\
\hline CHEMBL3685996 & 1528488 & 8.5229 & 8.3234 & TRN \\
\hline CHEMBL3686028 & 1528488 & 7.5229 & 7.6474 & TRN \\
\hline CHEMBL3685965 & 1528488 & 7.8697 & 7.8183 & TRN \\
\hline CHEMBL 3685874 & 1528488 & 8.5086 & 8.4779 & TRN \\
\hline CHEMBL3685926 & 1528488 & 10.0 & 9.6805 & TST \\
\hline CHEMBL3685909 & 1528488 & 8.585 & 7.8942 & TST \\
\hline CHEMBL3685989 & 1528488 & 6.9014 & 6.8675 & TRN \\
\hline CHEMBL 3685942 & 1528488 & 8.4202 & 8.3363 & TRN \\
\hline CHEMBL3685977 & 1528488 & 9.2218 & 9.112 & TRN \\
\hline CHEMBL3685896 & 1528488 & 8.2366 & 8.3454 & TRN \\
\hline CHEMBL3685991 & 1528488 & 5.8297 & 6.1468 & TRN \\
\hline CHEMBL3685865 & 1528488 & 8.4089 & 8.4197 & TRN \\
\hline CHEMBL3686012 & 1528488 & 7.8069 & 7.6249 & TST \\
\hline CHEMBL3685979 & 1528488 & 8.9586 & 8.6275 & TRN \\
\hline CHEMBL 3685877 & 1528488 & 7.9066 & 7.837000 & 0000000001 \\
\hline CHEMBL3685907 & 1528488 & 8.2366 & 8.061 & TRN \\
\hline CHEMBL3686017 & 1528488 & 9.301 & 9.248 & TRN \\
\hline CHEMBL3685955 & 1528488 & 7.7747 & 7.9013 & TRN \\
\hline CHEMBL3685957 & 1528488 & 7.4724 & 7.237 & TRN \\
\hline CHEMBL 3685898 & 1528488 & 9.301 & 9.3838 & TRN \\
\hline CHEMBL3685987 & 1528488 & 7.5834 & 7.4747 & TRN \\
\hline CHEMBL3686002 & 1528488 & 8.3188 & 8.5094 & TRN \\
\hline
\end{tabular}




\begin{tabular}{|c|c|c|c|c|c|}
\hline \multicolumn{6}{|c|}{ Supplemental Table S2.txt } \\
\hline CHEMBL3685949 & 1528488 & 10.0 & 10.0144 & TRN & \\
\hline CHEMBL3686043 & 1528488 & 6.5969 & 6.4341 & TRN & \\
\hline CHEMBL3685856 & 1528488 & 8.6021 & 8.6853 & TRN & \\
\hline CHEMBL3685976 & 1528488 & 8.7959 & 8.725 & TRN & \\
\hline CHEMBL3686046 & 1528488 & 6.2581 & 7.933 & TST & \\
\hline CHEMBL3685969 & 1528488 & 8.4685 & 8.6216 & TRN & \\
\hline CHEMBL3685938 & 1528488 & 7.556 & 7.4969 & TST & \\
\hline CHEMBL3685901 & 1528488 & 8.5528 & 8.6128 & TRN & \\
\hline CHEMBL3685943 & 1528488 & 9.5229 & 9.2758 & TRN & \\
\hline CHEMBL3685891 & 1528488 & 9.699 & 9.5784 & TRN & \\
\hline CHEMBL3685881 & 1528488 & 7.4881 & 7.542000 & 0000000001 & TRN \\
\hline CHEMBL3686029 & 1528488 & 5.9706 & 5.9201 & TRN & \\
\hline CHEMBL3685958 & 1528488 & 7.5143 & 7.5628 & TRN & \\
\hline CHEMBL3685993 & 1528488 & 8.0605 & 8.0534 & TRN & \\
\hline CHEMBL3685928 & 1528488 & 7.9914 & 8.0663 & TRN & \\
\hline CHEMBL3686024 & 1528488 & 7.5317 & 7.5752 & TRN & \\
\hline CHEMBL3685873 & 1528488 & 6.2573 & 6.1921 & TRN & \\
\hline CHEMBL 3686041 & 1528488 & 7.3665 & 7.4 & TRN & \\
\hline CHEMBL 3685870 & 1528488 & 7.0958 & 7.093999 & 7999999999 & TRN \\
\hline CHEMBL3685914 & 1528488 & 8.8861 & 8.7685 & TRN & \\
\hline CHEMBL3685975 & 1528488 & 8.8861 & 9.1051 & TRN & \\
\hline CHEMBL3685992 & 1528488 & 7.6108 & 7.6143 & TRN & \\
\hline CHEMBL3930139 & 1528488 & 9.0969 & 7.9135 & TST & \\
\hline CHEMBL3686036 & 1528488 & 7.7077 & 7.7071 & TST & \\
\hline CHEMBL3685850 & 1528488 & 8.5376 & 8.8221 & TRN & \\
\hline CHEMBL3686039 & 1528488 & 7.3019 & 7.6512 & TST & \\
\hline CHEMBL3685932 & 1528488 & 9.2218 & 9.1733 & TRN & \\
\hline CHEMBL 3685863 & 1528488 & 8.9586 & 8.4058 & TST & \\
\hline CHEMBL 3685986 & 1528488 & 5.4247 & 5.3596 & TRN & \\
\hline CHEMBL3685882 & 1528488 & 7.5258 & 6.8054 & TST & \\
\hline CHEMBL3685860 & 1528488 & 8.5686 & 8.1815 & TRN & \\
\hline CHEMBL3685892 & 1528488 & 8.8539 & 8.6979 & TRN & \\
\hline CHEMBL3685970 & 1528488 & 9.0969 & 9.2407 & TRN & \\
\hline CHEMBL3685930 & 1528488 & 9.2218 & 9.1315 & TRN & \\
\hline CHEMBL3685917 & 1528488 & 8.9208 & 8.8159 & TRN & \\
\hline CHEMBL3685920 & 1528488 & 9.1549 & 9.2296 & TST & \\
\hline CHEMBL3685867 & 1528488 & 7.7471 & 7.8588 & TRN & \\
\hline CHEMBL3685897 & 1528488 & 7.857 & 7.8827 & TRN & \\
\hline CHEMBL3685931 & 1528488 & 8.7447 & 8.5118 & TST & \\
\hline CHEMBL 3685861 & 1528488 & 7.8894 & 8.0063 & TRN & \\
\hline CHEMBL3685929 & 1528488 & 8.0506 & 8.3069 & TRN & \\
\hline CHEMBL3685886 & 1528488 & 8.9586 & 8.8054 & TRN & \\
\hline CHEMBL3685999 & 1528488 & 7.7122 & 7.5386 & TRN & \\
\hline CHEMBL 3686042 & 1528488 & 7.5376 & 7.5878 & TRN & \\
\hline CHEMBL3685911 & 1528488 & 8.3665 & 8.3729 & TRN & \\
\hline CHEMBL3685921 & 1528488 & 9.3979 & 9.4572 & TST & \\
\hline CHEMBL3685876 & 1528488 & 8.0315 & 7.9764 & TRN & \\
\hline CHEMBL 2181751 & 1528488 & 10.0 & 9.8731 & TRN & \\
\hline
\end{tabular}


Supplemental Table S2.txt

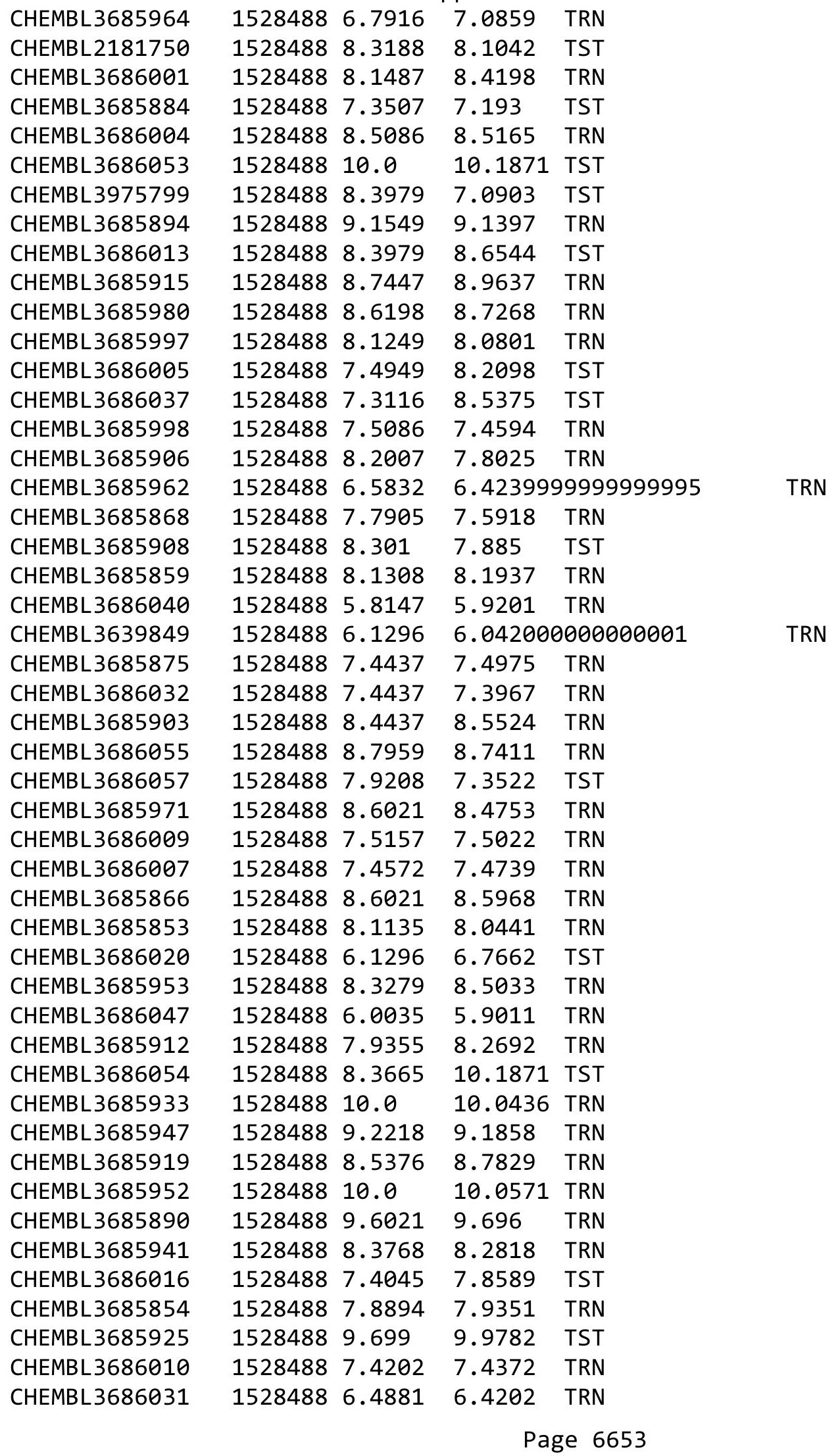


Supplemental Table S2.txt

\begin{tabular}{|c|c|c|c|c|}
\hline TL & & 114 & & \\
\hline & & 6.1047 & & \\
\hline HFMRI : & 38 & & & \\
\hline EMBL & & 5655 & & \\
\hline AEMBL3685923 & 528488 & 8.7959 & 6487 & \\
\hline HEMBL & 488 & 7.7747 & 76 & \\
\hline 5858 & 88 & & & \\
\hline AEMBL & & & & \\
\hline HEMBL3685857 & 528488 & 8.585 & 8.9809 & \\
\hline HEMBL3685936 & 528488 & 9.699 & 379 & \\
\hline HEMBL3686033 & 38 & 7.53 & & \\
\hline AEMBL & 88 & & 04 & \\
\hline AEMBL: & & & & \\
\hline HEMBL3686044 & 528488 & 6.3686 & & \\
\hline AEMBL3685960 & 88 & & & \\
\hline AEMBL3 & 8 & & 34 & \\
\hline AEME & 8 & & & 舟 \\
\hline 86049 & 88 & & & \\
\hline 86015 & 88 & & & \\
\hline HEMBL3686027 & & & & I \\
\hline HEMBL & 38 & & & RN \\
\hline HEN & & & & 列 \\
\hline 948 & 38 & & & ST \\
\hline 85995 & & & & KIV \\
\hline 586019 & 38 & 8. & 77 & RN \\
\hline AEMBL3 & & & & $\mathrm{RI}$ \\
\hline HFM & & & & $\mathbf{K} \mathbf{N}$ \\
\hline 74 & & & & RN \\
\hline HEMBL & & & & RIN \\
\hline HEMBL3685951 & 88 & & & RN \\
\hline 994 & & & & RN \\
\hline 9 & & & & ST \\
\hline 0 & & & & ST \\
\hline AEMBL3 & & & & IST \\
\hline HEMBL3686003 & 88 & & & RN \\
\hline 887 & 38 & & & RN \\
\hline 3 & & & & RN \\
\hline HEMBL3685924 & & & 479 & TST \\
\hline HEMBL3685944 & 38 & 9. & & RN \\
\hline כ & & & & ST \\
\hline HEMBL3 & & & & 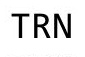 \\
\hline & 38 & 8. & & RN \\
\hline HEMBL3685880 & 88 & 7.7235 & 7572 & RN \\
\hline HEMBL3686045 & 38 & 6 . & & TS \\
\hline CHFMRI 3686921 & & & & \\
\hline HEMBL3686030 & 152 & 5.2083 & & \\
\hline CHEMBL3686038 & 88 & 8.301 & 987 & $\mathrm{~T}$ \\
\hline CHEMBL3685922 & 1528488 & 9.0 & 9.0749 & ГST \\
\hline
\end{tabular}

Page 6654 
Supplemental Table S2.txt

\begin{tabular}{|c|c|c|c|c|c|}
\hline CHEMBL3685935 & 1528488 & 9.301 & 9.4623 & TRN & \\
\hline CHEMBL 3686008 & 1528488 & 7.6038 & 7.4894 & TRN & \\
\hline CHEMBL3685978 & 1528488 & 8.4559 & 7.9596 & TST & \\
\hline CHEMBL463507 & 552452 & 6.2441 & 5.559 & TRN & \\
\hline CHEMBL499880 & 552452 & 5.8239 & 5.867999 & 9999999999 & TRN \\
\hline CHEMBL444920 & 552452 & 5.3188 & 5.4576 & TRN & \\
\hline CHEMBL504062 & 552452 & 5.9586 & 5.6552 & TRN & \\
\hline CHEMBL540 & 552452 & 3.75699 & 999999999 & 5.0589 & ול \\
\hline CHEMBL 362148 & 552452 & 6.3872 & 5.4984 & TST & \\
\hline CHEMBL482907 & 552452 & 5.8239 & 5.6402 & TRN & \\
\hline CHEMBL482688 & 552452 & 4.3468 & 4.1665 & TRN & \\
\hline CHEMBL482908 & 552452 & 6.7212 & 7.5432 & TRN & \\
\hline CHEMBL482687 & 552452 & 3.9031 & 4.343 & TRN & \\
\hline CHEMBL482492 & 552452 & 3.426 & 3.9634 & TST & \\
\hline CHEMBL450172 & 552452 & 6.4202 & 5.8952 & TST & \\
\hline CHEMBL484291 & 552452 & 4.2441 & 4.185 & TRN & \\
\hline CHEMBL356703 & 552452 & 6.7959 & 6.6204 & TRN & \\
\hline CHEMBL468421 & 552452 & 4.2218 & 4.8119 & TST & \\
\hline CHEMBL449294 & 552452 & 5.6778 & 6.3819 & TRN & \\
\hline CHEMBL502004 & 552452 & 4.9586 & 5.1432 & TRN & \\
\hline CHEMBL454459 & 552452 & 4.8539 & 5.2866 & TRN & \\
\hline CHEMBL501450 & 552452 & 6.6021 & 6.2694 & TRN & \\
\hline CHEMBL521452 & 552452 & 4.4559 & 3.9909 & TRN & \\
\hline CHEMBL44833 & 552452 & 6.8861 & 6.7927 & TRN & \\
\hline CHEMBL501448 & 552452 & 7.0 & 6.7492 & TRN & \\
\hline CHEMBL505019 & 552452 & 5.0 & 5.7269 & TST & \\
\hline CHEMBL162549 & 552452 & 3.9788 & 4.2893 & TST & \\
\hline CHEMBL524703 & 552452 & 6.7212 & 6.132999 & 9999999999 & \\
\hline CHEMBL504940 & 552452 & 4.8539 & 5.9199 & TRN & \\
\hline CHEMBL503085 & 552452 & 6.2518 & 6.4949 & TRN & \\
\hline CHEMBL504297 & 552452 & 3.7447 & 3.7756 & TRN & \\
\hline CHEMBL507240 & 552452 & 6.0 & 6.4226 & TST & \\
\hline CHEMBL321691 & 552452 & 7.5376 & 6.6621 & TRN & \\
\hline CHEMBL482912 & 552452 & 4.8539 & 4.7562 & TST & \\
\hline CHEMBL447128 & 552452 & 5.2218 & 5.2649 & TST & \\
\hline CHEMBL469352 & 552452 & 6.3468 & 6.4267 & TRN & \\
\hline CHEMBL11471 & 552452 & 5.7696 & 5.702000 & 0000000001 & H \\
\hline CHEMBL483706 & 552452 & 4.1249 & 4.0989 & TRN & \\
\hline CHEMBL452135 & 552452 & 4.9208 & 5.6113 & TST & \\
\hline CHEMBL451397 & 552452 & 3.4559 & 5.6833 & TST & \\
\hline CHEMBL449974 & 552452 & 5.699 & 5.2916 & TST & \\
\hline CHEMBL505665 & 552452 & 4.8539 & 6.0761 & TRN & \\
\hline CHEMBL502771 & 552452 & 4.301 & 4.5764 & TRN & \\
\hline CHEMBL453220 & 552452 & 6.0 & 6.5556 & TRN & \\
\hline CHEMBL476196 & 552452 & 6.7447 & 6.3159 & TRN & \\
\hline CHEMBL500923 & 552452 & 6.6778 & 6.8525 & TRN & \\
\hline CHEMBL485526 & 552452 & 4.0969 & 4.2851 & TST & \\
\hline CHEMBL107201 & 552452 & 6.6021 & 6.5792 & TRN & \\
\hline
\end{tabular}


Supplemental Table S2.txt

\begin{tabular}{|c|c|c|c|c|}
\hline CHEMBL500901 & 552452 & 5.7959 & 5.94 & TRN \\
\hline CHEMBL455310 & 552452 & 7.9586 & 7.7205 & TRN \\
\hline CHEMBL454812 & 552452 & 5.5229 & 5.0714 & TST \\
\hline CHEMBL482699 & 552452 & 7.3768 & 6.3313 & TRN \\
\hline CHEMBL447987 & 552452 & 4.1308 & 4.7806 & TST \\
\hline CHEMBL 227744 & 552452 & 6.301 & 6.1385 & TRN \\
\hline CHEMBL451408 & 552452 & 6.2076 & 6.349 & TRN \\
\hline CHEMBL483521 & 552452 & 4.3468 & 5.3181 & TST \\
\hline CHEMBL502814 & 552452 & 6.7696 & 6.531006 & 0000000001 \\
\hline CHEMBL484101 & 552452 & 6.0506 & 5.9735 & TST \\
\hline CHEMBL454761 & 552452 & 5.7447 & 6.7756 & TRN \\
\hline CHEMBL503073 & 552452 & 6.5376 & 6.6251 & TRN \\
\hline CHEMBL500924 & 552452 & 6.4685 & 6.414 & TRN \\
\hline CHEMBL482700 & 552452 & 6.4437 & 6.3915 & TRN \\
\hline CHEMBL500752 & 552452 & 4.5376 & 4.7604 & TRN \\
\hline CHEMBL501297 & 552452 & 5.9586 & 6.4009 & TRN \\
\hline CHEMBL483091 & 552452 & 7.4318 & 6.9745 & TRN \\
\hline CHEMBL96680 & 552452 & 8.2007 & 7.8691 & TRN \\
\hline CHEMBL 80352 & 552452 & 6.1675 & 6.566 & TST \\
\hline CHEMBL 262040 & 552452 & 8.0605 & 8.1646 & TRN \\
\hline CHEMBL499881 & 552452 & 5.8539 & 5.9439 & TRN \\
\hline CHEMBL451666 & 552452 & 6.9208 & 5.909 & TRN \\
\hline CHEMBL482686 & 552452 & 4.2218 & 4.0644 & TRN \\
\hline CHEMBL419740 & 552452 & 7.3979 & 7.0219 & TRN \\
\hline CHEMBL484914 & 552452 & 3.7696 & 5.3075 & TST \\
\hline CHEMBL228077 & 552452 & 7.0 & 6.6597 & TRN \\
\hline CHEMBL444422 & 552452 & 7.7959 & 7.0223 & TRN \\
\hline CHEMBL496134 & 552452 & 7.2518 & 6.5457 & TRN \\
\hline CHEMBL510382 & 552452 & 6.0969 & 5.9571 & TRN \\
\hline CHEMBL450160 & 552452 & 4.1549 & 4.1965 & TST \\
\hline CHEMBL507472 & 552452 & 5.5229 & 5.9375 & TRN \\
\hline CHEMBL500922 & 552452 & 6.1549 & 6.2192 & TRN \\
\hline CHEMBL442896 & 552452 & 5.2757 & 5.685 & TRN \\
\hline CHEMBL499879 & 552452 & 6.4815 & 6.5526 & TRN \\
\hline CHEMBL 323542 & 552452 & 6.4949 & 6.1495 & TRN \\
\hline CHEMBL502447 & 552452 & 5.9586 & 5.5743 & TST \\
\hline CHEMBL275066 & 552452 & 3.3665 & 3.2073 & TRN \\
\hline CHEMBL459840 & 552452 & 5.0969 & 5.3873 & TST \\
\hline CHEMBL506610 & 552452 & 5.3979 & 5.7099 & TRN \\
\hline CHEMBL482727 & 552452 & 5.699 & 6.4308 & TRN \\
\hline CHEMBL482911 & 552452 & 3.9031 & 3.7538 & TRN \\
\hline CHEMBL444240 & 552452 & 6.4815 & 6.7578 & TRN \\
\hline CHEMBL106820 & 552452 & 7.0 & 6.2891 & TRN \\
\hline CHEMBL524324 & 552452 & 5.9586 & 6.517 & TRN \\
\hline CHEMBL443450 & 552452 & 5.0 & 4.6148 & TRN \\
\hline CHEMBL483093 & 552452 & 6.0969 & 6.1556 & TRN \\
\hline CHEMBL447555 & 552452 & 4.8539 & 6.4245 & TST \\
\hline CHEMBL452156 & 552452 & 4.4949 & 4.2799 & TRN \\
\hline
\end{tabular}




\begin{tabular}{|c|c|c|c|c|c|c|}
\hline & & \multicolumn{5}{|c|}{ Supplemental Table S2.txt } \\
\hline CHEMBL466888 & 552452 & 6.4318 & 6.4342 & TRN & & \\
\hline CHEMBL449605 & 552452 & 6.8539 & 6.7396 & TRN & & \\
\hline CHEMBL499850 & 552452 & 5.9586 & 5.9097 & TRN & & \\
\hline CHEMBL503013 & 552452 & 4.0269 & 4.0757 & TRN & & \\
\hline CHEMBL510986 & 552452 & 5.699 & 6.0506 & TRN & & \\
\hline CHEMBL483092 & 552452 & 6.2007 & 6.2808 & TRN & & \\
\hline CHEMBL455224 & 552452 & 3.75699 & 99999999 & 997 & 3.8911 & TRN \\
\hline CHEMBL485527 & 552452 & 4.0 & 4.277 & TST & & \\
\hline CHEMBL447489 & 552452 & 3.8239 & 5.1764 & TST & & \\
\hline CHEMBL455809 & 552452 & 5.8539 & 5.9864 & TRN & & \\
\hline CHEMBL502800 & 552452 & 6.7696 & 6.2782 & TRN & & \\
\hline CHEMBL509902 & 552452 & 6.0 & 5.58299 & 9999999999 & & TRN \\
\hline CHEMBL476988 & 552452 & 7.9586 & 7.5006 & TRN & & \\
\hline CHEMBL502633 & 552452 & 5.5528 & 5.4302 & TRN & & \\
\hline CHEMBL500424 & 552452 & 5.8239 & 6.7305 & TRN & & \\
\hline CHEMBL501449 & 552452 & 5.3188 & 6.3439 & TRN & & \\
\hline CHEMBL448974 & 552452 & 6.7696 & 6.4732 & TRN & & \\
\hline CHEMBL468039 & 552452 & 6.5229 & 6.599 & TST & & \\
\hline CHEMBL469269 & 552452 & 5.699 & 5.1764 & TST & & \\
\hline CHEMBL500141 & 552452 & 6.1805 & 6.2835 & TRN & & \\
\hline CHEMBL484300 & 552452 & 3.9031 & 4.2818 & TRN & & \\
\hline CHEMBL484913 & 552452 & 4.1871 & 5.2823 & TST & & \\
\hline CHEMBL1398707 & 752494 & 5.8948 & 4.8221 & TRN & & \\
\hline CHEMBL1610756 & 752494 & 4.1901 & 4.7811 & TST & & \\
\hline CHEMBL1169627 & 752494 & 4.99100 & 300000006 & 205 & 4.835 & TST \\
\hline CHEMBL1728200 & 752494 & 4.811 & 4.8336 & TST & & \\
\hline CHEMBL1582232 & 752494 & 5.0515 & 4.7484 & TRN & & \\
\hline CHEMBL1579434 & 752494 & 4.7915 & 4.7654 & TRN & & \\
\hline CHEMBL1388222 & 752494 & 6.256 & 5.8287 & TRN & & \\
\hline CHEMBL1334918 & 752494 & 5.1527 & 4.7159 & TRN & & \\
\hline CHEMBL1513567 & 752494 & 5.0565 & 5.3808 & TRN & & \\
\hline CHEMBL1380599 & 752494 & 6.2719 & 6.1544 & TRN & & \\
\hline CHEMBL1370471 & 752494 & 4.979 & 4.7425 & TRN & & \\
\hline CHEMBL1588202 & 752494 & 5.8969 & 5.9384 & TRN & & \\
\hline CHEMBL1331866 & 752494 & 6.4191 & 6.2416 & TST & & \\
\hline CHEMBL1256770 & 752494 & 4.9162 & 4.7228 & TRN & & \\
\hline CHEMBL1898753 & 752494 & 3.0337 & 4.7667 & TRN & & \\
\hline CHEMBL1378959 & 752494 & 4.8246 & 4.7123 & TRN & & \\
\hline CHEMBL1515502 & 752494 & 5.1104 & 4.8182 & TRN & & \\
\hline CHEMBL1607240 & 752494 & 4.7619 & 4.7089 & TRN & & \\
\hline CHEMBL1563669 & 752494 & 4.6152 & 4.7855 & TRN & & \\
\hline CHEMBL1427690 & 752494 & 5.4062 & 4.6772 & TRN & & \\
\hline CHEMBL1387977 & 752494 & 4.9672 & 4.7368 & TST & & \\
\hline CHEMBL1407554 & 752494 & 5.3033 & 5.7319 & TRN & & \\
\hline CHEMBL1439686 & 752494 & 4.9589 & 5.0913 & TRN & & \\
\hline CHEMBL1533638 & 752494 & 5.341 & 5.4093 & TRN & & \\
\hline CHEMBL1522542 & 752494 & 5.4196 & 5.8976 & TRN & & \\
\hline CHEMBL1315948 & 752494 & 5.042 & 4.8387 & TST & & \\
\hline
\end{tabular}




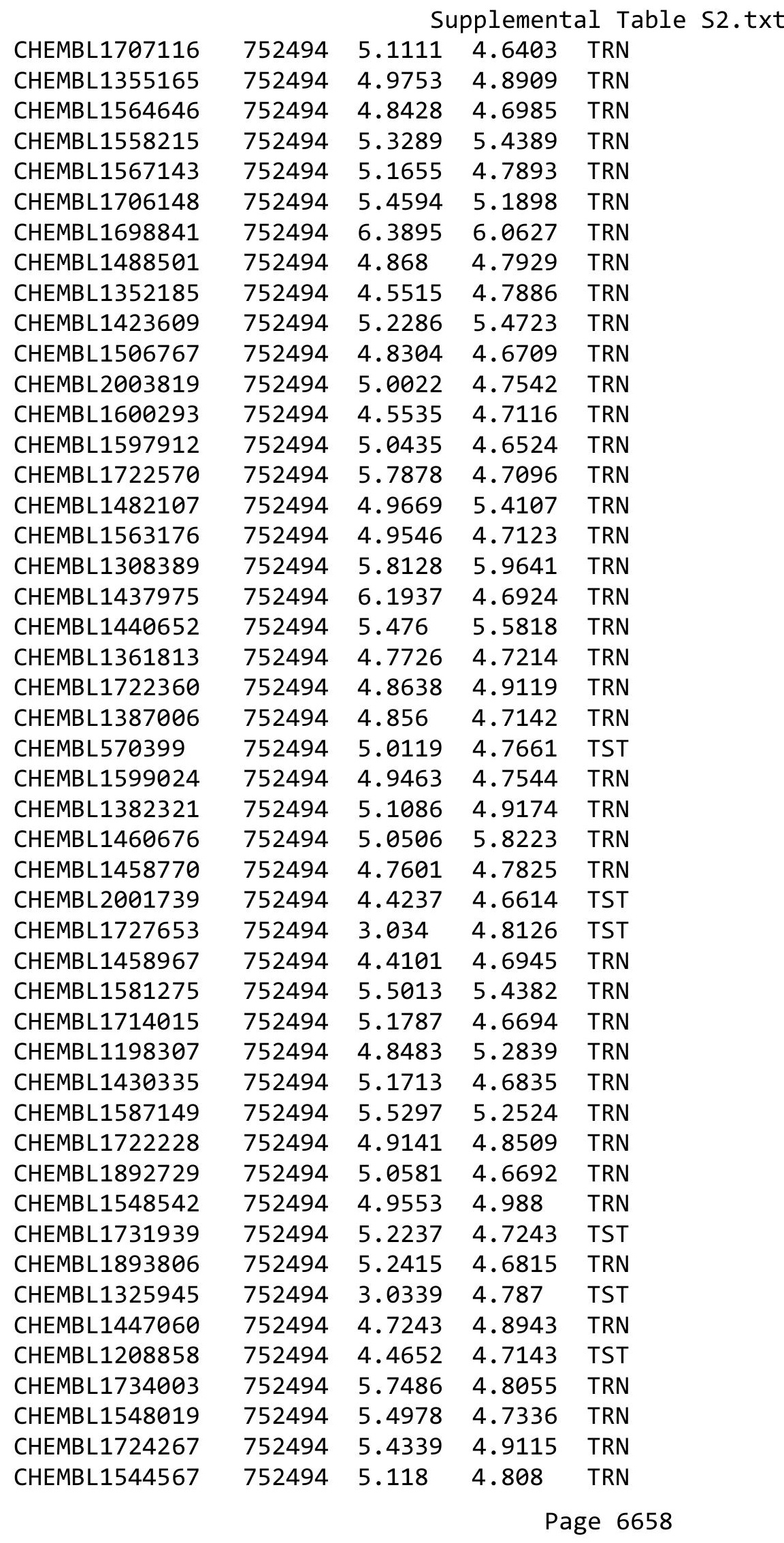




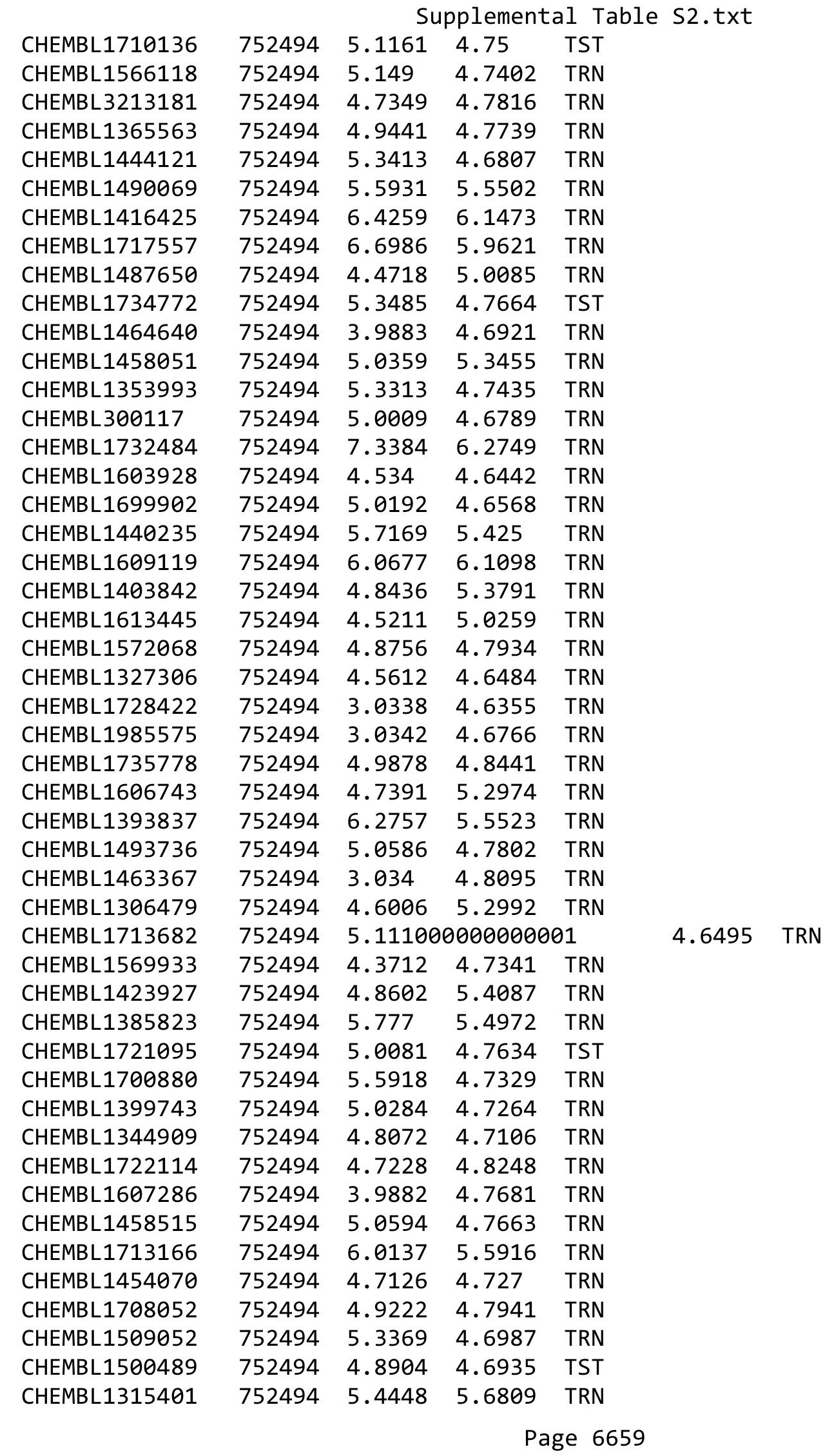


Supplemental Table S2.txt

\begin{tabular}{|c|c|c|c|c|c|}
\hline CHEMBL1392786 & 752494 & 4.2024 & 4.7538 & TRN & \\
\hline CHEMBL1587574 & 752494 & 5.0297 & 5.4237 & TRN & \\
\hline CHEMBL1422217 & 752494 & 4.9132 & 5.3033 & TRN & \\
\hline CHEMBL1425453 & 752494 & 5.6739 & 5.9412 & TST & \\
\hline CHEMBL1898602 & 752494 & 4.2665 & 4.7839 & TRN & \\
\hline CHEMBL1720300 & 752494 & 4.99 & 4.7315 & TRN & \\
\hline CHEMBL1379878 & 752494 & 4.5913 & 4.7364 & TRN & \\
\hline CHEMBL1550403 & 752494 & 4.6999 & 4.7441 & TRN & \\
\hline CHEMBL1332532 & 752494 & 4.4655 & 4.8329 & TRN & \\
\hline CHEMBL1902708 & 752494 & 5.7215 & 5.5632 & TRN & \\
\hline CHEMBL1548987 & 752494 & 5.5337 & 5.7043 & TST & \\
\hline CHEMBL1512925 & 752494 & 3.034 & 4.8285 & TRN & \\
\hline CHEMBL1540756 & 752494 & 4.7072 & 4.6871 & TRN & \\
\hline CHEMBL1345947 & 752494 & 4.7772 & 5.3486 & TRN & \\
\hline CHEMBL1708311 & 752494 & 4.6912 & 4.9656 & TRN & \\
\hline CHEMBL1307021 & 752494 & 5.8153 & 4.7276 & TST & \\
\hline CHEMBL1450071 & 752494 & 5.0656 & 5.3139 & TRN & \\
\hline CHEMBL1437660 & 752494 & 4.9333 & 5.4301 & TRN & \\
\hline CHEMBL1703982 & 752494 & 4.4653 & 5.2758 & TRN & \\
\hline CHEMBL1494093 & 752494 & 4.8282 & 4.7415 & TRN & \\
\hline CHEMBL1583291 & 752494 & 4.8181 & 4.7657 & TRN & \\
\hline CHEMBL3189940 & 752494 & 5.8601 & 4.6967 & TRN & \\
\hline CHEMBL1587837 & 752494 & 3.0339 & 4.7292 & TRN & \\
\hline CHEMBL1708714 & 752494 & 5.1348 & 4.7475 & TST & \\
\hline CHEMBL1463894 & 752494 & 6.8206 & 6.2212 & TRN & \\
\hline CHEMBL1700847 & 752494 & 6.2807 & 6.15 & TRN & \\
\hline CHEMBL1699738 & 752494 & 4.6398 & 4.7108 & TRN & \\
\hline CHEMBL1728158 & 752494 & 5.3226 & 5.4523 & TRN & \\
\hline CHEMBL1898779 & 752494 & 5.0185 & 4.7989 & TST & \\
\hline CHEMBL1378322 & 752494 & 3.034 & 4.7975 & TRN & \\
\hline CHEMBL1445858 & 752494 & 4.7444 & 4.735 & TST & \\
\hline CHEMBL1419563 & 752494 & 3.034 & 4.7122 & TRN & \\
\hline CHEMBL1507251 & 752494 & 4.89199 & 999999999 & 4.7906 & וSו \\
\hline CHEMBL1600506 & 752494 & 3.034 & 4.7612 & TST & \\
\hline CHEMBL1307063 & 752494 & 6.518 & 6.2799 & TRN & \\
\hline CHEMBL1472987 & 752494 & 6.0481 & 4.8129 & TRN & \\
\hline CHEMBL1332208 & 752494 & 6.852 & 4.7498 & TRN & \\
\hline CHEMBL1303361 & 752494 & 3.034 & 4.7332 & TRN & \\
\hline CHEMBL1604493 & 752494 & 6.852 & 5.1982 & TRN & \\
\hline CHEMBL1595735 & 752494 & 5.9735 & 4.6692 & TRN & \\
\hline CHEMBL1872339 & 752494 & 5.6271 & 4.8211 & TRN & \\
\hline CHEMBL 2005743 & 752494 & 4.9717 & 5.252999 & 9999999999 & TST \\
\hline CHEMBL1345157 & 752494 & 5.1031 & 4.773 & TRN & \\
\hline CHEMBL1705302 & 752494 & 5.6276 & 5.7884 & TRN & \\
\hline CHEMBL1165197 & 752494 & 3.034 & 4.6902 & TRN & \\
\hline CHEMBL1437810 & 752494 & 5.0001 & 4.8437 & TRN & \\
\hline CHEMBL1722730 & 752494 & 4.7514 & 4.6758 & TRN & \\
\hline CHEMBL1727246 & 752494 & 4.4653 & 4.7438 & TRN & \\
\hline
\end{tabular}


Supplemental Table S2.txt

\begin{tabular}{|c|c|c|c|c|c|c|}
\hline CHEMBL1256750 & 752494 & 4.8157 & 4.7482 & TRN & & \\
\hline CHEMBL1429212 & 752494 & 5.9017 & 5.6477 & TRN & & \\
\hline CHEMBL1356740 & 752494 & 5.4872 & 5.4547 & TRN & & \\
\hline CHEMBL1486861 & 752494 & 4.4454 & 4.7179 & TRN & & \\
\hline CHEMBL1596869 & 752494 & 4.657 & 4.6944 & TRN & & \\
\hline CHEMBL1473706 & 752494 & \multicolumn{3}{|c|}{5.252000000000001} & 5.5288 & TRN \\
\hline CHEMBL1348719 & 752494 & 4.9387 & 4.7418 & TRN & & \\
\hline CHEMBL1340264 & 752494 & 5.3302 & 4.8364 & TRN & & \\
\hline CHEMBL1545927 & 752494 & 3.0339 & 4.7433 & TRN & & \\
\hline CHEMBL67378 & 752494 & 6.3741 & 4.7565 & TRN & & \\
\hline CHEMBL1365254 & 752494 & 5.0059 & 4.7145 & TRN & & \\
\hline CHEMBL1732043 & 752494 & 4.8703 & 4.7686 & TRN & & \\
\hline CHEMBL1412340 & 752494 & \multicolumn{3}{|c|}{5.537000000000001} & 5.4854 & TST \\
\hline CHEMBL1986259 & 752494 & 4.833 & 4.6887 & TST & & \\
\hline CHEMBL1566963 & 752494 & 5.2324 & 5.7566 & TRN & & \\
\hline CHEMBL 3208729 & 752494 & 5.0034 & 4.7487 & TRN & & \\
\hline CHEMBL1363204 & 752494 & 4.8662 & 4.7648 & TRN & & \\
\hline CHEMBL1419241 & 752494 & 4.9053 & 4.7585 & TRN & & \\
\hline CHEMBL1531172 & 752494 & 4.7842 & 4.7581 & TRN & & \\
\hline CHEMBL1364960 & 752494 & 4.5439 & 4.702 & TRN & & \\
\hline CHEMBL1468190 & 752494 & 4.6809 & 4.8145 & TRN & & \\
\hline CHEMBL1304909 & 752494 & 3.0342 & 4.6579 & TRN & & \\
\hline CHEMBL1727052 & 752494 & 5.0054 & 5.1663 & TRN & & \\
\hline CHEMBL1581674 & 752494 & 5.8955 & 6.1357 & TST & & \\
\hline CHEMBL517986 & 752494 & 5.0191 & 4.7284 & TST & & \\
\hline CHEMBL1448229 & 752494 & 5.7572 & 5.5652 & TST & & \\
\hline CHEMBL1882125 & 752494 & 5.0162 & 4.8082 & TST & & \\
\hline CHEMBL 3191251 & 752494 & 3.034 & 4.7443 & TST & & \\
\hline CHEMBL1586285 & 752494 & 5.6572 & 5.7442 & TST & & \\
\hline CHEMBL1550356 & 752494 & 4.9845 & 4.7435 & TST & & \\
\hline CHEMBL1587604 & 752494 & 5.3228 & 4.7172 & TST & & \\
\hline CHEMBL1709988 & 752494 & 5.6946 & 5.5538 & TST & & \\
\hline CHEMBL1524932 & 752494 & 5.3765 & 4.9376 & TST & & \\
\hline CHEMBL1968356 & 752494 & 5.0131 & 4.7261 & TST & & \\
\hline CHEMBL1447552 & 752494 & 5.3404 & 4.7649 & TST & & \\
\hline CHEMBL1720903 & 752494 & 4.621 & 4.702 & TST & & \\
\hline CHEMBL1700227 & 752494 & 6.0386 & 4.6461 & TST & & \\
\hline CHEMBL1531675 & 752494 & 6.1845 & 5.7287 & TST & & \\
\hline CHEMBL1736138 & 752494 & 5.3927 & 4.7411 & TST & & \\
\hline CHEMBL1561591 & 752494 & 4.9764 & 4.8069 & TST & & \\
\hline CHEMBL1720091 & 752494 & 6.0079 & 5.5784 & TST & & \\
\hline CHEMBL 3213958 & 752494 & \multicolumn{3}{|c|}{5.2170000000000005} & 5.3416 & 1 \\
\hline CHEMBL1704769 & 752494 & 4.7434 & 4.717 & TST & & \\
\hline CHEMBL1719184 & 752494 & 5.9897 & 5.8593 & TST & & \\
\hline CHEMBL1584594 & 752494 & 5.026 & 5.4304 & TST & & \\
\hline CHEMBL1390846 & 752494 & 5.0293 & 4.6984 & TST & & \\
\hline CHEMBL1457803 & 752494 & 5.0727 & 4.7986 & TST & & \\
\hline CHEMBL1603547 & 752494 & 3.034 & 4.7281 & TST & & \\
\hline
\end{tabular}


Supplemental Table S2.txt

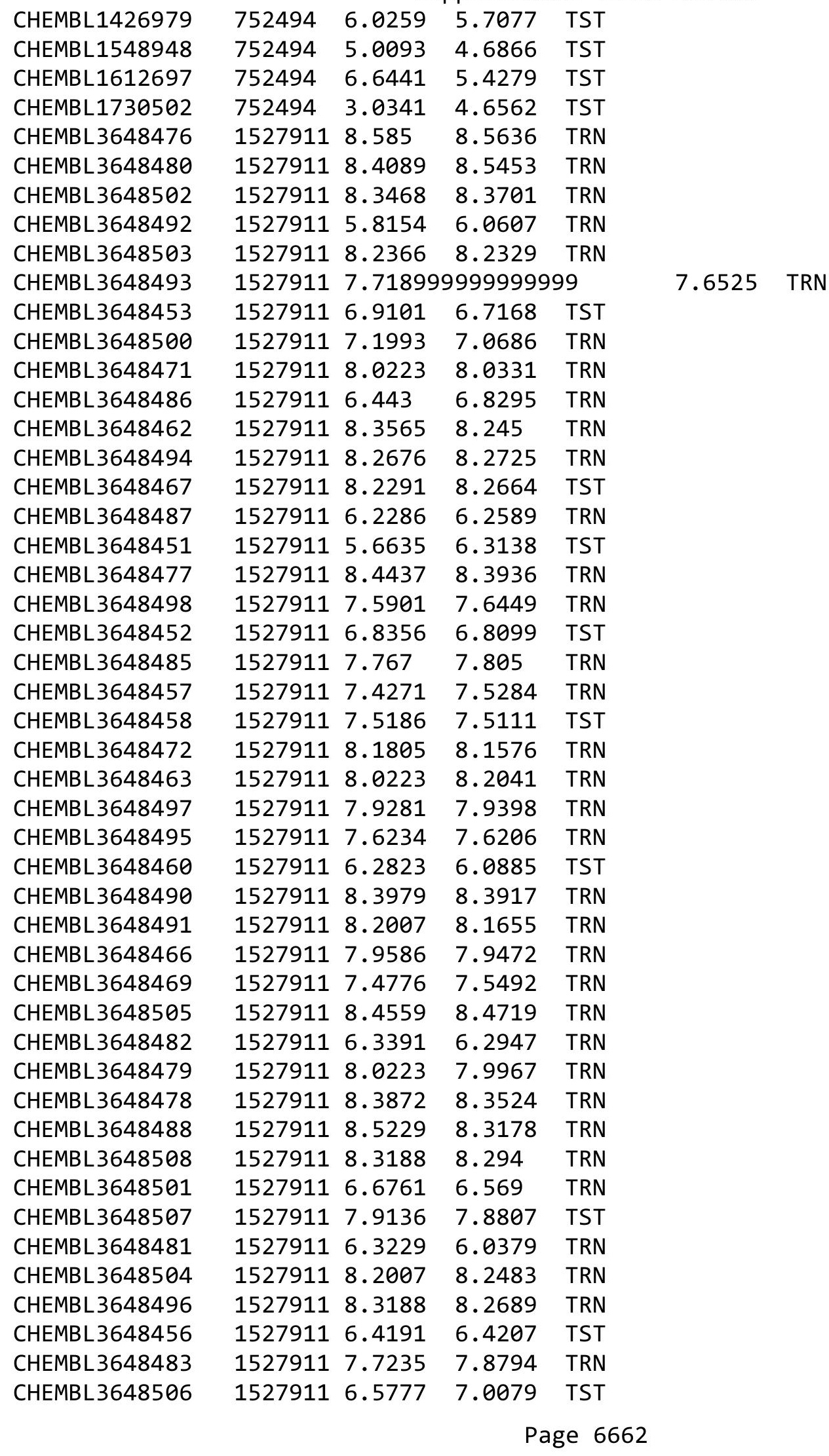




\begin{tabular}{|c|c|c|c|c|c|c|}
\hline CHEMBL3648484 & 1527911 & \multicolumn{4}{|c|}{ Supplemental Table S2.txt } & TRN \\
\hline CHEMBL 3648470 & 1527911 & 7.6198 & 7.6131 & TST & & \\
\hline CHEMBL3648499 & 1527911 & 8.4437 & 8.3277 & TRN & & \\
\hline CHEMBL 3648461 & 1527911 & 7.3809 & 7.3046 & TRN & & \\
\hline CHEMBL 3648465 & 1527911 & 6.7696 & 6.7059 & TST & & \\
\hline CHEMBL3648459 & 1527911 & 6.6271 & 6.2218 & TST & & \\
\hline CHEMBL3648473 & 1527911 & 6.1746 & 6.2491 & TRN & & \\
\hline CHEMBL3648475 & 1527911 & 8.5086 & 8.6141 & TRN & & \\
\hline CHEMBL3648509 & 1527911 & 8.1487 & 8.3094 & TST & & \\
\hline CHEMBL3648474 & 1527911 & 7.4389 & 7.2069 & TRN & & \\
\hline CHEMBL 3648468 & 1527911 & 8.1739 & 8.327 & TST & & \\
\hline CHEMBL 3648464 & 1527911 & 6.6737 & 6.6221 & TRN & & \\
\hline CHEMBL3648510 & 1527911 & 8.3565 & 8.5591 & TST & & \\
\hline CHEMBL341343 & 49848 & 6.5575 & 6.4372 & TRN & & \\
\hline CHEMBL124127 & 49848 & 5.6289 & 5.6554 & TRN & & \\
\hline CHEMBL411956 & 49848 & 8.5229 & 8.5466 & TRN & & \\
\hline CHEMBL441656 & 49848 & 8.0969 & 8.2435 & TRN & & \\
\hline CHEMBL 340853 & 49848 & 8.5229 & 8.373 & TRN & & \\
\hline CHEMBL19375 & 49848 & 5.0757 & 4.3153 & TST & & \\
\hline CHEMBL123585 & 49848 & 7.0915 & 7.1025 & TRN & & \\
\hline CHEMBL34166 & 49848 & 5.0458 & 5.2449 & TST & & \\
\hline CHEMBL124748 & 49848 & 6.2076 & 6.33299 & 9999999 & & \\
\hline CHEMBL339349 & 49848 & 5.0809 & 5.5962 & TRN & & \\
\hline CHEMBL124966 & 49848 & 6.585 & 6.3445 & TST & & \\
\hline CHEMBL419599 & 49848 & 9.0 & 8.7929 & TRN & & \\
\hline CHEMBL125643 & 49848 & 4.9208 & 6.2273 & TST & & \\
\hline CHEMBL126106 & 49848 & 4.301 & 5.9229 & TST & & \\
\hline CHEMBL340080 & 49848 & 6.8539 & 7.1237 & TRN & & \\
\hline CHEMBL125111 & 49848 & 4.9208 & 5.4844 & TST & & \\
\hline CHEMBL124669 & 49848 & 6.4425 & 6.4682 & TRN & & \\
\hline CHEMBL123791 & 49848 & 6.1249 & 6.2181 & TRN & & \\
\hline CHEMBL340797 & 49848 & 5.6517 & 5.5951 & TRN & & \\
\hline CHEMBL125549 & 49848 & 7.8539 & 7.7492 & TRN & & \\
\hline CHEMBL339884 & 49848 & 7.7696 & 7.715 & TRN & & \\
\hline CHEMBL126218 & 49848 & 7.2757 & 7.2704 & TRN & & \\
\hline CHEMBL124583 & 49848 & 5.75700 & 00000000 & & 5.6017 & RN \\
\hline CHEMBL123962 & 49848 & 6.6253 & 6.3852 & TRN & & \\
\hline CHEMBL 339752 & 49848 & 5.6576 & 5.375 & TRN & & \\
\hline CHEMBL333865 & 49848 & 5.284 & 5.3122 & TRN & & \\
\hline CHEMBL124813 & 49848 & 4.8386 & 4.9881 & TST & & \\
\hline CHEMBL421274 & 49848 & 5.4089 & 5.2766 & TRN & & \\
\hline CHEMBL339110 & 49848 & 8.585 & 8.0904 & TRN & & \\
\hline CHEMBL126163 & 49848 & 7.1739 & 7.3255 & TRN & & \\
\hline CHEMBL123837 & 49848 & 8.699 & 8.6059 & TRN & & \\
\hline CHEMBL333063 & 49848 & 5.7905 & 5.7193 & TRN & & \\
\hline CHEMBL124206 & 49848 & 6.6038 & 6.9443 & TRN & & \\
\hline CHEMBL126220 & 49848 & 7.3279 & 7.3116 & TRN & & \\
\hline CHEMBL337962 & 49848 & 9.0 & 8.9039 & TRN & & \\
\hline
\end{tabular}




\begin{tabular}{|c|c|c|c|c|c|c|}
\hline & & \multicolumn{5}{|c|}{ Supplemental Table S2.txt } \\
\hline CHEMBL124722 & 49848 & 8.699 & 8.9213 & TRN & & \\
\hline CHEMBL123957 & 49848 & 6.3468 & 6.1017 & TRN & & \\
\hline CHEMBL332591 & 49848 & 7.6778 & 7.9814 & TRN & & \\
\hline CHEMBL127590 & 49848 & 7.4559 & 7.516 & TRN & & \\
\hline CHEMBL125026 & 49848 & 5.585 & 5.5625 & TRN & & \\
\hline CHEMBL338543 & 49848 & 6.1249 & 6.2768 & TRN & & \\
\hline CHEMBL125325 & 49848 & 5.1192 & 5.3142 & TRN & & \\
\hline CHEMBL123917 & 49848 & 7.6778 & 7.6733 & TRN & & \\
\hline CHEMBL124473 & 49848 & 8.0969 & 8.0725 & TRN & & \\
\hline CHEMBL300905 & 49848 & 6.0 & 6.9363 & TST & & \\
\hline CHEMBL123580 & 49848 & 6.8508 & 7.0301 & TRN & & \\
\hline CHEMBL125695 & 49848 & 5.8861 & 5.7201 & TRN & & \\
\hline CHEMBL332227 & 49848 & 5.4318 & 5.6429 & TRN & & \\
\hline CHEMBL435812 & 49848 & 5.5229 & 5.5601 & TRN & & \\
\hline CHEMBL337990 & 49848 & 7.3979 & 7.4493 & TRN & & \\
\hline CHEMBL125108 & 49848 & 5.4089 & 5.3777 & TRN & & \\
\hline CHEMBL332277 & 49848 & 5.4559 & 5.347 & TRN & & \\
\hline CHEMBL124317 & 49848 & 6.9031 & 7.1595 & TRN & & \\
\hline CHEMBL126978 & 49848 & 5.2255 & 5.7911 & TST & & \\
\hline CHEMBL127534 & 49848 & 6.2765 & 6.2609 & TRN & & \\
\hline CHEMBL124336 & 49848 & 5.1337 & 5.3463 & TRN & & \\
\hline CHEMBL421273 & 49848 & 6.4437 & 6.5554 & TRN & & \\
\hline CHEMBL409001 & 49848 & 6.8153 & 6.9884 & TRN & & \\
\hline CHEMBL331530 & 49848 & 4.9586 & 5.0803 & TRN & & \\
\hline CHEMBL338624 & 49848 & 4.7144 & 5.5674 & TST & & \\
\hline CHEMBL124689 & 49848 & 8.699 & 8.6659 & TRN & & \\
\hline CHEMBL123616 & 49848 & 7.9586 & 7.9534 & TRN & & \\
\hline CHEMBL124272 & 49848 & 6.6421 & 6.6668 & TRN & & \\
\hline CHEMBL125618 & 49848 & 5.0088 & 5.6948 & TST & & \\
\hline CHEMBL445379 & 49848 & $5.7570 e$ & 00000000 & 01 & 5.5476 & TRN \\
\hline CHEMBL127281 & 49848 & 8.0969 & 8.1795 & TRN & & \\
\hline CHEMBL341144 & 49848 & 5.699 & 6.0416 & TST & & \\
\hline CHEMBL338389 & 49848 & 6.5086 & 6.8317 & TRN & & \\
\hline CHEMBL18222 & 49848 & 5.1487 & 5.4902 & TST & & \\
\hline CHEMBL124334 & 49848 & 8.699 & 8.6308 & TRN & & \\
\hline CHEMBL276784 & 49848 & 5.4202 & 5.4929 & TST & & \\
\hline CHEMBL124628 & 49848 & 8.1549 & 8.0558 & TRN & & \\
\hline CHEMBL341074 & 49848 & 7.9586 & 7.6767 & TRN & & \\
\hline CHEMBL125753 & 49848 & 5.0809 & 5.3514 & TST & & \\
\hline CHEMBL123961 & 49848 & 7.0706 & 7.1204 & TRN & & \\
\hline CHEMBL124134 & 49848 & 6.0458 & 5.9295 & TRN & & \\
\hline CHEMBL446164 & 49848 & 7.6198 & 7.4439 & TRN & & \\
\hline CHEMBL124390 & 49848 & 6.3468 & 6.2224 & TST & & \\
\hline CHEMBL123807 & 49848 & 5.5768 & 5.5455 & TRN & & \\
\hline CHEMBL331634 & 49848 & 6.7447 & 7.0736 & TRN & & \\
\hline CHEMBL124821 & 49848 & 7.9586 & 7.8339 & TRN & & \\
\hline CHEMBL124808 & 49848 & 4.8508 & 4.7316 & TST & & \\
\hline CHEMBL434437 & 49848 & 6.1096 & 6.2342 & TRN & & \\
\hline
\end{tabular}




\begin{tabular}{|c|c|c|c|c|c|}
\hline \multirow[b]{2}{*}{ CHEMBL124438 } & & \\
\hline & 49848 & 7.9586 & 7.7885 & TRN & \\
\hline CHEMBL413113 & 49848 & 8.0458 & 7.79 & TRN & \\
\hline CHEMBL339934 & 49848 & 5.5528 & 5.6917 & TRN & \\
\hline CHEMBL421634 & 49848 & 6.3872 & 6.6172 & TRN & \\
\hline CHEMBL125167 & 49848 & 5.4202 & 5.6026 & TRN & \\
\hline CHEMBL123622 & 49848 & 5.2147 & 5.93 & TST & \\
\hline CHEMBL124585 & 49848 & 5.2757 & 6.1121 & TST & \\
\hline CHEMBL125282 & 49848 & 5.6198 & 5.6172 & TRN & \\
\hline CHEMBL125884 & 49848 & 7.2596 & 7.4228 & TRN & \\
\hline CHEMBL442210 & 49848 & 6.3468 & 6.1724 & TST & \\
\hline CHEMBL127395 & 49848 & 5.3372 & 5.8466 & TST & \\
\hline CHEMBL124457 & 49848 & 5.0809 & 4.6811 & TST & \\
\hline CHEMBL123511 & 49848 & 6.2218 & 6.1558 & TRN & \\
\hline CHEMBL333422 & 49848 & 5.6576 & 5.8665 & TST & \\
\hline CHEMBL124084 & 49848 & 5.1192 & 6.035 & TST & \\
\hline CHEMBL124321 & 49848 & 5.4685 & 5.1247 & TRN & \\
\hline CHEMBL340656 & 49848 & 5.3325 & 5.3539 & TRN & \\
\hline CHEMBL126174 & 49848 & 6.9431 & 6.6351 & TRN & \\
\hline CHEMBL125220 & 49848 & 5.0362 & 4.6833 & TRN & \\
\hline CHEMBL340491 & 49848 & 5.2441 & 5.637006 & 00000000005 & TST \\
\hline CHEMBL341306 & 49848 & 5.6198 & 5.8128 & TST & \\
\hline CHEMBL126520 & 49848 & 7.1938 & 7.1047 & TRN & \\
\hline CHEMBL125012 & 49848 & 7.3768 & 7.41799 & 9999999999 & TRN \\
\hline CHEMBL123611 & 49848 & 9.0 & 9.1022 & TRN & \\
\hline CHEMBL125132 & 49848 & 7.3098 & 7.2089 & TRN & \\
\hline CHEMBL359738 & 311637 & 5.058 & 4.7959 & TRN & \\
\hline CHEMBL179385 & 311637 & 3.699 & 4.2871 & TRN & \\
\hline CHEMBL178535 & 311637 & 5.3872 & 5.2721 & TRN & \\
\hline CHEMBL180265 & 311637 & 3.699 & 4.2979 & TRN & \\
\hline CHEMBL179511 & 311637 & 3.699 & 3.3681 & TRN & \\
\hline CHEMBL178107 & 311637 & 5.0106 & 4.544 & TRN & \\
\hline CHEMBL362656 & 311637 & 5.5969 & 5.1729 & TRN & \\
\hline CHEMBL180916 & 311637 & 5.3468 & 5.0125 & TRN & \\
\hline CHEMBL181036 & 311637 & 5.9031 & 6.0341 & TRN & \\
\hline CHEMBL178827 & 311637 & 5.5638 & 5.17200 & 0000000001 & TRN \\
\hline CHEMBL178965 & 311637 & 4.8564 & 4.6808 & TRN & \\
\hline CHEMBL179599 & 311637 & 3.699 & 3.8788 & TRN & \\
\hline CHEMBL369522 & 311637 & 6.0362 & 6.1793 & TRN & \\
\hline CHEMBL360149 & 311637 & 5.0106 & 5.2887 & TRN & \\
\hline CHEMBL180379 & 311637 & 3.699 & 3.707 & TRN & \\
\hline CHEMBL361862 & 311637 & 3.699 & 4.2363 & TST & \\
\hline CHEMBL178544 & 311637 & 5.5376 & 5.2494 & TRN & \\
\hline CHEMBL368433 & 311637 & 3.699 & 4.5285 & TRN & \\
\hline CHEMBL360312 & 311637 & 5.0605 & 4.8505 & TRN & \\
\hline CHEMBL 367363 & 311637 & 5.3487 & 5.5431 & TRN & \\
\hline CHEMBL361595 & 311637 & 5.055 & 5.2954 & TRN & \\
\hline CHEMBL440379 & 311637 & 5.3915 & 5.4951 & TRN & \\
\hline CHEMBL554716 & 311637 & 6.3979 & 6.74799 & 9999999999 & TRN \\
\hline & & & & 6665 & \\
\hline
\end{tabular}




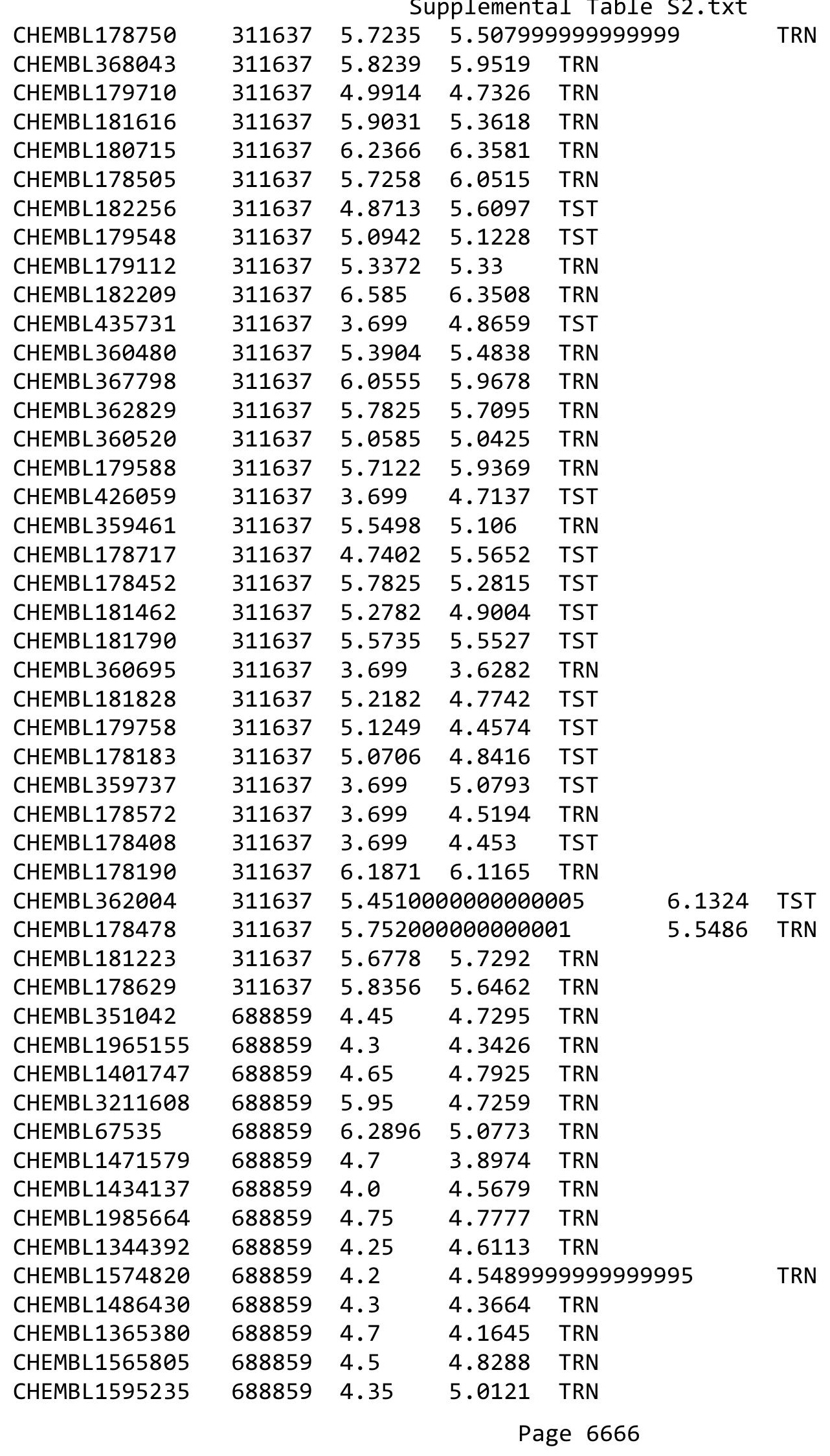




\begin{tabular}{|c|c|c|c|c|}
\hline \multicolumn{5}{|c|}{ Supplemental Table S2.txt } \\
\hline CHEMBL1390427 & 688859 & 5.1 & 5.3365 & TRN \\
\hline CHEMBL1612381 & 688859 & 4.65 & 4.3024 & TRN \\
\hline CHEMBL1402871 & 688859 & 4.45 & 4.3844 & TRN \\
\hline CHEMBL1589300 & 688859 & 4.5 & 4.9911 & TRN \\
\hline CHEMBL1557372 & 688859 & 4.1 & 4.622 & TRN \\
\hline CHEMBL1332402 & 688859 & 4.65 & 4.8669 & TRN \\
\hline CHEMBL1402957 & 688859 & 6.3 & 4.737 & TST \\
\hline CHEMBL1394649 & 688859 & 5.5396 & 4.92 & TRN \\
\hline CHEMBL1502839 & 688859 & 4.35 & 4.511 & TRN \\
\hline CHEMBL189438 & 688859 & 5.65 & 4.7987 & TST \\
\hline CHEMBL1348074 & 688859 & 6.5 & 4.3362 & TST \\
\hline CHEMBL1606751 & 688859 & 3.95 & 4.2593 & TRN \\
\hline CHEMBL1613634 & 688859 & 4.45 & 4.3804 & TRN \\
\hline CHEMBL3192701 & 688859 & 5.65 & 4.5844 & TRN \\
\hline CHEMBL446240 & 688859 & 7.6003 & 4.7994 & TST \\
\hline CHEMBL1410280 & 688859 & 4.15 & 4.4323 & TRN \\
\hline CHEMBL1426947 & 688859 & 4.6 & 4.3973 & TRN \\
\hline CHEMBL418068 & 688859 & 3.9 & 4.9504 & TRN \\
\hline CHEMBL1359797 & 688859 & 4.2 & 4.419 & TRN \\
\hline CHEMBL1305393 & 688859 & 6.45 & 4.7285 & TRN \\
\hline CHEMBL1304345 & 688859 & 4.3 & 4.7203 & TRN \\
\hline CHEMBL1324556 & 688859 & 4.6 & 4.8667 & TRN \\
\hline CHEMBL1390419 & 688859 & 5.25 & 4.4788 & TRN \\
\hline CHEMBL1609550 & 688859 & 4.3 & 4.529 & TRN \\
\hline CHEMBL198468 & 688859 & 6.0 & 5.2324 & TRN \\
\hline CHEMBL1505663 & 688859 & 4.65 & 4.7547 & TST \\
\hline CHEMBL1460436 & 688859 & 4.3 & 4.9379 & TST \\
\hline CHEMBL1352778 & 688859 & 4.3 & 3.7628 & TRN \\
\hline CHEMBL1427775 & 688859 & 4.7 & 4.2842 & TRN \\
\hline CHEMBL1429158 & 688859 & 5.25 & 4.7948 & TRN \\
\hline CHEMBL1366812 & 688859 & 3.95 & 4.6144 & TRN \\
\hline CHEMBL1527994 & 688859 & 4.2 & 4.4581 & TRN \\
\hline CHEMBL1343341 & 688859 & 3.95 & 4.0722 & TRN \\
\hline CHEMBL1352170 & 688859 & 4.85 & 4.4022 & TRN \\
\hline CHEMBL408994 & 688859 & 4.7 & 4.44 & TRN \\
\hline CHEMBL1372397 & 688859 & 4.5 & 5.0746 & TRN \\
\hline CHEMBL1578537 & 688859 & 4.6 & 4.7194 & TRN \\
\hline CHEMBL1516388 & 688859 & 4.65 & 4.4883 & TST \\
\hline CHEMBL 365327 & 688859 & 4.15 & 4.5994 & TRN \\
\hline CHEMBL1586339 & 688859 & 4.5 & 4.5238 & TRN \\
\hline CHEMBL1573953 & 688859 & 3.85 & 4.3779 & TRN \\
\hline CHEMBL1358777 & 688859 & 5.1 & 4.6077 & TRN \\
\hline CHEMBL1334484 & 688859 & 4.3 & 4.8936 & TST \\
\hline CHEMBL 2002767 & 688859 & 4.3 & 4.5241 & TRN \\
\hline CHEMBL1718398 & 688859 & 3.8 & 5.0218 & TRN \\
\hline CHEMBL1526663 & 688859 & 3.8 & 4.1862 & TRN \\
\hline CHEMBL1500768 & 688859 & 3.8 & 4.5848 & TRN \\
\hline CHEMBL1562801 & 688859 & 4.0 & 4.7492 & TRN \\
\hline
\end{tabular}




\begin{tabular}{|c|c|c|c|c|}
\hline \multicolumn{5}{|c|}{ Supplemental Table S2.txt } \\
\hline CHEMBL502044 & 688859 & 4.75 & 4.8795 & TST \\
\hline CHEMBL1493956 & 688859 & 4.05 & 4.1382 & TRN \\
\hline CHEMBL1313635 & 688859 & 4.85 & 4.6923 & TRN \\
\hline CHEMBL1471583 & 688859 & 4.7 & 4.4253 & TRN \\
\hline CHEMBL1256646 & 688859 & 6.8 & 5.152 & TST \\
\hline CHEMBL1522129 & 688859 & 4.05 & 4.5871 & TST \\
\hline CHEMBL1406457 & 688859 & 6.9 & 4.9736 & TRN \\
\hline CHEMBL584759 & 688859 & 4.2 & 4.7432 & TRN \\
\hline CHEMBL1308842 & 688859 & 5.0 & 4.3931 & TST \\
\hline CHEMBL3190368 & 688859 & 4.05 & 4.2579 & TRN \\
\hline CHEMBL1427330 & 688859 & 4.35 & 4.8724 & TRN \\
\hline CHEMBL1441583 & 688859 & 4.05 & 4.8348 & TRN \\
\hline CHEMBL1406195 & 688859 & 4.35 & 4.1947 & TRN \\
\hline CHEMBL1424412 & 688859 & 4.35 & 4.1971 & TRN \\
\hline CHEMBL1443059 & 688859 & 4.05 & 4.7127 & TRN \\
\hline CHEMBL1535956 & 688859 & 4.0 & 4.3257 & TRN \\
\hline CHEMBL1475999 & 688859 & 4.4 & 4.928 & TST \\
\hline CHEMBL1419637 & 688859 & 4.3 & 4.3506 & TRN \\
\hline CHEMBL1608979 & 688859 & 4.7 & 4.9771 & TRN \\
\hline CHEMBL1981243 & 688859 & 4.25 & 4.375 & TRN \\
\hline CHEMBL1301796 & 688859 & 4.85 & 4.1513 & TRN \\
\hline CHEMBL1571704 & 688859 & 3.9 & 4.4484 & TRN \\
\hline CHEMBL1533561 & 688859 & 4.35 & 4.1859 & TRN \\
\hline CHEMBL1589017 & 688859 & 4.15 & 4.1709 & TRN \\
\hline CHEMBL3199475 & 688859 & 3.85 & 4.6743 & TRN \\
\hline CHEMBL1495790 & 688859 & 4.2 & 4.4923 & TST \\
\hline CHEMBL1366359 & 688859 & 4.35 & 4.3892 & TRN \\
\hline CHEMBL1305289 & 688859 & 4.2 & 4.5771 & TRN \\
\hline CHEMBL 3198782 & 688859 & 4.05 & 4.3325 & TST \\
\hline CHEMBL1600012 & 688859 & 4.45 & 4.4325 & TRN \\
\hline CHEMBL1493011 & 688859 & 4.3 & 4.5809 & TRN \\
\hline CHEMBL1424340 & 688859 & 4.55 & 4.6919 & TRN \\
\hline CHEMBL1455554 & 688859 & 4.25 & 4.3622 & TRN \\
\hline CHEMBL1403572 & 688859 & 4.05 & 4.6961 & TRN \\
\hline CHEMBL1531008 & 688859 & 3.85 & 4.1089 & TRN \\
\hline CHEMBL1496441 & 688859 & 4.4 & 4.7587 & TRN \\
\hline CHEMBL1310907 & 688859 & 4.4 & 4.687 & TRN \\
\hline CHEMBL1200938 & 688859 & 3.85 & 5.0983 & TST \\
\hline CHEMBL1381627 & 688859 & 5.45 & 4.9499 & TRN \\
\hline CHEMBL1578687 & 688859 & 4.05 & 4.8479 & TRN \\
\hline CHEMBL1526624 & 688859 & 6.9 & 4.8582 & TRN \\
\hline CHEMBL599013 & 688859 & 4.4 & 4.5467 & TRN \\
\hline CHEMBL160053 & 688859 & 4.5 & 4.5973 & TRN \\
\hline CHEMBL1735892 & 688859 & 4.3 & 4.6391 & TRN \\
\hline CHEMBL1583998 & 688859 & 4.3 & 3.955 & TRN \\
\hline CHEMBL1373527 & 688859 & 4.25 & 4.2771 & TRN \\
\hline CHEMBL1505467 & 688859 & 4.4 & 5.2248 & TST \\
\hline CHEMBL1423129 & 688859 & 4.05 & 4.859 & TRN \\
\hline
\end{tabular}




\begin{tabular}{|c|c|c|c|c|c|}
\hline \multicolumn{6}{|c|}{ Supplemental Table S2.txt } \\
\hline CHEMBL1465322 & 688859 & 4.4 & 4.3711 & TRN & \\
\hline CHEMBL 2357911 & 688859 & 4.25 & 4.5653 & TRN & \\
\hline CHEMBL1463964 & 688859 & 4.05 & 4.4074 & TRN & \\
\hline CHEMBL1701224 & 688859 & 5.15 & 4.729 & TRN & \\
\hline CHEMBL1320230 & 688859 & 4.9 & 4.7931 & TRN & \\
\hline CHEMBL1458891 & 688859 & 4.65 & 4.7384 & TRN & \\
\hline CHEMBL 3189880 & 688859 & 6.05 & 5.0478 & TRN & \\
\hline CHEMBL1346456 & 688859 & 4.4 & 4.7855 & TST & \\
\hline CHEMBL20936 & 688859 & 6.6499 & 4.6547 & TST & \\
\hline CHEMBL1451790 & 688859 & 4.3 & 4.7217 & TRN & \\
\hline CHEMBL1592095 & 688859 & 4.35 & 5.3753 & TST & \\
\hline CHEMBL 1445030 & 688859 & 4.6 & 4.9181 & TRN & \\
\hline CHEMBL1301115 & 688859 & 4.4 & 4.8844 & TRN & \\
\hline CHEMBL1500912 & 688859 & 7.5498 & 4.9322 & TRN & \\
\hline CHEMBL1325440 & 688859 & 4.25 & 4.6172 & TRN & \\
\hline CHEMBL1346592 & 688859 & 4.5 & 4.2499 & TRN & \\
\hline CHEMBL1341927 & 688859 & 4.1 & 4.9225 & TRN & \\
\hline CHEMBL1447475 & 688859 & 5.95 & 5.0078 & TRN & \\
\hline CHEMBL1344248 & 688859 & 4.2 & 4.6277 & TRN & \\
\hline CHEMBL1527684 & 688859 & 3.85 & 4.6904 & TRN & \\
\hline CHEMBL1385679 & 688859 & 3.95 & 4.0678 & TRN & \\
\hline CHEMBL1581326 & 688859 & 4.25 & 4.5937 & TST & \\
\hline CHEMBL1555752 & 688859 & 3.85 & 4.2957 & TST & \\
\hline CHEMBL1481914 & 688859 & 4.55 & 4.9154 & TRN & \\
\hline CHEMBL1391063 & 688859 & 6.35 & 5.3944 & TRN & \\
\hline CHEMBL1349382 & 688859 & 5.15 & 5.3684 & TRN & \\
\hline CHEMBL1345825 & 688859 & 4.25 & 4.26 & TRN & \\
\hline CHEMBL1979849 & 688859 & 5.65 & 5.0087 & TRN & \\
\hline CHEMBL123 & 688859 & 4.5 & 4.9911 & TRN & \\
\hline CHEMBL1312514 & 688859 & 4.65 & 4.7262 & TRN & \\
\hline CHEMBL1472249 & 688859 & 4.45 & 5.0354 & TST & \\
\hline CHEMBL555689 & 688859 & 5.4 & 4.6045 & TST & \\
\hline CHEMBL1479248 & 688859 & 4.35 & 4.6363 & TRN & \\
\hline CHEMBL1477771 & 688859 & 4.5 & 4.4316 & TRN & \\
\hline CHEMBL1427289 & 688859 & 4.7 & 4.3889 & TRN & \\
\hline CHEMBL69612 & 688859 & 4.3 & 4.4617 & TRN & \\
\hline CHEMBL1514486 & 688859 & 4.3 & 4.6544 & TRN & \\
\hline CHEMBL1365895 & 688859 & 3.85 & 4.399 & TRN & \\
\hline CHEMBL1581193 & 688859 & 6.5 & 5.0258 & TRN & \\
\hline CHEMBL1528396 & 688859 & 5.45 & 4.5972 & TRN & \\
\hline CHEMBL240331 & 688859 & 4.0 & 4.687 & TRN & \\
\hline CHEMBL546257 & 688859 & 4.5 & 4.0674 & TST & \\
\hline CHEMBL3190370 & 688859 & 4.05 & 4.2745 & TRN & \\
\hline CHEMBL1511287 & 688859 & 4.05 & 3.9866 & TRN & \\
\hline CHEMBL1611734 & 688859 & 4.75 & 4.96399 & 99999999995 & TRN \\
\hline CHEMBL1518838 & 688859 & 4.4 & 4.5069 & TRN & \\
\hline CHEMBL578741 & 688859 & 4.55 & 5.0417 & TRN & \\
\hline CHEMBL3197851 & 688859 & 9.699 & 5.7641 & TRN & \\
\hline
\end{tabular}




\begin{tabular}{|c|c|c|c|c|c|}
\hline \multicolumn{6}{|c|}{ Supplemental Table S2.txt } \\
\hline CHEMBL1538254 & 688859 & 4.45 & 4.3583 & TRN & \\
\hline CHEMBL1553873 & 688859 & 4.0 & 4.3883 & TRN & \\
\hline CHEMBL1480797 & 688859 & 4.05 & 4.332 & TRN & \\
\hline CHEMBL1530437 & 688859 & 4.6 & 4.1031 & TRN & \\
\hline CHEMBL1544739 & 688859 & 3.9 & 4.9275 & TRN & \\
\hline CHEMBL1373095 & 688859 & 4.85 & 4.2199 & TRN & \\
\hline CHEMBL1580036 & 688859 & 4.3 & 3.9373 & TRN & \\
\hline CHEMBL1452561 & 688859 & 4.65 & 4.7729 & TRN & \\
\hline CHEMBL1575278 & 688859 & 4.55 & 4.8713 & TRN & \\
\hline CHEMBL1500249 & 688859 & 5.45 & 5.4676 & TRN & \\
\hline CHEMBL80941 & 688859 & 3.85 & 5.0472 & TRN & \\
\hline CHEMBL1559225 & 688859 & 4.6 & 5.0739 & TRN & \\
\hline CHEMBL1706577 & 688859 & 4.55 & 4.4243 & TRN & \\
\hline CHEMBL1588434 & 688859 & 4.7 & 5.121 & TRN & \\
\hline CHEMBL1576054 & 688859 & 4.75 & 5.3363 & TRN & \\
\hline CHEMBL1353907 & 688859 & 4.6 & 4.3372 & TRN & \\
\hline CHEMBL1987928 & 688859 & 4.35 & 5.1952 & TRN & \\
\hline CHEMBL1397833 & 688859 & 3.95 & 4.9174 & TST & \\
\hline CHEMBL580421 & 688859 & 6.3 & 4.9536 & TRN & \\
\hline CHEMBL1978364 & 688859 & 4.7 & 4.3892 & TRN & \\
\hline CHEMBL1471965 & 688859 & 5.45 & 4.5919 & TRN & \\
\hline CHEMBL1442633 & 688859 & 4.25 & 4.9388 & TRN & \\
\hline CHEMBL1597993 & 688859 & 4.05 & 4.8146 & TST & \\
\hline CHEMBL1555552 & 688859 & 4.3896 & 5.09399 & 9999999999 & TST \\
\hline CHEMBL 78573 & 688859 & 5.55 & 5.5098 & TRN & \\
\hline CHEMBL1430175 & 688859 & 4.15 & 4.4235 & TRN & \\
\hline CHEMBL1451483 & 688859 & 4.45 & 5.53700 & 2000000001 & TRN \\
\hline CHEMBL1589385 & 688859 & 5.55 & 5.0693 & TST & \\
\hline CHEMBL1464373 & 688859 & 4.5 & 4.5578 & TRN & \\
\hline CHEMBL1462808 & 688859 & 4.85 & 5.1148 & TRN & \\
\hline CHEMBL1504875 & 688859 & 4.3 & 4.2661 & TRN & \\
\hline CHEMBL1336709 & 688859 & 4.75 & 4.1759 & TRN & \\
\hline CHEMBL1493191 & 688859 & 4.15 & 4.5493 & TRN & \\
\hline CHEMBL1303309 & 688859 & 5.45 & 4.9471 & TRN & \\
\hline CHEMBL1385694 & 688859 & 4.4 & 4.4059 & TRN & \\
\hline CHEMBL1533269 & 688859 & 3.95 & 4.6231 & TRN & \\
\hline CHEMBL1443157 & 688859 & 4.4 & 4.8274 & TST & \\
\hline CHEMBL1527095 & 688859 & 4.05 & 4.2784 & TRN & \\
\hline CHEMBL 1730100 & 688859 & 4.95 & 4.8877 & TRN & \\
\hline CHEMBL1546414 & 688859 & 4.05 & 4.7224 & TRN & \\
\hline CHEMBL1423705 & 688859 & 4.75 & 4.4838 & TST & \\
\hline CHEMBL1441990 & 688859 & 4.55 & 4.4965 & TRN & \\
\hline CHEMBL1430727 & 688859 & 4.3 & 3.7928 & TRN & \\
\hline CHEMBL1423277 & 688859 & 5.05 & 4.8521 & TRN & \\
\hline CHEMBL1383746 & 688859 & 6.15 & 4.4757 & TRN & \\
\hline CHEMBL3193997 & 688859 & 6.5 & 5.1446 & TRN & \\
\hline CHEMBL1353420 & 688859 & 4.3 & 4.3903 & TRN & \\
\hline CHEMBL52 & 688859 & 4.35 & 4.7198 & TRN & \\
\hline
\end{tabular}




\begin{tabular}{|c|c|c|c|c|c|}
\hline \multirow[b]{2}{*}{ CHEMBL1521196 } & \multicolumn{5}{|c|}{ Supplemental Table S2.txt } \\
\hline & 688859 & 4.25 & 4.6992 & TRN & \\
\hline CHEMBL546649 & 688859 & 4.25 & 4.3551 & TRN & \\
\hline CHEMBL1575881 & 688859 & 4.3 & 4.51699 & 99999999995 & TRN \\
\hline CHEMBL1365599 & 688859 & 4.45 & 4.978 & TST & \\
\hline CHEMBL1390521 & 688859 & 6.05 & 5.2229 & TRN & \\
\hline CHEMBL109037 & 688859 & 4.35 & 4.9599 & TRN & \\
\hline CHEMBL1412163 & 688859 & 4.8 & 4.7116 & TST & \\
\hline CHEMBL1571649 & 688859 & 4.25 & 4.8151 & TST & \\
\hline CHEMBL187460 & 688859 & 4.0 & 4.7579 & TRN & \\
\hline CHEMBL1424746 & 688859 & 4.3 & 4.3864 & TRN & \\
\hline CHEMBL1532515 & 688859 & 4.35 & 4.5101 & TRN & \\
\hline CHEMBL399043 & 688859 & 4.4 & 4.8494 & TST & \\
\hline CHEMBL1367444 & 688859 & 7.8013 & 5.2408 & TRN & \\
\hline CHEMBL3196039 & 688859 & 4.35 & 4.5318 & TRN & \\
\hline CHEMBL1331134 & 688859 & 4.8 & 4.5022 & TRN & \\
\hline CHEMBL1312932 & 688859 & 4.45 & 4.5038 & TRN & \\
\hline CHEMBL370641 & 688859 & 4.85 & 5.1838 & TRN & \\
\hline CHEMBL1574133 & 688859 & 4.4 & 4.8671 & TRN & \\
\hline CHEMBL1699206 & 688859 & 4.35 & 4.4202 & TRN & \\
\hline CHEMBL1449836 & 688859 & 4.4 & 4.8094 & TRN & \\
\hline CHEMBL1539384 & 688859 & 5.25 & 5.0189 & TRN & \\
\hline CHEMBL1347829 & 688859 & 5.35 & 4.9064 & TRN & \\
\hline CHEMBL1539325 & 688859 & 4.7 & 4.3004 & TRN & \\
\hline CHEMBL1478395 & 688859 & 4.25 & 4.8759 & TRN & \\
\hline CHEMBL1470869 & 688859 & 3.8 & 4.8305 & TRN & \\
\hline CHEMBL1407306 & 688859 & 4.4 & 4.6974 & TRN & \\
\hline CHEMBL 22062 & 688859 & 4.65 & 4.4978 & TRN & \\
\hline CHEMBL1417268 & 688859 & 3.8 & 5.149 & TST & \\
\hline CHEMBL1592234 & 688859 & 5.1896 & 4.7487 & TRN & \\
\hline CHEMBL3189657 & 688859 & 4.05 & 5.0588 & TRN & \\
\hline CHEMBL1604163 & 688859 & 4.05 & 4.732 & TRN & \\
\hline CHEMBL 2005973 & 688859 & 4.05 & 4.8554 & TRN & \\
\hline CHEMBL1454643 & 688859 & 3.9 & 4.2325 & TRN & \\
\hline CHEMBL1993613 & 688859 & 4.25 & 4.1396 & TRN & \\
\hline CHEMBL1391256 & 688859 & 4.6 & 4.6263 & TST & \\
\hline CHEMBL1364573 & 688859 & 4.25 & 4.5372 & TRN & \\
\hline CHEMBL1432332 & 688859 & 5.2 & 4.6186 & TRN & \\
\hline CHEMBL1566610 & 688859 & 4.85 & 4.8471 & TST & \\
\hline CHEMBL1424694 & 688859 & 5.6397 & 4.4456 & TRN & \\
\hline CHEMBL1495778 & 688859 & 4.35 & 4.6206 & TRN & \\
\hline CHEMBL1464853 & 688859 & 4.3 & 4.71399 & 99999999995 & TST \\
\hline CHEMBL504791 & 688859 & 5.2 & 5.3686 & TRN & \\
\hline CHEMBL1366942 & 688859 & 4.65 & 4.5866 & TRN & \\
\hline CHEMBL1350435 & 688859 & 4.35 & 4.277 & TRN & \\
\hline CHEMBL1477068 & 688859 & 4.9 & 4.0504 & TRN & \\
\hline CHEMBL1393131 & 688859 & 4.35 & 4.3599 & TRN & \\
\hline CHEMBL1362935 & 688859 & 5.55 & 4.7792 & TRN & \\
\hline CHEMBL1568055 & 688859 & 4.55 & 4.8954 & TRN & \\
\hline
\end{tabular}




\begin{tabular}{|c|c|c|c|c|}
\hline \multicolumn{5}{|c|}{ Supplemental Table S2.txt } \\
\hline CHEMBL1325176 & 688859 & 4.3 & 4.5316 & TRN \\
\hline CHEMBL1572280 & 688859 & 5.85 & 4.5706 & TRN \\
\hline CHEMBL1350596 & 688859 & 4.3 & 4.4629 & TRN \\
\hline CHEMBL1562712 & 688859 & 5.5 & 4.1797 & TRN \\
\hline CHEMBL1538505 & 688859 & 4.4 & 4.3802 & TRN \\
\hline CHEMBL1457008 & 688859 & 6.15 & 5.4329 & TRN \\
\hline CHEMBL1560128 & 688859 & 4.35 & 3.8723 & TRN \\
\hline CHEMBL1452952 & 688859 & 4.45 & 4.9394 & TST \\
\hline CHEMBL1405054 & 688859 & 4.25 & 4.5678 & TRN \\
\hline CHEMBL1440951 & 688859 & 3.95 & 5.0598 & TRN \\
\hline CHEMBL1491702 & 688859 & 4.45 & 5.1648 & TST \\
\hline CHEMBL1494334 & 688859 & 4.1 & 4.5967 & TRN \\
\hline CHEMBL1530561 & 688859 & 4.25 & 4.4229 & TST \\
\hline CHEMBL1373950 & 688859 & 3.9 & 4.9173 & TST \\
\hline CHEMBL493863 & 688859 & 4.65 & 4.7002 & TST \\
\hline CHEMBL1704267 & 688859 & 4.4 & 4.5181 & TST \\
\hline CHEMBL3194626 & 688859 & 3.95 & 4.8267 & TST \\
\hline CHEMBL1405834 & 688859 & 4.4 & 4.8973 & TST \\
\hline CHEMBL151 & 688859 & 4.4 & 5.0386 & TST \\
\hline CHEMBL286494 & 688859 & 6.45 & 4.7705 & TST \\
\hline CHEMBL530280 & 688859 & 4.6 & 4.2095 & TST \\
\hline CHEMBL1432110 & 688859 & 4.4 & 4.3832 & TST \\
\hline CHEMBL1309506 & 688859 & 4.55 & 4.7935 & TST \\
\hline CHEMBL97453 & 688859 & 4.85 & 4.6382 & TST \\
\hline CHEMBL1546656 & 688859 & 4.55 & 4.4587 & TST \\
\hline CHEMBL 259355 & 688859 & 4.65 & 4.1548 & TST \\
\hline CHEMBL1468919 & 688859 & 4.15 & 4.293 & TST \\
\hline CHEMBL1527520 & 688859 & 5.3896 & 4.8506 & TST \\
\hline CHEMBL1353033 & 688859 & 4.2 & 4.4775 & TST \\
\hline CHEMBL1522300 & 688859 & 4.4 & 4.4374 & TST \\
\hline CHEMBL15192 & 688859 & 3.95 & 4.6845 & TST \\
\hline CHEMBL43612 & 688859 & 5.1 & 5.1823 & TST \\
\hline CHEMBL3193084 & 688859 & 9.2218 & 5.056 & TST \\
\hline CHEMBL3192160 & 688859 & 4.3 & 4.3564 & TST \\
\hline CHEMBL1390716 & 688859 & 5.65 & 4.8429 & TST \\
\hline CHEMBL1558621 & 688859 & 3.95 & 4.9157 & TST \\
\hline CHEMBL1610008 & 688859 & 4.65 & 4.0087 & TST \\
\hline CHEMBL1323619 & 688859 & 4.4396 & 4.5472 & TST \\
\hline CHEMBL1398645 & 688859 & 4.55 & 4.5199 & TST \\
\hline CHEMBL1607982 & 688859 & 4.55 & 4.1391 & TST \\
\hline CHEMBL1173475 & 688859 & 6.3 & 5.078 & TST \\
\hline CHEMBL1374242 & 688859 & 4.65 & 5.034 & TST \\
\hline CHEMBL1302742 & 688859 & 4.55 & 4.6093 & TST \\
\hline CHEMBL1540272 & 688859 & 4.45 & 4.4437 & TST \\
\hline CHEMBL106525 & 688859 & 4.95 & 4.2972 & TST \\
\hline CHEMBL1426001 & 688859 & 4.65 & 3.8153 & TST \\
\hline CHEMBL1935168 & 794420 & 3.0 & 2.6723 & TST \\
\hline CHEMBL1935060 & 794420 & 4.6064 & 3.7494 & TST \\
\hline
\end{tabular}




\begin{tabular}{|c|c|c|c|c|}
\hline \\
\hline CHEMBL1935056 & 794420 & 3.0 & 3.4795 & TRN \\
\hline CHEMBL1935042 & 794420 & 3.0 & 3.1339 & TRN \\
\hline CHEMBL1935061 & 794420 & 4.8545 & 3.535 & TRN \\
\hline CHEMBL1935017 & 794420 & 4.1715 & 4.1757 & TST \\
\hline CHEMBL1935018 & 794420 & 4.9889 & 3.8352 & TST \\
\hline CHEMBL1935045 & 794420 & 3.0 & 3.3535 & TST \\
\hline CHEMBL1935068 & 794420 & 3.0 & 3.3584 & TRN \\
\hline CHEMBL1935050 & 794420 & 3.0 & 3.1567 & TRN \\
\hline CHEMBL1935063 & 794420 & 3.0 & 3.6435 & TRN \\
\hline CHEMBL1935030 & 794420 & 3.0 & 3.4769 & TRN \\
\hline CHEMBL1935025 & 794420 & 3.0 & 3.2576 & TRN \\
\hline CHEMBL1935024 & 794420 & 3.0 & 3.1415 & TRN \\
\hline CHEMBL1935021 & 794420 & 3.0 & 3.2223 & TRN \\
\hline CHEMBL1935171 & 794420 & 5.0061 & 3.9613 & TST \\
\hline CHEMBL1935048 & 794420 & 3.0 & 3.4241 & TRN \\
\hline CHEMBL1935039 & 794420 & 3.0 & 3.0078 & TRN \\
\hline CHEMBL1935046 & 794420 & 3.0 & 3.2576 & TRN \\
\hline CHEMBL1935040 & 794420 & 3.0 & 3.1214 & TRN \\
\hline CHEMBL1935170 & 794420 & 3.0 & 3.5224 & TST \\
\hline CHEMBL1935041 & 794420 & 3.0 & 2.7883 & TRN \\
\hline CHEMBL1935023 & 794420 & 3.0 & 3.3585 & TRN \\
\hline CHEMBL1935029 & 794420 & 3.0 & 3.3609 & TRN \\
\hline CHEMBL1935036 & 794420 & 3.0 & 3.1339 & TRN \\
\hline CHEMBL1935051 & 794420 & 3.0 & 3.2878 & TRN \\
\hline CHEMBL1935052 & 794420 & 4.8 & 3.3079 & TRN \\
\hline CHEMBL1935057 & 794420 & 4.4264 & 3.7267 & TRN \\
\hline CHEMBL1935172 & 794420 & 5.3979 & 3.1415 & TST \\
\hline CHEMBL1935169 & 794420 & 3.0 & 2.8035 & TST \\
\hline CHEMBL1935035 & 794420 & 3.0 & 3.3634 & TRN \\
\hline CHEMBL1935027 & 794420 & 3.0 & 3.2272 & TRN \\
\hline CHEMBL 1935053 & 794420 & 3.0 & 3.255 & TRN \\
\hline CHEMBL1935019 & 794420 & 4.354 & 4.1354 & TRN \\
\hline CHEMBL1935034 & 794420 & 3.0 & 3.7418 & TST \\
\hline CHEMBL1935047 & 794420 & 3.0 & 2.9598 & TRN \\
\hline CHEMBL1935038 & 794420 & 3.0 & 3.583 & TST \\
\hline CHEMBL1933087 & 794420 & 3.0 & 3.1187 & TRN \\
\hline CHEMBL1935020 & 794420 & 4.7447 & 4.1606 & TRN \\
\hline CHEMBL1935055 & 794420 & 3.0 & 3.3836 & TRN \\
\hline CHEMBL1935064 & 794420 & 3.0 & 3.5427 & TST \\
\hline CHEMBL1935031 & 794420 & 3.0 & 3.6737 & TRN \\
\hline CHEMBL1935071 & 794420 & 3.0 & 3.2777 & TST \\
\hline CHEMBL1935066 & 794420 & 3.0 & 3.202 & TRN \\
\hline CHEMBL1935028 & 794420 & 3.0 & 2.8413 & TRN \\
\hline CHEMBL1935044 & 794420 & 4.2213 & 3.3584 & TRN \\
\hline CHEMBL1935058 & 794420 & 4.5036 & 3.4291 & TRN \\
\hline CHEMBL1935059 & 794420 & 3.0 & 3.1617 & TRN \\
\hline CHEMBL1935049 & 794420 & 3.0 & 2.9902 & TRN \\
\hline CHEMBL1935037 & 794420 & 3.0 & 3.7317 & TRN \\
\hline
\end{tabular}




\begin{tabular}{|c|c|c|c|c|c|}
\hline & & \multicolumn{4}{|c|}{ Supplemental Table S2.txt } \\
\hline CHEMBL1935072 & 794420 & 4.8153 & 3.4215 & TST & \\
\hline CHEMBL1935032 & 794420 & 3.0 & 3.1616 & TRN & \\
\hline CHEMBL1935070 & 794420 & 3.0 & 3.4719 & TRN & \\
\hline CHEMBL1935026 & 794420 & 3.0 & 3.0657 & TRN & \\
\hline CHEMBL1935054 & 794420 & 3.0 & 2.8514 & TRN & \\
\hline CHEMBL1935043 & 794420 & 3.0 & 2.7682 & TRN & \\
\hline CHEMBL1935062 & 794420 & 3.0 & 3.3005 & TRN & \\
\hline CHEMBL1935067 & 794420 & 3.0 & 3.207 & TRN & \\
\hline CHEMBL1935065 & 794420 & 5.2984 & 3.2046 & TRN & \\
\hline CHEMBL1935069 & 794420 & 5.2565 & 3.7796 & TST & \\
\hline CHEMBL299023 & 104538 & 7.9208 & 7.9905 & TRN & \\
\hline CHEMBL 300807 & 104538 & 8.5229 & 8.3626 & TST & \\
\hline CHEMBL 292657 & 104538 & 7.3872 & 7.3317 & TRN & \\
\hline CHEMBL301085 & 104538 & 8.5528 & 8.5434 & TRN & \\
\hline CHEMBL301977 & 104538 & 8.301 & 8.3058 & TRN & \\
\hline CHEMBL53009 & 104538 & 7.7212 & 7.6524 & TRN & \\
\hline CHEMBL54697 & 104538 & 8.0969 & 8.0988 & TRN & \\
\hline CHEMBL416304 & 104538 & 7.6198 & 7.7479 & TRN & \\
\hline CHEMBL52994 & 104538 & 7.7447 & 7.8409 & TRN & \\
\hline CHEMBL439931 & 104538 & 9.2218 & 9.1501 & TRN & \\
\hline CHEMBL55107 & 104538 & 7.4437 & 7.4888 & TRN & \\
\hline CHEMBL55110 & 104538 & 8.8239 & 8.8762 & TRN & \\
\hline CHEMBL55744 & 104538 & 7.8239 & 7.83700 & 0000000001 & TRN \\
\hline CHEMBL55521 & 104538 & 8.7959 & 8.8141 & TRN & \\
\hline CHEMBL 293528 & 104538 & 9.1549 & 9.0608 & TRN & \\
\hline CHEMBL56025 & 104538 & 8.5229 & 8.5357 & TRN & \\
\hline CHEMBL 298822 & 104538 & 7.8861 & 7.9178 & TST & \\
\hline CHEMBL54054 & 104538 & 8.9586 & 8.9374 & TRN & \\
\hline CHEMBL52532 & 104538 & 7.6021 & 7.63 & TRN & \\
\hline CHEMBL53044 & 104538 & 7.9208 & 7.9872 & TRN & \\
\hline CHEMBL54621 & 104538 & 8.301 & 8.5201 & TST & \\
\hline CHEMBL54406 & 104538 & 7.6778 & 7.6452 & TRN & \\
\hline CHEMBL55522 & 104538 & 8.8239 & 8.9085 & TRN & \\
\hline CHEMBL53091 & 104538 & 7.7447 & 7.7502 & TRN & \\
\hline CHEMBL53116 & 104538 & 7.7447 & 7.7587 & TRN & \\
\hline CHEMBL54617 & 104538 & 7.8861 & 8.1141 & TST & \\
\hline CHEMBL55236 & 104538 & 7.4089 & 7.4289 & TRN & \\
\hline CHEMBL 299091 & 104538 & 7.6021 & 7.6102 & TRN & \\
\hline CHEMBL54981 & 104538 & 7.7212 & 7.7475 & TRN & \\
\hline CHEMBL417200 & 104538 & 7.8861 & 8.2183 & TST & \\
\hline CHEMBL 297488 & 104538 & 8.0969 & 8.1867 & TST & \\
\hline CHEMBL 293305 & 104538 & 8.0 & 8.057 & TRN & \\
\hline CHEMBL53457 & 104538 & 7.8239 & 7.8213 & TRN & \\
\hline CHEMBL55984 & 104538 & 8.7447 & 8.7942 & TRN & \\
\hline CHEMBL301786 & 104538 & 8.0 & 7.9993 & TRN & \\
\hline CHEMBL54904 & 104538 & 9.0458 & 8.9858 & TRN & \\
\hline CHEMBL51862 & 104538 & 7.8239 & 7.8809 & TRN & \\
\hline CHEMBL54436 & 104538 & 8.6021 & 8.5632 & TRN & \\
\hline
\end{tabular}




\begin{tabular}{|c|c|c|c|c|c|c|}
\hline & & \multicolumn{5}{|c|}{ Supplemental Table S2.txt } \\
\hline CHEMBL301177 & 104538 & 7.8239 & 7.6897 & TRN & & \\
\hline CHEMBL54566 & 104538 & 7.6198 & 7.54 & TRN & & \\
\hline CHEMBL55561 & 104538 & 7.7447 & 7.7072 & TRN & & \\
\hline CHEMBL54483 & 104538 & 9.0969 & 9.0925 & TRN & & \\
\hline CHEMBL280017 & 104538 & 7.9586 & 7.9369 & TRN & & \\
\hline CHEMBL293504 & 104538 & 7.7212 & 7.6857 & TRN & & \\
\hline CHEMBL417757 & 104538 & 7.7959 & 7.8588 & TRN & & \\
\hline CHEMBL55907 & 104538 & 7.7696 & 7.7095 & TRN & & \\
\hline CHEMBL405600 & 104538 & 7.6778 & 7.7521 & TRN & & \\
\hline CHEMBL293357 & 104538 & 9.2218 & 9.1149 & TRN & & \\
\hline CHEMBL54965 & 104538 & 8.1549 & 8.259 & TST & & \\
\hline CHEMBL298606 & 104538 & 8.0458 & 7.9476 & TRN & & \\
\hline CHEMBL53094 & 104538 & 7.8239 & 7.8525 & TRN & & \\
\hline CHEMBL53949 & 104538 & 7.699 & 7.6424 & TRN & & \\
\hline CHEMBL54501 & 104538 & 7.4559 & 7.7119 & TST & & \\
\hline CHEMBL56498 & 104538 & 8.9208 & 8.9868 & TRN & & \\
\hline CHEMBL293503 & 104538 & 9.1549 & 9.1717 & TRN & & \\
\hline CHEMBL293774 & 104538 & 7.7447 & 7.6767 & TRN & & \\
\hline CHEMBL53051 & 104538 & 7.9208 & 8.1712 & TST & & \\
\hline CHEMBL54535 & 104538 & 8.699 & 8.8561 & TST & & \\
\hline CHEMBL52531 & 104538 & 8.2218 & 8.2656 & TST & & \\
\hline CHEMBL56065 & 104538 & 8.0458 & 8.0888 & TST & & \\
\hline CHEMBL53847 & 104538 & 8.6021 & 8.6822 & TRN & & \\
\hline CHEMBL55154 & 104538 & 8.0 & 8.1338 & TST & & \\
\hline CHEMBL417749 & 104538 & 7.4815 & 7.4865 & TRN & & \\
\hline CHEMBL300362 & 104538 & 8.5229 & 8.4254 & TST & & \\
\hline CHEMBL299600 & 104538 & 8.1549 & 8.1213 & TRN & & \\
\hline CHEMBL292431 & 104538 & 8.0 & 8.17 & TST & & \\
\hline CHEMBL56951 & 104538 & 7.8861 & 7.8112 & TST & & \\
\hline CHEMBL54915 & 104538 & 8.2218 & 8.3033 & TST & & \\
\hline CHEMBL1797464 & 753893 & 4.6889 & 4.9384 & TST & & \\
\hline CHEMBL1797357 & 753893 & 5.4828 & 5.4794 & TRN & & \\
\hline CHEMBL1797355 & 753893 & 5.6968 & 5.8101 & TRN & & \\
\hline CHEMBL1797190 & 753893 & 6.0 & 5.5621 & TRN & & \\
\hline CHEMBL1797459 & 753893 & 6.301 & 6.0754 & TRN & & \\
\hline CHEMBL1797480 & 753893 & 4.4634 & 4.3504 & TRN & & \\
\hline CHEMBL1773235 & 753893 & 5.9281 & 6.651 & TST & & \\
\hline CHEMBL1795365 & 753893 & $5.7620 e$ & 0000000 & 005 & 5.5997 & TRN \\
\hline CHEMBL1797343 & 753893 & 5.7747 & 5.8485 & TRN & & \\
\hline CHEMBL1797363 & 753893 & 5.8601 & 5.8535 & TRN & & \\
\hline CHEMBL1797346 & 753893 & 5.7825 & 5.7082 & TRN & & \\
\hline CHEMBL1797466 & 753893 & 5.8539 & 6.068 & TRN & & \\
\hline CHEMBL1797335 & 753893 & 3.0 & 3.3485 & TRN & & \\
\hline CHEMBL1797457 & 753893 & 5.5114 & 5.7741 & TRN & & \\
\hline CHEMBL1797360 & 753893 & 5.4908 & 5.7209 & TRN & & \\
\hline CHEMBL1797345 & 753893 & 5.2765 & 5.2822 & TRN & & \\
\hline CHEMBL1797487 & 753893 & 5.2549 & 4.8472 & TRN & & \\
\hline CHEMBL1797362 & 753893 & 5.2976 & 5.2668 & TRN & & \\
\hline
\end{tabular}


Supplemental Table S2.txt

\begin{tabular}{|c|c|c|c|c|}
\hline - & & & & \\
\hline HEMBL1797367 & & 7471 & 5.9243 & \\
\hline & & 927 & & \\
\hline 7603 & 33 & 969 & 157 & \\
\hline IEMBL1797497 & 3893 & 2676 & 7935 & \\
\hline AEMBL1797469 & 53893 & 3.0 & 2344 & \\
\hline HEMBL17 & 53893 & & 8948 & \\
\hline AEMBL1 & 3893 & & 2021 & \\
\hline IEMBL179 & 53893 & & 9599 & \\
\hline AEMBL1797322 & 53893 & 59 & 9216 & \\
\hline AEMBL1797326 & 53893 & 97 & 2768 & \\
\hline JEMBL17 & 53893 & 508 & 0345 & \\
\hline AEMBL17 & & & 369 & \\
\hline AEMBL17 & 893 & 28 & 5802 & \\
\hline HEMBL179 & 53893 & 301 & 5725 & \\
\hline AEMBL179 & 893 & 298 & 7356 & \\
\hline HEMBL17 & 3893 & 944 & 268 & \\
\hline HEMBL17 & & & & \\
\hline HEMBL17 & 893 & 696 & 1909 & \\
\hline AEMBL17 & 3893 & & 1802 & \\
\hline AEMBL1/ & 3893 & 8 & 3461 & 151 \\
\hline HEMBL17 & 893 & & 252 & \\
\hline HEMBL17 & & & 576 & \\
\hline 56 & & & 3264 & \\
\hline AEMBL17 & 93 & & 07 & KIV \\
\hline HEM & 893 & 2 & 815 & S \\
\hline AEMBL17 & 93 & & 678 & Niv \\
\hline 5 & & & 333 & \\
\hline AEMBL17 & & & 071 & TRN \\
\hline AEMBL17 & 93 & & 159 & $\mid$ \\
\hline AEMBL17 & 93 & & 948 & ST \\
\hline HFMRI 1 & 3 & & 516 & RN \\
\hline 48 & & & & RN \\
\hline HEMBL17 & & & 206 & RN \\
\hline HEMBL17 & 53893 & & 5799 & RN \\
\hline HEMBL1 & 3893 & & 685 & RN \\
\hline 1 & 3 & & & ST \\
\hline 70 & & 5 & & RN \\
\hline HEMBL179 & 53893 & & 4.0164 & TRN \\
\hline IEMBL17 & 3893 & & 5.2747 & IST \\
\hline HEMBL17 & 53893 & 97 & 5.5683 & ST \\
\hline 15MR & & & & RN \\
\hline HEMBL17 & 53893 & 327 & 5.4606 & $\mathrm{RN}$ \\
\hline AEMBL1797327 & 53893 & 5.4724 & 4.9889 & RN \\
\hline 3L1 & 53893 & & 5.7947 & I \\
\hline HEMBL17C & 53893 & & 4.5521 & \\
\hline HEMBL179 & 753893 & & 5.482 & \\
\hline CHEMBL1797496 & 753893 & 5.8125 & 6.6725 & ГST \\
\hline
\end{tabular}

Page 6676 


\begin{tabular}{|c|c|c|c|c|c|}
\hline & & \multicolumn{4}{|c|}{ Supplemental Table s2.txt } \\
\hline CHEMBL1797361 & 753893 & 5.5498 & 5.6377 & TRN & \\
\hline CHEMBL1797456 & 753893 & 5.8356 & 5.8752 & TRN & \\
\hline CHEMBL1797333 & 753893 & 3.0 & 3.2221 & TRN & \\
\hline CHEMBL1797351 & 753893 & 3.301 & 3.2796 & TRN & \\
\hline CHEMBL1797198 & 753893 & 4.0188 & 5.0571 & TST & \\
\hline CHEMBL1797483 & 753893 & 5.0645 & 4.9526 & TRN & \\
\hline CHEMBL1797475 & 753893 & 3.0 & 4.39 & TST & \\
\hline CHEMBL1797463 & 753893 & 3.301 & 3.8638 & TST & \\
\hline CHEMBL1797474 & 753893 & 4.9318 & 5.3939 & TRN & \\
\hline CHEMBL1797342 & 753893 & 5.8447 & 5.8097 & TRN & \\
\hline CHEMBL1797485 & 753893 & 3.0 & 3.2881 & TRN & \\
\hline CHEMBL1797458 & 753893 & 5.8894 & 5.9127 & TRN & \\
\hline CHEMBL1797465 & 753893 & 5.1593 & 5.2265 & TRN & \\
\hline CHEMBL1797370 & 753893 & 5.2055 & 5.4743 & TRN & \\
\hline CHEMBL1797462 & 753893 & 3.301 & 3.9391 & TST & \\
\hline CHEMBL1797358 & 753893 & 5.5376 & 5.3104 & TRN & \\
\hline CHEMBL1797479 & 753893 & 5.109 & 5.5192 & TRN & \\
\hline CHEMBL1797461 & 753893 & 6.1549 & 6.1669 & TRN & \\
\hline CHEMBL1797478 & 753893 & 5.2013 & 5.5751 & TRN & \\
\hline CHEMBL1797471 & 753893 & 5.7645 & 5.6162 & TRN & \\
\hline CHEMBL1773239 & 753893 & 5.9626 & 6.4313 & TST & \\
\hline CHEMBL1797368 & 753893 & 5.0088 & 5.2882 & TRN & \\
\hline CHEMBL1797477 & 753893 & 3.0 & 3.1881 & TRN & \\
\hline CHEMBL1797336 & 753893 & 3.0 & 3.0876 & TRN & \\
\hline CHEMBL1797498 & 753893 & 5.2815 & 6.0819 & TST & \\
\hline CHEMBL1797460 & 753893 & 5.8153 & 5.9973 & TRN & \\
\hline CHEMBL1797334 & 753893 & 5.8069 & 5.1407 & TRN & \\
\hline CHEMBL1797468 & 753893 & 5.0531 & 4.4332 & TRN & \\
\hline CHEMBL1797473 & 753893 & 3.0 & 3.2335 & TRN & \\
\hline CHEMBL1797347 & 753893 & 5.2782 & 5.67299 & 9999999999 & TST \\
\hline CHEMBL1797481 & 753893 & 4.6158 & 4.183 & TRN & \\
\hline CHEMBL1797340 & 753893 & 5.2628 & 4.834 & TRN & \\
\hline CHEMBL1797365 & 753893 & $5.8210 e$ & 30000000 & 5.6227 & TRN \\
\hline CHEMBL1797476 & 753893 & 3.0 & 3.3041 & TRN & \\
\hline CHEMBL1797484 & 753893 & 5.0458 & 4.9786 & TST & \\
\hline CHEMBL1797488 & 753893 & 5.1844 & 3.9616 & TRN & \\
\hline CHEMBL1613272 & 688243 & 3.301 & 3.3231 & TRN & \\
\hline CHEMBL1334062 & 688243 & 3.301 & 3.2335 & TRN & \\
\hline CHEMBL1375922 & 688243 & 3.301 & 3.5142 & TRN & \\
\hline CHEMBL3193664 & 688243 & 4.4379 & 4.1779 & TRN & \\
\hline CHEMBL1399109 & 688243 & 3.301 & 3.2909 & TRN & \\
\hline CHEMBL1418796 & 688243 & 3.301 & 3.6293 & TST & \\
\hline CHEMBL2005296 & 688243 & 3.301 & 3.1833 & TRN & \\
\hline CHEMBL1499658 & 688243 & 4.6765 & 4.6733 & TRN & \\
\hline CHEMBL1524172 & 688243 & 4.301 & 4.2584 & TRN & \\
\hline CHEMBL1329974 & 688243 & 3.301 & 3.3662 & TRN & \\
\hline CHEMBL1303508 & 688243 & 3.301 & 3.3087 & TRN & \\
\hline CHEMBL1307594 & 688243 & 3.301 & 3.16300 & 20000000003 & TRN \\
\hline & & & & 6677 & \\
\hline
\end{tabular}




\begin{tabular}{|c|c|c|c|c|c|}
\hline & & \multicolumn{4}{|c|}{ Supplemental Table S2.txt } \\
\hline CHEMBL1306425 & 688243 & 3.301 & 2.7536 & TST & \\
\hline CHEMBL1417692 & 688243 & 3.301 & 3.2012 & TRN & \\
\hline CHEMBL1302170 & 688243 & 3.301 & 3.3427 & TRN & \\
\hline CHEMBL1362734 & 688243 & 3.301 & 3.2601 & TRN & \\
\hline CHEMBL1511080 & 688243 & 3.301 & 3.2754 & TRN & \\
\hline CHEMBL 2001831 & 688243 & 3.301 & 3.4649 & TRN & \\
\hline CHEMBL63354 & 688243 & 5.0465 & 3.6325 & TST & \\
\hline CHEMBL1362595 & 688243 & 4.3746 & 3.2717 & TST & \\
\hline CHEMBL1484370 & 688243 & 3.301 & 3.8059 & TST & \\
\hline CHEMBL1418273 & 688243 & 3.301 & 3.4369 & TRN & \\
\hline CHEMBL463175 & 688243 & 4.3579 & 3.4773 & TST & \\
\hline CHEMBL1989852 & 688243 & 5.5877 & 5.5758 & TRN & \\
\hline CHEMBL1462375 & 688243 & 3.301 & 3.4105 & TRN & \\
\hline CHEMBL1972037 & 688243 & 3.301 & 3.3975 & TRN & \\
\hline CHEMBL1606112 & 688243 & 3.301 & 3.3111 & TRN & \\
\hline CHEMBL1458321 & 688243 & 3.301 & 3.2978 & TRN & \\
\hline CHEMBL1544997 & 688243 & 3.301 & 3.4135 & TRN & \\
\hline CHEMBL1426692 & 688243 & 3.301 & 3.3131 & TRN & \\
\hline CHEMBL1575869 & 688243 & 3.301 & 3.3929 & TRN & \\
\hline CHEMBL1603938 & 688243 & 3.301 & 3.2671 & TRN & \\
\hline CHEMBL449392 & 688243 & 5.3773 & 3.5685 & TST & \\
\hline CHEMBL1588106 & 688243 & 4.9531 & 5.0744 & TRN & \\
\hline CHEMBL1424118 & 688243 & 3.301 & 3.3132 & TRN & \\
\hline CHEMBL591404 & 688243 & 3.301 & 3.285 & TRN & \\
\hline CHEMBL601757 & 688243 & 3.301 & 3.3816 & TRN & \\
\hline CHEMBL1547025 & 688243 & 3.301 & 3.1987 & TRN & \\
\hline CHEMBL1306199 & 688243 & 3.301 & 3.2117 & TRN & \\
\hline CHEMBL1504948 & 688243 & 4.909 & 4.9158 & TRN & \\
\hline CHEMBL1306258 & 688243 & 3.301 & 3.3428 & TRN & \\
\hline CHEMBL 239103 & 688243 & 4.6169 & 4.4964 & TRN & \\
\hline CHEMBL1484618 & 688243 & 3.301 & 3.178 & TRN & \\
\hline CHEMBL1333429 & 688243 & 3.301 & 3.1802 & TRN & \\
\hline CHEMBL1416392 & 688243 & 4.6641 & 4.6324 & TRN & \\
\hline CHEMBL1404929 & 688243 & 3.301 & 3.4152 & TRN & \\
\hline CHEMBL1560833 & 688243 & 3.301 & 3.0767 & TST & \\
\hline CHEMBL51931 & 688243 & 3.301 & 3.1072 & TST & \\
\hline CHEMBL1529285 & 688243 & 4.7212 & 3.9171 & TST & \\
\hline CHEMBL3199301 & 688243 & 3.301 & 3.4458 & TST & \\
\hline CHEMBL1532953 & 688243 & 3.301 & 3.5674 & TST & \\
\hline CHEMBL1516388 & 688243 & 5.2687 & 3.6746 & TST & \\
\hline CHEMBL1344245 & 737535 & 2.699 & 3.0247 & TRN & \\
\hline CHEMBL1420123 & 737535 & 2.699 & 2.3359 & TRN & \\
\hline CHEMBL1352196 & 737535 & 2.699 & 2.9153 & TST & \\
\hline CHEMBL1995336 & 737535 & 2.699 & 2.65 & TRN & \\
\hline CHEMBL1354019 & 737535 & 2.699 & 2.47300 & 00000000003 & TRN \\
\hline CHEMBL1483823 & 737535 & 2.699 & 3.0137 & TRN & \\
\hline CHEMBL1300876 & 737535 & 2.699 & 2.9017 & TRN & \\
\hline CHEMBL1304979 & 737535 & 2.699 & 2.4475 & TRN & \\
\hline
\end{tabular}




\begin{tabular}{|c|c|c|c|c|c|}
\hline \multirow[b]{2}{*}{ CHEMBL1438567 } & \multicolumn{5}{|c|}{ Supplemental Table S2.txt } \\
\hline & 737535 & 4.6722 & 4.0511 & TRN & \\
\hline CHEMBL1302539 & 737535 & 2.699 & 2.5618 & TRN & \\
\hline CHEMBL1416302 & 737535 & 4.94 & 3.7834 & TRN & \\
\hline CHEMBL1320481 & 737535 & 2.699 & 2.6778 & TRN & \\
\hline CHEMBL1602055 & 737535 & 3.7676 & 4.19300 & 00000000005 & TRN \\
\hline CHEMBL1323252 & 737535 & 2.699 & 2.5306 & TRN & \\
\hline CHEMBL1509938 & 737535 & 2.699 & 3.1758 & TST & \\
\hline CHEMBL1344330 & 737535 & 2.699 & 2.8904 & TRN & \\
\hline CHEMBL1351935 & 737535 & 5.0901 & 3.6957 & TRN & \\
\hline CHEMBL1379737 & 737535 & 2.699 & 2.4278 & TRN & \\
\hline CHEMBL1462636 & 737535 & 4.762 & 4.0734 & TRN & \\
\hline CHEMBL1578893 & 737535 & 2.699 & 3.3792 & TST & \\
\hline CHEMBL1301828 & 737535 & 2.699 & 2.66 & TST & \\
\hline CHEMBL1368362 & 737535 & 2.699 & 2.8528 & TRN & \\
\hline CHEMBL1612112 & 737535 & 2.699 & 2.707 & TRN & \\
\hline CHEMBL1416360 & 737535 & 2.699 & 2.7742 & TRN & \\
\hline CHEMBL1389315 & 737535 & 2.699 & 2.3249 & TRN & \\
\hline CHEMBL1433585 & 737535 & 4.7757 & 3.8852 & TRN & \\
\hline CHEMBL1455832 & 737535 & 4.5922 & 3.9225 & TRN & \\
\hline CHEMBL1480087 & 737535 & 2.699 & 2.7753 & TRN & \\
\hline CHEMBL1454269 & 737535 & 4.2502 & 3.9072 & TRN & \\
\hline CHEMBL1522307 & 737535 & 2.699 & 3.9556 & TST & \\
\hline CHEMBL1346753 & 737535 & 4.2078 & 3.8437 & TRN & \\
\hline CHEMBL3210910 & 737535 & 2.699 & 2.8505 & TRN & \\
\hline CHEMBL1503523 & 737535 & 2.699 & 2.5293 & TRN & \\
\hline CHEMBL1415156 & 737535 & 2.699 & 2.7194 & TRN & \\
\hline CHEMBL1300769 & 737535 & 4.7079 & 3.7045 & TRN & \\
\hline CHEMBL3192206 & 737535 & 4.6031 & 4.3443 & TRN & \\
\hline CHEMBL1490594 & 737535 & 2.699 & 3.5042 & TRN & \\
\hline CHEMBL1451931 & 737535 & 2.699 & 3.2245 & TRN & \\
\hline CHEMBL1466913 & 737535 & 2.699 & 2.9931 & TST & \\
\hline CHEMBL1388952 & 737535 & 2.699 & 3.4993 & TST & \\
\hline CHEMBL1351543 & 737535 & 2.699 & 2.9423 & TRN & \\
\hline CHEMBL1587842 & 737535 & 2.699 & 2.6817 & TST & \\
\hline CHEMBL1411702 & 737535 & 2.699 & 2.0918 & TRN & \\
\hline CHEMBL1443623 & 737535 & 2.699 & 2.136 & TST & \\
\hline CHEMBL1559707 & 737535 & 2.699 & 2.8216 & TRN & \\
\hline CHEMBL1990694 & 737535 & 4.6363 & 3.6919 & TRN & \\
\hline CHEMBL1433943 & 737535 & 2.699 & 2.7807 & TRN & \\
\hline CHEMBL1572208 & 737535 & 4.4139 & 4.505 & TRN & \\
\hline CHEMBL1598597 & 737535 & 2.699 & 2.9052 & TRN & \\
\hline CHEMBL1308195 & 737535 & 2.699 & 3.3832 & TRN & \\
\hline CHEMBL1985649 & 737535 & 4.2826 & 4.3467 & TRN & \\
\hline CHEMBL1405964 & 737535 & 2.699 & 2.3815 & TRN & \\
\hline CHEMBL1310325 & 737535 & 4.9497 & 4.4159 & TRN & \\
\hline CHEMBL1527528 & 737535 & 2.699 & 2.8907 & TRN & \\
\hline CHEMBL1304114 & 737535 & 2.699 & 2.9165 & TRN & \\
\hline CHEMBL3193946 & 737535 & 4.3173 & 4.2361 & TRN & \\
\hline
\end{tabular}


Supplemental Table S2.txt

\begin{tabular}{|c|c|c|c|c|c|}
\hline CHEMBL269122 & 737535 & 2.699 & 3.2773 & TRN & \\
\hline CHEMBL1481369 & 737535 & 2.699 & \multicolumn{2}{|c|}{ 2.9019999999999997 } & TRN \\
\hline CHEMBL1503962 & 737535 & 2.699 & 3.1873 & TRN & \\
\hline CHEMBL1300620 & 737535 & 2.699 & 2.4805 & TRN & \\
\hline CHEMBL1334149 & 737535 & 4.4985 & 5.0223 & TRN & \\
\hline CHEMBL1352903 & 737535 & 2.699 & 3.6258 & TRN & \\
\hline CHEMBL1446738 & 737535 & 2.699 & 2.9753 & TRN & \\
\hline CHEMBL1423844 & 737535 & 2.699 & 2.3439 & TRN & \\
\hline CHEMBL1563488 & 737535 & 2.699 & 2.8147 & TRN & \\
\hline CHEMBL1309682 & 737535 & 2.699 & \multicolumn{2}{|c|}{3.2260000000000004} & TST \\
\hline CHEMBL3190895 & 737535 & 2.699 & 3.1141 & TRN & \\
\hline CHEMBL1550672 & 737535 & 2.699 & 2.947 & TRN & \\
\hline CHEMBL1384253 & 737535 & 2.699 & 3.3203 & TRN & \\
\hline CHEMBL1558097 & 737535 & 2.699 & 2.5275 & TRN & \\
\hline CHEMBL1440953 & 737535 & 2.699 & 2.5594 & TRN & \\
\hline CHEMBL1502870 & 737535 & 2.699 & 3.0119 & TRN & \\
\hline CHEMBL1360857 & 737535 & 2.699 & 3.5325 & TRN & \\
\hline CHEMBL1447326 & 737535 & 2.699 & 2.6194 & TRN & \\
\hline CHEMBL1427838 & 737535 & 2.699 & 2.8515 & TRN & \\
\hline CHEMBL1608791 & 737535 & 2.699 & 3.0312 & TST & \\
\hline CHEMBL1521960 & 737535 & 2.699 & \multicolumn{2}{|c|}{ 2.7939999999999996 } & TRN \\
\hline CHEMBL1469444 & 737535 & 4.9871 & 4.5874 & TRN & \\
\hline CHEMBL1998038 & 737535 & 2.699 & 2.4239 & TRN & \\
\hline CHEMBL1548333 & 737535 & 2.699 & 3.4067 & TRN & \\
\hline CHEMBL1527903 & 737535 & 2.699 & 3.1087 & TRN & \\
\hline CHEMBL3195461 & 737535 & 3.8932 & 4.12 & TRN & \\
\hline CHEMBL1594257 & 737535 & 2.699 & 3.0009 & TRN & \\
\hline CHEMBL1308993 & 737535 & 5.093 & 4.9259 & TRN & \\
\hline CHEMBL1440277 & 737535 & 2.699 & 3.0514 & TRN & \\
\hline CHEMBL1363428 & 737535 & 2.699 & 2.6501 & TRN & \\
\hline CHEMBL1367225 & 737535 & 2.699 & 2.844 & TST & \\
\hline CHEMBL1452593 & 737535 & 2.699 & 3.0111 & TRN & \\
\hline CHEMBL 2028186 & 737535 & 5.2902 & 3.9022 & TST & \\
\hline CHEMBL1546183 & 737535 & 3.8974 & 3.6609 & TRN & \\
\hline CHEMBL1569997 & 737535 & 2.699 & 2.7624 & TRN & \\
\hline CHEMBL1466263 & 737535 & 2.699 & 2.7037 & TRN & \\
\hline CHEMBL1369492 & 737535 & 4.7175 & 4.4555 & TRN & \\
\hline CHEMBL1302170 & 737535 & 2.699 & 2.445 & TRN & \\
\hline CHEMBL1447211 & 737535 & 4.6858 & 2.904 & TST & \\
\hline CHEMBL1564363 & 737535 & 2.699 & 3.5906 & TRN & \\
\hline CHEMBL 2000670 & 737535 & 4.4152 & 3.6639 & TRN & \\
\hline CHEMBL3211983 & 737535 & 2.699 & 3.3999 & TST & \\
\hline CHEMBL1320537 & 737535 & 2.699 & 3.7212 & TRN & \\
\hline CHEMBL1458402 & 737535 & 2.699 & 2.2708 & TRN & \\
\hline CHEMBL1529584 & 737535 & 4.6021 & 4.0605 & TRN & \\
\hline CHEMBL1365210 & 737535 & 2.699 & 2.496 & TRN & \\
\hline CHEMBL1427763 & 737535 & 4.9031 & 4.7411 & TRN & \\
\hline CHEMBL1478085 & 737535 & 2.699 & 3.2713 & TRN & \\
\hline
\end{tabular}




\begin{tabular}{|c|c|c|c|c|c|}
\hline & & \multicolumn{4}{|c|}{ Supplemental Table S2.txt } \\
\hline CHEMBL1585746 & 737535 & 4.6891 & 3.7556 & TRN & \\
\hline CHEMBL1362538 & 737535 & 2.699 & 2.6358 & TRN & \\
\hline CHEMBL1512862 & 737535 & 2.699 & 2.6872 & TRN & \\
\hline CHEMBL1548790 & 737535 & 2.699 & 2.9869 & TRN & \\
\hline CHEMBL1536144 & 737535 & 2.699 & 2.4873 & TRN & \\
\hline CHEMBL1308037 & 737535 & 2.699 & 1.9206 & TRN & \\
\hline CHEMBL1964978 & 737535 & 2.699 & 2.8394 & TRN & \\
\hline CHEMBL1505642 & 737535 & 2.699 & 2.8718 & TRN & \\
\hline CHEMBL1568206 & 737535 & 2.699 & 2.4253 & TRN & \\
\hline CHEMBL1603305 & 737535 & 2.699 & 3.1198 & TRN & \\
\hline CHEMBL1526865 & 737535 & 2.699 & 2.5467 & TRN & \\
\hline CHEMBL1380232 & 737535 & 2.699 & 3.6154 & TRN & \\
\hline CHEMBL1545384 & 737535 & 2.699 & 3.9493 & TRN & \\
\hline CHEMBL1379309 & 737535 & 2.699 & 2.6505 & TRN & \\
\hline CHEMBL1469472 & 737535 & 2.699 & 2.773 & TRN & \\
\hline CHEMBL1303641 & 737535 & 2.699 & 2.8293 & TRN & \\
\hline CHEMBL1348090 & 737535 & 2.699 & 3.4892 & TRN & \\
\hline CHEMBL418068 & 737535 & 3.8074 & 4.4694 & TRN & \\
\hline CHEMBL3208613 & 737535 & 2.699 & \multicolumn{2}{|c|}{3.2969999999999997} & TST \\
\hline CHEMBL1462687 & 737535 & 5.069 & 3.8359 & TRN & \\
\hline CHEMBL1312953 & 737535 & 2.699 & 3.0201 & TST & \\
\hline CHEMBL1447803 & 737535 & 4.731 & 3.8184 & TRN & \\
\hline CHEMBL1605743 & 737535 & 4.9539 & 4.9448 & TRN & \\
\hline CHEMBL 88326 & 737535 & 5.8187 & 5.4776 & TRN & \\
\hline CHEMBL1672292 & 737535 & 2.699 & 2.8265 & TRN & \\
\hline CHEMBL1367787 & 737535 & 2.699 & 2.4489 & TRN & \\
\hline CHEMBL1533336 & 737535 & 2.699 & 3.7086 & TRN & \\
\hline CHEMBL 2003304 & 737535 & 2.699 & 3.7949 & TST & \\
\hline CHEMBL1390860 & 737535 & 2.699 & 2.8491 & TST & \\
\hline CHEMBL1511181 & 737535 & 5.8069 & 4.3621 & TST & \\
\hline CHEMBL1999473 & 737535 & 2.699 & 2.9418 & TST & \\
\hline CHEMBL1532953 & 737535 & 2.699 & 2.3815 & TST & \\
\hline CHEMBL1410750 & 737535 & 2.699 & 2.7966 & TST & \\
\hline CHEMBL1325241 & 737535 & 2.699 & 4.0848 & TST & \\
\hline CHEMBL1334670 & 737535 & 5.3753 & 4.2344 & TST & \\
\hline CHEMBL1343560 & 737535 & 2.699 & 1.9303 & TST & \\
\hline CHEMBL1360708 & 737535 & 2.699 & 3.5933 & TST & \\
\hline CHEMBL1323674 & 737535 & 2.699 & 3.9681 & TST & \\
\hline CHEMBL1455712 & 737535 & 2.699 & 2.8338 & TST & \\
\hline CHEMBL1457702 & 737535 & 2.699 & 3.5689 & TST & \\
\hline CHEMBL1575065 & 737535 & 2.699 & 3.2352 & TST & \\
\hline CHEMBL1340316 & 737535 & 2.699 & 3.1345 & TST & \\
\hline CHEMBL1370375 & 737535 & 4.1252 & 3.7953 & TST & \\
\hline CHEMBL1445259 & 737535 & 4.8052 & 3.6968 & TST & \\
\hline CHEMBL1993173 & 737535 & 2.699 & 3.4284 & TST & \\
\hline CHEMBL1459861 & 737535 & 2.699 & 3.2932 & TST & \\
\hline CHEMBL3195851 & 737535 & 2.699 & 2.4989 & TST & \\
\hline \multirow[t]{2}{*}{ CHEMBL1302747 } & 737535 & 2.699 & 3.4706 & TST & \\
\hline & & \multicolumn{4}{|c|}{ Page 6681} \\
\hline
\end{tabular}




\begin{tabular}{|c|c|c|c|c|c|}
\hline \multicolumn{6}{|c|}{ Supplemental Table S2.txt } \\
\hline CHEMBL1995952 & 809297 & 4.2977 & 4.524 & TRN & \\
\hline CHEMBL1970462 & 809297 & 4.1996 & 3.66399 & 99999999997 & TRN \\
\hline CHEMBL1975135 & 809297 & 4.1264 & 4.0567 & TRN & \\
\hline CHEMBL1558834 & 809297 & 4.1102 & 3.4349 & TRN & \\
\hline CHEMBL1368914 & 809297 & 3.0044 & 3.1233 & TRN & \\
\hline CHEMBL1993276 & 809297 & 5.7932 & 5.5033 & TRN & \\
\hline CHEMBL1966161 & 809297 & 3.0044 & 3.8293 & TRN & \\
\hline CHEMBL 2006198 & 809297 & 4.1273 & 4.2145 & TRN & \\
\hline CHEMBL1979068 & 809297 & 4.1274 & 3.6827 & TRN & \\
\hline CHEMBL1305910 & 809297 & 4.5768 & 4.1505 & TRN & \\
\hline CHEMBL1500169 & 809297 & 4.7747 & 4.4623 & TST & \\
\hline CHEMBL1969580 & 809297 & 4.4313 & 4.6112 & TRN & \\
\hline CHEMBL1989549 & 809297 & 4.4519 & 4.6769 & TRN & \\
\hline CHEMBL1983298 & 809297 & 4.5622 & 3.5787 & TRN & \\
\hline CHEMBL1976967 & 809297 & 4.2 & 4.2397 & TRN & \\
\hline CHEMBL1992193 & 809297 & 3.0044 & 4.3264 & TST & \\
\hline CHEMBL1533040 & 809297 & 4.5976 & 4.9882 & TRN & \\
\hline CHEMBL1709744 & 809297 & 5.9666 & 4.8004 & TRN & \\
\hline CHEMBL1353222 & 809297 & 4.1275 & 3.8616 & TST & \\
\hline CHEMBL1965201 & 809297 & 3.0044 & 3.7355 & TRN & \\
\hline CHEMBL1968268 & 809297 & 5.1733 & 5.0219 & TRN & \\
\hline CHEMBL1993130 & 809297 & 5.9872 & 5.1795 & TRN & \\
\hline CHEMBL 2000042 & 809297 & 3.0044 & 3.7498 & TRN & \\
\hline CHEMBL1999938 & 809297 & 4.1281 & 3.9926 & TST & \\
\hline CHEMBL1311971 & 809297 & 3.0044 & 3.4395 & TRN & \\
\hline CHEMBL1965501 & 809297 & 3.0044 & 3.5613 & TRN & \\
\hline CHEMBL1964510 & 809297 & 4.103 & 3.9255 & TRN & \\
\hline CHEMBL1581799 & 809297 & 5.5901 & 4.9597 & TRN & \\
\hline CHEMBL1976098 & 809297 & 4.0965 & 3.9061 & TRN & \\
\hline CHEMBL1986991 & 809297 & 4.0829 & 4.3001 & TRN & \\
\hline CHEMBL 2002071 & 809297 & 5.9626 & 4.9976 & TRN & \\
\hline CHEMBL1999373 & 809297 & 4.1007 & 3.9155 & TST & \\
\hline CHEMBL1973444 & 809297 & 4.1087 & 3.5021 & TRN & \\
\hline CHEMBL1995649 & 809297 & 3.0044 & 4.3594 & TRN & \\
\hline CHEMBL1385744 & 809297 & 4.123 & 4.0121 & TRN & \\
\hline CHEMBL1869416 & 809297 & 3.0044 & 3.5525 & TRN & \\
\hline CHEMBL 2003811 & 809297 & 4.5664 & 5.0827 & TRN & \\
\hline CHEMBL1700836 & 809297 & 4.5918 & 4.6875 & TST & \\
\hline CHEMBL1993650 & 809297 & 4.0757 & 3.9589 & TRN & \\
\hline CHEMBL1974840 & 809297 & 3.0044 & 3.9452 & TST & \\
\hline CHEMBL1579264 & 809297 & 4.1742 & 4.6566 & TRN & \\
\hline CHEMBL1520311 & 809297 & 4.757 & 4.7966 & TST & \\
\hline CHEMBL1993743 & 809297 & 4.2991 & 4.268 & TRN & \\
\hline CHEMBL1475485 & 809297 & 4.1172 & 3.9564 & TRN & \\
\hline CHEMBL1977950 & 809297 & 4.5544 & 4.8437 & TRN & \\
\hline CHEMBL 2001665 & 809297 & 4.072 & 3.6313 & TRN & \\
\hline CHEMBL1336933 & 809297 & 3.0044 & 3.053 & TRN & \\
\hline CHEMBL1490308 & 809297 & 3.0044 & 4.6312 & TST & \\
\hline
\end{tabular}




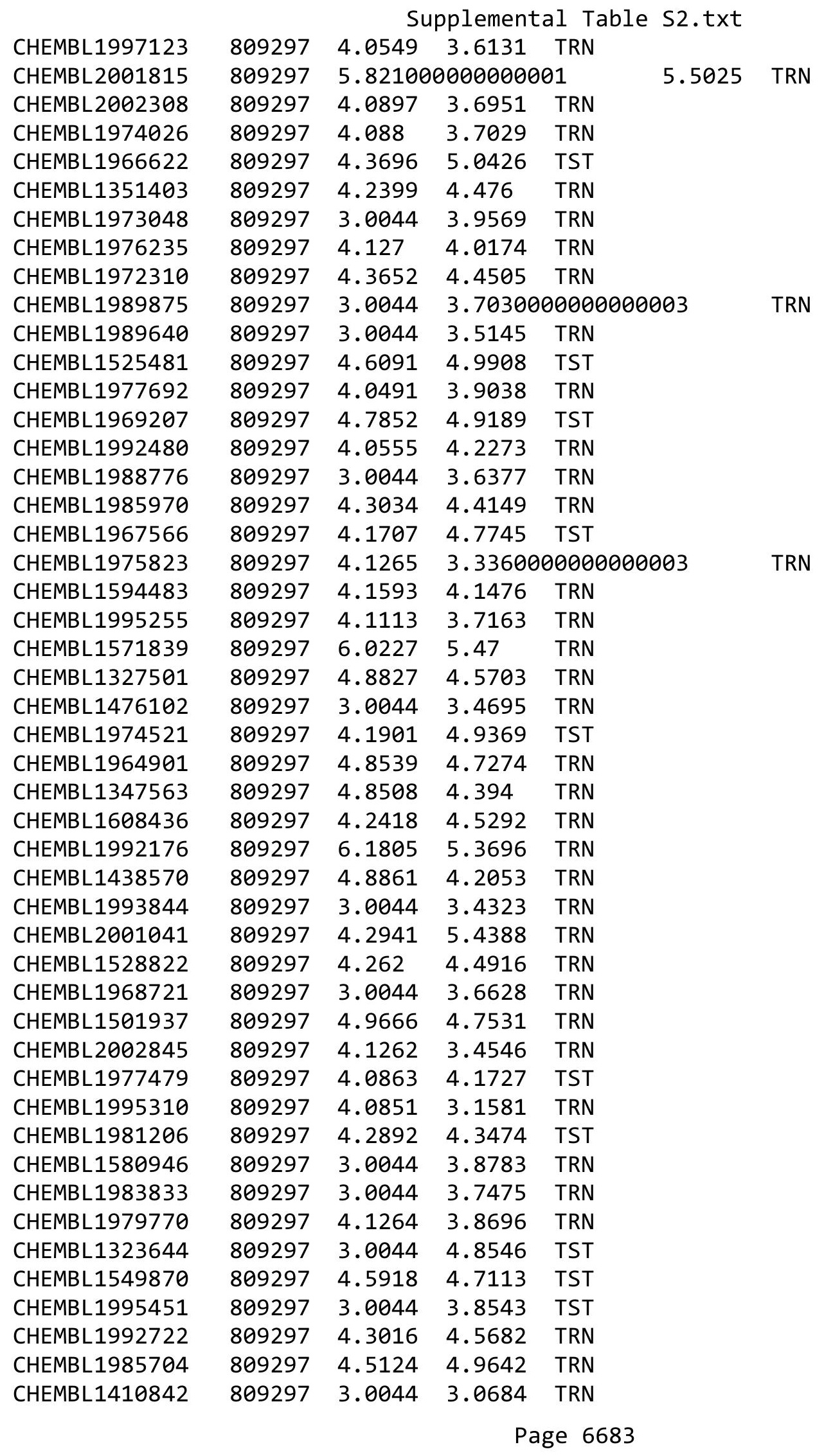




\begin{tabular}{|c|c|c|c|c|}
\hline & & & pplement & al $\mathrm{T}$ \\
\hline CHEMBL2006869 & 809297 & 3.0044 & 4.0394 & TST \\
\hline CHEMBL1392335 & 809297 & 5.4413 & 4.9963 & TST \\
\hline CHEMBL 2007065 & 809297 & 4.1702 & 3.6247 & TRN \\
\hline CHEMBL1363112 & 809297 & 5.7258 & 5.1388 & TRN \\
\hline CHEMBL246655 & 809297 & 4.9872 & 4.6125 & TST \\
\hline CHEMBL1972780 & 809297 & 3.0044 & 4.1648 & TRN \\
\hline CHEMBL 2006714 & 809297 & 4.2952 & 5.1884 & TRN \\
\hline CHEMBL1370417 & 809297 & 4.1971 & 3.7794 & TST \\
\hline CHEMBL1967430 & 809297 & 4.1071 & 3.795 & TRN \\
\hline CHEMBL1993846 & 809297 & 4.4034 & 4.3052 & TRN \\
\hline CHEMBL1309497 & 809297 & 4.2495 & 4.9814 & TST \\
\hline CHEMBL1990867 & 809297 & 4.3872 & 4.666 & TST \\
\hline CHEMBL1973984 & 809297 & 4.1156 & 3.8653 & TRN \\
\hline CHEMBL1987661 & 809297 & 5.4841 & 5.3089 & TRN \\
\hline CHEMBL1993943 & 809297 & 4.574 & 5.3315 & TRN \\
\hline CHEMBL1993417 & 809297 & 3.0044 & 3.3983 & TRN \\
\hline CHEMBL1565806 & 809297 & 5.9586 & 5.1595 & TRN \\
\hline CHEMBL1988067 & 809297 & 4.2666 & 4.1809 & TRN \\
\hline CHEMBL1991688 & 809297 & 4.1175 & 4.0125 & TRN \\
\hline CHEMBL1985596 & 809297 & 4.1746 & 3.6326 & TRN \\
\hline CHEMBL 2003655 & 809297 & 4.5923 & 5.1757 & TRN \\
\hline CHEMBL1997796 & 809297 & 4.1311 & 3.7943 & TRN \\
\hline CHEMBL1985130 & 809297 & 4.5991 & 5.1426 & TST \\
\hline CHEMBL1372180 & 809297 & 4.46 & 4.4823 & TST \\
\hline CHEMBL2006017 & 809297 & 5.9508 & 5.6305 & TST \\
\hline CHEMBL 2000599 & 809297 & 4.0924 & 3.88 & TST \\
\hline CHEMBL2005366 & 809297 & 4.0691 & 3.8018 & TST \\
\hline CHEMBL1507840 & 809297 & 4.1237 & 3.6822 & TST \\
\hline CHEMBL1452264 & 752480 & 5.0427 & 5.0856 & TRN \\
\hline CHEMBL1536733 & 752480 & 5.0171 & 5.4496 & TST \\
\hline CHEMBL1405150 & 752480 & 5.4277 & 5.4924 & TRN \\
\hline CHEMBL 2002008 & 752480 & 5.9462 & 5.8116 & TRN \\
\hline CHEMBL1709153 & 752480 & 5.3666 & 5.4437 & TRN \\
\hline CHEMBL1338045 & 752480 & 6.5361 & 6.2132 & TRN \\
\hline CHEMBL1733059 & 752480 & 6.6556 & 7.0886 & TST \\
\hline CHEMBL 240332 & 752480 & 5.5756 & 5.4798 & TRN \\
\hline CHEMBL1565674 & 752480 & 5.8041 & 5.9855 & TRN \\
\hline CHEMBL3199665 & 752480 & 5.3081 & 5.4143 & TRN \\
\hline CHEMBL1333510 & 752480 & 6.3615 & 6.6597 & TRN \\
\hline CHEMBL1485259 & 752480 & 6.1198 & 5.9467 & TRN \\
\hline CHEMBL1719093 & 752480 & 4.8061 & 4.8942 & TRN \\
\hline CHEMBL1698281 & 752480 & 5.3588 & 6.1197 & TST \\
\hline CHEMBL1431036 & 752480 & 5.3326 & 4.9983 & TRN \\
\hline CHEMBL1990174 & 752480 & 5.0806 & 5.1691 & TRN \\
\hline CHEMBL1461236 & 752480 & 5.0749 & 5.2361 & TRN \\
\hline CHEMBL1511179 & 752480 & 6.2007 & 5.9087 & TRN \\
\hline CHEMBL473721 & 752480 & 3.9757 & 4.8002 & TRN \\
\hline CHEMBL1359580 & 752480 & 5.3434 & 5.3185 & TRN \\
\hline
\end{tabular}




\begin{tabular}{|c|c|c|c|c|c|}
\hline & & & & & \\
\hline CHEMBL1452795 & 752480 & 6.1141 & 5.8798 & TST & \\
\hline CHEMBL1607437 & 752480 & 5.8921 & 6.0334 & TRN & \\
\hline CHEMBL1524172 & 752480 & 5.2434 & 5.2086 & TRN & \\
\hline CHEMBL1734025 & 752480 & 5.1852 & 5.3142 & TRN & \\
\hline CHEMBL1303373 & 752480 & 5.1706 & 5.82100 & 0000000001 & TRN \\
\hline CHEMBL1400889 & 752480 & 5.0604 & 5.0111 & TRN & \\
\hline CHEMBL547285 & 752480 & 5.4688 & 5.4522 & TRN & \\
\hline CHEMBL1508067 & 752480 & 5.0661 & 5.3381 & TRN & \\
\hline CHEMBL1901693 & 752480 & 5.9863 & 6.0219 & TRN & \\
\hline CHEMBL1699284 & 752480 & 5.159 & 4.8192 & TRN & \\
\hline CHEMBL1515668 & 752480 & 5.1081 & 5.2125 & TRN & \\
\hline CHEMBL1307980 & 752480 & 5.1325 & 5.353 & TRN & \\
\hline CHEMBL582099 & 752480 & 5.5819 & 5.349 & TRN & \\
\hline CHEMBL1417053 & 752480 & 5.8837 & 5.8446 & TRN & \\
\hline CHEMBL3198912 & 752480 & 5.8465 & 5.657 & TRN & \\
\hline CHEMBL 7135 & 752480 & 5.6859 & 5.8871 & TRN & \\
\hline CHEMBL1486503 & 752480 & 5.8722 & 5.7173 & TRN & \\
\hline CHEMBL1430790 & 752480 & 5.2029 & 5.3281 & TRN & \\
\hline CHEMBL1527251 & 752480 & 5.4799 & 5.6545 & TST & \\
\hline CHEMBL1713454 & 752480 & 5.3669 & 5.5358 & TRN & \\
\hline CHEMBL1386711 & 752480 & 5.3812 & 5.4121 & TRN & \\
\hline CHEMBL1719626 & 752480 & 7.71 & 7.3491 & TST & \\
\hline CHEMBL1468684 & 752480 & 5.3511 & 5.6296 & TRN & \\
\hline CHEMBL1454102 & 752480 & 5.5805 & 5.4696 & TRN & \\
\hline CHEMBL1707960 & 752480 & 5.4118 & 5.2142 & TRN & \\
\hline CHEMBL1543433 & 752480 & 5.3636 & 5.6214 & TST & \\
\hline CHEMBL1502723 & 752480 & 5.8438 & 5.6996 & TRN & \\
\hline CHEMBL1567814 & 752480 & 5.3412 & 5.4474 & TST & \\
\hline CHEMBL1578482 & 752480 & 4.7789 & 4.9357 & TRN & \\
\hline CHEMBL582983 & 752480 & 7.71 & 7.4385 & TST & \\
\hline CHEMBL1385558 & 752480 & 5.3764 & 5.3808 & TRN & \\
\hline CHEMBL1391094 & 752480 & 6.2182 & 6.7562 & TRN & \\
\hline CHEMBL1445658 & 752480 & 5.0462 & 5.3985 & TRN & \\
\hline CHEMBL1504077 & 752480 & 5.2455 & 5.6457 & TRN & \\
\hline CHEMBL1423096 & 752480 & 5.056 & 5.2921 & TST & \\
\hline CHEMBL1363361 & 752480 & 5.3893 & 5.6774 & TRN & \\
\hline CHEMBL1303689 & 752480 & 5.8817 & 5.7866 & TRN & \\
\hline CHEMBL1471900 & 752480 & 6.0132 & 5.8213 & TRN & \\
\hline CHEMBL1533963 & 752480 & 5.4947 & 5.4412 & TRN & \\
\hline CHEMBL 3194357 & 752480 & 5.3743 & 5.4933 & TRN & \\
\hline CHEMBL591363 & 752480 & 5.5887 & 5.5342 & TRN & \\
\hline CHEMBL1507130 & 752480 & 5.351 & 5.3849 & TRN & \\
\hline CHEMBL1571901 & 752480 & 5.3743 & 5.5011 & TRN & \\
\hline CHEMBL1986557 & 752480 & 5.1288 & 5.4719 & TST & \\
\hline CHEMBL1417329 & 752480 & 5.0855 & 5.1718 & TRN & \\
\hline CHEMBL548540 & 752480 & 5.3791 & 5.4115 & TRN & \\
\hline CHEMBL1412167 & 752480 & 5.3846 & 5.4665 & TRN & \\
\hline CHEMBL3197024 & 752480 & 5.2938 & 5.5292 & TRN & \\
\hline
\end{tabular}




\begin{tabular}{|c|c|c|c|c|c|c|}
\hline & & \multicolumn{5}{|c|}{ Supplemental Table S2.txt } \\
\hline CHEMBL1524958 & 752480 & 7.71 & 7.1906 & TRN & & \\
\hline CHEMBL1452646 & 752480 & 5.4431 & 5.388 & TRN & & \\
\hline CHEMBL1393829 & 752480 & 5.5659 & 5.3521 & TRN & & \\
\hline CHEMBL1511171 & 752480 & 5.1113 & 5.3449 & TRN & & \\
\hline CHEMBL1730870 & 752480 & 5.7812 & 5.595 & TRN & & \\
\hline CHEMBL1463563 & 752480 & 5.0589 & 5.1748 & TRN & & \\
\hline CHEMBL1556062 & 752480 & 5.077 & 5.2816 & TRN & & \\
\hline CHEMBL1536248 & 752480 & 7.71 & 7.2518 & TRN & & \\
\hline CHEMBL1900794 & 752480 & \multicolumn{3}{|c|}{5.382999999999999} & 5.4702 & TRN \\
\hline CHEMBL1357277 & 752480 & 5.678 & 5.5952 & TRN & & \\
\hline CHEMBL590927 & 752480 & 5.2109 & 5.3663 & TRN & & \\
\hline CHEMBL1540525 & 752480 & 5.3622 & 5.3528 & TRN & & \\
\hline CHEMBL1356238 & 752480 & 7.71 & 6.0211 & TST & & \\
\hline CHEMBL1987579 & 752480 & 5.067 & 5.2363 & TRN & & \\
\hline CHEMBL1866014 & 752480 & 5.4946 & 5.5674 & TST & & \\
\hline CHEMBL1503864 & 752480 & 5.3256 & 5.4261 & TST & & \\
\hline CHEMBL1726290 & 752480 & 5.4036 & 5.3735 & TRN & & \\
\hline CHEMBL1443660 & 752480 & 5.7115 & 5.8538 & TRN & & \\
\hline CHEMBL3192152 & 752480 & 5.3496 & 5.4452 & TRN & & \\
\hline CHEMBL1730502 & 752480 & 5.2905 & 5.2932 & TST & & \\
\hline CHEMBL1413626 & 752480 & \multicolumn{3}{|c|}{5.297000000000001} & 5.0591 & TRN \\
\hline CHEMBL1324303 & 752480 & 5.0813 & 5.2687 & TRN & & \\
\hline CHEMBL1490080 & 752480 & 5.2441 & 5.43 & TRN & & \\
\hline CHEMBL1510339 & 752480 & 5.3995 & 5.936 & TRN & & \\
\hline CHEMBL1403586 & 752480 & 5.3563 & 5.7902 & TRN & & \\
\hline CHEMBL1522545 & 752480 & 4.5819 & 5.1054 & TRN & & \\
\hline CHEMBL1481836 & 752480 & 5.3729 & 5.4099 & TRN & & \\
\hline CHEMBL1313412 & 752480 & 5.1135 & 5.1446 & TRN & & \\
\hline CHEMBL1897901 & 752480 & 5.1013 & 5.1161 & TST & & \\
\hline CHEMBL1586817 & 752480 & 7.71 & 5.0914 & TRN & & \\
\hline CHEMBL1985598 & 752480 & 5.477 & 5.585 & TRN & & \\
\hline CHEMBL1699691 & 752480 & 5.3686 & 6.0371 & TST & & \\
\hline CHEMBL1572553 & 752480 & 5.4391 & 5.6676 & TRN & & \\
\hline CHEMBL251369 & 752480 & 5.3557 & 5.4492 & TRN & & \\
\hline CHEMBL1712384 & 752480 & 5.5711 & 5.3872 & TST & & \\
\hline CHEMBL1969300 & 752480 & 6.1361 & 5.4324 & TRN & & \\
\hline CHEMBL1501645 & 752480 & 5.9512 & 6.0171 & TRN & & \\
\hline CHEMBL3190849 & 752480 & 5.3085 & 5.4403 & TRN & & \\
\hline CHEMBL1880070 & 752480 & 5.3612 & 5.6383 & TRN & & \\
\hline CHEMBL1301560 & 752480 & 5.0596 & 5.3342 & TST & & \\
\hline CHEMBL1988042 & 752480 & 5.5432 & 5.5896 & TRN & & \\
\hline CHEMBL520275 & 752480 & 7.71 & 6.7084 & TRN & & \\
\hline CHEMBL1586593 & 752480 & 5.2356 & 5.5747 & TRN & & \\
\hline CHEMBL1408181 & 752480 & 5.0692 & 5.2876 & TRN & & \\
\hline CHEMBL1349480 & 752480 & 5.3808 & 5.496 & TRN & & \\
\hline CHEMBL1518073 & 752480 & 6.0 & 5.8903 & TRN & & \\
\hline CHEMBL1874920 & 752480 & 5.5224 & 5.6822 & TRN & & \\
\hline CHEMBL1378300 & 752480 & 5.0755 & 5.3487 & TRN & & \\
\hline
\end{tabular}




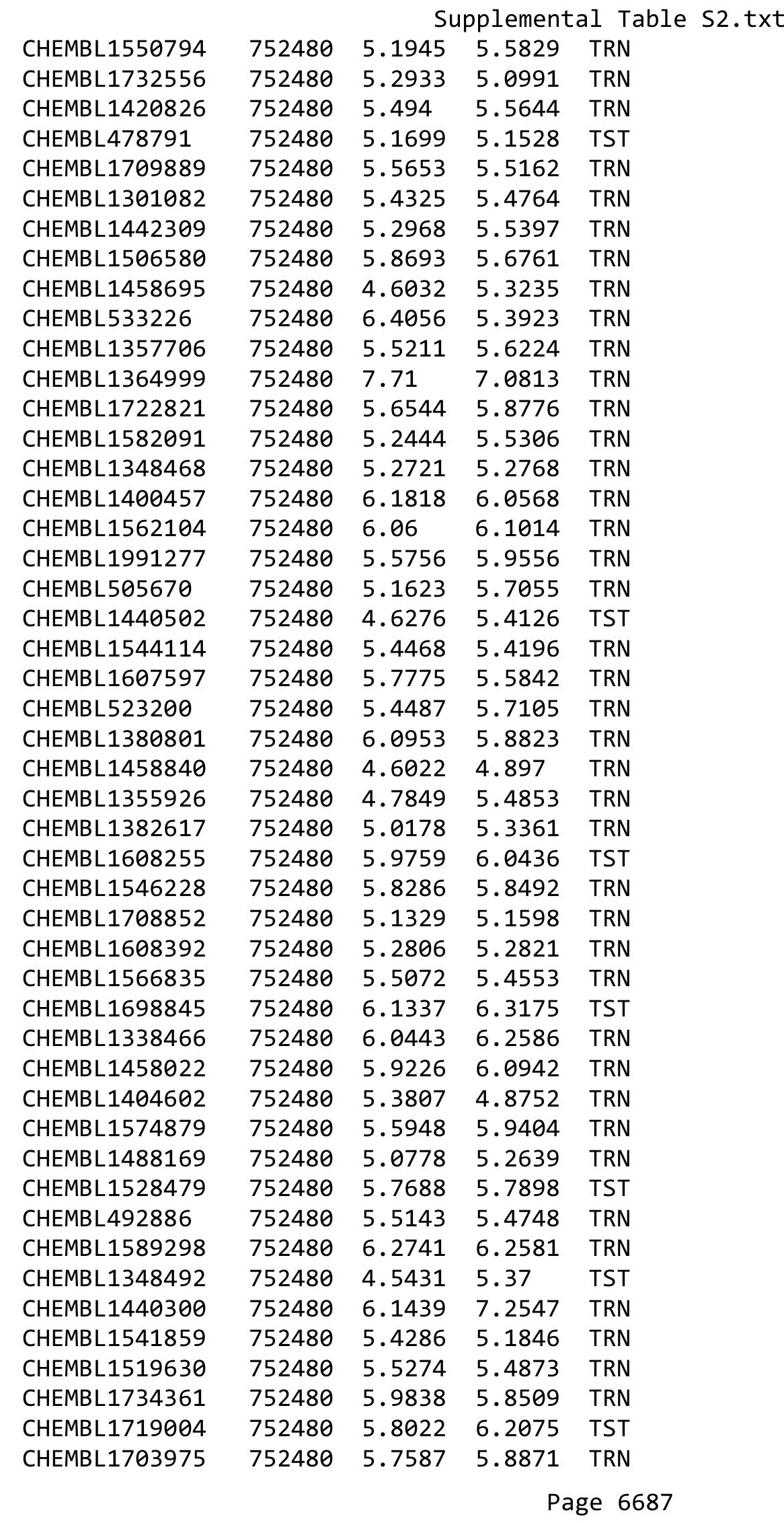


Supplemental Table S2.txt

\begin{tabular}{|c|c|c|c|c|c|c|}
\hline CHEMBL1348836 & 752480 & 5.9504 & 5.8128 & TRN & & \\
\hline CHEMBL1375045 & 752480 & 5.3934 & 5.7984 & TRN & & \\
\hline CHEMBL1478024 & 752480 & 4.7649 & 4.8478 & TRN & & \\
\hline CHEMBL1382939 & 752480 & 5.1656 & 5.4076 & TRN & & \\
\hline CHEMBL1789993 & 752480 & 5.3919 & 5.5617 & TST & & \\
\hline CHEMBL1488095 & 752480 & 7.71 & 6.6214 & TRN & & \\
\hline CHEMBL1587031 & 752480 & 5.1215 & 5.3198 & TST & & \\
\hline CHEMBL1327667 & 752480 & 4.7797 & 5.0909 & TRN & & \\
\hline CHEMBL1342145 & 752480 & 5.3769 & 5.5208 & TRN & & \\
\hline CHEMBL1521297 & 752480 & 5.0885 & 5.4908 & TRN & & \\
\hline CHEMBL1301371 & 752480 & 5.5014 & 5.7489 & TRN & & \\
\hline CHEMBL1413321 & 752480 & 5.0812 & 5.1385 & TRN & & \\
\hline CHEMBL1522175 & 752480 & 5.5653 & 5.4783 & TRN & & \\
\hline CHEMBL1384108 & 752480 & \multicolumn{3}{|c|}{5.332000000000001} & 5.4923 & TRN \\
\hline CHEMBL599098 & 752480 & 5.0688 & 5.3099 & TRN & & \\
\hline CHEMBL1708334 & 752480 & 5.4692 & 5.1202 & TST & & \\
\hline CHEMBL1487546 & 752480 & 5.8441 & 5.6771 & TRN & & \\
\hline CHEMBL1378952 & 752480 & 6.2111 & 6.1991 & TRN & & \\
\hline CHEMBL1400118 & 752480 & 5.2832 & 5.5924 & TRN & & \\
\hline CHEMBL1502607 & 752480 & 6.0605 & 5.8769 & TRN & & \\
\hline CHEMBL1573671 & 752480 & 4.9869 & 4.7571 & TRN & & \\
\hline CHEMBL1447284 & 752480 & 5.3368 & 5.4792 & TRN & & \\
\hline CHEMBL1404493 & 752480 & 6.0 & 5.825 & TST & & \\
\hline CHEMBL1361913 & 752480 & 5.767 & 6.0091 & TRN & & \\
\hline CHEMBL1366942 & 752480 & 5.4597 & 5.5021 & TRN & & \\
\hline CHEMBL1487639 & 752480 & 7.71 & 6.1325 & TRN & & \\
\hline CHEMBL1703914 & 752480 & 5.6421 & 5.6816 & TRN & & \\
\hline CHEMBL1560628 & 752480 & 5.0813 & 5.2308 & TRN & & \\
\hline CHEMBL1719994 & 752480 & 5.4562 & 5.6434 & TRN & & \\
\hline CHEMBL1326083 & 752480 & 6.2716 & 6.2179 & TRN & & \\
\hline CHEMBL1466490 & 752480 & 5.4064 & 5.4943 & TST & & \\
\hline CHEMBL1515267 & 752480 & 5.0903 & 5.2138 & TRN & & \\
\hline CHEMBL1404578 & 752480 & 5.3669 & 5.6249 & TRN & & \\
\hline CHEMBL3197109 & 752480 & 5.9412 & 5.4205 & TRN & & \\
\hline CHEMBL1559558 & 752480 & 5.1412 & 5.2466 & TST & & \\
\hline CHEMBL1506041 & 752480 & 5.5039 & 4.9834 & TRN & & \\
\hline CHEMBL1400298 & 752480 & 5.5748 & 5.6036 & TRN & & \\
\hline CHEMBL1393385 & 752480 & 5.4047 & 5.4834 & TRN & & \\
\hline CHEMBL 3195898 & 752480 & 5.2736 & 5.4786 & TRN & & \\
\hline CHEMBL1339270 & 752480 & 5.6478 & 5.4464 & TRN & & \\
\hline CHEMBL1570845 & 752480 & 6.3757 & 6.3077 & TRN & & \\
\hline CHEMBL1212972 & 752480 & 7.71 & 6.4208 & TST & & \\
\hline CHEMBL1500051 & 752480 & 5.5334 & 5.4369 & TRN & & \\
\hline CHEMBL1405524 & 752480 & 5.4538 & 5.3991 & TRN & & \\
\hline CHEMBL265699 & 752480 & 4.6509 & 4.9874 & TRN & & \\
\hline CHEMBL1332969 & 752480 & 5.369 & 5.6787 & TRN & & \\
\hline CHEMBL1447877 & 752480 & 5.7625 & 5.79200 & 0000000001 & & TRN \\
\hline CHEMBL1353371 & 752480 & 5.654 & 5.5471 & TRN & & \\
\hline
\end{tabular}


Supplemental Table S2.txt

\begin{tabular}{|c|c|c|c|c|c|}
\hline CHEMBL1522486 & 752480 & 5.1801 & 5.3658 & TRN & \\
\hline CHEMBL1409883 & 752480 & 5.8162 & 6.1714 & TRN & \\
\hline CHEMBL3145285 & 752480 & 5.6196 & 5.3757 & TRN & \\
\hline CHEMBL3194762 & 752480 & 5.0809 & 5.3255 & TRN & \\
\hline CHEMBL1581682 & 752480 & 5.477 & 5.6228 & TRN & \\
\hline CHEMBL1208858 & 752480 & \multicolumn{3}{|c|}{5.2620000000000005} & TST \\
\hline CHEMBL1478382 & 752480 & 5.6291 & 5.5214 & TRN & \\
\hline CHEMBL1557782 & 752480 & 5.2217 & 5.1619 & TRN & \\
\hline CHEMBL1370387 & 752480 & 5.141 & 5.1447 & TRN & \\
\hline CHEMBL1367860 & 752480 & 5.3409 & 5.5559 & TST & \\
\hline CHEMBL1968273 & 752480 & 4.9814 & 5.1554 & TRN & \\
\hline CHEMBL1703209 & 752480 & 6.3401 & 6.0859 & TRN & \\
\hline CHEMBL1725584 & 752480 & 6.1439 & 5.6284 & TST & \\
\hline CHEMBL3190542 & 752480 & 5.6536 & 5.4352 & TRN & \\
\hline CHEMBL1481281 & 752480 & 5.6173 & 5.7603 & TRN & \\
\hline CHEMBL3192061 & 752480 & 6.2336 & 5.7762 & TRN & \\
\hline CHEMBL1711514 & 752480 & 5.5936 & 5.6769 & TRN & \\
\hline CHEMBL1714574 & 752480 & 5.9492 & 6.301 & TRN & \\
\hline CHEMBL1612844 & 752480 & 5.0512 & 5.2471 & TRN & \\
\hline CHEMBL1568540 & 752480 & 7.71 & 5.231 & TRN & \\
\hline CHEMBL1379068 & 752480 & 6.0655 & 5.8572 & TRN & \\
\hline CHEMBL1606097 & 752480 & 5.1126 & 5.5204 & TRN & \\
\hline CHEMBL1528425 & 752480 & 6.1574 & 7.1189 & TRN & \\
\hline CHEMBL1519239 & 752480 & 5.6792 & 5.6729 & TRN & \\
\hline CHEMBL 3198438 & 752480 & 5.8254 & 5.7551 & TRN & \\
\hline CHEMBL1539339 & 752480 & 5.2043 & 5.4121 & TST & \\
\hline CHEMBL1336054 & 752480 & 5.7144 & 5.7618 & TRN & \\
\hline CHEMBL1362061 & 752480 & 5.0935 & 5.2041 & TST & \\
\hline CHEMBL1704798 & 752480 & 5.7305 & 5.0656 & TST & \\
\hline CHEMBL1575502 & 752480 & 5.091 & \multicolumn{2}{|c|}{5.257000000000001} & TST \\
\hline CHEMBL1733848 & 752480 & 5.36799 & 999999999 & 5.5956 & TRN \\
\hline CHEMBL1519298 & 752480 & 7.71 & 6.2887 & TRN & \\
\hline CHEMBL1609195 & 752480 & 4.4881 & 5.7867 & TRN & \\
\hline CHEMBL585827 & 752480 & 4.6278 & 4.6759 & TRN & \\
\hline CHEMBL1316838 & 752480 & 5.0726 & 5.2184 & TRN & \\
\hline CHEMBL1307271 & 752480 & 5.4734 & 5.3014 & TRN & \\
\hline CHEMBL1572001 & 752480 & 5.3659 & 5.7503 & TST & \\
\hline CHEMBL1451491 & 752480 & 6.5768 & 5.4925 & TST & \\
\hline CHEMBL1385989 & 752480 & 5.2371 & 5.4998 & TST & \\
\hline CHEMBL1727063 & 752480 & 5.5651 & 5.3942 & TST & \\
\hline CHEMBL1991736 & 752480 & 5.0793 & 5.2651 & TRN & \\
\hline CHEMBL3207561 & 752480 & 5.3829 & 5.3315 & TRN & \\
\hline CHEMBL1464948 & 752480 & 5.0443 & 5.3222 & TST & \\
\hline CHEMBL1563370 & 752480 & 5.1787 & 5.3152 & TST & \\
\hline CHEMBL169811 & 752480 & 5.5621 & 5.5793 & TRN & \\
\hline CHEMBL1703892 & 752480 & 6.4724 & 6.4861 & TRN & \\
\hline CHEMBL1712047 & 752480 & 7.71 & 5.579 & TRN & \\
\hline CHEMBL591137 & 752480 & 5.3544 & 5.4981 & TRN & \\
\hline
\end{tabular}


Supplemental Table S2.txt

\begin{tabular}{|c|c|c|c|c|c|}
\hline CHEMBL1443383 & 752480 & 5.0793 & 5.2427 & TRN & \\
\hline CHEMBL1467765 & 752480 & 5.4647 & 5.5676 & TRN & \\
\hline CHEMBL1386366 & 752480 & 5.5346 & 5.178 & TRN & \\
\hline CHEMBL3189590 & 752480 & 5.2343 & 5.2622 & TRN & \\
\hline CHEMBL1449794 & 752480 & 4.7663 & 4.9488 & TRN & \\
\hline CHEMBL1453657 & 752480 & 5.9404 & 5.6301 & TRN & \\
\hline CHEMBL560579 & 752480 & 7.71 & 7.4137 & TRN & \\
\hline CHEMBL1721165 & 752480 & 6.3936 & 6.3159 & TRN & \\
\hline CHEMBL1466186 & 752480 & 5.3069 & 5.485 & TRN & \\
\hline CHEMBL1567571 & 752480 & 5.1066 & 5.3226 & TRN & \\
\hline CHEMBL1727678 & 752480 & 5.1221 & 5.1283 & TRN & \\
\hline CHEMBL3198994 & 752480 & 5.3075 & 5.6243 & TRN & \\
\hline CHEMBL1375884 & 752480 & 5.5343 & 5.8335 & TRN & \\
\hline CHEMBL1431608 & 752480 & 5.4126 & 5.6653 & TRN & \\
\hline CHEMBL1688556 & 752480 & 7.71 & 5.4249 & TRN & \\
\hline CHEMBL1491222 & 752480 & 7.71 & 5.1981 & TRN & \\
\hline CHEMBL1345979 & 752480 & 5.473 & 5.6158 & TST & \\
\hline CHEMBL1716672 & 752480 & 5.3494 & 5.4723 & TRN & \\
\hline CHEMBL1536493 & 752480 & 5.5253 & 5.5586 & TRN & \\
\hline CHEMBL1580272 & 752480 & 4.7958 & 5.3805 & TRN & \\
\hline CHEMBL 2000750 & 752480 & 4.7698 & 5.1117 & TRN & \\
\hline CHEMBL1578641 & 752480 & 6.3036 & 6.047999 & 9999999999 & TRN \\
\hline CHEMBL1335220 & 752480 & 5.5494 & 5.484 & TST & \\
\hline CHEMBL1889980 & 752480 & 5.7775 & 5.8174 & TST & \\
\hline CHEMBL1539001 & 752480 & 5.5635 & 5.4442 & TRN & \\
\hline CHEMBL1365585 & 752480 & 5.6498 & 5.5626 & TRN & \\
\hline CHEMBL1709364 & 752480 & 5.7635 & 5.6712 & TRN & \\
\hline CHEMBL1333737 & 752480 & 5.8861 & 5.8903 & TRN & \\
\hline CHEMBL1531377 & 752480 & 6.1543 & 5.654 & TST & \\
\hline CHEMBL1394747 & 752480 & 5.324 & 5.3352 & TST & \\
\hline CHEMBL1714971 & 752480 & 5.1992 & 5.3965 & TRN & \\
\hline CHEMBL1327737 & 752480 & 5.5302 & 5.2303 & TRN & \\
\hline CHEMBL1508175 & 752480 & 5.3847 & 5.4409 & TRN & \\
\hline CHEMBL1374860 & 752480 & 5.8548 & 6.1348 & TRN & \\
\hline CHEMBL1596594 & 752480 & 5.3758 & 5.3524 & TST & \\
\hline CHEMBL1441486 & 752480 & 5.1148 & 5.2518 & TRN & \\
\hline CHEMBL1460705 & 752480 & 5.3553 & 5.4804 & TRN & \\
\hline CHEMBL1533279 & 752480 & 7.71 & 7.1135 & TRN & \\
\hline CHEMBL1403802 & 752480 & 5.5259 & 5.6697 & TST & \\
\hline CHEMBL1501558 & 752480 & 5.0923 & 5.4393 & TRN & \\
\hline CHEMBL1413680 & 752480 & 5.5207 & 5.8883 & TST & \\
\hline CHEMBL1710307 & 752480 & 5.1222 & 5.3686 & TRN & \\
\hline CHEMBL1544548 & 752480 & 5.4942 & 5.7109 & TRN & \\
\hline CHEMBL1482296 & 752480 & 7.71 & 6.1843 & TRN & \\
\hline CHEMBL1469579 & 752480 & 5.0964 & 5.521 & TRN & \\
\hline CHEMBL1502004 & 752480 & 5.3285 & 5.4998 & TRN & \\
\hline CHEMBL1585779 & 752480 & 5.8041 & 6.1804 & TRN & \\
\hline CHEMBL1423633 & 752480 & 5.2566 & 5.4304 & TST & \\
\hline
\end{tabular}


Supplemental Table S2.txt

\begin{tabular}{|c|c|c|c|c|c|}
\hline CHEMBL3199016 & 752480 & 5.0612 & 5.272 & TRN & \\
\hline CHEMBL3191762 & 752480 & 5.0812 & 5.3394 & TRN & \\
\hline CHEMBL1450526 & 752480 & 4.8091 & 5.0293 & TRN & \\
\hline CHEMBL601768 & 752480 & 5.1264 & 5.4056 & TRN & \\
\hline CHEMBL1480517 & 752480 & 5.5418 & 5.8621 & TRN & \\
\hline CHEMBL1330109 & 752480 & 5.6931 & 5.723 & TRN & \\
\hline CHEMBL1966952 & 752480 & 6.6655 & 5.7822 & TRN & \\
\hline CHEMBL1588513 & 752480 & 4.6063 & 4.8144 & TRN & \\
\hline CHEMBL1410326 & 752480 & 4.8685 & 5.28700 & 0000000001 & TRN \\
\hline CHEMBL1472307 & 752480 & 5.6949 & 5.6599 & TRN & \\
\hline CHEMBL1404086 & 752480 & 5.6586 & 5.71899 & 9999999999 & TRN \\
\hline CHEMBL1303810 & 752480 & 5.3675 & 5.3969 & TRN & \\
\hline CHEMBL1555652 & 752480 & 5.0845 & 5.3384 & TRN & \\
\hline CHEMBL1722849 & 752480 & 5.6353 & 5.6652 & TRN & \\
\hline CHEMBL1256686 & 752480 & 6.0899 & 5.7621 & TST & \\
\hline CHEMBL1453089 & 752480 & 5.3612 & 5.4692 & TRN & \\
\hline CHEMBL602363 & 752480 & 5.3982 & 5.4131 & TRN & \\
\hline CHEMBL1422477 & 752480 & 5.1592 & 4.8872 & TRN & \\
\hline CHEMBL1575756 & 752480 & 5.516 & 5.4734 & TRN & \\
\hline CHEMBL1540985 & 752480 & 5.2234 & 5.4565 & TRN & \\
\hline CHEMBL1570705 & 752480 & 5.8277 & 5.7902 & TRN & \\
\hline CHEMBL1418598 & 752480 & 5.0928 & 5.4331 & TRN & \\
\hline CHEMBL1699845 & 752480 & 7.71 & 5.9216 & TRN & \\
\hline CHEMBL1713163 & 752480 & 4.6173 & 5.0155 & TRN & \\
\hline CHEMBL1589425 & 752480 & 5.1991 & 5.2578 & TRN & \\
\hline CHEMBL1404113 & 752480 & 6.0937 & 5.8359 & TRN & \\
\hline CHEMBL453974 & 752480 & 5.5996 & 6.4398 & TST & \\
\hline CHEMBL 2002776 & 752480 & 4.5601 & 4.9073 & TRN & \\
\hline CHEMBL1529236 & 752480 & 5.251 & 5.237 & TRN & \\
\hline CHEMBL269163 & 752480 & 5.3344 & 5.4505 & TRN & \\
\hline CHEMBL1516922 & 752480 & 5.407 & 5.4805 & TRN & \\
\hline CHEMBL1311109 & 752480 & 5.1372 & 5.4497 & TST & \\
\hline CHEMBL1488923 & 752480 & 5.7349 & 5.5513 & TRN & \\
\hline CHEMBL1511794 & 752480 & 5.4624 & 5.8894 & TRN & \\
\hline CHEMBL1321527 & 752480 & 5.1162 & 5.4997 & TRN & \\
\hline CHEMBL1327183 & 752480 & 4.6664 & 5.0558 & TRN & \\
\hline CHEMBL567622 & 752480 & 7.71 & 6.6659 & TRN & \\
\hline CHEMBL1425137 & 752480 & 5.9727 & 6.0136 & TRN & \\
\hline CHEMBL1502104 & 752480 & 6.0737 & 5.9127 & TST & \\
\hline CHEMBL1549128 & 752480 & 5.0914 & 5.2705 & TST & \\
\hline CHEMBL1729168 & 752480 & 5.4697 & 5.6064 & TST & \\
\hline CHEMBL1477640 & 752480 & 5.3559 & 5.5046 & TRN & \\
\hline CHEMBL570345 & 752480 & 5.6613 & 5.7221 & TRN & \\
\hline CHEMBL1490222 & 752480 & 5.388 & 5.4775 & TRN & \\
\hline CHEMBL239275 & 752480 & \multicolumn{3}{|c|}{5.212999999999999} & TRN \\
\hline CHEMBL1446971 & 752480 & 5.5839 & 5.4533 & TRN & \\
\hline CHEMBL1583264 & 752480 & 5.4847 & 5.8814 & TRN & \\
\hline CHEMBL1576260 & 752480 & 5.1162 & 5.4578 & TST & \\
\hline
\end{tabular}




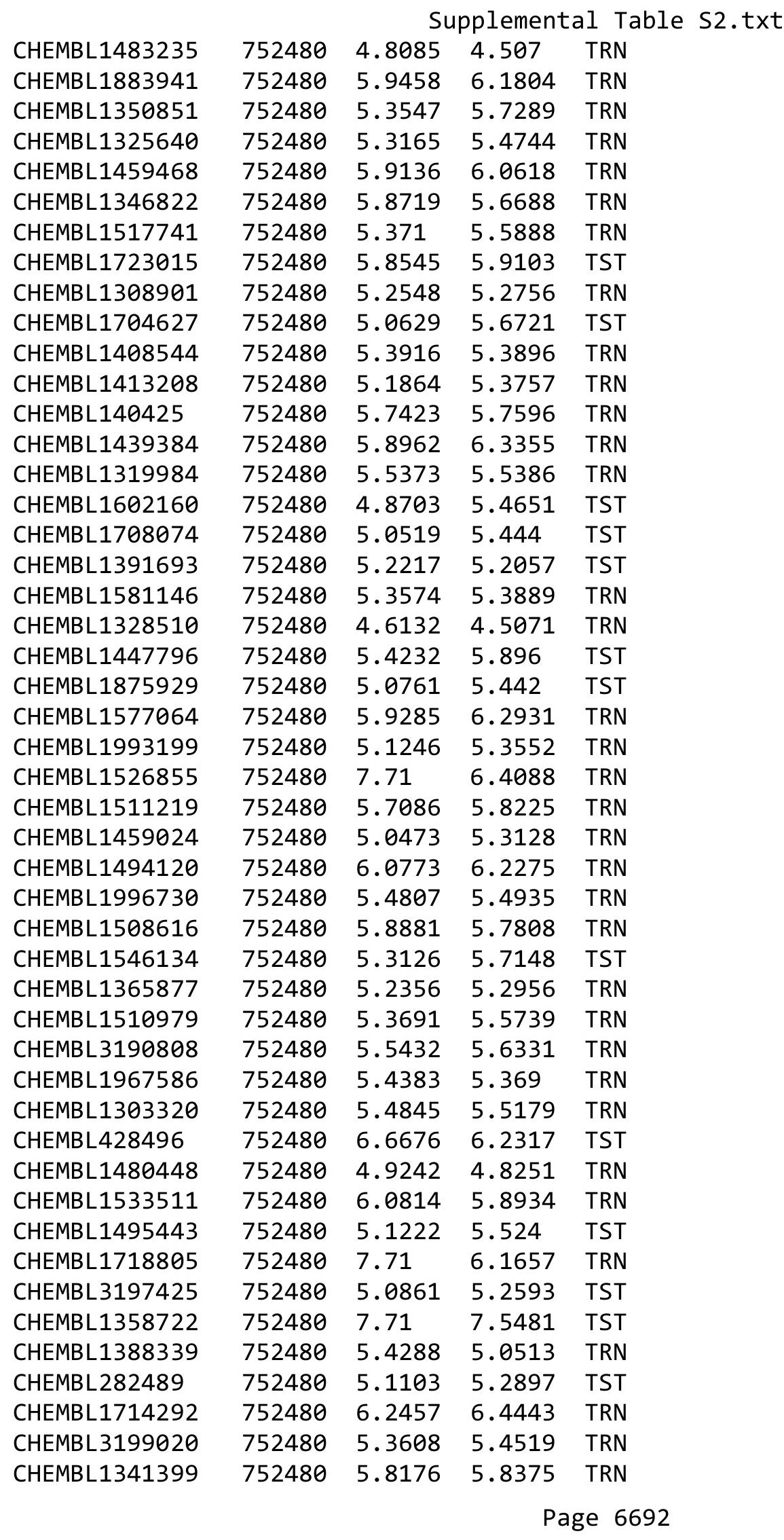




\begin{tabular}{|c|c|c|c|c|c|}
\hline \multicolumn{6}{|c|}{ Supplemental Table S2.txt } \\
\hline CHEMBL1554169 & 752480 & 4.58 & 5.1779 & TRN & \\
\hline CHEMBL1708706 & 752480 & 5.4605 & 5.5094 & TST & \\
\hline CHEMBL591126 & 752480 & 5.5308 & 5.2196 & TRN & \\
\hline CHEMBL1535361 & 752480 & 5.2882 & 5.3262 & TRN & \\
\hline CHEMBL1722933 & 752480 & 5.045 & 5.0579 & TRN & \\
\hline CHEMBL1578142 & 752480 & 5.3828 & 5.5225 & TRN & \\
\hline CHEMBL1439593 & 752480 & 5.3766 & 5.4059 & TRN & \\
\hline CHEMBL1424562 & 752480 & 7.71 & 7.3871 & TRN & \\
\hline CHEMBL1578946 & 752480 & 5.3881 & 5.49100 & 00000000005 & TRN \\
\hline CHEMBL1514534 & 752480 & 5.6955 & 5.5538 & TRN & \\
\hline CHEMBL1528094 & 752480 & 5.3473 & 5.2647 & TRN & \\
\hline CHEMBL1597585 & 752480 & 5.0785 & 5.2472 & TRN & \\
\hline CHEMBL1700323 & 752480 & 6.1244 & 5.8633 & TRN & \\
\hline CHEMBL1465946 & 752480 & 5.8693 & 5.8693 & TRN & \\
\hline CHEMBL1350780 & 752480 & 5.6221 & 5.2634 & TRN & \\
\hline CHEMBL1509060 & 752480 & 5.2602 & 5.3714 & TST & \\
\hline CHEMBL1724453 & 752480 & 7.71 & 5.3549 & TRN & \\
\hline CHEMBL1974389 & 752480 & 5.9126 & 6.0864 & TRN & \\
\hline CHEMBL1709779 & 752480 & 5.1183 & 5.3034 & TRN & \\
\hline CHEMBL1310234 & 752480 & 5.0835 & 5.387006 & 00000000005 & TRN \\
\hline CHEMBL1547395 & 752480 & 5.5825 & 5.8353 & TRN & \\
\hline CHEMBL1790039 & 752480 & 5.9642 & 6.2473 & TST & \\
\hline CHEMBL1492677 & 752480 & 5.7815 & 5.921 & TRN & \\
\hline CHEMBL1484318 & 752480 & 5.3853 & 5.4515 & TRN & \\
\hline CHEMBL1442788 & 752480 & 7.71 & 7.5063 & TRN & \\
\hline CHEMBL1698608 & 752480 & 5.5877 & 5.6415 & TRN & \\
\hline CHEMBL1539545 & 752480 & 5.3711 & 5.5809 & TRN & \\
\hline CHEMBL1727268 & 752480 & 7.71 & 6.621 & TRN & \\
\hline CHEMBL144514 & 752480 & 5.42299 & 99999999 & 5.5331 & TRN \\
\hline CHEMBL1448592 & 752480 & 5.5388 & 5.4793 & TRN & \\
\hline CHEMBL1410479 & 752480 & 5.3719 & 5.5889 & TRN & \\
\hline CHEMBL1725990 & 752480 & 4.7794 & 5.026 & TRN & \\
\hline CHEMBL1487183 & 752480 & 5.3623 & 5.3091 & TST & \\
\hline CHEMBL1520716 & 752480 & 5.3185 & 4.8621 & TRN & \\
\hline CHEMBL1419721 & 752480 & 5.0586 & 4.9181 & TRN & \\
\hline CHEMBL1335030 & 752480 & 5.3657 & 5.526 & TRN & \\
\hline CHEMBL3190482 & 752480 & 5.6379 & 5.8075 & TRN & \\
\hline CHEMBL1369200 & 752480 & 5.3883 & 5.5391 & TRN & \\
\hline CHEMBL1608776 & 752480 & 5.6778 & 6.0567 & TRN & \\
\hline CHEMBL1514530 & 752480 & 4.7857 & 4.9442 & TRN & \\
\hline CHEMBL567421 & 752480 & 6.4295 & 6.2841 & TRN & \\
\hline CHEMBL3193419 & 752480 & 5.3687 & 5.4349 & TRN & \\
\hline CHEMBL2369316 & 752480 & 5.8801 & 5.6983 & TST & \\
\hline CHEMBL1483252 & 752480 & 6.295 & 6.0168 & TRN & \\
\hline CHEMBL1585527 & 752480 & 5.4546 & 5.5536 & TRN & \\
\hline CHEMBL1986664 & 752480 & 5.2368 & 5.5181 & TRN & \\
\hline CHEMBL1576094 & 752480 & 6.4815 & 6.3039 & TRN & \\
\hline CHEMBL592600 & 752480 & 5.6499 & 5.4631 & TRN & \\
\hline
\end{tabular}




\begin{tabular}{|c|c|c|c|c|c|}
\hline & & \multicolumn{4}{|c|}{ Supplemental Table S2.txt } \\
\hline CHEMBL1418885 & 752480 & 5.8199 & 5.6503 & TRN & \\
\hline CHEMBL1973042 & 752480 & 5.4044 & 5.4416 & TRN & \\
\hline CHEMBL1447350 & 752480 & 5.6232 & 5.8156 & TRN & \\
\hline CHEMBL1399492 & 752480 & 5.6521 & 5.5045 & TRN & \\
\hline CHEMBL157707 & 752480 & 5.6733 & 5.4997 & TRN & \\
\hline CHEMBL1465511 & 752480 & 5.3483 & 5.0167 & TRN & \\
\hline CHEMBL1502605 & 752480 & 6.064 & 5.9745 & TRN & \\
\hline CHEMBL1458812 & 752480 & 5.8044 & 5.7803 & TRN & \\
\hline CHEMBL1388653 & 752480 & 5.2937 & 5.4767 & TRN & \\
\hline CHEMBL1986259 & 752480 & 6.224 & 6.285 & TRN & \\
\hline CHEMBL1441884 & 752480 & 5.475 & 5.41799 & 9999999999 & TRN \\
\hline CHEMBL89445 & 752480 & 5.9876 & 5.8584 & TRN & \\
\hline CHEMBL1387248 & 752480 & 5.7513 & 6.096 & TRN & \\
\hline CHEMBL1699032 & 752480 & 7.71 & 6.1796 & TRN & \\
\hline CHEMBL1582831 & 752480 & 5.8022 & 5.8343 & TRN & \\
\hline CHEMBL1368477 & 752480 & 5.3541 & 5.5317 & TRN & \\
\hline CHEMBL1401989 & 752480 & 6.0685 & 5.6212 & TRN & \\
\hline CHEMBL1384790 & 752480 & 5.5829 & 5.5287 & TRN & \\
\hline CHEMBL 3144906 & 752480 & 5.0684 & 5.1789 & TRN & \\
\hline CHEMBL1728993 & 752480 & 5.4844 & 5.3508 & TST & \\
\hline CHEMBL1313141 & 752480 & 6.3893 & 5.4575 & TRN & \\
\hline CHEMBL1345195 & 752480 & 5.0177 & 5.0831 & TRN & \\
\hline CHEMBL1588557 & 752480 & 5.1539 & 5.3415 & TRN & \\
\hline CHEMBL1712082 & 752480 & 5.8294 & 5.8603 & TST & \\
\hline CHEMBL1597289 & 752480 & 5.3736 & 5.3926 & TRN & \\
\hline CHEMBL1506823 & 752480 & 5.3599 & 5.5999 & TRN & \\
\hline CHEMBL1365431 & 752480 & 5.5862 & 5.5557 & TST & \\
\hline CHEMBL1308170 & 752480 & 5.1894 & 5.36100 & $\partial 000000001$ & TST \\
\hline CHEMBL1474113 & 752480 & 5.2613 & 5.1484 & TRN & \\
\hline CHEMBL1723955 & 752480 & 6.2549 & 5.9008 & TRN & \\
\hline CHEMBL1365242 & 752480 & 5.7768 & 5.6831 & TRN & \\
\hline CHEMBL1706082 & 752480 & 5.4034 & 5.3862 & TRN & \\
\hline CHEMBL565893 & 752480 & 5.8404 & 6.0148 & TRN & \\
\hline CHEMBL1407812 & 752480 & 5.4568 & 5.4838 & TRN & \\
\hline CHEMBL1984324 & 752480 & 7.71 & 5.9132 & TST & \\
\hline CHEMBL1467867 & 752480 & 5.1049 & 5.2388 & TRN & \\
\hline CHEMBL1542748 & 752480 & 5.5367 & 5.4738 & TST & \\
\hline CHEMBL1697947 & 752480 & 5.4124 & 5.4423 & TST & \\
\hline CHEMBL296527 & 752480 & 5.109 & 5.5017 & TST & \\
\hline CHEMBL1594984 & 752480 & 5.3323 & 4.8747 & TRN & \\
\hline CHEMBL1554214 & 752480 & 5.9311 & 6.0498 & TRN & \\
\hline CHEMBL1457995 & 752480 & 5.7807 & 5.9062 & TRN & \\
\hline CHEMBL1311826 & 752480 & 5.9296 & 5.7129 & TRN & \\
\hline CHEMBL1332139 & 752480 & 5.7031 & 5.5638 & TRN & \\
\hline CHEMBL1569871 & 752480 & 6.00700 & 00000000 & 5.8934 & TRN \\
\hline CHEMBL1098875 & 752480 & 5.5291 & 5.5527 & TRN & \\
\hline CHEMBL1890411 & 752480 & 6.0926 & 6.353 & TRN & \\
\hline CHEMBL1343392 & 752480 & 5.4904 & 5.5073 & TRN & \\
\hline
\end{tabular}




\begin{tabular}{|c|c|c|c|c|c|c|}
\hline & & \multicolumn{5}{|c|}{ Supplemental Table S2.txt } \\
\hline CHEMBL1469379 & 752480 & 5.3148 & 5.5654 & TRN & & \\
\hline CHEMBL1448722 & 752480 & 5.359 & 5.3493 & TRN & & \\
\hline CHEMBL1383414 & 752480 & 5.567 & 5.4586 & TRN & & \\
\hline CHEMBL1523475 & 752480 & \multicolumn{3}{|c|}{5.422999999999999} & 5.4732 & TRN \\
\hline CHEMBL1464547 & 752480 & 5.9014 & 5.7463 & TRN & & \\
\hline CHEMBL1736432 & 752480 & 6.057 & 5.8129 & TRN & & \\
\hline CHEMBL1471612 & 752480 & 5.2224 & 5.3115 & TRN & & \\
\hline CHEMBL1490677 & 752480 & 5.4716 & 5.7553 & TRN & & \\
\hline CHEMBL534423 & 752480 & 5.4075 & 5.4325 & TRN & & \\
\hline CHEMBL1438881 & 752480 & 5.5164 & 5.5352 & TRN & & \\
\hline CHEMBL578944 & 752480 & 5.3912 & 5.3942 & TRN & & \\
\hline CHEMBL1735872 & 752480 & 6.0052 & 5.6448 & TRN & & \\
\hline CHEMBL1479566 & 752480 & 5.3274 & 5.6538 & TRN & & \\
\hline CHEMBL1527151 & 752480 & 5.3883 & 5.296 & TRN & & \\
\hline CHEMBL1364435 & 752480 & 6.1512 & 5.9376 & TRN & & \\
\hline CHEMBL1287983 & 752480 & 5.3635 & 5.3368 & TRN & & \\
\hline CHEMBL1322089 & 752480 & 6.4123 & 5.4381 & TRN & & \\
\hline CHEMBL1733942 & 752480 & 5.6276 & 5.5585 & TRN & & \\
\hline CHEMBL488140 & 752480 & 7.71 & 4.9147 & TRN & & \\
\hline CHEMBL1315169 & 752480 & 5.4869 & 5.8644 & TRN & & \\
\hline CHEMBL 2004056 & 752480 & \multicolumn{3}{|c|}{5.638999999999999} & 5.555 & TRN \\
\hline CHEMBL1561312 & 752480 & 4.8076 & 4.9849 & TRN & & \\
\hline CHEMBL1439210 & 752480 & 5.2217 & 5.4648 & TRN & & \\
\hline CHEMBL1704558 & 752480 & 5.0635 & 5.2491 & TRN & & \\
\hline CHEMBL1700268 & 752480 & 5.9614 & 6.4085 & TST & & \\
\hline CHEMBL1600855 & 752480 & 5.0655 & 5.3388 & TRN & & \\
\hline CHEMBL1530584 & 752480 & 5.3785 & 5.4266 & TRN & & \\
\hline CHEMBL1300370 & 752480 & 5.8351 & 5.7598 & TRN & & \\
\hline CHEMBL1540682 & 752480 & 5.3901 & 5.7379 & TST & & \\
\hline CHEMBL1507251 & 752480 & 5.0795 & 5.1096 & TRN & & \\
\hline CHEMBL548615 & 752480 & 5.6607 & 5.5905 & TRN & & \\
\hline CHEMBL1571123 & 752480 & 5.3853 & 5.7002 & TRN & & \\
\hline CHEMBL1463674 & 752480 & 5.3227 & 5.5131 & TRN & & \\
\hline CHEMBL1698715 & 752480 & 5.5728 & 5.7901 & TST & & \\
\hline CHEMBL1578341 & 752480 & 5.3504 & 5.3877 & TRN & & \\
\hline CHEMBL1362832 & 752480 & 5.3387 & 5.4565 & TRN & & \\
\hline CHEMBL1717138 & 752480 & 5.4105 & 5.4972 & TRN & & \\
\hline CHEMBL1383799 & 752480 & 5.52 & 5.7706 & TRN & & \\
\hline CHEMBL1507679 & 752480 & 6.3665 & 5.9794 & TRN & & \\
\hline CHEMBL1704261 & 752480 & 7.71 & 7.4824 & TRN & & \\
\hline CHEMBL1464949 & 752480 & 5.5196 & 5.3323 & TRN & & \\
\hline CHEMBL1530503 & 752480 & \multicolumn{3}{|c|}{5.8629999999999995} & 5.6685 & TRN \\
\hline CHEMBL1415154 & 752480 & 5.3888 & 5.4082 & TRN & & \\
\hline CHEMBL1612634 & 752480 & 6.4377 & 5.6675 & TRN & & \\
\hline CHEMBL1315731 & 752480 & 6.3125 & 6.1889 & TRN & & \\
\hline CHEMBL1410758 & 752480 & 5.5642 & 5.5346 & TRN & & \\
\hline CHEMBL1560954 & 752480 & 7.71 & 7.7473 & TRN & & \\
\hline CHEMBL1608016 & 752480 & 4.8606 & 5.1404 & TRN & & \\
\hline
\end{tabular}




\begin{tabular}{|c|c|c|c|c|c|c|}
\hline & & \multicolumn{5}{|c|}{ Supplemental Table S2.txt } \\
\hline CHEMBL45152 & 752480 & 5.0366 & 5.0938 & TRN & & \\
\hline CHEMBL1328504 & 752480 & 5.2805 & 5.5399 & TRN & & \\
\hline CHEMBL1596094 & 752480 & 5.4336 & 5.4587 & TRN & & \\
\hline CHEMBL1597768 & 752480 & 5.0648 & 5.1428 & TRN & & \\
\hline CHEMBL1422849 & 752480 & 5.8125 & 5.7722 & TRN & & \\
\hline CHEMBL1373096 & 752480 & 5.7565 & 5.6005 & TRN & & \\
\hline CHEMBL1426440 & 752480 & 5.5521 & 5.7948 & TST & & \\
\hline CHEMBL1432633 & 752480 & 5.6576 & 5.7216 & TST & & \\
\hline CHEMBL1304402 & 752480 & 5.1033 & 5.5143 & TRN & & \\
\hline CHEMBL3196754 & 752480 & 4.8154 & 4.8517 & TRN & & \\
\hline CHEMBL1549308 & 752480 & 5.0991 & 5.3365 & TRN & & \\
\hline CHEMBL1610506 & 752480 & 5.3199 & 5.4182 & TRN & & \\
\hline CHEMBL1728153 & 752480 & 6.0773 & 6.1839 & TRN & & \\
\hline CHEMBL3196691 & 752480 & 5.5795 & 5.2928 & TRN & & \\
\hline CHEMBL1895325 & 752480 & 5.5278 & 5.5652 & TRN & & \\
\hline CHEMBL1309484 & 752480 & 5.3575 & 5.4712 & TRN & & \\
\hline CHEMBL1370513 & 752480 & 5.1143 & 5.2192 & TRN & & \\
\hline CHEMBL1224755 & 752480 & \multicolumn{3}{|c|}{5.372000000000001} & 5.376 & $T$ \\
\hline CHEMBL1998606 & 752480 & 5.3639 & 5.3394 & TRN & & \\
\hline CHEMBL1415447 & 752480 & 4.8202 & 4.8535 & TST & & \\
\hline CHEMBL1448161 & 752480 & 5.6574 & 5.7027 & TRN & & \\
\hline CHEMBL1427459 & 752480 & 5.1351 & 5.1949 & TRN & & \\
\hline CHEMBL1541834 & 752480 & 5.107 & 5.1278 & TRN & & \\
\hline CHEMBL1605052 & 752480 & 5.0228 & 5.518 & TST & & \\
\hline CHEMBL1571835 & 752480 & 6.5058 & 6.5046 & TRN & & \\
\hline CHEMBL1307050 & 752480 & 5.4553 & 5.8186 & TRN & & \\
\hline CHEMBL1450086 & 752480 & 5.1194 & 5.1333 & TRN & & \\
\hline CHEMBL1495939 & 752480 & 5.5331 & 5.2735 & TRN & & \\
\hline CHEMBL1427185 & 752480 & 6.1713 & 6.4597 & TRN & & \\
\hline CHEMBL1526174 & 752480 & 6.3969 & 6.0713 & TRN & & \\
\hline CHEMBL1468982 & 752480 & 5.4942 & 4.9976 & TRN & & \\
\hline CHEMBL1598383 & 752480 & 5.0628 & 5.1862 & TRN & & \\
\hline CHEMBL1563898 & 752480 & 5.4968 & 5.6243 & TST & & \\
\hline CHEMBL1382884 & 752480 & 6.0 & 5.8335 & TRN & & \\
\hline CHEMBL1720801 & 752480 & 5.8765 & 5.6713 & TRN & & \\
\hline CHEMBL131037 & 752480 & 5.7849 & 6.1858 & TRN & & \\
\hline CHEMBL1726787 & 752480 & 5.0861 & 5.1216 & TRN & & \\
\hline CHEMBL1328603 & 752480 & 5.4603 & 6.2735 & TRN & & \\
\hline CHEMBL1585138 & 752480 & 5.6919 & 5.17 & TRN & & \\
\hline CHEMBL1413988 & 752480 & 4.6204 & 4.9025 & TRN & & \\
\hline CHEMBL3189217 & 752480 & 6.0825 & 6.2266 & TRN & & \\
\hline CHEMBL1499233 & 752480 & \multicolumn{3}{|c|}{5.337000000000001} & 5.3143 & TRN \\
\hline CHEMBL260342 & 752480 & 5.1557 & 5.7047 & TRN & & \\
\hline CHEMBL1986678 & 752480 & 5.6291 & 5.5987 & TRN & & \\
\hline CHEMBL1382917 & 752480 & 5.1025 & 5.2151 & TST & & \\
\hline CHEMBL1349566 & 752480 & 5.3389 & 5.4331 & TST & & \\
\hline CHEMBL1366012 & 752480 & 4.8335 & 5.5225 & TRN & & \\
\hline CHEMBL1523997 & 752480 & 6.0757 & 6.0676 & TRN & & \\
\hline
\end{tabular}




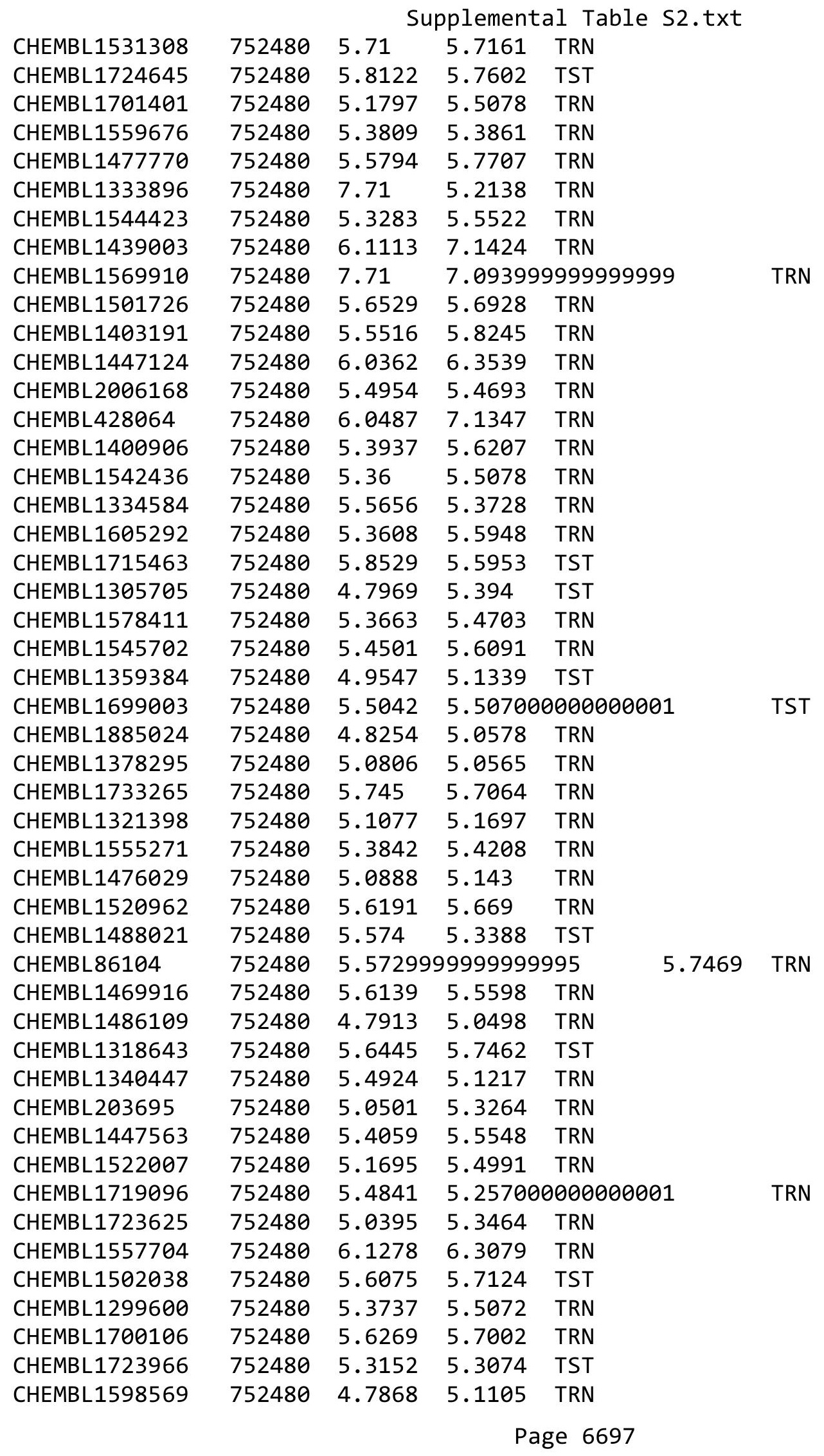


Supplemental Table S2.txt

\begin{tabular}{|c|c|c|c|c|c|}
\hline CHEMBL1717770 & 752480 & 6.6716 & 5.4023 & TRN & \\
\hline CHEMBL1354360 & 752480 & 5.0516 & 5.3186 & TRN & \\
\hline CHEMBL1598785 & 752480 & 5.3278 & 5.2406 & TRN & \\
\hline CHEMBL1711095 & 752480 & 5.0735 & 5.2577 & TRN & \\
\hline CHEMBL1605668 & 752480 & 5.2209 & 5.2574 & TRN & \\
\hline CHEMBL1330279 & 752480 & 5.1561 & 5.0944 & TRN & \\
\hline CHEMBL1435484 & 752480 & 5.2164 & \multicolumn{2}{|c|}{5.446000000000001} & TRN \\
\hline CHEMBL1392673 & 752480 & 5.3701 & 5.3672 & TRN & \\
\hline CHEMBL599255 & 752480 & 5.8245 & 5.6149 & TRN & \\
\hline CHEMBL1591223 & 752480 & 5.3143 & 5.2887 & TRN & \\
\hline CHEMBL1384167 & 752480 & 5.9562 & \multicolumn{2}{|c|}{ 5.712999999999999 } & TRN \\
\hline CHEMBL1528216 & 752480 & 5.9278 & 4.8752 & TRN & \\
\hline CHEMBL1406911 & 752480 & 5.1008 & 5.2258 & TRN & \\
\hline CHEMBL1581523 & 752480 & 5.8187 & 5.8081 & TRN & \\
\hline CHEMBL1328511 & 752480 & 5.5025 & 5.6052 & TRN & \\
\hline CHEMBL1511593 & 752480 & 5.0651 & 5.1981 & TRN & \\
\hline CHEMBL1572280 & 752480 & 5.3571 & 5.398 & TRN & \\
\hline CHEMBL1542804 & 752480 & 5.4653 & 5.6372 & TRN & \\
\hline CHEMBL1331822 & 752480 & 6.3645 & 6.415 & TRN & \\
\hline CHEMBL1712666 & 752480 & 5.9751 & 5.7463 & TRN & \\
\hline CHEMBL1465039 & 752480 & 5.0525 & 5.3453 & TRN & \\
\hline CHEMBL1894226 & 752480 & 7.71 & 5.5726 & TRN & \\
\hline CHEMBL1333830 & 752480 & 5.39 & 5.4606 & TST & \\
\hline CHEMBL1594483 & 752480 & 6.2993 & 5.6851 & TST & \\
\hline CHEMBL1306556 & 752480 & 4.8185 & 5.5684 & TRN & \\
\hline CHEMBL1736537 & 752480 & 6.1844 & 6.5506 & TRN & \\
\hline CHEMBL1325723 & 752480 & 5.7169 & 5.8569 & TRN & \\
\hline CHEMBL1561738 & 752480 & 5.2725 & 5.5168 & TST & \\
\hline CHEMBL1415813 & 752480 & 5.3732 & \multicolumn{2}{|c|}{5.712000000000001} & TRN \\
\hline CHEMBL1720380 & 752480 & 5.2841 & 5.5203 & TST & \\
\hline CHEMBL1887153 & 752480 & 5.7897 & 5.4406 & TRN & \\
\hline CHEMBL1562846 & 752480 & 5.8807 & 5.7723 & TRN & \\
\hline CHEMBL1863567 & 752480 & 7.71 & 7.6522 & TRN & \\
\hline CHEMBL1719154 & 752480 & 5.0609 & 5.2145 & TRN & \\
\hline CHEMBL1423567 & 752480 & 5.7815 & 5.4794 & TRN & \\
\hline CHEMBL1356395 & 752480 & 5.4406 & 5.5701 & TRN & \\
\hline CHEMBL1300443 & 752480 & 5.4089 & 5.6081 & TRN & \\
\hline CHEMBL591361 & 752480 & 5.1377 & \multicolumn{2}{|c|}{5.4479999999999995} & TRN \\
\hline CHEMBL1339522 & 752480 & 5.6461 & 5.7725 & TRN & \\
\hline CHEMBL1589118 & 752480 & 5.0774 & 5.5226 & TRN & \\
\hline CHEMBL 2000342 & 752480 & 5.4959 & 5.8792 & TST & \\
\hline CHEMBL591876 & 752480 & 4.816 & 5.016 & TRN & \\
\hline CHEMBL1520254 & 752480 & 5.3685 & 5.7226 & TRN & \\
\hline CHEMBL1556277 & 752480 & 5.053 & 5.3096 & TRN & \\
\hline CHEMBL1413418 & 752480 & 5.7752 & 5.9542 & TRN & \\
\hline CHEMBL1392793 & 752480 & 5.0475 & 5.3197 & TRN & \\
\hline CHEMBL469546 & 752480 & 6.0783 & 7.1767 & TST & \\
\hline CHEMBL590184 & 752480 & 4.7713 & 4.9999 & TRN & \\
\hline
\end{tabular}




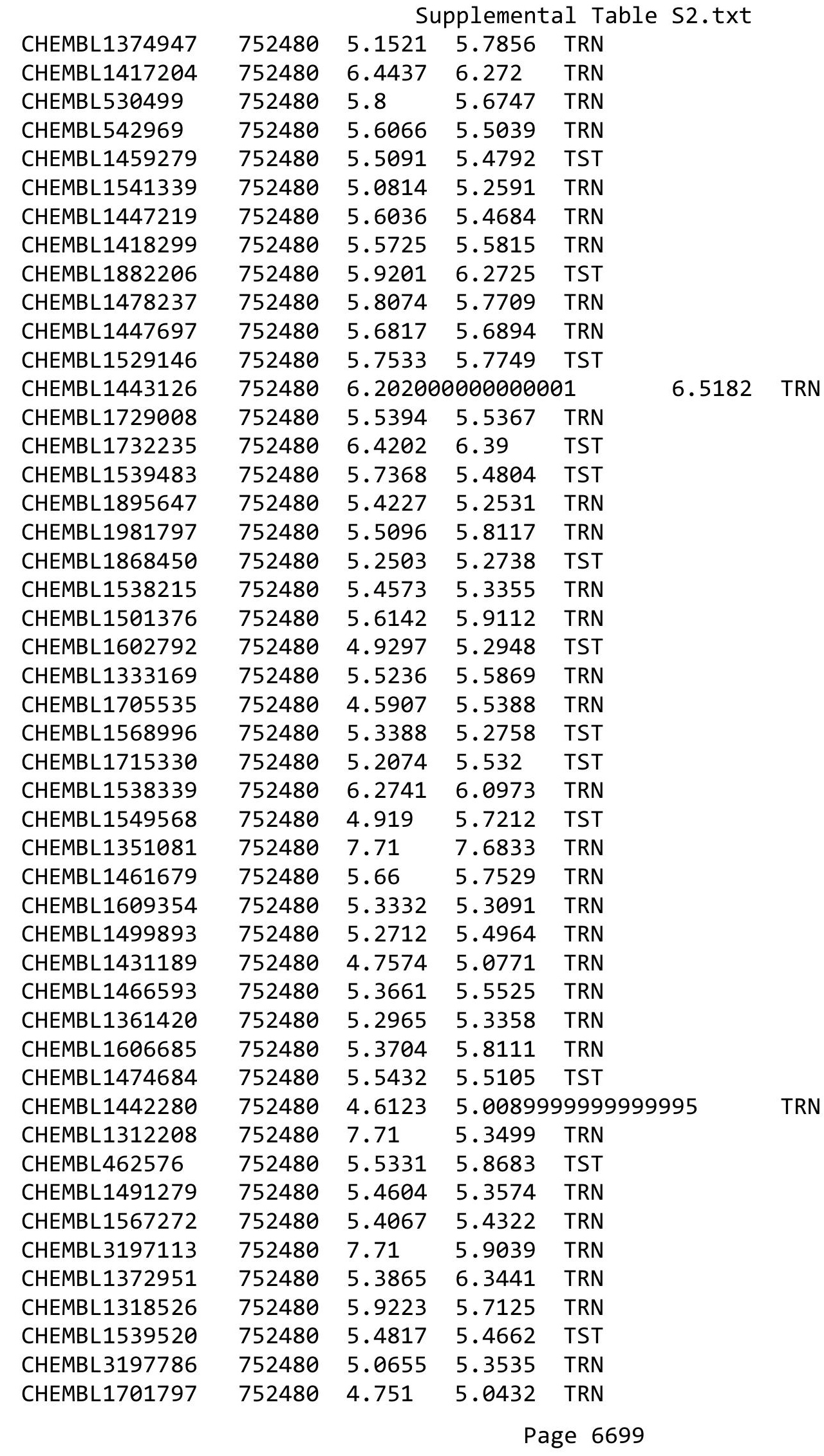




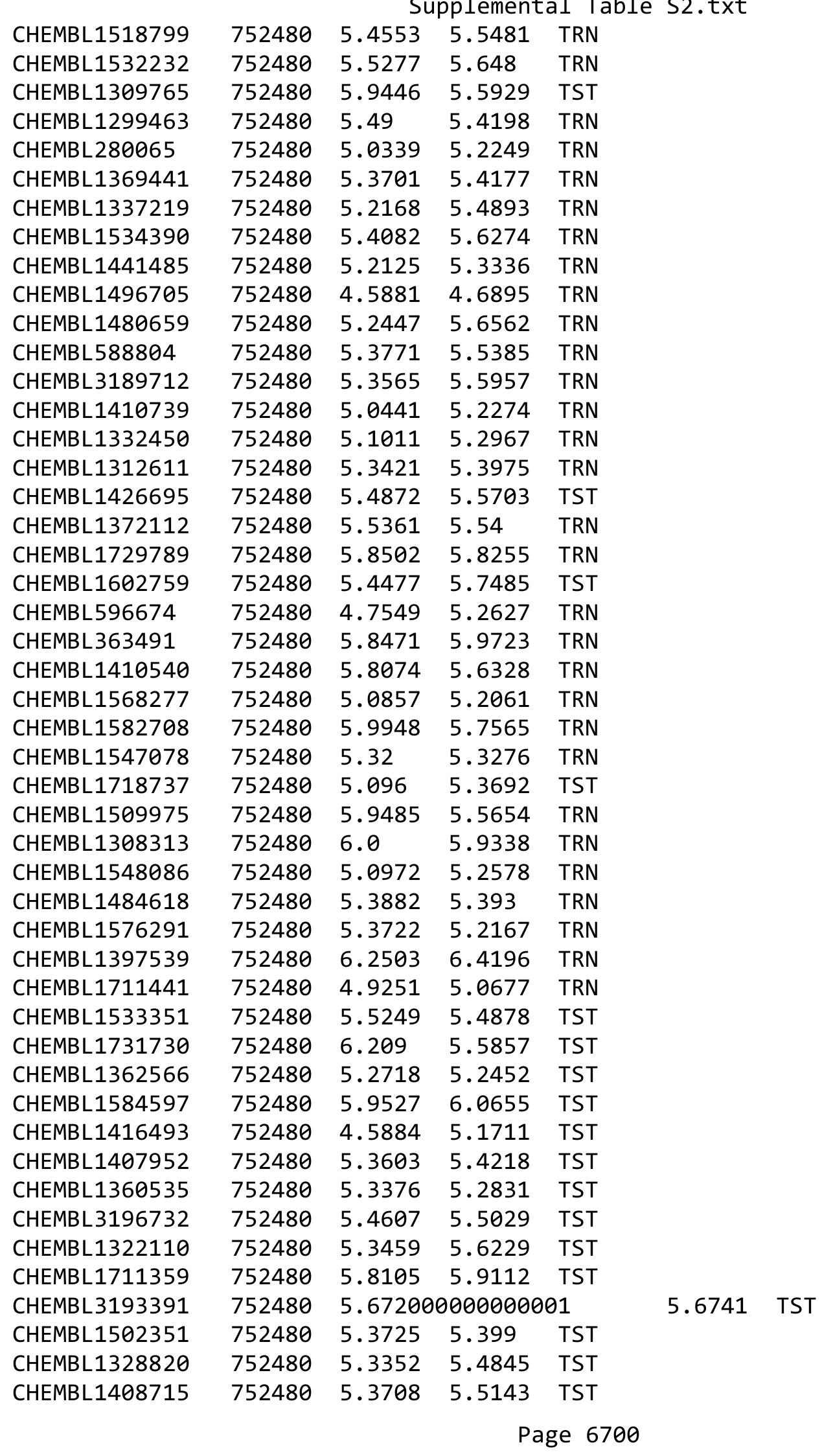


Supplemental Table S2.txt

\begin{tabular}{|c|c|c|c|c|c|}
\hline CHEMBL1458548 & 752480 & 6.1203 & 6.355 & TST & \\
\hline CHEMBL1448285 & 752480 & 5.5274 & 5.4087 & TST & \\
\hline CHEMBL69612 & 752480 & 5.6108 & 5.7964 & TST & \\
\hline CHEMBL1509380 & 752480 & \multicolumn{2}{|c|}{5.372000000000001} & 4.9305 & TST \\
\hline CHEMBL1411314 & 752480 & 5.3128 & 5.2217 & TST & \\
\hline CHEMBL1485335 & 752480 & 5.0906 & 5.1921 & TST & \\
\hline CHEMBL1998521 & 752480 & 5.6959 & 5.5043 & TST & \\
\hline CHEMBL1986690 & 752480 & 5.0704 & 5.3406 & TST & \\
\hline CHEMBL1404277 & 752480 & 5.9867 & 5.6334 & TST & \\
\hline CHEMBL1526505 & 752480 & 5.6328 & 5.5317 & TST & \\
\hline CHEMBL1726247 & 752480 & 5.9496 & \multicolumn{2}{|c|}{5.986000000000001} & \\
\hline CHEMBL1374672 & 752480 & 5.4722 & 5.5895 & TST & \\
\hline CHEMBL1976308 & 752480 & 5.7447 & 5.6845 & TST & \\
\hline CHEMBL3196404 & 752480 & 5.191 & 5.2599 & TST & \\
\hline CHEMBL1584720 & 752480 & 5.0916 & 5.1261 & TST & \\
\hline CHEMBL1499792 & 752480 & 7.71 & \multicolumn{2}{|c|}{5.507000000000001} & \\
\hline CHEMBL1986418 & 752480 & 5.3725 & 5.3937 & TST & \\
\hline CHEMBL568092 & 752480 & 5.1133 & 5.0965 & TST & \\
\hline CHEMBL1477528 & 752480 & 5.3914 & 5.7522 & TST & \\
\hline CHEMBL1966872 & 752480 & 4.8581 & 5.2851 & TST & \\
\hline CHEMBL1532068 & 752480 & 5.4022 & 5.3976 & TST & \\
\hline CHEMBL1376163 & 752480 & 5.0834 & 5.4371 & TST & \\
\hline CHEMBL1439833 & 752480 & 5.3518 & 5.4087 & TST & \\
\hline CHEMBL393136 & 752480 & 5.0579 & 5.1558 & TST & \\
\hline CHEMBL528694 & 752480 & 5.3647 & 5.3971 & TST & \\
\hline CHEMBL1340519 & 752480 & 5.8265 & 5.5793 & TST & \\
\hline CHEMBL1724522 & 752480 & 5.1006 & 5.4562 & TST & \\
\hline CHEMBL3144856 & 752480 & 5.1096 & 5.1909 & TST & \\
\hline CHEMBL1409985 & 752480 & 5.4868 & 5.5422 & TST & \\
\hline CHEMBL1348175 & 752480 & 5.3696 & \multicolumn{2}{|c|}{5.507000000000001} & \\
\hline CHEMBL1569107 & 752480 & 5.16 & 5.5092 & TST & \\
\hline CHEMBL1338958 & 752480 & 5.2626 & 5.3134 & TST & \\
\hline CHEMBL1332111 & 752480 & 5.6139 & 5.8185 & TST & \\
\hline CHEMBL 3197424 & 752480 & 5.4511 & 5.419 & TST & \\
\hline CHEMBL1325873 & 752480 & 5.6362 & 5.5959 & TST & \\
\hline CHEMBL1730243 & 752480 & 5.6478 & 5.6955 & TST & \\
\hline CHEMBL585071 & 752480 & 5.5478 & 5.5264 & TST & \\
\hline CHEMBL1528768 & 752480 & 5.8041 & 5.5095 & TST & \\
\hline CHEMBL1422997 & 752480 & 5.3585 & 5.5408 & TST & \\
\hline CHEMBL3199364 & 752480 & 5.0922 & 5.1809 & TST & \\
\hline CHEMBL1736490 & 752480 & 5.7165 & 5.7897 & TST & \\
\hline CHEMBL3192475 & 752480 & 5.8297 & 5.5798 & TST & \\
\hline CHEMBL1878494 & 752480 & 5.3962 & 5.4203 & TST & \\
\hline CHEMBL1339979 & 752480 & 5.3755 & 4.7161 & TST & \\
\hline CHEMBL1873093 & 752480 & 5.3152 & 5.3503 & TST & \\
\hline CHEMBL1388119 & 752480 & 4.7413 & 5.1194 & TST & \\
\hline CHEMBL1418428 & 752480 & 5.3339 & 5.5291 & TST & \\
\hline \multirow[t]{2}{*}{ CHEMBL1427633 } & 752480 & 5.0757 & 4.88399 & 99999999995 & \\
\hline & & \multicolumn{3}{|c|}{ Page 6701} & \\
\hline
\end{tabular}


Supplemental Table S2.txt

\begin{tabular}{|c|c|c|c|c|}
\hline CHEMBL1703955 & 752480 & 5.7226 & 5.5477 & TST \\
\hline CHEMBL1512306 & 752480 & 5.3233 & 5.4354 & TST \\
\hline CHEMBL1520233 & 752480 & 5.4109 & 5.5167 & TST \\
\hline CHEMBL1437683 & 752480 & 5.5988 & 5.8268 & TST \\
\hline CHEMBL1721015 & 752480 & 5.3349 & 5.606 & TST \\
\hline CHEMBL1729010 & 752480 & 5.9076 & 5.9763 & TST \\
\hline CHEMBL1471595 & 752480 & 5.6759 & 6.0185 & TST \\
\hline CHEMBL1305708 & 752480 & 5.11 & 5.2385 & TST \\
\hline CHEMBL1407401 & 752480 & 5.7565 & 5.7263 & TST \\
\hline CHEMBL1452421 & 752480 & 5.3516 & 5.2152 & TST \\
\hline CHEMBL1870867 & 752480 & 5.0751 & 5.2134 & TST \\
\hline CHEMBL1256761 & 752480 & 5.9104 & 5.8431 & TST \\
\hline CHEMBL3189413 & 752480 & 5.204 & 5.461 & TST \\
\hline CHEMBL1516785 & 752480 & 5.088 & 5.4407 & TST \\
\hline CHEMBL1398937 & 752480 & 5.0894 & 5.2971 & TST \\
\hline CHEMBL1484777 & 752480 & 5.4753 & 5.7989 & TST \\
\hline CHEMBL64391 & 752480 & 7.71 & 7.41299 & э999999999 \\
\hline CHEMBL1877661 & 752480 & 7.71 & 5.8499 & TST \\
\hline CHEMBL1715042 & 752480 & 5.2563 & 5.4136 & TST \\
\hline CHEMBL1448282 & 752480 & 5.4578 & 5.4726 & TST \\
\hline CHEMBL1400878 & 752480 & 4.6073 & 5.2674 & TST \\
\hline CHEMBL1337445 & 752480 & 5.3701 & 5.4332 & TST \\
\hline CHEMBL1703850 & 752480 & 5.3147 & 5.475 & TST \\
\hline CHEMBL473162 & 737146 & 5.6506 & 4.1532 & TRN \\
\hline CHEMBL1525922 & 737146 & 4.7856 & 5.47 & TRN \\
\hline CHEMBL1461680 & 737146 & 3.4948 & 4.8024 & TRN \\
\hline CHEMBL1458812 & 737146 & 3.4948 & 5.2141 & TST \\
\hline CHEMBL3195622 & 737146 & 5.0871 & 5.4193 & TRN \\
\hline CHEMBL1494709 & 737146 & 6.2809 & 6.0477 & TRN \\
\hline CHEMBL1497403 & 737146 & 4.9059 & 3.7872 & TRN \\
\hline CHEMBL1412583 & 737146 & 3.4948 & 3.9934 & TRN \\
\hline CHEMBL1412429 & 737146 & 3.4948 & 4.0516 & TRN \\
\hline CHEMBL1521425 & 737146 & 5.5073 & 5.3874 & TST \\
\hline CHEMBL1303719 & 737146 & 5.4234 & 5.7165 & TRN \\
\hline CHEMBL1533075 & 737146 & 3.4948 & 4.67 & TRN \\
\hline CHEMBL1339079 & 737146 & 5.1986 & 5.2917 & TRN \\
\hline CHEMBL1349137 & 737146 & 4.6996 & 5.1539 & TRN \\
\hline CHEMBL1532240 & 737146 & 7.301 & 6.0517 & TRN \\
\hline CHEMBL1537166 & 737146 & 3.4948 & 4.5943 & TRN \\
\hline CHEMBL1584949 & 737146 & 5.046 & 5.7496 & TRN \\
\hline CHEMBL1585996 & 737146 & 6.1615 & 6.1279 & TRN \\
\hline CHEMBL1566752 & 737146 & 5.5481 & 6.04700 & 0000000001 \\
\hline CHEMBL1544821 & 737146 & 6.0 & 4.1646 & TRN \\
\hline CHEMBL1310508 & 737146 & 3.4948 & 4.588 & TRN \\
\hline CHEMBL1502014 & 737146 & 3.4948 & 4.7542 & TST \\
\hline CHEMBL1545328 & 737146 & 6.0756 & 3.87100 & 90000000004 \\
\hline CHEMBL1333105 & 737146 & 5.5624 & 5.0229 & TRN \\
\hline CHEMBL1587881 & 737146 & 3.4948 & 4.592 & TRN \\
\hline
\end{tabular}




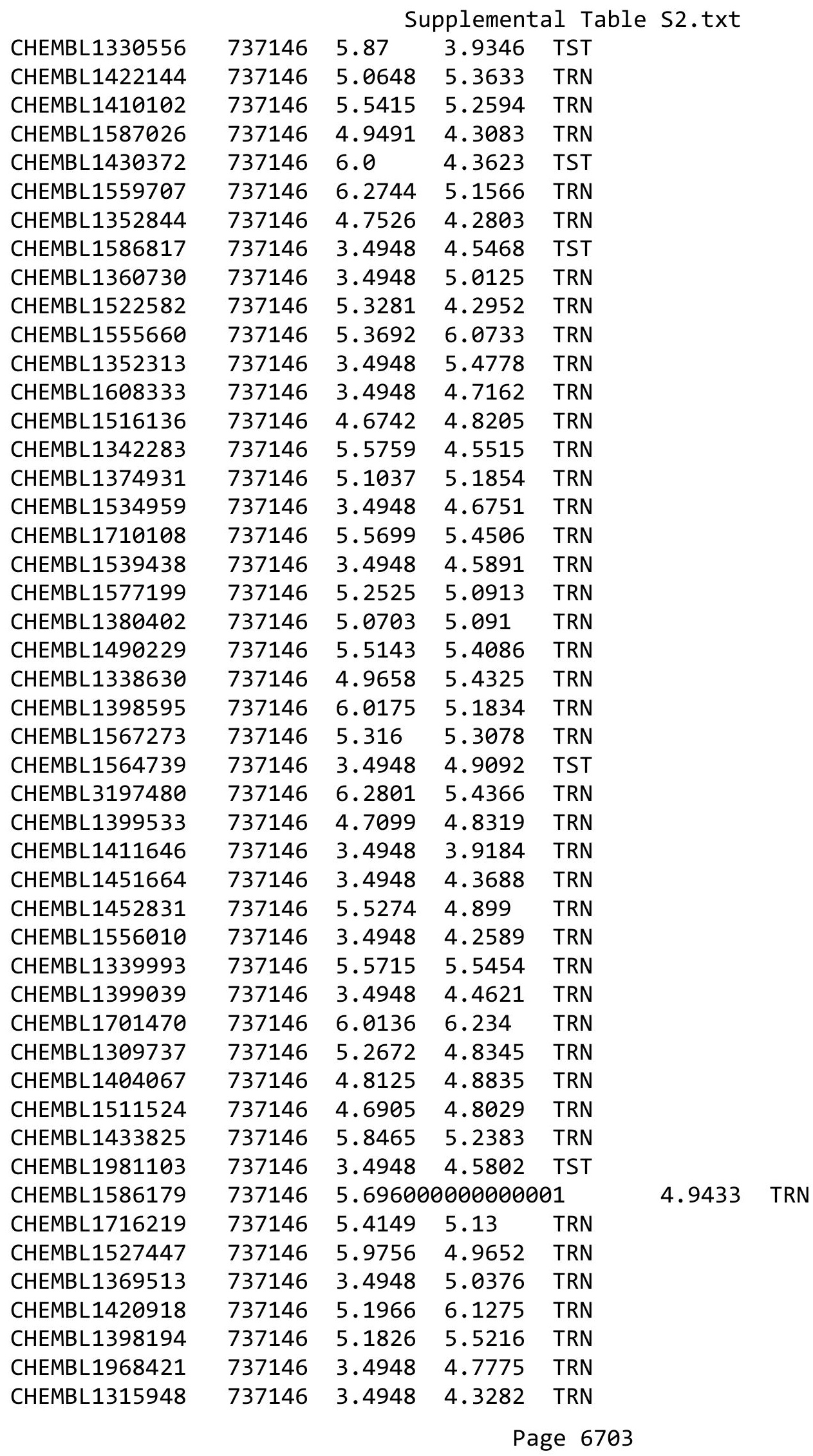




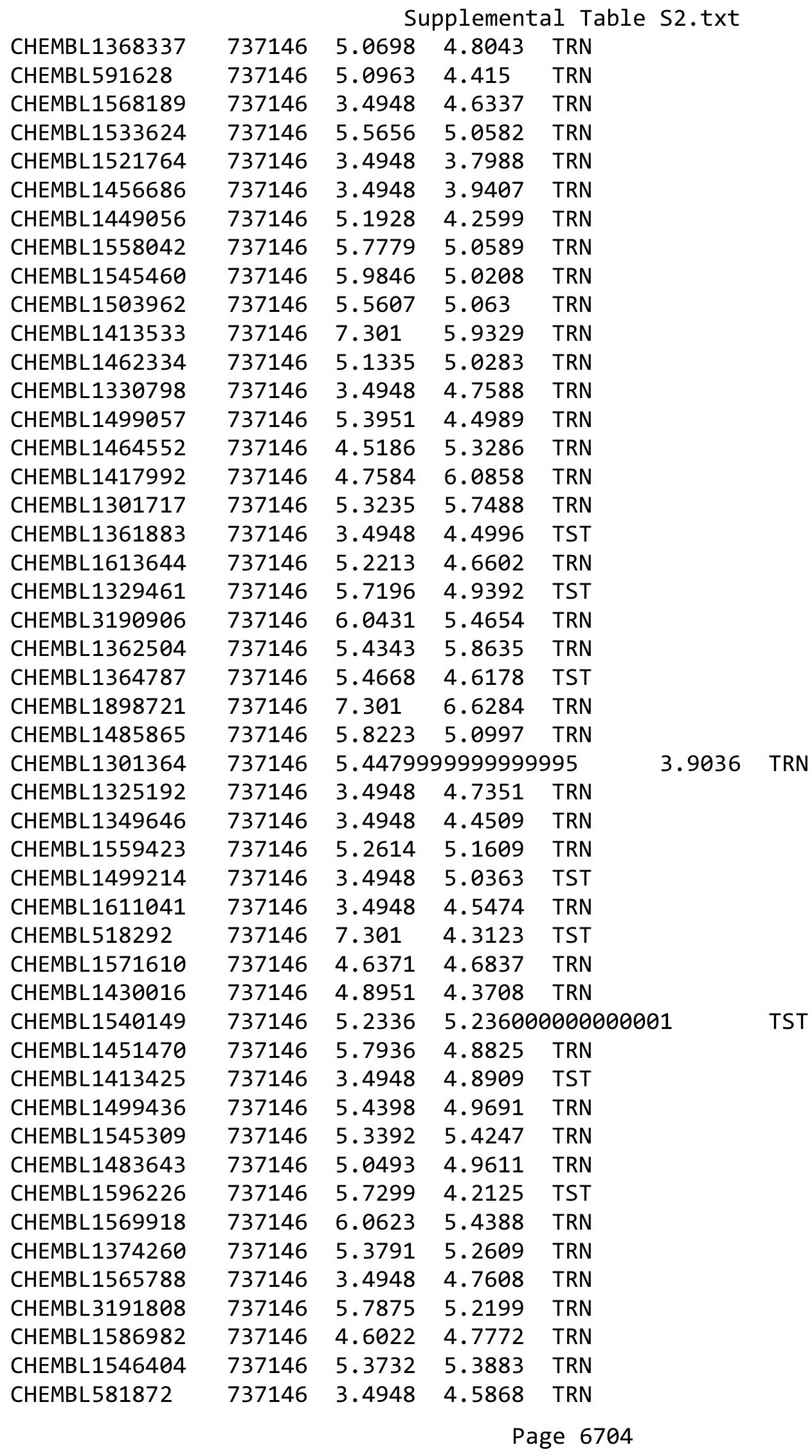




\begin{tabular}{|c|c|c|c|c|c|}
\hline & & \multicolumn{4}{|c|}{ Supplemental Table S2.txt } \\
\hline CHEMBL1416366 & 737146 & 7.301 & 6.0257 & TRN & \\
\hline CHEMBL1490677 & 737146 & 3.4948 & 4.777 & TST & \\
\hline CHEMBL1414034 & 737146 & 3.4948 & 4.749 & TRN & \\
\hline CHEMBL1718432 & 737146 & 7.301 & 4.7546 & TRN & \\
\hline CHEMBL1400132 & 737146 & 4.5931 & 4.3211 & TRN & \\
\hline CHEMBL1561279 & 737146 & 4.9726 & 5.90600 & 0000000001 & TST \\
\hline CHEMBL1417504 & 737146 & 5.9404 & 5.1925 & TRN & \\
\hline CHEMBL1540265 & 737146 & 5.8904 & 4.5511 & TRN & \\
\hline CHEMBL1418691 & 737146 & 4.6787 & 4.8105 & TRN & \\
\hline CHEMBL1579813 & 737146 & 3.4948 & 4.8156 & TRN & \\
\hline CHEMBL1483471 & 737146 & 6.1362 & 4.9235 & TRN & \\
\hline CHEMBL1335610 & 737146 & 5.5316 & 5.0804 & TRN & \\
\hline CHEMBL461579 & 737146 & 3.4948 & 4.3582 & TRN & \\
\hline CHEMBL1303193 & 737146 & 6.093 & 4.7889 & TRN & \\
\hline CHEMBL1596094 & 737146 & 3.4948 & 5.3484 & TRN & \\
\hline CHEMBL1428228 & 737146 & 3.4948 & 3.9216 & TRN & \\
\hline CHEMBL1358700 & 737146 & 5.1834 & 5.3443 & TRN & \\
\hline CHEMBL1385076 & 737146 & 6.2943 & 5.7635 & TRN & \\
\hline CHEMBL1558429 & 737146 & 3.4948 & 3.8101 & TRN & \\
\hline CHEMBL1494849 & 737146 & 3.4948 & 4.0151 & TRN & \\
\hline CHEMBL1603416 & 737146 & 5.7989 & 4.8199 & TRN & \\
\hline CHEMBL 3198300 & 737146 & 6.0583 & 5.2998 & TRN & \\
\hline CHEMBL3194269 & 737146 & 6.2043 & 5.16700 & 0000000001 & TRN \\
\hline CHEMBL1460351 & 737146 & 5.12 & 5.2081 & TRN & \\
\hline CHEMBL1523842 & 737146 & 3.4948 & 3.5822 & TST & \\
\hline CHEMBL1393740 & 737146 & 5.3275 & 4.752 & TRN & \\
\hline CHEMBL 3192498 & 737146 & 6.2209 & 5.6863 & TRN & \\
\hline CHEMBL1399348 & 737146 & 5.1339 & 5.4192 & TRN & \\
\hline CHEMBL1491626 & 737146 & 3.4948 & 4.5749 & TRN & \\
\hline CHEMBL1534620 & 737146 & 3.4948 & 4.4348 & TRN & \\
\hline CHEMBL1386216 & 737146 & 5.7735 & 6.4938 & TRN & \\
\hline CHEMBL1556022 & 737146 & 4.7342 & 4.5188 & TRN & \\
\hline CHEMBL585502 & 737146 & 3.4948 & 4.2424 & TRN & \\
\hline CHEMBL1384384 & 737146 & 5.395 & 6.1213 & TRN & \\
\hline CHEMBL1711214 & 737146 & 3.4948 & 4.6005 & TST & \\
\hline CHEMBL 3189850 & 737146 & 3.4948 & 5.2072 & TST & \\
\hline CHEMBL1331838 & 737146 & 3.4948 & 4.2284 & TRN & \\
\hline CHEMBL1526126 & 737146 & 7.301 & 5.7154 & TRN & \\
\hline CHEMBL1450615 & 737146 & 3.4948 & 4.5797 & TRN & \\
\hline CHEMBL3189750 & 737146 & 5.4673 & 5.3647 & TRN & \\
\hline CHEMBL1401555 & 737146 & 3.4948 & 4.6314 & TRN & \\
\hline CHEMBL1369478 & 737146 & 3.4948 & 4.0224 & TRN & \\
\hline CHEMBL1599391 & 737146 & 5.987 & 5.4747 & TRN & \\
\hline CHEMBL1488408 & 737146 & 5.6426 & 4.9584 & TST & \\
\hline CHEMBL1611770 & 737146 & 5.0409 & 4.5036 & TRN & \\
\hline CHEMBL3195036 & 737146 & 5.3808 & 4.7598 & TRN & \\
\hline CHEMBL1499155 & 737146 & 4.8165 & 4.7692 & TRN & \\
\hline CHEMBL1606490 & 737146 & 6.1346 & 3.9126 & TRN & \\
\hline
\end{tabular}




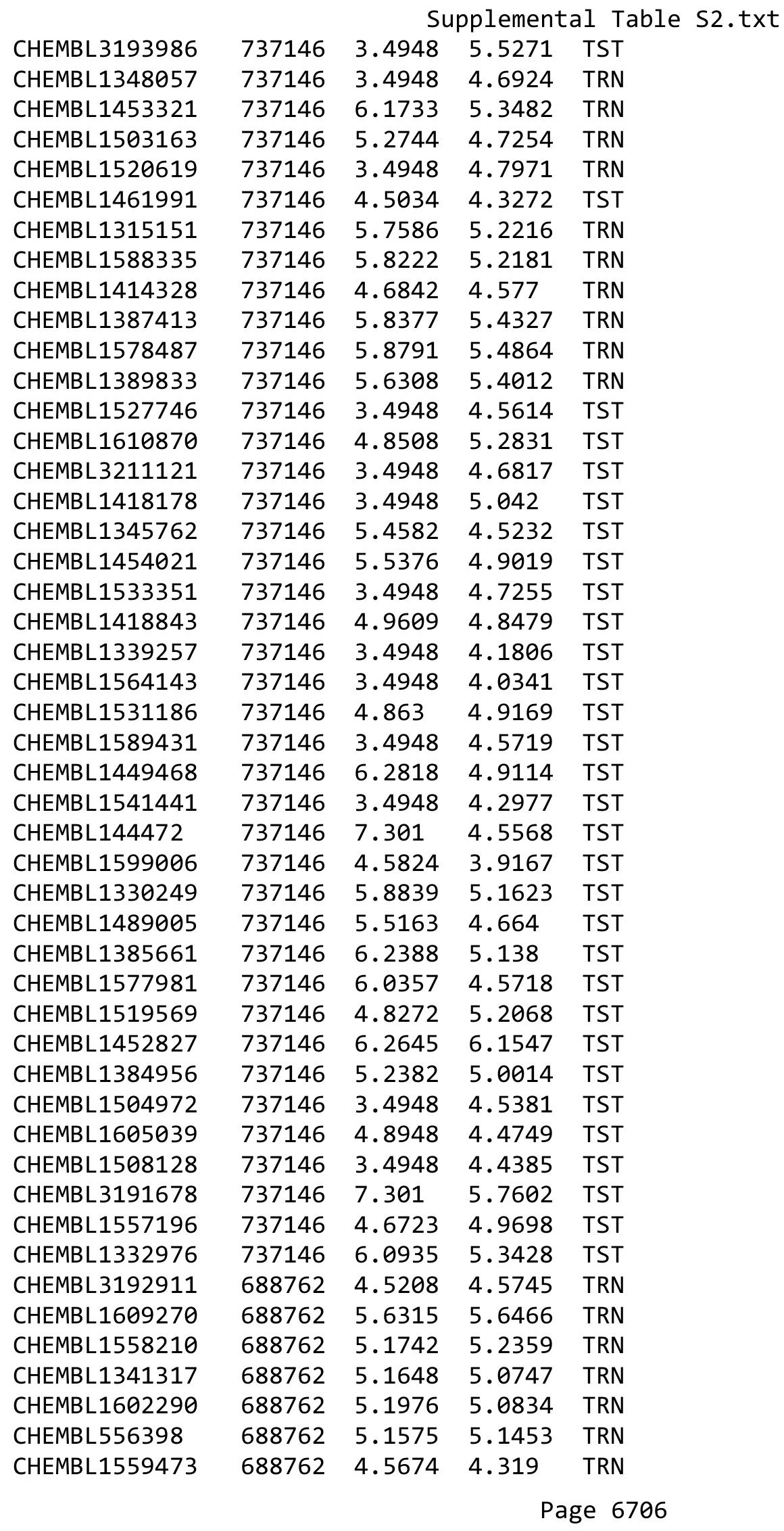


Supplemental Table S2.txt

\begin{tabular}{|c|c|c|c|c|c|}
\hline CHEMBL1492232 & 688762 & 3.7842 & 4.2267 & TRN & \\
\hline CHEMBL1353015 & 688762 & 5.8425 & 5.5516 & TRN & \\
\hline CHEMBL588038 & 688762 & 6.4935 & 6.4934 & TST & \\
\hline CHEMBL1341030 & 688762 & 4.7484 & 4.8006 & TRN & \\
\hline CHEMBL1487984 & 688762 & 5.0385 & 5.0389 & TRN & \\
\hline CHEMBL 3209511 & 688762 & 5.1226 & 4.96899 & (999999999 & TST \\
\hline CHEMBL1453825 & 688762 & 4.5568 & 4.5354 & TRN & \\
\hline CHEMBL1348219 & 688762 & 4.5134 & 4.57600 & 0000000005 & \\
\hline CHEMBL1550165 & 688762 & 5.2059 & 5.2449 & TRN & \\
\hline CHEMBL1443573 & 688762 & 4.7847 & 4.6544 & TRN & \\
\hline CHEMBL1441782 & 688762 & 4.7378 & 4.6499 & TRN & \\
\hline CHEMBL1515852 & 688762 & 5.7501 & 5.4502 & TRN & \\
\hline CHEMBL1363371 & 688762 & 4.4744 & 4.4489 & TRN & \\
\hline CHEMBL533602 & 688762 & 6.5735 & 6.7342 & TST & \\
\hline CHEMBL1560954 & 688762 & 4.6185 & 4.6179 & TRN & \\
\hline CHEMBL1998741 & 688762 & 4.6245 & 4.5144 & TRN & \\
\hline CHEMBL1531073 & 688762 & 5.4374 & 5.496 & TRN & \\
\hline CHEMBL1541809 & 688762 & 4.5595 & 4.6551 & TRN & \\
\hline CHEMBL1519629 & 688762 & 5.138 & 4.9648 & TRN & \\
\hline CHEMBL1599015 & 688762 & 4.8289 & 4.7764 & TRN & \\
\hline CHEMBL1405668 & 688762 & 4.6835 & 4.646 & TST & \\
\hline CHEMBL1975257 & 688762 & 4.7021 & 4.7779 & TRN & \\
\hline CHEMBL1466799 & 688762 & 3.9008 & 4.0919 & TRN & \\
\hline CHEMBL1384843 & 688762 & 4.8084 & 4.8409 & TRN & \\
\hline CHEMBL260775 & 688762 & 4.9866 & 5.0687 & TRN & \\
\hline CHEMBL1508582 & 688762 & 5.135 & 5.1262 & TRN & \\
\hline CHEMBL1368699 & 688762 & 4.7587 & 4.8517 & TRN & \\
\hline CHEMBL1597655 & 688762 & 5.8184 & 5.931 & TRN & \\
\hline CHEMBL1572896 & 688762 & 5.3249 & 5.1512 & TRN & \\
\hline CHEMBL448741 & 688762 & 5.1202 & 5.1038 & TST & \\
\hline CHEMBL1303908 & 688762 & 4.5934 & 4.559 & TST & \\
\hline CHEMBL1305478 & 688762 & 5.0612 & 5.0479 & TRN & \\
\hline CHEMBL1321297 & 688762 & 5.1804 & 5.1342 & TRN & \\
\hline CHEMBL1346716 & 688762 & 4.3576 & 4.5785 & TRN & \\
\hline CHEMBL1500315 & 688762 & \multicolumn{3}{|c|}{4.821000000000001} & \\
\hline CHEMBL1300477 & 688762 & 4.8384 & 4.6856 & TST & \\
\hline CHEMBL1409604 & 688762 & 5.3882 & 5.3134 & TRN & \\
\hline CHEMBL1594205 & 688762 & 4.5772 & 4.6062 & TRN & \\
\hline CHEMBL1369328 & 688762 & 4.595 & 4.4398 & TRN & \\
\hline CHEMBL1710 & 688762 & 4.9305 & 4.9208 & TST & \\
\hline CHEMBL1307474 & 688762 & 4.9838 & 4.9295 & TRN & \\
\hline CHEMBL1440017 & 688762 & 4.9601 & 5.1745 & TRN & \\
\hline CHEMBL1433138 & 688762 & 4.3119 & 4.1944 & TRN & \\
\hline CHEMBL1444896 & 688762 & 4.0706 & 4.1664 & TRN & \\
\hline CHEMBL1579805 & 688762 & 4.9612 & 4.9274 & TRN & \\
\hline CHEMBL 1407174 & 688762 & 4.4953 & 4.6199 & TST & \\
\hline CHEMBL1578945 & 688762 & 4.1114 & 4.3541 & TST & \\
\hline CHEMBL1980204 & 688762 & 4.5786 & 4.6593 & TST & \\
\hline
\end{tabular}


Supplemental Table S2.txt

\begin{tabular}{|c|c|c|c|c|c|}
\hline CHEMBL1393358 & 688762 & 4.4774 & 4.6631 & TRN & \\
\hline CHEMBL1360493 & 688762 & 4.6764 & 4.6324 & TST & \\
\hline CHEMBL472437 & 688762 & 5.9918 & 5.8767 & TST & \\
\hline CHEMBL1579471 & 688762 & 5.0094 & 4.9328 & TST & \\
\hline CHEMBL3197291 & 688762 & 5.1241 & 5.0607 & TRN & \\
\hline CHEMBL1342074 & 688762 & 4.952 & 4.8978 & TRN & \\
\hline CHEMBL1311740 & 688762 & 5.2579 & 5.3435 & TRN & \\
\hline CHEMBL1410678 & 688762 & 4.9561 & 4.8769 & TRN & \\
\hline CHEMBL1971901 & 688762 & 5.1713 & 5.0943 & TRN & \\
\hline CHEMBL1451470 & 688762 & 5.6223 & 5.5573 & TRN & \\
\hline CHEMBL1338960 & 688762 & 4.7402 & 4.8189 & TST & \\
\hline CHEMBL1329450 & 688762 & 4.9134 & 4.8261 & TRN & \\
\hline CHEMBL1503786 & 688762 & 5.0526 & 5.0299 & TRN & \\
\hline CHEMBL 3191251 & 688762 & 4.4513 & 4.7108 & TST & \\
\hline CHEMBL1369125 & 688762 & 4.794 & 4.7575 & TST & \\
\hline CHEMBL1461750 & 688762 & 5.0936 & 5.0253 & TST & \\
\hline CHEMBL1328429 & 688762 & 3.3278 & 4.8149 & TRN & \\
\hline CHEMBL1339245 & 688762 & 4.8583 & 4.9134 & TRN & \\
\hline CHEMBL3192609 & 688762 & 4.3651 & 3.9865 & TRN & \\
\hline CHEMBL1410009 & 688762 & 4.8315 & 4.8153 & TRN & \\
\hline CHEMBL1485218 & 688762 & 4.6612 & 4.6282 & TRN & \\
\hline CHEMBL1538079 & 688762 & 4.5356 & 4.6302 & TRN & \\
\hline CHEMBL1311961 & 688762 & 5.3809 & 5.3109 & TRN & \\
\hline CHEMBL1480241 & 688762 & 5.3547 & 5.25200 & 0000000001 & TRN \\
\hline CHEMBL1344767 & 688762 & 5.1791 & 5.1135 & TRN & \\
\hline CHEMBL1402807 & 688762 & 5.1583 & 5.1124 & TRN & \\
\hline CHEMBL1588476 & 688762 & 5.1727 & 4.9915 & TRN & \\
\hline CHEMBL1371805 & 688762 & 4.8493 & 4.7595 & TRN & \\
\hline CHEMBL1421559 & 688762 & 5.6271 & 5.7356 & TRN & \\
\hline CHEMBL1472532 & 688762 & 4.6166 & 4.4428 & TRN & \\
\hline CHEMBL2095095 & 688762 & 5.334 & 5.4739 & TRN & \\
\hline CHEMBL1529236 & 688762 & 4.7849 & 4.8125 & TRN & \\
\hline CHEMBL1405935 & 688762 & 5.1395 & 5.1726 & TRN & \\
\hline CHEMBL1345447 & 688762 & 4.9962 & 4.876 & TRN & \\
\hline CHEMBL1560561 & 688762 & 4.6046 & 4.6503 & TST & \\
\hline CHEMBL1389212 & 688762 & 4.6037 & 4.6027 & TST & \\
\hline CHEMBL1419733 & 688762 & 5.1403 & 5.1979 & TRN & \\
\hline CHEMBL1374260 & 688762 & 4.782 & 4.9152 & TRN & \\
\hline CHEMBL1495072 & 688762 & 5.4912 & 5.5449 & TRN & \\
\hline CHEMBL1588509 & 688762 & 5.1043 & 5.3684 & TRN & \\
\hline CHEMBL1303587 & 688762 & 4.8382 & 5.1675 & TRN & \\
\hline CHEMBL1537417 & 688762 & 5.5337 & 5.4069 & TST & \\
\hline CHEMBL3189770 & 688762 & 5.4756 & 5.4569 & TRN & \\
\hline CHEMBL1572904 & 688762 & 5.0227 & 5.0005 & TRN & \\
\hline CHEMBL 3193700 & 688762 & 4.4485 & 5.3356 & TRN & \\
\hline CHEMBL1505006 & 688762 & 4.841 & 5.007 & TRN & \\
\hline CHEMBL1549430 & 688762 & 4.5806 & 4.3309 & TRN & \\
\hline CHEMBL1606586 & 688762 & 5.0453 & 4.9877 & TRN & \\
\hline
\end{tabular}




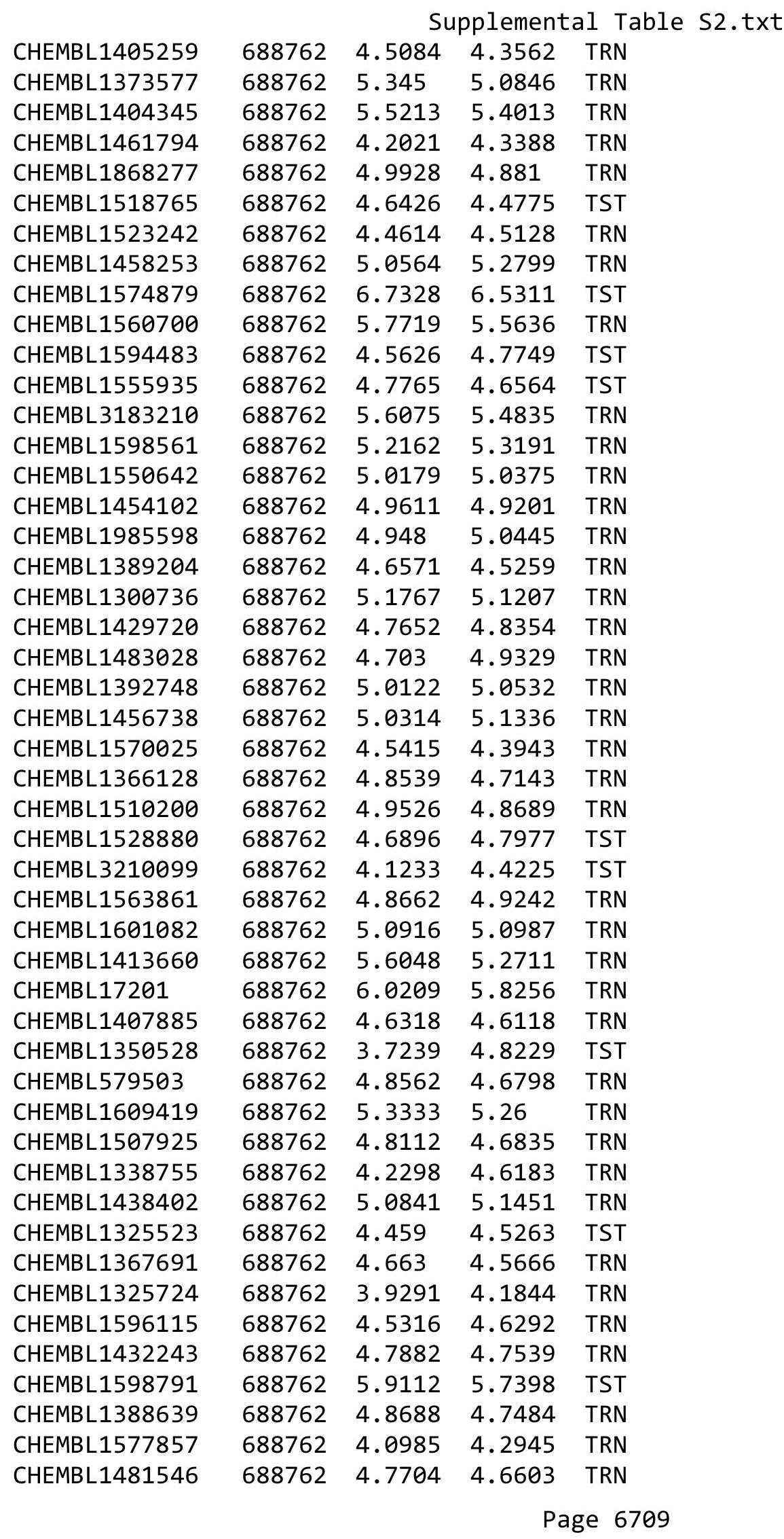


Supplemental Table S2.txt

\begin{tabular}{|c|c|c|c|c|c|c|}
\hline CHEMBL1313498 & 688762 & 4.9765 & 4.8757 & TST & & \\
\hline CHEMBL1461188 & 688762 & 4.4786 & 4.6356 & TST & & \\
\hline CHEMBL1541371 & 688762 & 4.8405 & 4.729 & TST & & \\
\hline CHEMBL1585657 & 688762 & 4.5824 & 4.5781 & TST & & \\
\hline CHEMBL1384265 & 688762 & 4.1603 & 4.2206 & TRN & & \\
\hline CHEMBL601547 & 688762 & 5.1516 & 5.0694 & TRN & & \\
\hline CHEMBL1300968 & 688762 & 4.9268 & 4.9789 & TST & & \\
\hline CHEMBL3193783 & 688762 & 4.9548 & 4.9065 & TRN & & \\
\hline CHEMBL1483878 & 688762 & 3.907 & 4.8854 & TST & & \\
\hline CHEMBL1341815 & 688762 & 4.863 & 4.8435 & TRN & & \\
\hline CHEMBL3195749 & 688762 & 5.087 & 5.255 & TRN & & \\
\hline CHEMBL1375849 & 688762 & 5.1571 & 5.07 & TRN & & \\
\hline CHEMBL3190941 & 688762 & 6.7167 & 6.6177 & TRN & & \\
\hline CHEMBL1542113 & 688762 & 5.4307 & 5.2392 & TRN & & \\
\hline CHEMBL1420524 & 688762 & 4.6702 & 4.6966 & TRN & & \\
\hline CHEMBL1536190 & 688762 & 5.3653 & 5.3258 & TRN & & \\
\hline CHEMBL1422472 & 688762 & 4.0537 & 4.1221 & TRN & & \\
\hline CHEMBL1406045 & 688762 & 4.5083 & 4.4788 & TRN & & \\
\hline CHEMBL1380396 & 688762 & 4.9905 & 4.2978 & TRN & & \\
\hline CHEMBL1611370 & 688762 & 5.0987 & 4.9957 & TRN & & \\
\hline CHEMBL1583276 & 688762 & 3.6211 & 4.0059 & TRN & & \\
\hline CHEMBL1352313 & 688762 & 5.4195 & 5.3802 & TRN & & \\
\hline CHEMBL1494870 & 688762 & 4.5576 & 4.6429 & TRN & & \\
\hline CHEMBL1612169 & 688762 & 4.7758 & 4.5909 & TRN & & \\
\hline CHEMBL1544793 & 688762 & 5.4814 & 5.6155 & TST & & \\
\hline CHEMBL1524916 & 688762 & 5.2175 & 5.3123 & TST & & \\
\hline CHEMBL1305695 & 688762 & 4.3211 & 4.3414 & TST & & \\
\hline CHEMBL1505158 & 688762 & 4.9224 & 5.0097 & TRN & & \\
\hline CHEMBL1498509 & 688762 & 5.9176 & 5.8799 & TRN & & \\
\hline CHEMBL1322066 & 688762 & \multicolumn{3}{|c|}{3.6860000000000004} & 4.6613 & TRN \\
\hline CHEMBL1498599 & 688762 & 5.0243 & 4.8575 & TRN & & \\
\hline CHEMBL1467655 & 688762 & 6.1959 & 6.4195 & TRN & & \\
\hline CHEMBL1367601 & 688762 & 4.8601 & 4.6845 & TRN & & \\
\hline CHEMBL1567008 & 688762 & 5.0991 & 5.1205 & TRN & & \\
\hline CHEMBL1382491 & 688762 & 4.3417 & 4.3393 & TRN & & \\
\hline CHEMBL1598093 & 688762 & 4.6443 & 4.691 & TST & & \\
\hline CHEMBL1416769 & 688762 & 4.7075 & 4.6242 & TRN & & \\
\hline CHEMBL1567571 & 688762 & 5.7414 & 5.7507 & TRN & & \\
\hline CHEMBL 2003909 & 688762 & 5.8716 & 5.7733 & TRN & & \\
\hline CHEMBL1463918 & 688762 & 4.5197 & 4.4435 & TRN & & \\
\hline CHEMBL1423839 & 688762 & 4.8226 & 4.8375 & TRN & & \\
\hline CHEMBL3207697 & 688762 & 4.7447 & 4.9661 & TRN & & \\
\hline CHEMBL1364787 & 688762 & 5.3002 & 5.3016 & TST & & \\
\hline CHEMBL1400909 & 688762 & 5.1742 & 5.1095 & TRN & & \\
\hline CHEMBL1595841 & 688762 & 5.8365 & 5.5643 & TRN & & \\
\hline CHEMBL1367572 & 688762 & 4.9462 & 4.8741 & TRN & & \\
\hline CHEMBL1307156 & 688762 & 4.4835 & 4.3541 & TRN & & \\
\hline CHEMBL1347582 & 688762 & 4.632 & 4.6577 & TRN & & \\
\hline
\end{tabular}


Supplemental Table S2.txt

\begin{tabular}{|c|c|c|c|c|}
\hline CHEMBL1304201 & 688762 & 4.9853 & 5.1871 & TRN \\
\hline CHEMBL1310857 & 688762 & 5.0784 & 5.0911 & TRN \\
\hline CHEMBL1570818 & 688762 & 4.8042 & 4.6612 & TRN \\
\hline CHEMBL1304623 & 688762 & 6.51 & 6.7317 & TRN \\
\hline CHEMBL1494087 & 688762 & 5.0364 & 5.052 & TRN \\
\hline CHEMBL1307371 & 688762 & 4.9168 & 4.74 & TRN \\
\hline CHEMBL1429966 & 688762 & 3.9786 & 4.2345 & TRN \\
\hline CHEMBL3211667 & 688762 & 4.6728 & 4.7209 & TRN \\
\hline CHEMBL1594604 & 688762 & 4.9692 & 4.8754 & TST \\
\hline CHEMBL1338041 & 688762 & 4.8507 & 4.7114 & TRN \\
\hline CHEMBL1341927 & 688762 & 5.5945 & 5.6626 & TRN \\
\hline CHEMBL1328397 & 688762 & 4.2073 & 4.2126 & TRN \\
\hline CHEMBL1533737 & 688762 & 3.9284 & 4.4618 & TRN \\
\hline CHEMBL1348026 & 688762 & 4.7196 & 4.669 & TRN \\
\hline CHEMBL1327880 & 688762 & 3.4377 & 4.3485 & TST \\
\hline CHEMBL1362247 & 688762 & 4.9723 & 4.9675 & TRN \\
\hline CHEMBL1412370 & 688762 & 4.6509 & 4.6908 & TRN \\
\hline CHEMBL1463649 & 688762 & 5.1905 & 5.0988 & TRN \\
\hline CHEMBL1568641 & 688762 & 4.9254 & 4.8704 & TRN \\
\hline CHEMBL1497286 & 688762 & \multicolumn{2}{|c|}{4.8260000000000005} & 4.8781 \\
\hline CHEMBL1605875 & 688762 & 4.1383 & 4.251 & TST \\
\hline CHEMBL1542070 & 688762 & 4.8469 & 4.7849 & TRN \\
\hline CHEMBL1352852 & 688762 & 4.7065 & 4.6317 & TRN \\
\hline CHEMBL1483460 & 688762 & 4.4489 & 4.2526 & TRN \\
\hline CHEMBL1360308 & 688762 & 4.5511 & 4.6743 & TRN \\
\hline CHEMBL1423338 & 688762 & 5.2501 & 5.0677 & TST \\
\hline CHEMBL1986259 & 688762 & 4.7858 & 4.882 & TRN \\
\hline CHEMBL1459696 & 688762 & 4.8454 & 4.8367 & TRN \\
\hline CHEMBL1978651 & 688762 & 4.7802 & 4.6964 & TRN \\
\hline CHEMBL1388457 & 688762 & 4.5941 & 4.6431 & TST \\
\hline CHEMBL1603270 & 688762 & 5.1267 & 5.0243 & TRN \\
\hline CHEMBL1349390 & 688762 & 5.2479 & 5.195 & TRN \\
\hline CHEMBL1506459 & 688762 & 4.5622 & 4.629 & TST \\
\hline CHEMBL1332277 & 688762 & 4.5361 & 4.5313 & TRN \\
\hline CHEMBL1518905 & 688762 & 8.2291 & 7.7512 & TRN \\
\hline CHEMBL1546223 & 688762 & 5.8713 & 5.7564 & TRN \\
\hline CHEMBL1348057 & 688762 & 5.3889 & 5.4448 & TRN \\
\hline CHEMBL1335633 & 688762 & 4.2529 & 4.3828 & TRN \\
\hline CHEMBL1379338 & 688762 & 4.9087 & 4.9749 & TRN \\
\hline CHEMBL1411285 & 688762 & 4.9793 & 4.8631 & TRN \\
\hline CHEMBL1580341 & 688762 & 3.9053 & 4.7429 & TRN \\
\hline CHEMBL1409389 & 688762 & 5.3299 & 5.1984 & TRN \\
\hline CHEMBL1351290 & 688762 & 5.2349 & 5.3061 & TST \\
\hline CHEMBL1584754 & 688762 & 6.224 & 6.1309 & TST \\
\hline CHEMBL582444 & 688762 & 4.9487 & 4.76 & TST \\
\hline CHEMBL 3189217 & 688762 & 5.5045 & 5.3317 & TRN \\
\hline CHEMBL1329772 & 688762 & 4.9474 & 4.826000 & 00000000005 \\
\hline CHEMBL1568653 & 688762 & 4.0435 & 4.7952 & TRN \\
\hline
\end{tabular}




\begin{tabular}{|c|c|c|c|c|c|}
\hline \multicolumn{6}{|c|}{ Supplemental Table S2.txt } \\
\hline CHEMBL1462615 & 688762 & 4.7425 & 4.7538 & TRN & \\
\hline CHEMBL589715 & 688762 & 5.3909 & 5.3076 & TRN & \\
\hline CHEMBL1390145 & 688762 & 4.6732 & 4.6667 & TRN & \\
\hline CHEMBL1342257 & 688762 & 4.5485 & 4.7812 & TST & \\
\hline CHEMBL3212479 & 688762 & 4.3581 & 4.7748 & TST & \\
\hline CHEMBL584015 & 688762 & 5.6055 & 5.5338 & TRN & \\
\hline CHEMBL 3196561 & 688762 & 4.4086 & 4.3918 & TRN & \\
\hline CHEMBL586029 & 688762 & 5.4787 & 5.4504 & TRN & \\
\hline CHEMBL1510643 & 688762 & 3.8316 & 3.8146 & TRN & \\
\hline CHEMBL1388353 & 688762 & 4.7171 & 4.8181 & TRN & \\
\hline CHEMBL1336187 & 688762 & 5.5547 & 5.5058 & TRN & \\
\hline CHEMBL1432585 & 688762 & 4.5914 & 4.5587 & TRN & \\
\hline CHEMBL1224757 & 688762 & 5.9618 & 5.87799 & 9999999999 & TRN \\
\hline CHEMBL1463786 & 688762 & 4.7786 & 4.6996 & TRN & \\
\hline CHEMBL1393129 & 688762 & 3.8652 & 4.1101 & TRN & \\
\hline CHEMBL1331050 & 688762 & 5.0757 & 4.9098 & TRN & \\
\hline CHEMBL1420268 & 688762 & 2.1235 & 3.4846 & TRN & \\
\hline CHEMBL1350552 & 688762 & 4.527 & 4.4555 & TRN & \\
\hline CHEMBL1461419 & 688762 & 4.7761 & 4.7937 & TST & \\
\hline CHEMBL1447872 & 688762 & 5.7071 & 5.7492 & TRN & \\
\hline CHEMBL1523568 & 688762 & 4.7214 & 4.7343 & TRN & \\
\hline CHEMBL1431763 & 688762 & 4.485 & 4.5713 & TRN & \\
\hline CHEMBL530361 & 688762 & 5.4022 & 5.3184 & TRN & \\
\hline CHEMBL1376749 & 688762 & 5.3091 & 5.7143 & TRN & \\
\hline CHEMBL1432626 & 688762 & 5.2406 & 5.1779 & TRN & \\
\hline CHEMBL1439181 & 688762 & 4.5464 & 4.7553 & TRN & \\
\hline CHEMBL1604884 & 688762 & 4.8977 & 4.7811 & TRN & \\
\hline CHEMBL1368116 & 688762 & 5.0809 & 4.9878 & TST & \\
\hline CHEMBL1556705 & 688762 & 4.8546 & 4.7744 & TRN & \\
\hline CHEMBL1344703 & 688762 & 4.2671 & 4.3465 & TST & \\
\hline CHEMBL1447148 & 688762 & 4.6934 & 4.6498 & TRN & \\
\hline CHEMBL1505185 & 688762 & 5.3607 & 5.3088 & TRN & \\
\hline CHEMBL1324917 & 688762 & 5.1903 & 5.067 & TST & \\
\hline CHEMBL1496095 & 688762 & 4.8147 & 4.6667 & TRN & \\
\hline CHEMBL1310332 & 688762 & 4.7208 & 4.7478 & TRN & \\
\hline CHEMBL1490042 & 688762 & 4.7524 & 4.6911 & TRN & \\
\hline CHEMBL1327548 & 688762 & 3.6791 & 4.4167 & TRN & \\
\hline CHEMBL1362660 & 688762 & 8.2291 & 7.5608 & TRN & \\
\hline CHEMBL1604007 & 688762 & 5.8881 & 5.8461 & TRN & \\
\hline CHEMBL3213019 & 688762 & 5.2456 & 5.1632 & TRN & \\
\hline CHEMBL1469736 & 688762 & 4.665 & 4.6916 & TRN & \\
\hline CHEMBL1392329 & 688762 & 4.5072 & 4.5217 & TST & \\
\hline CHEMBL1565623 & 688762 & 5.0721 & 4.914 & TRN & \\
\hline CHEMBL1427175 & 688762 & 4.4958 & 4.1533 & TST & \\
\hline CHEMBL1449459 & 688762 & 4.2213 & 4.3301 & TRN & \\
\hline CHEMBL1451808 & 688762 & 5.2999 & 5.0505 & TRN & \\
\hline CHEMBL1430068 & 688762 & 6.1421 & 6.0976 & TRN & \\
\hline CHEMBL1527872 & 688762 & 4.317 & 4.7076 & TRN & \\
\hline
\end{tabular}


Supplemental Table S2.txt

\begin{tabular}{|c|c|c|c|c|c|}
\hline CHEMBL1313522 & 688762 & 5.9201 & 5.5922 & TRN & \\
\hline CHEMBL1499027 & 688762 & 4.6826 & 4.7092 & TST & \\
\hline CHEMBL1477573 & 688762 & 3.4579 & 3.7985 & TRN & \\
\hline CHEMBL1511063 & 688762 & 5.7708 & 5.6779 & TRN & \\
\hline CHEMBL1303935 & 688762 & 4.0779 & 4.3868 & TRN & \\
\hline CHEMBL1578607 & 688762 & 4.7594 & 4.5691 & TRN & \\
\hline CHEMBL1428950 & 688762 & 6.0434 & 5.7252 & TRN & \\
\hline CHEMBL1574687 & 688762 & 4.4517 & 4.7628 & TRN & \\
\hline CHEMBL577419 & 688762 & 4.5729 & 4.6552 & TRN & \\
\hline CHEMBL1543341 & 688762 & 4.7618 & 4.8869 & TRN & \\
\hline CHEMBL1550490 & 688762 & 4.8616 & 4.8283 & TRN & \\
\hline CHEMBL1990214 & 688762 & 5.58700 & 00000000 & 1 & 5.7525 \\
\hline CHEMBL1479249 & 688762 & 4.9387 & 4.9427 & TRN & \\
\hline CHEMBL1407478 & 688762 & 4.834 & 4.9234 & TST & \\
\hline CHEMBL375905 & 688762 & 4.6975 & 4.7745 & TRN & \\
\hline CHEMBL581870 & 688762 & 5.3721 & 5.305 & TRN & \\
\hline CHEMBL1509961 & 688762 & 4.6735 & 4.6591 & TRN & \\
\hline CHEMBL1418568 & 688762 & 5.0671 & 5.1455 & TST & \\
\hline CHEMBL1610049 & 688762 & 5.3986 & 5.4083 & TRN & \\
\hline CHEMBL1489149 & 688762 & 5.2302 & 5.0686 & TRN & \\
\hline CHEMBL1336959 & 688762 & 4.6118 & 4.3982 & TRN & \\
\hline CHEMBL1497617 & 688762 & 4.6081 & 4.6395 & TRN & \\
\hline CHEMBL1496208 & 688762 & 4.4208 & 4.3205 & TRN & \\
\hline CHEMBL1360793 & 688762 & 6.2147 & 6.8477 & TRN & \\
\hline CHEMBL1349063 & 688762 & 6.4535 & 6.5498 & TRN & \\
\hline CHEMBL1453708 & 688762 & 5.1974 & 5.1876 & TRN & \\
\hline CHEMBL1583552 & 688762 & 5.277 & 5.2846 & TRN & \\
\hline CHEMBL1331503 & 688762 & 4.9054 & 4.894 & TRN & \\
\hline CHEMBL1461574 & 688762 & 4.7211 & 4.6671 & TST & \\
\hline CHEMBL1303044 & 688762 & 4.4865 & 4.5266 & TRN & \\
\hline CHEMBL1309229 & 688762 & 4.9014 & 4.962 & TST & \\
\hline CHEMBL1459140 & 688762 & 5.5024 & 5.6638 & TRN & \\
\hline CHEMBL1409104 & 688762 & 4.7899 & 4.9029 & TRN & \\
\hline CHEMBL1360014 & 688762 & 4.3841 & 4.7822 & TRN & \\
\hline CHEMBL1312486 & 688762 & 5.3077 & 5.2306 & TRN & \\
\hline CHEMBL1347975 & 688762 & 4.4384 & 4.5232 & TST & \\
\hline CHEMBL1470135 & 688762 & 5.6467 & 5.7139 & TRN & \\
\hline CHEMBL1517966 & 688762 & 4.2888 & 4.9312 & TRN & \\
\hline CHEMBL1419967 & 688762 & 5.0038 & 5.072 & TST & \\
\hline CHEMBL1359788 & 688762 & 4.6383 & 4.6134 & TRN & \\
\hline CHEMBL1328118 & 688762 & 4.9172 & 4.7667 & TRN & \\
\hline CHEMBL1565991 & 688762 & 5.0422 & 5.1063 & TRN & \\
\hline CHEMBL1574218 & 688762 & 5.6511 & 5.6647 & TRN & \\
\hline CHEMBL1523126 & 688762 & 4.7073 & 4.7077 & TRN & \\
\hline CHEMBL597251 & 688762 & 5.351 & 5.3188 & TRN & \\
\hline CHEMBL1564158 & 688762 & 4.779 & 4.7101 & TRN & \\
\hline CHEMBL1537070 & 688762 & 4.7384 & 4.6673 & TST & \\
\hline CHEMBL1541834 & 688762 & 6.0119 & 6.0788 & TRN & \\
\hline
\end{tabular}




\begin{tabular}{|c|c|c|c|c|c|c|}
\hline & & \multicolumn{5}{|c|}{ Supplemental Table S2.txt } \\
\hline CHEMBL1501302 & 688762 & 4.2884 & 4.4494 & TRN & & \\
\hline CHEMBL1509138 & 688762 & 4.6747 & 4.748 & TRN & & \\
\hline CHEMBL1466281 & 688762 & 4.47 & 4.4853 & TRN & & \\
\hline CHEMBL1349727 & 688762 & 5.5659 & 5.6908 & TRN & & \\
\hline CHEMBL528181 & 688762 & 5.1742 & 5.1984 & TRN & & \\
\hline CHEMBL579105 & 688762 & \multicolumn{3}{|c|}{4.9830000000000005} & 5.0039 & TRN \\
\hline CHEMBL1579152 & 688762 & 5.3178 & 5.351 & TST & & \\
\hline CHEMBL1531919 & 688762 & 4.3283 & 4.3683 & TRN & & \\
\hline CHEMBL 3213876 & 688762 & 5.2546 & 5.2769 & TRN & & \\
\hline CHEMBL148072 & 688762 & 4.9189 & 4.8473 & TST & & \\
\hline CHEMBL1578547 & 688762 & 4.5668 & 4.6359 & TRN & & \\
\hline CHEMBL1991885 & 688762 & 4.6534 & 4.5877 & TRN & & \\
\hline CHEMBL1363249 & 688762 & 4.8219 & 4.9575 & TRN & & \\
\hline CHEMBL1968458 & 688762 & 4.5848 & 4.5904 & TRN & & \\
\hline CHEMBL1550942 & 688762 & 5.0421 & 4.9461 & TRN & & \\
\hline CHEMBL1379675 & 688762 & 5.9813 & 5.8863 & TRN & & \\
\hline CHEMBL1580910 & 688762 & 5.3815 & 5.4105 & TST & & \\
\hline CHEMBL1438881 & 688762 & 6.7696 & 6.6673 & TST & & \\
\hline CHEMBL1489113 & 688762 & 4.798 & 4.7061 & TRN & & \\
\hline CHEMBL1585988 & 688762 & 4.6793 & 4.6562 & TST & & \\
\hline CHEMBL1545832 & 688762 & 5.0165 & 4.8932 & TST & & \\
\hline CHEMBL1524365 & 688762 & 5.3519 & 5.289 & TRN & & \\
\hline CHEMBL1384253 & 688762 & 6.3947 & 6.1843 & TRN & & \\
\hline CHEMBL1595052 & 688762 & 4.8446 & 4.7348 & TRN & & \\
\hline CHEMBL1988579 & 688762 & 4.9425 & 4.9665 & TRN & & \\
\hline CHEMBL1331573 & 688762 & 5.3574 & 5.0561 & TRN & & \\
\hline CHEMBL1973050 & 688762 & 5.8841 & 5.5911 & TRN & & \\
\hline CHEMBL1500910 & 688762 & 5.3244 & 5.4009 & TRN & & \\
\hline CHEMBL1471612 & 688762 & 4.8794 & 4.8028 & TRN & & \\
\hline CHEMBL1990659 & 688762 & \multicolumn{3}{|c|}{5.593999999999999} & 5.3801 & TR \\
\hline CHEMBL1541335 & 688762 & 5.1402 & 4.9461 & TRN & & \\
\hline CHEMBL1425943 & 688762 & 4.9643 & 4.8569 & TRN & & \\
\hline CHEMBL1372491 & 688762 & 4.6185 & 3.7885 & TST & & \\
\hline CHEMBL 2369277 & 688762 & \multicolumn{3}{|c|}{5.4879999999999995} & 5.4235 & $\mathrm{TR}$ \\
\hline CHEMBL1535276 & 688762 & 4.4204 & 4.5789 & TRN & & \\
\hline CHEMBL1372952 & 688762 & 5.0487 & 5.083 & TRN & & \\
\hline CHEMBL1422217 & 688762 & 5.295 & 5.3435 & TRN & & \\
\hline CHEMBL1410063 & 688762 & 5.1264 & 5.2095 & TRN & & \\
\hline CHEMBL1337592 & 688762 & 5.961 & 6.0112 & TRN & & \\
\hline CHEMBL1588357 & 688762 & 4.6051 & 4.492 & TRN & & \\
\hline CHEMBL1495763 & 688762 & 4.8443 & 4.8499 & TRN & & \\
\hline CHEMBL1326229 & 688762 & \multicolumn{3}{|c|}{3.7680000000000002} & 4.3476 & RI \\
\hline CHEMBL3212008 & 688762 & 4.6533 & 4.6513 & TRN & & \\
\hline CHEMBL1331865 & 688762 & 4.3325 & 4.2188 & TRN & & \\
\hline CHEMBL1532375 & 688762 & 4.8154 & 4.7388 & TRN & & \\
\hline CHEMBL1352836 & 688762 & 5.3667 & 5.3994 & TRN & & \\
\hline CHEMBL1444767 & 688762 & 5.0136 & 4.8586 & TRN & & \\
\hline CHEMBL1450537 & 688762 & 4.5746 & 4.7326 & TRN & & \\
\hline
\end{tabular}




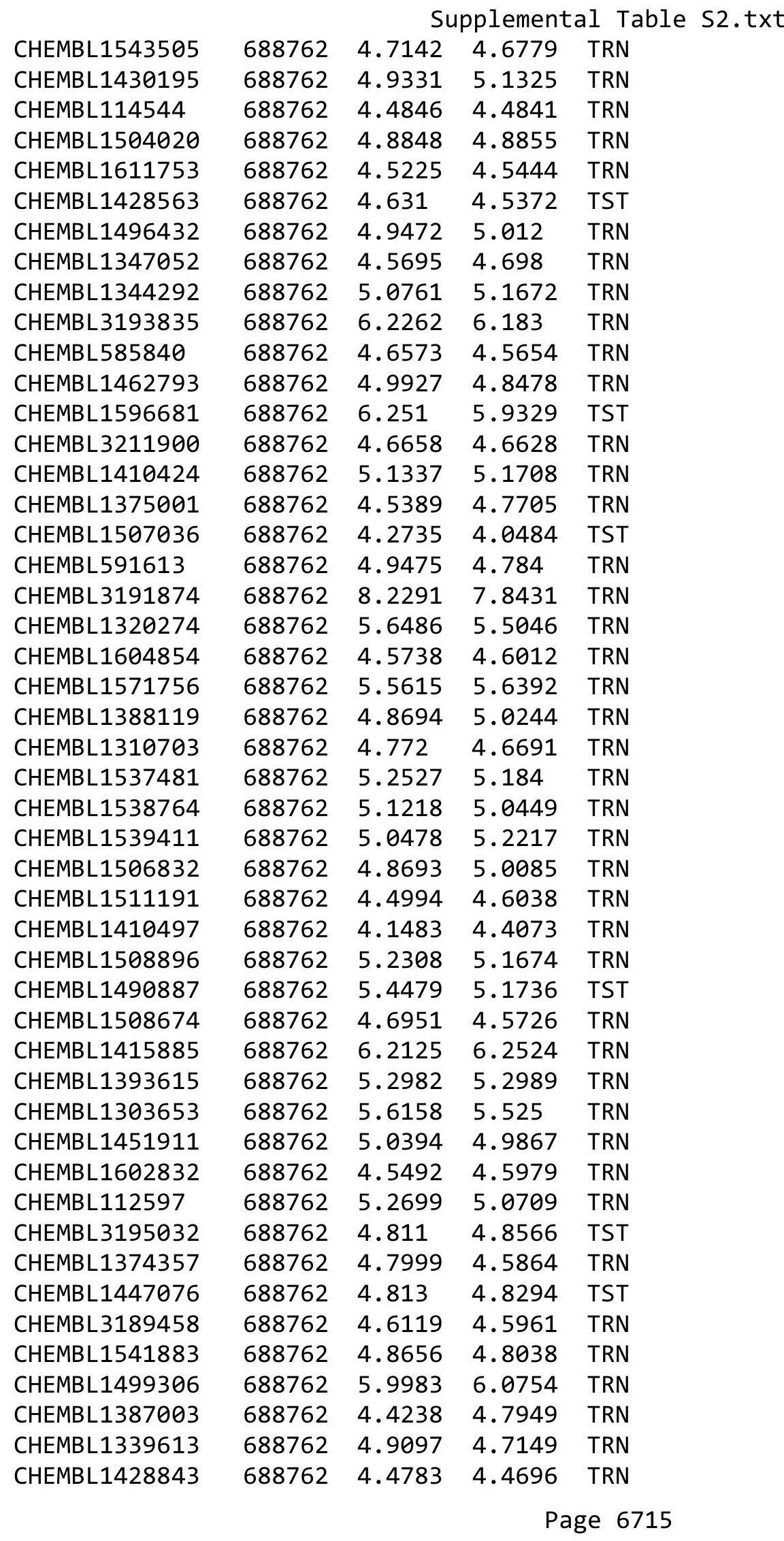


Supplemental Table S2.txt

\begin{tabular}{|c|c|c|c|c|}
\hline & & & & \\
\hline HEMBL1393582 & 38762 & 4.7659 & 855 & \\
\hline HEMBL134 & 62 & 3531 & & \\
\hline 85 & & & & \\
\hline EMBL15 & 762 & 0832 & 9706 & \\
\hline IEMBL1385690 & 88762 & 334 & 2559 & \\
\hline HEMBL1468664 & 38762 & .9406 & 0099 & \\
\hline HEMBL3207715 & & & & \\
\hline 17 & 38762 & 9031 & 8796 & \\
\hline IEMBL: & 762 & 8944 & 6868 & \\
\hline AEMBL1494973 & 88762 & . 9996 & 5.1987 & \\
\hline AEMBL1508699 & 762 & .5399 & 4.3199 & \\
\hline HEMBL1538234 & 52 & & & \\
\hline AEMBL & 762 & 258 & 392 & \\
\hline AEMBL: & 762 & 629 & 3601 & \\
\hline IEMBL] & 762 & 7235 & 4.5251 & \\
\hline AEMBL1310758 & 62 & & & \\
\hline AEMBL: & 52 & 39 & & \\
\hline AEMBL & 52 & & & \\
\hline 356 & 762 & & 29 & \\
\hline IEMBL & 62 & 85 & 4.7798 & \\
\hline IEMBL: & & & & \\
\hline AEMBL & 52 & & & \\
\hline IEMBL & & & 41 & . \\
\hline 805 & 62 & & 729 & \\
\hline 279 & & & & \\
\hline 06838 & & & & \\
\hline 25949 & & & & \\
\hline 113 & 52 & & 04 & 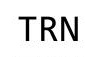 \\
\hline 381 & 762 & 69 & 547 & 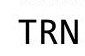 \\
\hline 13978 & & & & RI \\
\hline 38171 & & & & \\
\hline IEMBL & & & & $\mathrm{RN}$ \\
\hline 90 & 52 & & 92 & \\
\hline 02 & & & 851 & 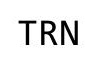 \\
\hline 52379 & & & 4083 & $\mathrm{R}$ \\
\hline AEMBL & 62 & & 671 & \\
\hline & & & & \\
\hline 94 & & & 77 & \\
\hline & & & 578 & $\mathrm{RN}$ \\
\hline IEMBL1599808 & 762 & 585 & 7258 & $\mathrm{RI}$ \\
\hline AEMBL & 62 & 16 & 444 & RI \\
\hline & & & & \\
\hline HEMBL: & & 818 & .1266 & \\
\hline CHEMBL] & & & 5.3297 & \\
\hline IEMBL: & 62 & 725 & 4.7286 & F \\
\hline 9 & & & & \\
\hline CHEMBL1344918 & & & & \\
\hline
\end{tabular}




\begin{tabular}{|c|c|c|c|c|c|}
\hline & & \multicolumn{4}{|c|}{ Supplemental Table S2.txt } \\
\hline CHEMBL1343720 & 688762 & 4.6992 & 4.6915 & TRN & \\
\hline CHEMBL1445146 & 688762 & 4.7996 & 4.836 & TRN & \\
\hline CHEMBL1366992 & 688762 & 5.9133 & 5.6343 & TRN & \\
\hline CHEMBL1463198 & 688762 & 5.1002 & 5.2012 & TRN & \\
\hline CHEMBL1595015 & 688762 & 5.6229 & 5.3398 & TRN & \\
\hline CHEMBL1509707 & 688762 & 4.6062 & 4.8061 & TRN & \\
\hline CHEMBL1358604 & 688762 & 4.971 & 4.8064 & TRN & \\
\hline CHEMBL1443454 & 688762 & 5.7263 & 5.6671 & TRN & \\
\hline CHEMBL1416184 & 688762 & 4.97 & 4.9355 & TRN & \\
\hline CHEMBL1549594 & 688762 & 4.7587 & 4.6629 & TRN & \\
\hline CHEMBL1527929 & 688762 & 5.2434 & 5.043 & TST & \\
\hline CHEMBL1557932 & 688762 & 5.0082 & 5.1397 & TST & \\
\hline CHEMBL1504385 & 688762 & 4.1456 & 4.2418 & TST & \\
\hline CHEMBL1598230 & 688762 & \multicolumn{3}{|c|}{5.6160000000000005} & TST \\
\hline CHEMBL1502980 & 688762 & 5.0406 & 4.8476 & TRN & \\
\hline CHEMBL1527739 & 688762 & 4.8142 & 4.7231 & TRN & \\
\hline CHEMBL1305472 & 688762 & 4.4357 & 4.4493 & TRN & \\
\hline CHEMBL1392378 & 688762 & 3.1894 & 4.0504 & TRN & \\
\hline CHEMBL1526149 & 688762 & 5.3683 & 5.3683 & TRN & \\
\hline CHEMBL1462585 & 688762 & 5.3679 & 5.319 & TRN & \\
\hline CHEMBL1408465 & 688762 & 4.3365 & 4.5611 & TRN & \\
\hline CHEMBL1596661 & 688762 & 5.0758 & 5.2434 & TRN & \\
\hline CHEMBL1484321 & 688762 & 5.3182 & 5.2359 & TRN & \\
\hline CHEMBL 1370387 & 688762 & 4.7811 & 4.6339 & TRN & \\
\hline CHEMBL1441938 & 688762 & 4.6237 & 4.5584 & TRN & \\
\hline CHEMBL1520214 & 688762 & 5.2999 & 5.2136 & TRN & \\
\hline CHEMBL1349440 & 688762 & 5.312 & 5.2583 & TRN & \\
\hline CHEMBL1577981 & 688762 & 5.2333 & 5.2241 & TRN & \\
\hline CHEMBL1351385 & 688762 & 4.7792 & 4.7541 & TRN & \\
\hline CHEMBL3212224 & 688762 & 4.6485 & 4.6306 & TRN & \\
\hline CHEMBL1337246 & 688762 & 4.8515 & 4.7166 & TRN & \\
\hline CHEMBL1306507 & 688762 & 5.0848 & 4.98300 & 00000000005 & $1 \mathrm{KI}$ \\
\hline CHEMBL1498173 & 688762 & 5.3656 & 5.1186 & TRN & \\
\hline CHEMBL1300625 & 688762 & 4.3855 & 4.1776 & TST & \\
\hline CHEMBL1390659 & 688762 & 4.8631 & 4.8774 & TRN & \\
\hline CHEMBL1428174 & 688762 & 4.9395 & 4.5925 & TRN & \\
\hline CHEMBL1528998 & 688762 & 4.6636 & 4.6015 & TST & \\
\hline CHEMBL1544947 & 688762 & 4.9501 & 4.9403 & TST & \\
\hline CHEMBL1519338 & 688762 & 5.5224 & 5.6256 & TRN & \\
\hline CHEMBL1535134 & 688762 & 4.9744 & 5.0079 & TRN & \\
\hline CHEMBL1525662 & 688762 & 4.5576 & 4.4838 & TRN & \\
\hline CHEMBL3196836 & 688762 & 4.607 & 4.7068 & TRN & \\
\hline CHEMBL1606504 & 688762 & 4.7582 & 4.5796 & TRN & \\
\hline CHEMBL1993788 & 688762 & 5.7111 & 5.5556 & TRN & \\
\hline CHEMBL248847 & 688762 & 4.0649 & 4.7515 & TRN & \\
\hline CHEMBL1328771 & 688762 & 4.5086 & 4.1815 & TRN & \\
\hline CHEMBL1469691 & 688762 & 5.1601 & 5.2136 & TRN & \\
\hline CHEMBL1999756 & 688762 & 5.1893 & 5.3632 & TRN & \\
\hline
\end{tabular}




\begin{tabular}{|c|c|c|c|c|c|c|}
\hline \multirow[b]{2}{*}{ CHEMBL1606382 } & \multicolumn{6}{|c|}{ Supplemental Table S2.txt } \\
\hline & 688762 & 4.7906 & 4.6529 & TRN & & \\
\hline CHEMBL1533494 & 688762 & 4.1349 & 4.2424 & TRN & & \\
\hline CHEMBL1407847 & 688762 & 4.6598 & 4.5702 & TRN & & \\
\hline CHEMBL1444221 & 688762 & 5.1467 & 5.1114 & TRN & & \\
\hline CHEMBL3145321 & 688762 & 5.0875 & 4.9408 & TST & & \\
\hline CHEMBL1532412 & 688762 & 4.9551 & 5.0113 & TRN & & \\
\hline CHEMBL 3214332 & 688762 & 4.5036 & 4.6397 & TST & & \\
\hline CHEMBL1541441 & 688762 & 5.05399 & 99999999 & 99 & .0919 & TST \\
\hline CHEMBL1598694 & 688762 & 4.3683 & 4.3975 & TRN & & \\
\hline CHEMBL1540956 & 688762 & 5.4338 & 5.2388 & TRN & & \\
\hline CHEMBL1594642 & 688762 & 4.8388 & 4.7399 & TRN & & \\
\hline CHEMBL1370757 & 688762 & 4.8792 & 4.8539 & TST & & \\
\hline CHEMBL1425039 & 688762 & 4.427 & 4.5533 & TST & & \\
\hline CHEMBL1425878 & 688762 & 4.4963 & 4.5871 & TRN & & \\
\hline CHEMBL1303626 & 688762 & 4.5483 & 4.6216 & TST & & \\
\hline CHEMBL1430872 & 688762 & 4.6114 & 4.6828 & TRN & & \\
\hline CHEMBL1599520 & 688762 & 5.6059 & 5.5224 & TRN & & \\
\hline CHEMBL1457929 & 688762 & 3.8104 & 3.0275 & TRN & & \\
\hline CHEMBL1418750 & 688762 & 5.1855 & 5.1857 & TRN & & \\
\hline CHEMBL1499273 & 688762 & 5.0572 & 4.9022 & TRN & & \\
\hline CHEMBL1458973 & 688762 & 3.3653 & 3.7872 & TRN & & \\
\hline CHEMBL1480464 & 688762 & 5.2329 & 5.039 & TST & & \\
\hline CHEMBL1484063 & 688762 & 4.9114 & 4.7944 & TRN & & \\
\hline CHEMBL1576310 & 688762 & 5.131 & 5.0223 & TRN & & \\
\hline CHEMBL1340619 & 688762 & 5.6287 & 5.4059 & TRN & & \\
\hline CHEMBL1487895 & 688762 & 3.1675 & 3.3813 & TRN & & \\
\hline CHEMBL1484934 & 688762 & 5.5235 & 5.5329 & TRN & & \\
\hline CHEMBL1312546 & 688762 & 4.6458 & 4.6754 & TRN & & \\
\hline CHEMBL1607286 & 688762 & 5.3957 & 5.2948 & TRN & & \\
\hline CHEMBL166209 & 688762 & 4.8714 & 4.86600 & 00000000005 & & TRN \\
\hline CHEMBL1458565 & 688762 & 4.9133 & 5.1218 & TRN & & \\
\hline CHEMBL3198933 & 688762 & 4.9155 & 4.9689 & TRN & & \\
\hline CHEMBL1405111 & 688762 & 4.658 & 4.583 & TRN & & \\
\hline CHEMBL601757 & 688762 & 6.1073 & 5.8644 & TST & & \\
\hline CHEMBL3211998 & 688762 & 5.5594 & 5.4084 & TRN & & \\
\hline CHEMBL1544097 & 688762 & 4.7926 & 4.8734 & TRN & & \\
\hline CHEMBL1365977 & 688762 & 4.5204 & 4.4656 & TRN & & \\
\hline CHEMBL1574540 & 688762 & 5.5261 & 5.21700 & 00000000005 & & TRN \\
\hline CHEMBL3208118 & 688762 & 4.5207 & 4.4729 & TRN & & \\
\hline CHEMBL1309785 & 688762 & 4.92399 & 79999999 & 995 & .8497 & TRN \\
\hline CHEMBL1326664 & 688762 & 4.1574 & 4.5884 & TRN & & \\
\hline CHEMBL1446491 & 688762 & 4.6846 & 4.7395 & TRN & & \\
\hline CHEMBL1538399 & 688762 & 5.6484 & 5.4797 & TRN & & \\
\hline CHEMBL1468793 & 688762 & 5.0698 & 5.0902 & TRN & & \\
\hline CHEMBL1429899 & 688762 & 4.8385 & 4.7711 & TST & & \\
\hline CHEMBL1557489 & 688762 & 4.6083 & 4.65600 & 0000000001 & & TRN \\
\hline CHEMBL3192856 & 688762 & 5.5519 & 5.3813 & TRN & & \\
\hline CHEMBL1341203 & 688762 & 5.7994 & 5.2724 & TRN & & \\
\hline
\end{tabular}


Supplemental Table S2.txt

\begin{tabular}{|c|c|c|c|c|}
\hline CHEMBL1479393 & 688762 & 5.0974 & 5.0695 & TRN \\
\hline CHEMBL1562333 & 688762 & 4.6696 & 4.6874 & TRN \\
\hline CHEMBL1455957 & 688762 & 5.5964 & 5.4392 & TST \\
\hline CHEMBL 3197459 & 688762 & 4.5272 & 4.7012 & TRN \\
\hline CHEMBL1582537 & 688762 & 4.7169 & 4.7223 & TRN \\
\hline CHEMBL1595499 & 688762 & 4.7087 & 4.7452 & TST \\
\hline CHEMBL1483073 & 688762 & 4.8575 & 4.9392 & TRN \\
\hline CHEMBL1445171 & 688762 & 5.1498 & 5.4676 & TRN \\
\hline CHEMBL1484167 & 688762 & 6.1107 & 5.8489 & TST \\
\hline CHEMBL1373720 & 688762 & 4.2106 & 4.5932 & TRN \\
\hline CHEMBL1404541 & 688762 & 4.7493 & 4.7545 & TRN \\
\hline CHEMBL1541283 & 688762 & 5.2819 & 5.3111 & TRN \\
\hline CHEMBL1998502 & 688762 & 4.5951 & 4.6723 & TRN \\
\hline CHEMBL1451772 & 688762 & 5.4043 & 5.21399 & 99999999995 \\
\hline CHEMBL1455813 & 688762 & 4.9467 & 4.9111 & TRN \\
\hline CHEMBL1424408 & 688762 & 4.5232 & 4.6036 & TRN \\
\hline CHEMBL1533225 & 688762 & 4.9955 & 4.9852 & TRN \\
\hline CHEMBL1417269 & 688762 & 4.5182 & 4.4946 & TRN \\
\hline CHEMBL1546832 & 688762 & 5.0888 & 4.813 & TRN \\
\hline CHEMBL1310008 & 688762 & 5.8511 & 5.8181 & TRN \\
\hline CHEMBL1526325 & 688762 & 5.2033 & 5.1736 & TRN \\
\hline CHEMBL1313121 & 688762 & 5.0397 & 5.0624 & TRN \\
\hline CHEMBL1311453 & 688762 & 5.7775 & 5.722 & TRN \\
\hline CHEMBL1598311 & 688762 & 4.6183 & 4.5801 & TRN \\
\hline CHEMBL1417120 & 688762 & 4.7374 & 4.7513 & TRN \\
\hline CHEMBL1305537 & 688762 & 4.8472 & 4.6584 & TRN \\
\hline CHEMBL1403122 & 688762 & 5.2421 & 5.3099 & TST \\
\hline CHEMBL1327470 & 688762 & 4.695 & 4.84699 & 99999999995 \\
\hline CHEMBL1429624 & 688762 & 5.1082 & 5.0064 & TRN \\
\hline CHEMBL3196039 & 688762 & 5.341 & 5.3014 & TRN \\
\hline CHEMBL1563156 & 688762 & 4.6196 & 4.7992 & TST \\
\hline CHEMBL1419587 & 688762 & 4.9496 & 4.7467 & TST \\
\hline CHEMBL1388241 & 688762 & 5.2141 & 4.9686 & TRN \\
\hline CHEMBL1562040 & 688762 & 5.6696 & 5.6042 & TRN \\
\hline CHEMBL1507490 & 688762 & 4.6596 & 4.3532 & TRN \\
\hline CHEMBL1570958 & 688762 & 5.3997 & 5.3162 & TRN \\
\hline CHEMBL1510394 & 688762 & 4.7769 & 4.7146 & TRN \\
\hline CHEMBL1300063 & 688762 & 4.6705 & 4.6447 & TRN \\
\hline CHEMBL 3211570 & 688762 & 4.1515 & 4.2296 & TST \\
\hline CHEMBL1538775 & 688762 & 4.6451 & 4.8271 & TRN \\
\hline CHEMBL3212190 & 688762 & 4.4077 & 4.6199 & TRN \\
\hline CHEMBL1608332 & 688762 & 4.775 & 5.0024 & TRN \\
\hline CHEMBL1504139 & 688762 & 5.0969 & 5.0548 & TST \\
\hline CHEMBL1572266 & 688762 & 5.0666 & 5.0407 & TST \\
\hline CHEMBL1430931 & 688762 & 5.2734 & 5.0757 & TRN \\
\hline CHEMBL1408368 & 688762 & 4.9658 & 4.1182 & TRN \\
\hline CHEMBL1539423 & 688762 & 4.2005 & 4.3415 & TRN \\
\hline CHEMBL1307764 & 688762 & 4.444 & 4.2916 & TRN \\
\hline
\end{tabular}




\begin{tabular}{|c|c|c|c|c|c|}
\hline & & \multicolumn{4}{|c|}{ Supplemental Table S2.txt } \\
\hline CHEMBL1578476 & 688762 & 4.8339 & 4.797 & TRN & \\
\hline CHEMBL1472126 & 688762 & 6.0061 & 6.1347 & TRN & \\
\hline CHEMBL1493442 & 688762 & 6.7696 & 6.8422 & TRN & \\
\hline CHEMBL1416808 & 688762 & 5.3569 & 5.3636 & TRN & \\
\hline CHEMBL1300414 & 688762 & 5.3269 & 5.0582 & TRN & \\
\hline CHEMBL512366 & 688762 & 4.7949 & 4.71399 & 99999999995 & TRN \\
\hline CHEMBL1484332 & 688762 & 8.2291 & 8.4768 & TRN & \\
\hline CHEMBL 3213238 & 688762 & 4.8365 & 4.8363 & TRN & \\
\hline CHEMBL1351426 & 688762 & 4.7065 & 4.8652 & TST & \\
\hline CHEMBL1508274 & 688762 & 5.1554 & 5.0291 & TRN & \\
\hline CHEMBL1338466 & 688762 & 4.7574 & 4.7716 & TRN & \\
\hline CHEMBL3213359 & 688762 & 4.2848 & 4.3073 & TRN & \\
\hline CHEMBL1459896 & 688762 & 4.7459 & 4.7039 & TRN & \\
\hline CHEMBL1529127 & 688762 & 5.687 & 5.4986 & TRN & \\
\hline CHEMBL1578082 & 688762 & 4.735 & 4.4825 & TST & \\
\hline CHEMBL1549574 & 688762 & 5.1516 & 5.169 & TRN & \\
\hline CHEMBL1338888 & 688762 & 4.6476 & 4.6569 & TRN & \\
\hline CHEMBL 2006338 & 688762 & 5.1874 & 5.1824 & TRN & \\
\hline CHEMBL1464561 & 688762 & 5.3491 & 5.2879 & TRN & \\
\hline CHEMBL1323000 & 688762 & 5.6733 & 5.5355 & TRN & \\
\hline CHEMBL1331809 & 688762 & 4.8003 & 4.7437 & TST & \\
\hline CHEMBL577102 & 688762 & 5.3104 & 5.3405 & TRN & \\
\hline CHEMBL591404 & 688762 & 5.3811 & 5.4038 & TRN & \\
\hline CHEMBL1438761 & 688762 & 4.7353 & 4.6578 & TRN & \\
\hline CHEMBL1302406 & 688762 & 4.738 & 4.7946 & TRN & \\
\hline CHEMBL1714669 & 688762 & 3.7184 & 4.8379 & TRN & \\
\hline CHEMBL1335358 & 688762 & 3.8279 & 4.2349 & TRN & \\
\hline CHEMBL1337997 & 688762 & 4.6035 & 4.586 & TRN & \\
\hline CHEMBL1410029 & 688762 & 4.3537 & 4.5065 & TRN & \\
\hline CHEMBL1611026 & 688762 & 5.0987 & 4.9097 & TRN & \\
\hline CHEMBL3210329 & 688762 & 4.9906 & 4.8672 & TRN & \\
\hline CHEMBL532160 & 688762 & 5.4793 & 5.5261 & TRN & \\
\hline CHEMBL1426358 & 688762 & 4.7781 & 4.7369 & TRN & \\
\hline CHEMBL1594222 & 688762 & 4.9522 & 4.9929 & TRN & \\
\hline CHEMBL1495237 & 688762 & 4.9265 & 4.8105 & TRN & \\
\hline CHEMBL1391184 & 688762 & 4.5858 & 4.6078 & TRN & \\
\hline CHEMBL1322082 & 688762 & 4.9116 & 5.0632 & TRN & \\
\hline CHEMBL3193284 & 688762 & 4.2174 & 4.3684 & TRN & \\
\hline CHEMBL1451528 & 688762 & 4.5866 & 4.3441 & TRN & \\
\hline CHEMBL3192555 & 688762 & 5.9682 & 5.95299 & 9999999999 & TRN \\
\hline CHEMBL1559880 & 688762 & 5.1299 & 4.8791 & TRN & \\
\hline CHEMBL1400751 & 688762 & 4.6966 & 4.6758 & TRN & \\
\hline CHEMBL1586472 & 688762 & 5.0983 & 5.0093 & TRN & \\
\hline CHEMBL1495592 & 688762 & 5.0478 & 4.9946 & TRN & \\
\hline CHEMBL1311671 & 688762 & 4.7746 & 4.7574 & TST & \\
\hline CHEMBL1323013 & 688762 & 4.7073 & 4.789 & TRN & \\
\hline CHEMBL3211050 & 688762 & 5.6299 & 5.45 & TRN & \\
\hline CHEMBL1599408 & 688762 & 4.2678 & 4.3752 & TRN & \\
\hline
\end{tabular}


Supplemental Table S2.txt

\begin{tabular}{|c|c|c|c|c|c|}
\hline CHEMBL1601153 & 688762 & 4.7309 & 4.8886 & TRN & \\
\hline CHEMBL3191705 & 688762 & 5.0283 & 5.1883 & TRN & \\
\hline CHEMBL1468192 & 688762 & 5.2868 & 5.2138 & TRN & \\
\hline CHEMBL 3145293 & 688762 & 3.9723 & 4.4187 & TST & \\
\hline CHEMBL1416348 & 688762 & 4.5173 & 4.5027 & TRN & \\
\hline CHEMBL1469035 & 688762 & 5.9359 & 5.8675 & TRN & \\
\hline CHEMBL1382429 & 688762 & 5.3118 & 5.0397 & TRN & \\
\hline CHEMBL1469733 & 688762 & 3.9514 & 4.2812 & TRN & \\
\hline CHEMBL1491541 & 688762 & 4.4719 & 4.3877 & TRN & \\
\hline CHEMBL1300065 & 688762 & 4.8701 & 4.7378 & TRN & \\
\hline CHEMBL1596484 & 688762 & 5.0761 & 5.0569 & TRN & \\
\hline CHEMBL580819 & 688762 & 4.27 & 4.3608 & TRN & \\
\hline CHEMBL1574219 & 688762 & 5.2154 & 5.2245 & TRN & \\
\hline CHEMBL1326118 & 688762 & 4.8909 & 4.9637 & TRN & \\
\hline CHEMBL1496534 & 688762 & 6.1124 & 6.1562 & TST & \\
\hline CHEMBL1506512 & 688762 & 5.0509 & 5.0126 & TRN & \\
\hline CHEMBL1532880 & 688762 & 4.7859 & 4.6151 & TRN & \\
\hline CHEMBL602400 & 688762 & 5.45799 & 999999999 & 9 & 5.3228 \\
\hline CHEMBL598885 & 688762 & 4.8033 & 5.0611 & TRN & \\
\hline CHEMBL1455873 & 688762 & 5.3285 & 5.3269 & TRN & \\
\hline CHEMBL1978564 & 688762 & 4.2366 & 4.4052 & TRN & \\
\hline CHEMBL1972824 & 688762 & 4.5878 & 4.8357 & TRN & \\
\hline CHEMBL 2003873 & 688762 & 4.9771 & 4.9512 & TRN & \\
\hline CHEMBL1462919 & 688762 & 4.8422 & 4.7948 & TST & \\
\hline CHEMBL1510634 & 688762 & 5.3959 & 5.3157 & TRN & \\
\hline CHEMBL1471698 & 688762 & 4.6493 & 4.4277 & TRN & \\
\hline CHEMBL1539616 & 688762 & 4.4739 & 4.5143 & TRN & \\
\hline CHEMBL1388234 & 688762 & 4.8679 & 4.9014 & TRN & \\
\hline CHEMBL1329138 & 688762 & 5.037 & 4.8662 & TRN & \\
\hline CHEMBL3210660 & 688762 & 4.4882 & 4.6272 & TRN & \\
\hline CHEMBL1542804 & 688762 & 5.1278 & 5.1329 & TRN & \\
\hline CHEMBL1588256 & 688762 & 4.7395 & 4.7312 & TRN & \\
\hline CHEMBL1384094 & 688762 & 4.6936 & 4.672 & TRN & \\
\hline CHEMBL1392894 & 688762 & 4.6553 & 4.7964 & TST & \\
\hline CHEMBL1374533 & 688762 & 4.9326 & 4.5913 & TRN & \\
\hline CHEMBL1460352 & 688762 & 6.0039 & 5.8892 & TRN & \\
\hline CHEMBL3198098 & 688762 & 3.8311 & 4.3683 & TRN & \\
\hline CHEMBL1314100 & 688762 & 4.7448 & 4.7066 & TRN & \\
\hline CHEMBL1977709 & 688762 & 4.7482 & 4.6622 & TRN & \\
\hline CHEMBL1446863 & 688762 & 4.6922 & 4.5734 & TST & \\
\hline CHEMBL1490873 & 688762 & 4.7532 & 4.6929 & TST & \\
\hline CHEMBL1304814 & 688762 & 5.0305 & 4.7921 & TST & \\
\hline CHEMBL1345993 & 688762 & 5.1676 & 5.1086 & TRN & \\
\hline CHEMBL1452109 & 688762 & 4.6489 & 4.7103 & TRN & \\
\hline CHEMBL1541405 & 688762 & 4.7612 & 4.6557 & TRN & \\
\hline CHEMBL1981058 & 688762 & 4.647 & 4.519 & TRN & \\
\hline CHEMBL3208420 & 688762 & 4.3338 & 4.1983 & TRN & \\
\hline CHEMBL1480101 & 688762 & 4.3502 & 4.6725 & TRN & \\
\hline
\end{tabular}


Supplemental Table S2.txt

\begin{tabular}{|c|c|c|c|c|}
\hline CHEMBL3192837 & 688762 & 4.4025 & 4.5287 & TRN \\
\hline CHEMBL1529687 & 688762 & 5.2325 & 5.1428 & TST \\
\hline CHEMBL523200 & 688762 & 5.254 & 5.1813 & TRN \\
\hline CHEMBL530664 & 688762 & 4.7688 & 4.7189 & TRN \\
\hline CHEMBL1411379 & 688762 & 5.0314 & 5.0498 & TRN \\
\hline CHEMBL3210045 & 688762 & 4.4054 & 4.4507 & TRN \\
\hline CHEMBL 2369241 & 688762 & 4.4894 & 4.4674 & TRN \\
\hline CHEMBL1526457 & 688762 & 4.742 & 4.7648 & TRN \\
\hline CHEMBL1570920 & 688762 & 5.5924 & 5.3449 & TRN \\
\hline CHEMBL1458165 & 688762 & 5.0031 & 4.7926 & TRN \\
\hline CHEMBL1519014 & 688762 & 5.1101 & 5.0578 & TRN \\
\hline CHEMBL1373255 & 688762 & 5.6726 & 5.4819 & TRN \\
\hline CHEMBL1332524 & 688762 & 4.3142 & 4.6552 & TRN \\
\hline CHEMBL1545024 & 688762 & 4.6666 & 4.7579 & TST \\
\hline CHEMBL1432593 & 688762 & 4.9942 & 4.8659 & TRN \\
\hline CHEMBL1504567 & 688762 & 4.5283 & 4.5681 & TRN \\
\hline CHEMBL1600768 & 688762 & 5.1542 & 5.0911 & TRN \\
\hline CHEMBL1423071 & 688762 & 4.4912 & 4.6216 & TRN \\
\hline CHEMBL1309295 & 688762 & 5.1453 & 5.1367 & TRN \\
\hline CHEMBL1423880 & 688762 & 4.5958 & 4.6097 & TRN \\
\hline CHEMBL1521830 & 688762 & 4.9297 & 4.9244 & TRN \\
\hline CHEMBL1305974 & 688762 & 4.5263 & 4.3315 & TRN \\
\hline CHEMBL1346881 & 688762 & 4.9798 & 4.9544 & TST \\
\hline CHEMBL1531138 & 688762 & 5.0206 & 5.0199 & TRN \\
\hline CHEMBL1585304 & 688762 & 4.5746 & 4.5834 & TRN \\
\hline CHEMBL1594171 & 688762 & 5.3796 & 5.3299 & TRN \\
\hline CHEMBL1511371 & 688762 & 5.817 & 5.6121 & TRN \\
\hline CHEMBL1310437 & 688762 & 3.2859 & 3.9077 & TRN \\
\hline CHEMBL1331801 & 688762 & 4.5789 & 4.7315 & TRN \\
\hline CHEMBL1543421 & 688762 & 5.0666 & 5.0228 & TRN \\
\hline CHEMBL528506 & 688762 & 5.0661 & 5.0771 & TRN \\
\hline CHEMBL1540231 & 688762 & 5.1065 & 5.0442 & TST \\
\hline CHEMBL1308032 & 688762 & 4.0253 & 4.43 & TRN \\
\hline CHEMBL1407401 & 688762 & 5.3658 & 5.3409 & TRN \\
\hline CHEMBL1479994 & 688762 & 4.6188 & 4.7192 & TRN \\
\hline CHEMBL1537747 & 688762 & 4.3286 & 4.3044 & TRN \\
\hline CHEMBL572994 & 688762 & 4.9045 & 4.8052 & TRN \\
\hline CHEMBL1479951 & 688762 & 4.7314 & 4.6389 & TRN \\
\hline CHEMBL576208 & 688762 & 5.7303 & 5.6845 & TRN \\
\hline CHEMBL1339696 & 688762 & 5.3325 & 5.2628 & TRN \\
\hline CHEMBL1405734 & 688762 & 5.2882 & 5.2184 & TRN \\
\hline CHEMBL1461881 & 688762 & 4.8844 & 5.0502 & TRN \\
\hline CHEMBL1306267 & 688762 & 5.7095 & 5.7741 & TRN \\
\hline CHEMBL1611832 & 688762 & 5.0306 & 4.9223 & TRN \\
\hline CHEMBL1544502 & 688762 & 4.7122 & 4.8222 & TRN \\
\hline CHEMBL1502712 & 688762 & 4.8145 & \multicolumn{2}{|c|}{ 4.7589999999999995 } \\
\hline CHEMBL1371943 & 688762 & 4.624 & \multicolumn{2}{|c|}{4.6419999999999995} \\
\hline CHEMBL1305234 & 688762 & 4.7104 & 4.7283 & TRN \\
\hline
\end{tabular}

Page 6722 


\begin{tabular}{|c|c|c|c|c|c|}
\hline & & \multicolumn{4}{|c|}{ Supplemental Table S2.txt } \\
\hline CHEMBL1581916 & 688762 & 4.2928 & 4.4672 & TST & \\
\hline CHEMBL3191116 & 688762 & 5.3207 & 5.3258 & TRN & \\
\hline CHEMBL1612392 & 688762 & 4.7356 & 4.8728 & TRN & \\
\hline CHEMBL1599800 & 688762 & 4.896 & 4.8029 & TRN & \\
\hline CHEMBL1542741 & 688762 & 5.0009 & 4.9587 & TRN & \\
\hline CHEMBL1565290 & 688762 & 4.747 & 4.7372 & TST & \\
\hline CHEMBL1546412 & 688762 & 5.1966 & 5.2295 & TRN & \\
\hline CHEMBL1350674 & 688762 & 4.7469 & 4.6188 & TRN & \\
\hline CHEMBL1350167 & 688762 & 3.6658 & 4.0556 & TRN & \\
\hline CHEMBL1307467 & 688762 & 4.6154 & 4.628 & TRN & \\
\hline CHEMBL1504234 & 688762 & 4.7963 & 4.7679 & TRN & \\
\hline CHEMBL1584502 & 688762 & 5.5249 & 5.2761 & TRN & \\
\hline CHEMBL1564753 & 688762 & 4.1378 & 4.402 & TRN & \\
\hline CHEMBL1347497 & 688762 & 5.1299 & 5.1233 & TST & \\
\hline CHEMBL1323568 & 688762 & 5.3183 & 5.3667 & TRN & \\
\hline CHEMBL1374947 & 688762 & 5.5071 & 5.5145 & TRN & \\
\hline CHEMBL1430815 & 688762 & 3.2517 & 4.5807 & TRN & \\
\hline CHEMBL1328083 & 688762 & 5.0306 & 4.9351 & TRN & \\
\hline CHEMBL1540346 & 688762 & 4.4659 & 4.4917 & TRN & \\
\hline CHEMBL1305918 & 688762 & 4.7158 & 4.6395 & TRN & \\
\hline CHEMBL1483161 & 688762 & 5.3504 & 5.2339 & TST & \\
\hline CHEMBL1991908 & 688762 & 5.1219 & 5.0126 & TRN & \\
\hline CHEMBL 1600480 & 688762 & 4.6817 & 4.7341 & TRN & \\
\hline CHEMBL1364051 & 688762 & 4.6585 & 4.426 & TRN & \\
\hline CHEMBL1453902 & 688762 & 4.7471 & 4.4782 & TRN & \\
\hline CHEMBL3198512 & 688762 & 5.44 & 5.1424 & TRN & \\
\hline CHEMBL1343568 & 688762 & 5.7064 & 5.5974 & TRN & \\
\hline CHEMBL1518926 & 688762 & 5.0462 & 5.03600 & 00000000005 & TRN \\
\hline CHEMBL1478893 & 688762 & 4.5567 & 4.6035 & TRN & \\
\hline CHEMBL3198581 & 688762 & 6.3449 & 5.9528 & TRN & \\
\hline CHEMBL1385055 & 688762 & 5.942 & 5.67700 & 00000000005 & TRN \\
\hline CHEMBL1410536 & 688762 & 4.48 & 3.9846 & TRN & \\
\hline CHEMBL3210366 & 688762 & 4.9372 & 4.9678 & TRN & \\
\hline CHEMBL1511882 & 688762 & 4.6828 & 4.6374 & TRN & \\
\hline CHEMBL1601175 & 688762 & 4.0858 & 4.1674 & TST & \\
\hline CHEMBL1335607 & 688762 & 4.9011 & 4.825 & TRN & \\
\hline CHEMBL1487635 & 688762 & 5.6012 & 5.5179 & TRN & \\
\hline CHEMBL1351519 & 688762 & 5.2753 & 5.2904 & TRN & \\
\hline CHEMBL1565721 & 688762 & 4.7543 & 4.758 & TRN & \\
\hline CHEMBL1576941 & 688762 & 4.6519 & 4.7973 & TRN & \\
\hline CHEMBL1362109 & 688762 & 5.3126 & 5.1008 & TRN & \\
\hline CHEMBL1439210 & 688762 & 8.2291 & 8.2091 & TRN & \\
\hline CHEMBL1549860 & 688762 & 5.36799 & 9999999 & 5.3492 & TRN \\
\hline CHEMBL1465751 & 688762 & 5.4142 & 5.4595 & TRN & \\
\hline CHEMBL1353693 & 688762 & 3.4731 & 4.6913 & TRN & \\
\hline CHEMBL1500966 & 688762 & 5.8821 & 5.6359 & TRN & \\
\hline CHEMBL1432711 & 688762 & 4.6197 & 4.5076 & TRN & \\
\hline CHEMBL1308487 & 688762 & 4.6682 & 4.6014 & TRN & \\
\hline
\end{tabular}


Supplemental Table S2.txt

\begin{tabular}{|c|c|c|c|c|}
\hline CHEMBL1363614 & 688762 & 5.7731 & 5.7447 & TRN \\
\hline CHEMBL1430531 & 688762 & 5.3241 & 5.1089 & TST \\
\hline CHEMBL1510922 & 688762 & 4.7568 & 4.7214 & TRN \\
\hline CHEMBL482116 & 688762 & 5.4563 & 5.6218 & TRN \\
\hline CHEMBL1558220 & 688762 & 4.5971 & 4.5923 & TRN \\
\hline CHEMBL1415310 & 688762 & 4.3278 & 4.0191 & TRN \\
\hline CHEMBL1541146 & 688762 & 4.5541 & 4.5883 & TST \\
\hline CHEMBL1442136 & 688762 & 5.5819 & 5.6744 & TRN \\
\hline CHEMBL1349590 & 688762 & 5.6515 & 5.4044 & TRN \\
\hline CHEMBL1506827 & 688762 & 4.7908 & 5.0415 & TRN \\
\hline CHEMBL45152 & 688762 & 4.6459 & 4.3436 & TRN \\
\hline CHEMBL1337500 & 688762 & 5.4721 & 5.2187 & TST \\
\hline CHEMBL1384702 & 688762 & 5.5929 & 5.6407 & TRN \\
\hline CHEMBL1465920 & 688762 & 4.6881 & 4.7827 & TRN \\
\hline CHEMBL1308329 & 688762 & 4.9104 & 4.8968 & TRN \\
\hline CHEMBL1974112 & 688762 & 4.9923 & 4.93199 & э9999999995 \\
\hline CHEMBL1375998 & 688762 & 5.4977 & 5.4576 & TRN \\
\hline CHEMBL1412039 & 688762 & 5.357 & 5.3894 & TRN \\
\hline CHEMBL1546684 & 688762 & 4.9921 & 4.9512 & TRN \\
\hline CHEMBL1326180 & 688762 & 5.9255 & 5.7808 & TRN \\
\hline CHEMBL1485865 & 688762 & 5.4152 & 5.3911 & TRN \\
\hline CHEMBL1349225 & 688762 & 4.8653 & 4.7756 & TRN \\
\hline CHEMBL1403470 & 688762 & 4.5432 & 4.4763 & TRN \\
\hline CHEMBL1538643 & 688762 & 4.9778 & 4.8309 & TRN \\
\hline CHEMBL1511409 & 688762 & 4.5283 & 4.6823 & TST \\
\hline CHEMBL1450086 & 688762 & 5.1901 & 5.2492 & TST \\
\hline CHEMBL1899958 & 688762 & 4.6613 & 4.8271 & TRN \\
\hline CHEMBL1311572 & 688762 & 4.9045 & 4.7927 & TRN \\
\hline CHEMBL1582448 & 688762 & 4.7108 & 4.5942 & TST \\
\hline CHEMBL 3195220 & 688762 & 5.0342 & 4.9434 & TRN \\
\hline CHEMBL1308346 & 688762 & 4.9871 & 4.8539 & TRN \\
\hline CHEMBL1417180 & 688762 & 5.0731 & 5.0334 & TRN \\
\hline CHEMBL1968355 & 688762 & 4.5888 & 4.2642 & TST \\
\hline CHEMBL1334040 & 688762 & 5.3456 & 5.2589 & TRN \\
\hline CHEMBL1601301 & 688762 & 4.8665 & 4.6669 & TST \\
\hline CHEMBL1575748 & 688762 & 4.7796 & 4.7642 & TRN \\
\hline CHEMBL1431928 & 688762 & 5.63700 & 00000000 & 5.6053 \\
\hline CHEMBL1606490 & 688762 & 4.0181 & 4.5792 & TRN \\
\hline CHEMBL1456753 & 688762 & 5.4085 & 5.365 & TRN \\
\hline CHEMBL1526910 & 688762 & 5.0872 & 5.0249 & TST \\
\hline CHEMBL1499792 & 688762 & 6.0535 & 5.9196 & TST \\
\hline CHEMBL1588525 & 688762 & 6.5768 & 6.6206 & TRN \\
\hline CHEMBL1441024 & 688762 & 4.6942 & 4.7855 & TRN \\
\hline CHEMBL1460871 & 688762 & 5.2854 & 4.5424 & TRN \\
\hline CHEMBL1303068 & 688762 & 5.2809 & 5.2446 & TRN \\
\hline CHEMBL1453859 & 688762 & 5.2743 & 5.1413 & TRN \\
\hline CHEMBL1340447 & 688762 & 4.8204 & 4.9305 & TRN \\
\hline CHEMBL1472199 & 688762 & 5.4204 & $5.34200 t$ & 30000000005 \\
\hline
\end{tabular}




\begin{tabular}{|c|c|c|c|c|}
\hline \multicolumn{5}{|c|}{ Supplemental Tab. } \\
\hline CHEMBL1588077 & 688762 & 4.8644 & 5.0162 & TRN \\
\hline CHEMBL1420457 & 688762 & 5.0456 & 4.9464 & TRN \\
\hline CHEMBL1340787 & 688762 & 5.2984 & 5.1252 & TRN \\
\hline CHEMBL1521989 & 688762 & 5.0943 & 5.0261 & TRN \\
\hline CHEMBL3207311 & 688762 & 4.6611 & 4.7848 & TRN \\
\hline CHEMBL1504171 & 688762 & 4.9824 & 5.0459 & TRN \\
\hline CHEMBL1470082 & 688762 & 4.6764 & 4.5272 & TRN \\
\hline CHEMBL1306011 & 688762 & 5.0784 & 5.0781 & TRN \\
\hline CHEMBL1336245 & 688762 & 3.8579 & 4.4618 & TST \\
\hline CHEMBL1441619 & 688762 & 5.2946 & 5.0743 & TRN \\
\hline CHEMBL1538354 & 688762 & 4.5992 & 4.6783 & TST \\
\hline CHEMBL1980684 & 688762 & 4.9639 & 4.8155 & TRN \\
\hline CHEMBL1486335 & 688762 & 4.7443 & 4.5768 & TRN \\
\hline CHEMBL1571495 & 688762 & 4.6466 & 4.6492 & TRN \\
\hline CHEMBL1327351 & 688762 & 4.6236 & 4.5686 & TRN \\
\hline CHEMBL1466897 & 688762 & 3.8755 & 4.4011 & TRN \\
\hline CHEMBL1559564 & 688762 & 4.5682 & 4.5954 & TRN \\
\hline CHEMBL1446445 & 688762 & 4.1195 & 4.1526 & TRN \\
\hline CHEMBL1348102 & 688762 & 5.1054 & 5.0744 & TRN \\
\hline CHEMBL1594535 & 688762 & 4.3153 & 4.4376 & TRN \\
\hline CHEMBL1546347 & 688762 & 5.6649 & 5.5937 & TRN \\
\hline CHEMBL1351388 & 688762 & 4.7179 & 4.6896 & TRN \\
\hline CHEMBL1419903 & 688762 & 4.2586 & 4.5842 & TST \\
\hline CHEMBL1471418 & 688762 & 5.0523 & 4.8566 & TRN \\
\hline CHEMBL1596003 & 688762 & 5.228 & 5.2882 & TRN \\
\hline CHEMBL1455524 & 688762 & 4.035 & 4.118 & TST \\
\hline CHEMBL1491019 & 688762 & 5.6513 & 5.718 & TRN \\
\hline CHEMBL1450507 & 688762 & 4.2603 & 4.5258 & TRN \\
\hline CHEMBL1479746 & 688762 & 4.2502 & 4.3484 & TST \\
\hline CHEMBL3190645 & 688762 & 4.7449 & 4.7616 & TRN \\
\hline CHEMBL1501645 & 688762 & 5.0407 & 4.9862 & TRN \\
\hline CHEMBL1036 & 688762 & 4.5464 & 4.5563 & TST \\
\hline CHEMBL1416149 & 688762 & 4.8008 & 4.8168 & TRN \\
\hline CHEMBL1510228 & 688762 & 5.0519 & 4.9861 & TRN \\
\hline CHEMBL1587655 & 688762 & 4.6731 & 4.8551 & TRN \\
\hline CHEMBL1418676 & 688762 & 4.9142 & 4.8013 & TST \\
\hline CHEMBL1568173 & 688762 & 5.2735 & 5.0423 & TRN \\
\hline CHEMBL3190733 & 688762 & 5.4778 & 5.5137 & TRN \\
\hline CHEMBL1523114 & 688762 & 4.6357 & 4.3996 & TRN \\
\hline CHEMBL1518508 & 688762 & 5.2525 & 5.2639 & TRN \\
\hline CHEMBL1388809 & 688762 & 4.6269 & 4.7115 & TRN \\
\hline CHEMBL1559813 & 688762 & 4.7178 & 4.752 & TRN \\
\hline CHEMBL3197643 & 688762 & 4.5821 & 4.542 & TRN \\
\hline CHEMBL1377813 & 688762 & 5.0208 & 4.9872 & TRN \\
\hline CHEMBL1482389 & 688762 & 5.1952 & 5.0387 & TRN \\
\hline CHEMBL1438624 & 688762 & 5.2759 & 5.1897 & TRN \\
\hline CHEMBL1376635 & 688762 & 4.5679 & 4.7466 & TRN \\
\hline CHEMBL3190703 & 688762 & 5.3037 & 5.1828 & TRN \\
\hline
\end{tabular}




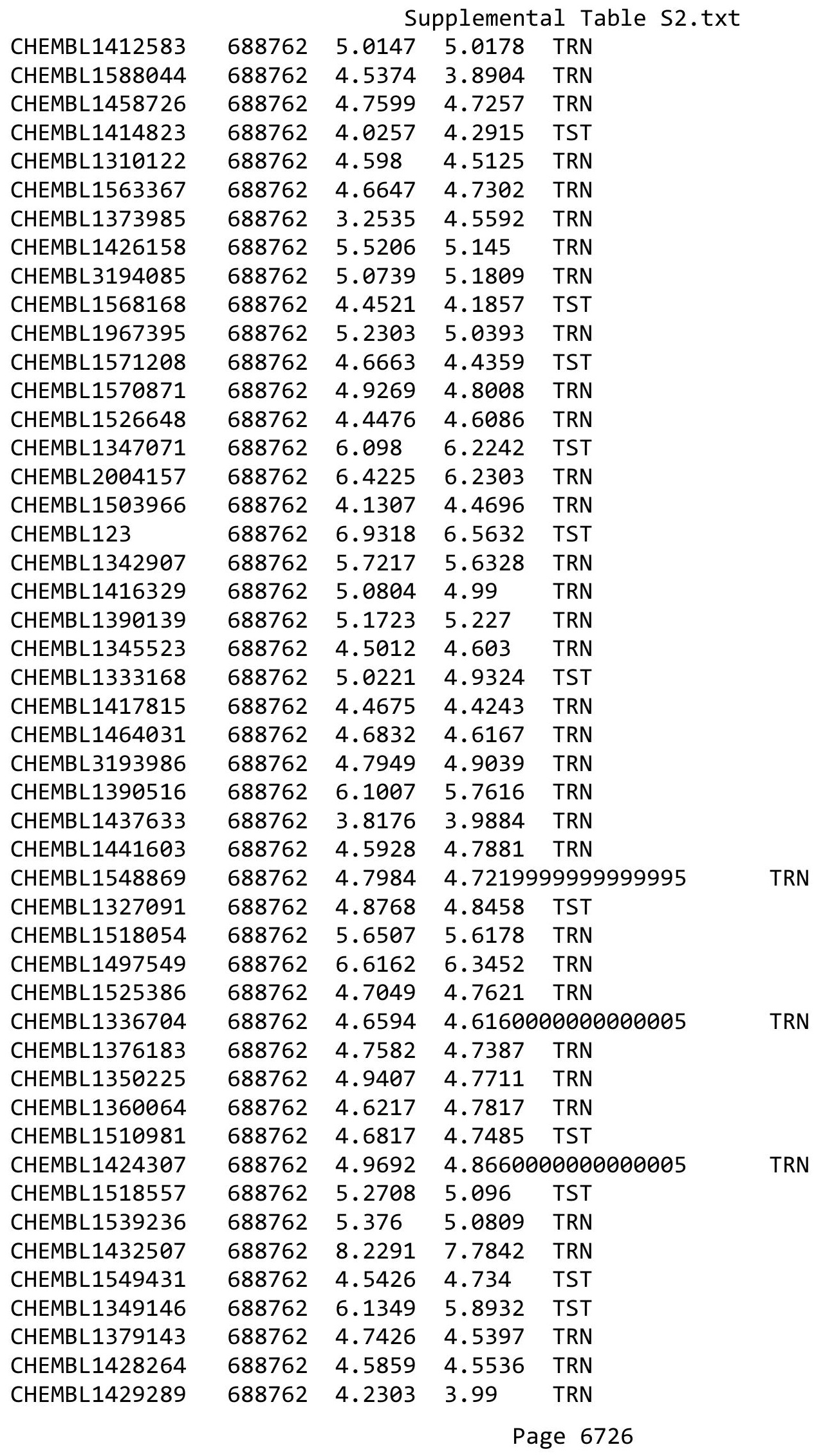



Supplemental Table S2.txt

\begin{tabular}{|c|c|c|c|c|}
\hline HEMBL1 & & 17 & 36 & TR \\
\hline HEMRI 1568997 & 38762 & 2008 & 10510 & \\
\hline AEMBL15 & 3762 & 182 & & \\
\hline AEMBL1451725 & 8762 & 3139 & 8899 & \\
\hline HEMBL3192475 & 88762 & 2761 & 2839 & \\
\hline HEMBL1C & 8762 & .0899 & 8967 & \\
\hline AEMBL1 & 8762 & & & \\
\hline HEMBL13 & 38762 & 395 & 7584 & \\
\hline HEMBL151946 & 88762 & 1959 & 9998 & \\
\hline HEMBL1573242 & 88762 & .7726 & 8662 & \\
\hline AEMBL14 & 38762 & 5874 & 5503 & \\
\hline AEMBL3: & 762 & 341 & & \\
\hline HEMBL15 & 8762 & 642 & 461 & \\
\hline AEMBL15 & 762 & 496 & 7228 & \\
\hline JEMBL14 & 8762 & 977 & & \\
\hline AEMBL1 & 62 & 13 & & \\
\hline AEMBL3 & & & & \\
\hline AEMBL1 & 762 & 492 & & \\
\hline AEMBL13 & 762 & 13 & & \\
\hline IEMBL13 & 62 & 969 & 005 & \\
\hline IEMBL1 & 52 & 777 & 32 & \\
\hline EMBL: & & 81 & & \\
\hline HEMBL 3 & 762 & 13 & & \\
\hline AEMBL1: & & & & \\
\hline AEMBL13 & 52 & 95 & & RIV \\
\hline IEMBL3 & 52 & & & RN \\
\hline$\theta$ & & & & \\
\hline 5 & & & & \\
\hline AEMBL3 & & & & IRN \\
\hline AEMBL15 & 52 & 83 & 303 & RN \\
\hline FMBL 1 & 52 & 29 & 38 & RN \\
\hline 3 & & & & $\mathrm{RN}$ \\
\hline & & & & RN \\
\hline IEMBL13 & & & & R \\
\hline AEMBL14 & 62 & & 29 & ГST \\
\hline AFMRI 1 & 52 & & & RN \\
\hline & & & & RN \\
\hline HEMBL1: & & & & RN \\
\hline AEMBL16 & 8762 & & 598 & $\Gamma R$ \\
\hline EMBL1 & & & & RN \\
\hline HEMBL1. & & & 39 & \\
\hline & & & & RN \\
\hline HEMBL4S & & & & 「RN \\
\hline IEMBL1C & 62 & & 581 & TR \\
\hline 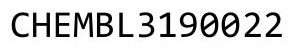 & & & & \\
\hline HEMBL16 & & & & \\
\hline HEMBL 32 & 88762 & 4.5884 & 4.6663 & \\
\hline CHEMBL1467750 & 688762 & 5.2297 & 5.2552 & \\
\hline
\end{tabular}

Page 6728 


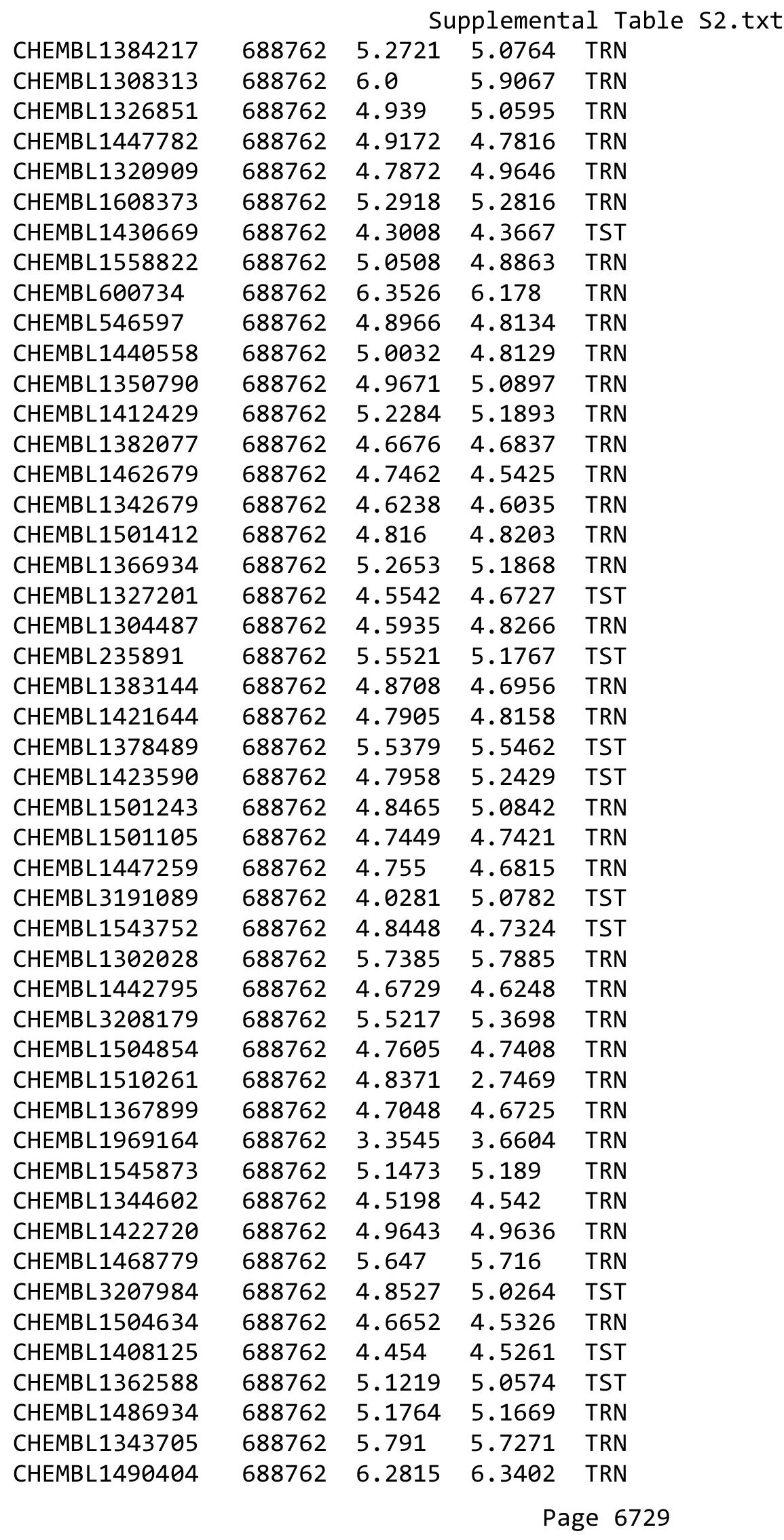




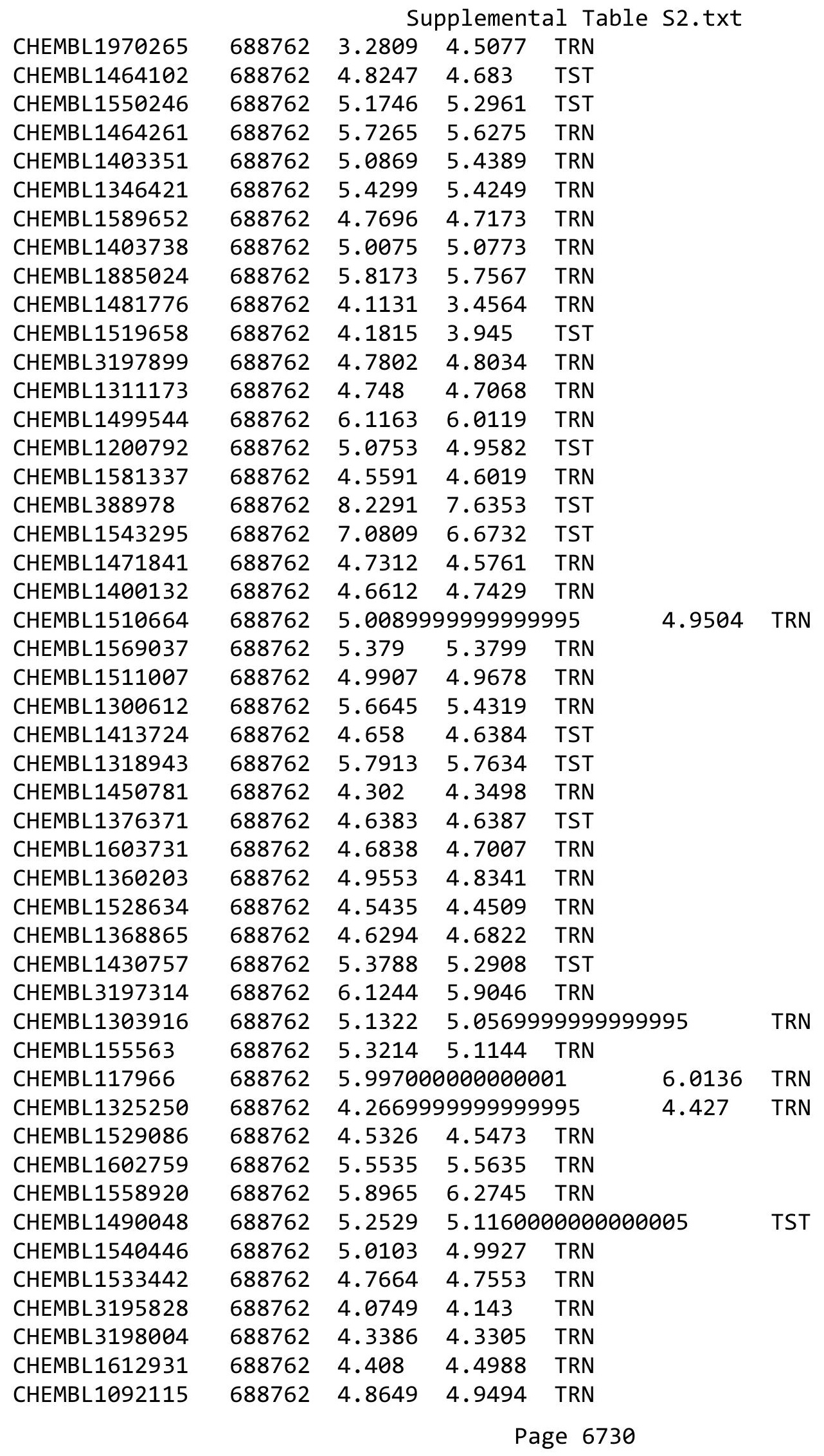




\begin{tabular}{|c|c|c|c|c|c|c|}
\hline & & \multicolumn{5}{|c|}{ Supplemental Table S2.txt } \\
\hline CHEMBL1588763 & 688762 & 4.7418 & 4.8569 & TRN & & \\
\hline CHEMBL1376851 & 688762 & 4.7226 & 4.8193 & TST & & \\
\hline CHEMBL1976567 & 688762 & 5.3023 & 5.3893 & TRN & & \\
\hline CHEMBL1531537 & 688762 & 4.1357 & 5.1223 & TRN & & \\
\hline CHEMBL 3145030 & 688762 & \multicolumn{3}{|c|}{5.367000000000001} & 5.2379 & TST \\
\hline CHEMBL3209649 & 688762 & 4.2565 & 4.2006 & TRN & & \\
\hline CHEMBL1566424 & 688762 & 5.0858 & 5.1257 & TRN & & \\
\hline CHEMBL1386172 & 688762 & \multicolumn{3}{|c|}{5.093999999999999} & 4.9308 & TRN \\
\hline CHEMBL1365192 & 688762 & 4.7684 & 4.9151 & TRN & & \\
\hline CHEMBL1611222 & 688762 & 4.6297 & 4.3911 & TRN & & \\
\hline CHEMBL1974389 & 688762 & 4.4248 & 4.4769 & TRN & & \\
\hline CHEMBL 3212447 & 688762 & 5.3022 & 5.4013 & TRN & & \\
\hline CHEMBL1587286 & 688762 & 4.6972 & 4.7389 & TST & & \\
\hline CHEMBL1493953 & 688762 & 4.8282 & 4.8593 & TRN & & \\
\hline CHEMBL3193133 & 688762 & 5.0727 & 4.9744 & TRN & & \\
\hline CHEMBL1485515 & 688762 & 5.4657 & 5.3803 & TRN & & \\
\hline CHEMBL1446480 & 688762 & 5.0798 & 5.1383 & TRN & & \\
\hline CHEMBL1352733 & 688762 & 5.3034 & 5.0618 & TRN & & \\
\hline CHEMBL1517141 & 688762 & 6.3675 & 5.9646 & TRN & & \\
\hline CHEMBL1485168 & 688762 & 5.8345 & 5.8283 & TRN & & \\
\hline CHEMBL1405281 & 688762 & 5.3016 & 5.1736 & TRN & & \\
\hline CHEMBL1301709 & 688762 & 5.0341 & 4.998 & TRN & & \\
\hline CHEMBL1556661 & 688762 & 5.3396 & 5.3171 & TRN & & \\
\hline CHEMBL1479550 & 688762 & 4.7125 & 4.7814 & TRN & & \\
\hline CHEMBL1319676 & 688762 & 5.4079 & 4.6259 & TRN & & \\
\hline CHEMBL1427637 & 688762 & 5.7228 & 5.7319 & TST & & \\
\hline CHEMBL604321 & 688762 & 6.0092 & 5.9788 & TRN & & \\
\hline CHEMBL1573754 & 688762 & 5.2354 & 5.385 & TST & & \\
\hline CHEMBL1333276 & 688762 & 4.5582 & 4.6187 & TRN & & \\
\hline CHEMBL1587031 & 688762 & 5.5686 & 5.5409 & TRN & & \\
\hline CHEMBL1529029 & 688762 & 4.7677 & 4.4237 & TRN & & \\
\hline CHEMBL1308845 & 688762 & 4.7813 & 4.6173 & TRN & & \\
\hline CHEMBL436913 & 688762 & 5.0126 & 5.0687 & TRN & & \\
\hline CHEMBL1442695 & 688762 & 5.7151 & 5.6772 & TRN & & \\
\hline CHEMBL1511795 & 688762 & 4.3865 & 4.5176 & TRN & & \\
\hline CHEMBL1444691 & 688762 & 5.0573 & 4.9804 & TRN & & \\
\hline CHEMBL1544694 & 688762 & 4.913 & 4.9032 & TST & & \\
\hline CHEMBL1490379 & 688762 & 5.5862 & 5.3858 & TRN & & \\
\hline CHEMBL1483847 & 688762 & 4.8808 & 4.9457 & TRN & & \\
\hline CHEMBL1501334 & 688762 & 4.4951 & 4.48300 & 0000000000 & 05 & TRN \\
\hline CHEMBL1585332 & 688762 & 5.8706 & 6.0931 & TRN & & \\
\hline CHEMBL1464853 & 688762 & 5.5602 & 5.4591 & TST & & \\
\hline CHEMBL1431017 & 688762 & 4.7469 & 4.6565 & TST & & \\
\hline CHEMBL1310221 & 688762 & 5.63299 & 99999999 & 99 & 5.4787 & TRN \\
\hline CHEMBL1372307 & 688762 & 5.6091 & 5.7642 & TST & & \\
\hline CHEMBL1378745 & 688762 & 4.3085 & 4.2975 & TRN & & \\
\hline CHEMBL1502346 & 688762 & 5.0075 & 4.9934 & TRN & & \\
\hline CHEMBL1403058 & 688762 & 5.0344 & 4.9684 & TRN & & \\
\hline
\end{tabular}




\begin{tabular}{|c|c|c|c|c|c|c|}
\hline & & \multicolumn{5}{|c|}{ Supplemental Table S2.txt } \\
\hline CHEMBL1308255 & 688762 & 4.9233 & 4.8671 & TRN & & \\
\hline CHEMBL1422690 & 688762 & 6.0301 & 5.92399 & 99999999 & 995 & TRN \\
\hline CHEMBL1458052 & 688762 & 4.4456 & 4.6257 & TRN & & \\
\hline CHEMBL1579599 & 688762 & 5.3314 & 5.3365 & TRN & & \\
\hline CHEMBL 2000338 & 688762 & 4.8865 & 5.604 & TRN & & \\
\hline CHEMBL1493907 & 688762 & 4.5093 & 4.4936 & TRN & & \\
\hline CHEMBL3196691 & 688762 & 4.7064 & 4.7297 & TRN & & \\
\hline CHEMBL1517752 & 688762 & 5.3937 & 5.2942 & TRN & & \\
\hline CHEMBL1411210 & 688762 & 6.1463 & 5.9107 & TST & & \\
\hline CHEMBL1390575 & 688762 & 4.7548 & 4.6516 & TRN & & \\
\hline CHEMBL1570537 & 688762 & 3.9911 & 4.1433 & TRN & & \\
\hline CHEMBL1601781 & 688762 & 4.9504 & 4.9557 & TRN & & \\
\hline CHEMBL1543857 & 688762 & 5.1318 & 5.1816 & TRN & & \\
\hline CHEMBL1351463 & 688762 & 4.487 & 4.5965 & TRN & & \\
\hline CHEMBL1581607 & 688762 & 4.9048 & 5.0371 & TRN & & \\
\hline CHEMBL1338862 & 688762 & $4.6560 e$ & 000000006 & 01 & 4.8563 & TRN \\
\hline CHEMBL1549192 & 688762 & 5.4617 & 5.6782 & TST & & \\
\hline CHEMBL1379761 & 688762 & 5.2876 & 5.0296 & TST & & \\
\hline CHEMBL1508917 & 688762 & 4.7147 & 4.7399 & TST & & \\
\hline CHEMBL1365226 & 688762 & 4.8589 & 4.8778 & TST & & \\
\hline CHEMBL1400568 & 688762 & 4.2024 & 4.4506 & TST & & \\
\hline CHEMBL1393341 & 688762 & 4.9663 & 4.8584 & TST & & \\
\hline CHEMBL1305054 & 688762 & 3.5453 & 4.0255 & TST & & \\
\hline CHEMBL1336887 & 688762 & 5.5067 & 5.7574 & TST & & \\
\hline CHEMBL1408215 & 688762 & 4.8442 & 4.8609 & TST & & \\
\hline CHEMBL1540229 & 688762 & 4.7305 & 4.9014 & TST & & \\
\hline CHEMBL1495939 & 688762 & 4.4048 & 4.5044 & TST & & \\
\hline CHEMBL3191811 & 688762 & 5.1382 & 4.967 & TST & & \\
\hline CHEMBL1425971 & 688762 & 4.6223 & 4.6602 & TST & & \\
\hline CHEMBL1461508 & 688762 & 4.9946 & 4.9894 & TST & & \\
\hline CHEMBL1387733 & 688762 & 4.4923 & 4.4515 & TST & & \\
\hline CHEMBL1607463 & 688762 & 4.3249 & 4.5099 & TST & & \\
\hline CHEMBL1976777 & 688762 & 4.1004 & 4.8746 & TST & & \\
\hline CHEMBL1504303 & 688762 & 4.5485 & 4.5177 & TST & & \\
\hline CHEMBL1505788 & 688762 & 4.7299 & 4.6458 & TST & & \\
\hline CHEMBL1314042 & 688762 & 4.4635 & 4.6903 & TST & & \\
\hline CHEMBL3190262 & 688762 & 4.603 & 4.6393 & TST & & \\
\hline CHEMBL1585191 & 688762 & 4.6693 & 4.5236 & TST & & \\
\hline CHEMBL1324897 & 688762 & 4.9124 & 4.8253 & TST & & \\
\hline CHEMBL1481903 & 688762 & 4.9813 & 4.8738 & TST & & \\
\hline CHEMBL1327816 & 688762 & 5.0796 & 5.1529 & TST & & \\
\hline CHEMBL1598882 & 688762 & 4.8972 & 4.7662 & TST & & \\
\hline CHEMBL1543733 & 688762 & 5.0388 & 4.7718 & TST & & \\
\hline CHEMBL1983745 & 688762 & 5.33299 & 99999999 & 99 & 5.265 & TST \\
\hline CHEMBL1407739 & 688762 & 4.4115 & 4.7792 & TST & & \\
\hline CHEMBL1582023 & 688762 & 4.5775 & 4.6517 & TST & & \\
\hline CHEMBL1413519 & 688762 & 4.4072 & 4.4185 & TST & & \\
\hline CHEMBL1571639 & 688762 & 5.4201 & 5.0272 & TST & & \\
\hline
\end{tabular}




\begin{tabular}{|c|c|c|c|c|c|c|}
\hline \multicolumn{7}{|c|}{ Supplemental Table s2.txt } \\
\hline CHEMBL1457697 & 688762 & 5.0161 & 5.0694 & TST & & \\
\hline CHEMBL1450097 & 688762 & 4.1374 & 4.1784 & TST & & \\
\hline CHEMBL3212953 & 688762 & 4.5994 & 4.6913 & TST & & \\
\hline CHEMBL1611684 & 688762 & 5.2091 & 5.1526 & TST & & \\
\hline CHEMBL1302139 & 688762 & 4.7687 & 4.6643 & TST & & \\
\hline CHEMBL1481525 & 688762 & 5.0344 & 4.8636 & TST & & \\
\hline CHEMBL1352555 & 688762 & 4.5469 & 4.4076 & TST & & \\
\hline CHEMBL3197094 & 688762 & 4.6523 & 4.68 & TST & & \\
\hline CHEMBL3198683 & 688762 & 4.7219 & 4.7424 & TST & & \\
\hline CHEMBL3195193 & 688762 & 3.5065 & 3.2067 & TST & & \\
\hline CHEMBL1332098 & 688762 & 4.4486 & 4.4467 & TST & & \\
\hline CHEMBL3212563 & 688762 & 4.6774 & 4.888 & TST & & \\
\hline CHEMBL1521425 & 688762 & 4.7452 & 4.8147 & TST & & \\
\hline CHEMBL1520800 & 688762 & 4.5654 & 4.5781 & TST & & \\
\hline CHEMBL 2369298 & 688762 & 4.5223 & 4.4203 & TST & & \\
\hline CHEMBL1536563 & 688762 & 4.6834 & 4.7936 & TST & & \\
\hline CHEMBL1444264 & 688762 & 4.3433 & 4.2912 & TST & & \\
\hline CHEMBL1411785 & 688762 & 4.5326 & 4.4487 & TST & & \\
\hline CHEMBL1471931 & 688762 & 4.58899 & 99999999 & 995 & 4.6295 TST & \\
\hline CHEMBL 1534756 & 688762 & 4.9825 & 4.9211 & TST & & \\
\hline CHEMBL1530525 & 688762 & 5.5875 & 5.4007 & TST & & \\
\hline CHEMBL1581335 & 688762 & 4.6082 & 4.6113 & TST & & \\
\hline CHEMBL1362972 & 688762 & 4.9936 & 4.9839 & TST & & \\
\hline CHEMBL1377078 & 688762 & 5.13399 & 99999999 & 995 & 5.162999999999999 & TST \\
\hline CHEMBL1390555 & 688762 & 4.6754 & 4.6587 & TST & & \\
\hline CHEMBL1452264 & 688762 & 6.0778 & 5.9939 & TST & & \\
\hline CHEMBL1499183 & 688762 & 4.9823 & 4.8859 & TST & & \\
\hline CHEMBL1499017 & 688762 & 5.1944 & 5.2709 & TST & & \\
\hline CHEMBL1365340 & 688762 & 4.8279 & 4.5807 & TST & & \\
\hline CHEMBL1542833 & 688762 & 6.7878 & 6.1883 & TST & & \\
\hline CHEMBL1500686 & 688762 & 5.4185 & 5.4888 & TST & & \\
\hline CHEMBL1538035 & 688762 & 5.3655 & 5.3718 & TST & & \\
\hline CHEMBL1421316 & 688762 & 4.6028 & 4.89 & TST & & \\
\hline CHEMBL1541657 & 688762 & 5.06 & 5.0183 & TST & & \\
\hline CHEMBL1457747 & 688762 & 4.9707 & 4.867 & TST & & \\
\hline CHEMBL1569910 & 688762 & 5.9838 & 6.0225 & TST & & \\
\hline CHEMBL1503034 & 688762 & 5.9722 & 5.8127 & TST & & \\
\hline CHEMBL3191649 & 688762 & 4.8273 & 4.9231 & TST & & \\
\hline CHEMBL1197556 & 688762 & 6.7773 & 6.5873 & TST & & \\
\hline CHEMBL1340713 & 688762 & 5.6682 & 5.6744 & TST & & \\
\hline CHEMBL1408774 & 688762 & 5.0479 & 4.8453 & TST & & \\
\hline CHEMBL1299464 & 688762 & 4.7637 & 4.7954 & TST & & \\
\hline CHEMBL1304034 & 688762 & 4.6861 & 4.8158 & TST & & \\
\hline CHEMBL1519457 & 688762 & 4.9886 & 4.9969 & TST & & \\
\hline CHEMBL1523019 & 688762 & 5.329 & 5.2543 & TST & & \\
\hline CHEMBL591126 & 688762 & 5.7865 & 5.8027 & TST & & \\
\hline CHEMBL3196451 & 688762 & 5.5493 & 5.5788 & TST & & \\
\hline CHEMBL1542862 & 688762 & 5.5748 & 5.7061 & TST & & \\
\hline
\end{tabular}


Supplemental Table S2.txt

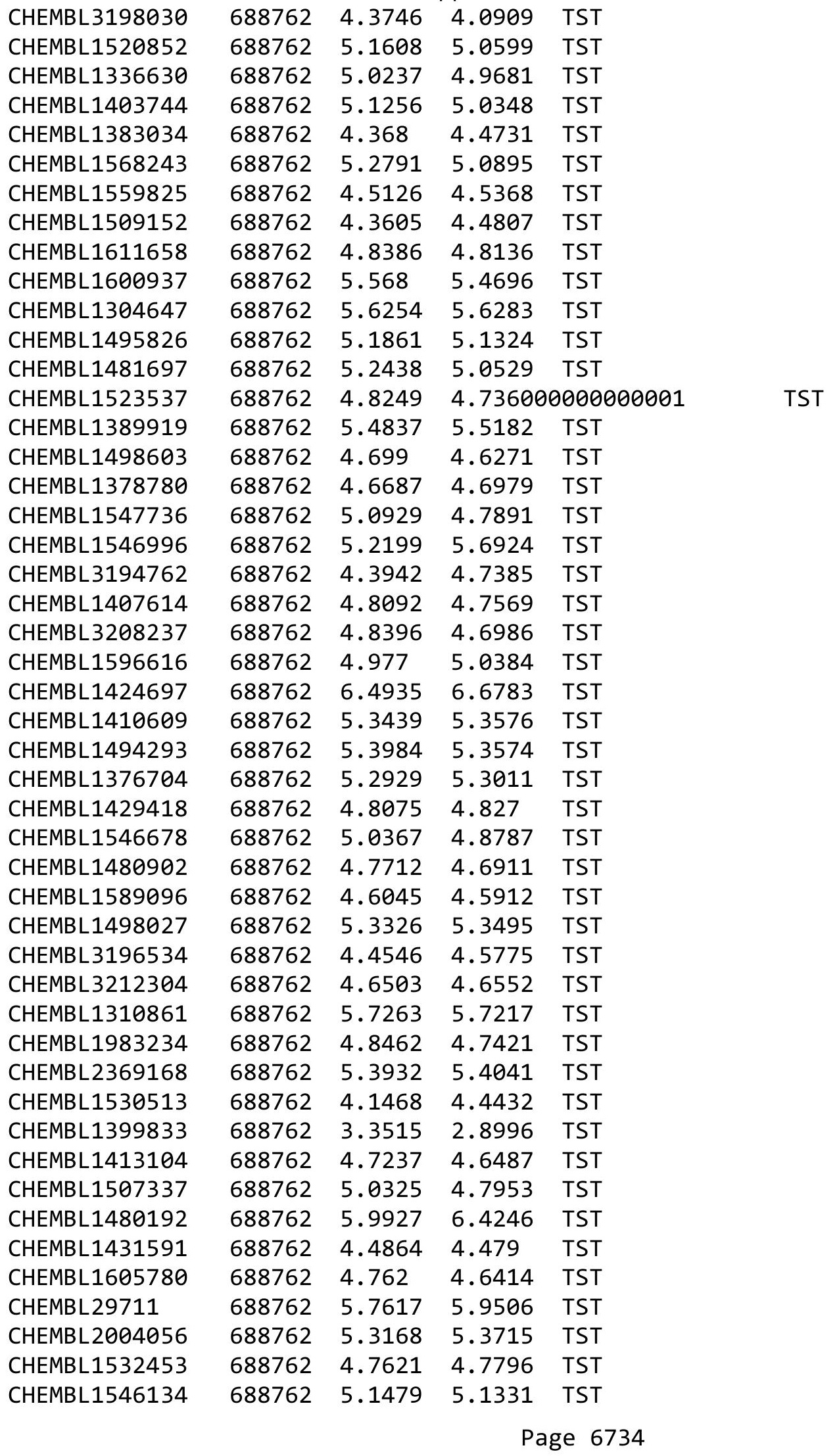


Supplemental Table S2.txt

\begin{tabular}{|c|c|c|c|c|}
\hline CHEMBL 3210140 & 688762 & 4.7512 & 4.7627 & TST \\
\hline CHEMBL1503152 & 688762 & 5.1439 & 4.975 & TST \\
\hline CHEMBL1543384 & 688762 & 4.479 & 4.7499 & TST \\
\hline CHEMBL1430328 & 688762 & 4.7697 & 4.7493 & TST \\
\hline CHEMBL1508591 & 688762 & 5.0951 & 5.1525 & TST \\
\hline CHEMBL 3397250 & 1462664 & 4.5361 & 4.9951 & TRN \\
\hline CHEMBL3397127 & 1462664 & 4.4045 & 4.2869 & TRN \\
\hline CHEMBL3397249 & 1462664 & 4.0414 & 4.4518 & TRN \\
\hline CHEMBL3397133 & 1462664 & 4.6696 & 5.1487 & TST \\
\hline CHEMBL 3397233 & 1462664 & 3.0 & 3.137 & TRN \\
\hline CHEMBL 3397145 & 1462664 & 6.5229 & 6.4076 & TRN \\
\hline CHEMBL3397112 & 1462664 & 4.4089 & 4.4014 & TST \\
\hline CHEMBL 3397246 & 1462664 & 5.3768 & 5.1631 & TRN \\
\hline CHEMBL 3397256 & 1462664 & 5.6383 & 5.7348 & TRN \\
\hline CHEMBL 3397116 & 1462664 & 4.1543 & 4.4756 & TST \\
\hline CHEMBL 3397138 & 1462664 & 4.0788 & 4.1671 & TRN \\
\hline CHEMBL3397121 & 1462664 & 4.5467 & 4.3367 & TRN \\
\hline CHEMBL3397262 & 1462664 & 4.3224 & 4.3416 & TRN \\
\hline CHEMBL3397113 & 1462664 & 4.2083 & 4.4157 & TST \\
\hline CHEMBL 3397137 & 1462664 & 4.2676 & 4.0505 & TRN \\
\hline CHEMBL 3397244 & 1462664 & 5.5376 & 4.4518 & TRN \\
\hline CHEMBL 3397140 & 1462664 & 6.301 & 5.9768 & TST \\
\hline CHEMBL3397231 & 1462664 & 4.5157 & 4.1483 & TRN \\
\hline CHEMBL3397123 & 1462664 & 4.4123 & 3.6994 & TRN \\
\hline CHEMBL 3397147 & 1462664 & 4.062 & 4.0334 & TRN \\
\hline CHEMBL 3397245 & 1462664 & 5.3565 & 5.4829 & TRN \\
\hline CHEMBL3397241 & 1462664 & 4.2815 & 3.8216 & TRN \\
\hline CHEMBL1492174 & 1462664 & 4.6676 & 4.2781 & TRN \\
\hline CHEMBL3397119 & 1462664 & 4.0453 & 3.6899 & TST \\
\hline CHEMBL 3397134 & 1462664 & 4.3947 & 4.8781 & TST \\
\hline CHEMBL 3397143 & 1462664 & 5.5086 & 5.6596 & TRN \\
\hline CHEMBL 3397240 & 1462664 & 4.1965 & 4.3063 & TRN \\
\hline CHEMBL3397118 & 1462664 & 3.0 & 3.9895 & TST \\
\hline CHEMBL 3397252 & 1462664 & 4.4202 & 4.7423 & TRN \\
\hline CHEMBL 3397110 & 1462664 & 4.4949 & 4.2217 & TST \\
\hline CHEMBL3397257 & 1462664 & 5.699 & 5.6913 & TRN \\
\hline CHEMBL 3397120 & 1462664 & 4.4976 & 4.4948 & TST \\
\hline CHEMBL 3397248 & 1462664 & 4.2573 & 4.9069 & TRN \\
\hline CHEMBL3397132 & 1462664 & 4.4437 & 4.34399 & 9999999999 \\
\hline CHEMBL 3397136 & 1462664 & 4.3696 & 4.0373 & TRN \\
\hline CHEMBL 3397255 & 1462664 & 5.5086 & 4.9648 & TRN \\
\hline CHEMBL 3397117 & 1462664 & 4.7055 & 4.4747 & TST \\
\hline CHEMBL 3397243 & 1462664 & 5.4437 & 4.9069 & TRN \\
\hline CHEMBL3397142 & 1462664 & 6.2218 & 6.1675 & TRN \\
\hline CHEMBL 3397251 & 1462664 & 4.2565 & 4.9648 & TRN \\
\hline CHEMBL 3397232 & 1462664 & 4.1599 & 4.0334 & TRN \\
\hline CHEMBL 3397146 & 1462664 & 4.0778 & 3.9955 & TRN \\
\hline CHEMBL3397259 & 1462664 & 5.7447 & 5.9096 & TRN \\
\hline
\end{tabular}


Supplemental Table S2.txt

\begin{tabular}{|c|c|c|}
\hline & & \\
\hline HEMBL 302245 & 52664 & 3.0 \\
\hline IEMBL3397253 & 462664 & 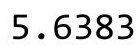 \\
\hline AEMBL3397258 & 64 & 5 \\
\hline 111 & & 4 \\
\hline 7234 & 64 & 387 \\
\hline AEMBL3397265 & -462664 & 4.531 \\
\hline AEMBL3397141 & 1462664 & 7.0 \\
\hline AEMBL3397236 & 64 & 4 \\
\hline IEMBL339 & 564 & 3.0 \\
\hline AEMBL3397109 & & 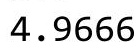 \\
\hline AEMBL3397230 & 1462664 & 3.0 \\
\hline AEMBL1452056 & L462664 & 447 \\
\hline IEMBL3397124 & 64 & 276 \\
\hline IEMBL339 & 64 & 19 \\
\hline IEMBL3397239 & & 55 \\
\hline AEMBL3397264 & 1462664 & 4.798 \\
\hline AEMBL3397247 & & $5.657 t$ \\
\hline IEMBL33 & 14 & 4. \\
\hline AEMBL33 & 14 & 4.172 \\
\hline AEMBL33 & 14 & \\
\hline HEMBL3397238 & 2664 & 3.0 \\
\hline HEMBL339 & & 3054 \\
\hline IEMBL3: & 14 & 4.4067 \\
\hline HEMBL3 & 14 & 884 \\
\hline AFMBI $3=$ & 64 & 311 \\
\hline AEMBL3397135 & 2664 & 4.3585 \\
\hline AEMBL3397237 & & 4.378 \\
\hline AEMBL3397261 & 1462664 & \\
\hline 260 & 14 & 752 \\
\hline 44 & 64 & 229 \\
\hline IEMBL3397266 & 1462664 & 4.415 \\
\hline AEMBL3397129 & 146 & 3.0 \\
\hline AEMBL1504404 & 2664 & 4.4365 \\
\hline AEMBL3: & 14 & 986 \\
\hline AEMBL33 & 64 & 3. \\
\hline AEMBL3397115 & 1462664 & 4.6904 \\
\hline AEMBL3397254 & 1462664 & 5.7959 \\
\hline AEMBL33 & 564 & \\
\hline 523 & 15 & $7.619 \varepsilon$ \\
\hline HEMBL 39 & 68 & 7.699 \\
\hline AEMBL3925213 & 1536468 & 6.0 \\
\hline AEMBL 39 & 1536468 & 6.7447 \\
\hline 005 & & $5.920 \varepsilon$ \\
\hline HEMBL 39 & 1536468 & 7.3979 \\
\hline CHEMBL3941396 & 1536468 & 6.5346 \\
\hline HEMBL3977380 & 1536468 & 8.699 \\
\hline HEMBL 3968922 & 1536468 & 7161 \\
\hline
\end{tabular}

4.3613 TST

3.8543 TRN

5.7454 TRN

5.4991 TRN

4.1988 TST

4.1483 TST

4.273 TRN

6.5228 TST

4.0523 TRN

3.6994 TRN

4.2342 TST

3.4347 TRN

4.3258 TRN

4.2216 TRN

4.1386 TRN

4.1386 TRN

4.6678 TRN

4.9951 TST

4.3475 TRN

4.3342 TST

2.9385 TRN

3.2084 TRN

4.5219 TRN

5.0047 TST

4.6610000000000005

TST

4.0245 TRN

4.2669 TRN

4.256 TRN

3.4054 TRN

3.4622 TRN

6.6499 TRN

4.5407 TRN

2.9456 TRN

4.4314 TRN

4.6039 TRN

3.8272 TRN

4.6121 TST

5.5486 TRN

3.137 TRN

7.1353 TRN

7.4437 TRN

6.3863 TRN

6.9047 TRN

6.4633 TRN

6.8983 TST

7.5829 TRN

8.5297 TRN

6.4814 TRN

Page 6736 
Supplemental Table S2.txt

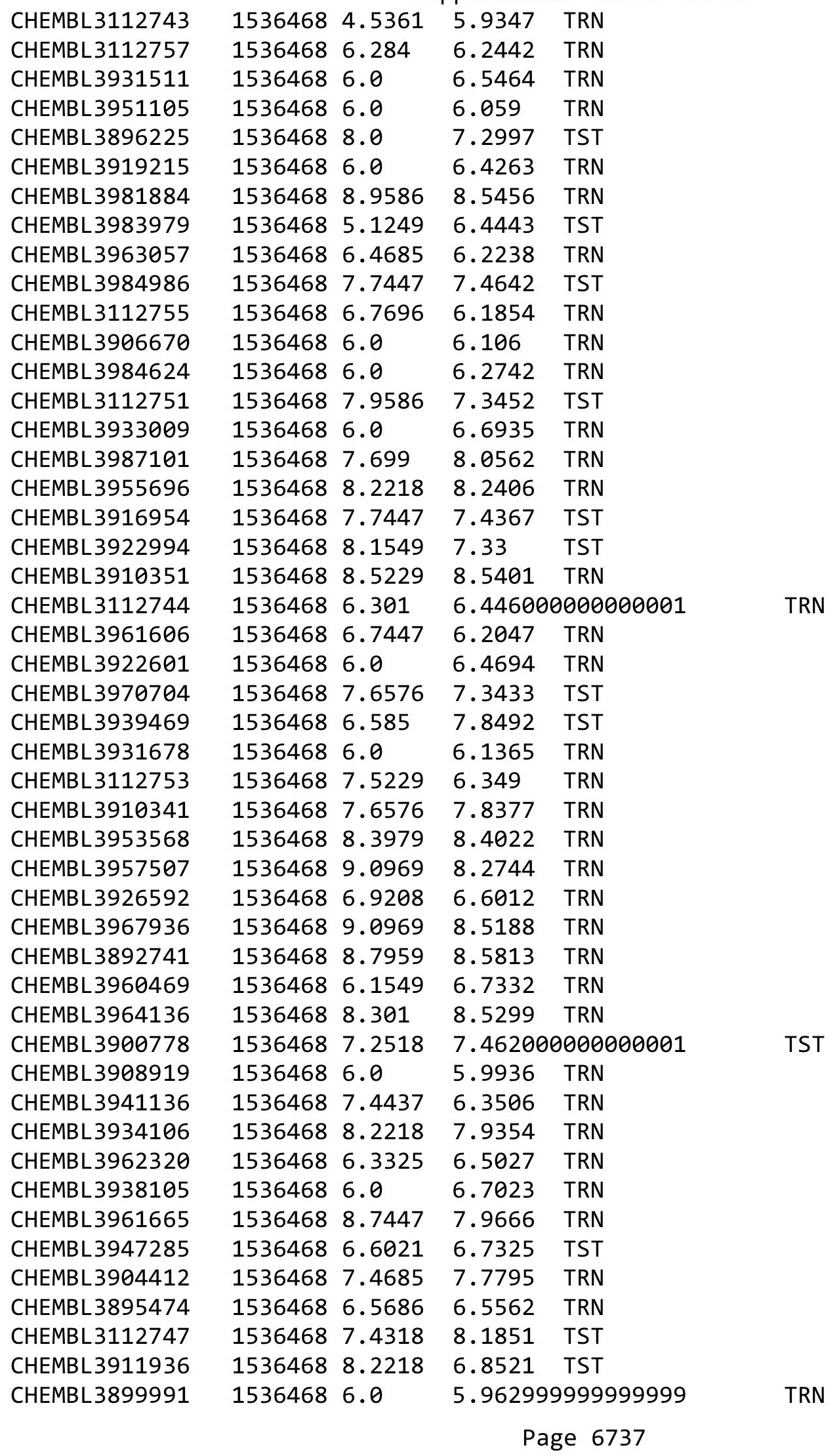


Supplemental Table S2.txt

\begin{tabular}{|c|c|c|c|c|}
\hline & & & & \\
\hline HEMBL3971570 & 536468 & 6.2757 & 646 & \\
\hline HEMBL 3981837 & & 6.5686 & & \\
\hline & & 229 & 37 & \\
\hline 657 & 8 & & 54 & \\
\hline AEMBL3112754 & 536468 & 6.5376 & 238 & \\
\hline AEMBL 3946631 & 536468 & 6.0862 & 508 & \\
\hline HEMBL & & 825 & 404 & \\
\hline IEMBL: & 8 & 8.0223 & 405 & \\
\hline EMBL & 53 & 6.2291 & 308 & \\
\hline AEMBL3932610 & 536468 & 6.1308 & 179 & \\
\hline AEMBL & 5364 & 7.1938 & 783 & \\
\hline 548 & 8 & 7.2147 & 095 & \\
\hline 749 & 8 & 8.5229 & 55 & \\
\hline 371 & 8 & 6.2218 & & \\
\hline IEMBL & 536 & 882 & 216 & \\
\hline 247 & 8 & 6.0 & & \\
\hline 25 & 8 & 959 & & \\
\hline 11 & & 6. & & \\
\hline 929 & 153 & 6.6 & & \\
\hline 748 & 8 & 08 & & \\
\hline 47 & 8 & & & \\
\hline 09 & 36 & 6. & & \\
\hline 06 & & 768 & & \\
\hline 42 & 150 & 549 & & \\
\hline 364 & 8 & & & \\
\hline 591 & 536 & & & \\
\hline 106 & 8 & 6. & & \\
\hline 30 & 8 & 6. & 85 & \\
\hline 19 & 152 & 8.1549 & & \\
\hline & 536 & & & \\
\hline 519 & 595 & 4. & & \\
\hline & & & & IJ \\
\hline 4 & בצניק & 4. & & \\
\hline 725 & 7 תחת & & & \\
\hline & 7595 & & & \\
\hline 19 & 595 & 6. & 32 & \\
\hline & & 6. & & \\
\hline 22 & & 6. & & \\
\hline 506 & 7595 & & & $\Gamma R$ \\
\hline CHEMBL & 7595 & 37 & 41 & \\
\hline CHEMB & 7595 & 28 & & \\
\hline & & 4. & & \\
\hline CHEMB & 7595 & 6.0 & 892 & \\
\hline 7521 & 759559 & 7.4202 & 7.6349 & $\mathrm{R}$ \\
\hline 1773 & 7595 & 6.1232 & 047 & \\
\hline & 759 & & & \\
\hline & 75955 & - & 5.9401 & \\
\hline
\end{tabular}

Page 6738 


\begin{tabular}{|c|c|c|c|c|c|c|}
\hline \multicolumn{7}{|c|}{ Supplemental Table s2.txt } \\
\hline CHEMBL1807520 & 759559 & 4.0 & 4.5499 & TRN & & \\
\hline CHEMBL1807781 & 759559 & 5.5243 & 6.0111 & TRN & & \\
\hline CHEMBL1807198 & 759559 & 6.7212 & 6.8793 & TRN & & \\
\hline CHEMBL223486 & 759559 & 4.0 & 5.9535 & TST & & \\
\hline CHEMBL1807717 & 759559 & 6.8239 & 6.0362 & TRN & & \\
\hline CHEMBL249500 & 759559 & 6.0 & 5.3602 & TRN & & \\
\hline CHEMBL1807715 & 759559 & 6.9547 & 6.4638 & TRN & & \\
\hline CHEMBL1807513 & 759559 & 5.3468 & 7.02 & TST & & \\
\hline CHEMBL396098 & 759559 & 7.301 & 6.4906 & TST & & \\
\hline CHEMBL426509 & 759559 & 6.4724 & 6.2229 & TRN & & \\
\hline CHEMBL1807515 & 759559 & 5.4293 & 4.7349 & TRN & & \\
\hline CHEMBL1807516 & 759559 & 4.9586 & 4.8205 & TRN & & \\
\hline CHEMBL 221224 & 759559 & 5.0 & 5.8471 & TST & & \\
\hline CHEMBL400859 & 759559 & 5.9586 & 5.7761 & TRN & & \\
\hline CHEMBL1808238 & 759559 & 5.0 & 5.5959 & TRN & & \\
\hline CHEMBL1807718 & 759559 & 6.6968 & 7.3091 & TRN & & \\
\hline CHEMBL1807777 & 759559 & 5.9112 & 5.8961 & TRN & & \\
\hline CHEMBL 248712 & 759559 & 7.4089 & 6.3346 & TRN & & \\
\hline CHEMBL1807720 & 759559 & 6.6615 & 6.3174 & TRN & & \\
\hline CHEMBL1807517 & 759559 & 4.2596 & 4.6542 & TRN & & \\
\hline CHEMBL 213277 & 759559 & 5.0 & 5.3385 & TRN & & \\
\hline CHEMBL1807714 & 759559 & 6.9586 & 5.9436 & TST & & \\
\hline CHEMBL1807784 & 759559 & 5.0 & 4.6024 & TRN & & \\
\hline CHEMBL1807507 & 759559 & 6.301 & 6.4469 & TRN & & \\
\hline CHEMBL385827 & 759559 & 5.0 & 4.8091 & TRN & & \\
\hline CHEMBL1807778 & 759559 & 5.9094 & 5.0505 & TRN & & \\
\hline CHEMBL1807514 & 759559 & 5.0 & 5.4208 & TRN & & \\
\hline CHEMBL1807512 & 759559 & 5.5686 & 6.1286 & TRN & & \\
\hline CHEMBL1807782 & 759559 & $5.3720 e$ & 30000000 & & .8757 & TST \\
\hline CHEMBL1808239 & 759559 & 4.0 & 4.7561 & TRN & & \\
\hline CHEMBL 220951 & 759559 & 6.0 & 6.1169 & TST & & \\
\hline CHEMBL1807721 & 759559 & 6.426 & 6.7214 & TRN & & \\
\hline CHEMBL1806508 & 759559 & 5.0 & 4.6594 & TRN & & \\
\hline CHEMBL1807196 & 759559 & 8.2218 & 5.7451 & TST & & \\
\hline CHEMBL249502 & 759559 & 6.3872 & 6.1248 & TRN & & \\
\hline CHEMBL 213207 & 759559 & 4.0 & 4.7856 & TRN & & \\
\hline CHEMBL251739 & 759559 & 5.9101 & 6.0702 & TRN & & \\
\hline CHEMBL214819 & 759559 & 6.0 & 5.7059 & TRN & & \\
\hline CHEMBL1807774 & 759559 & 6.0 & 5.6619 & TRN & & \\
\hline CHEMBL249303 & 759559 & 6.0 & 5.9795 & TRN & & \\
\hline CHEMBL1807779 & 759559 & 5.8989 & 6.4671 & TRN & & \\
\hline CHEMBL1807780 & 759559 & 5.8969 & 5.9815 & TRN & & \\
\hline CHEMBL1806510 & 759559 & 7.0458 & 5.86700 & 0000000001 & & TST \\
\hline CHEMBL1807723 & 759559 & 6.3152 & 6.5549 & TRN & & \\
\hline CHEMBL1807518 & 759559 & 4.0 & 5.3156 & TRN & & \\
\hline CHEMBL400569 & 759559 & 6.8539 & 6.6715 & TRN & & \\
\hline CHEMBL1807510 & 759559 & 5.7447 & 6.3744 & TST & & \\
\hline CHEMBL1807783 & 759559 & $5.0360 e$ & 30000000 & 205 & .7089 & TST \\
\hline
\end{tabular}


Supplemental Table S2.txt

\begin{tabular}{|c|c|c|c|c|}
\hline CHEMBL1807509 & 759559 & 5.7959 & 5.3321 & TST \\
\hline CHEMBL 212491 & 759559 & 5.0 & 5.1122 & TST \\
\hline CHEMBL1808237 & 759559 & 5.0 & 4.5571 & TST \\
\hline CHEMBL1807724 & 759559 & 6.27 & 6.1089 & TST \\
\hline CHEMBL 249518 & 759559 & 5.4908 & 6.2067 & TRN \\
\hline CHEMBL1807713 & 759559 & 6.983 & 6.3027 & TRN \\
\hline CHEMBL 3907320 & 1642379 & 8.5768 & 8.31 & TRN \\
\hline CHEMBL3966696 & 1642379 & 8.5058 & 8.1357 & TRN \\
\hline CHEMBL3936808 & 1642379 & 7.8268 & 7.8706 & TRN \\
\hline CHEMBL 3947309 & 1642379 & 8.3706 & 8.4854 & TRN \\
\hline CHEMBL 3953990 & 1642379 & 8.3947 & 8.0825 & TRN \\
\hline CHEMBL 3953164 & 1642379 & 9.5031 & 9.8666 & TRN \\
\hline CHEMBL 3909280 & 1642379 & 6.0 & 5.4851 & TRN \\
\hline CHEMBL 3951387 & 1642379 & 6.0 & 5.7416 & TRN \\
\hline CHEMBL 3960453 & 1642379 & 9.0937 & 8.5327 & TRN \\
\hline CHEMBL 3890745 & 1642379 & 7.9957 & 7.843 & TRN \\
\hline CHEMBL3972453 & 1642379 & 7.4584 & 8.0279 & TRN \\
\hline CHEMBL 3902417 & 1642379 & 8.9355 & 8.3836 & TRN \\
\hline CHEMBL3958785 & 1642379 & 8.9431 & 8.5576 & TRN \\
\hline CHEMBL 3939262 & 1642379 & 8.2924 & 7.9948 & TRN \\
\hline CHEMBL 3892536 & 1642379 & 7.9172 & 7.9066 & TRN \\
\hline CHEMBL 3892590 & 1642379 & 7.5482 & 7.4659 & TRN \\
\hline CHEMBL 3900425 & 1642379 & 9.2518 & 8.3083 & TST \\
\hline CHEMBL 3944819 & 1642379 & 7.7258 & 7.3973 & TRN \\
\hline CHEMBL 3980111 & 1642379 & 8.2692 & 8.4091 & TRN \\
\hline CHEMBL 3932475 & 1642379 & 10.1135 & 9.9352 & TRN \\
\hline CHEMBL 3917077 & 1642379 & 8.7282 & 8.6034 & TRN \\
\hline CHEMBL 3944757 & 1642379 & 8.4067 & 8.3613 & TRN \\
\hline CHEMBL3968874 & 1642379 & 7.3458 & 7.4093 & TRN \\
\hline CHEMBL 3959091 & 1642379 & 9.1261 & 9.3498 & TRN \\
\hline CHEMBL 3951088 & 1642379 & 8.4123 & 8.6149 & TRN \\
\hline CHEMBL 3955604 & 1642379 & 8.8447 & 8.28399 & 9999999999 \\
\hline CHEMBL 3943759 & 1642379 & 6.0 & 6.2607 & TRN \\
\hline CHEMBL 3906850 & 1642379 & 8.0168 & 7.7979 & TRN \\
\hline CHEMBL 3942446 & 1642379 & 8.8633 & 8.6653 & TRN \\
\hline CHEMBL3973175 & 1642379 & 8.0804 & 7.5676 & TST \\
\hline CHEMBL 3919520 & 1642379 & 8.58 & 8.7623 & TRN \\
\hline CHEMBL 3915913 & 1642379 & 8.5272 & 8.5419 & TST \\
\hline CHEMBL3986159 & 1642379 & 7.7825 & 7.7352 & TRN \\
\hline CHEMBL 3891387 & 1642379 & 8.6421 & 8.8252 & TRN \\
\hline CHEMBL 3947770 & 1642379 & 8.4789 & 8.1573 & TST \\
\hline CHEMBL 3959634 & 1642379 & 7.6904 & 7.9354 & TRN \\
\hline CHEMBL 3945513 & 1642379 & 5.6576 & 5.7369 & TST \\
\hline CHEMBL 3984232 & 1642379 & 8.0137 & 7.8866 & TST \\
\hline CHEMBL 3930402 & 1642379 & 7.5072 & 7.7587 & TST \\
\hline CHEMBL 3926146 & 1642379 & 5.9586 & 5.8452 & TST \\
\hline CHEMBL 3935018 & 1642379 & 9.1403 & 9.3992 & TRN \\
\hline CHEMBL 3965741 & 1642379 & 7.7721 & 7.8192 & TRN \\
\hline
\end{tabular}


Supplemental Table S2.txt

\begin{tabular}{|c|c|c|c|c|c|}
\hline CHEMBL 3907493 & 1642379 & 7.7447 & 8.3777 & TRN & \\
\hline CHEMBL3973544 & 1642379 & 8.4584 & 8.5327 & TRN & \\
\hline CHEMBL3944062 & 1642379 & 9.0491 & $8.69700 t$ & 0000000001 & TRN \\
\hline CHEMBL3924903 & 1642379 & 6.0 & 5.9256 & TST & \\
\hline CHEMBL3905519 & 1642379 & 8.8327 & 8.4882 & TRN & \\
\hline CHEMBL3960858 & 1642379 & 6.7077 & 7.1648 & TRN & \\
\hline CHEMBL3906798 & 1642379 & 9.2403 & 9.3531 & TRN & \\
\hline CHEMBL3985665 & 1642379 & 8.3655 & 8.1419 & TST & \\
\hline CHEMBL3908853 & 1642379 & 7.5591 & 7.6343 & TRN & \\
\hline CHEMBL3900258 & 1642379 & 8.8928 & 8.6716 & TST & \\
\hline CHEMBL3975756 & 1642379 & 8.4724 & 8.6748 & TRN & \\
\hline CHEMBL3901533 & 1642379 & 6.0 & 5.9848 & TRN & \\
\hline CHEMBL3956717 & 1642379 & 7.8633 & 7.9899 & TRN & \\
\hline CHEMBL3893598 & 1642379 & 8.4353 & 8.5419 & TRN & \\
\hline CHEMBL3970681 & 1642379 & 6.8268 & 7.2327 & TRN & \\
\hline CHEMBL3935096 & 1642379 & 9.3019 & 8.8329 & TRN & \\
\hline CHEMBL3922549 & 1642379 & 8.9136 & 9.0544 & TRN & \\
\hline CHEMBL3890953 & 1642379 & 8.7645 & 8.5233 & TRN & \\
\hline CHEMBL3895094 & 1642379 & \multicolumn{3}{|c|}{8.056000000000001} & TRN \\
\hline CHEMBL3985113 & 1642379 & 5.5376 & 6.0927 & TRN & \\
\hline CHEMBL3958302 & 1642379 & 7.8729 & 8.0184 & TRN & \\
\hline CHEMBL3983351 & 1642379 & \multicolumn{2}{|c|}{8.767000000000001} & 8.6473 & TRN \\
\hline CHEMBL3934298 & 1642379 & 7.6757 & 7.9149 & TRN & \\
\hline CHEMBL3934315 & 1642379 & 7.9031 & 8.2421 & TRN & \\
\hline CHEMBL3930725 & 1642379 & 6.0 & 5.5959 & TRN & \\
\hline CHEMBL3920503 & 1642379 & 8.1481 & 7.9724 & TRN & \\
\hline CHEMBL3959083 & 1642379 & 7.1986 & 7.195 & TST & \\
\hline CHEMBL3975199 & 1642379 & 7.7932 & 8.0249 & TRN & \\
\hline CHEMBL3907848 & 1642379 & 7.8239 & 8.0282 & TRN & \\
\hline CHEMBL3895531 & 1642379 & 8.6162 & 8.1001 & TRN & \\
\hline CHEMBL3970183 & 1642379 & 6.3757 & 6.38399 & 99999999995 & TRN \\
\hline CHEMBL3925403 & 1642379 & 6.0 & 5.6356 & TRN & \\
\hline CHEMBL3982539 & 1642379 & 9.8477 & 9.7538 & TRN & \\
\hline CHEMBL3972017 & 1642379 & 7.3883 & \multicolumn{2}{|c|}{7.502999999999999} & TRN \\
\hline CHEMBL3975787 & 1642379 & 8.0655 & 7.8143 & TST & \\
\hline CHEMBL3900834 & 1642379 & 8.1752 & 8.0266 & TRN & \\
\hline CHEMBL3981915 & 1642379 & 8.5302 & 8.4276 & TRN & \\
\hline CHEMBL3897351 & 1642379 & 5.6383 & 6.0022 & TRN & \\
\hline CHEMBL3915323 & 1642379 & 8.0711 & 8.2292 & TRN & \\
\hline CHEMBL3981104 & 1642379 & 8.0205 & 7.7866 & TRN & \\
\hline CHEMBL3943705 & 1642379 & 9.4776 & 9.3053 & TRN & \\
\hline CHEMBL3961823 & 1642379 & 9.9393 & 9.9641 & TRN & \\
\hline CHEMBL3976267 & 1642379 & 6.0 & 5.7771 & TRN & \\
\hline CHEMBL3970953 & 1642379 & 9.1487 & 8.818 & TRN & \\
\hline CHEMBL3900423 & 1642379 & \multicolumn{3}{|c|}{ 7.757000000000001 } & TRN \\
\hline CHEMBL3984839 & 1642379 & 6.7122 & 6.9773 & TRN & \\
\hline CHEMBL3963946 & 1642379 & 6.0 & 6.1785 & TRN & \\
\hline CHEMBL3900796 & 1642379 & 7.4989 & 7.8661 & TST & \\
\hline
\end{tabular}


Supplemental Table S2.txt

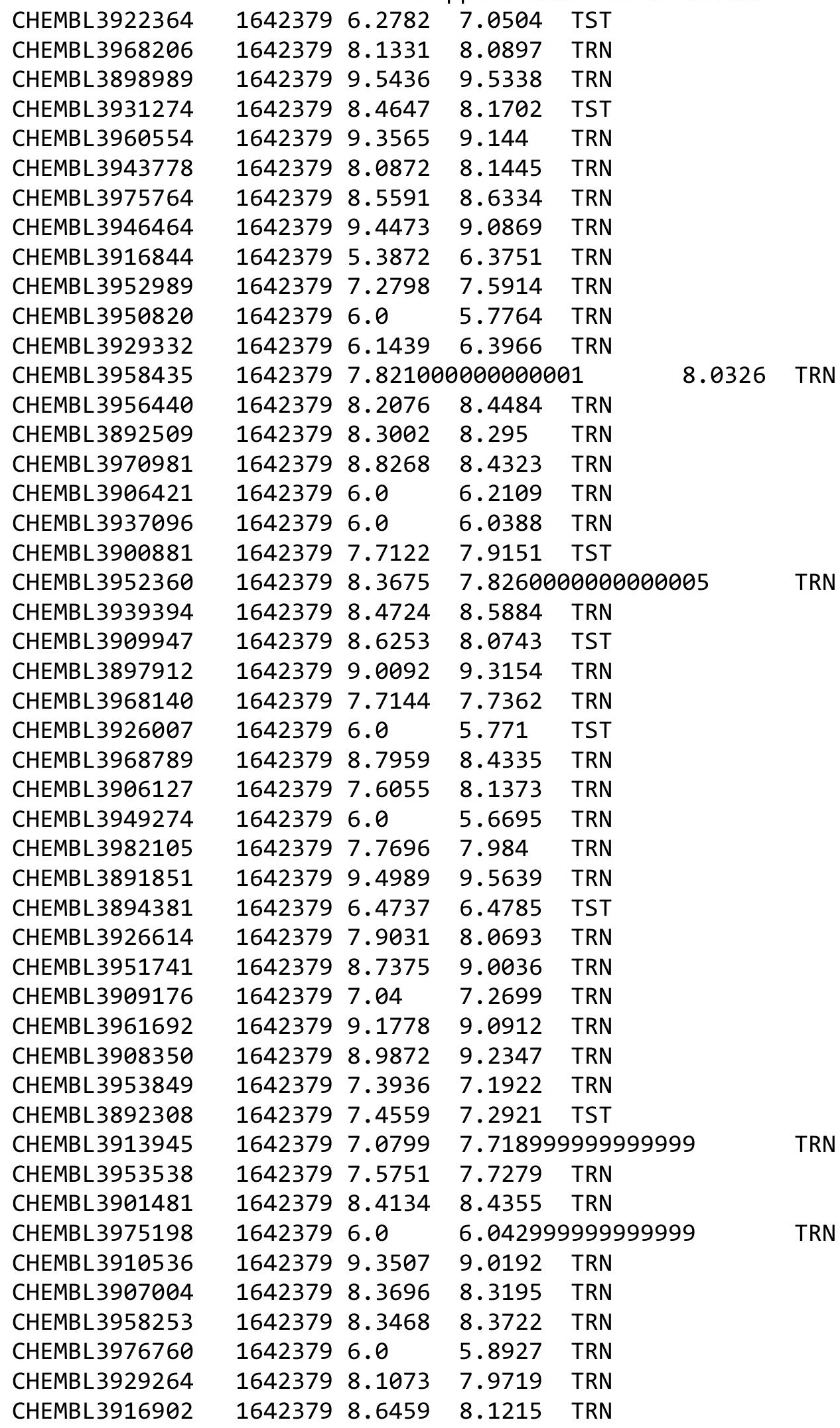


Supplemental Table S2.txt

\begin{tabular}{|c|c|c|c|c|c|}
\hline CHEMBL3963170 & 1642379 & 9.1284 & 8.5206 & TST & \\
\hline CHEMBL3940744 & 1642379 & 9.6326 & 9.6721 & TRN & \\
\hline CHEMBL3969289 & 1642379 & \multicolumn{3}{|c|}{7.3420000000000005} & TRN \\
\hline CHEMBL3939101 & 1642379 & 8.0438 & 8.2867 & TRN & \\
\hline CHEMBL3946970 & 1642379 & 9.1688 & 9.0001 & TRN & \\
\hline CHEMBL3924152 & 1642379 & 6.0 & 5.875 & TRN & \\
\hline CHEMBL3961525 & 1642379 & 7.8356 & 8.0239 & TRN & \\
\hline CHEMBL3927952 & 1642379 & 6.0 & 5.75799 & 9999999999 & TRN \\
\hline CHEMBL3930816 & 1642379 & 9.7282 & 9.5109 & TRN & \\
\hline CHEMBL3975766 & 1642379 & 7.5331 & 7.5503 & TRN & \\
\hline CHEMBL3937034 & 1642379 & 6.0 & 5.5944 & TRN & \\
\hline CHEMBL3961287 & 1642379 & 6.7423 & 7.0858 & TST & \\
\hline CHEMBL3983224 & 1642379 & 8.8297 & 8.6213 & TRN & \\
\hline CHEMBL3957118 & 1642379 & 6.1284 & 6.8032 & TRN & \\
\hline CHEMBL3914639 & 1642379 & 9.8729 & 9.81899 & 9999999999 & TRN \\
\hline CHEMBL3947484 & 1642379 & 8.1463 & 8.3233 & TRN & \\
\hline CHEMBL3942104 & 1642379 & 6.0 & 5.5906 & TRN & \\
\hline CHEMBL3983795 & 1642379 & 8.0942 & 8.4772 & TST & \\
\hline CHEMBL3940227 & 1642379 & 8.0794 & 8.2131 & TRN & \\
\hline CHEMBL3957997 & 1642379 & 8.399 & 8.3003 & TRN & \\
\hline CHEMBL3931279 & 1642379 & 8.3354 & 8.0509 & TRN & \\
\hline CHEMBL3952845 & 1642379 & 6.0 & 6.3235 & TRN & \\
\hline CHEMBL3937209 & 1642379 & 8.9747 & 8.9926 & TST & \\
\hline CHEMBL3938583 & 1642379 & 7.7986 & 7.9568 & TST & \\
\hline CHEMBL3974800 & 1642379 & 8.2549 & 7.8348 & TST & \\
\hline CHEMBL3980040 & 1642379 & 8.0405 & 8.2584 & TST & \\
\hline CHEMBL3985111 & 1642379 & 8.3316 & 8.5015 & TST & \\
\hline CHEMBL 3892885 & 1642379 & 9.4045 & 9.5464 & TST & \\
\hline CHEMBL3920778 & 1642379 & 9.5901 & 9.6013 & TST & \\
\hline CHEMBL3934383 & 1642379 & 9.6421 & 8.7662 & TST & \\
\hline CHEMBL3896312 & 1642379 & 9.4318 & 9.4469 & TST & \\
\hline CHEMBL3965243 & 1642379 & 8.4461 & 7.7315 & TST & \\
\hline CHEMBL3919378 & 1642379 & 7.6326 & 7.9551 & TST & \\
\hline CHEMBL3953482 & 1642379 & 7.9788 & 8.1026 & TST & \\
\hline CHEMBL3946306 & 1642379 & 8.2411 & 8.0672 & TST & \\
\hline CHEMBL3984183 & 1642379 & 9.0097 & 8.5864 & TST & \\
\hline CHEMBL3933868 & 1642379 & 8.3307 & 8.4359 & TST & \\
\hline CHEMBL3899519 & 1642379 & 7.5186 & 7.325 & TST & \\
\hline CHEMBL3972050 & 1642379 & 8.9957 & 8.4809 & TST & \\
\hline CHEMBL3918384 & 1642379 & 6.0 & 5.6526 & TST & \\
\hline CHEMBL3961360 & 1642379 & 8.5817 & 8.46600 & 3000000001 & TST \\
\hline CHEMBL3947370 & 1642379 & 7.983 & 8.6367 & TST & \\
\hline CHEMBL57761 & 216843 & 5.585 & 5.4298 & TRN & \\
\hline CHEMBL298620 & 216843 & 6.7447 & 6.6679 & TRN & \\
\hline CHEMBL294711 & 216843 & 6.7212 & 6.5894 & TRN & \\
\hline CHEMBL299687 & 216843 & 7.0362 & 7.0352 & TRN & \\
\hline CHEMBL443262 & 216843 & 6.8861 & 7.1062 & TRN & \\
\hline CHEMBL58652 & 216843 & 7.3979 & 7.3538 & TRN & \\
\hline
\end{tabular}


Supplemental Table S2.txt

\begin{tabular}{|c|c|c|c|c|}
\hline CHEMBL293132 & 216843 & 7.9208 & 7.7169 & TRN \\
\hline CHEMBL56380 & 216843 & 5.9586 & 5.8339 & TRN \\
\hline CHEMBL58628 & 216843 & 6.3665 & 5.1209 & TST \\
\hline CHEMBL57531 & 216843 & 5.7959 & 4.8908 & TST \\
\hline CHEMBL293322 & 216843 & 7.4437 & 7.3811 & TRN \\
\hline CHEMBL299270 & 216843 & 6.0706 & 6.0458 & TRN \\
\hline CHEMBL432708 & 216843 & 7.0 & 7.0225 & TRN \\
\hline CHEMBL300992 & 216843 & 5.5686 & 5.2236 & TRN \\
\hline CHEMBL60979 & 216843 & 7.5376 & 7.5198 & TRN \\
\hline CHEMBL58937 & 216843 & 5.8539 & \multicolumn{2}{|c|}{5.7410000000000005} \\
\hline CHEMBL57947 & 216843 & 6.6576 & \multicolumn{2}{|c|}{6.707999999999999} \\
\hline CHEMBL57347 & 216843 & 7.4949 & 7.4737 & TRN \\
\hline CHEMBL57207 & 216843 & 7.7212 & 7.6362 & TRN \\
\hline CHEMBL 299026 & 216843 & 7.1367 & \multicolumn{2}{|c|}{7.167999999999999} \\
\hline CHEMBL418111 & 216843 & 7.8239 & 7.8643 & TRN \\
\hline CHEMBL57022 & 216843 & 7.1079 & 7.3463 & TRN \\
\hline CHEMBL368189 & 216843 & 7.6576 & 7.9526 & TRN \\
\hline CHEMBL57229 & 216843 & 6.3468 & 5.7975 & TST \\
\hline CHEMBL57323 & 216843 & 6.9586 & 6.1013 & TST \\
\hline CHEMBL60690 & 216843 & 6.8861 & 6.9622 & TRN \\
\hline CHEMBL 291777 & 216843 & 7.0088 & 6.9876 & TRN \\
\hline CHEMBL58627 & 216843 & 6.6778 & 5.4668 & TST \\
\hline CHEMBL301641 & 216843 & 7.7959 & 7.6461 & TRN \\
\hline CHEMBL51485 & 216843 & 7.5229 & 7.7443 & TRN \\
\hline CHEMBL56942 & 216843 & 3.301 & 5.2251 & TST \\
\hline CHEMBL57803 & 216843 & 7.0132 & 6.9929 & TRN \\
\hline CHEMBL417961 & 216843 & 7.699 & 7.2318 & TRN \\
\hline CHEMBL57585 & 216843 & 6.9208 & 7.0931 & TRN \\
\hline CHEMBL57366 & 216843 & 6.6576 & 6.0991 & TST \\
\hline CHEMBL444829 & 216843 & 7.4815 & 7.5788 & TRN \\
\hline CHEMBL56983 & 216843 & 8.1249 & 8.2495 & TRN \\
\hline CHEMBL292146 & 216843 & 7.6576 & 7.8379 & TRN \\
\hline CHEMBL416501 & 216843 & 6.9208 & 7.1845 & TRN \\
\hline CHEMBL300335 & 216843 & 6.0655 & 6.1516 & TRN \\
\hline CHEMBL51028 & 216843 & 7.5086 & 7.4723 & TRN \\
\hline CHEMBL 264280 & 216843 & 7.2147 & 6.9067 & TRN \\
\hline CHEMBL58936 & 216843 & 5.4815 & 5.5948 & TRN \\
\hline CHEMBL300171 & 216843 & 6.6778 & 6.086 & TST \\
\hline CHEMBL417208 & 216843 & 7.6576 & 7.1441 & TRN \\
\hline CHEMBL417950 & 216843 & 4.7212 & 4.7484 & TRN \\
\hline CHEMBL 292701 & 216843 & 3.301 & 3.7886 & TRN \\
\hline CHEMBL294438 & 216843 & 6.9208 & 7.2282 & TRN \\
\hline CHEMBL431942 & 216843 & 8.0 & 8.0153 & TRN \\
\hline CHEMBL58684 & 216843 & 5.4559 & 5.4466 & TRN \\
\hline CHEMBL298679 & 216843 & 7.4815 & 7.4946 & TRN \\
\hline CHEMBL45827 & 216843 & 8.1308 & 7.8016 & TRN \\
\hline CHEMBL57451 & 216843 & 6.8239 & 7.00899 & 99999999995 \\
\hline CHEMBL 301483 & 216843 & 7.7447 & 7.9779 & TRN \\
\hline
\end{tabular}




\begin{tabular}{|c|c|c|c|c|}
\hline & & & pplement & al $\mathrm{T}$ \\
\hline CHEMBL418284 & 216843 & 7.7959 & 7.5569 & TRN \\
\hline CHEMBL 300784 & 216843 & 6.1249 & 6.0103 & TST \\
\hline CHEMBL301273 & 216843 & 7.0269 & 7.1315 & TRN \\
\hline CHEMBL 293592 & 216843 & 3.301 & 3.94 & TST \\
\hline CHEMBL57475 & 216843 & 5.3872 & 5.2812 & TRN \\
\hline CHEMBL60635 & 216843 & 5.0757 & 5.0024 & TST \\
\hline CHEMBL56184 & 216843 & 7.6576 & 6.8811 & TST \\
\hline CHEMBL 299763 & 216843 & 3.301 & 5.459 & TST \\
\hline CHEMBL61257 & 216843 & 7.6198 & 7.3373 & TST \\
\hline CHEMBL57035 & 216843 & 5.3979 & 5.1767 & TST \\
\hline CHEMBL56958 & 216843 & 6.1192 & 5.6134 & TST \\
\hline CHEMBL56236 & 216843 & 3.301 & 4.7151 & TST \\
\hline CHEMBL3217116 & 566779 & 7.7696 & 7.6792 & TRN \\
\hline CHEMBL3216891 & 566779 & 7.7212 & 8.0022 & TST \\
\hline CHEMBL22998 & 566779 & 7.6778 & 7.7687 & TRN \\
\hline CHEMBL935 & 566779 & 7.8539 & 7.8144 & TRN \\
\hline CHEMBL3216427 & 566779 & 8.0 & 7.4704 & TRN \\
\hline CHEMBL3216657 & 566779 & 7.699 & 7.0117 & TRN \\
\hline CHEMBL3216424 & 566779 & 5.0804 & 6.0889 & TST \\
\hline CHEMBL3215771 & 566779 & 7.3565 & 7.0123 & TRN \\
\hline CHEMBL3216013 & 566779 & 6.1931 & 6.8854 & TRN \\
\hline CHEMBL3217109 & 566779 & 6.6968 & 6.726 & TST \\
\hline CHEMBL 3216034 & 566779 & 7.7212 & 7.865 & TRN \\
\hline CHEMBL3216225 & 566779 & 7.585 & 8.0079 & TRN \\
\hline CHEMBL494404 & 566779 & 7.1549 & 6.9322 & TRN \\
\hline CHEMBL3216033 & 566779 & 7.6778 & 7.7262 & TRN \\
\hline CHEMBL3215765 & 566779 & 5.8508 & 5.9852 & TRN \\
\hline CHEMBL3215577 & 566779 & 5.2684 & 6.4836 & TRN \\
\hline CHEMBL3216425 & 566779 & 7.3188 & 7.0294 & TST \\
\hline CHEMBL 3215578 & 566779 & 7.8861 & 7.7667 & TRN \\
\hline CHEMBL3215565 & 566779 & 6.9706 & 6.6929 & TRN \\
\hline CHEMBL3216903 & 566779 & 7.7447 & 7.6608 & TRN \\
\hline CHEMBL3216889 & 566779 & 8.2218 & 8.0466 & TRN \\
\hline CHEMBL3215782 & 566779 & 7.2596 & 7.246 & TRN \\
\hline CHEMBL3215568 & 566779 & 5.8894 & 6.0971 & TRN \\
\hline CHEMBL3216423 & 566779 & 8.1549 & 7.8737 & TRN \\
\hline CHEMBL3216660 & 566779 & 7.2076 & 7.2346 & TRN \\
\hline CHEMBL3215566 & 566779 & 7.7212 & 8.0134 & TRN \\
\hline CHEMBL3216426 & 566779 & 8.2218 & 7.7325 & TRN \\
\hline CHEMBL3216214 & 566779 & 8.3979 & 8.0466 & TRN \\
\hline CHEMBL3217107 & 566779 & 7.4202 & 7.1125 & TRN \\
\hline CHEMBL 3217108 & 566779 & 8.3979 & 7.8492 & TRN \\
\hline CHEMBL3215567 & 566779 & 7.0088 & 6.2884 & TRN \\
\hline CHEMBL3216436 & 566779 & 7.8861 & 8.5398 & TRN \\
\hline CHEMBL3216670 & 566779 & 4.7959 & 5.3808 & TST \\
\hline CHEMBL3216229 & 566779 & 4.1439 & 4.9189 & TST \\
\hline CHEMBL 3217105 & 566779 & 7.6198 & 7.0117 & TRN \\
\hline CHEMBL3216017 & 566779 & 6.6308 & 6.7582 & TRN \\
\hline
\end{tabular}




\begin{tabular}{|c|c|c|c|c|c|c|}
\hline & & \multicolumn{5}{|c|}{ Supplemental Table S2.txt } \\
\hline CHEMBL3216016 & 566779 & 5.6498 & 6.2096 & TRN & & \\
\hline CHEMBL3216901 & 566779 & 7.6198 & 7.0517 & TST & & \\
\hline CHEMBL3216890 & 566779 & 6.2644 & 6.8009 & TRN & & \\
\hline CHEMBL3216032 & 566779 & 7.6778 & 7.8256 & TRN & & \\
\hline CHEMBL3215764 & 566779 & 9.0 & 9.3006 & TRN & & \\
\hline CHEMBL3215569 & 566779 & 7.4559 & 6.6454 & TST & & \\
\hline CHEMBL3216894 & 566779 & 4.7747 & 5.09 & TRN & & \\
\hline CHEMBL495012 & 566779 & 4.5528 & 4.1607 & TRN & & \\
\hline CHEMBL3215570 & 566779 & 7.5686 & 7.1011 & TST & & \\
\hline CHEMBL3217113 & 566779 & 7.8539 & 8.4966 & TST & & \\
\hline CHEMBL3216030 & 566779 & 7.7212 & 7.6495 & TRN & & \\
\hline CHEMBL3217106 & 566779 & 7.8239 & 7.9316 & TRN & & \\
\hline CHEMBL522874 & 566779 & 5.7825 & 6.0933 & TST & & \\
\hline CHEMBL494957 & 566779 & 8.699 & 8.6365 & TRN & & \\
\hline CHEMBL3216902 & 566779 & 7.8239 & 7.8144 & TRN & & \\
\hline CHEMBL3216215 & 566779 & 7.8861 & 8.0134 & TRN & & \\
\hline CHEMBL3215763 & 566779 & 6.2358 & 6.5336 & TRN & & \\
\hline CHEMBL3216216 & 566779 & 7.0088 & 6.0618 & TST & & \\
\hline CHEMBL3216662 & 566779 & 7.7447 & 6.8039 & TST & & \\
\hline CHEMBL3216228 & 566779 & 7.5686 & 7.5881 & TRN & & \\
\hline CHEMBL3216434 & 566779 & 7.7447 & 8.0625 & TRN & & \\
\hline CHEMBL3216663 & 566779 & 7.699 & 7.4195 & TRN & & \\
\hline CHEMBL3216658 & 566779 & 7.7212 & 8.0555 & TST & & \\
\hline CHEMBL3216217 & 566779 & 8.5229 & 8.1876 & TRN & & \\
\hline CHEMBL3216435 & 566779 & 7.6778 & 7.4819 & TST & & \\
\hline CHEMBL494956 & 566779 & 8.5229 & 8.1682 & TRN & & \\
\hline CHEMBL492579 & 566779 & 8.2218 & 8.9982 & TST & & \\
\hline CHEMBL3216031 & 566779 & 7.5086 & 7.8472 & TRN & & \\
\hline CHEMBL2360824 & 566779 & 7.7959 & 7.7495 & TST & & \\
\hline CHEMBL3215766 & 566779 & 7.6021 & 7.87299 & 99999999 & & TRN \\
\hline CHEMBL 255342 & 954964 & 3.7536 & 3.7537 & TRN & & \\
\hline CHEMBL483849 & 954964 & 1.4257 & 2.1605 & TST & & \\
\hline CHEMBL259181 & 954964 & 3.3329 & 3.3328 & TRN & & \\
\hline CHEMBL3186408 & 954964 & 3.5262 & 3.7845 & TST & & \\
\hline CHEMBL472940 & 954964 & 2.7202 & 2.7202 & TRN & & \\
\hline CHEMBL379300 & 954964 & 5.7448 & 5.7447 & TRN & & \\
\hline CHEMBL449158 & 954964 & 6.319 & 6.9143 & TST & & \\
\hline CHEMBL1357247 & 954964 & 3.0946 & 3.0941 & TRN & & \\
\hline CHEMBL102714 & 954964 & 3.158 & 3.158 & TRN & & \\
\hline CHEMBL393929 & 954964 & 3.9079 & 3.908 & TRN & & \\
\hline CHEMBL189584 & 954964 & 3.7349 & 3.7347 & TRN & & \\
\hline CHEMBL1190711 & 954964 & 4.5604 & 4.5605 & TRN & & \\
\hline CHEMBL379975 & 954964 & 5.3127 & 5.3128 & TRN & & \\
\hline CHEMBL 9470 & 954964 & 5.9658 & 5.3101 & TST & & \\
\hline CHEMBL1256459 & 954964 & 6.94799 & 99999999 & 995 & .9479 & TRN \\
\hline CHEMBL220241 & 954964 & 4.4268 & 4.4266 & TRN & & \\
\hline CHEMBL515416 & 954964 & 3.97899 & 99999999 & 996 & 3.9789 & TRN \\
\hline CHEMBL373751 & 954964 & 3.5044 & 3.5046 & TRN & & \\
\hline
\end{tabular}




\begin{tabular}{|c|c|c|c|c|}
\hline & & & & \\
\hline CHEMBL188678 & 954964 & 4.4947 & 4.4947 & 1 \\
\hline CHEMBL412142 & 954964 & 3.9229 & 3.9228 & \\
\hline CHEMBL2363137 & 54964 & 4.6732 & 6734 & \\
\hline HEMBL509032 & 54964 & 4.4908 & 4.4908 & \\
\hline CHEMBL209148 & 54964 & 3.5347 & & \\
\hline CHEMBL585951 & 54964 & 5.3054 & 3053 & \\
\hline HEMBL217354 & 54964 & 6.6064 & 6.6063 & \\
\hline CHEMBL1516890 & 54964 & 4.6506 & 4.6507 & \\
\hline HEMBL3392440 & 54964 & 4.8073 & 4.8075 & \\
\hline CHEMBL3199475 & & 3.8045 & & \\
\hline HEMBL 258844 & 954964 & 4.0257 & 4.0256 & \\
\hline HEMBL300389 & 954964 & 6.4496 & 6.4496 & \\
\hline CHEMBL392695 & 64 & 4.4756 & 759 & \\
\hline HEMBL 5 & 64 & 4.167 & 67 & \\
\hline CHEMBL65 & & 7.7118 & & \\
\hline CHEMBL 213 & 64 & 3.5779 & 3.5779 & \\
\hline HEMBL & 64 & 4.4574 & & \\
\hline CHEMBL1 & 954 & 3.6176 & 217 & \\
\hline HEMBLS & 54 & 31 & 63 & \\
\hline CHEMBL: & 4 & 07 & & \\
\hline HEMBL] & 64 & 24 & 25 & \\
\hline HEMBL & 95 & 81 & & \\
\hline CHEMBL & 4 & 3.9308 & 05 & \\
\hline HEMBL & 4 & 27 & 26 & \\
\hline CHEMBL & 4 & 38 & & \\
\hline HEMRI & 64 & & & \\
\hline CHEMBL 1 & 54 & & & \\
\hline CHEMBL 2 & 4 & 4.5874 & 76 & \\
\hline CHEMBL & 54 & 79 & 78 & \\
\hline CHEMBL: & 54 & 96 & 98 & \\
\hline 116 & & .775 & 73 & \\
\hline CHEMBL 1 & 954 & 4.6801 & 97 & $\mathrm{TP}$ \\
\hline CHEMBL1 & 4 & 4.5322 & 23 & \\
\hline CHEMBL: & 54 & 61 & 59 & \\
\hline $\mathrm{CHE}$ & 54 & 93 & 93 & 10 \\
\hline CHEMBL577784 & 954 & 4.6233 & 33 & \\
\hline CHEMBL202721 & 954964 & 4.9019 & 023 & $\mathrm{TP}$ \\
\hline CHEMBL & 4 & 22 & & \\
\hline CHEMBL 2 & $95<$ & 4.126 & 27 & \\
\hline CHEMBL 1 & 95 & 3.279 & 477 & TS \\
\hline CHEMBL1673039 & 954964 & 3.5275 & 4.2054 & $\mathrm{TS}$ \\
\hline CHEMBL1909414 & 954964 & 3.3793 & 683 & \\
\hline CHEMBL & & & & TS \\
\hline CHEMBL221137 & 954964 & 4.7093 & 4.5137 & TS \\
\hline CHEMBL1643959 & 954964 & 4.2775 & 3.675 & TS \\
\hline CHEMBL2134202 & 954964 & 4.4749 & 4.3204 & TS \\
\hline CHEMBL399530 & 954964 & 4.7994 & 4.274 & \\
\hline CHEMBL3687709 & 1528917 & 3.5229 & 3.9673 & $F_{-}$ \\
\hline
\end{tabular}


Supplemental Table S2.txt

\begin{tabular}{|c|c|c|c|c|}
\hline CHEMBL3682660 & 1528917 & 3.5229 & 3.4214 & TST \\
\hline CHEMBL3687728 & 1528917 & 3.5229 & 3.758 & TRN \\
\hline CHEMBL3687634 & 1528917 & 3.5229 & 3.5383 & TRN \\
\hline CHEMBL 3687601 & 1528917 & 5.6021 & 5.4483 & TRN \\
\hline CHEMBL3687614 & 1528917 & 3.5229 & 3.4214 & TRN \\
\hline CHEMBL3687595 & 1528917 & 3.5229 & 3.5892 & TST \\
\hline CHEMBL3687722 & 1528917 & 3.5229 & 3.50399 & 99999999996 \\
\hline CHEMBL 3677857 & 1528917 & 4.6234 & 4.4873 & TRN \\
\hline CHEMBL3682638 & 1528917 & 3.5229 & \multicolumn{2}{|c|}{3.5380000000000003} \\
\hline CHEMBL3682633 & 1528917 & 3.5229 & 4.207 & TRN \\
\hline CHEMBL3692152 & 1528917 & 3.5229 & 3.6757 & TST \\
\hline CHEMBL3687538 & 1528917 & 3.5229 & 3.8151 & TRN \\
\hline CHEMBL 3682645 & 1528917 & 5.2248 & 4.9499 & TRN \\
\hline CHEMBL 3687707 & 1528917 & 3.5229 & 3.6744 & TRN \\
\hline CHEMBL3692163 & 1528917 & 3.5229 & 3.3198 & TST \\
\hline CHEMBL3687698 & 1528917 & 3.5229 & 3.6175 & TRN \\
\hline CHEMBL3682650 & 1528917 & 5.1096 & 4.7637 & TRN \\
\hline CHEMBL3677853 & 1528917 & 4.6234 & 4.6674 & TRN \\
\hline CHEMBL 3687692 & 1528917 & 3.5229 & 3.5672 & TRN \\
\hline CHEMBL3687602 & 1528917 & 3.5229 & 3.4806 & TRN \\
\hline CHEMBL3687736 & 1528917 & 3.5229 & 3.3001 & TST \\
\hline CHEMBL3682767 & 1528917 & 3.5229 & 3.6182 & TRN \\
\hline CHEMBL 3677850 & 1528917 & 3.5229 & 3.8804 & TRN \\
\hline CHEMBL3692165 & 1528917 & 3.5229 & 3.2604 & TRN \\
\hline CHEMBL3687723 & 1528917 & 3.5229 & 3.3519 & TRN \\
\hline CHEMBL3687753 & 1528917 & 3.5229 & 3.6339 & TRN \\
\hline CHEMBL3692161 & 1528917 & 3.5229 & 3.7411 & TST \\
\hline CHEMBL3682648 & 1528917 & 4.8416 & 4.968 & TRN \\
\hline CHEMBL 3687603 & 1528917 & 3.5229 & 3.7684 & TRN \\
\hline CHEMBL3677851 & 1528917 & 4.6162 & 4.1484 & TRN \\
\hline CHEMBL3687608 & 1528917 & 3.5229 & 4.1464 & TRN \\
\hline CHEMBL3687689 & 1528917 & 3.5229 & 3.5764 & TRN \\
\hline CHEMBL3682769 & 1528917 & 3.5229 & 3.8062 & TRN \\
\hline CHEMBL 3687732 & 1528917 & 3.5229 & 3.3332 & TST \\
\hline CHEMBL 3687547 & 1528917 & 5.1284 & 3.7324 & TST \\
\hline CHEMBL3692157 & 1528917 & 3.5229 & 3.1634 & TST \\
\hline CHEMBL3682642 & 1528917 & 3.5229 & 3.6775 & TRN \\
\hline CHEMBL3687638 & 1528917 & 3.5229 & 3.2998 & TRN \\
\hline CHEMBL3687611 & 1528917 & 3.5229 & 3.3981 & TRN \\
\hline CHEMBL3692168 & 1528917 & 3.5229 & 3.2455 & TRN \\
\hline CHEMBL3687623 & 1528917 & 3.5229 & 3.5117 & TRN \\
\hline CHEMBL3682634 & 1528917 & 3.5229 & 4.248 & TRN \\
\hline CHEMBL3687548 & 1528917 & 3.5229 & 3.4338 & TST \\
\hline CHEMBL3682841 & 1528917 & 3.5229 & 4.0613 & TST \\
\hline CHEMBL3687697 & 1528917 & 3.5229 & 3.1818 & TST \\
\hline CHEMBL3687703 & 1528917 & 3.5229 & 3.353 & TRN \\
\hline CHEMBL3687618 & 1528917 & 3.5229 & 3.1805 & TRN \\
\hline CHEMBL3687705 & 1528917 & 3.5229 & 3.3844 & TRN \\
\hline
\end{tabular}


Supplemental Table S2.txt

\begin{tabular}{|c|c|c|c|c|}
\hline CHEMBL3687612 & 1528917 & 3.5229 & 3.6826 & TRN \\
\hline CHEMBL3687616 & 1528917 & 3.5229 & 3.4963 & TRN \\
\hline CHEMBL3687729 & 1528917 & 3.5229 & 3.8255 & TRN \\
\hline CHEMBL 3687748 & 1528917 & 3.5229 & 3.4635 & TRN \\
\hline CHEMBL3682626 & 1528917 & 5.8894 & 3.7107 & TST \\
\hline CHEMBL3687606 & 1528917 & 4.6925 & 4.3715 & TRN \\
\hline CHEMBL3687650 & 1528917 & 3.5229 & 3.6795 & TRN \\
\hline CHEMBL3687704 & 1528917 & 3.5229 & 3.3283 & TRN \\
\hline CHEMBL3687734 & 1528917 & 3.5229 & 3.4982 & TST \\
\hline CHEMBL3687617 & 1528917 & 3.5229 & 3.4728 & TRN \\
\hline CHEMBL 3682644 & 1528917 & 5.0186 & 4.6439 & TRN \\
\hline CHEMBL3687594 & 1528917 & 5.5544 & 5.2373 & TST \\
\hline CHEMBL3677858 & 1528917 & 5.1752 & 5.1495 & TRN \\
\hline CHEMBL3692149 & 1528917 & 3.5229 & 3.7486 & TST \\
\hline CHEMBL3687640 & 1528917 & 3.5229 & 3.912 & TRN \\
\hline CHEMBL3682661 & 1528917 & 3.5229 & 3.0732 & TRN \\
\hline CHEMBL3692162 & 1528917 & 3.5229 & 3.5034 & TRN \\
\hline CHEMBL3687687 & 1528917 & 3.5229 & 3.8081 & TRN \\
\hline CHEMBL 3687613 & 1528917 & 3.5229 & 3.5864 & TRN \\
\hline CHEMBL3687720 & 1528917 & 3.5229 & 3.5494 & TRN \\
\hline CHEMBL3687721 & 1528917 & 3.5229 & 3.6497 & TRN \\
\hline CHEMBL3687724 & 1528917 & 3.5229 & 3.7949 & TRN \\
\hline CHEMBL 3687750 & 1528917 & 3.5229 & 3.7431 & TRN \\
\hline CHEMBL 3687670 & 1528917 & 3.5229 & 3.7131 & TRN \\
\hline CHEMBL3682637 & 1528917 & 3.5229 & 3.5655 & TST \\
\hline CHEMBL3682785 & 1528917 & 3.5229 & 3.7259 & TRN \\
\hline CHEMBL3682640 & 1528917 & 3.5229 & 4.6772 & TRN \\
\hline CHEMBL 3687686 & 1528917 & 3.5229 & 3.7818 & TRN \\
\hline CHEMBL 3687620 & 1528917 & 3.5229 & 3.3741 & TRN \\
\hline CHEMBL3682789 & 1528917 & 3.5229 & 3.5408 & TRN \\
\hline CHEMBL3687727 & 1528917 & 3.5229 & 3.8156 & TRN \\
\hline CHEMBL3687629 & 1528917 & 3.5229 & 3.7827 & TRN \\
\hline CHEMBL3687672 & 1528917 & 3.5229 & 3.5266 & TRN \\
\hline CHEMBL 3682643 & 1528917 & 3.5229 & 3.8705 & TRN \\
\hline CHEMBL3692153 & 1528917 & 3.5229 & 3.5503 & TST \\
\hline CHEMBL3682657 & 1528917 & 5.2351 & 4.2637 & TST \\
\hline CHEMBL3687651 & 1528917 & 3.5229 & 3.3097 & TRN \\
\hline CHEMBL3682639 & 1528917 & 3.5229 & 3.4955 & TRN \\
\hline CHEMBL 3687688 & 1528917 & 3.5229 & 3.8492 & TRN \\
\hline CHEMBL 3687737 & 1528917 & 3.5229 & 4.23300 & 00000000005 \\
\hline CHEMBL3687621 & 1528917 & 3.5229 & 3.4849 & TRN \\
\hline CHEMBL3682641 & 1528917 & 4.7011 & 4.4859 & TRN \\
\hline CHEMBL3687566 & 1528917 & 3.5229 & 3.6525 & TST \\
\hline CHEMBL 3677849 & 1528917 & 7.5229 & 4.0644 & TST \\
\hline CHEMBL 3687635 & 1528917 & 3.5229 & 3.6745 & TRN \\
\hline CHEMBL3687658 & 1528917 & 3.5229 & 3.3768 & TST \\
\hline CHEMBL3687741 & 1528917 & 3.5229 & 3.9312 & TST \\
\hline CHEMBL3687622 & 1528917 & 3.5229 & 3.7364 & TRN \\
\hline
\end{tabular}


Supplemental Table S2.txt

\begin{tabular}{|c|c|c|c|c|c|}
\hline CHEMBL 3341980 & 1528917 & 5.3233 & 4.4156 & TRN & \\
\hline CHEMBL 3687751 & 1528917 & 3.5229 & 3.2732 & TRN & \\
\hline CHEMBL 3687619 & 1528917 & 3.5229 & 3.2677 & TRN & \\
\hline CHEMBL 3677852 & 1528917 & 4.9626 & 4.9735 & TRN & \\
\hline CHEMBL 3687738 & 1528917 & 3.5229 & 4.0867 & TST & \\
\hline CHEMBL 3687683 & 1528917 & 3.5229 & 3.6193 & TRN & \\
\hline CHEMBL 3687627 & 1528917 & 3.5229 & 3.3197 & TRN & \\
\hline CHEMBL 3687700 & 1528917 & 3.5229 & 3.5783 & TRN & \\
\hline CHEMBL 3687633 & 1528917 & 3.5229 & 3.2566 & TRN & \\
\hline CHEMBL 3687657 & 1528917 & 3.5229 & 3.553 & TST & \\
\hline CHEMBL 3682816 & 1528917 & 4.6904 & 4.0585 & TST & \\
\hline CHEMBL 3687725 & 1528917 & 3.5229 & 3.8466 & TRN & \\
\hline CHEMBL 3687639 & 1528917 & 3.5229 & 3.4254 & TRN & \\
\hline CHEMBL3692154 & 1528917 & 3.5229 & 3.7121 & TST & \\
\hline CHEMBL 3687740 & 1528917 & 3.5229 & 3.5498 & TST & \\
\hline CHEMBL 3682622 & 1528917 & 5.295 & 5.068006 & 00000000005 & TRN \\
\hline CHEMBL 3682649 & 1528917 & 6.3098 & 5.3743 & TRN & \\
\hline CHEMBL 3687726 & 1528917 & 3.5229 & 4.055 & TRN & \\
\hline CHEMBL 3692134 & 1528917 & 3.5229 & 3.22 & TRN & \\
\hline CHEMBL 3687730 & 1528917 & 4.71899 & 99999999 & 4.1183 & TRN \\
\hline CHEMBL 3687746 & 1528917 & 3.5229 & 4.0618 & TRN & \\
\hline CHEMBL 3687626 & 1528917 & 3.5229 & 3.2403 & TRN & \\
\hline CHEMBL 3687599 & 1528917 & 3.5229 & 3.5005 & TST & \\
\hline CHEMBL 3687747 & 1528917 & 5.1811 & 4.3318 & TRN & \\
\hline CHEMBL 3687596 & 1528917 & 3.5229 & 3.7131 & TRN & \\
\hline CHEMBL 3682623 & 1528917 & 4.9355 & 4.8673 & TRN & \\
\hline CHEMBL 3687624 & 1528917 & 4.5751 & 3.8197 & TRN & \\
\hline CHEMBL 3687605 & 1528917 & 4.684 & 4.0164 & TRN & \\
\hline CHEMBL 3687597 & 1528917 & 3.5229 & 3.7842 & TRN & \\
\hline CHEMBL 3687609 & 1528917 & 3.5229 & 3.4293 & TRN & \\
\hline CHEMBL 3687631 & 1528917 & 3.5229 & 3.6094 & TST & \\
\hline CHEMBL 3682647 & 1528917 & \multicolumn{3}{|c|}{4.821000000000001} & TRN \\
\hline CHEMBL 3687636 & 1528917 & 3.5229 & 3.5761 & TRN & \\
\hline CHEMBL3692164 & 1528917 & 3.5229 & 3.576 & TRN & \\
\hline CHEMBL 3687610 & 1528917 & 3.5229 & 3.2429 & TRN & \\
\hline CHEMBL3692135 & 1528917 & 3.5229 & 3.8946 & TST & \\
\hline CHEMBL 3682782 & 1528917 & 3.5229 & 3.247 & TST & \\
\hline CHEMBL 3687752 & 1528917 & 3.5229 & 3.3356 & TRN & \\
\hline CHEMBL 3687742 & 1528917 & 3.5229 & 3.5912 & TST & \\
\hline CHEMBL 3687685 & 1528917 & 3.5229 & 3.51899 & 99999999997 & $\mathrm{TN}$ \\
\hline CHEMBL 3677856 & 1528917 & 4.6716 & 4.5063 & TRN & \\
\hline CHEMBL 3687682 & 1528917 & 3.5229 & 3.6509 & TRN & \\
\hline CHEMBL 3687708 & 1528917 & 3.5229 & 3.7422 & TRN & \\
\hline CHEMBL 3682625 & 1528917 & 3.5229 & 3.487 & TST & \\
\hline CHEMBL 3687706 & 1528917 & 3.5229 & 3.5838 & TRN & \\
\hline CHEMBL 3687641 & 1528917 & 3.5229 & 3.7436 & TRN & \\
\hline CHEMBL 3682646 & 1528917 & 5.0004 & 4.6851 & TRN & \\
\hline CHEMBL 3687684 & 1528917 & 3.5229 & 3.5602 & TRN & \\
\hline
\end{tabular}

Page 6750 
Supplemental Table S2.txt

\begin{tabular}{|c|c|c|c|c|c|}
\hline CHEMBL3687553 & 1528917 & 4.9101 & 4.3292 & TST & \\
\hline CHEMBL3687690 & 1528917 & 3.5229 & 3.6287 & TRN & \\
\hline CHEMBL3687615 & 1528917 & 3.5229 & 3.4993 & TRN & \\
\hline CHEMBL3687549 & 1528917 & 3.5229 & 3.2715 & TST & \\
\hline CHEMBL3687701 & 1528917 & 3.5229 & 3.4982 & TRN & \\
\hline CHEMBL3692136 & 1528917 & 3.5229 & 3.2267 & TRN & \\
\hline CHEMBL3682651 & 1528917 & 3.5229 & 4.234 & TRN & \\
\hline CHEMBL3682636 & 1528917 & 3.5229 & 3.6792 & TST & \\
\hline CHEMBL3687652 & 1528917 & 3.5229 & 3.234 & TRN & \\
\hline CHEMBL3687739 & 1528917 & 3.5229 & 3.5636 & TST & \\
\hline CHEMBL3913046 & 1641887 & 7.1115 & 6.8411 & TRN & \\
\hline CHEMBL3913311 & 1641887 & 6.1498 & 4.6384 & TST & \\
\hline CHEMBL3960796 & 1641887 & 8.2503 & 7.9971 & TRN & \\
\hline CHEMBL3947642 & 1641887 & 6.0 & 5.974 & TRN & \\
\hline CHEMBL3930991 & 1641887 & 8.5907 & 8.5493 & TRN & \\
\hline CHEMBL3982915 & 1641887 & 8.8617 & 8.8328 & TRN & \\
\hline CHEMBL3910003 & 1641887 & 7.9784 & 7.5811 & TST & \\
\hline CHEMBL 3895714 & 1641887 & 8.0952 & 8.2659 & TRN & \\
\hline CHEMBL3961836 & 1641887 & 8.7135 & 8.8653 & TRN & \\
\hline CHEMBL3933494 & 1641887 & 8.4981 & 8.4112 & TRN & \\
\hline CHEMBL3964459 & 1641887 & 8.1594 & 8.0594 & TRN & \\
\hline CHEMBL3927591 & 1641887 & 8.0231 & 7.7807 & TRN & \\
\hline CHEMBL3922869 & 1641887 & 7.605 & 7.7699 & TRN & \\
\hline CHEMBL3919992 & 1641887 & 8.1375 & 7.8644 & TRN & \\
\hline CHEMBL3947778 & 1641887 & 6.0 & 6.1047 & TRN & \\
\hline CHEMBL3960822 & 1641887 & 6.4523 & 5.7561 & TST & \\
\hline CHEMBL3894421 & 1641887 & 8.1992 & 8.0756 & TRN & \\
\hline CHEMBL3927052 & 1641887 & 7.6955 & 7.5524 & TRN & \\
\hline CHEMBL3974309 & 1641887 & 8.4003 & 8.2087 & TRN & \\
\hline CHEMBL3967005 & 1641887 & 8.2311 & 8.09799 & 9999999999 & TRN \\
\hline CHEMBL3949897 & 1641887 & 8.2045 & 7.9999 & TRN & \\
\hline CHEMBL3949927 & 1641887 & 8.6682 & 8.5559 & TRN & \\
\hline CHEMBL3986495 & 1641887 & 8.0644 & 8.1802 & TRN & \\
\hline CHEMBL3934337 & 1641887 & 8.0155 & 8.2431 & TRN & \\
\hline CHEMBL3949157 & 1641887 & 7.9359 & 8.0626 & TRN & \\
\hline CHEMBL3890470 & 1641887 & 8.9662 & 9.0281 & TRN & \\
\hline CHEMBL3925436 & 1641887 & 8.6981 & 8.4068 & TRN & \\
\hline CHEMBL3938855 & 1641887 & 8.587 & 8.3865 & TRN & \\
\hline CHEMBL3940123 & 1641887 & 8.2083 & 8.1358 & TRN & \\
\hline CHEMBL3957232 & 1641887 & 8.515 & 8.5983 & TRN & \\
\hline CHEMBL3925629 & 1641887 & 6.3616 & 7.0432 & TRN & \\
\hline CHEMBL3958500 & 1641887 & 8.6302 & 8.609 & TRN & \\
\hline CHEMBL3983489 & 1641887 & 8.1775 & 7.9889 & TRN & \\
\hline CHEMBL 3978278 & 1641887 & 7.92299 & 99999999 & 8.2475 & TRN \\
\hline CHEMBL3963867 & 1641887 & 7.399 & 7.4726 & TRN & \\
\hline CHEMBL3954316 & 1641887 & 8.3164 & 8.0253 & TRN & \\
\hline CHEMBL3968491 & 1641887 & 7.8216 & 7.9976 & TRN & \\
\hline CHEMBL3920030 & 1641887 & 8.4924 & 8.1956 & TST & \\
\hline
\end{tabular}


Supplemental Table S2.txt

\begin{tabular}{|c|c|c|c|c|c|c|}
\hline CHEMBL 3898973 & 1641887 & 8.0468 & 8.3046 & TRN & & \\
\hline CHEMBL3932292 & 1641887 & 8.1537 & 8.324 & TST & & \\
\hline CHEMBL3955887 & 1641887 & 8.5556 & 8.543 & TST & & \\
\hline CHEMBL 3942127 & 1641887 & 7.9469 & 8.3572 & TRN & & \\
\hline CHEMBL3975365 & 1641887 & 7.8147 & 7.7446 & TST & & \\
\hline CHEMBL3972082 & 1641887 & 6.7918 & 7.0914 & TST & & \\
\hline CHEMBL3946725 & 1641887 & 8.3849 & 8.1602 & TRN & & \\
\hline CHEMBL3986806 & 1641887 & 8.5933 & 8.6618 & TST & & \\
\hline CHEMBL3949455 & 1641887 & 9.1148 & 8.5073 & TST & & \\
\hline CHEMBL3961240 & 1641887 & 8.4577 & 8.6407 & TRN & & \\
\hline CHEMBL3904432 & 1641887 & 6.8914 & 6.8933 & TST & & \\
\hline CHEMBL3959793 & 1641887 & 8.3048 & 7.8549 & TRN & & \\
\hline CHEMBL3901368 & 1641887 & 8.8294 & 8.7227 & TST & & \\
\hline CHEMBL3969256 & 1641887 & 8.3066 & 8.2467 & TRN & & \\
\hline CHEMBL3889513 & 1641887 & 8.1959 & 8.4447 & TRN & & \\
\hline CHEMBL3904223 & 1641887 & 7.78700 & 20000000 & $\partial 1$ & 7.9539 & TRN \\
\hline CHEMBL3972861 & 1641887 & 7.6249 & 7.6217 & TRN & & \\
\hline CHEMBL3936639 & 1641887 & 5.0492 & 4.8652 & TST & & \\
\hline CHEMBL3941710 & 1641887 & 8.7956 & 8.6753 & TST & & \\
\hline CHEMBL3945713 & 1641887 & 7.7894 & 7.9675 & TRN & & \\
\hline CHEMBL3982540 & 1641887 & 7.3502 & 7.4757 & TRN & & \\
\hline CHEMBL3966786 & 1641887 & 6.403 & 6.9574 & TST & & \\
\hline CHEMBL3974920 & 1641887 & 8.14200 & 00000000 & & 9.0115 & TST \\
\hline CHEMBL3656010 & 1527976 & 7.8861 & 7.8551 & TRN & & \\
\hline CHEMBL3655956 & 1527976 & 5.8969 & 5.7266 & TRN & & \\
\hline CHEMBL3655918 & 1527976 & 7.1135 & 7.0516 & TRN & & \\
\hline CHEMBL3655941 & 1527976 & 6.2168 & 6.2205 & TRN & & \\
\hline CHEMBL3656003 & 1527976 & 7.3279 & 7.4466 & TRN & & \\
\hline CHEMBL3655919 & 1527976 & 7.3979 & 7.2114 & TRN & & \\
\hline CHEMBL3655996 & 1527976 & 7.301 & 7.3402 & TRN & & \\
\hline CHEMBL 3656023 & 1527976 & 5.8626 & 5.7867 & TRN & & \\
\hline CHEMBL3655964 & 1527976 & 7.0706 & 7.0972 & TRN & & \\
\hline CHEMBL3655924 & 1527976 & 6.6696 & 6.562 & TRN & & \\
\hline CHEMBL3655911 & 1527976 & 6.9547 & 6.9021 & TRN & & \\
\hline CHEMBL3655982 & 1527976 & 6.6696 & 6.5268 & TST & & \\
\hline CHEMBL3655939 & 1527976 & 6.279 & 6.4052 & TRN & & \\
\hline CHEMBL3655949 & 1527976 & 5.2402 & 5.3529 & TRN & & \\
\hline CHEMBL3652235 & 1527976 & 5.8508 & 6.1535 & TRN & & \\
\hline CHEMBL3655936 & 1527976 & 7.6198 & 7.5256 & TRN & & \\
\hline CHEMBL3655916 & 1527976 & 6.9586 & 6.7624 & TRN & & \\
\hline CHEMBL3655912 & 1527976 & 6.3335 & 6.3275 & TST & & \\
\hline CHEMBL3655968 & 1527976 & 6.7959 & 6.9566 & TRN & & \\
\hline CHEMBL3655971 & 1527976 & 7.6576 & 7.544 & TRN & & \\
\hline CHEMBL3656014 & 1527976 & 6.983 & 7.1492 & TRN & & \\
\hline CHEMBL3655952 & 1527976 & 5.9423 & 6.1012 & TRN & & \\
\hline CHEMBL3655910 & 1527976 & 6.3799 & 6.4709 & TRN & & \\
\hline CHEMBL 3656024 & 1527976 & 6.5817 & 6.5923 & TRN & & \\
\hline \multirow[t]{2}{*}{ CHEMBL3655992 } & 1527976 & 7.8861 & 7.91200 & 0000000001 & & RN \\
\hline & & \multicolumn{4}{|c|}{ Page 6752} & \\
\hline
\end{tabular}


Supplemental Table S2.txt

\begin{tabular}{|c|c|c|c|c|c|}
\hline CHEMBL3656015 & 1527976 & 7.7959 & 7.7719 & TRN & \\
\hline CHEMBL3655989 & 1527976 & 7.4202 & 7.3837 & TRN & \\
\hline CHEMBL3655969 & 1527976 & 5.8668 & 5.8706 & TRN & \\
\hline CHEMBL3652236 & 1527976 & 6.4789 & 6.4082 & TST & \\
\hline CHEMBL3655932 & 1527976 & 6.6596 & 6.6531 & TRN & \\
\hline CHEMBL3655976 & 1527976 & 6.699 & 6.8366 & TRN & \\
\hline CHEMBL3655978 & 1527976 & 5.67299 & 99999999 & 5.6638 & TRN \\
\hline CHEMBL3655908 & 1527976 & 6.2874 & 6.3414 & TRN & \\
\hline CHEMBL3655913 & 1527976 & 7.0555 & 6.9445 & TRN & \\
\hline CHEMBL3655934 & 1527976 & 6.3298 & 6.4111 & TRN & \\
\hline CHEMBL3655925 & 1527976 & 7.1079 & 6.9789 & TRN & \\
\hline CHEMBL3656017 & 1527976 & 6.2343 & 6.0627 & TRN & \\
\hline CHEMBL3655972 & 1527976 & 6.2321 & 6.194 & TRN & \\
\hline CHEMBL 3655985 & 1527976 & 6.6596 & 6.59200 & 30000000005 & TRN \\
\hline CHEMBL 3655947 & 1527976 & 6.1904 & 6.0456 & TRN & \\
\hline CHEMBL3652239 & 1527976 & 6.6003 & 6.6555 & TRN & \\
\hline CHEMBL3655950 & 1527976 & 7.0269 & 6.9793 & TRN & \\
\hline CHEMBL 3655917 & 1527976 & 7.699 & 7.5398 & TRN & \\
\hline CHEMBL3655986 & 1527976 & 6.4895 & 6.4109 & TST & \\
\hline CHEMBL 3655966 & 1527976 & 6.6517 & 6.5721 & TST & \\
\hline CHEMBL3655991 & 1527976 & 6.0491 & 6.0943 & TRN & \\
\hline CHEMBL3655973 & 1527976 & 5.6306 & 5.6628 & TRN & \\
\hline CHEMBL3652242 & 1527976 & 6.6536 & 6.6809 & TRN & \\
\hline CHEMBL3655962 & 1527976 & 7.1739 & 6.8925 & TST & \\
\hline CHEMBL 3652226 & 1527976 & 6.5784 & 6.7735 & TRN & \\
\hline CHEMBL3655987 & 1527976 & 5.8511 & 5.8463 & TST & \\
\hline CHEMBL3656011 & 1527976 & 7.7696 & 7.7506 & TRN & \\
\hline CHEMBL 3656000 & 1527976 & 7.7696 & 7.7995 & TRN & \\
\hline CHEMBL3655930 & 1527976 & 6.6517 & 6.6405 & TRN & \\
\hline CHEMBL3656009 & 1527976 & 7.2596 & 7.4955 & TRN & \\
\hline CHEMBL3655993 & 1527976 & 8.301 & 8.1887 & TRN & \\
\hline CHEMBL3655999 & 1527976 & 6.8539 & 6.5942 & TRN & \\
\hline CHEMBL3655961 & 1527976 & 5.6525 & 5.6265 & TRN & \\
\hline CHEMBL3656021 & 1527976 & 6.6055 & 6.5525 & TRN & \\
\hline CHEMBL3656005 & 1527976 & 7.3468 & 7.5089 & TRN & \\
\hline CHEMBL3655938 & 1527976 & 6.3372 & 6.3924 & TRN & \\
\hline CHEMBL3655958 & 1527976 & 7.3279 & 7.171 & TRN & \\
\hline CHEMBL3655914 & 1527976 & 6.6861 & 6.6986 & TRN & \\
\hline CHEMBL3655923 & 1527976 & 7.4202 & 7.3975 & TRN & \\
\hline CHEMBL3655922 & 1527976 & 6.58 & 6.4436 & TRN & \\
\hline CHEMBL3655974 & 1527976 & 7.7212 & 7.5568 & TRN & \\
\hline CHEMBL 3652227 & 1527976 & 6.6778 & 6.6732 & TRN & \\
\hline CHEMBL 3655940 & 1527976 & 6.2581 & 6.175 & TST & \\
\hline CHEMBL3655926 & 1527976 & 7.0458 & 6.7825 & TST & \\
\hline CHEMBL3656001 & 1527976 & 7.0223 & \multicolumn{2}{|c|}{7.156000000000001} & TRN \\
\hline CHEMBL 3652228 & 1527976 & 6.71 & 6.7464 & TRN & \\
\hline CHEMBL 3655920 & 1527976 & 7.0506 & 7.0839 & TRN & \\
\hline CHEMBL 3655942 & 1527976 & 6.8894 & 6.7438 & TST & \\
\hline
\end{tabular}


Supplemental Table S2.txt

\begin{tabular}{|c|c|c|c|c|c|}
\hline CHEMBL3655980 & 1527976 & 6.2381 & 6.0965 & TST & \\
\hline CHEMBL3655995 & 1527976 & 8.1549 & 8.1607 & TRN & \\
\hline CHEMBL3655963 & 1527976 & 6.1035 & 5.9999 & TRN & \\
\hline CHEMBL3655975 & 1527976 & 6.8327 & 6.4645 & TRN & \\
\hline CHEMBL3655984 & 1527976 & 7.2218 & 7.7177 & TRN & \\
\hline CHEMBL3656013 & 1527976 & 7.6021 & 7.6609 & TRN & \\
\hline CHEMBL3656002 & 1527976 & 6.2262 & 6.6441 & TRN & \\
\hline CHEMBL3656008 & 1527976 & 6.4134 & 6.6026 & TRN & \\
\hline CHEMBL3655988 & 1527976 & 6.0405 & 6.2272 & TST & \\
\hline CHEMBL3652240 & 1527976 & 4.9748 & 5.191 & TRN & \\
\hline CHEMBL3655945 & 1527976 & 5.8401 & 5.9969 & TRN & \\
\hline CHEMBL3655907 & 1527976 & 6.8761 & 6.8297 & TRN & \\
\hline CHEMBL3652237 & 1527976 & 6.7399 & 6.9191 & TRN & \\
\hline CHEMBL3655979 & 1527976 & 7.8861 & 7.6681 & TRN & \\
\hline CHEMBL3655955 & 1527976 & 6.2233 & 6.2868 & TRN & \\
\hline CHEMBL3656004 & 1527976 & 6.8268 & 7.1963 & TST & \\
\hline CHEMBL3655997 & 1527976 & 7.7959 & 7.8671 & TST & \\
\hline CHEMBL3655928 & 1527976 & 6.4237 & 6.4829 & TRN & \\
\hline CHEMBL3656007 & 1527976 & 7.301 & 7.4008 & TST & \\
\hline CHEMBL3655983 & 1527976 & 7.0362 & 6.95299 & 9999999999 & TRN \\
\hline CHEMBL3655967 & 1527976 & 7.5686 & 7.484 & TST & \\
\hline CHEMBL3655933 & 1527976 & 5.9333 & 5.8894 & TRN & \\
\hline CHEMBL3655965 & 1527976 & 6.1481 & 5.9971 & TST & \\
\hline CHEMBL3655994 & 1527976 & 7.7447 & 7.7217 & TST & \\
\hline CHEMBL3655921 & 1527976 & 6.3279 & 6.3356 & TRN & \\
\hline CHEMBL3656016 & 1527976 & 7.1938 & 7.3015 & TST & \\
\hline CHEMBL3652229 & 1527976 & 6.6073 & 6.6483 & TRN & \\
\hline CHEMBL3655954 & 1527976 & 6.4841 & 6.6673 & TRN & \\
\hline CHEMBL3655935 & 1527976 & 6.7328 & 6.8231 & TRN & \\
\hline CHEMBL3655990 & 1527976 & 7.5686 & 7.5751 & TST & \\
\hline CHEMBL 3652243 & 1527976 & 6.8097 & 6.7434 & TRN & \\
\hline CHEMBL3655946 & 1527976 & 6.6904 & 6.8348 & TRN & \\
\hline CHEMBL3655909 & 1527976 & 6.7986 & 6.643 & TRN & \\
\hline CHEMBL3656018 & 1527976 & 6.4698 & \multicolumn{2}{|c|}{6.457000000000001} & TST \\
\hline CHEMBL3655953 & 1527976 & 6.2048 & 6.3045 & TRN & \\
\hline CHEMBL3652234 & 1527976 & 6.6737 & 6.4951 & TRN & \\
\hline CHEMBL 3652232 & 1527976 & 7.0862 & 6.9983 & TST & \\
\hline CHEMBL3655960 & 1527976 & 6.3497 & \multicolumn{2}{|c|}{6.327000000000001} & TRN \\
\hline CHEMBL3655929 & 1527976 & 7.3979 & 7.4398 & TST & \\
\hline CHEMBL3656022 & 1527976 & 6.2774 & 6.4294 & TST & \\
\hline CHEMBL 3655937 & 1527976 & 5.8633 & 6.0258 & TRN & \\
\hline CHEMBL3652231 & 1527976 & \multicolumn{2}{|c|}{6.382000000000001} & 6.2433 & TRN \\
\hline CHEMBL3655970 & 1527976 & 7.0969 & 7.2406 & TST & \\
\hline CHEMBL3655931 & 1527976 & 6.4401 & 6.3802 & TRN & \\
\hline CHEMBL3655951 & 1527976 & 6.0511 & 6.0524 & TRN & \\
\hline CHEMBL3655981 & 1527976 & 6.0899 & 6.0449 & TST & \\
\hline CHEMBL 3655948 & 1527976 & 6.301 & 6.0525 & TRN & \\
\hline CHEMBL3655927 & 1527976 & \multicolumn{3}{|c|}{6.7620000000000005} & TRN \\
\hline
\end{tabular}


Supplemental Table S2.txt

\begin{tabular}{|c|c|c|c|c|c|}
\hline CHEMBL3655959 & 1527976 & 7.7959 & 8.0064 & TST & \\
\hline CHEMBL 3652238 & 1527976 & 6.8665 & 6.9614 & TRN & \\
\hline CHEMBL3652233 & 1527976 & 6.4828 & 6.5983 & TST & \\
\hline CHEMBL 3656012 & 1527976 & 7.9208 & 7.994 & TST & \\
\hline CHEMBL 3656019 & 1527976 & 6.4949 & 6.4471 & TST & \\
\hline CHEMBL 3652230 & 1527976 & 6.6946 & 6.7299 & TRN & \\
\hline CHEMBL3655977 & 1527976 & 5.494 & 5.4521 & TST & \\
\hline CHEMBL 3655957 & 1527976 & 7.0706 & 6.8034 & TRN & \\
\hline CHEMBL 3639548 & 1527976 & 6.1186 & 6.042006 & 0000000001 & TRN \\
\hline CHEMBL 3656006 & 1527976 & 7.5686 & 7.7236 & TST & \\
\hline CHEMBL 3655998 & 1527976 & 7.3665 & 7.406006 & 0000000001 & TST \\
\hline CHEMBL 3652241 & 1527976 & 6.61799 & 999999995 & 6.4896 & TRा \\
\hline CHEMBL 3656020 & 1527976 & 6.2336 & 6.1571 & TST & \\
\hline CHEMBL590706 & 737293 & 5.0888 & 4.8629 & TST & \\
\hline CHEMBL1400385 & 737293 & 5.2154 & 4.7652 & TRN & \\
\hline CHEMBL1437053 & 737293 & 5.0301 & 4.7112 & TRN & \\
\hline CHEMBL1416848 & 737293 & 5.3778 & 5.1967 & TRN & \\
\hline CHEMBL1501375 & 737293 & 3.699 & 3.3222 & TRN & \\
\hline CHEMBL3189325 & 737293 & 3.699 & 4.4925 & TRN & \\
\hline CHEMBL1472748 & 737293 & 4.98300 & 000000000 & 4.7395 & 1. \\
\hline CHEMBL1454614 & 737293 & 4.8761 & 4.7523 & TST & \\
\hline CHEMBL1308936 & 737293 & 5.0301 & 4.6229 & TRN & \\
\hline CHEMBL1467115 & 737293 & 5.6536 & 4.7034 & TRN & \\
\hline CHEMBL1407401 & 737293 & 3.699 & 4.1082 & TST & \\
\hline CHEMBL1386337 & 737293 & 5.3233 & 4.8952 & TRN & \\
\hline CHEMBL1394121 & 737293 & 5.082 & 4.7222 & TST & \\
\hline CHEMBL1497439 & 737293 & 3.699 & 3.6377 & TRN & \\
\hline CHEMBL1573929 & 737293 & 5.0273 & 4.105 & TRN & \\
\hline CHEMBL3189344 & 737293 & 3.699 & 3.583999 & & TRN \\
\hline CHEMBL1598561 & 737293 & 3.699 & 4.2678 & TRN & \\
\hline CHEMBL1407286 & 737293 & 5.0575 & 4.9663 & TRN & \\
\hline CHEMBL1347274 & 737293 & 3.699 & 4.7915 & TRN & \\
\hline CHEMBL1457600 & 737293 & 3.699 & 4.1431 & TRN & \\
\hline CHEMBL1323456 & 737293 & 4.7258 & 4.791 & TRN & \\
\hline CHEMBL1525315 & 737293 & 3.699 & 4.7698 & TRN & \\
\hline CHEMBL1611106 & 737293 & 4.7773 & 4.6612 & TST & \\
\hline CHEMBL1464332 & 737293 & 5.4353 & 4.6275 & TRN & \\
\hline CHEMBL1411209 & 737293 & 5.4168 & 4.9942 & TRN & \\
\hline CHEMBL1444822 & 737293 & 3.699 & 4.3583 & TST & \\
\hline CHEMBL1301855 & 737293 & 3.699 & 4.2952 & TRN & \\
\hline CHEMBL1379291 & 737293 & 3.699 & 4.898 & TRN & \\
\hline CHEMBL1490563 & 737293 & 3.699 & 3.6683 & TRN & \\
\hline CHEMBL1334593 & 737293 & 5.7645 & 4.7552 & TST & \\
\hline CHEMBL1431769 & 737293 & 3.699 & 4.0853 & TRN & \\
\hline CHEMBL1330503 & 737293 & 4.8861 & 4.6332 & TRN & \\
\hline CHEMBL1382640 & 737293 & 4.9508 & 4.2126 & TRN & \\
\hline CHEMBL1516853 & 737293 & 5.1337 & 4.833 & TRN & \\
\hline CHEMBL3199186 & 737293 & 3.699 & 3.9113 & TRN & \\
\hline
\end{tabular}


Supplemental Table S2.txt

\begin{tabular}{|c|c|c|c|c|}
\hline CHEMBL1428415 & 737293 & 3.699 & 3.6773 & TRN \\
\hline CHEMBL1604797 & 737293 & 4.9393 & 4.7884 & TRN \\
\hline CHEMBL1424366 & 737293 & 3.699 & 4.49 & TRN \\
\hline CHEMBL1333987 & 737293 & 3.699 & 4.2321 & TRN \\
\hline CHEMBL1497669 & 737293 & 5.295 & 4.9243 & TRN \\
\hline CHEMBL1346782 & 737293 & 3.699 & 4.0611 & TRN \\
\hline CHEMBL1434502 & 737293 & 5.3516 & 4.4614 & TRN \\
\hline CHEMBL1503006 & 737293 & 3.699 & 3.8411 & TRN \\
\hline CHEMBL1380661 & 737293 & 6.6576 & 4.114 & TRN \\
\hline CHEMBL1466636 & 737293 & 5.4157 & 4.8658 & TST \\
\hline CHEMBL1444690 & 737293 & 3.699 & 4.0003 & TRN \\
\hline CHEMBL1475198 & 737293 & 5.0195 & 4.9554 & TRN \\
\hline CHEMBL1306839 & 737293 & 5.0386 & 4.559 & TRN \\
\hline CHEMBL1387990 & 737293 & 3.699 & 4.4849 & TST \\
\hline CHEMBL1497078 & 737293 & 4.7077 & 4.5687 & TRN \\
\hline CHEMBL1507128 & 737293 & 5.4789 & 3.9073 & TRN \\
\hline CHEMBL1588455 & 737293 & 5.3575 & 4.8573 & TRN \\
\hline CHEMBL3195189 & 737293 & 7.5086 & 5.6463 & TRN \\
\hline CHEMBL1504170 & 737293 & 3.699 & 4.4155 & TRN \\
\hline CHEMBL1556239 & 737293 & 4.9586 & 4.5668 & TST \\
\hline CHEMBL1493793 & 737293 & 3.699 & 4.6938 & TRN \\
\hline CHEMBL1303635 & 737293 & 3.699 & 3.9342 & TRN \\
\hline CHEMBL1347256 & 737293 & 5.1169 & 4.8075 & TRN \\
\hline CHEMBL1351159 & 737293 & 3.699 & 4.5779 & TRN \\
\hline CHEMBL1413565 & 737293 & 5.1891 & 4.4704 & TRN \\
\hline CHEMBL1509029 & 737293 & 5.0209 & 4.8414 & TRN \\
\hline CHEMBL1462357 & 737293 & 5.0575 & 5.1134 & TRN \\
\hline CHEMBL3193234 & 737293 & 3.699 & 3.6537 & TRN \\
\hline CHEMBL1458660 & 737293 & 4.9393 & 4.5154 & TRN \\
\hline CHEMBL1409423 & 737293 & 5.109 & 4.7864 & TRN \\
\hline CHEMBL1477528 & 737293 & 3.699 & 4.2856 & TRN \\
\hline CHEMBL1568614 & 737293 & 3.699 & 3.8046 & TRN \\
\hline CHEMBL1372398 & 737293 & 4.9101 & 4.7897 & TRN \\
\hline CHEMBL1507713 & 737293 & 5.6635 & 5.1881 & TRN \\
\hline CHEMBL3196263 & 737293 & 7.5086 & 5.5076 & TRN \\
\hline CHEMBL1482357 & 737293 & 3.699 & 3.5277 & TRN \\
\hline CHEMBL1323622 & 737293 & 3.699 & 5.5829 & TRN \\
\hline CHEMBL1383777 & 737293 & 5.3546 & 4.7413 & TRN \\
\hline CHEMBL1304363 & 737293 & 3.699 & 4.8536 & TRN \\
\hline CHEMBL1318742 & 737293 & 3.699 & 4.3103 & TRN \\
\hline CHEMBL1366153 & 737293 & 5.1574 & 4.8364 & TRN \\
\hline CHEMBL3197890 & 737293 & 3.699 & 4.5075 & TST \\
\hline CHEMBL1379347 & 737293 & 4.7905 & 5.0204 & TRN \\
\hline CHEMBL1573795 & 737293 & 3.699 & 3.3448 & TRN \\
\hline CHEMBL1490169 & 737293 & 3.699 & 4.7605 & TRN \\
\hline CHEMBL1349428 & 737293 & 5.2636 & 4.732 & TRN \\
\hline CHEMBL1312200 & 737293 & 5.1013 & \multicolumn{2}{|c|}{4.4510000000000005} \\
\hline CHEMBL1603938 & 737293 & 3.699 & 3.4602 & TRN \\
\hline
\end{tabular}




\begin{tabular}{|c|c|c|c|c|c|}
\hline & & \multicolumn{4}{|c|}{ Supplemental Table S2.txt } \\
\hline CHEMBL1581425 & 737293 & 3.699 & 4.2854 & TRN & \\
\hline CHEMBL1514917 & 737293 & 4.9101 & 5.0739 & TRN & \\
\hline CHEMBL1478220 & 737293 & 4.8268 & 4.3851 & TRN & \\
\hline CHEMBL1431608 & 737293 & 3.699 & 4.1521 & TRN & \\
\hline CHEMBL1586359 & 737293 & 4.7305 & 4.7287 & TRN & \\
\hline CHEMBL1377340 & 737293 & 5.2441 & 4.6891 & TST & \\
\hline CHEMBL1483308 & 737293 & 4.9872 & 4.7525 & TRN & \\
\hline CHEMBL1370183 & 737293 & 3.699 & 4.0957 & TRN & \\
\hline CHEMBL1496313 & 737293 & 3.699 & 4.2619 & TST & \\
\hline CHEMBL1484482 & 737293 & 3.699 & 4.0906 & TRN & \\
\hline CHEMBL1342784 & 737293 & 3.699 & 4.2199 & TRN & \\
\hline CHEMBL1541329 & 737293 & 4.8928 & 5.0105 & TRN & \\
\hline CHEMBL1612227 & 737293 & 5.1361 & 4.6875 & TST & \\
\hline CHEMBL1440735 & 737293 & 3.699 & 3.8885 & TST & \\
\hline CHEMBL1465119 & 737293 & 3.699 & 4.8456 & TRN & \\
\hline CHEMBL1586263 & 737293 & 3.699 & 4.7021 & TRN & \\
\hline CHEMBL1416682 & 737293 & 3.699 & 4.7571 & TST & \\
\hline CHEMBL1522043 & 737293 & 3.699 & 4.7681 & TRN & \\
\hline CHEMBL1457907 & 737293 & 4.8356 & 4.6695 & TRN & \\
\hline CHEMBL1583236 & 737293 & 5.3439 & 5.0934 & TRN & \\
\hline CHEMBL1455542 & 737293 & 5.2055 & 5.2101 & TRN & \\
\hline CHEMBL1520276 & 737293 & 3.699 & 4.0926 & TRN & \\
\hline CHEMBL1427335 & 737293 & 3.699 & 4.7277 & TRN & \\
\hline CHEMBL1417054 & 737293 & 3.699 & 4.251 & TRN & \\
\hline CHEMBL1309210 & 737293 & 4.8297 & 4.6932 & TRN & \\
\hline CHEMBL579621 & 737293 & 4.8928 & 4.7243 & TRN & \\
\hline CHEMBL1299319 & 737293 & 5.1343 & 5.1122 & TRN & \\
\hline CHEMBL1550032 & 737293 & 5.5317 & 4.2546 & TRN & \\
\hline CHEMBL1595790 & 737293 & 8.0 & 7.8882 & TST & \\
\hline CHEMBL1301733 & 737293 & 4.9393 & 5.1668 & TRN & \\
\hline CHEMBL1349146 & 737293 & 5.0814 & 4.5688 & TRN & \\
\hline CHEMBL1439315 & 737293 & 5.9586 & 5.4175 & TRN & \\
\hline CHEMBL1304065 & 737293 & 3.699 & 4.4941 & TRN & \\
\hline CHEMBL1468075 & 737293 & 5.2351 & 4.7255 & TRN & \\
\hline CHEMBL1407708 & 737293 & 3.699 & 4.5559 & TST & \\
\hline CHEMBL1520241 & 737293 & 3.699 & 4.61100 & 0000000001 & TRN \\
\hline CHEMBL3195322 & 737293 & 6.1079 & 4.8989 & TRN & \\
\hline CHEMBL 3194040 & 737293 & 3.699 & 3.6615 & TRN & \\
\hline CHEMBL 1347270 & 737293 & 5.301 & 5.2266 & TRN & \\
\hline CHEMBL1310435 & 737293 & 7.5086 & 4.8991 & TRN & \\
\hline CHEMBL1561275 & 737293 & 4.9788 & 4.3082 & TST & \\
\hline CHEMBL1465720 & 737293 & 5.109 & 5.4031 & TST & \\
\hline CHEMBL1602759 & 737293 & 3.699 & 3.83699 & 99999999997 & TST \\
\hline CHEMBL1350780 & 737293 & 3.699 & 3.582 & TRN & \\
\hline CHEMBL1449912 & 737293 & 5.3925 & 4.9528 & TRN & \\
\hline CHEMBL1447831 & 737293 & 3.699 & 4.8554 & TRN & \\
\hline CHEMBL1415844 & 737293 & 4.8416 & 5.7863 & TRN & \\
\hline CHEMBL1344292 & 737293 & 4.9431 & 4.0597 & TRN & \\
\hline
\end{tabular}




\begin{tabular}{|c|c|c|c|c|c|}
\hline & & \multicolumn{4}{|c|}{ Supplemental Table S2.txt } \\
\hline CHEMBL1332756 & 737293 & 3.699 & 3.5693 & TRN & \\
\hline CHEMBL1421605 & 737293 & 3.699 & 4.4987 & TST & \\
\hline CHEMBL1426978 & 737293 & 5.0747 & 4.8822 & TRN & \\
\hline CHEMBL1569724 & 737293 & 3.699 & 5.2562 & TRN & \\
\hline CHEMBL1606583 & 737293 & 5.0931 & 4.9221 & TRN & \\
\hline CHEMBL1542713 & 737293 & 3.699 & 5.7777 & TRN & \\
\hline CHEMBL1567684 & 737293 & 4.8962 & 4.7935 & TRN & \\
\hline CHEMBL1984298 & 737293 & 3.699 & 4.6929 & TRN & \\
\hline CHEMBL1376195 & 737293 & 3.699 & 4.6014 & TRN & \\
\hline CHEMBL1306769 & 737293 & 3.699 & 4.4241 & TRN & \\
\hline CHEMBL1320669 & 737293 & 7.5086 & 6.1016 & TRN & \\
\hline CHEMBL1993613 & 737293 & 5.0035 & 4.0627 & TRN & \\
\hline CHEMBL1462451 & 737293 & 4.7545 & 4.6359 & TRN & \\
\hline CHEMBL1456373 & 737293 & 4.8447 & 4.7899 & TRN & \\
\hline CHEMBL1468181 & 737293 & 7.3979 & 6.5186 & TRN & \\
\hline CHEMBL1520131 & 737293 & 3.699 & 4.7022 & TRN & \\
\hline CHEMBL1529494 & 737293 & 5.1675 & 4.5387 & TRN & \\
\hline CHEMBL578944 & 737293 & 5.0888 & 5.2438 & TST & \\
\hline CHEMBL3195760 & 737293 & 3.699 & 3.8602 & TRN & \\
\hline CHEMBL1433943 & 737293 & 4.7747 & 4.8115 & TRN & \\
\hline CHEMBL1393096 & 737293 & 4.7959 & 4.6649 & TRN & \\
\hline CHEMBL1521877 & 737293 & 4.9245 & 4.96 & TRN & \\
\hline CHEMBL1498436 & 737293 & 3.699 & 4.6179 & TRN & \\
\hline CHEMBL1386754 & 737293 & 5.1163 & 5.0589 & TRN & \\
\hline CHEMBL1344677 & 737293 & 7.5086 & 5.0926 & TST & \\
\hline CHEMBL1611733 & 737293 & 5.1062 & 4.6942 & TST & \\
\hline CHEMBL1550862 & 737293 & 3.699 & 3.8087 & TRN & \\
\hline CHEMBL1967099 & 737293 & 5.2565 & 4.2287 & TRN & \\
\hline CHEMBL1472304 & 737293 & 5.0097 & 5.3152 & TRN & \\
\hline CHEMBL1589670 & 737293 & 3.699 & 4.1014 & TRN & \\
\hline CHEMBL1525546 & 737293 & 3.699 & 4.0771 & TST & \\
\hline CHEMBL1544150 & 737293 & 4.8827 & 5.03100 & 0000000001 & TRN \\
\hline CHEMBL1586285 & 737293 & 5.279 & 4.9346 & TRN & \\
\hline CHEMBL1400275 & 737293 & 5.1433 & 4.9304 & TRN & \\
\hline CHEMBL1525940 & 737293 & 3.699 & 4.0646 & TRN & \\
\hline CHEMBL1581233 & 737293 & 3.699 & 3.9713 & TRN & \\
\hline CHEMBL1560539 & 737293 & 5.0762 & 5.3694 & TRN & \\
\hline CHEMBL1451348 & 737293 & 4.8239 & 5.1026 & TRN & \\
\hline CHEMBL599890 & 737293 & 4.9626 & 4.2548 & TRN & \\
\hline CHEMBL3194944 & 737293 & 7.0 & 7.4221 & TRN & \\
\hline CHEMBL169272 & 737293 & 5.1746 & 4.7072 & TRN & \\
\hline CHEMBL1528004 & 737293 & 5.3686 & 4.6723 & TST & \\
\hline CHEMBL1446827 & 737293 & 3.699 & 4.4354 & TRN & \\
\hline CHEMBL1390866 & 737293 & 3.699 & 4.8958 & TST & \\
\hline CHEMBL3197607 & 737293 & 5.308 & 3.677 & TST & \\
\hline CHEMBL1306900 & 737293 & 3.699 & 4.2023 & TRN & \\
\hline CHEMBL1994623 & 737293 & 3.699 & 3.4859 & TRN & \\
\hline CHEMBL1546267 & 737293 & 3.699 & 4.4246 & TRN & \\
\hline
\end{tabular}




\begin{tabular}{|c|c|c|c|c|}
\hline & & & pplement & al $\mathrm{T}$ \\
\hline CHEMBL1486619 & 737293 & 5.3251 & 5.0809 & TRN \\
\hline CHEMBL1333593 & 737293 & 4.857 & 4.5952 & TRN \\
\hline CHEMBL1332003 & 737293 & 3.699 & 3.074 & TRN \\
\hline CHEMBL1544114 & 737293 & 3.699 & 4.3261 & TRN \\
\hline CHEMBL1372308 & 737293 & 5.3307 & 4.7208 & TRN \\
\hline CHEMBL1556086 & 737293 & 4.9318 & 4.4864 & TRN \\
\hline CHEMBL585502 & 737293 & 5.1688 & 5.2103 & TRN \\
\hline CHEMBL1442136 & 737293 & 3.699 & 4.4427 & TRN \\
\hline CHEMBL1523659 & 737293 & 4.9355 & 5.0925 & TRN \\
\hline CHEMBL1411639 & 737293 & 3.699 & 4.8048 & TRN \\
\hline CHEMBL1582794 & 737293 & 3.699 & 4.8791 & TRN \\
\hline CHEMBL1608077 & 737293 & 4.9666 & 5.0303 & TRN \\
\hline CHEMBL1332684 & 737293 & 5.7328 & 4.7266 & TST \\
\hline CHEMBL1300239 & 737293 & 5.2013 & 5.3201 & TRN \\
\hline CHEMBL1376861 & 737293 & 3.699 & 4.8373 & TRN \\
\hline CHEMBL1542558 & 737293 & 4.9101 & 4.2219 & TRN \\
\hline CHEMBL1543588 & 737293 & 3.699 & 4.0134 & TST \\
\hline CHEMBL1586575 & 737293 & 5.3726 & 5.1262 & TRN \\
\hline CHEMBL1571150 & 737293 & 4.7055 & 5.6072 & TST \\
\hline CHEMBL1457134 & 737293 & 5.4486 & 4.6593 & TRN \\
\hline CHEMBL1301943 & 737293 & 3.699 & 4.1741 & TST \\
\hline CHEMBL1380813 & 737293 & 6.1367 & 4.8391 & TRN \\
\hline CHEMBL1374703 & 737293 & 3.699 & 4.0942 & TRN \\
\hline CHEMBL1510940 & 737293 & 4.8996 & 4.7989 & TRN \\
\hline CHEMBL1361509 & 737293 & 3.699 & 3.6902 & TRN \\
\hline CHEMBL1426152 & 737293 & 5.1694 & 4.7046 & TRN \\
\hline CHEMBL1586616 & 737293 & 4.8729 & 4.7021 & TST \\
\hline CHEMBL1369425 & 737293 & 5.2604 & 4.8454 & TRN \\
\hline CHEMBL1374160 & 737293 & 5.2418 & 4.7668 & TRN \\
\hline CHEMBL1455507 & 737293 & 3.699 & 4.746 & TRN \\
\hline CHEMBL1335978 & 737293 & 5.6498 & 4.5391 & TRN \\
\hline CHEMBL1500227 & 737293 & 3.699 & 4.0324 & TRN \\
\hline CHEMBL1328478 & 737293 & 3.699 & 3.8875 & TRN \\
\hline CHEMBL1495358 & 737293 & 3.699 & 4.6177 & TRN \\
\hline CHEMBL3145330 & 737293 & 3.699 & 3.9963 & TRN \\
\hline CHEMBL1555716 & 737293 & 5.2692 & 3.9827 & TRN \\
\hline CHEMBL3195658 & 737293 & 5.1898 & 4.4196 & TRN \\
\hline CHEMBL1997659 & 737293 & 4.9788 & 4.5222 & TRN \\
\hline CHEMBL1602150 & 737293 & 5.1871 & 5.3597 & TST \\
\hline CHEMBL1337833 & 737293 & 3.699 & 4.7748 & TRN \\
\hline CHEMBL1382232 & 737293 & 3.699 & 3.5072 & TRN \\
\hline CHEMBL1483975 & 737293 & 3.699 & 4.1142 & TRN \\
\hline CHEMBL1597561 & 737293 & 6.3372 & 5.8223 & TRN \\
\hline CHEMBL1612381 & 737293 & 5.1018 & 4.8556 & TRN \\
\hline CHEMBL1562819 & 737293 & 5.5817 & 4.8711 & TRN \\
\hline CHEMBL1558180 & 737293 & 3.699 & 3.9983 & TRN \\
\hline CHEMBL1507251 & 737293 & 6.2441 & 5.7454 & TRN \\
\hline CHEMBL1320494 & 737293 & 3.699 & 4.4413 & TRN \\
\hline
\end{tabular}




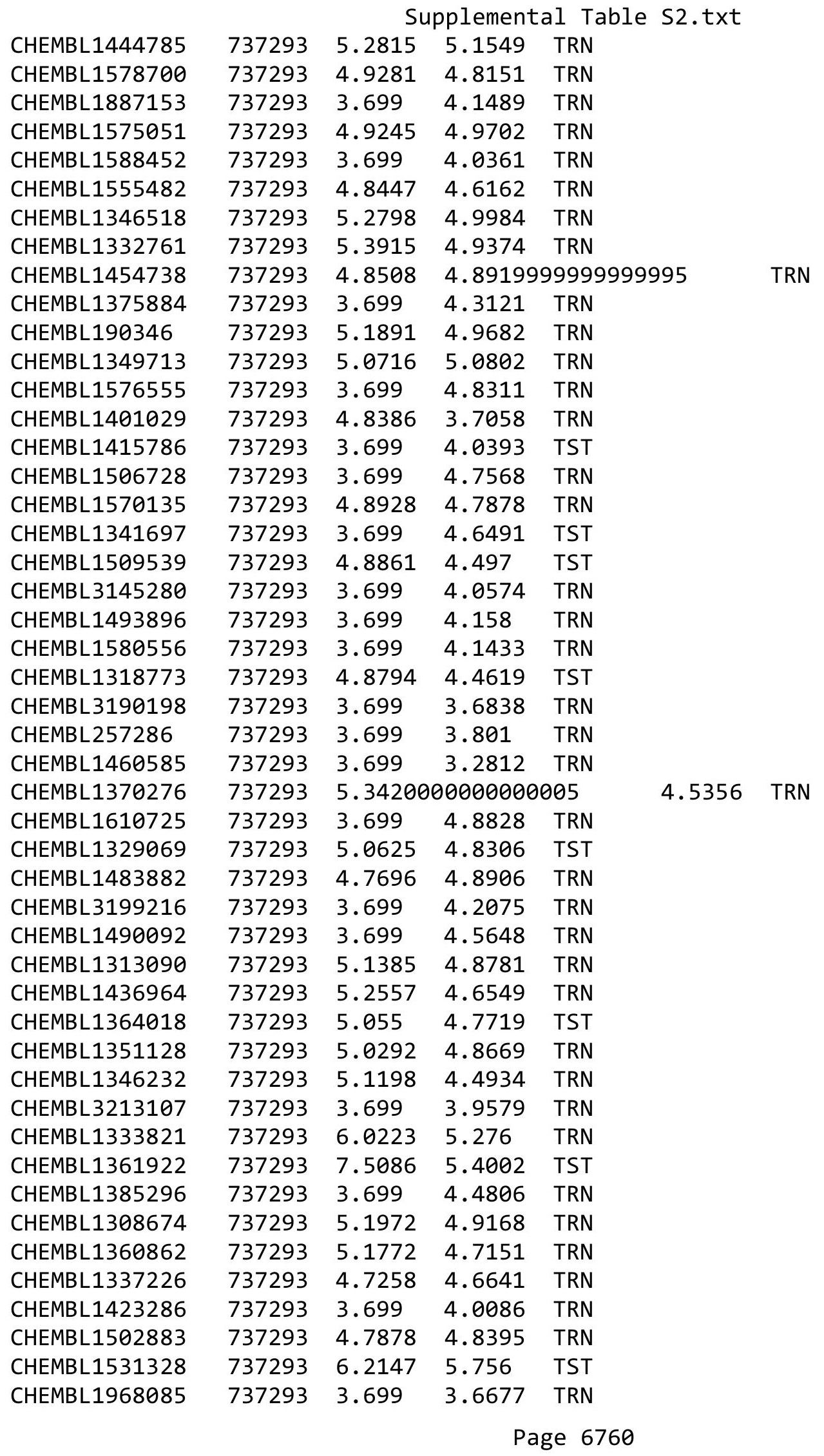


Supplemental Table S2.txt

\begin{tabular}{|c|c|c|c|c|c|c|}
\hline CHEMBL1464490 & 737293 & 3.699 & 4.2593 & TRN & & \\
\hline CHEMBL1604919 & 737293 & 4.9586 & 4.9173 & TST & & \\
\hline CHEMBL1349532 & 737293 & 4.7959 & 4.4587 & TRN & & \\
\hline CHEMBL1422567 & 737293 & 4.8356 & 4.7136 & TRN & & \\
\hline CHEMBL1607172 & 737293 & 4.9914 & 5.1234 & TRN & & \\
\hline CHEMBL1457068 & 737293 & 3.699 & 3.7529 & TRN & & \\
\hline CHEMBL1540477 & 737293 & 5.6536 & 4.9665 & TRN & & \\
\hline CHEMBL1338804 & 737293 & 5.0159 & 4.8451 & TRN & & \\
\hline CHEMBL3210725 & 737293 & 6.3098 & 5.51 & TRN & & \\
\hline CHEMBL1456848 & 737293 & 5.2472 & 4.4822 & TRN & & \\
\hline CHEMBL1611774 & 737293 & 5.4949 & 4.5793 & TST & & \\
\hline CHEMBL577660 & 737293 & 5.1325 & 4.8578 & TRN & & \\
\hline CHEMBL1361883 & 737293 & 3.699 & 4.4449 & TRN & & \\
\hline CHEMBL1468750 & 737293 & 5.0311 & 4.9422 & TRN & & \\
\hline CHEMBL1534959 & 737293 & 3.699 & 3.4674 & TST & & \\
\hline CHEMBL1504069 & 737293 & 3.699 & 4.003 & TST & & \\
\hline CHEMBL1470676 & 737293 & 7.5086 & 5.2371 & TST & & \\
\hline CHEMBL1558928 & 737293 & 5.0506 & 4.4871 & TST & & \\
\hline CHEMBL1543504 & 737293 & \multicolumn{3}{|c|}{4.9830000000000005} & 4.7298 & TS \\
\hline CHEMBL1501527 & 737293 & 4.8447 & 4.4321 & TST & & \\
\hline CHEMBL1461392 & 737293 & 5.2581 & 5.1705 & TST & & \\
\hline CHEMBL600778 & 737293 & 3.699 & 3.4621 & TST & & \\
\hline CHEMBL1480238 & 737293 & 6.5229 & 6.1647 & TST & & \\
\hline CHEMBL1439435 & 737293 & 4.7773 & 4.6862 & TST & & \\
\hline CHEMBL1351908 & 737293 & 7.699 & 5.3943 & TST & & \\
\hline CHEMBL1483105 & 737293 & 4.8069 & 4.6891 & TST & & \\
\hline CHEMBL1424697 & 737293 & 5.5229 & 4.8509 & TST & & \\
\hline CHEMBL1562608 & 737293 & 3.699 & 3.1436 & TST & & \\
\hline CHEMBL1408320 & 737293 & 3.699 & 3.7533 & TST & & \\
\hline CHEMBL1529741 & 737293 & 3.699 & 5.4588 & TST & & \\
\hline CHEMBL3197790 & 737293 & 3.699 & 3.6421 & TST & & \\
\hline CHEMBL1325644 & 737293 & 3.699 & 4.2237 & TST & & \\
\hline CHEMBL1385087 & 737293 & 3.699 & 4.5752 & TST & & \\
\hline CHEMBL1324011 & 737293 & 3.699 & 4.6128 & TST & & \\
\hline CHEMBL1536849 & 737293 & 5.3344 & 4.5271 & TST & & \\
\hline CHEMBL1512575 & 737293 & 5.3747 & 5.2863 & TST & & \\
\hline CHEMBL1570792 & 737293 & 5.1062 & 4.6933 & TST & & \\
\hline CHEMBL1299281 & 737293 & 5.3788 & 5.0891 & TST & & \\
\hline CHEMBL1321987 & 737293 & 3.699 & 5.1073 & TST & & \\
\hline CHEMBL1525735 & 737293 & 5.0778 & 5.1754 & TST & & \\
\hline CHEMBL1486981 & 737293 & 3.699 & 4.2907 & TST & & \\
\hline CHEMBL1495890 & 737293 & 5.2518 & 4.8178 & TST & & \\
\hline CHEMBL3195226 & 737293 & 3.699 & 4.8741 & TST & & \\
\hline CHEMBL1322356 & 737293 & 3.699 & 4.5793 & TST & & \\
\hline CHEMBL1544103 & 737293 & 4.757 & 5.1742 & TST & & \\
\hline CHEMBL1369671 & 737293 & 3.699 & 4.6785 & TST & & \\
\hline CHEMBL1549092 & 737293 & 5.0511 & 4.7102 & TST & & \\
\hline CHEMBL1599782 & 737293 & 5.2321 & 4.6831 & TST & & \\
\hline
\end{tabular}




\begin{tabular}{|c|c|c|c|c|c|}
\hline & & \multicolumn{4}{|c|}{ Supplemental Table S2.txt } \\
\hline CHEMBL1425054 & 737293 & 3.699 & 4.3651 & TST & \\
\hline CHEMBL1426966 & 737293 & 4.8794 & 4.428 & TST & \\
\hline CHEMBL1586401 & 737293 & 3.699 & 3.5251 & TST & \\
\hline CHEMBL3215592 & 596433 & 4.9586 & 4.4377 & TRN & \\
\hline CHEMBL3216687 & 596433 & 4.699 & 4.3365 & TRN & \\
\hline CHEMBL1197423 & 596433 & 5.3098 & 3.6181 & TRN & \\
\hline CHEMBL3216459 & 596433 & 3.0 & 3.4393 & TRN & \\
\hline CHEMBL3216685 & 596433 & 3.0 & 3.6066 & TRN & \\
\hline CHEMBL3216692 & 596433 & 3.0 & 3.5086 & TRN & \\
\hline CHEMBL3216042 & 596433 & 3.0 & 3.2817 & TRN & \\
\hline CHEMBL3216686 & 596433 & 5.041 & 4.7774 & TRN & \\
\hline CHEMBL3216693 & 596433 & 3.3979 & 4.2787 & TRN & \\
\hline CHEMBL3216241 & 596433 & 3.0 & 2.8438 & TRN & \\
\hline CHEMBL3215799 & 596433 & 3.0 & 2.9801 & TRN & \\
\hline CHEMBL3215589 & 596433 & 3.0 & 3.1738 & TST & \\
\hline CHEMBL3215594 & 596433 & 3.0 & 3.2507 & TRN & \\
\hline CHEMBL 3215800 & 596433 & 3.301 & 4.4549 & TRN & \\
\hline CHEMBL3216046 & 596433 & 3.0 & 3.63199 & 99999999997 & TRN \\
\hline CHEMBL3216690 & 596433 & 3.0 & 3.4477 & TST & \\
\hline CHEMBL3217130 & 596433 & 4.8861 & 4.4432 & TST & \\
\hline CHEMBL 3216454 & 596433 & 3.0 & 3.5827 & TRN & \\
\hline CHEMBL3216249 & 596433 & 4.6198 & 3.8205 & TRN & \\
\hline CHEMBL 3215801 & 596433 & 3.0 & 3.216 & TRN & \\
\hline CHEMBL3215590 & 596433 & 3.0 & 3.3255 & TST & \\
\hline CHEMBL 3217128 & 596433 & 4.4815 & 4.2443 & TRN & \\
\hline CHEMBL3215803 & 596433 & 3.0 & 4.23600 & 0000000001 & TST \\
\hline CHEMBL1198787 & 596433 & 3.0 & 3.2565 & TST & \\
\hline CHEMBL3216243 & 596433 & 3.0 & 3.6409 & TRN & \\
\hline CHEMBL3216918 & 596433 & 3.0 & 3.0482 & TRN & \\
\hline CHEMBL3215793 & 596433 & 4.3665 & 3.6481 & TRN & \\
\hline CHEMBL3216450 & 596433 & 4.7696 & 4.7402 & TRN & \\
\hline CHEMBL3215791 & 596433 & 3.0 & 4.1974 & TST & \\
\hline CHEMBL3216691 & 596433 & 4.6021 & 3.5351 & TRN & \\
\hline CHEMBL3216451 & 596433 & 3.0 & 2.8301 & TRN & \\
\hline CHEMBL 3216040 & 596433 & 4.3188 & 4.54 & TRN & \\
\hline CHEMBL3215593 & 596433 & 4.4949 & 3.2173 & TRN & \\
\hline CHEMBL569952 & 596433 & 3.0 & 3.1202 & TRN & \\
\hline CHEMBL 3216457 & 596433 & 4.5086 & 4.2834 & TRN & \\
\hline CHEMBL3216921 & 596433 & 3.0 & 4.1924 & TRN & \\
\hline CHEMBL 3216242 & 596433 & 3.0 & 3.2431 & TRN & \\
\hline CHEMBL 3215588 & 596433 & 5.0969 & 4.5959 & TRN & \\
\hline CHEMBL3216456 & 596433 & 3.0 & 3.1304 & TRN & \\
\hline CHEMBL3216916 & 596433 & 3.0 & 3.2272 & TST & \\
\hline CHEMBL3215792 & 596433 & 3.0 & 2.8922 & TRN & \\
\hline CHEMBL3216922 & 596433 & 3.301 & 3.3479 & TRN & \\
\hline CHEMBL 3216688 & 596433 & 3.0 & 3.1357 & TRN & \\
\hline CHEMBL3216248 & 596433 & 3.0 & 3.4533 & TRN & \\
\hline CHEMBL3217131 & 596433 & 3.0 & 3.0237 & TRN & \\
\hline
\end{tabular}




\begin{tabular}{|c|c|c|c|c|c|}
\hline \multicolumn{6}{|c|}{ Supplemental Table S2.txt } \\
\hline CHEMBL 3216449 & 596433 & 3.0 & 4.2389 & TST & \\
\hline CHEMBL 3216458 & 596433 & 3.0 & 3.3345 & TST & \\
\hline CHEMBL3216919 & 596433 & 3.0 & 3.3562 & TST & \\
\hline CHEMBL3216043 & 596433 & 3.0 & 2.9487 & TRN & \\
\hline CHEMBL3216044 & 596433 & 3.0 & 3.8397 & TRN & \\
\hline CHEMBL3216039 & 596433 & 3.0 & 3.9563 & TST & \\
\hline CHEMBL1197563 & 596433 & 5.3665 & 4.4041 & TST & \\
\hline CHEMBL3216915 & 596433 & 3.0 & 3.1028 & TRN & \\
\hline CHEMBL 3216920 & 596433 & 5.3665 & 4.6368 & TRN & \\
\hline CHEMBL3216463 & 596433 & 3.0 & 2.9603 & TRN & \\
\hline CHEMBL3215795 & 596433 & 4.2366 & 3.28 & TRN & \\
\hline CHEMBL 3216045 & 596433 & 4.9208 & 4.6845 & TRN & \\
\hline CHEMBL3216445 & 596433 & 3.0 & 4.0942 & TST & \\
\hline CHEMBL3216683 & 596433 & 3.0 & 3.2372 & TST & \\
\hline CHEMBL1197424 & 596433 & 3.0 & 3.41 & TRN & \\
\hline CHEMBL123656 & 3891 & 4.3979 & 4.4343 & TRN & \\
\hline CHEMBL124599 & 3891 & 6.8539 & 7.1855 & TRN & \\
\hline CHEMBL331788 & 3891 & 5.4559 & 5.4967 & TRN & \\
\hline CHEMBL52 & 3891 & 6.8239 & 6.9864 & TST & \\
\hline CHEMBL122809 & 3891 & 7.2366 & 7.1321 & TRN & \\
\hline CHEMBL332663 & 3891 & 6.7959 & 7.3534 & TST & \\
\hline CHEMBL123054 & 3891 & 7.2518 & 7.4096 & TRN & \\
\hline CHEMBL414425 & 3891 & 7.2676 & 7.4751 & TRN & \\
\hline CHEMBL331435 & 3891 & 5.2366 & 5.0562 & TRN & \\
\hline CHEMBL123819 & 3891 & 7.1135 & 7.3659 & TRN & \\
\hline CHEMBL123458 & 3891 & 6.7447 & 6.6876 & TRN & \\
\hline CHEMBL122780 & 3891 & 5.4559 & 5.2208 & TRN & \\
\hline CHEMBL126213 & 3891 & 7.2076 & 7.072 & TRN & \\
\hline CHEMBL123604 & 3891 & 6.8539 & 6.7177 & TRN & \\
\hline CHEMBL123219 & 3891 & 7.699 & 7.7922 & TRN & \\
\hline CHEMBL122984 & 3891 & 6.9208 & 6.8792 & TRN & \\
\hline CHEMBL421079 & 3891 & 7.4318 & 7.6627 & TRN & \\
\hline CHEMBL123080 & 3891 & 6.8861 & 7.1105 & TRN & \\
\hline CHEMBL172049 & 3891 & 6.6021 & 6.4329 & TST & \\
\hline CHEMBL123179 & 3891 & 5.3768 & 5.2922 & TRN & \\
\hline CHEMBL122929 & 3891 & 7.6198 & 7.8514 & TRN & \\
\hline CHEMBL122625 & 3891 & 6.8539 & 6.9059 & TRN & \\
\hline CHEMBL340821 & 3891 & 6.4089 & 6.1416 & TRN & \\
\hline CHEMBL122962 & 3891 & 6.1612 & 6.0195 & TRN & \\
\hline CHEMBL122930 & 3891 & 7.2924 & 7.16 & TRN & \\
\hline CHEMBL122175 & 3891 & 6.8539 & 6.67299 & 9999999999 & TRN \\
\hline CHEMBL332437 & 3891 & 7.2518 & 7.2086 & TRN & \\
\hline CHEMBL332588 & 3891 & 6.9208 & 7.0021 & TRN & \\
\hline CHEMBL122254 & 3891 & 6.7447 & 6.4589 & TRN & \\
\hline CHEMBL123388 & 3891 & 6.7959 & 6.76399 & 9999999999 & TRN \\
\hline CHEMBL544593 & 3891 & 5.041 & 4.8493 & TRN & \\
\hline CHEMBL331447 & 3891 & 7.5086 & 7.296 & TRN & \\
\hline CHEMBL331629 & 3891 & 5.0555 & 5.0919 & TRN & \\
\hline
\end{tabular}




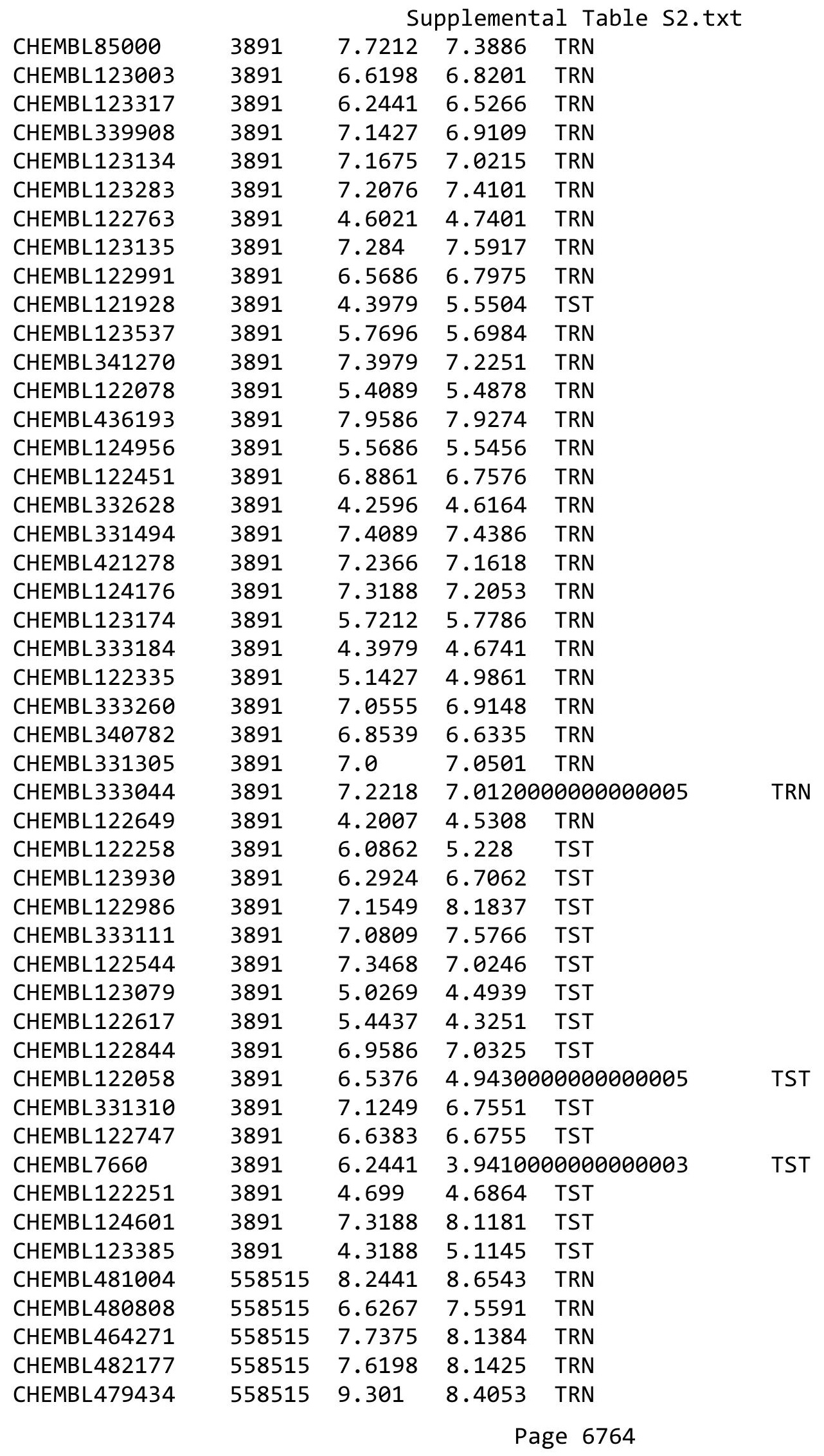




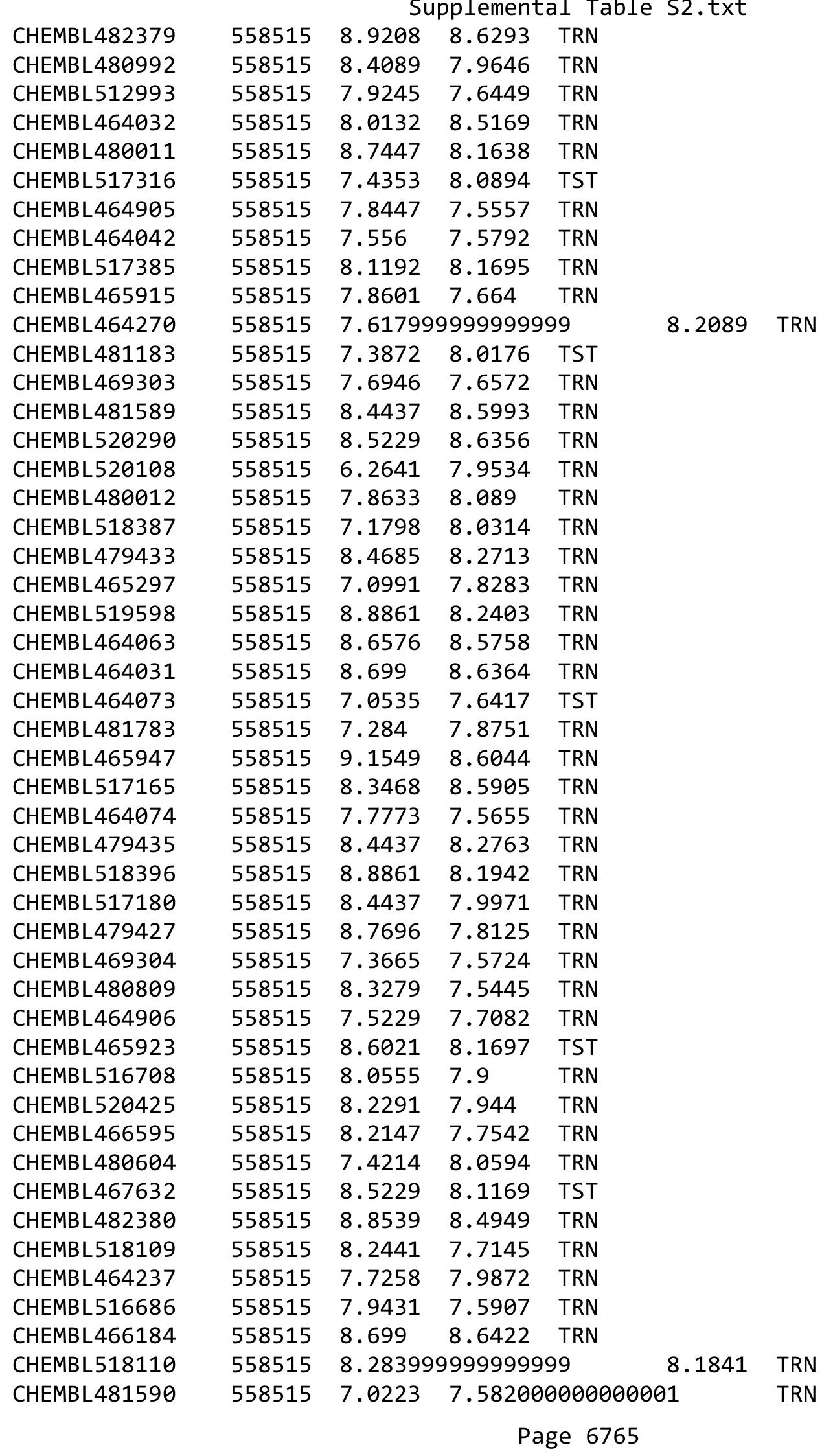




\begin{tabular}{|c|c|c|c|c|c|c|}
\hline & & \multicolumn{5}{|c|}{ Supplemental Table S2.txt } \\
\hline CHEMBL465122 & 558515 & 7.5591 & 8.1307 & TRN & & \\
\hline CHEMBL480416 & 558515 & 6.7033 & 7.6111 & TST & & \\
\hline CHEMBL464059 & 558515 & 8.0269 & 7.6807 & TRN & & \\
\hline CHEMBL480609 & 558515 & 7.3487 & 7.6246 & TST & & \\
\hline CHEMBL513305 & 558515 & 7.3565 & 7.7362 & TST & & \\
\hline CHEMBL520741 & 558515 & 8.0315 & 8.2786 & TST & & \\
\hline CHEMBL466594 & 558515 & 6.2636 & 8.0518 & TST & & \\
\hline CHEMBL520933 & 558515 & 8.3279 & 8.2732 & TST & & \\
\hline CHEMBL481984 & 558515 & 8.0862 & 8.0569 & TST & & \\
\hline CHEMBL465298 & 558515 & 7.3958 & 7.932 & TST & & \\
\hline CHEMBL481782 & 558515 & 8.0362 & 7.8869 & TST & & \\
\hline CHEMBL481582 & 558515 & 8.5528 & 8.0839 & TST & & \\
\hline CHEMBL521103 & 558515 & 7.7258 & 7.7924 & TST & & \\
\hline CHEMBL520757 & 558515 & 6.9133 & 8.6907 & TST & & \\
\hline CHEMBL3697961 & 1528054 & 8.0004 & 8.5064 & TRN & & \\
\hline CHEMBL3697971 & 1528054 & 8.5591 & 7.7738 & TRN & & \\
\hline CHEMBL3698024 & 1528054 & 8.98299 & 99999999 & 99 & 8.3161 & TST \\
\hline CHEMBL 3697973 & 1528054 & 8.6021 & 8.3414 & TRN & & \\
\hline CHEMBL3698002 & 1528054 & 8.4486 & 8.1404 & TRN & & \\
\hline CHEMBL3697975 & 1528054 & 6.0 & 6.8132 & TRN & & \\
\hline CHEMBL3697991 & 1528054 & 7.9038 & 8.0394 & TRN & & \\
\hline CHEMBL3697962 & 1528054 & 8.8894 & 8.7223 & TRN & & \\
\hline CHEMBL 3697992 & 1528054 & 8.6635 & 7.2876 & TRN & & \\
\hline CHEMBL3698011 & 1528054 & 8.3344 & 8.5794 & TRN & & \\
\hline CHEMBL3698023 & 1528054 & 8.6126 & 8.1146 & TRN & & \\
\hline CHEMBL3697999 & 1528054 & 8.3382 & 8.4787 & TRN & & \\
\hline CHEMBL3697994 & 1528054 & 7.9027 & 8.1172 & TRN & & \\
\hline CHEMBL3697997 & 1528054 & 8.6198 & 8.2925 & TST & & \\
\hline CHEMBL3698013 & 1528054 & 7.5616 & 8.4358 & TRN & & \\
\hline CHEMBL3697957 & 1528054 & 8.8928 & 8.7499 & TRN & & \\
\hline CHEMBL3698017 & 1528054 & 8.5406 & 8.5497 & TST & & \\
\hline CHEMBL3698006 & 1528054 & 8.4724 & 8.5698 & TRN & & \\
\hline CHEMBL3698012 & 1528054 & 7.8456 & 8.286 & TRN & & \\
\hline CHEMBL3697993 & 1528054 & 8.3487 & 8.1598 & TRN & & \\
\hline CHEMBL3697995 & 1528054 & 7.4547 & 7.4797 & TRN & & \\
\hline CHEMBL3698018 & 1528054 & 8.6576 & 8.3786 & TST & & \\
\hline CHEMBL3697956 & 1528054 & 8.5086 & 7.7122 & TRN & & \\
\hline CHEMBL 3697987 & 1528054 & 7.8044 & 8.1545 & TRN & & \\
\hline CHEMBL3698022 & 1528054 & 8.7375 & 8.6941 & TRN & & \\
\hline CHEMBL3697969 & 1528054 & 8.8013 & 8.4828 & TRN & & \\
\hline CHEMBL3698026 & 1528054 & 8.8894 & 8.4984 & TST & & \\
\hline CHEMBL3697966 & 1528054 & 8.8041 & 8.7906 & TRN & & \\
\hline CHEMBL3697951 & 1528054 & 8.9393 & 8.5127 & TRN & & \\
\hline CHEMBL3698025 & 1528054 & 8.4737 & 8.7556 & TST & & \\
\hline CHEMBL3697965 & 1528054 & 8.4584 & 8.3682 & TRN & & \\
\hline CHEMBL3697958 & 1528054 & 8.9101 & 8.863 & TRN & & \\
\hline CHEMBL3697985 & 1528054 & 8.2218 & 8.3247 & TRN & & \\
\hline CHEMBL3639968 & 1528054 & 8.6968 & 8.5773 & TST & & \\
\hline
\end{tabular}


Supplemental Table S2.txt

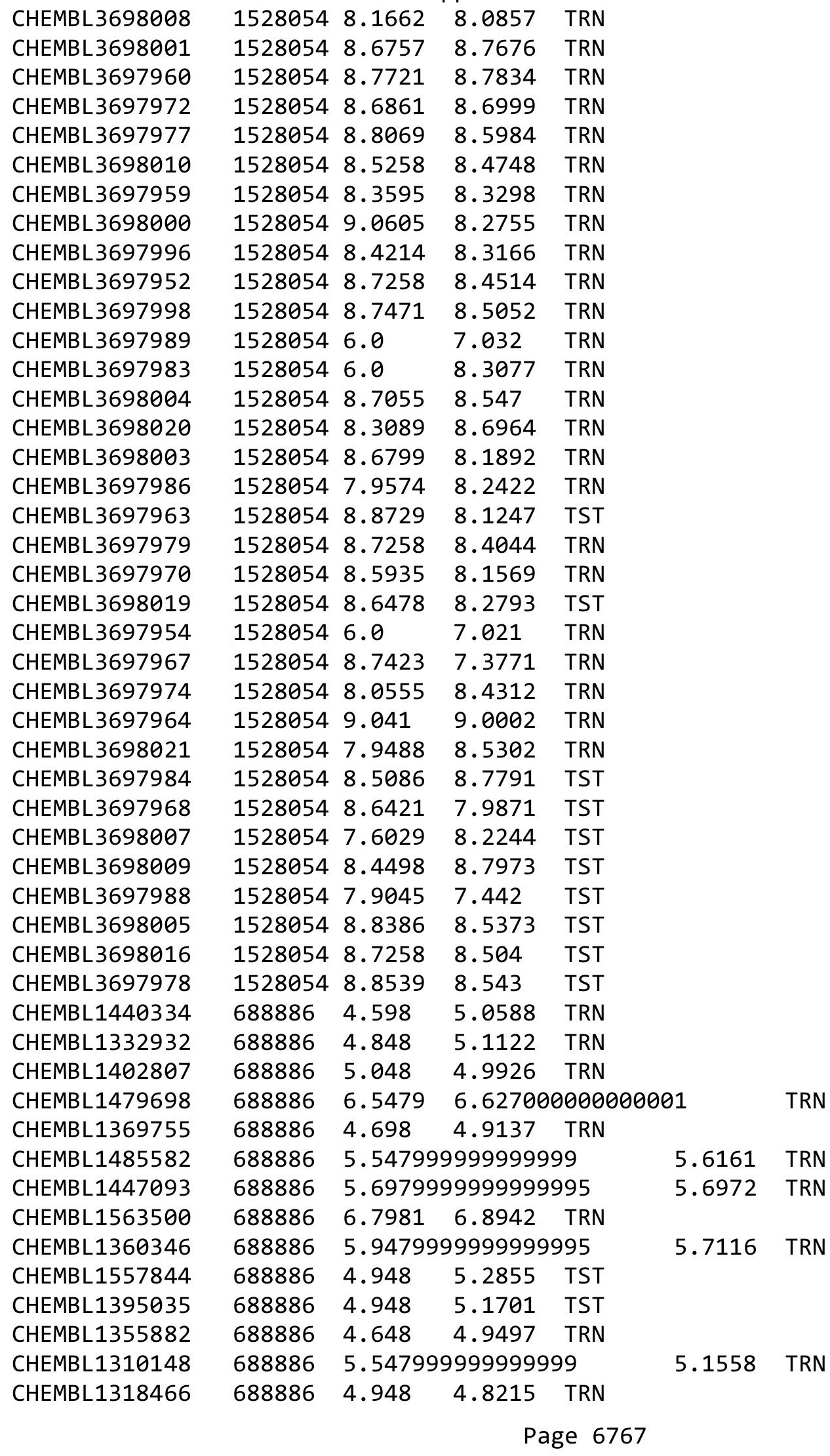




\begin{tabular}{|c|c|c|c|c|c|c|c|}
\hline & & & & & & & \\
\hline CHEMBL1370781 & 688886 & 4.648 & 5.1441 & TST & & & \\
\hline CHEMBL1314857 & 688886 & 4.948 & 5.4238 & TST & & & \\
\hline CHEMBL1475415 & 688886 & 5.048 & 4.8926 & TRN & & & \\
\hline CHEMBL1519660 & 688886 & 6.19799 & 999999995 & 995 & 6.2461 & TRN & \\
\hline CHEMBL1408294 & 688886 & 4.848 & 4.9551 & TRN & & & \\
\hline CHEMBL1512398 & 688886 & 5.44799 & 999999995 & 995 & 5.42 & TRN & \\
\hline CHEMBL1575603 & 688886 & 4.648 & 4.99 & TRN & & & \\
\hline CHEMBL1550055 & 688886 & 4.648 & 4.9846 & TRN & & & \\
\hline CHEMBL1339614 & 688886 & 4.898 & 5.1548 & TRN & & & \\
\hline CHEMBL1442023 & 688886 & 6.0979 & 6.1867 & TRN & & & \\
\hline CHEMBL1415176 & 688886 & 4.648 & 4.6745 & TRN & & & \\
\hline CHEMBL1364829 & 688886 & 6.24799 & 999999999 & & 5.9687 & TRN & \\
\hline CHEMBL1585477 & 688886 & 5.74799 & 999999999 & & 5.5044 & TRN & \\
\hline CHEMBL1552344 & 688886 & 4.998 & 5.0602 & TST & & & \\
\hline CHEMBL1512285 & 688886 & 5.69799 & 999999999 & 995 & 5.4104 & TRN & \\
\hline CHEMBL1376011 & 688886 & 4.898 & 4.9562 & TRN & & & \\
\hline CHEMBL1486491 & 688886 & 4.648 & 5.3093 & TRN & & & \\
\hline CHEMBL1392415 & 688886 & 4.998 & 4.9382 & TST & & & \\
\hline CHEMBL1473261 & 688886 & 6.04799 & 999999999 & & 5.4512 & TST & \\
\hline CHEMBL1356920 & 688886 & 5.098 & 4.8839 & TRN & & & \\
\hline CHEMBL1454968 & 688886 & 4.848 & 4.9809 & TRN & & & \\
\hline CHEMBL1578495 & 688886 & 6.19799 & 999999999 & 995 & 5.88399 & 99999999995 & TRN \\
\hline CHEMBL1597843 & 688886 & 5.19799 & 999999999 & 995 & 5.3696 & TRN & \\
\hline CHEMBL1314210 & 688886 & 4.848 & 5.0879 & TRN & & & \\
\hline CHEMBL1488897 & 688886 & 5.098 & 5.257999 & 999999999 & & TRN & \\
\hline CHEMBL1536547 & 688886 & 4.948 & 4.9178 & TRN & & & \\
\hline CHEMBL1481939 & 688886 & 5.19799 & 999999999 & 995 & 5.3482 & TRN & \\
\hline CHEMBL1435324 & 688886 & 5.94799 & 999999999 & 995 & 5.5436 & TRN & \\
\hline CHEMBL1316098 & 688886 & 5.598 & 6.116000 & 000000000 & 305 & TRN & \\
\hline CHEMBL1469922 & 688886 & 5.29799 & 999999999 & & 5.2951 & TRN & \\
\hline CHEMBL1394119 & 688886 & 6.04799 & 999999999 & & 5.9315 & TRN & \\
\hline CHEMBL1439235 & 688886 & 4.948 & 5.0312 & TRN & & & \\
\hline CHEMBL 1477014 & 688886 & 6.0979 & 5.8152 & TRN & & & \\
\hline CHEMBL1452988 & 688886 & 5.44799 & 999999999 & 995 & 5.5113 & TRN & \\
\hline CHEMBL1486413 & 688886 & 5.348 & 5.715 & TRN & & & \\
\hline CHEMBL1324664 & 688886 & 5.848 & 6.1856 & TRN & & & \\
\hline CHEMBL1409218 & 688886 & 5.148 & 5.581 & TRN & & & \\
\hline CHEMBL1467031 & 688886 & 5.29799 & 999999999 & & 5.362 & TRN & \\
\hline CHEMBL1329119 & 688886 & 4.648 & 4.9514 & TST & & & \\
\hline CHEMBL1480389 & 688886 & 5.648 & 5.3099 & TRN & & & \\
\hline CHEMBL1596742 & 688886 & 5.74799 & 999999999 & & 5.4639 & TRN & \\
\hline CHEMBL1365533 & 688886 & 4.998 & 4.8286 & TRN & & & \\
\hline CHEMBL1563130 & 688886 & 5.44799 & 999999999 & 995 & 5.4779 & TRN & \\
\hline CHEMBL1395322 & 688886 & 5.398 & 5.3569 & TRN & & & \\
\hline CHEMBL1598240 & 688886 & 5.94799 & 999999999 & 995 & 5.3618 & TRN & \\
\hline CHEMBL1325491 & 688886 & 4.648 & 4.7303 & TST & & & \\
\hline CHEMBL1563895 & 688886 & 5.598 & 5.7684 & TRN & & & \\
\hline CHEMBL1380559 & 688886 & 4.948 & 4.9248 & TRN & & & \\
\hline
\end{tabular}




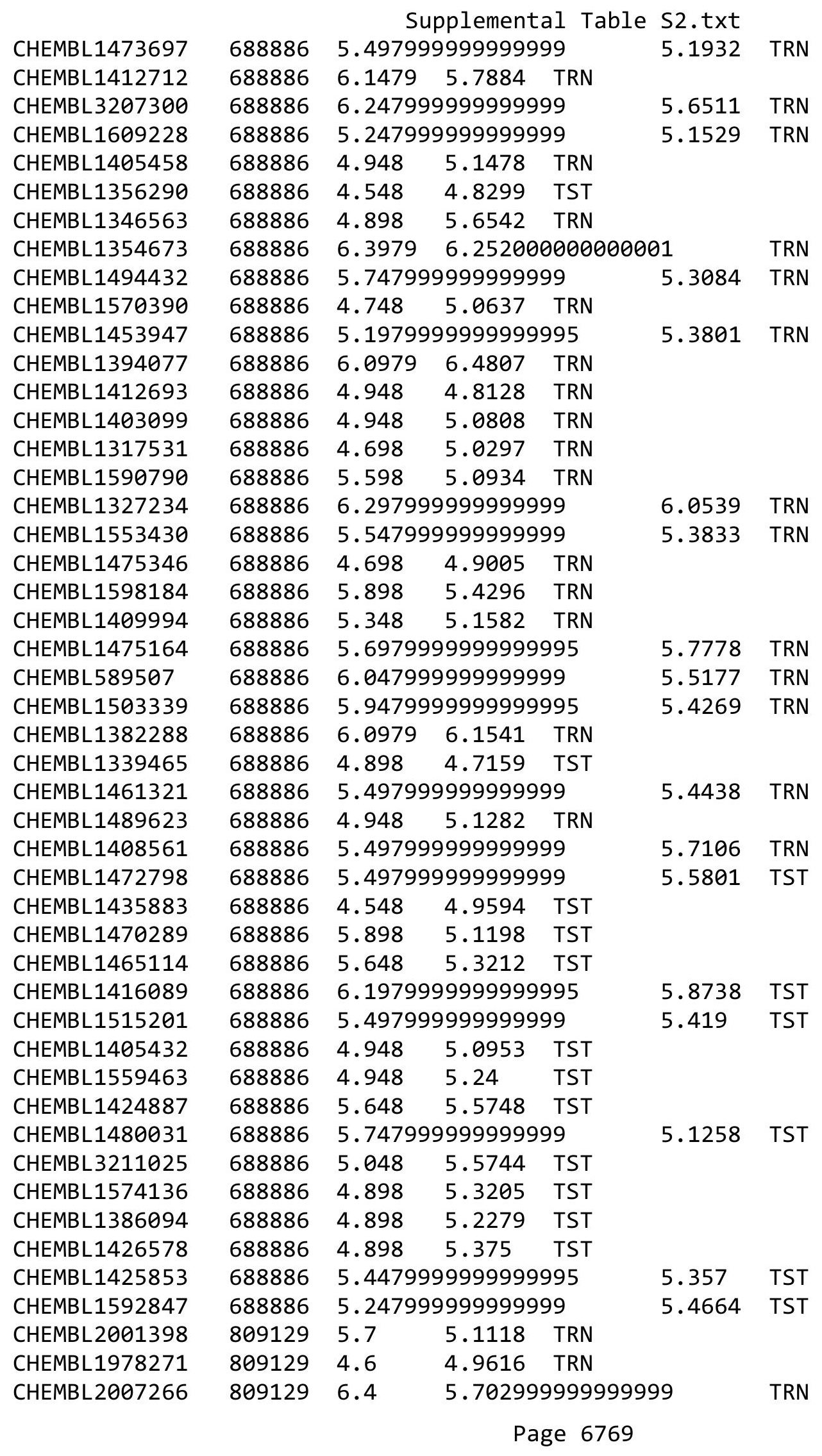




\begin{tabular}{|c|c|c|c|c|c|}
\hline \multicolumn{6}{|c|}{ Supplemental Table S2.txt } \\
\hline CHEMBL202721 & 809129 & 6.4 & 5.2236 & TRN & \\
\hline CHEMBL 2000568 & 809129 & 6.2 & 5.4827 & TRN & \\
\hline CHEMBL1994308 & 809129 & 4.6 & 4.8024 & TRN & \\
\hline CHEMBL1974328 & 809129 & 8.0 & 7.5596 & TRN & \\
\hline CHEMBL388311 & 809129 & 6.9 & 7.3487 & TRN & \\
\hline CHEMBL1964948 & 809129 & 4.6 & 4.9197 & TRN & \\
\hline CHEMBL1973013 & 809129 & 6.3 & 6.0658 & TRN & \\
\hline CHEMBL1164265 & 809129 & 8.7 & 8.007 & TST & \\
\hline CHEMBL1987430 & 809129 & 4.6 & 4.4697 & TRN & \\
\hline CHEMBL1993413 & 809129 & 4.6 & 4.7135 & TRN & \\
\hline CHEMBL205415 & 809129 & 4.6 & 4.8483 & TRN & \\
\hline CHEMBL1975927 & 809129 & 6.5 & 6.3096 & TRN & \\
\hline CHEMBL1986943 & 809129 & 6.6 & 5.82299 & & TRN \\
\hline CHEMBL289959 & 809129 & 4.9 & 4.8121 & TRN & \\
\hline CHEMBL1997119 & 809129 & 4.2 & 4.8477 & TRN & \\
\hline CHEMBL1977138 & 809129 & 7.9 & 7.4047 & TRN & \\
\hline CHEMBL 2000879 & 809129 & 4.7 & 4.7389 & TRN & \\
\hline CHEMBL1978448 & 809129 & 4.6 & 5.2317 & TST & \\
\hline CHEMBL1980329 & 809129 & 8.4 & 7.5309 & TRN & \\
\hline CHEMBL 2004515 & 809129 & 5.8 & 5.67899 & э999999999 & TRN \\
\hline CHEMBL 2001257 & 809129 & 5.6 & 5.8372 & TRN & \\
\hline CHEMBL1992042 & 809129 & 4.6 & 5.7236 & TRN & \\
\hline CHEMBL1986265 & 809129 & 4.6 & 4.7746 & TRN & \\
\hline CHEMBL1991734 & 809129 & 6.9 & 6.9178 & TST & \\
\hline CHEMBL 21156 & 809129 & 7.6 & 7.9266 & TRN & \\
\hline CHEMBL1994724 & 809129 & 4.6 & 4.2674 & TRN & \\
\hline CHEMBL1989267 & 809129 & 5.7 & 6.4757 & TRN & \\
\hline CHEMBL1991782 & 809129 & 4.3 & 4.0836 & TRN & \\
\hline CHEMBL2002105 & 809129 & 5.0 & 4.7897 & TRN & \\
\hline CHEMBL1983348 & 809129 & 6.3 & 5.7986 & TRN & \\
\hline CHEMBL1970290 & 809129 & 6.2 & 6.5233 & TRN & \\
\hline CHEMBL1993877 & 809129 & 7.0 & 6.4895 & TRN & \\
\hline CHEMBL 2000934 & 809129 & 4.5 & 4.3983 & TRN & \\
\hline CHEMBL1996500 & 809129 & 4.6 & 4.5611 & TRN & \\
\hline CHEMBL1980671 & 809129 & 5.4 & 5.4196 & TRN & \\
\hline CHEMBL1986177 & 809129 & 4.6 & 4.859 & TRN & \\
\hline CHEMBL1989708 & 809129 & 7.7 & 7.893 & TRN & \\
\hline CHEMBL1976420 & 809129 & 4.6 & 5.5926 & TRN & \\
\hline CHEMBL1981744 & 809129 & 4.6 & 4.39199 & 99999999995 & TRN \\
\hline CHEMBL1989423 & 809129 & 4.8 & 4.2768 & TRN & \\
\hline CHEMBL1985367 & 809129 & 5.6 & 4.8297 & TRN & \\
\hline CHEMBL1996510 & 809129 & 6.1 & 5.6978 & TRN & \\
\hline CHEMBL 2000029 & 809129 & 5.8 & 5.2464 & TRN & \\
\hline CHEMBL1995172 & 809129 & 5.7 & 4.7622 & TRN & \\
\hline CHEMBL 2001584 & 809129 & 4.6 & 4.3714 & TRN & \\
\hline CHEMBL1973961 & 809129 & 7.9 & 6.9892 & TRN & \\
\hline CHEMBL1967998 & 809129 & 7.6 & 7.6848 & TRN & \\
\hline CHEMBL1978562 & 809129 & 4.6 & 4.7729 & TRN & \\
\hline
\end{tabular}




\begin{tabular}{|c|c|c|c|c|}
\hline & & & & $a \perp 12$ \\
\hline CHEMBL1994977 & 809129 & 4.6 & 4.6659 & TRN \\
\hline CHEMBL2001149 & 809129 & 6.4 & 5.1672 & TRN \\
\hline CHEMBL1974875 & 809129 & 5.0 & 5.4176 & TRN \\
\hline CHEMBL 2005478 & 809129 & 4.6 & 4.8442 & TRN \\
\hline CHEMBL1996646 & 809129 & 5.7 & 6.3912 & TRN \\
\hline CHEMBL1979773 & 809129 & 4.6 & 5.19 & TRN \\
\hline CHEMBL1989471 & 809129 & 5.9 & 5.2999 & TST \\
\hline CHEMBL1996702 & 809129 & 6.4 & 6.857 & TRN \\
\hline CHEMBL 2007124 & 809129 & 4.6 & 4.735 & TRN \\
\hline CHEMBL1978195 & 809129 & 5.6 & 5.0086 & TRN \\
\hline CHEMBL 2006439 & 809129 & 4.6 & 4.9469 & TRN \\
\hline CHEMBL1985681 & 809129 & 6.3 & 5.5685 & TRN \\
\hline CHEMBL1991674 & 809129 & 4.6 & 5.2289 & TRN \\
\hline CHEMBL1982711 & 809129 & 6.2 & 5.1401 & TRN \\
\hline CHEMBL262623 & 809129 & 5.4 & 5.8788 & TRN \\
\hline CHEMBL1984842 & 809129 & 4.6 & 4.6051 & TRN \\
\hline CHEMBL2004118 & 809129 & 5.8 & 5.9434 & TRN \\
\hline CHEMBL1996795 & 809129 & 5.6 & 5.3744 & TST \\
\hline CHEMBL1996345 & 809129 & 4.6 & 5.0011 & TRN \\
\hline CHEMBL2004025 & 809129 & 6.2 & 5.394 & TRN \\
\hline CHEMBL1996048 & 809129 & 6.5 & 6.276 & TRN \\
\hline CHEMBL50894 & 809129 & 4.6 & 4.5666 & TRN \\
\hline CHEMBL1995211 & 809129 & 5.8 & 6.0089 & TRN \\
\hline CHEMBL1965033 & 809129 & 6.1 & 5.1207 & TRN \\
\hline CHEMBL461876 & 809129 & 8.8 & 8.707 & TRN \\
\hline CHEMBL1982753 & 809129 & 6.3 & 6.4999 & TRN \\
\hline CHEMBL 2006299 & 809129 & 4.6 & 4.3573 & TRN \\
\hline CHEMBL1972346 & 809129 & 6.5 & 6.572 & TST \\
\hline CHEMBL1971519 & 809129 & 4.5 & 4.9149 & TRN \\
\hline CHEMBL1997335 & 809129 & 7.6 & 6.9668 & TRN \\
\hline CHEMBL1965169 & 809129 & 4.6 & 4.7076 & TRN \\
\hline CHEMBL1991818 & 809129 & 5.7 & 5.2366 & TST \\
\hline CHEMBL1081312 & 809129 & 6.8 & 6.4946 & TRN \\
\hline CHEMBL1965170 & 809129 & 7.1 & 6.9854 & TRN \\
\hline CHEMBL 2005792 & 809129 & 4.6 & 4.6107 & TRN \\
\hline CHEMBL1991867 & 809129 & 4.8 & 4.8823 & TRN \\
\hline CHEMBL1972355 & 809129 & 6.8 & 6.3444 & TRN \\
\hline CHEMBL1997892 & 809129 & 4.6 & 5.2225 & TRN \\
\hline CHEMBL 2001641 & 809129 & 4.8 & 4.7048 & TRN \\
\hline CHEMBL399530 & 809129 & 5.6 & 5.3845 & TRN \\
\hline CHEMBL1997193 & 809129 & 4.6 & 5.2587 & TST \\
\hline CHEMBL1964902 & 809129 & 4.6 & 4.4018 & TRN \\
\hline CHEMBL1973868 & 809129 & 4.6 & 4.7348 & TRN \\
\hline CHEMBL1983715 & 809129 & 7.3 & 7.274 & TRN \\
\hline CHEMBL 2002992 & 809129 & 6.4 & 6.1542 & TRN \\
\hline CHEMBL1982700 & 809129 & 5.6 & 4.6983 & TRN \\
\hline CHEMBL1966799 & 809129 & 4.0 & 4.918 & TRN \\
\hline CHEMBL10 & 809129 & 4.6 & 4.6319 & TRN \\
\hline
\end{tabular}




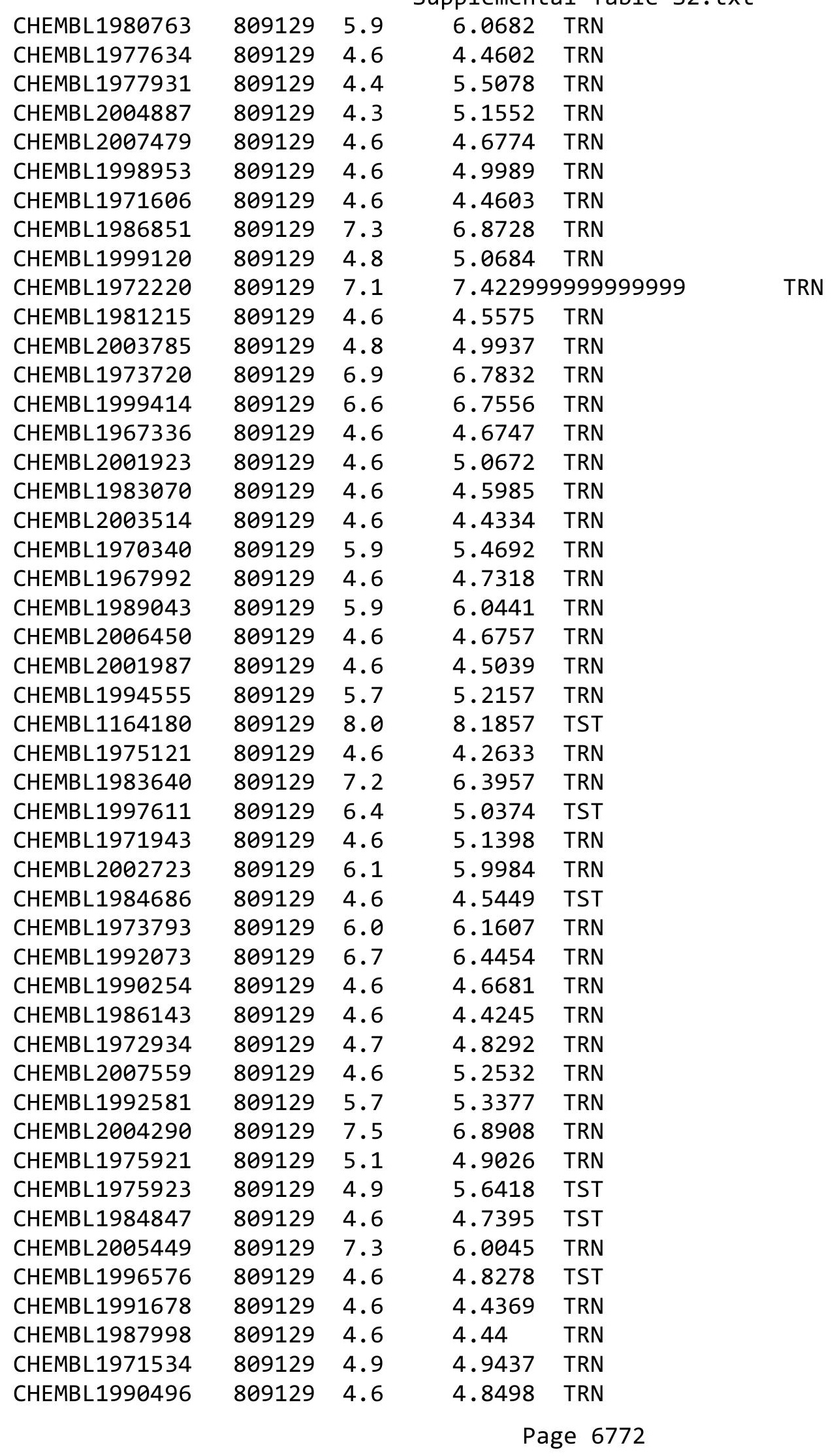




\begin{tabular}{|c|c|c|c|c|}
\hline & & & pplement & al $\mathrm{Ta}$ \\
\hline CHEMBL242865 & 809129 & 6.3 & 6.4582 & TRN \\
\hline CHEMBL235157 & 809129 & 4.6 & 5.1517 & TST \\
\hline CHEMBL1968460 & 809129 & 4.1 & 4.8488 & TRN \\
\hline CHEMBL2004159 & 809129 & 4.6 & 4.3985 & TRN \\
\hline CHEMBL1978371 & 809129 & 5.8 & 5.3128 & TST \\
\hline CHEMBL440084 & 809129 & 4.6 & 4.8635 & TRN \\
\hline CHEMBL1998110 & 809129 & 4.6 & 4.3409 & TRN \\
\hline CHEMBL1978166 & 809129 & 6.7 & 6.7669 & TRN \\
\hline CHEMBL1990590 & 809129 & 4.6 & 4.7154 & TRN \\
\hline CHEMBL1974617 & 809129 & 4.7 & 4.7906 & TRN \\
\hline CHEMBL86755 & 809129 & 6.0 & 6.5584 & TRN \\
\hline CHEMBL1965660 & 809129 & 4.6 & 5.0273 & TRN \\
\hline CHEMBL1992125 & 809129 & 5.8 & 6.3656 & TRN \\
\hline CHEMBL1966175 & 809129 & 6.0 & 5.4124 & TRN \\
\hline CHEMBL 2007375 & 809129 & 4.6 & 4.5329 & TRN \\
\hline CHEMBL1178727 & 809129 & 4.3 & 4.7854 & TRN \\
\hline CHEMBL379975 & 809129 & 6.0 & 5.7432 & TRN \\
\hline CHEMBL1967612 & 809129 & 4.5 & 5.067 & TST \\
\hline CHEMBL1965387 & 809129 & 4.6 & 5.0253 & TRN \\
\hline CHEMBL2001539 & 809129 & 5.2 & 4.7511 & TRN \\
\hline CHEMBL388978 & 809129 & 8.5 & 8.7365 & TST \\
\hline CHEMBL1997041 & 809129 & 4.0 & 5.4803 & TRN \\
\hline CHEMBL550418 & 809129 & 6.2 & 6.1626 & TRN \\
\hline CHEMBL398951 & 809129 & 4.6 & 4.9648 & TST \\
\hline CHEMBL 2004716 & 809129 & 7.2 & 6.8863 & TRN \\
\hline CHEMBL1971289 & 809129 & 4.6 & 5.0833 & TST \\
\hline CHEMBL1988437 & 809129 & 4.7 & 5.7793 & TST \\
\hline CHEMBL 2007603 & 809129 & 4.5 & 4.4555 & TRN \\
\hline CHEMBL1421720 & 809129 & 6.0 & 5.7414 & TRN \\
\hline CHEMBL1233887 & 809129 & 4.6 & 4.9998 & TRN \\
\hline CHEMBL1992607 & 809129 & 4.4 & 4.9645 & TRN \\
\hline CHEMBL576113 & 809129 & 5.7 & 5.3419 & TRN \\
\hline CHEMBL1996649 & 809129 & 6.1 & 6.5088 & TRN \\
\hline CHEMBL1986756 & 809129 & 4.6 & 4.5351 & TRN \\
\hline CHEMBL1949855 & 809129 & 5.6 & 5.3112 & TRN \\
\hline CHEMBL3109278 & 809129 & 4.6 & 4.7732 & TRN \\
\hline CHEMBL1727312 & 809129 & 4.2 & 4.5602 & TRN \\
\hline CHEMBL1990223 & 809129 & 4.6 & 4.8404 & TRN \\
\hline CHEMBL 2004438 & 809129 & 4.6 & 4.9657 & TRN \\
\hline CHEMBL1964382 & 809129 & 4.6 & 5.1835 & TST \\
\hline CHEMBL101311 & 809129 & 7.1 & 6.5738 & TRN \\
\hline CHEMBL191003 & 809129 & 4.8 & 6.011 & TRN \\
\hline CHEMBL1973359 & 809129 & 7.1 & 6.9759 & TST \\
\hline CHEMBL1988581 & 809129 & 7.7 & 7.585 & TST \\
\hline CHEMBL 2005699 & 809129 & 4.6 & 4.4367 & TRN \\
\hline CHEMBL 2006564 & 809129 & 7.1 & 7.4728 & TRN \\
\hline CHEMBL1979690 & 809129 & 7.8 & 7.8863 & TRN \\
\hline CHEMBL1991008 & 809129 & 4.3 & 4.7556 & TRN \\
\hline
\end{tabular}




\begin{tabular}{|c|c|c|c|c|}
\hline & & & ent & \\
\hline CHEMBL234085 & 809129 & 5.0 & 5.2189 & TRN \\
\hline CHEMBL1978167 & 809129 & 4.6 & 4.6065 & TRN \\
\hline CHEMBL418203 & 809129 & 6.2 & 5.8845 & TRN \\
\hline CHEMBL225519 & 809129 & 4.7 & 4.925 & TST \\
\hline CHEMBL1976376 & 809129 & 5.9 & 5.2341 & TRN \\
\hline CHEMBL1983575 & 809129 & 6.6 & 7.0714 & TRN \\
\hline CHEMBL1968868 & 809129 & 4.6 & 4.5668 & TRN \\
\hline CHEMBL1981047 & 809129 & 7.5 & 7.0603 & TRN \\
\hline CHEMBL1998470 & 809129 & 4.6 & 4.7459 & TRN \\
\hline CHEMBL1976196 & 809129 & 5.6 & 5.2044 & TRN \\
\hline CHEMBL1997197 & 809129 & 4.6 & 4.603 & TRN \\
\hline CHEMBL1975903 & 809129 & 4.6 & 4.7624 & TRN \\
\hline CHEMBL1983630 & 809129 & 4.8 & 4.687 & TRN \\
\hline CHEMBL1522508 & 809129 & 4.9 & 4.6154 & TRN \\
\hline CHEMBL1988805 & 809129 & 6.1 & 5.7294 & TRN \\
\hline CHEMBL458997 & 809129 & 8.1 & 8.3973 & TRN \\
\hline CHEMBL1969942 & 809129 & 4.6 & 4.747 & TRN \\
\hline CHEMBL1982660 & 809129 & 4.6 & 4.8773 & TRN \\
\hline CHEMBL1978567 & 809129 & 4.6 & 4.3409 & TRN \\
\hline CHEMBL1965838 & 809129 & 4.1 & 5.1378 & TST \\
\hline CHEMBL1995765 & 809129 & 5.4 & 5.1476 & TRN \\
\hline CHEMBL1984760 & 809129 & 5.8 & 5.8301 & TRN \\
\hline CHEMBL1997846 & 809129 & 4.6 & 5.1346 & TRN \\
\hline CHEMBL424872 & 809129 & 4.6 & 4.4457 & TST \\
\hline CHEMBL360847 & 809129 & 4.6 & 5.1546 & TRN \\
\hline CHEMBL1995811 & 809129 & 4.6 & 4.6319 & TRN \\
\hline CHEMBL1983111 & 809129 & 7.4 & 7.597 & TRN \\
\hline CHEMBL1988141 & 809129 & 7.1 & 6.5554 & TST \\
\hline CHEMBL1992937 & 809129 & 4.6 & 4.8861 & TRN \\
\hline CHEMBL451401 & 809129 & 4.6 & 4.4678 & TRN \\
\hline CHEMBL1977134 & 809129 & 4.6 & 5.3089 & TRN \\
\hline CHEMBL1985206 & 809129 & 4.6 & 5.1831 & TRN \\
\hline CHEMBL1991078 & 809129 & 4.6 & 4.176 & TRN \\
\hline CHEMBL1977749 & 809129 & 7.3 & 6.7958 & TST \\
\hline CHEMBL1975212 & 809129 & 4.8 & 5.4803 & TRN \\
\hline CHEMBL 2001613 & 809129 & 5.3 & 4.8574 & TRN \\
\hline CHEMBL261849 & 809129 & 4.6 & 4.5639 & TST \\
\hline CHEMBL1983923 & 809129 & 4.7 & 5.4335 & TRN \\
\hline CHEMBL1993904 & 809129 & 6.3 & 5.7472 & TRN \\
\hline CHEMBL1997275 & 809129 & 6.0 & 5.7305 & TRN \\
\hline CHEMBL1967513 & 809129 & 4.6 & 4.3804 & TRN \\
\hline CHEMBL1980376 & 809129 & 5.1 & 4.9689 & TRN \\
\hline CHEMBL 2000724 & 809129 & 4.6 & 4.7589 & TRN \\
\hline CHEMBL1982413 & 809129 & 6.0 & 6.066 & TRN \\
\hline CHEMBL 2002182 & 809129 & 4.4 & 4.7735 & TRN \\
\hline CHEMBL1985042 & 809129 & 4.7 & 5.228 & TRN \\
\hline CHEMBL1987535 & 809129 & 4.6 & 4.8633 & TRN \\
\hline CHEMBL1983393 & 809129 & 5.9 & 4.7982 & TRN \\
\hline
\end{tabular}




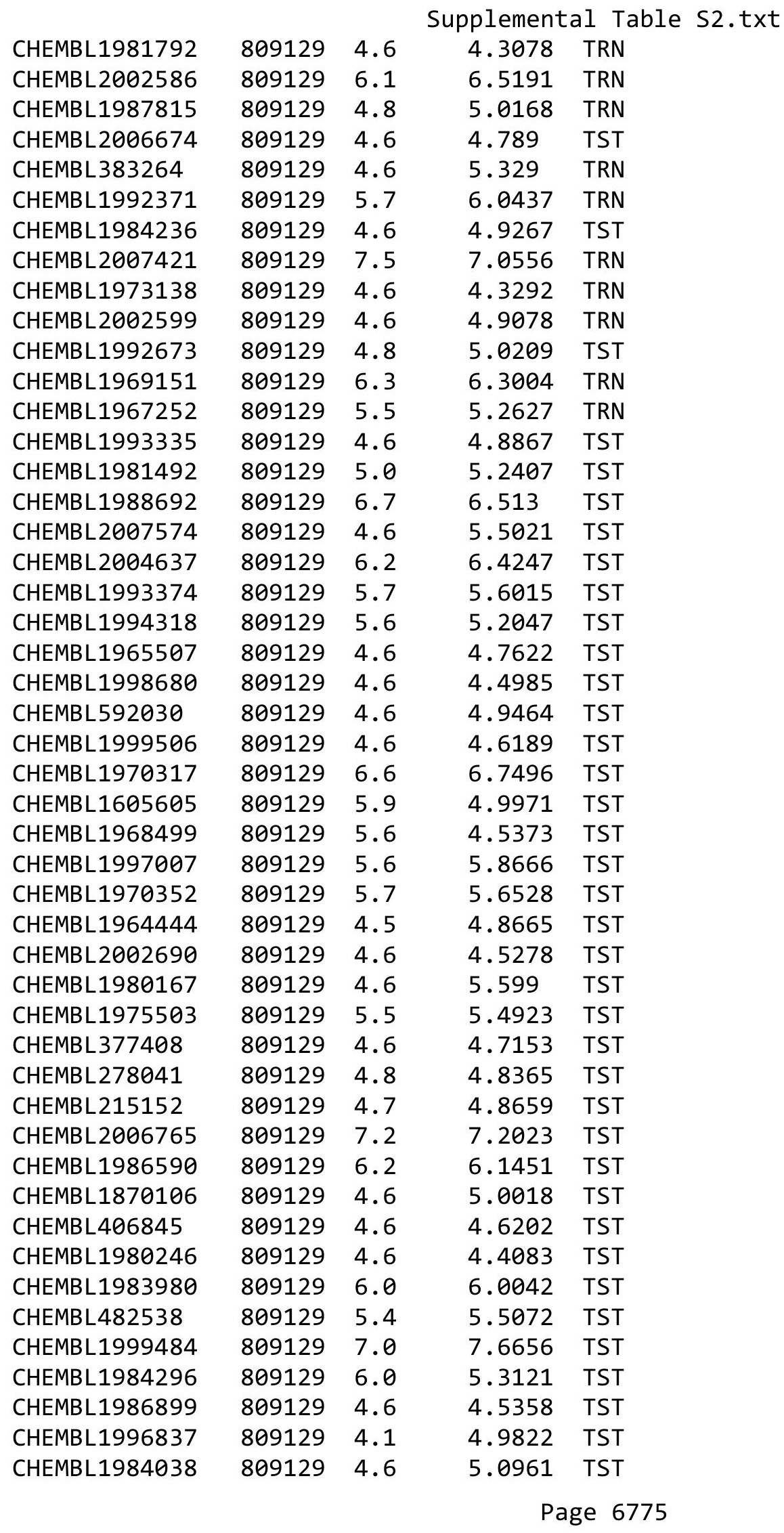




\begin{tabular}{|c|c|c|c|c|c|}
\hline & & & & & \\
\hline CHEMBL1964718 & 809129 & 4.5 & 5.1401 & TST & \\
\hline CHEMBL1993661 & 809129 & 8.5 & 8.913 & TST & \\
\hline CHEMBL1968705 & 809129 & 4.6 & 5.1399 & TST & \\
\hline CHEMBL1964441 & 809129 & 6.3 & 6.5091 & TST & \\
\hline CHEMBL1991410 & 809129 & 4.6 & 4.8734 & TST & \\
\hline CHEMBL1986684 & 809129 & 4.2 & 5.4785 & TST & \\
\hline CHEMBL546797 & 809129 & 4.6 & 5.4204 & TST & \\
\hline CHEMBL1543529 & 737242 & 3.699 & 3.75699 & 99999999997 & TST \\
\hline CHEMBL1434585 & 737242 & 3.699 & 3.6075 & TRN & \\
\hline CHEMBL1454967 & 737242 & 3.699 & 3.6779 & TRN & \\
\hline CHEMBL1444501 & 737242 & 3.699 & 4.0674 & TRN & \\
\hline CHEMBL2369277 & 737242 & 3.699 & 4.1198 & TRN & \\
\hline CHEMBL1450522 & 737242 & 3.699 & 3.7005 & TST & \\
\hline CHEMBL1725631 & 737242 & 3.699 & 3.7453 & TRN & \\
\hline CHEMBL1513972 & 737242 & 3.699 & 4.572 & TST & \\
\hline CHEMBL1316978 & 737242 & 5.0701 & 4.5031 & TRN & \\
\hline CHEMBL1347600 & 737242 & 3.699 & 3.3538 & TST & \\
\hline CHEMBL3197908 & 737242 & 4.7696 & 4.8811 & TRN & \\
\hline CHEMBL1535363 & 737242 & 3.699 & 3.6465 & TRN & \\
\hline CHEMBL1533968 & 737242 & 3.699 & 3.7596 & TST & \\
\hline CHEMBL1344491 & 737242 & 3.699 & 3.5927 & TRN & \\
\hline CHEMBL1349480 & 737242 & 3.699 & 3.7173 & TRN & \\
\hline CHEMBL1402922 & 737242 & 3.699 & 3.6958 & TRN & \\
\hline CHEMBL1730952 & 737242 & 3.699 & 3.8568 & TRN & \\
\hline CHEMBL1571934 & 737242 & 3.699 & 3.7643 & TRN & \\
\hline CHEMBL1512652 & 737242 & 3.699 & 4.0002 & TRN & \\
\hline CHEMBL1540419 & 737242 & 3.699 & 3.7317 & TRN & \\
\hline CHEMBL1728060 & 737242 & 3.699 & 3.6253 & TRN & \\
\hline CHEMBL1452154 & 737242 & 3.699 & 3.5033 & TRN & \\
\hline CHEMBL1328113 & 737242 & 3.699 & 3.6875 & TRN & \\
\hline CHEMBL2369228 & 737242 & 3.699 & 3.6466 & TRN & \\
\hline CHEMBL1495682 & 737242 & 3.699 & 3.6349 & TRN & \\
\hline CHEMBL1505944 & 737242 & 3.699 & 3.7243 & TRN & \\
\hline CHEMBL1518077 & 737242 & 3.699 & 3.63199 & 99999999997 & TRN \\
\hline CHEMBL1388253 & 737242 & 3.699 & 3.5724 & TRN & \\
\hline CHEMBL1525327 & 737242 & 3.699 & 3.6441 & TRN & \\
\hline CHEMBL1443214 & 737242 & 3.699 & 3.65 & TRN & \\
\hline CHEMBL1330103 & 737242 & 3.699 & 3.9843 & TRN & \\
\hline CHEMBL3192765 & 737242 & 3.699 & 3.7789 & TRN & \\
\hline CHEMBL1408030 & 737242 & 3.699 & 3.5992 & TST & \\
\hline CHEMBL1200847 & 737242 & 3.699 & 4.4808 & TST & \\
\hline CHEMBL1732411 & 737242 & 3.699 & 3.7905 & TRN & \\
\hline CHEMBL1429422 & 737242 & 3.699 & 3.7163 & TRN & \\
\hline CHEMBL1603662 & 737242 & 3.699 & 3.5584 & TRN & \\
\hline CHEMBL1462994 & 737242 & 3.699 & 3.6035 & TRN & \\
\hline CHEMBL1320017 & 737242 & 3.699 & 3.5299 & TRN & \\
\hline CHEMBL1984581 & 737242 & 5.6326 & 5.4862 & TRN & \\
\hline CHEMBL3213394 & 737242 & 3.699 & 3.8766 & TRN & \\
\hline
\end{tabular}


Supplemental Table S2.txt

\begin{tabular}{|c|c|c|c|c|c|}
\hline CHEMBL1715631 & 737242 & 3.699 & 3.7505 & TRN & \\
\hline CHEMBL1520667 & 737242 & 5.2351 & 4.3042 & TST & \\
\hline CHEMBL1547025 & 737242 & 4.9066 & 5.0264 & TRN & \\
\hline CHEMBL1336630 & 737242 & 3.699 & 3.7605 & TRN & \\
\hline CHEMBL1702693 & 737242 & 3.699 & 3.8135 & TRN & \\
\hline CHEMBL1982108 & 737242 & 3.699 & 3.6176 & TRN & \\
\hline CHEMBL1532960 & 737242 & 3.699 & 3.7391 & TRN & \\
\hline CHEMBL1704033 & 737242 & 3.699 & 3.7777 & TRN & \\
\hline CHEMBL1304615 & 737242 & 3.699 & 3.8541 & TRN & \\
\hline CHEMBL1413755 & 737242 & 3.699 & 3.7123 & TRN & \\
\hline CHEMBL 2369209 & 737242 & 3.699 & 3.6759 & TRN & \\
\hline CHEMBL1613445 & 737242 & 3.699 & 3.8193 & TRN & \\
\hline CHEMBL1318210 & 737242 & 3.699 & 3.6432 & TRN & \\
\hline CHEMBL1487035 & 737242 & 3.699 & 3.6072 & TRN & \\
\hline CHEMBL1461169 & 737242 & 3.699 & 3.6865 & TRN & \\
\hline CHEMBL1464838 & 737242 & 3.699 & 4.21899 & 9999999999 & TST \\
\hline CHEMBL1724877 & 737242 & 3.699 & 3.6524 & TRN & \\
\hline CHEMBL86464 & 737242 & 4.7399 & 4.8371 & TRN & \\
\hline CHEMBL1503928 & 737242 & 3.699 & 3.742 & TRN & \\
\hline CHEMBL1717208 & 737242 & 3.699 & 3.5335 & TST & \\
\hline CHEMBL1706626 & 737242 & 3.699 & 3.7467 & TRN & \\
\hline CHEMBL3192949 & 737242 & 3.699 & 3.6839 & TRN & \\
\hline CHEMBL1540627 & 737242 & 5.5243 & 5.5373 & TRN & \\
\hline CHEMBL1585763 & 737242 & 3.699 & 3.7476 & TRN & \\
\hline CHEMBL1402791 & 737242 & 3.699 & 3.5603 & TRN & \\
\hline CHEMBL3391727 & 737242 & 3.699 & 3.2912 & TST & \\
\hline CHEMBL503363 & 737242 & 3.699 & 4.1991 & TST & \\
\hline CHEMBL1448027 & 737242 & 3.699 & 3.6487 & TRN & \\
\hline CHEMBL532452 & 737242 & 3.699 & 3.5425 & TRN & \\
\hline CHEMBL1575772 & 737242 & 3.699 & 3.7711 & TRN & \\
\hline CHEMBL1343853 & 737242 & 5.7645 & 5.6354 & TRN & \\
\hline CHEMBL1356525 & 737242 & 3.699 & 3.5413 & TST & \\
\hline CHEMBL1596428 & 737242 & 3.699 & 3.6661 & TRN & \\
\hline CHEMBL3194432 & 737242 & 3.699 & 3.8669 & TRN & \\
\hline CHEMBL1734073 & 737242 & 3.699 & 3.7161 & TRN & \\
\hline CHEMBL1550174 & 737242 & 3.699 & 3.8763 & TRN & \\
\hline CHEMBL1418255 & 737242 & 3.699 & 3.8163 & TST & \\
\hline CHEMBL1460676 & 737242 & 3.699 & 3.8169 & TRN & \\
\hline CHEMBL1427545 & 737242 & 3.699 & 3.7194 & TRN & \\
\hline CHEMBL1980281 & 737242 & 4.7328 & 4.4179 & TRN & \\
\hline CHEMBL1591732 & 737242 & 3.699 & 3.8906 & TRN & \\
\hline CHEMBL 2369172 & 737242 & 4.7959 & 4.5613 & TRN & \\
\hline CHEMBL1589425 & 737242 & 5.0926 & 4.0435 & TST & \\
\hline CHEMBL1447539 & 737242 & 3.699 & 3.6418 & TRN & \\
\hline CHEMBL 2369258 & 737242 & 3.699 & 3.6508 & TRN & \\
\hline CHEMBL1336154 & 737242 & 3.699 & 3.7102 & TRN & \\
\hline CHEMBL1380969 & 737242 & 3.699 & 3.6082 & TRN & \\
\hline CHEMBL591404 & 737242 & 4.8861 & 4.8105 & TRN & \\
\hline
\end{tabular}




\begin{tabular}{|c|c|c|c|c|c|}
\hline & & \multicolumn{4}{|c|}{ Supplemental Table S2.txt } \\
\hline CHEMBL1511432 & 737242 & 3.699 & 3.7359 & TRN & \\
\hline CHEMBL1427763 & 737242 & 5.4634 & 5.5789 & TRN & \\
\hline CHEMBL1527341 & 737242 & 4.7352 & 4.6324 & TRN & \\
\hline CHEMBL1421924 & 737242 & 3.699 & 4.01699 & 99999999995 & TST \\
\hline CHEMBL1377868 & 737242 & 3.699 & 3.75600 & 00000000002 & TRN \\
\hline CHEMBL3209319 & 737242 & 3.699 & 3.7926 & TRN & \\
\hline CHEMBL1534034 & 737242 & 5.3116 & 5.2552 & TRN & \\
\hline CHEMBL1494987 & 737242 & 3.699 & 3.6532 & TRN & \\
\hline CHEMBL1532262 & 737242 & 3.699 & 3.74300 & 00000000003 & TRN \\
\hline CHEMBL1435941 & 737242 & 3.699 & 3.6083 & TRN & \\
\hline CHEMBL1478931 & 737242 & 3.699 & 3.7847 & TRN & \\
\hline CHEMBL1477355 & 737242 & 3.699 & 3.6393 & TRN & \\
\hline CHEMBL1974537 & 737242 & 4.7328 & 4.5624 & TRN & \\
\hline CHEMBL1428095 & 737242 & 3.699 & 3.5607 & TRN & \\
\hline CHEMBL1432123 & 737242 & 3.699 & 3.5556 & TRN & \\
\hline CHEMBL1448793 & 737242 & 5.0128 & 5.0178 & TRN & \\
\hline CHEMBL 1440558 & 737242 & 3.699 & 3.6035 & TRN & \\
\hline CHEMBL1305066 & 737242 & 3.699 & 3.7114 & TRN & \\
\hline CHEMBL3191507 & 737242 & 3.699 & 3.6045 & TRN & \\
\hline CHEMBL1548334 & 737242 & 3.699 & 3.7641 & TRN & \\
\hline CHEMBL1457115 & 737242 & 3.699 & 3.7629 & TST & \\
\hline CHEMBL451532 & 737242 & 3.699 & 4.022 & TST & \\
\hline CHEMBL1370042 & 737242 & 3.699 & 3.6775 & TRN & \\
\hline CHEMBL1409350 & 737242 & 3.699 & 3.6496 & TRN & \\
\hline CHEMBL1410483 & 737242 & 3.699 & 3.7846 & TRN & \\
\hline CHEMBL1592706 & 737242 & 5.1255 & 5.0121 & TRN & \\
\hline CHEMBL1530087 & 737242 & 3.699 & 3.6988 & TRN & \\
\hline CHEMBL1507137 & 737242 & 3.699 & 3.7484 & TRN & \\
\hline CHEMBL 1708596 & 737242 & 3.699 & 4.0517 & TRN & \\
\hline CHEMBL3192124 & 737242 & 3.699 & 3.8727 & TRN & \\
\hline CHEMBL1454777 & 737242 & 3.699 & 3.7881 & TST & \\
\hline CHEMBL1726406 & 737242 & 3.699 & 3.7629 & TRN & \\
\hline CHEMBL1528814 & 737242 & 5.9586 & 3.5083 & TST & \\
\hline CHEMBL1390705 & 737242 & 3.699 & 3.6172 & TRN & \\
\hline CHEMBL1564990 & 737242 & 5.3947 & 5.0967 & TRN & \\
\hline CHEMBL1604350 & 737242 & 3.699 & 3.596 & TRN & \\
\hline CHEMBL584444 & 737242 & 3.699 & 3.8511 & TRN & \\
\hline CHEMBL2369230 & 737242 & 3.699 & 3.7021 & TRN & \\
\hline CHEMBL1503253 & 737242 & 3.699 & 3.7685 & TRN & \\
\hline CHEMBL1734113 & 737242 & 3.699 & 3.9927 & TRN & \\
\hline CHEMBL1494737 & 737242 & 5.284 & 3.7388 & TST & \\
\hline CHEMBL1503520 & 737242 & 3.699 & 3.7837 & TRN & \\
\hline CHEMBL1322017 & 737242 & 3.699 & 3.7567 & TRN & \\
\hline CHEMBL1595936 & 737242 & 3.699 & 3.7936 & TRN & \\
\hline CHEMBL1315701 & 737242 & 3.699 & 3.8821 & TRN & \\
\hline CHEMBL1554781 & 737242 & 3.699 & 3.8463 & TRN & \\
\hline CHEMBL1483598 & 737242 & 3.699 & 3.661 & TRN & \\
\hline CHEMBL1366082 & 737242 & 3.699 & 3.5973 & TRN & \\
\hline
\end{tabular}




\begin{tabular}{|c|c|c|c|c|c|}
\hline \multicolumn{6}{|c|}{ supplemental } \\
\hline CHEMBL1374245 & 737242 & 4.9031 & 4.9625 & TRN & \\
\hline CHEMBL3212707 & 737242 & 3.699 & 3.6207 & TRN & \\
\hline CHEMBL1418004 & 737242 & 3.699 & 3.7249 & TRN & \\
\hline CHEMBL1381940 & 737242 & 3.699 & 3.6631 & TRN & \\
\hline CHEMBL1703098 & 737242 & 3.699 & 3.4328 & TRN & \\
\hline CHEMBL1402707 & 737242 & 3.699 & 3.7332 & TST & \\
\hline CHEMBL1414380 & 737242 & 3.699 & 3.6453 & TRN & \\
\hline CHEMBL1393812 & 737242 & 3.699 & 3.7438 & TRN & \\
\hline CHEMBL1521485 & 737242 & 3.699 & 3.7831 & TRN & \\
\hline CHEMBL1728596 & 737242 & 3.699 & 3.6038 & TRN & \\
\hline CHEMBL1455530 & 737242 & 3.699 & 4.0743 & TST & \\
\hline CHEMBL1704417 & 737242 & 3.699 & 3.7007 & TRN & \\
\hline CHEMBL1981002 & 737242 & 3.699 & 3.9433 & TST & \\
\hline CHEMBL1299925 & 737242 & 3.699 & 3.639 & TRN & \\
\hline CHEMBL1583807 & 737242 & 3.699 & 3.682 & TRN & \\
\hline CHEMBL1344488 & 737242 & 3.699 & 3.4797 & TRN & \\
\hline CHEMBL23194 & 737242 & 3.699 & 3.516 & TST & \\
\hline CHEMBL1709554 & 737242 & 3.699 & 3.6878 & TRN & \\
\hline CHEMBL1453208 & 737242 & 3.699 & 4.0315 & TST & \\
\hline CHEMBL1534719 & 737242 & 3.699 & 3.7315 & TRN & \\
\hline CHEMBL1507187 & 737242 & 3.699 & 3.6828 & TRN & \\
\hline CHEMBL1516412 & 737242 & 3.699 & 3.4365 & TST & \\
\hline CHEMBL1467095 & 737242 & 3.699 & 3.6946 & TRN & \\
\hline CHEMBL3211947 & 737242 & 3.699 & 3.8408 & TRN & \\
\hline CHEMBL1368012 & 737242 & 3.699 & 3.7481 & TRN & \\
\hline CHEMBL1537917 & 737242 & 3.699 & 3.8945 & TST & \\
\hline CHEMBL1290361 & 737242 & 3.699 & 3.8567 & TRN & \\
\hline CHEMBL1981290 & 737242 & 5.5114 & 5.58299 & 9999999999 & TRN \\
\hline CHEMBL1543903 & 737242 & 3.699 & 3.6672 & TRN & \\
\hline CHEMBL1995152 & 737242 & 5.4145 & 5.2171 & TRN & \\
\hline CHEMBL1609296 & 737242 & 3.699 & 3.8273 & TRN & \\
\hline CHEMBL1729974 & 737242 & 3.699 & 3.7063 & TRN & \\
\hline CHEMBL448741 & 737242 & 3.699 & 3.9371 & TST & \\
\hline CHEMBL1698838 & 737242 & 3.699 & 3.411 & TRN & \\
\hline CHEMBL1509316 & 737242 & 3.699 & 3.7493 & TRN & \\
\hline CHEMBL3197529 & 737242 & 3.699 & 3.706006 & 30000000004 & TRN \\
\hline CHEMBL1487895 & 737242 & 3.699 & 3.5286 & TRN & \\
\hline CHEMBL1478673 & 737242 & 3.699 & 3.8486 & TRN & \\
\hline CHEMBL1423463 & 737242 & 3.699 & 4.233006 & 00000000005 & TST \\
\hline CHEMBL1468776 & 737242 & 3.699 & 3.6467 & TRN & \\
\hline CHEMBL1337235 & 737242 & 3.699 & 3.8354 & TRN & \\
\hline CHEMBL1989158 & 737242 & 5.2588 & 5.3962 & TRN & \\
\hline CHEMBL1588275 & 737242 & 3.699 & 3.8259 & TRN & \\
\hline CHEMBL1595020 & 737242 & 3.699 & 3.6267 & TRN & \\
\hline CHEMBL1400908 & 737242 & 3.699 & 3.6907 & TRN & \\
\hline CHEMBL1310325 & 737242 & 6.2596 & 5.9691 & TRN & \\
\hline CHEMBL1729624 & 737242 & 3.699 & 3.7145 & TRN & \\
\hline CHEMBL1522211 & 737242 & 3.699 & 3.6645 & TRN & \\
\hline
\end{tabular}




\begin{tabular}{|c|c|c|c|c|c|}
\hline & & \multicolumn{4}{|c|}{ Supplemental Table S2.txt } \\
\hline CHEMBL 2004487 & 737242 & 3.699 & 4.1198 & TRN & \\
\hline CHEMBL1454899 & 737242 & 3.699 & 3.6133 & TRN & \\
\hline CHEMBL1538277 & 737242 & 4.7282 & 4.627 & TRN & \\
\hline CHEMBL1973159 & 737242 & 5.289 & 5.0792 & TRN & \\
\hline CHEMBL1548182 & 737242 & 3.699 & 3.7859 & TST & \\
\hline CHEMBL1710079 & 737242 & 3.699 & 3.6471 & TRN & \\
\hline CHEMBL1413902 & 737242 & 3.699 & 3.7745 & TRN & \\
\hline CHEMBL1565285 & 737242 & 3.699 & 3.6194 & TRN & \\
\hline CHEMBL1499578 & 737242 & 3.699 & 3.7385 & TRN & \\
\hline CHEMBL1409219 & 737242 & 3.699 & 3.6283 & TRN & \\
\hline CHEMBL1318088 & 737242 & 3.699 & 3.8674 & TRN & \\
\hline CHEMBL1509569 & 737242 & 3.699 & 3.85 & TRN & \\
\hline CHEMBL1602854 & 737242 & 3.699 & 3.6802 & TRN & \\
\hline CHEMBL1735976 & 737242 & 3.699 & 3.7401 & TRN & \\
\hline CHEMBL3198118 & 737242 & 3.699 & 3.8164 & TRN & \\
\hline CHEMBL1721463 & 737242 & 3.699 & 3.6308 & TRN & \\
\hline CHEMBL1436792 & 737242 & 5.1549 & 5.1887 & TRN & \\
\hline CHEMBL1599339 & 737242 & 3.699 & 3.7107 & TRN & \\
\hline CHEMBL1518668 & 737242 & 3.699 & 3.5961 & TRN & \\
\hline CHEMBL1387554 & 737242 & 3.699 & 3.5647 & TRN & \\
\hline CHEMBL1995720 & 737242 & 3.699 & 3.8947 & TRN & \\
\hline CHEMBL1591182 & 737242 & 3.699 & 3.6143 & TST & \\
\hline CHEMBL1319248 & 737242 & 3.699 & 3.7757 & TRN & \\
\hline CHEMBL1490987 & 737242 & 3.699 & 3.64899 & 99999999996 & TRN \\
\hline CHEMBL1523981 & 737242 & 3.699 & 3.7582 & TRN & \\
\hline CHEMBL1383214 & 737242 & 3.699 & 3.6762 & TRN & \\
\hline CHEMBL1425512 & 737242 & 3.699 & 3.5978 & TRN & \\
\hline CHEMBL1348428 & 737242 & 3.699 & 3.5691 & TRN & \\
\hline CHEMBL1595575 & 737242 & 3.699 & 3.5822 & TRN & \\
\hline CHEMBL1548086 & 737242 & 5.083 & 4.0435 & TST & \\
\hline CHEMBL1508818 & 737242 & 3.699 & 3.7454 & TRN & \\
\hline CHEMBL1730189 & 737242 & 3.699 & 3.5555 & TRN & \\
\hline CHEMBL1701840 & 737242 & 3.699 & 3.5962 & TRN & \\
\hline CHEMBL1346693 & 737242 & 3.699 & 3.8337 & TRN & \\
\hline CHEMBL1421282 & 737242 & 3.699 & 3.5585 & TST & \\
\hline CHEMBL1576266 & 737242 & 5.4789 & 5.3962 & TRN & \\
\hline CHEMBL1581789 & 737242 & 3.699 & 3.6186 & TRN & \\
\hline CHEMBL1403654 & 737242 & 3.699 & 3.7054 & TRN & \\
\hline CHEMBL1470791 & 737242 & 3.699 & 3.8655 & TRN & \\
\hline CHEMBL1322772 & 737242 & 3.699 & 3.7628 & TRN & \\
\hline CHEMBL1391818 & 737242 & 3.699 & 3.71100 & 00000000003 & TRN \\
\hline CHEMBL1587829 & 737242 & 3.699 & 3.7388 & TRN & \\
\hline CHEMBL1376371 & 737242 & 3.699 & 4.1425 & TST & \\
\hline CHEMBL1334739 & 737242 & 3.699 & 3.7911 & TRN & \\
\hline CHEMBL2369219 & 737242 & 3.699 & 3.7058 & TRN & \\
\hline CHEMBL1466441 & 737242 & 3.699 & 3.7249 & TRN & \\
\hline CHEMBL1428166 & 737242 & 3.699 & 3.7832 & TRN & \\
\hline CHEMBL1582369 & 737242 & 3.699 & 3.4823 & TRN & \\
\hline
\end{tabular}


Supplemental Table S2.txt

\begin{tabular}{|c|c|c|c|c|c|}
\hline CHEMBL1736446 & 737242 & 3.699 & 3.7306 & TRN & \\
\hline CHEMBL1550540 & 737242 & 3.699 & 3.6751 & TRN & \\
\hline CHEMBL1577297 & 737242 & 3.699 & 3.9798 & TRN & \\
\hline CHEMBL1981063 & 737242 & 5.5072 & 5.2626 & TRN & \\
\hline CHEMBL1709129 & 737242 & 3.699 & 3.9114 & TRN & \\
\hline CHEMBL1550225 & 737242 & 3.699 & 3.6473 & TRN & \\
\hline CHEMBL1705612 & 737242 & 3.699 & 3.49600 & 00000000004 & TRN \\
\hline CHEMBL1433248 & 737242 & 3.699 & 3.7283 & TRN & \\
\hline CHEMBL1408841 & 737242 & 3.699 & 3.4593 & TRN & \\
\hline CHEMBL1443947 & 737242 & 3.699 & 3.886 & TRN & \\
\hline CHEMBL1542113 & 737242 & 3.699 & 3.6373 & TRN & \\
\hline CHEMBL1452283 & 737242 & 3.699 & 3.4401 & TRN & \\
\hline CHEMBL1414734 & 737242 & 3.699 & 3.4929 & TST & \\
\hline CHEMBL1407747 & 737242 & 3.699 & 3.7213 & TST & \\
\hline CHEMBL1368514 & 737242 & 3.699 & 3.6645 & TRN & \\
\hline CHEMBL1604861 & 737242 & 3.699 & 3.7096 & TRN & \\
\hline CHEMBL1510761 & 737242 & 4.8827 & 4.8973 & TRN & \\
\hline CHEMBL1440827 & 737242 & 3.699 & 3.6018 & TRN & \\
\hline CHEMBL1517599 & 737242 & 3.699 & 3.6988 & TRN & \\
\hline CHEMBL461579 & 737242 & 4.8794 & 4.2774 & TST & \\
\hline CHEMBL1467505 & 737242 & 3.699 & 3.844 & TRN & \\
\hline CHEMBL1704192 & 737242 & 3.699 & 3.6762 & TRN & \\
\hline CHEMBL1561727 & 737242 & 3.699 & 3.6971 & TRN & \\
\hline CHEMBL3211086 & 737242 & 3.699 & 3.716 & TST & \\
\hline CHEMBL1554625 & 737242 & 3.699 & 3.4516 & TST & \\
\hline CHEMBL1729758 & 737242 & 3.699 & 3.6101 & TRN & \\
\hline CHEMBL1384172 & 737242 & 6.4437 & 4.4818 & TST & \\
\hline CHEMBL1306824 & 737242 & 3.699 & 3.7768 & TRN & \\
\hline CHEMBL1328510 & 737242 & \multicolumn{3}{|c|}{ 4.718999999999999 } & TRN \\
\hline CHEMBL1407381 & 737242 & 3.699 & 3.7641 & TRN & \\
\hline CHEMBL1549666 & 737242 & 3.699 & 3.6229 & TRN & \\
\hline CHEMBL1565576 & 737242 & 3.699 & 3.6908 & TRN & \\
\hline CHEMBL1594369 & 737242 & 3.699 & 3.78800 & 20000000003 & TRN \\
\hline CHEMBL1992490 & 737242 & 3.699 & 3.9891 & TRN & \\
\hline CHEMBL1394750 & 737242 & 3.699 & 3.755 & TRN & \\
\hline CHEMBL1599465 & 737242 & 3.699 & 3.4956 & TRN & \\
\hline CHEMBL1708056 & 737242 & 3.699 & 3.38 & TRN & \\
\hline CHEMBL1533093 & 737242 & 3.699 & 3.6129 & TRN & \\
\hline CHEMBL1326930 & 737242 & 3.699 & 3.7561 & TRN & \\
\hline CHEMBL1535340 & 737242 & 3.699 & 3.8869 & TST & \\
\hline CHEMBL1978733 & 737242 & 4.9431 & 4.9954 & TRN & \\
\hline CHEMBL1325858 & 737242 & 3.699 & 3.6211 & TRN & \\
\hline CHEMBL1705481 & 737242 & 3.699 & 3.8508 & TST & \\
\hline CHEMBL548017 & 737242 & 3.699 & 3.8734 & TRN & \\
\hline CHEMBL1532679 & 737242 & 5.6946 & 5.6282 & TRN & \\
\hline CHEMBL1509750 & 737242 & 3.699 & 3.7642 & TRN & \\
\hline CHEMBL1715362 & 737242 & 3.699 & 3.7109 & TRN & \\
\hline CHEMBL 3213571 & 737242 & 3.699 & 3.895 & TST & \\
\hline
\end{tabular}




\begin{tabular}{|c|c|c|c|c|c|}
\hline & & \multicolumn{4}{|c|}{ Supplemental Table S2.txt } \\
\hline CHEMBL1528513 & 737242 & 3.699 & 3.8376 & TST & \\
\hline CHEMBL1986183 & 737242 & 5.3372 & 4.6591 & TST & \\
\hline CHEMBL1613394 & 737242 & 3.699 & 4.9862 & TST & \\
\hline CHEMBL1996133 & 737242 & 3.699 & 4.0571 & TST & \\
\hline CHEMBL1346179 & 737242 & 3.699 & 3.5597 & TST & \\
\hline CHEMBL 3199272 & 737242 & 3.699 & 3.9914 & TST & \\
\hline CHEMBL1593484 & 737242 & 3.699 & 4.0457 & TST & \\
\hline CHEMBL1509229 & 737242 & 3.699 & 3.4525 & TST & \\
\hline CHEMBL157351 & 737242 & \multicolumn{3}{|c|}{5.2139999999999995} & TST \\
\hline CHEMBL1300583 & 737242 & 3.699 & 3.7784 & TST & \\
\hline CHEMBL1591106 & 737242 & 3.699 & 3.7644 & TST & \\
\hline CHEMBL1321398 & 737242 & 4.8268 & \multicolumn{2}{|c|}{4.3069999999999995} & IST \\
\hline CHEMBL1509380 & 737242 & 4.9957 & 4.3504 & TST & \\
\hline CHEMBL1496572 & 737242 & 3.699 & 3.6212 & TST & \\
\hline CHEMBL1319374 & 737242 & 3.699 & 3.6476 & TST & \\
\hline CHEMBL1464020 & 737242 & 3.699 & 3.3494 & TST & \\
\hline CHEMBL1487183 & 737242 & 5.2255 & 3.8708 & TST & \\
\hline CHEMBL1406738 & 737242 & 3.699 & 3.7334 & TST & \\
\hline CHEMBL1435164 & 737242 & 3.699 & 3.4704 & TST & \\
\hline CHEMBL581880 & 737242 & 3.699 & 4.335 & TST & \\
\hline CHEMBL1200792 & 737242 & 3.699 & 3.3472 & TST & \\
\hline CHEMBL1698828 & 737242 & 3.699 & 3.4267 & TST & \\
\hline CHEMBL1495340 & 737242 & 3.699 & 3.9121 & TST & \\
\hline CHEMBL1349892 & 737242 & 3.699 & 3.6561 & TST & \\
\hline CHEMBL1570706 & 737242 & 3.699 & 4.1018 & TST & \\
\hline CHEMBL1457602 & 737242 & 3.699 & 3.6778 & TST & \\
\hline CHEMBL1558306 & 737242 & 3.699 & 3.5158 & TST & \\
\hline CHEMBL1410019 & 737242 & 3.699 & 3.5623 & TST & \\
\hline CHEMBL1336152 & 737242 & 3.699 & 3.8588 & TST & \\
\hline CHEMBL1226 & 737242 & 4.9547 & 4.1763 & TST & \\
\hline CHEMBL1351737 & 737242 & 3.699 & 3.7466 & TST & \\
\hline CHEMBL1889837 & 737242 & 5.0575 & \multicolumn{2}{|c|}{3.8480000000000003} & TST \\
\hline CHEMBL1208858 & 737242 & 5.2055 & 4.6081 & TST & \\
\hline CHEMBL1724950 & 737242 & 3.699 & 4.0448 & TST & \\
\hline CHEMBL1577443 & 737242 & 3.699 & 3.79 & TST & \\
\hline CHEMBL476983 & 535399 & 3.0 & 3.6216 & TRN & \\
\hline CHEMBL489777 & 535399 & 3.0 & 3.0079 & TRN & \\
\hline CHEMBL489564 & 535399 & 5.0458 & 5.2173 & TRN & \\
\hline CHEMBL490396 & 535399 & 6.0458 & \multicolumn{2}{|c|}{5.382999999999999} & T \\
\hline CHEMBL498976 & 535399 & 3.5229 & 4.6308 & TRN & \\
\hline CHEMBL478880 & 535399 & 3.0 & 3.0559 & TRN & \\
\hline CHEMBL489981 & 535399 & 3.0458 & 2.7767 & TRN & \\
\hline CHEMBL445306 & 535399 & 4.7447 & 3.7879 & TRN & \\
\hline CHEMBL1203972 & 535399 & 5.1549 & 3.6422 & TRN & \\
\hline CHEMBL491005 & 535399 & 5.301 & 5.4387 & TRN & \\
\hline CHEMBL489779 & 535399 & 3.0 & 2.8658 & TRN & \\
\hline CHEMBL477607 & 535399 & 3.0 & 3.3896 & TRN & \\
\hline CHEMBL448665 & 535399 & 4.1249 & 4.1206 & TRN & \\
\hline
\end{tabular}




\begin{tabular}{|c|c|c|c|c|}
\hline \multicolumn{5}{|c|}{ Supplemental Table S2.txt } \\
\hline CHEMBL505701 & 535399 & 3.0 & 2.7502 & TRN \\
\hline CHEMBL442892 & 535399 & 3.0 & 3.5823 & TRN \\
\hline CHEMBL476148 & 535399 & 4.699 & 3.8754 & TRN \\
\hline CHEMBL476783 & 535399 & 3.1549 & 4.3765 & TST \\
\hline CHEMBL476358 & 535399 & 3.0 & 3.1323 & TRN \\
\hline CHEMBL476984 & 535399 & 3.3188 & 3.6587 & TRN \\
\hline CHEMBL446474 & 535399 & 3.0 & 3.6293 & TST \\
\hline CHEMBL478881 & 535399 & 3.0 & 3.6492 & TST \\
\hline CHEMBL477606 & 535399 & 3.0458 & 3.3021 & TRN \\
\hline CHEMBL489776 & 535399 & 3.0 & 2.8158 & TRN \\
\hline CHEMBL478882 & 535399 & 3.0315 & 3.0934 & TST \\
\hline CHEMBL515944 & 535399 & 3.0969 & 3.6386 & TST \\
\hline CHEMBL476784 & 535399 & 3.301 & 4.0985 & TST \\
\hline CHEMBL490061 & 535399 & 4.6021 & 3.7636 & TRN \\
\hline CHEMBL491007 & 535399 & 5.3979 & 4.4748 & TRN \\
\hline CHEMBL510108 & 535399 & 3.0362 & 3.585 & TRN \\
\hline CHEMBL477596 & 535399 & 4.5229 & 3.6741 & TRN \\
\hline CHEMBL490784 & 535399 & 3.8239 & 4.497 & TRN \\
\hline CHEMBL489168 & 535399 & 3.0706 & 3.6806 & TST \\
\hline CHEMBL502222 & 535399 & 3.0 & 3.3584 & TRN \\
\hline CHEMBL489982 & 535399 & 4.1249 & 3.0968 & TRN \\
\hline CHEMBL517807 & 535399 & 4.5229 & 4.1451 & TST \\
\hline CHEMBL477177 & 535399 & 4.7447 & 3.9017 & TRN \\
\hline CHEMBL518286 & 535399 & 3.0 & 3.2843 & TST \\
\hline CHEMBL478859 & 535399 & 3.0 & 3.448 & TRN \\
\hline CHEMBL450720 & 535399 & 3.0 & 3.5471 & TRN \\
\hline CHEMBL448446 & 535399 & 3.0 & 3.3581 & TRN \\
\hline CHEMBL452739 & 535399 & 3.0 & 3.4401 & TRN \\
\hline CHEMBL477176 & 535399 & 4.7447 & 3.866 & TRN \\
\hline CHEMBL522753 & 535399 & 3.0 & 2.8624 & TRN \\
\hline CHEMBL490999 & 535399 & 4.9586 & 5.2502 & TRN \\
\hline CHEMBL504564 & 535399 & 3.6576 & 4.599 & TRN \\
\hline CHEMBL499938 & 535399 & 3.0 & 3.1134 & TRN \\
\hline CHEMBL477550 & 535399 & 3.1549 & 3.3062 & TRN \\
\hline CHEMBL452676 & 535399 & 4.9208 & 3.6454 & TST \\
\hline CHEMBL476974 & 535399 & 4.699 & 4.0895 & TRN \\
\hline CHEMBL450704 & 535399 & 3.0 & 3.8935 & TRN \\
\hline CHEMBL476918 & 535399 & 3.0 & 3.147 & TRN \\
\hline CHEMBL522098 & 535399 & 3.0 & 3.0134 & TRN \\
\hline CHEMBL448250 & 535399 & 3.0 & 3.0545 & TRN \\
\hline CHEMBL501654 & 535399 & 4.8239 & 4.8397 & TRN \\
\hline CHEMBL478860 & 535399 & 3.0 & 3.0981 & TRN \\
\hline CHEMBL448063 & 535399 & 3.0 & 3.0043 & TRN \\
\hline CHEMBL518440 & 535399 & 3.0458 & 3.3854 & TRN \\
\hline CHEMBL502905 & 535399 & 3.0 & 3.0371 & TRN \\
\hline CHEMBL470505 & 535399 & 4.699 & 4.0253 & TST \\
\hline CHEMBL490998 & 535399 & 5.301 & 4.9652 & TRN \\
\hline CHEMBL523441 & 535399 & 5.2218 & 4.9673 & TRN \\
\hline
\end{tabular}




\begin{tabular}{|c|c|c|c|c|c|}
\hline \multicolumn{6}{|c|}{ Supplemental Table S2.txt } \\
\hline CHEMBL464086 & 535399 & 3.1487 & 3.677 & TRN & \\
\hline CHEMBL492036 & 535399 & 3.0 & 4.5419 & TST & \\
\hline CHEMBL489373 & 535399 & 5.2218 & 5.1095 & TRN & \\
\hline CHEMBL491207 & 535399 & 4.8861 & 4.6206 & TRN & \\
\hline CHEMBL522585 & 535399 & 3.0458 & 3.287 & TRN & \\
\hline CHEMBL491006 & 535399 & 5.1549 & 5.6286 & TRN & \\
\hline CHEMBL1162372 & 535399 & 3.1367 & 4.3794 & TST & \\
\hline CHEMBL477187 & 535399 & 4.699 & 4.0877 & TST & \\
\hline CHEMBL508059 & 535399 & 3.0969 & 3.2986 & TRN & \\
\hline CHEMBL477823 & 535399 & 3.0 & 3.2849 & TST & \\
\hline CHEMBL564201 & 535399 & 5.9208 & 4.0025 & TST & \\
\hline CHEMBL475475 & 535399 & 4.5229 & 4.5249 & TRN & \\
\hline CHEMBL476147 & 535399 & 3.0969 & 3.8499 & TST & \\
\hline CHEMBL490997 & 535399 & 5.1549 & 5.0115 & TRN & \\
\hline CHEMBL492037 & 535399 & 3.0 & 4.2147 & TST & \\
\hline CHEMBL476992 & 535399 & 4.1249 & 3.4035 & TST & \\
\hline CHEMBL418899 & 535399 & 3.0 & 3.9003 & TST & \\
\hline CHEMBL446919 & 535399 & 5.3979 & 4.8271 & TST & \\
\hline CHEMBL451317 & 535399 & 5.301 & 5.0541 & TRN & \\
\hline CHEMBL470987 & 535399 & 3.0 & 3.6665 & TRN & \\
\hline CHEMBL489169 & 535399 & 3.1249 & 3.86 & TRN & \\
\hline CHEMBL476973 & 535399 & 4.3979 & 4.0864 & TRN & \\
\hline CHEMBL442570 & 535399 & 3.0 & 4.2015 & TST & \\
\hline CHEMBL490761 & 535399 & 4.2218 & 3.67100 & 00000000003 & TRN \\
\hline CHEMBL 375884 & 430957 & 3.301 & 3.0977 & TRN & \\
\hline CHEMBL224984 & 430957 & 6.7212 & 6.6285 & TRN & \\
\hline CHEMBL224376 & 430957 & 4.0 & 2.1036 & TST & \\
\hline CHEMBL224910 & 430957 & 4.0 & 3.8859 & TRN & \\
\hline CHEMBL388377 & 430957 & 4.0 & 4.4912 & TRN & \\
\hline CHEMBL 388624 & 430957 & 4.0 & 3.9517 & TST & \\
\hline CHEMBL 224354 & 430957 & 5.8861 & 5.4978 & TRN & \\
\hline CHEMBL 225010 & 430957 & 4.0 & 4.1502 & TRN & \\
\hline CHEMBL 225107 & 430957 & 4.0 & 4.1562 & TRN & \\
\hline CHEMBL224958 & 430957 & 5.0088 & 5.0126 & TRN & \\
\hline CHEMBL 376134 & 430957 & 5.0809 & 4.7252 & TRN & \\
\hline CHEMBL386220 & 430957 & 6.6383 & 6.3889 & TRN & \\
\hline CHEMBL 224314 & 430957 & 3.0 & 3.9321 & TRN & \\
\hline CHEMBL 224495 & 430957 & 4.0 & 3.9451 & TRN & \\
\hline CHEMBL224677 & 430957 & 4.0 & 3.8164 & TRN & \\
\hline CHEMBL 388787 & 430957 & 4.0 & 4.1616 & TRN & \\
\hline CHEMBL225106 & 430957 & 4.0 & 3.2626 & TRN & \\
\hline CHEMBL 387882 & 430957 & 4.0 & 4.8755 & TRN & \\
\hline CHEMBL 225030 & 430957 & 4.0 & 4.6259 & TRN & \\
\hline CHEMBL375691 & 430957 & 4.0 & 4.3671 & TRN & \\
\hline CHEMBL223989 & 430957 & 4.0 & 3.9353 & TRN & \\
\hline CHEMBL224947 & 430957 & 5.0177 & 4.9789 & TRN & \\
\hline CHEMBL225105 & 430957 & 4.0 & 3.7738 & TRN & \\
\hline CHEMBL388826 & 430957 & 3.0 & 3.3211 & TRN & \\
\hline
\end{tabular}




\begin{tabular}{|c|c|c|c|c|}
\hline & & & pplement & al $\mathrm{T}$ \\
\hline CHEMBL225076 & 430957 & 5.2676 & 5.4564 & TRN \\
\hline CHEMBL374166 & 430957 & 5.0605 & 4.9003 & TRN \\
\hline CHEMBL390316 & 430957 & 4.0 & 4.1709 & TRN \\
\hline CHEMBL 225344 & 430957 & 4.0 & 4.0548 & TRN \\
\hline CHEMBL224764 & 430957 & 3.0 & 3.2259 & TRN \\
\hline CHEMBL389896 & 430957 & 4.0 & 4.239 & TRN \\
\hline CHEMBL 223988 & 430957 & 6.5229 & 5.6111 & TRN \\
\hline CHEMBL224959 & 430957 & 4.0 & 2.6742 & TST \\
\hline CHEMBL 224960 & 430957 & 4.0 & 3.4791 & TRN \\
\hline CHEMBL390825 & 430957 & 4.0 & 3.7263 & TST \\
\hline CHEMBL223987 & 430957 & 4.0 & 4.3179 & TRN \\
\hline CHEMBL 224045 & 430957 & 4.0 & 3.5252 & TST \\
\hline CHEMBL425120 & 430957 & 5.0362 & 4.9282 & TST \\
\hline CHEMBL 224934 & 430957 & 3.0 & 2.4836 & TRN \\
\hline CHEMBL375496 & 430957 & 5.8239 & 5.0234 & TST \\
\hline CHEMBL 224710 & 430957 & 5.1612 & 5.0489 & TRN \\
\hline CHEMBL376194 & 430957 & 4.0 & 4.0824 & TST \\
\hline CHEMBL 224044 & 430957 & 4.0 & 4.7141 & TST \\
\hline CHEMBL 225075 & 430957 & 5.8239 & 5.0628 & TRN \\
\hline CHEMBL427242 & 430957 & 5.3872 & 5.2217 & TST \\
\hline CHEMBL 224442 & 430957 & 5.8539 & 5.7642 & TRN \\
\hline CHEMBL224657 & 430957 & 4.0 & 2.8708 & TST \\
\hline CHEMBL 225031 & 430957 & 6.3872 & 6.1224 & TST \\
\hline CHEMBL390962 & 430957 & 5.0458 & 4.6161 & TRN \\
\hline CHEMBL224355 & 430957 & 4.0 & 4.6016 & TRN \\
\hline CHEMBL 388100 & 430957 & 4.0 & 4.0268 & TRN \\
\hline CHEMBL391005 & 430957 & 4.0 & 4.0633 & TRN \\
\hline CHEMBL 224712 & 430957 & 3.0 & 2.1231 & TST \\
\hline CHEMBL 224316 & 430957 & 4.0 & 3.7968 & TRN \\
\hline CHEMBL224711 & 430957 & 6.9586 & 5.3807 & TST \\
\hline CHEMBL 388980 & 430957 & 4.0 & 4.3189 & TRN \\
\hline CHEMBL 376377 & 430957 & 3.301 & 3.3952 & TRN \\
\hline CHEMBL 224371 & 430957 & 4.0 & 3.7307 & TRN \\
\hline CHEMBL 224980 & 430957 & 5.8861 & 6.1828 & TRN \\
\hline CHEMBL390375 & 430957 & 5.0809 & 3.8507 & TST \\
\hline CHEMBL3669031 & 1536128 & 7.6198 & 7.9511 & TST \\
\hline CHEMBL3704947 & 1536128 & 7.585 & 7.7444 & TRN \\
\hline CHEMBL 3704944 & 1536128 & 7.6383 & 7.5045 & TRN \\
\hline CHEMBL3669047 & 1536128 & 7.8239 & 7.9974 & TRN \\
\hline CHEMBL3704929 & 1536128 & 7.3979 & 6.9096 & TST \\
\hline CHEMBL3704950 & 1536128 & 7.2676 & 7.4437 & TRN \\
\hline CHEMBL3704951 & 1536128 & 7.9208 & 7.8463 & TRN \\
\hline CHEMBL3669043 & 1536128 & 6.9872 & 7.124 & TRN \\
\hline CHEMBL 3669040 & 1536128 & 7.3188 & 7.4895 & TRN \\
\hline CHEMBL3597969 & 1536128 & 8.0969 & 8.0824 & TRN \\
\hline CHEMBL3669026 & 1536128 & 7.3979 & 7.4031 & TRN \\
\hline CHEMBL3704931 & 1536128 & 6.3354 & 7.2175 & TST \\
\hline CHEMBL3905361 & 1536128 & 6.0 & 6.7894 & TST \\
\hline
\end{tabular}


Supplemental Table S2.txt

\begin{tabular}{|c|c|c|c|c|c|}
\hline CHEMBL3704967 & 1536128 & 7.9586 & 7.8026 & TRN & \\
\hline CHEMBL3597970 & 1536128 & 7.9208 & 7.7301 & TRN & \\
\hline CHEMBL3640038 & 1536128 & 6.9208 & 7.0659 & TRN & \\
\hline CHEMBL3669022 & 1536128 & 6.0 & 6.4601 & TRN & \\
\hline CHEMBL3704930 & 1536128 & 6.8996 & 7.3653 & TST & \\
\hline CHEMBL3669029 & 1536128 & 7.2441 & 6.8476 & TRN & \\
\hline CHEMBL3669023 & 1536128 & 7.9208 & 7.1858 & TRN & \\
\hline CHEMBL3704927 & 1536128 & 7.1079 & 6.6221 & TRN & \\
\hline CHEMBL3669036 & 1536128 & 6.6038 & 7.6624 & TST & \\
\hline CHEMBL3704934 & 1536128 & 5.0458 & 5.8298 & TRN & \\
\hline CHEMBL3893886 & 1536128 & 7.0458 & 7.1288 & TST & \\
\hline CHEMBL3669035 & 1536128 & 7.5528 & 7.2373 & TRN & \\
\hline CHEMBL3669025 & 1536128 & 7.6778 & 7.9143 & TRN & \\
\hline CHEMBL 3669048 & 1536128 & 6.3507 & 7.1817 & TST & \\
\hline CHEMBL3704932 & 1536128 & 5.1734 & 7.0362 & TST & \\
\hline CHEMBL3704925 & 1536128 & 6.3979 & 6.1717 & TRN & \\
\hline CHEMBL3669045 & 1536128 & 7.4949 & 7.7102 & TRN & \\
\hline CHEMBL3669042 & 1536128 & 7.4202 & 6.92399 & 99999999995 & TR \\
\hline CHEMBL 3926734 & 1536128 & 7.1427 & 7.3322 & TST & \\
\hline CHEMBL3669032 & 1536128 & 7.6383 & 7.6398 & TST & \\
\hline CHEMBL3704926 & 1536128 & 5.9727 & 6.0336 & TRN & \\
\hline CHEMBL3704965 & 1536128 & 6.8153 & 7.3418 & TRN & \\
\hline CHEMBL3669041 & 1536128 & 7.7447 & 7.8333 & TRN & \\
\hline CHEMBL3929103 & 1536128 & 7.1549 & 7.2827 & TST & \\
\hline CHEMBL3704928 & 1536128 & 6.2518 & 6.2539 & TRN & \\
\hline CHEMBL3704960 & 1536128 & 8.0458 & 7.9021 & TRN & \\
\hline CHEMBL3704943 & 1536128 & 7.7212 & 7.4469 & TRN & \\
\hline CHEMBL3704954 & 1536128 & 7.5376 & 7.2071 & TRN & \\
\hline CHEMBL3669028 & 1536128 & 7.2596 & 7.9631 & TST & \\
\hline CHEMBL3704958 & 1536128 & 7.9208 & 7.4854 & TRN & \\
\hline CHEMBL3669049 & 1536128 & 7.6021 & 7.5897 & TST & \\
\hline CHEMBL3669046 & 1536128 & 7.9208 & 7.178 & TRN & \\
\hline CHEMBL3704942 & 1536128 & 7.6021 & 7.6351 & TRN & \\
\hline CHEMBL 3704941 & 1536128 & 8.0969 & 7.8217 & TRN & \\
\hline CHEMBL3669037 & 1536128 & 7.6021 & 8.0091 & TRN & \\
\hline CHEMBL3704940 & 1536128 & 8.0 & 7.8955 & TRN & \\
\hline CHEMBL3704956 & 1536128 & 7.1487 & 7.6709 & TRN & \\
\hline CHEMBL3704945 & 1536128 & 7.7959 & 7.6102 & TRN & \\
\hline CHEMBL3704933 & 1536128 & 6.5017 & 6.0764 & TRN & \\
\hline CHEMBL3669039 & 1536128 & 7.7212 & 7.3493 & TRN & \\
\hline CHEMBL 3669024 & 1536128 & 6.0 & 6.7319 & TRN & \\
\hline CHEMBL3669038 & 1536128 & 8.0 & 7.2871 & TRN & \\
\hline CHEMBL3704946 & 1536128 & 7.8539 & 7.6043 & TRN & \\
\hline CHEMBL 3669051 & 1536128 & 6.76200 & 00000000 & 7.0154 & TST \\
\hline CHEMBL3669034 & 1536128 & 7.2757 & 7.3995 & TST & \\
\hline CHEMBL3704924 & 1536128 & 5.9855 & 6.2264 & TRN & \\
\hline CHEMBL3669050 & 1536128 & 7.0132 & 7.5587 & TST & \\
\hline CHEMBL3669044 & 1536128 & 7.3279 & 6.7198 & TRN & \\
\hline
\end{tabular}


Supplemental Table S2.txt

\begin{tabular}{|c|c|c|c|c|c|}
\hline CHEMBL3669030 & 1536128 & 8.1549 & 7.5795 & TRN & \\
\hline CHEMBL3704961 & 1536128 & 8.0 & 7.8281 & TRN & \\
\hline CHEMBL3669027 & 1536128 & 7.2076 & 7.1551 & TRN & \\
\hline CHEMBL3704964 & 1536128 & 7.585 & 7.9105 & TRN & \\
\hline CHEMBL3704938 & 1536128 & 7.4202 & 6.92 & TST & \\
\hline CHEMBL3704939 & 1536128 & 6.0 & \multicolumn{2}{|c|}{7.212999999999999} & TRN \\
\hline CHEMBL3669033 & 1536128 & 7.2366 & 7.4911 & TRN & \\
\hline CHEMBL3704957 & 1536128 & 6.0 & 7.4406 & TRN & \\
\hline CHEMBL3704952 & 1536128 & 6.7959 & 7.1708 & TRN & \\
\hline CHEMBL52068 & 307251 & 5.06 & 4.7905 & TRN & \\
\hline CHEMBL 292464 & 307251 & 5.57 & 5.4403 & TRN & \\
\hline CHEMBL51738 & 307251 & 5.82 & 5.7332 & TRN & \\
\hline CHEMBL296376 & 307251 & 6.02 & 5.8883 & TRN & \\
\hline CHEMBL51912 & 307251 & 5.24 & \multicolumn{2}{|c|}{4.861000000000001} & TRN \\
\hline CHEMBL300757 & 307251 & 5.14 & 5.1239 & TRN & \\
\hline CHEMBL55599 & 307251 & 4.8 & 5.6124 & TRN & \\
\hline CHEMBL55747 & 307251 & 4.92 & 4.9586 & TRN & \\
\hline CHEMBL56465 & 307251 & 4.82 & 5.6427 & TRN & \\
\hline CHEMBL449041 & 307251 & 4.92 & 5.2715 & TRN & \\
\hline CHEMBL59586 & 307251 & 5.04 & 4.8565 & TRN & \\
\hline CHEMBL 293806 & 307251 & 5.96 & 5.6155 & TRN & \\
\hline CHEMBL293963 & 307251 & 5.15 & 5.1943 & TRN & \\
\hline CHEMBL54698 & 307251 & 5.46 & 5.6177 & TRN & \\
\hline CHEMBL294627 & 307251 & 5.96 & 6.6369 & TRN & \\
\hline CHEMBL294179 & 307251 & 6.92 & 5.8945 & TRN & \\
\hline CHEMBL56324 & 307251 & 5.77 & 6.6325 & TST & \\
\hline CHEMBL292891 & 307251 & 6.85 & 6.5803 & TST & \\
\hline CHEMBL54970 & 307251 & 4.89 & 5.8893 & TST & \\
\hline CHEMBL293331 & 307251 & 4.92 & 5.4339 & TST & \\
\hline CHEMBL55007 & 307251 & 4.72 & 5.4885 & TST & \\
\hline CHEMBL53893 & 307251 & 5.0 & 5.6014 & TST & \\
\hline CHEMBL55998 & 307251 & 5.32 & \multicolumn{2}{|c|}{6.3660000000000005} & TST \\
\hline CHEMBL 294212 & 307251 & 5.01 & \multicolumn{2}{|c|}{5.127999999999999} & TST \\
\hline CHEMBL54318 & 307251 & 6.3 & 6.7404 & TST & \\
\hline CHEMBL292012 & 307251 & 5.21 & 5.5295 & TST & \\
\hline CHEMBL55862 & 307251 & 6.28 & 6.9789 & TST & \\
\hline CHEMBL55387 & 307251 & 6.05 & 6.0204 & TST & \\
\hline CHEMBL55271 & 307251 & 5.16 & 5.2631 & TRN & \\
\hline CHEMBL55308 & 307251 & 5.85 & 5.9726 & TRN & \\
\hline CHEMBL55199 & 307251 & 6.22 & 6.3987 & TRN & \\
\hline CHEMBL55043 & 307251 & 4.89 & 5.1179 & TRN & \\
\hline CHEMBL55997 & 307251 & 6.4 & 7.2183 & TRN & \\
\hline CHEMBL54444 & 307251 & 5.35 & 5.642 & TRN & \\
\hline CHEMBL297956 & 307251 & 6.0 & 5.4208 & TRN & \\
\hline CHEMBL54600 & 307251 & 6.7 & 6.9412 & TRN & \\
\hline CHEMBL53043 & 307251 & 7.53 & 5.9993 & TRN & \\
\hline CHEMBL53896 & 307251 & 5.14 & 5.4151 & TRN & \\
\hline CHEMBL301086 & 307251 & 5.23 & 5.2807 & TRN & \\
\hline
\end{tabular}




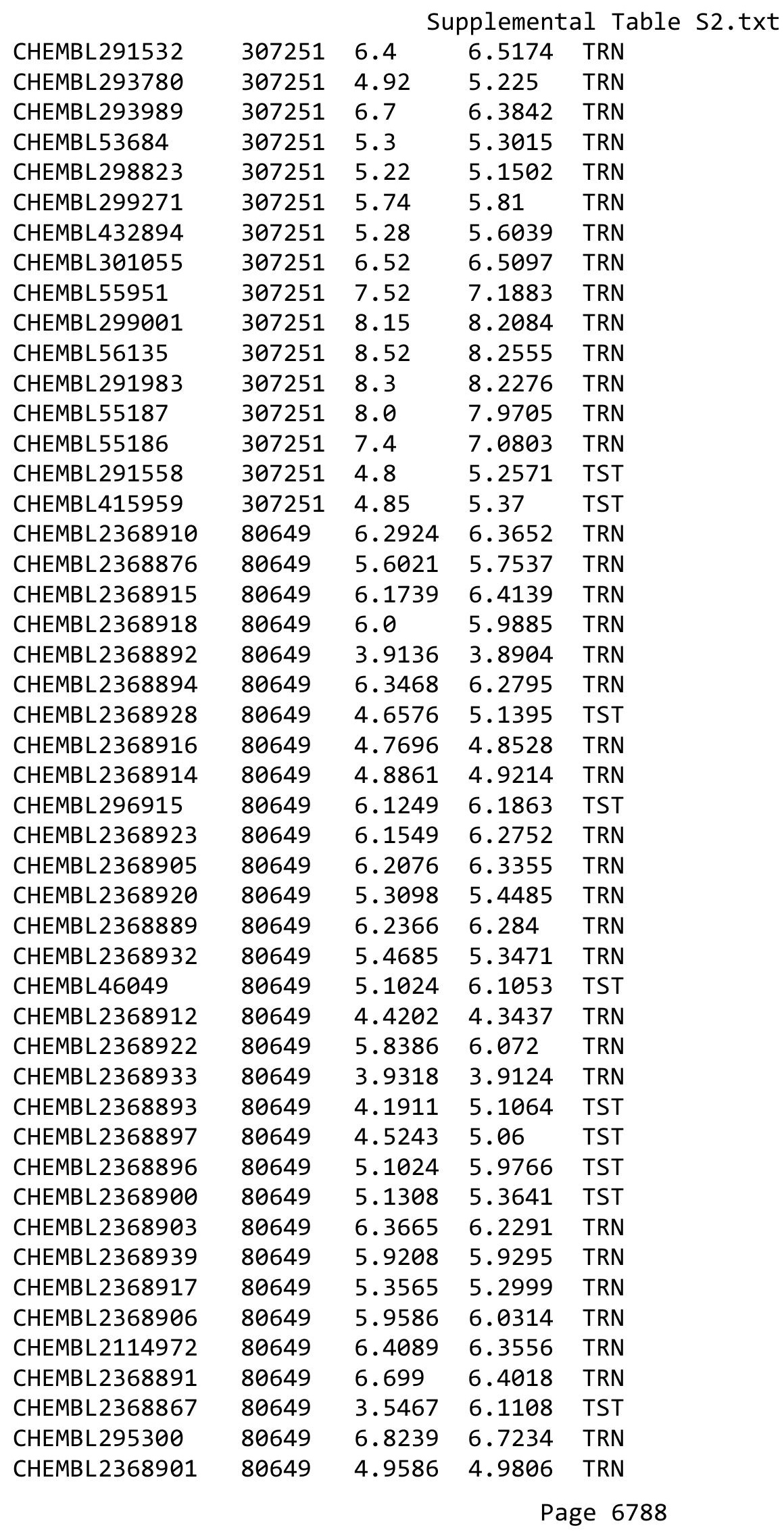




\begin{tabular}{|c|c|c|c|c|c|}
\hline \multicolumn{6}{|c|}{ Supplemental Table S2.txt } \\
\hline CHEMBL2368888 & 80649 & 5.2007 & 5.2111 & TRN & \\
\hline CHEMBL 2368921 & 80649 & 6.0 & 5.9255 & TRN & \\
\hline CHEMBL2368911 & 80649 & 5.5229 & 5.4917 & TST & \\
\hline CHEMBL2368904 & 80649 & 4.4559 & 5.6518 & TST & \\
\hline CHEMBL 2368938 & 80649 & 5.4318 & 5.3346 & TRN & \\
\hline CHEMBL47378 & 80649 & 6.6778 & 6.6391 & TRN & \\
\hline CHEMBL 2368919 & 80649 & 6.3188 & 6.2748 & TRN & \\
\hline CHEMBL 2368908 & 80649 & 5.585 & 5.6304 & TRN & \\
\hline CHEMBL 2368895 & 80649 & 6.1192 & 6.1134 & TRN & \\
\hline CHEMBL47537 & 80649 & 6.4815 & 6.4345 & TRN & \\
\hline CHEMBL 2368868 & 80649 & 4.2596 & 5.8626 & TST & \\
\hline CHEMBL298223 & 80649 & 4.8861 & 4.9024 & TRN & \\
\hline CHEMBL 2368886 & 80649 & 5.7212 & 5.6933 & TRN & \\
\hline CHEMBL 2368887 & 80649 & 6.2218 & 6.20200 & 0000000001 & TRN \\
\hline CHEMBL 2368913 & 80649 & 6.1192 & 6.0148 & TRN & \\
\hline CHEMBL 2115420 & 80649 & 6.7696 & 6.749 & TRN & \\
\hline CHEMBL 2368890 & 80649 & 6.2218 & 6.2407 & TRN & \\
\hline CHEMBL 2368875 & 80649 & 5.699 & 5.6982 & TRN & \\
\hline CHEMBL 2368907 & 80649 & 5.5229 & 5.6562 & TST & \\
\hline CHEMBL 2368926 & 80649 & 6.699 & 6.1206 & TST & \\
\hline CHEMBL207754 & 345663 & 7.3979 & 6.9116 & TRN & \\
\hline CHEMBL 205848 & 345663 & 6.5003 & 6.6647 & TRN & \\
\hline CHEMBL 207268 & 345663 & 6.1331 & 5.2588 & TRN & \\
\hline CHEMBL 208424 & 345663 & 8.7212 & 7.6428 & TRN & \\
\hline CHEMBL 205790 & 345663 & 4.0 & 5.3355 & TRN & \\
\hline CHEMBL203019 & 345663 & 6.8633 & 6.6208 & TST & \\
\hline CHEMBL407647 & 345663 & 4.0 & 5.032 & TRN & \\
\hline CHEMBL 205374 & 345663 & 7.8539 & 7.0422 & TRN & \\
\hline CHEMBL207792 & 345663 & 7.3098 & 7.3713 & TRN & \\
\hline CHEMBL 204776 & 345663 & 6.7447 & 6.9389 & TST & \\
\hline CHEMBL206820 & 345663 & 7.9208 & 7.4799 & TRN & \\
\hline CHEMBL 377305 & 345663 & 6.6253 & 5.3128 & TRN & \\
\hline CHEMBL 203578 & 345663 & 7.2076 & 6.8808 & TRN & \\
\hline CHEMBL 204880 & 345663 & 5.6055 & 5.2221 & TRN & \\
\hline CHEMBL 205794 & 345663 & 5.8477 & 6.7134 & TRN & \\
\hline CHEMBL381759 & 345663 & 7.4685 & 7.3446 & TRN & \\
\hline CHEMBL 205796 & 345663 & 7.7212 & 6.5553 & TST & \\
\hline CHEMBL383058 & 345663 & 6.4202 & 5.7015 & TRN & \\
\hline CHEMBL 382853 & 345663 & 6.7282 & 7.7907 & TRN & \\
\hline CHEMBL 204884 & 345663 & 5.5114 & 5.1911 & TRN & \\
\hline CHEMBL204835 & 345663 & 7.1612 & 5.5338 & TRN & \\
\hline CHEMBL 205711 & 345663 & 8.2676 & 7.0098 & TST & \\
\hline CHEMBL 205847 & 345663 & 5.8601 & 6.9487 & TRN & \\
\hline CHEMBL424860 & 345663 & 7.4202 & 6.8808 & TRN & \\
\hline CHEMBL 205896 & 345663 & 7.8861 & 7.5146 & TRN & \\
\hline CHEMBL 205995 & 345663 & 7.2441 & 6.8808 & TRN & \\
\hline CHEMBL 379887 & 345663 & 7.3872 & 7.4178 & TRN & \\
\hline CHEMBL382138 & 345663 & 7.0862 & 7.1288 & TRN & \\
\hline
\end{tabular}




\begin{tabular}{|c|c|c|c|c|c|}
\hline & & \multicolumn{4}{|c|}{ Supplemental Table S2.txt } \\
\hline CHEMBL206741 & 345663 & 8.0132 & 7.8425 & TRN & \\
\hline CHEMBL204266 & 345663 & 7.1612 & 7.4679 & TRN & \\
\hline CHEMBL205445 & 345663 & 8.1675 & 7.4553 & TRN & \\
\hline CHEMBL205484 & 345663 & 7.8539 & 6.5336 & TST & \\
\hline CHEMBL204322 & 345663 & 5.4647 & 6.4712 & TRN & \\
\hline CHEMBL382033 & 345663 & 8.041 & \multicolumn{2}{|c|}{7.367000000000001} & TRN \\
\hline CHEMBL206687 & 345663 & 6.6757 & \multicolumn{2}{|c|}{6.872999999999999} & TRN \\
\hline CHEMBL204897 & 345663 & 7.6778 & 6.5017 & TST & \\
\hline CHEMBL203948 & 345663 & 5.5884 & 6.9127 & TRN & \\
\hline CHEMBL381159 & 345663 & 6.1124 & 5.9015 & TRN & \\
\hline CHEMBL206638 & 345663 & 7.9586 & 7.0267 & TST & \\
\hline CHEMBL205955 & 345663 & 5.1451 & 7.0308 & TRN & \\
\hline CHEMBL383411 & 345663 & 8.0458 & 7.6223 & TRN & \\
\hline CHEMBL380971 & 345663 & 8.0177 & 8.0486 & TRN & \\
\hline CHEMBL203581 & 345663 & 4.0 & 5.8649 & TST & \\
\hline CHEMBL205963 & 345663 & 6.0246 & 6.5504 & TRN & \\
\hline CHEMBL383757 & 345663 & 7.4202 & 6.9898 & TST & \\
\hline CHEMBL205605 & 345663 & 7.4949 & 6.8776 & TRN & \\
\hline CHEMBL206672 & 345663 & 4.0 & \multicolumn{2}{|c|}{5.5889999999999995} & TRN \\
\hline CHEMBL377515 & 345663 & 7.2757 & 7.5932 & TRN & \\
\hline CHEMBL383454 & 345663 & 8.0 & 7.7206 & TRN & \\
\hline CHEMBL377514 & 345663 & 8.5229 & 6.9661 & TST & \\
\hline CHEMBL206673 & 345663 & \multicolumn{3}{|c|}{6.4510000000000005} & TST \\
\hline CHEMBL425594 & 345663 & 8.1487 & 8.0404 & TST & \\
\hline CHEMBL203280 & 345663 & 7.4318 & 6.2503 & TST & \\
\hline CHEMBL205294 & 345663 & 7.4437 & 6.4531 & TST & \\
\hline CHEMBL1964290 & 809189 & 7.0 & 6.9456 & TRN & \\
\hline CHEMBL 2003768 & 809189 & 4.2 & 4.1915 & TRN & \\
\hline CHEMBL 213505 & 809189 & 4.2 & 4.9871 & TRN & \\
\hline CHEMBL202721 & 809189 & 4.4 & 4.5245 & TRN & \\
\hline CHEMBL1987034 & 809189 & 5.2 & 5.19 & TRN & \\
\hline CHEMBL1993941 & 809189 & 4.2 & 4.044 & TRN & \\
\hline CHEMBL1980435 & 809189 & 5.9 & 5.7039 & TRN & \\
\hline CHEMBL377383 & 809189 & 4.2 & 3.9824 & TRN & \\
\hline CHEMBL 2005886 & 809189 & 4.2 & 3.9646 & TRN & \\
\hline CHEMBL481491 & 809189 & 4.2 & 4.092 & TST & \\
\hline CHEMBL1973142 & 809189 & 5.3 & 5.1211 & TRN & \\
\hline CHEMBL388311 & 809189 & 5.7 & 6.2756 & TRN & \\
\hline CHEMBL1998765 & 809189 & 5.4 & 5.0466 & TRN & \\
\hline CHEMBL1973145 & 809189 & 4.2 & 4.2791 & TRN & \\
\hline CHEMBL1982924 & 809189 & 4.2 & 4.0825 & TRN & \\
\hline CHEMBL 2005936 & 809189 & 4.2 & 4.5336 & TRN & \\
\hline CHEMBL1807515 & 809189 & 7.3 & 7.2916 & TRN & \\
\hline CHEMBL1964948 & 809189 & 4.4 & 4.8799 & TRN & \\
\hline CHEMBL1971141 & 809189 & 4.2 & 4.3376 & TRN & \\
\hline CHEMBL1995813 & 809189 & 6.0 & 6.3747 & TRN & \\
\hline CHEMBL206236 & 809189 & 4.2 & 4.4892 & TRN & \\
\hline CHEMBL1989834 & 809189 & 3.9 & 4.4137 & TRN & \\
\hline
\end{tabular}




\begin{tabular}{|c|c|c|c|c|}
\hline & & & ICI & al Ta \\
\hline CHEMBL1987430 & 809189 & 4.4 & 3.9758 & TRN \\
\hline CHEMBL244378 & 809189 & 6.0 & 6.4491 & TRN \\
\hline CHEMBL2001957 & 809189 & 6.0 & 6.5932 & TRN \\
\hline CHEMBL1969372 & 809189 & 6.2 & 5.9864 & TRN \\
\hline CHEMBL1993413 & 809189 & 4.6 & 4.288 & TRN \\
\hline CHEMBL1986943 & 809189 & 7.2 & 6.8715 & TRN \\
\hline CHEMBL289959 & 809189 & 5.5 & 4.4021 & TRN \\
\hline CHEMBL 2006263 & 809189 & 4.2 & 3.8645 & TST \\
\hline CHEMBL1993584 & 809189 & 4.2 & 4.2697 & TRN \\
\hline CHEMBL1986263 & 809189 & 6.0 & 6.0028 & TRN \\
\hline CHEMBL 2000114 & 809189 & 4.2 & 4.1472 & TRN \\
\hline CHEMBL210618 & 809189 & 4.2 & 4.4004 & TRN \\
\hline CHEMBL1986265 & 809189 & 4.4 & 4.3471 & TRN \\
\hline CHEMBL1971172 & 809189 & 4.4 & 4.8808 & TRN \\
\hline CHEMBL1975647 & 809189 & 4.2 & 4.3115 & TRN \\
\hline CHEMBL1968380 & 809189 & 4.2 & 4.5879 & TRN \\
\hline CHEMBL1964644 & 809189 & 4.2 & 3.8723 & TRN \\
\hline CHEMBL1991734 & 809189 & 5.9 & 5.6337 & TST \\
\hline CHEMBL1981782 & 809189 & 4.2 & 4.4598 & TRN \\
\hline CHEMBL1977681 & 809189 & 4.2 & 4.4084 & TRN \\
\hline CHEMBL1970142 & 809189 & 4.2 & 3.7995 & TRN \\
\hline CHEMBL1990912 & 809189 & 4.2 & 4.119 & TRN \\
\hline CHEMBL1991782 & 809189 & 3.1 & 3.8419 & TRN \\
\hline CHEMBL 2002105 & 809189 & 4.6 & 4.3562 & TRN \\
\hline CHEMBL1983348 & 809189 & 6.7 & 5.8493 & TRN \\
\hline CHEMBL1988163 & 809189 & 5.2 & 5.2303 & TRN \\
\hline CHEMBL 2000934 & 809189 & 4.4 & 3.9682 & TRN \\
\hline CHEMBL1980671 & 809189 & 5.1 & 5.4334 & TRN \\
\hline CHEMBL 2006493 & 809189 & 4.2 & 4.3852 & TST \\
\hline CHEMBL1986177 & 809189 & 4.4 & 4.1727 & TRN \\
\hline CHEMBL1996923 & 809189 & 4.2 & 4.3401 & TST \\
\hline CHEMBL1983449 & 809189 & 4.2 & 4.1226 & TRN \\
\hline CHEMBL1992323 & 809189 & 4.2 & 4.4129 & TRN \\
\hline CHEMBL1969735 & 809189 & 5.7 & 6.1218 & TRN \\
\hline CHEMBL 2002649 & 809189 & 4.2 & 5.07 & TRN \\
\hline CHEMBL1983589 & 809189 & 6.3 & 5.6873 & TRN \\
\hline CHEMBL1989423 & 809189 & 4.2 & 4.2916 & TRN \\
\hline CHEMBL1985367 & 809189 & 4.4 & 4.8494 & TST \\
\hline CHEMBL1996510 & 809189 & 4.4 & 5.5507 & TST \\
\hline CHEMBL 2005718 & 809189 & 5.9 & 4.888 & TRN \\
\hline CHEMBL1995172 & 809189 & 4.3 & 3.8054 & TST \\
\hline CHEMBL 2001584 & 809189 & 4.4 & 4.3086 & TRN \\
\hline CHEMBL1967998 & 809189 & 5.6 & 5.6555 & TRN \\
\hline CHEMBL1994321 & 809189 & 4.2 & 4.0125 & TRN \\
\hline CHEMBL1978562 & 809189 & 4.4 & 5.2975 & TST \\
\hline CHEMBL1997129 & 809189 & 7.3 & 6.3792 & TRN \\
\hline CHEMBL1984788 & 809189 & 4.2 & 4.2279 & TRN \\
\hline CHEMBL1974875 & 809189 & 4.7 & 4.7507 & TST \\
\hline
\end{tabular}




\begin{tabular}{|c|c|c|c|c|}
\hline \multicolumn{5}{|c|}{ lementa } \\
\hline CHEMBL1989471 & 809189 & 4.4 & 4.9168 & TST \\
\hline CHEMBL 2000508 & 809189 & 7.1 & 6.0674 & TRN \\
\hline CHEMBL1971694 & 809189 & 4.2 & 4.3518 & TST \\
\hline CHEMBL 2001547 & 809189 & 6.5 & 5.80399 & 9999999999 \\
\hline CHEMBL210928 & 809189 & 4.2 & 4.0644 & TRN \\
\hline CHEMBL1978195 & 809189 & 6.4 & 6.0402 & TRN \\
\hline CHEMBL1986603 & 809189 & 4.2 & 4.4512 & TST \\
\hline CHEMBL1977148 & 809189 & 4.2 & 4.1977 & TRN \\
\hline CHEMBL 2003286 & 809189 & 4.2 & 4.8254 & TRN \\
\hline CHEMBL1992306 & 809189 & 4.2 & 4.2759 & TRN \\
\hline CHEMBL 2002165 & 809189 & 4.2 & 4.3185 & TRN \\
\hline CHEMBL2001668 & 809189 & 4.2 & 4.792 & TST \\
\hline CHEMBL1979318 & 809189 & 4.2 & 4.4486 & TST \\
\hline CHEMBL 206382 & 809189 & 4.2 & 4.7886 & TRN \\
\hline CHEMBL1998585 & 809189 & 5.3 & 4.9516 & TRN \\
\hline CHEMBL127898 & 809189 & 4.2 & 4.2659 & TST \\
\hline CHEMBL519697 & 809189 & 5.3 & 5.2733 & TRN \\
\hline CHEMBL 2004934 & 809189 & 4.2 & 4.2945 & TRN \\
\hline CHEMBL1987261 & 809189 & 6.3 & 5.3749 & TRN \\
\hline CHEMBL1973516 & 809189 & 4.4 & 5.2429 & TRN \\
\hline CHEMBL1996345 & 809189 & 4.4 & 4.9606 & TST \\
\hline CHEMBL1975128 & 809189 & 4.2 & 5.1837 & TRN \\
\hline CHEMBL 2004025 & 809189 & 4.4 & 4.3815 & TRN \\
\hline CHEMBL1996048 & 809189 & 4.4 & 5.1518 & TST \\
\hline CHEMBL1970369 & 809189 & 4.2 & 4.2923 & TRN \\
\hline CHEMBL461876 & 809189 & 5.9 & 5.5031 & TRN \\
\hline CHEMBL1965033 & 809189 & 4.4 & 4.5962 & TRN \\
\hline CHEMBL 2001485 & 809189 & 4.2 & 3.9664 & TRN \\
\hline CHEMBL1971519 & 809189 & 5.1 & 5.0199 & TRN \\
\hline CHEMBL1997335 & 809189 & 7.9 & 5.6574 & TRN \\
\hline CHEMBL1966425 & 809189 & 5.9 & 5.2095 & TRN \\
\hline CHEMBL1984363 & 809189 & 4.2 & 4.218 & TRN \\
\hline CHEMBL1978099 & 809189 & 4.2 & 4.2704 & TRN \\
\hline CHEMBL1988608 & 809189 & 4.2 & 3.8942 & TRN \\
\hline CHEMBL184847 & 809189 & 4.2 & 4.0955 & TRN \\
\hline CHEMBL1971132 & 809189 & 4.4 & 4.3382 & TRN \\
\hline CHEMBL1984367 & 809189 & 4.2 & 4.0741 & TRN \\
\hline CHEMBL1985723 & 809189 & 5.8 & 5.4601 & TRN \\
\hline CHEMBL178737 & 809189 & 4.2 & 4.768 & TST \\
\hline CHEMBL226898 & 809189 & 5.6 & 6.0671 & TRN \\
\hline CHEMBL1982563 & 809189 & 6.1 & 6.335 & TRN \\
\hline CHEMBL1991377 & 809189 & 4.4 & 4.4636 & TRN \\
\hline CHEMBL539474 & 809189 & 4.2 & 4.4635 & TST \\
\hline CHEMBL575824 & 809189 & 4.2 & 5.2426 & TRN \\
\hline CHEMBL1988387 & 809189 & 4.2 & 4.2438 & TRN \\
\hline CHEMBL1973868 & 809189 & 4.4 & 5.072 & TRN \\
\hline CHEMBL1972462 & 809189 & 4.4 & 4.5139 & TRN \\
\hline CHEMBL1977128 & 809189 & 5.9 & 5.9721 & TRN \\
\hline
\end{tabular}

TRN 


\begin{tabular}{|c|c|c|c|c|}
\hline & & & IET & al Ta \\
\hline CHEMBL1989708 & 809189 & 4.2 & 4.3129 & TRN \\
\hline CHEMBL1974803 & 809189 & 4.2 & 4.5019 & TRN \\
\hline CHEMBL1970074 & 809189 & 4.2 & 4.4699 & TRN \\
\hline CHEMBL1965702 & 809189 & 5.9 & 6.0504 & TRN \\
\hline CHEMBL1984500 & 809189 & 4.2 & 3.7448 & TRN \\
\hline CHEMBL1986970 & 809189 & 4.2 & 4.1326 & TRN \\
\hline CHEMBL 2005112 & 809189 & 4.2 & 4.5562 & TST \\
\hline CHEMBL1958401 & 809189 & 6.2 & 5.7207 & TRN \\
\hline CHEMBL1984044 & 809189 & 4.2 & 4.6195 & TRN \\
\hline CHEMBL 2003456 & 809189 & 4.2 & 3.9815 & TRN \\
\hline CHEMBL1966816 & 809189 & 4.2 & 3.9798 & TRN \\
\hline CHEMBL1972584 & 809189 & 5.5 & 5.3668 & TRN \\
\hline CHEMBL 2002992 & 809189 & 4.4 & 4.7399 & TRN \\
\hline CHEMBL560813 & 809189 & 4.2 & 4.4417 & TRN \\
\hline CHEMBL 207253 & 809189 & 4.2 & 4.6947 & TST \\
\hline CHEMBL1982700 & 809189 & 7.3 & 3.9797 & TST \\
\hline CHEMBL1968791 & 809189 & 5.2 & 4.5913 & TRN \\
\hline CHEMBL 2002682 & 809189 & 5.3 & 4.2317 & TST \\
\hline CHEMBL1977634 & 809189 & 5.4 & 4.9247 & TRN \\
\hline CHEMBL1971186 & 809189 & 6.9 & 6.9006 & TRN \\
\hline CHEMBL 2003482 & 809189 & 4.2 & 3.7605 & TRN \\
\hline CHEMBL1976872 & 809189 & 4.5 & 4.4539 & TRN \\
\hline CHEMBL 2006456 & 809189 & 6.8 & 6.3004 & TRN \\
\hline CHEMBL1969156 & 809189 & 6.0 & 5.0671 & TRN \\
\hline CHEMBL1973211 & 809189 & 4.2 & 4.5844 & TRN \\
\hline CHEMBL1984700 & 809189 & 6.3 & 5.9365 & TRN \\
\hline CHEMBL1998953 & 809189 & 4.4 & 4.2127 & TRN \\
\hline CHEMBL1971606 & 809189 & 4.4 & 4.0932 & TRN \\
\hline CHEMBL1972125 & 809189 & 4.3 & 4.4819 & TRN \\
\hline CHEMBL1461728 & 809189 & 4.2 & 4.119 & TRN \\
\hline CHEMBL1999120 & 809189 & 4.7 & 4.5255 & TST \\
\hline CHEMBL1976134 & 809189 & 5.2 & 4.6143 & TRN \\
\hline CHEMBL1965131 & 809189 & 5.2 & 5.4531 & TRN \\
\hline CHEMBL1972158 & 809189 & 4.2 & 5.0316 & TRN \\
\hline CHEMBL1981215 & 809189 & 4.4 & 3.9878 & TRN \\
\hline CHEMBL 2006580 & 809189 & 4.2 & 4.4079 & TRN \\
\hline CHEMBL1999414 & 809189 & 4.4 & 4.6773 & TRN \\
\hline CHEMBL1967336 & 809189 & 4.4 & 4.4593 & TRN \\
\hline CHEMBL 2006481 & 809189 & 4.2 & 4.2204 & TRN \\
\hline CHEMBL1979855 & 809189 & 4.2 & 4.5188 & TRN \\
\hline CHEMBL1970340 & 809189 & 4.3 & 4.7797 & TRN \\
\hline CHEMBL1967992 & 809189 & 4.4 & 4.6311 & TRN \\
\hline CHEMBL2005186 & 809189 & 4.2 & 3.7624 & TRN \\
\hline CHEMBL1995927 & 809189 & 4.2 & 3.9789 & TRN \\
\hline CHEMBL 2001378 & 809189 & 4.7 & 4.6189 & TRN \\
\hline CHEMBL1981671 & 809189 & 4.4 & 4.5521 & TRN \\
\hline CHEMBL 2006450 & 809189 & 6.1 & 4.4039 & TRN \\
\hline CHEMBL1975534 & 809189 & 5.8 & 5.5165 & TRN \\
\hline
\end{tabular}




\begin{tabular}{|c|c|c|c|c|}
\hline & & & pplement & al $\mathrm{T}$ \\
\hline CHEMBL1993424 & 809189 & 4.2 & 4.2108 & TRN \\
\hline CHEMBL1966703 & 809189 & 4.2 & 4.8152 & TST \\
\hline CHEMBL2001987 & 809189 & 4.4 & 3.9789 & TRN \\
\hline CHEMBL1969561 & 809189 & 4.2 & 3.5808 & TRN \\
\hline CHEMBL1994555 & 809189 & 6.4 & 5.0111 & TRN \\
\hline CHEMBL1983640 & 809189 & 4.4 & 4.8467 & TRN \\
\hline CHEMBL1997023 & 809189 & 4.2 & 4.3891 & TST \\
\hline CHEMBL1964687 & 809189 & 4.2 & 4.3623 & TRN \\
\hline CHEMBL1971943 & 809189 & 4.5 & 4.4324 & TRN \\
\hline CHEMBL1974254 & 809189 & 4.2 & 3.9961 & TRN \\
\hline CHEMBL1988537 & 809189 & 4.2 & 4.8863 & TST \\
\hline CHEMBL1969049 & 809189 & 4.2 & 4.2545 & TRN \\
\hline CHEMBL 2005828 & 809189 & 5.7 & 5.7759 & TRN \\
\hline CHEMBL 2002240 & 809189 & 4.2 & 4.2753 & TRN \\
\hline CHEMBL1991143 & 809189 & 4.2 & 4.5417 & TST \\
\hline CHEMBL1980178 & 809189 & 5.7 & 5.8097 & TRN \\
\hline CHEMBL1998611 & 809189 & 4.3 & 4.8812 & TRN \\
\hline CHEMBL1975900 & 809189 & 4.2 & 4.5087 & TRN \\
\hline CHEMBL255822 & 809189 & 5.2 & 5.1355 & TRN \\
\hline CHEMBL1972221 & 809189 & 4.2 & 3.9975 & TRN \\
\hline CHEMBL2006778 & 809189 & 4.2 & 4.1259 & TRN \\
\hline CHEMBL378627 & 809189 & 4.2 & 4.048 & TRN \\
\hline CHEMBL1996979 & 809189 & 5.4 & 3.91 & TRN \\
\hline CHEMBL1997025 & 809189 & 4.2 & 4.3354 & TRN \\
\hline CHEMBL1968406 & 809189 & 4.2 & 4.3582 & TRN \\
\hline CHEMBL1975921 & 809189 & 5.2 & 4.3512 & TRN \\
\hline CHEMBL1984274 & 809189 & 4.2 & 4.3178 & TRN \\
\hline CHEMBL1998545 & 809189 & 4.2 & 4.2775 & TRN \\
\hline CHEMBL1986869 & 809189 & 4.2 & 4.4003 & TRN \\
\hline CHEMBL1975923 & 809189 & 4.7 & 4.666 & TST \\
\hline CHEMBL 2005449 & 809189 & 4.4 & 4.4716 & TRN \\
\hline CHEMBL1987998 & 809189 & 4.4 & 4.5269 & TRN \\
\hline CHEMBL 2006010 & 809189 & 4.2 & 3.6802 & TRN \\
\hline CHEMBL1682558 & 809189 & 4.2 & 4.9328 & TRN \\
\hline CHEMBL1971534 & 809189 & 5.8 & 5.4835 & TRN \\
\hline CHEMBL1990496 & 809189 & 4.6 & 5.2648 & TRN \\
\hline CHEMBL242865 & 809189 & 6.5 & 6.4196 & TRN \\
\hline CHEMBL 2002479 & 809189 & 4.2 & 5.5881 & TRN \\
\hline CHEMBL 2002480 & 809189 & 4.6 & 4.6599 & TRN \\
\hline CHEMBL1983884 & 809189 & 4.7 & 5.1857 & TST \\
\hline CHEMBL1967094 & 809189 & 4.2 & 3.7237 & TRN \\
\hline CHEMBL1966035 & 809189 & 4.2 & 4.1302 & TRN \\
\hline CHEMBL 2003341 & 809189 & 4.2 & 4.2481 & TRN \\
\hline CHEMBL1982992 & 809189 & 4.2 & 4.6201 & TRN \\
\hline CHEMBL1998110 & 809189 & 4.4 & 4.3036 & TRN \\
\hline CHEMBL1999590 & 809189 & 4.2 & 4.9211 & TST \\
\hline CHEMBL1981079 & 809189 & 7.8 & 7.5313 & TRN \\
\hline CHEMBL1978166 & 809189 & 6.2 & 5.2486 & TRN \\
\hline
\end{tabular}




\begin{tabular}{|c|c|c|c|c|c|}
\hline \\
\hline CHEMBL1972276 & 809189 & 4.2 & 4.4776 & TRN & \\
\hline CHEMBL1980489 & 809189 & 4.2 & 4.4298 & TRN & \\
\hline CHEMBL2000832 & 809189 & 4.2 & 4.5233 & TRN & \\
\hline CHEMBL1967116 & 809189 & 4.2 & 4.3162 & TRN & \\
\hline CHEMBL1972454 & 809189 & 4.7 & 4.8577 & TRN & \\
\hline CHEMBL1990590 & 809189 & 4.4 & 3.9075 & TRN & \\
\hline CHEMBL1977814 & 809189 & 4.4 & 4.4476 & TST & \\
\hline CHEMBL513846 & 809189 & 4.2 & 4.8965 & TRN & \\
\hline CHEMBL1970709 & 809189 & 4.2 & 3.8211 & TRN & \\
\hline CHEMBL1974617 & 809189 & 5.3 & 4.4042 & TRN & \\
\hline CHEMBL1965660 & 809189 & 8.1 & 7.7252 & TRN & \\
\hline CHEMBL1992125 & 809189 & 5.9 & 5.1899 & TRN & \\
\hline CHEMBL1998112 & 809189 & 4.2 & 4.3987 & TRN & \\
\hline CHEMBL1972290 & 809189 & 6.4 & 5.401 & TRN & \\
\hline CHEMBL1969126 & 809189 & 5.2 & 4.9809 & TRN & \\
\hline CHEMBL1980896 & 809189 & 4.2 & 4.5668 & TRN & \\
\hline CHEMBL1975208 & 809189 & 4.2 & 4.0911 & TST & \\
\hline CHEMBL1178727 & 809189 & 4.4 & 4.5479 & TRN & \\
\hline CHEMBL1970104 & 809189 & 5.9 & 5.5829 & TRN & \\
\hline CHEMBL1991429 & 809189 & 4.2 & 4.4329 & TRN & \\
\hline CHEMBL1967612 & 809189 & 4.0 & 4.5491 & TST & \\
\hline CHEMBL1964777 & 809189 & 5.3 & 5.4682 & TRN & \\
\hline CHEMBL1971149 & 809189 & 5.3 & 5.5744 & TRN & \\
\hline CHEMBL1999714 & 809189 & 4.2 & 4.6215 & TRN & \\
\hline CHEMBL1987533 & 809189 & 4.2 & 4.0194 & TRN & \\
\hline CHEMBL1994040 & 809189 & 6.2 & 5.9518 & TRN & \\
\hline CHEMBL388978 & 809189 & 5.9 & 6.0919 & TST & \\
\hline CHEMBL1984548 & 809189 & 6.7 & 6.2601 & TRN & \\
\hline CHEMBL579246 & 809189 & 4.2 & 4.63 & TRN & \\
\hline CHEMBL398951 & 809189 & 4.3 & 4.1889 & TRN & \\
\hline CHEMBL1982506 & 809189 & 4.2 & 4.2947 & TST & \\
\hline CHEMBL2004716 & 809189 & 4.3 & 4.5693 & TRN & \\
\hline CHEMBL1968127 & 809189 & 5.8 & 6.3153 & TRN & \\
\hline CHEMBL1975233 & 809189 & 4.2 & 4.227 & TRN & \\
\hline CHEMBL1985406 & 809189 & 4.2 & 4.2116 & TRN & \\
\hline CHEMBL2007603 & 809189 & 4.4 & 4.2936 & TRN & \\
\hline CHEMBL207400 & 809189 & 4.2 & 4.598 & TST & \\
\hline CHEMBL 2000894 & 809189 & 4.2 & 5.438 & TST & \\
\hline CHEMBL1421720 & 809189 & 6.2 & 5.6174 & TRN & \\
\hline CHEMBL1968130 & 809189 & 4.9 & 5.0408 & TST & \\
\hline CHEMBL1982135 & 809189 & 4.2 & 4.3569 & TRN & \\
\hline CHEMBL1976090 & 809189 & 6.0 & 5.7236 & TRN & \\
\hline CHEMBL1993243 & 809189 & 4.2 & 4.3237 & TRN & \\
\hline CHEMBL 2004771 & 809189 & 4.2 & 4.6008 & TRN & \\
\hline CHEMBL1992922 & 809189 & 4.2 & 3.96100 & 00000000003 & TRN \\
\hline CHEMBL1997597 & 809189 & 4.2 & 3.6627 & TRN & \\
\hline CHEMBL1969537 & 809189 & 4.2 & 4.2083 & TST & \\
\hline CHEMBL1972466 & 809189 & 5.7 & 4.8171 & TST & \\
\hline & & & & 6795 & \\
\hline
\end{tabular}




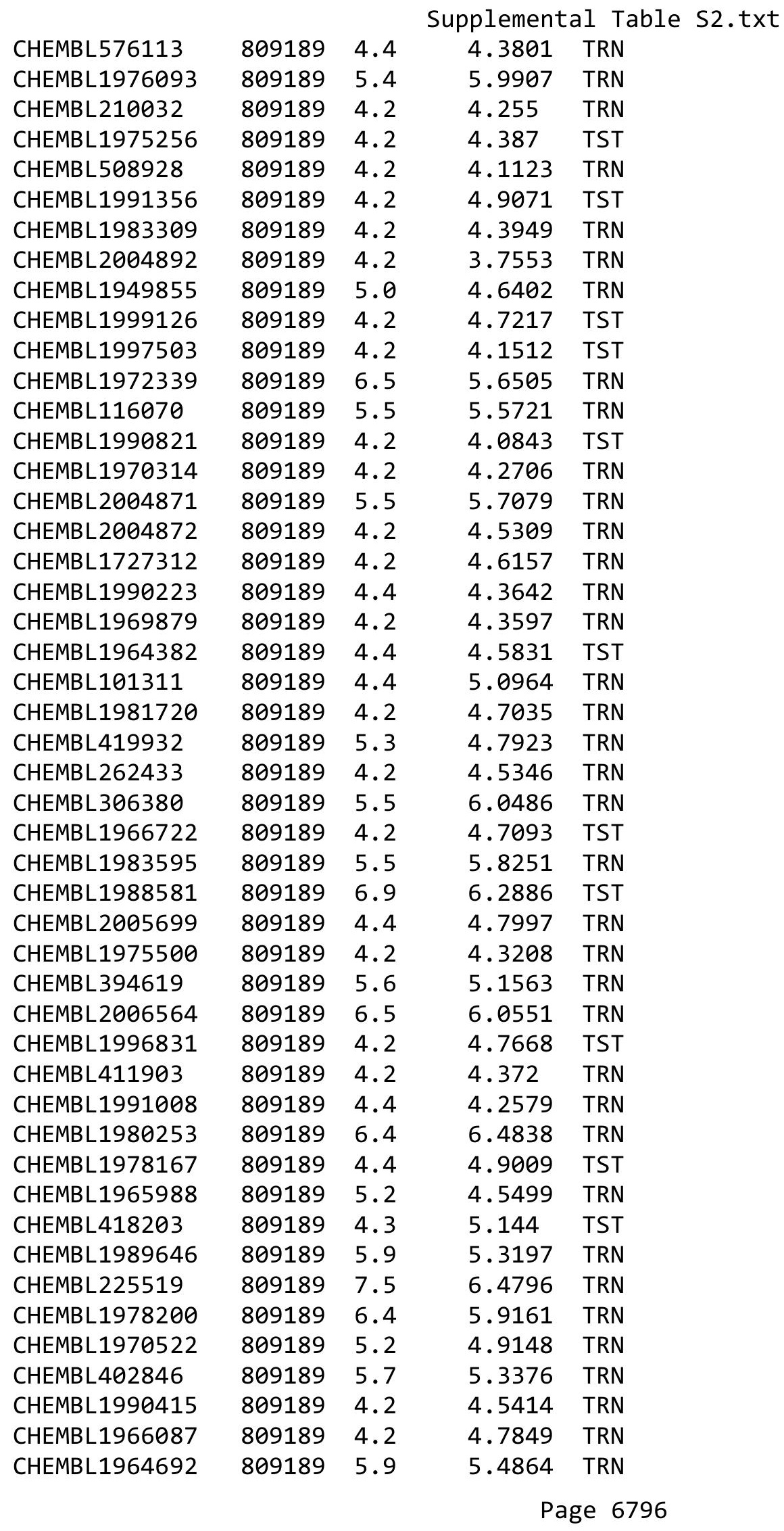




\begin{tabular}{|c|c|c|c|c|}
\hline \multicolumn{5}{|c|}{ Supplemental Table S2.txt } \\
\hline CHEMBL1996931 & 809189 & 4.2 & 4.356 & TRN \\
\hline CHEMBL1964413 & 809189 & 4.2 & 4.5738 & TRN \\
\hline CHEMBL1973483 & 809189 & 4.2 & 3.9738 & TRN \\
\hline CHEMBL1998470 & 809189 & 4.6 & 4.5049 & TRN \\
\hline CHEMBL1996980 & 809189 & 7.4 & 6.4752 & TRN \\
\hline CHEMBL1970735 & 809189 & 4.2 & 4.3187 & TRN \\
\hline CHEMBL1975903 & 809189 & 4.4 & 4.5037 & TRN \\
\hline CHEMBL1994669 & 809189 & 7.0 & 6.1195 & TRN \\
\hline CHEMBL1997340 & 809189 & 4.2 & 4.2693 & TRN \\
\hline CHEMBL2004365 & 809189 & 4.2 & 4.8595 & TST \\
\hline CHEMBL1522508 & 809189 & 4.1 & 4.3101 & TRN \\
\hline CHEMBL1989474 & 809189 & 5.8 & 5.3093 & TRN \\
\hline CHEMBL1090360 & 809189 & 4.2 & 4.7062 & TRN \\
\hline CHEMBL210887 & 809189 & 6.0 & 5.3537 & TRN \\
\hline CHEMBL1988805 & 809189 & 6.5 & 5.2907 & TST \\
\hline CHEMBL458997 & 809189 & 4.5 & 5.2606 & TRN \\
\hline CHEMBL1971021 & 809189 & 4.2 & 3.9684 & TRN \\
\hline CHEMBL 227271 & 809189 & 6.2 & 6.4178 & TRN \\
\hline CHEMBL583144 & 809189 & 4.2 & 4.3719 & TRN \\
\hline CHEMBL1974310 & 809189 & 5.8 & 6.2245 & TRN \\
\hline CHEMBL1969942 & 809189 & 4.4 & 4.19 & TRN \\
\hline CHEMBL1978567 & 809189 & 4.4 & 4.3036 & TRN \\
\hline CHEMBL1982660 & 809189 & 4.4 & 4.1035 & TRN \\
\hline CHEMBL1994693 & 809189 & 4.2 & 4.6603 & TRN \\
\hline CHEMBL1982957 & 809189 & 4.3 & 4.4218 & TRN \\
\hline CHEMBL1725279 & 809189 & 6.5 & 5.4208 & TST \\
\hline CHEMBL1975138 & 809189 & 4.2 & 4.822 & TST \\
\hline CHEMBL424872 & 809189 & 4.4 & 3.9852 & TRN \\
\hline CHEMBL2006836 & 809189 & 4.2 & 4.7489 & TST \\
\hline CHEMBL412142 & 809189 & 4.2 & 4.4213 & TST \\
\hline CHEMBL 2002802 & 809189 & 4.9 & 4.9856 & TRN \\
\hline CHEMBL1980704 & 809189 & 4.2 & 4.5128 & TST \\
\hline CHEMBL 2003271 & 809189 & 5.5 & 5.6183 & TRN \\
\hline CHEMBL1966808 & 809189 & 4.2 & 4.8964 & TRN \\
\hline CHEMBL 2004447 & 809189 & 4.2 & 4.3438 & TST \\
\hline CHEMBL1992231 & 809189 & 4.4 & 5.4384 & TRN \\
\hline CHEMBL1983111 & 809189 & 4.4 & 5.481 & TRN \\
\hline CHEMBL1973860 & 809189 & 4.2 & 3.8557 & TRN \\
\hline CHEMBL260135 & 809189 & 4.2 & 4.1999 & TRN \\
\hline CHEMBL 220241 & 809189 & 4.2 & 4.5345 & TRN \\
\hline CHEMBL 2004544 & 809189 & 4.2 & 4.0064 & TST \\
\hline CHEMBL1988141 & 809189 & 6.1 & 5.6917 & TST \\
\hline CHEMBL1982610 & 809189 & 4.2 & 4.629 & TST \\
\hline CHEMBL1977134 & 809189 & 4.4 & 4.4554 & TRN \\
\hline CHEMBL1999496 & 809189 & 4.2 & 4.4994 & TRN \\
\hline CHEMBL1989624 & 809189 & 4.3 & 4.9048 & TRN \\
\hline CHEMBL1985206 & 809189 & 4.4 & 4.4011 & TRN \\
\hline CHEMBL1988300 & 809189 & 4.2 & 4.6605 & TRN \\
\hline
\end{tabular}




\begin{tabular}{|c|c|c|c|c|c|}
\hline \\
\hline CHEMBL1991078 & 809189 & 6.4 & 5.8407 & TRN & \\
\hline CHEMBL1987359 & 809189 & 4.2 & 3.9147 & TST & \\
\hline CHEMBL1977749 & 809189 & 4.4 & 5.0738 & TST & \\
\hline CHEMBL1975212 & 809189 & 6.6 & 5.0958 & TRN & \\
\hline CHEMBL 2001613 & 809189 & 5.1 & 4.5584 & TRN & \\
\hline CHEMBL1997275 & 809189 & 5.6 & 5.1645 & TRN & \\
\hline CHEMBL1993904 & 809189 & 8.1 & 6.2875 & TRN & \\
\hline CHEMBL1994438 & 809189 & 4.4 & 6.046 & TRN & \\
\hline CHEMBL1980376 & 809189 & 4.6 & 4.874 & TRN & \\
\hline CHEMBL1967513 & 809189 & 4.4 & 4.0005 & TRN & \\
\hline CHEMBL 2000724 & 809189 & 4.4 & 3.9194 & TRN & \\
\hline CHEMBL1989265 & 809189 & 4.2 & 4.4088 & TST & \\
\hline CHEMBL1982413 & 809189 & 4.4 & 4.9471 & TRN & \\
\hline CHEMBL1969502 & 809189 & 4.2 & 3.9637 & TRN & \\
\hline CHEMBL1682553 & 809189 & 5.2 & 4.8158 & TRN & \\
\hline CHEMBL1971430 & 809189 & 6.1 & 4.9973 & TRN & \\
\hline CHEMBL1983963 & 809189 & 4.2 & 5.2813 & TRN & \\
\hline CHEMBL1997764 & 809189 & 4.2 & 4.1518 & TRN & \\
\hline CHEMBL1985042 & 809189 & 4.4 & 4.8101 & TRN & \\
\hline CHEMBL1981792 & 809189 & 4.4 & 4.2388 & TRN & \\
\hline CHEMBL1987535 & 809189 & 5.8 & 5.0312 & TRN & \\
\hline CHEMBL1985092 & 809189 & 4.2 & 4.7443 & TRN & \\
\hline CHEMBL 2004692 & 809189 & 4.2 & 4.3638 & TST & \\
\hline CHEMBL1981410 & 809189 & 4.2 & 4.0325 & TRN & \\
\hline CHEMBL 2002586 & 809189 & 6.1 & 5.2617 & TRN & \\
\hline CHEMBL1987815 & 809189 & 5.3 & 4.7182 & TST & \\
\hline CHEMBL1996234 & 809189 & 4.2 & 4.3891 & TRN & \\
\hline CHEMBL383264 & 809189 & 4.4 & 5.0608 & TRN & \\
\hline CHEMBL 2007421 & 809189 & 6.0 & 4.8828 & TRN & \\
\hline CHEMBL1991434 & 809189 & 4.2 & 4.2279 & TRN & \\
\hline CHEMBL1967544 & 809189 & 4.2 & $4.4830 e$ & 20000000005 & TRN \\
\hline CHEMBL1973138 & 809189 & 4.4 & 4.3401 & TRN & \\
\hline CHEMBL223367 & 809189 & 4.2 & 4.5228 & TST & \\
\hline CHEMBL1992673 & 809189 & 4.3 & 4.6638 & TRN & \\
\hline CHEMBL340384 & 809189 & 5.7 & 6.2153 & TST & \\
\hline CHEMBL1969151 & 809189 & 6.6 & 6.6656 & TRN & \\
\hline CHEMBL1996587 & 809189 & 4.2 & 4.5168 & TRN & \\
\hline CHEMBL1981492 & 809189 & 5.2 & 4.6294 & TRN & \\
\hline CHEMBL1993335 & 809189 & 4.4 & 5.5805 & TST & \\
\hline CHEMBL1988692 & 809189 & 4.4 & 4.3296 & TRN & \\
\hline CHEMBL 2007574 & 809189 & 5.4 & 5.9761 & TRN & \\
\hline CHEMBL1964804 & 809189 & 4.2 & 4.2212 & TRN & \\
\hline CHEMBL443962 & 809189 & 4.2 & 4.5991 & TRN & \\
\hline CHEMBL 2000354 & 809189 & 5.3 & 5.1181 & TRN & \\
\hline CHEMBL1965507 & 809189 & 4.3 & 3.9069 & TRN & \\
\hline CHEMBL 274064 & 809189 & 7.9 & 6.6917 & TRN & \\
\hline CHEMBL1998680 & 809189 & 4.4 & 4.7513 & TRN & \\
\hline CHEMBL1967564 & 809189 & 4.2 & 4.0145 & TRN & \\
\hline
\end{tabular}




\begin{tabular}{|c|c|c|c|c|}
\hline & & & ient & al Ta \\
\hline CHEMBL592030 & 809189 & 4.4 & 5.2687 & TST \\
\hline CHEMBL 2000071 & 809189 & 4.2 & 4.2148 & TRN \\
\hline CHEMBL1979176 & 809189 & 4.2 & 4.3135 & TRN \\
\hline CHEMBL1970317 & 809189 & 4.4 & 4.4794 & TRN \\
\hline CHEMBL 2002613 & 809189 & 4.4 & 5.7799 & TRN \\
\hline CHEMBL 2000408 & 809189 & 6.1 & 6.3612 & TRN \\
\hline CHEMBL248757 & 809189 & 4.2 & 3.8626 & TST \\
\hline CHEMBL1978014 & 809189 & 4.2 & 4.9121 & TRN \\
\hline CHEMBL 2002736 & 809189 & 4.4 & 4.4691 & TRN \\
\hline CHEMBL1997007 & 809189 & 6.0 & 5.3592 & TRN \\
\hline CHEMBL1994538 & 809189 & 4.2 & 4.0633 & TRN \\
\hline CHEMBL1983195 & 809189 & 4.2 & 5.0634 & TST \\
\hline CHEMBL1975490 & 809189 & 6.6 & 5.4948 & TRN \\
\hline CHEMBL1964444 & 809189 & 4.3 & 4.2128 & TRN \\
\hline CHEMBL 2002690 & 809189 & 4.4 & 4.2656 & TRN \\
\hline CHEMBL1986139 & 809189 & 4.2 & 4.3216 & TRN \\
\hline CHEMBL1980540 & 809189 & 4.2 & 3.7128 & TRN \\
\hline CHEMBL278041 & 809189 & 6.0 & 6.282 & TRN \\
\hline CHEMBL1979883 & 809189 & 4.2 & 4.6224 & TRN \\
\hline CHEMBL1984162 & 809189 & 4.2 & 5.2487 & TRN \\
\hline CHEMBL1998432 & 809189 & 6.7 & 6.3435 & TRN \\
\hline CHEMBL491758 & 809189 & 4.2 & 4.5185 & TRN \\
\hline CHEMBL1986590 & 809189 & 6.2 & 5.376 & TRN \\
\hline CHEMBL549730 & 809189 & 4.2 & 4.2707 & TRN \\
\hline CHEMBL1970189 & 809189 & 4.2 & 4.3432 & TST \\
\hline CHEMBL1870106 & 809189 & 4.4 & 5.1115 & TRN \\
\hline CHEMBL1996791 & 809189 & 6.8 & 6.0587 & TRN \\
\hline CHEMBL371206 & 809189 & 5.7 & 5.159 & TRN \\
\hline CHEMBL1974664 & 809189 & 4.2 & 4.3083 & TRN \\
\hline CHEMBL406845 & 809189 & 6.2 & 5.8075 & TRN \\
\hline CHEMBL482538 & 809189 & 4.9 & 4.8846 & TRN \\
\hline CHEMBL1974288 & 809189 & 4.2 & 4.4919 & TRN \\
\hline CHEMBL1984296 & 809189 & 5.7 & 5.3931 & TST \\
\hline CHEMBL196363 & 809189 & 4.2 & 4.7087 & TRN \\
\hline CHEMBL1996837 & 809189 & 6.4 & 5.2471 & TRN \\
\hline CHEMBL1190711 & 809189 & 4.2 & 4.5955 & TRN \\
\hline CHEMBL1964718 & 809189 & 4.1 & 4.7281 & TST \\
\hline CHEMBL1968705 & 809189 & 4.3 & 3.865 & TRN \\
\hline CHEMBL1991410 & 809189 & 4.4 & 4.2132 & TRN \\
\hline CHEMBL1964441 & 809189 & 4.4 & 4.4383 & TRN \\
\hline CHEMBL1986684 & 809189 & 5.1 & 4.9333 & TST \\
\hline CHEMBL546797 & 809189 & 4.4 & 5.052 & TRN \\
\hline CHEMBL404367 & 809189 & 5.8 & 5.4912 & TRN \\
\hline CHEMBL1966343 & 809189 & 4.2 & 4.5072 & TRN \\
\hline CHEMBL1978271 & 809189 & 4.4 & 4.6964 & TRN \\
\hline CHEMBL1967887 & 809189 & 5.5 & 5.8937 & TRN \\
\hline CHEMBL 2007266 & 809189 & 4.4 & 4.3472 & TRN \\
\hline CHEMBL 2000568 & 809189 & 4.3 & 4.4235 & TRN \\
\hline
\end{tabular}




\begin{tabular}{|c|c|c|c|c|c|}
\hline & & & & & \\
\hline CHEMBL1994308 & 809189 & 4.4 & 4.2818 & TRN & \\
\hline CHEMBL 2000335 & 809189 & 4.2 & 4.9118 & TRN & \\
\hline CHEMBL1977604 & 809189 & 4.2 & 4.2292 & TST & \\
\hline CHEMBL 2007097 & 809189 & 4.5 & 4.7688 & TRN & \\
\hline CHEMBL1988717 & 809189 & 4.2 & 3.8347 & TRN & \\
\hline CHEMBL1974328 & 809189 & 6.0 & 5.5682 & TRN & \\
\hline CHEMBL509032 & 809189 & 4.3 & 4.5383 & TRN & \\
\hline CHEMBL243298 & 809189 & 7.0 & 6.3231 & TRN & \\
\hline CHEMBL1973808 & 809189 & 4.2 & 4.2128 & TRN & \\
\hline CHEMBL 2000429 & 809189 & 6.0 & 6.2621 & TRN & \\
\hline CHEMBL1972576 & 809189 & 4.2 & 4.3855 & TRN & \\
\hline CHEMBL1992555 & 809189 & 4.2 & 4.6878 & TRN & \\
\hline CHEMBL1992342 & 809189 & 4.2 & 3.83699 & 99999999997 & TRN \\
\hline CHEMBL1980853 & 809189 & 4.0 & 4.7784 & TST & \\
\hline CHEMBL1988173 & 809189 & 4.2 & 4.4414 & TST & \\
\hline CHEMBL1973013 & 809189 & 4.4 & 4.7468 & TRN & \\
\hline CHEMBL535331 & 809189 & 4.2 & 4.6342 & TRN & \\
\hline CHEMBL1989805 & 809189 & 4.2 & 5.2265 & TST & \\
\hline CHEMBL1966204 & 809189 & 6.8 & 6.2481 & TRN & \\
\hline CHEMBL1982980 & 809189 & 4.2 & 4.3706 & TST & \\
\hline CHEMBL1965423 & 809189 & 4.2 & 5.3345 & TRN & \\
\hline CHEMBL1983025 & 809189 & 4.2 & 4.6269 & TRN & \\
\hline CHEMBL1975927 & 809189 & 4.4 & 5.0994 & TRN & \\
\hline CHEMBL205415 & 809189 & 4.3 & 4.5829 & TRN & \\
\hline CHEMBL1977135 & 809189 & 4.2 & 4.2176 & TRN & \\
\hline CHEMBL2001920 & 809189 & 4.2 & 4.2981 & TRN & \\
\hline CHEMBL1977138 & 809189 & 6.0 & 5.5564 & TST & \\
\hline CHEMBL1241473 & 809189 & 6.1 & 6.3069 & TRN & \\
\hline CHEMBL 2000879 & 809189 & 4.1 & 4.2903 & TST & \\
\hline CHEMBL1978448 & 809189 & 4.3 & 4.10800 & 00000000005 & TST \\
\hline CHEMBL1972258 & 809189 & 4.2 & 4.7715 & TRN & \\
\hline CHEMBL1980329 & 809189 & 4.4 & 5.3063 & TRN & \\
\hline CHEMBL 2004515 & 809189 & 5.5 & 5.5257 & TRN & \\
\hline CHEMBL 2001257 & 809189 & 4.3 & 4.4954 & TRN & \\
\hline CHEMBL1992042 & 809189 & 5.4 & 4.9131 & TRN & \\
\hline CHEMBL1987793 & 809189 & 5.3 & 4.4711 & TST & \\
\hline CHEMBL1992536 & 809189 & 4.2 & 3.9562 & TRN & \\
\hline CHEMBL21156 & 809189 & 4.4 & 5.6785 & TST & \\
\hline CHEMBL1992740 & 809189 & 4.2 & 4.1822 & TRN & \\
\hline CHEMBL1994724 & 809189 & 5.8 & 4.5278 & TRN & \\
\hline CHEMBL1989267 & 809189 & 4.4 & 4.6786 & TRN & \\
\hline CHEMBL 2002373 & 809189 & 6.1 & 5.315 & TRN & \\
\hline CHEMBL439340 & 809189 & 4.2 & 4.1728 & TRN & \\
\hline CHEMBL1974574 & 809189 & 5.6 & 4.9008 & TST & \\
\hline CHEMBL 2006188 & 809189 & 4.2 & 4.0303 & TRN & \\
\hline CHEMBL1970290 & 809189 & 5.6 & 5.1968 & TRN & \\
\hline CHEMBL1967531 & 809189 & 6.1 & 5.3366 & TRN & \\
\hline CHEMBL1970913 & 809189 & 4.2 & 4.4722 & TRN & \\
\hline
\end{tabular}




\begin{tabular}{|c|c|c|c|c|c|}
\hline & & & & & \\
\hline CHEMBL1973893 & 809189 & 4.2 & 4.0482 & TRN & \\
\hline CHEMBL1995736 & 809189 & 4.2 & 4.5079 & TRN & \\
\hline CHEMBL1997534 & 809189 & 4.2 & 4.4156 & TRN & \\
\hline CHEMBL1993877 & 809189 & 7.3 & 6.409 & TRN & \\
\hline CHEMBL1996500 & 809189 & 6.4 & 5.848 & TRN & \\
\hline CHEMBL1985095 & 809189 & 4.2 & 5.0289 & TST & \\
\hline CHEMBL1998551 & 809189 & 4.2 & 4.5073 & TRN & \\
\hline CHEMBL1977374 & 809189 & 4.2 & 4.40300 & 00000000005 & TRN \\
\hline CHEMBL1682540 & 809189 & 4.3 & 5.1245 & TRN & \\
\hline CHEMBL1976420 & 809189 & 4.3 & 4.7519 & TRN & \\
\hline CHEMBL1998253 & 809189 & 4.4 & 5.0335 & TST & \\
\hline CHEMBL1981744 & 809189 & 4.4 & 3.9991 & TRN & \\
\hline CHEMBL1994864 & 809189 & 4.2 & 4.7059 & TRN & \\
\hline CHEMBL 2002446 & 809189 & 4.2 & 3.7004 & TRN & \\
\hline CHEMBL497151 & 809189 & 5.3 & 5.0645 & TRN & \\
\hline CHEMBL2000029 & 809189 & 4.4 & 5.5155 & TRN & \\
\hline CHEMBL1973961 & 809189 & 4.4 & 4.3214 & TRN & \\
\hline CHEMBL 246970 & 809189 & 4.2 & 5.192 & TRN & \\
\hline CHEMBL340921 & 809189 & 4.2 & 6.0115 & TST & \\
\hline CHEMBL1994977 & 809189 & 4.4 & 4.6182 & TRN & \\
\hline CHEMBL 2001149 & 809189 & 4.4 & 5.4061 & TRN & \\
\hline CHEMBL1999718 & 809189 & 4.2 & 4.2457 & TRN & \\
\hline CHEMBL1987073 & 809189 & 5.6 & 5.8326 & TRN & \\
\hline CHEMBL 2005478 & 809189 & 4.4 & 5.2755 & TST & \\
\hline CHEMBL1276446 & 809189 & 6.1 & 4.7785 & TST & \\
\hline CHEMBL1996646 & 809189 & 4.4 & 4.8208 & TRN & \\
\hline CHEMBL1995712 & 809189 & 6.0 & 5.7695 & TRN & \\
\hline CHEMBL1979773 & 809189 & 4.4 & 4.935 & TRN & \\
\hline CHEMBL1977346 & 809189 & 5.5 & 4.8489 & TRN & \\
\hline CHEMBL1971649 & 809189 & 4.2 & 4.474 & TRN & \\
\hline CHEMBL1996702 & 809189 & 4.4 & 4.7839 & TRN & \\
\hline CHEMBL 2007124 & 809189 & 4.4 & 4.3698 & TRN & \\
\hline CHEMBL1998435 & 809189 & 4.2 & 4.0982 & TRN & \\
\hline CHEMBL 2006439 & 809189 & 5.8 & 5.7699 & TRN & \\
\hline CHEMBL 2006156 & 809189 & 4.2 & 4.675 & TST & \\
\hline CHEMBL1985681 & 809189 & 7.4 & 4.8955 & TST & \\
\hline CHEMBL1969190 & 809189 & 4.2 & 4.1724 & TRN & \\
\hline CHEMBL1973937 & 809189 & 4.2 & 4.1324 & TRN & \\
\hline CHEMBL1991674 & 809189 & 4.6 & 5.4541 & TRN & \\
\hline CHEMBL1982711 & 809189 & 5.4 & 5.6565 & TRN & \\
\hline CHEMBL262623 & 809189 & 4.8 & 4.9053 & TRN & \\
\hline CHEMBL1987982 & 809189 & 4.2 & 4.6385 & TST & \\
\hline CHEMBL1984842 & 809189 & 6.5 & 6.3915 & TRN & \\
\hline CHEMBL 2004118 & 809189 & 6.1 & 5.4407 & TRN & \\
\hline CHEMBL 2007044 & 809189 & 4.2 & 4.0256 & TRN & \\
\hline CHEMBL1994241 & 809189 & 4.2 & 4.5103 & TRN & \\
\hline CHEMBL1991973 & 809189 & 5.5 & 4.5349 & TST & \\
\hline CHEMBL223460 & 809189 & 4.2 & 3.9542 & TST & \\
\hline
\end{tabular}




\begin{tabular}{|c|c|c|c|c|c|}
\hline \\
\hline CHEMBL1998829 & 809189 & 4.2 & 3.695 & TRN & \\
\hline CHEMBL50894 & 809189 & 4.2 & 5.0829 & TST & \\
\hline CHEMBL1995211 & 809189 & 4.4 & 4.6317 & TRN & \\
\hline CHEMBL1988838 & 809189 & 4.2 & 4.7941 & TRN & \\
\hline CHEMBL1981725 & 809189 & 4.2 & 4.5132 & TRN & \\
\hline CHEMBL1982753 & 809189 & 5.8 & 5.0189 & TRN & \\
\hline CHEMBL 2006299 & 809189 & 4.4 & 4.5588 & TRN & \\
\hline CHEMBL1972346 & 809189 & 6.5 & 4.668 & TST & \\
\hline CHEMBL1980562 & 809189 & 5.8 & 5.9922 & TRN & \\
\hline CHEMBL1965169 & 809189 & 4.4 & 5.0697 & TST & \\
\hline CHEMBL1991818 & 809189 & 4.4 & 4.7359 & TST & \\
\hline CHEMBL1081312 & 809189 & 7.4 & 6.143 & TRN & \\
\hline CHEMBL1965170 & 809189 & 4.4 & 4.1921 & TRN & \\
\hline CHEMBL1982866 & 809189 & 4.2 & 5.0852 & TRN & \\
\hline CHEMBL 2005792 & 809189 & 6.7 & 6.6467 & TRN & \\
\hline CHEMBL1968926 & 809189 & 4.2 & 4.3349 & TRN & \\
\hline CHEMBL462120 & 809189 & 4.2 & 3.9883 & TRN & \\
\hline CHEMBL1991867 & 809189 & 4.7 & 4.4419 & TST & \\
\hline CHEMBL1979933 & 809189 & 5.8 & 5.5008 & TRN & \\
\hline CHEMBL1986503 & 809189 & 4.4 & 4.7636 & TST & \\
\hline CHEMBL1965570 & 809189 & 5.5 & 5.0923 & TRN & \\
\hline CHEMBL 2007592 & 809189 & 4.2 & 4.2994 & TRN & \\
\hline CHEMBL1972355 & 809189 & 5.8 & 5.57299 & 99999999995 & TRN \\
\hline CHEMBL1997892 & 809189 & 4.4 & 4.511 & TRN & \\
\hline CHEMBL 2001641 & 809189 & 5.0 & 4.5287 & TRN & \\
\hline CHEMBL1976936 & 809189 & 5.4 & 4.9379 & TRN & \\
\hline CHEMBL1997193 & 809189 & 4.4 & 4.6994 & TST & \\
\hline CHEMBL210963 & 809189 & 4.2 & 4.0736 & TRN & \\
\hline CHEMBL1964902 & 809189 & 4.4 & 4.7747 & TRN & \\
\hline CHEMBL1082440 & 809189 & 4.2 & 4.0368 & TST & \\
\hline CHEMBL1614705 & 809189 & 5.4 & 5.1815 & TRN & \\
\hline CHEMBL1984633 & 809189 & 4.2 & 4.4759 & TRN & \\
\hline CHEMBL1972988 & 809189 & 4.4 & 5.1403 & TRN & \\
\hline CHEMBL1965845 & 809189 & 4.2 & 4.2967 & TRN & \\
\hline CHEMBL 2007372 & 809189 & 4.2 & 5.7945 & TRN & \\
\hline CHEMBL1998228 & 809189 & 4.4 & 4.6027 & TRN & \\
\hline CHEMBL1983715 & 809189 & 7.2 & 6.6264 & TRN & \\
\hline CHEMBL 2006715 & 809189 & 4.2 & 4.3509 & TRN & \\
\hline CHEMBL1986597 & 809189 & 5.3 & 4.7775 & TRN & \\
\hline CHEMBL1990482 & 809189 & 4.2 & 5.1218 & TRN & \\
\hline CHEMBL1990904 & 809189 & 6.8 & 6.3023 & TRN & \\
\hline CHEMBL 2005475 & 809189 & 4.2 & 4.0276 & TRN & \\
\hline CHEMBL1987448 & 809189 & 5.9 & 5.6957 & TRN & \\
\hline CHEMBL1997349 & 809189 & 4.2 & 4.8233 & TST & \\
\hline CHEMBL183844 & 809189 & 4.2 & 3.9376 & TRN & \\
\hline CHEMBL220057 & 809189 & 4.2 & 4.6414 & TRN & \\
\hline CHEMBL1682545 & 809189 & 4.2 & 4.0206 & TRN & \\
\hline CHEMBL383541 & 809189 & 5.2 & 5.1158 & TRN & \\
\hline
\end{tabular}




\begin{tabular}{|c|c|c|c|c|c|}
\hline \\
\hline CHEMBL2001224 & 809189 & 4.2 & 4.0437 & TRN & \\
\hline CHEMBL1966799 & 809189 & 4.1 & 4.9001 & TST & \\
\hline CHEMBL10 & 809189 & 6.5 & 6.1437 & TRN & \\
\hline CHEMBL1976732 & 809189 & 4.2 & 4.6253 & TRN & \\
\hline CHEMBL2005216 & 809189 & 4.4 & 4.8616 & TRN & \\
\hline CHEMBL1969506 & 809189 & 4.2 & 3.7947 & TRN & \\
\hline CHEMBL1980763 & 809189 & 4.4 & 5.022 & TRN & \\
\hline CHEMBL1964937 & 809189 & 4.2 & 4.5657 & TRN & \\
\hline CHEMBL1980163 & 809189 & 4.2 & 4.0591 & TRN & \\
\hline CHEMBL1977931 & 809189 & 4.3 & 4.5963 & TRN & \\
\hline CHEMBL2005899 & 809189 & 4.2 & 4.3485 & TRN & \\
\hline CHEMBL1682552 & 809189 & 5.6 & 5.3703 & TRN & \\
\hline CHEMBL1972568 & 809189 & 4.2 & 4.57100 & 0000000001 & TRN \\
\hline CHEMBL2007479 & 809189 & 4.4 & 4.5555 & TRN & \\
\hline CHEMBL1986851 & 809189 & 4.4 & 4.4061 & TRN & \\
\hline CHEMBL229799 & 809189 & 6.9 & 6.5983 & TRN & \\
\hline CHEMBL1971223 & 809189 & 4.4 & 4.4844 & TRN & \\
\hline CHEMBL105739 & 809189 & 5.7 & 5.0849 & TRN & \\
\hline CHEMBL1972220 & 809189 & 4.4 & 4.6538 & TRN & \\
\hline CHEMBL379300 & 809189 & 5.6 & 6.1862 & TRN & \\
\hline CHEMBL2003785 & 809189 & 5.0 & 4.334 & TST & \\
\hline CHEMBL1973720 & 809189 & 7.8 & 7.1854 & TRN & \\
\hline CHEMBL1969523 & 809189 & 4.2 & 4.2652 & TRN & \\
\hline CHEMBL1988995 & 809189 & 4.2 & 4.8243 & TRN & \\
\hline CHEMBL2001923 & 809189 & 4.4 & 4.7998 & TST & \\
\hline CHEMBL1986781 & 809189 & 6.4 & 6.7209 & TRN & \\
\hline CHEMBL1983070 & 809189 & 4.4 & 4.1519 & TRN & \\
\hline CHEMBL526133 & 809189 & 5.2 & 4.8844 & TRN & \\
\hline CHEMBL2003514 & 809189 & 4.4 & 4.3167 & TRN & \\
\hline CHEMBL1989043 & 809189 & 4.4 & 5.2464 & TRN & \\
\hline CHEMBL1967538 & 809189 & 4.3 & 4.8115 & TRN & \\
\hline CHEMBL1979057 & 809189 & 4.2 & 4.4817 & TRN & \\
\hline CHEMBL387971 & 809189 & 4.2 & 3.7354 & TRN & \\
\hline CHEMBL1164180 & 809189 & 4.4 & 4.8046 & TST & \\
\hline CHEMBL1999428 & 809189 & 4.2 & 4.0128 & TRN & \\
\hline CHEMBL1967560 & 809189 & 4.2 & 4.3072 & TRN & \\
\hline CHEMBL1997611 & 809189 & 4.4 & 4.977 & TST & \\
\hline CHEMBL1516890 & 809189 & 5.8 & 5.7737 & TRN & \\
\hline CHEMBL211378 & 809189 & 4.2 & 4.6521 & TRN & \\
\hline CHEMBL1982465 & 809189 & 4.2 & 4.5589 & TRN & \\
\hline CHEMBL 2001751 & 809189 & 6.3 & 6.0876 & TRN & \\
\hline CHEMBL2003420 & 809189 & 4.2 & 3.9865 & TRN & \\
\hline CHEMBL1984586 & 809189 & 5.7 & 5.4429 & TRN & \\
\hline CHEMBL1972659 & 809189 & 4.2 & 3.9378 & TST & \\
\hline CHEMBL272453 & 809189 & 4.2 & 4.1771 & TRN & \\
\hline CHEMBL1970217 & 809189 & 4.2 & 4.3208 & TRN & \\
\hline CHEMBL2005528 & 809189 & 4.2 & 4.8853 & TST & \\
\hline CHEMBL1984686 & 809189 & 4.4 & 4.3979 & TRN & \\
\hline & & & & 6803 & \\
\hline
\end{tabular}




\begin{tabular}{|c|c|c|c|c|c|}
\hline \multicolumn{6}{|c|}{ Supplemental Table S2.txt } \\
\hline CHEMBL185569 & 809189 & 4.2 & 4.0076 & TRN & \\
\hline CHEMBL1969843 & 809189 & 4.2 & 4.8681 & TRN & \\
\hline CHEMBL 2007002 & 809189 & 4.2 & 4.1594 & TRN & \\
\hline CHEMBL1987007 & 809189 & 4.2 & 4.2951 & TRN & \\
\hline CHEMBL1973793 & 809189 & 4.4 & 3.6985 & TST & \\
\hline CHEMBL1969588 & 809189 & 6.7 & 5.6117 & TRN & \\
\hline CHEMBL1984711 & 809189 & 4.2 & 4.1863 & TRN & \\
\hline CHEMBL1992073 & 809189 & 4.4 & 4.4977 & TRN & \\
\hline CHEMBL484390 & 809189 & 5.2 & 5.2632 & TRN & \\
\hline CHEMBL1983255 & 809189 & 5.8 & 4.8621 & TST & \\
\hline CHEMBL1979252 & 809189 & 4.2 & 4.2526 & TRN & \\
\hline CHEMBL1986143 & 809189 & 4.4 & 4.5767 & TRN & \\
\hline CHEMBL1972934 & 809189 & 5.1 & 4.9519 & TRN & \\
\hline CHEMBL 2007559 & 809189 & 4.4 & 4.4747 & TRN & \\
\hline CHEMBL1992581 & 809189 & 4.4 & 4.7109 & TRN & \\
\hline CHEMBL 2004290 & 809189 & 4.3 & 4.1791 & TRN & \\
\hline CHEMBL1986499 & 809189 & 4.2 & 4.965 & TRN & \\
\hline CHEMBL1972937 & 809189 & 4.2 & 4.7713 & TRN & \\
\hline CHEMBL2000393 & 809189 & 4.2 & 4.6919 & TST & \\
\hline CHEMBL 2004311 & 809189 & 4.2 & 3.8639 & TRN & \\
\hline CHEMBL1992634 & 809189 & 4.2 & 3.6458 & TRN & \\
\hline CHEMBL1242373 & 809189 & 4.2 & 4.4173 & TRN & \\
\hline CHEMBL56543 & 809189 & 4.2 & 3.966 & TRN & \\
\hline CHEMBL1984847 & 809189 & 4.4 & 4.569 & TRN & \\
\hline CHEMBL1984402 & 809189 & 4.3 & 4.6148 & TRN & \\
\hline CHEMBL 316264 & 809189 & 6.2 & 6.1208 & TRN & \\
\hline CHEMBL1988075 & 809189 & 4.2 & 4.65300 & 00000000005 & TRN \\
\hline CHEMBL1996576 & 809189 & 4.4 & 5.0029 & TST & \\
\hline CHEMBL1991678 & 809189 & 5.1 & 6.2548 & TRN & \\
\hline CHEMBL 2001239 & 809189 & 5.5 & 4.8916 & TRN & \\
\hline CHEMBL1988594 & 809189 & 4.2 & 4.3118 & TRN & \\
\hline CHEMBL 2001288 & 809189 & 5.5 & 5.8363 & TRN & \\
\hline CHEMBL1992363 & 809189 & 5.8 & 6.1223 & TRN & \\
\hline CHEMBL1999811 & 809189 & 5.2 & 4.8905 & TRN & \\
\hline CHEMBL 235157 & 809189 & 4.4 & 4.6465 & TST & \\
\hline CHEMBL1985074 & 809189 & 5.6 & 4.6493 & TST & \\
\hline CHEMBL 2000481 & 809189 & 4.2 & 4.0998 & TRN & \\
\hline CHEMBL1982874 & 809189 & 4.2 & 5.356 & TRN & \\
\hline CHEMBL1991725 & 809189 & 4.2 & 4.3265 & TRN & \\
\hline CHEMBL1992242 & 809189 & 4.2 & 4.1264 & TRN & \\
\hline CHEMBL1982271 & 809189 & 7.1 & 6.5135 & TRN & \\
\hline CHEMBL 2007296 & 809189 & 4.2 & 4.2314 & TRN & \\
\hline CHEMBL208637 & 809189 & 4.2 & 4.3226 & TRN & \\
\hline CHEMBL2004159 & 809189 & 4.4 & 4.3655 & TRN & \\
\hline CHEMBL 396523 & 809189 & 6.3 & 6.5156 & TRN & \\
\hline CHEMBL1978371 & 809189 & 4.4 & 5.0209 & TST & \\
\hline CHEMBL1970203 & 809189 & 4.2 & 3.8235 & TRN & \\
\hline CHEMBL1986530 & 809189 & 4.2 & 4.2756 & TST & \\
\hline
\end{tabular}




\begin{tabular}{|c|c|c|c|c|c|}
\hline \multicolumn{6}{|c|}{ Supplemental Table S2.txt } \\
\hline CHEMBL440084 & 809189 & 7.0 & 5.7354 & TRN & \\
\hline CHEMBL1999321 & 809189 & 4.2 & 4.1908 & TRN & \\
\hline CHEMBL1968590 & 809189 & 4.2 & 4.2128 & TRN & \\
\hline CHEMBL 2005375 & 809189 & 4.2 & 4.3405 & TRN & \\
\hline CHEMBL1984191 & 809189 & 5.4 & 4.753 & TRN & \\
\hline CHEMBL1972183 & 809189 & 4.2 & 4.0156 & TST & \\
\hline CHEMBL1971029 & 809189 & 4.2 & 4.6481 & TRN & \\
\hline CHEMBL394790 & 809189 & 5.3 & 5.2561 & TRN & \\
\hline CHEMBL226471 & 809189 & 5.7 & 5.8883 & TRN & \\
\hline CHEMBL1974702 & 809189 & 4.2 & 4.2026 & TRN & \\
\hline CHEMBL1996111 & 809189 & 4.2 & 4.0965 & TRN & \\
\hline CHEMBL1966175 & 809189 & 4.4 & 4.7155 & TRN & \\
\hline CHEMBL1965589 & 809189 & 6.1 & 5.996 & TRN & \\
\hline CHEMBL 2007375 & 809189 & 4.4 & 3.9959 & TRN & \\
\hline CHEMBL1998193 & 809189 & 4.2 & 4.2936 & TRN & \\
\hline CHEMBL379975 & 809189 & 6.6 & 5.4819 & TRN & \\
\hline CHEMBL474432 & 809189 & 4.2 & 3.5554 & TST & \\
\hline CHEMBL1973016 & 809189 & 4.4 & 4.6838 & TRN & \\
\hline CHEMBL1965387 & 809189 & 4.4 & 4.2946 & TRN & \\
\hline CHEMBL 2001539 & 809189 & 4.6 & 4.448 & TST & \\
\hline CHEMBL1997041 & 809189 & 4.7 & 4.9102 & TRN & \\
\hline CHEMBL1988153 & 809189 & 5.4 & 5.072 & TRN & \\
\hline CHEMBL550418 & 809189 & 4.4 & 4.6277 & TRN & \\
\hline CHEMBL1986666 & 809189 & 5.7 & 5.5447 & TRN & \\
\hline CHEMBL1971289 & 809189 & 5.7 & 5.0875 & TRN & \\
\hline CHEMBL1988437 & 809189 & 4.3 & 3.9828 & TST & \\
\hline CHEMBL1979577 & 809189 & 5.2 & 4.6545 & TRN & \\
\hline CHEMBL1998121 & 809189 & 4.2 & 4.4179 & TRN & \\
\hline CHEMBL1233887 & 809189 & 4.4 & 4.7655 & TST & \\
\hline CHEMBL1992607 & 809189 & 4.7 & 5.1584 & TRN & \\
\hline CHEMBL1991800 & 809189 & 5.9 & 6.41799 & 7999999999 & TRN \\
\hline CHEMBL52387 & 809189 & 4.2 & 4.671 & TST & \\
\hline CHEMBL 2003689 & 809189 & 4.4 & 4.6561 & TRN & \\
\hline CHEMBL379835 & 809189 & 4.2 & 4.4543 & TST & \\
\hline CHEMBL1979357 & 809189 & 4.2 & 4.6708 & TRN & \\
\hline CHEMBL1996649 & 809189 & 4.4 & 4.4647 & TRN & \\
\hline CHEMBL1996817 & 809189 & 4.2 & 4.5618 & TRN & \\
\hline CHEMBL1986756 & 809189 & 4.4 & 3.9467 & TRN & \\
\hline CHEMBL3197315 & 809189 & 4.2 & 4.6365 & TST & \\
\hline CHEMBL468280 & 809189 & 4.2 & 4.3948 & TST & \\
\hline CHEMBL1990884 & 809189 & 4.2 & 4.2955 & TRN & \\
\hline CHEMBL3109278 & 809189 & 4.5 & 4.8507 & TRN & \\
\hline CHEMBL256835 & 809189 & 6.3 & 5.8518 & TRN & \\
\hline CHEMBL1974998 & 809189 & 4.4 & 4.8486 & TRN & \\
\hline CHEMBL1980142 & 809189 & 4.2 & 3.5815 & TRN & \\
\hline CHEMBL41783 & 809189 & 4.2 & 4.1799 & TRN & \\
\hline CHEMBL 2004438 & 809189 & 4.4 & 4.4069 & TRN & \\
\hline CHEMBL2006276 & 809189 & 4.2 & 4.2209 & TRN & \\
\hline
\end{tabular}




\begin{tabular}{|c|c|c|c|c|c|}
\hline \multicolumn{6}{|c|}{ plemental } \\
\hline CHEMBL191003 & 809189 & 4.4 & 5.0271 & TRN & \\
\hline CHEMBL271381 & 809189 & 4.2 & 3.9127 & TRN & \\
\hline CHEMBL2006785 & 809189 & 4.2 & 4.78600 & 00000000005 & TRN \\
\hline CHEMBL1982466 & 809189 & 4.2 & 4.2397 & TRN & \\
\hline CHEMBL1973359 & 809189 & 6.9 & 6.4317 & TST & \\
\hline CHEMBL1995740 & 809189 & 4.2 & 4.3112 & TRN & \\
\hline CHEMBL1990162 & 809189 & 6.6 & 6.0147 & TRN & \\
\hline CHEMBL1992220 & 809189 & 6.4 & 6.4751 & TRN & \\
\hline CHEMBL1979690 & 809189 & 5.4 & 5.8285 & TRN & \\
\hline CHEMBL234085 & 809189 & 4.4 & 4.5224 & TRN & \\
\hline CHEMBL1998414 & 809189 & 4.2 & 4.085 & TRN & \\
\hline CHEMBL1995832 & 809189 & 6.3 & 6.4407 & TRN & \\
\hline CHEMBL1969042 & 809189 & 4.2 & 4.4771 & TRN & \\
\hline CHEMBL 2000345 & 809189 & 4.2 & 4.4704 & TRN & \\
\hline CHEMBL1999931 & 809189 & 6.6 & 6.2696 & TRN & \\
\hline CHEMBL1976376 & 809189 & 4.4 & 5.3326 & TRN & \\
\hline CHEMBL1983575 & 809189 & 7.5 & 6.0019 & TRN & \\
\hline CHEMBL1968868 & 809189 & 6.0 & 4.45 & TRN & \\
\hline CHEMBL1375418 & 809189 & 4.2 & 4.1132 & TRN & \\
\hline CHEMBL2007064 & 809189 & 4.2 & 4.5723 & TRN & \\
\hline CHEMBL1981047 & 809189 & 4.4 & 4.0838 & TRN & \\
\hline CHEMBL229968 & 809189 & 6.5 & 6.6728 & TRN & \\
\hline CHEMBL1976196 & 809189 & 4.4 & 4.9347 & TST & \\
\hline CHEMBL1976240 & 809189 & 4.2 & 4.5027 & TRN & \\
\hline CHEMBL1987948 & 809189 & 5.5 & 5.5486 & TRN & \\
\hline CHEMBL1997197 & 809189 & 4.4 & 4.8612 & TRN & \\
\hline CHEMBL1983630 & 809189 & 4.4 & 4.1502 & TRN & \\
\hline CHEMBL1968151 & 809189 & 4.2 & 4.8429 & TRN & \\
\hline CHEMBL1979093 & 809189 & 4.2 & 4.126 & TRN & \\
\hline CHEMBL1987009 & 809189 & 4.2 & 4.0426 & TRN & \\
\hline CHEMBL379218 & 809189 & 5.9 & 6.20299 & 9999999999 & TRN \\
\hline CHEMBL 2003817 & 809189 & 4.2 & 4.352 & TRN & \\
\hline CHEMBL1994830 & 809189 & 5.9 & 5.3702 & TRN & \\
\hline CHEMBL 226403 & 809189 & 6.0 & 5.9858 & TRN & \\
\hline CHEMBL 2005631 & 809189 & 5.3 & 4.5459 & TRN & \\
\hline CHEMBL1994938 & 809189 & 4.2 & 4.0462 & TRN & \\
\hline CHEMBL1977223 & 809189 & 5.7 & 5.7128 & TRN & \\
\hline CHEMBL1995765 & 809189 & 4.7 & 5.2498 & TST & \\
\hline CHEMBL1966279 & 809189 & 4.2 & 3.9932 & TRN & \\
\hline CHEMBL1236126 & 809189 & 4.2 & 5.0865 & TRN & \\
\hline CHEMBL1997846 & 809189 & 4.3 & 4.8243 & TRN & \\
\hline CHEMBL1984760 & 809189 & 4.4 & 5.3657 & TRN & \\
\hline CHEMBL 2004419 & 809189 & 5.3 & 5.1187 & TRN & \\
\hline CHEMBL 360847 & 809189 & 4.4 & 5.226 & TST & \\
\hline CHEMBL 2007073 & 809189 & 4.4 & 4.6821 & TRN & \\
\hline CHEMBL1995811 & 809189 & 5.8 & 5.7957 & TRN & \\
\hline CHEMBL1972489 & 809189 & 4.2 & 4.1139 & TRN & \\
\hline CHEMBL1994074 & 809189 & 4.2 & 4.3209 & TRN & \\
\hline
\end{tabular}




\begin{tabular}{|c|c|c|c|c|}
\hline & & & & al lable s \\
\hline CHEMBL1992937 & 809189 & 5.5 & 5.5027 & TST \\
\hline CHEMBL451401 & 809189 & 4.2 & 4.5522 & TRN \\
\hline CHEMBL1968930 & 809189 & 6.0 & 6.0301 & TRN \\
\hline CHEMBL1972119 & 809189 & 4.2 & 4.1095 & TST \\
\hline CHEMBL1986328 & 809189 & 4.2 & 5.1251 & TST \\
\hline CHEMBL95692 & 809189 & 6.1 & 6.0921 & TST \\
\hline CHEMBL1090356 & 809189 & 4.2 & 4.7003 & TST \\
\hline CHEMBL1976455 & 809189 & 5.4 & 4.7313 & TST \\
\hline CHEMBL 261849 & 809189 & 4.4 & 4.4688 & TST \\
\hline CHEMBL1983923 & 809189 & 4.3 & 4.609 & TST \\
\hline CHEMBL1983534 & 809189 & 4.2 & 4.6833 & TST \\
\hline CHEMBL1982361 & 809189 & 4.2 & 4.2741 & TST \\
\hline CHEMBL1999112 & 809189 & 4.2 & 4.7007 & TST \\
\hline CHEMBL1982122 & 809189 & 4.2 & 4.9522 & TST \\
\hline CHEMBL2000801 & 809189 & 4.2 & 3.9403 & TST \\
\hline CHEMBL1682546 & 809189 & 4.2 & 3.648 & TST \\
\hline CHEMBL1991395 & 809189 & 5.9 & 6.2212 & TST \\
\hline CHEMBL1971245 & 809189 & 4.2 & 4.803 & TST \\
\hline CHEMBL1972142 & 809189 & 4.2 & 3.5194 & TST \\
\hline CHEMBL1966514 & 809189 & 5.8 & 5.1291 & TST \\
\hline CHEMBL 2003638 & 809189 & 6.6 & 6.1048 & TST \\
\hline CHEMBL1996066 & 809189 & 5.7 & 5.32 & TST \\
\hline CHEMBL1983393 & 809189 & 5.4 & 4.2509 & TST \\
\hline CHEMBL1970806 & 809189 & 4.2 & 4.3016 & TST \\
\hline CHEMBL1993722 & 809189 & 4.2 & 4.6777 & TST \\
\hline CHEMBL 2006674 & 809189 & 4.4 & 4.4111 & TST \\
\hline CHEMBL1984236 & 809189 & 4.4 & 4.2108 & TST \\
\hline CHEMBL1992371 & 809189 & 6.6 & 4.8634 & TST \\
\hline CHEMBL1375640 & 809189 & 6.0 & 5.8998 & TST \\
\hline CHEMBL1979970 & 809189 & 4.2 & 4.0819 & TST \\
\hline CHEMBL2002599 & 809189 & 5.5 & 4.6518 & TST \\
\hline CHEMBL 249282 & 809189 & 4.2 & 4.0912 & TST \\
\hline CHEMBL1967252 & 809189 & 5.1 & 5.3132 & TST \\
\hline CHEMBL2004637 & 809189 & 4.4 & 5.4901 & TST \\
\hline CHEMBL1993374 & 809189 & 4.4 & 4.4276 & TST \\
\hline CHEMBL1994318 & 809189 & 4.4 & 4.8021 & TST \\
\hline CHEMBL2006237 & 809189 & 4.2 & 4.3197 & TST \\
\hline CHEMBL1999506 & 809189 & 4.4 & 4.4095 & TST \\
\hline CHEMBL1967720 & 809189 & 5.4 & 4.7675 & TST \\
\hline CHEMBL2005509 & 809189 & 6.2 & 6.5019 & TST \\
\hline CHEMBL1572266 & 809189 & 4.2 & 4.659 & TST \\
\hline CHEMBL1991138 & 809189 & 4.2 & 4.2448 & TST \\
\hline CHEMBL1969755 & 809189 & 4.2 & 4.08899 & 99999999995 \\
\hline CHEMBL1979516 & 809189 & 4.2 & 3.9253 & TST \\
\hline CHEMBL1972820 & 809189 & 4.2 & 4.4237 & TST \\
\hline CHEMBL1605605 & 809189 & 4.4 & 4.8037 & TST \\
\hline CHEMBL1996208 & 809189 & 4.3 & 4.713 & TST \\
\hline CHEMBL1989029 & 809189 & 4.2 & 4.396 & TST \\
\hline
\end{tabular}




\begin{tabular}{|c|c|c|c|c|c|}
\hline \multirow[b]{2}{*}{ CHEMBL392642 } & \multirow[b]{2}{*}{809189} & \\
\hline & & 4.2 & 5.129 & TST & \\
\hline CHEMBL514499 & 809189 & 4.2 & 3.6857 & TST & \\
\hline CHEMBL1970352 & 809189 & 4.4 & 5.1346 & TST & \\
\hline CHEMBL1965631 & 809189 & 4.2 & 5.6241 & TST & \\
\hline CHEMBL1980144 & 809189 & 4.2 & 4.158 & TST & \\
\hline CHEMBL1991188 & 809189 & 4.2 & 4.1115 & TST & \\
\hline CHEMBL1980167 & 809189 & 4.4 & 4.72199 & 99999999995 & TST \\
\hline CHEMBL1972849 & 809189 & 4.2 & 4.8013 & TST & \\
\hline CHEMBL377408 & 809189 & 4.4 & 4.4343 & TST & \\
\hline CHEMBL1986855 & 809189 & 6.0 & 5.4212 & TST & \\
\hline CHEMBL215152 & 809189 & 4.4 & 4.336 & TST & \\
\hline CHEMBL231209 & 809189 & 5.4 & 5.2909 & TST & \\
\hline CHEMBL1975357 & 809189 & 4.2 & 4.6075 & TST & \\
\hline CHEMBL1976220 & 809189 & 5.3 & 5.0577 & TST & \\
\hline CHEMBL2006765 & 809189 & 6.4 & 5.9686 & TST & \\
\hline CHEMBL259922 & 809189 & 4.2 & 4.67899 & 9999999999 & TST \\
\hline CHEMBL1997617 & 809189 & 5.8 & 5.4262 & TST & \\
\hline CHEMBL1969301 & 809189 & 5.7 & 5.3581 & TST & \\
\hline CHEMBL1982383 & 809189 & 6.7 & 6.2313 & TST & \\
\hline CHEMBL17370 & 809189 & 6.3 & 6.1605 & TST & \\
\hline CHEMBL1980246 & 809189 & 4.4 & 4.3736 & TST & \\
\hline CHEMBL1987910 & 809189 & 5.5 & 4.9537 & TST & \\
\hline CHEMBL1983932 & 809189 & 4.2 & 4.3328 & TST & \\
\hline CHEMBL1983980 & 809189 & 6.0 & 5.3794 & TST & \\
\hline CHEMBL1999484 & 809189 & 7.1 & 6.8753 & TST & \\
\hline CHEMBL1973399 & 809189 & 4.8 & 5.1381 & TST & \\
\hline CHEMBL1986899 & 809189 & 4.4 & 4.7359 & TST & \\
\hline CHEMBL1991285 & 809189 & 4.2 & 4.003 & TST & \\
\hline CHEMBL1997822 & 809189 & 4.2 & 3.9569 & TST & \\
\hline CHEMBL243088 & 809189 & 6.2 & 6.28100 & 0000000001 & TST \\
\hline CHEMBL1984038 & 809189 & 4.3 & 3.74300 & 00000000003 & TST \\
\hline CHEMBL1974416 & 809189 & 4.2 & 3.8441 & TST & \\
\hline CHEMBL1993661 & 809189 & 4.4 & 5.145 & TST & \\
\hline CHEMBL2004615 & 809189 & 4.2 & 5.1469 & TST & \\
\hline CHEMBL1984039 & 809189 & 4.2 & 4.4032 & TST & \\
\hline CHEMBL1997872 & 809189 & 4.2 & 4.2666 & TST & \\
\hline CHEMBL1869506 & 752465 & 5.699 & 4.9651 & TST & \\
\hline CHEMBL1870529 & 752465 & 3.0044 & 3.0766 & TST & \\
\hline CHEMBL1899595 & 752465 & 5.5751 & 5.4905 & TRN & \\
\hline CHEMBL1877394 & 752465 & 3.0044 & 3.3504 & TST & \\
\hline CHEMBL1893861 & 752465 & 3.0044 & 3.0936 & TRN & \\
\hline CHEMBL1577231 & 752465 & 5.9245 & 5.9446 & TRN & \\
\hline CHEMBL1319405 & 752465 & 5.8894 & 5.7178 & TRN & \\
\hline CHEMBL1875484 & 752465 & 3.0044 & 3.225 & TRN & \\
\hline CHEMBL1904648 & 752465 & 5.7423 & 5.7588 & TRN & \\
\hline CHEMBL1878555 & 752465 & 3.0044 & 2.885 & TRN & \\
\hline CHEMBL1900875 & 752465 & 3.0044 & 2.877 & TRN & \\
\hline CHEMBL1868274 & 752465 & 5.6576 & 5.67700 & 00000000005 & TRN \\
\hline & & & & 6808 & \\
\hline
\end{tabular}




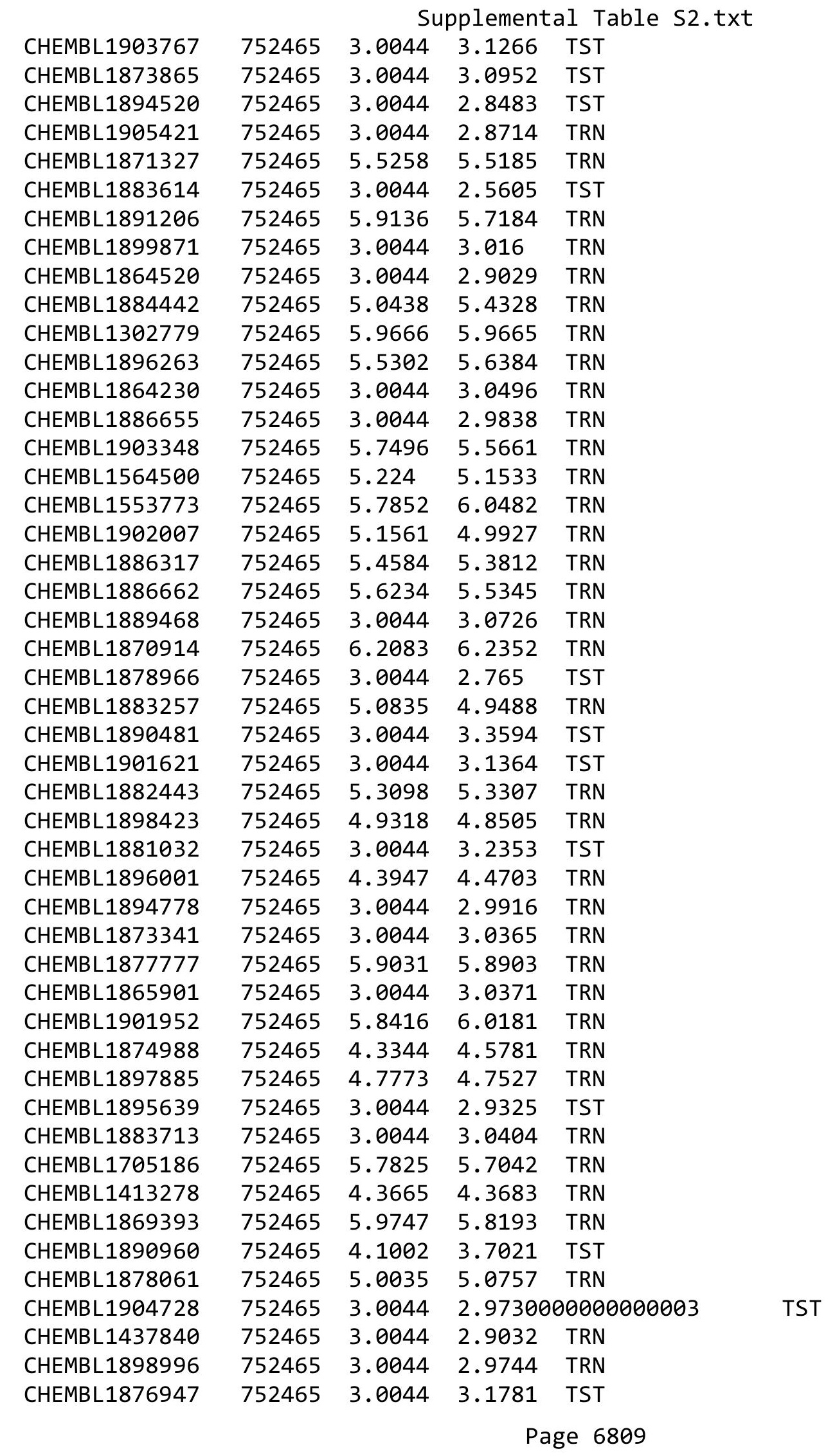




\begin{tabular}{|c|c|c|c|c|c|}
\hline \multicolumn{6}{|c|}{ Supplemental Table S2.txt } \\
\hline CHEMBL1882689 & 752465 & 3.0044 & 2.8858 & TST & \\
\hline CHEMBL1866613 & 752465 & 5.8097 & 5.7218 & TRN & \\
\hline CHEMBL1883149 & 752465 & 3.0044 & 3.1858 & TST & \\
\hline CHEMBL1879719 & 752465 & 3.0044 & 2.9816 & TRN & \\
\hline CHEMBL1885365 & 752465 & 3.0044 & 2.92 & TRN & \\
\hline CHEMBL1865625 & 752465 & 5.3036 & 5.27 & TRN & \\
\hline CHEMBL1878043 & 752465 & 5.1302 & 5.2343 & TRN & \\
\hline CHEMBL1874506 & 752465 & 4.6696 & 4.8443 & TRN & \\
\hline CHEMBL1897348 & 752465 & 3.0044 & 3.0445 & TRN & \\
\hline CHEMBL1887272 & 752465 & 5.2441 & 5.4642 & TRN & \\
\hline CHEMBL1872300 & 752465 & 3.0044 & 2.8807 & TRN & \\
\hline CHEMBL1483649 & 752465 & 5.8477 & 5.6365 & TRN & \\
\hline CHEMBL1316867 & 752465 & 6.2652 & 6.20799 & 9999999999 & TRN \\
\hline CHEMBL1404762 & 752465 & 3.0044 & 3.063 & TRN & \\
\hline CHEMBL1365469 & 752465 & 5.0137 & 5.16100 & 00000000005 & TRN \\
\hline CHEMBL1876444 & 752465 & 3.0044 & 3.1609 & TRN & \\
\hline CHEMBL1870753 & 752465 & 3.0044 & 2.9908 & TRN & \\
\hline CHEMBL1905960 & 752465 & 3.0044 & 3.2188 & TST & \\
\hline CHEMBL1899813 & 752465 & 4.0757 & 4.1762 & TRN & \\
\hline CHEMBL1864747 & 752465 & 5.5952 & 5.6917 & TRN & \\
\hline CHEMBL1872841 & 752465 & 4.9136 & 4.7926 & TRN & \\
\hline CHEMBL1333222 & 752465 & 5.7305 & 5.5133 & TRN & \\
\hline CHEMBL1899989 & 752465 & 5.684 & 5.7256 & TRN & \\
\hline CHEMBL1868902 & 752465 & 5.7447 & 5.5529 & TRN & \\
\hline CHEMBL1904269 & 752465 & 3.0044 & 2.9556 & TST & \\
\hline CHEMBL1865073 & 752465 & 3.0044 & 2.9771 & TST & \\
\hline CHEMBL1699684 & 752465 & 3.0044 & 3.0878 & TRN & \\
\hline CHEMBL1871228 & 752465 & 6.025 & 6.131 & TRN & \\
\hline CHEMBL1904010 & 752465 & 3.0044 & 2.8522 & TST & \\
\hline CHEMBL1904381 & 752465 & 3.0044 & 3.0674 & TRN & \\
\hline CHEMBL1896451 & 752465 & 3.0044 & 4.533 & TST & \\
\hline CHEMBL1903024 & 752465 & 4.1113 & 3.426 & TST & \\
\hline CHEMBL1409038 & 752465 & 3.0044 & 3.0299 & TRN & \\
\hline CHEMBL566295 & 752465 & 3.0044 & 2.8825 & TRN & \\
\hline CHEMBL3188020 & 752465 & 4.3893 & 4.1385 & TST & \\
\hline CHEMBL1885333 & 752465 & 3.0044 & 3.1077 & TRN & \\
\hline CHEMBL1885482 & 752465 & 3.0044 & 3.1969 & TRN & \\
\hline CHEMBL145850 & 752465 & 3.0044 & 2.928 & TRN & \\
\hline CHEMBL1877480 & 752465 & 3.0044 & 2.859 & TRN & \\
\hline CHEMBL1904649 & 752465 & 3.0044 & 3.0822 & TST & \\
\hline CHEMBL1888240 & 752465 & 3.0044 & 2.8071 & TST & \\
\hline CHEMBL 278564 & 208118 & 5.5376 & 5.4026 & TRN & \\
\hline CHEMBL279474 & 208118 & 6.7696 & 6.7949 & TRN & \\
\hline CHEMBL19791 & 208118 & 6.5229 & 6.5245 & TRN & \\
\hline CHEMBL19872 & 208118 & 5.3565 & 5.4922 & TST & \\
\hline CHEMBL19475 & 208118 & 5.3188 & 5.4194 & TRN & \\
\hline CHEMBL280921 & 208118 & 5.4202 & 5.4327 & TRN & \\
\hline CHEMBL19519 & 208118 & 6.6576 & 6.8315 & TRN & \\
\hline
\end{tabular}


Supplemental Table S2.txt

\begin{tabular}{|c|c|c|c|c|}
\hline CHEMBL 314322 & 08118 & 7.1871 & 6.1767 & TST \\
\hline CHEMBL19326 & 08118 & 4.8539 & 5.0293 & \\
\hline HEMBL408813 & 08118 & . 3979 & 3838 & \\
\hline HEMBL 279473 & 08118 & 699 & 8199 & DN \\
\hline HEMBL 277843 & 08118 & 6.0458 & 0175 & \\
\hline HEMBL 279080 & 08118 & 6.7447 & .7073 & \\
\hline HEMBL 278626 & 08118 & .699 & .6165 & \\
\hline HEMBL 278563 & 08118 & .7959 & 4809 & RN \\
\hline HEMBL 282690 & 208118 & 5.4089 & 6483 & PN \\
\hline HEMBL 283536 & 08118 & 5.3372 & 5.3142 & \\
\hline HEMBL 20687 & 08118 & 5.6383 & 5688 & \\
\hline HEMBL 283773 & 08118 & 6.2366 & 1917 & \\
\hline HEMBL1 & 208118 & 6.3665 & 4964 & RN \\
\hline HEMBL 282496 & 208118 & 5.0362 & 5.0796 & \\
\hline HEMBL 278372 & 08118 & .1549 & 1856 & \\
\hline HEMBL2 & 208118 & 6.0 & 6.0741 & \\
\hline HEMBL2 & 08118 & 4.301 & 4.7719 & ודנ \\
\hline HEMBL4 & 208118 & 5.0132 & 5.1426 & \\
\hline HEMBL 27 & 208118 & 6.8539 & 6.8252 & $\Gamma \mathrm{RN}$ \\
\hline HEMBL1 & 08118 & 49 & 6.51 & TRN \\
\hline HEMBL 27 & 2081 & 5.4202 & 5.3469 & $\mathrm{~N} N \mathrm{~V}$ \\
\hline HEMBL2 & 2081 & 5.7447 & 2574 & ST \\
\hline HEMBL4 & 208118 & 6.1308 & 6.1856 & $\mathrm{RN}$ \\
\hline HEMBL278769 & 208118 & 5.1871 & 2631 & $\Gamma \mathrm{RN}$ \\
\hline HEMBL 279208 & 081 & 96 & 5514 & $1 \mathrm{~K}$ \\
\hline HEMBL1 & 208118 & .2757 & 3341 & RN \\
\hline HEMBL1 & 18 & 086 & 283 & RN \\
\hline HEMBL1 & 208118 & 5.1612 & 2685 & 「RN \\
\hline HEMBL19602 & 208118 & 528 & 4189 & TS \\
\hline HEMBL 277 & 2081 & 6.6021 & 6.5939 & TRN \\
\hline HEMBL1 & 081 & 861 & 7895 & $\mathrm{RN}$ \\
\hline HEMBL 2 & 8 & 086 & 522 & TRN \\
\hline HEMBL4 & 8 & 5 . & 092 & TRN \\
\hline HEMBL19608 & 208118 & 6.4089 & 6.5017 & TRN \\
\hline HEMBL 278082 & 208118 & 6.2147 & 6.1442 & TRN \\
\hline HEMBL5 & 208 & 38 & 9478 & TST \\
\hline CHEMBL 2 & 8 & 49 & 2167 & TRN \\
\hline CHEMBL 2 & 208 & 6.2291 & 6.1856 & TRN \\
\hline HEMBL 276299 & 208118 & 6.4815 & 6.1856 & TRN \\
\hline CHEMBL19 & 208118 & . 3979 & 3982 & TRN \\
\hline CHEMBL 2 & 208118 & & 4.9659 & TST \\
\hline CHEMBL19 & 208118 & 5.2291 & 5.3372 & TST \\
\hline CHEMBL277844 & 208118 & 6.3565 & 6.1793 & TRN \\
\hline CHEMBL280960 & 208118 & 6.4559 & 5.3258 & TS \\
\hline CHEMBL17882 & 208118 & 6.0862 & 6.1856 & TRN \\
\hline CHEMBL27 & 208118 & 6.7959 & 6.684 & TS \\
\hline CHEMBL280394 & 208118 & 5.4685 & 5.1708 & TST \\
\hline CHEMBL19321 & 208118 & 6.6383 & 5.5304 & TST \\
\hline
\end{tabular}

Page 6811 


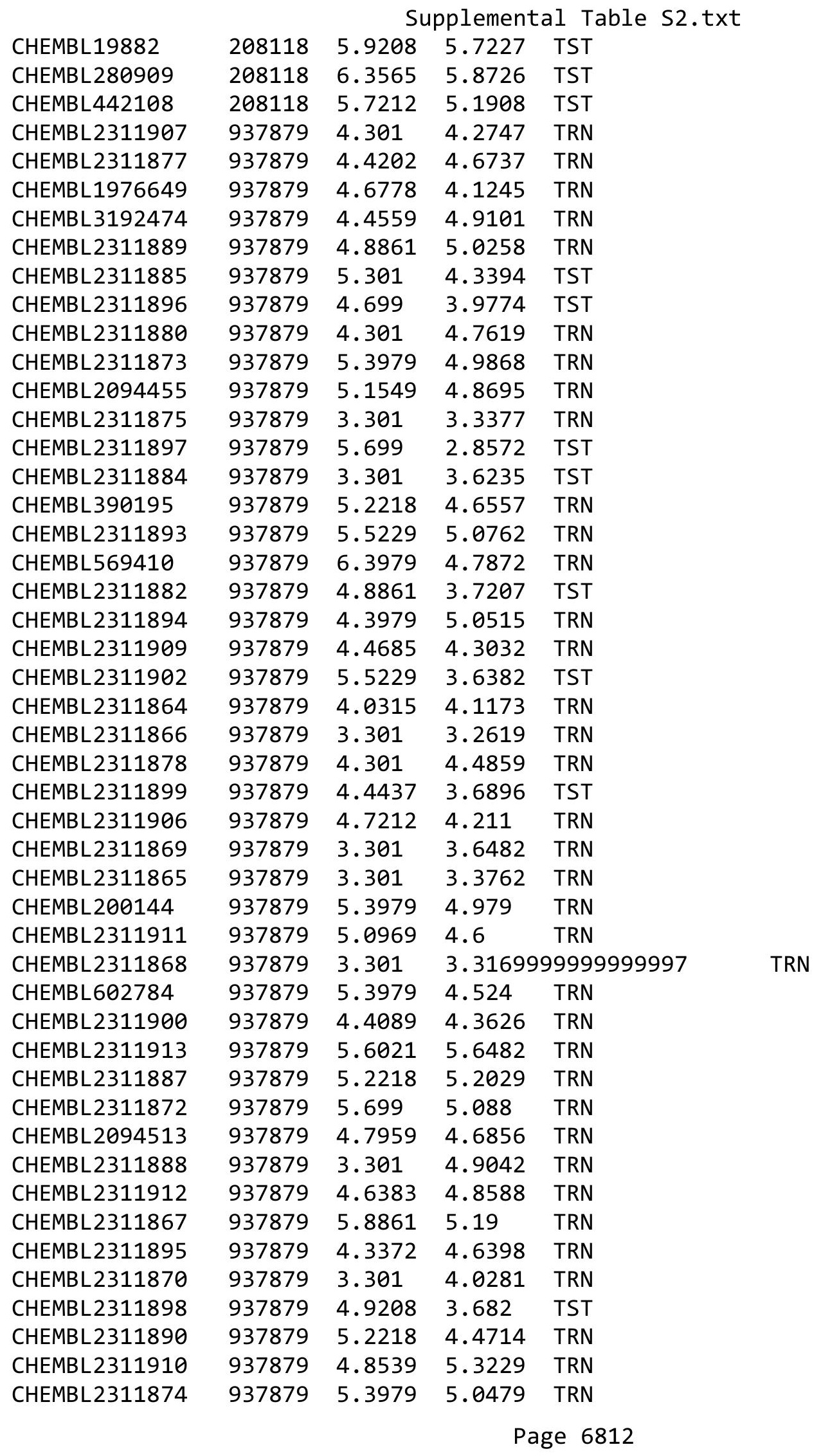




\begin{tabular}{|c|c|c|c|c|c|}
\hline & & \multicolumn{4}{|c|}{ Supplemental Table S2.txt } \\
\hline CHEMBL 2311881 & 937879 & 5.0969 & 3.7725 & TST & \\
\hline CHEMBL567420 & 937879 & 3.301 & 4.7239 & TRN & \\
\hline CHEMBL 2311905 & 937879 & 4.6198 & 4.378 & TRN & \\
\hline CHEMBL1489980 & 937879 & 4.6778 & 3.9261 & TST & \\
\hline CHEMBL2311903 & 937879 & 5.2218 & 3.4882 & TST & \\
\hline CHEMBL1597979 & 937879 & 5.2218 & 3.6156 & TST & \\
\hline CHEMBL 2311871 & 937879 & 3.301 & 3.8168 & TRN & \\
\hline CHEMBL 2311876 & 937879 & 3.301 & 2.9532 & TRN & \\
\hline CHEMBL 2311879 & 937879 & 4.301 & 4.4461 & TRN & \\
\hline CHEMBL 2311901 & 937879 & 3.301 & 4.4694 & TRN & \\
\hline CHEMBL1516329 & 937879 & 4.6021 & 5.0709 & TRN & \\
\hline CHEMBL 2311883 & 937879 & 3.301 & 4.2467 & TST & \\
\hline CHEMBL 2311908 & 937879 & 4.4949 & 4.2748 & TRN & \\
\hline CHEMBL3145360 & 937879 & 5.2218 & 4.3693 & TST & \\
\hline CHEMBL 2311886 & 937879 & 3.301 & 4.2193 & TST & \\
\hline CHEMBL189708 & 306314 & 10.0 & 9.9141 & TRN & \\
\hline CHEMBL363292 & 306314 & 9.301 & 9.6165 & TRN & \\
\hline CHEMBL185860 & 306314 & 10.0 & 9.923 & TRN & \\
\hline CHEMBL 364150 & 306314 & 8.5229 & 8.762 & TRN & \\
\hline CHEMBL366271 & 306314 & 8.3979 & 8.4466 & TRN & \\
\hline CHEMBL188471 & 306314 & 9.0969 & 9.0148 & TRN & \\
\hline CHEMBL186405 & 306314 & 9.3979 & 8.7705 & TST & \\
\hline CHEMBL186464 & 306314 & 7.6198 & 7.6319 & TRN & \\
\hline CHEMBL130327 & 306314 & 7.699 & 8.0247 & TST & \\
\hline CHEMBL185779 & 306314 & 8.699 & 8.8527 & TRN & \\
\hline CHEMBL188674 & 306314 & 6.4776 & 6.42299 & 9999999999 & TRN \\
\hline CHEMBL186608 & 306314 & 9.5229 & 9.375 & TRN & \\
\hline CHEMBL188408 & 306314 & 7.5229 & 7.5953 & TRN & \\
\hline CHEMBL189454 & 306314 & 9.3979 & 9.3575 & TRN & \\
\hline CHEMBL186423 & 306314 & 11.0 & 9.1631 & TST & \\
\hline CHEMBL186229 & 306314 & 7.699 & 8.1114 & TRN & \\
\hline CHEMBL441501 & 306314 & 8.699 & 8.7105 & TRN & \\
\hline CHEMBL188296 & 306314 & 9.301 & 9.0128 & TRN & \\
\hline CHEMBL364181 & 306314 & 10.1549 & 9.5858 & TST & \\
\hline CHEMBL186409 & 306314 & 8.0 & 8.0043 & TRN & \\
\hline CHEMBL359793 & 306314 & 8.699 & 8.6806 & TRN & \\
\hline CHEMBL360415 & 306314 & 8.0969 & 7.7528 & TRN & \\
\hline CHEMBL 364341 & 306314 & 7.0458 & 7.1268 & TRN & \\
\hline CHEMBL365433 & 306314 & 7.3979 & 7.3735 & TRN & \\
\hline CHEMBL365716 & 306314 & 10.0 & 9.7787 & TRN & \\
\hline CHEMBL189450 & 306314 & 9.699 & 9.5647 & TST & \\
\hline CHEMBL360179 & 306314 & 9.0458 & 9.7329 & TST & \\
\hline CHEMBL186814 & 306314 & 9.3979 & 8.5723 & TST & \\
\hline CHEMBL185899 & 306314 & 9.0 & 8.9396 & TRN & \\
\hline CHEMBL188183 & 306314 & 7.3979 & 7.3861 & TRN & \\
\hline CHEMBL188184 & 306314 & 7.0 & 6.7885 & TST & \\
\hline CHEMBL188625 & 306314 & 10.0 & 9.1254 & TST & \\
\hline CHEMBL186173 & 306314 & 8.699 & 8.7654 & TRN & \\
\hline
\end{tabular}




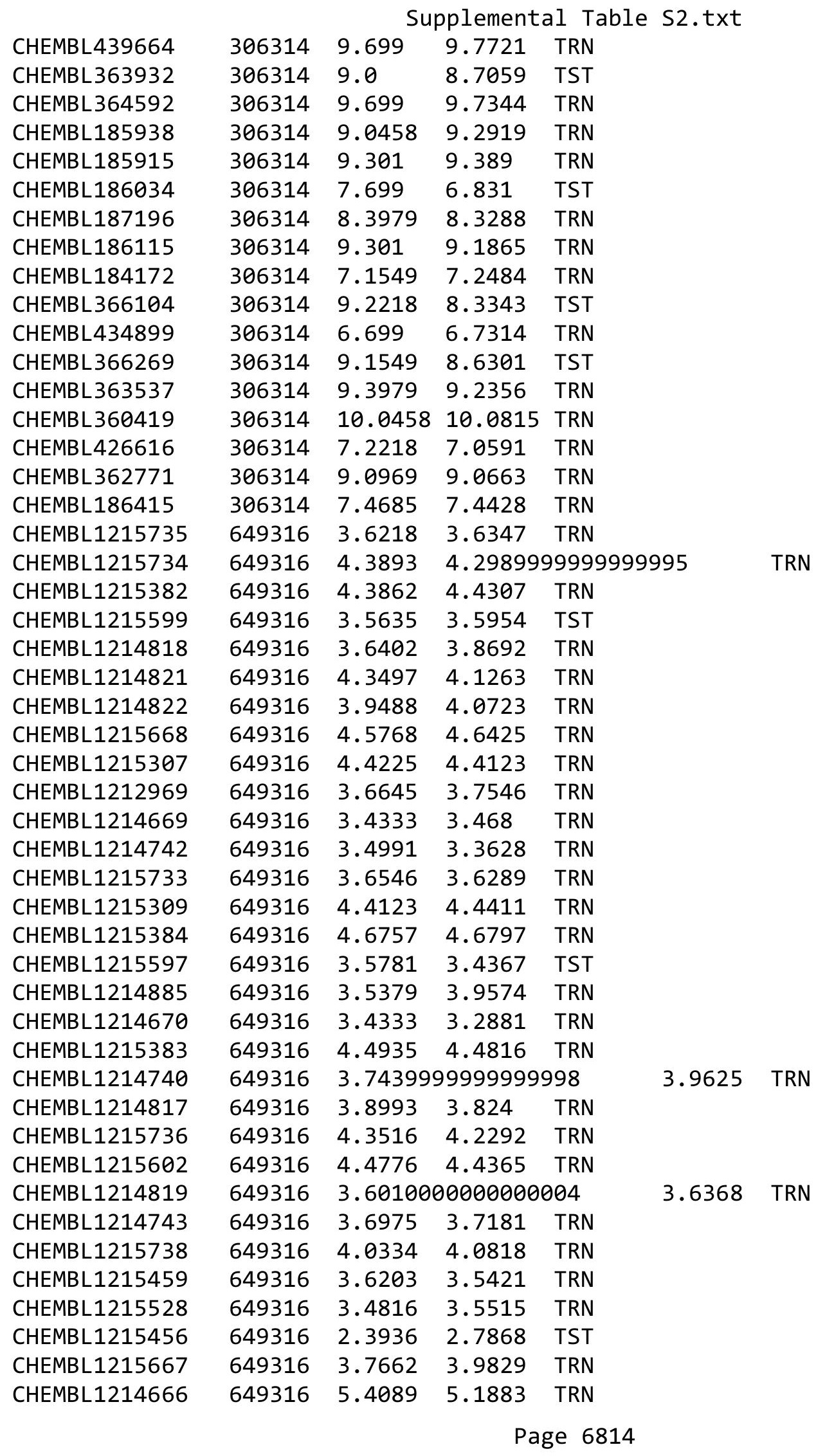




\begin{tabular}{|c|c|c|c|c|c|c|}
\hline & & \multicolumn{5}{|c|}{ Supplemental Table s2.txt } \\
\hline CHEMBL1214883 & 649316 & 3.852 & 3.7199 & TRN & & \\
\hline CHEMBL1215308 & 649316 & 4.3979 & 4.4505 & TRN & & \\
\hline CHEMBL1215670 & 649316 & 5.2441 & 5.24 & TRN & & \\
\hline CHEMBL1214667 & 649316 & 3.6998 & 3.5948 & TRN & & \\
\hline CHEMBL1215386 & 649316 & 3.6459 & 3.5079 & TST & & \\
\hline CHEMBL1215460 & 649316 & 3.6923 & 3.43399 & 7999999999 - n & & TST \\
\hline CHEMBL1215381 & 649316 & 4.5214 & 4.4428 & TRN & & \\
\hline CHEMBL1214668 & 649316 & 3.8136 & 3.8384 & TRN & & \\
\hline CHEMBL1215533 & 649316 & 3.5462 & 3.6992 & TST & & \\
\hline CHEMBL1215461 & 649316 & 5.0 & 4.4786 & TST & & \\
\hline CHEMBL1214741 & 649316 & 3.6786 & 3.5925 & TRN & & \\
\hline CHEMBL1215531 & 649316 & \multicolumn{3}{|c|}{3.6069999999999998} & .3978 & TST \\
\hline CHEMBL1215529 & 649316 & 3.6796 & 3.5744 & TST & & \\
\hline CHEMBL1214665 & 649316 & 5.0915 & 5.1937 & TRN & & \\
\hline CHEMBL1215600 & 649316 & 4.1891 & 4.2443 & TRN & & \\
\hline CHEMBL1215458 & 649316 & 3.6876 & 3.6839 & TST & & \\
\hline CHEMBL1215598 & 649316 & 3.8614 & 4.0573 & TST & & \\
\hline CHEMBL1215601 & 649316 & 3.415 & 3.5114 & TRN & & \\
\hline CHEMBL1215666 & 649316 & 4.0057 & 3.9247 & TRN & & \\
\hline CHEMBL1215457 & 649316 & 3.6463 & 3.2219 & TST & & \\
\hline CHEMBL1214820 & 649316 & 3.6985 & 3.7534 & TRN & & \\
\hline CHEMBL1212959 & 649316 & 3.4795 & 3.3703 & TRN & & \\
\hline CHEMBL1215671 & 649316 & 5.1367 & 5.1159 & TRN & & \\
\hline CHEMBL1215385 & 649316 & 3.7357 & 3.5459 & TST & & \\
\hline CHEMBL1215310 & 649316 & 4.4711 & 4.466 & TRN & & \\
\hline CHEMBL1214884 & 649316 & 4.2976 & 4.102 & TRN & & \\
\hline CHEMBL164129 & 649316 & 4.3028 & 4.2503 & TRN & & \\
\hline CHEMBL1215737 & 649316 & 4.4522 & 4.4987 & TRN & & \\
\hline CHEMBL1215534 & 649316 & \multicolumn{3}{|c|}{ 4. 2139999999999995} & .9848 & TST \\
\hline CHEMBL1215530 & 649316 & 4.0555 & 3.6058 & TST & & \\
\hline CHEMBL1215532 & 649316 & 3.6189 & 3.2997 & TST & & \\
\hline CHEMBL1215669 & 649316 & 4.4672 & 4.4231 & TRN & & \\
\hline CHEMBL38711 & 197283 & 7.9208 & 8.1213 & TRN & & \\
\hline CHEMBL133036 & 197283 & 7.8539 & 8.2276 & TRN & & \\
\hline CHEMBL291521 & 197283 & 5.6021 & 5.6994 & TRN & & \\
\hline CHEMBL 288688 & 197283 & 8.2291 & 7.6883 & TRN & & \\
\hline CHEMBL335584 & 197283 & 7.0223 & 6.6053 & TRN & & \\
\hline CHEMBL81028 & 197283 & 7.3872 & 7.2738 & TST & & \\
\hline CHEMBL274265 & 197283 & 8.301 & 8.3158 & TRN & & \\
\hline CHEMBL286769 & 197283 & 5.0506 & 5.4675 & TST & & \\
\hline CHEMBL337338 & 197283 & 8.3565 & 8.2005 & TRN & & \\
\hline CHEMBL276108 & 197283 & 8.5686 & 8.183 & TRN & & \\
\hline CHEMBL132865 & 197283 & 6.3468 & 6.07299 & 9999999999 & & TRN \\
\hline CHEMBL97745 & 197283 & 7.8861 & 7.0213 & TST & & \\
\hline CHEMBL279637 & 197283 & 4.0862 & 5.114 & TRN & & \\
\hline CHEMBL336762 & 197283 & 8.1308 & 7.989 & TRN & & \\
\hline CHEMBL336388 & 197283 & 7.9208 & 8.0654 & TRN & & \\
\hline CHEMBL16684 & 197283 & 7.8861 & 7.3736 & TRN & & \\
\hline
\end{tabular}




\begin{tabular}{|c|c|c|c|c|c|}
\hline \multicolumn{6}{|c|}{ Supplemental Table S2.txt } \\
\hline CHEMBL16535 & 197283 & 5.585 & 5.1914 & TRN & \\
\hline CHEMBL135444 & 197283 & 7.1079 & 7.4783 & TRN & \\
\hline CHEMBL319139 & 197283 & 9.2218 & 8.4821 & TST & \\
\hline CHEMBL431423 & 197283 & 6.6021 & 6.9306 & TST & \\
\hline CHEMBL16824 & 197283 & 4.4685 & 4.724 & TRN & \\
\hline CHEMBL340049 & 197283 & 7.8861 & 8.0906 & TRN & \\
\hline CHEMBL276058 & 197283 & 4.9208 & 4.8596 & TRN & \\
\hline CHEMBL275187 & 197283 & 7.2007 & 7.2823 & TRN & \\
\hline CHEMBL280279 & 197283 & 4.1487 & 5.7222 & TST & \\
\hline CHEMBL118759 & 197283 & 5.3279 & 6.0676 & TST & \\
\hline CHEMBL278186 & 197283 & 7.2291 & 7.4152 & TRN & \\
\hline CHEMBL135996 & 197283 & 6.6576 & 7.5208 & TST & \\
\hline CHEMBL328140 & 197283 & 7.284 & 7.5868 & TST & \\
\hline CHEMBL310976 & 197283 & 8.7959 & 7.7241 & TST & \\
\hline CHEMBL279579 & 197283 & 5.0 & 4.751 & TRN & \\
\hline CHEMBL96032 & 197283 & 7.2007 & 7.21299 & 9999999999 & TST \\
\hline CHEMBL39093 & 197283 & 7.0 & 6.5135 & TRN & \\
\hline CHEMBL135589 & 197283 & 7.2676 & 8.0846 & TRN & \\
\hline CHEMBL278905 & 197283 & 5.4815 & 4.9752 & TRN & \\
\hline CHEMBL117433 & 197283 & 5.1367 & 4.9704 & TRN & \\
\hline CHEMBL135532 & 197283 & 6.5376 & 7.1941 & TST & \\
\hline CHEMBL343948 & 197283 & 5.3979 & 5.7865 & TRN & \\
\hline CHEMBL335850 & 197283 & 5.4559 & 4.5548 & TRN & \\
\hline CHEMBL417626 & 197283 & 5.5686 & 5.3509 & TRN & \\
\hline CHEMBL37833 & 197283 & 5.0605 & 5.3991 & TRN & \\
\hline CHEMBL39047 & 197283 & 5.6778 & 5.67200 & 0000000001 & TRN \\
\hline CHEMBL16763 & 197283 & 5.1024 & 4.9124 & TRN & \\
\hline CHEMBL16793 & 197283 & 8.1079 & 7.5145 & TRN & \\
\hline CHEMBL 36427 & 197283 & 5.2441 & 5.7466 & TST & \\
\hline CHEMBL98679 & 197283 & 6.4559 & 6.5554 & TST & \\
\hline CHEMBL54817 & 197283 & 7.4089 & 7.6074 & TRN & \\
\hline CHEMBL17097 & 197283 & 4.6576 & 4.8193 & TRN & \\
\hline CHEMBL275599 & 197283 & 6.585 & 6.3355 & TRN & \\
\hline CHEMBL17070 & 197283 & 7.3665 & 7.4451 & TRN & \\
\hline CHEMBL279409 & 197283 & 6.6576 & 6.4962 & TRN & \\
\hline CHEMBL133084 & 197283 & 6.4685 & 7.5342 & TST & \\
\hline CHEMBL440274 & 197283 & 4.3468 & 4.5446 & TRN & \\
\hline CHEMBL288728 & 197283 & 5.9208 & 6.0592 & TRN & \\
\hline CHEMBL120146 & 197283 & 5.3665 & 5.814 & TRN & \\
\hline CHEMBL37067 & 197283 & 7.0555 & 6.5532 & TRN & \\
\hline CHEMBL39015 & 197283 & 8.5686 & 8.5112 & TRN & \\
\hline CHEMBL55277 & 197283 & 7.3979 & 7.438 & TRN & \\
\hline CHEMBL116501 & 197283 & 5.8861 & 6.2086 & TRN & \\
\hline CHEMBL133035 & 197283 & 8.1675 & 8.7043 & TRN & \\
\hline CHEMBL422622 & 197283 & 7.585 & 7.2548 & TRN & \\
\hline CHEMBL280068 & 197283 & 5.2441 & 5.0059 & TRN & \\
\hline CHEMBL134403 & 197283 & 8.1079 & 7.8772 & TRN & \\
\hline CHEMBL16628 & 197283 & 5.0 & 4.9693 & TRN & \\
\hline
\end{tabular}




\begin{tabular}{|c|c|c|c|c|}
\hline \multicolumn{5}{|c|}{ Supplemental Table S2.txt } \\
\hline CHEMBL135690 & 197283 & 6.4559 & 6.1704 & TRN \\
\hline CHEMBL16686 & 197283 & 3.6576 & 5.2175 & TRN \\
\hline CHEMBL 274458 & 197283 & 3.8539 & 5.3045 & TST \\
\hline CHEMBL135497 & 197283 & 8.1612 & 8.6209 & TRN \\
\hline CHEMBL291786 & 197283 & 6.7212 & 6.8237 & TRN \\
\hline CHEMBL291926 & 197283 & 8.4949 & 8.4491 & TRN \\
\hline CHEMBL56036 & 197283 & 7.0 & 5.5608 & TST \\
\hline CHEMBL132977 & 197283 & 7.0177 & 6.9238 & TRN \\
\hline CHEMBL417916 & 197283 & 7.0969 & 6.926 & TST \\
\hline CHEMBL418726 & 197283 & 4.8861 & 5.3512 & TRN \\
\hline CHEMBL 298821 & 197283 & 7.3979 & 7.5847 & TST \\
\hline CHEMBL38768 & 197283 & 5.6576 & 5.7982 & TRN \\
\hline CHEMBL 278944 & 197283 & 4.7212 & 5.7105 & TST \\
\hline CHEMBL40091 & 197283 & 5.4437 & 5.7714 & TRN \\
\hline CHEMBL336577 & 197283 & 5.7959 & 5.8915 & TRN \\
\hline CHEMBL135277 & 197283 & 7.041 & 7.1211 & TRN \\
\hline CHEMBL435961 & 197283 & 6.7696 & 6.817 & TST \\
\hline CHEMBL429778 & 197283 & 7.8539 & 7.3183 & TRN \\
\hline CHEMBL37743 & 197283 & 6.4815 & 6.1482 & TRN \\
\hline CHEMBL97347 & 197283 & 8.5686 & 7.6656 & TST \\
\hline CHEMBL36995 & 197283 & 7.7212 & 7.1601 & TRN \\
\hline CHEMBL3238246 & 1338729 & 6.8861 & 6.8867 & TRN \\
\hline CHEMBL3237914 & 1338729 & 5.5528 & 5.6068 & TRN \\
\hline CHEMBL3238215 & 1338729 & 6.9586 & 6.9709 & TRN \\
\hline CHEMBL3238229 & 1338729 & 6.699 & 6.6067 & TRN \\
\hline CHEMBL 3237925 & 1338729 & 6.5086 & 6.5115 & TRN \\
\hline CHEMBL 3238220 & 1338729 & 6.7212 & 6.9309 & TRN \\
\hline CHEMBL 3237886 & 1338729 & 4.0 & 3.005 & TST \\
\hline CHEMBL3237923 & 1338729 & 6.301 & 6.2934 & TRN \\
\hline CHEMBL3237907 & 1338729 & 5.7696 & 5.7389 & TRN \\
\hline CHEMBL3238219 & 1338729 & 7.0 & 6.9711 & TRN \\
\hline CHEMBL3237924 & 1338729 & 6.3768 & 6.4317 & TRN \\
\hline CHEMBL 3237922 & 1338729 & 6.4318 & 6.2708 & TRN \\
\hline CHEMBL3237916 & 1338729 & 5.2676 & 5.3022 & TRN \\
\hline CHEMBL 3238217 & 1338729 & 6.8539 & 6.8494 & TRN \\
\hline CHEMBL3238222 & 1338729 & 6.7696 & 6.7704 & TRN \\
\hline CHEMBL3237904 & 1338729 & 5.6021 & 5.5497 & TRN \\
\hline CHEMBL 3237887 & 1338729 & 4.0 & 4.1544 & TRN \\
\hline CHEMBL3238234 & 1338729 & 6.284 & 6.3702 & TRN \\
\hline CHEMBL3237900 & 1338729 & 6.0915 & 6.1282 & TRN \\
\hline CHEMBL3237908 & 1338729 & 5.4949 & 5.4544 & TRN \\
\hline CHEMBL3237906 & 1338729 & 5.4815 & 5.5586 & TRN \\
\hline CHEMBL3237927 & 1338729 & 6.3768 & 6.3313 & TST \\
\hline CHEMBL3237928 & 1338729 & 6.5528 & 6.695 & TST \\
\hline CHEMBL3237911 & 1338729 & 5.3979 & 5.3799 & TRN \\
\hline CHEMBL3237903 & 1338729 & 4.0 & 4.0674 & TRN \\
\hline CHEMBL3237909 & 1338729 & 5.3565 & 5.5038 & TRN \\
\hline CHEMBL3238218 & 1338729 & 6.8861 & 6.8794 & TST \\
\hline
\end{tabular}


Supplemental Table S2.txt

\begin{tabular}{|c|c|c|c|c|c|}
\hline CHEMBL 3238238 & 1338729 & 5.2147 & 5.1883 & TRN & \\
\hline CHEMBL 3238226 & 1338729 & 7.0757 & 7.046 & TST & \\
\hline CHEMBL 3238216 & 1338729 & 6.7959 & 7.2222 & TST & \\
\hline CHEMBL 3237897 & 1338729 & 5.8239 & 5.8794 & TRN & \\
\hline CHEMBL 3237885 & 1338729 & 5.0 & 4.8848 & TRN & \\
\hline CHEMBL 3237913 & 1338729 & 5.8239 & 5.8316 & TRN & \\
\hline CHEMBL 3238214 & 1338729 & 6.9586 & 6.9235 & TST & \\
\hline CHEMBL3237888 & 1338729 & 5.0177 & 4.7047 & TRN & \\
\hline CHEMBL 3237915 & 1338729 & 5.0969 & 5.0484 & TRN & \\
\hline CHEMBL 3238223 & 1338729 & 6.8539 & 7.2066 & TST & \\
\hline CHEMBL 3237899 & 1338729 & 5.8861 & 5.9221 & TRN & \\
\hline CHEMBL 3238228 & 1338729 & 7.0177 & 6.638 & TST & \\
\hline CHEMBL3237912 & 1338729 & 5.3372 & 5.2825 & TRN & \\
\hline CHEMBL3237895 & 1338729 & 5.9208 & 5.7037 & TRN & \\
\hline CHEMBL3237902 & 1338729 & 5.7696 & 5.7206 & TRN & \\
\hline CHEMBL 3237901 & 1338729 & 5.6576 & 5.7991 & TRN & \\
\hline CHEMBL3237917 & 1338729 & 6.3979 & 5.9866 & TST & \\
\hline CHEMBL3237910 & 1338729 & 5.2757 & 5.1465 & TRN & \\
\hline CHEMBL3237898 & 1338729 & 5.4815 & 5.3558 & TRN & \\
\hline CHEMBL3237921 & 1338729 & 6.1249 & 6.41299 & 999999999 & TST \\
\hline CHEMBL 3237889 & 1338729 & 4.0 & 4.0109 & TRN & \\
\hline CHEMBL 3237918 & 1338729 & 4.0 & 5.8062 & TST & \\
\hline CHEMBL 3237884 & 1338729 & 4.0 & 4.2692 & TRN & \\
\hline CHEMBL3238221 & 1338729 & 7.0458 & 6.6787 & TST & \\
\hline CHEMBL 3237905 & 1338729 & 5.6383 & 5.693 & TRN & \\
\hline CHEMBL512504 & 955014 & 3.98 & 3.98 & TRN & \\
\hline CHEMBL573107 & 955014 & 6.0708 & 6.0708 & TRN & \\
\hline CHEMBL 3186408 & 955014 & 4.1857 & 3.7179 & TST & \\
\hline CHEMBL412142 & 955014 & 4.6049 & 4.6049 & TRN & \\
\hline CHEMBL 2005886 & 955014 & \multicolumn{3}{|c|}{3.2689999999999997} & 3. 2689999999999997 \\
\hline CHEMBL191334 & 955014 & 3.7628 & 3.7628 & TRN & \\
\hline CHEMBL 3392440 & 955014 & 3.7221 & 3.7221 & TRN & \\
\hline CHEMBL189584 & 955014 & 5.365 & 5.365 & TRN & \\
\hline CHEMBL1516890 & 955014 & 3.764 & 3.764 & TRN & \\
\hline CHEMBL514499 & 955014 & 7.183 & 7.183 & TRN & \\
\hline CHEMBL 1230020 & 955014 & 4.1048 & 4.1048 & TRN & \\
\hline CHEMBL92309 & 955014 & 3.7354 & 3.0984 & TST & \\
\hline CHEMBL515416 & 955014 & 5.098 & 5.098 & TRN & \\
\hline CHEMBL 202721 & 955014 & 5.4172 & 5.4172 & TRN & \\
\hline CHEMBL472940 & 955014 & 3.2228 & 3.2228 & TRN & \\
\hline CHEMBL1643959 & 955014 & 2.8861 & 2.8861 & TRN & \\
\hline CHEMBL483847 & 955014 & 4.2001 & 4.2001 & TRN & \\
\hline CHEMBL209148 & 955014 & 4.2722 & 4.2722 & TRN & \\
\hline CHEMBL259181 & 955014 & 4.5819 & 4.5819 & TRN & \\
\hline CHEMBL 220241 & 955014 & 4.6533 & 4.6533 & TRN & \\
\hline CHEMBL300389 & 955014 & 6.8821 & 6.8821 & TRN & \\
\hline CHEMBL65 & 955014 & 7.7841 & 7.7841 & TRN & \\
\hline CHEMBL1909414 & 955014 & 5.2293 & 5.2293 & TRN & \\
\hline
\end{tabular}

Page 6818 


\begin{tabular}{|c|c|c|c|c|}
\hline \multicolumn{5}{|c|}{ Supplemental Table S2.txt } \\
\hline CHEMBL2363137 & 955014 & 4.8894 & 4.8894 & TRN \\
\hline CHEMBL3349342 & 955014 & 4.9582 & 4.9582 & TRN \\
\hline CHEMBL1590308 & 955014 & 3.7495 & 3.8644 & TST \\
\hline CHEMBL1673039 & 955014 & 5.1639 & 5.1639 & TRN \\
\hline CHEMBL135561 & 955014 & 3.8561 & 3.8561 & TRN \\
\hline CHEMBL1404918 & 955014 & 3.4268 & 3.4268 & TRN \\
\hline CHEMBL392695 & 955014 & 5.5359 & 5.5359 & TRN \\
\hline CHEMBL379975 & 955014 & 5.1236 & 5.1236 & TRN \\
\hline CHEMBL379300 & 955014 & 6.435 & 6.435 & TRN \\
\hline CHEMBL1256459 & 955014 & 6.8869 & 6.8869 & TRN \\
\hline CHEMBL449158 & 955014 & 6.3394 & 6.1939 & TST \\
\hline CHEMBL1970879 & 955014 & 3.383 & 3.383 & TRN \\
\hline CHEMBL102714 & 955014 & 3.3514 & 3.3514 & TRN \\
\hline CHEMBL1242367 & 955014 & 4.3201 & 4.3201 & TRN \\
\hline CHEMBL180127 & 955014 & 4.8525 & 4.8525 & TRN \\
\hline CHEMBL9470 & 955014 & 5.2031 & 5.7651 & TST \\
\hline CHEMBL585951 & 955014 & 5.7062 & 5.7062 & TRN \\
\hline CHEMBL 258844 & 955014 & 3.4442 & 3.4442 & TRN \\
\hline CHEMBL509032 & 955014 & 4.7195 & 4.7195 & TRN \\
\hline CHEMBL373751 & 955014 & 3.3079 & 3.3079 & TRN \\
\hline CHEMBL1190711 & 955014 & 4.3311 & 4.3311 & TRN \\
\hline CHEMBL1788116 & 955014 & 3.5505 & 3.5505 & TRN \\
\hline CHEMBL 2144069 & 955014 & 3.9098 & 3.9098 & TRN \\
\hline CHEMBL1357247 & 955014 & 2.6012 & 2.6012 & TRN \\
\hline CHEMBL483849 & 955014 & 3.0951 & 3.0378 & TST \\
\hline CHEMBL393929 & 955014 & 3.6268 & 4.4366 & TST \\
\hline CHEMBL240954 & 955014 & 4.2017 & 3.9338 & TST \\
\hline CHEMBL221137 & 955014 & 2.7296 & 4.7094 & TST \\
\hline CHEMBL192566 & 955014 & 7.4733 & 8.4079 & TST \\
\hline CHEMBL213100 & 955014 & 3.2779 & 3.7511 & TST \\
\hline CHEMBL558642 & 955014 & 2.7894 & 3.5946 & TST \\
\hline CHEMBL3199475 & 955014 & 3.9214 & 3.9819 & TST \\
\hline CHEMBL210618 & 955014 & 3.3807 & 3.5839 & TST \\
\hline CHEMBL1882992 & 954314 & 2.926 & 2.8582 & TRN \\
\hline CHEMBL1457229 & 954314 & 3.9935 & 4.5776 & TST \\
\hline CHEMBL1729277 & 954314 & 2.9265 & 3.3387 & TRN \\
\hline CHEMBL3195045 & 954314 & 3.4031 & 3.4282 & TRN \\
\hline CHEMBL 1702547 & 954314 & 2.9252 & 3.7612 & TST \\
\hline CHEMBL1564468 & 954314 & 2.926 & 3.2409 & TST \\
\hline CHEMBL 2130806 & 954314 & 3.4044 & 3.6585 & TRN \\
\hline CHEMBL366205 & 954314 & 2.9261 & 2.9621 & TRN \\
\hline CHEMBL1386178 & 954314 & 2.9262 & 3.3333 & TST \\
\hline CHEMBL1889525 & 954314 & 2.9253 & 3.0359 & TRN \\
\hline CHEMBL1325945 & 954314 & 2.9264 & 3.3333 & TST \\
\hline CHEMBL1410679 & 954314 & 2.9258 & 2.8196 & TRN \\
\hline CHEMBL1980600 & 954314 & 2.9257 & 2.9933 & TRN \\
\hline CHEMBL187263 & 954314 & 4.1974 & 4.3639 & TRN \\
\hline CHEMBL 364837 & 954314 & 2.9257 & 2.8106 & TRN \\
\hline
\end{tabular}


Supplemental Table S2.txt

\begin{tabular}{|c|c|c|c|c|c|}
\hline CHEMBL1543433 & 954314 & 4.0332 & 4.0162 & TRN & \\
\hline CHEMBL3197024 & 954314 & 4.0643 & 3.9736 & TRN & \\
\hline CHEMBL572994 & 954314 & \multicolumn{2}{|c|}{4.6610000000000005} & 4.2666 & TST \\
\hline CHEMBL3196837 & 954314 & 2.926 & 3.0159 & TRN & \\
\hline CHEMBL3195656 & 954314 & 2.926 & 4.2312 & TST & \\
\hline CHEMBL187866 & 954314 & 4.7295 & 4.481 & TRN & \\
\hline CHEMBL1596605 & 954314 & 4.5266 & 4.3648 & TRN & \\
\hline CHEMBL1463647 & 954314 & 2.9265 & 3.0088 & TST & \\
\hline CHEMBL1576260 & 954314 & 2.9256 & 2.9401 & TRN & \\
\hline CHEMBL2144049 & 954314 & 2.926 & 2.8757 & TST & \\
\hline CHEMBL1885868 & 954314 & 4.2126 & 4.3205 & TRN & \\
\hline CHEMBL23970 & 954314 & 4.2182 & 3.9128 & TST & \\
\hline CHEMBL2141005 & 954314 & 2.9266 & 2.627 & TRN & \\
\hline CHEMBL1901922 & 954314 & 2.9259 & 2.8633 & TST & \\
\hline CHEMBL1527664 & 954314 & 2.926 & 2.9594 & TST & \\
\hline CHEMBL1427717 & 954314 & 4.8351 & 4.8556 & TRN & \\
\hline CHEMBL1982539 & 954314 & 2.926 & 2.8039 & TRN & \\
\hline CHEMBL3145306 & 954314 & 2.926 & 4.1212 & TST & \\
\hline CHEMBL1878003 & 954314 & 2.9265 & 2.8506 & TRN & \\
\hline CHEMBL1351695 & 954314 & 2.9261 & 2.84899 & 99999999998 & TRN \\
\hline CHEMBL1863802 & 954314 & 2.9261 & 2.7614 & TST & \\
\hline CHEMBL1541943 & 954314 & 4.3144 & 4.2522 & TRN & \\
\hline CHEMBL1422429 & 954314 & 4.5218 & 4.4916 & TRN & \\
\hline CHEMBL1362047 & 954314 & 4.4957 & 4.3053 & TRN & \\
\hline CHEMBL3209165 & 954314 & 2.9261 & 2.9281 & TRN & \\
\hline CHEMBL2359471 & 954314 & 2.9264 & 2.9746 & TRN & \\
\hline CHEMBL1867000 & 954314 & 4.3856 & 4.6357 & TST & \\
\hline CHEMBL1735962 & 954314 & 4.57 & 4.3412 & TRN & \\
\hline CHEMBL1456115 & 954314 & 2.9264 & 3.1538 & TRN & \\
\hline CHEMBL1608727 & 954314 & 4.3268 & 4.2553 & TRN & \\
\hline CHEMBL1503864 & 954314 & 2.9264 & 2.7626 & TRN & \\
\hline CHEMBL1466490 & 954314 & 3.929 & 3.8405 & TRN & \\
\hline CHEMBL1985082 & 954314 & 4.3881 & 4.3518 & TRN & \\
\hline CHEMBL2135968 & 954314 & 4.0671 & 3.8097 & TRN & \\
\hline CHEMBL591363 & 954314 & 4.1557 & 4.3347 & TRN & \\
\hline CHEMBL1899240 & 954314 & 4.6364 & 4.5479 & TRN & \\
\hline CHEMBL1724744 & 954314 & 4.059 & 3.7769 & TRN & \\
\hline CHEMBL1894665 & 954314 & 2.9262 & 3.0366 & TST & \\
\hline CHEMBL2356469 & 954314 & 2.9253 & 3.3531 & TST & \\
\hline CHEMBL3145315 & 954314 & 4.072 & 4.3528 & TST & \\
\hline CHEMBL1348654 & 954314 & 2.9258 & 3.2844 & TRN & \\
\hline CHEMBL1979662 & 954314 & 3.4035 & 3.58399 & 99999999996 & TRN \\
\hline CHEMBL316589 & 954314 & 4.4695 & 4.5214 & TRN & \\
\hline CHEMBL1531670 & 954314 & 2.9264 & 2.8514 & TRN & \\
\hline CHEMBL1344875 & 954314 & 2.926 & 3.0135 & TRN & \\
\hline CHEMBL1310196 & 954314 & 3.4033 & 3.7166 & TRN & \\
\hline CHEMBL1490222 & 954314 & 2.9259 & 3.0649 & TRN & \\
\hline CHEMBL1560341 & 954314 & 3.4033 & 3.5699 & TRN & \\
\hline
\end{tabular}




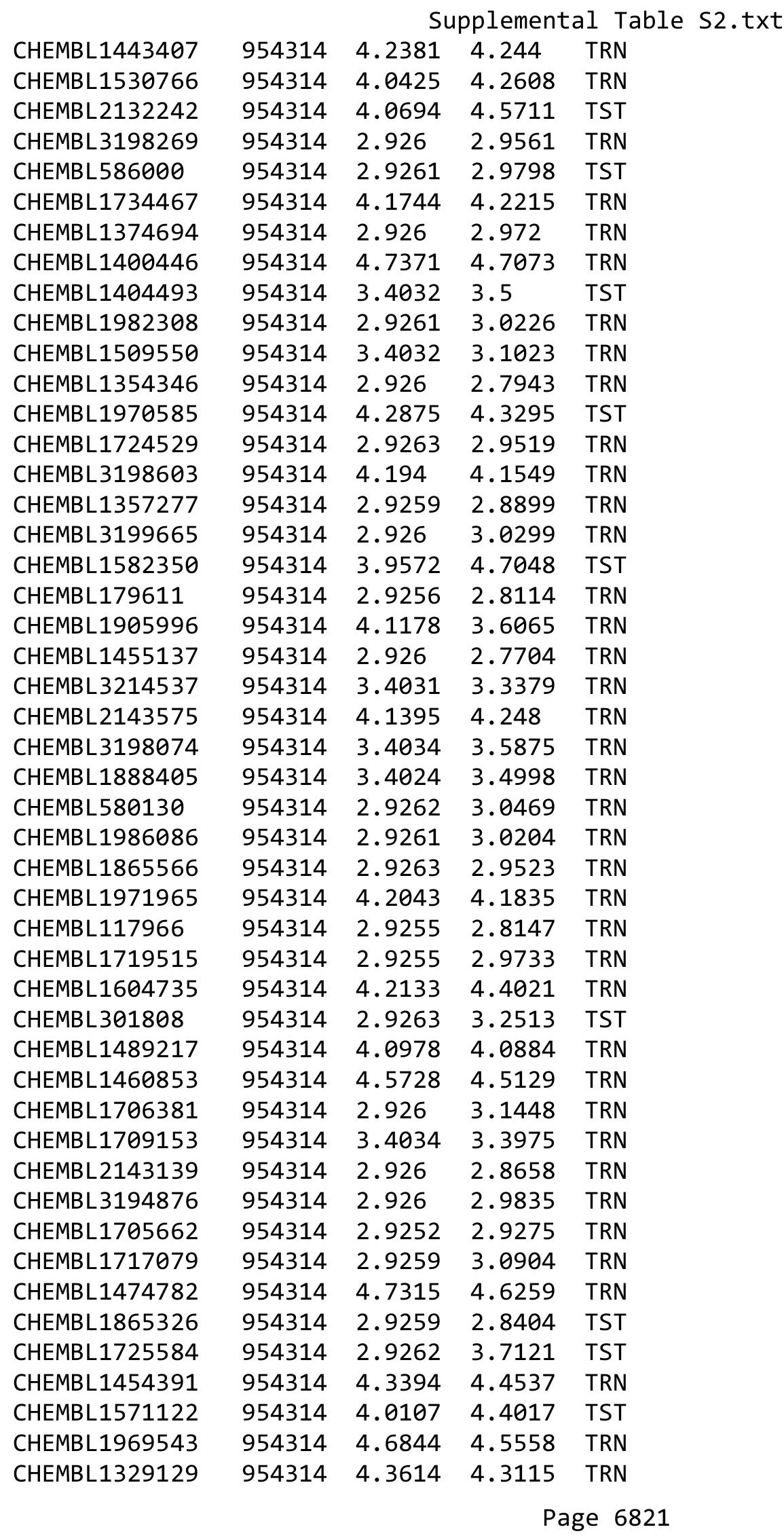




\begin{tabular}{|c|c|c|c|c|c|}
\hline & & \multicolumn{4}{|c|}{ Supplemental Table S2.txt } \\
\hline CHEMBL1718436 & 954314 & 2.926 & 2.9783 & TRN & \\
\hline CHEMBL1528479 & 954314 & 4.197 & 3.6403 & TST & \\
\hline CHEMBL1527358 & 954314 & 2.9263 & 2.6989 & TRN & \\
\hline CHEMBL1869423 & 954314 & 2.9253 & 2.9347 & TRN & \\
\hline CHEMBL1496329 & 954314 & 3.4033 & 3.2792 & TST & \\
\hline CHEMBL1310492 & 737240 & 3.301 & 1.6395 & TST & \\
\hline CHEMBL1589547 & 737240 & 3.301 & 3.4388 & TRN & \\
\hline CHEMBL1454442 & 737240 & 3.301 & 3.2761 & TRN & \\
\hline CHEMBL1434383 & 737240 & 3.301 & 3.4162 & TRN & \\
\hline CHEMBL1312974 & 737240 & 3.301 & 2.9025 & TST & \\
\hline CHEMBL1596823 & 737240 & 3.301 & 3.2949 & TST & \\
\hline CHEMBL1537130 & 737240 & 3.301 & 2.2295 & TST & \\
\hline CHEMBL1451762 & 737240 & 3.301 & 3.3866 & TRN & \\
\hline CHEMBL1466196 & 737240 & 3.301 & 3.1993 & TST & \\
\hline CHEMBL1309877 & 737240 & 3.301 & 3.3066 & TRN & \\
\hline CHEMBL1359716 & 737240 & 3.301 & 3.2283 & TRN & \\
\hline CHEMBL1441577 & 737240 & 3.301 & 3.279 & TRN & \\
\hline CHEMBL1586339 & 737240 & 3.301 & 3.3857 & TRN & \\
\hline CHEMBL1546036 & 737240 & 3.301 & 3.2402 & TRN & \\
\hline CHEMBL1501132 & 737240 & 3.301 & 3.3385 & TRN & \\
\hline CHEMBL1458891 & 737240 & 3.301 & 3.3165 & TRN & \\
\hline CHEMBL1526851 & 737240 & 3.301 & 3.3067 & TRN & \\
\hline CHEMBL530280 & 737240 & 3.301 & 3.1493 & TRN & \\
\hline CHEMBL1444899 & 737240 & 3.301 & 3.42199 & 99999999997 & TRN \\
\hline CHEMBL56731 & 737240 & 3.301 & 3.275 & TRN & \\
\hline CHEMBL 3145293 & 737240 & 3.301 & 3.3843 & TRN & \\
\hline CHEMBL1506144 & 737240 & 3.301 & 3.2053 & TRN & \\
\hline CHEMBL1575007 & 737240 & 3.301 & 3.3508 & TRN & \\
\hline CHEMBL1472502 & 737240 & 3.301 & 3.1399 & TRN & \\
\hline CHEMBL1431711 & 737240 & 3.301 & 2.7061 & TST & \\
\hline CHEMBL1312190 & 737240 & 8.0 & 8.0927 & TRN & \\
\hline CHEMBL1369365 & 737240 & 3.301 & 3.2548 & TRN & \\
\hline CHEMBL1496982 & 737240 & 3.301 & 3.3309 & TRN & \\
\hline CHEMBL3199462 & 737240 & 3.301 & 3.3097 & TRN & \\
\hline CHEMBL1556140 & 737240 & 3.301 & 3.3259 & TRN & \\
\hline CHEMBL1385760 & 737240 & 3.301 & 2.6547 & TST & \\
\hline CHEMBL1407961 & 737240 & 3.301 & 3.3767 & TRN & \\
\hline CHEMBL 3194268 & 737240 & 3.301 & 3.3226 & TRN & \\
\hline CHEMBL1417628 & 737240 & 3.301 & 3.2011 & TST & \\
\hline CHEMBL1421172 & 737240 & 3.301 & 3.2601 & TRN & \\
\hline CHEMBL1598721 & 737240 & 3.301 & 3.2545 & TRN & \\
\hline CHEMBL1486430 & 737240 & 3.301 & 3.2926 & TRN & \\
\hline CHEMBL1387152 & 737240 & 3.301 & 3.3427 & TRN & \\
\hline CHEMBL1371792 & 737240 & 3.301 & 3.30899 & 99999999997 & TRN \\
\hline CHEMBL1508933 & 737240 & 3.301 & 3.2656 & TRN & \\
\hline CHEMBL1173475 & 737240 & 3.301 & 3.3372 & TRN & \\
\hline CHEMBL1498308 & 737240 & 3.301 & 3.2644 & TRN & \\
\hline CHEMBL358546 & 737240 & 3.301 & 3.2144 & TRN & \\
\hline
\end{tabular}




\begin{tabular}{|c|c|c|c|c|c|}
\hline \multirow[b]{2}{*}{ CHEMBL3199536 } & \multicolumn{5}{|c|}{ Supplemental Table S2.txt } \\
\hline & 737240 & 3.301 & 3.3016 & TRN & \\
\hline CHEMBL1523997 & 737240 & 3.301 & 3.2910 & 00000000004 & TRN \\
\hline CHEMBL1480798 & 737240 & 3.301 & 3.3277 & TRN & \\
\hline CHEMBL1344574 & 737240 & 3.301 & 3.2427 & TRN & \\
\hline CHEMBL1383129 & 737240 & 3.301 & 3.3737 & TRN & \\
\hline CHEMBL3210076 & 737240 & 3.301 & 3.2753 & TRN & \\
\hline CHEMBL1340051 & 737240 & 3.301 & 4.1074 & TST & \\
\hline CHEMBL523200 & 737240 & 3.301 & 2.4972 & TST & \\
\hline CHEMBL258767 & 737240 & 3.301 & 3.3154 & TRN & \\
\hline CHEMBL1306556 & 737240 & 3.301 & 2.9717 & TST & \\
\hline CHEMBL1361740 & 737240 & 3.301 & 2.0903 & TST & \\
\hline CHEMBL1595327 & 737240 & 3.301 & 3.4488 & TRN & \\
\hline CHEMBL1365290 & 737240 & 8.0 & 7.7834 & TRN & \\
\hline CHEMBL1463061 & 737240 & 3.301 & 3.2771 & TRN & \\
\hline CHEMBL1517861 & 737240 & 3.301 & 3.2448 & TRN & \\
\hline CHEMBL3197916 & 737240 & 3.301 & 3.2471 & TRN & \\
\hline CHEMBL1471698 & 737240 & 3.301 & 3.2555 & TRN & \\
\hline CHEMBL1554169 & 737240 & 3.301 & 3.0881 & TST & \\
\hline CHEMBL1501392 & 737240 & 3.301 & 3.3594 & TST & \\
\hline CHEMBL1347768 & 737240 & 3.301 & 3.3406 & TRN & \\
\hline CHEMBL1469246 & 737240 & 3.301 & 3.3238 & TRN & \\
\hline CHEMBL1510704 & 737240 & 3.301 & 3.2923 & TRN & \\
\hline CHEMBL1487698 & 737240 & 3.301 & 3.3095 & TRN & \\
\hline CHEMBL1412746 & 737240 & 3.301 & 1.6093 & TST & \\
\hline CHEMBL1471396 & 737240 & 3.301 & 3.2321 & TRN & \\
\hline CHEMBL3193224 & 737240 & 3.301 & 3.6486 & TST & \\
\hline CHEMBL151146 & 737240 & 3.301 & 3.239 & TRN & \\
\hline CHEMBL1308404 & 737240 & 3.301 & 3.3058 & TRN & \\
\hline CHEMBL1986342 & 737240 & 8.0 & 3.2279 & TST & \\
\hline CHEMBL1505222 & 737240 & 3.301 & 3.3077 & TRN & \\
\hline CHEMBL1315133 & 737240 & 3.301 & 3.3157 & TRN & \\
\hline CHEMBL1309385 & 737240 & 3.301 & 3.5011 & TRN & \\
\hline CHEMBL1580799 & 737240 & 3.301 & 3.3792 & TRN & \\
\hline CHEMBL1603516 & 737240 & 3.301 & 3.3243 & TRN & \\
\hline CHEMBL1322695 & 737240 & 3.301 & 3.3341 & TRN & \\
\hline CHEMBL1412521 & 737240 & 3.301 & 2.7978 & TST & \\
\hline CHEMBL1522443 & 737240 & 3.301 & 3.2963 & TRN & \\
\hline CHEMBL 2006519 & 737240 & 3.301 & 3.3472 & TRN & \\
\hline CHEMBL1362221 & 737240 & 3.301 & 3.2857 & TRN & \\
\hline CHEMBL1699206 & 737240 & 3.301 & 3.3083 & TRN & \\
\hline CHEMBL3195953 & 737240 & 3.301 & 3.173 & TRN & \\
\hline CHEMBL1497139 & 737240 & 3.301 & 3.326 & TRN & \\
\hline CHEMBL1350320 & 737240 & 3.301 & 3.3708 & TRN & \\
\hline CHEMBL1976374 & 737240 & 3.301 & 3.2430 & 20000000003 & TRN \\
\hline CHEMBL3194699 & 737240 & 3.301 & 3.2352 & TRN & \\
\hline CHEMBL1464009 & 737240 & 3.301 & 3.3103 & TRN & \\
\hline CHEMBL1418103 & 737240 & 3.301 & 3.653 & TRN & \\
\hline CHEMBL1540581 & 737240 & 3.301 & 3.3114 & TRN & \\
\hline
\end{tabular}




\begin{tabular}{|c|c|c|c|c|c|c|}
\hline & & \multicolumn{5}{|c|}{ Supplemental Table s2.txt } \\
\hline CHEMBL1379418 & 737240 & 3.301 & 3.5396 & TRN & & \\
\hline CHEMBL3191661 & 737240 & 3.301 & 3.2644 & TRN & & \\
\hline CHEMBL1537276 & 737240 & 3.301 & 3.3291 & TRN & & \\
\hline CHEMBL1487716 & 737240 & 3.301 & 3.0272 & TRN & & \\
\hline CHEMBL1543965 & 737240 & 3.301 & 3.2488 & TRN & & \\
\hline CHEMBL1309165 & 737240 & 3.301 & 3.2816 & TRN & & \\
\hline CHEMBL1498201 & 737240 & 3.301 & 3.2032 & TRN & & \\
\hline CHEMBL576038 & 737240 & 3.301 & 3.2618 & TRN & & \\
\hline CHEMBL1986504 & 737240 & 3.301 & 3.3047 & TRN & & \\
\hline CHEMBL1308737 & 737240 & 3.301 & 3.0934 & TRN & & \\
\hline CHEMBL1585191 & 737240 & 3.301 & 2.4491 & TST & & \\
\hline CHEMBL1602106 & 737240 & 8.0 & 7.981 & TRN & & \\
\hline CHEMBL1353516 & 737240 & 3.301 & 3.3524 & TST & & \\
\hline CHEMBL1457008 & 737240 & 3.301 & 3.588 & TST & & \\
\hline CHEMBL1343429 & 737240 & 3.301 & 5.468 & TST & & \\
\hline CHEMBL1594057 & 737240 & 3.301 & 2.4725 & TST & & \\
\hline CHEMBL1608407 & 737240 & 3.301 & 3.43300 & 00000000003 & & TST \\
\hline CHEMBL1564288 & 737240 & 3.301 & 2.93600 & 00000000004 & & TST \\
\hline CHEMBL1594308 & 737240 & 3.301 & 4.1646 & TST & & \\
\hline CHEMBL1596841 & 737240 & 3.301 & 2.7082 & TST & & \\
\hline CHEMBL3198213 & 737240 & 8.0 & 3.79100 & 00000000004 & & TST \\
\hline CHEMBL1718985 & 737171 & 2.4559 & 3.4335 & TRN & & \\
\hline CHEMBL1608389 & 737171 & 3.6626 & 3.8972 & TRN & & \\
\hline CHEMBL1704223 & 737171 & 3.5238 & 3.6344 & TRN & & \\
\hline CHEMBL1406748 & 737171 & 4.5262 & 4.3349 & TRN & & \\
\hline CHEMBL1479166 & 737171 & 3.9054 & 3.6001 & TRN & & \\
\hline CHEMBL1380856 & 737171 & 2.4559 & 3.8268 & TRN & & \\
\hline CHEMBL1532350 & 737171 & 2.4559 & 3.3893 & TRN & & \\
\hline CHEMBL1504675 & 737171 & 3.8415 & 3.3983 & TRN & & \\
\hline CHEMBL1403497 & 737171 & 2.4559 & 3.2418 & TRN & & \\
\hline CHEMBL1728534 & 737171 & 2.4559 & 3.6388 & TRN & & \\
\hline CHEMBL1326833 & 737171 & $3.8710 €$ & 00000000 & 004 & .5618 & TRN \\
\hline CHEMBL3194360 & 737171 & $3.6180 e$ & 30000000 & 003 & .3265 & TRN \\
\hline CHEMBL1416556 & 737171 & 4.3513 & 3.3702 & TRN & & \\
\hline CHEMBL1422894 & 737171 & 3.5392 & 3.9373 & TRN & & \\
\hline CHEMBL1316831 & 737171 & 5.4951 & 5.2345 & TRN & & \\
\hline CHEMBL1399331 & 737171 & 3.7472 & 3.8232 & TST & & \\
\hline CHEMBL1502018 & 737171 & 4.4565 & 4.1478 & TRN & & \\
\hline CHEMBL1376974 & 737171 & 6.2013 & 3.9768 & TST & & \\
\hline CHEMBL1493379 & 737171 & 4.0261 & 4.3288 & TRN & & \\
\hline CHEMBL1386802 & 737171 & 3.5739 & 4.0162 & TRN & & \\
\hline CHEMBL1438979 & 737171 & 3.9458 & 3.96100 & 00000000003 & & TRN \\
\hline CHEMBL1735454 & 737171 & 4.489 & 3.863 & TRN & & \\
\hline CHEMBL1727708 & 737171 & 4.2814 & 3.6594 & TRN & & \\
\hline CHEMBL1586067 & 737171 & 4.0887 & 3.9232 & TRN & & \\
\hline CHEMBL1712572 & 737171 & 2.4559 & 3.0171 & TRN & & \\
\hline CHEMBL1609270 & 737171 & 4.6268 & 3.7468 & TRN & & \\
\hline CHEMBL1716317 & 737171 & 3.6176 & 3.7595 & TRN & & \\
\hline
\end{tabular}


Supplemental Table S2.txt

\begin{tabular}{|c|c|c|c|c|}
\hline CHEMBL1334412 & 737171 & 3.5782 & 3.6143 & TST \\
\hline CHEMBL1565979 & 737171 & 4.1668 & 3.9664 & TRN \\
\hline CHEMBL1722138 & 737171 & 4.3074 & 3.8907 & TRN \\
\hline CHEMBL1523317 & 737171 & 2.4559 & 3.5209 & TRN \\
\hline CHEMBL1562205 & 737171 & 2.4559 & 3.5844 & TRN \\
\hline CHEMBL1720921 & 737171 & 4.3318 & 4.3969 & TRN \\
\hline CHEMBL1365402 & 737171 & 4.1368 & 3.6351 & TRN \\
\hline CHEMBL1552090 & 737171 & 3.8692 & 3.3624 & TRN \\
\hline CHEMBL1304671 & 737171 & 3.5739 & 3.1478 & TRN \\
\hline CHEMBL1719807 & 737171 & 3.9251 & 3.7016 & TRN \\
\hline CHEMBL1451032 & 737171 & 4.2809 & \multicolumn{2}{|c|}{3.9930000000000003} \\
\hline CHEMBL66953 & 737171 & 3.988 & 3.9089 & TRN \\
\hline CHEMBL1412788 & 737171 & 2.4559 & 2.5427 & TRN \\
\hline CHEMBL1701594 & 737171 & 2.4559 & 3.1893 & TRN \\
\hline CHEMBL1593697 & 737171 & 4.2658 & 4.4643 & TST \\
\hline CHEMBL1300398 & 737171 & 4.1569 & \multicolumn{2}{|c|}{3.3689999999999998} \\
\hline CHEMBL1522155 & 737171 & 4.3583 & 3.8737 & TRN \\
\hline CHEMBL1539325 & 737171 & 4.0163 & 3.5345 & TRN \\
\hline CHEMBL1390056 & 737171 & 2.4559 & 3.1928 & TRN \\
\hline CHEMBL1548829 & 737171 & 3.5618 & 3.0139 & TST \\
\hline CHEMBL1423797 & 737171 & 4.0181 & 4.2577 & TRN \\
\hline CHEMBL1506185 & 737171 & 3.5179 & 3.9324 & TRN \\
\hline CHEMBL1707178 & 737171 & 4.2427 & 4.2121 & TRN \\
\hline CHEMBL1968732 & 737171 & 4.6362 & 4.6974 & TRN \\
\hline CHEMBL1540389 & 737171 & 4.2868 & 3.742 & TRN \\
\hline CHEMBL1527008 & 737171 & 4.1268 & 4.8153 & TRN \\
\hline CHEMBL1730051 & 737171 & 5.1122 & 3.8904 & TST \\
\hline CHEMBL1469411 & 737171 & 3.8779 & 3.8027 & TRN \\
\hline CHEMBL1402149 & 737171 & 3.6656 & 3.6567 & TRN \\
\hline CHEMBL1491519 & 737171 & 4.5798 & 3.7549 & TST \\
\hline CHEMBL1608727 & 737171 & 5.5906 & 4.0837 & TRN \\
\hline CHEMBL68096 & 737171 & 4.1858 & \multicolumn{2}{|c|}{3.9410000000000003} \\
\hline CHEMBL1558656 & 737171 & 3.6222 & 3.5821 & TRN \\
\hline CHEMBL1453723 & 737171 & 4.3732 & 3.8375 & TRN \\
\hline CHEMBL1399913 & 737171 & 3.4888 & 3.8082 & TRN \\
\hline CHEMBL1482277 & 737171 & 3.8585 & 3.7288 & TST \\
\hline CHEMBL210208 & 737171 & 5.0488 & 4.8896 & TRN \\
\hline CHEMBL1380078 & 737171 & 3.6715 & 3.6103 & TRN \\
\hline CHEMBL1709562 & 737171 & 4.9405 & 3.8895 & TRN \\
\hline CHEMBL1575811 & 737171 & 2.4559 & 3.6437 & TST \\
\hline CHEMBL1492819 & 737171 & 4.0153 & 3.2094 & TRN \\
\hline CHEMBL1708263 & 737171 & 2.4559 & 3.0578 & TRN \\
\hline CHEMBL1408747 & 737171 & 4.3498 & 3.6493 & TRN \\
\hline CHEMBL1346343 & 737171 & 4.0784 & 3.9005 & TRN \\
\hline CHEMBL1416439 & 737171 & 2.4559 & 3.3494 & TRN \\
\hline CHEMBL1471736 & 737171 & 4.3368 & 3.522 & TRN \\
\hline CHEMBL1556436 & 737171 & 4.1201 & 3.7354 & TRN \\
\hline CHEMBL1981657 & 737171 & 3.8222 & 3.9096 & TRN \\
\hline
\end{tabular}




\begin{tabular}{|c|c|c|c|c|c|c|}
\hline & & \multicolumn{5}{|c|}{ Supplemental Table S2.txt } \\
\hline CHEMBL1698202 & 737171 & 2.4559 & 4.1797 & TST & & \\
\hline CHEMBL1720785 & 737171 & 4.2489 & 4.0658 & TRN & & \\
\hline CHEMBL1398812 & 737171 & 4.1586 & 3.9493 & TRN & & \\
\hline CHEMBL1582006 & 737171 & 3.472 & 3.7348 & TST & & \\
\hline CHEMBL1303641 & 737171 & 4.18 & 4.627 & TRN & & \\
\hline CHEMBL1532953 & 737171 & 3.5043 & 3.5797 & TRN & & \\
\hline CHEMBL69612 & 737171 & \multicolumn{3}{|c|}{4.9030000000000005} & 3.9419 & TRN \\
\hline CHEMBL1709883 & 737171 & \multicolumn{3}{|c|}{5.071000000000001} & 5.0845 & TRN \\
\hline CHEMBL1699763 & 737171 & 3.4657 & 3.75 & TRN & & \\
\hline CHEMBL1460470 & 737171 & 2.4559 & 3.5893 & TRN & & \\
\hline CHEMBL1994837 & 737171 & 4.0724 & 4.0078 & TRN & & \\
\hline CHEMBL1328741 & 737171 & 3.9983 & 3.70600 & 00000 & 004 & TRN \\
\hline CHEMBL3189281 & 737171 & 4.0784 & 3.81399 & 99999 & 996 & TST \\
\hline CHEMBL1448906 & 737171 & 4.4991 & 4.1648 & TRN & & \\
\hline CHEMBL1553368 & 737171 & 4.4683 & 4.4544 & TRN & & \\
\hline CHEMBL1440225 & 737171 & 3.7403 & 4.033 & TRN & & \\
\hline CHEMBL1569232 & 737171 & 4.7675 & 4.5477 & TRN & & \\
\hline CHEMBL1329597 & 737171 & 3.9646 & 3.8151 & TRN & & \\
\hline CHEMBL1362716 & 737171 & \multicolumn{3}{|c|}{3.9410000000000003} & 3.3674 & TRN \\
\hline CHEMBL1545832 & 737171 & 3.5341 & 3.4352 & TRN & & \\
\hline CHEMBL1732480 & 737171 & 3.6086 & 3.6801 & TRN & & \\
\hline CHEMBL1528646 & 737171 & 4.166 & 3.8138 & TRN & & \\
\hline CHEMBL1541890 & 737171 & \multicolumn{3}{|c|}{3.5180000000000002} & 3.4287 & TRN \\
\hline CHEMBL1730100 & 737171 & 3.7482 & 4.2589 & TST & & \\
\hline CHEMBL1547448 & 737171 & 3.7416 & 3.5363 & TRN & & \\
\hline CHEMBL1459189 & 737171 & 4.7843 & 3.9351 & TST & & \\
\hline CHEMBL1469148 & 737171 & 2.4559 & 3.0407 & TRN & & \\
\hline CHEMBL1353231 & 737171 & 4.3716 & 3.7446 & TRN & & \\
\hline CHEMBL1990694 & 737171 & 2.4559 & 3.8195 & TRN & & \\
\hline CHEMBL1732334 & 737171 & 4.0875 & 3.5872 & TRN & & \\
\hline CHEMBL1730974 & 737171 & 3.6323 & 4.0412 & TRN & & \\
\hline CHEMBL1578670 & 737171 & 3.6863 & 3.4863 & TRN & & \\
\hline CHEMBL3193261 & 737171 & 3.5114 & 3.68899 & 99999 & 996 & TRN \\
\hline CHEMBL1341064 & 737171 & 4.6013 & 4.1133 & TRN & & \\
\hline CHEMBL1600449 & 737171 & 3.8789 & 3.4424 & TRN & & \\
\hline CHEMBL1526866 & 737171 & 2.4559 & 3.0696 & TRN & & \\
\hline CHEMBL1375215 & 737171 & 3.9127 & 3.3533 & TST & & \\
\hline CHEMBL1503852 & 737171 & 2.4559 & 3.5708 & TRN & & \\
\hline CHEMBL1510317 & 737171 & 4.6948 & 3.9086 & TRN & & \\
\hline CHEMBL1732657 & 737171 & 2.4559 & 4.0181 & TRN & & \\
\hline CHEMBL601385 & 737171 & 4.0075 & 3.7843 & TRN & & \\
\hline CHEMBL1733061 & 737171 & 4.2091 & 3.2828 & TST & & \\
\hline CHEMBL1398964 & 737171 & 4.6036 & 4.2713 & TRN & & \\
\hline CHEMBL1595246 & 737171 & 4.1897 & 3.8709 & TRN & & \\
\hline CHEMBL1720977 & 737171 & 3.8683 & 3.3314 & TRN & & \\
\hline CHEMBL1612106 & 737171 & 4.5066 & 3.1744 & TRN & & \\
\hline CHEMBL1371745 & 737171 & 4.2036 & 3.513 & TRN & & \\
\hline CHEMBL1509840 & 737171 & 3.5594 & 3.1295 & TRN & & \\
\hline
\end{tabular}


Supplemental Table S2.txt

\begin{tabular}{|c|c|c|c|c|c|}
\hline CHEMBL1323674 & 737171 & 2.4559 & 3.2099 & TRN & \\
\hline CHEMBL1473698 & 737171 & 4.0204 & 3.4691 & TRN & \\
\hline CHEMBL1464009 & 737171 & 3.5456 & 3.7571 & TRN & \\
\hline CHEMBL1402117 & 737171 & 2.4559 & 3.4274 & TST & \\
\hline CHEMBL1724719 & 737171 & 4.0365 & 3.8553 & TRN & \\
\hline CHEMBL1567396 & 737171 & 3.5574 & 3.3765 & TST & \\
\hline CHEMBL1468011 & 737171 & 3.5039 & 3.5521 & TRN & \\
\hline CHEMBL1704214 & 737171 & 3.9096 & 3.7663 & TRN & \\
\hline CHEMBL1450597 & 737171 & 4.2205 & 3.6191 & TRN & \\
\hline CHEMBL1393337 & 737171 & 2.4559 & 3.7101 & TRN & \\
\hline CHEMBL1390971 & 737171 & 3.5787 & 4.3569 & TRN & \\
\hline CHEMBL3212625 & 737171 & 4.3591 & 4.1894 & TRN & \\
\hline CHEMBL1432696 & 737171 & 3.6001 & 3.7878 & TRN & \\
\hline CHEMBL1566394 & 737171 & 2.4559 & 3.7185 & TRN & \\
\hline CHEMBL1394008 & 737171 & 4.3387 & 3.8245 & TST & \\
\hline CHEMBL1468698 & 737171 & 4.2381 & 3.8455 & TST & \\
\hline CHEMBL1999137 & 737171 & 2.4559 & 3.8787 & TST & \\
\hline CHEMBL1345866 & 737171 & 3.5275 & 4.2719 & TST & \\
\hline CHEMBL1606122 & 737171 & 4.3678 & 4.5786 & TST & \\
\hline CHEMBL 1300510 & 737171 & 3.7445 & 3.9875 & TST & \\
\hline CHEMBL1532925 & 737171 & 2.4559 & 4.1222 & TST & \\
\hline CHEMBL1393490 & 737171 & 4.4516 & 3.9132 & TST & \\
\hline CHEMBL1731790 & 737171 & 4.3596 & 4.0656 & TST & \\
\hline CHEMBL1736648 & 737171 & 2.4559 & 3.5313 & TST & \\
\hline CHEMBL1313968 & 737171 & 4.7832 & 4.2141 & TST & \\
\hline CHEMBL1711245 & 737171 & 5.9952 & 3.5582 & TST & \\
\hline CHEMBL1575701 & 737171 & 3.8225 & 4.2083 & TST & \\
\hline CHEMBL1363572 & 737171 & 2.4559 & 3.7695 & TST & \\
\hline CHEMBL201289 & 737171 & 3.9741 & 3.4632 & TST & \\
\hline CHEMBL1380219 & 737171 & 4.0894 & 3.3262 & TST & \\
\hline CHEMBL1401891 & 737171 & 4.1459 & 3.9513 & TST & \\
\hline CHEMBL1722325 & 737171 & 5.4706 & 5.3187 & TST & \\
\hline CHEMBL1534986 & 737171 & 4.1733 & 3.7886 & TST & \\
\hline CHEMBL1341565 & 737171 & 2.4559 & 3.3873 & TST & \\
\hline CHEMBL1426526 & 737171 & 3.5826 & 4.4192 & TST & \\
\hline CHEMBL1721855 & 737171 & 5.1001 & 3.6428 & TST & \\
\hline CHEMBL3964700 & 1640339 & 5.1805 & 5.6458 & TRN & \\
\hline CHEMBL3936165 & 1640339 & 5.1805 & 5.532999 & 99999999995 & TRN \\
\hline CHEMBL3891462 & 1640339 & 6.4577 & 6.9917 & TST & \\
\hline CHEMBL3943518 & 1640339 & 6.7881 & 7.5745 & TRN & \\
\hline CHEMBL3978975 & 1640339 & 9.0004 & 7.7635 & TRN & \\
\hline CHEMBL3967294 & 1640339 & 5.1805 & 5.3385 & TST & \\
\hline CHEMBL3966550 & 1640339 & 7.5249 & 6.4923 & TRN & \\
\hline CHEMBL3939258 & 1640339 & 7.0861 & 6.3676 & TRN & \\
\hline CHEMBL3940998 & 1640339 & 5.1805 & 5.7022 & TRN & \\
\hline CHEMBL3912324 & 1640339 & 7.6983 & 7.0164 & TRN & \\
\hline CHEMBL3954930 & 1640339 & 5.1805 & 5.5156 & TST & \\
\hline CHEMBL3920900 & 1640339 & 5.1805 & 6.6934 & TRN & \\
\hline
\end{tabular}




\begin{tabular}{|c|c|c|c|c|c|c|}
\hline \multicolumn{6}{|c|}{ Supplemental Table S2.txt } & TRN \\
\hline CHEMBL3985319 & 1640339 & 8.6494 & 7.0233 & TRN & & \\
\hline CHEMBL3978581 & 1640339 & 5.1805 & 5.4086 & TST & & \\
\hline CHEMBL3924508 & 1640339 & 5.1805 & 6.0146 & TRN & & \\
\hline CHEMBL3961388 & 1640339 & 5.1805 & 5.4871 & TRN & & \\
\hline CHEMBL3944877 & 1640339 & 5.1805 & 6.3623 & TRN & & \\
\hline CHEMBL3960779 & 1640339 & 7.1222 & 6.8268 & TST & & \\
\hline CHEMBL 3904260 & 1640339 & 8.0816 & 6.7705 & TRN & & \\
\hline CHEMBL3953668 & 1640339 & 8.4582 & 7.2063 & TRN & & \\
\hline CHEMBL3896071 & 1640339 & 7.7435 & 7.8482 & TRN & & \\
\hline CHEMBL3954186 & 1640339 & 7.1275 & 8.5741 & TRN & & \\
\hline CHEMBL3894614 & 1640339 & 5.1805 & 6.0666 & TRN & & \\
\hline CHEMBL3966122 & 1640339 & 5.1805 & 5.9017 & TRN & & \\
\hline CHEMBL3965616 & 1640339 & 7.6041 & 6.6166 & TRN & & \\
\hline CHEMBL3920721 & 1640339 & 8.3154 & 6.9407 & TRN & & \\
\hline CHEMBL3958568 & 1640339 & 5.1805 & 7.1151 & TST & & \\
\hline CHEMBL3978226 & 1640339 & 6.9235 & 6.7094 & TRN & & \\
\hline CHEMBL 3957503 & 1640339 & 7.9158 & 7.7756 & TRN & & \\
\hline CHEMBL3898333 & 1640339 & 5.1805 & 6.1779 & TRN & & \\
\hline CHEMBL3891608 & 1640339 & 6.7184 & 6.3116 & TST & & \\
\hline CHEMBL 3947347 & 1640339 & 5.1805 & 6.1446 & TRN & & \\
\hline CHEMBL3958319 & 1640339 & 5.1805 & 6.0302 & TRN & & \\
\hline CHEMBL 3917217 & 1640339 & 5.1805 & 7.1141 & TRN & & \\
\hline CHEMBL3900051 & 1640339 & 6.6752 & 6.9397 & TST & & \\
\hline CHEMBL 3903984 & 1640339 & 5.1805 & 5.8338 & TST & & \\
\hline CHEMBL 3924651 & 1640339 & 5.1805 & 6.1067 & TRN & & \\
\hline CHEMBL3896412 & 1640339 & 6.7693 & 7.3018 & TST & & \\
\hline CHEMBL 3952752 & 1640339 & 7.2086 & 6.7947 & TRN & & \\
\hline CHEMBL3916963 & 1640339 & 7.6108 & 6.5263 & TRN & & \\
\hline CHEMBL3902739 & 1640339 & 7.4944 & 6.4192 & TRN & & \\
\hline CHEMBL 3927297 & 1640339 & 5.1805 & 6.595 & TST & & \\
\hline CHEMBL 3986021 & 1640339 & 5.1805 & 5.6742 & TST & & \\
\hline CHEMBL 3940219 & 1640339 & 7.934 & 7.8463 & TRN & & \\
\hline CHEMBL3973269 & 1640339 & 5.1805 & 5.7357 & TRN & & \\
\hline CHEMBL 3976891 & 1640339 & 2.1805 & 5.1979 & TRN & & \\
\hline CHEMBL 3915240 & 1640339 & 7.7575 & 8.1526 & TRN & & \\
\hline CHEMBL3937978 & 1640339 & 8.1871 & 7.4877 & TRN & & \\
\hline CHEMBL 3975336 & 1640339 & 7.4579 & 6.1356 & TST & & \\
\hline CHEMBL3969380 & 1640339 & 9.3851 & 6.9689 & TRN & & \\
\hline CHEMBL 3919879 & 1640339 & 6.9275 & 6.2519 & TST & & \\
\hline CHEMBL3952182 & 1640339 & 7.3512 & 7.2935 & TST & & \\
\hline CHEMBL 3889500 & 1640339 & 7.0555 & 6.2142 & TRN & & \\
\hline CHEMBL3924145 & 1640339 & 7.7222 & 7.29899 & 99999999995 & TRN & \\
\hline CHEMBL3903112 & 1640339 & 7.519 & 7.4935 & TST & & \\
\hline CHEMBL 3936065 & 1640339 & 5.1805 & 5.612 & TRN & & \\
\hline CHEMBL 3903058 & 1640339 & 8.2996 & 6.5977 & TRN & & \\
\hline CHEMBL3958980 & 1640339 & 6.6666 & 6.2271 & TRN & & \\
\hline CHEMBL3942598 & 1640339 & 7.5702 & 8.587 & TRN & & \\
\hline
\end{tabular}


Supplemental Table S2.txt

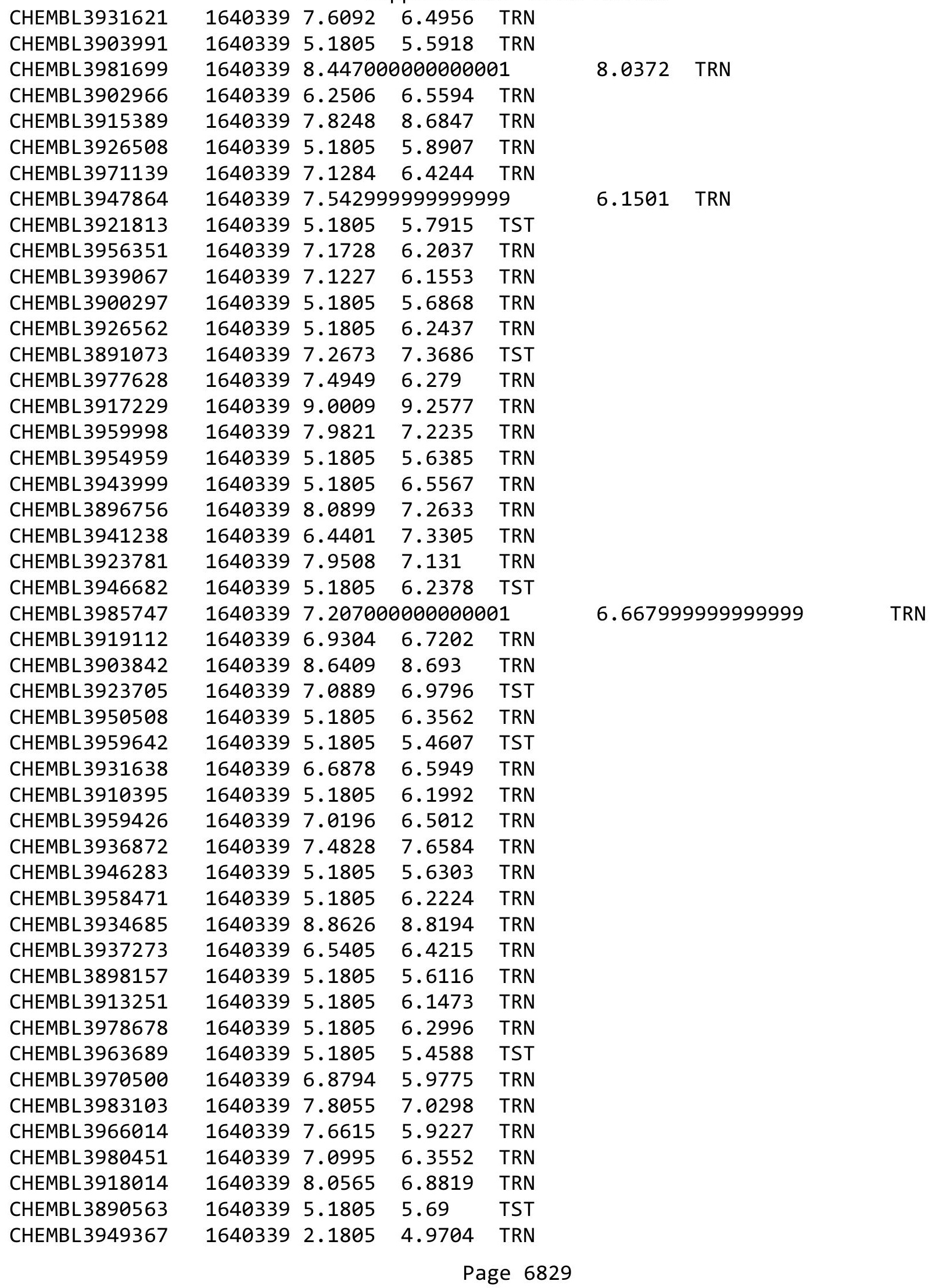


Supplemental Table S2.txt

\begin{tabular}{|c|c|c|c|c|c|}
\hline CHEMBL3966012 & 1640339 & 5.1805 & 5.5658 & TRN & \\
\hline CHEMBL3965940 & 1640339 & 7.8548 & 6.3415 & TRN & \\
\hline CHEMBL3944216 & 1640339 & 7.25700 & 20000000 & & 6.5897 \\
\hline CHEMBL3897955 & 1640339 & 5.1805 & 5.4153 & TRN & \\
\hline CHEMBL 3900203 & 1640339 & 5.1805 & 6.0555 & TRN & \\
\hline CHEMBL3961726 & 1640339 & 5.1805 & 5.5864 & TST & \\
\hline CHEMBL 3941440 & 1640339 & 6.8397 & 6.8914 & TRN & \\
\hline CHEMBL3927035 & 1640339 & 6.7422 & 6.9782 & TRN & \\
\hline CHEMBL3946235 & 1640339 & 8.2108 & 7.9673 & TRN & \\
\hline CHEMBL3934225 & 1640339 & 5.1805 & 5.4873 & TST & \\
\hline CHEMBL3964470 & 1640339 & 5.1805 & 6.2467 & TRN & \\
\hline CHEMBL3913917 & 1640339 & 6.6821 & 6.0576 & TRN & \\
\hline CHEMBL3931993 & 1640339 & 5.1805 & 5.5498 & TRN & \\
\hline CHEMBL3969409 & 1640339 & 6.9363 & 6.0574 & TRN & \\
\hline CHEMBL 3975600 & 1640339 & 5.1805 & 6.0554 & TRN & \\
\hline CHEMBL3973865 & 1640339 & 5.1805 & 5.9043 & TRN & \\
\hline CHEMBL3986307 & 1640339 & 5.1805 & 5.7801 & TRN & \\
\hline CHEMBL3959296 & 1640339 & 7.1862 & 6.5547 & TRN & \\
\hline CHEMBL3960071 & 1640339 & 6.3264 & 6.4369 & TRN & \\
\hline CHEMBL3901850 & 1640339 & 8.0807 & 7.7132 & TRN & \\
\hline CHEMBL3926441 & 1640339 & 7.7131 & 8.821 & TST & \\
\hline CHEMBL3933631 & 1640339 & 6.7775 & 6.5791 & TST & \\
\hline CHEMBL3964784 & 1640339 & 6.477 & 5.5978 & TST & \\
\hline CHEMBL3891258 & 1640339 & 8.0256 & 6.9877 & TRN & \\
\hline CHEMBL3925951 & 1640339 & 7.1825 & 6.2292 & TRN & \\
\hline CHEMBL3946628 & 1640339 & 5.1805 & 6.4064 & TRN & \\
\hline CHEMBL3898457 & 1640339 & 7.3524 & 5.982 & TRN & \\
\hline CHEMBL3896889 & 1640339 & 5.1805 & 5.3023 & TST & \\
\hline CHEMBL3925990 & 1640339 & 8.2663 & 7.9348 & TST & \\
\hline CHEMBL 3917378 & 1640339 & 5.1805 & 6.8961 & TRN & \\
\hline CHEMBL3941252 & 1640339 & 8.2573 & 6.9767 & TRN & \\
\hline CHEMBL3960235 & 1640339 & 7.3944 & 6.8983 & TST & \\
\hline CHEMBL3940132 & 1640339 & 7.6137 & 8.5371 & TRN & \\
\hline CHEMBL 3942674 & 1640339 & 5.1805 & 5.6582 & TRN & \\
\hline CHEMBL 3894740 & 1640339 & 6.2433 & 5.5852 & TRN & \\
\hline CHEMBL3970318 & 1640339 & 8.366 & 6.9399 & TRN & \\
\hline CHEMBL 3927113 & 1640339 & 8.4438 & 8.549 & TRN & \\
\hline CHEMBL3963652 & 1640339 & 5.1805 & 6.3068 & TRN & \\
\hline CHEMBL 3901008 & 1640339 & 7.6156 & 6.1986 & TRN & \\
\hline CHEMBL 3954914 & 1640339 & 8.0297 & 7.272 & TRN & \\
\hline CHEMBL3948846 & 1640339 & 7.0018 & 7.1069 & TRN & \\
\hline CHEMBL 3897821 & 1640339 & 6.7752 & 5.9809 & TRN & \\
\hline CHEMBL3947179 & 1640339 & 8.4855 & 7.3629 & TRN & \\
\hline CHEMBL3926835 & 1640339 & 7.8041 & 6.8741 & TRN & \\
\hline CHEMBL 3958123 & 1640339 & 5.1805 & 5.6408 & TRN & \\
\hline CHEMBL3898202 & 1640339 & 5.1805 & 5.8579 & TST & \\
\hline CHEMBL 3929366 & 1640339 & 6.7045 & 6.0156 & TRN & \\
\hline CHEMBL 3894022 & 1640339 & 5.1805 & 5.984 & TRN & \\
\hline
\end{tabular}


Supplemental Table S2.txt

\begin{tabular}{|c|c|c|c|c|c|}
\hline CHEMBL3902661 & 1640339 & 7.494 & 7.8993 & TRN & \\
\hline CHEMBL3933426 & 1640339 & 5.1805 & 4.6578 & TRN & \\
\hline CHEMBL 3958388 & 1640339 & 5.1805 & 5.4839 & TST & \\
\hline CHEMBL 3974371 & 1640339 & 5.1805 & 6.3761 & TST & \\
\hline CHEMBL3960525 & 1640339 & 7.6556 & 6.3376 & TRN & \\
\hline CHEMBL3928046 & 1640339 & 5.1805 & 5.7679 & TST & \\
\hline CHEMBL3951418 & 1640339 & 7.8677 & 7.2204 & TST & \\
\hline CHEMBL 3987182 & 1640339 & 6.8903 & 6.0608 & TRN & \\
\hline CHEMBL3896974 & 1640339 & 6.9818 & 6.6474 & TRN & \\
\hline CHEMBL3953586 & 1640339 & 7.2836 & 6.2076 & TRN & \\
\hline CHEMBL 3910443 & 1640339 & 5.1805 & 4.9686 & TST & \\
\hline CHEMBL3946148 & 1640339 & 7.1815 & 7.3527 & TST & \\
\hline CHEMBL 3937341 & 1640339 & 7.2863 & 6.4033 & TRN & \\
\hline CHEMBL3897702 & 1640339 & 7.6158 & 8.8991 & TRN & \\
\hline CHEMBL 3914675 & 1640339 & 7.713999 & 99999999 & 995 & 7.0805 \\
\hline CHEMBL3945131 & 1640339 & 8.1692 & 8.6516 & TRN & \\
\hline CHEMBL3972754 & 1640339 & 6.8861 & 6.5049 & TST & \\
\hline CHEMBL3962964 & 1640339 & 5.1805 & 5.686 & TST & \\
\hline CHEMBL3927254 & 1640339 & 5.1805 & 4.3415 & TRN & \\
\hline CHEMBL 3980235 & 1640339 & 6.869 & 7.6141 & TRN & \\
\hline CHEMBL376408 & 1640339 & 10.0969 & 7.1706 & TST & \\
\hline CHEMBL3969006 & 1640339 & 5.1805 & 6.3389 & TRN & \\
\hline CHEMBL3967495 & 1640339 & 5.1805 & 5.4195 & TRN & \\
\hline CHEMBL3936986 & 1640339 & 6.902 & 6.3097 & TRN & \\
\hline CHEMBL 3905314 & 1640339 & 5.1805 & 5.5246 & TRN & \\
\hline CHEMBL3913455 & 1640339 & 5.1805 & 6.095 & TRN & \\
\hline CHEMBL3903974 & 1640339 & 6.5469 & 7.0357 & TRN & \\
\hline CHEMBL3975869 & 1640339 & 7.1194 & 6.814 & TST & \\
\hline CHEMBL3907686 & 1640339 & 6.7105 & 6.9366 & TRN & \\
\hline CHEMBL3929559 & 1640339 & 5.1805 & 5.3035 & TST & \\
\hline CHEMBL3983530 & 1640339 & 5.1805 & 6.1067 & TRN & \\
\hline CHEMBL3920522 & 1640339 & 7.2351 & 6.2986 & TRN & \\
\hline CHEMBL3940891 & 1640339 & 8.2696 & 7.8458 & TRN & \\
\hline CHEMBL3947358 & 1640339 & 5.1805 & 5.5268 & TST & \\
\hline CHEMBL3906823 & 1640339 & 6.7204 & 6.025 & TRN & \\
\hline CHEMBL3921240 & 1640339 & 6.4185 & 6.309 & TRN & \\
\hline CHEMBL3912830 & 1640339 & 5.9014 & 6.4278 & TRN & \\
\hline CHEMBL3909402 & 1640339 & 7.013 & 6.4302 & TRN & \\
\hline CHEMBL3946863 & 1640339 & 6.8096 & 6.7102 & TRN & \\
\hline CHEMBL3910037 & 1640339 & 6.0 & 8.754 & TRN & \\
\hline CHEMBL3962755 & 1640339 & 7.7249 & 6.482 & TST & \\
\hline CHEMBL3939500 & 1640339 & 8.0031 & 7.4018 & TRN & \\
\hline CHEMBL3949068 & 1640339 & 5.1805 & 5.0858 & TRN & \\
\hline CHEMBL3975130 & 1640339 & 8.3147 & 7.029 & TRN & \\
\hline CHEMBL3907359 & 1640339 & 5.1805 & 5.8764 & TRN & \\
\hline CHEMBL3954743 & 1640339 & 7.0141 & 7.255 & TST & \\
\hline CHEMBL 3935047 & 1640339 & 8.8517 & 9.2059 & TRN & \\
\hline CHEMBL3949504 & 1640339 & 5.1805 & 6.023 & TRN & \\
\hline
\end{tabular}


Supplemental Table S2.txt

\begin{tabular}{|c|c|c|c|c|c|c|}
\hline CHEMBL 3892405 & 1640339 & 5.1805 & 5.9324 & TRN & & \\
\hline CHEMBL3976936 & 1640339 & 6.3507 & 6.3794 & TRN & & \\
\hline CHEMBL 3915506 & 1640339 & 7.5602 & 6.838999 & 999999999 & 95 & TRN \\
\hline CHEMBL 3963754 & 1640339 & 5.1805 & 6.0385 & TST & & \\
\hline CHEMBL 3940742 & 1640339 & 7.5379 & 6.7844 & TRN & & \\
\hline CHEMBL 3961029 & 1640339 & 5.1805 & 6.1067 & TRN & & \\
\hline CHEMBL 3942015 & 1640339 & 7.7964 & 7.518 & TST & & \\
\hline CHEMBL 3965839 & 1640339 & 7.0786 & 6.002000 & 0000000001 & & TRN \\
\hline CHEMBL 3915578 & 1640339 & 7.142 & 7.6761 & TST & & \\
\hline CHEMBL 3984191 & 1640339 & 5.1805 & 6.491000 & 3000000006 & 05 & TRN \\
\hline CHEMBL 3903430 & 1640339 & 6.9147 & 6.0478 & TST & & \\
\hline CHEMBL 3921893 & 1640339 & 5.1805 & 6.5588 & TRN & & \\
\hline CHEMBL 3966191 & 1640339 & 5.1805 & 6.8017 & TST & & \\
\hline CHEMBL 3974950 & 1640339 & 8.1277 & 7.7857 & TRN & & \\
\hline CHEMBL 3942110 & 1640339 & 6.99299 & 999999999 & 99 & 7.4827 & 13 \\
\hline CHEMBL 3964351 & 1640339 & 8.2814 & 7.7982 & TRN & & \\
\hline CHEMBL3912991 & 1640339 & 8.3333 & 7.0849 & TRN & & \\
\hline CHEMBL 3970422 & 1640339 & 7.0315 & 7.5811 & TRN & & \\
\hline CHEMBL 3936143 & 1640339 & 7.4738 & 8.8294 & TST & & \\
\hline CHEMBL 3937401 & 1640339 & 5.1805 & 6.3592 & TRN & & \\
\hline CHEMBL 3952778 & 1640339 & 5.1805 & 6.6025 & TST & & \\
\hline CHEMBL 3952543 & 1640339 & 8.42 & 6.5886 & TRN & & \\
\hline CHEMBL 3921268 & 1640339 & 6.2378 & 5.9783 & TRN & & \\
\hline CHEMBL 3909627 & 1640339 & 7.4384 & 7.9949 & TRN & & \\
\hline CHEMBL 3917155 & 1640339 & 5.1805 & 5.7269 & TRN & & \\
\hline CHEMBL 3961749 & 1640339 & 5.1805 & 6.2173 & TRN & & \\
\hline CHEMBL 3926217 & 1640339 & 5.1805 & 5.7976 & TRN & & \\
\hline CHEMBL 3980846 & 1640339 & 5.1805 & 5.2277 & TRN & & \\
\hline CHEMBL 3983012 & 1640339 & 5.1805 & 6.2569 & TRN & & \\
\hline CHEMBL 3948599 & 1640339 & 5.1805 & 7.4815 & TRN & & \\
\hline CHEMBL 3935432 & 1640339 & 5.1805 & 6.3511 & TRN & & \\
\hline CHEMBL 3942215 & 1640339 & 5.1805 & 6.202000 & 3000000001 & & \\
\hline CHEMBL3911950 & 1640339 & 6.8847 & 6.0788 & TRN & & \\
\hline CHEMBL 3924048 & 1640339 & 8.3817 & 7.3425 & TRN & & \\
\hline CHEMBL 3985520 & 1640339 & 5.1805 & 6.3162 & TRN & & \\
\hline CHEMBL3979135 & 1640339 & 5.1805 & 5.9712 & TRN & & \\
\hline CHEMBL 3974863 & 1640339 & 7.9918 & 7.4582 & TRN & & \\
\hline CHEMBL 3944409 & 1640339 & 6.8764 & 6.4703 & TRN & & \\
\hline CHEMBL 3931033 & 1640339 & 7.3088 & 6.4563 & TRN & & \\
\hline CHEMBL 3981492 & 1640339 & 8.2049 & 8.1887 & TRN & & \\
\hline CHEMBL 3900060 & 1640339 & 4.9999 & 6.6935 & TRN & & \\
\hline CHEMBL 3935346 & 1640339 & 5.1805 & 4.7205 & TRN & & \\
\hline CHEMBL 3945033 & 1640339 & 8.4401 & 8.957 & TRN & & \\
\hline CHEMBL 3935266 & 1640339 & \multicolumn{3}{|c|}{7.6160000000000005} & 6.5572 & \\
\hline CHEMBL 3904468 & 1640339 & 7.4827 & 7.5609 & TST & & \\
\hline CHEMBL 3913997 & 1640339 & 8.046 & 6.8497 & TRN & & \\
\hline CHEMBL 3979321 & 1640339 & \multicolumn{3}{|c|}{7.281000000000001} & 6.7786 & \\
\hline CHEMBL 3936256 & 1640339 & 8.2509 & 7.2159 & TRN & & \\
\hline
\end{tabular}


Supplemental Table S2.txt

\begin{tabular}{|c|c|c|c|c|c|}
\hline CHEMBL3972201 & 1640339 & 5.1805 & 5.8822 & TRN & \\
\hline CHEMBL3895642 & 1640339 & 5.1805 & 4.0685 & TRN & \\
\hline CHEMBL 3923448 & 1640339 & 8.6351 & 7.5706 & TST & \\
\hline CHEMBL3891905 & 1640339 & 6.4155 & 5.8537 & TRN & \\
\hline CHEMBL 3945520 & 1640339 & 6.2831 & 7.356 & TST & \\
\hline CHEMBL3966367 & 1640339 & 7.8582 & 7.7066 & TRN & \\
\hline CHEMBL3971312 & 1640339 & 8.3303 & 7.1605 & TRN & \\
\hline CHEMBL 3942371 & 1640339 & 7.3421 & 8.3667 & TRN & \\
\hline CHEMBL3977138 & 1640339 & 5.1805 & 5.4543 & TRN & \\
\hline CHEMBL3921039 & 1640339 & 6.6377 & 6.9104 & TRN & \\
\hline CHEMBL3926141 & 1640339 & 7.0673 & 7.7708 & TST & \\
\hline CHEMBL3909289 & 1640339 & 6.5844 & 6.3258 & TRN & \\
\hline CHEMBL3962175 & 1640339 & 7.1324 & 7.1808 & TRN & \\
\hline CHEMBL 3971663 & 1640339 & 7.4292 & 7.545 & TST & \\
\hline CHEMBL3910432 & 1640339 & 8.4377 & 7.0462 & TST & \\
\hline CHEMBL 3937253 & 1640339 & 7.7486 & 7.7429 & TST & \\
\hline CHEMBL3976616 & 1640339 & 5.1805 & 6.1244 & TRN & \\
\hline CHEMBL3935970 & 1640339 & 5.1805 & 6.1577 & TRN & \\
\hline CHEMBL3953161 & 1640339 & 5.1805 & 5.8759 & TST & \\
\hline CHEMBL 3920020 & 1640339 & 5.1805 & 6.79799 & 9999999999 & TST \\
\hline CHEMBL3907427 & 1640339 & 7.3491 & 6.9458 & TST & \\
\hline CHEMBL3794549 & 1640339 & 5.1805 & 7.1478 & TST & \\
\hline CHEMBL3945900 & 1640339 & 8.5832 & 6.9179 & TRN & \\
\hline CHEMBL3901351 & 1640339 & 8.3888 & 6.8672 & TRN & \\
\hline CHEMBL 3893467 & 1640339 & 7.5977 & 6.6672 & TRN & \\
\hline CHEMBL3969223 & 1640339 & 7.7233 & 8.2566 & TRN & \\
\hline CHEMBL3955794 & 1640339 & 7.0524 & 6.9343 & TST & \\
\hline CHEMBL3986974 & 1640339 & 8.1733 & 6.9572 & TRN & \\
\hline CHEMBL3919328 & 1640339 & 5.1805 & 6.0824 & TRN & \\
\hline CHEMBL 3897950 & 1640339 & \multicolumn{3}{|c|}{6.617000000000001} & TRN \\
\hline CHEMBL3899530 & 1640339 & 5.1805 & 5.6775 & TST & \\
\hline CHEMBL 3898982 & 1640339 & 5.1805 & 6.9242 & TRN & \\
\hline CHEMBL3916510 & 1640339 & 7.3197 & 6.5223 & TRN & \\
\hline CHEMBL3933468 & 1640339 & 9.4112 & 9.3064 & TRN & \\
\hline CHEMBL3910577 & 1640339 & 8.2862 & 7.3206 & TRN & \\
\hline CHEMBL3909113 & 1640339 & 5.1805 & 5.2465 & TRN & \\
\hline CHEMBL 3984987 & 1640339 & 8.2668 & 6.7373 & TRN & \\
\hline CHEMBL3976473 & 1640339 & 7.4366 & 6.9848 & TRN & \\
\hline CHEMBL3943823 & 1640339 & 7.0357 & 6.5493 & TST & \\
\hline CHEMBL3931934 & 1640339 & 5.1805 & 5.5787 & TRN & \\
\hline CHEMBL3963584 & 1640339 & 5.1805 & 5.5764 & TRN & \\
\hline CHEMBL3931238 & 1640339 & 5.1805 & 5.0403 & TRN & \\
\hline CHEMBL3952850 & 1640339 & 6.5384 & 6.8888 & TST & \\
\hline CHEMBL3965841 & 1640339 & 6.4887 & 6.5945 & TRN & \\
\hline CHEMBL3985947 & 1640339 & 7.1935 & 6.1574 & TRN & \\
\hline CHEMBL3961090 & 1640339 & 5.1805 & 6.841 & TST & \\
\hline CHEMBL 3946056 & 1640339 & 6.8603 & 7.0112 & TRN & \\
\hline CHEMBL3972195 & 1640339 & 7.0194 & 7.2201 & TST & \\
\hline
\end{tabular}


Supplemental Table S2.txt

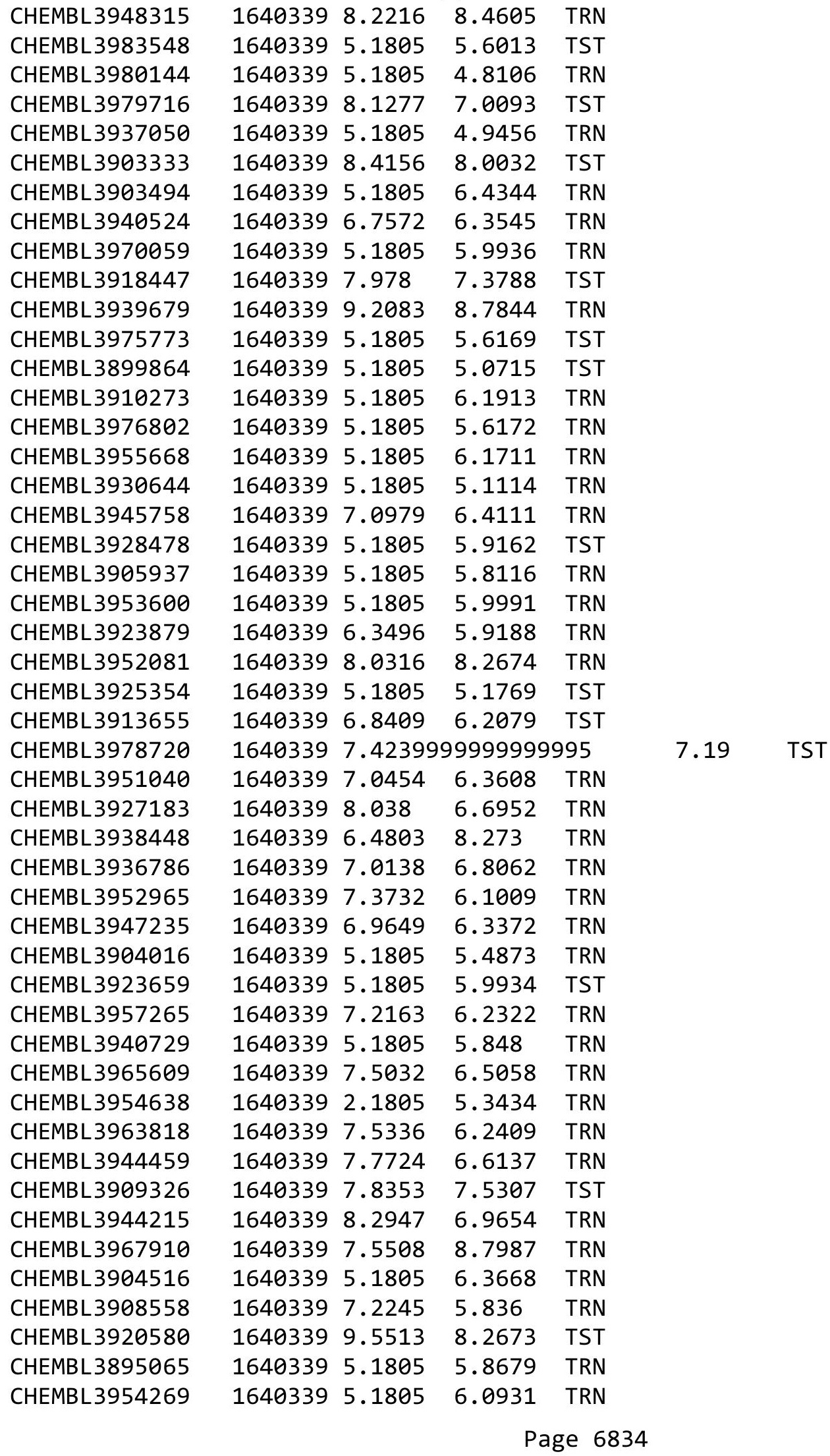


Supplemental Table S2.txt

\begin{tabular}{|c|c|c|c|c|}
\hline 93 & 540339 & 6.3906 & & \\
\hline HEMBL3987116 & 640339 & 7.8441 & 7.2751 & \\
\hline & 339 & 805 & & \\
\hline 89609 & 339 & 805 & & \\
\hline IEMBL 3930022 & 39 & 1805 & 486 & \\
\hline AEMBL3910657 & 540339 & .8058 & 7439 & \\
\hline AEMBL3903437 & 339 & 5.1805 & 3688 & \\
\hline 54 & 339 & 5719 & & \\
\hline EMBL3925983 & 339 & .8052 & .5229 & \\
\hline AEMBL3976629 & 640339 & 5.1805 & 5.9346 & \\
\hline HEMBL3925998 & 339 & 5.1805 & $\partial 5$ & \\
\hline IEMBL 3914764 & 339 & 382 & 03 & \\
\hline EMBL3 & & 577 & 34 & \\
\hline IEMBL39 & & .6249 & & \\
\hline AEMBL3916807 & 339 & .1805 & 002 & \\
\hline IEMBL 3966903 & 39 & 283 & 27 & \\
\hline IEMBL 3896724 & 39 & 598 & 51 & \\
\hline IEMBL 391 & & & 1 & \\
\hline AEMBL3 & & 359 & & \\
\hline IEMBL3902924 & 339 & 385 & & \\
\hline IEMBL 393 & 64 & 013 & 54 & \\
\hline IEMBL396 & 64 & 305 & 75 & \\
\hline IEMBL39. & & $\partial 5$ & & \\
\hline AEMBI 392 & 39 & 123 & 48 & \\
\hline IEMBL396 & 39 & 2676 & & \\
\hline EMBL3905 & 39 & 95 & 94 & \\
\hline AEMBL3982254 & 9 & 2 & 63 & \\
\hline IEMBL 39 & & 32 & 35 & \\
\hline 32 & & 902 & & RN \\
\hline IEMBL 389 & 39 & & & RI \\
\hline IEMBL3947666 & 64 & 531 & 558 & \\
\hline IEMBL 3939519 & 6 & 305 & 36 & \\
\hline 95 & & 99 & & \\
\hline & & & & \\
\hline IEMBL3951217 & 64 & 805 & 97 & \\
\hline EMBL3932261 & 6 & 7.9527 & 6.8612 & \\
\hline IEMBL 3913473 & $16<$ & 805 & 317 & \\
\hline & & & & \\
\hline IEMBL 3954325 & & & & \\
\hline EMBL3950951 & 39 & 645 & 6.9 & \\
\hline IEMBL 398 & 64 & 805 & 59 & \\
\hline AEMBL3977122 & 164 & 921 & . 1501 & \\
\hline & & & & \\
\hline AEMBL3945547 & 339 & 376 & 6.4651 & RI \\
\hline IEMBL 3894778 & 339 & 2 & 1494 & \\
\hline EMBL39 & 64 & & & \\
\hline CHEMBL395 & & & 6.6 & \\
\hline $15 M D I 2023$ & & & & \\
\hline
\end{tabular}

Page 6835 
Supplemental Table S2.txt

\begin{tabular}{|c|c|c|c|c|c|}
\hline CHEMBL 3980397 & 1640339 & 5.1805 & 6.3092 & TRN & \\
\hline CHEMBL 3976157 & 1640339 & 7.5643 & 6.9253 & TST & \\
\hline CHEMBL 3980509 & 1640339 & 5.1805 & 5.92700 & 00000000005 & TRN \\
\hline CHEMBL 3891501 & 1640339 & 5.1805 & 4.215 & TRN & \\
\hline CHEMBL 3917958 & 1640339 & 6.9725 & 6.7607 & TRN & \\
\hline CHEMBL 3933569 & 1640339 & 7.9197 & 6.9512 & TRN & \\
\hline CHEMBL 3927494 & 1640850 & 8.4976 & 8.2757 & TRN & \\
\hline CHEMBL 3958453 & 1640850 & 7.1841 & 7.2018 & TRN & \\
\hline CHEMBL 3948438 & 1640850 & 7.1786 & 7.1321 & TRN & \\
\hline CHEMBL 3900789 & 1640850 & 7.95700 & 30000000 & 7.8118 & TRN \\
\hline CHEMBL 3897802 & 1640850 & 7.697 & 7.6626 & TRN & \\
\hline CHEMBL 3949747 & 1640850 & 7.9957 & 7.9095 & TRN & \\
\hline CHEMBL1939972 & 1640850 & 8.251 & 7.6028 & TST & \\
\hline CHEMBL 3947821 & 1640850 & 8.6676 & 8.5067 & TRN & \\
\hline CHEMBL 3911625 & 1640850 & 6.8598 & 6.9803 & TRN & \\
\hline CHEMBL 3931880 & 1640850 & 8.0685 & 8.2196 & TRN & \\
\hline CHEMBL 3937790 & 1640850 & 7.3017 & 7.7909 & TST & \\
\hline CHEMBL 3891778 & 1640850 & 7.0982 & 7.24 & TRN & \\
\hline CHEMBL 3914637 & 1640850 & 7.2188 & 7.0641 & TRN & \\
\hline CHEMBL 3908909 & 1640850 & 7.7399 & 8.0857 & TRN & \\
\hline CHEMBL 3913924 & 1640850 & 7.9759 & 8.01 & TRN & \\
\hline CHEMBL 3953123 & 1640850 & 5.8013 & 8.0077 & TST & \\
\hline CHEMBL 3939180 & 1640850 & 7.3169 & 7.2852 & TRN & \\
\hline CHEMBL 3904770 & 1640850 & 8.4401 & 8.4108 & TRN & \\
\hline CHEMBL 3976217 & 1640850 & 8.6556 & 8.3599 & TRN & \\
\hline CHEMBL 3981620 & 1640850 & 7.3572 & 7.2622 & TRN & \\
\hline CHEMBL 3953065 & 1640850 & 7.0074 & 7.1724 & TRN & \\
\hline CHEMBL 3981381 & 1640850 & 7.7981 & 7.7516 & TRN & \\
\hline CHEMBL 3976535 & 1640850 & 8.8386 & 8.7717 & TRN & \\
\hline CHEMBL 3697701 & 1640850 & 7.0068 & 7.4132 & TST & \\
\hline CHEMBL 3943177 & 1640850 & \multicolumn{3}{|c|}{7.7620000000000005} & TRI \\
\hline CHEMBL 3974013 & 1640850 & 8.7747 & 8.6888 & TRN & \\
\hline CHEMBL 3985375 & 1640850 & 7.0114 & 7.0853 & TRN & \\
\hline CHEMBL 3984932 & 1640850 & 8.3565 & 8.4719 & TRN & \\
\hline CHEMBL 3973094 & 1640850 & 7.2867 & 7.2719 & TRN & \\
\hline CHEMBL 3944172 & 1640850 & 8.2765 & 8.3295 & TRN & \\
\hline CHEMBL 3947801 & 1640850 & 7.9412 & 7.8628 & TRN & \\
\hline CHEMBL 3906234 & 1640850 & 7.5758 & 7.6011 & TRN & \\
\hline CHEMBL 3905406 & 1640850 & 8.0496 & 7.7933 & TRN & \\
\hline CHEMBL 3896060 & 1640850 & 7.2325 & 7.2826 & TRN & \\
\hline CHEMBL 3897467 & 1640850 & 7.3171 & 7.7956 & TRN & \\
\hline CHEMBL 3977053 & 1640850 & 5.9281 & 8.3139 & TST & \\
\hline CHEMBL 3932546 & 1640850 & 8.0438 & 8.1661 & TRN & \\
\hline CHEMBL 3964272 & 1640850 & 7.9439 & 7.7082 & TRN & \\
\hline CHEMBL 3945471 & 1640850 & 8.2716 & 8.3662 & TRN & \\
\hline CHEMBL 3898239 & 1640850 & 8.3958 & 8.3924 & TRN & \\
\hline CHEMBL 3904057 & 1640850 & 7.4681 & 7.4069 & TRN & \\
\hline CHEMBL 3956560 & 1640850 & 8.3449 & 8.1159 & TRN & \\
\hline
\end{tabular}


Supplemental Table S2.txt

\begin{tabular}{|c|c|c|c|c|}
\hline CHEMBL3978811 & 1640850 & 8.1203 & 8.2014 & TRN \\
\hline CHEMBL 3954164 & 1640850 & 7.2653 & 8.384 & TST \\
\hline CHEMBL3912738 & 1640850 & 8.1713 & 8.0603 & TRN \\
\hline CHEMBL 3956711 & 1640850 & 7.3245 & 7.6721 & TRN \\
\hline CHEMBL 3924373 & 1640850 & 7.7418 & 7.7362 & TRN \\
\hline CHEMBL 3968269 & 1640850 & 7.2517 & 7.1446 & TRN \\
\hline CHEMBL 3894821 & 1640850 & 6.4182 & 7.6609 & TST \\
\hline CHEMBL3941901 & 1640850 & 8.2518 & 8.0892 & TRN \\
\hline CHEMBL3904928 & 1640850 & 7.9007 & 8.1259 & TRN \\
\hline CHEMBL 3892326 & 1640850 & 8.202 & 8.1998 & TRN \\
\hline CHEMBL 3936454 & 1640850 & 8.1487 & 8.1097 & TRN \\
\hline CHEMBL 3914798 & 1640850 & 7.9115 & 8.1561 & TST \\
\hline CHEMBL 3892970 & 1640850 & 8.0947 & 8.1186 & TRN \\
\hline CHEMBL 3920880 & 1640850 & 7.751 & 8.0773 & TRN \\
\hline CHEMBL 3987145 & 1640850 & 8.1878 & 7.9339 & TRN \\
\hline CHEMBL 3905460 & 1640850 & 8.5331 & 8.5202 & TRN \\
\hline CHEMBL3926532 & 1640850 & 7.6594 & 8.0834 & TST \\
\hline CHEMBL3906012 & 1640850 & 8.2248 & 8.1307 & TRN \\
\hline CHEMBL3948210 & 1640850 & 8.1605 & 8.2172 & TRN \\
\hline CHEMBL 3939505 & 1640850 & 8.1152 & 7.951000 & 00000000005 \\
\hline CHEMBL 3894760 & 1640850 & 7.7675 & 7.7617 & TRN \\
\hline CHEMBL 3894956 & 1640850 & 7.7765 & 7.7571 & TRN \\
\hline CHEMBL 3896353 & 1640850 & 8.4001 & 8.3192 & TRN \\
\hline CHEMBL3896592 & 1640850 & 7.2595 & 7.1992 & TST \\
\hline CHEMBL 3921886 & 1640850 & 7.1346 & 7.1307 & TRN \\
\hline CHEMBL 3935604 & 1640850 & 7.2296 & 7.8707 & TST \\
\hline CHEMBL3958126 & 1640850 & 8.2958 & 7.9073 & TRN \\
\hline CHEMBL 3929233 & 1640850 & 8.451 & 8.7031 & TRN \\
\hline CHEMBL3947368 & 1640850 & 8.27 & 7.859 & TRN \\
\hline CHEMBL 3968210 & 1640850 & 7.3303 & 7.3593 & TRN \\
\hline CHEMBL 3945044 & 1640850 & 7.5621 & 7.7976 & TRN \\
\hline CHEMBL 3930651 & 1640850 & 8.2882 & 8.3352 & TRN \\
\hline CHEMBL 3979456 & 1640850 & 7.71399 & 999999999 & 7.817 \\
\hline CHEMBL 3951379 & 1640850 & 7.2711 & 7.0924 & TRN \\
\hline CHEMBL 3931425 & 1640850 & 7.415 & 7.7302 & TST \\
\hline CHEMBL 3981050 & 1640850 & 8.4711 & 8.3289 & TRN \\
\hline CHEMBL 3902066 & 1640850 & 7.3347 & 7.5325 & TRN \\
\hline CHEMBL1086530 & 1640850 & 6.3454 & 7.3545 & TST \\
\hline CHEMBL3920312 & 1640850 & 8.4763 & 8.2169 & TRN \\
\hline CHEMBL 3965541 & 1640850 & 6.9893 & 7.0758 & TRN \\
\hline CHEMBL 3918948 & 1640850 & 7.3839 & 7.6596 & TRN \\
\hline CHEMBL 3987098 & 1640850 & 7.0531 & 8.3588 & TST \\
\hline CHEMBL 3956363 & 1640850 & 7.4735 & 7.4098 & TST \\
\hline CHEMBL 3944579 & 1640850 & 7.8668 & 8.3561 & TRN \\
\hline CHEMBL 3976638 & 1640850 & 7.7435 & 8.2205 & TST \\
\hline CHEMBL 3922771 & 1640850 & 8.2765 & 8.4215 & TRN \\
\hline CHEMBL 3897132 & 1640850 & 7.5829 & 7.6413 & TST \\
\hline CHEMBL 3920106 & 1640850 & 8.1772 & 8.0408 & TST \\
\hline
\end{tabular}


Supplemental Table S2.txt

\begin{tabular}{|c|c|c|c|c|c|}
\hline CHEMBL3977240 & 1640850 & 8.3152 & 7.9863 & TST & \\
\hline CHEMBL3920559 & 1640850 & 7.3196 & 7.7408 & TST & \\
\hline CHEMBL3915505 & 1640850 & 6.2524 & 8.0068 & TST & \\
\hline CHEMBL 3899453 & 1640850 & 8.3809 & 8.4219 & TST & \\
\hline CHEMBL3935137 & 1640850 & 7.8735 & 7.6466 & TST & \\
\hline CHEMBL 3924146 & 1640850 & 6.0358 & 7.5788 & TST & \\
\hline CHEMBL3942587 & 1640850 & 7.9252 & 8.0978 & TST & \\
\hline CHEMBL 3747200 & 1545039 & 3.699 & 3.6059 & TRN & \\
\hline CHEMBL 3746319 & 1545039 & 5.2426 & 5.1755 & TRN & \\
\hline CHEMBL3747686 & 1545039 & 5.8697 & 5.8791 & TRN & \\
\hline CHEMBL 3747176 & 1545039 & 5.6478 & 5.688 & TRN & \\
\hline CHEMBL 3747384 & 1545039 & 3.699 & 2.785 & TST & \\
\hline CHEMBL 3747242 & 1545039 & 3.699 & 3.6062 & TRN & \\
\hline CHEMBL 3746937 & 1545039 & 5.9101 & 5.9335 & TRN & \\
\hline CHEMBL3746560 & 1545039 & 3.699 & 3.6201 & TRN & \\
\hline CHEMBL 3747035 & 1545039 & 5.7959 & 5.7476 & TRN & \\
\hline CHEMBL3747142 & 1545039 & 5.8601 & 5.8959 & TRN & \\
\hline CHEMBL3747232 & 1545039 & 5.76200 & j00000006 & 005 & 5.7178 \\
\hline CHEMBL3745972 & 1545039 & 3.699 & 2.9885 & TST & \\
\hline CHEMBL 3747731 & 1545039 & 3.699 & 3.2522 & TST & \\
\hline CHEMBL3746132 & 1545039 & 6.3279 & 6.3335 & TRN & \\
\hline CHEMBL3746811 & 1545039 & 5.7852 & 5.8024 & TRN & \\
\hline CHEMBL3746684 & 1545039 & 5.8962 & 5.9719 & TRN & \\
\hline CHEMBL3747564 & 1545039 & 5.2055 & 5.2443 & TRN & \\
\hline CHEMBL 3747725 & 1545039 & 5.9208 & 5.8982 & TRN & \\
\hline CHEMBL 3746668 & 1545039 & 5.3335 & 5.2319 & TRN & \\
\hline CHEMBL 3746061 & 1545039 & 5.7773 & 5.7658 & TRN & \\
\hline CHEMBL3747101 & 1545039 & 5.9172 & 5.9463 & TRN & \\
\hline CHEMBL 3746905 & 1545039 & 5.8894 & 5.8921 & TRN & \\
\hline CHEMBL3746970 & 1545039 & 5.3716 & 5.4923 & TRN & \\
\hline CHEMBL 3746005 & 1545039 & 3.699 & 3.6931 & TRN & \\
\hline CHEMBL3746933 & 1545039 & 5.9172 & 5.8992 & TRN & \\
\hline CHEMBL3747409 & 1545039 & 5.5528 & 5.534 & TRN & \\
\hline CHEMBL 3746767 & 1545039 & 5.1107 & 5.0 & TRN & \\
\hline CHEMBL3746501 & 1545039 & 5.8861 & 5.7724 & TRN & \\
\hline CHEMBL 3747635 & 1545039 & 3.699 & 3.1623 & TST & \\
\hline CHEMBL3745869 & 1545039 & 5.2255 & 5.251 & TRN & \\
\hline CHEMBL3746688 & 1545039 & 5.5331 & 5.5343 & TRN & \\
\hline CHEMBL 3746788 & 1545039 & 5.1361 & 5.1302 & TRN & \\
\hline CHEMBL3747251 & 1545039 & 5.1574 & 5.175 & TRN & \\
\hline CHEMBL3746790 & 1545039 & 3.699 & 3.7346 & TRN & \\
\hline CHEMBL3746718 & 1545039 & 3.699 & 3.7695 & TRN & \\
\hline CHEMBL3746023 & 1545039 & 3.699 & 2.7495 & TST & \\
\hline CHEMBL3747627 & 1545039 & 5.2899 & 5.3337 & TRN & \\
\hline CHEMBL3746704 & 1545039 & 5.4295 & 5.4461 & TRN & \\
\hline CHEMBL3747598 & 1545039 & 5.8761 & 5.8337 & TRN & \\
\hline CHEMBL 3746367 & 1545039 & 3.699 & 3.8658 & TRN & \\
\hline CHEMBL3746503 & 1545039 & 3.699 & 3.6745 & TRN & \\
\hline
\end{tabular}


Supplemental Table S2.txt

\begin{tabular}{|c|c|c|c|c|c|}
\hline CHEMBL3747671 & 1545039 & 3.699 & 3.6983 & TRN & \\
\hline CHEMBL3747163 & 1545039 & 3.699 & 3.1046 & TST & \\
\hline CHEMBL3747127 & 1545039 & 3.699 & 2.8367 & TST & \\
\hline CHEMBL3747665 & 1545039 & 5.8097 & 5.8138 & TRN & \\
\hline CHEMBL3747374 & 1545039 & 3.699 & 2.9405 & TST & \\
\hline CHEMBL3745971 & 1545039 & 3.699 & 3.4904 & TRN & \\
\hline CHEMBL3746813 & 1545039 & 5.8327 & 5.6953 & TRN & \\
\hline CHEMBL3747658 & 1545039 & 3.699 & 2.9239 & TST & \\
\hline CHEMBL3746216 & 1545039 & 5.2233 & 5.2592 & TRN & \\
\hline CHEMBL3746987 & 1545039 & 3.699 & 3.72899 & 99999999996 & TRN \\
\hline CHEMBL 3747164 & 1545039 & 5.9031 & 5.8475 & TRN & \\
\hline CHEMBL3746194 & 1545039 & 3.699 & 3.352 & TST & \\
\hline CHEMBL3746360 & 1545039 & 3.699 & 3.4055 & TST & \\
\hline CHEMBL3745908 & 1545039 & 5.8697 & 5.885 & TRN & \\
\hline CHEMBL3746641 & 1545039 & 3.699 & 3.6182 & TST & \\
\hline CHEMBL 3745820 & 1545039 & 5.3788 & 5.3843 & TRN & \\
\hline CHEMBL3746698 & 1545039 & 5.6576 & 5.7323 & TRN & \\
\hline CHEMBL3747202 & 1545039 & 3.699 & 3.908 & TRN & \\
\hline CHEMBL3746628 & 1545039 & 5.8477 & 5.8313 & TRN & \\
\hline CHEMBL3747745 & 1545039 & 3.699 & 3.3253 & TST & \\
\hline CHEMBL 3746744 & 1545039 & 5.2262 & 5.2935 & TRN & \\
\hline CHEMBL3746903 & 1545039 & 3.699 & 2.7059 & TST & \\
\hline CHEMBL3746720 & 1545039 & 5.295 & 5.2407 & TRN & \\
\hline CHEMBL3747335 & 1545039 & 5.8182 & 5.7832 & TRN & \\
\hline CHEMBL 3747572 & 1545039 & 3.699 & 3.2599 & TST & \\
\hline CHEMBL540 & 1545039 & 3.699 & 3.8999 & TST & \\
\hline CHEMBL3746020 & 1545039 & 3.699 & 3.7725 & TRN & \\
\hline CHEMBL3746500 & 1545039 & 3.699 & 3.3027 & TST & \\
\hline CHEMBL3746326 & 1545039 & 5.0953 & 5.2324 & TRN & \\
\hline CHEMBL3746403 & 1545039 & 5.8268 & 5.8056 & TRN & \\
\hline CHEMBL3746096 & 1545039 & 5.7852 & 5.7458 & TST & \\
\hline CHEMBL3698727 & 1535927 & 6.4023 & 7.1895 & TRN & \\
\hline CHEMBL 3702210 & 1535927 & 7.8861 & \multicolumn{2}{|c|}{7.882000000000001} & TRN \\
\hline CHEMBL 3702227 & 1535927 & 7.2291 & 6.4623 & TRN & \\
\hline CHEMBL3702167 & 1535927 & 8.6576 & 8.1357 & TST & \\
\hline CHEMBL 3702200 & 1535927 & 7.3188 & 7.6558 & TRN & \\
\hline CHEMBL3702106 & 1535927 & 6.284 & 7.0935 & TRN & \\
\hline CHEMBL 3237445 & 1535927 & 7.3279 & 7.6023 & TRN & \\
\hline CHEMBL3702140 & 1535927 & 6.7496 & 7.6004 & TST & \\
\hline CHEMBL3702130 & 1535927 & 8.4089 & 7.7047 & TRN & \\
\hline CHEMBL3702236 & 1535927 & 7.301 & 6.4224 & TRN & \\
\hline CHEMBL3702230 & 1535927 & 7.9586 & 6.4519 & TRN & \\
\hline CHEMBL3702141 & 1535927 & 7.7696 & 7.8202 & TST & \\
\hline CHEMBL3641910 & 1535927 & 6.7545 & 6.9894 & TRN & \\
\hline CHEMBL3698732 & 1535927 & 7.9547 & \multicolumn{2}{|c|}{8.027999999999999} & TRN \\
\hline CHEMBL3642033 & 1535927 & 8.2441 & 8.2831 & TRN & \\
\hline CHEMBL3702212 & 1535927 & 6.1024 & 6.8409 & TRN & \\
\hline CHEMBL3702053 & 1535927 & 8.2366 & 8.2647 & TRN & \\
\hline
\end{tabular}


Supplemental Table S2.txt

\begin{tabular}{|c|c|c|c|}
\hline HEMBL3702191 & 1535927 & 8.1612 & 7.8621 \\
\hline HEMBL3971812 & 1535927 & 8.2291 & 8.1431 \\
\hline HEMBL3698662 & 535927 & 8.1549 & 7735 \\
\hline HEMBL3641979 & 535927 & 6.4318 & 5403 \\
\hline HEMBL3698638 & 535927 & 8.0 & .7458 \\
\hline HEMBL3642032 & .535927 & 8.2924 & 8.2568 \\
\hline HEMBL3702172 & 535927 & 7.4559 & 7.6196 \\
\hline AEMBL3698671 & 535927 & 8.3565 & 8.4929 \\
\hline HEMBL3702160 & 1535927 & 6.0 & 6.8073 \\
\hline HEMBL3642020 & 535927 & 7.9208 & 8.0814 \\
\hline HEMBL 3237448 & 1535927 & 7.8861 & 7.564 \\
\hline HEMBL3702162 & 1535927 & 7.2218 & 7.4375 \\
\hline HEMBL3642034 & 1535927 & 7.7696 & 7.9293 \\
\hline HEMBL3641909 & 1535927 & 6.9914 & 7.0282 \\
\hline HEMBL3698645 & 1535927 & 6.0 & 6.6674 \\
\hline HEMBL3702247 & 1535927 & 7.5686 & 7.5288 \\
\hline AEMBL3702132 & 1535927 & 7.7959 & 7.7181 \\
\hline HEMBL3702116 & 1535927 & 7.6778 & 7.6722 \\
\hline HEMBL3901859 & 1535927 & 6.2291 & 7.0724 \\
\hline HEMBL3702118 & 1535927 & 7.8239 & 7.7128 \\
\hline HEMBL3698683 & 1535927 & 8.2518 & 8.279 \\
\hline AEMBL3 & 1535927 & 7.8861 & 8.0947 \\
\hline HEMBL & 1535927 & 7.6576 & 7.6009 \\
\hline AEMBL3702166 & 1535927 & 7.7799 & 7.692 \\
\hline HEMBL3702201 & 1535927 & 7.6576 & 7.5412 \\
\hline HEMBL3698747 & 1535927 & 8.1675 & 8.0644 \\
\hline HEMBL & 1535927 & 7.7959 & 7.6847 \\
\hline HEMBL & 1535927 & 8.3372 & 8.0195 \\
\hline AEMBL3702245 & 1535927 & 7.8239 & 7.7344 \\
\hline HEMBL3698684 & 1535927 & 8.1871 & 7.8624 \\
\hline CHEMBL 3702131 & 1535927 & 7.6882 & 7.6119 \\
\hline CHEMBL & 1535927 & 8.0969 & 7.8659 \\
\hline HEMBL3702121 & 1535927 & 7.9586 & 7.9253 \\
\hline CHEMBL 3702093 & 1535927 & 8.5528 & 8.0205 \\
\hline HEMBL3698736 & 1535927 & 7.6144 & 8.1268 \\
\hline HEMBL3702115 & 1535927 & 7.284 & 7.2088 \\
\hline CHEMBL: & 535927 & 7.9208 & 8.0437 \\
\hline CHEMBL3642019 & 1535927 & 8.5086 & 8.0704 \\
\hline CHEMBL 3702088 & 1535927 & 6.983 & 7.2705 \\
\hline CHEMBL 3702243 & 1535927 & 7.5528 & 7.4711 \\
\hline CHEMBL3642017 & 1535927 & 6.4559 & 6.8847 \\
\hline CHEMBL3237702 & 1535927 & 8.3565 & 8.1105 \\
\hline CHEMBL3642030 & 1535927 & 6.0 & 6.6406 \\
\hline CHEMBL 3702048 & 1535927 & 5.0 & 7.3069 \\
\hline CHEMBL 3702064 & 1535927 & 7.6021 & 7.4921 \\
\hline CHEMBL 3642031 & 1535927 & 7.585 & 8.1368 \\
\hline CHEMBL3698681 & 1535927 & 9.1249 & 8.4056 \\
\hline CHEMBL 3702235 & 1535927 & 7.3768 & 6.4028 \\
\hline
\end{tabular}

Page 6840 
Supplemental Table S2.txt

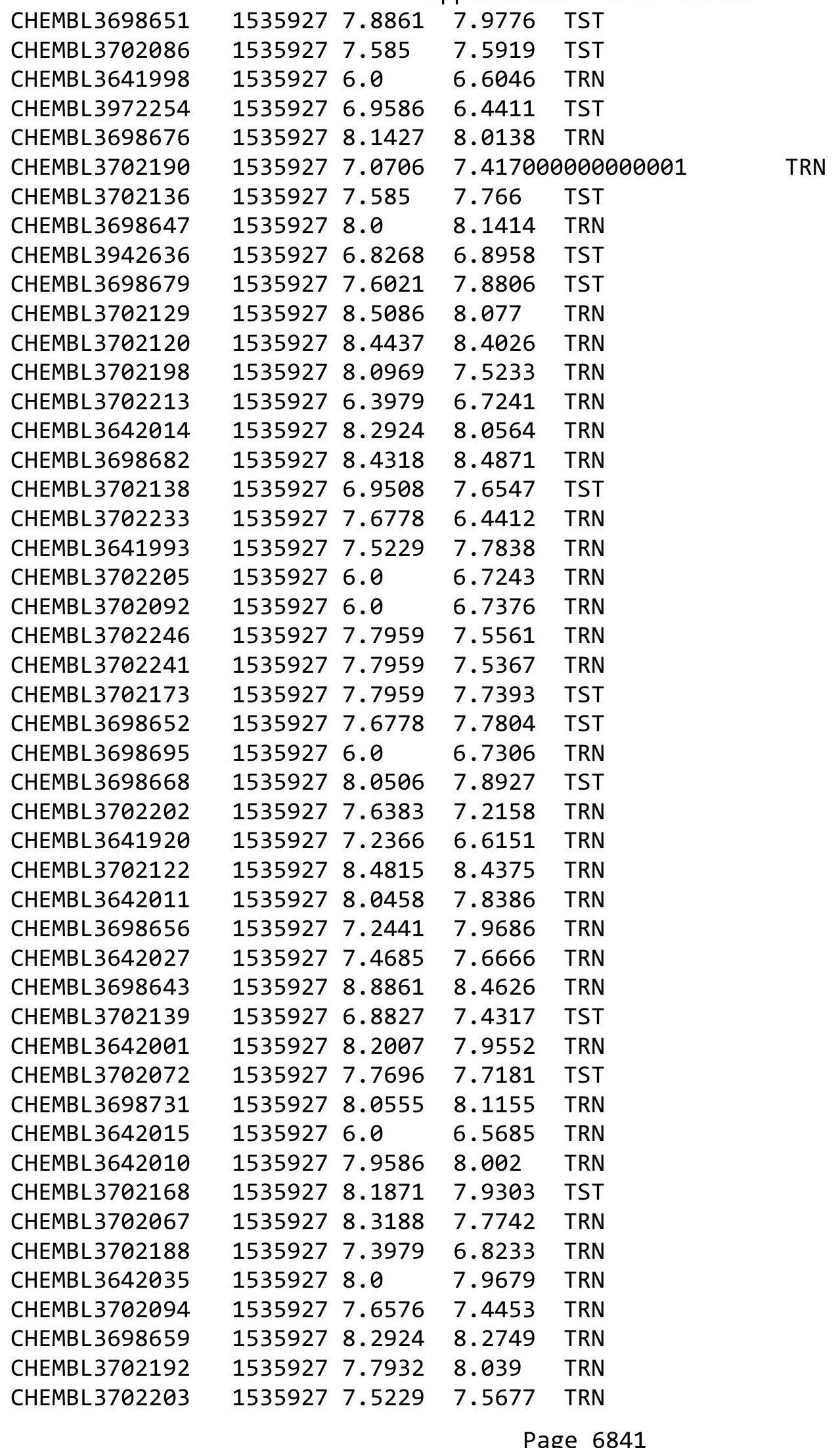


Supplemental Table S2.txt

\begin{tabular}{|c|c|c|c|c|c|}
\hline CHEMBL 3702248 & 1535927 & 7.9208 & 7.64 & TRN & \\
\hline CHEMBL 3702063 & 1535927 & 7.8539 & 7.4749 & TST & \\
\hline CHEMBL3702076 & 1535927 & 6.8239 & 7.0535 & TST & \\
\hline CHEMBL 3237449 & 1535927 & 7.5376 & 6.5124 & TRN & \\
\hline CHEMBL3698675 & 1535927 & 8.585 & 8.1926 & TRN & \\
\hline CHEMBL 3641994 & 1535927 & 7.9208 & 8.0872 & TRN & \\
\hline CHEMBL 3698723 & 1535927 & 7.7986 & 7.9978 & TST & \\
\hline CHEMBL 3702228 & 1535927 & 7.1135 & 6.399 & TRN & \\
\hline CHEMBL 3698658 & 1535927 & 8.6021 & 8.3732 & TRN & \\
\hline CHEMBL3642025 & 1535927 & 7.4202 & 7.7404 & TRN & \\
\hline CHEMBL 3641999 & 1535927 & 7.7959 & 8.0104 & TRN & \\
\hline CHEMBL 3702154 & 1535927 & 8.301 & 8.0761 & TRN & \\
\hline CHEMBL 3698686 & 1535927 & 6.3915 & 7.495 & TST & \\
\hline CHEMBL 3642013 & 1535927 & 7.4318 & 7.6769 & TRN & \\
\hline CHEMBL3702157 & 1535927 & 7.2218 & 7.9385 & TST & \\
\hline CHEMBL 3237443 & 1535927 & 7.7696 & 8.0611 & TRN & \\
\hline CHEMBL 3642021 & 1535927 & 7.8539 & 7.9046 & TRN & \\
\hline CHEMBL 3702075 & 1535927 & 5.0 & 6.4669 & TST & \\
\hline CHEMBL 3702214 & 1535927 & 5.8239 & 6.7183 & TRN & \\
\hline CHEMBL3698660 & 1535927 & 7.4202 & 7.6843 & TST & \\
\hline CHEMBL 3698700 & 1535927 & 7.5086 & 7.58899 & 99999999995 & TRN \\
\hline CHEMBL 3702047 & 1535927 & 8.1938 & 7.7301 & TRN & \\
\hline CHEMBL 3698642 & 1535927 & 8.1805 & 8.18700 & 0000000001 & TRN \\
\hline CHEMBL 3237451 & 1535927 & 7.8827 & 7.8697 & TRN & \\
\hline CHEMBL 3698726 & 1535927 & 7.9066 & 7.6534 & TRN & \\
\hline CHEMBL3698669 & 1535927 & 7.6778 & 7.8697 & TRN & \\
\hline CHEMBL 3641911 & 1535927 & 7.2757 & 6.9886 & TRN & \\
\hline CHEMBL 3702196 & 1535927 & 6.0 & 6.545 & TRN & \\
\hline CHEMBL 3702234 & 1535927 & 7.5686 & 6.4131 & TRN & \\
\hline CHEMBL 3698644 & 1535927 & 8.9586 & 8.7823 & TRN & \\
\hline CHEMBL3698696 & 1535927 & 7.6198 & 7.8801 & TST & \\
\hline CHEMBL 3702123 & 1535927 & 8.0969 & 8.2234 & TST & \\
\hline CHEMBL 3237446 & 1535927 & 7.9586 & 7.9643 & TRN & \\
\hline CHEMBL 3698724 & 1535927 & 8.0362 & 8.0344 & TRN & \\
\hline CHEMBL 3642024 & 1535927 & 7.699 & 7.7866 & TRN & \\
\hline CHEMBL 3702244 & 1535927 & 6.0 & 6.4394 & TRN & \\
\hline CHEMBL 3642018 & 1535927 & 7.7447 & 7.7212 & TRN & \\
\hline CHEMBL 3702051 & 1535927 & 7.8013 & 8.0468 & TRN & \\
\hline CHEMBL 3702194 & 1535927 & 6.0 & 6.3851 & TRN & \\
\hline CHEMBL 3698673 & 1535927 & 7.8153 & 8.2545 & TRN & \\
\hline CHEMBL3641990 & 1535927 & 7.7212 & 7.6735 & TRN & \\
\hline CHEMBL3702117 & 1535927 & 8.0862 & 8.0206 & TRN & \\
\hline CHEMBL 3941146 & 1535927 & 6.4685 & 6.9665 & TRN & \\
\hline CHEMBL 3698641 & 1535927 & 8.3768 & 8.2697 & TRN & \\
\hline CHEMBL 3698722 & 1535927 & 6.0 & 6.7176 & TRN & \\
\hline CHEMBL 3698680 & 1535927 & 6.8894 & 7.1635 & TRN & \\
\hline CHEMBL 3698744 & 1535927 & 8.0 & 8.1662 & TRN & \\
\hline CHEMBL3642003 & 1535927 & 7.585 & 8.1104 & TRN & \\
\hline
\end{tabular}


Supplemental Table S2.txt

\begin{tabular}{|c|c|c|c|c|c|}
\hline CHEMBL3702049 & 1535927 & 8.585 & 8.1661 & TRN & \\
\hline CHEMBL3907280 & 1535927 & 7.3098 & 7.3169 & TST & \\
\hline CHEMBL3702060 & 1535927 & 8.5528 & 8.1324 & TRN & \\
\hline CHEMBL3642029 & 1535927 & 7.9208 & 7.7606 & TRN & \\
\hline CHEMBL 3702070 & 1535927 & 7.7959 & 7.3698 & TRN & \\
\hline CHEMBL 3702127 & 1535927 & 8.5229 & 7.9975 & TRN & \\
\hline CHEMBL 3698650 & 1535927 & 8.0969 & 8.2977 & TST & \\
\hline CHEMBL3698667 & 1535927 & 7.5171 & 7.6019 & TST & \\
\hline CHEMBL 3698678 & 1535927 & 6.6615 & 7.1922 & TRN & \\
\hline CHEMBL 3237442 & 1535927 & 8.3565 & 8.1146 & TRN & \\
\hline CHEMBL 3702114 & 1535927 & 7.4815 & 7.654 & TRN & \\
\hline CHEMBL3702071 & 1535927 & 8.2076 & 7.9525 & TST & \\
\hline CHEMBL 3698687 & 1535927 & 7.6576 & 7.6712 & TRN & \\
\hline CHEMBL3642026 & 1535927 & 7.7447 & 7.9617 & TRN & \\
\hline CHEMBL 3641980 & 1535927 & 6.5031 & 6.5549 & TRN & \\
\hline CHEMBL 3641914 & 1535927 & 6.5607 & 6.59399 & 9999999999 & TRN \\
\hline CHEMBL3702163 & 1535927 & 6.4437 & 7.0472 & TST & \\
\hline CHEMBL3641996 & 1535927 & 7.8539 & 7.9486 & TRN & \\
\hline CHEMBL 3698741 & 1535927 & 7.7055 & 8.0523 & TRN & \\
\hline CHEMBL3698664 & 1535927 & 6.0 & 6.7689 & TST & \\
\hline CHEMBL 3702164 & 1535927 & 7.4202 & 7.2759 & TST & \\
\hline CHEMBL 3698655 & 1535927 & 6.0 & 6.6551 & TRN & \\
\hline CHEMBL 3237444 & 1535927 & 8.3665 & 8.1708 & TRN & \\
\hline CHEMBL 3698697 & 1535927 & 7.1367 & 7.9923 & TRN & \\
\hline CHEMBL3698639 & 1535927 & 8.5376 & 8.7029 & TRN & \\
\hline CHEMBL 3698685 & 1535927 & 6.9508 & 7.6709 & TST & \\
\hline CHEMBL3702065 & 1535927 & 8.2757 & 7.8343 & TRN & \\
\hline CHEMBL 3698728 & 1535927 & 7.5751 & 7.8478 & TRN & \\
\hline CHEMBL 3642022 & 1535927 & 7.6778 & 7.9703 & TRN & \\
\hline CHEMBL3702089 & 1535927 & 7.5086 & 7.6886 & TST & \\
\hline CHEMBL3702087 & 1535927 & 7.7959 & 7.1677 & TRN & \\
\hline CHEMBL 3642036 & 1535927 & 6.0 & 6.7104 & TRN & \\
\hline CHEMBL 3698674 & 1535927 & 8.5086 & 8.3732 & TRN & \\
\hline CHEMBL3698672 & 1535927 & 8.9208 & 8.1812 & TRN & \\
\hline CHEMBL 3698665 & 1535927 & 8.2147 & 8.0269 & TRN & \\
\hline CHEMBL3698708 & 1535927 & 7.9586 & 8.0544 & TRN & \\
\hline CHEMBL3702197 & 1535927 & 7.8861 & 8.1944 & TRN & \\
\hline CHEMBL3702119 & 1535927 & 8.0088 & 8.0286 & TRN & \\
\hline CHEMBL 3642023 & 1535927 & 7.7212 & 8.0488 & TRN & \\
\hline CHEMBL 3920794 & 1535927 & 7.5686 & 7.7434 & TST & \\
\hline CHEMBL3702096 & 1535927 & 8.3098 & 8.0558 & TRN & \\
\hline CHEMBL3702128 & 1535927 & 8.5686 & 8.1129 & TRN & \\
\hline CHEMBL3702211 & 1535927 & 7.6198 & 7.5495 & TRN & \\
\hline CHEMBL3702095 & 1535927 & 8.1192 & 7.9091 & TRN & \\
\hline CHEMBL 3702232 & 1535927 & 7.699 & \multicolumn{2}{|c|}{6.3870000000000005} & TRN \\
\hline CHEMBL3237704 & 1535927 & 8.9586 & 8.0384 & TRN & \\
\hline CHEMBL3955164 & 1535927 & 6.9872 & 7.1546 & TST & \\
\hline CHEMBL3702054 & 1535927 & 7.4815 & 7.4299 & TRN & \\
\hline
\end{tabular}


Supplemental Table S2.txt

\begin{tabular}{|c|c|c|c|c|c|}
\hline CHEMBL 3698677 & 1535927 & 6.301 & 7.0011 & TRN & \\
\hline CHEMBL 3702126 & 1535927 & 6.0655 & 7.1066 & TST & \\
\hline CHEMBL3702045 & 1535927 & 7.5686 & 7.8079 & TRN & \\
\hline CHEMBL3698661 & 1535927 & 8.4559 & 8.2165 & TST & \\
\hline CHEMBL 3702221 & 1535927 & 7.9586 & 6.3602 & TRN & \\
\hline CHEMBL 3642008 & 1535927 & 6.0 & 6.6528 & TRN & \\
\hline CHEMBL 3237447 & 1535927 & 7.8729 & 7.6829 & TRN & \\
\hline CHEMBL 3698670 & 1535927 & 7.6778 & 7.8406 & TRN & \\
\hline CHEMBL3702156 & 1535927 & 7.3979 & 7.6484 & TRN & \\
\hline CHEMBL 3698653 & 1535927 & 9.4437 & 8.8396 & TST & \\
\hline CHEMBL 3642028 & 1535927 & 7.5528 & 7.7818 & TRN & \\
\hline CHEMBL3702161 & 1535927 & 6.9957 & 7.3681 & TST & \\
\hline CHEMBL 3641913 & 1535927 & 6.0809 & 6.4578 & TRN & \\
\hline CHEMBL3641995 & 1535927 & 6.0 & 6.5165 & TRN & \\
\hline CHEMBL 3702050 & 1535927 & 8.3098 & 8.1173 & TRN & \\
\hline CHEMBL3702158 & 1535927 & 8.1549 & 8.2228 & TST & \\
\hline CHEMBL3702231 & 1535927 & 7.6383 & 6.3824 & TRN & \\
\hline CHEMBL 3702074 & 1535927 & 7.6778 & \multicolumn{2}{|c|}{7.5520000000000005} & TRN \\
\hline CHEMBL3702142 & 1535927 & 8.3372 & 7.9191 & TST & \\
\hline CHEMBL 3702174 & 1535927 & 6.9957 & 7.6165 & TRN & \\
\hline CHEMBL3698737 & 1535927 & 7.3188 & 7.9639 & TRN & \\
\hline CHEMBL3642012 & 1535927 & 6.4202 & 7.4252 & TRN & \\
\hline CHEMBL 3698649 & 1535927 & 8.585 & 8.1622 & TST & \\
\hline CHEMBL3698657 & 1535927 & 9.3872 & 8.5776 & TST & \\
\hline CHEMBL 3702199 & 1535927 & 7.4685 & 7.4467 & TST & \\
\hline CHEMBL3977134 & 1535927 & 7.0362 & 7.1969 & TST & \\
\hline CHEMBL3702137 & 1535927 & 6.5901 & 7.1458 & TST & \\
\hline CHEMBL 3702207 & 1535927 & 8.0555 & 7.8864 & TST & \\
\hline CHEMBL3698733 & 1535927 & 8.585 & 8.0554 & TST & \\
\hline CHEMBL 3702159 & 1535927 & 8.2757 & 7.8693 & TST & \\
\hline CHEMBL3698735 & 1535927 & 6.0 & 6.6494 & TST & \\
\hline CHEMBL3702206 & 1535927 & 7.4089 & 7.6605 & TST & \\
\hline CHEMBL3702209 & 1535927 & 7.9208 & \multicolumn{2}{|c|}{7.7139999999999995} & TST \\
\hline CHEMBL 260692 & 471788 & 6.41 & 6.4203 & TST & \\
\hline CHEMBL407204 & 471788 & 5.0 & 6.1257 & TST & \\
\hline CHEMBL259733 & 471788 & 6.49 & 6.52 & TRN & \\
\hline CHEMBL261068 & 471788 & 6.57 & 6.4991 & TST & \\
\hline CHEMBL410297 & 471788 & 6.45 & 6.4451 & TRN & \\
\hline CHEMBL 262333 & 471788 & 6.45 & 6.4194 & TRN & \\
\hline CHEMBL 262332 & 471788 & 6.97 & 6.9536 & TRN & \\
\hline CHEMBL412063 & 471788 & 6.88 & 6.8889 & TRN & \\
\hline CHEMBL440418 & 471788 & 6.74 & 6.4068 & TST & \\
\hline CHEMBL411075 & 471788 & 6.94 & 6.9336 & TRN & \\
\hline CHEMBL 261056 & 471788 & 6.4 & 6.444 & TRN & \\
\hline CHEMBL 260693 & 471788 & 6.81 & \multicolumn{2}{|c|}{6.832999999999999} & TRN \\
\hline CHEMBL 260051 & 471788 & 6.94 & 6.9986 & TRN & \\
\hline CHEMBL427602 & 471788 & 6.1 & 6.1061 & TRN & \\
\hline CHEMBL412275 & 471788 & 6.13 & 5.8926 & TST & \\
\hline
\end{tabular}




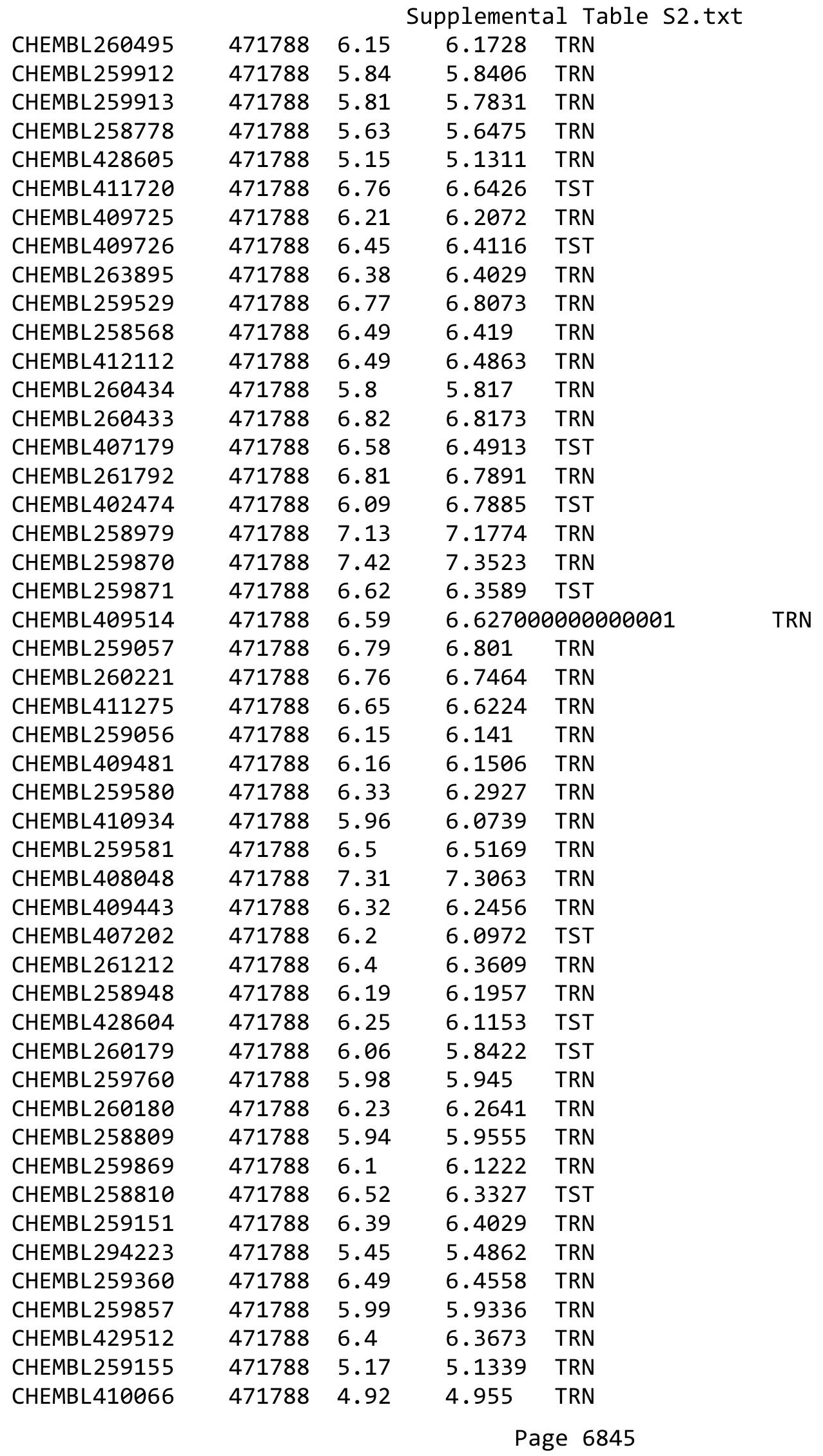




\begin{tabular}{|c|c|c|c|c|c|}
\hline \multicolumn{6}{|c|}{ Supplemental Table S2.txt } \\
\hline CHEMBL259104 & 471788 & 6.62 & 6.6251 & TRN & \\
\hline CHEMBL 259105 & 471788 & 6.37 & 6.2323 & TST & \\
\hline CHEMBL412293 & 471788 & 6.8 & 6.0495 & TST & \\
\hline CHEMBL 258978 & 471788 & 7.03 & 6.4414 & TST & \\
\hline CHEMBL 2336504 & 945919 & 4.8665 & 5.2677 & TRN & \\
\hline CHEMBL 2336515 & 945919 & 8.3979 & 6.3433 & TRN & \\
\hline CHEMBL 2336947 & 945919 & 5.7447 & 6.9441 & TST & \\
\hline CHEMBL 2336511 & 945919 & 3.0 & 5.2029 & TRN & \\
\hline CHEMBL 2336492 & 945919 & 6.041 & 6.6501 & TRN & \\
\hline CHEMBL 2336946 & 945919 & 7.4202 & 7.3998 & TRN & \\
\hline CHEMBL 2336491 & 945919 & 3.0 & 4.2245 & TRN & \\
\hline CHEMBL 2336501 & 945919 & 5.0362 & 4.7725 & TRN & \\
\hline CHEMBL 2336949 & 945919 & 5.7696 & 6.4409 & TRN & \\
\hline CHEMBL 2336503 & 945919 & 4.8996 & 4.9783 & TRN & \\
\hline CHEMBL 2336500 & 945919 & 5.1249 & 5.2582 & TRN & \\
\hline CHEMBL 2336519 & 945919 & 8.3372 & 8.5903 & TRN & \\
\hline CHEMBL 2336956 & 945919 & 4.4828 & 4.5078 & TRN & \\
\hline CHEMBL 2336512 & 945919 & 7.4815 & 6.6653 & TRN & \\
\hline CHEMBL 2336960 & 945919 & 6.5376 & 6.1427 & TRN & \\
\hline CHEMBL 2336957 & 945919 & 4.3429 & 4.5078 & TRN & \\
\hline CHEMBL 2336520 & 945919 & 8.699 & 9.0812 & TRN & \\
\hline CHEMBL 2336516 & 945919 & 8.0315 & 6.285 & TRN & \\
\hline CHEMBL 2336517 & 945919 & 8.699 & 8.3484 & TRN & \\
\hline CHEMBL 2336489 & 945919 & 5.6778 & 5.4993 & TRN & \\
\hline CHEMBL 2336494 & 945919 & 4.4881 & 4.7232 & TRN & \\
\hline CHEMBL 2336950 & 945919 & 5.7959 & 6.3007 & TST & \\
\hline CHEMBL 2336505 & 945919 & 7.2676 & 6.6085 & TRN & \\
\hline CHEMBL 2336518 & 945919 & 8.9586 & 9.0117 & TRN & \\
\hline CHEMBL1611199 & 945919 & 5.9208 & 7.0909 & TRN & \\
\hline CHEMBL2336945 & 945919 & 7.2441 & 7.5856 & TRN & \\
\hline CHEMBL 2336955 & 945919 & 5.5086 & 5.6647 & TRN & \\
\hline CHEMBL 2336495 & 945919 & 6.699 & 5.9138 & TRN & \\
\hline CHEMBL 2336509 & 945919 & 6.0969 & 6.2721 & TRN & \\
\hline CHEMBL 2336490 & 945919 & 4.2941 & 4.6855 & TRN & \\
\hline CHEMBL2336502 & 945919 & 4.7122 & 4.6328 & TRN & \\
\hline CHEMBL 2336951 & 945919 & 7.0 & 8.0132 & TRN & \\
\hline CHEMBL 2336943 & 945919 & 8.0 & 7.5429 & TRN & \\
\hline CHEMBL 2336508 & 945919 & 6.6198 & 6.2564 & TRN & \\
\hline CHEMBL 2336521 & 945919 & 8.1871 & 7.3849 & TRN & \\
\hline CHEMBL2336506 & 945919 & 7.0 & 6.4 & TRN & \\
\hline CHEMBL 2336488 & 945919 & 4.7496 & 4.5194 & TRN & \\
\hline CHEMBL 2336498 & 945919 & 5.2676 & 5.21899 & 7999999999 & TRN \\
\hline CHEMBL1349474 & 945919 & 5.301 & 5.3057 & TRN & \\
\hline CHEMBL 2336507 & 945919 & 6.1487 & 6.7699 & TRN & \\
\hline CHEMBL2336486 & 945919 & 5.0177 & 4.9645 & TRN & \\
\hline CHEMBL 2336961 & 945919 & 6.301 & 5.6707 & TRN & \\
\hline CHEMBL 2336952 & 945919 & 5.7696 & 7.2339 & TRN & \\
\hline CHEMBL 2336958 & 945919 & 6.3188 & 5.9638 & TRN & \\
\hline
\end{tabular}




\begin{tabular}{|c|c|c|c|c|c|c|}
\hline & & \multicolumn{5}{|c|}{ Supplemental Table S2.txt } \\
\hline CHEMBL2336959 & 945919 & 6.1938 & 5.2599 & TRN & & \\
\hline CHEMBL 2336493 & 945919 & 4.98300 & 00000000 & 205 & 5.0341 & TRN \\
\hline CHEMBL2336953 & 945919 & 5.301 & 5.2177 & TST & & \\
\hline CHEMBL2336944 & 945919 & 6.7696 & 7.4307 & TST & & \\
\hline CHEMBL2336942 & 945919 & 8.0132 & 8.0599 & TST & & \\
\hline CHEMBL2336497 & 945919 & 5.4437 & 5.374 & TST & & \\
\hline CHEMBL 2336485 & 945919 & 5.6021 & 4.6132 & TST & & \\
\hline CHEMBL2336510 & 945919 & 4.2636 & 6.3792 & TST & & \\
\hline CHEMBL412099 & 945919 & 8.5229 & 6.5024 & TST & & \\
\hline CHEMBL2336948 & 945919 & 7.0 & 7.0633 & TST & & \\
\hline CHEMBL517107 & 945919 & 8.7447 & 6.1215 & TST & & \\
\hline CHEMBL2336499 & 945919 & 5.2924 & 4.9321 & TST & & \\
\hline CHEMBL2336496 & 945919 & 6.0315 & 5.9915 & TST & & \\
\hline CHEMBL2336954 & 945919 & 6.0 & 5.2154 & TST & & \\
\hline CHEMBL2336487 & 945919 & 4.857 & 5.0729 & TST & & \\
\hline CHEMBL1366575 & 737545 & 4.3045 & 4.3044 & TRN & & \\
\hline CHEMBL1326265 & 737545 & 3.0 & 3.0001 & TRN & & \\
\hline CHEMBL1348355 & 737545 & 3.0 & 3.0 & TRN & & \\
\hline CHEMBL1387581 & 737545 & 4.1772 & 4.1772 & TRN & & \\
\hline CHEMBL1369513 & 737545 & 4.4763 & 4.4762 & TRN & & \\
\hline CHEMBL1701354 & 737545 & 4.2328 & 4.2328 & TRN & & \\
\hline CHEMBL1449875 & 737545 & 4.2652 & 4.7227 & TST & & \\
\hline CHEMBL1578178 & 737545 & 4.9393 & 4.4492 & TST & & \\
\hline CHEMBL1987472 & 737545 & 4.1319 & 4.1319 & TRN & & \\
\hline CHEMBL1350396 & 737545 & 4.4547 & 4.4547 & TRN & & \\
\hline CHEMBL1577632 & 737545 & 4.2013 & 4.2013 & TRN & & \\
\hline CHEMBL1405239 & 737545 & 4.5287 & 4.5287 & TRN & & \\
\hline CHEMBL3211705 & 737545 & 3.0 & 3.0 & TRN & & \\
\hline CHEMBL3213353 & 737545 & 3.0 & 3.0001 & TRN & & \\
\hline CHEMBL1323450 & 737545 & 4.2684 & 4.2684 & TRN & & \\
\hline CHEMBL1486470 & 737545 & 4.9747 & 4.9747 & TRN & & \\
\hline CHEMBL1730620 & 737545 & 4.0487 & 4.0487 & TRN & & \\
\hline CHEMBL1505198 & 737545 & 4.8477 & 4.8477 & TRN & & \\
\hline CHEMBL1381922 & 737545 & 4.1746 & 4.1746 & TRN & & \\
\hline CHEMBL1510541 & 737545 & 4.2464 & 4.2464 & TRN & & \\
\hline CHEMBL1732408 & 737545 & 4.4056 & 4.4057 & TRN & & \\
\hline CHEMBL1338507 & 737545 & 3.0 & 3.0 & TRN & & \\
\hline CHEMBL3193098 & 737545 & 4.1232 & 4.1232 & TRN & & \\
\hline CHEMBL1578931 & 737545 & 4.1925 & 4.1925 & TRN & & \\
\hline CHEMBL1425242 & 737545 & 4.3851 & 4.7945 & TST & & \\
\hline CHEMBL1319190 & 737545 & 4.158 & 4.158 & TRN & & \\
\hline CHEMBL3199286 & 737545 & 4.1079 & 4.1079 & TRN & & \\
\hline CHEMBL1371245 & 737545 & 4.3747 & 4.5637 & TST & & \\
\hline CHEMBL1300370 & 737545 & 5.0921 & 5.0921 & TRN & & \\
\hline CHEMBL1392848 & 737545 & 4.6925 & 4.6926 & TRN & & \\
\hline CHEMBL1476029 & 737545 & 5.0083 & 5.0084 & TRN & & \\
\hline CHEMBL1718303 & 737545 & 4.1765 & 4.1765 & TRN & & \\
\hline CHEMBL1499914 & 737545 & 4.1524 & 4.1525 & TRN & & \\
\hline
\end{tabular}




\begin{tabular}{|c|c|c|c|c|c|}
\hline \multirow[b]{2}{*}{ CHEMBL1355012 } & \multicolumn{5}{|c|}{ Supplemental Table S2.txt } \\
\hline & 737545 & 3.0 & 3.0 & TRN & \\
\hline CHEMBL1406348 & 737545 & 4.2984 & 4.2985 & TRN & \\
\hline CHEMBL1728960 & 737545 & 4.1543 & 4.1543 & TRN & \\
\hline CHEMBL1357122 & 737545 & 3.0 & 3.0 & TRN & \\
\hline CHEMBL1381655 & 737545 & 4.301 & 4.3011 & TRN & \\
\hline CHEMBL3207619 & 737545 & 3.0 & 3.0 & TRN & \\
\hline CHEMBL1610857 & 737545 & 4.1805 & 4.1805 & TRN & \\
\hline CHEMBL1443436 & 737545 & 4.1296 & 4.1296 & TRN & \\
\hline CHEMBL1255778 & 737545 & 4.2933 & 4.2932 & TRN & \\
\hline CHEMBL1323179 & 737545 & 4.466 & 4.4659 & TRN & \\
\hline CHEMBL1529932 & 737545 & 5.2343 & 4.8028 & TST & \\
\hline CHEMBL1548196 & 737545 & 3.0 & 4.5978 & TST & \\
\hline CHEMBL1506682 & 737545 & 5.4828 & 5.4827 & TRN & \\
\hline CHEMBL1474042 & 737545 & 4.4112 & 4.4112 & TRN & \\
\hline CHEMBL56393 & 737545 & 6.5867 & 6.5867 & TRN & \\
\hline CHEMBL1506262 & 737545 & 4.2976 & 4.2976 & TRN & \\
\hline CHEMBL70501 & 737545 & 5.1209 & 5.1209 & TRN & \\
\hline CHEMBL1449443 & 737545 & 4.4802 & 4.4803 & TRN & \\
\hline CHEMBL1588557 & 737545 & 4.7595 & 4.7594 & TRN & \\
\hline CHEMBL3191453 & 737545 & 4.0214 & 4.0213 & TRN & \\
\hline CHEMBL 89445 & 737545 & 3.0 & 3.603 & TST & \\
\hline CHEMBL1492396 & 737545 & 4.8239 & 4.8239 & TRN & \\
\hline CHEMBL1499077 & 737545 & 3.0 & 3.0 & TRN & \\
\hline CHEMBL1594374 & 737545 & 5.4157 & 4.9142 & TST & \\
\hline CHEMBL1393486 & 737545 & 4.3883 & 4.3883 & TRN & \\
\hline CHEMBL35228 & 737545 & 4.3925 & 4.2904 & TST & \\
\hline CHEMBL607979 & 737545 & 5.3197 & 5.3197 & TRN & \\
\hline CHEMBL1320007 & 737545 & 4.2984 & 4.2984 & TRN & \\
\hline CHEMBL3195463 & 737545 & 3.0 & 3.0 & TRN & \\
\hline CHEMBL1442460 & 737545 & 4.4498 & 4.4497 & TRN & \\
\hline CHEMBL1357672 & 737545 & 4.3261 & 4.32600 & 00000000005 & TRN \\
\hline CHEMBL1428985 & 737545 & 4.5114 & 4.5115 & TRN & \\
\hline CHEMBL3198618 & 737545 & 4.3565 & 4.3566 & TRN & \\
\hline CHEMBL3207974 & 737545 & 3.0 & 3.0 & TRN & \\
\hline CHEMBL1969992 & 737545 & 4.4377 & 4.4378 & TRN & \\
\hline CHEMBL3145067 & 737545 & 4.4342 & 4.4342 & TRN & \\
\hline CHEMBL1544375 & 737545 & 4.3028 & 4.3086 & TST & \\
\hline CHEMBL1509671 & 737545 & 4.4522 & 4.0757 & TST & \\
\hline CHEMBL1329826 & 737545 & 4.8539 & 4.9551 & TST & \\
\hline CHEMBL1514592 & 737545 & 4.4437 & 4.7535 & TST & \\
\hline CHEMBL1382917 & 737545 & 4.6819 & 4.5888 & TST & \\
\hline CHEMBL1541861 & 737545 & 4.9586 & 4.3907 & TST & \\
\hline CHEMBL3190268 & 737545 & 5.2976 & 3.5218 & TST & \\
\hline CHEMBL1590634 & 737545 & 4.1261 & 4.1129 & TST & \\
\hline CHEMBL1469921 & 737545 & 4.2197 & 4.30699 & 99999999995 & TST \\
\hline CHEMBL3189698 & 737545 & 4.2168 & 4.0674 & TST & \\
\hline CHEMBL1257003 & 737545 & 7.71 & 5.7099 & TST & \\
\hline CHEMBL1987094 & 809346 & 4.4248 & 3.9515 & TRN & \\
\hline
\end{tabular}




\begin{tabular}{|c|c|c|c|c|c|}
\hline \multicolumn{6}{|c|}{ Supplemental Table S2.txt } \\
\hline CHEMBL 2004144 & 809346 & 4.71 & 4.562 & TRN & \\
\hline CHEMBL1405103 & 809346 & 3.1024 & 3.5103 & TRN & \\
\hline CHEMBL1870332 & 809346 & 3.1024 & 4.0671 & TRN & \\
\hline CHEMBL1708119 & 809346 & 5.317 & 3.9591 & TRN & \\
\hline CHEMBL1902783 & 809346 & 4.6364 & 3.6606 & TRN & \\
\hline CHEMBL1474526 & 809346 & 4.6635 & 4.0424 & TRN & \\
\hline CHEMBL1725784 & 809346 & 3.1024 & 3.5355 & TRN & \\
\hline CHEMBL1712090 & 809346 & 4.5243 & 3.9107 & TRN & \\
\hline CHEMBL1530972 & 809346 & 4.2013 & 4.3164 & TRN & \\
\hline CHEMBL1462924 & 809346 & 3.1024 & 3.2045 & TRN & \\
\hline CHEMBL1969457 & 809346 & 3.1024 & 3.9819 & TST & \\
\hline CHEMBL1718652 & 809346 & 4.8794 & 4.4365 & TRN & \\
\hline CHEMBL1421091 & 809346 & 4.3536 & 3.9272 & TRN & \\
\hline CHEMBL1905593 & 809346 & 3.1024 & 3.9544 & TRN & \\
\hline CHEMBL1879523 & 809346 & 3.1024 & 3.1155 & TST & \\
\hline CHEMBL1494757 & 809346 & 3.1024 & 4.2157 & TRN & \\
\hline CHEMBL1558744 & 809346 & 4.4522 & 4.3532 & TRN & \\
\hline CHEMBL1448654 & 809346 & 4.9872 & 3.9643 & TRN & \\
\hline CHEMBL1393504 & 809346 & 3.1024 & 3.3954 & TRN & \\
\hline CHEMBL1581308 & 809346 & 3.1024 & 3.34 & TRN & \\
\hline CHEMBL1987344 & 809346 & 3.1024 & 3.9887 & TST & \\
\hline CHEMBL1904672 & 809346 & 4.4389 & 3.5947 & TRN & \\
\hline CHEMBL1891270 & 809346 & 4.6536 & 3.8134 & TRN & \\
\hline CHEMBL1412745 & 809346 & 4.3872 & 3.9532 & TRN & \\
\hline CHEMBL1967640 & 809346 & 3.1024 & 3.25600 & 00000000002 & TRN \\
\hline CHEMBL1440301 & 809346 & 3.1024 & 3.8741 & TST & \\
\hline CHEMBL1503376 & 809346 & 4.8827 & 5.0417 & TRN & \\
\hline CHEMBL1981303 & 809346 & 4.7435 & 4.0796 & TST & \\
\hline CHEMBL1557060 & 809346 & 3.1024 & 3.5817 & TRN & \\
\hline CHEMBL1427949 & 809346 & 5.3565 & 5.6381 & TRN & \\
\hline CHEMBL1468500 & 809346 & 3.1024 & 3.6848 & TST & \\
\hline CHEMBL1894456 & 809346 & 3.1024 & 4.1999 & TRN & \\
\hline CHEMBL1555363 & 809346 & 3.1024 & 3.8745 & TRN & \\
\hline CHEMBL1431520 & 809346 & 4.5157 & 4.0938 & TRN & \\
\hline CHEMBL1723414 & 809346 & 3.1024 & 3.7456 & TRN & \\
\hline CHEMBL1545153 & 809346 & 4.6716 & 5.1995 & TRN & \\
\hline CHEMBL 1888730 & 809346 & 4.3125 & 3.6299 & TRN & \\
\hline CHEMBL1588014 & 809346 & 5.1051 & 4.8558 & TRN & \\
\hline CHEMBL1884334 & 809346 & 5.1938 & 3.5246 & TRN & \\
\hline CHEMBL1423148 & 809346 & 4.6253 & 3.6281 & TRN & \\
\hline CHEMBL1598940 & 809346 & 4.7399 & 4.6818 & TRN & \\
\hline CHEMBL1489418 & 809346 & 5.0232 & 4.2493 & TST & \\
\hline CHEMBL1346278 & 809346 & 4.6253 & 4.4753 & TRN & \\
\hline CHEMBL1439268 & 809346 & 4.2798 & 4.0314 & TST & \\
\hline CHEMBL1557601 & 809346 & 3.1024 & 3.8969 & TRN & \\
\hline CHEMBL1701835 & 809346 & 4.1469 & 3.3642 & TRN & \\
\hline CHEMBL1486891 & 809346 & 5.2328 & 4.3724 & TRN & \\
\hline CHEMBL1550224 & 809346 & 4.3773 & 4.5765 & TRN & \\
\hline
\end{tabular}


Supplemental Table S2.txt

\begin{tabular}{|c|c|c|c|c|}
\hline . & ว9346 & & & \\
\hline CHEMBL1882485 & 09346 & 3.1024 & 3.5756 & \\
\hline HEMBL14 & 99346 & 1024 & & \\
\hline EMBL: & 9346 & 962 & 937 & \\
\hline EMBL1 & 9346 & 209 & & \\
\hline AEMBL1529401 & 09346 & 1024 & 8184 & \\
\hline HEMBL1877908 & 09346 & 4.7545 & 4.2813 & \\
\hline HEMBL1 & $\partial 9346$ & .1024 & & \\
\hline EMBI & 09346 & 2596 & & \\
\hline IEMBL: & 09346 & 1024 & & \\
\hline AEMBL1 & 09346 & .4737 & 4.2967 & \\
\hline AEMBL1 & 309346 & 4.8356 & 3.5812 & \\
\hline HEMBL & 09346 & 1024 & 19 & \\
\hline AEMBL & 309346 & 545 & & \\
\hline AEMBL & 809346 & .6882 & & \\
\hline AEMBL: & 09346 & 3.1024 & 3.403 & \\
\hline AEMBL1 & 309346 & 3.1024 & & \\
\hline AEMBL & 309346 & 01 & & \\
\hline HEMBL & 09346 & 1955 & & \\
\hline AEMB & 309346 & 447 & & \\
\hline EMBL: & 09346 & 3055 & & \\
\hline AEMBL & 309 & 3.1024 & & \\
\hline AEMBL & 309346 & .1024 & & RI \\
\hline IEMBL & 46 & & & \\
\hline 68 & 46 & & & נח \\
\hline EMBL & 09346 & 024 & & R \\
\hline AEMBL: & 809346 & 376 & 4. & $\mathrm{RN}$ \\
\hline AEMBL & 09346 & 874 & & 促 \\
\hline EMB & 6 & 4 & & RN \\
\hline AEMB & 46 & 24 & & . \\
\hline EMBL & 09346 & & & RN \\
\hline AEMBL: & 09346 & .1024 & & S \\
\hline IEMBL & 99346 & 4 & & RI \\
\hline 8 & 6 & 4 & & NIV \\
\hline & & & & 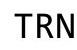 \\
\hline AEMBL & 09346 & & & RI \\
\hline AEMBL: & 29346 & .1024 & 2. & RI \\
\hline IEMBL & $\partial 9346$ & 2 & 38 & $\mathrm{RI}$ \\
\hline 5 & 6 & & & ונס \\
\hline AEMBL: & & & & RI \\
\hline AEMBL & $\partial 9346$ & 882 & 64 & RI \\
\hline EMBL & 09346 & 24 & & RI \\
\hline HEMBL & 809346 & & & \\
\hline & 809346 & & 4.0469 & 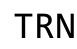 \\
\hline CHEMBL: & 99346 & 1024 & 3.6083 & RN \\
\hline HEMBL: & $\partial 9346$ & 1024 & 4.2146 & $S$ \\
\hline CHEME & & & & \\
\hline CHEMBL: & & & & \\
\hline
\end{tabular}

Page 6850 
Supplemental Table S2.txt

\begin{tabular}{|c|c|c|c|c|c|}
\hline CHEMBL1340521 & 809346 & 4.7471 & 3.5189 & TST & \\
\hline CHEMBL1878680 & 809346 & 4.4935 & 4.3577 & TRN & \\
\hline CHEMBL1397395 & 809346 & 3.1024 & 3.7075 & TRN & \\
\hline CHEMBL1588387 & 809346 & 5.1163 & 5.0351 & TRN & \\
\hline CHEMBL1534849 & 809346 & 4.9586 & 4.5158 & TST & \\
\hline CHEMBL1721546 & 809346 & 3.1024 & 3.5871 & TST & \\
\hline CHEMBL1393529 & 809346 & 3.1024 & 3.4613 & TRN & \\
\hline CHEMBL1865969 & 809346 & 3.1024 & 3.1353 & TST & \\
\hline CHEMBL1879313 & 809346 & 3.1024 & 3.5893 & TRN & \\
\hline CHEMBL1722488 & 809346 & 4.5107 & 4.0688 & TRN & \\
\hline CHEMBL1971872 & 809346 & 5.5376 & 4.3041 & TRN & \\
\hline CHEMBL1491564 & 809346 & 4.7033 & 4.407 & TRN & \\
\hline CHEMBL1730133 & 809346 & 3.1024 & 3.4209 & TST & \\
\hline CHEMBL1341199 & 809346 & 4.5272 & 3.8415 & TRN & \\
\hline CHEMBL1711830 & 809346 & 4.8633 & 4.4484 & TRN & \\
\hline CHEMBL1513925 & 809346 & 5.71 & 4.01699 & 99999999995 & TST \\
\hline CHEMBL1456690 & 809346 & 3.1024 & 3.5103 & TRN & \\
\hline CHEMBL1580989 & 809346 & 4.5792 & 4.3877 & TRN & \\
\hline CHEMBL1479362 & 809346 & 4.6073 & 4.1433 & TRN & \\
\hline CHEMBL1893210 & 809346 & 4.475 & 3.6625 & TRN & \\
\hline CHEMBL1364287 & 809346 & 3.1024 & 4.4068 & TRN & \\
\hline CHEMBL1476641 & 809346 & 4.1555 & 3.9071 & TRN & \\
\hline CHEMBL1880473 & 809346 & 3.1024 & 3.1916 & TRN & \\
\hline CHEMBL1601300 & 809346 & 4.3363 & 3.8226 & TST & \\
\hline CHEMBL1525055 & 809346 & 5.2248 & 4.8178 & TRN & \\
\hline CHEMBL1528726 & 809346 & 4.7852 & 4.1253 & TRN & \\
\hline CHEMBL1540513 & 809346 & 4.7721 & 3.7735 & TRN & \\
\hline CHEMBL1301826 & 809346 & 3.1024 & 4.2009 & TRN & \\
\hline CHEMBL1867718 & 809346 & 3.1024 & 3.5813 & TRN & \\
\hline CHEMBL1873328 & 809346 & 4.51 & 3.6642 & TRN & \\
\hline CHEMBL1337268 & 809346 & 3.1024 & 4.0552 & TRN & \\
\hline CHEMBL1572906 & 809346 & 3.1024 & 3.0236 & TRN & \\
\hline CHEMBL1891615 & 809346 & 4.7471 & 4.0523 & TST & \\
\hline CHEMBL1549839 & 809346 & 3.1024 & 4.0796 & TRN & \\
\hline CHEMBL1577620 & 809346 & 4.9586 & 4.4657 & TRN & \\
\hline CHEMBL1877015 & 809346 & 3.1024 & 3.8256 & TRN & \\
\hline CHEMBL 2006274 & 809346 & 3.1024 & 3.3852 & TRN & \\
\hline CHEMBL1376482 & 809346 & 4.3696 & 3.7946 & TST & \\
\hline CHEMBL1330873 & 809346 & 4.383 & 4.1615 & TRN & \\
\hline CHEMBL1422847 & 809346 & 4.563 & 3.9749 & TRN & \\
\hline CHEMBL1453916 & 809346 & 3.1024 & 4.6212 & TRN & \\
\hline CHEMBL1888908 & 809346 & 3.1024 & 3.9407 & TRN & \\
\hline CHEMBL1428783 & 809346 & 4.3883 & 4.6897 & TRN & \\
\hline CHEMBL1550633 & 809346 & 3.1024 & 4.189 & TST & \\
\hline CHEMBL1707466 & 809346 & 4.6596 & 4.7076 & TRN & \\
\hline CHEMBL1311274 & 809346 & 3.1024 & 3.7549 & TRN & \\
\hline CHEMBL 2001262 & 809346 & 3.1024 & 3.9704 & TRN & \\
\hline CHEMBL1975051 & 809346 & 3.1024 & 3.6131 & TRN & \\
\hline
\end{tabular}




\begin{tabular}{|c|c|c|c|c|}
\hline & & & pplement & \\
\hline CHEMBL1500468 & 809346 & 3.1024 & 3.9183 & TRN \\
\hline CHEMBL1475866 & 809346 & 3.1024 & 3.5228 & TRN \\
\hline CHEMBL1580522 & 809346 & 3.1024 & 3.3808 & TRN \\
\hline CHEMBL1525257 & 809346 & 4.4921 & 3.9575 & TRN \\
\hline CHEMBL1547685 & 809346 & 4.6207 & 4.4546 & TRN \\
\hline CHEMBL 2004928 & 809346 & 3.1024 & 4.1585 & TRN \\
\hline CHEMBL1482332 & 809346 & 3.1024 & 4.0944 & TRN \\
\hline CHEMBL1589231 & 809346 & 4.6737 & 4.0632 & TRN \\
\hline CHEMBL1901671 & 809346 & 4.5622 & 4.2608 & TRN \\
\hline CHEMBL1991618 & 809346 & 5.3036 & 4.6498 & TRN \\
\hline CHEMBL1491734 & 809346 & 3.1024 & 4.3907 & TST \\
\hline CHEMBL1883673 & 809346 & 4.6979 & 3.5759 & TRN \\
\hline CHEMBL1611803 & 809346 & 3.1024 & 3.6794 & TST \\
\hline CHEMBL1512072 & 809346 & 3.1024 & 3.7115 & TRN \\
\hline CHEMBL1975458 & 809346 & 5.2269 & 4.5631 & TRN \\
\hline CHEMBL1966961 & 809346 & 3.1024 & 3.3155 & TRN \\
\hline CHEMBL1559375 & 809346 & 4.2716 & 4.5676 & TRN \\
\hline CHEMBL1367230 & 809346 & 4.3382 & 4.0571 & TRN \\
\hline CHEMBL1397022 & 809346 & 4.8861 & 4.1471 & TRN \\
\hline CHEMBL1427663 & 809346 & 3.1024 & 3.6202 & TRN \\
\hline CHEMBL1524990 & 809346 & 4.3947 & 3.315 & TST \\
\hline CHEMBL1968095 & 809346 & 3.1024 & 4.1803 & TRN \\
\hline CHEMBL1999984 & 809346 & 3.1024 & 3.7088 & TRN \\
\hline CHEMBL1979976 & 809346 & 3.1024 & 3.9033 & TRN \\
\hline CHEMBL 1458710 & 809346 & 4.8827 & 4.3618 & TRN \\
\hline CHEMBL1443753 & 809346 & 5.0706 & 4.3208 & TRN \\
\hline CHEMBL1700311 & 809346 & 3.1024 & 3.6528 & TRN \\
\hline CHEMBL1395840 & 809346 & 4.5884 & 4.2493 & TRN \\
\hline CHEMBL1505748 & 809346 & 3.1024 & 3.9748 & TRN \\
\hline CHEMBL 1880550 & 809346 & 4.3595 & 4.7787 & TRN \\
\hline CHEMBL1880451 & 809346 & 4.9935 & 3.9075 & TST \\
\hline CHEMBL1307703 & 809346 & 5.0044 & 4.613 & TRN \\
\hline CHEMBL1442453 & 809346 & 6.585 & 4.4621 & TRN \\
\hline CHEMBL1985895 & 809346 & 3.1024 & 3.8816 & TST \\
\hline CHEMBL 2003436 & 809346 & 4.643 & 4.0996 & TST \\
\hline CHEMBL1403619 & 809346 & 3.1024 & 3.7222 & TST \\
\hline CHEMBL1346308 & 809346 & 4.6216 & 4.2175 & TST \\
\hline CHEMBL1408688 & 809346 & 5.9431 & 4.3073 & TST \\
\hline CHEMBL1969010 & 809346 & 4.6459 & 4.3698 & TST \\
\hline CHEMBL1450049 & 809346 & 3.1024 & 4.2878 & TST \\
\hline CHEMBL1319264 & 809346 & 3.1024 & 4.3147 & TST \\
\hline CHEMBL1399390 & 809346 & 3.1024 & 4.3024 & TST \\
\hline CHEMBL1343685 & 809346 & 3.1024 & 5.121 & TST \\
\hline CHEMBL1730650 & 809346 & 3.1024 & 3.5644 & TST \\
\hline CHEMBL1564224 & 809346 & 4.36 & 3.3817 & TST \\
\hline CHEMBL1731294 & 809346 & 5.3188 & 4.2495 & TST \\
\hline CHEMBL1575370 & 809346 & 4.4196 & 4.1761 & TST \\
\hline CHEMBL1994456 & 809346 & 3.1024 & 3.9542 & TST \\
\hline
\end{tabular}




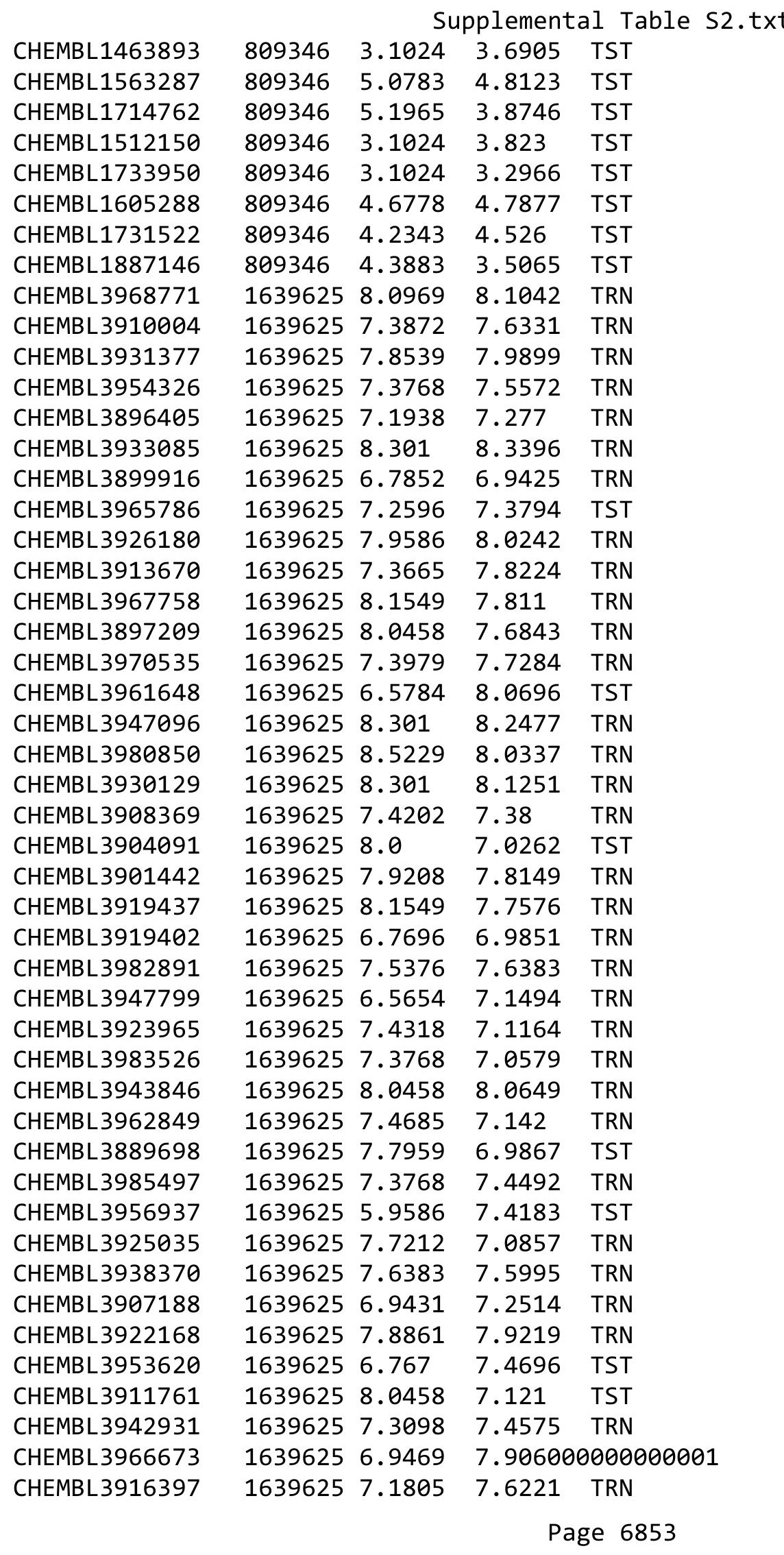


Supplemental Table S2.txt

\begin{tabular}{|c|c|c|c|c|}
\hline (1) & & 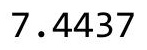 & & \\
\hline CHEMBL3909860 & 39625 & 8.1549 & 867 & \\
\hline IEMBL3949796 & 639625 & 8.3979 & 0339 & \\
\hline AEMBL3919154 & 639625 & 7.0044 & 5565 & \\
\hline AEMBL3895207 & 39625 & 7.2676 & 1889 & \\
\hline AEMBL3985771 & 39625 & 7.1487 & 3578 & \\
\hline AEMBL3940297 & 639625 & 7.7447 & 7.7917 & \\
\hline HEMBL3983794 & 639625 & 6.7167 & 7.5738 & \\
\hline AEMBL3951443 & 639625 & 7.3665 & 7.1983 & \\
\hline AEMBL3935525 & 639625 & 7.585 & .4733 & \\
\hline AEMBL3948826 & 639625 & 7.4815 & 7.3583 & \\
\hline HEMBL3970424 & 639625 & 6.9508 & 7.2066 & \\
\hline AEMBL3896690 & 639625 & 6.6198 & 6.6502 & \\
\hline AEMBL3956671 & 639625 & 6.7399 & 7.1602 & \\
\hline IEMBL 3968271 & 639625 & 7.7959 & 5263 & \\
\hline AEMBL3904143 & 639625 & 8.301 & 5543 & \\
\hline AEMBL3941646 & 639625 & 7.7447 & 7.1462 & \\
\hline AEMBL3916661 & 639625 & 7.3979 & 0695 & \\
\hline HEMBL 396 & 639 & 7.2518 & 7.3042 & \\
\hline AEMBL3933503 & 1639625 & 7.3768 & 5324 & \\
\hline AEMBL3950243 & 639625 & 6.8239 & 2904 & \\
\hline HEMBL3978421 & 639625 & 6.7423 & 7.3809 & \\
\hline AEMBL3935794 & 639625 & 8.3979 & 8.342 & \\
\hline AEMBL3960448 & 6396 & 6.8729 & 1838 & \\
\hline HEMBL 39 & 163 & 7.4949 & 42 & \\
\hline HFMRI 395 & 1639625 & 6.5376 & 1989 & \\
\hline HEMBL3929480 & 639625 & 7.1805 & 7.7447 & \\
\hline AEMBL3965842 & 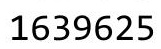 & 7.4815 & 374 & \\
\hline HEMBL3971801 & 1639625 & 7.8861 & 7.7127 & \\
\hline JEMBL 389 & 6396 & 7.301 & 7.2943 & \\
\hline HEMBL395 & 25 & 7.4089 & 7.2896 & \\
\hline AEMBL3982061 & 639625 & 7.3279 & 7.5437 & \\
\hline AEMBL3931050 & 639625 & 7.0969 & & \\
\hline AEMBL3904920 & 639625 & 7.1135 & 7.3734 & \\
\hline HEMBL 39 & $6:-1000$ & 7. & 838 & \\
\hline $3 L 389$ & 5 & 7. & 128 & \\
\hline HEMBL3902704 & 1639625 & 7.4202 & 7.2827 & \\
\hline AEMBL3939843 & 1639625 & 7.7696 & 7.4215 & \\
\hline HEMBL151 & 688633 & 942 & 3.7293 & \\
\hline HᄃMDI 121 & 88633 & 951 & 3.9362 & \\
\hline HEMBL150 & 688633 & 4.8729 & 737 & \\
\hline HEMBL2004417 & 688633 & 4.7135 & 4.5541 & \\
\hline AEMBL3191363 & 688633 & 4.0839 & 3.8957 & \\
\hline CHEMBL 319 & 688633 & 4.5588 & & \\
\hline HEMBL56 & & 4.9846 & 4.0553 & \\
\hline CHEMBL1604283 & 688633 & 6.0 & 6.1121 & \\
\hline HEMBL1404984 & 688633 & 4.0226 & 4.0454 & \\
\hline CHEMBL1366004 & 688633 & 4.1808 & 4.5402 & \\
\hline
\end{tabular}

Page 6854 
Supplemental Table S2.txt

\begin{tabular}{|c|c|c|c|c|}
\hline CHEMBL1323853 & 688633 & 4.4942 & 4.2167 & TRN \\
\hline CHEMBL1481849 & 688633 & 4.7036 & 4.5488 & TRN \\
\hline CHEMBL1329197 & 688633 & 4.4332 & 4.2479 & TRN \\
\hline CHEMBL1549574 & 688633 & 4.4084 & 4.1594 & TRN \\
\hline CHEMBL580183 & 688633 & 4.1641 & 3.929 & TRN \\
\hline CHEMBL1569989 & 688633 & 4.4144 & 4.3342 & TRN \\
\hline CHEMBL1426788 & 688633 & 4.3149 & 4.1868 & TRN \\
\hline CHEMBL1542057 & 688633 & 3.9827 & 3.9519 & TRN \\
\hline CHEMBL1456530 & 688633 & 3.8906 & 4.0193 & TRN \\
\hline CHEMBL1531676 & 688633 & 4.459 & 4.5272 & TRN \\
\hline CHEMBL1402405 & 688633 & 4.3154 & 4.5878 & TRN \\
\hline CHEMBL1971965 & 688633 & 4.5722 & 4.4643 & TRN \\
\hline CHEMBL1542560 & 688633 & 4.4208 & 4.4185 & TRN \\
\hline CHEMBL1373533 & 688633 & 4.1308 & 4.0385 & TRN \\
\hline CHEMBL1981840 & 688633 & 4.0221 & 4.2257 & TRN \\
\hline CHEMBL187866 & 688633 & 4.137 & 4.311 & TRN \\
\hline CHEMBL1466713 & 688633 & 4.4648 & 4.4626 & TRN \\
\hline CHEMBL1342570 & 688633 & 4.4064 & 4.2582 & TRN \\
\hline CHEMBL1256737 & 688633 & 4.4014 & 4.4049 & TRN \\
\hline CHEMBL1377709 & 688633 & 3.8746 & 4.2962 & TST \\
\hline CHEMBL3194737 & 688633 & 4.399 & 4.1773 & TRN \\
\hline CHEMBL1342852 & 688633 & 5.2426 & 5.254 & TRN \\
\hline CHEMBL1370195 & 688633 & 2.8239 & 3.7639 & TRN \\
\hline CHEMBL1358906 & 688633 & 4.1052 & 4.1636 & TRN \\
\hline CHEMBL1483252 & 688633 & 4.4314 & 4.5361 & TRN \\
\hline CHEMBL463175 & 688633 & 4.5634 & 4.437 & TST \\
\hline CHEMBL1562344 & 688633 & 4.7199 & 4.0765 & TRN \\
\hline CHEMBL1563766 & 688633 & 4.2099 & 4.3906 & TRN \\
\hline CHEMBL1391048 & 688633 & 4.5014 & 4.4202 & TRN \\
\hline CHEMBL3199665 & 688633 & 2.8239 & 4.1937 & TRN \\
\hline CHEMBL1468954 & 688633 & 4.595 & 4.1217 & TRN \\
\hline CHEMBL3193808 & 688633 & 4.1274 & 3.6898 & TST \\
\hline CHEMBL1971727 & 688633 & 4.4395 & 4.1144 & TRN \\
\hline CHEMBL235891 & 688633 & 2.8239 & 4.3129 & TST \\
\hline CHEMBL1333248 & 688633 & 3.8511 & 4.0263 & TRN \\
\hline CHEMBL584269 & 688633 & 5.4191 & 4.7326 & TRN \\
\hline CHEMBL1563862 & 688633 & 4.0773 & 3.8888 & TRN \\
\hline CHEMBL1361227 & 688633 & 2.8239 & 3.8429 & TRN \\
\hline CHEMBL1388616 & 688633 & 4.0643 & 4.0103 & TRN \\
\hline CHEMBL 3213606 & 688633 & 4.2946 & 4.5251 & TRN \\
\hline CHEMBL1341256 & 688633 & 2.8239 & 3.0827 & TRN \\
\hline CHEMBL1427617 & 688633 & 4.6998 & 4.4538 & TRN \\
\hline CHEMBL1583082 & 688633 & 4.1145 & 4.0936 & TRN \\
\hline CHEMBL578872 & 688633 & 4.3038 & \multicolumn{2}{|c|}{3.8760000000000003} \\
\hline CHEMBL1958251 & 688633 & 4.7066 & 4.7042 & TRN \\
\hline CHEMBL1986678 & 688633 & 4.1352 & 4.027 & TRN \\
\hline CHEMBL1328118 & 688633 & 4.1476 & 4.2672 & TRN \\
\hline CHEMBL2369168 & 688633 & 4.5065 & 4.4595 & TRN \\
\hline
\end{tabular}




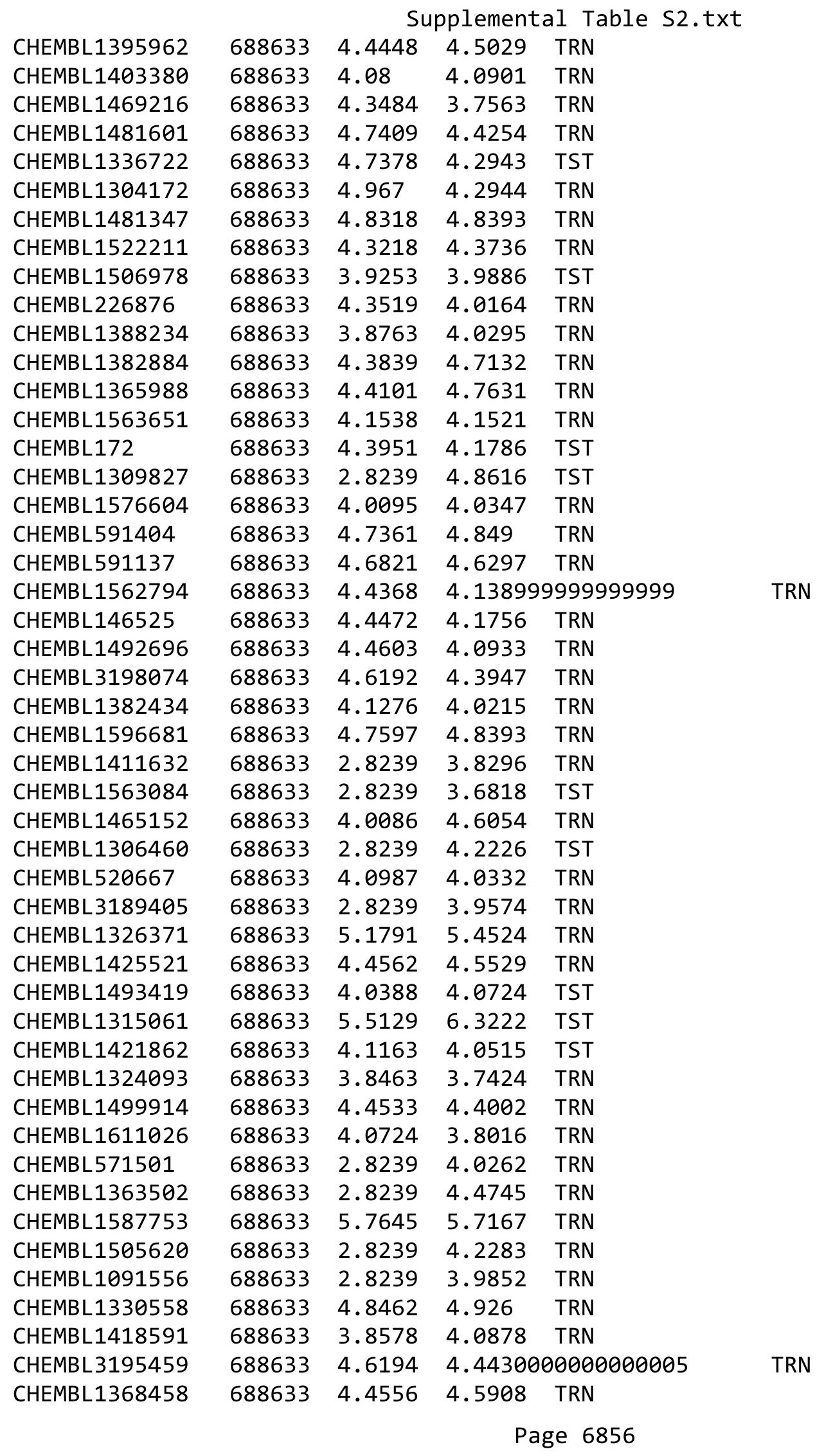


Supplemental Table S2.txt

\begin{tabular}{|c|c|c|c|c|}
\hline CHEMBL1560982 & 688633 & 4.6336 & 4.5732 & TRN \\
\hline CHEMBL1716494 & 688633 & 4.6297 & 4.5294 & TRN \\
\hline CHEMBL 2004056 & 688633 & 4.4461 & 4.3079 & TRN \\
\hline CHEMBL1467492 & 688633 & 2.8239 & 3.582 & TRN \\
\hline CHEMBL1450086 & 688633 & 4.9796 & 4.9941 & TRN \\
\hline CHEMBL1530234 & 688633 & 4.3608 & 3.8822 & TRN \\
\hline CHEMBL66953 & 688633 & 4.5879 & 4.6631 & TRN \\
\hline CHEMBL3195264 & 688633 & 3.9043 & 3.9508 & TRN \\
\hline CHEMBL 299228 & 688633 & 4.4399 & 3.8625 & TRN \\
\hline CHEMBL3199504 & 688633 & 4.5627 & 4.4773 & TRN \\
\hline CHEMBL1512990 & 688633 & 4.0247 & 3.91 & TRN \\
\hline CHEMBL1312441 & 688633 & 4.1763 & 4.2052 & TRN \\
\hline CHEMBL548615 & 688633 & 4.6209 & 4.7158 & TRN \\
\hline CHEMBL1586850 & 688633 & 4.147 & 3.9406 & TRN \\
\hline CHEMBL1606918 & 688633 & 4.2712 & 4.2834 & TST \\
\hline CHEMBL1503928 & 688633 & 4.3256 & 3.927 & TRN \\
\hline CHEMBL1974537 & 688633 & 3.8465 & 3.4448 & TST \\
\hline CHEMBL1353752 & 688633 & 4.4829 & 4.3908 & TRN \\
\hline CHEMBL1975961 & 688633 & 4.1126 & 4.0519 & TRN \\
\hline CHEMBL1560273 & 688633 & 4.2799 & 4.4338 & TST \\
\hline CHEMBL1586404 & 688633 & 4.4454 & 4.2058 & TRN \\
\hline CHEMBL1605613 & 688633 & 4.2056 & 3.9662 & TRN \\
\hline CHEMBL1484627 & 688633 & 4.5114 & 4.1286 & TRN \\
\hline CHEMBL3210835 & 688633 & 2.8239 & 3.9541 & TRN \\
\hline CHEMBL445102 & 688633 & 4.1581 & 4.2311 & TRN \\
\hline CHEMBL1505275 & 688633 & 5.2373 & 4.9595 & TRN \\
\hline CHEMBL1348503 & 688633 & 2.8239 & 3.14600 & 0000000004 \\
\hline CHEMBL186248 & 688633 & 2.8239 & 3.9958 & TRN \\
\hline CHEMBL1396209 & 688633 & 4.6962 & 4.831 & TST \\
\hline CHEMBL3197662 & 688633 & 4.3518 & 4.1992 & TRN \\
\hline CHEMBL1572266 & 688633 & 7.6383 & 6.7209 & TRN \\
\hline CHEMBL1301082 & 688633 & 4.5278 & 4.3706 & TRN \\
\hline CHEMBL1989158 & 688633 & 4.0826 & 3.5895 & TST \\
\hline CHEMBL1435878 & 688633 & 4.212 & 4.0291 & TRN \\
\hline CHEMBL1360037 & 688633 & 4.4751 & 4.4346 & TRN \\
\hline CHEMBL1430795 & 688633 & 4.0223 & 3.9663 & TRN \\
\hline CHEMBL124006 & 688633 & 4.4589 & 4.2172 & TRN \\
\hline CHEMBL1441196 & 688633 & 5.3737 & 5.1251 & TRN \\
\hline CHEMBL1524986 & 688633 & 4.7289 & 4.5986 & TRN \\
\hline CHEMBL1414846 & 688633 & 2.8239 & 4.5947 & TRN \\
\hline CHEMBL1438127 & 688633 & 4.1186 & 4.2833 & TRN \\
\hline CHEMBL1409001 & 688633 & 4.7678 & 4.6305 & TRN \\
\hline CHEMBL1462016 & 688633 & 3.8778 & 4.1684 & TRN \\
\hline CHEMBL1610733 & 688633 & 3.9593 & 3.8978 & TRN \\
\hline CHEMBL1578054 & 688633 & 4.1087 & 4.0996 & TRN \\
\hline CHEMBL1534782 & 688633 & 4.4138 & 4.2172 & TRN \\
\hline CHEMBL3190286 & 688633 & 3.9322 & 3.862 & TRN \\
\hline CHEMBL1406274 & 688633 & 6.0 & 5.8251 & TRN \\
\hline
\end{tabular}




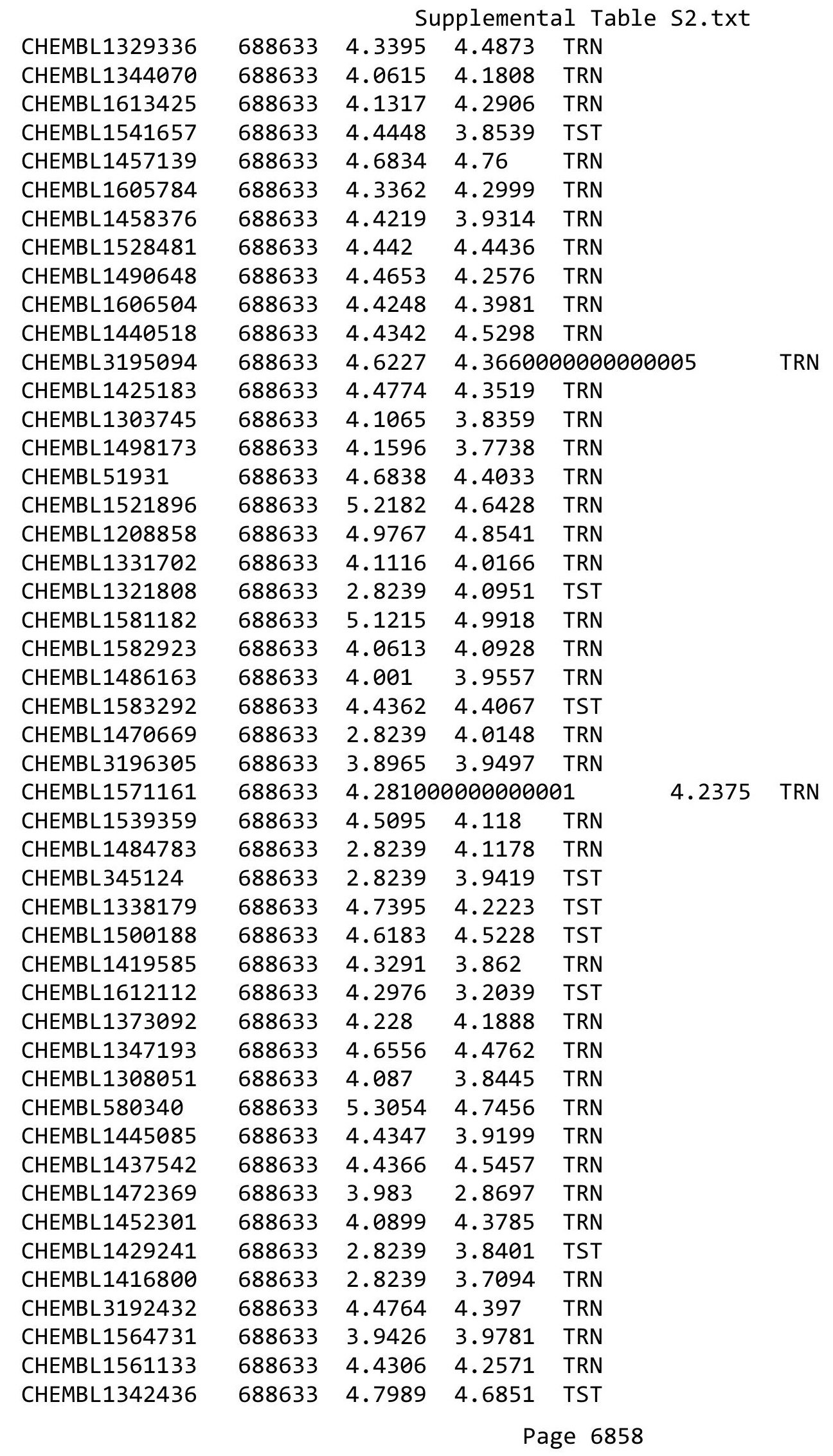


Supplemental Table S2.txt

\begin{tabular}{|c|c|c|c|c|}
\hline 3814 & & 8239 & & \\
\hline & & 2.8239 & 3.7457 & \\
\hline & & & & \\
\hline IEMBL1 & & & & \\
\hline IEMBL14 & & & 7583 & \\
\hline AEMBL1322645 & 38633 & .4774 & 1929 & \\
\hline IEMBL] & & & 982 & \\
\hline 298 & & & & \\
\hline IEMBL13 & 8633 & & 2323 & \\
\hline AEMBL68 & 633 & .4703 & 4752 & \\
\hline AEMBL2 & 3633 & 4.4 & 3977 & \\
\hline IEMBL1 & 33 & .2 & 545 & \\
\hline IEMBL: & & & & \\
\hline AEMBL1 & 3633 & 4.7238 & 591 & \\
\hline IEMBL1 & 633 & 2.8 & 6643 & \\
\hline EMBL: & 33 & 3.5 & 6525 & \\
\hline EMBL & & 9 & 307 & \\
\hline EMBL & & & & \\
\hline 561 & 633 & 4.2704 & 754 & \\
\hline EMBL & 33 & & & \\
\hline 978 & 3 & 4. & & \\
\hline 81 & & 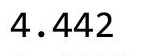 & & \\
\hline 72 & & & & \\
\hline 491 & & & & \\
\hline IEMBL: & & & & \\
\hline IEMBL & 3 & 4.6 & & \\
\hline 35 & & & & \\
\hline 49 & 33 & & 98 & \\
\hline 031 & & & & \\
\hline IEMBL1 & 33 & & & $\{\mathrm{~K}$ \\
\hline AEMBL: & 3 & & 008 & \\
\hline 51 & & & 65 & \\
\hline$\partial 0$ & 33 & 6 & 64 & \\
\hline EMBL & & & 291 & \\
\hline AEMBL1 & 633 & & 324 & \\
\hline 0 & & & & \\
\hline 4 & & 6 & 24 & \\
\hline AEMBL: & & & 225 & \\
\hline AEMBL1 & 8633 & 4.3189 & 391 & \\
\hline IEMBL: & 8633 & 4.6 & & \\
\hline 550 & & & & \\
\hline 896 & 633 & 4.2018 & 4.0341 & \\
\hline HEMBL & & 5.284 & & \\
\hline EMBL: & 8633 & 6345 & 703 & \\
\hline IEMBL & ת & 4.46 & 22 & \\
\hline CHEMBL & & & & \\
\hline CHEMBLI & 8633 & .0732 & 3.7017 & \\
\hline CHEMBL524376 & 688633 & 4.9931 & 4.5847 & \\
\hline
\end{tabular}

Page 6859 


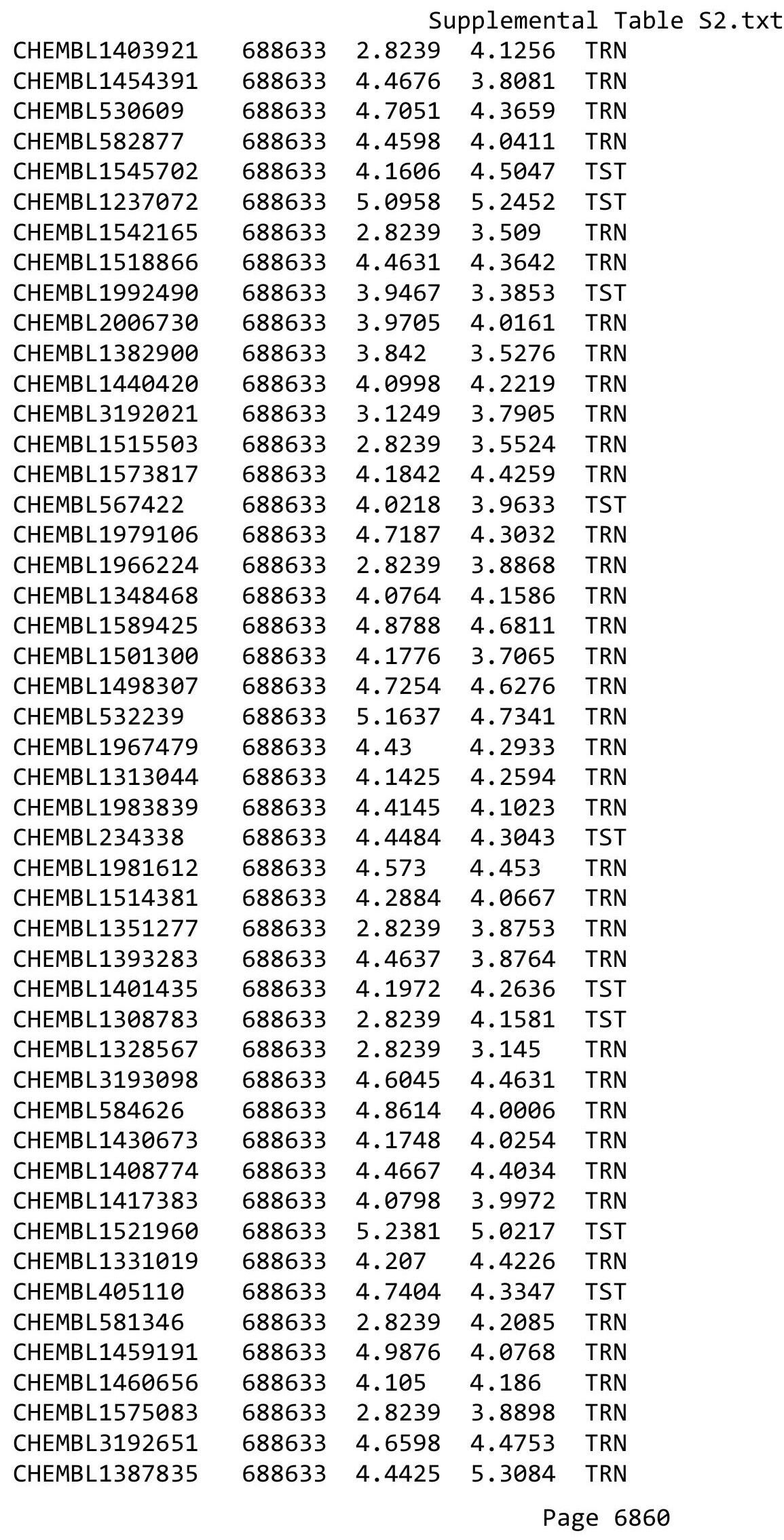




\begin{tabular}{|c|c|c|c|c|c|}
\hline & & \multicolumn{4}{|c|}{ Supplemental Table S2.txt } \\
\hline CHEMBL1339676 & 688633 & 4.4503 & 4.2793 & TRN & \\
\hline CHEMBL1389832 & 688633 & 4.3947 & 4.5331 & TST & \\
\hline CHEMBL1981667 & 688633 & 2.8239 & 4.0368 & TRN & \\
\hline CHEMBL1430611 & 688633 & 5.6946 & 5.5925 & TST & \\
\hline CHEMBL1597177 & 688633 & 4.6173 & 4.5791 & TST & \\
\hline CHEMBL1308845 & 688633 & 4.1639 & 4.2645 & TRN & \\
\hline CHEMBL1309128 & 688633 & 2.8239 & 3.8943 & TRN & \\
\hline CHEMBL581257 & 688633 & 4.471 & 4.305 & TST & \\
\hline CHEMBL1457463 & 688633 & 4.1752 & 4.4476 & TRN & \\
\hline CHEMBL606167 & 688633 & 5.4202 & 4.1981 & TST & \\
\hline CHEMBL1325502 & 688633 & 3.8707 & 4.064 & TRN & \\
\hline CHEMBL3195943 & 688633 & 4.7003 & 4.7074 & TRN & \\
\hline CHEMBL1478496 & 688633 & 4.6544 & 4.6473 & TRN & \\
\hline CHEMBL1482046 & 688633 & 4.109 & 3.8477 & TRN & \\
\hline CHEMBL1565592 & 688633 & 4.4949 & 4.4329 & TRN & \\
\hline CHEMBL1415035 & 688633 & 4.1136 & 4.1567 & TRN & \\
\hline CHEMBL71936 & 688633 & 2.8239 & 4.0494 & TRN & \\
\hline CHEMBL935 & 688633 & 4.3226 & 4.5278 & TRN & \\
\hline CHEMBL1485793 & 688633 & 4.4035 & 4.2886 & TRN & \\
\hline CHEMBL1392287 & 688633 & 4.427 & 4.1048 & TRN & \\
\hline CHEMBL1431862 & 688633 & 4.1874 & 3.9855 & TRN & \\
\hline CHEMBL601737 & 688633 & 3.824 & 3.931 & TST & \\
\hline CHEMBL1421542 & 688633 & 2.8239 & 3.8967 & TST & \\
\hline CHEMBL1446900 & 688633 & 4.1309 & 3.6369 & TRN & \\
\hline CHEMBL1499792 & 688633 & 4.5824 & 4.5269 & TRN & \\
\hline CHEMBL1433109 & 688633 & 4.325 & 4.0118 & TST & \\
\hline CHEMBL1504661 & 688633 & 4.4604 & 4.1361 & TST & \\
\hline CHEMBL1412497 & 688633 & 4.131 & 4.4625 & TRN & \\
\hline CHEMBL533082 & 688633 & 4.1128 & 3.9124 & TRN & \\
\hline CHEMBL1532828 & 688633 & 4.7794 & 4.9291 & TRN & \\
\hline CHEMBL1376732 & 688633 & 3.9808 & 3.8854 & TRN & \\
\hline CHEMBL1580510 & 688633 & 2.8239 & 4.0694 & TST & \\
\hline CHEMBL1593697 & 688633 & 6.0 & 6.7818 & TST & \\
\hline CHEMBL3196253 & 688633 & 4.3524 & 4.2963 & TST & \\
\hline CHEMBL1573630 & 688633 & 3.9065 & 4.2624 & TRN & \\
\hline CHEMBL1606583 & 688633 & 4.5289 & 4.5172 & TRN & \\
\hline CHEMBL1435343 & 688633 & 4.2033 & 4.15300 & 00000000005 & TRN \\
\hline CHEMBL67311 & 688633 & 4.8111 & 4.6477 & TST & \\
\hline CHEMBL 3195570 & 688633 & 4.3269 & 4.2848 & TRN & \\
\hline CHEMBL1623028 & 688633 & 4.6392 & 4.4978 & TRN & \\
\hline CHEMBL1564901 & 688633 & 3.9 & 4.0145 & TST & \\
\hline CHEMBL598270 & 688633 & 4.2622 & 4.3246 & TRN & \\
\hline CHEMBL1242180 & 688633 & 4.7291 & 4.7384 & TST & \\
\hline CHEMBL1561153 & 688633 & 4.8274 & 4.5115 & TRN & \\
\hline CHEMBL1352234 & 688633 & 4.6576 & 4.5584 & TRN & \\
\hline CHEMBL1321398 & 688633 & 4.739 & 4.607 & TRN & \\
\hline CHEMBL1348232 & 688633 & 4.1219 & 4.1548 & TRN & \\
\hline CHEMBL3194449 & 688633 & 4.1824 & 4.0003 & TRN & \\
\hline
\end{tabular}


Supplemental Table S2.txt

\begin{tabular}{|c|c|c|c|c|}
\hline CHEMBL578928 & 688633 & 4.4671 & 4.2146 & TRN \\
\hline CHEMBL1514790 & 688633 & 4.7022 & 4.6694 & TRN \\
\hline CHEMBL1403240 & 688633 & 4.1242 & 4.1387 & TRN \\
\hline CHEMBL1443407 & 688633 & 3.9754 & 4.3231 & TRN \\
\hline CHEMBL1321297 & 688633 & 4.1063 & 4.76 & TRN \\
\hline CHEMBL1611421 & 688633 & 2.8239 & 3.9608 & TST \\
\hline CHEMBL1339613 & 688633 & 4.5293 & 4.3692 & TRN \\
\hline CHEMBL1381313 & 688633 & 2.8239 & 3.8249 & TRN \\
\hline CHEMBL1522083 & 688633 & 4.42 & 4.096 & TRN \\
\hline CHEMBL1457644 & 688633 & 3.8326 & 4.0682 & TRN \\
\hline CHEMBL3190369 & 688633 & 4.5989 & 4.7198 & TST \\
\hline CHEMBL1487428 & 688633 & 2.8239 & 3.8462 & TRN \\
\hline CHEMBL1600855 & 688633 & 4.6158 & 4.6843 & TRN \\
\hline CHEMBL1609756 & 688633 & 4.524 & 4.1672 & TRN \\
\hline CHEMBL546344 & 688633 & 4.8156 & 4.6144 & TRN \\
\hline CHEMBL 3198170 & 688633 & 4.0071 & 3.9931 & TRN \\
\hline CHEMBL 3197064 & 688633 & 4.4796 & 4.5441 & TRN \\
\hline CHEMBL1482740 & 688633 & 5.1778 & 4.6856 & TRN \\
\hline CHEMBL532641 & 688633 & 4.7169 & 4.279 & TRN \\
\hline CHEMBL1422217 & 688633 & 4.2819 & 4.2822 & TRN \\
\hline CHEMBL1986151 & 688633 & 4.4503 & 4.1675 & TRN \\
\hline CHEMBL3192690 & 688633 & 4.2898 & 4.0724 & TRN \\
\hline CHEMBL1601781 & 688633 & $4.4860 e$ & 000000000 & 4.5323 \\
\hline CHEMBL11908 & 688633 & 4.1099 & 3.908 & TRN \\
\hline CHEMBL1532831 & 688633 & 4.2817 & 3.5891 & TRN \\
\hline CHEMBL27403 & 688633 & 4.1324 & 4.1727 & TRN \\
\hline CHEMBL1484943 & 688633 & 4.0902 & 3.8166 & TRN \\
\hline CHEMBL1520621 & 688633 & 4.0807 & 3.6504 & TRN \\
\hline CHEMBL1412114 & 688633 & 4.4843 & 4.3884 & TRN \\
\hline CHEMBL1388595 & 688633 & 2.8239 & 4.0988 & TRN \\
\hline CHEMBL1590547 & 688633 & 4.4608 & 4.4344 & TRN \\
\hline CHEMBL1386044 & 688633 & 4.0927 & 4.0175 & TRN \\
\hline CHEMBL1574121 & 688633 & 4.6394 & 4.318000 & 30000000005 \\
\hline CHEMBL1410230 & 688633 & 4.5998 & 4.0874 & TRN \\
\hline CHEMBL602363 & 688633 & 4.1535 & 4.2016 & TST \\
\hline CHEMBL1379600 & 688633 & 4.1042 & 3.8957 & TRN \\
\hline CHEMBL1403744 & 688633 & 4.103 & 4.2869 & TST \\
\hline CHEMBL1994463 & 688633 & 4.7312 & 4.5021 & TST \\
\hline CHEMBL1393472 & 688633 & 2.8239 & 3.995 & TRN \\
\hline CHEMBL1544460 & 688633 & 4.7042 & 4.2877 & TRN \\
\hline CHEMBL1472251 & 688633 & 4.0774 & 4.3984 & TRN \\
\hline CHEMBL609606 & 688633 & 4.4333 & 4.3123 & TST \\
\hline CHEMBL1474571 & 688633 & 4.5769 & 4.727 & TRN \\
\hline CHEMBL 2005743 & 688633 & 4.5227 & 4.0721 & TRN \\
\hline CHEMBL428064 & 688633 & 5.6635 & 5.7827 & TRN \\
\hline CHEMBL1518291 & 688633 & 4.1246 & 4.3968 & TST \\
\hline CHEMBL 3194579 & 688633 & 4.7305 & 4.5452 & TRN \\
\hline CHEMBL586135 & 688633 & 4.923 & 4.7868 & TRN \\
\hline
\end{tabular}




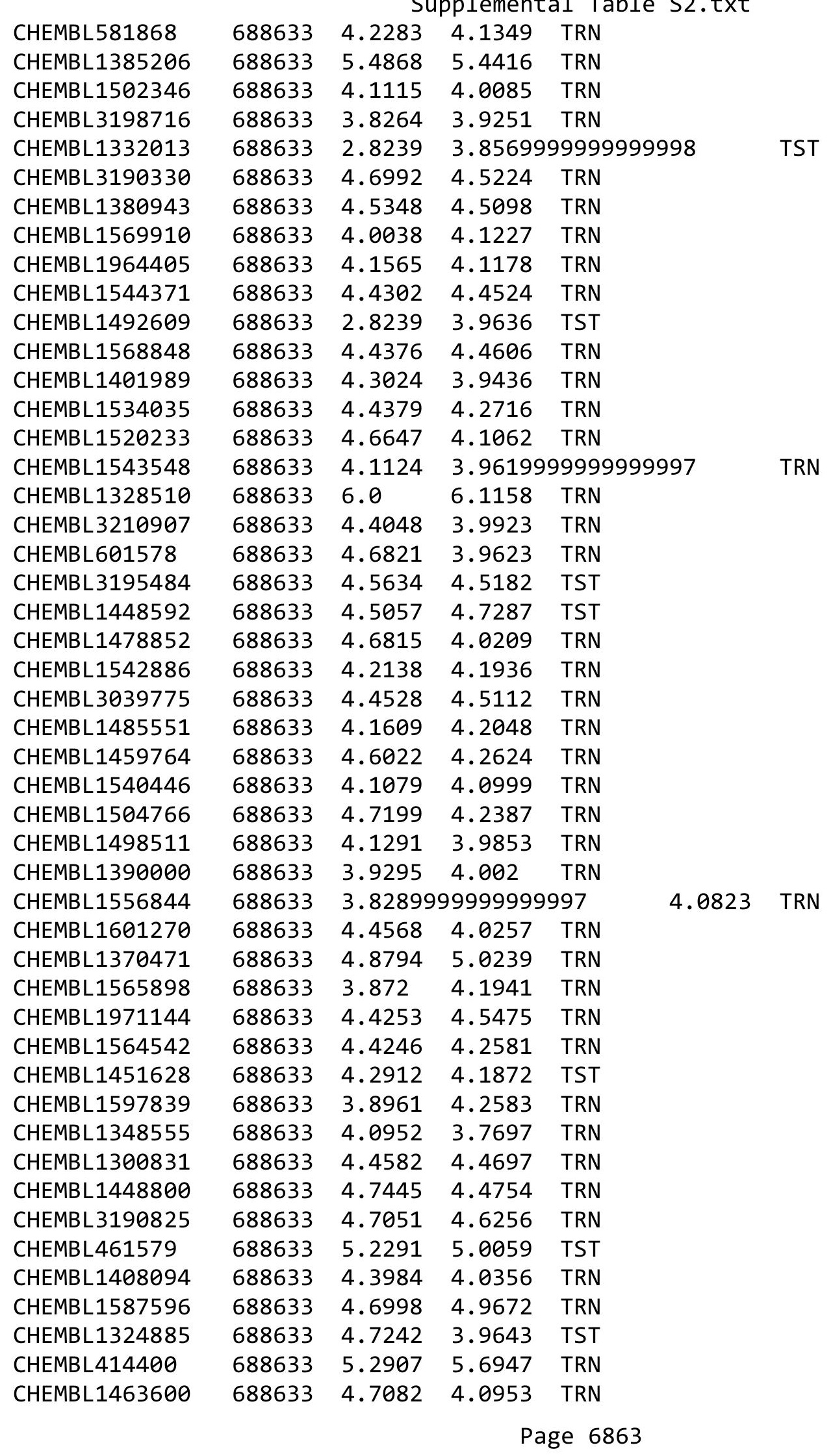




\begin{tabular}{|c|c|c|c|c|}
\hline & & \multicolumn{3}{|c|}{ Supplemental Table S2.txt } \\
\hline CHEMBL1495602 & 688633 & 4.4181 & 4.2864 & TRN \\
\hline CHEMBL1433069 & 688633 & 4.3589 & 4.0677 & TRN \\
\hline CHEMBL1440490 & 688633 & 4.461 & 4.1849 & TRN \\
\hline CHEMBL1517411 & 688633 & 2.8239 & 4.1431 & TRN \\
\hline CHEMBL1300557 & 688633 & 2.8239 & 2.9926 & TST \\
\hline CHEMBL1375045 & 688633 & 4.73 & 4.72 & TRN \\
\hline CHEMBL1331185 & 688633 & 4.6912 & 4.4171 & TRN \\
\hline CHEMBL1545719 & 688633 & 4.6082 & 4.2495 & TRN \\
\hline CHEMBL1518557 & 688633 & 4.4013 & 4.1055 & TRN \\
\hline CHEMBL3191530 & 688633 & 4.3334 & 4.2988 & TRN \\
\hline CHEMBL600121 & 688633 & 4.4265 & 4.1634 & TRN \\
\hline CHEMBL1988121 & 688633 & 4.4381 & 4.3706 & TRN \\
\hline CHEMBL1487183 & 688633 & 5.5638 & 5.2988 & TST \\
\hline CHEMBL1400005 & 688633 & 3.9679 & 4.073 & TST \\
\hline CHEMBL3189889 & 688633 & 2.8239 & 3.0939 & TRN \\
\hline CHEMBL1423096 & 688633 & 4.0989 & 3.9696 & TST \\
\hline CHEMBL3194811 & 688633 & 4.0363 & 4.1466 & TRN \\
\hline CHEMBL1301975 & 688633 & 2.8239 & 4.2485 & TRN \\
\hline CHEMBL1420457 & 688633 & 3.9038 & 4.0178 & TRN \\
\hline CHEMBL582030 & 688633 & 4.3738 & 4.0919 & TRN \\
\hline CHEMBL591126 & 688633 & 4.7503 & 4.8051 & TRN \\
\hline CHEMBL1451659 & 688633 & 4.4607 & 4.3599 & TRN \\
\hline CHEMBL1306267 & 688633 & 4.4176 & 4.2511 & TRN \\
\hline CHEMBL199405 & 688633 & 4.4571 & 4.5774 & TRN \\
\hline CHEMBL 3192557 & 688633 & 4.563 & 4.6127 & TRN \\
\hline CHEMBL1256876 & 688633 & 4.3003 & 4.4436 & TST \\
\hline CHEMBL3197977 & 688633 & 4.0563 & 3.9455 & TRN \\
\hline CHEMBL1478652 & 688633 & 4.458 & 4.2301 & TRN \\
\hline CHEMBL1555833 & 688633 & 4.2929 & 4.1379 & TRN \\
\hline CHEMBL1326817 & 688633 & 2.8239 & 4.0813 & TST \\
\hline CHEMBL1428563 & 688633 & 4.4949 & 4.2798 & TRN \\
\hline CHEMBL1308879 & 688633 & 5.224 & 4.6756 & TRN \\
\hline CHEMBL1322008 & 688633 & 4.4874 & 4.0908 & TRN \\
\hline CHEMBL1532568 & 688633 & 4.5953 & 3.9742 & TRN \\
\hline CHEMBL 3144932 & 688633 & 2.8239 & 4.0036 & TRN \\
\hline CHEMBL1411779 & 688633 & 4.1973 & 4.0317 & TRN \\
\hline CHEMBL1351158 & 688633 & 5.4841 & 4.6842 & TRN \\
\hline CHEMBL582980 & 688633 & 4.9821 & 4.2951 & TRN \\
\hline CHEMBL1314743 & 688633 & 4.3921 & 4.4233 & TRN \\
\hline CHEMBL1602553 & 688633 & 2.8239 & 4.0404 & TST \\
\hline CHEMBL1369287 & 688633 & 4.4486 & 4.4296 & TRN \\
\hline CHEMBL1423463 & 688633 & 4.7162 & 4.3347 & TRN \\
\hline CHEMBL1383414 & 688633 & 4.5438 & 4.5515 & TRN \\
\hline CHEMBL1399190 & 688633 & 2.8239 & 4.0969 & TRN \\
\hline CHEMBL1590885 & 688633 & 2.8239 & 4.0252 & TST \\
\hline CHEMBL1380132 & 688633 & 4.4109 & 3.9378 & TRN \\
\hline CHEMBL1387404 & 688633 & 2.8239 & 3.8191 & TRN \\
\hline CHEMBL1342357 & 688633 & 4.4339 & 4.28600 & 00000000005 \\
\hline & & & & 6864 \\
\hline
\end{tabular}




\begin{tabular}{|c|c|c|c|c|}
\hline \multicolumn{5}{|c|}{ Supplemental Tab. } \\
\hline CHEMBL1362047 & 688633 & 4.4365 & 4.1431 & TRN \\
\hline CHEMBL1378768 & 688633 & 4.4899 & 4.6238 & TRN \\
\hline CHEMBL1409219 & 688633 & 2.8239 & 3.9133 & TRN \\
\hline CHEMBL1612812 & 688633 & 4.0642 & 4.1315 & TST \\
\hline CHEMBL1416171 & 688633 & 4.4015 & 4.2077 & TRN \\
\hline CHEMBL1428566 & 688633 & 4.5127 & 3.9245 & TRN \\
\hline CHEMBL1565674 & 688633 & 4.7049 & 4.457 & TRN \\
\hline CHEMBL492886 & 688633 & 4.3883 & 4.271 & TRN \\
\hline CHEMBL3193651 & 688633 & 4.2584 & 4.1835 & TRN \\
\hline CHEMBL1326171 & 688633 & 4.0114 & 3.7683 & TRN \\
\hline CHEMBL1594055 & 688633 & 6.0969 & 7.1438 & TST \\
\hline CHEMBL1306583 & 688633 & 4.2887 & 4.2744 & TRN \\
\hline CHEMBL1463614 & 688633 & 4.6572 & 4.5674 & TRN \\
\hline CHEMBL1491847 & 688633 & 4.8931 & 4.9544 & TRN \\
\hline CHEMBL1449930 & 688633 & 4.4063 & 3.6701 & TRN \\
\hline CHEMBL1579535 & 688633 & 2.8239 & 4.2527 & TST \\
\hline CHEMBL1340754 & 688633 & 4.7167 & 4.577 & TRN \\
\hline CHEMBL1576581 & 688633 & 5.1062 & 5.1211 & TRN \\
\hline CHEMBL1443946 & 688633 & 4.0811 & 4.2816 & TRN \\
\hline CHEMBL436589 & 688633 & 4.4415 & 4.1913 & TST \\
\hline CHEMBL1477547 & 688633 & 4.3366 & 4.2056 & TRN \\
\hline CHEMBL1357255 & 688633 & 4.1489 & 4.1557 & TRN \\
\hline CHEMBL1403593 & 688633 & 2.8239 & 4.3908 & TRN \\
\hline CHEMBL1425438 & 688633 & 4.1479 & 3.8866 & TRN \\
\hline CHEMBL602413 & 688633 & 4.7293 & 4.3256 & TRN \\
\hline CHEMBL1460004 & 688633 & 4.3108 & 4.4605 & TRN \\
\hline CHEMBL1549308 & 688633 & 4.4465 & 4.2352 & TST \\
\hline CHEMBL1984876 & 688633 & 4.4368 & 4.3189 & TRN \\
\hline CHEMBL1456906 & 688633 & 5.8153 & 5.9279 & TST \\
\hline CHEMBL1389330 & 688633 & 3.9883 & 4.0117 & TRN \\
\hline CHEMBL1535991 & 688633 & 4.2503 & 4.1594 & TRN \\
\hline CHEMBL3191149 & 688633 & 4.7144 & 4.2887 & TRN \\
\hline CHEMBL1418885 & 688633 & 4.6105 & 4.4342 & TRN \\
\hline CHEMBL1505192 & 688633 & 4.4519 & 4.2956 & TRN \\
\hline CHEMBL1969543 & 688633 & 4.4359 & 4.4845 & TRN \\
\hline CHEMBL1490887 & 688633 & 4.4942 & 4.1736 & TST \\
\hline CHEMBL1527664 & 688633 & 6.3979 & 4.4096 & TST \\
\hline CHEMBL 309016 & 688633 & 3.9921 & 4.158 & TRN \\
\hline CHEMBL1383932 & 688633 & 2.8239 & 2.978 & TRN \\
\hline CHEMBL1332756 & 688633 & 2.8239 & 4.0195 & TRN \\
\hline CHEMBL1596066 & 688633 & 3.9289 & 3.9535 & TRN \\
\hline CHEMBL1986690 & 688633 & 4.2408 & 4.2397 & TRN \\
\hline CHEMBL1996376 & 688633 & 4.2633 & 4.0492 & TRN \\
\hline CHEMBL1550897 & 688633 & 4.4675 & 4.3438 & TRN \\
\hline CHEMBL1582968 & 688633 & 4.127 & 4.1295 & TRN \\
\hline CHEMBL1479637 & 688633 & 4.7409 & 4.2325 & TRN \\
\hline CHEMBL1411080 & 688633 & 4.1217 & 3.5743 & TRN \\
\hline CHEMBL1304363 & 688633 & 4.4793 & 4.6414 & TRN \\
\hline
\end{tabular}


Supplemental Table S2.txt

\begin{tabular}{|c|c|c|c|c|c|}
\hline CHEMBL1527341 & 688633 & 4.9927 & 4.8634 & TRN & \\
\hline CHEMBL1338004 & 688633 & 4.8952 & 5.4334 & TRN & \\
\hline CHEMBL585828 & 688633 & 4.1211 & 4.3157 & TST & \\
\hline CHEMBL1382265 & 688633 & 4.2147 & 4.19600 & 0000000001 & TRN \\
\hline CHEMBL1497697 & 688633 & 4.3592 & 4.1094 & TST & \\
\hline CHEMBL578294 & 688633 & 4.1301 & 4.1159 & TRN & \\
\hline CHEMBL1497059 & 688633 & 3.8449 & 3.9587 & TRN & \\
\hline CHEMBL1306438 & 688633 & 4.1915 & 4.261 & TRN & \\
\hline CHEMBL1964909 & 688633 & 4.197 & 5.0683 & TRN & \\
\hline CHEMBL1391894 & 688633 & 4.1576 & 4.2786 & TST & \\
\hline CHEMBL1349146 & 688633 & 4.4289 & 4.1501 & TRN & \\
\hline CHEMBL1548026 & 688633 & 4.157 & 4.1947 & TRN & \\
\hline CHEMBL1461446 & 688633 & 4.668 & 4.2172 & TRN & \\
\hline CHEMBL1389994 & 688633 & 4.4256 & 4.4716 & TRN & \\
\hline CHEMBL1406235 & 688633 & 3.932 & 3.8526 & TRN & \\
\hline CHEMBL1550442 & 688633 & 4.4494 & 4.3378 & TRN & \\
\hline CHEMBL3190747 & 688633 & 4.1095 & 4.1138 & TRN & \\
\hline CHEMBL1452644 & 688633 & 4.1216 & 3.9918 & TRN & \\
\hline CHEMBL1616787 & 688633 & 4.4577 & 4.2347 & TRN & \\
\hline CHEMBL1432427 & 688633 & 4.121 & 4.43 & TRN & \\
\hline CHEMBL1353553 & 688633 & 4.6832 & 4.4762 & TRN & \\
\hline CHEMBL1524052 & 688633 & 4.1249 & 4.3673 & TRN & \\
\hline CHEMBL1598087 & 688633 & 2.8239 & 4.1389 & TRN & \\
\hline CHEMBL1326083 & 688633 & 4.1656 & 4.5228 & TRN & \\
\hline CHEMBL193872 & 688633 & 5.3116 & 5.0713 & TST & \\
\hline CHEMBL580609 & 688633 & 4.1925 & 3.7689 & TRN & \\
\hline CHEMBL290077 & 688633 & 4.4824 & 4.8826 & TST & \\
\hline CHEMBL3196257 & 688633 & 4.1341 & 4.2349 & TRN & \\
\hline CHEMBL1415720 & 688633 & 4.2699 & 4.3472 & TST & \\
\hline CHEMBL1519160 & 688633 & 2.8239 & 4.1085 & TRN & \\
\hline CHEMBL1318993 & 688633 & 4.1458 & 4.1681 & TRN & \\
\hline CHEMBL1345865 & 688633 & 4.3959 & 3.8918 & TRN & \\
\hline CHEMBL1558968 & 688633 & 4.4339 & 4.1993 & TRN & \\
\hline CHEMBL531322 & 688633 & 4.458 & 4.1198 & TRN & \\
\hline CHEMBL1587760 & 688633 & 2.8239 & 3.7251 & TST & \\
\hline CHEMBL1496555 & 688633 & \multicolumn{2}{|c|}{3.8789999999999996} & 3.5919 & TRN \\
\hline CHEMBL1449349 & 688633 & 4.0588 & 3.9047 & TRN & \\
\hline CHEMBL1710 & 688633 & 4.3335 & 4.1312 & TRN & \\
\hline CHEMBL1553215 & 688633 & 4.2944 & 4.3034 & TRN & \\
\hline CHEMBL1524435 & 688633 & 4.4369 & 4.7365 & TRN & \\
\hline CHEMBL1142 & 688633 & 4.1489 & 4.0827 & TST & \\
\hline CHEMBL1964793 & 688633 & 4.7286 & 4.7006 & TRN & \\
\hline CHEMBL1398224 & 688633 & 4.4272 & 4.5132 & TST & \\
\hline CHEMBL1413504 & 688633 & 4.4711 & 4.2172 & TRN & \\
\hline CHEMBL3208669 & 688633 & 3.8744 & 3.8459 & TRN & \\
\hline CHEMBL3191293 & 688633 & 4.5306 & 4.5243 & TRN & \\
\hline CHEMBL1310009 & 688633 & 4.4455 & 4.2148 & TRN & \\
\hline CHEMBL255068 & 688633 & 4.1454 & 4.1421 & TRN & \\
\hline
\end{tabular}




\begin{tabular}{|c|c|c|c|c|}
\hline & & & pplement & al $\mathrm{Tc}$ \\
\hline CHEMBL169662 & 688633 & 4.484 & 3.9639 & TRN \\
\hline CHEMBL3192398 & 688633 & 4.105 & 4.0595 & TRN \\
\hline CHEMBL3145245 & 688633 & 4.1767 & 4.1936 & TRN \\
\hline CHEMBL 3214537 & 688633 & 4.5646 & 4.7545 & TRN \\
\hline CHEMBL528506 & 688633 & 4.6811 & 4.5157 & TRN \\
\hline CHEMBL1200792 & 688633 & 3.9803 & 3.968 & TRN \\
\hline CHEMBL1312977 & 688633 & 4.1155 & 4.0347 & TRN \\
\hline CHEMBL1589539 & 688633 & 2.8239 & 3.8092 & TRN \\
\hline CHEMBL 603020 & 688633 & 5.301 & 4.5867 & TRN \\
\hline CHEMBL1583127 & 688633 & 4.5308 & 4.4051 & TRN \\
\hline CHEMBL1326318 & 688633 & 4.1161 & 3.7946 & TRN \\
\hline CHEMBL 3194704 & 688633 & 4.1188 & 4.3159 & TRN \\
\hline CHEMBL 2002465 & 688633 & 4.3571 & 4.3207 & TRN \\
\hline CHEMBL1540231 & 688633 & 4.4472 & 4.1499 & TST \\
\hline CHEMBL1431118 & 688633 & 2.8239 & 4.1848 & TRN \\
\hline CHEMBL1532668 & 688633 & 4.4157 & 4.4945 & TST \\
\hline CHEMBL1372734 & 688633 & 4.4331 & 4.1743 & TRN \\
\hline CHEMBL1198307 & 688633 & 4.9893 & 4.498 & TRN \\
\hline CHEMBL3209306 & 688633 & 4.4843 & 4.4052 & TRN \\
\hline CHEMBL1543738 & 688633 & 3.8482 & 2.9949 & TRN \\
\hline CHEMBL1349892 & 688633 & 4.4573 & 4.4211 & TRN \\
\hline CHEMBL1416618 & 688633 & 4.3005 & 4.0956 & TST \\
\hline CHEMBL52101 & 688633 & 4.4505 & 4.3657 & TRN \\
\hline CHEMBL1424729 & 688633 & 4.3439 & 4.2164 & TRN \\
\hline CHEMBL104270 & 688633 & 7.6383 & 6.7502 & TRN \\
\hline CHEMBL1559564 & 688633 & 4.2388 & 4.4684 & TRN \\
\hline CHEMBL1987472 & 688633 & 3.8601 & 4.1431 & TRN \\
\hline CHEMBL1507990 & 688633 & 4.2567 & 4.292 & TRN \\
\hline CHEMBL1373096 & 688633 & 3.9751 & 4.1942 & TRN \\
\hline CHEMBL1345320 & 688633 & 4.2996 & 4.2877 & TRN \\
\hline CHEMBL1993199 & 688633 & 4.0625 & 4.249 & TRN \\
\hline CHEMBL1581725 & 688633 & 4.1965 & 3.9341 & TRN \\
\hline CHEMBL1983581 & 688633 & 4.0135 & 3.9717 & TRN \\
\hline CHEMBL 2000750 & 688633 & 4.1521 & 4.3838 & TRN \\
\hline CHEMBL1502340 & 688633 & 4.4279 & 4.0131 & TRN \\
\hline CHEMBL582444 & 688633 & 4.5979 & 4.4304 & TRN \\
\hline CHEMBL1542959 & 688633 & 5.7878 & 5.8854 & TRN \\
\hline CHEMBL1373650 & 688633 & 4.4339 & 3.8735 & TRN \\
\hline CHEMBL142816 & 688633 & 4.6927 & 4.3342 & TST \\
\hline CHEMBL1384700 & 688633 & 4.6811 & 4.4368 & TRN \\
\hline CHEMBL1382760 & 688633 & 3.9545 & 3.9484 & TRN \\
\hline CHEMBL 3195334 & 688633 & 4.1072 & 3.9627 & TST \\
\hline CHEMBL1539637 & 688633 & 4.4196 & 4.5709 & TST \\
\hline CHEMBL1443984 & 688633 & 4.183 & 4.0059 & TRN \\
\hline CHEMBL1382939 & 688633 & 4.2591 & 4.4365 & TST \\
\hline CHEMBL2369277 & 688633 & 4.4482 & 4.5667 & TRN \\
\hline CHEMBL3193099 & 688633 & 2.8239 & 4.2388 & TST \\
\hline CHEMBL3193701 & 688633 & 4.6902 & 4.3837 & TRN \\
\hline
\end{tabular}




\begin{tabular}{|c|c|c|c|c|c|}
\hline & & \multicolumn{4}{|c|}{ Supplemental Table S2.txt } \\
\hline CHEMBL 2359911 & 688633 & 3.9804 & 4.3764 & TRN & \\
\hline CHEMBL1405259 & 688633 & 4.8645 & 4.1592 & TRN & \\
\hline CHEMBL1496705 & 688633 & 4.9784 & 4.9981 & TRN & \\
\hline CHEMBL283849 & 688633 & 6.5086 & 6.3362 & TRN & \\
\hline CHEMBL1546374 & 688633 & 4.2059 & 4.6331 & TST & \\
\hline CHEMBL3195549 & 688633 & 4.4531 & 4.569 & TRN & \\
\hline CHEMBL570345 & 688633 & 4.5465 & 4.478 & TRN & \\
\hline CHEMBL1369623 & 688633 & 5.1925 & 4.5174 & TRN & \\
\hline CHEMBL1470633 & 688633 & 4.2981 & 4.2306 & TRN & \\
\hline CHEMBL1326203 & 688633 & 4.4571 & 4.3946 & TRN & \\
\hline CHEMBL1421128 & 688633 & 2.8239 & 4.1357 & TRN & \\
\hline CHEMBL1578958 & 688633 & 2.8239 & 3.9022 & TRN & \\
\hline CHEMBL1451888 & 688633 & 4.1264 & 4.2542 & TRN & \\
\hline CHEMBL1330992 & 688633 & 4.4194 & 3.9526 & TRN & \\
\hline CHEMBL1329129 & 688633 & 4.7254 & 4.6679 & TRN & \\
\hline CHEMBL1479530 & 688633 & 4.052 & 4.7545 & TST & \\
\hline CHEMBL1599208 & 688633 & 4.1637 & 4.2534 & TRN & \\
\hline CHEMBL1384026 & 688633 & 4.2053 & 4.2298 & TRN & \\
\hline CHEMBL1335846 & 688633 & 4.4558 & 4.59399 & & TST \\
\hline CHEMBL1595024 & 688633 & 4.6874 & 4.588 & TRN & \\
\hline CHEMBL1566424 & 688633 & 4.1006 & 4.0415 & TST & \\
\hline CHEMBL1555719 & 688633 & 2.8239 & 3.984 & TRN & \\
\hline CHEMBL1478435 & 688633 & 4.1453 & 3.1395 & TRN & \\
\hline CHEMBL1563943 & 688633 & 4.7291 & 4.3149 & TRN & \\
\hline CHEMBL1448161 & 688633 & 4.3197 & 3.8361 & TRN & \\
\hline CHEMBL1609529 & 688633 & 4.9686 & 4.4651 & TRN & \\
\hline CHEMBL1385558 & 688633 & 4.4303 & 4.4002 & TRN & \\
\hline CHEMBL1594766 & 688633 & 4.3996 & 4.1906 & TRN & \\
\hline CHEMBL 1470679 & 688633 & 2.8239 & 4.0722 & TRN & \\
\hline CHEMBL3196358 & 688633 & 4.2166 & 4.2597 & TRN & \\
\hline CHEMBL1347071 & 688633 & 4.7305 & 4.848 & TRN & \\
\hline CHEMBL1971316 & 688633 & 2.8239 & 4.28600 & 00000000005 & TRN \\
\hline CHEMBL1384387 & 688633 & 4.4192 & 4.6811 & TRN & \\
\hline CHEMBL1339092 & 688633 & 4.1658 & 4.1311 & TST & \\
\hline CHEMBL1572280 & 688633 & 4.5566 & 4.5632 & TST & \\
\hline CHEMBL1585197 & 688633 & 3.9747 & 3.7827 & TRN & \\
\hline CHEMBL1392912 & 688633 & 4.1096 & 4.605 & TRN & \\
\hline CHEMBL1340176 & 688633 & 2.8239 & 3.8222 & TST & \\
\hline CHEMBL139935 & 688633 & 5.1824 & 5.3139 & TRN & \\
\hline CHEMBL1542594 & 688633 & 4.605 & 4.4718 & TST & \\
\hline CHEMBL3195766 & 688633 & 2.8239 & 3.9078 & TRN & \\
\hline CHEMBL1200567 & 688633 & 5.4001 & 6.504 & TST & \\
\hline CHEMBL1335384 & 688633 & 4.4495 & 4.2975 & TRN & \\
\hline CHEMBL1419803 & 688633 & 4.0302 & 4.3646 & TRN & \\
\hline CHEMBL1503034 & 688633 & 4.4578 & 4.4052 & TRN & \\
\hline CHEMBL3197991 & 688633 & 4.1394 & 4.1753 & TRN & \\
\hline CHEMBL1542590 & 688633 & 4.2649 & 3.9832 & TRN & \\
\hline CHEMBL3194327 & 688633 & 4.1082 & 4.0704 & TRN & \\
\hline
\end{tabular}




\begin{tabular}{|c|c|c|c|c|c|}
\hline \multirow{3}{*}{$\begin{array}{l}\text { CHEMBL1339036 } \\
\text { CHFMBI } 1511913\end{array}$} & & \multicolumn{4}{|c|}{ Supplemental Table s2.txt } \\
\hline & 688633 & 3.8538 & 3.49300 & 00000000003 & TRN \\
\hline & 688633 & 4.1059 & 4.209 & TRN & \\
\hline CHEMBL1538399 & 688633 & 4.683 & 4.3636 & TRN & \\
\hline CHEMBL1528425 & 688633 & 4.8359 & 4.9142 & TRN & \\
\hline CHEMBL1437560 & 688633 & 4.6558 & 4.4466 & TRN & \\
\hline CHEMBL1511774 & 688633 & 4.5751 & 4.7504 & TRN & \\
\hline CHEMBL1432642 & 688633 & 4.038 & 3.8575 & TRN & \\
\hline CHEMBL 209101 & 688633 & 3.9887 & 4.0026 & TRN & \\
\hline CHEMBL 1378260 & 688633 & 4.9551 & 4.8692 & TRN & \\
\hline CHEMBL1331050 & 688633 & 2.8239 & 4.0408 & TST & \\
\hline CHEMBL1441888 & 688633 & 3.8579 & 4.1147 & TRN & \\
\hline CHEMBL1403529 & 688633 & 4.3891 & 3.7238 & TRN & \\
\hline CHEMBL1604894 & 688633 & 4.1197 & 3.99899 & 99999999997 & TRN \\
\hline CHEMBL1554214 & 688633 & 4.7162 & 4.3467 & TST & \\
\hline CHEMBL1395220 & 688633 & 4.1846 & 4.1725 & TST & \\
\hline CHEMBL1592917 & 688633 & 4.4182 & 4.6503 & TRN & \\
\hline CHEMBL1587804 & 688633 & 3.9247 & 3.6306 & TST & \\
\hline CHEMBL1412043 & 688633 & 2.8239 & 4.1241 & TRN & \\
\hline CHEMBL590666 & 688633 & 4.423 & 4.3284 & TRN & \\
\hline CHEMBL1550934 & 688633 & 4.4257 & 4.5158 & TST & \\
\hline CHEMBL1335155 & 688633 & 3.8684 & 4.4267 & TRN & \\
\hline CHEMBL1570835 & 688633 & 4.7196 & 4.3842 & TRN & \\
\hline CHEMBL1388836 & 688633 & 4.6931 & 4.1466 & TRN & \\
\hline CHEMBL1484328 & 688633 & 4.1148 & 4.1803 & TRN & \\
\hline CHEMBL1537268 & 688633 & 2.8239 & 3.9471 & TRN & \\
\hline CHEMBL1350506 & 688633 & 4.4171 & 4.0939 & TRN & \\
\hline CHEMBL1346881 & 688633 & 4.3469 & 4.2778 & TRN & \\
\hline CHEMBL3195608 & 688633 & 4.5068 & 4.3529 & TRN & \\
\hline CHEMBL3190546 & 688633 & 4.2195 & 4.1572 & TRN & \\
\hline CHEMBL1389315 & 688633 & 5.3002 & 4.8227 & TST & \\
\hline CHEMBL599890 & 688633 & 4.4259 & 4.4031 & TRN & \\
\hline CHEMBL1353170 & 688633 & 4.8297 & 4.4943 & TRN & \\
\hline CHEMBL1350693 & 688633 & 4.5746 & 4.5412 & TRN & \\
\hline CHEMBL1481934 & 688633 & 4.6847 & 4.665 & TRN & \\
\hline CHEMBL1452648 & 688633 & 4.5919 & 4.3409 & TRN & \\
\hline CHEMBL1159655 & 688633 & 2.8239 & 3.2016 & TST & \\
\hline CHEMBL1378952 & 688633 & 4.7064 & 4.6693 & TRN & \\
\hline CHEMBL1548086 & 688633 & 4.4093 & 4.6811 & TRN & \\
\hline CHEMBL1570336 & 688633 & 3.9458 & 3.6275 & TRN & \\
\hline CHEMBL1531172 & 688633 & 4.2832 & 4.0548 & TRN & \\
\hline CHEMBL1996133 & 688633 & 3.9447 & 3.5453 & TST & \\
\hline CHEMBL1397507 & 688633 & 5.289 & 4.871 & TST & \\
\hline CHEMBL1588476 & 688633 & 4.0384 & 4.1059 & TST & \\
\hline CHEMBL1504569 & 688633 & 4.6998 & 4.7125 & TRN & \\
\hline CHEMBL1527503 & 688633 & 3.8459 & 3.9368 & TST & \\
\hline CHEMBL1440037 & 688633 & 4.4547 & 4.1642 & TRN & \\
\hline CHEMBL1485275 & 688633 & 6.0 & 6.8158 & TST & \\
\hline CHEMBL1540555 & 688633 & 4.0217 & 3.9826 & TRN & \\
\hline
\end{tabular}




\begin{tabular}{|c|c|c|c|c|c|}
\hline \multicolumn{6}{|c|}{ Supplemental Table S2.txt } \\
\hline CHEMBL3211290 & 688633 & 4.7296 & 4.6084 & TRN & \\
\hline CHEMBL601757 & 688633 & 5.8894 & 5.8733 & TST & \\
\hline CHEMBL123 & 688633 & 4.7261 & 4.4604 & TST & \\
\hline CHEMBL1386054 & 688633 & 4.4121 & 4.297 & TRN & \\
\hline CHEMBL1411646 & 688633 & 4.2978 & 4.1788 & TRN & \\
\hline CHEMBL1524783 & 688633 & 2.8239 & 3.9726 & TRN & \\
\hline CHEMBL577546 & 688633 & 5.0419 & 4.1664 & TRN & \\
\hline CHEMBL3191484 & 688633 & 3.8564 & 3.79600 & 00000000003 & TRN \\
\hline CHEMBL1327202 & 688633 & 5.2418 & 5.4243 & TRN & \\
\hline CHEMBL3195685 & 688633 & 4.2174 & 4.1563 & TRN & \\
\hline CHEMBL1587205 & 688633 & 4.2856 & 4.3577 & TRN & \\
\hline CHEMBL1491389 & 688633 & 4.4331 & 4.0829 & TST & \\
\hline CHEMBL142630 & 688633 & 4.1576 & 3.0477 & TRN & \\
\hline CHEMBL585622 & 688633 & 4.4406 & 4.1673 & TRN & \\
\hline CHEMBL581870 & 688633 & 4.4304 & 4.5576 & TRN & \\
\hline CHEMBL1454171 & 688633 & 4.3833 & 4.3296 & TST & \\
\hline CHEMBL1360870 & 688633 & 4.2206 & 4.3321 & TST & \\
\hline CHEMBL1426691 & 688633 & 2.8239 & 4.1182 & TST & \\
\hline CHEMBL1342184 & 688633 & 2.8239 & 3.2496 & TRN & \\
\hline CHEMBL3190555 & 688633 & 4.2935 & 3.9848 & TRN & \\
\hline CHEMBL1468260 & 688633 & 4.5581 & 3.8545 & TRN & \\
\hline CHEMBL1325192 & 688633 & 4.4542 & 4.4337 & TRN & \\
\hline CHEMBL1359781 & 688633 & 3.8295 & 3.6964 & TRN & \\
\hline CHEMBL1401657 & 688633 & 4.5164 & 3.9928 & TRN & \\
\hline CHEMBL1472253 & 688633 & 4.0391 & 3.9042 & TRN & \\
\hline CHEMBL1482500 & 688633 & 4.7298 & 4.4924 & TRN & \\
\hline CHEMBL1450094 & 688633 & 4.127 & 3.9278 & TRN & \\
\hline CHEMBL1579686 & 688633 & 5.1952 & 4.7728 & TRN & \\
\hline CHEMBL1169627 & 688633 & 3.843 & 4.1303 & TST & \\
\hline CHEMBL1573754 & 688633 & 4.4983 & 4.2828 & TST & \\
\hline CHEMBL1464303 & 688633 & 2.8239 & 3.9781 & TRN & \\
\hline CHEMBL1528900 & 688633 & 4.1706 & 4.4583 & TST & \\
\hline CHEMBL1521705 & 688633 & 5.466 & 5.0012 & TRN & \\
\hline CHEMBL1581682 & 688633 & 3.838 & 3.7734 & TST & \\
\hline CHEMBL1303357 & 688633 & 4.2151 & 4.1325 & TRN & \\
\hline CHEMBL1523680 & 688633 & 2.8239 & 3.7205 & TRN & \\
\hline CHEMBL3191737 & 688633 & 3.8648 & 3.9809 & TRN & \\
\hline CHEMBL 2001316 & 688633 & 2.8239 & 3.6476 & TRN & \\
\hline CHEMBL1509380 & 688633 & 4.9872 & 5.4238 & TRN & \\
\hline CHEMBL1468104 & 688633 & 4.1265 & 4.0397 & TST & \\
\hline CHEMBL1360341 & 688633 & 4.26 & 4.417 & TST & \\
\hline CHEMBL1481342 & 688633 & 4.2827 & 3.1284 & TRN & \\
\hline CHEMBL1555739 & 688633 & 4.1349 & 4.1896 & TRN & \\
\hline CHEMBL1499014 & 688633 & 4.6801 & 4.4277 & TRN & \\
\hline CHEMBL1986183 & 688633 & 4.4776 & 3.736 & TST & \\
\hline CHEMBL1541943 & 688633 & 3.8385 & 4.2921 & TRN & \\
\hline CHEMBL1455197 & 688633 & 4.0537 & 3.9953 & TRN & \\
\hline CHEMBL204914 & 688633 & 4.0938 & 4.0216 & TRN & \\
\hline
\end{tabular}




\begin{tabular}{|c|c|c|c|c|c|c|}
\hline & & \multicolumn{5}{|c|}{ Supplemental Table S2.txt } \\
\hline CHEMBL1513816 & 688633 & 4.0481 & 4.2982 & TRN & & \\
\hline CHEMBL1598775 & 688633 & 4.3901 & 4.3714 & TRN & & \\
\hline CHEMBL251670 & 688633 & 7.6383 & 6.2654 & TRN & & \\
\hline CHEMBL1543780 & 688633 & 2.8239 & 3.9798 & TRN & & \\
\hline CHEMBL1321283 & 688633 & 2.8239 & 2.6815 & TRN & & \\
\hline CHEMBL1582934 & 688633 & 4.1683 & 3.9562 & TRN & & \\
\hline CHEMBL1594936 & 688633 & 4.1186 & 3.0652 & TRN & & \\
\hline CHEMBL1588107 & 688633 & 4.6052 & 4.3064 & TRN & & \\
\hline CHEMBL1398607 & 688633 & 2.8239 & 3.4446 & TRN & & \\
\hline CHEMBL1516070 & 688633 & 2.8239 & 3.7861 & TST & & \\
\hline CHEMBL3196495 & 688633 & 4.4561 & 4.3421 & TRN & & \\
\hline CHEMBL601547 & 688633 & 4.9927 & 4.3518 & TRN & & \\
\hline CHEMBL 3196813 & 688633 & \multicolumn{3}{|c|}{ 4.1819999999999995 } & 4.0683 & TRN \\
\hline CHEMBL1539127 & 688633 & 4.4077 & 4.2331 & TRN & & \\
\hline CHEMBL 3196279 & 688633 & 2.8239 & 2.9291 & TRN & & \\
\hline CHEMBL1522486 & 688633 & 6.0 & 5.9661 & TRN & & \\
\hline CHEMBL1502014 & 688633 & 4.4451 & 4.0881 & TST & & \\
\hline CHEMBL1330068 & 688633 & 3.9945 & 3.71 & TRN & & \\
\hline CHEMBL1315701 & 688633 & 4.1432 & 4.1153 & TRN & & \\
\hline CHEMBL 3194689 & 688633 & 2.8239 & 4.0567 & TRN & & \\
\hline CHEMBL1305911 & 688633 & 4.4085 & 4.2781 & TRN & & \\
\hline CHEMBL1580083 & 688633 & 4.0953 & 3.9063 & TRN & & \\
\hline CHEMBL1418750 & 688633 & 4.3607 & 4.2214 & TRN & & \\
\hline CHEMBL1413197 & 688633 & 2.8239 & 2.7305 & TRN & & \\
\hline CHEMBL1388845 & 688633 & 4.7951 & 4.7273 & TRN & & \\
\hline CHEMBL1501995 & 688633 & 4.4319 & 4.1166 & TRN & & \\
\hline CHEMBL19954 & 688633 & 4.6874 & 4.4079 & TST & & \\
\hline CHEMBL1501558 & 688633 & 4.4383 & 4.5425 & TRN & & \\
\hline CHEMBL1564526 & 688633 & 3.9389 & 4.0738 & TRN & & \\
\hline CHEMBL3189342 & 688633 & 4.9784 & 4.8018 & TRN & & \\
\hline CHEMBL1572436 & 688633 & 4.4268 & 4.4703 & TRN & & \\
\hline CHEMBL1567072 & 688633 & 4.1258 & 4.0436 & TRN & & \\
\hline CHEMBL1441677 & 688633 & 4.6668 & 4.202 & TRN & & \\
\hline CHEMBL1980226 & 688633 & 4.4506 & 4.3151 & TRN & & \\
\hline CHEMBL1387500 & 688633 & 4.3342 & 3.9622 & TRN & & \\
\hline CHEMBL1451747 & 688633 & 4.3849 & 4.1722 & TRN & & \\
\hline CHEMBL1444767 & 688633 & 4.4559 & 4.2052 & TRN & & \\
\hline CHEMBL1385701 & 688633 & 4.42 & 4.1228 & TRN & & \\
\hline CHEMBL1529086 & 688633 & 2.8239 & 4.106 & TST & & \\
\hline CHEMBL600778 & 688633 & 4.0198 & 4.4289 & TRN & & \\
\hline CHEMBL1483235 & 688633 & 4.9062 & 5.0933 & TRN & & \\
\hline CHEMBL1327205 & 688633 & 4.1824 & 4.079 & TRN & & \\
\hline CHEMBL1321232 & 688633 & 4.1344 & 4.0884 & TRN & & \\
\hline CHEMBL1440235 & 688633 & 4.5388 & 4.3607 & TRN & & \\
\hline CHEMBL1904459 & 688633 & 4.3219 & 4.1956 & TRN & & \\
\hline CHEMBL1467720 & 688633 & 4.6847 & 4.6504 & TRN & & \\
\hline CHEMBL1201074 & 688633 & 4.342 & 3.9553 & TRN & & \\
\hline CHEMBL1303009 & 688633 & 4.1129 & 3.6924 & TRN & & \\
\hline
\end{tabular}




\begin{tabular}{|c|c|c|c|c|}
\hline \multicolumn{5}{|c|}{ Supplemental Table S2.txt } \\
\hline CHEMBL1385808 & 688633 & 6.0 & 6.5424 & TST \\
\hline CHEMBL1375232 & 688633 & 3.9141 & 4.1035 & TRN \\
\hline CHEMBL458019 & 688633 & 6.2518 & 6.4081 & TST \\
\hline CHEMBL1350342 & 688633 & 3.8346 & 3.9438 & TRN \\
\hline CHEMBL1982032 & 688633 & 4.4426 & 4.5375 & TST \\
\hline CHEMBL3199025 & 688633 & 3.8608 & 3.9921 & TRN \\
\hline CHEMBL1413726 & 688633 & 4.289 & 4.1463 & TRN \\
\hline CHEMBL1472891 & 688633 & 4.1602 & 4.0539 & TRN \\
\hline CHEMBL578512 & 688633 & 5.8894 & 5.74299 & 9999999999 \\
\hline CHEMBL334707 & 688633 & 5.5157 & 5.5133 & TRN \\
\hline CHEMBL1430820 & 688633 & 2.8239 & 3.9655 & TRN \\
\hline CHEMBL3196547 & 688633 & 4.4494 & 4.4221 & TRN \\
\hline CHEMBL1390750 & 688633 & 3.8336 & 3.7635 & TRN \\
\hline CHEMBL1536493 & 688633 & 4.0343 & 3.9293 & TST \\
\hline CHEMBL1355961 & 688633 & 4.422 & 4.5909 & TST \\
\hline CHEMBL1455056 & 688633 & 4.1208 & 3.9821 & TST \\
\hline CHEMBL578061 & 688633 & 4.473 & 4.3267 & TST \\
\hline CHEMBL1447782 & 688633 & 4.3905 & 4.1967 & TST \\
\hline CHEMBL1348582 & 688633 & 4.4996 & 4.5669 & TST \\
\hline CHEMBL1500643 & 688633 & 4.5105 & 4.1001 & TST \\
\hline CHEMBL587892 & 688633 & 4.6776 & 4.2874 & TST \\
\hline CHEMBL606166 & 688633 & 4.909 & 3.8162 & TST \\
\hline CHEMBL1420648 & 688633 & 4.8471 & 4.9214 & TST \\
\hline CHEMBL1486325 & 688633 & 2.8239 & 3.7825 & TST \\
\hline CHEMBL1600854 & 688633 & 4.1186 & 3.8957 & TST \\
\hline CHEMBL1330113 & 688633 & 6.0 & 5.8812 & TST \\
\hline CHEMBL1332952 & 688633 & 5.1858 & 4.2222 & TST \\
\hline CHEMBL3197818 & 688633 & 4.2699 & 4.1762 & TST \\
\hline CHEMBL3191432 & 688633 & 4.2534 & 3.8732 & TST \\
\hline CHEMBL1584438 & 688633 & 4.4525 & 4.1794 & TST \\
\hline CHEMBL1483355 & 688633 & 4.2816 & 4.1281 & TST \\
\hline CHEMBL1308088 & 688633 & 4.4344 & 4.2769 & TST \\
\hline CHEMBL1556805 & 688633 & 4.4065 & 4.1759 & TST \\
\hline CHEMBL525826 & 688633 & 4.702 & 4.0859 & TST \\
\hline CHEMBL1996730 & 688633 & 4.8801 & 4.8819 & TST \\
\hline CHEMBL1478103 & 688633 & 4.5889 & 4.2029 & TST \\
\hline CHEMBL1427717 & 688633 & 3.9905 & 4.2832 & TST \\
\hline CHEMBL530049 & 688633 & 5.0287 & 5.1791 & TST \\
\hline CHEMBL1429304 & 688633 & 3.9878 & 4.0718 & TST \\
\hline CHEMBL1479316 & 688633 & 4.7503 & 4.7415 & TST \\
\hline CHEMBL1382888 & 688633 & 2.8239 & 3.6966 & TST \\
\hline CHEMBL3199489 & 688633 & 3.9739 & 3.7454 & TST \\
\hline CHEMBL1427228 & 688633 & 4.4195 & 4.2431 & TST \\
\hline CHEMBL1350245 & 688633 & 4.312 & 4.0705 & TST \\
\hline CHEMBL1330520 & 688633 & 4.8665 & 4.1828 & TST \\
\hline CHEMBL1975118 & 688633 & 4.4761 & 4.4553 & TST \\
\hline CHEMBL1449490 & 688633 & 4.3676 & 4.3361 & TST \\
\hline CHEMBL1607938 & 688633 & 4.4008 & 4.0284 & TST \\
\hline
\end{tabular}




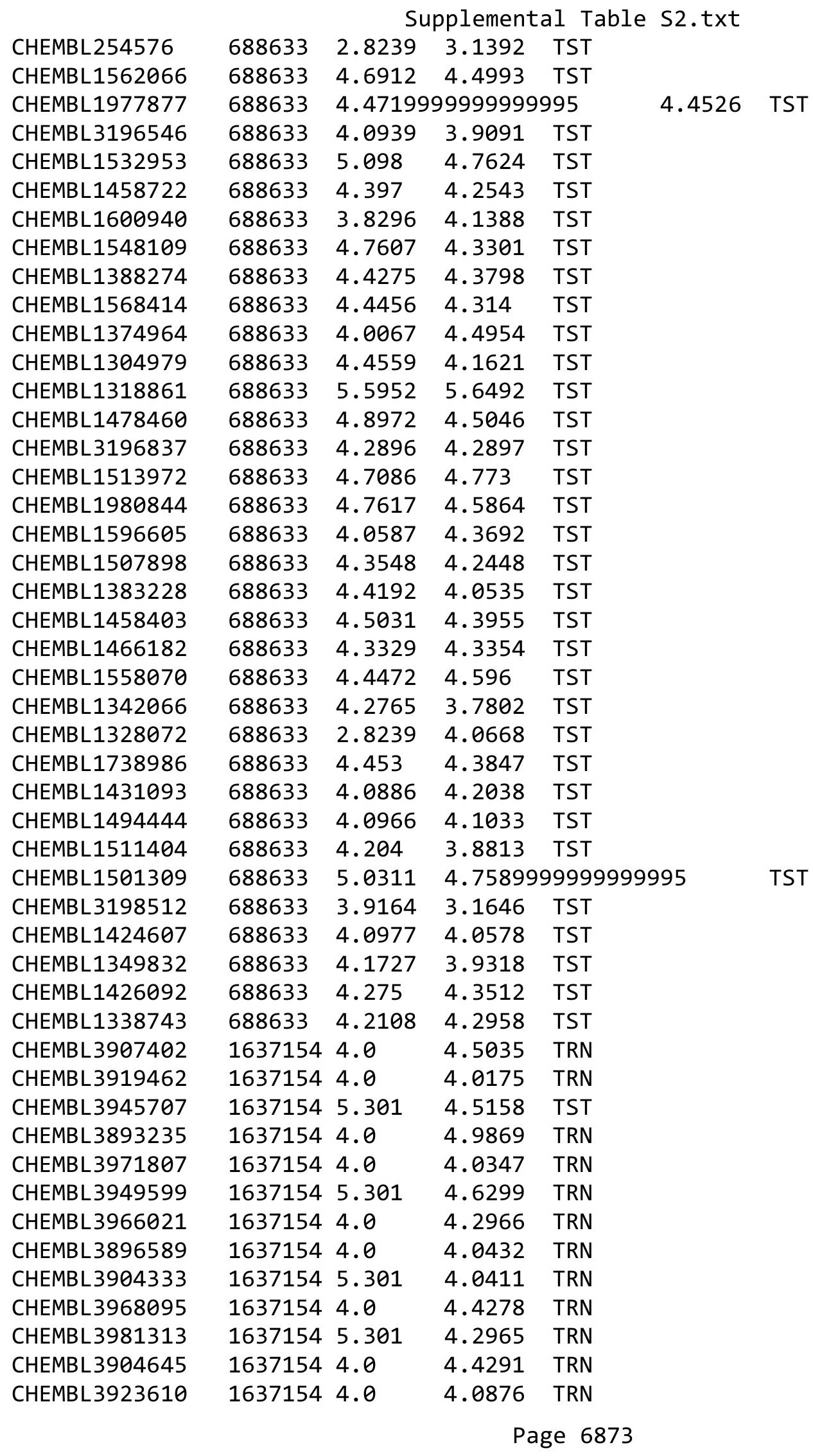


Supplemental Table S2.txt

\begin{tabular}{|c|c|c|}
\hline CHEMBL3911079 & 1637154 & 4.0 \\
\hline CHEMBL 3916725 & 1637154 & 4.0 \\
\hline CHEMBL3921859 & 1637154 & 5.301 \\
\hline CHEMBL3934437 & 1637154 & 4.0 \\
\hline CHEMBL3920821 & 1637154 & 4.0 \\
\hline CHEMBL3948750 & 1637154 & 4.0 \\
\hline CHEMBL3985076 & 1637154 & 4.0 \\
\hline CHEMBL3956565 & 1637154 & 5.301 \\
\hline CHEMBL3979042 & 1637154 & 4.0 \\
\hline CHEMBL3954395 & 1637154 & 5.301 \\
\hline CHEMBL3944290 & 1637154 & 4.0 \\
\hline CHEMBL3941703 & 1637154 & 4.0 \\
\hline CHEMBL3890467 & 1637154 & 5.301 \\
\hline CHEMBL3951586 & 1637154 & 4.0 \\
\hline CHEMBL3933168 & 1637154 & 4.0 \\
\hline CHEMBL3952336 & 1637154 & 6.301 \\
\hline CHEMBL3919966 & 1637154 & 4.0 \\
\hline CHEMBL3979361 & 1637154 & 4.0 \\
\hline CHEMBL3914107 & 1637154 & 5.301 \\
\hline CHEMBL3917962 & 1637154 & 4.0 \\
\hline CHEMBL3903656 & 1637 & 4.0 \\
\hline CHEMBL3913674 & 1637154 & 4.0 \\
\hline CHEMBL3968497 & 1637154 & 4.0 \\
\hline CHEMBL3971789 & 1637154 & 4.0 \\
\hline CHEMBL3958968 & 1637154 & 4.0 \\
\hline CHEMBL3979607 & 1637154 & 4.0 \\
\hline CHEMBL3967303 & 1637154 & 5.301 \\
\hline CHEMBL3918722 & 1637154 & 4.0 \\
\hline CHEMBL3940360 & 1637154 & 4.0 \\
\hline CHEMBL3986998 & 1637154 & 4.0 \\
\hline CHEMBL3949992 & 1637154 & 4.0 \\
\hline CHEMBL3969082 & 1637154 & 4.0 \\
\hline CHEMBL3948349 & 1637154 & 6.301 \\
\hline CHEMBL3896422 & 1637154 & 5.301 \\
\hline CHEMBL3899101 & 1637154 & 4.0 \\
\hline CHEMBL3907089 & 1637154 & 4.0 \\
\hline CHEMBL3896039 & 1637154 & 6.301 \\
\hline CHEMBL3895266 & 1637154 & 4.0 \\
\hline CHEMBL3942988 & 1637154 & 4.0 \\
\hline CHEMBL3912374 & 1637154 & 4.0 \\
\hline CHEMBL3928507 & 1637154 & 4.0 \\
\hline CHEMBL3890797 & 1637154 & 4.0 \\
\hline CHEMBL3981784 & 1637154 & 4.0 \\
\hline CHEMBL3945059 & 1637154 & 4.0 \\
\hline CHEMBL3941565 & 1637154 & 4.0 \\
\hline CHEMBL3968460 & 1637154 & 4.0 \\
\hline CHEMBL3942381 & 1637154 & 6.301 \\
\hline CHEMBL3899285 & 163715 & 4.0 \\
\hline
\end{tabular}

4.1344 TST

4.1473 TRN

5.0171 TRN

4.093 TRN

4.1069 TRN

4.5272 TRN

4.7618 TRN

4.9246 TRN

4.1693 TST

4.0963 TRN

4.0049 TRN

4.0433 TRN

5.202999999999999 TST

4.2598 TST

4.1569 TRN

4.2069 TST

4.2359 TRN

4.0409 TRN

5.528 TST

4.0354 TRN

4.056 TRN

4.1537 TST

4.0466 TRN

4.1225 TRN

4.2144 TST

4.2887 TST

5.4431 TRN

4.1505 TRN

4.0858 TRN

4.1222 TRN

4.4493 TST

4.1528 TRN

4.4648 TST

4.1757 TST

4.1236 TST

4.0603 TRN

4.5312 TST

4.0905 TRN

4.2349 TRN

4.0186 TRN

4.0809 TRN

4.1149 TST

4.1831 TRN

4.2332 TRN

4.245 TST

4.7254 TRN

4.1503 TRN

4.0396 TRN

Page 6874 


\begin{tabular}{|c|c|c|c|c|c|}
\hline \\
\hline CHEMBL3955478 & 1637154 & 4.0 & 4.0895 & TRN & \\
\hline CHEMBL3957835 & 1637154 & 4.0 & 4.1066 & TRN & \\
\hline CHEMBL3939013 & 1637154 & 4.0 & 4.0593 & TRN & \\
\hline CHEMBL3981425 & 1637154 & 4.0 & 4.0731 & TRN & \\
\hline CHEMBL3954978 & 1637154 & 4.0 & 4.744 & TST & \\
\hline CHEMBL3977421 & 1637154 & 6.301 & 5.5523 & TRN & \\
\hline CHEMBL3980636 & 1637154 & 4.0 & 4.8282 & TRN & \\
\hline CHEMBL3897700 & 1637154 & 4.0 & 4.0621 & TRN & \\
\hline CHEMBL3928847 & 1637154 & 4.0 & 4.1435 & TST & \\
\hline CHEMBL3968167 & 1637154 & 6.301 & 5.5579 & TRN & \\
\hline CHEMBL3935744 & 1637154 & 4.0 & 4.0656 & TRN & \\
\hline CHEMBL3928075 & 1637154 & 5.301 & 4.2632 & TRN & \\
\hline CHEMBL3935100 & 1637154 & 4.0 & 4.0557 & TRN & \\
\hline CHEMBL3964025 & 1637154 & 4.0 & 4.038 & TRN & \\
\hline CHEMBL3904980 & 1637154 & 4.0 & 4.1057 & TRN & \\
\hline CHEMBL3932389 & 1637154 & 4.0 & 4.1113 & TRN & \\
\hline CHEMBL3931676 & 1637154 & 4.0 & 4.0405 & TRN & \\
\hline CHEMBL3926189 & 1637154 & 4.0 & 4.1496 & TST & \\
\hline CHEMBL3956999 & 1637154 & 4.0 & 4.1095 & TRN & \\
\hline CHEMBL3917210 & 1637154 & 4.0 & 4.2853 & TST & \\
\hline CHEMBL3899027 & 1637154 & 4.0 & 4.0832 & TRN & \\
\hline CHEMBL3985717 & 1637154 & 4.0 & 4.104 & TST & \\
\hline CHEMBL3947313 & 1637154 & 4.0 & 4.0444 & TRN & \\
\hline CHEMBL3904681 & 1637154 & 4.0 & 4.083 & TRN & \\
\hline CHEMBL3092287 & 1641371 & 6.699 & 6.2454 & TST & \\
\hline CHEMBL3914559 & 1641371 & 4.8996 & 6.0276 & TST & \\
\hline CHEMBL3904300 & 1641371 & 6.6576 & 6.30200 & 00000000005 & TRN \\
\hline CHEMBL3911861 & 1641371 & 4.7435 & 6.0779 & TST & \\
\hline CHEMBL3921282 & 1641371 & 6.5086 & 6.6339 & TRN & \\
\hline CHEMBL3976506 & 1641371 & 8.0 & 7.1434 & TRN & \\
\hline CHEMBL3939063 & 1641371 & 7.699 & 7.4465 & TRN & \\
\hline CHEMBL3977534 & 1641371 & 6.0458 & 6.1407 & TRN & \\
\hline CHEMBL3899608 & 1641371 & 5.8671 & 6.6245 & TST & \\
\hline CHEMBL3899833 & 1641371 & 6.301 & 6.9968 & TRN & \\
\hline CHEMBL3915301 & 1641371 & 6.1427 & 6.5186 & TRN & \\
\hline CHEMBL3975179 & 1641371 & 5.7122 & 5.8148 & TRN & \\
\hline CHEMBL3977925 & 1641371 & 5.6576 & 6.1572 & TRN & \\
\hline CHEMBL3896707 & 1641371 & 6.1549 & 5.9862 & TRN & \\
\hline CHEMBL3899263 & 1641371 & 6.0969 & 5.4891 & TRN & \\
\hline CHEMBL3903912 & 1641371 & 7.0458 & 6.6626 & TRN & \\
\hline CHEMBL3899757 & 1641371 & 6.585 & 6.5035 & TST & \\
\hline CHEMBL3963093 & 1641371 & 6.5686 & 7.1215 & TRN & \\
\hline CHEMBL3894430 & 1641371 & 7.0 & 6.5085 & TRN & \\
\hline CHEMBL3928400 & 1641371 & 6.2676 & 6.4528 & TRN & \\
\hline CHEMBL3912902 & 1641371 & 6.2441 & 5.9378 & TRN & \\
\hline CHEMBL3955012 & 1641371 & 5.9547 & 5.7536 & TRN & \\
\hline CHEMBL3948003 & 1641371 & 6.4685 & 6.4004 & TST & \\
\hline CHEMBL3926716 & 1641371 & 6.4815 & 6.3864 & TRN & \\
\hline
\end{tabular}


Supplemental Table S2.txt

\begin{tabular}{|c|c|c|c|c|c|}
\hline CHEMBL3965292 & 1641371 & 7.0969 & 7.3122 & TRN & \\
\hline CHEMBL3919358 & 1641371 & 7.2218 & 6.8833 & TRN & \\
\hline CHEMBL3911209 & 1641371 & 6.2441 & 6.1758 & TRN & \\
\hline CHEMBL3963907 & 1641371 & 6.3372 & 5.9048 & TRN & \\
\hline CHEMBL3900543 & 1641371 & 6.8539 & 6.8819 & TRN & \\
\hline CHEMBL3921262 & 1641371 & 6.2518 & 6.1198 & TRN & \\
\hline CHEMBL3919495 & 1641371 & 6.2757 & 6.7478 & TRN & \\
\hline CHEMBL3964777 & 1641371 & 7.0 & 6.8393 & TRN & \\
\hline CHEMBL3947381 & 1641371 & 6.0458 & 5.841 & TRN & \\
\hline CHEMBL 3983263 & 1641371 & 7.1549 & 6.9602 & TRN & \\
\hline CHEMBL3945185 & 1641371 & 6.7696 & 6.2535 & TRN & \\
\hline CHEMBL3951285 & 1641371 & 6.8239 & 6.6565 & TRN & \\
\hline CHEMBL3931441 & 1641371 & 5.8013 & 5.982 & TRN & \\
\hline CHEMBL3939226 & 1641371 & 6.699 & 6.6125 & TRN & \\
\hline CHEMBL 3948947 & 1641371 & 6.5528 & 6.4096 & TRN & \\
\hline CHEMBL3923880 & 1641371 & 6.6198 & 6.6984 & TRN & \\
\hline CHEMBL3938926 & 1641371 & 6.6576 & 6.58899 & 99999999995 & TRN \\
\hline CHEMBL3908801 & 1641371 & 6.4089 & 6.2174 & TRN & \\
\hline CHEMBL3893402 & 1641371 & 7.1549 & 7.6206 & TRN & \\
\hline CHEMBL3923778 & 1641371 & 7.0 & 6.9751 & TRN & \\
\hline CHEMBL3949370 & 1641371 & 5.8861 & 5.9671 & TRN & \\
\hline CHEMBL3911969 & 1641371 & 7.5229 & 7.4674 & TRN & \\
\hline CHEMBL3896073 & 1641371 & 5.0846 & 6.3666 & TST & \\
\hline CHEMBL3946823 & 1641371 & 6.4437 & 6.5237 & TRN & \\
\hline CHEMBL3892982 & 1641371 & 7.0 & 6.8503 & TRN & \\
\hline CHEMBL3982791 & 1641371 & 6.0088 & 6.3567 & TRN & \\
\hline CHEMBL3939399 & 1641371 & 8.0 & 7.1544 & TRN & \\
\hline CHEMBL 3986724 & 1641371 & 5.6778 & 6.1799 & TRN & \\
\hline CHEMBL3903830 & 1641371 & 5.6576 & 5.7165 & TRN & \\
\hline CHEMBL3914005 & 1641371 & 6.3565 & 6.4181 & TRN & \\
\hline CHEMBL3963524 & 1641371 & 6.2441 & 6.5634 & TST & \\
\hline CHEMBL3985068 & 1641371 & 6.0969 & 6.5036 & TST & \\
\hline CHEMBL3977982 & 1641371 & 6.2218 & 6.37799 & 9999999999 & TRN \\
\hline CHEMBL3927291 & 1641371 & 6.0177 & 5.9543 & TRN & \\
\hline CHEMBL 3898803 & 1641371 & 8.0 & 7.1867 & TRN & \\
\hline CHEMBL3890306 & 1641371 & 6.2147 & 5.7547 & TRN & \\
\hline CHEMBL 3972329 & 1641371 & 6.0 & 6.1455 & TRN & \\
\hline CHEMBL3935390 & 1641371 & 7.0969 & 6.6885 & TRN & \\
\hline CHEMBL3984079 & 1641371 & 5.8861 & 6.0753 & TRN & \\
\hline CHEMBL3897007 & 1641371 & 7.1549 & 6.9344 & TRN & \\
\hline CHEMBL 3982560 & 1641371 & 5.523 & 6.0906 & TST & \\
\hline CHEMBL3901905 & 1641371 & 6.8861 & 6.6476 & TRN & \\
\hline CHEMBL3978725 & 1641371 & 6.6383 & 6.5355 & TRN & \\
\hline CHEMBL3940950 & 1641371 & 6.2366 & 6.3998 & TRN & \\
\hline CHEMBL3926634 & 1641371 & 6.0177 & 6.0709 & TRN & \\
\hline CHEMBL3949113 & 1641371 & 6.5086 & 6.4178 & TRN & \\
\hline CHEMBL3985403 & 1641371 & 7.0969 & 6.4754 & TRN & \\
\hline CHEMBL3946741 & 1641371 & 6.8239 & 6.5745 & TRN & \\
\hline
\end{tabular}


Supplemental Table S2.txt

\begin{tabular}{|c|c|c|c|c|c|}
\hline CHEMBL3916540 & 1641371 & 5.9788 & 6.0516 & TRN & \\
\hline CHEMBL3954679 & 1641371 & 6.1871 & 6.8016 & TST & \\
\hline CHEMBL3946372 & 1641371 & 5.8861 & 6.0021 & TRN & \\
\hline CHEMBL3899299 & 1641371 & 6.2291 & 6.6354 & TRN & \\
\hline CHEMBL3961023 & 1641371 & 5.6295 & 6.2126 & TST & \\
\hline CHEMBL3897715 & 1641371 & 7.1549 & 7.1044 & TRN & \\
\hline CHEMBL3900772 & 1641371 & 6.0044 & 5.9935 & TRN & \\
\hline CHEMBL3935598 & 1641371 & 7.5229 & 7.1003 & TST & \\
\hline CHEMBL3956109 & 1641371 & 6.5528 & 7.018 & TRN & \\
\hline CHEMBL3957733 & 1641371 & 6.4815 & 6.8451 & TRN & \\
\hline CHEMBL3950520 & 1641371 & 6.699 & 6.7748 & TRN & \\
\hline CHEMBL3930146 & 1641371 & 6.3979 & 6.7674 & TRN & \\
\hline CHEMBL3919010 & 1641371 & 5.6819 & 6.1623 & TRN & \\
\hline CHEMBL3896824 & 1641371 & 7.1549 & 7.2214 & TRN & \\
\hline CHEMBL3902340 & 1641371 & 6.8539 & 6.5675 & TRN & \\
\hline CHEMBL3933783 & 1641371 & 5.7447 & 6.0828 & TRN & \\
\hline CHEMBL3902167 & 1641371 & 6.4815 & 6.8975 & TRN & \\
\hline CHEMBL3979194 & 1641371 & 6.0 & 6.4368 & TST & \\
\hline CHEMBL3933979 & 1641371 & 5.4962 & 6.1753 & TST & \\
\hline CHEMBL3952550 & 1641371 & 5.8125 & 5.6566 & TRN & \\
\hline CHEMBL3941755 & 1641371 & 6.9586 & 6.3988 & TRN & \\
\hline CHEMBL3939850 & 1641371 & 6.0 & 6.3504 & TRN & \\
\hline CHEMBL3959519 & 1641371 & 5.8962 & 6.4152 & TRN & \\
\hline CHEMBL3968408 & 1641371 & 6.5528 & \multicolumn{2}{|c|}{6.247000000000001} & TRN \\
\hline CHEMBL3921566 & 1641371 & 7.1549 & 6.9976 & TRN & \\
\hline CHEMBL3915586 & 1641371 & 7.3979 & 6.9324 & TST & \\
\hline CHEMBL3970721 & 1641371 & 6.0 & 6.1912 & TST & \\
\hline CHEMBL3985065 & 1641371 & 5.104 & 5.4678 & TRN & \\
\hline CHEMBL3955923 & 1641371 & 7.2218 & 7.0465 & TRN & \\
\hline CHEMBL3892375 & 1641371 & 6.6021 & 6.6835 & TRN & \\
\hline CHEMBL3949101 & 1641371 & 6.2924 & 6.0694 & TRN & \\
\hline CHEMBL3948447 & 1641371 & 7.3979 & 6.5154 & TST & \\
\hline CHEMBL3907822 & 1641371 & 7.301 & 7.2089 & TRN & \\
\hline CHEMBL 3947524 & 1641371 & 5.3279 & 5.5339 & TRN & \\
\hline CHEMBL3921888 & 1641371 & 6.1427 & 6.1586 & TRN & \\
\hline CHEMBL3894433 & 1641371 & 6.0969 & 6.035 & TRN & \\
\hline CHEMBL3986303 & 1641371 & 6.1427 & 6.5437 & TST & \\
\hline CHEMBL3928980 & 1641371 & 5.6799 & 6.0136 & TST & \\
\hline CHEMBL3923914 & 1641371 & 5.6423 & 5.53 & TST & \\
\hline CHEMBL3926266 & 1641371 & 6.8861 & 6.4835 & TRN & \\
\hline CHEMBL3924802 & 1641371 & 6.8539 & 6.7896 & TRN & \\
\hline CHEMBL3919276 & 1641371 & 6.6021 & 7.0001 & TRN & \\
\hline CHEMBL3964034 & 1641371 & 6.0 & 7.1013 & TST & \\
\hline CHEMBL3979603 & 1641371 & 7.301 & 6.8915 & TRN & \\
\hline CHEMBL3932517 & 1641371 & 6.3872 & 7.034 & TRN & \\
\hline CHEMBL3945644 & 1641371 & 6.3188 & 5.9004 & TRN & \\
\hline CHEMBL3892633 & 1641371 & 5.5784 & 7.0221 & TST & \\
\hline CHEMBL3924674 & 1641371 & 6.6383 & 6.4912 & TRN & \\
\hline
\end{tabular}


Supplemental Table S2.txt

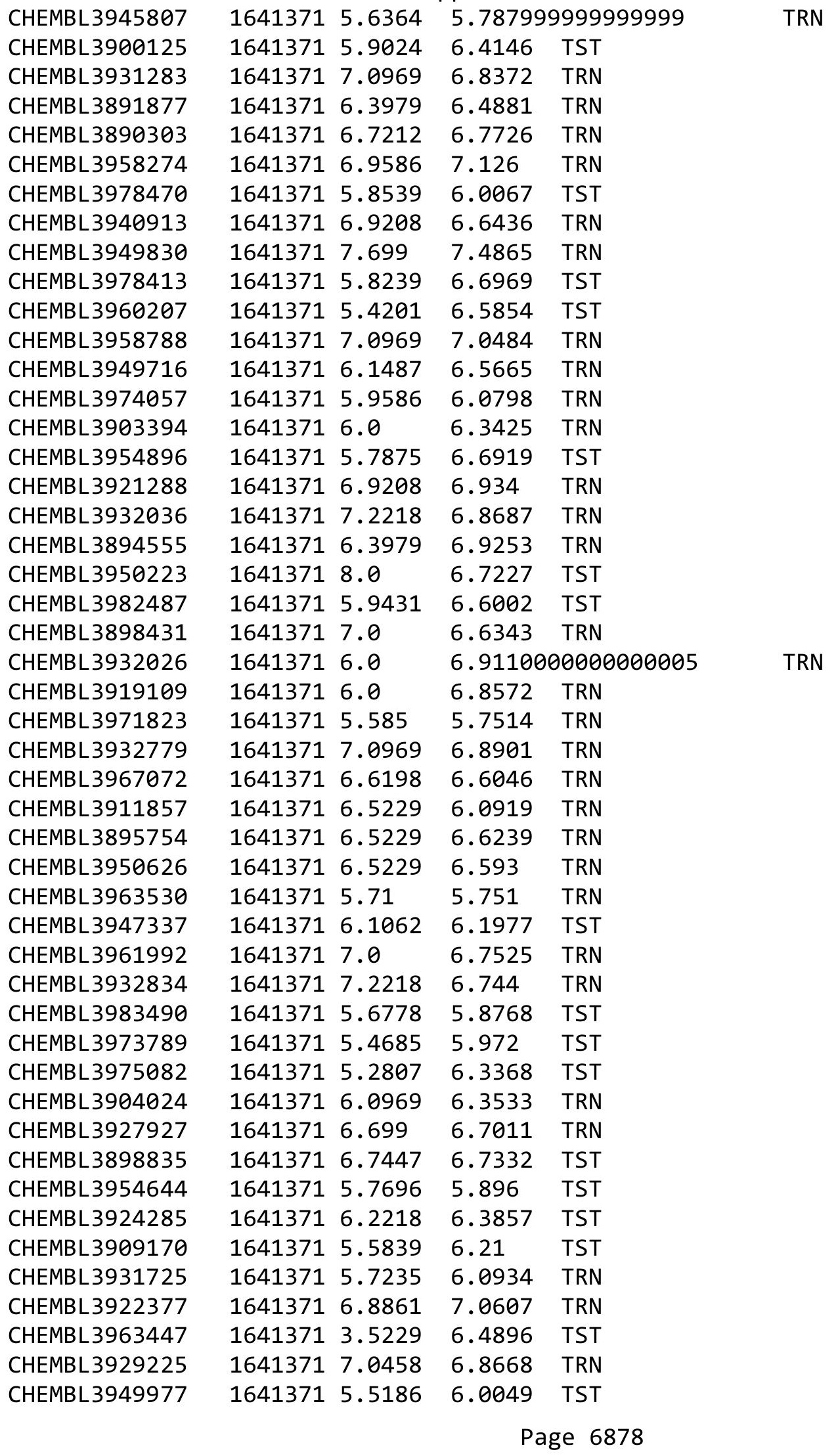


Supplemental Table S2.txt

\begin{tabular}{|c|c|c|c|c|c|}
\hline CHEMBL3953908 & 1641371 & 6.0177 & 6.1443 & TRN & \\
\hline CHEMBL3907992 & 1641371 & 5.5452 & 5.9593 & TRN & \\
\hline CHEMBL3973161 & 1641371 & 6.5229 & 7.1034 & TRN & \\
\hline CHEMBL3902192 & 1641371 & 7.699 & 7.393 & TRN & \\
\hline CHEMBL3890262 & 1641371 & 7.699 & 7.2967 & TRN & \\
\hline CHEMBL3941536 & 1641371 & 6.2757 & 5.7702 & TST & \\
\hline CHEMBL3911225 & 1641371 & 4.9586 & 6.9759 & TST & \\
\hline CHEMBL3927388 & 1641371 & 6.6383 & 6.6378 & TRN & \\
\hline CHEMBL3903256 & 1641371 & 5.0625 & 5.1286 & TRN & \\
\hline CHEMBL3927302 & 1641371 & 6.2366 & 6.5476 & TRN & \\
\hline CHEMBL3964716 & 1641371 & 7.0969 & 6.795 & TRN & \\
\hline CHEMBL3974121 & 1641371 & 6.0 & 6.6569 & TST & \\
\hline CHEMBL3956013 & 1641371 & 5.7825 & 6.8216 & TST & \\
\hline CHEMBL3950742 & 1641371 & 5.3737 & 6.2974 & TRN & \\
\hline CHEMBL3921539 & 1641371 & 5.5186 & 6.5378 & TST & \\
\hline CHEMBL3962515 & 1641371 & 6.3872 & 6.4167 & TST & \\
\hline CHEMBL3925139 & 1641371 & 6.699 & 6.5749 & TRN & \\
\hline CHEMBL3913309 & 1641371 & 5.6576 & 5.8468 & TST & \\
\hline CHEMBL3921270 & 1641371 & 6.0 & 5.9938 & TRN & \\
\hline CHEMBL3890651 & 1641371 & 6.1549 & 6.3696 & TRN & \\
\hline CHEMBL3935659 & 1641371 & 6.585 & 6.7231 & TRN & \\
\hline CHEMBL 3949748 & 1641371 & 5.9208 & 6.4122 & TRN & \\
\hline CHEMBL3901756 & 1641371 & 6.5528 & 6.4147 & TRN & \\
\hline CHEMBL3936756 & 1641371 & 6.5528 & 6.4729 & TRN & \\
\hline CHEMBL3953709 & 1641371 & 5.7328 & 5.825 & TRN & \\
\hline CHEMBL3910086 & 1641371 & 6.1308 & 6.5053 & TRN & \\
\hline CHEMBL 3912134 & 1641371 & 6.1675 & 6.9137 & TRN & \\
\hline CHEMBL3957404 & 1641371 & 6.699 & 6.2242 & TRN & \\
\hline CHEMBL3955459 & 1641371 & 5.8069 & 6.4407 & TST & \\
\hline CHEMBL3933031 & 1641371 & 7.699 & 6.9455 & TST & \\
\hline CHEMBL3979312 & 1641371 & 5.9355 & 5.9173 & TRN & \\
\hline CHEMBL 3967574 & 1641371 & 6.1249 & 5.9015 & TRN & \\
\hline CHEMBL3946779 & 1641371 & 6.0809 & 6.0533 & TRN & \\
\hline CHEMBL3919038 & 1641371 & 6.1549 & 6.48799 & 99999999995 & TRN \\
\hline CHEMBL3935648 & 1641371 & 7.699 & 6.354 & TST & \\
\hline CHEMBL3900806 & 1641371 & 7.2218 & 7.0147 & TRN & \\
\hline CHEMBL 3945434 & 1641371 & 6.7447 & 6.8177 & TRN & \\
\hline CHEMBL3911337 & 1641371 & 7.5229 & 7.1263 & TRN & \\
\hline CHEMBL3893359 & 1641371 & 6.2218 & 6.2131 & TRN & \\
\hline CHEMBL3891080 & 1641371 & 6.8861 & 6.9569 & TRN & \\
\hline CHEMBL3983515 & 1641371 & 5.0701 & 6.8332 & TST & \\
\hline CHEMBL3945679 & 1641371 & 7.5086 & 6.5133 & TST & \\
\hline CHEMBL3942213 & 1641371 & 5.5376 & 5.8826 & TRN & \\
\hline CHEMBL3980031 & 1641371 & 5.4237 & 5.7884 & TST & \\
\hline CHEMBL3918801 & 1641371 & 6.3098 & 6.0288 & TRN & \\
\hline CHEMBL3955448 & 1641371 & 4.9172 & 6.0385 & TST & \\
\hline CHEMBL3961048 & 1641371 & 6.4559 & 6.6562 & TRN & \\
\hline CHEMBL3896760 & 1641371 & 7.3979 & 7.2121 & TRN & \\
\hline
\end{tabular}


Supplemental Table S2.txt

\begin{tabular}{|c|c|c|c|c|}
\hline HEN & 541371 & & & \\
\hline HEMBL3953071 & 641371 & 6.5229 & 3732 & \\
\hline & 371 & 6 & & \\
\hline AEMBL: & & 49 & 17 & \\
\hline AEMBL3934773 & 371 & 6.7696 & 221 & \\
\hline HEMBL3913870 & 641371 & 7.0 & 1076 & \\
\hline & & & & \\
\hline IFMRI 393 & & & & \\
\hline AEMBL3904522 & & 6.585 & 9068 & \\
\hline HEMBL3976649 & 371 & 229 & $\partial 641$ & \\
\hline HEMBL3927851 & 71 & $5.5 \varepsilon$ & 1951 & \\
\hline IEMBL392 & 71 & & 383 & \\
\hline AEMBL38 & & & & \\
\hline HEMBL3982707 & 71 & 5021 & 5.5403 & \\
\hline HEMBL397 & 71 & 36 & & \\
\hline AEMBL391 & 1 & 61 & 56 & \\
\hline AEMBL39 & 71 & 69 & 41 & \\
\hline HEMBL39 & & & & \\
\hline HEMBL39 & & 218 & 7.145 & \\
\hline AEMBL398 & & & & \\
\hline HEIMBLSS & 1 & 6 & 27 & I RIV \\
\hline AEMBL3S & & & 16 & RN \\
\hline HEMBL3S & & & 61 & \\
\hline AFMR| 391 & & & & \\
\hline HEMBL 392 & & & & $\Gamma \mathrm{RN}$ \\
\hline HEMBL3S & 11 & & 55 & RN \\
\hline AEMBL3 & & & & RN \\
\hline HFMBI $3 c$ & & & 13 & \\
\hline HEMBL 39 & & & & 「RN \\
\hline HEMBL 392689 & & & 66 & IK \\
\hline HEMBL 389 & & & & RN \\
\hline HEMBL & & & 11 & RN \\
\hline 88 & & 5 & 53 & TRN \\
\hline HEMBL3926546 & 71 & 6 & 64 & 15 \\
\hline HEMBL 3957721 & 71 & 6.5086 & 055 & TST \\
\hline HEMBL 392 & 71 & & & RN \\
\hline HCMDI ? & & & 98 & RN \\
\hline HEMBL3 & & & & RN \\
\hline HEMBL3904739 & 371 & 6.6576 & 6.6804 & TRN \\
\hline AEMBL396 & & 8 & 948 & TRN \\
\hline HEMBL39 & 71 & $\partial 8$ & 5.5054 & \\
\hline HEMBL 390 & & & & RN \\
\hline HEMBL392 & 371 & 7.1549 & 6.7988 & RN \\
\hline AEMBL3978855 & 371 & 5.9586 & 81 & $\Gamma R$ \\
\hline MRI 3 & & 97 & & \\
\hline HEMBL 39 & & .2218 & 5.4845 & \\
\hline CHEMBL3956008 & & 5.2757 & 6.3344 & \\
\hline THEMBL392236e & 1641371 & 6.1367 & 5.5953 & IST \\
\hline
\end{tabular}

Page 6880 
Supplemental Table S2.txt

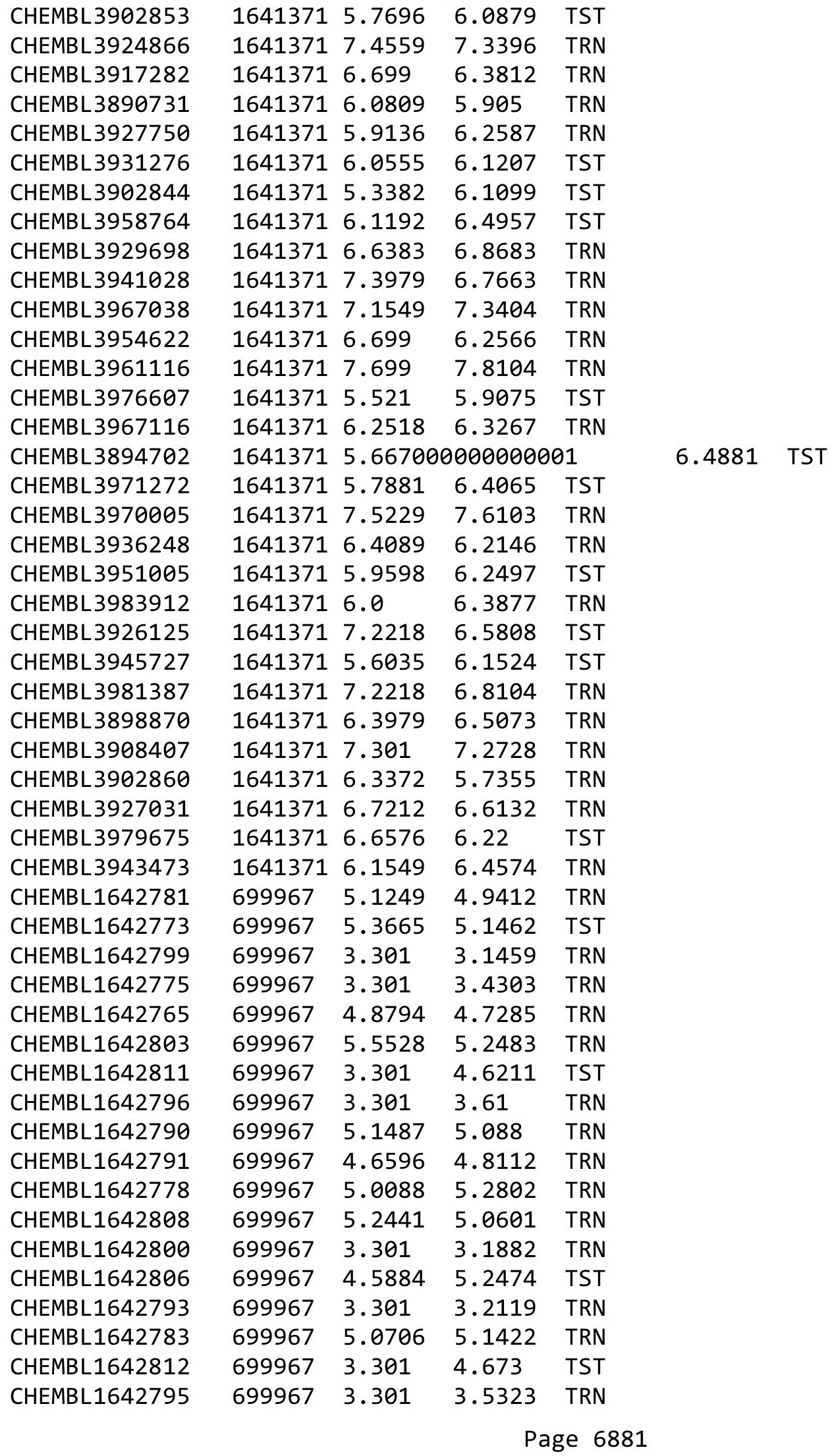


Supplemental Table S2.txt

\begin{tabular}{|c|c|c|c|c|c|}
\hline CHEMBL1642767 & 699967 & 5.2366 & 5.3217 & TRN & \\
\hline CHEMBL1642788 & 699967 & 5.1135 & 5.2802 & TRN & \\
\hline CHEMBL1642769 & 699967 & 5.3665 & 5.4196 & TRN & \\
\hline CHEMBL1642784 & 699967 & 5.0969 & 5.1913 & TRN & \\
\hline CHEMBL1642787 & 699967 & 5.1675 & 5.0632 & TRN & \\
\hline CHEMBL1642766 & 699967 & 4.7447 & 4.9792 & TRN & \\
\hline CHEMBL1642768 & 699967 & 5.0862 & 4.9499 & TRN & \\
\hline CHEMBL1642786 & 699967 & 5.0458 & 4.9498 & TRN & \\
\hline CHEMBL1642776 & 699967 & 3.301 & 3.3204 & TRN & \\
\hline CHEMBL1642802 & 699967 & 3.301 & 3.2266 & TRN & \\
\hline CHEMBL1642794 & 699967 & 3.301 & 3.2593 & TRN & \\
\hline CHEMBL1642815 & 699967 & 5.6778 & 5.4446 & TRN & \\
\hline CHEMBL1642801 & 699967 & 3.301 & 3.3107 & TRN & \\
\hline CHEMBL1642772 & 699967 & 5.2147 & 5.1502 & TST & \\
\hline CHEMBL1642785 & 699967 & 5.0706 & 5.2717 & TRN & \\
\hline CHEMBL1642807 & 699967 & 5.0223 & 5.2838 & TRN & \\
\hline CHEMBL1642804 & 699967 & 5.2366 & 5.5472 & TRN & \\
\hline CHEMBL1642780 & 699967 & 4.8928 & 4.90600 & 0000000001 & TRN \\
\hline CHEMBL1535664 & 699967 & 6.0458 & 5.08 & TRN & \\
\hline CHEMBL1642779 & 699967 & 5.0605 & 5.0085 & TRN & \\
\hline CHEMBL1642805 & 699967 & 4.475 & 5.2704 & TST & \\
\hline CHEMBL1642809 & 699967 & 3.301 & 4.9679 & TST & \\
\hline CHEMBL1642814 & 699967 & 3.301 & 4.3919 & TST & \\
\hline CHEMBL1642810 & 699967 & 3.301 & 4.742 & TST & \\
\hline CHEMBL1642771 & 699967 & 5.2596 & 5.2812 & TST & \\
\hline CHEMBL1642792 & 699967 & 3.301 & 3.2879 & TRN & \\
\hline CHEMBL1642816 & 699967 & 5.5686 & 5.0448 & TST & \\
\hline CHEMBL1642797 & 699967 & 3.301 & 3.3419 & TRN & \\
\hline CHEMBL1642798 & 699967 & 3.301 & 3.307 & TRN & \\
\hline CHEMBL1642782 & 699967 & 3.301 & 3.367 & TRN & \\
\hline CHEMBL1642777 & 699967 & 5.1612 & \multicolumn{2}{|c|}{5.3420000000000005} & TRN \\
\hline CHEMBL1642789 & 699967 & 5.301 & 5.3517 & TRN & \\
\hline CHEMBL1642770 & 699967 & 5.3768 & 5.1997 & TST & \\
\hline CHEMBL1642774 & 699967 & 4.8477 & 3.9063 & TST & \\
\hline CHEMBL1642813 & 699967 & 3.301 & 4.7866 & TST & \\
\hline CHEMBL294590 & 566531 & 3.5229 & 4.2029 & TST & \\
\hline CHEMBL449628 & 566531 & 3.5229 & 4.119 & TRN & \\
\hline CHEMBL449346 & 566531 & 3.5229 & 3.5497 & TRN & \\
\hline CHEMBL466044 & 566531 & 4.7212 & 4.6162 & TRN & \\
\hline CHEMBL449108 & 566531 & 3.5229 & 3.8014 & TRN & \\
\hline CHEMBL509367 & 566531 & 5.9208 & 5.8434 & TRN & \\
\hline CHEMBL63783 & 566531 & 3.5229 & 3.8929 & TST & \\
\hline CHEMBL510907 & 566531 & 3.5229 & 3.4904 & TRN & \\
\hline CHEMBL469409 & 566531 & 3.5229 & 4.0322 & TST & \\
\hline CHEMBL472147 & 566531 & 3.5229 & 3.5554 & TRN & \\
\hline CHEMBL67199 & 566531 & 4.7959 & 4.5292 & TRN & \\
\hline CHEMBL448396 & 566531 & 3.5229 & 4.0288 & TRN & \\
\hline CHEMBL505089 & 566531 & 5.2518 & 5.5978 & TRN & \\
\hline
\end{tabular}




\begin{tabular}{|c|c|c|c|c|c|c|}
\hline & & \multicolumn{5}{|c|}{ Supplemental Table S2.txt } \\
\hline CHEMBL474058 & 566531 & 5.5528 & 5.1868 & TRN & & \\
\hline CHEMBL474623 & 566531 & 3.5229 & 3.2962 & TRN & & \\
\hline CHEMBL503566 & 566531 & 3.5229 & 3.93 & TRN & & \\
\hline CHEMBL474396 & 566531 & 3.5229 & 4.9005 & TST & & \\
\hline CHEMBL151071 & 566531 & 3.5229 & 3.9216 & TRN & & \\
\hline CHEMBL474207 & 566531 & 5.3768 & 5.5586 & TRN & & \\
\hline CHEMBL508561 & 566531 & 3.5229 & 4.8925 & TRN & & \\
\hline CHEMBL449924 & 566531 & 6.0655 & 5.1937 & TST & & \\
\hline CHEMBL466850 & 566531 & 3.5229 & 3.1475 & TRN & & \\
\hline CHEMBL446264 & 566531 & 5.9586 & 5.8272 & TRN & & \\
\hline CHEMBL304009 & 566531 & 3.5229 & 4.1993 & TRN & & \\
\hline CHEMBL445974 & 566531 & 3.5229 & 3.6299 & TRN & & \\
\hline CHEMBL65976 & 566531 & 3.5229 & 4.1828 & TRN & & \\
\hline CHEMBL445696 & 566531 & 3.5229 & 2.5625 & TRN & & \\
\hline CHEMBL516238 & 566531 & 3.5229 & 4.9005 & TST & & \\
\hline CHEMBL505633 & 566531 & 5.1487 & 5.1912 & TRN & & \\
\hline CHEMBL65747 & 566531 & 3.5229 & 4.7651 & TST & & \\
\hline CHEMBL475030 & 566531 & 3.5229 & 4.0001 & TRN & & \\
\hline CHEMBL504495 & 566531 & 3.5229 & 4.2199 & TRN & & \\
\hline CHEMBL475617 & 566531 & 6.1938 & 5.6088 & TRN & & \\
\hline CHEMBL510288 & 566531 & 6.1427 & 5.5392 & TRN & & \\
\hline CHEMBL447623 & 566531 & 3.5229 & 3.1117 & TRN & & \\
\hline CHEMBL451363 & 566531 & 3.5229 & 3.6155 & TRN & & \\
\hline CHEMBL503376 & 566531 & 3.5229 & 3.8488 & TRN & & \\
\hline CHEMBL266094 & 566531 & 3.5229 & 2.6423 & TRN & & \\
\hline CHEMBL506450 & 566531 & 6.699 & 5.7322 & TRN & & \\
\hline CHEMBL515419 & 566531 & 5.3872 & 5.2504 & TST & & \\
\hline CHEMBL62835 & 566531 & 3.5229 & 3.8929 & TST & & \\
\hline CHEMBL468633 & 566531 & 6.0757 & 5.7369 & TRN & & \\
\hline CHEMBL455493 & 566531 & 4.7696 & 4.1989 & TST & & \\
\hline CHEMBL475456 & 566531 & 3.5229 & 3.6265 & TRN & & \\
\hline CHEMBL475023 & 566531 & 5.7696 & 4.3239 & TRN & & \\
\hline CHEMBL475455 & 566531 & 5.2924 & 5.2344 & TST & & \\
\hline CHEMBL506888 & 566531 & 5.3372 & 5.0067 & TST & & \\
\hline CHEMBL95897 & 566531 & 3.5229 & 3.7193 & TRN & & \\
\hline CHEMBL183 & 566531 & 6.0 & 5.1687 & TST & & \\
\hline CHEMBL494759 & 566531 & 3.5229 & 3.7737 & TRN & & \\
\hline CHEMBL1568184 & 688274 & $3.8710 e$ & 0000000 & 004 & 3.3188 & TRN \\
\hline CHEMBL1413726 & 688274 & 4.0356 & 3.8068 & TRN & & \\
\hline CHEMBL209101 & 688274 & 3.8684 & 3.4212 & TRN & & \\
\hline CHEMBL1974180 & 688274 & 2.8239 & 3.5589 & TRN & & \\
\hline CHEMBL1467720 & 688274 & 4.4298 & 4.135 & TRN & & \\
\hline CHEMBL1410381 & 688274 & 4.1459 & 4.4073 & TRN & & \\
\hline CHEMBL580340 & 688274 & 2.8239 & 4.3954 & TRN & & \\
\hline CHEMBL1410758 & 688274 & 2.8239 & 4.0596 & TRN & & \\
\hline CHEMBL1568414 & 688274 & 2.8239 & 3.5226 & TRN & & \\
\hline CHEMBL1562824 & 688274 & 4.3545 & 4.3042 & TRN & & \\
\hline CHEMBL1424833 & 688274 & 4.0918 & 3.6464 & TRN & & \\
\hline
\end{tabular}




\begin{tabular}{|c|c|c|c|c|c|}
\hline \multicolumn{6}{|c|}{ Supplemental Table S2.txt } \\
\hline CHEMBL1325945 & 688274 & 5.1331 & 5.3174 & TST & \\
\hline CHEMBL 3189743 & 688274 & 3.8878 & 3.6051 & TRN & \\
\hline CHEMBL1459764 & 688274 & 4.301 & 4.0578 & TRN & \\
\hline CHEMBL 2373661 & 688274 & 4.7395 & 4.8389 & TST & \\
\hline CHEMBL1384935 & 688274 & 4.5445 & 3.4571 & TRN & \\
\hline CHEMBL1340843 & 688274 & 2.8239 & 3.6859 & TRN & \\
\hline CHEMBL1569989 & 688274 & 4.0097 & 3.8578 & TRN & \\
\hline CHEMBL358644 & 688274 & 2.8239 & 3.9694 & TST & \\
\hline CHEMBL1323744 & 688274 & 4.2437 & 4.1768 & TRN & \\
\hline CHEMBL1470669 & 688274 & 3.937 & 3.8062 & TRN & \\
\hline CHEMBL 3191149 & 688274 & 4.0939 & 4.0813 & TRN & \\
\hline CHEMBL1462938 & 688274 & 4.7319 & 4.5702 & TRN & \\
\hline CHEMBL1520465 & 688274 & 4.2663 & 3.6893 & TRN & \\
\hline CHEMBL1401089 & 688274 & 3.8651 & 3.9146 & TRN & \\
\hline CHEMBL1415720 & 688274 & 4.3413 & 4.0536 & TST & \\
\hline CHEMBL1466123 & 688274 & 4.2036 & 4.1781 & TRN & \\
\hline CHEMBL 3192021 & 688274 & 4.0742 & 3.552 & TRN & \\
\hline CHEMBL1450615 & 688274 & 4.1487 & 3.9166 & TRN & \\
\hline CHEMBL1353170 & 688274 & 4.8703 & 4.3457 & TRN & \\
\hline CHEMBL1385616 & 688274 & 4.2915 & 4.0972 & TRN & \\
\hline CHEMBL586602 & 688274 & 4.5096 & 4.1969 & TRN & \\
\hline CHEMBL1492585 & 688274 & 4.2611 & 4.22 & TRN & \\
\hline CHEMBL1518625 & 688274 & 4.3216 & 4.0776 & TRN & \\
\hline CHEMBL1448592 & 688274 & 4.7675 & 4.6443 & TRN & \\
\hline CHEMBL1329235 & 688274 & 2.8239 & 3.9357 & TRN & \\
\hline CHEMBL1423463 & 688274 & 4.4102 & 4.1054 & TRN & \\
\hline CHEMBL1403156 & 688274 & 3.8778 & 3.6445 & TRN & \\
\hline CHEMBL581880 & 688274 & 4.1744 & 4.0733 & TRN & \\
\hline CHEMBL1369623 & 688274 & 4.2085 & 4.1836 & TRN & \\
\hline CHEMBL1994463 & 688274 & 4.7962 & 4.4296 & TST & \\
\hline CHEMBL1322516 & 688274 & 4.0676 & 3.59800 & 00000000003 & TRN \\
\hline CHEMBL51931 & 688274 & 4.9303 & 4.3805 & TRN & \\
\hline CHEMBL3209306 & 688274 & 4.3764 & 4.3923 & TRN & \\
\hline CHEMBL 3197628 & 688274 & 3.9571 & 3.8387 & TRN & \\
\hline CHEMBL1337033 & 688274 & 4.3936 & 4.3356 & TST & \\
\hline CHEMBL1495848 & 688274 & 2.8239 & 3.9748 & TST & \\
\hline CHEMBL19954 & 688274 & 4.4959 & 4.1712 & TRN & \\
\hline CHEMBL1581682 & 688274 & 4.2056 & 4.1996 & TRN & \\
\hline CHEMBL1304402 & 688274 & 4.0188 & 4.1669 & TRN & \\
\hline CHEMBL1522007 & 688274 & 4.6694 & 4.8009 & TST & \\
\hline CHEMBL1448161 & 688274 & 2.8239 & 3.8177 & TRN & \\
\hline CHEMBL1391048 & 688274 & 4.166 & 3.9243 & TST & \\
\hline CHEMBL1977877 & 688274 & 4.5113 & 4.3738 & TRN & \\
\hline CHEMBL1349832 & 688274 & 2.8239 & 3.8873 & TRN & \\
\hline CHEMBL1300831 & 688274 & 4.3918 & 4.0104 & TST & \\
\hline CHEMBL1309702 & 688274 & 3.1249 & 4.041 & TRN & \\
\hline CHEMBL 1500500 & 688274 & 4.1388 & 3.9867 & TRN & \\
\hline CHEMBL1986678 & 688274 & 3.9698 & 3.8447 & TRN & \\
\hline
\end{tabular}




\begin{tabular}{|c|c|c|c|c|c|}
\hline & & \multicolumn{4}{|c|}{ Supplemental Table S2.txt } \\
\hline CHEMBL142816 & 688274 & 4.3396 & 4.1658 & TST & \\
\hline CHEMBL1379286 & 688274 & 2.8239 & 3.8912 & TRN & \\
\hline CHEMBL1419557 & 688274 & 4.1328 & 4.0412 & TRN & \\
\hline CHEMBL1483252 & 688274 & 4.2557 & 4.3236 & TRN & \\
\hline CHEMBL1601781 & 688274 & 4.431 & 4.2186 & TRN & \\
\hline CHEMBL1380497 & 688274 & 3.8312 & 3.2935 & TRN & \\
\hline CHEMBL1519239 & 688274 & 4.2809 & 4.3035 & TRN & \\
\hline CHEMBL3191443 & 688274 & 4.2486 & 3.9368 & TRN & \\
\hline CHEMBL1360037 & 688274 & 4.2113 & 4.1387 & TRN & \\
\hline CHEMBL3198111 & 688274 & 4.0191 & 3.8794 & TRN & \\
\hline CHEMBL1418974 & 688274 & 3.9107 & 3.7275 & TRN & \\
\hline CHEMBL3198912 & 688274 & 3.8611 & 3.5891 & TRN & \\
\hline CHEMBL1387835 & 688274 & 4.3637 & 4.4994 & TRN & \\
\hline CHEMBL1385808 & 688274 & 6.0 & 6.6037 & TST & \\
\hline CHEMBL1548109 & 688274 & 4.4072 & 4.1431 & TRN & \\
\hline CHEMBL602377 & 688274 & 4.3947 & 4.1175 & TRN & \\
\hline CHEMBL1324885 & 688274 & 2.8239 & 3.545 & TRN & \\
\hline CHEMBL1330113 & 688274 & 6.0 & 5.6824 & TST & \\
\hline CHEMBL1487183 & 688274 & 5.1481 & 4.9895 & TST & \\
\hline CHEMBL1326371 & 688274 & 4.6527 & 4.8615 & TRN & \\
\hline CHEMBL1514790 & 688274 & 4.4791 & 4.2714 & TRN & \\
\hline CHEMBL1562066 & 688274 & 4.1062 & 3.8089 & TST & \\
\hline CHEMBL3197896 & 688274 & 4.0056 & 3.9413 & TRN & \\
\hline CHEMBL3191713 & 688274 & 4.4645 & 4.3054 & TRN & \\
\hline CHEMBL1607938 & 688274 & 4.0302 & 3.3437 & TRN & \\
\hline CHEMBL1584133 & 688274 & 3.904 & 3.708 & TRN & \\
\hline CHEMBL1521705 & 688274 & 5.3098 & 4.9734 & TRN & \\
\hline CHEMBL3199539 & 688274 & $3.9560 e$ & 00000000 & 3.6621 & I RIN \\
\hline CHEMBL334707 & 688274 & 5.5129 & 5.7868 & TRN & \\
\hline CHEMBL1528900 & 688274 & 4.0361 & 4.1646 & TRN & \\
\hline CHEMBL1336722 & 688274 & 3.8621 & 3.4735 & TRN & \\
\hline CHEMBL1589425 & 688274 & 4.7335 & 4.4318 & TRN & \\
\hline CHEMBL1310861 & 688274 & 4.0243 & 3.7908 & TRN & \\
\hline CHEMBL1594055 & 688274 & 5.6536 & 6.6703 & TST & \\
\hline CHEMBL587892 & 688274 & 4.17 & 3.9138 & TRN & \\
\hline CHEMBL1971144 & 688274 & 4.3074 & 4.3811 & TRN & \\
\hline CHEMBL1981840 & 688274 & 2.8239 & 3.7271 & TRN & \\
\hline CHEMBL1369571 & 688274 & 2.8239 & 3.77699 & 99999999997 & TRN \\
\hline CHEMBL1532668 & 688274 & 4.2392 & 4.1551 & TRN & \\
\hline CHEMBL1409001 & 688274 & 4.1229 & 3.6932 & TRN & \\
\hline CHEMBL1310009 & 688274 & 4.1231 & 3.8796 & TST & \\
\hline CHEMBL461579 & 688274 & 4.5763 & 4.5345 & TRN & \\
\hline CHEMBL1532828 & 688274 & 4.3802 & 4.2657 & TRN & \\
\hline CHEMBL1477268 & 688274 & 2.8239 & 3.3115 & TRN & \\
\hline CHEMBL 2001792 & 688274 & 2.8239 & 3.4288 & TRN & \\
\hline CHEMBL1330558 & 688274 & 4.5539 & 4.7506 & TRN & \\
\hline CHEMBL1500265 & 688274 & 2.8239 & 3.7274 & TRN & \\
\hline CHEMBL 2004417 & 688274 & 4.6144 & 4.4022 & TRN & \\
\hline
\end{tabular}




\begin{tabular}{|c|c|c|c|c|c|}
\hline & & \multicolumn{4}{|c|}{ Supplemental Table s2.txt } \\
\hline CHEMBL429095 & 688274 & 4.1491 & 3.8325 & TRN & \\
\hline CHEMBL1325192 & 688274 & 4.1407 & 4.0293 & TRN & \\
\hline CHEMBL1502014 & 688274 & 4.0991 & 3.8916 & TST & \\
\hline CHEMBL1422161 & 688274 & 4.2493 & 3.8254 & TRN & \\
\hline CHEMBL1521960 & 688274 & 4.9923 & 4.6791 & TRN & \\
\hline CHEMBL1322395 & 688274 & 4.417 & 4.0381 & TRN & \\
\hline CHEMBL199387 & 688274 & 4.2335 & 4.2198 & TRN & \\
\hline CHEMBL1483235 & 688274 & 4.7272 & 4.655 & TRN & \\
\hline CHEMBL1964793 & 688274 & 4.6286 & 4.3096 & TRN & \\
\hline CHEMBL1454171 & 688274 & 2.8239 & 3.8905 & TRN & \\
\hline CHEMBL1348018 & 688274 & 2.8239 & 3.5888 & TRN & \\
\hline CHEMBL3189712 & 688274 & 4.0849 & 3.877 & TRN & \\
\hline CHEMBL578294 & 688274 & 4.013 & 3.2531 & TRN & \\
\hline CHEMBL3194704 & 688274 & 4.2363 & 4.1335 & TRN & \\
\hline CHEMBL1441196 & 688274 & 4.9431 & 4.7512 & TRN & \\
\hline CHEMBL1984324 & 688274 & 4.4406 & 4.034 & TRN & \\
\hline CHEMBL1373503 & 688274 & 2.8239 & 3.9061 & TRN & \\
\hline CHEMBL1589298 & 688274 & 4.4892 & 3.8445 & TST & \\
\hline CHEMBL1300612 & 688274 & 4.372 & 4.148 & TRN & \\
\hline CHEMBL 2000750 & 688274 & 4.3726 & 4.1201 & TRN & \\
\hline CHEMBL1974450 & 688274 & 2.8239 & 3.7339 & TRN & \\
\hline CHEMBL1541657 & 688274 & 4.2538 & 3.9427 & TRN & \\
\hline CHEMBL3191293 & 688274 & 4.1772 & 4.1712 & TRN & \\
\hline CHEMBL1491847 & 688274 & 4.7423 & 4.5492 & TRN & \\
\hline CHEMBL1499792 & 688274 & 4.482 & 4.3373 & TRN & \\
\hline CHEMBL3192557 & 688274 & 3.9789 & 3.9905 & TRN & \\
\hline CHEMBL1425521 & 688274 & 4.046 & 3.8715 & TRN & \\
\hline CHEMBL 73451 & 688274 & 3.8747 & 3.7626 & TRN & \\
\hline CHEMBL1486366 & 688274 & 4.0157 & 4.0536 & TRN & \\
\hline CHEMBL3189889 & 688274 & 2.8239 & 3.347 & TRN & \\
\hline CHEMBL1454183 & 688274 & 2.8239 & 3.2665 & TST & \\
\hline CHEMBL140425 & 688274 & 5.2104 & 5.2958 & TRN & \\
\hline CHEMBL1460004 & 688274 & 4.1257 & 3.9804 & TRN & \\
\hline CHEMBL1455650 & 688274 & 4.099 & 4.0764 & TST & \\
\hline CHEMBL1420350 & 688274 & 3.9109 & 3.157 & TST & \\
\hline CHEMBL1304363 & 688274 & 4.1594 & 4.3277 & TRN & \\
\hline CHEMBL1494444 & 688274 & 2.8239 & 3.8387 & TRN & \\
\hline CHEMBL1327470 & 688274 & 4.5974 & 4.2388 & TRN & \\
\hline CHEMBL1594766 & 688274 & 3.9753 & 3.7325 & TRN & \\
\hline CHEMBL1561153 & 688274 & 4.4181 & 4.08899 & 99999999995 & TRN \\
\hline CHEMBL573543 & 688274 & 4.7873 & 4.7016 & TRN & \\
\hline CHEMBL1310632 & 688274 & 4.9465 & 4.5307 & TRN & \\
\hline CHEMBL1597655 & 688274 & 4.368 & 4.3372 & TRN & \\
\hline CHEMBL1528425 & 688274 & 4.3325 & 4.5432 & TRN & \\
\hline CHEMBL1443977 & 688274 & 2.8239 & 3.929 & TRN & \\
\hline CHEMBL3191503 & 688274 & 2.8239 & 3.3606 & TRN & \\
\hline CHEMBL1986183 & 688274 & 4.0923 & 3.6869 & TST & \\
\hline CHEMBL1606572 & 688274 & 3.83699 & 79999999 & 3.9681 & TRN \\
\hline
\end{tabular}


Supplemental Table S2.txt

\begin{tabular}{|c|c|c|c|c|c|}
\hline CHEMBL1503034 & 688274 & 4.3974 & 4.223 & TST & \\
\hline CHEMBL 3193964 & 688274 & 4.0228 & 3.7397 & TST & \\
\hline CHEMBL3190974 & 688274 & 4.3811 & 4.1385 & TRN & \\
\hline CHEMBL66953 & 688274 & 4.5604 & 4.4175 & TST & \\
\hline CHEMBL1522486 & 688274 & 4.4033 & 4.8333 & TRN & \\
\hline CHEMBL3195409 & 688274 & 4.3409 & 4.0283 & TRN & \\
\hline CHEMBL 3213876 & 688274 & 4.078 & 4.0473 & TRN & \\
\hline CHEMBL1928491 & 688274 & 4.1884 & 3.9724 & TRN & \\
\hline CHEMBL1549308 & 688274 & 3.9762 & 3.8843 & TST & \\
\hline CHEMBL1560982 & 688274 & 4.4938 & 4.154 & TRN & \\
\hline CHEMBL1501653 & 688274 & 4.5891 & 4.2333 & TRN & \\
\hline CHEMBL1588107 & 688274 & 4.3707 & 4.0682 & TRN & \\
\hline CHEMBL1588476 & 688274 & 2.8239 & 3.9289 & TRN & \\
\hline CHEMBL1444764 & 688274 & 2.8239 & 3.9181 & TRN & \\
\hline CHEMBL1308687 & 688274 & 4.7486 & 4.6701 & TRN & \\
\hline CHEMBL428064 & 688274 & 5.1124 & 5.4996 & TRN & \\
\hline CHEMBL601757 & 688274 & 5.9393 & 6.0136 & TST & \\
\hline CHEMBL1609529 & 688274 & 4.1634 & 4.0696 & TRN & \\
\hline CHEMBL 3208179 & 688274 & 4.3383 & 3.8441 & TRN & \\
\hline CHEMBL1503359 & 688274 & 4.838 & 4.5934 & TRN & \\
\hline CHEMBL3192400 & 688274 & 2.8239 & 3.8326 & TRN & \\
\hline CHEMBL1572827 & 688274 & 4.2735 & 3.5919 & TST & \\
\hline CHEMBL1330307 & 688274 & 4.0382 & 4.2957 & TRN & \\
\hline CHEMBL1478496 & 688274 & 4.3986 & 4.2463 & TST & \\
\hline CHEMBL1537189 & 688274 & 2.8239 & 3.62399 & 99999999997 & TRN \\
\hline CHEMBL1501309 & 688274 & 4.6492 & 4.3112 & TRN & \\
\hline CHEMBL584269 & 688274 & 4.4216 & 4.522 & TRN & \\
\hline CHEMBL1563898 & 688274 & 2.8239 & 4.1154 & TRN & \\
\hline CHEMBL1585390 & 688274 & 4.4318 & 3.9744 & TRN & \\
\hline CHEMBL1491222 & 688274 & 4.3101 & 4.2253 & TRN & \\
\hline CHEMBL1464731 & 688274 & 4.3325 & 4.0435 & TRN & \\
\hline CHEMBL1416618 & 688274 & 2.8239 & 3.8459 & TST & \\
\hline CHEMBL1403380 & 688274 & 4.0265 & 3.6984 & TRN & \\
\hline CHEMBL1492696 & 688274 & 3.9738 & 3.6045 & TRN & \\
\hline CHEMBL1983530 & 688274 & 4.1252 & 3.8552 & TRN & \\
\hline CHEMBL1416329 & 688274 & 3.9831 & 3.8436 & TRN & \\
\hline CHEMBL1309059 & 688274 & 4.4944 & 4.3368 & TRN & \\
\hline CHEMBL1363249 & 688274 & 4.105 & 4.1903 & TRN & \\
\hline CHEMBL 283849 & 688274 & 6.4318 & 6.2091 & TRN & \\
\hline CHEMBL1490728 & 688274 & 4.0819 & 3.8525 & TRN & \\
\hline CHEMBL1441481 & 688274 & 2.8239 & 3.648 & TRN & \\
\hline CHEMBL1309207 & 688274 & 4.332 & 3.5607 & TRN & \\
\hline CHEMBL1541468 & 688274 & 4.4046 & 4.0683 & TST & \\
\hline CHEMBL 3193515 & 688274 & 4.6077 & 4.3526 & TRN & \\
\hline CHEMBL414400 & 688274 & 5.0146 & 5.0982 & TRN & \\
\hline CHEMBL592124 & 688274 & 4.0025 & 3.7509 & TST & \\
\hline CHEMBL1424857 & 688274 & 3.8871 & 3.7706 & TST & \\
\hline CHEMBL 3192181 & 688274 & 3.8726 & 4.1078 & TRN & \\
\hline
\end{tabular}




\begin{tabular}{|c|c|c|c|c|c|}
\hline & & \multicolumn{4}{|c|}{ Supplemental Table S2.txt } \\
\hline CHEMBL1388038 & 688274 & 4.0249 & 3.5618 & TST & \\
\hline CHEMBL1549646 & 688274 & 2.8239 & 3.7423 & TST & \\
\hline CHEMBL193872 & 688274 & 4.7525 & 4.5328 & TRN & \\
\hline CHEMBL1329197 & 688274 & 4.074 & 3.8133 & TRN & \\
\hline CHEMBL68997 & 688274 & 4.3929 & 4.3303 & TRN & \\
\hline CHEMBL290077 & 688274 & 4.5558 & 4.3709 & TST & \\
\hline CHEMBL1481601 & 688274 & 4.0022 & 3.9715 & TST & \\
\hline CHEMBL533226 & 688274 & 2.8239 & 3.6339 & TRN & \\
\hline CHEMBL1331791 & 688274 & 2.8239 & 3.8994 & TST & \\
\hline CHEMBL1993199 & 688274 & 3.991 & 3.6547 & TRN & \\
\hline CHEMBL1570835 & 688274 & 3.8621 & 3.7076 & TRN & \\
\hline CHEMBL1419945 & 688274 & 4.6251 & 4.1639 & TRN & \\
\hline CHEMBL1482740 & 688274 & 4.1231 & 4.0913 & TRN & \\
\hline CHEMBL1558725 & 688274 & 4.1686 & 4.0056 & TRN & \\
\hline CHEMBL1507898 & 688274 & 3.9806 & 3.888 & TRN & \\
\hline CHEMBL1540231 & 688274 & 4.171 & 4.0192 & TRN & \\
\hline CHEMBL309016 & 688274 & 4.0838 & 3.924 & TRN & \\
\hline CHEMBL1490843 & 688274 & 2.8239 & 4.0149 & TRN & \\
\hline CHEMBL1576581 & 688274 & 4.7535 & 4.7552 & TRN & \\
\hline CHEMBL1593697 & 688274 & 6.0 & 6.6751 & TST & \\
\hline CHEMBL1385206 & 688274 & 5.3316 & 5.2818 & TRN & \\
\hline CHEMBL1980844 & 688274 & 4.6503 & 4.3296 & TST & \\
\hline CHEMBL1378952 & 688274 & 4.3559 & 4.397 & TRN & \\
\hline CHEMBL1565592 & 688274 & 4.1415 & 4.2472 & TST & \\
\hline CHEMBL3189460 & 688274 & 4.3708 & 4.1315 & TRN & \\
\hline CHEMBL1606504 & 688274 & 4.163 & 3.95600 & 00000000004 & TRN \\
\hline CHEMBL1496705 & 688274 & 4.7258 & 4.6656 & TRN & \\
\hline CHEMBL1990174 & 688274 & 4.4182 & 4.1315 & TRN & \\
\hline CHEMBL139935 & 688274 & 4.919 & 5.1832 & TRN & \\
\hline CHEMBL1318861 & 688274 & 5.5654 & 5.9281 & TST & \\
\hline CHEMBL1485793 & 688274 & 4.0797 & 3.9119 & TRN & \\
\hline CHEMBL1321398 & 688274 & 4.4972 & 4.2494 & TRN & \\
\hline CHEMBL1996730 & 688274 & 4.7701 & 4.7326 & TRN & \\
\hline CHEMBL1550897 & 688274 & 4.2303 & 4.1281 & TRN & \\
\hline CHEMBL1571161 & 688274 & 3.8969 & 3.7724 & TRN & \\
\hline CHEMBL1375045 & 688274 & 4.6123 & 4.4879 & TRN & \\
\hline CHEMBL1309484 & 688274 & 4.4972 & 4.1912 & TRN & \\
\hline CHEMBL1366942 & 688274 & 4.6772 & 4.4948 & TRN & \\
\hline CHEMBL1542886 & 688274 & 4.1046 & 3.8652 & TST & \\
\hline CHEMBL1587205 & 688274 & 4.1653 & 3.9224 & TRN & \\
\hline CHEMBL1315061 & 688274 & 5.4498 & 6.4348 & TST & \\
\hline CHEMBL1388152 & 688274 & 4.2102 & 3.9783 & TST & \\
\hline CHEMBL1505338 & 688274 & 3.8328 & 3.6602 & TRN & \\
\hline CHEMBL1456244 & 688274 & 2.8239 & 3.1424 & TST & \\
\hline CHEMBL1556805 & 688274 & 4.1572 & 3.9938 & TRN & \\
\hline CHEMBL3197991 & 688274 & 3.9643 & 3.7948 & TRN & \\
\hline CHEMBL1428407 & 688274 & 4.5153 & 4.2838 & TRN & \\
\hline CHEMBL1457463 & 688274 & 4.172 & 3.8292 & TRN & \\
\hline
\end{tabular}




\begin{tabular}{|c|c|c|c|c|c|}
\hline \multicolumn{6}{|c|}{ Supplemental Table s2.txt } \\
\hline CHEMBL589715 & 688274 & 3.8458 & 3.7604 & TRN & \\
\hline CHEMBL1312320 & 688274 & 3.9429 & 3.5644 & TST & \\
\hline CHEMBL1559564 & 688274 & 4.0822 & 3.8788 & TRN & \\
\hline CHEMBL530049 & 688274 & 4.7226 & 4.81 & TRN & \\
\hline CHEMBL1463614 & 688274 & 4.0715 & 3.9133 & TRN & \\
\hline CHEMBL1958251 & 688274 & 4.4202 & 4.4411 & TRN & \\
\hline CHEMBL1998521 & 688274 & 4.1316 & 4.2385 & TRN & \\
\hline CHEMBL1337416 & 688274 & 4.6358 & 4.484 & TRN & \\
\hline CHEMBL1604947 & 688274 & 4.5933 & 4.1921 & TRN & \\
\hline CHEMBL582980 & 688274 & 4.4151 & 4.0598 & TRN & \\
\hline CHEMBL1172192 & 688274 & 4.9296 & 4.2971 & TST & \\
\hline CHEMBL1485442 & 688274 & 4.3303 & 4.1658 & TST & \\
\hline CHEMBL1563943 & 688274 & 2.8239 & \multicolumn{2}{|c|}{3.9330000000000003} & TRN \\
\hline CHEMBL1424729 & 688274 & 3.9881 & 3.7879 & TST & \\
\hline CHEMBL1333537 & 688274 & 5.5331 & 4.8805 & TRN & \\
\hline CHEMBL1346468 & 688274 & 4.2156 & 4.2887 & TRN & \\
\hline CHEMBL1301480 & 688274 & 4.3554 & 4.5995 & TRN & \\
\hline CHEMBL1348582 & 688274 & 4.4098 & \multicolumn{2}{|c|}{ 4. 388999999999999} & TRN \\
\hline CHEMBL1995715 & 688274 & 4.1592 & 3.9406 & TRN & \\
\hline CHEMBL3195334 & 688274 & 2.8239 & 3.7366 & TST & \\
\hline CHEMBL580918 & 688274 & 4.1707 & 4.1969 & TRN & \\
\hline CHEMBL1968732 & 688274 & 4.2694 & 3.9877 & TST & \\
\hline CHEMBL1612634 & 688274 & 4.3125 & 4.36 & TRN & \\
\hline CHEMBL1459734 & 688274 & 2.8239 & 3.7999 & TST & \\
\hline CHEMBL417727 & 688274 & 4.9245 & 4.5297 & TRN & \\
\hline CHEMBL1577829 & 688274 & 4.0877 & 3.763 & TRN & \\
\hline CHEMBL1448800 & 688274 & 4.9788 & 4.3805 & TRN & \\
\hline CHEMBL1509380 & 688274 & 4.7104 & 4.7307 & TRN & \\
\hline CHEMBL1604283 & 688274 & 6.0 & 6.2503 & TST & \\
\hline CHEMBL1198307 & 688274 & 4.1097 & 3.8723 & TRN & \\
\hline CHEMBL591834 & 688274 & 4.1585 & 4.0324 & TST & \\
\hline CHEMBL1237072 & 688274 & 4.4804 & 4.8579 & TST & \\
\hline CHEMBL3190369 & 688274 & 4.83 & 4.6267 & TST & \\
\hline CHEMBL1588223 & 688274 & 4.6934 & 4.4666 & TRN & \\
\hline CHEMBL1425316 & 688274 & 4.4254 & 4.5043 & TRN & \\
\hline CHEMBL1608375 & 688274 & 4.1813 & 3.793 & TST & \\
\hline CHEMBL1469579 & 688274 & 4.3709 & 4.1854 & TST & \\
\hline CHEMBL1505275 & 688274 & 5.2182 & 4.9753 & TRN & \\
\hline CHEMBL1404086 & 688274 & 4.0488 & 4.1383 & TST & \\
\hline CHEMBL1242180 & 688274 & 4.7284 & 4.5225 & TRN & \\
\hline CHEMBL1454614 & 688274 & 4.2904 & 3.8817 & TRN & \\
\hline CHEMBL1427508 & 688274 & 2.8239 & 3.5253 & TST & \\
\hline CHEMBL146525 & 688274 & 4.2351 & 4.1798 & TRN & \\
\hline CHEMBL586135 & 688274 & 4.4896 & 4.6169 & TRN & \\
\hline CHEMBL3190468 & 688274 & 3.9296 & 3.8422 & TRN & \\
\hline CHEMBL520667 & 688274 & 4.0815 & 3.7311 & TRN & \\
\hline CHEMBL1583127 & 688274 & 4.1456 & 4.0629 & TRN & \\
\hline \multirow[t]{2}{*}{ CHEMBL1305997 } & 688274 & 4.6137 & \multicolumn{2}{|c|}{ 4. 343999999999999} & TRN \\
\hline & & & & 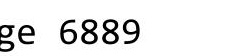 & \\
\hline
\end{tabular}




\begin{tabular}{|c|c|c|c|c|c|}
\hline & & & & & \\
\hline CHEMBL1309890 & 688274 & 4.4345 & 4.3244 & TRN & \\
\hline CHEMBL1546767 & 688274 & 4.4176 & 4.4355 & TRN & \\
\hline CHEMBL1576087 & 688274 & 4.5232 & 4.0926 & TRN & \\
\hline CHEMBL1502937 & 688274 & 3.8966 & 3.6925 & TRN & \\
\hline CHEMBL590408 & 688274 & 3.9095 & 3.616 & TRN & \\
\hline CHEMBL1600855 & 688274 & 4.4646 & 4.3341 & TRN & \\
\hline CHEMBL1378260 & 688274 & 4.9638 & 4.5908 & TRN & \\
\hline CHEMBL1526539 & 688274 & 4.2359 & 3.9884 & TRN & \\
\hline CHEMBL32793 & 688274 & 4.0417 & 4.0883 & TRN & \\
\hline CHEMBL1980226 & 688274 & 4.1434 & 4.0707 & TRN & \\
\hline CHEMBL601547 & 688274 & 4.0859 & 3.8939 & TRN & \\
\hline CHEMBL1983839 & 688274 & 4.2092 & 4.1444 & TRN & \\
\hline CHEMBL3191273 & 688274 & 4.4618 & 4.4013 & TRN & \\
\hline CHEMBL1403593 & 688274 & 2.8239 & 3.1333 & TRN & \\
\hline CHEMBL104270 & 688274 & 6.3098 & 6.8381 & TRN & \\
\hline CHEMBL1541834 & 688274 & 4.6572 & 4.5672 & TRN & \\
\hline CHEMBL1426059 & 688274 & 3.1249 & 3.7655 & TRN & \\
\hline CHEMBL1200567 & 688274 & 5.2041 & 6.251 & TST & \\
\hline CHEMBL1438881 & 688274 & 4.6035 & 4.5793 & TRN & \\
\hline CHEMBL1323853 & 688274 & 4.1347 & 3.8169 & TRN & \\
\hline CHEMBL531322 & 688274 & 2.8239 & 4.0996 & TRN & \\
\hline CHEMBL475335 & 688274 & 3.9229 & 3.9168 & TST & \\
\hline CHEMBL 251670 & 688274 & 6.4437 & 6.5568 & TRN & \\
\hline CHEMBL1461972 & 688274 & 4.3943 & 3.8189 & TRN & \\
\hline CHEMBL1567315 & 688274 & 3.9144 & 4.1018 & TRN & \\
\hline CHEMBL1478652 & 688274 & 3.9468 & 4.0953 & TRN & \\
\hline CHEMBL3199504 & 688274 & 4.03100 & 000000006 & 3.8 & TRN \\
\hline CHEMBL1530097 & 688274 & 2.8239 & 3.9145 & TRN & \\
\hline CHEMBL1577983 & 688274 & 3.9557 & 3.5407 & TRN & \\
\hline CHEMBL1870697 & 688274 & 2.8239 & 3.5705 & TRN & \\
\hline CHEMBL1414291 & 688274 & 3.9463 & 3.2287 & TRN & \\
\hline CHEMBL582444 & 688274 & 4.1237 & 3.895 & TST & \\
\hline CHEMBL572203 & 688274 & 2.8239 & 3.2619 & TRN & \\
\hline CHEMBL1482500 & 688274 & 4.738 & 4.1868 & TRN & \\
\hline CHEMBL1485275 & 688274 & 6.0 & 6.681 & TST & \\
\hline CHEMBL1986342 & 688274 & 4.1357 & 3.9135 & TST & \\
\hline CHEMBL1579686 & 688274 & 5.0448 & 4.7711 & TRN & \\
\hline CHEMBL1596681 & 688274 & 4.4296 & 4.2016 & TRN & \\
\hline CHEMBL1365456 & 688274 & 4.2585 & 4.0772 & TRN & \\
\hline CHEMBL1331185 & 688274 & 4.3094 & 3.98100 & 00000000003 & TRN \\
\hline CHEMBL523200 & 688274 & 3.9311 & 3.7803 & TRN & \\
\hline CHEMBL1431928 & 688274 & 2.8239 & 3.90199 & 99999999997 & TRN \\
\hline CHEMBL1327202 & 688274 & 5.0013 & 4.9204 & TRN & \\
\hline CHEMBL351660 & 688274 & 5.3036 & 5.7734 & TRN & \\
\hline CHEMBL1497597 & 688274 & 4.4549 & 4.0472 & TRN & \\
\hline CHEMBL1386820 & 688274 & 4.0146 & 3.9763 & TRN & \\
\hline CHEMBL3192690 & 688274 & 3.9733 & 3.654 & TRN & \\
\hline CHEMBL1430611 & 688274 & 5.4078 & 5.9271 & TRN & \\
\hline
\end{tabular}




\begin{tabular}{|c|c|c|c|c|c|c|}
\hline & & \multicolumn{5}{|c|}{ Supplemental Table S2.txt } \\
\hline CHEMBL1587753 & 688274 & 5.1261 & 5.3953 & TRN & & \\
\hline CHEMBL1319643 & 688274 & 2.8239 & 3.3317 & TST & & \\
\hline CHEMBL1572134 & 688274 & 4.3424 & 3.8837 & TRN & & \\
\hline CHEMBL1542959 & 688274 & 5.2652 & 5.37299 & 999999999 & & TRN \\
\hline CHEMBL1437516 & 688274 & 4.4961 & 4.2657 & TRN & & \\
\hline CHEMBL1382884 & 688274 & 4.5976 & 4.4278 & TRN & & \\
\hline CHEMBL1404984 & 688274 & 2.8239 & 3.7011 & TRN & & \\
\hline CHEMBL3195484 & 688274 & 4.7647 & 4.6348 & TST & & \\
\hline CHEMBL1387843 & 688274 & 3.9774 & 4.0093 & TST & & \\
\hline CHEMBL1479316 & 688274 & 4.2498 & 4.2869 & TRN & & \\
\hline CHEMBL2006909 & 688274 & 2.8239 & 3.3942 & TRN & & \\
\hline CHEMBL1352234 & 688274 & 4.3218 & 4.1085 & TST & & \\
\hline CHEMBL1351542 & 688274 & 4.4688 & 4.4415 & TRN & & \\
\hline CHEMBL67311 & 688274 & 4.8972 & 3.9833 & TST & & \\
\hline CHEMBL1398224 & 688274 & 4.26399 & 99999999 & 99 & 4.19 & TST \\
\hline CHEMBL81782 & 688274 & 4.4746 & 4.3427 & TRN & & \\
\hline CHEMBL1342436 & 688274 & 4.6238 & 3.9009 & TST & & \\
\hline CHEMBL1968085 & 688274 & 3.8588 & 4.3429 & TRN & & \\
\hline CHEMBL1388845 & 688274 & 4.8318 & 4.3752 & TRN & & \\
\hline CHEMBL3196813 & 688274 & 2.8239 & 3.6075 & TRN & & \\
\hline CHEMBL2359911 & 688274 & 3.9132 & 4.0612 & TRN & & \\
\hline CHEMBL3145303 & 688274 & 4.5303 & 4.1442 & TRN & & \\
\hline CHEMBL1309806 & 688274 & 4.2759 & 3.9253 & TRN & & \\
\hline CHEMBL1405776 & 688274 & 3.9985 & 3.8356 & TST & & \\
\hline CHEMBL1555739 & 688274 & 3.8592 & 3.7346 & TRN & & \\
\hline CHEMBL1326083 & 688274 & 4.51699 & 99999999 & 995 & 4.4244 & TRN \\
\hline CHEMBL3189791 & 688274 & 4.1163 & 4.0175 & TRN & & \\
\hline CHEMBL1443946 & 688274 & 4.1642 & 4.2127 & TRN & & \\
\hline CHEMBL1332756 & 688274 & 3.9777 & 3.78899 & 999999999 & 97 & TRN \\
\hline CHEMBL1497059 & 688274 & 2.8239 & 3.8539 & TRN & & \\
\hline CHEMBL1413908 & 688274 & 2.8239 & 3.9013 & TRN & & \\
\hline CHEMBL1427717 & 688274 & 2.8239 & 4.0129 & TRN & & \\
\hline CHEMBL1608143 & 688274 & 4.1176 & 3.8173 & TST & & \\
\hline CHEMBL3196837 & 688274 & 4.1392 & 4.2999 & TRN & & \\
\hline CHEMBL570345 & 688274 & 4.47199 & 99999999 & 995 & 4.3135 & TRN \\
\hline CHEMBL1463234 & 688274 & 4.3168 & 3.9026 & TST & & \\
\hline CHEMBL1568848 & 688274 & 4.3973 & 4.2388 & TST & & \\
\hline CHEMBL3197372 & 688274 & 2.8239 & 3.2551 & TST & & \\
\hline CHEMBL1411646 & 688274 & 4.0775 & 3.8855 & TST & & \\
\hline CHEMBL1572266 & 688274 & 6.1249 & 6.8179 & TST & & \\
\hline CHEMBL1505902 & 688274 & 2.8239 & 3.9664 & TST & & \\
\hline CHEMBL89445 & 688274 & $4.3660 e$ & 00000000 & 005 & 4.4263 & TST \\
\hline CHEMBL1422849 & 688274 & 4.25899 & 99999999 & 995 & 4.2383 & TST \\
\hline CHEMBL1342852 & 688274 & 4.4292 & 4.5888 & TST & & \\
\hline CHEMBL3189342 & 688274 & 4.7675 & 4.73 & TST & & \\
\hline CHEMBL590186 & 688274 & 4.122 & 3.8353 & TST & & \\
\hline CHEMBL1557213 & 688274 & 3.9936 & 3.7725 & TST & & \\
\hline CHEMBL3191504 & 688274 & 4.1603 & 3.7074 & TST & & \\
\hline
\end{tabular}




\begin{tabular}{|c|c|c|c|c|c|c|}
\hline & & \multicolumn{5}{|c|}{ Supplemental Table S2.txt } \\
\hline CHEMBL1534053 & 688274 & 4.6351 & 4.1922 & TST & & \\
\hline CHEMBL69612 & 688274 & 4.654 & 4.2184 & TST & & \\
\hline CHEMBL123 & 688274 & 4.5805 & 4.1949 & TST & & \\
\hline CHEMBL1527341 & 688274 & 4.5444 & 4.5668 & TST & & \\
\hline CHEMBL1470712 & 688274 & 2.8239 & 3.8852 & TST & & \\
\hline CHEMBL1524986 & 688274 & 4.2777 & 4.1781 & TST & & \\
\hline CHEMBL2369277 & 688274 & 4.4046 & 4.149 & TST & & \\
\hline CHEMBL1432427 & 688274 & 3.9802 & 3.9016 & TST & & \\
\hline CHEMBL1428562 & 688274 & 2.8239 & 4.1797 & TST & & \\
\hline CHEMBL1329974 & 688274 & 3.8751 & 3.7846 & TST & & \\
\hline CHEMBL1513972 & 688274 & 4.5672 & 4.4055 & TST & & \\
\hline CHEMBL1487639 & 688274 & 4.9905 & 4.7828 & TST & & \\
\hline CHEMBL532641 & 688274 & 3.8541 & 3.7764 & TST & & \\
\hline CHEMBL1520777 & 688274 & 4.3604 & 4.0054 & TST & & \\
\hline CHEMBL1939764 & 797692 & 6.7496 & 6.7582 & TRN & & \\
\hline CHEMBL1939755 & 797692 & 9.9393 & 10.0524 & TRN & & \\
\hline CHEMBL1939936 & 797692 & 8.9626 & 8.9714 & TRN & & \\
\hline CHEMBL1939924 & 797692 & 7.5867 & 7.5754 & TRN & & \\
\hline CHEMBL1939768 & 797692 & 7.6655 & 7.6755 & TRN & & \\
\hline CHEMBL1939942 & 797692 & 9.5086 & 9.9107 & TST & & \\
\hline CHEMBL1939761 & 797692 & 8.4815 & 8.4715 & TRN & & \\
\hline CHEMBL1939951 & 797692 & 8.3233 & 8.324 & TRN & & \\
\hline CHEMBL1938412 & 797692 & 8.5686 & 7.595 & TST & & \\
\hline CHEMBL1939933 & 797692 & 9.2924 & 9.2946 & TRN & & \\
\hline CHEMBL1939762 & 797692 & 6.0778 & 7.4538 & TST & & \\
\hline CHEMBL1939767 & 797692 & 7.7282 & 7.7307 & TRN & & \\
\hline CHEMBL1939947 & 797692 & 7.7212 & 8.5659 & TST & & \\
\hline CHEMBL1939939 & 797692 & 9.6073 & 9.6115 & TRN & & \\
\hline CHEMBL1939772 & 797692 & 8.1244 & 8.119 & TRN & & \\
\hline CHEMBL1939950 & 797692 & 7.6308 & 9.244 & TST & & \\
\hline CHEMBL1939923 & 797692 & 6.5031 & 6.5231 & TRN & & \\
\hline CHEMBL1939920 & 797692 & 8.8327 & 8.8186 & TRN & & \\
\hline CHEMBL1939941 & 797692 & 9.5528 & 10.6365 & TST & & \\
\hline CHEMBL1939944 & 797692 & 9.6576 & 11.4435 & TST & & \\
\hline CHEMBL1939928 & 797692 & 7.5986 & 7.6162 & TRN & & \\
\hline CHEMBL1939766 & 797692 & 7.4425 & 7.4887 & TRN & & \\
\hline CHEMBL1939937 & 797692 & 8.9508 & 8.9367 & TRN & & \\
\hline CHEMBL1939925 & 797692 & 7.75200 & 000000000 & 01 & 7.7425 & TRN \\
\hline CHEMBL1939765 & 797692 & 8.0482 & 8.0029 & TRN & & \\
\hline CHEMBL1939758 & 797692 & 10.0757 & 9.9551 & TRN & & \\
\hline CHEMBL1939938 & 797692 & 9.1308 & 9.119 & TRN & & \\
\hline CHEMBL1939934 & 797692 & 9.0655 & 9.0613 & TRN & & \\
\hline CHEMBL1939927 & 797692 & 7.0762 & 7.091 & TRN & & \\
\hline CHEMBL1939932 & 797692 & 9.2007 & 9.2239 & TRN & & \\
\hline CHEMBL1939940 & 797692 & 9.1871 & 8.9556 & TST & & \\
\hline CHEMBL1939922 & 797692 & 6.0044 & 6.002999 & 9999999999 & & TRN \\
\hline CHEMBL1939952 & 797692 & 6.8665 & 8.9243 & TST & & \\
\hline CHEMBL1939763 & 797692 & 7.0237 & 7.0299 & TRN & & \\
\hline
\end{tabular}


Supplemental Table S2.txt

\begin{tabular}{|c|c|c|c|c|}
\hline CHEMBL1939948 & 797692 & 6.8182 & 7.4857 & TST \\
\hline CHEMBL1939931 & 797692 & 9.3768 & 9.3712 & TRN \\
\hline CHEMBL1939921 & 797692 & 8.8794 & 8.89 & TRN \\
\hline CHEMBL1939935 & 797692 & 8.8601 & 8.8533 & TRN \\
\hline CHEMBL1939756 & 797692 & 9.5528 & 9.5647 & TRN \\
\hline CHEMBL1939769 & 797692 & 7.1415 & 7.1559 & TRN \\
\hline CHEMBL1939926 & 797692 & 5.6904 & 5.6634 & TRN \\
\hline CHEMBL1939771 & 797692 & 7.3893 & 7.3588 & TRN \\
\hline CHEMBL1777958 & 797692 & 9.6576 & 9.6373 & TRN \\
\hline CHEMBL1939953 & 797692 & 8.8153 & 7.9481 & TST \\
\hline CHEMBL1777973 & 797692 & 6.6234 & 6.6347 & TRN \\
\hline CHEMBL1939757 & 797692 & 9.6778 & 9.6935 & TRN \\
\hline CHEMBL1939770 & 797692 & 7.0177 & 7.0047 & TRN \\
\hline CHEMBL1939760 & 797692 & 9.3979 & 9.40299 & 999999999 \\
\hline CHEMBL1939943 & 797692 & 9.5528 & 10.5171 & TST \\
\hline CHEMBL1939759 & 797692 & 9.6383 & $9.64200 t$ & 000000001 \\
\hline CHEMBL1939949 & 797692 & 7.4202 & 8.9713 & TST \\
\hline CHEMBL524309 & 508163 & 6.0 & 6.1986 & TRN \\
\hline CHEMBL503495 & 508163 & 6.0 & 6.3752 & TRN \\
\hline CHEMBL510125 & 508163 & 6.0 & 5.9192 & TRN \\
\hline CHEMBL510495 & 508163 & 6.0 & 6.1267 & TST \\
\hline CHEMBL509545 & 508163 & 6.0 & 6.1218 & TRN \\
\hline CHEMBL525793 & 508163 & 6.0 & 6.0325 & TRN \\
\hline CHEMBL499187 & 508163 & 7.2441 & 6.2924 & TRN \\
\hline CHEMBL501797 & 508163 & 7.1871 & 6.5288 & TRN \\
\hline CHEMBL525568 & 508163 & 6.0 & 6.0186 & TRN \\
\hline CHEMBL446476 & 508163 & 6.8962 & 7.0198 & TST \\
\hline CHEMBL448061 & 508163 & 6.0 & 5.9039 & TRN \\
\hline CHEMBL451033 & 508163 & 6.0 & 6.1986 & TRN \\
\hline CHEMBL509996 & 508163 & 6.0 & 6.0603 & TRN \\
\hline CHEMBL498967 & 508163 & 6.0 & 6.2223 & TRN \\
\hline CHEMBL504990 & 508163 & 6.0 & 6.5482 & TRN \\
\hline CHEMBL504259 & 508163 & 6.0 & 6.6694 & TRN \\
\hline CHEMBL500028 & 508163 & 6.0 & 6.1627 & TRN \\
\hline CHEMBL526675 & 508163 & 7.0969 & 6.4694 & TRN \\
\hline CHEMBL455792 & 508163 & 7.4815 & 6.6821 & TRN \\
\hline CHEMBL506492 & 508163 & 6.0 & 5.9468 & TRN \\
\hline CHEMBL506175 & 508163 & 7.2518 & 6.3996 & TRN \\
\hline CHEMBL503285 & 508163 & 6.0 & 5.8987 & TRN \\
\hline CHEMBL505648 & 508163 & 6.0 & 5.9468 & TRN \\
\hline CHEMBL525798 & 508163 & 6.0 & 6.1986 & TRN \\
\hline CHEMBL524653 & 508163 & 6.0 & 5.8089 & TRN \\
\hline CHEMBL525221 & 508163 & 6.0 & 6.2241 & TST \\
\hline CHEMBL504714 & 508163 & 6.0 & 6.4155 & TRN \\
\hline CHEMBL509645 & 508163 & 7.2441 & 6.1218 & TRN \\
\hline CHEMBL506900 & 508163 & 6.0 & 5.94799 & 9999999995 \\
\hline CHEMBL524696 & 508163 & 6.0 & 5.7367 & TRN \\
\hline CHEMBL507415 & 508163 & 6.9872 & 6.3771 & TRN \\
\hline
\end{tabular}




\begin{tabular}{|c|c|c|c|c|c|}
\hline & & & & & \\
\hline CHEMBL526517 & 508163 & 6.0 & 6.0164 & TST & \\
\hline CHEMBL526733 & 508163 & 6.0 & 6.6603 & TST & \\
\hline CHEMBL500277 & 508163 & 6.0 & 6.7225 & TRN & \\
\hline CHEMBL509365 & 508163 & 6.0 & 5.9522 & TRN & \\
\hline CHEMBL507713 & 508163 & 6.0 & 5.9727 & TRN & \\
\hline CHEMBL501598 & 508163 & 6.0 & 5.9468 & TRN & \\
\hline CHEMBL526711 & 508163 & 6.0 & 6.4904 & TST & \\
\hline CHEMBL506987 & 508163 & 6.0 & 5.8818 & TST & \\
\hline CHEMBL505040 & 508163 & 6.0 & 6.2272 & TRN & \\
\hline CHEMBL526190 & 508163 & 6.0 & 5.9959 & TRN & \\
\hline CHEMBL505277 & 508163 & 6.0 & 5.9486 & TRN & \\
\hline CHEMBL510027 & 508163 & 6.0 & 6.0603 & TRN & \\
\hline CHEMBL507702 & 508163 & 6.0 & 6.0042 & TST & \\
\hline CHEMBL506122 & 508163 & 6.0 & 6.0603 & TRN & \\
\hline CHEMBL524519 & 508163 & 6.0 & 5.9435 & TRN & \\
\hline CHEMBL499709 & 508163 & 6.0 & 5.79700 & 0000000001 & TRN \\
\hline CHEMBL524695 & 508163 & 7.4202 & 6.88 & TRN & \\
\hline CHEMBL506911 & 508163 & 6.0 & 6.1093 & TST & \\
\hline CHEMBL503500 & 508163 & 7.0969 & 6.4985 & TRN & \\
\hline CHEMBL506435 & 508163 & 6.0 & 6.5178 & TST & \\
\hline CHEMBL504503 & 508163 & 6.0 & 5.9468 & TRN & \\
\hline CHEMBL525949 & 508163 & 6.0 & 6.2535 & TRN & \\
\hline CHEMBL524520 & 508163 & 6.0 & 6.0603 & TRN & \\
\hline CHEMBL525961 & 508163 & 7.6383 & 6.5691 & TRN & \\
\hline CHEMBL500506 & 508163 & 7.301 & 6.5818 & TRN & \\
\hline CHEMBL504050 & 508163 & 6.0 & 6.2223 & TRN & \\
\hline CHEMBL508029 & 508163 & 6.0 & 6.2223 & TRN & \\
\hline CHEMBL501093 & 508163 & 6.0 & 6.49100 & 00000000005 & TRN \\
\hline CHEMBL505864 & 508163 & 6.0 & 5.8157 & TRN & \\
\hline CHEMBL526689 & 508163 & 6.0 & 6.4962 & TRN & \\
\hline CHEMBL454768 & 508163 & 7.1871 & 6.5725 & TRN & \\
\hline CHEMBL507852 & 508163 & 6.0 & 6.1336 & TST & \\
\hline CHEMBL504834 & 508163 & 6.0 & 6.4449 & TRN & \\
\hline CHEMBL504517 & 508163 & 6.0 & 6.1986 & TRN & \\
\hline CHEMBL453476 & 508163 & 6.0 & 6.476 & TRN & \\
\hline CHEMBL507620 & 508163 & 6.0 & 5.9815 & TRN & \\
\hline CHEMBL509851 & 508163 & 6.0 & 5.9468 & TRN & \\
\hline CHEMBL504326 & 508163 & 6.0 & 5.9577 & TRN & \\
\hline CHEMBL504943 & 508163 & 6.0 & 5.8557 & TRN & \\
\hline CHEMBL511102 & 508163 & 6.0 & 6.0422 & TRN & \\
\hline CHEMBL509958 & 508163 & 6.0 & 5.9817 & TST & \\
\hline CHEMBL526361 & 508163 & 6.0 & 6.0964 & TRN & \\
\hline CHEMBL506287 & 508163 & 6.0 & 5.9468 & TRN & \\
\hline CHEMBL 2372270 & 508163 & 7.2757 & 7.058 & TRN & \\
\hline CHEMBL526873 & 508163 & 6.9393 & 6.5773 & TRN & \\
\hline CHEMBL448278 & 508163 & 7.2757 & 7.0847 & TRN & \\
\hline CHEMBL500226 & 508163 & 6.0 & 6.0439 & TRN & \\
\hline CHEMBL524502 & 508163 & 6.0 & 5.8032 & TRN & \\
\hline
\end{tabular}




\begin{tabular}{|c|c|c|c|c|c|}
\hline \multirow[b]{2}{*}{ CHEMBL499784 } & \multicolumn{5}{|c|}{$c 0$} \\
\hline & 508163 & 6.0 & 6.0603 & TRN & \\
\hline CHEMBL506673 & 508163 & 6.0 & 6.1149 & TRN & \\
\hline CHEMBL502596 & 508163 & 6.0 & 5.8307 & TRN & \\
\hline CHEMBL455783 & 508163 & 6.0 & 5.91299 & 9999999999 & TRN \\
\hline CHEMBL508266 & 508163 & 6.0 & 6.1381 & TRN & \\
\hline CHEMBL527040 & 508163 & 6.0 & 6.0603 & TRN & \\
\hline CHEMBL443121 & 508163 & 6.0 & 6.0942 & TST & \\
\hline CHEMBL477091 & 508163 & 6.0 & 6.5474 & TRN & \\
\hline CHEMBL 2372271 & 508163 & 6.0 & 6.0642 & TRN & \\
\hline CHEMBL506216 & 508163 & 6.0 & 5.9334 & TRN & \\
\hline CHEMBL499484 & 508163 & 6.0 & 5.9948 & TRN & \\
\hline CHEMBL509399 & 508163 & 6.0 & 6.1254 & TST & \\
\hline CHEMBL499438 & 508163 & 7.3279 & 7.2048 & TRN & \\
\hline CHEMBL447161 & 508163 & 6.0 & 6.0429 & TST & \\
\hline CHEMBL501270 & 508163 & 7.3468 & 7.0003 & TST & \\
\hline CHEMBL526115 & 508163 & 6.0 & 5.9468 & TRN & \\
\hline CHEMBL509337 & 508163 & 7.3279 & 6.3485 & TST & \\
\hline CHEMBL525574 & 508163 & 7.2518 & 6.46200 & 0000000001 & TRN \\
\hline CHEMBL499154 & 508163 & 6.0 & 6.0433 & TRN & \\
\hline CHEMBL506106 & 508163 & 6.0 & 6.6527 & TRN & \\
\hline CHEMBL526488 & 508163 & 6.0 & 6.4585 & TRN & \\
\hline CHEMBL525632 & 508163 & 7.3188 & 6.5974 & TRN & \\
\hline CHEMBL505368 & 508163 & 6.0 & 6.3424 & TRN & \\
\hline CHEMBL525764 & 508163 & 6.0 & 6.0451 & TST & \\
\hline CHEMBL503598 & 508163 & 6.0 & 5.9334 & TRN & \\
\hline CHEMBL505995 & 508163 & 6.0 & 5.9334 & TRN & \\
\hline CHEMBL451290 & 508163 & 7.4202 & 6.9797 & TRN & \\
\hline CHEMBL510816 & 508163 & 6.0 & 6.3504 & TST & \\
\hline CHEMBL526506 & 508163 & 7.0915 & 6.5487 & TRN & \\
\hline CHEMBL507872 & 508163 & 6.0 & 5.9728 & TRN & \\
\hline CHEMBL504271 & 508163 & 7.3768 & 7.0695 & TST & \\
\hline CHEMBL526143 & 508163 & 6.0 & 6.3083 & TST & \\
\hline CHEMBL501366 & 508163 & 6.0 & 5.7503 & TST & \\
\hline CHEMBL455229 & 508163 & 6.0 & 5.9302 & TRN & \\
\hline CHEMBL525438 & 508163 & 6.0 & 6.2223 & TRN & \\
\hline CHEMBL505540 & 508163 & 6.0 & 5.9334 & TRN & \\
\hline CHEMBL499493 & 508163 & 6.0 & 5.9972 & TST & \\
\hline CHEMBL526491 & 508163 & 6.0 & 5.9945 & TRN & \\
\hline CHEMBL508995 & 508163 & 6.0 & 5.9008 & TRN & \\
\hline CHEMBL498887 & 508163 & 6.0 & 5.681 & TRN & \\
\hline CHEMBL524356 & 508163 & 7.2676 & 7.0695 & TST & \\
\hline CHEMBL500058 & 508163 & 6.0 & 5.8116 & TRN & \\
\hline CHEMBL502642 & 508163 & 7.6383 & 6.57 & TRN & \\
\hline CHEMBL508140 & 508163 & 6.0 & 6.4962 & TRN & \\
\hline CHEMBL503782 & 508163 & 6.0 & 6.3247 & TRN & \\
\hline CHEMBL451629 & 508163 & 6.0 & 6.5894 & TRN & \\
\hline CHEMBL506607 & 508163 & 6.0 & 5.8423 & TST & \\
\hline CHEMBL524846 & 508163 & 6.0 & 6.2223 & TRN & \\
\hline
\end{tabular}




\begin{tabular}{|c|c|c|c|c|c|}
\hline \\
\hline CHEMBL506081 & 508163 & 6.0 & 6.1817 & TRN & \\
\hline CHEMBL498821 & 508163 & 6.0 & 6.2202 & TRN & \\
\hline CHEMBL504445 & 508163 & 7.1739 & 7.2033 & TST & \\
\hline CHEMBL526912 & 508163 & 6.0 & 6.1986 & TRN & \\
\hline CHEMBL503047 & 508163 & 6.0 & 5.9468 & TRN & \\
\hline CHEMBL443085 & 508163 & 6.0 & 6.0429 & TST & \\
\hline CHEMBL508133 & 508163 & 6.0 & 6.0981 & TRN & \\
\hline CHEMBL503414 & 508163 & 6.0 & 5.9334 & TRN & \\
\hline CHEMBL455538 & 508163 & 6.0 & 6.0712 & TRN & \\
\hline CHEMBL505375 & 508163 & 7.1739 & 7.0003 & TST & \\
\hline CHEMBL507314 & 508163 & 6.0 & 6.1986 & TRN & \\
\hline CHEMBL451041 & 508163 & 6.0 & 6.2223 & TRN & \\
\hline CHEMBL507432 & 508163 & 6.0 & 5.8423 & TST & \\
\hline CHEMBL525026 & 508163 & 6.0 & 6.0868 & TST & \\
\hline CHEMBL500991 & 508163 & 6.0 & 6.2202 & TRN & \\
\hline CHEMBL527104 & 508163 & 6.0 & 6.0607 & TRN & \\
\hline CHEMBL505193 & 508163 & 6.0 & 5.9336 & TRN & \\
\hline CHEMBL524837 & 508163 & 7.1805 & 6.5223 & TST & \\
\hline CHEMBL506161 & 508163 & 7.3468 & 6.6664 & TRN & \\
\hline CHEMBL524342 & 508163 & 6.0 & 6.4585 & TRN & \\
\hline CHEMBL527078 & 508163 & 6.0 & 6.1986 & TRN & \\
\hline CHEMBL504132 & 508163 & 7.2366 & 6.7117 & TRN & \\
\hline CHEMBL500223 & 508163 & 6.0 & 6.2301 & TRN & \\
\hline CHEMBL498889 & 508163 & 6.0 & 6.1986 & TRN & \\
\hline CHEMBL506236 & 508163 & 6.0 & 6.1986 & TRN & \\
\hline CHEMBL525575 & 508163 & 6.0 & 6.0386 & TRN & \\
\hline CHEMBL509594 & 508163 & 6.0 & 6.2969 & TST & \\
\hline CHEMBL526886 & 508163 & 6.0 & 6.0603 & TRN & \\
\hline CHEMBL509010 & 508163 & 6.0 & 6.0377 & TRN & \\
\hline CHEMBL526742 & 508163 & 6.0 & 6.0255 & TRN & \\
\hline CHEMBL508365 & 508163 & 6.0 & 6.1336 & TST & \\
\hline CHEMBL501011 & 508163 & 7.3279 & 6.6296 & TRN & \\
\hline CHEMBL446203 & 508163 & 7.0315 & 6.7053 & TRN & \\
\hline CHEMBL526545 & 508163 & 6.0 & 5.94799 & 99999999995 & TRN \\
\hline CHEMBL524725 & 508163 & 6.0 & 5.8399 & TRN & \\
\hline CHEMBL521894 & 508163 & 6.0 & 5.7851 & TRN & \\
\hline CHEMBL500774 & 508163 & 6.0 & 6.1406 & TST & \\
\hline CHEMBL505833 & 508163 & 7.3279 & 6.5895 & TRN & \\
\hline CHEMBL504529 & 508163 & 6.0 & 6.473 & TRN & \\
\hline CHEMBL505449 & 508163 & 6.0 & 6.0735 & TRN & \\
\hline CHEMBL525570 & 508163 & 6.0 & 6.4377 & TRN & \\
\hline CHEMBL453162 & 508163 & 6.0 & 6.3767 & TST & \\
\hline CHEMBL499741 & 508163 & 6.0 & 5.7829 & TST & \\
\hline CHEMBL504115 & 508163 & 6.0 & 6.4894 & TRN & \\
\hline CHEMBL499409 & 508163 & 6.0 & 6.0685 & TRN & \\
\hline CHEMBL503701 & 508163 & 6.0 & 6.4155 & TRN & \\
\hline CHEMBL509957 & 508163 & 6.0 & 6.4841 & TST & \\
\hline CHEMBL504014 & 508163 & 6.0 & 6.0603 & TRN & \\
\hline
\end{tabular}




\begin{tabular}{|c|c|c|c|c|c|}
\hline \\
\hline CHEMBL503700 & 508163 & 6.0 & 6.6961 & TST & \\
\hline CHEMBL507283 & 508163 & 6.0 & 6.186 & TRN & \\
\hline CHEMBL524480 & 508163 & 6.0 & 6.5193 & TRN & \\
\hline CHEMBL501099 & 508163 & 6.0 & 6.2223 & TRN & \\
\hline CHEMBL507851 & 508163 & 6.0 & 5.8264 & TST & \\
\hline CHEMBL509925 & 508163 & 6.0 & 6.71399 & 99999999995 & TRN \\
\hline CHEMBL502324 & 508163 & 6.0 & 5.9972 & TST & \\
\hline CHEMBL524315 & 508163 & 7.2518 & 6.8096 & TST & \\
\hline CHEMBL526874 & 508163 & 6.0 & 5.8166 & TRN & \\
\hline CHEMBL504546 & 508163 & 6.0 & 6.0988 & TRN & \\
\hline CHEMBL525807 & 508163 & 6.0 & 5.9465 & TRN & \\
\hline CHEMBL503520 & 508163 & 7.4685 & 7.1739 & TST & \\
\hline CHEMBL524690 & 508163 & 7.2441 & 6.8587 & TST & \\
\hline CHEMBL506650 & 508163 & 6.0 & 6.8209 & TST & \\
\hline CHEMBL444768 & 508163 & 6.0 & 6.4144 & TST & \\
\hline CHEMBL509937 & 508163 & 6.0 & 6.1528 & TRN & \\
\hline CHEMBL506239 & 508163 & 7.2291 & 7.0628 & TST & \\
\hline CHEMBL506778 & 508163 & 6.0 & 6.5138 & TRN & \\
\hline CHEMBL506996 & 508163 & 6.0 & 6.5194 & TRN & \\
\hline CHEMBL526518 & 508163 & 7.4089 & 6.5223 & TST & \\
\hline CHEMBL526902 & 508163 & 6.0 & 5.8772 & TST & \\
\hline CHEMBL504578 & 508163 & 7.5229 & 6.4805 & TST & \\
\hline CHEMBL526497 & 508163 & 6.0 & 6.2629 & TRN & \\
\hline CHEMBL525599 & 508163 & 6.0 & 5.8055 & TRN & \\
\hline CHEMBL508148 & 508163 & 6.0 & 6.4962 & TRN & \\
\hline CHEMBL509320 & 508163 & 6.0 & 5.9466 & TRN & \\
\hline CHEMBL526690 & 508163 & 6.0 & 6.1986 & TRN & \\
\hline CHEMBL525940 & 508163 & 6.0 & 6.1528 & TRN & \\
\hline CHEMBL507172 & 508163 & 6.0 & 6.4949 & TST & \\
\hline CHEMBL 500184 & 508163 & 7.4202 & 7.1137 & TRN & \\
\hline CHEMBL503342 & 508163 & 6.0 & 5.9367 & TRN & \\
\hline CHEMBL526903 & 508163 & 6.0 & 5.9204 & TRN & \\
\hline CHEMBL505072 & 508163 & 6.0 & 5.83700 & 2000000001 & TRN \\
\hline CHEMBL510847 & 508163 & 7.0555 & 7.2033 & TST & \\
\hline CHEMBL507627 & 508163 & 6.8601 & 6.4962 & TRN & \\
\hline CHEMBL525801 & 508163 & 6.0 & 6.6461 & TRN & \\
\hline CHEMBL525939 & 508163 & 6.0 & 6.1186 & TST & \\
\hline CHEMBL498977 & 508163 & 6.0 & 6.1254 & TST & \\
\hline CHEMBL526181 & 508163 & 7.3468 & 6.6628 & TRN & \\
\hline CHEMBL525808 & 508163 & 6.0 & 6.4694 & TRN & \\
\hline CHEMBL526717 & 508163 & 6.0 & 5.9057 & TRN & \\
\hline CHEMBL500965 & 508163 & 6.0 & 6.0701 & TRN & \\
\hline CHEMBL506476 & 508163 & 6.0 & 6.6077 & TST & \\
\hline CHEMBL524532 & 508163 & 6.0 & 6.0642 & TST & \\
\hline CHEMBL 524333 & 508163 & 6.0 & 5.9468 & TRN & \\
\hline CHEMBL526502 & 508163 & 6.0 & 5.8854 & TRN & \\
\hline CHEMBL508784 & 508163 & 6.0 & 5.9445 & TRN & \\
\hline CHEMBL502435 & 508163 & 6.0 & 5.7722 & TRN & \\
\hline
\end{tabular}




\begin{tabular}{|c|c|c|c|c|c|}
\hline \\
\hline CHEMBL507997 & 508163 & 6.0 & 5.9746 & TRN & \\
\hline CHEMBL524850 & 508163 & 6.0 & 6.3083 & TST & \\
\hline CHEMBL443694 & 508163 & 6.0 & 6.2223 & TRN & \\
\hline CHEMBL508462 & 508163 & 6.0 & 6.0439 & TRN & \\
\hline CHEMBL507284 & 508163 & 6.0 & 5.8709 & TRN & \\
\hline CHEMBL503035 & 508163 & 7.0915 & 6.6008 & TRN & \\
\hline CHEMBL525429 & 508163 & 6.0 & 6.5209 & TST & \\
\hline CHEMBL506912 & 508163 & 6.0 & 6.6296 & TRN & \\
\hline CHEMBL525748 & 508163 & 7.5229 & 6.487 & TST & \\
\hline CHEMBL510367 & 508163 & 6.0 & 6.0046 & TST & \\
\hline CHEMBL477297 & 508163 & 6.0 & 6.2223 & TRN & \\
\hline CHEMBL506870 & 508163 & 6.0 & 6.0402 & TRN & \\
\hline CHEMBL526121 & 508163 & 6.0 & 6.246 & TRN & \\
\hline CHEMBL526151 & 508163 & 6.0 & 5.9142 & TRN & \\
\hline CHEMBL509993 & 508163 & 6.0 & 6.3752 & TRN & \\
\hline CHEMBL503841 & 508163 & 6.0 & 5.8968 & TRN & \\
\hline CHEMBL503599 & 508163 & 6.0 & 6.2969 & TST & \\
\hline CHEMBL527041 & 508163 & 7.2291 & 6.9911 & TST & \\
\hline CHEMBL500451 & 508163 & 6.0 & 6.1986 & TRN & \\
\hline CHEMBL501230 & 508163 & 6.0 & 6.2223 & TRN & \\
\hline CHEMBL525027 & 508163 & 6.0 & 6.0942 & TST & \\
\hline CHEMBL510198 & 508163 & 6.0 & 6.0603 & TRN & \\
\hline CHEMBL41004 & 192642 & 6.5229 & 6.0522 & TRN & \\
\hline CHEMBL43205 & 192642 & 6.699 & 6.6636 & TRN & \\
\hline CHEMBL295796 & 192642 & 5.6021 & 7.0232 & TST & \\
\hline CHEMBL42570 & 192642 & 5.699 & 6.8098 & TST & \\
\hline CHEMBL42680 & 192642 & 6.699 & 6.0958 & TRN & \\
\hline CHEMBL42988 & 192642 & 7.3979 & 7.6948 & TRN & \\
\hline CHEMBL298478 & 192642 & 9.0 & 8.595 & TRN & \\
\hline CHEMBL295613 & 192642 & 6.5229 & 5.9994 & TRN & \\
\hline CHEMBL290694 & 192642 & 8.0 & 7.6389 & TRN & \\
\hline CHEMBL439923 & 192642 & 7.699 & 6.7837 & TRN & \\
\hline CHEMBL43320 & 192642 & 5.8239 & 6.6339 & TRN & \\
\hline CHEMBL298295 & 192642 & 7.301 & 7.57299 & 99999999995 & TRN \\
\hline CHEMBL295329 & 192642 & 8.0 & 7.8559 & TRN & \\
\hline CHEMBL42435 & 192642 & 6.1549 & 6.9809 & TST & \\
\hline CHEMBL46416 & 192642 & 6.0 & 5.7033 & TRN & \\
\hline CHEMBL46639 & 192642 & 5.8239 & 6.9399 & TST & \\
\hline CHEMBL47108 & 192642 & 5.699 & 5.6563 & TRN & \\
\hline CHEMBL296071 & 192642 & 6.699 & 6.9698 & TRN & \\
\hline CHEMBL42796 & 192642 & 6.4559 & 6.4961 & TRN & \\
\hline CHEMBL45039 & 192642 & 6.3468 & 6.8723 & TRN & \\
\hline CHEMBL288061 & 192642 & 6.8239 & 6.608 & TRN & \\
\hline CHEMBL297864 & 192642 & 6.0 & 6.6185 & TRN & \\
\hline CHEMBL42172 & 192642 & 6.0458 & 6.6295 & TRN & \\
\hline CHEMBL42563 & 192642 & 5.1249 & 6.5852 & TST & \\
\hline CHEMBL42713 & 192642 & 5.699 & 6.3533 & TST & \\
\hline CHEMBL290402 & 192642 & 7.0 & 6.8371 & TRN & \\
\hline
\end{tabular}




\begin{tabular}{|c|c|c|c|c|}
\hline \multicolumn{5}{|c|}{ Supplemental Table S2.txt } \\
\hline CHEMBL295224 & 192642 & 4.0 & 5.3823 & TRN \\
\hline CHEMBL43665 & 192642 & 8.0 & 6.6852 & TRN \\
\hline CHEMBL295614 & 192642 & 8.0 & 7.2235 & TRN \\
\hline CHEMBL42886 & 192642 & 6.0458 & 6.8414 & TRN \\
\hline CHEMBL46693 & 192642 & 6.0 & 6.9782 & TST \\
\hline CHEMBL298282 & 192642 & 8.0 & 7.1215 & TRN \\
\hline CHEMBL46831 & 192642 & 5.8239 & 6.8069 & TST \\
\hline CHEMBL297763 & 192642 & 6.699 & 7.3607 & TRN \\
\hline CHEMBL43617 & 192642 & 4.0 & 6.6123 & TST \\
\hline CHEMBL45367 & 192642 & 6.4559 & 6.0859 & TRN \\
\hline CHEMBL289344 & 192642 & 6.5229 & 7.1467 & TRN \\
\hline CHEMBL298294 & 192642 & 6.699 & 6.813 & TRN \\
\hline CHEMBL289701 & 192642 & 7.2218 & 7.0314 & TRN \\
\hline CHEMBL43225 & 192642 & 7.301 & 7.4583 & TRN \\
\hline CHEMBL43862 & 192642 & 7.3979 & 7.1891 & TRN \\
\hline CHEMBL44467 & 192642 & 6.699 & 6.2923 & TRN \\
\hline CHEMBL44508 & 192642 & 4.0 & 6.5733 & TST \\
\hline CHEMBL42272 & 192642 & 8.0 & 7.7162 & TRN \\
\hline CHEMBL46621 & 192642 & 6.3979 & 7.1642 & TRN \\
\hline CHEMBL42776 & 192642 & 5.8239 & 6.8002 & TRN \\
\hline CHEMBL42779 & 192642 & 6.5229 & 6.7602 & TRN \\
\hline CHEMBL43443 & 192642 & 7.3979 & 7.4187 & TRN \\
\hline CHEMBL46714 & 192642 & 8.0 & 6.87 & TRN \\
\hline CHEMBL416267 & 192642 & 7.5229 & 8.106 & TRN \\
\hline CHEMBL291178 & 192642 & 7.0 & 7.2733 & TST \\
\hline CHEMBL43795 & 192642 & 5.0 & 6.7732 & TST \\
\hline CHEMBL46771 & 192642 & 9.0 & 7.8898 & TST \\
\hline CHEMBL296294 & 192642 & 9.0 & 7.3601 & TST \\
\hline CHEMBL65291 & 155494 & 6.4437 & 6.4994 & TST \\
\hline CHEMBL294495 & 155494 & 7.2147 & 7.3531 & TRN \\
\hline CHEMBL62628 & 155494 & 7.041 & 6.7775 & TRN \\
\hline CHEMBL417568 & 155494 & 6.301 & 6.2856 & TRN \\
\hline CHEMBL66139 & 155494 & 7.1739 & 7.2639 & TRN \\
\hline CHEMBL417042 & 155494 & 6.4437 & 6.3979 & TRN \\
\hline CHEMBL416872 & 155494 & 5.4815 & 6.0213 & TRN \\
\hline CHEMBL64943 & 155494 & 5.6778 & 7.3682 & TST \\
\hline CHEMBL63729 & 155494 & 6.6383 & 7.0782 & TST \\
\hline CHEMBL65546 & 155494 & 4.4685 & 7.1086 & TST \\
\hline CHEMBL418136 & 155494 & 7.3098 & 7.0782 & TRN \\
\hline CHEMBL65105 & 155494 & 7.2676 & 6.4305 & TRN \\
\hline CHEMBL545219 & 155494 & 6.0 & 7.3327 & TRN \\
\hline CHEMBL411944 & 155494 & 7.4949 & 7.5398 & TRN \\
\hline CHEMBL303332 & 155494 & 6.7447 & 6.5428 & TRN \\
\hline CHEMBL64131 & 155494 & 6.8861 & 7.1119 & TRN \\
\hline CHEMBL291412 & 155494 & 4.4089 & 6.0088 & TRN \\
\hline CHEMBL65462 & 155494 & 6.0 & 6.0216 & TRN \\
\hline CHEMBL65548 & 155494 & 6.7447 & 7.2991 & TST \\
\hline CHEMBL294775 & 155494 & 7.5086 & 7.3738 & TRN \\
\hline
\end{tabular}


Supplemental Table S2.txt

\begin{tabular}{|c|c|c|c|c|c|}
\hline CHEMBL294546 & 155494 & 6.699 & 6.9649 & TRN & \\
\hline CHEMBL63556 & 155494 & 7.1367 & 7.3704 & TRN & \\
\hline CHEMBL65864 & 155494 & 7.3565 & 7.2611 & TRN & \\
\hline CHEMBL555652 & 155494 & 7.5229 & 7.0766 & TRN & \\
\hline CHEMBL446655 & 155494 & 5.0 & 7.3537 & TST & \\
\hline CHEMBL63837 & 155494 & 6.7447 & 7.2888 & TST & \\
\hline CHEMBL424230 & 155494 & 6.6778 & 6.6365 & TST & \\
\hline CHEMBL65876 & 155494 & 7.0223 & 6.9344 & TRN & \\
\hline CHEMBL65404 & 155494 & 7.1871 & 7.0404 & TRN & \\
\hline CHEMBL276296 & 155494 & 7.5086 & 7.1344 & TRN & \\
\hline CHEMBL64236 & 155494 & 7.5086 & 7.2121 & TRN & \\
\hline CHEMBL292804 & 155494 & 4.4559 & 7.2276 & TST & \\
\hline CHEMBL291638 & 155494 & 6.6778 & 7.4216 & TST & \\
\hline CHEMBL292282 & 155494 & 7.1612 & 7.1104 & TRN & \\
\hline CHEMBL293610 & 155494 & 6.7696 & 6.7754 & TST & \\
\hline CHEMBL430944 & 155494 & 5.2007 & 7.1078 & TST & \\
\hline CHEMBL62526 & 155494 & 7.1739 & 7.2811 & TRN & \\
\hline CHEMBL65713 & 155494 & 6.7959 & 6.8884 & TRN & \\
\hline CHEMBL64594 & 155494 & 7.1675 & 6.9822 & TRN & \\
\hline CHEMBL62925 & 155494 & 7.3565 & 7.2832 & TRN & \\
\hline CHEMBL62924 & 155494 & 7.0555 & 7.3417 & TRN & \\
\hline CHEMBL64968 & 155494 & 7.4949 & 7.2486 & TRN & \\
\hline CHEMBL292784 & 155494 & 7.2596 & 7.5071 & TRN & \\
\hline CHEMBL304242 & 155494 & 7.3872 & 7.4315 & TRN & \\
\hline CHEMBL63445 & 155494 & 6.7447 & 7.1587 & TST & \\
\hline CHEMBL65526 & 155494 & 7.3279 & 7.1917 & TRN & \\
\hline CHEMBL63308 & 155494 & 7.301 & 6.2942 & TRN & \\
\hline CHEMBL305596 & 155494 & 6.8539 & 6.721 & TRN & \\
\hline CHEMBL62555 & 155494 & 6.7696 & 6.3227 & TRN & \\
\hline CHEMBL64535 & 155494 & 7.3279 & 7.444 & TRN & \\
\hline CHEMBL65734 & 155494 & 6.2441 & 6.5485 & TRN & \\
\hline CHEMBL 304240 & 155494 & 7.4437 & 7.2085 & TRN & \\
\hline CHEMBL62827 & 155494 & 6.6778 & 6.3226 & TST & \\
\hline CHEMBL3098984 & 1281779 & 3.0 & 3.0945 & TRN & \\
\hline CHEMBL3099009 & 1281779 & 3.0 & 3.1576 & TRN & \\
\hline CHEMBL3098975 & 1281779 & 3.0 & 3.1704 & TRN & \\
\hline CHEMBL3099014 & 1281779 & 3.0 & 2.84899 & 99999999998 & TRN \\
\hline CHEMBL3099008 & 1281779 & 3.0 & 3.23 & TRN & \\
\hline CHEMBL 3099021 & 1281779 & 3.0 & 3.2044 & TRN & \\
\hline CHEMBL3099002 & 1281779 & 3.0 & 3.1151 & TRN & \\
\hline CHEMBL3098998 & 1281779 & 4.1675 & 4.022 & TRN & \\
\hline CHEMBL3098978 & 1281779 & 4.3872 & 4.2489 & TRN & \\
\hline CHEMBL3098981 & 1281779 & 4.2076 & 4.2467 & TRN & \\
\hline CHEMBL3098974 & 1281779 & 3.0 & 3.1198 & TRN & \\
\hline CHEMBL3098989 & 1281779 & 3.0 & 3.2378 & TST & \\
\hline CHEMBL87699 & 1281779 & 3.0 & 2.7459 & TRN & \\
\hline CHEMBL3098973 & 1281779 & 3.0 & 3.1836 & TRN & \\
\hline CHEMBL3098972 & 1281779 & 3.0 & 2.6578 & TRN & \\
\hline
\end{tabular}




\begin{tabular}{|c|c|c|c|c|c|}
\hline \multicolumn{6}{|c|}{ Supplemental Table s2.txt } \\
\hline CHEMBL 3098970 & 1281779 & 3.0 & 2.7997 & TRN & \\
\hline CHEMBL 3099028 & 1281779 & 4.4559 & 3.6645 & TST & \\
\hline CHEMBL3099004 & 1281779 & 3.0 & 2.7747 & TRN & \\
\hline CHEMBL 3099022 & 1281779 & 3.0 & 3.5803 & TRN & \\
\hline CHEMBL3099011 & 1281779 & 3.0 & 3.0526 & TRN & \\
\hline CHEMBL 3098982 & 1281779 & 4.1739 & 3.9252 & TRN & \\
\hline CHEMBL3098997 & 1281779 & 3.0 & 3.4151 & TRN & \\
\hline CHEMBL3098971 & 1281779 & 3.0 & 2.9023 & TRN & \\
\hline CHEMBL 3098992 & 1281779 & 4.1871 & 3.68399 & 99999999997 & TRN \\
\hline CHEMBL 3098140 & 1281779 & 3.0 & 3.38100 & 00000000002 & TST \\
\hline CHEMBL3098999 & 1281779 & 4.1024 & 4.0237 & TRN & \\
\hline CHEMBL 3099031 & 1281779 & 4.4202 & 4.2147 & TRN & \\
\hline CHEMBL3099006 & 1281779 & 3.0 & 2.762 & TRN & \\
\hline CHEMBL 3098988 & 1281779 & 3.0 & 2.863 & TRN & \\
\hline CHEMBL3098985 & 1281779 & 4.1612 & 3.8313 & TRN & \\
\hline CHEMBL 3099025 & 1281779 & 4.5686 & 3.6017 & TST & \\
\hline CHEMBL 3098990 & 1281779 & 3.0 & 2.6529 & TRN & \\
\hline CHEMBL3098993 & 1281779 & 4.4685 & 4.2783 & TRN & \\
\hline CHEMBL3099007 & 1281779 & 3.0 & 2.8602 & TRN & \\
\hline CHEMBL3099026 & 1281779 & 3.0 & 3.2423 & TST & \\
\hline CHEMBL3098979 & 1281779 & 4.2924 & 4.2381 & TRN & \\
\hline CHEMBL 3099024 & 1281779 & 3.0 & 3.4102 & TRN & \\
\hline CHEMBL3099013 & 1281779 & 3.0 & 3.1227 & TRN & \\
\hline CHEMBL 3099010 & 1281779 & 3.0 & 3.092 & TRN & \\
\hline CHEMBL3098976 & 1281779 & 4.3872 & 3.9418 & TST & \\
\hline CHEMBL 3098994 & 1281779 & 4.1871 & 4.2769 & TRN & \\
\hline CHEMBL 3099023 & 1281779 & 4.3279 & 3.3706 & TST & \\
\hline CHEMBL3098980 & 1281779 & 4.4949 & 4.3347 & TRN & \\
\hline CHEMBL 3099029 & 1281779 & 3.0 & 3.6648 & TRN & \\
\hline CHEMBL3098986 & 1281779 & 3.0 & 3.6875 & TRN & \\
\hline CHEMBL 3099005 & 1281779 & 3.0 & 2.8512 & TRN & \\
\hline CHEMBL3098995 & 1281779 & 4.585 & 4.1188 & TRN & \\
\hline CHEMBL 3099000 & 1281779 & 3.0 & 3.1787 & TRN & \\
\hline CHEMBL 3099027 & 1281779 & 3.0 & 3.2299 & TST & \\
\hline CHEMBL3098977 & 1281779 & 4.1024 & 4.2434 & TRN & \\
\hline CHEMBL 3098991 & 1281779 & 3.0 & 3.6597 & TRN & \\
\hline CHEMBL3098987 & 1281779 & 3.0 & 3.1877 & TST & \\
\hline CHEMBL3099012 & 1281779 & 3.0 & 3.0393 & TRN & \\
\hline CHEMBL3099030 & 1281779 & 4.6383 & 3.9918 & TRN & \\
\hline CHEMBL3099015 & 1281779 & 3.0 & 2.7777 & TST & \\
\hline CHEMBL3099001 & 1281779 & 3.0 & 2.9861 & TST & \\
\hline CHEMBL3099003 & 1281779 & 3.0 & 2.9381 & TST & \\
\hline CHEMBL3098996 & 1281779 & 4.3468 & 3.4331 & TST & \\
\hline CHEMBL3098983 & 1281779 & 3.0 & 3.2326 & TST & \\
\hline CHEMBL3099020 & 1281779 & 3.0 & 3.4104 & TST & \\
\hline CHEMBL307657 & 160234 & 5.699 & 5.0476 & TRN & \\
\hline CHEMBL 74582 & 160234 & 8.0969 & 8.0828 & TRN & \\
\hline CHEMBL 308548 & 160234 & 6.6198 & 7.2631 & TST & \\
\hline
\end{tabular}




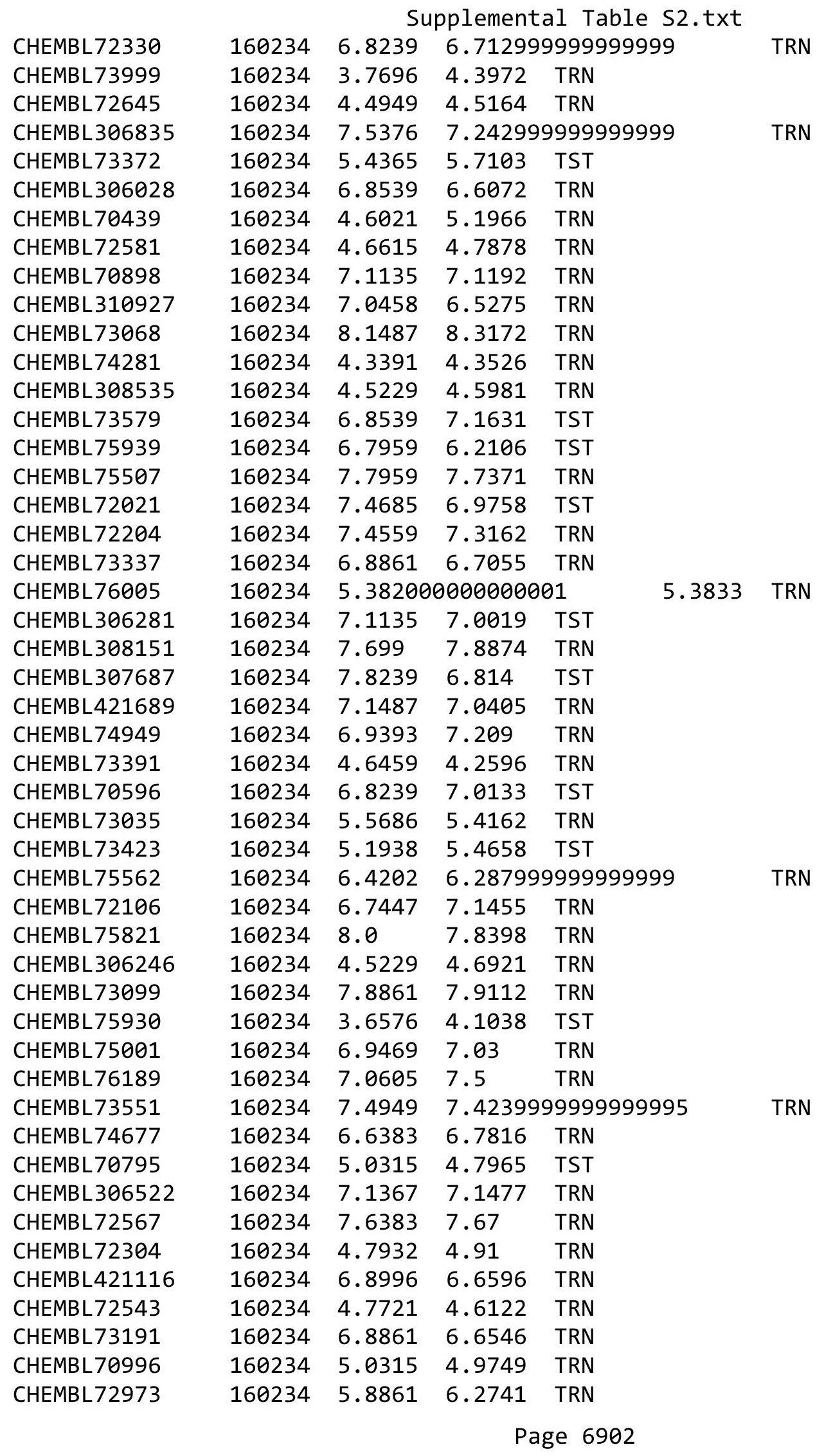




\begin{tabular}{|c|c|c|c|c|c|}
\hline \multicolumn{6}{|c|}{ Supplemental Table S2.txt } \\
\hline CHEMBL73011 & 160234 & 3.6925 & 4.4223 & TRN & \\
\hline CHEMBL 308601 & 160234 & 5.699 & 5.7744 & TRN & \\
\hline CHEMBL415267 & 160234 & 7.1805 & 7.3076 & TRN & \\
\hline CHEMBL308156 & 160234 & 6.9586 & 6.579 & TST & \\
\hline CHEMBL71015 & 160234 & 4.2111 & 4.1927 & TRN & \\
\hline CHEMBL73204 & 160234 & 8.0757 & 8.2217 & TRN & \\
\hline CHEMBL311348 & 160234 & 4.3757 & 4.5025 & TRN & \\
\hline CHEMBL73014 & 160234 & 5.5229 & 5.0044 & TRN & \\
\hline CHEMBL73062 & 160234 & 5.3251 & 5.33200 & 0000000001 & TRN \\
\hline CHEMBL 74399 & 160234 & 7.2147 & 7.0306 & TRN & \\
\hline CHEMBL 74225 & 160234 & 5.9208 & 6.084 & TRN & \\
\hline CHEMBL 73437 & 160234 & 6.2248 & 5.7711 & TRN & \\
\hline CHEMBL72298 & 160234 & 7.699 & 7.7361 & TRN & \\
\hline CHEMBL 72716 & 160234 & 5.8239 & 6.1279 & TRN & \\
\hline CHEMBL 70916 & 160234 & 7.0088 & 7.0224 & TRN & \\
\hline CHEMBL76001 & 160234 & 6.5229 & 6.3546 & TRN & \\
\hline CHEMBL 306972 & 160234 & 7.7212 & 7.9618 & TRN & \\
\hline CHEMBL309817 & 160234 & 4.6536 & 4.8205 & TRN & \\
\hline CHEMBL73109 & 160234 & 6.6596 & 6.5662 & TRN & \\
\hline CHEMBL450618 & 160234 & 7.7959 & 7.7483 & TRN & \\
\hline CHEMBL73578 & 160234 & 4.0969 & 3.9512 & TRN & \\
\hline CHEMBL73100 & 160234 & 7.3279 & 7.1229 & TRN & \\
\hline CHEMBL 305623 & 160234 & 5.4202 & 5.3017 & TRN & \\
\hline CHEMBL73660 & 160234 & 4.2218 & 4.2229 & TRN & \\
\hline CHEMBL73048 & 160234 & 7.1549 & 7.1156 & TRN & \\
\hline CHEMBL 308412 & 160234 & 3.8386 & 4.0034 & TRN & \\
\hline CHEMBL 74290 & 160234 & 4.762 & 4.4634 & TRN & \\
\hline CHEMBL 308560 & 160234 & 5.6198 & 5.4897 & TST & \\
\hline CHEMBL 305640 & 160234 & 5.8268 & 6.2218 & TST & \\
\hline CHEMBL 74006 & 160234 & 6.0 & 4.6497 & TST & \\
\hline CHEMBL306926 & 160234 & 5.7447 & 5.7779 & TST & \\
\hline CHEMBL 303468 & 160234 & 6.9586 & 6.7895 & TST & \\
\hline CHEMBL 72128 & 160234 & 5.5528 & 5.0812 & TST & \\
\hline CHEMBL 72582 & 160234 & 4.3242 & 4.1394 & TST & \\
\hline CHEMBL 70343 & 160234 & 6.2518 & 6.0039 & TST & \\
\hline CHEMBL73494 & 160234 & 6.0362 & 7.6726 & TST & \\
\hline CHEMBL 72892 & 160234 & 4.752 & 5.8866 & TST & \\
\hline CHEMBL72149 & 160234 & 6.4202 & 5.7399 & TST & \\
\hline CHEMBL51682 & 139463 & 7.8539 & 7.5096 & TRN & \\
\hline CHEMBL77870 & 139463 & 5.769 & 5.4625 & TRN & \\
\hline CHEMBL75026 & 139463 & 6.9586 & 6.4186 & TRN & \\
\hline CHEMBL 77533 & 139463 & 5.3748 & 5.1157 & TRN & \\
\hline CHEMBL75358 & 139463 & 4.0 & 3.6751 & TRN & \\
\hline CHEMBL 307512 & 139463 & 6.2924 & 6.5699 & TST & \\
\hline CHEMBL 307600 & 139463 & 7.0132 & 6.996 & TRN & \\
\hline CHEMBL 78304 & 139463 & 4.0 & 4.5586 & TRN & \\
\hline CHEMBL 308605 & 139463 & 5.7286 & 5.4097 & TRN & \\
\hline CHEMBL75111 & 139463 & 7.9355 & 8.1182 & TRN & \\
\hline
\end{tabular}




\begin{tabular}{|c|c|c|c|c|c|c|}
\hline \multicolumn{7}{|c|}{ Supplemental Table S2.txt } \\
\hline CHEMBL 77218 & 139463 & 4.0 & 4.9676 & TRN & & \\
\hline CHEMBL306376 & 139463 & 7.7212 & 7.7336 & TRN & & \\
\hline CHEMBL307265 & 139463 & 4.0 & 3.5375 & TRN & & \\
\hline CHEMBL77079 & 139463 & 6.7447 & 6.1945 & TST & & \\
\hline CHEMBL73909 & 139463 & 6.2457 & 6.2263 & TRN & & \\
\hline CHEMBL310852 & 139463 & 7.6308 & 6.8021 & TST & & \\
\hline CHEMBL73404 & 139463 & 4.0 & 4.3027 & TRN & & \\
\hline CHEMBL309829 & 139463 & 5.9996 & 5.4729 & TRN & & \\
\hline CHEMBL 74264 & 139463 & 4.0 & 4.8018 & TST & & \\
\hline CHEMBL307612 & 139463 & 7.7747 & 7.6977 & TRN & & \\
\hline CHEMBL 307014 & 139463 & 4.0 & 4.1194 & TRN & & \\
\hline CHEMBL 74792 & 139463 & 5.8658 & 6.5251 & TST & & \\
\hline CHEMBL421127 & 139463 & 6.7447 & 5.0499 & TST & & \\
\hline CHEMBL306366 & 139463 & 6.2218 & 6.1384 & TRN & & \\
\hline CHEMBL76385 & 139463 & 6.0969 & 5.0174 & TST & & \\
\hline CHEMBL 309054 & 139463 & 4.0 & 4.7976 & TRN & & \\
\hline CHEMBL 78262 & 139463 & 6.7352 & 6.7909 & TRN & & \\
\hline CHEMBL 76647 & 139463 & 4.0 & 5.0396 & TRN & & \\
\hline CHEMBL 307051 & 139463 & 6.767 & 6.4131 & TRN & & \\
\hline CHEMBL7634 & 139463 & 6.7144 & 6.9951 & TRN & & \\
\hline CHEMBL76059 & 139463 & 4.0 & 4.1083 & TRN & & \\
\hline CHEMBL77886 & 139463 & 4.0 & 3.7672 & TST & & \\
\hline CHEMBL48269 & 139463 & 6.1612 & 6.274 & TRN & & \\
\hline CHEMBL 309000 & 139463 & 4.0 & 5.4111 & TRN & & \\
\hline CHEMBL41779 & 139463 & 5.585 & 5.9864 & TRN & & \\
\hline CHEMBL 74425 & 139463 & 5.397 & 5.4991 & TRN & & \\
\hline CHEMBL 75417 & 139463 & 4.0 & 3.6209 & TRN & & \\
\hline CHEMBL51405 & 139463 & 7.8539 & 7.8027 & TRN & & \\
\hline CHEMBL 77432 & 139463 & 6.4237 & 6.6012 & TRN & & \\
\hline CHEMBL 73848 & 139463 & 6.4191 & 6.4309 & TRN & & \\
\hline CHEMBL 75144 & 139463 & 7.2449 & 7.3158 & TRN & & \\
\hline CHEMBL 78046 & 139463 & 6.5186 & 6.7038 & TRN & & \\
\hline CHEMBL 74265 & 139463 & 4.0 & 4.8951 & TST & & \\
\hline CHEMBL 77793 & 139463 & 8.4202 & 8.3594 & TRN & & \\
\hline CHEMBL 76995 & 139463 & 4.0 & 5.5403 & TST & & \\
\hline CHEMBL77348 & 139463 & 4.0 & 3.2936 & TST & & \\
\hline CHEMBL 74424 & 139463 & $6.8210 e$ & 00000000 & 01 & 6.8872 & TRN \\
\hline CHEMBL77160 & 139463 & 5.8239 & 5.1256 & TRN & & \\
\hline CHEMBL 310020 & 139463 & 4.0 & 3.7427 & TRN & & \\
\hline CHEMBL75295 & 139463 & 6.032 & 5.7844 & TRN & & \\
\hline CHEMBL 75027 & 139463 & 6.2457 & 5.1189 & TRN & & \\
\hline CHEMBL 309080 & 139463 & 5.8681 & 5.4695 & TRN & & \\
\hline CHEMBL76067 & 139463 & 7.1938 & 6.9866 & TST & & \\
\hline CHEMBL311856 & 139463 & 6.2549 & 6.1452 & TRN & & \\
\hline CHEMBL77763 & 139463 & 4.0 & 3.8051 & TRN & & \\
\hline CHEMBL 75086 & 139463 & 6.7959 & 6.7634 & TRN & & \\
\hline CHEMBL73871 & 139463 & 4.0 & 3.234 & TST & & \\
\hline CHEMBL306825 & 139463 & 7.1938 & 7.392 & TRN & & \\
\hline
\end{tabular}




\begin{tabular}{|c|c|c|c|c|c|}
\hline \multicolumn{6}{|c|}{ Supplemental Table s2.txt } \\
\hline CHEMBL 74426 & 139463 & 6.8861 & 6.843 & TRN & \\
\hline CHEMBL11081 & 139463 & 6.585 & 5.8504 & TST & \\
\hline CHEMBL75805 & 139463 & 6.7645 & 6.1159 & TRN & \\
\hline CHEMBL 73257 & 139463 & 6.2596 & 5.6361 & TST & \\
\hline CHEMBL75033 & 139463 & 6.2118 & 5.8291 & TST & \\
\hline CHEMBL77636 & 139463 & 4.0 & 4.6324 & TRN & \\
\hline CHEMBL 74917 & 139463 & 6.8539 & 5.4365 & TST & \\
\hline CHEMBL307955 & 139463 & 5.1659 & 5.2532 & TRN & \\
\hline CHEMBL3646749 & 1528636 & 8.0 & 8.6595 & TRN & \\
\hline CHEMBL3646715 & 1528636 & 8.0 & 8.5953 & TRN & \\
\hline CHEMBL3646696 & 1528636 & 8.0 & 8.7694 & TRN & \\
\hline CHEMBL3646760 & 1528636 & 9.5229 & 9.2796 & TRN & \\
\hline CHEMBL3639456 & 1528636 & 9.5229 & 8.1116 & TRN & \\
\hline CHEMBL3646754 & 1528636 & 5.301 & 7.76399 & 9999999999 & TRN \\
\hline CHEMBL3646739 & 1528636 & 5.301 & 5.9014 & TRN & \\
\hline CHEMBL3646720 & 1528636 & 5.301 & 8.1087 & TRN & \\
\hline CHEMBL3646753 & 1528636 & 9.5229 & 8.7298 & TRN & \\
\hline CHEMBL3646727 & 1528636 & 8.0 & 7.7588 & TRN & \\
\hline CHEMBL3646751 & 1528636 & 5.301 & 7.4202 & TRN & \\
\hline CHEMBL3646709 & 1528636 & 8.0 & 7.6201 & TRN & \\
\hline CHEMBL3646697 & 1528636 & 8.0 & 8.8242 & TRN & \\
\hline CHEMBL3646712 & 1528636 & 9.5229 & 8.5731 & TRN & \\
\hline CHEMBL3646752 & 1528636 & 9.5229 & 8.1179 & TRN & \\
\hline CHEMBL3646724 & 1528636 & 9.5229 & 8.0863 & TRN & \\
\hline CHEMBL 3646745 & 1528636 & 9.5229 & 8.1646 & TRN & \\
\hline CHEMBL 3646714 & 1528636 & 8.0 & 8.8787 & TRN & \\
\hline CHEMBL3646713 & 1528636 & 8.0 & 8.6177 & TRN & \\
\hline CHEMBL3646750 & 1528636 & 9.5229 & 8.4004 & TRN & \\
\hline CHEMBL3646771 & 1528636 & 8.0 & 8.43700 & 3000000001 & TRN \\
\hline CHEMBL3646711 & 1528636 & 9.5229 & 8.9796 & TRN & \\
\hline CHEMBL3646729 & 1528636 & 8.0 & 7.7124 & TRN & \\
\hline CHEMBL3646717 & 1528636 & 8.0 & 8.3657 & TRN & \\
\hline CHEMBL3646732 & 1528636 & 9.5229 & 7.7093 & TRN & \\
\hline CHEMBL3646710 & 1528636 & 8.0 & 8.1087 & TRN & \\
\hline CHEMBL 3646764 & 1528636 & 8.0 & 8.4565 & TRN & \\
\hline CHEMBL3646730 & 1528636 & 8.0 & 8.039 & TRN & \\
\hline CHEMBL3646763 & 1528636 & 8.0 & 8.1611 & TST & \\
\hline CHEMBL3646773 & 1528636 & 8.0 & 7.0976 & TST & \\
\hline CHEMBL3646719 & 1528636 & 9.5229 & 9.2645 & TRN & \\
\hline CHEMBL 3646725 & 1528636 & 5.301 & 6.1257 & TRN & \\
\hline CHEMBL3646718 & 1528636 & 9.5229 & 9.9123 & TRN & \\
\hline CHEMBL3646748 & 1528636 & 8.0 & 7.5641 & TRN & \\
\hline CHEMBL3646743 & 1528636 & 5.301 & 6.2868 & TRN & \\
\hline CHEMBL3646735 & 1528636 & 9.5229 & 7.591 & TRN & \\
\hline CHEMBL 3646758 & 1528636 & 9.5229 & 9.4269 & TRN & \\
\hline CHEMBL 3646731 & 1528636 & 5.301 & 7.3723 & TRN & \\
\hline CHEMBL3646747 & 1528636 & 8.0 & 7.9394 & TRN & \\
\hline CHEMBL3646722 & 1528636 & 9.5229 & 6.8481 & TRN & \\
\hline
\end{tabular}




\begin{tabular}{|c|c|c|c|c|c|}
\hline \multicolumn{6}{|c|}{ Supplemental Table S2.txt } \\
\hline CHEMBL3646698 & 1528636 & 8.0 & 8.834 & TRN & \\
\hline CHEMBL3646700 & 1528636 & 8.0 & 8.5225 & TRN & \\
\hline CHEMBL3646769 & 1528636 & 8.0 & 8.8082 & TST & \\
\hline CHEMBL 3646757 & 1528636 & 5.301 & 6.3383 & TRN & \\
\hline CHEMBL3646767 & 1528636 & 5.301 & 9.6362 & TST & \\
\hline CHEMBL3646695 & 1528636 & 8.0 & 9.3368 & TST & \\
\hline CHEMBL3646733 & 1528636 & 8.0 & 7.67299 & 9999999999 & TRN \\
\hline CHEMBL3646737 & 1528636 & 8.0 & 7.3622 & TRN & \\
\hline CHEMBL3646699 & 1528636 & 8.0 & 8.8409 & TRN & \\
\hline CHEMBL3646762 & 1528636 & 8.0 & 8.8229 & TRN & \\
\hline CHEMBL3646721 & 1528636 & 8.0 & 7.6411 & TRN & \\
\hline CHEMBL3646766 & 1528636 & 8.0 & 9.6377 & TST & \\
\hline CHEMBL3646706 & 1528636 & 8.0 & 6.3374 & TRN & \\
\hline CHEMBL3646736 & 1528636 & 8.0 & 7.734 & TRN & \\
\hline CHEMBL3646759 & 1528636 & 8.0 & 8.4186 & TRN & \\
\hline CHEMBL3646768 & 1528636 & 9.5229 & 6.1685 & TST & \\
\hline CHEMBL3646746 & 1528636 & 8.0 & 8.5083 & TRN & \\
\hline CHEMBL3646701 & 1528636 & 8.0 & 9.243 & TST & \\
\hline CHEMBL3646708 & 1528636 & 9.5229 & 8.3438 & TRN & \\
\hline CHEMBL3646756 & 1528636 & 9.5229 & 8.5298 & TRN & \\
\hline CHEMBL3646723 & 1528636 & 5.301 & 6.3267 & TRN & \\
\hline CHEMBL3646734 & 1528636 & 6.0 & 5.9014 & TRN & \\
\hline CHEMBL3646705 & 1528636 & 8.0 & 6.7769 & TRN & \\
\hline CHEMBL3646755 & 1528636 & 9.5229 & 8.8533 & TRN & \\
\hline CHEMBL3646738 & 1528636 & 5.301 & 6.1364 & TRN & \\
\hline CHEMBL3646772 & 1528636 & 8.0 & 8.1663 & TST & \\
\hline CHEMBL3646707 & 1528636 & 5.301 & 7.9226 & TST & \\
\hline CHEMBL 3646770 & 1528636 & 8.0 & 7.0272 & TST & \\
\hline CHEMBL3646761 & 1528636 & 9.5229 & 9.0042 & TST & \\
\hline CHEMBL3646765 & 1528636 & 8.0 & 9.8531 & TST & \\
\hline CHEMBL 3646740 & 1528636 & 5.301 & 7.4736 & TST & \\
\hline CHEMBL3646742 & 1528636 & 9.5229 & 6.6107 & TST & \\
\hline CHEMBL 3646744 & 1528636 & 9.5229 & 8.0354 & TST & \\
\hline CHEMBL3646716 & 1528636 & 5.301 & 8.9007 & TST & \\
\hline CHEMBL3646741 & 1528636 & 9.5229 & 6.4398 & TST & \\
\hline CHEMBL3646728 & 1528636 & 8.0 & 7.7975 & TST & \\
\hline CHEMBL3646726 & 1528636 & 9.5229 & 7.8876 & TST & \\
\hline CHEMBL3648154 & 1527780 & 6.8794 & 6.35 & TRN & \\
\hline CHEMBL3648137 & 1527780 & 6.0 & 6.2526 & TRN & \\
\hline CHEMBL3648175 & 1527780 & 6.3645 & 6.11600 & 00000000005 & TRN \\
\hline CHEMBL3648139 & 1527780 & 6.0 & 6.6826 & TRN & \\
\hline CHEMBL3648147 & 1527780 & 7.0079 & 6.8269 & TRN & \\
\hline CHEMBL 3648142 & 1527780 & 6.9872 & 7.0523 & TRN & \\
\hline CHEMBL2381829 & 1527780 & 6.6326 & 6.5799 & TRN & \\
\hline CHEMBL 3648130 & 1527780 & 5.8758 & 6.8953 & TST & \\
\hline CHEMBL3648187 & 1527780 & 6.0 & 6.7173 & TRN & \\
\hline CHEMBL2381850 & 1527780 & 6.6925 & 6.8075 & TRN & \\
\hline CHEMBL3648148 & 1527780 & 6.7932 & 6.6504 & TRN & \\
\hline
\end{tabular}


Supplemental Table S2.txt

\begin{tabular}{|c|c|c|c|c|c|}
\hline CHEMBL3648165 & 1527780 & 6.6289 & 6.5711 & TRN & \\
\hline CHEMBL 3648134 & 1527780 & 7.1561 & 6.6656 & TST & \\
\hline CHEMBL 3648173 & 1527780 & 6.0 & 7.3158 & TST & \\
\hline CHEMBL 3648183 & 1527780 & 7.3497 & 7.0271 & TRN & \\
\hline CHEMBL3648163 & 1527780 & 7.4535 & 7.1104 & TRN & \\
\hline CHEMBL 3648129 & 1527780 & 6.1772 & 6.3638 & TRN & \\
\hline CHEMBL 3648146 & 1527780 & 7.0535 & 6.9293 & TRN & \\
\hline CHEMBL 3648179 & 1527780 & 6.75700 & 00000000 & 01 & 6.6208 TRN \\
\hline CHEMBL3648195 & 1527780 & 7.3872 & 7.1074 & TRN & \\
\hline CHEMBL 3648131 & 1527780 & 6.2549 & 6.8506 & TST & \\
\hline CHEMBL3648132 & 1527780 & 6.0 & 6.7312 & TRN & \\
\hline CHEMBL 3648162 & 1527780 & 6.3507 & 6.8371 & TRN & \\
\hline CHEMBL 3648185 & 1527780 & 6.0 & 6.7273 & TRN & \\
\hline CHEMBL 3648150 & 1527780 & 6.6819 & 6.7854 & TRN & \\
\hline CHEMBL 3648182 & 1527780 & 6.399 & 6.9977 & TST & \\
\hline CHEMBL3648168 & 1527780 & 7.1811 & 6.558 & TRN & \\
\hline CHEMBL 3648174 & 1527780 & 6.9957 & 6.8896 & TRN & \\
\hline CHEMBL 3648138 & 1527780 & 6.0 & 6.307 & TRN & \\
\hline CHEMBL 3648140 & 1527780 & 6.3335 & 6.6964 & TRN & \\
\hline CHEMBL 3648151 & 1527780 & 6.0 & 6.4952 & TRN & \\
\hline CHEMBL 3648177 & 1527780 & 6.6198 & 6.8576 & TRN & \\
\hline CHEMBL 3648136 & 1527780 & 7.1451 & 6.8963 & TRN & \\
\hline CHEMBL3648167 & 1527780 & 6.0 & 6.5449 & TRN & \\
\hline CHEMBL 3648153 & 1527780 & 7.2924 & 7.1083 & TST & \\
\hline CHEMBL 3648159 & 1527780 & 7.0482 & 6.774 & TST & \\
\hline CHEMBL 3648170 & 1527780 & 6.8477 & 6.7886 & TRN & \\
\hline CHEMBL 3648145 & 1527780 & 7.3401 & 6.8854 & TRN & \\
\hline CHEMBL 3648157 & 1527780 & \multicolumn{3}{|c|}{6.4510000000000005} & 6.321000000000001 \\
\hline CHEMBL2381823 & 1527780 & 7.4179 & 6.9794 & TRN & \\
\hline CHEMBL 3648144 & 1527780 & 6.5258 & 6.3233 & TRN & \\
\hline CHEMBL 3617567 & 1527780 & 8.2557 & 7.0647 & TRN & \\
\hline CHEMBL 3648194 & 1527780 & 6.6003 & 7.2331 & TRN & \\
\hline CHEMBL3648161 & 1527780 & 6.9031 & 6.7403 & TST & \\
\hline CHEMBL 2381825 & 1527780 & 6.9626 & 6.7727 & TST & \\
\hline CHEMBL 3648143 & 1527780 & 6.6478 & 6.5715 & TRN & \\
\hline CHEMBL2381830 & 1527780 & 5.9788 & 6.8654 & TRN & \\
\hline CHEMBL 3648176 & 1527780 & 7.0595 & 6.4786 & TRN & \\
\hline CHEMBL 3648169 & 1527780 & 6.7167 & 6.379 & TRN & \\
\hline CHEMBL 3648166 & 1527780 & 6.5017 & 6.7949 & TRN & \\
\hline CHEMBL 3648135 & 1527780 & 7.0367 & 6.6095 & TRN & \\
\hline CHEMBL 3648141 & 1527780 & 6.0 & 7.3315 & TST & \\
\hline CHEMBL 3648191 & 1527780 & 6.0 & 6.686 & TRN & \\
\hline CHEMBL3648152 & 1527780 & 6.0 & 6.3923 & TRN & \\
\hline CHEMBL 2381840 & 1527780 & 5.7802 & 6.8852 & TST & \\
\hline CHEMBL 3648164 & 1527780 & 7.4908 & 6.6623 & TRN & \\
\hline CHEMBL 3648178 & 1527780 & 6.8633 & 6.7868 & TST & \\
\hline CHEMBL 3648184 & 1527780 & 6.0 & 6.6964 & TST & \\
\hline CHEMBL3648160 & 1527780 & 7.2034 & 7.0173 & TRN & \\
\hline
\end{tabular}


Supplemental Table S2.txt

\begin{tabular}{|c|c|c|c|c|c|c|}
\hline CHEMBL 3648155 & 1527780 & 7.2366 & 6.5048 & TRN & & \\
\hline CHEMBL 3648158 & 1527780 & 7.20200 & 000000000 & 31 & 6.4588 & TST \\
\hline CHEMBL 3648149 & 1527780 & 6.5003 & 6.7712 & TST & & \\
\hline CHEMBL 3648193 & 1527780 & 7.0227 & 7.1568 & TRN & & \\
\hline CHEMBL 3648171 & 1527780 & 6.0 & 6.996 & TST & & \\
\hline CHEMBL1880833 & 752371 & 3.0044 & 3.318 & TRN & & \\
\hline CHEMBL1906451 & 752371 & 3.0044 & 2.9977 & TST & & \\
\hline CHEMBL1883288 & 752371 & 3.0044 & 3.0999 & TST & & \\
\hline CHEMBL1892270 & 752371 & 5.1993 & 4.6628 & TRN & & \\
\hline CHEMBL1900453 & 752371 & 4.4776 & 4.8869 & TST & & \\
\hline CHEMBL1884442 & 752371 & 6.1135 & 6.3033 & TRN & & \\
\hline CHEMBL 1879256 & 752371 & 3.0044 & 2.9718 & TRN & & \\
\hline CHEMBL1486906 & 752371 & 3.0044 & 2.7783 & TRN & & \\
\hline CHEMBL 2448581 & 752371 & 3.0044 & 2.938999 & 999999999 & 96 & 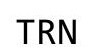 \\
\hline CHEMBL1869875 & 752371 & 6.1002 & 5.3169 & TRN & & \\
\hline CHEMBL 1864818 & 752371 & 3.0044 & 2.8309 & TRN & & \\
\hline CHEMBL1876946 & 752371 & 3.0044 & 2.743999 & 999999999 & 98 & \\
\hline CHEMBL1412015 & 752371 & 5.6234 & 5.5062 & TST & & \\
\hline CHEMBL1891206 & 752371 & 6.1487 & 6.4269 & TRN & & \\
\hline CHEMBL1506656 & 752371 & 3.0044 & 3.1228 & TST & & \\
\hline CHEMBL1887414 & 752371 & 3.0044 & 3.9042 & TST & & \\
\hline CHEMBL1483649 & 752371 & 5.6778 & 5.5608 & TRN & & \\
\hline CHEMBL 1878172 & 752371 & 3.0044 & 3.0941 & TST & & \\
\hline CHEMBL1577231 & 752371 & 5.8861 & 5.4017 & TRN & & \\
\hline CHEMBL1904443 & 752371 & 3.0044 & 3.0507 & TRN & & \\
\hline CHEMBL1864637 & 752371 & 3.0044 & 3.0245 & TST & & \\
\hline CHEMBL1903194 & 752371 & 3.0044 & 2.9007 & TRN & & \\
\hline CHEMBL1885482 & 752371 & 4.3665 & 4.4021 & TRN & & \\
\hline CHEMBL1773702 & 752371 & 5.7545 & 4.9569 & TRN & & \\
\hline CHEMBL1877777 & 752371 & 5.8239 & 5.8148 & TRN & & \\
\hline CHEMBL1864747 & 752371 & 4.1487 & 4.9129 & TRN & & \\
\hline CHEMBL1884495 & 752371 & 6.0809 & 5.9924 & TRN & & \\
\hline CHEMBL1875486 & 752371 & 3.0044 & 3.0556 & TRN & & \\
\hline CHEMBL1888321 & 752371 & 3.0044 & 2.6889 & TRN & & \\
\hline CHEMBL1891588 & 752371 & 6.2076 & 6.2786 & TRN & & \\
\hline CHEMBL1874319 & 752371 & 5.1302 & 4.4889 & TRN & & \\
\hline CHEMBL 1902173 & 752371 & 5.0953 & 4.7071 & TRN & & \\
\hline CHEMBL1882443 & 752371 & 5.2676 & 5.5204 & TRN & & \\
\hline CHEMBL1905817 & 752371 & 5.1785 & 4.7323 & TRN & & \\
\hline CHEMBL 1886693 & 752371 & 4.5302 & 4.1207 & TRN & & \\
\hline CHEMBL1902151 & 752371 & 3.0044 & 2.7401 & TRN & & \\
\hline CHEMBL 1890186 & 752371 & 4.0146 & 3.8339 & TST & & \\
\hline CHEMBL 1470146 & 752371 & \multicolumn{3}{|c|}{5.202000000000001} & 5.0686 & IST \\
\hline CHEMBL1333222 & 752371 & 3.0044 & 3.5173 & TRN & & \\
\hline CHEMBL1408953 & 752371 & 3.0044 & 3.9292 & TST & & \\
\hline CHEMBL1873019 & 752371 & 3.0044 & 3.2576 & TRN & & \\
\hline CHEMBL1881903 & 752371 & 3.0044 & 3.1093 & TRN & & \\
\hline CHEMBL1898917 & 752371 & 3.0044 & 2.8806 & TRN & & \\
\hline
\end{tabular}


Supplemental Table S2.txt

\begin{tabular}{|c|c|c|c|c|c|}
\hline CHEMBL3195749 & 752371 & 5.3958 & 5.0688 & TST & \\
\hline CHEMBL1884064 & 752371 & 3.0044 & 2.8364 & TRN & \\
\hline CHEMBL1510959 & 752371 & 3.0044 & 3.9125 & TST & \\
\hline CHEMBL1877931 & 752371 & 3.0044 & 2.6501 & TRN & \\
\hline CHEMBL1884437 & 752371 & 4.3449 & 3.6988 & TRN & \\
\hline CHEMBL1872457 & 752371 & 3.0044 & 4.5388 & TRN & \\
\hline CHEMBL1898553 & 752371 & 3.0044 & 3.7556 & TST & \\
\hline CHEMBL1460250 & 752371 & 5.0778 & 4.5217 & TST & \\
\hline CHEMBL1865625 & 752371 & 3.0044 & 3.2075 & TRN & \\
\hline CHEMBL1866357 & 752371 & 3.0044 & 3.0681 & TRN & \\
\hline CHEMBL1871384 & 752371 & 3.0044 & 2.7029 & TRN & \\
\hline CHEMBL1880304 & 752371 & 3.0044 & 3.2402 & TRN & \\
\hline CHEMBL1864057 & 752371 & 3.0044 & 3.4122 & TRN & \\
\hline CHEMBL1553773 & 752371 & 3.0044 & 4.6782 & TRN & \\
\hline CHEMBL1898951 & 752371 & 3.0044 & 2.9724 & TRN & \\
\hline CHEMBL1414729 & 752371 & 3.0044 & 3.1922 & TST & \\
\hline CHEMBL1897885 & 752371 & 4.3188 & 4.0719 & TRN & \\
\hline CHEMBL1881371 & 752371 & 3.0044 & \multicolumn{2}{|c|}{3.0260000000000002} & TRN \\
\hline CHEMBL1867839 & 752371 & 3.0044 & 2.7104 & TRN & \\
\hline CHEMBL1895014 & 752371 & 3.0044 & 3.1285 & TRN & \\
\hline CHEMBL1897633 & 752371 & 3.0044 & 2.9782 & TRN & \\
\hline CHEMBL1895637 & 752371 & 4.7447 & 4.2999 & TRN & \\
\hline CHEMBL1871956 & 752371 & 3.0044 & 4.8323 & TST & \\
\hline CHEMBL1890591 & 752371 & 5.8268 & 5.232 & TST & \\
\hline CHEMBL1864348 & 752371 & 3.0044 & 4.4816 & TRN & \\
\hline CHEMBL1888458 & 752371 & 3.0044 & 2.7066 & TST & \\
\hline CHEMBL1873053 & 752371 & 3.0044 & 2.9148 & TRN & \\
\hline CHEMBL1875316 & 752371 & 3.0044 & 2.6809 & TST & \\
\hline CHEMBL1544489 & 752371 & 5.6021 & 5.3959 & TST & \\
\hline CHEMBL1893628 & 752371 & 3.0044 & 2.9224 & TRN & \\
\hline CHEMBL1469489 & 752371 & 4.0325 & 3.865 & TST & \\
\hline CHEMBL1306211 & 752371 & 4.5229 & 4.4221 & TST & \\
\hline CHEMBL1868274 & 752371 & 3.0044 & 4.1958 & TRN & \\
\hline CHEMBL1906504 & 752371 & 3.0044 & 2.9135 & TRN & \\
\hline CHEMBL1405521 & 752371 & 3.0044 & 2.9675 & TST & \\
\hline CHEMBL1609828 & 752371 & 5.426 & 4.8087 & TST & \\
\hline CHEMBL1863714 & 752371 & 3.0044 & 3.0546 & TRN & \\
\hline CHEMBL1902007 & 752371 & 4.8239 & 4.3937 & TRN & \\
\hline CHEMBL1902079 & 752371 & 3.0044 & 3.9792 & TRN & \\
\hline CHEMBL1903946 & 752371 & 3.0044 & 2.8373 & TRN & \\
\hline CHEMBL1866663 & 752371 & 3.0044 & 2.946 & TRN & \\
\hline CHEMBL1620972 & 752371 & 3.0044 & 2.9437 & TRN & \\
\hline CHEMBL1899989 & 752371 & 5.6778 & 5.5442 & TRN & \\
\hline CHEMBL1892809 & 752371 & 3.0044 & 3.2936 & TST & \\
\hline CHEMBL1886476 & 752371 & 3.0044 & 2.9903 & TRN & \\
\hline CHEMBL1897928 & 752371 & 3.0044 & 3.2749 & TST & \\
\hline CHEMBL1542557 & 752371 & 3.0044 & 3.0539 & TST & \\
\hline CHEMBL1904202 & 752371 & 3.0044 & 2.8397 & TST & \\
\hline
\end{tabular}

Page 6909 
Supplemental Table S2.txt

\begin{tabular}{|c|c|c|c|c|c|}
\hline CHEMBL1893535 & 752371 & 4.2518 & 4.4249 & TST & \\
\hline CHEMBL1870597 & 752371 & 3.0044 & 2.8775 & TRN & \\
\hline CHEMBL1897477 & 752371 & 3.0044 & 2.8593 & TRN & \\
\hline CHEMBL233119 & 752371 & 3.0044 & 3.1818 & TRN & \\
\hline CHEMBL1877822 & 752371 & 3.0044 & 3.1015 & TRN & \\
\hline CHEMBL1890161 & 752371 & 3.0044 & 3.7965 & TRN & \\
\hline CHEMBL1904348 & 752371 & 4.8861 & 5.0129 & TST & \\
\hline CHEMBL1880791 & 752371 & 3.0044 & 3.0947 & TRN & \\
\hline CHEMBL1613411 & 752371 & 3.0044 & 3.33699 & 99999999997 & TRN \\
\hline CHEMBL1896157 & 752371 & 3.0044 & 3.1596 & TRN & \\
\hline CHEMBL1867387 & 752371 & 3.0044 & 2.89300 & 00000000002 & TRN \\
\hline CHEMBL1877896 & 752371 & 3.0044 & 2.8024 & TRN & \\
\hline CHEMBL1898778 & 752371 & 3.0044 & 2.9806 & TRN & \\
\hline CHEMBL1888516 & 752371 & 5.8013 & 4.8782 & TST & \\
\hline CHEMBL1877317 & 752371 & 3.0044 & 2.6685 & TRN & \\
\hline CHEMBL1878061 & 752371 & 5.8539 & 6.0559 & TRN & \\
\hline CHEMBL1586985 & 752371 & 6.061 & 5.3103 & TRN & \\
\hline CHEMBL1870590 & 752371 & 3.0044 & 2.8587 & TST & \\
\hline CHEMBL1865265 & 752371 & 3.0044 & 2.8318 & TST & \\
\hline CHEMBL1886235 & 752371 & 3.0044 & 2.6137 & TRN & \\
\hline CHEMBL1309254 & 752371 & 3.0044 & 3.3268 & TST & \\
\hline CHEMBL1881590 & 752371 & 3.0044 & 2.9835 & TRN & \\
\hline CHEMBL1880043 & 752371 & 3.0044 & 2.8065 & TRN & \\
\hline CHEMBL1547213 & 752371 & 3.0044 & 3.2779 & TRN & \\
\hline CHEMBL1477200 & 752371 & 3.0044 & 3.9017 & TRN & \\
\hline CHEMBL1900215 & 752371 & 3.0044 & 2.8444 & TRN & \\
\hline CHEMBL68442 & 752371 & 3.0044 & 2.8035 & TRN & \\
\hline CHEMBL1705186 & 752371 & 5.5229 & 4.311 & TRN & \\
\hline CHEMBL1582654 & 752371 & 5.5935 & 5.319 & TRN & \\
\hline CHEMBL1534143 & 752371 & 5.6778 & 5.5314 & TRN & \\
\hline CHEMBL1892775 & 752371 & 3.0044 & 2.9324 & TRN & \\
\hline CHEMBL1884507 & 752371 & 4.8239 & 4.8213 & TRN & \\
\hline CHEMBL1899595 & 752371 & 5.3872 & 5.2068 & TRN & \\
\hline CHEMBL1316867 & 752371 & 6.1805 & 6.0133 & TRN & \\
\hline CHEMBL1896895 & 752371 & 3.0044 & 2.9523 & TRN & \\
\hline CHEMBL1319405 & 752371 & 5.9208 & 5.364 & TRN & \\
\hline CHEMBL1893046 & 752371 & 3.0044 & 3.0689 & TRN & \\
\hline CHEMBL1449672 & 752371 & 3.0044 & 3.3607 & TRN & \\
\hline CHEMBL1893952 & 752371 & 3.0044 & 3.1539 & TRN & \\
\hline CHEMBL1870966 & 752371 & 5.1694 & 4.2886 & TRN & \\
\hline CHEMBL1477061 & 752371 & 5.3575 & 5.0462 & TRN & \\
\hline CHEMBL1879394 & 752371 & 6.1726 & 6.1027 & TRN & \\
\hline CHEMBL1906573 & 752371 & 3.0044 & 2.7602 & TRN & \\
\hline CHEMBL1599544 & 752371 & 3.0044 & 3.0251 & TST & \\
\hline CHEMBL1888528 & 752371 & 4.4989 & 4.4568 & TRN & \\
\hline CHEMBL1887272 & 752371 & 3.0044 & 3.3135 & TRN & \\
\hline CHEMBL1874506 & 752371 & 5.4949 & 5.265 & TRN & \\
\hline CHEMBL1869393 & 752371 & 6.0044 & 6.0744 & TRN & \\
\hline
\end{tabular}




\begin{tabular}{|c|c|c|c|c|c|c|}
\hline & & \multicolumn{5}{|c|}{ Supplemental Table S2.txt } \\
\hline CHEMBL1870914 & 752371 & 6.284 & 5.9438 & TRN & & \\
\hline CHEMBL1877788 & 752371 & 3.0044 & 2.7988 & TST & & \\
\hline CHEMBL1866897 & 752371 & 3.0044 & 3.1262 & TRN & & \\
\hline CHEMBL1905093 & 752371 & 4.1215 & 4.5402 & TRN & & \\
\hline CHEMBL1571012 & 752371 & 3.0044 & 3.2078 & TST & & \\
\hline CHEMBL1867373 & 752371 & 3.0044 & 2.9204 & TRN & & \\
\hline CHEMBL1893076 & 752371 & 3.0044 & 3.0814 & TRN & & \\
\hline CHEMBL546865 & 752371 & 3.0044 & 3.3667 & TST & & \\
\hline CHEMBL1882084 & 752371 & 3.0044 & 3.1736 & TRN & & \\
\hline CHEMBL1885269 & 752371 & 5.8861 & 5.7049 & TRN & & \\
\hline CHEMBL1880875 & 752371 & 5.1249 & 4.2675 & TST & & \\
\hline CHEMBL1598762 & 752371 & 4.4486 & 4.3169 & TST & & \\
\hline CHEMBL1888478 & 752371 & 3.0044 & 3.0378 & TRN & & \\
\hline CHEMBL1345096 & 752371 & 4.8013 & 4.6307 & TST & & \\
\hline CHEMBL1886298 & 752371 & 3.0044 & 2.9722 & TRN & & \\
\hline CHEMBL1877442 & 752371 & 3.0044 & 3.2914 & TRN & & \\
\hline CHEMBL1873238 & 752371 & $4.1530 e$ & 00000000 & 205 & 3.7685 & TST \\
\hline CHEMBL1869876 & 752371 & 3.0044 & 3.2203 & TRN & & \\
\hline CHEMBL1495113 & 752371 & 3.0044 & 3.1646 & TRN & & \\
\hline CHEMBL1867713 & 752371 & 3.0044 & 3.2541 & TRN & & \\
\hline CHEMBL1883428 & 752371 & 3.0044 & 2.8141 & TRN & & \\
\hline CHEMBL1901952 & 752371 & 3.0044 & 3.7748 & TRN & & \\
\hline CHEMBL1904648 & 752371 & 4.7959 & 5.0068 & TRN & & \\
\hline CHEMBL1872249 & 752371 & 3.0044 & 4.4068 & TRN & & \\
\hline CHEMBL1872841 & 752371 & 4.284 & 4.0327 & TRN & & \\
\hline CHEMBL1876217 & 752371 & 5.7305 & 5.7198 & TRN & & \\
\hline CHEMBL1302779 & 752371 & 5.7696 & 5.6796 & TRN & & \\
\hline CHEMBL1877261 & 752371 & 3.0044 & 2.9816 & TRN & & \\
\hline CHEMBL1892979 & 752371 & 3.0044 & 2.8788 & TRN & & \\
\hline CHEMBL1870930 & 752371 & 5.4763 & 4.8964 & TRN & & \\
\hline CHEMBL1888363 & 752371 & 3.0044 & 3.3528 & TRN & & \\
\hline CHEMBL1866145 & 752371 & 3.0044 & 2.6763 & TRN & & \\
\hline CHEMBL1868306 & 752371 & 3.0044 & 4.1353 & TRN & & \\
\hline CHEMBL1869120 & 752371 & 3.0044 & 2.9066 & TRN & & \\
\hline CHEMBL1897044 & 752371 & 4.061 & 4.1967 & TST & & \\
\hline CHEMBL1879721 & 752371 & 3.0044 & 3.5941 & TRN & & \\
\hline CHEMBL1874988 & 752371 & 3.0044 & 3.2968 & TRN & & \\
\hline CHEMBL1901962 & 752371 & 3.0044 & 2.9856 & TRN & & \\
\hline CHEMBL1435486 & 752371 & 3.0044 & 3.2006 & TRN & & \\
\hline CHEMBL1497617 & 752371 & 3.0044 & 3.2362 & TST & & \\
\hline CHEMBL1514860 & 752371 & 3.0044 & 3.2368 & TRN & & \\
\hline CHEMBL1865565 & 752371 & 3.0044 & 2.946 & TST & & \\
\hline CHEMBL1468256 & 752371 & 3.0044 & 3.5053 & TRN & & \\
\hline CHEMBL1517170 & 752371 & 3.0044 & 2.9693 & TRN & & \\
\hline CHEMBL1879541 & 752371 & 3.0044 & 3.0925 & TRN & & \\
\hline CHEMBL1868902 & 752371 & 5.5086 & 5.5395 & TRN & & \\
\hline CHEMBL1889650 & 752371 & 5.6576 & 5.1916 & TRN & & \\
\hline CHEMBL1885809 & 752371 & 3.0044 & 3.0411 & TRN & & \\
\hline
\end{tabular}


Supplemental Table S2.txt

\begin{tabular}{|c|c|c|c|c|}
\hline & & & & \\
\hline AEMBL1. & 2371 & 4.8962 & 4.6665 & \\
\hline IEMBL1869506 & 2371 & 3098 & 6932 & \\
\hline AEMBL 2448582 & 52371 & 044 & 9293 & \\
\hline & 371 & 622 & & \\
\hline HEMBL153 & 2371 & 044 & 5026 & \\
\hline AEMBL1425795 & 52371 & 279 & 6536 & \\
\hline AEMBL1886662 & 52371 & 559 & 6979 & \\
\hline AEMBL1322894 & 52371 & 628 & 8103 & \\
\hline IEMBL1894672 & 52371 & 044 & 1702 & \\
\hline IEMBL1892009 & 52371 & 044 & 127 & \\
\hline AEMBL1899771 & 52371 & 615 & 5296 & \\
\hline AEMBL1898423 & 52371 & 815 & 9866 & w \\
\hline IEMBL1905640 & 52 & 3. & 7966 & \\
\hline IEMBL188 & 2371 & 244 & 676 & \\
\hline HEMBL 202 & 31 & & 778 & \\
\hline AEMBL1872062 & 52371 & 279 & 7679 & $S$ \\
\hline AEMBL189 & & & 9923 & \\
\hline IEMBL189 & 71 & 44 & 937 & \\
\hline IEMBL189 & 71 & 44 & 385 & \\
\hline AEMBL156 & 71 & 44 & 367 & RN \\
\hline AEMBL1896263 & 71 & & 183 & RN \\
\hline IEMBL1866613 & & & 997 & \\
\hline EMBL186 & 1 & 14 & 844 & RI \\
\hline EMBL19 & 71 & 44 & 622 & RN \\
\hline FMRI 18 & 71 & 44 & 102 & וכ \\
\hline JEMBL143 & & 044 & 722 & S \\
\hline AEMBL14 & & & & ST \\
\hline EMBL188 & 1 & 44 & 347 & RN \\
\hline 69 & 71 & 83 & 304 & r \\
\hline 57 & 1 & 44 & 95 & RN \\
\hline IEMBL1906326 & & & & $S$ \\
\hline AEMBL1379448 & 1 & & 864 & ST \\
\hline IEMBL1413278 & 1 & 44 & 867 & RN \\
\hline 317 & 1 & 44 & & m \\
\hline 498 & & & 533 & RN \\
\hline AEMBL1613216 & 71 & & 662 & ГST \\
\hline AEMBL1876647 & 1 & & 952 & ST \\
\hline EMBL190 & 1 & 44 & 569 & $\mathrm{RI}$ \\
\hline 168 & & 44 & 259 & Mru \\
\hline & & & 772 & RN \\
\hline AEMBL1876316 & 52371 & 841 & 7087 & $\mathrm{R}$ \\
\hline IEMBL1880120 & 1 & & 173 & $\mathrm{R}$ \\
\hline HEMBL189 & & & 167 & $\mathrm{R}$ \\
\hline HEMBL187 & & & & \\
\hline CHEMBL 1892581 & & 044 & 3.1855 & ST \\
\hline AEMBL1525161 & 52371 & 5.9508 & 5.8144 & TST \\
\hline HEMBL1883048 & 52371 & 3.0044 & 2.8103 & \\
\hline
\end{tabular}

Page 6912 
Supplemental Table S2.txt

\begin{tabular}{|c|c|c|c|c|c|}
\hline CHEMBL1575970 & 752371 & 5.4225 & 4.9369 & TRN & \\
\hline CHEMBL1864262 & 752371 & 3.0044 & 2.8454 & TRN & \\
\hline CHEMBL576846 & 752371 & 3.0044 & 3.2184 & TRN & \\
\hline CHEMBL1878043 & 752371 & 4.6383 & 4.668 & TRN & \\
\hline CHEMBL1863755 & 752371 & 3.0044 & 3.1811 & TRN & \\
\hline CHEMBL1565912 & 752371 & 5.6021 & 5.5359 & TST & \\
\hline CHEMBL1416561 & 752371 & 3.0044 & 2.6026 & TRN & \\
\hline CHEMBL1865088 & 752371 & 3.0044 & 2.8036 & TRN & \\
\hline CHEMBL1892075 & 752371 & 3.0044 & 3.4205 & TRN & \\
\hline CHEMBL1891751 & 752371 & 5.2757 & 4.8051 & TRN & \\
\hline CHEMBL1894125 & 752371 & 3.0044 & 3.028 & TST & \\
\hline CHEMBL1322834 & 752371 & 5.0691 & 4.86600 & 00000000005 & TRN \\
\hline CHEMBL1887007 & 752371 & 3.0044 & 2.8769 & TST & \\
\hline CHEMBL1903693 & 752371 & 3.0044 & 2.8979 & TST & \\
\hline CHEMBL1554455 & 752371 & 3.0044 & 3.1176 & TRN & \\
\hline CHEMBL1895018 & 752371 & 3.0044 & 3.0131 & TRN & \\
\hline CHEMBL1898718 & 752371 & 3.0044 & 2.8661 & TST & \\
\hline CHEMBL1883257 & 752371 & 3.0044 & 3.157 & TRN & \\
\hline CHEMBL1901170 & 752371 & 5.6861 & 5.3877 & TRN & \\
\hline CHEMBL1876373 & 752371 & 3.0044 & 3.04 & TRN & \\
\hline CHEMBL1905211 & 752371 & 3.0044 & 3.0877 & TRN & \\
\hline CHEMBL1898076 & 752371 & 3.0044 & 2.6016 & TRN & \\
\hline CHEMBL1408676 & 752371 & 3.0044 & 2.9594 & TRN & \\
\hline CHEMBL1873343 & 752371 & 3.0044 & 3.1002 & TRN & \\
\hline CHEMBL1892340 & 752371 & 3.0044 & 2.6221 & TRN & \\
\hline CHEMBL1881878 & 752371 & 3.0044 & 2.7648 & TRN & \\
\hline CHEMBL1898479 & 752371 & 3.0044 & 4.30399 & 9999999999 & TST \\
\hline CHEMBL3144856 & 752371 & 4.5513 & 4.4899 & TST & \\
\hline CHEMBL1471498 & 752371 & 3.0044 & 3.7311 & TST & \\
\hline CHEMBL1883060 & 752371 & 3.0044 & 2.8182 & TRN & \\
\hline CHEMBL1899086 & 752371 & 3.0044 & 2.8715 & TRN & \\
\hline CHEMBL558642 & 954795 & 3.0629 & 3.0637 & TRN & \\
\hline CHEMBL472940 & 954795 & 4.8946 & 4.8956 & TRN & \\
\hline CHEMBL514499 & 954795 & 6.269 & 6.2842 & TRN & \\
\hline CHEMBL1190711 & 954795 & 5.1781 & 5.1578 & TRN & \\
\hline CHEMBL202721 & 954795 & 5.2053 & 5.2224 & TRN & \\
\hline CHEMBL483847 & 954795 & 3.7485 & 3.8127 & TRN & \\
\hline CHEMBL 9470 & 954795 & 6.1389 & 5.9771 & TST & \\
\hline CHEMBL209148 & 954795 & 4.0477 & 4.063 & TRN & \\
\hline CHEMBL 65 & 954795 & 8.9352 & 8.9109 & TRN & \\
\hline CHEMBL1590308 & 954795 & 2.8529 & 3.4284 & TST & \\
\hline CHEMBL379975 & 954795 & 5.8869 & 5.9111 & TRN & \\
\hline CHEMBL1970879 & 954795 & 3.18399 & 99999999 & 3.1586 & IRI \\
\hline CHEMBL300389 & 954795 & 6.8612 & 6.8639 & TRN & \\
\hline CHEMBL3199475 & 954795 & 4.1515 & 4.1902 & TRN & \\
\hline CHEMBL1909414 & 954795 & 4.6907 & 4.7179 & TRN & \\
\hline CHEMBL189584 & 954795 & 5.0907 & 5.0764 & TRN & \\
\hline CHEMBL 2144069 & 954795 & 3.4293 & 3.4616 & TRN & \\
\hline
\end{tabular}




\begin{tabular}{|c|c|c|c|c|c|c|}
\hline \multirow[b]{2}{*}{ CHEMBL191334 } & \multicolumn{6}{|c|}{ Supplemental Table S2.txt } \\
\hline & 954795 & 4.6663 & 4.6808 & TRN & & \\
\hline CHEMBL 213100 & 954795 & 3.03 & 3.0415 & TRN & & \\
\hline CHEMBL1256459 & 954795 & 6.3006 & 6.28100 & 00000000 & & TRN \\
\hline CHEMBL 3186408 & 954795 & 2.897 & 3.68300 & 00000000 & $\partial 03$ & TST \\
\hline CHEMBL509032 & 954795 & 4.2389 & 4.2251 & TRN & & \\
\hline CHEMBL483849 & 954795 & 4.0397 & 4.0585 & TRN & & \\
\hline CHEMBL 2363137 & 954795 & 5.0878 & 5.1368 & TRN & & \\
\hline CHEMBL577784 & 954795 & 5.6724 & 5.6353 & TRN & & \\
\hline CHEMBL393929 & 954795 & 5.0963 & 5.0876 & TRN & & \\
\hline CHEMBL449158 & 954795 & 6.0793 & 6.4058 & TST & & \\
\hline CHEMBL1404918 & 954795 & 3.0319 & 3.0187 & TRN & & \\
\hline CHEMBL192566 & 954795 & 8.5929 & 8.2989 & TST & & \\
\hline CHEMBL92309 & 954795 & 4.2804 & 2.9831 & TST & & \\
\hline CHEMBL1788116 & 954795 & 4.5796 & 4.584 & TRN & & \\
\hline CHEMBL222102 & 954795 & 4.4211 & 4.4121 & TRN & & \\
\hline CHEMBL585951 & 954795 & 6.2138 & 6.224 & TRN & & \\
\hline CHEMBL 221137 & 954795 & 3.752 & 4.6299 & TST & & \\
\hline CHEMBL3349342 & 954795 & 3.6629 & 3.6432 & TRN & & \\
\hline CHEMBL210618 & 954795 & 4.2844 & 4.2108 & TRN & & \\
\hline CHEMBL259181 & 954795 & 5.1754 & 5.2157 & TRN & & \\
\hline CHEMBL188678 & 954795 & 4.6179 & 4.6586 & TRN & & \\
\hline CHEMBL512504 & 954795 & 6.3108 & 6.2904 & TRN & & \\
\hline CHEMBL573107 & 954795 & 5.5934 & 5.601 & TRN & & \\
\hline CHEMBL1673039 & 954795 & 4.3474 & 4.3028 & TRN & & \\
\hline CHEMBL1516890 & 954795 & 4.1915 & 4.1601 & TRN & & \\
\hline CHEMBL 220241 & 954795 & 4.3266 & 4.324 & TRN & & \\
\hline CHEMBL180127 & 954795 & 4.48 & 4.4691 & TRN & & \\
\hline CHEMBL 373751 & 954795 & 2.9482 & 2.9326 & TRN & & \\
\hline CHEMBL258844 & 954795 & 3.4406 & 3.4124 & TRN & & \\
\hline CHEMBL 3392440 & 954795 & 4.1846 & 4.1936 & TRN & & \\
\hline CHEMBL1357247 & 954795 & 2.773 & 2.7613 & TRN & & \\
\hline CHEMBL392695 & 954795 & 4.7164 & 4.7637 & TRN & & \\
\hline CHEMBL412142 & 954795 & 4.2841 & 4.2716 & TRN & & \\
\hline CHEMBL1242367 & 954795 & 5.0052 & 4.9701 & TRN & & \\
\hline CHEMBL515416 & 954795 & 3.0735 & 4.372 & TST & & \\
\hline CHEMBL2005886 & 954795 & 2.9115 & 4.1668 & TST & & \\
\hline CHEMBL 379300 & 954795 & 6.4262 & 5.5944 & TST & & \\
\hline CHEMBL102714 & 954795 & 3.73100 & 00000000 & 203 & 4.169 & TST \\
\hline CHEMBL135561 & 954795 & 4.163 & 3.7142 & TST & & \\
\hline CHEMBL1643959 & 954795 & 2.8883 & 2.9505 & TST & & \\
\hline CHEMBL1230020 & 954795 & 4.289 & 4.6114 & TST & & \\
\hline CHEMBL240954 & 954795 & 4.0144 & 4.3296 & TST & & \\
\hline CHEMBL1083274 & 634305 & 8.8239 & 8.5023 & TRN & & \\
\hline CHEMBL1085800 & 634305 & 8.4089 & 8.6146 & TRN & & \\
\hline CHEMBL1085964 & 634305 & 9.2924 & 9.1267 & TRN & & \\
\hline CHEMBL1086032 & 634305 & 7.3872 & 7.5597 & TRN & & \\
\hline CHEMBL1084294 & 634305 & 7.2596 & 7.0601 & TRN & & \\
\hline CHEMBL442242 & 634305 & 8.7959 & 8.7741 & TRN & & \\
\hline
\end{tabular}




\begin{tabular}{|c|c|c|c|c|c|}
\hline & & \multicolumn{4}{|c|}{ Supplemental Table s2.txt } \\
\hline CHEMBL1082488 & 634305 & 8.8539 & 8.2412 & TRN & \\
\hline CHEMBL1086561 & 634305 & 8.5376 & 8.5657 & TRN & \\
\hline CHEMBL237191 & 634305 & 9.1427 & 9.0522 & TRN & \\
\hline CHEMBL1082489 & 634305 & 9.0 & 9.0196 & TRN & \\
\hline CHEMBL1086292 & 634305 & 8.3468 & 8.4292 & TRN & \\
\hline CHEMBL1084827 & 634305 & 9.1675 & 9.1772 & TRN & \\
\hline CHEMBL1085336 & 634305 & 8.6383 & 8.6346 & TRN & \\
\hline CHEMBL1086074 & 634305 & 8.585 & 8.5619 & TRN & \\
\hline CHEMBL1085828 & 634305 & 9.1805 & 9.0604 & TRN & \\
\hline CHEMBL1084560 & 634305 & 9.301 & 9.2909 & TRN & \\
\hline CHEMBL1084559 & 634305 & 8.8539 & 8.8343 & TRN & \\
\hline CHEMBL1082606 & 634305 & 8.7212 & 9.0888 & TRN & \\
\hline CHEMBL1085124 & 634305 & 7.1487 & 7.4621 & TRN & \\
\hline CHEMBL1083463 & 634305 & 8.6778 & 8.8726 & TRN & \\
\hline CHEMBL1086315 & 634305 & 8.9208 & 8.5093 & TRN & \\
\hline CHEMBL1082496 & 634305 & 8.1427 & 8.338 & TRN & \\
\hline CHEMBL1086514 & 634305 & 9.5229 & 9.163 & TRN & \\
\hline CHEMBL393581 & 634305 & 9.041 & 9.105 & TRN & \\
\hline CHEMBL1085560 & 634305 & 8.699 & 8.9029 & TRN & \\
\hline CHEMBL1084583 & 634305 & 7.7959 & 8.0552 & TST & \\
\hline CHEMBL1085866 & 634305 & 8.6383 & 8.7923 & TRN & \\
\hline CHEMBL1083462 & 634305 & 8.9586 & 9.2022 & TRN & \\
\hline CHEMBL1086521 & 634305 & 8.7959 & 8.5564 & TRN & \\
\hline CHEMBL1085325 & 634305 & 7.2924 & 7.2423 & TRN & \\
\hline CHEMBL1083562 & 634305 & 8.0706 & 7.8504 & TRN & \\
\hline CHEMBL1085398 & 634305 & 9.5086 & 9.1226 & TRN & \\
\hline CHEMBL1084584 & 634305 & 8.2676 & 8.3919 & TST & \\
\hline CHEMBL1085572 & 634305 & 8.1612 & 8.1602 & TRN & \\
\hline CHEMBL1086098 & 634305 & 9.4559 & 8.8521 & TST & \\
\hline CHEMBL1085829 & 634305 & 8.4437 & 8.1909 & TRN & \\
\hline CHEMBL351231 & 634305 & 8.8539 & 8.3184 & TST & \\
\hline CHEMBL1085591 & 634305 & 7.7696 & 7.836 & TRN & \\
\hline CHEMBL1085841 & 634305 & 8.5528 & 8.8603 & TRN & \\
\hline CHEMBL392573 & 634305 & 9.0315 & 9.0668 & TRN & \\
\hline CHEMBL1083407 & 634305 & 9.3188 & 9.0766 & TRN & \\
\hline CHEMBL1083448 & 634305 & 8.6383 & 8.7454 & TRN & \\
\hline CHEMBL1084879 & 634305 & 7.2366 & 6.9997 & TRN & \\
\hline CHEMBL1085142 & 634305 & 9.1079 & 8.6479 & TST & \\
\hline CHEMBL1084878 & 634305 & 7.5086 & 7.38700 & 00000000005 & TRN \\
\hline CHEMBL1084826 & 634305 & 8.2676 & 8.421 & TRN & \\
\hline CHEMBL1084384 & 634305 & 8.3098 & 8.3999 & TST & \\
\hline CHEMBL1084616 & 634305 & 8.5528 & 8.509 & TST & \\
\hline CHEMBL237394 & 634305 & 9.3098 & 9.2689 & TRN & \\
\hline CHEMBL1085783 & 634305 & 6.0 & 6.7762 & TST & \\
\hline CHEMBL1082447 & 634305 & 8.6576 & 8.7136 & TRN & \\
\hline CHEMBL1086534 & 634305 & 8.6383 & 8.5219 & TRN & \\
\hline CHEMBL1084385 & 634305 & 9.301 & 8.9407 & TST & \\
\hline CHEMBL1086034 & 634305 & 7.3279 & 7.4492 & TRN & \\
\hline
\end{tabular}




\begin{tabular}{|c|c|c|c|c|}
\hline & & Su & oplement & al $\mathrm{T}$ \\
\hline CHEMBL1084314 & 634305 & 8.8239 & 8.8892 & TRN \\
\hline CHEMBL1085326 & 634305 & 7.699 & 7.8821 & TRN \\
\hline CHEMBL1083447 & 634305 & 8.7696 & 8.8018 & TRN \\
\hline CHEMBL1082781 & 634305 & 9.3468 & 9.2022 & TRN \\
\hline CHEMBL1084582 & 634305 & 8.2291 & 8.6165 & TRN \\
\hline CHEMBL1086513 & 634305 & 8.1675 & 8.3399 & TRN \\
\hline CHEMBL1085396 & 634305 & 9.3979 & 9.1446 & TRN \\
\hline CHEMBL1085592 & 634305 & 8.8539 & 9.0149 & TRN \\
\hline CHEMBL1085782 & 634305 & 8.2596 & 8.4852 & TRN \\
\hline CHEMBL1086033 & 634305 & 7.1871 & 7.3967 & TRN \\
\hline CHEMBL263101 & 634305 & 8.699 & 8.826 & TRN \\
\hline CHEMBL1084383 & 634305 & 9.6021 & 9.0666 & TST \\
\hline CHEMBL1084581 & 634305 & 7.8539 & 8.1666 & TST \\
\hline CHEMBL1085397 & 634305 & 9.2291 & 8.5901 & TST \\
\hline CHEMBL1086520 & 634305 & 8.2596 & 8.0728 & TST \\
\hline CHEMBL1086072 & 634305 & 7.9586 & 7.8832 & TST \\
\hline CHEMBL1085641 & 634305 & 7.4437 & 8.1172 & TST \\
\hline CHEMBL1086073 & 634305 & 8.3098 & 8.0567 & TST \\
\hline CHEMBL1084877 & 634305 & 8.2291 & 8.4591 & TST \\
\hline CHEMBL1083406 & 634305 & 8.7212 & 8.8737 & TST \\
\hline CHEMBL1085337 & 634305 & 10.0969 & 8.8477 & TST \\
\hline CHEMBL315218 & 675275 & 6.7447 & 6.902 & TRN \\
\hline CHEMBL50024 & 675275 & 7.9586 & 9.3447 & TST \\
\hline CHEMBL1271265 & 675275 & 10.3979 & 10.2712 & TRN \\
\hline CHEMBL1270952 & 675275 & 8.699 & 8.7451 & TRN \\
\hline CHEMBL1271264 & 675275 & 10.5229 & 10.6059 & TRN \\
\hline CHEMBL593461 & 675275 & 9.301 & 9.0985 & TRN \\
\hline CHEMBL233992 & 675275 & 9.3665 & 9.4082 & TRN \\
\hline CHEMBL8382 & 675275 & 7.3665 & 7.3138 & TRN \\
\hline CHEMBL 283765 & 675275 & 7.7959 & 7.7336 & TRN \\
\hline CHEMBL351298 & 675275 & 8.3979 & 8.3982 & TRN \\
\hline CHEMBL 279287 & 675275 & 8.8239 & 8.8345 & TRN \\
\hline CHEMBL1271369 & 675275 & 9.2218 & 9.3116 & TRN \\
\hline CHEMBL487105 & 675275 & 8.699 & 8.7997 & TRN \\
\hline CHEMBL1271162 & 675275 & 8.3372 & 8.3249 & TRN \\
\hline CHEMBL140072 & 675275 & 9.8239 & 9.8805 & TRN \\
\hline CHEMBL 20912 & 675275 & 5.9586 & 6.1102 & TRN \\
\hline CHEMBL182746 & 675275 & 8.5229 & 9.35 & TST \\
\hline CHEMBL 233984 & 675275 & 9.1739 & 9.1239 & TRN \\
\hline CHEMBL 327600 & 675275 & 7.3279 & 6.9051 & TRN \\
\hline CHEMBL 1270555 & 675275 & 4.7959 & 4.8659 & TRN \\
\hline CHEMBL 279486 & 675275 & 9.1549 & 9.1266 & TRN \\
\hline CHEMBL331943 & 675275 & 8.1549 & 8.0539 & TRN \\
\hline CHEMBL251409 & 675275 & 8.3979 & 8.4731 & TST \\
\hline CHEMBL595475 & 675275 & 9.699 & 10.3618 & TRN \\
\hline CHEMBL1270752 & 675275 & 7.0 & 8.6929 & TST \\
\hline CHEMBL1270158 & 675275 & 9.0132 & 9.185 & TRN \\
\hline CHEMBL1271160 & 675275 & 11.0 & 10.3614 & TRN \\
\hline
\end{tabular}




\begin{tabular}{|c|c|c|c|c|c|c|}
\hline & & \multicolumn{5}{|c|}{ Supplemental Table S2.txt } \\
\hline CHEMBL1271368 & 675275 & 9.2596 & 9.2989 & TRN & & \\
\hline CHEMBL139063 & 675275 & 8.2007 & 8.2971 & TRN & & \\
\hline CHEMBL1270651 & 675275 & 10.0 & 10.0045 & TRN & & \\
\hline CHEMBL221906 & 675275 & 10.3565 & 10.1198 & TRN & & \\
\hline CHEMBL438647 & 675275 & 9.7696 & 9.754 & TRN & & \\
\hline CHEMBL92988 & 675275 & 7.0269 & 6.7292 & TRN & & \\
\hline CHEMBL 293610 & 675275 & 4.4089 & 8.2747 & TST & & \\
\hline CHEMBL471725 & 675275 & 10.3565 & 10.5444 & TRN & & \\
\hline CHEMBL402109 & 675275 & 9.699 & 9.5365 & TRN & & \\
\hline CHEMBL1269030 & 675275 & 8.3979 & 8.811 & TST & & \\
\hline CHEMBL333678 & 675275 & 7.6576 & 7.6705 & TRN & & \\
\hline CHEMBL450578 & 675275 & 9.2924 & 8.4043 & TST & & \\
\hline CHEMBL1271161 & 675275 & 9.0458 & 9.0214 & TST & & \\
\hline CHEMBL1269203 & 675275 & 3.6021 & 6.9908 & TST & & \\
\hline CHEMBL367953 & 675275 & 8.8239 & 8.8373 & TRN & & \\
\hline CHEMBL93796 & 675275 & 6.6383 & 7.0565 & TRN & & \\
\hline CHEMBL423417 & 675275 & 8.9586 & 8.7726 & TRN & & \\
\hline CHEMBL316053 & 675275 & 7.6576 & 7.553 & TRN & & \\
\hline CHEMBL 369086 & 675275 & 8.8861 & 8.8991 & TRN & & \\
\hline CHEMBL 260085 & 675275 & 10.2441 & 10.3205 & TRN & & \\
\hline CHEMBL1270853 & 675275 & 8.5229 & 8.5371 & TST & & \\
\hline CHEMBL350169 & 675275 & 8.3979 & 8.5391 & TRN & & \\
\hline CHEMBL427421 & 675275 & 11.3009 & 999999999 & 998 & 11.4485 & TRN \\
\hline CHEMBL 385587 & 675275 & 8.2218 & 8.3456 & TRN & & \\
\hline CHEMBL176140 & 675275 & 9.8239 & 9.5504 & TRN & & \\
\hline CHEMBL 294121 & 675275 & 8.7212 & 9.5508 & TST & & \\
\hline CHEMBL1182177 & 675275 & 7.7212 & 8.817 & TST & & \\
\hline CHEMBL37251 & 675275 & 10.8861 & 10.9225 & TRN & & \\
\hline CHEMBL 20240 & 675275 & 8.8861 & 8.8428 & TRN & & \\
\hline CHEMBL54237 & 675275 & 9.4949 & 9.9345 & TST & & \\
\hline CHEMBL 220050 & 675275 & 8.3979 & 8.5498 & TRN & & \\
\hline CHEMBL169975 & 675275 & 7.9393 & 7.9278 & TRN & & \\
\hline CHEMBL222079 & 675275 & 9.7447 & 9.7524 & TRN & & \\
\hline CHEMBL1271056 & 675275 & 9.1549 & 9.1099 & TST & & \\
\hline CHEMBL3979386 & 675275 & 8.5229 & 9.2431 & TST & & \\
\hline CHEMBL 378093 & 675275 & 10.5229 & 10.4308 & TRN & & \\
\hline CHEMBL19902 & 675275 & 7.3872 & 7.5184 & TRN & & \\
\hline CHEMBL551991 & 675275 & 8.1871 & 7.7911 & TST & & \\
\hline CHEMBL 384526 & 675275 & 8.9586 & 9.0401 & TST & & \\
\hline CHEMBL173650 & 675275 & 9.0969 & 9.1382 & TRN & & \\
\hline CHEMBL85938 & 675275 & 8.2218 & 8.2895 & TRN & & \\
\hline CHEMBL182597 & 675275 & 9.0 & 9.7217 & TST & & \\
\hline CHEMBL455932 & 675275 & 8.301 & 9.5049 & TST & & \\
\hline CHEMBL 255053 & 675275 & 8.3565 & 8.4161 & TRN & & \\
\hline CHEMBL153640 & 675275 & 8.2218 & 8.3469 & TRN & & \\
\hline CHEMBL 275368 & 675275 & 7.7447 & 7.6177 & TRN & & \\
\hline CHEMBL151939 & 675275 & 9.041 & 8.9934 & TRN & & \\
\hline CHEMBL176243 & 675275 & 9.2218 & 9.1174 & TRN & & \\
\hline
\end{tabular}


Supplemental Table S2.txt

\begin{tabular}{|c|c|c|}
\hline 35 & 675275 & \\
\hline CHEMBL3426095 & 1476004 & \\
\hline CHEMBL3426076 & 476004 & \\
\hline EMBL3 & 76004 & \\
\hline EMBL34 & 1476004 & \\
\hline AEMBL3426094 & 1476004 & \\
\hline HEMBL3426037 & 476004 & \\
\hline CHEMBL3426058 & 1476004 & \\
\hline IEMBL3 3 & 1476004 & \\
\hline EMBL3 & 1476004 & \\
\hline AEMBL 3426028 & 1476004 & \\
\hline AEMBL3426073 & 1476004 & \\
\hline CHEMBL34 & 1476004 & 6.8 \\
\hline AEMBL3 3 & 5004 & \\
\hline HEMBL3 & 5004 & \\
\hline AEMBL34 & 5004 & \\
\hline CHEMBL34 & 5004 & \\
\hline AEMBL34 & 5004 & \\
\hline IEMBL3 & 5004 & \\
\hline IEMBL3 & 5004 & \\
\hline AEMBL3 & 5004 & \\
\hline CHEMBL3 3 & 304 & \\
\hline AEMBL34 & 5004 & \\
\hline HEMBL3 & 5004 & \\
\hline 6031 & 5004 & \\
\hline 6096 & 5004 & \\
\hline CHEMBL3426183 & 304 & \\
\hline CHEMBL 34 & 5004 & \\
\hline AEMBL: & 204 & \\
\hline 5087 & 5004 & 7.5 \\
\hline CHEMBL3 34 & 5004 & \\
\hline CHEMBL3426053 & 5004 & \\
\hline CHEMBL3 & 5004 & \\
\hline CHEMB & 14 & \\
\hline CHEMBL & 04 & \\
\hline CHEMBL3426074 & 1476004 & \\
\hline CHEMBL 3426033 & 1476004 & \\
\hline CHEMBL & 004 & \\
\hline CHEMBL3 & 5004 & \\
\hline CHEMBL3 3 & 1476004 & 7.4 \\
\hline CHEMBL 3426051 & 1476004 & 6.5 \\
\hline CHEMBL3426061 & 1476004 & \\
\hline CHEMBL3426059 & 1476004 & \\
\hline CHEMBL3426090 & 1476004 & \\
\hline CHEMBL 3426041 & 1476004 & 6.7 \\
\hline CHEMBL 3426079 & 1476004 & \\
\hline CHEMBL 3426047 & 1476004 & \\
\hline CHEMBL3426 & & \\
\hline
\end{tabular}

8.6322 TRN

7.1196 TRN

7.1413 TRN

8.2601 TRN

8.5017 TRN

7.9124 TRN

9.4285 TRN

8.4995 TST

7.3016 TRN

8.6378 TRN

7.9039 TRN

7.1761 TRN

7.2385 TRN

7.3179 TRN

7.7375 TRN

7.5583 TRN

7.7769 TRN

6.3781 TRN

7.0137 TST

8.4325 TRN

7.8816 TRN

7.6885 TRN

8.2189 TRN

8.5172 TRN

8.0864 TRN

7.0618 TRN

6.3896 TRN

7.4974 TRN

7.915 TRN

7.5917 TST

8.3475 TST

8.4483 TRN

7.4216 TST

7.4704 TRN

7.7612 TRN

7.5217 TRN

9.3813 TRN

8.0005 TRN

7.2868 TRN

7.5852 TRN

6.9095 TST

8.4468 TST

8.1694 TRN

7.5642 TRN

7.4034 TST

7.1699 TRN

7.002999999999999

TST

8.8767 TRN

Page 6918 
Supplemental Table S2.txt

\begin{tabular}{|c|c|c|c|c|c|c|}
\hline CHEMBL 3426091 & 1476004 & 6.8416 & 7.2842 & TRN & & \\
\hline CHEMBL3426068 & 1476004 & 7.7212 & 7.6463 & TRN & & \\
\hline CHEMBL3426088 & 1476004 & 7.0132 & 6.903 & TRN & & \\
\hline CHEMBL 3426049 & 1476004 & 7.1805 & 7.3185 & TST & & \\
\hline CHEMBL3426065 & 1476004 & 10.7447 & 9.8943 & TRN & & \\
\hline CHEMBL3426034 & 1476004 & 8.7212 & 8.6522 & TRN & & \\
\hline CHEMBL 3426044 & 1476004 & 6.8697 & 7.2482 & TST & & \\
\hline CHEMBL 3426030 & 1476004 & 7.8239 & 7.8058 & TRN & & \\
\hline CHEMBL 3426092 & 1476004 & 7.5086 & 7.4483 & TST & & \\
\hline CHEMBL3426056 & 1476004 & 8.0 & 7.9388 & TRN & & \\
\hline CHEMBL3426066 & 1476004 & 8.9586 & 9.0327 & TRN & & \\
\hline CHEMBL3426036 & 1476004 & 8.283999 & 9999999 & 99 & 8.2308 & TRN \\
\hline CHEMBL3426075 & 1476004 & 7.5086 & 7.6047 & TRN & & \\
\hline CHEMBL3426190 & 1476004 & 7.6021 & 7.6457 & TST & & \\
\hline CHEMBL3426069 & 1476004 & 7.3372 & 7.4332 & TRN & & \\
\hline CHEMBL548252 & 1476004 & 6.6882 & 7.4396 & TST & & \\
\hline CHEMBL3426086 & 1476004 & 7.585 & 7.6333 & TRN & & \\
\hline CHEMBL3426063 & 1476004 & 8.1549 & 8.6846 & TST & & \\
\hline CHEMBL3426083 & 1476004 & 7.5086 & 7.4082 & TRN & & \\
\hline CHEMBL3426191 & 1476004 & 8.0458 & 7.9345 & TST & & \\
\hline CHEMBL3426186 & 1476004 & 8.1549 & 7.8186 & TST & & \\
\hline CHEMBL3426189 & 1476004 & 7.8239 & 7.7862 & TST & & \\
\hline CHEMBL 3426188 & 1476004 & 6.0 & 7.6391 & TST & & \\
\hline CHEMBL3426078 & 1476004 & 7.7696 & 7.8174 & TRN & & \\
\hline CHEMBL 3426071 & 1476004 & 7.585 & 7.6455 & TRN & & \\
\hline CHEMBL3426077 & 1476004 & 7.6576 & 7.8328 & TRN & & \\
\hline CHEMBL 3426082 & 1476004 & 7.301 & 7.4494 & TRN & & \\
\hline CHEMBL 3426185 & 1476004 & 7.0706 & 7.3831 & TST & & \\
\hline CHEMBL3426032 & 1476004 & 8.8861 & 8.8374 & TRN & & \\
\hline CHEMBL3426039 & 1476004 & 8.8539 & 8.8863 & TRN & & \\
\hline CHEMBL 3426067 & 1476004 & 9.1079 & 9.2819 & TRN & & \\
\hline CHEMBL 3426064 & 1476004 & 9.0458 & 9.2595 & TRN & & \\
\hline CHEMBL1491238 & 737022 & 5.9547 & 5.1406 & TRN & & \\
\hline CHEMBL277148 & 737022 & 3.0969 & 3.3562 & TRN & & \\
\hline CHEMBL3197908 & 737022 & 5.6819 & 4.7998 & TRN & & \\
\hline CHEMBL1359872 & 737022 & 3.0969 & 3.2726 & TRN & & \\
\hline CHEMBL1396619 & 737022 & 5.9666 & 4.9545 & TRN & & \\
\hline CHEMBL3190028 & 737022 & 4.6326 & 4.0526 & TRN & & \\
\hline CHEMBL1448627 & 737022 & 5.9914 & 5.0927 & TST & & \\
\hline CHEMBL1448282 & 737022 & 3.0969 & 4.7722 & TRN & & \\
\hline CHEMBL3195389 & 737022 & 7.7959 & 6.9102 & TRN & & \\
\hline CHEMBL1491637 & 737022 & 3.0969 & 4.7128 & TRN & & \\
\hline CHEMBL1416089 & 737022 & 5.8477 & 5.2129 & TRN & & \\
\hline CHEMBL1983939 & 737022 & 3.0969 & 4.0886 & TRN & & \\
\hline CHEMBL577635 & 737022 & 5.4841 & 4.9122 & TST & & \\
\hline CHEMBL 2005364 & 737022 & 3.0969 & 3.5485 & TRN & & \\
\hline CHEMBL1326180 & 737022 & 5.4283 & 4.5579 & TRN & & \\
\hline CHEMBL1590553 & 737022 & 3.0969 & 3.5353 & TRN & & \\
\hline
\end{tabular}

Page 6919 
Supplemental Table S2.txt

\begin{tabular}{|c|c|c|c|c|}
\hline CHEMBL1380996 & 737022 & 4.1343 & 3.6757 & TRN \\
\hline CHEMBL1467533 & 737022 & 4.7328 & 3.4773 & TRN \\
\hline CHEMBL1577966 & 737022 & 3.0969 & 3.6949 & TST \\
\hline CHEMBL1484487 & 737022 & 4.6459 & 3.4074 & TST \\
\hline CHEMBL1547706 & 737022 & 3.0969 & 4.1419 & TRN \\
\hline CHEMBL1553738 & 737022 & 4.3233 & 4.3841 & TRN \\
\hline CHEMBL1486253 & 737022 & 3.0969 & 4.3606 & TST \\
\hline CHEMBL1608078 & 737022 & 6.4089 & 4.585 & TRN \\
\hline CHEMBL 297323 & 737022 & 4.2255 & 3.1681 & TRN \\
\hline CHEMBL1368007 & 737022 & 3.0969 & 3.4402 & TRN \\
\hline CHEMBL1341442 & 737022 & 3.0969 & 3.3369 & TRN \\
\hline CHEMBL1370513 & 737022 & 3.0969 & 4.3838 & TRN \\
\hline CHEMBL1475824 & 737022 & 3.0969 & 3.1744 & TRN \\
\hline CHEMBL1504565 & 737022 & 4.3595 & 3.3823 & TST \\
\hline CHEMBL1461730 & 737022 & 5.8327 & 6.2249 & TRN \\
\hline CHEMBL1481543 & 737022 & 6.0706 & 6.461 & TRN \\
\hline CHEMBL1419096 & 737022 & 3.0969 & 3.6918 & TRN \\
\hline CHEMBL1514534 & 737022 & 4.8386 & 4.7355 & TRN \\
\hline CHEMBL1465706 & 737022 & 3.0969 & 3.227 & TRN \\
\hline CHEMBL1425889 & 737022 & 4.3635 & 4.151 & TRN \\
\hline CHEMBL1450116 & 737022 & 4.2373 & 3.8465 & TRN \\
\hline CHEMBL1325943 & 737022 & 5.6757 & 6.081 & TRN \\
\hline CHEMBL1200512 & 737022 & 3.0969 & 4.9131 & TST \\
\hline CHEMBL1391582 & 737022 & 3.0969 & 3.2571 & TST \\
\hline CHEMBL1328466 & 737022 & 4.2255 & 3.6614 & TRN \\
\hline CHEMBL1415844 & 737022 & 3.0969 & 3.5212 & TRN \\
\hline CHEMBL1453108 & 737022 & 5.3307 & 4.6376 & TRN \\
\hline CHEMBL1491981 & 737022 & 3.0969 & 3.67100 & 0000000003 \\
\hline CHEMBL1520424 & 737022 & 3.0969 & 4.0846 & TRN \\
\hline CHEMBL1612997 & 737022 & 3.0969 & 3.4012 & TRN \\
\hline CHEMBL1339678 & 737022 & 6.3872 & 5.8388 & TRN \\
\hline CHEMBL1735990 & 737022 & 3.0969 & 3.0549 & TRN \\
\hline CHEMBL1990582 & 737022 & 5.9101 & 3.8129 & TRN \\
\hline CHEMBL1411912 & 737022 & 3.0969 & 3.9623 & TRN \\
\hline CHEMBL1309059 & 737022 & 4.8356 & 4.5442 & TRN \\
\hline CHEMBL1452795 & 737022 & 5.6421 & 5.2973 & TRN \\
\hline CHEMBL1562712 & 737022 & 4.9208 & 5.6046 & TRN \\
\hline CHEMBL590665 & 737022 & 3.0969 & 4.7567 & TRN \\
\hline CHEMBL1524929 & 737022 & 6.2757 & 4.9981 & TRN \\
\hline CHEMBL1387181 & 737022 & 3.0969 & 4.0357 & TST \\
\hline CHEMBL601180 & 737022 & 3.0969 & 3.2202 & TRN \\
\hline CHEMBL1732859 & 737022 & 3.0969 & 3.5766 & TRN \\
\hline CHEMBL 2007135 & 737022 & 4.341 & 3.5956 & TRN \\
\hline CHEMBL1362055 & 737022 & 3.0969 & 4.1414 & TRN \\
\hline CHEMBL1454029 & 737022 & 3.0969 & 3.9795 & TRN \\
\hline CHEMBL1729978 & 737022 & 3.0969 & 4.1588 & TRN \\
\hline CHEMBL 303579 & 737022 & 5.2449 & 5.3168 & TRN \\
\hline CHEMBL551783 & 737022 & 4.4522 & 4.3237 & TRN \\
\hline
\end{tabular}


Supplemental Table S2.txt

\begin{tabular}{|c|c|c|c|c|}
\hline CHEMBL3189714 & 737022 & 5.1746 & 5.6081 & TRN \\
\hline CHEMBL1479240 & 737022 & 4.5129 & 3.6957 & TRN \\
\hline CHEMBL1309487 & 737022 & 3.0969 & 3.2452 & TRN \\
\hline CHEMBL1486874 & 737022 & 7.7959 & 5.6304 & TRN \\
\hline CHEMBL1300302 & 737022 & 4.2161 & 4.067 & TRN \\
\hline CHEMBL1490339 & 737022 & 3.0969 & 3.2515 & TRN \\
\hline CHEMBL1441701 & 737022 & 3.0969 & 3.2469 & TST \\
\hline CHEMBL1492096 & 737022 & 5.6003 & 3.3519 & TRN \\
\hline CHEMBL1577016 & 737022 & 3.0969 & 3.49 & TST \\
\hline CHEMBL1399125 & 737022 & 3.0969 & 5.5559 & TRN \\
\hline CHEMBL1600855 & 737022 & 5.0888 & 4.8404 & TRN \\
\hline CHEMBL1482542 & 737022 & 4.2865 & 5.7932 & TRN \\
\hline CHEMBL1367034 & 737022 & 3.0969 & 3.3274 & TRN \\
\hline CHEMBL1412127 & 737022 & 3.0969 & 4.3692 & TRN \\
\hline CHEMBL1547979 & 737022 & 3.0969 & 4.1324 & TST \\
\hline CHEMBL1321427 & 737022 & 4.1561 & 3.2782 & TRN \\
\hline CHEMBL3198970 & 737022 & 3.0969 & 4.1544 & TRN \\
\hline CHEMBL1322272 & 737022 & 3.0969 & 3.3249 & TRN \\
\hline CHEMBL1451284 & 737022 & 3.0969 & 3.4141 & TRN \\
\hline CHEMBL1504204 & 737022 & 5.2757 & 5.1214 & TRN \\
\hline CHEMBL1411639 & 737022 & 3.0969 & 3.0982 & TRN \\
\hline CHEMBL3195749 & 737022 & 5.3089 & 5.4821 & TRN \\
\hline CHEMBL532160 & 737022 & 5.3188 & 4.4354 & TRN \\
\hline CHEMBL1387610 & 737022 & 5.8962 & 5.6532 & TRN \\
\hline CHEMBL1544634 & 737022 & 3.0969 & 3.4409 & TST \\
\hline CHEMBL1393480 & 737022 & 4.1085 & 4.6779 & TRN \\
\hline CHEMBL1348108 & 737022 & 3.0969 & 3.1654 & TRN \\
\hline CHEMBL1326803 & 737022 & 3.0969 & 3.2399 & TRN \\
\hline CHEMBL1349116 & 737022 & 3.0969 & 3.6488 & TRN \\
\hline CHEMBL1387172 & 737022 & 3.0969 & 3.9251 & TRN \\
\hline CHEMBL1344838 & 737022 & 4.857 & 4.2057 & TRN \\
\hline CHEMBL1346039 & 737022 & 3.0969 & 3.3092 & TRN \\
\hline CHEMBL1577720 & 737022 & 5.2277 & 4.5975 & TST \\
\hline CHEMBL1486690 & 737022 & 4.5935 & 3.5251 & TST \\
\hline CHEMBL1714557 & 737022 & 3.0969 & 3.1728 & TRN \\
\hline CHEMBL1987894 & 737022 & 5.2848 & 5.6159 & TRN \\
\hline CHEMBL1487720 & 737022 & 3.0969 & 3.2625 & TRN \\
\hline CHEMBL1998940 & 737022 & 4.8928 & 4.1936 & TST \\
\hline CHEMBL1304363 & 737022 & 7.7959 & 4.908 & TRN \\
\hline CHEMBL1357620 & 737022 & 3.0969 & 3.5281 & TST \\
\hline CHEMBL1460440 & 737022 & 3.0969 & 3.261 & TRN \\
\hline CHEMBL1300273 & 737022 & 3.0969 & 3.0869 & TRN \\
\hline CHEMBL1565338 & 737022 & 3.0969 & 3.7079 & TRN \\
\hline CHEMBL579322 & 737022 & 3.0969 & 3.1539 & TRN \\
\hline CHEMBL1327693 & 737022 & 3.0969 & 3.4595 & TRN \\
\hline CHEMBL1357385 & 737022 & 3.0969 & 4.1099 & TRN \\
\hline CHEMBL1548471 & 737022 & 4.4225 & 4.74100 & 00000000005 \\
\hline CHEMBL1606309 & 737022 & 5.2757 & 3.5608 & TRN \\
\hline
\end{tabular}




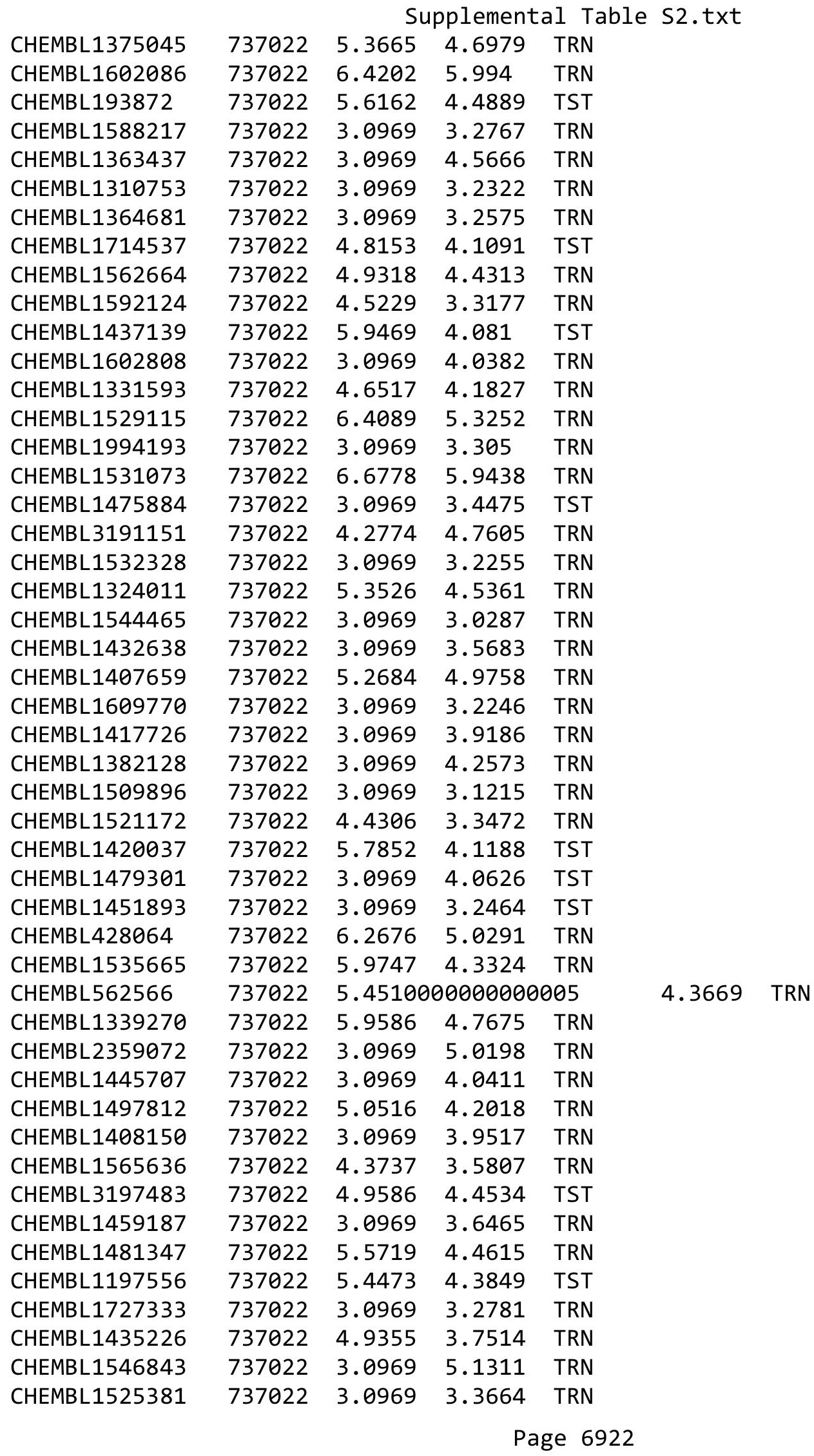




\begin{tabular}{|c|c|c|c|c|c|}
\hline & & \multicolumn{4}{|c|}{ Supplemental Table S2.txt } \\
\hline CHEMBL603129 & 737022 & 3.0969 & 3.4688 & TRN & \\
\hline CHEMBL3191453 & 737022 & 4.4597 & 3.4985 & TRN & \\
\hline CHEMBL1348332 & 737022 & 3.0969 & 3.4692 & TST & \\
\hline CHEMBL1544486 & 737022 & 3.0969 & 4.3235 & TRN & \\
\hline CHEMBL1482145 & 737022 & 3.0969 & 3.1642 & TRN & \\
\hline CHEMBL1548492 & 737022 & 3.0969 & 4.6532 & TRN & \\
\hline CHEMBL1461400 & 737022 & 5.7959 & 4.9438 & TRN & \\
\hline CHEMBL1524095 & 737022 & 3.0969 & 3.3023 & TRN & \\
\hline CHEMBL3191855 & 737022 & 5.6615 & 5.6014 & TRN & \\
\hline CHEMBL1519651 & 737022 & 3.0969 & 3.4362 & TRN & \\
\hline CHEMBL1418818 & 737022 & 5.8013 & 4.7908 & TRN & \\
\hline CHEMBL1343568 & 737022 & \multicolumn{2}{|c|}{5.4510000000000005} & 5.0911 & TRN \\
\hline CHEMBL580955 & 737022 & 3.0969 & 5.3491 & TRN & \\
\hline CHEMBL1501242 & 737022 & 3.0969 & 3.8679 & TST & \\
\hline CHEMBL1422161 & 737022 & 4.8239 & 4.4419 & TRN & \\
\hline CHEMBL1424127 & 737022 & 3.0969 & 4.4254 & TRN & \\
\hline CHEMBL482116 & 737022 & 5.3757 & 5.5861 & TRN & \\
\hline CHEMBL1364793 & 737022 & 3.0969 & 3.0276 & TRN & \\
\hline CHEMBL1321754 & 737022 & 6.0269 & 4.7288 & TRN & \\
\hline CHEMBL1574879 & 737022 & 6.2218 & 5.4598 & TRN & \\
\hline CHEMBL1506503 & 737022 & 7.7959 & 5.9087 & TRN & \\
\hline CHEMBL1371989 & 737022 & 3.0969 & 3.2653 & TRN & \\
\hline CHEMBL1533321 & 737022 & 3.0969 & 3.4576 & TST & \\
\hline CHEMBL1343823 & 737022 & 6.1024 & 4.245 & TRN & \\
\hline CHEMBL1526339 & 737022 & 3.0969 & 3.2856 & TRN & \\
\hline CHEMBL1513046 & 737022 & 4.8729 & 3.5848 & TRN & \\
\hline CHEMBL1361989 & 737022 & 3.0969 & 3.9532 & TRN & \\
\hline CHEMBL1964614 & 737022 & 4.2097 & 4.2721 & TRN & \\
\hline CHEMBL1505088 & 737022 & 3.0969 & 3.2192 & TRN & \\
\hline CHEMBL1612042 & 737022 & 5.9872 & 4.8674 & TRN & \\
\hline CHEMBL1407572 & 737022 & 3.0969 & 3.4366 & TST & \\
\hline CHEMBL 78150 & 737022 & 3.0969 & 3.69199 & 99999999997 & TST \\
\hline CHEMBL1489779 & 737022 & 3.0969 & 4.1851 & TRN & \\
\hline CHEMBL1310479 & 737022 & 4.5086 & 3.5365 & TRN & \\
\hline CHEMBL1329237 & 737022 & 3.0969 & 4.1903 & TRN & \\
\hline CHEMBL1723154 & 737022 & 3.0969 & 3.2329 & TRN & \\
\hline CHEMBL1613639 & 737022 & 3.0969 & 2.9799 & TRN & \\
\hline CHEMBL600100 & 737022 & 3.0969 & 3.3069 & TRN & \\
\hline CHEMBL1460007 & 737022 & 3.0969 & 3.2416 & TRN & \\
\hline CHEMBL1529161 & 737022 & 5.0862 & 4.2772 & TRN & \\
\hline CHEMBL600060 & 737022 & 3.0969 & 3.1227 & TRN & \\
\hline CHEMBL1360484 & 737022 & 3.0969 & 3.0823 & TRN & \\
\hline CHEMBL1343705 & 737022 & 6.4685 & 4.7654 & TRN & \\
\hline CHEMBL414890 & 737022 & 5.7905 & 5.2934 & TST & \\
\hline CHEMBL1712891 & 737022 & 3.0969 & 3.4633 & TRN & \\
\hline CHEMBL1373096 & 737022 & 3.0969 & 4.8868 & TRN & \\
\hline CHEMBL1713509 & 737022 & 3.0969 & 3.0932 & TRN & \\
\hline CHEMBL 261113 & 737022 & 3.0969 & 3.0787 & TRN & \\
\hline
\end{tabular}




\begin{tabular}{|c|c|c|c|c|c|}
\hline & & \multicolumn{4}{|c|}{ Supplemental Table S2.txt } \\
\hline CHEMBL1515023 & 737022 & 3.0969 & 3.9309 & TRN & \\
\hline CHEMBL3199403 & 737022 & 5.5086 & 4.3863 & TRN & \\
\hline CHEMBL1368418 & 737022 & 3.0969 & 3.2248 & TRN & \\
\hline CHEMBL15968 & 737022 & 3.0969 & 3.9793 & TRN & \\
\hline CHEMBL1466542 & 737022 & 3.0969 & 3.1621 & TRN & \\
\hline CHEMBL1528469 & 737022 & 4.9914 & 4.8119 & TST & \\
\hline CHEMBL1377737 & 737022 & 5.8041 & 5.23600 & 0000000001 & TRN \\
\hline CHEMBL 222409 & 737022 & 3.0969 & 3.6804 & TRN & \\
\hline CHEMBL1362402 & 737022 & 3.0969 & 3.1995 & TRN & \\
\hline CHEMBL1439227 & 737022 & 4.1192 & 3.1443 & TRN & \\
\hline CHEMBL1444542 & 737022 & 3.0969 & 4.1732 & TST & \\
\hline CHEMBL1300558 & 737022 & 3.0969 & 2.9722 & TRN & \\
\hline CHEMBL1468181 & 737022 & 6.0555 & 5.5839 & TRN & \\
\hline CHEMBL1467599 & 737022 & 3.0969 & 3.155 & TST & \\
\hline CHEMBL1374527 & 737022 & 3.0969 & 4.3395 & TRN & \\
\hline CHEMBL1422378 & 737022 & 4.6421 & 3.6291 & TRN & \\
\hline CHEMBL1493942 & 737022 & 4.2147 & 4.2821 & TRN & \\
\hline CHEMBL1605536 & 737022 & 5.4112 & 4.6399 & TRN & \\
\hline CHEMBL576349 & 737022 & 4.2034 & 4.2794 & TRN & \\
\hline CHEMBL1498959 & 737022 & 3.0969 & 3.2717 & TRN & \\
\hline CHEMBL1447442 & 737022 & 3.0969 & 3.2215 & TRN & \\
\hline CHEMBL1564136 & 737022 & 6.6383 & 6.5824 & TST & \\
\hline CHEMBL1335846 & 737022 & 6.1549 & 4.5695 & TRN & \\
\hline CHEMBL1304383 & 737022 & 3.0969 & 3.1348 & TRN & \\
\hline CHEMBL1457201 & 737022 & 4.7235 & 4.1049 & TRN & \\
\hline CHEMBL1704858 & 737022 & 3.0969 & 3.458 & TRN & \\
\hline CHEMBL1494120 & 737022 & 6.7447 & 5.4698 & TRN & \\
\hline CHEMBL1515116 & 737022 & 3.0969 & 3.3624 & TRN & \\
\hline CHEMBL1528118 & 737022 & 3.0969 & 3.2037 & TRN & \\
\hline CHEMBL252387 & 737022 & 4.2581 & 4.3775 & TRN & \\
\hline CHEMBL1390968 & 737022 & 3.0969 & 3.1728 & TRN & \\
\hline CHEMBL1400298 & 737022 & 5.4921 & 5.2865 & TRN & \\
\hline CHEMBL1379970 & 737022 & 5.9469 & 5.4261 & TRN & \\
\hline CHEMBL1346034 & 737022 & 3.0969 & 4.0314 & TRN & \\
\hline CHEMBL590927 & 737022 & 3.0969 & 5.0252 & TRN & \\
\hline CHEMBL1469379 & 737022 & 3.0969 & 3.33399 & 99999999996 & TRN \\
\hline CHEMBL3145303 & 737022 & 3.0969 & 4.7162 & TRN & \\
\hline CHEMBL1580219 & 737022 & 3.0969 & 3.2068 & TRN & \\
\hline CHEMBL1569585 & 737022 & 5.9957 & 4.67399 & 99999999995 & TRN \\
\hline CHEMBL1448642 & 737022 & 4.2907 & 3.9249 & TRN & \\
\hline CHEMBL585502 & 737022 & 5.5467 & 3.8913 & TRN & \\
\hline CHEMBL1346432 & 737022 & 3.0969 & 4.0348 & TRN & \\
\hline CHEMBL1497999 & 737022 & 4.4698 & 3.3252 & TRN & \\
\hline CHEMBL1359789 & 737022 & 3.0969 & 5.3543 & TRN & \\
\hline CHEMBL1524791 & 737022 & 3.0969 & 3.2524 & TRN & \\
\hline CHEMBL1564737 & 737022 & 5.1778 & 3.4793 & TRN & \\
\hline CHEMBL1445297 & 737022 & 3.0969 & 3.9773 & TRN & \\
\hline CHEMBL1418095 & 737022 & 3.0969 & 3.1716 & TRN & \\
\hline
\end{tabular}


Supplemental Table S2.txt

\begin{tabular}{|c|c|c|c|c|}
\hline W & & & & \\
\hline & 37022 & 3.0969 & 3.9781 & \\
\hline$-\sigma_{2}$ & 22 & & & \\
\hline AEMBL15 & 7022 & & & S \\
\hline AEMBL 374107 & 37022 & & & \\
\hline HEMBL 580918 & 37022 & 5607 & 5706 & \\
\hline HEMBL1 & 22 & 969 & & \\
\hline AFMBI 13 & & & & \\
\hline HEMBL15 & 22 & 5364 & 2848 & \\
\hline HEMBL1566488 & 37022 & 739 & .8945 & \\
\hline HEMBL1306460 & 37 & 59 & 89 & \\
\hline EMBL15 & 22 & 69 & 83 & \\
\hline AEMBL1: & & & & \\
\hline HEMBL15. & 22 & 729 & 5.1767 & \\
\hline HEMBL151 & 2 & 59 & & \\
\hline AEMBL13 & 2 & 969 & 89 & \\
\hline AEMBL14 & 2 & 59 & & \\
\hline HEMBL14 & 2 & & 1938 & \\
\hline HEMBL14 & 2 & 969 & 3.36 & \\
\hline AEMBL15 & & & & \\
\hline EIMBLI & 2 & 33 & 12 & NIV \\
\hline HEMBLI & 2 & & & 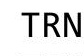 \\
\hline HEMBL1C & 2 & & & \\
\hline 20 & & & & \\
\hline AEMBL14 & & & & 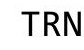 \\
\hline HEMBL5 & 2 & & 29 & KIV \\
\hline HEMBLI & 2 & & & RN \\
\hline HFMBI 1 & 2 & & 358 & RN \\
\hline AEMBL15 & & & & זער \\
\hline HEMBL136 & & & & ISI \\
\hline HEMBL31 & 2 & 6 & & RIV \\
\hline HEMBLI & 2 & & 01 & \\
\hline $15 \mathrm{MPI}$ & & 9 & & \\
\hline HEMBL1609686 & & & & IRN \\
\hline HEMBL1392570 & 2 & & 31 & TRN \\
\hline HEMBL1: & & 5 & 87 & \\
\hline HEMRI 1 & 2 & 9 & 76 & RN \\
\hline HEMBL15 & & & & RN \\
\hline HEMBL131037 & 2 & 3947 & 183 & TRN \\
\hline AEMBL15 & & 59 & 261 & RN \\
\hline HEMBL1S & & 969 & 986 & \\
\hline HEMBL15 & & .0969 & 835 & TRN \\
\hline HEMBL14 & 2 & .0969 & 4108 & $\Gamma \mathrm{RN}$ \\
\hline HEMBL894 & 37 & 1938 & 139 & TRN \\
\hline MBL1 & & & 591 & $\mathrm{~N}$ \\
\hline HEMBL16 & & & & \\
\hline CHEMBL1469247 & & & 3.9394 & \\
\hline CHEMBL3196472 & 737022 & 4.2147 & 3.7545 & \\
\hline
\end{tabular}

Page 6925 
Supplemental Table S2.txt

\begin{tabular}{|c|c|c|c|c|}
\hline CHEMBL578944 & 737022 & 4.7905 & 4.6168 & TRN \\
\hline CHEMBL1397089 & 737022 & 5.4045 & 5.0419 & TRN \\
\hline CHEMBL1510984 & 737022 & 3.0969 & 4.5092 & TRN \\
\hline CHEMBL147514 & 737022 & 5.5918 & 4.5314 & TRN \\
\hline CHEMBL1372199 & 737022 & 3.0969 & 3.5964 & TRN \\
\hline CHEMBL1442155 & 737022 & 3.0969 & 3.4065 & TST \\
\hline CHEMBL467987 & 737022 & 4.8447 & 4.3424 & TST \\
\hline CHEMBL1354093 & 737022 & 3.0969 & 5.6706 & TRN \\
\hline CHEMBL1489149 & 737022 & 3.0969 & 3.199 & TRN \\
\hline CHEMBL 274070 & 737022 & 6.2076 & 5.5672 & TST \\
\hline CHEMBL1536342 & 737022 & 3.0969 & 4.0263 & TRN \\
\hline CHEMBL1499414 & 737022 & 3.0969 & 3.3705 & TRN \\
\hline CHEMBL585071 & 737022 & 5.0762 & 4.6658 & TST \\
\hline CHEMBL1979536 & 737022 & 4.118 & 4.06800 & 00000000005 \\
\hline CHEMBL1387338 & 737022 & 4.3947 & 5.396 & TRN \\
\hline CHEMBL154358 & 737022 & 3.0969 & 3.6023 & TRN \\
\hline CHEMBL1509493 & 737022 & 4.9469 & 3.4555 & TRN \\
\hline CHEMBL1515368 & 737022 & 3.0969 & 3.4049 & TRN \\
\hline CHEMBL1368103 & 737022 & 3.0969 & 3.3307 & TRN \\
\hline CHEMBL1493731 & 737022 & 3.0969 & 3.8262 & TRN \\
\hline CHEMBL1432368 & 737022 & 3.0969 & 3.2068 & TRN \\
\hline CHEMBL1331541 & 737022 & 3.0969 & 3.5211 & TRN \\
\hline CHEMBL1402010 & 737022 & 6.5229 & 5.5612 & TRN \\
\hline CHEMBL1350673 & 737022 & 3.0969 & 3.8054 & TRN \\
\hline CHEMBL1331836 & 737022 & 3.0969 & 3.2306 & TRN \\
\hline CHEMBL1445650 & 737022 & 5.9788 & 4.9472 & TRN \\
\hline CHEMBL1519279 & 737022 & 3.0969 & 3.1754 & TRN \\
\hline CHEMBL1465527 & 737022 & 6.5528 & 5.4522 & TST \\
\hline CHEMBL1463659 & 737022 & 5.3851 & 4.7196 & TRN \\
\hline CHEMBL1432251 & 737022 & 5.4789 & 5.1162 & TRN \\
\hline CHEMBL1427457 & 737022 & 3.0969 & 3.2854 & TRN \\
\hline CHEMBL1708144 & 737022 & 5.6421 & 4.342 & TRN \\
\hline CHEMBL1401965 & 737022 & 3.0969 & 4.0863 & TST \\
\hline CHEMBL1558755 & 737022 & 3.0969 & 3.3171 & TRN \\
\hline CHEMBL1596798 & 737022 & 4.4353 & 4.3733 & TRN \\
\hline CHEMBL1505209 & 737022 & 3.0969 & 4.0987 & TST \\
\hline CHEMBL1971142 & 737022 & 5.983 & 5.4641 & TRN \\
\hline CHEMBL316589 & 737022 & 4.7144 & 4.5172 & TRN \\
\hline CHEMBL 3199673 & 737022 & 6.0809 & 5.9828 & TRN \\
\hline CHEMBL1318526 & 737022 & 5.0655 & 4.704 & TRN \\
\hline CHEMBL1537452 & 737022 & 3.0969 & 3.8598 & TRN \\
\hline CHEMBL1734695 & 737022 & 3.0969 & 3.8311 & TRN \\
\hline CHEMBL1339245 & 737022 & 3.0969 & 4.67399 & 99999999995 \\
\hline CHEMBL1976638 & 737022 & 3.0969 & 5.9104 & TST \\
\hline CHEMBL1593286 & 737022 & 5.6904 & 5.1094 & TRN \\
\hline CHEMBL1971727 & 737022 & 5.4572 & 4.9412 & TRN \\
\hline CHEMBL1500188 & 737022 & 4.4737 & 3.4916 & TRN \\
\hline CHEMBL1481122 & 737022 & 3.0969 & 3.2949 & TST \\
\hline
\end{tabular}




\begin{tabular}{|c|c|c|c|c|c|}
\hline & & \multicolumn{4}{|c|}{ Supplemental Table S2.txt } \\
\hline CHEMBL1579258 & 737022 & 4.684 & 5.2898 & TST & \\
\hline CHEMBL265686 & 737022 & 6.1367 & 5.95 & TRN & \\
\hline CHEMBL1470568 & 737022 & 6.0655 & 6.1894 & TRN & \\
\hline CHEMBL1393195 & 737022 & 3.0969 & 4.2789 & TRN & \\
\hline CHEMBL1327496 & 737022 & 3.0969 & 4.0589 & TRN & \\
\hline CHEMBL1426542 & 737022 & 3.0969 & 3.2952 & TRN & \\
\hline CHEMBL1572746 & 737022 & 3.0969 & 3.7917 & TRN & \\
\hline CHEMBL1499792 & 737022 & 4.8861 & 4.8853 & TRN & \\
\hline CHEMBL1483593 & 737022 & 3.0969 & 3.4486 & TRN & \\
\hline CHEMBL3199286 & 737022 & 5.8239 & 4.5848 & TRN & \\
\hline CHEMBL1536981 & 737022 & 3.0969 & 4.168 & TRN & \\
\hline CHEMBL1547232 & 737022 & 4.8962 & 3.38 & TST & \\
\hline CHEMBL1538267 & 737022 & 4.5302 & 3.5742 & TRN & \\
\hline CHEMBL3195657 & 737022 & 4.9706 & 6.1486 & TRN & \\
\hline CHEMBL1332955 & 737022 & 4.7496 & 4.5571 & TST & \\
\hline CHEMBL1573994 & 737022 & 7.7959 & 6.8855 & TST & \\
\hline CHEMBL1492399 & 737022 & 5.9508 & 5.7203 & TRN & \\
\hline CHEMBL1530673 & 737022 & 3.0969 & 3.508 & TST & \\
\hline CHEMBL578502 & 737022 & 4.7471 & 4.1388 & TRN & \\
\hline CHEMBL1456851 & 737022 & 3.0969 & 3.4769 & TRN & \\
\hline CHEMBL1300908 & 737022 & 5.8633 & 4.9603 & TRN & \\
\hline CHEMBL1331290 & 737022 & 3.0969 & 3.4836 & TRN & \\
\hline CHEMBL1452130 & 737022 & 5.4841 & 3.6849 & TRN & \\
\hline CHEMBL1438667 & 737022 & 3.0969 & 4.0293 & TRN & \\
\hline CHEMBL1422513 & 737022 & 3.0969 & 4.6993 & TRN & \\
\hline CHEMBL1301125 & 737022 & 5.3536 & 5.6815 & TST & \\
\hline CHEMBL1441122 & 737022 & 5.7773 & 5.2813 & TRN & \\
\hline CHEMBL1450086 & 737022 & 5.0545 & 4.8221 & TRN & \\
\hline CHEMBL1592774 & 737022 & 4.1096 & 3.4519 & TRN & \\
\hline CHEMBL1331733 & 737022 & 3.0969 & 3.0829 & TRN & \\
\hline CHEMBL1564935 & 737022 & 3.0969 & 3.8504 & TRN & \\
\hline CHEMBL602722 & 737022 & 3.0969 & 4.2063 & TRN & \\
\hline CHEMBL1515626 & 737022 & 4.1701 & 4.1597 & TRN & \\
\hline CHEMBL1372889 & 737022 & 7.7959 & 5.7735 & TRN & \\
\hline CHEMBL1437715 & 737022 & 3.0969 & 3.17199 & 99999999997 & TRN \\
\hline CHEMBL486504 & 737022 & 3.0969 & 3.2144 & TRN & \\
\hline CHEMBL1542713 & 737022 & 3.0969 & 3.3393 & TRN & \\
\hline CHEMBL1371264 & 737022 & 3.0969 & 3.3915 & TRN & \\
\hline CHEMBL1427279 & 737022 & 5.1361 & 5.6615 & TRN & \\
\hline CHEMBL 2004141 & 737022 & 6.4089 & 6.4983 & TRN & \\
\hline CHEMBL1309542 & 737022 & 3.0969 & 3.6396 & TRN & \\
\hline CHEMBL1392611 & 737022 & 5.1163 & 6.1834 & TRN & \\
\hline CHEMBL1319502 & 737022 & 4.3363 & 3.839 & TRN & \\
\hline CHEMBL1543337 & 737022 & 5.3391 & 5.325 & TST & \\
\hline CHEMBL1409398 & 737022 & 4.4776 & 4.3453 & TRN & \\
\hline CHEMBL1720876 & 737022 & 5.4962 & 5.4639 & TST & \\
\hline CHEMBL1723033 & 737022 & 3.0969 & 4.352 & TRN & \\
\hline CHEMBL1309091 & 737022 & 5.0846 & 4.4035 & TRN & \\
\hline
\end{tabular}


Supplemental Table S2.txt

\begin{tabular}{|c|c|c|c|c|}
\hline CHEMBL 2135351 & 737022 & 3.0969 & 3.8737 & TRN \\
\hline CHEMBL1333314 & 737022 & 3.0969 & 3.1378 & TRN \\
\hline CHEMBL1420393 & 737022 & 5.4949 & 4.3471 & TRN \\
\hline CHEMBL1566108 & 737022 & 3.0969 & 3.6479 & TRN \\
\hline CHEMBL1606115 & 737022 & 3.0969 & 3.3602 & TRN \\
\hline CHEMBL1467999 & 737022 & 5.0757 & 3.612 & TRN \\
\hline CHEMBL1332347 & 737022 & 3.0969 & 3.3077 & TRN \\
\hline CHEMBL1429782 & 737022 & 3.0969 & 2.997 & TRN \\
\hline CHEMBL1600399 & 737022 & 5.4584 & 4.9343 & TRN \\
\hline CHEMBL1444020 & 737022 & 7.7959 & 5.46200 & 0000000001 \\
\hline CHEMBL1469224 & 737022 & 4.7167 & 4.1453 & TRN \\
\hline CHEMBL3199744 & 737022 & 3.0969 & 3.5414 & TST \\
\hline CHEMBL1412747 & 737022 & 3.0969 & 3.3317 & TST \\
\hline CHEMBL1346112 & 737022 & 3.0969 & 3.4284 & TRN \\
\hline CHEMBL1486664 & 737022 & 4.1824 & 3.8708 & TRN \\
\hline CHEMBL3194944 & 737022 & 5.3072 & 5.4673 & TRN \\
\hline CHEMBL1565007 & 737022 & 3.0969 & 4.1385 & TRN \\
\hline CHEMBL1440300 & 737022 & 6.2757 & 5.2749 & TRN \\
\hline CHEMBL1584985 & 737022 & 3.0969 & 4.0668 & TST \\
\hline CHEMBL1403322 & 737022 & 3.0969 & 3.011 & TRN \\
\hline CHEMBL3197767 & 737022 & 3.0969 & 4.756 & TRN \\
\hline CHEMBL1429850 & 737022 & 4.2457 & 3.5012 & TST \\
\hline CHEMBL1565526 & 737022 & 3.0969 & 3.3895 & TRN \\
\hline CHEMBL1430060 & 737022 & 3.0969 & 3.7211 & TRN \\
\hline CHEMBL1310995 & 737022 & 3.0969 & 4.2131 & TRN \\
\hline CHEMBL1335110 & 737022 & 3.0969 & 3.9143 & TRN \\
\hline CHEMBL 3190965 & 737022 & 5.6234 & 4.1151 & TRN \\
\hline CHEMBL1532525 & 737022 & 3.0969 & 4.276 & TRN \\
\hline CHEMBL1590016 & 737022 & 3.0969 & 4.3321 & TRN \\
\hline CHEMBL1303623 & 737022 & 4.6925 & 4.4746 & TRN \\
\hline CHEMBL3196754 & 737022 & 4.4001 & 5.1053 & TRN \\
\hline CHEMBL1602385 & 737022 & 3.0969 & 5.6808 & TRN \\
\hline CHEMBL579318 & 737022 & 5.3288 & 5.5998 & TRN \\
\hline CHEMBL1318350 & 737022 & 5.0273 & 4.7033 & TST \\
\hline CHEMBL1398260 & 737022 & 5.7959 & 4.2142 & TST \\
\hline CHEMBL1354927 & 737022 & 3.0969 & 3.4925 & TST \\
\hline CHEMBL1469102 & 737022 & 3.0969 & 3.4769 & TST \\
\hline CHEMBL1610875 & 737022 & 6.4318 & 4.9203 & TRN \\
\hline CHEMBL1538784 & 737022 & 6.1427 & 3.0553 & TRN \\
\hline CHEMBL1488760 & 737022 & 5.7144 & 4.8801 & TST \\
\hline CHEMBL1966865 & 737022 & 5.2487 & 3.6328 & TRN \\
\hline CHEMBL1481849 & 737022 & 5.3116 & 4.6011 & TST \\
\hline CHEMBL1444065 & 737022 & 3.0969 & 3.1066 & TRN \\
\hline CHEMBL1450748 & 737022 & 6.3279 & 5.1871 & TRN \\
\hline CHEMBL1452379 & 737022 & 5.1884 & 5.2701 & TST \\
\hline CHEMBL1339830 & 737022 & 4.6716 & 4.7936 & TRN \\
\hline CHEMBL1521217 & 737022 & 3.0969 & 5.4682 & TRN \\
\hline CHEMBL1610821 & 737022 & 4.2984 & 3.4002 & TRN \\
\hline
\end{tabular}




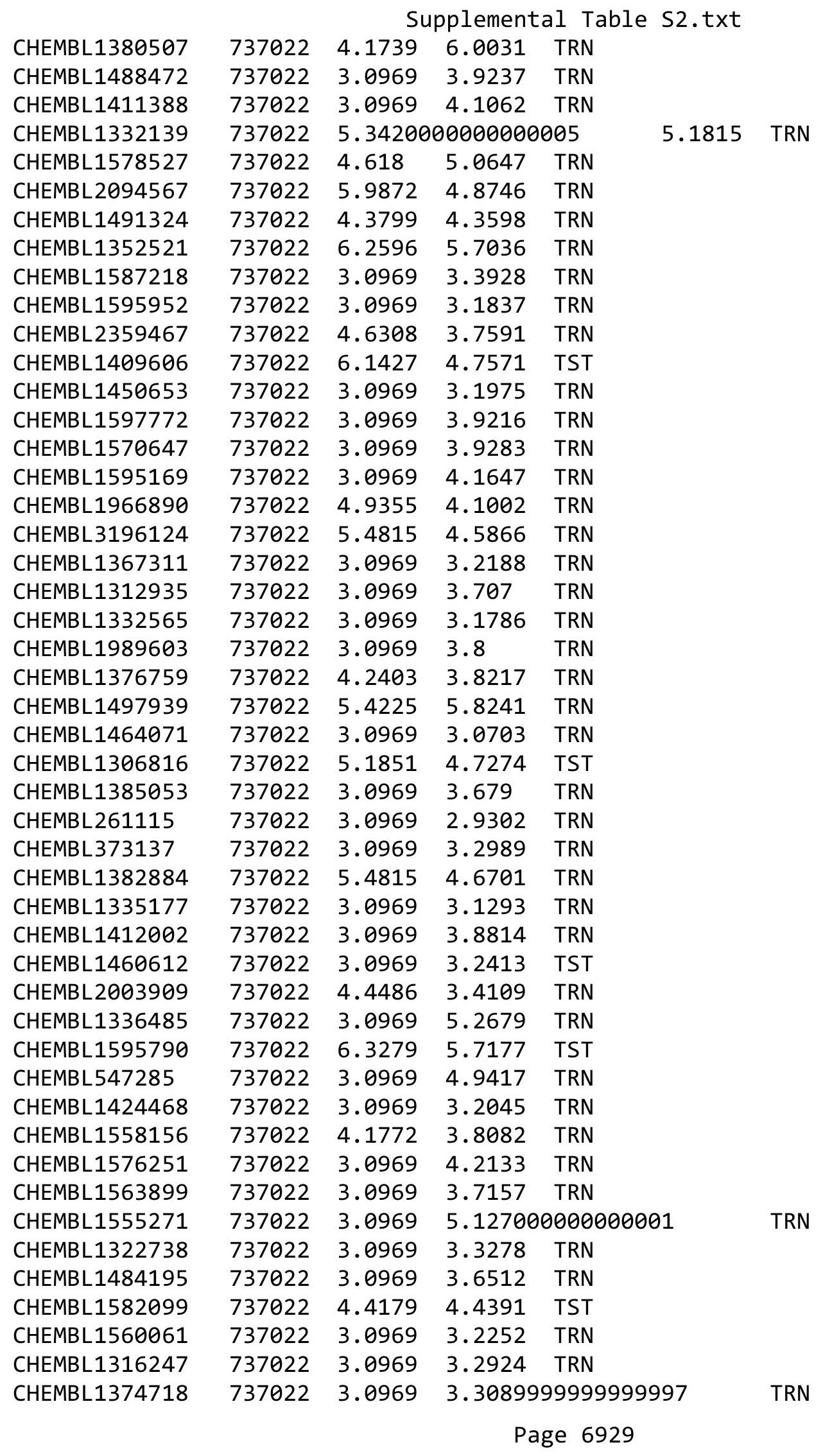


Supplemental Table S2.txt

\begin{tabular}{|c|c|c|c|c|}
\hline CHEMBL1456060 & 737022 & 3.0969 & 3.4965 & TST \\
\hline CHEMBL1495527 & 737022 & 3.0969 & 3.2007 & TRN \\
\hline CHEMBL1410857 & 737022 & 3.0969 & 3.4467 & TST \\
\hline CHEMBL1465720 & 737022 & 5.0804 & 3.1884 & TRN \\
\hline CHEMBL1585715 & 737022 & 3.0969 & 3.301 & TRN \\
\hline CHEMBL1524014 & 737022 & 3.0969 & 3.2782 & TST \\
\hline CHEMBL1480238 & 737022 & 4.6091 & 4.9599 & TRN \\
\hline CHEMBL 2002162 & 737022 & 5.9747 & 5.1937 & TST \\
\hline CHEMBL518292 & 737022 & 5.0985 & 5.1824 & TST \\
\hline CHEMBL1305054 & 737022 & 3.0969 & 3.488 & TRN \\
\hline CHEMBL1537124 & 737022 & 6.1024 & 3.2734 & TRN \\
\hline CHEMBL1307769 & 737022 & 3.0969 & 4.0324 & TRN \\
\hline CHEMBL408702 & 737022 & 3.0969 & 3.8654 & TRN \\
\hline CHEMBL1468786 & 737022 & 4.4101 & 4.3799 & TST \\
\hline CHEMBL578257 & 737022 & 5.0867 & 3.6977 & TST \\
\hline CHEMBL1317996 & 737022 & 3.0969 & 3.6245 & TRN \\
\hline CHEMBL455284 & 737022 & 6.2147 & 4.8896 & TRN \\
\hline CHEMBL1256655 & 737022 & 4.8013 & 4.23 & TRN \\
\hline CHEMBL578512 & 737022 & 5.5452 & 5.0595 & TRN \\
\hline CHEMBL1347071 & 737022 & 5.7033 & 4.4625 & TRN \\
\hline CHEMBL1365398 & 737022 & 3.0969 & 3.8514 & TRN \\
\hline CHEMBL1457561 & 737022 & 4.1035 & 3.5883 & TRN \\
\hline CHEMBL1558285 & 737022 & 4.3391 & 4.3732 & TRN \\
\hline CHEMBL1995045 & 737022 & 5.5884 & 4.2711 & TST \\
\hline CHEMBL577662 & 737022 & 5.4318 & 4.2848 & TRN \\
\hline CHEMBL1568294 & 737022 & 3.0969 & 4.0393 & TRN \\
\hline CHEMBL1599776 & 737022 & 5.6144 & 4.88 & TRN \\
\hline CHEMBL1522289 & 737022 & 3.0969 & 4.6943 & TRN \\
\hline CHEMBL1531170 & 737022 & 3.0969 & 4.3347 & TRN \\
\hline CHEMBL1586489 & 737022 & 3.0969 & 3.6182 & TRN \\
\hline CHEMBL1308547 & 737022 & 3.0969 & 4.2913 & TST \\
\hline CHEMBL1337659 & 737022 & 3.0969 & 3.8079 & TRN \\
\hline CHEMBL1468134 & 737022 & 5.3288 & 4.3149 & TRN \\
\hline CHEMBL586602 & 737022 & 6.4815 & 4.5706 & TRN \\
\hline CHEMBL1497681 & 737022 & 4.8041 & 3.9113 & TST \\
\hline CHEMBL1497989 & 737022 & 3.0969 & 3.4087 & TRN \\
\hline CHEMBL1538246 & 737022 & 4.7747 & 4.1531 & TST \\
\hline CHEMBL1596681 & 737022 & 4.9706 & 4.4615 & TRN \\
\hline CHEMBL1344025 & 737022 & 5.3979 & 3.6816 & TST \\
\hline CHEMBL1542868 & 737022 & 4.1549 & 3.7744 & TRN \\
\hline CHEMBL299613 & 737022 & 3.0969 & 3.6274 & TST \\
\hline CHEMBL1391377 & 737022 & 3.0969 & 3.8129 & TRN \\
\hline CHEMBL1608412 & 737022 & 3.0969 & 3.0617 & TRN \\
\hline CHEMBL1716112 & 737022 & 7.7959 & 4.5768 & TST \\
\hline CHEMBL3196134 & 737022 & 4.2336 & 4.5898 & TRN \\
\hline CHEMBL1396209 & 737022 & 6.5376 & 4.6422 & TRN \\
\hline CHEMBL1451921 & 737022 & 3.0969 & 4.45100 & 00000000005 \\
\hline CHEMBL1514530 & 737022 & 3.0969 & 4.8173 & TRN \\
\hline
\end{tabular}


Supplemental Table S2.txt

\begin{tabular}{|c|c|c|c|c|}
\hline CHEMBL1550278 & 737022 & 3.0969 & 3.5268 & TST \\
\hline CHEMBL1491621 & 737022 & 3.0969 & 3.3782 & TST \\
\hline CHEMBL1319414 & 737022 & 3.0969 & 3.2757 & TRN \\
\hline CHEMBL1393625 & 737022 & 5.2774 & 4.6614 & TRN \\
\hline CHEMBL1535490 & 737022 & 6.1308 & 5.2531 & TST \\
\hline CHEMBL1334514 & 737022 & 5.6144 & 5.1064 & TRN \\
\hline CHEMBL1330459 & 737022 & 5.7905 & 4.8735 & TST \\
\hline CHEMBL1302238 & 737022 & 4.6308 & 4.3768 & TRN \\
\hline CHEMBL1700777 & 737022 & 4.342 & 3.9513 & TRN \\
\hline CHEMBL1711969 & 737022 & 4.5331 & 3.7793 & TST \\
\hline CHEMBL3196351 & 737022 & 4.7305 & 4.2464 & TRN \\
\hline CHEMBL1400322 & 737022 & 3.0969 & 3.4291 & TST \\
\hline CHEMBL1569988 & 737022 & 6.7696 & 5.9955 & TRN \\
\hline CHEMBL1476264 & 737022 & 3.0969 & 4.5866 & TST \\
\hline CHEMBL1504701 & 737022 & 6.1427 & 3.9069 & TRN \\
\hline CHEMBL1381439 & 737022 & 4.8539 & 4.8929 & TST \\
\hline CHEMBL1462064 & 737022 & 3.0969 & 3.4589 & TRN \\
\hline CHEMBL1458747 & 737022 & 3.0969 & 3.3563 & TRN \\
\hline CHEMBL1483112 & 737022 & 5.1549 & 4.5043 & TRN \\
\hline CHEMBL1391387 & 737022 & 3.0969 & 4.5022 & TRN \\
\hline CHEMBL1502133 & 737022 & 5.7696 & 4.7478 & TRN \\
\hline CHEMBL1392776 & 737022 & 6.3372 & 5.7922 & TRN \\
\hline CHEMBL1420462 & 737022 & 4.8827 & 4.6673 & TST \\
\hline CHEMBL1519450 & 737022 & 3.0969 & 4.7498 & TRN \\
\hline CHEMBL1535161 & 737022 & 3.0969 & 3.5267 & TRN \\
\hline CHEMBL1363043 & 737022 & 3.0969 & 3.4675 & TRN \\
\hline CHEMBL1377693 & 737022 & 6.6021 & 3.3146 & TRN \\
\hline CHEMBL1344225 & 737022 & 7.7959 & 5.4046 & TRN \\
\hline CHEMBL1417428 & 737022 & 5.2916 & 5.0321 & TST \\
\hline CHEMBL1571885 & 737022 & 5.3429 & 3.9454 & TRN \\
\hline CHEMBL1575557 & 737022 & 3.0969 & 4.1256 & TST \\
\hline CHEMBL1303161 & 737022 & 3.0969 & 3.1409 & TRN \\
\hline CHEMBL1482052 & 737022 & 3.0969 & 3.3255 & TRN \\
\hline CHEMBL1561596 & 737022 & 3.0969 & 3.1088 & TRN \\
\hline CHEMBL 2360527 & 737022 & 3.0969 & 4.2382 & TRN \\
\hline CHEMBL1501091 & 737022 & 3.0969 & 3.4299 & TRN \\
\hline CHEMBL1995692 & 737022 & 3.0969 & 4.8582 & TRN \\
\hline CHEMBL1397445 & 737022 & 3.0969 & 3.938 & TRN \\
\hline CHEMBL1426762 & 737022 & 4.9706 & 4.7088 & TST \\
\hline CHEMBL1540099 & 737022 & 3.0969 & 3.3333 & TRN \\
\hline CHEMBL1300193 & 737022 & 3.0969 & 3.3744 & TRN \\
\hline CHEMBL1736070 & 737022 & 3.0969 & 3.4141 & TRN \\
\hline CHEMBL1459746 & 737022 & 4.5986 & 4.0191 & TRN \\
\hline CHEMBL1383415 & 737022 & 3.0969 & 3.2056 & TRN \\
\hline CHEMBL1457403 & 737022 & 4.2403 & 4.6684 & TRN \\
\hline CHEMBL1370884 & 737022 & 6.4949 & 5.86799 & 9999999999 \\
\hline CHEMBL1988042 & 737022 & 4.7305 & 4.3843 & TRN \\
\hline CHEMBL1989858 & 737022 & 4.5436 & 4.2245 & TST \\
\hline
\end{tabular}


Supplemental Table S2.txt

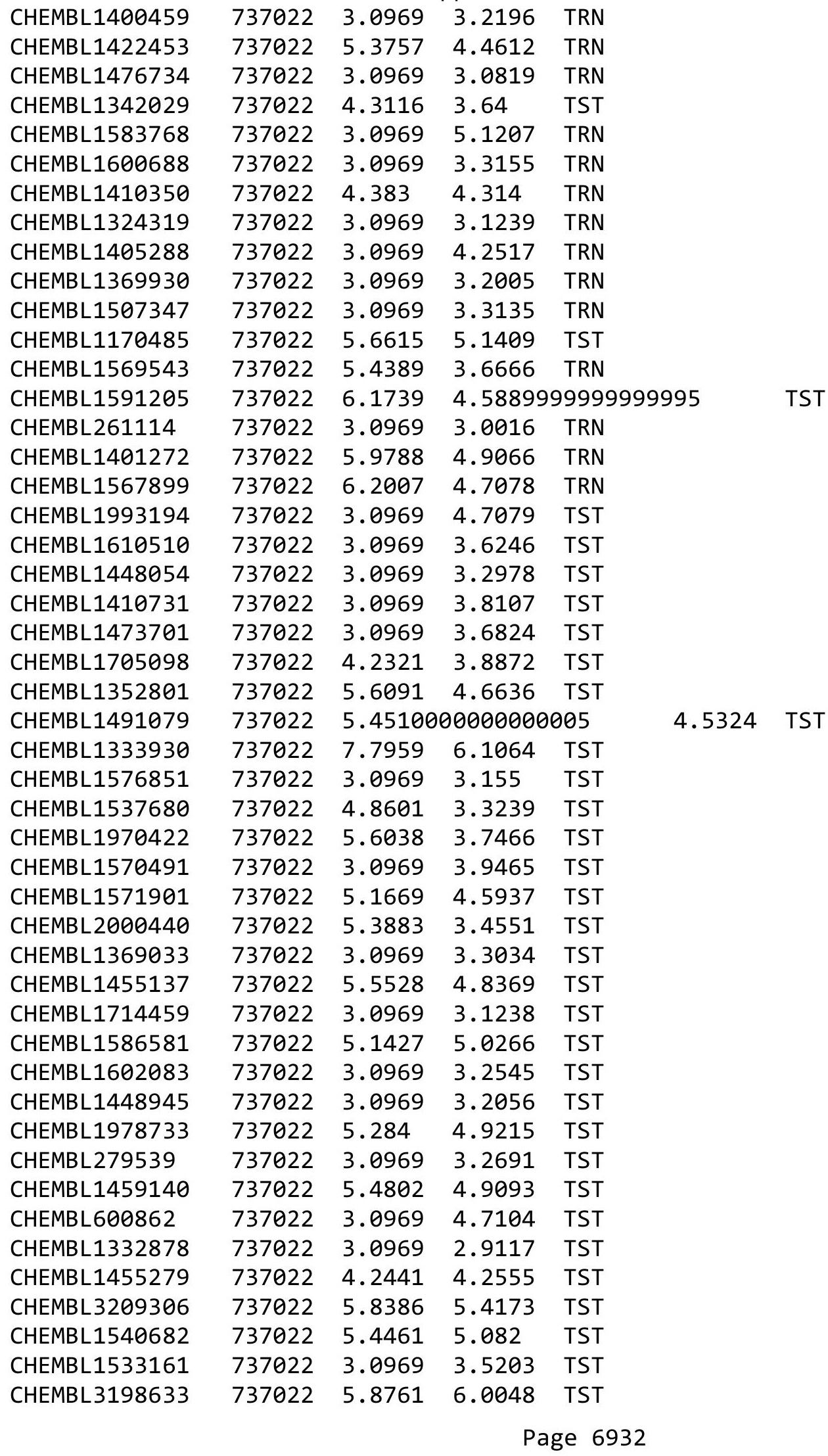


Supplemental Table S2.txt

\begin{tabular}{|c|c|c|c|c|}
\hline CHEMBL1372082 & 737022 & 3.0969 & 3.2615 & TST \\
\hline CHEMBL1382438 & 737022 & 5.8962 & 5.2942 & TST \\
\hline CHEMBL1587868 & 737022 & 3.0969 & 3.4748 & TST \\
\hline CHEMBL1703925 & 737022 & 3.0969 & 3.1289 & TST \\
\hline CHEMBL1383397 & 737022 & 4.1568 & 3.5549 & TST \\
\hline CHEMBL1598986 & 737022 & 3.0969 & 3.3068 & TST \\
\hline CHEMBL 2002169 & 737022 & 3.0969 & 3.4105 & TST \\
\hline CHEMBL1717082 & 737022 & 3.0969 & 3.3761 & TST \\
\hline CHEMBL 3194964 & 737022 & 4.9469 & 4.3551 & TST \\
\hline CHEMBL592600 & 737022 & 3.0969 & 5.1427 & TST \\
\hline CHEMBL1701791 & 737022 & 3.0969 & 3.4707 & TST \\
\hline CHEMBL1491534 & 737022 & 3.0969 & 3.13 & TST \\
\hline CHEMBL1720152 & 737022 & 4.1302 & 3.395 & TST \\
\hline CHEMBL1338667 & 737022 & 4.9957 & 4.5511 & TST \\
\hline CHEMBL1323433 & 737022 & 3.0969 & 3.2349 & TST \\
\hline CHEMBL1454000 & 737022 & 3.0969 & 3.2209 & TST \\
\hline CHEMBL601757 & 737022 & 5.4737 & 4.8687 & TST \\
\hline CHEMBL1573050 & 737022 & 3.0969 & 3.2533 & TST \\
\hline CHEMBL1309521 & 737022 & 3.0969 & 3.3178 & TST \\
\hline CHEMBL1459767 & 737022 & 5.2941 & 5.4159 & TST \\
\hline CHEMBL 3193419 & 737022 & 3.0969 & 4.6278 & TST \\
\hline CHEMBL494255 & 737022 & 5.9031 & 5.0431 & TST \\
\hline CHEMBL1332916 & 737022 & 3.0969 & 3.6153 & TST \\
\hline CHEMBL1299946 & 737022 & 3.0969 & 3.3384 & TST \\
\hline CHEMBL1410008 & 737022 & 3.0969 & 3.0931 & TST \\
\hline CHEMBL 586135 & 737022 & 6.0223 & 4.6671 & TST \\
\hline CHEMBL1333294 & 737022 & 3.0969 & 3.2349 & TST \\
\hline CHEMBL1491847 & 737022 & 5.1118 & $4.77800 e$ & 00000000005 \\
\hline CHEMBL1346284 & 737022 & 4.2749 & 4.2599 & TST \\
\hline CHEMBL1702373 & 737022 & 3.0969 & 3.1272 & TST \\
\hline CHEMBL1986418 & 737022 & 3.0969 & 3.6909 & TST \\
\hline CHEMBL1432507 & 737022 & 4.3279 & 3.5 & TST \\
\hline CHEMBL1545191 & 737022 & 3.0969 & 4.28 & TST \\
\hline CHEMBL195090 & 303552 & 9.2218 & 7.9142 & TRN \\
\hline CHEMBL 372508 & 303552 & 7.284 & 7.4009 & TRN \\
\hline CHEMBL436087 & 303552 & 6.0768 & 5.9068 & TRN \\
\hline CHEMBL363618 & 303552 & 7.5086 & 7.3596 & TRN \\
\hline CHEMBL193866 & 303552 & 8.0458 & 7.2118 & TRN \\
\hline CHEMBL195592 & 303552 & 7.5376 & 6.2577 & TST \\
\hline CHEMBL 372253 & 303552 & 7.4685 & 7.51 & TRN \\
\hline CHEMBL193743 & 303552 & 8.0 & 6.1673 & TST \\
\hline CHEMBL371851 & 303552 & 6.2832 & 7.6651 & TRN \\
\hline CHEMBL193632 & 303552 & 6.1739 & 7.4749 & TRN \\
\hline CHEMBL372317 & 303552 & 6.8729 & 7.6402 & TRN \\
\hline CHEMBL 370080 & 303552 & 5.1689 & 5.4311 & TRN \\
\hline CHEMBL191897 & 303552 & 5.0497 & 7.2858 & TST \\
\hline CHEMBL426090 & 303552 & 7.3665 & 7.4746 & TRN \\
\hline CHEMBL193608 & 303552 & 5.0922 & 7.1982 & TST \\
\hline
\end{tabular}


Supplemental Table S2.txt

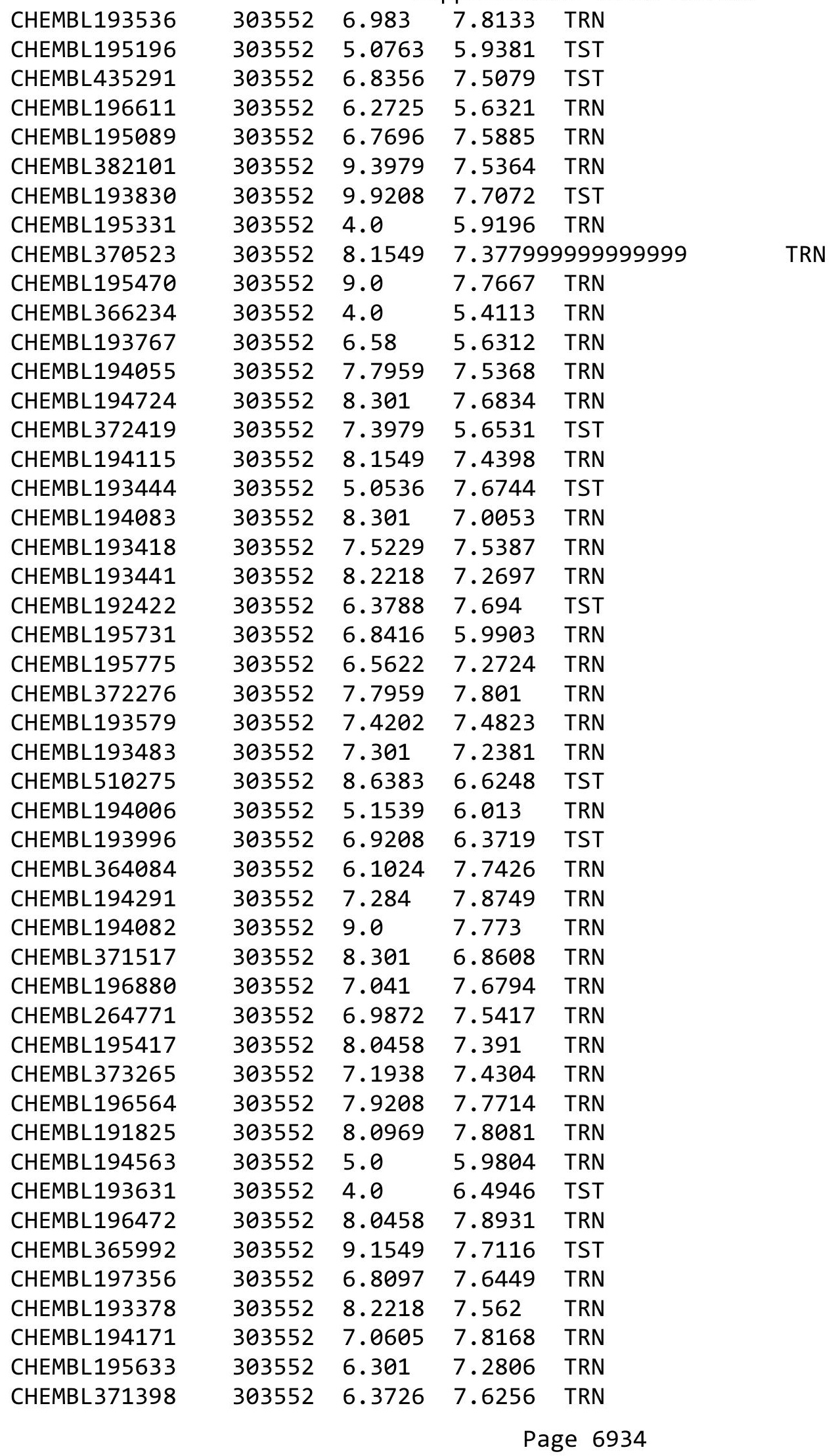




\begin{tabular}{|c|c|c|c|c|c|}
\hline \multirow[b]{2}{*}{ CHEMBL195601 } & \multicolumn{5}{|c|}{ Supplemental Table S2.txt } \\
\hline & 303552 & 7.4318 & 7.2984 & TRN & \\
\hline CHEMBL195873 & 303552 & 5.9234 & 5.4973 & TRN & \\
\hline CHEMBL194927 & 303552 & 7.2757 & 6.3551 & TST & \\
\hline CHEMBL193419 & 303552 & 7.3979 & 6.129 & TRN & \\
\hline CHEMBL193640 & 303552 & 7.1308 & 7.6121 & TST & \\
\hline CHEMBL197307 & 303552 & 6.6308 & 5.7056 & TST & \\
\hline CHEMBL194390 & 303552 & 8.2218 & 7.6992 & TST & \\
\hline CHEMBL1709821 & 737705 & 3.0 & 2.9241 & TRN & \\
\hline CHEMBL1726321 & 737705 & 5.1255 & 4.9497 & TRN & \\
\hline CHEMBL1508177 & 737705 & 3.0 & 2.971 & TRN & \\
\hline CHEMBL1548422 & 737705 & 4.1931 & 4.2435 & TRN & \\
\hline CHEMBL1495764 & 737705 & 3.0 & 2.9631 & TRN & \\
\hline CHEMBL1349518 & 737705 & 5.0269 & 3.648 & TST & \\
\hline CHEMBL1731262 & 737705 & 3.0 & 3.1023 & TRN & \\
\hline CHEMBL1497773 & 737705 & 5.8794 & 5.8775 & TRN & \\
\hline CHEMBL 1703558 & 737705 & 3.0 & 3.0647 & TRN & \\
\hline CHEMBL1715789 & 737705 & 3.0 & 2.9943 & TRN & \\
\hline CHEMBL 286404 & 737705 & 3.0 & 3.823 & TST & \\
\hline CHEMBL1462740 & 737705 & 4.6946 & $4.66100 t$ & 00000000005 & TRN \\
\hline CHEMBL1709549 & 737705 & 4.1586 & 4.17 & TRN & \\
\hline CHEMBL 3207758 & 737705 & 3.0 & 2.9446 & TRN & \\
\hline CHEMBL1732622 & 737705 & 3.0 & 3.017 & TRN & \\
\hline CHEMBL1581190 & 737705 & 3.0 & 3.0331 & TRN & \\
\hline CHEMBL1718734 & 737705 & 3.0 & 3.0328 & TRN & \\
\hline CHEMBL 3207500 & 737705 & 3.0 & 2.9185 & TRN & \\
\hline CHEMBL1699486 & 737705 & 3.0 & 2.968 & TRN & \\
\hline CHEMBL1387505 & 737705 & 3.0 & 3.0278 & TRN & \\
\hline CHEMBL1583797 & 737705 & 4.118 & 4.0717 & TRN & \\
\hline CHEMBL1522300 & 737705 & 4.9914 & 4.9694 & TRN & \\
\hline CHEMBL1722484 & 737705 & 3.0 & 3.0216 & TRN & \\
\hline CHEMBL1587882 & 737705 & 3.0 & 3.906 & TST & \\
\hline CHEMBL1599517 & 737705 & 4.8041 & 3.1638 & TST & \\
\hline CHEMBL 1445700 & 737705 & 4.8601 & 4.3477 & TST & \\
\hline CHEMBL1428441 & 737705 & 3.0 & 2.9982 & TRN & \\
\hline CHEMBL1524163 & 737705 & 3.0 & 3.0449 & TRN & \\
\hline CHEMBL1463019 & 737705 & 5.5544 & 4.8254 & TST & \\
\hline CHEMBL1540272 & 737705 & 3.0 & 3.0863 & TRN & \\
\hline CHEMBL1588650 & 737705 & 3.0 & 4.5556 & TST & \\
\hline CHEMBL1416302 & 737705 & 4.1051 & 3.3738 & TST & \\
\hline CHEMBL1385027 & 737705 & 4.1911 & 4.1804 & TRN & \\
\hline CHEMBL1699657 & 737705 & 3.0 & 4.7302 & TST & \\
\hline CHEMBL1313635 & 737705 & 3.0 & 2.9683 & TRN & \\
\hline CHEMBL1582492 & 737705 & 4.6536 & 3.5739 & TST & \\
\hline CHEMBL1422967 & 737705 & 3.0 & 3.0367 & TRN & \\
\hline CHEMBL1705486 & 737705 & 3.0 & 3.0262 & TRN & \\
\hline CHEMBL1485592 & 737705 & 5.3575 & 3.9926 & TST & \\
\hline CHEMBL1730395 & 737705 & 3.0 & 3.0477 & TRN & \\
\hline CHEMBL1715163 & 737705 & 3.0 & 2.9482 & TRN & \\
\hline
\end{tabular}




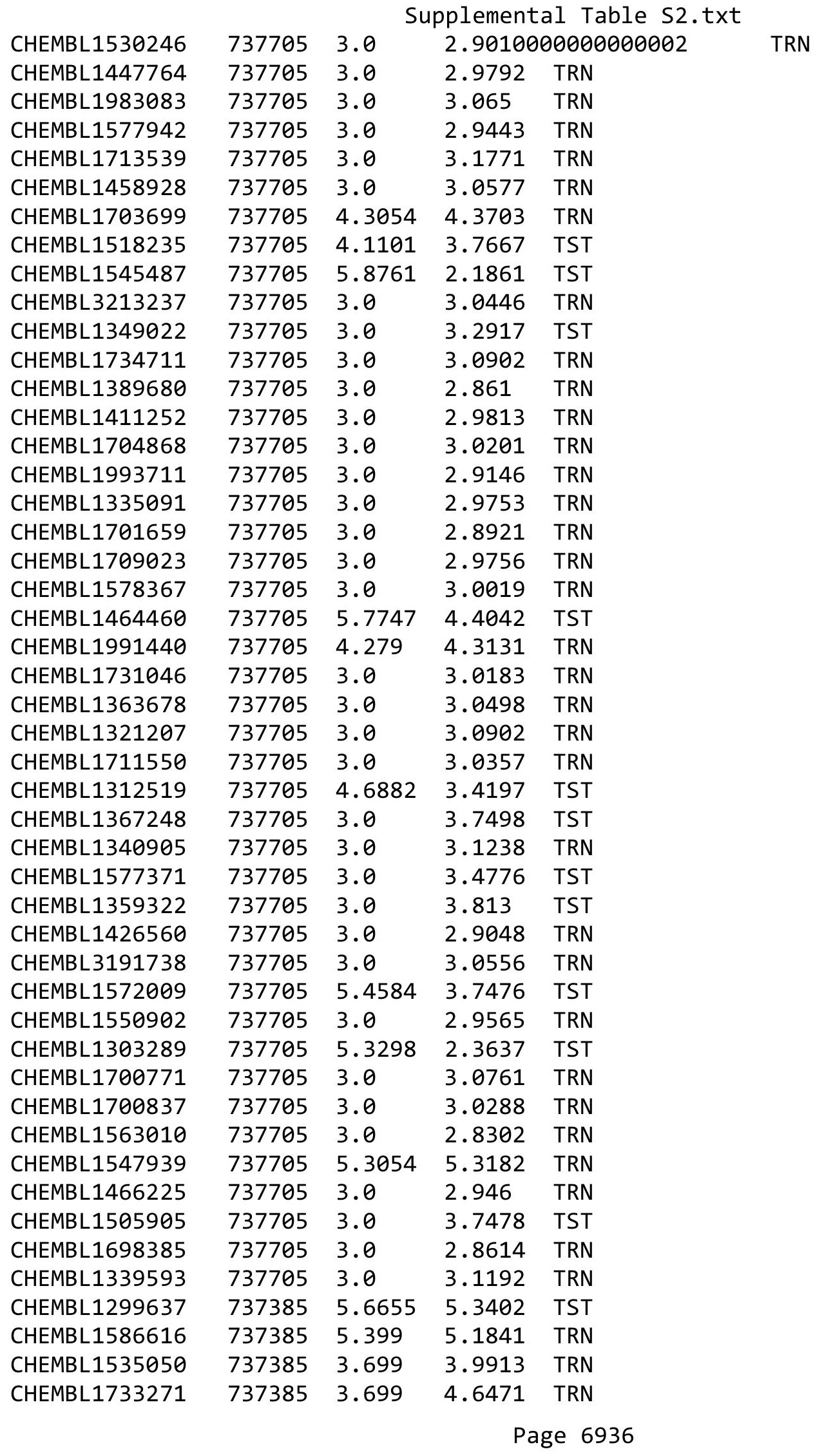




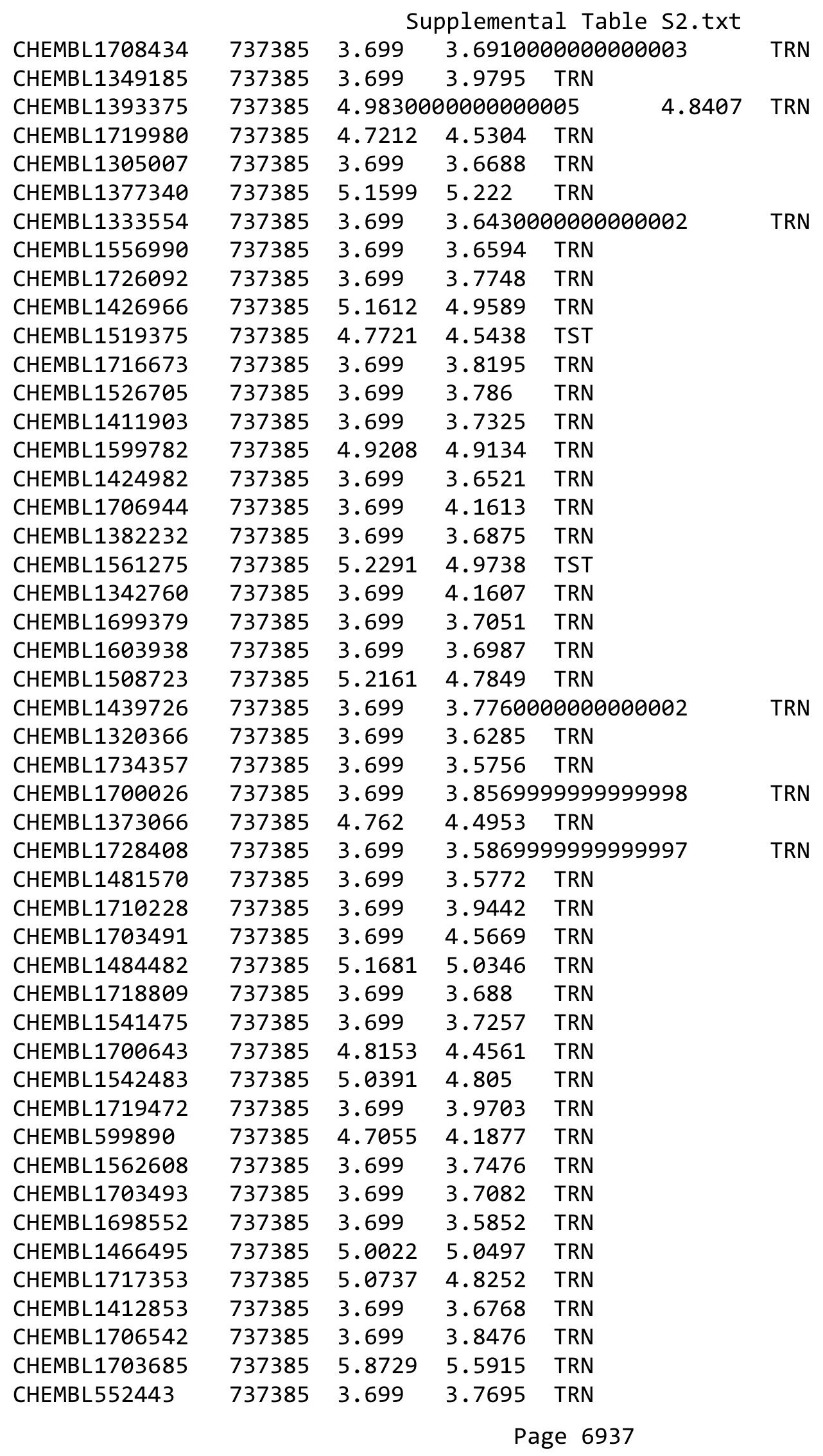




\begin{tabular}{|c|c|c|c|c|c|}
\hline & & \multicolumn{4}{|c|}{ Supplemental Table S2.txt } \\
\hline CHEMBL1332003 & 737385 & 3.699 & 3.5626 & TRN & \\
\hline CHEMBL1405985 & 737385 & 5.5331 & 5.2346 & TRN & \\
\hline CHEMBL1427550 & 737385 & 3.699 & 4.2821 & TST & \\
\hline CHEMBL1732865 & 737385 & 3.699 & 3.6036 & TRN & \\
\hline CHEMBL1333987 & 737385 & 3.699 & 5.0388 & TST & \\
\hline CHEMBL1405076 & 737385 & 3.699 & 3.9717 & TRN & \\
\hline CHEMBL1370066 & 737385 & 3.699 & 3.5686 & TRN & \\
\hline CHEMBL1446570 & 737385 & 4.7352 & 4.9129 & TRN & \\
\hline CHEMBL1542558 & 737385 & 4.7799 & 4.6583 & TRN & \\
\hline CHEMBL1574961 & 737385 & 3.699 & 3.9377 & TRN & \\
\hline CHEMBL1717950 & 737385 & 3.699 & 3.6566 & TRN & \\
\hline CHEMBL1729430 & 737385 & 5.1007 & 4.9397 & TST & \\
\hline CHEMBL1387448 & 737385 & 3.699 & 3.6571 & TRN & \\
\hline CHEMBL1543504 & 737385 & 5.2291 & 5.0472 & TST & \\
\hline CHEMBL1521474 & 737385 & 4.7055 & 3.6824 & TRN & \\
\hline CHEMBL1731582 & 737385 & 3.699 & 4.6029 & TRN & \\
\hline CHEMBL229012 & 737385 & 3.699 & 3.6907 & TRN & \\
\hline CHEMBL1732890 & 737385 & 3.699 & 4.6935 & TRN & \\
\hline CHEMBL1735630 & 737385 & 3.699 & 3.5994 & TRN & \\
\hline CHEMBL1388356 & 737385 & 4.7496 & 4.6962 & TST & \\
\hline CHEMBL1708503 & 737385 & 5.7645 & 5.375 & TRN & \\
\hline CHEMBL1488993 & 737385 & 3.699 & 3.8144 & TRN & \\
\hline CHEMBL3145330 & 737385 & 3.699 & 4.0682 & TST & \\
\hline CHEMBL1482357 & 737385 & 3.699 & 3.9458 & TRN & \\
\hline CHEMBL1721154 & 737385 & 3.699 & 4.0172 & TRN & \\
\hline CHEMBL1716972 & 737385 & 3.699 & 4.05399 & 9999999999 & TRN \\
\hline CHEMBL1407805 & 737385 & 3.699 & 3.7435 & TRN & \\
\hline CHEMBL1487641 & 737385 & 3.699 & 3.5944 & TRN & \\
\hline CHEMBL1710033 & 737385 & 5.7905 & 5.4983 & TRN & \\
\hline CHEMBL1445071 & 737385 & 3.699 & 4.209 & TST & \\
\hline CHEMBL1462906 & 737385 & 5.1249 & 5.1618 & TRN & \\
\hline CHEMBL1434502 & 737385 & 4.8996 & 5.1084 & TRN & \\
\hline CHEMBL1445206 & 737385 & 3.699 & 3.9013 & TRN & \\
\hline CHEMBL1464332 & 737385 & 5.2984 & 5.1334 & TST & \\
\hline CHEMBL3192230 & 737385 & 5.2306 & 4.8289 & TRN & \\
\hline CHEMBL1731580 & 737385 & 3.699 & 3.6573 & TRN & \\
\hline CHEMBL1441295 & 737385 & 3.699 & 3.7073 & TRN & \\
\hline CHEMBL1730320 & 737385 & 3.699 & 3.9056 & TRN & \\
\hline CHEMBL1532172 & 737385 & 3.699 & 3.7437 & TRN & \\
\hline CHEMBL1717510 & 737385 & 3.699 & 3.5685 & TRN & \\
\hline CHEMBL1534716 & 737385 & 3.699 & 3.553 & TRN & \\
\hline CHEMBL1700382 & 737385 & 3.699 & 3.5985 & TRN & \\
\hline CHEMBL1701049 & 737385 & 3.699 & 3.6472 & TRN & \\
\hline CHEMBL1500624 & 737385 & 3.699 & 3.80899 & 99999999997 & TRN \\
\hline CHEMBL1384652 & 737385 & 5.1618 & 5.1474 & TRN & \\
\hline CHEMBL1712022 & 737385 & 4.7328 & 4.0041 & TRN & \\
\hline CHEMBL3199186 & 737385 & 3.699 & 4.048 & TST & \\
\hline CHEMBL1525546 & 737385 & 3.699 & 4.1153 & TST & \\
\hline
\end{tabular}




\begin{tabular}{|c|c|c|c|c|}
\hline \multicolumn{5}{|c|}{ Supplemental Table s2.txt } \\
\hline CHEMBL1716085 & 737385 & 3.699 & 3.6468 & TRN \\
\hline CHEMBL1354394 & 737385 & 4.8069 & 4.8495 & TRN \\
\hline CHEMBL1718692 & 737385 & 3.699 & 3.8548 & TRN \\
\hline CHEMBL1410618 & 737385 & 4.8013 & 3.6048 & TRN \\
\hline CHEMBL1387990 & 737385 & 4.8268 & 4.3525 & TST \\
\hline CHEMBL1581027 & 737385 & 3.699 & 3.705 & TRN \\
\hline CHEMBL1325644 & 737385 & 3.699 & 4.0003 & TRN \\
\hline CHEMBL1723575 & 737385 & 3.699 & 3.5568 & TRN \\
\hline CHEMBL1706268 & 737385 & 5.0343 & 4.7075 & TRN \\
\hline CHEMBL1730398 & 737385 & 3.699 & 4.0206 & TRN \\
\hline CHEMBL1312200 & 737385 & 5.1524 & 5.1673 & TST \\
\hline CHEMBL1736760 & 737385 & 3.699 & 3.6125 & TST \\
\hline CHEMBL1714566 & 737385 & 3.699 & 4.1595 & TST \\
\hline CHEMBL1724688 & 737385 & 3.699 & 3.6073 & TST \\
\hline CHEMBL1729147 & 737385 & 3.699 & 3.6949 & TST \\
\hline CHEMBL1491541 & 737385 & 4.9431 & 4.8522 & TST \\
\hline CHEMBL1529494 & 737385 & 5.0857 & 4.8954 & TST \\
\hline CHEMBL1611733 & 737385 & 5.0942 & 5.1156 & TST \\
\hline CHEMBL1323512 & 737385 & 5.4522 & 5.2749 & TST \\
\hline CHEMBL1993613 & 737385 & 3.699 & 4.1504 & TST \\
\hline CHEMBL1370183 & 737385 & 5.1543 & 4.9106 & TST \\
\hline CHEMBL1719579 & 737385 & 3.699 & 4.7664 & TST \\
\hline CHEMBL1704929 & 737385 & 3.699 & 3.6593 & TST \\
\hline CHEMBL1433326 & 737385 & 3.699 & 3.8308 & TST \\
\hline CHEMBL1338507 & 737385 & 3.699 & 3.7748 & TST \\
\hline CHEMBL1698647 & 737385 & 3.699 & 4.0047 & TST \\
\hline CHEMBL1387232 & 737385 & 3.699 & 4.2025 & TST \\
\hline CHEMBL1729457 & 737385 & 3.699 & 4.1585 & TST \\
\hline CHEMBL 2002446 & 809170 & 4.1 & 4.2283 & TST \\
\hline CHEMBL497151 & 809170 & 5.5 & 4.9681 & TRN \\
\hline CHEMBL1973961 & 809170 & 4.8 & 4.7231 & TRN \\
\hline CHEMBL 246970 & 809170 & 4.1 & 4.0403 & TRN \\
\hline CHEMBL340921 & 809170 & 7.8 & 7.5862 & TRN \\
\hline CHEMBL373598 & 809170 & 4.1 & 3.5779 & TST \\
\hline CHEMBL1999718 & 809170 & 4.1 & 4.2029 & TRN \\
\hline CHEMBL1987073 & 809170 & 4.4 & 5.6706 & TRN \\
\hline CHEMBL1276446 & 809170 & 7.3 & 6.2024 & TST \\
\hline CHEMBL1995712 & 809170 & 5.8 & 7.0246 & TRN \\
\hline CHEMBL1977346 & 809170 & 4.1 & 3.9621 & TRN \\
\hline CHEMBL 2003657 & 809170 & 4.1 & 3.931 & TRN \\
\hline CHEMBL1971649 & 809170 & 6.3 & 5.1808 & TRN \\
\hline CHEMBL1975440 & 809170 & 6.6 & 6.1576 & TRN \\
\hline CHEMBL1998435 & 809170 & 5.5 & 5.4541 & TRN \\
\hline CHEMBL2006439 & 809170 & 6.9 & 8.0402 & TRN \\
\hline CHEMBL 2006156 & 809170 & 4.1 & 4.1178 & TST \\
\hline CHEMBL1969190 & 809170 & 6.5 & 6.1981 & TRN \\
\hline CHEMBL1973937 & 809170 & 6.1 & 5.6228 & TRN \\
\hline CHEMBL1991674 & 809170 & 7.9 & 7.3562 & TRN \\
\hline
\end{tabular}




\begin{tabular}{|c|c|c|c|c|c|}
\hline \\
\hline CHEMBL1982711 & 809170 & 6.1 & 6.0875 & TRN & \\
\hline CHEMBL1987982 & 809170 & 4.1 & 4.2996 & TST & \\
\hline CHEMBL1984842 & 809170 & 4.1 & 4.1612 & TRN & \\
\hline CHEMBL1969102 & 809170 & 7.3 & 7.2823 & TRN & \\
\hline CHEMBL1682346 & 809170 & 7.1 & 6.4248 & TRN & \\
\hline CHEMBL 2007044 & 809170 & 4.1 & 4.1145 & TST & \\
\hline CHEMBL 2001998 & 809170 & 4.1 & 4.1821 & TST & \\
\hline CHEMBL1994241 & 809170 & 4.1 & 5.3609 & TRN & \\
\hline CHEMBL223460 & 809170 & 4.1 & 3.9671 & TST & \\
\hline CHEMBL1998829 & 809170 & 4.1 & 4.3689 & TRN & \\
\hline CHEMBL50894 & 809170 & 5.7 & 5.4045 & TRN & \\
\hline CHEMBL1988838 & 809170 & 6.8 & 6.4839 & TRN & \\
\hline CHEMBL1981725 & 809170 & 6.1 & 5.4298 & TRN & \\
\hline CHEMBL1982753 & 809170 & 6.6 & 6.6994 & TRN & \\
\hline CHEMBL 375284 & 809170 & 6.4 & 6.6703 & TRN & \\
\hline CHEMBL1972346 & 809170 & 6.9 & 5.3175 & TST & \\
\hline CHEMBL1980562 & 809170 & 7.4 & 7.0756 & TRN & \\
\hline CHEMBL1081312 & 809170 & 7.4 & 6.7619 & TRN & \\
\hline CHEMBL1982866 & 809170 & 4.1 & 4.3067 & TRN & \\
\hline CHEMBL 2004156 & 809170 & 4.1 & 4.9307 & TRN & \\
\hline CHEMBL 2005792 & 809170 & 4.1 & 4.1214 & TRN & \\
\hline CHEMBL1968926 & 809170 & 5.4 & 4.4762 & TRN & \\
\hline CHEMBL365617 & 809170 & 5.6 & 5.3312 & TST & \\
\hline CHEMBL1984206 & 809170 & 4.1 & 4.4453 & TRN & \\
\hline CHEMBL462120 & 809170 & 5.3 & 4.2539 & TST & \\
\hline CHEMBL1991577 & 809170 & 6.4 & 6.0403 & TRN & \\
\hline CHEMBL1979933 & 809170 & 4.3 & 6.0437 & TRN & \\
\hline CHEMBL1965570 & 809170 & 5.7 & 5.8378 & TRN & \\
\hline CHEMBL 2007592 & 809170 & 4.1 & 4.2296 & TST & \\
\hline CHEMBL1976936 & 809170 & 5.6 & 6.5925 & TRN & \\
\hline CHEMBL210963 & 809170 & 4.1 & 3.932 & TRN & \\
\hline CHEMBL 2005387 & 809170 & 7.8 & 7.67399 & 99999999995 & TRN \\
\hline CHEMBL1082440 & 809170 & 8.1 & 6.6164 & TST & \\
\hline CHEMBL1614705 & 809170 & 4.1 & 4.8575 & TRN & \\
\hline CHEMBL1972362 & 809170 & 5.4 & 5.2485 & TRN & \\
\hline CHEMBL1982400 & 809170 & 7.2 & 5.53700 & 0000000001 & TRN \\
\hline CHEMBL1972988 & 809170 & 5.3 & 7.44799 & 99999999995 & TRN \\
\hline CHEMBL 2007372 & 809170 & 4.1 & 3.96100 & 00000000003 & TRN \\
\hline CHEMBL1982167 & 809170 & 4.1 & 4.1955 & TRN & \\
\hline CHEMBL1971017 & 809170 & 4.1 & 5.0037 & TRN & \\
\hline CHEMBL 2006715 & 809170 & 4.1 & 3.6761 & TRN & \\
\hline CHEMBL1986597 & 809170 & 7.0 & 5.7714 & TRN & \\
\hline CHEMBL1990482 & 809170 & 7.0 & 6.209 & TRN & \\
\hline CHEMBL1990904 & 809170 & 4.1 & 4.1361 & TRN & \\
\hline CHEMBL 2000104 & 809170 & 5.5 & 5.3638 & TRN & \\
\hline CHEMBL1987448 & 809170 & 8.1 & 8.1838 & TRN & \\
\hline CHEMBL1975121 & 809170 & 6.7 & 8.3966 & TRN & \\
\hline CHEMBL 2005475 & 809170 & 4.1 & 4.0255 & TRN & \\
\hline
\end{tabular}




\begin{tabular}{|c|c|c|c|c|c|}
\hline \multicolumn{6}{|c|}{ Supplemental Table S2.txt } \\
\hline CHEMBL402846 & 809170 & 5.8 & 6.2885 & TRN & \\
\hline CHEMBL1997349 & 809170 & 4.1 & 4.0076 & TST & \\
\hline CHEMBL183844 & 809170 & 6.5 & 4.5373 & TRN & \\
\hline CHEMBL220057 & 809170 & 6.7 & 7.0042 & TRN & \\
\hline CHEMBL1682545 & 809170 & 6.1 & 6.5403 & TRN & \\
\hline CHEMBL383541 & 809170 & 7.8 & 7.9989 & TRN & \\
\hline CHEMBL 2001224 & 809170 & 4.1 & 3.9014 & TRN & \\
\hline CHEMBL10 & 809170 & 4.3 & 4.5063 & TRN & \\
\hline CHEMBL1976732 & 809170 & 4.1 & 3.928 & TRN & \\
\hline CHEMBL1982982 & 809170 & 5.3 & 6.135 & TRN & \\
\hline CHEMBL2005216 & 809170 & 7.2 & 7.4349 & TRN & \\
\hline CHEMBL1969506 & 809170 & 6.7 & 6.1958 & TRN & \\
\hline CHEMBL1964937 & 809170 & 7.4 & 6.88299 & 7999999999 & TRN \\
\hline CHEMBL1980163 & 809170 & 4.1 & 4.2899 & TRN & \\
\hline CHEMBL590109 & 809170 & 6.5 & 6.4499 & TST & \\
\hline CHEMBL1970879 & 809170 & 4.1 & 6.0648 & TRN & \\
\hline CHEMBL1989856 & 809170 & 4.1 & 4.2046 & TST & \\
\hline CHEMBL 2005899 & 809170 & 7.4 & 5.92200 & 3000000001 & TRN \\
\hline CHEMBL1682552 & 809170 & 6.2 & 6.5914 & TRN & \\
\hline CHEMBL 259850 & 809170 & 4.1 & 4.2683 & TRN & \\
\hline CHEMBL1972568 & 809170 & 6.2 & 6.2071 & TRN & \\
\hline CHEMBL1996155 & 809170 & 5.9 & 5.6701 & TST & \\
\hline CHEMBL1987745 & 809170 & 6.2 & 5.3182 & TRN & \\
\hline CHEMBL105739 & 809170 & 4.1 & 5.1593 & TRN & \\
\hline CHEMBL1682359 & 809170 & 7.1 & 6.6373 & TRN & \\
\hline CHEMBL379300 & 809170 & 8.1 & 8.2286 & TRN & \\
\hline CHEMBL203673 & 809170 & 6.7 & 7.3113 & TRN & \\
\hline CHEMBL1973720 & 809170 & 8.7 & 8.6057 & TRN & \\
\hline CHEMBL1969523 & 809170 & 6.3 & 5.6131 & TRN & \\
\hline CHEMBL1988995 & 809170 & 4.1 & 3.9181 & TRN & \\
\hline CHEMBL207995 & 809170 & 4.1 & 4.8154 & TRN & \\
\hline CHEMBL 2001923 & 809170 & 6.0 & 4.5425 & TRN & \\
\hline CHEMBL1986781 & 809170 & 4.1 & 4.1344 & TRN & \\
\hline CHEMBL526133 & 809170 & 6.0 & 5.814 & TRN & \\
\hline CHEMBL1979057 & 809170 & 6.8 & 6.3445 & TRN & \\
\hline CHEMBL1981045 & 809170 & 4.1 & 4.3214 & TRN & \\
\hline CHEMBL387971 & 809170 & 4.1 & 4.4508 & TST & \\
\hline CHEMBL1975418 & 809170 & 8.6 & 7.3252 & TRN & \\
\hline CHEMBL1992796 & 809170 & 5.3 & 4.9095 & TST & \\
\hline CHEMBL1164180 & 809170 & 5.2 & 5.0533 & TST & \\
\hline CHEMBL223257 & 809170 & 4.1 & 3.9138 & TST & \\
\hline CHEMBL1999428 & 809170 & 8.2 & 7.9688 & TRN & \\
\hline CHEMBL1967560 & 809170 & 4.1 & 4.2986 & TRN & \\
\hline CHEMBL1516890 & 809170 & 5.8 & 5.7607 & TRN & \\
\hline CHEMBL 211378 & 809170 & 5.8 & 4.8902 & TRN & \\
\hline CHEMBL1682358 & 809170 & 7.6 & 6.2197 & TRN & \\
\hline CHEMBL1982465 & 809170 & 6.8 & 6.9422 & TRN & \\
\hline CHEMBL 2001751 & 809170 & 7.9 & 7.3007 & TRN & \\
\hline
\end{tabular}




\begin{tabular}{|c|c|c|c|c|c|}
\hline CHEMBL 2003420 & 809170 & 4.1 & \multicolumn{2}{|c|}{4.428999999999999} & TRN \\
\hline CHEMBL1984586 & 809170 & 5.2 & 5.433 & TRN & \\
\hline CHEMBL1999774 & 809170 & 4.1 & 4.2286 & TST & \\
\hline CHEMBL1972659 & 809170 & 4.1 & 4.5018 & TST & \\
\hline CHEMBL1973395 & 809170 & 6.3 & 6.0172 & TRN & \\
\hline CHEMBL 272453 & 809170 & 7.5 & 7.1667 & TRN & \\
\hline CHEMBL1971801 & 809170 & 4.1 & 4.2104 & TRN & \\
\hline CHEMBL1968850 & 809170 & 4.1 & 4.0844 & TRN & \\
\hline CHEMBL2005528 & 809170 & 4.1 & 4.5003 & TST & \\
\hline CHEMBL185569 & 809170 & 7.3 & 5.9539 & TRN & \\
\hline CHEMBL1969843 & 809170 & 6.5 & \multicolumn{2}{|c|}{6.3260000000000005} & TRN \\
\hline CHEMBL 2007002 & 809170 & 4.1 & 4.4576 & TRN & \\
\hline CHEMBL1990288 & 809170 & 4.1 & 4.0914 & TRN & \\
\hline CHEMBL1987007 & 809170 & 4.1 & 4.0006 & TRN & \\
\hline CHEMBL1969588 & 809170 & 8.0 & 7.9023 & TRN & \\
\hline CHEMBL1984711 & 809170 & 4.1 & 4.5556 & TRN & \\
\hline CHEMBL1992073 & 809170 & 7.9 & 7.5005 & TST & \\
\hline CHEMBL1990212 & 809170 & 4.1 & 4.2152 & TRN & \\
\hline CHEMBL484390 & 809170 & 4.1 & 4.0124 & TST & \\
\hline CHEMBL1990254 & 809170 & 8.5 & 8.1809 & TRN & \\
\hline CHEMBL1979252 & 809170 & 6.0 & 6.5261 & TRN & \\
\hline CHEMBL1682341 & 809170 & 7.4 & 7.0994 & TRN & \\
\hline CHEMBL 2004290 & 809170 & 5.4 & \multicolumn{2}{|c|}{6.582000000000001} & TRN \\
\hline CHEMBL1986499 & 809170 & 7.8 & 7.1009 & TRN & \\
\hline CHEMBL1972937 & 809170 & 4.1 & 4.3466 & TRN & \\
\hline CHEMBL1972250 & 809170 & 4.1 & 4.0536 & TST & \\
\hline CHEMBL 2000393 & 809170 & 5.8 & 5.4166 & TST & \\
\hline CHEMBL 2004072 & 809170 & 4.1 & 4.3374 & TRN & \\
\hline CHEMBL2001477 & 809170 & 5.3 & 6.3677 & TRN & \\
\hline CHEMBL1986166 & 809170 & 5.6 & 5.0404 & TRN & \\
\hline CHEMBL 2004311 & 809170 & 7.6 & 6.4782 & TRN & \\
\hline CHEMBL1992634 & 809170 & 5.2 & 4.4061 & TRN & \\
\hline CHEMBL1242373 & 809170 & 7.1 & 6.0987 & TRN & \\
\hline CHEMBL 2000433 & 809170 & 4.1 & 4.345 & TST & \\
\hline CHEMBL56543 & 809170 & 4.1 & 4.0917 & TST & \\
\hline CHEMBL316264 & 809170 & 4.1 & 4.2511 & TRN & \\
\hline CHEMBL1988075 & 809170 & 6.2 & 6.2995 & TRN & \\
\hline CHEMBL1991678 & 809170 & 4.1 & 4.2688 & TRN & \\
\hline CHEMBL2001239 & 809170 & 5.8 & 5.8247 & TST & \\
\hline CHEMBL1988594 & 809170 & 4.1 & 4.1181 & TRN & \\
\hline CHEMBL2001288 & 809170 & 4.1 & 4.6789 & TRN & \\
\hline CHEMBL1992363 & 809170 & 6.3 & 6.1758 & TRN & \\
\hline CHEMBL 260092 & 809170 & 6.4 & 5.9631 & TRN & \\
\hline CHEMBL1999811 & 809170 & 5.9 & 5.3731 & TST & \\
\hline CHEMBL1965495 & 809170 & 5.8 & 5.7558 & TRN & \\
\hline CHEMBL1985074 & 809170 & 4.1 & 4.2777 & TST & \\
\hline CHEMBL 2000481 & 809170 & 7.8 & 7.0922 & TRN & \\
\hline CHEMBL1982874 & 809170 & 4.1 & 4.1189 & TRN & \\
\hline
\end{tabular}




\begin{tabular}{|c|c|c|c|c|}
\hline \multicolumn{5}{|c|}{ plemental T } \\
\hline CHEMBL1991725 & 809170 & 7.5 & 6.7441 & TRN \\
\hline CHEMBL1992242 & 809170 & 4.1 & 4.6632 & TRN \\
\hline CHEMBL1982271 & 809170 & 8.1 & 8.1059 & TRN \\
\hline CHEMBL208637 & 809170 & 4.1 & 4.0353 & TRN \\
\hline CHEMBL396523 & 809170 & 6.6 & 6.9575 & TRN \\
\hline CHEMBL1970203 & 809170 & 4.1 & 4.3469 & TRN \\
\hline CHEMBL1986530 & 809170 & 4.1 & 4.4151 & TST \\
\hline CHEMBL440084 & 809170 & 4.4 & 4.8171 & TRN \\
\hline CHEMBL1999321 & 809170 & 4.1 & 4.6232 & TRN \\
\hline CHEMBL1968590 & 809170 & 4.1 & 4.5571 & TRN \\
\hline CHEMBL1999749 & 809170 & 4.1 & 4.374 & TRN \\
\hline CHEMBL 2005375 & 809170 & 4.1 & 4.0044 & TRN \\
\hline CHEMBL1984191 & 809170 & 4.4 & 4.7826 & TRN \\
\hline CHEMBL1983006 & 809170 & 4.1 & 3.9712 & TRN \\
\hline CHEMBL1972183 & 809170 & 4.1 & 4.5399 & TST \\
\hline CHEMBL1971029 & 809170 & 5.7 & 5.9765 & TRN \\
\hline CHEMBL383527 & 809170 & 7.6 & 7.3355 & TRN \\
\hline CHEMBL394790 & 809170 & 6.9 & 6.7391 & TRN \\
\hline CHEMBL1980592 & 809170 & 5.4 & 5.3996 & TST \\
\hline CHEMBL 226471 & 809170 & 4.1 & 4.4968 & TRN \\
\hline CHEMBL 1974702 & 809170 & 4.1 & 4.4579 & TST \\
\hline CHEMBL1996111 & 809170 & 7.4 & 6.7172 & TRN \\
\hline CHEMBL1965589 & 809170 & 4.1 & 4.3176 & TRN \\
\hline CHEMBL1998193 & 809170 & 4.1 & 4.388 & TRN \\
\hline CHEMBL379975 & 809170 & 5.0 & 4.9407 & TST \\
\hline CHEMBL474432 & 809170 & 4.1 & 4.4892 & TST \\
\hline CHEMBL1988153 & 809170 & 4.1 & 4.2795 & TRN \\
\hline CHEMBL 2003637 & 809170 & 4.1 & 4.5905 & TST \\
\hline CHEMBL1986666 & 809170 & 4.3 & 6.2276 & TRN \\
\hline CHEMBL1972584 & 809170 & 6.4 & 6.3923 & TRN \\
\hline CHEMBL1999556 & 809170 & 4.1 & 5.4493 & TRN \\
\hline CHEMBL1988437 & 809170 & 5.5 & 4.9182 & TST \\
\hline CHEMBL1968245 & 809170 & 8.0 & 7.6423 & TRN \\
\hline CHEMBL1979577 & 809170 & 7.6 & 7.2737 & TRN \\
\hline CHEMBL1998121 & 809170 & 8.4 & 7.4213 & TRN \\
\hline CHEMBL1991800 & 809170 & 4.1 & 3.9966 & TRN \\
\hline CHEMBL52387 & 809170 & 4.1 & 4.322 & TST \\
\hline CHEMBL379835 & 809170 & 4.1 & 4.1441 & TRN \\
\hline CHEMBL1979357 & 809170 & 6.5 & 6.7705 & TRN \\
\hline CHEMBL1980802 & 809170 & 4.1 & 3.9866 & TST \\
\hline CHEMBL1989006 & 809170 & 7.7 & 7.6927 & TRN \\
\hline CHEMBL1996817 & 809170 & 6.4 & 6.1604 & TRN \\
\hline CHEMBL1979554 & 809170 & 8.5 & 7.4426 & TRN \\
\hline CHEMBL3197315 & 809170 & 5.2 & 4.2705 & TST \\
\hline CHEMBL 2004355 & 809170 & 5.3 & 4.3464 & TRN \\
\hline CHEMBL468280 & 809170 & 4.1 & 4.0224 & TST \\
\hline CHEMBL1990884 & 809170 & 5.7 & 5.8533 & TRN \\
\hline CHEMBL1996339 & 809170 & 7.9 & 7.6388 & TRN \\
\hline
\end{tabular}




\begin{tabular}{|c|c|c|c|c|}
\hline & & & ient & al Ta \\
\hline CHEMBL3109278 & 809170 & 6.0 & 5.0763 & TRN \\
\hline CHEMBL 256835 & 809170 & 4.1 & 4.1325 & TRN \\
\hline CHEMBL1980142 & 809170 & 4.1 & 3.8638 & TRN \\
\hline CHEMBL41783 & 809170 & 4.1 & 4.2343 & TRN \\
\hline CHEMBL 2004438 & 809170 & 6.2 & 4.7343 & TRN \\
\hline CHEMBL 2006276 & 809170 & 4.3 & 5.4037 & TRN \\
\hline CHEMBL191003 & 809170 & 7.2 & 6.5004 & TRN \\
\hline CHEMBL271381 & 809170 & 6.0 & 6.1981 & TRN \\
\hline CHEMBL 2006785 & 809170 & 4.1 & 4.4898 & TST \\
\hline CHEMBL1982466 & 809170 & 7.0 & 7.1317 & TRN \\
\hline CHEMBL1995740 & 809170 & 5.2 & 4.0126 & TRN \\
\hline CHEMBL1996390 & 809170 & 4.1 & 4.3913 & TRN \\
\hline CHEMBL1990162 & 809170 & 5.4 & 5.7128 & TRN \\
\hline CHEMBL1992220 & 809170 & 7.5 & 8.1992 & TRN \\
\hline CHEMBL1986943 & 809170 & 7.4 & 8.0966 & TRN \\
\hline CHEMBL 234085 & 809170 & 6.4 & 6.3802 & TST \\
\hline CHEMBL1995832 & 809170 & 4.1 & 3.9431 & TRN \\
\hline CHEMBL1998414 & 809170 & 4.1 & 4.1561 & TRN \\
\hline CHEMBL1969042 & 809170 & 7.3 & 5.7475 & TST \\
\hline CHEMBL 2000345 & 809170 & 4.1 & 5.184 & TRN \\
\hline CHEMBL1999931 & 809170 & 6.6 & 6.1701 & TRN \\
\hline CHEMBL1991640 & 809170 & 4.1 & 4.61 & TST \\
\hline CHEMBL1375418 & 809170 & 4.1 & 4.0881 & TRN \\
\hline CHEMBL 302449 & 809170 & 6.5 & 7.2432 & TST \\
\hline CHEMBL 2007064 & 809170 & 5.4 & 5.6372 & TRN \\
\hline CHEMBL1981047 & 809170 & 4.1 & 4.7422 & TRN \\
\hline CHEMBL1976240 & 809170 & 8.3 & 8.5619 & TRN \\
\hline CHEMBL1987948 & 809170 & 7.5 & 7.6099 & TRN \\
\hline CHEMBL1979093 & 809170 & 6.6 & 6.6178 & TRN \\
\hline CHEMBL1968151 & 809170 & 6.3 & 5.56 & TST \\
\hline CHEMBL1381197 & 809170 & 4.1 & 4.0293 & TRN \\
\hline CHEMBL1987009 & 809170 & 5.3 & 4.2059 & TRN \\
\hline CHEMBL379218 & 809170 & 7.5 & 8.1306 & TRN \\
\hline CHEMBL 2003817 & 809170 & 4.1 & 3.9257 & TRN \\
\hline CHEMBL336961 & 809170 & 4.1 & 4.5255 & TRN \\
\hline CHEMBL1994830 & 809170 & 4.1 & 4.2519 & TRN \\
\hline CHEMBL1987054 & 809170 & 7.1 & 7.3716 & TRN \\
\hline CHEMBL226403 & 809170 & 4.1 & 4.7064 & TRN \\
\hline CHEMBL 2005631 & 809170 & 6.1 & 6.5866 & TRN \\
\hline CHEMBL1994938 & 809170 & 4.1 & 4.6815 & TRN \\
\hline CHEMBL1977223 & 809170 & 5.2 & 5.4333 & TRN \\
\hline CHEMBL1966279 & 809170 & 7.8 & 6.9952 & TRN \\
\hline CHEMBL1236126 & 809170 & 4.1 & 4.3304 & TST \\
\hline CHEMBL1997846 & 809170 & 5.5 & 6.4976 & TRN \\
\hline CHEMBL 2004419 & 809170 & 4.1 & 4.0024 & TRN \\
\hline CHEMBL1991728 & 809170 & 6.1 & 5.7744 & TRN \\
\hline CHEMBL1995811 & 809170 & 4.3 & 4.5948 & TRN \\
\hline CHEMBL1975787 & 809170 & 5.3 & 4.5531 & TRN \\
\hline
\end{tabular}




\begin{tabular}{|c|c|c|c|c|c|}
\hline \\
\hline CHEMBL 2002407 & 809170 & 4.1 & 4.3715 & TRN & \\
\hline CHEMBL1972489 & 809170 & 4.1 & 4.5478 & TRN & \\
\hline CHEMBL1994074 & 809170 & 4.1 & 4.452 & TRN & \\
\hline CHEMBL1992937 & 809170 & 4.1 & 4.4407 & TST & \\
\hline CHEMBL1968930 & 809170 & 8.4 & 8.9323 & TRN & \\
\hline CHEMBL1985566 & 809170 & 4.1 & 4.3165 & TRN & \\
\hline CHEMBL1972119 & 809170 & 4.1 & 4.1001 & TRN & \\
\hline CHEMBL1986328 & 809170 & 4.1 & 4.0835 & TST & \\
\hline CHEMBL95692 & 809170 & 4.1 & 4.3569 & TRN & \\
\hline CHEMBL1090356 & 809170 & 4.1 & 4.079 & TRN & \\
\hline CHEMBL1976455 & 809170 & 4.1 & 4.0152 & TRN & \\
\hline CHEMBL1983923 & 809170 & 4.1 & 5.1417 & TST & \\
\hline CHEMBL1983534 & 809170 & 8.4 & 7.4601 & TRN & \\
\hline CHEMBL1970950 & 809170 & 4.1 & 4.898 & TRN & \\
\hline CHEMBL1982361 & 809170 & 4.3 & 6.1759 & TRN & \\
\hline CHEMBL1999112 & 809170 & 4.1 & 4.0294 & TST & \\
\hline CHEMBL 2000801 & 809170 & 4.1 & 4.3454 & TRN & \\
\hline CHEMBL1682546 & 809170 & 6.9 & 6.9359 & TRN & \\
\hline CHEMBL1991395 & 809170 & 4.1 & 4.0638 & TRN & \\
\hline CHEMBL1971245 & 809170 & 4.1 & 4.3673 & TRN & \\
\hline CHEMBL1987648 & 809170 & 4.1 & 3.9087 & TRN & \\
\hline CHEMBL1996780 & 809170 & 7.5 & 7.2432 & TRN & \\
\hline CHEMBL1972142 & 809170 & 4.6 & 5.8922 & TRN & \\
\hline CHEMBL1966514 & 809170 & 6.0 & 5.9211 & TRN & \\
\hline CHEMBL 2003638 & 809170 & 5.0 & 5.09699 & 99999999995 & TRN \\
\hline CHEMBL296586 & 809170 & 5.6 & 5.3462 & TRN & \\
\hline CHEMBL1996066 & 809170 & 4.1 & 4.3907 & TST & \\
\hline CHEMBL516429 & 809170 & 8.0 & 7.6625 & TRN & \\
\hline CHEMBL1993722 & 809170 & 5.8 & 6.1124 & TRN & \\
\hline CHEMBL1970806 & 809170 & 4.1 & 4.1762 & TST & \\
\hline CHEMBL1375640 & 809170 & 6.4 & 6.6001 & TST & \\
\hline CHEMBL1979970 & 809170 & 4.1 & 4.1066 & TRN & \\
\hline CHEMBL249282 & 809170 & 4.1 & 4.0969 & TST & \\
\hline CHEMBL1970821 & 809170 & 7.8 & 7.6398 & TRN & \\
\hline CHEMBL1969264 & 809170 & 4.1 & 4.5212 & TST & \\
\hline CHEMBL1973711 & 809170 & 4.1 & 4.2349 & TST & \\
\hline CHEMBL 2006237 & 809170 & 4.1 & 4.1804 & TRN & \\
\hline CHEMBL1967720 & 809170 & 7.1 & 6.5282 & TRN & \\
\hline CHEMBL2005509 & 809170 & 7.6 & 8.1776 & TRN & \\
\hline CHEMBL1572266 & 809170 & 4.1 & 4.5515 & TST & \\
\hline CHEMBL1991138 & 809170 & 6.4 & 5.7639 & TRN & \\
\hline CHEMBL1979516 & 809170 & 6.1 & 5.8652 & TRN & \\
\hline CHEMBL1969755 & 809170 & 6.9 & 6.6783 & TRN & \\
\hline CHEMBL1972820 & 809170 & 4.1 & 4.308 & TST & \\
\hline CHEMBL1605605 & 809170 & 7.1 & 8.2454 & TRN & \\
\hline CHEMBL1996208 & 809170 & 4.3 & 4.7177 & TST & \\
\hline CHEMBL1989029 & 809170 & 4.1 & 4.4787 & TST & \\
\hline CHEMBL392642 & 809170 & 4.1 & 4.0164 & TRN & \\
\hline
\end{tabular}




\begin{tabular}{|c|c|c|c|c|}
\hline \multicolumn{5}{|c|}{ Supplemental Table S2.txt } \\
\hline CHEMBL514499 & 809170 & 4.1 & 4.2808 & TST \\
\hline CHEMBL1965631 & 809170 & 5.8 & 5.7031 & TRN \\
\hline CHEMBL1980144 & 809170 & 4.1 & 4.5412 & TRN \\
\hline CHEMBL1682554 & 809170 & 7.2 & \multicolumn{2}{|c|}{6.787000000000001} \\
\hline CHEMBL1972849 & 809170 & 4.1 & 3.8862 & TRN \\
\hline CHEMBL 377408 & 809170 & 5.7 & 5.1382 & TRN \\
\hline CHEMBL1986855 & 809170 & 6.7 & 6.9438 & TRN \\
\hline CHEMBL215152 & 809170 & 4.4 & 4.7118 & TRN \\
\hline CHEMBL231209 & 809170 & 6.5 & 6.5577 & TRN \\
\hline CHEMBL1975357 & 809170 & 4.1 & 4.3822 & TST \\
\hline CHEMBL1976220 & 809170 & 7.0 & 6.9255 & TRN \\
\hline CHEMBL1989136 & 809170 & 6.5 & 5.8702 & TRN \\
\hline CHEMBL259922 & 809170 & 4.1 & 4.3758 & TST \\
\hline CHEMBL1997617 & 809170 & 4.1 & 5.0426 & TRN \\
\hline CHEMBL1969301 & 809170 & 4.1 & 4.2137 & TST \\
\hline CHEMBL1982383 & 809170 & 4.1 & 4.0063 & TRN \\
\hline CHEMBL17370 & 809170 & 4.1 & 4.9099 & TRN \\
\hline CHEMBL1987910 & 809170 & 5.5 & 6.2249 & TRN \\
\hline CHEMBL1983932 & 809170 & 4.1 & 4.315 & TRN \\
\hline CHEMBL1991285 & 809170 & 4.1 & 3.8661 & TRN \\
\hline CHEMBL1997822 & 809170 & 5.9 & 5.8049 & TRN \\
\hline CHEMBL243088 & 809170 & 5.8 & 5.6522 & TRN \\
\hline CHEMBL1984038 & 809170 & 4.2 & 4.5123 & TRN \\
\hline CHEMBL1974416 & 809170 & 6.5 & 4.9404 & TRN \\
\hline CHEMBL1993661 & 809170 & 7.6 & 7.5576 & TRN \\
\hline CHEMBL 2004615 & 809170 & 5.3 & 5.4035 & TST \\
\hline CHEMBL1984039 & 809170 & 4.1 & 4.1098 & TST \\
\hline CHEMBL1997872 & 809170 & 4.1 & 5.6896 & TRN \\
\hline CHEMBL1964290 & 809170 & 6.5 & 5.9096 & TRN \\
\hline CHEMBL2003768 & 809170 & 4.1 & 5.3255 & TRN \\
\hline CHEMBL 213505 & 809170 & 6.2 & 5.5899 & TRN \\
\hline CHEMBL 202721 & 809170 & 6.3 & 4.8143 & TRN \\
\hline CHEMBL1982880 & 809170 & 4.1 & 4.0015 & TRN \\
\hline CHEMBL1987034 & 809170 & 6.7 & 6.1923 & TRN \\
\hline CHEMBL1993941 & 809170 & 6.8 & 6.4548 & TRN \\
\hline CHEMBL1980435 & 809170 & 5.8 & 5.7 & TRN \\
\hline CHEMBL1989293 & 809170 & 6.9 & 5.2908 & TRN \\
\hline CHEMBL377383 & 809170 & 4.1 & 4.1164 & TRN \\
\hline CHEMBL 2005886 & 809170 & 5.3 & 6.0944 & TST \\
\hline CHEMBL481491 & 809170 & 4.1 & 4.3897 & TST \\
\hline CHEMBL1682345 & 809170 & 7.5 & 6.9977 & TRN \\
\hline CHEMBL1973142 & 809170 & 6.6 & 6.1651 & TST \\
\hline CHEMBL1973145 & 809170 & 4.1 & 5.2557 & TRN \\
\hline CHEMBL1982924 & 809170 & 6.2 & 5.1313 & TRN \\
\hline CHEMBL2005936 & 809170 & 7.4 & 6.4856 & TRN \\
\hline CHEMBL1971141 & 809170 & 4.1 & 4.5201 & TRN \\
\hline CHEMBL1979718 & 809170 & 6.9 & 5.9685 & TRN \\
\hline CHEMBL206236 & 809170 & 6.8 & 6.5966 & TRN \\
\hline
\end{tabular}




\begin{tabular}{|c|c|c|c|c|}
\hline \multicolumn{5}{|c|}{ lemental T } \\
\hline CHEMBL1964288 & 809170 & 6.9 & 5.5362 & TRN \\
\hline CHEMBL523823 & 809170 & 4.1 & 4.0421 & TST \\
\hline CHEMBL1562756 & 809170 & 5.4 & 5.1065 & TST \\
\hline CHEMBL 244378 & 809170 & 6.8 & 6.6541 & TRN \\
\hline CHEMBL 2001957 & 809170 & 4.1 & 3.9617 & TRN \\
\hline CHEMBL1969372 & 809170 & 4.1 & 4.0842 & TRN \\
\hline CHEMBL1993413 & 809170 & 5.0 & 5.9927 & TRN \\
\hline CHEMBL1990583 & 809170 & 4.1 & 6.6263 & TRN \\
\hline CHEMBL 2006263 & 809170 & 4.1 & 4.5846 & TST \\
\hline CHEMBL1988662 & 809170 & 6.6 & 6.2971 & TRN \\
\hline CHEMBL1993584 & 809170 & 5.7 & 6.9222 & TRN \\
\hline CHEMBL1986263 & 809170 & 5.9 & 5.56 & TRN \\
\hline CHEMBL 2000114 & 809170 & 5.4 & 5.0722 & TRN \\
\hline CHEMBL 210618 & 809170 & 4.1 & 4.0724 & TRN \\
\hline CHEMBL1971172 & 809170 & 5.8 & 7.6842 & TRN \\
\hline CHEMBL1975647 & 809170 & 4.1 & 3.96 & TRN \\
\hline CHEMBL1968380 & 809170 & 4.1 & 3.8944 & TRN \\
\hline CHEMBL1997643 & 809170 & 4.1 & 5.3678 & TRN \\
\hline CHEMBL1964644 & 809170 & 4.1 & 4.1897 & TRN \\
\hline CHEMBL1981782 & 809170 & 7.2 & 6.8793 & TRN \\
\hline CHEMBL1977681 & 809170 & 4.5 & 4.7963 & TRN \\
\hline CHEMBL1970142 & 809170 & 7.0 & 7.1472 & TRN \\
\hline CHEMBL1990912 & 809170 & 5.3 & 4.213 & TRN \\
\hline CHEMBL1988163 & 809170 & 5.7 & 5.7969 & TRN \\
\hline CHEMBL1995592 & 809170 & 6.0 & 5.7455 & TRN \\
\hline CHEMBL 2000934 & 809170 & 4.4 & 4.7286 & TRN \\
\hline CHEMBL 2006493 & 809170 & 4.1 & 4.1128 & TST \\
\hline CHEMBL1996923 & 809170 & 4.1 & 4.3292 & TST \\
\hline CHEMBL1983449 & 809170 & 6.3 & 6.2679 & TRN \\
\hline CHEMBL1992323 & 809170 & 4.1 & 4.5006 & TST \\
\hline CHEMBL1969735 & 809170 & 4.1 & 3.9549 & TRN \\
\hline CHEMBL 2003524 & 809170 & 4.1 & 4.3658 & TST \\
\hline CHEMBL2002649 & 809170 & 5.7 & 5.0532 & TRN \\
\hline CHEMBL1983589 & 809170 & 8.5 & 7.8269 & TRN \\
\hline CHEMBL1996510 & 809170 & 4.4 & 5.1974 & TST \\
\hline CHEMBL437747 & 809170 & 4.1 & 5.2735 & TRN \\
\hline CHEMBL 2005718 & 809170 & 7.7 & 7.7913 & TRN \\
\hline CHEMBL1995172 & 809170 & 4.1 & 4.3952 & TST \\
\hline CHEMBL507936 & 809170 & 6.4 & 4.735 & TRN \\
\hline CHEMBL104264 & 809170 & 7.1 & 7.112 & TST \\
\hline CHEMBL1994321 & 809170 & 7.3 & 7.261 & TRN \\
\hline CHEMBL1997129 & 809170 & 6.4 & 5.9338 & TRN \\
\hline CHEMBL1984788 & 809170 & 4.1 & 4.1427 & TRN \\
\hline CHEMBL451964 & 809170 & 4.1 & 4.2249 & TRN \\
\hline CHEMBL1964307 & 809170 & 6.6 & 6.9325 & TRN \\
\hline CHEMBL 2000508 & 809170 & 4.1 & 4.0901 & TRN \\
\hline CHEMBL1971694 & 809170 & 4.1 & 4.4337 & TST \\
\hline CHEMBL 2001547 & 809170 & 4.1 & 4.0323 & TRN \\
\hline
\end{tabular}




\begin{tabular}{|c|c|c|c|c|c|}
\hline \multicolumn{6}{|c|}{ Supplemental Table S2.txt } \\
\hline CHEMBL210928 & 809170 & 4.1 & 4.0444 & TRN & \\
\hline CHEMBL1994361 & 809170 & 4.1 & 5.3074 & TRN & \\
\hline CHEMBL1986603 & 809170 & 4.1 & 4.413 & TST & \\
\hline CHEMBL1972840 & 809170 & 7.1 & 7.1708 & TRN & \\
\hline CHEMBL1977148 & 809170 & 4.1 & 5.2179 & TRN & \\
\hline CHEMBL 2004443 & 809170 & 4.1 & 4.8565 & TRN & \\
\hline CHEMBL 2003286 & 809170 & 4.1 & 3.99300 & 00000000003 & TRN \\
\hline CHEMBL1992306 & 809170 & 4.1 & 4.3762 & TRN & \\
\hline CHEMBL 2002165 & 809170 & 6.9 & 6.3061 & TRN & \\
\hline CHEMBL 2001668 & 809170 & 4.1 & 4.2846 & TRN & \\
\hline CHEMBL1979318 & 809170 & 4.1 & 3.9751 & TST & \\
\hline CHEMBL206382 & 809170 & 6.5 & 6.9664 & TRN & \\
\hline CHEMBL1998585 & 809170 & 6.3 & 6.6276 & TRN & \\
\hline CHEMBL127898 & 809170 & 4.1 & 4.5137 & TST & \\
\hline CHEMBL519697 & 809170 & 4.1 & 4.0746 & TST & \\
\hline CHEMBL1987261 & 809170 & 7.5 & 7.2785 & TRN & \\
\hline CHEMBL1968459 & 809170 & 7.7 & 6.9534 & TRN & \\
\hline CHEMBL1975128 & 809170 & 7.1 & 6.6747 & TRN & \\
\hline CHEMBL1970369 & 809170 & 5.5 & 4.7515 & TRN & \\
\hline CHEMBL 2001485 & 809170 & 6.5 & 6.6668 & TRN & \\
\hline CHEMBL504950 & 809170 & 7.2 & 6.4631 & TRN & \\
\hline CHEMBL1966425 & 809170 & 6.5 & 6.4351 & TRN & \\
\hline CHEMBL1984363 & 809170 & 6.8 & 6.5952 & TRN & \\
\hline CHEMBL1978099 & 809170 & 4.1 & 5.0433 & TRN & \\
\hline CHEMBL1977041 & 809170 & 7.4 & 6.1362 & TRN & \\
\hline CHEMBL1968070 & 809170 & 4.1 & 4.1794 & TRN & \\
\hline CHEMBL1988608 & 809170 & 7.3 & 6.5907 & TRN & \\
\hline CHEMBL184847 & 809170 & 6.7 & 6.3086 & TRN & \\
\hline CHEMBL1984367 & 809170 & 4.1 & 4.1389 & TRN & \\
\hline CHEMBL1985723 & 809170 & 6.1 & 8.0726 & TRN & \\
\hline CHEMBL178737 & 809170 & 4.1 & 4.5925 & TST & \\
\hline CHEMBL226898 & 809170 & 7.7 & 7.5034 & TRN & \\
\hline CHEMBL1982563 & 809170 & 4.1 & 3.9396 & TRN & \\
\hline CHEMBL539474 & 809170 & 4.1 & 4.0019 & TST & \\
\hline CHEMBL575824 & 809170 & 6.7 & 6.9143 & TRN & \\
\hline CHEMBL1988387 & 809170 & 6.5 & 6.9999 & TRN & \\
\hline CHEMBL1977128 & 809170 & 5.5 & 5.6758 & TRN & \\
\hline CHEMBL1997759 & 809170 & 4.1 & 4.3701 & TRN & \\
\hline CHEMBL1974803 & 809170 & 4.1 & 4.0271 & TST & \\
\hline CHEMBL1970074 & 809170 & 4.1 & 6.0268 & TRN & \\
\hline CHEMBL1965702 & 809170 & 7.5 & 7.8969 & TRN & \\
\hline CHEMBL1986970 & 809170 & 7.5 & 6.8223 & TRN & \\
\hline CHEMBL 2002456 & 809170 & 7.3 & 6.4353 & TRN & \\
\hline CHEMBL 2005112 & 809170 & 4.1 & 4.2055 & TST & \\
\hline CHEMBL1958401 & 809170 & 6.4 & 6.0263 & TRN & \\
\hline CHEMBL1984044 & 809170 & 4.1 & 4.2135 & TRN & \\
\hline CHEMBL 2003456 & 809170 & 4.1 & 4.2089 & TRN & \\
\hline CHEMBL1966816 & 809170 & 4.1 & 4.0307 & TRN & \\
\hline
\end{tabular}




\begin{tabular}{|c|c|c|c|c|c|}
\hline & & & & & \\
\hline CHEMBL2002992 & 809170 & 7.6 & 7.1646 & TRN & \\
\hline CHEMBL560813 & 809170 & 4.1 & 4.4016 & TRN & \\
\hline CHEMBL207253 & 809170 & 4.1 & 4.1796 & TRN & \\
\hline CHEMBL1890036 & 809170 & 5.2 & 5.0499 & TST & \\
\hline CHEMBL1990635 & 809170 & 5.6 & 5.2389 & TST & \\
\hline CHEMBL1968791 & 809170 & 6.1 & 5.9268 & TRN & \\
\hline CHEMBL326282 & 809170 & 4.1 & 4.3494 & TST & \\
\hline CHEMBL 2002682 & 809170 & 4.1 & 5.1807 & TST & \\
\hline CHEMBL1992732 & 809170 & 4.1 & 4.2916 & TST & \\
\hline CHEMBL1971186 & 809170 & 4.1 & 4.0646 & TRN & \\
\hline CHEMBL2003482 & 809170 & 4.6 & 4.2114 & TRN & \\
\hline CHEMBL 2006456 & 809170 & 7.8 & 8.0117 & TRN & \\
\hline CHEMBL1973211 & 809170 & 7.2 & 7.146 & TRN & \\
\hline CHEMBL1984700 & 809170 & 4.1 & 3.9392 & TRN & \\
\hline CHEMBL 2007151 & 809170 & 5.9 & 5.483 & TRN & \\
\hline CHEMBL1998953 & 809170 & 4.4 & 5.1651 & TRN & \\
\hline CHEMBL1964340 & 809170 & 8.3 & 7.6931 & TRN & \\
\hline CHEMBL1972125 & 809170 & 4.1 & 4.6172 & TRN & \\
\hline CHEMBL1461728 & 809170 & 5.8 & 5.5339 & TRN & \\
\hline CHEMBL1976134 & 809170 & 5.6 & 5.9122 & TRN & \\
\hline CHEMBL1965131 & 809170 & 6.6 & 6.1151 & TST & \\
\hline CHEMBL1995448 & 809170 & 6.2 & 6.1127 & TRN & \\
\hline CHEMBL1972158 & 809170 & 7.9 & 7.3 & TRN & \\
\hline CHEMBL1974457 & 809170 & 4.1 & 4.2508 & TRN & \\
\hline CHEMBL1967662 & 809170 & 8.0 & 7.5857 & TRN & \\
\hline CHEMBL 2006580 & 809170 & 4.1 & 4.1222 & TRN & \\
\hline CHEMBL 2006581 & 809170 & 4.1 & 4.3682 & TRN & \\
\hline CHEMBL 2006481 & 809170 & 5.7 & 4.8305 & TRN & \\
\hline CHEMBL1979855 & 809170 & 4.1 & 4.6535 & TST & \\
\hline CHEMBL1970340 & 809170 & 6.6 & 6.5456 & TRN & \\
\hline CHEMBL 2005186 & 809170 & 7.0 & 6.45799 & 9999999999 & TRN \\
\hline CHEMBL1995927 & 809170 & 4.1 & 4.2204 & TST & \\
\hline CHEMBL 2006450 & 809170 & 6.8 & 6.8728 & TRN & \\
\hline CHEMBL1975534 & 809170 & 5.4 & 5.7288 & TRN & \\
\hline CHEMBL1993424 & 809170 & 5.5 & 4.63899 & 9999999999 & TRN \\
\hline CHEMBL1966703 & 809170 & 4.1 & 4.2425 & TST & \\
\hline CHEMBL 243518 & 809170 & 4.1 & 5.4958 & TRN & \\
\hline CHEMBL1969561 & 809170 & 7.5 & 6.4968 & TRN & \\
\hline CHEMBL1997554 & 809170 & 6.3 & 5.8904 & TRN & \\
\hline CHEMBL1997023 & 809170 & 5.3 & 4.3739 & TST & \\
\hline CHEMBL1964687 & 809170 & 7.5 & 5.8057 & TRN & \\
\hline CHEMBL1999918 & 809170 & 4.1 & 5.2995 & TRN & \\
\hline CHEMBL1974254 & 809170 & 4.1 & 6.6155 & TRN & \\
\hline CHEMBL1988537 & 809170 & 6.3 & 6.1627 & TST & \\
\hline CHEMBL 2005828 & 809170 & 5.8 & 6.0628 & TRN & \\
\hline CHEMBL 2002240 & 809170 & 4.1 & 4.188 & TRN & \\
\hline CHEMBL1991143 & 809170 & 4.1 & 4.1653 & TRN & \\
\hline CHEMBL1980178 & 809170 & 7.1 & 7.50299 & 9999999999 & TRN \\
\hline & & & & e 6949 & \\
\hline
\end{tabular}




\begin{tabular}{|c|c|c|c|c|c|}
\hline \\
\hline CHEMBL1998611 & 809170 & 6.6 & 6.3356 & TST & \\
\hline CHEMBL485556 & 809170 & 4.1 & 4.1427 & TST & \\
\hline CHEMBL1975900 & 809170 & 7.3 & 6.96700 & 00000000005 & TRN \\
\hline CHEMBL255822 & 809170 & 4.1 & 4.0012 & TRN & \\
\hline CHEMBL1972221 & 809170 & 4.1 & 4.5187 & TRN & \\
\hline CHEMBL 2006778 & 809170 & 5.2 & 5.1264 & TRN & \\
\hline CHEMBL1981511 & 809170 & 5.5 & 4.7029 & TRN & \\
\hline CHEMBL378627 & 809170 & 4.1 & 3.9898 & TRN & \\
\hline CHEMBL1996979 & 809170 & 4.3 & 5.1359 & TRN & \\
\hline CHEMBL1997025 & 809170 & 4.1 & 4.0868 & TRN & \\
\hline CHEMBL1968406 & 809170 & 6.8 & 6.0644 & TRN & \\
\hline CHEMBL1982476 & 809170 & 6.7 & 6.5271 & TRN & \\
\hline CHEMBL1984274 & 809170 & 4.1 & 3.9417 & TST & \\
\hline CHEMBL1998545 & 809170 & 7.4 & 7.0813 & TRN & \\
\hline CHEMBL1986869 & 809170 & 7.3 & 6.7253 & TST & \\
\hline CHEMBL 2006010 & 809170 & 4.1 & 4.0706 & TRN & \\
\hline CHEMBL1682558 & 809170 & 4.1 & 4.7054 & TRN & \\
\hline CHEMBL1990496 & 809170 & 4.2 & 4.6527 & TST & \\
\hline CHEMBL1998068 & 809170 & 8.1 & 7.519 & TRN & \\
\hline CHEMBL1997623 & 809170 & 5.9 & 4.6683 & TRN & \\
\hline CHEMBL 2002479 & 809170 & 7.2 & 6.489 & TRN & \\
\hline CHEMBL1993166 & 809170 & 6.3 & 5.9019 & TRN & \\
\hline CHEMBL1967094 & 809170 & 4.1 & 3.8569 & TRN & \\
\hline CHEMBL1966035 & 809170 & 5.8 & 5.474 & TRN & \\
\hline CHEMBL 2003341 & 809170 & 7.6 & 7.4741 & TRN & \\
\hline CHEMBL1992645 & 809170 & 4.1 & 4.4649 & TST & \\
\hline CHEMBL1990708 & 809170 & 5.7 & 5.9561 & TRN & \\
\hline CHEMBL1982992 & 809170 & 4.1 & 4.5268 & TRN & \\
\hline CHEMBL1999590 & 809170 & 4.1 & 4.2343 & TST & \\
\hline CHEMBL1981079 & 809170 & 5.2 & 5.5423 & TRN & \\
\hline CHEMBL1978166 & 809170 & 6.4 & 7.5677 & TRN & \\
\hline CHEMBL1972276 & 809170 & 4.1 & 4.15600 & 0000000001 & TRN \\
\hline CHEMBL1980489 & 809170 & 4.3 & 6.3632 & TRN & \\
\hline CHEMBL 2000832 & 809170 & 4.1 & 5.5589 & TRN & \\
\hline CHEMBL1967116 & 809170 & 7.6 & 7.2482 & TRN & \\
\hline CHEMBL1977814 & 809170 & 4.1 & 4.4547 & TRN & \\
\hline CHEMBL513846 & 809170 & 4.1 & 4.6758 & TRN & \\
\hline CHEMBL1970709 & 809170 & 7.0 & 7.0635 & TRN & \\
\hline CHEMBL1965660 & 809170 & 6.5 & 6.29899 & 99999999995 & TRN \\
\hline CHEMBL1998112 & 809170 & 4.1 & 4.7483 & TRN & \\
\hline CHEMBL1972290 & 809170 & 7.8 & 7.9967 & TRN & \\
\hline CHEMBL1969126 & 809170 & 4.1 & 4.0316 & TRN & \\
\hline CHEMBL1980896 & 809170 & 4.1 & 4.6085 & TRN & \\
\hline CHEMBL1975208 & 809170 & 4.1 & 4.1419 & TST & \\
\hline CHEMBL1970104 & 809170 & 6.0 & 6.0734 & TST & \\
\hline CHEMBL1991429 & 809170 & 4.1 & 3.9342 & TRN & \\
\hline CHEMBL1964777 & 809170 & 5.1 & 4.5558 & TRN & \\
\hline CHEMBL1971149 & 809170 & 4.1 & 4.0466 & TRN & \\
\hline
\end{tabular}




\begin{tabular}{|c|c|c|c|c|c|}
\hline \multirow{2}{*}{ CHEMBL1999714 } & \multirow{2}{*}{809170} & \\
\hline & & 4.1 & 3.9219 & TRN & \\
\hline CHEMBL1987533 & 809170 & 4.1 & 4.5838 & TRN & \\
\hline CHEMBL1994040 & 809170 & 4.1 & 3.9626 & TRN & \\
\hline CHEMBL388978 & 809170 & 9.3 & 8.1424 & TST & \\
\hline CHEMBL1984548 & 809170 & 6.8 & 6.2266 & TRN & \\
\hline CHEMBL579246 & 809170 & 6.8 & 6.7927 & TRN & \\
\hline CHEMBL398951 & 809170 & 4.1 & 4.1835 & TST & \\
\hline CHEMBL1982506 & 809170 & 4.1 & 4.3808 & TST & \\
\hline CHEMBL 2004716 & 809170 & 7.7 & 6.8094 & TRN & \\
\hline CHEMBL1968127 & 809170 & 4.1 & 3.9843 & TRN & \\
\hline CHEMBL1975233 & 809170 & 4.1 & \multicolumn{2}{|c|}{3.9530000000000003} & TRN \\
\hline CHEMBL1985406 & 809170 & 4.1 & 4.3527 & TRN & \\
\hline CHEMBL 2007603 & 809170 & 4.4 & 4.5996 & TRN & \\
\hline CHEMBL 207400 & 809170 & 4.1 & 4.2959 & TRN & \\
\hline CHEMBL 2000894 & 809170 & 8.0 & 7.581 & TRN & \\
\hline CHEMBL1982135 & 809170 & 4.1 & 4.5656 & TRN & \\
\hline CHEMBL1976090 & 809170 & 6.4 & 6.5618 & TRN & \\
\hline CHEMBL1993243 & 809170 & 4.1 & 4.7005 & TRN & \\
\hline CHEMBL 2004771 & 809170 & 7.3 & 7.0543 & TRN & \\
\hline CHEMBL1992922 & 809170 & 5.8 & 6.3546 & TRN & \\
\hline CHEMBL399021 & 809170 & 6.0 & 5.689 & TRN & \\
\hline CHEMBL1997597 & 809170 & 5.7 & 5.7498 & TRN & \\
\hline CHEMBL1969537 & 809170 & 4.1 & 4.3326 & TST & \\
\hline CHEMBL1976093 & 809170 & 4.1 & 4.0994 & TRN & \\
\hline CHEMBL 210032 & 809170 & 4.1 & 4.0687 & TRN & \\
\hline CHEMBL1996543 & 809170 & 5.4 & 5.7648 & TRN & \\
\hline CHEMBL1975256 & 809170 & 5.7 & 5.0554 & TST & \\
\hline CHEMBL508928 & 809170 & 6.2 & \multicolumn{2}{|c|}{5.6770000000000005} & TRN \\
\hline CHEMBL1991356 & 809170 & 4.1 & 4.312 & TST & \\
\hline CHEMBL1983309 & 809170 & 4.1 & 4.4781 & TST & \\
\hline CHEMBL 2004892 & 809170 & 6.0 & 5.6851 & TRN & \\
\hline CHEMBL1999126 & 809170 & 4.1 & 4.0355 & TST & \\
\hline CHEMBL1997503 & 809170 & 4.1 & 4.3798 & TST & \\
\hline CHEMBL1972339 & 809170 & 7.5 & 6.7243 & TRN & \\
\hline CHEMBL116070 & 809170 & 5.4 & 5.5177 & TRN & \\
\hline CHEMBL1990821 & 809170 & 4.1 & 3.9705 & TST & \\
\hline CHEMBL1970314 & 809170 & 4.1 & 4.3508 & TRN & \\
\hline CHEMBL 2004871 & 809170 & 4.1 & 3.8467 & TRN & \\
\hline CHEMBL1727312 & 809170 & 4.1 & 3.904 & TRN & \\
\hline CHEMBL1969879 & 809170 & 4.1 & 4.9227 & TST & \\
\hline CHEMBL1995932 & 809170 & 7.9 & 7.1966 & TRN & \\
\hline CHEMBL1981720 & 809170 & 4.1 & 4.1081 & TRN & \\
\hline CHEMBL1967704 & 809170 & 6.8 & 6.3439 & TRN & \\
\hline CHEMBL419932 & 809170 & 6.7 & \multicolumn{2}{|c|}{6.7860000000000005} & TRN \\
\hline CHEMBL262433 & 809170 & 5.7 & 5.8258 & TRN & \\
\hline CHEMBL 306380 & 809170 & 5.5 & 5.5888 & TRN & \\
\hline CHEMBL1966722 & 809170 & 4.1 & 3.9165 & TST & \\
\hline CHEMBL1983595 & 809170 & 4.3 & 5.6477 & TRN & \\
\hline
\end{tabular}




\begin{tabular}{|c|c|c|c|c|c|}
\hline \\
\hline CHEMBL1975500 & 809170 & 4.1 & 4.4695 & TRN & \\
\hline CHEMBL1976328 & 809170 & 6.7 & 6.5672 & TRN & \\
\hline CHEMBL394619 & 809170 & 6.8 & 6.9749 & TRN & \\
\hline CHEMBL1964399 & 809170 & 6.2 & 5.6626 & TRN & \\
\hline CHEMBL1996831 & 809170 & 4.1 & 4.1726 & TST & \\
\hline CHEMBL411903 & 809170 & 6.5 & 6.1213 & TRN & \\
\hline CHEMBL1980253 & 809170 & 7.1 & 8.0574 & TRN & \\
\hline CHEMBL1965988 & 809170 & 7.1 & 7.1463 & TRN & \\
\hline CHEMBL1969221 & 809170 & 7.7 & 7.0819 & TRN & \\
\hline CHEMBL418203 & 809170 & 4.2 & 4.1556 & TST & \\
\hline CHEMBL1989646 & 809170 & 7.0 & 6.7031 & TRN & \\
\hline CHEMBL1682357 & 809170 & 7.4 & 7.0085 & TRN & \\
\hline CHEMBL225519 & 809170 & 7.3 & 6.4796 & TRN & \\
\hline CHEMBL209534 & 809170 & 5.1 & 4.2946 & TRN & \\
\hline CHEMBL1978200 & 809170 & 4.1 & 4.1283 & TRN & \\
\hline CHEMBL2006631 & 809170 & 5.2 & 4.2276 & TRN & \\
\hline CHEMBL1970522 & 809170 & 4.1 & 4.7735 & TRN & \\
\hline CHEMBL1990415 & 809170 & 4.1 & 4.452 & TRN & \\
\hline CHEMBL1966087 & 809170 & 6.7 & 6.87200 & 0000000001 & TRN \\
\hline CHEMBL1986767 & 809170 & 5.5 & 5.8697 & TRN & \\
\hline CHEMBL1996931 & 809170 & 6.9 & 6.7224 & TRN & \\
\hline CHEMBL1964692 & 809170 & 6.5 & 6.3806 & TRN & \\
\hline CHEMBL1964413 & 809170 & 6.7 & 6.7789 & TRN & \\
\hline CHEMBL1973483 & 809170 & 4.1 & 4.2986 & TRN & \\
\hline CHEMBL1998470 & 809170 & 7.4 & 6.891 & TRN & \\
\hline CHEMBL1996980 & 809170 & 8.1 & 8.4405 & TRN & \\
\hline CHEMBL1984432 & 809170 & 7.4 & 7.2366 & TRN & \\
\hline CHEMBL1970735 & 809170 & 4.1 & 4.1022 & TRN & \\
\hline CHEMBL219722 & 809170 & 6.5 & 6.388 & TRN & \\
\hline CHEMBL1969920 & 809170 & 7.7 & 7.6013 & TRN & \\
\hline CHEMBL1994669 & 809170 & 7.8 & 6.1455 & TRN & \\
\hline CHEMBL1997340 & 809170 & 5.6 & 5.2699 & TRN & \\
\hline CHEMBL2004365 & 809170 & 4.1 & 3.9174 & TST & \\
\hline CHEMBL1522508 & 809170 & 4.1 & 4.15 & TRN & \\
\hline CHEMBL1989474 & 809170 & 4.4 & 4.0716 & TRN & \\
\hline CHEMBL1090360 & 809170 & 4.1 & 4.0254 & TRN & \\
\hline CHEMBL226232 & 809170 & 5.2 & 5.1817 & TRN & \\
\hline CHEMBL210887 & 809170 & 6.5 & 4.425 & TST & \\
\hline CHEMBL458997 & 809170 & 4.2 & 4.9669 & TRN & \\
\hline CHEMBL1971021 & 809170 & 7.4 & 6.2425 & TRN & \\
\hline CHEMBL583144 & 809170 & 6.0 & 5.3218 & TST & \\
\hline CHEMBL1974310 & 809170 & 4.1 & 4.4698 & TRN & \\
\hline CHEMBL1982660 & 809170 & 4.1 & 4.3816 & TRN & \\
\hline CHEMBL1994693 & 809170 & 6.5 & 5.1615 & TRN & \\
\hline CHEMBL1982957 & 809170 & 7.2 & 6.1713 & TRN & \\
\hline CHEMBL1725279 & 809170 & 5.5 & 5.28600 & 20000000005 & TST \\
\hline CHEMBL 2002346 & 809170 & 8.4 & 7.2166 & TRN & \\
\hline CHEMBL1975138 & 809170 & 4.1 & 4.0666 & TST & \\
\hline & & & & 6952 & \\
\hline
\end{tabular}




\begin{tabular}{|c|c|c|c|c|}
\hline \multicolumn{5}{|c|}{ Supplemental Table S2.txt } \\
\hline CHEMBL424872 & 809170 & 4.3 & 4.1856 & TRN \\
\hline CHEMBL 2006836 & 809170 & 4.1 & 4.122 & TST \\
\hline CHEMBL1971947 & 809170 & 6.9 & 7.1327 & TRN \\
\hline CHEMBL412142 & 809170 & 4.1 & 4.505 & TST \\
\hline CHEMBL1985153 & 809170 & 4.1 & 5.4108 & TRN \\
\hline CHEMBL1980704 & 809170 & 5.3 & 4.4049 & TST \\
\hline CHEMBL 2003271 & 809170 & 6.6 & 6.0639 & TST \\
\hline CHEMBL1966808 & 809170 & 5.4 & 5.2355 & TST \\
\hline CHEMBL 2004447 & 809170 & 4.1 & 3.877 & TST \\
\hline CHEMBL1992231 & 809170 & 4.3 & 5.8833 & TRN \\
\hline CHEMBL1983111 & 809170 & 6.8 & 6.3394 & TRN \\
\hline CHEMBL1973860 & 809170 & 4.1 & 4.3201 & TRN \\
\hline CHEMBL1977713 & 809170 & 4.1 & 4.4829 & TRN \\
\hline CHEMBL260135 & 809170 & 4.1 & 4.703 & TRN \\
\hline CHEMBL 2004544 & 809170 & 4.1 & 4.2177 & TST \\
\hline CHEMBL1983157 & 809170 & 7.2 & 6.2989 & TRN \\
\hline CHEMBL1982610 & 809170 & 4.1 & 4.1424 & TRN \\
\hline CHEMBL1966040 & 809170 & 6.9 & 6.9151 & TRN \\
\hline CHEMBL1999496 & 809170 & 4.1 & 4.8831 & TRN \\
\hline CHEMBL 2006933 & 809170 & 6.9 & 6.0429 & TST \\
\hline CHEMBL1988300 & 809170 & 4.1 & 4.545 & TRN \\
\hline CHEMBL1991078 & 809170 & 6.1 & 6.0119 & TRN \\
\hline CHEMBL1987359 & 809170 & 4.1 & 4.2884 & TST \\
\hline CHEMBL2000685 & 809170 & 6.8 & 6.3799 & TRN \\
\hline CHEMBL1994438 & 809170 & 8.0 & 8.3033 & TRN \\
\hline CHEMBL1985311 & 809170 & 6.7 & 6.5486 & TRN \\
\hline CHEMBL1989265 & 809170 & 4.1 & 4.1344 & TST \\
\hline CHEMBL 2004647 & 809170 & 4.1 & 4.2383 & TST \\
\hline CHEMBL1969502 & 809170 & 6.1 & 6.0302 & TRN \\
\hline CHEMBL1965910 & 809170 & 5.2 & 5.1262 & TRN \\
\hline CHEMBL1996447 & 809170 & 6.9 & 6.2939 & TRN \\
\hline CHEMBL1682553 & 809170 & 7.0 & 6.8979 & TRN \\
\hline CHEMBL1971430 & 809170 & 4.1 & 4.1826 & TST \\
\hline CHEMBL1983963 & 809170 & 7.0 & 6.1528 & TRN \\
\hline CHEMBL1997764 & 809170 & 6.2 & 5.1123 & TRN \\
\hline CHEMBL 2000271 & 809170 & 8.1 & 8.2359 & TRN \\
\hline CHEMBL1985092 & 809170 & 7.2 & 5.9004 & TST \\
\hline CHEMBL2004692 & 809170 & 5.2 & 4.8655 & TST \\
\hline CHEMBL1981410 & 809170 & 5.8 & 5.6428 & TRN \\
\hline CHEMBL1996234 & 809170 & 5.7 & 5.7422 & TRN \\
\hline CHEMBL1991434 & 809170 & 4.1 & 4.2161 & TST \\
\hline CHEMBL1967544 & 809170 & 8.3 & 7.3588 & TRN \\
\hline CHEMBL223367 & 809170 & 4.1 & 3.6483 & TST \\
\hline CHEMBL340384 & 809170 & 8.5 & 7.84 & TRN \\
\hline CHEMBL1969151 & 809170 & 8.6 & 8.6449 & TRN \\
\hline CHEMBL1996587 & 809170 & 4.1 & 3.9703 & TRN \\
\hline CHEMBL1964804 & 809170 & 6.8 & 6.4484 & TRN \\
\hline CHEMBL443962 & 809170 & 4.1 & 4.404 & TST \\
\hline
\end{tabular}




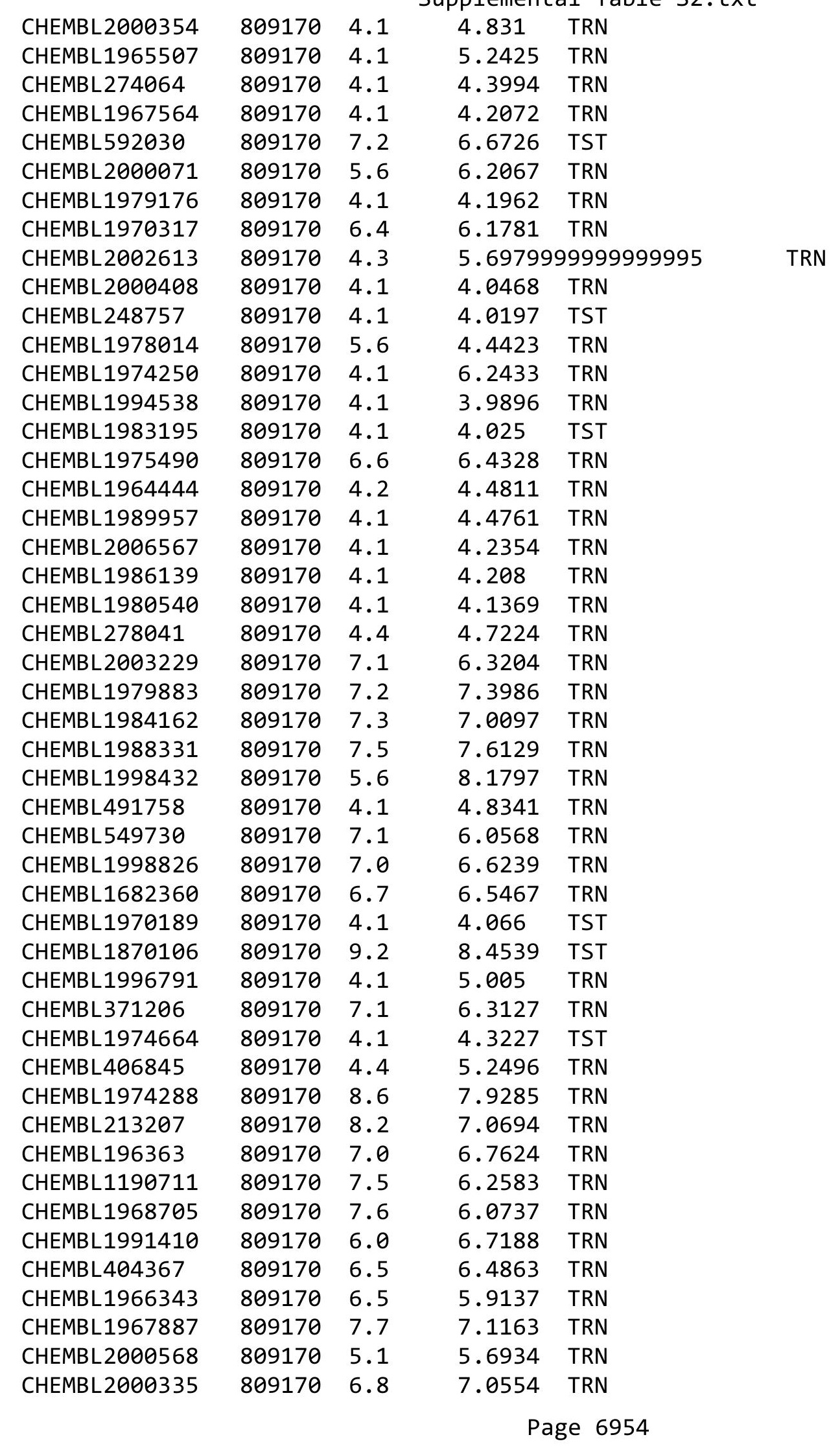




\begin{tabular}{|c|c|c|c|c|}
\hline \multicolumn{5}{|c|}{ mental T } \\
\hline CHEMBL1977604 & 809170 & 4.1 & 4.0781 & TST \\
\hline CHEMBL1993648 & 809170 & 6.5 & 6.3243 & TRN \\
\hline CHEMBL1988717 & 809170 & 4.1 & 4.565 & TRN \\
\hline CHEMBL1974328 & 809170 & 7.6 & 7.3554 & TRN \\
\hline CHEMBL509032 & 809170 & 6.8 & 6.9236 & TRN \\
\hline CHEMBL243298 & 809170 & 4.3 & 5.7913 & TRN \\
\hline CHEMBL1971951 & 809170 & 5.8 & 5.3248 & TRN \\
\hline CHEMBL1973808 & 809170 & 6.0 & 5.6504 & TRN \\
\hline CHEMBL 2000429 & 809170 & 4.1 & 3.9395 & TRN \\
\hline CHEMBL1972576 & 809170 & 4.1 & 4.2363 & TRN \\
\hline CHEMBL1992555 & 809170 & 6.6 & 5.791 & TST \\
\hline CHEMBL1992342 & 809170 & 6.1 & 6.0289 & TRN \\
\hline CHEMBL 2003682 & 809170 & 6.1 & 5.7036 & TRN \\
\hline CHEMBL1988173 & 809170 & 5.3 & 3.9305 & TST \\
\hline CHEMBL535331 & 809170 & 4.1 & 4.4199 & TST \\
\hline CHEMBL1989805 & 809170 & 4.1 & 4.2576 & TST \\
\hline CHEMBL1966204 & 809170 & 5.6 & 5.7097 & TST \\
\hline CHEMBL1982980 & 809170 & 4.1 & 4.1251 & TST \\
\hline CHEMBL1965423 & 809170 & 4.1 & 4.0501 & TST \\
\hline CHEMBL1983025 & 809170 & 7.0 & 6.9445 & TST \\
\hline CHEMBL 205415 & 809170 & 8.4 & 7.9302 & TST \\
\hline CHEMBL1977135 & 809170 & 7.7 & 7.2908 & TST \\
\hline CHEMBL 2001920 & 809170 & 6.1 & 5.0974 & TST \\
\hline CHEMBL 2002322 & 809170 & 4.1 & 4.5103 & TST \\
\hline CHEMBL1985654 & 809170 & 7.4 & 7.6023 & TST \\
\hline CHEMBL 2002323 & 809170 & 4.1 & 4.3145 & TST \\
\hline CHEMBL1241473 & 809170 & 5.9 & 6.5122 & TST \\
\hline CHEMBL1978448 & 809170 & 4.1 & 3.9717 & TST \\
\hline CHEMBL 2004513 & 809170 & 5.9 & 5.2828 & TST \\
\hline CHEMBL1972258 & 809170 & 6.3 & 7.2265 & TST \\
\hline CHEMBL1983855 & 809170 & 7.7 & 6.3736 & TST \\
\hline CHEMBL 2001257 & 809170 & 6.7 & 7.251 & TST \\
\hline CHEMBL 2005548 & 809170 & 7.6 & 6.72 & TST \\
\hline CHEMBL1987793 & 809170 & 4.1 & 4.5949 & TST \\
\hline CHEMBL1992536 & 809170 & 6.0 & 6.39 & TST \\
\hline CHEMBL1992740 & 809170 & 4.1 & 4.1703 & TST \\
\hline CHEMBL1966354 & 809170 & 5.6 & 4.8925 & TST \\
\hline CHEMBL 2002373 & 809170 & 4.1 & 4.1142 & TST \\
\hline CHEMBL439340 & 809170 & 4.1 & 4.4133 & TST \\
\hline CHEMBL1967531 & 809170 & 6.5 & 5.9997 & TST \\
\hline CHEMBL1970913 & 809170 & 4.1 & 4.3224 & TST \\
\hline CHEMBL1973893 & 809170 & 4.1 & 4.6006 & TST \\
\hline CHEMBL2004631 & 809170 & 7.7 & 6.7172 & TST \\
\hline CHEMBL1995736 & 809170 & 4.1 & 4.3991 & TST \\
\hline CHEMBL1996500 & 809170 & 4.1 & 4.3827 & TST \\
\hline CHEMBL1985095 & 809170 & 6.5 & 6.0382 & TST \\
\hline CHEMBL1998551 & 809170 & 4.1 & 3.9283 & TST \\
\hline CHEMBL1977374 & 809170 & 4.1 & 4.0158 & TST \\
\hline
\end{tabular}




\begin{tabular}{|c|c|c|c|c|}
\hline & & & pplement & al Ta \\
\hline CHEMBL1991180 & 809170 & 6.2 & 6.3415 & TST \\
\hline CHEMBL1682540 & 809170 & 6.5 & 6.5023 & TST \\
\hline CHEMBL1978656 & 809170 & 4.1 & 4.2275 & TST \\
\hline CHEMBL1976420 & 809170 & 4.1 & 5.0819 & TST \\
\hline CHEMBL413779 & 809170 & 4.1 & 3.6631 & TST \\
\hline CHEMBL1994864 & 809170 & 4.3 & 6.3156 & TST \\
\hline CHEMBL153735 & 201814 & 7.857 & 7.8827 & TRN \\
\hline CHEMBL347298 & 201814 & 6.9059 & 6.8569 & TRN \\
\hline CHEMBL152914 & 201814 & 7.5817 & 7.7972 & TRN \\
\hline CHEMBL356400 & 201814 & 6.0 & 7.3686 & TRN \\
\hline CHEMBL153185 & 201814 & 8.1249 & 7.7927 & TRN \\
\hline CHEMBL150959 & 201814 & 7.4921 & 8.205 & TRN \\
\hline CHEMBL152254 & 201814 & 6.0 & 6.8521 & TRN \\
\hline CHEMBL348704 & 201814 & 6.0 & 7.1691 & TRN \\
\hline CHEMBL423407 & 201814 & 7.6676 & 6.5555 & TRN \\
\hline CHEMBL358939 & 201814 & 6.8719 & 8.6201 & TST \\
\hline CHEMBL149641 & 201814 & 6.0 & 6.474 & TRN \\
\hline CHEMBL149626 & 201814 & 7.3915 & 6.8105 & TRN \\
\hline CHEMBL153274 & 201814 & 6.9788 & 6.7576 & TST \\
\hline CHEMBL348492 & 201814 & 7.1694 & 7.1426 & TST \\
\hline CHEMBL150958 & 201814 & 7.6819 & 8.7287 & TRN \\
\hline CHEMBL153756 & 201814 & 7.7122 & 7.7259 & TRN \\
\hline CHEMBL152930 & 201814 & 8.0044 & 8.2852 & TRN \\
\hline CHEMBL155037 & 201814 & 7.6308 & 7.2913 & TRN \\
\hline CHEMBL153036 & 201814 & 7.5114 & 8.0751 & TST \\
\hline CHEMBL356403 & 201814 & 8.2366 & 6.7624 & TRN \\
\hline CHEMBL358474 & 201814 & 7.6459 & 7.8338 & TRN \\
\hline CHEMBL153127 & 201814 & 8.0458 & 7.5387 & TRN \\
\hline CHEMBL153093 & 201814 & 6.0 & 7.1522 & TRN \\
\hline CHEMBL356849 & 201814 & 8.585 & 7.4973 & TRN \\
\hline CHEMBL150442 & 201814 & 9.0458 & 8.6774 & TRN \\
\hline CHEMBL149697 & 201814 & 8.699 & 7.9449 & TRN \\
\hline CHEMBL151010 & 201814 & 8.0 & 7.7343 & TRN \\
\hline CHEMBL358168 & 201814 & 8.7212 & 8.8889 & TRN \\
\hline CHEMBL153532 & 201814 & 7.8069 & 8.042 & TST \\
\hline CHEMBL153504 & 201814 & 8.2757 & 7.169 & TRN \\
\hline CHEMBL436069 & 201814 & 8.4089 & 8.5179 & TRN \\
\hline CHEMBL152707 & 201814 & 6.6838 & 8.2913 & TST \\
\hline CHEMBL150932 & 201814 & 6.0 & 6.4183 & TRN \\
\hline CHEMBL359345 & 201814 & 7.8508 & 7.4512 & TRN \\
\hline CHEMBL345277 & 201814 & 6.0 & 6.1931 & TRN \\
\hline CHEMBL153533 & 201814 & 7.9136 & 7.9475 & TRN \\
\hline CHEMBL150562 & 201814 & 7.7721 & 7.2524 & TST \\
\hline CHEMBL151140 & 201814 & 8.3768 & 8.0088 & TRN \\
\hline CHEMBL152935 & 201814 & 6.0 & 6.6219 & TRN \\
\hline CHEMBL149971 & 201814 & 6.0 & 6.4227 & TRN \\
\hline CHEMBL149970 & 201814 & 8.4318 & 7.6516 & TRN \\
\hline CHEMBL356482 & 201814 & 8.0862 & 7.5268 & TRN \\
\hline
\end{tabular}




\begin{tabular}{|c|c|c|c|c|c|c|}
\hline \multicolumn{7}{|c|}{ Supplemental Table S2.txt } \\
\hline CHEMBL152141 & 201814 & 6.0 & 6.6658 & TRN & & \\
\hline CHEMBL155619 & 201814 & 7.3279 & 8.7555 & TST & & \\
\hline CHEMBL149855 & 201814 & 7.6861 & 7.6636 & TRN & & \\
\hline CHEMBL149694 & 201814 & 7.3979 & 7.3732 & TRN & & \\
\hline CHEMBL357051 & 201814 & 9.0458 & 7.1848 & TST & & \\
\hline CHEMBL348005 & 201814 & 7.1062 & 6.8164 & TST & & \\
\hline CHEMBL153676 & 201814 & 7.8097 & 6.9031 & TST & & \\
\hline CHEMBL357943 & 201814 & 7.6716 & 7.965 & TST & & \\
\hline CHEMBL447188 & 201814 & 8.6383 & 6.9419 & TST & & \\
\hline CHEMBL3798009 & 1575201 & 6.068 & 6.0187 & TRN & & \\
\hline CHEMBL 3799445 & 1575201 & 6.6596 & 6.2876 & TRN & & \\
\hline CHEMBL3798291 & 1575201 & 7.0132 & 6.7297 & TRN & & \\
\hline CHEMBL3797894 & 1575201 & 5.5421 & 6.3683 & TST & & \\
\hline CHEMBL 3797588 & 1575201 & 7.3768 & 7.2074 & TRN & & \\
\hline CHEMBL3797909 & 1575201 & 6.4449 & 6.4736 & TRN & & \\
\hline CHEMBL3799901 & 1575201 & 5.7375 & 5.3553 & TRN & & \\
\hline CHEMBL3799588 & 1575201 & 5.4855 & 6.2732 & TRN & & \\
\hline CHEMBL3799322 & 1575201 & 5.4486 & 5.109 & TRN & & \\
\hline CHEMBL 3800221 & 1575201 & 5.6289 & 5.3251 & TRN & & \\
\hline CHEMBL3797794 & 1575201 & 5.7258 & 6.6775 & TST & & \\
\hline CHEMBL3799272 & 1575201 & 6.9281 & 6.0043 & TST & & \\
\hline CHEMBL3797438 & 1575201 & 6.8041 & 6.8554 & TRN & & \\
\hline CHEMBL3798904 & 1575201 & 5.1273 & 4.9568 & TRN & & \\
\hline CHEMBL3799273 & 1575201 & 5.9547 & 5.6697 & TRN & & \\
\hline CHEMBL3798678 & 1575201 & 7.0605 & 6.7902 & TRN & & \\
\hline CHEMBL3797564 & 1575201 & 6.8996 & 6.8067 & TRN & & \\
\hline CHEMBL 3800124 & 1575201 & 6.5317 & 6.6041 & TRN & & \\
\hline CHEMBL3797730 & 1575201 & 5.8327 & 5.8944 & TRN & & \\
\hline CHEMBL 3799000 & 1575201 & 5.3344 & 5.9657 & TRN & & \\
\hline CHEMBL3799911 & 1575201 & 6.2396 & 6.2807 & TRN & & \\
\hline CHEMBL3799974 & 1575201 & 5.6326 & 5.7473 & TRN & & \\
\hline CHEMBL3799114 & 1575201 & 6.6253 & 6.75700 & 0000000001 & & TRN \\
\hline CHEMBL3797847 & 1575201 & 5.2782 & 5.8551 & TRN & & \\
\hline CHEMBL3799772 & 1575201 & 6.7305 & 6.6238 & TST & & \\
\hline CHEMBL3799566 & 1575201 & 6.3036 & 6.7629 & TRN & & \\
\hline CHEMBL3798898 & 1575201 & 5.4389 & 5.324 & TRN & & \\
\hline CHEMBL3799688 & 1575201 & 4.7352 & 4.9028 & TRN & & \\
\hline CHEMBL3797301 & 1575201 & 6.2807 & 6.0767 & TRN & & \\
\hline CHEMBL3799717 & 1575201 & 5.5544 & 5.1702 & TRN & & \\
\hline CHEMBL3797448 & 1575201 & 6.0883 & 6.1956 & TRN & & \\
\hline CHEMBL3797742 & 1575201 & 6.4597 & 6.3449 & TRN & & \\
\hline CHEMBL3800536 & 1575201 & 5.2526 & 5.7532 & TRN & & \\
\hline CHEMBL3797643 & 1575201 & 6.6271 & 6.7614 & TRN & & \\
\hline CHEMBL3798241 & 1575201 & 5.9431 & 5.9938 & TST & & \\
\hline CHEMBL3797306 & 1575201 & 6.3468 & 6.5982 & TST & & \\
\hline CHEMBL 3798653 & 1575201 & 6.4949 & 6.2027 & TST & & \\
\hline CHEMBL3798765 & 1575201 & 4.98300 & $\partial 0000000$ & 205 & 5.1649 & TRN \\
\hline CHEMBL3799353 & 1575201 & 4.9586 & 5.3312 & TRN & & \\
\hline
\end{tabular}


Supplemental Table S2.txt

\begin{tabular}{|c|c|c|c|c|c|c|}
\hline CHEMBL3799541 & 1575201 & 7.5528 & 7.3244 & TRN & & \\
\hline CHEMBL 3799922 & 1575201 & 6.6882 & 6.8369 & TRN & & \\
\hline CHEMBL 3800229 & 1575201 & \multicolumn{3}{|c|}{5.327000000000001} & 5.4535 & TRN \\
\hline CHEMBL 3797697 & 1575201 & 6.317 & 5.5825 & TST & & \\
\hline CHEMBL 3797218 & 1575201 & 7.284 & 7.2086 & TRN & & \\
\hline CHEMBL 3797664 & 1575201 & 5.1986 & 5.002 & TST & & \\
\hline CHEMBL 3800323 & 1575201 & 4.9431 & 6.2676 & TST & & \\
\hline CHEMBL 3797517 & 1575201 & 6.6402 & 6.4332 & TRN & & \\
\hline CHEMBL 3797653 & 1575201 & 7.0915 & 6.8387 & TRN & & \\
\hline CHEMBL 3798893 & 1575201 & 6.5317 & 6.0688 & TST & & \\
\hline CHEMBL 3798251 & 1575201 & 5.1518 & 5.619 & TST & & \\
\hline CHEMBL 3798981 & 1575201 & 5.6655 & 5.6144 & TRN & & \\
\hline CHEMBL 3798946 & 1575201 & 6.063 & 6.5957 & TST & & \\
\hline CHEMBL 3800319 & 1575201 & 5.7305 & 5.5159 & TRN & & \\
\hline CHEMBL 3800258 & 1575201 & 6.8297 & 6.7128 & TRN & & \\
\hline CHEMBL 3797970 & 1575201 & 6.8386 & 6.8246 & TRN & & \\
\hline CHEMBL 3799484 & 1575201 & 6.1959 & 6.3444 & TST & & \\
\hline CHEMBL 240954 & 954746 & 3.4733 & 3.5001 & TST & & \\
\hline CHEMBL 2005886 & 954746 & 5.0699 & 5.0163 & TRN & & \\
\hline CHEMBL1909414 & 954746 & \multicolumn{3}{|c|}{3.3930000000000002} & 3.3839 & TRN \\
\hline CHEMBL1190711 & 954746 & 5.4728 & 5.4264 & TRN & & \\
\hline CHEMBL412142 & 954746 & 5.1927 & 5.1875 & TRN & & \\
\hline CHEMBL 379975 & 954746 & 4.0227 & 4.0285 & TRN & & \\
\hline CHEMBL1256459 & 954746 & 6.7343 & 6.7746 & TRN & & \\
\hline CHEMBL1404918 & 954746 & 3.4476 & 3.4194 & TRN & & \\
\hline CHEMBL65 & 954746 & 8.4848 & 8.4744 & TRN & & \\
\hline CHEMBL392695 & 954746 & 4.7647 & 4.7738 & TRN & & \\
\hline CHEMBL 2144069 & 954746 & 6.9161 & 6.8694 & TRN & & \\
\hline CHEMBL 2134202 & 954746 & 3.2022 & 3.1772 & TRN & & \\
\hline CHEMBL585951 & 954746 & 7.0838 & 7.0617 & TRN & & \\
\hline CHEMBL1590308 & 954746 & 2.8892 & 3.5103 & TST & & \\
\hline CHEMBL558642 & 954746 & 5.6785 & 5.7132 & TRN & & \\
\hline CHEMBL449158 & 954746 & 6.6171 & 6.882999 & 9999999999 & & IJ \\
\hline CHEMBL135561 & 954746 & 5.876 & 5.8104 & TRN & & \\
\hline CHEMBL102714 & 954746 & 3.7185 & 3.7596 & TRN & & \\
\hline CHEMBL1970879 & 954746 & 3.4767 & 3.378 & TRN & & \\
\hline CHEMBL180127 & 954746 & 3.8443 & 3.824 & TRN & & \\
\hline CHEMBL 2137530 & 954746 & 4.4535 & 4.4927 & TRN & & \\
\hline CHEMBL 258844 & 954746 & 4.9037 & 4.9362 & TRN & & \\
\hline CHEMBL573107 & 954746 & 5.4051 & 5.4169 & TRN & & \\
\hline CHEMBL509032 & 954746 & 4.7291 & 4.808 & TRN & & \\
\hline CHEMBL393929 & 954746 & 4.6007 & 4.6322 & TRN & & \\
\hline CHEMBL1673039 & 954746 & 5.0894 & 5.0565 & TRN & & \\
\hline CHEMBL 255342 & 954746 & 3.5322 & 3.4692 & TRN & & \\
\hline CHEMBL 217354 & 954746 & 6.7305 & 6.7406 & TRN & & \\
\hline CHEMBL472940 & 954746 & 2.6041 & 2.5758 & TRN & & \\
\hline CHEMBL 3392440 & 954746 & 4.0273 & 4.0688 & TRN & & \\
\hline CHEMBL483847 & 954746 & 4.3298 & 4.3504 & TRN & & \\
\hline
\end{tabular}


Supplemental Table S2.txt

\begin{tabular}{|c|c|c|c|c|}
\hline CHEMBL 379300 & 954746 & 6.6097 & 6.6344 & TRN \\
\hline CHEMBL 213100 & 954746 & 3.7077 & 3.7242 & TRN \\
\hline CHEMBL191334 & 954746 & 3.5133 & 3.497 & TRN \\
\hline CHEMBL 9470 & 954746 & 6.3011 & 5.8587 & TST \\
\hline CHEMBL512504 & 954746 & 4.0279 & 4.0433 & TRN \\
\hline CHEMBL1643959 & 954746 & 4.2482 & 4.3464 & TRN \\
\hline CHEMBL1788116 & 954746 & 5.2564 & 5.2301 & TRN \\
\hline CHEMBL1242367 & 954746 & 4.1929 & 4.2238 & TRN \\
\hline CHEMBL 220241 & 954746 & 3.8789 & 3.8815 & TRN \\
\hline CHEMBL221137 & 954746 & 4.7754 & 4.5026 & TST \\
\hline CHEMBL1230020 & 954746 & 3.7527 & 3.7725 & TRN \\
\hline CHEMBL 259181 & 954746 & 4.5188 & 4.4577 & TRN \\
\hline CHEMBL3186408 & 954746 & 3.3729 & 3.9861 & TST \\
\hline CHEMBL 202721 & 954746 & 5.5811 & 5.5481 & TRN \\
\hline CHEMBL192566 & 954746 & 10.6803 & 7.9074 & TST \\
\hline CHEMBL188678 & 954746 & 4.6371 & 4.6621 & TRN \\
\hline CHEMBL222102 & 954746 & 3.6073 & 3.7211 & TRN \\
\hline CHEMBL 209148 & 954746 & 3.6608 & 3.6628 & TRN \\
\hline CHEMBL514499 & 954746 & 5.8333 & 5.8676 & TRN \\
\hline CHEMBL483849 & 954746 & 2.6864 & 2.2027 & TST \\
\hline CHEMBL 2363137 & 954746 & 4.9251 & 4.871 & TRN \\
\hline CHEMBL577784 & 954746 & 6.0127 & 6.0161 & TRN \\
\hline CHEMBL1357247 & 954746 & 3.4513 & 3.5088 & TRN \\
\hline CHEMBL92309 & 954746 & 3.3104 & 2.7301 & TST \\
\hline CHEMBL210618 & 954746 & 3.1511 & 3.0742 & TRN \\
\hline CHEMBL 300389 & 954746 & 7.0982 & 7.0806 & TRN \\
\hline CHEMBL189584 & 954746 & 4.2489 & 4.3853 & TST \\
\hline CHEMBL3349342 & 954746 & 5.5646 & 5.2657 & TST \\
\hline CHEMBL1516890 & 954746 & 4.5384 & 4.9283 & TST \\
\hline CHEMBL373751 & 954746 & 3.4724 & 3.8152 & TST \\
\hline CHEMBL515416 & 954746 & 3.7811 & 4.3514 & TST \\
\hline CHEMBL1186585 & 954746 & 3.6391 & 3.473006 & 00000000003 \\
\hline CHEMBL3199475 & 954746 & 3.9452 & 4.3766 & TST \\
\hline CHEMBL399530 & 954746 & 3.6613 & 4.4818 & TST \\
\hline CHEMBL2313456 & 934450 & 6.8239 & 6.6827 & TST \\
\hline CHEMBL 2313804 & 934450 & 7.0969 & 6.8088 & TRN \\
\hline CHEMBL 2313791 & 934450 & 6.9208 & 7.7817 & TRN \\
\hline CHEMBL 2313790 & 934450 & 9.0 & 8.2444 & TRN \\
\hline CHEMBL 2313471 & 934450 & 6.699 & 6.8803 & TRN \\
\hline CHEMBL 2313482 & 934450 & 6.3468 & 6.6223 & TRN \\
\hline CHEMBL 2313466 & 934450 & 6.699 & 6.5985 & TRN \\
\hline CHEMBL 2313797 & 934450 & 7.3979 & 7.1875 & TRN \\
\hline CHEMBL 2313485 & 934450 & 7.5229 & 7.3498 & TST \\
\hline CHEMBL 2313468 & 934450 & 6.7447 & 6.7659 & TRN \\
\hline CHEMBL 2313811 & 934450 & 7.301 & 7.1134 & TRN \\
\hline CHEMBL 2313452 & 934450 & 6.9586 & 6.7205 & TRN \\
\hline CHEMBL 2313807 & 934450 & 7.0605 & 6.9535 & TRN \\
\hline CHEMBL 2313792 & 934450 & 7.9586 & 7.9588 & TRN \\
\hline
\end{tabular}


Supplemental Table S2.txt

\begin{tabular}{|c|c|c|c|c|}
\hline 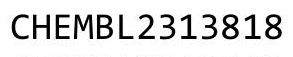 & & 367 & 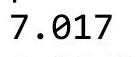 & \\
\hline HEMBL2313469 & 450 & 4815 & 9869 & \\
\hline HEMBL2313795 & 34450 & . 3979 & & \\
\hline IEMBL 2313 & 50 & 539 & & \\
\hline IEMBL 2313462 & 50 & & & \\
\hline HEMBL2313488 & 34450 & 2218 & & \\
\hline HEMBL 2313806 & 34450 & .284 & 0129 & \\
\hline HEMBL2313789 & 50 & .5686 & & \\
\hline AEMBL 2313809 & 50 & 549 & 74 & \\
\hline AEMBL2313793 & 50 & 596 & & \\
\hline HEMBL2313800 & 34 & . 7959 & 9754 & \\
\hline AEMBL2313461 & 50 & 8239 & 31 & \\
\hline HEMBL2313798 & 50 & 585 & 15 & \\
\hline HEMBL2313813 & & & 49 & \\
\hline HEMBL 231 & 5 & & & \\
\hline HEMBL2313481 & 50 & & & \\
\hline HEMBL2313817 & 50 & 57 & 98 & \\
\hline HEMBL2. & ;0 & & 96 & \\
\hline HEMBL2 & & & & \\
\hline HEMBL23 & & & & RN \\
\hline HEMBL23 & & & & 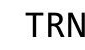 \\
\hline HEMBL 2313483 & 50 & 39 & 24 & KIV \\
\hline HEMBL2: & ;0 & 12 & & \\
\hline HEMBL2: & & & & \\
\hline HEMBL2: & & & & RN \\
\hline HEMBL 231 & & & & RN \\
\hline HEMBL 2313458 & 50 & & & ST \\
\hline HEMBL2313788 & & & 46 & RN \\
\hline HEM & & & 97 & RN \\
\hline HEMBL 2 & & & & RN \\
\hline HEMBL 67 & & & & ST \\
\hline HEMBL2313812 & 50 & 7. & & TRN \\
\hline HEMBL2313787 & & 7. & & ГRN \\
\hline 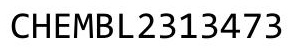 & & & & ST \\
\hline HEMBL2313470 & & & & TST \\
\hline HEMBL2313808 & & & & TST \\
\hline HEMBL2313457 & 50 & 586 & & TST \\
\hline HEMBL23 & & & 89 & ST \\
\hline M & & & & RN \\
\hline HEMBL398708 & & & & RN \\
\hline HEMBL 254619 & & 85 & & RN \\
\hline HEMBL400096 & & & & RN \\
\hline HEMBL 253611 & & 4.7212 & & \\
\hline CHEMBL 255080 & & & 4.9097 & RN \\
\hline HEMBL2 & & 8 & & RN \\
\hline HEMBL400 & 46 & 5 . & 57 & N \\
\hline-4 & & & & \\
\hline & 40 & 3.6021 & 4.2239 & \\
\hline
\end{tabular}

Page 6960 


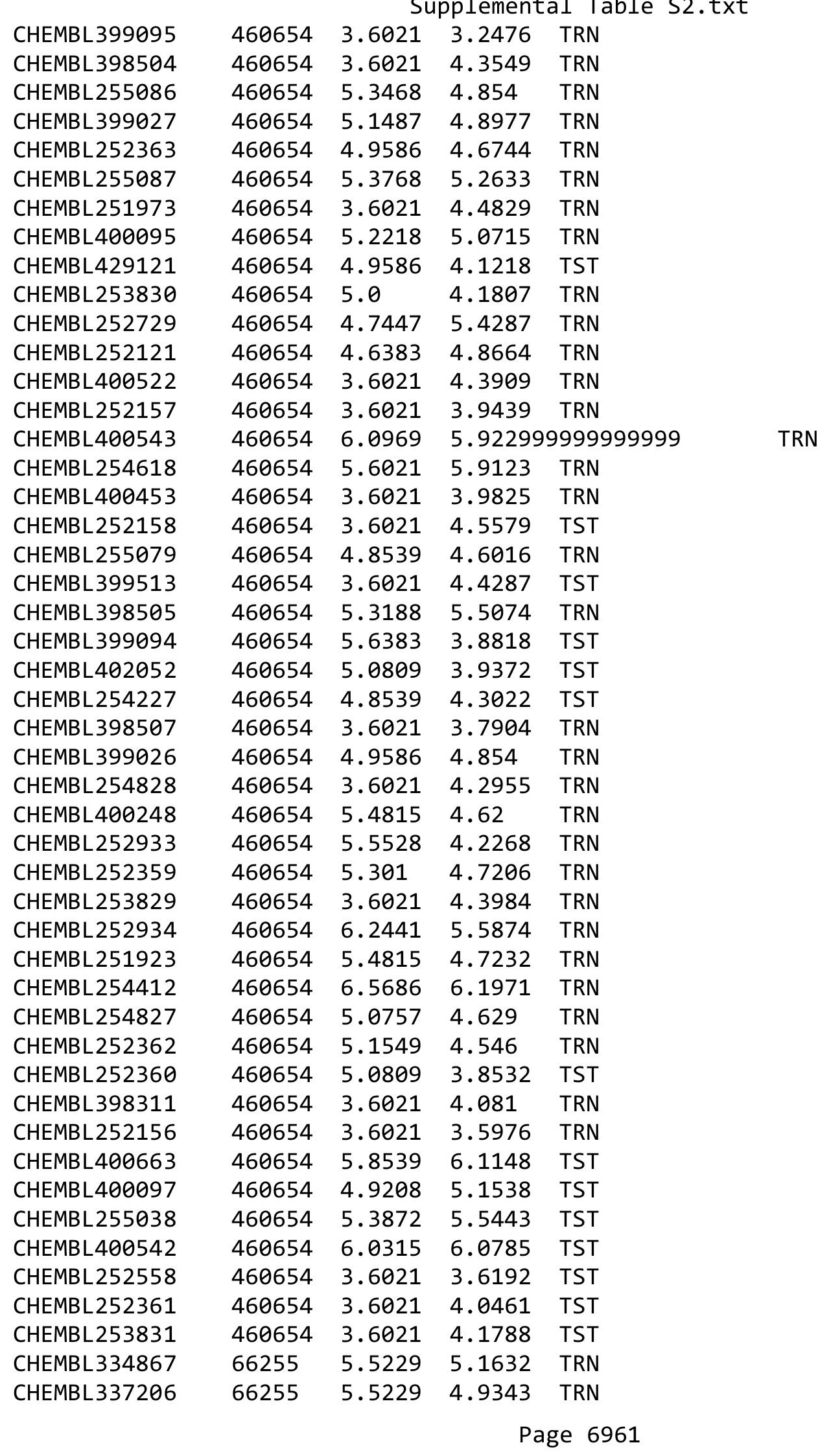




\begin{tabular}{|c|c|c|c|c|c|}
\hline \multicolumn{6}{|c|}{ Supplemental Table S2.txt } \\
\hline CHEMBL341377 & 66255 & 3.9208 & 5.0805 & TST & \\
\hline CHEMBL137274 & 66255 & 3.0 & 5.0191 & TST & \\
\hline CHEMBL343711 & 66255 & 4.3979 & 4.8455 & TRN & \\
\hline CHEMBL135292 & 66255 & 6.5229 & 5.2518 & TRN & \\
\hline CHEMBL343604 & 66255 & 5.5229 & 5.0833 & TRN & \\
\hline CHEMBL337402 & 66255 & 4.1249 & 5.0784 & TRN & \\
\hline CHEMBL136079 & 66255 & 5.301 & 4.6901 & TRN & \\
\hline CHEMBL436578 & 66255 & 6.0 & 5.0189 & TRN & \\
\hline CHEMBL343270 & 66255 & 4.4559 & 5.0614 & TRN & \\
\hline CHEMBL344929 & 66255 & 3.0 & 4.4091 & TST & \\
\hline CHEMBL335253 & 66255 & 4.2076 & 4.8073 & TRN & \\
\hline CHEMBL439980 & 66255 & 4.0809 & 4.2399 & TRN & \\
\hline CHEMBL137465 & 66255 & 6.0 & 5.0739 & TRN & \\
\hline CHEMBL134811 & 66255 & 4.8861 & 5.5587 & TRN & \\
\hline CHEMBL137644 & 66255 & 4.3979 & 4.9149 & TRN & \\
\hline CHEMBL132759 & 66255 & 4.1871 & 5.117 & TRN & \\
\hline CHEMBL137595 & 66255 & 5.699 & 4.8645 & TRN & \\
\hline CHEMBL335288 & 66255 & 5.0458 & 5.1078 & TST & \\
\hline CHEMBL134909 & 66255 & 4.041 & 3.8943 & TRN & \\
\hline CHEMBL137358 & 66255 & 4.9208 & 4.7225 & TRN & \\
\hline CHEMBL410292 & 66255 & 4.5229 & 4.9359 & TRN & \\
\hline CHEMBL135875 & 66255 & 4.9208 & 4.914 & TRN & \\
\hline CHEMBL335474 & 66255 & 3.0 & 4.8804 & TST & \\
\hline CHEMBL342021 & 66255 & 4.6576 & 3.9372 & TRN & \\
\hline CHEMBL422996 & 66255 & 4.8239 & 4.8348 & TRN & \\
\hline CHEMBL339186 & 66255 & 3.0 & 4.3772 & TST & \\
\hline CHEMBL434044 & 66255 & 4.585 & 5.1073 & TRN & \\
\hline CHEMBL137751 & 66255 & 5.2218 & 5.086 & TRN & \\
\hline CHEMBL132751 & 66255 & 3.0 & 4.0269 & TRN & \\
\hline CHEMBL341764 & 66255 & 4.7447 & 5.0957 & TRN & \\
\hline CHEMBL136383 & 66255 & 3.0 & 3.61899 & 99999999998 & TRN \\
\hline CHEMBL133252 & 66255 & 4.2218 & 5.0629 & TST & \\
\hline CHEMBL421756 & 66255 & 4.8539 & 4.9701 & TRN & \\
\hline CHEMBL137401 & 66255 & 3.0 & 4.9146 & TST & \\
\hline CHEMBL335583 & 66255 & 4.5686 & 4.4227 & TRN & \\
\hline CHEMBL137173 & 66255 & 4.3768 & 4.9523 & TRN & \\
\hline CHEMBL344197 & 66255 & 6.0 & 5.397 & TRN & \\
\hline CHEMBL137029 & 66255 & 5.0969 & 4.1763 & TRN & \\
\hline CHEMBL342591 & 66255 & 5.0 & 4.9092 & TRN & \\
\hline CHEMBL135264 & 66255 & 4.6383 & 3.9221 & TRN & \\
\hline CHEMBL134547 & 66255 & 3.0 & 4.6026 & TST & \\
\hline CHEMBL343061 & 66255 & 4.1549 & 4.7058 & TRN & \\
\hline CHEMBL336357 & 66255 & 4.4559 & 4.9392 & TRN & \\
\hline CHEMBL137533 & 66255 & 3.9208 & 5.1323 & TST & \\
\hline CHEMBL410491 & 66255 & 3.0 & 4.4378 & TRN & \\
\hline CHEMBL135809 & 66255 & 6.0 & 4.7046 & TRN & \\
\hline CHEMBL336579 & 66255 & 4.699 & 5.3226 & TST & \\
\hline CHEMBL341765 & 66255 & 5.699 & 4.8707 & TST & \\
\hline
\end{tabular}




\begin{tabular}{|c|c|c|c|c|c|c|}
\hline & & \multicolumn{5}{|c|}{ Supplemental Table S2.txt } \\
\hline CHEMBL343284 & 66255 & 4.9586 & 4.9328 & TST & & \\
\hline CHEMBL1214920 & 649997 & 8.0 & 7.8452 & TRN & & \\
\hline CHEMBL1215334 & 649997 & 7.9208 & 7.8027 & TRN & & \\
\hline CHEMBL1215637 & 649997 & 9.699 & 10.1701 & TRN & & \\
\hline CHEMBL1215207 & 649997 & 7.1871 & 7.6106 & TRN & & \\
\hline CHEMBL1214919 & 649997 & 7.8539 & 8.4972 & TRN & & \\
\hline CHEMBL1215337 & 649997 & 9.0 & 9.1816 & TRN & & \\
\hline CHEMBL1215490 & 649997 & 8.0969 & 8.4714 & TRN & & \\
\hline CHEMBL1215628 & 649997 & 9.3979 & 8.8915 & TRN & & \\
\hline CHEMBL1628251 & 649997 & 8.1549 & 8.3999 & TST & & \\
\hline CHEMBL1214852 & 649997 & 8.699 & 8.1692 & TRN & & \\
\hline CHEMBL1215493 & 649997 & 8.699 & 8.8829 & TRN & & \\
\hline CHEMBL1215631 & 649997 & 8.5229 & 8.711 & TRN & & \\
\hline CHEMBL1215342 & 649997 & 8.699 & 8.5371 & TRN & & \\
\hline CHEMBL1215204 & 649997 & 9.0 & 9.133 & TRN & & \\
\hline CHEMBL1214694 & 649997 & 9.301 & 9.5541 & TRN & & \\
\hline CHEMBL1214778 & 649997 & 8.5229 & 8.2348 & TRN & & \\
\hline CHEMBL1215055 & 649997 & 7.9208 & 7.4415 & TST & & \\
\hline CHEMBL1215136 & 649997 & 7.1805 & 7.4934 & TRN & & \\
\hline CHEMBL1215491 & 649997 & 8.0969 & 8.1166 & TRN & & \\
\hline CHEMBL1215413 & 649997 & 8.5229 & 8.6402 & TRN & & \\
\hline CHEMBL1212965 & 649997 & 7.4815 & 7.1299 & TRN & & \\
\hline CHEMBL1215201 & 649997 & 3.6021 & 5.1776 & TRN & & \\
\hline CHEMBL1215629 & 649997 & 7.7212 & 8.3939 & TRN & & \\
\hline CHEMBL1215426 & 649997 & 9.0 & 8.371 & TST & & \\
\hline CHEMBL1215635 & 649997 & 10.3009 & 799999999 & 998 & 349 & TRN \\
\hline CHEMBL1215134 & 649997 & 6.9914 & 6.7711 & TST & & \\
\hline CHEMBL1215211 & 649997 & 7.8239 & 8.3684 & TST & & \\
\hline CHEMBL1214849 & 649997 & 8.699 & 7.9937 & TST & & \\
\hline CHEMBL1215566 & 649997 & 10.3009 & 999999999 & 998 & 9.7173 & TRN \\
\hline CHEMBL1215203 & 649997 & 8.5229 & 8.695 & TRN & & \\
\hline CHEMBL1215638 & 649997 & 9.1549 & 9.9357 & TRN & & \\
\hline CHEMBL1215561 & 649997 & 8.1549 & 8.5574 & TRN & & \\
\hline CHEMBL1215333 & 649997 & 8.699 & 8.6623 & TRN & & \\
\hline CHEMBL1215064 & 649997 & 7.1871 & 7.6782 & TRN & & \\
\hline CHEMBL1215137 & 649997 & 8.2218 & 7.9091 & TRN & & \\
\hline CHEMBL1215633 & 649997 & 8.301 & 8.2746 & TRN & & \\
\hline CHEMBL1215702 & 649997 & 9.0 & 8.6709 & TRN & & \\
\hline CHEMBL1215068 & 649997 & 9.301 & 9.3181 & TRN & & \\
\hline CHEMBL1215775 & 649997 & 8.0458 & 8.5178 & TST & & \\
\hline CHEMBL1628255 & 649997 & 7.7447 & 7.4597 & TRN & & \\
\hline CHEMBL1215632 & 649997 & 8.3979 & 8.1459 & TRN & & \\
\hline CHEMBL1215558 & 649997 & 7.585 & 8.3976 & TRN & & \\
\hline CHEMBL1628247 & 649997 & 8.0969 & 8.2033 & TRN & & \\
\hline CHEMBL1214699 & 649997 & 7.6021 & 7.3793 & TRN & & \\
\hline CHEMBL1215494 & 649997 & 8.3979 & 7.8386 & TST & & \\
\hline CHEMBL1215766 & 649997 & 6.7282 & 7.2427 & TRN & & \\
\hline CHEMBL1215213 & 649997 & 7.9586 & 8.1232 & TST & & \\
\hline
\end{tabular}




\begin{tabular}{|c|c|c|c|c|c|c|}
\hline & & \multicolumn{5}{|c|}{ Supplemental Table s2.txt } \\
\hline CHEMBL1215495 & 649997 & 8.699 & 8.1788 & TST & & \\
\hline CHEMBL1628253 & 649997 & 8.301 & 7.7443 & TST & & \\
\hline CHEMBL1215141 & 649997 & 7.7447 & 8.6998 & TRN & & \\
\hline CHEMBL1215699 & 649997 & 9.0458 & 8.8446 & TRN & & \\
\hline CHEMBL1215140 & 649997 & 9.0 & 9.1601 & TRN & & \\
\hline CHEMBL1215133 & 649997 & 6.2104 & 6.9652 & TST & & \\
\hline CHEMBL1215569 & 649997 & 9.0969 & 10.0067 & TRN & & \\
\hline CHEMBL1215060 & 649997 & 8.699 & 8.0765 & TRN & & \\
\hline CHEMBL1214777 & 649997 & 8.8239 & 8.4724 & TRN & & \\
\hline CHEMBL1215765 & 649997 & 7.5376 & 7.38399 & 9999999999 & 95 & TRN \\
\hline CHEMBL1215275 & 649997 & 7.8239 & 7.3572 & TRN & & \\
\hline CHEMBL1214695 & 649997 & 8.699 & 9.4172 & TRN & & \\
\hline CHEMBL1214780 & 649997 & 8.5229 & 7.3624 & TST & & \\
\hline CHEMBL1214981 & 649997 & 5.3439 & 6.3856 & TRN & & \\
\hline CHEMBL1215059 & 649997 & 8.0458 & 8.0654 & TRN & & \\
\hline CHEMBL1215067 & 649997 & 8.5229 & 9.8527 & TRN & & \\
\hline CHEMBL1215131 & 649997 & 7.3979 & 7.3473 & TRN & & \\
\hline CHEMBL1214697 & 649997 & 7.699 & 7.9663 & TRN & & \\
\hline CHEMBL1628250 & 649997 & 8.5229 & 7.7774 & TRN & & \\
\hline CHEMBL1215138 & 649997 & 8.1549 & 7.9265 & TRN & & \\
\hline CHEMBL1215772 & 649997 & 9.0 & 8.5478 & TRN & & \\
\hline CHEMBL1215063 & 649997 & 8.0969 & 8.7311 & TRN & & \\
\hline CHEMBL1215700 & 649997 & 10.3009 & 79999999ऽ & 998 & 9.6069 & TRN \\
\hline CHEMBL1215423 & 649997 & 9.0 & 8.7228 & TRN & & \\
\hline CHEMBL1215143 & 649997 & 8.2218 & 8.7885 & TRN & & \\
\hline CHEMBL1215704 & 649997 & 9.0969 & 8.0549 & TRN & & \\
\hline CHEMBL1215774 & 649997 & 8.1549 & 8.6363 & TST & & \\
\hline CHEMBL1215557 & 649997 & 8.699 & 8.5998 & TRN & & \\
\hline CHEMBL1214848 & 649997 & 8.699 & 8.5143 & TRN & & \\
\hline CHEMBL1215422 & 649997 & 8.699 & 8.2229 & TRN & & \\
\hline CHEMBL1215132 & 649997 & 8.5229 & 8.0705 & TRN & & \\
\hline CHEMBL1214982 & 649997 & 7.1938 & 6.9912 & TRN & & \\
\hline CHEMBL1215412 & 649997 & 7.4685 & 7.8391 & TRN & & \\
\hline CHEMBL1215142 & 649997 & 8.3979 & 8.9779 & TRN & & \\
\hline CHEMBL1215416 & 649997 & 8.699 & 8.9161 & TRN & & \\
\hline CHEMBL1214773 & 649997 & 8.301 & 8.065 & TRN & & \\
\hline CHEMBL1215267 & 649997 & 6.5901 & 7.42899 & 9999999999 & & TRN \\
\hline CHEMBL1214851 & 649997 & 8.3979 & 8.1719 & TRN & & \\
\hline CHEMBL1215272 & 649997 & 6.61799 & 99999999 & & 7.6158 & TRN \\
\hline CHEMBL1214698 & 649997 & 8.301 & 8.4059 & TRN & & \\
\hline CHEMBL1215139 & 649997 & 8.1549 & 7.8379 & TRN & & \\
\hline CHEMBL1214846 & 649997 & 10.3009 & 79999999ऽ & 998 & 9.0186 & TRN \\
\hline CHEMBL1215273 & 649997 & 8.2218 & 7.4842 & TRN & & \\
\hline CHEMBL1215144 & 649997 & 8.2218 & 8.2606 & TST & & \\
\hline CHEMBL1214980 & 649997 & 7.2291 & 6.5968 & TST & & \\
\hline CHEMBL1215568 & 649997 & 9.0 & 9.7653 & TRN & & \\
\hline CHEMBL1215764 & 649997 & 8.699 & 8.6014 & TRN & & \\
\hline CHEMBL1215697 & 649997 & 7.0915 & 7.7526 & TRN & & \\
\hline
\end{tabular}




\begin{tabular}{|c|c|c|c|c|c|c|}
\hline & & & oplement & al Table & s2.txt & \\
\hline CHEMBL1215560 & 649997 & 10.3009 & 79999999 & 998 & 8.7774 & TRN \\
\hline CHEMBL1214701 & 649997 & 8.5229 & 7.7731 & TRN & & \\
\hline CHEMBL1215771 & 649997 & 8.5229 & 8.5445 & TST & & \\
\hline CHEMBL1215499 & 649997 & 10.3009 & 99999999 & 998 & 9.2355 & TRN \\
\hline CHEMBL1215417 & 649997 & 7.8539 & 8.298 & TRN & & \\
\hline CHEMBL1215135 & 649997 & 7.1024 & 7.0526 & TRN & & \\
\hline CHEMBL1214700 & 649997 & 8.2218 & 7.6075 & TRN & & \\
\hline CHEMBL1215344 & 649997 & 9.1549 & 9.4194 & TRN & & \\
\hline CHEMBL1628249 & 649997 & 7.0 & 7.5706 & TST & & \\
\hline CHEMBL1215271 & 649997 & 9.1549 & 8.4198 & TRN & & \\
\hline CHEMBL1215500 & 649997 & 10.3009 & 79999999ऽ & 998 & 10.8852 & TRN \\
\hline CHEMBL1215706 & 649997 & 8.5229 & 9.182 & TRN & & \\
\hline CHEMBL1214693 & 649997 & 8.5229 & 8.7821 & TRN & & \\
\hline CHEMBL1215770 & 649997 & 8.699 & 8.1745 & TST & & \\
\hline CHEMBL1214987 & 649997 & 8.3979 & 8.1912 & TRN & & \\
\hline CHEMBL1215200 & 649997 & 5.0757 & 5.9033 & TRN & & \\
\hline CHEMBL1215421 & 649997 & 9.699 & 8.4684 & TRN & & \\
\hline CHEMBL1215065 & 649997 & 8.8239 & 9.7823 & TRN & & \\
\hline CHEMBL1215345 & 649997 & 9.699 & 9.3046 & TRN & & \\
\hline CHEMBL1215341 & 649997 & 6.21899 & 99999999 & 99 & 5.7393 & TRN \\
\hline CHEMBL1214988 & 649997 & 8.699 & 8.2662 & TRN & & \\
\hline CHEMBL1628254 & 649997 & 9.0 & 8.705 & TRN & & \\
\hline CHEMBL1215773 & 649997 & 7.9586 & 8.7408 & TST & & \\
\hline CHEMBL1214991 & 649997 & 6.1701 & 7.472 & TST & & \\
\hline CHEMBL1215269 & 649997 & 7.7696 & 7.7214 & TRN & & \\
\hline CHEMBL1215564 & 649997 & 8.5229 & 8.1112 & TRN & & \\
\hline CHEMBL1215266 & 649997 & 7.6021 & 8.2325 & TRN & & \\
\hline CHEMBL1215206 & 649997 & 9.0 & 8.3978 & TRN & & \\
\hline CHEMBL1215767 & 649997 & 8.301 & 8.3056 & TRN & & \\
\hline CHEMBL1215425 & 649997 & 10.3009 & 79999999 & 998 & 9.1781 & TRN \\
\hline CHEMBL1215215 & 649997 & 7.3979 & 7.2866 & TST & & \\
\hline CHEMBL1215708 & 649997 & 8.2218 & 8.9743 & TST & & \\
\hline CHEMBL1215276 & 649997 & 8.1549 & 8.6051 & TST & & \\
\hline CHEMBL1215501 & 649997 & 10.3009 & 99999999 & 998 & 10.1792 & TRN \\
\hline CHEMBL1215279 & 649997 & 8.5229 & 8.4283 & TRN & & \\
\hline CHEMBL1215492 & 649997 & 7.2218 & 8.0439 & TRN & & \\
\hline CHEMBL1214774 & 649997 & 7.6383 & 8.2978 & TRN & & \\
\hline CHEMBL1214772 & 649997 & 8.3979 & 8.9567 & TRN & & \\
\hline CHEMBL1215418 & 649997 & 8.699 & 8.1559 & TRN & & \\
\hline CHEMBL1214984 & 649997 & 6.7077 & 6.4418 & TST & & \\
\hline CHEMBL1215497 & 649997 & 7.5528 & 7.4816 & TRN & & \\
\hline CHEMBL1628246 & 649997 & 8.3979 & 7.5772 & TST & & \\
\hline CHEMBL1215062 & 649997 & 10.3009 & 99999999 & 998 & 9.0544 & TRN \\
\hline CHEMBL1214985 & 649997 & 8.699 & 8.5981 & TRN & & \\
\hline CHEMBL1215069 & 649997 & 9.0 & 8.8707 & TRN & & \\
\hline CHEMBL1628257 & 649997 & 8.0458 & 8.1571 & TST & & \\
\hline CHEMBL1215705 & 649997 & 8.3979 & 9.2665 & TRN & & \\
\hline CHEMBL1215058 & 649997 & 8.5229 & 8.1645 & TST & & \\
\hline
\end{tabular}




\begin{tabular}{|c|c|c|c|c|c|c|}
\hline & & \multicolumn{5}{|c|}{ Supplemental Table S2.txt } \\
\hline CHEMBL1628248 & 649997 & 7.699 & 8.2883 & TRN & & \\
\hline CHEMBL1215419 & 649997 & 9.301 & 8.3894 & TST & & \\
\hline CHEMBL1215270 & 649997 & 7.0315 & 7.51 & TST & & \\
\hline CHEMBL1212968 & 649997 & 8.5229 & 8.2008 & TRN & & \\
\hline CHEMBL1215208 & 649997 & 6.6517 & 7.2429 & TRN & & \\
\hline CHEMBL1215339 & 649997 & 8.3979 & 7.8142 & TST & & \\
\hline CHEMBL1215277 & 649997 & \multicolumn{3}{|c|}{10.300999999999998} & 8.9404 & TRN \\
\hline CHEMBL1212963 & 649997 & 9.0 & 8.1491 & TRN & & \\
\hline CHEMBL1215567 & 649997 & 9.1549 & 9.945 & TRN & & \\
\hline CHEMBL1214916 & 649997 & 9.0458 & 8.8305 & TRN & & \\
\hline CHEMBL1215565 & 649997 & 8.0969 & 7.4766 & TRN & & \\
\hline CHEMBL1215769 & 649997 & 8.0969 & 8.1928 & TST & & \\
\hline CHEMBL1215424 & 649997 & 9.3979 & 8.8312 & TRN & & \\
\hline CHEMBL1215336 & 649997 & 8.0458 & 8.3587 & TST & & \\
\hline CHEMBL1215278 & 649997 & \multicolumn{3}{|c|}{10.699000000000002} & 8.9492 & TRN \\
\hline CHEMBL1214845 & 649997 & 8.699 & 9.0186 & TRN & & \\
\hline CHEMBL1215420 & 649997 & 9.699 & 8.714 & TRN & & \\
\hline CHEMBL1215696 & 649997 & 8.699 & 8.6389 & TRN & & \\
\hline CHEMBL 1628256 & 649997 & 8.699 & 8.1278 & TRN & & \\
\hline CHEMBL1214775 & 649997 & 9.1549 & 9.074 & TRN & & \\
\hline CHEMBL1215340 & 649997 & 8.5229 & 7.915 & TST & & \\
\hline CHEMBL1215338 & 649997 & 6.9872 & 6.79200 & 0000000001 & & TRN \\
\hline CHEMBL1215202 & 649997 & 8.1549 & 8.036 & TST & & \\
\hline CHEMBL1215634 & 649997 & \multicolumn{3}{|c|}{10.300999999999998} & 9.2922 & TRN \\
\hline CHEMBL1214776 & 649997 & 7.8539 & 8.2144 & TRN & & \\
\hline CHEMBL1215335 & 649997 & 7.8861 & 8.3587 & TST & & \\
\hline CHEMBL1215209 & 649997 & 6.7375 & 7.3374 & TRN & & \\
\hline CHEMBL1215698 & 649997 & 6.5331 & 7.7931 & TRN & & \\
\hline CHEMBL1214986 & 649997 & 7.9586 & 8.4527 & TRN & & \\
\hline CHEMBL1215056 & 649997 & 7.2218 & 7.0569 & TST & & \\
\hline CHEMBL1215343 & 649997 & 9.699 & 8.65 & TRN & & \\
\hline CHEMBL1215212 & 649997 & 7.9208 & 7.9945 & TST & & \\
\hline CHEMBL1215630 & 649997 & 8.3979 & 8.5663 & TRN & & \\
\hline CHEMBL1215268 & 649997 & 7.1938 & 7.6199 & TST & & \\
\hline CHEMBL1215489 & 649997 & 8.1549 & 8.4097 & TST & & \\
\hline CHEMBL1215559 & 649997 & 6.0448 & 7.2559 & TST & & \\
\hline CHEMBL1215214 & 649997 & 7.9208 & 7.9154 & TST & & \\
\hline CHEMBL1215639 & 649997 & 8.5229 & 9.3242 & TRN & & \\
\hline CHEMBL1215274 & 649997 & 9.0 & 8.0629 & TRN & & \\
\hline CHEMBL1628252 & 649997 & 8.3979 & 7.966 & TST & & \\
\hline CHEMBL1215332 & 649997 & 8.699 & 8.7522 & TST & & \\
\hline CHEMBL1214696 & 649997 & 8.301 & 9.1188 & TRN & & \\
\hline CHEMBL1628244 & 649997 & 6.3915 & 7.3044 & TRN & & \\
\hline CHEMBL1215205 & 649997 & 7.6198 & 8.4833 & TST & & \\
\hline CHEMBL1215210 & 649997 & 7.3372 & 7.7342 & TRN & & \\
\hline CHEMBL1215498 & 649997 & 9.699 & 9.0677 & TRN & & \\
\hline CHEMBL1215066 & 649997 & 9.0 & 9.7183 & TRN & & \\
\hline CHEMBL1215057 & 649997 & 7.6198 & 7.4968 & TST & & \\
\hline
\end{tabular}




\begin{tabular}{|c|c|c|c|c|c|}
\hline \multirow[b]{2}{*}{ CHEMBL1215061 } & \multicolumn{5}{|c|}{ Supplemental Table S2.txt } \\
\hline & 649997 & 9.0458 & 9.1934 & TRN & \\
\hline CHEMBL1628245 & 649997 & 7.9208 & 7.15799 & 99999999995 & TST \\
\hline CHEMBL1215707 & 649997 & 8.301 & 8.9309 & TRN & \\
\hline CHEMBL1214847 & 649997 & 9.301 & 9.6356 & TRN & \\
\hline CHEMBL1214983 & 649997 & 4.0 & 5.1758 & TST & \\
\hline CHEMBL1214979 & 649997 & 6.2154 & 5.5378 & TST & \\
\hline CHEMBL1215496 & 649997 & 7.6021 & 7.6039 & TST & \\
\hline CHEMBL1215701 & 649997 & 9.0969 & 9.1693 & TRN & \\
\hline CHEMBL1215636 & 649997 & 9.1549 & 9.9202 & TRN & \\
\hline CHEMBL3687492 & 1534938 & 6.0 & 6.1631 & TRN & \\
\hline CHEMBL3691933 & 1534938 & 8.0516 & 8.1869 & TRN & \\
\hline CHEMBL 3687497 & 1534938 & 9.1308 & 8.9688 & TST & \\
\hline CHEMBL3687417 & 1534938 & 8.3686 & 8.6203 & TRN & \\
\hline CHEMBL 3687448 & 1534938 & 6.0 & 5.6476 & TRN & \\
\hline CHEMBL3687512 & 1534938 & 6.0 & 5.9003 & TRN & \\
\hline CHEMBL3691962 & 1534938 & 7.8256 & 8.06200 & 0000000001 & TRN \\
\hline CHEMBL3687446 & 1534938 & 6.0 & 5.6598 & TST & \\
\hline CHEMBL3687529 & 1534938 & 6.8339 & 7.42 & TST & \\
\hline CHEMBL3691971 & 1534938 & 8.5544 & 8.3338 & TST & \\
\hline CHEMBL3687474 & 1534938 & 6.0 & 6.2297 & TRN & \\
\hline CHEMBL3691981 & 1534938 & 8.2882 & 8.2535 & TST & \\
\hline CHEMBL 3691972 & 1534938 & 8.2782 & 7.9193 & TST & \\
\hline CHEMBL 3687507 & 1534938 & 8.8761 & 8.4529 & TRN & \\
\hline CHEMBL 3687531 & 1534938 & 8.4145 & 8.1858 & TRN & \\
\hline CHEMBL3691913 & 1534938 & 8.6091 & 8.3318 & TRN & \\
\hline CHEMBL3687514 & 1534938 & 6.869 & 7.17 & TRN & \\
\hline CHEMBL3691984 & 1534938 & 7.6295 & 7.8603 & TRN & \\
\hline CHEMBL3687475 & 1534938 & 5.5528 & 7.0431 & TRN & \\
\hline CHEMBL 3687526 & 1534938 & 8.2381 & 8.1467 & TRN & \\
\hline CHEMBL3691917 & 1534938 & 7.5427 & 7.7506 & TST & \\
\hline CHEMBL3691942 & 1534938 & 9.0915 & 8.5377 & TRN & \\
\hline CHEMBL3687536 & 1534938 & 6.0 & 6.3077 & TRN & \\
\hline CHEMBL3691960 & 1534938 & 9.1135 & 9.0335 & TST & \\
\hline CHEMBL3691944 & 1534938 & 8.7212 & 8.3261 & TRN & \\
\hline CHEMBL3687482 & 1534938 & 9.0809 & 8.9567 & TST & \\
\hline CHEMBL3687440 & 1534938 & 6.0 & 5.6597 & TST & \\
\hline CHEMBL3687431 & 1534938 & 8.5867 & 8.4933 & TRN & \\
\hline CHEMBL3691914 & 1534938 & 8.5952 & 8.7661 & TRN & \\
\hline CHEMBL3691929 & 1534938 & 9.0458 & 8.7282 & TRN & \\
\hline CHEMBL 3687521 & 1534938 & 9.1308 & 8.5367 & TST & \\
\hline CHEMBL3687459 & 1534938 & 6.0 & 6.0726 & TST & \\
\hline CHEMBL3691937 & 1534938 & 9.1308 & 8.6493 & TRN & \\
\hline CHEMBL3691921 & 1534938 & 8.9872 & 8.8417 & TRN & \\
\hline CHEMBL3691932 & 1534938 & 9.1024 & 8.7411 & TRN & \\
\hline CHEMBL3691964 & 1534938 & 8.1267 & 7.9389 & TRN & \\
\hline CHEMBL3691983 & 1534938 & 8.2848 & 7.6902 & TST & \\
\hline CHEMBL3691955 & 1534938 & 7.9923 & 8.5576 & TST & \\
\hline CHEMBL3691941 & 1534938 & 8.9208 & 8.5692 & TRN & \\
\hline
\end{tabular}




\begin{tabular}{|c|c|c|c|c|c|c|}
\hline \multicolumn{7}{|c|}{ Supplemental Table s2.txt } \\
\hline CHEMBL3691926 & 1534938 & 6.0 & 6.3369 & TRN & & \\
\hline CHEMBL 3691922 & 1534938 & 6.0 & 6.336 & TRN & & \\
\hline CHEMBL3691978 & 1534938 & 8.8125 & 8.6895 & TRN & & \\
\hline CHEMBL 3687533 & 1534938 & 6.0 & 7.5285 & TRN & & \\
\hline CHEMBL 3687518 & 1534938 & 8.6308 & 8.4515 & TRN & & \\
\hline CHEMBL3691948 & 1534938 & 6.5683 & 8.4816 & TRN & & \\
\hline CHEMBL3691950 & 1534938 & 9.3979 & 8.8446 & TRN & & \\
\hline CHEMBL3691940 & 1534938 & 9.1135 & 8.7893 & TST & & \\
\hline CHEMBL 3687465 & 1534938 & 7.9516 & 8.2964 & TRN & & \\
\hline CHEMBL3691970 & 1534938 & 8.3925 & 8.3504 & TST & & \\
\hline CHEMBL3691943 & 1534938 & 8.9626 & 8.5972 & TRN & & \\
\hline CHEMBL3691966 & 1534938 & 7.4268 & 7.9368 & TRN & & \\
\hline CHEMBL 3687517 & 1534938 & 8.1141 & 8.5067 & TRN & & \\
\hline CHEMBL 3687519 & 1534938 & 8.7932 & 7.9618 & TST & & \\
\hline CHEMBL 3687530 & 1534938 & 8.2269 & 8.38 & TRN & & \\
\hline CHEMBL 3687424 & 1534938 & 7.4774 & 7.6125 & TST & & \\
\hline CHEMBL3691963 & 1534938 & 8.4962 & 8.3585 & TST & & \\
\hline CHEMBL 3687528 & 1534938 & 8.0424 & 8.4006 & TRN & & \\
\hline CHEMBL 3687470 & 1534938 & 6.0 & 5.5649 & TRN & & \\
\hline CHEMBL 3687457 & 1534938 & 6.0 & 5.8278 & TRN & & \\
\hline CHEMBL3691938 & 1534938 & 8.98299 & 99999999 & 99 & 8.7205 & \\
\hline CHEMBL3691928 & 1534938 & 8.7305 & 8.9022 & TRN & & \\
\hline CHEMBL 3687427 & 1534938 & 8.7645 & 8.8117 & TRN & & \\
\hline CHEMBL 3687476 & 1534938 & 8.9281 & 8.9578 & TRN & & \\
\hline CHEMBL3687466 & 1534938 & 8.821 & 8.9246 & TRN & & \\
\hline CHEMBL3687509 & 1534938 & 8.9666 & 8.8593 & TRN & & \\
\hline CHEMBL3691918 & 1534938 & 6.0 & 5.9056 & TST & & \\
\hline CHEMBL3691947 & 1534938 & 8.7375 & 8.0382 & TRN & & \\
\hline CHEMBL 3687535 & 1534938 & 8.5918 & 7.8068 & TST & & \\
\hline CHEMBL3691961 & 1534938 & 8.7235 & 8.3186 & TRN & & \\
\hline CHEMBL 3687515 & 1534938 & 8.4271 & 8.4767 & TRN & & \\
\hline CHEMBL 3687445 & 1534938 & 6.0 & 5.7444 & TRN & & \\
\hline CHEMBL 3687438 & 1534938 & 6.0 & 5.9853 & TRN & & \\
\hline CHEMBL 3687418 & 1534938 & 8.9066 & 9.0194 & TRN & & \\
\hline CHEMBL3691954 & 1534938 & 7.8589 & 8.3189 & TRN & & \\
\hline CHEMBL 3687414 & 1534938 & 8.5969 & 8.5301 & TST & & \\
\hline CHEMBL3691986 & 1534938 & 8.7773 & 8.5094 & TRN & & \\
\hline CHEMBL3687510 & 1534938 & 6.0 & 5.974 & TRN & & \\
\hline CHEMBL3691977 & 1534938 & 8.7471 & 8.6941 & TRN & & \\
\hline CHEMBL3687467 & 1534938 & 8.1891 & 8.4688 & TRN & & \\
\hline CHEMBL 3687480 & 1534938 & 6.0 & 6.126 & TRN & & \\
\hline CHEMBL 3687447 & 1534938 & 6.0 & 6.4208 & TRN & & \\
\hline CHEMBL3691916 & 1534938 & 6.0 & 6.2106 & TST & & \\
\hline CHEMBL 3687501 & 1534938 & 6.0 & 5.6059 & TRN & & \\
\hline CHEMBL3691923 & 1534938 & 8.9066 & 8.7444 & TRN & & \\
\hline CHEMBL3687493 & 1534938 & 6.0 & 5.9872 & TRN & & \\
\hline CHEMBL3691953 & 1534938 & 7.1827 & 7.9723 & TST & & \\
\hline CHEMBL3687436 & 1534938 & 6.0 & 6.0221 & TRN & & \\
\hline
\end{tabular}


Supplemental Table S2.txt

\begin{tabular}{|c|c|c|c|c|c|c|}
\hline CHEMBL3691969 & 1534938 & 7.8752 & 7.9204 & TST & & \\
\hline CHEMBL3687495 & 1534938 & 6.0 & 5.6488 & TRN & & \\
\hline CHEMBL3691919 & 1534938 & 9.1079 & 9.0108 & TRN & & \\
\hline CHEMBL3687516 & 1534938 & 7.6126 & 8.0236 & TRN & & \\
\hline CHEMBL3639863 & 1534938 & 8.8153 & 8.0952 & TRN & & \\
\hline CHEMBL3687422 & 1534938 & 7.2264 & 7.5981 & TRN & & \\
\hline CHEMBL3691931 & 1534938 & 8.7721 & 8.6234 & TRN & & \\
\hline CHEMBL3691982 & 1534938 & 8.5513 & 8.2554 & TRN & & \\
\hline CHEMBL3687463 & 1534938 & 6.0 & 5.7781 & TRN & & \\
\hline CHEMBL3687490 & 1534938 & 9.0862 & 8.8281 & TRN & & \\
\hline CHEMBL3691946 & 1534938 & 8.7747 & 8.4127 & TRN & & \\
\hline CHEMBL3687522 & 1534938 & 8.1325 & 8.5684 & TRN & & \\
\hline CHEMBL3691945 & 1534938 & 9.0605 & 8.8603 & TRN & & \\
\hline CHEMBL3687464 & 1534938 & 8.3298 & 8.5203 & TST & & \\
\hline CHEMBL 3687487 & 1534938 & 6.0 & 5.9705 & TRN & & \\
\hline CHEMBL3691951 & 1534938 & 8.2168 & 8.0902 & TRN & & \\
\hline CHEMBL3691967 & 1534938 & 8.5114 & 9.1028 & TRN & & \\
\hline CHEMBL 3687423 & 1534938 & 6.0 & 6.2043 & TRN & & \\
\hline CHEMBL 3687504 & 1534938 & 8.6289 & 8.6038 & TRN & & \\
\hline CHEMBL3691949 & 1534938 & 8.9469 & 8.8769 & TRN & & \\
\hline CHEMBL3691915 & 1534938 & 8.5935 & 8.7171 & TST & & \\
\hline CHEMBL 3687426 & 1534938 & 6.0 & 6.2015 & TST & & \\
\hline CHEMBL3687483 & 1534938 & 6.0 & 6.0075 & TRN & & \\
\hline CHEMBL3691924 & 1534938 & 8.5702 & 8.8358 & TRN & & \\
\hline CHEMBL3691968 & 1534938 & 8.6904 & 8.788 & TRN & & \\
\hline CHEMBL 3687525 & 1534938 & 8.6055 & 8.4978 & TRN & & \\
\hline CHEMBL3691965 & 1534938 & 8.6778 & 8.5458 & TST & & \\
\hline CHEMBL3687421 & 1534938 & 7.6882 & 7.6571 & TRN & & \\
\hline CHEMBL3691975 & 1534938 & 7.5658 & 8.3046 & TRN & & \\
\hline CHEMBL3687532 & 1534938 & 6.0 & 5.7593 & TRN & & \\
\hline CHEMBL3687419 & 1534938 & 8.1669 & 7.7364 & TST & & \\
\hline CHEMBL 3687534 & 1534938 & 8.7471 & 8.3715 & TRN & & \\
\hline CHEMBL3691939 & 1534938 & 8.6576 & 8.1888 & TST & & \\
\hline CHEMBL 3687461 & 1534938 & 7.1605 & 7.175 & TRN & & \\
\hline CHEMBL3691927 & 1534938 & 8.52 & 8.4916 & TRN & & \\
\hline CHEMBL3687468 & 1534938 & 8.821 & 8.7779 & TRN & & \\
\hline CHEMBL3691980 & 1534938 & 8.585 & 7.9681 & TST & & \\
\hline CHEMBL3691976 & 1534938 & 8.3546 & 8.395 & TST & & \\
\hline CHEMBL3691979 & 1534938 & 7.862 & 8.0264 & TST & & \\
\hline CHEMBL 3687520 & 1534938 & 7.9838 & 8.0703 & TRN & & \\
\hline CHEMBL 3687420 & 1534938 & 8.85700 & 00000006 & 31 & 8.8842 & TRN \\
\hline CHEMBL3687432 & 1534938 & 8.1752 & 8.1365 & TRN & & \\
\hline CHEMBL3639862 & 1534938 & 8.4486 & 8.4187 & TRN & & \\
\hline CHEMBL3691930 & 1534938 & 9.3279 & 9.1961 & TRN & & \\
\hline CHEMBL3639908 & 1534938 & 8.6615 & 8.0794 & TST & & \\
\hline CHEMBL 3687502 & 1534938 & 6.0 & 5.6944 & TRN & & \\
\hline CHEMBL3687498 & 1534938 & 6.0 & 5.7781 & TRN & & \\
\hline CHEMBL 3691985 & 1534938 & 7.7921 & 7.754 & TRN & & \\
\hline
\end{tabular}




\begin{tabular}{|c|c|c|c|c|c|c|}
\hline \multicolumn{7}{|c|}{ Supplemental Table s2.txt } \\
\hline CHEMBL3691974 & 1534938 & 6.0 & 5.6918 & TRN & & \\
\hline CHEMBL 3687527 & 1534938 & 8.9066 & 8.7695 & TRN & & \\
\hline CHEMBL3687433 & 1534938 & 8.1158 & 8.8241 & TRN & & \\
\hline CHEMBL 3691958 & 1534938 & 9.1871 & 8.9604 & TRN & & \\
\hline CHEMBL3687481 & 1534938 & 8.7696 & 8.4525 & TRN & & \\
\hline CHEMBL3691957 & 1534938 & 8.5735 & 8.5877 & TRN & & \\
\hline CHEMBL3687416 & 1534938 & 7.3061 & 7.5996 & TRN & & \\
\hline CHEMBL 3687430 & 1534938 & 9.0655 & 8.8974 & TRN & & \\
\hline CHEMBL3691959 & 1534938 & 8.6676 & 8.5839 & TRN & & \\
\hline CHEMBL3687537 & 1534938 & 8.9172 & 8.2574 & TST & & \\
\hline CHEMBL3691925 & 1534938 & 8.9318 & 8.7031 & TRN & & \\
\hline CHEMBL 3687415 & 1534938 & 7.5219 & 7.6178 & TRN & & \\
\hline CHEMBL3691956 & 1534938 & 8.7721 & 8.446 & TST & & \\
\hline CHEMBL 3687505 & 1534938 & 8.8601 & 8.4375 & TRN & & \\
\hline CHEMBL3687452 & 1534938 & 6.0 & 5.9429 & TST & & \\
\hline CHEMBL3691935 & 1534938 & 8.6904 & 8.3385 & TRN & & \\
\hline CHEMBL3687491 & 1534938 & 9.0506 & 8.9945 & TRN & & \\
\hline CHEMBL3687471 & 1534938 & 8.9706 & 8.7789 & TRN & & \\
\hline CHEMBL287092 & 510893 & 9.9586 & 10.5704 & TST & & \\
\hline CHEMBL260664 & 510893 & 9.0 & 8.9756 & TRN & & \\
\hline CHEMBL261596 & 510893 & 7.7212 & 7.7241 & TRN & & \\
\hline CHEMBL 260345 & 510893 & 8.0969 & 8.0987 & TRN & & \\
\hline CHEMBL261439 & 510893 & 6.3665 & 6.1996 & TST & & \\
\hline CHEMBL406062 & 510893 & 6.7721 & 6.7869 & TRN & & \\
\hline CHEMBL259925 & 510893 & 5.8996 & 6.143 & TST & & \\
\hline CHEMBL407981 & 510893 & 8.3979 & 8.4385 & TRN & & \\
\hline CHEMBL407980 & 510893 & 8.1549 & 8.203 & TRN & & \\
\hline CHEMBL260329 & 510893 & 6.61799 & 999999999 & 99 & 6.6186 & TRN \\
\hline CHEMBL101747 & 510893 & 7.7447 & 7.7438 & TRN & & \\
\hline CHEMBL261518 & 510893 & 8.301 & 8.3102 & TRN & & \\
\hline CHEMBL 259744 & 510893 & 7.6576 & 7.6522 & TRN & & \\
\hline CHEMBL260929 & 510893 & 6.4949 & 6.5094 & TRN & & \\
\hline CHEMBL408979 & 510893 & 5.7978 & 5.8113 & TRN & & \\
\hline CHEMBL 39300 & 510893 & 9.0223 & 9.6121 & TST & & \\
\hline CHEMBL 288143 & 510893 & 8.3979 & 8.3763 & TRN & & \\
\hline CHEMBL406620 & 510893 & 6.9031 & 6.9134 & TRN & & \\
\hline CHEMBL408564 & 510893 & 8.1549 & 8.1727 & TRN & & \\
\hline CHEMBL264161 & 510893 & 8.1549 & 8.1782 & TRN & & \\
\hline CHEMBL406701 & 510893 & 7.3665 & 7.3758 & TRN & & \\
\hline CHEMBL261264 & 510893 & 6.3536 & 6.3662 & TRN & & \\
\hline CHEMBL408634 & 510893 & 6.2757 & 7.9028 & TST & & \\
\hline CHEMBL38425 & 510893 & 9.7212 & 10.0435 & TST & & \\
\hline CHEMBL261882 & 510893 & 6.4168 & 6.468999 & 9999999999 & & TRN \\
\hline CHEMBL 260243 & 510893 & 7.4559 & 7.4571 & TRN & & \\
\hline CHEMBL260417 & 510893 & 9.0969 & 9.1325 & TRN & & \\
\hline CHEMBL 259270 & 510893 & 7.1249 & 7.0382 & TRN & & \\
\hline CHEMBL407730 & 510893 & 7.6778 & 7.6767 & TRN & & \\
\hline CHEMBL 260928 & 510893 & 6.4828 & 6.4574 & TRN & & \\
\hline
\end{tabular}




\begin{tabular}{|c|c|c|c|c|c|c|}
\hline & & \multicolumn{5}{|c|}{ Supplemental Table s2.txt } \\
\hline CHEMBL408809 & 510893 & 5.5513 & 5.5596 & TRN & & \\
\hline CHEMBL500804 & 510893 & 7.8239 & 6.9994 & TST & & \\
\hline CHEMBL406644 & 510893 & 7.7959 & 7.8319 & TRN & & \\
\hline CHEMBL261883 & 510893 & 6.6308 & 6.6819 & TRN & & \\
\hline CHEMBL259271 & 510893 & 8.301 & 8.2705 & TRN & & \\
\hline CHEMBL 258483 & 510893 & 8.301 & 8.2544 & TRN & & \\
\hline CHEMBL407113 & 510893 & 6.3179 & 6.3541 & TRN & & \\
\hline CHEMBL408019 & 510893 & 7.9208 & 7.9253 & TRN & & \\
\hline CHEMBL261366 & 510893 & 7.0044 & 7.0028 & TRN & & \\
\hline CHEMBL260663 & 510893 & 7.4437 & 7.4347 & TRN & & \\
\hline CHEMBL261441 & 510893 & 7.9586 & 7.943 & TRN & & \\
\hline CHEMBL427909 & 510893 & 7.6198 & 7.6249 & TRN & & \\
\hline CHEMBL261660 & 510893 & \multicolumn{3}{|c|}{6.082000000000001} & 6.0689 & TRN \\
\hline CHEMBL 260135 & 510893 & 6.6021 & 6.4226 & TST & & \\
\hline CHEMBL35785 & 510893 & 10.0969 & 10.123 & TRN & & \\
\hline CHEMBL260231 & 510893 & 7.4089 & 7.3692 & TRN & & \\
\hline CHEMBL407374 & 510893 & 5.6302 & 5.6037 & TRN & & \\
\hline CHEMBL410926 & 510893 & 7.9208 & 7.9214 & TRN & & \\
\hline CHEMBL 317657 & 510893 & 7.8539 & \multicolumn{3}{|c|}{7.8629999999999995} & TRN \\
\hline CHEMBL261052 & 510893 & 6.0701 & 6.0476 & TRN & & \\
\hline CHEMBL409738 & 510893 & 8.1549 & 8.1651 & TRN & & \\
\hline CHEMBL260662 & 510893 & 8.2218 & 8.2383 & TRN & & \\
\hline CHEMBL405021 & 510893 & 6.3028 & 6.3457 & TRN & & \\
\hline CHEMBL260416 & 510893 & 8.301 & 8.2831 & TRN & & \\
\hline CHEMBL407003 & 510893 & 7.5686 & 6.8714 & TST & & \\
\hline CHEMBL261129 & 510893 & 9.0 & 8.9133 & TRN & & \\
\hline CHEMBL41783 & 510893 & 8.301 & 8.5834 & TST & & \\
\hline CHEMBL263907 & 510893 & 7.699 & 6.8184 & TST & & \\
\hline CHEMBL405145 & 510893 & 8.0969 & 8.1258 & TRN & & \\
\hline CHEMBL407002 & 510893 & 7.9586 & 7.6037 & TST & & \\
\hline CHEMBL261127 & 510893 & 6.1605 & 6.9142 & TST & & \\
\hline CHEMBL498663 & 510893 & 6.4486 & 7.9477 & TST & & \\
\hline CHEMBL261661 & 510893 & 5.5691 & 6.1751 & TST & & \\
\hline CHEMBL261659 & 510893 & 7.3768 & 7.3462 & TRN & & \\
\hline CHEMBL261549 & 510893 & 8.1549 & 6.6817 & TST & & \\
\hline CHEMBL288448 & 510893 & 6.5361 & 6.6015 & TST & & \\
\hline CHEMBL101804 & 510893 & 6.8508 & 6.7957 & TRN & & \\
\hline CHEMBL 258701 & 510893 & 7.2518 & 6.3149 & TST & & \\
\hline CHEMBL287731 & 510893 & 5.4471 & 6.0441 & TST & & \\
\hline CHEMBL261690 & 510893 & 7.0044 & 6.9705 & TRN & & \\
\hline CHEMBL407958 & 510893 & \multicolumn{3}{|c|}{6.382000000000001} & 6.3888 & TRN \\
\hline CHEMBL261881 & 510893 & 7.0605 & 7.0653 & TRN & & \\
\hline CHEMBL318522 & 510893 & 6.6676 & 6.6765 & TRN & & \\
\hline CHEMBL502011 & 510893 & 6.3716 & 6.355 & TRN & & \\
\hline CHEMBL406125 & 510893 & 8.0458 & 8.0509 & TRN & & \\
\hline CHEMBL407373 & 510893 & 7.7447 & 7.7172 & TST & & \\
\hline CHEMBL421207 & 510893 & 7.301 & 7.3032 & TRN & & \\
\hline CHEMBL1082492 & 715420 & 8.2218 & 8.1519 & TRN & & \\
\hline
\end{tabular}




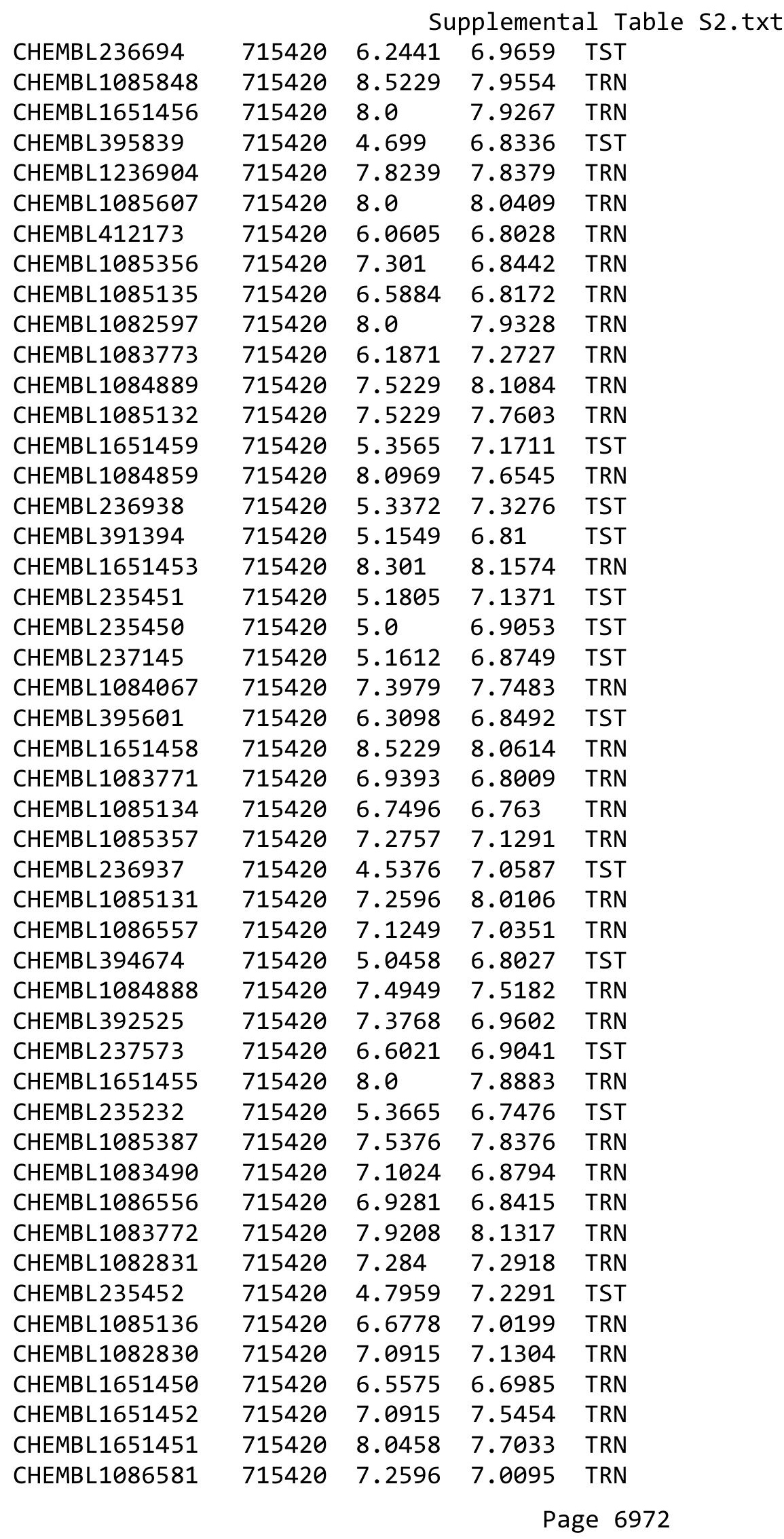




\begin{tabular}{|c|c|c|c|c|}
\hline \multicolumn{5}{|c|}{ Supplemental Table S2.txt } \\
\hline CHEMBL237369 & 715420 & 5.6198 & 6.859 & TST \\
\hline CHEMBL1086219 & 715420 & 7.0915 & 7.2537 & TRN \\
\hline CHEMBL1084860 & 715420 & 8.2218 & 8.1236 & TRN \\
\hline CHEMBL1086309 & 715420 & 7.2596 & 6.8601 & TRN \\
\hline CHEMBL1651454 & 715420 & 7.8539 & 7.7143 & TRN \\
\hline CHEMBL1082507 & 715420 & 7.7959 & 7.2673 & TRN \\
\hline CHEMBL1084079 & 715420 & 8.699 & 8.2392 & TRN \\
\hline CHEMBL1651457 & 715420 & 8.0 & 8.0383 & TRN \\
\hline CHEMBL1083774 & 715420 & 7.7696 & 7.7156 & TRN \\
\hline CHEMBL1460877 & 688685 & 4.6 & 4.5711 & TRN \\
\hline CHEMBL3212538 & 688685 & 4.9 & 4.7112 & TST \\
\hline CHEMBL1553179 & 688685 & 4.6 & 4.5105 & TRN \\
\hline CHEMBL1501864 & 688685 & 4.4 & 4.3974 & TRN \\
\hline CHEMBL516616 & 688685 & 5.4 & 4.8697 & TST \\
\hline CHEMBL1435028 & 688685 & 4.5 & 4.492 & TRN \\
\hline CHEMBL1426049 & 688685 & 6.5 & 4.9278 & TST \\
\hline CHEMBL1558135 & 688685 & 4.5 & 4.5678 & TRN \\
\hline CHEMBL1576376 & 688685 & 4.5 & 4.5173 & TRN \\
\hline CHEMBL1592452 & 688685 & 4.5 & 4.4337 & TRN \\
\hline CHEMBL1612246 & 688685 & 4.5 & 4.5021 & TRN \\
\hline CHEMBL1374715 & 688685 & 4.4 & 4.3841 & TRN \\
\hline CHEMBL1317506 & 688685 & 5.5 & 4.7265 & TST \\
\hline CHEMBL1407137 & 688685 & 4.4 & 4.4677 & TRN \\
\hline CHEMBL1492884 & 688685 & 4.5 & 4.5335 & TRN \\
\hline CHEMBL1489906 & 688685 & 4.6 & 4.6312 & TRN \\
\hline CHEMBL1369243 & 688685 & 4.8 & 4.8038 & TRN \\
\hline CHEMBL1712181 & 688685 & 5.5 & 4.5105 & TST \\
\hline CHEMBL1491210 & 688685 & 4.6 & 4.5859 & TRN \\
\hline CHEMBL1410132 & 688685 & 4.5 & 4.4983 & TRN \\
\hline CHEMBL1789988 & 688685 & 5.3 & 4.7485 & TST \\
\hline CHEMBL 1476670 & 688685 & 5.0 & 4.9324 & TRN \\
\hline CHEMBL1354961 & 688685 & 5.4 & 4.7786 & TST \\
\hline CHEMBL1502667 & 688685 & 4.8 & 4.7579 & TRN \\
\hline CHEMBL1442704 & 688685 & 5.0 & 4.9745 & TRN \\
\hline CHEMBL1415957 & 688685 & 4.5 & 4.521 & TRN \\
\hline CHEMBL1557778 & 688685 & 4.5 & 4.4988 & TRN \\
\hline CHEMBL1344503 & 688685 & 4.9 & 4.5935 & TST \\
\hline CHEMBL1496345 & 688685 & 4.5 & 4.5295 & TRN \\
\hline CHEMBL1513300 & 688685 & 5.0 & 4.9918 & TRN \\
\hline CHEMBL1366061 & 688685 & 4.5 & 4.5987 & TRN \\
\hline CHEMBL1556956 & 688685 & 4.6 & 4.6023 & TRN \\
\hline CHEMBL1590321 & 688685 & 4.9 & 4.8732 & TRN \\
\hline CHEMBL 72365 & 688685 & 4.5 & 4.4888 & TRN \\
\hline CHEMBL1415790 & 688685 & 4.5 & 4.493 & TRN \\
\hline CHEMBL458765 & 688685 & 5.5 & 5.506 & TRN \\
\hline CHEMBL 1307737 & 688685 & 4.5 & 4.5121 & TRN \\
\hline CHEMBL3197413 & 688685 & 6.9 & 6.8935 & TRN \\
\hline CHEMBL1479654 & 688685 & 4.9 & 4.9162 & TRN \\
\hline
\end{tabular}




\begin{tabular}{|c|c|c|c|c|}
\hline & & & ient & al Ta \\
\hline CHEMBL374632 & 688685 & 6.1 & 6.0882 & TRN \\
\hline CHEMBL1318140 & 688685 & 5.5 & 4.7722 & TST \\
\hline CHEMBL1466278 & 688685 & 4.5 & 5.0828 & TST \\
\hline CHEMBL1437263 & 688685 & 4.8 & 4.8235 & TRN \\
\hline CHEMBL1355720 & 688685 & 4.5 & 4.5502 & TRN \\
\hline CHEMBL1520346 & 688685 & 5.0 & 5.0443 & TRN \\
\hline CHEMBL1590982 & 688685 & 4.5 & 4.6289 & TRN \\
\hline CHEMBL1593056 & 688685 & 5.2 & 5.2335 & TRN \\
\hline CHEMBL1549473 & 688685 & 4.5 & 4.4993 & TRN \\
\hline CHEMBL1493502 & 688685 & 7.0 & 7.0039 & TRN \\
\hline CHEMBL1466554 & 688685 & 4.5 & 4.4962 & TRN \\
\hline CHEMBL1515004 & 688685 & 4.5 & 4.489 & TRN \\
\hline CHEMBL1995336 & 688685 & 4.5 & 4.4978 & TRN \\
\hline CHEMBL 123 & 688685 & 6.0 & 4.8948 & TST \\
\hline CHEMBL1463304 & 688685 & 4.6 & 4.5676 & TRN \\
\hline CHEMBL1318083 & 688685 & 4.9 & 4.8781 & TRN \\
\hline CHEMBL1402299 & 688685 & 4.5 & 4.3703 & TRN \\
\hline CHEMBL605003 & 688685 & 5.4 & 5.3865 & TRN \\
\hline CHEMBL1539285 & 688685 & 5.3 & 5.3 & TRN \\
\hline CHEMBL1551477 & 688685 & 4.5 & 4.4862 & TRN \\
\hline CHEMBL1420829 & 688685 & 5.5 & 5.5134 & TRN \\
\hline CHEMBL1446951 & 688685 & 4.5 & 4.5352 & TRN \\
\hline CHEMBL1399913 & 688685 & 4.7 & 4.7081 & TRN \\
\hline CHEMBL1493644 & 688685 & 4.5 & 4.5233 & TRN \\
\hline CHEMBL1458942 & 688685 & 4.5 & 4.88 & TST \\
\hline CHEMBL1370068 & 688685 & 4.7 & 4.6966 & TRN \\
\hline CHEMBL1162521 & 688685 & 5.3 & 5.2915 & TRN \\
\hline CHEMBL3207650 & 688685 & 5.2 & 5.1889 & TRN \\
\hline CHEMBL1569400 & 688685 & 4.6 & 4.5752 & TRN \\
\hline CHEMBL105739 & 688685 & 4.5 & 4.4736 & TRN \\
\hline CHEMBL1551049 & 688685 & 4.5 & 4.4239 & TRN \\
\hline CHEMBL1578974 & 688685 & 4.5 & 4.4407 & TRN \\
\hline CHEMBL1388744 & 688685 & 4.5 & 4.4579 & TRN \\
\hline CHEMBL1355537 & 688685 & 4.9 & 4.8969 & TRN \\
\hline CHEMBL1414269 & 688685 & 4.5 & 4.538 & TRN \\
\hline CHEMBL1471112 & 688685 & 4.6 & 4.6046 & TRN \\
\hline CHEMBL1326646 & 688685 & 5.4 & 5.3955 & TRN \\
\hline CHEMBL1337500 & 688685 & 5.2 & 5.1324 & TST \\
\hline CHEMBL1517390 & 688685 & 4.7 & 4.6944 & TRN \\
\hline CHEMBL1612796 & 688685 & 4.4 & 4.413 & TRN \\
\hline CHEMBL1595910 & 688685 & 4.6 & 4.5113 & TRN \\
\hline CHEMBL1321887 & 688685 & 4.7 & 4.8026 & TRN \\
\hline CHEMBL1368728 & 688685 & 4.7 & 4.7141 & TRN \\
\hline CHEMBL1403497 & 688685 & 4.5 & 4.4694 & TRN \\
\hline CHEMBL1527923 & 688685 & 5.0 & 4.9443 & TRN \\
\hline CHEMBL1448375 & 688685 & 4.5 & 4.5138 & TRN \\
\hline CHEMBL1528677 & 688685 & 4.8 & 4.8557 & TRN \\
\hline CHEMBL2003304 & 688685 & 5.0 & 5.0005 & TRN \\
\hline
\end{tabular}




\begin{tabular}{|c|c|c|c|c|c|}
\hline \\
\hline CHEMBL1328324 & 688685 & 4.5 & 4.4795 & TRN & \\
\hline CHEMBL1410702 & 688685 & 4.8 & 4.7838 & TRN & \\
\hline CHEMBL1532633 & 688685 & 4.4 & 4.3791 & TRN & \\
\hline CHEMBL1329499 & 688685 & 4.7 & 4.6472 & TRN & \\
\hline CHEMBL473106 & 688685 & 4.9 & 4.9151 & TRN & \\
\hline CHEMBL1489365 & 688685 & 4.6 & 4.5673 & TST & \\
\hline CHEMBL1536805 & 688685 & 4.4 & 5.2332 & TST & \\
\hline CHEMBL338790 & 688685 & 4.5 & 4.4802 & TRN & \\
\hline CHEMBL1447588 & 688685 & 6.3 & 4.6095 & TST & \\
\hline CHEMBL2001481 & 688685 & 4.5 & 4.4685 & TRN & \\
\hline CHEMBL83154 & 688685 & 6.1 & 6.1166 & TRN & \\
\hline CHEMBL1489356 & 688685 & 4.5 & 5.3345 & TST & \\
\hline CHEMBL1613725 & 688685 & 4.5 & 4.4751 & TRN & \\
\hline CHEMBL1395997 & 688685 & 4.5 & 4.5318 & TRN & \\
\hline CHEMBL1508452 & 688685 & 5.3 & 5.2847 & TRN & \\
\hline CHEMBL1590831 & 688685 & 4.5 & 4.5832 & TRN & \\
\hline CHEMBL1553136 & 688685 & 4.7 & 4.7331 & TRN & \\
\hline CHEMBL1601997 & 688685 & 4.5 & 4.6193 & TST & \\
\hline CHEMBL1309478 & 688685 & 4.8 & 4.8086 & TRN & \\
\hline CHEMBL1256024 & 688685 & 4.9 & 5.1885 & TST & \\
\hline CHEMBL137246 & 688685 & 5.5 & 5.4831 & TRN & \\
\hline CHEMBL1539013 & 688685 & 4.5 & 4.4869 & TRN & \\
\hline CHEMBL1361552 & 688685 & 4.5 & 4.5079 & TRN & \\
\hline CHEMBL1532679 & 688685 & 4.5 & 4.5375 & TRN & \\
\hline CHEMBL1582416 & 688685 & 4.4 & 4.4404 & TRN & \\
\hline CHEMBL1475686 & 688685 & 5.2 & 5.08899 & 99999999995 & TRN \\
\hline CHEMBL1564313 & 688685 & 5.5 & 5.4779 & TRN & \\
\hline CHEMBL1330323 & 688685 & 5.3 & 5.3211 & TRN & \\
\hline CHEMBL1385972 & 688685 & 4.5 & 4.4733 & TRN & \\
\hline CHEMBL1421207 & 688685 & 4.9 & 4.9964 & TRN & \\
\hline CHEMBL1537680 & 688685 & 5.4 & 5.4215 & TRN & \\
\hline CHEMBL1322401 & 688685 & 4.8 & 4.8043 & TRN & \\
\hline CHEMBL1598064 & 688685 & 5.0 & 4.9828 & TRN & \\
\hline CHEMBL1445473 & 688685 & 4.9 & 4.8557 & TRN & \\
\hline CHEMBL1606330 & 688685 & 4.6 & 4.3099 & TST & \\
\hline CHEMBL1344297 & 688685 & 5.2 & 5.1908 & TRN & \\
\hline CHEMBL1340762 & 688685 & 4.5 & 4.4714 & TRN & \\
\hline CHEMBL1322881 & 688685 & 5.0 & 5.0142 & TRN & \\
\hline CHEMBL1474151 & 688685 & 4.6 & 4.5756 & TRN & \\
\hline CHEMBL1376056 & 688685 & 4.5 & 4.8969 & TST & \\
\hline CHEMBL1323897 & 688685 & 4.6 & 4.6565 & TRN & \\
\hline CHEMBL1513223 & 688685 & 4.5 & 4.5419 & TRN & \\
\hline CHEMBL102714 & 688685 & 5.0 & 5.0235 & TRN & \\
\hline CHEMBL1530331 & 688685 & 7.0 & 6.9979 & TRN & \\
\hline CHEMBL140 & 688685 & 4.4 & 4.941 & TST & \\
\hline CHEMBL1422008 & 688685 & 4.5 & 4.4793 & TRN & \\
\hline CHEMBL3194691 & 688685 & 4.4 & 4.3559 & TST & \\
\hline CHEMBL327035 & 688685 & 4.5 & 4.5272 & TRN & \\
\hline
\end{tabular}




\begin{tabular}{|c|c|c|c|c|c|}
\hline \multicolumn{6}{|c|}{ Supplemental Table S2.txt } \\
\hline CHEMBL1515348 & 688685 & 5.4 & 5.15 & TRN & \\
\hline CHEMBL1605510 & 688685 & 4.8 & 4.8161 & TRN & \\
\hline CHEMBL1300617 & 688685 & 4.5 & 5.3462 & TST & \\
\hline CHEMBL1548291 & 688685 & 4.5 & 4.1358 & TST & \\
\hline CHEMBL119171 & 688685 & 5.9 & 4.4617 & TST & \\
\hline CHEMBL1598161 & 688685 & 4.6 & 5.4833 & TST & \\
\hline CHEMBL1590886 & 688685 & 4.5 & 4.4759 & TRN & \\
\hline CHEMBL1550045 & 688685 & 4.7 & 4.6458 & TRN & \\
\hline CHEMBL1373845 & 688685 & 4.7 & 5.1489 & TST & \\
\hline CHEMBL1356721 & 688685 & 4.8 & 4.7716 & TRN & \\
\hline CHEMBL515505 & 688685 & 5.5 & 5.4638 & TST & \\
\hline CHEMBL1551284 & 688685 & 4.5 & 4.6121 & TRN & \\
\hline CHEMBL1310499 & 688685 & 4.7 & $4.7010 e$ & 00000000005 & TRN \\
\hline CHEMBL1423165 & 688685 & 5.2 & 5.1724 & TRN & \\
\hline CHEMBL1392975 & 688685 & 4.6 & 4.6275 & TRN & \\
\hline CHEMBL1379720 & 688685 & 4.6 & 5.0638 & TST & \\
\hline CHEMBL544348 & 688685 & 4.5 & 4.5161 & TRN & \\
\hline CHEMBL1420184 & 688685 & 5.1 & 5.1352 & TRN & \\
\hline CHEMBL1551009 & 688685 & 4.8 & 4.708 & TRN & \\
\hline CHEMBL1553808 & 688685 & 5.0 & 5.0561 & TRN & \\
\hline CHEMBL1372207 & 688685 & 4.5 & 4.5129 & TRN & \\
\hline CHEMBL1373796 & 688685 & 4.5 & 4.5596 & TRN & \\
\hline CHEMBL1557057 & 688685 & 7.3002 & 7.32299 & 99999999995 & TRN \\
\hline CHEMBL1357186 & 688685 & 4.5 & 4.6202 & TRN & \\
\hline CHEMBL1515691 & 688685 & 4.9 & 5.3556 & TST & \\
\hline CHEMBL1337146 & 688685 & 4.9 & 4.9141 & TRN & \\
\hline CHEMBL1473055 & 688685 & 4.6 & 4.5592 & TRN & \\
\hline CHEMBL1490835 & 688685 & 4.5 & 4.4962 & TRN & \\
\hline CHEMBL374107 & 688685 & 6.1 & 4.3373 & TST & \\
\hline CHEMBL1604074 & 688685 & 4.9 & $4.6110 e$ & 2000000001 & TST \\
\hline CHEMBL1584646 & 688685 & 4.5 & 4.5197 & TRN & \\
\hline CHEMBL1582760 & 688685 & 4.5 & 4.5166 & TRN & \\
\hline CHEMBL1317748 & 688685 & 4.6 & 4.6621 & TRN & \\
\hline CHEMBL1340140 & 688685 & 4.5 & 4.4994 & TRN & \\
\hline CHEMBL1321902 & 688685 & 4.5 & 4.485 & TRN & \\
\hline CHEMBL1576762 & 688685 & 4.8 & 4.7832 & TRN & \\
\hline CHEMBL1524650 & 688685 & 4.8 & 4.7499 & TRN & \\
\hline CHEMBL1375551 & 688685 & 4.5 & 4.4832 & TRN & \\
\hline CHEMBL212242 & 688685 & 6.1 & 6.0933 & TRN & \\
\hline CHEMBL1566571 & 688685 & 4.6 & 4.7369 & TRN & \\
\hline CHEMBL1437747 & 688685 & 4.9 & 4.8321 & TRN & \\
\hline CHEMBL1473755 & 688685 & 4.5 & 4.5107 & TRN & \\
\hline CHEMBL521970 & 688685 & 4.6 & 5.7189 & TST & \\
\hline CHEMBL1314906 & 688685 & 4.5 & 4.3853 & TST & \\
\hline CHEMBL1559211 & 688685 & 4.5 & 5.192 & TST & \\
\hline CHEMBL1555938 & 688685 & 4.9 & 4.0079 & TST & \\
\hline CHEMBL1389510 & 688685 & 4.5 & 4.9001 & TST & \\
\hline CHEMBL1580259 & 688685 & 5.4 & 5.0744 & TST & \\
\hline
\end{tabular}




\begin{tabular}{|c|c|c|c|c|c|}
\hline \multicolumn{6}{|c|}{ ole s2.txt } \\
\hline CHEMBL1561363 & 688685 & 5.3 & 5.0457 & TST & \\
\hline CHEMBL3213103 & 688685 & 4.7 & 4.5128 & TST & \\
\hline CHEMBL1727680 & 688685 & 5.4 & 5.5014 & TST & \\
\hline CHEMBL1313353 & 688685 & 5.3 & 4.6818 & TST & \\
\hline CHEMBL1561538 & 688685 & 4.7 & 5.2438 & TST & \\
\hline CHEMBL1487918 & 688685 & 4.7 & 4.2838 & TST & \\
\hline CHEMBL1446025 & 688685 & 4.6 & 4.4739 & TST & \\
\hline CHEMBL1382686 & 688685 & 5.0 & 4.6074 & TST & \\
\hline CHEMBL1413787 & 688685 & 4.8 & 5.2492 & TST & \\
\hline CHEMBL1325335 & 688685 & 4.7 & 4.3067 & TST & \\
\hline CHEMBL3986689 & 1642118 & 7.2218 & 7.1507 & TRN & \\
\hline CHEMBL3981349 & 1642118 & 6.7773 & 6.8003 & TRN & \\
\hline CHEMBL3970835 & 1642118 & 7.4318 & 7.09 & TST & \\
\hline CHEMBL3948019 & 1642118 & 6.1931 & 6.2082 & TRN & \\
\hline CHEMBL3962927 & 1642118 & 5.699 & 6.4966 & TST & \\
\hline CHEMBL3915969 & 1642118 & 6.6556 & 6.671 & TRN & \\
\hline CHEMBL3597964 & 1642118 & 7.0862 & 7.3025 & TRN & \\
\hline CHEMBL3983952 & 1642118 & 6.7496 & 6.7804 & TRN & \\
\hline CHEMBL 3938546 & 1642118 & 5.9355 & 5.9396 & TRN & \\
\hline CHEMBL3890542 & 1642118 & 6.2343 & 6.1985 & TRN & \\
\hline CHEMBL 3923037 & 1642118 & 6.209 & 5.9542 & TRN & \\
\hline CHEMBL3909062 & 1642118 & 5.9208 & 5.8558 & TRN & \\
\hline CHEMBL3956526 & 1642118 & 6.1733 & 6.2493 & TRN & \\
\hline CHEMBL3972793 & 1642118 & 6.0625 & 6.6553 & TST & \\
\hline CHEMBL3894582 & 1642118 & 7.3665 & 7.274 & TRN & \\
\hline CHEMBL3917373 & 1642118 & 7.3372 & 7.5201 & TRN & \\
\hline CHEMBL3979924 & 1642118 & 5.9101 & 6.0856 & TST & \\
\hline CHEMBL3954049 & 1642118 & 6.9208 & 6.5474 & TRN & \\
\hline CHEMBL 3908104 & 1642118 & 6.5901 & 6.7834 & TST & \\
\hline CHEMBL3915192 & 1642118 & 5.9469 & 5.8039 & TRN & \\
\hline CHEMBL 3912551 & 1642118 & 6.5406 & 6.4179 & TRN & \\
\hline CHEMBL3919098 & 1642118 & 4.8729 & 5.7057 & TST & \\
\hline CHEMBL3968605 & 1642118 & 5.75700 & 000000006 & 5.7239 & TRN \\
\hline CHEMBL3920867 & 1642118 & 6.4168 & 6.3344 & TST & \\
\hline CHEMBL3941583 & 1642118 & 7.4202 & 6.9363 & TRN & \\
\hline CHEMBL3979585 & 1642118 & 5.7959 & 5.7305 & TRN & \\
\hline CHEMBL3970228 & 1642118 & 5.2306 & 6.33899 & 99999999995 & TST \\
\hline CHEMBL3965076 & 1642118 & 6.0031 & 6.0723 & TRN & \\
\hline CHEMBL 3896226 & 1642118 & 6.5017 & 6.729 & TST & \\
\hline CHEMBL3973919 & 1642118 & 6.0867 & 6.1861 & TRN & \\
\hline CHEMBL3978561 & 1642118 & 7.0809 & 7.1544 & TST & \\
\hline CHEMBL3893903 & 1642118 & 6.9136 & 7.0223 & TRN & \\
\hline CHEMBL3946962 & 1642118 & 7.3665 & 7.579 & TRN & \\
\hline CHEMBL 3902440 & 1642118 & 6.4711 & 6.3978 & TRN & \\
\hline CHEMBL3932276 & 1642118 & 7.0862 & 6.8766 & TRN & \\
\hline CHEMBL 3925873 & 1642118 & 6.2104 & 6.3602 & TRN & \\
\hline CHEMBL 3982171 & 1642118 & 5.9626 & 5.8852 & TRN & \\
\hline CHEMBL3981923 & 1642118 & 6.5302 & 6.6388 & TRN & \\
\hline
\end{tabular}


Supplemental Table S2.txt

\begin{tabular}{|c|c|c|c|c|c|c|}
\hline CHEMBL3949525 & 1642118 & 5.9208 & 5.9024 & TRN & & \\
\hline CHEMBL3954052 & 1642118 & 5.5638 & 5.8343 & TRN & & \\
\hline CHEMBL3929213 & 1642118 & 6.5498 & 6.6657 & TRN & & \\
\hline CHEMBL3965816 & 1642118 & 7.3872 & 7.2555 & TRN & & \\
\hline CHEMBL3960974 & 1642118 & 5.8477 & 5.8197 & TRN & & \\
\hline CHEMBL3975924 & 1642118 & 6.7144 & 6.6884 & TRN & & \\
\hline CHEMBL3892874 & 1642118 & 6.4389 & 6.4326 & TST & & \\
\hline CHEMBL3917431 & 1642118 & 5.8861 & 6.1099 & TRN & & \\
\hline CHEMBL3964868 & 1642118 & \multicolumn{3}{|c|}{6.007000000000001} & 6.4043 & TST \\
\hline CHEMBL 3932670 & 1642118 & 6.3391 & 6.3598 & TRN & & \\
\hline CHEMBL3982843 & 1642118 & 6.4868 & 6.6522 & TRN & & \\
\hline CHEMBL3971174 & 1642118 & 5.9872 & 6.1399 & TRN & & \\
\hline CHEMBL3916868 & 1642118 & 6.4225 & 6.3951 & TRN & & \\
\hline CHEMBL3895717 & 1642118 & 5.4179 & 5.3579 & TRN & & \\
\hline CHEMBL3950689 & 1642118 & 5.6038 & 5.5582 & TRN & & \\
\hline CHEMBL3944467 & 1642118 & 7.1675 & 7.0737 & TRN & & \\
\hline CHEMBL3899022 & 1642118 & 5.6144 & \multicolumn{3}{|c|}{6.712000000000001} & TST \\
\hline CHEMBL 3982470 & 1642118 & 6.3605 & 6.2946 & TRN & & \\
\hline CHEMBL 3945488 & 1642118 & 5.9914 & \multicolumn{3}{|c|}{6.053999999999999} & TRN \\
\hline CHEMBL3965024 & 1642118 & 6.1838 & 6.5635 & TRN & & \\
\hline CHEMBL3966231 & 1642118 & 7.0132 & 7.0418 & TRN & & \\
\hline CHEMBL3946611 & 1642118 & 7.4685 & 7.2015 & TRN & & \\
\hline CHEMBL 3948694 & 1642118 & 6.8794 & \multicolumn{3}{|c|}{7.122000000000001} & TRN \\
\hline CHEMBL3916956 & 1642118 & 6.7959 & 6.9685 & TRN & & \\
\hline CHEMBL3904615 & 1642118 & 6.251 & 6.6402 & TST & & \\
\hline CHEMBL3920218 & 1642118 & 6.3575 & 6.2318 & TRN & & \\
\hline CHEMBL3900012 & 1642118 & 7.0506 & 6.7371 & TST & & \\
\hline CHEMBL3957590 & 1642118 & 6.6576 & 6.4742 & TRN & & \\
\hline CHEMBL3918089 & 1642118 & 6.0904 & 6.0004 & TRN & & \\
\hline CHEMBL3894851 & 1642118 & 7.7696 & 7.5931 & TST & & \\
\hline CHEMBL3927468 & 1642118 & 6.1593 & 6.2784 & TST & & \\
\hline CHEMBL3985158 & 1642118 & 6.3036 & 6.755 & TST & & \\
\hline CHEMBL3915380 & 1642118 & 6.6108 & 7.1103 & TST & & \\
\hline CHEMBL3903036 & 1642118 & 6.6234 & 6.6106 & TRN & & \\
\hline CHEMBL3955074 & 1642118 & 5.8539 & 5.7714 & TST & & \\
\hline CHEMBL3939929 & 1642118 & 7.1549 & 7.20799 & 9999999999 & & TRN \\
\hline CHEMBL 3984374 & 1642118 & 5.6904 & 6.0179 & TST & & \\
\hline CHEMBL3934595 & 1642118 & \multicolumn{3}{|c|}{6.7620000000000005} & 6.6403 & TRN \\
\hline CHEMBL3929858 & 1642118 & 6.3261 & 6.3328 & TRN & & \\
\hline CHEMBL3958706 & 1642118 & 5.8729 & 5.933 & TRN & & \\
\hline CHEMBL3923722 & 1642118 & 6.5346 & 6.5644 & TRN & & \\
\hline CHEMBL3911441 & 1642118 & 6.4711 & 6.4064 & TRN & & \\
\hline CHEMBL3963773 & 1642118 & 6.4921 & 6.6034 & TRN & & \\
\hline CHEMBL3958954 & 1642118 & 6.1278 & 6.1547 & TRN & & \\
\hline CHEMBL3905668 & 1642118 & 6.475 & 6.3422 & TRN & & \\
\hline CHEMBL3910736 & 1642118 & 6.38299 & 99999999 & 99 & 7.1291 & TST \\
\hline CHEMBL3959128 & 1642118 & 5.6383 & 6.3749 & TST & & \\
\hline CHEMBL3926359 & 1642118 & 6.1198 & 6.1281 & TRN & & \\
\hline
\end{tabular}


Supplemental Table S2.txt

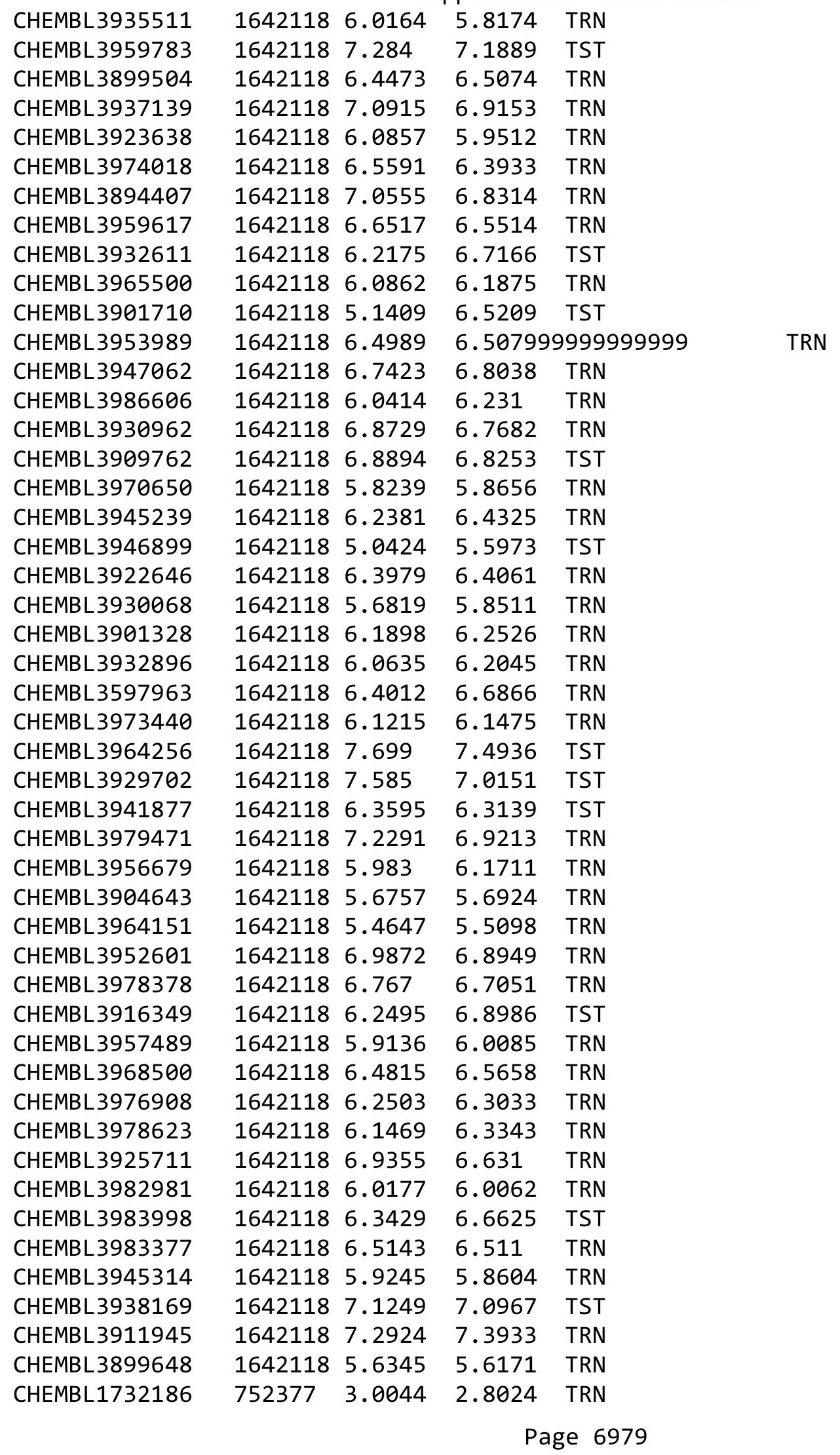




\begin{tabular}{|c|c|c|c|c|c|}
\hline \multirow[b]{2}{*}{ CHEMBL1730304 } & \multicolumn{5}{|c|}{ Supplemental Table S2.txt } \\
\hline & 752377 & 4.1824 & 4.2071 & TRN & \\
\hline CHEMBL1403754 & 752377 & 3.0 & 2.8652 & TST & \\
\hline CHEMBL1412998 & 752377 & 3.0 & 2.6777 & TRN & \\
\hline CHEMBL1608642 & 752377 & 3.0 & 3.0243 & TRN & \\
\hline CHEMBL1385949 & 752377 & 3.0044 & 3.1507 & TST & \\
\hline CHEMBL1727280 & 752377 & 3.0044 & 2.7643 & TRN & \\
\hline CHEMBL1554052 & 752377 & 3.0 & 3.2927 & TRN & \\
\hline CHEMBL1606056 & 752377 & 3.0 & 3.2301 & TRN & \\
\hline CHEMBL1708834 & 752377 & 3.0044 & 3.3587 & TRN & \\
\hline CHEMBL1702283 & 752377 & 3.0 & 3.0805 & TRN & \\
\hline CHEMBL1527023 & 752377 & 3.0 & 3.247 & TRN & \\
\hline CHEMBL1447034 & 752377 & 5.2245 & 5.0041 & TRN & \\
\hline CHEMBL1328398 & 752377 & 3.0 & 2.7664 & TST & \\
\hline CHEMBL501993 & 752377 & 5.3778 & 4.5895 & TST & \\
\hline CHEMBL1708418 & 752377 & 3.0044 & 3.25399 & 99999999996 & TRN \\
\hline CHEMBL1430473 & 752377 & 4.4511 & 4.4335 & TRN & \\
\hline CHEMBL1445488 & 752377 & 4.2418 & 3.6269 & TST & \\
\hline CHEMBL1727679 & 752377 & 3.0 & 2.9788 & TRN & \\
\hline CHEMBL458328 & 752377 & 4.5171 & 3.86 & TST & \\
\hline CHEMBL1489665 & 752377 & 3.0 & 2.7997 & TST & \\
\hline CHEMBL1484942 & 752377 & 3.0 & 3.063 & TRN & \\
\hline CHEMBL1371777 & 752377 & 4.6162 & 4.6069 & TST & \\
\hline CHEMBL1371869 & 752377 & 5.3082 & 4.8199 & TRN & \\
\hline CHEMBL1427609 & 752377 & 5.0264 & 4.6757 & TST & \\
\hline CHEMBL1343331 & 752377 & 3.0 & 3.6651 & TRN & \\
\hline CHEMBL1721385 & 752377 & 3.0044 & 3.1899 & TST & \\
\hline CHEMBL1709810 & 752377 & 4.3039 & 3.885 & TRN & \\
\hline CHEMBL1608654 & 752377 & 4.8075 & 4.7801 & TRN & \\
\hline CHEMBL1698303 & 752377 & 3.0 & 2.8235 & TRN & \\
\hline CHEMBL1608225 & 752377 & 3.0 & 4.1907 & TRN & \\
\hline CHEMBL1713322 & 752377 & 3.0 & 2.8548 & TRN & \\
\hline CHEMBL1483741 & 752377 & 3.0 & 2.6424 & TRN & \\
\hline CHEMBL1714877 & 752377 & 3.0 & 2.9958 & TRN & \\
\hline CHEMBL1414381 & 752377 & 3.0 & 3.0528 & TRN & \\
\hline CHEMBL1492839 & 752377 & 3.0 & 3.3904 & TST & \\
\hline CHEMBL1448629 & 752377 & 3.0 & 3.0295 & TRN & \\
\hline CHEMBL1734920 & 752377 & 3.0044 & 2.827 & TRN & \\
\hline CHEMBL1409373 & 752377 & 3.0 & 3.3582 & TRN & \\
\hline CHEMBL1454310 & 752377 & 3.0 & 2.8595 & TRN & \\
\hline CHEMBL1735408 & 752377 & 3.0 & 3.1334 & TRN & \\
\hline CHEMBL1449334 & 752377 & 4.0013 & 4.231 & TST & \\
\hline CHEMBL1328729 & 752377 & 3.0 & 3.0037 & TRN & \\
\hline CHEMBL1491919 & 752377 & 3.0 & 3.0021 & TST & \\
\hline CHEMBL1721618 & 752377 & 3.0 & 4.1589 & TRN & \\
\hline CHEMBL1493399 & 752377 & 3.0 & 2.8614 & TRN & \\
\hline CHEMBL1715760 & 752377 & 3.0 & 3.1161 & TRN & \\
\hline CHEMBL1407027 & 752377 & 3.0 & 2.7422 & TRN & \\
\hline CHEMBL1462768 & 752377 & 3.0 & 2.9137 & TRN & \\
\hline
\end{tabular}




\begin{tabular}{|c|c|c|c|c|c|}
\hline CHEMBL1732183 & 752377 & 3.0 & \multicolumn{2}{|c|}{3.0460000000000003} & TRN \\
\hline CHEMBL1333960 & 752377 & 3.0 & 2.7945 & TST & \\
\hline CHEMBL1599376 & 752377 & 3.0 & 3.1711 & TST & \\
\hline CHEMBL1526610 & 752377 & 3.0 & 2.926 & TST & \\
\hline CHEMBL1717227 & 752377 & 3.0 & 2.7348 & TRN & \\
\hline CHEMBL1569076 & 752377 & 3.0044 & 2.8314 & TRN & \\
\hline CHEMBL1456035 & 752377 & 4.9208 & 4.8036 & TRN & \\
\hline CHEMBL1491991 & 752377 & 4.2211 & 4.4561 & TRN & \\
\hline CHEMBL1597781 & 752377 & 3.0 & 3.0239 & TRN & \\
\hline CHEMBL1452440 & 752377 & 4.2314 & 4.45100 & 00000000005 & TRN \\
\hline CHEMBL1408008 & 752377 & 3.0 & 3.2077 & TRN & \\
\hline CHEMBL1374065 & 752377 & 3.0 & 2.8434 & TST & \\
\hline CHEMBL1708751 & 752377 & 3.0044 & 2.7408 & TRN & \\
\hline CHEMBL1328309 & 752377 & 3.0 & 2.9482 & TRN & \\
\hline CHEMBL1304974 & 752377 & 4.8794 & 3.162 & TST & \\
\hline CHEMBL1373210 & 752377 & 4.7496 & 4.1607 & TRN & \\
\hline CHEMBL244695 & 752377 & 4.809 & 4.7177 & TRN & \\
\hline CHEMBL1526088 & 752377 & 4.3473 & 4.0714 & TRN & \\
\hline CHEMBL1672291 & 752377 & 4.3785 & 4.32100 & 0000000001 & TRN \\
\hline CHEMBL601167 & 752377 & 4.295 & 4.1211 & TRN & \\
\hline CHEMBL1373495 & 752377 & 3.0 & 3.0669 & TRN & \\
\hline CHEMBL1570803 & 752377 & 5.3958 & 4.6158 & TRN & \\
\hline CHEMBL1491672 & 752377 & 3.0 & 2.8219 & TST & \\
\hline CHEMBL1328061 & 752377 & 3.0 & 3.0878 & TRN & \\
\hline CHEMBL1608153 & 752377 & 4.6077 & 4.8943 & TRN & \\
\hline CHEMBL1713941 & 752377 & 3.0 & 3.1306 & TRN & \\
\hline CHEMBL1408579 & 752377 & 3.0044 & 2.8779 & TST & \\
\hline CHEMBL578585 & 752377 & 4.8827 & 4.0964 & TST & \\
\hline CHEMBL1701471 & 752377 & 3.0 & 3.1155 & TRN & \\
\hline CHEMBL1565097 & 752377 & 3.0 & 2.9317 & TRN & \\
\hline CHEMBL1531431 & 752377 & 3.0 & 2.7923 & TRN & \\
\hline CHEMBL201289 & 752377 & 4.9109 & 4.9251 & TRN & \\
\hline CHEMBL1536551 & 752377 & 3.0044 & 3.0348 & TST & \\
\hline CHEMBL1386069 & 752377 & 3.0 & 2.94100 & 00000000003 & TST \\
\hline CHEMBL1605172 & 752377 & 3.0044 & 2.9082 & TST & \\
\hline CHEMBL1400895 & 752377 & 3.0 & 2.8219 & TST & \\
\hline CHEMBL1557930 & 752377 & 3.0 & 2.8219 & TST & \\
\hline CHEMBL1736022 & 752377 & 3.0 & 3.0375 & TRN & \\
\hline CHEMBL1566708 & 752377 & 3.0 & 3.1421 & TRN & \\
\hline CHEMBL1489917 & 752377 & 3.0 & 2.9877 & TRN & \\
\hline CHEMBL1733670 & 752377 & 3.0 & 3.2151 & TRN & \\
\hline CHEMBL1489619 & 752377 & 3.0 & 2.9989 & TRN & \\
\hline CHEMBL 271690 & 752377 & 4.2557 & 4.427 & TRN & \\
\hline CHEMBL1722185 & 752377 & 3.0 & 3.1165 & TRN & \\
\hline CHEMBL1322542 & 752377 & 3.0044 & 2.8799 & TRN & \\
\hline CHEMBL259355 & 752377 & 3.0 & 2.9605 & TRN & \\
\hline CHEMBL1333555 & 752377 & 5.1124 & 5.0102 & TRN & \\
\hline CHEMBL1732016 & 752377 & 4.5768 & 4.2301 & TRN & \\
\hline
\end{tabular}




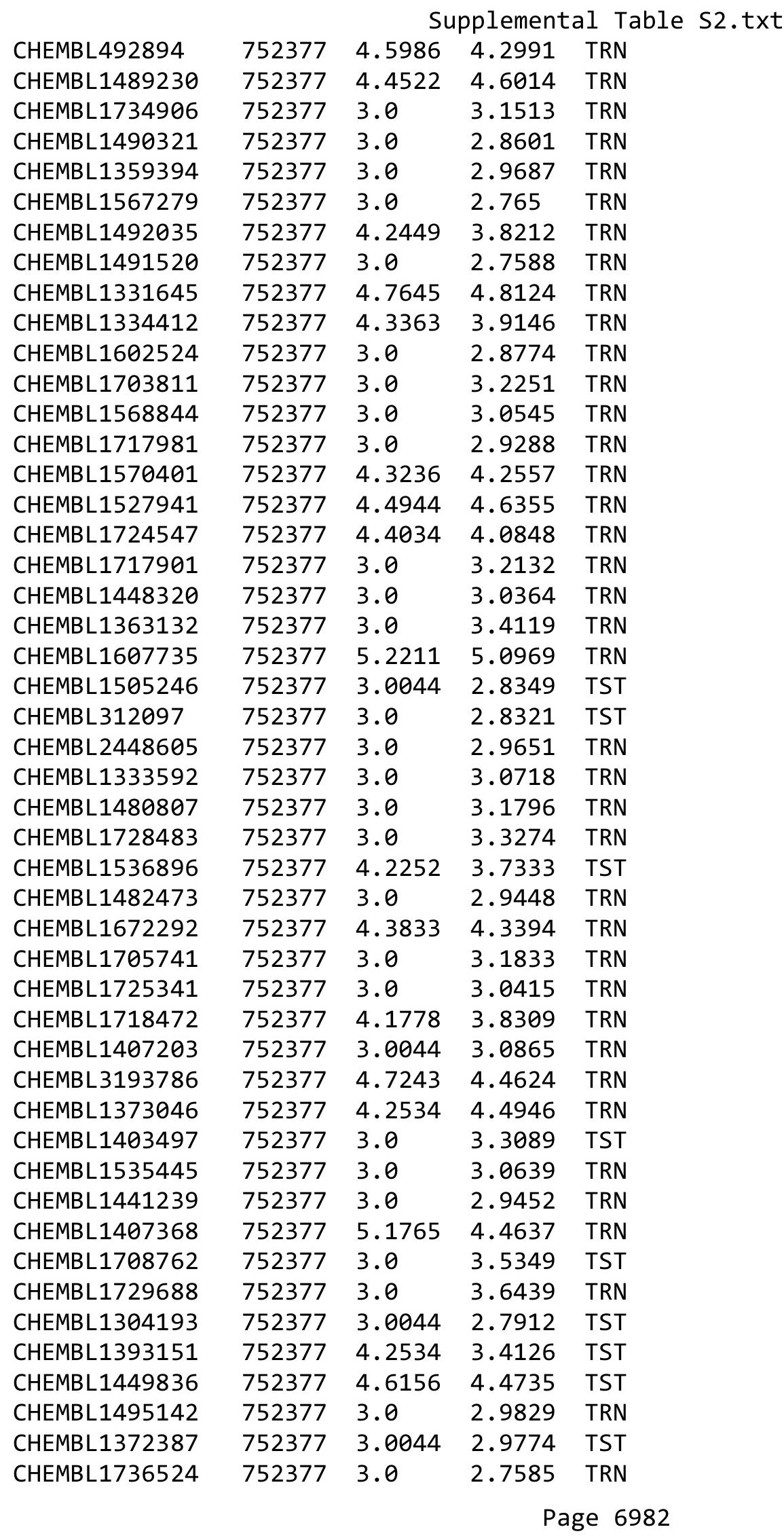




\begin{tabular}{|c|c|c|c|c|}
\hline \multicolumn{5}{|c|}{ Supplemental Table S2.txt } \\
\hline CHEMBL1425948 & 752377 & 3.0 & 3.2817 & TRN \\
\hline CHEMBL1451516 & 752377 & 4.3768 & 4.1613 & TST \\
\hline CHEMBL1727475 & 752377 & 3.0 & 3.1903 & TRN \\
\hline CHEMBL1447397 & 752377 & 3.0044 & 3.065 & TRN \\
\hline CHEMBL1606543 & 752377 & 4.7652 & 4.8816 & TRN \\
\hline CHEMBL1363824 & 752377 & 4.2757 & 4.2398 & TRN \\
\hline CHEMBL1483335 & 752377 & 5.1811 & 4.9093 & TRN \\
\hline CHEMBL1353227 & 752377 & 4.7645 & 4.3266 & TST \\
\hline CHEMBL1721258 & 752377 & 3.0 & 3.1904 & TRN \\
\hline CHEMBL1410909 & 752377 & 4.0635 & 3.24 & TRN \\
\hline CHEMBL1334633 & 752377 & 5.0056 & 4.9959 & TRN \\
\hline CHEMBL1490701 & 752377 & 5.4553 & 5.3828 & TRN \\
\hline CHEMBL1376870 & 752377 & 5.1013 & 4.7657 & TRN \\
\hline CHEMBL1319451 & 752377 & 3.0 & 2.8865 & TST \\
\hline CHEMBL1426947 & 752377 & 3.0 & 2.9129 & TST \\
\hline CHEMBL1526353 & 752377 & 3.0 & 2.7641 & TST \\
\hline CHEMBL1530080 & 752377 & 4.5786 & 5.0082 & TRN \\
\hline CHEMBL1329983 & 752377 & 3.0 & 2.9777 & TST \\
\hline CHEMBL1368913 & 752377 & 4.8069 & 4.9861 & TRN \\
\hline CHEMBL1441524 & 752377 & 3.0 & 3.3192 & TRN \\
\hline CHEMBL1603381 & 752377 & 5.1816 & 4.8845 & TRN \\
\hline CHEMBL1715328 & 752377 & 3.0044 & 3.0988 & TST \\
\hline CHEMBL3196667 & 752377 & 3.301 & 3.7693 & TRN \\
\hline CHEMBL1702303 & 752377 & 3.0 & 2.8842 & TRN \\
\hline CHEMBL1452974 & 752377 & 3.0 & 3.7576 & TST \\
\hline CHEMBL1719276 & 752377 & 3.0 & 2.915 & TRN \\
\hline CHEMBL1373509 & 752377 & 3.0 & 3.1465 & TRN \\
\hline CHEMBL1525859 & 752377 & 3.0 & 2.5118 & TST \\
\hline CHEMBL1443006 & 752377 & 3.0 & 2.8619 & TRN \\
\hline CHEMBL1735040 & 752377 & 3.0 & 3.0995 & TRN \\
\hline CHEMBL1724311 & 752377 & 3.0 & 3.6493 & TRN \\
\hline CHEMBL1447461 & 752377 & 3.0 & 2.8698 & TRN \\
\hline CHEMBL1530046 & 752377 & 3.0 & 2.8055 & TST \\
\hline CHEMBL1578067 & 752377 & 3.0 & 2.7535 & TRN \\
\hline CHEMBL1606748 & 752377 & 3.0 & 3.0048 & TRN \\
\hline CHEMBL1517389 & 752377 & 4.3706 & 4.4341 & TRN \\
\hline CHEMBL1526669 & 752377 & 4.2559 & 4.3487 & TST \\
\hline CHEMBL1719568 & 752377 & 3.0 & 3.1548 & TRN \\
\hline CHEMBL1381392 & 688485 & 6.6846 & 6.1016 & TRN \\
\hline CHEMBL3193835 & 688485 & 5.7296 & 5.4949 & TST \\
\hline CHEMBL1331514 & 688485 & 5.6012 & 5.8492 & TRN \\
\hline CHEMBL1571647 & 688485 & 5.7314 & 5.8601 & TRN \\
\hline CHEMBL1333987 & 688485 & 5.7219 & 5.5717 & TRN \\
\hline CHEMBL1581759 & 688485 & 6.2995 & 6.1515 & TST \\
\hline CHEMBL1539359 & 688485 & 5.5983 & 5.5417 & TRN \\
\hline CHEMBL1430094 & 688485 & 5.6299 & 6.004 & TRN \\
\hline CHEMBL1342896 & 688485 & 6.3814 & 6.1495 & TRN \\
\hline CHEMBL405317 & 688485 & 6.4442 & 6.1909 & TRN \\
\hline
\end{tabular}


Supplemental Table S2.txt

\begin{tabular}{|c|c|c|c|c|}
\hline CHEMBL1390450 & 688485 & 5.9367 & 6.3673 & TRN \\
\hline CHEMBL1468181 & 688485 & 6.5684 & 6.6002 & TRN \\
\hline CHEMBL602218 & 688485 & 5.7897 & 5.5093 & TRN \\
\hline CHEMBL1526738 & 688485 & 6.2624 & 6.4138 & TRN \\
\hline CHEMBL1545660 & 688485 & 5.7711 & 5.9097 & TRN \\
\hline CHEMBL1972959 & 688485 & 6.2095 & 6.1982 & TRN \\
\hline CHEMBL1576870 & 688485 & 6.8747 & 6.8327 & TRN \\
\hline CHEMBL1332533 & 688485 & 5.6868 & 5.9334 & TRN \\
\hline CHEMBL1519239 & 688485 & 5.7399 & 5.3211 & TRN \\
\hline CHEMBL1998606 & 688485 & 6.2504 & 6.0698 & TRN \\
\hline CHEMBL1370087 & 688485 & 6.5741 & 6.2706 & TST \\
\hline CHEMBL578905 & 688485 & 4.8714 & 5.6313 & TRN \\
\hline CHEMBL1595582 & 688485 & 5.3943 & 5.4959 & TRN \\
\hline CHEMBL1371650 & 688485 & 5.8677 & 5.7641 & TRN \\
\hline CHEMBL1491705 & 688485 & 5.8904 & 5.961 & TRN \\
\hline CHEMBL1971379 & 688485 & 5.7825 & 5.8877 & TRN \\
\hline CHEMBL1973921 & 688485 & 7.2168 & 6.1316 & TRN \\
\hline CHEMBL530049 & 688485 & 5.6115 & 5.5039 & TRN \\
\hline CHEMBL3195997 & 688485 & 3.3997 & 5.0336 & TRN \\
\hline CHEMBL 3197344 & 688485 & 5.6094 & 5.5118 & TRN \\
\hline CHEMBL3197906 & 688485 & 5.8236 & 5.6052 & TRN \\
\hline CHEMBL1427072 & 688485 & 5.4523 & 5.74799 & 9999999999 \\
\hline CHEMBL1384292 & 688485 & 6.3731 & 6.2208 & TRN \\
\hline CHEMBL1975754 & 688485 & 5.2909 & 5.3708 & TRN \\
\hline CHEMBL1338085 & 688485 & 6.9693 & 6.2075 & TRN \\
\hline CHEMBL1582665 & 688485 & 5.8324 & 6.2611 & TRN \\
\hline CHEMBL1571615 & 688485 & 5.54299 & 99999999 & 5.8004 \\
\hline CHEMBL1442500 & 688485 & 5.4977 & 5.2277 & TRN \\
\hline CHEMBL1983939 & 688485 & 5.7496 & 5.3783 & TRN \\
\hline CHEMBL1468011 & 688485 & 6.4169 & 6.6332 & TRN \\
\hline CHEMBL3196134 & 688485 & 5.7716 & 5.5912 & TRN \\
\hline CHEMBL1517002 & 688485 & 5.4583 & 5.7019 & TRN \\
\hline CHEMBL1382820 & 688485 & 4.8309 & 5.5332 & TRN \\
\hline CHEMBL3192873 & 688485 & 6.0863 & 6.3248 & TRN \\
\hline CHEMBL1495977 & 688485 & 8.1561 & 6.8501 & TRN \\
\hline CHEMBL1371507 & 688485 & 5.9048 & 6.1106 & TRN \\
\hline CHEMBL3199428 & 688485 & 5.8259 & 5.4825 & TRN \\
\hline CHEMBL1506926 & 688485 & 5.8105 & 6.1234 & TRN \\
\hline CHEMBL1562712 & 688485 & 5.6847 & 6.2966 & TRN \\
\hline CHEMBL 2007601 & 688485 & 6.001 & 5.734 & TRN \\
\hline CHEMBL3189791 & 688485 & 5.7192 & 5.6606 & TRN \\
\hline CHEMBL1979727 & 688485 & 5.7802 & 5.7933 & TRN \\
\hline CHEMBL1470568 & 688485 & 5.5524 & 5.9074 & TRN \\
\hline CHEMBL1605021 & 688485 & 5.8533 & 6.0775 & TST \\
\hline CHEMBL3199020 & 688485 & 5.3877 & 5.7541 & TRN \\
\hline CHEMBL1456353 & 688485 & 5.7853 & 6.1403 & TRN \\
\hline CHEMBL513150 & 688485 & 6.4038 & 5.8567 & TST \\
\hline CHEMBL1397452 & 688485 & 5.8996 & 5.7211 & TST \\
\hline
\end{tabular}




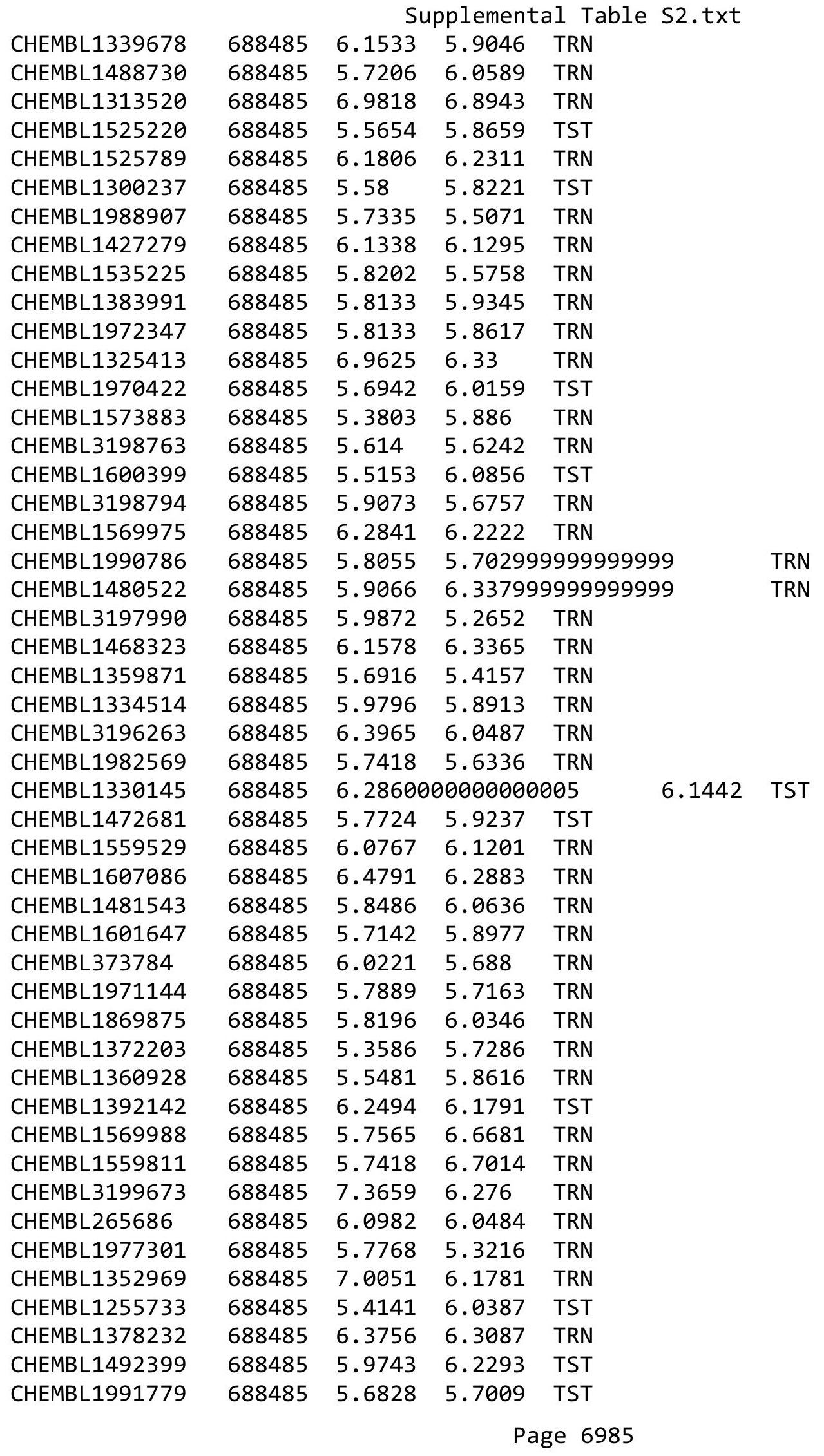




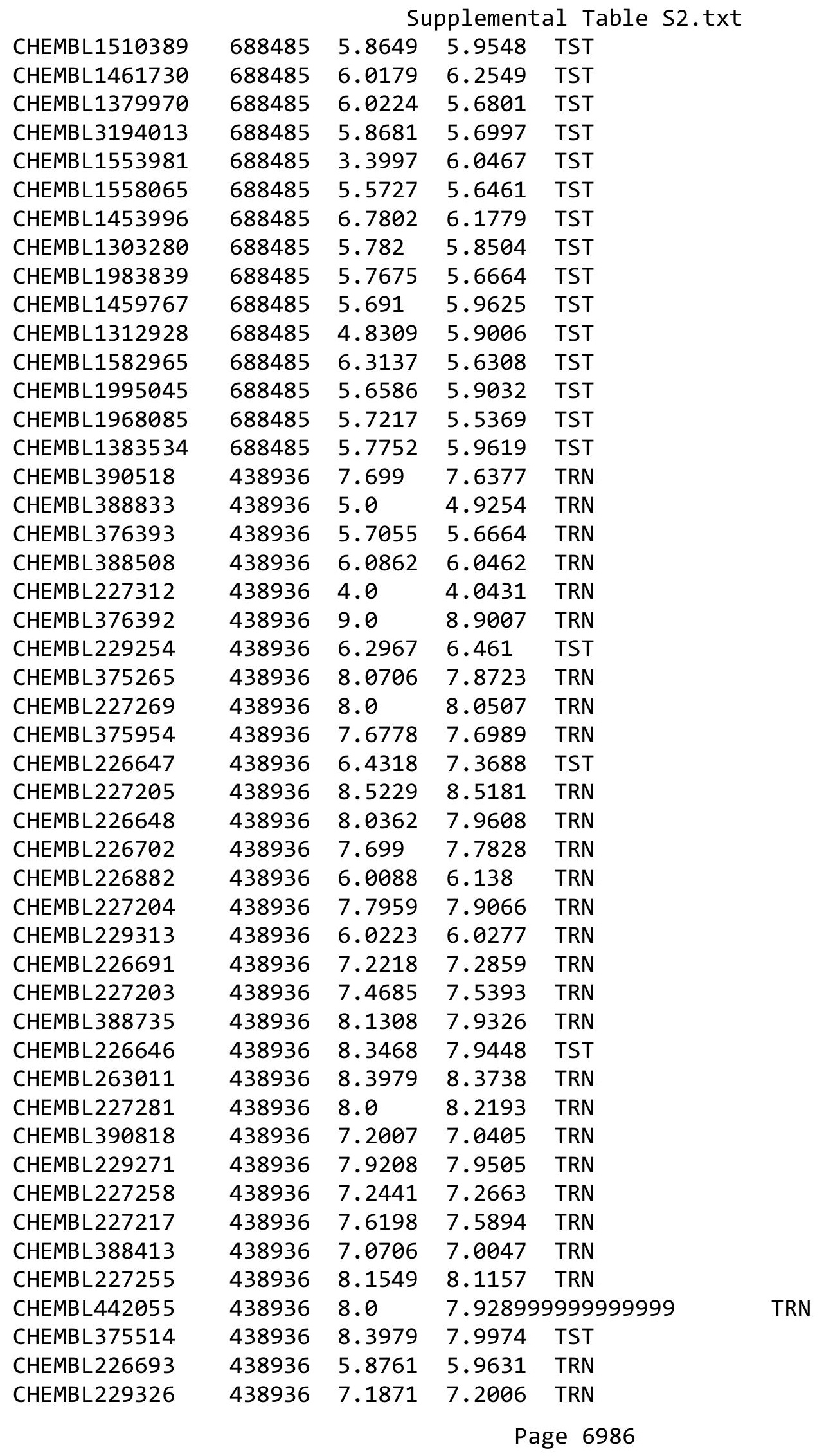




\begin{tabular}{|c|c|c|c|c|}
\hline & & & oplement & al $\mathrm{Ta}$ \\
\hline CHEMBL227256 & 438936 & 8.301 & 8.3943 & TRN \\
\hline CHEMBL227270 & 438936 & 7.1549 & 7.1346 & TRN \\
\hline CHEMBL229269 & 438936 & 6.4045 & 6.4024 & TRN \\
\hline CHEMBL226692 & 438936 & 6.6576 & 6.6826 & TRN \\
\hline CHEMBL226597 & 438936 & 7.9208 & 7.965 & TRN \\
\hline CHEMBL226701 & 438936 & 7.4949 & 7.5327 & TRN \\
\hline CHEMBL227257 & 438936 & 8.1487 & 8.264 & TRN \\
\hline CHEMBL229212 & 438936 & 6.2027 & 6.1693 & TRN \\
\hline CHEMBL376117 & 438936 & 8.0 & 7.9697 & TRN \\
\hline CHEMBL227152 & 438936 & 6.8239 & 6.8256 & TRN \\
\hline CHEMBL227280 & 438936 & 8.0 & 7.4273 & TST \\
\hline CHEMBL229327 & 438936 & 7.7212 & 7.2471 & TST \\
\hline CHEMBL226649 & 438936 & 9.3979 & 7.7227 & TST \\
\hline CHEMBL229270 & 438936 & 7.699 & 6.0864 & TST \\
\hline CHEMBL427416 & 438936 & 8.2757 & 7.0542 & TST \\
\hline CHEMBL375515 & 438936 & 9.3979 & 8.6791 & TST \\
\hline CHEMBL229328 & 438936 & 7.8539 & 6.3743 & TST \\
\hline CHEMBL227282 & 438936 & 7.585 & 8.661 & TST \\
\hline CHEMBL227206 & 438936 & 6.6021 & 6.5501 & TST \\
\hline CHEMBL227313 & 438936 & 8.2218 & 6.3632 & TST \\
\hline CHEMBL235616 & 448695 & 5.041 & 4.9202 & TRN \\
\hline CHEMBL237291 & 448695 & 4.9208 & 4.978 & TRN \\
\hline CHEMBL237693 & 448695 & 4.4559 & 4.8536 & TST \\
\hline CHEMBL237687 & 448695 & 4.7959 & 4.7131 & TRN \\
\hline CHEMBL393753 & 448695 & 4.3098 & 4.8857 & TRN \\
\hline CHEMBL236626 & 448695 & 4.0132 & 4.8591 & TRN \\
\hline CHEMBL394645 & 448695 & 5.0506 & 4.4897 & TRN \\
\hline CHEMBL235139 & 448695 & 4.0177 & 5.3532 & TRN \\
\hline CHEMBL393557 & 448695 & 4.7212 & 4.6094 & TRN \\
\hline CHEMBL237299 & 448695 & 4.6021 & 4.7893 & TST \\
\hline CHEMBL236447 & 448695 & 4.7447 & 4.6645 & TRN \\
\hline CHEMBL236003 & 448695 & 4.8861 & 4.8175 & TST \\
\hline CHEMBL235617 & 448695 & 5.0605 & 4.8287 & TRN \\
\hline CHEMBL237957 & 448695 & 4.9208 & 4.6273 & TRN \\
\hline CHEMBL237070 & 448695 & 5.1427 & 4.9778 & TRN \\
\hline CHEMBL237910 & 448695 & 5.0969 & 4.835 & TRN \\
\hline CHEMBL392521 & 448695 & 4.4949 & 4.7339 & TRN \\
\hline CHEMBL399810 & 448695 & 6.0 & 5.6304 & TRN \\
\hline CHEMBL394647 & 448695 & 4.041 & 4.5917 & TST \\
\hline CHEMBL394646 & 448695 & 4.7959 & 4.6515 & TRN \\
\hline CHEMBL235798 & 448695 & 4.8861 & 4.7231 & TRN \\
\hline CHEMBL392094 & 448695 & 4.4559 & 5.1384 & TST \\
\hline CHEMBL398980 & 448695 & 4.6576 & 4.6692 & TRN \\
\hline CHEMBL238367 & 448695 & 4.3979 & 4.6986 & TRN \\
\hline CHEMBL394669 & 448695 & 4.6383 & 4.439 & TRN \\
\hline CHEMBL391823 & 448695 & 6.0315 & 4.8508 & TRN \\
\hline CHEMBL393553 & 448695 & 5.0 & 4.8291 & TRN \\
\hline CHEMBL238135 & 448695 & 5.0605 & 4.8667 & TRN \\
\hline
\end{tabular}




\begin{tabular}{|c|c|c|c|c|c|}
\hline \multirow[b]{2}{*}{ CHEMBL399624 } & \multicolumn{5}{|c|}{ Supplemental Table S2.txt } \\
\hline & 448695 & 5.3098 & 4.9402 & TRN & \\
\hline CHEMBL237528 & 448695 & 3.5735 & 4.9104 & TRN & \\
\hline CHEMBL236840 & 448695 & 4.2518 & 5.0581 & TST & \\
\hline CHEMBL428903 & 448695 & 4.9208 & 5.1499 & TST & \\
\hline CHEMBL237478 & 448695 & 3.3893 & 4.0061 & TRN & \\
\hline CHEMBL236847 & 448695 & 4.699 & 4.9925 & TST & \\
\hline CHEMBL394074 & 448695 & 5.1612 & 5.1698 & TRN & \\
\hline CHEMBL393918 & 448695 & 4.9586 & 4.7254 & TRN & \\
\hline CHEMBL393755 & 448695 & 4.6021 & 4.6944 & TST & \\
\hline CHEMBL238136 & 448695 & 4.7696 & 4.8949 & TRN & \\
\hline CHEMBL429269 & 448695 & 3.7545 & 4.4799 & TRN & \\
\hline CHEMBL237919 & 448695 & 6.0 & 5.403 & TRN & \\
\hline CHEMBL393994 & 448695 & 5.0177 & 5.1252 & TRN & \\
\hline CHEMBL237702 & 448695 & 6.0 & 5.7667 & TST & \\
\hline CHEMBL429983 & 448695 & 3.556 & 5.1376 & TRN & \\
\hline CHEMBL236022 & 448695 & 4.9586 & 4.632 & TRN & \\
\hline CHEMBL235358 & 448695 & 5.284 & 4.9641 & TRN & \\
\hline CHEMBL236450 & 448695 & 4.7212 & 5.0864 & TST & \\
\hline CHEMBL237930 & 448695 & 5.0132 & 4.7578 & TRN & \\
\hline CHEMBL237719 & 448695 & 4.8861 & 4.7662 & TRN & \\
\hline CHEMBL236645 & 448695 & 4.7696 & 4.8148 & TRN & \\
\hline CHEMBL445669 & 448695 & 5.1739 & 4.7702 & TRN & \\
\hline CHEMBL410179 & 448695 & 4.5376 & 4.9729 & TRN & \\
\hline CHEMBL268395 & 448695 & 3.2557 & 4.7155 & TRN & \\
\hline CHEMBL394149 & 448695 & 4.2596 & 4.5394 & TST & \\
\hline CHEMBL237483 & 448695 & 4.3372 & 4.8231 & TST & \\
\hline CHEMBL392315 & 448695 & 5.4202 & 4.7699 & TRN & \\
\hline CHEMBL236002 & 448695 & 4.7447 & 4.7566 & TRN & \\
\hline CHEMBL237698 & 448695 & 4.6576 & 4.9037 & TRN & \\
\hline CHEMBL394394 & 448695 & 4.4437 & 4.6772 & TRN & \\
\hline CHEMBL236630 & 448695 & 4.0706 & 4.9729 & TRN & \\
\hline CHEMBL235356 & 448695 & 5.0969 & 5.2875 & TST & \\
\hline CHEMBL397324 & 448695 & 3.5751 & 5.1916 & TRN & \\
\hline CHEMBL237315 & 448695 & 4.6383 & 4.8435 & TRN & \\
\hline CHEMBL238153 & 448695 & 6.0 & 5.79299 & 9999999999 & TRN \\
\hline CHEMBL393919 & 448695 & 4.6778 & 4.9729 & TRN & \\
\hline CHEMBL235590 & 448695 & 5.0809 & 4.5633 & TRN & \\
\hline CHEMBL238158 & 448695 & 4.284 & 4.4691 & TRN & \\
\hline CHEMBL 237502 & 448695 & 6.0 & 5.6442 & TRN & \\
\hline CHEMBL235359 & 448695 & 4.0809 & 4.8268 & TRN & \\
\hline CHEMBL394073 & 448695 & 4.6778 & 4.6587 & TRN & \\
\hline CHEMBL399811 & 448695 & 5.1427 & 5.0496 & TRN & \\
\hline CHEMBL238144 & 448695 & 5.1135 & 5.1925 & TRN & \\
\hline CHEMBL 237694 & 448695 & 4.6383 & 4.76699 & 99999999995 & TRN \\
\hline CHEMBL236629 & 448695 & 3.4522 & 4.6074 & TST & \\
\hline CHEMBL238180 & 448695 & 4.6383 & 4.4979 & TST & \\
\hline CHEMBL235815 & 448695 & 4.2366 & 5.0468 & TRN & \\
\hline CHEMBL236649 & 448695 & 4.3979 & 4.835 & TRN & \\
\hline
\end{tabular}




\begin{tabular}{|c|c|c|c|c|c|}
\hline & & & & & \\
\hline CHEMBL235382 & 448695 & 4.7447 & 4.6317 & TRN & \\
\hline CHEMBL237920 & 448695 & 6.0 & 5.5806 & TRN & \\
\hline CHEMBL238342 & 448695 & 6.0 & 5.4435 & TRN & \\
\hline CHEMBL396341 & 448695 & 4.6021 & 4.6652 & TRN & \\
\hline CHEMBL235147 & 448695 & 4.7696 & 4.6897 & TRN & \\
\hline CHEMBL237912 & 448695 & 5.6576 & 4.8303 & TRN & \\
\hline CHEMBL235802 & 448695 & 4.6778 & 4.7042 & TRN & \\
\hline CHEMBL235627 & 448695 & 4.9208 & 4.7089 & TST & \\
\hline CHEMBL236443 & 448695 & 5.1938 & 4.9246 & TRN & \\
\hline CHEMBL429451 & 448695 & 5.0223 & 4.97 & TRN & \\
\hline CHEMBL237692 & 448695 & 4.9586 & 4.9612 & TST & \\
\hline CHEMBL393552 & 448695 & 4.7447 & 4.8187 & TRN & \\
\hline CHEMBL238149 & 448695 & 5.2147 & 4.9227 & TRN & \\
\hline CHEMBL236841 & 448695 & 5.3372 & 4.72199 & 99999999995 & TST \\
\hline CHEMBL393125 & 448695 & 4.7447 & 4.8898 & TRN & \\
\hline CHEMBL236842 & 448695 & 5.284 & 4.7131 & TRN & \\
\hline CHEMBL237937 & 448695 & 5.3665 & 5.1928 & TRN & \\
\hline CHEMBL235137 & 448695 & 5.3372 & 4.7699 & TRN & \\
\hline CHEMBL396303 & 448695 & 4.0506 & 4.7647 & TRN & \\
\hline CHEMBL392316 & 448695 & 4.5086 & 4.869 & TST & \\
\hline CHEMBL237714 & 448695 & 5.041 & 4.8062 & TRN & \\
\hline CHEMBL393359 & 448695 & 5.1367 & 4.7591 & TRN & \\
\hline CHEMBL235140 & 448695 & 5.284 & 5.0681 & TRN & \\
\hline CHEMBL238159 & 448695 & 5.0 & 5.0719 & TRN & \\
\hline CHEMBL238353 & 448695 & 4.8239 & 4.6778 & TRN & \\
\hline CHEMBL237051 & 448695 & 4.4685 & 4.8949 & TRN & \\
\hline CHEMBL396111 & 448695 & 4.9586 & 5.1236 & TRN & \\
\hline CHEMBL 237479 & 448695 & 3.1669 & 4.3152 & TST & \\
\hline CHEMBL237743 & 448695 & 4.8861 & 4.8888 & TRN & \\
\hline CHEMBL235136 & 448695 & 4.699 & 4.9501 & TRN & \\
\hline CHEMBL235176 & 448695 & 4.9586 & 4.8153 & TRN & \\
\hline CHEMBL396638 & 448695 & 5.4685 & 5.3846 & TST & \\
\hline CHEMBL 237504 & 448695 & 5.0 & 4.6718 & TRN & \\
\hline CHEMBL392223 & 448695 & 5.0 & 4.9589 & TRN & \\
\hline CHEMBL237079 & 448695 & 4.5376 & 4.8098 & TST & \\
\hline CHEMBL391706 & 448695 & 4.5528 & 4.9729 & TRN & \\
\hline CHEMBL235162 & 448695 & 4.3098 & 4.3942 & TRN & \\
\hline CHEMBL394667 & 448695 & 5.6576 & 4.5398 & TRN & \\
\hline CHEMBL235797 & 448695 & 4.5686 & 4.6762 & TRN & \\
\hline CHEMBL237911 & 448695 & 5.1739 & 4.8609 & TST & \\
\hline CHEMBL394075 & 448695 & 5.041 & 5.0397 & TRN & \\
\hline CHEMBL237052 & 448695 & 5.1024 & 4.6786 & TRN & \\
\hline CHEMBL398777 & 448695 & 5.1805 & 4.7704 & TRN & \\
\hline CHEMBL438334 & 448695 & 4.699 & 4.7699 & TRN & \\
\hline CHEMBL238368 & 448695 & 4.9586 & 4.9175 & TRN & \\
\hline CHEMBL235582 & 448695 & 6.0 & 5.6479 & TRN & \\
\hline CHEMBL393568 & 448695 & 4.3565 & 4.5616 & TRN & \\
\hline CHEMBL236638 & 448695 & 5.6778 & 4.72199 & 99999999995 & TST \\
\hline & & & & $0>07$ & \\
\hline
\end{tabular}




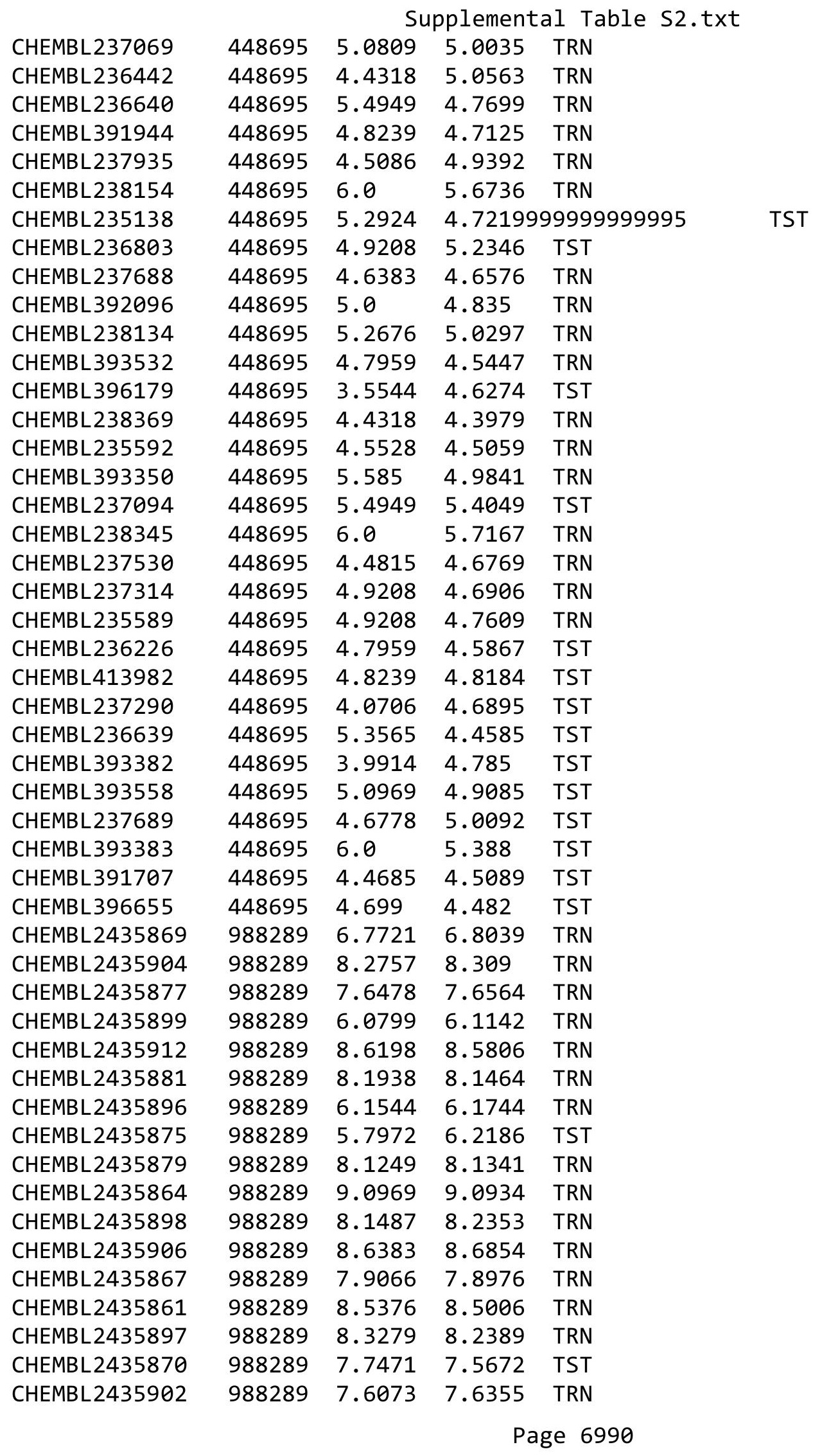




\begin{tabular}{|c|c|c|c|c|c|c|}
\hline & & \multicolumn{5}{|c|}{ Supplemental Table s2.txt } \\
\hline CHEMBL2435863 & 988289 & 8.4685 & 8.4461 & TRN & & \\
\hline CHEMBL 2435894 & 988289 & 7.4921 & 7.4678 & TRN & & \\
\hline CHEMBL2435860 & 988289 & 8.8861 & 8.911 & TRN & & \\
\hline CHEMBL 2435901 & 988289 & 6.8245 & 6.8121 & TRN & & \\
\hline CHEMBL2435893 & 988289 & 7.8239 & 7.7681 & TRN & & \\
\hline CHEMBL 2435848 & 988289 & 8.3768 & 9.2159 & TST & & \\
\hline CHEMBL 2435908 & 988289 & 8.2007 & 8.2664 & TRN & & \\
\hline CHEMBL 2435865 & 988289 & 6.093 & 6.0347 & TRN & & \\
\hline CHEMBL 2435876 & 988289 & 7.8013 & 7.9707 & TST & & \\
\hline CHEMBL 2435888 & 988289 & 7.041 & \multicolumn{3}{|c|}{7.087999999999999} & TRN \\
\hline CHEMBL 2435905 & 988289 & 8.4437 & 8.4524 & TRN & & \\
\hline CHEMBL 2435887 & 988289 & 6.4921 & 6.4737 & TRN & & \\
\hline CHEMBL 2435878 & 988289 & 7.9355 & 7.8468 & TST & & \\
\hline CHEMBL 2435847 & 988289 & 8.2366 & 8.5026 & TST & & \\
\hline CHEMBL2435903 & 988289 & 8.1249 & 8.1292 & TRN & & \\
\hline CHEMBL 2435910 & 988289 & 7.0706 & 7.0442 & TRN & & \\
\hline CHEMBL 2435874 & 988289 & 7.041 & 7.8762 & TST & & \\
\hline CHEMBL 2435880 & 988289 & 8.1612 & \multicolumn{3}{|c|}{7.872999999999999} & TST \\
\hline CHEMBL 2435895 & 988289 & 6.8024 & 6.855 & TRN & & \\
\hline CHEMBL2435862 & 988289 & 8.9208 & 8.9448 & TRN & & \\
\hline CHEMBL 2435909 & 988289 & 9.0969 & 8.9992 & TRN & & \\
\hline CHEMBL 2435873 & 988289 & 7.8182 & 7.704 & TST & & \\
\hline CHEMBL 2435866 & 988289 & 8.4437 & 8.4986 & TRN & & \\
\hline CHEMBL 2435868 & 988289 & \multicolumn{3}{|c|}{7.7620000000000005} & .9112 & TST \\
\hline CHEMBL2435892 & 988289 & 8.2366 & 8.2336 & TRN & & \\
\hline CHEMBL 2435891 & 988289 & 8.2924 & 8.323 & TRN & & \\
\hline CHEMBL 2435889 & 988289 & 5.8164 & 5.7965 & TRN & & \\
\hline CHEMBL 2435859 & 988289 & 8.7447 & 8.8073 & TRN & & \\
\hline CHEMBL 2435846 & 988289 & 7.8962 & 7.8351 & TST & & \\
\hline CHEMBL2435907 & 988289 & 9.0458 & 8.9408 & TRN & & \\
\hline CHEMBL 2435890 & 988289 & 8.2218 & 8.2529 & TRN & & \\
\hline CHEMBL2435872 & 988289 & 7.3595 & 7.1329 & TST & & \\
\hline CHEMBL 2435871 & 988289 & 7.3615 & 7.6283 & TST & & \\
\hline CHEMBL2435900 & 988289 & 6.5219 & 6.4853 & TRN & & \\
\hline CHEMBL435901 & 63356 & 6.6383 & 6.6376 & TRN & & \\
\hline CHEMBL177023 & 63356 & 6.5528 & 6.5538 & TRN & & \\
\hline CHEMBL366387 & 63356 & 5.5229 & 5.6113 & TST & & \\
\hline CHEMBL176913 & 63356 & 6.1871 & 6.1752 & TRN & & \\
\hline CHEMBL176430 & 63356 & 6.0 & 6.0189 & TST & & \\
\hline CHEMBL172178 & 63356 & 5.0605 & 6.6101 & TST & & \\
\hline CHEMBL177431 & 63356 & 7.2366 & 7.2384 & TRN & & \\
\hline CHEMBL435156 & 63356 & 4.7905 & 5.9795 & TST & & \\
\hline CHEMBL175924 & 63356 & 5.7212 & 5.7195 & TRN & & \\
\hline CHEMBL441112 & 63356 & 6.6576 & 6.6314 & TRN & & \\
\hline CHEMBL368360 & 63356 & 7.4815 & 6.7447 & TST & & \\
\hline CHEMBL177602 & 63356 & 5.5376 & 5.5357 & TRN & & \\
\hline CHEMBL174818 & 63356 & 6.9208 & 6.9396 & TRN & & \\
\hline \multirow[t]{2}{*}{ CHEMBL369874 } & 63356 & 5.4498 & \multicolumn{3}{|c|}{5.446000000000001} & TRN \\
\hline & & & & e 6991 & & \\
\hline
\end{tabular}




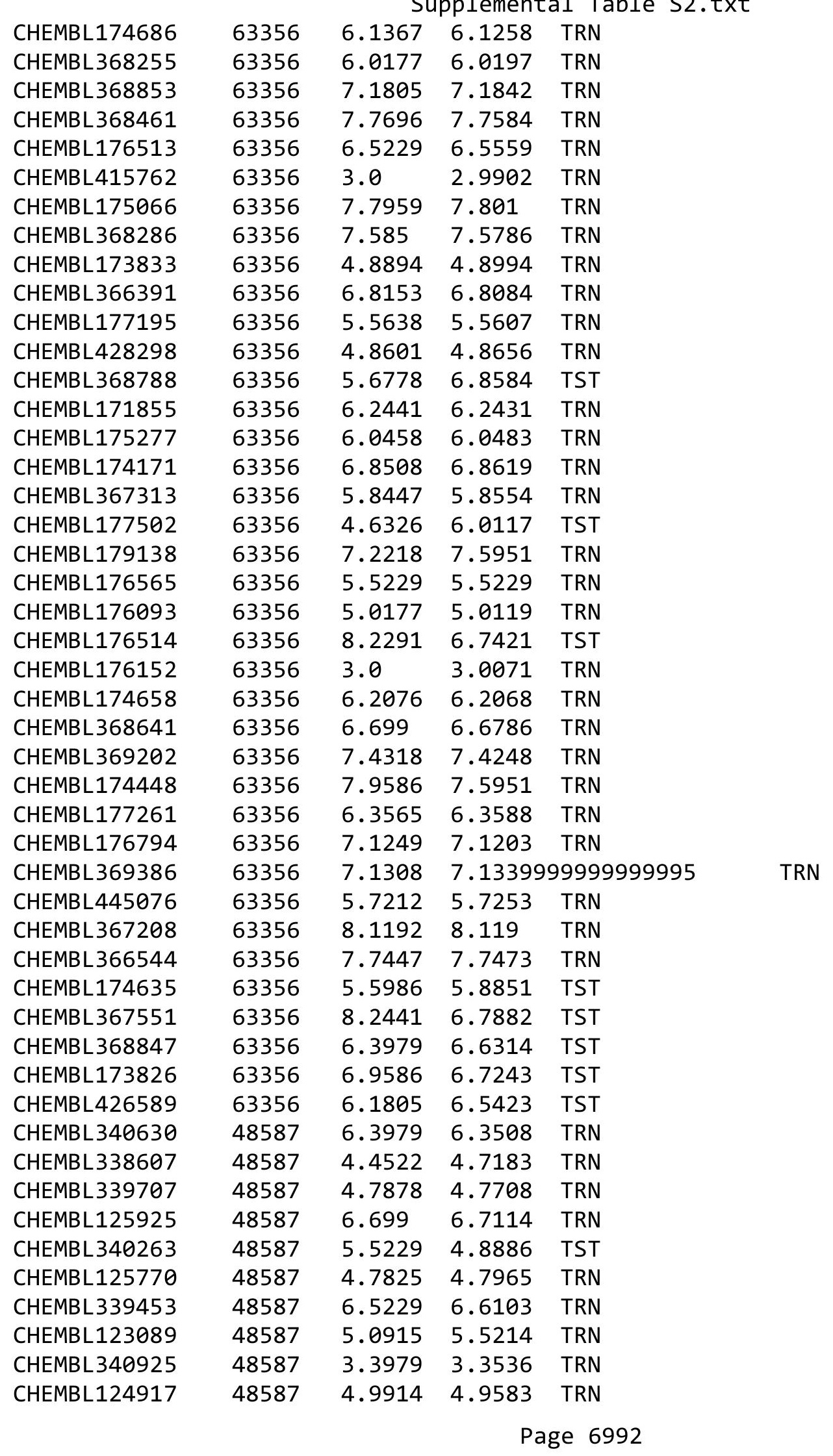




\begin{tabular}{|c|c|c|c|c|c|}
\hline \multicolumn{6}{|c|}{ supplementa1 Iable s2 } \\
\hline CHEMBL124822 & 48587 & 6.0 & 5.65 & TRN & \\
\hline CHEMBL123852 & 48587 & 5.4437 & 5.7106 & TRN & \\
\hline CHEMBL124751 & 48587 & 4.5186 & 4.5883 & TRN & \\
\hline CHEMBL124261 & 48587 & 5.2076 & 5.2405 & TRN & \\
\hline CHEMBL339041 & 48587 & 6.3979 & 6.4219 & TRN & \\
\hline CHEMBL125703 & 48587 & 5.4949 & 5.4902 & TRN & \\
\hline CHEMBL340463 & 48587 & 6.0 & 6.2545 & TRN & \\
\hline CHEMBL421474 & 48587 & 6.0969 & 6.1999 & TRN & \\
\hline CHEMBL341505 & 48587 & 4.7932 & 4.8757 & TRN & \\
\hline CHEMBL338929 & 48587 & 5.7212 & 5.6751 & TRN & \\
\hline CHEMBL123720 & 48587 & 5.4202 & 5.6178 & TRN & \\
\hline CHEMBL124712 & 48587 & 5.2366 & 5.0042 & TRN & \\
\hline CHEMBL332674 & 48587 & 4.5528 & 4.5699 & TRN & \\
\hline CHEMBL124732 & 48587 & 5.6383 & 5.7254 & TRN & \\
\hline CHEMBL127604 & 48587 & 4.4413 & 4.6681 & TRN & \\
\hline CHEMBL125316 & 48587 & 3.3979 & 3.2662 & TRN & \\
\hline CHEMBL125829 & 48587 & 4.2958 & 4.6623 & TST & \\
\hline CHEMBL435587 & 48587 & 4.9788 & 5.0033 & TRN & \\
\hline CHEMBL124780 & 48587 & 5.6383 & 5.6436 & TST & \\
\hline CHEMBL124396 & 48587 & 6.5229 & 5.3967 & TST & \\
\hline CHEMBL123785 & 48587 & 5.0969 & 5.2649 & TRN & \\
\hline CHEMBL339115 & 48587 & 5.4815 & 5.3183 & TRN & \\
\hline CHEMBL331413 & 48587 & 6.0458 & 5.536006 & 00000000005 & TST \\
\hline CHEMBL124832 & 48587 & 6.301 & 5.8259 & TST & \\
\hline CHEMBL338134 & 48587 & 5.9208 & 6.3922 & TST & \\
\hline CHEMBL124378 & 48587 & 5.5376 & 6.1524 & TST & \\
\hline CHEMBL124764 & 48587 & 6.0 & 5.1953 & TRN & \\
\hline CHEMBL338045 & 48587 & 4.7212 & 4.8391 & TRN & \\
\hline CHEMBL125083 & 48587 & 4.3143 & 5.2233 & TST & \\
\hline CHEMBL124459 & 48587 & 5.1549 & 5.1953 & TRN & \\
\hline CHEMBL340413 & 48587 & 6.0 & 5.7827 & TRN & \\
\hline CHEMBL340755 & 48587 & 4.6676 & 4.5699 & TST & \\
\hline CHEMBL334171 & 48587 & 6.0969 & 5.8143 & TRN & \\
\hline CHEMBL 124802 & 48587 & 4.6819 & 5.1953 & TRN & \\
\hline CHEMBL125551 & 48587 & 5.5086 & 6.1535 & TST & \\
\hline CHEMBL434250 & 48587 & 5.1079 & 5.3137 & TRN & \\
\hline CHEMBL122922 & 48587 & 5.6383 & 6.6308 & TST & \\
\hline CHEMBL124509 & 48587 & 5.7959 & 5.6305 & TST & \\
\hline CHEMBL127551 & 48587 & 4.0177 & 4.1551 & TST & \\
\hline CHEMBL124805 & 48587 & 5.2218 & 5.4102 & TRN & \\
\hline CHEMBL123684 & 48587 & 6.0969 & 5.7277 & TRN & \\
\hline CHEMBL124155 & 48587 & 5.5686 & 5.5432 & TRN & \\
\hline CHEMBL341143 & 48587 & 5.7212 & 5.4161 & TRN & \\
\hline CHEMBL339134 & 48587 & 6.1549 & 5.7991 & TRN & \\
\hline CHEMBL1773810 & 746660 & 5.3468 & 5.0843 & TRN & \\
\hline CHEMBL1773700 & 746660 & 5.8239 & 5.1442 & TRN & \\
\hline CHEMBL1773832 & 746660 & 3.5229 & 3.9708 & TRN & \\
\hline CHEMBL1773842 & 746660 & 3.5229 & 3.8515 & TRN & \\
\hline
\end{tabular}


Supplemental Table S2.txt

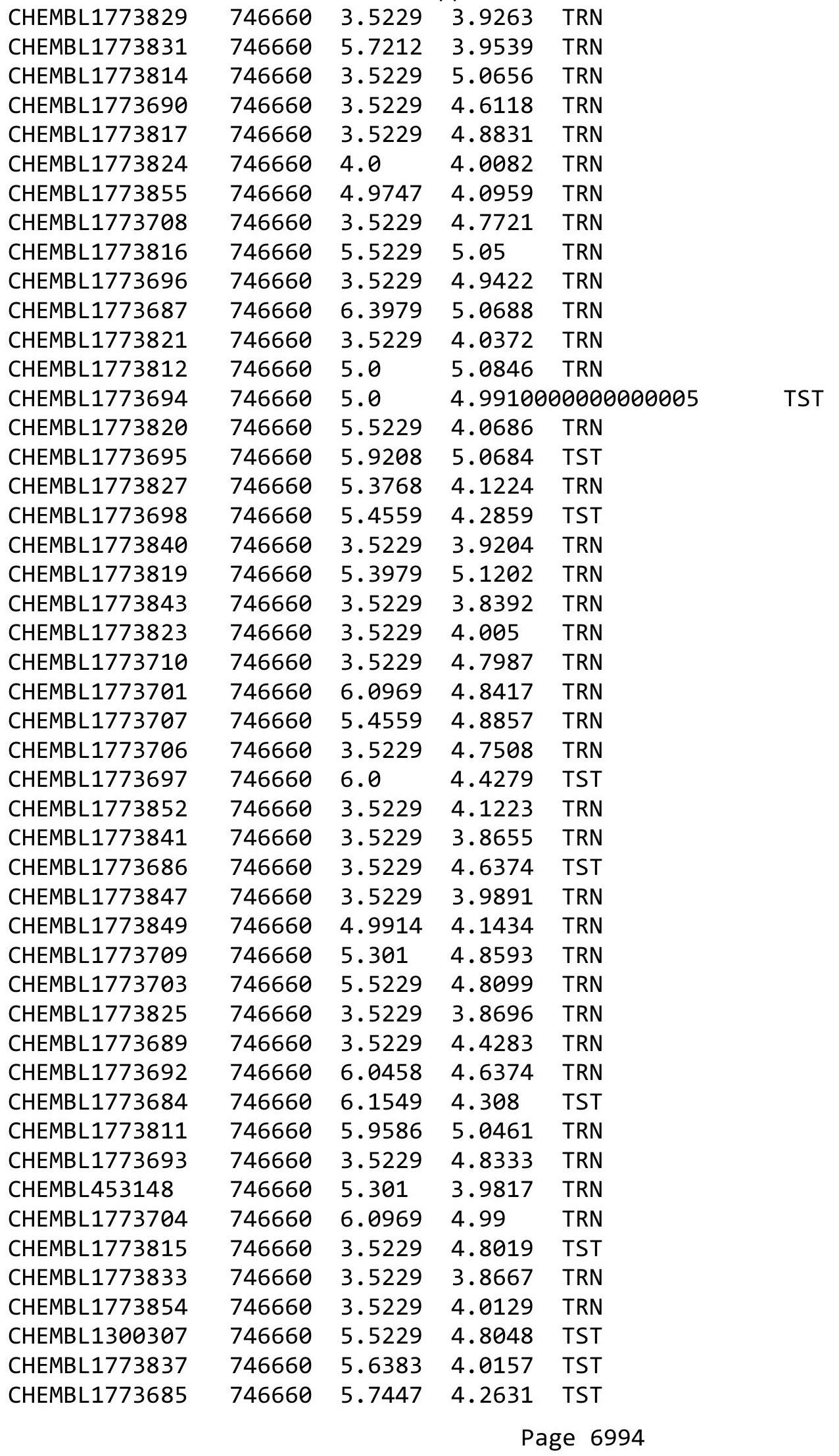




\begin{tabular}{|c|c|c|c|c|c|}
\hline \multicolumn{6}{|c|}{ Supplemental Table S2.txt } \\
\hline CHEMBL1773683 & 746660 & 6.041 & 3.8986 & TST & \\
\hline CHEMBL1773688 & 746660 & 3.5229 & 4.6877 & TST & \\
\hline CHEMBL1773809 & 746660 & 6.0458 & 5.0841 & TST & \\
\hline CHEMBL1773818 & 746660 & 3.5229 & 5.0705 & TST & \\
\hline CHEMBL3959026 & 1641200 & 5.6664 & 5.5673 & TRN & \\
\hline CHEMBL3970113 & 1641200 & 5.5577 & 5.5503 & TRN & \\
\hline CHEMBL3955142 & 1641200 & 7.0315 & 6.9036 & TRN & \\
\hline CHEMBL3929227 & 1641200 & 9.0 & 8.93700 & 0000000001 & TRN \\
\hline CHEMBL3943738 & 1641200 & 6.4685 & 5.8484 & TST & \\
\hline CHEMBL3957993 & 1641200 & 5.3676 & 5.4043 & TRN & \\
\hline CHEMBL3901338 & 1641200 & 5.6409 & 5.6581 & TRN & \\
\hline CHEMBL3923211 & 1641200 & 7.3872 & 7.2483 & TRN & \\
\hline CHEMBL3969043 & 1641200 & 6.9355 & 7.0382 & TRN & \\
\hline CHEMBL3930490 & 1641200 & 5.135 & 6.1357 & TST & \\
\hline CHEMBL3941154 & 1641200 & 5.5626 & 5.5409 & TRN & \\
\hline CHEMBL3929299 & 1641200 & 6.5017 & 6.4576 & TRN & \\
\hline CHEMBL3952463 & 1641200 & 5.3039 & 5.2402 & TRN & \\
\hline CHEMBL3913142 & 1641200 & 5.4393 & 5.4622 & TRN & \\
\hline CHEMBL3915777 & 1641200 & 7.8239 & 7.7158 & TRN & \\
\hline CHEMBL3986011 & 1641200 & 5.5891 & 5.4699 & TRN & \\
\hline CHEMBL3957995 & 1641200 & 4.8204 & 4.5641 & TST & \\
\hline CHEMBL3928237 & 1641200 & 7.1079 & 7.0938 & TRN & \\
\hline CHEMBL3975877 & 1641200 & 7.8239 & 7.8784 & TRN & \\
\hline CHEMBL3931529 & 1641200 & 5.2275 & 5.1827 & TRN & \\
\hline CHEMBL3960445 & 1641200 & 6.7258 & 6.6648 & TRN & \\
\hline CHEMBL3906797 & 1641200 & 6.9666 & 7.0018 & TRN & \\
\hline CHEMBL3945899 & 1641200 & 5.8324 & 5.9255 & TRN & \\
\hline CHEMBL3898998 & 1641200 & 6.71 & 6.7952 & TRN & \\
\hline CHEMBL 3969548 & 1641200 & 5.2965 & 7.0518 & TST & \\
\hline CHEMBL3967322 & 1641200 & 6.9393 & 6.8733 & TRN & \\
\hline CHEMBL3938332 & 1641200 & 6.0 & 5.9687 & TRN & \\
\hline CHEMBL3978628 & 1641200 & 6.4145 & 6.477 & TRN & \\
\hline CHEMBL3946504 & 1641200 & 7.6198 & 7.51 & TRN & \\
\hline CHEMBL3932853 & 1641200 & 8.0 & 7.9035 & TRN & \\
\hline CHEMBL3926020 & 1641200 & 6.098 & 6.0978 & TRN & \\
\hline CHEMBL3983236 & 1641200 & 5.7445 & 5.7859 & TRN & \\
\hline CHEMBL3924954 & 1641200 & 5.2248 & 5.2401 & TRN & \\
\hline CHEMBL3929533 & 1641200 & 5.0189 & 5.0415 & TRN & \\
\hline CHEMBL3923542 & 1641200 & 6.8386 & 6.8631 & TRN & \\
\hline CHEMBL3935909 & 1641200 & 8.0 & 8.13 & TRN & \\
\hline CHEMBL3958644 & 1641200 & 6.1261 & 6.1227 & TRN & \\
\hline CHEMBL3963989 & 1641200 & 6.7852 & 6.6249 & TST & \\
\hline CHEMBL3959673 & 1641200 & 6.251 & 6.4018 & TRN & \\
\hline CHEMBL3946563 & 1641200 & 5.6944 & 5.7418 & TRN & \\
\hline CHEMBL3936420 & 1641200 & 6.6364 & 6.4574 & TRN & \\
\hline CHEMBL3932220 & 1641200 & 5.9559 & 6.1483 & TRN & \\
\hline CHEMBL3932969 & 1641200 & 6.4078 & 6.4826 & TRN & \\
\hline CHEMBL3953439 & 1641200 & 7.301 & 7.97 & TST & \\
\hline
\end{tabular}


Supplemental Table S2.txt

\begin{tabular}{|c|c|c|c|c|c|}
\hline CHEMBL 3889562 & 1641200 & 6.4989 & 6.9956 & TST & \\
\hline CHEMBL3971543 & 1641200 & 6.6635 & 6.8093 & TRN & \\
\hline CHEMBL3946388 & 1641200 & 7.8239 & 7.8919 & TRN & \\
\hline CHEMBL 3937728 & 1641200 & 6.4034 & 6.2082 & TRN & \\
\hline CHEMBL3916269 & 1641200 & 7.6576 & 7.706 & TRN & \\
\hline CHEMBL 3927049 & 1641200 & 6.4283 & 6.5513 & TRN & \\
\hline CHEMBL 3944851 & 1641200 & 7.4949 & 7.4607 & TST & \\
\hline CHEMBL3959727 & 1641200 & 5.678 & 6.1254 & TST & \\
\hline CHEMBL 3975253 & 1641200 & 5.8483 & 5.2449 & TST & \\
\hline CHEMBL 3951871 & 1641200 & 6.5528 & 6.7037 & TST & \\
\hline CHEMBL 3983891 & 1641200 & 5.9893 & 5.5752 & TST & \\
\hline CHEMBL 3935993 & 1641200 & 7.6383 & 7.7226 & TST & \\
\hline CHEMBL 3937672 & 1641200 & 7.3979 & 6.9086 & TST & \\
\hline CHEMBL 3949256 & 1641200 & 5.0596 & 5.2467 & TST & \\
\hline CHEMBL 3646884 & 1642490 & 6.0 & 6.3946 & TRN & \\
\hline CHEMBL 3644282 & 1642490 & 5.3672 & 5.0201 & TRN & \\
\hline CHEMBL3901972 & 1642490 & 8.2218 & 8.23899 & 9999999999 & TST \\
\hline CHEMBL 3646890 & 1642490 & 8.0969 & 7.9906 & TRN & \\
\hline CHEMBL 3927218 & 1642490 & 7.4815 & 7.6722 & TST & \\
\hline CHEMBL 3644357 & 1642490 & 8.0458 & 8.47299 & 9999999999 & TRN \\
\hline CHEMBL 3644348 & 1642490 & 9.1549 & 9.0335 & TRN & \\
\hline CHEMBL3979009 & 1642490 & 8.0458 & 7.6266 & TST & \\
\hline CHEMBL 3646875 & 1642490 & 8.3979 & 8.4225 & TRN & \\
\hline CHEMBL 3646889 & 1642490 & 8.3979 & 8.2015 & TRN & \\
\hline CHEMBL 3949958 & 1642490 & 7.5229 & 7.7926 & TST & \\
\hline CHEMBL 3644294 & 1642490 & 7.6383 & 7.6005 & TRN & \\
\hline CHEMBL3646869 & 1642490 & 9.0 & 9.0853 & TRN & \\
\hline CHEMBL 3901055 & 1642490 & 7.9208 & 6.5483 & TST & \\
\hline CHEMBL 3644311 & 1642490 & 7.0 & 7.0408 & TRN & \\
\hline CHEMBL 3644296 & 1642490 & 8.5229 & 7.8579 & TRN & \\
\hline CHEMBL 3646860 & 1642490 & 7.6021 & 7.5714 & TRN & \\
\hline CHEMBL 3644345 & 1642490 & 8.2218 & 8.3345 & TRN & \\
\hline CHEMBL 3646892 & 1642490 & 8.301 & 8.351 & TST & \\
\hline CHEMBL 3644325 & 1642490 & 7.8539 & 7.7539 & TRN & \\
\hline CHEMBL 3644306 & 1642490 & 7.8239 & 7.7774 & TRN & \\
\hline CHEMBL 3644330 & 1642490 & 7.3665 & 7.3559 & TRN & \\
\hline CHEMBL 3644315 & 1642490 & 7.8239 & 7.8408 & TRN & \\
\hline CHEMBL 3644331 & 1642490 & 8.3979 & 8.5481 & TRN & \\
\hline CHEMBL 3644279 & 1642490 & 6.0 & 6.3395 & TRN & \\
\hline CHEMBL 3644305 & 1642490 & 7.6383 & 7.6025 & TRN & \\
\hline CHEMBL 3646861 & 1642490 & 7.4559 & 7.6437 & TRN & \\
\hline CHEMBL 3646881 & 1642490 & 8.3979 & 8.1011 & TRN & \\
\hline CHEMBL3646867 & 1642490 & 9.3979 & 9.2401 & TRN & \\
\hline CHEMBL 3646879 & 1642490 & 8.1549 & 8.3791 & TRN & \\
\hline CHEMBL 3644351 & 1642490 & 8.2218 & 8.515 & TRN & \\
\hline CHEMBL 3644339 & 1642490 & 6.7773 & 6.8537 & TRN & \\
\hline CHEMBL 3644307 & 1642490 & 7.5229 & 7.5087 & TRN & \\
\hline CHEMBL 3646888 & 1642490 & 7.301 & 7.0555 & TRN & \\
\hline
\end{tabular}


Supplemental Table S2.txt

\begin{tabular}{|c|c|c|c|c|}
\hline CHEMBL 3644323 & 1642490 & 8.5229 & 8.2374 & TRN \\
\hline CHEMBL3644324 & 1642490 & 9.2218 & 9.0755 & TRN \\
\hline CHEMBL3646859 & 1642490 & 7.4559 & 8.4422 & TRN \\
\hline CHEMBL3646873 & 1642490 & 7.8861 & 8.119 & TRN \\
\hline CHEMBL3928099 & 1642490 & 8.3979 & 8.4159 & TST \\
\hline CHEMBL 3644320 & 1642490 & 6.0 & 6.0881 & TRN \\
\hline CHEMBL3646872 & 1642490 & 7.8239 & 7.6334 & TRN \\
\hline CHEMBL3646868 & 1642490 & 9.0969 & 9.0998 & TRN \\
\hline CHEMBL 3646887 & 1642490 & 7.3768 & 7.1043 & TRN \\
\hline CHEMBL3646885 & 1642490 & 8.301 & 8.266 & TRN \\
\hline CHEMBL3646877 & 1642490 & 7.699 & 7.7441 & TRN \\
\hline CHEMBL3644326 & 1642490 & 8.1549 & 7.9998 & TRN \\
\hline CHEMBL3973691 & 1642490 & 9.0 & 8.7525 & TST \\
\hline CHEMBL 3646878 & 1642490 & 6.2418 & 6.5087 & TRN \\
\hline CHEMBL3646851 & 1642490 & 9.3979 & 9.1226 & TRN \\
\hline CHEMBL3646870 & 1642490 & 8.699 & 8.7025 & TRN \\
\hline CHEMBL3906011 & 1642490 & 6.9393 & 7.5809 & TST \\
\hline CHEMBL3955246 & 1642490 & 8.5229 & 8.2765 & TST \\
\hline CHEMBL 3646883 & 1642490 & 6.4377 & 6.9869 & TST \\
\hline CHEMBL3973826 & 1642490 & 8.5229 & 8.5969 & TST \\
\hline CHEMBL3646852 & 1642490 & 8.5229 & 8.3487 & TRN \\
\hline CHEMBL3644346 & 1642490 & 8.0969 & 8.3324 & TRN \\
\hline CHEMBL 3644338 & 1642490 & 8.0458 & 7.8019 & TRN \\
\hline CHEMBL 3646874 & 1642490 & 7.3468 & 7.4679 & TRN \\
\hline CHEMBL3893727 & 1642490 & 8.5229 & 8.5182 & TST \\
\hline CHEMBL3646891 & 1642490 & 8.2218 & 8.1311 & TRN \\
\hline CHEMBL3644349 & 1642490 & 7.8239 & 7.7494 & TRN \\
\hline CHEMBL3646880 & 1642490 & 6.0 & 6.33700 & 0000000001 \\
\hline CHEMBL3900116 & 1642490 & 8.301 & 8.1844 & TST \\
\hline CHEMBL3644312 & 1642490 & 7.6383 & 7.5681 & TST \\
\hline CHEMBL1464805 & 809110 & 4.52 & 3.5504 & TRN \\
\hline CHEMBL1881326 & 809110 & 4.5346 & 4.6818 & TST \\
\hline CHEMBL1414513 & 809110 & 4.341 & 4.0541 & TRN \\
\hline CHEMBL1727049 & 809110 & 3.0 & 3.2255 & TRN \\
\hline CHEMBL1481077 & 809110 & 4.4698 & 4.3685 & TRN \\
\hline CHEMBL1983460 & 809110 & 3.0 & 3.4713 & TRN \\
\hline CHEMBL1970785 & 809110 & 4.6635 & 4.2388 & TRN \\
\hline CHEMBL1354909 & 809110 & 4.1586 & 4.0356 & TRN \\
\hline CHEMBL2005518 & 809110 & 5.4191 & 5.1582 & TRN \\
\hline CHEMBL1525735 & 809110 & 4.3372 & 4.3117 & TRN \\
\hline CHEMBL1308055 & 809110 & 4.6757 & 4.2897 & TRN \\
\hline CHEMBL1347610 & 809110 & 5.1124 & 5.5355 & TRN \\
\hline CHEMBL1387744 & 809110 & 4.6799 & 4.7048 & TST \\
\hline CHEMBL1976919 & 809110 & 4.3635 & 4.8657 & TST \\
\hline CHEMBL1325757 & 809110 & 4.0691 & 4.667 & TRN \\
\hline CHEMBL1971051 & 809110 & 4.4789 & 4.0319 & TRN \\
\hline CHEMBL1875123 & 809110 & 4.1831 & 4.4874 & TRN \\
\hline CHEMBL1340766 & 809110 & 4.3526 & 4.2643 & TRN \\
\hline
\end{tabular}




\begin{tabular}{|c|c|c|c|c|}
\hline \multicolumn{5}{|c|}{ Supplemental Table S2.txt } \\
\hline CHEMBL1556780 & 809110 & 3.0 & 3.7442 & TRN \\
\hline CHEMBL1532956 & 809110 & 4.4225 & 4.4558 & TRN \\
\hline CHEMBL1569215 & 809110 & 4.7033 & 4.6067 & TRN \\
\hline CHEMBL1375551 & 809110 & 4.2182 & 3.7621 & TRN \\
\hline CHEMBL1536896 & 809110 & 4.1397 & 4.2215 & TRN \\
\hline CHEMBL1886491 & 809110 & 4.2976 & 4.4427 & TRN \\
\hline CHEMBL1973435 & 809110 & 4.5702 & 4.9062 & TST \\
\hline CHEMBL1612291 & 809110 & 4.8097 & 4.4816 & TRN \\
\hline CHEMBL1451107 & 809110 & 3.0 & 3.7703 & TST \\
\hline CHEMBL1431909 & 809110 & 4.2154 & 4.2101 & TRN \\
\hline CHEMBL1438370 & 809110 & 4.2967 & 3.7271 & TRN \\
\hline CHEMBL1429479 & 809110 & 4.0721 & 4.3574 & TRN \\
\hline CHEMBL1460857 & 809110 & 4.2007 & 3.6878 & TRN \\
\hline CHEMBL1583854 & 809110 & 4.2765 & 4.4609 & TRN \\
\hline CHEMBL1427486 & 809110 & 4.2351 & 3.7064 & TRN \\
\hline CHEMBL1438210 & 809110 & 4.3125 & 3.8865 & TRN \\
\hline CHEMBL1581048 & 809110 & 4.3261 & 4.0843 & TRN \\
\hline CHEMBL1549732 & 809110 & 3.0 & 3.5051 & TRN \\
\hline CHEMBL1327091 & 809110 & 4.4067 & 4.3623 & TST \\
\hline CHEMBL1404120 & 809110 & 4.5114 & 4.8004 & TRN \\
\hline CHEMBL1580664 & 809110 & 4.2757 & 4.7727 & TRN \\
\hline CHEMBL1480262 & 809110 & 4.1062 & 4.1826 & TRN \\
\hline CHEMBL1418430 & 809110 & 4.2062 & 4.3006 & TRN \\
\hline CHEMBL1309895 & 809110 & 4.2104 & 4.2402 & TRN \\
\hline CHEMBL1564141 & 809110 & 4.2027 & 4.44 & TST \\
\hline CHEMBL1971033 & 809110 & 4.1244 & 4.7747 & TRN \\
\hline CHEMBL1992681 & 809110 & 4.4089 & 3.6203 & TRN \\
\hline CHEMBL1509913 & 809110 & 4.6021 & 4.8333 & TRN \\
\hline CHEMBL1983001 & 809110 & 3.0 & 3.3229 & TRN \\
\hline CHEMBL1448606 & 809110 & 4.4634 & 4.0617 & TRN \\
\hline CHEMBL1980308 & 809110 & 4.5421 & 4.2441 & TRN \\
\hline CHEMBL1996548 & 809110 & 3.0 & 3.6592 & TRN \\
\hline CHEMBL1581301 & 809110 & 4.3429 & 4.4696 & TRN \\
\hline CHEMBL1450813 & 809110 & 4.5272 & 4.4944 & TRN \\
\hline CHEMBL1701401 & 809110 & 4.3458 & 4.5683 & TST \\
\hline CHEMBL1985667 & 809110 & 4.4711 & 4.5385 & TRN \\
\hline CHEMBL1303333 & 809110 & 4.7077 & 4.7989 & TRN \\
\hline CHEMBL579028 & 809110 & 4.3143 & 4.1648 & TRN \\
\hline CHEMBL1610814 & 809110 & 4.4283 & 4.2529 & TST \\
\hline CHEMBL1997797 & 809110 & 4.2373 & 4.3758 & TRN \\
\hline CHEMBL1871747 & 809110 & 4.2426 & 4.6776 & TST \\
\hline CHEMBL1976161 & 809110 & 4.4461 & 4.277 & TRN \\
\hline CHEMBL1711830 & 809110 & 4.5331 & 4.0112 & TRN \\
\hline CHEMBL1578629 & 809110 & 4.4763 & 4.3143 & TRN \\
\hline CHEMBL1401522 & 809110 & 4.4168 & 4.6394 & TRN \\
\hline CHEMBL1974063 & 809110 & 5.5901 & 5.6308 & TRN \\
\hline CHEMBL1979539 & 809110 & 3.0 & 3.8447 & TRN \\
\hline CHEMBL1709966 & 809110 & 4.3716 & 4.5962 & TST \\
\hline
\end{tabular}




\begin{tabular}{|c|c|c|c|c|c|c|}
\hline \multicolumn{7}{|c|}{ Supplemental Table S2.txt } \\
\hline CHEMBL1384550 & 809110 & 3.0 & 3.3159 & TRN & & \\
\hline CHEMBL1454680 & 809110 & 4.4089 & 4.0575 & TRN & & \\
\hline CHEMBL1876111 & 809110 & 5.0814 & 4.3688 & TRN & & \\
\hline CHEMBL1993220 & 809110 & 3.0 & 4.3466 & TST & & \\
\hline CHEMBL1995152 & 809110 & 4.3788 & 4.4542 & TRN & & \\
\hline CHEMBL1479139 & 809110 & 4.5017 & 4.4166 & TRN & & \\
\hline CHEMBL1580600 & 809110 & 4.556 & 4.7116 & TRN & & \\
\hline CHEMBL1443088 & 809110 & 4.3478 & 4.9061 & TRN & & \\
\hline CHEMBL1864040 & 809110 & 4.1656 & 3.9893 & TRN & & \\
\hline CHEMBL1460470 & 809110 & 4.6108 & 4.337 & TRN & & \\
\hline CHEMBL1363662 & 809110 & 4.5272 & 4.275 & TRN & & \\
\hline CHEMBL1433546 & 809110 & 4.2565 & 4.1829 & TRN & & \\
\hline CHEMBL1378569 & 809110 & 4.2848 & 4.1695 & TRN & & \\
\hline CHEMBL1491016 & 809110 & 5.5376 & 4.8287 & TRN & & \\
\hline CHEMBL1610433 & 809110 & 6.8297 & 5.1517 & TRN & & \\
\hline CHEMBL1351704 & 809110 & 4.2692 & 4.1418 & TRN & & \\
\hline CHEMBL1990774 & 809110 & 4.7696 & 4.7514 & TRN & & \\
\hline CHEMBL1421745 & 809110 & 5.083 & 4.4347 & TRN & & \\
\hline CHEMBL1486470 & 809110 & 6.0 & 5.0594 & TRN & & \\
\hline CHEMBL1469245 & 809110 & 4.066 & 4.5452 & TRN & & \\
\hline CHEMBL1576310 & 809110 & 4.1101 & 4.4887 & TRN & & \\
\hline CHEMBL1384373 & 809110 & $4.8210 e$ & 00000000 & 01 & 4.2014 & TRN \\
\hline CHEMBL1345800 & 809110 & 4.3152 & 4.1007 & TRN & & \\
\hline CHEMBL1342085 & 809110 & 4.301 & 4.2721 & TRN & & \\
\hline CHEMBL1595766 & 809110 & 4.3788 & 4.1851 & TRN & & \\
\hline CHEMBL473314 & 809110 & 4.202 & 4.9132 & TST & & \\
\hline CHEMBL1982026 & 809110 & 4.3605 & 4.0961 & TRN & & \\
\hline CHEMBL1509867 & 809110 & 4.3958 & 4.1826 & TRN & & \\
\hline CHEMBL1613540 & 809110 & 4.0825 & 4.686 & TRN & & \\
\hline CHEMBL1542128 & 809110 & 4.6421 & 4.7608 & TRN & & \\
\hline CHEMBL1986889 & 809110 & 6.2487 & 6.0329 & TRN & & \\
\hline CHEMBL1361889 & 809110 & 4.8297 & 4.6111 & TRN & & \\
\hline CHEMBL1325818 & 809110 & 4.5452 & 4.478 & TRN & & \\
\hline CHEMBL1526763 & 809110 & 3.0 & 3.6841 & TRN & & \\
\hline CHEMBL1966700 & 809110 & 3.0 & 3.8393 & TRN & & \\
\hline CHEMBL1352624 & 809110 & 4.4001 & 4.1901 & TRN & & \\
\hline CHEMBL1405120 & 809110 & 4.4584 & 4.4264 & TRN & & \\
\hline CHEMBL1994935 & 809110 & 4.4711 & 4.3559 & TST & & \\
\hline CHEMBL1569092 & 809110 & 4.71 & 4.6949 & TRN & & \\
\hline CHEMBL1528476 & 809110 & 4.0287 & 4.46 & TRN & & \\
\hline CHEMBL1730686 & 809110 & 4.301 & 4.489 & TST & & \\
\hline CHEMBL1883011 & 809110 & 3.0 & 3.383 & TRN & & \\
\hline CHEMBL1571625 & 809110 & 4.2774 & 4.4988 & TRN & & \\
\hline CHEMBL1975801 & 809110 & 4.6003 & 4.0763 & TRN & & \\
\hline CHEMBL1411673 & 809110 & 4.2668 & 4.4584 & TRN & & \\
\hline CHEMBL1453126 & 809110 & 3.0 & 4.0005 & TRN & & \\
\hline CHEMBL1722566 & 809110 & 5.1733 & 4.9073 & TRN & & \\
\hline CHEMBL1318608 & 809110 & 3.0 & 3.9074 & TRN & & \\
\hline
\end{tabular}




\begin{tabular}{|c|c|c|c|c|}
\hline \multicolumn{5}{|c|}{ Supplemental Table S2.txt } \\
\hline CHEMBL1586269 & 809110 & 3.0 & 3.5218 & TRN \\
\hline CHEMBL1460896 & 809110 & 4.289 & 4.206 & TRN \\
\hline CHEMBL1411168 & 809110 & 4.3969 & 4.1888 & TRN \\
\hline CHEMBL1568373 & 809110 & 4.5817 & 4.6038 & TRN \\
\hline CHEMBL1591691 & 809110 & 4.3197 & 4.1674 & TRN \\
\hline CHEMBL1984584 & 809110 & 5.6882 & 5.218 & TRN \\
\hline CHEMBL1367703 & 809110 & 3.0 & 3.5556 & TRN \\
\hline CHEMBL1482670 & 809110 & 4.289 & 4.3282 & TRN \\
\hline CHEMBL1335064 & 809110 & 4.1073 & 3.8123 & TRN \\
\hline CHEMBL1873454 & 809110 & 4.2807 & 4.3209 & TST \\
\hline CHEMBL1526150 & 809110 & 4.6289 & 4.566 & TRN \\
\hline CHEMBL1343853 & 809110 & 4.251 & 5.1297 & TRN \\
\hline CHEMBL1971127 & 809110 & 4.6108 & 4.4754 & TST \\
\hline CHEMBL1445488 & 809110 & 4.2472 & 4.1226 & TRN \\
\hline CHEMBL1439933 & 809110 & 4.3768 & 4.2062 & TRN \\
\hline CHEMBL 2003445 & 809110 & 5.1475 & 5.3648 & TRN \\
\hline CHEMBL1484632 & 809110 & 4.2132 & 4.6056 & TRN \\
\hline CHEMBL1994463 & 809110 & 4.2668 & 4.3762 & TST \\
\hline CHEMBL1459808 & 809110 & 4.1367 & 4.0587 & TRN \\
\hline CHEMBL1487024 & 809110 & 4.6216 & 4.2619 & TRN \\
\hline CHEMBL1503793 & 809110 & 4.0066 & 4.3737 & TRN \\
\hline CHEMBL1470199 & 809110 & 4.3206 & 4.1387 & TRN \\
\hline CHEMBL1548928 & 809110 & 6.3298 & 4.864 & TRN \\
\hline CHEMBL1569364 & 809110 & 4.2549 & 4.5097 & TRN \\
\hline CHEMBL1428997 & 809110 & 4.6655 & 4.4075 & TRN \\
\hline CHEMBL1344023 & 809110 & 4.5513 & 3.9465 & TRN \\
\hline CHEMBL 2002565 & 809110 & 4.1107 & 4.4223 & TRN \\
\hline CHEMBL1345911 & 809110 & 5.1878 & 4.5517 & TRN \\
\hline CHEMBL1369893 & 809110 & 3.0 & 3.3817 & TRN \\
\hline CHEMBL1540680 & 809110 & 4.4828 & 4.6725 & TRN \\
\hline CHEMBL1532025 & 809110 & 4.4101 & 4.8102 & TRN \\
\hline CHEMBL1505300 & 809110 & 3.0 & 3.775 & TRN \\
\hline CHEMBL1316472 & 809110 & 4.4449 & 4.4644 & TRN \\
\hline CHEMBL1342836 & 809110 & 4.4078 & 4.1602 & TST \\
\hline CHEMBL1982195 & 809110 & 4.6968 & 4.6958 & TRN \\
\hline CHEMBL1726180 & 809110 & 4.5171 & 4.5645 & TRN \\
\hline CHEMBL1480073 & 809110 & 3.0 & 3.8305 & TRN \\
\hline CHEMBL1317897 & 809110 & 4.0531 & 4.1826 & TRN \\
\hline CHEMBL1329487 & 809110 & 4.1337 & 4.2505 & TRN \\
\hline CHEMBL1566994 & 809110 & 4.6882 & 4.282 & TRN \\
\hline CHEMBL1545927 & 809110 & 4.5575 & 4.1658 & TRN \\
\hline CHEMBL1976317 & 809110 & 3.0 & 3.1358 & TRN \\
\hline CHEMBL1555215 & 809110 & 4.5784 & 4.6096 & TRN \\
\hline CHEMBL1458593 & 809110 & 4.9431 & 4.7541 & TRN \\
\hline CHEMBL1366289 & 809110 & 4.4895 & 4.4301 & TST \\
\hline CHEMBL1564638 & 809110 & 4.4815 & 4.8258 & TRN \\
\hline CHEMBL1378952 & 809110 & 4.1215 & 3.4971 & TRN \\
\hline CHEMBL1381815 & 809110 & 4.1415 & 3.8091 & TRN \\
\hline
\end{tabular}




\begin{tabular}{|c|c|c|c|c|}
\hline \multicolumn{5}{|c|}{ Supplemental Table s2.txt } \\
\hline CHEMBL1361742 & 809110 & 3.0 & 3.3786 & TRN \\
\hline CHEMBL1964690 & 809110 & 4.5302 & 4.8016 & TRN \\
\hline CHEMBL1520551 & 809110 & 4.1675 & 5.0481 & TST \\
\hline CHEMBL1982202 & 809110 & 3.0 & 4.57100 & 0000000001 \\
\hline CHEMBL1422472 & 809110 & 4.9431 & 4.603 & TRN \\
\hline CHEMBL1538322 & 809110 & 4.3915 & 4.3686 & TRN \\
\hline CHEMBL1473121 & 809110 & 3.0 & 3.9353 & TST \\
\hline CHEMBL1434377 & 809110 & 4.3575 & 4.1935 & TRN \\
\hline CHEMBL1982308 & 809110 & 4.289 & 4.9156 & TST \\
\hline CHEMBL1511181 & 809110 & 4.4763 & 4.4747 & TRN \\
\hline CHEMBL1529328 & 809110 & 4.5003 & 4.4175 & TRN \\
\hline CHEMBL1431851 & 809110 & 4.1273 & 4.3241 & TRN \\
\hline CHEMBL1977596 & 809110 & 4.4828 & 4.6654 & TST \\
\hline CHEMBL1313324 & 809110 & 5.2916 & 5.4107 & TRN \\
\hline CHEMBL1306521 & 809110 & 4.4112 & 4.2566 & TRN \\
\hline CHEMBL1590386 & 809110 & 4.1331 & 4.2846 & TRN \\
\hline CHEMBL1299980 & 809110 & 4.3152 & 3.6748 & TRN \\
\hline CHEMBL1705518 & 809110 & 4.757 & 4.3688 & TRN \\
\hline CHEMBL1884200 & 809110 & 3.0 & 4.0547 & TST \\
\hline CHEMBL1484595 & 809110 & 4.4498 & 4.7461 & TRN \\
\hline CHEMBL1463203 & 809110 & 4.5498 & 3.8188 & TRN \\
\hline CHEMBL1396811 & 809110 & 4.3206 & 4.1393 & TST \\
\hline CHEMBL1438503 & 809110 & 4.3645 & 4.3653 & TRN \\
\hline CHEMBL1597650 & 809110 & 4.3497 & 3.9838 & TRN \\
\hline CHEMBL 2007227 & 809110 & 4.8539 & 4.1276 & TRN \\
\hline CHEMBL1381264 & 809110 & 4.5452 & 4.7422 & TRN \\
\hline CHEMBL1548770 & 809110 & 4.1669 & 4.7126 & TRN \\
\hline CHEMBL1393151 & 809110 & 4.2168 & 4.1969 & TRN \\
\hline CHEMBL1467881 & 809110 & 3.0 & 3.8711 & TRN \\
\hline CHEMBL1609744 & 809110 & 4.4425 & 4.8797 & TRN \\
\hline CHEMBL1534006 & 809110 & 5.0017 & 3.8063 & TRN \\
\hline CHEMBL1333181 & 809110 & 5.8633 & 4.775 & TRN \\
\hline CHEMBL1414362 & 809110 & 4.1612 & 4.5432 & TRN \\
\hline CHEMBL1543841 & 809110 & 4.4895 & 4.4363 & TRN \\
\hline CHEMBL56731 & 809110 & 4.1681 & 4.5823 & TRN \\
\hline CHEMBL1481605 & 809110 & 4.2765 & 4.7976 & TRN \\
\hline CHEMBL1545846 & 809110 & 4.2549 & 4.8605 & TRN \\
\hline CHEMBL1706207 & 809110 & 5.3179 & 4.8127 & TST \\
\hline CHEMBL1402117 & 809110 & 4.6819 & 4.1122 & TST \\
\hline CHEMBL1428264 & 809110 & 4.1838 & 4.0362 & TRN \\
\hline CHEMBL1387761 & 809110 & 4.0937 & 4.1831 & TST \\
\hline CHEMBL1410895 & 809110 & 3.0 & 4.203 & TST \\
\hline CHEMBL1996519 & 809110 & 3.0 & 4.5378 & TST \\
\hline CHEMBL 2005671 & 809110 & 4.2865 & 3.8912 & TRN \\
\hline CHEMBL1409822 & 809110 & 4.4841 & 4.5733 & TRN \\
\hline CHEMBL1996139 & 809110 & 3.0 & 3.4148 & TRN \\
\hline CHEMBL1988686 & 809110 & 4.056 & 4.4897 & TRN \\
\hline CHEMBL1365706 & 809110 & 4.2596 & 4.1943 & TRN \\
\hline
\end{tabular}


Supplemental Table S2.txt

\begin{tabular}{|c|c|c|c|c|}
\hline AEMBL1598236 & 09110 & 4.2526 & & \\
\hline & 09110 & 4.1918 & 4.8083 & \\
\hline 24 & 9110 & & & \\
\hline IEMBL1 & 9110 & 1013 & & \\
\hline HEMBL1 & $\partial 9110$ & 2865 & & \\
\hline HEMBL1302889 & 29110 & 0173 & & \\
\hline AEMBL] & 99110 & 3.0 & & \\
\hline EMBL & 99110 & & & \\
\hline AEMBL1482795 & 309110 & 4.1244 & & \\
\hline AEMBL1898074 & 09110 & 4342 & & \\
\hline 92359 & 09110 & 0985 & & \\
\hline IEMBL: & 09110 & & & \\
\hline EMBL & $\partial 9110$ & & & \\
\hline AEMBL & 309110 & 2534 & & \\
\hline AEMBLI & 09110 & 362 & & \\
\hline AEMBL & 09110 & 281 & & \\
\hline AEMBL & 09110 & & & \\
\hline AEMBL & 09110 & & & \\
\hline IEMBL & 09110 & 269 & & \\
\hline IEMBL & 10 & & & \\
\hline AEMBL & 10 & & & \\
\hline EMBL & 0 & & & \\
\hline IEMBL & 10 & & & \\
\hline 38 & & 993 & & \\
\hline IEMBL: & 10 & & & \\
\hline IEMBL & 0 & 4 & & S \\
\hline IEMBL & 10 & 51 & & \\
\hline 17 & 10 & 389 & & \\
\hline 67 & 09110 & & & \\
\hline AEMBL] & 9110 & 425 & & $2 \mathrm{~N}$ \\
\hline AEMBL & 0 & & & \\
\hline IEMB & 0 & & & \\
\hline 56 & 10 & & & \\
\hline 20702 & 09110 & & & \\
\hline HEMBL1999908 & 09110 & & & \\
\hline EMBL & & & & \\
\hline 75 & 0 & 51 & & \\
\hline & & & & \\
\hline AEMBL2006357 & $\partial 9110$ & 4.7033 & & \\
\hline AEMBL: & 9110 & & & \\
\hline HEMBL & 09110 & 284 & & \\
\hline 48574 & 809110 & & & \\
\hline CHEMBL & 09110 & & & $\mathrm{RI}$ \\
\hline IEMBL1575767 & 29110 & 1232 & & \\
\hline AEMBL & 99110 & 4.2534 & & \\
\hline CHEMBL & 809110 & & & \\
\hline CHEMBL 2004916 & 09110 & & & \\
\hline CHEMBL1968356 & 809110 & 4.117 & 4.2227 & \\
\hline
\end{tabular}

Page 7002 


\begin{tabular}{|c|c|c|c|c|c|c|}
\hline \multirow[b]{2}{*}{ CHEMBL1350299 } & & \multicolumn{5}{|c|}{ Supplemental Table S2.txt } \\
\hline & 809110 & 4.6289 & 4.3771 & TRN & & \\
\hline CHEMBL1362650 & 809110 & 4.1113 & 4.2861 & TST & & \\
\hline CHEMBL1702964 & 809110 & 4.3458 & 4.3882 & TRN & & \\
\hline CHEMBL1375814 & 809110 & 4.82100 & 0000000 & 01 & 4.0242 & TRN \\
\hline CHEMBL1985696 & 809110 & 3.0 & 4.1334 & TRN & & \\
\hline CHEMBL1471990 & 809110 & 4.1469 & 3.7476 & TRN & & \\
\hline CHEMBL1427763 & 809110 & 4.5421 & 4.7492 & TRN & & \\
\hline CHEMBL1364454 & 809110 & 4.4295 & 4.2454 & TRN & & \\
\hline CHEMBL1437190 & 809110 & 4.4724 & 4.0175 & TRN & & \\
\hline CHEMBL1497338 & 809110 & 3.0 & 4.3224 & TST & & \\
\hline CHEMBL1560147 & 809110 & 4.3161 & 3.6782 & TRN & & \\
\hline CHEMBL1491272 & 809110 & 4.6198 & 4.6765 & TRN & & \\
\hline CHEMBL1351250 & 809110 & 4.4473 & 3.9074 & TRN & & \\
\hline CHEMBL1997827 & 809110 & 4.2628 & 4.3176 & TRN & & \\
\hline CHEMBL1351925 & 809110 & 4.5638 & 4.3463 & TRN & & \\
\hline CHEMBL1315298 & 809110 & 4.2062 & 4.6643 & TST & & \\
\hline CHEMBL1602055 & 809110 & 3.0 & 3.7618 & TRN & & \\
\hline CHEMBL1537847 & 809110 & 4.3936 & 4.3566 & TRN & & \\
\hline CHEMBL1870454 & 809110 & 4.6536 & 4.6206 & TRN & & \\
\hline CHEMBL1719956 & 809110 & 4.6198 & 4.7196 & TRN & & \\
\hline CHEMBL1350703 & 809110 & 4.5229 & 4.1744 & TRN & & \\
\hline CHEMBL1591174 & 809110 & 4.05399 & 99999999 & & 4.1605 & TRN \\
\hline CHEMBL1544407 & 809110 & 3.0 & 3.5423 & TRN & & \\
\hline CHEMBL1492305 & 809110 & 6.0 & $5.46200 t$ & 0000000001 & & TRN \\
\hline CHEMBL1347547 & 809110 & 4.0555 & 4.3954 & TRN & & \\
\hline CHEMBL1972750 & 809110 & 4.5575 & 5.2003 & TST & & \\
\hline CHEMBL490355 & 809110 & 4.6635 & 4.9034 & TRN & & \\
\hline CHEMBL1548704 & 809110 & 4.3019 & 4.5998 & TRN & & \\
\hline CHEMBL1444386 & 809110 & 4.2248 & 3.8525 & TRN & & \\
\hline CHEMBL1482926 & 809110 & 4.3019 & 4.01399 & 9999999999 & & TRN \\
\hline CHEMBL1596745 & 809110 & 4.279 & 4.3516 & TRN & & \\
\hline CHEMBL1587149 & 809110 & 4.0101 & 4.3133 & TRN & & \\
\hline CHEMBL1425576 & 809110 & 5.1415 & 4.9017 & TST & & \\
\hline CHEMBL1595376 & 809110 & 4.3696 & 5.0425 & TST & & \\
\hline CHEMBL1326271 & 809110 & 4.4377 & 4.5804 & TRN & & \\
\hline CHEMBL1966168 & 809110 & 4.0835 & 4.0364 & TRN & & \\
\hline CHEMBL1434555 & 809110 & 4.061 & 3.7781 & TRN & & \\
\hline CHEMBL1612000 & 809110 & 4.1163 & 3.4848 & TRN & & \\
\hline CHEMBL1552672 & 809110 & 4.8447 & 4.6205 & TRN & & \\
\hline CHEMBL1316089 & 809110 & 3.0 & 3.8193 & TRN & & \\
\hline CHEMBL1348946 & 809110 & 4.1475 & 4.1263 & TRN & & \\
\hline CHEMBL1339485 & 809110 & 4.3316 & 4.2175 & TRN & & \\
\hline CHEMBL1604122 & 809110 & 4.2175 & 4.1889 & TRN & & \\
\hline CHEMBL1545689 & 809110 & 4.4401 & 4.4761 & TRN & & \\
\hline CHEMBL1710601 & 809110 & 4.5229 & 4.2977 & TRN & & \\
\hline CHEMBL1969992 & 809110 & 4.0381 & 4.0682 & TRN & & \\
\hline CHEMBL1364731 & 809110 & 4.1085 & 4.0287 & TRN & & \\
\hline CHEMBL1727678 & 809110 & 4.9281 & 4.7845 & TST & & \\
\hline
\end{tabular}




\begin{tabular}{|c|c|c|c|c|c|c|}
\hline & & \multicolumn{5}{|c|}{ Supplemental Table S2.txt } \\
\hline CHEMBL1873140 & 809110 & 4.752 & 4.5244 & TRN & & \\
\hline CHEMBL1326349 & 809110 & 4.382 & 4.2082 & TRN & & \\
\hline CHEMBL56542 & 809110 & 4.3382 & 4.6166 & TRN & & \\
\hline CHEMBL1388156 & 809110 & 4.6091 & 4.0801 & TRN & & \\
\hline CHEMBL1552304 & 809110 & 4.4522 & 4.41100 & 00000000 & 005 & TRN \\
\hline CHEMBL1556531 & 809110 & 4.3391 & 4.4714 & TRN & & \\
\hline CHEMBL1346025 & 809110 & 4.3915 & 4.5354 & TRN & & \\
\hline CHEMBL1328104 & 809110 & 4.0691 & 4.3822 & TRN & & \\
\hline CHEMBL1412423 & 809110 & 4.5129 & 4.4089 & TRN & & \\
\hline CHEMBL1416348 & 809110 & 4.2757 & 4.7743 & TRN & & \\
\hline CHEMBL1570668 & 809110 & 4.5719 & 4.0307 & TRN & & \\
\hline CHEMBL1381406 & 809110 & 4.4647 & 3.7512 & TRN & & \\
\hline CHEMBL1979696 & 809110 & 3.0 & 3.7358 & TRN & & \\
\hline CHEMBL1336874 & 809110 & 4.0438 & 4.0216 & TRN & & \\
\hline CHEMBL1998061 & 809110 & 4.3107 & 4.4265 & TRN & & \\
\hline CHEMBL1308195 & 809110 & 4.5331 & 4.5007 & TRN & & \\
\hline CHEMBL1307663 & 809110 & 4.4881 & 4.2446 & TRN & & \\
\hline CHEMBL1452939 & 809110 & 4.3958 & 4.4558 & TRN & & \\
\hline CHEMBL1501577 & 809110 & 3.0 & 3.1329 & TRN & & \\
\hline CHEMBL1376556 & 809110 & 4.2967 & 4.1885 & TRN & & \\
\hline CHEMBL2359510 & 809110 & 4.3686 & 4.341 & TRN & & \\
\hline CHEMBL1988376 & 809110 & 3.0 & 3.9505 & TRN & & \\
\hline CHEMBL1481627 & 809110 & 4.5935 & 4.4952 & TRN & & \\
\hline CHEMBL1497731 & 809110 & 4.8729 & 4.4131 & TRN & & \\
\hline CHEMBL1346724 & 809110 & 4.3391 & 4.2935 & TRN & & \\
\hline CHEMBL1546767 & 809110 & 4.0778 & 3.4542 & TRN & & \\
\hline CHEMBL1498705 & 809110 & 4.1624 & 4.3515 & TST & & \\
\hline CHEMBL1717770 & 809110 & 4.4271 & 4.4389 & TST & & \\
\hline CHEMBL129208 & 809110 & 4.8633 & 4.4917 & TST & & \\
\hline CHEMBL1984772 & 809110 & 4.0137 & 3.9132 & TRN & & \\
\hline CHEMBL1447158 & 809110 & 4.5884 & 4.3524 & TRN & & \\
\hline CHEMBL1558644 & 809110 & 5.1057 & 4.7 & TST & & \\
\hline CHEMBL1699206 & 809110 & 4.1215 & 4.7586 & TRN & & \\
\hline CHEMBL1993978 & 809110 & 3.0 & 3.2596 & TRN & & \\
\hline CHEMBL1991303 & 809110 & 5.7905 & 5.4045 & TRN & & \\
\hline CHEMBL1398357 & 809110 & 4.2125 & 4.4032 & TRN & & \\
\hline CHEMBL1332854 & 809110 & 4.5901 & 4.8006 & TRN & & \\
\hline CHEMBL1509590 & 809110 & 4.1002 & 4.0863 & TST & & \\
\hline CHEMBL1385587 & 809110 & 4.5686 & 4.188 & TST & & \\
\hline CHEMBL1528977 & 809110 & 4.5918 & 4.6712 & TST & & \\
\hline CHEMBL1340228 & 809110 & 4.061 & 4.3976 & TST & & \\
\hline CHEMBL1899457 & 809110 & 4.4271 & 4.5822 & TST & & \\
\hline CHEMBL1983530 & 809110 & 5.007 & 5.193 & TST & & \\
\hline CHEMBL1535349 & 809110 & 4.1385 & 4.0653 & TST & & \\
\hline CHEMBL1443805 & 809110 & 4.699 & 4.7044 & TST & & \\
\hline CHEMBL1994877 & 809110 & 4.6108 & 4.9772 & TST & & \\
\hline CHEMBL1480510 & 809110 & 4.8827 & 4.9256 & TST & & \\
\hline CHEMBL1360824 & 809110 & 4.38399 & 99999999 & 995 & 3.9168 & וב \\
\hline
\end{tabular}




\begin{tabular}{|c|c|c|c|c|c|}
\hline & & \multicolumn{4}{|c|}{ Supplemental Table S2.txt } \\
\hline CHEMBL1336784 & 809110 & 4.4935 & 4.147 & TST & \\
\hline CHEMBL1550553 & 809110 & 4.4225 & 4.4145 & TST & \\
\hline CHEMBL 2006338 & 809110 & 4.6925 & 4.7643 & TST & \\
\hline CHEMBL1600901 & 809110 & 4.0391 & 5.0313 & TST & \\
\hline CHEMBL1552053 & 809110 & 4.4498 & 4.2965 & TST & \\
\hline CHEMBL1723045 & 809110 & 4.3979 & 4.4927 & TST & \\
\hline CHEMBL1313755 & 809110 & 4.6676 & 4.9585 & TST & \\
\hline CHEMBL1422807 & 809110 & 4.4012 & 4.1181 & TST & \\
\hline CHEMBL1452158 & 809110 & 5.2916 & 4.5257 & TST & \\
\hline CHEMBL1997413 & 809110 & 4.6757 & 4.4141 & TST & \\
\hline CHEMBL1461524 & 809110 & 4.248 & 4.756 & TST & \\
\hline CHEMBL1306897 & 809110 & 4.2874 & 4.284 & TST & \\
\hline CHEMBL1362445 & 809110 & 4.0857 & 3.6854 & TST & \\
\hline CHEMBL1976677 & 809110 & 4.4078 & 4.3452 & TST & \\
\hline CHEMBL1509380 & 809110 & 4.3507 & 4.2027 & TST & \\
\hline CHEMBL1528327 & 809110 & 4.4841 & 4.5093 & TST & \\
\hline CHEMBL1726773 & 809110 & 4.618 & 4.1674 & TST & \\
\hline CHEMBL1493011 & 809110 & 4.058 & 4.2095 & TST & \\
\hline CHEMBL1505688 & 809110 & 4.5376 & 4.46399 & 99999999995 & TST \\
\hline CHEMBL1320653 & 809110 & 4.4225 & 4.4209 & TST & \\
\hline CHEMBL1320535 & 809110 & 4.9172 & 4.3765 & TST & \\
\hline CHEMBL1427330 & 809110 & 4.7122 & 4.8295 & TST & \\
\hline CHEMBL1522018 & 809110 & 4.1643 & 4.4106 & TST & \\
\hline CHEMBL1610506 & 809110 & 4.466 & 3.9739 & TST & \\
\hline CHEMBL1537781 & 809110 & 4.5331 & 4.8785 & TST & \\
\hline CHEMBL1970867 & 809110 & $4.0680 e$ & 00000000 & 4.587 & TST \\
\hline CHEMBL 2001433 & 809110 & 4.4389 & 5.6926 & TST & \\
\hline CHEMBL1972506 & 809110 & 4.1124 & 4.7552 & TST & \\
\hline CHEMBL1518982 & 809110 & 4.8097 & 4.2943 & TST & \\
\hline CHEMBL1468383 & 809110 & 4.3686 & 4.8682 & TST & \\
\hline CHEMBL1996136 & 809110 & 4.3872 & 3.9669 & TST & \\
\hline CHEMBL1888496 & 809110 & 4.8861 & 4.3256 & TST & \\
\hline CHEMBL1604247 & 809110 & 4.4547 & 4.4558 & TST & \\
\hline CHEMBL1518206 & 809110 & 4.7959 & 4.7713 & TST & \\
\hline CHEMBL 2003808 & 809110 & 4.9706 & 5.0501 & TST & \\
\hline CHEMBL1564058 & 809110 & 4.7645 & 4.3866 & TST & \\
\hline CHEMBL302825 & 49425 & 4.7447 & 4.8677 & TST & \\
\hline CHEMBL 70405 & 49425 & 4.0 & 3.7622 & TRN & \\
\hline CHEMBL1907841 & 49425 & 6.0 & 5.8438 & TRN & \\
\hline CHEMBL 74515 & 49425 & 3.3979 & 3.8249 & TRN & \\
\hline CHEMBL 307370 & 49425 & 5.0757 & 4.8643 & TRN & \\
\hline CHEMBL308111 & 49425 & 4.9208 & 4.2708 & TRN & \\
\hline CHEMBL 73563 & 49425 & 5.4815 & 4.3634 & TST & \\
\hline CHEMBL1907842 & 49425 & 6.0 & 5.74 & TRN & \\
\hline CHEMBL310250 & 49425 & 4.0 & 3.8059 & TRN & \\
\hline CHEMBL40668 & 49425 & 5.7212 & 5.9479 & TRN & \\
\hline CHEMBL 73096 & 49425 & 3.0 & 3.2755 & TST & \\
\hline CHEMBL 70896 & 49425 & 4.0969 & 3.7002 & TRN & \\
\hline
\end{tabular}




\begin{tabular}{|c|c|c|c|c|c|}
\hline & & \multicolumn{4}{|c|}{ Supplemental Table s2.txt } \\
\hline CHEMBL72894 & 49425 & 4.4815 & 4.4362 & TRN & \\
\hline CHEMBL1907848 & 49425 & 5.5229 & 5.4555 & TRN & \\
\hline CHEMBL74580 & 49425 & 3.3979 & 4.3522 & TRN & \\
\hline CHEMBL 74170 & 49425 & 5.0969 & 4.6938 & TRN & \\
\hline CHEMBL72550 & 49425 & 4.0 & 4.223 & TRN & \\
\hline CHEMBL70856 & 49425 & 4.4949 & 4.7559 & TRN & \\
\hline CHEMBL 302359 & 49425 & 4.1871 & 4.3573 & TRN & \\
\hline CHEMBL73110 & 49425 & 3.0 & 4.6804 & TRN & \\
\hline CHEMBL73745 & 49425 & 3.0 & 3.2692 & TRN & \\
\hline CHEMBL307878 & 49425 & 4.5376 & 4.5135 & TRN & \\
\hline CHEMBL70549 & 49425 & 4.4559 & 3.7519 & TST & \\
\hline CHEMBL70499 & 49425 & 3.0 & 3.3152 & TRN & \\
\hline CHEMBL72570 & 49425 & 5.5376 & 4.6678 & TRN & \\
\hline CHEMBL1907667 & 49425 & 4.7959 & 4.6805 & TRN & \\
\hline CHEMBL 74181 & 49425 & 4.0 & 4.6053 & TRN & \\
\hline CHEMBL72491 & 49425 & 3.3979 & 3.2325 & TRN & \\
\hline CHEMBL1907663 & 49425 & 3.0 & 3.5286 & TRN & \\
\hline CHEMBL 304768 & 49425 & 4.585 & 4.5365 & TRN & \\
\hline CHEMBL13095 & 49425 & 3.0 & 2.8359 & TST & \\
\hline CHEMBL73272 & 49425 & 4.0 & 3.9309 & TRN & \\
\hline CHEMBL1907852 & 49425 & 6.0 & 5.3975 & TRN & \\
\hline CHEMBL306271 & 49425 & 3.0 & 2.7877 & TST & \\
\hline CHEMBL 307661 & 49425 & 5.2518 & 5.9326 & TRN & \\
\hline CHEMBL1907660 & 49425 & 3.0 & 4.0092 & TRN & \\
\hline CHEMBL1907851 & 49425 & 5.4559 & 5.6542 & TRN & \\
\hline CHEMBL 72841 & 49425 & 3.3979 & 3.37 & TRN & \\
\hline CHEMBL 72428 & 49425 & 5.6198 & 5.3314 & TRN & \\
\hline CHEMBL73892 & 49425 & 3.3979 & 3.6263 & TRN & \\
\hline CHEMBL39263 & 49425 & 6.0 & 5.9424 & TRN & \\
\hline CHEMBL72300 & 49425 & 4.3979 & 4.2007 & TRN & \\
\hline CHEMBL1907839 & 49425 & 4.1487 & 4.287 & TRN & \\
\hline CHEMBL71079 & 49425 & 4.8239 & 5.3018 & TRN & \\
\hline CHEMBL306394 & 49425 & 4.3665 & 4.3221 & TRN & \\
\hline CHEMBL73885 & 49425 & 5.1549 & 5.0176 & TRN & \\
\hline CHEMBL431185 & 49425 & 4.0 & 2.6976 & TST & \\
\hline CHEMBL72616 & 49425 & 3.0 & 3.4576 & TRN & \\
\hline CHEMBL72057 & 49425 & 3.3979 & 3.0683 & TRN & \\
\hline CHEMBL1907665 & 49425 & 3.0 & 3.4117 & TRN & \\
\hline CHEMBL1907661 & 49425 & 6.1938 & 6.1597 & TRN & \\
\hline CHEMBL308414 & 49425 & 4.4202 & 4.5594 & TRN & \\
\hline CHEMBL72710 & 49425 & 3.0 & 3.483 & TRN & \\
\hline CHEMBL70883 & 49425 & 6.699 & 7.04799 & 9999999999 & TRN \\
\hline CHEMBL308756 & 49425 & 4.9208 & 4.7927 & TRN & \\
\hline CHEMBL73522 & 49425 & 6.0 & 6.1476 & TRN & \\
\hline CHEMBL309017 & 49425 & 4.9208 & 4.3175 & TRN & \\
\hline CHEMBL 308297 & 49425 & 3.0 & 3.523 & TST & \\
\hline CHEMBL72151 & 49425 & 3.0 & 2.9128 & TST & \\
\hline CHEMBL 303227 & 49425 & 6.0 & 5.5735 & TRN & \\
\hline
\end{tabular}




\begin{tabular}{|c|c|c|c|c|c|}
\hline \multicolumn{6}{|c|}{ Supplemental Table S2.txt } \\
\hline CHEMBL302282 & 49425 & 4.0 & 4.1652 & TRN & \\
\hline CHEMBL74066 & 49425 & 4.7959 & 4.2739 & TRN & \\
\hline CHEMBL419997 & 49425 & 4.0969 & 3.4403 & TRN & \\
\hline CHEMBL306958 & 49425 & 4.0 & 3.6365 & TRN & \\
\hline CHEMBL303724 & 49425 & 3.301 & 3.326 & TRN & \\
\hline CHEMBL 2114102 & 49425 & 6.0 & 5.3212 & TST & \\
\hline CHEMBL70550 & 49425 & 3.301 & 3.3833 & TRN & \\
\hline CHEMBL443009 & 49425 & 5.2596 & 5.0306 & TRN & \\
\hline CHEMBL422411 & 49425 & 4.9586 & 4.779 & TRN & \\
\hline CHEMBL307659 & 49425 & 3.3979 & 4.0118 & TRN & \\
\hline CHEMBL73561 & 49425 & 4.3979 & 4.5386 & TRN & \\
\hline CHEMBL70593 & 49425 & 5.4318 & 5.0546 & TRN & \\
\hline CHEMBL306369 & 49425 & 3.3979 & 3.6789 & TST & \\
\hline CHEMBL72670 & 49425 & 4.7447 & 3.3944 & TRN & \\
\hline CHEMBL 303386 & 49425 & 4.8861 & 4.4302 & TST & \\
\hline CHEMBL1907847 & 49425 & 4.5086 & 4.2864 & TRN & \\
\hline CHEMBL72546 & 49425 & 5.4949 & 5.4016 & TRN & \\
\hline CHEMBL 2092869 & 49425 & 6.0 & 5.374 & TRN & \\
\hline CHEMBL 72073 & 49425 & 4.3979 & 4.9414 & TRN & \\
\hline CHEMBL73510 & 49425 & 4.8539 & 4.8977 & TRN & \\
\hline CHEMBL1907849 & 49425 & 6.0 & 5.6565 & TRN & \\
\hline CHEMBL 72738 & 49425 & 4.3188 & 4.323 & TST & \\
\hline CHEMBL306396 & 49425 & 3.0 & 2.7574 & TST & \\
\hline CHEMBL306806 & 49425 & 5.5229 & 5.1619 & TRN & \\
\hline CHEMBL72667 & 49425 & 4.301 & 4.2007 & TRN & \\
\hline CHEMBL1907850 & 49425 & 5.3979 & 5.61799 & 9999999999 & TRN \\
\hline CHEMBL 72599 & 49425 & 3.3979 & 4.7076 & TST & \\
\hline CHEMBL73621 & 49425 & 4.6778 & 4.4435 & TST & \\
\hline CHEMBL 72727 & 49425 & 3.3979 & 3.7612 & TST & \\
\hline CHEMBL308769 & 49425 & 4.9208 & 3.2979 & TST & \\
\hline CHEMBL74125 & 49425 & 4.1249 & 4.0598 & TST & \\
\hline CHEMBL 309575 & 49425 & 4.6383 & 4.4644 & TST & \\
\hline CHEMBL 2092866 & 49425 & 6.0 & 5.2381 & TST & \\
\hline CHEMBL1907846 & 49425 & 6.0 & 5.70700 & 0000000001 & TST \\
\hline CHEMBL306760 & 49425 & 5.0969 & 5.3331 & TST & \\
\hline CHEMBL422951 & 49425 & 4.9208 & 4.4214 & TST & \\
\hline CHEMBL70456 & 49425 & 5.2218 & 5.761 & TST & \\
\hline CHEMBL3930277 & 1528110 & 7.1192 & 7.2231 & TRN & \\
\hline CHEMBL3969939 & 1528110 & 7.1192 & 6.8492 & TST & \\
\hline CHEMBL3939159 & 1528110 & 3.9586 & 4.2486 & TST & \\
\hline CHEMBL3957770 & 1528110 & 6.0915 & 6.103 & TRN & \\
\hline CHEMBL3978292 & 1528110 & 3.8861 & 3.8638 & TRN & \\
\hline CHEMBL3916593 & 1528110 & 5.7447 & 5.8213 & TRN & \\
\hline CHEMBL 3934842 & 1528110 & 6.9208 & 6.8919 & TRN & \\
\hline CHEMBL3985523 & 1528110 & 7.1308 & 6.7258 & TRN & \\
\hline CHEMBL3949832 & 1528110 & 7.3665 & 7.1709 & TRN & \\
\hline CHEMBL3898175 & 1528110 & 7.041 & 6.8118 & TRN & \\
\hline CHEMBL3918246 & 1528110 & 5.7696 & 5.731 & TRN & \\
\hline
\end{tabular}


Supplemental Table S2.txt

\begin{tabular}{|c|c|c|c|c|}
\hline TLTIS & & & & \\
\hline HFMRI 3973868 & 28110 & 7.1427 & 7096 & \\
\hline HEMBL & & 2924 & 62 & \\
\hline AEMBL3956708 & 528110 & 6.0223 & 9048 & \\
\hline HEMBL3957412 & 528110 & 7.301 & .7068 & \\
\hline HEMBL 394 & 10 & 5.7447 & 7587 & \\
\hline AEMBL: & & 7.3098 & 5857 & \\
\hline HEMBL 394 & 10 & 7.2757 & 2621 & \\
\hline HEMBL3929540 & 528110 & 5.7959 & 7481 & \\
\hline HEMBL3889471 & 528110 & 6.6576 & .7632 & \\
\hline AEMBL39 & 10 & 5.2218 & 2729 & \\
\hline AEMBL3 & & 7.3372 & 2996 & RN \\
\hline HEMBL 389 & 10 & 7.0315 & 8295 & \\
\hline HEMBL 392 & 10 & 6.6576 & 5673 & \\
\hline HEMBL391 & 10 & 7.3098 & 319 & \\
\hline AEMBL & 10 & 202 & & \\
\hline AEMBL & & 38 & & RN \\
\hline HEMBL; & 10 & 3979 & 14 & RN \\
\hline AEMBL3 & 10 & 7.0555 & & \\
\hline AEMBL3 & 10 & 5. & 305 & ISI \\
\hline IEMBL & 10 & 212 & 72 & RN \\
\hline AEMBL & & 98 & & RIV \\
\hline HEMBL & 10 & 872 & & ST \\
\hline HEMBL: & & 655 & & \\
\hline AEMBL3 & 10 & 7.1871 & 33 & $R N$ \\
\hline IEMBL: & 0 & 596 & 55 & RN \\
\hline AEM & & & & ST \\
\hline 13 & & & & RN \\
\hline IEMBL: & & & & $|S|$ \\
\hline AEMBL 39 & Lo & 586 & 902 & 「RN \\
\hline IEMBL & LO & 86 & 71 & $\mathrm{RN}$ \\
\hline 4 & & 6 & & RN \\
\hline & & & & ST \\
\hline AEMBL3 & & 7 & & 「RN \\
\hline HEMBL 389 & 10 & 6 & 591 & 「RN \\
\hline HEMBL3 & 10 & & 777 & RN \\
\hline & & & & RN \\
\hline HEMBL3 & & & & ГST \\
\hline HEMBL391 & 10 & 5.8239 & 906 & TRN \\
\hline EMBL: & Lo & 5.5086 & 934 & 「RN \\
\hline HEMBL3 & & 586 & 862 & \\
\hline & & & 363 & $\mathrm{RN}$ \\
\hline HEMBL3 & & 6.4437 & 072 & 「RN \\
\hline AEMBL3 & 10 & 6.6576 & 186 & TR \\
\hline met & & & & \\
\hline HEMBL39 & & 6.0177 & 5.0319 & \\
\hline LHEMBL 397 & 10 & 6.9586 & 7.0876 & \\
\hline CHEMBL 390529 & 1528110 & 7.3372 & 7.3813 & \\
\hline
\end{tabular}

Page 7008 
Supplemental Table S2.txt

\begin{tabular}{|c|c|c|c|c|}
\hline THTL 25 & & 599 & 84 & \\
\hline HFMRI 3917969 & 528110 & 6.5086 & 6.4329 & \\
\hline HEMBL & & 249 & & \\
\hline AEMBL3969866 & 528110 & 1938 & 1529 & \\
\hline HEMBL3952047 & 528110 & 6.8861 & .7674 & \\
\hline AEMBL3 & 10 & 596 & & \\
\hline FMBI & & 862 & & \\
\hline HEMBL 391 & 10 & 3555 & 9958 & PN \\
\hline HEMBL3951919 & 528110 & 7.3279 & 1637 & \\
\hline HEMBL3899412 & 10 & 6.5528 & 5461 & \\
\hline AEMBL3S & 10 & 1739 & 518 & \\
\hline AEMBL: & & 366 & & \\
\hline HEMBL3S & 10 & 3979 & 7942 & \\
\hline AEMBL3 & 10 & 6.6576 & 7519 & \\
\hline HEMBL 369 & 10 & 6.0 & 8491 & \\
\hline AEMBL & 0 & 757 & 931 & \\
\hline AEMBL & & 468 & & RN \\
\hline HEMBL; & 10 & 3539 & 354 & \\
\hline AEMBL3 & 10 & & & \\
\hline AEMBL3 & 10 & 132 & 28 & KIV \\
\hline IEMBL & 0 & 308 & 59 & RN \\
\hline IEME & & 586 & & RN \\
\hline HEMBL & 10 & 576 & 83 & RN \\
\hline HEMBL: & & 44 & & \\
\hline AEMBL 3 & 10 & 024 & 12 & RN \\
\hline IEMBL & & 586 & 54 & RN \\
\hline IEM & & 135 & 68 & $\mathrm{RN}$ \\
\hline 9 & & 596 & & \\
\hline AEMBL & & & & IRN \\
\hline HEMBL 389 & 10 & 376 & & $\mathrm{RN}$ \\
\hline IEMBL & LO & 778 & 19 & $\mathrm{RN}$ \\
\hline 9 & & 65 & 68 & RN \\
\hline & & & & TST \\
\hline AEMBL3 & & & & RN \\
\hline AEMBL3S & 10 & 805 & 897 & RN \\
\hline IEMPI: & & 308 & 858 & RN \\
\hline & & & & RN \\
\hline HEMBL & & & & RN \\
\hline HEMBL 396 & 10 & & 074 & TST \\
\hline EMBL & 10 & 239 & 378 & 「RN \\
\hline HEMBL3 & & 861 & 587 & \\
\hline & & 5.9586 & & $\mathrm{RN}$ \\
\hline HEMBL3 & & 4.7212 & 6719 & TST \\
\hline AEMBL3 & 10 & 383 & 389 & TR \\
\hline Not & & 586 & & \\
\hline HEMBL 39 & & .7212 & 6.6195 & \\
\hline HEMBL 39 & & .8239 & 6.9239 & \\
\hline CHEMBL3966152 & 1528110 & 7.1871 & 7.0621 & \\
\hline
\end{tabular}

Page 7009 
Supplemental Table S2.txt

\begin{tabular}{|c|c|c|c|c|}
\hline CHEMBL3896567 & 1528110 & 4.2291 & 4.5058 & TST \\
\hline CHEMBL3932028 & 1528110 & 6.4202 & 6.4459 & TRN \\
\hline CHEMBL3963204 & 1528110 & 5.8239 & 5.8307 & TRN \\
\hline CHEMBL 3890445 & 1528110 & 6.6576 & 6.6607 & TRN \\
\hline CHEMBL3979774 & 1528110 & 5.0555 & 5.1885 & TRN \\
\hline CHEMBL3889468 & 1528110 & 5.8861 & 6.6054 & TST \\
\hline CHEMBL3962909 & 1528110 & 5.8539 & 5.9322 & TRN \\
\hline CHEMBL3941819 & 1528110 & 7.0862 & 7.0972 & TST \\
\hline CHEMBL 3974640 & 1528110 & 7.3279 & 7.1882 & TRN \\
\hline CHEMBL3980206 & 1528110 & 6.3098 & 6.5065 & TRN \\
\hline CHEMBL3973548 & 1528110 & 4.7447 & 5.54200 & 0000000001 \\
\hline CHEMBL3927839 & 1528110 & 6.9208 & 6.6901 & TRN \\
\hline CHEMBL3986243 & 1528110 & 6.9586 & 6.6386 & TRN \\
\hline CHEMBL3893033 & 1528110 & 5.2291 & 4.0805 & TST \\
\hline CHEMBL3968146 & 1528110 & 6.7959 & 6.7467 & TRN \\
\hline CHEMBL3915512 & 1528110 & 6.3768 & 5.8756 & TRN \\
\hline CHEMBL3927178 & 1528110 & 6.4815 & 6.2318 & TRN \\
\hline CHEMBL 3986735 & 1528110 & 5.6021 & 5.735 & TST \\
\hline CHEMBL3938927 & 1528110 & 7.2007 & 7.1381 & TST \\
\hline CHEMBL3925189 & 1528110 & 6.7447 & 6.7305 & TRN \\
\hline CHEMBL3905715 & 1528110 & 7.1739 & 7.1575 & TRN \\
\hline CHEMBL3957818 & 1528110 & 6.1487 & 5.9695 & TRN \\
\hline CHEMBL3946573 & 1528110 & 6.0 & 5.9753 & TRN \\
\hline CHEMBL 3957277 & 1528110 & 5.0458 & 4.9566 & TST \\
\hline CHEMBL3907773 & 1528110 & 4.2924 & 4.2549 & TST \\
\hline CHEMBL3898669 & 1528110 & 5.9586 & 5.1405 & TST \\
\hline CHEMBL 3943974 & 1528110 & 6.041 & 4.9457 & TST \\
\hline CHEMBL3949861 & 1528110 & 5.8861 & 5.9291 & TRN \\
\hline CHEMBL3922666 & 1528110 & 5.8239 & 5.7063 & TRN \\
\hline CHEMBL3979285 & 1528110 & 6.4685 & 6.2136 & TRN \\
\hline CHEMBL3940031 & 1528110 & 7.0706 & 7.1181 & TRN \\
\hline CHEMBL3913165 & 1528110 & 6.3098 & 6.4444 & TRN \\
\hline CHEMBL3890198 & 1528110 & 7.301 & 7.3 & TRN \\
\hline CHEMBL3985431 & 1528110 & 7.2366 & 7.3626 & TRN \\
\hline CHEMBL3903501 & 1528110 & 6.3279 & 5.6268 & TST \\
\hline CHEMBL3896425 & 1528110 & 6.4685 & 6.53 & TRN \\
\hline CHEMBL3909039 & 1528110 & 6.1938 & 6.3607 & TST \\
\hline CHEMBL3933045 & 1528110 & 7.3279 & 7.29 & TRN \\
\hline CHEMBL3986756 & 1528110 & 6.7959 & 6.6661 & TRN \\
\hline CHEMBL3906236 & 1528110 & 6.6198 & 6.5308 & TRN \\
\hline CHEMBL3907697 & 1528110 & 6.7696 & 6.8802 & TRN \\
\hline CHEMBL3943322 & 1528110 & 7.041 & 6.7674 & TRN \\
\hline CHEMBL3966406 & 1528110 & 6.7696 & \multicolumn{2}{|c|}{6.747999999999999} \\
\hline CHEMBL3977395 & 1528110 & 7.2007 & 7.1781 & TRN \\
\hline CHEMBL3973068 & 1528110 & 5.1427 & 5.1855 & TRN \\
\hline CHEMBL3915371 & 1528110 & 7.1367 & 6.9983 & TRN \\
\hline CHEMBL3911776 & 1528110 & 7.1249 & 6.8359 & TRN \\
\hline CHEMBL3941780 & 1528110 & 5.8239 & 6.2362 & TST \\
\hline
\end{tabular}


Supplemental Table S2.txt

\begin{tabular}{|c|c|c|c|c|}
\hline HEMB I & 528110 & 5.6198 & 5.8967 & \\
\hline & 528110 & 6.0 & 6.431 & \\
\hline & 28110 & 5.13 & 501 & \\
\hline AEMBL & 8110 & 9208 & 9687 & \\
\hline AEMBL3923665 & 528110 & 7.0757 & 0221 & \\
\hline HEMBL3951354 & 528110 & 3.8239 & 4.8005 & \\
\hline 453 & 10 & 696 & 3589 & \\
\hline 548 & & & 9695 & \\
\hline AEMBL3974086 & 528110 & & 0172 & \\
\hline HEMBL3936617 & 528110 & 6.6198 & 7359 & \\
\hline HEMBL3907579 & 528110 & 4 . & 359 & \\
\hline IEMBL397 & 10 & 24 & 582 & \\
\hline AEMBL38 & & & & \\
\hline HEMBL3964819 & 528110 & 7.2596 & 2066 & \\
\hline AEMBL3903014 & 10 & 88 & 672 & \\
\hline AEMBL3974689 & 10 & 41 & 9429 & \\
\hline AEMBL39 & 10 & 7. & 136 & \\
\hline HEMBL39 & 10 & 6 . & 124 & \\
\hline HEMBL3960559 & 10 & & 8799 & \\
\hline AEMBL3S & 10 & & 776 & \\
\hline$A \in M B L 3 S$ & LO & & 393 & \\
\hline HEMBL3 & LO & & 247 & 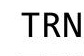 \\
\hline HEMBL3S & 10 & & 03 & \\
\hline 9514 & & & 699 & \\
\hline AEMBL39 & & & & ( \\
\hline HEMBL3S & 10 & & 148 & RN \\
\hline HEMBL3 & 0 & & 78 & Niv \\
\hline HFMBI 36 & 10 & & 146 & \\
\hline HEMBL3S & & & & in \\
\hline HEMBL3900532 & 10 & & 615 & 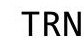 \\
\hline HEMBL3S & 6 & & 564 & SI \\
\hline HEMBL; & 0 & & 095 & RN \\
\hline HEMBL3 & 10 & & & ST \\
\hline HEMBL3902909 & & & 905 & IRN \\
\hline HEMBL3927650 & 10 & & 3969 & TRN \\
\hline HEMBL3S & & & 607 & ST \\
\hline HFMRI 3 & 0 & & 572 & RN \\
\hline HEMBL3 & & & 3036 & IRN \\
\hline HEMBL3930995 & 10 & 5.5 & 995 & TST \\
\hline AEMBL21 & 79 & & 984 & $\Gamma \mathrm{RN}$ \\
\hline HEMBL21 & & 2 & 761 & \\
\hline HEMBL 37 & & 7.3261 & & RIV \\
\hline HEMBL380030 & 46 & & 8657 & $\Gamma \mathrm{RN}$ \\
\hline HEMBL 377757 & 6 & 7. & 3163 & TRN \\
\hline 1. & & & 9443 & \\
\hline HEMBL2 & & 10 & 3566 & \\
\hline CHEMBL377165 & 79746 & & . 9782 & \\
\hline HEMBL 212341 & 379746 & 7.3979 & 7.4036 & ГRN \\
\hline
\end{tabular}

Page 7011 


\begin{tabular}{|c|c|c|c|c|c|}
\hline \multicolumn{6}{|c|}{ Supplemental Table S2 } \\
\hline CHEMBL212708 & 379746 & 7.8508 & 7.7948 & TRN & \\
\hline CHEMBL214310 & 379746 & 7.2218 & 7.2846 & TRN & \\
\hline CHEMBL386904 & 379746 & 6.7825 & 6.8891 & TST & \\
\hline CHEMBL212038 & 379746 & 7.1481 & 7.1502 & TRN & \\
\hline CHEMBL378328 & 379746 & 7.1549 & 7.1514 & TRN & \\
\hline CHEMBL213159 & 379746 & 8.0 & 7.4848 & TST & \\
\hline CHEMBL384967 & 379746 & 6.5751 & 6.5949 & TRN & \\
\hline CHEMBL378697 & 379746 & 7.2411 & 7.2521 & TRN & \\
\hline CHEMBL386742 & 379746 & 4.301 & 6.3455 & TST & \\
\hline CHEMBL215858 & 379746 & 7.9355 & 7.9387 & TRN & \\
\hline CHEMBL377319 & 379746 & 7.3391 & 7.3226 & TST & \\
\hline CHEMBL213258 & 379746 & 8.0 & 7.99 & TRN & \\
\hline CHEMBL379590 & 379746 & 7.699 & 7.7011 & TRN & \\
\hline CHEMBL213521 & 379746 & 4.699 & 4.7134 & TRN & \\
\hline CHEMBL213501 & 379746 & 6.3279 & 6.3098 & TRN & \\
\hline CHEMBL378752 & 379746 & 7.3098 & 7.3037 & TRN & \\
\hline CHEMBL213522 & 379746 & 6.2007 & 6.2063 & TRN & \\
\hline CHEMBL211151 & 379746 & 6.8297 & 6.8296 & TRN & \\
\hline CHEMBL379374 & 379746 & 7.3979 & 7.4311 & TRN & \\
\hline CHEMBL384117 & 379746 & 6.8697 & 6.86299 & 99999999995 & TRN \\
\hline CHEMBL386869 & 379746 & 6.8239 & 6.9594 & TRN & \\
\hline CHEMBL212849 & 379746 & 7.5003 & 7.5082 & TRN & \\
\hline CHEMBL379394 & 379746 & 7.4123 & 7.433 & TRN & \\
\hline CHEMBL379929 & 379746 & 7.1463 & 7.1428 & TRN & \\
\hline CHEMBL213451 & 379746 & 7.284 & 7.2898 & TRN & \\
\hline CHEMBL211735 & 379746 & 7.3979 & 7.3906 & TRN & \\
\hline CHEMBL212238 & 379746 & 8.0 & 8.0043 & TRN & \\
\hline CHEMBL384990 & 379746 & 6.4437 & 6.4672 & TRN & \\
\hline CHEMBL213002 & 379746 & 5.8416 & 6.2725 & TST & \\
\hline CHEMBL377841 & 379746 & 7.0969 & 6.8317 & TST & \\
\hline CHEMBL439321 & 379746 & 8.0 & 7.4649 & TST & \\
\hline CHEMBL215652 & 379746 & 7.6108 & 7.6498 & TRN & \\
\hline CHEMBL377875 & 379746 & 7.6108 & 7.6426 & TRN & \\
\hline CHEMBL379866 & 379746 & 7.6021 & 7.7245 & TRN & \\
\hline CHEMBL211628 & 379746 & 7.5229 & 7.4675 & TST & \\
\hline CHEMBL211919 & 379746 & 7.4609 & 6.6715 & TST & \\
\hline CHEMBL213423 & 379746 & 7.7055 & 7.7552 & TRN & \\
\hline CHEMBL210060 & 379746 & 7.2218 & 7.2213 & TRN & \\
\hline CHEMBL212898 & 379746 & 7.3391 & 7.5245 & TST & \\
\hline CHEMBL439540 & 379746 & 6.9136 & 6.9039 & TRN & \\
\hline CHEMBL378919 & 379746 & 8.0 & 7.9931 & TRN & \\
\hline CHEMBL211362 & 379746 & 7.5229 & 7.5103 & TRN & \\
\hline CHEMBL212968 & 379746 & 8.0809 & 7.9934 & TRN & \\
\hline CHEMBL386807 & 379746 & 7.284 & 6.75 & TST & \\
\hline CHEMBL212294 & 379746 & 7.2411 & 7.1949 & TRN & \\
\hline CHEMBL377606 & 379746 & 6.699 & 6.7191 & TRN & \\
\hline CHEMBL212655 & 379746 & 7.1549 & 7.1487 & TRN & \\
\hline CHEMBL215680 & 379746 & 6.1726 & 6.1652 & TRN & \\
\hline
\end{tabular}




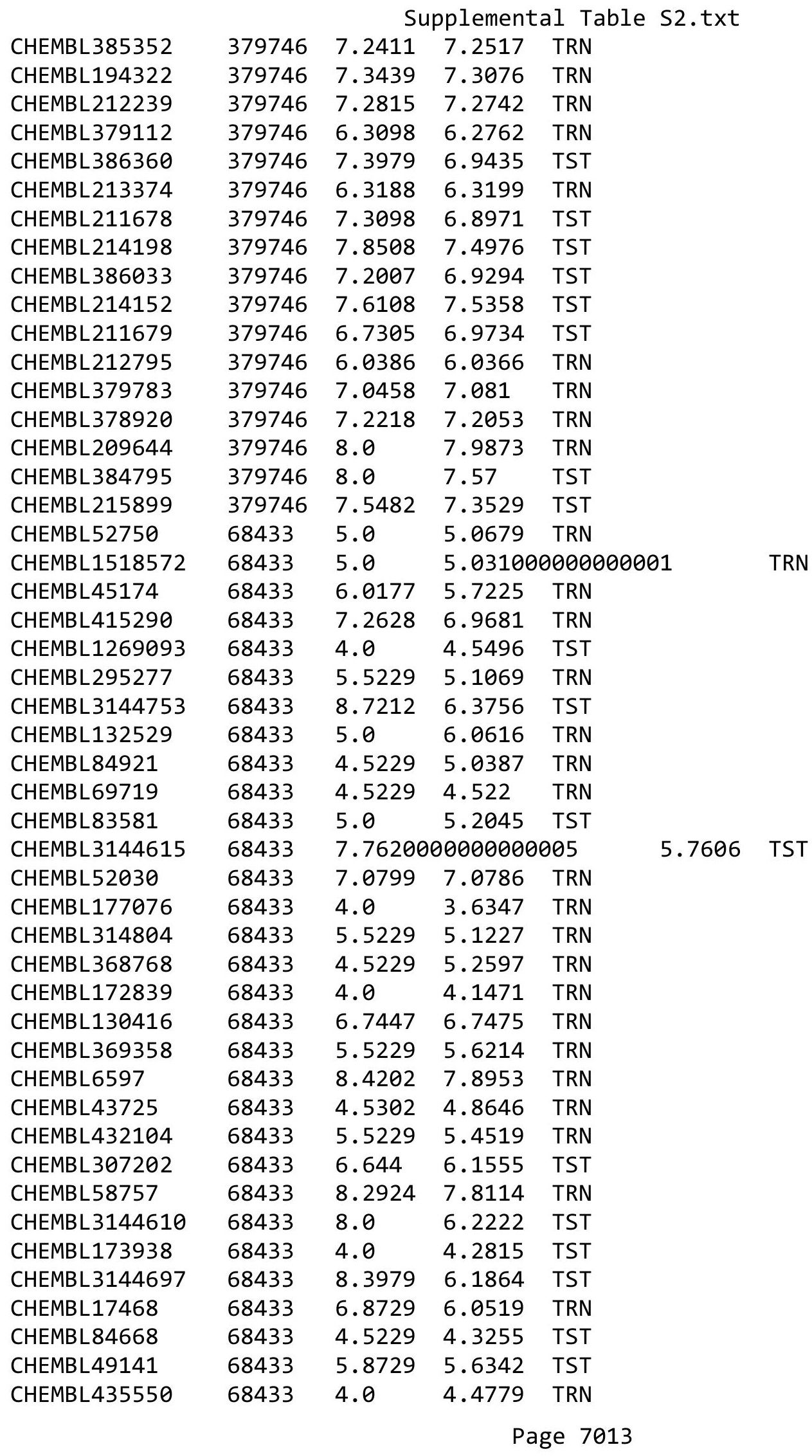




\begin{tabular}{|c|c|c|c|c|c|}
\hline \multicolumn{6}{|c|}{ Supplemental Table S2.txt } \\
\hline CHEMBL368171 & 68433 & 4.0 & 3.5618 & TRN & \\
\hline CHEMBL173339 & 68433 & 5.5229 & 5.8193 & TRN & \\
\hline CHEMBL173219 & 68433 & 4.0 & 3.996006 & 00000000004 & TRN \\
\hline CHEMBL59181 & 68433 & 6.9431 & 6.4653 & TRN & \\
\hline CHEMBL47853 & 68433 & 4.52 & 4.7977 & TRN & \\
\hline CHEMBL298561 & 68433 & 4.0 & 4.2798 & TRN & \\
\hline CHEMBL368919 & 68433 & 5.5229 & 5.8311 & TRN & \\
\hline CHEMBL171302 & 68433 & 5.0 & 4.8821 & TST & \\
\hline CHEMBL176307 & 68433 & 5.5229 & 5.0709 & TRN & \\
\hline CHEMBL336728 & 68433 & 7.3768 & 7.2096 & TRN & \\
\hline CHEMBL43718 & 68433 & 5.4377 & 5.4557 & TRN & \\
\hline CHEMBL53651 & 68433 & 4.0 & 3.9948 & TRN & \\
\hline CHEMBL19732 & 68433 & 7.7696 & 5.21399 & 99999999995 & TST \\
\hline CHEMBL173082 & 68433 & 5.5229 & 6.0659 & TRN & \\
\hline CHEMBL13458 & 68433 & 4.5229 & 4.1272 & TST & \\
\hline CHEMBL173347 & 68433 & 4.5229 & 4.4879 & TRN & \\
\hline CHEMBL301605 & 68433 & 5.0 & 4.5033 & TST & \\
\hline CHEMBL78766 & 68433 & 4.0 & 3.3214 & TST & \\
\hline CHEMBL73096 & 68433 & 4.5229 & 4.3201 & TRN & \\
\hline CHEMBL 6440 & 68433 & 6.7747 & 6.4823 & TRN & \\
\hline CHEMBL416450 & 68433 & 7.2882 & 7.109 & TRN & \\
\hline CHEMBL133705 & 68433 & 6.5735 & 6.6305 & TRN & \\
\hline CHEMBL267665 & 68433 & 5.5229 & 6.2989 & TRN & \\
\hline CHEMBL3144698 & 68433 & 7.3979 & 6.2399 & TST & \\
\hline CHEMBL44784 & 68433 & 5.5229 & 5.4435 & TRN & \\
\hline CHEMBL415293 & 68433 & 8.3979 & 7.7057 & TRN & \\
\hline CHEMBL10483 & 68433 & 6.3197 & 5.8311 & TRN & \\
\hline CHEMBL133219 & 68433 & 7.6576 & 7.4984 & TRN & \\
\hline CHEMBL45346 & 68433 & 5.5229 & 5.5581 & TRN & \\
\hline CHEMBL 300840 & 68433 & 7.2321 & 7.2623 & TRN & \\
\hline CHEMBL10195 & 68433 & 5.5229 & 5.8724 & TRN & \\
\hline CHEMBL46957 & 68433 & 5.0655 & 4.8446 & TRN & \\
\hline CHEMBL58570 & 68433 & 7.6402 & 7.8145 & TRN & \\
\hline CHEMBL 368130 & 68433 & 5.5229 & 5.3859 & TRN & \\
\hline CHEMBL367639 & 68433 & 4.0 & 3.9463 & TST & \\
\hline CHEMBL309267 & 68433 & 4.0 & 3.7354 & TRN & \\
\hline CHEMBL134175 & 68433 & 6.8239 & 6.7541 & TRN & \\
\hline CHEMBL170808 & 68433 & 4.0 & 4.463 & TRN & \\
\hline CHEMBL175427 & 68433 & 4.301 & 4.7051 & TST & \\
\hline CHEMBL 84842 & 68433 & 4.5229 & 4.5046 & TST & \\
\hline CHEMBL6814 & 68433 & 7.5129 & 7.7858 & TRN & \\
\hline CHEMBL 7290 & 68433 & 7.6478 & 7.0786 & TRN & \\
\hline CHEMBL173193 & 68433 & 4.0 & 4.4709 & TST & \\
\hline CHEMBL 314844 & 68433 & 4.0 & 4.4038 & TST & \\
\hline CHEMBL367051 & 68433 & 5.5229 & 5.3027 & TRN & \\
\hline CHEMBL273464 & 68433 & 4.0 & 4.7153 & TRN & \\
\hline CHEMBL66902 & 68433 & 5.0 & 5.0441 & TRN & \\
\hline CHEMBL 85861 & 68433 & 7.1255 & 6.3514 & TRN & \\
\hline
\end{tabular}




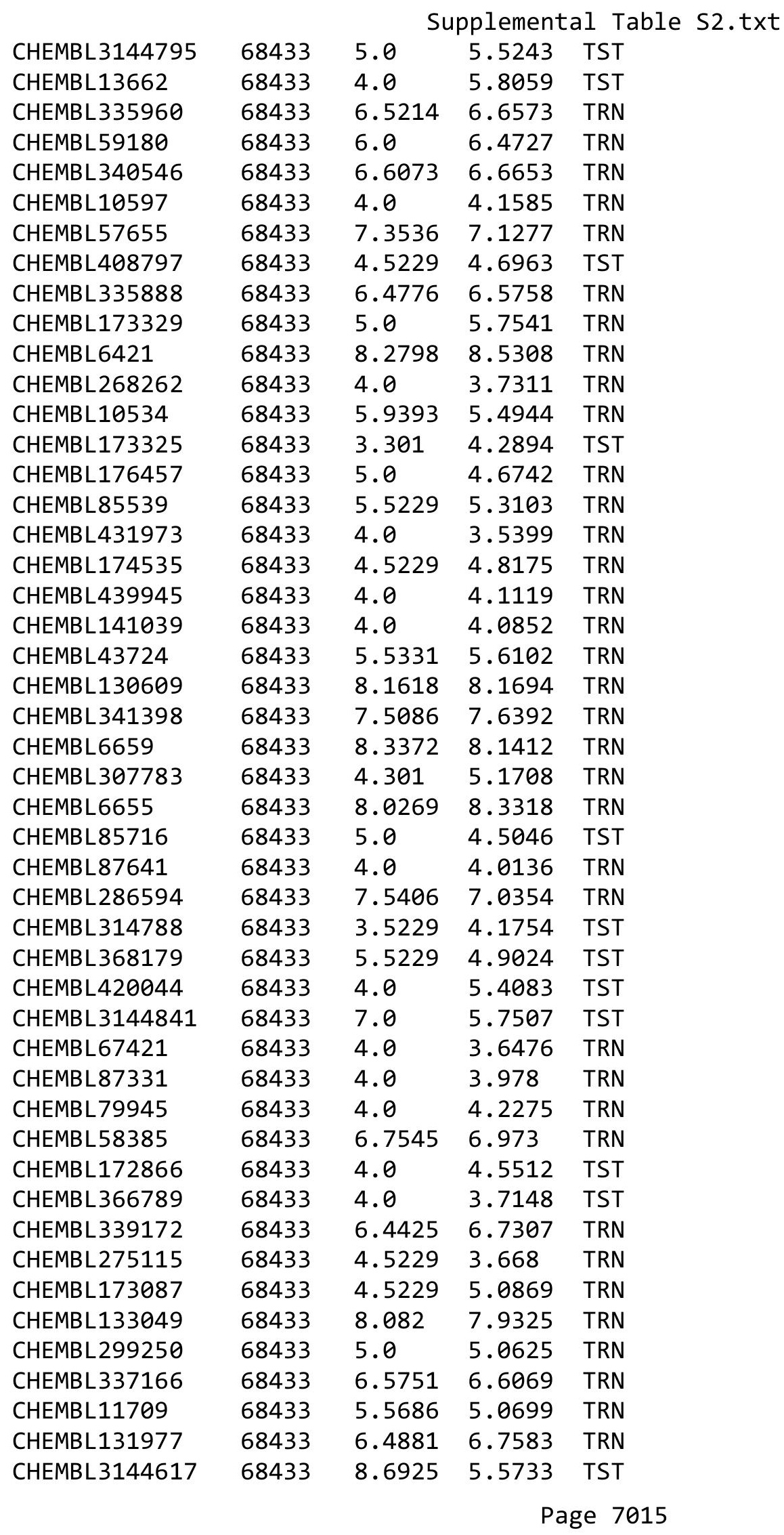




\begin{tabular}{|c|c|c|c|c|c|}
\hline \multicolumn{6}{|c|}{ Supplemental Table S2.txt } \\
\hline CHEMBL295981 & 68433 & 5.5229 & 5.6727 & TRN & \\
\hline CHEMBL339165 & 68433 & 6.9281 & 7.2944 & TRN & \\
\hline CHEMBL3586352 & 1501401 & 6.699 & 6.4238 & TRN & \\
\hline CHEMBL3586332 & 1501401 & 4.9208 & 4.6731 & TRN & \\
\hline CHEMBL3586338 & 1501401 & 5.5686 & 6.3777 & TRN & \\
\hline CHEMBL3586316 & 1501401 & 5.0 & 4.7806 & TRN & \\
\hline CHEMBL3586318 & 1501401 & 4.5229 & 4.6072 & TRN & \\
\hline CHEMBL3586359 & 1501401 & 7.699 & 7.4592 & TST & \\
\hline CHEMBL3586337 & 1501401 & 6.5229 & 6.7753 & TRN & \\
\hline CHEMBL3586351 & 1501401 & 3.5229 & 5.2068 & TRN & \\
\hline CHEMBL3586334 & 1501401 & 5.0 & 4.399 & TRN & \\
\hline CHEMBL 3586344 & 1501401 & 5.2518 & 5.2444 & TRN & \\
\hline CHEMBL3586341 & 1501401 & 6.3979 & 6.4608 & TRN & \\
\hline CHEMBL3586319 & 1501401 & 5.7447 & 4.7331 & TRN & \\
\hline CHEMBL3586335 & 1501401 & 6.3979 & 6.7226 & TRN & \\
\hline CHEMBL3586326 & 1501401 & 5.5528 & 6.0208 & TRN & \\
\hline CHEMBL3586343 & 1501401 & 6.0969 & 6.3537 & TST & \\
\hline CHEMBL3586324 & 1501401 & 7.0 & 6.4951 & TRN & \\
\hline CHEMBL3586320 & 1501401 & 6.2218 & 4.7503 & TRN & \\
\hline CHEMBL3586339 & 1501401 & 5.9586 & 6.3791 & TRN & \\
\hline CHEMBL3586328 & 1501401 & 6.5229 & 6.3005 & TRN & \\
\hline CHEMBL3586353 & 1501401 & 7.0969 & 6.4562 & TRN & \\
\hline CHEMBL3586314 & 1501401 & 7.0 & 6.5508 & TRN & \\
\hline CHEMBL3586321 & 1501401 & 6.2218 & 5.0619 & TRN & \\
\hline CHEMBL3586358 & 1501401 & 3.5229 & 4.8354 & TRN & \\
\hline CHEMBL3586350 & 1501401 & 4.8539 & 5.0609 & TRN & \\
\hline CHEMBL3586309 & 1501401 & 7.1549 & 6.6177 & TRN & \\
\hline CHEMBL3586349 & 1501401 & 5.8239 & 6.275 & TRN & \\
\hline CHEMBL 3586327 & 1501401 & 4.8239 & 4.5778 & TRN & \\
\hline CHEMBL3586348 & 1501401 & 5.9586 & 4.952 & TRN & \\
\hline CHEMBL3586313 & 1501401 & 6.699 & 6.7697 & TRN & \\
\hline CHEMBL3586342 & 1501401 & 7.0969 & 6.88899 & 9999999999 & TST \\
\hline CHEMBL3586317 & 1501401 & 4.5229 & 4.7432 & TRN & \\
\hline CHEMBL3586325 & 1501401 & 3.5229 & 4.708 & TRN & \\
\hline CHEMBL3586322 & 1501401 & 7.0 & 5.0137 & TRN & \\
\hline CHEMBL3586329 & 1501401 & 3.5229 & 4.7126 & TRN & \\
\hline CHEMBL3586315 & 1501401 & 6.699 & 6.5689 & TRN & \\
\hline CHEMBL3586311 & 1501401 & 6.699 & 6.74200 & 0000000001 & TRN \\
\hline CHEMBL3586347 & 1501401 & 7.5229 & 7.2709 & TST & \\
\hline CHEMBL3586360 & 1501401 & 8.0969 & 8.2297 & TST & \\
\hline CHEMBL3586333 & 1501401 & 6.1549 & 5.9517 & TRN & \\
\hline CHEMBL3586331 & 1501401 & 3.5229 & 4.2882 & TRN & \\
\hline CHEMBL3586336 & 1501401 & 5.1938 & 6.0311 & TST & \\
\hline CHEMBL3586355 & 1501401 & 5.2218 & 4.7005 & TST & \\
\hline CHEMBL3586330 & 1501401 & 4.8239 & 5.3579 & TRN & \\
\hline CHEMBL 3586357 & 1501401 & 4.8861 & 4.8283 & TRN & \\
\hline CHEMBL3586354 & 1501401 & 5.7959 & 4.6219 & TST & \\
\hline CHEMBL3586310 & 1501401 & 6.1549 & 6.5237 & TRN & \\
\hline
\end{tabular}


Supplemental Table S2.txt

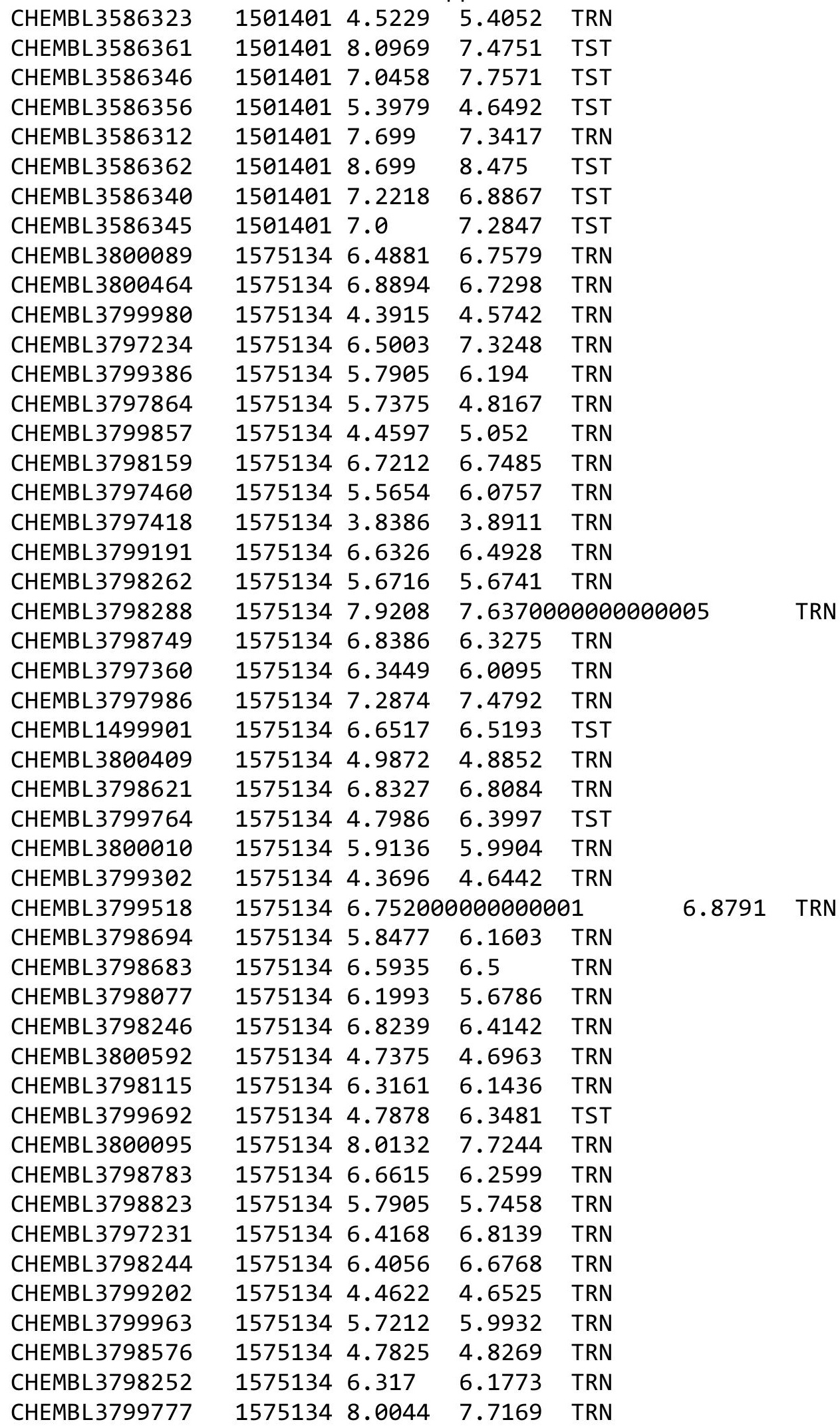


Supplemental Table S2.txt

\begin{tabular}{|c|c|c|c|c|c|c|}
\hline CHEMBL 3800211 & 1575134 & 6.767 & 6.4012 & TRN & & \\
\hline CHEMBL 3797566 & 1575134 & 6.75200 & 000000000 & 31 & 6.8228 & TRN \\
\hline CHEMBL 3798764 & 1575134 & 6.8069 & 6.1342 & TRN & & \\
\hline CHEMBL 3797550 & 1575134 & 7.6904 & 7.4792 & TRN & & \\
\hline CHEMBL 3800501 & 1575134 & 5.7595 & 5.6131 & TRN & & \\
\hline CHEMBL 3798920 & 1575134 & 6.7852 & 6.9027 & TRN & & \\
\hline CHEMBL3799598 & 1575134 & 6.9031 & 7.1651 & TRN & & \\
\hline CHEMBL 3798869 & 1575134 & 6.8861 & 6.7786 & TRN & & \\
\hline CHEMBL 3797612 & 1575134 & 2.51 & 2.5027 & TRN & & \\
\hline CHEMBL 3799413 & 1575134 & 6.7167 & 6.5957 & TST & & \\
\hline CHEMBL 3797414 & 1575134 & 6.7905 & 6.4121 & TRN & & \\
\hline CHEMBL 3798290 & 1575134 & 4.5143 & 4.6796 & TST & & \\
\hline CHEMBL 3799110 & 1575134 & 4.0453 & 3.9041 & TRN & & \\
\hline CHEMBL 3798596 & 1575134 & 5.8182 & 6.1368 & TST & & \\
\hline CHEMBL 3800201 & 1575134 & 4.9957 & 6.2097 & TST & & \\
\hline CHEMBL 3800249 & 1575134 & 7.3054 & 7.6054 & TST & & \\
\hline CHEMBL 3798890 & 1575134 & 5.6968 & 6.1922 & TRN & & \\
\hline CHEMBL 3800126 & 1575134 & 5.3335 & 5.449 & TRN & & \\
\hline CHEMBL 3797236 & 1575134 & 6.4685 & 6.7447 & TRN & & \\
\hline CHEMBL 3797719 & 1575134 & 5.5969 & 5.8783 & TRN & & \\
\hline CHEMBL 3797408 & 1575134 & 4.1203 & 5.4397 & TST & & \\
\hline CHEMBL3799121 & 1575134 & 5.8239 & 6.1527 & TRN & & \\
\hline CHEMBL 3797477 & 1575134 & 6.8268 & 7.0643 & TRN & & \\
\hline CHEMBL 3799989 & 1575134 & 8.0458 & 7.9438 & TST & & \\
\hline CHEMBL 3797511 & 1575134 & 4.8761 & 4.7738 & TRN & & \\
\hline CHEMBL 3797291 & 1575134 & 6.5719 & 6.5919 & TST & & \\
\hline CHEMBL3799915 & 1575134 & 6.1925 & 6.1078 & TST & & \\
\hline CHEMBL 3800484 & 1575134 & \multicolumn{3}{|c|}{5.2139999999999995} & 5.4335 & III \\
\hline CHEMBL 3800083 & 1575134 & 4.9431 & 4.7589 & TST & & \\
\hline CHEMBL 3799384 & 1575134 & 5.7878 & 5.9125 & TRN & & \\
\hline CHEMBL 3800173 & 1575134 & 4.209 & 5.2338 & TST & & \\
\hline CHEMBL 3799844 & 1575134 & 5.6576 & 5.6497 & TST & & \\
\hline CHEMBL 3800520 & 1575134 & 6.2924 & 6.6554 & TST & & \\
\hline CHEMBL 3797545 & 1575134 & 6.6968 & 6.4592 & TST & & \\
\hline CHEMBL 3800344 & 1575134 & 4.5331 & 4.8477 & TRN & & \\
\hline CHEMBL 3800370 & 1575134 & 6.7825 & 6.2343 & TST & & \\
\hline CHEMBL 3798472 & 1575134 & 6.8761 & 6.6684 & TRN & & \\
\hline CHEMBL3799479 & 1575134 & 6.2573 & 5.9559 & TRN & & \\
\hline CHEMBL 3799240 & 1575134 & 7.2865 & 7.6336 & TST & & \\
\hline CHEMBL 3799164 & 1575134 & 4.2765 & 5.0797 & TST & & \\
\hline CHEMBL 3798255 & 1575134 & 5.7986 & 5.7943 & TRN & & \\
\hline CHEMBL 3799714 & 1575134 & 6.3372 & 6.4084 & TRN & & \\
\hline CHEMBL 3800117 & 1575134 & 6.983 & 6.7047 & TRN & & \\
\hline CHEMBL1459740 & 1575134 & 6.2708 & 6.3688 & TST & & \\
\hline CHEMBL 3797262 & 1575134 & 6.0742 & 6.7962 & TST & & \\
\hline CHEMBL 3799277 & 1575134 & 5.4401 & 5.3024 & TRN & & \\
\hline CHEMBL1700889 & 812916 & 5.0825 & 5.2168 & TRN & & \\
\hline CHEMBL1706542 & 812916 & 3.699 & 3.6848 & TRN & & \\
\hline
\end{tabular}




\begin{tabular}{|c|c|c|c|c|c|}
\hline & & \multicolumn{4}{|c|}{ Supplemental Table s2.txt } \\
\hline CHEMBL1710228 & 812916 & 3.699 & 3.7837 & TRN & \\
\hline CHEMBL1713298 & 812916 & 7.5229 & 7.5925 & TRN & \\
\hline CHEMBL1736791 & 812916 & 3.699 & 3.6647 & TRN & \\
\hline CHEMBL1733280 & 812916 & 5.4622 & 5.2781 & TRN & \\
\hline CHEMBL1363341 & 812916 & 3.699 & 2.7185 & TST & \\
\hline CHEMBL1728652 & 812916 & 3.699 & 3.7953 & TRN & \\
\hline CHEMBL1721360 & 812916 & 3.699 & 3.7066 & TRN & \\
\hline CHEMBL1728008 & 812916 & 3.699 & 4.9527 & TRN & \\
\hline CHEMBL1723582 & 812916 & 3.699 & 3.6919 & TRN & \\
\hline CHEMBL1721926 & 812916 & 5.8013 & 6.0128 & TRN & \\
\hline CHEMBL1716972 & 812916 & 3.699 & 3.7385 & TRN & \\
\hline CHEMBL1734509 & 812916 & 5.4461 & 5.5385 & TRN & \\
\hline CHEMBL1706382 & 812916 & 3.699 & 3.7305 & TRN & \\
\hline CHEMBL1729949 & 812916 & 3.699 & 3.7485 & TRN & \\
\hline CHEMBL1411903 & 812916 & 3.699 & 2.7505 & TST & \\
\hline CHEMBL1704728 & 812916 & 6.585 & 6.5246 & TRN & \\
\hline CHEMBL1569954 & 812916 & 6.2441 & 4.9527 & TRN & \\
\hline CHEMBL1433326 & 812916 & 3.699 & 3.3893 & TST & \\
\hline CHEMBL1569174 & 812916 & 6.3979 & 6.2892 & TRN & \\
\hline CHEMBL1719579 & 812916 & 3.699 & 4.6003 & TRN & \\
\hline CHEMBL1717353 & 812916 & 5.0731 & 5.0874 & TRN & \\
\hline CHEMBL1719980 & 812916 & 3.699 & 3.7766 & TRN & \\
\hline CHEMBL1731582 & 812916 & 3.699 & 3.7094 & TRN & \\
\hline CHEMBL1521474 & 812916 & 4.7011 & 5.0982 & TST & \\
\hline CHEMBL1718692 & 812916 & 3.699 & 3.67100 & 00000000003 & TRN \\
\hline CHEMBL1532328 & 812916 & 5.7328 & 5.6751 & TRN & \\
\hline CHEMBL1732337 & 812916 & 6.699 & 6.7642 & TRN & \\
\hline CHEMBL1731586 & 812916 & 3.699 & 3.5978 & TRN & \\
\hline CHEMBL1314048 & 812916 & 4.9245 & 4.4205 & TST & \\
\hline CHEMBL1700826 & 812916 & 3.699 & 3.825 & TRN & \\
\hline CHEMBL1720257 & 812916 & 5.75700 & 00000000 & 5.7054 & TRN \\
\hline CHEMBL1716673 & 812916 & 3.699 & 3.6711 & TRN & \\
\hline CHEMBL1720861 & 812916 & 3.699 & 3.5132 & TRN & \\
\hline CHEMBL1708215 & 812916 & 3.699 & 3.6653 & TRN & \\
\hline CHEMBL1726725 & 812916 & 3.699 & 3.7379 & TRN & \\
\hline CHEMBL1450407 & 812916 & 6.4089 & 6.3681 & TRN & \\
\hline CHEMBL1412853 & 812916 & 3.699 & 3.9743 & TST & \\
\hline CHEMBL1321508 & 812916 & 3.699 & 4.4146 & TST & \\
\hline CHEMBL1732890 & 812916 & 3.699 & 3.6873 & TRN & \\
\hline CHEMBL1316316 & 812916 & 3.699 & 4.162 & TST & \\
\hline CHEMBL1519988 & 812916 & 3.699 & 3.6526 & TST & \\
\hline CHEMBL1725712 & 812916 & 3.699 & 3.8357 & TRN & \\
\hline CHEMBL1717116 & 812916 & 5.4828 & 5.5986 & TRN & \\
\hline CHEMBL1700026 & 812916 & 3.699 & 3.6987 & TRN & \\
\hline CHEMBL1709705 & 812916 & 6.2218 & 6.2162 & TRN & \\
\hline CHEMBL1364793 & 812916 & 5.8097 & 5.7449 & TRN & \\
\hline CHEMBL 2018276 & 812916 & 3.699 & 4.3329 & TST & \\
\hline CHEMBL1727158 & 812916 & 3.699 & 3.6883 & TRN & \\
\hline
\end{tabular}




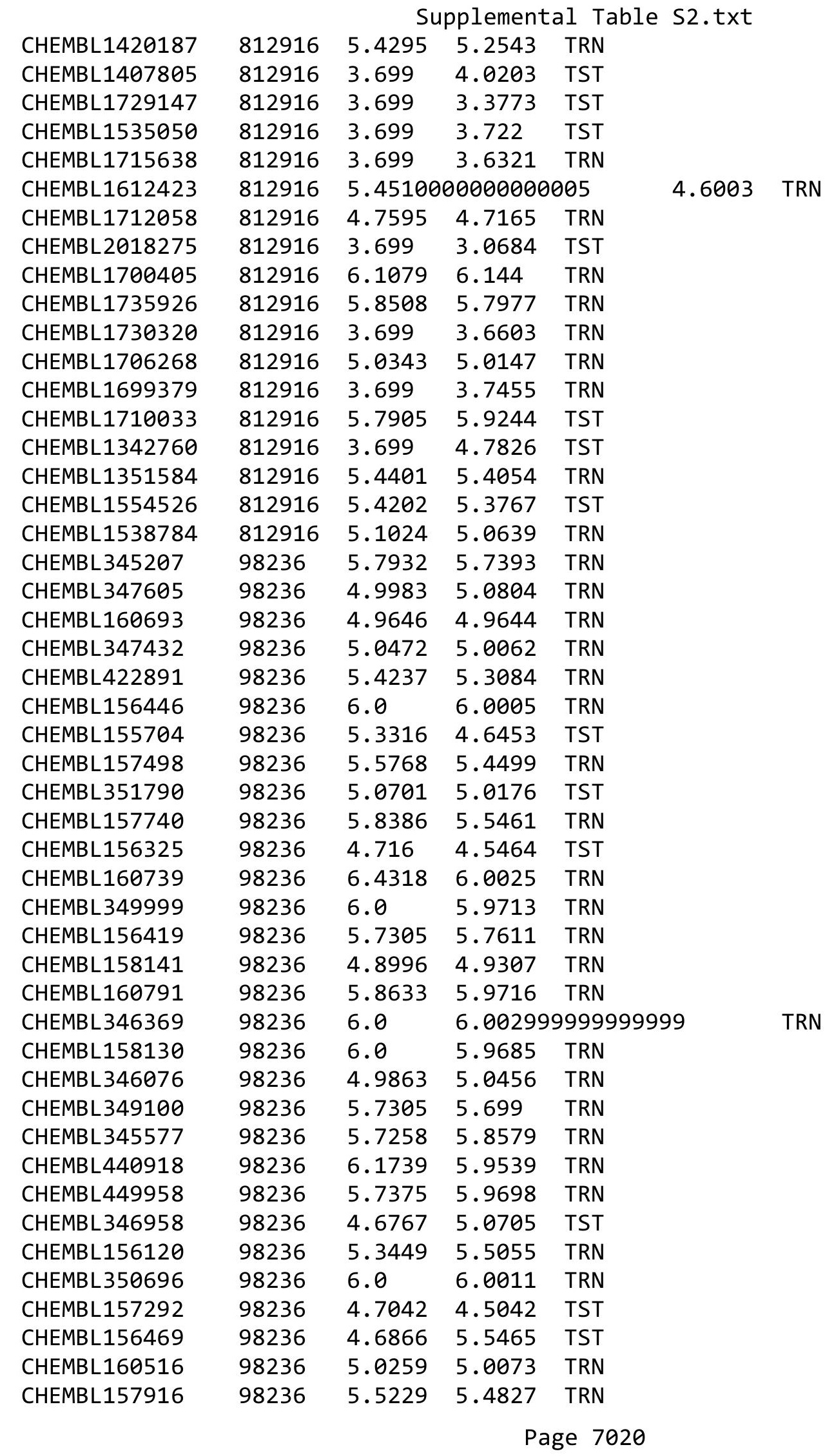




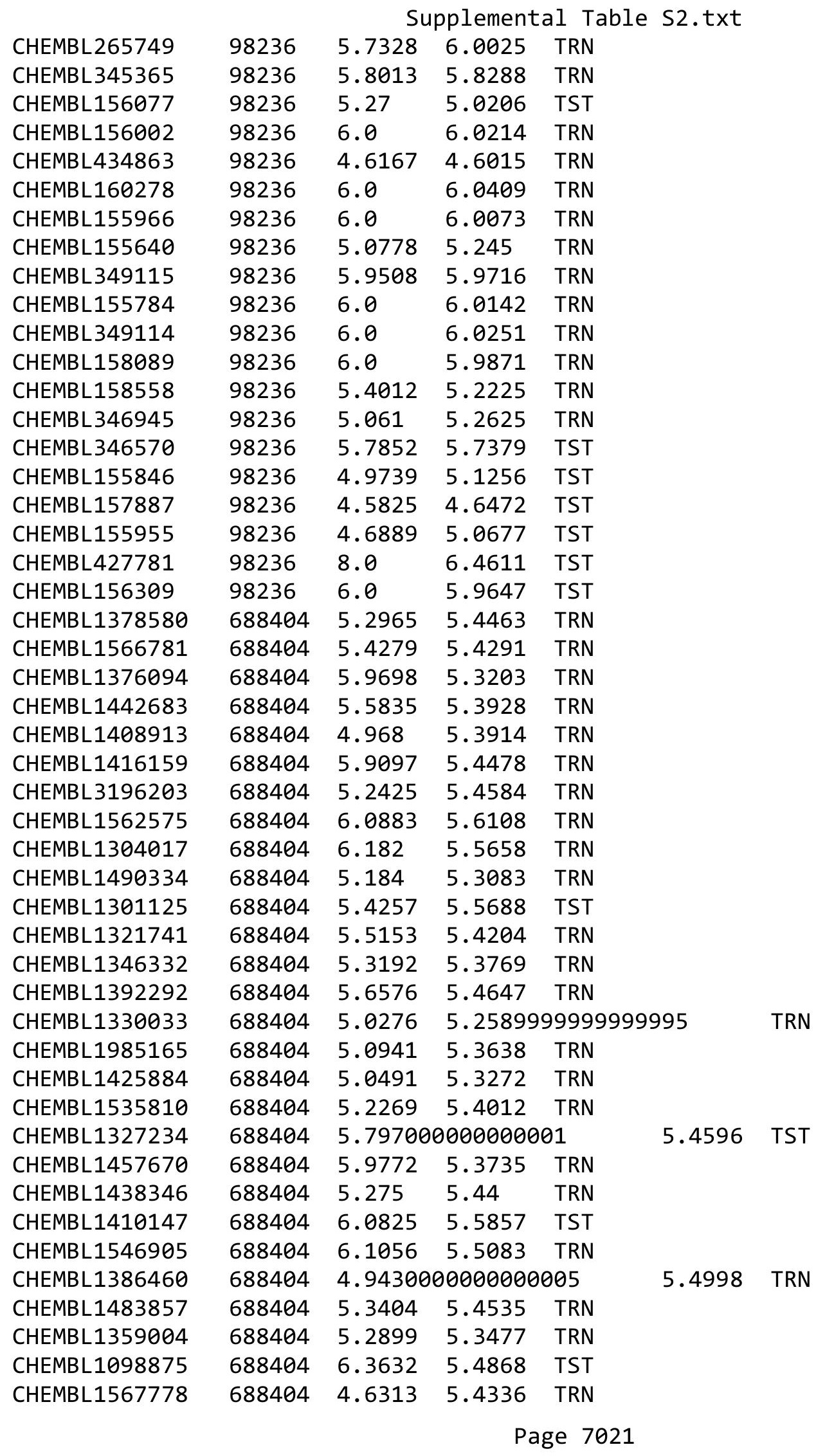




\begin{tabular}{|c|c|c|c|c|c|c|}
\hline & & & & & & \\
\hline CHEMBL3145193 & 688404 & 5.3565 & 5.3599 & TRN & & \\
\hline CHEMBL1607801 & 688404 & 5.857 & 5.6066 & TRN & & \\
\hline CHEMBL3198324 & 688404 & 5.8791 & 5.6795 & TRN & & \\
\hline CHEMBL3195410 & 688404 & 6.015 & 6.2325 & TRN & & \\
\hline CHEMBL1457822 & 688404 & 3.2218 & 5.3004 & TRN & & \\
\hline CHEMBL1491705 & 688404 & 3.2218 & 5.367006 & 0000000001 & & TST \\
\hline CHEMBL1311354 & 688404 & 5.5634 & 5.3592 & TRN & & \\
\hline CHEMBL1453089 & 688404 & 5.5265 & 5.332006 & 0000000001 & & TRN \\
\hline CHEMBL1613374 & 688404 & 5.4458 & 5.371 & TRN & & \\
\hline CHEMBL1432707 & 688404 & 5.492999 & 99999999 & 99 & 5.6704 & TST \\
\hline CHEMBL1326315 & 688404 & 7.5229 & 5.4799 & TST & & \\
\hline CHEMBL1393965 & 688404 & 5.1939 & 5.3439 & TRN & & \\
\hline CHEMBL1392762 & 688404 & 5.2326 & 5.2811 & TRN & & \\
\hline CHEMBL1575869 & 688404 & 5.2112 & 5.5507 & TRN & & \\
\hline CHEMBL1536318 & 688404 & 5.4177 & 5.372006 & 0000000001 & & TRN \\
\hline CHEMBL1987894 & 688404 & 5.8918 & 6.2575 & TRN & & \\
\hline CHEMBL1462497 & 688404 & 5.6212 & 5.5225 & TRN & & \\
\hline CHEMBL1320669 & 688404 & 6.9749 & 5.6528 & TRN & & \\
\hline CHEMBL1343916 & 688404 & 5.6405 & 5.3515 & TRN & & \\
\hline CHEMBL1545123 & 688404 & 6.0555 & 5.3946 & TRN & & \\
\hline CHEMBL1525749 & 688404 & 5.1535 & 5.3893 & TRN & & \\
\hline CHEMBL1508721 & 688404 & 5.0953 & 5.4172 & TRN & & \\
\hline CHEMBL1407606 & 688404 & 8.3925 & 5.7051 & TRN & & \\
\hline CHEMBL1562186 & 688404 & 5.0645 & 5.4226 & TST & & \\
\hline CHEMBL3209766 & 688404 & 5.7075 & 5.6904 & TRN & & \\
\hline CHEMBL1468337 & 688404 & 6.3287 & 5.4264 & TRN & & \\
\hline CHEMBL1998302 & 688404 & 6.0146 & 6.2935 & TRN & & \\
\hline CHEMBL1506658 & 688404 & 5.8814 & 5.3991 & TST & & \\
\hline CHEMBL1320096 & 688404 & 5.366006 & 000000006 & 205 & 5.3148 & TST \\
\hline CHEMBL3197091 & 688404 & 5.7755 & 6.2721 & TRN & & \\
\hline CHEMBL1346027 & 688404 & 4.1549 & 5.2746 & TRN & & \\
\hline CHEMBL1458996 & 688404 & 5.0165 & 5.3403 & TRN & & \\
\hline CHEMBL 3190880 & 688404 & 6.0334 & 6.2339 & TRN & & \\
\hline CHEMBL1325440 & 688404 & 5.7825 & 5.4654 & TRN & & \\
\hline CHEMBL1394002 & 688404 & 6.4858 & 5.4557 & TRN & & \\
\hline CHEMBL 2000517 & 688404 & 6.1828 & 6.4236 & TRN & & \\
\hline CHEMBL1495525 & 688404 & 4.776 & 5.4166 & TST & & \\
\hline CHEMBL1452159 & 688404 & 4.7499 & 5.329 & TRN & & \\
\hline CHEMBL3189714 & 688404 & 6.3589 & 6.4101 & TRN & & \\
\hline CHEMBL3196762 & 688404 & 6.0585 & 5.6438 & TRN & & \\
\hline CHEMBL1521872 & 688404 & 6.1376 & 5.4349 & TST & & \\
\hline CHEMBL1308342 & 688404 & 5.204 & 5.3713 & TST & & \\
\hline CHEMBL 2095095 & 688404 & 6.4583 & 6.4539 & TRN & & \\
\hline CHEMBL1546535 & 688404 & 6.4079 & 5.47 & TRN & & \\
\hline CHEMBL1999630 & 688404 & 6.2827 & 6.2682 & TRN & & \\
\hline CHEMBL482642 & 688404 & 5.1423 & 5.2746 & TRN & & \\
\hline CHEMBL1457057 & 688404 & 3.699 & 5.205 & TRN & & \\
\hline CHEMBL574583 & 688404 & 5.4698 & 5.4562 & TST & & \\
\hline
\end{tabular}




\begin{tabular}{|c|c|c|c|c|c|c|}
\hline & & \\
\hline CHEMBL1489355 & 688404 & 6.0395 & 5.4216 & TRN & & \\
\hline CHEMBL1982305 & 688404 & 6.2806 & 6.2515 & TRN & & \\
\hline CHEMBL1363786 & 688404 & 5.5552 & 5.3962 & TRN & & \\
\hline CHEMBL1454886 & 688404 & 5.1788 & 5.4805 & TRN & & \\
\hline CHEMBL1593722 & 688404 & 5.4833 & 5.5829 & TRN & & \\
\hline CHEMBL3197637 & 688404 & 5.8993 & 6.2376 & TRN & & \\
\hline CHEMBL1530789 & 688404 & 5.5986 & 5.3493 & TRN & & \\
\hline CHEMBL1430889 & 688404 & 5.4261 & 5.3478 & TRN & & \\
\hline CHEMBL1365827 & 688404 & 4.1549 & 5.4279 & TRN & & \\
\hline CHEMBL1451365 & 688404 & 6.0438 & 5.2057 & TRN & & \\
\hline CHEMBL 3194804 & 688404 & 5.9755 & 5.6906 & TRN & & \\
\hline CHEMBL1360123 & 688404 & 4.5363 & 5.2466 & TRN & & \\
\hline CHEMBL1581153 & 688404 & 5.5361 & 5.5743 & TRN & & \\
\hline CHEMBL1384677 & 688404 & 5.2641 & 5.4761 & TRN & & \\
\hline CHEMBL1612112 & 688404 & 5.7943 & 5.4704 & TRN & & \\
\hline CHEMBL1403324 & 688404 & 4.4524 & 5.3958 & TRN & & \\
\hline CHEMBL1592829 & 688404 & 5.2613 & 5.5279 & TRN & & \\
\hline CHEMBL1300605 & 688404 & 4.9888 & 5.2746 & TRN & & \\
\hline CHEMBL1535899 & 688404 & 6.6287 & 5.4517 & TRN & & \\
\hline CHEMBL1996724 & 688404 & 5.7926 & 6.3749 & TRN & & \\
\hline CHEMBL1583282 & 688404 & 6.1645 & 5.5094 & TRN & & \\
\hline CHEMBL1491154 & 688404 & 5.4161 & 5.4431 & TRN & & \\
\hline CHEMBL1561767 & 688404 & 5.2868 & 5.5149 & TRN & & \\
\hline CHEMBL1479424 & 688404 & 5.0771 & 5.4654 & TST & & \\
\hline CHEMBL1603549 & 688404 & 5.3438 & 5.4142 & TRN & & \\
\hline CHEMBL 3144973 & 688404 & \multicolumn{3}{|c|}{4.678999999999999} & 5.3744 & TRN \\
\hline CHEMBL1562712 & 688404 & 5.1353 & 5.4256 & TRN & & \\
\hline CHEMBL1389427 & 688404 & 5.166 & 5.4118 & TRN & & \\
\hline CHEMBL1412954 & 688404 & 5.671 & 5.4701 & TRN & & \\
\hline CHEMBL1521861 & 688404 & \multicolumn{3}{|c|}{5.622000000000001} & 5.5527 & TRN \\
\hline CHEMBL1503659 & 688404 & 5.0966 & 5.5303 & TST & & \\
\hline CHEMBL1310221 & 688404 & 6.4923 & 5.6348 & TRN & & \\
\hline CHEMBL2003651 & 688404 & 6.195 & 6.2756 & TRN & & \\
\hline CHEMBL1969046 & 688404 & 6.0367 & 6.2117 & TRN & & \\
\hline CHEMBL1428735 & 688404 & 5.3335 & 5.4645 & TRN & & \\
\hline CHEMBL1318777 & 688404 & 5.6014 & 5.3862 & TRN & & \\
\hline CHEMBL1321622 & 688404 & 5.3764 & 5.5447 & TST & & \\
\hline CHEMBL1505173 & 688404 & 6.2589 & 5.2563 & TST & & \\
\hline CHEMBL3195965 & 688404 & 5.8228 & 5.58799 & 9999999999 & & TST \\
\hline CHEMBL1505517 & 688404 & 3.2218 & 5.4423 & TST & & \\
\hline CHEMBL1567471 & 688404 & 5.0065 & 5.5771 & TST & & \\
\hline CHEMBL1418208 & 688404 & 5.31 & 5.5401 & TST & & \\
\hline CHEMBL1310341 & 688404 & 5.6115 & 5.5912 & TST & & \\
\hline CHEMBL1323055 & 688404 & 4.9182 & 5.4253 & TST & & \\
\hline CHEMBL1507355 & 688404 & 5.0922 & 5.4018 & TST & & \\
\hline CHEMBL1514691 & 688404 & 4.9911 & 5.3002 & TST & & \\
\hline CHEMBL3190098 & 688404 & 4.699 & 5.5511 & TST & & \\
\hline CHEMBL1977983 & 688404 & 6.1013 & 5.5747 & TST & & \\
\hline
\end{tabular}




\begin{tabular}{|c|c|c|c|c|c|c|}
\hline \multirow[b]{2}{*}{ CHEMBL1369231 } & & \multicolumn{5}{|c|}{ Supplemental Table S2.txt } \\
\hline & 688404 & 3.2218 & 5.4371 & TST & & \\
\hline CHEMBL1380039 & 688404 & 5.4285 & 5.4027 & TST & & \\
\hline CHEMBL1335818 & 688404 & \multicolumn{3}{|c|}{5.757999999999999} & 5.2543 & TST \\
\hline CHEMBL1349639 & 688404 & 6.5033 & 5.6734 & TST & & \\
\hline CHEMBL188678 & 954721 & 3.9692 & 4.2551 & TRN & & \\
\hline CHEMBL 3186408 & 954721 & 5.2433 & 3.7978 & TST & & \\
\hline CHEMBL1673039 & 954721 & 5.1479 & 4.8232 & TRN & & \\
\hline CHEMBL191334 & 954721 & 4.9256 & 5.24 & TRN & & \\
\hline CHEMBL1970879 & 954721 & 4.1593 & 4.0518 & TRN & & \\
\hline CHEMBL558642 & 954721 & 3.4137 & 3.1959 & TRN & & \\
\hline CHEMBL1788116 & 954721 & 3.8557 & 3.8239 & TRN & & \\
\hline CHEMBL220241 & 954721 & 5.0602 & 4.8769 & TRN & & \\
\hline CHEMBL379975 & 954721 & 3.8588 & 4.1877 & TRN & & \\
\hline CHEMBL180127 & 954721 & 4.5607 & 4.3931 & TRN & & \\
\hline CHEMBL 209148 & 954721 & 4.9053 & 4.707 & TRN & & \\
\hline CHEMBL221137 & 954721 & 4.3644 & 4.2353 & TST & & \\
\hline CHEMBL483849 & 954721 & 1.0922 & 2.5624 & TST & & \\
\hline CHEMBL92309 & 954721 & 2.9614 & 2.7594 & TST & & \\
\hline CHEMBL 2363137 & 954721 & 5.4156 & 5.2247 & TRN & & \\
\hline CHEMBL577784 & 954721 & 4.5002 & 4.315 & TRN & & \\
\hline CHEMBL449158 & 954721 & 6.6625 & 6.3266 & TST & & \\
\hline CHEMBL 2134202 & 954721 & 4.8714 & 4.9666 & TRN & & \\
\hline CHEMBL 2005886 & 954721 & \multicolumn{3}{|c|}{5.0680000000000005} & 4.9524 & TRN \\
\hline CHEMBL1230020 & 954721 & 4.4113 & 4.8929 & TRN & & \\
\hline CHEMBL222102 & 954721 & 3.6306 & 3.4986 & TRN & & \\
\hline CHEMBL102714 & 954721 & 4.5568 & 4.3789 & TRN & & \\
\hline CHEMBL3199475 & 954721 & 3.9538 & 3.9604 & TRN & & \\
\hline CHEMBL1190711 & 954721 & 3.2494 & 3.7279 & TRN & & \\
\hline CHEMBL1357247 & 954721 & 3.0136 & 2.9849 & TRN & & \\
\hline CHEMBL392695 & 954721 & 5.2421 & 5.1818 & TRN & & \\
\hline CHEMBL512504 & 954721 & 4.3324 & 4.4287 & TRN & & \\
\hline CHEMBL 3392440 & 954721 & 3.7628 & 3.8656 & TRN & & \\
\hline CHEMBL412142 & 954721 & 3.6627 & 4.1285 & TRN & & \\
\hline CHEMBL9470 & 954721 & 4.5791 & 5.0496 & TST & & \\
\hline CHEMBL399530 & 954721 & 3.4776 & 3.9788 & TRN & & \\
\hline CHEMBL202721 & 954721 & 4.25 & 4.5556 & TRN & & \\
\hline CHEMBL472940 & 954721 & 3.5068 & 2.9727 & TRN & & \\
\hline CHEMBL573107 & 954721 & 3.3634 & 4.1648 & TRN & & \\
\hline CHEMBL189584 & 954721 & 3.6543 & 4.2291 & TRN & & \\
\hline CHEMBL514499 & 954721 & 6.8851 & 6.6434 & TRN & & \\
\hline CHEMBL255342 & 954721 & 4.0405 & 3.8648 & TRN & & \\
\hline CHEMBL217354 & 954721 & 6.2582 & 5.8426 & TRN & & \\
\hline CHEMBL1242367 & 954721 & 4.3024 & 3.9195 & TRN & & \\
\hline CHEMBL1909414 & 954721 & 5.9464 & 5.2247 & TRN & & \\
\hline CHEMBL393929 & 954721 & 3.4425 & 3.5947 & TRN & & \\
\hline CHEMBL483847 & 954721 & 4.4494 & 4.4671 & TRN & & \\
\hline CHEMBL259181 & 954721 & 3.4358 & 3.8864 & TRN & & \\
\hline CHEMBL585951 & 954721 & 5.9057 & 5.581 & TRN & & \\
\hline
\end{tabular}


Supplemental Table S2.txt

\begin{tabular}{|c|c|c|c|c|c|}
\hline CHEMBL192566 & 954721 & 6.9378 & 6.2657 & TST & \\
\hline CHEMBL515416 & 954721 & 3.6555 & 3.7404 & TRN & \\
\hline CHEMBL379300 & 954721 & 5.2219 & 5.4096 & TRN & \\
\hline CHEMBL 2144069 & 954721 & 7.5608 & 8.0326 & TRN & \\
\hline CHEMBL65 & 954721 & 6.9357 & 6.8472 & TRN & \\
\hline CHEMBL258844 & 954721 & 4.0846 & 3.8665 & TRN & \\
\hline CHEMBL135561 & 954721 & 4.9893 & 4.4934 & TRN & \\
\hline CHEMBL300389 & 954721 & 5.8617 & 5.7357 & TRN & \\
\hline CHEMBL1256459 & 954721 & 7.0073 & 6.9943 & TRN & \\
\hline CHEMBL1643959 & 954721 & 3.2771 & 2.9422 & TRN & \\
\hline CHEMBL210618 & 954721 & 3.264 & 3.2546 & TRN & \\
\hline CHEMBL213100 & 954721 & 3.5418 & 4.9088 & TST & \\
\hline CHEMBL373751 & 954721 & 3.5237 & 3.8266 & TST & \\
\hline CHEMBL509032 & 954721 & 4.8752 & 4.8178 & TST & \\
\hline CHEMBL1516890 & 954721 & 5.8161 & 4.0763 & TST & \\
\hline CHEMBL1590308 & 954721 & 2.9884 & 3.69 & TST & \\
\hline CHEMBL240954 & 954721 & 3.65100 & 00000000 & 3.617 & TST \\
\hline CHEMBL 3349342 & 954721 & 7.1759 & 5.8672 & TST & \\
\hline CHEMBL1404918 & 954721 & 3.1622 & 3.2472 & TST & \\
\hline CHEMBL 2137530 & 954721 & 5.0147 & 4.477 & TST & \\
\hline CHEMBL1186585 & 954721 & 4.5883 & 4.8039 & TST & \\
\hline CHEMBL573107 & 954972 & 6.2033 & 6.2005 & TRN & \\
\hline CHEMBL449158 & 954972 & 7.6189 & 7.2857 & TST & \\
\hline CHEMBL483847 & 954972 & 3.4603 & 3.4594 & TRN & \\
\hline CHEMBL 2363137 & 954972 & 5.1424 & 5.1401 & TRN & \\
\hline CHEMBL379975 & 954972 & 4.1122 & 4.1129 & TRN & \\
\hline CHEMBL509032 & 954972 & 5.1919 & 5.1891 & TRN & \\
\hline CHEMBL379300 & 954972 & 7.0155 & 7.0176 & TRN & \\
\hline CHEMBL1190711 & 954972 & 5.3726 & 5.3679 & TRN & \\
\hline CHEMBL1970879 & 954972 & 4.9703 & 4.968 & TRN & \\
\hline CHEMBL180127 & 954972 & 4.7631 & 4.7643 & TRN & \\
\hline CHEMBL259181 & 954972 & \multicolumn{3}{|c|}{6.196000000000001} & TRN \\
\hline CHEMBL585951 & 954972 & 6.4714 & 6.4749 & TRN & \\
\hline CHEMBL1357247 & 954972 & 4.0825 & 4.0836 & TRN & \\
\hline CHEMBL 2144069 & 954972 & 5.0954 & 5.0989 & TRN & \\
\hline CHEMBL392695 & 954972 & 5.1347 & 5.1353 & TRN & \\
\hline CHEMBL515416 & 954972 & 4.5977 & 4.59699 & 99999999995 & $1 \mathrm{NI}$ \\
\hline CHEMBL412142 & 954972 & 4.8691 & 4.8692 & TRN & \\
\hline CHEMBL192566 & 954972 & 8.6741 & 8.81 & TST & \\
\hline CHEMBL512504 & 954972 & 4.8552 & 4.8589 & TRN & \\
\hline CHEMBL1404918 & 954972 & 4.5525 & 4.5526 & TRN & \\
\hline CHEMBL1909414 & 954972 & 5.0936 & 5.08899 & 99999999995 & $1 \mathrm{NI}$ \\
\hline CHEMBL1256459 & 954972 & 7.8874 & 7.8887 & TRN & \\
\hline CHEMBL1230020 & 954972 & 4.2514 & 4.25 & TRN & \\
\hline CHEMBL221137 & 954972 & 3.9058 & 4.8935 & TST & \\
\hline CHEMBL209148 & 954972 & 5.0473 & 5.0485 & TRN & \\
\hline CHEMBL1242367 & 954972 & 5.0421 & 5.0426 & TRN & \\
\hline CHEMBL 9470 & 954972 & 8.0806 & 7.4513 & TST & \\
\hline
\end{tabular}




\begin{tabular}{|c|c|c|c|c|c|}
\hline & & \multicolumn{4}{|c|}{ Supplemental Table S2.txt } \\
\hline CHEMBL1590308 & 954972 & 3.7907 & 3.4139 & TST & \\
\hline CHEMBL220241 & 954972 & 4.6292 & 4.6291 & TRN & \\
\hline CHEMBL373751 & 954972 & 2.9157 & 2.9189 & TRN & \\
\hline CHEMBL258844 & 954972 & 5.7629 & 5.7602 & TRN & \\
\hline CHEMBL1673039 & 954972 & 5.1291 & 5.1302 & TRN & \\
\hline CHEMBL213100 & 954972 & 5.0764 & 5.0774 & TRN & \\
\hline CHEMBL3186408 & 954972 & 4.0298 & 3.3368 & TST & \\
\hline CHEMBL3392440 & 954972 & 4.4613 & 4.4649 & TRN & \\
\hline CHEMBL514499 & 954972 & 7.0697 & 7.0687 & TRN & \\
\hline CHEMBL 3349342 & 954972 & 6.6219 & 6.6214 & TRN & \\
\hline CHEMBL300389 & 954972 & 7.3465 & 7.3458 & TRN & \\
\hline CHEMBL 202721 & 954972 & 5.1312 & 5.1294 & TRN & \\
\hline CHEMBL1643959 & 954972 & 4.5722 & 4.576000 & 00000000005 & TRN \\
\hline CHEMBL135561 & 954972 & 4.1137 & 4.1096 & TRN & \\
\hline CHEMBL472940 & 954972 & 5.5592 & 5.5584 & TRN & \\
\hline CHEMBL1516890 & 954972 & 3.8441 & 3.8429 & TRN & \\
\hline CHEMBL92309 & 954972 & 4.5458 & 3.4032 & TST & \\
\hline CHEMBL3199475 & 954972 & 3.3939 & 3.3941 & TRN & \\
\hline CHEMBL240954 & 954972 & 3.6215 & 3.621000 & 00000000004 & TRN \\
\hline CHEMBL393929 & 954972 & 3.4503 & 3.4504 & TRN & \\
\hline CHEMBL558642 & 954972 & 5.6601 & 5.2179 & TST & \\
\hline CHEMBL65 & 954972 & 8.0775 & 7.9004 & TST & \\
\hline CHEMBL1788116 & 954972 & 5.1775 & 5.6146 & TST & \\
\hline CHEMBL 2005886 & 954972 & 4.4883 & 6.0149 & TST & \\
\hline CHEMBL210618 & 954972 & 3.1869 & 2.5595 & TST & \\
\hline CHEMBL191334 & 954972 & 4.101 & 3.9957 & TST & \\
\hline CHEMBL189584 & 954972 & 4.96899 & 999999999 & 4.0962 & TST \\
\hline CHEMBL 2331562 & 1466704 & 6.2147 & 6.0404 & TRN & \\
\hline CHEMBL 2332079 & 1466704 & 3.699 & 5.6715 & TRN & \\
\hline CHEMBL3402465 & 1466704 & 6.2291 & 6.2044 & TRN & \\
\hline CHEMBL3402451 & 1466704 & 6.1284 & 5.6739 & TST & \\
\hline CHEMBL3402460 & 1466704 & 3.699 & 5.0732 & TRN & \\
\hline CHEMBL 2332058 & 1466704 & 6.4101 & 5.8543 & TST & \\
\hline CHEMBL 2332085 & 1466704 & 3.699 & 4.5645 & TRN & \\
\hline CHEMBL 2332091 & 1466704 & 6.2857 & 4.7493 & TRN & \\
\hline CHEMBL 2332065 & 1466704 & 5.5246 & 5.5945 & TRN & \\
\hline CHEMBL 3402447 & 1466704 & 6.0883 & 5.8288 & TRN & \\
\hline CHEMBL3402459 & 1466704 & 5.2819 & 5.0685 & TRN & \\
\hline CHEMBL 2332059 & 1466704 & 6.6234 & 5.7334 & TST & \\
\hline CHEMBL 2332069 & 1466704 & 6.2668 & 5.4727 & TRN & \\
\hline CHEMBL 2332078 & 1466704 & 5.5089 & 5.8212 & TRN & \\
\hline CHEMBL3402468 & 1466704 & 3.699 & 5.2321 & TST & \\
\hline CHEMBL3402470 & 1466704 & 4.9205 & 4.8546 & TST & \\
\hline CHEMBL 2332083 & 1466704 & 5.0969 & 5.5455 & TST & \\
\hline CHEMBL3402458 & 1466704 & 5.447 & 5.9813 & TRN & \\
\hline CHEMBL3402445 & 1466704 & 6.3429 & 6.4757 & TRN & \\
\hline CHEMBL 2332073 & 1466704 & 6.4711 & 5.4779 & TRN & \\
\hline CHEMBL3402453 & 1466704 & 6.7878 & 5.4904 & TRN & \\
\hline
\end{tabular}


Supplemental Table S2.txt

\begin{tabular}{|c|c|c|c|c|}
\hline 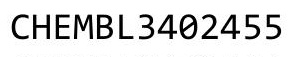 & 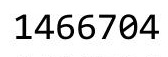 & & & \\
\hline HEMBL 3402444 & 466704 & 3925 & 6.2239 & \\
\hline HEMBL2332072 & 466704 & 6.1403 & 5076 & \\
\hline & 704 & & 903 & \\
\hline IEMBL23320 & 704 & & & \\
\hline AEMBL3402450 & 466704 & .2889 & .5695 & \\
\hline HEMBL 2332071 & 466704 & 5.4176 & .4904 & \\
\hline HEMBL2332075 & 466704 & 931 & 5.2954 & \\
\hline AEMBL23 & 704 & & 9475 & \\
\hline IEMBL 34 & 704 & & & \\
\hline HEMBL2332088 & 466704 & 4.8703 & .5522 & \\
\hline HEMBL 2332098 & 466704 & 5.331 & 5.4361 & \\
\hline HEMBL3402448 & 704 & 75 & 5.7653 & \\
\hline AEMBL23 & 104 & & 589 & \\
\hline HEMBL23 & 104 & & 5787 & \\
\hline HEMBL2332066 & 466704 & 4.9776 & 5.4191 & \\
\hline AEMBL 340 & 466704 & 5.58 & & \\
\hline HEMBL 23 & 04 & 5 & 5.3482 & \\
\hline L23 & 04 & & 18 & \\
\hline HEM & & & 83 & \\
\hline HEMBL 340 & 466704 & & 4927 & \\
\hline AEMB L 3402441 & & & & \\
\hline HEMBL 23 & 04 & 5 & 5.5531 & RN \\
\hline HEN & & & 18 & \\
\hline 7 & & & 17 & \\
\hline L34 & 5704 & & 4.8731 & \\
\hline AEMBL 2332 & & & & I RN \\
\hline HEMBL34 & 04 & & 289 & RN \\
\hline HEN & & & 77 & \\
\hline L34 & 04 & 6 . & & RN \\
\hline AEMBL2332068 & & & & $5 \mathrm{~T}$ \\
\hline HEMBL 2332060 & 466704 & & 78 & TRN \\
\hline HEMBL2 & & & 956 & RN \\
\hline IIN & & & 93 & RIN \\
\hline 9 & & & 242 & RN \\
\hline AEMBL2332067 & & & 761 & IST \\
\hline AEMBL3402452 & 6704 & & 511 & TRN \\
\hline LI & & & & \\
\hline 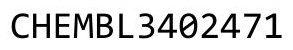 & & & & II \\
\hline & & & 134 & TRN \\
\hline AEMBL3402454 & 466704 & & & ГRN \\
\hline AEMBL3 & 504 & & 507 & ГRN \\
\hline & & & & \\
\hline CHEMBL 23 & & & 1544 & \\
\hline HEMBL3402466 & 6704 & 6.0545 & 7919 & RN \\
\hline AEMBL 38 & 7340 & & 5.9916 & \\
\hline & & & & \\
\hline & מריר & & & \\
\hline
\end{tabular}

Page 7027 
Supplemental Table S2.txt

\begin{tabular}{|c|c|c|c|c|}
\hline CHEMBL 2448545 & 327340 & 5.5129 & 5.9234 & TST \\
\hline CHEMBL 380751 & 327340 & 5.7773 & 5.7724 & TRN \\
\hline CHEMBL202778 & 327340 & 5.2874 & 5.2861 & TRN \\
\hline CHEMBL 203140 & 327340 & 5.5834 & 5.8142 & TST \\
\hline CHEMBL198407 & 327340 & 5.6968 & 5.7234 & TRN \\
\hline CHEMBL 201545 & 327340 & 5.6968 & 5.6486 & TRN \\
\hline CHEMBL 201487 & 327340 & 5.8539 & 5.8994 & TRN \\
\hline CHEMBL201579 & 327340 & 4.3247 & 4.3128 & TRN \\
\hline CHEMBL 382137 & 327340 & 5.6383 & 5.6157 & TRN \\
\hline CHEMBL201380 & 327340 & 6.4437 & 6.3305 & TRN \\
\hline CHEMBL199942 & 327340 & 5.5607 & 5.5622 & TRN \\
\hline CHEMBL 202379 & 327340 & 5.3382 & 5.4715 & TRN \\
\hline CHEMBL201704 & 327340 & 5.9626 & 6.007006 & 0000000001 \\
\hline CHEMBL 201734 & 327340 & 5.6289 & 5.6397 & TRN \\
\hline CHEMBL199332 & 327340 & 6.3468 & 6.3861 & TRN \\
\hline CHEMBL370376 & 327340 & 5.3645 & 5.4092 & TRN \\
\hline CHEMBL199601 & 327340 & 6.1024 & 6.0763 & TRN \\
\hline CHEMBL202976 & 327340 & 5.3595 & 5.3425 & TRN \\
\hline CHEMBL 201590 & 327340 & 6.0605 & 5.9643 & TRN \\
\hline CHEMBL381989 & 327340 & 5.4134 & 5.4167 & TRN \\
\hline CHEMBL 202975 & 327340 & 5.4685 & 5.5153 & TRN \\
\hline CHEMBL201637 & 327340 & 5.1733 & 5.2801 & TST \\
\hline CHEMBL199889 & 327340 & 5.5017 & 5.4765 & TRN \\
\hline CHEMBL 380823 & 327340 & 6.1549 & 6.1153 & TRN \\
\hline CHEMBL202978 & 327340 & 5.8182 & 5.7621 & TRN \\
\hline CHEMBL437138 & 327340 & 5.5346 & 5.5103 & TRN \\
\hline CHEMBL 201078 & 327340 & 5.6696 & 5.6372 & TRN \\
\hline CHEMBL437511 & 327340 & 5.2774 & 5.2845 & TRN \\
\hline CHEMBL 200132 & 327340 & 6.0605 & 6.0728 & TRN \\
\hline CHEMBL201345 & 327340 & 5.7423 & 5.8222 & TRN \\
\hline CHEMBL199556 & 327340 & 5.5391 & 5.528 & TRN \\
\hline CHEMBL199604 & 327340 & 6.0362 & 6.0226 & TRN \\
\hline CHEMBL201503 & 327340 & 3.2596 & 4.4966 & TST \\
\hline CHEMBL199953 & 327340 & 5.8268 & 5.8805 & TRN \\
\hline CHEMBL 201238 & 327340 & 6.0757 & 6.1028 & TRN \\
\hline CHEMBL383494 & 327340 & 3.2291 & 4.6507 & TST \\
\hline CHEMBL381737 & 327340 & 5.213999 & 99999999 & 5.1929 \\
\hline CHEMBL383608 & 327340 & 5.6108 & 5.6116 & TRN \\
\hline CHEMBL 201123 & 327340 & 6.0 & 5.7695 & TST \\
\hline CHEMBL381044 & 327340 & 5.7375 & 5.7244 & TRN \\
\hline CHEMBL380413 & 327340 & 3.2411 & 4.6861 & TST \\
\hline CHEMBL382849 & 327340 & 5.9281 & 5.9962 & TRN \\
\hline CHEMBL201319 & 327340 & 5.2716 & 5.2596 & TRN \\
\hline CHEMBL 380657 & 327340 & 6.0177 & 5.9911 & TRN \\
\hline CHEMBL 382802 & 327340 & 5.1113 & 5.0955 & TRN \\
\hline CHEMBL 201134 & 327340 & 5.475 & 5.489 & TRN \\
\hline CHEMBL 377948 & 327340 & 5.2351 & 5.6351 & TST \\
\hline CHEMBL201356 & 327340 & 5.6696 & 5.6919 & TST \\
\hline
\end{tabular}




\begin{tabular}{|c|c|c|c|c|c|}
\hline & & & & & \\
\hline CHEMBL413570 & 327340 & 5.6596 & 5.6064 & TST & \\
\hline CHEMBL202664 & 327340 & 5.5513 & 5.5598 & TST & \\
\hline CHEMBL201682 & 327340 & 5.1343 & 5.6137 & TST & \\
\hline CHEMBL369978 & 327340 & 5.5376 & 5.7257 & TST & \\
\hline CHEMBL197594 & 327340 & 4.2599 & 5.1241 & TST & \\
\hline CHEMBL3189740 & 688648 & 2.8239 & 2.603 & TRN & \\
\hline CHEMBL1392351 & 688648 & 4.6663 & 3.5238 & TRN & \\
\hline CHEMBL1417780 & 688648 & 2.8239 & 3.4031 & TRN & \\
\hline CHEMBL461820 & 688648 & 2.8239 & 3.8935 & TST & \\
\hline CHEMBL1457311 & 688648 & 2.8239 & 2.8857 & TRN & \\
\hline CHEMBL1443632 & 688648 & 4.7643 & 4.606 & TRN & \\
\hline CHEMBL1376810 & 688648 & 2.8239 & 3.8884 & TRN & \\
\hline CHEMBL1530220 & 688648 & 2.8239 & 3.4272 & TST & \\
\hline CHEMBL1532436 & 688648 & 4.8492 & 4.6165 & TRN & \\
\hline CHEMBL1500382 & 688648 & 4.7486 & 3.5104 & TRN & \\
\hline CHEMBL1540477 & 688648 & 2.8239 & 3.6588 & TRN & \\
\hline CHEMBL1472773 & 688648 & 2.8239 & 3.5145 & TST & \\
\hline CHEMBL1446364 & 688648 & 3.9448 & 3.5589 & TRN & \\
\hline CHEMBL1605668 & 688648 & 5.0548 & 3.8768 & TRN & \\
\hline CHEMBL1443936 & 688648 & 4.3373 & 3.5847 & TST & \\
\hline CHEMBL1305787 & 688648 & 4.9384 & 3.5552 & TST & \\
\hline CHEMBL1428221 & 688648 & 2.8239 & 3.9891 & TRN & \\
\hline CHEMBL1390437 & 688648 & 2.8239 & 3.09899 & 99999999998 & TRN \\
\hline CHEMBL1434750 & 688648 & 3.301 & 3.7509 & TRN & \\
\hline CHEMBL1425861 & 688648 & 2.8239 & 3.3507 & TRN & \\
\hline CHEMBL1399731 & 688648 & 2.8239 & 3.2026 & TRN & \\
\hline CHEMBL1332013 & 688648 & 2.8239 & 3.1152 & TRN & \\
\hline CHEMBL1508440 & 688648 & 5.155 & 4.3413 & TST & \\
\hline CHEMBL1331573 & 688648 & 4.9231 & 4.3064 & TRN & \\
\hline CHEMBL1546634 & 688648 & 4.4322 & 3.8901 & TRN & \\
\hline CHEMBL1472532 & 688648 & 4.5452 & 3.4385 & TRN & \\
\hline CHEMBL1466495 & 688648 & 4.3709 & 4.2971 & TRN & \\
\hline CHEMBL1312303 & 688648 & 2.8239 & 2.5574 & TRN & \\
\hline CHEMBL1385676 & 688648 & 2.8239 & 3.139 & TRN & \\
\hline CHEMBL1451873 & 688648 & 2.8239 & 3.4451 & TRN & \\
\hline CHEMBL533226 & 688648 & 3.301 & 3.3685 & TRN & \\
\hline CHEMBL1997052 & 688648 & 2.8239 & 3.6254 & TRN & \\
\hline CHEMBL1609988 & 688648 & 4.6807 & 4.0291 & TST & \\
\hline CHEMBL1547031 & 688648 & 4.1338 & 4.2291 & TRN & \\
\hline CHEMBL1403172 & 688648 & 2.8239 & 3.3477 & TRN & \\
\hline CHEMBL1306690 & 688648 & 2.8239 & 3.9851 & TST & \\
\hline CHEMBL1494353 & 688648 & 2.8239 & 2.5594 & TRN & \\
\hline CHEMBL1388702 & 688648 & 4.3313 & 3.5551 & TRN & \\
\hline CHEMBL1435933 & 688648 & 2.8239 & 3.5695 & TRN & \\
\hline CHEMBL1470633 & 688648 & 2.8239 & 3.0746 & TRN & \\
\hline CHEMBL1391179 & 688648 & 2.8239 & 3.0612 & TST & \\
\hline CHEMBL1355233 & 688648 & 2.8239 & 3.5742 & TST & \\
\hline CHEMBL1476032 & 688648 & 2.8239 & 3.1518 & TRN & \\
\hline
\end{tabular}




\begin{tabular}{|c|c|c|c|c|c|}
\hline \multicolumn{6}{|c|}{ Supplemental Table S2.txt } \\
\hline CHEMBL1347282 & 688648 & 3.301 & 3.446 & TST & \\
\hline CHEMBL 3193835 & 688648 & 4.6213 & 3.8322 & TRN & \\
\hline CHEMBL1547685 & 688648 & 2.8239 & 3.4941 & TRN & \\
\hline CHEMBL1487432 & 688648 & 2.8239 & 3.6405 & TST & \\
\hline CHEMBL1568696 & 688648 & 2.8239 & 2.6836 & TST & \\
\hline CHEMBL1336052 & 688648 & 2.8239 & 3.6792 & TST & \\
\hline CHEMBL1417731 & 688648 & 2.8239 & 3.6749 & TRN & \\
\hline CHEMBL1450537 & 688648 & 4.0133 & 3.8425 & TRN & \\
\hline CHEMBL1364447 & 688648 & 2.8239 & 4.0803 & TRN & \\
\hline CHEMBL1579808 & 688648 & 2.8239 & 3.5458 & TRN & \\
\hline CHEMBL 3190585 & 688648 & 2.8239 & 3.5863 & TRN & \\
\hline CHEMBL1387503 & 688648 & 2.8239 & 3.0575 & TRN & \\
\hline CHEMBL1471698 & 688648 & 2.8239 & 3.2564 & TRN & \\
\hline CHEMBL1478856 & 688648 & 4.7237 & 3.5322 & TRN & \\
\hline CHEMBL1548396 & 688648 & 5.1198 & 4.0924 & TRN & \\
\hline CHEMBL1441983 & 688648 & 4.0022 & 3.5485 & TRN & \\
\hline CHEMBL1502401 & 688648 & 2.8239 & 3.3151 & TRN & \\
\hline CHEMBL1459931 & 688648 & 2.8239 & 2.5694 & TRN & \\
\hline CHEMBL1589219 & 688648 & 4.7756 & 3.5389 & TST & \\
\hline CHEMBL1309059 & 688648 & 4.7823 & 4.0791 & TRN & \\
\hline CHEMBL1359788 & 688648 & 2.8239 & 3.3156 & TRN & \\
\hline CHEMBL1585628 & 688648 & 5.6629 & 3.9768 & TRN & \\
\hline CHEMBL1391928 & 688648 & 5.7066 & 4.1933 & TRN & \\
\hline CHEMBL3195171 & 688648 & 2.8239 & 2.6137 & TRN & \\
\hline CHEMBL1398406 & 688648 & 2.8239 & 2.81 & TRN & \\
\hline CHEMBL1308319 & 688648 & 2.8239 & 3.0508 & TRN & \\
\hline CHEMBL1411063 & 688648 & 2.8239 & 3.0606 & TRN & \\
\hline CHEMBL1994935 & 688648 & 2.8239 & 3.4529 & TRN & \\
\hline CHEMBL1559226 & 688648 & 2.8239 & 3.4754 & TRN & \\
\hline CHEMBL3190592 & 688648 & 2.8239 & 2.95899 & 99999999996 & TRN \\
\hline CHEMBL1353339 & 688648 & 2.8239 & 3.839 & TRN & \\
\hline CHEMBL1388295 & 688648 & 2.8239 & 2.6525 & TRN & \\
\hline CHEMBL1993291 & 688648 & 5.2352 & 3.8662 & TRN & \\
\hline CHEMBL1305128 & 688648 & 4.3352 & 2.3475 & TRN & \\
\hline CHEMBL1328229 & 688648 & 4.3625 & 4.4841 & TRN & \\
\hline CHEMBL1301129 & 688648 & 4.6961 & 4.0683 & TRN & \\
\hline CHEMBL1610654 & 688648 & 2.8239 & 3.2186 & TRN & \\
\hline CHEMBL1302620 & 688648 & 2.8239 & 2.8672 & TST & \\
\hline CHEMBL1520325 & 688648 & 2.8239 & 3.5088 & TRN & \\
\hline CHEMBL1603147 & 688648 & 4.3847 & 4.295 & TST & \\
\hline CHEMBL1562963 & 688648 & 2.8239 & 2.6525 & TRN & \\
\hline CHEMBL45152 & 688648 & 2.8239 & 3.2298 & TRN & \\
\hline CHEMBL1387906 & 688648 & 2.8239 & 3.5054 & TRN & \\
\hline CHEMBL1325639 & 688648 & 2.8239 & 2.8538 & TRN & \\
\hline CHEMBL 3198213 & 688648 & 2.8239 & 3.1278 & TST & \\
\hline CHEMBL1520460 & 688648 & 2.8239 & 3.6477 & TRN & \\
\hline CHEMBL1569639 & 688648 & 2.8239 & 3.5051 & TRN & \\
\hline CHEMBL1550490 & 688648 & 5.0029 & 3.3675 & TRN & \\
\hline
\end{tabular}


Supplemental Table S2.txt

\begin{tabular}{|c|c|c|c|c|c|}
\hline CHEMBL1578492 & 688648 & 4.828 & 3.286 & TRN & \\
\hline CHEMBL1312746 & 688648 & 4.9014 & 4.0471 & TRN & \\
\hline CHEMBL1580339 & 688648 & 4.7336 & 3.8267 & TRN & \\
\hline CHEMBL1353506 & 688648 & 4.7562 & 3.6172 & TRN & \\
\hline CHEMBL1313236 & 688648 & 4.6906 & 3.7103 & TRN & \\
\hline CHEMBL1518998 & 688648 & 2.8239 & 2.6356 & TRN & \\
\hline CHEMBL1467238 & 688648 & 4.1642 & 3.2741 & TRN & \\
\hline CHEMBL1343537 & 688648 & 2.8239 & 4.1643 & TRN & \\
\hline CHEMBL1466193 & 688648 & 4.9259 & 3.9117 & TRN & \\
\hline CHEMBL1301353 & 688648 & 2.8239 & 3.7957 & TRN & \\
\hline CHEMBL1386178 & 688648 & 2.8239 & 3.8007 & TRN & \\
\hline CHEMBL1382418 & 688648 & 2.8239 & 3.0698 & TRN & \\
\hline CHEMBL1595276 & 688648 & 2.8239 & 3.5852 & TST & \\
\hline CHEMBL1417429 & 688648 & 4.5341 & 3.8279 & TRN & \\
\hline CHEMBL1558070 & 688648 & 2.8239 & 3.0679 & TRN & \\
\hline CHEMBL1437942 & 688648 & 2.8239 & 3.5715 & TRN & \\
\hline CHEMBL1371792 & 688648 & 2.8239 & 3.4424 & TRN & \\
\hline CHEMBL1546381 & 688648 & 2.8239 & 4.4311 & TRN & \\
\hline CHEMBL1419772 & 688648 & 5.4793 & 3.8207 & TST & \\
\hline CHEMBL1989426 & 688648 & 4.4888 & 3.1883 & TRN & \\
\hline CHEMBL1313074 & 688648 & 4.5724 & 3.9434 & TST & \\
\hline CHEMBL1580583 & 688648 & 2.8239 & 3.1775 & TRN & \\
\hline CHEMBL1452467 & 688648 & 2.8239 & 3.8396 & TRN & \\
\hline CHEMBL1407656 & 688648 & 2.8239 & 2.701 & TRN & \\
\hline CHEMBL1461337 & 688648 & 2.8239 & 3.353 & TRN & \\
\hline CHEMBL1378852 & 688648 & 2.8239 & 2.9944 & TRN & \\
\hline CHEMBL1373490 & 688648 & 2.8239 & 4.2854 & TRN & \\
\hline CHEMBL1351081 & 688648 & 5.1753 & 3.7874 & TRN & \\
\hline CHEMBL1973886 & 688648 & 4.9818 & 3.4865 & TRN & \\
\hline CHEMBL1325982 & 688648 & 2.8239 & 3.3133 & TRN & \\
\hline CHEMBL1424933 & 688648 & 4.6328 & 3.9909 & TRN & \\
\hline CHEMBL1384205 & 688648 & 2.8239 & 3.7549 & TST & \\
\hline CHEMBL1329336 & 688648 & 2.8239 & \multicolumn{2}{|c|}{3.4210000000000003} & TRN \\
\hline CHEMBL1313861 & 688648 & 2.8239 & 3.8683 & TRN & \\
\hline CHEMBL1409965 & 688648 & 2.8239 & 3.1166 & TRN & \\
\hline CHEMBL1535539 & 688648 & 5.8153 & 3.3117 & TST & \\
\hline CHEMBL1544097 & 688648 & 5.3532 & 4.4949 & TRN & \\
\hline CHEMBL1550591 & 688648 & 5.6227 & 3.8991 & TST & \\
\hline CHEMBL1567571 & 688648 & 5.1476 & 4.2322 & TRN & \\
\hline CHEMBL1377648 & 688648 & 2.8239 & 2.8661 & TRN & \\
\hline CHEMBL1426469 & 688648 & 2.8239 & 2.7278 & TRN & \\
\hline CHEMBL 3193184 & 688648 & 4.6901 & 3.8698 & TRN & \\
\hline CHEMBL2002849 & 688648 & 2.8239 & 3.4129 & TRN & \\
\hline CHEMBL1547804 & 688648 & 5.2509 & 3.6155 & TRN & \\
\hline CHEMBL1389269 & 688648 & 4.5321 & 4.1727 & TRN & \\
\hline CHEMBL1466353 & 688648 & 3.301 & 3.3786 & TRN & \\
\hline CHEMBL1387036 & 688648 & 2.8239 & 3.0509 & TST & \\
\hline CHEMBL1536372 & 688648 & 2.8239 & 2.9842 & TRN & \\
\hline
\end{tabular}

Page 7031 


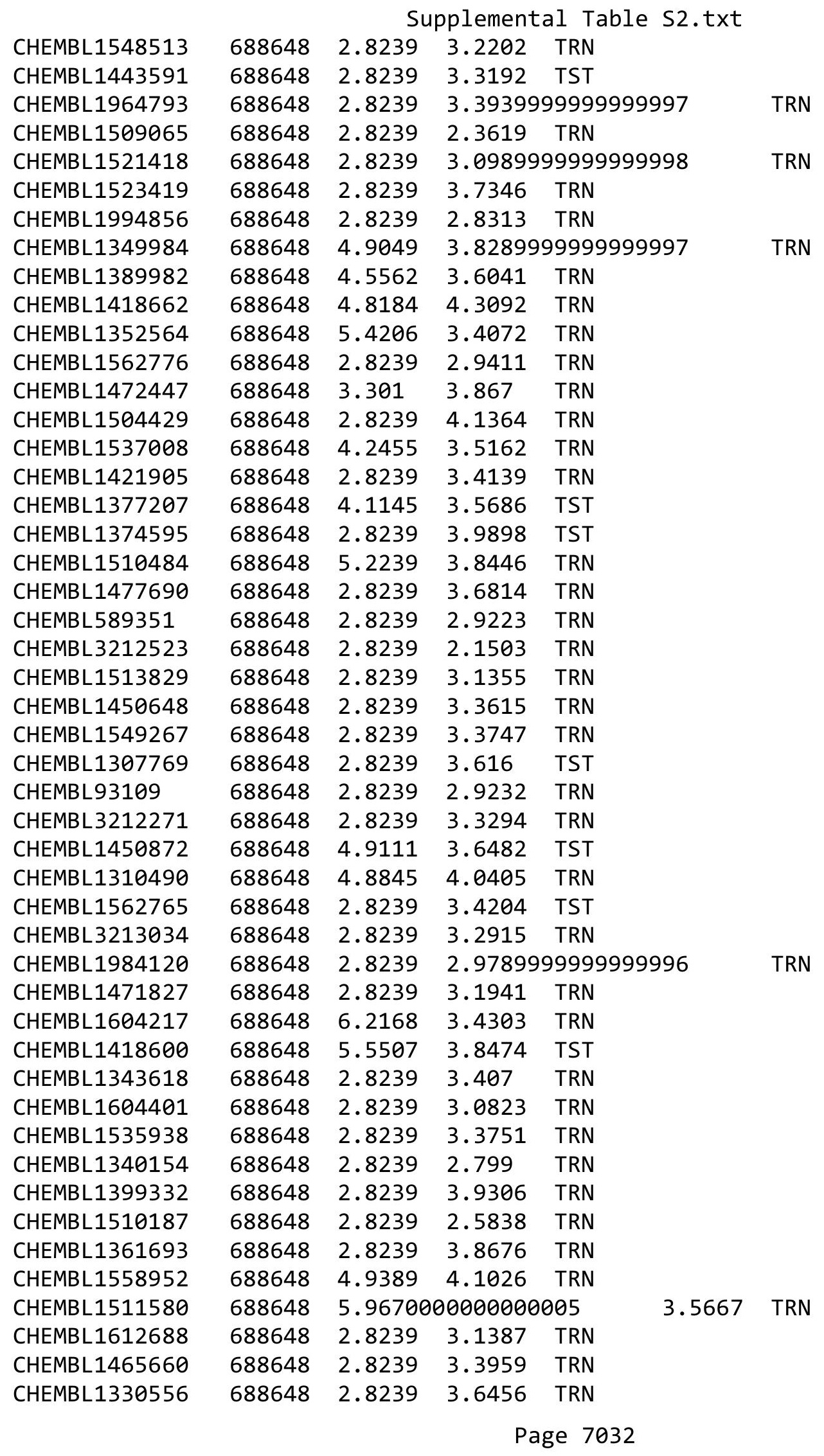




\begin{tabular}{|c|c|c|c|c|}
\hline \multicolumn{5}{|c|}{ Supplemental Tab. } \\
\hline CHEMBL1430718 & 688648 & 5.4325 & 3.9733 & TRN \\
\hline CHEMBL1383321 & 688648 & 5.5284 & 3.5812 & TRN \\
\hline CHEMBL1965860 & 688648 & 2.8239 & 3.4788 & TRN \\
\hline CHEMBL1430093 & 688648 & 2.8239 & 3.6849 & TRN \\
\hline CHEMBL1469656 & 688648 & 2.8239 & 2.3755 & TRN \\
\hline CHEMBL1331770 & 688648 & 2.8239 & 3.0247 & TRN \\
\hline CHEMBL1551022 & 688648 & 2.8239 & 3.7099 & TRN \\
\hline CHEMBL1436748 & 688648 & 4.8233 & 4.6244 & TRN \\
\hline CHEMBL1422750 & 688648 & 2.8239 & 3.2228 & TRN \\
\hline CHEMBL1559100 & 688648 & 5.4332 & 4.1853 & TRN \\
\hline CHEMBL 3198398 & 688648 & 4.8734 & 3.5635 & TRN \\
\hline CHEMBL1572214 & 688648 & 2.8239 & 3.3225 & TST \\
\hline CHEMBL1335027 & 688648 & 2.8239 & 3.4323 & TRN \\
\hline CHEMBL1458441 & 688648 & 4.8341 & 3.9306 & TRN \\
\hline CHEMBL1392438 & 688648 & 2.8239 & 3.2191 & TRN \\
\hline CHEMBL1984315 & 688648 & 2.8239 & 3.0647 & TRN \\
\hline CHEMBL1585375 & 688648 & 4.2871 & 2.7402 & TRN \\
\hline CHEMBL1471046 & 688648 & 2.8239 & 3.1622 & TRN \\
\hline CHEMBL1361680 & 688648 & 4.5623 & 3.9739 & TRN \\
\hline CHEMBL1385886 & 688648 & 2.8239 & 3.2034 & TRN \\
\hline CHEMBL1534716 & 688648 & 2.8239 & 2.6972 & TRN \\
\hline CHEMBL1587142 & 688648 & 2.8239 & 2.9508 & TRN \\
\hline CHEMBL1475733 & 688648 & 4.0374 & 4.3812 & TRN \\
\hline CHEMBL1977078 & 688648 & 2.8239 & 3.5081 & TST \\
\hline CHEMBL1601265 & 688648 & 4.7549 & 4.079 & TRN \\
\hline CHEMBL1428875 & 688648 & 2.8239 & 3.4517 & TST \\
\hline CHEMBL3192533 & 688648 & 5.0417 & 3.0479 & TST \\
\hline CHEMBL1536073 & 688648 & 2.8239 & 3.4688 & TRN \\
\hline CHEMBL1375741 & 688648 & 4.7225 & 3.9664 & TRN \\
\hline CHEMBL1606330 & 688648 & 4.7948 & 3.8061 & TST \\
\hline CHEMBL1452379 & 688648 & 5.3156 & 3.5766 & TRN \\
\hline CHEMBL1584229 & 688648 & 2.8239 & 2.8233 & TRN \\
\hline CHEMBL1310223 & 688648 & 2.8239 & 2.3705 & TRN \\
\hline CHEMBL1494800 & 688648 & 4.7304 & 4.2569 & TRN \\
\hline CHEMBL1459691 & 688648 & 2.8239 & 3.4024 & TRN \\
\hline CHEMBL3191453 & 688648 & 2.8239 & 3.0372 & TRN \\
\hline CHEMBL1570378 & 688648 & 2.8239 & 3.5959 & TST \\
\hline CHEMBL1428417 & 688648 & 2.8239 & 3.509 & TRN \\
\hline CHEMBL171637 & 688648 & 4.7986 & 4.1769 & TST \\
\hline CHEMBL1358861 & 688648 & 2.8239 & 2.6912 & TRN \\
\hline CHEMBL3196688 & 688648 & 4.1818 & 3.2336 & TRN \\
\hline CHEMBL3192479 & 688648 & 4.4896 & 3.6776 & TRN \\
\hline CHEMBL1494433 & 688648 & 4.6682 & 3.5723 & TRN \\
\hline CHEMBL1600566 & 688648 & 5.2009 & 3.7858 & TRN \\
\hline CHEMBL1383632 & 688648 & 5.4199 & 3.7008 & TRN \\
\hline CHEMBL1478680 & 688648 & 2.8239 & 3.5553 & TRN \\
\hline CHEMBL1384209 & 688648 & 2.8239 & 2.9992 & TRN \\
\hline CHEMBL3196681 & 688648 & 2.8239 & 3.1841 & TRN \\
\hline
\end{tabular}




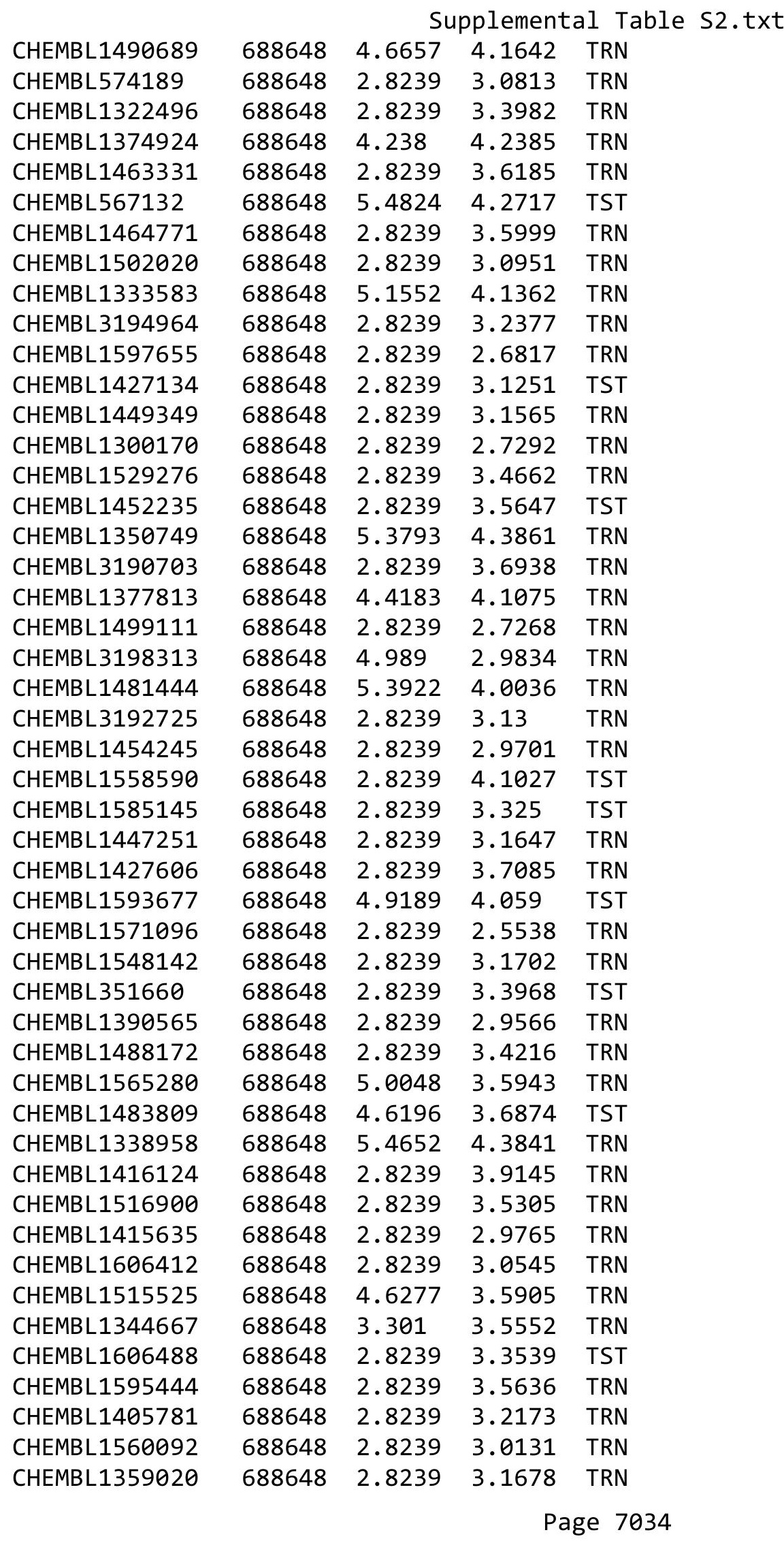




\begin{tabular}{|c|c|c|c|c|c|}
\hline & & \multicolumn{4}{|c|}{ Supplemental Table S2.txt } \\
\hline CHEMBL1501475 & 688648 & 4.6764 & 3.6296 & TRN & \\
\hline CHEMBL1576431 & 688648 & 2.8239 & 3.1042 & TRN & \\
\hline CHEMBL1404312 & 688648 & 2.8239 & 3.3541 & TRN & \\
\hline CHEMBL1353166 & 688648 & 2.8239 & 2.95 & TRN & \\
\hline CHEMBL1305864 & 688648 & 2.8239 & 2.9471 & TRN & \\
\hline CHEMBL1998531 & 688648 & 2.8239 & 3.0821 & TRN & \\
\hline CHEMBL1371940 & 688648 & 5.0967 & 4.2536 & TRN & \\
\hline CHEMBL1304179 & 688648 & 4.4958 & 3.1121 & TST & \\
\hline CHEMBL1391280 & 688648 & 2.8239 & 2.9017 & TST & \\
\hline CHEMBL3195410 & 688648 & 2.8239 & 3.2338 & TRN & \\
\hline CHEMBL1515506 & 688648 & 4.2931 & 4.328 & TRN & \\
\hline CHEMBL1443649 & 688648 & 2.8239 & 3.595 & TST & \\
\hline CHEMBL1477091 & 688648 & 2.8239 & 3.3851 & TRN & \\
\hline CHEMBL1582690 & 688648 & \multicolumn{3}{|c|}{4.6930000000000005} & 3.8443 \\
\hline CHEMBL1587181 & 688648 & 5.7462 & 4.2426 & TRN & \\
\hline CHEMBL1325622 & 688648 & 5.6419 & 4.405 & TST & \\
\hline CHEMBL1366790 & 688648 & 2.8239 & 2.2526 & TST & \\
\hline CHEMBL 3210250 & 688648 & 2.8239 & 2.9744 & TRN & \\
\hline CHEMBL1605304 & 688648 & 4.7153 & 4.0097 & TRN & \\
\hline CHEMBL1307382 & 688648 & 2.8239 & 2.8951 & TST & \\
\hline CHEMBL1460692 & 688648 & 4.9969 & 3.9577 & TRN & \\
\hline CHEMBL1357163 & 688648 & 2.8239 & 4.0041 & TST & \\
\hline CHEMBL1610738 & 688648 & 2.8239 & 2.7945 & TRN & \\
\hline CHEMBL1601747 & 688648 & 2.8239 & 3.708 & TST & \\
\hline CHEMBL1484669 & 688648 & 2.8239 & 3.0946 & TRN & \\
\hline CHEMBL1339728 & 688648 & 4.2332 & 4.1344 & TRN & \\
\hline CHEMBL1545093 & 688648 & 5.7683 & 3.5439 & TST & \\
\hline CHEMBL1605733 & 688648 & 2.8239 & 3.4795 & TST & \\
\hline CHEMBL1887153 & 688648 & 2.8239 & 3.4729 & TRN & \\
\hline CHEMBL1534138 & 688648 & 2.8239 & 2.9665 & TST & \\
\hline CHEMBL1499597 & 688648 & 4.65 & 3.9788 & TRN & \\
\hline CHEMBL1421884 & 688648 & 2.8239 & 3.8386 & TRN & \\
\hline CHEMBL1402502 & 688648 & 4.8516 & 4.3261 & TRN & \\
\hline CHEMBL1344663 & 688648 & 2.8239 & 2.9249 & TRN & \\
\hline CHEMBL1469698 & 688648 & 2.8239 & 3.4355 & TRN & \\
\hline CHEMBL1584002 & 688648 & 3.9123 & 3.3258 & TRN & \\
\hline CHEMBL1549391 & 688648 & 2.8239 & 3.9175 & TRN & \\
\hline CHEMBL1312122 & 688648 & 5.4828 & 4.3118 & TRN & \\
\hline CHEMBL1344875 & 688648 & 2.8239 & 4.0797 & TRN & \\
\hline CHEMBL1383809 & 688648 & 4.7675 & 4.0085 & TRN & \\
\hline CHEMBL1487959 & 688648 & 4.7483 & 3.7235 & TRN & \\
\hline CHEMBL 1558771 & 688648 & 2.8239 & 4.3639 & TRN & \\
\hline CHEMBL1430060 & 688648 & 5.7091 & 4.1605 & TRN & \\
\hline CHEMBL1426507 & 688648 & 2.8239 & 3.5677 & TRN & \\
\hline CHEMBL1501495 & 688648 & 5.2991 & 4.6504 & TRN & \\
\hline CHEMBL1418112 & 688648 & 2.8239 & 2.9216 & TRN & \\
\hline CHEMBL1303303 & 688648 & 2.8239 & 2.5855 & TRN & \\
\hline CHEMBL1510346 & 688648 & 2.8239 & 2.9412 & TRN & \\
\hline
\end{tabular}




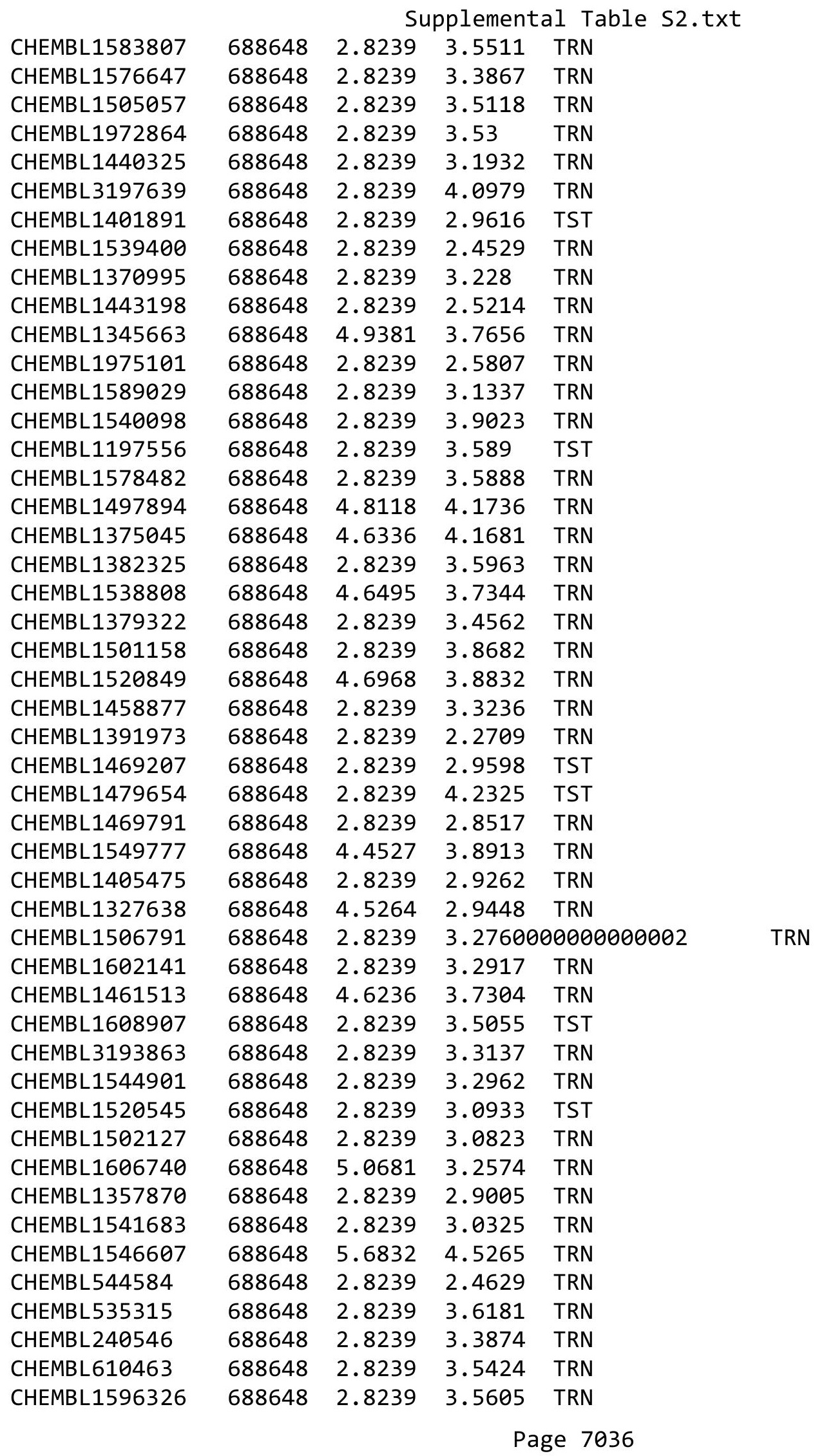




\begin{tabular}{|c|c|c|c|c|c|}
\hline & & \multicolumn{4}{|c|}{ Supplemental Table S2.txt } \\
\hline CHEMBL1596319 & 688648 & 2.8239 & 3.2896 & TRN & \\
\hline CHEMBL1594585 & 688648 & 2.8239 & 2.9841 & TRN & \\
\hline CHEMBL1565897 & 688648 & 4.6801 & 3.6447 & TST & \\
\hline CHEMBL1450597 & 688648 & 4.7578 & 3.605 & TRN & \\
\hline CHEMBL1982915 & 688648 & 5.2593 & 3.52399 & 99999999996 & TRN \\
\hline CHEMBL3191019 & 688648 & 5.012 & 3.7459 & TRN & \\
\hline CHEMBL1350867 & 688648 & 2.8239 & 2.9619 & TRN & \\
\hline CHEMBL1469659 & 688648 & 4.8502 & 3.2979 & TRN & \\
\hline CHEMBL1374908 & 688648 & 4.6297 & 4.1034 & TRN & \\
\hline CHEMBL1371929 & 688648 & 4.6597 & 3.6989 & TRN & \\
\hline CHEMBL1429718 & 688648 & 2.8239 & 3.2959 & TRN & \\
\hline CHEMBL1348356 & 688648 & 2.8239 & 2.967 & TRN & \\
\hline CHEMBL3145042 & 688648 & 2.8239 & 3.1654 & TST & \\
\hline CHEMBL1308201 & 688648 & 4.822 & 3.79699 & 99999999997 & TST \\
\hline CHEMBL1530694 & 688648 & 2.8239 & 3.3248 & TRN & \\
\hline CHEMBL1605015 & 688648 & 2.8239 & 2.8428 & TRN & \\
\hline CHEMBL1422976 & 688648 & 2.8239 & 2.7331 & TRN & \\
\hline CHEMBL1583579 & 688648 & 2.8239 & 3.5691 & TRN & \\
\hline CHEMBL1508055 & 688648 & 4.8824 & 3.7674 & TRN & \\
\hline CHEMBL1432380 & 688648 & 2.8239 & 2.9835 & TRN & \\
\hline CHEMBL1361361 & 688648 & 4.773 & 3.6202 & TRN & \\
\hline CHEMBL1991388 & 688648 & 2.8239 & 3.7405 & TRN & \\
\hline CHEMBL1537032 & 688648 & 2.8239 & 3.1971 & TST & \\
\hline CHEMBL1561240 & 688648 & 4.7658 & 3.6049 & TRN & \\
\hline CHEMBL1995336 & 688648 & 2.8239 & 2.8553 & TST & \\
\hline CHEMBL1528043 & 688648 & 4.9451 & 3.9673 & TRN & \\
\hline CHEMBL1375825 & 688648 & 4.4795 & 4.4867 & TRN & \\
\hline CHEMBL1583914 & 688648 & 4.6315 & 3.4324 & TRN & \\
\hline CHEMBL1412177 & 688648 & 2.8239 & 2.7392 & TRN & \\
\hline CHEMBL1507251 & 688648 & 2.8239 & 3.1477 & TRN & \\
\hline CHEMBL1529093 & 688648 & 5.3779 & 3.9295 & TST & \\
\hline CHEMBL1519374 & 688648 & 5.2066 & 3.6796 & TST & \\
\hline CHEMBL1340482 & 688648 & 2.8239 & 3.1685 & TRN & \\
\hline CHEMBL1458809 & 688648 & 2.8239 & 3.0542 & TRN & \\
\hline CHEMBL1518285 & 688648 & 5.2381 & 3.925 & TRN & \\
\hline CHEMBL1343674 & 688648 & 4.3151 & 3.0577 & TRN & \\
\hline CHEMBL1351805 & 688648 & 2.8239 & 3.2492 & TRN & \\
\hline CHEMBL1327412 & 688648 & 4.8171 & 3.7077 & TRN & \\
\hline CHEMBL1459036 & 688648 & 4.6429 & 4.4829 & TRN & \\
\hline CHEMBL1299745 & 688648 & 4.7742 & 3.9012 & TRN & \\
\hline CHEMBL1393796 & 688648 & 2.8239 & 3.6849 & TRN & \\
\hline CHEMBL3192972 & 688648 & 2.8239 & 3.5457 & TRN & \\
\hline CHEMBL1970867 & 688648 & 2.8239 & 3.182 & TRN & \\
\hline CHEMBL3197766 & 688648 & 2.8239 & 3.0097 & TRN & \\
\hline CHEMBL1349635 & 688648 & 2.8239 & 2.235 & TRN & \\
\hline CHEMBL1359684 & 688648 & 2.8239 & 4.0229 & TRN & \\
\hline CHEMBL1435719 & 688648 & 2.8239 & 2.9765 & TRN & \\
\hline CHEMBL1409950 & 688648 & 4.2906 & 3.6759 & TRN & \\
\hline
\end{tabular}




\begin{tabular}{|c|c|c|c|c|c|}
\hline & & \multicolumn{4}{|c|}{ Supplemental Table s2.txt } \\
\hline CHEMBL1383757 & 688648 & 2.8239 & 2.7275 & TRN & \\
\hline CHEMBL1466240 & 688648 & 2.8239 & 2.85 & TRN & \\
\hline CHEMBL1534540 & 688648 & 2.8239 & 3.2999 & TRN & \\
\hline CHEMBL 3197982 & 688648 & 2.8239 & 2.6591 & TRN & \\
\hline CHEMBL1492135 & 688648 & 2.8239 & 2.8258 & TRN & \\
\hline CHEMBL1527573 & 688648 & 2.8239 & 2.2206 & TRN & \\
\hline CHEMBL1419303 & 688648 & 2.8239 & 3.7139 & TRN & \\
\hline CHEMBL1427185 & 688648 & 2.8239 & 3.7249 & TRN & \\
\hline CHEMBL1573692 & 688648 & 2.8239 & 3.6718 & TRN & \\
\hline CHEMBL1430586 & 688648 & 2.8239 & 2.9845 & TRN & \\
\hline CHEMBL1579503 & 688648 & 2.8239 & 3.0123 & TRN & \\
\hline CHEMBL1311879 & 688648 & 2.8239 & 2.8094 & TRN & \\
\hline CHEMBL1344289 & 688648 & 2.8239 & 3.0766 & TRN & \\
\hline CHEMBL1439499 & 688648 & 2.8239 & 3.8823 & TRN & \\
\hline CHEMBL1582575 & 688648 & 2.8239 & 3.4674 & TRN & \\
\hline CHEMBL1606837 & 688648 & 4.8627 & 4.1337 & TRN & \\
\hline CHEMBL1999166 & 688648 & 2.8239 & 3.2786 & TST & \\
\hline CHEMBL1372064 & 688648 & 4.4452 & 3.6696 & TRN & \\
\hline CHEMBL1339350 & 688648 & 4.8584 & 3.97300 & 00000000003 & TRN \\
\hline CHEMBL1390139 & 688648 & 2.8239 & 3.8467 & TRN & \\
\hline CHEMBL1568457 & 688648 & 2.8239 & 3.1855 & TRN & \\
\hline CHEMBL1467222 & 688648 & 2.8239 & 2.4766 & TRN & \\
\hline CHEMBL1438570 & 688648 & 2.8239 & 3.0093 & TRN & \\
\hline CHEMBL1604723 & 688648 & 2.8239 & 3.0422 & TRN & \\
\hline CHEMBL1428514 & 688648 & 2.8239 & 3.5236 & TRN & \\
\hline CHEMBL1528266 & 688648 & 5.2541 & 4.0388 & TRN & \\
\hline CHEMBL1341108 & 688648 & 5.7525 & 4.0467 & TRN & \\
\hline CHEMBL1416440 & 688648 & 4.2223 & 3.2689 & TRN & \\
\hline CHEMBL1469980 & 688648 & 2.8239 & 3.79699 & 99999999997 & TRN \\
\hline CHEMBL2369228 & 688648 & 2.8239 & 3.4327 & TST & \\
\hline CHEMBL1536256 & 688648 & 2.8239 & 2.9743 & TRN & \\
\hline CHEMBL1594907 & 688648 & 2.8239 & 3.19100 & 00000000003 & TRN \\
\hline CHEMBL 2005664 & 688648 & 2.8239 & 3.3202 & TRN & \\
\hline CHEMBL1501277 & 688648 & 2.8239 & 3.7267 & TRN & \\
\hline CHEMBL1407907 & 688648 & $5.2120 t$ & 00000000 & 4.6111 & TRN \\
\hline CHEMBL1576863 & 688648 & 2.8239 & 2.8794 & TST & \\
\hline CHEMBL1351309 & 688648 & 2.8239 & 3.4457 & TST & \\
\hline CHEMBL 3213534 & 688648 & 2.8239 & 2.9203 & TRN & \\
\hline CHEMBL3210860 & 688648 & 2.8239 & 2.8457 & TRN & \\
\hline CHEMBL1394479 & 688648 & 2.8239 & 3.1922 & TRN & \\
\hline CHEMBL1367313 & 688648 & 4.6714 & 4.1585 & TRN & \\
\hline CHEMBL1603454 & 688648 & 2.8239 & 2.8496 & TRN & \\
\hline CHEMBL3195488 & 688648 & 2.8239 & 3.0834 & TRN & \\
\hline CHEMBL3199104 & 688648 & 2.8239 & 3.2554 & TRN & \\
\hline CHEMBL1381360 & 688648 & 5.3842 & 3.4913 & TST & \\
\hline CHEMBL1999480 & 688648 & 4.8087 & 3.83100 & 00000000004 & TST \\
\hline CHEMBL1504806 & 688648 & 2.8239 & 4.2271 & TST & \\
\hline CHEMBL1504675 & 688648 & 2.8239 & 3.2724 & TRN & \\
\hline
\end{tabular}




\begin{tabular}{|c|c|c|c|c|c|}
\hline & & \multicolumn{4}{|c|}{ Supplemental Table S2.txt } \\
\hline CHEMBL1532783 & 688648 & 2.8239 & 3.2554 & TRN & \\
\hline CHEMBL1561190 & 688648 & 2.8239 & 3.7324 & TRN & \\
\hline CHEMBL1478693 & 688648 & 5.3325 & 3.9694 & TRN & \\
\hline CHEMBL1337018 & 688648 & 5.6515 & 4.1027 & TRN & \\
\hline CHEMBL1411001 & 688648 & 2.8239 & 3.1703 & TRN & \\
\hline CHEMBL1599815 & 688648 & 2.8239 & 3.0725 & TRN & \\
\hline CHEMBL3196175 & 688648 & 2.8239 & 2.9873 & TRN & \\
\hline CHEMBL1326819 & 688648 & 5.3378 & 4.5007 & TRN & \\
\hline CHEMBL1468351 & 688648 & 2.8239 & 3.6535 & TRN & \\
\hline CHEMBL1380762 & 688648 & 2.8239 & 3.3529 & TRN & \\
\hline CHEMBL1981303 & 688648 & 2.8239 & 3.29 & TST & \\
\hline CHEMBL1405668 & 688648 & 5.2524 & 3.7035 & TST & \\
\hline CHEMBL1506021 & 688648 & 4.647 & 3.6541 & TST & \\
\hline CHEMBL1448808 & 688648 & 5.6146 & 4.08 & TRN & \\
\hline CHEMBL1612250 & 688648 & 2.8239 & 3.4927 & TRN & \\
\hline CHEMBL1416159 & 688648 & 2.8239 & 2.8762 & TRN & \\
\hline CHEMBL1566354 & 688648 & 2.8239 & 3.35600 & 00000000003 & TRN \\
\hline CHEMBL1602590 & 688648 & 2.8239 & 3.7178 & TRN & \\
\hline CHEMBL1588416 & 688648 & 4.2309 & 3.929 & TRN & \\
\hline CHEMBL3199916 & 688648 & 2.8239 & 4.0769 & TRN & \\
\hline CHEMBL1992174 & 688648 & 5.0241 & 3.8905 & TST & \\
\hline CHEMBL1431056 & 688648 & 2.8239 & 3.33699 & 99999 & TST \\
\hline CHEMBL1434604 & 688648 & 2.8239 & 3.2907 & TRN & \\
\hline CHEMBL1598101 & 688648 & 2.8239 & 3.4683 & TRN & \\
\hline CHEMBL1323757 & 688648 & 5.0207 & 4.2397 & TRN & \\
\hline CHEMBL3193542 & 688648 & 2.8239 & 3.162 & TRN & \\
\hline CHEMBL1299367 & 688648 & 2.8239 & 3.2376 & TRN & \\
\hline CHEMBL1975032 & 688648 & 2.8239 & 3.7208 & TRN & \\
\hline CHEMBL1496642 & 688648 & 5.3937 & 3.426 & TST & \\
\hline CHEMBL1463734 & 688648 & 2.8239 & 3.1773 & TRN & \\
\hline CHEMBL1372805 & 688648 & 5.6055 & 4.9436 & TRN & \\
\hline CHEMBL1327509 & 688648 & 4.261 & 4.2604 & TRN & \\
\hline CHEMBL1442884 & 688648 & 5.1494 & 3.4406 & TRN & \\
\hline CHEMBL3208035 & 688648 & 2.8239 & 2.8729 & TRN & \\
\hline CHEMBL1395220 & 688648 & 2.8239 & 3.4673 & TRN & \\
\hline CHEMBL1337364 & 688648 & 2.8239 & 2.7237 & TRN & \\
\hline CHEMBL1488364 & 688648 & 2.8239 & 3.582 & TRN & \\
\hline CHEMBL1374455 & 688648 & 2.8239 & 3.9279 & TRN & \\
\hline CHEMBL1454212 & 688648 & 2.8239 & 2.6135 & TRN & \\
\hline CHEMBL1503123 & 688648 & 4.5917 & 3.9115 & TRN & \\
\hline CHEMBL1347538 & 688648 & 2.8239 & 3.4757 & TST & \\
\hline CHEMBL3193178 & 688648 & 4.7073 & 3.3947 & TRN & \\
\hline CHEMBL1448654 & 688648 & 2.8239 & 3.5299 & TRN & \\
\hline CHEMBL1548682 & 688648 & 2.8239 & 3.1071 & TRN & \\
\hline CHEMBL1463624 & 688648 & 2.8239 & 3.3298 & TRN & \\
\hline CHEMBL1559169 & 688648 & 2.8239 & 3.6802 & TST & \\
\hline CHEMBL1332598 & 688648 & 4.5852 & 3.1836 & TRN & \\
\hline CHEMBL1358873 & 688648 & 2.8239 & 3.237 & TRN & \\
\hline
\end{tabular}




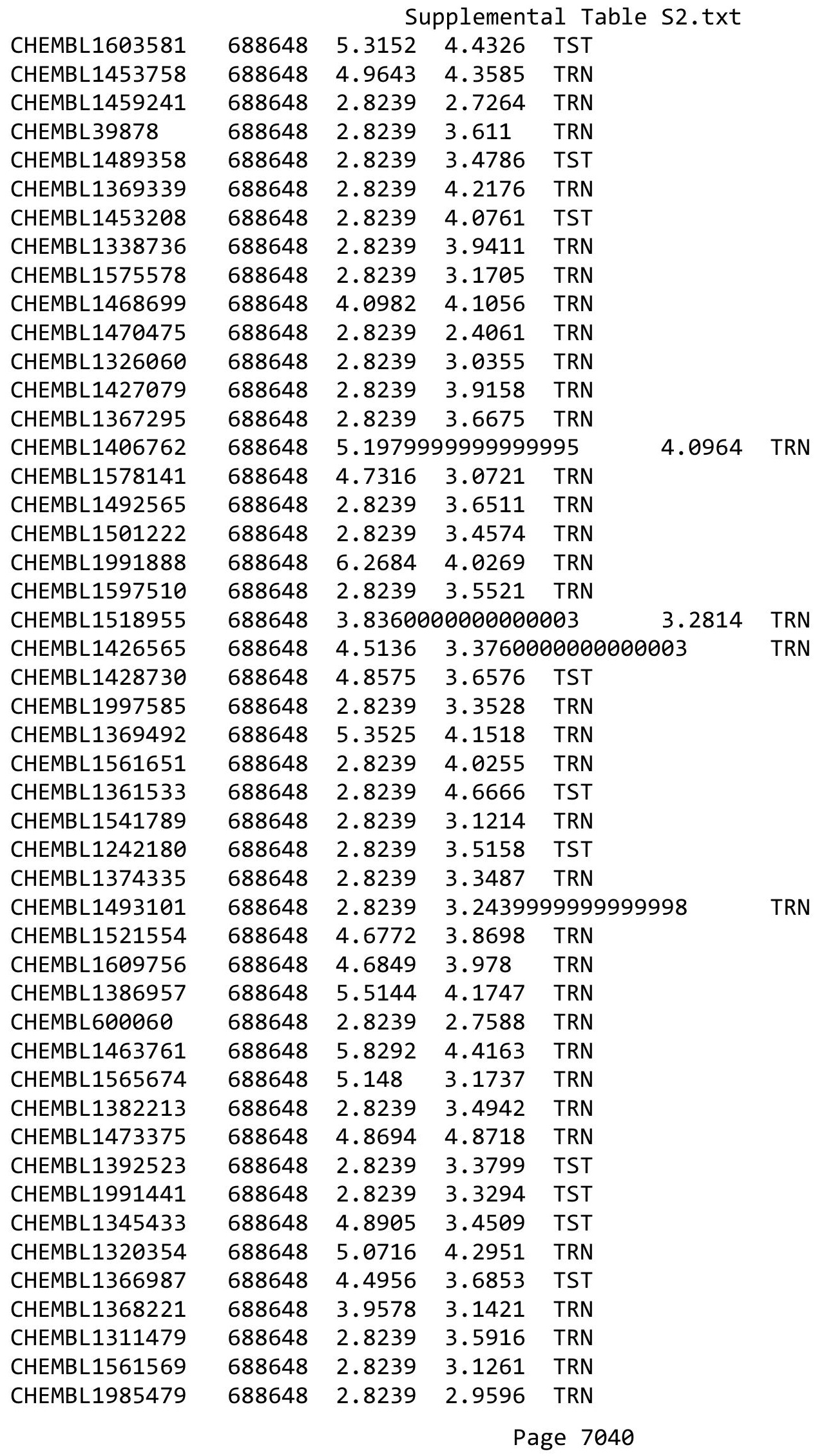


Supplemental Table S2.txt

\begin{tabular}{|c|c|c|c|c|c|}
\hline CHEMBL1378513 & 688648 & 4.109 & 4.0904 & TRN & \\
\hline CHEMBL1337445 & 688648 & 5.4669 & 4.0577 & TST & \\
\hline CHEMBL1466628 & 688648 & 2.8239 & 3.0708 & TRN & \\
\hline CHEMBL1376578 & 688648 & 4.7638 & 3.6285 & TRN & \\
\hline CHEMBL1588987 & 688648 & 2.8239 & 3.2889 & TRN & \\
\hline CHEMBL1582424 & 688648 & 2.8239 & 2.8127 & TRN & \\
\hline CHEMBL1334928 & 688648 & 2.8239 & 2.7329 & TRN & \\
\hline CHEMBL1431751 & 688648 & 2.8239 & 3.4512 & TRN & \\
\hline CHEMBL1566084 & 688648 & 2.8239 & 3.3405 & TRN & \\
\hline CHEMBL1576710 & 688648 & 2.8239 & $3.94100 t$ & 30000000003 & TRN \\
\hline CHEMBL1583236 & 688648 & 2.8239 & 3.3043 & TRN & \\
\hline CHEMBL1368535 & 688648 & 2.8239 & 2.7253 & TRN & \\
\hline CHEMBL 3197633 & 688648 & 2.8239 & 3.3658 & TRN & \\
\hline CHEMBL1493766 & 688648 & 3.301 & 3.5764 & TRN & \\
\hline CHEMBL1423933 & 688648 & 4.6239 & 3.3759 & TST & \\
\hline CHEMBL 3213413 & 688648 & 2.8239 & 3.4103 & TRN & \\
\hline CHEMBL1972143 & 688648 & 3.7959 & 3.0842 & TRN & \\
\hline CHEMBL1558175 & 688648 & 2.8239 & 3.8622 & TRN & \\
\hline CHEMBL1577983 & 688648 & 2.8239 & 3.3978 & TRN & \\
\hline CHEMBL193627 & 688648 & 2.8239 & 3.5149 & TST & \\
\hline CHEMBL1550334 & 688648 & 2.8239 & 4.0038 & TRN & \\
\hline CHEMBL1327628 & 688648 & 2.8239 & 3.4128 & TRN & \\
\hline CHEMBL1439185 & 688648 & 2.8239 & 3.3721 & TST & \\
\hline CHEMBL1418469 & 688648 & 4.7997 & 3.7128 & TRN & \\
\hline CHEMBL1435818 & 688648 & 2.8239 & 4.3432 & TRN & \\
\hline CHEMBL 3190739 & 688648 & 2.8239 & 2.7357 & TRN & \\
\hline CHEMBL1594349 & 688648 & 2.8239 & 4.1503 & TRN & \\
\hline CHEMBL1401984 & 688648 & 2.8239 & 3.3048 & TRN & \\
\hline CHEMBL3195036 & 688648 & 4.5081 & 3.3326 & TRN & \\
\hline CHEMBL1965348 & 688648 & 5.2962 & 3.5869 & TRN & \\
\hline CHEMBL1583802 & 688648 & 2.8239 & 3.7748 & TRN & \\
\hline CHEMBL1448984 & 688648 & 2.8239 & 2.6087 & TRN & \\
\hline CHEMBL1303940 & 688648 & 2.8239 & 3.3619 & TST & \\
\hline CHEMBL1520898 & 688648 & 2.8239 & 3.596 & TST & \\
\hline CHEMBL1300497 & 688648 & 2.8239 & 3.2787 & TRN & \\
\hline CHEMBL586937 & 688648 & 5.6236 & 4.1012 & TRN & \\
\hline CHEMBL1426136 & 688648 & 2.8239 & 1.9457 & TRN & \\
\hline CHEMBL1575271 & 688648 & 2.8239 & 2.3448 & TRN & \\
\hline CHEMBL1347270 & 688648 & 4.8304 & 4.0634 & TRN & \\
\hline CHEMBL1299640 & 688648 & 4.6916 & 3.4991 & TRN & \\
\hline CHEMBL1315948 & 688648 & 5.1305 & 4.0352 & TRN & \\
\hline CHEMBL1414465 & 688648 & 2.8239 & 4.261 & TRN & \\
\hline CHEMBL1596460 & 688648 & 2.8239 & 3.4324 & TRN & \\
\hline CHEMBL1473916 & 688648 & \multicolumn{4}{|c|}{4.6339999999999995} \\
\hline CHEMBL1322943 & 688648 & 2.8239 & 3.1678 & TRN & \\
\hline CHEMBL 3194024 & 688648 & 2.8239 & 3.2451 & TRN & \\
\hline CHEMBL1477597 & 688648 & 4.5162 & 3.9842 & TRN & \\
\hline CHEMBL1523130 & 688648 & 2.8239 & 3.5319 & TST & \\
\hline
\end{tabular}




\begin{tabular}{|c|c|c|c|c|c|c|}
\hline & & \multicolumn{5}{|c|}{ Supplemental Table S2.txt } \\
\hline CHEMBL1410625 & 688648 & 2.8239 & 3.8769 & TRN & & \\
\hline CHEMBL1407094 & 688648 & 2.8239 & 3.1611 & TRN & & \\
\hline CHEMBL1971379 & 688648 & 5.9527 & 3.3102 & TRN & & \\
\hline CHEMBL1483038 & 688648 & 2.8239 & 3.1334 & TRN & & \\
\hline CHEMBL1525347 & 688648 & 2.8239 & 2.4844 & TRN & & \\
\hline CHEMBL1529121 & 688648 & 2.8239 & 3.7145 & TRN & & \\
\hline CHEMBL1569755 & 688648 & 2.8239 & 3.3212 & TRN & & \\
\hline CHEMBL1544494 & 688648 & 5.3965 & 4.1147 & TST & & \\
\hline CHEMBL1461196 & 688648 & 2.8239 & 3.1358 & TRN & & \\
\hline CHEMBL1492642 & 688648 & 2.8239 & 3.4514 & TRN & & \\
\hline CHEMBL1548086 & 688648 & 5.0851 & 4.1385 & TST & & \\
\hline CHEMBL1469901 & 688648 & 2.8239 & 2.3547 & TRN & & \\
\hline CHEMBL1324032 & 688648 & 2.8239 & 3.9394 & TRN & & \\
\hline CHEMBL1327366 & 688648 & 5.04 & 4.5476 & TRN & & \\
\hline CHEMBL1606646 & 688648 & 2.8239 & 3.71 & TRN & & \\
\hline CHEMBL1541391 & 688648 & 5.3392 & 3.6951 & TST & & \\
\hline CHEMBL1502939 & 688648 & 2.8239 & 2.9307 & TRN & & \\
\hline CHEMBL1346860 & 688648 & 5.9344 & 4.1392 & TRN & & \\
\hline CHEMBL1313141 & 688648 & 2.8239 & 4.0036 & TRN & & \\
\hline CHEMBL1513407 & 688648 & 2.8239 & 3.6959 & TRN & & \\
\hline CHEMBL1315795 & 688648 & 5.3022 & 3.5701 & TRN & & \\
\hline CHEMBL1341913 & 688648 & 5.4985 & 3.3503 & TST & & \\
\hline CHEMBL1371877 & 688648 & 2.8239 & 3.9014 & TST & & \\
\hline CHEMBL1461193 & 688648 & \multicolumn{3}{|c|}{4.8660000000000005} & 3.9007 & TRN \\
\hline CHEMBL 1600280 & 688648 & 2.8239 & 3.3209 & TRN & & \\
\hline CHEMBL1507262 & 688648 & 5.1724 & 3.9401 & TST & & \\
\hline CHEMBL3191818 & 688648 & 3.9855 & 3.1831 & TRN & & \\
\hline CHEMBL1310221 & 688648 & 2.8239 & 3.7548 & TRN & & \\
\hline CHEMBL1426440 & 688648 & 4.1998 & 3.7314 & TST & & \\
\hline CHEMBL1586416 & 688648 & 4.6537 & 2.506 & TRN & & \\
\hline CHEMBL1583801 & 688648 & 2.8239 & 2.8414 & TRN & & \\
\hline CHEMBL 246338 & 688648 & 2.8239 & 3.3459 & TRN & & \\
\hline CHEMBL3189736 & 688648 & 2.8239 & 3.1827 & TRN & & \\
\hline CHEMBL1533770 & 688648 & 2.8239 & 3.3186 & TRN & & \\
\hline CHEMBL1550672 & 688648 & 2.8239 & 3.9216 & TRN & & \\
\hline CHEMBL1542862 & 688648 & 2.8239 & 4.0105 & TRN & & \\
\hline CHEMBL1408752 & 688648 & 2.8239 & 2.7045 & TRN & & \\
\hline CHEMBL3198095 & 688648 & 2.8239 & 2.7933 & TRN & & \\
\hline CHEMBL1605393 & 688648 & 2.8239 & 3.4871 & TST & & \\
\hline CHEMBL1443499 & 688648 & 2.8239 & 2.6433 & TRN & & \\
\hline CHEMBL 251148 & 688648 & 2.8239 & 2.6421 & TST & & \\
\hline CHEMBL1410739 & 688648 & 2.8239 & 3.7744 & TRN & & \\
\hline CHEMBL1402670 & 688648 & 2.8239 & 3.0844 & TRN & & \\
\hline CHEMBL1387581 & 688648 & 5.0775 & 3.1387 & TRN & & \\
\hline CHEMBL1562570 & 688648 & 5.0135 & 3.9075 & TRN & & \\
\hline CHEMBL1387393 & 688648 & 2.8239 & 3.5438 & TRN & & \\
\hline CHEMBL1497950 & 688648 & 2.8239 & 4.0814 & TRN & & \\
\hline CHEMBL1360492 & 688648 & 2.8239 & 2.5031 & TRN & & \\
\hline
\end{tabular}




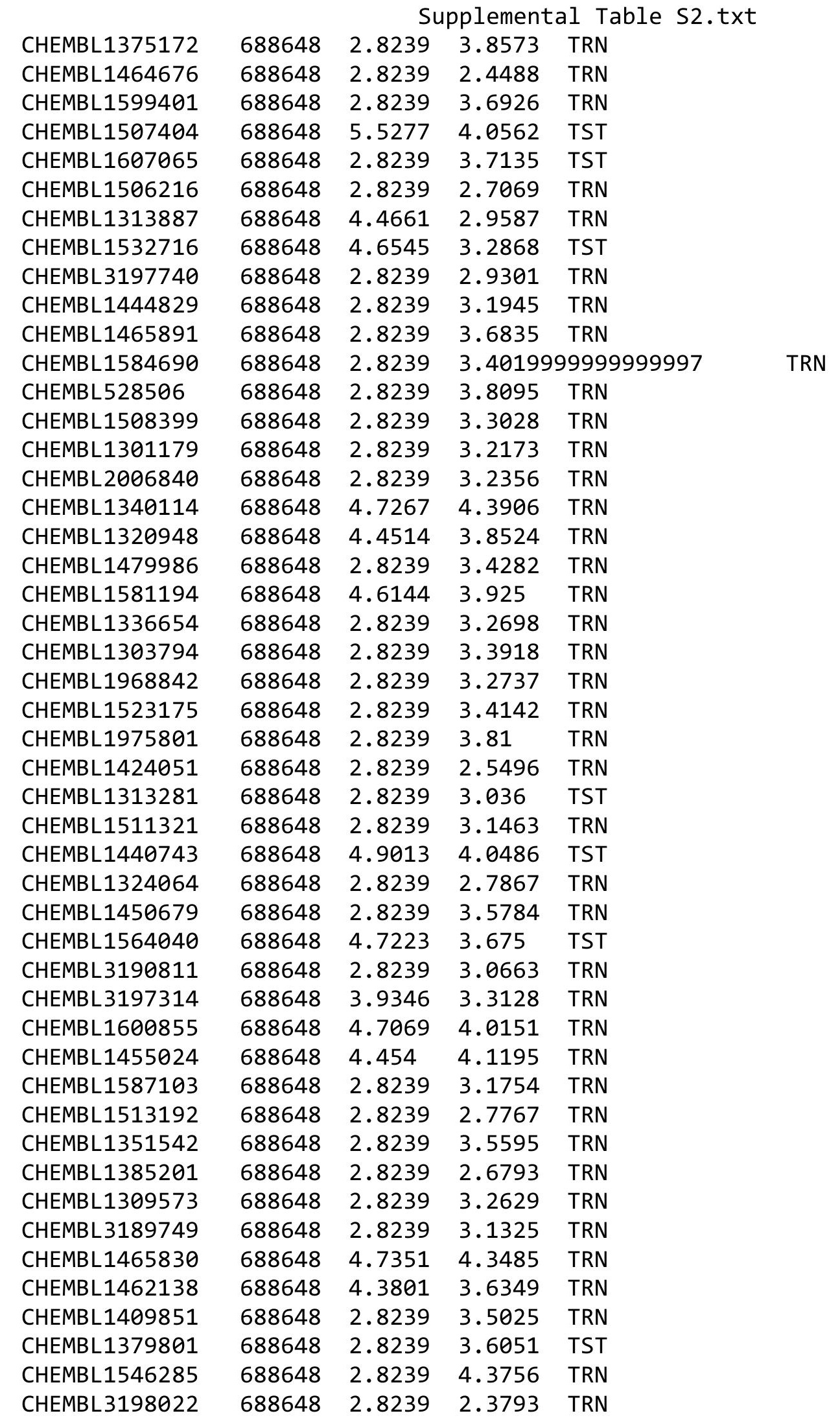




\begin{tabular}{|c|c|c|c|c|c|}
\hline \multirow[b]{2}{*}{ CHEMBL1480439 } & \multicolumn{5}{|c|}{ Supplemental Table S2.txt } \\
\hline & 688648 & 4.0487 & 3.6636 & TST & \\
\hline CHEMBL1540340 & 688648 & 2.8239 & 3.3127 & TRN & \\
\hline CHEMBL1475279 & 688648 & 2.8239 & 3.0208 & TRN & \\
\hline CHEMBL1326490 & 688648 & 2.8239 & 3.4905 & TRN & \\
\hline CHEMBL3196295 & 688648 & 2.8239 & 3.5198 & TRN & \\
\hline CHEMBL1602964 & 688648 & 2.8239 & 3.5072 & TRN & \\
\hline CHEMBL3190546 & 688648 & 2.8239 & 3.4666 & TRN & \\
\hline CHEMBL1380969 & 688648 & 4.748 & 4.2037 & TRN & \\
\hline CHEMBL1461496 & 688648 & 2.8239 & 3.0894 & TRN & \\
\hline CHEMBL1478237 & 688648 & 5.0139 & 4.4372 & TRN & \\
\hline CHEMBL1480252 & 688648 & 5.1416 & 3.7565 & TRN & \\
\hline CHEMBL1361046 & 688648 & 2.8239 & 3.0941 & TRN & \\
\hline CHEMBL1544859 & 688648 & 2.8239 & 3.1274 & TRN & \\
\hline CHEMBL1419484 & 688648 & 2.8239 & 3.7089 & TRN & \\
\hline CHEMBL935 & 688648 & 4.5542 & 3.6161 & TST & \\
\hline CHEMBL1401191 & 688648 & 2.8239 & 3.4311 & TRN & \\
\hline CHEMBL1594106 & 688648 & 4.6328 & 4.0155 & TRN & \\
\hline CHEMBL1361740 & 688648 & 2.8239 & 3.5619 & TST & \\
\hline CHEMBL1400432 & 688648 & 2.8239 & 3.8624 & TST & \\
\hline CHEMBL1430631 & 688648 & 2.8239 & 3.173 & TRN & \\
\hline CHEMBL 2003819 & 688648 & 2.8239 & 3.1698 & TRN & \\
\hline CHEMBL1386918 & 688648 & 2.8239 & 4.0179 & TRN & \\
\hline CHEMBL1602902 & 688648 & 2.8239 & 3.6395 & TRN & \\
\hline CHEMBL1344358 & 688648 & 2.8239 & 3.2435 & TRN & \\
\hline CHEMBL1568771 & 688648 & 2.8239 & 2.7789 & TRN & \\
\hline CHEMBL1428358 & 688648 & 2.8239 & 3.6529 & TRN & \\
\hline CHEMBL1494940 & 688648 & 2.8239 & 3.8173 & TST & \\
\hline CHEMBL1508058 & 688648 & 4.4515 & 3.3585 & TRN & \\
\hline CHEMBL1370922 & 688648 & 2.8239 & 2.9134 & TRN & \\
\hline CHEMBL 1240788 & 688648 & 2.8239 & 2.7144 & TRN & \\
\hline CHEMBL1498473 & 688648 & 2.8239 & 3.4905 & TST & \\
\hline CHEMBL1441888 & 688648 & 2.8239 & 3.41600 & 00000000004 & TRN \\
\hline CHEMBL1540742 & 688648 & 5.5931 & 4.2496 & TST & \\
\hline CHEMBL3198912 & 688648 & 2.8239 & 3.0434 & TRN & \\
\hline CHEMBL1497725 & 688648 & 2.8239 & 2.7137 & TRN & \\
\hline CHEMBL1308615 & 688648 & 2.8239 & 3.266 & TRN & \\
\hline CHEMBL1602058 & 688648 & 2.8239 & 3.1327 & TRN & \\
\hline CHEMBL1463268 & 688648 & 2.8239 & 3.0049 & TRN & \\
\hline CHEMBL1513240 & 688648 & 5.0044 & 5.0335 & TRN & \\
\hline CHEMBL1443674 & 688648 & 2.8239 & 3.2392 & TRN & \\
\hline CHEMBL1453391 & 688648 & 2.8239 & 2.7842 & TRN & \\
\hline CHEMBL1449558 & 688648 & 4.9705 & 3.6448 & TRN & \\
\hline CHEMBL1477640 & 688648 & 4.6313 & 3.3853 & TRN & \\
\hline CHEMBL1527664 & 688648 & 2.8239 & 3.7136 & TST & \\
\hline CHEMBL1495819 & 688648 & 5.1713 & 3.5364 & TST & \\
\hline CHEMBL1540901 & 688648 & 2.8239 & 2.6714 & TRN & \\
\hline CHEMBL 1577440 & 688648 & 2.8239 & 3.0822 & TRN & \\
\hline CHEMBL1526636 & 688648 & 2.8239 & 3.2499 & TRN & \\
\hline
\end{tabular}




\begin{tabular}{|c|c|c|c|c|}
\hline & & \multicolumn{3}{|c|}{ Supplemental Tab. } \\
\hline CHEMBL1433263 & 688648 & 2.8239 & 3.5307 & TRN \\
\hline CHEMBL1407952 & 688648 & 2.8239 & 3.2421 & TRN \\
\hline CHEMBL1493438 & 688648 & 2.8239 & 3.3303 & TRN \\
\hline CHEMBL1300890 & 688648 & 2.8239 & 4.0544 & TRN \\
\hline CHEMBL1523842 & 688648 & 2.8239 & 3.6573 & TRN \\
\hline CHEMBL1454827 & 688648 & 2.8239 & 3.4592 & TRN \\
\hline CHEMBL3190609 & 688648 & 5.1284 & 3.2593 & TST \\
\hline CHEMBL1504588 & 688648 & 2.8239 & 2.8938 & TRN \\
\hline CHEMBL1303164 & 688648 & 2.8239 & 2.9332 & TRN \\
\hline CHEMBL1428886 & 688648 & 5.5902 & 3.9002 & TRN \\
\hline CHEMBL1564099 & 688648 & 5.0798 & 3.701 & TRN \\
\hline CHEMBL1452612 & 688648 & 5.0641 & 3.8238 & TRN \\
\hline CHEMBL1467188 & 688648 & 2.8239 & 3.3214 & TRN \\
\hline CHEMBL1351737 & 688648 & 2.8239 & 3.2989 & TRN \\
\hline CHEMBL1428000 & 688648 & 2.8239 & 3.0832 & TST \\
\hline CHEMBL1395907 & 688648 & 4.7504 & 4.2561 & TRN \\
\hline CHEMBL1379443 & 688648 & 2.8239 & 3.7797 & TRN \\
\hline CHEMBL1447772 & 688648 & 2.8239 & 3.4075 & TST \\
\hline CHEMBL1321111 & 688648 & 2.8239 & 3.2529 & TRN \\
\hline CHEMBL1511561 & 688648 & 4.5642 & 3.6523 & TRN \\
\hline CHEMBL1492564 & 688648 & 2.8239 & 3.1951 & TRN \\
\hline CHEMBL1363199 & 688648 & 2.8239 & 3.3036 & TRN \\
\hline CHEMBL1508930 & 688648 & 2.8239 & 3.7813 & TST \\
\hline CHEMBL1452652 & 688648 & 2.8239 & 2.9832 & TRN \\
\hline CHEMBL1423723 & 688648 & 5.307 & 4.3725 & TRN \\
\hline CHEMBL1314913 & 688648 & 5.5659 & 4.0058 & TST \\
\hline CHEMBL1335546 & 688648 & 2.8239 & 3.3845 & TST \\
\hline CHEMBL1391560 & 688648 & 2.8239 & 2.9331 & TRN \\
\hline CHEMBL1371013 & 688648 & 2.8239 & 3.5524 & TST \\
\hline CHEMBL3207339 & 688648 & 5.3749 & 3.9408 & TRN \\
\hline CHEMBL1501022 & 688648 & 4.649 & 4.1063 & TRN \\
\hline CHEMBL1471286 & 688648 & 2.8239 & 3.1632 & TRN \\
\hline CHEMBL3211356 & 688648 & 2.8239 & 3.6307 & TRN \\
\hline CHEMBL1437052 & 688648 & 2.8239 & 3.9055 & TST \\
\hline CHEMBL1496648 & 688648 & 4.8364 & 3.8727 & TRN \\
\hline CHEMBL1425743 & 688648 & 2.8239 & 3.8082 & TST \\
\hline CHEMBL1313588 & 688648 & 2.8239 & 3.216 & TRN \\
\hline CHEMBL1386200 & 688648 & 2.8239 & 2.8755 & TRN \\
\hline CHEMBL3191568 & 688648 & 2.8239 & 3.2436 & TRN \\
\hline CHEMBL1491222 & 688648 & 2.8239 & 2.931 & TRN \\
\hline CHEMBL3208362 & 688648 & 4.4732 & 3.5637 & TRN \\
\hline CHEMBL1418885 & 688648 & 2.8239 & 4.2242 & TRN \\
\hline CHEMBL1395972 & 688648 & 5.7706 & 4.3807 & TST \\
\hline CHEMBL1420051 & 688648 & 2.8239 & 2.8299 & TRN \\
\hline CHEMBL1517264 & 688648 & 3.301 & 3.198 & TRN \\
\hline CHEMBL1969094 & 688648 & 2.8239 & 3.1752 & TRN \\
\hline CHEMBL1526472 & 688648 & 2.8239 & 3.3442 & TRN \\
\hline CHEMBL1375734 & 688648 & 2.8239 & 3.3552 & TRN \\
\hline
\end{tabular}




\begin{tabular}{|c|c|c|c|c|c|}
\hline \multicolumn{6}{|c|}{ Supplemental Table s2.txt } \\
\hline CHEMBL1513743 & 688648 & 4.77 & 3.9019 & TST & \\
\hline CHEMBL1602581 & 688648 & 5.1638 & 4.3135 & TRN & \\
\hline CHEMBL1376130 & 688648 & 4.2114 & 3.6056 & TRN & \\
\hline CHEMBL1365357 & 688648 & 2.8239 & 3.662 & TRN & \\
\hline CHEMBL1402267 & 688648 & 4.7271 & 3.4556 & TRN & \\
\hline CHEMBL1340213 & 688648 & 2.8239 & 3.5751 & TRN & \\
\hline CHEMBL1353666 & 688648 & 4.9888 & 4.53600 & 00000000005 & TRN \\
\hline CHEMBL1605217 & 688648 & 3.8347 & 4.3062 & TRN & \\
\hline CHEMBL1510981 & 688648 & 4.7739 & 4.0273 & TST & \\
\hline CHEMBL1330687 & 688648 & 2.8239 & 2.7451 & TST & \\
\hline CHEMBL1536775 & 688648 & 5.7655 & 3.5326 & TST & \\
\hline CHEMBL1419518 & 688648 & 2.8239 & 2.7642 & TRN & \\
\hline CHEMBL1598704 & 688648 & 3.9952 & 3.4819 & TRN & \\
\hline CHEMBL1444102 & 688648 & 4.6569 & 3.7085 & TST & \\
\hline CHEMBL1494274 & 688648 & 2.8239 & 2.8994 & TRN & \\
\hline CHEMBL1373166 & 688648 & 2.8239 & 3.25699 & 99999999997 & TRN \\
\hline CHEMBL1447526 & 688648 & 5.0352 & 4.185 & TRN & \\
\hline CHEMBL1384094 & 688648 & 2.8239 & 3.3295 & TRN & \\
\hline CHEMBL1420123 & 688648 & 2.8239 & 3.013 & TRN & \\
\hline CHEMBL1430319 & 688648 & 5.109 & 3.992 & TRN & \\
\hline CHEMBL1542491 & 688648 & 2.8239 & 3.6746 & TRN & \\
\hline CHEMBL1568695 & 688648 & 4.8578 & 4.1315 & TRN & \\
\hline CHEMBL1555769 & 688648 & 2.8239 & 3.4536 & TRN & \\
\hline CHEMBL3209772 & 688648 & 5.1771 & 3.3326 & TRN & \\
\hline CHEMBL1372397 & 688648 & 2.8239 & 3.0189 & TRN & \\
\hline CHEMBL3191323 & 688648 & 2.8239 & 3.4176 & TRN & \\
\hline CHEMBL1302865 & 688648 & 2.8239 & 3.51899 & 99999999997 & TRN \\
\hline CHEMBL1981541 & 688648 & 2.8239 & 2.8443 & TRN & \\
\hline CHEMBL 3195852 & 688648 & 2.8239 & 3.8774 & TRN & \\
\hline CHEMBL1353738 & 688648 & 4.7842 & 3.9683 & TRN & \\
\hline CHEMBL3191406 & 688648 & 2.8239 & 3.7648 & TRN & \\
\hline CHEMBL3210497 & 688648 & 2.8239 & 2.5769 & TST & \\
\hline CHEMBL1981667 & 688648 & 2.8239 & 2.6736 & TRN & \\
\hline CHEMBL1431276 & 688648 & 2.8239 & 3.9168 & TRN & \\
\hline CHEMBL1343800 & 688648 & 5.1138 & 4.3913 & TRN & \\
\hline CHEMBL1511495 & 688648 & 2.8239 & 3.3839 & TRN & \\
\hline CHEMBL1450659 & 688648 & 2.8239 & 2.4558 & TST & \\
\hline CHEMBL3193769 & 688648 & 2.8239 & 3.3965 & TRN & \\
\hline CHEMBL1400889 & 688648 & 2.8239 & 3.2165 & TRN & \\
\hline CHEMBL1346853 & 688648 & 4.3354 & 3.661 & TRN & \\
\hline CHEMBL1586806 & 688648 & 5.209 & 4.0596 & TST & \\
\hline CHEMBL1705518 & 688648 & 2.8239 & 3.7268 & TRN & \\
\hline CHEMBL1326559 & 688648 & 2.8239 & 3.3259 & TST & \\
\hline CHEMBL1445145 & 688648 & 4.8503 & 4.7752 & TRN & \\
\hline CHEMBL1407961 & 688648 & 6.1805 & 4.5334 & TRN & \\
\hline CHEMBL1320542 & 688648 & 2.8239 & 3.1205 & TRN & \\
\hline CHEMBL1334134 & 688648 & 2.8239 & 2.89300 & 00000000002 & TRN \\
\hline CHEMBL1305498 & 688648 & 2.8239 & 3.5131 & TST & \\
\hline
\end{tabular}




\begin{tabular}{|c|c|c|c|c|}
\hline \multicolumn{5}{|c|}{ Supplemental Table } \\
\hline CHEMBL1971033 & 688648 & 2.8239 & 3.2196 & TRN \\
\hline CHEMBL597251 & 688648 & 5.1417 & 4.3904 & TRN \\
\hline CHEMBL1520507 & 688648 & 4.7551 & 4.4732 & TRN \\
\hline CHEMBL1359037 & 688648 & 2.8239 & 3.3859 & TRN \\
\hline CHEMBL1340792 & 688648 & 4.8643 & 3.9165 & TST \\
\hline CHEMBL1452706 & 688648 & 2.8239 & 3.6717 & TRN \\
\hline CHEMBL1576050 & 688648 & 2.8239 & 2.4214 & TRN \\
\hline CHEMBL1990772 & 688648 & 2.8239 & 3.3415 & TRN \\
\hline CHEMBL 254576 & 688648 & 6.1232 & 4.1174 & TRN \\
\hline CHEMBL1429171 & 688648 & 4.8544 & 4.5491 & TRN \\
\hline CHEMBL1422170 & 688648 & 2.8239 & 3.0902 & TRN \\
\hline CHEMBL1505044 & 688648 & 4.8168 & 4.0865 & TRN \\
\hline CHEMBL1982305 & 688648 & 4.3247 & 3.4375 & TRN \\
\hline CHEMBL1303357 & 688648 & 2.8239 & 2.4413 & TRN \\
\hline CHEMBL1362163 & 688648 & 4.8753 & 3.508 & TST \\
\hline CHEMBL1411838 & 688648 & 2.8239 & 3.1209 & TRN \\
\hline CHEMBL1377903 & 688648 & 2.8239 & 3.5998 & TRN \\
\hline CHEMBL1497721 & 688648 & 2.8239 & 3.2707 & TRN \\
\hline CHEMBL3193338 & 688648 & 2.8239 & 3.2364 & TRN \\
\hline CHEMBL1510769 & 688648 & 2.8239 & 3.1012 & TST \\
\hline CHEMBL1320397 & 688648 & 2.8239 & 3.3516 & TRN \\
\hline CHEMBL1571348 & 688648 & 2.8239 & 3.3387 & TRN \\
\hline CHEMBL1460903 & 688648 & 2.8239 & 3.878 & TRN \\
\hline CHEMBL1562454 & 688648 & 2.8239 & 3.659 & TRN \\
\hline CHEMBL1575038 & 688648 & 2.8239 & 3.2932 & TRN \\
\hline CHEMBL1390702 & 688648 & 2.8239 & 3.3461 & TRN \\
\hline CHEMBL1609914 & 688648 & 2.8239 & 3.0308 & TRN \\
\hline CHEMBL1973532 & 688648 & 2.8239 & 3.5029 & TRN \\
\hline CHEMBL601768 & 688648 & 2.8239 & 3.2237 & TRN \\
\hline CHEMBL1609420 & 688648 & 2.8239 & 2.8482 & TRN \\
\hline CHEMBL1520702 & 688648 & 2.8239 & 3.2834 & TRN \\
\hline CHEMBL1592387 & 688648 & 2.8239 & 3.6069 & TRN \\
\hline CHEMBL1446971 & 688648 & 5.3251 & 4.2776 & TRN \\
\hline CHEMBL1416526 & 688648 & 2.8239 & 3.1867 & TRN \\
\hline CHEMBL1520777 & 688648 & 4.8683 & 4.3695 & TRN \\
\hline CHEMBL3194807 & 688648 & 2.8239 & 3.2046 & TRN \\
\hline CHEMBL1533308 & 688648 & 4.9975 & 4.5485 & TRN \\
\hline CHEMBL3211496 & 688648 & 2.8239 & 2.7744 & TRN \\
\hline CHEMBL3193726 & 688648 & 2.8239 & 2.7359 & TRN \\
\hline CHEMBL1605457 & 688648 & 2.8239 & 2.91 & TRN \\
\hline CHEMBL1461661 & 688648 & 5.5209 & 4.2286 & TRN \\
\hline CHEMBL1458785 & 688648 & 2.8239 & 3.0293 & TST \\
\hline CHEMBL1540122 & 688648 & 2.8239 & 3.6277 & TRN \\
\hline CHEMBL1332241 & 688648 & 5.3038 & 3.2732 & TST \\
\hline CHEMBL3214096 & 688648 & 4.4042 & 3.7781 & TRN \\
\hline CHEMBL1584753 & 688648 & 2.8239 & 2.9168 & TRN \\
\hline CHEMBL3191692 & 688648 & 2.8239 & 3.5582 & TRN \\
\hline CHEMBL1373110 & 688648 & 4.657 & 2.9503 & TST \\
\hline
\end{tabular}




\begin{tabular}{|c|c|c|c|c|c|}
\hline \multicolumn{6}{|c|}{ Supplemental Table S2.txt } \\
\hline CHEMBL1363271 & 688648 & 2.8239 & 2.9359 & TRN & \\
\hline CHEMBL1301901 & 688648 & 2.8239 & 3.08 & TRN & \\
\hline CHEMBL 3191846 & 688648 & 2.8239 & 1.9808 & TRN & \\
\hline CHEMBL1451360 & 688648 & 2.8239 & 3.3273 & TRN & \\
\hline CHEMBL1361033 & 688648 & 3.301 & 3.6644 & TRN & \\
\hline CHEMBL1405742 & 688648 & 2.8239 & 3.653 & TRN & \\
\hline CHEMBL1399229 & 688648 & 2.8239 & 2.8603 & TRN & \\
\hline CHEMBL1549816 & 688648 & 5.5535 & 4.2839 & TRN & \\
\hline CHEMBL1464544 & 688648 & 5.2768 & 3.8671 & TRN & \\
\hline CHEMBL1309248 & 688648 & 2.8239 & 2.8718 & TRN & \\
\hline CHEMBL587849 & 688648 & 2.8239 & 4.1192 & TRN & \\
\hline CHEMBL1369522 & 688648 & 4.6644 & 3.4974 & TST & \\
\hline CHEMBL1333989 & 688648 & 4.567 & 3.6063 & TRN & \\
\hline CHEMBL 3210228 & 688648 & 2.8239 & 3.9172 & TRN & \\
\hline CHEMBL1483746 & 688648 & 2.8239 & 3.0953 & TRN & \\
\hline CHEMBL1582520 & 688648 & 2.8239 & 3.1184 & TRN & \\
\hline CHEMBL1383511 & 688648 & 4.5945 & 3.9497 & TST & \\
\hline CHEMBL1610489 & 688648 & 4.7441 & 3.9391 & TST & \\
\hline CHEMBL1532819 & 688648 & 2.8239 & 3.0497 & TRN & \\
\hline CHEMBL1584456 & 688648 & 2.8239 & 2.7926 & TRN & \\
\hline CHEMBL411070 & 688648 & 2.8239 & 2.8741 & TST & \\
\hline CHEMBL1516792 & 688648 & 2.8239 & 3.50600 & 00000000002 & TRN \\
\hline CHEMBL1495140 & 688648 & 2.8239 & 3.5432 & TRN & \\
\hline CHEMBL1350984 & 688648 & 4.6631 & 3.74600 & 00000000004 & TRN \\
\hline CHEMBL1584720 & 688648 & 2.8239 & 3.4642 & TRN & \\
\hline CHEMBL1602709 & 688648 & 4.3145 & 4.0178 & TRN & \\
\hline CHEMBL1588356 & 688648 & 2.8239 & 4.083 & TRN & \\
\hline CHEMBL3190142 & 688648 & 4.7345 & 3.4554 & TRN & \\
\hline CHEMBL1341676 & 688648 & 4.4854 & 3.9007 & TRN & \\
\hline CHEMBL1542682 & 688648 & 5.5293 & 4.2986 & TRN & \\
\hline CHEMBL1479116 & 688648 & 2.8239 & 3.2347 & TST & \\
\hline CHEMBL1602836 & 688648 & 2.8239 & 2.9184 & TRN & \\
\hline CHEMBL1557952 & 688648 & 2.8239 & 4.2545 & TRN & \\
\hline CHEMBL1405059 & 688648 & 2.8239 & 3.3332 & TRN & \\
\hline CHEMBL1392311 & 688648 & 2.8239 & 1.8083 & TRN & \\
\hline CHEMBL1471932 & 688648 & 2.8239 & 3.5367 & TRN & \\
\hline CHEMBL1384359 & 688648 & 2.8239 & 3.8901 & TST & \\
\hline CHEMBL1430426 & 688648 & 2.8239 & 3.0913 & TRN & \\
\hline CHEMBL1341100 & 688648 & 5.1902 & 3.0577 & TRN & \\
\hline CHEMBL1587932 & 688648 & 2.8239 & 3.2484 & TRN & \\
\hline CHEMBL1336236 & 688648 & 3.301 & 3.3001 & TRN & \\
\hline CHEMBL1312788 & 688648 & 6.1851 & 3.3998 & TRN & \\
\hline CHEMBL1418178 & 688648 & 4.0564 & 3.4393 & TST & \\
\hline CHEMBL1325258 & 688648 & 2.8239 & 3.2455 & TRN & \\
\hline CHEMBL1557859 & 688648 & 2.8239 & 3.4591 & TRN & \\
\hline CHEMBL1592582 & 688648 & 2.8239 & 3.5861 & TRN & \\
\hline CHEMBL 299853 & 688648 & 2.8239 & 3.5517 & TRN & \\
\hline CHEMBL3190753 & 688648 & 4.7935 & 3.5352 & TRN & \\
\hline
\end{tabular}




\begin{tabular}{|c|c|c|c|c|}
\hline & & & pplement & al $\mathrm{T}$ \\
\hline CHEMBL1484547 & 688648 & 2.8239 & 3.7383 & TRN \\
\hline CHEMBL1605854 & 688648 & 2.8239 & 3.8994 & TRN \\
\hline CHEMBL1302439 & 688648 & 2.8239 & 3.3209 & TRN \\
\hline CHEMBL1456968 & 688648 & 2.8239 & 3.1949 & TRN \\
\hline CHEMBL1610644 & 688648 & 2.8239 & 2.8645 & TRN \\
\hline CHEMBL3198239 & 688648 & 2.8239 & 3.0335 & TRN \\
\hline CHEMBL3192542 & 688648 & 2.8239 & 3.9174 & TRN \\
\hline CHEMBL1339245 & 688648 & 2.8239 & 3.855 & TRN \\
\hline CHEMBL1991751 & 688648 & 4.586 & 3.2399 & TRN \\
\hline CHEMBL1580116 & 688648 & 2.8239 & 4.3534 & TRN \\
\hline CHEMBL1525576 & 688648 & 3.301 & 3.253 & TRN \\
\hline CHEMBL1572382 & 688648 & 2.8239 & 3.7365 & TRN \\
\hline CHEMBL3191452 & 688648 & 2.8239 & 2.8902 & TRN \\
\hline CHEMBL1534655 & 688648 & 2.8239 & 2.6354 & TRN \\
\hline CHEMBL1303280 & 688648 & 2.8239 & 3.003 & TRN \\
\hline CHEMBL1570705 & 688648 & 4.5235 & 3.3528 & TRN \\
\hline CHEMBL1369125 & 688648 & 5.7038 & 3.5704 & TST \\
\hline CHEMBL1346468 & 688648 & 2.8239 & 3.0394 & TRN \\
\hline CHEMBL3207920 & 688648 & 4.4537 & 4.1471 & TRN \\
\hline CHEMBL1486739 & 688648 & 2.8239 & 3.3344 & TRN \\
\hline CHEMBL1361896 & 688648 & 2.8239 & 3.6398 & TRN \\
\hline CHEMBL1315704 & 688648 & 4.1631 & 3.4908 & TRN \\
\hline CHEMBL1568971 & 688648 & 4.7686 & 4.1422 & TRN \\
\hline CHEMBL3197439 & 688648 & 4.7037 & 4.1632 & TRN \\
\hline CHEMBL1468577 & 688648 & 4.9513 & 4.1774 & TRN \\
\hline CHEMBL1573833 & 688648 & 2.8239 & 3.1147 & TRN \\
\hline CHEMBL1367662 & 688648 & 5.1492 & 3.5958 & TRN \\
\hline CHEMBL1416666 & 688648 & 2.8239 & 3.3103 & TRN \\
\hline CHEMBL1546886 & 688648 & 2.8239 & 2.7215 & TRN \\
\hline CHEMBL1326194 & 688648 & 3.301 & 3.555 & TRN \\
\hline CHEMBL1387517 & 688648 & 2.8239 & 3.5921 & TST \\
\hline CHEMBL1355961 & 688648 & 2.8239 & 3.9406 & TST \\
\hline CHEMBL3191808 & 688648 & 4.3942 & 3.3485 & TRN \\
\hline CHEMBL1487004 & 688648 & 2.8239 & 3.9545 & TST \\
\hline CHEMBL1477881 & 688648 & 2.8239 & 3.1692 & TRN \\
\hline CHEMBL1481600 & 688648 & 2.8239 & 3.95 & TST \\
\hline CHEMBL1398910 & 688648 & 2.8239 & 3.1703 & TRN \\
\hline CHEMBL1582878 & 688648 & 4.5681 & 4.4317 & TRN \\
\hline CHEMBL1320543 & 688648 & 2.8239 & 2.6515 & TRN \\
\hline CHEMBL1382763 & 688648 & 4.1288 & 3.7604 & TRN \\
\hline CHEMBL1426978 & 688648 & 2.8239 & 3.9446 & TRN \\
\hline CHEMBL1518515 & 688648 & 5.5832 & 4.0331 & TST \\
\hline CHEMBL1464597 & 688648 & 2.8239 & 4.2305 & TRN \\
\hline CHEMBL1532546 & 688648 & 2.8239 & 3.9693 & TRN \\
\hline CHEMBL1613220 & 688648 & 4.9193 & 3.8365 & TRN \\
\hline CHEMBL1499320 & 688648 & 2.8239 & 3.1544 & TRN \\
\hline CHEMBL1456926 & 688648 & 2.8239 & 3.6639 & TRN \\
\hline CHEMBL1438096 & 688648 & 4.2424 & 3.845 & TRN \\
\hline
\end{tabular}




\begin{tabular}{|c|c|c|c|c|}
\hline & & & oplement & al $\mathrm{T}$ \\
\hline CHEMBL3199364 & 688648 & 2.8239 & 3.3193 & TRN \\
\hline CHEMBL1596779 & 688648 & 2.8239 & 2.9618 & TST \\
\hline CHEMBL1498998 & 688648 & 2.8239 & 3.7378 & TST \\
\hline CHEMBL1576055 & 688648 & 2.8239 & 4.1241 & TRN \\
\hline CHEMBL1992702 & 688648 & 3.301 & 3.1363 & TRN \\
\hline CHEMBL1350869 & 688648 & 2.8239 & 3.5023 & TRN \\
\hline CHEMBL1478241 & 688648 & 2.8239 & 3.7221 & TRN \\
\hline CHEMBL1994815 & 688648 & 2.8239 & 3.1313 & TRN \\
\hline CHEMBL1384748 & 688648 & 4.8461 & 4.0605 & TRN \\
\hline CHEMBL1522582 & 688648 & 2.8239 & 3.9533 & TRN \\
\hline CHEMBL3194847 & 688648 & 2.8239 & 3.8511 & TRN \\
\hline CHEMBL1502412 & 688648 & 2.8239 & 3.3033 & TRN \\
\hline CHEMBL1488576 & 688648 & 4.7555 & 4.1588 & TRN \\
\hline CHEMBL1409443 & 688648 & 4.7447 & 3.4294 & TRN \\
\hline CHEMBL1596647 & 688648 & 4.5404 & 3.2338 & TRN \\
\hline CHEMBL1335383 & 688648 & 3.301 & 3.8504 & TST \\
\hline CHEMBL1598882 & 688648 & 2.8239 & 2.9037 & TRN \\
\hline CHEMBL1430495 & 688648 & 2.8239 & 3.1929 & TST \\
\hline CHEMBL3145192 & 688648 & 2.8239 & 4.2402 & TST \\
\hline CHEMBL1470353 & 688648 & 2.8239 & 3.3296 & TST \\
\hline CHEMBL532363 & 688648 & 5.5864 & 4.0459 & TRN \\
\hline CHEMBL1427125 & 688648 & 2.8239 & 4.4815 & TST \\
\hline CHEMBL3191296 & 688648 & 2.8239 & 2.1969 & TRN \\
\hline CHEMBL1564523 & 688648 & 2.8239 & 3.2573 & TRN \\
\hline CHEMBL2000750 & 688648 & 2.8239 & 3.1764 & TRN \\
\hline CHEMBL1539510 & 688648 & 2.8239 & 3.824 & TRN \\
\hline CHEMBL1496962 & 688648 & 2.8239 & 3.7549 & TRN \\
\hline CHEMBL3190827 & 688648 & 2.8239 & 2.9988 & TRN \\
\hline CHEMBL1414361 & 688648 & 2.8239 & 2.7902 & TST \\
\hline CHEMBL1560358 & 688648 & 2.8239 & 3.6917 & TRN \\
\hline CHEMBL3196941 & 688648 & 5.3939 & 3.2007 & TST \\
\hline CHEMBL1494782 & 688648 & 2.8239 & 2.8957 & TRN \\
\hline CHEMBL1463272 & 688648 & 2.8239 & 3.0492 & TRN \\
\hline CHEMBL1437208 & 688648 & 5.2868 & 4.2977 & TRN \\
\hline CHEMBL1429861 & 688648 & 2.8239 & 3.2863 & TRN \\
\hline CHEMBL1302158 & 688648 & 2.8239 & 3.5048 & TRN \\
\hline CHEMBL1359157 & 688648 & 2.8239 & 3.867 & TST \\
\hline CHEMBL221907 & 688648 & 2.8239 & 3.7275 & TST \\
\hline CHEMBL1351562 & 688648 & 2.8239 & 3.7854 & TRN \\
\hline CHEMBL1576333 & 688648 & 2.8239 & 2.625 & TRN \\
\hline CHEMBL1441897 & 688648 & 4.2584 & 3.7839 & TRN \\
\hline CHEMBL1351184 & 688648 & 5.1041 & 4.0886 & TST \\
\hline CHEMBL3209974 & 688648 & 4.7656 & 3.13 & TRN \\
\hline CHEMBL1304666 & 688648 & 2.8239 & 3.8856 & TRN \\
\hline CHEMBL1398075 & 688648 & 2.8239 & 2.6876 & TRN \\
\hline CHEMBL1445327 & 688648 & 4.5827 & 3.8018 & TRN \\
\hline CHEMBL1503248 & 688648 & 2.8239 & 4.2852 & TRN \\
\hline CHEMBL3191413 & 688648 & 2.8239 & 3.0632 & TRN \\
\hline
\end{tabular}




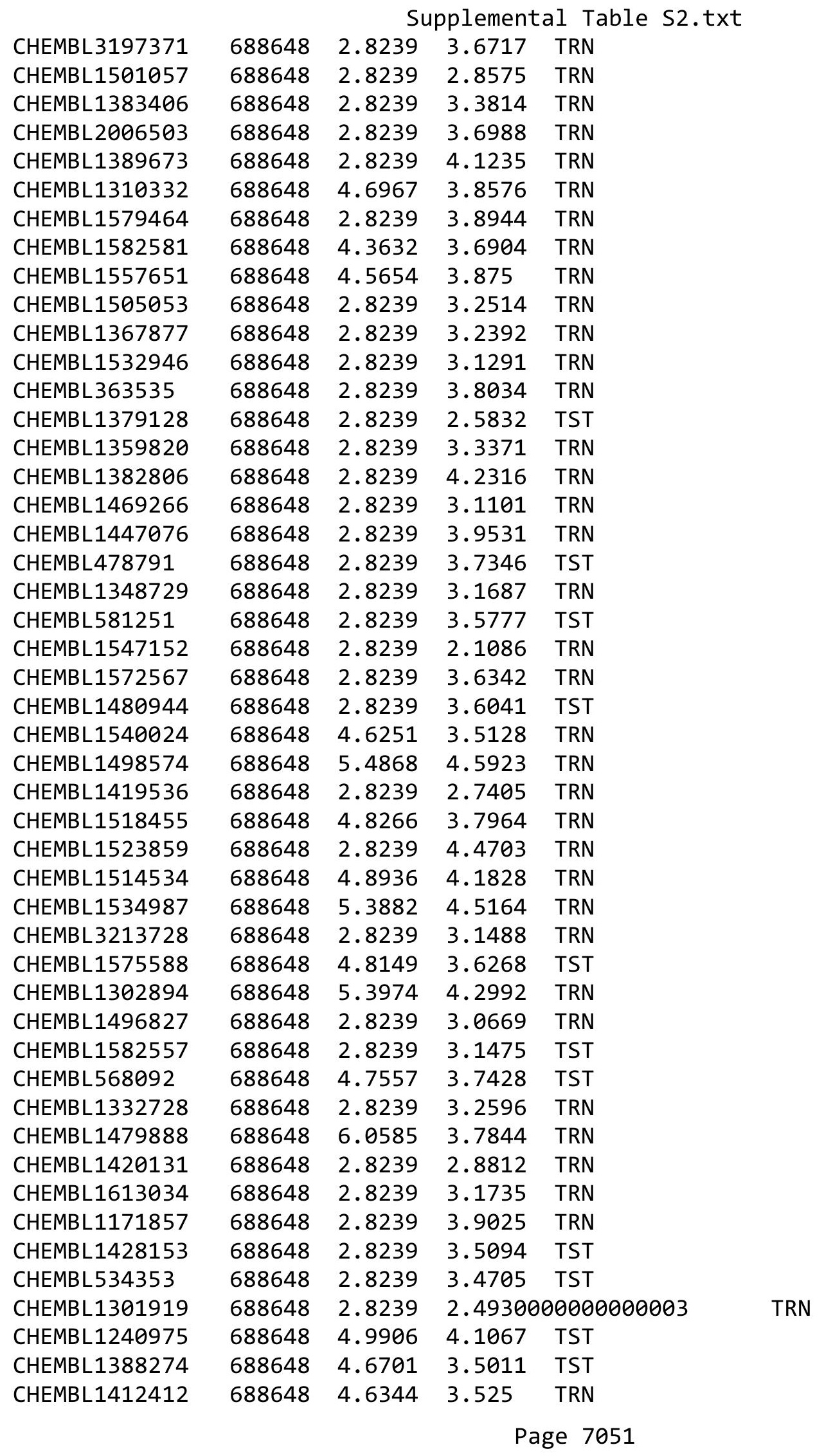




\begin{tabular}{|c|c|c|c|c|c|c|}
\hline & & \multicolumn{5}{|c|}{ Supplemental Table S2.txt } \\
\hline CHEMBL1567899 & 688648 & 2.8239 & 3.5202 & TRN & & \\
\hline CHEMBL1410436 & 688648 & 2.8239 & 2.81699 & 99999 & 997 & TRN \\
\hline CHEMBL3191706 & 688648 & 4.6709 & 3.8431 & TRN & & \\
\hline CHEMBL1427576 & 688648 & 2.8239 & 3.7285 & TRN & & \\
\hline CHEMBL1559999 & 688648 & 2.8239 & 4.2533 & TRN & & \\
\hline CHEMBL530682 & 688648 & $4.2780 e$ & 30000000 & 005 & 3.7267 & TRN \\
\hline CHEMBL1423338 & 688648 & 3.8915 & 3.0828 & TRN & & \\
\hline CHEMBL1510680 & 688648 & 2.8239 & 3.0179 & TRN & & \\
\hline CHEMBL1425091 & 688648 & 5.3083 & 4.6543 & TRN & & \\
\hline CHEMBL1465980 & 688648 & 2.8239 & 2.8527 & TRN & & \\
\hline CHEMBL1429841 & 688648 & 2.8239 & 2.3972 & TRN & & \\
\hline CHEMBL1583785 & 688648 & 4.6507 & 3.6899 & TRN & & \\
\hline CHEMBL3196386 & 688648 & 4.8712 & 3.8228 & TRN & & \\
\hline CHEMBL1376204 & 688648 & 2.8239 & 2.8643 & TST & & \\
\hline CHEMBL1977376 & 688648 & 2.8239 & 2.3781 & TRN & & \\
\hline CHEMBL1384068 & 688648 & 4.9663 & 4.2318 & TRN & & \\
\hline CHEMBL1388118 & 688648 & 4.0498 & 3.8105 & TST & & \\
\hline CHEMBL1580555 & 688648 & 4.2628 & 3.9245 & TRN & & \\
\hline CHEMBL1323512 & 688648 & 2.8239 & 3.4992 & TRN & & \\
\hline CHEMBL1407438 & 688648 & 4.7197 & 4.5875 & TRN & & \\
\hline CHEMBL1522645 & 688648 & 4.6342 & 3.8412 & TRN & & \\
\hline CHEMBL1976312 & 688648 & 2.8239 & 3.2504 & TRN & & \\
\hline CHEMBL1342990 & 688648 & 5.4345 & 3.9764 & TRN & & \\
\hline CHEMBL1478319 & 688648 & 2.8239 & 3.8732 & TST & & \\
\hline CHEMBL1495714 & 688648 & 4.0479 & 3.6127 & TRN & & \\
\hline CHEMBL1602599 & 688648 & 4.1215 & 3.6187 & TRN & & \\
\hline CHEMBL1604622 & 688648 & 4.7076 & 3.4408 & TST & & \\
\hline CHEMBL1469052 & 688648 & 2.8239 & 3.3359 & TRN & & \\
\hline CHEMBL1307746 & 688648 & 2.8239 & 3.0217 & TST & & \\
\hline CHEMBL1342093 & 688648 & 2.8239 & 4.1021 & TRN & & \\
\hline CHEMBL1994371 & 688648 & 2.8239 & 3.3957 & TRN & & \\
\hline CHEMBL3213459 & 688648 & 5.2052 & 3.7147 & TRN & & \\
\hline CHEMBL1302758 & 688648 & 2.8239 & 2.9768 & TRN & & \\
\hline CHEMBL1508616 & 688648 & 2.8239 & 3.3755 & TRN & & \\
\hline CHEMBL162783 & 688648 & 5.7597 & 4.2 & TST & & \\
\hline CHEMBL1334663 & 688648 & 2.8239 & 3.0647 & TST & & \\
\hline CHEMBL459022 & 688648 & 2.8239 & 3.9378 & TST & & \\
\hline CHEMBL3195943 & 688648 & 4.4314 & 3.4655 & TRN & & \\
\hline CHEMBL1600587 & 688648 & 6.0526 & 3.8278 & TRN & & \\
\hline CHEMBL1505821 & 688648 & 5.2677 & 4.0667 & TRN & & \\
\hline CHEMBL1408463 & 688648 & 2.8239 & 3.4808 & TRN & & \\
\hline CHEMBL1459918 & 688648 & 2.8239 & 2.7301 & TRN & & \\
\hline CHEMBL1580922 & 688648 & 5.376 & 3.7741 & TRN & & \\
\hline CHEMBL1435040 & 688648 & 2.8239 & 3.147 & TRN & & \\
\hline CHEMBL1965791 & 688648 & 2.8239 & 3.37600 & 00000 & 003 & TRN \\
\hline CHEMBL 2005079 & 688648 & 2.8239 & 3.1817 & TRN & & \\
\hline CHEMBL1595152 & 688648 & 5.391 & 3.9203 & TST & & \\
\hline CHEMBL3190103 & 688648 & 2.8239 & 3.445 & TRN & & \\
\hline
\end{tabular}




\begin{tabular}{|c|c|c|c|c|c|}
\hline & & \multicolumn{4}{|c|}{ Supplemental Table s2.txt } \\
\hline CHEMBL1390121 & 688648 & 2.8239 & 3.1573 & TRN & \\
\hline CHEMBL1547867 & 688648 & 2.8239 & 3.4155 & TRN & \\
\hline CHEMBL1502724 & 688648 & 2.8239 & 3.1263 & TRN & \\
\hline CHEMBL1347479 & 688648 & 2.8239 & 3.6591 & TST & \\
\hline CHEMBL1338713 & 688648 & 2.8239 & 3.0627 & TRN & \\
\hline CHEMBL1567814 & 688648 & 5.5753 & 4.1466 & TRN & \\
\hline CHEMBL1425314 & 688648 & 2.8239 & 3.4551 & TRN & \\
\hline CHEMBL1991450 & 688648 & 2.8239 & 3.3473 & TRN & \\
\hline CHEMBL1311812 & 688648 & 2.8239 & 4.7342 & TRN & \\
\hline CHEMBL1306480 & 688648 & 2.8239 & 3.5055 & TRN & \\
\hline CHEMBL3195997 & 688648 & 2.8239 & 2.636 & TRN & \\
\hline CHEMBL 1358550 & 688648 & 2.8239 & 2.6783 & TRN & \\
\hline CHEMBL1484097 & 688648 & 2.8239 & 3.0835 & TRN & \\
\hline CHEMBL1524252 & 688648 & 2.8239 & 2.3914 & TST & \\
\hline CHEMBL1483281 & 688648 & 2.8239 & 3.6236 & TRN & \\
\hline CHEMBL1310411 & 688648 & 2.8239 & 3.2432 & TRN & \\
\hline CHEMBL1436666 & 688648 & 2.8239 & 3.1036 & TRN & \\
\hline CHEMBL1470030 & 688648 & 2.8239 & 2.9511 & TRN & \\
\hline CHEMBL1505788 & 688648 & 2.8239 & 3.1947 & TRN & \\
\hline CHEMBL45281 & 688648 & 5.8837 & 4.3966 & TST & \\
\hline CHEMBL1572056 & 688648 & 4.498 & 3.5187 & TRN & \\
\hline CHEMBL3199856 & 688648 & 2.8239 & 3.5684 & TRN & \\
\hline CHEMBL1378331 & 688648 & 4.9696 & 4.2531 & TRN & \\
\hline CHEMBL1339368 & 688648 & 5.082 & 4.0063 & TST & \\
\hline CHEMBL1416769 & 688648 & 5.4072 & 4.3401 & TRN & \\
\hline CHEMBL1529106 & 688648 & 2.8239 & 4.0047 & TRN & \\
\hline CHEMBL1584810 & 688648 & 2.8239 & 2.9789 & 99999999996 & TRN \\
\hline CHEMBL1606526 & 688648 & $5.2070 e$ & 3000000 & $01 \quad 3.8855$ & TRN \\
\hline CHEMBL1579217 & 688648 & 2.8239 & 3.281 & TRN & \\
\hline CHEMBL1396215 & 688648 & 4.2689 & 3.4084 & TRN & \\
\hline CHEMBL1599495 & 688648 & 3.9724 & 3.3202 & TRN & \\
\hline CHEMBL3212930 & 688648 & 2.8239 & 2.5409 & TRN & \\
\hline CHEMBL1550132 & 688648 & 2.8239 & 2.9585 & TRN & \\
\hline CHEMBL1316798 & 688648 & 4.7494 & 3.5257 & TRN & \\
\hline CHEMBL3195933 & 688648 & 2.8239 & 2.9224 & TRN & \\
\hline CHEMBL1334272 & 688648 & 2.8239 & 3.1210 & 00000000004 & TRN \\
\hline CHEMBL1467377 & 688648 & 2.8239 & 2.7868 & TRN & \\
\hline CHEMBL1523620 & 688648 & 4.1158 & 3.7615 & TRN & \\
\hline CHEMBL1333993 & 688648 & 4.6108 & 4.3169 & TRN & \\
\hline CHEMBL1426383 & 688648 & 2.8239 & 3.8088 & TRN & \\
\hline CHEMBL1535622 & 688648 & 4.749 & 3.2523 & TRN & \\
\hline CHEMBL197014 & 688648 & 2.8239 & 3.3354 & TRN & \\
\hline CHEMBL1367033 & 688648 & 2.8239 & 2.1285 & TRN & \\
\hline CHEMBL1587655 & 688648 & 2.8239 & 4.1518 & TRN & \\
\hline CHEMBL 3190608 & 688648 & 2.8239 & 3.7676 & TRN & \\
\hline CHEMBL1313731 & 688648 & 2.8239 & 2.8810 & 00000000002 & TRN \\
\hline CHEMBL 3191394 & 688648 & 2.8239 & 2.5935 & TRN & \\
\hline CHEMBL1534433 & 688648 & 2.8239 & 3.4142 & TRN & \\
\hline
\end{tabular}




\begin{tabular}{|c|c|c|c|c|c|}
\hline & & \multicolumn{4}{|c|}{ Supplemental Table S2.txt } \\
\hline CHEMBL1481198 & 688648 & 2.8239 & 3.1449 & TRN & \\
\hline CHEMBL1519764 & 688648 & 4.8484 & 3.6966 & TST & \\
\hline CHEMBL3195273 & 688648 & 2.8239 & 2.9359 & TRN & \\
\hline CHEMBL1520896 & 688648 & 2.8239 & 2.7198 & TRN & \\
\hline CHEMBL1597758 & 688648 & 2.8239 & 2.94199 & 99999999997 & TST \\
\hline CHEMBL1556485 & 688648 & 2.8239 & 3.1729 & TRN & \\
\hline CHEMBL1411897 & 688648 & 2.8239 & 4.1312 & TST & \\
\hline CHEMBL1501558 & 688648 & 2.8239 & 3.1477 & TRN & \\
\hline CHEMBL1538099 & 688648 & 5.6227 & 4.6324 & TRN & \\
\hline CHEMBL1557756 & 688648 & 4.6488 & 3.5655 & TRN & \\
\hline CHEMBL 3211754 & 688648 & 4.8339 & 3.0409 & TRN & \\
\hline CHEMBL1333755 & 688648 & 2.8239 & 3.6623 & TST & \\
\hline CHEMBL1306265 & 688648 & 2.8239 & 4.0631 & TST & \\
\hline CHEMBL1487505 & 688648 & 2.8239 & 3.0162 & TRN & \\
\hline CHEMBL1583060 & 688648 & 2.8239 & 3.3745 & TRN & \\
\hline CHEMBL1411744 & 688648 & 2.8239 & 3.0943 & TRN & \\
\hline CHEMBL1610800 & 688648 & 2.8239 & 3.4714 & TRN & \\
\hline CHEMBL1401144 & 688648 & 2.8239 & 3.5254 & TRN & \\
\hline CHEMBL1346056 & 688648 & 5.3863 & 3.2933 & TRN & \\
\hline CHEMBL1337203 & 688648 & 2.8239 & 3.2628 & TRN & \\
\hline CHEMBL 3145107 & 688648 & 2.8239 & 3.4854 & TRN & \\
\hline CHEMBL1299653 & 688648 & 4.8785 & 4.0094 & TST & \\
\hline CHEMBL1509762 & 688648 & 2.8239 & 3.9774 & TRN & \\
\hline CHEMBL1531676 & 688648 & 4.6588 & 3.8329 & TST & \\
\hline CHEMBL1476225 & 688648 & 5.4923 & 3.614 & TRN & \\
\hline CHEMBL1603550 & 688648 & 2.8239 & 2.8833 & TRN & \\
\hline CHEMBL180905 & 688648 & 2.8239 & 3.2296 & TRN & \\
\hline CHEMBL1558160 & 688648 & 2.8239 & 3.3881 & TRN & \\
\hline CHEMBL3189802 & 688648 & 2.8239 & 2.8812 & TRN & \\
\hline CHEMBL1420253 & 688648 & 4.4918 & 4.1706 & TST & \\
\hline CHEMBL1371119 & 688648 & 4.6691 & 3.8216 & TRN & \\
\hline CHEMBL1571208 & 688648 & 2.8239 & 3.6059 & TST & \\
\hline CHEMBL1433095 & 688648 & 2.8239 & 4.835 & TRN & \\
\hline CHEMBL1427059 & 688648 & 4.393 & 4.0544 & TRN & \\
\hline CHEMBL517514 & 688648 & 4.97 & 3.9104 & TST & \\
\hline CHEMBL1355133 & 688648 & 2.8239 & 2.9419 & TRN & \\
\hline CHEMBL1597234 & 688648 & 2.8239 & 3.8827 & TRN & \\
\hline CHEMBL1366319 & 688648 & 2.8239 & 2.5407 & TRN & \\
\hline CHEMBL1584143 & 688648 & 2.8239 & 3.3743 & TRN & \\
\hline CHEMBL1406455 & 688648 & 2.8239 & 3.252 & TRN & \\
\hline CHEMBL1421347 & 688648 & 2.8239 & 3.3472 & TRN & \\
\hline CHEMBL1302569 & 688648 & 2.8239 & 3.9288 & TRN & \\
\hline CHEMBL1441418 & 688648 & 5.5449 & 3.7334 & TRN & \\
\hline CHEMBL1966798 & 688648 & 2.8239 & 3.6387 & TRN & \\
\hline CHEMBL1541525 & 688648 & 2.8239 & 2.3995 & TRN & \\
\hline CHEMBL1573962 & 688648 & 2.8239 & 3.8931 & TRN & \\
\hline CHEMBL1413672 & 688648 & 2.8239 & 3.7246 & TRN & \\
\hline CHEMBL1430138 & 688648 & 4.5066 & 3.7082 & TRN & \\
\hline
\end{tabular}




\begin{tabular}{|c|c|c|c|c|c|}
\hline & & \multicolumn{4}{|c|}{ Supplemental Table S2.txt } \\
\hline CHEMBL1446293 & 688648 & 2.8239 & 3.4366 & TRN & \\
\hline CHEMBL1536217 & 688648 & 2.8239 & 2.9553 & TRN & \\
\hline CHEMBL1402496 & 688648 & 4.9324 & 3.3129 & TST & \\
\hline CHEMBL 3192977 & 688648 & 2.8239 & 3.6923 & TRN & \\
\hline CHEMBL1511739 & 688648 & 2.8239 & 3.9801 & TRN & \\
\hline CHEMBL1359345 & 688648 & 2.8239 & 3.1433 & TRN & \\
\hline CHEMBL1553636 & 688648 & 2.8239 & 3.3771 & TRN & \\
\hline CHEMBL1503359 & 688648 & 3.8862 & 3.2145 & TRN & \\
\hline CHEMBL1376070 & 688648 & 5.5325 & 4.5678 & TRN & \\
\hline CHEMBL1469449 & 688648 & 4.3674 & 4.0765 & TRN & \\
\hline CHEMBL1491621 & 688648 & 2.8239 & 3.6752 & TRN & \\
\hline CHEMBL1417620 & 688648 & 5.9194 & 4.1983 & TRN & \\
\hline CHEMBL3199820 & 688648 & 2.8239 & 2.74899 & 99999999997 & TRN \\
\hline CHEMBL1996376 & 688648 & 3.8797 & 3.3874 & TRN & \\
\hline CHEMBL1426149 & 688648 & 2.8239 & 2.8218 & TRN & \\
\hline CHEMBL1329634 & 688648 & 2.8239 & 3.1363 & TRN & \\
\hline CHEMBL1391743 & 688648 & 2.8239 & 3.4976 & TRN & \\
\hline CHEMBL3196513 & 688648 & 4.2034 & 3.3143 & TRN & \\
\hline CHEMBL1468929 & 688648 & 2.8239 & 3.2851 & TRN & \\
\hline CHEMBL1536606 & 688648 & 5.4706 & 4.3762 & TRN & \\
\hline CHEMBL1718568 & 688648 & 2.8239 & 3.5731 & TRN & \\
\hline CHEMBL1540682 & 688648 & 6.1284 & 3.6704 & TST & \\
\hline CHEMBL1471371 & 688648 & 2.8239 & 3.935 & TRN & \\
\hline CHEMBL1343073 & 688648 & 5.4878 & 4.1271 & TST & \\
\hline CHEMBL1384179 & 688648 & 2.8239 & 2.8482 & TRN & \\
\hline CHEMBL1553969 & 688648 & 2.8239 & 3.8339 & TRN & \\
\hline CHEMBL1455824 & 688648 & 2.8239 & 3.1577 & TRN & \\
\hline CHEMBL1377417 & 688648 & 2.8239 & 3.2101 & TRN & \\
\hline CHEMBL1357155 & 688648 & 2.8239 & 3.6685 & TRN & \\
\hline CHEMBL1400764 & 688648 & 4.7528 & 3.6794 & TRN & \\
\hline CHEMBL1559496 & 688648 & 2.8239 & 3.6048 & TRN & \\
\hline CHEMBL1458596 & 688648 & 2.8239 & 3.3911 & TRN & \\
\hline CHEMBL1462041 & 688648 & 2.8239 & 3.5363 & TRN & \\
\hline CHEMBL1389315 & 688648 & 5.2858 & 4.0238 & TRN & \\
\hline CHEMBL1519807 & 688648 & 2.8239 & 3.9535 & TST & \\
\hline CHEMBL1503729 & 688648 & 2.8239 & 3.7056 & TRN & \\
\hline CHEMBL1381353 & 688648 & 2.8239 & 4.0179 & TRN & \\
\hline CHEMBL1345480 & 688648 & 2.8239 & 3.5226 & TRN & \\
\hline CHEMBL1491933 & 688648 & 2.8239 & 2.7912 & TRN & \\
\hline CHEMBL1559500 & 688648 & 2.8239 & 3.8494 & TRN & \\
\hline CHEMBL1453924 & 688648 & 2.8239 & 3.5065 & TRN & \\
\hline CHEMBL1420365 & 688648 & 2.8239 & 2.6827 & TRN & \\
\hline CHEMBL1595732 & 688648 & 2.8239 & 2.30400 & 00000000003 & TST \\
\hline CHEMBL1500199 & 688648 & 2.8239 & 4.1221 & TRN & \\
\hline CHEMBL1585758 & 688648 & 5.4254 & 4.0149 & TRN & \\
\hline CHEMBL1401629 & 688648 & 2.8239 & 4.2795 & TRN & \\
\hline CHEMBL1384341 & 688648 & 4.6948 & 3.42 & TRN & \\
\hline CHEMBL1610002 & 688648 & 5.3817 & 3.7621 & TST & \\
\hline
\end{tabular}




\begin{tabular}{|c|c|c|c|c|}
\hline \multicolumn{5}{|c|}{ Supplemental Tab. } \\
\hline CHEMBL1348268 & 688648 & 4.6344 & 4.0795 & TRN \\
\hline CHEMBL1510940 & 688648 & 4.8929 & 4.0753 & TST \\
\hline CHEMBL1304168 & 688648 & 3.301 & 3.6639 & TRN \\
\hline CHEMBL1582537 & 688648 & 5.684 & 3.707 & TRN \\
\hline CHEMBL1459313 & 688648 & 3.9833 & 3.1464 & TST \\
\hline CHEMBL1346232 & 688648 & 5.0684 & 4.1242 & TRN \\
\hline CHEMBL3194209 & 688648 & 2.8239 & 2.4972 & TRN \\
\hline CHEMBL187460 & 688648 & 4.8293 & 4.1851 & TST \\
\hline CHEMBL1483287 & 688648 & 2.8239 & 2.9075 & TRN \\
\hline CHEMBL1403620 & 688648 & 2.8239 & 2.6598 & TRN \\
\hline CHEMBL1476229 & 688648 & 2.8239 & 3.7287 & TRN \\
\hline CHEMBL598903 & 688648 & 2.8239 & 3.9932 & TRN \\
\hline CHEMBL539027 & 688648 & 5.0021 & 3.9507 & TST \\
\hline CHEMBL1374801 & 688648 & 2.8239 & 3.3432 & TRN \\
\hline CHEMBL1578127 & 688648 & 2.8239 & 3.4401 & TST \\
\hline CHEMBL1303391 & 688648 & 2.8239 & 3.3008 & TRN \\
\hline CHEMBL1338825 & 688648 & 2.8239 & 3.5461 & TRN \\
\hline CHEMBL1569543 & 688648 & 2.8239 & 3.57 & TRN \\
\hline CHEMBL1354631 & 688648 & 2.8239 & 2.9049 & TRN \\
\hline CHEMBL1578252 & 688648 & 2.8239 & 3.0831 & TRN \\
\hline CHEMBL1428343 & 688648 & 2.8239 & 3.5027 & TRN \\
\hline CHEMBL1609090 & 688648 & 2.8239 & 3.0586 & TRN \\
\hline CHEMBL1528835 & 688648 & 2.8239 & 3.6898 & TRN \\
\hline CHEMBL1449111 & 688648 & 2.8239 & 3.075 & TRN \\
\hline CHEMBL256042 & 688648 & 2.8239 & 3.5712 & TRN \\
\hline CHEMBL1497685 & 688648 & 4.5094 & 3.4555 & TRN \\
\hline CHEMBL1408102 & 688648 & 2.8239 & 3.2734 & TST \\
\hline CHEMBL3210126 & 688648 & 4.7721 & 3.6193 & TRN \\
\hline CHEMBL1574982 & 688648 & 2.8239 & 3.3204 & TRN \\
\hline CHEMBL1430636 & 688648 & 2.8239 & 3.4069 & TRN \\
\hline CHEMBL1490966 & 688648 & 2.8239 & 3.4503 & TRN \\
\hline CHEMBL3199832 & 688648 & 2.8239 & 3.7892 & TRN \\
\hline CHEMBL1354041 & 688648 & 2.8239 & 4.137 & TRN \\
\hline CHEMBL1386564 & 688648 & 4.7728 & 4.2085 & TST \\
\hline CHEMBL1306986 & 688648 & 2.8239 & 3.6723 & TRN \\
\hline CHEMBL1976000 & 688648 & 2.8239 & 3.2359 & TRN \\
\hline CHEMBL1371733 & 688648 & 2.8239 & 3.0766 & TRN \\
\hline CHEMBL1302315 & 688648 & 5.4323 & 4.3208 & TRN \\
\hline CHEMBL1382628 & 688648 & 2.8239 & 3.1576 & TRN \\
\hline CHEMBL1329067 & 688648 & 5.4406 & 3.7103 & TRN \\
\hline CHEMBL1414460 & 688648 & 2.8239 & 3.1337 & TRN \\
\hline CHEMBL3195963 & 688648 & 2.8239 & 3.6506 & TRN \\
\hline CHEMBL1342028 & 688648 & 2.8239 & 2.8876 & TRN \\
\hline CHEMBL1327470 & 688648 & 5.239 & 4.3906 & TRN \\
\hline CHEMBL1496635 & 688648 & 5.2337 & 3.928 & TST \\
\hline CHEMBL1573330 & 688648 & 2.8239 & 3.108 & TRN \\
\hline CHEMBL1517469 & 688648 & 3.9728 & 3.1277 & TRN \\
\hline CHEMBL1482296 & 688648 & 2.8239 & 4.3484 & TRN \\
\hline
\end{tabular}




\begin{tabular}{|c|c|c|c|c|c|c|}
\hline \multicolumn{7}{|c|}{ Supplemental Table s2.txt } \\
\hline CHEMBL3197099 & 688648 & 2.8239 & 2.9714 & TRN & & \\
\hline CHEMBL1511033 & 688648 & 4.8963 & 4.0531 & TST & & \\
\hline CHEMBL1522419 & 688648 & 4.7362 & 3.8223 & TST & & \\
\hline CHEMBL1541834 & 688648 & 2.8239 & 2.9738 & TRN & & \\
\hline CHEMBL1323631 & 688648 & 5.1854 & 3.7565 & TRN & & \\
\hline CHEMBL1420623 & 688648 & 4.3056 & 3.3812 & TRN & & \\
\hline CHEMBL1588411 & 688648 & 4.6733 & 4.1863 & TRN & & \\
\hline CHEMBL1527660 & 688648 & 2.8239 & 3.589 & TRN & & \\
\hline CHEMBL1432081 & 688648 & 2.8239 & 3.3822 & TRN & & \\
\hline CHEMBL1568310 & 688648 & 2.8239 & 3.105 & TRN & & \\
\hline CHEMBL1604028 & 688648 & 2.8239 & 3.9078 & TRN & & \\
\hline CHEMBL1375468 & 688648 & 2.8239 & 3.1144 & TRN & & \\
\hline CHEMBL1376019 & 688648 & 2.8239 & 4.1339 & TRN & & \\
\hline CHEMBL1533152 & 688648 & 3.98199 & 99999999 & 998 & 3.5198 TRN & \\
\hline CHEMBL1526855 & 688648 & 2.8239 & 4.4026 & TRN & & \\
\hline CHEMBL1609481 & 688648 & 2.8239 & 2.7391 & TRN & & \\
\hline CHEMBL1978479 & 688648 & 4.5535 & 3.2454 & TST & & \\
\hline CHEMBL1480647 & 688648 & 2.8239 & 3.8017 & TRN & & \\
\hline CHEMBL1365611 & 688648 & 2.8239 & 3.7572 & TRN & & \\
\hline CHEMBL1405968 & 688648 & 5.73799 & 99999999 & 995 & 4.4239999999999995 & TRN \\
\hline CHEMBL1453089 & 688648 & 5.2114 & 3.9171 & TRN & & \\
\hline CHEMBL532160 & 688648 & 5.2273 & 3.9041 & TST & & \\
\hline CHEMBL1433385 & 688648 & 4.4093 & 3.7082 & TRN & & \\
\hline CHEMBL1586809 & 688648 & 5.0503 & 3.9342 & TRN & & \\
\hline CHEMBL63354 & 688648 & 2.8239 & 3.9458 & TST & & \\
\hline CHEMBL1299566 & 688648 & 4.8598 & 3.8289 & TRN & & \\
\hline CHEMBL1582355 & 688648 & 2.8239 & 3.4371 & TRN & & \\
\hline CHEMBL1603844 & 688648 & 5.845 & 3.0339 & TST & & \\
\hline CHEMBL1376311 & 688648 & 2.8239 & 4.3489 & TRN & & \\
\hline CHEMBL1560126 & 688648 & 5.2921 & 3.9701 & TRN & & \\
\hline CHEMBL1984816 & 688648 & 2.8239 & 3.0731 & TRN & & \\
\hline CHEMBL1522803 & 688648 & 2.8239 & 3.3542 & TRN & & \\
\hline CHEMBL1422471 & 688648 & 5.2812 & 3.6331 & TRN & & \\
\hline CHEMBL1535443 & 688648 & 2.8239 & 3.8483 & TRN & & \\
\hline CHEMBL1494267 & 688648 & 2.8239 & 3.8817 & TST & & \\
\hline CHEMBL3190482 & 688648 & 2.8239 & 3.0966 & TRN & & \\
\hline CHEMBL 1489757 & 688648 & 5.5 & 4.3035 & TRN & & \\
\hline CHEMBL406652 & 688648 & 4.8077 & 3.6204 & TST & & \\
\hline CHEMBL1496338 & 688648 & 2.8239 & 3.4317 & TRN & & \\
\hline CHEMBL1308594 & 688648 & 5.1746 & 3.8568 & TST & & \\
\hline CHEMBL1387605 & 688648 & 2.8239 & 3.2641 & TRN & & \\
\hline CHEMBL1453753 & 688648 & 2.8239 & 3.7769 & TRN & & \\
\hline CHEMBL212314 & 688648 & 5.4006 & 4.2102 & TST & & \\
\hline CHEMBL1557619 & 688648 & 2.8239 & 3.6871 & TRN & & \\
\hline CHEMBL1562524 & 688648 & 2.8239 & 3.5728 & TRN & & \\
\hline CHEMBL1524764 & 688648 & 2.8239 & 3.5292 & TRN & & \\
\hline CHEMBL1407235 & 688648 & 4.8212 & 3.787 & TRN & & \\
\hline CHEMBL1531512 & 688648 & 2.8239 & 4.1426 & TST & & \\
\hline
\end{tabular}




\begin{tabular}{|c|c|c|c|c|c|}
\hline & & \multicolumn{4}{|c|}{ Supplemental Table S2.txt } \\
\hline CHEMBL1415587 & 688648 & 2.8239 & 3.7217 & TRN & \\
\hline CHEMBL1328707 & 688648 & 2.8239 & 2.7766 & TRN & \\
\hline CHEMBL1486092 & 688648 & 2.8239 & 3.2777 & TRN & \\
\hline CHEMBL1463163 & 688648 & 5.2531 & 3.7895 & TRN & \\
\hline CHEMBL1340487 & 688648 & 2.8239 & 3.6897 & TRN & \\
\hline CHEMBL3196614 & 688648 & 2.8239 & 4.1518 & TRN & \\
\hline CHEMBL1305393 & 688648 & 4.3128 & 2.95 & TRN & \\
\hline CHEMBL1354009 & 688648 & 2.8239 & 2.9939 & TRN & \\
\hline CHEMBL1461547 & 688648 & 2.8239 & 3.6836 & TRN & \\
\hline CHEMBL1424836 & 688648 & 2.8239 & 2.9511 & TRN & \\
\hline CHEMBL1566076 & 688648 & 2.8239 & 3.3298 & TRN & \\
\hline CHEMBL1326381 & 688648 & 2.8239 & 3.3939 & TRN & \\
\hline CHEMBL1402220 & 688648 & 2.8239 & 3.3122 & TRN & \\
\hline CHEMBL1500712 & 688648 & 2.8239 & 3.495 & TST & \\
\hline CHEMBL1515251 & 688648 & 2.8239 & 3.5897 & TRN & \\
\hline CHEMBL1444941 & 688648 & 4.7435 & 3.5252 & TRN & \\
\hline CHEMBL1449354 & 688648 & 4.3966 & 3.1095 & TRN & \\
\hline CHEMBL1376174 & 688648 & 4.624 & 3.5853 & TST & \\
\hline CHEMBL1601701 & 688648 & 4.8329 & 3.3998 & TST & \\
\hline CHEMBL606167 & 688648 & 5.3094 & 3.5415 & TST & \\
\hline CHEMBL1613066 & 688648 & 2.8239 & 2.4377 & TRN & \\
\hline CHEMBL1538317 & 688648 & 2.8239 & 3.47 & TRN & \\
\hline CHEMBL482116 & 688648 & 2.8239 & 3.0807 & TRN & \\
\hline CHEMBL1341308 & 688648 & 3.301 & 3.752 & TRN & \\
\hline CHEMBL1314461 & 688648 & 2.8239 & 4.7366 & TRN & \\
\hline CHEMBL1538986 & 688648 & 2.8239 & 3.5025 & TRN & \\
\hline CHEMBL1381257 & 688648 & 2.8239 & 3.5018 & TRN & \\
\hline CHEMBL1480812 & 688648 & 2.8239 & 4.0338 & TRN & \\
\hline CHEMBL1472530 & 688648 & 4.387 & 3.5549 & TRN & \\
\hline CHEMBL1499828 & 688648 & 2.8239 & 3.5445 & TRN & \\
\hline CHEMBL1970859 & 688648 & 2.8239 & 3.5372 & TRN & \\
\hline CHEMBL1370252 & 688648 & 2.8239 & 3.4643 & TRN & \\
\hline CHEMBL1422231 & 688648 & 2.8239 & 2.78899 & 99999999997 & TRN \\
\hline CHEMBL1414059 & 688648 & 4.9865 & 3.7995 & TRN & \\
\hline CHEMBL1520696 & 688648 & 2.8239 & 3.9557 & TST & \\
\hline CHEMBL1532727 & 688648 & 2.8239 & 2.9645 & TRN & \\
\hline CHEMBL1173823 & 688648 & 2.8239 & 3.2815 & TRN & \\
\hline CHEMBL1309958 & 688648 & 4.9271 & 4.2542 & TST & \\
\hline CHEMBL1369724 & 688648 & 5.4006 & 4.1622 & TRN & \\
\hline CHEMBL1460352 & 688648 & 4.3484 & 3.7579 & TRN & \\
\hline CHEMBL1473799 & 688648 & 2.8239 & 3.2017 & TRN & \\
\hline CHEMBL1524865 & 688648 & 2.8239 & 4.1154 & TRN & \\
\hline CHEMBL1326901 & 688648 & 2.8239 & 3.2487 & TRN & \\
\hline CHEMBL1549202 & 688648 & 2.8239 & 3.3561 & TRN & \\
\hline CHEMBL1449811 & 688648 & 5.2955 & 4.6575 & TRN & \\
\hline CHEMBL1336054 & 688648 & 2.8239 & 3.6889 & TRN & \\
\hline CHEMBL3191958 & 688648 & 2.8239 & 2.3085 & TRN & \\
\hline CHEMBL1446095 & 688648 & 5.1354 & 4.383 & TST & \\
\hline
\end{tabular}


Supplemental Table S2.txt

\begin{tabular}{|c|c|c|c|c|c|}
\hline CHEMBL1327721 & 688648 & 5.2607 & 4.1682 & TRN & \\
\hline CHEMBL1407786 & 688648 & 4.7684 & 3.6779 & TST & \\
\hline CHEMBL1360618 & 688648 & 2.8239 & 3.3217 & TRN & \\
\hline CHEMBL1300169 & 688648 & 2.8239 & 3.5115 & TRN & \\
\hline CHEMBL1400092 & 688648 & 2.8239 & 3.3761 & TRN & \\
\hline CHEMBL3191058 & 688648 & 2.8239 & 3.5811 & TRN & \\
\hline CHEMBL1392551 & 688648 & 2.8239 & 3.5104 & TST & \\
\hline CHEMBL479765 & 688648 & 2.8239 & 2.6711 & TRN & \\
\hline CHEMBL601757 & 688648 & 2.8239 & 3.0304 & TST & \\
\hline CHEMBL225963 & 688648 & 4.6827 & 3.6981 & TRN & \\
\hline CHEMBL1305704 & 688648 & 5.4517 & 4.465 & TRN & \\
\hline CHEMBL1568852 & 688648 & 4.3608 & 4.1563 & TRN & \\
\hline CHEMBL1440974 & 688648 & 2.8239 & 2.5723 & TRN & \\
\hline CHEMBL1479657 & 688648 & 2.8239 & 3.4488 & TRN & \\
\hline CHEMBL1346621 & 688648 & 5.1933 & 3.5372 & TRN & \\
\hline CHEMBL1452090 & 688648 & 4.2479 & 3.4033 & TRN & \\
\hline CHEMBL1495462 & 688648 & 2.8239 & 2.9245 & TST & \\
\hline CHEMBL1336728 & 688648 & 5.1596 & 4.1802 & TRN & \\
\hline CHEMBL1469460 & 688648 & 4.8952 & 3.5906 & TST & \\
\hline CHEMBL1580917 & 688648 & 2.8239 & 3.3423 & TRN & \\
\hline CHEMBL1552296 & 688648 & 2.8239 & 3.343 & TRN & \\
\hline CHEMBL1391272 & 688648 & 4.9453 & 3.9459 & TRN & \\
\hline CHEMBL1470520 & 688648 & 2.8239 & 3.3852 & TRN & \\
\hline CHEMBL3195536 & 688648 & 2.8239 & 3.8609 & TRN & \\
\hline CHEMBL1598340 & 688648 & 2.8239 & 4.1368 & TST & \\
\hline CHEMBL1607698 & 688648 & 5.03 & 3.2907 & TRN & \\
\hline CHEMBL1360393 & 688648 & 4.808 & 4.1967 & TRN & \\
\hline CHEMBL1449291 & 688648 & 2.8239 & 3.5841 & TRN & \\
\hline CHEMBL3194563 & 688648 & 2.8239 & 3.2822 & TRN & \\
\hline CHEMBL1604302 & 688648 & 2.8239 & 3.4129 & TRN & \\
\hline CHEMBL1573462 & 688648 & 2.8239 & 2.8092 & TRN & \\
\hline CHEMBL1992276 & 688648 & 4.5156 & 3.9106 & TRN & \\
\hline CHEMBL1394121 & 688648 & 4.9447 & 3.551 & TRN & \\
\hline CHEMBL1540328 & 688648 & 4.3297 & 3.6922 & TRN & \\
\hline CHEMBL1489865 & 688648 & 3.9887 & 3.28899 & 99999999997 & TRN \\
\hline CHEMBL1589298 & 688648 & 2.8239 & 3.6517 & TRN & \\
\hline CHEMBL1377316 & 688648 & 2.8239 & 2.9321 & TRN & \\
\hline CHEMBL1574738 & 688648 & 2.8239 & 2.6976 & TRN & \\
\hline CHEMBL1594517 & 688648 & 4.6706 & 3.8239 & TRN & \\
\hline CHEMBL1404750 & 688648 & 2.8239 & 3.5401 & TST & \\
\hline CHEMBL1324715 & 688648 & 5.2872 & 3.6557 & TRN & \\
\hline CHEMBL1354346 & 688648 & 4.246 & 3.7194 & TRN & \\
\hline CHEMBL1488021 & 688648 & 4.7417 & 2.9716 & TST & \\
\hline CHEMBL3183210 & 688648 & 2.8239 & 3.2008 & TRN & \\
\hline CHEMBL1520712 & 688648 & 2.8239 & 3.2753 & TST & \\
\hline CHEMBL1543052 & 688648 & 4.8015 & 4.4057 & TRN & \\
\hline CHEMBL1587193 & 688648 & 5.2596 & 4.0956 & TRN & \\
\hline CHEMBL1533489 & 688648 & 2.8239 & 2.9353 & TRN & \\
\hline
\end{tabular}

Page 7059 


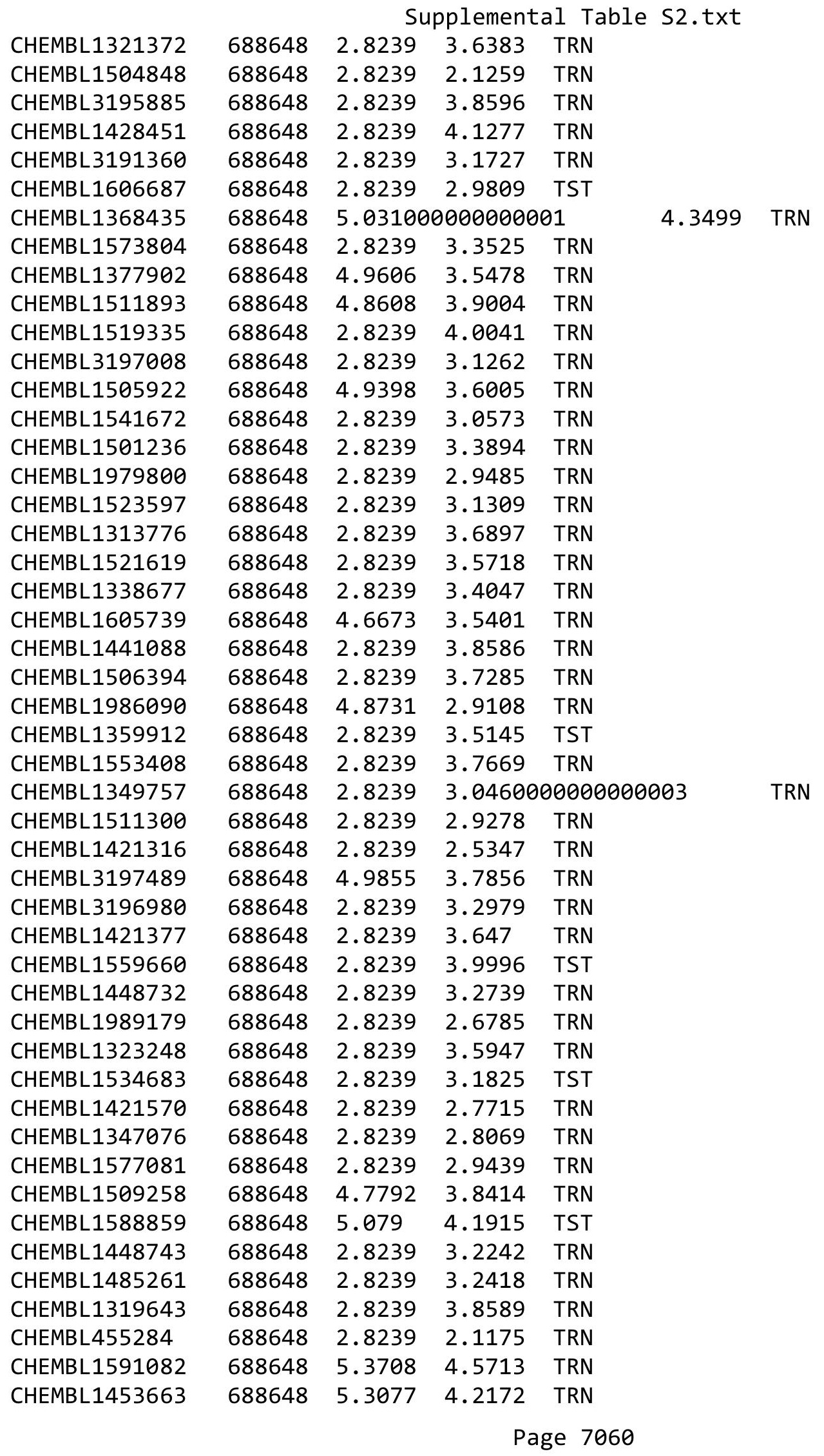


Supplemental Table S2.txt

\begin{tabular}{|c|c|c|c|c|c|}
\hline CHEMBL1303651 & 688648 & 5.8099 & 3.9844 & TRN & \\
\hline CHEMBL1353219 & 688648 & 2.8239 & 3.5907 & TRN & \\
\hline CHEMBL1506966 & 688648 & 2.8239 & 3.2573 & TST & \\
\hline CHEMBL1391621 & 688648 & 2.8239 & 3.4042 & TRN & \\
\hline CHEMBL1314859 & 688648 & 2.8239 & 3.0671 & TST & \\
\hline CHEMBL1473543 & 688648 & 4.9999 & \multicolumn{2}{|c|}{3.7689999999999997} & TST \\
\hline CHEMBL1482979 & 688648 & 5.0801 & 3.9215 & TST & \\
\hline CHEMBL1449595 & 688648 & 2.8239 & 2.6018 & TRN & \\
\hline CHEMBL1584486 & 688648 & 2.8239 & 3.1891 & TRN & \\
\hline CHEMBL3193488 & 688648 & 2.8239 & 2.1432 & TRN & \\
\hline CHEMBL1598442 & 688648 & 2.8239 & 2.9671 & TRN & \\
\hline CHEMBL1531070 & 688648 & 5.6507 & 4.0215 & TST & \\
\hline CHEMBL1466352 & 688648 & 2.8239 & 3.1634 & TRN & \\
\hline CHEMBL1438582 & 688648 & 2.8239 & 3.1381 & TRN & \\
\hline CHEMBL1581270 & 688648 & 2.8239 & 3.4504 & TRN & \\
\hline CHEMBL1451132 & 688648 & 2.8239 & 4.0014 & TRN & \\
\hline CHEMBL1419323 & 688648 & 2.8239 & 2.4097 & TST & \\
\hline CHEMBL1542604 & 688648 & 5.0062 & 3.785 & TRN & \\
\hline CHEMBL1608631 & 688648 & 4.9036 & \multicolumn{2}{|c|}{3.8569999999999998} & TRN \\
\hline CHEMBL1438071 & 688648 & 4.7573 & 3.7295 & TRN & \\
\hline CHEMBL1328048 & 688648 & 2.8239 & 3.0344 & TRN & \\
\hline CHEMBL3199301 & 688648 & 2.8239 & 3.7105 & TRN & \\
\hline CHEMBL3191762 & 688648 & 3.301 & 3.2886 & TRN & \\
\hline CHEMBL1490049 & 688648 & 4.4759 & 2.8035 & TRN & \\
\hline CHEMBL1583194 & 688648 & 2.8239 & 3.3159 & TRN & \\
\hline CHEMBL1483676 & 688648 & 2.8239 & 2.8575 & TRN & \\
\hline CHEMBL1457780 & 688648 & 2.8239 & 3.1133 & TRN & \\
\hline CHEMBL1492510 & 688648 & 4.5237 & 3.2481 & TST & \\
\hline CHEMBL1587283 & 688648 & 2.8239 & 3.4149 & TRN & \\
\hline CHEMBL1304997 & 688648 & 4.5581 & 4.0439 & TRN & \\
\hline CHEMBL1346975 & 688648 & 2.8239 & 3.3812 & TRN & \\
\hline CHEMBL1599744 & 688648 & 2.8239 & 3.5696 & TRN & \\
\hline CHEMBL1402915 & 688648 & 2.8239 & 2.4007 & TRN & \\
\hline CHEMBL3191218 & 688648 & 2.8239 & 3.1831 & TRN & \\
\hline CHEMBL1414817 & 688648 & 2.8239 & 3.6173 & TRN & \\
\hline CHEMBL3191810 & 688648 & 2.8239 & 3.0417 & TRN & \\
\hline CHEMBL1511114 & 688648 & 2.8239 & 3.2714 & TRN & \\
\hline CHEMBL1348216 & 688648 & 3.8568 & 3.2293 & TRN & \\
\hline CHEMBL3195662 & 688648 & 5.3851 & 3.1811 & TST & \\
\hline CHEMBL 1427340 & 688648 & 4.6514 & 4.1746 & TRN & \\
\hline CHEMBL1519755 & 688648 & 2.8239 & 2.9695 & TRN & \\
\hline CHEMBL179611 & 688648 & 2.8239 & 3.24300 & 00000000003 & TST \\
\hline CHEMBL1367268 & 688648 & 2.8239 & 3.6623 & TRN & \\
\hline CHEMBL1424380 & 688648 & 2.8239 & 2.9039 & TRN & \\
\hline CHEMBL1505586 & 688648 & 2.8239 & 4.3327 & TST & \\
\hline CHEMBL1400768 & 688648 & 2.8239 & 4.3548 & TST & \\
\hline CHEMBL1608787 & 688648 & 4.4254 & 3.8621 & TRN & \\
\hline \multirow[t]{2}{*}{ CHEMBL1584796 } & 688648 & 5.1357 & \multicolumn{2}{|c|}{4.031000000000001} & TRN \\
\hline & & & & e 7061 & \\
\hline
\end{tabular}




\begin{tabular}{|c|c|c|c|c|}
\hline & & & pplement & al $\mathrm{T}$ \\
\hline CHEMBL1605464 & 688648 & 2.8239 & 3.7583 & TRN \\
\hline CHEMBL1539522 & 688648 & 5.8801 & 4.3528 & TRN \\
\hline CHEMBL1584779 & 688648 & 4.4722 & 4.0942 & TRN \\
\hline CHEMBL 3211808 & 688648 & 2.8239 & 3.1654 & TRN \\
\hline CHEMBL1413931 & 688648 & 5.8914 & 4.7086 & TRN \\
\hline CHEMBL3189295 & 688648 & 4.921 & 3.6604 & TRN \\
\hline CHEMBL1361520 & 688648 & 2.8239 & 2.6323 & TRN \\
\hline CHEMBL1386616 & 688648 & 2.8239 & 2.1155 & TRN \\
\hline CHEMBL1379894 & 688648 & 2.8239 & 3.6838 & TST \\
\hline CHEMBL3197433 & 688648 & 2.8239 & 2.6764 & TRN \\
\hline CHEMBL1311547 & 688648 & 2.8239 & 2.7961 & TRN \\
\hline CHEMBL1546249 & 688648 & 4.9145 & 3.8416 & TRN \\
\hline CHEMBL1523275 & 688648 & 4.5203 & 3.5119 & TST \\
\hline CHEMBL1365325 & 688648 & 2.8239 & 2.7552 & TRN \\
\hline CHEMBL1612159 & 688648 & 5.6536 & 3.9981 & TST \\
\hline CHEMBL1371298 & 688648 & 2.8239 & 2.8179 & TRN \\
\hline CHEMBL1599981 & 688648 & 4.6298 & 3.3364 & TRN \\
\hline CHEMBL3199132 & 688648 & 4.6797 & 3.2938 & TRN \\
\hline CHEMBL1341947 & 688648 & 4.9245 & 4.0589 & TST \\
\hline CHEMBL1483261 & 688648 & 5.3161 & 4.1341 & TRN \\
\hline CHEMBL1344526 & 688648 & 2.8239 & 3.0606 & TRN \\
\hline CHEMBL1606903 & 688648 & 2.8239 & 4.1435 & TRN \\
\hline CHEMBL1518264 & 688648 & 4.7137 & 3.9244 & TRN \\
\hline CHEMBL1506301 & 688648 & 2.8239 & 4.1106 & TRN \\
\hline CHEMBL1586817 & 688648 & 2.8239 & 3.5818 & TRN \\
\hline CHEMBL1562446 & 688648 & 2.8239 & 2.6216 & TRN \\
\hline CHEMBL 3197243 & 688648 & 5.2431 & 3.6401 & TRN \\
\hline CHEMBL1338481 & 688648 & 4.9566 & 4.7033 & TRN \\
\hline CHEMBL1426455 & 688648 & 2.8239 & 2.9789 & TRN \\
\hline CHEMBL2369316 & 688648 & 2.8239 & 3.5117 & TRN \\
\hline CHEMBL 2007593 & 688648 & 4.6976 & 3.4904 & TRN \\
\hline CHEMBL1498273 & 688648 & 2.8239 & 2.8482 & TRN \\
\hline CHEMBL1580874 & 688648 & 4.7329 & 3.1809 & TRN \\
\hline CHEMBL448741 & 688648 & 2.8239 & 3.9962 & TST \\
\hline CHEMBL1303126 & 688648 & 2.8239 & 3.0597 & TRN \\
\hline CHEMBL1496786 & 688648 & 2.8239 & 4.4521 & TRN \\
\hline CHEMBL1579796 & 688648 & 2.8239 & 3.1086 & TRN \\
\hline CHEMBL1358081 & 688648 & 2.8239 & 3.258 & TRN \\
\hline CHEMBL1542654 & 688648 & 2.8239 & 3.1436 & TRN \\
\hline CHEMBL1538328 & 688648 & 5.6243 & 4.0803 & TRN \\
\hline CHEMBL1588074 & 688648 & 2.8239 & 3.7153 & TST \\
\hline CHEMBL1346307 & 688648 & 2.8239 & 3.5054 & TRN \\
\hline CHEMBL1429121 & 688648 & 5.2205 & 3.5347 & TRN \\
\hline CHEMBL1582307 & 688648 & 2.8239 & 3.801 & TRN \\
\hline CHEMBL1372076 & 688648 & 2.8239 & 4.1216 & TST \\
\hline CHEMBL1097074 & 688648 & 2.8239 & 2.8934 & TST \\
\hline CHEMBL1402051 & 688648 & 2.8239 & 2.8511 & TRN \\
\hline CHEMBL 2007163 & 688648 & 2.8239 & 3.1263 & TRN \\
\hline
\end{tabular}




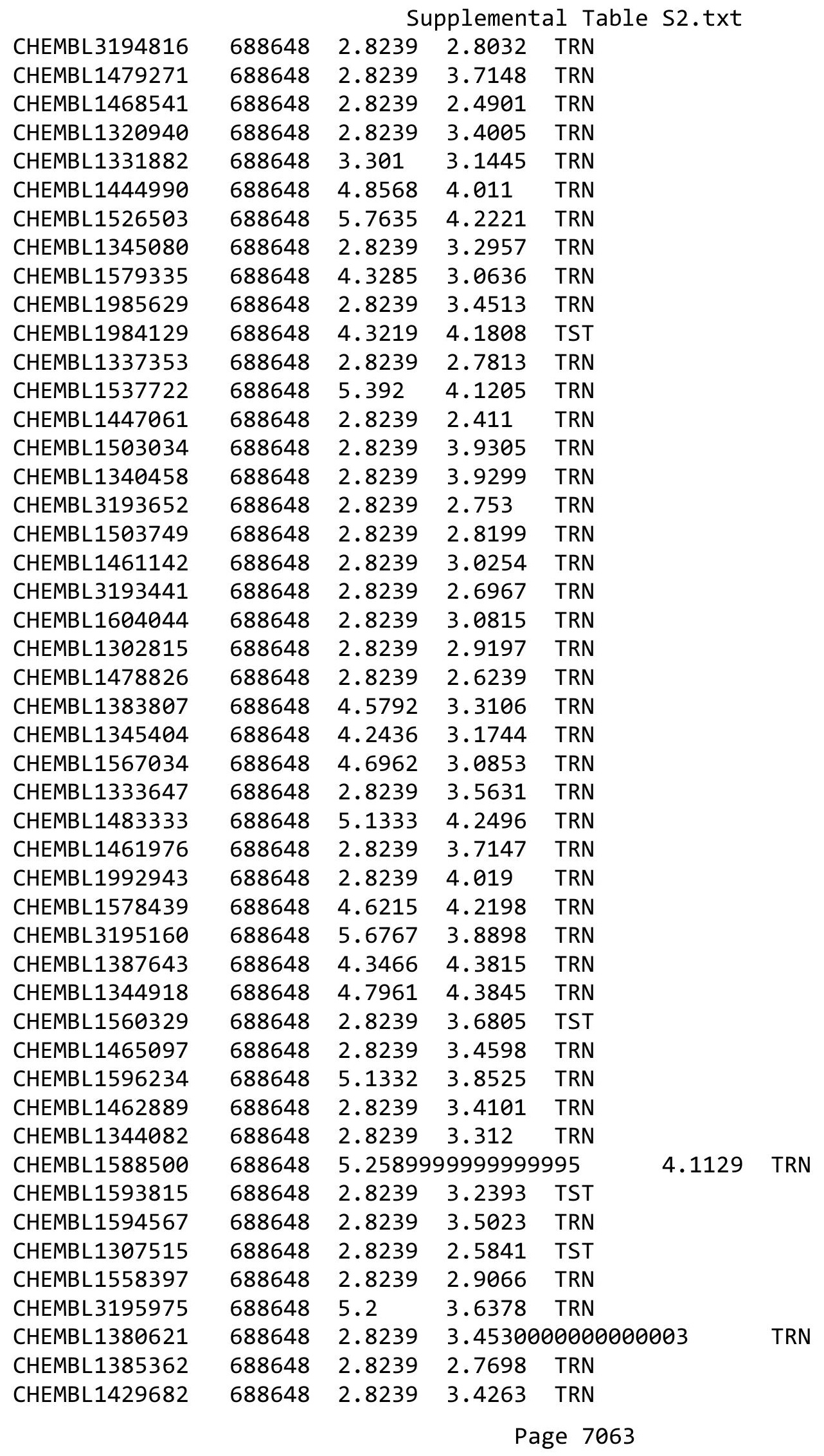




\begin{tabular}{|c|c|c|c|c|c|}
\hline & & \multicolumn{4}{|c|}{ Supplemental Table S2.txt } \\
\hline CHEMBL1415442 & 688648 & 2.8239 & 3.8082 & TRN & \\
\hline CHEMBL1463088 & 688648 & 2.8239 & 3.1946 & TRN & \\
\hline CHEMBL1492045 & 688648 & 2.8239 & 3.7195 & TRN & \\
\hline CHEMBL1511193 & 688648 & 2.8239 & 3.7077 & TRN & \\
\hline CHEMBL1516527 & 688648 & 2.8239 & 3.1749 & TRN & \\
\hline CHEMBL1508232 & 688648 & 2.8239 & 4.1931 & TRN & \\
\hline CHEMBL1548017 & 688648 & 2.8239 & 3.4629 & TRN & \\
\hline CHEMBL1529203 & 688648 & 2.8239 & 3.3025 & TRN & \\
\hline CHEMBL1505192 & 688648 & 4.5672 & 4.4082 & TRN & \\
\hline CHEMBL1364216 & 688648 & 2.8239 & 3.9232 & TRN & \\
\hline CHEMBL1555719 & 688648 & 4.1802 & 3.4388 & TRN & \\
\hline CHEMBL1352903 & 688648 & 4.0738 & 3.9391 & TRN & \\
\hline CHEMBL1896972 & 688648 & 2.8239 & 2.9681 & TRN & \\
\hline CHEMBL3190404 & 688648 & 2.8239 & 3.6028 & TRN & \\
\hline CHEMBL473107 & 688648 & 2.8239 & 3.4065 & TRN & \\
\hline CHEMBL1449956 & 688648 & 2.8239 & 2.972 & TRN & \\
\hline CHEMBL1510905 & 688648 & 5.1578 & 3.5343 & TRN & \\
\hline CHEMBL1333275 & 688648 & 2.8239 & 4.0076 & TRN & \\
\hline CHEMBL1320170 & 688648 & 4.8288 & 3.93300 & 00000000003 & TST \\
\hline CHEMBL1535538 & 688648 & 4.5853 & 3.3044 & TRN & \\
\hline CHEMBL1517661 & 688648 & 2.8239 & 2.8225 & TRN & \\
\hline CHEMBL1580856 & 688648 & 2.8239 & 3.0241 & TRN & \\
\hline CHEMBL1401900 & 688648 & 4.3753 & 3.4946 & TRN & \\
\hline CHEMBL1595850 & 688648 & 2.8239 & 2.9566 & TRN & \\
\hline CHEMBL1609818 & 688648 & 5.33 & 3.8947 & TRN & \\
\hline CHEMBL1353949 & 688648 & 2.8239 & 3.3363 & TST & \\
\hline CHEMBL1557538 & 688648 & 5.1426 & 3.8311 & TRN & \\
\hline CHEMBL1489078 & 688648 & 2.8239 & 3.4312 & TRN & \\
\hline CHEMBL1374864 & 688648 & 4.8426 & 3.9318 & TRN & \\
\hline CHEMBL 2006856 & 688648 & 2.8239 & 3.068 & TRN & \\
\hline CHEMBL1414413 & 688648 & 2.8239 & 3.4743 & TRN & \\
\hline CHEMBL1450554 & 688648 & 2.8239 & 2.9829 & TRN & \\
\hline CHEMBL1520328 & 688648 & 2.8239 & 4.1707 & TRN & \\
\hline CHEMBL1589425 & 688648 & 5.1782 & 4.1385 & TST & \\
\hline CHEMBL3189832 & 688648 & 3.301 & 3.6591 & TST & \\
\hline CHEMBL1528933 & 688648 & 2.8239 & 3.9534 & TRN & \\
\hline CHEMBL1563827 & 688648 & 4.6051 & 4.2523 & TST & \\
\hline CHEMBL3193491 & 688648 & 2.8239 & 3.0632 & TST & \\
\hline CHEMBL1379744 & 688648 & 2.8239 & 3.8234 & TRN & \\
\hline CHEMBL1548761 & 688648 & 4.7293 & 3.9442 & TRN & \\
\hline CHEMBL314962 & 688648 & 2.8239 & 2.9606 & TST & \\
\hline CHEMBL1413355 & 688648 & 2.8239 & 3.5715 & TRN & \\
\hline CHEMBL1392741 & 688648 & 2.8239 & 2.7732 & TRN & \\
\hline CHEMBL1541862 & 688648 & 3.301 & 3.0879 & TRN & \\
\hline CHEMBL1987622 & 688648 & 6.3002 & 3.6714 & TRN & \\
\hline CHEMBL1346881 & 688648 & 2.8239 & 4.3734 & TST & \\
\hline CHEMBL1364626 & 688648 & 2.8239 & 3.4608 & TRN & \\
\hline CHEMBL257286 & 688648 & 2.8239 & 3.0708 & TRN & \\
\hline
\end{tabular}




\begin{tabular}{|c|c|c|c|c|c|c|}
\hline & & \multicolumn{5}{|c|}{ Supplemental Table S2.txt } \\
\hline CHEMBL 3190262 & 688648 & 5.3538 & 3.6236 & TRN & & \\
\hline CHEMBL1360808 & 688648 & 3.8843 & 3.5878 & TRN & & \\
\hline CHEMBL1341979 & 688648 & 4.4384 & 3.4017 & TRN & & \\
\hline CHEMBL1461204 & 688648 & 2.8239 & 3.1631 & TRN & & \\
\hline CHEMBL1588702 & 688648 & 2.8239 & 2.8208 & TRN & & \\
\hline CHEMBL1535525 & 688648 & 2.8239 & 3.4462 & TRN & & \\
\hline CHEMBL1343528 & 688648 & 2.8239 & 2.9362 & TRN & & \\
\hline CHEMBL1430072 & 688648 & 2.8239 & 3.5262 & TRN & & \\
\hline CHEMBL1588408 & 688648 & 4.1958 & 3.2638 & TRN & & \\
\hline CHEMBL3213747 & 688648 & 2.8239 & 3.4226 & TRN & & \\
\hline CHEMBL1428166 & 688648 & 2.8239 & 4.1532 & TST & & \\
\hline CHEMBL3197936 & 688648 & 2.8239 & 3.0081 & TRN & & \\
\hline CHEMBL1611858 & 688648 & 3.301 & 3.5587 & TRN & & \\
\hline CHEMBL1537118 & 688648 & 2.8239 & 2.8793 & TRN & & \\
\hline CHEMBL1302367 & 688648 & 2.8239 & 2.8051 & TRN & & \\
\hline CHEMBL1523566 & 688648 & 2.8239 & 3.1114 & TRN & & \\
\hline CHEMBL1330307 & 688648 & 2.8239 & 2.6331 & TRN & & \\
\hline CHEMBL1563623 & 688648 & 4.857 & 3.3737 & TRN & & \\
\hline CHEMBL1480524 & 688648 & 2.8239 & 3.1275 & TRN & & \\
\hline CHEMBL1306854 & 688648 & \multicolumn{3}{|c|}{ 4. 2589999999999995} & 3.3165 & TRN \\
\hline CHEMBL1475524 & 688648 & 2.8239 & 3.6997 & TRN & & \\
\hline CHEMBL1433219 & 688648 & 2.8239 & 2.4289 & TST & & \\
\hline CHEMBL1599173 & 688648 & 2.8239 & 4.5604 & TRN & & \\
\hline CHEMBL1518155 & 688648 & 4.7596 & 3.8108 & TRN & & \\
\hline CHEMBL1589444 & 688648 & 2.8239 & 3.3205 & TRN & & \\
\hline CHEMBL1496647 & 688648 & 5.6227 & 4.3075 & TRN & & \\
\hline CHEMBL1533974 & 688648 & 5.0725 & 4.0705 & TRN & & \\
\hline CHEMBL1322039 & 688648 & 2.8239 & 2.8718 & TRN & & \\
\hline CHEMBL1542652 & 688648 & 4.7686 & 4.0842 & TST & & \\
\hline CHEMBL1347710 & 688648 & 5.3365 & 3.9911 & TRN & & \\
\hline CHEMBL1592505 & 688648 & 2.8239 & 3.1112 & TRN & & \\
\hline CHEMBL1384672 & 688648 & 2.8239 & 2.9125 & TST & & \\
\hline CHEMBL1575766 & 688648 & 2.8239 & 3.5044 & TRN & & \\
\hline CHEMBL123 & 688648 & 2.8239 & 2.6805 & TST & & \\
\hline CHEMBL1422414 & 688648 & 5.2323 & 3.8173 & TRN & & \\
\hline CHEMBL1336205 & 688648 & 4.254 & 3.9763 & TST & & \\
\hline CHEMBL1346628 & 688648 & 2.8239 & 2.8432 & TRN & & \\
\hline CHEMBL1333575 & 688648 & 2.8239 & 3.0627 & TRN & & \\
\hline CHEMBL1341945 & 688648 & 2.8239 & 2.8523 & TRN & & \\
\hline CHEMBL3196810 & 688648 & 2.8239 & 3.0973 & TRN & & \\
\hline CHEMBL1387953 & 688648 & 2.8239 & 3.3626 & TRN & & \\
\hline CHEMBL1306406 & 688648 & 2.8239 & 3.6967 & TRN & & \\
\hline CHEMBL1318412 & 688648 & 4.8222 & 3.3065 & TST & & \\
\hline CHEMBL1515140 & 688648 & 2.8239 & 4.0832 & TRN & & \\
\hline CHEMBL3199742 & 688648 & 2.8239 & 3.3277 & TRN & & \\
\hline CHEMBL1343581 & 688648 & 2.8239 & 4.3124 & TRN & & \\
\hline CHEMBL1429365 & 688648 & 2.8239 & 3.6086 & TRN & & \\
\hline CHEMBL1497898 & 688648 & 2.8239 & 4.2089 & TRN & & \\
\hline
\end{tabular}




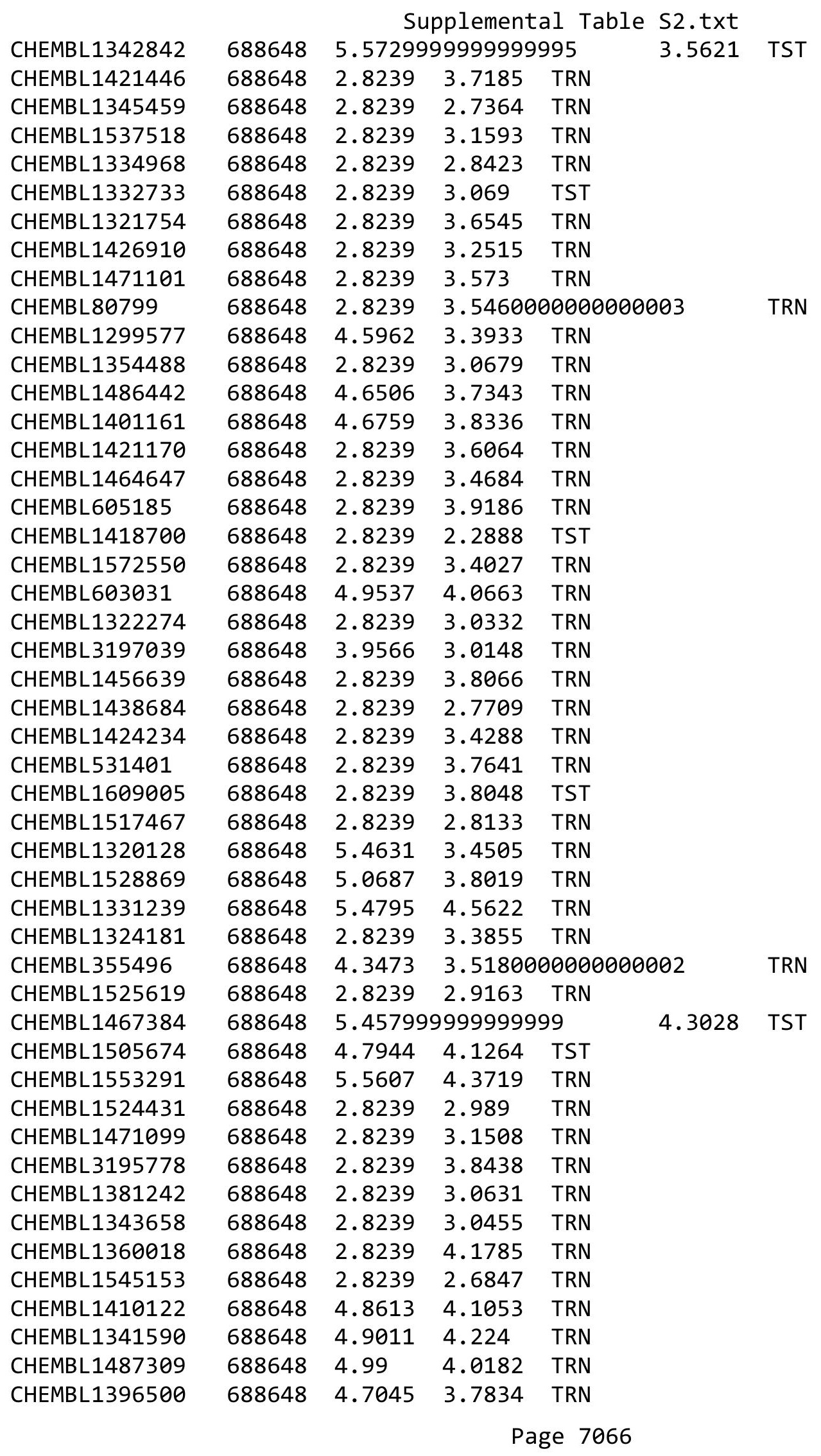


Supplemental Table S2.txt

\begin{tabular}{|c|c|c|c|c|}
\hline CHEMBL1389601 & 688648 & 5.1972 & 3.4284 & TRN \\
\hline CHEMBL1427233 & 688648 & 4.5223 & 4.0571 & TRN \\
\hline CHEMBL1526490 & 688648 & 2.8239 & 2.8893 & TRN \\
\hline CHEMBL1482215 & 688648 & 2.8239 & 3.1936 & TRN \\
\hline CHEMBL1382445 & 688648 & 2.8239 & 2.9766 & TRN \\
\hline CHEMBL1544460 & 688648 & 2.8239 & 3.3652 & TRN \\
\hline CHEMBL3198791 & 688648 & 2.8239 & 3.6132 & TRN \\
\hline CHEMBL3194892 & 688648 & 2.8239 & 3.0326 & TRN \\
\hline CHEMBL1486883 & 688648 & 5.165 & 3.5422 & TRN \\
\hline CHEMBL1478252 & 688648 & 2.8239 & 4.2444 & TST \\
\hline CHEMBL1445659 & 688648 & 2.8239 & 3.7016 & TST \\
\hline CHEMBL1580638 & 688648 & 2.8239 & 3.1539 & TRN \\
\hline CHEMBL1302276 & 688648 & 4.2517 & 3.4299 & TRN \\
\hline CHEMBL1379467 & 688648 & 2.8239 & 3.3197 & TRN \\
\hline CHEMBL1333978 & 688648 & 4.3746 & 2.9089 & TRN \\
\hline CHEMBL1310080 & 688648 & 2.8239 & 3.5594 & TRN \\
\hline CHEMBL1482637 & 688648 & 5.5661 & 3.8536 & TRN \\
\hline CHEMBL1355704 & 688648 & 2.8239 & 3.615 & TRN \\
\hline CHEMBL1504972 & 688648 & 4.427 & 3.4432 & TRN \\
\hline CHEMBL1572768 & 688648 & 2.8239 & 3.5736 & TRN \\
\hline CHEMBL1525780 & 688648 & 2.8239 & 3.0489 & TRN \\
\hline CHEMBL1392637 & 688648 & 2.8239 & 3.3484 & TRN \\
\hline CHEMBL1547350 & 688648 & 2.8239 & 3.6884 & TRN \\
\hline CHEMBL1527120 & 688648 & 2.8239 & 3.3247 & TRN \\
\hline CHEMBL1370217 & 688648 & 2.8239 & 3.1969 & TRN \\
\hline CHEMBL1559624 & 688648 & 5.2928 & 4.0345 & TRN \\
\hline CHEMBL1536034 & 688648 & 4.7692 & 4.0114 & TRN \\
\hline CHEMBL1546374 & 688648 & 5.1872 & 3.36800 & 00000000003 \\
\hline CHEMBL1302253 & 688648 & 2.8239 & 3.2263 & TRN \\
\hline CHEMBL1585480 & 688648 & 2.8239 & 3.1975 & TRN \\
\hline CHEMBL1383044 & 688648 & 2.8239 & 3.29 & TRN \\
\hline CHEMBL1416184 & 688648 & 2.8239 & 4.2472 & TRN \\
\hline CHEMBL1350708 & 688648 & 2.8239 & 3.3204 & TRN \\
\hline CHEMBL1988686 & 688648 & 4.4906 & 3.1842 & TRN \\
\hline CHEMBL1986418 & 688648 & 5.2579 & 2.4007 & TRN \\
\hline CHEMBL1545578 & 688648 & 4.7796 & 3.8711 & TRN \\
\hline CHEMBL1459494 & 688648 & 2.8239 & 4.1421 & TST \\
\hline CHEMBL1579026 & 688648 & 2.8239 & 2.6615 & TRN \\
\hline CHEMBL1415312 & 688648 & 5.1797 & 3.9791 & TRN \\
\hline CHEMBL3198659 & 688648 & 5.1013 & 3.9624 & TST \\
\hline CHEMBL1378065 & 688648 & 2.8239 & 3.1368 & TRN \\
\hline CHEMBL1383799 & 688648 & 2.8239 & 3.4083 & TRN \\
\hline CHEMBL1520217 & 688648 & 4.761 & 3.9945 & TRN \\
\hline CHEMBL1427991 & 688648 & 2.8239 & 3.7437 & TRN \\
\hline CHEMBL1563898 & 688648 & 4.9511 & 3.7706 & TRN \\
\hline CHEMBL3199654 & 688648 & 4.8551 & 2.8235 & TRN \\
\hline CHEMBL 2005619 & 688648 & 4.6737 & 3.7951 & TRN \\
\hline CHEMBL1335214 & 688648 & 4.2942 & 4.3547 & TRN \\
\hline
\end{tabular}




\begin{tabular}{|c|c|c|c|c|c|}
\hline & & \multicolumn{4}{|c|}{ Supplemental Table S2.txt } \\
\hline CHEMBL1582609 & 688648 & 2.8239 & 2.516 & TRN & \\
\hline CHEMBL1604272 & 688648 & 4.1794 & 3.5043 & TRN & \\
\hline CHEMBL1422465 & 688648 & 4.6982 & 3.8845 & TST & \\
\hline CHEMBL1571174 & 688648 & 2.8239 & 2.7871 & TRN & \\
\hline CHEMBL504598 & 688648 & 2.8239 & 3.15199 & 99999999997 & TRN \\
\hline CHEMBL1547542 & 688648 & 2.8239 & 3.0397 & TRN & \\
\hline CHEMBL1462906 & 688648 & 5.1983 & 4.648 & TRN & \\
\hline CHEMBL1593484 & 688648 & 4.0628 & 3.556 & TRN & \\
\hline CHEMBL1461674 & 688648 & 2.8239 & 3.3627 & TRN & \\
\hline CHEMBL1413629 & 688648 & 2.8239 & 2.8714 & TRN & \\
\hline CHEMBL1533170 & 688648 & 2.8239 & 3.4931 & TRN & \\
\hline CHEMBL1455266 & 688648 & 2.8239 & 4.0348 & TST & \\
\hline CHEMBL1328544 & 688648 & 2.8239 & 3.4763 & TRN & \\
\hline CHEMBL1498722 & 688648 & 2.8239 & 2.6866 & TRN & \\
\hline CHEMBL1403854 & 688648 & 2.8239 & 3.4786 & TRN & \\
\hline CHEMBL3207294 & 688648 & 2.8239 & 2.0979 & TRN & \\
\hline CHEMBL3144931 & 688648 & 2.8239 & 3.4042 & TST & \\
\hline CHEMBL1511380 & 688648 & 2.8239 & 3.6457 & TST & \\
\hline CHEMBL1575421 & 688648 & 4.4638 & 4.1193 & TRN & \\
\hline CHEMBL3209776 & 688648 & 2.8239 & 2.8776 & TRN & \\
\hline CHEMBL1375559 & 688648 & 2.8239 & 3.19100 & 00000000003 & TST \\
\hline CHEMBL1435487 & 688648 & 5.0546 & 4.359 & TRN & \\
\hline CHEMBL1481361 & 688648 & 2.8239 & 3.8688 & TST & \\
\hline CHEMBL1499084 & 688648 & 2.8239 & 3.4937 & TRN & \\
\hline CHEMBL1328350 & 688648 & 2.8239 & 2.6302 & TRN & \\
\hline CHEMBL1315402 & 688648 & 2.8239 & 3.3029 & TRN & \\
\hline CHEMBL1400237 & 688648 & 2.8239 & 3.01 & TRN & \\
\hline CHEMBL1373424 & 688648 & 2.8239 & 3.5259 & TRN & \\
\hline CHEMBL1506533 & 688648 & 2.8239 & 3.9596 & TRN & \\
\hline CHEMBL1564731 & 688648 & 2.8239 & 2.7977 & TRN & \\
\hline CHEMBL1978354 & 688648 & 2.8239 & 2.8853 & TRN & \\
\hline CHEMBL1381704 & 688648 & 2.8239 & 2.5608 & TRN & \\
\hline CHEMBL1405964 & 688648 & 4.7387 & 3.94100 & 00000000003 & TRN \\
\hline CHEMBL1410901 & 688648 & 4.723 & 4.3639 & TRN & \\
\hline CHEMBL1447853 & 688648 & 5.136 & 3.9573 & TRN & \\
\hline CHEMBL1450825 & 688648 & 5.2535 & 4.0086 & TRN & \\
\hline CHEMBL1353013 & 688648 & 5.7042 & 4.4219 & TRN & \\
\hline CHEMBL1335732 & 688648 & 5.1667 & 4.1885 & TRN & \\
\hline CHEMBL3194106 & 688648 & 2.8239 & 2.7449 & TRN & \\
\hline CHEMBL1478231 & 688648 & 4.8809 & 4.3028 & TRN & \\
\hline CHEMBL1325303 & 688648 & 5.3364 & 4.588 & TRN & \\
\hline CHEMBL1517346 & 688648 & 2.8239 & 3.8664 & TST & \\
\hline CHEMBL601751 & 688648 & 2.8239 & 2.7577 & TRN & \\
\hline CHEMBL1581963 & 688648 & 4.4611 & 3.5623 & TRN & \\
\hline CHEMBL1494214 & 688648 & 2.8239 & 3.3059 & TRN & \\
\hline CHEMBL1429311 & 688648 & 5.0287 & 4.6707 & TRN & \\
\hline CHEMBL1574271 & 688648 & 2.8239 & 3.7782 & TRN & \\
\hline CHEMBL1356182 & 688648 & 5.0562 & 4.3792 & TRN & \\
\hline
\end{tabular}




\begin{tabular}{|c|c|c|c|c|c|}
\hline \multirow[b]{2}{*}{ CHEMBL1420800 } & & \multicolumn{4}{|c|}{ Supplemental Table S2.txt } \\
\hline & 688648 & 5.2106 & 3.33699 & 99999999997 & TRN \\
\hline CHEMBL1505450 & 688648 & 2.8239 & 2.7452 & TRN & \\
\hline CHEMBL1330429 & 688648 & 5.3033 & 3.6099 & TRN & \\
\hline CHEMBL1432065 & 688648 & 2.8239 & 3.4978 & TST & \\
\hline CHEMBL1586932 & 688648 & 2.8239 & 3.6997 & TRN & \\
\hline CHEMBL1369254 & 688648 & 2.8239 & 3.443 & TRN & \\
\hline CHEMBL1390925 & 688648 & 4.9764 & 3.6888 & TRN & \\
\hline CHEMBL1537093 & 688648 & 2.8239 & 4.0094 & TST & \\
\hline CHEMBL1612732 & 688648 & 2.8239 & 3.4238 & TRN & \\
\hline CHEMBL81935 & 688648 & 4.8743 & 3.9343 & TST & \\
\hline CHEMBL1407688 & 688648 & 2.8239 & 3.7844 & TRN & \\
\hline CHEMBL1565132 & 688648 & 2.8239 & 2.7422 & TRN & \\
\hline CHEMBL1530378 & 688648 & 2.8239 & 2.9694 & TST & \\
\hline CHEMBL1300408 & 688648 & 2.8239 & 3.8202 & TRN & \\
\hline CHEMBL1372434 & 688648 & 4.6937 & 3.6564 & TRN & \\
\hline CHEMBL1394159 & 688648 & 2.8239 & 3.7338 & TRN & \\
\hline CHEMBL1417529 & 688648 & 4.7574 & 3.9083 & TRN & \\
\hline CHEMBL1483252 & 688648 & 2.8239 & 3.5673 & TRN & \\
\hline CHEMBL1482477 & 688648 & 3.9713 & 2.7648 & TST & \\
\hline CHEMBL1424562 & 688648 & 5.9739 & 3.449 & TRN & \\
\hline CHEMBL1566748 & 688648 & 2.8239 & 3.9137 & TRN & \\
\hline CHEMBL1497196 & 688648 & 2.8239 & 3.6709 & TRN & \\
\hline CHEMBL1564641 & 688648 & 2.8239 & 2.5061 & TRN & \\
\hline CHEMBL1426113 & 688648 & 2.8239 & 3.5968 & TRN & \\
\hline CHEMBL1382575 & 688648 & 4.8166 & 4.3071 & TRN & \\
\hline CHEMBL1453837 & 688648 & 5.2068 & 3.9333 & TRN & \\
\hline CHEMBL1410479 & 688648 & 4.7246 & 3.7519 & TRN & \\
\hline CHEMBL1370022 & 688648 & 4.3467 & 3.7348 & TRN & \\
\hline CHEMBL1310744 & 688648 & 3.301 & 3.5823 & TRN & \\
\hline CHEMBL1561338 & 688648 & 2.8239 & 4.1872 & TRN & \\
\hline CHEMBL1530048 & 688648 & 5.1258 & 3.7736 & TRN & \\
\hline CHEMBL1531654 & 688648 & 2.8239 & 2.71100 & 00000000003 & TRN \\
\hline CHEMBL1553151 & 688648 & 2.8239 & 3.3235 & TRN & \\
\hline CHEMBL1466362 & 688648 & 2.8239 & 3.0457 & TRN & \\
\hline CHEMBL1450959 & 688648 & 2.8239 & 3.9109 & TRN & \\
\hline CHEMBL1985061 & 688648 & 4.8882 & 3.4979 & TRN & \\
\hline CHEMBL1559190 & 688648 & 4.5822 & 4.2453 & TRN & \\
\hline CHEMBL1585579 & 688648 & 2.8239 & 3.3383 & TRN & \\
\hline CHEMBL1359318 & 688648 & 4.8858 & 4.2332 & TRN & \\
\hline CHEMBL1336879 & 688648 & 4.9902 & 4.2426 & TRN & \\
\hline CHEMBL1487657 & 688648 & 5.2331 & 3.6381 & TRN & \\
\hline CHEMBL19954 & 688648 & 2.8239 & 2.7457 & TST & \\
\hline CHEMBL1444471 & 688648 & 2.8239 & 3.2453 & TRN & \\
\hline CHEMBL1533320 & 688648 & 2.8239 & 3.1664 & TRN & \\
\hline CHEMBL1574757 & 688648 & 2.8239 & 3.6277 & TST & \\
\hline CHEMBL1445024 & 688648 & 2.8239 & 2.741 & TRN & \\
\hline CHEMBL1585843 & 688648 & 2.8239 & 2.8471 & TRN & \\
\hline CHEMBL1322304 & 688648 & 2.8239 & 3.6527 & TST & \\
\hline
\end{tabular}




\begin{tabular}{|c|c|c|c|c|}
\hline & & & oplement & al $\mathrm{T}$ \\
\hline CHEMBL1990783 & 688648 & 2.8239 & 2.2354 & TRN \\
\hline CHEMBL1323869 & 688648 & 2.8239 & 3.3099 & TST \\
\hline CHEMBL461579 & 688648 & 4.8771 & 3.6381 & TST \\
\hline CHEMBL1351595 & 688648 & 4.9595 & 3.7627 & TRN \\
\hline CHEMBL1503549 & 688648 & 2.8239 & 3.5455 & TST \\
\hline CHEMBL1524515 & 688648 & 2.8239 & 3.6921 & TRN \\
\hline CHEMBL1390112 & 688648 & 2.8239 & 3.1576 & TRN \\
\hline CHEMBL1481347 & 688648 & 5.3138 & 4.2315 & TST \\
\hline CHEMBL1501917 & 688648 & 2.8239 & 2.7375 & TRN \\
\hline CHEMBL1387737 & 688648 & 2.8239 & 2.7071 & TRN \\
\hline CHEMBL1992164 & 688648 & 4.3577 & 2.8479 & TRN \\
\hline CHEMBL1367339 & 688648 & 5.2665 & 4.5109 & TRN \\
\hline CHEMBL 2004978 & 688648 & 2.8239 & 3.1909 & TRN \\
\hline CHEMBL3194900 & 688648 & 2.8239 & 3.0643 & TRN \\
\hline CHEMBL1966025 & 688648 & 2.8239 & 3.2869 & TRN \\
\hline CHEMBL2004918 & 688648 & 2.8239 & 3.8491 & TRN \\
\hline CHEMBL1457515 & 688648 & 2.8239 & 3.487 & TST \\
\hline CHEMBL1462381 & 688648 & 3.301 & 3.6945 & TRN \\
\hline CHEMBL1336959 & 688648 & 2.8239 & 3.3603 & TRN \\
\hline CHEMBL1331801 & 688648 & 2.8239 & 3.8224 & TST \\
\hline CHEMBL1300229 & 688648 & 2.8239 & 2.8733 & TST \\
\hline CHEMBL1448529 & 688648 & 5.2543 & 4.3787 & TRN \\
\hline CHEMBL1536558 & 688648 & 2.8239 & 3.5468 & TRN \\
\hline CHEMBL1518905 & 688648 & 4.8058 & 3.7735 & TST \\
\hline CHEMBL1473268 & 688648 & 2.8239 & 3.9444 & TRN \\
\hline CHEMBL1586207 & 688648 & 4.6902 & 3.5938 & TST \\
\hline CHEMBL1523242 & 688648 & 2.8239 & 3.8092 & TRN \\
\hline CHEMBL1488035 & 688648 & 2.8239 & 3.5351 & TST \\
\hline CHEMBL 381033 & 688648 & 4.6689 & 3.3235 & TRN \\
\hline CHEMBL550826 & 688648 & 4.6463 & 3.9094 & TRN \\
\hline CHEMBL1417054 & 688648 & 2.8239 & 3.6687 & TRN \\
\hline CHEMBL1367946 & 688648 & 2.8239 & 2.4246 & TRN \\
\hline CHEMBL188423 & 688648 & 2.8239 & 4.0182 & TRN \\
\hline CHEMBL1308056 & 688648 & 2.8239 & 3.6953 & TRN \\
\hline CHEMBL1535529 & 688648 & 2.8239 & 3.0996 & TRN \\
\hline CHEMBL1510316 & 688648 & 2.8239 & 3.0983 & TRN \\
\hline CHEMBL1326349 & 688648 & 2.8239 & 3.6396 & TRN \\
\hline CHEMBL1531320 & 688648 & 2.8239 & 2.6518 & TRN \\
\hline CHEMBL1523312 & 688648 & 2.8239 & 2.344 & TRN \\
\hline CHEMBL1451491 & 688648 & 2.8239 & 4.1127 & TST \\
\hline CHEMBL1306856 & 688648 & 2.8239 & 2.8096 & TRN \\
\hline CHEMBL1502201 & 688648 & 2.8239 & 3.9339 & TRN \\
\hline CHEMBL1440300 & 688648 & 6.4802 & 3.8423 & TST \\
\hline CHEMBL1495849 & 688648 & 2.8239 & 3.0853 & TRN \\
\hline CHEMBL1583716 & 688648 & 4.7759 & 3.5347 & TRN \\
\hline CHEMBL1506230 & 688648 & 4.0099 & 3.9128 & TRN \\
\hline CHEMBL1454738 & 688648 & 2.8239 & 3.7094 & TRN \\
\hline CHEMBL1471592 & 688648 & 2.8239 & 3.0512 & TRN \\
\hline
\end{tabular}




\begin{tabular}{|c|c|c|c|c|c|}
\hline \multicolumn{6}{|c|}{ Supplemental Table S2.txt } \\
\hline CHEMBL1524916 & 688648 & 2.8239 & 4.1653 & TST & \\
\hline CHEMBL1494458 & 688648 & 4.0293 & 4.0002 & TST & \\
\hline CHEMBL463175 & 688648 & 2.8239 & 4.4112 & TST & \\
\hline CHEMBL1302551 & 688648 & 2.8239 & 3.6608 & TRN & \\
\hline CHEMBL 1450241 & 688648 & 5.3024 & 4.3971 & TRN & \\
\hline CHEMBL390559 & 688648 & 4.3903 & 3.0684 & TRN & \\
\hline CHEMBL1453497 & 688648 & 2.8239 & 3.2838 & TRN & \\
\hline CHEMBL1375254 & 688648 & 2.8239 & 2.94 & TRN & \\
\hline CHEMBL1333826 & 688648 & 5.2339 & 3.9168 & TRN & \\
\hline CHEMBL1560273 & 688648 & 2.8239 & 3.3288 & TST & \\
\hline CHEMBL1545702 & 688648 & 2.8239 & 3.6243 & TST & \\
\hline CHEMBL1530170 & 688648 & 2.8239 & 2.2722 & TRN & \\
\hline CHEMBL1421625 & 688648 & 2.8239 & 3.0877 & TRN & \\
\hline CHEMBL3194133 & 688648 & 2.8239 & 4.1775 & TRN & \\
\hline CHEMBL1500128 & 688648 & 4.7024 & 4.391 & TRN & \\
\hline CHEMBL1505665 & 688648 & 2.8239 & 3.6361 & TRN & \\
\hline CHEMBL1467901 & 688648 & 2.8239 & 3.1 & TRN & \\
\hline CHEMBL1423049 & 688648 & 2.8239 & 3.4496 & TST & \\
\hline CHEMBL1440838 & 688648 & 2.8239 & 1.9298 & TRN & \\
\hline CHEMBL1449124 & 688648 & 5.3818 & 4.6152 & TRN & \\
\hline CHEMBL3189325 & 688648 & 4.9551 & 2.8087 & TRN & \\
\hline CHEMBL 3197446 & 688648 & 2.8239 & 2.5591 & TRN & \\
\hline CHEMBL1708832 & 688648 & 2.8239 & 3.427 & TRN & \\
\hline CHEMBL1566530 & 688648 & 2.8239 & 4.0101 & TRN & \\
\hline CHEMBL1486881 & 688648 & 2.8239 & 3.5321 & TRN & \\
\hline CHEMBL3197605 & 688648 & 2.8239 & 3.1296 & TRN & \\
\hline CHEMBL1479408 & 688648 & 4.6758 & 3.5213 & TRN & \\
\hline CHEMBL1555602 & 688648 & 2.8239 & 2.8324 & TRN & \\
\hline CHEMBL1529601 & 688648 & 4.9996 & 3.7344 & TRN & \\
\hline CHEMBL1537431 & 688648 & 4.30699 & 999999999 & 3.8993 & TRN \\
\hline CHEMBL1320591 & 688648 & 2.8239 & 3.958999 & 99999999996 & TRN \\
\hline CHEMBL1533132 & 688648 & 2.8239 & 2.7216 & TRN & \\
\hline CHEMBL 3211464 & 688648 & 2.8239 & 2.8196 & TRN & \\
\hline CHEMBL1575707 & 688648 & 2.8239 & 2.6509 & TRN & \\
\hline CHEMBL1468737 & 688648 & 2.8239 & 4.0949 & TRN & \\
\hline CHEMBL1542640 & 688648 & 2.8239 & 3.1527 & TRN & \\
\hline CHEMBL1499286 & 688648 & 2.8239 & 3.8891 & TRN & \\
\hline CHEMBL3211198 & 688648 & 2.8239 & 3.3337 & TRN & \\
\hline CHEMBL1343705 & 688648 & 2.8239 & 2.631000 & 00000000002 & TRN \\
\hline CHEMBL1579548 & 688648 & 5.3005 & 4.0696 & TRN & \\
\hline CHEMBL1365902 & 688648 & 5.3339 & 3.5811 & TRN & \\
\hline CHEMBL1442742 & 688648 & 5.2356 & 4.2291 & TRN & \\
\hline CHEMBL1532303 & 688648 & 4.8955 & 3.5169 & TRN & \\
\hline CHEMBL1540469 & 688648 & 3.301 & 4.0344 & TRN & \\
\hline CHEMBL1398268 & 688648 & 2.8239 & 2.9829 & TRN & \\
\hline CHEMBL1463856 & 688648 & 2.8239 & 3.0718 & TRN & \\
\hline CHEMBL1406224 & 688648 & 2.8239 & 2.2826 & TRN & \\
\hline CHEMBL1350958 & 688648 & 2.8239 & 3.6767 & TRN & \\
\hline
\end{tabular}




\begin{tabular}{|c|c|c|c|c|}
\hline \multicolumn{5}{|c|}{ Supplemental Tabl } \\
\hline CHEMBL1510339 & 688648 & 2.8239 & 4.359 & TRN \\
\hline CHEMBL1611483 & 688648 & 4.9843 & 4.1114 & TST \\
\hline CHEMBL1521230 & 688648 & 2.8239 & 3.1052 & TRN \\
\hline CHEMBL1303975 & 688648 & 5.1144 & 4.4768 & TRN \\
\hline CHEMBL1598676 & 688648 & 2.8239 & 4.0949 & TST \\
\hline CHEMBL1503572 & 688648 & 2.8239 & 3.1959 & TRN \\
\hline CHEMBL1965679 & 688648 & 2.8239 & 3.0569 & TRN \\
\hline CHEMBL1545839 & 688648 & 2.8239 & 3.5087 & TRN \\
\hline CHEMBL1572935 & 688648 & 3.9763 & 2.6226 & TRN \\
\hline CHEMBL518430 & 688648 & 2.8239 & 3.4473 & TRN \\
\hline CHEMBL1387128 & 688648 & 2.8239 & 2.4771 & TRN \\
\hline CHEMBL3190657 & 688648 & 2.8239 & 2.9937 & TRN \\
\hline CHEMBL1519450 & 688648 & 2.8239 & 2.9854 & TRN \\
\hline CHEMBL1371202 & 688648 & 4.9639 & 3.9256 & TRN \\
\hline CHEMBL1433404 & 688648 & 2.8239 & 3.0623 & TRN \\
\hline CHEMBL1442713 & 688648 & 5.3007 & 4.0179 & TRN \\
\hline CHEMBL1334670 & 688648 & 2.8239 & 3.4297 & TRN \\
\hline CHEMBL1308687 & 688648 & 2.8239 & 3.577 & TRN \\
\hline CHEMBL1558361 & 688648 & 2.8239 & 3.2901 & TRN \\
\hline CHEMBL1333637 & 688648 & 2.8239 & 3.4156 & TST \\
\hline CHEMBL1399370 & 688648 & 4.4172 & 3.9129 & TRN \\
\hline CHEMBL1320465 & 688648 & 2.8239 & 4.025 & TRN \\
\hline CHEMBL1535900 & 688648 & 2.8239 & 2.8089 & TST \\
\hline CHEMBL1594171 & 688648 & 5.0118 & 3.6727 & TRN \\
\hline CHEMBL1445650 & 688648 & 2.8239 & 3.3924 & TRN \\
\hline CHEMBL1405262 & 688648 & 2.8239 & 3.3375 & TRN \\
\hline CHEMBL1415308 & 688648 & 4.6212 & 3.9168 & TRN \\
\hline CHEMBL1587636 & 688648 & 2.8239 & 3.5139 & TRN \\
\hline CHEMBL3196117 & 688648 & 2.8239 & 3.2131 & TRN \\
\hline CHEMBL1705092 & 688648 & 2.8239 & 3.3271 & TRN \\
\hline CHEMBL1524393 & 688648 & 2.8239 & 3.0361 & TRN \\
\hline CHEMBL3190533 & 688648 & 2.8239 & 2.2454 & TRN \\
\hline CHEMBL1431676 & 688648 & 2.8239 & 2.5473 & TRN \\
\hline CHEMBL1611182 & 688648 & 5.2536 & 3.9558 & TRN \\
\hline CHEMBL1329925 & 688648 & 2.8239 & 3.8419 & TRN \\
\hline CHEMBL1406942 & 688648 & 5.2463 & 4.0547 & TRN \\
\hline CHEMBL1598413 & 688648 & 2.8239 & 3.4402 & TRN \\
\hline CHEMBL 3194940 & 688648 & 2.8239 & 3.4536 & TRN \\
\hline CHEMBL1445161 & 688648 & 4.1989 & 3.8873 & TST \\
\hline CHEMBL1488865 & 688648 & 2.8239 & 3.6221 & TRN \\
\hline CHEMBL 3189643 & 688648 & 2.8239 & 3.2457 & TRN \\
\hline CHEMBL1604790 & 688648 & 3.301 & 3.4409 & TRN \\
\hline CHEMBL1344571 & 688648 & 2.8239 & 3.4019 & TRN \\
\hline CHEMBL1464261 & 688648 & 5.1759 & 3.6318 & TST \\
\hline CHEMBL1412704 & 688648 & 2.8239 & 4.2992 & TRN \\
\hline CHEMBL1318350 & 688648 & 2.8239 & 3.7457 & TST \\
\hline CHEMBL1372388 & 688648 & 2.8239 & 3.7638 & TST \\
\hline CHEMBL1384702 & 688648 & 2.8239 & 3.9558 & TRN \\
\hline
\end{tabular}




\begin{tabular}{|c|c|c|c|c|c|}
\hline & & \multicolumn{4}{|c|}{ Supplemental Table S2.txt } \\
\hline CHEMBL1478040 & 688648 & 2.8239 & 3.1152 & TST & \\
\hline CHEMBL1594317 & 688648 & 2.8239 & 2.9165 & TRN & \\
\hline CHEMBL1361114 & 688648 & 4.4874 & 4.4683 & TST & \\
\hline CHEMBL1714915 & 688648 & 4.3118 & 3.81100 & 00000000004 & TRN \\
\hline CHEMBL1334290 & 688648 & 2.8239 & 2.8444 & TRN & \\
\hline CHEMBL 2004157 & 688648 & 2.8239 & 3.0986 & TRN & \\
\hline CHEMBL1330453 & 688648 & 4.5792 & 2.8905 & TRN & \\
\hline CHEMBL1371231 & 688648 & 2.8239 & 2.83399 & 99999999996 & TST \\
\hline CHEMBL1370387 & 688648 & 2.8239 & 3.7706 & TRN & \\
\hline CHEMBL1382035 & 688648 & 2.8239 & 3.6809 & TRN & \\
\hline CHEMBL1354211 & 688648 & 2.8239 & 3.0807 & TRN & \\
\hline CHEMBL3198009 & 688648 & 4.7244 & 2.6306 & TRN & \\
\hline CHEMBL1325551 & 688648 & 4.1844 & 3.1015 & TRN & \\
\hline CHEMBL3196257 & 688648 & 2.8239 & 3.2908 & TRN & \\
\hline CHEMBL1200847 & 688648 & 4.6999 & 3.1551 & TST & \\
\hline CHEMBL1516308 & 688648 & 4.5077 & 3.8565 & TRN & \\
\hline CHEMBL1334308 & 688648 & 2.8239 & 3.3125 & TRN & \\
\hline CHEMBL1447541 & 688648 & 2.8239 & 3.1338 & TRN & \\
\hline CHEMBL1472418 & 688648 & 2.8239 & 2.8229 & TRN & \\
\hline CHEMBL1350336 & 688648 & 2.8239 & 2.9881 & TRN & \\
\hline CHEMBL1494569 & 688648 & 2.8239 & 3.0215 & TRN & \\
\hline CHEMBL1540014 & 688648 & 2.8239 & 3.2429 & TRN & \\
\hline CHEMBL 2358514 & 688648 & 5.8091 & 4.2401 & TST & \\
\hline CHEMBL1586774 & 688648 & 4.4663 & 3.3565 & TRN & \\
\hline CHEMBL1359609 & 688648 & 2.8239 & 3.1417 & TRN & \\
\hline CHEMBL1478041 & 688648 & 2.8239 & 2.7531 & TRN & \\
\hline CHEMBL464006 & 688648 & 5.9397 & 3.5725 & TST & \\
\hline CHEMBL1392828 & 688648 & 4.5904 & 3.5582 & TST & \\
\hline CHEMBL1557920 & 688648 & 2.8239 & 3.9353 & TRN & \\
\hline CHEMBL1713905 & 688648 & 2.8239 & 3.7515 & TST & \\
\hline CHEMBL1609332 & 688648 & 2.8239 & 3.9016 & TRN & \\
\hline CHEMBL1304605 & 688648 & 2.8239 & 3.7046 & TRN & \\
\hline CHEMBL1523997 & 688648 & 5.4735 & 4.5426 & TRN & \\
\hline CHEMBL1502019 & 688648 & 2.8239 & 2.9178 & TRN & \\
\hline CHEMBL1487834 & 688648 & 2.8239 & 3.8006 & TRN & \\
\hline CHEMBL1545384 & 688648 & 2.8239 & 3.4581 & TST & \\
\hline CHEMBL 1413726 & 688648 & 4.9023 & 3.964 & TST & \\
\hline CHEMBL1569352 & 688648 & 4.6153 & 3.6573 & TRN & \\
\hline CHEMBL1541350 & 688648 & 2.8239 & 2.7222 & TRN & \\
\hline CHEMBL1334100 & 688648 & 4.8378 & 3.6232 & TST & \\
\hline CHEMBL 2002776 & 688648 & 2.8239 & 2.8716 & TRN & \\
\hline CHEMBL1328493 & 688648 & 2.8239 & 2.8662 & TRN & \\
\hline CHEMBL1546791 & 688648 & 4.7801 & 3.5896 & TRN & \\
\hline CHEMBL 1344556 & 688648 & 2.8239 & 3.4901 & TRN & \\
\hline CHEMBL1585840 & 688648 & 2.8239 & 3.3509 & TRN & \\
\hline CHEMBL1560195 & 688648 & 2.8239 & 2.7756 & TRN & \\
\hline CHEMBL 1607840 & 688648 & 2.8239 & 3.5053 & TST & \\
\hline CHEMBL3193603 & 688648 & 4.5837 & 3.3786 & TRN & \\
\hline
\end{tabular}




\begin{tabular}{|c|c|c|c|c|c|}
\hline & & \multicolumn{4}{|c|}{ Supplemental Table S2.txt } \\
\hline CHEMBL3195381 & 688648 & 2.8239 & 2.3162 & TRN & \\
\hline CHEMBL1482990 & 688648 & 2.8239 & 4.1749 & TRN & \\
\hline CHEMBL1555435 & 688648 & 5.3994 & 4.0451 & TRN & \\
\hline CHEMBL1387110 & 688648 & 2.8239 & 3.0575 & TRN & \\
\hline CHEMBL 1484658 & 688648 & 2.8239 & 3.4087 & TRN & \\
\hline CHEMBL1439990 & 688648 & 4.4643 & 3.8711 & TRN & \\
\hline CHEMBL3194766 & 688648 & 2.8239 & 2.5328 & TRN & \\
\hline CHEMBL1305375 & 688648 & 4.9627 & 3.9307 & TRN & \\
\hline CHEMBL1560408 & 688648 & 5.0647 & 3.79600 & 00000000003 & TRN \\
\hline CHEMBL1311742 & 688648 & 5.1509 & 4.0414 & TRN & \\
\hline CHEMBL1541410 & 688648 & 2.8239 & 3.6208 & TST & \\
\hline CHEMBL1470545 & 688648 & 4.5994 & 3.8697 & TRN & \\
\hline CHEMBL1327034 & 688648 & 2.8239 & 3.2038 & TRN & \\
\hline CHEMBL1971370 & 688648 & 2.8239 & 2.98199 & 99999999998 & TRN \\
\hline CHEMBL1415494 & 688648 & 4.18 & 3.8072 & TRN & \\
\hline CHEMBL1988657 & 688648 & 2.8239 & 2.8517 & TRN & \\
\hline CHEMBL1513972 & 688648 & 2.8239 & 3.8388 & TST & \\
\hline CHEMBL1531919 & 688648 & 4.5207 & 2.9883 & TRN & \\
\hline CHEMBL1596985 & 688648 & 2.8239 & 3.0879 & TRN & \\
\hline CHEMBL1357862 & 688648 & 4.6217 & 3.7067 & TRN & \\
\hline CHEMBL1426228 & 688648 & 2.8239 & 4.0283 & TRN & \\
\hline CHEMBL1432309 & 688648 & 2.8239 & 3.8331 & TRN & \\
\hline CHEMBL1495998 & 688648 & 2.8239 & 3.5146 & TRN & \\
\hline CHEMBL1404929 & 688648 & 2.8239 & 2.8711 & TRN & \\
\hline CHEMBL1462007 & 688648 & 4.4902 & 3.9731 & TST & \\
\hline CHEMBL1459514 & 688648 & 2.8239 & 3.9401 & TRN & \\
\hline CHEMBL1611585 & 688648 & 4.5707 & 3.451 & TRN & \\
\hline CHEMBL1990694 & 688648 & 4.6687 & 3.9472 & TST & \\
\hline CHEMBL1493705 & 688648 & 2.8239 & 3.3142 & TRN & \\
\hline CHEMBL1489407 & 688648 & 2.8239 & 3.3611 & TRN & \\
\hline CHEMBL1545247 & 688648 & 2.8239 & 2.6245 & TRN & \\
\hline CHEMBL1509694 & 688648 & 4.5304 & 3.4972 & TRN & \\
\hline CHEMBL1493953 & 688648 & 2.8239 & 3.8542 & TRN & \\
\hline CHEMBL1481109 & 688648 & 2.8239 & 3.66899 & 99999999996 & TRN \\
\hline CHEMBL1424264 & 688648 & 2.8239 & 4.0612 & TRN & \\
\hline CHEMBL1536264 & 688648 & 2.8239 & 3.4574 & TRN & \\
\hline CHEMBL1969492 & 688648 & 2.8239 & 2.6199 & TRN & \\
\hline CHEMBL1511042 & 688648 & 5.1774 & 3.3038 & TST & \\
\hline CHEMBL1524131 & 688648 & 2.8239 & 3.3532 & TRN & \\
\hline CHEMBL1555362 & 688648 & 5.0306 & 3.9108 & TRN & \\
\hline CHEMBL1487952 & 688648 & 5.6747 & 4.0165 & TRN & \\
\hline CHEMBL1423051 & 688648 & 4.7132 & 3.5742 & TRN & \\
\hline CHEMBL1453819 & 688648 & 2.8239 & 4.0936 & TRN & \\
\hline CHEMBL1431888 & 688648 & 4.1304 & 3.7104 & TRN & \\
\hline CHEMBL1505552 & 688648 & 2.8239 & 3.49 & TRN & \\
\hline CHEMBL3199044 & 688648 & 2.8239 & 2.7196 & TRN & \\
\hline CHEMBL1377978 & 688648 & 3.301 & 3.5195 & TST & \\
\hline CHEMBL1388595 & 688648 & 2.8239 & 4.5546 & TRN & \\
\hline
\end{tabular}




\begin{tabular}{|c|c|c|c|c|c|}
\hline \multirow[b]{2}{*}{ CHEMBL1581000 } & \multicolumn{5}{|c|}{ Supplemental Table S2.txt } \\
\hline & 688648 & 4.6101 & 3.9817 & TRN & \\
\hline CHEMBL1965821 & 688648 & 2.8239 & 2.9696 & TRN & \\
\hline CHEMBL3214119 & 688648 & 2.8239 & 3.6628 & TST & \\
\hline CHEMBL1301734 & 688648 & 5.691 & 3.4675 & TST & \\
\hline CHEMBL3193092 & 688648 & 4.1937 & 3.2431 & TRN & \\
\hline CHEMBL1546810 & 688648 & 3.9114 & 3.8586 & TRN & \\
\hline CHEMBL1327389 & 688648 & 2.8239 & 3.2153 & TST & \\
\hline CHEMBL1525775 & 688648 & 4.4716 & 3.8494 & TRN & \\
\hline CHEMBL1506926 & 688648 & 2.8239 & 2.9675 & TRN & \\
\hline CHEMBL1416756 & 688648 & 2.8239 & 3.3084 & TRN & \\
\hline CHEMBL1428217 & 688648 & 2.8239 & 3.8746 & TRN & \\
\hline CHEMBL1362528 & 688648 & 2.8239 & 3.1893 & TRN & \\
\hline CHEMBL1428827 & 688648 & 2.8239 & 3.5932 & TRN & \\
\hline CHEMBL1533269 & 688648 & 5.3597 & 3.3119 & TRN & \\
\hline CHEMBL1555899 & 688648 & 4.8 & 3.5142 & TRN & \\
\hline CHEMBL1995800 & 688648 & 2.8239 & 2.8056 & TRN & \\
\hline CHEMBL1425761 & 688648 & 2.8239 & 2.6208 & TRN & \\
\hline CHEMBL1503381 & 688648 & 2.8239 & 3.8785 & TST & \\
\hline CHEMBL1504469 & 688648 & 2.8239 & 3.7427 & TST & \\
\hline CHEMBL1446290 & 688648 & 2.8239 & 2.8983 & TST & \\
\hline CHEMBL1453335 & 688648 & 4.7058 & 3.81600 & 00000000003 & TST \\
\hline CHEMBL1385499 & 688648 & 5.7212 & 3.8013 & TST & \\
\hline CHEMBL1378290 & 688648 & 5.0287 & 3.7799 & TST & \\
\hline CHEMBL1331692 & 688648 & 2.8239 & 3.7542 & TST & \\
\hline CHEMBL1343101 & 688648 & 2.8239 & 3.1832 & TST & \\
\hline CHEMBL1550760 & 688648 & 5.1221 & 3.5561 & TST & \\
\hline CHEMBL1478456 & 688648 & 2.8239 & 3.3961 & TST & \\
\hline CHEMBL1301717 & 688648 & 2.8239 & 3.9052 & TST & \\
\hline CHEMBL1382853 & 688648 & 2.8239 & 3.4134 & TST & \\
\hline CHEMBL3198425 & 688648 & 2.8239 & 3.6022 & TST & \\
\hline CHEMBL1329980 & 688648 & 2.8239 & 3.3545 & TST & \\
\hline CHEMBL1407300 & 688648 & 2.8239 & 3.5651 & TST & \\
\hline CHEMBL3199403 & 688648 & 2.8239 & 2.9468 & TST & \\
\hline CHEMBL1536017 & 688648 & 4.7692 & 3.7419 & TST & \\
\hline CHEMBL1543879 & 688648 & 2.8239 & 3.0232 & TST & \\
\hline CHEMBL1571801 & 688648 & 2.8239 & 2.5418 & TST & \\
\hline CHEMBL1501874 & 688648 & 4.6821 & 4.5085 & TST & \\
\hline CHEMBL1534816 & 688648 & 4.8773 & 4.4156 & TST & \\
\hline CHEMBL1457175 & 688648 & 2.8239 & 3.977 & TST & \\
\hline CHEMBL1390021 & 688648 & 2.8239 & 3.7572 & TST & \\
\hline CHEMBL1355207 & 688648 & 2.8239 & 3.4254 & TST & \\
\hline CHEMBL1370838 & 688648 & 2.8239 & 3.3833 & TST & \\
\hline CHEMBL 3190644 & 688648 & 3.301 & 3.7636 & TST & \\
\hline CHEMBL1375199 & 688648 & 4.8157 & 4.0959 & TST & \\
\hline CHEMBL1377629 & 688648 & 4.4772 & 3.91399 & 99999999997 & TST \\
\hline CHEMBL1461561 & 688648 & 2.8239 & 3.1607 & TST & \\
\hline CHEMBL1505080 & 688648 & 2.8239 & 4.4062 & TST & \\
\hline CHEMBL1336274 & 688648 & 2.8239 & 3.48100 & 0000000003 & TST \\
\hline & & & & 7075 & \\
\hline
\end{tabular}




\begin{tabular}{|c|c|c|c|c|c|c|}
\hline \multirow[b]{2}{*}{ CHEMBL1427455 } & \multirow[b]{2}{*}{688648} & \multicolumn{5}{|c|}{ Supplemental Table S2.txt } \\
\hline & & 2.8239 & 3.7979 & TST & & \\
\hline CHEMBL1366395 & 688648 & 2.8239 & 3.8164 & TST & & \\
\hline CHEMBL1329561 & 688648 & $4.7780 e$ & 00000000 & 205 & 4.1406 & TST \\
\hline CHEMBL 2000517 & 688648 & 2.8239 & 3.0055 & TST & & \\
\hline CHEMBL1346995 & 688648 & 2.8239 & 3.2492 & TST & & \\
\hline CHEMBL1539127 & 688648 & 2.8239 & 2.5956 & TST & & \\
\hline CHEMBL1422105 & 688648 & 5.4785 & 3.6474 & TST & & \\
\hline CHEMBL1530542 & 688648 & 2.8239 & 2.5574 & TST & & \\
\hline CHEMBL1543776 & 688648 & 2.8239 & 2.7259 & TST & & \\
\hline CHEMBL1586706 & 688648 & 5.0268 & 3.9305 & TST & & \\
\hline CHEMBL1409680 & 688648 & 5.4915 & 4.4386 & TST & & \\
\hline CHEMBL1564233 & 688648 & 2.8239 & 3.4428 & TST & & \\
\hline CHEMBL1323151 & 688648 & 4.697 & 4.0561 & TST & & \\
\hline CHEMBL1504973 & 688648 & 2.8239 & 4.2126 & TST & & \\
\hline CHEMBL1451125 & 688648 & 2.8239 & 3.0251 & TST & & \\
\hline CHEMBL1340519 & 688648 & 2.8239 & 3.3064 & TST & & \\
\hline CHEMBL1350930 & 688648 & 2.8239 & 2.6288 & TST & & \\
\hline CHEMBL1334456 & 688648 & 6.4413 & 4.0817 & TST & & \\
\hline CHEMBL1502639 & 688648 & 2.8239 & 2.9668 & TST & & \\
\hline CHEMBL1455577 & 688648 & 2.8239 & 3.2111 & TST & & \\
\hline CHEMBL1478211 & 688648 & 2.8239 & 3.3607 & TST & & \\
\hline CHEMBL1383137 & 688648 & 5.3866 & 4.3609 & TST & & \\
\hline CHEMBL1470321 & 688648 & 5.8242 & 4.17 & TST & & \\
\hline CHEMBL1464202 & 688648 & 4.5416 & 4.1217 & TST & & \\
\hline CHEMBL1477844 & 688648 & 2.8239 & 3.35 & TST & & \\
\hline CHEMBL1393529 & 688648 & 3.9528 & 3.8637 & TST & & \\
\hline CHEMBL1579058 & 688648 & 2.8239 & 3.0053 & TST & & \\
\hline CHEMBL1466644 & 688648 & 2.8239 & 2.9373 & TST & & \\
\hline CHEMBL1563370 & 688648 & 2.8239 & 4.4812 & TST & & \\
\hline CHEMBL1967772 & 688648 & 2.8239 & 3.1527 & TST & & \\
\hline CHEMBL3189161 & 688648 & 2.8239 & 3.0973 & TST & & \\
\hline CHEMBL1975652 & 688648 & 4.3309 & 3.8721 & TST & & \\
\hline CHEMBL3191951 & 688648 & 2.8239 & 2.7896 & TST & & \\
\hline CHEMBL1988829 & 688648 & 2.8239 & 2.6843 & TST & & \\
\hline CHEMBL1568686 & 688648 & 4.3768 & 2.7401 & TST & & \\
\hline CHEMBL1481836 & 688648 & 2.8239 & 4.2769 & TST & & \\
\hline CHEMBL 1360376 & 688648 & 5.289 & 4.6947 & TST & & \\
\hline CHEMBL1580328 & 688648 & 2.8239 & 3.7907 & TST & & \\
\hline CHEMBL1304970 & 688648 & 4.6676 & 4.1274 & TST & & \\
\hline CHEMBL1517683 & 688648 & 2.8239 & 3.4742 & TST & & \\
\hline CHEMBL1305871 & 688648 & 2.8239 & 2.895 & TST & & \\
\hline CHEMBL1598311 & 688648 & 2.8239 & 3.5417 & TST & & \\
\hline CHEMBL1487434 & 688648 & 2.8239 & 2.7727 & TST & & \\
\hline CHEMBL1321386 & 688648 & 4.7907 & 4.2433 & TST & & \\
\hline CHEMBL1610443 & 688648 & 2.8239 & 2.6541 & TST & & \\
\hline CHEMBL1338335 & 688648 & 2.8239 & 3.3457 & TST & & \\
\hline CHEMBL 1442412 & 688648 & 2.8239 & 3.9899 & TST & & \\
\hline CHEMBL1464656 & 688648 & 2.8239 & 3.0411 & TST & & \\
\hline
\end{tabular}




\begin{tabular}{|c|c|c|c|c|}
\hline & & & pplement & al $\mathrm{T}$ \\
\hline CHEMBL 3192328 & 688648 & 2.8239 & 3.0871 & TST \\
\hline CHEMBL1300745 & 688648 & 2.8239 & 4.0365 & TST \\
\hline CHEMBL1404493 & 688648 & 2.8239 & 3.8936 & TST \\
\hline CHEMBL 3190835 & 688648 & 2.8239 & 3.0256 & TST \\
\hline CHEMBL1482053 & 688648 & 2.8239 & 3.75 & TST \\
\hline CHEMBL1304742 & 688648 & 2.8239 & 4.0005 & TST \\
\hline CHEMBL1527341 & 688648 & 2.8239 & 3.3812 & TST \\
\hline CHEMBL1381519 & 688648 & 2.8239 & 3.239 & TST \\
\hline CHEMBL1360597 & 688648 & 4.648 & 3.8222 & TST \\
\hline CHEMBL3193792 & 688648 & 4.6275 & 3.0177 & TST \\
\hline CHEMBL1377690 & 688648 & 5.6442 & 3.6789 & TST \\
\hline CHEMBL1495893 & 688648 & 5.5555 & 3.8871 & TST \\
\hline CHEMBL1532148 & 688648 & 4.7769 & 4.3076 & TST \\
\hline CHEMBL1441083 & 688648 & 4.6248 & 3.5574 & TST \\
\hline CHEMBL1491019 & 688648 & 2.8239 & 3.983 & TST \\
\hline CHEMBL1478314 & 688648 & 2.8239 & 4.1187 & TST \\
\hline CHEMBL1971127 & 688648 & 4.857 & 3.5523 & TST \\
\hline CHEMBL1373002 & 688648 & 2.8239 & 4.477 & TST \\
\hline CHEMBL1384325 & 688648 & 2.8239 & 3.3726 & TST \\
\hline CHEMBL588804 & 688648 & 2.8239 & 3.5597 & TST \\
\hline CHEMBL1560219 & 688648 & 5.1832 & 4.8256 & TST \\
\hline CHEMBL1491007 & 688648 & 5.4166 & 3.352 & TST \\
\hline CHEMBL1332873 & 688648 & 2.8239 & 3.3333 & TST \\
\hline CHEMBL1549870 & 688648 & 2.8239 & 3.3861 & TST \\
\hline CHEMBL3196731 & 688648 & 4.4832 & 3.6253 & TST \\
\hline CHEMBL1468612 & 688648 & 2.8239 & 4.2736 & TST \\
\hline CHEMBL1403442 & 688648 & 2.8239 & 2.734 & TST \\
\hline CHEMBL1541449 & 688648 & 4.8417 & 4.1373 & TST \\
\hline CHEMBL1604383 & 688648 & 2.8239 & 3.6021 & TST \\
\hline CHEMBL1326851 & 688648 & 4.7259 & 3.949 & TST \\
\hline CHEMBL1441999 & 688648 & 2.8239 & 3.0246 & TST \\
\hline CHEMBL1396209 & 688648 & 5.4421 & 4.1712 & TST \\
\hline CHEMBL1390546 & 688648 & 4.989 & 4.3121 & TST \\
\hline CHEMBL1391055 & 688648 & 4.9327 & 3.423 & TST \\
\hline CHEMBL1339872 & 688648 & 2.8239 & 3.5644 & TST \\
\hline CHEMBL1418598 & 688648 & 3.301 & 4.0385 & TST \\
\hline CHEMBL1380929 & 688648 & 5.5117 & 4.0624 & TST \\
\hline CHEMBL1566130 & 688648 & 4.5599 & 3.3199 & TST \\
\hline CHEMBL1400025 & 688648 & 2.8239 & 2.9256 & TST \\
\hline CHEMBL1536360 & 688648 & 4.2049 & 4.2091 & TST \\
\hline CHEMBL1605916 & 688648 & 5.7491 & 3.9991 & TST \\
\hline CHEMBL1978315 & 688648 & 2.8239 & 3.5469 & TST \\
\hline CHEMBL1603420 & 688648 & 2.8239 & 3.7901 & TST \\
\hline CHEMBL1383327 & 688648 & 2.8239 & 3.4445 & TST \\
\hline CHEMBL1436608 & 688648 & 5.0045 & 4.051 & TST \\
\hline CHEMBL1450105 & 688648 & 2.8239 & 4.3174 & TST \\
\hline CHEMBL1328384 & 688648 & 4.7888 & 3.7408 & TST \\
\hline CHEMBL1573586 & 688648 & 3.9343 & 3.1018 & TST \\
\hline
\end{tabular}




\begin{tabular}{|c|c|c|c|c|c|}
\hline & & \multicolumn{4}{|c|}{ Supplemental Table S2.txt } \\
\hline CHEMBL1477713 & 688648 & 4.8357 & 4.0278 & TST & \\
\hline CHEMBL1345584 & 688648 & 3.8405 & 3.2613 & TST & \\
\hline CHEMBL1499220 & 688648 & 2.8239 & 3.2999 & TST & \\
\hline CHEMBL496633 & 688648 & 2.8239 & 3.7284 & TST & \\
\hline CHEMBL1604261 & 688648 & 4.9382 & 4.3102 & TST & \\
\hline CHEMBL3198068 & 688648 & 2.8239 & 3.1234 & TST & \\
\hline CHEMBL584668 & 688648 & 2.8239 & 3.3325 & TST & \\
\hline CHEMBL29097 & 688648 & 5.9076 & 4.2596 & TST & \\
\hline CHEMBL1344296 & 688648 & 4.3187 & 3.79600 & 00000000003 & TST \\
\hline CHEMBL1562608 & 688648 & 2.8239 & 3.2282 & TST & \\
\hline CHEMBL1604156 & 688648 & 2.8239 & 3.9226 & TST & \\
\hline CHEMBL1316800 & 688648 & 2.8239 & 3.0356 & TST & \\
\hline CHEMBL1395871 & 688648 & 5.2684 & 4.6702 & TST & \\
\hline CHEMBL1545468 & 688648 & 2.8239 & 3.114 & TST & \\
\hline CHEMBL1496705 & 688648 & 2.8239 & 3.7649 & TST & \\
\hline CHEMBL1350169 & 688648 & 5.5382 & 4.449 & TST & \\
\hline CHEMBL1477341 & 688648 & 4.7087 & 3.5214 & TST & \\
\hline CHEMBL1609828 & 688648 & 2.8239 & 4.0665 & TST & \\
\hline CHEMBL3191950 & 688648 & 2.8239 & 3.2902 & TST & \\
\hline CHEMBL1380959 & 688648 & 4.7582 & 4.0143 & TST & \\
\hline CHEMBL3190775 & 688648 & 2.8239 & 3.0638 & TST & \\
\hline CHEMBL1486418 & 688648 & 2.8239 & 3.6905 & TST & \\
\hline CHEMBL1438389 & 688648 & 2.8239 & 3.0307 & TST & \\
\hline CHEMBL1407260 & 688648 & 2.8239 & 3.74899 & 99999999997 & TST \\
\hline CHEMBL1378397 & 688648 & 2.8239 & 3.2965 & TST & \\
\hline CHEMBL1415338 & 688648 & 4.794 & 4.4774 & TST & \\
\hline CHEMBL1358236 & 688648 & 5.63299 & 99999999 & 3.484 & 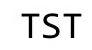 \\
\hline CHEMBL1575184 & 688648 & 4.7563 & 4.2054 & TST & \\
\hline CHEMBL1547641 & 688648 & 4.4253 & 3.406 & TST & \\
\hline CHEMBL1977596 & 688648 & 2.8239 & 3.5589 & TST & \\
\hline CHEMBL3189459 & 688648 & 4.13 & 2.7844 & TST & \\
\hline CHEMBL1550274 & 688648 & 3.877 & 3.8211 & TST & \\
\hline CHEMBL1520763 & 688648 & 4.5973 & 3.2164 & TST & \\
\hline CHEMBL530038 & 688648 & 2.8239 & 3.4585 & TST & \\
\hline CHEMBL3189712 & 688648 & 5.0856 & 3.1097 & TST & \\
\hline CHEMBL1533459 & 688648 & 2.8239 & 3.6367 & TST & \\
\hline CHEMBL1539224 & 688648 & 5.3046 & 4.2925 & TST & \\
\hline CHEMBL1315224 & 688648 & 5.5065 & 3.3737 & TST & \\
\hline CHEMBL1569929 & 688648 & 4.6284 & 2.735 & TST & \\
\hline CHEMBL3193204 & 688648 & 4.7889 & 3.72 & TST & \\
\hline CHEMBL1500487 & 688648 & 4.4479 & 3.4728 & TST & \\
\hline CHEMBL1591445 & 688648 & 5.1004 & 4.1529 & TST & \\
\hline CHEMBL1597289 & 688648 & 4.1074 & 3.322 & TST & \\
\hline CHEMBL1322375 & 688648 & 2.8239 & 3.1762 & TST & \\
\hline CHEMBL1569782 & 688648 & 5.3433 & 3.7299 & TST & \\
\hline CHEMBL3193666 & 688648 & 2.8239 & 2.6277 & TST & \\
\hline CHEMBL1597967 & 688648 & 4.734 & 4.0574 & TST & \\
\hline CHEMBL1964891 & 688648 & 2.8239 & 3.1331 & TST & \\
\hline
\end{tabular}




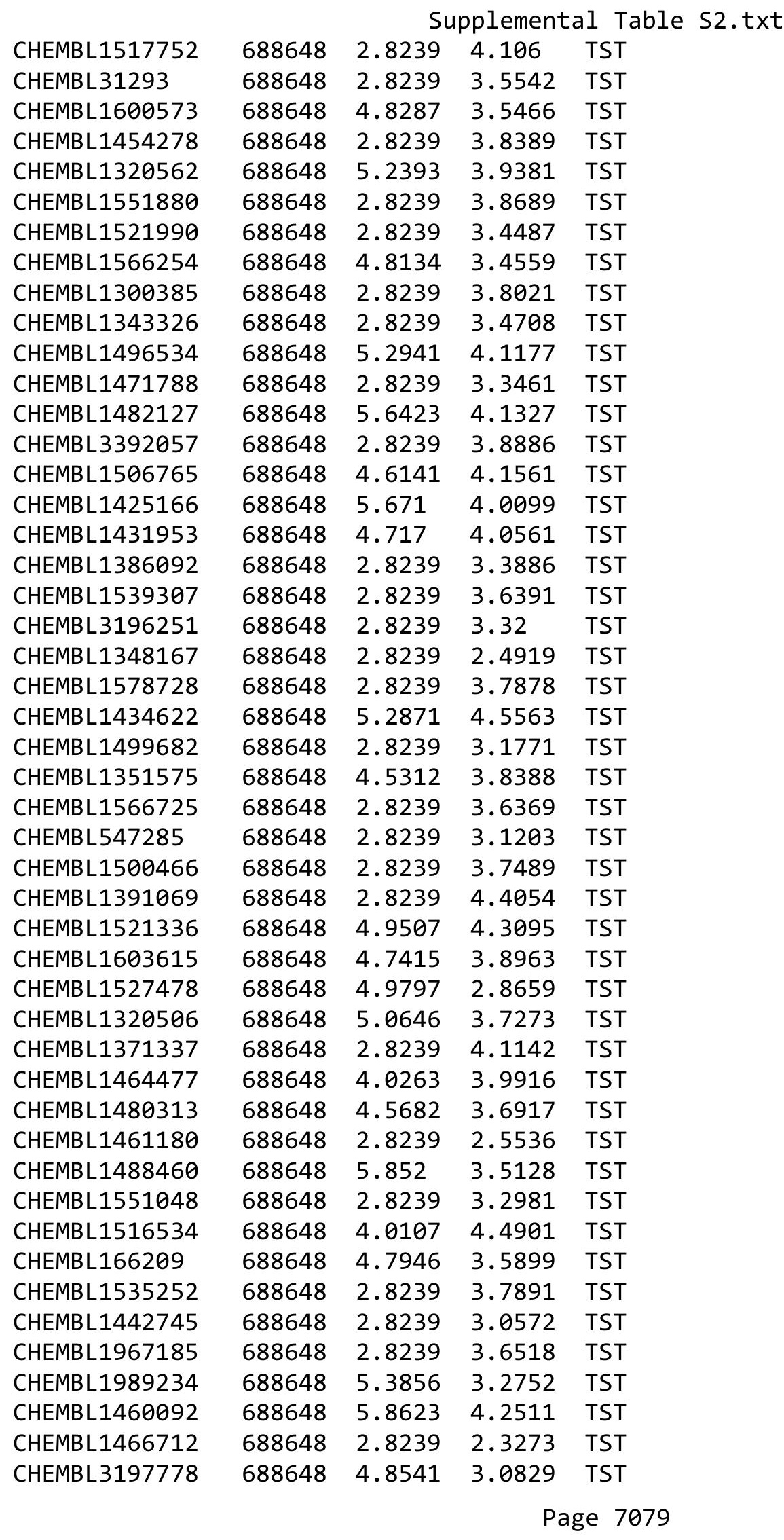


Supplemental Table S2.txt

\begin{tabular}{|c|c|c|c|c|}
\hline CHEMBL3194931 & 688648 & 4.6309 & 3.7029 & TST \\
\hline CHEMBL1409596 & 688648 & 2.8239 & 3.1264 & TST \\
\hline CHEMBL1595700 & 688648 & 4.7811 & 3.2186 & TST \\
\hline CHEMBL1466932 & 688648 & 2.8239 & 3.9342 & TST \\
\hline CHEMBL1613678 & 688648 & 2.8239 & 4.0193 & TST \\
\hline CHEMBL1358867 & 688648 & 2.8239 & 4.0862 & TST \\
\hline CHEMBL1492378 & 688648 & 2.8239 & 3.6024 & TST \\
\hline CHEMBL1508334 & 688648 & 2.8239 & 3.4907 & TST \\
\hline CHEMBL1469579 & 688648 & 2.8239 & 3.8544 & TST \\
\hline CHEMBL 3196125 & 688648 & 5.1499 & 3.7702 & TST \\
\hline CHEMBL1339600 & 688648 & 2.8239 & 3.593 & TST \\
\hline CHEMBL1534368 & 688648 & 2.8239 & 3.3335 & TST \\
\hline CHEMBL1437924 & 688648 & 2.8239 & 4.2137 & TST \\
\hline CHEMBL1502251 & 688648 & 5.4889 & 3.7655 & TST \\
\hline CHEMBL1541490 & 688648 & 3.301 & 3.7679 & TST \\
\hline CHEMBL1359792 & 688648 & 3.301 & 3.4791 & TST \\
\hline CHEMBL1468147 & 688648 & 2.8239 & 3.8157 & TST \\
\hline CHEMBL1321627 & 688648 & 4.8342 & 3.5174 & TST \\
\hline CHEMBL1567674 & 688648 & 2.8239 & 3.4613 & TST \\
\hline CHEMBL1361866 & 688648 & 4.408 & 3.9135 & TST \\
\hline CHEMBL1478587 & 688648 & 5.135 & 4.1994 & TST \\
\hline CHEMBL1302146 & 688648 & 2.8239 & 3.0021 & TST \\
\hline CHEMBL 399530 & 954990 & 4.7429 & 4.8327 & TRN \\
\hline CHEMBL240954 & 954990 & 4.1316 & 4.2895 & TST \\
\hline CHEMBL 221137 & 954990 & 4.3495 & 4.8137 & TST \\
\hline CHEMBL 2144069 & 954990 & 4.9443 & 5.083 & TRN \\
\hline CHEMBL180127 & 954990 & 5.3023 & 4.4647 & TRN \\
\hline CHEMBL 2005886 & 954990 & 3.7784 & 5.195 & TRN \\
\hline CHEMBL 379975 & 954990 & 6.4041 & 5.4351 & TRN \\
\hline CHEMBL1256459 & 954990 & 3.925 & 5.8551 & TRN \\
\hline CHEMBL 258844 & 954990 & 4.0416 & 4.501 & TRN \\
\hline CHEMBL515416 & 954990 & 6.1558 & 4.784 & TRN \\
\hline CHEMBL 213100 & 954990 & 3.3981 & 4.6027 & TRN \\
\hline CHEMBL102714 & 954990 & 5.1919 & 4.4456 & TRN \\
\hline CHEMBL189584 & 954990 & 4.3212 & 4.7512 & TRN \\
\hline CHEMBL512504 & 954990 & 4.2343 & 4.9206 & TRN \\
\hline CHEMBL 220241 & 954990 & 4.9766 & 5.0595 & TRN \\
\hline CHEMBL 259181 & 954990 & 4.542 & 4.5911 & TRN \\
\hline CHEMBL188678 & 954990 & 5.6693 & 4.901 & TRN \\
\hline CHEMBL 300389 & 954990 & 4.7666 & 5.8869 & TRN \\
\hline CHEMBL585951 & 954990 & 6.1348 & 5.7174 & TRN \\
\hline CHEMBL 1242367 & 954990 & 3.6541 & 4.2956 & TRN \\
\hline CHEMBL 202721 & 954990 & 5.9822 & 5.3245 & TRN \\
\hline CHEMBL393929 & 954990 & 3.7081 & 4.2799 & TRN \\
\hline CHEMBL483849 & 954990 & 2.8623 & 3.4306 & TST \\
\hline CHEMBL412142 & 954990 & 3.7325 & 4.3723 & TRN \\
\hline CHEMBL1190711 & 954990 & 5.3072 & 5.0013 & TRN \\
\hline CHEMBL 3349342 & 954990 & 5.4817 & 5.31 & TRN \\
\hline
\end{tabular}




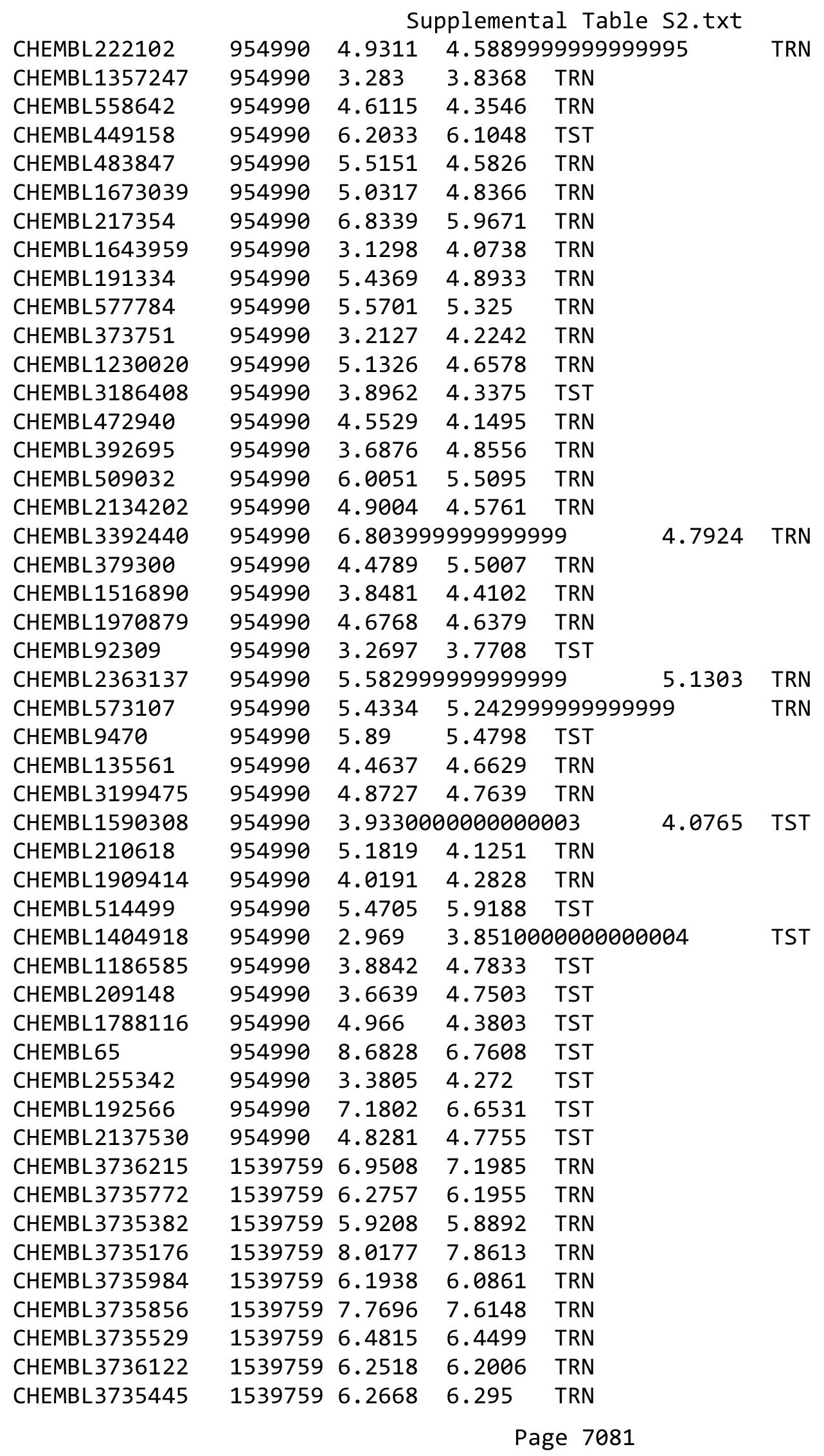


Supplemental Table S2.txt

\begin{tabular}{|c|c|c|c|c|c|}
\hline CHEMBL 3735637 & 1539759 & 5.9469 & 5.9616 & TRN & \\
\hline CHEMBL 3735215 & 1539759 & 7.9208 & 7.7848 & TRN & \\
\hline CHEMBL 3735863 & 1539759 & 6.2924 & 6.3036 & TRN & \\
\hline CHEMBL 3736196 & 1539759 & 6.2518 & 6.0081 & TRN & \\
\hline CHEMBL 3735522 & 1539759 & 7.585 & 7.5587 & TRN & \\
\hline CHEMBL3736449 & 1539759 & 7.3979 & 7.322 & TRN & \\
\hline CHEMBL3735095 & 1539759 & 6.2757 & 6.4306 & TST & \\
\hline CHEMBL 3734776 & 1539759 & 5.6778 & 5.7488 & TRN & \\
\hline CHEMBL 3736216 & 1539759 & 6.4559 & 6.3576 & TRN & \\
\hline CHEMBL3735246 & 1539759 & 7.1427 & 7.0561 & TRN & \\
\hline CHEMBL 3735967 & 1539759 & 7.5086 & 7.4862 & TRN & \\
\hline CHEMBL3735681 & 1539759 & 6.0 & 5.9758 & TRN & \\
\hline CHEMBL 3735347 & 1539759 & 6.3098 & 6.5059 & TST & \\
\hline CHEMBL 3735500 & 1539759 & 6.6778 & 6.1312 & TST & \\
\hline CHEMBL 3734895 & 1539759 & 6.5229 & 6.6516 & TRN & \\
\hline CHEMBL3735061 & 1539759 & 7.4089 & 7.5616 & TRN & \\
\hline CHEMBL3734924 & 1539759 & 6.4437 & 6.435 & TRN & \\
\hline CHEMBL 3735220 & 1539759 & 5.7696 & 5.8237 & TRN & \\
\hline CHEMBL 3736164 & 1539759 & 6.699 & 6.5666 & TRN & \\
\hline CHEMBL 3734973 & 1539759 & 6.0223 & 6.2807 & TST & \\
\hline CHEMBL 3735079 & 1539759 & 7.3468 & 7.4619 & TRN & \\
\hline CHEMBL3735779 & 1539759 & 7.301 & 6.4092 & TST & \\
\hline CHEMBL 3735579 & 1539759 & 6.8861 & 6.2883 & TST & \\
\hline CHEMBL3734985 & 1539759 & 6.5086 & 6.7742 & TST & \\
\hline CHEMBL3736399 & 1539759 & 6.3979 & 6.5183 & TRN & \\
\hline CHEMBL 3735962 & 1539759 & 6.6021 & 6.545 & TRN & \\
\hline CHEMBL3735730 & 1539759 & 6.6778 & 6.6376 & TRN & \\
\hline CHEMBL 3735796 & 1539759 & 7.1739 & 7.3486 & TRN & \\
\hline CHEMBL3735613 & 1539759 & 6.585 & 6.6306 & TRN & \\
\hline CHEMBL 3735835 & 1539759 & 7.3468 & 7.3114 & TRN & \\
\hline CHEMBL3734956 & 1539759 & 6.6383 & 6.392 & TRN & \\
\hline CHEMBL3735459 & 1539759 & 7.3979 & 7.2286 & TRN & \\
\hline CHEMBL 3736462 & 1539759 & 6.4559 & 6.593 & TRN & \\
\hline CHEMBL3736223 & 1539759 & 7.1938 & 7.2505 & TRN & \\
\hline CHEMBL3736396 & 1539759 & 6.2366 & 6.2924 & TRN & \\
\hline CHEMBL3734911 & 1539759 & 6.4437 & 6.4415 & TRN & \\
\hline CHEMBL3735627 & 1539759 & 7.2757 & 7.3205 & TRN & \\
\hline CHEMBL 3736455 & 1539759 & 7.7447 & 7.7256 & TRN & \\
\hline CHEMBL3736035 & 1539759 & 7.6778 & 7.7284 & TRN & \\
\hline CHEMBL 3735291 & 1539759 & 6.6383 & 6.2579 & TST & \\
\hline CHEMBL 3735154 & 1539759 & 6.5686 & 6.454 & TRN & \\
\hline CHEMBL 3736476 & 1539759 & 6.4437 & 6.3996 & TST & \\
\hline CHEMBL 3735293 & 1539759 & 6.1612 & 6.3338 & TRN & \\
\hline CHEMBL3736418 & 1539759 & 6.2366 & 6.3168 & TRN & \\
\hline CHEMBL 3735621 & 1539759 & 6.4949 & 6.596 & TRN & \\
\hline CHEMBL 3736086 & 1539759 & 7.1549 & 6.2499 & TST & \\
\hline CHEMBL 3735527 & 1539759 & 5.82100 & 000000000 & 1 & 5.8299 \\
\hline CHEMBL 3736404 & 1539759 & 6.1739 & 6.244 & TRN & \\
\hline
\end{tabular}


Supplemental Table S2.txt

\begin{tabular}{|c|c|c|c|c|}
\hline CHEMBL3735837 & 1539759 & 6.3979 & 6.6149 & TRN \\
\hline CHEMBL3735497 & 1539759 & 6.0605 & 6.0537 & TRN \\
\hline CHEMBL3736167 & 1539759 & 7.5686 & 7.4828 & TST \\
\hline CHEMBL3734853 & 1539759 & 5.8539 & 5.9941 & TST \\
\hline CHEMBL3735603 & 1539759 & 7.699 & 7.5266 & TST \\
\hline CHEMBL3735506 & 1539759 & 7.7447 & 7.2221 & TST \\
\hline CHEMBL3735986 & 1539759 & 8.2218 & 7.4993 & TST \\
\hline CHEMBL3735882 & 1539759 & 5.8539 & 5.7757 & TST \\
\hline CHEMBL3736458 & 1539759 & 6.1249 & 5.9814 & TST \\
\hline CHEMBL1402286 & 688600 & 4.4 & 4.454 & TRN \\
\hline CHEMBL1255647 & 688600 & 4.65 & 5.3485 & TRN \\
\hline CHEMBL1563861 & 688600 & 4.85 & 5.1246 & TRN \\
\hline CHEMBL1527520 & 688600 & 5.35 & 5.2633 & TRN \\
\hline CHEMBL1613528 & 688600 & 4.5 & 4.5242 & TRN \\
\hline CHEMBL1317451 & 688600 & 4.4 & 4.8871 & TST \\
\hline CHEMBL1414360 & 688600 & 5.05 & 4.9036 & TRN \\
\hline CHEMBL1569086 & 688600 & 4.4 & 4.3684 & TRN \\
\hline CHEMBL295316 & 688600 & 4.5 & 5.1059 & TRN \\
\hline CHEMBL1503386 & 688600 & 4.65 & 5.1569 & TST \\
\hline CHEMBL129795 & 688600 & 4.3 & 5.0053 & TRN \\
\hline CHEMBL1502716 & 688600 & 4.9 & 4.7412 & TRN \\
\hline CHEMBL1473205 & 688600 & 4.4 & 5.5995 & TRN \\
\hline CHEMBL1364873 & 688600 & 4.65 & 4.7117 & TRN \\
\hline CHEMBL192566 & 688600 & 4.9 & 3.6277 & TST \\
\hline CHEMBL274619 & 688600 & 4.7 & 5.4581 & TRN \\
\hline CHEMBL1555810 & 688600 & 4.55 & 5.6464 & TST \\
\hline CHEMBL365327 & 688600 & 4.85 & 4.857 & TRN \\
\hline CHEMBL1966298 & 688600 & 4.4 & 4.7054 & TRN \\
\hline CHEMBL1358402 & 688600 & 7.9508 & 5.28600 & 00000000005 \\
\hline CHEMBL90472 & 688600 & 9.2218 & 5.4728 & TST \\
\hline CHEMBL109037 & 688600 & 5.5 & 6.6772 & TRN \\
\hline CHEMBL 2005484 & 688600 & 4.4 & 4.4689 & TRN \\
\hline CHEMBL1390605 & 688600 & 5.0 & 5.1518 & TRN \\
\hline CHEMBL16081 & 688600 & 8.9586 & 6.7842 & TST \\
\hline CHEMBL1366071 & 688600 & 4.45 & 6.8076 & TST \\
\hline CHEMBL1462808 & 688600 & 4.7 & 4.4953 & TRN \\
\hline CHEMBL1596675 & 688600 & 4.5 & 4.9591 & TRN \\
\hline CHEMBL1577300 & 688600 & 5.1 & 5.5673 & TRN \\
\hline CHEMBL1594626 & 688600 & 8.5528 & 5.7076 & TST \\
\hline CHEMBL303579 & 688600 & 4.8 & 5.5964 & TRN \\
\hline CHEMBL1365850 & 688600 & 4.4 & 4.9295 & TRN \\
\hline CHEMBL1479123 & 688600 & 4.7 & 5.1393 & TRN \\
\hline CHEMBL1409207 & 688600 & 4.4 & 4.0115 & TRN \\
\hline CHEMBL1419792 & 688600 & 4.6 & \multicolumn{2}{|c|}{4.4910000000000005} \\
\hline CHEMBL1584969 & 688600 & 4.9 & 4.7903 & TRN \\
\hline CHEMBL1387843 & 688600 & 5.4 & 5.5955 & TST \\
\hline CHEMBL448741 & 688600 & 4.3 & 5.7925 & TRN \\
\hline CHEMBL1533351 & 688600 & 4.45 & 4.5514 & TRN \\
\hline
\end{tabular}




\begin{tabular}{|c|c|c|c|c|}
\hline \multicolumn{5}{|c|}{ Supplemental Table S2.txt } \\
\hline CHEMBL3392427 & 688600 & 4.55 & 4.7433 & TRN \\
\hline CHEMBL1331939 & 688600 & 5.8 & 5.9918 & TST \\
\hline CHEMBL1432831 & 688600 & 4.4 & 4.808 & TRN \\
\hline CHEMBL1507430 & 688600 & 4.65 & 4.7761 & TRN \\
\hline CHEMBL1450897 & 688600 & 4.75 & 4.8262 & TRN \\
\hline CHEMBL3191022 & 688600 & 5.2 & 5.0477 & TRN \\
\hline CHEMBL66105 & 688600 & 4.8 & 6.4624 & TRN \\
\hline CHEMBL1538505 & 688600 & 4.75 & 4.7615 & TRN \\
\hline CHEMBL1339695 & 688600 & 4.55 & 5.2815 & TRN \\
\hline CHEMBL1504679 & 688600 & 4.7 & 4.6181 & TRN \\
\hline CHEMBL1567682 & 688600 & 4.55 & 4.6966 & TRN \\
\hline CHEMBL1331022 & 688600 & 4.6 & 5.0995 & TRN \\
\hline CHEMBL1255659 & 688600 & 4.3 & 4.8244 & TST \\
\hline CHEMBL299613 & 688600 & 8.1487 & 5.9852 & TST \\
\hline CHEMBL1424551 & 688600 & 5.15 & 5.0302 & TRN \\
\hline CHEMBL559612 & 688600 & 4.55 & 5.0909 & TST \\
\hline CHEMBL1536273 & 688600 & 4.45 & 4.6788 & TRN \\
\hline CHEMBL1302035 & 688600 & 4.65 & 5.1059 & TRN \\
\hline CHEMBL1379600 & 688600 & 4.4 & 4.7734 & TRN \\
\hline CHEMBL1368302 & 688600 & 4.6 & 4.72 & TRN \\
\hline CHEMBL1257080 & 688600 & 8.4949 & 5.3727 & TST \\
\hline CHEMBL1417815 & 688600 & 4.45 & 5.0978 & TRN \\
\hline CHEMBL1382616 & 688600 & 4.55 & 4.6119 & TRN \\
\hline CHEMBL1305427 & 688600 & 5.15 & 5.0326 & TRN \\
\hline CHEMBL3192197 & 688600 & 4.6 & 4.6083 & TRN \\
\hline CHEMBL1448985 & 688600 & 5.15 & 5.2285 & TRN \\
\hline CHEMBL1471220 & 688600 & 4.8 & 4.3896 & TRN \\
\hline CHEMBL3191714 & 688600 & 5.25 & 5.0775 & TRN \\
\hline CHEMBL1329119 & 688600 & 4.4 & 4.3787 & TRN \\
\hline CHEMBL1255733 & 688600 & 8.5528 & 5.6277 & TST \\
\hline CHEMBL1588351 & 688600 & 4.7 & 5.2486 & TRN \\
\hline CHEMBL1335254 & 688600 & 4.55 & 4.5835 & TRN \\
\hline CHEMBL3199060 & 688600 & 4.45 & 4.8367 & TRN \\
\hline CHEMBL1398645 & 688600 & 4.75 & 4.9617 & TRN \\
\hline CHEMBL 3190558 & 688600 & 4.4 & 4.1985 & TRN \\
\hline CHEMBL40998 & 688600 & 6.05 & 5.3098 & TRN \\
\hline CHEMBL440464 & 688600 & 6.05 & 6.0522 & TRN \\
\hline CHEMBL1571760 & 688600 & 4.8 & 5.1456 & TRN \\
\hline CHEMBL1531491 & 688600 & 5.2 & 4.7325 & TRN \\
\hline CHEMBL1096009 & 688600 & 4.4 & 5.7626 & TST \\
\hline CHEMBL1345320 & 688600 & 4.4 & 5.7269 & TST \\
\hline CHEMBL1435381 & 688600 & 4.45 & 4.8583 & TRN \\
\hline CHEMBL 32307 & 688600 & 6.0 & 6.4499 & TST \\
\hline CHEMBL1607675 & 688600 & 4.45 & 5.1908 & TRN \\
\hline CHEMBL281211 & 688600 & 4.6 & 4.9126 & TRN \\
\hline CHEMBL449392 & 688600 & 5.25 & 5.5609 & TRN \\
\hline CHEMBL1517470 & 688600 & 4.45 & 4.265 & TRN \\
\hline CHEMBL1424749 & 688600 & 4.5 & 4.4838 & TRN \\
\hline
\end{tabular}




\begin{tabular}{|c|c|c|c|c|}
\hline \multicolumn{5}{|c|}{ Supplemental Table } \\
\hline CHEMBL1413956 & 688600 & 4.85 & 4.6247 & TRN \\
\hline CHEMBL1417521 & 688600 & 4.7 & 5.0435 & TRN \\
\hline CHEMBL3192969 & 688600 & 5.2 & 4.5165 & TRN \\
\hline CHEMBL1534284 & 688600 & 4.6 & 5.4317 & TRN \\
\hline CHEMBL1412087 & 688600 & 4.5 & 4.2909 & TRN \\
\hline CHEMBL1422133 & 688600 & 4.6 & 4.6479 & TRN \\
\hline CHEMBL 1477786 & 688600 & 4.75 & 4.6977 & TRN \\
\hline CHEMBL1501990 & 688600 & 4.4 & 4.8341 & TRN \\
\hline CHEMBL39839 & 688600 & 4.8 & 5.325 & TRN \\
\hline CHEMBL29726 & 688600 & 9.699 & 5.4993 & TST \\
\hline CHEMBL1483889 & 688600 & 4.75 & 5.541 & TST \\
\hline CHEMBL1562713 & 688600 & 4.55 & 4.7689 & TRN \\
\hline CHEMBL1256866 & 688600 & 6.0 & 5.9323 & TRN \\
\hline CHEMBL1411856 & 688600 & 4.55 & 5.2435 & TRN \\
\hline CHEMBL1361855 & 688600 & 5.4 & 4.9128 & TRN \\
\hline CHEMBL 302783 & 688600 & 8.301 & 7.1835 & TRN \\
\hline CHEMBL1406513 & 688600 & 7.6003 & 6.7724 & TRN \\
\hline CHEMBL1353738 & 688600 & 4.65 & 4.5835 & TRN \\
\hline CHEMBL1459786 & 688600 & 4.45 & 5.035 & TRN \\
\hline CHEMBL1500636 & 688600 & 4.85 & 4.5636 & TRN \\
\hline CHEMBL1428997 & 688600 & 4.55 & 5.0646 & TRN \\
\hline CHEMBL1388603 & 688600 & 5.15 & 4.4785 & TRN \\
\hline CHEMBL 3190368 & 688600 & 4.45 & 4.4071 & TRN \\
\hline CHEMBL1517686 & 688600 & 5.1 & 4.7596 & TRN \\
\hline CHEMBL24983 & 688600 & 7.0 & 4.9442 & TST \\
\hline CHEMBL1511673 & 688600 & 4.4 & 4.7551 & TRN \\
\hline CHEMBL1499658 & 688600 & 5.0 & 4.8007 & TRN \\
\hline CHEMBL1077990 & 688600 & 4.8 & 4.5085 & TRN \\
\hline CHEMBL1364172 & 688600 & 4.6 & 5.099 & TRN \\
\hline CHEMBL1367952 & 688600 & 4.5 & 5.0089 & TRN \\
\hline CHEMBL1374495 & 688600 & 4.7 & 4.9326 & TRN \\
\hline CHEMBL107514 & 688600 & 7.8013 & 5.5622 & TRN \\
\hline CHEMBL1255655 & 688600 & 7.8013 & 6.0824 & TST \\
\hline CHEMBL 76897 & 688600 & 7.6003 & 5.4891 & TRN \\
\hline CHEMBL1555684 & 688600 & 4.6 & 4.2049 & TRN \\
\hline CHEMBL1595975 & 688600 & 4.5 & 4.6095 & TRN \\
\hline CHEMBL1373577 & 688600 & 4.55 & 4.1302 & TRN \\
\hline CHEMBL1366939 & 688600 & 4.6 & 4.7402 & TRN \\
\hline CHEMBL1579535 & 688600 & 4.9 & 4.9099 & TRN \\
\hline CHEMBL1447101 & 688600 & 6.15 & 4.7543 & TRN \\
\hline CHEMBL3193664 & 688600 & 4.55 & 4.6896 & TRN \\
\hline CHEMBL1368261 & 688600 & 4.7 & 4.9365 & TRN \\
\hline CHEMBL1477081 & 688600 & 4.55 & 4.9366 & TST \\
\hline CHEMBL1316831 & 688600 & 4.85 & 4.7357 & TST \\
\hline CHEMBL1560740 & 688600 & 4.4 & 4.8542 & TRN \\
\hline CHEMBL1541973 & 688600 & 4.5 & 5.0779 & TRN \\
\hline CHEMBL3197100 & 688600 & 4.4 & 5.0227 & TRN \\
\hline CHEMBL1455369 & 688600 & 6.95 & 6.4516 & TRN \\
\hline
\end{tabular}




\begin{tabular}{|c|c|c|c|c|}
\hline \multicolumn{5}{|c|}{ Supplemental T } \\
\hline CHEMBL1565040 & 688600 & 4.6 & 4.7886 & TRN \\
\hline CHEMBL1255657 & 688600 & 4.9 & 6.9555 & TRN \\
\hline CHEMBL1975120 & 688600 & 4.85 & 4.6567 & TRN \\
\hline CHEMBL72365 & 688600 & 6.0 & 4.8249 & TRN \\
\hline CHEMBL26915 & 688600 & 4.55 & 4.7134 & TRN \\
\hline CHEMBL1491340 & 688600 & 7.7496 & 5.8262 & TST \\
\hline CHEMBL1593851 & 688600 & 5.4 & 6.0923 & TRN \\
\hline CHEMBL1307180 & 688600 & 5.0 & 5.2552 & TRN \\
\hline CHEMBL1464146 & 688600 & 4.5 & 4.5076 & TRN \\
\hline CHEMBL1450525 & 688600 & 7.0 & 5.725 & TST \\
\hline CHEMBL1979756 & 688600 & 4.5 & 4.5226 & TRN \\
\hline CHEMBL1441918 & 688600 & 4.55 & 5.1434 & TRN \\
\hline CHEMBL3196684 & 688600 & 4.8 & 4.8118 & TRN \\
\hline CHEMBL1582403 & 688600 & 4.6 & 4.8826 & TRN \\
\hline CHEMBL1481725 & 688600 & 4.45 & 5.4446 & TRN \\
\hline CHEMBL 2000172 & 688600 & 4.4 & 4.6844 & TRN \\
\hline CHEMBL67535 & 688600 & 4.4 & 5.019 & TRN \\
\hline CHEMBL587856 & 688600 & 4.7 & 5.3767 & TRN \\
\hline CHEMBL1331605 & 688600 & 4.55 & 4.6682 & TRN \\
\hline CHEMBL1340059 & 688600 & 4.4 & 5.0707 & TRN \\
\hline CHEMBL1389510 & 688600 & 4.4 & 4.4964 & TRN \\
\hline CHEMBL1586803 & 688600 & 4.45 & 5.7333 & TST \\
\hline CHEMBL1429070 & 688600 & 5.55 & 4.8485 & TRN \\
\hline CHEMBL1533621 & 688600 & 4.6 & 3.9358 & TRN \\
\hline CHEMBL1506843 & 688600 & 4.75 & 4.4259 & TRN \\
\hline CHEMBL1988133 & 688600 & 4.8 & 4.8703 & TRN \\
\hline CHEMBL1332524 & 688600 & 4.4 & 4.2869 & TRN \\
\hline CHEMBL3189918 & 688600 & 4.6 & 4.6968 & TRN \\
\hline CHEMBL1539905 & 688600 & 5.05 & 4.6127 & TRN \\
\hline CHEMBL429095 & 688600 & 6.0 & 5.5433 & TRN \\
\hline CHEMBL1255746 & 688600 & 6.25 & 5.5325 & TST \\
\hline CHEMBL3145192 & 688600 & 4.55 & 4.8673 & TRN \\
\hline CHEMBL1543940 & 688600 & 4.9 & 4.7377 & TRN \\
\hline CHEMBL3392069 & 688600 & 4.5 & 4.3878 & TRN \\
\hline CHEMBL1399979 & 688600 & 5.5 & 4.9079 & TRN \\
\hline CHEMBL286494 & 688600 & 4.7 & 5.5116 & TST \\
\hline CHEMBL1554479 & 688600 & 6.5 & 6.8701 & TST \\
\hline CHEMBL3196884 & 688600 & 4.45 & 4.6335 & TRN \\
\hline CHEMBL1426947 & 688600 & 4.8 & 4.7902 & TRN \\
\hline CHEMBL1586948 & 688600 & 4.7 & 4.9564 & TRN \\
\hline CHEMBL1532407 & 688600 & 4.4 & 4.4822 & TRN \\
\hline CHEMBL1372387 & 688600 & 4.6 & 4.4263 & TRN \\
\hline CHEMBL1439172 & 688600 & 4.9 & 6.5468 & TRN \\
\hline CHEMBL1256147 & 688600 & 6.8 & 7.0783 & TRN \\
\hline CHEMBL1443157 & 688600 & 4.75 & 5.5312 & TST \\
\hline CHEMBL1313635 & 688600 & 4.75 & 4.7984 & TRN \\
\hline CHEMBL1423709 & 688600 & 4.5 & 4.9797 & TRN \\
\hline CHEMBL1484206 & 688600 & 4.65 & 5.0498 & TRN \\
\hline
\end{tabular}




\begin{tabular}{|c|c|c|c|c|c|}
\hline \multicolumn{6}{|c|}{ Supplemental Table S2.txt } \\
\hline CHEMBL1304408 & 688600 & 4.45 & 4.2833 & TRN & \\
\hline CHEMBL1449923 & 688600 & 5.25 & 5.07 & TRN & \\
\hline CHEMBL1596271 & 688600 & 5.1 & 5.5072 & TST & \\
\hline CHEMBL1384854 & 688600 & 4.75 & 5.0763 & TRN & \\
\hline CHEMBL1470366 & 688600 & 4.55 & 4.9986 & TRN & \\
\hline CHEMBL310798 & 688600 & 4.65 & 4.8409 & TRN & \\
\hline CHEMBL1419637 & 688600 & 4.95 & 5.3486 & TRN & \\
\hline CHEMBL1464036 & 688600 & 4.45 & 4.8452 & TRN & \\
\hline CHEMBL1585944 & 688600 & 7.2503 & 5.7462 & TST & \\
\hline CHEMBL187734 & 688600 & 7.0501 & 5.8098 & TRN & \\
\hline CHEMBL507122 & 688600 & 3.4 & 5.3683 & TRN & \\
\hline CHEMBL310396 & 688600 & 4.4 & 5.7897 & TRN & \\
\hline CHEMBL338314 & 688600 & 5.0 & 5.3787 & TRN & \\
\hline CHEMBL1548326 & 688600 & 5.0 & 4.98300 & 00000000005 & TRN \\
\hline CHEMBL1475581 & 688600 & 4.95 & 4.3916 & TRN & \\
\hline CHEMBL1603311 & 688600 & 4.55 & 4.7335 & TRN & \\
\hline CHEMBL1512190 & 688600 & 4.55 & 4.3 & TRN & \\
\hline CHEMBL1508173 & 688600 & 4.85 & 4.5119 & TRN & \\
\hline CHEMBL1994556 & 688600 & 4.4 & 4.4037 & TRN & \\
\hline CHEMBL1529601 & 688600 & 4.5 & 4.5496 & TRN & \\
\hline CHEMBL1314703 & 688600 & 5.2 & 5.579 & TRN & \\
\hline CHEMBL1538976 & 688600 & 4.45 & 4.3994 & TRN & \\
\hline CHEMBL1357401 & 688600 & 9.0458 & 5.6022 & TRN & \\
\hline CHEMBL1337575 & 688600 & 4.75 & 4.3861 & TRN & \\
\hline CHEMBL 204914 & 688600 & 4.4 & 4.8861 & TRN & \\
\hline CHEMBL1995550 & 688600 & 4.8 & 4.8723 & TRN & \\
\hline CHEMBL1377223 & 688600 & 4.9 & 4.4432 & TRN & \\
\hline CHEMBL1339157 & 688600 & 4.95 & 5.1437 & TRN & \\
\hline CHEMBL1504221 & 688600 & 4.4 & 4.4606 & TRN & \\
\hline CHEMBL3212073 & 688600 & 4.55 & 4.9571 & TRN & \\
\hline CHEMBL1596115 & 688600 & 4.55 & 4.5697 & TRN & \\
\hline CHEMBL1472773 & 688600 & 4.5 & 5.6353 & TST & \\
\hline CHEMBL3856090 & 688600 & 4.75 & 4.7296 & TST & \\
\hline CHEMBL1605962 & 688600 & 4.8 & 4.7981 & TRN & \\
\hline CHEMBL1502381 & 688600 & 5.55 & 5.2494 & TRN & \\
\hline CHEMBL1537534 & 688600 & 4.45 & 4.8326 & TRN & \\
\hline CHEMBL1373896 & 688600 & 5.0 & 4.9488 & TRN & \\
\hline CHEMBL1093246 & 688600 & 4.55 & 4.7644 & TRN & \\
\hline CHEMBL193872 & 688600 & 4.6 & 5.02800 & 00000000005 & TRN \\
\hline CHEMBL1451931 & 688600 & 4.4 & 4.0861 & TRN & \\
\hline CHEMBL39879 & 688600 & 7.8508 & 5.4738 & TRN & \\
\hline CHEMBL3209341 & 688600 & 4.55 & 4.5092 & TRN & \\
\hline CHEMBL1580335 & 688600 & 5.1 & 4.8677 & TRN & \\
\hline CHEMBL1589300 & 688600 & 4.7 & 5.3238 & TRN & \\
\hline CHEMBL1448979 & 688600 & 4.9 & 5.0686 & TST & \\
\hline CHEMBL1576730 & 688600 & 4.45 & 4.4892 & TRN & \\
\hline CHEMBL260374 & 688600 & 9.2218 & 5.9259 & TST & \\
\hline CHEMBL12998 & 688600 & 4.4 & 4.6143 & TST & \\
\hline
\end{tabular}




\begin{tabular}{|c|c|c|c|c|}
\hline \multicolumn{5}{|c|}{ Supplemental Table S2.txt } \\
\hline CHEMBL1468919 & 688600 & 4.65 & 5.5109 & TRN \\
\hline CHEMBL1329974 & 688600 & 4.75 & 4.7734 & TRN \\
\hline CHEMBL 3197060 & 688600 & 4.5 & 4.8184 & TRN \\
\hline CHEMBL1381310 & 688600 & 5.35 & 4.498 & TRN \\
\hline CHEMBL1399702 & 688600 & 8.9586 & 7.5488 & TRN \\
\hline CHEMBL1464053 & 688600 & 4.45 & 4.2288 & TRN \\
\hline CHEMBL1555120 & 688600 & 4.55 & 6.0051 & TST \\
\hline CHEMBL579837 & 688600 & 4.85 & 4.6205 & TRN \\
\hline CHEMBL1589514 & 688600 & 4.9 & 4.9788 & TRN \\
\hline CHEMBL1438439 & 688600 & 4.95 & 5.4035 & TRN \\
\hline CHEMBL1370165 & 688600 & 6.0 & 5.0122 & TRN \\
\hline CHEMBL66953 & 688600 & 6.0 & 5.6648 & TRN \\
\hline CHEMBL1967938 & 688600 & 4.4 & 4.715 & TRN \\
\hline CHEMBL1407056 & 688600 & 4.4 & 4.5738 & TRN \\
\hline CHEMBL63154 & 688600 & 4.95 & 5.1366 & TST \\
\hline CHEMBL1497427 & 688600 & 4.55 & 4.8342 & TRN \\
\hline CHEMBL1430175 & 688600 & 4.4 & 4.9457 & TRN \\
\hline CHEMBL 2132953 & 688600 & 5.15 & 4.9213 & TST \\
\hline CHEMBL1495462 & 688600 & 4.55 & 4.774 & TRN \\
\hline CHEMBL1321116 & 688600 & 5.55 & 6.0647 & TRN \\
\hline CHEMBL1518838 & 688600 & 4.9 & 4.2837 & TRN \\
\hline CHEMBL1377148 & 688600 & 4.85 & 4.3638 & TRN \\
\hline CHEMBL1555938 & 688600 & 5.8 & 4.8661 & TRN \\
\hline CHEMBL80155 & 688600 & 4.6 & 4.846 & TRN \\
\hline CHEMBL515252 & 688600 & 4.9 & 5.5157 & TRN \\
\hline CHEMBL1352607 & 688600 & 4.45 & 5.0187 & TRN \\
\hline CHEMBL1376723 & 688600 & 5.8 & 5.0911 & TRN \\
\hline CHEMBL592414 & 688600 & 4.45 & 4.2823 & TRN \\
\hline CHEMBL 30707 & 688600 & 4.55 & 4.9884 & TRN \\
\hline CHEMBL 3197412 & 688600 & 4.4 & 4.1536 & TRN \\
\hline CHEMBL1333929 & 688600 & 4.5 & 4.8422 & TRN \\
\hline CHEMBL1452939 & 688600 & 4.6 & 4.4153 & TRN \\
\hline CHEMBL1380020 & 688600 & 4.8 & 4.4827 & TRN \\
\hline CHEMBL1573910 & 688600 & 4.4 & 4.8972 & TRN \\
\hline CHEMBL1349474 & 688600 & 4.85 & 4.859 & TRN \\
\hline CHEMBL1458321 & 688600 & 4.55 & 4.6275 & TRN \\
\hline CHEMBL1566610 & 688600 & 4.65 & 5.1436 & TST \\
\hline CHEMBL1398373 & 688600 & 4.85 & 4.7939 & TST \\
\hline CHEMBL1394801 & 688600 & 8.6021 & 6.2594 & TRN \\
\hline CHEMBL1514090 & 688600 & 4.85 & 6.17899 & 9999999999 \\
\hline CHEMBL1334591 & 688600 & 4.5 & 4.5199 & TRN \\
\hline CHEMBL1498113 & 688600 & 4.55 & 5.3062 & TRN \\
\hline CHEMBL1585706 & 688600 & 4.4 & 4.8364 & TRN \\
\hline CHEMBL1527442 & 688600 & 7.6003 & 4.8093 & TST \\
\hline CHEMBL1312353 & 688600 & 4.6 & 4.5321 & TRN \\
\hline CHEMBL1309643 & 688600 & 4.6 & 4.4973 & TRN \\
\hline CHEMBL1357562 & 688600 & 4.5 & 4.7355 & TST \\
\hline CHEMBL1309506 & 688600 & 4.55 & 4.7867 & TRN \\
\hline
\end{tabular}




\begin{tabular}{|c|c|c|c|c|c|}
\hline & & & & & \\
\hline CHEMBL1309737 & 688600 & 5.3 & 5.0619 & TRN & \\
\hline CHEMBL222838 & 688600 & 4.9 & 6.37799 & 9999999999 & TRN \\
\hline CHEMBL1338027 & 688600 & 4.5 & 4.5914 & TRN & \\
\hline CHEMBL1386015 & 688600 & 4.95 & 4.713 & TRN & \\
\hline CHEMBL21823 & 688600 & 8.5528 & 6.2672 & TRN & \\
\hline CHEMBL3209441 & 688600 & 4.75 & 5.0645 & TRN & \\
\hline CHEMBL223453 & 688600 & 4.4 & 4.119 & TRN & \\
\hline CHEMBL1426498 & 688600 & 4.6 & 5.0557 & TRN & \\
\hline CHEMBL1403488 & 688600 & 4.6 & 4.7732 & TST & \\
\hline CHEMBL1465727 & 688600 & 4.4 & 5.0842 & TRN & \\
\hline CHEMBL3199039 & 688600 & 4.6 & 4.6648 & TRN & \\
\hline CHEMBL1993780 & 688600 & 4.9 & 4.6665 & TRN & \\
\hline CHEMBL1497894 & 688600 & 4.65 & 4.5523 & TRN & \\
\hline CHEMBL68500 & 688600 & 3.8 & 5.3744 & TRN & \\
\hline CHEMBL1438598 & 688600 & 4.75 & 4.4919 & TRN & \\
\hline CHEMBL1486180 & 688600 & 4.6 & 4.5677 & TRN & \\
\hline CHEMBL201289 & 688600 & 4.8 & 5.1172 & TRN & \\
\hline CHEMBL1208858 & 688600 & 6.0 & 4.7068 & TST & \\
\hline CHEMBL1452186 & 688600 & 4.45 & 5.11100 & 0000000001 & TRN \\
\hline CHEMBL1978236 & 688600 & 4.5 & 4.9492 & TRN & \\
\hline CHEMBL 8260 & 688600 & 6.0 & 5.2732 & TRN & \\
\hline CHEMBL1256576 & 688600 & 7.0 & 6.5664 & TST & \\
\hline CHEMBL1170688 & 688600 & 4.5 & 4.8908 & TRN & \\
\hline CHEMBL1579973 & 688600 & 4.7 & 4.8907 & TRN & \\
\hline CHEMBL1472492 & 688600 & 4.4 & 4.8523 & TST & \\
\hline CHEMBL434778 & 688600 & 4.5 & 4.2226 & TRN & \\
\hline CHEMBL3192632 & 688600 & 5.4 & 4.5993 & TRN & \\
\hline CHEMBL1255583 & 688600 & 9.1549 & 6.7364 & TRN & \\
\hline CHEMBL1312514 & 688600 & 4.85 & 5.0083 & TRN & \\
\hline CHEMBL1417070 & 688600 & 4.6 & 4.8895 & TRN & \\
\hline CHEMBL78764 & 688600 & 4.4 & 5.7004 & TRN & \\
\hline CHEMBL1256813 & 688600 & 4.55 & 5.2164 & TRN & \\
\hline CHEMBL1980308 & 688600 & 4.55 & 4.294 & TRN & \\
\hline CHEMBL1542748 & 688600 & 4.4 & 5.0286 & TRN & \\
\hline CHEMBL1526543 & 688600 & 5.6 & 5.8138 & TST & \\
\hline CHEMBL1413246 & 688600 & 4.6 & 4.7311 & TRN & \\
\hline CHEMBL267373 & 688600 & 8.5528 & 6.2686 & TRN & \\
\hline CHEMBL1534566 & 688600 & 4.65 & 5.056 & TRN & \\
\hline CHEMBL1480797 & 688600 & 4.75 & 5.2724 & TRN & \\
\hline CHEMBL 270299 & 688600 & 8.2518 & 5.1945 & TST & \\
\hline CHEMBL1461772 & 688600 & 4.9 & 4.7984 & TRN & \\
\hline CHEMBL1427609 & 688600 & 4.7 & 4.5585 & TRN & \\
\hline CHEMBL1545093 & 688600 & 4.8 & 4.9718 & TRN & \\
\hline CHEMBL1302012 & 688600 & 4.6 & 4.999 & TRN & \\
\hline CHEMBL3187659 & 688600 & 4.6 & 5.2548 & TRN & \\
\hline CHEMBL1359564 & 688600 & 4.5 & 4.0845 & TRN & \\
\hline CHEMBL502044 & 688600 & 5.05 & 5.5688 & TRN & \\
\hline CHEMBL1499346 & 688600 & 4.55 & 4.2527 & TRN & \\
\hline
\end{tabular}




\begin{tabular}{|c|c|c|c|c|c|}
\hline \multicolumn{6}{|c|}{ Supplemental Table S2.txt } \\
\hline CHEMBL1582121 & 688600 & 4.55 & 4.7611 & TRN & \\
\hline CHEMBL58033 & 688600 & 4.7 & 5.8215 & TRN & \\
\hline CHEMBL1532953 & 688600 & 5.15 & 5.1208 & TRN & \\
\hline CHEMBL1373210 & 688600 & 4.6 & 4.6448 & TRN & \\
\hline CHEMBL1985327 & 688600 & 4.9 & 4.0456 & TRN & \\
\hline CHEMBL1586269 & 688600 & 4.7 & 4.6675 & TRN & \\
\hline CHEMBL1541592 & 688600 & 4.55 & 4.3569 & TRN & \\
\hline CHEMBL3193997 & 688600 & 4.45 & 4.2618 & TRN & \\
\hline CHEMBL1255662 & 688600 & 9.0 & 5.9617 & TRN & \\
\hline CHEMBL1376711 & 688600 & 5.5 & 5.019 & TRN & \\
\hline CHEMBL1417929 & 688600 & 4.55 & 4.3993 & TRN & \\
\hline CHEMBL1556559 & 688600 & 4.6 & 4.6686 & TRN & \\
\hline CHEMBL1520976 & 688600 & 8.3468 & 6.4893 & TST & \\
\hline CHEMBL 309176 & 688600 & 8.5528 & 5.8859 & TRN & \\
\hline CHEMBL1528208 & 688600 & 4.55 & 5.1288 & TRN & \\
\hline CHEMBL1256839 & 688600 & 8.7959 & 6.6963 & TRN & \\
\hline CHEMBL1356230 & 688600 & 4.85 & 4.4541 & TRN & \\
\hline CHEMBL35482 & 688600 & 4.2 & 4.6051 & TRN & \\
\hline CHEMBL 1406387 & 688600 & 4.6 & 4.7532 & TST & \\
\hline CHEMBL1576140 & 688600 & 5.85 & 4.6122 & TRN & \\
\hline CHEMBL1560698 & 688600 & 4.6 & 5.1801 & TRN & \\
\hline CHEMBL 2000167 & 688600 & 4.8 & 4.4046 & TRN & \\
\hline CHEMBL1543134 & 688600 & 4.7 & 4.6649 & TRN & \\
\hline CHEMBL394197 & 688600 & 4.4 & 4.3845 & TRN & \\
\hline CHEMBL1590552 & 688600 & 8.5528 & 7.2612 & TRN & \\
\hline CHEMBL1339153 & 688600 & 4.4 & 5.0101 & TRN & \\
\hline CHEMBL1535723 & 688600 & 6.05 & 4.8152 & TRN & \\
\hline CHEMBL17331 & 688600 & 4.7 & 5.2434 & TST & \\
\hline CHEMBL518292 & 688600 & 4.4 & 5.5443 & TST & \\
\hline CHEMBL286722 & 688600 & 9.3979 & 5.6753 & TRN & \\
\hline CHEMBL1517511 & 688600 & 4.5 & 4.6341 & TRN & \\
\hline CHEMBL1469743 & 688600 & 4.55 & 4.6299 & TST & \\
\hline CHEMBL1440703 & 688600 & 5.8 & 5.2592 & TRN & \\
\hline CHEMBL1365599 & 688600 & 6.0 & 4.9477 & TST & \\
\hline CHEMBL1413371 & 688600 & 4.05 & 5.08899 & 99999999995 & TRN \\
\hline CHEMBL252909 & 688600 & 8.6576 & 6.006 & TST & \\
\hline CHEMBL1589580 & 688600 & 4.5 & 4.8083 & TRN & \\
\hline CHEMBL1231330 & 688600 & 7.5498 & 7.0792 & TRN & \\
\hline CHEMBL106525 & 688600 & 4.7 & 5.1198 & TRN & \\
\hline CHEMBL1423479 & 688600 & 4.6 & 5.3331 & TRN & \\
\hline CHEMBL1536813 & 688600 & 4.4 & 4.3084 & TRN & \\
\hline CHEMBL1377316 & 688600 & 4.85 & 4.3323 & TRN & \\
\hline CHEMBL1511226 & 688600 & 4.5 & 5.3436 & TST & \\
\hline CHEMBL1464373 & 688600 & 4.85 & 4.5141 & TRN & \\
\hline CHEMBL1575701 & 688600 & 4.8 & 4.8561 & TRN & \\
\hline CHEMBL1543611 & 688600 & 4.55 & 4.9282 & TRN & \\
\hline CHEMBL1201088 & 688600 & 4.4 & 5.3455 & TST & \\
\hline CHEMBL1586973 & 688600 & 4.85 & 5.6928 & TRN & \\
\hline
\end{tabular}




\begin{tabular}{|c|c|c|c|c|c|}
\hline \multicolumn{6}{|c|}{ Supplemental Table S2.txt } \\
\hline CHEMBL541505 & 688600 & 4.55 & 5.7232 & TST & \\
\hline CHEMBL 8320 & 688600 & 8.7959 & 5.7298 & TST & \\
\hline CHEMBL1301573 & 688600 & 4.4 & 4.5425 & TRN & \\
\hline CHEMBL377295 & 688600 & 4.45 & 4.1438 & TST & \\
\hline CHEMBL1976042 & 688600 & 5.15 & 4.5048 & TRN & \\
\hline CHEMBL1607062 & 688600 & 6.5501 & 5.5589 & TST & \\
\hline CHEMBL1341064 & 688600 & 4.45 & 4.3651 & TRN & \\
\hline CHEMBL1494231 & 688600 & 4.8 & 4.6963 & TRN & \\
\hline CHEMBL1578670 & 688600 & 4.55 & 5.1262 & TRN & \\
\hline CHEMBL1470408 & 688600 & 4.45 & 4.4408 & TRN & \\
\hline CHEMBL1504021 & 688600 & 4.45 & 4.8742 & TRN & \\
\hline CHEMBL1172912 & 688600 & 4.4 & 5.0462 & TRN & \\
\hline CHEMBL53898 & 688600 & 6.0 & 5.0469 & TRN & \\
\hline CHEMBL1412163 & 688600 & 5.4 & 5.8181 & TRN & \\
\hline CHEMBL1484403 & 688600 & 4.75 & 5.1147 & TST & \\
\hline CHEMBL 275311 & 688600 & 4.4 & 4.8918 & TRN & \\
\hline CHEMBL1305292 & 688600 & 4.55 & 4.3259 & TRN & \\
\hline CHEMBL1348645 & 688600 & 5.05 & 4.5705 & TRN & \\
\hline CHEMBL1425261 & 688600 & 2.65 & 5.0737 & TST & \\
\hline CHEMBL1311453 & 688600 & 4.55 & 4.9528 & TRN & \\
\hline CHEMBL1333858 & 688600 & 4.6 & 4.4169 & TRN & \\
\hline CHEMBL1450238 & 688600 & 4.65 & 4.3848 & TRN & \\
\hline CHEMBL3196704 & 688600 & 5.0 & 5.1581 & TRN & \\
\hline CHEMBL1514251 & 688600 & 4.55 & 4.8455 & TRN & \\
\hline CHEMBL1485442 & 688600 & 4.4 & 5.33 & TRN & \\
\hline CHEMBL1431206 & 688600 & 4.65 & 4.6797 & TRN & \\
\hline CHEMBL1431163 & 688600 & 4.4 & 5.2097 & TRN & \\
\hline CHEMBL3191560 & 688600 & 4.5 & 5.0011 & TRN & \\
\hline CHEMBL1490049 & 688600 & 6.15 & 5.3685 & TRN & \\
\hline CHEMBL1449644 & 688600 & 4.4 & 4.7727 & TRN & \\
\hline CHEMBL604119 & 688600 & 5.5 & 4.9003 & TST & \\
\hline CHEMBL1566165 & 688600 & 5.25 & 4.7358 & TRN & \\
\hline CHEMBL1437846 & 688600 & 5.85 & 4.9478 & TST & \\
\hline CHEMBL163316 & 688600 & 4.95 & 5.4455 & TRN & \\
\hline CHEMBL1542128 & 688600 & 4.85 & 5.12200 & 0000000001 & TRN \\
\hline CHEMBL1453375 & 688600 & 4.6 & 5.2464 & TRN & \\
\hline CHEMBL1554098 & 688600 & 4.0 & 5.074 & TST & \\
\hline CHEMBL536950 & 688600 & 7.6003 & 5.2704 & TRN & \\
\hline CHEMBL1605563 & 688600 & 6.15 & 5.37 & TRN & \\
\hline CHEMBL1331912 & 688600 & 4.75 & 5.0264 & TRN & \\
\hline CHEMBL1302696 & 688600 & 4.65 & 4.2821 & TRN & \\
\hline CHEMBL307639 & 688600 & 5.45 & 6.3974 & TST & \\
\hline CHEMBL1587145 & 688600 & 5.6 & 4.7666 & TRN & \\
\hline CHEMBL1577661 & 688600 & 4.6 & 4.7041 & TRN & \\
\hline CHEMBL1369634 & 688600 & 4.65 & 4.6301 & TRN & \\
\hline CHEMBL1964614 & 688600 & 4.45 & 4.7365 & TRN & \\
\hline CHEMBL340807 & 688600 & 4.45 & 5.2822 & TRN & \\
\hline CHEMBL1613175 & 688600 & 4.6 & 4.9628 & TRN & \\
\hline
\end{tabular}




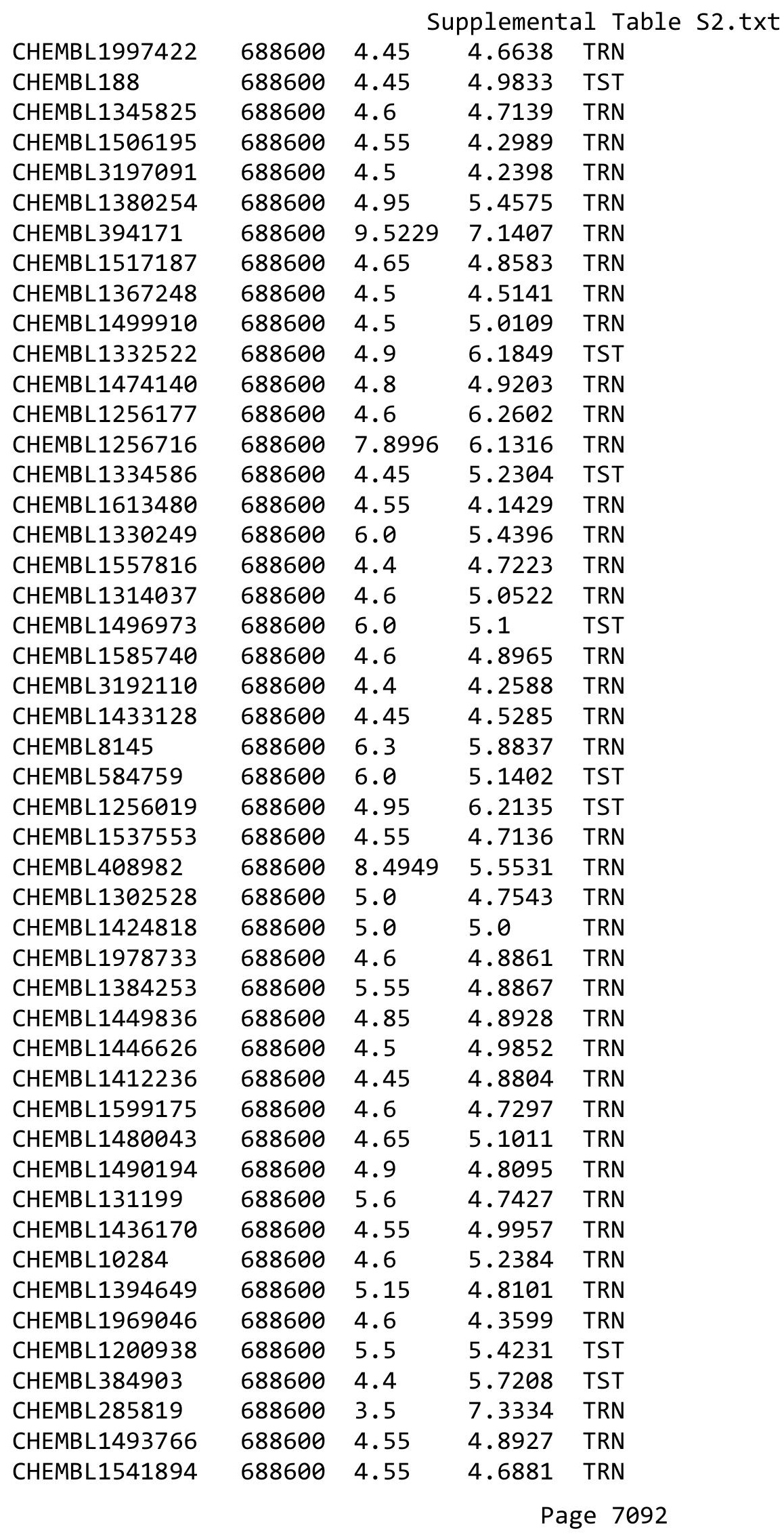




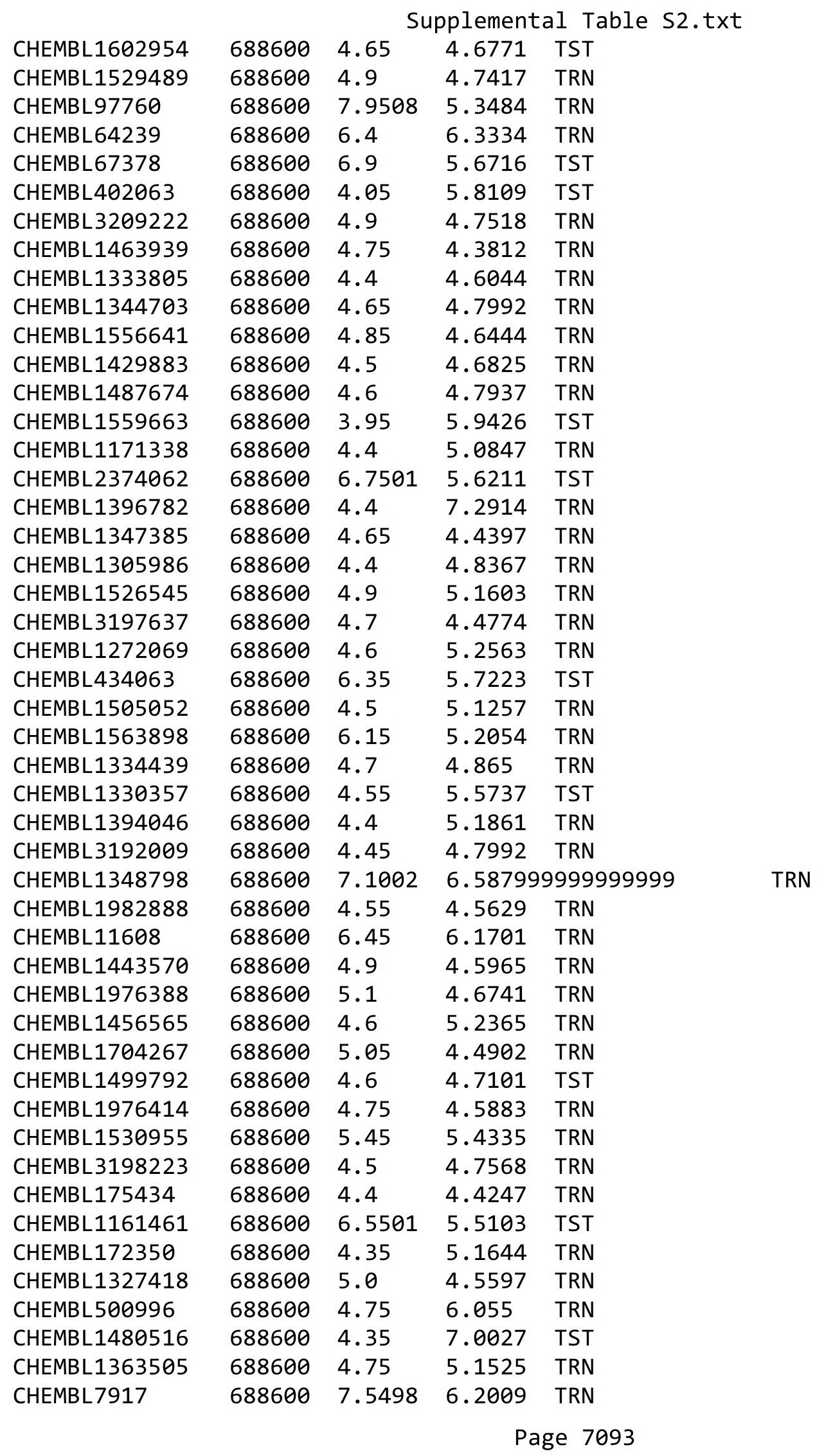




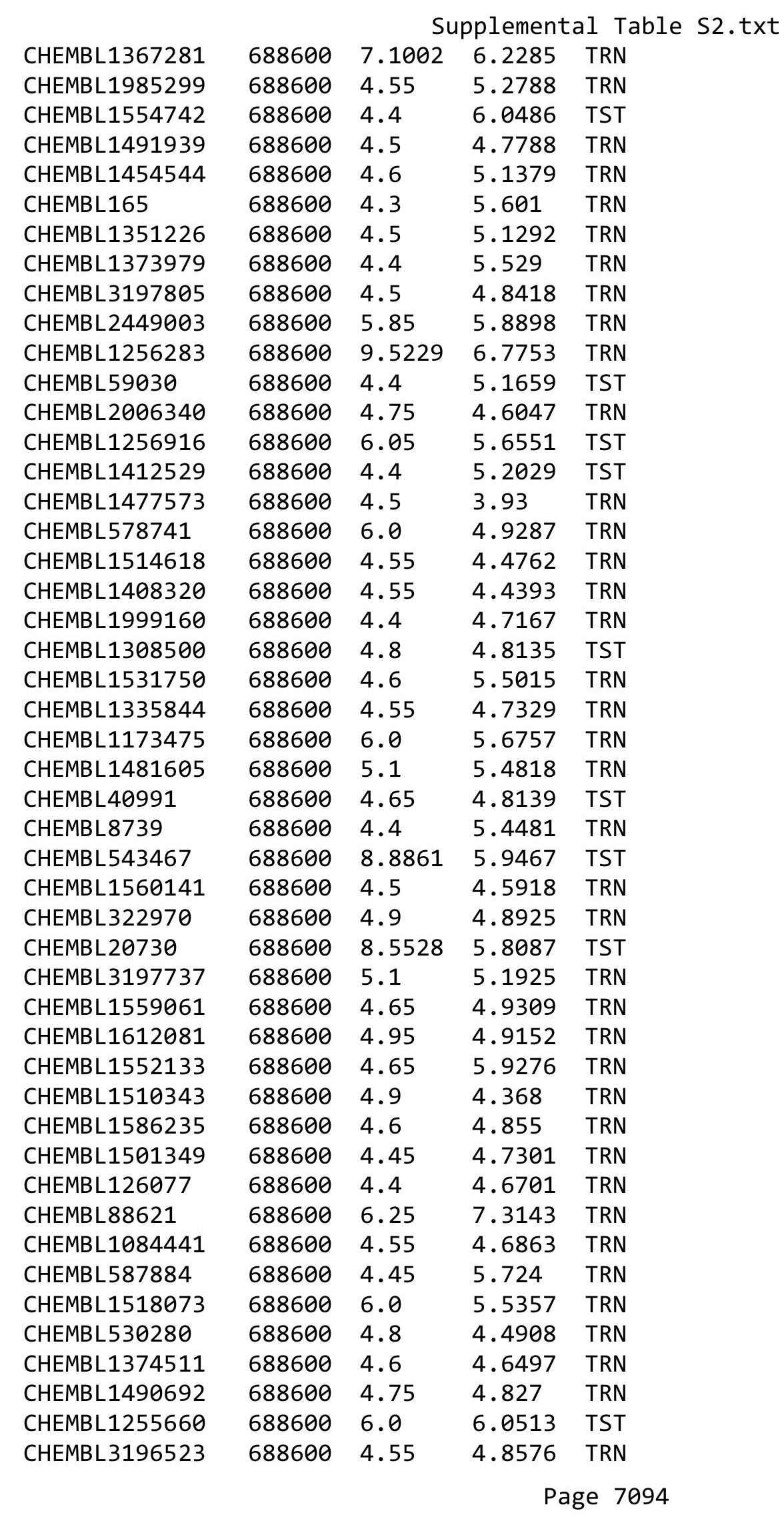




\begin{tabular}{|c|c|c|c|c|c|}
\hline \multicolumn{6}{|c|}{ Supplemental Table S2.txt } \\
\hline CHEMBL 3199284 & 688600 & 4.55 & 4.4779 & TRN & \\
\hline CHEMBL1496732 & 688600 & 4.55 & 4.9809 & TRN & \\
\hline CHEMBL3193531 & 688600 & 4.6 & 4.7224 & TRN & \\
\hline CHEMBL1506921 & 688600 & 4.5 & 5.6704 & TRN & \\
\hline CHEMBL1324710 & 688600 & 4.4 & 5.0232 & TRN & \\
\hline CHEMBL65 & 688600 & 4.45 & 4.9189 & TST & \\
\hline CHEMBL1256647 & 688600 & 7.15 & 6.4918 & TRN & \\
\hline CHEMBL1965679 & 688600 & 4.4 & 4.1143 & TRN & \\
\hline CHEMBL1971613 & 688600 & 5.0 & 4.7634 & TRN & \\
\hline CHEMBL1492565 & 688600 & 4.5 & 5.5506 & TRN & \\
\hline CHEMBL1532956 & 688600 & 4.45 & 4.4153 & TRN & \\
\hline CHEMBL88326 & 688600 & 4.85 & 4.2658 & TRN & \\
\hline CHEMBL464859 & 688600 & 9.0969 & 7.4615 & TRN & \\
\hline CHEMBL1432342 & 688600 & 4.65 & 5.0016 & TRN & \\
\hline CHEMBL1321703 & 688600 & 4.8 & 4.4887 & TRN & \\
\hline CHEMBL1328822 & 688600 & 4.6 & 4.2975 & TRN & \\
\hline CHEMBL1256865 & 688600 & 4.8 & 5.0927 & TRN & \\
\hline CHEMBL 3207444 & 688600 & 4.4 & 4.5716 & TRN & \\
\hline CHEMBL1407852 & 688600 & 4.25 & 5.7566 & TRN & \\
\hline CHEMBL1406708 & 688600 & 4.6 & 5.6955 & TRN & \\
\hline CHEMBL1440415 & 688600 & 4.6 & 4.7658 & TRN & \\
\hline CHEMBL1430005 & 688600 & 4.6 & 5.46 & TST & \\
\hline CHEMBL1301115 & 688600 & 5.0 & 4.9573 & TRN & \\
\hline CHEMBL1549629 & 688600 & 4.8 & 4.6781 & TRN & \\
\hline CHEMBL1255935 & 688600 & 9.2218 & 6.8379 & TRN & \\
\hline CHEMBL1256686 & 688600 & 4.8 & 5.4826 & TST & \\
\hline CHEMBL1255656 & 688600 & 9.3979 & 6.4738 & TRN & \\
\hline CHEMBL1331005 & 688600 & 4.4 & 4.79899 & 99999999995 & TRN \\
\hline CHEMBL1256776 & 688600 & 4.7 & 5.6007 & TRN & \\
\hline CHEMBL1392911 & 688600 & 5.4 & 5.2023 & TRN & \\
\hline CHEMBL3192738 & 688600 & 4.9 & 4.8398 & TRN & \\
\hline CHEMBL1329790 & 688600 & 9.699 & 5.3218 & TST & \\
\hline CHEMBL299853 & 688600 & 4.45 & 4.2191 & TRN & \\
\hline CHEMBL441618 & 688600 & 4.35 & 4.9965 & TRN & \\
\hline CHEMBL1362734 & 688600 & 4.55 & 5.1175 & TST & \\
\hline CHEMBL1527303 & 688600 & 4.65 & 4.7449 & TRN & \\
\hline CHEMBL1526171 & 688600 & 5.35 & 5.0736 & TRN & \\
\hline CHEMBL1387355 & 688600 & 4.95 & 4.5431 & TRN & \\
\hline CHEMBL1564286 & 688600 & 4.4 & 4.4608 & TRN & \\
\hline CHEMBL1431104 & 688600 & 4.85 & 5.5234 & TST & \\
\hline CHEMBL 2000670 & 688600 & 4.5 & 4.6 & TRN & \\
\hline CHEMBL1445535 & 688600 & 5.05 & 5.5505 & TRN & \\
\hline CHEMBL1531363 & 688600 & 4.4 & 5.4555 & TRN & \\
\hline CHEMBL1569790 & 688600 & 4.5 & 4.7747 & TRN & \\
\hline CHEMBL256098 & 688600 & 4.6 & 4.9097 & TRN & \\
\hline CHEMBL1520394 & 688600 & 6.25 & 5.9361 & TRN & \\
\hline CHEMBL1587260 & 688600 & 4.6 & 4.9649 & TRN & \\
\hline CHEMBL1437053 & 688600 & 4.85 & 4.7856 & TRN & \\
\hline
\end{tabular}




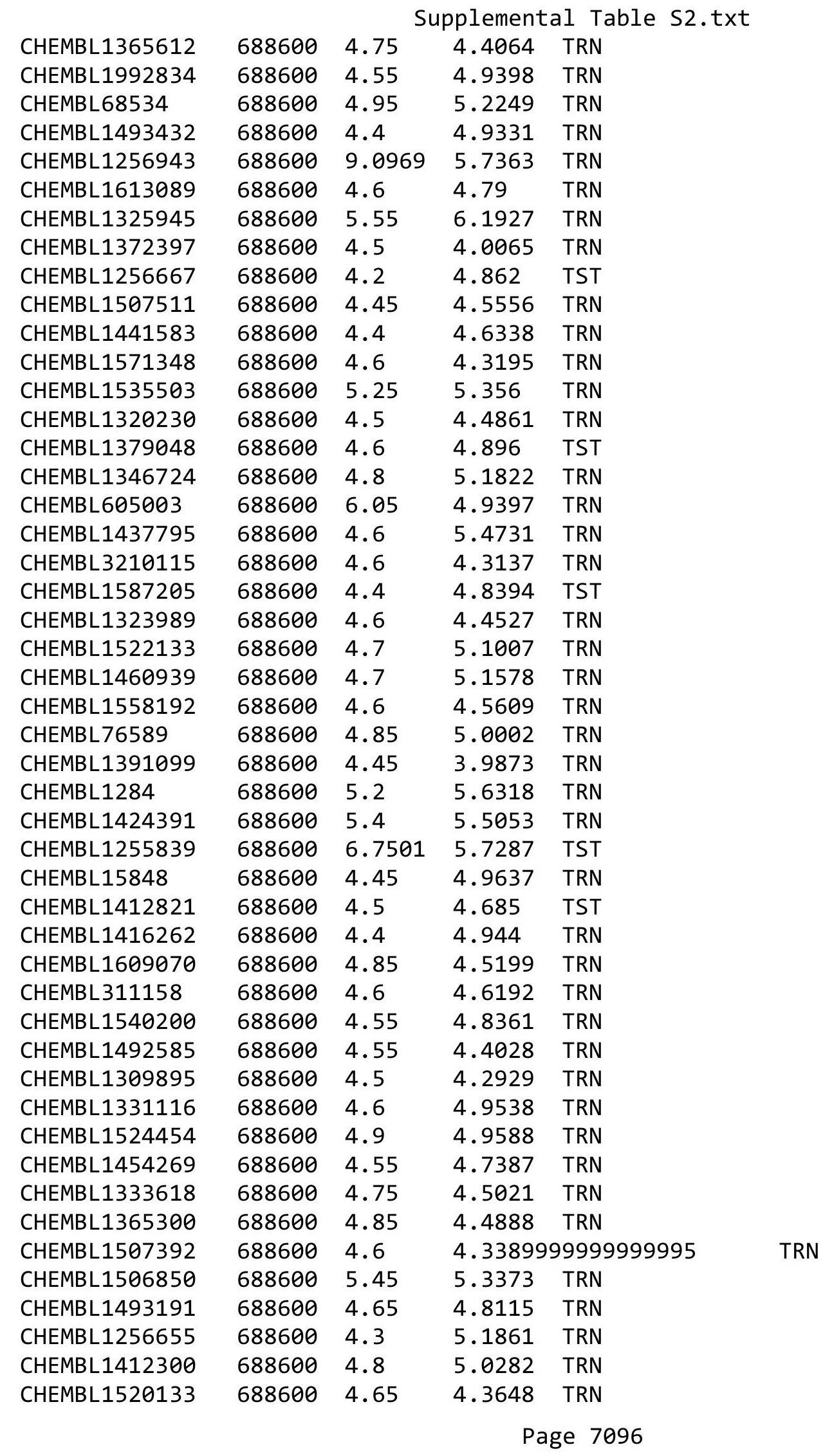




\begin{tabular}{|c|c|c|c|c|c|}
\hline \multicolumn{6}{|c|}{ Supplemental Table S2.txt } \\
\hline CHEMBL1481914 & 688600 & 4.85 & 4.6793 & TRN & \\
\hline CHEMBL1508858 & 688600 & 4.65 & 4.8742 & TRN & \\
\hline CHEMBL1307209 & 688600 & 4.9 & 4.9189 & TRN & \\
\hline CHEMBL1376754 & 688600 & 4.8 & 5.3321 & TRN & \\
\hline CHEMBL1301710 & 688600 & 4.4 & 4.6741 & TRN & \\
\hline CHEMBL 278041 & 688600 & 4.3 & 5.2149 & TST & \\
\hline CHEMBL553503 & 688600 & 4.25 & 5.7155 & TRN & \\
\hline CHEMBL1985649 & 688600 & 4.5 & 5.1133 & TRN & \\
\hline CHEMBL3212972 & 688600 & 4.55 & 4.4738 & TRN & \\
\hline CHEMBL1405684 & 688600 & 4.45 & 4.67899 & 9999999999 & TRN \\
\hline CHEMBL1310336 & 688600 & 4.55 & 4.001 & TRN & \\
\hline CHEMBL608555 & 688600 & 4.05 & 6.5083 & TRN & \\
\hline CHEMBL1474329 & 688600 & 4.8 & 4.82600 & 00000000005 & TRN \\
\hline CHEMBL1334684 & 688600 & 4.8 & 4.418 & TRN & \\
\hline CHEMBL418509 & 688600 & 7.8996 & 7.604 & TRN & \\
\hline CHEMBL1363764 & 688600 & 5.05 & 4.4968 & TRN & \\
\hline CHEMBL1386851 & 688600 & 4.6 & 5.2383 & TRN & \\
\hline CHEMBL1446668 & 688600 & 4.85 & 4.8628 & TRN & \\
\hline CHEMBL3209766 & 688600 & 5.45 & 4.5628 & TRN & \\
\hline CHEMBL1406655 & 688600 & 4.55 & 5.5103 & TST & \\
\hline CHEMBL1404231 & 688600 & 4.55 & 4.4029 & TRN & \\
\hline CHEMBL1346456 & 688600 & 4.6 & 5.3497 & TRN & \\
\hline CHEMBL1564477 & 688600 & 4.45 & 5.0401 & TST & \\
\hline CHEMBL1399109 & 688600 & 4.45 & 4.8505 & TRN & \\
\hline CHEMBL1256910 & 688600 & 4.1 & 5.44 & TRN & \\
\hline CHEMBL1584917 & 688600 & 4.9 & 4.0478 & TST & \\
\hline CHEMBL1318957 & 688600 & 4.6 & 4.9833 & TRN & \\
\hline CHEMBL508779 & 688600 & 4.85 & 4.8139 & TRN & \\
\hline CHEMBL1497651 & 688600 & 5.15 & 5.1111 & TRN & \\
\hline CHEMBL136344 & 688600 & 4.55 & 5.1051 & TRN & \\
\hline CHEMBL1601599 & 688600 & 4.45 & 4.8602 & TRN & \\
\hline CHEMBL1461843 & 688600 & 4.95 & 4.7374 & TRN & \\
\hline CHEMBL280998 & 688600 & 4.35 & 5.5003 & TRN & \\
\hline CHEMBL1394464 & 688600 & 4.4 & 4.237 & TRN & \\
\hline CHEMBL1366942 & 688600 & 4.45 & 4.4595 & TRN & \\
\hline CHEMBL1460037 & 688600 & 4.6 & 4.6846 & TRN & \\
\hline CHEMBL1998302 & 688600 & 4.85 & 4.4223 & TRN & \\
\hline CHEMBL1575869 & 688600 & 4.5 & 4.4018 & TRN & \\
\hline CHEMBL1406195 & 688600 & 4.95 & 5.169 & TRN & \\
\hline CHEMBL1548363 & 688600 & 4.4 & 5.3578 & TST & \\
\hline CHEMBL1378335 & 688600 & 4.4 & 5.0559 & TRN & \\
\hline CHEMBL1592944 & 688600 & 4.7 & 5.1996 & TRN & \\
\hline CHEMBL574181 & 688600 & 4.6 & 5.9656 & TRN & \\
\hline CHEMBL 3144984 & 688600 & 4.75 & 5.0142 & TRN & \\
\hline CHEMBL1489449 & 688600 & 4.6 & 5.1859 & TRN & \\
\hline CHEMBL1505679 & 688600 & 4.55 & 5.2669 & TRN & \\
\hline CHEMBL1451216 & 688600 & 5.2 & 5.581 & TST & \\
\hline CHEMBL1413473 & 688600 & 4.6 & 5.4924 & TST & \\
\hline
\end{tabular}




\begin{tabular}{|c|c|c|c|c|c|}
\hline \\
\hline CHEMBL2001685 & 688600 & 4.4 & 5.4351 & TRN & \\
\hline CHEMBL1990742 & 688600 & 4.6 & 4.9975 & TRN & \\
\hline CHEMBL523844 & 688600 & 4.95 & 5.0539 & TRN & \\
\hline CHEMBL3196857 & 688600 & 4.4 & 4.9955 & TRN & \\
\hline CHEMBL1365692 & 688600 & 4.45 & 4.8223 & TRN & \\
\hline CHEMBL1965471 & 688600 & 5.1 & 4.4022 & TRN & \\
\hline CHEMBL18879 & 688600 & 5.2 & 4.672 & TST & \\
\hline CHEMBL1576900 & 688600 & 4.4 & 4.8079 & TRN & \\
\hline CHEMBL1379677 & 688600 & 4.45 & 4.5788 & TRN & \\
\hline CHEMBL1548822 & 688600 & 4.7 & 5.25799 & 9999999999 & TRN \\
\hline CHEMBL1360774 & 688600 & 4.5 & 5.4861 & TRN & \\
\hline CHEMBL16410 & 688600 & 9.3979 & 6.795 & TRN & \\
\hline CHEMBL1470483 & 688600 & 4.5 & 4.4887 & TRN & \\
\hline CHEMBL1612974 & 688600 & 4.55 & 4.2785 & TRN & \\
\hline CHEMBL227744 & 688600 & 5.75 & 7.0368 & TRN & \\
\hline CHEMBL1578157 & 688600 & 4.4 & 4.5056 & TRN & \\
\hline CHEMBL 20936 & 688600 & 7.0501 & 6.3089 & TRN & \\
\hline CHEMBL1325252 & 688600 & 4.5 & 5.1538 & TRN & \\
\hline CHEMBL1500600 & 688600 & 4.8 & 5.1209 & TRN & \\
\hline CHEMBL1612112 & 688600 & 5.35 & 5.0294 & TRN & \\
\hline CHEMBL1454614 & 688600 & 5.05 & 4.0077 & TRN & \\
\hline CHEMBL1160160 & 688600 & 4.9 & 5.8893 & TRN & \\
\hline CHEMBL355496 & 688600 & 5.15 & 4.5118 & TRN & \\
\hline CHEMBL1527722 & 688600 & 7.699 & 6.2526 & TRN & \\
\hline CHEMBL1572216 & 688600 & 4.4 & 4.7945 & TRN & \\
\hline CHEMBL1421953 & 688600 & 4.75 & 4.9261 & TRN & \\
\hline CHEMBL1331279 & 688600 & 4.55 & 4.7453 & TRN & \\
\hline CHEMBL454580 & 688600 & 4.55 & 5.4454 & TST & \\
\hline CHEMBL1336680 & 688600 & 5.0 & 4.8801 & TRN & \\
\hline CHEMBL1607905 & 688600 & 4.95 & 4.8474 & TRN & \\
\hline CHEMBL1545679 & 688600 & 5.35 & 4.7236 & TRN & \\
\hline CHEMBL13791 & 688600 & 2.65 & 5.5049 & TRN & \\
\hline CHEMBL1998184 & 688600 & 4.4 & 4.6264 & TRN & \\
\hline CHEMBL1570760 & 688600 & 4.75 & 5.57700 & 0000000001 & TRN \\
\hline CHEMBL1594376 & 688600 & 5.3 & 4.4846 & TRN & \\
\hline CHEMBL376505 & 688600 & 4.2 & 5.7185 & TST & \\
\hline CHEMBL1426948 & 688600 & 8.5528 & 5.7416 & TST & \\
\hline CHEMBL1394559 & 688600 & 4.85 & 4.6899 & TRN & \\
\hline CHEMBL1359048 & 688600 & 4.55 & 4.8108 & TRN & \\
\hline CHEMBL1501995 & 688600 & 4.7 & 4.5526 & TRN & \\
\hline CHEMBL1417710 & 688600 & 4.8 & 4.7762 & TRN & \\
\hline CHEMBL 3190880 & 688600 & 4.6 & 4.6496 & TRN & \\
\hline CHEMBL1382884 & 688600 & 4.4 & 5.6547 & TST & \\
\hline CHEMBL1406250 & 688600 & 4.5 & 5.0551 & TRN & \\
\hline CHEMBL1405834 & 688600 & 4.4 & 4.6865 & TRN & \\
\hline CHEMBL 234338 & 688600 & 5.0 & 5.1202 & TRN & \\
\hline CHEMBL 286077 & 688600 & 6.25 & 7.2696 & TRN & \\
\hline CHEMBL1421023 & 688600 & 4.55 & 5.0737 & TRN & \\
\hline
\end{tabular}




\begin{tabular}{|c|c|c|c|c|c|}
\hline \\
\hline CHEMBL1397270 & 688600 & 4.8 & 5.8937 & TST & \\
\hline CHEMBL1460836 & 688600 & 4.6 & 4.7062 & TRN & \\
\hline CHEMBL1519313 & 688600 & 4.55 & 5.676 & TST & \\
\hline CHEMBL1979849 & 688600 & 5.7 & 4.5409 & TRN & \\
\hline CHEMBL1507813 & 688600 & 4.4 & 4.8563 & TRN & \\
\hline CHEMBL1454808 & 688600 & 4.55 & 4.0658 & TRN & \\
\hline CHEMBL1550052 & 688600 & 6.5501 & 6.1775 & TRN & \\
\hline CHEMBL1392258 & 688600 & 4.4 & 4.5585 & TRN & \\
\hline CHEMBL1966952 & 688600 & 4.8 & 5.1486 & TRN & \\
\hline CHEMBL1607263 & 688600 & 4.75 & 4.6792 & TRN & \\
\hline CHEMBL1348837 & 688600 & 5.05 & 5.0695 & TRN & \\
\hline CHEMBL1533561 & 688600 & 4.8 & 5.022 & TRN & \\
\hline CHEMBL1305014 & 688600 & 4.45 & 4.9157 & TRN & \\
\hline CHEMBL1554717 & 688600 & 4.25 & 5.6398 & TRN & \\
\hline CHEMBL1506031 & 688600 & 4.65 & 4.6363 & TST & \\
\hline CHEMBL1590378 & 688600 & 4.65 & 5.6444 & TST & \\
\hline CHEMBL1556000 & 688600 & 8.4949 & 5.314 & TST & \\
\hline CHEMBL1544660 & 688600 & 4.6 & 5.5895 & TST & \\
\hline CHEMBL1552181 & 688600 & 4.55 & 4.9473 & TST & \\
\hline CHEMBL 2374063 & 688600 & 4.25 & 5.1415 & TST & \\
\hline CHEMBL153036 & 688600 & 9.301 & 5.4144 & TST & \\
\hline CHEMBL3212691 & 688600 & 4.7 & 4.9406 & TRN & \\
\hline CHEMBL1366616 & 688600 & 4.7 & 5.3295 & TRN & \\
\hline CHEMBL1369513 & 688600 & 4.9 & 4.9877 & TRN & \\
\hline CHEMBL1354492 & 688600 & 4.8 & 6.4161 & TRN & \\
\hline CHEMBL351042 & 688600 & 6.0 & 6.0841 & TRN & \\
\hline CHEMBL3144856 & 688600 & 4.5 & 4.9482 & TRN & \\
\hline CHEMBL62350 & 688600 & 6.5501 & 5.7594 & TRN & \\
\hline CHEMBL297784 & 688600 & 4.85 & 5.1145 & TRN & \\
\hline CHEMBL1394733 & 688600 & 6.8 & 5.1687 & TRN & \\
\hline CHEMBL1554131 & 688600 & 6.45 & 7.9813 & TRN & \\
\hline CHEMBL1347052 & 688600 & 4.85 & 4.3121 & TRN & \\
\hline CHEMBL 2007180 & 688600 & 4.4 & 4.6684 & TRN & \\
\hline CHEMBL3195304 & 688600 & 4.6 & 4.3306 & TRN & \\
\hline CHEMBL72631 & 688600 & 4.35 & 5.4326 & TRN & \\
\hline CHEMBL1349509 & 688600 & 5.0 & 4.9511 & TRN & \\
\hline CHEMBL1359782 & 688600 & 4.55 & 4.7692 & TRN & \\
\hline CHEMBL1353412 & 688600 & 4.8 & 4.5831 & TST & \\
\hline CHEMBL1371055 & 688600 & 4.45 & 4.27800 & 00000000005 & TRN \\
\hline CHEMBL1518886 & 688600 & 4.9 & 5.4537 & TST & \\
\hline CHEMBL1308931 & 688600 & 4.4 & 5.9238 & TST & \\
\hline CHEMBL1429415 & 688600 & 4.8 & 4.7347 & TRN & \\
\hline CHEMBL1362890 & 688600 & 4.85 & 5.49 & TRN & \\
\hline CHEMBL1505878 & 688600 & 4.4 & 4.5125 & TRN & \\
\hline CHEMBL1256697 & 688600 & 4.9 & 5.1054 & TRN & \\
\hline CHEMBL15594 & 688600 & 4.6 & 5.3382 & TRN & \\
\hline CHEMBL1535609 & 688600 & 4.8 & 5.2779 & TRN & \\
\hline CHEMBL187460 & 688600 & 4.4 & 4.8775 & TST & \\
\hline
\end{tabular}




\begin{tabular}{|c|c|c|c|c|}
\hline \multicolumn{5}{|c|}{ Supplemental Table S2.txt } \\
\hline CHEMBL1332689 & 688600 & 4.8 & 5.3787 & TRN \\
\hline CHEMBL323542 & 688600 & 4.25 & 5.8023 & TST \\
\hline CHEMBL259355 & 688600 & 4.7 & 5.65600 & 0000000001 \\
\hline CHEMBL1256719 & 688600 & 4.65 & 5.1312 & TST \\
\hline CHEMBL1306565 & 688600 & 4.6 & 4.882 & TST \\
\hline CHEMBL1566530 & 688600 & 4.5 & 4.731 & TRN \\
\hline CHEMBL48449 & 688600 & 7.3497 & 6.3969 & TST \\
\hline CHEMBL1256797 & 688600 & 4.95 & 6.782 & TRN \\
\hline CHEMBL 1404792 & 688600 & 4.7 & 5.2777 & TRN \\
\hline CHEMBL3196837 & 688600 & 4.9 & 5.1377 & TRN \\
\hline CHEMBL 313833 & 688600 & 4.6 & 5.7649 & TST \\
\hline CHEMBL1533230 & 688600 & 4.85 & 5.7841 & TST \\
\hline CHEMBL1330161 & 688600 & 4.85 & 4.5767 & TRN \\
\hline CHEMBL1543241 & 688600 & 4.4 & 4.7294 & TST \\
\hline CHEMBL1434057 & 688600 & 5.65 & 5.2272 & TRN \\
\hline CHEMBL1356280 & 688600 & 5.05 & 5.4954 & TST \\
\hline CHEMBL1532453 & 688600 & 5.0 & 4.9274 & TRN \\
\hline CHEMBL 3190350 & 688600 & 4.85 & 4.3412 & TRN \\
\hline CHEMBL1375019 & 688600 & 4.45 & 4.6533 & TRN \\
\hline CHEMBL293749 & 688600 & 4.5 & 5.2026 & TRN \\
\hline CHEMBL1507934 & 688600 & 4.9 & 5.0987 & TST \\
\hline CHEMBL153057 & 688600 & 4.3 & 5.4198 & TRN \\
\hline CHEMBL1411962 & 688600 & 5.45 & 4.9008 & TRN \\
\hline CHEMBL 3193295 & 688600 & 5.0 & 4.6251 & TRN \\
\hline CHEMBL86676 & 688600 & 4.35 & 5.2102 & TST \\
\hline CHEMBL3392440 & 688600 & 4.5 & 5.112 & TRN \\
\hline CHEMBL1547641 & 688600 & 4.5 & 4.5807 & TRN \\
\hline CHEMBL 3191015 & 688600 & 6.1 & 5.3745 & TRN \\
\hline CHEMBL433461 & 688600 & 3.95 & 4.7564 & TRN \\
\hline CHEMBL 1420111 & 688600 & 4.65 & 4.4044 & TRN \\
\hline CHEMBL50267 & 688600 & 8.5528 & 5.9342 & TRN \\
\hline CHEMBL1987928 & 688600 & 5.85 & 5.1427 & TRN \\
\hline CHEMBL1569094 & 688600 & 4.45 & 4.1652 & TRN \\
\hline CHEMBL1542903 & 688600 & 4.6 & 5.0468 & TRN \\
\hline CHEMBL1387580 & 688600 & 4.55 & 4.3652 & TRN \\
\hline CHEMBL1410465 & 688600 & 4.4 & 4.6518 & TRN \\
\hline CHEMBL1378659 & 688600 & 5.2 & 6.1051 & TRN \\
\hline CHEMBL1408535 & 688600 & 4.45 & 4.5257 & TRN \\
\hline CHEMBL1478 & 688600 & 6.0 & 5.7687 & TST \\
\hline CHEMBL1331211 & 688600 & 4.55 & 4.692 & TRN \\
\hline CHEMBL1451377 & 688600 & 8.0 & 4.8246 & TST \\
\hline CHEMBL1395060 & 688600 & 4.55 & 4.4278 & TRN \\
\hline CHEMBL1552414 & 688600 & 4.4 & 4.3724 & TRN \\
\hline CHEMBL1432243 & 688600 & 5.0 & 4.6147 & TRN \\
\hline CHEMBL1417901 & 688600 & 4.8 & 5.0719 & TRN \\
\hline CHEMBL1445109 & 688600 & 4.4 & 5.1302 & TRN \\
\hline CHEMBL3197208 & 688600 & 5.2 & 4.8782 & TRN \\
\hline CHEMBL1434334 & 688600 & 6.5 & 5.8107 & TST \\
\hline
\end{tabular}

TRN 


\begin{tabular}{|c|c|c|c|c|}
\hline \multicolumn{5}{|c|}{ Supplemental Table s2.txt } \\
\hline CHEMBL1257003 & 688600 & 5.0 & 5.0841 & TRN \\
\hline CHEMBL1550788 & 688600 & 4.4 & 4.2691 & TRN \\
\hline CHEMBL1570525 & 688600 & 4.4 & 5.0948 & TRN \\
\hline CHEMBL1504738 & 688600 & 4.4 & 4.738 & TRN \\
\hline CHEMBL1611030 & 688600 & 4.4 & 4.4038 & TRN \\
\hline CHEMBL2374032 & 688600 & 5.5 & 4.9296 & TST \\
\hline CHEMBL1482883 & 688600 & 4.6 & 4.8823 & TRN \\
\hline CHEMBL1353716 & 688600 & 4.45 & 4.4262 & TRN \\
\hline CHEMBL1256761 & 688600 & 4.35 & 4.8937 & TRN \\
\hline CHEMBL1256646 & 688600 & 6.0 & 5.8055 & TRN \\
\hline CHEMBL1582667 & 688600 & 6.15 & 5.5759 & TST \\
\hline CHEMBL1334633 & 688600 & 4.55 & 5.2583 & TRN \\
\hline CHEMBL1471193 & 688600 & 4.55 & 4.247 & TRN \\
\hline CHEMBL1378864 & 688600 & 4.35 & 4.7941 & TRN \\
\hline CHEMBL1329033 & 688600 & 4.6 & 5.15 & TRN \\
\hline CHEMBL1426692 & 688600 & 4.55 & 4.5103 & TRN \\
\hline CHEMBL1577815 & 688600 & 4.6 & 5.4572 & TRN \\
\hline CHEMBL1392651 & 688600 & 4.45 & 4.1601 & TRN \\
\hline CHEMBL3197368 & 688600 & 4.7 & 4.1307 & TRN \\
\hline CHEMBL1328733 & 688600 & 4.65 & 4.8705 & TRN \\
\hline CHEMBL457504 & 688600 & 5.15 & 4.6543 & TST \\
\hline CHEMBL1509590 & 688600 & 4.4 & 4.1612 & TRN \\
\hline CHEMBL1255966 & 688600 & 9.0969 & 6.95299 & 9999999999 \\
\hline CHEMBL1321572 & 688600 & 4.6 & 4.9652 & TRN \\
\hline CHEMBL1527095 & 688600 & 4.45 & 4.5233 & TRN \\
\hline CHEMBL1413866 & 688600 & 4.95 & 5.0258 & TRN \\
\hline CHEMBL1424486 & 688600 & 4.6 & 4.5344 & TRN \\
\hline CHEMBL418068 & 688600 & 4.45 & 4.878 & TRN \\
\hline CHEMBL3191942 & 688600 & 6.0 & 4.9917 & TRN \\
\hline CHEMBL1613004 & 688600 & 4.8 & 5.0286 & TRN \\
\hline CHEMBL1596594 & 688600 & 5.0 & 4.9834 & TRN \\
\hline CHEMBL1440119 & 688600 & 4.95 & 5.4053 & TRN \\
\hline CHEMBL370152 & 688600 & 4.45 & 5.3656 & TRN \\
\hline CHEMBL1568730 & 688600 & 6.1 & 4.7725 & TRN \\
\hline CHEMBL3198816 & 688600 & 4.5 & 4.8636 & TRN \\
\hline CHEMBL257359 & 688600 & 5.45 & 5.1441 & TRN \\
\hline CHEMBL1541214 & 688600 & 4.35 & 4.6908 & TRN \\
\hline CHEMBL1530999 & 688600 & 4.55 & 4.2142 & TRN \\
\hline CHEMBL1478592 & 688600 & 4.7 & 4.8718 & TRN \\
\hline CHEMBL1583406 & 688600 & 4.4 & 4.8213 & TRN \\
\hline CHEMBL1374573 & 688600 & 4.85 & 4.467 & TRN \\
\hline CHEMBL1722566 & 688600 & 4.85 & 4.6826 & TRN \\
\hline CHEMBL3199394 & 688600 & 4.7 & 4.817 & TRN \\
\hline CHEMBL542700 & 688600 & 6.5 & 6.0067 & TRN \\
\hline CHEMBL1378418 & 688600 & 4.45 & 4.4879 & TRN \\
\hline CHEMBL1991710 & 688600 & 4.7 & 4.728 & TRN \\
\hline CHEMBL321691 & 688600 & 8.5528 & 6.6382 & TRN \\
\hline CHEMBL1434513 & 688600 & 6.0 & 5.8165 & TRN \\
\hline
\end{tabular}

TRN 


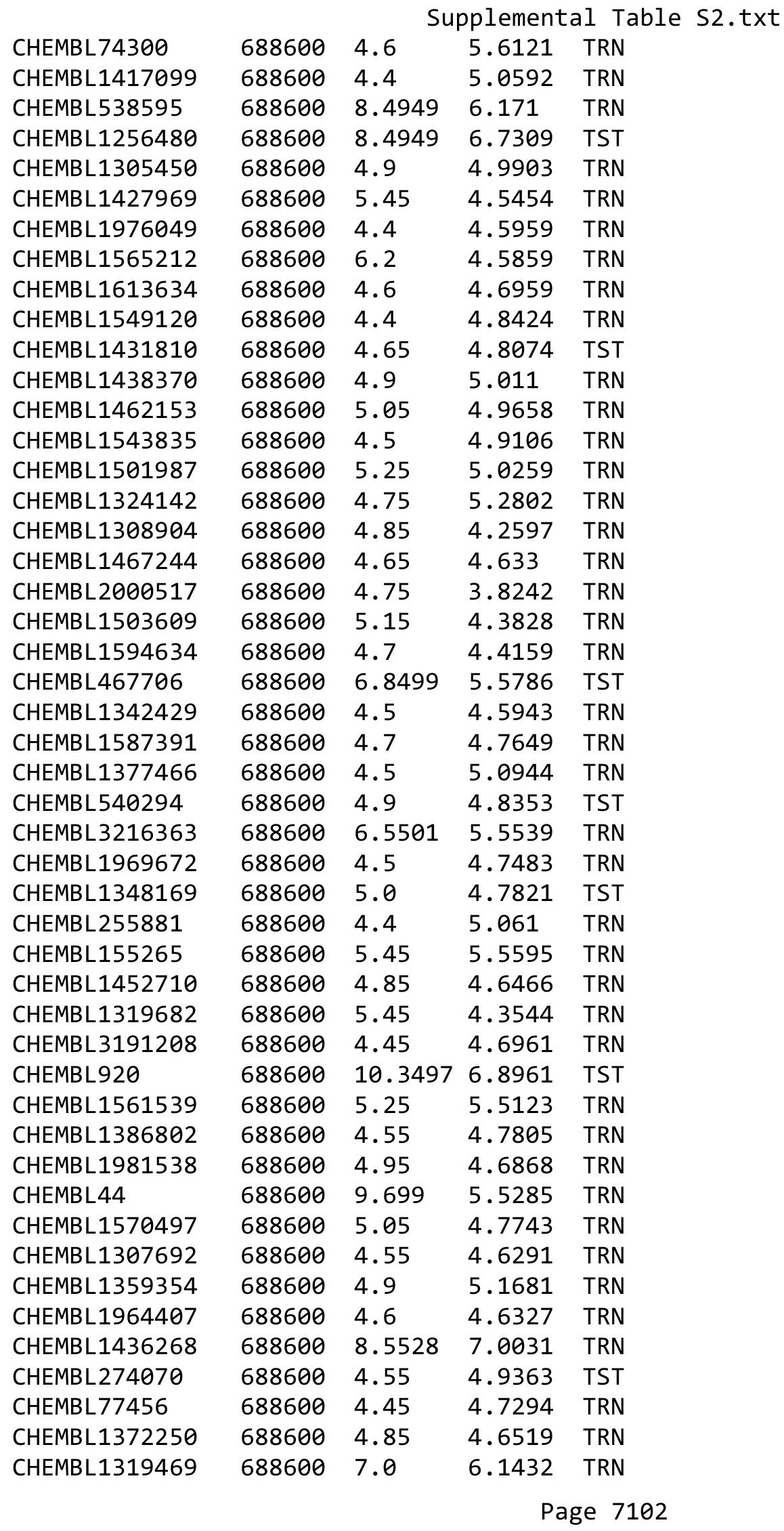




\begin{tabular}{|c|c|c|c|c|c|}
\hline \multicolumn{6}{|c|}{ Supplemental Table S2.txt } \\
\hline CHEMBL1305050 & 688600 & 5.05 & 4.7958 & TRN & \\
\hline CHEMBL1456412 & 688600 & 4.75 & 4.9729 & TST & \\
\hline CHEMBL1534959 & 688600 & 4.65 & 4.7918 & TRN & \\
\hline CHEMBL1374242 & 688600 & 4.95 & 4.959 & TRN & \\
\hline CHEMBL1403154 & 688600 & 4.6 & 4.7789 & TRN & \\
\hline CHEMBL1306714 & 688600 & 5.45 & 5.0667 & TRN & \\
\hline CHEMBL1488393 & 688600 & 4.65 & 5.2423 & TRN & \\
\hline CHEMBL1407368 & 688600 & 5.0 & 4.6967 & TRN & \\
\hline CHEMBL493863 & 688600 & 4.4 & 4.3749 & TST & \\
\hline CHEMBL1542842 & 688600 & 4.5 & 4.7145 & TRN & \\
\hline CHEMBL1462469 & 688600 & 4.5 & 4.5671 & TRN & \\
\hline CHEMBL1418208 & 688600 & 5.1 & 4.6688 & TRN & \\
\hline CHEMBL1299634 & 688600 & 4.5 & 4.699 & TRN & \\
\hline CHEMBL1492716 & 688600 & 5.0 & 5.1633 & TRN & \\
\hline CHEMBL1588753 & 688600 & 4.9 & 4.8534 & TRN & \\
\hline CHEMBL1419578 & 688600 & 5.15 & 4.98 & TRN & \\
\hline CHEMBL1256511 & 688600 & 8.5528 & 6.7007 & TRN & \\
\hline CHEMBL1604163 & 688600 & 5.15 & 4.6139 & TRN & \\
\hline CHEMBL110739 & 688600 & 4.05 & 5.8967 & TST & \\
\hline CHEMBL1404459 & 688600 & 4.7 & 5.11600 & 00000000005 & TRN \\
\hline CHEMBL1373849 & 688600 & 4.65 & 4.4326 & TRN & \\
\hline CHEMBL1581949 & 688600 & 4.5 & 4.6503 & TRN & \\
\hline CHEMBL1313140 & 688600 & 4.5 & 5.1189 & TRN & \\
\hline CHEMBL1532186 & 688600 & 4.6 & 4.909 & TRN & \\
\hline CHEMBL1553873 & 688600 & 4.85 & 5.59 & TRN & \\
\hline CHEMBL1587708 & 688600 & 4.7 & 4.4955 & TRN & \\
\hline CHEMBL1407306 & 688600 & 4.85 & 5.0335 & TRN & \\
\hline CHEMBL1528575 & 688600 & 4.8 & 4.896 & TRN & \\
\hline CHEMBL 2007077 & 688600 & 4.75 & 4.7745 & TRN & \\
\hline CHEMBL1342894 & 688600 & 4.5 & 4.9954 & TRN & \\
\hline CHEMBL1340299 & 688600 & 4.45 & 4.9712 & TRN & \\
\hline CHEMBL1405763 & 688600 & 4.8 & 5.2226 & TRN & \\
\hline CHEMBL1256959 & 688600 & 9.3979 & 5.8728 & TST & \\
\hline CHEMBL1400145 & 688600 & 4.65 & 5.0506 & TRN & \\
\hline CHEMBL1445336 & 688600 & 4.45 & 4.4148 & TRN & \\
\hline CHEMBL1456440 & 688600 & 5.4 & 4.9682 & TRN & \\
\hline CHEMBL1555552 & 688600 & 4.45 & 4.5597 & TST & \\
\hline CHEMBL1376870 & 688600 & 4.85 & 5.28100 & 0000000001 & TRN \\
\hline CHEMBL1394337 & 688600 & 5.1 & 5.2893 & TRN & \\
\hline CHEMBL1381419 & 688600 & 4.7 & 4.9787 & TRN & \\
\hline CHEMBL1325681 & 688600 & 4.45 & 5.2298 & TST & \\
\hline CHEMBL1390521 & 688600 & 5.6 & 6.351 & TRN & \\
\hline CHEMBL1983530 & 688600 & 4.65 & 4.8066 & TRN & \\
\hline CHEMBL541543 & 688600 & 9.0458 & 5.3657 & TST & \\
\hline CHEMBL1328224 & 688600 & 4.5 & 4.2766 & TRN & \\
\hline CHEMBL1381644 & 688600 & 5.6 & 4.6861 & TRN & \\
\hline CHEMBL576349 & 688600 & 4.8 & 5.2271 & TRN & \\
\hline CHEMBL97453 & 688600 & 6.0 & 5.6236 & TRN & \\
\hline
\end{tabular}




\begin{tabular}{|c|c|c|c|c|c|}
\hline & & \multicolumn{4}{|c|}{ Supplemental Table S2.txt } \\
\hline CHEMBL1257014 & 688600 & 7.6498 & 5.2819 & TRN & \\
\hline CHEMBL1304974 & 688600 & 4.55 & 4.6655 & TRN & \\
\hline CHEMBL3193560 & 688600 & 5.35 & 5.586 & TST & \\
\hline CHEMBL1340051 & 688600 & 4.85 & 4.7375 & TRN & \\
\hline CHEMBL1301380 & 688600 & 4.5 & 5.4315 & TRN & \\
\hline CHEMBL1600383 & 688600 & 4.6 & 4.7298 & TRN & \\
\hline CHEMBL1460740 & 688600 & 4.6 & 5.1185 & TRN & \\
\hline CHEMBL1420312 & 688600 & 4.5 & 4.8487 & TRN & \\
\hline CHEMBL1968928 & 688600 & 5.5 & 4.8771 & TRN & \\
\hline CHEMBL1971361 & 688600 & 4.7 & 4.5492 & TRN & \\
\hline CHEMBL1539579 & 688600 & 4.7 & 4.7137 & TRN & \\
\hline CHEMBL 277362 & 688600 & 9.0458 & 7.0849 & TRN & \\
\hline CHEMBL1478395 & 688600 & 4.4 & 5.28299 & 99999999995 & TRN \\
\hline CHEMBL545050 & 688600 & 7.5498 & 6.1503 & TST & \\
\hline CHEMBL1304024 & 688600 & 4.85 & 5.1174 & TST & \\
\hline CHEMBL13790 & 688600 & 4.7 & 5.8935 & TRN & \\
\hline CHEMBL1342119 & 688600 & 4.6 & 4.6842 & TRN & \\
\hline CHEMBL1505905 & 688600 & 4.4 & 4.6826 & TRN & \\
\hline CHEMBL3392043 & 688600 & 4.4 & 5.3969 & TRN & \\
\hline CHEMBL596674 & 688600 & 4.65 & 4.9573 & TRN & \\
\hline CHEMBL1395737 & 688600 & 8.301 & 6.2934 & TRN & \\
\hline CHEMBL1408648 & 688600 & 4.4 & 5.5005 & TRN & \\
\hline CHEMBL1256751 & 688600 & 5.2 & 5.3323 & TRN & \\
\hline CHEMBL1407175 & 688600 & 4.85 & 4.4435 & TRN & \\
\hline CHEMBL1350167 & 688600 & 4.55 & 4.1535 & TRN & \\
\hline CHEMBL1735892 & 688600 & 4.7 & 4.6062 & TRN & \\
\hline CHEMBL1576815 & 688600 & 4.7 & 5.5212 & TST & \\
\hline CHEMBL1319601 & 688600 & 4.65 & 5.1198 & TST & \\
\hline CHEMBL1478825 & 688600 & 4.5 & 4.3159 & TRN & \\
\hline CHEMBL1522351 & 688600 & 4.9 & 4.5748 & TRN & \\
\hline CHEMBL76904 & 688600 & 4.4 & 4.459 & TRN & \\
\hline CHEMBL111545 & 688600 & 4.8 & 5.4364 & TST & \\
\hline CHEMBL1424300 & 688600 & 4.55 & 5.2546 & TRN & \\
\hline CHEMBL1612018 & 688600 & 4.45 & 4.1105 & TRN & \\
\hline CHEMBL1417159 & 688600 & 4.6 & 5.8879 & TRN & \\
\hline CHEMBL1309165 & 688600 & 4.7 & 4.5429 & TRN & \\
\hline CHEMBL1543956 & 688600 & 4.75 & 4.9315 & TRN & \\
\hline CHEMBL1578235 & 688600 & 4.6 & 4.4586 & TRN & \\
\hline CHEMBL1423632 & 688600 & 5.35 & 5.3777 & TRN & \\
\hline CHEMBL1554829 & 688600 & 4.75 & 5.2685 & TST & \\
\hline CHEMBL1255837 & 688600 & 4.35 & 6.0907 & TST & \\
\hline CHEMBL1386963 & 688600 & 4.7 & 4.8478 & TRN & \\
\hline CHEMBL1354019 & 688600 & 4.65 & 4.3176 & TRN & \\
\hline CHEMBL1561474 & 688600 & 7.0 & 7.1193 & TRN & \\
\hline CHEMBL 29097 & 688600 & 6.0 & 4.7353 & TRN & \\
\hline CHEMBL1576746 & 688600 & 5.05 & 4.6347 & TRN & \\
\hline CHEMBL 8165 & 688600 & 8.4949 & 6.5976 & TRN & \\
\hline CHEMBL1336428 & 688600 & 4.5 & 4.2178 & TRN & \\
\hline
\end{tabular}




\begin{tabular}{|c|c|c|c|c|}
\hline \multicolumn{5}{|c|}{ Supplemental Table S2.txt } \\
\hline CHEMBL1596753 & 688600 & 4.6 & 4.2264 & TRN \\
\hline CHEMBL1321082 & 688600 & 4.5 & 4.4841 & TRN \\
\hline CHEMBL1338825 & 688600 & 5.4 & 4.3242 & TRN \\
\hline CHEMBL26318 & 688600 & 8.6021 & 6.5463 & TST \\
\hline CHEMBL275516 & 688600 & 4.2 & 6.3839 & TST \\
\hline CHEMBL1456343 & 688600 & 4.55 & 4.1121 & TRN \\
\hline CHEMBL1491441 & 688600 & 4.8 & 4.937 & TRN \\
\hline CHEMBL1308842 & 688600 & 5.95 & 4.4925 & TRN \\
\hline CHEMBL1520667 & 688600 & 4.85 & 4.8382 & TRN \\
\hline CHEMBL7634 & 688600 & 7.6003 & 6.34200 & 00000000005 \\
\hline CHEMBL1504113 & 688600 & 4.85 & 6.021 & TST \\
\hline CHEMBL1345124 & 688600 & 5.25 & 4.3702 & TRN \\
\hline CHEMBL1310865 & 688600 & 4.45 & 4.4665 & TRN \\
\hline CHEMBL1501307 & 688600 & 4.8 & 5.2894 & TRN \\
\hline CHEMBL1430473 & 688600 & 5.75 & 5.5095 & TRN \\
\hline CHEMBL1387220 & 688600 & 4.65 & 4.0656 & TRN \\
\hline CHEMBL1436882 & 688600 & 8.0 & 6.8634 & TRN \\
\hline CHEMBL1325961 & 688600 & 4.45 & 4.7113 & TRN \\
\hline CHEMBL1367262 & 688600 & 4.45 & 4.6302 & TRN \\
\hline CHEMBL1322478 & 688600 & 9.301 & 4.9126 & TRN \\
\hline CHEMBL1491258 & 688600 & 4.85 & 6.191 & TRN \\
\hline CHEMBL1410381 & 688600 & 4.9 & 4.9818 & TRN \\
\hline CHEMBL1526852 & 688600 & 9.0969 & 6.1996 & TRN \\
\hline CHEMBL168279 & 688600 & 8.5528 & 7.1475 & TRN \\
\hline CHEMBL1445742 & 688600 & 4.75 & 4.726 & TRN \\
\hline CHEMBL1464803 & 688600 & 4.55 & 4.2804 & TRN \\
\hline CHEMBL258893 & 688600 & 5.5 & 5.0323 & TRN \\
\hline CHEMBL1464853 & 688600 & 4.85 & 4.4095 & TST \\
\hline CHEMBL1605094 & 688600 & 4.45 & 4.6591 & TRN \\
\hline CHEMBL121915 & 688600 & 9.0 & 6.8261 & TRN \\
\hline CHEMBL1576458 & 688600 & 4.4 & 4.9712 & TRN \\
\hline CHEMBL56731 & 688600 & 4.65 & 4.2519 & TRN \\
\hline CHEMBL1427775 & 688600 & 4.5 & 5.3309 & TRN \\
\hline CHEMBL1483843 & 688600 & 5.05 & 5.1248 & TRN \\
\hline CHEMBL1326833 & 688600 & 4.55 & 5.3604 & TRN \\
\hline CHEMBL1373007 & 688600 & 5.25 & 5.2302 & TST \\
\hline CHEMBL1256291 & 688600 & 4.65 & 4.6285 & TRN \\
\hline CHEMBL1554486 & 688600 & 4.35 & 7.4182 & TRN \\
\hline CHEMBL1396203 & 688600 & 4.85 & 4.5603 & TRN \\
\hline CHEMBL1342723 & 688600 & 4.85 & 4.9503 & TRN \\
\hline CHEMBL1256289 & 688600 & 8.5528 & 6.4253 & TST \\
\hline CHEMBL1543789 & 688600 & 4.6 & 5.0901 & TRN \\
\hline CHEMBL1427289 & 688600 & 4.85 & 5.0793 & TRN \\
\hline CHEMBL1487660 & 688600 & 4.85 & 4.8666 & TRN \\
\hline CHEMBL1590980 & 688600 & 8.4949 & 6.1821 & TRN \\
\hline CHEMBL1307453 & 688600 & 5.05 & 5.2366 & TRN \\
\hline CHEMBL 327708 & 688600 & 9.3979 & 6.6765 & TRN \\
\hline CHEMBL 2000196 & 688600 & 4.5 & 4.8914 & TRN \\
\hline
\end{tabular}




\begin{tabular}{|c|c|c|c|c|}
\hline \multicolumn{5}{|c|}{ Supplemental Tabl } \\
\hline CHEMBL1255934 & 688600 & 8.2007 & 5.7976 & TST \\
\hline CHEMBL1414236 & 688600 & 8.699 & 5.2732 & TST \\
\hline CHEMBL1256772 & 688600 & 8.0 & 6.7171 & TST \\
\hline CHEMBL33171 & 688600 & 8.3468 & 6.3385 & TRN \\
\hline CHEMBL3189879 & 688600 & 4.55 & 4.5369 & TRN \\
\hline CHEMBL521083 & 688600 & 4.4 & 5.1251 & TRN \\
\hline CHEMBL1518374 & 688600 & 5.05 & 4.5552 & TRN \\
\hline CHEMBL1491773 & 688600 & 4.85 & 5.8167 & TST \\
\hline CHEMBL119171 & 688600 & 5.1 & 7.5057 & TRN \\
\hline CHEMBL 250711 & 688600 & 4.7 & 4.356 & TRN \\
\hline CHEMBL1469839 & 688600 & 4.75 & 4.9164 & TRN \\
\hline CHEMBL544115 & 688600 & 4.75 & 5.3613 & TRN \\
\hline CHEMBL560919 & 688600 & 4.9 & 4.711 & TRN \\
\hline CHEMBL3235881 & 688600 & 4.55 & 4.7833 & TRN \\
\hline CHEMBL3194778 & 688600 & 4.5 & 4.9271 & TRN \\
\hline CHEMBL 3194737 & 688600 & 4.55 & 4.6783 & TRN \\
\hline CHEMBL1993746 & 688600 & 4.75 & 4.5458 & TRN \\
\hline CHEMBL1495592 & 688600 & 4.85 & 4.899 & TRN \\
\hline CHEMBL1308936 & 688600 & 4.9 & 5.5215 & TRN \\
\hline CHEMBL1392313 & 688600 & 4.55 & 4.0845 & TRN \\
\hline CHEMBL1342299 & 688600 & 4.6 & 5.1215 & TRN \\
\hline CHEMBL1429479 & 688600 & 4.8 & 5.0136 & TRN \\
\hline CHEMBL1447467 & 688600 & 4.85 & 5.8645 & TST \\
\hline CHEMBL1378036 & 688600 & 4.4 & 4.563 & TRN \\
\hline CHEMBL567130 & 688600 & 4.6 & 4.7781 & TRN \\
\hline CHEMBL3190321 & 688600 & 5.05 & 5.0263 & TRN \\
\hline CHEMBL1347080 & 688600 & 4.45 & 4.6953 & TRN \\
\hline CHEMBL1553871 & 688600 & 4.9 & 4.8377 & TRN \\
\hline CHEMBL3189623 & 688600 & 4.85 & 4.8035 & TST \\
\hline CHEMBL1256396 & 688600 & 4.9 & 5.7007 & TRN \\
\hline CHEMBL1329497 & 688600 & 4.4 & 5.0866 & TRN \\
\hline CHEMBL1470728 & 688600 & 4.9 & 5.2239 & TST \\
\hline CHEMBL1384172 & 688600 & 4.85 & 5.1834 & TRN \\
\hline CHEMBL1507308 & 688600 & 4.65 & 4.9677 & TRN \\
\hline CHEMBL1336166 & 688600 & 4.6 & 4.7499 & TRN \\
\hline CHEMBL1326902 & 688600 & 4.5 & 5.6357 & TRN \\
\hline CHEMBL1965911 & 688600 & 4.7 & 4.5117 & TRN \\
\hline CHEMBL1312363 & 688600 & 4.4 & 4.567 & TRN \\
\hline CHEMBL1585182 & 688600 & 4.65 & 4.7732 & TRN \\
\hline CHEMBL1588058 & 688600 & 4.6 & 4.2369 & TRN \\
\hline CHEMBL1546136 & 688600 & 4.75 & 4.9577 & TRN \\
\hline CHEMBL1399331 & 688600 & 4.4 & 4.9725 & TRN \\
\hline CHEMBL1313554 & 688600 & 4.4 & 4.7537 & TRN \\
\hline CHEMBL1320902 & 688600 & 5.25 & 5.5031 & TRN \\
\hline CHEMBL1236602 & 688600 & 8.1024 & 6.5191 & TRN \\
\hline CHEMBL1327940 & 688600 & 5.0 & 4.4352 & TRN \\
\hline CHEMBL177820 & 688600 & 6.0 & 5.79 & TST \\
\hline CHEMBL1512440 & 688600 & 4.55 & 5.8509 & TRN \\
\hline
\end{tabular}




\begin{tabular}{|c|c|c|c|c|c|}
\hline & & \multicolumn{4}{|c|}{ Supplemental Table S2.txt } \\
\hline CHEMBL1255650 & 688600 & 8.5528 & 5.7684 & TST & \\
\hline CHEMBL1431490 & 688600 & 4.85 & 4.8421 & TRN & \\
\hline CHEMBL1438520 & 688600 & 4.55 & 4.9806 & TRN & \\
\hline CHEMBL1256131 & 688600 & 8.5528 & 6.1371 & TRN & \\
\hline CHEMBL1369691 & 688600 & 6.0 & 4.6186 & TRN & \\
\hline CHEMBL399043 & 688600 & 6.5 & 5.3714 & TST & \\
\hline CHEMBL1381495 & 688600 & 4.5 & 5.0907 & TRN & \\
\hline CHEMBL1455292 & 688600 & 4.75 & 5.1638 & TRN & \\
\hline CHEMBL1548422 & 688600 & 4.9 & 5.0381 & TRN & \\
\hline CHEMBL1357213 & 688600 & 5.0 & 4.9711 & TRN & \\
\hline CHEMBL 208926 & 688600 & 4.55 & 4.7284 & TRN & \\
\hline CHEMBL1304979 & 688600 & 5.85 & 4.9703 & TRN & \\
\hline CHEMBL3196591 & 688600 & 4.85 & 4.3944 & TRN & \\
\hline CHEMBL1416846 & 688600 & 5.6 & 4.8804 & TRN & \\
\hline CHEMBL1587521 & 688600 & 4.8 & 4.2982 & TRN & \\
\hline CHEMBL1342337 & 688600 & 4.8 & 4.5387 & TRN & \\
\hline CHEMBL1492541 & 688600 & 4.45 & 4.6771 & TST & \\
\hline CHEMBL1577081 & 688600 & 4.85 & 4.1463 & TRN & \\
\hline CHEMBL433238 & 688600 & 7.8013 & 6.9764 & TRN & \\
\hline CHEMBL1440277 & 688600 & 4.4 & 4.4474 & TRN & \\
\hline CHEMBL8747 & 688600 & 4.45 & 4.8305 & TRN & \\
\hline CHEMBL1403564 & 688600 & 4.45 & 4.4831 & TRN & \\
\hline CHEMBL1390647 & 688600 & 4.65 & 4.5145 & TRN & \\
\hline CHEMBL1315178 & 688600 & 4.8 & 4.8576 & TRN & \\
\hline CHEMBL1408519 & 688600 & 6.5501 & 5.4092 & TST & \\
\hline CHEMBL1531754 & 688600 & 6.25 & 5.9732 & TRN & \\
\hline CHEMBL1523894 & 688600 & 9.3979 & 5.7216 & TST & \\
\hline CHEMBL 371811 & 688600 & 4.35 & 5.3349 & TRN & \\
\hline CHEMBL1493936 & 688600 & 4.7 & 5.3293 & TRN & \\
\hline CHEMBL233149 & 688600 & 4.6 & 5.1003 & TRN & \\
\hline CHEMBL1405054 & 688600 & 4.5 & 4.96899 & 9999999999 & TRN \\
\hline CHEMBL1256287 & 688600 & 3.3 & 5.7197 & TST & \\
\hline CHEMBL1353227 & 688600 & 4.65 & 4.3654 & TRN & \\
\hline CHEMBL1463326 & 688600 & 4.75 & 4.0835 & TRN & \\
\hline CHEMBL1389315 & 688600 & 5.0 & 4.7009 & TRN & \\
\hline CHEMBL1991442 & 688600 & 4.4 & 5.3987 & TST & \\
\hline CHEMBL 3145086 & 688600 & 4.8 & 4.8551 & TRN & \\
\hline CHEMBL 305978 & 688600 & 4.8 & 5.0326 & TRN & \\
\hline CHEMBL 30432 & 688600 & 5.95 & 5.3072 & TRN & \\
\hline CHEMBL1505467 & 688600 & 4.8 & 4.8514 & TRN & \\
\hline CHEMBL1472455 & 688600 & 4.75 & 5.2476 & TRN & \\
\hline CHEMBL1256759 & 688600 & 8.7447 & 5.2267 & TRN & \\
\hline CHEMBL1547640 & 688600 & 4.45 & 5.0362 & TRN & \\
\hline CHEMBL1984240 & 688600 & 5.0 & 4.8661 & TRN & \\
\hline CHEMBL1315457 & 688600 & 4.55 & 5.1515 & TST & \\
\hline CHEMBL1565830 & 688600 & 4.85 & 4.6234 & TRN & \\
\hline CHEMBL1604803 & 688600 & 4.5 & 5.2142 & TRN & \\
\hline CHEMBL1411673 & 688600 & 4.65 & 4.7823 & TRN & \\
\hline
\end{tabular}




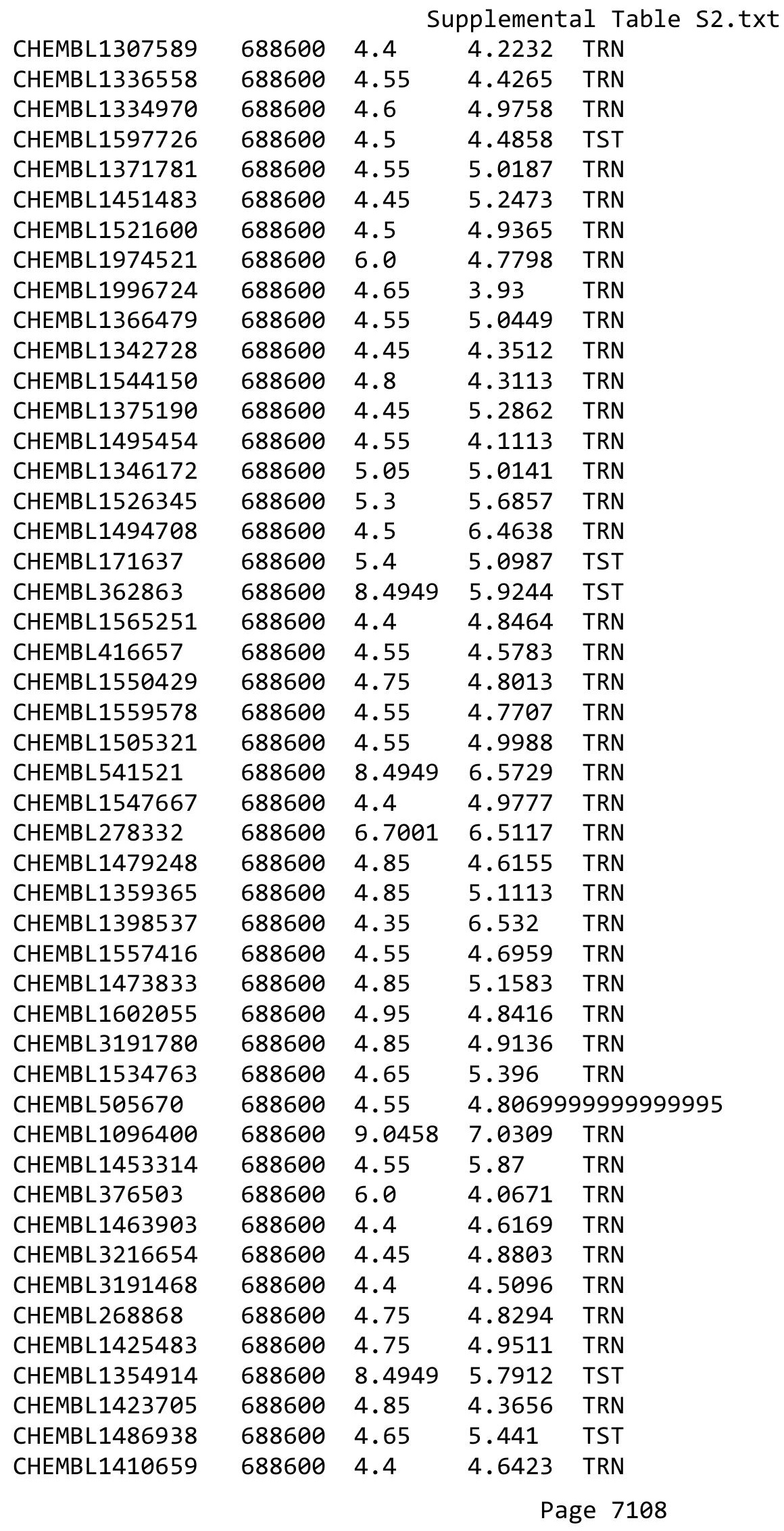




\begin{tabular}{|c|c|c|c|c|}
\hline \multicolumn{5}{|c|}{ Supplemental Table S2.txt } \\
\hline CHEMBL1366516 & 688600 & 4.6 & 5.2511 & TST \\
\hline CHEMBL1551433 & 688600 & 4.55 & 4.5205 & TRN \\
\hline CHEMBL1464110 & 688600 & 4.55 & 4.8245 & TRN \\
\hline CHEMBL1160028 & 688600 & 4.55 & 4.4017 & TRN \\
\hline CHEMBL1256693 & 688600 & 4.25 & 5.8368 & TRN \\
\hline CHEMBL1301743 & 688600 & 4.4 & 4.2552 & TRN \\
\hline CHEMBL1460470 & 688600 & 5.05 & 5.0995 & TRN \\
\hline CHEMBL1455226 & 688600 & 6.05 & 5.0647 & TRN \\
\hline CHEMBL8151 & 688600 & 8.9586 & 6.102 & TST \\
\hline CHEMBL1414452 & 688600 & 4.45 & 5.6673 & TST \\
\hline CHEMBL1506225 & 688600 & 4.6 & 6.3299 & TRN \\
\hline CHEMBL1332879 & 688600 & 4.4 & 5.1835 & TRN \\
\hline CHEMBL3197887 & 688600 & 4.5 & 4.8694 & TRN \\
\hline CHEMBL1553584 & 688600 & 4.7 & 5.0497 & TRN \\
\hline CHEMBL1392551 & 688600 & 4.6 & 4.7501 & TRN \\
\hline CHEMBL1335406 & 688600 & 5.8 & 4.9555 & TST \\
\hline CHEMBL1588106 & 688600 & 4.75 & 4.7531 & TRN \\
\hline CHEMBL296586 & 688600 & 4.25 & 4.3308 & TRN \\
\hline CHEMBL1578290 & 688600 & 4.4 & 5.1616 & TRN \\
\hline CHEMBL1335356 & 688600 & 4.65 & 5.7993 & TST \\
\hline CHEMBL1996376 & 688600 & 4.45 & 4.4941 & TRN \\
\hline CHEMBL1304783 & 688600 & 4.45 & 4.4611 & TRN \\
\hline CHEMBL1418235 & 688600 & 4.5 & 4.1053 & TRN \\
\hline CHEMBL525267 & 688600 & 4.4 & 5.4875 & TST \\
\hline CHEMBL1450458 & 688600 & 4.9 & 4.4918 & TRN \\
\hline CHEMBL56543 & 688600 & 4.6 & 4.2049 & TRN \\
\hline CHEMBL1519231 & 688600 & 4.5 & 4.3437 & TRN \\
\hline CHEMBL1315743 & 688600 & 10.5498 & 6.0693 & TRN \\
\hline CHEMBL1471865 & 688600 & 4.55 & 4.7694 & TRN \\
\hline CHEMBL1201304 & 688600 & 4.5 & 5.1889 & TRN \\
\hline CHEMBL1582927 & 688600 & 4.55 & 4.9165 & TRN \\
\hline CHEMBL3198060 & 688600 & 4.55 & 4.8647 & TRN \\
\hline CHEMBL1255940 & 688600 & 5.7 & 5.8169 & TST \\
\hline CHEMBL1566050 & 688600 & 4.7 & 5.2339 & TRN \\
\hline CHEMBL164 & 688600 & 6.0 & 6.1562 & TRN \\
\hline CHEMBL101849 & 688600 & 5.1 & 5.5119 & TRN \\
\hline CHEMBL1612983 & 688600 & 4.5 & 4.1803 & TRN \\
\hline CHEMBL1344422 & 688600 & 4.6 & 4.4334 & TRN \\
\hline CHEMBL498373 & 688600 & 4.65 & 5.3909 & TRN \\
\hline CHEMBL 297453 & 688600 & 4.6 & 5.484 & TRN \\
\hline CHEMBL60518 & 688600 & 4.65 & 5.6606 & TRN \\
\hline CHEMBL1460491 & 688600 & 5.4 & 4.3227 & TRN \\
\hline CHEMBL1427447 & 688600 & 4.55 & 4.5999 & TRN \\
\hline CHEMBL1713905 & 688600 & 4.55 & 4.8938 & TRN \\
\hline CHEMBL1458486 & 688600 & 4.7 & 4.4722 & TRN \\
\hline CHEMBL1438907 & 688600 & 4.7 & 5.0371 & TRN \\
\hline CHEMBL3191845 & 688600 & 4.4 & 4.9481 & TST \\
\hline CHEMBL1458891 & 688600 & 5.45 & 4.9789 & TRN \\
\hline
\end{tabular}




\begin{tabular}{|c|c|c|c|c|c|}
\hline \multicolumn{6}{|c|}{ Supplemental Table S2.txt } \\
\hline CHEMBL580421 & 688600 & 6.0 & 4.7322 & TRN & \\
\hline CHEMBL1545527 & 688600 & 5.2 & 5.2127 & TRN & \\
\hline CHEMBL1256851 & 688600 & 4.6 & 5.2073 & TST & \\
\hline CHEMBL417727 & 688600 & 5.2 & 4.2753 & TRN & \\
\hline CHEMBL1504595 & 688600 & 5.0 & 4.8525 & TST & \\
\hline CHEMBL1384567 & 688600 & 4.6 & 4.59399 & 9999999999 & TRN \\
\hline CHEMBL1464954 & 688600 & 4.55 & 5.0649 & TRN & \\
\hline CHEMBL1524347 & 688600 & 4.5 & 4.8125 & TRN & \\
\hline CHEMBL1481083 & 688600 & 4.55 & 4.3981 & TRN & \\
\hline CHEMBL1342736 & 688600 & 4.6 & 4.5606 & TRN & \\
\hline CHEMBL1440076 & 688600 & 4.95 & 4.4585 & TRN & \\
\hline CHEMBL1299566 & 688600 & 4.75 & 4.4152 & TRN & \\
\hline CHEMBL1496473 & 688600 & 4.5 & 5.6214 & TST & \\
\hline CHEMBL1497838 & 688600 & 4.75 & 5.1698 & TRN & \\
\hline CHEMBL1256687 & 688600 & 4.7 & 6.0884 & TRN & \\
\hline CHEMBL1342410 & 688600 & 4.8 & 4.6231 & TRN & \\
\hline CHEMBL1594931 & 688600 & 4.65 & 4.8673 & TRN & \\
\hline CHEMBL1362307 & 688600 & 4.85 & 4.5468 & TRN & \\
\hline CHEMBL3196877 & 688600 & 4.95 & 4.9591 & TRN & \\
\hline CHEMBL1443059 & 688600 & 4.8 & 4.8551 & TRN & \\
\hline CHEMBL1488875 & 688600 & 4.5 & 4.8919 & TRN & \\
\hline CHEMBL1990081 & 688600 & 4.6 & 4.385 & TRN & \\
\hline CHEMBL1349451 & 688600 & 4.5 & 4.7519 & TRN & \\
\hline CHEMBL282038 & 688600 & 4.8 & 6.295 & TRN & \\
\hline CHEMBL1422553 & 688600 & 5.3 & 5.4505 & TST & \\
\hline CHEMBL1485960 & 688600 & 4.55 & 4.6431 & TRN & \\
\hline CHEMBL1329141 & 688600 & 5.8 & 5.1872 & TRN & \\
\hline CHEMBL 78150 & 688600 & 4.6 & 4.6256 & TRN & \\
\hline CHEMBL3199632 & 688600 & 5.0 & 5.2008 & TRN & \\
\hline CHEMBL51931 & 688600 & 4.7 & 4.76 & TRN & \\
\hline CHEMBL1382305 & 688600 & 4.95 & 4.8892 & TRN & \\
\hline CHEMBL1789983 & 688600 & 4.4 & 5.1334 & TST & \\
\hline CHEMBL1507494 & 688600 & 4.55 & 4.8375 & TST & \\
\hline CHEMBL1592234 & 688600 & 5.35 & 5.2454 & TRN & \\
\hline CHEMBL3212373 & 688600 & 5.7 & 4.6953 & TRN & \\
\hline CHEMBL1336122 & 688600 & 8.4949 & 7.0246 & TST & \\
\hline CHEMBL79824 & 688600 & 8.4949 & 5.8883 & TST & \\
\hline CHEMBL1423852 & 688600 & 4.65 & 4.9147 & TRN & \\
\hline CHEMBL539947 & 688600 & 4.75 & 4.6774 & TRN & \\
\hline CHEMBL1381413 & 688600 & 4.8 & 4.7838 & TRN & \\
\hline CHEMBL1976499 & 688600 & 4.6 & 4.7201 & TRN & \\
\hline CHEMBL363535 & 688600 & 4.6 & 4.8895 & TST & \\
\hline CHEMBL66654 & 688600 & 10.1002 & 5.7593 & TST & \\
\hline CHEMBL1608604 & 688600 & 4.4 & 4.8358 & TRN & \\
\hline CHEMBL1255836 & 688600 & 4.5 & 7.0458 & TRN & \\
\hline CHEMBL1528565 & 688600 & 9.699 & 5.2925 & TST & \\
\hline CHEMBL3144987 & 688600 & 4.75 & 4.8652 & TRN & \\
\hline CHEMBL1400375 & 688600 & 4.6 & 5.1701 & TRN & \\
\hline
\end{tabular}




\begin{tabular}{|c|c|c|c|c|}
\hline \multicolumn{5}{|c|}{ Supplemental Table S2.txt } \\
\hline CHEMBL 3199590 & 688600 & 6.0 & 4.7332 & TRN \\
\hline CHEMBL1553049 & 688600 & 4.8 & 5.9309 & TST \\
\hline CHEMBL479014 & 688600 & 7.8996 & 5.5152 & TRN \\
\hline CHEMBL1345979 & 688600 & 4.4 & 5.3037 & TST \\
\hline CHEMBL1564253 & 688600 & 4.8 & 4.5424 & TRN \\
\hline CHEMBL1573613 & 688600 & 4.7 & 5.1103 & TRN \\
\hline CHEMBL21241 & 688600 & 6.0 & 5.4453 & TST \\
\hline CHEMBL1981200 & 688600 & 4.8 & 4.3002 & TRN \\
\hline CHEMBL88584 & 688600 & 8.5528 & 6.228 & TRN \\
\hline CHEMBL1500909 & 688600 & 4.85 & 4.2529 & TRN \\
\hline CHEMBL1388300 & 688600 & 4.6 & 4.4883 & TRN \\
\hline CHEMBL1430383 & 688600 & 4.8 & 5.1969 & TRN \\
\hline CHEMBL8867 & 688600 & 10.0 & 5.2973 & TST \\
\hline CHEMBL498423 & 688600 & 4.65 & 4.1426 & TRN \\
\hline CHEMBL1256924 & 688600 & 8.4559 & 6.6251 & TRN \\
\hline CHEMBL1380801 & 688600 & 5.45 & 4.6986 & TRN \\
\hline CHEMBL1413806 & 688600 & 4.5 & 4.3124 & TRN \\
\hline CHEMBL1474151 & 688600 & 4.4 & 4.7706 & TRN \\
\hline CHEMBL1402056 & 688600 & 4.55 & 4.8023 & TRN \\
\hline CHEMBL1501132 & 688600 & 4.9 & 4.8837 & TRN \\
\hline CHEMBL1514550 & 688600 & 4.6 & 4.6241 & TRN \\
\hline CHEMBL1503294 & 688600 & 5.05 & 4.9478 & TST \\
\hline CHEMBL63329 & 688600 & 5.0 & 5.2519 & TST \\
\hline CHEMBL353764 & 688600 & 4.4 & 5.1587 & TST \\
\hline CHEMBL574779 & 688600 & 4.85 & 4.8268 & TRN \\
\hline CHEMBL35228 & 688600 & 4.4 & 5.4107 & TRN \\
\hline CHEMBL602375 & 688600 & 4.9 & 5.391 & TST \\
\hline CHEMBL1460092 & 688600 & 4.65 & 4.9753 & TRN \\
\hline CHEMBL 28862 & 688600 & 5.35 & 7.4294 & TRN \\
\hline CHEMBL10247 & 688600 & 5.55 & 5.5544 & TRN \\
\hline CHEMBL200027 & 688600 & 4.45 & 4.3896 & TST \\
\hline CHEMBL1256739 & 688600 & 7.8996 & 5.9414 & TRN \\
\hline CHEMBL1991426 & 688600 & 4.4 & 4.7491 & TRN \\
\hline CHEMBL1370459 & 688600 & 4.4 & 4.6987 & TRN \\
\hline CHEMBL1566720 & 688600 & 4.75 & 4.6281 & TRN \\
\hline CHEMBL1567601 & 688600 & 4.4 & 4.7047 & TRN \\
\hline CHEMBL1597827 & 688600 & 4.6 & 4.7001 & TRN \\
\hline CHEMBL 275854 & 688600 & 8.699 & 7.0838 & TRN \\
\hline CHEMBL1731995 & 688600 & 5.05 & 4.7522 & TRN \\
\hline CHEMBL57978 & 688600 & 4.4 & 5.4384 & TRN \\
\hline CHEMBL1300008 & 688600 & 4.7 & 4.1262 & TRN \\
\hline CHEMBL1256623 & 688600 & 5.2 & 5.7794 & TRN \\
\hline CHEMBL3192113 & 688600 & 4.5 & 5.192 & TRN \\
\hline CHEMBL1462360 & 688600 & 5.0 & 5.0065 & TRN \\
\hline CHEMBL1062 & 688600 & 5.3 & 5.6703 & TST \\
\hline CHEMBL1971727 & 688600 & 4.5 & 4.6403 & TRN \\
\hline CHEMBL1256181 & 688600 & 8.5528 & 6.8553 & TST \\
\hline CHEMBL1305658 & 688600 & 4.7 & 5.4315 & TRN \\
\hline
\end{tabular}




\begin{tabular}{|c|c|c|c|c|}
\hline \multicolumn{5}{|c|}{ Supplemental Table S2.txt } \\
\hline CHEMBL1501392 & 688600 & 5.05 & 5.0361 & TRN \\
\hline CHEMBL 3190625 & 688600 & 4.4 & 5.24100 & 00000000005 \\
\hline CHEMBL1421590 & 688600 & 5.3 & 5.2765 & TRN \\
\hline CHEMBL1587837 & 688600 & 4.55 & 4.6665 & TRN \\
\hline CHEMBL1400512 & 688600 & 4.45 & 4.7669 & TRN \\
\hline CHEMBL 272465 & 688600 & 5.1 & 5.3148 & TRN \\
\hline CHEMBL1367035 & 688600 & 4.45 & 4.4323 & TRN \\
\hline CHEMBL1445648 & 688600 & 4.35 & 5.3204 & TRN \\
\hline CHEMBL 1484989 & 688600 & 4.55 & 4.6654 & TRN \\
\hline CHEMBL3191913 & 688600 & 4.45 & 5.4374 & TRN \\
\hline CHEMBL3208556 & 688600 & 4.6 & 5.1676 & TRN \\
\hline CHEMBL 3145049 & 688600 & 4.4 & 4.8867 & TRN \\
\hline CHEMBL1511859 & 688600 & 5.0 & 5.231 & TST \\
\hline CHEMBL1256625 & 688600 & 8.4949 & 6.058 & TRN \\
\hline CHEMBL3199324 & 688600 & 4.55 & 4.0843 & TRN \\
\hline CHEMBL1488710 & 688600 & 4.45 & 4.9242 & TRN \\
\hline CHEMBL288174 & 688600 & 4.6 & 4.5975 & TST \\
\hline CHEMBL1509747 & 688600 & 4.65 & 4.8421 & TRN \\
\hline CHEMBL1345724 & 688600 & 4.7 & 4.6235 & TRN \\
\hline CHEMBL1465659 & 688600 & 4.95 & 4.4901 & TST \\
\hline CHEMBL1605526 & 688600 & 4.5 & 4.7417 & TRN \\
\hline CHEMBL 3856144 & 688600 & 4.5 & 6.5055 & TST \\
\hline CHEMBL45281 & 688600 & 5.4 & 5.5323 & TST \\
\hline CHEMBL1449334 & 688600 & 4.7 & 4.8152 & TRN \\
\hline CHEMBL1397308 & 688600 & 4.4 & 5.5187 & TRN \\
\hline CHEMBL469424 & 688600 & 5.05 & 5.7026 & TST \\
\hline CHEMBL1357911 & 688600 & 4.55 & 5.3009 & TRN \\
\hline CHEMBL1362650 & 688600 & 5.15 & 5.3636 & TRN \\
\hline CHEMBL 247378 & 688600 & 8.8539 & 5.6888 & TRN \\
\hline CHEMBL 3193786 & 688600 & 4.65 & 4.8616 & TRN \\
\hline CHEMBL1413583 & 688600 & 4.4 & 4.4212 & TRN \\
\hline CHEMBL85139 & 688600 & 4.7 & 5.0282 & TRN \\
\hline CHEMBL1503307 & 688600 & 4.55 & 4.9675 & TRN \\
\hline CHEMBL3193946 & 688600 & 4.9 & 4.9841 & TRN \\
\hline CHEMBL1541631 & 688600 & 4.8 & 5.0001 & TRN \\
\hline CHEMBL 236614 & 688600 & 4.5 & 4.633 & TRN \\
\hline CHEMBL1338358 & 688600 & 4.9 & 4.9909 & TRN \\
\hline CHEMBL1599161 & 688600 & 5.05 & 4.4446 & TRN \\
\hline CHEMBL1326606 & 688600 & 4.55 & 4.8183 & TRN \\
\hline CHEMBL1256663 & 688600 & 8.2007 & 5.9786 & TRN \\
\hline CHEMBL1508839 & 688600 & 4.55 & 4.4282 & TRN \\
\hline CHEMBL416615 & 688600 & 6.15 & 5.7699 & TRN \\
\hline CHEMBL224916 & 688600 & 4.7 & 4.622 & TRN \\
\hline CHEMBL 338790 & 688600 & 4.55 & 4.7507 & TRN \\
\hline CHEMBL1364881 & 688600 & 4.6 & 4.7324 & TRN \\
\hline CHEMBL 247484 & 688600 & 4.6 & 5.7876 & TRN \\
\hline CHEMBL1571442 & 688600 & 4.8 & 4.6815 & TRN \\
\hline CHEMBL1256984 & 688600 & 4.55 & 5.1996 & TST \\
\hline
\end{tabular}




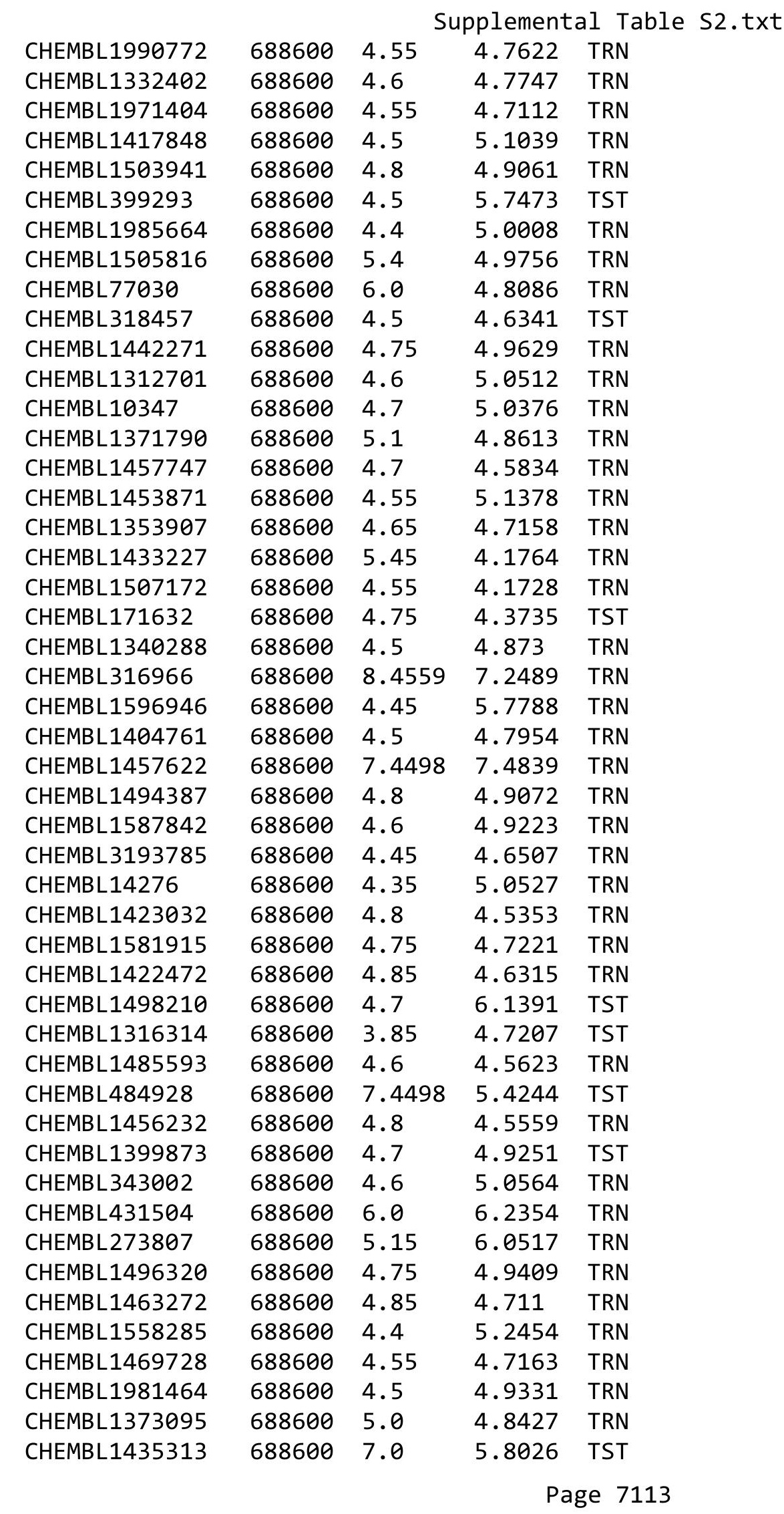




\begin{tabular}{|c|c|c|c|c|c|}
\hline \multicolumn{6}{|c|}{ Supplemental Table S2.txt } \\
\hline CHEMBL299052 & 688600 & 5.9 & 5.6692 & TST & \\
\hline CHEMBL1404559 & 688600 & 4.9 & 4.4275 & TRN & \\
\hline CHEMBL3191896 & 688600 & 4.4 & 4.4148 & TRN & \\
\hline CHEMBL1575767 & 688600 & 4.65 & 5.0215 & TRN & \\
\hline CHEMBL124267 & 688600 & 9.0 & 6.0439 & TRN & \\
\hline CHEMBL1430266 & 688600 & 4.7 & 4.8916 & TRN & \\
\hline CHEMBL534084 & 688600 & 4.95 & 5.8457 & TRN & \\
\hline CHEMBL1256835 & 688600 & 5.0 & 5.4201 & TRN & \\
\hline CHEMBL3195461 & 688600 & 4.7 & 4.4331 & TRN & \\
\hline CHEMBL1471055 & 688600 & 4.55 & 5.0404 & TST & \\
\hline CHEMBL1465297 & 688600 & 4.5 & 4.2303 & TRN & \\
\hline CHEMBL1509755 & 688600 & 4.6 & 4.1846 & TRN & \\
\hline CHEMBL1612163 & 688600 & 4.55 & 4.8291 & TRN & \\
\hline CHEMBL1383639 & 688600 & 4.85 & 4.2201 & TRN & \\
\hline CHEMBL1390568 & 688600 & 4.65 & 4.7038 & TRN & \\
\hline CHEMBL1986690 & 688600 & 4.7 & 4.8726 & TST & \\
\hline CHEMBL1498398 & 688600 & 4.55 & 4.7045 & TST & \\
\hline CHEMBL 2448607 & 688600 & 7.1002 & 5.7032 & TST & \\
\hline CHEMBL1374536 & 688600 & 4.5 & 4.8838 & TRN & \\
\hline CHEMBL1309432 & 688600 & 5.4 & 4.66100 & 00000000005 & TRN \\
\hline CHEMBL1561877 & 688600 & 4.55 & 4.9028 & TRN & \\
\hline CHEMBL1411304 & 688600 & 5.1 & 4.495 & TRN & \\
\hline CHEMBL1391063 & 688600 & 7.0 & 6.2478 & TRN & \\
\hline CHEMBL 3925157 & 688600 & 5.15 & 5.0244 & TRN & \\
\hline CHEMBL1476362 & 688600 & 4.45 & 5.8565 & TST & \\
\hline CHEMBL1522786 & 688600 & 4.45 & 5.02 & TRN & \\
\hline CHEMBL1556654 & 688600 & 8.5528 & 6.316 & TST & \\
\hline CHEMBL 290904 & 688600 & 5.1 & 4.9885 & TRN & \\
\hline CHEMBL3348955 & 688600 & 5.9 & 5.6546 & TST & \\
\hline CHEMBL1504661 & 688600 & 4.5 & 5.056 & TRN & \\
\hline CHEMBL2001904 & 688600 & 4.55 & 4.7227 & TST & \\
\hline CHEMBL 70880 & 688600 & 6.3 & 5.0079 & TRN & \\
\hline CHEMBL3190873 & 688600 & 4.55 & 4.042 & TRN & \\
\hline CHEMBL1437711 & 688600 & 10.15 & 5.7345 & TST & \\
\hline CHEMBL1399039 & 688600 & 4.4 & 4.3418 & TRN & \\
\hline CHEMBL11475 & 688600 & 4.75 & 5.2674 & TRN & \\
\hline CHEMBL1600325 & 688600 & 8.4949 & 7.0921 & TRN & \\
\hline CHEMBL1339591 & 688600 & 4.6 & 4.7598 & TRN & \\
\hline CHEMBL1180496 & 688600 & 8.5528 & 6.2636 & TRN & \\
\hline CHEMBL3191034 & 688600 & 5.0 & 5.1055 & TRN & \\
\hline CHEMBL1414558 & 688600 & 4.8 & 4.871 & TRN & \\
\hline CHEMBL1504875 & 688600 & 4.85 & 5.1996 & TRN & \\
\hline CHEMBL1541861 & 688600 & 4.4 & 5.0048 & TRN & \\
\hline CHEMBL1499451 & 688600 & 4.75 & 4.968 & TRN & \\
\hline CHEMBL1493528 & 688600 & 4.85 & 5.1562 & TRN & \\
\hline CHEMBL1499653 & 688600 & 4.6 & 4.7509 & TRN & \\
\hline CHEMBL1498509 & 688600 & 5.05 & 4.6776 & TRN & \\
\hline CHEMBL1516388 & 688600 & 6.0 & 5.2675 & TST & \\
\hline
\end{tabular}




\begin{tabular}{|c|c|c|c|c|c|}
\hline \multicolumn{6}{|c|}{ Supplemental Table S2.txt } \\
\hline CHEMBL1373937 & 688600 & 4.4 & 4.9309 & TRN & \\
\hline CHEMBL 3195410 & 688600 & 4.6 & 4.5981 & TRN & \\
\hline CHEMBL1369461 & 688600 & 7.0501 & 7.3251 & TRN & \\
\hline CHEMBL1393087 & 688600 & 4.5 & 4.7542 & TRN & \\
\hline CHEMBL1339512 & 688600 & 4.75 & 5.1228 & TRN & \\
\hline CHEMBL3197042 & 688600 & 4.8 & 5.3206 & TST & \\
\hline CHEMBL1360102 & 688600 & 4.45 & 4.8959 & TRN & \\
\hline CHEMBL1447667 & 688600 & 4.9 & 4.6238 & TRN & \\
\hline CHEMBL559934 & 688600 & 9.0969 & 5.7174 & TST & \\
\hline CHEMBL1598865 & 688600 & 4.7 & 5.3253 & TRN & \\
\hline CHEMBL15192 & 688600 & 4.6 & 4.6483 & TRN & \\
\hline CHEMBL1200450 & 688600 & 7.4001 & 5.9655 & TRN & \\
\hline CHEMBL 28449 & 688600 & 5.5 & 7.28 & TRN & \\
\hline CHEMBL1416169 & 688600 & 4.8 & 4.3713 & TRN & \\
\hline CHEMBL578585 & 688600 & 4.75 & 4.6805 & TRN & \\
\hline CHEMBL1257106 & 688600 & 6.6 & 6.3336 & TRN & \\
\hline CHEMBL1566067 & 688600 & 4.4 & 4.8668 & TRN & \\
\hline CHEMBL180427 & 688600 & 8.4949 & 5.1861 & TST & \\
\hline CHEMBL3193805 & 688600 & 4.55 & 4.2449 & TRN & \\
\hline CHEMBL3197841 & 688600 & 4.5 & 4.6315 & TRN & \\
\hline CHEMBL1312 & 688600 & 4.85 & 5.7752 & TRN & \\
\hline CHEMBL34704 & 688600 & 8.2518 & 5.1384 & TST & \\
\hline CHEMBL1500249 & 688600 & 6.3 & 6.2115 & TRN & \\
\hline CHEMBL2110371 & 688600 & 4.65 & 5.5209 & TRN & \\
\hline CHEMBL1493257 & 688600 & 4.45 & 5.0582 & TRN & \\
\hline CHEMBL1492622 & 688600 & 4.6 & 4.4329 & TRN & \\
\hline CHEMBL47529 & 688600 & 8.9586 & 5.226 & TRN & \\
\hline CHEMBL1469245 & 688600 & 4.5 & 4.501 & TRN & \\
\hline CHEMBL1530518 & 688600 & 4.45 & 4.8967 & TST & \\
\hline CHEMBL1344248 & 688600 & 4.95 & 4.98300 & 00000000005 & TRN \\
\hline CHEMBL1463829 & 688600 & 4.5 & 4.4197 & TRN & \\
\hline CHEMBL1255737 & 688600 & 8.5528 & 5.86700 & 0000000001 & TRN \\
\hline CHEMBL1331957 & 688600 & 6.45 & 7.1156 & TRN & \\
\hline CHEMBL1381627 & 688600 & 5.0 & 5.6843 & TRN & \\
\hline CHEMBL1384217 & 688600 & 4.95 & 4.6324 & TRN & \\
\hline CHEMBL3208140 & 688600 & 4.55 & 4.7133 & TRN & \\
\hline CHEMBL1256659 & 688600 & 4.45 & 5.2831 & TRN & \\
\hline CHEMBL1365058 & 688600 & 4.85 & 4.985 & TRN & \\
\hline CHEMBL366489 & 688600 & 4.2 & 6.5701 & TRN & \\
\hline CHEMBL1540637 & 688600 & 4.9 & 5.0094 & TRN & \\
\hline CHEMBL1375934 & 688600 & 4.55 & 4.7527 & TRN & \\
\hline CHEMBL1541005 & 688600 & 4.55 & 4.6038 & TRN & \\
\hline CHEMBL1255653 & 688600 & 8.6576 & 5.8257 & TST & \\
\hline CHEMBL1502633 & 688600 & 4.6 & 4.7109 & TRN & \\
\hline CHEMBL1536896 & 688600 & 5.45 & 4.7799 & TRN & \\
\hline CHEMBL1576658 & 688600 & 6.1 & 5.7135 & TRN & \\
\hline CHEMBL1997990 & 688600 & 5.1 & 4.7322 & TRN & \\
\hline CHEMBL1543646 & 688600 & 4.6 & 4.5864 & TRN & \\
\hline
\end{tabular}




\begin{tabular}{|c|c|c|c|c|c|}
\hline \multicolumn{6}{|c|}{ Supplemental Table S2.txt } \\
\hline CHEMBL1522941 & 688600 & 4.5 & 4.2825 & TRN & \\
\hline CHEMBL1522262 & 688600 & 5.0 & 5.0589 & TST & \\
\hline CHEMBL289277 & 688600 & 5.45 & 5.8279 & TRN & \\
\hline CHEMBL1381257 & 688600 & 4.5 & 6.0051 & TST & \\
\hline CHEMBL1589017 & 688600 & 4.6 & 4.7629 & TRN & \\
\hline CHEMBL1387693 & 688600 & 4.9 & 4.8387 & TRN & \\
\hline CHEMBL1416439 & 688600 & 4.4 & 4.4645 & TRN & \\
\hline CHEMBL66 & 688600 & 5.35 & 5.3431 & TRN & \\
\hline CHEMBL1450648 & 688600 & 4.5 & 4.5446 & TRN & \\
\hline CHEMBL458328 & 688600 & 4.9 & 6.1166 & TRN & \\
\hline CHEMBL1441044 & 688600 & 4.75 & 4.6965 & TRN & \\
\hline CHEMBL45244 & 688600 & 9.0969 & 5.9986 & TRN & \\
\hline CHEMBL1609566 & 688600 & 4.7 & 4.8629 & TRN & \\
\hline CHEMBL1577193 & 688600 & 4.4 & 4.6169 & TRN & \\
\hline CHEMBL1509585 & 688600 & 4.4 & 4.64199 & 99999999995 & TRN \\
\hline CHEMBL1989234 & 688600 & 4.4 & 5.7671 & TRN & \\
\hline CHEMBL18686 & 688600 & 3.85 & 6.0737 & TST & \\
\hline CHEMBL1323714 & 688600 & 6.9 & 5.0717 & TST & \\
\hline CHEMBL2373666 & 688600 & 8.5528 & 5.6099 & TST & \\
\hline CHEMBL45245 & 688600 & 4.55 & 4.993 & TRN & \\
\hline CHEMBL1385027 & 688600 & 4.85 & 5.011 & TRN & \\
\hline CHEMBL6634 & 688600 & 6.95 & 5.6748 & TST & \\
\hline CHEMBL1374385 & 688600 & 4.6 & 4.587 & TST & \\
\hline CHEMBL490577 & 688600 & 4.55 & 5.0039 & TRN & \\
\hline CHEMBL222759 & 688600 & 4.55 & 4.5245 & TRN & \\
\hline CHEMBL1564699 & 688600 & 4.6 & 4.837 & TRN & \\
\hline CHEMBL3144999 & 688600 & 4.4 & 4.8263 & TRN & \\
\hline CHEMBL 282489 & 688600 & 4.75 & 5.8574 & TRN & \\
\hline CHEMBL52 & 688600 & 4.65 & 5.5064 & TRN & \\
\hline CHEMBL1322708 & 688600 & 5.6 & 5.2284 & TST & \\
\hline CHEMBL1256484 & 688600 & 4.85 & 5.6726 & TRN & \\
\hline CHEMBL1586326 & 688600 & 4.5 & 3.8612 & TRN & \\
\hline CHEMBL1368934 & 688600 & 4.55 & 5.397 & TRN & \\
\hline CHEMBL1973501 & 688600 & 4.4 & 4.4404 & TRN & \\
\hline CHEMBL1443688 & 688600 & 4.75 & 4.926 & TRN & \\
\hline CHEMBL554041 & 688600 & 4.5 & 5.9737 & TST & \\
\hline CHEMBL1416258 & 688600 & 4.7 & 4.7362 & TRN & \\
\hline CHEMBL478 & 688600 & 9.3979 & 6.3238 & TRN & \\
\hline CHEMBL1427691 & 688600 & 4.7 & 4.5893 & TRN & \\
\hline CHEMBL1329465 & 688600 & 4.8 & 4.721 & TRN & \\
\hline CHEMBL531322 & 688600 & 4.75 & 4.4883 & TRN & \\
\hline CHEMBL334378 & 688600 & 4.4 & 4.917 & TRN & \\
\hline CHEMBL299683 & 688600 & 6.45 & 5.9597 & TRN & \\
\hline CHEMBL321585 & 688600 & 4.55 & 4.6947 & TRN & \\
\hline CHEMBL1422442 & 688600 & 4.65 & 5.8294 & TST & \\
\hline CHEMBL3195834 & 688600 & 5.1 & 4.615 & TST & \\
\hline CHEMBL3192276 & 688600 & 4.85 & 4.4233 & TRN & \\
\hline CHEMBL1538986 & 688600 & 4.45 & 4.218 & TRN & \\
\hline
\end{tabular}




\begin{tabular}{|c|c|c|c|c|}
\hline \multicolumn{5}{|c|}{ Supplemental Table S2.txt } \\
\hline CHEMBL1555135 & 688600 & 4.65 & 4.5004 & TRN \\
\hline CHEMBL1982305 & 688600 & 4.7 & 4.4277 & TRN \\
\hline CHEMBL1495306 & 688600 & 4.85 & 4.3898 & TRN \\
\hline CHEMBL1419900 & 688600 & 5.3 & 4.6303 & TRN \\
\hline CHEMBL1532063 & 688600 & 4.75 & 4.5299 & TRN \\
\hline CHEMBL1499111 & 688600 & 4.6 & 4.5905 & TRN \\
\hline CHEMBL 3192017 & 688600 & 4.65 & 4.6546 & TRN \\
\hline CHEMBL1539557 & 688600 & 4.55 & 4.9366 & TRN \\
\hline CHEMBL1553128 & 688600 & 4.45 & 5.2917 & TRN \\
\hline CHEMBL34730 & 688600 & 10.2503 & 6.9931 & TRN \\
\hline CHEMBL1523317 & 688600 & 5.25 & 5.3298 & TST \\
\hline CHEMBL601757 & 688600 & 6.1 & 6.0859 & TRN \\
\hline CHEMBL1672292 & 688600 & 4.4 & 4.7143 & TRN \\
\hline CHEMBL1426378 & 688600 & 4.75 & 4.6407 & TRN \\
\hline CHEMBL388054 & 688600 & 8.4949 & 5.3879 & TRN \\
\hline CHEMBL1572403 & 688600 & 4.65 & 4.6845 & TRN \\
\hline CHEMBL1445776 & 688600 & 4.45 & 4.2042 & TRN \\
\hline CHEMBL1301243 & 688600 & 4.65 & 4.3242 & TRN \\
\hline CHEMBL599013 & 688600 & 4.85 & 4.5796 & TRN \\
\hline CHEMBL1432333 & 688600 & 4.55 & 4.647 & TRN \\
\hline CHEMBL1471583 & 688600 & 4.7 & 5.4145 & TRN \\
\hline CHEMBL1514486 & 688600 & 4.8 & 4.8781 & TST \\
\hline CHEMBL432608 & 688600 & 8.4949 & 5.6963 & TST \\
\hline CHEMBL1256325 & 688600 & 9.0458 & 7.0438 & TRN \\
\hline CHEMBL405110 & 688600 & 4.5 & 4.2826 & TST \\
\hline CHEMBL1440291 & 688600 & 4.4 & 4.8998 & TRN \\
\hline CHEMBL1459125 & 688600 & 5.55 & 4.4727 & TRN \\
\hline CHEMBL1598087 & 688600 & 4.4 & 5.2733 & TRN \\
\hline CHEMBL 3193134 & 688600 & 4.95 & 5.0964 & TRN \\
\hline CHEMBL 3195635 & 688600 & 4.7 & 4.6153 & TRN \\
\hline CHEMBL 294590 & 688600 & 3.65 & 6.5438 & TRN \\
\hline CHEMBL117405 & 688600 & 4.1 & 5.7222 & TST \\
\hline CHEMBL1570161 & 688600 & 4.55 & 5.3344 & TRN \\
\hline CHEMBL1701224 & 688600 & 5.45 & 4.3119 & TRN \\
\hline CHEMBL1332039 & 688600 & 4.4 & 4.7918 & TRN \\
\hline CHEMBL1367496 & 688600 & 4.4 & 4.2303 & TRN \\
\hline CHEMBL1320310 & 688600 & 5.8 & 5.7229 & TST \\
\hline CHEMBL1532268 & 688600 & 4.4 & 4.7013 & TRN \\
\hline CHEMBL1546183 & 688600 & 4.5 & 4.7313 & TRN \\
\hline CHEMBL 274438 & 688600 & 4.65 & 5.0192 & TRN \\
\hline CHEMBL1381868 & 688600 & 4.7 & 4.5252 & TRN \\
\hline CHEMBL1397706 & 688600 & 4.45 & 5.7732 & TST \\
\hline CHEMBL3191236 & 688600 & 4.5 & 4.5956 & TRN \\
\hline CHEMBL1543635 & 688600 & 4.9 & 5.2342 & TRN \\
\hline CHEMBL1299502 & 688600 & 4.45 & 4.4947 & TRN \\
\hline CHEMBL1369813 & 688600 & 4.6 & 5.1401 & TRN \\
\hline CHEMBL1424208 & 688600 & 4.9 & 4.3948 & TRN \\
\hline CHEMBL1571803 & 688600 & 4.4 & 4.3019 & TRN \\
\hline
\end{tabular}




\begin{tabular}{|c|c|c|c|c|c|}
\hline & & \multicolumn{4}{|c|}{ Supplemental Table S2.txt } \\
\hline CHEMBL1256132 & 688600 & 9.3979 & 7.1433 & TRN & \\
\hline CHEMBL1568915 & 688600 & 4.6 & 4.9359 & TST & \\
\hline CHEMBL1531824 & 688600 & 4.55 & 4.8494 & TST & \\
\hline CHEMBL1600232 & 688600 & 6.0 & 5.4369 & TST & \\
\hline CHEMBL1453208 & 688600 & 4.35 & 5.4741 & TRN & \\
\hline CHEMBL33103 & 688600 & 8.4949 & 6.8911 & TRN & \\
\hline CHEMBL1450165 & 688600 & 5.5 & 5.45200 & 0000000001 & TRN \\
\hline CHEMBL1256362 & 688600 & 7.3002 & 6.4098 & TST & \\
\hline CHEMBL1470375 & 688600 & 6.15 & 5.6049 & TRN & \\
\hline CHEMBL1362935 & 688600 & 5.5 & 6.0578 & TRN & \\
\hline CHEMBL1310699 & 688600 & 4.85 & 5.3181 & TRN & \\
\hline CHEMBL1493117 & 688600 & 8.4949 & 5.4494 & TRN & \\
\hline CHEMBL1999630 & 688600 & 5.15 & 4.5184 & TRN & \\
\hline CHEMBL1606403 & 688600 & 4.55 & 4.5558 & TRN & \\
\hline CHEMBL1302100 & 688600 & 4.65 & 5.3626 & TST & \\
\hline CHEMBL1412043 & 688600 & 5.35 & 4.6381 & TRN & \\
\hline CHEMBL1360155 & 688600 & 4.65 & 4.8593 & TRN & \\
\hline CHEMBL1496237 & 688600 & 4.65 & 5.20700 & 0000000001 & TRN \\
\hline CHEMBL1504918 & 688600 & 4.5 & 5.1094 & TRN & \\
\hline CHEMBL540303 & 688600 & 8.4949 & 6.2072 & TST & \\
\hline CHEMBL1484657 & 688600 & 4.7 & 4.8491 & TRN & \\
\hline CHEMBL1575652 & 688600 & 4.75 & 4.3038 & TRN & \\
\hline CHEMBL1975756 & 688600 & 4.95 & 4.9557 & TRN & \\
\hline CHEMBL1465322 & 688600 & 4.85 & 5.0757 & TRN & \\
\hline CHEMBL1459161 & 688600 & 4.65 & 4.8975 & TRN & \\
\hline CHEMBL1576781 & 688600 & 4.4 & 4.1812 & TRN & \\
\hline CHEMBL1485261 & 688600 & 4.7 & 4.4813 & TRN & \\
\hline CHEMBL1412842 & 688600 & 8.4949 & 6.4568 & TRN & \\
\hline CHEMBL1968732 & 688600 & 4.8 & 4.8355 & TRN & \\
\hline CHEMBL1323529 & 688600 & 4.6 & 4.9287 & TRN & \\
\hline CHEMBL1583199 & 688600 & 5.55 & 4.0593 & TRN & \\
\hline CHEMBL1699206 & 688600 & 4.55 & 4.7547 & TRN & \\
\hline CHEMBL 2005973 & 688600 & 5.05 & 4.4089 & TRN & \\
\hline CHEMBL 24510 & 688600 & 8.4949 & 5.9628 & TST & \\
\hline CHEMBL1255758 & 688600 & 6.9 & 5.8976 & TST & \\
\hline CHEMBL1381676 & 688600 & 4.85 & 4.9991 & TRN & \\
\hline CHEMBL 328710 & 688600 & 4.65 & 4.1114 & TRN & \\
\hline CHEMBL1256740 & 688600 & 9.3979 & 6.0392 & TRN & \\
\hline CHEMBL1508684 & 688600 & 4.55 & 4.9322 & TRN & \\
\hline CHEMBL1500751 & 688600 & 4.55 & 4.8311 & TST & \\
\hline CHEMBL1424878 & 688600 & 4.55 & 4.8347 & TRN & \\
\hline CHEMBL1539986 & 688600 & 5.0 & 5.2124 & TRN & \\
\hline CHEMBL3196071 & 688600 & 4.85 & 4.3369 & TST & \\
\hline CHEMBL1364903 & 688600 & 4.9 & 4.9225 & TRN & \\
\hline CHEMBL 276727 & 688600 & 6.2 & 6.7888 & TST & \\
\hline CHEMBL1383746 & 688600 & 4.55 & 5.0998 & TRN & \\
\hline CHEMBL47940 & 688600 & 4.65 & 4.7753 & TRN & \\
\hline CHEMBL391997 & 688600 & 4.7 & 5.5305 & TRN & \\
\hline
\end{tabular}




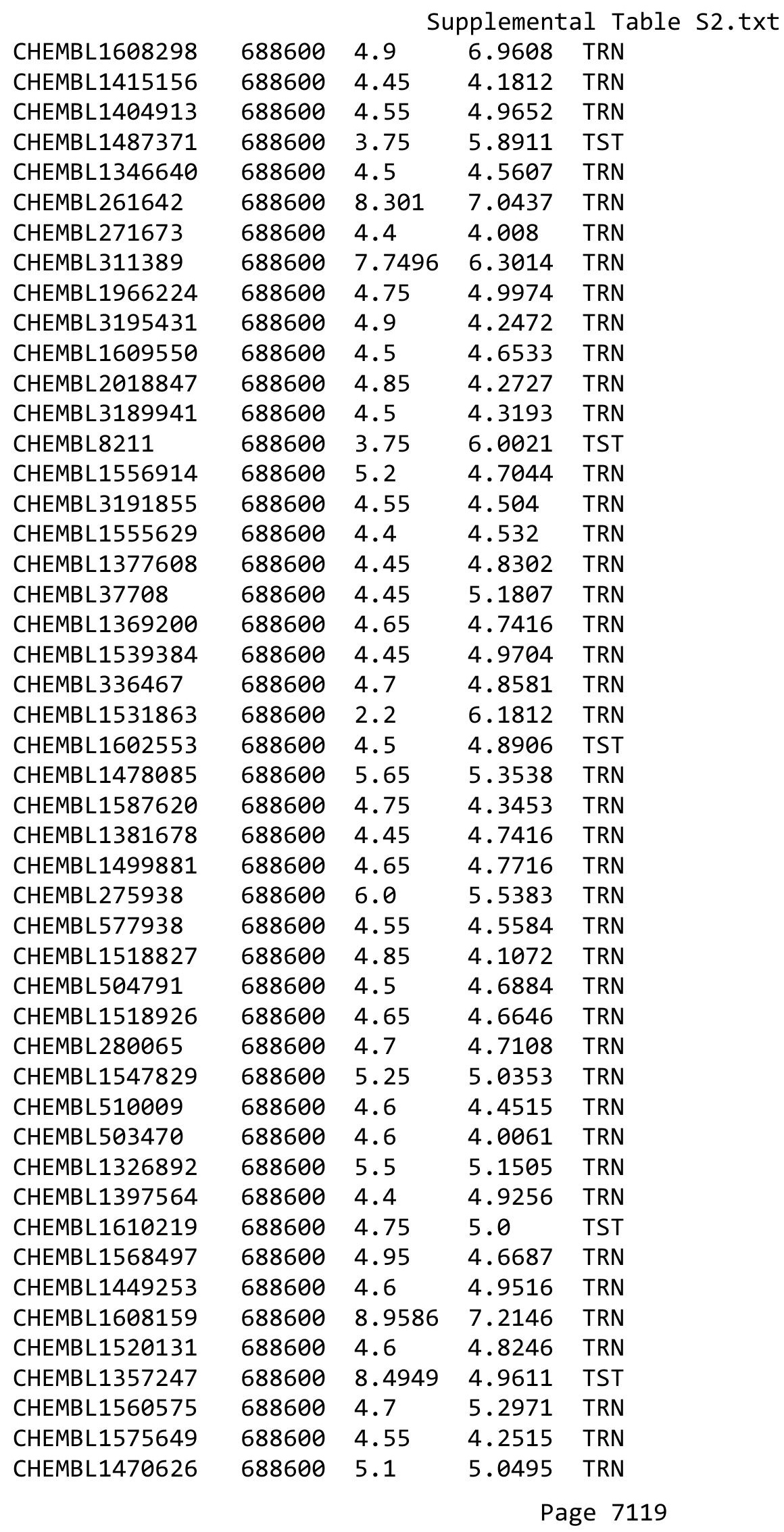




\begin{tabular}{|c|c|c|c|c|c|}
\hline \multicolumn{6}{|c|}{ Supplemental Table S2.txt } \\
\hline CHEMBL1316599 & 688600 & 4.55 & 6.3097 & TST & \\
\hline CHEMBL1436598 & 688600 & 4.6 & 4.5704 & TRN & \\
\hline CHEMBL1408395 & 688600 & 5.15 & 5.3835 & TST & \\
\hline CHEMBL1437486 & 688600 & 5.45 & 5.2671 & TST & \\
\hline CHEMBL1469489 & 688600 & 4.5 & 4.7244 & TRN & \\
\hline CHEMBL1582759 & 688600 & 6.1 & 4.5469 & TRN & \\
\hline CHEMBL66966 & 688600 & 4.65 & 5.1459 & TRN & \\
\hline CHEMBL1521960 & 688600 & 4.5 & 5.1005 & TRN & \\
\hline CHEMBL585591 & 688600 & 4.65 & 5.1826 & TST & \\
\hline CHEMBL1411862 & 688600 & 4.4 & 4.9678 & TRN & \\
\hline CHEMBL1325390 & 688600 & 5.2 & 5.4642 & TRN & \\
\hline CHEMBL1532650 & 688600 & 4.4 & 4.3541 & TRN & \\
\hline CHEMBL113180 & 688600 & 8.6021 & 6.2993 & TRN & \\
\hline CHEMBL1302170 & 688600 & 5.3 & 5.0334 & TRN & \\
\hline CHEMBL1597692 & 688600 & 4.9 & 5.916 & TST & \\
\hline CHEMBL1544915 & 688600 & 4.7 & 4.9852 & TRN & \\
\hline CHEMBL1470357 & 688600 & 4.5 & 4.8959 & TST & \\
\hline CHEMBL323356 & 688600 & 6.0 & 5.2309 & TRN & \\
\hline CHEMBL1583534 & 688600 & 5.0 & 5.1299 & TST & \\
\hline CHEMBL1407297 & 688600 & 4.55 & 5.3798 & TRN & \\
\hline CHEMBL1436121 & 688600 & 5.1 & 5.1046 & TST & \\
\hline CHEMBL1542560 & 688600 & 4.4 & 5.3983 & TRN & \\
\hline CHEMBL1501032 & 688600 & 4.55 & 5.1899 & TRN & \\
\hline CHEMBL1311527 & 688600 & 4.95 & 5.0624 & TRN & \\
\hline CHEMBL1305537 & 688600 & 4.5 & 4.7213 & TRN & \\
\hline CHEMBL1584150 & 688600 & 4.4 & 4.4693 & TRN & \\
\hline CHEMBL1457048 & 688600 & 4.45 & 4.6919 & TRN & \\
\hline CHEMBL1379656 & 688600 & 4.65 & 4.7346 & TRN & \\
\hline CHEMBL451226 & 688600 & 6.2 & 6.1394 & TRN & \\
\hline CHEMBL1569992 & 688600 & 5.05 & 5.2817 & TRN & \\
\hline CHEMBL1334484 & 688600 & 4.8 & 4.9088 & TRN & \\
\hline CHEMBL1988686 & 688600 & 5.4 & 5.2905 & TRN & \\
\hline CHEMBL1330381 & 688600 & 4.85 & 5.0242 & TRN & \\
\hline CHEMBL1256573 & 688600 & 10.3002 & 6.5363 & TRN & \\
\hline CHEMBL151 & 688600 & 6.0 & 5.4698 & TRN & \\
\hline CHEMBL58343 & 688600 & 8.5528 & 7.1491 & TRN & \\
\hline CHEMBL345124 & 688600 & 5.3 & 5.6602 & TST & \\
\hline CHEMBL1988202 & 688600 & 4.4 & 4.4504 & TRN & \\
\hline CHEMBL1376622 & 688600 & 5.0 & 5.0785 & TRN & \\
\hline CHEMBL1465618 & 688600 & 4.8 & 4.7648 & TST & \\
\hline CHEMBL1378634 & 688600 & 4.4 & 4.7739 & TRN & \\
\hline CHEMBL1310169 & 688600 & 4.4 & 4.88399 & 99999999995 & TRN \\
\hline CHEMBL1505994 & 688600 & 4.5 & 4.4096 & TRN & \\
\hline CHEMBL1465049 & 688600 & 4.45 & 4.5417 & TRN & \\
\hline CHEMBL41680 & 688600 & 6.0 & 6.193 & TRN & \\
\hline CHEMBL182461 & 688600 & 4.35 & 7.0677 & TRN & \\
\hline CHEMBL18132 & 688600 & 4.3 & 4.6587 & TRN & \\
\hline CHEMBL1348345 & 688600 & 4.8 & 5.3317 & TRN & \\
\hline
\end{tabular}




\begin{tabular}{|c|c|c|c|c|}
\hline \multirow[b]{2}{*}{ CHEMBL1403970 } & \multicolumn{4}{|c|}{ Supplemental Table S2.txt } \\
\hline & 688600 & 5.1 & 5.4717 & TRN \\
\hline CHEMBL1360857 & 688600 & 5.55 & 5.5647 & TRN \\
\hline CHEMBL1384094 & 688600 & 4.55 & 5.195 & TRN \\
\hline CHEMBL1474468 & 688600 & 4.8 & 4.4729 & TRN \\
\hline CHEMBL1464457 & 688600 & 4.75 & 4.5318 & TRN \\
\hline CHEMBL1968095 & 688600 & 4.55 & 5.1512 & TRN \\
\hline CHEMBL1986284 & 688600 & 4.5 & 4.3785 & TRN \\
\hline CHEMBL3189714 & 688600 & 4.7 & 4.0019 & TRN \\
\hline CHEMBL1351846 & 688600 & 4.7 & 4.9808 & TRN \\
\hline CHEMBL1603643 & 688600 & 4.5 & 4.5945 & TRN \\
\hline CHEMBL2374060 & 688600 & 5.5 & 5.187 & TST \\
\hline CHEMBL1471337 & 688600 & 4.6 & 4.6116 & TRN \\
\hline CHEMBL3195386 & 688600 & 4.6 & 5.0392 & TRN \\
\hline CHEMBL1535661 & 688600 & 4.45 & 4.6708 & TRN \\
\hline CHEMBL1323320 & 688600 & 4.6 & 4.9029 & TRN \\
\hline CHEMBL592124 & 688600 & 4.65 & 4.9195 & TRN \\
\hline CHEMBL1537381 & 688600 & 4.8 & 4.8426 & TRN \\
\hline CHEMBL1355634 & 688600 & 7.15 & 6.7283 & TRN \\
\hline CHEMBL1533549 & 688600 & 4.7 & 4.305 & TRN \\
\hline CHEMBL1480136 & 688600 & 9.3979 & 5.7262 & TST \\
\hline CHEMBL1302595 & 688600 & 4.8 & 4.9526 & TRN \\
\hline CHEMBL1604357 & 688600 & 4.95 & 5.1126 & TRN \\
\hline CHEMBL1966168 & 688600 & 5.05 & 5.0652 & TRN \\
\hline CHEMBL2003806 & 688600 & 5.0 & 4.4487 & TRN \\
\hline CHEMBL1482554 & 688600 & 4.7 & 4.7399 & TRN \\
\hline CHEMBL1608374 & 688600 & 4.3 & 5.0977 & TST \\
\hline CHEMBL1555791 & 688600 & 4.75 & 5.2725 & TRN \\
\hline CHEMBL1605235 & 688600 & 4.65 & 4.4409 & TRN \\
\hline CHEMBL601140 & 688600 & 6.0 & 5.4139 & TRN \\
\hline CHEMBL1242180 & 688600 & 4.5 & 4.2302 & TRN \\
\hline CHEMBL1494334 & 688600 & 4.5 & 5.1198 & TRN \\
\hline CHEMBL1405964 & 688600 & 4.5 & 5.1208 & TRN \\
\hline CHEMBL1526240 & 688600 & 4.65 & 4.9653 & TST \\
\hline CHEMBL1541779 & 688600 & 4.85 & 5.0741 & TST \\
\hline CHEMBL1518681 & 688600 & 4.55 & 5.4739 & TRN \\
\hline CHEMBL319244 & 688600 & 4.55 & 5.0749 & TRN \\
\hline CHEMBL1607463 & 688600 & 4.6 & 4.5318 & TRN \\
\hline CHEMBL285480 & 688600 & 4.5 & 4.4327 & TRN \\
\hline CHEMBL1606122 & 688600 & 4.6 & 4.4068 & TRN \\
\hline CHEMBL1344390 & 688600 & 5.1 & 5.2655 & TRN \\
\hline CHEMBL1305341 & 688600 & 4.55 & 4.5159 & TRN \\
\hline CHEMBL1453902 & 688600 & 6.0 & 4.5739 & TRN \\
\hline CHEMBL1498097 & 688600 & 4.4 & 4.8482 & TRN \\
\hline CHEMBL93655 & 688600 & 4.7 & 5.2168 & TRN \\
\hline CHEMBL1305764 & 688600 & 5.55 & 4.9394 & TRN \\
\hline CHEMBL1366025 & 688600 & 4.5 & 4.2973 & TRN \\
\hline CHEMBL1461491 & 688600 & 8.2518 & 6.1709 & TRN \\
\hline CHEMBL169272 & 688600 & 4.8 & 5.0799 & TRN \\
\hline
\end{tabular}




\begin{tabular}{|c|c|c|c|c|}
\hline \multicolumn{5}{|c|}{ Supplemental Table S2.txt } \\
\hline CHEMBL1518265 & 688600 & 4.55 & 4.4876 & TRN \\
\hline CHEMBL3212590 & 688600 & 4.85 & 5.3029 & TRN \\
\hline CHEMBL1447002 & 688600 & 5.4 & 4.6669 & TRN \\
\hline CHEMBL1255936 & 688600 & 4.85 & 5.6818 & TRN \\
\hline CHEMBL1337224 & 688600 & 4.7 & 4.3571 & TRN \\
\hline CHEMBL441282 & 688600 & 4.7 & 5.7456 & TRN \\
\hline CHEMBL1522300 & 688600 & 4.75 & 4.2336 & TRN \\
\hline CHEMBL60718 & 688600 & 4.3 & 5.516 & TRN \\
\hline CHEMBL1706577 & 688600 & 4.95 & 4.8382 & TRN \\
\hline CHEMBL3211856 & 688600 & 4.85 & 4.7531 & TST \\
\hline CHEMBL1256718 & 688600 & 7.1002 & 5.4901 & TST \\
\hline CHEMBL56 & 688600 & 6.6499 & 6.9937 & TRN \\
\hline CHEMBL1461574 & 688600 & 4.5 & 5.1345 & TRN \\
\hline CHEMBL 28626 & 688600 & 4.7 & 5.9125 & TRN \\
\hline CHEMBL120526 & 688600 & 4.5 & 4.9866 & TRN \\
\hline CHEMBL1256186 & 688600 & 6.45 & 5.5018 & TST \\
\hline CHEMBL1427047 & 688600 & 5.1 & 4.8564 & TRN \\
\hline CHEMBL1626274 & 688600 & 3.95 & 6.4335 & TRN \\
\hline CHEMBL543876 & 688600 & 4.7 & 5.6431 & TRN \\
\hline CHEMBL1595235 & 688600 & 4.45 & 4.8504 & TRN \\
\hline CHEMBL3190112 & 688600 & 4.7 & 4.8335 & TRN \\
\hline CHEMBL1456417 & 688600 & 4.25 & 5.7898 & TRN \\
\hline CHEMBL429023 & 688600 & 4.65 & 6.2181 & TST \\
\hline CHEMBL1427517 & 688600 & 4.5 & 4.9993 & TRN \\
\hline CHEMBL 22870 & 688600 & 4.65 & 5.8194 & TRN \\
\hline CHEMBL1435814 & 688600 & 4.4 & 4.4283 & TRN \\
\hline CHEMBL1364521 & 688600 & 4.45 & 4.947 & TRN \\
\hline CHEMBL 876 & 688600 & 8.3979 & 5.3472 & TRN \\
\hline CHEMBL1505688 & 688600 & 4.8 & 4.3186 & TRN \\
\hline CHEMBL1465370 & 688600 & 4.45 & 4.6061 & TRN \\
\hline CHEMBL582473 & 688600 & 4.5 & 4.8113 & TRN \\
\hline CHEMBL 2374077 & 688600 & 5.4 & 5.5948 & TST \\
\hline CHEMBL1543965 & 688600 & 4.45 & 5.0964 & TRN \\
\hline CHEMBL1420318 & 688600 & 4.85 & 4.1119 & TRN \\
\hline CHEMBL1363824 & 688600 & 4.9 & 5.3566 & TRN \\
\hline CHEMBL1326167 & 688600 & 4.9 & 4.7337 & TRN \\
\hline CHEMBL3197580 & 688600 & 4.65 & 5.0489 & TRN \\
\hline CHEMBL43612 & 688600 & 6.0 & 5.4627 & TRN \\
\hline CHEMBL1502018 & 688600 & 4.75 & 4.7641 & TRN \\
\hline CHEMBL1467222 & 688600 & 4.4 & 4.8907 & TRN \\
\hline CHEMBL1608911 & 688600 & 4.4 & 4.8678 & TRN \\
\hline CHEMBL1301714 & 688600 & 4.5 & 5.0039 & TRN \\
\hline CHEMBL1358313 & 688600 & 4.8 & 5.1846 & TST \\
\hline CHEMBL3351065 & 688600 & 4.6 & 5.6208 & TST \\
\hline CHEMBL1360080 & 688600 & 4.75 & 4.417 & TRN \\
\hline CHEMBL139935 & 688600 & 4.5 & 4.5884 & TRN \\
\hline CHEMBL 1256875 & 688600 & 8.9586 & 5.7514 & TRN \\
\hline CHEMBL1224512 & 688600 & 5.35 & 5.2517 & TRN \\
\hline
\end{tabular}




\begin{tabular}{|c|c|c|c|c|}
\hline \multirow[b]{2}{*}{ CHEMBL1346879 } & \multicolumn{4}{|c|}{ Supplemental Table S2.txt } \\
\hline & 688600 & 4.4 & 4.4876 & TRN \\
\hline CHEMBL1972346 & 688600 & 4.6 & 5.2086 & TRN \\
\hline CHEMBL1437272 & 688600 & 4.6 & 5.0474 & TRN \\
\hline CHEMBL1388790 & 688600 & 4.5 & 4.3674 & TRN \\
\hline CHEMBL1304265 & 688600 & 4.8 & 4.6239 & TRN \\
\hline CHEMBL137743 & 688600 & 6.0 & 5.8825 & TRN \\
\hline CHEMBL1584828 & 688600 & 4.6 & 4.9591 & TRN \\
\hline CHEMBL407874 & 688600 & 7.8013 & 5.4547 & TST \\
\hline CHEMBL1389066 & 688600 & 5.45 & 5.4953 & TRN \\
\hline CHEMBL1319741 & 688600 & 6.8499 & 4.8663 & TST \\
\hline CHEMBL3198598 & 688600 & 4.75 & 5.0184 & TRN \\
\hline CHEMBL1503652 & 688600 & 4.4 & 4.8689 & TRN \\
\hline CHEMBL1730100 & 688600 & 6.0 & 5.2938 & TST \\
\hline CHEMBL1455542 & 688600 & 4.45 & 4.3048 & TRN \\
\hline CHEMBL1398964 & 688600 & 5.2 & 4.8261 & TRN \\
\hline CHEMBL1325176 & 688600 & 4.45 & 4.565 & TRN \\
\hline CHEMBL1255841 & 688600 & 9.699 & 7.3297 & TRN \\
\hline CHEMBL285123 & 688600 & 8.6021 & 7.1053 & TRN \\
\hline CHEMBL47814 & 688600 & 9.3979 & 5.858 & TRN \\
\hline CHEMBL1300769 & 688600 & 4.5 & 4.6395 & TST \\
\hline CHEMBL1303651 & 688600 & 4.5 & 4.6528 & TRN \\
\hline CHEMBL1447034 & 688600 & 6.0 & 5.7058 & TRN \\
\hline CHEMBL1334062 & 688600 & 5.25 & 5.6561 & TRN \\
\hline CHEMBL333985 & 688600 & 5.05 & 5.2611 & TST \\
\hline CHEMBL77387 & 688600 & 5.55 & 4.7532 & TRN \\
\hline CHEMBL1165239 & 688600 & 6.0 & 6.3448 & TRN \\
\hline CHEMBL 213432 & 688600 & 4.5 & 5.3883 & TRN \\
\hline CHEMBL1586610 & 688600 & 4.65 & 4.7313 & TRN \\
\hline CHEMBL1313909 & 688600 & 4.8 & 4.52 & TRN \\
\hline CHEMBL1431851 & 688600 & 4.5 & 4.8695 & TRN \\
\hline CHEMBL1587422 & 688600 & 4.7 & 5.1117 & TST \\
\hline CHEMBL1562712 & 688600 & 4.4 & 4.9204 & TRN \\
\hline CHEMBL1256885 & 688600 & 6.05 & 5.7268 & TRN \\
\hline CHEMBL1380131 & 688600 & 4.4 & 4.7858 & TRN \\
\hline CHEMBL1570004 & 688600 & 5.0 & 4.4841 & TRN \\
\hline CHEMBL1331134 & 688600 & 4.4 & 4.9478 & TRN \\
\hline CHEMBL1256746 & 688600 & 4.75 & 4.9246 & TRN \\
\hline CHEMBL1548022 & 688600 & 4.45 & 5.935 & TST \\
\hline CHEMBL578512 & 688600 & 5.95 & 6.053 & TRN \\
\hline CHEMBL1507473 & 688600 & 4.55 & 4.5615 & TRN \\
\hline CHEMBL1511067 & 688600 & 4.6 & 5.098 & TRN \\
\hline CHEMBL1452766 & 688600 & 4.6 & 4.6465 & TRN \\
\hline CHEMBL1256139 & 688600 & 10.4001 & 6.905 & TRN \\
\hline CHEMBL1362933 & 688600 & 4.45 & 4.9051 & TST \\
\hline CHEMBL1308055 & 688600 & 4.55 & 5.0286 & TST \\
\hline CHEMBL1439893 & 688600 & 4.55 & 4.6184 & TST \\
\hline CHEMBL607979 & 688600 & 4.65 & 4.337 & TST \\
\hline CHEMBL1379894 & 688600 & 4.65 & 5.1049 & TST \\
\hline
\end{tabular}




\begin{tabular}{|c|c|c|c|c|}
\hline \multicolumn{5}{|c|}{ Supplemental Table S2.txt } \\
\hline CHEMBL3189236 & 688600 & 5.35 & 5.0781 & TST \\
\hline CHEMBL 284028 & 688600 & 4.2 & 5.4554 & TST \\
\hline CHEMBL1534034 & 688600 & 4.4 & 5.2852 & TST \\
\hline CHEMBL1515224 & 688600 & 4.6 & 5.3305 & TST \\
\hline CHEMBL1361703 & 688600 & 4.95 & 4.8058 & TST \\
\hline CHEMBL1310886 & 688600 & 4.75 & 5.2802 & TST \\
\hline CHEMBL 286204 & 688600 & 4.0 & 5.6223 & TST \\
\hline CHEMBL1365553 & 688600 & 5.2 & 3.7676 & TST \\
\hline CHEMBL1721986 & 688600 & 5.0 & 4.8906 & TST \\
\hline CHEMBL56393 & 688600 & 5.05 & 4.8254 & TST \\
\hline CHEMBL1974143 & 688600 & 4.6 & 4.0919 & TST \\
\hline CHEMBL1531919 & 688600 & 4.5 & 4.3835 & TST \\
\hline CHEMBL445969 & 688600 & 4.75 & 4.7593 & TST \\
\hline CHEMBL1299529 & 688600 & 4.4 & 4.8047 & TST \\
\hline CHEMBL1335321 & 688600 & 5.2 & 5.0284 & TST \\
\hline CHEMBL1559657 & 688600 & 4.95 & 5.2376 & TST \\
\hline CHEMBL1578127 & 688600 & 4.55 & 4.4571 & TST \\
\hline CHEMBL1400571 & 688600 & 4.55 & 5.0735 & TST \\
\hline CHEMBL1382304 & 688600 & 4.75 & 4.3265 & TST \\
\hline CHEMBL1320977 & 688600 & 4.45 & 4.4322 & TST \\
\hline CHEMBL331372 & 688600 & 9.2218 & 6.4662 & TST \\
\hline CHEMBL1452952 & 688600 & 5.0 & 4.6993 & TST \\
\hline CHEMBL1374526 & 688600 & 4.45 & 4.4798 & TST \\
\hline CHEMBL581868 & 688600 & 4.4 & 5.4133 & TST \\
\hline CHEMBL1306199 & 688600 & 4.85 & 4.1806 & TST \\
\hline CHEMBL444422 & 688600 & 5.5 & 6.0292 & TST \\
\hline CHEMBL1435221 & 688600 & 5.6 & 4.6972 & TST \\
\hline CHEMBL1358778 & 688600 & 4.75 & 5.0619 & TST \\
\hline CHEMBL1410173 & 688600 & 4.55 & 4.9472 & TST \\
\hline CHEMBL1438722 & 688600 & 5.4 & 4.5859 & TST \\
\hline CHEMBL1377709 & 688600 & 4.45 & 4.7359 & TST \\
\hline CHEMBL1543944 & 688600 & 4.5 & 4.4132 & TST \\
\hline CHEMBL1300312 & 688600 & 4.8 & 4.9484 & TST \\
\hline CHEMBL1603208 & 688600 & 4.45 & 5.0385 & TST \\
\hline CHEMBL1463659 & 688600 & 6.0 & 5.7796 & TST \\
\hline CHEMBL1458111 & 688600 & 4.4 & 4.7198 & TST \\
\hline CHEMBL1567020 & 688600 & 6.0 & 6.5889 & TST \\
\hline CHEMBL1330736 & 688600 & 4.4 & 4.2779 & TST \\
\hline CHEMBL1979747 & 688600 & 4.55 & 4.3469 & TST \\
\hline CHEMBL1536878 & 688600 & 4.85 & 5.3297 & TST \\
\hline CHEMBL1972037 & 688600 & 4.8 & 4.8319 & TST \\
\hline CHEMBL1485170 & 688600 & 5.0 & 4.9085 & TST \\
\hline CHEMBL1488474 & 688600 & 4.9 & 4.4253 & TST \\
\hline CHEMBL1376200 & 688600 & 5.0 & 4.7224 & TST \\
\hline CHEMBL3191795 & 688600 & 4.4 & 4.6113 & TST \\
\hline CHEMBL1302551 & 688600 & 5.4 & 4.8691 & TST \\
\hline CHEMBL1488035 & 688600 & 5.85 & 5.9207 & TST \\
\hline CHEMBL1358338 & 688600 & 5.0 & 4.6758 & TST \\
\hline
\end{tabular}




\begin{tabular}{|c|c|c|c|c|}
\hline \multicolumn{5}{|c|}{ Supplemental Table S2.txt } \\
\hline CHEMBL1329140 & 688600 & 4.6 & 4.2928 & TST \\
\hline CHEMBL1235717 & 688600 & 4.55 & 4.75 & TST \\
\hline CHEMBL1360615 & 688600 & 4.6 & 4.7452 & TST \\
\hline CHEMBL1349813 & 688600 & 4.65 & 4.76399 & 9999999999 \\
\hline CHEMBL1335064 & 688600 & 4.4 & 5.2294 & TST \\
\hline CHEMBL98350 & 688600 & 7.3002 & 4.478 & TST \\
\hline CHEMBL1082832 & 688600 & 5.1 & 5.4894 & TST \\
\hline CHEMBL1253351 & 688600 & 6.0 & 5.1904 & TST \\
\hline CHEMBL3198259 & 688600 & 4.4 & 4.9804 & TST \\
\hline CHEMBL1314768 & 688600 & 5.5 & 4.8808 & TST \\
\hline CHEMBL1972915 & 688600 & 4.5 & 4.1724 & TST \\
\hline CHEMBL1540272 & 688600 & 4.8 & 4.3414 & TST \\
\hline CHEMBL1468277 & 688600 & 4.5 & 4.8073 & TST \\
\hline CHEMBL17468 & 688600 & 5.05 & 6.0888 & TST \\
\hline CHEMBL402468 & 688600 & 4.3 & 5.1145 & TST \\
\hline CHEMBL1518905 & 688600 & 5.1 & 5.5151 & TST \\
\hline CHEMBL1531830 & 688600 & 4.45 & 4.7646 & TST \\
\hline CHEMBL2003651 & 688600 & 5.05 & 4.2869 & TST \\
\hline CHEMBL1162110 & 688600 & 4.65 & 5.1427 & TST \\
\hline CHEMBL1428731 & 688600 & 4.5 & 4.5851 & TST \\
\hline CHEMBL1459809 & 688600 & 4.5 & 5.3831 & TST \\
\hline CHEMBL1444094 & 688600 & 4.7 & 4.7632 & TST \\
\hline CHEMBL1316953 & 688600 & 4.25 & 5.5607 & TST \\
\hline CHEMBL1314469 & 688600 & 4.8 & 5.1517 & TST \\
\hline CHEMBL1522044 & 688600 & 4.65 & 5.8706 & TST \\
\hline CHEMBL1361904 & 688600 & 4.4 & 4.4936 & TST \\
\hline CHEMBL1412226 & 688600 & 4.45 & 4.7194 & TST \\
\hline CHEMBL36028 & 688600 & 8.5528 & 5.2002 & TST \\
\hline CHEMBL1256360 & 688600 & 6.0 & 5.8987 & TST \\
\hline CHEMBL1588702 & 688600 & 4.7 & 5.6128 & TST \\
\hline CHEMBL1439068 & 688600 & 4.8 & 4.5037 & TST \\
\hline CHEMBL1456371 & 688600 & 5.4 & 4.5546 & TST \\
\hline CHEMBL1313195 & 688600 & 4.85 & 4.8216 & TST \\
\hline CHEMBL1256364 & 688600 & 8.4559 & 4.8773 & TST \\
\hline CHEMBL1255755 & 688600 & 4.9 & 4.4118 & TST \\
\hline CHEMBL1473252 & 688600 & 4.5 & 4.898 & TST \\
\hline CHEMBL1489711 & 688600 & 4.9 & 5.0659 & TST \\
\hline CHEMBL447876 & 688600 & 4.55 & 5.1462 & TST \\
\hline CHEMBL1420591 & 688600 & 4.6 & 3.9877 & TST \\
\hline CHEMBL1358724 & 688600 & 4.55 & 4.9913 & TST \\
\hline CHEMBL1340251 & 688600 & 4.85 & 5.5962 & TST \\
\hline CHEMBL1406990 & 688600 & 4.9 & 4.9304 & TST \\
\hline CHEMBL1412008 & 688600 & 4.5 & 4.4725 & TST \\
\hline CHEMBL1455813 & 688600 & 4.85 & 5.0989 & TST \\
\hline CHEMBL1447158 & 688600 & 4.5 & 4.5344 & TST \\
\hline CHEMBL1450334 & 688600 & 8.4949 & 5.4405 & TST \\
\hline CHEMBL1256836 & 688600 & 4.1 & 5.0064 & TST \\
\hline CHEMBL3199451 & 688600 & 4.55 & 4.7051 & TST \\
\hline
\end{tabular}




\begin{tabular}{|c|c|c|c|c|c|}
\hline \multirow[b]{2}{*}{ CHEMBL1255578 } & \multicolumn{5}{|c|}{ Supplemental Table S2.txt } \\
\hline & 688600 & 8.5528 & 6.3674 & TST & \\
\hline CHEMBL1305771 & 688600 & 4.5 & 4.6867 & TST & \\
\hline CHEMBL1546396 & 688600 & 5.25 & 4.7335 & TST & \\
\hline CHEMBL1390703 & 688600 & 4.45 & 4.9807 & TST & \\
\hline CHEMBL26320 & 688600 & 4.25 & 5.6668 & TST & \\
\hline CHEMBL1303551 & 688600 & 4.4 & 4.4835 & TST & \\
\hline CHEMBL1540929 & 688600 & 4.45 & 4.6283 & TST & \\
\hline CHEMBL 9843 & 688600 & 5.2 & 4.7789 & TST & \\
\hline CHEMBL1500710 & 688600 & 4.55 & 4.5833 & TST & \\
\hline CHEMBL1318512 & 688600 & 9.0458 & 7.4351 & TST & \\
\hline CHEMBL 1257130 & 688600 & 4.5 & 5.022 & TST & \\
\hline CHEMBL1441738 & 688600 & 4.85 & 4.743 & TST & \\
\hline CHEMBL1418174 & 688600 & 4.75 & 4.4778 & TST & \\
\hline CHEMBL305469 & 688600 & 4.55 & 4.7398 & TST & \\
\hline CHEMBL1364584 & 688600 & 4.75 & 4.6864 & TST & \\
\hline CHEMBL326958 & 688600 & 9.0969 & 7.2394 & TST & \\
\hline CHEMBL1584818 & 688600 & 4.65 & 4.425 & TST & \\
\hline CHEMBL1429228 & 688600 & 5.1 & 4.8606 & TST & \\
\hline CHEMBL1553428 & 688600 & 5.05 & 5.4685 & TST & \\
\hline CHEMBL1386493 & 688600 & 4.5 & 4.2951 & TST & \\
\hline CHEMBL1545068 & 688600 & 4.75 & 4.9455 & TST & \\
\hline CHEMBL1412370 & 688600 & 4.9 & 4.5633 & TST & \\
\hline CHEMBL189382 & 688600 & 4.75 & 6.1998 & TST & \\
\hline CHEMBL555689 & 688600 & 5.95 & 5.5695 & TST & \\
\hline CHEMBL1390112 & 688600 & 4.45 & 4.6159 & TST & \\
\hline CHEMBL481537 & 688600 & 4.6 & 4.984 & TST & \\
\hline CHEMBL1382279 & 688600 & 4.5 & 4.0045 & TST & \\
\hline CHEMBL1535261 & 688600 & 4.55 & 5.2753 & TST & \\
\hline CHEMBL1310031 & 688600 & 4.65 & 4.8812 & TST & \\
\hline CHEMBL313938 & 688600 & 6.2 & 5.0196 & TST & \\
\hline CHEMBL 3145071 & 688600 & 4.4 & 5.1317 & TST & \\
\hline CHEMBL1460436 & 688600 & 5.1 & 4.7094 & TST & \\
\hline CHEMBL1494725 & 688600 & 4.5 & 5.7553 & TST & \\
\hline CHEMBL1547684 & 688600 & 5.25 & 5.1955 & TST & \\
\hline CHEMBL1312235 & 688600 & 4.45 & 4.0133 & TST & \\
\hline CHEMBL1573198 & 688600 & 4.55 & 4.3427 & TST & \\
\hline CHEMBL1442153 & 688600 & 6.5 & 7.16100 & 00000000005 & TST \\
\hline CHEMBL1323619 & 688600 & 4.55 & 5.5109 & TST & \\
\hline CHEMBL1519408 & 688600 & 5.1 & 4.5516 & TST & \\
\hline CHEMBL571296 & 688600 & 4.55 & 5.28600 & 00000000005 & TST \\
\hline CHEMBL1401841 & 688600 & 5.45 & 5.0613 & TST & \\
\hline CHEMBL1438567 & 688600 & 4.6 & 4.8841 & TST & \\
\hline CHEMBL1323290 & 688600 & 4.65 & 4.8881 & TST & \\
\hline CHEMBL1607586 & 688600 & 4.7 & 4.9787 & TST & \\
\hline CHEMBL1350028 & 688600 & 4.65 & 5.2939 & TST & \\
\hline CHEMBL164747 & 688600 & 7.5498 & 5.9125 & TST & \\
\hline CHEMBL269733 & 688600 & 4.55 & 6.2336 & TST & \\
\hline CHEMBL 3197870 & 688600 & 4.5 & 4.3139 & TST & \\
\hline
\end{tabular}




\begin{tabular}{|c|c|c|c|c|}
\hline \\
\hline CHEMBL258767 & 688600 & 6.0 & 4.5868 & TST \\
\hline CHEMBL1500840 & 688600 & 4.6 & 4.7352 & TST \\
\hline CHEMBL1557518 & 688600 & 5.15 & 5.7522 & TST \\
\hline CHEMBL3198017 & 688600 & 4.5 & 4.4333 & TST \\
\hline CHEMBL77971 & 688600 & 5.8 & 4.7941 & TST \\
\hline CHEMBL26138 & 688600 & 4.85 & 5.5043 & TST \\
\hline CHEMBL1405759 & 688600 & 8.6576 & 4.6953 & TST \\
\hline CHEMBL1589385 & 688600 & 5.0 & 5.86700 & 0000000001 \\
\hline CHEMBL397209 & 688600 & 7.8508 & 6.2874 & TST \\
\hline CHEMBL1351158 & 688600 & 4.55 & 4.0287 & TST \\
\hline CHEMBL1158 & 688600 & 6.2 & 6.5409 & TST \\
\hline CHEMBL1256844 & 688600 & 8.3979 & 6.4571 & TST \\
\hline CHEMBL1367076 & 688600 & 4.7 & 4.3362 & TST \\
\hline CHEMBL1991440 & 688600 & 4.55 & 4.9085 & TST \\
\hline CHEMBL1092473 & 688600 & 5.6 & 5.3633 & TST \\
\hline CHEMBL1975054 & 688600 & 4.95 & 4.5786 & TST \\
\hline CHEMBL1256191 & 688600 & 9.0458 & 5.528 & TST \\
\hline CHEMBL3216928 & 688600 & 8.2518 & 5.2283 & TST \\
\hline CHEMBL1394945 & 688600 & 8.0506 & 7.4423 & TST \\
\hline CHEMBL1516834 & 688600 & 4.55 & 4.4882 & TST \\
\hline CHEMBL1432707 & 688600 & 5.05 & 4.4595 & TST \\
\hline CHEMBL1566010 & 688600 & 4.5 & 4.5048 & TST \\
\hline CHEMBL1572785 & 688600 & 4.55 & 4.7247 & TST \\
\hline CHEMBL1319645 & 688600 & 5.0 & 4.5555 & TST \\
\hline CHEMBL1345786 & 688600 & 4.4 & 5.3945 & TST \\
\hline CHEMBL1383849 & 688600 & 4.55 & 4.6921 & TST \\
\hline CHEMBL160145 & 688600 & 4.35 & 5.4368 & TST \\
\hline CHEMBL1972249 & 688600 & 4.55 & 4.2798 & TST \\
\hline CHEMBL1409344 & 688600 & 5.05 & 4.2148 & TST \\
\hline CHEMBL1604132 & 688600 & 4.85 & 4.8509 & TST \\
\hline CHEMBL1373305 & 688600 & 4.6 & 4.7429 & TST \\
\hline CHEMBL1530147 & 688600 & 6.0 & 4.2683 & TST \\
\hline CHEMBL1509862 & 688600 & 4.4 & 5.025 & TST \\
\hline CHEMBL1327390 & 688600 & 4.55 & 4.2554 & TST \\
\hline CHEMBL1573754 & 688600 & 6.0 & 5.3149 & TST \\
\hline CHEMBL1606751 & 688600 & 4.8 & 5.0079 & TST \\
\hline CHEMBL1551643 & 688600 & 8.5528 & 6.9008 & TST \\
\hline CHEMBL1336561 & 688600 & 4.6 & 5.0292 & TST \\
\hline CHEMBL1395381 & 688600 & 4.4 & 4.655 & TST \\
\hline CHEMBL1372997 & 688600 & 4.95 & 6.4407 & TST \\
\hline CHEMBL1591158 & 688600 & 5.6 & 5.8209 & TST \\
\hline CHEMBL487203 & 688600 & 4.85 & 5.5095 & TST \\
\hline CHEMBL3189477 & 688600 & 4.4 & 4.6923 & TST \\
\hline CHEMBL1371777 & 688600 & 4.85 & 4.6304 & TST \\
\hline CHEMBL18238 & 688600 & 7.15 & 7.075 & TST \\
\hline CHEMBL 2374058 & 688600 & 4.7 & 4.618 & TST \\
\hline CHEMBL1256698 & 688600 & 8.4949 & 5.8357 & TST \\
\hline CHEMBL1405468 & 688600 & 4.4 & 4.7659 & TST \\
\hline
\end{tabular}




\begin{tabular}{|c|c|c|c|c|c|}
\hline \multirow[b]{2}{*}{ CHEMBL295212 } & \multicolumn{5}{|c|}{ Supplemental Table s2.txt } \\
\hline & 688600 & 4.45 & 5.3282 & TST & \\
\hline CHEMBL1560245 & 688600 & 4.5 & 5.2622 & TST & \\
\hline CHEMBL1442224 & 688600 & 4.9 & 5.0515 & TST & \\
\hline CHEMBL1440857 & 688600 & 4.5 & 5.20100 & 00000000005 & TST \\
\hline CHEMBL1539720 & 688600 & 4.85 & 4.7402 & TST & \\
\hline CHEMBL1528814 & 688600 & 4.8 & 5.5145 & TST & \\
\hline CHEMBL1485159 & 688600 & 4.75 & 5.3941 & TST & \\
\hline CHEMBL1590373 & 688600 & 4.5 & 4.4186 & TST & \\
\hline CHEMBL1424694 & 688600 & 5.45 & 5.5886 & TST & \\
\hline CHEMBL1321933 & 688600 & 5.45 & 4.8516 & TST & \\
\hline CHEMBL310578 & 688600 & 9.1549 & 6.07 & TST & \\
\hline CHEMBL50378 & 688600 & 4.85 & 5.305 & TST & \\
\hline CHEMBL1597782 & 688600 & 4.75 & 4.8996 & TST & \\
\hline CHEMBL1503523 & 688600 & 4.55 & 4.3693 & TST & \\
\hline CHEMBL1361503 & 688600 & 4.4 & 4.8947 & TST & \\
\hline CHEMBL34241 & 688600 & 4.5 & 4.6255 & TST & \\
\hline CHEMBL23832 & 688600 & 10.0 & 5.056 & TST & \\
\hline CHEMBL 3668224 & 1528626 & 7.0 & 7.2089 & TRN & \\
\hline CHEMBL3668305 & 1528626 & 7.0 & 8.2465 & TRN & \\
\hline CHEMBL3668290 & 1528626 & 6.0 & 5.5333 & TRN & \\
\hline CHEMBL 3668340 & 1528626 & 9.0 & 8.4872 & TRN & \\
\hline CHEMBL3668331 & 1528626 & 9.0 & 8.0756 & TRN & \\
\hline CHEMBL 3673390 & 1528626 & 7.0 & 7.6668 & TST & \\
\hline CHEMBL 3668222 & 1528626 & 5.0 & 4.9597 & TRN & \\
\hline CHEMBL3668326 & 1528626 & 7.0 & 7.7369 & TRN & \\
\hline CHEMBL 3668274 & 1528626 & 4.0 & 6.1385 & TRN & \\
\hline CHEMBL3673325 & 1528626 & 8.0 & 8.1561 & TRN & \\
\hline CHEMBL3673316 & 1528626 & 8.0 & 7.4093 & TRN & \\
\hline CHEMBL3673369 & 1528626 & 8.0 & 7.5265 & TRN & \\
\hline CHEMBL3673379 & 1528626 & 9.0 & 6.8946 & TST & \\
\hline CHEMBL3673326 & 1528626 & 8.0 & 8.1034 & TRN & \\
\hline CHEMBL 3668264 & 1528626 & 9.0 & 8.3595 & TRN & \\
\hline CHEMBL3673332 & 1528626 & 6.0 & 6.9053 & TRN & \\
\hline CHEMBL3673406 & 1528626 & 4.0 & 5.3595 & TRN & \\
\hline CHEMBL3673304 & 1528626 & 8.0 & 7.7672 & TST & \\
\hline CHEMBL3673305 & 1528626 & 7.0 & 7.8605 & TST & \\
\hline CHEMBL3668313 & 1528626 & 7.0 & 7.5869 & TRN & \\
\hline CHEMBL3673281 & 1528626 & 7.0 & 8.21 & TST & \\
\hline CHEMBL3673285 & 1528626 & 9.0 & 8.8597 & TRN & \\
\hline CHEMBL3673362 & 1528626 & 9.0 & 7.7566 & TRN & \\
\hline CHEMBL3668329 & 1528626 & 8.0 & 7.9737 & TRN & \\
\hline CHEMBL3673426 & 1528626 & 8.0 & 8.7962 & TRN & \\
\hline CHEMBL3668341 & 1528626 & 9.0 & 8.6828 & TRN & \\
\hline CHEMBL3673428 & 1528626 & 9.0 & 8.9372 & TRN & \\
\hline CHEMBL3673344 & 1528626 & 8.0 & 8.0861 & TRN & \\
\hline CHEMBL3673312 & 1528626 & 9.0 & 7.83200 & 0000000001 & TRN \\
\hline CHEMBL3673368 & 1528626 & 8.0 & 7.7104 & TST & \\
\hline CHEMBL3668295 & 1528626 & 6.0 & 7.42700 & 00000000005 & TRN \\
\hline & & & & 7128 & \\
\hline
\end{tabular}




\begin{tabular}{|c|c|c|c|c|c|}
\hline CHEMBL 3668318 & 1528626 & 8.0 & 8.0977 & TRN & \\
\hline CHEMBL 3668303 & 1528626 & 9.0 & 7.75799 & 9999999999 & TRN \\
\hline CHEMBL 3668277 & 1528626 & 7.0 & 7.6237 & TRN & \\
\hline CHEMBL 3668231 & 1528626 & 6.0 & 5.3498 & TRN & \\
\hline CHEMBL3668270 & 1528626 & 6.0 & 5.9785 & TRN & \\
\hline CHEMBL3673386 & 1528626 & 6.0 & 6.2646 & TRN & \\
\hline CHEMBL 3673421 & 1528626 & 7.0 & 7.983 & TST & \\
\hline CHEMBL 3668261 & 1528626 & 6.0 & 6.2561 & TRN & \\
\hline CHEMBL3673333 & 1528626 & 6.0 & 6.5994 & TRN & \\
\hline CHEMBL3673385 & 1528626 & 6.0 & 6.2566 & TST & \\
\hline CHEMBL 3673430 & 1528626 & 7.0 & 8.1972 & TRN & \\
\hline CHEMBL 3668223 & 1528626 & 5.0 & 5.2079 & TRN & \\
\hline CHEMBL 3673330 & 1528626 & 7.0 & 7.2058 & TRN & \\
\hline CHEMBL3668320 & 1528626 & 8.0 & 7.938 & TRN & \\
\hline CHEMBL3673279 & 1528626 & 8.0 & 8.5867 & TRN & \\
\hline CHEMBL3673407 & 1528626 & 9.0 & 8.7127 & TRN & \\
\hline CHEMBL3673283 & 1528626 & 9.0 & 8.5346 & TRN & \\
\hline CHEMBL 3668214 & 1528626 & 9.0 & 8.5413 & TRN & \\
\hline CHEMBL3673395 & 1528626 & 9.0 & 8.5021 & TRN & \\
\hline CHEMBL3668330 & 1528626 & 8.0 & 8.2587 & TRN & \\
\hline CHEMBL3668256 & 1528626 & 9.0 & 9.171 & TRN & \\
\hline CHEMBL3668211 & 1528626 & 6.0 & 5.0531 & TRN & \\
\hline CHEMBL 3673298 & 1528626 & 8.0 & 8.2403 & TRN & \\
\hline CHEMBL3673345 & 1528626 & 8.0 & 8.0097 & TST & \\
\hline CHEMBL 3668228 & 1528626 & 6.0 & 6.7625 & TRN & \\
\hline CHEMBL 3673327 & 1528626 & 8.0 & 8.0899 & TRN & \\
\hline CHEMBL3673338 & 1528626 & 7.0 & 7.8153 & TRN & \\
\hline CHEMBL 3673387 & 1528626 & 6.0 & 5.7012 & TRN & \\
\hline CHEMBL3673352 & 1528626 & 8.0 & 7.6919 & TST & \\
\hline CHEMBL 3668242 & 1528626 & 7.0 & 7.8801 & TST & \\
\hline CHEMBL 3668212 & 1528626 & 8.0 & 6.5195 & TRN & \\
\hline CHEMBL 3668236 & 1528626 & 9.0 & 8.9563 & TRN & \\
\hline CHEMBL 3673381 & 1528626 & 8.0 & 6.9791 & TRN & \\
\hline CHEMBL3673301 & 1528626 & 7.0 & 7.2837 & TRN & \\
\hline CHEMBL3668299 & 1528626 & 7.0 & 7.5596 & TRN & \\
\hline CHEMBL3673311 & 1528626 & 6.0 & 7.3783 & TRN & \\
\hline CHEMBL3668282 & 1528626 & 7.0 & 6.9738 & TRN & \\
\hline CHEMBL 3673427 & 1528626 & 8.0 & 8.666 & TRN & \\
\hline CHEMBL3673373 & 1528626 & 7.0 & 7.7443 & TST & \\
\hline CHEMBL 3673300 & 1528626 & 9.0 & 8.5951 & TST & \\
\hline CHEMBL3668327 & 1528626 & 7.0 & 7.52 & TRN & \\
\hline CHEMBL3668263 & 1528626 & 6.0 & 5.2875 & TRN & \\
\hline CHEMBL 3673280 & 1528626 & 7.0 & 8.1544 & TRN & \\
\hline CHEMBL3668310 & 1528626 & 6.0 & 6.8466 & TST & \\
\hline CHEMBL3668239 & 1528626 & 5.0 & 6.9927 & TST & \\
\hline CHEMBL 3668250 & 1528626 & 6.0 & 6.5271 & TRN & \\
\hline CHEMBL3673366 & 1528626 & 7.0 & \multicolumn{2}{|c|}{8.283999999999999} & TRN \\
\hline CHEMBL3673314 & 1528626 & 6.0 & 6.1786 & TRN & \\
\hline
\end{tabular}




\begin{tabular}{|c|c|c|c|c|}
\hline & & & & \\
\hline CHEMBL3673351 & 1528626 & 8.0 & 8.0021 & TST \\
\hline CHEMBL3673302 & 1528626 & 9.0 & 7.7787 & TRN \\
\hline CHEMBL3673349 & 1528626 & 9.0 & 7.9656 & TST \\
\hline CHEMBL 3935638 & 1528626 & 8.0 & 7.4067 & TST \\
\hline CHEMBL3668233 & 1528626 & 8.0 & 7.0812 & TRN \\
\hline CHEMBL 3668254 & 1528626 & 8.0 & 7.7277 & TST \\
\hline CHEMBL3673294 & 1528626 & 9.0 & 8.1187 & TST \\
\hline CHEMBL3668225 & 1528626 & 6.0 & 6.8797 & TRN \\
\hline CHEMBL 3673393 & 1528626 & 6.0 & 7.8322 & TST \\
\hline CHEMBL3673309 & 1528626 & 9.0 & 7.5064 & TRN \\
\hline CHEMBL3668304 & 1528626 & 7.0 & 7.8734 & TRN \\
\hline CHEMBL3668335 & 1528626 & 8.0 & 8.0894 & TRN \\
\hline CHEMBL3673431 & 1528626 & 9.0 & 8.4816 & TRN \\
\hline CHEMBL 3668293 & 1528626 & 6.0 & 7.7458 & TST \\
\hline CHEMBL3668216 & 1528626 & 8.0 & 7.4218 & TRN \\
\hline CHEMBL3668312 & 1528626 & 8.0 & 8.125 & TRN \\
\hline CHEMBL3673371 & 1528626 & 7.0 & 7.8096 & TRN \\
\hline CHEMBL 3673422 & 1528626 & 7.0 & 7.6982 & TRN \\
\hline CHEMBL 3668258 & 1528626 & 5.0 & 5.9008 & TRN \\
\hline CHEMBL3673383 & 1528626 & 8.0 & 8.0626 & TST \\
\hline CHEMBL 3668227 & 1528626 & 9.0 & 7.8839 & TRN \\
\hline CHEMBL 3673402 & 1528626 & 7.0 & 7.2505 & TRN \\
\hline CHEMBL3673413 & 1528626 & 8.0 & 7.4192 & TRN \\
\hline CHEMBL3668279 & 1528626 & 8.0 & 8.1596 & TRN \\
\hline CHEMBL 3668280 & 1528626 & 9.0 & 8.2175 & TRN \\
\hline CHEMBL 3639722 & 1528626 & 7.0 & 7.228 & TRN \\
\hline CHEMBL3668288 & 1528626 & 8.0 & 8.022 & TRN \\
\hline CHEMBL 3673405 & 1528626 & 6.0 & 5.976 & TRN \\
\hline CHEMBL 3673408 & 1528626 & 9.0 & 7.8783 & TRN \\
\hline CHEMBL3673409 & 1528626 & 8.0 & 7.9172 & TRN \\
\hline CHEMBL 3673355 & 1528626 & 6.0 & 6.1596 & TRN \\
\hline CHEMBL3668322 & 1528626 & 8.0 & 8.0049 & TRN \\
\hline CHEMBL3673303 & 1528626 & 8.0 & 7.1051 & TRN \\
\hline CHEMBL 3673331 & 1528626 & 8.0 & 7.8068 & TRN \\
\hline CHEMBL 3668287 & 1528626 & 6.0 & 6.2303 & TRN \\
\hline CHEMBL3668292 & 1528626 & 7.0 & 7.6565 & TST \\
\hline CHEMBL3673418 & 1528626 & 8.0 & 7.5457 & TRN \\
\hline CHEMBL3673342 & 1528626 & 8.0 & 8.0092 & TRN \\
\hline CHEMBL 3673320 & 1528626 & 8.0 & 8.0972 & TRN \\
\hline CHEMBL3673289 & 1528626 & 9.0 & 8.967 & TRN \\
\hline CHEMBL 3673397 & 1528626 & 6.0 & 6.3286 & TRN \\
\hline CHEMBL3673403 & 1528626 & 8.0 & 8.2423 & TRN \\
\hline CHEMBL3673293 & 1528626 & 8.0 & 7.7587 & TRN \\
\hline CHEMBL 3673414 & 1528626 & 9.0 & 8.4516 & TRN \\
\hline CHEMBL 3668247 & 1528626 & 5.0 & 5.3557 & TST \\
\hline CHEMBL 3668255 & 1528626 & 7.0 & 6.4429 & TRN \\
\hline CHEMBL3668219 & 1528626 & 7.0 & 6.2213 & TRN \\
\hline CHEMBL3668289 & 1528626 & 7.0 & 7.1889 & TRN \\
\hline
\end{tabular}




\begin{tabular}{|c|c|c|c|c|}
\hline & & & pplement & al $\mathrm{Ta}$ \\
\hline CHEMBL3668266 & 1528626 & 7.0 & 7.5758 & TRN \\
\hline CHEMBL 3673380 & 1528626 & 8.0 & 8.6738 & TST \\
\hline CHEMBL3673292 & 1528626 & 6.0 & 7.2116 & TRN \\
\hline CHEMBL 3673277 & 1528626 & 9.0 & 8.651 & TRN \\
\hline CHEMBL 3668217 & 1528626 & 6.0 & 5.6158 & TRN \\
\hline CHEMBL3673367 & 1528626 & 8.0 & 7.7843 & TRN \\
\hline CHEMBL 3668284 & 1528626 & 7.0 & 7.1787 & TRN \\
\hline CHEMBL 3673273 & 1528626 & 8.0 & 7.5697 & TRN \\
\hline CHEMBL3668306 & 1528626 & 8.0 & 7.4962 & TRN \\
\hline CHEMBL3668302 & 1528626 & 8.0 & 7.2166 & TRN \\
\hline CHEMBL 3668265 & 1528626 & 8.0 & 8.1089 & TRN \\
\hline CHEMBL3668337 & 1528626 & 8.0 & 7.9052 & TRN \\
\hline CHEMBL3673296 & 1528626 & 7.0 & 7.228 & TST \\
\hline CHEMBL 3673346 & 1528626 & 8.0 & 7.2103 & TST \\
\hline CHEMBL 3673288 & 1528626 & 9.0 & 8.4527 & TRN \\
\hline CHEMBL3668226 & 1528626 & 7.0 & 7.182 & TRN \\
\hline CHEMBL3673282 & 1528626 & 8.0 & 7.8983 & TRN \\
\hline CHEMBL 3668237 & 1528626 & 9.0 & 8.9992 & TRN \\
\hline CHEMBL3673295 & 1528626 & 9.0 & 8.1035 & TRN \\
\hline CHEMBL 3668243 & 1528626 & 6.0 & 5.4238 & TST \\
\hline CHEMBL3673419 & 1528626 & 8.0 & 7.9677 & TRN \\
\hline CHEMBL3673372 & 1528626 & 8.0 & 7.9743 & TRN \\
\hline CHEMBL 3668220 & 1528626 & 6.0 & 5.265 & TRN \\
\hline CHEMBL 3668338 & 1528626 & 8.0 & 8.4415 & TRN \\
\hline CHEMBL 3668332 & 1528626 & 9.0 & 8.0291 & TRN \\
\hline CHEMBL3673308 & 1528626 & 7.0 & 7.3328 & TST \\
\hline CHEMBL3673339 & 1528626 & 8.0 & 8.3306 & TRN \\
\hline CHEMBL3668215 & 1528626 & 7.0 & 7.2163 & TRN \\
\hline CHEMBL 3673420 & 1528626 & 8.0 & 8.7713 & TST \\
\hline CHEMBL 3673410 & 1528626 & 8.0 & 7.856 & TRN \\
\hline CHEMBL 3668257 & 1528626 & 9.0 & 9.1524 & TRN \\
\hline CHEMBL 3673334 & 1528626 & 6.0 & 6.9229 & TRN \\
\hline CHEMBL3668309 & 1528626 & 7.0 & 7.5311 & TRN \\
\hline CHEMBL 3668324 & 1528626 & 6.0 & 6.7184 & TST \\
\hline CHEMBL 3668273 & 1528626 & 6.0 & 4.9448 & TRN \\
\hline CHEMBL3673317 & 1528626 & 8.0 & 7.7555 & TRN \\
\hline CHEMBL 3673394 & 1528626 & 6.0 & 6.3772 & TRN \\
\hline CHEMBL 3668300 & 1528626 & 8.0 & 7.1863 & TRN \\
\hline CHEMBL3673376 & 1528626 & 7.0 & 7.1648 & TST \\
\hline CHEMBL 3673321 & 1528626 & 9.0 & 7.026 & TRN \\
\hline CHEMBL3673306 & 1528626 & 8.0 & 7.5883 & TST \\
\hline CHEMBL 3673363 & 1528626 & 8.0 & 7.94 & TRN \\
\hline CHEMBL3668311 & 1528626 & 7.0 & 7.9202 & TRN \\
\hline CHEMBL3673319 & 1528626 & 8.0 & 6.3527 & TST \\
\hline CHEMBL 3668275 & 1528626 & 8.0 & 8.2416 & TRN \\
\hline CHEMBL 3668252 & 1528626 & 8.0 & 7.2286 & TST \\
\hline CHEMBL 3668301 & 1528626 & 7.0 & 7.2086 & TRN \\
\hline CHEMBL3673350 & 1528626 & 8.0 & 7.7495 & TST \\
\hline
\end{tabular}




\begin{tabular}{|c|c|c|c|c|c|}
\hline \multirow{3}{*}{ CHEMBL 3668269} & \multirow{2}{*}{1528626} & \multirow[b]{2}{*}{6.0} & \\
\hline & & & 5.2319 & TRN & \\
\hline & 1528626 & 4.0 & 5.1783 & TRN & \\
\hline CHEMBL3673365 & 1528626 & 9.0 & 7.5334 & TST & \\
\hline CHEMBL3673286 & 1528626 & 9.0 & 8.3743 & TRN & \\
\hline CHEMBL3668249 & 1528626 & 6.0 & 6.45 & TRN & \\
\hline CHEMBL3673315 & 1528626 & 6.0 & 7.1636 & TRN & \\
\hline CHEMBL3673307 & 1528626 & 7.0 & 7.7921 & TRN & \\
\hline CHEMBL3668333 & 1528626 & 8.0 & 8.3374 & TRN & \\
\hline CHEMBL3673423 & 1528626 & 7.0 & 8.5811 & TRN & \\
\hline CHEMBL3673313 & 1528626 & 7.0 & 7.8346 & TST & \\
\hline CHEMBL3668267 & 1528626 & 7.0 & 7.7005 & TST & \\
\hline CHEMBL3639671 & 1528626 & 7.0 & 7.5768 & TRN & \\
\hline CHEMBL3673290 & 1528626 & 8.0 & 7.5418 & TRN & \\
\hline CHEMBL3673328 & 1528626 & 8.0 & 8.4234 & TRN & \\
\hline CHEMBL3673348 & 1528626 & 9.0 & 8.2731 & TST & \\
\hline CHEMBL3673375 & 1528626 & 7.0 & 8.0165 & TRN & \\
\hline CHEMBL3673412 & 1528626 & 8.0 & 7.9194 & TRN & \\
\hline CHEMBL3668316 & 1528626 & 8.0 & 8.2926 & TRN & \\
\hline CHEMBL3673360 & 1528626 & 9.0 & 7.54 & TRN & \\
\hline CHEMBL3673404 & 1528626 & 8.0 & 7.9424 & TRN & \\
\hline CHEMBL3668334 & 1528626 & 8.0 & 7.7334 & TRN & \\
\hline CHEMBL3673424 & 1528626 & 8.0 & 8.4508 & TRN & \\
\hline CHEMBL3673318 & 1528626 & 8.0 & 8.3358 & TST & \\
\hline CHEMBL3668278 & 1528626 & 7.0 & 7.2992 & TRN & \\
\hline CHEMBL3668268 & 1528626 & 7.0 & 7.6276 & TRN & \\
\hline CHEMBL3673415 & 1528626 & 9.0 & 8.1164 & TRN & \\
\hline CHEMBL3673433 & 1528626 & 7.0 & 7.6887 & TRN & \\
\hline CHEMBL3673398 & 1528626 & 9.0 & 8.2991 & TRN & \\
\hline CHEMBL3668246 & 1528626 & 6.0 & 5.7572 & TST & \\
\hline CHEMBL3673364 & 1528626 & 9.0 & 7.6902 & TRN & \\
\hline CHEMBL3673401 & 1528626 & 6.0 & $6.6170 e$ & 0000000001 & TRN \\
\hline CHEMBL3673425 & 1528626 & 9.0 & 8.8897 & TRN & \\
\hline CHEMBL3673396 & 1528626 & 4.0 & 6.3011 & TST & \\
\hline CHEMBL3668281 & 1528626 & 6.0 & 7.1915 & TRN & \\
\hline CHEMBL 3673278 & 1528626 & 8.0 & 8.5011 & TRN & \\
\hline CHEMBL3673287 & 1528626 & 9.0 & 8.4794 & TRN & \\
\hline CHEMBL3673276 & 1528626 & 9.0 & 9.0912 & TRN & \\
\hline CHEMBL 3673322 & 1528626 & 8.0 & 8.1537 & TRN & \\
\hline CHEMBL3673374 & 1528626 & 7.0 & 7.6233 & TRN & \\
\hline CHEMBL3673432 & 1528626 & 7.0 & 7.6061 & TRN & \\
\hline CHEMBL3673323 & 1528626 & 8.0 & 7.795 & TST & \\
\hline CHEMBL3668339 & 1528626 & 9.0 & 8.3473 & TRN & \\
\hline CHEMBL3668308 & 1528626 & 8.0 & 8.0207 & TRN & \\
\hline CHEMBL3668244 & 1528626 & 3.0 & 6.2488 & TST & \\
\hline CHEMBL3673356 & 1528626 & 9.0 & 8.6325 & TRN & \\
\hline CHEMBL3668259 & 1528626 & 7.0 & 6.3031 & TRN & \\
\hline CHEMBL3673429 & 1528626 & 9.0 & 9.0178 & TRN & \\
\hline CHEMBL3668298 & 1528626 & 8.0 & 7.9303 & TRN & \\
\hline & & & & 7132 & \\
\hline
\end{tabular}




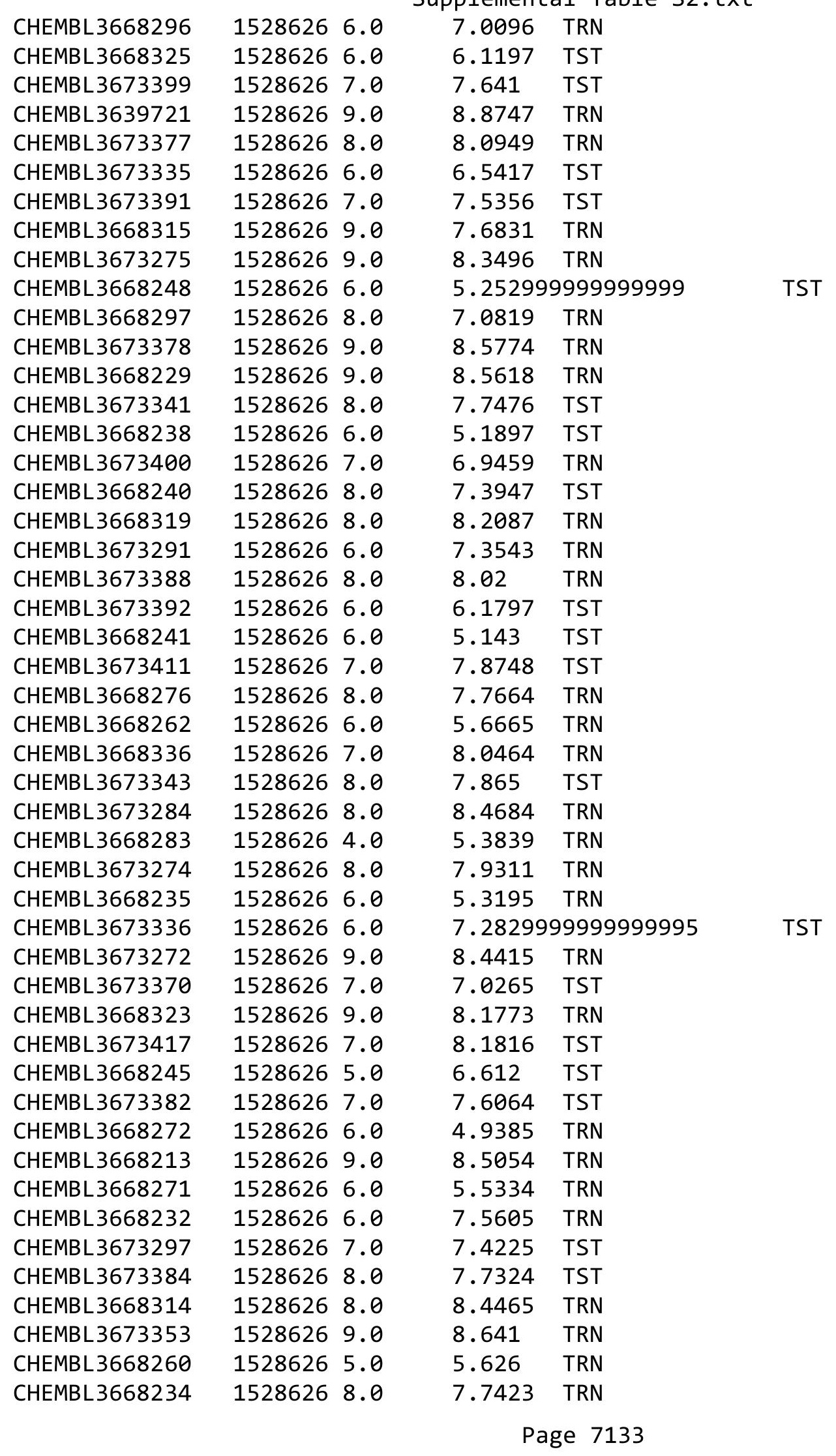




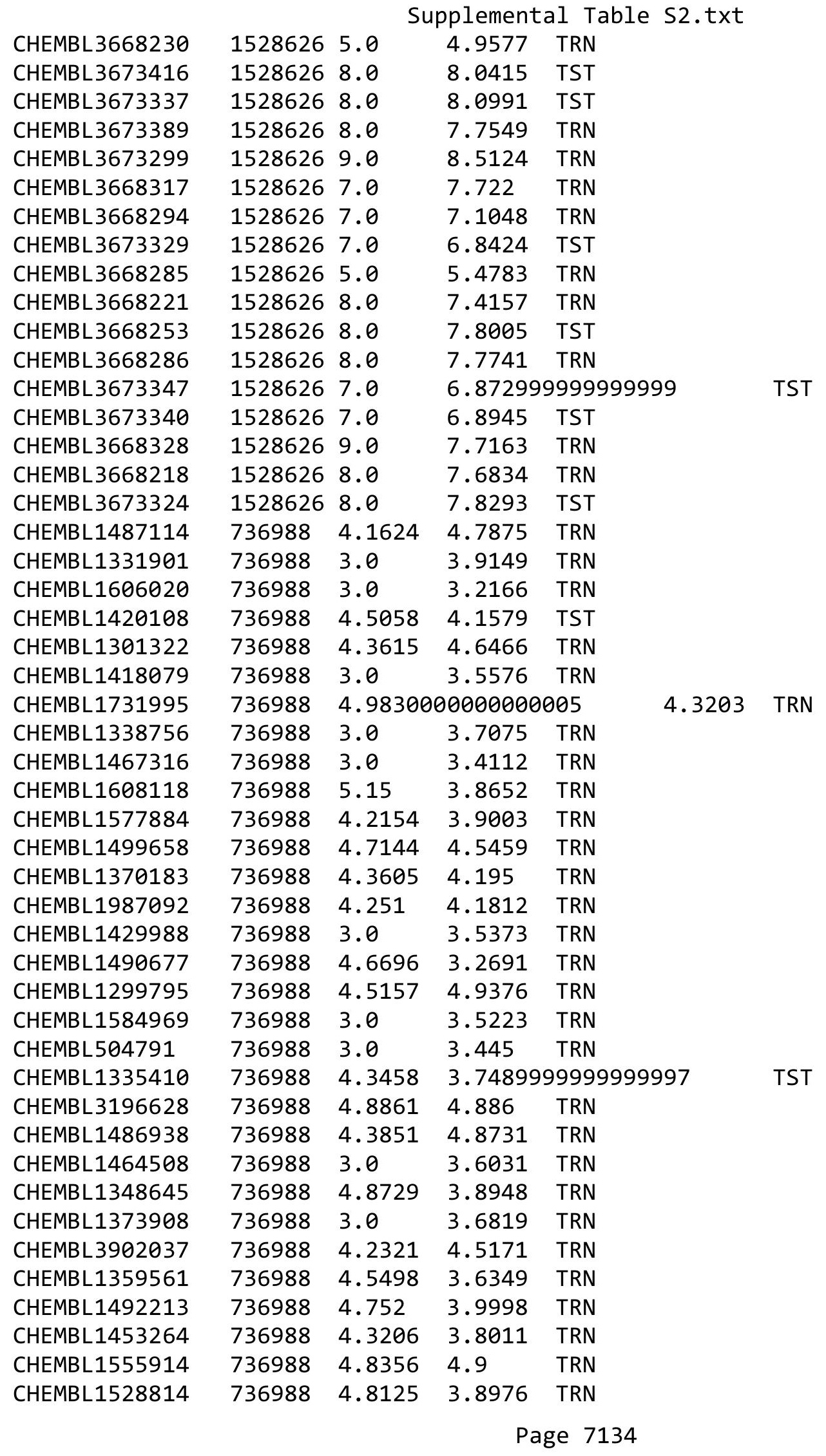




\begin{tabular}{|c|c|c|c|c|}
\hline \multicolumn{5}{|c|}{ Supplemental Table S2.txt } \\
\hline CHEMBL3192906 & 736988 & 3.0 & 4.5408 & TRN \\
\hline CHEMBL1311027 & 736988 & 3.0 & 3.1757 & TRN \\
\hline CHEMBL1340799 & 736988 & 4.5017 & 4.5776 & TRN \\
\hline CHEMBL1613571 & 736988 & 3.0 & 4.1052 & TST \\
\hline CHEMBL3207893 & 736988 & 4.1325 & 4.2489 & TRN \\
\hline CHEMBL3190303 & 736988 & 4.9957 & 4.5743 & TRN \\
\hline CHEMBL1350226 & 736988 & 4.2495 & 3.804 & TRN \\
\hline CHEMBL3209562 & 736988 & 4.9355 & 4.9603 & TRN \\
\hline CHEMBL1340587 & 736988 & 4.4685 & 4.1376 & TRN \\
\hline CHEMBL427876 & 736988 & 3.0 & 2.8708 & TRN \\
\hline CHEMBL1582936 & 736988 & 4.2716 & 3.2915 & TRN \\
\hline CHEMBL1722566 & 736988 & 3.0 & 3.7872 & TRN \\
\hline CHEMBL1736377 & 736988 & 5.1844 & 4.5363 & TRN \\
\hline CHEMBL 3925157 & 736988 & 4.2403 & 4.1687 & TRN \\
\hline CHEMBL1371568 & 736988 & 4.7799 & 4.1089 & TST \\
\hline CHEMBL1382392 & 736988 & 3.0 & 3.635 & TRN \\
\hline CHEMBL1303198 & 736988 & 3.0 & 3.1355 & TRN \\
\hline CHEMBL1327880 & 736988 & 4.6882 & 3.5834 & TRN \\
\hline CHEMBL1864716 & 736988 & 4.2182 & 3.9612 & TRN \\
\hline CHEMBL1428024 & 736988 & 3.0 & 3.7358 & TRN \\
\hline CHEMBL1519408 & 736988 & 4.7595 & 3.8975 & TRN \\
\hline CHEMBL 244683 & 736988 & 3.0 & 3.3763 & TRN \\
\hline CHEMBL1360981 & 736988 & 4.8153 & 4.9133 & TRN \\
\hline CHEMBL1426072 & 736988 & 3.0 & 3.4942 & TRN \\
\hline CHEMBL1323994 & 736988 & 4.6198 & 4.0664 & TRN \\
\hline CHEMBL1410686 & 736988 & 4.7077 & 4.6515 & TRN \\
\hline CHEMBL1361904 & 736988 & 3.0 & 3.8764 & TST \\
\hline CHEMBL1541466 & 736988 & 3.0 & 4.2022 & TST \\
\hline CHEMBL1450458 & 736988 & 4.9747 & 4.4163 & TRN \\
\hline CHEMBL1328822 & 736988 & 3.0 & 4.0745 & TRN \\
\hline CHEMBL1339329 & 736988 & 3.0 & 4.2864 & TST \\
\hline CHEMBL1544951 & 736988 & 3.0 & 3.7393 & TST \\
\hline CHEMBL1548014 & 736988 & 4.7959 & 4.0564 & TRN \\
\hline CHEMBL1419943 & 736988 & 3.0 & 3.3342 & TRN \\
\hline CHEMBL1378709 & 736988 & 5.1002 & 4.6449 & TRN \\
\hline CHEMBL1604389 & 736988 & 4.1675 & 4.5436 & TRN \\
\hline CHEMBL1333600 & 736988 & 3.0 & 3.8298 & TST \\
\hline CHEMBL1412731 & 736988 & 5.0665 & 4.5168 & TRN \\
\hline CHEMBL1471909 & 736988 & 3.0 & 3.4522 & TRN \\
\hline CHEMBL1596011 & 736988 & 3.0 & 3.5937 & TRN \\
\hline CHEMBL1529346 & 736988 & 4.4365 & 4.4626 & TRN \\
\hline CHEMBL1303465 & 736988 & 3.0 & 3.4904 & TRN \\
\hline CHEMBL1609317 & 736988 & 3.0 & 3.9628 & TST \\
\hline CHEMBL1424123 & 736988 & 3.0 & 4.0746 & TST \\
\hline CHEMBL1465475 & 736988 & 4.064 & 3.8268 & TST \\
\hline CHEMBL 3214124 & 736988 & 3.0 & 3.801 & TST \\
\hline CHEMBL1567923 & 736988 & 3.0 & 3.9421 & TST \\
\hline CHEMBL1349913 & 736988 & 3.0 & 3.7951 & TST \\
\hline
\end{tabular}




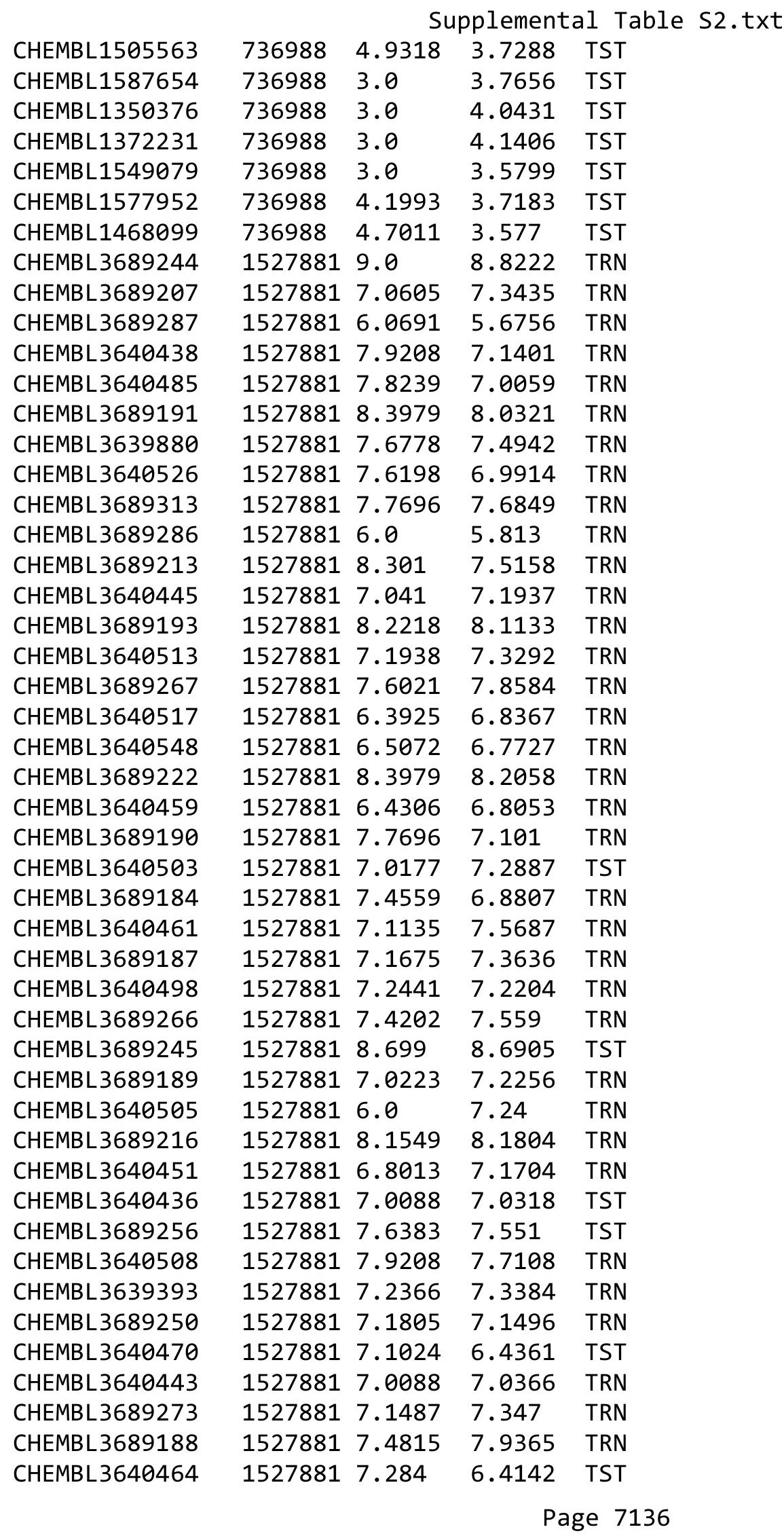


Supplemental Table S2.txt

\begin{tabular}{|c|c|c|c|c|}
\hline - & & & & \\
\hline HEMBL3689214 & 527881 & 7.9586 & 2883 & \\
\hline & & & & \\
\hline 457 & 881 & 51 & 51 & \\
\hline AEMBL3689255 & 527881 & 655 & 2535 & \\
\hline HEMBL3689228 & 527881 & 8.0969 & 4375 & \\
\hline HEMBL3689297 & 527881 & .301 & 9738 & \\
\hline 06 & 881 & 468 & 35 & \\
\hline 589269 & 881 & 3539 & 8542 & \\
\hline HEMBL3640504 & 527881 & 7.699 & 8077 & \\
\hline HEMBL3640500 & 527881 & 7.8539 & 6074 & \\
\hline AEMBL3640530 & 881 & 767 & 4361 & \\
\hline AEM & 381 & & & \\
\hline HEMBL. & 527881 & 969 & & \\
\hline AEMBL3689197 & 881 & 306 & & \\
\hline AEMBL3640492 & 527881 & 18 & 09 & \\
\hline HEMBL368 & 881 & 549 & 74 & \\
\hline HEMBL36 & 881 & & & \\
\hline HEMBL & 381 & 318 & & \\
\hline HEMBL 368 & 381 & & & RN \\
\hline HEMBL3689280 & 81 & 76 & 08 & RN \\
\hline HEMBL3689301 & 81 & & 86 & \\
\hline HEMBL3689249 & 81 & & & \\
\hline 285 & 881 & & & 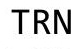 \\
\hline HEMBL 364 & 81 & 2 & 96 & RIN \\
\hline AEMBL3689271 & 81 & 51 & 73 & RN \\
\hline HEMBL36 & 81 & & 56 & - \\
\hline HEM & 81 & & & RN \\
\hline HEMBL3 & 381 & & & RIN \\
\hline AEMBL36 & 81 & 52 & 51 & RN \\
\hline AEMBL3640510 & 81 & 757 & 16 & RN \\
\hline HFMB 3 & & & & RN \\
\hline 99 & & & & RN \\
\hline HEMBL3689185 & & & & RN \\
\hline AEMBL3689247 & 81 & 88 & 408 & RN \\
\hline HEMBL3640501 & 81 & 441 & 86 & $\mathrm{RN}$ \\
\hline 3 & & & & RN \\
\hline & 31 & 7.6778 & & ST \\
\hline HEMBL3640524 & 527881 & 7.8539 & 831 & TST \\
\hline AEMBL3689209 & 81 & 18 & 993 & RN \\
\hline HEMBL3689251 & 81 & 45 & 168 & I \\
\hline HEMBL3640469 & & & & ST \\
\hline HEMBL3640496 & 527881 & 8.0458 & 4718 & ST \\
\hline HEMBL3640532 & 527881 & 6.1656 & 5229 & RN \\
\hline EMBL364e & 52 & 644 & 142 & KT \\
\hline HEMBL 3640472 & 152 & .2291 & & \\
\hline HEMBL 3640543 & 1527881 & & . 3929 & \\
\hline HEMBL 3640488 & 1527881 & 6.1135 & 6.6507 & ГST \\
\hline
\end{tabular}

Page 7137 
Supplemental Table S2.txt

\begin{tabular}{|c|c|c|c|c|c|}
\hline CHEMBL 3689314 & 1527881 & 8.699 & 8.0268 & TRN & \\
\hline CHEMBL 3640484 & 1527881 & 6.9318 & 7.4591 & TST & \\
\hline CHEMBL 3640487 & 1527881 & 6.7399 & 6.9275 & TST & \\
\hline CHEMBL 3640533 & 1527881 & 6.5591 & 6.6546 & TRN & \\
\hline CHEMBL 3689262 & 1527881 & 7.9208 & 7.7921 & TRN & \\
\hline CHEMBL 3689253 & 1527881 & 7.6778 & 6.9934 & TST & \\
\hline CHEMBL 3689227 & 1527881 & 8.0458 & 8.2384 & TRN & \\
\hline CHEMBL 3640520 & 1527881 & 7.6198 & 7.6002 & TRN & \\
\hline CHEMBL 3640537 & 1527881 & 6.8327 & 6.7781 & TRN & \\
\hline CHEMBL 3640480 & 1527881 & 8.0969 & 6.7515 & TST & \\
\hline CHEMBL 3689224 & 1527881 & 8.0969 & 8.3044 & TRN & \\
\hline CHEMBL 3689219 & 1527881 & 8.0458 & 7.9428 & TRN & \\
\hline CHEMBL 3689260 & 1527881 & 7.4202 & 7.7196 & TRN & \\
\hline CHEMBL 3689310 & 1527881 & 8.699 & 7.7589 & TRN & \\
\hline CHEMBL3689196 & 1527881 & 7.3768 & 6.7769 & TRN & \\
\hline CHEMBL 3689296 & 1527881 & 8.301 & 7.7056 & TRN & \\
\hline CHEMBL 3640446 & 1527881 & 6.3536 & 6.8433 & TRN & \\
\hline CHEMBL 3640463 & 1527881 & 6.7011 & 6.9774 & TST & \\
\hline CHEMBL 3640495 & 1527881 & 8.0 & 6.9204 & TST & \\
\hline CHEMBL 3689237 & 1527881 & 6.0269 & 6.55399 & 9999999999 & TRN \\
\hline CHEMBL 3689186 & 1527881 & 7.5686 & 7.1394 & TRN & \\
\hline CHEMBL 3640493 & 1527881 & 8.2218 & 7.4449 & TST & \\
\hline CHEMBL 3640479 & 1527881 & 6.1568 & 6.3183 & TST & \\
\hline CHEMBL 3640440 & 1527881 & 6.8729 & 6.9639 & TRN & \\
\hline CHEMBL 3689263 & 1527881 & 7.2596 & 7.9182 & TRN & \\
\hline CHEMBL 3640441 & 1527881 & 7.585 & 6.9143 & TRN & \\
\hline CHEMBL 3689248 & 1527881 & 7.0969 & 7.2668 & TST & \\
\hline CHEMBL 3689282 & 1527881 & 7.8239 & 7.9334 & TRN & \\
\hline CHEMBL 3689316 & 1527881 & 8.3979 & 8.4383 & TRN & \\
\hline CHEMBL 3689208 & 1527881 & 8.301 & 7.9491 & TRN & \\
\hline CHEMBL 3689268 & 1527881 & 7.4437 & 7.9881 & TRN & \\
\hline CHEMBL 3640539 & 1527881 & 6.38299 & 79999999ऽ & 6.4956 & \multirow[t]{2}{*}{ TRN } \\
\hline CHEMBL 3640515 & 1527881 & 6.2749 & 6.5424 & TRN & \\
\hline CHEMBL3689292 & 1527881 & 8.699 & \multicolumn{2}{|c|}{8.693999999999999} & TRN \\
\hline CHEMBL 3689200 & 1527881 & 7.3872 & 7.5451 & TRN & \\
\hline CHEMBL 3640546 & 1527881 & 6.9872 & 7.3114 & TRN & \\
\hline CHEMBL 3640453 & 1527881 & 6.6615 & 6.6585 & TRN & \\
\hline CHEMBL 3640540 & 1527881 & 8.5229 & 8.079 & TRN & \\
\hline CHEMBL 3640437 & 1527881 & 6.9355 & 6.9451 & TST & \\
\hline CHEMBL 3640448 & 1527881 & 6.8697 & 6.8055 & TRN & \\
\hline CHEMBL 3689239 & 1527881 & 9.0 & 8.3137 & TRN & \\
\hline CHEMBL 3640477 & 1527881 & 7.1308 & 7.016 & TST & \\
\hline CHEMBL3689264 & 1527881 & 7.4815 & 8.0788 & TRN & \\
\hline CHEMBL 3640489 & 1527881 & 8.2218 & 7.7081 & TST & \\
\hline CHEMBL 3689202 & 1527881 & 8.301 & 8.168 & TRN & \\
\hline CHEMBL 3689226 & 1527881 & 8.5229 & 8.0772 & TRN & \\
\hline CHEMBL 3640507 & 1527881 & 7.5086 & 7.278 & TRN & \\
\hline CHEMBL 3640499 & 1527881 & 7.7959 & 7.4156 & TRN & \\
\hline
\end{tabular}

Page 7138 
Supplemental Table S2.txt

$\begin{array}{lllll}\text { CHEMBL3640474 } & 1527881 & 7.3565 & 6.6937 & \text { TST } \\ \text { CHEMBL3640491 } & 1527881 & 8.0969 & 7.3842 & \text { TST } \\ \text { CHEMBL3640545 } & 1527881 & 7.0555 & 7.3769 & \text { TRN } \\ \text { CHEMBL3640514 } & 1527881 & 7.699 & 7.2433 & \text { TRN } \\ \text { CHEMBL3689298 } & 1527881 & 7.9208 & 8.2886 & \text { TST } \\ \text { CHEMBL3640435 } & 1527881 & 7.0655 & 6.9672 & \text { TST } \\ \text { CHEMBL3950250 } & 1527881 & 6.7328 & 6.9823 & \text { TST } \\ \text { CHEMBL3689238 } & 1527881 & 6.6326 & 6.7705 & \text { TRN } \\ \text { CHEMBL3689258 } & 1527881 & 7.6383 & 7.6172 & \text { TRN } \\ \text { CHEMBL3640511 } & 1527881 & 6.3958 & 6.8093 & \text { TRN } \\ \text { CHEMBL3640452 } & 1527881 & 6.3516 & 6.4619 & \text { TRN } \\ \text { CHEMBL3640442 } & 1527881 & 7.7959 & 6.9888 & \text { TRN } \\ \text { CHEMBL3689295 } & 1527881 & 6.0 & 7.9956 & \text { TRN } \\ \text { CHEMBL3689241 } & 1527881 & 8.699 & 8.5013 & \text { TRN } \\ \text { CHEMBL3640535 } & 1527881 & 6.06 & 6.1568 & \text { TRN } \\ \text { CHEMBL3640465 } & 1527881 & 6.9586 & 7.0497 & \text { TST } \\ \text { CHEMBL3689221 } & 1527881 & 8.699 & 8.3661 & \text { TST } \\ \text { CHEMBL3922103 } & 1527881 & 7.0269 & 7.1069 & \text { TST } \\ \text { CHEMBL3640542 } & 1527881 & 7.9586 & 7.2536 & \text { TST } \\ \text { CHEMBL3689252 } & 1527881 & 7.2076 & 7.317 & \text { TST } \\ \text { CHEMBL3689257 } & 1527881 & 7.8239 & 7.9332 & \text { TRN } \\ \text { CHEMBL3689198 } & 1527881 & 8.5229 & 8.0625 & \text { TRN } \\ \text { CHEMBL3689283 } & 1527881 & 7.6383 & 7.7769 & \text { TRN } \\ \text { CHEMBL3640462 } & 1527881 & 6.8996 & 6.9641 & \text { TRN } \\ \text { CHEMBL3640527 } & 1527881 & 7.5686 & 6.8964 & \text { TRN } \\ \text { CHEMBL3689215 } & 1527881 & 6.0 & 7.055 & \text { TRN } \\ \text { CHEMBL3689278 } & 1527881 & 6.7799 & 6.9527 & \text { TRN } \\ \text { CHEMBL3640439 } & 1527881 & 6.767 & 7.0261 & \text { TRN } \\ \text { CHEMBL3689212 } & 1527881 & 8.5229 & 8.1988 & \text { TRN } \\ \text { CHEMBL3640536 } & 1527881 & 7.1135 & 6.6721 & \text { TRN } \\ \text { CHEMBL3689284 } & 1527881 & 6.1079 & 6.2058 & \text { TRN } \\ \text { CHEMBLB } 3689291 & 1527881 & 8.5229 & 8.7416 & \text { TRN } \\ \text { CHEMBL3689281 } & 1527881 & 7.1487 & 7.5032 & \text { TRN } \\ \text { CHEMBEM } & & & \end{array}$


Supplemental Table S2.txt

\begin{tabular}{|c|c|c|c|c|c|}
\hline CHEMBL 3689194 & 1527881 & 8.0969 & 8.2416 & TRN & \\
\hline CHEMBL 3640523 & 1527881 & 7.0655 & 7.3413 & TST & \\
\hline CHEMBL3689218 & 1527881 & 8.5229 & 8.2453 & TRN & \\
\hline CHEMBL 3640460 & 1527881 & 6.8477 & 7.1114 & TRN & \\
\hline CHEMBL 3689203 & 1527881 & 8.0969 & 8.392999 & 9999999999 & TRN \\
\hline CHEMBL 3689201 & 1527881 & 8.699 & 8.4507 & TRN & \\
\hline CHEMBL 3640502 & 1527881 & 7.0088 & 6.7455 & TRN & \\
\hline CHEMBL 3640468 & 1527881 & 6.9431 & 6.6287 & TST & \\
\hline CHEMBL3689236 & 1527881 & 6.1844 & 6.728 & TRN & \\
\hline CHEMBL 3640475 & 1527881 & 7.0132 & 6.5765 & TST & \\
\hline CHEMBL3689299 & 1527881 & 7.7959 & 8.0153 & TRN & \\
\hline CHEMBL 3640544 & 1527881 & 7.1675 & 7.1406 & TST & \\
\hline CHEMBL 3689254 & 1527881 & 6.7328 & 7.1638 & TST & \\
\hline CHEMBL3689311 & 1527881 & 8.699 & 8.0257 & TRN & \\
\hline CHEMBL3689309 & 1527881 & 7.9586 & 8.0749 & TST & \\
\hline CHEMBL 3640482 & 1527881 & 7.2007 & 7.4075 & TST & \\
\hline CHEMBL3689259 & 1527881 & 6.9586 & 7.2387 & TRN & \\
\hline CHEMBL 3689233 & 1527881 & 8.3979 & 8.4594 & TRN & \\
\hline CHEMBL 3640455 & 1527881 & 7.3872 & 7.2644 & TRN & \\
\hline CHEMBL 3689270 & 1527881 & 8.301 & 7.8702 & TRN & \\
\hline CHEMBL 3640497 & 1527881 & 8.0969 & 7.4964 & TST & \\
\hline CHEMBL 3689204 & 1527881 & 6.0 & 7.4829 & TRN & \\
\hline CHEMBL 3640456 & 1527881 & 6.301 & 7.0057 & TRN & \\
\hline CHEMBL 3640454 & 1527881 & 6.3116 & 6.6429 & TST & \\
\hline CHEMBL 3640490 & 1527881 & 6.3134 & 6.5403 & TRN & \\
\hline CHEMBL 3640512 & 1527881 & 6.6968 & 7.1384 & TRN & \\
\hline CHEMBL 3640447 & 1527881 & 6.6402 & 6.8762 & TRN & \\
\hline CHEMBL 3689294 & 1527881 & 8.699 & 8.3103 & TST & \\
\hline CHEMBL3689302 & 1527881 & 7.3372 & 7.5188 & TRN & \\
\hline CHEMBL 3640471 & 1527881 & 7.2291 & 6.9249 & TST & \\
\hline CHEMBL3689261 & 1527881 & 6.8928 & 7.5413 & TRN & \\
\hline CHEMBL 3689293 & 1527881 & 8.699 & 8.1844 & TST & \\
\hline CHEMBL 3640521 & 1527881 & 7.7212 & 7.28 & TRN & \\
\hline CHEMBL3640481 & 1527881 & 7.3979 & 7.2176 & TST & \\
\hline CHEMBL 3689276 & 1527881 & 6.6737 & 7.2319 & TRN & \\
\hline CHEMBL3689230 & 1527881 & 8.1549 & 8.0853 & TRN & \\
\hline CHEMBL 3640494 & 1527881 & 6.4473 & 7.1022 & TST & \\
\hline CHEMBL 3689300 & 1527881 & 7.585 & 7.7264 & TRN & \\
\hline CHEMBL 3689315 & 1527881 & 8.5229 & 7.672999 & 9999999999 & TRN \\
\hline CHEMBL 3640476 & 1527881 & 6.8633 & 6.8895 & TST & \\
\hline CHEMBL3689225 & 1527881 & 8.3979 & 8.1924 & TRN & \\
\hline CHEMBL 3689290 & 1527881 & 6.8069 & 7.0173 & TRN & \\
\hline CHEMBL3689275 & 1527881 & 6.9245 & 7.2575 & TRN & \\
\hline CHEMBL3689307 & 1527881 & 8.2218 & 7.7825 & TRN & \\
\hline CHEMBL 3689304 & 1527881 & 8.5229 & 8.1918 & TRN & \\
\hline CHEMBL3689272 & 1527881 & 7.4815 & 7.4402 & TRN & \\
\hline CHEMBL3689308 & 1527881 & 7.2218 & 8.0255 & TST & \\
\hline CHEMBL3689206 & 1527881 & 7.6778 & 7.3318 & TRN & \\
\hline
\end{tabular}


Supplemental Table S2.txt

\begin{tabular}{|c|c|c|c|c|c|}
\hline CHEMBL 3640529 & 1527881 & 6.2168 & 6.3834 & TRN & \\
\hline CHEMBL 3689234 & 1527881 & 8.301 & 8.1907 & TRN & \\
\hline CHEMBL3640522 & 1527881 & 7.4559 & 7.2661 & TRN & \\
\hline CHEMBL 3689274 & 1527881 & 7.3279 & 7.3099 & TRN & \\
\hline CHEMBL 3640478 & 1527881 & 7.2147 & 6.9795 & TST & \\
\hline CHEMBL 3689240 & 1527881 & 8.3979 & 8.4345 & TRN & \\
\hline CHEMBL 3640547 & 1527881 & 6.6402 & 6.7562 & TST & \\
\hline CHEMBL3639881 & 1527881 & 7.9586 & 8.3969 & TST & \\
\hline CHEMBL 3640534 & 1527881 & 6.8297 & 6.7192 & TST & \\
\hline CHEMBL 3689246 & 1527881 & 8.3979 & 8.5479 & TRN & \\
\hline CHEMBL 3640541 & 1527881 & 8.0969 & 7.2658 & TST & \\
\hline CHEMBL 3640466 & 1527881 & 6.8069 & 6.7794 & TST & \\
\hline CHEMBL 3689192 & 1527881 & 6.8268 & 7.6975 & TRN & \\
\hline CHEMBL 3689232 & 1527881 & 8.699 & 8.5037 & TRN & \\
\hline CHEMBL 2179837 & 877366 & 5.8861 & 5.8088 & TRN & \\
\hline CHEMBL195090 & 877366 & 6.0458 & 5.7207 & TST & \\
\hline CHEMBL105374 & 877366 & 8.5376 & 6.0951 & TST & \\
\hline CHEMBL 2179838 & 877366 & 6.0458 & 6.047006 & 0000000001 & TRN \\
\hline CHEMBL 2179857 & 877366 & 6.8539 & 6.5403 & TRN & \\
\hline CHEMBL 2179840 & 877366 & 5.9208 & 5.5546 & TRN & \\
\hline CHEMBL2179866 & 877366 & 6.301 & 5.8704 & TRN & \\
\hline CHEMBL2179868 & 877366 & 5.4437 & 5.2255 & TRN & \\
\hline CHEMBL 2180256 & 877366 & 5.9586 & 6.0151 & TRN & \\
\hline CHEMBL2179855 & 877366 & 4.301 & 5.0395 & TRN & \\
\hline CHEMBL 2180250 & 877366 & 6.3979 & 6.3046 & TRN & \\
\hline CHEMBL2179852 & 877366 & 6.301 & 6.16200 & 2000000001 & TRN \\
\hline CHEMBL2180262 & 877366 & 5.0458 & 6.0696 & TST & \\
\hline CHEMBL 370523 & 877366 & 6.0458 & 6.1388 & TRN & \\
\hline CHEMBL372317 & 877366 & 6.5229 & 6.5312 & TRN & \\
\hline CHEMBL 2179860 & 877366 & 6.301 & 6.0521 & TST & \\
\hline CHEMBL2179872 & 877366 & 6.3979 & 5.9371 & TST & \\
\hline CHEMBL2180258 & 877366 & 6.0 & 6.1862 & TRN & \\
\hline CHEMBL2179845 & 877366 & 5.7959 & 5.8369 & TRN & \\
\hline CHEMBL 2179853 & 877366 & 6.699 & 6.4661 & TRN & \\
\hline CHEMBL 2180257 & 877366 & 6.4815 & 6.2894 & TRN & \\
\hline CHEMBL2179870 & 877366 & 5.6383 & 5.4537 & TRN & \\
\hline CHEMBL 2179875 & 877366 & 6.0458 & 5.4844 & TST & \\
\hline CHEMBL2179849 & 877366 & 6.2218 & 5.9461 & TRN & \\
\hline CHEMBL2180253 & 877366 & 6.1308 & 5.7885 & TRN & \\
\hline CHEMBL 2179858 & 877366 & 6.301 & 6.5954 & TRN & \\
\hline CHEMBL2179851 & 877366 & 5.6383 & 5.5515 & TRN & \\
\hline CHEMBL365992 & 877366 & 5.8861 & 5.9706 & TST & \\
\hline CHEMBL2179880 & 877366 & 5.9208 & 6.0046 & TRN & \\
\hline CHEMBL2179883 & 877366 & 5.7959 & 6.2262 & TST & \\
\hline CHEMBL 2179869 & 877366 & 5.6778 & 5.8901 & TRN & \\
\hline CHEMBL2179873 & 877366 & 6.0 & 5.933 & TST & \\
\hline CHEMBL 2179841 & 877366 & 6.301 & 6.2767 & TRN & \\
\hline CHEMBL2180255 & 877366 & 5.8861 & 6.0444 & TRN & \\
\hline
\end{tabular}




\begin{tabular}{|c|c|c|c|c|c|}
\hline & & \multicolumn{4}{|c|}{ Supplemental Table S2.txt } \\
\hline CHEMBL 2179850 & 877366 & 6.0458 & 6.2049 & TRN & \\
\hline CHEMBL 2179842 & 877366 & 5.8539 & 6.0587 & TRN & \\
\hline CHEMBL 2179863 & 877366 & 5.6778 & 5.7778 & TRN & \\
\hline CHEMBL 2180260 & 877366 & 6.1192 & 6.2223 & TRN & \\
\hline CHEMBL 2179881 & 877366 & 6.301 & 6.1645 & TRN & \\
\hline CHEMBL 2179856 & 877366 & 6.3979 & 6.3741 & TRN & \\
\hline CHEMBL 2180251 & 877366 & 6.2076 & 6.21299 & 9999999999 & TRN \\
\hline CHEMBL 2179882 & 877366 & 6.0809 & 6.1651 & TST & \\
\hline CHEMBL193830 & 877366 & 6.699 & 5.818 & TST & \\
\hline CHEMBL 2179865 & 877366 & 5.8239 & 5.778 & TRN & \\
\hline CHEMBL196564 & 877366 & 6.1549 & 5.9183 & TRN & \\
\hline CHEMBL 2180252 & 877366 & 5.8239 & 6.0141 & TRN & \\
\hline CHEMBL 2179847 & 877366 & 5.3565 & 5.5079 & TRN & \\
\hline CHEMBL 2179879 & 877366 & 6.0 & 6.0043 & TRN & \\
\hline CHEMBL 2179846 & 877366 & 5.9586 & 6.0577 & TRN & \\
\hline CHEMBL 2179854 & 877366 & 5.8239 & 6.063 & TRN & \\
\hline CHEMBL 2180261 & 877366 & 5.8861 & 5.8422 & TRN & \\
\hline CHEMBL 2179844 & 877366 & 6.0458 & 6.318 & TRN & \\
\hline CHEMBL 2180259 & 877366 & 6.0088 & 5.8288 & TRN & \\
\hline CHEMBL 2151441 & 877366 & 5.8861 & 5.9963 & TST & \\
\hline CHEMBL 2179878 & 877366 & 6.2218 & 5.79899 & 99999999995 & TST \\
\hline CHEMBL 2179861 & 877366 & 5.7959 & 5.8317 & TRN & \\
\hline CHEMBL194291 & 877366 & 5.699 & 5.9331 & TRN & \\
\hline CHEMBL 2179862 & 877366 & 6.699 & 6.5991 & TRN & \\
\hline CHEMBL 2180263 & 877366 & 5.2924 & 5.9001 & TST & \\
\hline CHEMBL 2179859 & 877366 & 6.2218 & 6.5288 & TRN & \\
\hline CHEMBL 2179848 & 877366 & 5.9208 & 5.9401 & TRN & \\
\hline CHEMBL1789658 & 877366 & 7.4949 & 6.1053 & TST & \\
\hline CHEMBL 2179876 & 877366 & 5.8239 & 5.6507 & TST & \\
\hline CHEMBL 2179864 & 877366 & 5.8539 & 5.7023 & TRN & \\
\hline CHEMBL 2180254 & 877366 & 5.8861 & 5.7826 & TRN & \\
\hline CHEMBL 2179867 & 877366 & 5.4815 & 5.8701 & TST & \\
\hline CHEMBL343926 & 201877 & 7.9586 & 7.4552 & TST & \\
\hline CHEMBL422627 & 201877 & 7.4815 & 7.6084 & TRN & \\
\hline CHEMBL555993 & 201877 & 7.7447 & 7.6368 & TRN & \\
\hline CHEMBL137159 & 201877 & 8.5229 & 8.211 & TRN & \\
\hline CHEMBL544147 & 201877 & 8.1549 & 8.2291 & TRN & \\
\hline CHEMBL139578 & 201877 & 8.301 & 8.1891 & TRN & \\
\hline CHEMBL46463 & 201877 & 8.0 & 8.0558 & TRN & \\
\hline CHEMBL555975 & 201877 & 8.0969 & 8.0807 & TRN & \\
\hline CHEMBL555544 & 201877 & 7.4815 & 7.5653 & TRN & \\
\hline CHEMBL543674 & 201877 & 8.2518 & 8.0732 & TRN & \\
\hline CHEMBL422993 & 201877 & 6.5086 & 6.9854 & TST & \\
\hline CHEMBL545549 & 201877 & 8.1549 & 7.9234 & TRN & \\
\hline CHEMBL538532 & 201877 & 8.699 & 8.7856 & TRN & \\
\hline CHEMBL424091 & 201877 & 4.0 & 3.9053 & TRN & \\
\hline CHEMBL544372 & 201877 & 7.2924 & 7.4066 & TRN & \\
\hline CHEMBL539553 & 201877 & 8.3468 & 7.9658 & TST & \\
\hline
\end{tabular}




\begin{tabular}{|c|c|c|c|c|c|c|}
\hline & & \\
\hline CHEMBL139110 & 201877 & 8.1549 & 8.2104 & TRN & & \\
\hline CHEMBL136205 & 201877 & 6.6615 & 7.0201 & TRN & & \\
\hline CHEMBL440345 & 201877 & 7.2924 & 7.5806 & TRN & & \\
\hline CHEMBL442965 & 201877 & 8.5229 & 8.4498 & TRN & & \\
\hline CHEMBL139102 & 201877 & 6.75700 & 900000000 & $\partial 1$ & 7.353 & TRN \\
\hline CHEMBL136590 & 201877 & 7.2757 & 7.102 & TRN & & \\
\hline CHEMBL60859 & 201877 & 6.7595 & 6.1656 & TST & & \\
\hline CHEMBL555865 & 201877 & 8.301 & 8.0663 & TRN & & \\
\hline CHEMBL540578 & 201877 & 8.301 & 8.4245 & TRN & & \\
\hline CHEMBL136794 & 201877 & 8.0458 & 8.1939 & TRN & & \\
\hline CHEMBL138382 & 201877 & 8.301 & 8.3878 & TRN & & \\
\hline CHEMBL543440 & 201877 & 7.585 & 7.9697 & TRN & & \\
\hline CHEMBL539042 & 201877 & 7.699 & 7.7748 & TRN & & \\
\hline CHEMBL136509 & 201877 & 7.3979 & 6.9576 & TST & & \\
\hline CHEMBL424281 & 201877 & 8.2218 & 8.5146 & TRN & & \\
\hline CHEMBL136495 & 201877 & 8.699 & 8.6266 & TRN & & \\
\hline CHEMBL134578 & 201877 & 8.3979 & 8.3191 & TRN & & \\
\hline CHEMBL136702 & 201877 & 7.0088 & 6.8192 & TRN & & \\
\hline CHEMBL136789 & 201877 & 8.0969 & 8.3521 & TRN & & \\
\hline CHEMBL136615 & 201877 & 8.699 & 8.0469 & TST & & \\
\hline CHEMBL134527 & 201877 & 8.0969 & 8.2721 & TRN & & \\
\hline CHEMBL544375 & 201877 & 7.7447 & 8.3174 & TST & & \\
\hline CHEMBL334466 & 201877 & 8.5229 & 8.454 & TRN & & \\
\hline CHEMBL137776 & 201877 & 7.9586 & 7.8933 & TRN & & \\
\hline CHEMBL335327 & 201877 & 8.699 & 8.3384 & TRN & & \\
\hline CHEMBL543917 & 201877 & 7.3468 & 7.6487 & TRN & & \\
\hline CHEMBL136621 & 201877 & 8.1549 & 7.8081 & TRN & & \\
\hline CHEMBL136768 & 201877 & 8.5229 & 8.4875 & TRN & & \\
\hline CHEMBL136622 & 201877 & 7.9586 & 7.1322 & TST & & \\
\hline CHEMBL545784 & 201877 & 7.8539 & 7.9602 & TRN & & \\
\hline CHEMBL342948 & 201877 & 7.7447 & 7.8756 & TRN & & \\
\hline CHEMBL344240 & 201877 & 7.7447 & 7.7648 & TRN & & \\
\hline CHEMBL540322 & 201877 & 8.3979 & 8.5235 & TRN & & \\
\hline CHEMBL555443 & 201877 & 8.0969 & 8.2065 & TRN & & \\
\hline CHEMBL540585 & 201877 & 8.3979 & 8.2027 & TRN & & \\
\hline CHEMBL423355 & 201877 & 7.4685 & 7.4262 & TRN & & \\
\hline CHEMBL136963 & 201877 & 8.3979 & 8.1514 & TRN & & \\
\hline CHEMBL139963 & 201877 & 8.301 & 8.4087 & TRN & & \\
\hline CHEMBL136877 & 201877 & 7.4559 & 7.1575 & TRN & & \\
\hline CHEMBL337711 & 201877 & 7.6198 & 7.8938 & TRN & & \\
\hline CHEMBL137768 & 201877 & 8.699 & 8.4245 & TRN & & \\
\hline CHEMBL137658 & 201877 & 7.699 & 7.6826 & TRN & & \\
\hline CHEMBL137183 & 201877 & 6.8097 & 6.936 & TRN & & \\
\hline CHEMBL542737 & 201877 & 8.5229 & 8.8382 & TRN & & \\
\hline CHEMBL343802 & 201877 & 7.5229 & 8.0913 & TRN & & \\
\hline CHEMBL542246 & 201877 & 8.0809 & 8.2172 & TRN & & \\
\hline CHEMBL439609 & 201877 & 8.301 & 5.8852 & TST & & \\
\hline CHEMBL539567 & 201877 & 8.699 & 8.7412 & TRN & & \\
\hline
\end{tabular}




\begin{tabular}{|c|c|c|c|c|c|}
\hline \multicolumn{6}{|c|}{ Supplemental Table s2.txt } \\
\hline CHEMBL552676 & 201877 & 6.5171 & 7.0572 & TRN & \\
\hline CHEMBL134684 & 201877 & 8.699 & 8.2673 & TRN & \\
\hline CHEMBL558819 & 201877 & 8.1549 & 8.0592 & TRN & \\
\hline CHEMBL139370 & 201877 & 8.301 & 8.0478 & TST & \\
\hline CHEMBL137250 & 201877 & 7.5086 & 7.6415 & TRN & \\
\hline CHEMBL544847 & 201877 & 8.699 & 8.6451 & TRN & \\
\hline CHEMBL545081 & 201877 & 7.5686 & 7.6761 & TRN & \\
\hline CHEMBL544614 & 201877 & 8.0969 & 8.1065 & TRN & \\
\hline CHEMBL136594 & 201877 & 8.0 & 7.9374 & TRN & \\
\hline CHEMBL138281 & 201877 & 8.5229 & 8.514 & TRN & \\
\hline CHEMBL136068 & 201877 & 8.0 & 8.2488 & TRN & \\
\hline CHEMBL544616 & 201877 & 7.9586 & 7.7336 & TRN & \\
\hline CHEMBL136835 & 201877 & 8.0969 & 8.3273 & TRN & \\
\hline CHEMBL539358 & 201877 & 8.699 & 8.6052 & TRN & \\
\hline CHEMBL555093 & 201877 & 8.0458 & 7.9963 & TRN & \\
\hline CHEMBL540066 & 201877 & 7.3565 & 7.1901 & TRN & \\
\hline CHEMBL545781 & 201877 & 7.8239 & 7.9908 & TRN & \\
\hline CHEMBL136701 & 201877 & 8.1549 & 7.0078 & TST & \\
\hline CHEMBL337124 & 201877 & 8.1549 & 8.0321 & TRN & \\
\hline CHEMBL136743 & 201877 & 7.7696 & 7.9413 & TRN & \\
\hline CHEMBL539291 & 201877 & 6.4597 & 6.7382 & TRN & \\
\hline CHEMBL545546 & 201877 & 8.5229 & 8.3856 & TST & \\
\hline CHEMBL543438 & 201877 & 8.0 & 7.8173 & TST & \\
\hline CHEMBL542740 & 201877 & 8.3979 & 8.047 & TRN & \\
\hline CHEMBL137339 & 201877 & 7.5528 & 6.32299 & 99999999995 & TST \\
\hline CHEMBL543437 & 201877 & 8.2218 & 7.8657 & TRN & \\
\hline CHEMBL543439 & 201877 & 8.0969 & 8.168 & TRN & \\
\hline CHEMBL422634 & 201877 & 8.0458 & 7.9382 & TRN & \\
\hline CHEMBL136395 & 201877 & 7.8861 & 7.8348 & TRN & \\
\hline CHEMBL545552 & 201877 & 7.6576 & 7.7934 & TRN & \\
\hline CHEMBL342267 & 201877 & 9.0 & 8.5968 & TRN & \\
\hline CHEMBL541603 & 201877 & 7.301 & 7.1723 & TRN & \\
\hline CHEMBL136381 & 201877 & 8.1549 & 8.2522 & TRN & \\
\hline CHEMBL136429 & 201877 & 8.4559 & 8.3614 & TRN & \\
\hline CHEMBL136388 & 201877 & 7.5086 & 7.381 & TRN & \\
\hline CHEMBL136589 & 201877 & 7.4318 & 8.7843 & TST & \\
\hline CHEMBL137321 & 201877 & 8.301 & 7.5322 & TST & \\
\hline CHEMBL136064 & 201877 & 7.585 & 7.5911 & TRN & \\
\hline CHEMBL539302 & 201877 & 8.3979 & 8.0075 & TRN & \\
\hline CHEMBL554678 & 201877 & 8.699 & 8.0867 & TRN & \\
\hline CHEMBL137163 & 201877 & 6.8356 & 6.4717 & TRN & \\
\hline CHEMBL544146 & 201877 & 8.3979 & 8.5771 & TRN & \\
\hline CHEMBL137563 & 201877 & 7.8539 & 8.1241 & TST & \\
\hline CHEMBL543910 & 201877 & 7.2596 & 7.8058 & TST & \\
\hline CHEMBL137502 & 201877 & 7.301 & 6.8328 & TST & \\
\hline CHEMBL543412 & 201877 & 8.0 & 8.2576 & TST & \\
\hline CHEMBL543206 & 201877 & 7.4815 & 5.1896 & TST & \\
\hline CHEMBL136642 & 201877 & 8.699 & 7.7942 & TST & \\
\hline
\end{tabular}




\begin{tabular}{|c|c|c|c|c|c|}
\hline & & & & & \\
\hline CHEMBL423353 & 201877 & 8.5229 & 7.5151 & TST & \\
\hline CHEMBL344422 & 201877 & 8.699 & 8.3259 & TST & \\
\hline CHEMBL137085 & 201877 & 8.301 & 8.14 & TST & \\
\hline CHEMBL337337 & 201877 & 8.1549 & 8.0896 & TST & \\
\hline CHEMBL138992 & 201877 & 7.0809 & 7.4284 & TST & \\
\hline CHEMBL337810 & 201877 & 8.4949 & 8.4169 & TST & \\
\hline CHEMBL335019 & 201877 & 7.9208 & 7.4898 & TST & \\
\hline CHEMBL136781 & 201877 & 7.8539 & 8.4758 & TST & \\
\hline CHEMBL337148 & 201877 & 7.2757 & 7.37299 & 9999999999 & TST \\
\hline CHEMBL1549039 & 752398 & 3.0969 & 3.321 & TRN & \\
\hline CHEMBL1556634 & 752398 & 4.27 & 4.1949 & TRN & \\
\hline CHEMBL1565164 & 752398 & 3.0969 & 3.7356 & TRN & \\
\hline CHEMBL1548507 & 752398 & 4.1675 & 4.072 & TRN & \\
\hline CHEMBL1504286 & 752398 & 4.3045 & 3.822 & TRN & \\
\hline CHEMBL1536873 & 752398 & 3.0969 & 3.6418 & TRN & \\
\hline CHEMBL1312502 & 752398 & 4.2692 & 3.5466 & TRN & \\
\hline CHEMBL1968789 & 752398 & 4.2343 & 3.5984 & TRN & \\
\hline CHEMBL1564355 & 752398 & 4.1746 & 3.69199 & 99999999997 & TRN \\
\hline CHEMBL1568124 & 752398 & 4.2111 & 3.1278 & TRN & \\
\hline CHEMBL1607263 & 752398 & 4.3507 & 4.0723 & TRN & \\
\hline CHEMBL1385230 & 752398 & 4.752 & 3.9645 & TRN & \\
\hline CHEMBL1318998 & 752398 & 4.2541 & 3.7048 & TRN & \\
\hline CHEMBL1324790 & 752398 & 3.0969 & 3.5228 & TRN & \\
\hline CHEMBL1574351 & 752398 & 4.9318 & 4.7602 & TRN & \\
\hline CHEMBL1409735 & 752398 & 3.0969 & 3.5764 & TRN & \\
\hline CHEMBL1529183 & 752398 & 3.0969 & 3.1278 & TRN & \\
\hline CHEMBL1729008 & 752398 & 4.4389 & 3.9261 & TST & \\
\hline CHEMBL3199003 & 752398 & 3.0969 & 3.2609 & TRN & \\
\hline CHEMBL1444986 & 752398 & 3.0969 & 3.4425 & TRN & \\
\hline CHEMBL1322398 & 752398 & 4.5272 & 3.886 & TRN & \\
\hline CHEMBL2000342 & 752398 & 3.0969 & 3.8705 & TRN & \\
\hline CHEMBL1595227 & 752398 & 3.0969 & 3.0345 & TST & \\
\hline CHEMBL1255656 & 752398 & 4.4622 & 4.2532 & TRN & \\
\hline CHEMBL1590378 & 752398 & 4.3307 & 3.9522 & TST & \\
\hline CHEMBL1396393 & 752398 & 4.4389 & 3.4372 & TRN & \\
\hline CHEMBL3194574 & 752398 & 3.0969 & 3.8433 & TRN & \\
\hline CHEMBL1698802 & 752398 & 4.3458 & 3.8337 & TRN & \\
\hline CHEMBL1443982 & 752398 & 4.2218 & 3.3985 & TRN & \\
\hline CHEMBL3189722 & 752398 & 4.8962 & 3.8161 & TRN & \\
\hline CHEMBL1722539 & 752398 & 3.0969 & 3.2887 & TRN & \\
\hline CHEMBL1529325 & 752398 & 4.5622 & 4.2675 & TRN & \\
\hline CHEMBL1989090 & 752398 & 3.0969 & 3.5805 & TRN & \\
\hline CHEMBL1504939 & 752398 & 4.2388 & 3.9201 & TRN & \\
\hline CHEMBL1546172 & 752398 & 3.0969 & 3.9565 & TRN & \\
\hline CHEMBL1703714 & 752398 & 4.6861 & 4.0905 & TRN & \\
\hline CHEMBL1462764 & 752398 & 3.0969 & 3.8757 & TRN & \\
\hline CHEMBL1366942 & 752398 & 4.3536 & 3.648 & TRN & \\
\hline CHEMBL1428615 & 752398 & 3.0969 & 3.5422 & TST & \\
\hline
\end{tabular}




\begin{tabular}{|c|c|c|c|c|c|c|}
\hline & & \multicolumn{5}{|c|}{ Supplemental Table S2.txt } \\
\hline CHEMBL1390710 & 752398 & 3.0969 & 3.5709 & TRN & & \\
\hline CHEMBL1719817 & 752398 & 4.5302 & 3.6672 & TRN & & \\
\hline CHEMBL1475746 & 752398 & 3.0969 & 3.4634 & TRN & & \\
\hline CHEMBL3190727 & 752398 & 3.0969 & 3.826 & TRN & & \\
\hline CHEMBL1340352 & 752398 & 3.0969 & 3.4715 & TST & & \\
\hline CHEMBL1533008 & 752398 & 3.0969 & 3.5702 & TRN & & \\
\hline CHEMBL98386 & 752398 & \multicolumn{3}{|c|}{ 4.76699999999999995 } & 4.8583 & TRN \\
\hline CHEMBL1348445 & 752398 & 4.4498 & 4.1338 & TRN & & \\
\hline CHEMBL3196050 & 752398 & \multicolumn{3}{|c|}{4.7669999999999995} & 4.0345 & TRN \\
\hline CHEMBL1969672 & 752398 & 3.0969 & 3.5855 & TRN & & \\
\hline CHEMBL1610025 & 752398 & 3.0969 & 3.2843 & TRN & & \\
\hline CHEMBL3196881 & 752398 & 3.0969 & 3.4444 & TRN & & \\
\hline CHEMBL1698608 & 752398 & 3.0969 & 3.3776 & TRN & & \\
\hline CHEMBL45152 & 752398 & 5.0119 & 5.1828 & TRN & & \\
\hline CHEMBL1313139 & 752398 & 3.0969 & 3.654 & TRN & & \\
\hline CHEMBL1571835 & 752398 & 4.4318 & 4.0257 & TRN & & \\
\hline CHEMBL3199870 & 752398 & 3.0969 & 3.5862 & TST & & \\
\hline CHEMBL1713817 & 752398 & 4.1911 & 3.9882 & TST & & \\
\hline CHEMBL1564773 & 752398 & 3.0969 & 3.7016 & TRN & & \\
\hline CHEMBL510515 & 752398 & 4.6498 & 3.7954 & TRN & & \\
\hline CHEMBL1606460 & 752398 & 3.0969 & 3.3929 & TST & & \\
\hline CHEMBL 2006418 & 752398 & 4.1221 & 3.8029 & TRN & & \\
\hline CHEMBL1377465 & 752398 & 4.5467 & 3.7993 & TRN & & \\
\hline CHEMBL1471841 & 752398 & 4.3152 & 3.9779 & TRN & & \\
\hline CHEMBL1496195 & 752398 & 4.5302 & 4.1622 & TRN & & \\
\hline CHEMBL1585127 & 752398 & 4.5834 & 4.1929 & TRN & & \\
\hline CHEMBL1589526 & 752398 & 3.0969 & 3.4707 & TST & & \\
\hline CHEMBL1342337 & 752398 & 4.383 & 4.0905 & TRN & & \\
\hline CHEMBL1486503 & 752398 & 3.0969 & 3.3521 & TRN & & \\
\hline CHEMBL1594545 & 752398 & 3.0969 & 3.583 & TRN & & \\
\hline CHEMBL1391094 & 752398 & 3.0969 & 3.6774 & TRN & & \\
\hline CHEMBL1715088 & 752398 & 3.0969 & 3.0375 & TRN & & \\
\hline CHEMBL119878 & 752398 & 4.4389 & 3.8784 & TST & & \\
\hline CHEMBL1401342 & 752398 & 4.3134 & 3.9752 & TRN & & \\
\hline CHEMBL1557018 & 752398 & 3.0969 & 3.8813 & TRN & & \\
\hline CHEMBL288096 & 752398 & 3.0969 & 3.4077 & TST & & \\
\hline CHEMBL1347600 & 752398 & 3.0969 & 3.4003 & TST & & \\
\hline CHEMBL1608402 & 752398 & 3.0969 & 3.4745 & TRN & & \\
\hline CHEMBL1336959 & 752398 & 4.71899 & 99999999 & 99 & 4.9283 & I \\
\hline CHEMBL1578299 & 752398 & 4.1555 & 3.5199 & TRN & & \\
\hline CHEMBL1707960 & 752398 & 3.0969 & 3.0854 & TRN & & \\
\hline CHEMBL1368818 & 752398 & 3.0969 & 3.2084 & TRN & & \\
\hline CHEMBL1702981 & 752398 & 4.8097 & 4.9722 & TRN & & \\
\hline CHEMBL441433 & 752398 & 4.2581 & 4.5097 & TRN & & \\
\hline CHEMBL1710816 & 752398 & 4.71 & 4.2861 & TRN & & \\
\hline CHEMBL1465511 & 752398 & 3.0969 & 4.0546 & TRN & & \\
\hline CHEMBL463783 & 752398 & 3.0969 & 3.12399 & 99999 & 997 & \\
\hline CHEMBL3193252 & 752398 & 3.0969 & 3.21199 & 9999 & 997 & \\
\hline
\end{tabular}


Supplemental Table S2.txt

\begin{tabular}{|c|c|c|c|c|}
\hline & & & & \\
\hline AEMBL1699398 & 2398 & 3.0969 & & \\
\hline IEMBL1441974 & 2398 & 969 & 1145 & \\
\hline HEMBL1336825 & 2398 & 969 & 102 & \\
\hline & 398 & 802 & & \\
\hline AEMBL17 & 2398 & 969 & 37 & \\
\hline AEMBL1361252 & 52398 & 733 & 2 & \\
\hline AEMBL1342666 & 52398 & 3.0969 & & \\
\hline AEMBL3196864 & 52398 & 4.383 & & \\
\hline IEMBL1406389 & 52398 & 449 & & \\
\hline AEMBL1487368 & 52398 & 972 & & \\
\hline AEMBL1713097 & 52398 & 969 & 7312 & \\
\hline AEMBL1491019 & 52398 & 969 & & \\
\hline IEMBL1398142 & 398 & 4. & 94 & \\
\hline IEMBL1489664 & 398 & & & \\
\hline AEMBL1337166 & 398 & & & \\
\hline AEMBL1348294 & 52398 & 969 & & \\
\hline AEMBL1579122 & 52398 & 969 & & \\
\hline IEMBL1481364 & 8 & 4. & & \\
\hline AEMBL138 & 8 & & & \\
\hline AEMBL1702711 & 98 & & & RN \\
\hline AEMBL1318818 & 52398 & 969 & & RN \\
\hline AEMBL1586360 & & & & \\
\hline IEMBL 3213331 & 8 & & & \\
\hline EMMBL1308549 & 8 & & & . \\
\hline IEMBL1498754 & 98 & 4. & & $\mathrm{RN}$ \\
\hline AEMBL1392034 & 98 & 969 & & RN \\
\hline AEMBL1310865 & & & & \\
\hline IEMBL608699 & 98 & 4. & & RI \\
\hline 529 & 8 & & & 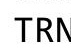 \\
\hline JEMBL173 & 8 & & & $\mathrm{RN}$ \\
\hline AEMBL3208936 & & & & RN \\
\hline AEMBL1385343 & & & & RI \\
\hline EMBL1736559 & 98 & & & RI \\
\hline 659 & 8 & & & . \\
\hline 1569991 & & & & ST \\
\hline AEMBL3189803 & 523 & & 3262 & rRN \\
\hline AEMBL1523225 & 98 & & & $S T$ \\
\hline EMBL1734268 & 98 & & & RI \\
\hline 503 & & & & \\
\hline 4 & & & & RN \\
\hline AEMBL1733684 & 52398 & 984 & 7974 & $\Gamma S T$ \\
\hline IEMBL1716493 & 98 & & & $\Gamma R$ \\
\hline HEMBL1471711 & & & & \\
\hline HEMBL1521312 & & & & \\
\hline CHEMBL 3214350 & & 4. & 11 & RI \\
\hline AEMBL1329615 & 52398 & 4.1637 & 6472 & $T R$ \\
\hline HEMBL1729592 & 52398 & 3.0969 & 3.0848 & \\
\hline
\end{tabular}


Supplemental Table S2.txt

\begin{tabular}{|c|c|c|c|c|c|}
\hline CHEMBL1477589 & 752398 & 4.4559 & 3.6545 & TRN & \\
\hline CHEMBL1385949 & 752398 & 4.2472 & 3.4329 & TRN & \\
\hline CHEMBL1451538 & 752398 & 3.0969 & 3.5835 & TRN & \\
\hline CHEMBL445304 & 752398 & 4.3883 & \multicolumn{2}{|c|}{4.343999999999999} & TST \\
\hline CHEMBL1966224 & 752398 & 4.2628 & 4.4425 & TRN & \\
\hline CHEMBL1557622 & 752398 & 4.4365 & 3.5977 & TRN & \\
\hline CHEMBL1701411 & 752398 & 3.0969 & 3.3429 & TRN & \\
\hline CHEMBL1353285 & 752398 & 3.0969 & 3.3255 & TRN & \\
\hline CHEMBL1501009 & 752398 & 3.0969 & 3.3457 & TRN & \\
\hline CHEMBL1524715 & 752398 & 3.0969 & 3.4977 & TRN & \\
\hline CHEMBL3192578 & 752398 & 5.0424 & 3.7896 & TRN & \\
\hline CHEMBL1553409 & 752398 & 4.2749 & 4.0567 & TRN & \\
\hline CHEMBL1504429 & 752398 & 4.8268 & 3.3718 & TRN & \\
\hline CHEMBL1427185 & 752398 & 4.4584 & 3.9369 & TRN & \\
\hline CHEMBL1304584 & 752398 & 4.1141 & 3.3814 & TST & \\
\hline CHEMBL1700720 & 752398 & 3.0969 & 3.4211 & TST & \\
\hline CHEMBL1374016 & 752398 & 4.3893 & 3.674 & TST & \\
\hline CHEMBL1323484 & 752398 & 4.5045 & 3.6444 & TRN & \\
\hline CHEMBL1320696 & 752398 & 3.0969 & 3.5051 & TRN & \\
\hline CHEMBL1426299 & 752398 & 3.0969 & \multicolumn{2}{|c|}{3.5789999999999997} & TRN \\
\hline CHEMBL1393447 & 752398 & 3.0969 & 3.6639 & TRN & \\
\hline CHEMBL1582210 & 752398 & 3.0969 & 3.4562 & TST & \\
\hline CHEMBL1324104 & 752398 & 4.2899 & 3.4799 & TST & \\
\hline CHEMBL1422613 & 752398 & 3.0969 & \multicolumn{2}{|c|}{3.3989999999999996} & TRN \\
\hline CHEMBL1546332 & 752398 & 4.3625 & 3.9669 & TRN & \\
\hline CHEMBL1717890 & 752398 & 4.4179 & 3.9473 & TRN & \\
\hline CHEMBL1714283 & 752398 & 3.0969 & \multicolumn{2}{|c|}{3.2089999999999996} & TRN \\
\hline CHEMBL1703503 & 752398 & 4.4023 & 4.6775 & TRN & \\
\hline CHEMBL1707222 & 752398 & 3.0969 & 3.8972 & TST & \\
\hline CHEMBL1530439 & 752398 & 3.0969 & 4.1142 & TRN & \\
\hline CHEMBL1548574 & 752398 & 3.0969 & 3.7593 & TRN & \\
\hline CHEMBL1348432 & 752398 & 3.0969 & 3.2027 & TRN & \\
\hline CHEMBL75913 & 752398 & 4.4685 & 4.2446 & TRN & \\
\hline CHEMBL116548 & 752398 & 4.3507 & 4.0914 & TRN & \\
\hline CHEMBL1707641 & 752398 & 5.0315 & 4.1215 & TRN & \\
\hline CHEMBL1453017 & 752398 & 3.0969 & 3.678 & TST & \\
\hline CHEMBL1465049 & 752398 & 4.2684 & 3.1663 & TRN & \\
\hline CHEMBL1412731 & 752398 & 4.5045 & 4.1837 & TRN & \\
\hline CHEMBL1972037 & 752398 & 3.0969 & 3.8294 & TRN & \\
\hline CHEMBL 1717420 & 752398 & 4.9031 & 4.9776 & TRN & \\
\hline CHEMBL1702253 & 752398 & 3.0969 & 3.4465 & TRN & \\
\hline CHEMBL1566068 & 752398 & 3.0969 & 3.279 & TRN & \\
\hline CHEMBL1704186 & 752398 & 5.0635 & 4.0658 & TRN & \\
\hline CHEMBL1509648 & 752398 & 3.0969 & 3.3874 & TRN & \\
\hline CHEMBL1378223 & 752398 & 4.1624 & 3.7959 & TST & \\
\hline CHEMBL244649 & 752398 & 3.0969 & 3.8302 & TRN & \\
\hline CHEMBL1380978 & 752398 & 3.0969 & 3.7364 & TRN & \\
\hline CHEMBL1413554 & 752398 & 4.5186 & 3.364 & TST & \\
\hline
\end{tabular}


Supplemental Table S2.txt

\begin{tabular}{|c|c|c|c|c|c|}
\hline CHEMBL1452103 & 752398 & 4.2262 & 4.4039 & TRN & \\
\hline CHEMBL1092816 & 752398 & 3.0969 & 3.5897 & TRN & \\
\hline CHEMBL1572324 & 752398 & 4.5058 & 4.047 & TRN & \\
\hline CHEMBL3189238 & 752398 & 4.6635 & 3.7019 & TRN & \\
\hline CHEMBL1966295 & 752398 & 4.3344 & 3.3423 & TRN & \\
\hline CHEMBL1503335 & 752398 & 3.0969 & 3.7108 & TRN & \\
\hline CHEMBL1389498 & 752398 & 3.0969 & 3.5702 & TRN & \\
\hline CHEMBL1723964 & 752398 & 4.5498 & 4.3527 & TST & \\
\hline CHEMBL1581385 & 752398 & 3.0969 & 3.7719 & TRN & \\
\hline CHEMBL1461413 & 752398 & 4.2549 & 3.9143 & TST & \\
\hline CHEMBL1447124 & 752398 & 4.3615 & 4.0196 & TRN & \\
\hline CHEMBL1726592 & 752398 & 4.6925 & 4.9514 & TRN & \\
\hline CHEMBL1715126 & 752398 & 3.0969 & 3.8434 & TRN & \\
\hline CHEMBL1327721 & 752398 & 4.1325 & 2.77 & TRN & \\
\hline CHEMBL1702248 & 752398 & 3.0969 & 3.7606 & TST & \\
\hline CHEMBL3191188 & 752398 & 3.0969 & 4.0484 & TRN & \\
\hline CHEMBL1374979 & 752398 & 3.0969 & 3.5838 & TST & \\
\hline CHEMBL1790039 & 752398 & 3.0969 & 3.4079 & TST & \\
\hline CHEMBL1368578 & 752398 & 4.2916 & 3.4538 & TRN & \\
\hline CHEMBL1393611 & 752398 & 3.0969 & 3.3785 & TRN & \\
\hline CHEMBL458114 & 752398 & 3.0969 & 3.0391 & TRN & \\
\hline CHEMBL1501723 & 752398 & 4.3915 & 3.9103 & TRN & \\
\hline CHEMBL1365064 & 752398 & 3.0969 & 3.2101 & TST & \\
\hline CHEMBL1539384 & 752398 & 3.0969 & 3.5474 & TRN & \\
\hline CHEMBL1579380 & 752398 & 4.2336 & 4.148 & TRN & \\
\hline CHEMBL1503768 & 752398 & 4.3645 & 3.6013 & TRN & \\
\hline CHEMBL1447350 & 752398 & 4.5498 & 4.4286 & TRN & \\
\hline CHEMBL3192179 & 752398 & 4.4377 & 3.7035 & TRN & \\
\hline CHEMBL1300266 & 752398 & 4.58 & 3.9948 & TRN & \\
\hline CHEMBL1587245 & 752398 & 3.0969 & 3.7066 & TRN & \\
\hline CHEMBL1719648 & 752398 & 4.6421 & 4.1797 & TST & \\
\hline CHEMBL1408718 & 752398 & 4.4841 & 4.2784 & TRN & \\
\hline CHEMBL1481042 & 752398 & 4.6498 & 3.6232 & TST & \\
\hline CHEMBL1560188 & 752398 & 3.0969 & 3.5017 & TRN & \\
\hline CHEMBL1698845 & 752398 & 4.7932 & 3.7977 & TST & \\
\hline CHEMBL452751 & 752398 & 3.0969 & 3.4045 & TST & \\
\hline CHEMBL1720314 & 752398 & 4.3675 & 3.64300 & 00000000002 & TRN \\
\hline CHEMBL3195177 & 752398 & 4.4067 & 4.0863 & TRN & \\
\hline CHEMBL1463161 & 752398 & 3.0969 & 3.6423 & TRN & \\
\hline CHEMBL1484167 & 752398 & 4.6144 & 3.4226 & TST & \\
\hline CHEMBL1724452 & 752398 & 4.2882 & 3.2499 & TRN & \\
\hline CHEMBL483531 & 752398 & 4.7122 & 4.0459 & TRN & \\
\hline CHEMBL1339993 & 752398 & 4.8268 & 3.6033 & TRN & \\
\hline CHEMBL3198590 & 752398 & 3.0969 & 3.0032 & TRN & \\
\hline CHEMBL1706548 & 752398 & 4.8069 & 4.7099 & TRN & \\
\hline CHEMBL257286 & 752398 & 4.6799 & 4.1909 & TRN & \\
\hline CHEMBL1414687 & 752398 & 3.0969 & 3.6157 & TRN & \\
\hline CHEMBL3196863 & 752398 & 3.0969 & 3.6847 & TRN & \\
\hline
\end{tabular}

Page 7149 
Supplemental Table S2.txt

\begin{tabular}{|c|c|c|c|c|}
\hline CHEMBL1391552 & 752398 & 4.6364 & 4.6046 & TRN \\
\hline CHEMBL1497146 & 752398 & 3.0969 & 3.8562 & TRN \\
\hline CHEMBL1736648 & 752398 & 4.7077 & 4.6382 & TRN \\
\hline CHEMBL1537872 & 752398 & 4.2411 & 3.8281 & TST \\
\hline CHEMBL3197607 & 752398 & 3.0969 & 3.398 & TRN \\
\hline CHEMBL3191855 & 752398 & 3.0969 & 3.50600 & 30000000002 \\
\hline CHEMBL1418971 & 752398 & 4.3883 & 3.8998 & TRN \\
\hline CHEMBL220845 & 752398 & 4.3134 & 4.0475 & TRN \\
\hline CHEMBL1472466 & 752398 & 3.0969 & 3.9098 & TST \\
\hline CHEMBL1355212 & 752398 & 4.3595 & 3.9848 & TST \\
\hline CHEMBL1609529 & 752398 & 3.0969 & 3.7739 & TRN \\
\hline CHEMBL3197471 & 752398 & 3.0969 & 3.8567 & TRN \\
\hline CHEMBL1438567 & 752398 & 4.3458 & 3.5975 & TRN \\
\hline CHEMBL1402525 & 752398 & 4.3958 & 3.8546 & TRN \\
\hline CHEMBL1537984 & 752398 & 3.0969 & 3.7554 & TRN \\
\hline CHEMBL1702945 & 752398 & 3.0969 & 3.39399 & 99999999997 \\
\hline CHEMBL1310318 & 752398 & 4.9914 & 4.9546 & TRN \\
\hline CHEMBL 7660 & 752398 & 3.0969 & 3.929 & TRN \\
\hline CHEMBL1514916 & 752398 & 4.2336 & 3.8547 & TST \\
\hline CHEMBL1335844 & 752398 & 4.6216 & 3.8709 & TRN \\
\hline CHEMBL1698737 & 752398 & 3.0969 & 3.3632 & TRN \\
\hline CHEMBL1580845 & 752398 & 3.0969 & 3.5129 & TRN \\
\hline CHEMBL1993855 & 752398 & 4.2899 & 3.9506 & TRN \\
\hline CHEMBL1318817 & 752398 & 4.4342 & 4.2821 & TRN \\
\hline CHEMBL3198312 & 752398 & 3.0969 & 3.4534 & TRN \\
\hline CHEMBL1514534 & 752398 & 3.0969 & 2.7829 & TRN \\
\hline CHEMBL1718995 & 752398 & 4.202 & 3.5177 & TRN \\
\hline CHEMBL1463638 & 752398 & 3.0969 & 3.3234 & TRN \\
\hline CHEMBL1475724 & 752398 & 4.1543 & 3.877 & TRN \\
\hline CHEMBL1532997 & 752398 & 4.2503 & 4.1502 & TRN \\
\hline CHEMBL14702 & 752398 & 3.0969 & 3.6444 & TRN \\
\hline CHEMBL1419121 & 752398 & 4.2933 & 3.81699 & 99999999997 \\
\hline CHEMBL1556351 & 752398 & 4.1129 & 3.7053 & TRN \\
\hline CHEMBL1509920 & 752398 & 4.618 & 4.2126 & TRN \\
\hline CHEMBL1510664 & 752398 & 4.2132 & 4.1559 & TST \\
\hline CHEMBL1530404 & 752398 & 3.0969 & 3.7781 & TST \\
\hline CHEMBL1319596 & 752398 & 4.2373 & 3.7457 & TRN \\
\hline CHEMBL1331149 & 752398 & 3.0969 & 3.3183 & TRN \\
\hline CHEMBL3195749 & 752398 & 4.4473 & 3.9354 & TRN \\
\hline CHEMBL1466201 & 752398 & 5.1681 & 4.1633 & TRN \\
\hline CHEMBL1736254 & 752398 & 3.0969 & 3.7599 & TRN \\
\hline CHEMBL3189811 & 752398 & 3.0969 & 4.0011 & TRN \\
\hline CHEMBL327502 & 752398 & 4.8327 & 4.9769 & TRN \\
\hline CHEMBL3197910 & 752398 & 3.0969 & 3.4515 & TRN \\
\hline CHEMBL1607035 & 752398 & 4.2277 & 3.5539 & TRN \\
\hline CHEMBL1405717 & 752398 & 4.382 & 3.7015 & TRN \\
\hline CHEMBL1432204 & 752398 & 3.0969 & 3.697 & TST \\
\hline \multirow[t]{2}{*}{ CHEMBL1556561 } & 752398 & 4.4342 & 3.7960 & 20000000003 \\
\hline & & \multicolumn{3}{|c|}{ Page 7150} \\
\hline
\end{tabular}


Supplemental Table S2.txt

\begin{tabular}{|c|c|c|c|c|}
\hline CHEMBL3192506 & 752398 & 4.3969 & 3.8111 & TRN \\
\hline CHEMBL1485717 & 752398 & 3.0969 & 3.6099 & TRN \\
\hline CHEMBL1717650 & 752398 & 3.0969 & 3.8197 & TRN \\
\hline CHEMBL1397665 & 752398 & 4.4763 & 4.0844 & TRN \\
\hline CHEMBL1427991 & 752398 & 3.0969 & 4.043 & TRN \\
\hline CHEMBL1567773 & 752398 & 4.6696 & 4.4135 & TRN \\
\hline CHEMBL1725665 & 752398 & 3.0969 & 3.81699 & 99999999997 \\
\hline CHEMBL1359359 & 752398 & 4.2636 & 3.7981 & TRN \\
\hline CHEMBL1304996 & 752398 & 3.0969 & 3.7859 & TRN \\
\hline CHEMBL3190002 & 752398 & 4.1884 & 3.8466 & TRN \\
\hline CHEMBL1562104 & 752398 & 4.1778 & 4.2661 & TRN \\
\hline CHEMBL1703976 & 752398 & 3.0969 & 3.7909 & TRN \\
\hline CHEMBL1613270 & 752398 & 3.0969 & 3.4994 & TST \\
\hline CHEMBL1343630 & 752398 & 3.0969 & 3.4073 & TRN \\
\hline CHEMBL1360765 & 752398 & 3.0969 & 3.0999 & TST \\
\hline CHEMBL3212746 & 752398 & 4.2815 & 3.8715 & TRN \\
\hline CHEMBL1422971 & 752398 & 4.2013 & 3.9441 & TRN \\
\hline CHEMBL1408295 & 752398 & 3.0969 & 3.6348 & TRN \\
\hline CHEMBL1444730 & 752398 & 3.0969 & 3.8911 & TRN \\
\hline CHEMBL1388125 & 752398 & 3.0969 & 3.4295 & TRN \\
\hline CHEMBL1493248 & 752398 & 4.4225 & 4.1744 & TRN \\
\hline CHEMBL1392315 & 752398 & 4.5467 & 4.5555 & TRN \\
\hline CHEMBL1304193 & 752398 & 4.2984 & 4.3886 & TRN \\
\hline CHEMBL1470492 & 752398 & 3.0969 & 3.7116 & TRN \\
\hline CHEMBL52 & 752398 & 4.2604 & 3.9873 & TRN \\
\hline CHEMBL1527565 & 752398 & 4.3516 & 3.9751 & TRN \\
\hline CHEMBL463563 & 752398 & 4.3947 & 3.3768 & TRN \\
\hline CHEMBL1720128 & 752398 & 4.8416 & 4.7003 & TRN \\
\hline CHEMBL1565894 & 752398 & 3.0969 & 3.542 & TRN \\
\hline CHEMBL1701533 & 752398 & 3.0969 & 3.8399 & TRN \\
\hline CHEMBL1411593 & 752398 & 3.0969 & 3.6711 & TRN \\
\hline CHEMBL1449479 & 752398 & 3.0969 & 3.7969 & TRN \\
\hline CHEMBL1372495 & 752398 & 3.0969 & 3.6047 & TRN \\
\hline CHEMBL1413005 & 752398 & 3.0969 & 3.8285 & TRN \\
\hline CHEMBL1411556 & 752398 & 3.0969 & 3.5161 & TRN \\
\hline CHEMBL3189691 & 752398 & 3.0969 & 3.6259 & TRN \\
\hline CHEMBL1480663 & 752398 & 4.4547 & 3.8181 & TRN \\
\hline CHEMBL1333181 & 752398 & 3.0969 & 3.7974 & TRN \\
\hline CHEMBL1703189 & 752398 & 4.7986 & 4.63 & TRN \\
\hline CHEMBL1609490 & 752398 & 3.0969 & 3.114 & TRN \\
\hline CHEMBL1699355 & 752398 & 4.8894 & 4.9421 & TRN \\
\hline CHEMBL1716105 & 752398 & 3.0969 & 3.6952 & TST \\
\hline CHEMBL3191780 & 752398 & 4.6055 & 4.1083 & TRN \\
\hline CHEMBL1385889 & 752398 & 3.0969 & 3.4891 & TRN \\
\hline CHEMBL1506351 & 752398 & 3.0969 & 3.3751 & TST \\
\hline CHEMBL1576254 & 752398 & 3.0969 & 3.2659 & TST \\
\hline CHEMBL1590701 & 752398 & 3.0969 & 3.5154 & TRN \\
\hline CHEMBL1410860 & 752398 & 4.4724 & 3.5835 & TRN \\
\hline
\end{tabular}

Page 7151 


\begin{tabular}{|c|c|c|c|c|c|c|}
\hline \multirow[b]{2}{*}{ CHEMBL3192682 } & & \multicolumn{5}{|c|}{ Supplemental Table S2.txt } \\
\hline & 752398 & 4.8041 & 3.6894 & TRN & & \\
\hline CHEMBL3194593 & 752398 & 4.2716 & 3.8525 & TRN & & \\
\hline CHEMBL1710798 & 752398 & 4.618 & 4.7781 & TRN & & \\
\hline CHEMBL1410383 & 752398 & 4.3391 & 3.6206 & TRN & & \\
\hline CHEMBL1449785 & 752398 & 3.0969 & 3.5842 & TRN & & \\
\hline CHEMBL1477787 & 752398 & 4.6946 & 3.471 & TRN & & \\
\hline CHEMBL1489399 & 752398 & 3.0969 & 3.7037 & TRN & & \\
\hline CHEMBL1468193 & 752398 & 3.0969 & 3.9757 & TRN & & \\
\hline CHEMBL1713376 & 752398 & \multicolumn{3}{|c|}{ 4. 218999999999999} & 4.0046 & TRN \\
\hline CHEMBL1465837 & 752398 & 3.0969 & 3.6525 & TRN & & \\
\hline CHEMBL1735864 & 752398 & 4.4413 & 4.0738 & TRN & & \\
\hline CHEMBL1524916 & 752398 & 4.4486 & 3.8587 & TST & & \\
\hline CHEMBL1409836 & 752398 & 4.4828 & 4.0372 & TRN & & \\
\hline CHEMBL1336386 & 752398 & 3.0969 & 3.7824 & TRN & & \\
\hline CHEMBL1370822 & 752398 & 4.5918 & 4.0772 & TRN & & \\
\hline CHEMBL1982688 & 752398 & 4.2269 & 3.8997 & TRN & & \\
\hline CHEMBL1324935 & 752398 & 4.2034 & 3.3181 & TRN & & \\
\hline CHEMBL1477845 & 752398 & 3.0969 & 3.6913 & TRN & & \\
\hline CHEMBL1545058 & 752398 & 3.0969 & 3.6063 & TRN & & \\
\hline CHEMBL1698123 & 752398 & 4.8477 & 4.9173 & TRN & & \\
\hline CHEMBL1330951 & 752398 & 3.0969 & 3.6313 & TST & & \\
\hline CHEMBL1480186 & 752398 & 4.2426 & 3.9248 & TST & & \\
\hline CHEMBL3198697 & 752398 & 4.4935 & 3.6678 & TRN & & \\
\hline CHEMBL1351333 & 752398 & 3.0969 & 3.5111 & TRN & & \\
\hline CHEMBL512216 & 752398 & 3.0969 & 3.8333 & TST & & \\
\hline CHEMBL1319488 & 752398 & 4.2262 & 4.003 & TRN & & \\
\hline CHEMBL1542413 & 752398 & 3.0969 & 3.6462 & TST & & \\
\hline CHEMBL1442252 & 752398 & 3.0969 & 3.0933 & TRN & & \\
\hline CHEMBL 3208664 & 752398 & 3.0969 & 3.4342 & TRN & & \\
\hline CHEMBL 3197242 & 752398 & 3.0969 & 4.2028 & TRN & & \\
\hline CHEMBL1449018 & 752398 & 3.0969 & 3.6381 & TRN & & \\
\hline CHEMBL225903 & 752398 & 4.752 & 3.7998 & TRN & & \\
\hline CHEMBL1390450 & 752398 & 4.8962 & 3.7111 & TRN & & \\
\hline CHEMBL1359410 & 752398 & 4.426 & 3.8834 & TRN & & \\
\hline CHEMBL1423667 & 752398 & 3.0969 & 3.2524 & TRN & & \\
\hline CHEMBL1423122 & 752398 & 3.0969 & 3.10699 & 9999 & 1998 & TRN \\
\hline CHEMBL1412489 & 752398 & 4.38399 & 79999999 & 995 & 4.3902 & \\
\hline CHEMBL1334300 & 752398 & 4.5243 & 3.9773 & TRN & & \\
\hline CHEMBL1723607 & 752398 & 4.7696 & 5.0185 & TRN & & \\
\hline CHEMBL1735740 & 752398 & 3.0969 & 3.1992 & TRN & & \\
\hline CHEMBL1426550 & 752398 & 3.0969 & 3.6054 & TRN & & \\
\hline CHEMBL1473548 & 752398 & 4.6234 & 4.2051 & TRN & & \\
\hline CHEMBL1715446 & 752398 & 3.0969 & 3.8937 & TRN & & \\
\hline CHEMBL1727678 & 752398 & 3.0969 & 3.6218 & TRN & & \\
\hline CHEMBL1489240 & 752398 & 3.0969 & 3.4317 & TRN & & \\
\hline CHEMBL1370221 & 752398 & 4.2916 & 4.0499 & TRN & & \\
\hline CHEMBL1312318 & 752398 & 4.567 & 4.258 & TRN & & \\
\hline CHEMBL1597427 & 752398 & 3.0969 & 3.082 & TRN & & \\
\hline
\end{tabular}


Supplemental Table S2.txt

\begin{tabular}{|c|c|c|c|c|}
\hline CHEMBL131037 & 752398 & 4.6925 & 4.2248 & TRN \\
\hline CHEMBL3189471 & 752398 & 4.9508 & 3.6042 & TRN \\
\hline CHEMBL1734152 & 752398 & 4.3726 & 3.9237 & TRN \\
\hline CHEMBL1531345 & 752398 & 4.6536 & 3.9416 & TRN \\
\hline CHEMBL1504634 & 752398 & 4.295 & 4.2258 & TRN \\
\hline CHEMBL1712082 & 752398 & 4.3401 & 3.4515 & TST \\
\hline CHEMBL1456393 & 752398 & 4.52 & 3.9836 & TRN \\
\hline CHEMBL1699137 & 752398 & 3.0969 & 3.5954 & TRN \\
\hline CHEMBL1319020 & 752398 & 4.8508 & 4.2051 & TRN \\
\hline CHEMBL1312788 & 752398 & 3.0969 & 3.5891 & TRN \\
\hline CHEMBL1487716 & 752398 & 3.0969 & 3.302 & TRN \\
\hline CHEMBL1362714 & 752398 & 3.0969 & 3.739 & TST \\
\hline CHEMBL1719734 & 752398 & 4.4841 & 3.7966 & TRN \\
\hline CHEMBL1699069 & 752398 & 3.0969 & 3.6031 & TRN \\
\hline CHEMBL477855 & 752398 & 3.0969 & 4.0192 & TST \\
\hline CHEMBL1322745 & 752398 & 3.0969 & 3.6042 & TRN \\
\hline CHEMBL1699039 & 752398 & 4.8962 & 4.6283 & TRN \\
\hline CHEMBL1427539 & 752398 & 5.0269 & 3.8533 & TRN \\
\hline CHEMBL1705207 & 752398 & 4.7959 & 4.8039 & TRN \\
\hline CHEMBL1599312 & 752398 & 4.3958 & 4.1711 & TRN \\
\hline CHEMBL1719965 & 752398 & 4.466 & 3.8969 & TRN \\
\hline CHEMBL1448440 & 752398 & 3.0969 & 3.7699 & TRN \\
\hline CHEMBL1352170 & 752398 & 3.0969 & 3.8594 & TST \\
\hline CHEMBL1411806 & 752398 & 4.1713 & 3.5163 & TRN \\
\hline CHEMBL1472879 & 752398 & 4.8182 & 4.5027 & TRN \\
\hline CHEMBL3213086 & 752398 & 3.0969 & 3.8683 & TRN \\
\hline CHEMBL1277060 & 752398 & 3.0969 & 3.4097 & TRN \\
\hline CHEMBL225230 & 752398 & 3.0969 & 3.5024 & TST \\
\hline CHEMBL1338317 & 752398 & 4.9031 & 4.7884 & TRN \\
\hline CHEMBL1583540 & 752398 & 3.0969 & 3.8596 & TRN \\
\hline CHEMBL1096834 & 752398 & 3.0969 & 3.398999 & 99999999996 \\
\hline CHEMBL1703200 & 752398 & 4.8125 & 4.9957 & TRN \\
\hline CHEMBL1424911 & 752398 & 3.0969 & 3.9818 & TRN \\
\hline CHEMBL1320096 & 752398 & 4.1152 & 3.3691 & TRN \\
\hline CHEMBL1339349 & 752398 & 3.0969 & 3.1504 & TRN \\
\hline CHEMBL1702473 & 752398 & 3.0969 & 3.9409 & TST \\
\hline CHEMBL1432420 & 752398 & 4.4318 & 3.9647 & TRN \\
\hline CHEMBL1542003 & 752398 & 3.0969 & 3.7099 & TRN \\
\hline CHEMBL1351081 & 752398 & 3.0969 & 3.4566 & TRN \\
\hline CHEMBL1717071 & 752398 & 4.4486 & 4.3309 & TRN \\
\hline CHEMBL1728065 & 752398 & 4.262 & 3.8996 & TRN \\
\hline CHEMBL 3195533 & 752398 & 3.0969 & 3.9075 & TRN \\
\hline CHEMBL1312836 & 752398 & 3.0969 & 3.9786 & TRN \\
\hline CHEMBL1509082 & 752398 & 4.3809 & 3.9715 & TRN \\
\hline CHEMBL1364896 & 752398 & 3.0969 & 3.8021 & TRN \\
\hline CHEMBL1381271 & 752398 & 3.0969 & 3.3649 & TRN \\
\hline CHEMBL1353918 & 752398 & 3.0969 & 3.929 & TST \\
\hline CHEMBL1366328 & 752398 & 3.0969 & 3.5691 & TRN \\
\hline
\end{tabular}

Page 7153 


\begin{tabular}{|c|c|c|c|c|c|c|}
\hline \multirow[b]{2}{*}{ CHEMBL1287980 } & & \multicolumn{5}{|c|}{ Supplemental Table s2.txt } \\
\hline & 752398 & 4.4547 & \multicolumn{3}{|c|}{3.7289999999999996} & TRN \\
\hline CHEMBL1732317 & 752398 & 3.0969 & 3.5901 & TST & & \\
\hline CHEMBL1553163 & 752398 & 4.6308 & 4.8241 & TRN & & \\
\hline CHEMBL3192006 & 752398 & 4.284 & 3.3274 & TST & & \\
\hline CHEMBL3192556 & 752398 & 3.0969 & 3.5593 & TRN & & \\
\hline CHEMBL1723955 & 752398 & 4.15300 & 30000000 & 005 & 3.8358 & TRN \\
\hline CHEMBL1481150 & 752398 & 3.0969 & 3.022 & TRN & & \\
\hline CHEMBL1717300 & 752398 & 4.3391 & 3.6134 & TRN & & \\
\hline CHEMBL1703892 & 752398 & 3.0969 & 2.9891 & TRN & & \\
\hline CHEMBL1092115 & 752398 & 3.0969 & 3.3507 & TRN & & \\
\hline CHEMBL1971154 & 752398 & 3.0969 & 3.7477 & TRN & & \\
\hline CHEMBL 3197134 & 752398 & 4.5157 & 3.6206 & TRN & & \\
\hline CHEMBL3214079 & 752398 & 3.0969 & 3.8357 & TRN & & \\
\hline CHEMBL1533968 & 752398 & 4.6289 & 3.91300 & 00006 & 203 & TRN \\
\hline CHEMBL1600326 & 752398 & 3.0969 & 3.2499 & TRN & & \\
\hline CHEMBL1572332 & 752398 & 3.0969 & 3.516 & TRN & & \\
\hline CHEMBL1465240 & 752398 & 4.38399 & 99999999 & 995 & 3.9206 & TRN \\
\hline CHEMBL1412451 & 752398 & 4.2204 & 4.3039 & TRN & & \\
\hline CHEMBL1480480 & 752398 & 3.0969 & 3.4475 & TRN & & \\
\hline CHEMBL1379740 & 752398 & 3.0969 & 3.7062 & TRN & & \\
\hline CHEMBL118678 & 752398 & 4.1931 & 4.0053 & TST & & \\
\hline CHEMBL1721015 & 752398 & 4.1457 & 3.4574 & TRN & & \\
\hline CHEMBL1347633 & 752398 & 3.0969 & 3.6312 & TRN & & \\
\hline CHEMBL1370704 & 752398 & 3.0969 & 3.8753 & TRN & & \\
\hline CHEMBL1714971 & 752398 & 4.1911 & 3.6917 & TRN & & \\
\hline CHEMBL1705412 & 752398 & 4.4112 & 3.4825 & TRN & & \\
\hline CHEMBL1478652 & 752398 & 3.0969 & 3.4758 & TST & & \\
\hline CHEMBL1968290 & 752398 & 3.0969 & 3.5865 & TST & & \\
\hline CHEMBL1310862 & 752398 & 4.2366 & 3.6394 & TRN & & \\
\hline CHEMBL1712649 & 752398 & 5.0964 & 3.9518 & TRN & & \\
\hline CHEMBL1426134 & 752398 & 4.4145 & 3.6957 & TRN & & \\
\hline CHEMBL103583 & 752398 & 4.38399 & 79999999 & 995 & 3.6962 & TST \\
\hline CHEMBL1479427 & 752398 & 3.0969 & 3.0805 & TRN & & \\
\hline CHEMBL1302099 & 752398 & 3.0969 & 3.5833 & TRN & & \\
\hline CHEMBL1523343 & 752398 & 3.0969 & 3.2632 & TRN & & \\
\hline CHEMBL1431126 & 752398 & 4.8794 & 4.0469 & TRN & & \\
\hline CHEMBL1601716 & 752398 & 4.9431 & 4.9484 & TRN & & \\
\hline CHEMBL1442120 & 752398 & 3.0969 & 3.6468 & TST & & \\
\hline CHEMBL1333250 & 752398 & 4.8153 & 4.8595 & TRN & & \\
\hline CHEMBL1471698 & 752398 & 4.8697 & 4.9644 & TRN & & \\
\hline CHEMBL1332203 & 752398 & 3.0969 & 3.0021 & TRN & & \\
\hline CHEMBL1339149 & 752398 & 4.8928 & 4.8806 & TRN & & \\
\hline CHEMBL3190599 & 752398 & 3.0969 & 3.3386 & TRN & & \\
\hline CHEMBL1415566 & 752398 & 3.0969 & 3.5061 & TRN & & \\
\hline CHEMBL1570127 & 752398 & 3.0969 & 3.5994 & TRN & & \\
\hline CHEMBL498373 & 752398 & 3.0969 & 3.7364 & TRN & & \\
\hline CHEMBL1425837 & 752398 & 4.2328 & 3.897 & TRN & & \\
\hline CHEMBL3197706 & 752398 & 3.0969 & 3.4752 & TRN & & \\
\hline
\end{tabular}




\begin{tabular}{|c|c|c|c|c|c|}
\hline \multirow{3}{*}{$\begin{array}{l}\text { CHEMBL1394863 } \\
\text { CHFMRI } 1566895\end{array}$} & & \multicolumn{4}{|c|}{ Supplemental Table S2.txt } \\
\hline & 752398 & 3.0969 & \multicolumn{2}{|c|}{3.3960000000000004} & TRN \\
\hline & 752398 & 4.2924 & 3.5341 & TRN & \\
\hline CHEMBL1401754 & 752398 & 3.0969 & 3.7206 & TST & \\
\hline CHEMBL1419822 & 752398 & 3.0969 & 3.1559 & TST & \\
\hline CHEMBL1700880 & 752398 & 3.0969 & 3.7135 & TST & \\
\hline CHEMBL1736502 & 752398 & 3.0969 & 3.7339 & TRN & \\
\hline CHEMBL1481413 & 752398 & 3.0969 & 3.6282 & TRN & \\
\hline CHEMBL1605172 & 752398 & 4.1512 & 4.4078 & TRN & \\
\hline CHEMBL3191533 & 752398 & 3.0969 & 3.0178 & TRN & \\
\hline CHEMBL1409586 & 752398 & 3.0969 & 3.4572 & TRN & \\
\hline CHEMBL51085 & 752398 & 4.6556 & 4.753 & TRN & \\
\hline CHEMBL1257041 & 752398 & 3.0969 & 3.7014 & TST & \\
\hline CHEMBL1095207 & 752398 & 3.0969 & 3.4235 & TRN & \\
\hline CHEMBL3197161 & 752398 & 3.0969 & 3.8555 & TRN & \\
\hline CHEMBL1566610 & 752398 & 3.0969 & 3.6332 & TST & \\
\hline CHEMBL1465938 & 752398 & 4.3478 & 4.0306 & TRN & \\
\hline CHEMBL1527929 & 752398 & 4.1993 & 3.3443 & TST & \\
\hline CHEMBL1342570 & 752398 & 3.0969 & 3.5799 & TRN & \\
\hline CHEMBL1391746 & 752398 & 3.0969 & 3.7173 & TRN & \\
\hline CHEMBL1567159 & 752398 & 3.0969 & 3.5831 & TRN & \\
\hline CHEMBL1707429 & 752398 & 4.3851 & 4.1864 & TRN & \\
\hline CHEMBL363221 & 752398 & 3.0969 & 3.5775 & TRN & \\
\hline CHEMBL1441874 & 752398 & 3.0969 & 3.5359 & TRN & \\
\hline CHEMBL1461457 & 752398 & 3.0969 & 3.5882 & TRN & \\
\hline CHEMBL1706151 & 752398 & 3.0969 & 3.6529 & TRN & \\
\hline CHEMBL1329974 & 752398 & 3.0969 & 3.6598 & TRN & \\
\hline CHEMBL1599257 & 752398 & 3.0969 & 3.5854 & TRN & \\
\hline CHEMBL1613004 & 752398 & 4.3325 & 3.74600 & 00000000004 & TST \\
\hline CHEMBL1305916 & 752398 & 3.0969 & 3.7133 & TRN & \\
\hline CHEMBL1565767 & 752398 & 4.5918 & 3.775 & TRN & \\
\hline CHEMBL1440703 & 752398 & 3.0969 & 3.6288 & TST & \\
\hline CHEMBL1727570 & 752398 & 3.0969 & 2.7524 & TRN & \\
\hline CHEMBL467987 & 752398 & 4.6021 & 4.2522 & TRN & \\
\hline CHEMBL1730100 & 752398 & 4.4225 & 3.7676 & TST & \\
\hline CHEMBL1598737 & 752398 & 3.0969 & 3.9857 & TRN & \\
\hline CHEMBL1392885 & 752398 & 4.3391 & 3.8167 & TST & \\
\hline CHEMBL1416184 & 752398 & 3.0969 & 3.3003 & TRN & \\
\hline CHEMBL3190856 & 752398 & 4.5157 & 3.6001 & TRN & \\
\hline CHEMBL1712663 & 752398 & 4.5686 & 4.2665 & TST & \\
\hline CHEMBL1998566 & 752398 & 3.0969 & 3.3144 & TRN & \\
\hline CHEMBL1454269 & 752398 & 4.3307 & 3.4885 & TRN & \\
\hline CHEMBL1709419 & 752398 & 4.8601 & 4.6963 & TRN & \\
\hline CHEMBL1708074 & 752398 & 3.0969 & 4.2117 & TST & \\
\hline CHEMBL1982454 & 752398 & 3.0969 & 3.4108 & TRN & \\
\hline CHEMBL527584 & 752398 & 3.0969 & 3.0598 & TRN & \\
\hline CHEMBL1721597 & 752398 & 3.0969 & 3.335 & TST & \\
\hline CHEMBL1414595 & 752398 & 3.0969 & 3.3789 & TST & \\
\hline CHEMBL1567402 & 752398 & 3.0969 & 3.6814 & TST & \\
\hline
\end{tabular}


Supplemental Table S2.txt

\begin{tabular}{|c|c|c|c|c|c|c|}
\hline CHEMBL1304359 & 752398 & 3.0969 & 3.8239 & TST & & \\
\hline CHEMBL1380069 & 752398 & 3.0969 & 3.1177 & TST & & \\
\hline CHEMBL1462691 & 752398 & 3.0969 & 3.74 & TST & & \\
\hline CHEMBL1563951 & 752398 & 3.0969 & 3.6085 & TST & & \\
\hline CHEMBL1469008 & 752398 & 3.0969 & 3.1428 & TST & & \\
\hline CHEMBL1528757 & 752398 & 3.0969 & 3.3596 & TST & & \\
\hline CHEMBL3210640 & 752398 & 3.0969 & 3.4132 & TST & & \\
\hline CHEMBL1709564 & 752398 & 3.0969 & 3.7339 & TST & & \\
\hline CHEMBL1471361 & 752398 & 3.0969 & 3.4642 & TST & & \\
\hline CHEMBL3189615 & 752398 & 3.0969 & 3.2945 & TST & & \\
\hline CHEMBL1305744 & 752398 & 3.0969 & 3.8236 & TST & & \\
\hline CHEMBL1731090 & 752398 & 3.0969 & 3.7857 & TST & & \\
\hline CHEMBL542493 & 752398 & 3.0969 & 3.5359 & TST & & \\
\hline CHEMBL1387028 & 752398 & 4.4597 & 3.8407 & TST & & \\
\hline CHEMBL1729300 & 752398 & 4.6326 & 4.1455 & TST & & \\
\hline CHEMBL1698153 & 752398 & 3.0969 & 3.6823 & TST & & \\
\hline CHEMBL1531200 & 752398 & 3.0969 & 3.7989 & TST & & \\
\hline CHEMBL1375198 & 752398 & 4.1379 & 4.0011 & TST & & \\
\hline CHEMBL1380844 & 752398 & 3.0969 & 3.7221 & TST & & \\
\hline CHEMBL536950 & 752398 & 4.6861 & 4.64 & TST & & \\
\hline CHEMBL1330954 & 752398 & 4.2668 & 4.1517 & TST & & \\
\hline CHEMBL1558563 & 752398 & 3.0969 & 3.9063 & TST & & \\
\hline CHEMBL1453822 & 752398 & 3.0969 & 3.8032 & TST & & \\
\hline CHEMBL1718737 & 752398 & 5.7447 & 3.8277 & TST & & \\
\hline CHEMBL 82134 & 752398 & 3.0969 & 3.4357 & TST & & \\
\hline CHEMBL1427925 & 752398 & 3.0969 & 3.7685 & TST & & \\
\hline CHEMBL1583616 & 752398 & 3.0969 & 3.8369 & TST & & \\
\hline CHEMBL3191304 & 752398 & 4.7799 & 3.2775 & TST & & \\
\hline CHEMBL1706062 & 752398 & 4.1367 & 4.2696 & TST & & \\
\hline CHEMBL1479190 & 752398 & 3.0969 & 3.4521 & TST & & \\
\hline CHEMBL1466117 & 752398 & 3.0969 & 3.0469 & TST & & \\
\hline CHEMBL1572924 & 752398 & 3.0969 & 3.8798 & TST & & \\
\hline CHEMBL1710047 & 752398 & 4.4034 & 5.0764 & TST & & \\
\hline CHEMBL1708363 & 752398 & 3.0969 & 3.2536 & TST & & \\
\hline CHEMBL1585485 & 752398 & 3.0969 & 3.5264 & TST & & \\
\hline CHEMBL1567962 & 752398 & 4.3862 & 3.7402 & TST & & \\
\hline CHEMBL1519531 & 752398 & 3.0969 & 3.6333 & TST & & \\
\hline CHEMBL1449526 & 752398 & 3.0969 & 3.5099 & TST & & \\
\hline CHEMBL1402473 & 752398 & 3.0969 & 3.8264 & TST & & \\
\hline CHEMBL1542823 & 752398 & 5.0315 & 3.5969 & TST & & \\
\hline CHEMBL1301842 & 752398 & 3.0969 & 3.3191 & TST & & \\
\hline CHEMBL1397145 & 752398 & 4.7721 & 4.1669 & TST & & \\
\hline CHEMBL1560740 & 752398 & $4.98300 t$ & 00000000 & 05 & 3.5032 & TST \\
\hline CHEMBL1345026 & 752398 & 5.1367 & 3.2348 & TST & & \\
\hline CHEMBL1346883 & 752398 & 3.0969 & 3.7836 & TST & & \\
\hline CHEMBL1609871 & 752398 & 3.0969 & 4.2162 & TST & & \\
\hline CHEMBL1555928 & 752398 & 4.2993 & 4.0684 & TST & & \\
\hline CHEMBL1460878 & 752398 & 3.0969 & 3.0443 & TST & & \\
\hline
\end{tabular}




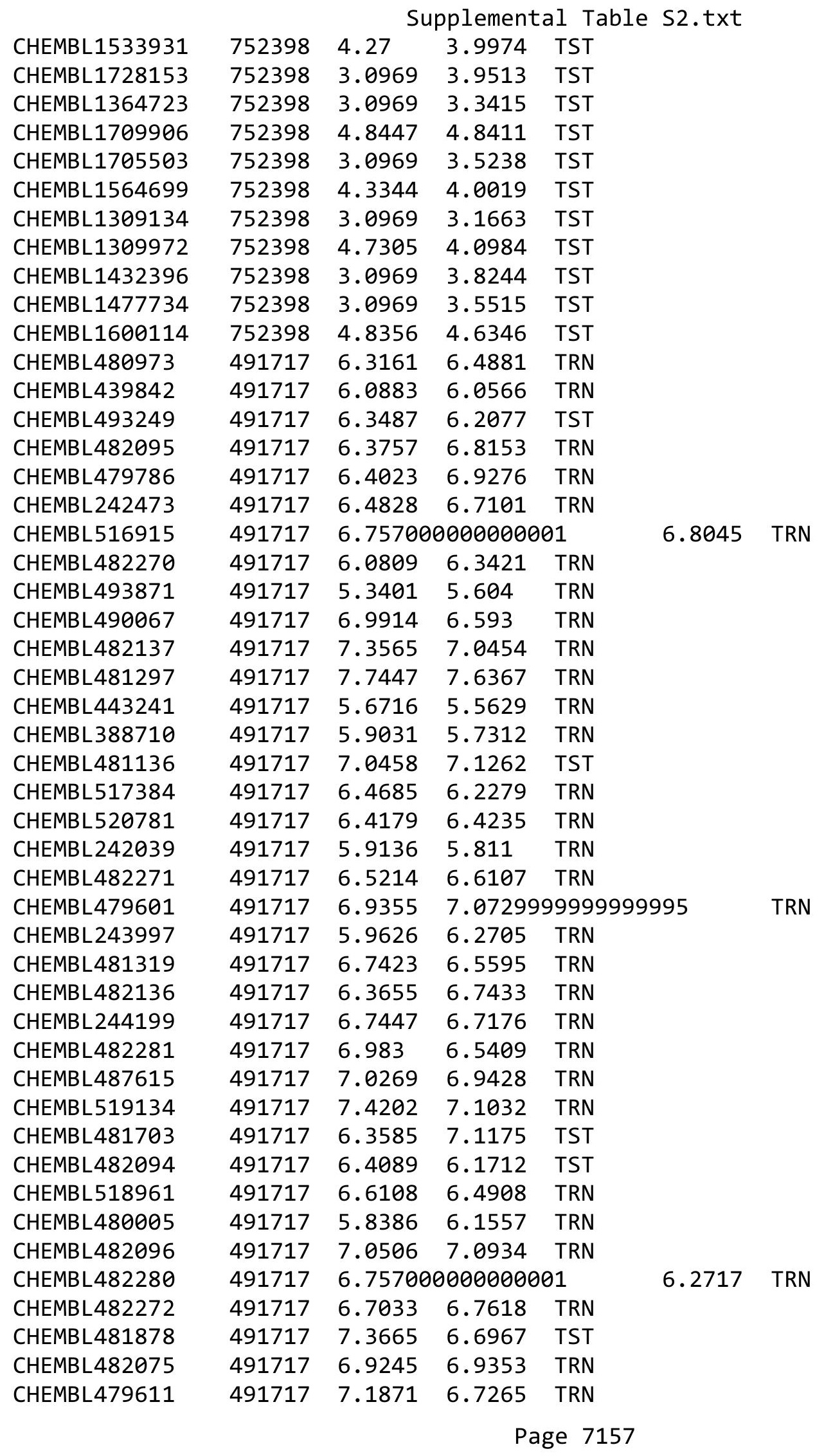




\begin{tabular}{|c|c|c|c|c|c|}
\hline & & & oplement & al Table S2 & \\
\hline CHEMBL480884 & 491717 & 6.4609 & 6.2421 & TRN & \\
\hline CHEMBL482765 & 491717 & 7.6383 & 7.50299 & 9999999999 & TRN \\
\hline CHEMBL481955 & 491717 & 5.9031 & 6.0967 & TRN & \\
\hline CHEMBL481148 & 491717 & 6.2848 & 6.449 & TRN & \\
\hline CHEMBL471044 & 491717 & 6.8794 & 6.7123 & TRN & \\
\hline CHEMBL451289 & 491717 & 6.71 & 6.7387 & TRN & \\
\hline CHEMBL481311 & 491717 & 5.6904 & 5.6621 & TRN & \\
\hline CHEMBL481922 & 491717 & 6.2865 & 6.7057 & TRN & \\
\hline CHEMBL510856 & 491717 & 6.7825 & 6.9733 & TRN & \\
\hline CHEMBL482287 & 491717 & 6.5918 & 6.1351 & TST & \\
\hline CHEMBL479970 & 491717 & 6.6108 & 6.4721 & TRN & \\
\hline CHEMBL445518 & 491717 & 6.9586 & 6.7474 & TST & \\
\hline CHEMBL479971 & 491717 & 6.6021 & 7.0857 & TST & \\
\hline CHEMBL517997 & 491717 & 6.8697 & 6.9004 & TST & \\
\hline CHEMBL517076 & 491717 & 6.2832 & 6.138 & TST & \\
\hline CHEMBL493872 & 491717 & 5.7852 & 5.9272 & TST & \\
\hline CHEMBL450723 & 491717 & 6.0092 & 6.2279 & TST & \\
\hline CHEMBL470470 & 491717 & 5.2708 & 5.8204 & TST & \\
\hline CHEMBL479602 & 491717 & 6.6904 & 6.9992 & TST & \\
\hline CHEMBL481131 & 491717 & 6.2175 & 6.1907 & TST & \\
\hline CHEMBL1978271 & 809117 & 4.4 & 4.6204 & TRN & \\
\hline CHEMBL 2007266 & 809117 & 4.4 & 4.453 & TRN & \\
\hline CHEMBL202721 & 809117 & 4.4 & 4.32600 & 00000000005 & TRN \\
\hline CHEMBL1985469 & 809117 & 6.4 & 4.7575 & TST & \\
\hline CHEMBL 2000568 & 809117 & 5.6 & 5.1737 & TRN & \\
\hline CHEMBL1994308 & 809117 & 4.4 & 4.386 & TRN & \\
\hline CHEMBL 2007097 & 809117 & 4.2 & 4.2572 & TRN & \\
\hline CHEMBL1974328 & 809117 & 6.7 & 7.0606 & TRN & \\
\hline CHEMBL509032 & 809117 & 6.9 & 7.4965 & TRN & \\
\hline CHEMBL388311 & 809117 & 8.8 & 8.8645 & TRN & \\
\hline CHEMBL1964948 & 809117 & 4.4 & 4.9282 & TRN & \\
\hline CHEMBL 2002202 & 809117 & 4.1 & 4.4935 & TRN & \\
\hline CHEMBL1973013 & 809117 & 5.8 & 5.6497 & TRN & \\
\hline CHEMBL1989834 & 809117 & 3.7 & 4.0089 & TRN & \\
\hline CHEMBL1987430 & 809117 & 4.4 & 4.5054 & TRN & \\
\hline CHEMBL1993413 & 809117 & 4.4 & 3.9492 & TRN & \\
\hline CHEMBL 205415 & 809117 & 4.4 & 4.4334 & TRN & \\
\hline CHEMBL1975927 & 809117 & 4.4 & 5.2948 & TRN & \\
\hline CHEMBL1986943 & 809117 & 7.0 & 6.9502 & TRN & \\
\hline CHEMBL1997119 & 809117 & 4.3 & 4.4532 & TRN & \\
\hline CHEMBL1977138 & 809117 & 6.8 & 6.8016 & TRN & \\
\hline CHEMBL1978448 & 809117 & 4.4 & 4.3773 & TST & \\
\hline CHEMBL1980329 & 809117 & 7.2 & 7.6029 & TRN & \\
\hline CHEMBL 2004515 & 809117 & 5.5 & 5.2935 & TRN & \\
\hline CHEMBL1992042 & 809117 & 4.4 & 5.2712 & TRN & \\
\hline CHEMBL1986265 & 809117 & 4.4 & 4.373 & TRN & \\
\hline CHEMBL1991734 & 809117 & 6.0 & 5.8015 & TRN & \\
\hline CHEMBL 21156 & 809117 & 7.5 & 6.7851 & TRN & \\
\hline
\end{tabular}




\begin{tabular}{|c|c|c|c|c|c|}
\hline \\
\hline CHEMBL1994724 & 809117 & 4.4 & 4.8122 & & \\
\hline CHEMBL1989267 & 809117 & 6.1 & 6.3085 & TRN & \\
\hline CHEMBL1991782 & 809117 & 4.3 & 3.5671 & TRN & \\
\hline CHEMBL 2002105 & 809117 & 4.4 & 4.105 & TRN & \\
\hline CHEMBL1983348 & 809117 & 5.9 & 6.3083 & TRN & \\
\hline CHEMBL1974574 & 809117 & 4.4 & 4.4947 & TRN & \\
\hline CHEMBL1993877 & 809117 & 6.2 & 5.9715 & TRN & \\
\hline CHEMBL1974480 & 809117 & 5.5 & 5.2427 & TRN & \\
\hline CHEMBL 2000934 & 809117 & 4.4 & 4.5758 & TRN & \\
\hline CHEMBL1996500 & 809117 & 4.4 & 4.4097 & TRN & \\
\hline CHEMBL1980671 & 809117 & 4.5 & 4.7458 & TRN & \\
\hline CHEMBL1973363 & 809117 & 5.5 & 5.0996 & TRN & \\
\hline CHEMBL1986177 & 809117 & 4.4 & 4.4209 & TRN & \\
\hline CHEMBL1989708 & 809117 & 7.5 & 7.0751 & TRN & \\
\hline CHEMBL1976420 & 809117 & 4.4 & 5.403 & TRN & \\
\hline CHEMBL1998253 & 809117 & 4.4 & 4.3362 & TST & \\
\hline CHEMBL1981744 & 809117 & 4.4 & 4.6701 & TRN & \\
\hline CHEMBL1989423 & 809117 & 4.1 & 4.2274 & TST & \\
\hline CHEMBL1985367 & 809117 & 4.4 & 4.8741 & TRN & \\
\hline CHEMBL1996510 & 809117 & 7.0 & 7.1518 & TRN & \\
\hline CHEMBL 2000029 & 809117 & 6.0 & 5.7303 & TRN & \\
\hline CHEMBL1995172 & 809117 & 4.4 & 4.2272 & TST & \\
\hline CHEMBL 2001584 & 809117 & 4.4 & 4.1829 & TRN & \\
\hline CHEMBL1973961 & 809117 & 5.9 & 5.2443 & TRN & \\
\hline CHEMBL1967998 & 809117 & 6.3 & 6.51399 & 9999999999 & TRN \\
\hline CHEMBL1978562 & 809117 & 5.6 & 5.4645 & TRN & \\
\hline CHEMBL1994977 & 809117 & 4.4 & 4.6025 & TRN & \\
\hline CHEMBL 2001149 & 809117 & 4.4 & 4.6582 & TRN & \\
\hline CHEMBL1974875 & 809117 & 4.2 & 4.3625 & TST & \\
\hline CHEMBL 2005478 & 809117 & 5.7 & 5.4467 & TRN & \\
\hline CHEMBL1996646 & 809117 & 6.1 & 6.0898 & TRN & \\
\hline CHEMBL1979773 & 809117 & 4.4 & 4.8398 & TRN & \\
\hline CHEMBL1989471 & 809117 & 4.4 & 5.2019 & TST & \\
\hline CHEMBL 2002099 & 809117 & 4.4 & 5.3269 & TRN & \\
\hline CHEMBL1996702 & 809117 & 5.6 & 5.5076 & TRN & \\
\hline CHEMBL 2007124 & 809117 & 4.4 & 4.2626 & TRN & \\
\hline CHEMBL1978195 & 809117 & 5.5 & 5.4947 & TRN & \\
\hline CHEMBL 2006439 & 809117 & 4.4 & 5.3444 & TRN & \\
\hline CHEMBL1985681 & 809117 & 6.5 & 5.7463 & TRN & \\
\hline CHEMBL1982711 & 809117 & 6.1 & 6.0364 & TRN & \\
\hline CHEMBL 262623 & 809117 & 5.7 & 5.0 & TRN & \\
\hline CHEMBL1984842 & 809117 & 4.4 & 4.2444 & TRN & \\
\hline CHEMBL 2004118 & 809117 & 6.0 & 5.9018 & TRN & \\
\hline CHEMBL1996345 & 809117 & 4.4 & 4.6397 & TRN & \\
\hline CHEMBL 2004025 & 809117 & 5.8 & 5.7593 & TRN & \\
\hline CHEMBL1996048 & 809117 & 6.5 & 6.4757 & TRN & \\
\hline CHEMBL50894 & 809117 & 6.0 & 6.1084 & TRN & \\
\hline CHEMBL1995211 & 809117 & 6.5 & 6.3432 & TRN & \\
\hline
\end{tabular}




\begin{tabular}{|c|c|c|c|c|c|}
\hline \\
\hline CHEMBL1965033 & 809117 & 4.4 & 4.4099 & TRN & \\
\hline CHEMBL461876 & 809117 & 4.4 & 5.7846 & TRN & \\
\hline CHEMBL2006299 & 809117 & 4.4 & 4.3739 & TRN & \\
\hline CHEMBL1971519 & 809117 & 4.2 & 4.4316 & TRN & \\
\hline CHEMBL1997335 & 809117 & 6.3 & 5.3058 & TRN & \\
\hline CHEMBL1965169 & 809117 & 4.4 & 4.768 & TRN & \\
\hline CHEMBL1081312 & 809117 & 6.9 & 6.3769 & TRN & \\
\hline CHEMBL1965170 & 809117 & 6.6 & 6.4035 & TRN & \\
\hline CHEMBL2005792 & 809117 & 4.4 & 4.2599 & TRN & \\
\hline CHEMBL1986503 & 809117 & 4.4 & 4.3325 & TST & \\
\hline CHEMBL1972355 & 809117 & 5.8 & 6.0328 & TRN & \\
\hline CHEMBL1997892 & 809117 & 4.4 & 4.6805 & TRN & \\
\hline CHEMBL 2001641 & 809117 & 4.4 & 4.5008 & TRN & \\
\hline CHEMBL1997193 & 809117 & 6.1 & 5.027 & TST & \\
\hline CHEMBL1964902 & 809117 & 4.4 & 4.452 & TRN & \\
\hline CHEMBL1973868 & 809117 & 4.4 & 4.2455 & TRN & \\
\hline CHEMBL1972462 & 809117 & 4.4 & 4.2749 & TRN & \\
\hline CHEMBL1983715 & 809117 & 6.2 & 6.1971 & TRN & \\
\hline CHEMBL1984500 & 809117 & 3.1 & 3.6319 & TRN & \\
\hline CHEMBL 2002992 & 809117 & 5.7 & 5.6649 & TRN & \\
\hline CHEMBL1982700 & 809117 & 4.4 & 4.5768 & TRN & \\
\hline CHEMBL10 & 809117 & 4.4 & 4.465 & TRN & \\
\hline CHEMBL1980763 & 809117 & 6.0 & 5.7775 & TRN & \\
\hline CHEMBL1977634 & 809117 & 4.4 & 4.5008 & TRN & \\
\hline CHEMBL1977931 & 809117 & 4.1 & 4.5807 & TRN & \\
\hline CHEMBL2007479 & 809117 & 4.4 & 4.1683 & TRN & \\
\hline CHEMBL1971606 & 809117 & 4.4 & 4.4052 & TRN & \\
\hline CHEMBL1971223 & 809117 & 4.4 & 4.7686 & TRN & \\
\hline CHEMBL1972220 & 809117 & 7.5 & 7.4424 & TRN & \\
\hline CHEMBL1981215 & 809117 & 4.4 & 4.6373 & TRN & \\
\hline CHEMBL2003785 & 809117 & 4.5 & 4.6488 & TRN & \\
\hline CHEMBL1973720 & 809117 & 7.2 & 7.4005 & TRN & \\
\hline CHEMBL1999414 & 809117 & 6.5 & 6.4605 & TRN & \\
\hline CHEMBL1967336 & 809117 & 4.4 & 4.36600 & 00000000005 & TRN \\
\hline CHEMBL2001923 & 809117 & 4.4 & 4.0979 & TRN & \\
\hline CHEMBL1983070 & 809117 & 4.4 & 4.5904 & TRN & \\
\hline CHEMBL 2003514 & 809117 & 6.4 & 4.5313 & TRN & \\
\hline CHEMBL1970340 & 809117 & 4.7 & 4.3296 & TRN & \\
\hline CHEMBL1967992 & 809117 & 4.4 & 4.2244 & TRN & \\
\hline CHEMBL1989043 & 809117 & 4.4 & 4.8782 & TRN & \\
\hline CHEMBL2006450 & 809117 & 4.4 & 3.7721 & TRN & \\
\hline CHEMBL 2001987 & 809117 & 4.4 & 4.6406 & TRN & \\
\hline CHEMBL1994555 & 809117 & 4.4 & 5.0969 & TRN & \\
\hline CHEMBL1164180 & 809117 & 7.0 & 6.1092 & TST & \\
\hline CHEMBL1975121 & 809117 & 4.4 & 4.3717 & TRN & \\
\hline CHEMBL1983640 & 809117 & 4.4 & 5.0604 & TRN & \\
\hline CHEMBL1997611 & 809117 & 4.4 & 4.811 & TRN & \\
\hline CHEMBL1971943 & 809117 & 4.4 & 4.5065 & TRN & \\
\hline
\end{tabular}




\begin{tabular}{|c|c|c|c|c|}
\hline & & & pplement & al $\mathrm{Ta}$ \\
\hline CHEMBL2002723 & 809117 & 5.6 & 5.0578 & TRN \\
\hline CHEMBL1984686 & 809117 & 4.4 & 4.1932 & TST \\
\hline CHEMBL1973793 & 809117 & 4.4 & 5.0319 & TRN \\
\hline CHEMBL1992073 & 809117 & 5.7 & 5.7144 & TRN \\
\hline CHEMBL1990254 & 809117 & 4.4 & 4.5047 & TRN \\
\hline CHEMBL1986143 & 809117 & 4.4 & 4.1543 & TRN \\
\hline CHEMBL1972934 & 809117 & 4.4 & 4.2424 & TRN \\
\hline CHEMBL2007559 & 809117 & 4.4 & 4.9204 & TRN \\
\hline CHEMBL1992581 & 809117 & 4.4 & 5.2438 & TRN \\
\hline CHEMBL 2004290 & 809117 & 6.5 & 6.4887 & TRN \\
\hline CHEMBL1975921 & 809117 & 4.2 & 4.4231 & TRN \\
\hline CHEMBL1975923 & 809117 & 4.7 & 4.7648 & TST \\
\hline CHEMBL1984847 & 809117 & 4.4 & 4.5582 & TRN \\
\hline CHEMBL 2005449 & 809117 & 6.2 & 5.5361 & TRN \\
\hline CHEMBL1996576 & 809117 & 4.4 & 4.7307 & TST \\
\hline CHEMBL1991678 & 809117 & 4.4 & 4.3317 & TRN \\
\hline CHEMBL1987998 & 809117 & 4.4 & 4.435 & TRN \\
\hline CHEMBL1971534 & 809117 & 4.4 & 4.5219 & TRN \\
\hline CHEMBL1990496 & 809117 & 4.4 & 4.618 & TRN \\
\hline CHEMBL 242865 & 809117 & 5.7 & 5.5895 & TRN \\
\hline CHEMBL235157 & 809117 & 4.4 & 4.7294 & TST \\
\hline CHEMBL 2004159 & 809117 & 4.4 & 4.4782 & TRN \\
\hline CHEMBL1978371 & 809117 & 4.4 & 5.1354 & TST \\
\hline CHEMBL440084 & 809117 & 4.4 & 4.4707 & TRN \\
\hline CHEMBL550275 & 809117 & 5.5 & 4.8103 & TST \\
\hline CHEMBL1998110 & 809117 & 4.4 & 4.4206 & TRN \\
\hline CHEMBL1978166 & 809117 & 6.1 & 6.2203 & TRN \\
\hline CHEMBL1990590 & 809117 & 4.4 & 4.1022 & TRN \\
\hline CHEMBL1977814 & 809117 & 5.6 & 4.6683 & TST \\
\hline CHEMBL1974617 & 809117 & 4.4 & 4.217 & TRN \\
\hline CHEMBL1965660 & 809117 & 4.4 & 4.3773 & TRN \\
\hline CHEMBL1992125 & 809117 & 5.6 & 5.5671 & TRN \\
\hline CHEMBL1966175 & 809117 & 4.6 & 4.8627 & TRN \\
\hline CHEMBL 2007375 & 809117 & 4.4 & 4.4791 & TRN \\
\hline CHEMBL379975 & 809117 & 6.8 & 6.7936 & TST \\
\hline CHEMBL1973016 & 809117 & 5.5 & 4.4768 & TRN \\
\hline CHEMBL1965387 & 809117 & 4.4 & 4.1147 & TRN \\
\hline CHEMBL388978 & 809117 & 9.6 & 9.2886 & TST \\
\hline CHEMBL1997041 & 809117 & 5.6 & 5.1131 & TRN \\
\hline CHEMBL550418 & 809117 & 4.4 & 4.9297 & TRN \\
\hline CHEMBL398951 & 809117 & 4.4 & 4.7588 & TST \\
\hline CHEMBL1971289 & 809117 & 4.4 & 4.7603 & TST \\
\hline CHEMBL1988437 & 809117 & 6.6 & 6.5589 & TST \\
\hline CHEMBL 2007603 & 809117 & 4.4 & 4.5472 & TRN \\
\hline CHEMBL1421720 & 809117 & 5.7 & 5.3781 & TRN \\
\hline CHEMBL1233887 & 809117 & 4.4 & 4.3746 & TRN \\
\hline CHEMBL1968130 & 809117 & 4.2 & 4.3297 & TST \\
\hline CHEMBL2003689 & 809117 & 4.4 & 4.5164 & TRN \\
\hline
\end{tabular}




\begin{tabular}{|c|c|c|c|c|c|}
\hline \multirow[b]{2}{*}{ CHEMBL1996649 } & \multirow[b]{2}{*}{809117} & \\
\hline & & 6.6 & 6.3312 & TRN & \\
\hline CHEMBL1986756 & 809117 & 6.4 & \multicolumn{2}{|c|}{4.7139999999999995} & TRN \\
\hline CHEMBL1949855 & 809117 & 4.6 & 4.5072 & TRN & \\
\hline CHEMBL3109278 & 809117 & 7.6 & 7.3072 & TRN & \\
\hline CHEMBL1974998 & 809117 & 4.4 & 4.7468 & TRN & \\
\hline CHEMBL1990223 & 809117 & 4.4 & 4.164 & TRN & \\
\hline CHEMBL 2004438 & 809117 & 4.4 & \multicolumn{2}{|c|}{3.9589999999999996} & TRN \\
\hline CHEMBL1964382 & 809117 & 4.4 & 4.9295 & TST & \\
\hline CHEMBL101311 & 809117 & 4.4 & 4.6471 & TRN & \\
\hline CHEMBL191003 & 809117 & 7.0 & 6.1432 & TRN & \\
\hline CHEMBL1973359 & 809117 & 6.3 & 6.0873 & TST & \\
\hline CHEMBL1988581 & 809117 & 7.0 & 6.4881 & TST & \\
\hline CHEMBL 2005699 & 809117 & 4.4 & 4.4284 & TRN & \\
\hline CHEMBL 2006564 & 809117 & 7.6 & 6.8294 & TRN & \\
\hline CHEMBL1979690 & 809117 & 6.4 & 6.6648 & TRN & \\
\hline CHEMBL 234085 & 809117 & 4.4 & 4.8579 & TRN & \\
\hline CHEMBL1978167 & 809117 & 4.4 & 5.1436 & TRN & \\
\hline CHEMBL418203 & 809117 & 4.4 & 5.3734 & TST & \\
\hline CHEMBL225519 & 809117 & 4.6 & 4.5833 & TRN & \\
\hline CHEMBL1994159 & 809117 & 4.3 & 4.3631 & TRN & \\
\hline CHEMBL1976376 & 809117 & 4.4 & 4.7203 & TRN & \\
\hline CHEMBL1983575 & 809117 & 6.7 & 6.5493 & TRN & \\
\hline CHEMBL1968868 & 809117 & 4.4 & 4.4216 & TRN & \\
\hline CHEMBL1981047 & 809117 & 7.2 & 7.4765 & TRN & \\
\hline CHEMBL1998470 & 809117 & 4.4 & 4.2904 & TRN & \\
\hline CHEMBL1976196 & 809117 & 4.4 & 4.7639 & TRN & \\
\hline CHEMBL1997197 & 809117 & 4.4 & 4.2322 & TRN & \\
\hline CHEMBL1975903 & 809117 & 5.4 & 4.7005 & TRN & \\
\hline CHEMBL1983630 & 809117 & 4.1 & 4.3039 & TRN & \\
\hline CHEMBL1988805 & 809117 & 4.4 & 4.7536 & TRN & \\
\hline CHEMBL458997 & 809117 & 6.1 & 5.86299 & 99999999995 & TRN \\
\hline CHEMBL1969942 & 809117 & 4.4 & 4.3199 & TRN & \\
\hline CHEMBL1982660 & 809117 & 4.4 & 5.0885 & TRN & \\
\hline CHEMBL1978567 & 809117 & 4.4 & 4.4206 & TRN & \\
\hline CHEMBL1995765 & 809117 & 4.3 & 4.3534 & TRN & \\
\hline CHEMBL1984760 & 809117 & 6.1 & 5.8212 & TRN & \\
\hline CHEMBL1997846 & 809117 & 6.1 & 5.7893 & TRN & \\
\hline CHEMBL 360847 & 809117 & 6.7 & 5.7652 & TRN & \\
\hline CHEMBL1995811 & 809117 & 5.6 & 5.5602 & TRN & \\
\hline CHEMBL1983111 & 809117 & 7.7 & 7.4757 & TRN & \\
\hline CHEMBL1988141 & 809117 & 6.2 & $5.7470 e$ & 0000000001 & TST \\
\hline CHEMBL1992937 & 809117 & 4.4 & 4.5116 & TRN & \\
\hline CHEMBL451401 & 809117 & 4.6 & 4.44 & TRN & \\
\hline CHEMBL1977134 & 809117 & 4.4 & 4.3961 & TRN & \\
\hline CHEMBL1985206 & 809117 & 4.4 & 4.3376 & TRN & \\
\hline CHEMBL1991078 & 809117 & 6.1 & 6.3069 & TRN & \\
\hline CHEMBL1977749 & 809117 & 4.4 & 5.4702 & TST & \\
\hline CHEMBL1975212 & 809117 & 4.4 & 4.4608 & TRN & \\
\hline & & & & e 7162 & \\
\hline
\end{tabular}




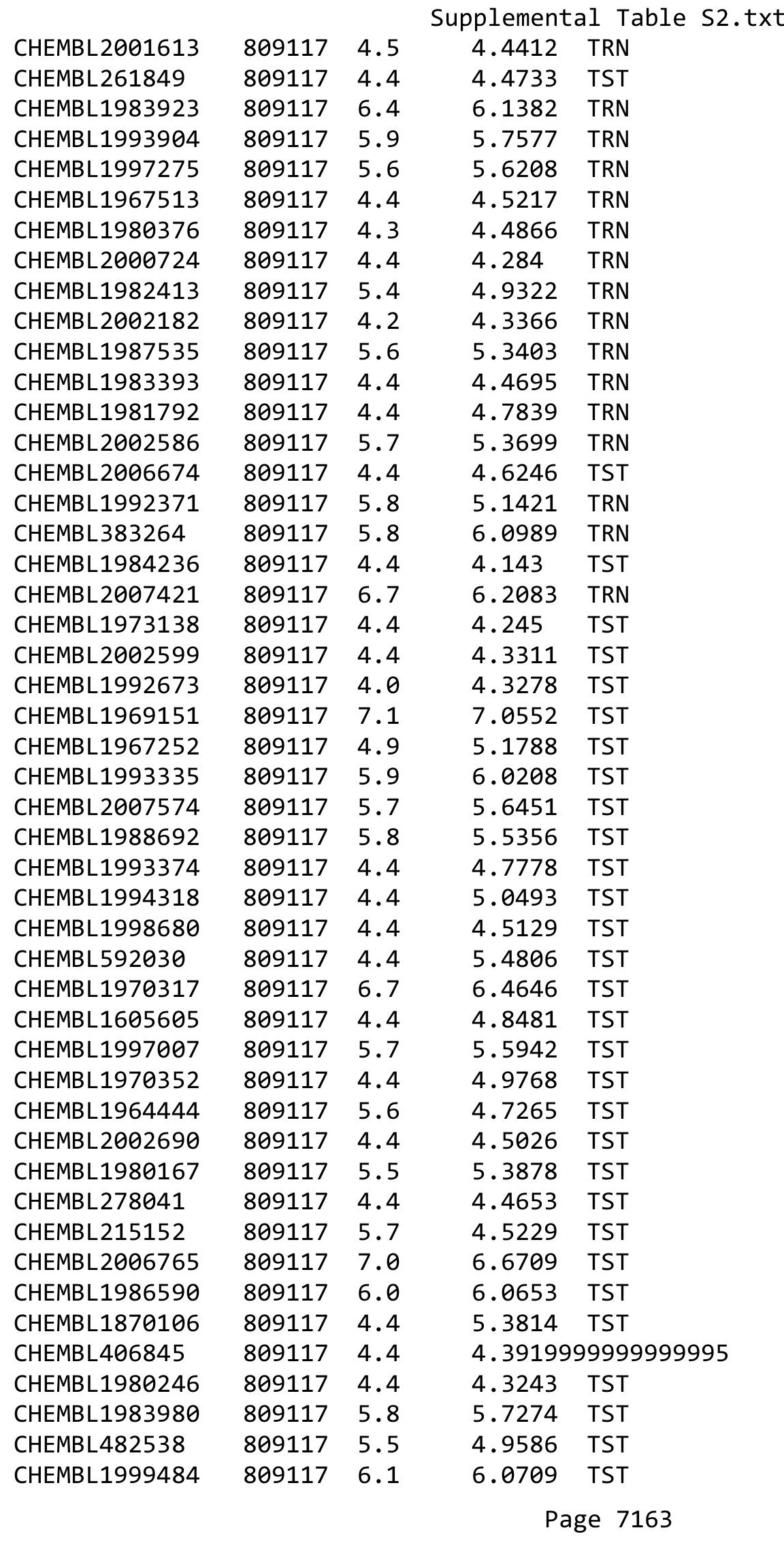




\begin{tabular}{|c|c|c|c|c|c|}
\hline & & & & & \\
\hline CHEMBL1984296 & 809117 & 5.4 & 5.4038 & TST & \\
\hline CHEMBL1986899 & 809117 & 4.4 & 4.4226 & TST & \\
\hline CHEMBL1984038 & 809117 & 4.4 & 4.6873 & TST & \\
\hline CHEMBL1993661 & 809117 & 8.1 & 7.4909 & TST & \\
\hline CHEMBL1968705 & 809117 & 5.5 & 4.8287 & TST & \\
\hline CHEMBL1991410 & 809117 & 4.4 & 3.8622 & TST & \\
\hline CHEMBL1964441 & 809117 & 6.3 & 5.6752 & TST & \\
\hline CHEMBL546797 & 809117 & 4.4 & 4.7769 & TST & \\
\hline CHEMBL 3947879 & 1639066 & 4.0 & 4.4696 & TST & \\
\hline CHEMBL 3945232 & 1639066 & 4.0 & 4.2235 & TRN & \\
\hline CHEMBL3915033 & 1639066 & 4.0 & 4.3415 & TRN & \\
\hline CHEMBL 3907275 & 1639066 & 4.0 & 4.625 & TRN & \\
\hline CHEMBL3953700 & 1639066 & 4.0 & 4.5817 & TRN & \\
\hline CHEMBL 3956290 & 1639066 & 4.0 & 4.3739 & TRN & \\
\hline CHEMBL3908998 & 1639066 & 4.0 & 4.5817 & TRN & \\
\hline CHEMBL3918734 & 1639066 & 4.0 & 5.5035 & TRN & \\
\hline CHEMBL 3970042 & 1639066 & 5.0 & 5.4292 & TST & \\
\hline CHEMBL3972692 & 1639066 & 5.0 & 5.9286 & TST & \\
\hline CHEMBL 3930409 & 1639066 & 5.0 & 5.1429 & TST & \\
\hline CHEMBL3933111 & 1639066 & 5.0 & 5.2115 & TST & \\
\hline CHEMBL3892368 & 1639066 & 5.0 & 5.3382 & TRN & \\
\hline CHEMBL3895106 & 1639066 & 5.0 & 4.98600 & 0000000001 & TRN \\
\hline CHEMBL3915431 & 1639066 & 5.0 & 6.1209 & TRN & \\
\hline CHEMBL 3912744 & 1639066 & 5.0 & 5.7308 & TRN & \\
\hline CHEMBL3953181 & 1639066 & 5.0 & 4.59699 & 99999999995 & TRN \\
\hline CHEMBL3950495 & 1639066 & 5.0 & 5.3854 & TRN & \\
\hline CHEMBL3901018 & 1639066 & 5.0 & 5.81 & TRN & \\
\hline CHEMBL3964255 & 1639066 & 6.0 & 5.853 & TRN & \\
\hline CHEMBL 3894386 & 1639066 & 6.0 & 7.9402 & TRN & \\
\hline CHEMBL3936313 & 1639066 & 6.0 & 4.5456 & TST & \\
\hline CHEMBL3927539 & 1639066 & 6.0 & 4.0561 & TST & \\
\hline CHEMBL 3975615 & 1639066 & 6.0 & 5.3631 & TRN & \\
\hline CHEMBL3976509 & 1639066 & 6.0 & 6.022 & TRN & \\
\hline CHEMBL 3936880 & 1639066 & 6.0 & 4.3979 & TRN & \\
\hline CHEMBL3915885 & 1639066 & 6.0 & 6.7832 & TST & \\
\hline CHEMBL3933988 & 1639066 & 6.0 & 5.9153 & TST & \\
\hline CHEMBL 3960422 & 1639066 & 6.0 & 5.0812 & TST & \\
\hline CHEMBL3905119 & 1639066 & 6.0 & 7.6025 & TRN & \\
\hline CHEMBL 3901448 & 1639066 & 6.0 & 5.5035 & TRN & \\
\hline CHEMBL3944964 & 1639066 & 6.0 & 6.8239 & TST & \\
\hline CHEMBL3895601 & 1639066 & 6.0 & 6.1528 & TRN & \\
\hline CHEMBL 3903529 & 1639066 & 6.0 & 5.9411 & TRN & \\
\hline CHEMBL3962425 & 1639066 & 6.0 & 4.5456 & TST & \\
\hline CHEMBL3920731 & 1639066 & 6.0 & 7.6025 & TRN & \\
\hline CHEMBL3978422 & 1639066 & 6.0 & 6.1381 & TRN & \\
\hline CHEMBL3939463 & 1639066 & 6.0 & 6.4608 & TRN & \\
\hline CHEMBL 3942154 & 1639066 & 8.0 & 6.8799 & TST & \\
\hline CHEMBL3956291 & 1639066 & 8.0 & 8.1564 & TRN & \\
\hline
\end{tabular}




\begin{tabular}{|c|c|c|c|c|c|c|}
\hline & & & & & & \\
\hline CHEMBL3926730 & 1639066 & 8.0 & 6.5702 & TRN & & \\
\hline CHEMBL3934078 & 1639066 & 8.0 & 7.385 & TRN & & \\
\hline CHEMBL3903758 & 1639066 & 8.0 & 6.9005 & TRN & & \\
\hline CHEMBL3936290 & 1639066 & 8.0 & 8.2606 & TRN & & \\
\hline CHEMBL3975591 & 1639066 & 8.0 & 6.87299 & 999999999 & & TRN \\
\hline CHEMBL3975361 & 1639066 & 8.0 & 4.8517 & TST & & \\
\hline CHEMBL3969300 & 1639066 & 8.0 & 6.5039 & TRN & & \\
\hline CHEMBL 3905983 & 1639066 & 8.0 & 6.7235 & TRN & & \\
\hline CHEMBL3908793 & 1639066 & 8.0 & 7.0238 & TRN & & \\
\hline CHEMBL3897159 & 1639066 & 8.0 & 6.9086 & TRN & & \\
\hline CHEMBL3889736 & 1639066 & 8.0 & 7.4513 & TRN & & \\
\hline CHEMBL3908921 & 1639066 & 8.0 & 6.4413 & TRN & & \\
\hline CHEMBL3918931 & 1639066 & 6.0 & 6.6254 & TRN & & \\
\hline CHEMBL473129 & 1503354 & 7.6126 & 7.4229 & TRN & & \\
\hline CHEMBL3589862 & 1503354 & 6.0 & 5.8709 & TST & & \\
\hline CHEMBL3589712 & 1503354 & 5.6221 & 5.9945 & TRN & & \\
\hline CHEMBL3589718 & 1503354 & 5.5634 & 4.9562 & TRN & & \\
\hline CHEMBL3589868 & 1503354 & 5.4711 & 5.3396 & TRN & & \\
\hline CHEMBL3589719 & 1503354 & 5.8867 & 5.4877 & TRN & & \\
\hline CHEMBL3589723 & 1503354 & 4.0 & 4.3755 & TRN & & \\
\hline CHEMBL3589713 & 1503354 & 5.20799 & 99999999 & 99 & 4.9206 & TRN \\
\hline CHEMBL1271793 & 1503354 & 7.7077 & 7.7663 & TRN & & \\
\hline CHEMBL264437 & 1503354 & 7.7352 & 8.0224 & TRN & & \\
\hline CHEMBL3590029 & 1503354 & 6.0768 & 6.03 & TRN & & \\
\hline CHEMBL 3589872 & 1503354 & 5.7945 & 6.0251 & TST & & \\
\hline CHEMBL3589722 & 1503354 & 5.2334 & 4.901 & TRN & & \\
\hline CHEMBL3589863 & 1503354 & 5.8356 & 5.8929 & TST & & \\
\hline CHEMBL3589873 & 1503354 & 6.5003 & 6.1408 & TRN & & \\
\hline CHEMBL3589864 & 1503354 & 5.1734 & 6.1602 & TST & & \\
\hline CHEMBL3589726 & 1503354 & 7.2518 & 7.3361 & TRN & & \\
\hline CHEMBL3589728 & 1503354 & 7.9393 & 7.2269 & TST & & \\
\hline CHEMBL3589867 & 1503354 & 5.2919 & 5.0957 & TRN & & \\
\hline CHEMBL3590031 & 1503354 & 4.0 & 6.0625 & TST & & \\
\hline CHEMBL3589711 & 1503354 & 5.8693 & 5.7216 & TRN & & \\
\hline CHEMBL3589731 & 1503354 & 7.7144 & 7.3885 & TRN & & \\
\hline CHEMBL3589871 & 1503354 & 6.5086 & 6.5376 & TRN & & \\
\hline CHEMBL3589724 & 1503354 & 7.3206 & 8.05299 & 999999999 & & TRN \\
\hline CHEMBL3589865 & 1503354 & 6.1891 & 6.5062 & TRN & & \\
\hline CHEMBL3589725 & 1503354 & 7.2248 & 6.6704 & TRN & & \\
\hline CHEMBL3589874 & 1503354 & 6.585 & 6.0535 & TRN & & \\
\hline CHEMBL3590030 & 1503354 & 6.3575 & 6.4029 & TST & & \\
\hline CHEMBL3589734 & 1503354 & 6.2782 & 5.9083 & TRN & & \\
\hline CHEMBL1089853 & 1503354 & 5.4896 & 5.6126 & TRN & & \\
\hline CHEMBL3589730 & 1503354 & 6.9496 & 6.9978 & TRN & & \\
\hline CHEMBL3589716 & 1503354 & 4.0 & 4.7591 & TRN & & \\
\hline CHEMBL3589878 & 1503354 & 5.3198 & 5.3563 & TRN & & \\
\hline CHEMBL3589720 & 1503354 & 4.0 & 4.3019 & TRN & & \\
\hline CHEMBL87381 & 1503354 & 7.6003 & 7.9422 & TRN & & \\
\hline
\end{tabular}




\begin{tabular}{|c|c|c|c|c|c|c|}
\hline \multicolumn{7}{|c|}{ Supplemental Table S2.txt } \\
\hline CHEMBL87379 & 1503354 & 8.8794 & 8.5661 & TRN & & \\
\hline CHEMBL3589875 & 1503354 & 6.2197 & 6.3509 & TRN & & \\
\hline CHEMBL3589879 & 1503354 & 5.9889 & 6.2784 & TRN & & \\
\hline CHEMBL3589715 & 1503354 & 5.7142 & 5.7461 & TST & & \\
\hline CHEMBL3589735 & 1503354 & 6.7258 & 6.6897 & TRN & & \\
\hline CHEMBL3589729 & 1503354 & 7.6345 & 7.6897 & TRN & & \\
\hline CHEMBL3589717 & 1503354 & 4.0 & 4.681 & TRN & & \\
\hline CHEMBL3589732 & 1503354 & 6.4698 & 8.0057 & TST & & \\
\hline CHEMBL3589869 & 1503354 & 7.6003 & 7.39 & TRN & & \\
\hline CHEMBL3589736 & 1503354 & 4.0 & 5.9934 & TST & & \\
\hline CHEMBL20730 & 1503354 & 7.3242 & 7.2983 & TST & & \\
\hline CHEMBL3589876 & 1503354 & 6.9586 & 6.86 & TRN & & \\
\hline CHEMBL3589721 & 1503354 & 4.0 & 4.0337 & TRN & & \\
\hline CHEMBL3589870 & 1503354 & 6.1568 & 6.2776 & TRN & & \\
\hline CHEMBL3589733 & 1503354 & 6.8069 & 6.6055 & TST & & \\
\hline CHEMBL3589877 & 1503354 & 5.3305 & 5.6561 & TRN & & \\
\hline CHEMBL3589727 & 1503354 & 8.1367 & 7.6834 & TST & & \\
\hline CHEMBL3589866 & 1503354 & 4.0 & 5.4191 & TST & & \\
\hline CHEMBL3589714 & 1503354 & 5.54899 & 99999999 & 995 & 5.1826 & TRN \\
\hline CHEMBL3979137 & 1639644 & 6.6021 & 6.8129 & TRN & & \\
\hline CHEMBL3921580 & 1639644 & 5.0 & 6.3191 & TRN & & \\
\hline CHEMBL3891415 & 1639644 & 6.6021 & 6.9258 & TST & & \\
\hline CHEMBL3894261 & 1639644 & 6.6021 & 6.7418 & TRN & & \\
\hline CHEMBL3968247 & 1639644 & 5.0 & 6.0921 & TRN & & \\
\hline CHEMBL3908198 & 1639644 & 6.6021 & 6.7043 & TRN & & \\
\hline CHEMBL3917108 & 1639644 & 6.6021 & 6.0263 & TRN & & \\
\hline CHEMBL3890844 & 1639644 & 6.6021 & 6.726 & TST & & \\
\hline CHEMBL3923001 & 1639644 & 6.6021 & 6.9248 & TRN & & \\
\hline CHEMBL3898691 & 1639644 & 6.6021 & 6.3417 & TRN & & \\
\hline CHEMBL3973106 & 1639644 & 6.6021 & 6.364 & TST & & \\
\hline CHEMBL3915154 & 1639644 & 6.6021 & 6.9979 & TRN & & \\
\hline CHEMBL3986506 & 1639644 & 6.6021 & 6.4186 & TST & & \\
\hline CHEMBL3934556 & 1639644 & 6.6021 & 6.8878 & TRN & & \\
\hline CHEMBL3907857 & 1639644 & 6.6021 & 6.2145 & TRN & & \\
\hline CHEMBL3961913 & 1639644 & 6.6021 & 6.6666 & TRN & & \\
\hline CHEMBL502652 & 1639644 & 6.6021 & 6.3682 & TRN & & \\
\hline CHEMBL3946744 & 1639644 & 6.6021 & 6.4869 & TRN & & \\
\hline CHEMBL3954571 & 1639644 & 6.6021 & 6.5597 & TRN & & \\
\hline CHEMBL3972006 & 1639644 & 7.6021 & 7.1927 & TST & & \\
\hline CHEMBL3919927 & 1639644 & 7.6021 & 7.1226 & TRN & & \\
\hline CHEMBL3890964 & 1639644 & 7.6021 & 7.2706 & TST & & \\
\hline CHEMBL3959181 & 1639644 & 6.6021 & 7.0004 & TRN & & \\
\hline CHEMBL3960623 & 1639644 & 6.6021 & 6.3258 & TST & & \\
\hline CHEMBL3902608 & 1639644 & 6.6021 & 6.5247 & TRN & & \\
\hline CHEMBL3905860 & 1639644 & 7.6021 & 7.3534 & TRN & & \\
\hline CHEMBL3901819 & 1639644 & 6.6021 & 6.78 & TST & & \\
\hline CHEMBL3946116 & 1639644 & 5.0 & 6.3312 & TRN & & \\
\hline CHEMBL3905410 & 1639644 & 6.6021 & 6.8464 & TST & & \\
\hline
\end{tabular}


Supplemental Table S2.txt

\begin{tabular}{|c|c|c|c|c|c|}
\hline CHEMBL3968197 & 1639644 & 6.6021 & 6.1479 & TRN & \\
\hline CHEMBL3956956 & 1639644 & 6.6021 & 6.2341 & TST & \\
\hline CHEMBL3976855 & 1639644 & 7.6021 & 6.7231 & TRN & \\
\hline CHEMBL3910989 & 1639644 & 6.6021 & 6.6626 & TST & \\
\hline CHEMBL3896094 & 1639644 & 7.6021 & 6.834 & TST & \\
\hline CHEMBL3964932 & 1639644 & 6.6021 & 6.3267 & TRN & \\
\hline CHEMBL3971629 & 1639644 & 7.6021 & 6.7301 & TRN & \\
\hline CHEMBL 3940401 & 1639644 & 5.0 & 6.6458 & TRN & \\
\hline CHEMBL 3963200 & 1639644 & 6.6021 & 6.8844 & TRN & \\
\hline CHEMBL3904450 & 1639644 & 6.6021 & 6.8217 & TRN & \\
\hline CHEMBL3918937 & 1639644 & 7.6021 & 6.7597 & TST & \\
\hline CHEMBL 3936820 & 1639644 & 7.6021 & 6.812 & TRN & \\
\hline CHEMBL 3903740 & 1639644 & 7.6021 & 6.2597 & TRN & \\
\hline CHEMBL3930497 & 1639644 & 6.6021 & 6.6158 & TRN & \\
\hline CHEMBL3907042 & 1639644 & 7.6021 & 7.08899 & 99999999995 & TRN \\
\hline CHEMBL3926128 & 1639644 & 6.6021 & 6.6565 & TRN & \\
\hline CHEMBL3974124 & 1639644 & 6.6021 & 6.1704 & TRN & \\
\hline CHEMBL448668 & 1639644 & 7.6021 & 6.327006 & 3000000001 & TST \\
\hline CHEMBL447639 & 1639644 & 6.6021 & 6.6668 & TRN & \\
\hline CHEMBL3918216 & 1639644 & 6.6021 & 6.1494 & TRN & \\
\hline CHEMBL3950577 & 1639644 & 7.6021 & 6.3537 & TRN & \\
\hline CHEMBL3937247 & 1639644 & 6.6021 & 6.8732 & TRN & \\
\hline CHEMBL3894895 & 1639644 & 7.6021 & 7.1051 & TRN & \\
\hline CHEMBL 3973792 & 1639644 & 6.6021 & 7.1041 & TRN & \\
\hline CHEMBL 3982596 & 1639644 & 7.6021 & 6.6754 & TRN & \\
\hline CHEMBL 3904524 & 1639644 & 6.6021 & 6.8833 & TST & \\
\hline CHEMBL 3967372 & 1639644 & 7.6021 & 7.2198 & TRN & \\
\hline CHEMBL3973006 & 1639644 & 6.6021 & 6.3969 & TST & \\
\hline CHEMBL 3937160 & 1639644 & 6.6021 & 6.3655 & TRN & \\
\hline CHEMBL 3903251 & 1639644 & 6.6021 & 6.0745 & TRN & \\
\hline CHEMBL 3982401 & 1639644 & 7.6021 & 7.2149 & TRN & \\
\hline CHEMBL3898274 & 1639644 & 7.6021 & 6.9363 & TST & \\
\hline CHEMBL3981747 & 1639644 & 6.6021 & 6.36 & TRN & \\
\hline CHEMBL 3961740 & 1639644 & 6.6021 & 6.4101 & TRN & \\
\hline CHEMBL3944498 & 1639644 & 6.6021 & 6.0861 & TRN & \\
\hline CHEMBL3901509 & 1639644 & 6.6021 & 6.6097 & TRN & \\
\hline CHEMBL3951670 & 1639644 & 6.6021 & 6.9421 & TRN & \\
\hline CHEMBL3913651 & 1639644 & 6.6021 & 6.9642 & TRN & \\
\hline CHEMBL 3928784 & 1639644 & 6.6021 & 6.7457 & TST & \\
\hline CHEMBL3950255 & 1639644 & 6.6021 & 6.7158 & TRN & \\
\hline CHEMBL3983122 & 1639644 & 6.6021 & 6.8046 & TRN & \\
\hline CHEMBL3937303 & 1639644 & 7.6021 & 6.9058 & TST & \\
\hline CHEMBL3978486 & 1639644 & 6.6021 & 6.3561 & TST & \\
\hline CHEMBL3902678 & 1639644 & 6.6021 & 6.3365 & TRN & \\
\hline CHEMBL3954082 & 1639644 & 6.6021 & 6.9389 & TRN & \\
\hline CHEMBL 3899043 & 1639644 & 5.0 & 6.3048 & TRN & \\
\hline CHEMBL3934152 & 1639644 & 7.6021 & 6.9522 & TRN & \\
\hline CHEMBL3931447 & 1639644 & 5.0 & 6.2723 & TRN & \\
\hline
\end{tabular}


Supplemental Table S2.txt

\begin{tabular}{|c|c|c|c|c|}
\hline CHEMBL3951411 & 1639644 & 6.6021 & 6.8557 & TRN \\
\hline CHEMBL 3896361 & 1639644 & 6.6021 & 6.978 & TRN \\
\hline CHEMBL 3983417 & 1639644 & 5.0 & 6.0803 & TRN \\
\hline CHEMBL 3904361 & 1639644 & 7.6021 & 6.8145 & TRN \\
\hline CHEMBL 3898780 & 1639644 & 6.6021 & 6.1944 & TST \\
\hline CHEMBL 3951002 & 1639644 & 7.6021 & 7.1297 & TRN \\
\hline CHEMBL 3984698 & 1639644 & 5.0 & 6.2138 & TST \\
\hline CHEMBL 3903866 & 1639644 & 6.6021 & 7.1092 & TST \\
\hline CHEMBL 3914814 & 1639644 & 6.6021 & 6.7174 & TST \\
\hline CHEMBL 3912542 & 1639644 & 6.6021 & 6.8281 & TRN \\
\hline CHEMBL 3918852 & 1639644 & 6.6021 & 6.21200 & 0000000001 \\
\hline CHEMBL 3920947 & 1639644 & 6.6021 & 6.7239 & TRN \\
\hline CHEMBL 3891515 & 1639644 & 6.6021 & 6.0643 & TRN \\
\hline CHEMBL 3937417 & 1639644 & 6.6021 & 6.9393 & TRN \\
\hline CHEMBL 3896056 & 1639644 & 5.0 & 5.6232 & TRN \\
\hline CHEMBL 3985754 & 1639644 & 6.6021 & 6.3416 & TRN \\
\hline CHEMBL3946368 & 1639644 & 7.6021 & 7.2896 & TRN \\
\hline CHEMBL 3955829 & 1639644 & 6.6021 & 6.4986 & TRN \\
\hline CHEMBL 3971673 & 1639644 & 6.6021 & 6.9621 & TRN \\
\hline CHEMBL3906473 & 1639644 & 6.6021 & 6.3426 & TRN \\
\hline CHEMBL 3915202 & 1639644 & 6.6021 & 6.894 & TRN \\
\hline CHEMBL 3930321 & 1639644 & 6.6021 & 6.6548 & TRN \\
\hline CHEMBL 3936478 & 1639644 & 6.6021 & 6.6718 & TST \\
\hline CHEMBL 3905921 & 1639644 & 6.6021 & 6.6111 & TRN \\
\hline CHEMBL 3952208 & 1639644 & 6.6021 & 6.6003 & TRN \\
\hline CHEMBL 3948450 & 1639644 & 6.6021 & 6.92899 & 9999999999 \\
\hline CHEMBL 3972228 & 1639644 & 7.6021 & 7.1057 & TRN \\
\hline CHEMBL 3901948 & 1639644 & 6.6021 & 6.78299 & \\
\hline CHEMBL 3908294 & 1639644 & 6.6021 & 6.28799 & 9999999999 \\
\hline CHEMBL 3940382 & 1639644 & 6.6021 & 6.5923 & TST \\
\hline CHEMBL 3927744 & 1639644 & 6.6021 & 6.6202 & TRN \\
\hline CHEMBL 3950296 & 1639644 & 6.6021 & 6.7393 & TRN \\
\hline CHEMBL3963196 & 1639644 & 7.6021 & 7.2997 & TRN \\
\hline CHEMBL 3919366 & 1639644 & 6.6021 & 6.8275 & TST \\
\hline CHEMBL 3953006 & 1639644 & 6.6021 & 6.1131 & TRN \\
\hline CHEMBL506862 & 1639644 & 6.6021 & 6.5247 & TRN \\
\hline CHEMBL 3975048 & 1639644 & 5.0 & 5.5813 & TST \\
\hline CHEMBL 3896003 & 1639644 & 5.0 & 5.4843 & TRN \\
\hline CHEMBL 3947685 & 1639644 & 6.6021 & 6.8901 & TRN \\
\hline CHEMBL 3941932 & 1639644 & 7.6021 & 7.1777 & TRN \\
\hline CHEMBL 3916077 & 1639644 & 6.6021 & 6.3251 & TST \\
\hline CHEMBL 3910640 & 1639644 & 6.6021 & 6.9114 & TRN \\
\hline CHEMBL 3930141 & 1639644 & 6.6021 & 6.865 & TRN \\
\hline CHEMBL507714 & 1639644 & 6.6021 & 6.8512 & TRN \\
\hline CHEMBL 3956400 & 1639644 & 5.0 & 6.6956 & TRN \\
\hline CHEMBL 3970170 & 1639644 & 7.6021 & 7.1194 & TRN \\
\hline CHEMBL 3909461 & 1639644 & 7.6021 & 7.279 & TRN \\
\hline CHEMBL 3896493 & 1639644 & 7.6021 & 6.9508 & TST \\
\hline
\end{tabular}


Supplemental Table S2.txt

\begin{tabular}{|c|c|c|c|c|c|}
\hline CHEMBL449110 & 1639644 & 7.6021 & 6.3816 & TRN & \\
\hline CHEMBL3896138 & 1639644 & 7.6021 & 7.1954 & TRN & \\
\hline CHEMBL3943489 & 1639644 & 6.6021 & 7.0694 & TRN & \\
\hline CHEMBL 3938043 & 1639644 & 6.6021 & 6.4989 & TST & \\
\hline CHEMBL3980159 & 1639644 & 6.6021 & 6.6917 & TRN & \\
\hline CHEMBL3913169 & 1639644 & 5.0 & 6.0582 & TRN & \\
\hline CHEMBL3951885 & 1639644 & 7.6021 & 7.2176 & TRN & \\
\hline CHEMBL3907756 & 1639644 & 6.6021 & 6.4553 & TRN & \\
\hline CHEMBL3930437 & 1639644 & 5.0 & 6.7242 & TRN & \\
\hline CHEMBL3895710 & 1639644 & 6.6021 & 6.635 & TST & \\
\hline CHEMBL3938801 & 1639644 & 6.6021 & 7.09 & TRN & \\
\hline CHEMBL3973742 & 1639644 & 7.6021 & \multicolumn{2}{|c|}{7.0760000000000005} & TRN \\
\hline CHEMBL3925159 & 1639644 & 6.6021 & 6.3176 & TST & \\
\hline CHEMBL3967622 & 1639644 & 6.6021 & 6.185 & TRN & \\
\hline CHEMBL3934156 & 1639644 & 6.6021 & 7.1712 & TRN & \\
\hline CHEMBL3918769 & 1639644 & 6.6021 & 6.2408 & TRN & \\
\hline CHEMBL3947568 & 1639644 & 5.0 & 6.5793 & TST & \\
\hline CHEMBL3940222 & 1639644 & 5.0 & 5.8258 & TRN & \\
\hline CHEMBL3951967 & 1639644 & 6.6021 & 6.3811 & TRN & \\
\hline CHEMBL3950784 & 1639644 & 7.6021 & 7.1778 & TRN & \\
\hline CHEMBL3950325 & 1639644 & 6.6021 & 7.0688 & TRN & \\
\hline CHEMBL3893256 & 1639644 & 6.6021 & 6.8706 & TST & \\
\hline CHEMBL3915736 & 1639644 & 6.6021 & 6.3658 & TST & \\
\hline CHEMBL3984255 & 1639644 & 7.6021 & 7.2792 & TST & \\
\hline CHEMBL3953680 & 1639644 & 6.6021 & 7.0486 & TRN & \\
\hline CHEMBL3976565 & 1639644 & 7.6021 & 7.1848 & TRN & \\
\hline CHEMBL3969290 & 1639644 & 6.6021 & 6.9496 & TRN & \\
\hline CHEMBL 3894234 & 1639644 & 6.6021 & 7.0575 & TRN & \\
\hline CHEMBL3922091 & 1639644 & 6.6021 & 6.8066 & TST & \\
\hline CHEMBL3933134 & 1639644 & 6.6021 & 6.4697 & TRN & \\
\hline CHEMBL453438 & 1639644 & 7.6021 & 6.1332 & TST & \\
\hline CHEMBL3970155 & 1639644 & 6.6021 & 6.0854 & TRN & \\
\hline CHEMBL3957976 & 1639644 & 7.6021 & 6.3036 & TST & \\
\hline CHEMBL502198 & 1639644 & 7.6021 & 6.4908 & TRN & \\
\hline CHEMBL3950746 & 1639644 & 7.6021 & 7.1559 & TRN & \\
\hline CHEMBL3941287 & 1639644 & 6.6021 & 6.2635 & TST & \\
\hline CHEMBL3949909 & 1639644 & 7.6021 & 7.2711 & TRN & \\
\hline CHEMBL3949038 & 1639644 & 7.6021 & 7.1072 & TST & \\
\hline CHEMBL3912500 & 1639644 & 7.6021 & 7.1524 & TRN & \\
\hline CHEMBL 3984843 & 1639644 & 7.6021 & 6.8177 & TRN & \\
\hline CHEMBL3968940 & 1639644 & 6.6021 & 6.6841 & TST & \\
\hline CHEMBL3895132 & 1639644 & 7.6021 & 6.8001 & TRN & \\
\hline CHEMBL3927527 & 1639644 & 7.6021 & 7.1312 & TRN & \\
\hline CHEMBL3920487 & 1639644 & 6.6021 & 6.2643 & TRN & \\
\hline CHEMBL3982306 & 1639644 & 6.6021 & 6.495 & TRN & \\
\hline CHEMBL3967147 & 1639644 & 7.6021 & 7.3314 & TRN & \\
\hline CHEMBL3911054 & 1639644 & 6.6021 & 6.4216 & TRN & \\
\hline CHEMBL3920934 & 1639644 & 6.6021 & 7.0415 & TRN & \\
\hline
\end{tabular}

Page 7169 
Supplemental Table S2.txt

\begin{tabular}{|c|c|c|c|c|}
\hline 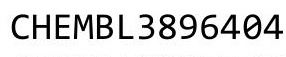 & 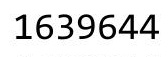 & & & \\
\hline HEMBL3927706 & 639644 & 6.6021 & 6.1455 & \\
\hline HEMBL; & 9644 & 6.6021 & 354 & \\
\hline 809 & 644 & 21 & & \\
\hline AEMBL3 & 9644 & 021 & & \\
\hline AEMBL3915209 & 639644 & 6.6021 & .5833 & \\
\hline HEMBL3907119 & 639644 & 6.6021 & .5595 & \\
\hline HEMBL3911340 & 639644 & 6 . & & \\
\hline HEMBL3 & 544 & $7.6 e$ & 1802 & \\
\hline HEMBL 389 & 644 & 5.0 & & DN \\
\hline HEMBL3973285 & 639644 & 7.60 & .7416 & \\
\hline HEMBL3913225 & 639644 & 5.0 & .0935 & \\
\hline HEMBL 388 & 44 & 5.0 & 7377 & \\
\hline HEMBL3 & 44 & 6. & 362 & \\
\hline HEMBL3 & 44 & & & \\
\hline HEMBL466397 & 44 & 7. & 7.2386 & \\
\hline HEMBL3 & 44 & 6. & & \\
\hline HEMBL3 & 44 & 6. & 82 & \\
\hline HEM & 44 & 6. & & \\
\hline HEMBL3 & & & & \\
\hline HEMBL3 & 644 & 6. & & \\
\hline HEMBL3937659 & 44 & 6.6 & & \\
\hline HEMBL3 & 44 & 7.6 & 53 & SI \\
\hline HEN & 14 & 7. & 03 & \\
\hline HEM & & 6. & & \\
\hline 973 & & 6. & & בט \\
\hline AEMBL3976571 & & 6.6 & & I RN \\
\hline HEMBL3 & 44 & 7. & & \\
\hline HEN & & 6. & & RN \\
\hline HEMRI & 44 & 6. & & RN \\
\hline AEMBL3 & & & & IRN \\
\hline AEMBL 3898863 & 544 & 6. & & RN \\
\hline AEMBL3 & & & & RN \\
\hline 99 & & 7. & & RN \\
\hline 49 & 44 & 6. & & RN \\
\hline AEMBL3902796 & 639644 & 6.6 & & IRN \\
\hline HEMBL3915988 & 639644 & 7. & & RN \\
\hline 43 & & 5 & & RN \\
\hline 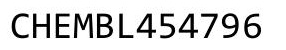 & & & & RIN \\
\hline HEMBL3 & & 6. & & $\mathrm{RN}$ \\
\hline AEMBL3983732 & 639644 & 6. & & RN \\
\hline HEMBL 3982002 & 44 & 6. & & ST \\
\hline & & & & \\
\hline HEMBL3 & & 6.6 & & RN \\
\hline HEMBL3 & 644 & 6.6021 & & RN \\
\hline AEMBL3936093 & 1639644 & 6.66 & 966 & RN \\
\hline & & & & \\
\hline & & & & \\
\hline
\end{tabular}

Page 7170 
Supplemental Table S2.txt

\begin{tabular}{|c|c|c|c|c|c|}
\hline CHEMBL3979736 & 1617699 & 4.7212 & 4.7209 & TRN & \\
\hline CHEMBL3903813 & 1617699 & 5.3372 & 5.3371 & TRN & \\
\hline CHEMBL3928317 & 1617699 & 2.6021 & 2.6017 & TRN & \\
\hline CHEMBL3040216 & 1617699 & 2.6021 & 3.7961 & TST & \\
\hline CHEMBL3943318 & 1617699 & 5.7696 & 5.7697 & TRN & \\
\hline CHEMBL3899371 & 1617699 & 4.6778 & 4.6778 & TRN & \\
\hline CHEMBL3924724 & 1617699 & 4.0809 & 4.0811 & TRN & \\
\hline CHEMBL3951335 & 1617699 & 6.2596 & 6.2596 & TRN & \\
\hline CHEMBL 3980253 & 1617699 & 5.7696 & 5.7698 & TRN & \\
\hline CHEMBL3115908 & 1617699 & 4.3372 & 2.985 & TST & \\
\hline CHEMBL3938421 & 1617699 & 6.1024 & 6.1026 & TRN & \\
\hline CHEMBL3947125 & 1617699 & 2.6021 & 2.6017 & TRN & \\
\hline CHEMBL3986320 & 1617699 & 6.5086 & 6.5084 & TRN & \\
\hline CHEMBL3913878 & 1617699 & 5.3665 & 5.3663 & TRN & \\
\hline CHEMBL3906378 & 1617699 & 2.6021 & 2.6023 & TRN & \\
\hline CHEMBL3966262 & 1617699 & 5.0177 & 5.0175 & TRN & \\
\hline CHEMBL3912547 & 1617699 & 3.8962 & 3.8963 & TRN & \\
\hline CHEMBL3947198 & 1617699 & 4.0757 & 4.0755 & TRN & \\
\hline CHEMBL3915348 & 1617699 & 2.6021 & 2.602 & TRN & \\
\hline CHEMBL3978029 & 1617699 & 2.6021 & 2.6023 & TRN & \\
\hline CHEMBL3953543 & 1617699 & 2.6021 & 2.3226 & TST & \\
\hline CHEMBL3954893 & 1617699 & 2.6021 & 2.6018 & TRN & \\
\hline CHEMBL3924343 & 1617699 & 2.6021 & 2.6016 & TRN & \\
\hline CHEMBL3934352 & 1617699 & 5.3872 & 5.3871 & TRN & \\
\hline CHEMBL3960743 & 1617699 & 4.2757 & 4.276 & TRN & \\
\hline CHEMBL3967047 & 1617699 & 5.5086 & 5.5087 & TRN & \\
\hline CHEMBL3952045 & 1617699 & 4.041 & 4.0408 & TRN & \\
\hline CHEMBL3890411 & 1617699 & 2.6021 & 2.6021 & TRN & \\
\hline CHEMBL3975456 & 1617699 & 5.1739 & 4.5435 & TST & \\
\hline CHEMBL3978830 & 1617699 & 2.6021 & 2.6022 & TRN & \\
\hline CHEMBL3919336 & 1617699 & 3.6819 & 3.5177 & TST & \\
\hline CHEMBL3908434 & 1617699 & 2.6021 & 2.6022 & TRN & \\
\hline CHEMBL3933283 & 1617699 & 2.6021 & 2.6019 & TRN & \\
\hline CHEMBL3904891 & 1617699 & 2.6021 & 2.602 & TRN & \\
\hline CHEMBL3942054 & 1617699 & 4.3468 & 4.3471 & TRN & \\
\hline CHEMBL3950773 & 1617699 & 3.7122 & 3.71199 & 99999999997 & TRN \\
\hline CHEMBL3894125 & 1617699 & 2.6021 & 3.1431 & TST & \\
\hline CHEMBL3955935 & 1617699 & 2.6021 & 2.6023 & TRN & \\
\hline CHEMBL3983712 & 1617699 & 3.8827 & 3.883 & TRN & \\
\hline CHEMBL3910488 & 1617699 & 4.4437 & 4.444 & TRN & \\
\hline CHEMBL3970551 & 1617699 & 3.6655 & 3.6655 & TRN & \\
\hline CHEMBL3983061 & 1617699 & 3.8416 & 3.8419 & TRN & \\
\hline CHEMBL3919412 & 1617699 & 2.6021 & 2.6024 & TRN & \\
\hline CHEMBL3952406 & 1617699 & 4.1739 & 4.4736 & TST & \\
\hline CHEMBL3922861 & 1617699 & 2.6021 & 5.067 & TST & \\
\hline CHEMBL3934460 & 1617699 & 4.2676 & 4.047 & TST & \\
\hline CHEMBL3907505 & 1617699 & 2.6021 & 1.569 & TST & \\
\hline CHEMBL3975683 & 1617699 & 4.4559 & 3.6292 & TST & \\
\hline
\end{tabular}

Page 7171 
Supplemental Table S2.txt

\begin{tabular}{|c|c|c|c|c|}
\hline & 699 & 2.6021 & & \\
\hline HEMBL3 & 617699 & 5.2924 & 4.4969 & \\
\hline & 790 & & & \\
\hline 799 & 790 & 685 & 63 & \\
\hline IEMBL 3919017 & 640790 & 8.699 & 66 & \\
\hline AEMBL3973607 & 640790 & 9.3979 & 549 & \\
\hline AEMBL3 & 790 & 8.0 & 999 & \\
\hline 29 & 790 & 01 & 635 & \\
\hline EMBL3952587 & 790 & 8.699 & 882 & \\
\hline IEMBL 3913185 & 790 & 6.0 & 264 & \\
\hline AEMBL 3896710 & 790 & 301 & 542 & \\
\hline 58 & 790 & 9.0 & 168 & \\
\hline & 790 & 01 & 585 & \\
\hline 48 & 790 & 8.7212 & 868 & \\
\hline IEMBL 3948118 & 790 & 8.8239 & 811 & \\
\hline 7396 & 790 & 8.301 & 064 & \\
\hline 25 & 790 & 99 & 351 & \\
\hline & 790 & 8.699 & 326 & \\
\hline 02972 & 790 & 8.301 & 295 & \\
\hline 3400 & 790 & 8.0 & 309 & \\
\hline 10 & 790 & 8.301 & 131 & \\
\hline 07 & 790 & 8 & 564 & \\
\hline & 790 & 6.0 & 94 & \\
\hline & 790 & 8.699 & 861 & \\
\hline 28 & 90 & 0 & & \\
\hline 08 & 790 & 8.36 & 891 & \\
\hline 50 & 790 & 8 . & 02 & \\
\hline & 90 & 5 . & & \\
\hline & 190 & 9. & & \\
\hline & & & & \\
\hline 334 & 164 & 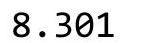 & 098 & \\
\hline 50 & 790 & . & 59 & \\
\hline & 16 & 0 & 93 & \\
\hline & & 778 & & \\
\hline & 90 & & 62 & \\
\hline & 790 & 21 & 88 & \\
\hline & 16 & 1 & & \\
\hline & 16 & 8. & 07 & \\
\hline AEMBL3913922 & 790 & 5.4942 & 198 & TS \\
\hline & 164 & $5 . \varepsilon$ & 027 & \\
\hline & 164 & & & $\mathrm{n}$ \\
\hline & 164 & 9. & 63 & \\
\hline & 1640790 & 8.699 & 8.6922 & $\Gamma R$ \\
\hline 3L3923980 & 1640790 & 5.5525 & 5.3623 & TS \\
\hline 429 & 1640790 & 8.699 & 456 & $\Gamma R$ \\
\hline & 164 & & 612 & \\
\hline & 1640790 & 0 & 5.2578 & \\
\hline CHEMBL3920832 & 1640790 & 8.301 & 7.527 & \\
\hline
\end{tabular}

Page 7172 
Supplemental Table S2.txt

\begin{tabular}{|c|c|c|c|c|c|}
\hline CHEMBL3938419 & 1640790 & 5.4015 & 5.3462 & TST & \\
\hline CHEMBL3934070 & 1640790 & 5.7296 & 5.5059 & TST & \\
\hline CHEMBL3936864 & 1640790 & 9.5229 & 9.0944 & TRN & \\
\hline CHEMBL3897894 & 1640790 & 8.699 & 8.6969 & TST & \\
\hline CHEMBL3965155 & 1640790 & 8.301 & 8.2881 & TRN & \\
\hline CHEMBL3964648 & 1640790 & 8.699 & 8.5339 & TRN & \\
\hline CHEMBL3942552 & 1640790 & 9.2218 & 9.0573 & TRN & \\
\hline CHEMBL3960661 & 1640790 & 8.0 & 7.1124 & TST & \\
\hline CHEMBL3944361 & 1640790 & 8.301 & 8.3613 & TRN & \\
\hline CHEMBL3933119 & 1640790 & 8.0 & 7.4679 & TST & \\
\hline CHEMBL3981231 & 1640790 & 8.699 & 8.7707 & TRN & \\
\hline CHEMBL3904196 & 1640790 & 5.9638 & 6.2306 & TRN & \\
\hline CHEMBL3941514 & 1640790 & 8.0 & 8.0224 & TST & \\
\hline CHEMBL3930012 & 1640790 & 6.0 & 6.1671 & TST & \\
\hline CHEMBL3900066 & 1640790 & 8.8861 & 9.0508 & TRN & \\
\hline CHEMBL3938241 & 1640790 & 9.5229 & 9.1104 & TRN & \\
\hline CHEMBL3964308 & 1640790 & 8.699 & 8.3987 & TRN & \\
\hline CHEMBL3986161 & 1640790 & 8.6778 & 8.88600 & 0000000001 & TRN \\
\hline CHEMBL3919160 & 1640790 & 8.3565 & 8.6153 & TRN & \\
\hline CHEMBL3973891 & 1640790 & 6.0292 & 5.8213 & TST & \\
\hline CHEMBL3915097 & 1640790 & 6.1343 & 6.5669 & TST & \\
\hline CHEMBL3911217 & 1640790 & 8.699 & 8.5603 & TRN & \\
\hline CHEMBL3949683 & 1640790 & 8.699 & 8.729 & TST & \\
\hline CHEMBL 3950248 & 1640790 & 8.301 & 8.5788 & TST & \\
\hline CHEMBL3983432 & 1640790 & 8.699 & 8.7694 & TRN & \\
\hline CHEMBL3261079 & 1640790 & 8.699 & 8.0459 & TST & \\
\hline CHEMBL3912689 & 1640790 & 8.0 & 7.3629 & TST & \\
\hline CHEMBL3906518 & 1640790 & 8.301 & 7.8408 & TRN & \\
\hline CHEMBL3926569 & 1640790 & 6.1457 & 6.1247 & TRN & \\
\hline CHEMBL3922395 & 1640790 & 8.699 & 8.5079 & TRN & \\
\hline CHEMBL3985039 & 1640790 & 8.6576 & 8.7293 & TRN & \\
\hline CHEMBL3937899 & 1640790 & 8.301 & 8.2883 & TRN & \\
\hline CHEMBL3944434 & 1640790 & 6.8729 & 6.5078 & TRN & \\
\hline CHEMBL 3930090 & 1640790 & 8.699 & 8.5624 & TRN & \\
\hline CHEMBL3904740 & 1640790 & 8.699 & 8.8628 & TST & \\
\hline CHEMBL3923790 & 1640790 & 8.3768 & 8.7314 & TRN & \\
\hline CHEMBL3896157 & 1640790 & 8.699 & 8.6936 & TRN & \\
\hline CHEMBL3921902 & 1640790 & 8.301 & 8.5399 & TRN & \\
\hline CHEMBL3985208 & 1640790 & 9.0969 & 9.1918 & TRN & \\
\hline CHEMBL3983399 & 1640790 & 8.7959 & 8.5934 & TRN & \\
\hline CHEMBL3914455 & 1640790 & 8.699 & 8.4979 & TRN & \\
\hline CHEMBL3954768 & 1640790 & 8.301 & 8.3631 & TRN & \\
\hline CHEMBL3923660 & 1640790 & 8.301 & 8.4093 & TRN & \\
\hline CHEMBL3971718 & 1640790 & 8.301 & 8.2708 & TRN & \\
\hline CHEMBL3966558 & 1640790 & 8.301 & 8.4736 & TRN & \\
\hline CHEMBL3936701 & 1640790 & 6.3325 & 6.4037 & TRN & \\
\hline CHEMBL3969079 & 1640790 & 8.8539 & 8.872 & TRN & \\
\hline CHEMBL3966088 & 1640790 & 8.699 & 8.6847 & TRN & \\
\hline
\end{tabular}


Supplemental Table S2.txt

\begin{tabular}{|c|c|c|c|c|}
\hline CHEMBL3931727 & 1640790 & 8.699 & 8.6043 & TRN \\
\hline CHEMBL3941251 & 1640790 & 8.0 & 7.7733 & TRN \\
\hline CHEMBL3929668 & 1640790 & 8.0 & 6.6717 & TST \\
\hline CHEMBL3980201 & 1640790 & 8.699 & 8.6954 & TRN \\
\hline CHEMBL3909483 & 1640790 & 8.5086 & 8.4084 & TRN \\
\hline CHEMBL1416169 & 737419 & 3.4948 & 3.3095 & TRN \\
\hline CHEMBL1704084 & 737419 & 3.4948 & 4.0486 & TST \\
\hline CHEMBL1729109 & 737419 & 3.4948 & 3.4626 & TRN \\
\hline CHEMBL1705660 & 737419 & 5.5214 & 5.2964 & TRN \\
\hline CHEMBL1710129 & 737419 & 3.4948 & 3.3261 & TRN \\
\hline CHEMBL1542448 & 737419 & 3.4948 & 3.4731 & TRN \\
\hline CHEMBL1728454 & 737419 & 3.4948 & 4.1282 & TST \\
\hline CHEMBL1733320 & 737419 & 3.4948 & 3.7306 & TRN \\
\hline CHEMBL1449870 & 737419 & 3.4948 & 3.8984 & TRN \\
\hline CHEMBL1534425 & 737419 & 3.4948 & 3.4984 & TRN \\
\hline CHEMBL1382214 & 737419 & 3.4948 & 3.6628 & TRN \\
\hline CHEMBL1411573 & 737419 & 3.4948 & 3.5774 & TRN \\
\hline CHEMBL1698243 & 737419 & 4.5003 & 3.0302 & TST \\
\hline CHEMBL1715078 & 737419 & 5.066 & 5.2976 & TRN \\
\hline CHEMBL1703615 & 737419 & 5.6326 & 5.6379 & TRN \\
\hline CHEMBL1484306 & 737419 & 4.5498 & 4.5079 & TRN \\
\hline CHEMBL1702412 & 737419 & 3.4948 & 3.8045 & TRN \\
\hline CHEMBL1703772 & 737419 & 3.4948 & 4.0027 & TST \\
\hline CHEMBL1730076 & 737419 & 3.4948 & 3.5964 & TRN \\
\hline CHEMBL1708243 & 737419 & 3.4948 & 3.0177 & TST \\
\hline CHEMBL1443900 & 737419 & 4.5622 & 3.4238 & TST \\
\hline CHEMBL1706882 & 737419 & 4.5719 & 4.6187 & TRN \\
\hline CHEMBL1701998 & 737419 & 3.4948 & 3.6547 & TRN \\
\hline CHEMBL1698983 & 737419 & 3.4948 & 3.4827 & TRN \\
\hline CHEMBL1481494 & 737419 & 3.4948 & 3.6461 & TRN \\
\hline CHEMBL1720072 & 737419 & 5.1002 & 5.267 & TRN \\
\hline CHEMBL1727053 & 737419 & 3.4948 & 3.7523 & TST \\
\hline CHEMBL1420151 & 737419 & 3.4948 & 3.2807 & TRN \\
\hline CHEMBL1713756 & 737419 & 3.4948 & 3.4775 & TRN \\
\hline CHEMBL1725618 & 737419 & 3.4948 & 3.4158 & TST \\
\hline CHEMBL1715275 & 737419 & 4.618 & 4.34399 & 9999999999 \\
\hline CHEMBL1402210 & 737419 & 3.4948 & 3.659 & TRN \\
\hline CHEMBL1703896 & 737419 & 3.4948 & 3.1864 & TRN \\
\hline CHEMBL1305795 & 737419 & 3.4948 & 3.3738 & TRN \\
\hline CHEMBL1734939 & 737419 & 3.4948 & 3.5271 & TST \\
\hline CHEMBL1736309 & 737419 & 3.4948 & 3.8935 & TST \\
\hline CHEMBL1718220 & 737419 & 3.4948 & 3.4058 & TRN \\
\hline CHEMBL1721058 & 737419 & 5.4425 & 5.49799 & 9999999999 \\
\hline CHEMBL1726224 & 737419 & 3.4948 & 3.5851 & TRN \\
\hline CHEMBL1719526 & 737419 & 3.4948 & 3.5252 & TST \\
\hline CHEMBL1727434 & 737419 & 3.4948 & 3.4249 & TRN \\
\hline CHEMBL1698745 & 737419 & 3.4948 & 3.51899 & 99999999997 \\
\hline CHEMBL1703285 & 737419 & 3.4948 & 3.6976 & TRN \\
\hline
\end{tabular}




\begin{tabular}{|c|c|c|c|c|c|}
\hline & & \multicolumn{4}{|c|}{ Supplemental Table S2.txt } \\
\hline CHEMBL1705807 & 737419 & 3.4948 & 3.4823 & TRN & \\
\hline CHEMBL1700716 & 737419 & 5.0429 & 4.9997 & TRN & \\
\hline CHEMBL1310336 & 737419 & 3.4948 & 3.5505 & TRN & \\
\hline CHEMBL1736438 & 737419 & 3.4948 & 3.5651 & TRN & \\
\hline CHEMBL1729479 & 737419 & 3.4948 & 4.148 & TST & \\
\hline CHEMBL1430124 & 737419 & 3.4948 & 3.4363 & TRN & \\
\hline CHEMBL1368569 & 737419 & 3.4948 & 3.2928 & TRN & \\
\hline CHEMBL1465869 & 737419 & 3.4948 & 3.4813 & TRN & \\
\hline CHEMBL1730381 & 737419 & 5.8827 & 5.4677 & TRN & \\
\hline CHEMBL1336209 & 737419 & 3.4948 & 3.4185 & TRN & \\
\hline CHEMBL1717402 & 737419 & 5.5986 & 5.21200 & 0000000001 & TRN \\
\hline CHEMBL1718537 & 737419 & 3.4948 & 3.3694 & TRN & \\
\hline CHEMBL1721827 & 737419 & 3.4948 & 3.7665 & TRN & \\
\hline CHEMBL1709480 & 737419 & 3.4948 & 3.9864 & TST & \\
\hline CHEMBL1386647 & 737419 & 3.4948 & 3.5098 & TRN & \\
\hline CHEMBL1722450 & 737419 & 3.4948 & 3.5682 & TRN & \\
\hline CHEMBL1586567 & 737419 & 5.6716 & 5.8175 & TRN & \\
\hline CHEMBL1725686 & 737419 & 3.4948 & 3.1876 & TRN & \\
\hline CHEMBL1719423 & 737419 & 3.4948 & 4.0268 & TST & \\
\hline CHEMBL1713770 & 737419 & 3.4948 & 3.5372 & TST & \\
\hline CHEMBL1586706 & 737419 & 3.4948 & 3.682 & TRN & \\
\hline CHEMBL1726562 & 737419 & 3.4948 & 3.4273 & TST & \\
\hline CHEMBL1707517 & 737419 & 3.4948 & 3.3827 & TST & \\
\hline CHEMBL 3912864 & 1641738 & 6.0 & 5.7291 & TRN & \\
\hline CHEMBL 3891072 & 1641738 & 4.7799 & 6.2549 & TRN & \\
\hline CHEMBL 3980346 & 1641738 & 6.0716 & 6.511 & TRN & \\
\hline CHEMBL 3920080 & 1641738 & 6.9355 & 6.09200 & 00000000005 & TRN \\
\hline CHEMBL 3935281 & 1641738 & 6.4559 & 6.9419 & TRN & \\
\hline CHEMBL 3970313 & 1641738 & 7.6968 & 7.0815 & TRN & \\
\hline CHEMBL 3933073 & 1641738 & 5.6778 & 6.1667 & TRN & \\
\hline CHEMBL 3892522 & 1641738 & 8.1605 & 7.0583 & TST & \\
\hline CHEMBL 3911267 & 1641738 & 6.0851 & 5.9376 & TRN & \\
\hline CHEMBL 3917693 & 1641738 & 6.0 & 6.9213 & TRN & \\
\hline CHEMBL 3968203 & 1641738 & 8.2733 & 8.3776 & TRN & \\
\hline CHEMBL3949580 & 1641738 & 7.1146 & 6.754 & TRN & \\
\hline CHEMBL 3925784 & 1641738 & 6.4225 & 6.6302 & TRN & \\
\hline CHEMBL2381960 & 1641738 & 7.7747 & 6.1131 & TRN & \\
\hline CHEMBL 3925312 & 1641738 & 6.8477 & 7.1267 & TRN & \\
\hline CHEMBL 3970582 & 1641738 & 6.6576 & 7.1249 & TRN & \\
\hline CHEMBL 3889842 & 1641738 & 6.0 & 5.9749 & TRN & \\
\hline CHEMBL3912326 & 1641738 & 8.1175 & 7.6256 & TST & \\
\hline CHEMBL3951014 & 1641738 & 6.6536 & 6.5525 & TRN & \\
\hline CHEMBL2381939 & 1641738 & 6.0 & 7.3883 & TRN & \\
\hline CHEMBL 3940813 & 1641738 & 6.2612 & 5.928 & TRN & \\
\hline CHEMBL3935830 & 1641738 & 6.0 & 6.1883 & TRN & \\
\hline CHEMBL 2381944 & 1641738 & 6.8447 & 7.9287 & TRN & \\
\hline CHEMBL3909106 & 1641738 & 5.9031 & 5.9648 & TRN & \\
\hline CHEMBL3986106 & 1641738 & 6.1221 & 6.2812 & TRN & \\
\hline
\end{tabular}




$$
\text { Supplemental Table S2.txt }
$$

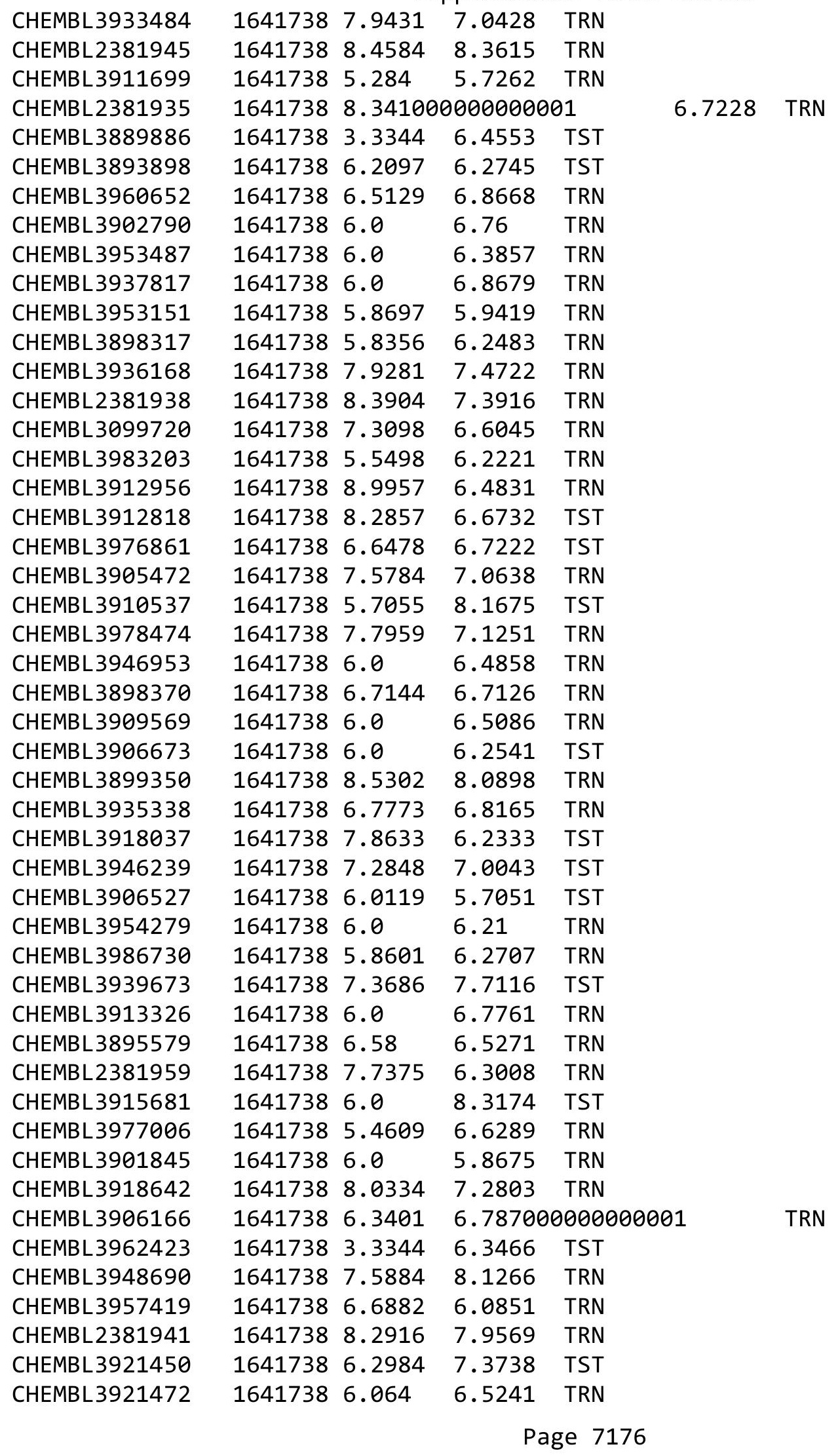


Supplemental Table S2.txt

\begin{tabular}{|c|c|c|c|c|}
\hline CHEMBL 3941477 & 1641738 & 5.1518 & 5.118 & TST \\
\hline CHEMBL 2381946 & 1641738 & 8.9626 & 8.3287 & TRN \\
\hline CHEMBL 3963080 & 1641738 & 5.7033 & 7.0998 & TST \\
\hline CHEMBL 3927399 & 1641738 & 8.8297 & 7.2573 & TRN \\
\hline CHEMBL 2381942 & 1641738 & 8.9508 & 8.0329 & TRN \\
\hline CHEMBL 3973361 & 1641738 & 6.3497 & 6.7027 & TRN \\
\hline CHEMBL 3906594 & 1641738 & 5.6345 & 6.9769 & TRN \\
\hline CHEMBL 3902644 & 1641738 & 8.1296 & 7.8385 & TRN \\
\hline CHEMBL 3940611 & 1641738 & 6.0362 & 7.1295 & TRN \\
\hline CHEMBL 2381937 & 1641738 & 6.0 & 6.9739 & TRN \\
\hline CHEMBL 3926356 & 1641738 & 8.1858 & 7.8397 & TRN \\
\hline CHEMBL 3099717 & 1641738 & 6.0 & 6.4281 & TRN \\
\hline CHEMBL 3935903 & 1641738 & 7.7905 & 6.9091 & TRN \\
\hline CHEMBL 3978820 & 1641738 & 7.1203 & 7.0573 & TRN \\
\hline CHEMBL 2381943 & 1641738 & 8.4486 & 7.8472 & TRN \\
\hline CHEMBL 3955689 & 1641738 & 6.5528 & 6.0066 & TRN \\
\hline CHEMBL 3903856 & 1641738 & 7.0209 & $6.55200 e$ & 30000000005 \\
\hline CHEMBL 3903797 & 1641738 & 6.9957 & 7.3357 & TST \\
\hline CHEMBL 3986563 & 1641738 & 6.0 & 6.5765 & TRN \\
\hline CHEMBL 3890044 & 1641738 & 6.1593 & 6.3921 & TST \\
\hline CHEMBL3966809 & 1641738 & 5.7375 & 6.1787 & TRN \\
\hline CHEMBL2381936 & 1641738 & 8.4134 & 7.4706 & TRN \\
\hline CHEMBL 3910878 & 1641738 & 6.6576 & 6.4666 & TST \\
\hline CHEMBL 3934977 & 1641738 & 7.4935 & 6.1912 & TST \\
\hline CHEMBL 3964088 & 1641738 & 5.8268 & 7.1945 & TST \\
\hline CHEMBL 3936768 & 1641738 & 8.46600 & 00000006 & 8.9835 \\
\hline CHEMBL3926391 & 1641738 & 5.8069 & 6.1939 & TST \\
\hline CHEMBL 3925979 & 1641738 & 5.8125 & 5.9131 & TST \\
\hline CHEMBL 3918984 & 1641738 & 5.2815 & 7.3694 & TST \\
\hline CHEMBL 3949034 & 1641738 & 6.9788 & 6.7005 & TRN \\
\hline CHEMBL 3962794 & 1641738 & 7.6144 & 6.6021 & TRN \\
\hline CHEMBL 3926435 & 1641738 & 6.8239 & 6.5845 & TRN \\
\hline CHEMBL3970169 & 1641738 & 7.0315 & 7.9246 & TRN \\
\hline CHEMBL 3895243 & 1641738 & 6.1046 & 5.9838 & TRN \\
\hline CHEMBL 3893116 & 1641738 & 6.9431 & 6.4146 & TRN \\
\hline CHEMBL 3922372 & 1641738 & 6.585 & 6.8453 & TRN \\
\hline CHEMBL 3952354 & 1641738 & 6.0 & 7.5696 & TST \\
\hline CHEMBL 3910076 & 1641738 & 5.2865 & 6.0199 & TRN \\
\hline CHEMBL 3930085 & 1641738 & 7.9281 & 6.3141 & TRN \\
\hline CHEMBL 3896548 & 1641738 & 7.4685 & 7.1461 & TRN \\
\hline CHEMBL 3893214 & 1641738 & 7.8447 & 7.3247 & TRN \\
\hline CHEMBL 3912260 & 1641738 & 7.2832 & 6.9298 & TRN \\
\hline CHEMBL3949605 & 1641738 & 5.5114 & 6.9986 & TST \\
\hline CHEMBL 3927898 & 1641738 & 8.1273 & 6.5605 & TST \\
\hline CHEMBL 3962475 & 1641738 & 8.4045 & 6.2474 & TST \\
\hline CHEMBL 2381934 & 1641738 & 6.0 & 5.8911 & TRN \\
\hline CHEMBL 3950105 & 1641738 & 3.3344 & 6.3062 & TST \\
\hline CHEMBL 3099718 & 1641738 & 8.1561 & 6.9736 & TRN \\
\hline
\end{tabular}




\begin{tabular}{|c|c|c|c|c|}
\hline \multirow[b]{2}{*}{ CHEMBL 2381940} & \multicolumn{4}{|c|}{ Supplemental Table S2.txt } \\
\hline & 1641738 & 6.0 & 7.2872 & TRN \\
\hline CHEMBL 3940257 & 1641738 & 5.6861 & 6.5918 & TRN \\
\hline CHEMBL 3933300 & 1641738 & 6.2069 & 6.2317 & TRN \\
\hline CHEMBL 3919133 & 1641738 & 6.6421 & 6.4834 & TST \\
\hline CHEMBL 3940510 & 1641738 & 6.0 & 6.881 & TRN \\
\hline CHEMBL3951869 & 1641738 & 6.0 & 8.2591 & TST \\
\hline CHEMBL 3948927 & 1641738 & 5.8447 & 6.526 & TRN \\
\hline CHEMBL 2381958 & 1641738 & 6.0 & 5.9066 & TRN \\
\hline CHEMBL 3932980 & 1641738 & 5.8729 & 6.6227 & TRN \\
\hline CHEMBL3913507 & 1641738 & 7.0706 & 7.3776 & TRN \\
\hline CHEMBL 3895512 & 1641738 & 6.1062 & 6.9256 & TRN \\
\hline CHEMBL 3943612 & 1641738 & 5.8297 & 5.9851 & TRN \\
\hline CHEMBL3896062 & 1641738 & 6.0 & 6.0667 & TST \\
\hline CHEMBL 3907921 & 1641738 & 7.0526 & 7.0944 & TRN \\
\hline CHEMBL 3942458 & 1641738 & 8.0372 & 7.1266 & TST \\
\hline CHEMBL 2178179 & 873597 & 8.0 & 7.8071 & TRN \\
\hline CHEMBL 2178203 & 873597 & 5.3979 & 6.5194 & TST \\
\hline CHEMBL 2178165 & 873597 & 8.301 & 8.3274 & TRN \\
\hline CHEMBL 2178167 & 873597 & 6.5686 & 6.5795 & TRN \\
\hline CHEMBL 2178185 & 873597 & 7.301 & 7.3588 & TRN \\
\hline CHEMBL 2178183 & 873597 & 7.3979 & 7.3223 & TRN \\
\hline CHEMBL 2178206 & 873597 & 5.5528 & 5.6421 & TRN \\
\hline CHEMBL 2178752 & 873597 & 5.0555 & 5.0988 & TRN \\
\hline CHEMBL 2178184 & 873597 & 7.5229 & 7.5124 & TRN \\
\hline CHEMBL 2178187 & 873597 & 7.5229 & 7.5461 & TRN \\
\hline CHEMBL 2178172 & 873597 & 6.8539 & 6.8451 & TRN \\
\hline CHEMBL 2178166 & 873597 & 6.0605 & 6.2394 & TST \\
\hline CHEMBL 2178204 & 873597 & 6.5376 & 6.5389 & TRN \\
\hline CHEMBL 2178173 & 873597 & 6.0706 & 6.0826 & TRN \\
\hline CHEMBL 2178161 & 873597 & 8.0 & 8.0516 & TRN \\
\hline CHEMBL 2178198 & 873597 & 5.4089 & 5.2664 & TRN \\
\hline CHEMBL 2178192 & 873597 & 7.301 & 7.2556 & TRN \\
\hline CHEMBL 2178194 & 873597 & 7.699 & 7.5698 & TRN \\
\hline CHEMBL 2178208 & 873597 & 4.0 & 3.9991 & TRN \\
\hline CHEMBL2178199 & 873597 & 5.6576 & 5.7192 & TRN \\
\hline CHEMBL 2178193 & 873597 & 7.699 & 7.7149 & TRN \\
\hline CHEMBL 2178162 & 873597 & 8.0 & 7.8715 & TRN \\
\hline CHEMBL 2178177 & 873597 & 6.9208 & 6.8812 & TRN \\
\hline CHEMBL 2178200 & 873597 & 6.1739 & 6.2517 & TRN \\
\hline CHEMBL 2178175 & 873597 & 6.3188 & 6.3414 & TRN \\
\hline CHEMBL 2178195 & 873597 & 8.2218 & 8.2108 & TRN \\
\hline CHEMBL 2178188 & 873597 & 7.301 & 7.5899 & TRN \\
\hline CHEMBL 2178191 & 873597 & 7.301 & 7.3763 & TRN \\
\hline CHEMBL 2178202 & 873597 & 6.6778 & 6.4297 & TST \\
\hline CHEMBL 2178163 & 873597 & 7.699 & 7.7268 & TRN \\
\hline CHEMBL 2178201 & 873597 & 6.0655 & 6.4475 & TST \\
\hline CHEMBL 2178169 & 873597 & 5.9208 & 5.8801 & TRN \\
\hline CHEMBL 2178180 & 873597 & 8.301 & 8.1313 & TRN \\
\hline
\end{tabular}




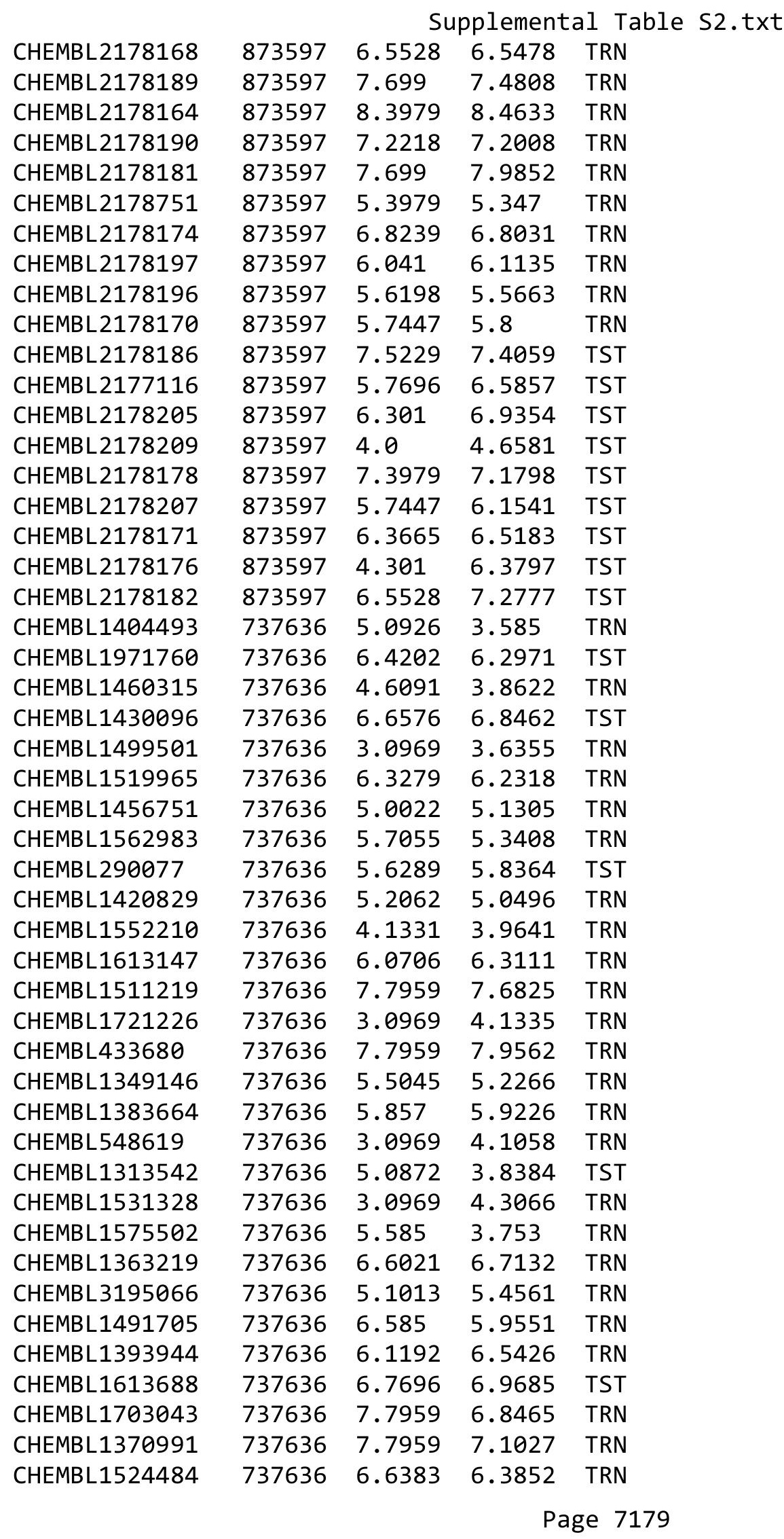




\begin{tabular}{|c|c|c|c|c|c|c|}
\hline & & \multicolumn{5}{|c|}{ Supplemental Table S2.txt } \\
\hline CHEMBL1384292 & 737636 & 6.1135 & 6.1856 & TRN & & \\
\hline CHEMBL81782 & 737636 & $5.7620 e$ & 30000000 & 005 & .5925 & TRN \\
\hline CHEMBL1603001 & 737636 & 4.3439 & 4.6533 & TRN & & \\
\hline CHEMBL1310617 & 737636 & 6.4949 & 5.999 & TRN & & \\
\hline CHEMBL507237 & 737636 & 5.5186 & 5.2963 & TST & & \\
\hline CHEMBL1486109 & 737636 & 6.0555 & 6.2215 & TRN & & \\
\hline CHEMBL533602 & 737636 & 4.4622 & 3.8586 & TST & & \\
\hline CHEMBL1448592 & 737636 & 5.7773 & 5.0488 & TRN & & \\
\hline CHEMBL1432721 & 737636 & 3.0969 & 3.534 & TRN & & \\
\hline CHEMBL1521023 & 737636 & 6.7212 & 7.3846 & TRN & & \\
\hline CHEMBL1486585 & 737636 & 6.0969 & 6.0561 & TRN & & \\
\hline CHEMBL1472773 & 737636 & 3.0969 & 3.7507 & TST & & \\
\hline CHEMBL1729737 & 737636 & 6.6021 & 6.3385 & TRN & & \\
\hline CHEMBL1425552 & 737636 & 3.0969 & 4.1095 & TRN & & \\
\hline CHEMBL1712104 & 737636 & 4.5421 & 4.6863 & TRN & & \\
\hline CHEMBL1521681 & 737636 & 6.4685 & 6.8066 & TST & & \\
\hline CHEMBL453974 & 737636 & 6.6778 & 6.3682 & TRN & & \\
\hline CHEMBL1372292 & 737636 & 3.0969 & 3.1912 & TRN & & \\
\hline CHEMBL1382917 & 737636 & 4.8097 & 3.6027 & TRN & & \\
\hline CHEMBL1490503 & 737636 & 3.0969 & 3.2849 & TRN & & \\
\hline CHEMBL1404792 & 737636 & 4.6968 & 3.7975 & TRN & & \\
\hline CHEMBL1339737 & 737636 & 3.0969 & 4.1058 & TRN & & \\
\hline CHEMBL1462745 & 737636 & 3.0969 & 5.3671 & TRN & & \\
\hline CHEMBL1492752 & 737636 & 3.0969 & 3.7767 & TRN & & \\
\hline CHEMBL1415885 & 737636 & 5.0809 & 4.78600 & 00000000005 & & TST \\
\hline CHEMBL590706 & 737636 & 3.0969 & 4.1058 & TRN & & \\
\hline CHEMBL1566610 & 737636 & 6.5376 & 5.9471 & TRN & & \\
\hline CHEMBL3189250 & 737636 & 6.7696 & 5.8225 & TST & & \\
\hline CHEMBL1526615 & 737636 & 3.0969 & 3.555 & TRN & & \\
\hline CHEMBL1492936 & 737636 & 3.0969 & 3.4448 & TRN & & \\
\hline CHEMBL1485727 & 737636 & 3.0969 & 3.6092 & TRN & & \\
\hline CHEMBL1543215 & 737636 & 5.9666 & 6.2532 & TRN & & \\
\hline CHEMBL461579 & 737636 & 5.8153 & 5.4311 & TRN & & \\
\hline CHEMBL338474 & 737636 & 5.9914 & 4.0277 & TRN & & \\
\hline CHEMBL1544743 & 737636 & 3.0969 & 3.3363 & TRN & & \\
\hline CHEMBL1518672 & 737636 & 5.7399 & 6.20200 & 0000000001 & & TRN \\
\hline CHEMBL1423192 & 737636 & 5.8041 & 5.84200 & 00000000005 & & TRN \\
\hline CHEMBL1563943 & 737636 & 3.0969 & 3.7666 & TRN & & \\
\hline CHEMBL1386804 & 737636 & 6.1938 & 7.0366 & TRN & & \\
\hline CHEMBL1513566 & 737636 & 5.9318 & 6.3784 & TRN & & \\
\hline CHEMBL1340715 & 737636 & 3.0969 & 3.7892 & TRN & & \\
\hline CHEMBL405317 & 737636 & 5.9318 & 6.2231 & TRN & & \\
\hline CHEMBL1378232 & 737636 & 6.1938 & 6.4608 & TRN & & \\
\hline CHEMBL1589677 & 737636 & 5.0937 & 3.7039 & TRN & & \\
\hline CHEMBL1437030 & 737636 & 3.0969 & 3.72399 & 99999999998 & & TRN \\
\hline CHEMBL1549500 & 737636 & 4.5229 & 4.15300 & 00000000005 & & TRN \\
\hline CHEMBL584442 & 737636 & 5.399 & 3.8567 & TRN & & \\
\hline CHEMBL1360997 & 737636 & 3.0969 & 3.2661 & TRN & & \\
\hline
\end{tabular}


Supplemental Table S2.txt

\begin{tabular}{|c|c|c|c|c|}
\hline HEN & & 7.7959 & & \\
\hline & & 3.0969 & 4.5125 & \\
\hline- & & & & \\
\hline AEMBL15 & 636 & 399 & 7683 & \\
\hline AEMBL1358722 & 37636 & 1669 & 5717 & \\
\hline HEMBL1527341 & 37636 & 3565 & 6959 & \\
\hline HEMBL1316828 & 36 & & & \\
\hline IFMBI 1597245 & & & & (2) \\
\hline AEMBL598263 & 36 & 7959 & .1187 & \\
\hline HEMBL1978117 & 36 & 9872 & .1516 & \\
\hline HEMBL1319304 & 36 & 969 & 49 & \\
\hline IEMBL198 & & 65 & 3661 & \\
\hline IEMBL 14 & & & & \\
\hline HEMBL 145 & 36 & 969 & 3.4172 & \\
\hline AEMBL13؟ & & 69 & 8241 & \\
\hline AEMBL173 & 36 & 59 & 71 & \\
\hline HEMBL 14 & & 59 & 13 & \\
\hline HEMBL14 & & & & \\
\hline AEMBL 267 & & 62 & 6.1324 & \\
\hline AEMBL14 & & & & \\
\hline $\mathrm{E} / \mathrm{MBL} 13$ & 36 & 59 & -1 & II \\
\hline AEMBL27 & & & 88 & 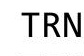 \\
\hline HEMBL13 & & & & \\
\hline IEMBL14 & & & 2447 & \\
\hline AEMBL15 & & & & 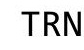 \\
\hline HEMBL13 & & & 019 & KIV \\
\hline HEMBL3 & & & 08 & RN \\
\hline HFMBI 14 & & & 736 & \\
\hline HEMBL16 & & & 5077 & I KT \\
\hline HEMBL1516365 & & & & ISI \\
\hline HEMBL13 & & 59 & 2038 & RN \\
\hline HEMBL1 & & & 987 & RN \\
\hline HFMPI 6 & & & 84 & \\
\hline HEMBL530 & & & 384 & IRN \\
\hline HEMBL1302130 & & 59 & 4314 & TRN \\
\hline HEMBL15 & & & 8036 & RN \\
\hline HEMRI 1 & & & 199 & $\Gamma \mathrm{RN}$ \\
\hline HEMBL1€ & & & 349 & TRN \\
\hline HEMBL1607801 & & & 9338 & TRN \\
\hline AEMBL14 & & 02 & 2223 & TRN \\
\hline HEMBL19 & & & 177 & \\
\hline HEMBL 14 & & & 4.3708 & I NIV \\
\hline HEMBL994 & 36 & 02 & 3.6419 & TRN \\
\hline AEMBL1434 & 37636 & 969 & 3.7565 & TRN \\
\hline HEMBL138 & & 72 & 005 & 1 \\
\hline HEMBL17 & & & .0458 & \\
\hline HEMBL145 & & & 3.8561 & \\
\hline CHEMBL581868 & 737636 & 5.3298 & 3.765 & ГRN \\
\hline
\end{tabular}

Page 7181 


\begin{tabular}{|c|c|c|c|c|c|c|}
\hline \multirow[b]{2}{*}{ CHEMBL1715314 } & \multicolumn{6}{|c|}{ Supplemental Table S2.txt } \\
\hline & 737636 & 3.0969 & 5.2375 & TST & & \\
\hline CHEMBL533388 & 737636 & 6.3872 & 6.5718 & TRN & & \\
\hline CHEMBL581880 & 737636 & 5.3645 & 4.6754 & TRN & & \\
\hline CHEMBL3193058 & 737636 & 6.5086 & 6.7633 & TRN & & \\
\hline CHEMBL1559529 & 737636 & $5.7520 e$ & 00000000 & & 6.2622 & TRN \\
\hline CHEMBL1729353 & 737636 & 6.7212 & 6.0587 & TRN & & \\
\hline CHEMBL1699881 & 737636 & 7.7959 & 6.2658 & TRN & & \\
\hline CHEMBL1489605 & 737636 & 7.7959 & 7.0615 & TRN & & \\
\hline CHEMBL601933 & 737636 & 5.1979 & 4.1058 & TRN & & \\
\hline CHEMBL1711914 & 737636 & 5.0862 & 3.8525 & TRN & & \\
\hline CHEMBL1389543 & 737636 & 3.0969 & 4.1169 & TRN & & \\
\hline CHEMBL1441604 & 737636 & 4.4179 & 4.5501 & TRN & & \\
\hline CHEMBL1409554 & 737636 & 4.1931 & 3.3798 & TST & & \\
\hline CHEMBL1430094 & 737636 & 7.7959 & 7.0624 & TRN & & \\
\hline CHEMBL1537098 & 737636 & 7.7959 & 7.7273 & TST & & \\
\hline CHEMBL1462900 & 737636 & 6.4949 & 6.7073 & TST & & \\
\hline CHEMBL1304342 & 737636 & 4.3354 & 4.2242 & TST & & \\
\hline CHEMBL328834 & 737636 & 7.7959 & 7.3839 & TST & & \\
\hline CHEMBL225963 & 737636 & 3.0969 & 3.8747 & TST & & \\
\hline CHEMBL3191989 & 737636 & 7.7959 & 7.2536 & TST & & \\
\hline CHEMBL568092 & 737636 & 6.0362 & 4.1058 & TST & & \\
\hline CHEMBL1511555 & 737636 & 3.0969 & 3.6945 & TST & & \\
\hline CHEMBL1569724 & 737636 & 3.0969 & 3.5982 & TST & & \\
\hline CHEMBL1333449 & 737636 & 3.0969 & 3.7391 & TST & & \\
\hline CHEMBL1544103 & 737636 & 3.0969 & 3.5578 & TST & & \\
\hline CHEMBL1459468 & 737636 & 6.2441 & 6.7185 & TST & & \\
\hline CHEMBL1329446 & 737636 & 7.7959 & 6.8405 & TST & & \\
\hline CHEMBL517341 & 737636 & 5.4962 & 6.3317 & TST & & \\
\hline CHEMBL1428735 & 737636 & 5.8041 & 6.1597 & TST & & \\
\hline CHEMBL1712044 & 737636 & 3.0969 & 4.0095 & TST & & \\
\hline CHEMBL1519558 & 737636 & 5.3556 & 4.8992 & TST & & \\
\hline CHEMBL1565349 & 737636 & 5.1085 & 4.9456 & TST & & \\
\hline CHEMBL3185655 & 737636 & 7.7959 & 7.4728 & TST & & \\
\hline CHEMBL1301042 & 737636 & 7.7959 & 7.3548 & TST & & \\
\hline CHEMBL3704096 & 1528576 & 7.6576 & 7.385 & TRN & & \\
\hline CHEMBL3704076 & 1528576 & 7.041 & 7.1804 & TRN & & \\
\hline CHEMBL3704034 & 1528576 & 7.3098 & 7.4015 & TRN & & \\
\hline CHEMBL3906803 & 1528576 & 8.1549 & 7.9113 & TST & & \\
\hline CHEMBL3704091 & 1528576 & 6.8861 & 7.5859 & TST & & \\
\hline CHEMBL3704104 & 1528576 & 7.6778 & 6.8764 & TRN & & \\
\hline CHEMBL3704102 & 1528576 & 7.7959 & 7.7713 & TRN & & \\
\hline CHEMBL3934728 & 1528576 & 7.1427 & 7.5205 & TST & & \\
\hline CHEMBL3704089 & 1528576 & 7.6778 & 8.1054 & TRN & & \\
\hline CHEMBL3704068 & 1528576 & 6.0915 & 6.1722 & TRN & & \\
\hline CHEMBL3914065 & 1528576 & 7.2596 & 8.8291 & TST & & \\
\hline CHEMBL3704134 & 1528576 & 7.041 & 6.4906 & TRN & & \\
\hline CHEMBL3704039 & 1528576 & 7.2366 & 7.6565 & TRN & & \\
\hline CHEMBL3704130 & 1528576 & 6.9208 & 7.4742 & TRN & & \\
\hline
\end{tabular}


Supplemental Table S2.txt

\begin{tabular}{|c|c|c|c|c|}
\hline Th & & 249 & & \\
\hline HEMPI 2791960 & 528576 & 7.4318 & .0069 & \\
\hline & & & & \\
\hline AEMBL & 576 & 5021 & & $\mathrm{MI}$ \\
\hline AEMBL3 & 528576 & 366 & 4845 & \\
\hline HEMBL3889833 & 528576 & 7.6383 & .8191 & \\
\hline & 576 & 366 & 1608 & \\
\hline 37 & 28576 & & & \\
\hline AEMBL3 & 528576 & 586 & 7.53 & \\
\hline HEMBL37 & 528576 & 861 & 0983 & \\
\hline AEMBL3 & 528576 & 088 & 2062 & \\
\hline IEMBL & 28576 & 212 & 2874 & \\
\hline AEMBL. & & & & \\
\hline HEMBL 3 & 528576 & 8.0458 & 7.7532 & \\
\hline AEMBL 2 & 528576 & 7.301 & 3096 & \\
\hline AEMBL3 & 528576 & 6.8539 & .7332 & \\
\hline HEMBL3 & 16 & 229 & 325 & \\
\hline HEMBL3 & & & & \\
\hline HEMBL3 & 528576 & 218 & 8.1509 & \\
\hline IEMBL3 & 76 & 96 & 86 & \\
\hline AEMBL & 6 & 89 & 342 & RIN \\
\hline HEMBL & 6 & 539 & 524 & RN \\
\hline HEMBL & 76 & 6. & 82 & \\
\hline 13 & 3576 & & 5786 & \\
\hline AEMBL3 & & & & ISI \\
\hline HEMBL & 16 & 7. & 3237 & RN \\
\hline HEM & 6 & 09 & 776 & וכד \\
\hline HFMBL & 76 & 89 & 38 & \\
\hline HEMBL3 & & & & $\ln$ \\
\hline HEMBL3 & 76 & & .9778 & IS \\
\hline HEMBL3 & 76 & 29 & 5 & RN \\
\hline HEMBL & 6 & 39 & 82 & RN \\
\hline 57 & 76 & 59 & 34 & ל \\
\hline HEMBL3 & & & 7.5362 & IRN \\
\hline HEMBL37 & 528576 & 5.7212 & 5.8297 & TRN \\
\hline HEMBL & 6 & 757 & 387 & ST \\
\hline HEMRI & 76 & & 35 & TRN \\
\hline HEMBL; & & 6.5528 & 6.7162 & IRN \\
\hline HEMBL3 & 528576 & 6 & .9354 & TST \\
\hline AEMBL & 528576 & & 7.8724 & TRN \\
\hline HEMBL3 & 528576 & 29 & 6.2655 & DN \\
\hline HEMBL3 & & & 6.77 & TRN \\
\hline HEMBL3 & 528576 & 7.4559 & 7.3163 & TRN \\
\hline HEMBL3 & 528576 & 8 & 7.6134 & TR \\
\hline 1 & 16 & & 1954 & RN \\
\hline HEMBL3 & & 212 & 7.7233 & \\
\hline HEMBL3 & & 5.2976 & 5.9717 & \\
\hline CHEMBL3659041 & 1528576 & 8.0362 & 7.3464 & \\
\hline
\end{tabular}

Page 7183 
Supplemental Table S2.txt

\begin{tabular}{|c|c|c|c|c|}
\hline 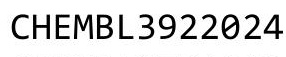 & 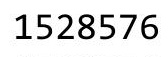 & a & & \\
\hline HEMBL3704043 & 528576 & 7.5528 & 7.2442 & \\
\hline HEMBL3659045 & 528576 & 6.0 & 3472 & \\
\hline 434 & & 7.7696 & & \\
\hline AEMBL3 & 28576 & 212 & & \\
\hline AEMBL3704114 & 528576 & 6.2757 & .6405 & \\
\hline HEMBL3704093 & .528576 & 7.7212 & .7334 & \\
\hline HEMBL3704070 & 528576 & 7.1938 & & \\
\hline AEMBL23 & 28576 & 7.8239 & 61 & \\
\hline AEMBL37 & 576 & & & \\
\hline HEMBL3704097 & 528576 & 7.6576 & .3343 & \\
\hline HEMBL2315940 & 528576 & 7.6383 & 7.4323 & \\
\hline HEMBL3704132 & .528576 & 6.6778 & 152 & \\
\hline HEMBL3 & 56 & 6 & & \\
\hline HEMBL3 & 76 & & & \\
\hline HEMBL3704042 & .528576 & 6.1463 & & \\
\hline HEMBL37e & 528576 & 6.1427 & & \\
\hline HEMBL3 & 16 & 7. & & \\
\hline HEN & 76 & 79 & & \\
\hline AEMBL 3 & 76 & 079 & & \\
\hline HEMBL 370 & 528576 & 6.0 & & \\
\hline HEMBL37e & 576 & 7. & & \\
\hline HEMBL3 & 576 & 7.5528 & & \\
\hline HEM & 76 & & & \\
\hline HEM & 76 & 7. & & \\
\hline HEMBL3 & 576 & 7.2518 & & \\
\hline AEMBL 231 & 76 & 7.3 & & \\
\hline HEMBL3 & 76 & & & \\
\hline HEM & 76 & & & \\
\hline 54 & 76 & 7. & & RN \\
\hline AEMBL3 & & & & \\
\hline AEMBL3704087 & 576 & 8. & & $\mathrm{RN}$ \\
\hline HEMBL3 & 76 & & & \\
\hline 9 & 76 & 75 & & \\
\hline HEN & 76 & 6. & & RN \\
\hline HEMBL37e & 528576 & & & RI \\
\hline AEMBL3704127 & 528576 & 7. & & RN \\
\hline HEN & & & & \\
\hline 1 & 76 & 8 & 23 & NIV \\
\hline HEMBL 370 & 576 & 8. & & ST \\
\hline AEMBL3704131 & 528576 & 6.8861 & & RN \\
\hline HEMBL $37 €$ & 528576 & 7.8861 & & R \\
\hline & 576 & & & \\
\hline HEMBL3 & 528576 & 70 & & \\
\hline HEMBL3 & 576 & $\sigma_{1}$ & 755 & RN \\
\hline IEMBL 37 & 1528576 & 6.4559 & 371 & RN \\
\hline & & & & \\
\hline CHEN & 15285 & & & \\
\hline
\end{tabular}

Page 7184 
Supplemental Table S2.txt

\begin{tabular}{|c|c|c|c|c|}
\hline CHEMBL3659053 & 1528576 & 7.4559 & 7.3849 & TRN \\
\hline CHEMBL3704066 & 1528576 & 6.7959 & 7.2347 & TRN \\
\hline CHEMBL3704147 & 1528576 & 5.8386 & 5.4292 & TRN \\
\hline CHEMBL3704032 & 1528576 & 8.0 & 7.4702 & TRN \\
\hline CHEMBL3704038 & 1528576 & 7.7959 & 7.8385 & TRN \\
\hline CHEMBL3704053 & 1528576 & 7.1367 & 7.1708 & TRN \\
\hline CHEMBL3704108 & 1528576 & 7.0506 & 6.9492 & TRN \\
\hline CHEMBL3659039 & 1528576 & 6.0 & 6.2427 & TRN \\
\hline CHEMBL3704026 & 1528576 & 8.301 & 8.0431 & TRN \\
\hline CHEMBL3704120 & 1528576 & 7.4318 & 7.2574 & TRN \\
\hline CHEMBL3704101 & 1528576 & 7.8861 & 7.4757 & TRN \\
\hline CHEMBL3704058 & 1528576 & 6.6364 & 6.6713 & TRN \\
\hline CHEMBL3704103 & 1528576 & 7.7959 & 7.49700 & 0000000001 \\
\hline CHEMBL 3704074 & 1528576 & 6.2596 & 6.4547 & TRN \\
\hline CHEMBL3966845 & 1528576 & 8.0969 & 7.8662 & TST \\
\hline CHEMBL3704073 & 1528576 & 7.8239 & 7.3009 & TRN \\
\hline CHEMBL3704028 & 1528576 & 8.0458 & 7.5003 & TRN \\
\hline CHEMBL3704121 & 1528576 & 7.0915 & 7.2439 & TRN \\
\hline CHEMBL3965110 & 1528576 & 6.699 & 7.6846 & TST \\
\hline CHEMBL3704062 & 1528576 & 6.2924 & 6.7731 & TRN \\
\hline CHEMBL3957648 & 1528576 & 6.4437 & 6.7533 & TST \\
\hline CHEMBL3659037 & 1528576 & 5.9101 & 6.0882 & TRN \\
\hline CHEMBL3986134 & 1528576 & 7.0706 & 7.2557 & TST \\
\hline CHEMBL3704078 & 1528576 & 7.3979 & 7.3221 & TRN \\
\hline CHEMBL 2315922 & 1528576 & 6.0 & 7.3431 & TST \\
\hline CHEMBL3704122 & 1528576 & 6.9208 & 7.186 & TST \\
\hline CHEMBL3704067 & 1528576 & 6.0223 & 5.4919 & TST \\
\hline CHEMBL3704086 & 1528576 & 8.1549 & 8.4565 & TST \\
\hline CHEMBL3704051 & 1528576 & 6.1612 & 6.8967 & TST \\
\hline CHEMBL 2315920 & 1528576 & 7.8239 & 8.5951 & TST \\
\hline CHEMBL3704123 & 1528576 & 6.5528 & 7.46899 & э999999999 \\
\hline CHEMBL3704065 & 1528576 & 6.0915 & 6.5823 & TST \\
\hline CHEMBL3953959 & 1642417 & 8.0915 & 8.2126 & TST \\
\hline CHEMBL3915775 & 1642417 & 8.2076 & 7.4911 & TST \\
\hline CHEMBL3904911 & 1642417 & 8.4437 & 8.4636 & TRN \\
\hline CHEMBL3949998 & 1642417 & 6.5378 & 6.129 & TRN \\
\hline CHEMBL3966738 & 1642417 & 7.9666 & 8.3805 & TRN \\
\hline CHEMBL3948576 & 1642417 & 7.6383 & 8.0273 & TST \\
\hline CHEMBL3947477 & 1642417 & 7.9172 & 8.5435 & TST \\
\hline CHEMBL3983704 & 1642417 & 8.4202 & 7.4529 & TST \\
\hline CHEMBL3956381 & 1642417 & 6.0 & 6.0517 & TRN \\
\hline CHEMBL3948891 & 1642417 & 6.0 & 6.0639 & TRN \\
\hline CHEMBL3903623 & 1642417 & 9.2218 & 9.1524 & TRN \\
\hline CHEMBL3984807 & 1642417 & 7.3036 & 6.9454 & TRN \\
\hline CHEMBL3941684 & 1642417 & 8.8861 & 9.2929 & TRN \\
\hline CHEMBL3932801 & 1642417 & 6.9931 & 7.1779 & TRN \\
\hline CHEMBL 3914222 & 1642417 & 7.6162 & 7.2209 & TRN \\
\hline CHEMBL3903186 & 1642417 & 6.0 & 4.7874 & TST \\
\hline
\end{tabular}


Supplemental Table S2.txt

\begin{tabular}{|c|c|c|c|c|}
\hline CHEMBL3905721 & 1642417 & 7.1898 & 7.3359 & TRN \\
\hline CHEMBL3984063 & 1642417 & 8.1308 & 7.4792 & TRN \\
\hline CHEMBL3963353 & 1642417 & 7.58 & 7.75 & TRN \\
\hline CHEMBL3961738 & 1642417 & 7.1694 & 7.3367 & TRN \\
\hline CHEMBL3919647 & 1642417 & 8.2676 & 8.1434 & TRN \\
\hline CHEMBL3929452 & 1642417 & 8.4202 & 8.3084 & TRN \\
\hline CHEMBL3949293 & 1642417 & 9.5229 & 9.6129 & TRN \\
\hline CHEMBL3891310 & 1642417 & 7.3516 & 8.1488 & TRN \\
\hline CHEMBL3910438 & 1642417 & 7.5157 & 7.8729 & TST \\
\hline CHEMBL3916247 & 1642417 & 5.6364 & 5.3953 & TRN \\
\hline CHEMBL3977269 & 1642417 & 8.2757 & 8.5882 & TRN \\
\hline CHEMBL3896435 & 1642417 & 8.7447 & 8.3492 & TRN \\
\hline CHEMBL3967255 & 1642417 & 6.0 & 7.1263 & TST \\
\hline CHEMBL 3890670 & 1642417 & 6.0 & 6.7149 & TST \\
\hline CHEMBL3945460 & 1642417 & 8.5686 & 8.5038 & TRN \\
\hline CHEMBL3971133 & 1642417 & 8.6198 & 8.3953 & TRN \\
\hline CHEMBL3918143 & 1642417 & 8.2291 & 8.2629 & TRN \\
\hline CHEMBL3917247 & 1642417 & 6.9914 & 6.8332 & TRN \\
\hline CHEMBL3977321 & 1642417 & 6.2008 & 6.0983 & TRN \\
\hline CHEMBL3921496 & 1642417 & 8.2076 & 7.8163 & TST \\
\hline CHEMBL3961764 & 1642417 & 7.7595 & 7.9049 & TRN \\
\hline CHEMBL3917814 & 1642417 & 8.5686 & 9.0476 & TRN \\
\hline CHEMBL3941012 & 1642417 & 8.4815 & 8.0664 & TRN \\
\hline CHEMBL3952856 & 1642417 & 6.9759 & 5.6382 & TST \\
\hline CHEMBL3915604 & 1642417 & 7.8182 & 7.9895 & TRN \\
\hline CHEMBL3907300 & 1642417 & 9.0 & 8.9255 & TRN \\
\hline CHEMBL3972902 & 1642417 & 9.0969 & 9.152006 & 0000000001 \\
\hline CHEMBL3979497 & 1642417 & 7.7545 & 8.3967 & TRN \\
\hline CHEMBL3933475 & 1642417 & 6.0 & 5.9557 & TRN \\
\hline CHEMBL 3907834 & 1642417 & 7.7595 & 6.8551 & TST \\
\hline CHEMBL3946346 & 1642417 & 7.2557 & 7.2046 & TRN \\
\hline CHEMBL3921773 & 1642417 & 8.7447 & 7.2359 & TRN \\
\hline CHEMBL3893973 & 1642417 & 8.3565 & 8.8429 & TRN \\
\hline CHEMBL3890259 & 1642417 & 8.6576 & 8.6492 & TRN \\
\hline CHEMBL3976040 & 1642417 & 6.0 & 6.2237 & TRN \\
\hline CHEMBL3948722 & 1642417 & 8.0915 & 7.4645 & TRN \\
\hline CHEMBL3964317 & 1642417 & 6.0 & 6.5892 & TRN \\
\hline CHEMBL3970767 & 1642417 & 9.0 & 8.8089 & TST \\
\hline CHEMBL3934247 & 1642417 & 8.9208 & 9.2747 & TRN \\
\hline CHEMBL3909842 & 1642417 & 8.301 & 8.2904 & TRN \\
\hline CHEMBL3918725 & 1642417 & 7.4401 & 7.4412 & TRN \\
\hline CHEMBL3895949 & 1642417 & 8.1427 & 10.4002 & TST \\
\hline CHEMBL3902074 & 1642417 & 6.0 & 5.6689 & TST \\
\hline CHEMBL3974698 & 1642417 & 8.7447 & 7.9104 & TST \\
\hline CHEMBL3913317 & 1642417 & 6.4896 & 8.0307 & TST \\
\hline CHEMBL3971817 & 1642417 & 6.1297 & 8.5491 & TST \\
\hline CHEMBL3896949 & 1642417 & 7.9101 & 6.7762 & TST \\
\hline CHEMBL3975656 & 1642417 & 6.9698 & 6.5184 & TRN \\
\hline
\end{tabular}


Supplemental Table S2.txt

\begin{tabular}{|c|c|c|c|c|}
\hline CHEMBL3912684 & 1642417 & 7.4461 & 7.8557 & TST \\
\hline CHEMBL3956210 & 1642417 & 7.9066 & 7.4661 & TST \\
\hline CHEMBL3914146 & 1642417 & 8.4559 & 8.0452 & TRN \\
\hline CHEMBL3936150 & 1642417 & 8.8539 & 8.5753 & TRN \\
\hline CHEMBL3903667 & 1642417 & 9.3979 & 8.9739 & TRN \\
\hline CHEMBL3975226 & 1642417 & 9.699 & 8.9784 & TST \\
\hline CHEMBL3900847 & 1642417 & 8.6576 & 8.3719 & TRN \\
\hline CHEMBL3958841 & 1642417 & 8.6778 & 7.9805 & TRN \\
\hline CHEMBL3908995 & 1642417 & 6.0 & 6.4087 & TRN \\
\hline CHEMBL3918526 & 1642417 & 9.0 & 9.0043 & TST \\
\hline CHEMBL3931194 & 1642417 & 8.8539 & 7.9049 & TST \\
\hline CHEMBL3908541 & 1642417 & 8.1135 & 8.4167 & TRN \\
\hline CHEMBL3927237 & 1642417 & 8.3188 & 8.6009 & TRN \\
\hline CHEMBL3901508 & 1642417 & 8.9208 & 9.4247 & TRN \\
\hline CHEMBL3919815 & 1642417 & 9.0458 & 9.3524 & TRN \\
\hline CHEMBL3950991 & 1642417 & 7.3002 & 7.3835 & TRN \\
\hline CHEMBL3940117 & 1642417 & 6.529 & 6.7791 & TRN \\
\hline CHEMBL3960639 & 1642417 & 9.0458 & 8.8065 & TRN \\
\hline CHEMBL3968369 & 1642417 & 7.7721 & 7.9174 & TRN \\
\hline CHEMBL3985354 & 1642417 & 7.1278 & 7.2901 & TRN \\
\hline CHEMBL3960362 & 1642417 & 5.8455 & 8.3621 & TST \\
\hline CHEMBL3947724 & 1642417 & 8.4437 & 8.5291 & TRN \\
\hline CHEMBL3899715 & 1642417 & 7.2636 & 9.31299 & 7999999999 \\
\hline CHEMBL3902832 & 1642417 & 7.6676 & 7.4925 & TRN \\
\hline CHEMBL3915210 & 1642417 & 7.9957 & 7.8643 & TST \\
\hline CHEMBL3955311 & 1642417 & 7.8447 & 7.9745 & TRN \\
\hline CHEMBL3939209 & 1642417 & 8.5686 & 8.7002 & TRN \\
\hline CHEMBL3935238 & 1642417 & 6.529 & 5.9985 & TRN \\
\hline CHEMBL3904003 & 1642417 & 8.3372 & 7.9811 & TRN \\
\hline CHEMBL3918412 & 1642417 & 7.5114 & 7.2512 & TRN \\
\hline CHEMBL3958431 & 1642417 & 8.2924 & 8.2837 & TRN \\
\hline CHEMBL3945588 & 1642417 & 5.6253 & 6.4036 & TST \\
\hline CHEMBL3912151 & 1642417 & 8.3565 & 8.3691 & TRN \\
\hline CHEMBL3918292 & 1642417 & 8.1135 & 7.3405 & TST \\
\hline CHEMBL3905624 & 1642417 & 6.0 & 6.2511 & TRN \\
\hline CHEMBL3974740 & 1642417 & 6.2825 & 9.0882 & TST \\
\hline CHEMBL3893555 & 1642417 & 6.0 & 6.2865 & TRN \\
\hline CHEMBL3929794 & 1642417 & 8.7959 & 8.657 & TRN \\
\hline CHEMBL3904872 & 1642417 & 8.3098 & 7.6737 & TRN \\
\hline CHEMBL3895886 & 1642417 & 8.6198 & 8.7518 & TRN \\
\hline CHEMBL3919850 & 1642417 & 6.6232 & 6.5879 & TRN \\
\hline CHEMBL3932905 & 1642417 & 7.5302 & 7.7753 & TRN \\
\hline CHEMBL3938990 & 1642417 & 9.0 & 8.6211 & TRN \\
\hline CHEMBL3946662 & 1642417 & 8.4437 & 8.5125 & TRN \\
\hline CHEMBL3900637 & 1642417 & 7.5901 & 7.6191 & TRN \\
\hline CHEMBL3925072 & 1642417 & 8.3565 & 8.8383 & TRN \\
\hline CHEMBL3955268 & 1642417 & 6.5098 & 7.7156 & TST \\
\hline CHEMBL3892560 & 1642417 & 8.2518 & 7.5732 & TRN \\
\hline
\end{tabular}


Supplemental Table S2.txt

\begin{tabular}{|c|c|c|c|c|}
\hline 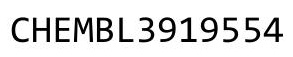 & & & & \\
\hline HEMBL3910611 & 642417 & 8.6021 & 8.2125 & \\
\hline & & 72 & 957 & \\
\hline 34374 & 417 & 6.0 & 8113 & \\
\hline JEMBL3925002 & 642417 & 8.5686 & 8741 & \\
\hline HEMBL3939787 & 642417 & 8.3098 & .4263 & \\
\hline HEMBL3953678 & 642417 & 215 & .3269 & \\
\hline 595 & 17 & 622 & & \\
\hline EMBL3960135 & 417 & 5615 & .4135 & \\
\hline AEMBL3921016 & 417 & 7.0264 & .8031 & \\
\hline HEMBL3924064 & 642417 & 9.301 & 2937 & \\
\hline HEMBL3914186 & 417 & 8.8539 & 7083 & \\
\hline AEMBL3S & & 576 & & \\
\hline HEMBL3903844 & & 5.5257 & 9081 & \\
\hline AEMBL3977618 & 17 & 6. & 9749 & \\
\hline AEMBL3971995 & 17 & 6 & 3525 & \\
\hline HEMBL39 & 17 & 7.6882 & 416 & \\
\hline HEMBL39 & & 6. & & \\
\hline HEMBL38 & & & 305 & \\
\hline AEMBL3927271 & 17 & & & \\
\hline $\mathrm{E} \in \mathrm{MBL} 3911027$ & L/ & 539 & 3409 & \\
\hline HEMBL39 & 17 & 6 & 804 & \\
\hline HEMBL39 & & 737 & 84 & $2 \mathrm{~N}$ \\
\hline 780 & & 7. & 5466 & $3 \mu$ \\
\hline AEMBL39 & 17 & 6 & 67 & RIV \\
\hline AEMBL3S & .1 & 97 & 38 & RN \\
\hline HEMBL38 & 7 & 39 & 941 & RN \\
\hline 13 & & & 45 & RN \\
\hline HEMBL 394 & 17 & 3565 & & RIN \\
\hline HEMBL 391 & 17 & 6 & 09 & RN \\
\hline IEMBL38 & & & .724 & ST \\
\hline AEMBL 35 & & 7. & 744 & RN \\
\hline 52 & & 8 & 358 & RN \\
\hline HEMBL3924590 & & & & SI \\
\hline AEMBL3971608 & 64 & 7.0773 & 313 & ST \\
\hline HEMBL3909541 & 17 & 8. & 43 & RN \\
\hline 2 & & & 95 & RN \\
\hline HEMBL3960690 & 17 & & 459 & RN \\
\hline HEMBL3900664 & 17 & 7.9281 & 3469 & RN \\
\hline AEMBL3S & 17 & 7. & 206 & RN \\
\hline HEMBL3979004 & 6 & 7.8447 & 7.8643 & 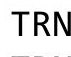 \\
\hline HEMBL 3922853 & & & & RN \\
\hline HEMBL3908667 & & 7.9957 & 8.2341 & RN \\
\hline HEMBL3960884 & 17 & 8.699 & 2799 & RN \\
\hline EMBL3S & & 066 & 1486 & N \\
\hline HEMBL 3903151 & & 8.1739 & .2367 & \\
\hline CHEMBL3918569 & 164 & 6.0 & .0571 & \\
\hline CHEMBL3900861 & 1642417 & 9.0458 & 9.2766 & \\
\hline
\end{tabular}

Page 7188 
Supplemental Table S2.txt

\begin{tabular}{|c|c|c|c|c|c|c|}
\hline CHEMBL3953805 & 1642417 & 8.6576 & 8.0889 & TRN & & \\
\hline CHEMBL3946932 & 1642417 & 8.8539 & 8.8547 & TRN & & \\
\hline CHEMBL3895239 & 1642417 & 7.7696 & 7.6507 & TRN & & \\
\hline CHEMBL3949981 & 1642417 & 8.3665 & 8.1801 & TRN & & \\
\hline CHEMBL3977707 & 1642417 & 8.9586 & 8.5156 & TRN & & \\
\hline CHEMBL3909852 & 1642417 & 6.0 & 6.6307 & TRN & & \\
\hline CHEMBL3939738 & 1642417 & 7.5544 & 7.4201 & TRN & & \\
\hline CHEMBL3917049 & 1642417 & 8.1612 & 8.0173 & TRN & & \\
\hline CHEMBL3983166 & 1642417 & 7.9431 & 7.6213 & TRN & & \\
\hline CHEMBL3919814 & 1642417 & 7.4989 & 7.7453 & TRN & & \\
\hline CHEMBL3926524 & 1642417 & 8.8239 & 8.4951 & TRN & & \\
\hline CHEMBL3948537 & 1642417 & 6.0 & 6.067 & TRN & & \\
\hline CHEMBL3899407 & 1642417 & 6.6704 & 7.9994 & TST & & \\
\hline CHEMBL3945506 & 1642417 & 8.1549 & 7.4927 & TRN & & \\
\hline CHEMBL3905302 & 1642417 & 8.8539 & 8.6313 & TRN & & \\
\hline CHEMBL3895354 & 1642417 & 8.5528 & 8.2282 & TRN & & \\
\hline CHEMBL3932953 & 1642417 & 6.4448 & 6.2509 & TST & & \\
\hline CHEMBL3955119 & 1642417 & 9.0458 & 9.2107 & TRN & & \\
\hline CHEMBL3912071 & 1642417 & 8.5086 & 8.9911 & TRN & & \\
\hline CHEMBL3926846 & 1642417 & 7.2175 & 7.3389 & TRN & & \\
\hline CHEMBL3941142 & 1642417 & 7.426 & 8.5641 & TRN & & \\
\hline CHEMBL3900792 & 1642417 & 6.4217 & 6.9611 & TRN & & \\
\hline CHEMBL3965641 & 1642417 & 7.7986 & 8.2483 & TST & & \\
\hline CHEMBL3955400 & 1642417 & 7.4191 & 7.3356 & TRN & & \\
\hline CHEMBL3979600 & 1642417 & \multicolumn{3}{|c|}{7.4510000000000005} & 7.7275 & TRN \\
\hline CHEMBL3974109 & 1642417 & 8.699 & 8.6984 & TRN & & \\
\hline CHEMBL3950745 & 1642417 & 7.2161 & 7.2991 & TRN & & \\
\hline CHEMBL3894865 & 1642417 & 8.8861 & 8.6967 & TRN & & \\
\hline CHEMBL3967293 & 1642417 & 9.0969 & 7.2269 & TST & & \\
\hline CHEMBL 3927266 & 1642417 & 8.2596 & 7.3375 & TRN & & \\
\hline CHEMBL3923910 & 1642417 & 6.0 & 7.225 & TRN & & \\
\hline CHEMBL3912641 & 1642417 & 8.9208 & 8.8181 & TRN & & \\
\hline CHEMBL3946727 & 1642417 & 7.9469 & 8.27 & TRN & & \\
\hline CHEMBL3910248 & 1642417 & 7.9626 & 8.0974 & TRN & & \\
\hline CHEMBL 3927247 & 1642417 & 8.4437 & 8.529 & TRN & & \\
\hline CHEMBL3911618 & 1642417 & 8.3188 & 7.6866 & TRN & & \\
\hline CHEMBL3893119 & 1642417 & 8.1135 & 8.0285 & TRN & & \\
\hline CHEMBL3912121 & 1642417 & 7.6234 & 7.5045 & TRN & & \\
\hline CHEMBL3919936 & 1642417 & 7.7235 & 7.7777 & TRN & & \\
\hline CHEMBL3926095 & 1642417 & 7.4179 & 7.7175 & TRN & & \\
\hline CHEMBL3944214 & 1642417 & 8.2076 & 8.2293 & TRN & & \\
\hline CHEMBL3946449 & 1642417 & 7.3862 & 6.6691 & TRN & & \\
\hline CHEMBL3894818 & 1642417 & 6.0 & 6.5314 & TRN & & \\
\hline CHEMBL3893342 & 1642417 & 6.0 & 6.6827 & TRN & & \\
\hline CHEMBL3895372 & 1642417 & 7.0343 & 7.5392 & TRN & & \\
\hline CHEMBL3927727 & 1642417 & 7.0665 & 8.7169 & TST & & \\
\hline CHEMBL3899215 & 1642417 & 9.1549 & 8.7286 & TRN & & \\
\hline CHEMBL3919845 & 1642417 & 6.49 & 6.4627 & TRN & & \\
\hline
\end{tabular}


Supplemental Table S2.txt

\begin{tabular}{|c|c|c|c|c|}
\hline CHEMBL3932914 & 1642417 & 6.0 & 5.0059 & TST \\
\hline CHEMBL 3936493 & 1642417 & 8.0605 & 7.7893 & TRN \\
\hline CHEMBL3909321 & 1642417 & 8.1249 & 7.99 & TRN \\
\hline CHEMBL3920026 & 1642417 & 6.0 & 6.5461 & TRN \\
\hline CHEMBL3907384 & 1642417 & 6.1905 & 7.06 & TST \\
\hline CHEMBL3981605 & 1642417 & 7.8729 & 7.1942 & TST \\
\hline CHEMBL3959457 & 1642417 & 5.9536 & 6.0526 & TRN \\
\hline CHEMBL3913699 & 1642417 & 9.3979 & 9.1841 & TRN \\
\hline CHEMBL3925365 & 1642417 & 6.0 & 6.8587 & TRN \\
\hline CHEMBL3932004 & 1642417 & 6.7587 & 8.0734 & TST \\
\hline CHEMBL3919696 & 1642417 & 8.1308 & 7.6733 & TRN \\
\hline CHEMBL3895348 & 1642417 & 6.0 & 6.4974 & TRN \\
\hline CHEMBL3979014 & 1642417 & 7.8013 & 8.1695 & TRN \\
\hline CHEMBL3927652 & 1642417 & 7.5017 & 7.5612 & TRN \\
\hline CHEMBL3889958 & 1642417 & 5.7523 & 5.7143 & TST \\
\hline CHEMBL3912277 & 1642417 & 7.2125 & 7.3872 & TRN \\
\hline CHEMBL3948357 & 1642417 & 8.8539 & 8.1038 & TRN \\
\hline CHEMBL3976930 & 1642417 & 7.7144 & 8.1524 & TRN \\
\hline CHEMBL3967938 & 1642417 & 7.5591 & 8.1572 & TRN \\
\hline CHEMBL3928552 & 1642417 & 8.3979 & 8.6218 & TRN \\
\hline CHEMBL 3942181 & 1642417 & 8.5376 & 7.46200 & 2000000001 \\
\hline CHEMBL3971752 & 1642417 & 6.3249 & 6.586 & TST \\
\hline CHEMBL3979296 & 1642417 & 8.8539 & 8.349 & TST \\
\hline CHEMBL 3890475 & 1642417 & 8.7959 & 8.5454 & TRN \\
\hline CHEMBL3950870 & 1642417 & 8.2518 & 8.2113 & TRN \\
\hline CHEMBL 3897246 & 1642417 & 7.6596 & 7.5262 & TST \\
\hline CHEMBL3959211 & 1642417 & 7.9172 & 7.591 & TRN \\
\hline CHEMBL3979686 & 1642417 & 6.9355 & 7.0629 & TRN \\
\hline CHEMBL3936207 & 1642417 & 8.6576 & 8.3931 & TRN \\
\hline CHEMBL3902799 & 1642417 & 8.9586 & 8.4128 & TRN \\
\hline CHEMBL 3979942 & 1642417 & 7.9431 & 8.1532 & TST \\
\hline CHEMBL3956149 & 1642417 & 7.9208 & 7.6074 & TRN \\
\hline CHEMBL 3903043 & 1642417 & 7.0721 & 6.6318 & TRN \\
\hline CHEMBL3982641 & 1642417 & 6.0 & 6.7414 & TRN \\
\hline CHEMBL3926868 & 1642417 & 6.0 & 6.5118 & TST \\
\hline CHEMBL3957579 & 1642417 & 9.2218 & 8.874 & TRN \\
\hline CHEMBL3961463 & 1642417 & 9.0 & 8.6278 & TST \\
\hline CHEMBL 3976460 & 1642417 & 7.0487 & 7.4117 & TRN \\
\hline CHEMBL 3898173 & 1642417 & 6.0 & 6.6683 & TST \\
\hline CHEMBL3900340 & 1642417 & 7.8697 & 8.3443 & TRN \\
\hline CHEMBL 3978844 & 1642417 & 9.0 & 8.3387 & TST \\
\hline CHEMBL3986472 & 1642417 & 8.6198 & 7.433 & TST \\
\hline CHEMBL3950408 & 1642417 & 8.9586 & 8.8771 & TRN \\
\hline CHEMBL3901175 & 1642417 & 6.9147 & 6.6575 & TRN \\
\hline CHEMBL3900886 & 1642417 & 7.0022 & 7.6182 & TRN \\
\hline CHEMBL 3932272 & 1642417 & 6.0 & 6.7932 & TST \\
\hline CHEMBL3918479 & 1642417 & 6.1906 & 5.8218 & TRN \\
\hline CHEMBL3950913 & 1642417 & 7.9281 & 7.6697 & TRN \\
\hline
\end{tabular}


Supplemental Table S2.txt

\begin{tabular}{|c|c|c|c|c|}
\hline CHEMBL 3940799 & 1642417 & 8.5686 & 8.4827 & TRN \\
\hline CHEMBL3904711 & 1642417 & 8.699 & 8.8113 & TRN \\
\hline CHEMBL3984826 & 1642417 & 6.4927 & 6.4715 & TST \\
\hline CHEMBL3913229 & 1642417 & 8.0915 & 8.0087 & TRN \\
\hline CHEMBL 3804850 & 1577525 & 5.3778 & 5.5769 & TRN \\
\hline CHEMBL 3806073 & 1577525 & 2.699 & 3.0941 & TRN \\
\hline CHEMBL 3804923 & 1577525 & 4.7055 & 4.1245 & TST \\
\hline CHEMBL 3806221 & 1577525 & 4.3507 & 3.7587 & TRN \\
\hline CHEMBL3805790 & 1577525 & 4.1858 & 3.9015 & TST \\
\hline CHEMBL3343652 & 1577525 & 4.9208 & 4.1521 & TST \\
\hline CHEMBL 3805728 & 1577525 & 4.5031 & 4.4828 & TRN \\
\hline CHEMBL 3804891 & 1577525 & 5.7905 & 4.6675 & TST \\
\hline CHEMBL 3805112 & 1577525 & 4.2832 & 5.4201 & TRN \\
\hline CHEMBL3804901 & 1577525 & 2.699 & 3.4012 & TRN \\
\hline CHEMBL 3805331 & 1577525 & 4.4776 & 4.2331 & TRN \\
\hline CHEMBL3805427 & 1577525 & 6.1726 & 5.3166 & TRN \\
\hline CHEMBL 3805072 & 1577525 & 5.857 & 5.3801 & TRN \\
\hline CHEMBL 3805267 & 1577525 & 5.0958 & 4.9527 & TRN \\
\hline CHEMBL3804896 & 1577525 & 4.52 & 4.4669 & TRN \\
\hline CHEMBL 3806268 & 1577525 & 6.0114 & 5.9223 & TRN \\
\hline CHEMBL 3805063 & 1577525 & 5.9101 & 5.5867 & TRN \\
\hline CHEMBL3805694 & 1577525 & 4.7258 & 4.6492 & TRN \\
\hline CHEMBL3805950 & 1577525 & 6.6253 & 5.7133 & TRN \\
\hline CHEMBL 3805001 & 1577525 & 4.8069 & 3.7106 & TRN \\
\hline CHEMBL 3805831 & 1577525 & 5.5214 & 5.34399 & 9999999999 \\
\hline CHEMBL 3805641 & 1577525 & 4.8327 & 5.1135 & TRN \\
\hline CHEMBL 3805035 & 1577525 & 5.2472 & 5.7334 & TRN \\
\hline CHEMBL 3804834 & 1577525 & 6.4353 & 5.76 & TRN \\
\hline CHEMBL3805586 & 1577525 & 3.9393 & 4.665 & TRN \\
\hline CHEMBL3806063 & 1577525 & 4.7282 & 4.7449 & TRN \\
\hline CHEMBL 3806001 & 1577525 & 4.5171 & 4.5249 & TRN \\
\hline CHEMBL 3805244 & 1577525 & 4.3726 & 3.7463 & TST \\
\hline CHEMBL 3805547 & 1577525 & 5.4597 & 5.3903 & TST \\
\hline CHEMBL3805890 & 1577525 & 4.9469 & 5.0481 & TST \\
\hline CHEMBL 3805464 & 1577525 & 5.1349 & 5.2431 & TRN \\
\hline CHEMBL3805568 & 1577525 & 3.8477 & 3.7926 & TRN \\
\hline CHEMBL3805929 & 1577525 & 6.3161 & 6.0679 & TRN \\
\hline CHEMBL 3805478 & 1577525 & 5.1463 & 4.7964 & TST \\
\hline CHEMBL3806257 & 1577525 & 5.6091 & 5.3958 & TRN \\
\hline CHEMBL 3805479 & 1577525 & 3.9747 & 4.7068 & TRN \\
\hline CHEMBL 3805847 & 1577525 & 5.8097 & 5.8444 & TRN \\
\hline CHEMBL 3806211 & 1577525 & 4.3143 & 4.6667 & TST \\
\hline CHEMBL3805709 & 1577525 & 4.6615 & 4.2339 & TST \\
\hline CHEMBL3805574 & 1577525 & 5.5498 & 5.1434 & TRN \\
\hline CHEMBL 3805070 & 1577525 & 4.9788 & 5.1091 & TRN \\
\hline CHEMBL 3805022 & 1577525 & 4.6925 & 4.2939 & TRN \\
\hline CHEMBL 3805224 & 1577525 & 4.8697 & 5.2925 & TRN \\
\hline CHEMBL 3805130 & 1577525 & 5.0031 & 4.9377 & TRN \\
\hline
\end{tabular}

Page 7191 
Supplemental Table S2.txt

\begin{tabular}{|c|c|c|c|c|c|}
\hline CHEMBL 3805107 & 1577525 & 5.5186 & 5.0658 & TRN & \\
\hline CHEMBL 3805503 & 1577525 & 4.0414 & 4.1956 & TRN & \\
\hline CHEMBL 3805740 & 1577525 & 5.6517 & 5.8837 & TRN & \\
\hline CHEMBL 3805492 & 1577525 & 5.6517 & 5.5192 & TRN & \\
\hline CHEMBL3804932 & 1577525 & 4.8097 & 4.3875 & TRN & \\
\hline CHEMBL3805277 & 1577525 & 5.0921 & 4.5346 & TRN & \\
\hline CHEMBL3805923 & 1577525 & 2.699 & 3.6987 & TRN & \\
\hline CHEMBL 3805306 & 1577525 & 4.1457 & 4.8821 & TRN & \\
\hline CHEMBL 3805630 & 1577525 & 5.4547 & 5.606 & TRN & \\
\hline CHEMBL3805304 & 1577525 & 5.7258 & 5.1128 & TRN & \\
\hline CHEMBL3806238 & 1577525 & 4.6778 & 4.9449 & TRN & \\
\hline CHEMBL3806092 & 1577525 & 5.0685 & 4.9715 & TRN & \\
\hline CHEMBL 3805825 & 1577525 & 4.9469 & 5.499 & TRN & \\
\hline CHEMBL 3805578 & 1577525 & 3.8386 & 4.061 & TRN & \\
\hline CHEMBL 3805724 & 1577525 & 5.2027 & 4.96899 & 9999999999 & TRN \\
\hline CHEMBL3806033 & 1577525 & 4.8153 & 4.8953 & TRN & \\
\hline CHEMBL 3805426 & 1577525 & 5.0985 & 5.5388 & TRN & \\
\hline CHEMBL 3804908 & 1577525 & 4.8729 & 5.2981 & TRN & \\
\hline CHEMBL 3804871 & 1577525 & 4.9031 & 4.1087 & TRN & \\
\hline CHEMBL 3806274 & 1577525 & 2.699 & 3.0369 & TST & \\
\hline CHEMBL 3805835 & 1577525 & 5.5935 & 5.7057 & TRN & \\
\hline CHEMBL 3806225 & 1577525 & 5.0223 & 4.6124 & TRN & \\
\hline CHEMBL3805639 & 1577525 & 4.8268 & 5.2744 & TRN & \\
\hline CHEMBL 3805778 & 1577525 & 5.7423 & 5.004 & TRN & \\
\hline CHEMBL 3805538 & 1577525 & 5.6819 & 6.0972 & TRN & \\
\hline CHEMBL 3805381 & 1577525 & 3.7167 & 4.6759 & TRN & \\
\hline CHEMBL 3805632 & 1577525 & 5.1993 & 5.5129 & TST & \\
\hline CHEMBL3805934 & 1577525 & 5.644 & 5.8463 & TST & \\
\hline CHEMBL 3805997 & 1577525 & 3.7167 & 3.7073 & TST & \\
\hline CHEMBL3805448 & 1577525 & 4.9393 & 5.0042 & TST & \\
\hline CHEMBL 3806002 & 1577525 & 4.2941 & 3.5844 & TST & \\
\hline CHEMBL 3804859 & 1577525 & 5.1013 & 4.9294 & TST & \\
\hline CHEMBL3805687 & 1577525 & 4.618 & 4.6406 & TST & \\
\hline CHEMBL 3805650 & 1577525 & 4.9957 & 5.0865 & TST & \\
\hline CHEMBL3805692 & 1577525 & 5.1831 & 5.9695 & TST & \\
\hline CHEMBL1682983 & 728290 & 4.7696 & 4.8077 & TRN & \\
\hline CHEMBL1683142 & 728290 & 4.3188 & 4.2909 & TRN & \\
\hline CHEMBL1683087 & 728290 & 3.0 & 3.0047 & TRN & \\
\hline CHEMBL1683102 & 728290 & 3.0 & 2.9543 & TRN & \\
\hline CHEMBL1683090 & 728290 & 4.4559 & 4.488 & TRN & \\
\hline CHEMBL1683141 & 728290 & 4.3768 & 4.3849 & TRN & \\
\hline CHEMBL1683144 & 728290 & 4.0706 & 4.1309 & TST & \\
\hline CHEMBL1683138 & 728290 & 4.6576 & 4.6982 & TRN & \\
\hline CHEMBL1683100 & 728290 & 3.0 & 2.9375 & TRN & \\
\hline CHEMBL1683137 & 728290 & 4.9586 & 4.9901 & TRN & \\
\hline CHEMBL1683092 & 728290 & 4.5376 & 4.5007 & TRN & \\
\hline CHEMBL1682982 & 728290 & 4.8239 & 4.7776 & TRN & \\
\hline CHEMBL1683134 & 728290 & 4.4089 & 4.3206 & TRN & \\
\hline
\end{tabular}




\begin{tabular}{|c|c|c|c|c|}
\hline & & & oplement & al Ta \\
\hline CHEMBL1683135 & 728290 & 4.5528 & 4.5764 & TRN \\
\hline CHEMBL1683093 & 728290 & 5.0 & 5.0459 & TRN \\
\hline CHEMBL1683105 & 728290 & 4.7447 & 4.74 & TRN \\
\hline CHEMBL1683123 & 728290 & 3.0 & 4.3206 & TST \\
\hline CHEMBL1683125 & 728290 & 4.9208 & 4.9497 & TRN \\
\hline CHEMBL1683106 & 728290 & 4.2366 & 4.2312 & TRN \\
\hline CHEMBL1683109 & 728290 & 4.6778 & 4.6808 & TRN \\
\hline CHEMBL1683136 & 728290 & 4.284 & 4.2899 & TRN \\
\hline CHEMBL1682978 & 728290 & 4.6383 & 4.6661 & TRN \\
\hline CHEMBL1683094 & 728290 & 4.3979 & 4.4357 & TRN \\
\hline CHEMBL1683127 & 728290 & 4.5686 & 4.5477 & TRN \\
\hline CHEMBL1683096 & 728290 & 4.9586 & 4.9434 & TRN \\
\hline CHEMBL1683130 & 728290 & 4.1871 & 4.1843 & TRN \\
\hline CHEMBL1682977 & 728290 & 5.0177 & 4.9873 & TRN \\
\hline CHEMBL1683104 & 728290 & 4.2366 & 4.2233 & TRN \\
\hline CHEMBL1683111 & 728290 & 4.7696 & 4.6728 & TRN \\
\hline CHEMBL1683139 & 728290 & 4.5229 & 3.7225 & TST \\
\hline CHEMBL1682985 & 728290 & 5.0706 & 5.0705 & TRN \\
\hline CHEMBL1683124 & 728290 & 5.3188 & 4.329 & TST \\
\hline CHEMBL1683116 & 728290 & 6.0 & 4.1496 & TST \\
\hline CHEMBL1682984 & 728290 & 4.8861 & 4.8738 & TRN \\
\hline CHEMBL25211 & 728290 & 5.9281 & 5.5938 & TST \\
\hline CHEMBL1683091 & 728290 & 4.2007 & 4.1889 & TRN \\
\hline CHEMBL1683107 & 728290 & 5.4437 & 4.9528 & TST \\
\hline CHEMBL1683133 & 728290 & 4.4685 & 4.5048 & TST \\
\hline CHEMBL1683140 & 728290 & 4.4559 & 4.2943 & TST \\
\hline CHEMBL1683145 & 728290 & 4.6383 & 4.3347 & TST \\
\hline CHEMBL1683088 & 728290 & 4.3665 & 4.3927 & TRN \\
\hline CHEMBL1683097 & 728290 & 4.0655 & 4.117 & TRN \\
\hline CHEMBL1683095 & 728290 & 4.1675 & 4.1155 & TRN \\
\hline CHEMBL1682974 & 728290 & 6.1612 & 5.7479 & TST \\
\hline CHEMBL1683143 & 728290 & 4.8861 & 4.4072 & TST \\
\hline CHEMBL1683132 & 728290 & 4.4318 & 4.4478 & TST \\
\hline CHEMBL1682979 & 728290 & 4.7212 & 4.7335 & TRN \\
\hline CHEMBL1683101 & 728290 & 4.0915 & 4.133 & TRN \\
\hline CHEMBL1683103 & 728290 & 3.0 & 3.0577 & TRN \\
\hline CHEMBL1682975 & 728290 & 4.699 & 4.6272 & TRN \\
\hline CHEMBL1682981 & 728290 & 4.699 & 4.7327 & TRN \\
\hline CHEMBL1683126 & 728290 & 4.8539 & 4.9153 & TRN \\
\hline CHEMBL1683129 & 728290 & 4.1805 & 4.1574 & TRN \\
\hline CHEMBL1683108 & 728290 & 4.4949 & 4.4915 & TRN \\
\hline CHEMBL1682976 & 728290 & 4.699 & 4.7117 & TRN \\
\hline CHEMBL1682980 & 728290 & 4.5376 & 4.4947 & TRN \\
\hline CHEMBL1683122 & 728290 & 4.1427 & 4.5389 & TST \\
\hline CHEMBL1683131 & 728290 & 4.7212 & 4.1941 & TST \\
\hline CHEMBL1683128 & 728290 & 4.6383 & 4.6868 & TRN \\
\hline CHEMBL1683110 & 728290 & 3.0 & 3.1333 & TRN \\
\hline CHEMBL1683112 & 728290 & 4.2924 & 4.2128 & TRN \\
\hline
\end{tabular}




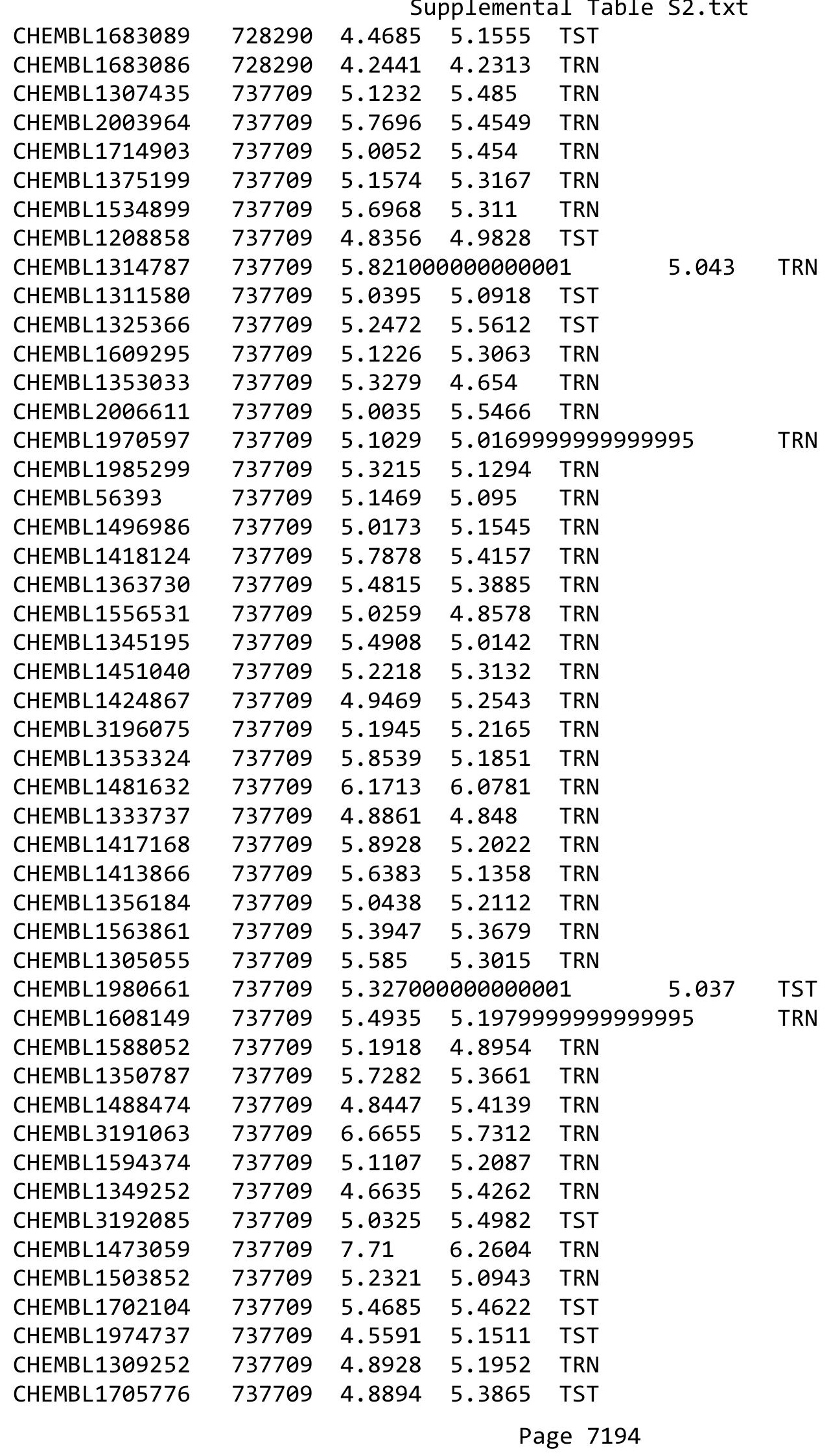




\begin{tabular}{|c|c|c|c|c|c|}
\hline \multicolumn{6}{|c|}{ supplemental } \\
\hline CHEMBL1503175 & 737709 & 5.0214 & 5.2564 & TRN & \\
\hline CHEMBL81782 & 737709 & 5.8097 & 5.1584 & TST & \\
\hline CHEMBL1733511 & 737709 & 5.585 & 5.54799 & 9999999999 & TST \\
\hline CHEMBL1471932 & 737709 & 3.0 & 5.0621 & TRN & \\
\hline CHEMBL1446839 & 737709 & 5.1007 & 5.37 & TRN & \\
\hline CHEMBL1698793 & 737709 & 5.2336 & 5.3727 & TRN & \\
\hline CHEMBL1532097 & 737709 & 5.1421 & 5.2927 & TRN & \\
\hline CHEMBL1340338 & 737709 & 6.6861 & 5.7035 & TST & \\
\hline CHEMBL1398188 & 737709 & 5.1073 & 5.0497 & TRN & \\
\hline CHEMBL1508055 & 737709 & 5.6289 & 5.4962 & TRN & \\
\hline CHEMBL179512 & 737709 & 5.0768 & 4.8043 & TRN & \\
\hline CHEMBL1472524 & 737709 & 5.2204 & 5.0204 & TST & \\
\hline CHEMBL1505816 & 737709 & 4.8297 & 5.0612 & TRN & \\
\hline CHEMBL1574218 & 737709 & 5.15 & 5.1672 & TST & \\
\hline CHEMBL1727453 & 737709 & 4.857 & 5.3764 & TRN & \\
\hline CHEMBL1375627 & 737709 & 5.1844 & 5.1645 & TRN & \\
\hline CHEMBL1417524 & 737709 & 4.9136 & 4.9522 & TRN & \\
\hline CHEMBL1313502 & 737709 & 5.4763 & 5.6257 & TRN & \\
\hline CHEMBL1602709 & 737709 & 5.1524 & 5.3209 & TRN & \\
\hline CHEMBL210208 & 737709 & 4.9066 & 5.1824 & TRN & \\
\hline CHEMBL1322977 & 737709 & 5.2832 & 5.5253 & TRN & \\
\hline CHEMBL1536250 & 737709 & 5.0783 & 5.5974 & TRN & \\
\hline CHEMBL116438 & 737709 & 4.9208 & 4.8371 & TRN & \\
\hline CHEMBL1421399 & 737709 & 4.9586 & 5.2748 & TRN & \\
\hline CHEMBL3194421 & 737709 & 5.5467 & 5.4562 & TRN & \\
\hline CHEMBL1397359 & 737709 & 5.056 & 5.8658 & TRN & \\
\hline CHEMBL1574857 & 737709 & 5.8539 & 5.2009 & TRN & \\
\hline CHEMBL1712676 & 737709 & 5.5768 & 5.5832 & TRN & \\
\hline CHEMBL1342091 & 737709 & 5.4225 & 5.3694 & TRN & \\
\hline CHEMBL1498044 & 737709 & 4.9666 & 5.1398 & TRN & \\
\hline CHEMBL1566994 & 737709 & 4.7352 & 5.3708 & TRN & \\
\hline CHEMBL1441918 & 737709 & 4.8894 & 5.0364 & TRN & \\
\hline CHEMBL140 & 737709 & 4.7282 & 4.9863 & TRN & \\
\hline CHEMBL1981446 & 737709 & 5.5686 & 5.1663 & TRN & \\
\hline CHEMBL1497487 & 737709 & 4.8601 & 5.3856 & TRN & \\
\hline CHEMBL1371869 & 737709 & 5.1965 & 4.9966 & TRN & \\
\hline CHEMBL164 & 737709 & 4.9031 & 5.6559 & TST & \\
\hline CHEMBL1401747 & 737709 & 4.8697 & 4.9594 & TRN & \\
\hline CHEMBL1490685 & 737709 & 4.7258 & 5.13399 & 99999999995 & TRN \\
\hline CHEMBL1315784 & 737709 & 4.8928 & 5.4668 & TRN & \\
\hline CHEMBL1600440 & 737709 & 5.5272 & 5.2767 & TRN & \\
\hline CHEMBL1525897 & 737709 & 5.1898 & 4.8738 & TRN & \\
\hline CHEMBL1330039 & 737709 & 5.2472 & 5.5796 & TRN & \\
\hline CHEMBL1390605 & 737709 & 4.3726 & 5.0344 & TST & \\
\hline CHEMBL1989158 & 737709 & 5.7799 & 5.181 & TST & \\
\hline CHEMBL1500102 & 737709 & 5.6635 & 5.5551 & TRN & \\
\hline CHEMBL1406077 & 737709 & 5.0625 & 5.2532 & TRN & \\
\hline CHEMBL1333659 & 737709 & 5.983 & 5.7671 & TRN & \\
\hline
\end{tabular}




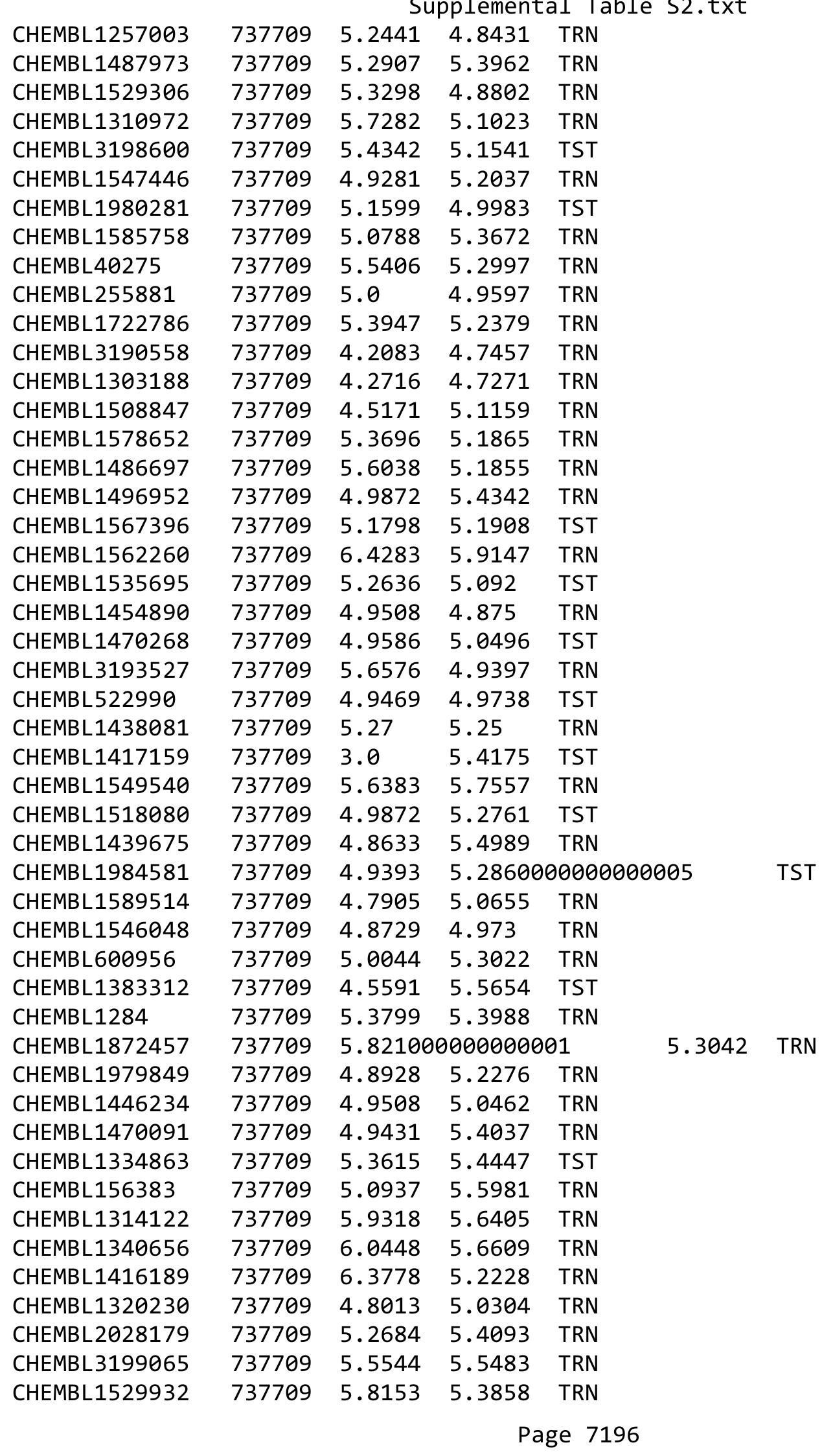




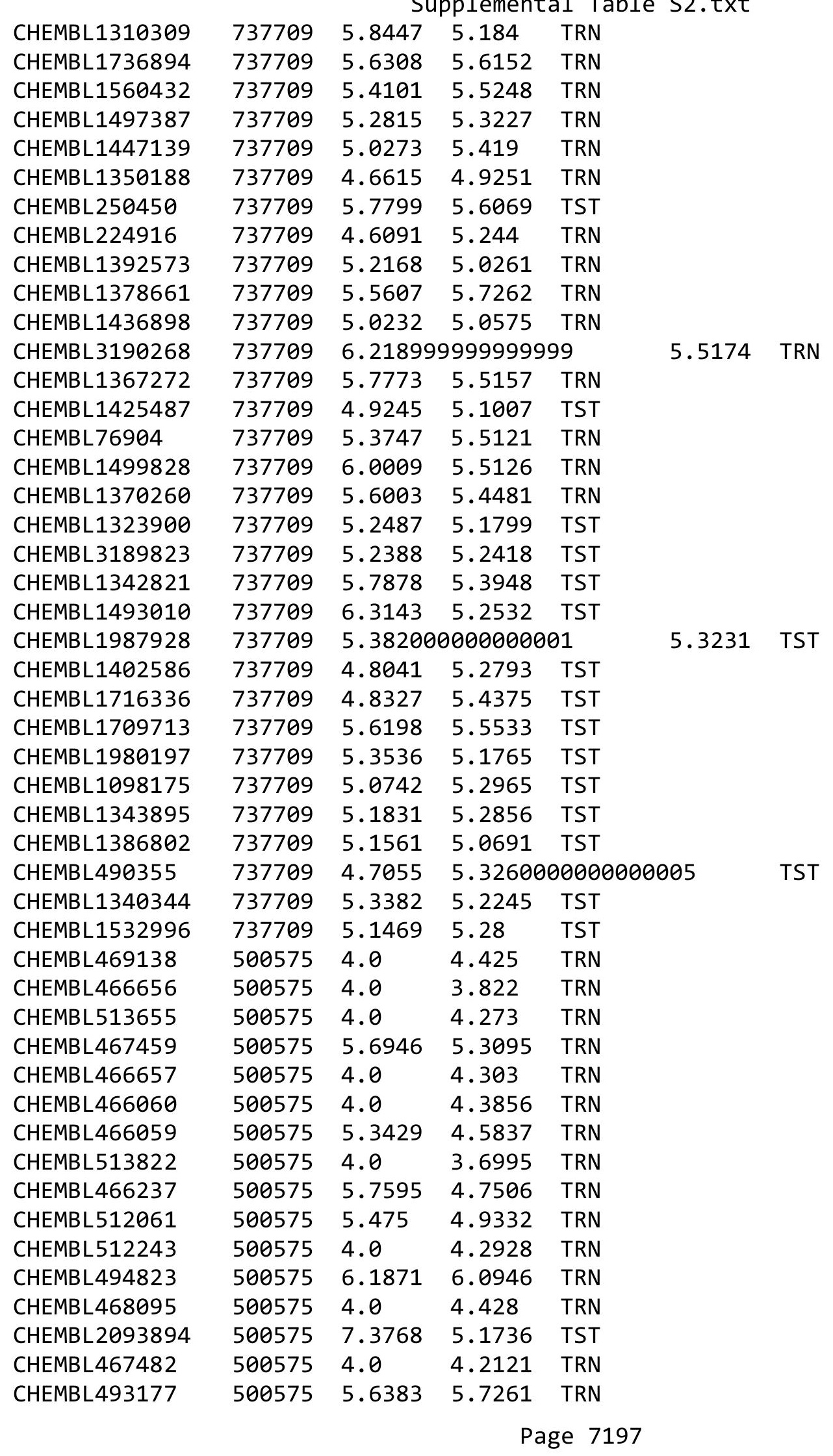




\begin{tabular}{|c|c|c|c|c|c|}
\hline & & \multicolumn{4}{|c|}{ Supplemental Table S2.txt } \\
\hline CHEMBL512237 & 500575 & 5.8894 & 5.6263 & TRN & \\
\hline CHEMBL466024 & 500575 & 4.0 & 3.9684 & TRN & \\
\hline CHEMBL493179 & 500575 & 4.0 & 3.8455 & TRN & \\
\hline CHEMBL494167 & 500575 & 4.0 & 4.4056 & TRN & \\
\hline CHEMBL466045 & 500575 & 4.0 & 5.4099 & TST & \\
\hline CHEMBL468096 & 500575 & 4.0 & 4.0881 & TRN & \\
\hline CHEMBL512275 & 500575 & 5.0301 & 4.2556 & TRN & \\
\hline CHEMBL492383 & 500575 & 4.0 & 4.0111 & TRN & \\
\hline CHEMBL513823 & 500575 & 4.0 & 4.6164 & TRN & \\
\hline CHEMBL511433 & 500575 & 4.0 & 4.1143 & TRN & \\
\hline CHEMBL466249 & 500575 & 5.1831 & 4.5271 & TRN & \\
\hline CHEMBL513645 & 500575 & 4.0 & 4.0704 & TRN & \\
\hline CHEMBL466208 & 500575 & 4.0 & 5.0956 & TRN & \\
\hline CHEMBL499159 & 500575 & 6.0223 & 5.9083 & TRN & \\
\hline CHEMBL468739 & 500575 & 6.1675 & 5.6313 & TRN & \\
\hline CHEMBL466445 & 500575 & 4.0 & 4.1857 & TRN & \\
\hline CHEMBL511729 & 500575 & 5.4437 & 4.8298 & TRN & \\
\hline CHEMBL493178 & 500575 & 5.3788 & 5.79899 & 99999999995 & TRN \\
\hline CHEMBL493989 & 500575 & 5.3665 & 5.9611 & TRN & \\
\hline CHEMBL440498 & 500575 & 6.4486 & 5.239 & TST & \\
\hline CHEMBL467460 & 500575 & 5.1959 & 4.8789 & TRN & \\
\hline CHEMBL512613 & 500575 & 4.0 & 4.622 & TRN & \\
\hline CHEMBL466461 & 500575 & 4.0 & 3.9336 & TRN & \\
\hline CHEMBL468737 & 500575 & 4.0 & 4.3398 & TRN & \\
\hline CHEMBL466625 & 500575 & 4.0 & 4.421 & TST & \\
\hline CHEMBL468708 & 500575 & 4.0 & 3.891 & TRN & \\
\hline CHEMBL466664 & 500575 & 4.0 & 4.9425 & TST & \\
\hline CHEMBL468738 & 500575 & 5.4908 & 5.42200 & $\partial 000000001$ & TRN \\
\hline CHEMBL492384 & 500575 & 4.0 & 4.0706 & TST & \\
\hline CHEMBL466663 & 500575 & 4.0 & 3.8889 & TST & \\
\hline CHEMBL494824 & 500575 & 4.8894 & 4.7283 & TST & \\
\hline CHEMBL467687 & 500575 & 4.0 & 4.3608 & TST & \\
\hline CHEMBL466460 & 500575 & 4.0 & 4.1979 & TST & \\
\hline CHEMBL467262 & 500575 & 4.0 & 4.3731 & TST & \\
\hline CHEMBL468731 & 500575 & 5.1518 & 4.4802 & TST & \\
\hline CHEMBL466052 & 500575 & 6.1135 & 5.8892 & TST & \\
\hline CHEMBL2004871 & 809236 & 4.1 & 4.3308 & TRN & \\
\hline CHEMBL2004872 & 809236 & 4.1 & 4.2583 & TRN & \\
\hline CHEMBL1727312 & 809236 & 3.2 & 3.6254 & TRN & \\
\hline CHEMBL1990223 & 809236 & 4.6 & 4.2063 & TRN & \\
\hline CHEMBL1969879 & 809236 & 4.1 & 4.394 & TRN & \\
\hline CHEMBL1964382 & 809236 & 6.1 & 5.5019 & TST & \\
\hline CHEMBL101311 & 809236 & 5.8 & 5.3001 & TRN & \\
\hline CHEMBL1981720 & 809236 & 5.5 & 4.9966 & TRN & \\
\hline CHEMBL419932 & 809236 & 4.1 & 4.0783 & TRN & \\
\hline CHEMBL 373798 & 809236 & 8.3 & 8.6868 & TRN & \\
\hline CHEMBL 2005699 & 809236 & 4.6 & 4.1969 & TRN & \\
\hline CHEMBL1976328 & 809236 & 6.4 & 6.4456 & TRN & \\
\hline
\end{tabular}




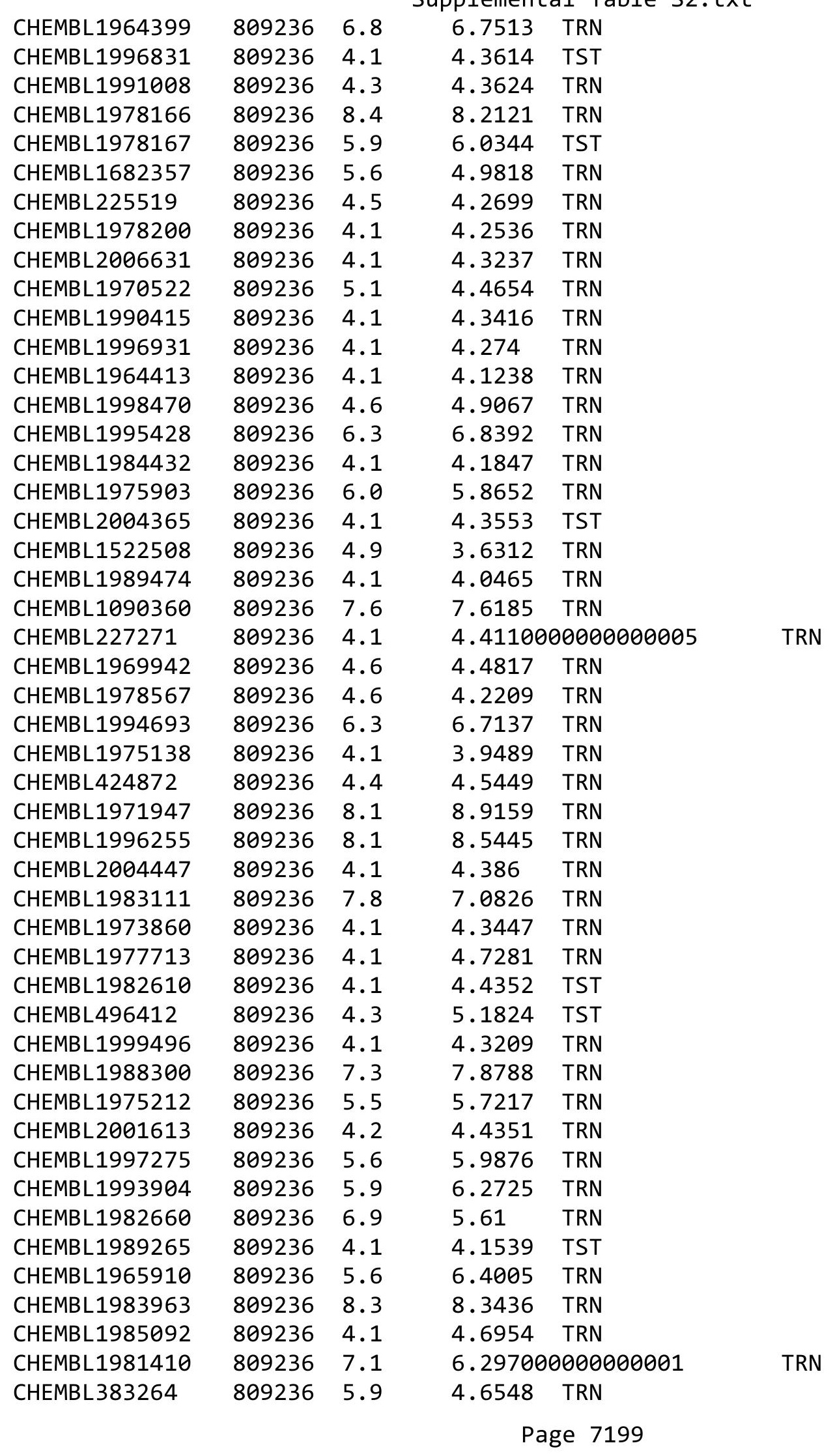




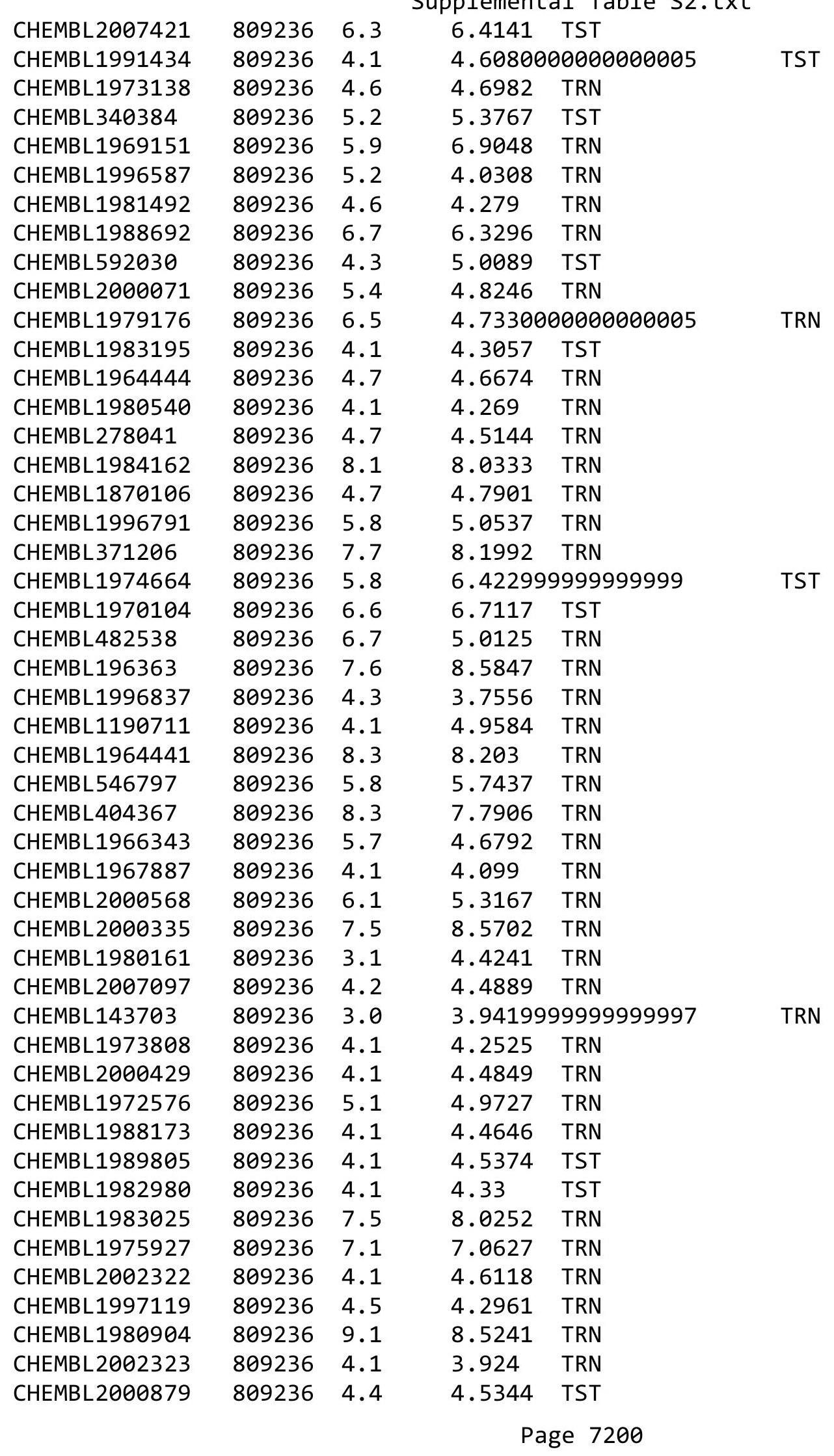




\begin{tabular}{|c|c|c|c|c|c|}
\hline \multicolumn{6}{|c|}{ Supplemental Table S2.txt } \\
\hline CHEMBL 2005548 & 809236 & 4.1 & 4.194 & TRN & \\
\hline CHEMBL271441 & 809236 & 8.7 & 8.5757 & TRN & \\
\hline CHEMBL1987793 & 809236 & 4.1 & 4.1784 & TST & \\
\hline CHEMBL21156 & 809236 & 5.8 & 5.4242 & TST & \\
\hline CHEMBL1992740 & 809236 & 4.1 & 4.1734 & TRN & \\
\hline CHEMBL1989267 & 809236 & 6.3 & 6.9694 & TRN & \\
\hline CHEMBL 2002373 & 809236 & 4.1 & 4.3572 & TRN & \\
\hline CHEMBL439340 & 809236 & 4.1 & 4.0656 & TRN & \\
\hline CHEMBL 2006188 & 809236 & 4.1 & 4.188 & TRN & \\
\hline CHEMBL1973893 & 809236 & 4.1 & 4.2808 & TRN & \\
\hline CHEMBL1995736 & 809236 & 4.1 & 4.5662 & TRN & \\
\hline CHEMBL1985095 & 809236 & 5.9 & 5.0016 & TST & \\
\hline CHEMBL1996500 & 809236 & 4.4 & 4.14199 & 99999999995 & TRN \\
\hline CHEMBL1682540 & 809236 & 4.1 & 4.2413 & TRN & \\
\hline CHEMBL1986979 & 809236 & 8.5 & 8.8974 & TRN & \\
\hline CHEMBL413779 & 809236 & 4.1 & 5.0733 & TST & \\
\hline CHEMBL497151 & 809236 & 4.1 & 4.9233 & TRN & \\
\hline CHEMBL 2000029 & 809236 & 4.6 & 4.5887 & TRN & \\
\hline CHEMBL1973961 & 809236 & 4.6 & 4.1905 & TRN & \\
\hline CHEMBL 2001099 & 809236 & 5.7 & 5.2288 & TRN & \\
\hline CHEMBL1994977 & 809236 & 4.6 & 4.4591 & TRN & \\
\hline CHEMBL373598 & 809236 & 4.1 & 4.9944 & TST & \\
\hline CHEMBL1999718 & 809236 & 4.1 & 4.5398 & TRN & \\
\hline CHEMBL 2000078 & 809236 & 7.2 & 6.8084 & TRN & \\
\hline CHEMBL1996646 & 809236 & 9.0 & 6.5378 & TRN & \\
\hline CHEMBL1979773 & 809236 & 4.6 & 5.1071 & TRN & \\
\hline CHEMBL1977346 & 809236 & 5.7 & 5.4862 & TRN & \\
\hline CHEMBL1996702 & 809236 & 6.3 & 4.8788 & TRN & \\
\hline CHEMBL1969190 & 809236 & 6.9 & 6.5048 & TRN & \\
\hline CHEMBL1973937 & 809236 & 7.7 & 7.5216 & TRN & \\
\hline CHEMBL 2002099 & 809236 & 4.6 & 5.1181 & TRN & \\
\hline CHEMBL1982711 & 809236 & 6.4 & 5.4037 & TRN & \\
\hline CHEMBL1987982 & 809236 & 4.1 & 4.5606 & TST & \\
\hline CHEMBL1969102 & 809236 & 8.5 & 8.6227 & TRN & \\
\hline CHEMBL 2004118 & 809236 & 7.0 & 6.2531 & TRN & \\
\hline CHEMBL1682346 & 809236 & 5.3 & 5.0707 & TRN & \\
\hline CHEMBL 2007044 & 809236 & 4.1 & 4.5009 & TST & \\
\hline CHEMBL 2001998 & 809236 & 5.7 & 5.5408 & TST & \\
\hline CHEMBL1994241 & 809236 & 5.7 & 5.5653 & TRN & \\
\hline CHEMBL50894 & 809236 & 4.8 & 5.9163 & TRN & \\
\hline CHEMBL1995211 & 809236 & 4.6 & 4.8346 & TRN & \\
\hline CHEMBL1988838 & 809236 & 7.0 & 7.4943 & TRN & \\
\hline CHEMBL1981725 & 809236 & 7.8 & 7.4614 & TRN & \\
\hline CHEMBL1982753 & 809236 & 4.6 & 5.1442 & TST & \\
\hline CHEMBL1965169 & 809236 & 5.9 & 5.5403 & TST & \\
\hline CHEMBL1081312 & 809236 & 8.3 & 6.7417 & TRN & \\
\hline CHEMBL1965170 & 809236 & 8.9 & 8.6282 & TRN & \\
\hline CHEMBL1393571 & 809236 & 3.0 & 3.9777 & TRN & \\
\hline
\end{tabular}




\begin{tabular}{|c|c|c|c|c|c|}
\hline & & & & & \\
\hline CHEMBL 2005792 & 809236 & 4.3 & 4.1801 & TRN & \\
\hline CHEMBL1984206 & 809236 & 4.1 & 4.7273 & TRN & \\
\hline CHEMBL462120 & 809236 & 4.1 & 4.8143 & TRN & \\
\hline CHEMBL1991577 & 809236 & 4.1 & 4.42899 & 9999999999 & TRN \\
\hline CHEMBL 2007592 & 809236 & 4.1 & 4.2739 & TRN & \\
\hline CHEMBL1997892 & 809236 & 6.5 & 6.1956 & TRN & \\
\hline CHEMBL 210963 & 809236 & 4.1 & 3.9343 & TRN & \\
\hline CHEMBL1984633 & 809236 & 4.1 & 4.3278 & TRN & \\
\hline CHEMBL1965845 & 809236 & 5.7 & 5.8948 & TRN & \\
\hline CHEMBL1983715 & 809236 & 7.6 & 7.0543 & TRN & \\
\hline CHEMBL1682545 & 809236 & 5.5 & 4.7996 & TRN & \\
\hline CHEMBL1992195 & 809236 & 5.9 & 5.1095 & TST & \\
\hline CHEMBL1976732 & 809236 & 4.1 & 3.9467 & TRN & \\
\hline CHEMBL1980163 & 809236 & 4.1 & 4.1472 & TRN & \\
\hline CHEMBL1989856 & 809236 & 4.1 & 4.898 & TST & \\
\hline CHEMBL1972568 & 809236 & 4.1 & 3.9197 & TRN & \\
\hline CHEMBL259850 & 809236 & 4.1 & 4.2254 & TRN & \\
\hline CHEMBL1986851 & 809236 & 9.0 & 8.5361 & TRN & \\
\hline CHEMBL105739 & 809236 & 7.0 & 7.322 & TRN & \\
\hline CHEMBL 203673 & 809236 & 4.1 & 3.9032 & TRN & \\
\hline CHEMBL1972583 & 809236 & 3.0 & 3.8064 & TRN & \\
\hline CHEMBL 2003785 & 809236 & 4.6 & 4.5549 & TST & \\
\hline CHEMBL1983070 & 809236 & 4.6 & 5.1626 & TRN & \\
\hline CHEMBL1981045 & 809236 & 4.1 & 4.2559 & TRN & \\
\hline CHEMBL 387971 & 809236 & 7.7 & 7.9639 & TST & \\
\hline CHEMBL1975418 & 809236 & 5.1 & 4.7375 & TRN & \\
\hline CHEMBL1992796 & 809236 & 4.1 & 4.599 & TRN & \\
\hline CHEMBL1968515 & 809236 & 3.0 & 4.0943 & TST & \\
\hline CHEMBL1164180 & 809236 & 6.6 & 6.0725 & TST & \\
\hline CHEMBL223257 & 809236 & 4.1 & 4.9332 & TST & \\
\hline CHEMBL1516890 & 809236 & 6.6 & 6.2514 & TRN & \\
\hline CHEMBL2001751 & 809236 & 6.4 & 6.3012 & TRN & \\
\hline CHEMBL1984586 & 809236 & 6.5 & 6.5451 & TRN & \\
\hline CHEMBL1999774 & 809236 & 4.1 & 4.5532 & TST & \\
\hline CHEMBL1972659 & 809236 & 4.1 & 4.659 & TST & \\
\hline CHEMBL1973395 & 809236 & 6.0 & 5.1433 & TRN & \\
\hline CHEMBL1984686 & 809236 & 4.6 & 4.5658 & TRN & \\
\hline CHEMBL1969843 & 809236 & 4.1 & 4.3493 & TRN & \\
\hline CHEMBL1990288 & 809236 & 4.1 & 4.3854 & TRN & \\
\hline CHEMBL1992935 & 809236 & 4.3 & 5.0414 & TRN & \\
\hline CHEMBL1981183 & 809236 & 6.2 & 5.0045 & TST & \\
\hline CHEMBL1992073 & 809236 & 6.0 & 6.102 & TRN & \\
\hline CHEMBL484390 & 809236 & 4.1 & 4.7134 & TST & \\
\hline CHEMBL 2007559 & 809236 & 4.6 & 5.0297 & TRN & \\
\hline CHEMBL 2000393 & 809236 & 5.9 & 5.9826 & TST & \\
\hline CHEMBL403402 & 809236 & 9.5 & 8.81299 & 9999999999 & TRN \\
\hline CHEMBL1993510 & 809236 & 8.5 & 6.2284 & TRN & \\
\hline CHEMBL 2004072 & 809236 & 4.1 & 5.3558 & TRN & \\
\hline & & & & 7202 & \\
\hline
\end{tabular}




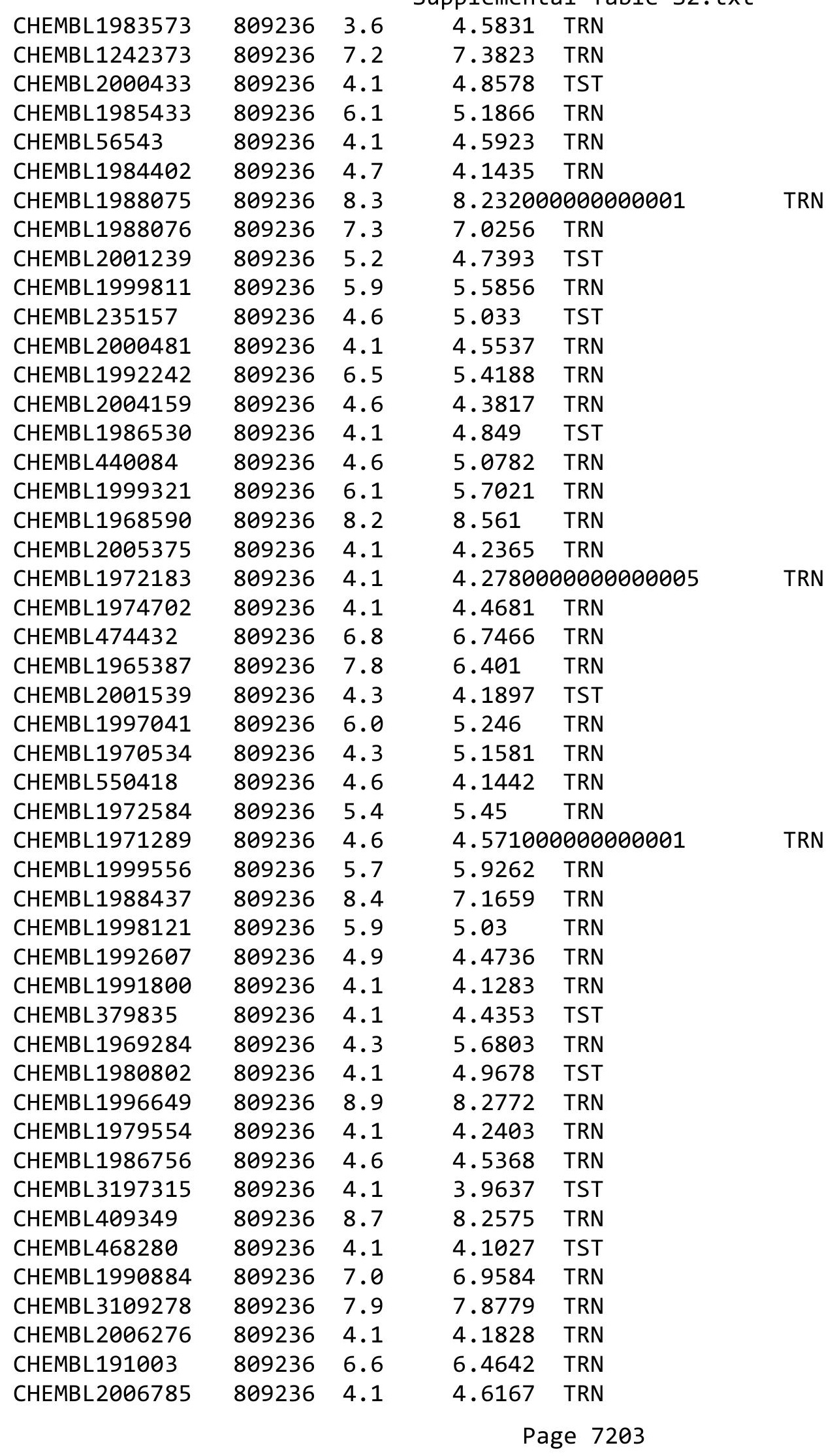




\begin{tabular}{|c|c|c|c|c|}
\hline & & & & \\
\hline CHEMBL1973359 & 809236 & 4.6 & 5.4691 & TST \\
\hline CHEMBL1995740 & 809236 & 4.1 & 4.3458 & TRN \\
\hline CHEMBL1985888 & 809236 & 9.2 & 9.0405 & TRN \\
\hline CHEMBL1986943 & 809236 & 6.6 & 7.1946 & TRN \\
\hline CHEMBL1979690 & 809236 & 7.9 & 7.7507 & TRN \\
\hline CHEMBL1995832 & 809236 & 4.1 & 4.3424 & TRN \\
\hline CHEMBL 2000345 & 809236 & 5.7 & 5.6826 & TRN \\
\hline CHEMBL1965303 & 809236 & 5.4 & 5.723 & TRN \\
\hline CHEMBL1988622 & 809236 & 3.0 & 4.3209 & TRN \\
\hline CHEMBL1983575 & 809236 & 6.7 & 6.3332 & TRN \\
\hline CHEMBL 2006873 & 809236 & 5.7 & 5.1144 & TRN \\
\hline CHEMBL1375418 & 809236 & 4.1 & 4.1299 & TRN \\
\hline CHEMBL 302449 & 809236 & 6.9 & 7.232 & TST \\
\hline CHEMBL1981047 & 809236 & 7.0 & 7.7397 & TRN \\
\hline CHEMBL229968 & 809236 & 4.1 & 4.6362 & TRN \\
\hline CHEMBL1976196 & 809236 & 4.6 & 4.9659 & TST \\
\hline CHEMBL1976240 & 809236 & 4.1 & 4.3163 & TRN \\
\hline CHEMBL1983630 & 809236 & 4.5 & 4.3182 & TRN \\
\hline CHEMBL1979093 & 809236 & 7.0 & 7.3539 & TRN \\
\hline CHEMBL336961 & 809236 & 4.1 & 4.8048 & TRN \\
\hline CHEMBL1970083 & 809236 & 7.9 & 8.2505 & TRN \\
\hline CHEMBL1994938 & 809236 & 7.9 & 8.5067 & TRN \\
\hline CHEMBL1977223 & 809236 & 4.1 & 4.1002 & TRN \\
\hline CHEMBL1976290 & 809236 & 3.0 & 4.1976 & TRN \\
\hline CHEMBL1236126 & 809236 & 4.1 & 4.4984 & TST \\
\hline CHEMBL1997846 & 809236 & 4.7 & 5.6745 & TRN \\
\hline CHEMBL2004419 & 809236 & 4.1 & 4.2777 & TRN \\
\hline CHEMBL1992937 & 809236 & 6.6 & 5.5019 & TST \\
\hline CHEMBL1985566 & 809236 & 4.1 & 4.2554 & TRN \\
\hline CHEMBL1972119 & 809236 & 4.1 & 4.0558 & TRN \\
\hline CHEMBL95692 & 809236 & 4.1 & 4.4492 & TRN \\
\hline CHEMBL1976455 & 809236 & 5.2 & 4.2075 & TRN \\
\hline CHEMBL1983923 & 809236 & 7.5 & 6.7798 & TRN \\
\hline CHEMBL1983534 & 809236 & 4.1 & 4.2536 & TRN \\
\hline CHEMBL1982361 & 809236 & 4.1 & 4.7687 & TRN \\
\hline CHEMBL2000801 & 809236 & 6.6 & 5.8831 & TRN \\
\hline CHEMBL1991395 & 809236 & 4.1 & 4.1214 & TRN \\
\hline CHEMBL1971245 & 809236 & 5.9 & 6.1362 & TRN \\
\hline CHEMBL1987648 & 809236 & 4.1 & 4.1022 & TRN \\
\hline CHEMBL1972142 & 809236 & 6.0 & 5.3796 & TRN \\
\hline CHEMBL1966514 & 809236 & 7.7 & 8.1275 & TRN \\
\hline CHEMBL 2003638 & 809236 & 5.4 & 5.7635 & TRN \\
\hline CHEMBL1983393 & 809236 & 4.6 & 4.716 & TRN \\
\hline CHEMBL516429 & 809236 & 6.1 & 5.5285 & TRN \\
\hline CHEMBL1999910 & 809236 & 5.5 & 5.0528 & TRN \\
\hline CHEMBL1972152 & 809236 & 4.1 & 4.8539 & TST \\
\hline CHEMBL1970806 & 809236 & 4.1 & 4.3106 & TRN \\
\hline CHEMBL1992371 & 809236 & 4.6 & 4.8061 & TRN \\
\hline
\end{tabular}




\begin{tabular}{|c|c|c|c|c|c|}
\hline & & & & & \\
\hline CHEMBL1979970 & 809236 & 4.1 & 4.494 & TRN & \\
\hline CHEMBL1967252 & 809236 & 5.2 & 4.4256 & TRN & \\
\hline CHEMBL1992473 & 809236 & 5.7 & 6.1006 & TRN & \\
\hline CHEMBL1993966 & 809236 & 6.2 & 6.19 & TRN & \\
\hline CHEMBL 2004637 & 809236 & 4.6 & 5.117 & TRN & \\
\hline CHEMBL1993374 & 809236 & 4.6 & 5.2583 & TST & \\
\hline CHEMBL1969264 & 809236 & 5.4 & 5.4852 & TST & \\
\hline CHEMBL 2006237 & 809236 & 5.1 & 4.8212 & TRN & \\
\hline CHEMBL1572266 & 809236 & 4.1 & 5.7041 & TST & \\
\hline CHEMBL1972820 & 809236 & 4.1 & 4.1664 & TST & \\
\hline CHEMBL1605605 & 809236 & 4.6 & 4.2548 & TRN & \\
\hline CHEMBL1989029 & 809236 & 6.3 & 5.0731 & TRN & \\
\hline CHEMBL392642 & 809236 & 4.1 & 4.16100 & 00000000005 & TRN \\
\hline CHEMBL1980167 & 809236 & 5.7 & 5.4065 & TST & \\
\hline CHEMBL1972849 & 809236 & 4.1 & 3.8827 & TRN & \\
\hline CHEMBL1975357 & 809236 & 4.1 & 5.0378 & TST & \\
\hline CHEMBL259922 & 809236 & 4.1 & 4.8778 & TST & \\
\hline CHEMBL1997617 & 809236 & 7.5 & 7.76200 & 00000000005 & TRN \\
\hline CHEMBL1969301 & 809236 & 4.1 & 4.811 & TST & \\
\hline CHEMBL1987910 & 809236 & 6.0 & 7.0197 & TRN & \\
\hline CHEMBL374044 & 809236 & 8.8 & 9.0249 & TRN & \\
\hline CHEMBL1983932 & 809236 & 7.6 & 5.1865 & TRN & \\
\hline CHEMBL1983980 & 809236 & 5.7 & 5.5046 & TRN & \\
\hline CHEMBL1973399 & 809236 & 3.0 & 4.1003 & TST & \\
\hline CHEMBL1966069 & 809236 & 4.1 & 4.4604 & TRN & \\
\hline CHEMBL1986899 & 809236 & 4.6 & 5.4535 & TRN & \\
\hline CHEMBL243088 & 809236 & 6.3 & 6.9201 & TRN & \\
\hline CHEMBL1993661 & 809236 & 7.8 & 7.6851 & TRN & \\
\hline CHEMBL202721 & 809236 & 6.4 & 5.7281 & TRN & \\
\hline CHEMBL1988038 & 809236 & 6.1 & 5.3514 & TRN & \\
\hline CHEMBL1987034 & 809236 & 7.3 & 7.0271 & TRN & \\
\hline CHEMBL 2005886 & 809236 & 6.5 & 7.2648 & TRN & \\
\hline CHEMBL1682345 & 809236 & 4.1 & 4.5711 & TRN & \\
\hline CHEMBL481491 & 809236 & 5.6 & 5.1974 & TRN & \\
\hline CHEMBL388311 & 809236 & 9.2 & 7.4847 & TRN & \\
\hline CHEMBL1807515 & 809236 & 4.1 & 6.1304 & TRN & \\
\hline CHEMBL 2005936 & 809236 & 4.1 & 4.1237 & TRN & \\
\hline CHEMBL1968565 & 809236 & 5.4 & 4.9273 & TST & \\
\hline CHEMBL1987430 & 809236 & 4.6 & 4.3595 & TRN & \\
\hline CHEMBL1562756 & 809236 & 4.1 & 4.7184 & TST & \\
\hline CHEMBL1993413 & 809236 & 4.6 & 4.9926 & TRN & \\
\hline CHEMBL1969372 & 809236 & 5.1 & 4.7224 & TRN & \\
\hline CHEMBL2001957 & 809236 & 5.1 & 4.3988 & TRN & \\
\hline CHEMBL1986263 & 809236 & 6.0 & 6.5725 & TRN & \\
\hline CHEMBL1986265 & 809236 & 4.6 & 4.2769 & TRN & \\
\hline CHEMBL1964644 & 809236 & 4.1 & 4.209 & TRN & \\
\hline CHEMBL1967211 & 809236 & 4.1 & 3.7436 & TRN & \\
\hline CHEMBL1981782 & 809236 & 4.1 & 4.0833 & TRN & \\
\hline
\end{tabular}




\begin{tabular}{|c|c|c|c|c|c|}
\hline \\
\hline CHEMBL1970142 & 809236 & 8.2 & 8.8845 & TRN & \\
\hline CHEMBL1977681 & 809236 & 6.4 & 5.9443 & TRN & \\
\hline CHEMBL2002105 & 809236 & 4.7 & 4.78600 & 00000000005 & TRN \\
\hline CHEMBL1983348 & 809236 & 6.9 & 6.4575 & TST & \\
\hline CHEMBL1995592 & 809236 & 6.2 & 6.409 & TST & \\
\hline CHEMBL 2000934 & 809236 & 4.6 & 4.26 & TRN & \\
\hline CHEMBL1986177 & 809236 & 4.6 & 4.8382 & TRN & \\
\hline CHEMBL1992323 & 809236 & 4.1 & 4.2663 & TRN & \\
\hline CHEMBL1983449 & 809236 & 4.1 & 4.35800 & 00000000005 & TRN \\
\hline CHEMBL1996510 & 809236 & 6.1 & 4.9047 & TST & \\
\hline CHEMBL1977874 & 809236 & 4.1 & 4.8926 & TST & \\
\hline CHEMBL437747 & 809236 & 5.6 & 5.0906 & TRN & \\
\hline CHEMBL507936 & 809236 & 7.2 & 6.5562 & TRN & \\
\hline CHEMBL 2001584 & 809236 & 4.6 & 4.7876 & TRN & \\
\hline CHEMBL1995172 & 809236 & 5.3 & 4.7745 & TST & \\
\hline CHEMBL1967998 & 809236 & 7.7 & 7.689 & TRN & \\
\hline CHEMBL104264 & 809236 & 5.1 & 4.4716 & TST & \\
\hline CHEMBL1997129 & 809236 & 6.5 & 5.6236 & TRN & \\
\hline CHEMBL1984788 & 809236 & 4.1 & 5.3206 & TRN & \\
\hline CHEMBL451964 & 809236 & 4.1 & 4.1908 & TRN & \\
\hline CHEMBL1974875 & 809236 & 3.0 & 4.044 & TST & \\
\hline CHEMBL 2001547 & 809236 & 4.1 & 4.0685 & TRN & \\
\hline CHEMBL210928 & 809236 & 4.1 & 3.9371 & TRN & \\
\hline CHEMBL 2005800 & 809236 & 6.0 & 5.1199 & TRN & \\
\hline CHEMBL1972840 & 809236 & 5.3 & 5.1197 & TRN & \\
\hline CHEMBL 2001668 & 809236 & 4.1 & 4.3971 & TST & \\
\hline CHEMBL 2004934 & 809236 & 4.1 & 4.4894 & TRN & \\
\hline CHEMBL1996048 & 809236 & 4.9 & 5.7087 & TST & \\
\hline CHEMBL 2004025 & 809236 & 5.9 & 5.7139 & TRN & \\
\hline CHEMBL461876 & 809236 & 4.6 & 3.9364 & TST & \\
\hline CHEMBL1971519 & 809236 & 4.9 & 5.0204 & TRN & \\
\hline CHEMBL1997335 & 809236 & 4.6 & 4.5032 & TRN & \\
\hline CHEMBL1978099 & 809236 & 7.1 & 7.0215 & TRN & \\
\hline CHEMBL1984363 & 809236 & 7.7 & 7.3475 & TRN & \\
\hline CHEMBL1977041 & 809236 & 7.1 & 7.7182 & TRN & \\
\hline CHEMBL1968070 & 809236 & 5.7 & 5.1337 & TRN & \\
\hline CHEMBL1994808 & 809236 & 4.4 & 4.65600 & 0000000001 & TRN \\
\hline CHEMBL1997759 & 809236 & 4.1 & 4.029 & TRN & \\
\hline CHEMBL1981556 & 809236 & 4.3 & 5.0037 & TST & \\
\hline CHEMBL1970074 & 809236 & 7.7 & 6.8657 & TRN & \\
\hline CHEMBL1974803 & 809236 & 4.1 & 4.5179 & TRN & \\
\hline CHEMBL 2005112 & 809236 & 4.1 & 4.5521 & TST & \\
\hline CHEMBL 2003456 & 809236 & 5.5 & 5.34200 & 00000000005 & TRN \\
\hline CHEMBL1966816 & 809236 & 4.1 & 5.0072 & TRN & \\
\hline CHEMBL 2002992 & 809236 & 4.3 & 4.6511 & TRN & \\
\hline CHEMBL560813 & 809236 & 5.5 & 4.8455 & TRN & \\
\hline CHEMBL 207253 & 809236 & 4.1 & 4.7058 & TST & \\
\hline CHEMBL1968791 & 809236 & 6.5 & 6.2089 & TRN & \\
\hline
\end{tabular}




\begin{tabular}{|c|c|c|c|c|}
\hline & & & upplement & al $\mathrm{T}$ \\
\hline CHEMBL 2002682 & 809236 & 4.1 & 4.5934 & TST \\
\hline CHEMBL1984700 & 809236 & 4.1 & 4.3412 & TRN \\
\hline CHEMBL1998953 & 809236 & 4.6 & 4.7814 & TRN \\
\hline CHEMBL 2007151 & 809236 & 6.3 & 5.8687 & TRN \\
\hline CHEMBL1971606 & 809236 & 4.6 & 4.2688 & TRN \\
\hline CHEMBL1972125 & 809236 & 4.1 & 4.1282 & TRN \\
\hline CHEMBL1461728 & 809236 & 4.1 & 4.2123 & TRN \\
\hline CHEMBL1995448 & 809236 & 4.1 & 4.8206 & TRN \\
\hline CHEMBL1972158 & 809236 & 4.1 & 4.4329 & TRN \\
\hline CHEMBL1999414 & 809236 & 9.2 & 8.9291 & TRN \\
\hline CHEMBL1967336 & 809236 & 4.6 & 4.5893 & TRN \\
\hline CHEMBL1967992 & 809236 & 4.6 & 4.3455 & TRN \\
\hline CHEMBL1993424 & 809236 & 7.2 & 6.8761 & TRN \\
\hline CHEMBL1975534 & 809236 & 4.1 & 4.533 & TRN \\
\hline CHEMBL1966703 & 809236 & 4.1 & 4.3251 & TST \\
\hline CHEMBL1969561 & 809236 & 4.1 & 4.5158 & TRN \\
\hline CHEMBL1983640 & 809236 & 8.9 & 8.2859 & TRN \\
\hline CHEMBL1964687 & 809236 & 7.2 & 7.2549 & TRN \\
\hline CHEMBL1999918 & 809236 & 5.9 & 5.8302 & TRN \\
\hline CHEMBL1974254 & 809236 & 8.4 & 8.5721 & TRN \\
\hline CHEMBL1988537 & 809236 & 5.6 & 4.8617 & TST \\
\hline CHEMBL 2002240 & 809236 & 4.1 & 4.2329 & TRN \\
\hline CHEMBL1978267 & 809236 & 6.4 & 5.5889 & TRN \\
\hline CHEMBL485556 & 809236 & 6.0 & 4.77 & TST \\
\hline CHEMBL1972221 & 809236 & 4.1 & 4.3301 & TRN \\
\hline CHEMBL1984274 & 809236 & 4.1 & 4.5138 & TST \\
\hline CHEMBL1998545 & 809236 & 4.1 & 4.1852 & TRN \\
\hline CHEMBL 2004033 & 809236 & 5.7 & 4.9218 & TST \\
\hline CHEMBL1986869 & 809236 & 4.1 & 4.3108 & TRN \\
\hline CHEMBL1987998 & 809236 & 4.6 & 4.2179 & TRN \\
\hline CHEMBL1971534 & 809236 & 5.1 & 4.0818 & TRN \\
\hline CHEMBL 242865 & 809236 & 6.6 & 5.6478 & TRN \\
\hline CHEMBL1997623 & 809236 & 8.1 & 7.6146 & TRN \\
\hline CHEMBL1978973 & 809236 & 6.3 & 4.9075 & TRN \\
\hline CHEMBL2002479 & 809236 & 4.1 & 5.1023 & TRN \\
\hline CHEMBL1472492 & 809236 & 4.1 & 5.1368 & TST \\
\hline CHEMBL1972276 & 809236 & 4.1 & 4.6012 & TRN \\
\hline CHEMBL1970709 & 809236 & 4.1 & 4.1177 & TRN \\
\hline CHEMBL1992125 & 809236 & 6.1 & 5.7787 & TRN \\
\hline CHEMBL1998724 & 809236 & 5.4 & 6.1073 & TRN \\
\hline CHEMBL1964777 & 809236 & 5.3 & 5.0184 & TRN \\
\hline CHEMBL1987533 & 809236 & 4.1 & 4.3567 & TRN \\
\hline CHEMBL579246 & 809236 & 4.1 & 4.4348 & TRN \\
\hline CHEMBL 398951 & 809236 & 6.0 & 5.5476 & TST \\
\hline CHEMBL1982506 & 809236 & 5.7 & 5.3791 & TST \\
\hline CHEMBL1968127 & 809236 & 4.1 & 4.0625 & TRN \\
\hline CHEMBL 2007603 & 809236 & 4.6 & 4.4758 & TRN \\
\hline CHEMBL1985406 & 809236 & 4.1 & 4.5378 & TRN \\
\hline
\end{tabular}




\begin{tabular}{|c|c|c|c|c|c|}
\hline \\
\hline CHEMBL 2000894 & 809236 & 4.1 & 4.2227 & TST & \\
\hline CHEMBL207400 & 809236 & 4.1 & 4.1614 & TST & \\
\hline CHEMBL1968130 & 809236 & 4.5 & 4.2047 & TRN & \\
\hline CHEMBL1993243 & 809236 & 7.5 & 8.3003 & TRN & \\
\hline CHEMBL399021 & 809236 & 5.5 & 5.9629 & TRN & \\
\hline CHEMBL1969537 & 809236 & 5.5 & 5.1991 & TST & \\
\hline CHEMBL 210032 & 809236 & 4.1 & 4.301 & TRN & \\
\hline CHEMBL 2004892 & 809236 & 5.3 & 4.4954 & TRN & \\
\hline CHEMBL1970314 & 809236 & 4.1 & 4.1362 & TRN & \\
\hline CHEMBL1987658 & 809236 & 5.4 & 5.1446 & TRN & \\
\hline CHEMBL 262433 & 809236 & 7.7 & 8.0763 & TRN & \\
\hline CHEMBL 306380 & 809236 & 6.7 & 6.8536 & TRN & \\
\hline CHEMBL1966722 & 809236 & 4.1 & 3.8739 & TRN & \\
\hline CHEMBL1986588 & 809236 & 3.1 & 4.1389 & TRN & \\
\hline CHEMBL1975500 & 809236 & 5.2 & 4.5008 & TRN & \\
\hline CHEMBL1988581 & 809236 & 6.3 & 5.9978 & TST & \\
\hline CHEMBL394619 & 809236 & 8.0 & 8.3331 & TRN & \\
\hline CHEMBL 2006564 & 809236 & 7.2 & 6.6669 & TRN & \\
\hline CHEMBL1965988 & 809236 & 8.1 & 8.6011 & TRN & \\
\hline CHEMBL418203 & 809236 & 4.3 & 4.3438 & TST & \\
\hline CHEMBL1989646 & 809236 & 4.1 & 4.6801 & TRN & \\
\hline CHEMBL209534 & 809236 & 4.1 & 4.6156 & TRN & \\
\hline CHEMBL1994159 & 809236 & 4.2 & 4.206 & TRN & \\
\hline CHEMBL1966087 & 809236 & 4.1 & 4.0663 & TRN & \\
\hline CHEMBL1973483 & 809236 & 5.5 & 4.708 & TRN & \\
\hline CHEMBL 219722 & 809236 & 7.7 & 7.8523 & TRN & \\
\hline CHEMBL1970735 & 809236 & 4.1 & 3.97300 & 00000000003 & TRN \\
\hline CHEMBL1997340 & 809236 & 4.1 & 4.2818 & TRN & \\
\hline CHEMBL458997 & 809236 & 6.3 & 6.0035 & TRN & \\
\hline CHEMBL1988805 & 809236 & 4.6 & 4.9452 & TST & \\
\hline CHEMBL1971021 & 809236 & 5.5 & 5.1352 & TRN & \\
\hline CHEMBL1974310 & 809236 & 5.7 & 5.0754 & TRN & \\
\hline CHEMBL583144 & 809236 & 4.1 & 3.9824 & TRN & \\
\hline CHEMBL1982957 & 809236 & 6.7 & 5.6368 & TRN & \\
\hline CHEMBL1725279 & 809236 & 6.2 & 7.2934 & TST & \\
\hline CHEMBL 2002346 & 809236 & 6.5 & 6.1881 & TRN & \\
\hline CHEMBL 2006836 & 809236 & 4.1 & 4.3899 & TST & \\
\hline CHEMBL412142 & 809236 & 4.1 & 4.3241 & TST & \\
\hline CHEMBL 2003271 & 809236 & 5.1 & 5.0694 & TRN & \\
\hline CHEMBL1980704 & 809236 & 4.1 & 4.4739 & TST & \\
\hline CHEMBL1966808 & 809236 & 4.1 & 4.1712 & TRN & \\
\hline CHEMBL1972365 & 809236 & 5.1 & 4.7261 & TRN & \\
\hline CHEMBL260135 & 809236 & 5.1 & 5.2178 & TRN & \\
\hline CHEMBL 220241 & 809236 & 4.1 & 5.3519 & TRN & \\
\hline CHEMBL 2004544 & 809236 & 4.1 & 4.7332 & TST & \\
\hline CHEMBL1988141 & 809236 & 5.8 & 5.9406 & TST & \\
\hline CHEMBL1977134 & 809236 & 7.9 & 7.5733 & TRN & \\
\hline CHEMBL1970873 & 809236 & 3.3 & 3.6131 & TRN & \\
\hline
\end{tabular}




\begin{tabular}{|c|c|c|c|c|}
\hline & & & pplement & $\mathrm{a} \perp \mathrm{Ta}$ \\
\hline CHEMBL1986996 & 809236 & 5.4 & 5.3882 & TST \\
\hline CHEMBL1985206 & 809236 & 5.9 & 5.6177 & TST \\
\hline CHEMBL2006933 & 809236 & 5.6 & 5.2275 & TST \\
\hline CHEMBL1991078 & 809236 & 6.4 & 6.0324 & TRN \\
\hline CHEMBL1974365 & 809236 & 7.1 & 4.155 & TRN \\
\hline CHEMBL1987359 & 809236 & 4.1 & 4.726 & TST \\
\hline CHEMBL1977749 & 809236 & 6.0 & 4.58 & TST \\
\hline CHEMBL 2000685 & 809236 & 4.1 & 4.4302 & TRN \\
\hline CHEMBL1967513 & 809236 & 4.6 & 4.4593 & TRN \\
\hline CHEMBL1980376 & 809236 & 4.0 & 5.1692 & TRN \\
\hline CHEMBL1985311 & 809236 & 8.1 & 7.9055 & TRN \\
\hline CHEMBL 2000724 & 809236 & 4.6 & 4.6979 & TRN \\
\hline CHEMBL1965660 & 809236 & 6.1 & 4.6346 & TRN \\
\hline CHEMBL1982413 & 809236 & 4.6 & 4.9775 & TST \\
\hline CHEMBL1682553 & 809236 & 4.1 & 3.8611 & TRN \\
\hline CHEMBL1969502 & 809236 & 7.0 & 6.2846 & TRN \\
\hline CHEMBL2004647 & 809236 & 4.1 & 5.1751 & TST \\
\hline CHEMBL1971430 & 809236 & 4.1 & 4.2847 & TRN \\
\hline CHEMBL 2000271 & 809236 & 5.3 & 4.4537 & TRN \\
\hline CHEMBL562488 & 809236 & 3.1 & 4.011 & TRN \\
\hline CHEMBL354676 & 809236 & 3.0 & 4.178 & TRN \\
\hline CHEMBL1987535 & 809236 & 5.7 & 5.0105 & TRN \\
\hline CHEMBL1981792 & 809236 & 4.6 & 5.0312 & TRN \\
\hline CHEMBL 2002586 & 809236 & 4.6 & 5.5168 & TRN \\
\hline CHEMBL 2004692 & 809236 & 4.1 & 4.1974 & TST \\
\hline CHEMBL1987815 & 809236 & 4.2 & 3.8947 & TST \\
\hline CHEMBL1996234 & 809236 & 5.9 & 6.091 & TRN \\
\hline CHEMBL1967544 & 809236 & 4.1 & 4.4029 & TRN \\
\hline CHEMBL1992673 & 809236 & 4.7 & 4.2833 & TRN \\
\hline CHEMBL 223367 & 809236 & 4.1 & 5.0812 & TST \\
\hline CHEMBL1993335 & 809236 & 6.8 & 6.9349 & TST \\
\hline CHEMBL 2007574 & 809236 & 4.6 & 5.3831 & TRN \\
\hline CHEMBL1964804 & 809236 & 4.1 & 4.3605 & TRN \\
\hline CHEMBL443962 & 809236 & 5.9 & 5.7422 & TST \\
\hline CHEMBL1965507 & 809236 & 4.4 & 4.9771 & TRN \\
\hline CHEMBL 2000354 & 809236 & 4.1 & 4.3714 & TRN \\
\hline CHEMBL1998680 & 809236 & 4.6 & 4.2961 & TRN \\
\hline CHEMBL 274064 & 809236 & 5.3 & 4.9737 & TRN \\
\hline CHEMBL1967564 & 809236 & 4.1 & 4.1266 & TRN \\
\hline CHEMBL1985491 & 809236 & 7.5 & 8.1979 & TRN \\
\hline CHEMBL1970317 & 809236 & 8.3 & 8.1142 & TRN \\
\hline CHEMBL 2000408 & 809236 & 4.1 & 4.095 & TRN \\
\hline CHEMBL1978014 & 809236 & 4.1 & 4.3107 & TRN \\
\hline CHEMBL 248757 & 809236 & 4.1 & 5.9523 & TST \\
\hline CHEMBL1997007 & 809236 & 6.7 & 5.8592 & TRN \\
\hline CHEMBL1994538 & 809236 & 4.1 & 4.5792 & TRN \\
\hline CHEMBL1975490 & 809236 & 4.1 & 5.4161 & TRN \\
\hline CHEMBL 2002690 & 809236 & 6.9 & 5.3639 & TRN \\
\hline
\end{tabular}




\begin{tabular}{|c|c|c|c|c|}
\hline \multicolumn{5}{|c|}{ Supplemental Table S2.txt } \\
\hline CHEMBL383527 & 809236 & 4.1 & 4.0075 & TRN \\
\hline CHEMBL1975503 & 809236 & 4.4 & 4.1599 & TRN \\
\hline CHEMBL1986139 & 809236 & 4.1 & 4.55 & TRN \\
\hline CHEMBL 2006567 & 809236 & 4.1 & 4.6852 & TRN \\
\hline CHEMBL1979883 & 809236 & 7.9 & 8.3651 & TRN \\
\hline CHEMBL1997051 & 809236 & 5.7 & 6.3008 & TRN \\
\hline CHEMBL491758 & 809236 & 6.4 & 6.724 & TRN \\
\hline CHEMBL1986590 & 809236 & 6.1 & 6.2931 & TRN \\
\hline CHEMBL1682360 & 809236 & 4.1 & 4.5304 & TRN \\
\hline CHEMBL549730 & 809236 & 4.1 & 4.4057 & TRN \\
\hline CHEMBL1970189 & 809236 & 4.1 & 4.4163 & TRN \\
\hline CHEMBL406845 & 809236 & 6.4 & 5.2422 & TRN \\
\hline CHEMBL1974288 & 809236 & 4.1 & 4.2733 & TRN \\
\hline CHEMBL1990346 & 809236 & 5.2 & 5.2255 & TRN \\
\hline CHEMBL1964718 & 809236 & 3.0 & 4.0584 & TST \\
\hline CHEMBL1991410 & 809236 & 4.6 & 4.6317 & TRN \\
\hline CHEMBL1968705 & 809236 & 4.4 & 4.6161 & TRN \\
\hline CHEMBL1986684 & 809236 & 3.0 & 4.5679 & TST \\
\hline CHEMBL1978271 & 809236 & 4.6 & 4.707 & TRN \\
\hline CHEMBL 2007266 & 809236 & 7.9 & 7.2212 & TRN \\
\hline CHEMBL1977604 & 809236 & 4.1 & 4.2314 & TST \\
\hline CHEMBL1974328 & 809236 & 6.4 & 6.1909 & TST \\
\hline CHEMBL509032 & 809236 & 6.9 & 6.9604 & TRN \\
\hline CHEMBL1992342 & 809236 & 5.6 & 4.4031 & TRN \\
\hline CHEMBL 2002202 & 809236 & 4.1 & 4.1938 & TRN \\
\hline CHEMBL1973013 & 809236 & 6.7 & 6.1254 & TST \\
\hline CHEMBL1164265 & 809236 & 4.6 & 6.2158 & TST \\
\hline CHEMBL1965423 & 809236 & 4.3 & 4.791 & TRN \\
\hline CHEMBL 205415 & 809236 & 4.3 & 4.5746 & TRN \\
\hline CHEMBL1977135 & 809236 & 4.1 & 4.325 & TRN \\
\hline CHEMBL 2001920 & 809236 & 4.1 & 4.3581 & TRN \\
\hline CHEMBL1241473 & 809236 & 7.5 & 7.4761 & TRN \\
\hline CHEMBL1978448 & 809236 & 4.3 & 4.7302 & TST \\
\hline CHEMBL 2004513 & 809236 & 5.1 & 4.5118 & TRN \\
\hline CHEMBL1972258 & 809236 & 4.1 & 3.951 & TRN \\
\hline CHEMBL1969483 & 809236 & 6.9 & 6.0982 & TRN \\
\hline CHEMBL 2001257 & 809236 & 7.7 & 7.5829 & TRN \\
\hline CHEMBL 2004515 & 809236 & 6.6 & 5.2644 & TRN \\
\hline CHEMBL1980329 & 809236 & 7.9 & 7.1045 & TRN \\
\hline CHEMBL1992042 & 809236 & 4.6 & 5.2886 & TST \\
\hline CHEMBL1968271 & 809236 & 4.3 & 5.1488 & TRN \\
\hline CHEMBL1992536 & 809236 & 4.1 & 4.195 & TRN \\
\hline CHEMBL1994724 & 809236 & 4.6 & 4.4196 & TRN \\
\hline CHEMBL1970290 & 809236 & 5.8 & 5.0972 & TRN \\
\hline CHEMBL1967531 & 809236 & 6.8 & 7.5525 & TRN \\
\hline CHEMBL1970913 & 809236 & 4.1 & 4.1004 & TRN \\
\hline CHEMBL1997534 & 809236 & 4.1 & 4.4826 & TRN \\
\hline CHEMBL1993877 & 809236 & 6.7 & 6.5766 & TRN \\
\hline
\end{tabular}




\begin{tabular}{|c|c|c|c|c|c|}
\hline \\
\hline CHEMBL1977374 & 809236 & 4.1 & 4.0346 & TRN & \\
\hline CHEMBL1998551 & 809236 & 4.1 & 4.0071 & TRN & \\
\hline CHEMBL273187 & 809236 & 9.6 & 9.0895 & TRN & \\
\hline CHEMBL1991180 & 809236 & 5.5 & 4.9596 & TST & \\
\hline CHEMBL1978656 & 809236 & 4.1 & 3.9668 & TRN & \\
\hline CHEMBL1976420 & 809236 & 5.7 & 5.5466 & TST & \\
\hline CHEMBL1981744 & 809236 & 4.6 & 4.9345 & TRN & \\
\hline CHEMBL1994864 & 809236 & 4.1 & 4.2953 & TRN & \\
\hline CHEMBL 2002446 & 809236 & 8.0 & 7.8585 & TST & \\
\hline CHEMBL 246970 & 809236 & 4.1 & 4.2151 & TRN & \\
\hline CHEMBL340921 & 809236 & 4.1 & 4.4826 & TST & \\
\hline CHEMBL 2005478 & 809236 & 4.6 & 6.8078 & TST & \\
\hline CHEMBL1276446 & 809236 & 7.6 & 7.9702 & TST & \\
\hline CHEMBL1971649 & 809236 & 6.8 & 5.4533 & TRN & \\
\hline CHEMBL 2003657 & 809236 & 5.4 & 4.9221 & TRN & \\
\hline CHEMBL 2005482 & 809236 & 7.7 & 7.2111 & TRN & \\
\hline CHEMBL1992723 & 809236 & 4.6 & 3.9972 & TRN & \\
\hline CHEMBL 2007124 & 809236 & 4.6 & 6.0709 & TRN & \\
\hline CHEMBL1997909 & 809236 & 7.6 & 7.126 & TRN & \\
\hline CHEMBL2006439 & 809236 & 5.6 & 6.0966 & TRN & \\
\hline CHEMBL 2006156 & 809236 & 4.1 & 4.4259 & TST & \\
\hline CHEMBL1985681 & 809236 & 6.8 & 6.3832 & TST & \\
\hline CHEMBL1991674 & 809236 & 5.9 & 6.4962 & TRN & \\
\hline CHEMBL262623 & 809236 & 5.7 & 4.4295 & TRN & \\
\hline CHEMBL1984842 & 809236 & 4.3 & 4.2239 & TRN & \\
\hline CHEMBL223460 & 809236 & 4.1 & 5.376 & TST & \\
\hline CHEMBL1998829 & 809236 & 5.4 & 4.3622 & TRN & \\
\hline CHEMBL2006299 & 809236 & 4.6 & 4.3302 & TRN & \\
\hline CHEMBL375284 & 809236 & 7.5 & 6.6681 & TRN & \\
\hline CHEMBL1972346 & 809236 & 4.6 & 4.8461 & TST & \\
\hline CHEMBL1968926 & 809236 & 4.1 & 4.4876 & TRN & \\
\hline CHEMBL1991867 & 809236 & 3.0 & 4.1298 & TST & \\
\hline CHEMBL1965570 & 809236 & 8.3 & 8.02799 & 9999999999 & TRN \\
\hline CHEMBL 2001641 & 809236 & 4.4 & 4.435 & TRN & \\
\hline CHEMBL1972355 & 809236 & 5.6 & 5.6139 & TST & \\
\hline CHEMBL1997193 & 809236 & 6.2 & 5.8016 & TST & \\
\hline CHEMBL1964902 & 809236 & 4.6 & 4.2275 & TRN & \\
\hline CHEMBL 1082440 & 809236 & 5.7 & 5.6365 & TST & \\
\hline CHEMBL1972362 & 809236 & 5.6 & 5.2306 & TRN & \\
\hline CHEMBL1614705 & 809236 & 4.1 & 4.2676 & TRN & \\
\hline CHEMBL 2003948 & 809236 & 4.3 & 5.3209 & TRN & \\
\hline CHEMBL 2007372 & 809236 & 4.1 & 4.0736 & TRN & \\
\hline CHEMBL1982167 & 809236 & 4.1 & 4.0333 & TRN & \\
\hline CHEMBL1986597 & 809236 & 5.1 & 5.3157 & TRN & \\
\hline CHEMBL 2006715 & 809236 & 7.3 & 7.1769 & TRN & \\
\hline CHEMBL1971017 & 809236 & 5.9 & 5.8505 & TRN & \\
\hline CHEMBL1990482 & 809236 & 4.1 & 4.3922 & TRN & \\
\hline CHEMBL1990904 & 809236 & 4.1 & 4.7995 & TRN & \\
\hline
\end{tabular}




\begin{tabular}{|c|c|c|c|c|}
\hline & & & CIIL & al Ta \\
\hline CHEMBL 2005475 & 809236 & 6.2 & 6.3291 & TRN \\
\hline CHEMBL 2000104 & 809236 & 6.0 & 5.2419 & TRN \\
\hline CHEMBL183844 & 809236 & 8.3 & 6.7856 & TRN \\
\hline CHEMBL1997349 & 809236 & 4.1 & 4.2093 & TST \\
\hline CHEMBL 220057 & 809236 & 8.3 & 8.2405 & TRN \\
\hline CHEMBL383541 & 809236 & 4.1 & 3.9755 & TRN \\
\hline CHEMBL 2001224 & 809236 & 4.1 & 4.5258 & TRN \\
\hline CHEMBL10 & 809236 & 4.6 & 4.4619 & TRN \\
\hline CHEMBL1964937 & 809236 & 4.1 & 5.0467 & TRN \\
\hline CHEMBL1980763 & 809236 & 7.0 & 6.4771 & TRN \\
\hline CHEMBL1969506 & 809236 & 4.1 & 4.428 & TRN \\
\hline CHEMBL590109 & 809236 & 4.1 & 5.2012 & TST \\
\hline CHEMBL1977931 & 809236 & 4.8 & 4.2794 & TRN \\
\hline CHEMBL1970879 & 809236 & 4.1 & 4.6836 & TRN \\
\hline CHEMBL1682552 & 809236 & 4.1 & 4.1129 & TRN \\
\hline CHEMBL2005899 & 809236 & 5.2 & 4.9259 & TRN \\
\hline CHEMBL 2007479 & 809236 & 4.6 & 4.5971 & TRN \\
\hline CHEMBL1996155 & 809236 & 4.1 & 4.0306 & TRN \\
\hline CHEMBL229799 & 809236 & 5.4 & 4.7841 & TRN \\
\hline CHEMBL1682359 & 809236 & 4.1 & 4.3121 & TRN \\
\hline CHEMBL 379300 & 809236 & 5.4 & 4.6299 & TRN \\
\hline CHEMBL1972220 & 809236 & 8.9 & 8.4832 & TRN \\
\hline CHEMBL1973720 & 809236 & 6.1 & 7.2379 & TRN \\
\hline CHEMBL1969523 & 809236 & 6.8 & 6.9303 & TRN \\
\hline CHEMBL207995 & 809236 & 4.1 & 5.022 & TRN \\
\hline CHEMBL1988995 & 809236 & 4.1 & 3.9219 & TRN \\
\hline CHEMBL1986781 & 809236 & 4.1 & 4.2212 & TRN \\
\hline CHEMBL 2001923 & 809236 & 4.3 & 4.1734 & TRN \\
\hline CHEMBL 2003514 & 809236 & 4.6 & 4.2974 & TRN \\
\hline CHEMBL526133 & 809236 & 4.1 & 5.0843 & TRN \\
\hline CHEMBL1966836 & 809236 & 8.9 & 8.5992 & TRN \\
\hline CHEMBL1989043 & 809236 & 4.6 & 4.6743 & TRN \\
\hline CHEMBL1979057 & 809236 & 4.1 & 4.9623 & TRN \\
\hline CHEMBL1967538 & 809236 & 3.1 & 3.5957 & TRN \\
\hline CHEMBL1999428 & 809236 & 5.2 & 5.4132 & TRN \\
\hline CHEMBL1967560 & 809236 & 4.1 & 4.6556 & TRN \\
\hline CHEMBL 211378 & 809236 & 7.0 & 7.7084 & TRN \\
\hline CHEMBL1982465 & 809236 & 8.5 & 8.5212 & TRN \\
\hline CHEMBL 2003420 & 809236 & 4.1 & 4.9844 & TRN \\
\hline CHEMBL 272938 & 809236 & 8.9 & 8.6805 & TRN \\
\hline CHEMBL1971801 & 809236 & 4.1 & 4.8934 & TRN \\
\hline CHEMBL1970217 & 809236 & 4.1 & 4.2611 & TRN \\
\hline CHEMBL1987143 & 809236 & 4.8 & 4.2771 & TRN \\
\hline CHEMBL1968850 & 809236 & 5.6 & 5.1832 & TRN \\
\hline CHEMBL 2005528 & 809236 & 5.2 & 4.7005 & TST \\
\hline CHEMBL185569 & 809236 & 7.7 & 7.4465 & TRN \\
\hline CHEMBL1973793 & 809236 & 5.6 & 5.0859 & TRN \\
\hline CHEMBL1969588 & 809236 & 6.0 & 6.5638 & TRN \\
\hline
\end{tabular}




\begin{tabular}{|c|c|c|c|c|}
\hline \multicolumn{5}{|c|}{ Supplemental Table S2.txt } \\
\hline CHEMBL1984711 & 809236 & 7.2 & 6.0596 & TRN \\
\hline CHEMBL1990212 & 809236 & 4.1 & 4.0575 & TRN \\
\hline CHEMBL1986143 & 809236 & 4.6 & 4.3697 & TRN \\
\hline CHEMBL1979252 & 809236 & 4.1 & 4.4002 & TRN \\
\hline CHEMBL1972934 & 809236 & 4.3 & 4.7285 & TRN \\
\hline CHEMBL1682341 & 809236 & 4.1 & 4.5239 & TRN \\
\hline CHEMBL1992581 & 809236 & 7.2 & 6.1203 & TRN \\
\hline CHEMBL1972937 & 809236 & 4.1 & 4.2904 & TRN \\
\hline CHEMBL1986499 & 809236 & 4.1 & 4.5902 & TRN \\
\hline CHEMBL2004311 & 809236 & 6.7 & 6.6209 & TRN \\
\hline CHEMBL1992634 & 809236 & 6.0 & 5.5676 & TRN \\
\hline CHEMBL316264 & 809236 & 4.1 & 4.1286 & TRN \\
\hline CHEMBL1984847 & 809236 & 4.6 & 5.4201 & TST \\
\hline CHEMBL1996576 & 809236 & 4.6 & 4.6521 & TST \\
\hline CHEMBL1991678 & 809236 & 4.5 & 4.0855 & TRN \\
\hline CHEMBL1988594 & 809236 & 4.1 & 4.9885 & TRN \\
\hline CHEMBL1965495 & 809236 & 6.3 & 6.2759 & TRN \\
\hline CHEMBL1985074 & 809236 & 4.1 & 4.4795 & TST \\
\hline CHEMBL1982874 & 809236 & 5.9 & 4.6827 & TRN \\
\hline CHEMBL1991725 & 809236 & 5.3 & 4.7814 & TRN \\
\hline CHEMBL 2007296 & 809236 & 4.1 & 4.2086 & TRN \\
\hline CHEMBL396523 & 809236 & 6.6 & 6.7548 & TRN \\
\hline CHEMBL208637 & 809236 & 4.1 & 3.9466 & TRN \\
\hline CHEMBL1978371 & 809236 & 4.6 & 5.0056 & TST \\
\hline CHEMBL1970203 & 809236 & 5.9 & 5.0984 & TRN \\
\hline CHEMBL 385478 & 809236 & 6.2 & 5.8386 & TRN \\
\hline CHEMBL1999749 & 809236 & 4.1 & 4.0758 & TRN \\
\hline CHEMBL1983006 & 809236 & 5.3 & 4.8638 & TRN \\
\hline CHEMBL1984191 & 809236 & 4.1 & 4.1616 & TRN \\
\hline CHEMBL1971029 & 809236 & 6.8 & 6.7404 & TRN \\
\hline CHEMBL 394790 & 809236 & 8.1 & 7.7871 & TRN \\
\hline CHEMBL226471 & 809236 & 5.1 & 4.4088 & TRN \\
\hline CHEMBL1966175 & 809236 & 5.9 & 5.0768 & TRN \\
\hline CHEMBL1996111 & 809236 & 4.1 & 4.438 & TRN \\
\hline CHEMBL2007375 & 809236 & 4.6 & 4.3546 & TRN \\
\hline CHEMBL1965589 & 809236 & 4.1 & 4.2371 & TRN \\
\hline CHEMBL1998193 & 809236 & 4.1 & 5.3572 & TRN \\
\hline CHEMBL379975 & 809236 & 5.7 & 4.7818 & TRN \\
\hline CHEMBL1988153 & 809236 & 5.1 & 4.4566 & TRN \\
\hline CHEMBL1968245 & 809236 & 4.1 & 4.0013 & TRN \\
\hline CHEMBL1233887 & 809236 & 4.6 & 5.2681 & TST \\
\hline CHEMBL1979577 & 809236 & 8.0 & 8.5792 & TRN \\
\hline CHEMBL52387 & 809236 & 4.1 & 4.3883 & TST \\
\hline CHEMBL1979357 & 809236 & 4.1 & 4.1962 & TRN \\
\hline CHEMBL1996817 & 809236 & 6.1 & 5.4201 & TRN \\
\hline CHEMBL 2004355 & 809236 & 4.1 & 4.7348 & TRN \\
\hline CHEMBL 256835 & 809236 & 4.1 & 4.4917 & TRN \\
\hline CHEMBL1980142 & 809236 & 4.1 & 4.4514 & TRN \\
\hline
\end{tabular}




\begin{tabular}{|c|c|c|c|c|}
\hline \multicolumn{5}{|c|}{ plemental } \\
\hline CHEMBL 2004438 & 809236 & 7.4 & 7.3553 & TRN \\
\hline CHEMBL41783 & 809236 & 4.1 & 4.1469 & TRN \\
\hline CHEMBL271381 & 809236 & 6.9 & 7.0733 & TRN \\
\hline CHEMBL1982466 & 809236 & 8.4 & 8.7719 & TRN \\
\hline CHEMBL1994638 & 809236 & 8.1 & 8.5588 & TRN \\
\hline CHEMBL1996390 & 809236 & 4.1 & 4.9352 & TRN \\
\hline CHEMBL234085 & 809236 & 5.0 & 4.3196 & TRN \\
\hline CHEMBL1969042 & 809236 & 5.9 & 5.5537 & TRN \\
\hline CHEMBL1999931 & 809236 & 5.9 & 6.2148 & TRN \\
\hline CHEMBL1976376 & 809236 & 6.4 & 6.0451 & TRN \\
\hline CHEMBL1991640 & 809236 & 4.1 & 4.3594 & TST \\
\hline CHEMBL1968868 & 809236 & 4.6 & 4.583 & TRN \\
\hline CHEMBL 2007064 & 809236 & 6.4 & 7.315 & TRN \\
\hline CHEMBL1997197 & 809236 & 4.6 & 4.4371 & TRN \\
\hline CHEMBL1968151 & 809236 & 4.1 & 4.2429 & TRN \\
\hline CHEMBL1381197 & 809236 & 4.1 & 4.2716 & TRN \\
\hline CHEMBL1987009 & 809236 & 6.2 & 6.6347 & TRN \\
\hline CHEMBL1973795 & 809236 & 3.0 & 4.2574 & TRN \\
\hline CHEMBL 2003817 & 809236 & 6.0 & 5.1639 & TRN \\
\hline CHEMBL379218 & 809236 & 4.1 & 4.5708 & TRN \\
\hline CHEMBL1994830 & 809236 & 4.1 & 5.2255 & TRN \\
\hline CHEMBL1987054 & 809236 & 7.6 & 7.7752 & TRN \\
\hline CHEMBL1977652 & 809236 & 5.5 & 5.079 & TRN \\
\hline CHEMBL 226403 & 809236 & 4.1 & 4.5854 & TRN \\
\hline CHEMBL1995765 & 809236 & 4.4 & 4.2731 & TST \\
\hline CHEMBL1966279 & 809236 & 4.1 & 4.4684 & TRN \\
\hline CHEMBL1984760 & 809236 & 6.3 & 6.2326 & TRN \\
\hline CHEMBL1991728 & 809236 & 4.1 & 4.2663 & TRN \\
\hline CHEMBL360847 & 809236 & 5.7 & 4.636 & TST \\
\hline CHEMBL1995811 & 809236 & 4.6 & 4.9853 & TRN \\
\hline CHEMBL1975787 & 809236 & 6.1 & 5.8351 & TRN \\
\hline CHEMBL 2002407 & 809236 & 5.9 & 4.933 & TRN \\
\hline CHEMBL1995916 & 809236 & 3.0 & 4.1301 & TRN \\
\hline CHEMBL1972489 & 809236 & 4.1 & 4.3576 & TRN \\
\hline CHEMBL451401 & 809236 & 4.3 & 4.7049 & TRN \\
\hline CHEMBL536151 & 809236 & 5.5 & 4.9692 & TST \\
\hline CHEMBL1090356 & 809236 & 7.3 & 7.2142 & TRN \\
\hline CHEMBL1986328 & 809236 & 4.1 & 4.2641 & TST \\
\hline CHEMBL 2002450 & 809236 & 3.1 & 3.9797 & TRN \\
\hline CHEMBL261849 & 809236 & 4.6 & 5.7795 & TST \\
\hline CHEMBL1982122 & 809236 & 4.1 & 4.5469 & TRN \\
\hline CHEMBL1999112 & 809236 & 5.1 & 4.8853 & TST \\
\hline CHEMBL1682546 & 809236 & 4.1 & 4.4372 & TRN \\
\hline CHEMBL1996780 & 809236 & 4.1 & 4.1351 & TST \\
\hline CHEMBL1996066 & 809236 & 7.9 & 6.5001 & TST \\
\hline CHEMBL296586 & 809236 & 5.7 & 5.3315 & TRN \\
\hline CHEMBL1993722 & 809236 & 6.0 & 6.3892 & TRN \\
\hline CHEMBL 2006674 & 809236 & 4.6 & 4.5975 & TST \\
\hline
\end{tabular}




\begin{tabular}{|c|c|c|c|c|c|}
\hline \\
\hline CHEMBL1984236 & 809236 & 4.6 & 4.6217 & TST & \\
\hline CHEMBL 202635 & 809236 & 4.1 & 5.0442 & TRN & \\
\hline CHEMBL2002599 & 809236 & 5.7 & 4.7873 & TRN & \\
\hline CHEMBL1375640 & 809236 & 4.1 & 4.4801 & TST & \\
\hline CHEMBL 249282 & 809236 & 4.1 & 5.0444 & TST & \\
\hline CHEMBL1973711 & 809236 & 4.1 & 4.9146 & TRN & \\
\hline CHEMBL1967720 & 809236 & 8.3 & 8.3947 & TRN & \\
\hline CHEMBL1969755 & 809236 & 4.1 & 3.9819 & TRN & \\
\hline CHEMBL1991138 & 809236 & 4.1 & 5.6175 & TRN & \\
\hline CHEMBL 2000652 & 809236 & 8.5 & 8.09799 & 9999999999 & TRN \\
\hline CHEMBL514499 & 809236 & 6.6 & 6.2169 & TRN & \\
\hline CHEMBL1970352 & 809236 & 4.6 & 4.2749 & TST & \\
\hline CHEMBL1965631 & 809236 & 4.1 & 4.2742 & TRN & \\
\hline CHEMBL1980144 & 809236 & 4.1 & 4.684 & TRN & \\
\hline CHEMBL1991188 & 809236 & 4.1 & 4.0949 & TRN & \\
\hline CHEMBL 377408 & 809236 & 4.6 & 4.4488 & TRN & \\
\hline CHEMBL215152 & 809236 & 6.6 & 5.8311 & TRN & \\
\hline CHEMBL231209 & 809236 & 7.1 & 7.1025 & TRN & \\
\hline CHEMBL 2006765 & 809236 & 6.6 & 6.2384 & TRN & \\
\hline CHEMBL1976220 & 809236 & 8.4 & 8.0583 & TRN & \\
\hline CHEMBL1982383 & 809236 & 5.1 & 4.5202 & TRN & \\
\hline CHEMBL17370 & 809236 & 4.1 & 4.3211 & TRN & \\
\hline CHEMBL1980246 & 809236 & 4.6 & 5.1567 & TST & \\
\hline CHEMBL404366 & 809236 & 8.5 & 8.8627 & TRN & \\
\hline CHEMBL1999484 & 809236 & 7.8 & 7.1876 & TRN & \\
\hline CHEMBL487402 & 809236 & 6.1 & 4.7816 & TST & \\
\hline CHEMBL1997822 & 809236 & 8.2 & 7.8682 & TRN & \\
\hline CHEMBL1991285 & 809236 & 5.3 & 6.0695 & TRN & \\
\hline CHEMBL1984038 & 809236 & 4.3 & 4.3242 & TRN & \\
\hline CHEMBL1965683 & 809236 & 4.3 & 4.9027 & TST & \\
\hline CHEMBL1984039 & 809236 & 4.1 & 4.342 & TST & \\
\hline CHEMBL 2004615 & 809236 & 4.1 & 4.2718 & TST & \\
\hline CHEMBL1997872 & 809236 & 6.1 & 5.733 & TRN & \\
\hline CHEMBL1964290 & 809236 & 4.1 & 4.761 & TRN & \\
\hline CHEMBL 213505 & 809236 & 7.9 & 7.9074 & TRN & \\
\hline CHEMBL1982880 & 809236 & 4.1 & 4.2245 & TRN & \\
\hline CHEMBL1993941 & 809236 & 8.4 & 8.2695 & TRN & \\
\hline CHEMBL 377383 & 809236 & 4.1 & 4.2427 & TRN & \\
\hline CHEMBL1973142 & 809236 & 6.2 & 5.4578 & TRN & \\
\hline CHEMBL1973145 & 809236 & 7.6 & 7.7084 & TRN & \\
\hline CHEMBL1964948 & 809236 & 4.6 & 5.0651 & TRN & \\
\hline CHEMBL1995813 & 809236 & 5.1 & 5.6237 & TRN & \\
\hline CHEMBL1979718 & 809236 & 4.1 & 4.6094 & TRN & \\
\hline CHEMBL206236 & 809236 & 4.1 & 3.9762 & TRN & \\
\hline CHEMBL1989834 & 809236 & 3.9 & 4.1916 & TRN & \\
\hline CHEMBL523823 & 809236 & 5.5 & 3.9703 & TST & \\
\hline CHEMBL1973178 & 809236 & 9.0 & 7.6935 & TRN & \\
\hline CHEMBL244378 & 809236 & 6.6 & 6.7412 & TRN & \\
\hline
\end{tabular}




\begin{tabular}{|c|c|c|c|c|}
\hline & & & 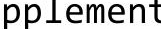 & al Ta \\
\hline CHEMBL1988778 & 809236 & 7.9 & 8.2724 & TRN \\
\hline CHEMBL1990583 & 809236 & 6.0 & 4.7957 & TRN \\
\hline CHEMBL289959 & 809236 & 3.2 & 3.4568 & TRN \\
\hline CHEMBL 2006263 & 809236 & 4.1 & 4.8299 & TST \\
\hline CHEMBL1993584 & 809236 & 4.1 & 4.1094 & TRN \\
\hline CHEMBL 210618 & 809236 & 4.1 & 4.1144 & TRN \\
\hline CHEMBL1975647 & 809236 & 5.8 & 5.0945 & TRN \\
\hline CHEMBL1968380 & 809236 & 4.1 & 4.2043 & TRN \\
\hline CHEMBL1991734 & 809236 & 5.7 & 5.6288 & TST \\
\hline CHEMBL1990912 & 809236 & 4.1 & 4.6361 & TRN \\
\hline CHEMBL1991782 & 809236 & 3.3 & 3.3992 & TRN \\
\hline CHEMBL1968394 & 809236 & 3.0 & 4.3969 & TRN \\
\hline CHEMBL1988163 & 809236 & 7.8 & 7.5582 & TRN \\
\hline CHEMBL1980671 & 809236 & 6.0 & 4.9907 & TRN \\
\hline CHEMBL2006493 & 809236 & 4.1 & 4.3216 & TST \\
\hline CHEMBL1996923 & 809236 & 4.1 & 4.2179 & TST \\
\hline CHEMBL1969735 & 809236 & 4.1 & 4.2136 & TRN \\
\hline CHEMBL 2003524 & 809236 & 5.7 & 5.3712 & TST \\
\hline CHEMBL 2002649 & 809236 & 6.0 & 6.5868 & TRN \\
\hline CHEMBL1989423 & 809236 & 3.3 & 3.7376 & TST \\
\hline CHEMBL1985367 & 809236 & 5.8 & 4.9129 & TST \\
\hline CHEMBL1994321 & 809236 & 8.1 & 8.4208 & TRN \\
\hline CHEMBL1978562 & 809236 & 4.6 & 6.3525 & TST \\
\hline CHEMBL1964307 & 809236 & 7.8 & 7.2957 & TRN \\
\hline CHEMBL1989471 & 809236 & 6.9 & 5.6606 & TST \\
\hline CHEMBL1991095 & 809236 & 4.0 & 5.0651 & TRN \\
\hline CHEMBL 2000508 & 809236 & 4.1 & 4.3315 & TRN \\
\hline CHEMBL1971694 & 809236 & 4.1 & 4.5423 & TST \\
\hline CHEMBL 2005824 & 809236 & 6.1 & 6.6853 & TRN \\
\hline CHEMBL1978195 & 809236 & 6.3 & 5.1828 & TRN \\
\hline CHEMBL1994361 & 809236 & 4.1 & 3.9357 & TRN \\
\hline CHEMBL1986603 & 809236 & 4.1 & 4.3204 & TST \\
\hline CHEMBL1977148 & 809236 & 7.5 & 8.2454 & TRN \\
\hline CHEMBL1966842 & 809236 & 5.8 & 6.3934 & TRN \\
\hline CHEMBL 2003286 & 809236 & 4.1 & 4.205 & TRN \\
\hline CHEMBL 2002165 & 809236 & 8.3 & 8.359 & TRN \\
\hline CHEMBL1979318 & 809236 & 5.5 & 4.4693 & TRN \\
\hline CHEMBL206382 & 809236 & 4.1 & 4.0116 & TRN \\
\hline CHEMBL127898 & 809236 & 4.1 & 4.3326 & TST \\
\hline CHEMBL519697 & 809236 & 4.1 & 4.7955 & TST \\
\hline CHEMBL1977619 & 809236 & 3.1 & 3.8767 & TST \\
\hline CHEMBL1996345 & 809236 & 4.6 & 5.1495 & TST \\
\hline CHEMBL1975128 & 809236 & 5.4 & 5.1289 & TRN \\
\hline CHEMBL1970369 & 809236 & 4.1 & 4.2665 & TRN \\
\hline CHEMBL1965033 & 809236 & 4.6 & 6.1746 & TRN \\
\hline CHEMBL 2001485 & 809236 & 7.4 & 8.0192 & TRN \\
\hline CHEMBL504950 & 809236 & 5.4 & 4.8285 & TRN \\
\hline CHEMBL1966425 & 809236 & 4.1 & 5.1928 & TRN \\
\hline
\end{tabular}




\begin{tabular}{|c|c|c|c|c|c|}
\hline \\
\hline CHEMBL1988608 & 809236 & 5.1 & 4.4483 & TRN & \\
\hline CHEMBL184847 & 809236 & 4.1 & 5.9611 & TRN & \\
\hline CHEMBL178737 & 809236 & 4.1 & 4.1953 & TST & \\
\hline CHEMBL226898 & 809236 & 4.1 & 4.6698 & TRN & \\
\hline CHEMBL1982563 & 809236 & 4.1 & 4.1586 & TRN & \\
\hline CHEMBL539474 & 809236 & 4.1 & 5.0544 & TST & \\
\hline CHEMBL575824 & 809236 & 4.1 & 4.2975 & TRN & \\
\hline CHEMBL1988387 & 809236 & 8.1 & 8.5268 & TRN & \\
\hline CHEMBL1973868 & 809236 & 4.6 & 4.3325 & TRN & \\
\hline CHEMBL1989708 & 809236 & 8.1 & 8.3266 & TRN & \\
\hline CHEMBL1986970 & 809236 & 4.1 & 4.4508 & TRN & \\
\hline CHEMBL1958401 & 809236 & 4.1 & 4.6501 & TRN & \\
\hline CHEMBL1984044 & 809236 & 5.3 & 4.8509 & TRN & \\
\hline CHEMBL1982700 & 809236 & 4.6 & 4.5642 & TST & \\
\hline CHEMBL1980521 & 809236 & 5.9 & 5.3021 & TST & \\
\hline CHEMBL326282 & 809236 & 4.1 & 4.3334 & TST & \\
\hline CHEMBL1992732 & 809236 & 4.1 & 4.2363 & TST & \\
\hline CHEMBL1971186 & 809236 & 4.1 & 4.28100 & 0000000001 & TRN \\
\hline CHEMBL 2003482 & 809236 & 4.1 & 4.2068 & TRN & \\
\hline CHEMBL1976872 & 809236 & 3.2 & 3.5561 & TRN & \\
\hline CHEMBL1969156 & 809236 & 4.3 & 4.4996 & TRN & \\
\hline CHEMBL1973211 & 809236 & 8.0 & 8.5211 & TRN & \\
\hline CHEMBL1999120 & 809236 & 3.0 & 4.5528 & TST & \\
\hline CHEMBL1976134 & 809236 & 6.6 & 5.9501 & TRN & \\
\hline CHEMBL1965131 & 809236 & 5.7 & 5.4369 & TRN & \\
\hline CHEMBL1981215 & 809236 & 4.8 & 4.7754 & TRN & \\
\hline CHEMBL1974457 & 809236 & 5.1 & 5.1759 & TRN & \\
\hline CHEMBL 2006580 & 809236 & 5.1 & 4.9651 & TRN & \\
\hline CHEMBL2001228 & 809236 & 6.7 & 5.6827 & TRN & \\
\hline CHEMBL2006581 & 809236 & 4.1 & 4.43199 & 99999999995 & TRN \\
\hline CHEMBL1979855 & 809236 & 4.1 & 4.4539 & TRN & \\
\hline CHEMBL1970340 & 809236 & 5.1 & 4.9754 & TRN & \\
\hline CHEMBL 2005186 & 809236 & 4.1 & 4.4514 & TRN & \\
\hline CHEMBL1995927 & 809236 & 4.1 & 4.327 & TST & \\
\hline CHEMBL 2006450 & 809236 & 4.6 & 4.7533 & TRN & \\
\hline CHEMBL2001987 & 809236 & 4.6 & 4.5675 & TRN & \\
\hline CHEMBL1994555 & 809236 & 5.9 & 5.1557 & TST & \\
\hline CHEMBL1997023 & 809236 & 4.1 & 4.3294 & TST & \\
\hline CHEMBL1971943 & 809236 & 4.6 & 5.2335 & TRN & \\
\hline CHEMBL1987334 & 809236 & 6.9 & 5.2618 & TRN & \\
\hline CHEMBL1997924 & 809236 & 7.5 & 6.8282 & TRN & \\
\hline CHEMBL1969049 & 809236 & 4.1 & 4.3033 & TRN & \\
\hline CHEMBL2005828 & 809236 & 7.6 & 7.2197 & TRN & \\
\hline CHEMBL1982388 & 809236 & 5.4 & 5.1554 & TST & \\
\hline CHEMBL1998611 & 809236 & 5.8 & 5.2831 & TRN & \\
\hline CHEMBL1975900 & 809236 & 4.1 & 4.2743 & TRN & \\
\hline CHEMBL 255822 & 809236 & 4.1 & 4.2012 & TRN & \\
\hline CHEMBL2006778 & 809236 & 8.2 & 8.9284 & TST & \\
\hline
\end{tabular}




\begin{tabular}{|c|c|c|c|c|}
\hline & & & $=111$ & al Tab \\
\hline CHEMBL 378627 & 809236 & 4.1 & 4.065 & TST \\
\hline CHEMBL1996979 & 809236 & 5.6 & 4.4011 & TST \\
\hline CHEMBL1997025 & 809236 & 4.1 & 4.9943 & TST \\
\hline CHEMBL1968406 & 809236 & 7.5 & 7.3008 & TST \\
\hline CHEMBL1966411 & 809236 & 5.8 & 5.2467 & TST \\
\hline CHEMBL1975921 & 809236 & 4.7 & 4.5515 & TST \\
\hline CHEMBL1975923 & 809236 & 4.9 & 4.9808 & TST \\
\hline CHEMBL 2005449 & 809236 & 6.7 & 6.2405 & TST \\
\hline CHEMBL 2006010 & 809236 & 4.1 & 4.4963 & TST \\
\hline CHEMBL1682558 & 809236 & 4.1 & 4.4499 & TST \\
\hline CHEMBL1990496 & 809236 & 4.4 & \multicolumn{2}{|c|}{4.1819999999999995} \\
\hline CHEMBL1993166 & 809236 & 4.1 & 4.2624 & TST \\
\hline CHEMBL1967094 & 809236 & 6.2 & 6.5282 & TST \\
\hline CHEMBL 2003341 & 809236 & 4.1 & 4.2443 & TST \\
\hline CHEMBL1992645 & 809236 & 4.1 & 4.6902 & TST \\
\hline CHEMBL 2000746 & 809236 & 5.4 & 4.4661 & TST \\
\hline CHEMBL1998110 & 809236 & 4.6 & 4.2209 & TST \\
\hline CHEMBL1999590 & 809236 & 5.4 & 4.1316 & TST \\
\hline CHEMBL1981079 & 809236 & 4.1 & 4.4704 & TST \\
\hline CHEMBL1980489 & 809236 & 4.1 & 4.6201 & TST \\
\hline CHEMBL 2000832 & 809236 & 5.2 & 4.9186 & TST \\
\hline CHEMBL1967116 & 809236 & 8.5 & 8.4312 & TST \\
\hline CHEMBL1972454 & 809236 & 3.0 & 4.3355 & TST \\
\hline CHEMBL1990590 & 809236 & 4.6 & 4.6226 & TST \\
\hline CHEMBL1977814 & 809236 & 4.3 & 4.5957 & TST \\
\hline CHEMBL513846 & 809236 & 4.1 & 4.7089 & TST \\
\hline CHEMBL1974617 & 809236 & 5.1 & 3.9721 & TST \\
\hline CHEMBL1998112 & 809236 & 7.1 & 5.2382 & TST \\
\hline CHEMBL1993996 & 809236 & 8.8 & 8.9144 & TST \\
\hline CHEMBL1969126 & 809236 & 4.1 & 4.5772 & TST \\
\hline CHEMBL1980896 & 809236 & 6.2 & 6.7997 & TST \\
\hline CHEMBL1975208 & 809236 & 4.1 & 4.3361 & TST \\
\hline CHEMBL1991429 & 809236 & 7.7 & 7.6622 & TST \\
\hline CHEMBL1971149 & 809236 & 4.1 & 4.1617 & TST \\
\hline CHEMBL1999714 & 809236 & 4.1 & 4.018 & TST \\
\hline CHEMBL1994040 & 809236 & 4.1 & 4.0902 & TST \\
\hline CHEMBL 388978 & 809236 & 8.2 & 8.5839 & TST \\
\hline CHEMBL1969834 & 809236 & 7.9 & 6.0204 & TST \\
\hline CHEMBL 2004716 & 809236 & 8.3 & 8.8815 & TST \\
\hline CHEMBL1975233 & 809236 & 4.1 & 5.188 & TST \\
\hline CHEMBL1421720 & 809236 & 4.6 & 4.8318 & TST \\
\hline CHEMBL1982135 & 809236 & 5.8 & 5.8124 & TST \\
\hline CHEMBL1976090 & 809236 & 5.9 & 5.0621 & TST \\
\hline CHEMBL 2004771 & 809236 & 6.1 & 5.4209 & TST \\
\hline CHEMBL1992922 & 809236 & 5.8 & 4.7971 & TST \\
\hline CHEMBL1997597 & 809236 & 4.1 & 4.3737 & TST \\
\hline CHEMBL1996539 & 809236 & 4.3 & 5.1666 & TST \\
\hline CHEMBL1976093 & 809236 & 4.1 & 4.1123 & TST \\
\hline
\end{tabular}




\begin{tabular}{|c|c|c|c|c|}
\hline \multicolumn{5}{|c|}{ Supplemental Table S2.txt } \\
\hline CHEMBL1996543 & 809236 & 4.1 & 4.0619 & TST \\
\hline CHEMBL1975256 & 809236 & 4.1 & 4.1851 & TST \\
\hline CHEMBL1949855 & 809236 & 3.1 & 4.2967 & TST \\
\hline CHEMBL1999126 & 809236 & 4.1 & 4.3052 & TST \\
\hline CHEMBL1997503 & 809236 & 4.1 & 4.9529 & TST \\
\hline CHEMBL116070 & 809236 & 4.1 & 4.936 & TST \\
\hline CHEMBL1990821 & 809236 & 4.1 & 4.1871 & TST \\
\hline CHEMBL 213537 & 404671 & 7.0 & 8.2199 & TRN \\
\hline CHEMBL211531 & 404671 & 7.1549 & 8.1644 & TST \\
\hline CHEMBL213406 & 404671 & 9.3979 & 8.8257 & TRN \\
\hline CHEMBL213731 & 404671 & 9.3979 & 8.4224 & TRN \\
\hline CHEMBL386782 & 404671 & 9.0 & 9.19 & TRN \\
\hline CHEMBL424702 & 404671 & 9.3979 & 9.4687 & TRN \\
\hline CHEMBL211530 & 404671 & 10.0 & 8.2869 & TRN \\
\hline CHEMBL426694 & 404671 & 9.0 & 8.7781 & TRN \\
\hline CHEMBL386576 & 404671 & 9.3979 & 9.2309 & TRN \\
\hline CHEMBL211987 & 404671 & 8.3979 & 9.1057 & TRN \\
\hline CHEMBL211305 & 404671 & 9.0 & 8.7924 & TRN \\
\hline CHEMBL210172 & 404671 & 8.699 & 9.2605 & TRN \\
\hline CHEMBL215972 & 404671 & 4.0 & 7.5941 & TST \\
\hline CHEMBL215922 & 404671 & 8.0969 & 8.5078 & TRN \\
\hline CHEMBL214231 & 404671 & 9.301 & 9.4741 & TRN \\
\hline CHEMBL 380180 & 404671 & 9.0969 & 9.155 & TRN \\
\hline CHEMBL 379626 & 404671 & 9.1549 & 9.6724 & TRN \\
\hline CHEMBL214249 & 404671 & 9.2218 & 8.8223 & TRN \\
\hline CHEMBL211988 & 404671 & 5.6383 & 7.2517 & TRN \\
\hline CHEMBL 387097 & 404671 & 8.5229 & 8.16 & TRN \\
\hline CHEMBL378322 & 404671 & 9.2218 & 9.4973 & TST \\
\hline CHEMBL 386554 & 404671 & 9.301 & 9.5351 & TRN \\
\hline CHEMBL 378320 & 404671 & 8.301 & 7.9011 & TRN \\
\hline CHEMBL377047 & 404671 & 8.0969 & 8.1537 & TRN \\
\hline CHEMBL 211565 & 404671 & 9.0 & 9.5238 & TST \\
\hline CHEMBL213535 & 404671 & 9.699 & 9.753 & TRN \\
\hline CHEMBL 378245 & 404671 & 9.1549 & 8.6979 & TRN \\
\hline CHEMBL384624 & 404671 & 5.2218 & 6.8207 & TRN \\
\hline CHEMBL210112 & 404671 & 9.0 & 9.0871 & TRN \\
\hline CHEMBL 386702 & 404671 & 9.0 & 8.6015 & TRN \\
\hline CHEMBL215534 & 404671 & 8.1549 & 8.2579 & TST \\
\hline CHEMBL 379078 & 404671 & 6.8539 & 8.1447 & TRN \\
\hline CHEMBL385586 & 404671 & 9.301 & 9.7263 & TRN \\
\hline CHEMBL212387 & 404671 & 8.699 & 9.2433 & TRN \\
\hline CHEMBL441852 & 404671 & 9.0458 & 8.0487 & TRN \\
\hline CHEMBL411713 & 404671 & 8.2218 & 8.8087 & TRN \\
\hline CHEMBL 213740 & 404671 & 9.3979 & 8.2176 & TRN \\
\hline CHEMBL215720 & 404671 & 9.699 & 7.9963 & TRN \\
\hline CHEMBL426328 & 404671 & 9.5229 & 9.412 & TST \\
\hline CHEMBL 378172 & 404671 & 9.1549 & 9.4747 & TST \\
\hline CHEMBL212806 & 404671 & 9.0969 & 9.4142 & TRN \\
\hline
\end{tabular}




\begin{tabular}{|c|c|c|c|c|}
\hline & & & oplement & al $\mathrm{T}$ \\
\hline CHEMBL 213701 & 404671 & 9.301 & 7.8118 & TST \\
\hline CHEMBL 215937 & 404671 & 8.3979 & 8.5401 & TRN \\
\hline CHEMBL213309 & 404671 & 9.301 & 8.8838 & TRN \\
\hline CHEMBL 211418 & 404671 & 6.3979 & 8.2302 & TST \\
\hline CHEMBL209529 & 404671 & 9.5229 & 8.9635 & TST \\
\hline CHEMBL 214490 & 404671 & 8.699 & 9.1268 & TRN \\
\hline CHEMBL 214058 & 404671 & 7.7212 & 7.2771 & TRN \\
\hline CHEMBL387091 & 404671 & 9.2218 & 8.6635 & TRN \\
\hline CHEMBL214797 & 404671 & 6.585 & 7.2858 & TRN \\
\hline CHEMBL 377331 & 404671 & 10.0 & 8.3823 & TRN \\
\hline CHEMBL425061 & 404671 & 9.0 & 8.7472 & TRN \\
\hline CHEMBL 378701 & 404671 & 10.0 & 8.4286 & TRN \\
\hline CHEMBL385053 & 404671 & 9.0 & 8.7414 & TRN \\
\hline CHEMBL 212970 & 404671 & 7.0 & 7.9193 & TRN \\
\hline CHEMBL209950 & 404671 & 9.301 & 8.9521 & TST \\
\hline CHEMBL213182 & 404671 & 8.3979 & 9.165 & TRN \\
\hline CHEMBL214191 & 404671 & 4.0 & 8.9443 & TST \\
\hline CHEMBL 378755 & 404671 & 9.0 & 9.4229 & TST \\
\hline CHEMBL211935 & 404671 & 9.3979 & 9.3112 & TRN \\
\hline CHEMBL214589 & 404671 & 9.0 & 8.6696 & TRN \\
\hline CHEMBL451253 & 404671 & 9.0 & 8.8485 & TRN \\
\hline CHEMBL 213900 & 404671 & 9.0969 & 9.165 & TRN \\
\hline CHEMBL 214232 & 404671 & 9.301 & 9.2719 & TST \\
\hline CHEMBL 384758 & 404671 & 5.9586 & 8.9616 & TST \\
\hline CHEMBL386498 & 404671 & 9.301 & 9.0417 & TRN \\
\hline CHEMBL 209949 & 404671 & 9.0 & 9.6066 & TRN \\
\hline CHEMBL 380063 & 404671 & 8.5229 & 8.8856 & TST \\
\hline CHEMBL 214306 & 404671 & 8.699 & 8.7431 & TRN \\
\hline CHEMBL 212840 & 404671 & 7.2366 & 8.0781 & TST \\
\hline CHEMBL 214060 & 404671 & 9.0969 & 9.1367 & TST \\
\hline CHEMBL 213333 & 404671 & 9.2218 & 9.4298 & TRN \\
\hline CHEMBL 379857 & 404671 & 9.0 & 9.0347 & TST \\
\hline CHEMBL 215921 & 404671 & 6.9586 & 7.5083 & TRN \\
\hline CHEMBL438252 & 404671 & 9.0 & 9.2107 & TRN \\
\hline CHEMBL 212343 & 404671 & 9.2218 & 9.1856 & TRN \\
\hline CHEMBL215408 & 404671 & 7.2218 & 8.463 & TST \\
\hline CHEMBL214196 & 404671 & 8.1549 & 9.0454 & TST \\
\hline CHEMBL 386781 & 404671 & 8.5229 & 8.8472 & TRN \\
\hline CHEMBL213794 & 404671 & 9.1549 & 9.4372 & TRN \\
\hline CHEMBL209898 & 404671 & 10.0 & 9.7703 & TRN \\
\hline CHEMBL79050 & 28185 & 5.7447 & 5.9385 & TRN \\
\hline CHEMBL 81910 & 28185 & 7.0132 & 6.4645 & TST \\
\hline CHEMBL310147 & 28185 & 6.1249 & 6.15 & TRN \\
\hline CHEMBL79936 & 28185 & 4.301 & 4.7395 & TRN \\
\hline CHEMBL80134 & 28185 & 6.4089 & 6.4089 & TRN \\
\hline CHEMBL79170 & 28185 & 4.301 & 4.1565 & TRN \\
\hline CHEMBL 76835 & 28185 & 7.301 & 7.3122 & TRN \\
\hline CHEMBL80753 & 28185 & 4.301 & 4.5033 & TRN \\
\hline
\end{tabular}




\begin{tabular}{|c|c|c|c|c|}
\hline & & & oplement & al Ta \\
\hline CHEMBL79179 & 28185 & 7.2366 & 7.4073 & TRN \\
\hline CHEMBL77339 & 28185 & 8.0458 & 7.3122 & TRN \\
\hline CHEMBL79163 & 28185 & 7.2757 & 7.3122 & TRN \\
\hline CHEMBL309560 & 28185 & 8.0969 & 8.0109 & TRN \\
\hline CHEMBL 309744 & 28185 & 7.3372 & 6.4089 & TRN \\
\hline CHEMBL77443 & 28185 & 5.9747 & 6.0923 & TRN \\
\hline CHEMBL80805 & 28185 & 5.0 & 4.7716 & TRN \\
\hline CHEMBL 78754 & 28185 & 6.6021 & 7.3122 & TRN \\
\hline CHEMBL81537 & 28185 & 6.6021 & 6.5569 & TST \\
\hline CHEMBL78829 & 28185 & 7.3098 & 7.4073 & TRN \\
\hline CHEMBL309297 & 28185 & 5.1675 & 6.4089 & TRN \\
\hline CHEMBL80332 & 28185 & 8.0 & 7.3122 & TRN \\
\hline CHEMBL 80752 & 28185 & 6.3565 & 6.2651 & TRN \\
\hline CHEMBL80281 & 28185 & 6.7696 & 7.0744 & TRN \\
\hline CHEMBL 80720 & 28185 & 6.3279 & 6.2359 & TRN \\
\hline CHEMBL 78833 & 28185 & 7.6778 & 7.7247 & TRN \\
\hline CHEMBL311438 & 28185 & 7.1308 & 7.3122 & TRN \\
\hline CHEMBL78506 & 28185 & 5.7696 & 5.8403 & TRN \\
\hline CHEMBL 80131 & 28185 & 4.301 & 4.888 & TRN \\
\hline CHEMBL439763 & 28185 & 7.699 & 7.6163 & TRN \\
\hline CHEMBL80697 & 28185 & 4.301 & 6.7388 & TST \\
\hline CHEMBL 78384 & 28185 & 6.8539 & 7.3122 & TRN \\
\hline CHEMBL 80951 & 28185 & 5.0 & 5.3759 & TRN \\
\hline CHEMBL430621 & 28185 & 6.3565 & 6.32 & TRN \\
\hline CHEMBL309867 & 28185 & 6.0458 & 5.8747 & TST \\
\hline CHEMBL421700 & 28185 & 5.1079 & 5.5292 & TRN \\
\hline CHEMBL80570 & 28185 & 5.0 & 4.8876 & TRN \\
\hline CHEMBL78626 & 28185 & 6.4559 & 6.4089 & TRN \\
\hline CHEMBL 78142 & 28185 & 6.9208 & 6.3508 & TRN \\
\hline CHEMBL441992 & 28185 & 6.4559 & 6.2465 & TRN \\
\hline CHEMBL312501 & 28185 & 6.4559 & 6.1925 & TRN \\
\hline CHEMBL78394 & 28185 & 7.0132 & 7.4073 & TRN \\
\hline CHEMBL 79147 & 28185 & 7.1612 & 6.9377 & TRN \\
\hline CHEMBL80887 & 28185 & 4.301 & 2.1728 & TST \\
\hline CHEMBL77900 & 28185 & 6.1249 & 6.4089 & TRN \\
\hline CHEMBL 78717 & 28185 & 6.8861 & 7.2098 & TRN \\
\hline CHEMBL80201 & 28185 & 5.9208 & 5.3372 & TST \\
\hline CHEMBL 80841 & 28185 & 7.6778 & 7.3122 & TRN \\
\hline CHEMBL310909 & 28185 & 6.4685 & 6.2633 & TRN \\
\hline CHEMBL309442 & 28185 & 5.0 & 4.5633 & TRN \\
\hline CHEMBL 79146 & 28185 & 5.983 & 5.7355 & TRN \\
\hline CHEMBL311427 & 28185 & 6.0555 & 6.4851 & TRN \\
\hline CHEMBL312412 & 28185 & 6.6383 & 5.5224 & TST \\
\hline CHEMBL 80825 & 28185 & 7.1938 & 7.1112 & TRN \\
\hline CHEMBL77841 & 28185 & 6.6778 & 7.2098 & TRN \\
\hline CHEMBL312643 & 28185 & 4.301 & 4.2405 & TRN \\
\hline CHEMBL 78577 & 28185 & 7.7959 & 7.2098 & TRN \\
\hline CHEMBL 78361 & 28185 & 6.9586 & 6.2395 & TRN \\
\hline
\end{tabular}




\begin{tabular}{|c|c|c|c|c|c|}
\hline & & \multicolumn{4}{|c|}{ Supplemental Table s2.txt } \\
\hline CHEMBL80818 & 28185 & 7.1135 & 7.0361 & TRN & \\
\hline CHEMBL312795 & 28185 & 4.301 & 4.5735 & TRN & \\
\hline CHEMBL421320 & 28185 & 5.4949 & 4.9629 & TRN & \\
\hline CHEMBL78193 & 28185 & 6.7959 & 7.2098 & TRN & \\
\hline CHEMBL80561 & 28185 & 6.0506 & 5.9221 & TRN & \\
\hline CHEMBL309676 & 28185 & 7.7696 & 7.4073 & TRN & \\
\hline CHEMBL 78948 & 28185 & 6.7959 & 5.1952 & TST & \\
\hline CHEMBL78581 & 28185 & 4.301 & 5.1878 & TST & \\
\hline CHEMBL431783 & 28185 & 6.6021 & 5.5568 & TST & \\
\hline CHEMBL78522 & 28185 & 5.4318 & 6.9756 & TST & \\
\hline CHEMBL431003 & 28185 & 6.0269 & 6.1276 & TST & \\
\hline CHEMBL80836 & 28185 & 7.1871 & 6.7557 & TST & \\
\hline CHEMBL 78143 & 28185 & 6.0088 & 6.4677 & TST & \\
\hline CHEMBL312356 & 28185 & 6.0506 & 5.1883 & TST & \\
\hline CHEMBL79600 & 28185 & 6.1805 & 6.9391 & TST & \\
\hline CHEMBL 78542 & 28185 & 6.5686 & 7.4073 & TST & \\
\hline CHEMBL78828 & 28185 & 5.7212 & 4.7712 & TST & \\
\hline CHEMBL76951 & 28185 & 6.0 & 7.3122 & TST & \\
\hline CHEMBL1684636 & 899886 & 4.3678 & 4.3729 & TRN & \\
\hline CHEMBL1684756 & 899886 & 5.4001 & 5.2052 & TST & \\
\hline CHEMBL 2237905 & 899886 & 5.7471 & 5.7405 & TRN & \\
\hline CHEMBL2237903 & 899886 & 5.0057 & 5.0104 & TRN & \\
\hline CHEMBL1684777 & 899886 & 4.6323 & 4.6856 & TRN & \\
\hline CHEMBL 2237896 & 899886 & 5.4737 & 5.4661 & TRN & \\
\hline CHEMBL1684779 & 899886 & 4.909 & 4.8788 & TRN & \\
\hline CHEMBL1209915 & 899886 & 4.8049 & 4.8233 & TRN & \\
\hline CHEMBL1684765 & 899886 & 4.5364 & 4.569 & TRN & \\
\hline CHEMBL 2237898 & 899886 & 6.1739 & 6.1903 & TST & \\
\hline CHEMBL1684766 & 899886 & 4.5547 & 4.4241 & TST & \\
\hline CHEMBL2237893 & 899886 & 5.0 & 5.4027 & TST & \\
\hline CHEMBL1684753 & 899886 & 5.4023 & 5.3967 & TRN & \\
\hline CHEMBL1684771 & 899886 & 4.8401 & 4.7943 & TRN & \\
\hline CHEMBL1684642 & 899886 & 5.1029 & 5.1232 & TRN & \\
\hline CHEMBL2237895 & 899886 & 5.8069 & 5.92899 & 9999999999 & TST \\
\hline CHEMBL1684773 & 899886 & 4.927 & 4.9698 & TRN & \\
\hline CHEMBL1684641 & 899886 & 5.0048 & 5.0147 & TRN & \\
\hline CHEMBL1684754 & 899886 & 5.3019 & 5.303 & TRN & \\
\hline CHEMBL2237655 & 899886 & 4.7642 & 5.2206 & TST & \\
\hline CHEMBL1684761 & 899886 & 5.7496 & 5.7198 & TRN & \\
\hline CHEMBL1684763 & 899886 & 5.71899 & 99999999 & 5.7342 & TRN \\
\hline CHEMBL1684644 & 899886 & 5.2062 & 5.2032 & TRN & \\
\hline CHEMBL1684758 & 899886 & 5.7747 & 5.8276 & TRN & \\
\hline CHEMBL2237894 & 899886 & 5.4841 & 5.4496 & TST & \\
\hline CHEMBL1209917 & 899886 & 4.6492 & 4.6572 & TRN & \\
\hline CHEMBL1684635 & 899886 & 5.015 & 5.0026 & TRN & \\
\hline CHEMBL 2237892 & 899886 & 4.574 & 4.92899 & 9999999999 & TST \\
\hline CHEMBL1449501 & 899886 & 4.3208 & 4.3328 & TRN & \\
\hline CHEMBL562142 & 899886 & 5.3478 & 5.3408 & TRN & \\
\hline
\end{tabular}


Supplemental Table S2.txt

\begin{tabular}{|c|c|c|c|c|}
\hline 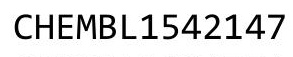 & & & & \\
\hline HEMBL1684774 & 886 & 057 & & \\
\hline AEMBL1684759 & 886 & 125 & 200 & \\
\hline AEMBL16 & 386 & 278 & & \\
\hline IEMBL2237654 & 386 & 212 & & \\
\hline AEMBL1684640 & 99886 & 3404 & 3369 & \\
\hline AEMBL1684643 & 399886 & 5.1772 & 1923 & \\
\hline HEMBL 223 & & 851 & & \\
\hline HEMBL 223 & 86 & 969 & & \\
\hline AEMBL1684772 & & 929 & & \\
\hline AEMBL1684751 & 399886 & 5.1101 & $\partial 931$ & \\
\hline AEMBL1353302 & 86 & 4.5364 & & \\
\hline AEMBL1684764 & 86 & 686 & 96 & \\
\hline HEMBL 168 & & 102 & & \\
\hline HEMBL 168 & & $\partial 29$ & & \\
\hline AEMBL1684638 & 386 & 711 & 17 & \\
\hline AEMBL2237899 & & & & \\
\hline AEMBL1684 & 36 & 4. & 96 & \\
\hline HEMBL168 & & & & \\
\hline HEMBL168 & & & & \\
\hline AEMBL 2237 & 86 & 86 & 21 & \\
\hline HEMBL1684 & & & & \\
\hline HEMBL168 & 36 & & & \\
\hline JEMBL16 & & & & \\
\hline JEMBL12 & & & & \\
\hline AEMBL1684 & & & & \\
\hline HEMBL2237 & & & & \\
\hline AEMBL 223 & & & & \\
\hline AEMBL 22 & & & & \\
\hline$H F M$ & & 55 & 81 & \\
\hline AEMBL 2237 & & & & \\
\hline HEMBL1684762 & 89 & & 528 & \\
\hline 6 & 36 & & & \\
\hline 8 & & & & \\
\hline HEMBL 1684 & & & & RN \\
\hline HEMBL1684778 & 899 & & & ST \\
\hline AEMBL3413 & & & & \\
\hline & & & & \\
\hline 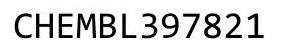 & & & & \\
\hline HEMBL 344706 & & & & RN \\
\hline AEMBL335950 & 131 & & & $\mathrm{R}$ \\
\hline HEMBL315150 & 31 & & & IK \\
\hline 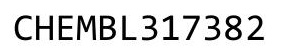 & & & 125 & \\
\hline CHEMBL138332 & & & & \\
\hline HEMBL 209943 & & 8.5376 & .4159 & RN \\
\hline HEMBL6527 & 744131 & 9.2218 & 9.2125 & TR \\
\hline MBL135 & & & & \\
\hline HEMBL16508 & & & .5579 & \\
\hline
\end{tabular}

Page 7223 


\begin{tabular}{|c|c|c|c|c|c|}
\hline \multirow[b]{2}{*}{ CHEMBL236958 } & \multicolumn{5}{|c|}{ Supplemental Table S2.txt } \\
\hline & 744131 & 7.4609 & 6.6085 & TST & \\
\hline CHEMBL134566 & 744131 & 6.9172 & 7.0725 & TRN & \\
\hline CHEMBL211713 & 744131 & 7.0 & 6.9724 & TRN & \\
\hline CHEMBL179638 & 744131 & 7.1871 & 7.1652 & TRN & \\
\hline CHEMBL353299 & 744131 & 8.6021 & 8.6284 & TRN & \\
\hline CHEMBL164867 & 744131 & 7.3979 & 7.381 & TRN & \\
\hline CHEMBL165910 & 744131 & 9.1871 & 9.1974 & TRN & \\
\hline CHEMBL16488 & 744131 & 8.8327 & 8.8769 & TRN & \\
\hline CHEMBL165224 & 744131 & 9.6198 & 9.6129 & TRN & \\
\hline CHEMBL16254 & 744131 & 6.5591 & 6.5268 & TRN & \\
\hline CHEMBL276321 & 744131 & 7.5607 & 5.8123 & TST & \\
\hline CHEMBL324735 & 744131 & 9.7959 & 9.7993 & TRN & \\
\hline CHEMBL177524 & 744131 & 7.1871 & 7.2724 & TRN & \\
\hline CHEMBL348925 & 744131 & 9.3372 & 9.3397 & TRN & \\
\hline CHEMBL350830 & 744131 & 9.041 & 9.0538 & TRN & \\
\hline CHEMBL1771603 & 744131 & 11.0 & 11.0484 & TRN & \\
\hline CHEMBL273578 & 744131 & 7.3161 & 6.7773 & TST & \\
\hline CHEMBL1770311 & 744131 & 8.0716 & 8.0566 & TRN & \\
\hline CHEMBL473650 & 744131 & 7.153 & 7.1 & TRN & \\
\hline CHEMBL352796 & 744131 & 9.7447 & 9.7469 & TRN & \\
\hline CHEMBL322983 & 744131 & 8.6778 & 9.0514 & TST & \\
\hline CHEMBL16687 & 744131 & 7.8601 & 6.9356 & TST & \\
\hline CHEMBL474977 & 744131 & 6.8013 & 6.7586 & TST & \\
\hline CHEMBL354161 & 744131 & 9.3665 & 9.384 & TRN & \\
\hline CHEMBL330286 & 744131 & 9.4949 & 9.4984 & TRN & \\
\hline CHEMBL16643 & 744131 & 6.8041 & 7.1453 & TST & \\
\hline CHEMBL105913 & 744131 & 7.0448 & 6.7701 & TST & \\
\hline CHEMBL137879 & 744131 & 6.4802 & 6.4825 & TRN & \\
\hline CHEMBL16416 & 744131 & 7.3439 & 6.6785 & TST & \\
\hline CHEMBL141154 & 744131 & 8.7959 & 8.8 & TRN & \\
\hline CHEMBL168018 & 744131 & 9.8239 & 9.8299 & TRN & \\
\hline CHEMBL16715 & 744131 & 7.251 & 5.57100 & 0000000001 & TST \\
\hline CHEMBL352707 & 744131 & 8.4318 & 8.4468 & TRN & \\
\hline CHEMBL350205 & 744131 & 9.3468 & 9.3277 & TRN & \\
\hline CHEMBL16774 & 744131 & 6.76200 & 00000000 & 6.1331 & TST \\
\hline CHEMBL515433 & 744131 & 6.3098 & 6.1143 & TST & \\
\hline CHEMBL16820 & 744131 & 6.4828 & 6.8338 & TST & \\
\hline CHEMBL361412 & 744131 & 8.0458 & 7.9839 & TRN & \\
\hline CHEMBL329791 & 744131 & 9.699 & 9.7072 & TRN & \\
\hline CHEMBL175494 & 744131 & 8.3098 & 8.2188 & TRN & \\
\hline CHEMBL349464 & 744131 & 8.9957 & 8.9948 & TRN & \\
\hline CHEMBL167915 & 744131 & 9.2596 & 9.2454 & TRN & \\
\hline CHEMBL342906 & 744131 & 7.2218 & 7.2545 & TRN & \\
\hline CHEMBL165600 & 744131 & 9.4318 & 9.4175 & TRN & \\
\hline CHEMBL416537 & 744131 & 7.5452 & 6.8054 & TST & \\
\hline CHEMBL176010 & 744131 & 6.7878 & 6.8447 & TRN & \\
\hline CHEMBL 344501 & 744131 & 9.3979 & 9.3762 & TRN & \\
\hline CHEMBL423934 & 744131 & 9.2218 & 9.2133 & TRN & \\
\hline
\end{tabular}


Supplemental Table S2.txt

\begin{tabular}{|c|c|c|c|c|c|}
\hline CHEMBL435022 & 744131 & 7.301 & 7.354 & TRN & \\
\hline CHEMBL474016 & 744131 & 8.3429 & 8.4654 & TRN & \\
\hline CHEMBL138593 & 744131 & 7.3979 & 7.1096 & TRN & \\
\hline CHEMBL355415 & 744131 & 9.0915 & 9.124 & TRN & \\
\hline CHEMBL88147 & 744131 & 9.1871 & 8.9467 & TST & \\
\hline CHEMBL390407 & 744131 & 8.4685 & 8.8268 & TST & \\
\hline CHEMBL 280278 & 744131 & 7.2565 & 5.949 & TST & \\
\hline CHEMBL 235075 & 744131 & 7.2924 & 6.3508 & TST & \\
\hline CHEMBL341777 & 744131 & 6.5229 & 6.7094 & TRN & \\
\hline CHEMBL423542 & 744131 & 6.3665 & 6.3868 & TRN & \\
\hline CHEMBL16215 & 744131 & 6.0177 & 6.04 & TRN & \\
\hline CHEMBL165073 & 744131 & 8.9872 & 8.9995 & TRN & \\
\hline CHEMBL541455 & 744131 & 7.3468 & 7.2919 & TRN & \\
\hline CHEMBL324512 & 744131 & 7.6021 & \multicolumn{2}{|c|}{7.587999999999999} & TRN \\
\hline CHEMBL 280080 & 744131 & 8.426 & 8.414 & TRN & \\
\hline CHEMBL163968 & 744131 & 8.9547 & 8.9255 & TRN & \\
\hline CHEMBL166301 & 744131 & 9.5229 & 9.5218 & TRN & \\
\hline CHEMBL 274273 & 744131 & 7.8013 & 7.8692 & TRN & \\
\hline CHEMBL352192 & 744131 & 9.301 & 9.3117 & TRN & \\
\hline CHEMBL 235071 & 744131 & 6.4336 & 7.1464 & TST & \\
\hline CHEMBL342059 & 744131 & 6.5229 & 6.5041 & TRN & \\
\hline CHEMBL16894 & 744131 & 6.2218 & 6.1796 & TRN & \\
\hline CHEMBL16867 & 744131 & 6.5528 & 6.553 & TRN & \\
\hline CHEMBL3917516 & 1642274 & 8.699 & 8.5448 & TRN & \\
\hline CHEMBL 3890332 & 1642274 & 8.9586 & 9.0341 & TRN & \\
\hline CHEMBL 3907704 & 1642274 & 7.6021 & 7.6407 & TST & \\
\hline CHEMBL3936210 & 1642274 & 9.0 & 8.9478 & TRN & \\
\hline CHEMBL3967441 & 1642274 & 7.7959 & 7.9457 & TRN & \\
\hline CHEMBL3928562 & 1642274 & 8.3979 & 8.7058 & TRN & \\
\hline CHEMBL3980081 & 1642274 & 8.7447 & 8.5153 & TRN & \\
\hline CHEMBL 3903685 & 1642274 & 9.0458 & 7.8286 & TST & \\
\hline CHEMBL3949368 & 1642274 & 9.1549 & 9.1887 & TRN & \\
\hline CHEMBL3968963 & 1642274 & 8.5376 & 8.8187 & TRN & \\
\hline CHEMBL 3896264 & 1642274 & 9.0 & 8.8429 & TRN & \\
\hline CHEMBL3899917 & 1642274 & 8.8239 & 9.1385 & TRN & \\
\hline CHEMBL3956402 & 1642274 & 9.0458 & 9.166 & TRN & \\
\hline CHEMBL 3924656 & 1642274 & 8.8861 & 7.5952 & TST & \\
\hline CHEMBL3975857 & 1642274 & 8.8239 & 6.9886 & TST & \\
\hline CHEMBL 3904090 & 1642274 & 8.3468 & 8.0267 & TRN & \\
\hline CHEMBL3973511 & 1642274 & 8.9586 & 8.2628 & TST & \\
\hline CHEMBL3921483 & 1642274 & 8.7447 & 8.6979 & TRN & \\
\hline CHEMBL 3922444 & 1642274 & 9.0 & 8.5395 & TRN & \\
\hline CHEMBL3937711 & 1642274 & 9.0 & 8.5018 & TST & \\
\hline CHEMBL 3929793 & 1642274 & 8.8239 & 8.6765 & TRN & \\
\hline CHEMBL3914152 & 1642274 & 9.301 & 8.5656 & TST & \\
\hline CHEMBL 3913520 & 1642274 & 8.9208 & 8.8469 & TRN & \\
\hline CHEMBL 3963248 & 1642274 & 9.0458 & 8.9841 & TRN & \\
\hline CHEMBL3980515 & 1642274 & 8.5229 & 8.3175 & TRN & \\
\hline
\end{tabular}

Page 7225 
Supplemental Table S2.txt

\begin{tabular}{|c|c|c|c|c|}
\hline CHEMBL3965169 & 1642274 & 9.2218 & 8.3713 & TST \\
\hline CHEMBL3919654 & 1642274 & 8.4685 & 8.7181 & TRN \\
\hline CHEMBL 3980778 & 1642274 & 9.2218 & 10.3338 & TST \\
\hline CHEMBL 3927910 & 1642274 & 8.2924 & 8.3543 & TRN \\
\hline CHEMBL 3973864 & 1642274 & 7.8633 & 8.0903 & TRN \\
\hline CHEMBL 3908821 & 1642274 & 8.6383 & 8.7253 & TRN \\
\hline CHEMBL3951139 & 1642274 & 8.4437 & 8.1943 & TRN \\
\hline CHEMBL 3905150 & 1642274 & 9.301 & 9.9827 & TST \\
\hline CHEMBL3966881 & 1642274 & 8.7696 & 8.8691 & TRN \\
\hline CHEMBL 3975940 & 1642274 & 9.301 & \multicolumn{2}{|c|}{10.479000000000001} \\
\hline CHEMBL 3905704 & 1642274 & 9.2218 & 9.0594 & TRN \\
\hline CHEMBL 3951604 & 1642274 & 8.9586 & 9.11 & TRN \\
\hline CHEMBL 3957930 & 1642274 & 8.9208 & 9.1123 & TRN \\
\hline CHEMBL 3952688 & 1642274 & 8.7959 & 9.2619 & TRN \\
\hline CHEMBL 3923936 & 1642274 & 8.8861 & \multicolumn{2}{|c|}{7.9079999999999995} \\
\hline CHEMBL 3960021 & 1642274 & 8.7959 & 8.4336 & TRN \\
\hline CHEMBL3906388 & 1642274 & 8.4318 & 8.4796 & TRN \\
\hline CHEMBL 3938736 & 1642274 & 6.0 & 6.3328 & TRN \\
\hline CHEMBL3983334 & 1642274 & 8.8861 & 8.5959 & TRN \\
\hline CHEMBL 3958864 & 1642274 & 8.699 & 8.7449 & TRN \\
\hline CHEMBL3973287 & 1642274 & 9.0 & \multicolumn{2}{|c|}{8.937999999999999} \\
\hline CHEMBL3891603 & 1642274 & 8.6021 & 8.4694 & TRN \\
\hline CHEMBL 3922873 & 1642274 & 6.0 & 5.0599 & TST \\
\hline CHEMBL3950992 & 1642274 & 8.8239 & 8.9074 & TRN \\
\hline CHEMBL 3942856 & 1642274 & 9.1549 & 9.432 & TRN \\
\hline CHEMBL3957457 & 1642274 & 8.8861 & 7.8906 & TRN \\
\hline CHEMBL3985826 & 1642274 & 8.5086 & 8.4633 & TST \\
\hline CHEMBL3923801 & 1642274 & 8.8539 & \multicolumn{2}{|c|}{7.986000000000001} \\
\hline CHEMBL3922507 & 1642274 & 8.6576 & 8.5722 & TRN \\
\hline CHEMBL 3963792 & 1642274 & 6.0 & 6.8072 & TRN \\
\hline CHEMBL3896771 & 1642274 & 9.1549 & 8.8254 & TRN \\
\hline CHEMBL 3935662 & 1642274 & 9.301 & 9.1236 & TRN \\
\hline CHEMBL3980209 & 1642274 & 8.9586 & 8.8693 & TRN \\
\hline CHEMBL3943940 & 1642274 & 8.6021 & 8.6031 & TRN \\
\hline CHEMBL 3890788 & 1642274 & 8.3565 & 8.2302 & TRN \\
\hline CHEMBL3982270 & 1642274 & 9.0 & 9.2814 & TRN \\
\hline CHEMBL3949959 & 1642274 & 8.9208 & 8.0065 & TST \\
\hline CHEMBL3939580 & 1642274 & 9.0969 & 9.3746 & TRN \\
\hline CHEMBL55216 & 34827 & 7.3665 & 7.5627 & TRN \\
\hline CHEMBL 299954 & 34827 & 8.3179 & 8.2525 & TRN \\
\hline CHEMBL57677 & 34827 & 6.8962 & 6.853 & TRN \\
\hline CHEMBL55231 & 34827 & 6.6021 & 6.6268 & TRN \\
\hline CHEMBL 293495 & 34827 & 6.585 & 6.4941 & TRN \\
\hline CHEMBL57309 & 34827 & 9.0 & 8.9356 & TRN \\
\hline CHEMBL 294415 & 34827 & 9.0969 & 8.717 & TRN \\
\hline CHEMBL291329 & 34827 & 6.7878 & 6.7451 & TRN \\
\hline CHEMBL301632 & 34827 & 7.2757 & 7.1564 & TST \\
\hline CHEMBL 37679 & 34827 & 8.8386 & 8.9212 & TRN \\
\hline
\end{tabular}




\begin{tabular}{|c|c|c|c|c|c|}
\hline \multicolumn{6}{|c|}{ Supplemental Table S2.txt } \\
\hline CHEMBL291905 & 34827 & 6.3809 & 6.3317 & TRN & \\
\hline CHEMBL54696 & 34827 & 6.6383 & 6.7327 & TRN & \\
\hline CHEMBL55357 & 34827 & 7.2007 & 7.1894 & TRN & \\
\hline CHEMBL292165 & 34827 & 6.7447 & 6.7933 & TRN & \\
\hline CHEMBL55508 & 34827 & 5.3439 & 5.4081 & TRN & \\
\hline CHEMBL57335 & 34827 & 5.1337 & 5.0854 & TRN & \\
\hline CHEMBL54576 & 34827 & 6.9281 & 6.8992 & TRN & \\
\hline CHEMBL56522 & 34827 & 8.301 & 8.5296 & TRN & \\
\hline CHEMBL56497 & 34827 & 8.4815 & 8.4915 & TRN & \\
\hline CHEMBL293091 & 34827 & 9.3979 & 9.3311 & TRN & \\
\hline CHEMBL291688 & 34827 & 7.4711 & 8.1093 & TST & \\
\hline CHEMBL294686 & 34827 & 9.5229 & 9.5908 & TRN & \\
\hline CHEMBL58981 & 34827 & 6.6778 & 6.6695 & TRN & \\
\hline CHEMBL40089 & 34827 & 7.6778 & 7.6619 & TRN & \\
\hline CHEMBL54645 & 34827 & 7.8239 & 7.5968 & TRN & \\
\hline CHEMBL54421 & 34827 & 8.6021 & 8.6608 & TRN & \\
\hline CHEMBL56211 & 34827 & 9.2518 & 9.342 & TRN & \\
\hline CHEMBL54745 & 34827 & 6.3279 & 7.4249 & TST & \\
\hline CHEMBL59043 & 34827 & 7.0 & 8.3025 & TST & \\
\hline CHEMBL291466 & 34827 & 5.3215 & 5.4453 & TRN & \\
\hline CHEMBL55825 & 34827 & 5.2218 & 6.9927 & TST & \\
\hline CHEMBL54754 & 34827 & 5.8861 & 6.1232 & TRN & \\
\hline CHEMBL54459 & 34827 & 6.9101 & 6.96700 & 20000000005 & TRN \\
\hline CHEMBL 287762 & 34827 & 6.2076 & 6.2331 & TRN & \\
\hline CHEMBL55510 & 34827 & 9.2291 & 9.3053 & TRN & \\
\hline CHEMBL289543 & 34827 & 6.3565 & 6.75899 & 99999999995 & TRN \\
\hline CHEMBL55950 & 34827 & 7.5591 & 7.5341 & TRN & \\
\hline CHEMBL56085 & 34827 & 7.2218 & 7.2633 & TRN & \\
\hline CHEMBL56333 & 34827 & 8.4881 & 8.576 & TRN & \\
\hline CHEMBL54711 & 34827 & 7.6576 & 7.7012 & TRN & \\
\hline CHEMBL298897 & 34827 & 5.9851 & 5.9935 & TRN & \\
\hline CHEMBL54982 & 34827 & 7.1805 & 7.1568 & TRN & \\
\hline CHEMBL293706 & 34827 & 7.4089 & 7.4532 & TRN & \\
\hline CHEMBL 300551 & 34827 & 6.2441 & 6.3363 & TRN & \\
\hline CHEMBL293940 & 34827 & 6.5086 & 6.0963 & TRN & \\
\hline CHEMBL56574 & 34827 & 7.4559 & 7.4074 & TRN & \\
\hline CHEMBL291086 & 34827 & 7.5086 & 7.4585 & TRN & \\
\hline CHEMBL417752 & 34827 & 7.3372 & 7.0281 & TRN & \\
\hline CHEMBL56160 & 34827 & 8.3468 & 8.2887 & TRN & \\
\hline CHEMBL57622 & 34827 & 6.4078 & 6.4103 & TRN & \\
\hline CHEMBL287936 & 34827 & 7.4685 & 7.3065 & TRN & \\
\hline CHEMBL 291955 & 34827 & 8.3706 & 8.3933 & TRN & \\
\hline CHEMBL59157 & 34827 & 6.8861 & 6.0381 & TST & \\
\hline CHEMBL59094 & 34827 & 6.6055 & 7.8543 & TST & \\
\hline CHEMBL57620 & 34827 & 7.6345 & 7.9525 & TST & \\
\hline CHEMBL56167 & 34827 & 5.8962 & 6.665 & TST & \\
\hline CHEMBL 299064 & 34827 & 8.3372 & 8.4364 & TST & \\
\hline CHEMBL300566 & 34827 & 7.6778 & 9.0858 & TST & \\
\hline
\end{tabular}




\begin{tabular}{|c|c|c|c|c|c|}
\hline \multicolumn{6}{|c|}{ Supplemental Table S2.txt } \\
\hline CHEMBL56690 & 34827 & 8.1805 & 8.2372 & TST & \\
\hline CHEMBL54446 & 34827 & 7.0259 & 8.4037 & TST & \\
\hline CHEMBL 292892 & 34827 & 9.8239 & 9.1003 & TST & \\
\hline CHEMBL 39349 & 34827 & 5.2218 & 7.5641 & TST & \\
\hline CHEMBL59580 & 34827 & 7.4737 & 7.3696 & TST & \\
\hline CHEMBL1818554 & 762864 & 5.6576 & 5.6572 & TRN & \\
\hline CHEMBL1818558 & 762864 & 6.0555 & 6.0555 & TRN & \\
\hline CHEMBL1818561 & 762864 & 4.4191 & 4.4193 & TRN & \\
\hline CHEMBL1818566 & 762864 & 4.4685 & 4.4701 & TRN & \\
\hline CHEMBL1818551 & 762864 & 5.5528 & 5.5526 & TRN & \\
\hline CHEMBL1818682 & 762864 & 4.1798 & 4.1794 & TRN & \\
\hline CHEMBL1818583 & 762864 & 4.4202 & 4.4198 & TRN & \\
\hline CHEMBL1818578 & 762864 & 3.3979 & 3.3211 & TST & \\
\hline CHEMBL1818686 & 762864 & 4.6757 & 4.6769 & TRN & \\
\hline CHEMBL1428181 & 762864 & 4.5258 & 3.9842 & TST & \\
\hline CHEMBL1818679 & 762864 & 4.4377 & 4.4381 & TRN & \\
\hline CHEMBL1818572 & 762864 & 4.8729 & 4.8724 & TRN & \\
\hline CHEMBL1818573 & 762864 & 3.3979 & 3.3985 & TRN & \\
\hline CHEMBL 93224 & 762864 & 5.0655 & 5.0654 & TRN & \\
\hline CHEMBL1818557 & 762864 & 4.5544 & 4.55399 & 9999999999 & TRN \\
\hline CHEMBL1818687 & 762864 & 5.0555 & 5.0546 & TRN & \\
\hline CHEMBL1818552 & 762864 & 6.5229 & 6.5238 & TRN & \\
\hline CHEMBL1818585 & 762864 & 4.4318 & 4.4322 & TRN & \\
\hline CHEMBL1818569 & 762864 & 5.7959 & 5.7967 & TRN & \\
\hline CHEMBL1818567 & 762864 & 4.6459 & 4.6448 & TRN & \\
\hline CHEMBL1818562 & 762864 & 4.699 & 4.6983 & TRN & \\
\hline CHEMBL1818575 & 762864 & 3.3979 & 3.3984 & TRN & \\
\hline CHEMBL1818570 & 762864 & 3.3979 & 3.3978 & TRN & \\
\hline CHEMBL1818574 & 762864 & 3.3979 & 3.4586 & TST & \\
\hline CHEMBL1818565 & 762864 & 4.4789 & 4.4783 & TRN & \\
\hline CHEMBL573226 & 762864 & 3.1549 & 3.1544 & TRN & \\
\hline CHEMBL1818584 & 762864 & 3.3979 & 3.3974 & TRN & \\
\hline CHEMBL1818581 & 762864 & 3.3979 & 3.3988 & TRN & \\
\hline CHEMBL1818577 & 762864 & 3.3979 & 3.9123 & TST & \\
\hline CHEMBL1818556 & 762864 & 5.1805 & 5.1809 & TRN & \\
\hline CHEMBL1818582 & 762864 & 4.4763 & 4.476 & TRN & \\
\hline CHEMBL1818681 & 762864 & 5.0915 & 5.0914 & TRN & \\
\hline CHEMBL565269 & 762864 & 4.3979 & 4.3976 & TRN & \\
\hline CHEMBL1818685 & 762864 & 5.0969 & 5.0968 & TRN & \\
\hline CHEMBL1818550 & 762864 & 4.6478 & 4.6481 & TRN & \\
\hline CHEMBL1818563 & 762864 & 3.3979 & 3.3984 & TRN & \\
\hline CHEMBL1818579 & 762864 & 4.5513 & 4.5506 & TRN & \\
\hline CHEMBL1818684 & 762864 & 4.5003 & 4.4999 & TRN & \\
\hline CHEMBL1818576 & 762864 & 4.6536 & 4.6535 & TRN & \\
\hline CHEMBL1818564 & 762864 & 4.8153 & 3.9074 & TST & \\
\hline CHEMBL1818580 & 762864 & 4.4976 & 4.4967 & TRN & \\
\hline CHEMBL 1818560 & 762864 & 4.3979 & 4.3993 & TRN & \\
\hline CHEMBL1818571 & 762864 & 5.4089 & 5.4088 & TRN & \\
\hline
\end{tabular}


Supplemental Table S2.txt

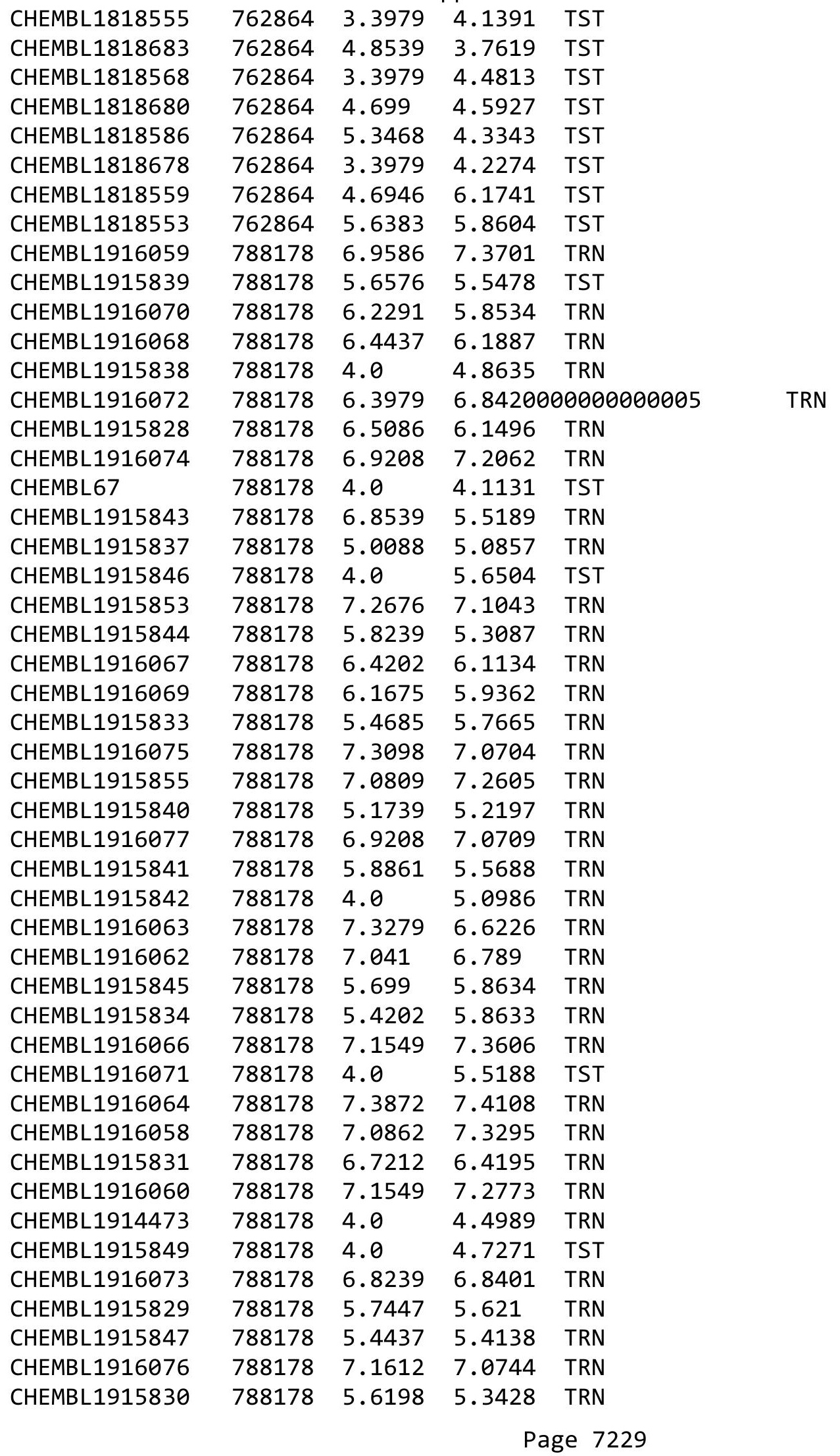


Supplemental Table S2.txt

\begin{tabular}{|c|c|c|c|c|}
\hline CHEMBL1916061 & 788178 & 6.699 & 7.1026 & TRN \\
\hline CHEMBL1915835 & 788178 & 5.7212 & 5.6212 & TRN \\
\hline CHEMBL1915848 & 788178 & 5.4559 & 5.7437 & TST \\
\hline CHEMBL1915851 & 788178 & 4.0 & 4.5304 & TST \\
\hline CHEMBL1915836 & 788178 & 5.6198 & 5.2792 & TST \\
\hline CHEMBL1915854 & 788178 & 7.1549 & 7.229 & TST \\
\hline CHEMBL1916065 & 788178 & 7.284 & 7.1762 & TST \\
\hline CHEMBL1915852 & 788178 & 4.0 & 4.5834 & TST \\
\hline CHEMBL1915832 & 788178 & 6.7959 & 6.3373 & TST \\
\hline CHEMBL1915850 & 788178 & 4.0 & 4.71399 & 99999999995 \\
\hline CHEMBL252523 & 459969 & 4.0 & 4.0568 & TRN \\
\hline CHEMBL249249 & 459969 & 3.8268 & 3.5119 & TRN \\
\hline CHEMBL251425 & 459969 & 3.9586 & 4.0736 & TRN \\
\hline CHEMBL254838 & 459969 & 3.9957 & 4.1754 & TST \\
\hline CHEMBL254627 & 459969 & 4.1427 & 4.232 & TRN \\
\hline CHEMBL253801 & 459969 & 4.1367 & 4.314 & TRN \\
\hline CHEMBL253189 & 459969 & 3.9706 & 4.2303 & TRN \\
\hline CHEMBL1162966 & 459969 & 3.9508 & 4.3903 & TRN \\
\hline CHEMBL251426 & 459969 & 4.3768 & 4.2049 & TRN \\
\hline CHEMBL 253372 & 459969 & 4.0458 & 4.4466 & TRN \\
\hline CHEMBL400358 & 459969 & 2.8239 & 3.8276 & TST \\
\hline CHEMBL250057 & 459969 & 3.9666 & 4.0158 & TRN \\
\hline CHEMBL400449 & 459969 & 4.1024 & 3.9974 & TRN \\
\hline CHEMBL252965 & 459969 & 4.1549 & 4.4495 & TRN \\
\hline CHEMBL 251465 & 459969 & 2.8239 & 3.8625 & TST \\
\hline CHEMBL399999 & 459969 & 4.1135 & 3.9051 & TRN \\
\hline CHEMBL254610 & 459969 & 4.2007 & 4.0533 & TRN \\
\hline CHEMBL399504 & 459969 & 3.9626 & 4.2172 & TST \\
\hline CHEMBL398838 & 459969 & 4.1871 & 4.2595 & TST \\
\hline CHEMBL 249860 & 459969 & 2.8239 & 3.3305 & TST \\
\hline CHEMBL253820 & 459969 & 4.1938 & 4.3291 & TRN \\
\hline CHEMBL250069 & 459969 & 4.3372 & 4.3297 & TRN \\
\hline CHEMBL399685 & 459969 & 4.1612 & 4.3609 & TRN \\
\hline CHEMBL254406 & 459969 & 4.0458 & 4.0636 & TRN \\
\hline CHEMBL399998 & 459969 & 4.3188 & 3.8599 & TST \\
\hline CHEMBL438519 & 459969 & 5.8239 & 4.4849 & TRN \\
\hline CHEMBL252522 & 459969 & 3.9245 & 4.0837 & TRN \\
\hline CHEMBL253188 & 459969 & 3.9031 & 4.3254 & TST \\
\hline CHEMBL254039 & 459969 & 4.1367 & 4.1644 & TST \\
\hline CHEMBL 254240 & 459969 & 4.1675 & 4.4461 & TRN \\
\hline CHEMBL251423 & 459969 & 4.0088 & 3.8585 & TRN \\
\hline CHEMBL252326 & 459969 & 3.9872 & 4.0139 & TRN \\
\hline CHEMBL428762 & 459969 & 2.8239 & 3.8402 & TST \\
\hline CHEMBL250059 & 459969 & 4.0458 & 3.9726 & TRN \\
\hline CHEMBL 253172 & 459969 & 3.9586 & \multicolumn{2}{|c|}{4.263999999999999} \\
\hline CHEMBL254611 & 459969 & 3.9066 & 4.0856 & TRN \\
\hline CHEMBL251081 & 459969 & 4.0177 & 4.0237 & TRN \\
\hline CHEMBL399908 & 459969 & 4.041 & 3.8991 & TRN \\
\hline
\end{tabular}




\begin{tabular}{|c|c|c|c|c|c|}
\hline \multirow[b]{2}{*}{ CHEMBL 254404} & \multicolumn{5}{|c|}{ supps } \\
\hline & 459969 & 4.0088 & 3.9092 & TRN & \\
\hline CHEMBL 250058 & 459969 & 4.1805 & 3.9436 & TRN & \\
\hline CHEMBL 254405 & 459969 & 3.9586 & 4.1626 & TRN & \\
\hline CHEMBL 254238 & 459969 & 4.1612 & 4.4213 & TRN & \\
\hline CHEMBL402720 & 459969 & 4.0706 & 4.1408 & TRN & \\
\hline CHEMBL398662 & 459969 & 3.9031 & 4.0043 & TRN & \\
\hline CHEMBL 254006 & 459969 & 5.8239 & 4.5805 & TRN & \\
\hline CHEMBL399684 & 459969 & 4.1612 & 4.4202 & TRN & \\
\hline CHEMBL 254657 & 459969 & 4.0458 & 4.3619 & TRN & \\
\hline CHEMBL 254837 & 459969 & 4.1549 & 4.2735 & TRN & \\
\hline CHEMBL253373 & 459969 & 4.1487 & 4.3567 & TRN & \\
\hline CHEMBL 398450 & 459969 & 4.0655 & 4.3678 & TRN & \\
\hline CHEMBL400357 & 459969 & 2.8239 & 3.8793 & TST & \\
\hline CHEMBL 254038 & 459969 & 5.8239 & 4.7425 & TRN & \\
\hline CHEMBL 253375 & 459969 & 4.1805 & 4.3442 & TRN & \\
\hline CHEMBL399070 & 459969 & 4.1871 & 4.5576 & TRN & \\
\hline CHEMBL252327 & 459969 & 2.8239 & 3.8227 & TST & \\
\hline CHEMBL399997 & 459969 & 3.9666 & 3.8827 & TRN & \\
\hline CHEMBL399304 & 459969 & 4.1549 & 4.3824 & TRN & \\
\hline CHEMBL 254821 & 459969 & 3.9547 & 4.16100 & 00000000005 & TST \\
\hline CHEMBL 249861 & 459969 & 2.8239 & 2.9806 & TRN & \\
\hline CHEMBL 250070 & 459969 & 4.0315 & 4.1945 & TRN & \\
\hline CHEMBL 253823 & 459969 & 5.301 & 4.5776 & TRN & \\
\hline CHEMBL445939 & 459969 & 4.1739 & 4.1732 & TST & \\
\hline CHEMBL398892 & 459969 & 4.1549 & 4.4919 & TRN & \\
\hline CHEMBL442286 & 459969 & 4.1367 & 3.838 & TST & \\
\hline CHEMBL 249859 & 459969 & 4.0706 & 3.5891 & TRN & \\
\hline CHEMBL 253835 & 459969 & 4.4815 & 4.6224 & TRN & \\
\hline CHEMBL400850 & 459969 & 2.8239 & 2.9806 & TRN & \\
\hline CHEMBL 254403 & 459969 & 5.1549 & 4.0686 & TRN & \\
\hline CHEMBL254448 & 459969 & 3.9706 & 4.3134 & TRN & \\
\hline CHEMBL 251424 & 459969 & 4.0 & 3.9888 & TRN & \\
\hline CHEMBL404205 & 459969 & 2.8239 & 3.8121 & TST & \\
\hline CHEMBL 249863 & 459969 & 2.8239 & 3.518006 & 00000000002 & TST \\
\hline CHEMBL400851 & 459969 & 2.8239 & 3.5626 & TST & \\
\hline CHEMBL255051 & 459969 & 4.1612 & 4.4902 & TRN & \\
\hline CHEMBL254239 & 459969 & 4.2441 & 4.3145 & TRN & \\
\hline CHEMBL 249862 & 459969 & 2.8239 & 3.6193 & TST & \\
\hline CHEMBL 253374 & 459969 & 4.1487 & 4.3923 & TRN & \\
\hline CHEMBL 251937 & 459969 & 4.1805 & 4.1755 & TST & \\
\hline CHEMBL253605 & 459969 & 4.4089 & 4.3845 & TRN & \\
\hline CHEMBL 3287263 & 1641012 & 6.0191 & 5.9606 & TRN & \\
\hline CHEMBL 3948298 & 1641012 & 7.0362 & 6.5929 & TRN & \\
\hline CHEMBL3287255 & 1641012 & 6.1051 & 6.1454 & TRN & \\
\hline CHEMBL 3934705 & 1641012 & 5.4472 & 6.1754 & TRN & \\
\hline CHEMBL3287250 & 1641012 & 5.9147 & 5.8051 & TRN & \\
\hline CHEMBL3287262 & 1641012 & 5.75799 & 79999999 & 6.0719 & TRN \\
\hline CHEMBL3897044 & 1641012 & 5.7542 & 6.4252 & TRN & \\
\hline
\end{tabular}


Supplemental Table S2.txt

\begin{tabular}{|c|c|c|c|c|c|}
\hline CHEMBL 3959685 & 1641012 & 6.1599 & 5.8939 & TRN & \\
\hline CHEMBL 3287260 & 1641012 & 5.2858 & 5.6452 & TRN & \\
\hline CHEMBL3919167 & 1641012 & 5.7788 & 5.9205 & TRN & \\
\hline CHEMBL 3911545 & 1641012 & 8.0 & 6.9893 & TRN & \\
\hline CHEMBL3971832 & 1641012 & 6.061 & 5.6469 & TRN & \\
\hline CHEMBL 3287252 & 1641012 & 6.0278 & 5.8495 & TRN & \\
\hline CHEMBL 3942298 & 1641012 & 5.937 & 5.8138 & TST & \\
\hline CHEMBL 3287017 & 1641012 & 4.5309 & 5.1833 & TRN & \\
\hline CHEMBL 3287258 & 1641012 & 6.3002 & 5.8666 & TRN & \\
\hline CHEMBL3947538 & 1641012 & 6.7212 & 5.9205 & TRN & \\
\hline CHEMBL 3287259 & 1641012 & 5.3018 & 5.4623 & TRN & \\
\hline CHEMBL 3947397 & 1641012 & 5.5005 & 5.6859 & TRN & \\
\hline CHEMBL 3952593 & 1641012 & 5.5131 & 5.8528 & TRN & \\
\hline CHEMBL 3943359 & 1641012 & 5.6893 & 5.8143 & TRN & \\
\hline CHEMBL3287254 & 1641012 & 6.2069 & 5.8625 & TRN & \\
\hline CHEMBL 3930328 & 1641012 & 6.3116 & 6.6739 & TRN & \\
\hline CHEMBL 3919448 & 1641012 & 7.1249 & 6.252000 & 0000000001 & TST \\
\hline CHEMBL 3977346 & 1641012 & 7.699 & 6.4704 & TST & \\
\hline CHEMBL 3933987 & 1641012 & 5.8894 & 6.4464 & TRN & \\
\hline CHEMBL 3984885 & 1641012 & 6.7423 & 6.1774 & TRN & \\
\hline CHEMBL 3939518 & 1641012 & 6.8729 & 6.9893 & TRN & \\
\hline CHEMBL 3891163 & 1641012 & 6.5157 & 5.8219 & TST & \\
\hline CHEMBL 3287257 & 1641012 & 6.3307 & 5.9824 & TRN & \\
\hline CHEMBL 3901200 & 1641012 & 4.7097 & 5.9032 & TRN & \\
\hline CHEMBL 3925099 & 1641012 & 6.24799 & 99999999 & 6.4633 & TRN \\
\hline CHEMBL 3976623 & 1641012 & 5.7392 & 6.3473 & TRN & \\
\hline CHEMBL 3968861 & 1641012 & 6.7328 & 6.5804 & TRN & \\
\hline CHEMBL 3933626 & 1641012 & 6.2403 & 6.2179 & TRN & \\
\hline CHEMBL 3287008 & 1641012 & 5.4299 & 5.7927 & TST & \\
\hline CHEMBL 3287251 & 1641012 & 5.9562 & 5.7431 & TRN & \\
\hline CHEMBL 3287022 & 1641012 & 5.92299 & 99999999 & 5.5804 & TRN \\
\hline CHEMBL3939120 & 1641012 & 6.3036 & 6.2179 & TRN & \\
\hline CHEMBL 3961083 & 1641012 & 5.9045 & 6.2179 & TRN & \\
\hline CHEMBL 3287268 & 1641012 & 6.7773 & 6.1022 & TRN & \\
\hline CHEMBL 3287021 & 1641012 & 5.8758 & 5.7227 & TRN & \\
\hline CHEMBL 3287261 & 1641012 & 5.9718 & 6.0007 & TRN & \\
\hline CHEMBL 3902539 & 1641012 & 5.7312 & 6.5459 & TRN & \\
\hline CHEMBL 3903212 & 1641012 & 6.9788 & 6.9893 & TRN & \\
\hline CHEMBL 3963714 & 1641012 & 6.2161 & 6.1956 & TST & \\
\hline CHEMBL 3935445 & 1641012 & 6.5302 & 5.5747 & TST & \\
\hline CHEMBL 3287269 & 1641012 & 6.7258 & 5.8501 & TST & \\
\hline CHEMBL 3961271 & 1641012 & 7.3098 & 6.8361 & TRN & \\
\hline CHEMBL3891112 & 1641012 & 6.1096 & 6.3187 & TRN & \\
\hline CHEMBL 3968356 & 1641012 & 6.2472 & 5.9867 & TST & \\
\hline CHEMBL 3287010 & 1641012 & 5.3641 & 5.8119 & TST & \\
\hline CHEMBL 3287023 & 1641012 & 5.9547 & 6.0424 & TST & \\
\hline CHEMBL 3287266 & 1641012 & 6.4248 & 6.1299 & TST & \\
\hline CHEMBL 3968415 & 1641012 & 7.0555 & 5.8648 & TRN & \\
\hline
\end{tabular}


Supplemental Table S2.txt

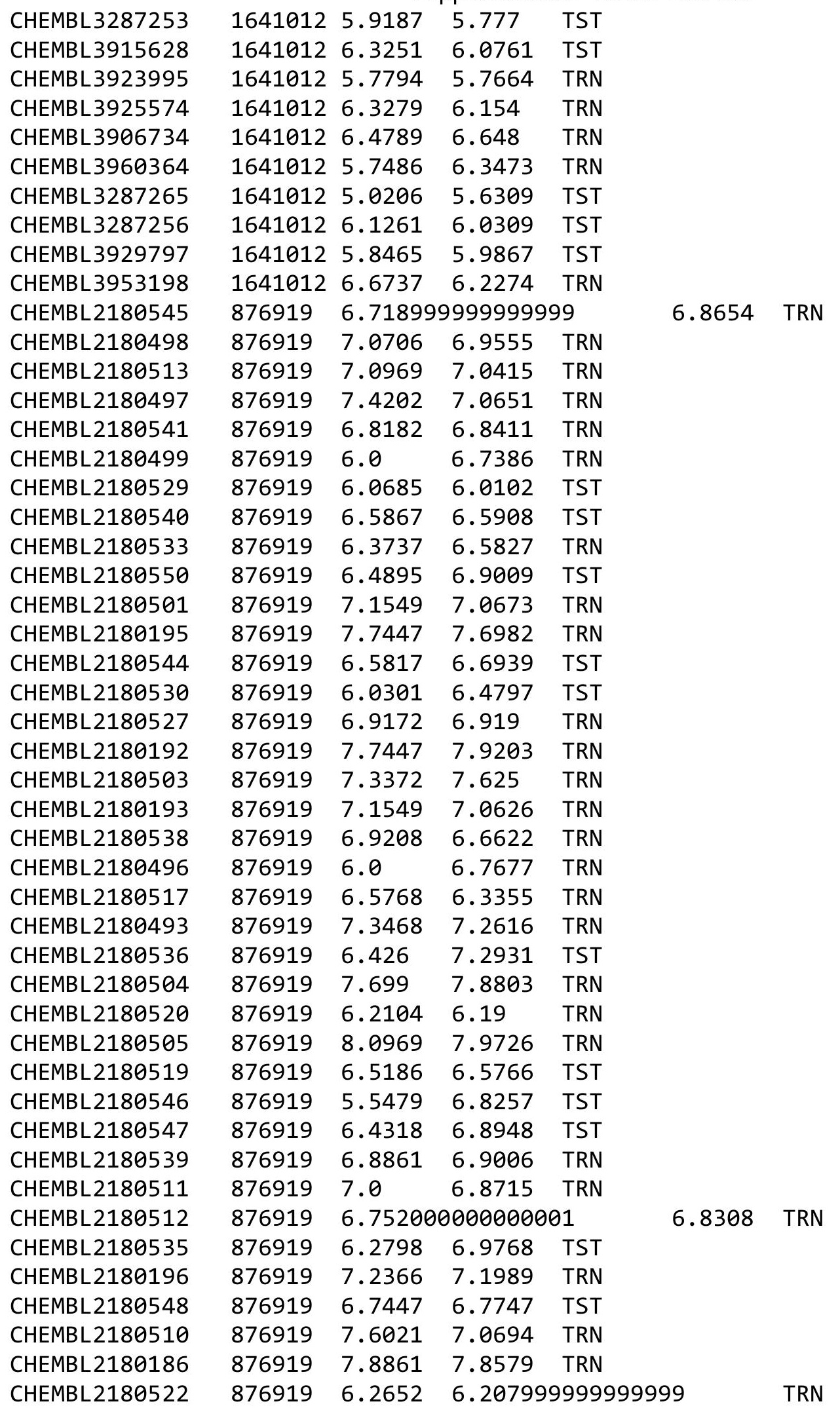

Page 7233 


\begin{tabular}{|c|c|c|c|c|c|}
\hline \multirow[b]{2}{*}{ CHEMBL2180551 } & \multicolumn{5}{|c|}{ Supplemental Table S2.txt } \\
\hline & 876919 & 6.2684 & 6.7979 & TST & \\
\hline CHEMBL 2180518 & 876919 & 5.9678 & 5.942 & TRN & \\
\hline CHEMBL2180508 & 876919 & 7.8539 & 7.586 & TRN & \\
\hline CHEMBL2180494 & 876919 & 6.9172 & 6.9464 & TST & \\
\hline CHEMBL2180531 & 876919 & 6.7645 & 6.6431 & TST & \\
\hline CHEMBL 2180524 & 876919 & 6.8182 & 7.3296 & TRN & \\
\hline CHEMBL 2180526 & 876919 & 7.4685 & 7.5027 & TRN & \\
\hline CHEMBL2180549 & 876919 & 6.2832 & 6.6669 & TST & \\
\hline CHEMBL2180190 & 876919 & 7.7212 & 7.678999 & 9999999999 & TRN \\
\hline CHEMBL2180187 & 876919 & 7.3565 & 7.4847 & TRN & \\
\hline CHEMBL2180194 & 876919 & 6.9788 & 7.1317 & TRN & \\
\hline CHEMBL 2180188 & 876919 & 6.9393 & 7.0068 & TRN & \\
\hline CHEMBL2180500 & 876919 & 7.1805 & 7.0637 & TRN & \\
\hline CHEMBL2177135 & 876919 & 7.3468 & 7.0715 & TRN & \\
\hline CHEMBL2180521 & 876919 & 6.7447 & 6.6428 & TRN & \\
\hline CHEMBL 2180525 & 876919 & 7.4949 & 7.2413 & TRN & \\
\hline CHEMBL2180191 & 876919 & 7.6576 & 7.426 & TRN & \\
\hline CHEMBL2180537 & 876919 & 6.4112 & 6.8856 & TRN & \\
\hline CHEMBL2180506 & 876919 & 7.6198 & 7.6565 & TRN & \\
\hline CHEMBL2180532 & 876919 & 6.7328 & 7.0219 & TST & \\
\hline CHEMBL 2180543 & 876919 & 7.0555 & 7.0481 & TRN & \\
\hline CHEMBL2180516 & 876919 & 7.0223 & 6.8459 & TRN & \\
\hline CHEMBL2180189 & 876919 & 6.8539 & 7.1723 & TRN & \\
\hline CHEMBL2180507 & 876919 & 6.9281 & 6.9822 & TRN & \\
\hline CHEMBL2180502 & 876919 & 7.585 & 7.3078 & TRN & \\
\hline CHEMBL2180495 & 876919 & 7.301 & 6.9406 & TRN & \\
\hline CHEMBL3923455 & 1641701 & 10.2596 & 10.5071 & TRN & \\
\hline CHEMBL3905903 & 1641701 & 10.2596 & 9.9379 & TRN & \\
\hline CHEMBL3965713 & 1641701 & 10.2596 & 10.2325 & TRN & \\
\hline CHEMBL3953590 & 1641701 & 8.699 & 9.2012 & TST & \\
\hline CHEMBL3912482 & 1641701 & 10.2596 & 10.2054 & TRN & \\
\hline CHEMBL3891549 & 1641701 & 10.2596 & 9.7033 & TRN & \\
\hline CHEMBL3955368 & 1641701 & 6.9245 & 7.5048 & TRN & \\
\hline CHEMBL3917937 & 1641701 & 10.2596 & 10.3663 & TRN & \\
\hline CHEMBL3959770 & 1641701 & 10.2596 & 10.1535 & TRN & \\
\hline CHEMBL3911472 & 1641701 & 10.2596 & 10.2671 & TRN & \\
\hline CHEMBL3950650 & 1641701 & 10.2596 & 10.3479 & 99999999999 & TRN \\
\hline CHEMBL3955948 & 1641701 & 10.2596 & 10.3187 & TRN & \\
\hline CHEMBL3949238 & 1641701 & 10.2596 & 10.3347 & TRN & \\
\hline CHEMBL3909092 & 1641701 & 10.2596 & 10.3825 & TRN & \\
\hline CHEMBL3897417 & 1641701 & 10.2596 & 10.2188 & TST & \\
\hline CHEMBL3975430 & 1641701 & 10.2596 & 10.2903 & TRN & \\
\hline CHEMBL3892184 & 1641701 & 10.2596 & 10.3533 & TRN & \\
\hline CHEMBL3943572 & 1641701 & 10.2596 & 10.4297 & TRN & \\
\hline CHEMBL3948216 & 1641701 & 10.2596 & 10.3585 & TRN & \\
\hline CHEMBL3975138 & 1641701 & 10.2596 & 9.9768 & TRN & \\
\hline CHEMBL3914438 & 1641701 & 10.2596 & 10.6239 & TST & \\
\hline CHEMBL3949513 & 1641701 & 10.2596 & 10.2873 & TRN & \\
\hline
\end{tabular}


Supplemental Table S2.txt

CHEMBL3920484

CHEMBL 3937835

CHEMBL 3966939

CHEMBL 3983040

CHEMBL 3902579

CHEMBL3961670

CHEMBL3959421

CHEMBL 3899672

CHEMBL 3932862

CHEMBL3939379

CHEMBL3963513

CHEMBL3920398

CHEMBL 3890701

CHEMBL3928129

CHEMBL3946118

CHEMBL 3951178

CHEMBL3926865

CHEMBL 3937190

CHEMBL3959909

CHEMBL 3930305

CHEMBL 3905754

CHEMBL 3956880

CHEMBL3935913

CHEMBL 3979629

CHEMBL3917626

CHEMBL 3959358

CHEMBL 3917906

CHEMBL 3951700

CHEMBL 3945908

CHEMBL3956529

CHEMBL271181

CHEMBL269891

CHEMBL272827

CHEMBL 270258

CHEMBL413933

CHEMBL272670

CHEMBL410093

CHEMBL273064

CHEMBL273062

CHEMBL429743

CHEMBL272449

CHEMBL1242387

CHEMBL272823

CHEMBL272824

CHEMBL270547

CHEMBL412291

CHEMBL410841

CHEMBL270092
164170110.259610 .5998 TRN

$\begin{array}{lll}1641701 & 10.2596 & 10.5198 \\ \text { TRN }\end{array}$

$\begin{array}{lll}1641701 & 10.2596 & 10.0386\end{array}$

$\begin{array}{llll}1641701 & 10.2596 & 10.1176 & \text { TRN }\end{array}$

$\begin{array}{llll}1641701 & 10.2596 & 9.5801 & \text { TRN }\end{array}$

$\begin{array}{llll}1641701 & 10.2596 & 9.9962 & \text { TRN }\end{array}$

$\begin{array}{llll}1641701 & 8.0269 & 8.2656 & \text { TRN }\end{array}$

$\begin{array}{lll}1641701 & 10.2596 & 10.0455 \\ \text { TRN }\end{array}$

$\begin{array}{lll}1641701 & 10.2596 & 10.2815 \text { TRN }\end{array}$

$\begin{array}{llll}1641701 & 10.2596 & 10.077 & \text { TRN }\end{array}$

$\begin{array}{llll}1641701 & 10.2596 & 9.9764 & \text { TRN }\end{array}$

$\begin{array}{lll}1641701 & 10.2596 & 10.1788 \text { TRN }\end{array}$

$\begin{array}{lll}1641701 & 10.2596 & 10.1808 \text { TRN }\end{array}$

$\begin{array}{lll}1641701 & 10.2596 & 10.4087\end{array}$

$\begin{array}{llll}1641701 & 7.8539 & 9.1885 & \text { TST }\end{array}$

$\begin{array}{lll}1641701 & 10.2596 & 10.4009 \\ \text { TRN }\end{array}$

$\begin{array}{llll}1641701 & 10.2596 & 10.442 & \text { TRN }\end{array}$

$\begin{array}{llll}1641701 & 10.2596 & 9.8525 & \text { TRN }\end{array}$

$\begin{array}{lll}1641701 & 10.2596 & 10.6063\end{array}$

$\begin{array}{lll}1641701 & 10.2596 & 10.4946 \text { TRN }\end{array}$

$\begin{array}{lll}1641701 & 10.2596 & 10.4974 \text { TRN }\end{array}$

$\begin{array}{llll}1641701 & 10.2596 & 10.0788 \text { TRN }\end{array}$

$\begin{array}{lll}1641701 & 10.2596 & 10.3315\end{array}$

$\begin{array}{lll}1641701 & 10.2596 & 9.8531\end{array}$

$\begin{array}{lll}1641701 & 10.2596 & 10.5074\end{array}$

$\begin{array}{lll}1641701 & 10.2596 & 10.4836\end{array}$

$\begin{array}{lll}1641701 & 10.2596 & 10.4557\end{array}$

$\begin{array}{lll}1641701 & 10.2596 & 10.4881\end{array}$

$\begin{array}{lll}1641701 & 10.2596 & 10.568\end{array}$

$\begin{array}{lll}1641701 & 10.2596 & 10.145\end{array}$

$\begin{array}{llll}655558 & 8.52 & 8.7331 & \text { TST }\end{array}$

$\begin{array}{llll}655558 & 7.74 & 7.3948 & \text { TST }\end{array}$

$\begin{array}{llll}655558 & 8.15 & 8.3277 & \text { TST }\end{array}$

$\begin{array}{llll}655558 & 6.51 & 7.562 & \text { TST }\end{array}$

$\begin{array}{llll}655558 & 7.34 & 8.6991 & \text { TST }\end{array}$

$\begin{array}{llll}655558 & 7.7 & 8.1737 & \text { TST }\end{array}$

$\begin{array}{llll}655558 & 7.55 & 8.4496 & \text { TST }\end{array}$

$\begin{array}{llll}655558 & 8.4 & 8.4182 & \text { TRN }\end{array}$

$\begin{array}{llll}655558 & 9.0 & 9.1392 & \text { TRN }\end{array}$

$\begin{array}{llll}655558 & 9.31 & 9.3946 & \text { TRN }\end{array}$

$\begin{array}{llll}655558 & 7.7 & 7.6389 & \text { TRN }\end{array}$

$\begin{array}{llll}655558 & 9.7 & 9.5399 & \text { TRN }\end{array}$

$\begin{array}{llll}655558 & 8.7 & 8.6021 & \text { TRN }\end{array}$

$\begin{array}{llll}655558 & 9.7 & 9.6166 & \text { TRN }\end{array}$

$\begin{array}{llll}655558 & 8.7 & 8.6941 & \text { TRN }\end{array}$

$\begin{array}{llll}655558 & 9.22 & 9.243 & \text { TRN }\end{array}$

$\begin{array}{llll}655558 & 9.0 & 8.8678 & \text { TRN }\end{array}$

$\begin{array}{lll}655558 & 9.52 & 9.5438\end{array}$ 


\begin{tabular}{|c|c|c|c|c|c|}
\hline CHEMBL411091 & 655558 & 9.3 & \multicolumn{2}{|c|}{9.466000000000001} & \multirow[t]{2}{*}{ TRN } \\
\hline CHEMBL 271563 & 655558 & 9.3 & 9.3151 & TRN & \\
\hline CHEMBL270985 & 655558 & 9.3 & 9.3087 & TRN & \\
\hline CHEMBL407715 & 655558 & 9.15 & 9.1747 & TRN & \\
\hline CHEMBL 270983 & 655558 & 8.7 & 8.6822 & TRN & \\
\hline CHEMBL269916 & 655558 & 9.52 & 9.5634 & TRN & \\
\hline CHEMBL269914 & 655558 & 9.0 & 9.0404 & TRN & \\
\hline CHEMBL269915 & 655558 & 9.1 & 9.0541 & TRN & \\
\hline CHEMBL406388 & 655558 & 9.1 & 9.0694 & TRN & \\
\hline CHEMBL272693 & 655558 & 8.7 & 8.6862 & TRN & \\
\hline CHEMBL 272691 & 655558 & 9.52 & 9.4838 & TRN & \\
\hline CHEMBL409538 & 655558 & 9.7 & 9.7046 & TRN & \\
\hline CHEMBL259461 & 655558 & 9.22 & 9.1974 & TRN & \\
\hline CHEMBL 270978 & 655558 & 9.0 & 8.9514 & TRN & \\
\hline CHEMBL408478 & 655558 & 9.1 & 9.0947 & TRN & \\
\hline CHEMBL 272198 & 655558 & 9.22 & 9.3453 & TRN & \\
\hline CHEMBL428961 & 655558 & 7.82 & 7.8337 & TRN & \\
\hline CHEMBL259252 & 655558 & 8.67 & 8.52 & TRN & \\
\hline CHEMBL410903 & 655558 & 7.92 & 8.0327 & TRN & \\
\hline CHEMBL409103 & 655558 & 8.89 & 8.8839 & TRN & \\
\hline CHEMBL408211 & 655558 & 8.26 & 8.25 & TRN & \\
\hline CHEMBL429585 & 655558 & 9.52 & 7.4517 & TST & \\
\hline CHEMBL 270745 & 655558 & 7.66 & 7.7003 & TRN & \\
\hline CHEMBL446367 & 655558 & 7.64 & 7.6449 & TRN & \\
\hline CHEMBL 270277 & 655558 & 8.1 & 8.224 & TST & \\
\hline CHEMBL 270755 & 655558 & 7.96 & 7.9122 & TRN & \\
\hline CHEMBL 270754 & 655558 & 8.42 & 8.4752 & TRN & \\
\hline CHEMBL 269871 & 655558 & 8.89 & 8.868 & TRN & \\
\hline CHEMBL406914 & 655558 & 5.82 & 5.7811 & TRN & \\
\hline CHEMBL1242667 & 655558 & 8.42 & 8.4106 & TRN & \\
\hline CHEMBL271188 & 655558 & 7.92 & 7.7024 & TRN & \\
\hline CHEMBL 271189 & 655558 & 8.38 & 8.4346 & TRN & \\
\hline CHEMBL 271984 & 655558 & 9.05 & 9.0376 & TRN & \\
\hline CHEMBL411284 & 655558 & 8.54 & 8.5264 & TRN & \\
\hline CHEMBL412278 & 655558 & 6.5 & 6.6738 & TRN & \\
\hline CHEMBL 272252 & 655558 & 8.89 & 8.8911 & TRN & \\
\hline CHEMBL 270342 & 655558 & 9.35 & 9.2745 & TRN & \\
\hline CHEMBL 272251 & 655558 & 7.55 & 7.5319 & TRN & \\
\hline CHEMBL1241685 & 655558 & 8.92 & 9.0572 & TRN & \\
\hline CHEMBL1241686 & 655558 & 9.43 & 9.4299 & TRN & \\
\hline CHEMBL1241777 & 655558 & 7.66 & 7.7297 & TRN & \\
\hline CHEMBL429430 & 655558 & 9.0 & 9.0886 & TRN & \\
\hline CHEMBL 270058 & 655558 & 9.0 & 9.0041 & TRN & \\
\hline CHEMBL 270057 & 655558 & 9.0 & 8.9975 & TRN & \\
\hline CHEMBL411630 & 655558 & 9.7 & 9.5443 & TRN & \\
\hline CHEMBL 270550 & 655558 & 7.72 & 7.6267 & TRN & \\
\hline CHEMBL 272878 & 655558 & 9.0 & 9.05600 & 0000000001 & TRN \\
\hline CHEMBL 270548 & 655558 & 9.3 & 9.2994 & TRN & \\
\hline & & & & 7236 & \\
\hline
\end{tabular}




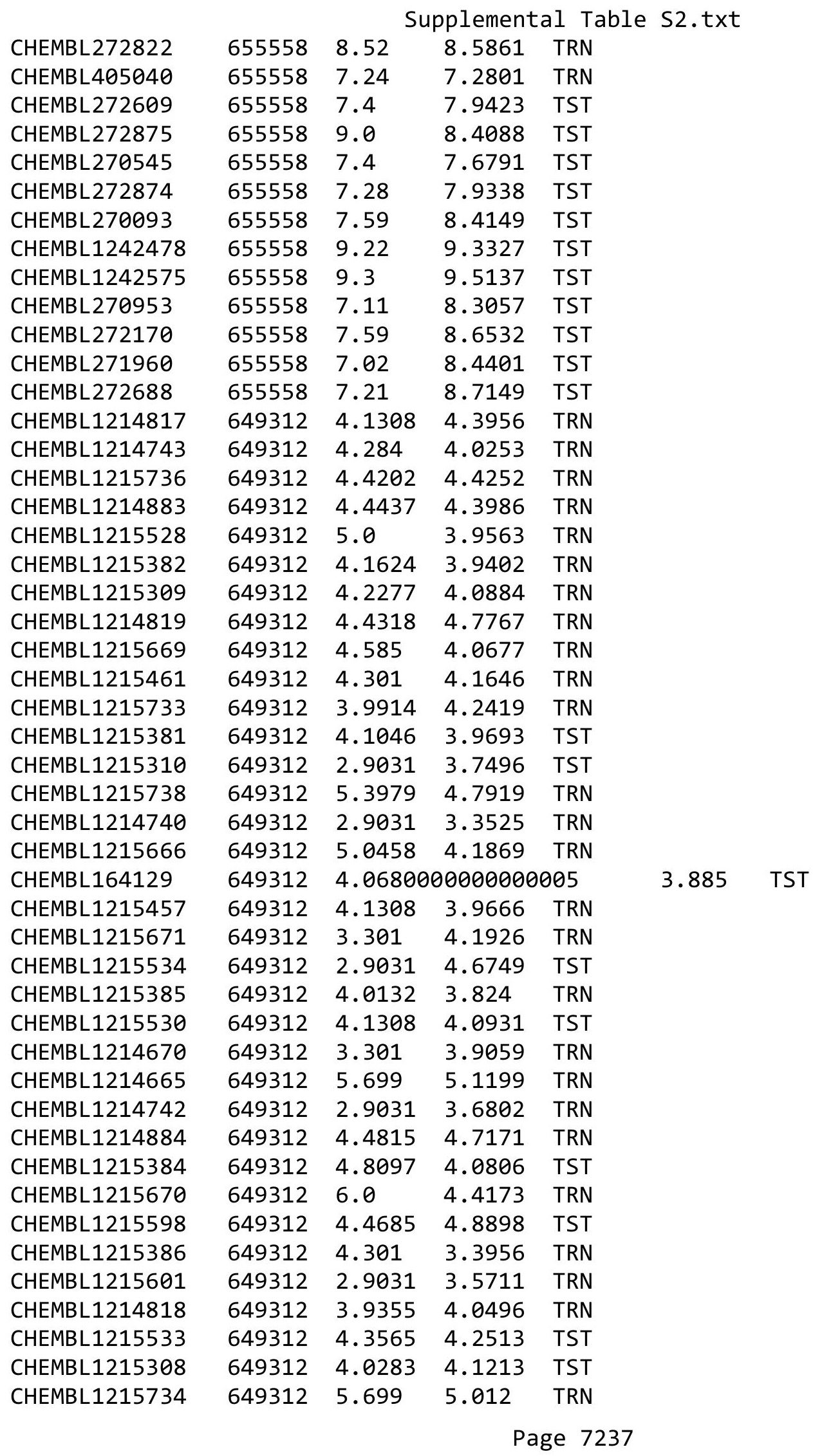


Supplemental Table S2.txt

\begin{tabular}{|c|c|c|c|c|}
\hline CHEMBL1215667 & 649312 & 4.3279 & 3.6881 & TRN \\
\hline CHEMBL1215597 & 649312 & 5.0 & 4.6004 & TST \\
\hline CHEMBL1215599 & 649312 & 5.7212 & 4.7 & TST \\
\hline CHEMBL1214666 & 649312 & 2.9031 & 4.9067 & TRN \\
\hline CHEMBL1212959 & 649312 & 2.9031 & 3.7981 & TRN \\
\hline CHEMBL1215460 & 649312 & 4.6576 & \multicolumn{2}{|c|}{3.8360000000000003} \\
\hline CHEMBL1214668 & 649312 & 3.9666 & 3.3442 & TRN \\
\hline CHEMBL1215737 & 649312 & 4.5229 & 4.887 & TRN \\
\hline CHEMBL1215459 & 649312 & 2.9031 & 3.9022 & TRN \\
\hline CHEMBL1215600 & 649312 & 4.4437 & 4.0534 & TRN \\
\hline CHEMBL1215531 & 649312 & 2.9031 & 4.7881 & TST \\
\hline CHEMBL1215602 & 649312 & 4.301 & 4.3454 & TRN \\
\hline CHEMBL1214822 & 649312 & 4.4685 & 4.5082 & TRN \\
\hline CHEMBL1214741 & 649312 & 2.9031 & 3.7874 & TRN \\
\hline CHEMBL1214820 & 649312 & 4.6778 & 4.6373 & TRN \\
\hline CHEMBL1215383 & 649312 & 5.0757 & 4.1783 & TST \\
\hline CHEMBL1215668 & 649312 & 4.4437 & 4.1628 & TRN \\
\hline CHEMBL1215456 & 649312 & 5.0 & 4.0726 & TRN \\
\hline CHEMBL1212969 & 649312 & 4.5686 & 4.7941 & TRN \\
\hline CHEMBL1215735 & 649312 & 4.5376 & 4.8685 & TRN \\
\hline CHEMBL1215532 & 649312 & 3.9066 & 4.6766 & TST \\
\hline CHEMBL1214669 & 649312 & 5.301 & 4.065 & TRN \\
\hline CHEMBL1214821 & 649312 & 2.9031 & 4.0643 & TRN \\
\hline CHEMBL1215307 & 649312 & 2.9031 & 3.6537 & TST \\
\hline CHEMBL1215458 & 649312 & 2.9031 & 3.4851 & TRN \\
\hline CHEMBL1214667 & 649312 & 2.9031 & 3.6614 & TRN \\
\hline CHEMBL1215529 & 649312 & 4.4437 & 4.612 & TST \\
\hline CHEMBL1447972 & 688420 & 3.301 & 3.3003 & TRN \\
\hline CHEMBL1471099 & 688420 & 3.301 & 3.2994 & TRN \\
\hline CHEMBL1586876 & 688420 & 3.301 & 3.3015 & TRN \\
\hline CHEMBL1409828 & 688420 & 5.7016 & \multicolumn{2}{|c|}{5.702999999999999} \\
\hline CHEMBL1559327 & 688420 & 3.301 & 3.3008 & TRN \\
\hline CHEMBL1426635 & 688420 & 3.301 & 3.3006 & TRN \\
\hline CHEMBL3208498 & 688420 & 5.7929 & 4.7756 & TST \\
\hline CHEMBL1594342 & 688420 & 3.301 & 4.2992 & TST \\
\hline CHEMBL1579396 & 688420 & 3.301 & 3.3021 & TRN \\
\hline CHEMBL1447076 & 688420 & 6.057 & 6.0567 & TRN \\
\hline CHEMBL1373985 & 688420 & 3.301 & 3.3021 & TRN \\
\hline CHEMBL1584523 & 688420 & 5.1323 & 5.1318 & TRN \\
\hline CHEMBL1308408 & 688420 & 5.5393 & 5.5361 & TRN \\
\hline CHEMBL1537907 & 688420 & 5.5677 & 5.567 & TRN \\
\hline CHEMBL1450522 & 688420 & 3.301 & 4.4421 & TST \\
\hline CHEMBL1419836 & 688420 & 5.3183 & 5.3201 & TRN \\
\hline CHEMBL1530797 & 688420 & 6.4711 & 6.4712 & TRN \\
\hline CHEMBL1328358 & 688420 & 5.8768 & 4.3944 & TST \\
\hline CHEMBL1432243 & 688420 & 5.5835 & 5.5785 & TRN \\
\hline CHEMBL1409782 & 688420 & 3.301 & 4.149 & TST \\
\hline CHEMBL1597823 & 688420 & 5.3266 & 5.3264 & TRN \\
\hline
\end{tabular}




\begin{tabular}{|c|c|c|c|c|}
\hline & & & oplement & al Ta \\
\hline CHEMBL1576724 & 688420 & 3.301 & 3.3009 & TRN \\
\hline CHEMBL1497556 & 688420 & 3.301 & 3.3015 & TRN \\
\hline CHEMBL1337081 & 688420 & 3.301 & 3.3005 & TRN \\
\hline CHEMBL1380269 & 688420 & 3.301 & 3.3001 & TRN \\
\hline CHEMBL1451347 & 688420 & 3.301 & 3.3013 & TRN \\
\hline CHEMBL1499346 & 688420 & 5.6578 & 5.6568 & TRN \\
\hline CHEMBL1313669 & 688420 & 3.301 & 3.3013 & TRN \\
\hline CHEMBL1382779 & 688420 & 3.301 & 3.3023 & TRN \\
\hline CHEMBL1404241 & 688420 & 3.301 & 3.3011 & TRN \\
\hline CHEMBL1432395 & 688420 & 3.301 & 3.3002 & TRN \\
\hline CHEMBL1506434 & 688420 & 3.301 & 3.3016 & TRN \\
\hline CHEMBL1539075 & 688420 & 5.8742 & 5.8728 & TRN \\
\hline CHEMBL1300662 & 688420 & 4.1908 & 4.1918 & TRN \\
\hline CHEMBL1301975 & 688420 & 3.301 & 4.0239 & TST \\
\hline CHEMBL1582179 & 688420 & 5.3826 & 5.3854 & TRN \\
\hline CHEMBL1611963 & 688420 & 3.301 & 3.3004 & TRN \\
\hline CHEMBL1531320 & 688420 & 5.4836 & 5.4822 & TRN \\
\hline CHEMBL1584869 & 688420 & 5.3421 & 5.3429 & TRN \\
\hline CHEMBL3213728 & 688420 & 4.9674 & 4.9675 & TRN \\
\hline CHEMBL1326646 & 688420 & 3.301 & 3.3008 & TRN \\
\hline CHEMBL1566841 & 688420 & 3.301 & 3.3006 & TRN \\
\hline CHEMBL1312915 & 688420 & 3.301 & 3.3024 & TRN \\
\hline CHEMBL1342332 & 688420 & 5.1276 & 5.1265 & TRN \\
\hline CHEMBL1408303 & 688420 & 3.301 & 3.3006 & TRN \\
\hline CHEMBL1419505 & 688420 & 3.301 & 3.3011 & TRN \\
\hline CHEMBL1416312 & 688420 & 3.301 & 3.301 & TRN \\
\hline CHEMBL1585097 & 688420 & 5.6607 & 5.6645 & TRN \\
\hline CHEMBL1441251 & 688420 & 3.301 & 4.0345 & TST \\
\hline CHEMBL1530136 & 688420 & 3.301 & 3.3008 & TRN \\
\hline CHEMBL1404553 & 688420 & 5.5447 & 5.5451 & TRN \\
\hline CHEMBL1447632 & 688420 & 5.7719 & 5.776 & TRN \\
\hline CHEMBL1376622 & 688420 & 5.3369 & 5.3356 & TRN \\
\hline CHEMBL1372018 & 688420 & 3.301 & 3.3013 & TRN \\
\hline CHEMBL1456142 & 688420 & 3.301 & 4.3153 & TST \\
\hline CHEMBL1425529 & 688420 & 3.301 & 3.1044 & TST \\
\hline CHEMBL1533401 & 688420 & 5.7102 & 6.0545 & TST \\
\hline CHEMBL1534344 & 688420 & 3.301 & 3.9441 & TST \\
\hline CHEMBL1305537 & 688420 & 5.6174 & 5.4945 & TST \\
\hline CHEMBL1374449 & 688420 & 3.301 & 4.2194 & TST \\
\hline CHEMBL1450864 & 688420 & 3.301 & 3.7508 & TST \\
\hline CHEMBL1443309 & 688420 & 5.4093 & 4.2076 & TST \\
\hline CHEMBL1400890 & 688420 & 3.301 & 5.0181 & TST \\
\hline CHEMBL1186585 & 954904 & 3.1857 & 3.1857 & TRN \\
\hline CHEMBL1357247 & 954904 & 3.7209 & 3.7209 & TRN \\
\hline CHEMBL210618 & 954904 & 3.7829 & 3.7829 & TRN \\
\hline CHEMBL9470 & 954904 & 5.9352 & 6.2036 & TST \\
\hline CHEMBL1788116 & 954904 & 4.6209 & 4.6208 & TRN \\
\hline CHEMBL1516890 & 954904 & 6.4916 & 6.4917 & TRN \\
\hline
\end{tabular}




\begin{tabular}{|c|c|c|c|c|c|c|}
\hline \multicolumn{7}{|c|}{ Supplemental Table S2.txt } \\
\hline CHEMBL412142 & 954904 & 5.4736 & 5.4736 & TRN & & \\
\hline CHEMBL3392440 & 954904 & 3.7745 & 3.7745 & TRN & & \\
\hline CHEMBL65 & 954904 & 5.4823 & 5.4823 & TRN & & \\
\hline CHEMBL585951 & 954904 & 6.6064 & 6.6064 & TRN & & \\
\hline CHEMBL449158 & 954904 & 7.1027 & 6.7047 & TST & & \\
\hline CHEMBL1404918 & 954904 & 2.8503 & 2.8503 & TRN & & \\
\hline CHEMBL102714 & 954904 & 6.0693 & 6.0693 & TRN & & \\
\hline CHEMBL188678 & 954904 & 4.9299 & 4.9299 & TRN & & \\
\hline CHEMBL373751 & 954904 & 3.8419 & 3.8419 & TRN & & \\
\hline CHEMBL300389 & 954904 & 7.3852 & 7.3852 & TRN & & \\
\hline CHEMBL259181 & 954904 & 5.4627 & 5.4627 & TRN & & \\
\hline CHEMBL192566 & 954904 & 9.2209 & 7.575 & TST & & \\
\hline CHEMBL515416 & 954904 & 5.1041 & 5.104 & TRN & & \\
\hline CHEMBL 213100 & 954904 & 6.0381 & 6.0381 & TRN & & \\
\hline CHEMBL483849 & 954904 & 1.406 & 1.406 & TRN & & \\
\hline CHEMBL558642 & 954904 & 4.7345 & 4.7345 & TRN & & \\
\hline CHEMBL1673039 & 954904 & 5.1802 & 5.1802 & TRN & & \\
\hline CHEMBL392695 & 954904 & 5.5258 & 5.5258 & TRN & & \\
\hline CHEMBL2363137 & 954904 & 5.2942 & 5.2942 & TRN & & \\
\hline CHEMBL1230020 & 954904 & 4.5419 & 4.5419 & TRN & & \\
\hline CHEMBL3199475 & 954904 & 5.5946 & 5.5946 & TRN & & \\
\hline CHEMBL 209148 & 954904 & 4.8617 & 4.8617 & TRN & & \\
\hline CHEMBL573107 & 954904 & 5.3657 & 5.3657 & TRN & & \\
\hline CHEMBL1190711 & 954904 & 5.7581 & 5.7581 & TRN & & \\
\hline CHEMBL 255342 & 954904 & 3.7031 & 3.58100 & 00000000004 & TST & \\
\hline CHEMBL221137 & 954904 & 5.2447 & 4.6588 & TST & & \\
\hline CHEMBL222102 & 954904 & 3.3626 & 3.3626 & TRN & & \\
\hline CHEMBL92309 & 954904 & 3.7764 & 3.2612 & TST & & \\
\hline CHEMBL483847 & 954904 & 3.8108 & 3.8108 & TRN & & \\
\hline CHEMBL1242367 & 954904 & 4.3582 & 4.3582 & TRN & & \\
\hline CHEMBL 258844 & 954904 & 4.5775 & 4.5775 & TRN & & \\
\hline CHEMBL509032 & 954904 & 6.1869 & 6.1869 & TRN & & \\
\hline CHEMBL135561 & 954904 & 5.769 & 5.769 & TRN & & \\
\hline CHEMBL1256459 & 954904 & 7.449 & 7.449 & TRN & & \\
\hline CHEMBL1970879 & 954904 & 6.3232 & 6.3232 & TRN & & \\
\hline CHEMBL 2137530 & 954904 & 4.9598 & 4.9598 & TRN & & \\
\hline CHEMBL399530 & 954904 & 3.772 & 3.772 & TRN & & \\
\hline CHEMBL 2005886 & 954904 & 6.0289 & 6.0289 & TRN & & \\
\hline CHEMBL2144069 & 954904 & 5.21700 & 00000000 & 005 & 000000000005 & TRN \\
\hline CHEMBL2134202 & 954904 & 3.3274 & 3.3274 & TRN & & \\
\hline CHEMBL 220241 & 954904 & 4.6206 & 4.6206 & TRN & & \\
\hline CHEMBL1643959 & 954904 & 3.9954 & 3.9953 & TRN & & \\
\hline CHEMBL514499 & 954904 & 7.3491 & 7.0084 & TST & & \\
\hline CHEMBL3186408 & 954904 & 4.4299 & 3.7423 & TST & & \\
\hline CHEMBL240954 & 954904 & 3.3361 & 3.2128 & TST & & \\
\hline CHEMBL180127 & 954904 & 4.3218 & 5.0136 & TST & & \\
\hline CHEMBL217354 & 954904 & 6.4372 & 6.6299 & TST & & \\
\hline CHEMBL 379300 & 954904 & 6.8528 & 6.931 & TST & & \\
\hline
\end{tabular}




\begin{tabular}{|c|c|c|c|c|c|}
\hline & & & & & \\
\hline CHEMBL472940 & 954904 & 4.2134 & 4.0839 & TST & \\
\hline CHEMBL512504 & 954904 & 4.0393 & 4.8891 & TST & \\
\hline CHEMBL1590308 & 954904 & 2.7949 & 3.2857 & TST & \\
\hline CHEMBL201916 & 331362 & 5.0 & 5.0283 & TRN & \\
\hline CHEMBL201925 & 331362 & 5.0 & 4.9497 & TRN & \\
\hline CHEMBL370342 & 331362 & 5.0 & 5.0101 & TRN & \\
\hline CHEMBL 203247 & 331362 & 5.0 & 4.992 & TRN & \\
\hline CHEMBL201805 & 331362 & 7.0809 & 7.0408 & TRN & \\
\hline CHEMBL201104 & 331362 & 5.0 & 4.9893 & TRN & \\
\hline CHEMBL203256 & 331362 & 5.0 & 5.0058 & TRN & \\
\hline CHEMBL201826 & 331362 & 6.5376 & 6.4901 & TRN & \\
\hline CHEMBL381507 & 331362 & 5.0 & 5.0306 & TRN & \\
\hline CHEMBL425225 & 331362 & 6.2676 & 6.3057 & TRN & \\
\hline CHEMBL 372332 & 331362 & 5.0 & 5.03600 & 00000000005 & TRN \\
\hline CHEMBL 202091 & 331362 & 6.4685 & 6.188 & TRN & \\
\hline CHEMBL200987 & 331362 & 5.0 & 4.9703 & TRN & \\
\hline CHEMBL369962 & 331362 & 5.0 & 4.9685 & TRN & \\
\hline CHEMBL202121 & 331362 & 5.0 & 5.1141 & TRN & \\
\hline CHEMBL202069 & 331362 & 5.0 & 4.9644 & TRN & \\
\hline CHEMBL 382257 & 331362 & 5.0 & 4.9474 & TRN & \\
\hline CHEMBL201163 & 331362 & 5.0 & 4.9756 & TRN & \\
\hline CHEMBL 202492 & 331362 & 7.6198 & 7.6464 & TRN & \\
\hline CHEMBL 383489 & 331362 & 6.0458 & 6.1522 & TRN & \\
\hline CHEMBL 202575 & 331362 & 6.2007 & 6.2276 & TRN & \\
\hline CHEMBL427376 & 331362 & 5.0 & 4.9439 & TRN & \\
\hline CHEMBL200998 & 331362 & 5.0 & 5.0049 & TRN & \\
\hline CHEMBL 202443 & 331362 & 8.0862 & 8.0822 & TRN & \\
\hline CHEMBL203469 & 331362 & 5.0 & 5.3118 & TRN & \\
\hline CHEMBL 202435 & 331362 & 5.0 & 5.0118 & TRN & \\
\hline CHEMBL370866 & 331362 & 5.0 & 5.02800 & 00000000005 & TRN \\
\hline CHEMBL201181 & 331362 & 6.1367 & 6.2542 & TRN & \\
\hline CHEMBL 202306 & 331362 & 5.0 & 5.0894 & TRN & \\
\hline CHEMBL381287 & 331362 & 7.5229 & 7.5637 & TRN & \\
\hline CHEMBL426303 & 331362 & 6.4559 & 6.3634 & TRN & \\
\hline CHEMBL 202204 & 331362 & 7.301 & 7.251 & TRN & \\
\hline CHEMBL 202220 & 331362 & 6.6383 & 6.6972 & TRN & \\
\hline CHEMBL 372353 & 331362 & 5.0 & 5.0584 & TRN & \\
\hline CHEMBL 202442 & 331362 & 5.0 & 4.9166 & TRN & \\
\hline CHEMBL200995 & 331362 & 5.0 & 6.0365 & TST & \\
\hline CHEMBL370599 & 331362 & 5.0 & 5.155 & TRN & \\
\hline CHEMBL 202280 & 331362 & 5.0 & 4.9755 & TRN & \\
\hline CHEMBL 202590 & 331362 & 5.0 & 5.0336 & TRN & \\
\hline CHEMBL437128 & 331362 & 5.0 & 4.9068 & TRN & \\
\hline CHEMBL201945 & 331362 & 9.5686 & 6.9279 & TST & \\
\hline CHEMBL 373020 & 331362 & 5.0 & 4.9615 & TRN & \\
\hline CHEMBL372726 & 331362 & 5.0 & 4.9332 & TRN & \\
\hline CHEMBL202059 & 331362 & 6.7696 & 6.7793 & TRN & \\
\hline CHEMBL202067 & 331362 & 5.0 & 4.9226 & TRN & \\
\hline
\end{tabular}




\begin{tabular}{|c|c|c|c|c|}
\hline \multicolumn{5}{|c|}{ Supplemental Table S2.txt } \\
\hline CHEMBL381240 & 331362 & 5.0 & 5.5134 & TST \\
\hline CHEMBL381508 & 331362 & 5.0 & 4.9577 & TRN \\
\hline CHEMBL202322 & 331362 & 7.6778 & 7.7067 & TRN \\
\hline CHEMBL202604 & 331362 & 6.4815 & 6.3509 & TRN \\
\hline CHEMBL380786 & 331362 & 6.8827 & 6.881 & TRN \\
\hline CHEMBL202438 & 331362 & 5.0 & 4.8926 & TST \\
\hline CHEMBL357076 & 331362 & 8.6198 & 5.6169 & TST \\
\hline CHEMBL202541 & 331362 & 5.0 & 4.5173 & TST \\
\hline CHEMBL201694 & 331362 & 6.2366 & 6.3275 & TST \\
\hline CHEMBL202401 & 331362 & 5.0 & 4.2859 & TST \\
\hline CHEMBL202152 & 331362 & 6.0605 & 4.8891 & TST \\
\hline CHEMBL202094 & 331362 & 6.4437 & 5.9547 & TST \\
\hline CHEMBL201964 & 331362 & 5.0 & 6.1301 & TST \\
\hline CHEMBL202388 & 331362 & 5.0 & 5.6731 & TST \\
\hline CHEMBL369907 & 331362 & 5.0 & 5.6619 & TST \\
\hline CHEMBL413571 & 331362 & 8.0 & 7.2911 & TST \\
\hline CHEMBL201103 & 331362 & 5.0 & 4.2426 & TST \\
\hline CHEMBL202092 & 331362 & 5.0 & 6.2372 & TST \\
\hline CHEMBL1964290 & 809200 & 4.8 & 4.8107 & TST \\
\hline CHEMBL 213505 & 809200 & 6.5 & 6.8793 & TRN \\
\hline CHEMBL1987034 & 809200 & 7.3 & 6.6269 & TRN \\
\hline CHEMBL1993941 & 809200 & 7.9 & 8.1347 & TRN \\
\hline CHEMBL377383 & 809200 & 4.8 & 4.6227 & TRN \\
\hline CHEMBL578061 & 809200 & 6.4 & 5.4764 & TRN \\
\hline CHEMBL 2005886 & 809200 & 7.8 & 6.9012 & TST \\
\hline CHEMBL481491 & 809200 & 4.8 & 5.4715 & TST \\
\hline CHEMBL1682345 & 809200 & 4.8 & 4.6488 & TRN \\
\hline CHEMBL1973142 & 809200 & 4.8 & 4.9567 & TST \\
\hline CHEMBL1973145 & 809200 & 4.8 & 4.9048 & TRN \\
\hline CHEMBL1982924 & 809200 & 6.9 & 6.0738 & TRN \\
\hline CHEMBL 2005936 & 809200 & 4.8 & 4.7577 & TRN \\
\hline CHEMBL1807515 & 809200 & 4.8 & 5.4344 & TRN \\
\hline CHEMBL1971141 & 809200 & 4.8 & 5.0262 & TRN \\
\hline CHEMBL1995813 & 809200 & 4.8 & 5.2741 & TRN \\
\hline CHEMBL1979718 & 809200 & 4.8 & 5.0356 & TRN \\
\hline CHEMBL206236 & 809200 & 4.8 & 4.9206 & TRN \\
\hline CHEMBL523823 & 809200 & 4.8 & 4.7981 & TST \\
\hline CHEMBL1973178 & 809200 & 7.8 & 7.8999 & TRN \\
\hline CHEMBL 244378 & 809200 & 6.3 & 6.3061 & TRN \\
\hline CHEMBL1988778 & 809200 & 6.6 & 6.3835 & TRN \\
\hline CHEMBL 2001957 & 809200 & 4.8 & 4.9447 & TRN \\
\hline CHEMBL1969372 & 809200 & 4.8 & 4.8337 & TRN \\
\hline CHEMBL1990583 & 809200 & 7.5 & 6.9386 & TRN \\
\hline CHEMBL1986943 & 809200 & 4.8 & 5.2903 & TRN \\
\hline CHEMBL 2006263 & 809200 & 4.8 & 4.7647 & TST \\
\hline CHEMBL1993584 & 809200 & 4.8 & 5.263 & TRN \\
\hline CHEMBL1986263 & 809200 & 4.8 & 4.8888 & TRN \\
\hline CHEMBL 2000114 & 809200 & 4.8 & 5.0523 & TRN \\
\hline
\end{tabular}




\begin{tabular}{|c|c|c|c|c|c|}
\hline \multicolumn{6}{|c|}{ Supplemental Table S2.txt } \\
\hline CHEMBL210618 & 809200 & 4.8 & 4.9056 & TRN & \\
\hline CHEMBL1975647 & 809200 & 4.8 & 4.7824 & TRN & \\
\hline CHEMBL1968380 & 809200 & 4.8 & 4.8175 & TRN & \\
\hline CHEMBL1964644 & 809200 & 4.8 & 4.7644 & TRN & \\
\hline CHEMBL1981782 & 809200 & 4.8 & 4.8787 & TRN & \\
\hline CHEMBL1977681 & 809200 & 4.8 & 4.8172 & TRN & \\
\hline CHEMBL1970142 & 809200 & 8.8 & 8.6615 & TRN & \\
\hline CHEMBL1990912 & 809200 & 4.8 & 4.7113 & TRN & \\
\hline CHEMBL1988163 & 809200 & 4.8 & 6.3499 & TRN & \\
\hline CHEMBL1995592 & 809200 & 6.6 & 5.2776 & TST & \\
\hline CHEMBL1975128 & 809200 & 4.8 & 4.7149 & TRN & \\
\hline CHEMBL 2006493 & 809200 & 4.8 & 4.71399 & 99999999995 & TST \\
\hline CHEMBL1992323 & 809200 & 4.8 & 4.9958 & TST & \\
\hline CHEMBL1969735 & 809200 & 4.8 & 4.9348 & TRN & \\
\hline CHEMBL 2003524 & 809200 & 4.8 & 4.9735 & TST & \\
\hline CHEMBL 2002649 & 809200 & 5.9 & 5.6925 & TRN & \\
\hline CHEMBL437747 & 809200 & 4.8 & 4.8038 & TRN & \\
\hline CHEMBL507936 & 809200 & 6.2 & 5.3674 & TRN & \\
\hline CHEMBL104264 & 809200 & 4.8 & 4.7368 & TST & \\
\hline CHEMBL1994321 & 809200 & 7.6 & 6.8905 & TRN & \\
\hline CHEMBL1997129 & 809200 & 6.3 & 5.3775 & TRN & \\
\hline CHEMBL229799 & 809200 & 4.8 & 4.9024 & TRN & \\
\hline CHEMBL451964 & 809200 & 4.8 & 4.7779 & TRN & \\
\hline CHEMBL1964307 & 809200 & 4.8 & 5.0723 & TRN & \\
\hline CHEMBL 2000508 & 809200 & 4.8 & 4.5955 & TRN & \\
\hline CHEMBL 2001547 & 809200 & 4.8 & 4.7685 & TRN & \\
\hline CHEMBL210928 & 809200 & 4.8 & 4.9554 & TRN & \\
\hline CHEMBL1994361 & 809200 & 4.8 & 5.143 & TRN & \\
\hline CHEMBL1986603 & 809200 & 4.8 & 5.1117 & TST & \\
\hline CHEMBL1972840 & 809200 & 4.8 & 4.9354 & TRN & \\
\hline CHEMBL1977148 & 809200 & 8.9 & 8.551 & TRN & \\
\hline CHEMBL2003286 & 809200 & 4.8 & 4.9402 & TRN & \\
\hline CHEMBL1992306 & 809200 & 5.9 & 6.4041 & TRN & \\
\hline CHEMBL2002165 & 809200 & 7.9 & 8.0816 & TRN & \\
\hline CHEMBL1998585 & 809200 & 7.0 & 7.3765 & TRN & \\
\hline CHEMBL519697 & 809200 & 4.8 & 5.251 & TST & \\
\hline CHEMBL 2004934 & 809200 & 4.8 & 4.6138 & TRN & \\
\hline CHEMBL 2000652 & 809200 & 6.7 & 6.5286 & TRN & \\
\hline CHEMBL1996048 & 809200 & 5.9 & 5.2721 & TST & \\
\hline CHEMBL461876 & 809200 & 4.8 & 4.4997 & TST & \\
\hline CHEMBL 2001485 & 809200 & 7.7 & 8.38600 & 0000000001 & TRN \\
\hline CHEMBL504950 & 809200 & 4.8 & 5.2219 & TRN & \\
\hline CHEMBL1984363 & 809200 & 4.8 & 5.3864 & TRN & \\
\hline CHEMBL1978099 & 809200 & 6.4 & 6.1675 & TRN & \\
\hline CHEMBL1977041 & 809200 & 7.4 & 7.5672 & TRN & \\
\hline CHEMBL1968070 & 809200 & 4.8 & 4.7488 & TRN & \\
\hline CHEMBL1988608 & 809200 & 4.8 & 4.9493 & TRN & \\
\hline CHEMBL184847 & 809200 & 6.0 & 5.5003 & TRN & \\
\hline
\end{tabular}




\begin{tabular}{|c|c|c|c|c|}
\hline \multicolumn{5}{|c|}{ pplemental T } \\
\hline CHEMBL1984367 & 809200 & 4.8 & 4.8535 & TRN \\
\hline CHEMBL226898 & 809200 & 4.8 & 4.6786 & TRN \\
\hline CHEMBL1982563 & 809200 & 4.8 & 4.9049 & TRN \\
\hline CHEMBL539474 & 809200 & 5.8 & 5.3439 & TST \\
\hline CHEMBL575824 & 809200 & 4.8 & 5.0917 & TRN \\
\hline CHEMBL1988387 & 809200 & 8.5 & 8.9455 & TRN \\
\hline CHEMBL1990288 & 809200 & 4.8 & 4.9358 & TRN \\
\hline CHEMBL1970074 & 809200 & 4.8 & 5.2267 & TRN \\
\hline CHEMBL1986970 & 809200 & 4.8 & 4.8563 & TRN \\
\hline CHEMBL1958401 & 809200 & 4.8 & 4.4678 & TRN \\
\hline CHEMBL2003456 & 809200 & 5.9 & 5.3431 & TRN \\
\hline CHEMBL1966816 & 809200 & 4.8 & 4.6444 & TRN \\
\hline CHEMBL 2002992 & 809200 & 4.8 & 5.2163 & TST \\
\hline CHEMBL560813 & 809200 & 4.8 & 5.1506 & TRN \\
\hline CHEMBL1968791 & 809200 & 6.6 & 6.3187 & TST \\
\hline CHEMBL326282 & 809200 & 4.8 & 4.7066 & TST \\
\hline CHEMBL1992732 & 809200 & 4.8 & 5.0924 & TST \\
\hline CHEMBL1971186 & 809200 & 4.8 & 4.6652 & TRN \\
\hline CHEMBL 2003482 & 809200 & 4.8 & 4.8625 & TRN \\
\hline CHEMBL1973211 & 809200 & 7.2 & 6.6713 & TRN \\
\hline CHEMBL1984700 & 809200 & 4.8 & 4.9098 & TRN \\
\hline CHEMBL 2007151 & 809200 & 6.2 & 6.3583 & TST \\
\hline CHEMBL1972125 & 809200 & 4.8 & 5.0717 & TRN \\
\hline CHEMBL1976134 & 809200 & 6.4 & 5.7156 & TRN \\
\hline CHEMBL1965131 & 809200 & 5.9 & 4.9478 & TST \\
\hline CHEMBL1972158 & 809200 & 4.8 & 4.6302 & TRN \\
\hline CHEMBL1999414 & 809200 & 6.9 & 7.0772 & TRN \\
\hline CHEMBL 2006581 & 809200 & 4.8 & 4.7381 & TRN \\
\hline CHEMBL1970340 & 809200 & 4.8 & 4.9467 & TRN \\
\hline CHEMBL 2005186 & 809200 & 6.0 & 5.1823 & TRN \\
\hline CHEMBL1975534 & 809200 & 4.8 & 5.459 & TST \\
\hline CHEMBL1993424 & 809200 & 4.8 & 6.3759 & TRN \\
\hline CHEMBL1966703 & 809200 & 4.8 & 4.4628 & TST \\
\hline CHEMBL1969561 & 809200 & 4.8 & 4.8703 & TRN \\
\hline CHEMBL1975121 & 809200 & 4.8 & 4.7589 & TRN \\
\hline CHEMBL1997023 & 809200 & 4.8 & 5.0624 & TST \\
\hline CHEMBL1964687 & 809200 & 6.1 & 6.3378 & TRN \\
\hline CHEMBL1971943 & 809200 & 6.6 & 5.1098 & TST \\
\hline CHEMBL1999918 & 809200 & 4.8 & 5.0251 & TRN \\
\hline CHEMBL1974254 & 809200 & 8.3 & 8.8437 & TRN \\
\hline CHEMBL1988537 & 809200 & 4.8 & 5.0482 & TST \\
\hline CHEMBL1969049 & 809200 & 4.8 & 4.7021 & TRN \\
\hline CHEMBL 2005828 & 809200 & 7.5 & 7.2387 & TRN \\
\hline CHEMBL1998611 & 809200 & 4.8 & 4.833 & TST \\
\hline CHEMBL485556 & 809200 & 4.8 & 5.5142 & TST \\
\hline CHEMBL1975900 & 809200 & 4.8 & 4.6076 & TRN \\
\hline CHEMBL 255822 & 809200 & 4.8 & 4.9533 & TRN \\
\hline CHEMBL1972221 & 809200 & 4.8 & 4.7853 & TRN \\
\hline
\end{tabular}




\begin{tabular}{|c|c|c|c|c|c|}
\hline & & & & & \\
\hline CHEMBL2006778 & 809200 & 7.5 & 7.6162 & TRN & \\
\hline CHEMBL378627 & 809200 & 4.8 & 4.9965 & TRN & \\
\hline CHEMBL1996979 & 809200 & 7.2 & 7.46200 & 0000000001 & TRN \\
\hline CHEMBL1968406 & 809200 & 7.0 & 6.8474 & TRN & \\
\hline CHEMBL1982476 & 809200 & 8.5 & 8.4945 & TRN & \\
\hline CHEMBL1998545 & 809200 & 4.8 & 4.8827 & TRN & \\
\hline CHEMBL1986869 & 809200 & 4.8 & 4.9334 & TRN & \\
\hline CHEMBL1682558 & 809200 & 4.8 & 4.7576 & TRN & \\
\hline CHEMBL1990496 & 809200 & 4.8 & 4.9504 & TRN & \\
\hline CHEMBL1997623 & 809200 & 7.1 & 6.5792 & TRN & \\
\hline CHEMBL2002479 & 809200 & 4.8 & 5.4424 & TRN & \\
\hline CHEMBL1967094 & 809200 & 4.8 & 4.9398 & TRN & \\
\hline CHEMBL2003341 & 809200 & 4.8 & 4.7517 & TRN & \\
\hline CHEMBL1992644 & 809200 & 4.4 & 4.958 & TRN & \\
\hline CHEMBL1982992 & 809200 & 4.8 & 4.7288 & TRN & \\
\hline CHEMBL1999590 & 809200 & 4.8 & 6.3115 & TST & \\
\hline CHEMBL1981079 & 809200 & 4.8 & 4.7914 & TST & \\
\hline CHEMBL1980489 & 809200 & 4.8 & 4.6639 & TRN & \\
\hline CHEMBL2000832 & 809200 & 4.8 & 4.5058 & TRN & \\
\hline CHEMBL1967116 & 809200 & 8.8 & 8.72200 & 0000000001 & TRN \\
\hline CHEMBL1970709 & 809200 & 4.8 & 4.8943 & TRN & \\
\hline CHEMBL1965660 & 809200 & 4.8 & 4.9231 & TST & \\
\hline CHEMBL1998112 & 809200 & 7.4 & 6.6114 & TRN & \\
\hline CHEMBL1993996 & 809200 & 6.3 & 6.6899 & TRN & \\
\hline CHEMBL1969126 & 809200 & 4.8 & 4.8592 & TRN & \\
\hline CHEMBL1980896 & 809200 & 6.5 & 6.5444 & TRN & \\
\hline CHEMBL1970104 & 809200 & 6.7 & 6.3275 & TRN & \\
\hline CHEMBL1991429 & 809200 & 6.9 & 7.4309 & TRN & \\
\hline CHEMBL1971149 & 809200 & 4.8 & 4.8992 & TRN & \\
\hline CHEMBL1999714 & 809200 & 4.8 & 4.6231 & TRN & \\
\hline CHEMBL1994040 & 809200 & 4.8 & 4.7588 & TRN & \\
\hline CHEMBL388978 & 809200 & 8.8 & 6.9488 & TST & \\
\hline CHEMBL579246 & 809200 & 4.8 & 5.0721 & TRN & \\
\hline CHEMBL398951 & 809200 & 4.8 & 4.7043 & TST & \\
\hline CHEMBL1982506 & 809200 & 4.8 & 5.2388 & TST & \\
\hline CHEMBL2004716 & 809200 & 7.0 & 7.724 & TRN & \\
\hline CHEMBL1968127 & 809200 & 4.8 & 4.8657 & TRN & \\
\hline CHEMBL1975233 & 809200 & 4.8 & 5.0021 & TRN & \\
\hline CHEMBL1985406 & 809200 & 4.8 & 4.5386 & TRN & \\
\hline CHEMBL207400 & 809200 & 4.8 & 4.7248 & TST & \\
\hline CHEMBL 2000894 & 809200 & 6.1 & 4.7592 & TST & \\
\hline CHEMBL1982135 & 809200 & 7.2 & 6.5881 & TRN & \\
\hline CHEMBL1976090 & 809200 & 4.8 & 5.3121 & TRN & \\
\hline CHEMBL1993243 & 809200 & 7.9 & 7.9351 & TRN & \\
\hline CHEMBL1992922 & 809200 & 6.3 & 5.8818 & TRN & \\
\hline CHEMBL2004771 & 809200 & 4.8 & 5.0085 & TRN & \\
\hline CHEMBL399021 & 809200 & 6.7 & 6.4664 & TST & \\
\hline CHEMBL1997597 & 809200 & 4.8 & 4.7401 & TRN & \\
\hline & & & & e 7245 & \\
\hline
\end{tabular}




\begin{tabular}{|c|c|c|c|c|}
\hline & & & & \\
\hline CHEMBL1969537 & 809200 & 6.2 & 5.1951 & TST \\
\hline CHEMBL1976093 & 809200 & 4.8 & 4.7784 & TRN \\
\hline CHEMBL1975256 & 809200 & 4.8 & 4.8862 & TST \\
\hline CHEMBL 2004892 & 809200 & 4.8 & 4.6408 & TRN \\
\hline CHEMBL116070 & 809200 & 4.8 & 4.7429 & TRN \\
\hline CHEMBL1990821 & 809200 & 5.9 & 5.1195 & TST \\
\hline CHEMBL1970314 & 809200 & 4.8 & 4.8797 & TRN \\
\hline CHEMBL 2004871 & 809200 & 4.8 & 4.688 & TRN \\
\hline CHEMBL 2004872 & 809200 & 4.8 & 5.1393 & TRN \\
\hline CHEMBL1969879 & 809200 & 4.8 & 5.2083 & TST \\
\hline CHEMBL1981720 & 809200 & 4.8 & 5.1284 & TRN \\
\hline CHEMBL419932 & 809200 & 4.8 & 5.0929 & TRN \\
\hline CHEMBL262433 & 809200 & 6.6 & 6.9152 & TRN \\
\hline CHEMBL373798 & 809200 & 6.9 & 6.5016 & TRN \\
\hline CHEMBL 306380 & 809200 & 8.0 & 7.6434 & TRN \\
\hline CHEMBL1966722 & 809200 & 4.8 & 5.1201 & TST \\
\hline CHEMBL1975500 & 809200 & 4.8 & 4.8995 & TRN \\
\hline CHEMBL1976328 & 809200 & 4.8 & 5.3296 & TRN \\
\hline CHEMBL394619 & 809200 & 6.4 & 5.8009 & TRN \\
\hline CHEMBL1964399 & 809200 & 4.8 & 5.2333 & TRN \\
\hline CHEMBL1996831 & 809200 & 4.8 & 5.0309 & TST \\
\hline CHEMBL411903 & 809200 & 6.7 & 6.9262 & TRN \\
\hline CHEMBL1965988 & 809200 & 7.1 & 6.6542 & TRN \\
\hline CHEMBL418203 & 809200 & 4.8 & 4.3047 & TST \\
\hline CHEMBL1989646 & 809200 & 4.8 & 4.7084 & TRN \\
\hline CHEMBL1682357 & 809200 & 4.8 & 4.7979 & TRN \\
\hline CHEMBL225519 & 809200 & 4.8 & 4.5038 & TRN \\
\hline CHEMBL 209534 & 809200 & 4.8 & 4.7241 & TRN \\
\hline CHEMBL1978200 & 809200 & 4.8 & 4.7452 & TRN \\
\hline CHEMBL1970522 & 809200 & 4.8 & 5.2443 & TRN \\
\hline CHEMBL402846 & 809200 & 6.3 & 5.9777 & TRN \\
\hline CHEMBL1964692 & 809200 & 7.1 & 7.0312 & TRN \\
\hline CHEMBL1996931 & 809200 & 4.8 & 4.8044 & TRN \\
\hline CHEMBL1964413 & 809200 & 4.8 & 4.7556 & TRN \\
\hline CHEMBL1973483 & 809200 & 4.8 & 4.6967 & TRN \\
\hline CHEMBL1984432 & 809200 & 4.8 & 4.7912 & TRN \\
\hline CHEMBL 219722 & 809200 & 6.8 & 6.1625 & TRN \\
\hline CHEMBL1997340 & 809200 & 4.8 & 4.9468 & TRN \\
\hline CHEMBL1522508 & 809200 & 4.8 & 5.1335 & TRN \\
\hline CHEMBL1989474 & 809200 & 4.8 & 4.9438 & TRN \\
\hline CHEMBL1090360 & 809200 & 7.3 & 7.3018 & TRN \\
\hline CHEMBL 210887 & 809200 & 4.8 & 4.8587 & TST \\
\hline CHEMBL458997 & 809200 & 4.8 & 5.5692 & TRN \\
\hline CHEMBL1971021 & 809200 & 4.8 & 5.1948 & TRN \\
\hline CHEMBL 227271 & 809200 & 4.8 & 4.9113 & TRN \\
\hline CHEMBL583144 & 809200 & 4.8 & 4.7001 & TST \\
\hline CHEMBL1974310 & 809200 & 4.8 & 4.7819 & TRN \\
\hline CHEMBL1982660 & 809200 & 5.0 & 4.9256 & TRN \\
\hline
\end{tabular}




\begin{tabular}{|c|c|c|c|c|c|}
\hline \multicolumn{6}{|c|}{ dole } \\
\hline CHEMBL1994693 & 809200 & 7.2 & 6.9198 & TRN & \\
\hline CHEMBL1982957 & 809200 & 5.9 & 6.0724 & TRN & \\
\hline CHEMBL1725279 & 809200 & 6.7 & 5.3835 & TST & \\
\hline CHEMBL1975138 & 809200 & 4.8 & 5.0106 & TST & \\
\hline CHEMBL424872 & 809200 & 4.8 & 4.5557 & TRN & \\
\hline CHEMBL1971947 & 809200 & 8.2 & 7.0964 & TRN & \\
\hline CHEMBL412142 & 809200 & 4.8 & 4.6799 & TST & \\
\hline CHEMBL1980704 & 809200 & 4.8 & 4.902 & TST & \\
\hline CHEMBL 2003271 & 809200 & 4.8 & 4.9624 & TST & \\
\hline CHEMBL1966808 & 809200 & 4.8 & 4.7463 & TST & \\
\hline CHEMBL1996255 & 809200 & 5.8 & 6.4693 & TRN & \\
\hline CHEMBL 2004447 & 809200 & 4.8 & 4.79 & TST & \\
\hline CHEMBL1983111 & 809200 & 7.0 & 5.9469 & TST & \\
\hline CHEMBL1973860 & 809200 & 4.8 & 4.6432 & TRN & \\
\hline CHEMBL260135 & 809200 & 4.8 & 4.7918 & TRN & \\
\hline CHEMBL 220241 & 809200 & 4.8 & 5.4638 & TST & \\
\hline CHEMBL1982610 & 809200 & 6.2 & 5.1314 & TST & \\
\hline CHEMBL 2006933 & 809200 & 4.8 & 4.808 & TST & \\
\hline CHEMBL1988300 & 809200 & 6.9 & 6.8887 & TRN & \\
\hline CHEMBL1991078 & 809200 & 5.9 & 6.0037 & TRN & \\
\hline CHEMBL1987359 & 809200 & 4.8 & 4.7236 & TST & \\
\hline CHEMBL 2000685 & 809200 & 4.8 & 4.9662 & TRN & \\
\hline CHEMBL1985311 & 809200 & 4.8 & 5.5573 & TRN & \\
\hline CHEMBL1969502 & 809200 & 7.8 & 6.4271 & TST & \\
\hline CHEMBL1965910 & 809200 & 6.4 & 6.2518 & TST & \\
\hline CHEMBL1682553 & 809200 & 4.8 & 4.6866 & TRN & \\
\hline CHEMBL1997764 & 809200 & 6.0 & 5.9704 & TRN & \\
\hline CHEMBL1983963 & 809200 & 7.2 & 7.263 & TRN & \\
\hline CHEMBL 2000271 & 809200 & 4.8 & 5.34399 & 9999999999 & TRN \\
\hline CHEMBL1985092 & 809200 & 4.8 & 4.7712 & TRN & \\
\hline CHEMBL1981410 & 809200 & 4.8 & 5.4292 & TRN & \\
\hline CHEMBL1996234 & 809200 & 6.5 & 5.6584 & TST & \\
\hline CHEMBL1967544 & 809200 & 4.8 & 4.7213 & TRN & \\
\hline CHEMBL 223367 & 809200 & 4.8 & 4.7285 & TST & \\
\hline CHEMBL340384 & 809200 & 4.8 & 4.8953 & TST & \\
\hline CHEMBL1996587 & 809200 & 4.8 & 4.7678 & TRN & \\
\hline CHEMBL1964804 & 809200 & 4.8 & 4.7512 & TRN & \\
\hline CHEMBL 2000354 & 809200 & 4.8 & 5.3069 & TRN & \\
\hline CHEMBL1965507 & 809200 & 5.1 & 5.9732 & TRN & \\
\hline CHEMBL 274064 & 809200 & 4.8 & 5.3585 & TRN & \\
\hline CHEMBL1967564 & 809200 & 4.8 & 4.9165 & TRN & \\
\hline CHEMBL592030 & 809200 & 4.8 & 4.5911 & TST & \\
\hline CHEMBL 2000071 & 809200 & 5.0 & 5.6679 & TRN & \\
\hline CHEMBL1979176 & 809200 & 4.8 & 5.0981 & TRN & \\
\hline CHEMBL1985491 & 809200 & 4.8 & 5.4772 & TRN & \\
\hline CHEMBL1970317 & 809200 & 8.5 & 8.6601 & TRN & \\
\hline CHEMBL2000408 & 809200 & 4.8 & 4.7919 & TRN & \\
\hline CHEMBL248757 & 809200 & 4.8 & 4.7496 & TST & \\
\hline & & & & e 7247 & \\
\hline
\end{tabular}




\begin{tabular}{|c|c|c|c|c|c|}
\hline \multicolumn{6}{|c|}{ Supplemental Table S2.txt } \\
\hline CHEMBL1978014 & 809200 & 4.8 & 4.8702 & TRN & \\
\hline CHEMBL1994538 & 809200 & 4.8 & 4.8575 & TRN & \\
\hline CHEMBL1975490 & 809200 & 4.8 & 5.2783 & TRN & \\
\hline CHEMBL1964444 & 809200 & 4.8 & 4.7043 & TRN & \\
\hline CHEMBL 2006567 & 809200 & 4.8 & 4.5471 & TRN & \\
\hline CHEMBL1986139 & 809200 & 4.8 & 4.7969 & TRN & \\
\hline CHEMBL383527 & 809200 & 4.8 & 5.0708 & TRN & \\
\hline CHEMBL1980540 & 809200 & 4.8 & 4.7095 & TRN & \\
\hline CHEMBL1979883 & 809200 & 7.1 & 6.7198 & TRN & \\
\hline CHEMBL1984162 & 809200 & 7.8 & 8.2809 & TRN & \\
\hline CHEMBL491758 & 809200 & 6.3 & 5.9654 & TRN & \\
\hline CHEMBL549730 & 809200 & 4.8 & 4.618 & TRN & \\
\hline CHEMBL1970189 & 809200 & 4.8 & 4.8024 & TST & \\
\hline CHEMBL1996791 & 809200 & 6.5 & 6.0953 & TST & \\
\hline CHEMBL371206 & 809200 & 6.9 & 7.41299 & & TRN \\
\hline CHEMBL1974664 & 809200 & 6.9 & 7.13 & TST & \\
\hline CHEMBL1974288 & 809200 & 4.8 & 4.8707 & TRN & \\
\hline CHEMBL196363 & 809200 & 7.1 & 7.0811 & TRN & \\
\hline CHEMBL1190711 & 809200 & 4.8 & 5.7831 & TRN & \\
\hline CHEMBL1990346 & 809200 & 6.4 & 5.2443 & TRN & \\
\hline CHEMBL1968705 & 809200 & 4.8 & 5.1397 & TRN & \\
\hline CHEMBL404367 & 809200 & 6.1 & 5.6737 & TRN & \\
\hline CHEMBL1966343 & 809200 & 4.8 & 4.9508 & TRN & \\
\hline CHEMBL1967887 & 809200 & 4.8 & 4.7667 & TRN & \\
\hline CHEMBL 2000568 & 809200 & 6.1 & 4.9364 & TRN & \\
\hline CHEMBL 2000335 & 809200 & 7.3 & 7.482 & TRN & \\
\hline CHEMBL1988717 & 809200 & 9.0 & 8.4224 & TRN & \\
\hline CHEMBL1974328 & 809200 & 6.9 & 5.3333 & TST & \\
\hline CHEMBL509032 & 809200 & 7.2 & 6.3734 & TRN & \\
\hline CHEMBL1973808 & 809200 & 4.8 & 5.1732 & TRN & \\
\hline CHEMBL 2000429 & 809200 & 4.8 & 4.8838 & TRN & \\
\hline CHEMBL1972576 & 809200 & 6.9 & 6.4549 & TRN & \\
\hline CHEMBL1990254 & 809200 & 4.8 & 4.8157 & TRN & \\
\hline CHEMBL1992342 & 809200 & 4.8 & 4.6782 & TRN & \\
\hline CHEMBL1988173 & 809200 & 4.8 & 5.1134 & TST & \\
\hline CHEMBL1164265 & 809200 & 4.8 & 5.1446 & TST & \\
\hline CHEMBL1965423 & 809200 & 5.0 & 4.7001 & TRN & \\
\hline CHEMBL1983025 & 809200 & 6.4 & 6.1168 & TRN & \\
\hline CHEMBL205415 & 809200 & 4.8 & 5.151 & TRN & \\
\hline CHEMBL1977135 & 809200 & 4.8 & 4.8868 & TRN & \\
\hline CHEMBL 2001920 & 809200 & 4.8 & 4.8231 & TST & \\
\hline CHEMBL 2002322 & 809200 & 4.8 & 4.6078 & TRN & \\
\hline CHEMBL1980904 & 809200 & 6.6 & 6.8109 & TRN & \\
\hline CHEMBL1241473 & 809200 & 8.0 & 7.5114 & TRN & \\
\hline CHEMBL 2002323 & 809200 & 4.8 & 5.1316 & TST & \\
\hline CHEMBL1978448 & 809200 & 6.5 & 5.0958 & TST & \\
\hline CHEMBL 2001257 & 809200 & 4.8 & 6.0391 & TRN & \\
\hline CHEMBL 271441 & 809200 & 6.8 & 6.7592 & TRN & \\
\hline
\end{tabular}




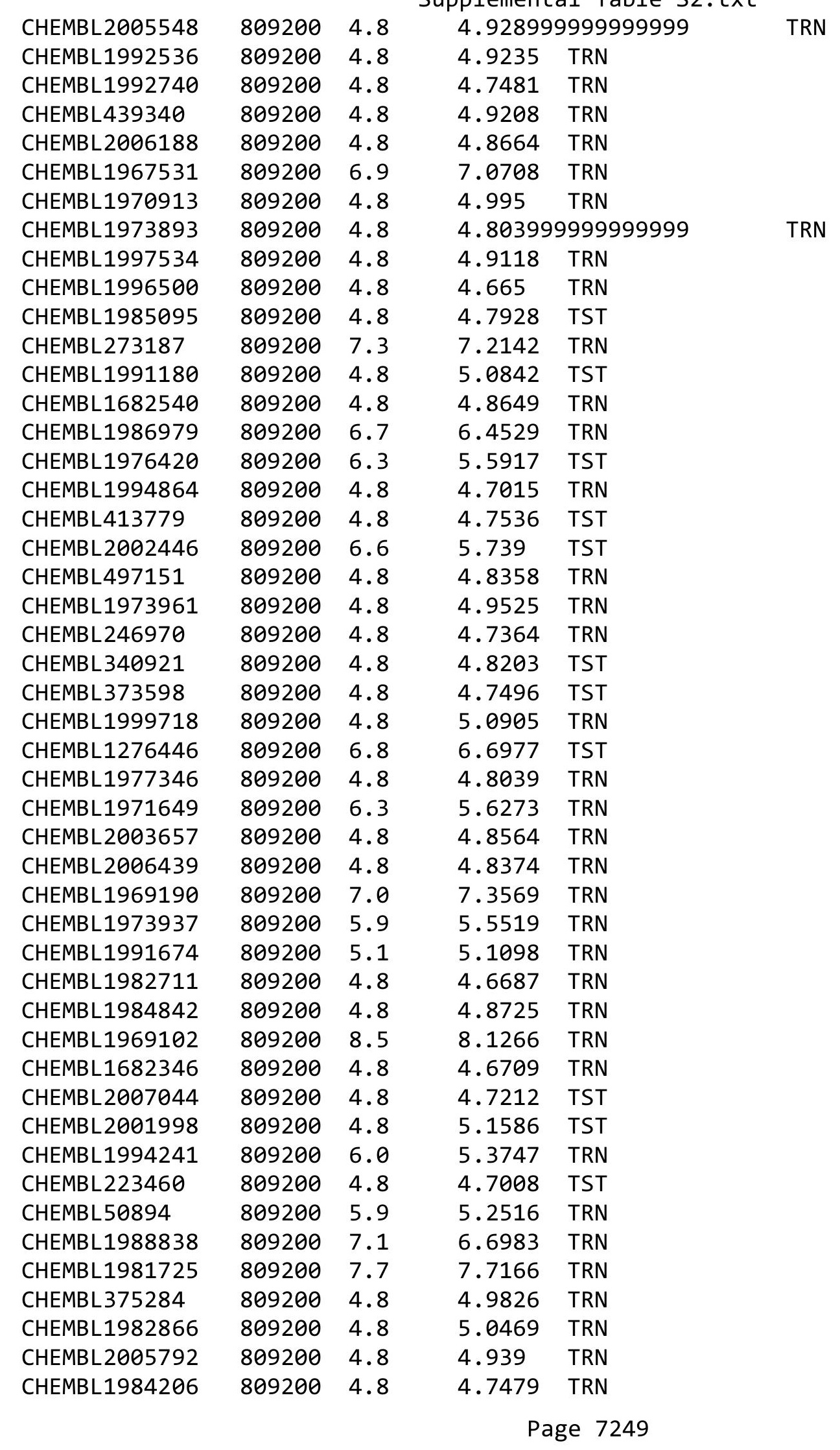




\begin{tabular}{|c|c|c|c|c|}
\hline & & & & al lable \\
\hline CHEMBL1965570 & 809200 & 7.8 & 7.8868 & TRN \\
\hline CHEMBL2007592 & 809200 & 4.8 & 4.8662 & TST \\
\hline CHEMBL210963 & 809200 & 4.8 & 4.9339 & TRN \\
\hline CHEMBL1082440 & 809200 & 4.8 & 4.96899 & 9999999999 \\
\hline CHEMBL1614705 & 809200 & 4.8 & 4.787 & TST \\
\hline CHEMBL1972362 & 809200 & 4.8 & 4.7158 & TRN \\
\hline CHEMBL1984633 & 809200 & 4.8 & 4.9387 & TRN \\
\hline CHEMBL1965845 & 809200 & 4.8 & 5.2358 & TRN \\
\hline CHEMBL 2006715 & 809200 & 7.2 & 7.6145 & TRN \\
\hline CHEMBL1986597 & 809200 & 4.8 & 4.9637 & TRN \\
\hline CHEMBL1971017 & 809200 & 5.9 & 4.6005 & TRN \\
\hline CHEMBL1990482 & 809200 & 4.8 & 4.91 & TRN \\
\hline CHEMBL1990904 & 809200 & 4.8 & 4.7006 & TRN \\
\hline CHEMBL 2005475 & 809200 & 4.8 & 4.8524 & TRN \\
\hline CHEMBL2000104 & 809200 & 4.8 & 4.5586 & TRN \\
\hline CHEMBL183844 & 809200 & 4.8 & 4.9783 & TRN \\
\hline CHEMBL220057 & 809200 & 5.0 & 5.6988 & TRN \\
\hline CHEMBL1682545 & 809200 & 4.8 & 4.6883 & TRN \\
\hline CHEMBL383541 & 809200 & 4.8 & 5.0481 & TRN \\
\hline CHEMBL2001224 & 809200 & 4.8 & 4.9867 & TRN \\
\hline CHEMBL10 & 809200 & 4.8 & 4.8025 & TRN \\
\hline CHEMBL1976732 & 809200 & 4.8 & 4.8061 & TRN \\
\hline CHEMBL1969506 & 809200 & 4.8 & 4.7721 & TRN \\
\hline CHEMBL1964937 & 809200 & 4.8 & 5.2779 & TRN \\
\hline CHEMBL1980163 & 809200 & 4.8 & 5.3194 & TRN \\
\hline CHEMBL590109 & 809200 & 5.9 & 4.8338 & TST \\
\hline CHEMBL1989856 & 809200 & 6.5 & 5.7514 & TST \\
\hline CHEMBL2005899 & 809200 & 4.8 & 4.9777 & TRN \\
\hline CHEMBL1682552 & 809200 & 4.8 & 4.6454 & TRN \\
\hline CHEMBL259850 & 809200 & 4.8 & 4.8404 & TRN \\
\hline CHEMBL1986851 & 809200 & 7.5 & 7.6265 & TRN \\
\hline CHEMBL1682359 & 809200 & 4.8 & 4.7777 & TRN \\
\hline CHEMBL105739 & 809200 & 7.0 & 6.3029 & TRN \\
\hline CHEMBL 379300 & 809200 & 4.8 & 5.1458 & TRN \\
\hline CHEMBL 203673 & 809200 & 4.8 & 4.9168 & TRN \\
\hline CHEMBL1969523 & 809200 & 4.8 & 4.68 & TRN \\
\hline CHEMBL207995 & 809200 & 4.8 & 4.9717 & TRN \\
\hline CHEMBL 2001923 & 809200 & 4.8 & 4.7196 & TRN \\
\hline CHEMBL1986781 & 809200 & 4.8 & 4.7885 & TRN \\
\hline CHEMBL526133 & 809200 & 4.8 & 4.8839 & TRN \\
\hline CHEMBL1966836 & 809200 & 6.9 & 6.7233 & TRN \\
\hline CHEMBL1981045 & 809200 & 4.8 & 4.8973 & TRN \\
\hline CHEMBL387971 & 809200 & 6.6 & 5.4532 & TST \\
\hline CHEMBL1979057 & 809200 & 4.8 & 4.9191 & TRN \\
\hline CHEMBL1975418 & 809200 & 4.8 & 4.7877 & TRN \\
\hline CHEMBL1992796 & 809200 & 4.8 & 4.8463 & TST \\
\hline CHEMBL1999428 & 809200 & 4.8 & 5.0105 & TRN \\
\hline CHEMBL 223257 & 809200 & 4.8 & 4.812 & TST \\
\hline
\end{tabular}




\begin{tabular}{|c|c|c|c|c|c|}
\hline \\
\hline CHEMBL1967560 & 809200 & 4.8 & 4.8397 & TRN & \\
\hline CHEMBL 211378 & 809200 & 6.5 & 6.305 & TRN & \\
\hline CHEMBL1516890 & 809200 & 6.4 & 6.3324 & TRN & \\
\hline CHEMBL1982465 & 809200 & 7.3 & 6.7575 & TRN & \\
\hline CHEMBL 2001751 & 809200 & 6.7 & 6.7156 & TRN & \\
\hline CHEMBL 2003420 & 809200 & 4.8 & 4.6697 & TRN & \\
\hline CHEMBL1984586 & 809200 & 6.7 & 6.8741 & TRN & \\
\hline CHEMBL1999774 & 809200 & 4.8 & 4.7533 & TST & \\
\hline CHEMBL 272938 & 809200 & 6.5 & 6.5044 & TRN & \\
\hline CHEMBL1972659 & 809200 & 4.8 & 4.8693 & TST & \\
\hline CHEMBL1973395 & 809200 & 6.2 & 5.94600 & 0000000001 & TRN \\
\hline CHEMBL 272453 & 809200 & 6.8 & 6.4667 & TRN & \\
\hline CHEMBL1970217 & 809200 & 4.8 & 4.8432 & TRN & \\
\hline CHEMBL1971801 & 809200 & 5.9 & 5.1278 & TRN & \\
\hline CHEMBL1968850 & 809200 & 4.8 & 4.5632 & TRN & \\
\hline CHEMBL 2005528 & 809200 & 4.8 & 4.9135 & TST & \\
\hline CHEMBL185569 & 809200 & 6.2 & 5.3424 & TRN & \\
\hline CHEMBL1969843 & 809200 & 4.8 & 4.7566 & TRN & \\
\hline CHEMBL 2007002 & 809200 & 4.8 & 5.2945 & TRN & \\
\hline CHEMBL1987007 & 809200 & 4.8 & 4.8381 & TRN & \\
\hline CHEMBL1969588 & 809200 & 7.3 & 6.5243 & TRN & \\
\hline CHEMBL1984711 & 809200 & 7.1 & 7.3206 & TRN & \\
\hline CHEMBL484390 & 809200 & 4.8 & 5.1205 & TST & \\
\hline CHEMBL1979252 & 809200 & 4.8 & 4.5226 & TRN & \\
\hline CHEMBL1682341 & 809200 & 4.8 & 4.6872 & TRN & \\
\hline CHEMBL 2004290 & 809200 & 8.0 & 8.2112 & TRN & \\
\hline CHEMBL1986499 & 809200 & 4.8 & 4.6851 & TRN & \\
\hline CHEMBL1972937 & 809200 & 4.8 & 4.8917 & TRN & \\
\hline CHEMBL1972250 & 809200 & 4.8 & 5.0321 & TST & \\
\hline CHEMBL 2000393 & 809200 & 5.8 & 5.5399 & TST & \\
\hline CHEMBL403402 & 809200 & 6.9 & 7.1104 & TRN & \\
\hline CHEMBL 2004311 & 809200 & 6.1 & 5.9039 & TRN & \\
\hline CHEMBL1992634 & 809200 & 4.8 & 5.3227 & TRN & \\
\hline CHEMBL1242373 & 809200 & 6.9 & 6.6717 & TRN & \\
\hline CHEMBL1988075 & 809200 & 7.0 & 7.0222 & TRN & \\
\hline CHEMBL316264 & 809200 & 4.8 & 4.7049 & TRN & \\
\hline CHEMBL1991678 & 809200 & 4.8 & 4.5989 & TRN & \\
\hline CHEMBL2001239 & 809200 & 6.2 & 5.0675 & TST & \\
\hline CHEMBL1988594 & 809200 & 6.9 & 6.4586 & TRN & \\
\hline CHEMBL2001288 & 809200 & 4.8 & 5.5516 & TST & \\
\hline CHEMBL260092 & 809200 & 6.8 & 6.7583 & TRN & \\
\hline CHEMBL1999811 & 809200 & 4.8 & 5.4808 & TST & \\
\hline CHEMBL1965495 & 809200 & 4.8 & 4.9395 & TRN & \\
\hline CHEMBL1985074 & 809200 & 4.8 & 4.7862 & TST & \\
\hline CHEMBL1982874 & 809200 & 4.8 & 4.9173 & TRN & \\
\hline CHEMBL2000481 & 809200 & 4.8 & 4.8798 & TRN & \\
\hline CHEMBL1991725 & 809200 & 7.0 & 5.5391 & TRN & \\
\hline CHEMBL1992242 & 809200 & 4.8 & 4.8292 & TRN & \\
\hline
\end{tabular}




\begin{tabular}{|c|c|c|c|c|}
\hline \multicolumn{5}{|c|}{ 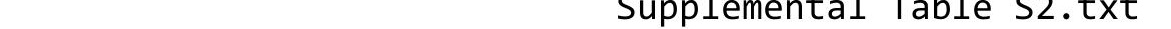 } \\
\hline CHEMBL2007296 & 809200 & 4.8 & 4.649 & TRN \\
\hline CHEMBL396523 & 809200 & 6.4 & 6.3322 & TRN \\
\hline CHEMBL1970203 & 809200 & 7.2 & 6.2477 & TRN \\
\hline CHEMBL1986530 & 809200 & 4.8 & 4.9409 & TST \\
\hline CHEMBL1999321 & 809200 & 4.8 & 4.7887 & TRN \\
\hline CHEMBL1968590 & 809200 & 7.5 & 7.3814 & TRN \\
\hline CHEMBL1999749 & 809200 & 7.9 & \multicolumn{2}{|c|}{6.827999999999999} \\
\hline CHEMBL 2005375 & 809200 & 4.8 & 4.7892 & TRN \\
\hline CHEMBL1984191 & 809200 & 4.8 & 5.0838 & TRN \\
\hline CHEMBL1983006 & 809200 & 4.8 & 5.0558 & TRN \\
\hline CHEMBL1971029 & 809200 & 7.1 & 6.8631 & TRN \\
\hline CHEMBL394790 & 809200 & 6.1 & 5.9439 & TRN \\
\hline CHEMBL226471 & 809200 & 4.8 & 4.8502 & TRN \\
\hline CHEMBL1974702 & 809200 & 4.8 & 4.6767 & TST \\
\hline CHEMBL1996111 & 809200 & 4.8 & 4.9834 & TRN \\
\hline CHEMBL1965589 & 809200 & 4.8 & 4.6853 & TRN \\
\hline CHEMBL1998193 & 809200 & 4.8 & 4.7795 & TRN \\
\hline CHEMBL474432 & 809200 & 7.2 & 6.5934 & TST \\
\hline CHEMBL1988153 & 809200 & 4.8 & 4.7322 & TRN \\
\hline CHEMBL1999556 & 809200 & 6.0 & 4.7923 & TRN \\
\hline CHEMBL1988437 & 809200 & 6.3 & 5.7299 & TST \\
\hline CHEMBL1968245 & 809200 & 4.8 & 5.2192 & TRN \\
\hline CHEMBL1998121 & 809200 & 6.3 & 5.4875 & TRN \\
\hline CHEMBL1979577 & 809200 & 6.8 & 6.6216 & TRN \\
\hline CHEMBL1991800 & 809200 & 4.8 & 4.8293 & TRN \\
\hline CHEMBL1985566 & 809200 & 4.8 & 4.7788 & TRN \\
\hline CHEMBL1996649 & 809200 & 7.0 & 7.2569 & TRN \\
\hline CHEMBL1980802 & 809200 & 4.8 & 4.8039 & TST \\
\hline CHEMBL1979357 & 809200 & 4.8 & 4.9033 & TRN \\
\hline CHEMBL1979554 & 809200 & 4.8 & 4.772 & TRN \\
\hline CHEMBL1996817 & 809200 & 6.6 & 6.1682 & TRN \\
\hline CHEMBL409349 & 809200 & 7.1 & 6.6663 & TRN \\
\hline CHEMBL 2004355 & 809200 & 4.8 & 4.5174 & TRN \\
\hline CHEMBL468280 & 809200 & 4.8 & 4.6396 & TST \\
\hline CHEMBL1990884 & 809200 & 5.9 & 6.0282 & TRN \\
\hline CHEMBL3109278 & 809200 & 7.2 & 6.7432 & TRN \\
\hline CHEMBL256835 & 809200 & 4.8 & 5.1667 & TRN \\
\hline CHEMBL1980142 & 809200 & 4.8 & 4.8402 & TRN \\
\hline CHEMBL41783 & 809200 & 4.8 & 4.7109 & TRN \\
\hline CHEMBL 2004438 & 809200 & 6.4 & 5.7398 & TRN \\
\hline CHEMBL 2006276 & 809200 & 4.8 & 4.75 & TRN \\
\hline CHEMBL271381 & 809200 & 6.9 & 6.7814 & TRN \\
\hline CHEMBL 2006785 & 809200 & 4.8 & 4.9165 & TST \\
\hline CHEMBL1982466 & 809200 & 8.7 & 8.9806 & TRN \\
\hline CHEMBL1994638 & 809200 & 6.2 & 6.2306 & TRN \\
\hline CHEMBL1995740 & 809200 & 4.8 & 4.8022 & TRN \\
\hline CHEMBL1985888 & 809200 & 6.4 & 6.9645 & TRN \\
\hline CHEMBL1996390 & 809200 & 4.8 & 4.7234 & TRN \\
\hline
\end{tabular}

TRN 


\begin{tabular}{|c|c|c|c|c|c|}
\hline \multicolumn{6}{|c|}{ Supplemental Table S2.txt } \\
\hline CHEMBL234085 & 809200 & 4.8 & 5.1058 & TST & \\
\hline CHEMBL1995832 & 809200 & 4.8 & 4.9818 & TRN & \\
\hline CHEMBL1969042 & 809200 & 4.8 & 5.0164 & TRN & \\
\hline CHEMBL 2000345 & 809200 & 6.1 & 5.3488 & TRN & \\
\hline CHEMBL1999931 & 809200 & 5.9 & 5.5157 & TRN & \\
\hline CHEMBL1991640 & 809200 & 4.8 & 4.7245 & TST & \\
\hline CHEMBL302449 & 809200 & 7.5 & 5.5495 & TST & \\
\hline CHEMBL 2007064 & 809200 & 6.9 & 6.16299 & 9999999999 & TRN \\
\hline CHEMBL1981047 & 809200 & 7.4 & 7.1994 & TRN & \\
\hline CHEMBL229968 & 809200 & 4.8 & 4.8969 & TRN & \\
\hline CHEMBL1976240 & 809200 & 4.8 & 4.7537 & TRN & \\
\hline CHEMBL1979093 & 809200 & 6.8 & 7.2825 & TRN & \\
\hline CHEMBL1968151 & 809200 & 4.8 & 4.7238 & TST & \\
\hline CHEMBL1381197 & 809200 & 6.6 & 5.74100 & 00000000005 & TRN \\
\hline CHEMBL1987009 & 809200 & 4.8 & 4.9781 & TRN & \\
\hline CHEMBL379218 & 809200 & 4.8 & 4.9275 & TRN & \\
\hline CHEMBL2003817 & 809200 & 4.8 & 4.9189 & TRN & \\
\hline CHEMBL336961 & 809200 & 4.8 & 5.3727 & TRN & \\
\hline CHEMBL1994830 & 809200 & 4.8 & 4.6218 & TRN & \\
\hline CHEMBL1987054 & 809200 & 7.3 & 7.8454 & TRN & \\
\hline CHEMBL1970083 & 809200 & 7.5 & 8.0488 & TRN & \\
\hline CHEMBL226403 & 809200 & 4.8 & 4.9278 & TRN & \\
\hline CHEMBL 2005631 & 809200 & 8.3 & 8.0628 & TRN & \\
\hline CHEMBL1994938 & 809200 & 9.1 & 8.4073 & TRN & \\
\hline CHEMBL1977223 & 809200 & 4.8 & 4.6198 & TRN & \\
\hline CHEMBL1236126 & 809200 & 4.8 & 4.8058 & TST & \\
\hline CHEMBL1966279 & 809200 & 4.8 & 4.9866 & TRN & \\
\hline CHEMBL1997846 & 809200 & 6.4 & 5.0832 & TRN & \\
\hline CHEMBL 2004419 & 809200 & 4.8 & 4.9085 & TRN & \\
\hline CHEMBL1975787 & 809200 & 4.8 & 4.7357 & TRN & \\
\hline CHEMBL 2002407 & 809200 & 6.1 & 5.5797 & TRN & \\
\hline CHEMBL1994074 & 809200 & 4.8 & 4.9401 & TRN & \\
\hline CHEMBL1992937 & 809200 & 4.8 & 4.6309 & TST & \\
\hline CHEMBL1972119 & 809200 & 4.8 & 4.9725 & TRN & \\
\hline CHEMBL1090356 & 809200 & 7.6 & 6.9347 & TRN & \\
\hline CHEMBL95692 & 809200 & 4.8 & 4.9563 & TRN & \\
\hline CHEMBL1986507 & 809200 & 6.1 & 6.5451 & TRN & \\
\hline CHEMBL1976455 & 809200 & 4.8 & 5.1132 & TRN & \\
\hline CHEMBL1983923 & 809200 & 7.2 & 6.5245 & TST & \\
\hline CHEMBL1983534 & 809200 & 4.8 & 4.9603 & TRN & \\
\hline CHEMBL1982361 & 809200 & 4.8 & 4.7285 & TRN & \\
\hline CHEMBL1999112 & 809200 & 7.4 & 5.7946 & TST & \\
\hline CHEMBL1982122 & 809200 & 4.8 & 4.6663 & TRN & \\
\hline CHEMBL2000801 & 809200 & 4.8 & 4.7543 & TRN & \\
\hline CHEMBL1682546 & 809200 & 4.8 & 4.6851 & TRN & \\
\hline CHEMBL1991395 & 809200 & 4.8 & 4.8847 & TRN & \\
\hline CHEMBL1971245 & 809200 & 4.8 & 5.4333 & TRN & \\
\hline CHEMBL1987648 & 809200 & 4.8 & 4.8699 & TRN & \\
\hline
\end{tabular}




\begin{tabular}{|c|c|c|c|c|}
\hline & & & oplement & $d+1$ \\
\hline CHEMBL1996780 & 809200 & 4.8 & 4.6765 & TST \\
\hline CHEMBL1972142 & 809200 & 4.8 & 5.0038 & TRN \\
\hline CHEMBL1966514 & 809200 & 8.3 & 7.7227 & TRN \\
\hline CHEMBL 2003638 & 809200 & 4.8 & 5.2345 & TRN \\
\hline CHEMBL 296586 & 809200 & 4.8 & 5.7076 & TRN \\
\hline CHEMBL1996066 & 809200 & 6.0 & 5.8552 & TST \\
\hline CHEMBL516429 & 809200 & 4.8 & 5.0068 & TRN \\
\hline CHEMBL1993722 & 809200 & 4.8 & 5.1025 & TRN \\
\hline CHEMBL1375640 & 809200 & 4.8 & 4.8713 & TST \\
\hline CHEMBL1979970 & 809200 & 4.8 & 4.5943 & TRN \\
\hline CHEMBL 249282 & 809200 & 4.8 & 4.7625 & TST \\
\hline CHEMBL1969264 & 809200 & 4.8 & 5.0493 & TRN \\
\hline CHEMBL1973711 & 809200 & 4.8 & 4.9951 & TST \\
\hline CHEMBL 2006237 & 809200 & 4.8 & 4.9005 & TRN \\
\hline CHEMBL1967720 & 809200 & 7.6 & 8.0713 & TRN \\
\hline CHEMBL1572266 & 809200 & 4.8 & 4.7709 & TST \\
\hline CHEMBL1991138 & 809200 & 5.1 & 5.4192 & TST \\
\hline CHEMBL1969755 & 809200 & 4.8 & 4.8555 & TRN \\
\hline CHEMBL1979516 & 809200 & 7.9 & 7.5372 & TRN \\
\hline CHEMBL1605605 & 809200 & 4.8 & 4.8904 & TST \\
\hline CHEMBL1989029 & 809200 & 6.2 & 5.8809 & TST \\
\hline CHEMBL392642 & 809200 & 4.8 & 4.8078 & TRN \\
\hline CHEMBL514499 & 809200 & 4.8 & 6.3746 & TST \\
\hline CHEMBL1965631 & 809200 & 4.8 & 4.6885 & TRN \\
\hline CHEMBL1980144 & 809200 & 6.5 & 6.4466 & TST \\
\hline CHEMBL1991188 & 809200 & 4.8 & 4.9672 & TST \\
\hline CHEMBL1972849 & 809200 & 4.8 & 4.8409 & TST \\
\hline CHEMBL 377408 & 809200 & 6.0 & 4.7373 & TST \\
\hline CHEMBL 215152 & 809200 & 6.2 & 5.7615 & TST \\
\hline CHEMBL231209 & 809200 & 6.2 & 5.9516 & TST \\
\hline CHEMBL1976220 & 809200 & 6.1 & 6.0244 & TST \\
\hline CHEMBL 259922 & 809200 & 5.0 & 6.2411 & TST \\
\hline CHEMBL1982383 & 809200 & 4.8 & 5.1801 & TST \\
\hline CHEMBL1969301 & 809200 & 4.8 & 4.9304 & TST \\
\hline CHEMBL17370 & 809200 & 4.8 & 5.023 & TST \\
\hline CHEMBL1987910 & 809200 & 4.8 & 5.6653 & TST \\
\hline CHEMBL374044 & 809200 & 6.8 & 6.4942 & TST \\
\hline CHEMBL1983932 & 809200 & 4.8 & 5.0445 & TST \\
\hline CHEMBL404366 & 809200 & 6.8 & 6.4053 & TST \\
\hline CHEMBL1966069 & 809200 & 4.8 & 4.7315 & TST \\
\hline CHEMBL1997822 & 809200 & 6.4 & 5.8614 & TST \\
\hline CHEMBL1991285 & 809200 & 4.8 & 5.1428 & TST \\
\hline CHEMBL 243088 & 809200 & 6.2 & 5.8892 & TST \\
\hline CHEMBL1984038 & 809200 & 4.8 & 4.8493 & TST \\
\hline CHEMBL1993661 & 809200 & 9.0 & 6.4746 & TST \\
\hline CHEMBL1974416 & 809200 & 6.6 & 6.9069 & TST \\
\hline CHEMBL 1783876 & 749913 & 8.6778 & 8.7619 & TRN \\
\hline CHEMBL1783858 & 749913 & 8.699 & 8.4519 & TRN \\
\hline
\end{tabular}


Supplemental Table S2.txt

\begin{tabular}{|c|c|c|c|c|}
\hline HEMBL & 913 & 852 & 6502 & \\
\hline HEMPI 1701961 & 49913 & .7696 & 8.7007 & \\
\hline JEN & & & & \\
\hline AEMBL1 & 3 & 031 & 6697 & \\
\hline JEMBL17 & 49913 & 778 & 3696 & \\
\hline HEMBL1783872 & 49913 & 7077 & 3364 & \\
\hline HEMBL1 & 49913 & & 3616 & \\
\hline IEMBL: & 49913 & & & \\
\hline AEMBL4 & 49913 & 23 & .9738 & \\
\hline HEMBL17 & 49913 & 96 & .6169 & \\
\hline HEMBL1 & 49913 & & 2766 & \\
\hline AEMBL1 & 49913 & 75 & .2189 & \\
\hline HEMBL: & & & & \\
\hline HEMBL1 & 49913 & 29 & 8.401 & \\
\hline AEMBL1 & 499 & & 1329 & \\
\hline AEMBL1 & 495 & 7 & 8.8789 & \\
\hline HEMBLI & 495 & & 761 & \\
\hline HEMBLI & $196 \mathrm{c}+2>$ & & 923 & \\
\hline HEMBL1 & 495 & & 6.9863 & \\
\hline AEMBL1 & 49 & & & \\
\hline AEMIBL & 49 & & 34 & NIN \\
\hline HEMBL & +9 & & 341 & RN \\
\hline HEMBL & 3 & & 171 & \\
\hline 360 & $190 \mathrm{c}+2>$ & & & \\
\hline AEMBL1 & 3 & & & IRIV \\
\hline HEMBL & 49 & & & RIV \\
\hline HEMBL & 19 & & & וכד \\
\hline HFMRI & 19 & & 04 & PN \\
\hline HEMBL1 & $198 \mathrm{c}+2>$ & & 8.3689 & $\ln$ \\
\hline HEMBL1 & 49 & & 546 & I RN \\
\hline HEMBLI & 495 & & 3335 & RN \\
\hline HEMBL & 495 & & 43 & RN \\
\hline HEMBL & 3 & & 8.5802 & RN \\
\hline HEMBL1 & 495 & & 5748 & IRN \\
\hline HEMBL17 & 499 & & 7.6283 & TS \\
\hline HEMBL & 49 & & 855 & ГST \\
\hline HFMRI - & 19 & & & TRN \\
\hline HEMBLI & 100 & & 238 & TRN \\
\hline HEMBL1 & 499 & & & TRN \\
\hline AEMBL1 & 499 & & 7.9597 & TRN \\
\hline HEMBL1 & r & & 219 & \\
\hline CHEMBL1 & & & 8.3986 & TRN \\
\hline HEMBL17 & 499 & & 8.509 & TST \\
\hline HEMBL1 & 499 & & 8.5551 & TS \\
\hline HEMBL1 & 190 & & 7.8866 & is \\
\hline CHEMBL1 & - & & 7.7066 & \\
\hline CHEMBL17 & 499 & & 7.4966 & \\
\hline HEMBL1783861 & 749913 & 7.8996 & 7.7495 & ГRN \\
\hline
\end{tabular}

Page 7255 


\begin{tabular}{|c|c|c|c|c|c|c|}
\hline \multirow[b]{2}{*}{ CHEMBL1784066 } & \multicolumn{6}{|c|}{ Supplemental Table S2.txt } \\
\hline & 749913 & 7.4815 & 7.7224 & TST & & \\
\hline CHEMBL1783866 & 749913 & 7.1805 & 8.7817 & TST & & \\
\hline CHEMBL1783873 & 749913 & 6.617999 & 99999999 & 99 & 7.2869 & TST \\
\hline CHEMBL1784068 & 749913 & 8.4089 & 8.066 & TRN & & \\
\hline CHEMBL 3647082 & 1528198 & 7.8125 & 9.1923 & TRN & & \\
\hline CHEMBL3981777 & 1528198 & 7.9547 & 8.9307 & TRN & & \\
\hline CHEMBL1450458 & 1528198 & 8.1232 & 7.8943 & TRN & & \\
\hline CHEMBL3914870 & 1528198 & 8.3947 & 8.4669 & TRN & & \\
\hline CHEMBL1505563 & 1528198 & 8.02 & 8.0201 & TRN & & \\
\hline CHEMBL 3647138 & 1528198 & 9.8601 & 9.2766 & TRN & & \\
\hline CHEMBL 3647137 & 1528198 & 9.083 & 9.3011 & TRN & & \\
\hline CHEMBL1333600 & 1528198 & 8.5935 & 8.3654 & TST & & \\
\hline CHEMBL1419943 & 1528198 & 8.4486 & 7.9319 & TRN & & \\
\hline CHEMBL3647135 & 1528198 & 10.2277 & 9.2755 & TRN & & \\
\hline CHEMBL 3927567 & 1528198 & 8.8665 & $8.65200 t$ & 0000000001 & & TRN \\
\hline CHEMBL3939444 & 1528198 & 9.1512 & 9.0487 & TRN & & \\
\hline CHEMBL3647074 & 1528198 & 9.4949 & 9.1285 & TRN & & \\
\hline CHEMBL 3647258 & 1528198 & 7.9914 & 8.8729 & TRN & & \\
\hline CHEMBL3647081 & 1528198 & 8.4647 & 9.1912 & TRN & & \\
\hline CHEMBL3647129 & 1528198 & 7.8356 & 8.6995 & TRN & & \\
\hline CHEMBL3647085 & 1528198 & 9.4802 & 9.3103 & TRN & & \\
\hline CHEMBL3647132 & 1528198 & 9.2676 & 9.2204 & TRN & & \\
\hline CHEMBL1606020 & 1528198 & 8.8386 & 8.0212 & TRN & & \\
\hline CHEMBL3973212 & 1528198 & 9.7447 & 9.0449 & TRN & & \\
\hline CHEMBL3647126 & 1528198 & 9.3696 & 9.3622 & TRN & & \\
\hline CHEMBL3961895 & 1528198 & 9.4271 & 8.9876 & TRN & & \\
\hline CHEMBL1736377 & 1528198 & 7.857 & 8.1257 & TRN & & \\
\hline CHEMBL3190303 & 1528198 & 7.983 & 7.9837 & TRN & & \\
\hline CHEMBL3978300 & 1528198 & 9.5751 & 8.9827 & TRN & & \\
\hline CHEMBL1987092 & 1528198 & 8.7011 & 8.1551 & TRN & & \\
\hline CHEMBL1584969 & 1528198 & 8.4056 & 8.0587 & TST & & \\
\hline CHEMBL1464508 & 1528198 & 8.1694 & 8.1323 & TRN & & \\
\hline CHEMBL 3892214 & 1528198 & 9.0752 & 8.8463 & TRN & & \\
\hline CHEMBL3647090 & 1528198 & 9.1361 & 9.1286 & TRN & & \\
\hline CHEMBL1956131 & 1528198 & 9.8729 & 9.40899 & 9999999999 & & TRN \\
\hline CHEMBL1426072 & 1528198 & 8.9547 & 8.2274 & TRN & & \\
\hline CHEMBL 3647181 & 1528198 & 8.4895 & 8.9834 & TRN & & \\
\hline CHEMBL3647176 & 1528198 & 9.3556 & 9.2089 & TRN & & \\
\hline CHEMBL1548014 & 1528198 & 8.4191 & 7.9621 & TRN & & \\
\hline CHEMBL3647095 & 1528198 & 9.4486 & 9.2821 & TRN & & \\
\hline CHEMBL1577884 & 1528198 & 8.4584 & 8.0754 & TRN & & \\
\hline CHEMBL3647099 & 1528198 & 9.3487 & 9.0872 & TRN & & \\
\hline CHEMBL3977768 & 1528198 & 8.7595 & 9.0389 & TRN & & \\
\hline CHEMBL1373908 & 1528198 & 7.9031 & 8.0748 & TRN & & \\
\hline CHEMBL3647096 & 1528198 & 9.1314 & 9.275 & TRN & & \\
\hline CHEMBL1410686 & 1528198 & 9.4056 & 8.073 & TST & & \\
\hline CHEMBL1382392 & 1528198 & 7.9788 & 7.93 & TRN & & \\
\hline CHEMBL1370183 & 1528198 & 8.1427 & 8.4686 & TRN & & \\
\hline
\end{tabular}


Supplemental Table S2.txt

\begin{tabular}{|c|c|c|c|c|c|c|}
\hline CHEMBL3647102 & 1528198 & 9.5751 & 9.3477 & TRN & & \\
\hline CHEMBL3647142 & 1528198 & 9.1993 & 9.0844 & TRN & & \\
\hline CHEMBL1323994 & 1528198 & 8.8125 & 8.2902 & TRN & & \\
\hline CHEMBL3647116 & 1528198 & 9.475 & 9.4178 & TRN & & \\
\hline CHEMBL1339329 & 1528198 & 8.3072 & 8.3601 & TRN & & \\
\hline CHEMBL3647122 & 1528198 & 9.618 & 9.2868 & TRN & & \\
\hline CHEMBL3647117 & 1528198 & 9.4724 & 9.1789 & TRN & & \\
\hline CHEMBL1492213 & 1528198 & 6.9788 & 8.1625 & TST & & \\
\hline CHEMBL3647148 & 1528198 & 8.9666 & 9.1065 & TRN & & \\
\hline CHEMBL3896920 & 1528198 & 9.1481 & 8.8972 & TRN & & \\
\hline CHEMBL3950184 & 1528198 & 9.6198 & 8.7395 & TRN & & \\
\hline CHEMBL 3647087 & 1528198 & 9.475 & 9.2534 & TRN & & \\
\hline CHEMBL1424123 & 1528198 & 8.341000 & 000000000 & $\partial 1$ & 8.054 & TRN \\
\hline CHEMBL1453264 & 1528198 & 9.1232 & 8.1894 & TST & & \\
\hline CHEMBL3647097 & 1528198 & 9.0039 & 9.2077 & TRN & & \\
\hline CHEMBL1350376 & 1528198 & 8.2526 & 8.2195 & TST & & \\
\hline CHEMBL3647088 & 1528198 & 10.1746 & 9.4414 & TRN & & \\
\hline CHEMBL3968395 & 1528198 & 7.055 & 8.9865 & TRN & & \\
\hline CHEMBL1378709 & 1528198 & 9.02 & 8.2115 & TRN & & \\
\hline CHEMBL3916698 & 1528198 & 9.2733 & 8.8659 & TRN & & \\
\hline CHEMBL1582936 & 1528198 & 9.1864 & 8.0209 & TST & & \\
\hline CHEMBL3647113 & 1528198 & 9.6345 & 9.4118 & TRN & & \\
\hline CHEMBL 3647084 & 1528198 & 8.6234 & 8.868 & TRN & & \\
\hline CHEMBL1562983 & 1528198 & 6.0 & 7.975 & TRN & & \\
\hline CHEMBL3647163 & 1528198 & 8.6904 & 9.2601 & TRN & & \\
\hline CHEMBL3647125 & 1528198 & 9.6289 & 9.2296 & TRN & & \\
\hline CHEMBL1604389 & 1528198 & 8.0 & 8.2482 & TST & & \\
\hline CHEMBL3647127 & 1528198 & 6.0 & 9.2558 & TRN & & \\
\hline CHEMBL3647083 & 1528198 & 9.0353 & 9.3157 & TRN & & \\
\hline CHEMBL1452295 & 1528198 & 6.0 & 8.1188 & TRN & & \\
\hline CHEMBL1541466 & 1528198 & 8.2749 & 8.2647 & TST & & \\
\hline CHEMBL3647149 & 1528198 & 9.1349 & 8.9764 & TRN & & \\
\hline CHEMBL3913240 & 1528198 & 8.3958 & 8.9006 & TRN & & \\
\hline CHEMBL3647112 & 1528198 & 9.8239 & 9.4571 & TRN & & \\
\hline CHEMBL3644543 & 1528198 & 9.585 & 9.0562 & TRN & & \\
\hline CHEMBL3647160 & 1528198 & 7.6289 & 9.1477 & TRN & & \\
\hline CHEMBL3647089 & 1528198 & 9.8794 & 9.2897 & TRN & & \\
\hline CHEMBL 3647094 & 1528198 & 9.7328 & 9.1673 & TRN & & \\
\hline CHEMBL3647107 & 1528198 & 9.8416 & 9.3494 & TRN & & \\
\hline CHEMBL3902037 & 1528198 & 8.2358 & 8.1477 & TST & & \\
\hline CHEMBL3903915 & 1528198 & 7.2676 & 8.7903 & TRN & & \\
\hline CHEMBL504791 & 1528198 & 9.2798 & 8.1554 & TST & & \\
\hline CHEMBL3647177 & 1528198 & 8.7258 & 9.1767 & TRN & & \\
\hline CHEMBL3905906 & 1528198 & 8.3468 & 8.0603 & TST & & \\
\hline CHEMBL1371568 & 1528198 & 8.8153 & 8.3526 & TST & & \\
\hline CHEMBL1340587 & 1528198 & 9.1838 & 7.8851 & TST & & \\
\hline CHEMBL3647078 & 1528198 & 8.3002 & 8.7592 & TRN & & \\
\hline CHEMBL3647161 & 1528198 & 8.1494 & 9.2284 & TRN & & \\
\hline
\end{tabular}


Supplemental Table S2.txt

\begin{tabular}{|c|c|c|c|c|c|c|}
\hline CHEMBL 3647171 & 1528198 & 8.9172 & 8.9075 & TRN & & \\
\hline CHEMBL1567923 & 1528198 & 8.3716 & 8.2866 & TST & & \\
\hline CHEMBL 3647110 & 1528198 & 9.3089 & 9.3735 & TRN & & \\
\hline CHEMBL 3987119 & 1528198 & 9.295 & 8.8746 & TRN & & \\
\hline CHEMBL 3647073 & 1528198 & 9.5086 & 8.8412 & TRN & & \\
\hline CHEMBL3647179 & 1528198 & 7.9431 & 9.2154 & TRN & & \\
\hline CHEMBL1587654 & 1528198 & 8.6271 & 8.0857 & TST & & \\
\hline CHEMBL1519408 & 1528198 & 8.1215 & 8.1792 & TST & & \\
\hline CHEMBL 3647080 & 1528198 & 9.2007 & 8.9736 & TRN & & \\
\hline CHEMBL3647076 & 1528198 & 9.5376 & 9.2089 & TRN & & \\
\hline CHEMBL1361904 & 1528198 & 8.4841 & 8.2025 & TST & & \\
\hline CHEMBL1731995 & 1528198 & 9.0899 & 7.9704 & TST & & \\
\hline CHEMBL1299795 & 1528198 & 7.8633 & 8.3746 & TST & & \\
\hline CHEMBL 3647143 & 1528198 & 9.4584 & 9.1508 & TRN & & \\
\hline CHEMBL3647100 & 1528198 & 9.6162 & 9.2876 & TRN & & \\
\hline CHEMBL3924968 & 1528198 & 9.6091 & 8.9893 & TRN & & \\
\hline CHEMBL3647151 & 1528198 & 8.1481 & 8.9277 & TRN & & \\
\hline CHEMBL1331901 & 1528198 & 8.5544 & 8.5264 & TST & & \\
\hline CHEMBL 3639460 & 1528198 & 9.5143 & 9.2702 & TRN & & \\
\hline CHEMBL 3647098 & 1528198 & 9.3526 & 9.1175 & TRN & & \\
\hline CHEMBL3961535 & 1528198 & 8.5918 & 8.3097 & TST & & \\
\hline CHEMBL 3647109 & 1528198 & 9.4112 & 9.2468 & TRN & & \\
\hline CHEMBL 3647092 & 1528198 & 9.5302 & 9.2189 & TRN & & \\
\hline CHEMBL 3647114 & 1528198 & 9.0066 & 9.0643 & TRN & & \\
\hline CHEMBL1956134 & 1528198 & 9.4134 & 8.8891 & TRN & & \\
\hline CHEMBL1380684 & 1528198 & 6.0 & 8.1025 & TST & & \\
\hline CHEMBL 3647180 & 1528198 & 8.4841 & 9.11 & TRN & & \\
\hline CHEMBL 3935743 & 1528198 & \multicolumn{3}{|c|}{9.556000000000001} & 9.0272 & TRN \\
\hline CHEMBL3647071 & 1528198 & 9.9208 & 9.356 & TRN & & \\
\hline CHEMBL 3944252 & 1528198 & 8.8297 & 8.79 & TRN & & \\
\hline CHEMBL 3647139 & 1528198 & 9.4123 & 9.2248 & TRN & & \\
\hline CHEMBL1338756 & 1528198 & 9.0788 & 8.0574 & TST & & \\
\hline CHEMBL1467316 & 1528198 & 8.567 & 8.0919 & TRN & & \\
\hline CHEMBL3647111 & 1528198 & 9.4828 & 9.3989 & TRN & & \\
\hline CHEMBL 3986978 & 1528198 & 9.054 & 8.3531 & TST & & \\
\hline CHEMBL 3957683 & 1528198 & 8.4698 & 8.8721 & TRN & & \\
\hline CHEMBL 3647093 & 1528198 & 9.6716 & 9.1485 & TRN & & \\
\hline CHEMBL1486938 & 1528198 & 8.8962 & 8.3626 & TST & & \\
\hline CHEMBL 3647101 & 1528198 & 9.4389 & 9.252 & TRN & & \\
\hline CHEMBL 3925157 & 1528198 & 9.71 & 8.0038 & TST & & \\
\hline CHEMBL1428024 & 1528198 & 8.2708 & 8.1664 & TST & & \\
\hline CHEMBL1349913 & 1528198 & 8.0329 & 8.0354 & TST & & \\
\hline CHEMBL 3647124 & 1528198 & 8.9318 & 9.0407 & TRN & & \\
\hline CHEMBL1864716 & 1528198 & 8.4921 & 7.932 & TRN & & \\
\hline CHEMBL1328822 & 1528198 & 8.2248 & 8.0908 & TST & & \\
\hline CHEMBL3196628 & 1528198 & 7.9245 & 8.2436 & TST & & \\
\hline CHEMBL1465475 & 1528198 & 7.8601 & 8.1332 & TST & & \\
\hline CHEMBL1722566 & 1528198 & 8.7799 & 8.0095 & TST & & \\
\hline
\end{tabular}

Page 7258 
Supplemental Table S2.txt

\begin{tabular}{|c|c|c|c|c|}
\hline CHEMBL3943333 & 1528198 & 7.8356 & 8.9153 & TRN \\
\hline CHEMBL3647157 & 1528198 & 9.1811 & 9.1333 & TRN \\
\hline CHEMBL3647154 & 1528198 & 9.3344 & 8.9171 & TRN \\
\hline CHEMBL3647108 & 1528198 & 9.8297 & 9.287 & TRN \\
\hline CHEMBL1359561 & 1528198 & 9.1463 & 8.1166 & TST \\
\hline CHEMBL3209562 & 1528198 & 8.5031 & 8.3115 & TST \\
\hline CHEMBL3647119 & 1528198 & 8.2534 & 8.8987 & TRN \\
\hline CHEMBL3647140 & 1528198 & 9.8097 & 9.3583 & TRN \\
\hline CHEMBL3904237 & 1528198 & 10.4685 & 8.7562 & TRN \\
\hline CHEMBL1418079 & 1528198 & 7.9031 & 8.148 & TST \\
\hline CHEMBL 3898761 & 1528198 & 9.3307 & 8.8411 & TRN \\
\hline CHEMBL1499658 & 1528198 & 8.6819 & 7.8126 & TST \\
\hline CHEMBL3647178 & 1528198 & 9.4949 & 9.2087 & TRN \\
\hline CHEMBL3647106 & 1528198 & 9.7545 & 9.2745 & TRN \\
\hline CHEMBL1597286 & 1528198 & 6.0 & 8.3052 & TST \\
\hline CHEMBL3207893 & 1528198 & 8.8665 & 8.0615 & TST \\
\hline CHEMBL3647167 & 1528198 & 9.2857 & 9.0842 & TRN \\
\hline CHEMBL1555914 & 1528198 & 8.9172 & 8.4379 & TST \\
\hline CHEMBL1956114 & 1528198 & 8.4157 & 9.0063 & TRN \\
\hline CHEMBL1956144 & 1528198 & 9.7645 & 8.9893 & TRN \\
\hline CHEMBL3986406 & 1528198 & 8.58 & 8.9071 & TRN \\
\hline CHEMBL1311027 & 1528198 & 9.2226 & 8.0457 & TST \\
\hline CHEMBL1372231 & 1528198 & 7.8013 & 8.2281 & TRN \\
\hline CHEMBL3948562 & 1528198 & 7.7399 & 8.907 & TRN \\
\hline CHEMBL 3644542 & 1528198 & 8.7747 & 8.9571 & TRN \\
\hline CHEMBL3960664 & 1528198 & 9.0926 & 8.9936 & TRN \\
\hline CHEMBL1340799 & 1528198 & 8.1993 & 8.5473 & TST \\
\hline CHEMBL 3647120 & 1528198 & 8.5952 & 9.1777 & TRN \\
\hline CHEMBL3891005 & 1528198 & 8.8794 & 8.3404 & TST \\
\hline CHEMBL 3647141 & 1528198 & 8.2062 & 9.0754 & TRN \\
\hline CHEMBL3647115 & 1528198 & 9.6882 & 9.2258 & TRN \\
\hline CHEMBL3925623 & 1528198 & 9.2907 & 8.7677 & TRN \\
\hline CHEMBL3192906 & 1528198 & 7.983 & 7.9271 & TST \\
\hline CHEMBL3914898 & 1528198 & 8.1945 & 8.2206 & TST \\
\hline CHEMBL3647118 & 1528198 & 9.1911 & 9.3171 & TRN \\
\hline CHEMBL3647150 & 1528198 & 9.2 & 9.1113 & TRN \\
\hline CHEMBL3917201 & 1528198 & 10.1713 & 9.0451 & TRN \\
\hline CHEMBL1348645 & 1528198 & 8.3391 & 8.0128 & TST \\
\hline CHEMBL3647104 & 1528198 & 9.8962 & 9.4649 & TRN \\
\hline CHEMBL3647086 & 1528198 & 9.1238 & 9.3284 & TRN \\
\hline CHEMBL3647075 & 1528198 & 7.9245 & 8.8759 & TRN \\
\hline CHEMBL3647121 & 1528198 & 9.1397 & 9.277006 & 0000000001 \\
\hline CHEMBL3647091 & 1528198 & 9.3799 & 9.213 & TRN \\
\hline CHEMBL3647123 & 1528198 & 9.5302 & 9.0301 & TRN \\
\hline CHEMBL 3979146 & 1528198 & 9.6253 & 8.8645 & TRN \\
\hline CHEMBL3647131 & 1528198 & 8.5719 & 9.2831 & TRN \\
\hline CHEMBL1490677 & 1528198 & 9.0035 & 8.0784 & TST \\
\hline CHEMBL3647103 & 1528198 & 8.9101 & 9.2601 & TRN \\
\hline
\end{tabular}


Supplemental Table S2.txt

\begin{tabular}{|c|c|c|c|c|c|}
\hline CHEMBL573107 & 954851 & 5.9919 & 5.9915 & TRN & \\
\hline CHEMBL202721 & 954851 & 6.7286 & 6.7285 & TRN & \\
\hline CHEMBL213100 & 954851 & 11.0217 & 11.0216 & TRN & \\
\hline CHEMBL 373751 & 954851 & 3.8897 & 3.8872 & TRN & \\
\hline CHEMBL483847 & 954851 & 3.8405 & 3.8401 & TRN & \\
\hline CHEMBL 300389 & 954851 & 5.8079 & 5.8075 & TRN & \\
\hline CHEMBL472940 & 954851 & 4.0384 & 4.0376 & TRN & \\
\hline CHEMBL379300 & 954851 & 6.7828 & 6.7827 & TRN & \\
\hline CHEMBL192566 & 954851 & 7.6165 & 9.4484 & TST & \\
\hline CHEMBL449158 & 954851 & 7.815 & 7.5277 & TST & \\
\hline CHEMBL2144069 & 954851 & 5.0027 & 5.0024 & TRN & \\
\hline CHEMBL210618 & 954851 & 3.9015 & 3.901999 & 9999999997 & TRN \\
\hline CHEMBL240954 & 954851 & 4.2023 & 4.2045 & TRN & \\
\hline CHEMBL585951 & 954851 & 6.3003 & 6.3001 & TRN & \\
\hline CHEMBL379975 & 954851 & 5.6021 & 5.6027 & TRN & \\
\hline CHEMBL1242367 & 954851 & 4.1228 & 4.1241 & TRN & \\
\hline CHEMBL3349342 & 954851 & 6.3987 & 6.3998 & TRN & \\
\hline CHEMBL92309 & 954851 & 3.9126 & 3.7268 & TST & \\
\hline CHEMBL65 & 954851 & 9.5674 & 9.5675 & TRN & \\
\hline CHEMBL2005886 & 954851 & 5.8043 & 5.803 & TRN & \\
\hline CHEMBL509032 & 954851 & 4.1923 & 4.1928 & TRN & \\
\hline CHEMBL220241 & 954851 & 4.0788 & 4.0784 & TRN & \\
\hline CHEMBL514499 & 954851 & 7.3736 & 7.3755 & TRN & \\
\hline CHEMBL412142 & 954851 & 4.6608 & 4.6609 & TRN & \\
\hline CHEMBL180127 & 954851 & 4.2887 & 4.2862 & TRN & \\
\hline CHEMBL1404918 & 954851 & 3.1091 & 3.1103 & TRN & \\
\hline CHEMBL3199475 & 954851 & 4.8847 & 4.8828 & TRN & \\
\hline CHEMBL221137 & 954851 & \multicolumn{3}{|c|}{5.172000000000001} & TST \\
\hline CHEMBL1516890 & 954851 & 4.6213 & 4.6235 & TRN & \\
\hline CHEMBL392695 & 954851 & 5.9261 & 5.9264 & TRN & \\
\hline CHEMBL1590308 & 954851 & 4.7306 & 3.5916 & TST & \\
\hline CHEMBL2363137 & 954851 & 5.3056 & 5.3055 & TRN & \\
\hline CHEMBL9470 & 954851 & 6.2935 & 6.0607 & TST & \\
\hline CHEMBL1230020 & 954851 & 6.8488 & 6.8498 & TRN & \\
\hline CHEMBL1673039 & 954851 & 4.4986 & 4.4981 & TRN & \\
\hline CHEMBL512504 & 954851 & 7.0196 & 7.0186 & TRN & \\
\hline CHEMBL189584 & 954851 & 6.4817 & 6.4829 & TRN & \\
\hline CHEMBL1190711 & 954851 & 6.4779 & 6.4763 & TRN & \\
\hline CHEMBL1970879 & 954851 & \multicolumn{3}{|c|}{5.3420000000000005} & TRN \\
\hline CHEMBL515416 & 954851 & 3.2382 & 3.2387 & TRN & \\
\hline CHEMBL3186408 & 954851 & 3.7843 & 3.9301 & TST & \\
\hline CHEMBL135561 & 954851 & 4.5201 & 4.5209 & TRN & \\
\hline CHEMBL191334 & 954851 & 5.8972 & 5.8949 & TRN & \\
\hline CHEMBL259181 & 954851 & 5.7261 & 5.7263 & TRN & \\
\hline CHEMBL3392440 & 954851 & 4.7339 & 4.7342 & TRN & \\
\hline CHEMBL1256459 & 954851 & 7.5235 & 7.5234 & TRN & \\
\hline CHEMBL558642 & 954851 & 4.9458 & 4.9459 & TRN & \\
\hline CHEMBL1788116 & 954851 & 5.6046 & 4.7851 & TST & \\
\hline
\end{tabular}




\begin{tabular}{|c|c|c|c|c|}
\hline & & & oplement & al $\mathrm{T}$ \\
\hline CHEMBL209148 & 954851 & 4.5339 & 5.3466 & TST \\
\hline CHEMBL1909414 & 954851 & 6.7442 & 5.6 & TST \\
\hline CHEMBL 258844 & 954851 & 4.5674 & 4.4159 & TST \\
\hline CHEMBL1357247 & 954851 & 3.2774 & 3.6932 & TST \\
\hline CHEMBL393929 & 954851 & 3.9013 & 3.9702 & TST \\
\hline CHEMBL1643959 & 954851 & 5.3561 & 4.0858 & TST \\
\hline CHEMBL409066 & 466211 & 6.7352 & 6.7378 & TRN \\
\hline CHEMBL405878 & 466211 & 6.7305 & 6.1073 & TST \\
\hline CHEMBL270100 & 466211 & 6.9666 & 6.9641 & TRN \\
\hline CHEMBL219333 & 466211 & 7.2076 & 6.7594 & TST \\
\hline CHEMBL414194 & 466211 & 6.9872 & 6.9955 & TRN \\
\hline CHEMBL405857 & 466211 & 6.2168 & 6.218 & TRN \\
\hline CHEMBL 273120 & 466211 & 6.5591 & 6.5523 & TRN \\
\hline CHEMBL 219708 & 466211 & 6.2848 & 6.2809 & TRN \\
\hline CHEMBL 277982 & 466211 & 6.7595 & 6.7609 & TRN \\
\hline CHEMBL 271152 & 466211 & 4.5229 & 4.5224 & TRN \\
\hline CHEMBL407276 & 466211 & 5.1888 & 4.2688 & TST \\
\hline CHEMBL407590 & 466211 & 6.8477 & 6.8489 & TRN \\
\hline CHEMBL270539 & 466211 & 6.3936 & 6.6462 & TST \\
\hline CHEMBL 260304 & 466211 & 6.6778 & 6.6757 & TRN \\
\hline CHEMBL 271976 & 466211 & 6.4881 & 6.4869 & TRN \\
\hline CHEMBL404600 & 466211 & 6.7055 & 6.7044 & TRN \\
\hline CHEMBL405859 & 466211 & 6.3439 & 6.3413 & TRN \\
\hline CHEMBL1162972 & 466211 & 6.9136 & 6.9153 & TRN \\
\hline CHEMBL 272907 & 466211 & 7.1858 & 7.1855 & TRN \\
\hline CHEMBL 272879 & 466211 & 6.0061 & 6.0125 & TRN \\
\hline CHEMBL 272451 & 466211 & 6.8794 & 6.8851 & TRN \\
\hline CHEMBL 219420 & 466211 & 6.6778 & 6.6872 & TRN \\
\hline CHEMBL259676 & 466211 & 6.0259 & 6.0208 & TRN \\
\hline CHEMBL 271977 & 466211 & 6.7235 & 6.7193 & TRN \\
\hline CHEMBL 273085 & 466211 & 7.6696 & 7.6751 & TRN \\
\hline CHEMBL408243 & 466211 & 7.1445 & 6.6474 & TST \\
\hline CHEMBL 270768 & 466211 & 6.9393 & 6.9378 & TRN \\
\hline CHEMBL 270273 & 466211 & 6.1192 & 6.1186 & TRN \\
\hline CHEMBL406344 & 466211 & 6.8794 & 6.8686 & TRN \\
\hline CHEMBL 270767 & 466211 & 7.1367 & 7.1353 & TRN \\
\hline CHEMBL273045 & 466211 & 5.3695 & 5.3157 & TST \\
\hline CHEMBL218891 & 466211 & 7.0026 & 7.0021 & TRN \\
\hline CHEMBL270259 & 466211 & 7.4486 & 7.4437 & TRN \\
\hline CHEMBL438457 & 466211 & 7.0141 & 7.0158 & TRN \\
\hline CHEMBL 270937 & 466211 & 6.4597 & 6.4613 & TRN \\
\hline CHEMBL271204 & 466211 & 6.8386 & 6.8437 & TRN \\
\hline CHEMBL 270772 & 466211 & 7.3161 & 7.3165 & TRN \\
\hline CHEMBL408323 & 466211 & 6.6737 & 6.6745 & TRN \\
\hline CHEMBL 219478 & 466211 & 7.4067 & 7.4018 & TRN \\
\hline CHEMBL443575 & 466211 & 6.4711 & 6.4706 & TRN \\
\hline CHEMBL405475 & 466211 & 6.1457 & 6.151 & TRN \\
\hline CHEMBL 270549 & 466211 & 5.2334 & 4.8978 & TST \\
\hline
\end{tabular}




\begin{tabular}{|c|c|c|c|c|c|c|}
\hline \multirow[b]{2}{*}{ CHEMBL271153 } & & \multicolumn{5}{|c|}{ Supplemental Table S2.txt } \\
\hline & 466211 & 6.2441 & 6.2491 & TRN & & \\
\hline CHEMBL273070 & 466211 & 7.6055 & 7.6065 & TRN & & \\
\hline CHEMBL273071 & 466211 & $6.7570 e$ & 00000000 & & 6.7497 & TRN \\
\hline CHEMBL271415 & 466211 & 6.209 & 6.2069 & TRN & & \\
\hline CHEMBL270538 & 466211 & 6.3546 & 6.3548 & TRN & & \\
\hline CHEMBL408245 & 466211 & 6.2976 & 6.1777 & TST & & \\
\hline CHEMBL218355 & 466211 & 7.5391 & 7.5549 & TST & & \\
\hline CHEMBL405606 & 466211 & 6.0227 & 6.3769 & TST & & \\
\hline CHEMBL270757 & 466211 & 4.0 & 4.0706 & TST & & \\
\hline CHEMBL1162971 & 466211 & 5.934 & 5.1937 & TST & & \\
\hline CHEMBL426525 & 466211 & 7.0835 & 6.9612 & TST & & \\
\hline CHEMBL271166 & 466211 & 6.7055 & 6.8487 & TST & & \\
\hline CHEMBL1083911 & 635559 & 6.6 & 4.9063 & TRN & & \\
\hline CHEMBL1082341 & 635559 & 6.6 & 3.7951 & TST & & \\
\hline CHEMBL1082342 & 635559 & 6.1 & 5.3116 & TRN & & \\
\hline CHEMBL1082343 & 635559 & 4.0 & 4.3897 & TST & & \\
\hline CHEMBL1082344 & 635559 & 4.0 & 3.9879 & TRN & & \\
\hline CHEMBL1082659 & 635559 & 4.0 & 4.711 & TRN & & \\
\hline CHEMBL1082989 & 635559 & 4.0 & 4.4469 & TRN & & \\
\hline CHEMBL1082990 & 635559 & 4.0 & 3.8537 & TRN & & \\
\hline CHEMBL1082991 & 635559 & 4.0 & 4.6299 & TRN & & \\
\hline CHEMBL1082672 & 635559 & 4.0 & 4.0703 & TRN & & \\
\hline CHEMBL1082673 & 635559 & 4.0 & 3.9533 & TRN & & \\
\hline CHEMBL1082992 & 635559 & 4.0 & 4.7515 & TRN & & \\
\hline CHEMBL1085251 & 635559 & 4.0 & 4.1539 & TRN & & \\
\hline CHEMBL1085252 & 635559 & 4.0 & 3.785 & TRN & & \\
\hline CHEMBL1085253 & 635559 & 4.0 & 4.2933 & TRN & & \\
\hline CHEMBL1085506 & 635559 & 4.0 & 4.6846 & TRN & & \\
\hline CHEMBL1085507 & 635559 & 7.2 & 5.1716 & TRN & & \\
\hline CHEMBL1084501 & 635559 & 4.0 & 3.8062 & TRN & & \\
\hline CHEMBL1084502 & 635559 & 4.0 & 4.4003 & TRN & & \\
\hline CHEMBL1084503 & 635559 & 4.0 & 4.0119 & TRN & & \\
\hline CHEMBL1084504 & 635559 & 4.0 & 4.1162 & TRN & & \\
\hline CHEMBL1084749 & 635559 & 4.0 & 4.8661 & TRN & & \\
\hline CHEMBL1083327 & 635559 & 4.0 & 3.5839 & TRN & & \\
\hline CHEMBL1085071 & 635559 & 4.0 & 3.9364 & TRN & & \\
\hline CHEMBL1085072 & 635559 & 4.0 & 4.0458 & TRN & & \\
\hline CHEMBL1085073 & 635559 & 4.0 & 4.445 & TRN & & \\
\hline CHEMBL1083736 & 635559 & 4.0 & 3.7034 & TRN & & \\
\hline CHEMBL1083737 & 635559 & 4.0 & 3.6609 & TRN & & \\
\hline CHEMBL1082805 & 635559 & 4.0 & 3.8337 & TRN & & \\
\hline CHEMBL1086055 & 635559 & 4.0 & 3.7738 & TRN & & \\
\hline CHEMBL1086056 & 635559 & 4.0 & 3.7732 & TRN & & \\
\hline CHEMBL1086057 & 635559 & 4.0 & 3.9958 & TRN & & \\
\hline CHEMBL1086058 & 635559 & 4.0 & 3.5788 & TRN & & \\
\hline CHEMBL1085303 & 635559 & 4.0 & 3.7769 & TRN & & \\
\hline CHEMBL1085304 & 635559 & 4.0 & 4.1899 & TRN & & \\
\hline CHEMBL1084287 & 635559 & 4.0 & 3.7892 & TRN & & \\
\hline
\end{tabular}




\begin{tabular}{|c|c|c|c|c|}
\hline \multicolumn{5}{|c|}{ Supplemental Table S2.txt } \\
\hline CHEMBL1084718 & 635559 & 4.0 & 3.0461 & TST \\
\hline CHEMBL1084288 & 635559 & 4.0 & 3.1968 & TST \\
\hline CHEMBL1084289 & 635559 & 4.0 & 3.4004 & TST \\
\hline CHEMBL1086027 & 635559 & 4.0 & 3.3516 & TST \\
\hline CHEMBL1086267 & 635559 & 4.0 & 3.452 & TST \\
\hline CHEMBL1086268 & 635559 & 4.0 & 3.267 & TST \\
\hline CHEMBL1086269 & 635559 & 4.0 & 3.6686 & TST \\
\hline CHEMBL1086270 & 635559 & 4.0 & 5.593 & TST \\
\hline CHEMBL1085057 & 635559 & 4.0 & 4.2648 & TRN \\
\hline CHEMBL1084572 & 635559 & 6.0 & 5.1095 & TRN \\
\hline CHEMBL1084817 & 635559 & 4.0 & 4.1894 & TRN \\
\hline CHEMBL1085241 & 635559 & 4.0 & 4.6508 & TRN \\
\hline CHEMBL1084818 & 635559 & 7.6 & 8.3519 & TRN \\
\hline CHEMBL1084819 & 635559 & 7.3 & 7.7439 & TRN \\
\hline CHEMBL1083723 & 635559 & 7.9 & 7.1207 & TRN \\
\hline CHEMBL1084303 & 635559 & 4.0 & 5.6316 & TRN \\
\hline CHEMBL1085502 & 635559 & 4.0 & 5.2643 & TRN \\
\hline CHEMBL1083107 & 635559 & 5.8 & 5.5644 & TRN \\
\hline CHEMBL1083108 & 635559 & 8.0 & 7.2814 & TRN \\
\hline CHEMBL1083109 & 635559 & 7.4 & 7.3634 & TRN \\
\hline CHEMBL1083419 & 635559 & 6.8 & 6.8339 & TRN \\
\hline CHEMBL1085513 & 635559 & 4.0 & 4.2121 & TRN \\
\hline CHEMBL1085739 & 635559 & 4.0 & 4.6489 & TRN \\
\hline CHEMBL1084993 & 635559 & 7.7 & 6.0221 & TRN \\
\hline CHEMBL1084994 & 635559 & 4.0 & 4.7627 & TST \\
\hline CHEMBL1084995 & 635559 & 4.0 & 5.0304 & TST \\
\hline CHEMBL1084996 & 635559 & 4.0 & 4.1488 & TRN \\
\hline CHEMBL1082694 & 635559 & 4.0 & 6.3753 & TST \\
\hline CHEMBL1082695 & 635559 & 4.0 & 4.5392 & TST \\
\hline CHEMBL1083013 & 635559 & 4.0 & 4.8757 & TST \\
\hline CHEMBL1085525 & 635559 & 4.0 & 4.5515 & TST \\
\hline CHEMBL1085752 & 635559 & 4.0 & 4.8711 & TST \\
\hline CHEMBL1086465 & 635559 & 4.0 & 4.0034 & TST \\
\hline CHEMBL1081896 & 620938 & 5.2351 & 4.9025 & TRN \\
\hline CHEMBL1080875 & 620938 & 5.9788 & 2.9343 & TST \\
\hline CHEMBL1075707 & 620938 & 3.5229 & 2.6767 & TST \\
\hline CHEMBL1080874 & 620938 & 5.8996 & 3.6275 & TST \\
\hline CHEMBL1079740 & 620938 & 5.7496 & 4.4942 & TST \\
\hline CHEMBL1081894 & 620938 & 5.2782 & 5.0077 & TRN \\
\hline CHEMBL1076240 & 620938 & 5.1085 & 4.128 & TST \\
\hline CHEMBL1086752 & 620938 & 3.5229 & 3.9069 & TRN \\
\hline CHEMBL1080811 & 620938 & 3.5229 & 3.7752 & TRN \\
\hline CHEMBL1086879 & 620938 & 3.5229 & 3.4897 & TRN \\
\hline CHEMBL1082076 & 620938 & 3.5229 & 3.4985 & TRN \\
\hline CHEMBL1079741 & 620938 & 3.5229 & 4.1783 & TST \\
\hline CHEMBL1082169 & 620938 & 3.5229 & 3.8516 & TRN \\
\hline CHEMBL1087768 & 620938 & 3.5229 & 3.596 & TRN \\
\hline CHEMBL1086899 & 620938 & 3.5229 & 3.5362 & TRN \\
\hline
\end{tabular}




\begin{tabular}{|c|c|c|c|c|c|}
\hline & & \multicolumn{4}{|c|}{ Supplemental Table S2.txt } \\
\hline CHEMBL1081188 & 620938 & 5.8697 & 5.6817 & TRN & \\
\hline CHEMBL1086898 & 620938 & 3.5229 & 3.2874 & TRN & \\
\hline CHEMBL1088449 & 620938 & 3.5229 & 3.5733 & TRN & \\
\hline CHEMBL1088173 & 620938 & 3.5229 & 3.6766 & TRN & \\
\hline CHEMBL1081906 & 620938 & 3.5229 & 3.43899 & 99999999996 & TRN \\
\hline CHEMBL1081043 & 620938 & 3.5229 & 3.5609 & TST & \\
\hline CHEMBL1080451 & 620938 & 5.4461 & 3.9135 & TST & \\
\hline CHEMBL1080989 & 620938 & 3.5229 & 3.4172 & TRN & \\
\hline CHEMBL1080482 & 620938 & 7.1135 & 3.6324 & TST & \\
\hline CHEMBL1076408 & 620938 & 5.1884 & 5.3187 & TRN & \\
\hline CHEMBL1086750 & 620938 & 3.5229 & 3.0197 & TRN & \\
\hline CHEMBL1087659 & 620938 & 3.5229 & 3.5907 & TRN & \\
\hline CHEMBL1086751 & 620938 & 3.5229 & 3.1478 & TRN & \\
\hline CHEMBL1086897 & 620938 & 3.5229 & 3.2583 & TRN & \\
\hline CHEMBL1087264 & 620938 & 3.5229 & 3.4928 & TRN & \\
\hline CHEMBL1087394 & 620938 & 3.5229 & 2.5903 & TST & \\
\hline CHEMBL1086753 & 620938 & 3.5229 & 3.9635 & TRN & \\
\hline CHEMBL1082077 & 620938 & 3.5229 & 3.8312 & TRN & \\
\hline CHEMBL1082170 & 620938 & 3.5229 & 4.5045 & TST & \\
\hline CHEMBL1087265 & 620938 & 3.5229 & 3.4544 & TRN & \\
\hline CHEMBL1081053 & 620938 & 3.5229 & 3.3996 & TST & \\
\hline CHEMBL1082168 & 620938 & 5.3458 & 5.0013 & TRN & \\
\hline CHEMBL1081848 & 620938 & 3.5229 & 3.8303 & TRN & \\
\hline CHEMBL1081892 & 620938 & 7.0706 & 1.1282 & TST & \\
\hline CHEMBL1081367 & 620938 & 5.7447 & 5.6334 & TRN & \\
\hline CHEMBL1080481 & 620938 & 6.0555 & 6.1084 & TRN & \\
\hline CHEMBL1082088 & 620938 & 4.9747 & 5.1305 & TRN & \\
\hline CHEMBL1080810 & 620938 & 5.0985 & 5.084 & TRN & \\
\hline CHEMBL1080452 & 620938 & 3.5229 & 4.5418 & TST & \\
\hline CHEMBL1081717 & 620938 & 3.5229 & 4.0308 & TRN & \\
\hline CHEMBL1081895 & 620938 & 5.6517 & 5.2395 & TRN & \\
\hline CHEMBL1081893 & 620938 & 3.5229 & 3.4588 & TRN & \\
\hline CHEMBL1076498 & 620938 & 3.5229 & 3.6228 & TRN & \\
\hline CHEMBL1081847 & 620938 & 3.5229 & 3.5634 & TRN & \\
\hline CHEMBL1087769 & 620938 & 3.5229 & 3.5759 & TRN & \\
\hline CHEMBL1088448 & 620938 & 3.5229 & 3.6706 & TRN & \\
\hline CHEMBL1076483 & 620938 & 3.5229 & 3.3259 & TRN & \\
\hline CHEMBL1088311 & 620938 & 5.5817 & 5.7946 & TRN & \\
\hline CHEMBL1088463 & 620938 & 3.5229 & 3.4007 & TRN & \\
\hline CHEMBL1523792 & 737473 & 5.2057 & 5.0819 & TRN & \\
\hline CHEMBL1987546 & 737473 & 5.586 & 5.0818 & TRN & \\
\hline CHEMBL1998429 & 737473 & 4.9827 & 5.1329 & TRN & \\
\hline CHEMBL1460312 & 737473 & 6.0755 & 5.2248 & TRN & \\
\hline CHEMBL269410 & 737473 & 5.5372 & 5.4387 & TRN & \\
\hline CHEMBL1446983 & 737473 & 5.2123 & 5.5085 & TRN & \\
\hline CHEMBL1478947 & 737473 & 4.6558 & 4.9018 & TRN & \\
\hline CHEMBL1553837 & 737473 & 5.2585 & 5.64 & TRN & \\
\hline CHEMBL 294264 & 737473 & 5.1747 & 5.6466 & TRN & \\
\hline
\end{tabular}




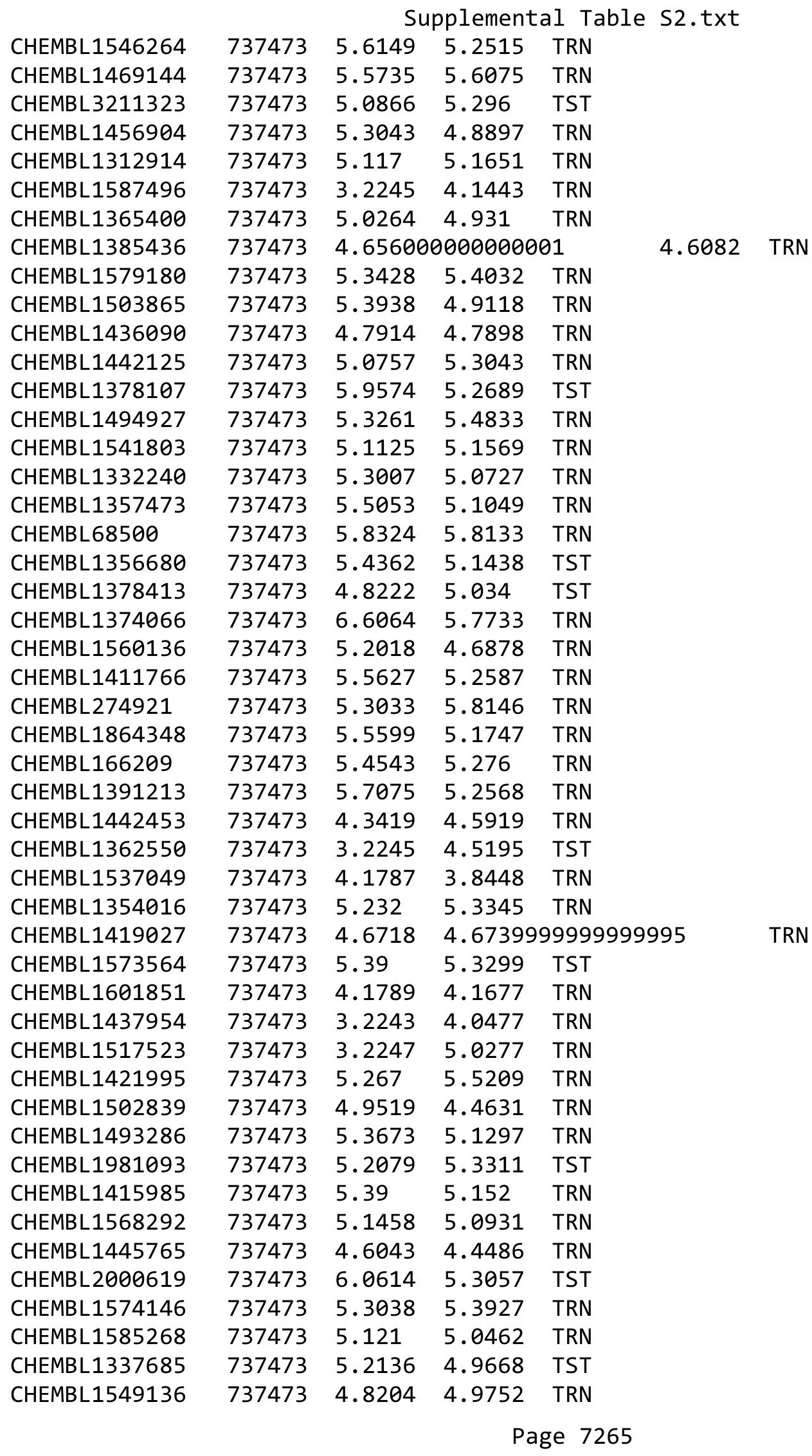




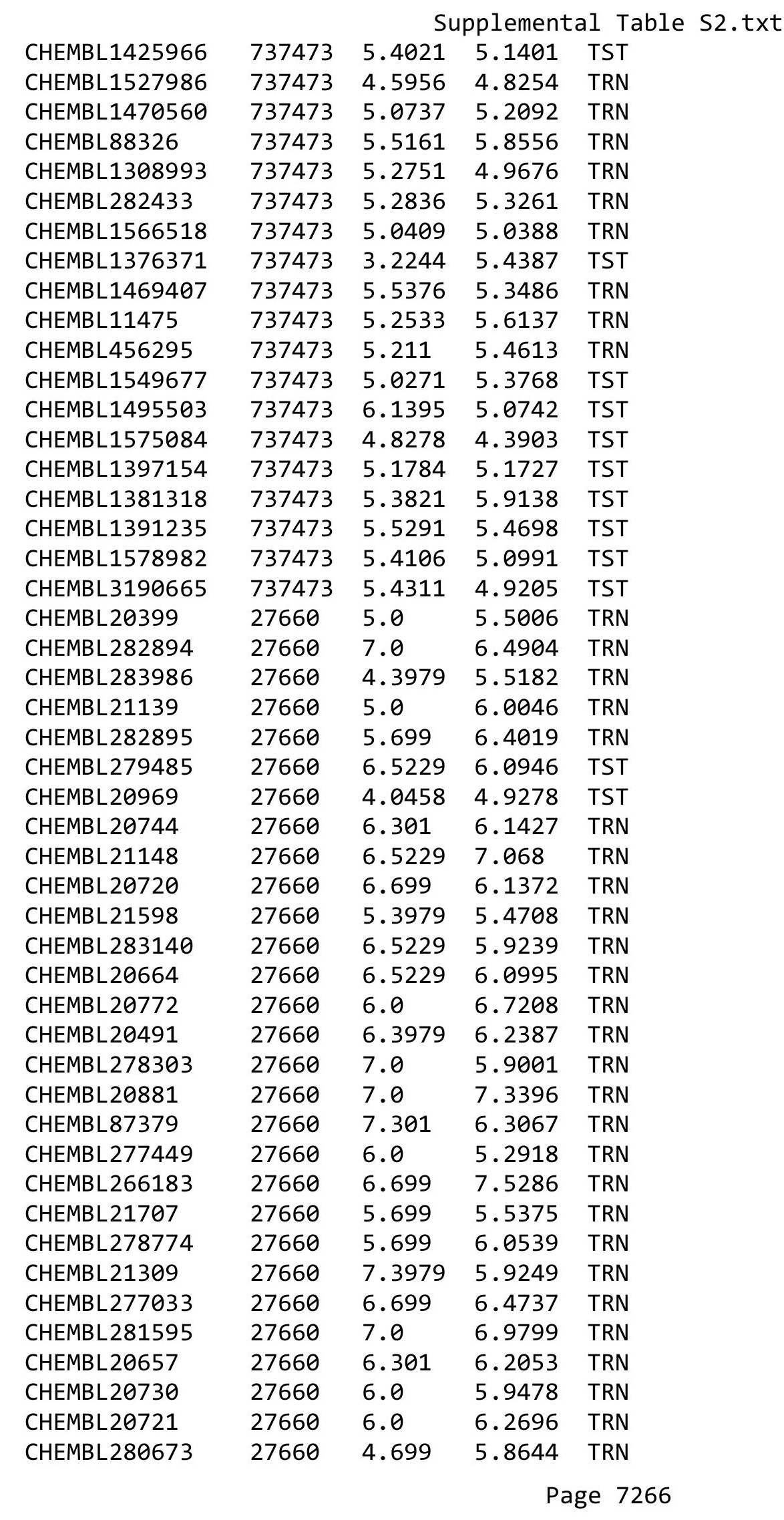




\begin{tabular}{|c|c|c|c|c|c|}
\hline & & \multicolumn{4}{|c|}{ Supplemental Table S2.txt } \\
\hline CHEMBL278137 & 27660 & 3.3979 & 5.7823 & TRN & \\
\hline CHEMBL 20656 & 27660 & 5.0 & 5.9567 & TRN & \\
\hline CHEMBL278758 & 27660 & 5.0 & 5.4624 & TRN & \\
\hline CHEMBL20499 & 27660 & 7.301 & 6.8073 & TRN & \\
\hline CHEMBL20593 & 27660 & 6.2218 & 5.8022 & TRN & \\
\hline CHEMBL20382 & 27660 & 7.301 & 6.7707 & TRN & \\
\hline CHEMBL418373 & 27660 & 5.301 & 5.2036 & TRN & \\
\hline CHEMBL21271 & 27660 & 7.301 & 6.2605 & TST & \\
\hline CHEMBL21093 & 27660 & 5.699 & 5.5141 & TST & \\
\hline CHEMBL20481 & 27660 & 7.0 & 6.7984 & TRN & \\
\hline CHEMBL21165 & 27660 & 7.0 & 6.04899 & 99999999995 & TRN \\
\hline CHEMBL3590030 & 27660 & 6.699 & 6.4216 & TRN & \\
\hline CHEMBL20429 & 27660 & 6.699 & 5.7869 & TRN & \\
\hline CHEMBL3589732 & 27660 & 6.5229 & 6.5588 & TRN & \\
\hline CHEMBL20601 & 27660 & 6.0 & 6.5423 & TST & \\
\hline CHEMBL20462 & 27660 & 4.3979 & 5.28100 & 0000000001 & TRN \\
\hline CHEMBL282241 & 27660 & 4.699 & 5.2479 & TST & \\
\hline CHEMBL3590029 & 27660 & 6.5229 & 6.7647 & TRN & \\
\hline CHEMBL 283141 & 27660 & 6.0 & 5.7689 & TRN & \\
\hline CHEMBL21270 & 27660 & 5.0 & 5.273 & TST & \\
\hline CHEMBL21722 & 27660 & 7.0458 & 6.434 & TRN & \\
\hline CHEMBL22052 & 27660 & 6.5229 & 6.8076 & TRN & \\
\hline CHEMBL 21243 & 27660 & 7.1549 & 6.2439 & TRN & \\
\hline CHEMBL 20526 & 27660 & 5.5229 & 5.4391 & TRN & \\
\hline CHEMBL282727 & 27660 & 3.0 & 6.8791 & TST & \\
\hline CHEMBL20431 & 27660 & 6.699 & 5.7258 & TRN & \\
\hline CHEMBL20439 & 27660 & 5.5229 & 5.8146 & TRN & \\
\hline CHEMBL280364 & 27660 & 6.0 & 5.9783 & TRN & \\
\hline CHEMBL87381 & 27660 & 7.0 & 6.6073 & TRN & \\
\hline CHEMBL3589727 & 27660 & 7.0 & 6.9355 & TRN & \\
\hline CHEMBL20502 & 27660 & 6.0969 & 5.6978 & TRN & \\
\hline CHEMBL20571 & 27660 & 4.0969 & 6.6482 & TST & \\
\hline CHEMBL20689 & 27660 & 6.5229 & 5.9978 & TRN & \\
\hline CHEMBL 20464 & 27660 & 5.699 & 5.9598 & TRN & \\
\hline CHEMBL21234 & 27660 & 5.0969 & 5.2998 & TRN & \\
\hline CHEMBL417277 & 27660 & 6.301 & 6.7423 & TRN & \\
\hline CHEMBL 21244 & 27660 & 5.2218 & 5.565 & TRN & \\
\hline CHEMBL 21227 & 27660 & 5.0 & 5.9236 & TRN & \\
\hline CHEMBL 20463 & 27660 & 7.699 & 6.4854 & TST & \\
\hline CHEMBL20856 & 27660 & 5.0458 & 5.5103 & TST & \\
\hline CHEMBL 21375 & 27660 & 6.0969 & 6.353 & TST & \\
\hline CHEMBL20646 & 27660 & 4.699 & 6.778 & TST & \\
\hline CHEMBL 20647 & 27660 & 4.699 & 5.7711 & TST & \\
\hline CHEMBL 22117 & 27660 & 5.3979 & 5.9676 & TST & \\
\hline CHEMBL3589865 & 27660 & 6.5229 & 6.2955 & TST & \\
\hline CHEMBL20615 & 27660 & 5.5229 & 5.9612 & TST & \\
\hline CHEMBL 278634 & 27660 & 5.699 & 5.8752 & TST & \\
\hline CHEMBL278382 & 27660 & 6.5229 & 6.9398 & TST & \\
\hline
\end{tabular}




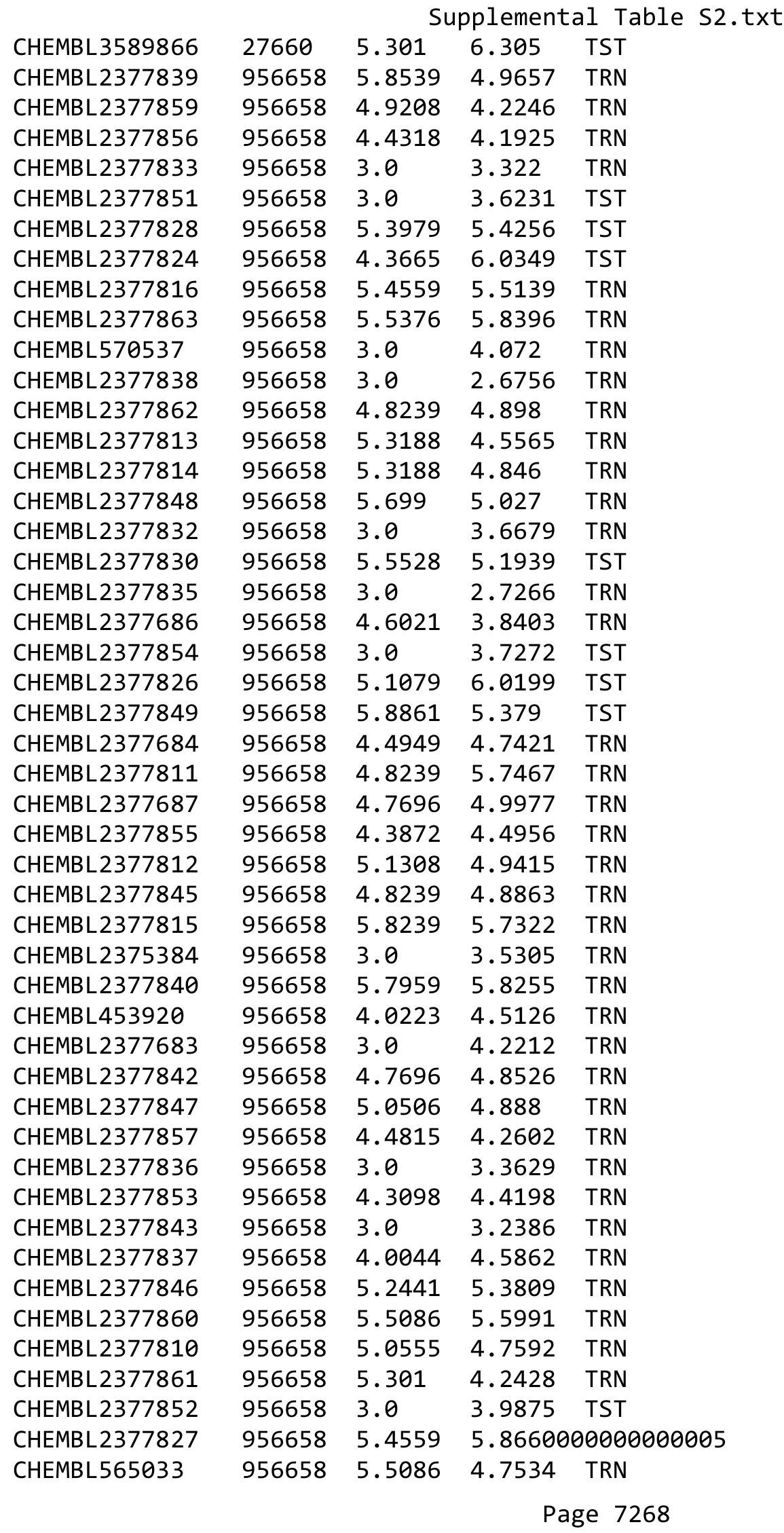




\begin{tabular}{|c|c|c|c|c|c|}
\hline \multicolumn{6}{|c|}{ Supplemental Table S2.txt } \\
\hline CHEMBL 2377834 & 956658 & 3.0 & 2.9247 & TRN & \\
\hline CHEMBL 2377858 & 956658 & 4.4559 & 4.4262 & TST & \\
\hline CHEMBL 2377685 & 956658 & 4.0862 & 4.6818 & TST & \\
\hline CHEMBL 2377850 & 956658 & 3.0 & 5.5016 & TST & \\
\hline CHEMBL 2377841 & 956658 & 5.6576 & 5.1279 & TST & \\
\hline CHEMBL1604618 & 744200 & 4.0 & 4.3451 & TRN & \\
\hline CHEMBL1515144 & 744200 & 7.4202 & 7.5598 & TRN & \\
\hline CHEMBL1405981 & 744200 & 5.0452 & 5.1312 & TRN & \\
\hline CHEMBL1513850 & 744200 & 4.0 & 4.0507 & TRN & \\
\hline CHEMBL1724489 & 744200 & 4.0 & 3.6613 & TRN & \\
\hline CHEMBL1329116 & 744200 & 4.0 & 4.2826 & TRN & \\
\hline CHEMBL1407164 & 744200 & 6.8097 & 6.7456 & TRN & \\
\hline CHEMBL1397997 & 744200 & 4.0 & 4.1893 & TRN & \\
\hline CHEMBL1473127 & 744200 & 7.0315 & 6.5441 & TRN & \\
\hline CHEMBL1552755 & 744200 & 7.5229 & 7.5509 & TRN & \\
\hline CHEMBL1354134 & 744200 & 7.1192 & 7.3057 & TRN & \\
\hline CHEMBL1707127 & 744200 & 4.0 & 4.2581 & TRN & \\
\hline CHEMBL1394132 & 744200 & 5.3451 & 5.0336 & TRN & \\
\hline CHEMBL 1555138 & 744200 & 6.7852 & 7.0582 & TRN & \\
\hline CHEMBL1535925 & 744200 & 5.8425 & 5.88200 & 0000000001 & TRN \\
\hline CHEMBL1410859 & 744200 & 5.8989 & 6.05399 & 9999999999 & TRN \\
\hline CHEMBL1734733 & 744200 & 6.8697 & 7.1218 & TRN & \\
\hline CHEMBL1318637 & 744200 & 6.585 & 6.7826 & TRN & \\
\hline CHEMBL 1435542 & 744200 & 6.6861 & 6.9332 & TRN & \\
\hline CHEMBL1704879 & 744200 & 7.585 & 7.3026 & TRN & \\
\hline CHEMBL1705549 & 744200 & 7.1549 & 7.1654 & TRN & \\
\hline CHEMBL1436585 & 744200 & 7.0315 & 7.0847 & TRN & \\
\hline CHEMBL1770624 & 744200 & 6.2262 & 4.8047 & TST & \\
\hline CHEMBL 1357975 & 744200 & 7.1308 & 7.1215 & TRN & \\
\hline CHEMBL1725513 & 744200 & 7.0757 & 6.9821 & TRN & \\
\hline CHEMBL1315944 & 744200 & 5.5014 & 5.5282 & TRN & \\
\hline CHEMBL1329627 & 744200 & 5.4402 & 5.3383 & TRN & \\
\hline CHEMBL1396306 & 744200 & 4.0 & 3.9258 & TRN & \\
\hline CHEMBL1599314 & 744200 & 5.9363 & 5.8775 & TRN & \\
\hline CHEMBL567331 & 744200 & 7.2076 & 7.0235 & TRN & \\
\hline CHEMBL1609579 & 744200 & 4.0 & 3.9106 & TRN & \\
\hline CHEMBL1733003 & 744200 & 5.3319 & 5.0777 & TRN & \\
\hline CHEMBL1476609 & 744200 & 6.2541 & 5.0137 & TST & \\
\hline CHEMBL1397614 & 744200 & 6.0353 & 6.8536 & TST & \\
\hline CHEMBL1320749 & 744200 & 4.0 & 3.8633 & TRN & \\
\hline CHEMBL566900 & 744200 & 6.8996 & 6.8823 & TRN & \\
\hline CHEMBL1495595 & 744200 & 4.0 & 4.0522 & TRN & \\
\hline CHEMBL1437638 & 744200 & 6.9208 & 6.6422 & TST & \\
\hline CHEMBL1474834 & 744200 & 7.8539 & 7.5176 & TRN & \\
\hline CHEMBL1374544 & 744200 & 7.0088 & 7.1357 & TRN & \\
\hline CHEMBL1591577 & 744200 & 7.5086 & 7.414 & TRN & \\
\hline CHEMBL565654 & 744200 & 5.2444 & 5.1793 & TRN & \\
\hline CHEMBL1612677 & 744200 & 5.9446 & 5.9532 & TST & \\
\hline
\end{tabular}




\begin{tabular}{|c|c|c|c|c|c|}
\hline \multicolumn{6}{|c|}{ Supplemental Table S2.txt } \\
\hline CHEMBL1476499 & 744200 & 7.2441 & 6.5574 & TST & \\
\hline CHEMBL566687 & 744200 & 6.7447 & 6.6506 & TST & \\
\hline CHEMBL1396654 & 744200 & 7.4559 & 6.4206 & TST & \\
\hline CHEMBL1515868 & 744200 & 6.2668 & 6.5792 & TST & \\
\hline CHEMBL1396483 & 744200 & 7.2924 & 7.4605 & TST & \\
\hline CHEMBL566062 & 744200 & 5.4584 & 5.6248 & TST & \\
\hline CHEMBL1551169 & 744200 & 7.7696 & 6.8433 & TST & \\
\hline CHEMBL1433941 & 744200 & 4.0 & 4.4437 & TST & \\
\hline CHEMBL 3093232 & 1278696 & 5.3045 & 5.2471 & TRN & \\
\hline CHEMBL3093319 & 1278696 & 4.0 & 3.7406 & TRN & \\
\hline CHEMBL3093228 & 1278696 & 5.2314 & 5.24 & TRN & \\
\hline CHEMBL3093233 & 1278696 & 5.0 & 4.8134 & TRN & \\
\hline CHEMBL 3091482 & 1278696 & 4.0 & 4.0271 & TRN & \\
\hline CHEMBL 3093217 & 1278696 & 4.0 & 4.0392 & TRN & \\
\hline CHEMBL3093224 & 1278696 & 5.1945 & 4.7565 & TRN & \\
\hline CHEMBL3093316 & 1278696 & 4.0 & 4.0126 & TRN & \\
\hline CHEMBL26138 & 1278696 & 7.7496 & 5.2967 & TST & \\
\hline CHEMBL3093329 & 1278696 & 4.0 & 4.1911 & TRN & \\
\hline CHEMBL 3091481 & 1278696 & 4.0 & 3.99600 & 00000000004 & TRN \\
\hline CHEMBL3093234 & 1278696 & 5.0 & 5.3263 & TRN & \\
\hline CHEMBL3093218 & 1278696 & 5.0 & 4.7997 & TRN & \\
\hline CHEMBL3093236 & 1278696 & 7.2013 & 7.5255 & TRN & \\
\hline CHEMBL 3093235 & 1278696 & 4.0 & 4.5315 & TRN & \\
\hline CHEMBL 3093241 & 1278696 & 5.6576 & 5.6345 & TRN & \\
\hline CHEMBL3093314 & 1278696 & 4.0 & 4.0133 & TRN & \\
\hline CHEMBL3093226 & 1278696 & 4.0 & 4.4398 & TRN & \\
\hline CHEMBL3093230 & 1278696 & 5.4295 & 4.5961 & TST & \\
\hline CHEMBL 3093220 & 1278696 & 4.0 & 3.7814 & TRN & \\
\hline CHEMBL3093239 & 1278696 & 7.061 & 6.7492 & TRN & \\
\hline CHEMBL3093317 & 1278696 & 4.0 & 3.9809 & TRN & \\
\hline CHEMBL 3093237 & 1278696 & 6.7144 & 6.2828 & TRN & \\
\hline CHEMBL3093311 & 1278696 & 5.7447 & 5.6524 & TRN & \\
\hline CHEMBL3093223 & 1278696 & 5.4437 & 5.2581 & TRN & \\
\hline CHEMBL3093320 & 1278696 & 4.0 & 4.2665 & TRN & \\
\hline CHEMBL3093326 & 1278696 & 5.0 & 4.0156 & TST & \\
\hline CHEMBL3093323 & 1278696 & 4.0 & 4.2769 & TRN & \\
\hline CHEMBL3093318 & 1278696 & 4.0 & 4.2502 & TRN & \\
\hline CHEMBL3093325 & 1278696 & 5.0 & 4.909 & TST & \\
\hline CHEMBL 241618 & 1278696 & 6.4634 & 6.6705 & TRN & \\
\hline CHEMBL 3093240 & 1278696 & 5.0 & 4.8802 & TRN & \\
\hline CHEMBL3093221 & 1278696 & 5.5258 & 4.2012 & TST & \\
\hline CHEMBL3093219 & 1278696 & 5.0 & 5.5536 & TST & \\
\hline CHEMBL282038 & 1278696 & 4.0 & 4.2473 & TST & \\
\hline CHEMBL3093331 & 1278696 & 5.0 & 4.9687 & TRN & \\
\hline CHEMBL3093315 & 1278696 & 5.0 & 4.7956 & TRN & \\
\hline CHEMBL3093231 & 1278696 & 4.0 & 4.6697 & TST & \\
\hline CHEMBL3093312 & 1278696 & 5.0 & 4.9178 & TRN & \\
\hline CHEMBL3093215 & 1278696 & 4.0 & 5.0201 & TST & \\
\hline
\end{tabular}




\begin{tabular}{|c|c|c|c|c|c|}
\hline \multicolumn{6}{|c|}{ Supplemental Table S2.txt } \\
\hline CHEMBL 3093313 & 1278696 & 5.0 & 5.3664 & TRN & \\
\hline CHEMBL239230 & 1278696 & 6.2048 & 5.9911 & TST & \\
\hline CHEMBL3093333 & 1278696 & 5.0 & 4.92399 & 99999999995 & TRN \\
\hline CHEMBL 3093330 & 1278696 & 4.0 & 4.1678 & TRN & \\
\hline CHEMBL3093227 & 1278696 & 5.3224 & 4.683 & TRN & \\
\hline CHEMBL 3093214 & 1278696 & 5.0 & 3.8401 & TST & \\
\hline CHEMBL3093225 & 1278696 & 5.4868 & 5.732 & TRN & \\
\hline CHEMBL3093332 & 1278696 & 4.0 & 3.9879 & TRN & \\
\hline CHEMBL241617 & 1278696 & 6.6615 & 6.6387 & TST & \\
\hline CHEMBL3093310 & 1278696 & 5.4248 & 5.1649 & TRN & \\
\hline CHEMBL 3093222 & 1278696 & 4.0 & 5.1093 & TST & \\
\hline CHEMBL 3093322 & 1278696 & 4.0 & 4.2671 & TRN & \\
\hline CHEMBL3093229 & 1278696 & 4.0 & 4.2547 & TRN & \\
\hline CHEMBL3093238 & 1278696 & 5.8697 & 5.8852 & TST & \\
\hline CHEMBL3093321 & 1278696 & 4.0 & 3.9407 & TRN & \\
\hline CHEMBL3093216 & 1278696 & 5.4584 & 4.1961 & TST & \\
\hline CHEMBL3093324 & 1278696 & 4.0 & 3.6969 & TRN & \\
\hline CHEMBL1964253 & 50508 & 8.2518 & 8.2797 & TRN & \\
\hline CHEMBL 271160 & 50508 & 8.4685 & 8.4416 & TRN & \\
\hline CHEMBL271594 & 50508 & 7.1249 & 6.8445 & TRN & \\
\hline CHEMBL269850 & 50508 & 6.1612 & 6.0488 & TRN & \\
\hline CHEMBL1964256 & 50508 & 7.585 & 7.9193 & TRN & \\
\hline CHEMBL410883 & 50508 & 8.3468 & 8.1305 & TRN & \\
\hline CHEMBL271778 & 50508 & 5.0 & 5.0982 & TRN & \\
\hline CHEMBL1276446 & 50508 & 8.0132 & 8.0695 & TRN & \\
\hline CHEMBL235849 & 50508 & 7.301 & 7.3416 & TRN & \\
\hline CHEMBL271182 & 50508 & 7.6778 & 7.3686 & TRN & \\
\hline CHEMBL271822 & 50508 & 7.2676 & 7.4504 & TST & \\
\hline CHEMBL272885 & 50508 & 4.0 & 4.447 & TRN & \\
\hline CHEMBL272028 & 50508 & 7.9208 & 7.9183 & TRN & \\
\hline CHEMBL1964260 & 50508 & 8.2441 & 8.3726 & TRN & \\
\hline CHEMBL314397 & 50508 & 8.3372 & 7.8777 & TST & \\
\hline CHEMBL273060 & 50508 & 7.9586 & 8.0106 & TRN & \\
\hline CHEMBL412097 & 50508 & 7.6576 & 7.4292 & TST & \\
\hline CHEMBL407709 & 50508 & 8.1487 & 8.2405 & TRN & \\
\hline CHEMBL1964259 & 50508 & 9.2676 & 8.925 & TRN & \\
\hline CHEMBL1964251 & 50508 & 8.4437 & 8.5426 & TRN & \\
\hline CHEMBL272165 & 50508 & 8.0506 & 8.13600 & 0000000001 & TRN \\
\hline CHEMBL270544 & 50508 & 8.8239 & 8.7392 & TRN & \\
\hline CHEMBL271842 & 50508 & 7.1308 & 7.2272 & TRN & \\
\hline CHEMBL1234088 & 50508 & 6.0 & 5.7574 & TST & \\
\hline CHEMBL410072 & 50508 & 8.1675 & 7.9751 & TRN & \\
\hline CHEMBL269883 & 50508 & 8.5229 & 8.8299 & TRN & \\
\hline CHEMBL1964248 & 50508 & 6.0 & 6.0237 & TST & \\
\hline CHEMBL429142 & 50508 & 8.7212 & 8.7855 & TST & \\
\hline CHEMBL 272833 & 50508 & 7.8861 & 8.0174 & TST & \\
\hline CHEMBL271777 & 50508 & 4.0 & 4.1338 & TRN & \\
\hline CHEMBL411491 & 50508 & 7.2218 & 7.3209 & TRN & \\
\hline
\end{tabular}




\begin{tabular}{|c|c|c|c|c|c|}
\hline & & \multicolumn{4}{|c|}{ Supplemental Table S2.txt } \\
\hline CHEMBL412091 & 50508 & 7.8239 & 7.8259 & TRN & \\
\hline CHEMBL269882 & 50508 & 8.6576 & 8.4772 & TST & \\
\hline CHEMBL409690 & 50508 & 8.0 & 7.8736 & TRN & \\
\hline CHEMBL1964250 & 50508 & 8.3468 & 8.4439 & TRN & \\
\hline CHEMBL409619 & 50508 & 5.6198 & 5.9356 & TRN & \\
\hline CHEMBL411426 & 50508 & 8.6021 & 8.622 & TRN & \\
\hline CHEMBL411696 & 50508 & 7.0315 & 7.402 & TRN & \\
\hline CHEMBL271136 & 50508 & 8.7696 & 8.7334 & TRN & \\
\hline CHEMBL269846 & 50508 & 4.0 & 3.281 & TST & \\
\hline CHEMBL1964246 & 50508 & 8.3279 & 8.52 & TRN & \\
\hline CHEMBL271595 & 50508 & 8.5528 & 8.6967 & TRN & \\
\hline CHEMBL409731 & 50508 & 8.6778 & 8.6301 & TST & \\
\hline CHEMBL410517 & 50508 & 4.0 & 3.3008 & TST & \\
\hline CHEMBL1964245 & 50508 & 8.2518 & 8.3058 & TRN & \\
\hline CHEMBL 271952 & 50508 & 8.0223 & 7.9038 & TST & \\
\hline CHEMBL1234085 & 50508 & 6.2518 & 5.9308 & TST & \\
\hline CHEMBL 272389 & 50508 & 7.7959 & 7.853 & TRN & \\
\hline CHEMBL438721 & 50508 & 6.9208 & 6.7451 & TRN & \\
\hline CHEMBL411887 & 50508 & 8.699 & 8.5511 & TRN & \\
\hline CHEMBL1234087 & 50508 & 8.0506 & 8.28399 & 9999999999 & TRN \\
\hline CHEMBL1964252 & 50508 & 6.5513 & 5.9017 & TRN & \\
\hline CHEMBL 2112297 & 50508 & 8.0223 & 8.5252 & TRN & \\
\hline CHEMBL 270054 & 50508 & 7.3665 & 7.4333 & TRN & \\
\hline CHEMBL272414 & 50508 & 6.5086 & 6.7086 & TST & \\
\hline CHEMBL272668 & 50508 & 7.5528 & 7.5614 & TST & \\
\hline CHEMBL1964243 & 50508 & 7.1249 & 7.4091 & TRN & \\
\hline CHEMBL 260103 & 50508 & 7.9208 & 7.8323 & TRN & \\
\hline CHEMBL409892 & 50508 & 8.7959 & 8.9287 & TRN & \\
\hline CHEMBL1234086 & 50508 & 8.2441 & 7.9574 & TRN & \\
\hline CHEMBL271953 & 50508 & 8.6778 & 8.5157 & TRN & \\
\hline CHEMBL269827 & 50508 & 8.6383 & 8.6581 & TRN & \\
\hline CHEMBL 270132 & 50508 & 8.6021 & 8.5312 & TRN & \\
\hline CHEMBL411425 & 50508 & 8.1024 & 8.2924 & TRN & \\
\hline CHEMBL1964255 & 50508 & 8.4815 & 8.2357 & TRN & \\
\hline CHEMBL410293 & 50508 & 7.2147 & 7.081 & TST & \\
\hline CHEMBL1964247 & 50508 & 8.3372 & 8.3601 & TRN & \\
\hline CHEMBL408210 & 50508 & 8.0506 & 7.8899 & TST & \\
\hline CHEMBL411490 & 50508 & 7.8861 & 7.7156 & TST & \\
\hline CHEMBL 271843 & 50508 & 7.3372 & 7.2533 & TRN & \\
\hline CHEMBL411886 & 50508 & 7.8239 & 7.6772 & TRN & \\
\hline CHEMBL1234089 & 50508 & 6.1805 & 6.0101 & TST & \\
\hline CHEMBL1794054 & 50508 & 7.6778 & 7.7855 & TRN & \\
\hline CHEMBL411865 & 50508 & 7.9208 & 7.9402 & TRN & \\
\hline CHEMBL409104 & 50508 & 7.8861 & 7.5294 & TRN & \\
\hline CHEMBL272684 & 50508 & 7.7212 & 7.5057 & TST & \\
\hline CHEMBL1964242 & 50508 & 8.2518 & 8.4092 & TRN & \\
\hline CHEMBL 272026 & 50508 & 7.6021 & 7.6878 & TRN & \\
\hline CHEMBL405042 & 50508 & 6.4437 & 6.5864 & TST & \\
\hline
\end{tabular}




\begin{tabular}{|c|c|c|c|c|c|}
\hline \multirow[b]{2}{*}{ CHEMBL272380 } & \multicolumn{5}{|c|}{ Supplemental Table S2.txt } \\
\hline & 50508 & 8.0315 & 7.9255 & TRN & \\
\hline CHEMBL 271137 & 50508 & 7.2676 & 7.5868 & TST & \\
\hline CHEMBL 272667 & 50508 & 8.3372 & 8.1448 & TRN & \\
\hline CHEMBL 271183 & 50508 & 7.3665 & 6.88200 & 0000000001 & TRN \\
\hline CHEMBL445945 & 50508 & 8.8239 & 8.9694 & TRN & \\
\hline CHEMBL272387 & 50508 & 7.3665 & 7.4671 & TRN & \\
\hline CHEMBL1964258 & 50508 & 7.8861 & 7.8359 & TRN & \\
\hline CHEMBL391229 & 50508 & 7.8539 & 8.1993 & TST & \\
\hline CHEMBL408131 & 50508 & 4.0 & 3.3693 & TST & \\
\hline CHEMBL1964244 & 50508 & 8.3665 & 8.4298 & TRN & \\
\hline CHEMBL409868 & 50508 & 7.7696 & 7.7458 & TRN & \\
\hline CHEMBL411224 & 50508 & 8.9208 & 9.0481 & TRN & \\
\hline CHEMBL1964257 & 50508 & 8.1249 & 8.0721 & TRN & \\
\hline CHEMBL 273061 & 50508 & 7.4685 & 7.5322 & TRN & \\
\hline CHEMBL1964249 & 50508 & 9.0 & 8.3813 & TRN & \\
\hline CHEMBL3765621 & 1555281 & 5.5638 & 6.0181 & TRN & \\
\hline CHEMBL3764473 & 1555281 & 6.3468 & 5.9563 & TRN & \\
\hline CHEMBL 3763250 & 1555281 & 3.5229 & 4.7143 & TRN & \\
\hline CHEMBL 3764478 & 1555281 & 6.0706 & 5.1252 & TRN & \\
\hline CHEMBL3764243 & 1555281 & 5.0237 & 4.5897 & TRN & \\
\hline CHEMBL3765082 & 1555281 & 5.6716 & 5.7174 & TRN & \\
\hline CHEMBL 3764852 & 1555281 & 5.9172 & 5.3875 & TRN & \\
\hline CHEMBL3763984 & 1555281 & 6.4089 & 6.027 & TRN & \\
\hline CHEMBL3764130 & 1555281 & 5.1391 & 5.4738 & TST & \\
\hline CHEMBL3763431 & 1555281 & 6.9586 & 6.0203 & TRN & \\
\hline CHEMBL 3763744 & 1555281 & 6.2596 & 6.0326 & TRN & \\
\hline CHEMBL 3764498 & 1555281 & 5.1343 & 4.8867 & TRN & \\
\hline CHEMBL3764827 & 1555281 & 3.5229 & 4.5859 & TRN & \\
\hline CHEMBL3763901 & 1555281 & 5.7235 & 6.026 & TRN & \\
\hline CHEMBL3763515 & 1555281 & 6.2518 & 6.1475 & TRN & \\
\hline CHEMBL3763686 & 1555281 & 5.1506 & 4.829 & TRN & \\
\hline CHEMBL3763713 & 1555281 & 5.1331 & 4.8596 & TRN & \\
\hline CHEMBL3765028 & 1555281 & 5.7033 & 6.0739 & TRN & \\
\hline CHEMBL3765176 & 1555281 & 3.5229 & 4.8552 & TST & \\
\hline CHEMBL3765201 & 1555281 & 5.1002 & 4.7737 & TST & \\
\hline CHEMBL3764789 & 1555281 & 6.0506 & 5.9658 & TRN & \\
\hline CHEMBL 3765388 & 1555281 & 4.633 & 5.9027 & TRN & \\
\hline CHEMBL3763732 & 1555281 & 5.7011 & 5.7811 & TRN & \\
\hline CHEMBL 3765489 & 1555281 & 5.7447 & 6.0343 & TRN & \\
\hline CHEMBL3764213 & 1555281 & 3.5229 & 5.0924 & TST & \\
\hline CHEMBL3764915 & 1555281 & 5.6819 & 4.8954 & TST & \\
\hline CHEMBL 3765450 & 1555281 & 6.0088 & 6.044 & TRN & \\
\hline CHEMBL3763365 & 1555281 & 5.426 & 5.9731 & TRN & \\
\hline CHEMBL 3764337 & 1555281 & 5.9355 & 5.7916 & TRN & \\
\hline CHEMBL3764727 & 1555281 & 5.5686 & 5.5179 & TRN & \\
\hline CHEMBL3765297 & 1555281 & 5.9355 & 6.0313 & TRN & \\
\hline CHEMBL3764237 & 1555281 & 3.5229 & 4.7088 & TST & \\
\hline CHEMBL3764462 & 1555281 & 5.3675 & 4.9122 & TST & \\
\hline
\end{tabular}


Supplemental Table S2.txt

\begin{tabular}{|c|c|c|c|c|}
\hline CHEMBL3763518 & 1555281 & 5.8125 & 5.2709 & TST \\
\hline CHEMBL3764985 & 1555281 & 5.9393 & 6.0559 & TRN \\
\hline CHEMBL3765100 & 1555281 & 5.6091 & 6.0157 & TRN \\
\hline CHEMBL3764938 & 1555281 & 5.4214 & 6.016 & TRN \\
\hline CHEMBL 3764266 & 1555281 & 5.9872 & 5.9989 & TRN \\
\hline CHEMBL3764343 & 1555281 & 5.7122 & 6.1795 & TRN \\
\hline CHEMBL3764937 & 1555281 & 3.5229 & 4.9403 & TST \\
\hline CHEMBL 3764841 & 1555281 & 5.5544 & 6.0543 & TRN \\
\hline CHEMBL3763721 & 1555281 & 5.75700 & 00000006 & 6.1756 \\
\hline CHEMBL3765821 & 1555281 & 5.7852 & 6.0046 & TRN \\
\hline CHEMBL3765433 & 1555281 & 5.5229 & 5.4374 & TRN \\
\hline CHEMBL3764165 & 1555281 & 5.8097 & 6.0833 & TRN \\
\hline CHEMBL3765036 & 1555281 & 4.7991 & 4.8062 & TST \\
\hline CHEMBL3763693 & 1555281 & 5.0429 & 5.5132 & TRN \\
\hline CHEMBL 3765400 & 1555281 & 5.2815 & 5.5198 & TRN \\
\hline CHEMBL3765156 & 1555281 & 6.3665 & 5.4669 & TST \\
\hline CHEMBL3765228 & 1555281 & 6.1249 & 5.3377 & TRN \\
\hline CHEMBL3764368 & 1555281 & 5.4157 & 5.1939 & TST \\
\hline CHEMBL3765085 & 1555281 & 5.3335 & 5.4542 & TRN \\
\hline CHEMBL 3765788 & 1555281 & 5.5436 & 6.1546 & TRN \\
\hline CHEMBL 3763284 & 1555281 & 5.3625 & 5.692 & TRN \\
\hline CHEMBL3763251 & 1555281 & 5.644 & 5.4795 & TRN \\
\hline CHEMBL3764309 & 1555281 & 3.5229 & 6.0364 & TRN \\
\hline CHEMBL3765309 & 1555281 & 6.7447 & 6.0376 & TRN \\
\hline CHEMBL 3763501 & 1555281 & 6.3872 & 6.1369 & TRN \\
\hline CHEMBL3763615 & 1555281 & 5.1524 & $5.49200 e$ & 0000000001 \\
\hline CHEMBL3764411 & 1555281 & 5.8894 & 5.9621 & TRN \\
\hline CHEMBL 3764145 & 1555281 & 7.2218 & 6.1373 & TRN \\
\hline CHEMBL3764077 & 1555281 & 5.7905 & 6.0279 & TRN \\
\hline CHEMBL3764709 & 1555281 & 5.8928 & 6.2687 & TRN \\
\hline CHEMBL 3764082 & 1555281 & 6.1805 & 6.0042 & TRN \\
\hline CHEMBL3763507 & 1555281 & 6.0362 & 5.5873 & TST \\
\hline CHEMBL3765281 & 1555281 & 5.9355 & 6.1755 & TRN \\
\hline CHEMBL 3764204 & 1555281 & 6.0862 & 5.3573 & TST \\
\hline CHEMBL3764571 & 1555281 & 7.3979 & 6.1512 & TRN \\
\hline CHEMBL3764734 & 1555281 & 3.5229 & 5.0683 & TST \\
\hline CHEMBL3763460 & 1555281 & 5.8508 & 5.6741 & TRN \\
\hline CHEMBL3765216 & 1555281 & 5.5317 & 5.5244 & TRN \\
\hline CHEMBL3764992 & 1555281 & 5.9586 & 5.5894 & TRN \\
\hline CHEMBL3764717 & 1555281 & 5.2351 & 5.943 & TRN \\
\hline CHEMBL 3763838 & 1555281 & 5.3002 & 5.5372 & TRN \\
\hline CHEMBL3765427 & 1555281 & 5.6345 & 5.2084 & TST \\
\hline CHEMBL3764526 & 1555281 & 6.1938 & 5.365 & TST \\
\hline CHEMBL3765678 & 1555281 & 5.9431 & 6.1253 & TRN \\
\hline CHEMBL3765501 & 1555281 & 6.3372 & 5.4255 & TRN \\
\hline CHEMBL 3765392 & 1555281 & 6.3565 & 6.0427 & TRN \\
\hline CHEMBL 3765748 & 1555281 & 5.7959 & 6.0467 & TRN \\
\hline CHEMBL3763253 & 1555281 & 5.3883 & 5.5153 & TRN \\
\hline
\end{tabular}


Supplemental Table S2.txt

\begin{tabular}{|c|c|c|c|c|c|}
\hline CHEMBL3763958 & 1555281 & 5.1972 & 4.6595 & TST & \\
\hline CHEMBL3765087 & 1555281 & 3.5229 & 4.86 & TST & \\
\hline CHEMBL3764031 & 1555281 & 5.9666 & 6.1546 & TRN & \\
\hline CHEMBL3763839 & 1555281 & 5.8508 & 5.9991 & TRN & \\
\hline CHEMBL3763924 & 1555281 & 5.8239 & 5.989 & TRN & \\
\hline CHEMBL3763682 & 1555281 & 5.7399 & 5.8629 & TRN & \\
\hline CHEMBL3764758 & 1555281 & 6.7696 & 5.9731 & TST & \\
\hline CHEMBL3764248 & 1555281 & 4.9504 & 5.8027 & TRN & \\
\hline CHEMBL3764747 & 1555281 & 6.4685 & 5.6313 & TRN & \\
\hline CHEMBL 3764378 & 1555281 & 5.8962 & 5.4225 & TST & \\
\hline CHEMBL3765068 & 1555281 & 8.0 & 6.16 & TRN & \\
\hline CHEMBL3764210 & 1555281 & 6.3372 & 6.1869 & TRN & \\
\hline CHEMBL3764257 & 1555281 & 6.3098 & 5.9882 & TRN & \\
\hline CHEMBL3764863 & 1555281 & 6.0458 & 5.9651 & TRN & \\
\hline CHEMBL 3765772 & 1555281 & 4.9974 & 5.3475 & TST & \\
\hline CHEMBL3764652 & 1555281 & 6.2518 & 6.037999 & 9999999999 & TRN \\
\hline CHEMBL3763692 & 1555281 & 7.2218 & 6.3163 & TRN & \\
\hline CHEMBL3765695 & 1555281 & 4.8617 & 5.5039 & TST & \\
\hline CHEMBL3765781 & 1555281 & 6.0223 & 5.9747 & TRN & \\
\hline CHEMBL3764291 & 1555281 & 6.0969 & 6.2188 & TRN & \\
\hline CHEMBL3765548 & 1555281 & 5.0799 & 5.4857 & TRN & \\
\hline CHEMBL3764499 & 1555281 & 5.3507 & 4.8182 & TST & \\
\hline CHEMBL3764094 & 1555281 & 4.672 & 4.8211 & TST & \\
\hline CHEMBL3765368 & 1555281 & 5.5638 & 5.5002 & TST & \\
\hline CHEMBL3765439 & 1555281 & 6.3565 & 6.0026 & TRN & \\
\hline CHEMBL3765009 & 1555281 & 5.9666 & 6.05 & TRN & \\
\hline CHEMBL3765328 & 1555281 & 6.9208 & 5.9941 & TRN & \\
\hline CHEMBL3763949 & 1555281 & 5.7696 & 4.8377 & TST & \\
\hline CHEMBL3764399 & 1555281 & 5.5214 & 4.9491 & TST & \\
\hline CHEMBL3765166 & 1555281 & 5.9431 & 5.2527 & TRN & \\
\hline CHEMBL3765683 & 1555281 & 7.5229 & 6.2722 & TRN & \\
\hline CHEMBL3765633 & 1555281 & 5.8827 & 6.0389 & TRN & \\
\hline CHEMBL3764380 & 1555281 & 5.0947 & 5.0156 & TST & \\
\hline CHEMBL3764269 & 1555281 & 5.6819 & 5.4612 & TRN & \\
\hline CHEMBL3764776 & 1555281 & 4.8972 & 6.0394 & TRN & \\
\hline CHEMBL3983925 & 1641374 & 8.8861 & 9.0536 & TRN & \\
\hline CHEMBL 3978253 & 1641374 & 10.0 & 10.2616 & TRN & \\
\hline CHEMBL3924374 & 1641374 & 10.0 & 9.5132 & TRN & \\
\hline CHEMBL3899958 & 1641374 & 10.0 & 9.8045 & TRN & \\
\hline CHEMBL3893435 & 1641374 & 8.9208 & 9.2644 & TRN & \\
\hline CHEMBL 3902948 & 1641374 & 10.0 & 10.4605 & TRN & \\
\hline CHEMBL3925529 & 1641374 & 7.3546 & 8.8226 & TST & \\
\hline CHEMBL3920727 & 1641374 & 10.0 & 9.7425 & TRN & \\
\hline CHEMBL3915608 & 1641374 & 10.0 & 9.8959 & TRN & \\
\hline CHEMBL3912107 & 1641374 & 7.8041 & 7.6711 & TST & \\
\hline CHEMBL3902891 & 1641374 & 7.9508 & 7.5692 & TRN & \\
\hline CHEMBL3916521 & 1641374 & 7.8268 & 9.2389 & TST & \\
\hline CHEMBL3910007 & 1641374 & 7.9626 & 8.0341 & TRN & \\
\hline
\end{tabular}


Supplemental Table S2.txt

\begin{tabular}{|c|c|c|c|c|c|}
\hline CHEMBL3959572 & 1641374 & 8.6198 & 8.8776 & TRN & \\
\hline CHEMBL3951082 & 1641374 & 10.0 & 9.7149 & TRN & \\
\hline CHEMBL3911507 & 1641374 & 9.0 & 9.4994 & TRN & \\
\hline CHEMBL3972892 & 1641374 & 7.4353 & 7.261 & TRN & \\
\hline CHEMBL3935475 & 1641374 & 10.0 & 10.4995 & TRN & \\
\hline CHEMBL3961790 & 1641374 & 8.4089 & 8.5702 & TRN & \\
\hline CHEMBL3929258 & 1641374 & 6.0 & 7.6755 & TST & \\
\hline CHEMBL3908485 & 1641374 & 10.0 & 9.5921 & TRN & \\
\hline CHEMBL3937642 & 1641374 & 10.0 & 9.6403 & TRN & \\
\hline CHEMBL3924472 & 1641374 & 10.0 & 9.5413 & TRN & \\
\hline CHEMBL3941639 & 1641374 & 10.0 & 9.9179 & TRN & \\
\hline CHEMBL3965522 & 1641374 & 10.0 & 9.6388 & TRN & \\
\hline CHEMBL3904744 & 1641374 & 10.0 & 9.972999 & 999999999 & TRN \\
\hline CHEMBL3926343 & 1641374 & 8.4949 & 8.1936 & TST & \\
\hline CHEMBL3971109 & 1641374 & 10.0 & 9.1808 & TRN & \\
\hline CHEMBL3973301 & 1641374 & 9.0 & 9.134 & TRN & \\
\hline CHEMBL3902673 & 1641374 & 10.0 & 9.9469 & TRN & \\
\hline CHEMBL 3912644 & 1641374 & 7.6364 & 7.8602 & TRN & \\
\hline CHEMBL3907339 & 1641374 & 8.1871 & 8.3887 & TST & \\
\hline CHEMBL3947394 & 1641374 & 8.0 & 8.3442 & TRN & \\
\hline CHEMBL3901565 & 1641374 & 10.0 & 9.8612 & TRN & \\
\hline CHEMBL3904603 & 1641374 & 8.7696 & 9.7211 & TST & \\
\hline CHEMBL3982911 & 1641374 & 8.585 & 8.0779 & TRN & \\
\hline CHEMBL3935205 & 1641374 & 10.0 & 9.7013 & TRN & \\
\hline CHEMBL3926599 & 1641374 & 8.9586 & 9.0878 & TRN & \\
\hline CHEMBL3919916 & 1641374 & 8.8239 & 9.2477 & TRN & \\
\hline CHEMBL3934725 & 1641374 & 6.0 & 7.3834 & TRN & \\
\hline CHEMBL3951195 & 1641374 & 8.0132 & 8.014 & TRN & \\
\hline CHEMBL3914740 & 1641374 & 10.0 & 9.9082 & TRN & \\
\hline CHEMBL3917611 & 1641374 & 6.9606 & 8.2783 & TST & \\
\hline CHEMBL3924681 & 1641374 & 10.0 & 9.7932 & TRN & \\
\hline CHEMBL3933665 & 1641374 & 10.0 & 9.872 & TRN & \\
\hline CHEMBL3973297 & 1641374 & 8.7212 & 8.6115 & TST & \\
\hline CHEMBL3977042 & 1641374 & 8.5376 & 8.2892 & TRN & \\
\hline CHEMBL3982691 & 1641374 & 7.5719 & 7.792999 & 999999999 & TST \\
\hline CHEMBL3953062 & 1641374 & 7.684 & 7.5866 & TST & \\
\hline CHEMBL3940212 & 1641374 & 8.9208 & 9.1061 & TRN & \\
\hline CHEMBL3974823 & 1641374 & 8.4202 & 8.273 & TRN & \\
\hline CHEMBL3916431 & 1641374 & 7.4672 & 7.7476 & TRN & \\
\hline CHEMBL3917681 & 1641374 & 7.4237 & 7.8647 & TST & \\
\hline CHEMBL3891647 & 1641374 & 8.8239 & 9.2326 & TST & \\
\hline CHEMBL3940364 & 1641374 & 8.8239 & 9.0785 & TRN & \\
\hline CHEMBL3922473 & 1641374 & 8.9586 & 8.9317 & TRN & \\
\hline CHEMBL3946695 & 1641374 & 7.4271 & 8.6999 & TST & \\
\hline CHEMBL3978724 & 1641374 & 8.1675 & 8.3114 & TST & \\
\hline CHEMBL3983194 & 1641374 & 8.4202 & 8.3808 & TRN & \\
\hline CHEMBL3919083 & 1641374 & 8.7696 & 8.8839 & TRN & \\
\hline CHEMBL3944242 & 1641374 & 8.0132 & 8.0421 & TRN & \\
\hline
\end{tabular}


Supplemental Table S2.txt

\begin{tabular}{|c|c|c|c|c|}
\hline 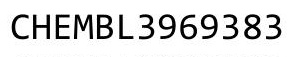 & & & 5051 & TRN \\
\hline HEMBL3926529 & 41374 & 8.9586 & 6289 & \\
\hline HEMBL3947551 & 641374 & 10.0 & 8096 & \\
\hline 779 & 374 & 7959 & & \\
\hline EMBL3 & 374 & 223 & 268 & \\
\hline HEMBL3933928 & 641374 & 10.0 & .2203 & \\
\hline HEMBL3917443 & 641374 & 10.0 & .2485 & \\
\hline HEMBL 39 & 374 & 7.5436 & 9227 & \\
\hline IEMBL & 374 & .9355 & 14 & \\
\hline IEMBL3S & 374 & 7.3757 & 382 & \\
\hline HEMBL3954413 & 374 & 10.0 & .1514 & \\
\hline HEMBL3959177 & 374 & 8.4089 & .3743 & \\
\hline HEMBL 396 & 374 & .5918 & 883 & \\
\hline HEMBL39 & & 10.0 & 671 & \\
\hline HEMBL3S & 74 & 8.4815 & & \\
\hline HEMBL39 & 374 & 7.8327 & & \\
\hline HEMBL394 & 374 & 8.3768 & 57 & \\
\hline HEMBL3S & 74 & 586 & 85 & RIV \\
\hline HEMBL3S & & & 673 & \\
\hline HEMBL3S & 74 & 7.8041 & 98 & RN \\
\hline HEMBL3S & 74 & 147 & & \\
\hline HEMBL3948503 & 74 & 10.0 & 46 & I RN \\
\hline HEMBL39 & 74 & 208 & 54 & 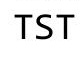 \\
\hline HEMBL3S & & 685 & & RN \\
\hline HEMB & 74 & 10.0 & 044 & TRN \\
\hline HEMBL 39 & & & 034 & T. \\
\hline HEMBL3919503 & 74 & 8.4685 & 47 & RIN \\
\hline HEMBL39 & 74 & 576 & 18 & RN \\
\hline HEM & 74 & 85 & & $\mathrm{RN}$ \\
\hline HEMBL3 & 74 & 10.0 & 96 & RN \\
\hline HEMBL39 & & 7. & & IRN \\
\hline HEMBL3978576 & 74 & & & RN \\
\hline HEMBL39 & 74 & 0 & 07 & RN \\
\hline 5 & & 605 & & RN \\
\hline HEMBL3S & 74 & & 872 & TRN \\
\hline HEMBL3973650 & & & & TRN \\
\hline HEMBL39 & 74 & & 04 & RN \\
\hline HEMBL38 & & 686 & 66 & $\mathrm{RN}$ \\
\hline 3 & & 305 & & RIN \\
\hline HEMBL39 & & & & TRN \\
\hline HEMBL395 & 374 & & 645 & TR \\
\hline HEMBL 38 & & & 265 & TRN \\
\hline HEMBL33 & & 3.431 & & (1) \\
\hline CHEMBL3904005 & & & & ST \\
\hline HEMBL 39 & 374 & 10.0 & 0.0713 & TS \\
\hline HEMBL393 & 374 & 10.0 & & $\mathrm{R}$ \\
\hline HEM & & & & ST \\
\hline & & & & \\
\hline
\end{tabular}




\begin{tabular}{|c|c|c|c|c|c|c|}
\hline \multicolumn{7}{|c|}{ Supplemental Table S2.txt } \\
\hline CHEMBL 3980274 & 1641374 & 10.0 & 9.6688 & TRN & & \\
\hline CHEMBL 3889979 & 1641374 & 8.3768 & 8.0614 & TRN & & \\
\hline CHEMBL 3909666 & 1641374 & 8.8539 & 9.2997 & TRN & & \\
\hline CHEMBL 3978111 & 1641374 & 6.0 & 8.3332 & TST & & \\
\hline CHEMBL 3985012 & 1641374 & 8.3098 & 8.6653 & TRN & & \\
\hline CHEMBL 3907765 & 1641374 & 10.0 & 10.1478 & TRN & & \\
\hline CHEMBL 3984789 & 1641374 & 10.0 & 10.0299 & TRN & & \\
\hline CHEMBL 3973176 & 1641374 & 7.8761 & 7.5446 & TRN & & \\
\hline CHEMBL 3910942 & 1641374 & 10.0 & 9.1484 & TRN & & \\
\hline CHEMBL 3902446 & 1641374 & 7.4572 & 7.2821 & TRN & & \\
\hline CHEMBL 3924349 & 1641374 & 7.8013 & 7.9012 & TRN & & \\
\hline CHEMBL 3962564 & 1641374 & 10.0 & 10.0405 & TRN & & \\
\hline CHEMBL 3926170 & 1641374 & 10.0 & 9.1071 & TST & & \\
\hline CHEMBL 3958895 & 1641374 & 8.8861 & 9.4489 & TRN & & \\
\hline CHEMBL 3894939 & 1641374 & 7.7471 & 8.8389 & TST & & \\
\hline CHEMBL 3900281 & 1641374 & 8.8539 & 9.4426 & TRN & & \\
\hline CHEMBL 3907698 & 1641374 & 8.3979 & 8.0427 & TRN & & \\
\hline CHEMBL 3984582 & 1641374 & 8.7696 & 8.9359 & TRN & & \\
\hline CHEMBL 3985135 & 1641374 & 8.5229 & 8.3151 & TRN & & \\
\hline CHEMBL 3908888 & 1641374 & 8.9586 & 8.3592 & TRN & & \\
\hline CHEMBL 3963281 & 1641374 & 10.0 & 10.1157 & TRN & & \\
\hline CHEMBL 3889573 & 1641374 & 7.3605 & 9.5491 & TST & & \\
\hline CHEMBL 3957518 & 1641374 & 10.0 & 10.2006 & TRN & & \\
\hline CHEMBL 3954809 & 1641374 & 10.0 & 9.8754 & TRN & & \\
\hline CHEMBL 3967520 & 1641374 & 10.0 & 9.9733 & TRN & & \\
\hline CHEMBL 3967343 & 1641374 & 8.9208 & 9.0143 & TRN & & \\
\hline CHEMBL 3916304 & 1641374 & 10.0 & 10.2933 & TRN & & \\
\hline CHEMBL 3963475 & 1641374 & 8.5376 & 9.3742 & TST & & \\
\hline CHEMBL 3935275 & 1641374 & 7.76200 & 000000000 & 005 & 7.9378 & TRN \\
\hline CHEMBL 3911289 & 1641374 & 8.1938 & 7.9614 & TRN & & \\
\hline CHEMBL 3902357 & 1641374 & 9.0 & 9.1973 & TRN & & \\
\hline CHEMBL 3968538 & 1641374 & 8.0809 & 8.6939 & TRN & & \\
\hline CHEMBL 3952994 & 1641374 & 8.5686 & 8.2293 & TRN & & \\
\hline CHEMBL 3979785 & 1641374 & 8.2218 & 8.4914 & TRN & & \\
\hline CHEMBL 3956012 & 1641374 & 7.5817 & 7.7154 & TRN & & \\
\hline CHEMBL 3919852 & 1641374 & 7.6737 & 8.2565 & TRN & & \\
\hline CHEMBL3981839 & 1641374 & 10.0 & 10.2057 & TRN & & \\
\hline CHEMBL 3980137 & 1641374 & 8.2366 & 7.4642 & TRN & & \\
\hline CHEMBL 3966931 & 1641374 & 8.1487 & 7.7108 & TRN & & \\
\hline CHEMBL 3959423 & 1641374 & 8.4815 & 8.2375 & TRN & & \\
\hline CHEMBL 3983571 & 1641374 & 8.1549 & 8.2281 & TRN & & \\
\hline CHEMBL 3911204 & 1641374 & 10.0 & 9.7282 & TRN & & \\
\hline CHEMBL 3953017 & 1641374 & 10.0 & 10.1866 & TRN & & \\
\hline CHEMBL 3918402 & 1641374 & 6.0 & 7.3449 & TRN & & \\
\hline CHEMBL 3896337 & 1641374 & 7.8601 & 7.9614 & TRN & & \\
\hline CHEMBL 3934000 & 1641374 & 8.0315 & 7.811 & TST & & \\
\hline CHEMBL 3973912 & 1641374 & 10.0 & 9.9875 & TRN & & \\
\hline CHEMBL 3902266 & 1641374 & 6.0 & 10.041 & TST & & \\
\hline
\end{tabular}


Supplemental Table S2.txt

\begin{tabular}{|c|c|c|c|c|c|}
\hline CHEMBL3904052 & 1641374 & 7.8447 & 8.0008 & TRN & \\
\hline CHEMBL3944244 & 1641374 & 8.2007 & 8.2425 & TRN & \\
\hline CHEMBL3979685 & 1641374 & 6.0 & 8.5394 & TST & \\
\hline CHEMBL3926578 & 1641374 & 7.1805 & 8.5132 & TST & \\
\hline CHEMBL3892133 & 1641374 & 8.3372 & 8.3308 & TRN & \\
\hline CHEMBL3946602 & 1641374 & 8.9208 & 9.5522 & TRN & \\
\hline CHEMBL3905297 & 1641374 & 7.9281 & 7.9971 & TRN & \\
\hline CHEMBL3916264 & 1641374 & 10.0 & 9.8949 & TRN & \\
\hline CHEMBL3962375 & 1641374 & 8.041 & 8.9012 & TST & \\
\hline CHEMBL3890309 & 1641374 & 8.041 & 8.0305 & TRN & \\
\hline CHEMBL3904304 & 1641374 & 10.0 & 9.8741 & TRN & \\
\hline CHEMBL3910897 & 1641374 & 10.0 & 9.8084 & TRN & \\
\hline CHEMBL3922485 & 1641374 & 8.1427 & 7.7911 & TST & \\
\hline CHEMBL3923264 & 1641374 & 8.4559 & 8.4929 & TRN & \\
\hline CHEMBL3910290 & 1641374 & 8.4437 & 8.3258 & TRN & \\
\hline CHEMBL3970348 & 1641374 & 7.7282 & 8.0677 & TRN & \\
\hline CHEMBL3894570 & 1641374 & 10.0 & 9.8275 & TRN & \\
\hline CHEMBL3970037 & 1641374 & 8.3979 & 9.2666 & TST & \\
\hline CHEMBL 3895383 & 1641374 & 10.0 & 9.7853 & TRN & \\
\hline CHEMBL3892815 & 1641374 & 10.0 & 10.007 & TRN & \\
\hline CHEMBL3926400 & 1641374 & 8.9586 & 9.3989 & TST & \\
\hline CHEMBL3950839 & 1641374 & 10.0 & 9.4744 & TRN & \\
\hline CHEMBL3953171 & 1641374 & 6.0 & 9.2501 & TST & \\
\hline CHEMBL3978810 & 1641374 & 7.0482 & 8.3721 & TST & \\
\hline CHEMBL3917849 & 1641374 & 10.0 & 9.8721 & TST & \\
\hline CHEMBL3971561 & 1641374 & 10.0 & 9.8146 & TRN & \\
\hline CHEMBL3908128 & 1641374 & 10.0 & 9.7946 & TRN & \\
\hline CHEMBL3965478 & 1641374 & 6.0 & 6.9157 & TRN & \\
\hline CHEMBL3920706 & 1641374 & 10.0 & 9.7261 & TRN & \\
\hline CHEMBL3959206 & 1641374 & 8.2218 & 8.5646 & TRN & \\
\hline CHEMBL3960408 & 1641374 & 6.6968 & 8.2258 & TST & \\
\hline CHEMBL3986833 & 1641374 & 10.0 & 9.767999 & & TRN \\
\hline CHEMBL3920287 & 1641374 & 8.5686 & 8.7643 & TRN & \\
\hline CHEMBL3978869 & 1641374 & 8.9208 & 8.9053 & TRN & \\
\hline CHEMBL3922883 & 1641374 & 10.0 & 9.4405 & TRN & \\
\hline CHEMBL3938834 & 1641374 & 10.0 & 9.7352 & TRN & \\
\hline CHEMBL3921937 & 1641374 & 10.0 & 9.6447 & TRN & \\
\hline CHEMBL3897616 & 1641374 & 8.1739 & 8.2069 & TRN & \\
\hline CHEMBL3954303 & 1641374 & 8.4685 & 8.6753 & TRN & \\
\hline CHEMBL3935075 & 1641374 & 10.0 & 9.6961 & TRN & \\
\hline CHEMBL3901620 & 1641374 & 8.0223 & 8.1142 & TST & \\
\hline CHEMBL3953099 & 1641374 & 10.0 & 10.4151 & TRN & \\
\hline CHEMBL3903693 & 1641374 & 7.6459 & 8.1212 & TST & \\
\hline CHEMBL3922863 & 1641374 & 10.0 & 9.5957 & TST & \\
\hline CHEMBL3963348 & 1641374 & 7.7696 & 7.928 & TST & \\
\hline CHEMBL3955022 & 1641374 & 8.4318 & 7.7701 & TST & \\
\hline CHEMBL3963039 & 1641374 & 10.0 & 10.2053 & TST & \\
\hline CHEMBL3959458 & 1641374 & 10.0 & 10.0542 & TST & \\
\hline
\end{tabular}


Supplemental Table S2.txt

\begin{tabular}{|c|c|c|c|c|}
\hline CHEMBL3909394 & 1641374 & 7.5214 & 9.0247 & TST \\
\hline CHEMBL 3892781 & 1641374 & 8.7696 & 8.65 & TST \\
\hline CHEMBL3938790 & 1641374 & 10.0 & 9.5017 & TST \\
\hline CHEMBL3910865 & 1641374 & 10.0 & 9.6102 & TST \\
\hline CHEMBL3904324 & 1641374 & 10.0 & 10.2944 & TST \\
\hline CHEMBL3894823 & 1641374 & 10.0 & 10.2945 & TST \\
\hline CHEMBL3925766 & 1641374 & 8.6576 & 8.1899 & TST \\
\hline CHEMBL1964290 & 809154 & 4.9 & 4.7348 & TRN \\
\hline CHEMBL213505 & 809154 & 8.0 & 7.8634 & TRN \\
\hline CHEMBL202721 & 809154 & 7.3 & 6.2204 & TRN \\
\hline CHEMBL1987034 & 809154 & 7.9 & 7.7445 & TRN \\
\hline CHEMBL377383 & 809154 & 4.9 & 4.3708 & TST \\
\hline CHEMBL 2005886 & 809154 & 8.5 & 8.2168 & TRN \\
\hline CHEMBL1973142 & 809154 & 4.9 & 5.4839 & TRN \\
\hline CHEMBL388311 & 809154 & 8.3 & 9.0766 & TRN \\
\hline CHEMBL1973145 & 809154 & 7.1 & 6.3326 & TRN \\
\hline CHEMBL1982924 & 809154 & 4.9 & 5.1378 & TRN \\
\hline CHEMBL2005936 & 809154 & 4.9 & 4.952 & TRN \\
\hline CHEMBL1807515 & 809154 & 4.9 & 5.5683 & TRN \\
\hline CHEMBL1964948 & 809154 & 5.8 & 5.3444 & TRN \\
\hline CHEMBL1971141 & 809154 & 4.9 & 5.1252 & TRN \\
\hline CHEMBL1995813 & 809154 & 6.6 & 5.5576 & TRN \\
\hline CHEMBL1989834 & 809154 & 3.8 & 4.0563 & TRN \\
\hline CHEMBL1987430 & 809154 & 4.5 & 4.7158 & TRN \\
\hline CHEMBL244378 & 809154 & 7.1 & 6.5183 & TRN \\
\hline CHEMBL1969372 & 809154 & 4.9 & 5.0496 & TRN \\
\hline CHEMBL1993413 & 809154 & 4.5 & 4.3521 & TRN \\
\hline CHEMBL1986943 & 809154 & 5.9 & 6.2187 & TRN \\
\hline CHEMBL289959 & 809154 & 3.7 & 3.9894 & TRN \\
\hline CHEMBL 2006263 & 809154 & 4.9 & 4.9452 & TST \\
\hline CHEMBL1993584 & 809154 & 4.9 & 4.4101 & TRN \\
\hline CHEMBL1986263 & 809154 & 6.1 & 5.7919 & TRN \\
\hline CHEMBL 2000114 & 809154 & 4.9 & 5.329 & TRN \\
\hline CHEMBL1986265 & 809154 & 4.5 & 4.7387 & TRN \\
\hline CHEMBL1975647 & 809154 & 4.9 & 5.307 & TRN \\
\hline CHEMBL1968380 & 809154 & 4.9 & 4.9018 & TRN \\
\hline CHEMBL1967211 & 809154 & 4.1 & 4.5139 & TRN \\
\hline CHEMBL1964644 & 809154 & 4.9 & 4.6313 & TRN \\
\hline CHEMBL1991734 & 809154 & 6.5 & 5.7626 & TST \\
\hline CHEMBL1981782 & 809154 & 4.9 & 5.0114 & TRN \\
\hline CHEMBL1977681 & 809154 & 6.1 & 6.1973 & TRN \\
\hline CHEMBL1970142 & 809154 & 8.5 & 8.2756 & TRN \\
\hline CHEMBL1990912 & 809154 & 4.9 & 4.956 & TRN \\
\hline CHEMBL1991782 & 809154 & 3.2 & 3.9495 & TRN \\
\hline CHEMBL 2002105 & 809154 & 4.9 & 4.4331 & TRN \\
\hline CHEMBL1983348 & 809154 & 6.5 & 7.2421 & TRN \\
\hline CHEMBL1988163 & 809154 & 7.5 & 7.6369 & TRN \\
\hline CHEMBL1974480 & 809154 & 5.9 & 5.7058 & TRN \\
\hline
\end{tabular}




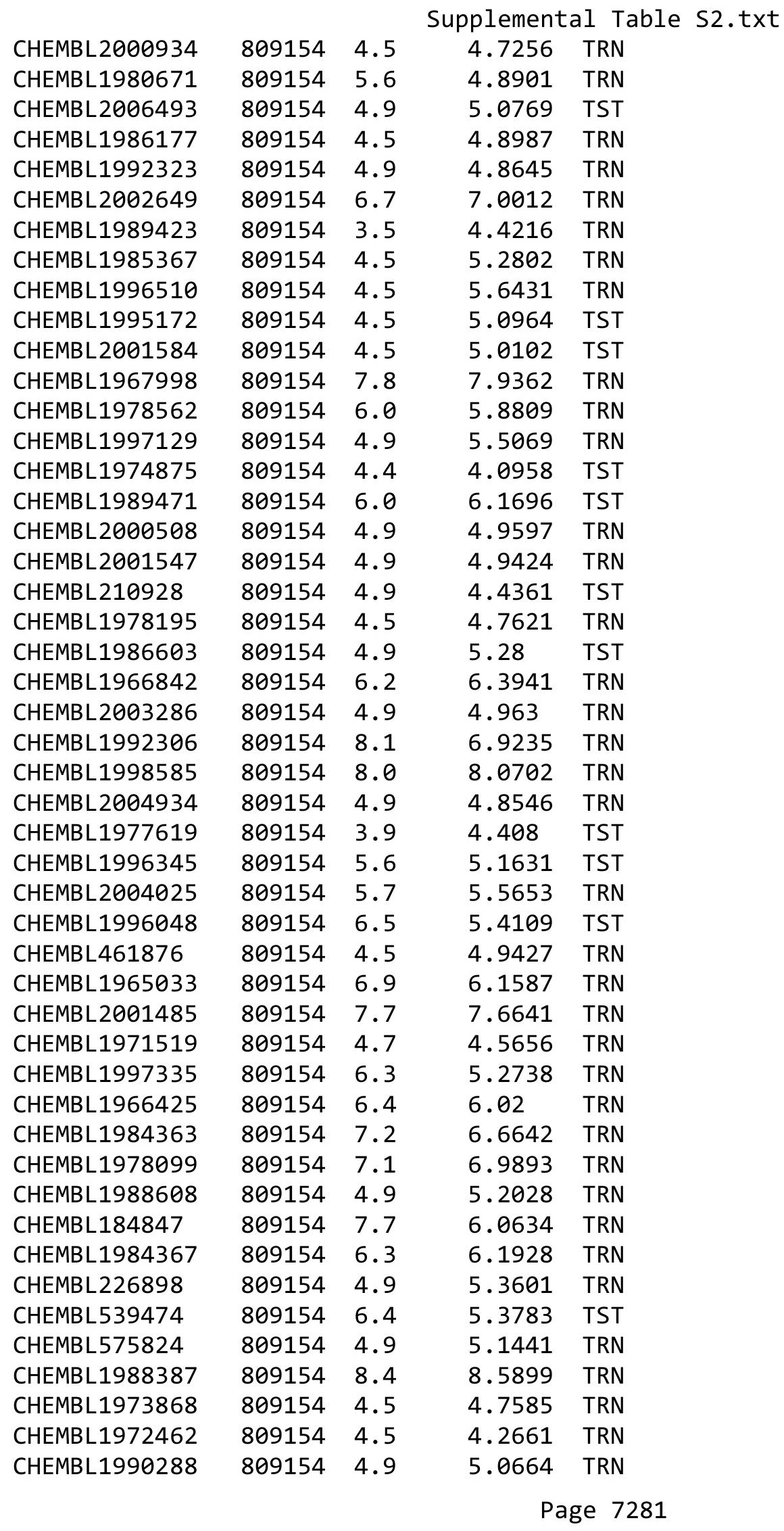




\begin{tabular}{|c|c|c|c|c|}
\hline & & & oplement & 0 \\
\hline CHEMBL1958401 & 809154 & 4.9 & 4.8041 & TRN \\
\hline CHEMBL 2003456 & 809154 & 6.0 & 4.8392 & TRN \\
\hline CHEMBL1966816 & 809154 & 4.9 & 5.1556 & TRN \\
\hline CHEMBL1972584 & 809154 & 6.5 & 6.9855 & TRN \\
\hline CHEMBL 2002992 & 809154 & 4.6 & 4.3723 & TRN \\
\hline CHEMBL560813 & 809154 & 6.6 & 5.3269 & TRN \\
\hline CHEMBL1982700 & 809154 & 4.5 & 4.9004 & TST \\
\hline CHEMBL1968791 & 809154 & 6.5 & 6.0214 & TRN \\
\hline CHEMBL1977634 & 809154 & 4.5 & 4.6732 & TRN \\
\hline CHEMBL1971186 & 809154 & 4.9 & 5.2102 & TRN \\
\hline CHEMBL 2003482 & 809154 & 4.9 & 4.9586 & TRN \\
\hline CHEMBL1976872 & 809154 & 3.9 & 4.2383 & TRN \\
\hline CHEMBL1969156 & 809154 & 4.7 & 4.503 & TRN \\
\hline CHEMBL1973211 & 809154 & 7.6 & 7.8496 & TRN \\
\hline CHEMBL1998953 & 809154 & 4.5 & 4.3195 & TRN \\
\hline CHEMBL1971606 & 809154 & 4.5 & 4.454 & TRN \\
\hline CHEMBL1972125 & 809154 & 4.9 & 4.5266 & TRN \\
\hline CHEMBL1999120 & 809154 & 4.5 & 4.1414 & TST \\
\hline CHEMBL1976134 & 809154 & 6.3 & 6.3206 & TRN \\
\hline CHEMBL1965131 & 809154 & 4.9 & 5.3108 & TRN \\
\hline CHEMBL1972158 & 809154 & 4.9 & 4.8492 & TRN \\
\hline CHEMBL1981215 & 809154 & 4.5 & 4.9843 & TRN \\
\hline CHEMBL1999414 & 809154 & 8.8 & 8.5603 & TRN \\
\hline CHEMBL1967336 & 809154 & 4.5 & 4.7173 & TRN \\
\hline CHEMBL2001228 & 809154 & 6.0 & 6.3423 & TRN \\
\hline CHEMBL1994056 & 809154 & 4.1 & 5.182 & TST \\
\hline CHEMBL1970340 & 809154 & 6.1 & 4.6432 & TRN \\
\hline CHEMBL1967992 & 809154 & 4.5 & 4.5578 & TRN \\
\hline CHEMBL 2005186 & 809154 & 4.9 & 4.9898 & TRN \\
\hline CHEMBL 2006450 & 809154 & 4.5 & 4.1143 & TRN \\
\hline CHEMBL1975534 & 809154 & 4.9 & 4.7426 & TRN \\
\hline CHEMBL1993424 & 809154 & 6.8 & 7.6803 & TRN \\
\hline CHEMBL1966703 & 809154 & 4.9 & 4.8462 & TST \\
\hline CHEMBL 2001987 & 809154 & 4.5 & 4.7595 & TRN \\
\hline CHEMBL1994555 & 809154 & 5.9 & 5.5105 & TRN \\
\hline CHEMBL1975121 & 809154 & 4.5 & 4.6972 & TRN \\
\hline CHEMBL1983640 & 809154 & 7.8 & 7.9351 & TRN \\
\hline CHEMBL1997023 & 809154 & 4.9 & 4.9339 & TST \\
\hline CHEMBL1964687 & 809154 & 6.9 & 6.8486 & TRN \\
\hline CHEMBL1971943 & 809154 & 4.6 & 4.6242 & TRN \\
\hline CHEMBL1997924 & 809154 & 8.1 & 8.0847 & TRN \\
\hline CHEMBL1988537 & 809154 & 4.9 & 5.397 & TST \\
\hline CHEMBL1969049 & 809154 & 4.9 & 4.7799 & TRN \\
\hline CHEMBL 2005828 & 809154 & 7.6 & 6.8875 & TRN \\
\hline CHEMBL1971485 & 809154 & 6.2 & 6.5555 & TRN \\
\hline CHEMBL1978267 & 809154 & 4.5 & 6.2227 & TRN \\
\hline CHEMBL1998611 & 809154 & 4.9 & 4.9707 & TRN \\
\hline CHEMBL1975900 & 809154 & 4.9 & 5.1173 & TRN \\
\hline
\end{tabular}




\begin{tabular}{|c|c|c|c|c|}
\hline \multicolumn{5}{|c|}{ Supplemental Table S2.txt } \\
\hline CHEMBL255822 & 809154 & 4.9 & 5.0273 & TRN \\
\hline CHEMBL1972221 & 809154 & 4.9 & 4.7968 & TRN \\
\hline CHEMBL378627 & 809154 & 4.9 & 4.6071 & TST \\
\hline CHEMBL1996979 & 809154 & 4.9 & 5.8593 & TRN \\
\hline CHEMBL1968406 & 809154 & 7.7 & 7.5996 & TRN \\
\hline CHEMBL1975921 & 809154 & 4.5 & 4.5968 & TRN \\
\hline CHEMBL1998545 & 809154 & 4.9 & 4.6916 & TRN \\
\hline CHEMBL1986869 & 809154 & 4.9 & 4.7119 & TRN \\
\hline CHEMBL1975923 & 809154 & 4.8 & 5.4078 & TST \\
\hline CHEMBL 2005449 & 809154 & 6.7 & 6.9472 & TRN \\
\hline CHEMBL1987998 & 809154 & 4.5 & 4.3364 & TRN \\
\hline CHEMBL1682558 & 809154 & 4.9 & 5.1254 & TRN \\
\hline CHEMBL1971534 & 809154 & 4.2 & 4.5486 & TRN \\
\hline CHEMBL1990496 & 809154 & 4.6 & 4.9641 & TRN \\
\hline CHEMBL 242865 & 809154 & 5.9 & 5.7918 & TRN \\
\hline CHEMBL 2002479 & 809154 & 7.0 & 5.9086 & TRN \\
\hline CHEMBL 2002480 & 809154 & 4.6 & 4.7259 & TRN \\
\hline CHEMBL1967094 & 809154 & 6.6 & 6.1884 & TRN \\
\hline CHEMBL1982992 & 809154 & 6.7 & 5.3327 & TRN \\
\hline CHEMBL1998110 & 809154 & 4.5 & 4.6365 & TRN \\
\hline CHEMBL1999590 & 809154 & 4.9 & 5.6664 & TST \\
\hline CHEMBL1981079 & 809154 & 4.9 & 4.7168 & TRN \\
\hline CHEMBL1978166 & 809154 & 7.5 & 7.8766 & TRN \\
\hline CHEMBL1980489 & 809154 & 4.9 & 5.0125 & TRN \\
\hline CHEMBL 2000832 & 809154 & 4.9 & 5.529 & TRN \\
\hline CHEMBL1990590 & 809154 & 4.5 & 5.0154 & TRN \\
\hline CHEMBL1977814 & 809154 & 5.6 & 4.8818 & TST \\
\hline CHEMBL1974617 & 809154 & 4.3 & 4.9884 & TRN \\
\hline CHEMBL1970709 & 809154 & 4.9 & 4.8436 & TRN \\
\hline CHEMBL1965660 & 809154 & 4.9 & 5.1255 & TRN \\
\hline CHEMBL1992125 & 809154 & 5.8 & 6.1567 & TRN \\
\hline CHEMBL1998112 & 809154 & 6.7 & 5.9063 & TRN \\
\hline CHEMBL1969126 & 809154 & 4.9 & 5.1119 & TRN \\
\hline CHEMBL1980896 & 809154 & 4.9 & 6.2914 & TRN \\
\hline CHEMBL1970104 & 809154 & 7.3 & 7.5649 & TRN \\
\hline CHEMBL1991429 & 809154 & 7.7 & 8.2253 & TRN \\
\hline CHEMBL1967612 & 809154 & 4.0 & 4.6896 & TRN \\
\hline CHEMBL1971149 & 809154 & 4.9 & 4.7426 & TRN \\
\hline CHEMBL1999714 & 809154 & 4.9 & 4.4975 & TRN \\
\hline CHEMBL1994040 & 809154 & 4.9 & 4.9614 & TRN \\
\hline CHEMBL388978 & 809154 & 8.6 & 10.0968 & TST \\
\hline CHEMBL579246 & 809154 & 4.9 & 4.8879 & TRN \\
\hline CHEMBL398951 & 809154 & 6.4 & 5.9215 & TRN \\
\hline CHEMBL1982506 & 809154 & 4.9 & 5.6845 & TST \\
\hline CHEMBL 2004716 & 809154 & 8.3 & 8.5635 & TRN \\
\hline CHEMBL1968127 & 809154 & 4.9 & 5.1604 & TRN \\
\hline CHEMBL1975233 & 809154 & 6.5 & 5.3296 & TRN \\
\hline CHEMBL1985406 & 809154 & 4.9 & 4.9978 & TRN \\
\hline
\end{tabular}




\begin{tabular}{|c|c|c|c|c|c|}
\hline \multicolumn{6}{|c|}{ Supplemental Table S2.txt } \\
\hline CHEMBL 2007603 & 809154 & 4.5 & 4.7256 & TRN & \\
\hline CHEMBL207400 & 809154 & 4.9 & 4.957 & TST & \\
\hline CHEMBL1421720 & 809154 & 5.5 & 5.4579 & TRN & \\
\hline CHEMBL1968130 & 809154 & 5.0 & 4.3226 & TRN & \\
\hline CHEMBL1982135 & 809154 & 4.9 & 6.0851 & TRN & \\
\hline CHEMBL1976090 & 809154 & 6.1 & 4.7988 & TRN & \\
\hline CHEMBL1993243 & 809154 & 7.7 & 8.2725 & TRN & \\
\hline CHEMBL 2004771 & 809154 & 6.5 & 6.0896 & TRN & \\
\hline CHEMBL1997597 & 809154 & 4.9 & 4.6171 & TRN & \\
\hline CHEMBL1969537 & 809154 & 4.9 & 6.1073 & TST & \\
\hline CHEMBL1976093 & 809154 & 4.9 & 4.9028 & TRN & \\
\hline CHEMBL508928 & 809154 & 8.0 & 8.1135 & TRN & \\
\hline CHEMBL 2004892 & 809154 & 4.9 & 4.76399 & 9999999999 & TRN \\
\hline CHEMBL1949855 & 809154 & 5.3 & 4.3394 & TRN & \\
\hline CHEMBL116070 & 809154 & 4.9 & 4.8091 & TRN & \\
\hline CHEMBL1970314 & 809154 & 4.9 & 4.5057 & TRN & \\
\hline CHEMBL 2004872 & 809154 & 4.9 & 4.8523 & TRN & \\
\hline CHEMBL1727312 & 809154 & 4.1 & 4.1992 & TRN & \\
\hline CHEMBL1990223 & 809154 & 4.5 & 4.4828 & TRN & \\
\hline CHEMBL1969879 & 809154 & 4.9 & 4.728 & TRN & \\
\hline CHEMBL1964382 & 809154 & 7.8 & 5.3475 & TST & \\
\hline CHEMBL101311 & 809154 & 4.5 & 5.7766 & TRN & \\
\hline CHEMBL262433 & 809154 & 7.4 & 7.6473 & TRN & \\
\hline CHEMBL 306380 & 809154 & 8.0 & 7.4668 & TRN & \\
\hline CHEMBL1966722 & 809154 & 4.9 & 4.5706 & TRN & \\
\hline CHEMBL1988581 & 809154 & 7.3 & 7.0187 & TST & \\
\hline CHEMBL 2005699 & 809154 & 4.5 & 4.6837 & TRN & \\
\hline CHEMBL1975500 & 809154 & 4.9 & 5.4978 & TRN & \\
\hline CHEMBL394619 & 809154 & 7.3 & 7.1119 & TRN & \\
\hline CHEMBL 2006564 & 809154 & 8.1 & 7.5391 & TRN & \\
\hline CHEMBL1996831 & 809154 & 4.9 & 5.0604 & TST & \\
\hline CHEMBL1978167 & 809154 & 6.1 & 5.4743 & TRN & \\
\hline CHEMBL418203 & 809154 & 4.7 & 4.98600 & 0000000001 & TST \\
\hline CHEMBL1989646 & 809154 & 4.9 & 5.0235 & TRN & \\
\hline CHEMBL 225519 & 809154 & 4.6 & 4.4188 & TRN & \\
\hline CHEMBL1978200 & 809154 & 4.9 & 4.9426 & TRN & \\
\hline CHEMBL1994159 & 809154 & 4.2 & 4.6836 & TRN & \\
\hline CHEMBL1970522 & 809154 & 4.9 & 5.2598 & TRN & \\
\hline CHEMBL1964692 & 809154 & 9.2 & 8.6725 & TRN & \\
\hline CHEMBL1996931 & 809154 & 4.9 & 4.7664 & TRN & \\
\hline CHEMBL1964413 & 809154 & 4.9 & 5.0671 & TRN & \\
\hline CHEMBL1973483 & 809154 & 4.9 & 5.5434 & TRN & \\
\hline CHEMBL1992354 & 809154 & 5.8 & 5.8462 & TRN & \\
\hline CHEMBL1998470 & 809154 & 4.5 & 4.2358 & TRN & \\
\hline CHEMBL1975903 & 809154 & 4.5 & 5.3567 & TRN & \\
\hline CHEMBL1997340 & 809154 & 4.9 & 4.9615 & TRN & \\
\hline CHEMBL1522508 & 809154 & 3.7 & 4.3038 & TRN & \\
\hline CHEMBL1989474 & 809154 & 4.9 & 5.0337 & TRN & \\
\hline
\end{tabular}




\begin{tabular}{|c|c|c|c|c|c|}
\hline \multirow{2}{*}{ CHEMBL1090360 } & \multirow{2}{*}{809154} & \multirow{2}{*}{7.7} & \multirow{2}{*}{7.9307} & \multirow{2}{*}{\multicolumn{2}{|c|}{ TRN }} \\
\hline & & & & & \\
\hline CHEMBL210887 & 809154 & 4.9 & 4.9861 & \multicolumn{2}{|l|}{ TRN } \\
\hline CHEMBL1988805 & 809154 & 4.5 & 4.6762 & \multicolumn{2}{|l|}{ TST } \\
\hline CHEMBL458997 & 809154 & 6.4 & 6.3723 & \multicolumn{2}{|l|}{ TRN } \\
\hline CHEMBL1971021 & 809154 & 4.9 & 5.9833 & \multicolumn{2}{|l|}{ TRN } \\
\hline CHEMBL227271 & 809154 & 4.9 & 5.4271 & \multicolumn{2}{|l|}{ TRN } \\
\hline CHEMBL583144 & 809154 & 5.9 & 4.5867 & \multicolumn{2}{|l|}{ TRN } \\
\hline CHEMBL1974310 & 809154 & 4.9 & 4.9865 & \multicolumn{2}{|l|}{ TRN } \\
\hline CHEMBL1969942 & 809154 & 4.5 & 4.9358 & \multicolumn{2}{|l|}{ TRN } \\
\hline CHEMBL1978567 & 809154 & 4.5 & 4.6365 & \multicolumn{2}{|l|}{ TRN } \\
\hline CHEMBL1982660 & 809154 & 7.0 & 6.0925 & \multicolumn{2}{|l|}{ TRN } \\
\hline CHEMBL1994693 & 809154 & 7.0 & 6.6827 & \multicolumn{2}{|l|}{ TRN } \\
\hline CHEMBL1982957 & 809154 & 4.9 & 5.8027 & \multicolumn{2}{|l|}{ TRN } \\
\hline CHEMBL1725279 & 809154 & 7.2 & 6.3261 & \multicolumn{2}{|l|}{ TST } \\
\hline CHEMBL1975138 & 809154 & 4.9 & 4.5466 & \multicolumn{2}{|l|}{ TRN } \\
\hline CHEMBL 2002346 & 809154 & 6.5 & 5.8286 & \multicolumn{2}{|l|}{ TRN } \\
\hline CHEMBL424872 & 809154 & 4.5 & 4.3952 & \multicolumn{2}{|l|}{ TST } \\
\hline CHEMBL412142 & 809154 & 4.9 & 5.0638 & TST & \\
\hline CHEMBL1980704 & 809154 & 4.9 & 5.0457 & TST & \\
\hline CHEMBL2003271 & 809154 & 4.9 & 5.0469 & TRN & \\
\hline CHEMBL1972365 & 809154 & 5.2 & 5.4833 & TRN & \\
\hline CHEMBL1966808 & 809154 & 4.9 & 5.0439 & TRN & \\
\hline CHEMBL 2004447 & 809154 & 4.9 & 4.7514 & TST & \\
\hline CHEMBL1983111 & 809154 & 8.5 & 7.86 & TRN & \\
\hline CHEMBL1973860 & 809154 & 4.9 & 5.0419 & TRN & \\
\hline CHEMBL 260135 & 809154 & 4.9 & 4.7334 & TRN & \\
\hline CHEMBL220241 & 809154 & 4.9 & 5.239 & TRN & \\
\hline CHEMBL1988141 & 809154 & 6.9 & 6.2113 & TST & \\
\hline CHEMBL1982610 & 809154 & 4.9 & 5.2462 & TST & \\
\hline CHEMBL1977134 & 809154 & 8.4 & 8.3344 & TRN & \\
\hline CHEMBL1985206 & 809154 & 6.0 & 5.325 & TRN & \\
\hline CHEMBL1988300 & 809154 & 7.3 & 7.6377 & TRN & \\
\hline CHEMBL1991078 & 809154 & 6.9 & 7.1232 & TRN & \\
\hline CHEMBL1987359 & 809154 & 4.9 & 4.9409 & TST & \\
\hline CHEMBL1977749 & 809154 & 5.8 & 5.1408 & TST & \\
\hline CHEMBL1975212 & 809154 & 5.5 & 4.8075 & TRN & \\
\hline CHEMBL2001613 & 809154 & 4.6 & 4.4445 & TRN & \\
\hline CHEMBL1997275 & 809154 & 5.6 & 5.7743 & TRN & \\
\hline CHEMBL1993904 & 809154 & 5.6 & 5.62700 & 2000000001 & TRN \\
\hline CHEMBL1967513 & 809154 & 4.5 & 4.6615 & TRN & \\
\hline CHEMBL 2000724 & 809154 & 4.5 & 4.8619 & TRN & \\
\hline CHEMBL1982413 & 809154 & 6.1 & 5.2537 & TRN & \\
\hline CHEMBL1969502 & 809154 & 8.0 & 6.78700 & 0000000001 & TST \\
\hline CHEMBL1682553 & 809154 & 4.9 & 5.1239 & TRN & \\
\hline CHEMBL1983963 & 809154 & 7.8 & 7.46399 & 99999999995 & TRN \\
\hline CHEMBL1997764 & 809154 & 4.9 & 4.8154 & TRN & \\
\hline CHEMBL1981792 & 809154 & 6.0 & 4.9067 & TRN & \\
\hline CHEMBL1987535 & 809154 & 4.5 & 4.69300 & 00000000005 & TRN \\
\hline & & & & e 7285 & \\
\hline
\end{tabular}




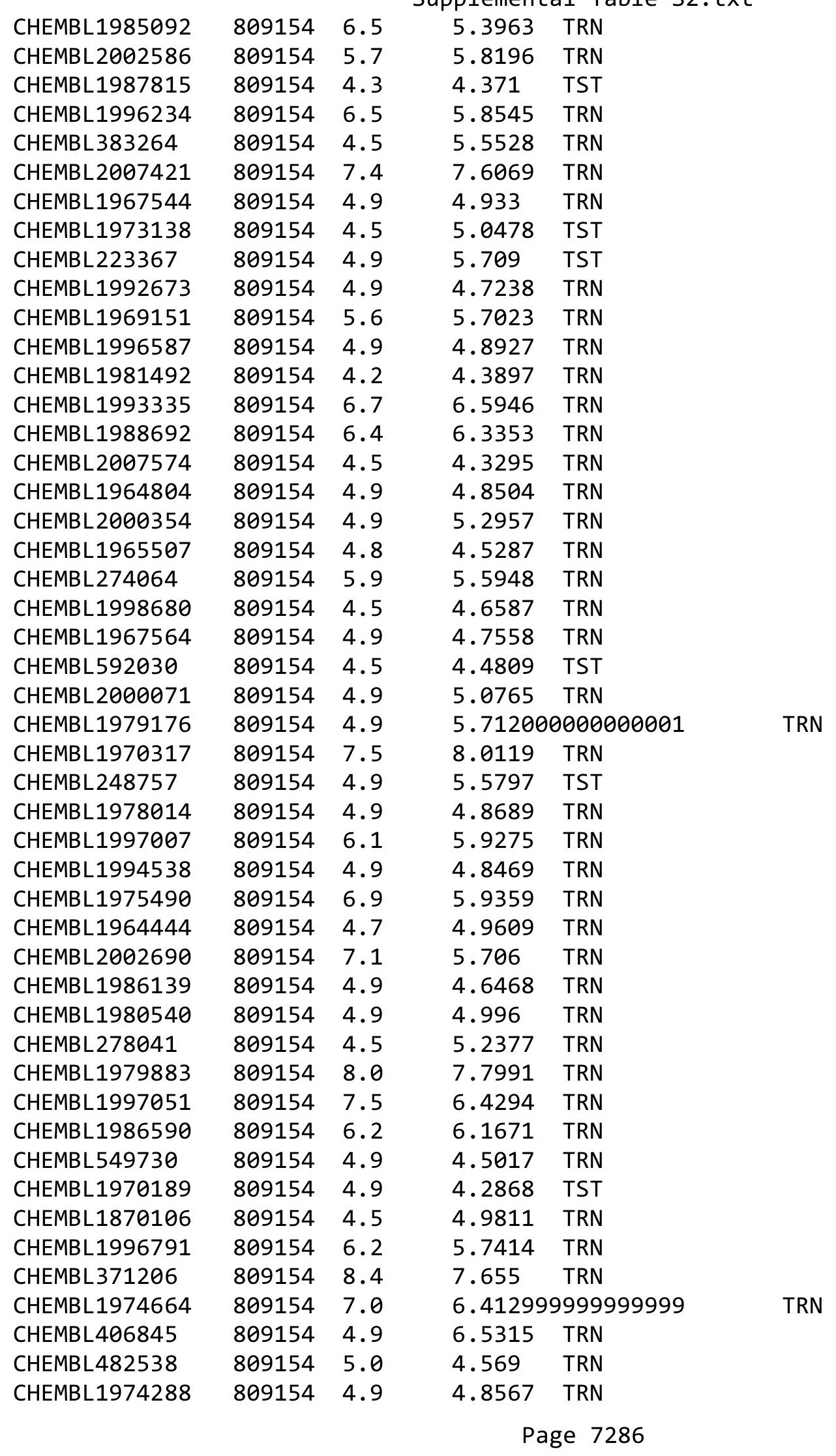




\begin{tabular}{|c|c|c|c|c|}
\hline \multicolumn{5}{|c|}{ emental T } \\
\hline CHEMBL1984296 & 809154 & 5.5 & 5.2245 & TST \\
\hline CHEMBL196363 & 809154 & 8.1 & 7.4039 & TRN \\
\hline CHEMBL1996837 & 809154 & 3.9 & 4.3743 & TRN \\
\hline CHEMBL1190711 & 809154 & 4.9 & 4.6311 & TRN \\
\hline CHEMBL1964718 & 809154 & 4.3 & 4.7988 & TST \\
\hline CHEMBL1968705 & 809154 & 4.6 & 5.0161 & TRN \\
\hline CHEMBL1964441 & 809154 & 7.6 & 7.5844 & TRN \\
\hline CHEMBL1991410 & 809154 & 4.5 & 4.3016 & TRN \\
\hline CHEMBL1986684 & 809154 & 4.1 & 4.3243 & TST \\
\hline CHEMBL546797 & 809154 & 5.6 & 5.4263 & TST \\
\hline CHEMBL404367 & 809154 & 6.4 & 6.8768 & TRN \\
\hline CHEMBL1966343 & 809154 & 5.9 & 5.1891 & TRN \\
\hline CHEMBL1978271 & 809154 & 5.9 & 5.1998 & TRN \\
\hline CHEMBL1967887 & 809154 & 4.9 & 4.793 & TRN \\
\hline CHEMBL 2007266 & 809154 & 6.3 & 6.1885 & TRN \\
\hline CHEMBL 2000568 & 809154 & 4.7 & 5.4691 & TRN \\
\hline CHEMBL 2000335 & 809154 & 8.6 & 7.9821 & TRN \\
\hline CHEMBL1994308 & 809154 & 4.5 & 4.8813 & TST \\
\hline CHEMBL 2007097 & 809154 & 4.6 & 4.3927 & TRN \\
\hline CHEMBL1974328 & 809154 & 7.1 & 5.9043 & TRN \\
\hline CHEMBL509032 & 809154 & 7.4 & 6.9796 & TRN \\
\hline CHEMBL1973808 & 809154 & 4.9 & 4.444 & TRN \\
\hline CHEMBL1992342 & 809154 & 4.9 & 4.8594 & TRN \\
\hline CHEMBL1988173 & 809154 & 4.9 & 4.7155 & TRN \\
\hline CHEMBL1973013 & 809154 & 6.2 & 6.2114 & TRN \\
\hline CHEMBL1164265 & 809154 & 6.0 & 5.8477 & TST \\
\hline CHEMBL1965423 & 809154 & 4.9 & 5.1401 & TRN \\
\hline CHEMBL1975927 & 809154 & 6.5 & 6.7936 & TRN \\
\hline CHEMBL205415 & 809154 & 4.7 & 4.3946 & TRN \\
\hline CHEMBL 2001920 & 809154 & 4.9 & 4.8924 & TRN \\
\hline CHEMBL1977138 & 809154 & 6.4 & 6.5032 & TST \\
\hline CHEMBL1241473 & 809154 & 7.6 & 7.8562 & TRN \\
\hline CHEMBL 2000879 & 809154 & 4.4 & 4.7541 & TST \\
\hline CHEMBL1978448 & 809154 & 4.8 & 4.8971 & TST \\
\hline CHEMBL1969483 & 809154 & 4.5 & 6.3583 & TRN \\
\hline CHEMBL2001257 & 809154 & 7.0 & 7.1461 & TRN \\
\hline CHEMBL 2004515 & 809154 & 5.6 & 5.7137 & TRN \\
\hline CHEMBL1980329 & 809154 & 8.1 & 8.2783 & TRN \\
\hline CHEMBL1992042 & 809154 & 4.5 & 5.0979 & TST \\
\hline CHEMBL1992536 & 809154 & 4.9 & 4.8132 & TRN \\
\hline CHEMBL21156 & 809154 & 6.7 & 5.655 & TST \\
\hline CHEMBL1992740 & 809154 & 4.9 & 4.8403 & TRN \\
\hline CHEMBL1994724 & 809154 & 4.5 & 4.837 & TRN \\
\hline CHEMBL1989267 & 809154 & 5.6 & 7.7064 & TRN \\
\hline CHEMBL439340 & 809154 & 4.9 & 4.3297 & TRN \\
\hline CHEMBL 2006188 & 809154 & 4.9 & 5.0169 & TRN \\
\hline CHEMBL1970290 & 809154 & 6.3 & 6.5766 & TRN \\
\hline CHEMBL1967531 & 809154 & 7.1 & 6.6755 & TRN \\
\hline
\end{tabular}




\begin{tabular}{|c|c|c|c|c|}
\hline & & & plem & \\
\hline CHEMBL1970913 & 809154 & 4.9 & 4.8527 & TRN \\
\hline CHEMBL1973893 & 809154 & 4.9 & 4.8339 & TRN \\
\hline CHEMBL1997534 & 809154 & 4.9 & 5.0753 & TRN \\
\hline CHEMBL1993877 & 809154 & 6.9 & 6.2565 & TRN \\
\hline CHEMBL1996500 & 809154 & 4.6 & 4.7851 & TRN \\
\hline CHEMBL1973363 & 809154 & 5.7 & 5.0465 & TRN \\
\hline CHEMBL1989708 & 809154 & 8.8 & 8.2711 & TRN \\
\hline CHEMBL1682540 & 809154 & 4.9 & 5.0468 & TRN \\
\hline CHEMBL1976420 & 809154 & 6.5 & 6.1046 & TRN \\
\hline CHEMBL1981744 & 809154 & 5.7 & 4.8174 & TRN \\
\hline CHEMBL1994864 & 809154 & 4.9 & 4.9016 & TRN \\
\hline CHEMBL497151 & 809154 & 4.9 & 5.3458 & TRN \\
\hline CHEMBL 2000029 & 809154 & 4.5 & 4.6665 & TRN \\
\hline CHEMBL1973961 & 809154 & 4.5 & 5.2991 & TRN \\
\hline CHEMBL 246970 & 809154 & 4.9 & 5.0802 & TRN \\
\hline CHEMBL340921 & 809154 & 4.9 & 4.7938 & TST \\
\hline CHEMBL1994977 & 809154 & 4.5 & 4.9483 & TRN \\
\hline CHEMBL1999718 & 809154 & 4.9 & 5.0614 & TRN \\
\hline CHEMBL 2001149 & 809154 & 4.5 & 5.0734 & TRN \\
\hline CHEMBL 2000078 & 809154 & 6.9 & 6.9219 & TRN \\
\hline CHEMBL 2005478 & 809154 & 6.4 & 6.0164 & TRN \\
\hline CHEMBL1276446 & 809154 & 7.9 & 7.7822 & TST \\
\hline CHEMBL1996646 & 809154 & 8.1 & 7.7406 & TRN \\
\hline CHEMBL1979773 & 809154 & 5.8 & 5.5346 & TRN \\
\hline CHEMBL1977346 & 809154 & 6.1 & 6.0035 & TRN \\
\hline CHEMBL1971649 & 809154 & 4.9 & 6.35 & TRN \\
\hline CHEMBL 2005482 & 809154 & 7.9 & 7.4272 & TRN \\
\hline CHEMBL1996702 & 809154 & 6.2 & 5.8482 & TRN \\
\hline CHEMBL1997909 & 809154 & 6.7 & 6.5023 & TRN \\
\hline CHEMBL 2007124 & 809154 & 6.5 & 6.2359 & TRN \\
\hline CHEMBL 2006439 & 809154 & 4.7 & 5.4839 & TRN \\
\hline CHEMBL1985681 & 809154 & 6.6 & 6.1285 & TST \\
\hline CHEMBL1969190 & 809154 & 7.1 & 7.5249 & TRN \\
\hline CHEMBL1973937 & 809154 & 7.0 & 7.2774 & TRN \\
\hline CHEMBL1991674 & 809154 & 4.6 & 5.5242 & TRN \\
\hline CHEMBL1982711 & 809154 & 4.6 & 4.5269 & TRN \\
\hline CHEMBL262623 & 809154 & 4.9 & 4.6704 & TRN \\
\hline CHEMBL1984842 & 809154 & 4.5 & 4.8788 & TRN \\
\hline CHEMBL 2004118 & 809154 & 6.3 & 6.2376 & TRN \\
\hline CHEMBL 2007044 & 809154 & 4.9 & 5.6652 & TRN \\
\hline CHEMBL1994241 & 809154 & 4.9 & 5.7521 & TST \\
\hline CHEMBL223460 & 809154 & 4.9 & 5.6773 & TST \\
\hline CHEMBL50894 & 809154 & 4.7 & 5.4293 & TST \\
\hline CHEMBL1995211 & 809154 & 4.5 & 4.5753 & TRN \\
\hline CHEMBL1988838 & 809154 & 7.1 & 7.303 & TRN \\
\hline CHEMBL1981725 & 809154 & 8.2 & 8.0999 & TRN \\
\hline CHEMBL1982753 & 809154 & 4.7 & 5.1261 & TRN \\
\hline CHEMBL 2006299 & 809154 & 4.5 & 4.7181 & TRN \\
\hline
\end{tabular}




\begin{tabular}{|c|c|c|c|c|c|}
\hline \\
\hline CHEMBL1972346 & 809154 & 6.4 & 5.4533 & TST & \\
\hline CHEMBL1965169 & 809154 & 5.6 & 5.2261 & TRN & \\
\hline CHEMBL1991818 & 809154 & 5.6 & 4.8974 & TST & \\
\hline CHEMBL1081312 & 809154 & 8.9 & 7.5264 & TRN & \\
\hline CHEMBL1965170 & 809154 & 9.0 & 8.8369 & TRN & \\
\hline CHEMBL1982866 & 809154 & 4.9 & 5.126 & TRN & \\
\hline CHEMBL2005792 & 809154 & 4.5 & 4.9341 & TRN & \\
\hline CHEMBL1965570 & 809154 & 7.6 & 8.2232 & TRN & \\
\hline CHEMBL2007592 & 809154 & 4.9 & 4.9847 & TRN & \\
\hline CHEMBL1972355 & 809154 & 5.9 & 6.1041 & TST & \\
\hline CHEMBL1997892 & 809154 & 8.5 & 6.7382 & TRN & \\
\hline CHEMBL2001641 & 809154 & 4.6 & 4.5013 & TRN & \\
\hline CHEMBL1997193 & 809154 & 6.1 & 6.1358 & TST & \\
\hline CHEMBL210963 & 809154 & 4.9 & 4.5253 & TST & \\
\hline CHEMBL1964902 & 809154 & 4.5 & 4.6852 & TRN & \\
\hline CHEMBL1082440 & 809154 & 4.9 & 5.6143 & TST & \\
\hline CHEMBL1614705 & 809154 & 4.9 & 4.9649 & TRN & \\
\hline CHEMBL1984633 & 809154 & 4.9 & 4.853 & TRN & \\
\hline CHEMBL1965845 & 809154 & 6.1 & 5.6837 & TRN & \\
\hline CHEMBL1983715 & 809154 & 6.9 & 7.1698 & TRN & \\
\hline CHEMBL2006715 & 809154 & 8.0 & 7.8607 & TRN & \\
\hline CHEMBL1986597 & 809154 & 4.9 & 5.0927 & TRN & \\
\hline CHEMBL1990482 & 809154 & 4.9 & 4.5303 & TRN & \\
\hline CHEMBL1990904 & 809154 & 4.9 & 5.02800 & 00000000005 & TRN \\
\hline CHEMBL2005475 & 809154 & 6.8 & 6.4897 & TRN & \\
\hline CHEMBL402846 & 809154 & 6.3 & 7.0818 & TRN & \\
\hline CHEMBL183844 & 809154 & 7.9 & 7.3664 & TRN & \\
\hline CHEMBL220057 & 809154 & 7.0 & 7.1116 & TRN & \\
\hline CHEMBL1682545 & 809154 & 4.9 & 4.7263 & TRN & \\
\hline CHEMBL383541 & 809154 & 4.9 & 4.5034 & TRN & \\
\hline CHEMBL2001224 & 809154 & 4.9 & 5.3818 & TRN & \\
\hline CHEMBL10 & 809154 & 4.5 & 4.8709 & TRN & \\
\hline CHEMBL1976732 & 809154 & 4.9 & 4.53600 & 00000000005 & TRN \\
\hline CHEMBL1969506 & 809154 & 4.9 & 4.7266 & TRN & \\
\hline CHEMBL1964937 & 809154 & 4.9 & 4.8683 & TRN & \\
\hline CHEMBL1980763 & 809154 & 6.9 & 6.3187 & TRN & \\
\hline CHEMBL1980163 & 809154 & 4.9 & 4.7127 & TRN & \\
\hline CHEMBL1977931 & 809154 & 4.4 & 4.4214 & TRN & \\
\hline CHEMBL2005899 & 809154 & 4.9 & 5.1074 & TRN & \\
\hline CHEMBL1682552 & 809154 & 4.9 & 5.2019 & TRN & \\
\hline CHEMBL 2007479 & 809154 & 4.5 & 4.2838 & TRN & \\
\hline CHEMBL1986851 & 809154 & 9.0 & 8.8093 & TRN & \\
\hline CHEMBL229799 & 809154 & 6.0 & 5.6012 & TRN & \\
\hline CHEMBL105739 & 809154 & 7.5 & 7.6062 & TRN & \\
\hline CHEMBL1972220 & 809154 & 9.2 & 9.1183 & TRN & \\
\hline CHEMBL 379300 & 809154 & 4.9 & 5.3645 & TRN & \\
\hline CHEMBL1973720 & 809154 & 5.7 & 5.7225 & TRN & \\
\hline CHEMBL1987003 & 809154 & 4.0 & 4.6874 & TRN & \\
\hline
\end{tabular}




\begin{tabular}{|c|c|c|c|c|}
\hline & & & plem & \\
\hline CHEMBL 2003785 & 809154 & 4.9 & 4.7643 & TRN \\
\hline CHEMBL1969523 & 809154 & 6.6 & 5.7324 & TRN \\
\hline CHEMBL 2001923 & 809154 & 4.5 & 4.8605 & TST \\
\hline CHEMBL1986781 & 809154 & 4.9 & 4.9509 & TRN \\
\hline CHEMBL1983070 & 809154 & 7.2 & 5.1585 & TRN \\
\hline CHEMBL526133 & 809154 & 4.9 & 5.0616 & TRN \\
\hline CHEMBL 2003514 & 809154 & 4.5 & 4.5543 & TRN \\
\hline CHEMBL1989043 & 809154 & 4.5 & 4.4906 & TRN \\
\hline CHEMBL1979057 & 809154 & 4.9 & 5.4945 & TRN \\
\hline CHEMBL387971 & 809154 & 6.1 & 7.6519 & TST \\
\hline CHEMBL1968515 & 809154 & 4.3 & 4.7234 & TST \\
\hline CHEMBL1164180 & 809154 & 6.2 & 6.6404 & TST \\
\hline CHEMBL1997611 & 809154 & 4.5 & 4.7407 & TST \\
\hline CHEMBL1516890 & 809154 & 7.3 & 6.9376 & TRN \\
\hline CHEMBL211378 & 809154 & 6.0 & 6.7584 & TRN \\
\hline CHEMBL 2001751 & 809154 & 7.3 & 7.2115 & TRN \\
\hline CHEMBL 2003420 & 809154 & 6.0 & 4.7995 & TRN \\
\hline CHEMBL1984586 & 809154 & 5.9 & 6.3541 & TRN \\
\hline CHEMBL1972659 & 809154 & 4.9 & 5.1425 & TST \\
\hline CHEMBL 2002723 & 809154 & 5.8 & 5.3181 & TST \\
\hline CHEMBL 272453 & 809154 & 8.1 & 8.0691 & TRN \\
\hline CHEMBL1987143 & 809154 & 5.0 & 4.9376 & TRN \\
\hline CHEMBL1970217 & 809154 & 4.9 & 4.9687 & TRN \\
\hline CHEMBL 2005528 & 809154 & 4.9 & 5.1633 & TRN \\
\hline CHEMBL1984686 & 809154 & 4.5 & 4.7128 & TRN \\
\hline CHEMBL185569 & 809154 & 7.6 & 7.3361 & TRN \\
\hline CHEMBL1969843 & 809154 & 4.9 & 5.0893 & TRN \\
\hline CHEMBL 2007002 & 809154 & 4.9 & 4.9791 & TRN \\
\hline CHEMBL1987007 & 809154 & 4.9 & 6.1765 & TRN \\
\hline CHEMBL1973793 & 809154 & 4.5 & 5.0081 & TST \\
\hline CHEMBL1969588 & 809154 & 6.7 & 6.8537 & TRN \\
\hline CHEMBL1992073 & 809154 & 6.3 & 5.9296 & TRN \\
\hline CHEMBL1986143 & 809154 & 4.5 & 4.4549 & TRN \\
\hline CHEMBL1979252 & 809154 & 4.9 & 5.3402 & TRN \\
\hline CHEMBL1972934 & 809154 & 4.6 & 4.0504 & TRN \\
\hline CHEMBL 2007559 & 809154 & 4.5 & 5.2084 & TRN \\
\hline CHEMBL1992581 & 809154 & 6.7 & 6.0668 & TRN \\
\hline CHEMBL 2004290 & 809154 & 8.5 & 8.4852 & TRN \\
\hline CHEMBL1986499 & 809154 & 4.9 & 4.6696 & TRN \\
\hline CHEMBL1972937 & 809154 & 4.9 & 5.033 & TRN \\
\hline CHEMBL 2000393 & 809154 & 6.7 & 7.1382 & TST \\
\hline CHEMBL 2004311 & 809154 & 7.0 & 6.5521 & TRN \\
\hline CHEMBL1983573 & 809154 & 4.3 & 4.6223 & TRN \\
\hline CHEMBL1992634 & 809154 & 4.9 & 5.3863 & TRN \\
\hline CHEMBL1242373 & 809154 & 7.3 & 7.3443 & TRN \\
\hline CHEMBL1984847 & 809154 & 7.7 & 5.1401 & TST \\
\hline CHEMBL316264 & 809154 & 4.9 & 4.8604 & TRN \\
\hline CHEMBL1996576 & 809154 & 4.5 & 4.8226 & TST \\
\hline
\end{tabular}




\begin{tabular}{|c|c|c|c|c|c|}
\hline \\
\hline CHEMBL1988076 & 809154 & 7.2 & 6.4933 & TRN & \\
\hline CHEMBL1991678 & 809154 & 4.5 & 4.6886 & TRN & \\
\hline CHEMBL2001239 & 809154 & 4.9 & 5.2379 & TRN & \\
\hline CHEMBL2001288 & 809154 & 4.9 & 5.504 & TRN & \\
\hline CHEMBL1999811 & 809154 & 7.4 & 5.8894 & TRN & \\
\hline CHEMBL 235157 & 809154 & 4.5 & 4.7896 & TST & \\
\hline CHEMBL1985074 & 809154 & 4.9 & 5.1359 & TST & \\
\hline CHEMBL2000481 & 809154 & 6.0 & 5.0818 & TRN & \\
\hline CHEMBL1991725 & 809154 & 4.9 & 5.2394 & TRN & \\
\hline CHEMBL2007296 & 809154 & 4.9 & 4.6106 & TRN & \\
\hline CHEMBL396523 & 809154 & 7.2 & 6.6454 & TRN & \\
\hline CHEMBL2004159 & 809154 & 4.5 & 4.5423 & TRN & \\
\hline CHEMBL1978371 & 809154 & 4.5 & 5.269 & TST & \\
\hline CHEMBL1986530 & 809154 & 4.9 & 5.1806 & TST & \\
\hline CHEMBL440084 & 809154 & 4.5 & 4.8559 & TRN & \\
\hline CHEMBL1999321 & 809154 & 4.9 & 5.6789 & TRN & \\
\hline CHEMBL385478 & 809154 & 4.9 & 5.75 & TRN & \\
\hline CHEMBL1968590 & 809154 & 7.7 & 7.9755 & TRN & \\
\hline CHEMBL2005375 & 809154 & 4.9 & 5.0408 & TRN & \\
\hline CHEMBL1984191 & 809154 & 4.9 & 4.7348 & TRN & \\
\hline CHEMBL1971029 & 809154 & 7.7 & 7.5066 & TRN & \\
\hline CHEMBL 394790 & 809154 & 7.3 & 7.2779 & TRN & \\
\hline CHEMBL2001451 & 809154 & 6.0 & 5.574 & TRN & \\
\hline CHEMBL1974702 & 809154 & 4.9 & 5.0684 & TRN & \\
\hline CHEMBL1996111 & 809154 & 4.9 & 5.2224 & TRN & \\
\hline CHEMBL1966175 & 809154 & 5.6 & 5.5958 & TRN & \\
\hline CHEMBL1965589 & 809154 & 4.9 & 4.9274 & TRN & \\
\hline CHEMBL2007375 & 809154 & 4.5 & 4.7443 & TRN & \\
\hline CHEMBL1998193 & 809154 & 4.9 & 4.6417 & TRN & \\
\hline CHEMBL379975 & 809154 & 4.5 & 5.296 & TST & \\
\hline CHEMBL474432 & 809154 & 4.9 & 6.945 & TST & \\
\hline CHEMBL1966976 & 809154 & 4.0 & 5.2113 & TST & \\
\hline CHEMBL1965387 & 809154 & 4.5 & 5.6937 & TRN & \\
\hline CHEMBL2001539 & 809154 & 3.9 & 4.7332 & TST & \\
\hline CHEMBL1997041 & 809154 & 5.1 & 5.2547 & TRN & \\
\hline CHEMBL1988153 & 809154 & 4.9 & 5.4944 & TRN & \\
\hline CHEMBL550418 & 809154 & 4.5 & 4.6028 & TRN & \\
\hline CHEMBL1971289 & 809154 & 4.5 & 4.8755 & TRN & \\
\hline CHEMBL1988437 & 809154 & 6.8 & 7.0476 & TRN & \\
\hline CHEMBL1998121 & 809154 & 4.9 & 5.7935 & TRN & \\
\hline CHEMBL1233887 & 809154 & 4.5 & 5.062 & TRN & \\
\hline CHEMBL1992607 & 809154 & 4.5 & 4.7387 & TRN & \\
\hline CHEMBL1991800 & 809154 & 4.9 & 5.01399 & 9999999999 & TRN \\
\hline CHEMBL1979357 & 809154 & 4.9 & 5.0581 & TRN & \\
\hline CHEMBL1996649 & 809154 & 7.4 & 8.1635 & TRN & \\
\hline CHEMBL1996817 & 809154 & 4.9 & 5.3848 & TRN & \\
\hline CHEMBL1986756 & 809154 & 4.5 & 4.7967 & TRN & \\
\hline CHEMBL468280 & 809154 & 4.9 & 4.8531 & TST & \\
\hline
\end{tabular}




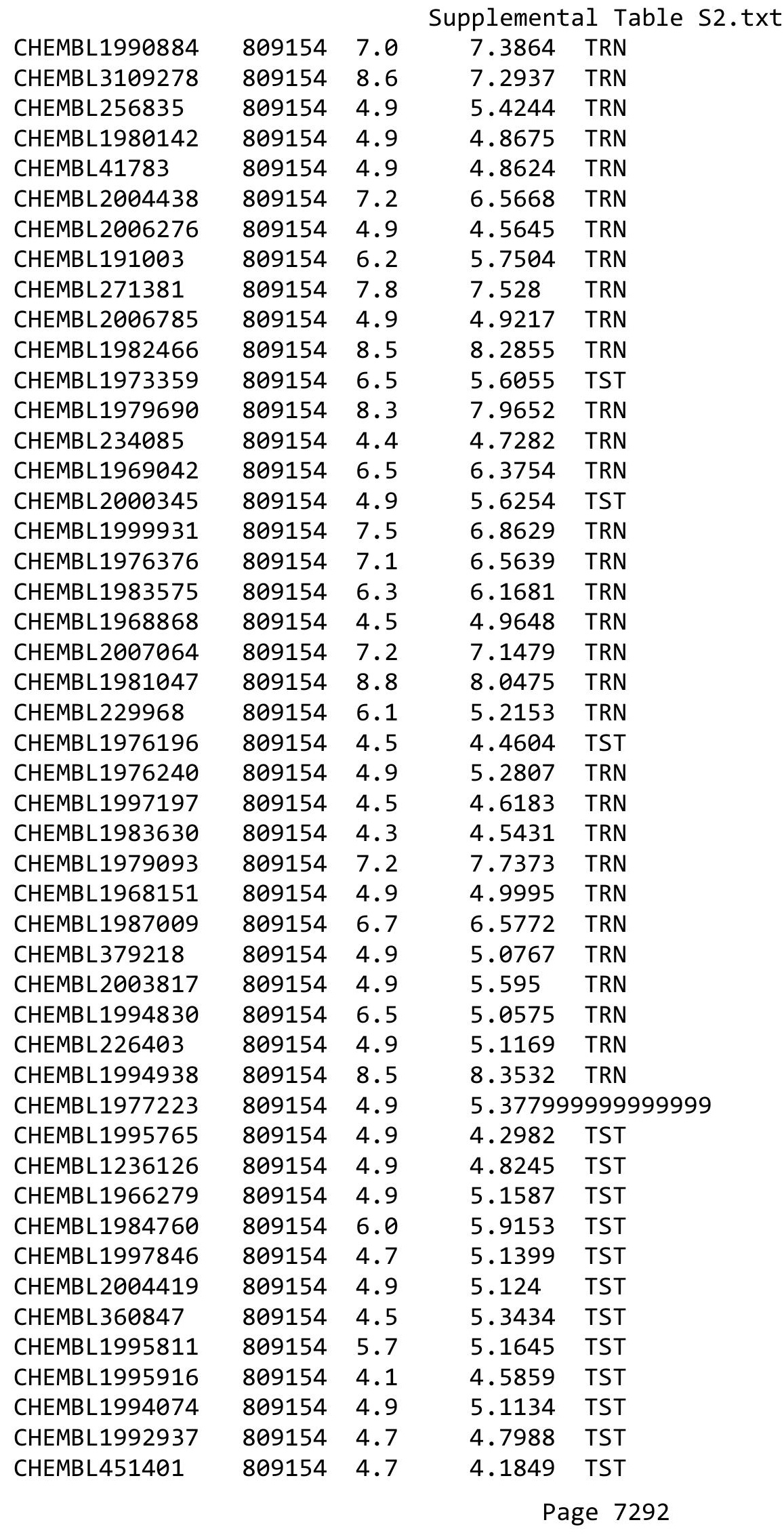




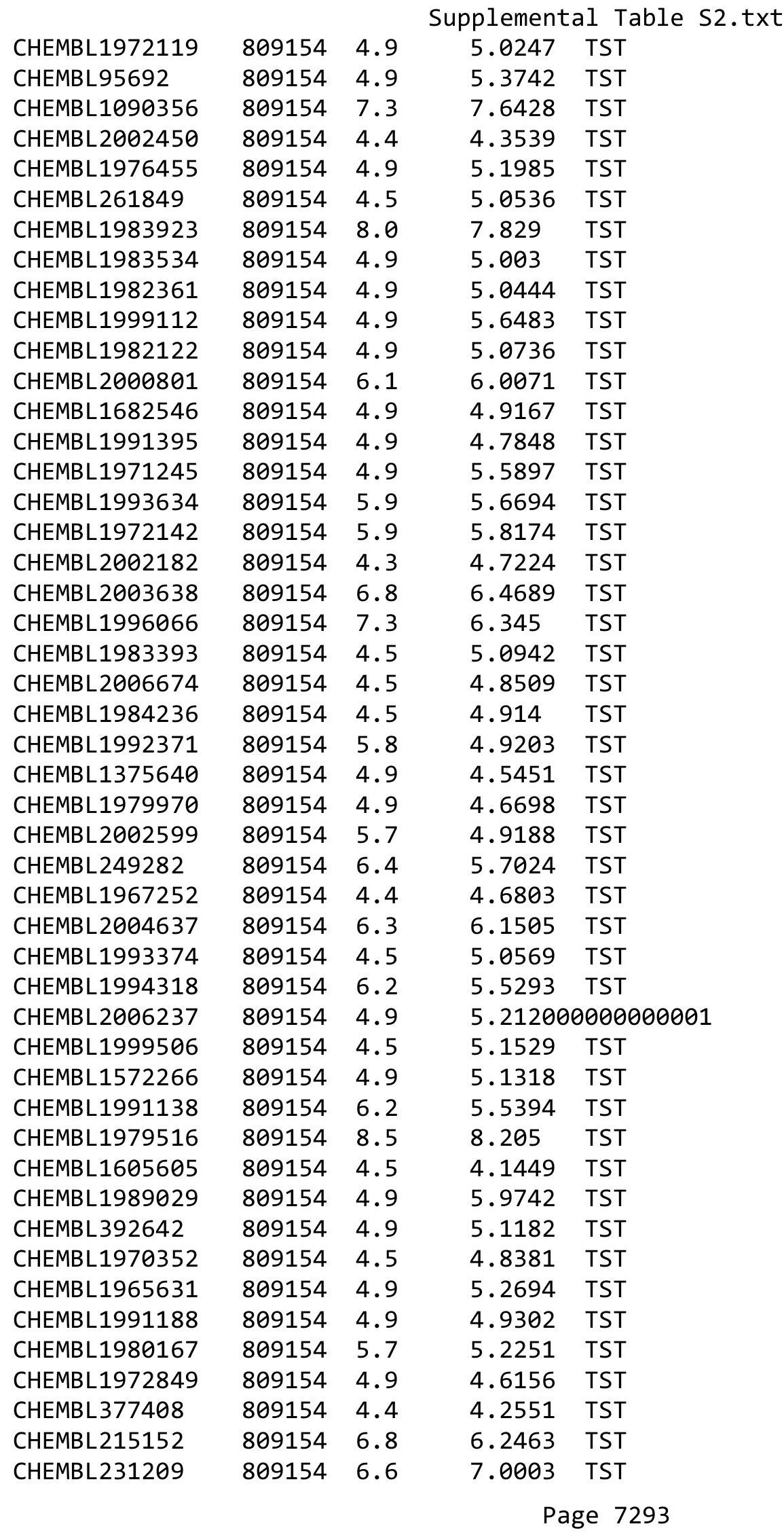




\begin{tabular}{|c|c|c|c|c|c|c|}
\hline \multicolumn{7}{|c|}{ Supplemental Table s2.txt } \\
\hline CHEMBL 2006765 & 809154 & 7.2 & 6.9527 & TST & & \\
\hline CHEMBL1976220 & 809154 & 8.0 & 7.6616 & TST & & \\
\hline CHEMBL259922 & 809154 & 4.9 & 5.1643 & TST & & \\
\hline CHEMBL1997617 & 809154 & 8.1 & 6.7741 & TST & & \\
\hline CHEMBL17370 & 809154 & 6.0 & 4.8929 & TST & & \\
\hline CHEMBL1987910 & 809154 & 4.9 & 6.5523 & TST & & \\
\hline CHEMBL1983932 & 809154 & 4.9 & 6.3822 & TST & & \\
\hline CHEMBL1980246 & 809154 & 4.5 & 4.6043 & TST & & \\
\hline CHEMBL1983980 & 809154 & 5.9 & 5.8724 & TST & & \\
\hline CHEMBL1999484 & 809154 & 7.1 & 6.9232 & TST & & \\
\hline CHEMBL1986899 & 809154 & 6.0 & 4.6965 & TST & & \\
\hline CHEMBL1991285 & 809154 & 7.2 & 5.8106 & TST & & \\
\hline CHEMBL243088 & 809154 & 7.2 & 6.5789 & TST & & \\
\hline CHEMBL1984038 & 809154 & 4.6 & 4.8995 & TST & & \\
\hline CHEMBL1993661 & 809154 & 8.4 & 7.8206 & TST & & \\
\hline CHEMBL1974416 & 809154 & 4.9 & 5.3182 & TST & & \\
\hline CHEMBL 291784 & 715421 & \multicolumn{3}{|c|}{5.462999999999999} & 5.2392 & TRN \\
\hline CHEMBL567053 & 715421 & \multicolumn{3}{|c|}{5.0969999999999995} & 5.5184 & TST \\
\hline CHEMBL56002 & 715421 & 4.699 & 5.3392 & TST & & \\
\hline CHEMBL576628 & 715421 & 5.46 & 5.8213 & TRN & & \\
\hline CHEMBL578410 & 715421 & 5.602 & 5.7648 & TRN & & \\
\hline CHEMBL577905 & 715421 & \multicolumn{3}{|c|}{5.5089999999999995} & 5.5839 & TRN \\
\hline CHEMBL566007 & 715421 & 5.648 & 5.585 & TRN & & \\
\hline CHEMBL585952 & 715421 & 5.815 & 5.421 & TST & & \\
\hline CHEMBL566198 & 715421 & 6.481 & 6.4725 & TST & & \\
\hline CHEMBL585286 & 715421 & 6.06 & 6.5818 & TST & & \\
\hline CHEMBL583899 & 715421 & \multicolumn{3}{|c|}{6.327999999999999} & 6.3767 & TST \\
\hline CHEMBL584694 & 715421 & 6.553 & 6.3538 & TST & & \\
\hline CHEMBL567485 & 715421 & 6.569 & 6.5576 & TST & & \\
\hline CHEMBL566200 & 715421 & 7.398 & 7.2657 & TRN & & \\
\hline CHEMBL566403 & 715421 & 7.046 & 7.0709 & TRN & & \\
\hline CHEMBL566406 & 715421 & 7.301 & 7.2541 & TRN & & \\
\hline CHEMBL566407 & 715421 & 7.301 & 7.3383 & TRN & & \\
\hline CHEMBL567061 & 715421 & 7.301 & 7.3363 & TRN & & \\
\hline CHEMBL567687 & 715421 & 7.222 & 7.2166 & TRN & & \\
\hline CHEMBL566638 & 715421 & 7.155 & 6.9703 & TRN & & \\
\hline CHEMBL565790 & 715421 & 6.921 & 6.9902 & TRN & & \\
\hline CHEMBL566223 & 715421 & 7.301 & 7.4586 & TRN & & \\
\hline CHEMBL565996 & 715421 & 7.444 & 7.1985 & TRN & & \\
\hline CHEMBL585289 & 715421 & 7.398 & 7.4122 & TRN & & \\
\hline CHEMBL568114 & 715421 & 6.824 & 7.1256 & TRN & & \\
\hline CHEMBL565995 & 715421 & 6.886 & 7.2534 & TRN & & \\
\hline CHEMBL566414 & 715421 & 6.921 & 6.9282 & TRN & & \\
\hline CHEMBL584917 & 715421 & 7.046 & 6.8245 & TRN & & \\
\hline CHEMBL566011 & 715421 & 7.699 & 7.8081 & TRN & & \\
\hline CHEMBL584695 & 715421 & 8.0 & 7.8401 & TRN & & \\
\hline CHEMBL1271140 & 715421 & 7.222 & 7.3831 & TRN & & \\
\hline CHEMBL566212 & 715421 & 6.046 & 7.1664 & TST & & \\
\hline
\end{tabular}


Supplemental Table S2.txt

\begin{tabular}{|c|c|c|c|c|c|}
\hline CHEMBL566012 & 715421 & 7.523 & 7.3377 & TRN & \\
\hline CHEMBL567688 & 715421 & 7.699 & 7.9298 & TRN & \\
\hline CHEMBL1651460 & 715421 & 7.699 & 7.6872 & TRN & \\
\hline CHEMBL597233 & 715421 & 5.572 & 5.7825 & TRN & \\
\hline CHEMBL598876 & 715421 & 6.886 & 6.5312 & TRN & \\
\hline CHEMBL1092124 & 715421 & 7.523 & 7.2321 & TRN & \\
\hline CHEMBL1092475 & 715421 & 7.398 & 7.1947 & TRN & \\
\hline CHEMBL1092476 & 715421 & 7.301 & 7.4402 & TRN & \\
\hline CHEMBL1092786 & 715421 & 7.398 & 7.6022 & TRN & \\
\hline CHEMBL1092787 & 715421 & 7.699 & 7.6917 & TRN & \\
\hline CHEMBL1091463 & 715421 & 7.222 & 7.4469 & TRN & \\
\hline CHEMBL1090026 & 715421 & 7.155 & 7.1016 & TRN & \\
\hline CHEMBL604590 & 715421 & 7.222 & 7.0101 & TRN & \\
\hline CHEMBL1090027 & 715421 & 7.523 & 7.677006 & 00000000005 & TRN \\
\hline CHEMBL598257 & 715421 & 7.0 & 6.9373 & TRN & \\
\hline CHEMBL598258 & 715421 & 7.097 & 7.1126 & TRN & \\
\hline CHEMBL598259 & 715421 & 7.523 & 7.3094 & TRN & \\
\hline CHEMBL590492 & 715421 & 7.155 & 7.2324 & TRN & \\
\hline CHEMBL597062 & 715421 & 6.854 & 6.9209 & TRN & \\
\hline CHEMBL603664 & 715421 & 6.824 & 7.2028 & TRN & \\
\hline CHEMBL597277 & 715421 & 7.523 & 7.1948 & TRN & \\
\hline CHEMBL605133 & 715421 & 8.0 & 7.6203 & TRN & \\
\hline CHEMBL599965 & 715421 & 6.004 & 5.2658 & TST & \\
\hline CHEMBL593979 & 715421 & 5.857 & 5.6454 & TST & \\
\hline CHEMBL607527 & 715421 & 6.022 & 5.5877 & TST & \\
\hline CHEMBL585215 & 715421 & 5.907 & 5.3473 & TST & \\
\hline CHEMBL592533 & 715421 & \multicolumn{2}{|c|}{5.9670000000000005} & 6.1069 & TST \\
\hline CHEMBL592534 & 715421 & 5.983 & 5.6864 & TST & \\
\hline CHEMBL605079 & 715421 & 5.319 & 5.5053 & TST & \\
\hline CHEMBL176031 & 305283 & 8.301 & 8.2488 & TRN & \\
\hline CHEMBL175464 & 305283 & 6.0 & 6.8105 & TRN & \\
\hline CHEMBL179210 & 305283 & 7.9586 & 7.2627 & TRN & \\
\hline CHEMBL175497 & 305283 & 4.8539 & 6.1966 & TRN & \\
\hline CHEMBL176143 & 305283 & 4.6778 & 4.5437 & TRN & \\
\hline CHEMBL368937 & 305283 & 7.3188 & 7.4939 & TRN & \\
\hline CHEMBL176016 & 305283 & 6.0 & 6.2437 & TRN & \\
\hline CHEMBL179735 & 305283 & 6.4318 & 5.9019 & TRN & \\
\hline CHEMBL257898 & 305283 & 7.2518 & 6.3427 & TST & \\
\hline CHEMBL176385 & 305283 & 8.3468 & 7.7354 & TRN & \\
\hline CHEMBL368900 & 305283 & 6.9586 & 7.1825 & TRN & \\
\hline CHEMBL435514 & 305283 & 6.301 & 6.2996 & TRN & \\
\hline CHEMBL272931 & 305283 & 5.8239 & 6.0948 & TRN & \\
\hline CHEMBL176063 & 305283 & 6.3565 & 6.0059 & TST & \\
\hline CHEMBL179961 & 305283 & 6.3098 & 6.0506 & TRN & \\
\hline CHEMBL369008 & 305283 & 8.1549 & 8.0048 & TRN & \\
\hline CHEMBL176491 & 305283 & 7.3468 & 7.8897 & TRN & \\
\hline CHEMBL367973 & 305283 & 6.3372 & 6.2203 & TRN & \\
\hline CHEMBL175599 & 305283 & 3.301 & 4.8843 & TST & \\
\hline
\end{tabular}




\begin{tabular}{|c|c|c|c|c|c|}
\hline & & \multicolumn{4}{|c|}{ Supplemental Table S2.txt } \\
\hline CHEMBL176000 & 305283 & 7.8239 & 7.3624 & TRN & \\
\hline CHEMBL177769 & 305283 & 6.9508 & 7.0506 & TRN & \\
\hline CHEMBL180112 & 305283 & 4.8861 & 5.0021 & TRN & \\
\hline CHEMBL368960 & 305283 & 7.4685 & 7.2325 & TRN & \\
\hline CHEMBL366653 & 305283 & 6.3665 & 6.2444 & TRN & \\
\hline CHEMBL176329 & 305283 & 4.7696 & 5.2456 & TRN & \\
\hline CHEMBL179081 & 305283 & 6.0809 & 6.28600 & 00000000005 & TRN \\
\hline CHEMBL366882 & 305283 & 7.0223 & 6.9013 & TRN & \\
\hline CHEMBL367647 & 305283 & 6.9747 & 7.0677 & TRN & \\
\hline CHEMBL414655 & 305283 & 6.4437 & 6.7919 & TRN & \\
\hline CHEMBL322205 & 305283 & 7.7212 & 7.8066 & TRN & \\
\hline CHEMBL363003 & 305283 & 8.2757 & 7.7161 & TRN & \\
\hline CHEMBL176348 & 305283 & 6.5686 & 6.6921 & TST & \\
\hline CHEMBL 3084979 & 305283 & 4.7696 & 5.3344 & TRN & \\
\hline CHEMBL361822 & 305283 & 7.4202 & 7.3671 & TRN & \\
\hline CHEMBL367237 & 305283 & 5.4318 & 5.4761 & TRN & \\
\hline CHEMBL175738 & 305283 & 6.9208 & 7.0693 & TRN & \\
\hline CHEMBL427125 & 305283 & 8.1249 & 8.2432 & TRN & \\
\hline CHEMBL175612 & 305283 & 5.7212 & 5.6151 & TRN & \\
\hline CHEMBL401737 & 305283 & 7.0223 & 7.2252 & TRN & \\
\hline CHEMBL367890 & 305283 & 7.4202 & 7.815 & TRN & \\
\hline CHEMBL361379 & 305283 & 6.9586 & 6.7933 & TST & \\
\hline CHEMBL 2096762 & 305283 & 5.0757 & 5.1457 & TRN & \\
\hline CHEMBL366902 & 305283 & 8.4559 & 7.8646 & TRN & \\
\hline CHEMBL360751 & 305283 & 6.8239 & 6.5421 & TRN & \\
\hline CHEMBL368894 & 305283 & 7.5376 & 7.519 & TRN & \\
\hline CHEMBL175473 & 305283 & 3.0 & 2.9659 & TRN & \\
\hline CHEMBL179910 & 305283 & 7.6778 & 6.9179 & TRN & \\
\hline CHEMBL175735 & 305283 & 6.9586 & 7.1379 & TRN & \\
\hline CHEMBL179189 & 305283 & 4.3372 & 3.4776 & TRN & \\
\hline CHEMBL361377 & 305283 & 7.2218 & 7.3834 & TST & \\
\hline CHEMBL360071 & 305283 & 7.8239 & 7.2437 & TST & \\
\hline CHEMBL369868 & 305283 & 6.1871 & 4.3592 & TST & \\
\hline CHEMBL176660 & 305283 & 8.5229 & 7.879 & TST & \\
\hline CHEMBL360684 & 305283 & 4.0862 & 4.6344 & TST & \\
\hline CHEMBL175620 & 305283 & 7.0969 & 7.0437 & TST & \\
\hline CHEMBL360542 & 305283 & 5.3979 & 5.8465 & TST & \\
\hline CHEMBL180219 & 305283 & 3.0 & 5.1053 & TST & \\
\hline CHEMBL179245 & 305283 & 8.301 & 8.1462 & TST & \\
\hline CHEMBL404728 & 305283 & 6.0315 & 6.4188 & TST & \\
\hline CHEMBL 3668845 & 1528122 & 8.6576 & 8.2582 & TRN & \\
\hline CHEMBL 3668871 & 1528122 & 8.4202 & 8.5086 & TRN & \\
\hline CHEMBL 3664146 & 1528122 & 7.4353 & 7.7709 & TRN & \\
\hline CHEMBL 3668856 & 1528122 & 8.4318 & 8.3262 & TRN & \\
\hline CHEMBL 3668875 & 1528122 & 7.9208 & 8.0581 & TRN & \\
\hline CHEMBL 3668818 & 1528122 & 8.7696 & 8.3311 & TRN & \\
\hline CHEMBL 3668832 & 1528122 & 8.3468 & 8.304 & TRN & \\
\hline CHEMBL 3668878 & 1528122 & 8.2007 & 8.2208 & TRN & \\
\hline
\end{tabular}


Supplemental Table S2.txt

\begin{tabular}{|c|c|c|c|c|}
\hline The & 28122 & & & \\
\hline & 528122 & 8.6778 & 8.4031 & \\
\hline & 122 & 576 & & \\
\hline AEMBL & & 0177 & 3993 & \\
\hline HEMBL & 528122 & 3861 & 2.0 & \\
\hline HEMBL3668860 & 528122 & 8.2924 & .2872 & \\
\hline 64 & 122 & 9586 & 5887 & \\
\hline IFMPI & & & & \\
\hline AEMBL3 & 528122 & 7.9393 & 3.1398 & \\
\hline HEMBL366 & 528122 & 592 & 9534 & \\
\hline HEMBL3668 & 528122 & 5108 & .0019 & \\
\hline IEMBL & 528122 & 73 & 2874 & \\
\hline AEMBL. & & & & \\
\hline HEMBL 3 & 528122 & & 8.289 & \\
\hline AEMBL3 & 22 & 61 & 6768 & \\
\hline IEMBL366 & 22 & 92 & 8.2455 & \\
\hline AEMBL & 22 & & 64 & \\
\hline HEMBL; & & & & \\
\hline HEMBL 3 & 22 & 68 & 7.9748 & \\
\hline AEMBL3 & 22 & 32 & & \\
\hline AEMIBL & 22 & 7. & 06 & Niv \\
\hline AEMBL & 2 & & 16 & \\
\hline HEMBL & 22 & 85 & 47 & \\
\hline 11 & & 18 & & \\
\hline AEMBL3 & & & & 151 \\
\hline HEMBL; & 22 & 38 & 87 & RN \\
\hline HEMBL & 2 & & 62 & וד וכ \\
\hline HFMBL & 22 & 72 & 568 & \\
\hline HEMBL3 & & & 9907 & RIV \\
\hline HEMBL 366 & 22 & & 973 & $\Gamma \mathrm{RN}$ \\
\hline HEMBL3 & 22 & & & SI \\
\hline HEMBL & 22 & $\partial 9$ & 89 & RN \\
\hline HEMBL & 22 & 25 & 344 & 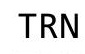 \\
\hline HEMBL36 & & & 804 & IRN \\
\hline HEMBL 366 & $52 \varepsilon$ & & 3906 & TST \\
\hline HEMBL & 122 & & 736 & TST \\
\hline HCMDI & 22 & & 872 & RN \\
\hline HEMBL. & & & 3071 & RN \\
\hline HEMBL 366 & 528122 & 737 & 5958 & TRN \\
\hline AEMBL & 5281 & 809 & & TRN \\
\hline HEMBL3 & 22 & 665 & 771 & \\
\hline HEMBL3 & 1528122 & & & RN \\
\hline HEMBL3 & 122 & 7.6073 & 7.8593 & RN \\
\hline AEMBL 3668 & 528122 & 7.8729 & 0338 & TR \\
\hline HEMBL36688 & $2 \angle$ & 14 & 7.8065 & RN \\
\hline HEMBL3 & & 376 & 3.3298 & \\
\hline HEMBL3 & 528122 & .9031 & 8.2733 & \\
\hline HEMBL3668842 & 1528122 & 7.6655 & 7.8341 & RN \\
\hline
\end{tabular}

Page 7297 
Supplemental Table S2.txt

\begin{tabular}{|c|c|c|}
\hline S & & \\
\hline HEMBL3664160 & 528122 & \\
\hline HEMBL3668852 & 528122 & \\
\hline HEMBL3664165 & 528122 & \\
\hline HEMBL3668805 & 528122 & \\
\hline HEMBL3668851 & 1528122 & \\
\hline HEMBL3668806 & 528122 & \\
\hline HEMBL3664161 & 528122 & \\
\hline HEMBL3668865 & 1528122 & \\
\hline HEMBL3668821 & 1528122 & \\
\hline HEMBL3664151 & 1528122 & \\
\hline AEMBL3668831 & 1528122 & \\
\hline HEMBL3668844 & 528122 & \\
\hline HEMBL3668829 & 1528122 & \\
\hline HEMBL3668807 & 1528122 & \\
\hline HEMBL3639630 & 1528122 & \\
\hline HEMBL3664170 & 1528122 & \\
\hline HEMBL3668830 & 1528122 & \\
\hline HEMBL3668827 & 1528122 & \\
\hline HEMBL 3668861 & 528122 & \\
\hline HEMBL3668835 & 1528122 & \\
\hline HEMBL3668809 & 1528122 & \\
\hline HEMBL3668826 & 1528 & \\
\hline HEMBL3668867 & 1528 & \\
\hline HEMBL 3668874 & 52 & \\
\hline HEMBL3639676 & 1528 & \\
\hline HEMBL3668808 & 1528122 & \\
\hline CHEMBL3668841 & 1528122 & \\
\hline CHEMBL 3664144 & 1528122 & \\
\hline CHEMBL3668868 & 1528 & \\
\hline CHEMBL3668838 & 1528122 & \\
\hline HEMBL3668839 & 1528122 & \\
\hline CHEMBL3668812 & 1528122 & \\
\hline CHEMBL3668859 & 1528122 & \\
\hline CHEMBL 3668843 & 1528122 & \\
\hline HEMBL3668834 & 1528122 & \\
\hline CHEMBL3664156 & 1528122 & \\
\hline CHEMBL3668840 & 1528122 & \\
\hline CHEMBL3668816 & 1528122 & 7.8 \\
\hline CHEMBL3664157 & 1528122 & 5.9 \\
\hline CHEMBL 3664164 & 1528122 & \\
\hline CHEMBL 3664147 & 1528122 & \\
\hline CHEMBL3664162 & 1528122 & \\
\hline CHEMBL3664169 & 1528122 & \\
\hline CHEMBL 3664167 & 1528122 & 7.6 \\
\hline CHEMBL 3668846 & 1528122 & \\
\hline CHEMBL 3668810 & 1528122 & \\
\hline CHEMBL1673039 & 955066 & \\
\hline
\end{tabular}

7.5298 TRN

\subsection{1}

TST

7.6429 TRN

6.5083 TRN

7.7441 TST

8.2271 TST

8.2785 TRN

7.117000000000001

TRN

8.257 TRN

7.9401 TST

8.1391 TRN

8.4779 TRN

8.0685 TST

8.4441 TRN

8.3234 TRN

7.2761 TST

8.0498 TRN

8.4325 TRN

8.3111 TRN

8.0973 TRN

8.3637 TRN

8.0049 TRN

8.3159 TRN

8.0768 TRN

7.5138 TRN

8.305 TRN

8.174 TRN

8.2162 TRN

8.5137 TRN

7.9952 TST

8.3228 TRN

8.4742 TRN

8.3863 TRN

8.2886 TRN

8.3236 TRN

7.8747 TST

8.4645 TRN

8.0181 TST

7.8303 TRN

7.0191 TST

6.7367 TRN

8.1987 TRN

6.6837 TRN

8.3042 TRN

7.5954 TST

7.9371 TRN

8.1715 TST

4.7095 TRN

Page 7298 


\begin{tabular}{|c|c|c|c|c|c|c|}
\hline \multicolumn{7}{|c|}{ Supplemental Table S2.txt } \\
\hline CHEMBL 2144069 & 955066 & 6.5529 & 6.5529 & TRN & & \\
\hline CHEMBL577784 & 955066 & 5.2716 & 5.2716 & TRN & & \\
\hline CHEMBL210618 & 955066 & 3.1842 & 3.1842 & TRN & & \\
\hline CHEMBL180127 & 955066 & 3.6526 & 3.6526 & TRN & & \\
\hline CHEMBL220241 & 955066 & 3.5106 & 3.5106 & TRN & & \\
\hline CHEMBL65 & 955066 & 7.6919 & 7.6919 & TRN & & \\
\hline CHEMBL 2134202 & 955066 & 3.3388 & 3.3388 & TRN & & \\
\hline CHEMBL1256459 & 955066 & 7.1806 & 7.1806 & TRN & & \\
\hline CHEMBL1190711 & 955066 & 5.4577 & 5.4577 & TRN & & \\
\hline CHEMBL1788116 & 955066 & 5.0056 & 5.0056 & TRN & & \\
\hline CHEMBL558642 & 955066 & 4.507 & 4.5069 & TRN & & \\
\hline CHEMBL1516890 & 955066 & 4.0359 & 4.0359 & TRN & & \\
\hline CHEMBL 255342 & 955066 & 3.4774 & 3.4774 & TRN & & \\
\hline CHEMBL392695 & 955066 & 5.7874 & 5.7873 & TRN & & \\
\hline CHEMBL1643959 & 955066 & 5.1 & 5.1 & TRN & & \\
\hline CHEMBL373751 & 955066 & 3.3402 & 3.3402 & TRN & & \\
\hline CHEMBL509032 & 955066 & 6.7487 & 6.7487 & TRN & & \\
\hline CHEMBL92309 & 955066 & 4.3373 & 3.1071 & TST & & \\
\hline CHEMBL514499 & 955066 & 7.6535 & 7.6535 & TRN & & \\
\hline CHEMBL393929 & 955066 & 3.8569 & 3.8569 & TRN & & \\
\hline CHEMBL573107 & 955066 & 5.4169 & 5.4169 & TRN & & \\
\hline CHEMBL 213100 & 955066 & 6.6437 & 6.6437 & TRN & & \\
\hline CHEMBL449158 & 955066 & 6.2567 & 6.862 & TST & & \\
\hline CHEMBL 209148 & 955066 & 5.4248 & 5.4248 & TRN & & \\
\hline CHEMBL1404918 & 955066 & 3.8532 & 3.8532 & TRN & & \\
\hline CHEMBL2363137 & 955066 & 5.1997 & 5.1996 & TRN & & \\
\hline CHEMBL1590308 & 955066 & 3.4614 & 2.8771 & TST & & \\
\hline CHEMBL192566 & 955066 & 9.8179 & 9.5066 & TST & & \\
\hline CHEMBL 259181 & 955066 & 5.1567 & 5.1567 & TRN & & \\
\hline CHEMBL472940 & 955066 & 4.2382 & 4.2382 & TRN & & \\
\hline CHEMBL483849 & 955066 & 2.5388 & 2.5496 & TST & & \\
\hline CHEMBL9470 & 955066 & 7.7149 & 6.331 & TST & & \\
\hline CHEMBL1186585 & 955066 & 3.2172 & 3.2172 & TRN & & \\
\hline CHEMBL202721 & 955066 & 4.6478 & 4.6478 & TRN & & \\
\hline CHEMBL1230020 & 955066 & 3.4138 & 3.4138 & TRN & & \\
\hline CHEMBL102714 & 955066 & 3.485 & 3.485 & TRN & & \\
\hline CHEMBL1909414 & 955066 & 3.5899 & 3.5899 & TRN & & \\
\hline CHEMBL300389 & 955066 & 7.3696 & 7.3696 & TRN & & \\
\hline CHEMBL191334 & 955066 & 3.6852 & 3.6852 & TRN & & \\
\hline CHEMBL515416 & 955066 & 5.535 & 5.535 & TRN & & \\
\hline CHEMBL 379300 & 955066 & 7.0994 & 7.0994 & TRN & & \\
\hline CHEMBL 399530 & 955066 & 3.7423 & 3.7423 & TRN & & \\
\hline CHEMBL 222102 & 955066 & 3.5586 & 3.5586 & TRN & & \\
\hline CHEMBL 2137530 & 955066 & 5.0089 & 5.0089 & TRN & & \\
\hline CHEMBL 2005886 & 955066 & 6.11700 & 30000000 & & 6.117000000000001 & TRN \\
\hline CHEMBL412142 & 955066 & 4.0241 & 4.0241 & TRN & & \\
\hline CHEMBL 258844 & 955066 & 4.711 & 4.711 & TRN & & \\
\hline CHEMBL3186408 & 955066 & 3.49600 & 00000000 & 204 & 3.6059 TST & \\
\hline
\end{tabular}




\begin{tabular}{|c|c|c|c|c|c|}
\hline \multicolumn{6}{|c|}{ Supplemental Table S2.txt } \\
\hline CHEMBL240954 & 955066 & 3.9818 & 3.6254 & TST & \\
\hline CHEMBL3392440 & 955066 & 3.9303 & 3.9303 & TRN & \\
\hline CHEMBL512504 & 955066 & 4.471 & 4.471 & TRN & \\
\hline CHEMBL217354 & 955066 & 6.1973 & 6.1973 & TRN & \\
\hline CHEMBL483847 & 955066 & 5.4937 & 5.4937 & TRN & \\
\hline CHEMBL1357247 & 955066 & 3.3354 & 3.3354 & TRN & \\
\hline CHEMBL3349342 & 955066 & 5.8723 & 5.8723 & TRN & \\
\hline CHEMBL188678 & 955066 & 3.9939 & 4.0467 & TST & \\
\hline CHEMBL379975 & 955066 & 4.4138 & 4.627 & TST & \\
\hline CHEMBL 221137 & 955066 & 5.2431 & 4.9859 & TST & \\
\hline CHEMBL1970879 & 955066 & 6.2254 & 6.1992 & TST & \\
\hline CHEMBL3199475 & 955066 & 4.8304 & 4.3658 & TST & \\
\hline CHEMBL585951 & 955066 & 6.7107 & 6.1209 & TST & \\
\hline CHEMBL189584 & 955066 & 4.2531 & 4.6936 & TST & \\
\hline CHEMBL1242367 & 955066 & 4.9813 & 5.2576 & TST & \\
\hline CHEMBL135561 & 955066 & 4.845 & 5.0071 & TST & \\
\hline CHEMBL3093324 & 1278706 & 5.6073 & 5.8488 & TRN & \\
\hline CHEMBL 3093224 & 1278706 & 5.27 & 5.6541 & TRN & \\
\hline CHEMBL3093233 & 1278706 & 5.9172 & 5.3076 & TRN & \\
\hline CHEMBL 3093241 & 1278706 & 4.0 & 4.101 & TRN & \\
\hline CHEMBL3093316 & 1278706 & 6.0825 & 6.2378 & TRN & \\
\hline CHEMBL 3093236 & 1278706 & 5.433 & 5.4366 & TRN & \\
\hline CHEMBL3093219 & 1278706 & 4.0 & 3.9493 & TRN & \\
\hline CHEMBL3093321 & 1278706 & 6.4425 & 6.2736 & TRN & \\
\hline CHEMBL 3093322 & 1278706 & 5.8447 & 6.1705 & TRN & \\
\hline CHEMBL3093313 & 1278706 & 5.5186 & 5.8576 & TRN & \\
\hline CHEMBL3093232 & 1278706 & 5.4248 & 5.4463 & TRN & \\
\hline CHEMBL241617 & 1278706 & 5.1409 & 5.26200 & 00000000005 & TRN \\
\hline CHEMBL 3093223 & 1278706 & 4.0 & 4.1654 & TRN & \\
\hline CHEMBL3093221 & 1278706 & 5.1361 & 4.4161 & TRN & \\
\hline CHEMBL 3093234 & 1278706 & 5.3279 & 5.5014 & TRN & \\
\hline CHEMBL 3093237 & 1278706 & 5.7852 & 5.42700 & 00000000005 & TRN \\
\hline CHEMBL 3091482 & 1278706 & 6.4202 & 6.26200 & 00000000005 & TRN \\
\hline CHEMBL413079 & 1278706 & 8.0947 & 5.7226 & TST & \\
\hline CHEMBL3093318 & 1278706 & 6.5406 & 6.1373 & TRN & \\
\hline CHEMBL3093217 & 1278706 & 4.0 & 4.6455 & TRN & \\
\hline CHEMBL3093323 & 1278706 & 6.3028 & 6.157 & TRN & \\
\hline CHEMBL3093326 & 1278706 & 6.0458 & 5.5785 & TST & \\
\hline CHEMBL 3093226 & 1278706 & 5.5768 & 5.7398 & TRN & \\
\hline CHEMBL3093214 & 1278706 & 4.8539 & 4.6892 & TRN & \\
\hline CHEMBL3093222 & 1278706 & 4.0 & 4.4084 & TRN & \\
\hline CHEMBL241618 & 1278706 & 6.0958 & 5.3958 & TRN & \\
\hline CHEMBL3093325 & 1278706 & 5.7258 & 5.7467 & TST & \\
\hline CHEMBL3093314 & 1278706 & 5.2062 & 6.0207 & TRN & \\
\hline CHEMBL 3093225 & 1278706 & 5.7375 & 5.8062 & TRN & \\
\hline CHEMBL3093218 & 1278706 & 4.0 & 4.4007 & TST & \\
\hline CHEMBL3093317 & 1278706 & 6.5591 & 6.0596 & TRN & \\
\hline CHEMBL3093220 & 1278706 & 5.0851 & 4.5225 & TST & \\
\hline
\end{tabular}


Supplemental Table S2.txt

\begin{tabular}{|c|c|c|c|c|c|}
\hline CHEMBL3093311 & 1278706 & 6.1931 & 6.0788 & TRN & \\
\hline CHEMBL3091481 & 1278706 & 4.0 & 4.4934 & TST & \\
\hline CHEMBL3093228 & 1278706 & 5.7258 & 5.7835 & TRN & \\
\hline CHEMBL282038 & 1278706 & 5.2518 & 6.3591 & TST & \\
\hline CHEMBL3093230 & 1278706 & 5.7696 & 5.9281 & TST & \\
\hline CHEMBL3093315 & 1278706 & 6.5867 & 6.2315 & TRN & \\
\hline CHEMBL3093319 & 1278706 & 6.1409 & 6.2134 & TRN & \\
\hline CHEMBL3093239 & 1278706 & 6.1079 & 5.5496 & TST & \\
\hline CHEMBL3093328 & 1278706 & 6.8327 & 5.8729 & TRN & \\
\hline CHEMBL3093332 & 1278706 & 5.6904 & 6.0055 & TRN & \\
\hline CHEMBL3093229 & 1278706 & 5.4123 & 5.8441 & TRN & \\
\hline CHEMBL239230 & 1278706 & 6.2882 & 5.4102 & TST & \\
\hline CHEMBL 3093240 & 1278706 & 4.0 & 4.5669 & TST & \\
\hline CHEMBL3093331 & 1278706 & 6.0306 & 6.0652 & TRN & \\
\hline CHEMBL3093216 & 1278706 & 4.0 & 4.5611 & TST & \\
\hline CHEMBL3093320 & 1278706 & 6.1487 & 6.3376 & TRN & \\
\hline CHEMBL3093231 & 1278706 & 4.0 & 5.8416 & TST & \\
\hline CHEMBL 3093329 & 1278706 & 5.7122 & 6.0985 & TRN & \\
\hline CHEMBL3093235 & 1278706 & 5.2565 & 5.4793 & TRN & \\
\hline CHEMBL3093310 & 1278706 & 6.2733 & 5.9386 & TRN & \\
\hline CHEMBL3093333 & 1278706 & 5.8297 & 5.8335 & TRN & \\
\hline CHEMBL 3093238 & 1278706 & 6.7799 & 5.5104 & TST & \\
\hline CHEMBL3093330 & 1278706 & 5.5186 & 5.9914 & TRN & \\
\hline CHEMBL3093215 & 1278706 & 5.0259 & 4.3121 & TST & \\
\hline CHEMBL 3093227 & 1278706 & 6.2048 & 5.7927 & TRN & \\
\hline CHEMBL3093312 & 1278706 & 6.1574 & 5.9943 & TRN & \\
\hline CHEMBL 3919001 & 1637102 & 6.0 & 6.9181 & TST & \\
\hline CHEMBL3941546 & 1637102 & 7.0 & 6.8271 & TST & \\
\hline CHEMBL3918763 & 1637102 & 8.0 & 7.6284 & TRN & \\
\hline CHEMBL3946144 & 1637102 & 7.0 & \multicolumn{2}{|c|}{7.4510000000000005} & TRN \\
\hline CHEMBL3951879 & 1637102 & 7.0 & 6.9809 & TRN & \\
\hline CHEMBL3927115 & 1637102 & 6.0 & 6.4033 & TRN & \\
\hline CHEMBL3895375 & 1637102 & 7.0 & 7.1354 & TRN & \\
\hline CHEMBL3972055 & 1637102 & 8.0 & 7.0941 & TRN & \\
\hline CHEMBL3925971 & 1637102 & 8.0 & 7.7771 & TRN & \\
\hline CHEMBL3889919 & 1637102 & 8.0 & 7.9497 & TST & \\
\hline CHEMBL3980396 & 1637102 & 7.0 & 6.6397 & TRN & \\
\hline CHEMBL3974367 & 1637102 & 8.0 & 8.0492 & TRN & \\
\hline CHEMBL3985393 & 1637102 & 6.0 & 6.4387 & TRN & \\
\hline CHEMBL3974628 & 1637102 & 8.0 & 7.8726 & TRN & \\
\hline CHEMBL3912530 & 1637102 & 8.0 & 8.0086 & TRN & \\
\hline CHEMBL3964189 & 1637102 & 8.0 & 8.0036 & TRN & \\
\hline CHEMBL3928104 & 1637102 & 8.0 & 7.9348 & TRN & \\
\hline CHEMBL3911034 & 1637102 & 8.0 & 7.8521 & TRN & \\
\hline CHEMBL3934621 & 1637102 & 8.0 & \multicolumn{2}{|c|}{7.117999999999999} & TST \\
\hline CHEMBL3960126 & 1637102 & 8.0 & 8.0154 & TRN & \\
\hline CHEMBL3978491 & 1637102 & 8.0 & 8.16 & TRN & \\
\hline CHEMBL3913415 & 1637102 & 7.0 & 7.6109 & TRN & \\
\hline
\end{tabular}




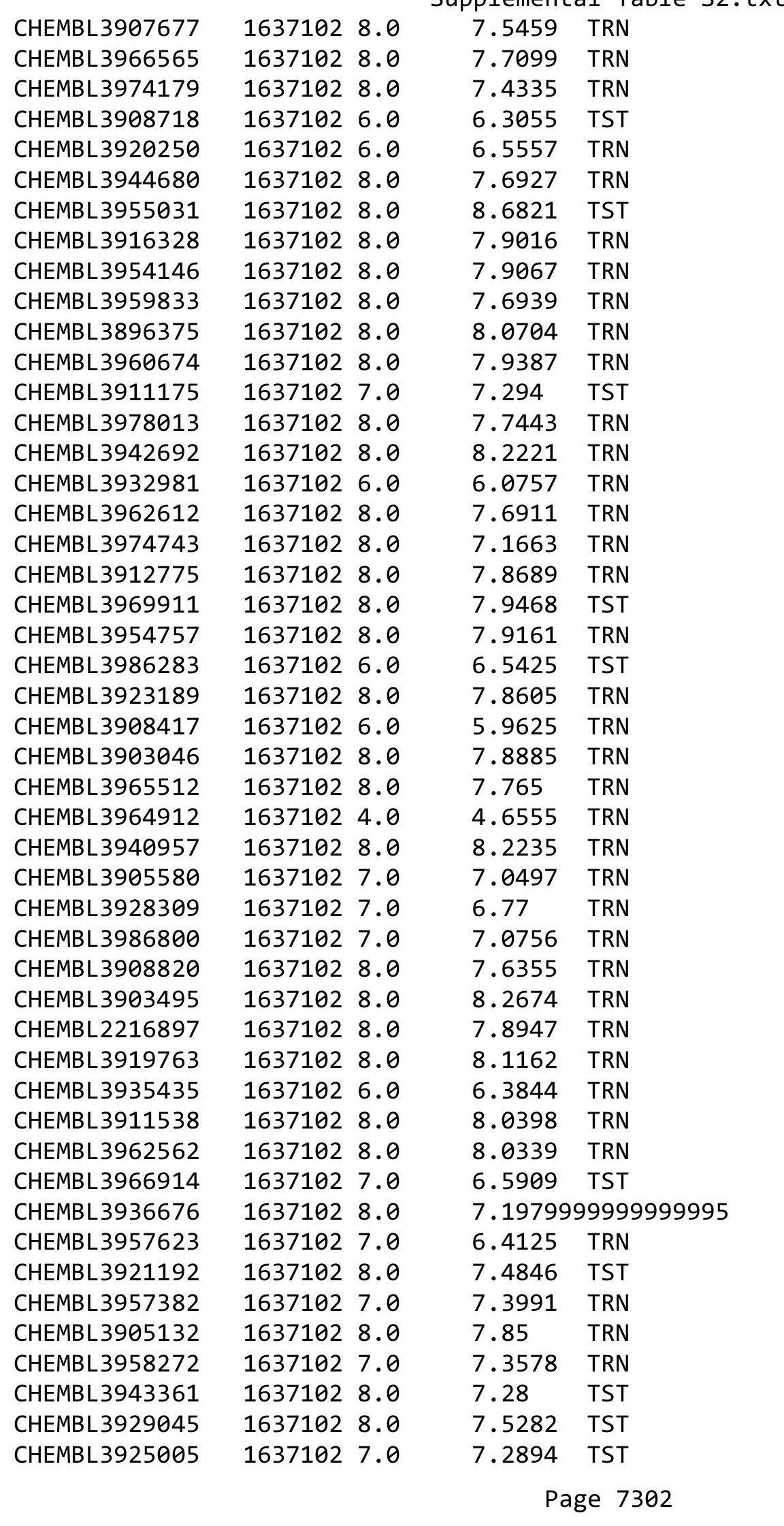

Supplemental Table S2.txt 


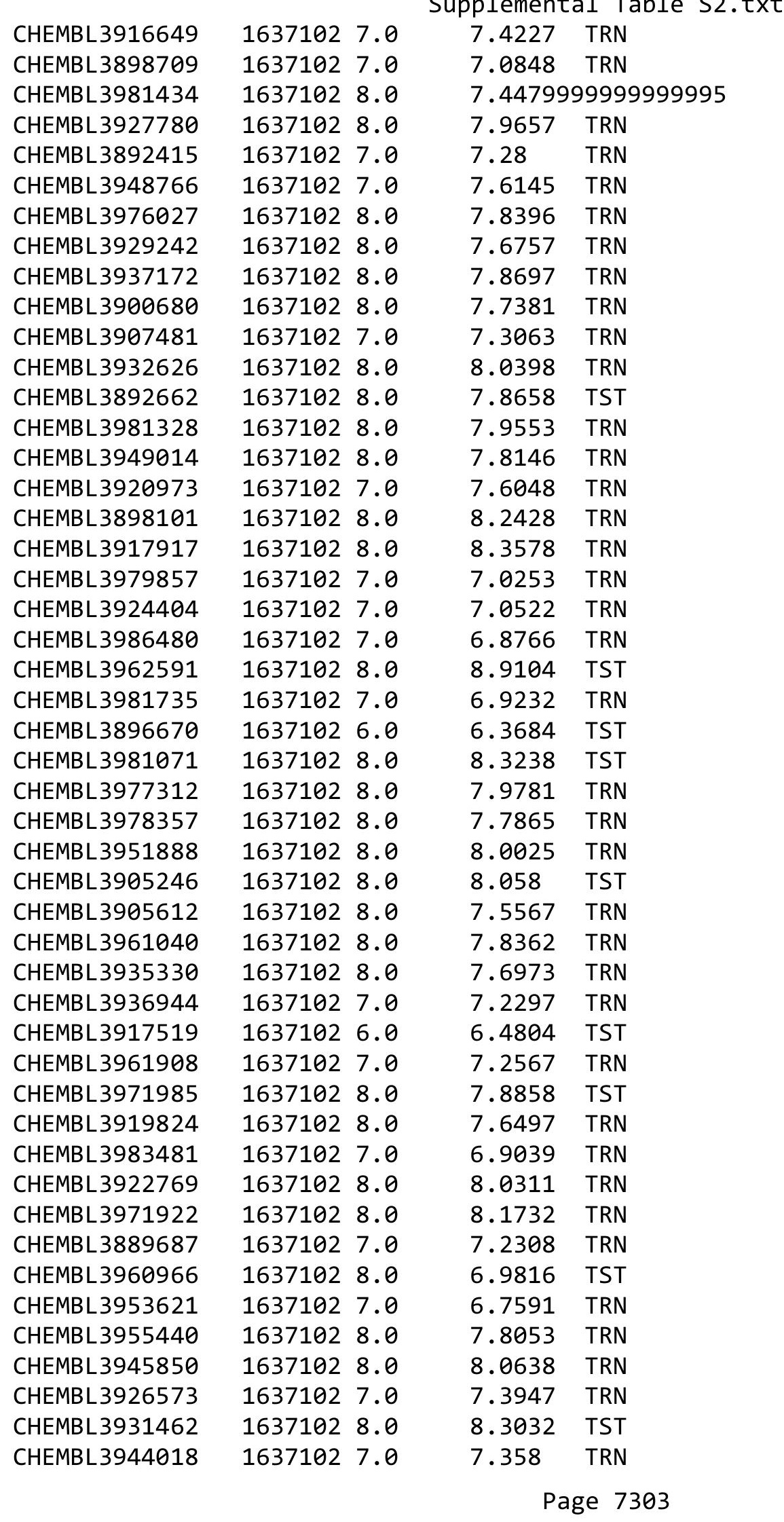




\begin{tabular}{|c|c|c|c|c|}
\hline CHEMBL3959902 & 16371028.0 & 8.9915 & TST & \\
\hline CHEMBL 3969492 & 16371028.0 & 8.2719 & TRN & \\
\hline CHEMBL3986855 & 16371026.0 & 7.1871 & TRN & \\
\hline CHEMBL 3922415 & 16371028.0 & 8.0904 & TRN & \\
\hline CHEMBL 3920543 & 16371028.0 & 7.4719 & TRN & \\
\hline CHEMBL 3917027 & 16371028.0 & 7.9201 & TST & \\
\hline CHEMBL3902945 & 16371028.0 & 8.0148 & TRN & \\
\hline CHEMBL 3905083 & 16371027.0 & 6.9179 & TRN & \\
\hline CHEMBL3969965 & 16371028.0 & 8.2636 & TST & \\
\hline CHEMBL 3900764 & 16371027.0 & 7.1005 & TST & \\
\hline CHEMBL 3944887 & 16371028.0 & 8.0508 & TRN & \\
\hline CHEMBL3901409 & 16371027.0 & 7.00299 & & TRN \\
\hline CHEMBL3955730 & 16371028.0 & 8.5405 & TST & \\
\hline CHEMBL3915138 & 16371028.0 & 8.4121 & TST & \\
\hline CHEMBL3962803 & 16371028.0 & 7.9891 & TRN & \\
\hline CHEMBL 3938839 & 16371028.0 & 7.7437 & TST & \\
\hline CHEMBL 3974554 & 16371026.0 & 6.5592 & TST & \\
\hline CHEMBL3919689 & 16371028.0 & 8.2881 & TRN & \\
\hline CHEMBL3966715 & 16371028.0 & 8.401 & TST & \\
\hline CHEMBL3983816 & 16371028.0 & 7.7729 & TRN & \\
\hline CHEMBL 3957119 & 16371028.0 & 7.9572 & TRN & \\
\hline CHEMBL 3927712 & 16371027.0 & 7.4557 & TRN & \\
\hline CHEMBL 3948475 & 16371028.0 & 7.98600 & 0000000001 & TRN \\
\hline CHEMBL 3924168 & 16371028.0 & 8.1791 & TRN & \\
\hline CHEMBL 3907964 & 16371027.0 & 7.1456 & TST & \\
\hline CHEMBL3956971 & 16371028.0 & 7.8334 & TRN & \\
\hline CHEMBL 3977886 & 16371027.0 & 7.5215 & TRN & \\
\hline CHEMBL 3927820 & 16371026.0 & 6.4642 & TRN & \\
\hline CHEMBL 3972682 & 16371028.0 & 7.7293 & TRN & \\
\hline CHEMBL 3980844 & 16371026.0 & 6.9687 & TST & \\
\hline CHEMBL 3948376 & 16371028.0 & 7.7484 & TRN & \\
\hline CHEMBL 3891079 & 16371028.0 & 7.8853 & TST & \\
\hline CHEMBL3981319 & 16371028.0 & 7.981 & TRN & \\
\hline CHEMBL3981906 & 16371028.0 & 7.9485 & TRN & \\
\hline CHEMBL 3979331 & 16371027.0 & 7.376 & TRN & \\
\hline CHEMBL 3895422 & 16371027.0 & 6.3443 & TRN & \\
\hline CHEMBL 3918477 & 16371028.0 & 7.599 & TRN & \\
\hline CHEMBL 3972206 & 16371028.0 & 7.5075 & TRN & \\
\hline CHEMBL 3940977 & 16371028.0 & 7.7622 & TRN & \\
\hline CHEMBL 3939554 & 16371028.0 & 7.9243 & TRN & \\
\hline CHEMBL 3949031 & 16371028.0 & 7.7219 & TRN & \\
\hline CHEMBL 3932575 & 16371026.0 & 7.9456 & TST & \\
\hline CHEMBL 3913845 & 16371028.0 & 7.9072 & TRN & \\
\hline CHEMBL 3953679 & 16371028.0 & 7.4083 & TST & \\
\hline CHEMBL 3979467 & 16371028.0 & 8.0297 & TRN & \\
\hline CHEMBL 3965684 & 16371028.0 & 8.051 & TST & \\
\hline CHEMBL 3958075 & 16371028.0 & 8.0919 & TRN & \\
\hline CHEMBL 3910674 & 16371028.0 & 7.7384 & TRN & \\
\hline
\end{tabular}




\begin{tabular}{|c|c|c|c|c|c|}
\hline & & & & & \\
\hline CHEMBL 3952054 & 1637102 & 8.0 & 7.7757 & TRN & \\
\hline CHEMBL3893036 & 1637102 & 7.0 & 7.2082 & TRN & \\
\hline CHEMBL3905598 & 1637102 & 6.0 & 5.2793 & TRN & \\
\hline CHEMBL3915590 & 1637102 & 7.0 & 7.9029 & TST & \\
\hline CHEMBL3920483 & 1637102 & 7.0 & 7.5946 & TRN & \\
\hline CHEMBL3941010 & 1637102 & 7.0 & 7.3404 & TRN & \\
\hline CHEMBL3922621 & 1637102 & 8.0 & 8.1598 & TST & \\
\hline CHEMBL3915312 & 1637102 & 8.0 & 8.7063 & TST & \\
\hline CHEMBL3950472 & 1637102 & 7.0 & 7.0541 & TRN & \\
\hline CHEMBL3986828 & 1637102 & 7.0 & 6.9545 & TRN & \\
\hline CHEMBL3947007 & 1637102 & 7.0 & 6.8603 & TRN & \\
\hline CHEMBL3925129 & 1637102 & 8.0 & 8.8245 & TST & \\
\hline CHEMBL3944656 & 1637102 & 8.0 & 7.9644 & TRN & \\
\hline CHEMBL3922817 & 1637102 & 7.0 & 7.2699 & TRN & \\
\hline CHEMBL 2216876 & 1637102 & 8.0 & 8.1601 & TRN & \\
\hline CHEMBL3969058 & 1637102 & 8.0 & 7.7302 & TRN & \\
\hline CHEMBL3891368 & 1637102 & 8.0 & 7.9796 & TRN & \\
\hline CHEMBL3969470 & 1637102 & 7.0 & 6.5152 & TRN & \\
\hline CHEMBL3971853 & 1637102 & 7.0 & 6.9715 & TRN & \\
\hline CHEMBL3939953 & 1637102 & 8.0 & 7.7961 & TRN & \\
\hline CHEMBL3969273 & 1637102 & 8.0 & 8.3209 & TST & \\
\hline CHEMBL3983246 & 1637102 & 8.0 & 7.6777 & TST & \\
\hline CHEMBL3985898 & 1637102 & 8.0 & 8.2094 & TST & \\
\hline CHEMBL3907233 & 1637102 & 7.0 & 6.5717 & TST & \\
\hline CHEMBL3920111 & 1637102 & 7.0 & 6.7794 & TRN & \\
\hline CHEMBL3958796 & 1637102 & 7.0 & 6.9091 & TRN & \\
\hline CHEMBL3915193 & 1637102 & 8.0 & 8.191 & TST & \\
\hline CHEMBL3910833 & 1637102 & 7.0 & 7.4098 & TST & \\
\hline CHEMBL3954505 & 1637102 & 8.0 & 8.0295 & TRN & \\
\hline CHEMBL3918718 & 1637102 & 8.0 & 7.9739 & TRN & \\
\hline CHEMBL3969872 & 1637102 & 8.0 & 8.5003 & TST & \\
\hline CHEMBL3920754 & 1637102 & 7.0 & 7.3395 & TRN & \\
\hline CHEMBL3891191 & 1637102 & 8.0 & 7.6755 & TRN & \\
\hline CHEMBL3969116 & 1637102 & 7.0 & 7.0404 & TRN & \\
\hline CHEMBL3897922 & 1637102 & 7.0 & 7.5559 & TRN & \\
\hline CHEMBL3975817 & 1637102 & 7.0 & 7.3476 & TRN & \\
\hline CHEMBL3939713 & 1637102 & 8.0 & 7.7803 & TRN & \\
\hline CHEMBL3931051 & 1637102 & 7.0 & 7.46706 & 00000000005 & TRN \\
\hline CHEMBL3892966 & 1637102 & 8.0 & 7.4353 & TST & \\
\hline CHEMBL3957361 & 1637102 & 8.0 & 8.4475 & TRN & \\
\hline CHEMBL3937104 & 1637102 & 7.0 & 7.1636 & TRN & \\
\hline CHEMBL3929965 & 1637102 & 8.0 & 8.0048 & TRN & \\
\hline CHEMBL3918112 & 1637102 & 8.0 & 8.0178 & TST & \\
\hline CHEMBL3923662 & 1637102 & 8.0 & 7.9331 & TRN & \\
\hline CHEMBL3666203 & 1528696 & 8.2441 & 8.3785 & TRN & \\
\hline CHEMBL 3666221 & 1528696 & 7.8239 & 7.8913 & TRN & \\
\hline CHEMBL3666218 & 1528696 & 8.7696 & 8.7051 & TRN & \\
\hline CHEMBL 3671162 & 1528696 & 7.7212 & 7.8688 & TRN & \\
\hline
\end{tabular}


Supplemental Table S2.txt

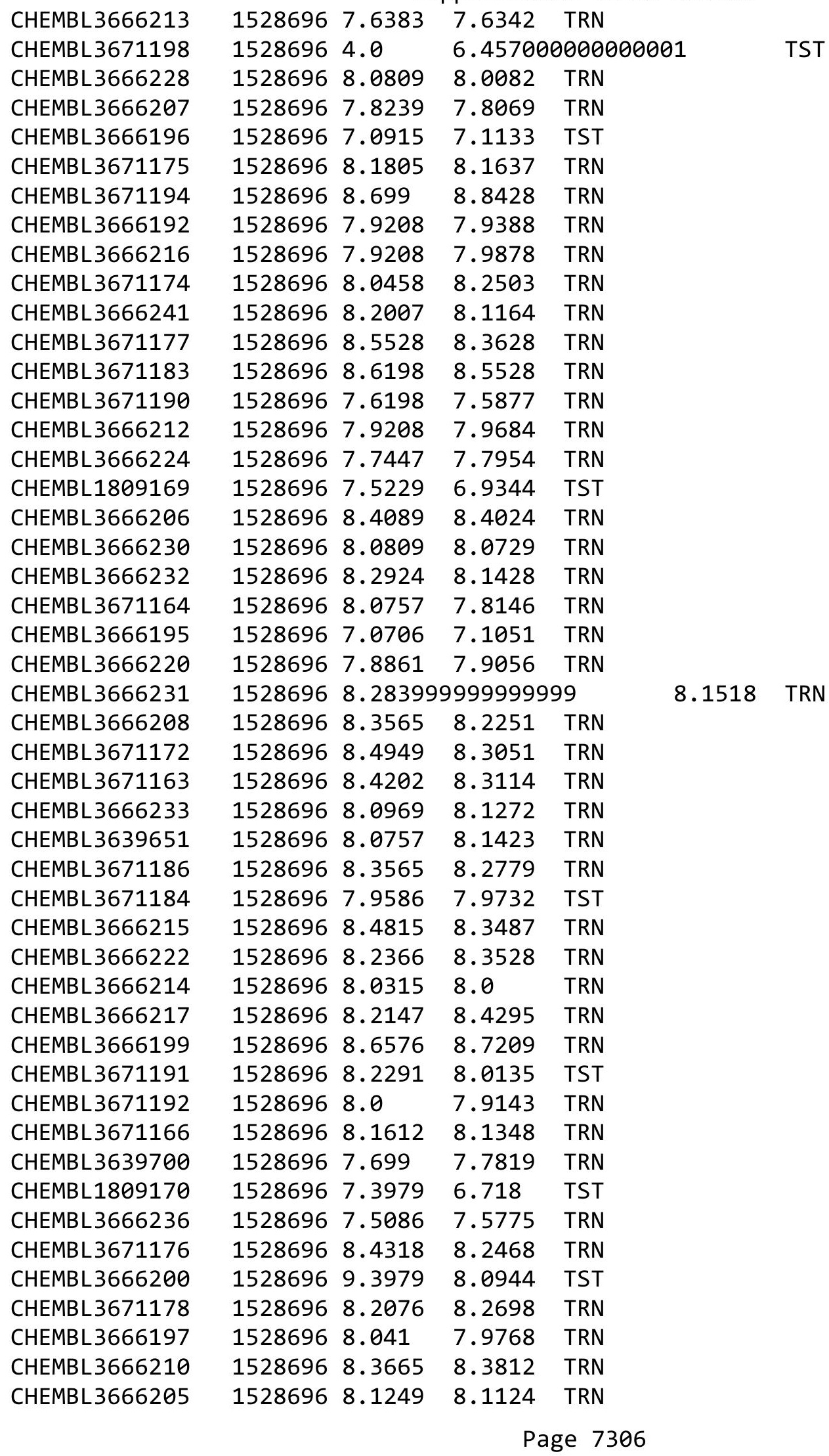


Supplemental Table S2.txt

\begin{tabular}{|c|c|c|c|c|}
\hline CHEMBL3671196 & 1528696 & 7.5528 & 7.7461 & TRN \\
\hline CHEMBL 3671168 & 1528696 & 8.0223 & 8.07 & TRN \\
\hline CHEMBL 3666244 & 1528696 & 8.1675 & 8.2347 & TRN \\
\hline CHEMBL 3666198 & 1528696 & 8.6778 & 8.6324 & TRN \\
\hline CHEMBL3671169 & 1528696 & 7.9586 & $7.86600 e$ & 0000000005 \\
\hline CHEMBL1809167 & 1528696 & 7.3979 & 6.76 & TST \\
\hline CHEMBL 3666229 & 1528696 & 8.5229 & 8.3714 & TRN \\
\hline CHEMBL 3666201 & 1528696 & 8.041 & 8.1727 & TRN \\
\hline CHEMBL 3666193 & 1528696 & 8.1192 & 8.1912 & TRN \\
\hline CHEMBL3671173 & 1528696 & 8.3279 & 8.3166 & TRN \\
\hline CHEMBL 3671165 & 1528696 & 7.8539 & 7.983 & TRN \\
\hline CHEMBL 3671158 & 1528696 & 6.0 & 8.3025 & TST \\
\hline CHEMBL 3671195 & 1528696 & 8.3279 & 8.3937 & TRN \\
\hline CHEMBL 3666209 & 1528696 & 8.0757 & 7.9854 & TRN \\
\hline CHEMBL 3666226 & 1528696 & 8.28399 & 99999999 & 7.9874 \\
\hline CHEMBL 3666204 & 1528696 & 8.4089 & 8.5391 & TRN \\
\hline CHEMBL 3666225 & 1528696 & 8.301 & 8.2513 & TRN \\
\hline CHEMBL 3666211 & 1528696 & 7.7696 & 7.6024 & TRN \\
\hline CHEMBL 3671181 & 1528696 & 8.8861 & 8.6947 & TRN \\
\hline CHEMBL 3671179 & 1528696 & 8.7696 & 8.7448 & TRN \\
\hline CHEMBL 3671182 & 1528696 & 8.9208 & 8.9943 & TRN \\
\hline CHEMBL 3671167 & 1528696 & 8.1249 & 8.2867 & TRN \\
\hline CHEMBL 3666202 & 1528696 & 8.0506 & 8.1605 & TRN \\
\hline CHEMBL 3671188 & 1528696 & 7.8239 & 7.9959 & TRN \\
\hline CHEMBL 3671187 & 1528696 & 7.7696 & 7.9481 & TRN \\
\hline CHEMBL 3666234 & 1528696 & 7.2757 & 7.3474 & TRN \\
\hline CHEMBL 3666238 & 1528696 & 8.0 & 7.9266 & TRN \\
\hline CHEMBL 3671171 & 1528696 & 8.3565 & 8.4443 & TRN \\
\hline CHEMBL 3666239 & 1528696 & 8.3665 & 8.2788 & TST \\
\hline CHEMBL 3666223 & 1528696 & 8.0506 & 7.9539 & TST \\
\hline CHEMBL 3671180 & 1528696 & 8.7696 & 8.0562 & TST \\
\hline CHEMBL 3666194 & 1528696 & 8.0655 & 7.2853 & TST \\
\hline CHEMBL 3666237 & 1528696 & 8.1549 & 7.1247 & TST \\
\hline CHEMBL 3666191 & 1528696 & 7.7447 & 7.1094 & TST \\
\hline CHEMBL 3671185 & 1528696 & 7.7959 & 7.8487 & TST \\
\hline CHEMBL 3671170 & 1528696 & 8.2441 & 7.8381 & TST \\
\hline CHEMBL 3666235 & 1528696 & 7.4949 & 8.2523 & TST \\
\hline CHEMBL 3671161 & 1528696 & 8.3279 & 8.1078 & TST \\
\hline CHEMBL 3671160 & 1528696 & 8.4559 & 7.9041 & TST \\
\hline CHEMBL 3666227 & 1528696 & 8.9586 & 7.9112 & TST \\
\hline CHEMBL 3666240 & 1528696 & 8.6021 & 8.3231 & TST \\
\hline CHEMBL 3671193 & 1528696 & 8.4815 & 8.5333 & TST \\
\hline CHEMBL3671197 & 1528696 & 8.0088 & 8.2915 & TST \\
\hline CHEMBL 3965965 & 1641033 & 7.585 & 6.5354 & TRN \\
\hline CHEMBL 3954454 & 1641033 & 6.699 & 6.7875 & TRN \\
\hline CHEMBL 3926516 & 1641033 & 6.699 & 6.6795 & TST \\
\hline CHEMBL 3962232 & 1641033 & 5.0 & 5.2503 & TRN \\
\hline CHEMBL 3911874 & 1641033 & 6.585 & 5.8848 & TST \\
\hline
\end{tabular}


Supplemental Table S2.txt

\begin{tabular}{|c|c|c|c|c|}
\hline CHEMBL3918943 & 1641033 & 5.0 & 5.6117 & TRN \\
\hline CHEMBL3979388 & 1641033 & 6.2218 & 5.6961 & TRN \\
\hline CHEMBL3971389 & 1641033 & 5.6778 & 5.6606 & TST \\
\hline CHEMBL 3984960 & 1641033 & 6.6576 & 6.7474 & TRN \\
\hline CHEMBL 3956311 & 1641033 & 5.0 & 4.7707 & TRN \\
\hline CHEMBL3973453 & 1641033 & 5.0 & 4.989 & TRN \\
\hline CHEMBL3979340 & 1641033 & 7.2218 & 6.9888 & TRN \\
\hline CHEMBL3985391 & 1641033 & 6.9208 & 6.5216 & TRN \\
\hline CHEMBL3929096 & 1641033 & 6.3565 & 6.0287 & TRN \\
\hline CHEMBL 3954249 & 1641033 & 7.2676 & 6.2492 & TST \\
\hline CHEMBL 3959692 & 1641033 & 6.1805 & 6.3207 & TST \\
\hline CHEMBL3907227 & 1641033 & 5.0 & 4.5818 & TST \\
\hline CHEMBL 3928338 & 1641033 & 6.4089 & 6.4071 & TST \\
\hline CHEMBL3979988 & 1641033 & 6.7696 & 6.9935 & TRN \\
\hline CHEMBL 3962451 & 1641033 & 6.2076 & 5.8554 & TRN \\
\hline CHEMBL 3975439 & 1641033 & 6.0362 & 6.0796 & TST \\
\hline CHEMBL3949257 & 1641033 & 6.3665 & 6.4566 & TRN \\
\hline CHEMBL 3897131 & 1641033 & 5.0 & 4.8985 & TST \\
\hline CHEMBL 3928091 & 1641033 & 5.0 & 5.8921 & TRN \\
\hline CHEMBL 3978189 & 1641033 & 6.0269 & 5.9288 & TRN \\
\hline CHEMBL3911362 & 1641033 & 6.4089 & 6.2655 & TRN \\
\hline CHEMBL 3898786 & 1641033 & 6.5376 & 6.0941 & TST \\
\hline CHEMBL3942120 & 1641033 & 5.0 & 5.9891 & TRN \\
\hline CHEMBL 3983447 & 1641033 & 6.3872 & 5.9907 & TRN \\
\hline CHEMBL 3975090 & 1641033 & 5.0 & 5.6218 & TRN \\
\hline CHEMBL3960910 & 1641033 & 7.1135 & 6.4639 & TRN \\
\hline CHEMBL3908073 & 1641033 & 5.0 & 6.2303 & TST \\
\hline CHEMBL3906687 & 1641033 & 6.2366 & 5.8441 & TRN \\
\hline CHEMBL 3983344 & 1641033 & 6.1249 & 6.1137 & TRN \\
\hline CHEMBL3927649 & 1641033 & 7.3768 & 6.8522 & TRN \\
\hline CHEMBL3949461 & 1641033 & 6.0458 & 5.8008 & TRN \\
\hline CHEMBL3923711 & 1641033 & 5.0 & 6.2247 & TRN \\
\hline CHEMBL3935688 & 1641033 & 6.1367 & 6.1031 & TRN \\
\hline CHEMBL3977496 & 1641033 & 5.3665 & 4.8863 & TRN \\
\hline CHEMBL 3890660 & 1641033 & 5.0 & 5.1003 & TRN \\
\hline CHEMBL3917056 & 1641033 & 6.1871 & 5.8235 & TRN \\
\hline CHEMBL 3912553 & 1641033 & 8.0088 & 6.7353 & TRN \\
\hline CHEMBL 3900224 & 1641033 & 5.0 & 6.2928 & TRN \\
\hline CHEMBL 3973072 & 1641033 & 5.0 & 5.7396 & TRN \\
\hline CHEMBL3981130 & 1641033 & 6.585 & 5.9669 & TRN \\
\hline CHEMBL 3905617 & 1641033 & 5.0 & 5.4002 & TRN \\
\hline CHEMBL 3978202 & 1641033 & 6.9586 & 6.8284 & TRN \\
\hline CHEMBL 3921202 & 1641033 & 5.0 & 5.8259 & TRN \\
\hline CHEMBL 3905358 & 1641033 & 5.0 & 5.4624 & TST \\
\hline CHEMBL3956611 & 1641033 & 6.0 & \multicolumn{2}{|c|}{ 4.7989999999999995 } \\
\hline CHEMBL 3929398 & 1641033 & 5.0 & 5.2816 & TRN \\
\hline CHEMBL 3931293 & 1641033 & 5.0 & 5.2616 & TST \\
\hline CHEMBL 3951060 & 1641033 & 6.1079 & 6.0057 & TRN \\
\hline
\end{tabular}

Page 7308 


\begin{tabular}{|c|c|c|c|c|c|}
\hline \multicolumn{6}{|c|}{ Supplemental Table S2.txt } \\
\hline CHEMBL3900631 & 1641033 & 5.0 & 6.0168 & TRN & \\
\hline CHEMBL3899570 & 1641033 & 6.2076 & 6.2549 & TRN & \\
\hline CHEMBL3962117 & 1641033 & 6.301 & 6.1835 & TRN & \\
\hline CHEMBL 3894161 & 1641033 & 7.4949 & 6.7133 & TRN & \\
\hline CHEMBL 3922180 & 1641033 & 6.2007 & 5.6441 & TRN & \\
\hline CHEMBL3985119 & 1641033 & 6.4202 & 6.2067 & TRN & \\
\hline CHEMBL3986618 & 1641033 & 7.1487 & 6.6386 & TRN & \\
\hline CHEMBL3902992 & 1641033 & 6.0 & 5.2819 & TRN & \\
\hline CHEMBL3945787 & 1641033 & 6.2757 & 5.7927 & TRN & \\
\hline CHEMBL3978620 & 1641033 & 6.7447 & 6.2818 & TRN & \\
\hline CHEMBL3921442 & 1641033 & 5.0 & 6.3979 & TRN & \\
\hline CHEMBL3920329 & 1641033 & 7.4559 & 6.4716 & TRN & \\
\hline CHEMBL3981393 & 1641033 & 6.6383 & 6.4093 & TRN & \\
\hline CHEMBL3934943 & 1641033 & 6.2076 & 5.7609 & TRN & \\
\hline CHEMBL3949248 & 1641033 & 6.284 & 6.26399 & 9999999999 & TRN \\
\hline CHEMBL3903353 & 1641033 & 5.0 & 5.322 & TRN & \\
\hline CHEMBL 3972475 & 1641033 & 7.6198 & 7.2063 & TRN & \\
\hline CHEMBL3933612 & 1641033 & 5.0 & 5.3484 & TST & \\
\hline CHEMBL3969811 & 1641033 & 6.1675 & 5.5902 & TRN & \\
\hline CHEMBL3947749 & 1641033 & 5.0 & 5.7387 & TRN & \\
\hline CHEMBL3927682 & 1641033 & 5.0 & 5.6115 & TST & \\
\hline CHEMBL 3943994 & 1641033 & 6.1487 & 6.5279 & TRN & \\
\hline CHEMBL3897849 & 1641033 & 6.2366 & 6.1475 & TRN & \\
\hline CHEMBL3957937 & 1641033 & 6.6576 & 6.2989 & TRN & \\
\hline CHEMBL3930431 & 1641033 & 6.2441 & 6.1425 & TRN & \\
\hline CHEMBL3913693 & 1641033 & 5.0 & 5.8245 & TRN & \\
\hline CHEMBL3919766 & 1641033 & 6.2518 & 6.1593 & TRN & \\
\hline CHEMBL3973060 & 1641033 & 6.2076 & 5.6708 & TST & \\
\hline CHEMBL 3897850 & 1641033 & 5.0 & 4.5581 & TRN & \\
\hline CHEMBL3902205 & 1641033 & 6.8239 & 5.8042 & TRN & \\
\hline CHEMBL3918854 & 1641033 & 6.5086 & 5.8912 & TRN & \\
\hline CHEMBL3935408 & 1641033 & 6.2441 & 6.053 & TST & \\
\hline CHEMBL3973429 & 1641033 & 6.4202 & 5.5522 & TRN & \\
\hline CHEMBL3926894 & 1641033 & 6.7447 & 6.1298 & TRN & \\
\hline CHEMBL3976356 & 1641033 & 5.0 & 5.2288 & TRN & \\
\hline CHEMBL3980369 & 1641033 & 5.0 & 5.5177 & TRN & \\
\hline CHEMBL3891030 & 1641033 & 6.5086 & 6.4129 & TRN & \\
\hline CHEMBL3920352 & 1641033 & 5.0 & 4.3767 & TRN & \\
\hline CHEMBL3986686 & 1641033 & 6.0 & 5.3749 & TRN & \\
\hline CHEMBL3906210 & 1641033 & 5.0 & 6.2445 & TRN & \\
\hline CHEMBL3901676 & 1641033 & 5.0 & 5.1867 & TRN & \\
\hline CHEMBL3972962 & 1641033 & 5.0 & 5.5373 & TRN & \\
\hline CHEMBL3946758 & 1641033 & 5.0 & 6.1285 & TRN & \\
\hline CHEMBL3906986 & 1641033 & 5.0 & 6.1324 & TRN & \\
\hline CHEMBL3956418 & 1641033 & 6.4949 & 6.4047 & TRN & \\
\hline CHEMBL3955720 & 1641033 & 6.5686 & 6.7414 & TRN & \\
\hline CHEMBL3980992 & 1641033 & 5.0 & 5.8977 & TRN & \\
\hline CHEMBL3915165 & 1641033 & 5.0 & 5.7634 & TRN & \\
\hline
\end{tabular}


Supplemental Table S2.txt

\begin{tabular}{|c|c|c|c|c|c|}
\hline CHEMBL3968041 & 1641033 & 6.4318 & 6.9047 & TRN & \\
\hline CHEMBL3927252 & 1641033 & 7.5229 & 7.1677 & TRN & \\
\hline CHEMBL3896712 & 1641033 & 5.2757 & 4.9209 & TRN & \\
\hline CHEMBL 3973276 & 1641033 & 5.0 & 4.6947 & TRN & \\
\hline CHEMBL3970198 & 1641033 & 5.0 & 5.5737 & TRN & \\
\hline CHEMBL 3900724 & 1641033 & 5.0 & 4.6893 & TRN & \\
\hline CHEMBL 3949242 & 1641033 & 6.4815 & 6.0282 & TRN & \\
\hline CHEMBL 3915844 & 1641033 & 6.3979 & 5.5156 & TST & \\
\hline CHEMBL 3919034 & 1641033 & 5.0 & 5.8507 & TST & \\
\hline CHEMBL3933671 & 1641033 & 5.0 & 5.1314 & TRN & \\
\hline CHEMBL 3924291 & 1641033 & 5.8539 & 5.4506 & TST & \\
\hline CHEMBL 3899587 & 1641033 & 5.0 & 4.9347 & TST & \\
\hline CHEMBL3981443 & 1641033 & 6.3565 & \multicolumn{2}{|c|}{6.071000000000001} & TRN \\
\hline CHEMBL3926817 & 1641033 & 6.7696 & 6.6189 & TRN & \\
\hline CHEMBL3932581 & 1641033 & 6.3188 & 5.6918 & TST & \\
\hline CHEMBL3912503 & 1641033 & 6.0 & 5.1921 & TRN & \\
\hline CHEMBL3892296 & 1641033 & 7.3188 & 6.731 & TRN & \\
\hline CHEMBL3944831 & 1641033 & 6.4202 & 6.1272 & TRN & \\
\hline CHEMBL3896566 & 1641033 & 6.3872 & 6.5946 & TRN & \\
\hline CHEMBL3973017 & 1641033 & 5.0 & 5.4131 & TRN & \\
\hline CHEMBL 3909793 & 1641033 & 5.0 & 4.9123 & TRN & \\
\hline CHEMBL3977017 & 1641033 & 7.3979 & 6.5838 & TRN & \\
\hline CHEMBL3904571 & 1641033 & 6.6576 & 6.5516 & TRN & \\
\hline CHEMBL 3906967 & 1641033 & 6.0 & 5.1529 & TRN & \\
\hline CHEMBL3899650 & 1641033 & 5.0 & 5.6631 & TRN & \\
\hline CHEMBL 3940782 & 1641033 & 6.3979 & 6.1681 & TRN & \\
\hline CHEMBL 3938277 & 1641033 & 5.0 & 5.5912 & TST & \\
\hline CHEMBL3905498 & 1641033 & 6.2147 & 6.1949 & TRN & \\
\hline CHEMBL 3902333 & 1641033 & 5.0 & 6.067 & TRN & \\
\hline CHEMBL 3889789 & 1641033 & 6.0 & 4.8896 & TST & \\
\hline CHEMBL 3902428 & 1641033 & 5.0 & \multicolumn{2}{|c|}{5.672000000000001} & TRN \\
\hline CHEMBL3924572 & 1641033 & 6.7696 & 6.5221 & TRN & \\
\hline CHEMBL3911186 & 1641033 & 5.0 & 5.7137 & TRN & \\
\hline CHEMBL3903941 & 1641033 & 5.0 & 4.7326 & TRN & \\
\hline CHEMBL3905627 & 1641033 & 7.2596 & 7.0376 & TRN & \\
\hline CHEMBL3951107 & 1641033 & 7.5229 & 7.0321 & TRN & \\
\hline CHEMBL3907503 & 1641033 & 6.1487 & 6.2035 & TRN & \\
\hline CHEMBL3937822 & 1641033 & 5.0 & 5.5566 & TST & \\
\hline CHEMBL3939232 & 1641033 & 6.1024 & 6.0801 & TRN & \\
\hline CHEMBL3958797 & 1641033 & 6.6576 & 5.9965 & TRN & \\
\hline CHEMBL3923513 & 1641033 & 6.7447 & 6.9 & TRN & \\
\hline CHEMBL3892562 & 1641033 & 5.0 & 5.1314 & TRN & \\
\hline CHEMBL3896784 & 1641033 & 6.0 & 5.0174 & TRN & \\
\hline CHEMBL 3941925 & 1641033 & 6.6198 & 6.527 & TST & \\
\hline CHEMBL3962364 & 1641033 & 5.0 & 4.9445 & TRN & \\
\hline CHEMBL 3894366 & 1641033 & 5.0 & 5.7931 & TRN & \\
\hline CHEMBL3907394 & 1641033 & 5.0 & 5.4393 & TRN & \\
\hline CHEMBL3904453 & 1641033 & 5.0 & 5.1836 & TRN & \\
\hline
\end{tabular}


Supplemental Table S2.txt

\begin{tabular}{|c|c|c|c|c|}
\hline CHEMBL 3934440 & 1641033 & 6.3098 & 5.8694 & TRN \\
\hline CHEMBL3985390 & 1641033 & 6.3188 & 5.8119 & TRN \\
\hline CHEMBL3925854 & 1641033 & 7.0 & 6.4795 & TRN \\
\hline CHEMBL 3963480 & 1641033 & 6.2291 & 5.731 & TST \\
\hline CHEMBL3952261 & 1641033 & 7.2676 & 6.749 & TRN \\
\hline CHEMBL3962138 & 1641033 & 6.5528 & 6.3851 & TRN \\
\hline CHEMBL3917774 & 1641033 & 7.0655 & 6.6406 & TRN \\
\hline CHEMBL3972506 & 1641033 & 6.5528 & 6.4777 & TRN \\
\hline CHEMBL 3940267 & 1641033 & 6.5086 & 6.6209 & TRN \\
\hline CHEMBL 3984424 & 1641033 & 6.0 & 4.9187 & TRN \\
\hline CHEMBL3933458 & 1641033 & 5.0 & 5.0256 & TRN \\
\hline CHEMBL3976885 & 1641033 & 5.0 & 5.2154 & TRN \\
\hline CHEMBL3919050 & 1641033 & 6.1249 & 6.4006 & TRN \\
\hline CHEMBL3931935 & 1641033 & 5.0 & 4.7212 & TRN \\
\hline CHEMBL 3964008 & 1641033 & 7.1024 & 6.2844 & TRN \\
\hline CHEMBL3904186 & 1641033 & 6.0757 & 6.1964 & TRN \\
\hline CHEMBL3971373 & 1641033 & 6.2676 & 6.2841 & TRN \\
\hline CHEMBL 3949323 & 1641033 & 6.6576 & 6.6425 & TRN \\
\hline CHEMBL3892159 & 1641033 & 6.1739 & 6.0749 & TRN \\
\hline CHEMBL3949285 & 1641033 & 7.3872 & 7.066 & TRN \\
\hline CHEMBL 3904312 & 1641033 & 6.3665 & 6.3265 & TRN \\
\hline CHEMBL3963387 & 1641033 & 6.284 & 5.9514 & TRN \\
\hline CHEMBL3958601 & 1641033 & 5.0 & 5.4298 & TST \\
\hline CHEMBL3959556 & 1641033 & 5.0 & 6.232 & TRN \\
\hline CHEMBL3975158 & 1641033 & 6.3279 & 6.3035 & TRN \\
\hline CHEMBL3940483 & 1641033 & 5.0 & 5.6933 & TRN \\
\hline CHEMBL 3922240 & 1641033 & 7.2676 & 6.5901 & TRN \\
\hline CHEMBL3965670 & 1641033 & 6.4685 & 6.4146 & TST \\
\hline CHEMBL3962300 & 1641033 & 5.0 & 5.8944 & TRN \\
\hline CHEMBL3910017 & 1641033 & 5.0 & 5.7186 & TRN \\
\hline CHEMBL3902123 & 1641033 & 6.5528 & 6.308 & TRN \\
\hline CHEMBL3957990 & 1641033 & 6.7959 & 6.6393 & TRN \\
\hline CHEMBL 3948605 & 1641033 & 7.2147 & 6.4146 & TST \\
\hline CHEMBL3922520 & 1641033 & 6.4559 & 6.1127 & TRN \\
\hline CHEMBL3967735 & 1641033 & 6.0 & 5.2288 & TRN \\
\hline CHEMBL3902431 & 1641033 & 6.6576 & 5.8 & TST \\
\hline CHEMBL3936877 & 1641033 & 6.6383 & 6.4114 & TRN \\
\hline CHEMBL 3942741 & 1641033 & 7.1871 & 6.7964 & TRN \\
\hline CHEMBL 3926748 & 1641033 & 5.0 & 5.3437 & TRN \\
\hline CHEMBL3918308 & 1641033 & 7.1308 & 7.2554 & TRN \\
\hline CHEMBL 3975088 & 1641033 & 6.1308 & 6.4773 & TRN \\
\hline CHEMBL3963555 & 1641033 & 6.0458 & 5.6428 & TST \\
\hline CHEMBL 3937326 & 1641033 & 5.0 & 5.6061 & TRN \\
\hline CHEMBL3913397 & 1641033 & 5.0 & 6.0649 & TRN \\
\hline CHEMBL3907770 & 1641033 & 6.6383 & 6.4671 & TRN \\
\hline CHEMBL 3894516 & 1641033 & 6.1612 & 6.3943 & TRN \\
\hline CHEMBL 3937827 & 1641033 & 5.0 & \multicolumn{2}{|c|}{5.667000000000001} \\
\hline CHEMBL3986377 & 1641033 & 7.0969 & 6.6497 & TRN \\
\hline
\end{tabular}

Page 7311 


\begin{tabular}{|c|c|c|c|c|}
\hline \multicolumn{5}{|c|}{ Supplemental Table S2.txt } \\
\hline CHEMBL3939331 & 1641033 & 5.0 & 5.4873 & TRN \\
\hline CHEMBL3953229 & 1641033 & 6.699 & 6.9893 & TRN \\
\hline CHEMBL3920091 & 1641033 & 6.8539 & 6.7857 & TST \\
\hline CHEMBL3917860 & 1641033 & 5.0 & 5.9268 & TRN \\
\hline CHEMBL 3945378 & 1641033 & 5.0 & 6.0296 & TRN \\
\hline CHEMBL3967749 & 1641033 & 7.2596 & 6.9783 & TRN \\
\hline CHEMBL3936565 & 1641033 & 6.0223 & 6.0316 & TRN \\
\hline CHEMBL3977129 & 1641033 & 5.0 & 6.1487 & TRN \\
\hline CHEMBL3941431 & 1641033 & 6.1024 & 6.1301 & TRN \\
\hline CHEMBL3986660 & 1641033 & 6.2924 & 6.3827 & TRN \\
\hline CHEMBL3972353 & 1641033 & 6.8861 & 6.3907 & TRN \\
\hline CHEMBL3943501 & 1641033 & 5.0 & 5.983 & TRN \\
\hline CHEMBL3939325 & 1641033 & 6.8239 & 5.8965 & TRN \\
\hline CHEMBL 3897648 & 1641033 & 5.0 & 5.7037 & TRN \\
\hline CHEMBL3953550 & 1641033 & 7.5086 & 6.5536 & TRN \\
\hline CHEMBL3934116 & 1641033 & 7.2676 & 6.9916 & TRN \\
\hline CHEMBL3971898 & 1641033 & 6.0132 & 5.7021 & TRN \\
\hline CHEMBL3908040 & 1641033 & 6.5086 & 6.4717 & TRN \\
\hline CHEMBL3984562 & 1641033 & 7.5229 & 7.3473 & TRN \\
\hline CHEMBL3965217 & 1641033 & 6.3565 & 6.06 & TRN \\
\hline CHEMBL3949195 & 1641033 & 5.0 & 4.9071 & TRN \\
\hline CHEMBL3917783 & 1641033 & 5.0 & 5.3343 & TST \\
\hline CHEMBL3973302 & 1641033 & 6.0969 & 6.3854 & TRN \\
\hline CHEMBL3961357 & 1641033 & 6.4949 & 6.2639 & TRN \\
\hline CHEMBL3963532 & 1641033 & 5.8539 & 5.5761 & TST \\
\hline CHEMBL3931435 & 1641033 & 5.0 & 5.7333 & TST \\
\hline CHEMBL 3894535 & 1641033 & 6.2147 & 6.1095 & TST \\
\hline CHEMBL3963994 & 1641033 & 5.0 & 5.4397 & TRN \\
\hline CHEMBL3934426 & 1641033 & 6.3098 & 6.3369 & TRN \\
\hline CHEMBL3935714 & 1641033 & 6.3665 & 6.266 & TST \\
\hline CHEMBL3965485 & 1641033 & 5.0 & 5.018 & TRN \\
\hline CHEMBL3926766 & 1641033 & 6.8239 & 6.5645 & TST \\
\hline CHEMBL3907648 & 1641033 & 6.3188 & 5.7513 & TRN \\
\hline CHEMBL3896766 & 1641033 & 5.0 & 6.0695 & TRN \\
\hline CHEMBL3899634 & 1641033 & 7.4318 & 6.8633 & TRN \\
\hline CHEMBL3943768 & 1641033 & 5.0 & 5.3512 & TST \\
\hline CHEMBL 3934580 & 1641033 & 7.2757 & 6.9174 & TRN \\
\hline CHEMBL3956911 & 1641033 & 6.0 & 4.9356 & TRN \\
\hline CHEMBL3975123 & 1641033 & 5.0 & 5.2662 & TRN \\
\hline CHEMBL 3951710 & 1641033 & 5.0 & 5.6695 & TRN \\
\hline CHEMBL 3976587 & 1641033 & 5.0 & 5.9649 & TRN \\
\hline CHEMBL3973486 & 1641033 & 5.0 & 5.2652 & TRN \\
\hline CHEMBL 3892138 & 1641033 & 6.585 & 6.3281 & TRN \\
\hline CHEMBL3960109 & 1641033 & 6.2757 & 6.1983 & TST \\
\hline CHEMBL3948921 & 1641033 & 6.0969 & 6.3435 & TRN \\
\hline CHEMBL3950680 & 1641033 & 6.6021 & 6.5434 & TRN \\
\hline CHEMBL3916915 & 1641033 & 7.1079 & 6.2208 & TRN \\
\hline CHEMBL3975250 & 1641033 & 5.0 & 6.0791 & TRN \\
\hline
\end{tabular}




\begin{tabular}{|c|c|c|c|c|c|}
\hline \multicolumn{6}{|c|}{ Supplemental Table S2.txt } \\
\hline CHEMBL3956966 & 1641033 & 5.0 & 5.8497 & TST & \\
\hline CHEMBL3956550 & 1641033 & 5.0 & 5.7466 & TRN & \\
\hline CHEMBL3973102 & 1641033 & 6.0 & 5.1713 & TRN & \\
\hline CHEMBL3900738 & 1641033 & 5.0 & 5.5203 & TRN & \\
\hline CHEMBL3909814 & 1641033 & 6.6198 & 5.9171 & TRN & \\
\hline CHEMBL3902256 & 1641033 & 5.0 & 4.7124 & TRN & \\
\hline CHEMBL3931713 & 1641033 & 6.2757 & 6.0019 & TRN & \\
\hline CHEMBL3972033 & 1641033 & 6.4437 & 6.2711 & TRN & \\
\hline CHEMBL3970109 & 1641033 & 5.0 & 5.4815 & TRN & \\
\hline CHEMBL3896324 & 1641033 & 7.1612 & 6.7243 & TRN & \\
\hline CHEMBL3985597 & 1641033 & 5.1612 & 4.9851 & TRN & \\
\hline CHEMBL3943946 & 1641033 & 5.0 & 4.6258 & TRN & \\
\hline CHEMBL3922303 & 1641033 & 5.0 & 5.7211 & TST & \\
\hline CHEMBL3950399 & 1641033 & 5.0 & 5.7813 & TRN & \\
\hline CHEMBL3981338 & 1641033 & 6.3872 & 6.32600 & 00000000005 & TRN \\
\hline CHEMBL3951230 & 1641033 & 6.699 & 6.5653 & TRN & \\
\hline CHEMBL3983856 & 1641033 & 5.0 & 5.6358 & TRN & \\
\hline CHEMBL3986588 & 1641033 & 5.0 & 5.7194 & TRN & \\
\hline CHEMBL3922488 & 1641033 & 5.0 & 5.5711 & TRN & \\
\hline CHEMBL3954894 & 1641033 & 7.4949 & 7.4391 & TRN & \\
\hline CHEMBL3956945 & 1641033 & 7.0862 & 6.2661 & TRN & \\
\hline CHEMBL3931093 & 1641033 & 7.8239 & 7.0505 & TRN & \\
\hline CHEMBL3907944 & 1641033 & 5.0 & 6.1299 & TRN & \\
\hline CHEMBL3927827 & 1641033 & 5.0 & 6.0014 & TST & \\
\hline CHEMBL3910680 & 1641033 & 5.0 & 5.52 & TRN & \\
\hline CHEMBL3947782 & 1641033 & 5.0 & 6.1823 & TRN & \\
\hline CHEMBL3975255 & 1641033 & 5.0 & 4.8033 & TRN & \\
\hline CHEMBL3909751 & 1641033 & 6.1249 & 5.7714 & TRN & \\
\hline CHEMBL3963319 & 1641033 & 6.3565 & 5.0369 & TRN & \\
\hline CHEMBL3916457 & 1641033 & 6.3279 & 6.5231 & TRN & \\
\hline CHEMBL3909024 & 1641033 & 6.2441 & 6.3766 & TST & \\
\hline CHEMBL3934192 & 1641033 & 5.0 & 6.0688 & TRN & \\
\hline CHEMBL3911142 & 1641033 & 6.6198 & 6.4373 & TRN & \\
\hline CHEMBL3964133 & 1641033 & 6.0177 & 5.9063 & TRN & \\
\hline CHEMBL3969473 & 1641033 & 6.8239 & 6.6406 & TRN & \\
\hline CHEMBL3906872 & 1641033 & 6.0 & 5.4571 & TST & \\
\hline CHEMBL3947889 & 1641033 & 6.2757 & 6.2645 & TRN & \\
\hline CHEMBL3935174 & 1641033 & 5.0 & 5.3011 & TRN & \\
\hline CHEMBL3954792 & 1641033 & 5.0 & 5.354 & TRN & \\
\hline CHEMBL 3980120 & 1641033 & 5.0 & 5.8056 & TRN & \\
\hline CHEMBL3891947 & 1641033 & 6.5528 & 6.6872 & TRN & \\
\hline CHEMBL3908624 & 1641033 & 6.284 & 6.2398 & TRN & \\
\hline CHEMBL3936616 & 1641033 & 6.2757 & 5.8063 & TRN & \\
\hline CHEMBL3896777 & 1641033 & 6.6778 & 6.2012 & TRN & \\
\hline CHEMBL3983231 & 1641033 & 6.0 & 4.784 & TRN & \\
\hline CHEMBL3945740 & 1641033 & 6.301 & 6.0441 & TST & \\
\hline CHEMBL3929124 & 1641033 & 6.4089 & 6.5038 & TRN & \\
\hline CHEMBL3931226 & 1641033 & 6.7696 & 6.3314 & TRN & \\
\hline
\end{tabular}


Supplemental Table S2.txt

\begin{tabular}{|c|c|c|c|c|}
\hline HEMBL3969865 & & & 5.8655 & TST \\
\hline HFMRI 3965397 & & 6.1427 & 61812 & \\
\hline HEMBL39856 & & 605 & & \\
\hline HEMBL3906460 & 641033 & 5.0 & 5378 & \\
\hline HEMBL3933397 & 641033 & 5.0 & 3433 & \\
\hline HEMBL3930389 & 333 & 6.7696 & 5994 & \\
\hline AEMBL3967397 & & & 521 & \\
\hline HEMBL3896461 & 233 & 5.0 & 6973 & \\
\hline HEMBL3946125 & 233 & 7.1192 & 3301 & \\
\hline HEMBL3907076 & 233 & 5.0 & 9924 & \\
\hline HEMBL3962689 & 33 & 5 & 533 & \\
\hline HEMBL3949040 & & 1 & 759 & \\
\hline HEMBL3896215 & 33 & & 174 & \\
\hline HEMBL3953381 & 33 & & 1803 & \\
\hline HEMBL3972067 & 33 & 5 . & 606 & \\
\hline AEMBL & 33 & 6 & 95 & \\
\hline HEMBL; & & & & \\
\hline HEMBL & 33 & 6 . & 991 & \\
\hline HEMBL3 & & 6. & 3753 & \\
\hline AEMBL3945676 & 33 & 6. & 865 & KIV \\
\hline AEMBL & 33 & & 963 & \\
\hline AEMBL & & & & NIV \\
\hline HEMBL; & & 6 . & 46 & \\
\hline HEMBL & & 5.0 & & \\
\hline AEMBL3916687 & 33 & 86 & 61 & RN \\
\hline AEMBL 3 & & & 45 & RN \\
\hline HEMBL & & & & $\mathrm{RN}$ \\
\hline ALMP & & 5. & & \\
\hline AEMBL & & & & IRN \\
\hline AEMBL3942459 & 33 & 5. & 677 & RN \\
\hline AEMBL & & & & RN \\
\hline HFM & & & & RN \\
\hline & & & & TST \\
\hline AEMBL3 & & & & 「RN \\
\hline HEMBL3946824 & 33 & 6. & 974 & 「RN \\
\hline HEMBL3 & & 5 & 877 & RN \\
\hline לים & & & & RN \\
\hline HEMBL3 & & & 474 & TRN \\
\hline HEMBL3956450 & & 6.481 & 348 & $\Gamma \mathrm{R}$ \\
\hline AEMBL3900189 & 6 & 5. & 845 & TST \\
\hline HEMBL 3983078 & & 7. & & \\
\hline HEMBL3912419 & & 6.2 & 115 & $\mathrm{RN}$ \\
\hline HEMBL 3986443 & & 5.0 & 282 & TRN \\
\hline AEMBL3973343 & & 6 & 644 & TR \\
\hline EMBL3 & & 7. & 5712 & TST \\
\hline CHEMBL3921365 & & & 4.7142 & \\
\hline CHEMBL3936927 & & 5.0 & 4.5424 & \\
\hline CHEMBL3978366 & 1641033 & 6.0269 & 5.9853 & \\
\hline
\end{tabular}

Page 7314 
Supplemental Table S2.txt

\begin{tabular}{|c|c|c|c|c|}
\hline CHEMBL 3947422 & 1641033 & 5.0 & 4.5477 & TRN \\
\hline CHEMBL3937067 & 1641033 & 7.2676 & 7.0229 & TRN \\
\hline CHEMBL3938593 & 1641033 & 6.4685 & 6.1085 & TRN \\
\hline CHEMBL 3959789 & 1641033 & 5.0 & 4.5133 & TST \\
\hline CHEMBL 3924171 & 1641033 & 5.0 & 4.6086 & TRN \\
\hline CHEMBL 3893196 & 1641033 & 5.0 & 5.5391 & TRN \\
\hline CHEMBL3916636 & 1641033 & 6.4089 & 6.4523 & TRN \\
\hline CHEMBL3941680 & 1641033 & 5.0 & 5.50299 & 9999999999 \\
\hline CHEMBL 3889588 & 1641033 & 6.0809 & 6.3083 & TST \\
\hline CHEMBL3898916 & 1641033 & 5.0 & 4.4189 & TST \\
\hline CHEMBL 3913565 & 1641033 & 6.4949 & 6.1833 & TST \\
\hline CHEMBL3927316 & 1641033 & 5.0 & 4.6696 & TST \\
\hline CHEMBL 3898818 & 1641033 & 6.5376 & 6.3299 & TST \\
\hline CHEMBL3974989 & 1641033 & 6.6198 & 6.5254 & TST \\
\hline CHEMBL 3962051 & 1641033 & 6.6021 & 6.6111 & TST \\
\hline CHEMBL 3931368 & 1641033 & 5.0 & 5.7115 & TST \\
\hline CHEMBL3978777 & 1641033 & 5.0 & 5.5168 & TST \\
\hline CHEMBL 3932456 & 1641033 & 6.2147 & 6.313 & TST \\
\hline CHEMBL 3965520 & 1641033 & 5.0 & 5.7031 & TST \\
\hline CHEMBL 3974289 & 1641033 & 6.0 & 5.003 & TST \\
\hline CHEMBL3955793 & 1641033 & 5.0 & 5.1417 & TST \\
\hline CHEMBL3985220 & 1641033 & 6.3098 & 6.5751 & TST \\
\hline CHEMBL 3913228 & 1641033 & 5.0 & 5.0675 & TST \\
\hline CHEMBL 3983303 & 1641033 & 5.0 & 5.0583 & TST \\
\hline CHEMBL 3890951 & 1641033 & 5.0 & 4.9947 & TST \\
\hline CHEMBL 3940421 & 1641033 & 5.0 & 5.5982 & TST \\
\hline CHEMBL 3940644 & 1641033 & 5.0 & 5.845 & TST \\
\hline CHEMBL3957659 & 1641033 & 6.4559 & 6.3746 & TST \\
\hline CHEMBL 3955496 & 1641033 & 6.3665 & 6.1172 & TST \\
\hline CHEMBL3944859 & 1641033 & 6.9208 & 6.8999 & TST \\
\hline CHEMBL 3974904 & 1641033 & 5.0 & 4.5454 & TST \\
\hline CHEMBL3941598 & 1641033 & 6.2147 & 5.7919 & TST \\
\hline CHEMBL 3981542 & 1641033 & 5.0 & 6.2887 & TST \\
\hline CHEMBL3938956 & 1641033 & 5.0 & 5.9779 & TST \\
\hline CHEMBL 3897798 & 1641033 & 7.3872 & 6.4551 & TST \\
\hline CHEMBL3985243 & 1641033 & 7.2441 & 6.7284 & TST \\
\hline CHEMBL 3891204 & 1641033 & 6.1871 & 5.8475 & TST \\
\hline CHEMBL3955124 & 1641033 & 5.0 & 5.3329 & TST \\
\hline CHEMBL3917954 & 1641033 & 6.0706 & 6.0505 & TST \\
\hline CHEMBL3953486 & 1641033 & 6.7696 & 6.3449 & TST \\
\hline CHEMBL3902770 & 1641033 & 5.0 & 5.4892 & TST \\
\hline CHEMBL3940316 & 1641033 & 5.0 & 5.3317 & TST \\
\hline CHEMBL3958508 & 1641033 & 5.0 & 5.5535 & TST \\
\hline CHEMBL3948691 & 1641033 & 6.5528 & 6.5166 & TST \\
\hline CHEMBL 3923184 & 1641033 & 6.4089 & 6.3552 & TST \\
\hline CHEMBL3917030 & 1641033 & 6.1938 & 5.749 & TST \\
\hline CHEMBL3934664 & 1641033 & 6.284 & 5.8289 & TST \\
\hline CHEMBL 3902447 & 1641033 & 5.0 & 5.1736 & TST \\
\hline
\end{tabular}


Supplemental Table S2.txt

\begin{tabular}{|c|c|c|c|c|}
\hline CHEMBL3983127 & 1641033 & 6.0315 & 5.8647 & TST \\
\hline CHEMBL3971717 & 1641033 & 5.0 & 5.8897 & TST \\
\hline CHEMBL3942304 & 1641033 & 5.0 & 6.0179 & TST \\
\hline CHEMBL3911332 & 1641033 & 5.0 & 5.0929 & TST \\
\hline CHEMBL3361183 & 1443970 & 5.66 & 6.022 & TRN \\
\hline CHEMBL3361175 & 1443970 & 5.9622 & 5.9321 & TRN \\
\hline CHEMBL3360666 & 1443970 & 6.2381 & 6.631 & TRN \\
\hline CHEMBL3361207 & 1443970 & 5.2979 & 5.0609 & TRN \\
\hline CHEMBL3361192 & 1443970 & 6.0061 & 6.6521 & TRN \\
\hline CHEMBL3360644 & 1443970 & 4.6882 & 4.7344 & TST \\
\hline CHEMBL3361198 & 1443970 & 5.7749 & 6.0107 & TRN \\
\hline CHEMBL3361199 & 1443970 & 6.3242 & 5.971 & TRN \\
\hline CHEMBL3361173 & 1443970 & 6.6556 & 6.4291 & TRN \\
\hline CHEMBL3360654 & 1443970 & 4.9431 & 5.3836 & TRN \\
\hline CHEMBL3360668 & 1443970 & 6.3161 & 6.4807 & TRN \\
\hline CHEMBL3361210 & 1443970 & 7.3372 & 7.0515 & TRN \\
\hline CHEMBL3360672 & 1443970 & 6.056 & 7.0582 & TST \\
\hline CHEMBL3360657 & 1443970 & 5.5686 & 4.7238 & TRN \\
\hline CHEMBL3360643 & 1443970 & 3.4318 & 5.3637 & TST \\
\hline CHEMBL3360642 & 1443970 & 4.6655 & 4.2384 & TST \\
\hline CHEMBL3360669 & 1443970 & 6.2652 & \multicolumn{2}{|c|}{5.837000000000001} \\
\hline CHEMBL 3361180 & 1443970 & 6.2441 & 6.1295 & TRN \\
\hline CHEMBL3361211 & 1443970 & 7.0605 & 6.8704 & TRN \\
\hline CHEMBL3361209 & 1443970 & 4.0 & 5.0799 & TRN \\
\hline CHEMBL 3360650 & 1443970 & 5.585 & 4.7392 & TRN \\
\hline CHEMBL3361216 & 1443970 & 7.2291 & 7.4217 & TRN \\
\hline CHEMBL3360664 & 1443970 & 6.1549 & 6.1223 & TRN \\
\hline CHEMBL3361188 & 1443970 & 6.8962 & 6.5124 & TRN \\
\hline CHEMBL3352905 & 1443970 & 6.8268 & 6.0849 & TRN \\
\hline CHEMBL3361217 & 1443970 & 7.0506 & 6.6266 & TRN \\
\hline CHEMBL 3360645 & 1443970 & 3.4318 & 4.1404 & TST \\
\hline CHEMBL3361222 & 1443970 & 6.5243 & 6.7632 & TRN \\
\hline CHEMBL3361174 & 1443970 & 6.0357 & 5.8113 & TRN \\
\hline CHEMBL3360661 & 1443970 & 6.5229 & 6.2433 & TRN \\
\hline CHEMBL3361191 & 1443970 & 6.5784 & 6.2085 & TRN \\
\hline CHEMBL3361203 & 1443970 & 5.1186 & 5.3999 & TRN \\
\hline CHEMBL3361189 & 1443970 & 6.3487 & 6.9652 & TRN \\
\hline CHEMBL3361213 & 1443970 & 6.8697 & 7.0341 & TRN \\
\hline CHEMBL3361197 & 1443970 & 5.0526 & 4.4308 & TRN \\
\hline CHEMBL3361178 & 1443970 & 7.2218 & 6.7923 & TRN \\
\hline CHEMBL3361176 & 1443970 & 5.6598 & 5.9264 & TRN \\
\hline CHEMBL3361201 & 1443970 & 5.2483 & 5.2656 & TRN \\
\hline CHEMBL3361200 & 1443970 & 5.5588 & 5.8327 & TRN \\
\hline CHEMBL1404283 & 1443970 & 5.3188 & 4.0852 & TST \\
\hline CHEMBL3360649 & 1443970 & 3.4318 & 5.6837 & TST \\
\hline CHEMBL3361190 & 1443970 & 6.8761 & 6.6626 & TRN \\
\hline CHEMBL3361220 & 1443970 & 6.6536 & 6.8695 & TRN \\
\hline CHEMBL3361171 & 1443970 & 6.2388 & 6.2489 & TRN \\
\hline
\end{tabular}


Supplemental Table S2.txt

\begin{tabular}{|c|c|c|c|c|c|}
\hline CHEMBL3361186 & 1443970 & 5.3652 & 5.3591 & TRN & \\
\hline CHEMBL 3361218 & 1443970 & 6.9914 & 6.8198 & TRN & \\
\hline CHEMBL 3361219 & 1443970 & 6.9747 & 6.7699 & TRN & \\
\hline CHEMBL 3360663 & 1443970 & 6.8508 & 6.933 & TRN & \\
\hline CHEMBL 3361226 & 1443970 & 7.0862 & 7.4393 & TRN & \\
\hline CHEMBL3361212 & 1443970 & 6.9747 & 6.826000 & 30000000005 & TRN \\
\hline CHEMBL 3361225 & 1443970 & 7.1308 & 6.3234 & TST & \\
\hline CHEMBL 3361187 & 1443970 & 4.0 & 5.4189 & TST & \\
\hline CHEMBL 3361215 & 1443970 & 6.6253 & 6.8003 & TRN & \\
\hline CHEMBL 3361172 & 1443970 & 6.1296 & 6.5435 & TRN & \\
\hline CHEMBL3361196 & 1443970 & 5.1483 & 4.9879 & TRN & \\
\hline CHEMBL 3360660 & 1443970 & 3.4318 & 4.1194 & TRN & \\
\hline CHEMBL 3361214 & 1443970 & 6.7375 & 6.8681 & TRN & \\
\hline CHEMBL 3361195 & 1443970 & 5.1587 & 4.7767 & TRN & \\
\hline CHEMBL 3360653 & 1443970 & 3.4318 & 3.8154 & TRN & \\
\hline CHEMBL 3360648 & 1443970 & 4.8125 & 4.9063 & TST & \\
\hline CHEMBL 3360647 & 1443970 & 3.4318 & 3.6135 & TST & \\
\hline CHEMBL 3361229 & 1443970 & 6.3089 & 6.3721 & TRN & \\
\hline CHEMBL 3360655 & 1443970 & 5.3188 & 5.0472 & TRN & \\
\hline CHEMBL 3361223 & 1443970 & 7.2147 & 6.3131 & TST & \\
\hline CHEMBL 3360652 & 1443970 & 3.4318 & 3.7943 & TRN & \\
\hline CHEMBL 3360656 & 1443970 & 3.4318 & 4.2647 & TRN & \\
\hline CHEMBL 3361181 & 1443970 & 5.9205 & 6.0636 & TRN & \\
\hline CHEMBL 3361182 & 1443970 & 5.7781 & 5.8692 & TRN & \\
\hline CHEMBL 3361205 & 1443970 & 5.6139 & 5.6207 & TRN & \\
\hline CHEMBL 3360659 & 1443970 & 5.0757 & 4.8049 & TRN & \\
\hline CHEMBL 3361206 & 1443970 & 5.4593 & 5.5705 & TRN & \\
\hline CHEMBL 3360670 & 1443970 & 6.9355 & 6.432 & TRN & \\
\hline CHEMBL 3361221 & 1443970 & 6.6091 & 6.6796 & TRN & \\
\hline CHEMBL 3361185 & 1443970 & 7.4437 & 7.2688 & TRN & \\
\hline CHEMBL 3361194 & 1443970 & 5.7719 & 5.86 & TRN & \\
\hline CHEMBL 3361204 & 1443970 & 5.6613 & 5.5918 & TRN & \\
\hline CHEMBL 3361177 & 1443970 & 6.9508 & 6.7136 & TRN & \\
\hline CHEMBL 3361179 & 1443970 & 6.8239 & 7.1017 & TRN & \\
\hline CHEMBL 3361224 & 1443970 & 7.1487 & 7.5633 & TRN & \\
\hline CHEMBL 3361202 & 1443970 & 5.3365 & 5.3727 & TRN & \\
\hline CHEMBL 3361227 & 1443970 & 6.9626 & 6.5177 & TRN & \\
\hline CHEMBL 3361208 & 1443970 & 5.2869 & 5.0511 & TST & \\
\hline CHEMBL 3360651 & 1443970 & 5.0605 & 5.6748 & TST & \\
\hline CHEMBL 3360646 & 1443970 & 3.4318 & 4.5304 & TST & \\
\hline CHEMBL 3361228 & 1443970 & 6.3449 & 6.6106 & TST & \\
\hline CHEMBL 3360671 & 1443970 & 6.6968 & 6.0958 & TST & \\
\hline CHEMBL3360665 & 1443970 & 5.517 & 5.5381 & TST & \\
\hline CHEMBL 3361193 & 1443970 & 5.0321 & 4.3594 & TST & \\
\hline CHEMBL 3360662 & 1443970 & 6.17200 & 000000000 & 5.2856 & 15 \\
\hline CHEMBL 3360658 & 1443970 & 5.585 & 4.8158 & TST & \\
\hline CHEMBL 3360667 & 1443970 & 6.2581 & 6.6032 & TST & \\
\hline CHEMBL 3361184 & 1443970 & 7.5686 & 6.7619 & TST & \\
\hline
\end{tabular}




\begin{tabular}{|c|c|c|c|c|}
\hline & & \multicolumn{3}{|c|}{ Supplemental Tab] } \\
\hline CHEMBL368614 & 48627 & 7.8239 & 7.8224 & TRN \\
\hline CHEMBL366647 & 48627 & 6.767 & 6.7666 & TRN \\
\hline CHEMBL369681 & 48627 & 9.1549 & 9.1554 & TRN \\
\hline CHEMBL368126 & 48627 & 7.9586 & 7.9588 & TRN \\
\hline CHEMBL177109 & 48627 & 8.699 & 8.6987 & TRN \\
\hline CHEMBL174870 & 48627 & 7.4559 & 7.4566 & TRN \\
\hline CHEMBL175329 & 48627 & 6.2581 & 6.2577 & TRN \\
\hline CHEMBL175130 & 48627 & 9.5229 & 9.5236 & TRN \\
\hline CHEMBL369023 & 48627 & 8.8861 & 8.8855 & TRN \\
\hline CHEMBL174558 & 48627 & 9.0 & 8.9994 & TRN \\
\hline CHEMBL435741 & 48627 & 9.0969 & 9.0961 & TRN \\
\hline CHEMBL368914 & 48627 & 7.3979 & 7.3979 & TRN \\
\hline CHEMBL175125 & 48627 & 6.7545 & 6.7549 & TRN \\
\hline CHEMBL368494 & 48627 & 8.4559 & 8.4557 & TRN \\
\hline CHEMBL175014 & 48627 & 8.1675 & 8.1682 & TRN \\
\hline CHEMBL172256 & 48627 & 8.1612 & 8.1606 & TRN \\
\hline CHEMBL426416 & 48627 & 8.6383 & 8.3856 & TST \\
\hline CHEMBL176757 & 48627 & 8.0 & 8.5693 & TST \\
\hline CHEMBL174968 & 48627 & 8.0 & 7.9997 & TRN \\
\hline CHEMBL425859 & 48627 & 7.7959 & 7.7973 & TRN \\
\hline CHEMBL175033 & 48627 & 8.4202 & 8.4205 & TRN \\
\hline CHEMBL175122 & 48627 & 7.5229 & 7.5238 & TRN \\
\hline CHEMBL174111 & 48627 & 6.6383 & 6.6381 & TRN \\
\hline CHEMBL176736 & 48627 & 7.3979 & 7.3979 & TRN \\
\hline CHEMBL369015 & 48627 & 8.4437 & 8.4432 & TRN \\
\hline CHEMBL366894 & 48627 & 7.1192 & 7.1198 & TRN \\
\hline CHEMBL425858 & 48627 & 8.1549 & 8.1552 & TRN \\
\hline CHEMBL172360 & 48627 & 8.8239 & 8.8233 & TRN \\
\hline CHEMBL175031 & 48627 & 7.7696 & 7.7697 & TRN \\
\hline CHEMBL174499 & 48627 & 9.0969 & 9.0968 & TRN \\
\hline CHEMBL176451 & 48627 & 7.2757 & 7.2749 & TRN \\
\hline CHEMBL367340 & 48627 & 7.8239 & 7.824 & TRN \\
\hline CHEMBL174791 & 48627 & 8.9586 & 8.9591 & TRN \\
\hline CHEMBL175142 & 48627 & 6.8069 & 6.8068 & TRN \\
\hline CHEMBL369177 & 48627 & 7.9208 & 7.9208 & TRN \\
\hline CHEMBL369086 & 48627 & 8.3979 & 8.3982 & TRN \\
\hline CHEMBL368323 & 48627 & 7.4559 & 7.4561 & TRN \\
\hline CHEMBL355807 & 48627 & 8.699 & 8.8753 & TST \\
\hline CHEMBL173832 & 48627 & 8.2366 & 7.1553 & TST \\
\hline CHEMBL177444 & 48627 & 8.8539 & 8.8543 & TRN \\
\hline CHEMBL368744 & 48627 & 6.8539 & 6.8539 & TRN \\
\hline CHEMBL366358 & 48627 & 8.8239 & 8.3492 & TST \\
\hline CHEMBL174740 & 48627 & 6.8665 & 6.8661 & TRN \\
\hline CHEMBL174731 & 48627 & 8.2007 & 8.3676 & TST \\
\hline CHEMBL368095 & 48627 & 8.8861 & 7.6819 & TST \\
\hline CHEMBL176268 & 48627 & 7.8239 & 8.139 & TST \\
\hline CHEMBL176210 & 48627 & 8.301 & 8.3123 & TST \\
\hline CHEMBL176856 & 48627 & 7.0862 & 7.8393 & TST \\
\hline
\end{tabular}




\begin{tabular}{|c|c|c|c|c|c|}
\hline & & & & & \\
\hline CHEMBL176243 & 48627 & 9.0458 & 9.1973 & TST & \\
\hline CHEMBL367953 & 48627 & 9.699 & 8.0074 & TST & \\
\hline CHEMBL176671 & 48627 & 9.0458 & 8.3347 & TST & \\
\hline CHEMBL1336046 & 737359 & 5.2083 & 4.3871 & TRN & \\
\hline CHEMBL1525161 & 737359 & 5.3925 & 3.9192 & TRN & \\
\hline CHEMBL1413278 & 737359 & 3.0 & 3.9171 & TRN & \\
\hline CHEMBL573627 & 737359 & 4.4724 & 4.6467 & TRN & \\
\hline CHEMBL1324155 & 737359 & 3.0 & 3.8042 & TRN & \\
\hline CHEMBL1575869 & 737359 & 6.0061 & 6.0069 & TRN & \\
\hline CHEMBL1565609 & 737359 & 5.0969 & 5.1458 & TRN & \\
\hline CHEMBL3209723 & 737359 & 4.7773 & 4.8884 & TRN & \\
\hline CHEMBL1707247 & 737359 & 5.1451 & 4.9383 & TRN & \\
\hline CHEMBL1585064 & 737359 & 4.5622 & 4.4885 & TRN & \\
\hline CHEMBL1361810 & 737359 & 5.1931 & 4.9106 & TRN & \\
\hline CHEMBL1575970 & 737359 & 3.0 & 5.1717 & TRN & \\
\hline CHEMBL1319534 & 737359 & 3.0 & 3.5583 & TRN & \\
\hline CHEMBL1376949 & 737359 & 4.6144 & 4.6163 & TRN & \\
\hline CHEMBL1582494 & 737359 & 3.0 & 4.4081 & TRN & \\
\hline CHEMBL3191759 & 737359 & 3.0 & $3.58100 t$ & 00000000004 & TRN \\
\hline CHEMBL1307513 & 737359 & 4.7447 & 4.9618 & TRN & \\
\hline CHEMBL1576896 & 737359 & 5.6556 & 5.7217 & TRN & \\
\hline CHEMBL1322948 & 737359 & 4.5918 & 4.5344 & TRN & \\
\hline CHEMBL1532928 & 737359 & 5.4377 & 4.4131 & TRN & \\
\hline CHEMBL3198813 & 737359 & 3.0 & 3.7858 & TRN & \\
\hline CHEMBL1462406 & 737359 & 4.4353 & 4.6271 & TRN & \\
\hline CHEMBL1499296 & 737359 & 4.5452 & 4.5015 & TRN & \\
\hline CHEMBL1515340 & 737359 & 3.0 & 3.7731 & TRN & \\
\hline CHEMBL1400093 & 737359 & 4.9431 & 5.0735 & TST & \\
\hline CHEMBL1534289 & 737359 & 5.6234 & 3.685 & TRN & \\
\hline CHEMBL1307207 & 737359 & 5.2336 & 5.2689 & TRN & \\
\hline CHEMBL1708850 & 737359 & 4.8239 & 4.7393 & TST & \\
\hline CHEMBL1387749 & 737359 & 4.6253 & 4.7182 & TRN & \\
\hline CHEMBL1306211 & 737359 & 4.8861 & 4.9983 & TRN & \\
\hline CHEMBL2369298 & 737359 & 4.0292 & 3.8391 & TST & \\
\hline CHEMBL1515473 & 737359 & 5.1433 & 5.3976 & TRN & \\
\hline CHEMBL1478825 & 737359 & 5.3904 & 5.3536 & TRN & \\
\hline CHEMBL1504853 & 737359 & 5.3575 & 5.473 & TRN & \\
\hline CHEMBL1471358 & 737359 & 4.6596 & 4.5972 & TRN & \\
\hline CHEMBL1564015 & 737359 & 4.6757 & 4.5032 & TRN & \\
\hline CHEMBL1379448 & 737359 & 5.7423 & 5.5041 & TRN & \\
\hline CHEMBL1405100 & 737359 & 5.0448 & 4.8851 & TRN & \\
\hline CHEMBL1309946 & 737359 & 5.1203 & 4.6708 & TRN & \\
\hline CHEMBL1395615 & 737359 & 4.857 & 4.9616 & TRN & \\
\hline CHEMBL1483847 & 737359 & 4.5622 & 4.6911 & TRN & \\
\hline CHEMBL1501843 & 737359 & 4.5129 & 4.4274 & TST & \\
\hline CHEMBL1313107 & 737359 & 4.1568 & 4.4819 & TRN & \\
\hline CHEMBL1302524 & 737359 & 5.3893 & 5.4803 & TRN & \\
\hline CHEMBL1458444 & 737359 & 5.3382 & 5.4689 & TRN & \\
\hline
\end{tabular}


Supplemental Table S2.txt

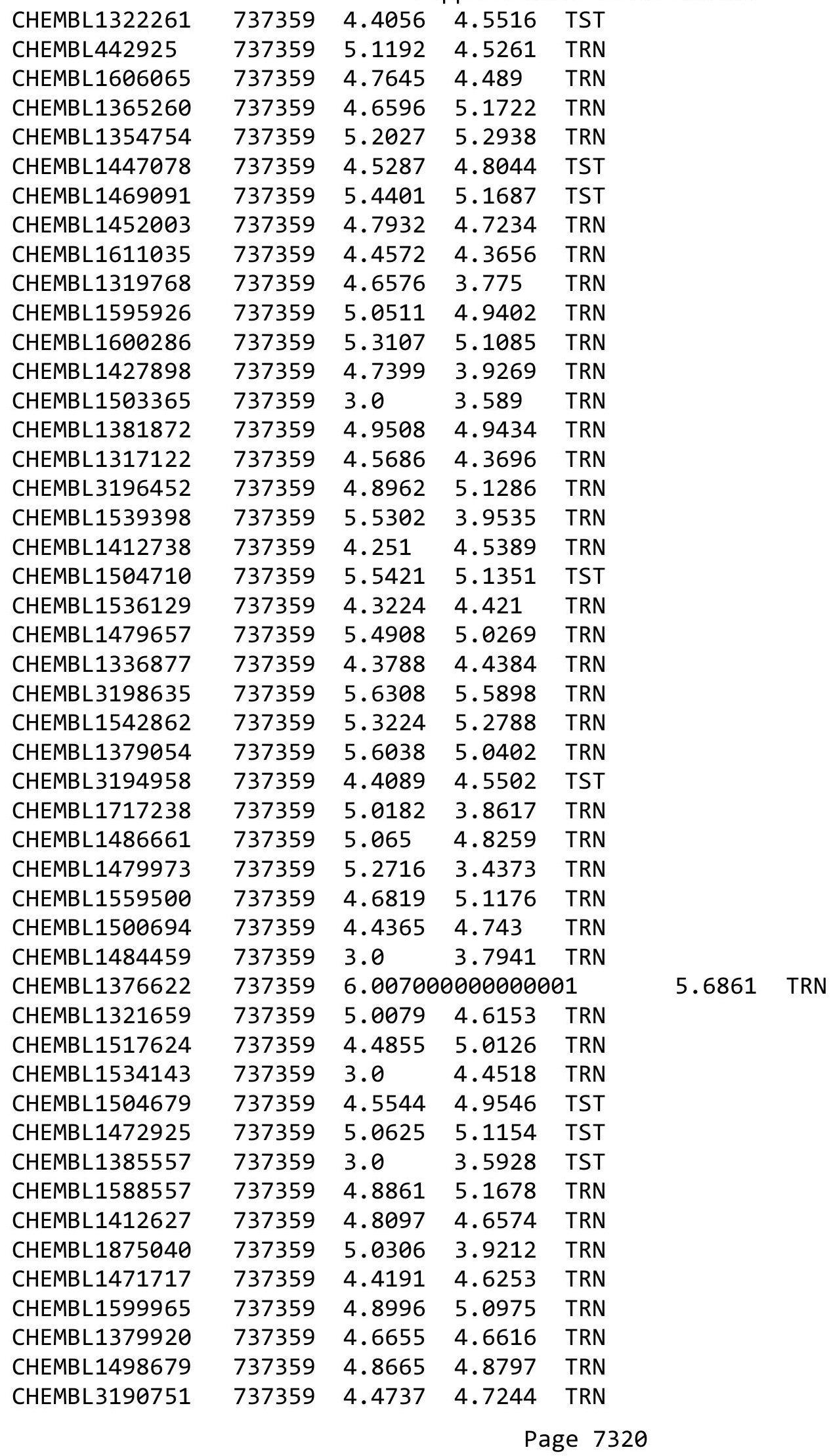




\begin{tabular}{|c|c|c|c|c|c|}
\hline & & \multicolumn{4}{|c|}{ Supplemental Table S2.txt } \\
\hline CHEMBL1393780 & 737359 & 4.9586 & 4.8863 & TRN & \\
\hline CHEMBL1559546 & 737359 & 4.6904 & 4.3898 & TRN & \\
\hline CHEMBL1410437 & 737359 & 4.8069 & 4.4863 & TRN & \\
\hline CHEMBL1500091 & 737359 & 4.6216 & 4.7879 & TST & \\
\hline CHEMBL281980 & 737359 & 6.1029 & 5.8931 & TST & \\
\hline CHEMBL1489745 & 737359 & 5.1858 & 5.4536 & TRN & \\
\hline CHEMBL1478934 & 737359 & 4.2336 & 4.5564 & TRN & \\
\hline CHEMBL1564821 & 737359 & 5.0655 & 4.7666 & TRN & \\
\hline CHEMBL3209654 & 737359 & 5.6799 & 4.0054 & TST & \\
\hline CHEMBL1584379 & 737359 & 5.8539 & 4.2721 & TRN & \\
\hline CHEMBL1970753 & 737359 & 4.7545 & 4.8786 & TRN & \\
\hline CHEMBL1459215 & 737359 & 4.3768 & 4.1699 & TRN & \\
\hline CHEMBL1519862 & 737359 & 3.0 & 3.6863 & TRN & \\
\hline CHEMBL1470146 & 737359 & 3.0 & 5.4188 & TRN & \\
\hline CHEMBL3197545 & 737359 & 4.7282 & 4.869 & TRN & \\
\hline CHEMBL1407928 & 737359 & 4.5171 & 4.6635 & TST & \\
\hline CHEMBL1463739 & 737359 & 4.3439 & 4.3789 & TRN & \\
\hline CHEMBL1518707 & 737359 & 3.0 & 3.64300 & 00000000002 & TRN \\
\hline CHEMBL1568996 & 737359 & 3.0 & 4.0916 & TST & \\
\hline CHEMBL1409773 & 737359 & 4.6126 & 4.7941 & TRN & \\
\hline CHEMBL1441265 & 737359 & 5.2255 & 4.8874 & TRN & \\
\hline CHEMBL576846 & 737359 & 3.0 & 3.6734 & TRN & \\
\hline CHEMBL1414729 & 737359 & 3.0 & 3.6406 & TRN & \\
\hline CHEMBL1440488 & 737359 & 4.4295 & 5.0876 & TRN & \\
\hline CHEMBL1377488 & 737359 & 4.5482 & 4.7775 & TST & \\
\hline CHEMBL1494975 & 737359 & 4.9747 & 4.0324 & TST & \\
\hline CHEMBL1424024 & 737359 & 4.4921 & 4.7452 & TRN & \\
\hline CHEMBL1475673 & 737359 & 3.0 & 3.5256 & TRN & \\
\hline CHEMBL1423071 & 737359 & 4.1778 & 4.0015 & TRN & \\
\hline CHEMBL1964664 & 737359 & 4.9747 & 4.4356 & TRN & \\
\hline CHEMBL1707033 & 737359 & 6.8097 & 5.9311 & TRN & \\
\hline CHEMBL1301243 & 737359 & 6.8097 & 5.5658 & TST & \\
\hline CHEMBL1569914 & 737359 & 4.5086 & 4.6991 & TRN & \\
\hline CHEMBL1569446 & 737359 & 5.0804 & 4.76 & TRN & \\
\hline CHEMBL1462107 & 737359 & 5.399 & 5.5495 & TST & \\
\hline CHEMBL3214026 & 737359 & 4.5513 & 4.6597 & TRN & \\
\hline CHEMBL1332602 & 737359 & 4.1891 & 4.2498 & TRN & \\
\hline CHEMBL1490198 & 737359 & 4.9066 & 4.90300 & 00000000005 & TRN \\
\hline CHEMBL1541408 & 737359 & 4.9355 & 4.9612 & TRN & \\
\hline CHEMBL1499090 & 737359 & 5.06800 & 30000000 & 5.0919 & TRN \\
\hline CHEMBL1453498 & 737359 & 5.1273 & 5.1055 & TST & \\
\hline CHEMBL1491232 & 737359 & 4.202 & 3.873 & TST & \\
\hline CHEMBL1351535 & 737359 & 3.0 & 3.8187 & TRN & \\
\hline CHEMBL1530147 & 737359 & 6.8097 & 6.6084 & TRN & \\
\hline CHEMBL1535290 & 737359 & 4.4976 & 4.708 & TRN & \\
\hline CHEMBL1568555 & 737359 & 4.7447 & 4.9509 & TRN & \\
\hline CHEMBL 3145370 & 737359 & 4.7235 & 4.9033 & TST & \\
\hline CHEMBL175434 & 737359 & 5.5391 & 5.70799 & 9999999999 & TRN \\
\hline & & & & 732 & \\
\hline
\end{tabular}




\begin{tabular}{|c|c|c|c|c|c|}
\hline \multicolumn{6}{|c|}{ Supplemental Table S2.txt } \\
\hline CHEMBL1384143 & 737359 & 3.0 & 3.7638 & TRN & \\
\hline CHEMBL1329906 & 737359 & 4.9747 & 4.734 & TRN & \\
\hline CHEMBL570468 & 737359 & 4.4622 & 4.8029 & TRN & \\
\hline CHEMBL1504945 & 737359 & 4.5214 & 4.6448 & TRN & \\
\hline CHEMBL 236899 & 737359 & 5.0969 & 5.0371 & TRN & \\
\hline CHEMBL1321156 & 737359 & 4.4425 & 4.5917 & TRN & \\
\hline CHEMBL1304247 & 737359 & 4.4789 & 4.6112 & TST & \\
\hline CHEMBL1570637 & 737359 & 5.1409 & 5.1204 & TST & \\
\hline CHEMBL1338502 & 737359 & 4.2173 & 4.0322 & TRN & \\
\hline CHEMBL1309678 & 737359 & 4.4698 & 4.6171 & TRN & \\
\hline CHEMBL3196882 & 737359 & 5.0177 & 4.8807 & TST & \\
\hline CHEMBL1414754 & 737359 & 5.2815 & 4.5206 & TRN & \\
\hline CHEMBL1313683 & 737359 & 4.7932 & 4.9906 & TRN & \\
\hline CHEMBL1323994 & 737359 & 4.6021 & 4.728 & TST & \\
\hline CHEMBL1342287 & 737359 & 4.8069 & 3.6138 & TRN & \\
\hline CHEMBL3199860 & 737359 & 4.8928 & 4.7019 & TRN & \\
\hline CHEMBL1467987 & 737359 & $4.9830 e$ & 00000000 & 4.9555 & TRN \\
\hline CHEMBL1345096 & 737359 & 4.7986 & 5.5482 & TST & \\
\hline CHEMBL3193011 & 737359 & 5.2503 & 5.29899 & 99999999995 & TRN \\
\hline CHEMBL1519816 & 737359 & 4.9136 & 3.4923 & TRN & \\
\hline CHEMBL3196108 & 737359 & 5.567 & 5.2288 & TRN & \\
\hline CHEMBL1584073 & 737359 & 4.6498 & 4.5877 & TRN & \\
\hline CHEMBL208926 & 737359 & 4.7696 & 4.5802 & TST & \\
\hline CHEMBL1337075 & 737359 & 5.3206 & 3.5567 & TRN & \\
\hline CHEMBL1870966 & 737359 & 5.1018 & 5.0157 & TRN & \\
\hline CHEMBL1165723 & 737359 & 5.0424 & 5.2842 & TRN & \\
\hline CHEMBL1539876 & 737359 & 4.8239 & 4.8297 & TRN & \\
\hline CHEMBL1367313 & 737359 & 4.9136 & 4.8938 & TRN & \\
\hline CHEMBL 3197446 & 737359 & 4.8447 & 4.8662 & TRN & \\
\hline CHEMBL1732501 & 737359 & 4.8928 & 4.5739 & TST & \\
\hline CHEMBL1613638 & 737359 & 4.2765 & 4.8648 & TRN & \\
\hline CHEMBL1586735 & 737359 & 4.71899 & 99999999 & 4.8356 & TRN \\
\hline CHEMBL1520808 & 737359 & 4.6459 & 4.7444 & TRN & \\
\hline CHEMBL3197805 & 737359 & 5.3686 & 5.3895 & TST & \\
\hline CHEMBL1389833 & 737359 & 4.5867 & 4.5762 & TRN & \\
\hline CHEMBL1545955 & 737359 & 3.0 & 3.4354 & TRN & \\
\hline CHEMBL1537846 & 737359 & 4.7399 & 4.8654 & TRN & \\
\hline CHEMBL1301037 & 737359 & 4.7645 & 4.7357 & TRN & \\
\hline CHEMBL1379892 & 737359 & 5.2857 & 5.0879 & TRN & \\
\hline CHEMBL1477061 & 737359 & 6.0768 & 5.2276 & TRN & \\
\hline CHEMBL1319104 & 737359 & 4.1494 & 3.8094 & TRN & \\
\hline CHEMBL1550291 & 737359 & 4.5129 & 4.5894 & TRN & \\
\hline CHEMBL1982945 & 737359 & 5.0405 & 5.2949 & TRN & \\
\hline CHEMBL1429243 & 737359 & 4.8182 & 4.731 & TRN & \\
\hline CHEMBL1532037 & 737359 & 4.9508 & 4.8472 & TRN & \\
\hline CHEMBL1408395 & 737359 & 5.061 & 4.905 & TST & \\
\hline CHEMBL1598920 & 737359 & 3.0 & 3.5495 & TRN & \\
\hline CHEMBL3193997 & 737359 & 5.0339 & 5.1062 & TRN & \\
\hline
\end{tabular}




\begin{tabular}{|c|c|c|c|c|c|c|}
\hline \multicolumn{7}{|c|}{ Supplemental Table S2.txt } \\
\hline CHEMBL1361268 & 737359 & 3.0 & 4.7382 & TRN & & \\
\hline CHEMBL1586985 & 737359 & 4.8697 & 3.8914 & TRN & & \\
\hline CHEMBL1322449 & 737359 & 4.4976 & 4.6736 & TRN & & \\
\hline CHEMBL1898479 & 737359 & 5.1746 & 4.9661 & TRN & & \\
\hline CHEMBL1613323 & 737359 & 4.6882 & 4.6191 & TRN & & \\
\hline CHEMBL1542356 & 737359 & 5.3107 & 3.7648 & TRN & & \\
\hline CHEMBL546865 & 737359 & 3.0 & 3.5399 & TRN & & \\
\hline CHEMBL1569920 & 737359 & 5.4112 & 5.2711 & TST & & \\
\hline CHEMBL1332928 & 737359 & 4.9101 & 4.8878 & TST & & \\
\hline CHEMBL205040 & 737359 & 6.0942 & 5.6782 & TRN & & \\
\hline CHEMBL1477920 & 737359 & 4.251 & 4.6587 & TRN & & \\
\hline CHEMBL 299853 & 737359 & 5.2366 & 5.4884 & TRN & & \\
\hline CHEMBL1479061 & 737359 & 3.0 & 3.844 & TRN & & \\
\hline CHEMBL1333579 & 737359 & 3.0 & 4.9675 & TRN & & \\
\hline CHEMBL1426692 & 737359 & 5.083 & 5.4043 & TST & & \\
\hline CHEMBL1487632 & 737359 & 4.5287 & 4.6101 & TRN & & \\
\hline CHEMBL1534545 & 737359 & 4.7799 & 4.8283 & TRN & & \\
\hline CHEMBL1535487 & 737359 & 3.0 & 3.7928 & TRN & & \\
\hline CHEMBL1425035 & 737359 & 5.118 & 5.0428 & TRN & & \\
\hline CHEMBL1570824 & 737359 & 5.1772 & 4.5379 & TRN & & \\
\hline CHEMBL1403154 & 737359 & 5.5969 & 5.4932 & TST & & \\
\hline CHEMBL1468876 & 737359 & 3.0 & 3.8075 & TST & & \\
\hline CHEMBL1582178 & 737359 & 5.1325 & 5.1268 & TST & & \\
\hline CHEMBL1971324 & 737359 & 3.0 & 4.1157 & TRN & & \\
\hline CHEMBL1421255 & 737359 & 6.0173 & 5.6617 & TRN & & \\
\hline CHEMBL1510959 & 737359 & 5.1688 & 4.9344 & TST & & \\
\hline CHEMBL1305329 & 737359 & 5.2118 & 4.6043 & TST & & \\
\hline CHEMBL3190318 & 737359 & 3.0 & 3.9114 & TRN & & \\
\hline CHEMBL 1705186 & 737359 & 3.0 & 3.8364 & TRN & & \\
\hline CHEMBL3145381 & 737359 & 4.8097 & 5.5787 & TST & & \\
\hline CHEMBL 1575677 & 737359 & 3.0 & 3.77 & TRN & & \\
\hline CHEMBL3193861 & 737359 & 4.5817 & 3.5972 & TRN & & \\
\hline CHEMBL1343697 & 737359 & 4.9666 & 5.078 & TST & & \\
\hline CHEMBL3191524 & 737359 & 4.2782 & 4.4036 & TRN & & \\
\hline CHEMBL1379048 & 737359 & 5.52 & 5.4518 & TST & & \\
\hline CHEMBL1405521 & 737359 & 3.0 & 3.7041 & TRN & & \\
\hline CHEMBL1556089 & 737359 & 4.341 & 4.5448 & TRN & & \\
\hline CHEMBL1447830 & 737359 & 3.0 & 3.8223 & TRN & & \\
\hline CHEMBL2000196 & 737359 & 5.71899 & 79999999 & 99 & 5.45 & \\
\hline CHEMBL1392911 & 737359 & 5.6383 & 5.4344 & TRN & & \\
\hline CHEMBL3196451 & 737359 & 6.7305 & 6.5912 & TRN & & \\
\hline CHEMBL1484644 & 737359 & 5.2865 & 5.1318 & TRN & & \\
\hline CHEMBL1381587 & 737359 & 4.5361 & 4.5016 & TRN & & \\
\hline CHEMBL1421377 & 737359 & 5.7235 & 5.4175 & TST & & \\
\hline CHEMBL1423084 & 737359 & 4.4559 & 4.5037 & TRN & & \\
\hline CHEMBL1447111 & 737359 & 5.2069 & 4.6633 & TRN & & \\
\hline CHEMBL1975547 & 737359 & 5.4179 & 5.4149 & TRN & & \\
\hline CHEMBL1429870 & 737359 & 4.8356 & 4.8638 & TRN & & \\
\hline
\end{tabular}


Supplemental Table S2.txt

\begin{tabular}{|c|c|c|c|c|}
\hline CHEMBL1965415 & 737359 & 4.9872 & 5.0696 & TRN \\
\hline CHEMBL1523355 & 737359 & 4.6596 & 4.7807 & TRN \\
\hline CHEMBL1511922 & 737359 & 4.8894 & 4.3318 & TRN \\
\hline CHEMBL159895 & 737359 & 4.5482 & 4.6106 & TRN \\
\hline CHEMBL1999511 & 737359 & 4.8182 & 4.4528 & TRN \\
\hline CHEMBL3193863 & 737359 & 4.4078 & 4.5593 & TRN \\
\hline CHEMBL1434792 & 737359 & 5.3261 & 5.4256 & TRN \\
\hline CHEMBL1464550 & 737359 & 4.5406 & 4.5487 & TRN \\
\hline CHEMBL1392424 & 737359 & 4.5436 & 4.5463 & TRN \\
\hline CHEMBL1439396 & 737359 & 3.0 & 3.8627 & TRN \\
\hline CHEMBL1421460 & 737359 & 5.0964 & 4.6701 & TRN \\
\hline CHEMBL1435486 & 737359 & 3.0 & 3.84899 & 99999999998 \\
\hline CHEMBL1463363 & 737359 & 5.3152 & 3.9299 & TRN \\
\hline CHEMBL1507251 & 737359 & 5.3316 & 5.1336 & TRN \\
\hline CHEMBL1494979 & 737359 & 5.4597 & 3.6925 & TRN \\
\hline CHEMBL1424355 & 737359 & 4.9872 & 5.0297 & TRN \\
\hline CHEMBL3213606 & 737359 & 4.5467 & 4.688 & TRN \\
\hline CHEMBL1506796 & 737359 & 6.104 & 5.4897 & TRN \\
\hline CHEMBL3195897 & 737359 & 4.5638 & 4.7013 & TST \\
\hline CHEMBL88811 & 737359 & 4.9747 & 4.8258 & TRN \\
\hline CHEMBL1309184 & 737359 & 4.4962 & 4.5388 & TRN \\
\hline CHEMBL1342873 & 737359 & 4.7235 & 4.8554 & TRN \\
\hline CHEMBL1577193 & 737359 & 5.5686 & 5.1215 & TST \\
\hline CHEMBL1564777 & 737359 & 4.9172 & 4.8793 & TRN \\
\hline CHEMBL1542961 & 737359 & 4.5935 & 4.5482 & TRN \\
\hline CHEMBL1482438 & 737359 & 4.9066 & 4.7867 & TRN \\
\hline CHEMBL1542876 & 737359 & 4.3487 & 4.8686 & TST \\
\hline CHEMBL1340332 & 737359 & 5.1543 & 5.1647 & TRN \\
\hline CHEMBL1531037 & 737359 & 4.9281 & 4.5446 & TRN \\
\hline CHEMBL1528674 & 737359 & 5.3382 & 5.352 & TRN \\
\hline CHEMBL3210944 & 737359 & 4.6021 & 4.51399 & э999999999 \\
\hline CHEMBL1719382 & 737359 & 3.0 & 3.5082 & TRN \\
\hline CHEMBL1371275 & 737359 & 3.0 & 3.7847 & TRN \\
\hline CHEMBL3189672 & 737359 & 5.1838 & 3.9632 & TRN \\
\hline CHEMBL1980744 & 737359 & 5.2815 & 5.006 & TRN \\
\hline CHEMBL1711590 & 737359 & 5.2218 & 5.1285 & TST \\
\hline CHEMBL1609498 & 737359 & 3.0 & 3.9581 & TRN \\
\hline CHEMBL1530356 & 737359 & 4.0079 & 3.7307 & TRN \\
\hline CHEMBL1472308 & 737359 & 4.7055 & 4.7134 & TST \\
\hline CHEMBL1490171 & 737359 & 4.8268 & 4.8801 & TST \\
\hline CHEMBL1306742 & 737359 & 3.0 & 3.4191 & TRN \\
\hline CHEMBL3199870 & 737359 & 5.0726 & 4.8668 & TRN \\
\hline CHEMBL1307406 & 737359 & 5.6968 & 5.37299 & 9999999999 \\
\hline CHEMBL1613479 & 737359 & 4.9031 & 4.9463 & TRN \\
\hline CHEMBL1395201 & 737359 & 4.5834 & 4.6258 & TST \\
\hline CHEMBL1353712 & 737359 & 4.5884 & 4.8508 & TRN \\
\hline CHEMBL1969046 & 737359 & 6.0867 & 5.8855 & TRN \\
\hline CHEMBL1383632 & 737359 & 5.2573 & 5.2517 & TRN \\
\hline
\end{tabular}




\begin{tabular}{|c|c|c|c|c|c|c|}
\hline & & \multicolumn{5}{|c|}{ Supplemental Table s2.txt } \\
\hline CHEMBL3209095 & 737359 & 5.3904 & 4.0293 & TRN & & \\
\hline CHEMBL3196057 & 737359 & 5.4389 & 3.9896 & TST & & \\
\hline CHEMBL1404312 & 737359 & 4.4237 & 4.4488 & TST & & \\
\hline CHEMBL1998302 & 737359 & 6.129 & 6.216 & TRN & & \\
\hline CHEMBL1463989 & 737359 & 4.6819 & 4.6704 & TRN & & \\
\hline CHEMBL1402456 & 737359 & 6.4622 & 6.0858 & TRN & & \\
\hline CHEMBL1495016 & 737359 & 5.5317 & 5.6771 & TRN & & \\
\hline CHEMBL1722874 & 737359 & 3.0 & 3.6902 & TRN & & \\
\hline CHEMBL1336070 & 737359 & 4.58 & 4.605 & TRN & & \\
\hline CHEMBL551004 & 737359 & 4.7375 & 4.5886 & TRN & & \\
\hline CHEMBL1352627 & 737359 & 4.4473 & 4.6622 & TST & & \\
\hline CHEMBL1418096 & 737359 & 5.8996 & 5.4598 & TRN & & \\
\hline CHEMBL1389299 & 737359 & 4.8041 & 4.7877 & TST & & \\
\hline CHEMBL1569645 & 737359 & \multicolumn{3}{|c|}{4.821000000000001} & 4.409 & TRN \\
\hline CHEMBL600313 & 737359 & 4.7773 & 5.0407 & TRN & & \\
\hline CHEMBL355496 & 737359 & 3.0 & 3.8753 & TRN & & \\
\hline CHEMBL1445676 & 737359 & 5.3947 & 4.0491 & TST & & \\
\hline CHEMBL392680 & 737359 & 5.0269 & 5.0461 & TRN & & \\
\hline CHEMBL3196248 & 737359 & 4.4425 & 4.5883 & TRN & & \\
\hline CHEMBL1397706 & 737359 & 4.9245 & 4.8626 & TST & & \\
\hline CHEMBL1700539 & 737359 & 4.6326 & 4.6023 & TRN & & \\
\hline CHEMBL1525146 & 737359 & 3.0 & 3.8466 & TRN & & \\
\hline CHEMBL1969992 & 737359 & 3.0 & 3.8012 & TST & & \\
\hline CHEMBL1411203 & 737359 & 4.9872 & 3.7803 & TRN & & \\
\hline CHEMBL1547222 & 737359 & 5.1739 & 5.1388 & TRN & & \\
\hline CHEMBL1573586 & 737359 & 4.8794 & 5.0826 & TST & & \\
\hline CHEMBL1430214 & 737359 & 4.5436 & 4.467 & TRN & & \\
\hline CHEMBL 3210723 & 737359 & 5.2248 & 5.1743 & TRN & & \\
\hline CHEMBL1328930 & 737359 & 4.8356 & 4.7841 & TRN & & \\
\hline CHEMBL1540987 & 737359 & 4.9393 & 4.3442 & TRN & & \\
\hline CHEMBL1573910 & 737359 & 5.1726 & 5.3069 & TRN & & \\
\hline CHEMBL1432027 & 737359 & 4.6144 & 4.5213 & TRN & & \\
\hline CHEMBL1469807 & 737359 & 5.6778 & 5.1971 & TRN & & \\
\hline CHEMBL1401768 & 737359 & 4.327 & 4.4962 & TRN & & \\
\hline CHEMBL1731096 & 737359 & 4.4724 & 3.8339 & TRN & & \\
\hline CHEMBL1381205 & 737359 & 5.4962 & 5.1293 & TRN & & \\
\hline CHEMBL1415156 & 737359 & 5.6925 & 5.402 & TRN & & \\
\hline CHEMBL1507023 & 737359 & 4.6635 & 3.7435 & TRN & & \\
\hline CHEMBL1387558 & 737359 & 4.1349 & 4.3836 & TRN & & \\
\hline CHEMBL1559362 & 737359 & 4.8356 & 4.5726 & TRN & & \\
\hline CHEMBL1513162 & 737359 & 4.7721 & 4.8198 & TRN & & \\
\hline CHEMBL3193227 & 737359 & 3.0 & 3.4322 & TRN & & \\
\hline CHEMBL1443965 & 737359 & 4.9208 & 4.8969 & TRN & & \\
\hline CHEMBL1374950 & 737359 & 4.9355 & 4.9624 & TRN & & \\
\hline CHEMBL1521514 & 737359 & 5.3565 & 5.4676 & TRN & & \\
\hline CHEMBL1471498 & 737359 & 6.0287 & 5.426 & TRN & & \\
\hline CHEMBL1563664 & 737359 & 3.0 & 3.7423 & TRN & & \\
\hline CHEMBL1408066 & 737359 & 3.0 & 3.5378 & TRN & & \\
\hline
\end{tabular}




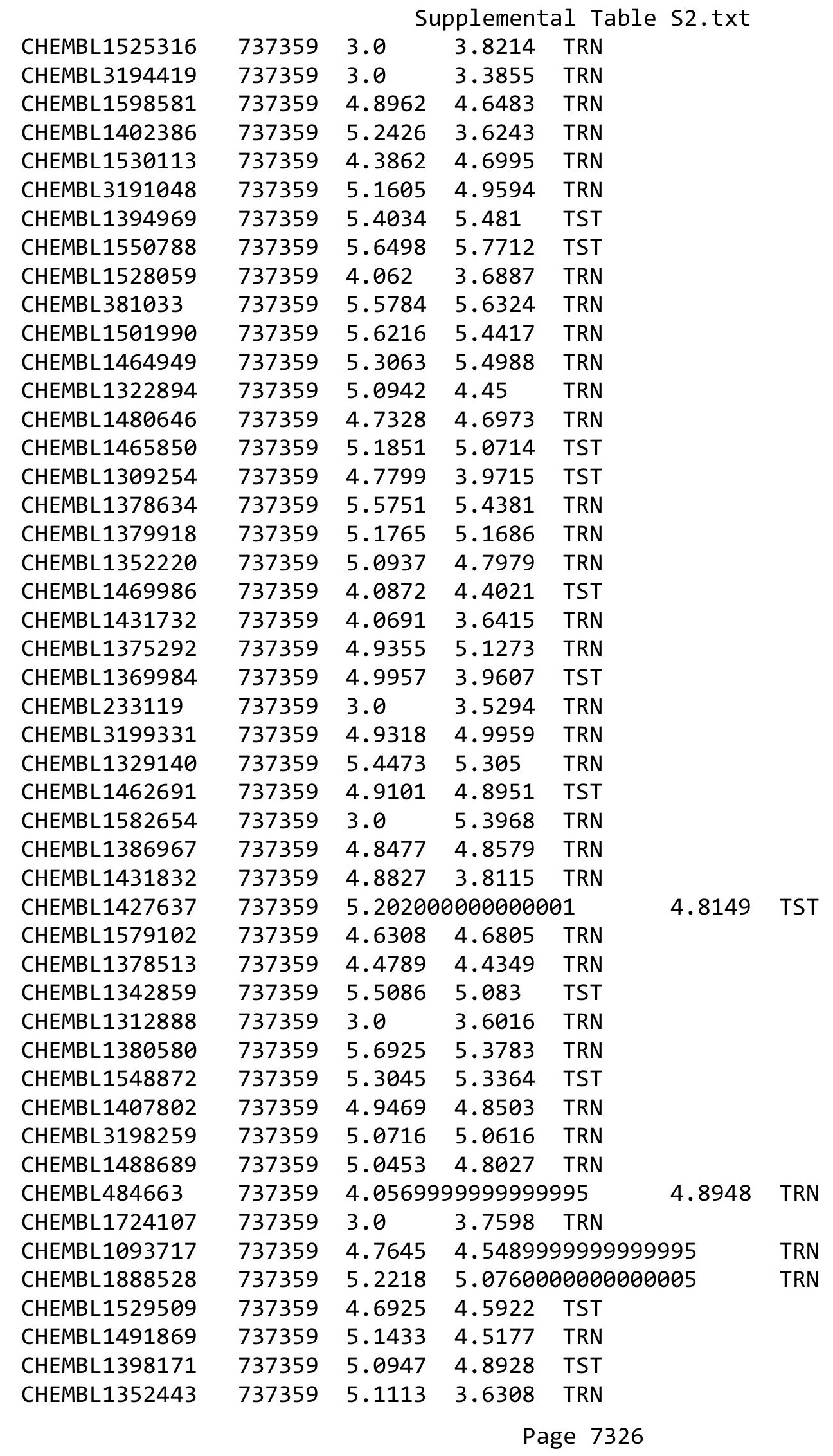




\begin{tabular}{|c|c|c|c|c|c|}
\hline & & \multicolumn{4}{|c|}{ Supplemental Table s2.txt } \\
\hline CHEMBL1506756 & 737359 & 5.2457 & 5.4252 & TRN & \\
\hline CHEMBL1300177 & 737359 & 4.3251 & 4.2887 & TRN & \\
\hline CHEMBL1319034 & 737359 & 3.0 & 3.5061 & TRN & \\
\hline CHEMBL1381216 & 737359 & 4.5391 & 4.5839 & TRN & \\
\hline CHEMBL1714407 & 737359 & 4.7328 & 4.4458 & TRN & \\
\hline CHEMBL1719113 & 737359 & 5.4214 & 5.5096 & TST & \\
\hline CHEMBL1438627 & 737359 & 5.2798 & 5.1449 & TRN & \\
\hline CHEMBL1339228 & 737359 & 5.466 & 3.8891 & TRN & \\
\hline CHEMBL1864348 & 737359 & 5.2182 & 5.0104 & TRN & \\
\hline CHEMBL1582309 & 737359 & 4.4841 & 4.5878 & TRN & \\
\hline CHEMBL1380540 & 737359 & 3.0 & 3.7975 & TRN & \\
\hline CHEMBL1449597 & 737359 & 3.0 & 3.842 & TRN & \\
\hline CHEMBL1473428 & 737359 & 5.1681 & 5.3635 & TRN & \\
\hline CHEMBL1584930 & 737359 & 5.04 & 3.80899 & 99999999997 & TRN \\
\hline CHEMBL494082 & 737359 & 5.3747 & 5.2789 & TRN & \\
\hline CHEMBL595840 & 737359 & 5.82100 & 000000006 & 5.4222 & TRN \\
\hline CHEMBL1535900 & 737359 & 3.0 & 4.0356 & TRN & \\
\hline CHEMBL3194086 & 737359 & 5.699 & 5.7442 & TRN & \\
\hline CHEMBL1465938 & 737359 & 5.4191 & 5.1154 & TRN & \\
\hline CHEMBL1421263 & 737359 & 4.6655 & 4.2646 & TST & \\
\hline CHEMBL1457057 & 737359 & 5.3546 & 5.0339 & TRN & \\
\hline CHEMBL1591913 & 737359 & 5.1871 & 5.4629 & TRN & \\
\hline CHEMBL1386457 & 737359 & 4.3757 & 3.851006 & 00000000004 & TRN \\
\hline CHEMBL1718258 & 737359 & 3.0 & 3.6368 & TRN & \\
\hline CHEMBL1349748 & 737359 & 5.6271 & 5.6475 & TST & \\
\hline CHEMBL1545387 & 737359 & 4.383 & 4.857 & TRN & \\
\hline CHEMBL1526853 & 737359 & 3.0 & 3.5543 & TRN & \\
\hline CHEMBL1349632 & 737359 & 3.0 & 3.6667 & TRN & \\
\hline CHEMBL1392845 & 737359 & 3.0 & 3.5359 & TST & \\
\hline CHEMBL1703849 & 737359 & 3.0 & 3.88 & TRN & \\
\hline CHEMBL1372256 & 737359 & 4.6882 & 4.6664 & TRN & \\
\hline CHEMBL1566434 & 737359 & 3.0 & 3.8156 & TRN & \\
\hline CHEMBL1577291 & 737359 & 3.0 & 3.9876 & TRN & \\
\hline CHEMBL1574587 & 737359 & 3.0 & 3.8775 & TRN & \\
\hline CHEMBL1563939 & 737359 & 5.4023 & 5.6149 & TST & \\
\hline CHEMBL1444349 & 737359 & 4.8508 & 4.9646 & TST & \\
\hline CHEMBL1473955 & 737359 & 5.4179 & 5.5087 & TRN & \\
\hline CHEMBL 3210574 & 737359 & 3.0 & 3.9822 & TST & \\
\hline CHEMBL1425406 & 737359 & 5.3526 & 3.4968 & TRN & \\
\hline CHEMBL1578879 & 737359 & 3.0 & 3.4807 & TRN & \\
\hline CHEMBL1458321 & 737359 & 5.4522 & 5.3341 & TRN & \\
\hline CHEMBL1589837 & 737359 & 5.4413 & 5.3746 & TST & \\
\hline CHEMBL1450897 & 737359 & 5.6253 & 5.1908 & TST & \\
\hline CHEMBL1584557 & 737359 & 4.0635 & 3.788006 & 00000000003 & TST \\
\hline CHEMBL1348741 & 737359 & 4.9747 & 4.8963 & TRN & \\
\hline CHEMBL1988699 & 737359 & 4.5901 & 4.599 & TRN & \\
\hline CHEMBL1404207 & 737359 & 4.8928 & 5.2201 & TRN & \\
\hline CHEMBL108660 & 737359 & 4.618 & 4.7665 & TRN & \\
\hline
\end{tabular}




\begin{tabular}{|c|c|c|c|c|c|}
\hline & & \multicolumn{4}{|c|}{ Supplemental Table S2.txt } \\
\hline CHEMBL241862 & 737359 & 5.2218 & 4.9979 & TRN & \\
\hline CHEMBL1356235 & 737359 & 3.0 & 3.6336 & TRN & \\
\hline CHEMBL1394975 & 737359 & 4.9508 & 4.6795 & TRN & \\
\hline CHEMBL1523828 & 737359 & 4.8239 & 4.5999 & TRN & \\
\hline CHEMBL1565912 & 737359 & 5.0462 & 5.5409 & TRN & \\
\hline CHEMBL1497694 & 737359 & 4.6904 & 4.602 & TRN & \\
\hline CHEMBL1904348 & 737359 & 5.1487 & 4.7099 & TST & \\
\hline CHEMBL1568641 & 737359 & 4.7825 & 4.6763 & TRN & \\
\hline CHEMBL1460321 & 737359 & 4.5045 & 4.4496 & TRN & \\
\hline CHEMBL3210366 & 737359 & 5.3915 & 5.1514 & TRN & \\
\hline CHEMBL1544489 & 737359 & 5.6596 & 5.4082 & TRN & \\
\hline CHEMBL1573380 & 737359 & 3.0 & 3.7935 & TRN & \\
\hline CHEMBL1491894 & 737359 & 5.2381 & 4.7622 & TRN & \\
\hline CHEMBL1457356 & 737359 & 4.6757 & 4.6238 & TRN & \\
\hline CHEMBL510279 & 737359 & 5.0 & 4.7673 & TST & \\
\hline CHEMBL1708975 & 737359 & 4.6696 & 4.505 & TRN & \\
\hline CHEMBL1508306 & 737359 & 3.0 & 3.8846 & TRN & \\
\hline CHEMBL1518285 & 737359 & 4.9547 & 4.685 & TST & \\
\hline CHEMBL1327265 & 737359 & 4.3969 & 3.7329 & TRN & \\
\hline CHEMBL1521296 & 737359 & 5.3197 & 5.42399 & 99999999995 & TRN \\
\hline CHEMBL1329446 & 737359 & 5.0306 & 5.0742 & TRN & \\
\hline CHEMBL1532623 & 737359 & 4.9172 & 4.8939 & TRN & \\
\hline CHEMBL 3209143 & 737359 & 4.8356 & 4.8214 & TRN & \\
\hline CHEMBL3144898 & 737359 & 3.0 & 3.88100 & 00000000002 & TST \\
\hline CHEMBL1719459 & 737359 & 5.5031 & 5.8357 & TRN & \\
\hline CHEMBL1521051 & 737359 & 5.6253 & 4.8988 & TRN & \\
\hline CHEMBL1509368 & 737359 & 4.6968 & 4.7485 & TRN & \\
\hline CHEMBL1395570 & 737359 & 4.8601 & 4.6017 & TRN & \\
\hline CHEMBL1498118 & 737359 & 3.0 & 3.9512 & TST & \\
\hline CHEMBL1413787 & 737359 & 4.3737 & 4.1753 & TRN & \\
\hline CHEMBL1594943 & 737359 & 4.8928 & 4.9067 & TRN & \\
\hline CHEMBL1428684 & 737359 & 4.7033 & 4.864 & TRN & \\
\hline CHEMBL1992801 & 737359 & 5.2541 & 5.1102 & TRN & \\
\hline CHEMBL1605599 & 737359 & 5.3363 & 5.0069 & TRN & \\
\hline CHEMBL1586401 & 737359 & 5.1158 & 3.9096 & TRN & \\
\hline CHEMBL1521600 & 737359 & 5.3354 & 5.3649 & TRN & \\
\hline CHEMBL1597726 & 737359 & 4.7122 & 4.9342 & TST & \\
\hline CHEMBL1522941 & 737359 & 5.5243 & 5.7948 & TRN & \\
\hline CHEMBL1605940 & 737359 & 5.4547 & 5.0886 & TRN & \\
\hline CHEMBL1313386 & 737359 & 4.1765 & 3.8916 & TRN & \\
\hline CHEMBL1988780 & 737359 & 5.8477 & 5.8265 & TST & \\
\hline CHEMBL1373107 & 737359 & 4.8633 & 4.7033 & TRN & \\
\hline CHEMBL1304004 & 737359 & 4.118 & 3.5741 & TRN & \\
\hline CHEMBL1351708 & 737359 & 4.5045 & 4.6145 & TST & \\
\hline CHEMBL1538518 & 737359 & 4.3615 & 4.6157 & TST & \\
\hline CHEMBL1714229 & 737359 & 4.9318 & 4.5205 & TRN & \\
\hline CHEMBL 3199687 & 737359 & 4.9747 & 3.8854 & TST & \\
\hline CHEMBL1328084 & 737359 & 4.9393 & 4.9932 & TRN & \\
\hline
\end{tabular}




\begin{tabular}{|c|c|c|c|c|c|c|}
\hline & & \multicolumn{5}{|c|}{ Supplemental Table S2.txt } \\
\hline CHEMBL1408715 & 737359 & 4.9393 & 5.0805 & TRN & & \\
\hline CHEMBL1463829 & 737359 & 5.4881 & 5.4545 & TRN & & \\
\hline CHEMBL1505544 & 737359 & 5.3045 & 5.1433 & TRN & & \\
\hline CHEMBL1370387 & 737359 & 4.5768 & 4.6274 & TRN & & \\
\hline CHEMBL1432894 & 737359 & 4.1593 & 3.9003 & TRN & & \\
\hline CHEMBL1583785 & 737359 & 4.9957 & 3.8257 & TST & & \\
\hline CHEMBL1360419 & 737359 & 4.5186 & 4.8131 & TRN & & \\
\hline CHEMBL1446989 & 737359 & 4.6925 & 4.5175 & TRN & & \\
\hline CHEMBL3197065 & 737359 & 4.9872 & 5.0032 & TRN & & \\
\hline CHEMBL3199034 & 737359 & 4.6556 & 4.5817 & TRN & & \\
\hline CHEMBL1598139 & 737359 & 4.8601 & 4.4706 & TRN & & \\
\hline CHEMBL1314088 & 737359 & 3.0 & 3.4578 & TRN & & \\
\hline CHEMBL1378542 & 737359 & 3.0 & 3.8492 & TRN & & \\
\hline CHEMBL1380030 & 737359 & 4.5935 & 4.7418 & TRN & & \\
\hline CHEMBL 2000670 & 737359 & 4.7852 & 4.8867 & TRN & & \\
\hline CHEMBL1480814 & 737359 & 5.1451 & 5.4367 & TRN & & \\
\hline CHEMBL1303887 & 737359 & 5.3063 & 5.2569 & TST & & \\
\hline CHEMBL3197208 & 737359 & 5.2175 & 5.1821 & TST & & \\
\hline CHEMBL1449672 & 737359 & 3.0 & 3.5798 & TRN & & \\
\hline CHEMBL1432218 & 737359 & 4.6216 & 4.3864 & TRN & & \\
\hline CHEMBL1730590 & 737359 & 4.5086 & 4.4979 & TRN & & \\
\hline CHEMBL1475128 & 737359 & 5.9666 & 5.6848 & TRN & & \\
\hline CHEMBL1486728 & 737359 & 3.0 & 3.6945 & TRN & & \\
\hline CHEMBL63883 & 737359 & 4.1391 & 3.6113 & TRN & & \\
\hline CHEMBL1406151 & 737359 & 4.4486 & 4.5623 & TRN & & \\
\hline CHEMBL1363615 & 737359 & 4.7545 & 4.9023 & TRN & & \\
\hline CHEMBL1493528 & 737359 & 5.0926 & 5.05 & TRN & & \\
\hline CHEMBL1492590 & 737359 & 5.1355 & 5.3854 & TRN & & \\
\hline CHEMBL3190038 & 737359 & 3.0 & 3.8911 & TRN & & \\
\hline CHEMBL1519485 & 737359 & 4.82100 & 00000000 & 01 & .7072 & TRN \\
\hline CHEMBL1581330 & 737359 & 3.0 & 3.8776 & TRN & & \\
\hline CHEMBL1504125 & 737359 & 5.5287 & 5.3799 & TST & & \\
\hline CHEMBL1333044 & 737359 & 4.4841 & 4.6164 & TRN & & \\
\hline CHEMBL1609828 & 737359 & 5.3686 & 5.0511 & TRN & & \\
\hline CHEMBL1563249 & 737359 & 4.8633 & 4.3262 & TRN & & \\
\hline CHEMBL1613216 & 737359 & 4.76699 & 99999999 & 995 & 5.4899 & TRN \\
\hline CHEMBL1585372 & 737359 & 4.5528 & 4.9757 & TRN & & \\
\hline CHEMBL3213561 & 737359 & 4.5591 & 4.7087 & TRN & & \\
\hline CHEMBL1341243 & 737359 & 4.6289 & 4.6093 & TRN & & \\
\hline CHEMBL1502410 & 737359 & 5.0731 & 5.0981 & TRN & & \\
\hline CHEMBL1493516 & 737359 & 4.8665 & 4.9674 & TRN & & \\
\hline CHEMBL1874620 & 737359 & 5.5017 & 5.0945 & TRN & & \\
\hline CHEMBL1365705 & 737359 & 4.7077 & 4.7548 & TRN & & \\
\hline CHEMBL3197063 & 737359 & 5.585 & 5.3236 & TRN & & \\
\hline CHEMBL1528847 & 737359 & 4.4389 & 4.8742 & TRN & & \\
\hline CHEMBL1426867 & 737359 & 4.9914 & 4.8424 & TRN & & \\
\hline CHEMBL1466087 & 737359 & 4.8601 & 5.1631 & TST & & \\
\hline CHEMBL1365257 & 737359 & 4.3288 & 4.3932 & TRN & & \\
\hline
\end{tabular}




\begin{tabular}{|c|c|c|c|c|c|}
\hline & & \multicolumn{4}{|c|}{ Supplemental Table S2.txt } \\
\hline CHEMBL1503246 & 737359 & 4.4789 & 4.6944 & TRN & \\
\hline CHEMBL 1405940 & 737359 & 4.4802 & 4.9285 & TRN & \\
\hline CHEMBL1521074 & 737359 & 4.6091 & 4.7831 & TRN & \\
\hline CHEMBL1468761 & 737359 & 5.1057 & 4.4938 & TRN & \\
\hline CHEMBL1392754 & 737359 & 4.6021 & 4.7878 & TST & \\
\hline CHEMBL1608383 & 737359 & 4.1409 & 4.2247 & TST & \\
\hline CHEMBL1516968 & 737359 & 4.475 & 4.4772 & TRN & \\
\hline CHEMBL1527802 & 737359 & 4.5986 & 4.5566 & TRN & \\
\hline CHEMBL1522796 & 737359 & 5.0931 & 5.2866 & TRN & \\
\hline CHEMBL3211987 & 737359 & 4.6478 & 3.7291 & TRN & \\
\hline CHEMBL1539910 & 737359 & 4.4724 & 4.8428 & TRN & \\
\hline CHEMBL1391158 & 737359 & 5.2749 & 3.9332 & TRN & \\
\hline CHEMBL3190081 & 737359 & 4.5686 & 3.7126 & TRN & \\
\hline CHEMBL1447460 & 737359 & 4.7773 & 4.223 & TRN & \\
\hline CHEMBL1522470 & 737359 & 4.7305 & 4.7338 & TRN & \\
\hline CHEMBL1606690 & 737359 & 4.5058 & 4.7347 & TST & \\
\hline CHEMBL1595804 & 737359 & 5.0315 & 4.6875 & TRN & \\
\hline CHEMBL1412678 & 737359 & 5.0255 & 4.8811 & TRN & \\
\hline CHEMBL1544497 & 737359 & 4.3325 & 4.4605 & TRN & \\
\hline CHEMBL1573287 & 737359 & 4.4547 & 3.6853 & TRN & \\
\hline CHEMBL1560004 & 737359 & 5.3757 & 3.5532 & TRN & \\
\hline CHEMBL 3189585 & 737359 & 4.5157 & 4.0354 & TRN & \\
\hline CHEMBL1361392 & 737359 & 5.2277 & 5.29 & TRN & \\
\hline CHEMBL1890591 & 737359 & 4.9469 & 5.1253 & TRN & \\
\hline CHEMBL1343309 & 737359 & 3.0 & 3.8973 & TRN & \\
\hline CHEMBL1506031 & 737359 & 5.0255 & 5.1334 & TST & \\
\hline CHEMBL1492642 & 737359 & 5.5058 & 5.5546 & TRN & \\
\hline CHEMBL1460564 & 737359 & 5.0872 & 4.9219 & TST & \\
\hline CHEMBL1318212 & 737359 & 4.8508 & 4.5027 & TRN & \\
\hline CHEMBL1384146 & 737359 & 5.3615 & 4.5448 & TRN & \\
\hline CHEMBL1501135 & 737359 & 4.7212 & 5.0099 & TST & \\
\hline CHEMBL1405401 & 737359 & 3.0 & 3.4744 & TRN & \\
\hline CHEMBL1462381 & 737359 & 4.6198 & 4.67899 & 9999999999 & TRN \\
\hline CHEMBL1387142 & 737359 & 4.8069 & 4.8984 & TRN & \\
\hline CHEMBL1308385 & 737359 & 5.0535 & 4.9119 & TRN & \\
\hline CHEMBL1373577 & 737359 & 4.8697 & 5.3397 & TRN & \\
\hline CHEMBL1531764 & 737359 & 4.5171 & 4.8449 & TRN & \\
\hline CHEMBL1323510 & 737359 & 4.0991 & 4.3589 & TRN & \\
\hline CHEMBL3197982 & 737359 & 5.7645 & 5.532 & TRN & \\
\hline CHEMBL1440766 & 737359 & 3.0 & 3.5929 & TRN & \\
\hline CHEMBL428789 & 737359 & 4.7167 & 4.6114 & TRN & \\
\hline CHEMBL1571012 & 737359 & 3.0 & 3.508 & TRN & \\
\hline CHEMBL1338489 & 737359 & 5.1871 & 5.0659 & TRN & \\
\hline CHEMBL1712864 & 737359 & 6.8097 & 5.8048 & TRN & \\
\hline CHEMBL340701 & 737359 & 5.6021 & 5.4472 & TRN & \\
\hline CHEMBL3192901 & 737359 & 3.0 & 3.5404 & TRN & \\
\hline CHEMBL1698189 & 737359 & 3.0 & 3.4716 & TRN & \\
\hline CHEMBL 3145048 & 737359 & 4.6676 & 4.5951 & TST & \\
\hline
\end{tabular}


Supplemental Table S2.txt

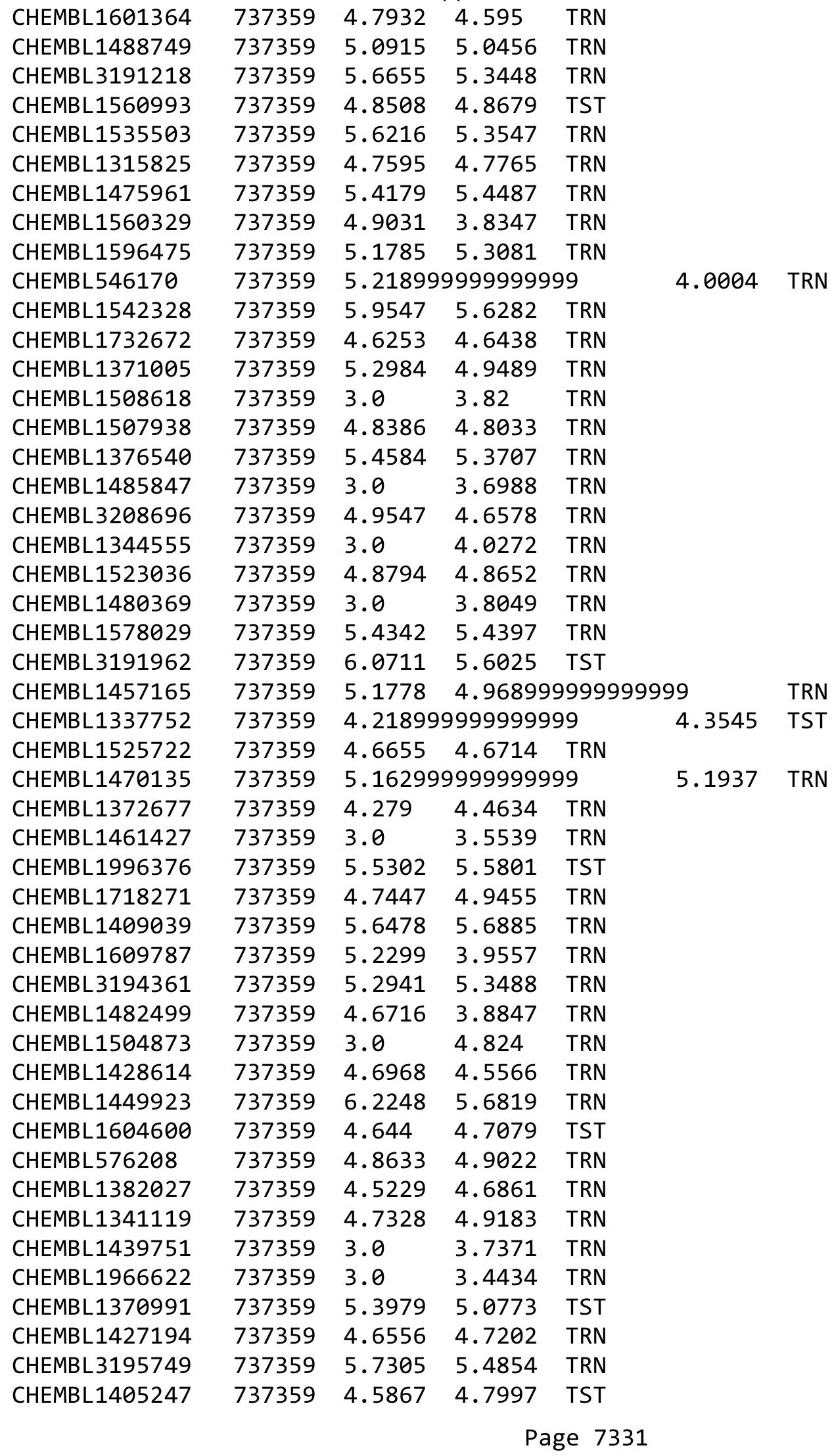


Supplemental Table S2.txt

\begin{tabular}{|c|c|c|c|c|c|}
\hline CHEMBL1342723 & 737359 & 5.5622 & 5.4227 & TRN & \\
\hline CHEMBL1460126 & 737359 & 4.7645 & 4.64 & TRN & \\
\hline CHEMBL1602108 & 737359 & 4.6478 & 4.7299 & TRN & \\
\hline CHEMBL1409277 & 737359 & 5.0595 & 4.7693 & TST & \\
\hline CHEMBL 3191871 & 737359 & 3.0 & 3.59 & TRN & \\
\hline CHEMBL1392564 & 737359 & 4.8665 & 4.7121 & TRN & \\
\hline CHEMBL1364988 & 737359 & 5.4112 & 5.506 & TRN & \\
\hline CHEMBL1533086 & 737359 & 4.9508 & 4.8993 & TRN & \\
\hline CHEMBL1605528 & 737359 & 4.8508 & 4.9411 & TRN & \\
\hline CHEMBL1560459 & 737359 & 4.2644 & 4.6169 & TST & \\
\hline CHEMBL1322521 & 737359 & 4.8239 & 4.7229 & TRN & \\
\hline CHEMBL 3194932 & 737359 & 4.6459 & 3.6691 & TRN & \\
\hline CHEMBL1417815 & 737359 & 6.0958 & 5.6823 & TRN & \\
\hline CHEMBL1407136 & 737359 & 4.5157 & 4.6898 & TRN & \\
\hline CHEMBL1365104 & 737359 & 4.9666 & 4.928 & TST & \\
\hline CHEMBL1432131 & 737359 & 3.0 & 4.9994 & TRN & \\
\hline CHEMBL1967857 & 737359 & 5.9393 & 5.484 & TST & \\
\hline CHEMBL1475973 & 737359 & 4.7496 & 4.5078 & TRN & \\
\hline CHEMBL1546423 & 737359 & 4.6799 & 4.8022 & TRN & \\
\hline CHEMBL1545215 & 737359 & 3.0 & 3.7988 & TRN & \\
\hline CHEMBL1501910 & 737359 & 4.5935 & 4.659 & TST & \\
\hline CHEMBL1504289 & 737359 & 4.9245 & 4.9374 & TST & \\
\hline CHEMBL1412597 & 737359 & 4.9747 & 4.7709 & TST & \\
\hline CHEMBL584668 & 737359 & 4.7055 & 4.7753 & TST & \\
\hline CHEMBL1489817 & 737359 & 5.083 & 4.8221 & TST & \\
\hline CHEMBL1483444 & 737359 & 4.6126 & 4.4916 & TST & \\
\hline CHEMBL1432044 & 737359 & 3.0 & 5.056 & TST & \\
\hline CHEMBL1422087 & 737359 & 5.1707 & 5.2771 & TST & \\
\hline CHEMBL1422056 & 737359 & 4.9914 & 5.0485 & TST & \\
\hline CHEMBL1371119 & 737359 & 4.757 & 4.7545 & TST & \\
\hline CHEMBL412603 & 737359 & 4.6326 & 4.7694 & TST & \\
\hline CHEMBL 3192913 & 737359 & 5.0237 & 5.0204 & TST & \\
\hline CHEMBL1892270 & 737359 & 3.0 & 3.9032 & TST & \\
\hline CHEMBL1558497 & 737359 & 4.6126 & 4.7365 & TST & \\
\hline CHEMBL1426042 & 737359 & 3.0 & 3.5581 & TST & \\
\hline CHEMBL1389725 & 737359 & 4.5622 & 4.5517 & TST & \\
\hline CHEMBL 378903 & 737359 & 5.1561 & 3.6507 & TST & \\
\hline CHEMBL1093346 & 737359 & 4.9318 & 4.8517 & TST & \\
\hline CHEMBL1342479 & 737359 & 3.0 & 3.7947 & TST & \\
\hline CHEMBL1556319 & 737359 & 4.9547 & 5.5518 & TST & \\
\hline CHEMBL1449493 & 737359 & 4.6925 & 4.6402 & TST & \\
\hline CHEMBL1700085 & 737359 & 5.3904 & 5.4923 & TST & \\
\hline CHEMBL1355280 & 737359 & 5.3487 & 5.5732 & TST & \\
\hline CHEMBL 3195061 & 737359 & 4.7905 & 4.9573 & TST & \\
\hline CHEMBL1528211 & 737359 & 4.5591 & 4.6729 & TST & \\
\hline CHEMBL1398836 & 737359 & 4.6038 & 4.7364 & TST & \\
\hline CHEMBL1379026 & 737359 & \multicolumn{3}{|c|}{5.2620000000000005} & 5.2809 \\
\hline CHEMBL1563187 & 737359 & 3.0 & 3.642 & TST & \\
\hline
\end{tabular}




\begin{tabular}{|c|c|c|c|c|c|c|}
\hline & & \multicolumn{5}{|c|}{ Supplemental Table S2.txt } \\
\hline CHEMBL1314677 & 737359 & 5.1733 & 5.3457 & TST & & \\
\hline CHEMBL1610992 & 737359 & 4.7799 & 4.5575 & TST & & \\
\hline CHEMBL3192666 & 737359 & 3.0 & 3.9894 & TST & & \\
\hline CHEMBL1500164 & 737359 & \multicolumn{3}{|c|}{4.4510000000000005} & 3.9717 & TST \\
\hline CHEMBL1320578 & 737359 & 4.4685 & 5.1782 & TST & & \\
\hline CHEMBL336718 & 737359 & 4.762 & 4.1458 & TST & & \\
\hline CHEMBL1387710 & 737359 & 4.9208 & 4.7766 & TST & & \\
\hline CHEMBL1342248 & 737359 & 5.0675 & 4.9745 & TST & & \\
\hline CHEMBL1701182 & 737359 & 5.3625 & 5.5494 & TST & & \\
\hline CHEMBL 3208275 & 737359 & 3.0 & 3.8423 & TST & & \\
\hline CHEMBL1390831 & 737359 & 4.6498 & 4.6504 & TST & & \\
\hline CHEMBL1301421 & 737359 & 4.1785 & 3.7417 & TST & & \\
\hline CHEMBL1342938 & 737359 & 3.0 & 3.4258 & TST & & \\
\hline CHEMBL1556240 & 737359 & 5.0 & 5.194 & TST & & \\
\hline CHEMBL1427991 & 737359 & \multicolumn{3}{|c|}{4.821000000000001} & 4.9177 & TST \\
\hline CHEMBL1582665 & 737359 & \multicolumn{3}{|c|}{4.821000000000001} & 4.588 & TST \\
\hline CHEMBL1475285 & 737359 & 4.5243 & 4.5357 & TST & & \\
\hline CHEMBL1306782 & 737359 & 4.9318 & 4.8543 & TST & & \\
\hline CHEMBL1354548 & 737359 & 4.71 & 4.8143 & TST & & \\
\hline CHEMBL1472212 & 737359 & 4.4157 & 5.15 & TST & & \\
\hline CHEMBL1372464 & 737359 & 3.0 & 3.5553 & TST & & \\
\hline CHEMBL1412585 & 737359 & 4.6596 & 4.6012 & TST & & \\
\hline CHEMBL1604550 & 737359 & 5.4921 & 5.276 & TST & & \\
\hline CHEMBL3144856 & 737359 & 5.1487 & 4.873 & TST & & \\
\hline CHEMBL602561 & 737359 & 4.8182 & 4.5653 & TST & & \\
\hline CHEMBL1497617 & 737359 & 3.0 & 3.7434 & TST & & \\
\hline CHEMBL1556284 & 737359 & 4.2636 & 4.3739 & TST & & \\
\hline CHEMBL1438722 & 737359 & 5.7825 & 5.3415 & TST & & \\
\hline CHEMBL1613412 & 737359 & 3.0 & 3.443 & TST & & \\
\hline CHEMBL3195102 & 737359 & 5.8827 & 5.4183 & TST & & \\
\hline CHEMBL 2018062 & 814256 & 6.0 & 6.0972 & TRN & & \\
\hline CHEMBL 2018076 & 814256 & 7.4559 & 7.5409 & TRN & & \\
\hline CHEMBL 2018053 & 814256 & 3.6021 & 3.6358 & TRN & & \\
\hline CHEMBL 2018067 & 814256 & 7.0 & 6.9827 & TRN & & \\
\hline CHEMBL 2018196 & 814256 & 7.5229 & 7.5394 & TRN & & \\
\hline CHEMBL 2018078 & 814256 & 7.3979 & 7.4269 & TRN & & \\
\hline CHEMBL 2018063 & 814256 & 7.4559 & 7.2801 & TRN & & \\
\hline CHEMBL 2018072 & 814256 & 6.6021 & 6.7081 & TRN & & \\
\hline CHEMBL 2018071 & 814256 & 7.301 & 7.2183 & TRN & & \\
\hline CHEMBL 2018057 & 814256 & 6.1871 & 6.1503 & TRN & & \\
\hline CHEMBL 2018048 & 814256 & 3.6021 & 3.6043 & TRN & & \\
\hline CHEMBL 2018065 & 814256 & 6.8861 & 6.9859 & TRN & & \\
\hline CHEMBL2018079 & 814256 & 6.0458 & 5.9895 & TRN & & \\
\hline CHEMBL 2018060 & 814256 & 7.301 & 7.2226 & TRN & & \\
\hline CHEMBL 2018074 & 814256 & 4.8861 & 4.8287 & TRN & & \\
\hline CHEMBL2018181 & 814256 & 7.3979 & 7.4119 & TRN & & \\
\hline CHEMBL2018066 & 814256 & 7.301 & 7.438 & TRN & & \\
\hline CHEMBL2018198 & 814256 & 7.8239 & 7.814 & TRN & & \\
\hline
\end{tabular}


Supplemental Table S2.txt

\begin{tabular}{|c|c|c|c|c|c|}
\hline CHEMBL 2018199 & 814256 & 7.5229 & 7.4834 & TRN & \\
\hline CHEMBL 2016593 & 814256 & 7.0458 & 7.0388 & TRN & \\
\hline CHEMBL 2018070 & 814256 & 7.2218 & 7.24100 & 00000000005 & TRN \\
\hline CHEMBL 2018194 & 814256 & 8.2218 & 8.2398 & TRN & \\
\hline CHEMBL 2018188 & 814256 & 7.5229 & 7.541 & TRN & \\
\hline CHEMBL 2018058 & 814256 & 7.3468 & 7.3848 & TRN & \\
\hline CHEMBL 2018197 & 814256 & 7.5229 & 7.4816 & TRN & \\
\hline CHEMBL 2018195 & 814256 & 7.8239 & 7.7983 & TRN & \\
\hline CHEMBL 2018044 & 814256 & 3.6021 & 3.6 & TRN & \\
\hline CHEMBL 2018068 & 814256 & 6.5086 & 6.4818 & TRN & \\
\hline CHEMBL 2018069 & 814256 & 6.7959 & 6.7823 & TRN & \\
\hline CHEMBL 2018054 & 814256 & 7.301 & 4.5336 & TST & \\
\hline CHEMBL 2018184 & 814256 & 6.1549 & 6.5723 & TST & \\
\hline CHEMBL 2018180 & 814256 & 6.585 & 6.6548 & TRN & \\
\hline CHEMBL 2018064 & 814256 & 6.699 & 5.4313 & TST & \\
\hline CHEMBL 2018075 & 814256 & 7.4559 & 7.4642 & TRN & \\
\hline CHEMBL 2018046 & 814256 & 3.6021 & 3.6592 & TRN & \\
\hline CHEMBL 2018073 & 814256 & 6.8539 & 6.7122 & TRN & \\
\hline CHEMBL 2018045 & 814256 & 3.6021 & 3.5801 & TRN & \\
\hline CHEMBL 2018192 & 814256 & 5.3468 & 5.3068 & TRN & \\
\hline CHEMBL 2018056 & 814256 & 6.7447 & 6.7705 & TRN & \\
\hline CHEMBL 2018059 & 814256 & 7.5229 & 7.5629 & TRN & \\
\hline CHEMBL 2018187 & 814256 & 7.5229 & 7.4711 & TRN & \\
\hline CHEMBL 2018077 & 814256 & 7.699 & 7.7102 & TRN & \\
\hline CHEMBL 2018061 & 814256 & 7.699 & 7.9348 & TST & \\
\hline CHEMBL 2018051 & 814256 & 5.1549 & 3.8845 & TST & \\
\hline CHEMBL 2018190 & 814256 & 6.4815 & 6.6539 & TST & \\
\hline CHEMBL 2018047 & 814256 & 5.3979 & 3.3684 & TST & \\
\hline CHEMBL 2018193 & 814256 & 7.5229 & 7.845 & TST & \\
\hline CHEMBL 2018191 & 814256 & 6.1135 & 6.4641 & TST & \\
\hline CHEMBL 2018189 & 814256 & 6.5528 & 6.9206 & TST & \\
\hline CHEMBL 2018050 & 814256 & 5.5229 & 4.1439 & TST & \\
\hline CHEMBL 2018055 & 814256 & 7.699 & 5.9311 & TST & \\
\hline CHEMBL 2018052 & 814256 & 6.5229 & 3.702 & TST & \\
\hline CHEMBL 2018049 & 814256 & 3.6021 & 3.1712 & TST & \\
\hline CHEMBL1951106 & 803805 & 3.0 & 3.0024 & TRN & \\
\hline CHEMBL1951291 & 803805 & 5.9208 & 5.9474 & TRN & \\
\hline CHEMBL1951257 & 803805 & 3.0 & 5.6324 & TST & \\
\hline CHEMBL1951265 & 803805 & 5.3188 & 5.3182 & TRN & \\
\hline CHEMBL1951266 & 803805 & 5.7212 & 5.7262 & TRN & \\
\hline CHEMBL1951278 & 803805 & 6.0 & 6.024 & TRN & \\
\hline CHEMBL1951260 & 803805 & 3.0 & 3.0089 & TRN & \\
\hline CHEMBL1951295 & 803805 & 8.301 & 8.2828 & TRN & \\
\hline CHEMBL1951247 & 803805 & 3.0 & 2.9935 & TRN & \\
\hline CHEMBL1951261 & 803805 & 4.5528 & 4.5495 & TRN & \\
\hline CHEMBL1951107 & 803805 & 4.5528 & 4.5593 & TRN & \\
\hline CHEMBL1951263 & 803805 & 6.0 & 6.0057 & TRN & \\
\hline CHEMBL1951259 & 803805 & 3.0 & 2.99 & TRN & \\
\hline
\end{tabular}




\begin{tabular}{|c|c|c|c|c|}
\hline & & & pplement & al $\mathrm{Ta}$ \\
\hline CHEMBL1951252 & 803805 & 5.0 & 4.997 & TRN \\
\hline CHEMBL1951288 & 803805 & 4.0 & 3.9974 & TRN \\
\hline CHEMBL1951285 & 803805 & 5.8861 & 5.8717 & TRN \\
\hline CHEMBL1951276 & 803805 & 4.4202 & 4.4046 & TRN \\
\hline CHEMBL1951290 & 803805 & 4.3098 & 4.3218 & TRN \\
\hline CHEMBL1951294 & 803805 & 5.3665 & 5.3666 & TRN \\
\hline CHEMBL1951111 & 803805 & 3.0 & 3.0795 & TST \\
\hline CHEMBL1951253 & 803805 & 3.0 & 2.9975 & TRN \\
\hline CHEMBL1951292 & 803805 & 4.9586 & 4.9356 & TRN \\
\hline CHEMBL1230468 & 803805 & 8.699 & 8.6933 & TRN \\
\hline CHEMBL1951296 & 803805 & 7.699 & 7.7128 & TRN \\
\hline CHEMBL1951275 & 803805 & 6.4437 & 6.4444 & TRN \\
\hline CHEMBL1951279 & 803805 & 4.8539 & 4.8545 & TRN \\
\hline CHEMBL1951280 & 803805 & 5.0 & 5.008 & TRN \\
\hline CHEMBL1951287 & 803805 & 7.5229 & 7.523 & TRN \\
\hline CHEMBL1951274 & 803805 & 6.4815 & 6.4748 & TRN \\
\hline CHEMBL1951277 & 803805 & 6.8539 & 6.8004 & TRN \\
\hline CHEMBL1951109 & 803805 & 3.0 & 4.4107 & TST \\
\hline CHEMBL1951249 & 803805 & 3.0 & 2.4534 & TST \\
\hline CHEMBL1951110 & 803805 & 3.0 & 2.8006 & TST \\
\hline CHEMBL1951108 & 803805 & 3.0 & 3.5556 & TST \\
\hline CHEMBL1951246 & 803805 & 4.7212 & 3.0173 & TST \\
\hline CHEMBL1951289 & 803805 & 4.0 & 3.9981 & TRN \\
\hline CHEMBL1951269 & 803805 & 5.0655 & 6.0268 & TST \\
\hline CHEMBL1951262 & 803805 & 4.4949 & 4.4802 & TRN \\
\hline CHEMBL1405634 & 803805 & 4.9208 & 4.9102 & TRN \\
\hline CHEMBL1951258 & 803805 & 3.0 & 3.4746 & TST \\
\hline CHEMBL1951283 & 803805 & 5.0 & 5.0115 & TRN \\
\hline CHEMBL1951293 & 803805 & 6.5376 & 6.5334 & TRN \\
\hline CHEMBL1951267 & 803805 & 4.9208 & 4.9208 & TRN \\
\hline CHEMBL1951251 & 803805 & 4.8539 & 4.8776 & TRN \\
\hline CHEMBL1951270 & 803805 & 5.5528 & 5.5458 & TRN \\
\hline CHEMBL1951273 & 803805 & 5.8861 & 5.9016 & TRN \\
\hline CHEMBL1951112 & 803805 & 3.0 & 1.8417 & TST \\
\hline CHEMBL1951113 & 803805 & 5.0 & 3.306 & TST \\
\hline CHEMBL1951271 & 803805 & 6.0458 & 6.0376 & TRN \\
\hline CHEMBL1951250 & 803805 & 3.0 & 3.0673 & TST \\
\hline CHEMBL1951248 & 803805 & 3.0 & 1.6509 & TST \\
\hline CHEMBL1951286 & 803805 & 6.9586 & 6.9653 & TRN \\
\hline CHEMBL1951105 & 803805 & 5.7212 & 4.5078 & TST \\
\hline CHEMBL1951284 & 803805 & 6.9586 & 6.9802 & TRN \\
\hline CHEMBL1951254 & 803805 & 3.0 & 3.8708 & TST \\
\hline CHEMBL1951255 & 803805 & 3.0 & 2.9948 & TRN \\
\hline CHEMBL1951268 & 803805 & 5.4815 & 5.7447 & TST \\
\hline CHEMBL1951281 & 803805 & 5.6778 & 5.6819 & TRN \\
\hline CHEMBL1951282 & 803805 & 7.5229 & 7.5272 & TRN \\
\hline CHEMBL1951272 & 803805 & 4.585 & 4.5907 & TRN \\
\hline CHEMBL1951256 & 803805 & 4.3768 & 4.3827 & TRN \\
\hline
\end{tabular}




\begin{tabular}{|c|c|c|c|c|c|}
\hline & & \multicolumn{4}{|c|}{ Supplemental Table S2.txt } \\
\hline CHEMBL1951264 & 803805 & 6.4685 & 6.4721 & TRN & \\
\hline CHEMBL1405150 & 737425 & 2.926 & 2.9546 & TRN & \\
\hline CHEMBL1369571 & 737425 & 2.926 & 3.0789 & TST & \\
\hline CHEMBL1303076 & 737425 & 2.9261 & 2.9747 & TRN & \\
\hline CHEMBL1607070 & 737425 & 2.9257 & 3.1651 & TRN & \\
\hline CHEMBL1323467 & 737425 & 2.926 & 2.9546 & TRN & \\
\hline CHEMBL547285 & 737425 & 2.9257 & 2.9546 & TRN & \\
\hline CHEMBL570105 & 737425 & 5.4782 & 4.1808 & TRN & \\
\hline CHEMBL3194449 & 737425 & 3.9429 & 3.0515 & TRN & \\
\hline CHEMBL3195241 & 737425 & 2.926 & 3.013 & TRN & \\
\hline CHEMBL1436964 & 737425 & 2.9263 & 3.7892 & TRN & \\
\hline CHEMBL1564355 & 737425 & 2.9261 & 2.9882 & TST & \\
\hline CHEMBL1461482 & 737425 & 4.157 & 3.7686 & TRN & \\
\hline CHEMBL1427508 & 737425 & 2.926 & 2.9994 & TRN & \\
\hline CHEMBL1299566 & 737425 & 2.926 & 3.8655 & TRN & \\
\hline CHEMBL1577983 & 737425 & 3.4032 & 3.1397 & TRN & \\
\hline CHEMBL2359911 & 737425 & 2.926 & 3.0441 & TRN & \\
\hline CHEMBL1400298 & 737425 & 2.9264 & 2.9984 & TRN & \\
\hline CHEMBL1709779 & 737425 & 2.9261 & 2.9984 & TRN & \\
\hline CHEMBL1546374 & 737425 & 4.7733 & 3.9143 & TRN & \\
\hline CHEMBL1382917 & 737425 & 4.4265 & 3.7354 & TST & \\
\hline CHEMBL2006168 & 737425 & 2.9262 & 3.0528 & TRN & \\
\hline CHEMBL1380414 & 737425 & 4.0332 & 4.066 & TRN & \\
\hline CHEMBL1311879 & 737425 & 2.926 & 3.0029 & TRN & \\
\hline CHEMBL1396349 & 737425 & 2.9256 & 3.0287 & TRN & \\
\hline CHEMBL588804 & 737425 & 2.926 & 2.9787 & TRN & \\
\hline CHEMBL1393829 & 737425 & 2.926 & 2.9699 & TRN & \\
\hline CHEMBL1353878 & 737425 & 2.9261 & 2.9748 & TRN & \\
\hline CHEMBL505734 & 737425 & 2.926 & 2.9917 & TST & \\
\hline CHEMBL1979954 & 737425 & 2.9261 & 3.0373 & TRN & \\
\hline CHEMBL1588926 & 737425 & 4.4464 & 3.8028 & TST & \\
\hline CHEMBL1539624 & 737425 & 2.9261 & 3.0618 & TRN & \\
\hline CHEMBL1404029 & 737425 & 2.926 & 3.0733 & TRN & \\
\hline CHEMBL3214118 & 737425 & 2.9261 & 3.2349 & TRN & \\
\hline CHEMBL1600086 & 737425 & 2.926 & 2.9723 & TRN & \\
\hline CHEMBL1603704 & 737425 & 2.9261 & 2.99 & TRN & \\
\hline CHEMBL1602962 & 737425 & 2.9261 & 3.0477 & TRN & \\
\hline CHEMBL1583914 & 737425 & 2.9257 & 2.9807 & TRN & \\
\hline CHEMBL1545729 & 737425 & 2.9259 & 3.0067 & TRN & \\
\hline CHEMBL1365411 & 737425 & 2.9258 & 2.9738 & TRN & \\
\hline CHEMBL1484231 & 737425 & 2.926 & 3.0486 & TRN & \\
\hline CHEMBL1336535 & 737425 & 2.9263 & 3.0857 & TRN & \\
\hline CHEMBL3196163 & 737425 & 2.926 & 3.0966 & TRN & \\
\hline CHEMBL1456876 & 737425 & 2.9257 & 2.9824 & TRN & \\
\hline CHEMBL1448282 & 737425 & 2.9261 & 2.9546 & TRN & \\
\hline CHEMBL3197259 & 737425 & 2.926 & 2.9841 & TRN & \\
\hline CHEMBL584626 & 737425 & 3.4029 & 3.55899 & 99999999997 & TST \\
\hline CHEMBL1479316 & 737425 & 4.4485 & 3.8381 & TRN & \\
\hline
\end{tabular}




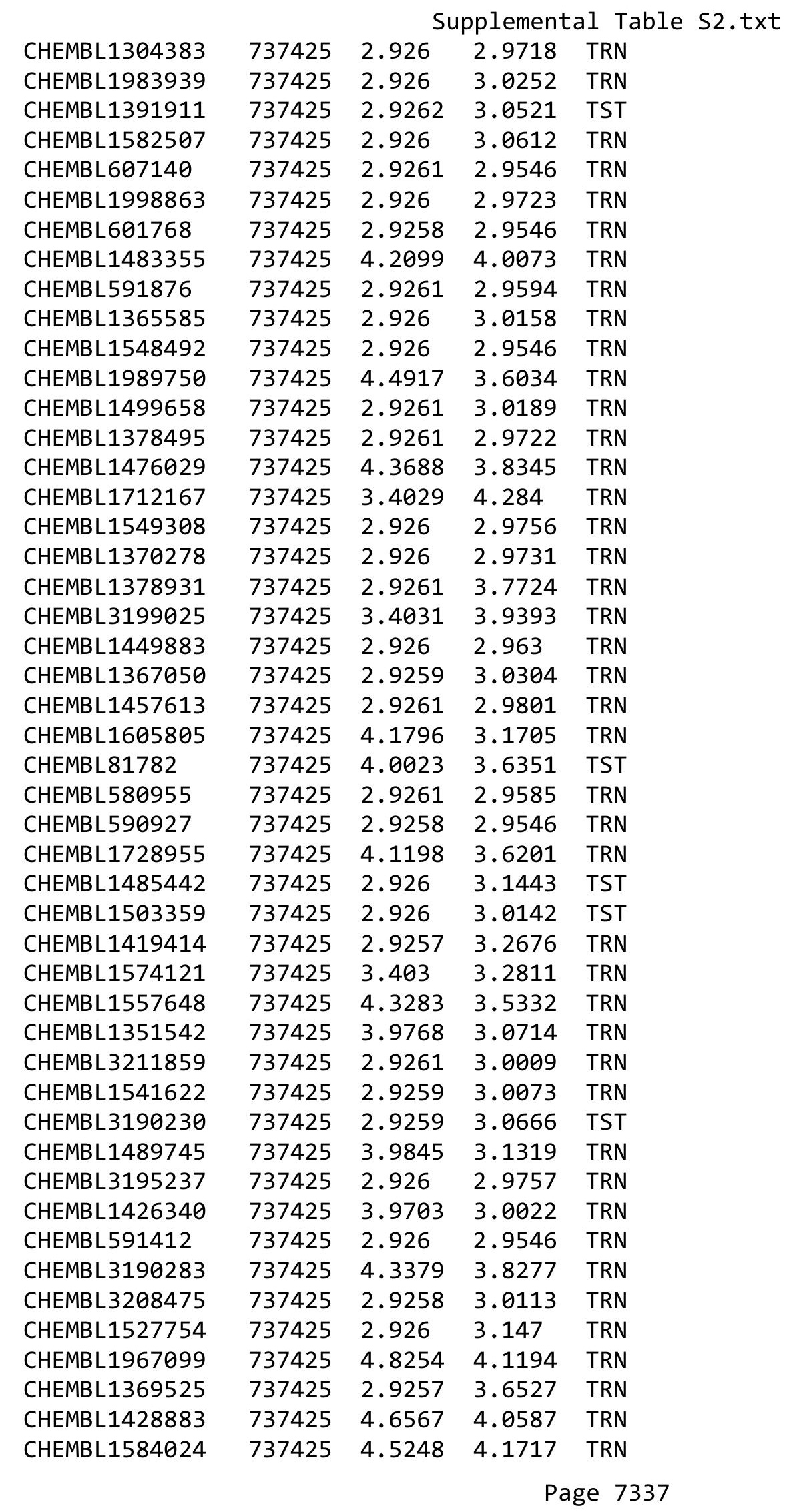




\begin{tabular}{|c|c|c|c|c|c|}
\hline & & \multicolumn{4}{|c|}{ Supplemental Table S2.txt } \\
\hline CHEMBL1560066 & 737425 & 2.9264 & 2.9837 & TRN & \\
\hline CHEMBL 3212273 & 737425 & 2.9264 & 2.9969 & TRN & \\
\hline CHEMBL1480659 & 737425 & 2.9263 & 4.1303 & TRN & \\
\hline CHEMBL1410758 & 737425 & 2.926 & 3.0317 & TRN & \\
\hline CHEMBL600862 & 737425 & 2.9261 & 2.9768 & TRN & \\
\hline CHEMBL1372509 & 737425 & 2.926 & 2.9915 & TRN & \\
\hline CHEMBL1439833 & 737425 & 2.9261 & 2.9854 & TRN & \\
\hline CHEMBL1427059 & 737425 & 2.9257 & 3.0349 & TRN & \\
\hline CHEMBL3198128 & 737425 & 2.9262 & 3.6647 & TST & \\
\hline CHEMBL1585527 & 737425 & 4.0209 & 3.444 & TRN & \\
\hline CHEMBL517615 & 737425 & 2.9261 & 2.9917 & TST & \\
\hline CHEMBL1557815 & 737425 & 2.9261 & 3.0133 & TRN & \\
\hline CHEMBL1502000 & 737425 & 2.9261 & 2.9832 & TRN & \\
\hline CHEMBL1443977 & 737425 & 2.9261 & 2.9729 & TRN & \\
\hline CHEMBL585827 & 737425 & 2.9263 & 2.9583 & TRN & \\
\hline CHEMBL1407684 & 737425 & 4.3385 & 3.8284 & TRN & \\
\hline CHEMBL1499914 & 737425 & 3.9615 & 3.0019 & TRN & \\
\hline CHEMBL3192868 & 737425 & 2.9264 & 3.0308 & TRN & \\
\hline CHEMBL305469 & 737425 & 3.403 & 3.9755 & TRN & \\
\hline CHEMBL1396797 & 737425 & 2.9259 & 3.0389 & TRN & \\
\hline CHEMBL32793 & 737425 & 4.0696 & 3.6589 & TST & \\
\hline CHEMBL602718 & 737425 & 2.926 & 2.9546 & TRN & \\
\hline CHEMBL1528900 & 737425 & 4.4372 & 3.7701 & TST & \\
\hline CHEMBL1998606 & 737425 & 4.008 & 2.9972 & TRN & \\
\hline CHEMBL1312320 & 737425 & 2.926 & 2.9638 & TRN & \\
\hline CHEMBL1979957 & 737425 & 2.9259 & 3.0657 & TST & \\
\hline CHEMBL1724246 & 737425 & 4.6772 & 4.1658 & TRN & \\
\hline CHEMBL3194594 & 737425 & 2.9259 & 3.9674 & TRN & \\
\hline CHEMBL3191835 & 737425 & 2.9257 & 2.986 & TRN & \\
\hline CHEMBL1605292 & 737425 & 4.1878 & 3.737 & TRN & \\
\hline CHEMBL1598785 & 737425 & 2.9261 & 2.9546 & TRN & \\
\hline CHEMBL1342357 & 737425 & 4.0142 & 3.5248 & TRN & \\
\hline CHEMBL1736757 & 737425 & 2.9266 & 3.0261 & TRN & \\
\hline CHEMBL1481632 & 737425 & 3.4032 & 3.3117 & TRN & \\
\hline CHEMBL 2004141 & 737425 & 2.9261 & 3.0482 & TRN & \\
\hline CHEMBL1543157 & 737425 & 2.9262 & 3.0217 & TRN & \\
\hline CHEMBL1413203 & 737425 & 2.9261 & 3.0768 & TST & \\
\hline CHEMBL1339797 & 737425 & 3.9904 & 3.83399 & 99999999996 & TRN \\
\hline CHEMBL1977995 & 737425 & 2.9258 & 3.2045 & TRN & \\
\hline CHEMBL1321620 & 737425 & 2.9259 & 3.5574 & TRN & \\
\hline CHEMBL1385451 & 737425 & 2.926 & 2.9978 & TRN & \\
\hline CHEMBL1531670 & 737425 & 2.9261 & 3.0365 & TRN & \\
\hline CHEMBL1569910 & 737425 & 2.926 & 4.217 & TRN & \\
\hline CHEMBL1535139 & 737425 & 2.9255 & 2.9956 & TRN & \\
\hline CHEMBL1381627 & 737425 & 2.9261 & 3.0617 & TRN & \\
\hline CHEMBL1977678 & 737425 & 2.9261 & 3.0135 & TRN & \\
\hline CHEMBL1729758 & 737425 & 4.7569 & 3.8382 & TST & \\
\hline CHEMBL1305375 & 737425 & 2.9259 & 3.0219 & TRN & \\
\hline
\end{tabular}




\begin{tabular}{|c|c|c|c|c|c|}
\hline & & \multicolumn{4}{|c|}{ Supplemental Table S2.txt } \\
\hline CHEMBL1370879 & 737425 & 3.4035 & 4.1547 & TRN & \\
\hline CHEMBL1386049 & 737425 & 2.926 & 3.0299 & TRN & \\
\hline CHEMBL1388595 & 737425 & 2.9259 & 4.0311 & TRN & \\
\hline CHEMBL1532238 & 737425 & 4.2143 & 3.5026 & TST & \\
\hline CHEMBL1530412 & 737425 & 2.926 & 2.9751 & TRN & \\
\hline CHEMBL1887153 & 737425 & 2.926 & 2.9838 & TRN & \\
\hline CHEMBL1454721 & 737425 & 4.1954 & 3.8368 & TRN & \\
\hline CHEMBL3193510 & 737425 & 2.9261 & 2.966 & TRN & \\
\hline CHEMBL1542074 & 737425 & 2.9263 & 2.9889 & TRN & \\
\hline CHEMBL1347598 & 737425 & 2.926 & 3.0431 & TST & \\
\hline CHEMBL1330558 & 737425 & 4.3821 & 3.6516 & TRN & \\
\hline CHEMBL1337086 & 737425 & 2.926 & 3.0322 & TST & \\
\hline CHEMBL1342907 & 737425 & 2.9261 & 3.0408 & TRN & \\
\hline CHEMBL3195943 & 737425 & 4.7804 & 4.1986 & TRN & \\
\hline CHEMBL3193098 & 737425 & 2.9261 & 2.9546 & TRN & \\
\hline CHEMBL 3190268 & 737425 & 2.9259 & 2.96 & TRN & \\
\hline CHEMBL1552296 & 737425 & 2.9259 & 2.9822 & TRN & \\
\hline CHEMBL 2004847 & 737425 & 4.2555 & 3.9419 & TRN & \\
\hline CHEMBL592600 & 737425 & 2.9263 & 2.9636 & TRN & \\
\hline CHEMBL1511879 & 737425 & 2.9257 & 3.0517 & TRN & \\
\hline CHEMBL1448965 & 737425 & 2.9259 & 2.9826 & TRN & \\
\hline CHEMBL1407952 & 737425 & 2.926 & 2.9596 & TRN & \\
\hline CHEMBL1588513 & 737425 & 2.9261 & 2.9891 & TRN & \\
\hline CHEMBL1728763 & 737425 & 2.9263 & 3.0602 & TST & \\
\hline CHEMBL1519450 & 737425 & 2.9261 & 2.9645 & TRN & \\
\hline CHEMBL1392820 & 737425 & 2.926 & 3.0235 & TRN & \\
\hline CHEMBL1527155 & 737425 & 3.9297 & 3.55899 & 99999999997 & TRN \\
\hline CHEMBL3199020 & 737425 & 2.9263 & 3.0503 & TRN & \\
\hline CHEMBL1968085 & 737425 & 2.9259 & 2.9918 & TRN & \\
\hline CHEMBL1502014 & 737425 & 4.8207 & 3.821 & TST & \\
\hline CHEMBL1350252 & 737425 & 2.926 & 2.9784 & TRN & \\
\hline CHEMBL1484328 & 737425 & 3.4031 & 4.0876 & TRN & \\
\hline CHEMBL1516451 & 737425 & 2.9263 & 3.0042 & TRN & \\
\hline CHEMBL1426155 & 737425 & 2.926 & 2.9788 & TRN & \\
\hline CHEMBL1499233 & 737425 & 2.926 & 2.9673 & TRN & \\
\hline CHEMBL3191064 & 737425 & 2.926 & 3.696 & TST & \\
\hline CHEMBL1574982 & 737425 & 2.926 & 3.0324 & TRN & \\
\hline CHEMBL1983530 & 737425 & 2.926 & 3.0614 & TRN & \\
\hline CHEMBL1396209 & 737425 & 4.7324 & 3.7909 & TST & \\
\hline CHEMBL533226 & 737425 & 3.4034 & 3.4742 & TST & \\
\hline CHEMBL3192656 & 737425 & 2.926 & 3.0013 & TRN & \\
\hline CHEMBL1373096 & 737425 & 2.9264 & 2.95899 & 99999999996 & TRN \\
\hline CHEMBL1508788 & 737425 & 2.9261 & 2.9936 & TRN & \\
\hline CHEMBL 273103 & 737425 & 2.926 & 3.0261 & TST & \\
\hline CHEMBL1412002 & 737425 & 2.926 & 2.9546 & TRN & \\
\hline CHEMBL530499 & 737425 & 2.9262 & 2.9546 & TRN & \\
\hline CHEMBL1522486 & 737425 & 4.4536 & 3.6352 & TRN & \\
\hline CHEMBL1397742 & 737425 & 2.9258 & 2.9606 & TRN & \\
\hline
\end{tabular}


Supplemental Table S2.txt

\begin{tabular}{|c|c|c|c|c|}
\hline CHEMBL1988851 & 737425 & 2.9264 & 3.8652 & TST \\
\hline CHEMBL1431189 & 737425 & 4.4089 & 3.5875 & TST \\
\hline CHEMBL1420791 & 737425 & 2.9263 & 2.9922 & TST \\
\hline CHEMBL1532068 & 737425 & 2.926 & 2.9546 & TST \\
\hline CHEMBL1328653 & 737425 & 2.9264 & 3.8527 & TST \\
\hline CHEMBL1567847 & 737425 & 2.9257 & 3.3076 & TST \\
\hline CHEMBL1423626 & 737425 & 4.6634 & 3.9506 & TST \\
\hline CHEMBL1372085 & 737425 & 2.9259 & 3.0974 & TST \\
\hline CHEMBL1514530 & 737425 & 2.926 & 2.9546 & TST \\
\hline CHEMBL1994963 & 737425 & 2.926 & 2.9734 & TST \\
\hline CHEMBL3194778 & 737425 & 4.4971 & 3.6225 & TST \\
\hline CHEMBL 2004978 & 737425 & 2.926 & 3.0272 & TST \\
\hline CHEMBL1332139 & 737425 & 2.926 & 3.0313 & TST \\
\hline CHEMBL1447058 & 737425 & 4.4957 & 4.213 & TST \\
\hline CHEMBL1502020 & 737425 & 2.926 & 3.0777 & TST \\
\hline CHEMBL1547780 & 737425 & 2.9261 & 3.0591 & TST \\
\hline CHEMBL1430038 & 737425 & 4.2201 & 3.9659 & TST \\
\hline CHEMBL1342852 & 737425 & 2.926 & 3.0058 & TST \\
\hline CHEMBL3193844 & 737425 & 2.926 & 3.02699 & 79999999997 \\
\hline CHEMBL1414746 & 737425 & 2.9257 & 3.639 & TST \\
\hline CHEMBL1559564 & 737425 & 4.078 & 3.2916 & TST \\
\hline CHEMBL548540 & 737425 & 2.9261 & 2.9624 & TST \\
\hline CHEMBL67311 & 737425 & 4.1102 & 3.4983 & TST \\
\hline CHEMBL1986418 & 737425 & 2.926 & 3.0107 & TST \\
\hline CHEMBL1414846 & 737425 & 4.5675 & 3.9993 & TST \\
\hline CHEMBL1588557 & 737425 & 2.9263 & 2.9807 & TST \\
\hline CHEMBL1396843 & 737425 & 4.5375 & 3.9657 & TST \\
\hline CHEMBL1999960 & 737425 & 4.0389 & 3.6997 & TST \\
\hline CHEMBL1376516 & 752319 & 4.2831 & 3.5057 & TRN \\
\hline CHEMBL 250711 & 752319 & 3.262 & 3.7202 & TRN \\
\hline CHEMBL1971127 & 752319 & 5.0129 & 3.708 & TST \\
\hline CHEMBL1536835 & 752319 & 4.5255 & 3.5486 & TRN \\
\hline CHEMBL1460004 & 752319 & 3.2621 & 3.6495 & TRN \\
\hline CHEMBL422692 & 752319 & 3.262 & 3.2405 & TRN \\
\hline CHEMBL 1578670 & 752319 & 4.7629 & 4.3876 & TRN \\
\hline CHEMBL1393761 & 752319 & 3.262 & 3.7632 & TST \\
\hline CHEMBL1602206 & 752319 & 3.2619 & 3.324 & TRN \\
\hline CHEMBL1492044 & 752319 & 3.2619 & 3.2648 & TRN \\
\hline CHEMBL1893003 & 752319 & 3.2624 & 3.2491 & TRN \\
\hline CHEMBL1597733 & 752319 & 3.262 & 3.2669 & TRN \\
\hline CHEMBL1362746 & 752319 & 3.2621 & 3.3588 & TST \\
\hline CHEMBL1571034 & 752319 & 3.2621 & 3.4956 & TRN \\
\hline CHEMBL1397114 & 752319 & 3.2618 & 3.2578 & TST \\
\hline CHEMBL1458111 & 752319 & 5.1743 & 4.1865 & TRN \\
\hline CHEMBL1500686 & 752319 & 3.262 & 3.8799 & TRN \\
\hline CHEMBL496633 & 752319 & 3.2621 & 3.6161 & TST \\
\hline CHEMBL1549982 & 752319 & 3.2617 & 3.2651 & TST \\
\hline CHEMBL1518886 & 752319 & 3.2623 & 3.201 & TST \\
\hline
\end{tabular}


Supplemental Table S2.txt

\begin{tabular}{|c|c|c|c|c|c|}
\hline CHEMBL1403262 & 752319 & 4.7712 & 4.0351 & TRN & \\
\hline CHEMBL1394552 & 752319 & 3.2624 & 3.272 & TST & \\
\hline CHEMBL1574420 & 752319 & 4.8546 & 4.2253 & TRN & \\
\hline CHEMBL1873186 & 752319 & 3.262 & 3.3626 & TRN & \\
\hline CHEMBL1473205 & 752319 & 3.2627 & 3.252 & TST & \\
\hline CHEMBL1341102 & 752319 & 3.2619 & 3.2552 & TRN & \\
\hline CHEMBL1724937 & 752319 & 3.2623 & 3.2331 & TRN & \\
\hline CHEMBL1990694 & 752319 & 3.2621 & 3.2328 & TRN & \\
\hline CHEMBL1880442 & 752319 & 3.262 & 3.2501 & TST & \\
\hline CHEMBL1471509 & 752319 & 3.262 & 3.2894 & TST & \\
\hline CHEMBL1365476 & 752319 & 3.262 & 3.2803 & TRN & \\
\hline CHEMBL3198737 & 752319 & 3.2624 & 3.2101 & TRN & \\
\hline CHEMBL1511114 & 752319 & 3.2621 & 3.2335 & TRN & \\
\hline CHEMBL1545734 & 752319 & 3.2619 & 3.3243 & TRN & \\
\hline CHEMBL1545021 & 752319 & 3.2623 & 3.2576 & TST & \\
\hline CHEMBL1513972 & 752319 & 3.262 & 3.8455 & TRN & \\
\hline CHEMBL1410739 & 752319 & 3.262 & 3.2537 & TRN & \\
\hline CHEMBL1576059 & 752319 & 3.2619 & 3.5982 & TRN & \\
\hline CHEMBL1500754 & 752319 & 3.2623 & 3.2236 & TRN & \\
\hline CHEMBL1489159 & 752319 & 3.2621 & 3.2064 & TST & \\
\hline CHEMBL1731264 & 752319 & 3.2616 & 3.2112 & TRN & \\
\hline CHEMBL1381946 & 752319 & 3.262 & 3.2847 & TRN & \\
\hline CHEMBL1370456 & 752319 & 3.2623 & 3.4966 & TST & \\
\hline CHEMBL1591708 & 752319 & 3.2618 & 3.2053 & TRN & \\
\hline CHEMBL1474602 & 752319 & 3.262 & 3.2234 & TRN & \\
\hline CHEMBL1361615 & 752319 & 3.2621 & 3.2017 & TRN & \\
\hline CHEMBL1355072 & 752319 & 3.262 & 3.2646 & TRN & \\
\hline CHEMBL1605743 & 752319 & 3.2624 & 3.2136 & TRN & \\
\hline CHEMBL1370322 & 752319 & 3.262 & 3.2191 & TRN & \\
\hline CHEMBL1361924 & 752319 & 3.2619 & 3.6445 & TRN & \\
\hline CHEMBL1331010 & 752319 & 3.2621 & 3.2396 & TRN & \\
\hline CHEMBL3193419 & 752319 & 3.2617 & 3.5876 & TRN & \\
\hline CHEMBL1389301 & 752319 & 3.2617 & 3.3353 & TRN & \\
\hline CHEMBL1390912 & 752319 & 3.262 & 3.2258 & TRN & \\
\hline CHEMBL1429269 & 752319 & 3.2619 & 3.2478 & TRN & \\
\hline CHEMBL1321530 & 752319 & 3.2623 & 3.2269 & TRN & \\
\hline CHEMBL589245 & 752319 & 3.262 & 3.2151 & TRN & \\
\hline CHEMBL1452571 & 752319 & 3.2621 & 3.2124 & TRN & \\
\hline CHEMBL1577275 & 752319 & 3.2623 & 3.2443 & TRN & \\
\hline CHEMBL1328504 & 752319 & 3.2624 & 3.2652 & TRN & \\
\hline CHEMBL1484627 & 752319 & 3.262 & 3.2056 & TRN & \\
\hline CHEMBL1903746 & 752319 & 3.262 & 3.2313 & TRN & \\
\hline CHEMBL1313831 & 752319 & 3.2619 & 3.2274 & TRN & \\
\hline CHEMBL1314272 & 752319 & 3.2618 & 3.308006 & 00000000003 & TRN \\
\hline CHEMBL1486690 & 752319 & 3.2618 & 3.8187 & TST & \\
\hline CHEMBL1980281 & 752319 & 3.2618 & 3.5846 & TST & \\
\hline CHEMBL1527008 & 752319 & 3.2618 & 3.3442 & TRN & \\
\hline CHEMBL1491750 & 752319 & 3.262 & 3.2392 & TST & \\
\hline
\end{tabular}




\begin{tabular}{|c|c|c|c|c|c|}
\hline \multicolumn{6}{|c|}{ Supplemental Table S2.txt } \\
\hline CHEMBL1598570 & 752319 & 3.262 & 3.1993 & TRN & \\
\hline CHEMBL601385 & 752319 & 3.2619 & 3.3717 & TRN & \\
\hline CHEMBL1605224 & 752319 & 3.262 & 3.6667 & TRN & \\
\hline CHEMBL1730051 & 752319 & 3.262 & 3.299 & TST & \\
\hline CHEMBL 1462480 & 752319 & 3.262 & 3.2803 & TRN & \\
\hline CHEMBL1418096 & 752319 & 3.2617 & 3.3096 & TRN & \\
\hline CHEMBL1986183 & 752319 & 4.6936 & 3.7992 & TST & \\
\hline CHEMBL1353338 & 752319 & 3.2621 & 3.2179 & TRN & \\
\hline CHEMBL1992490 & 752319 & 4.2162 & 3.3748 & TST & \\
\hline CHEMBL1576297 & 752319 & 3.2617 & 3.2676 & TRN & \\
\hline CHEMBL1723816 & 752319 & 3.2621 & 3.2607 & TRN & \\
\hline CHEMBL1392848 & 752319 & 3.2618 & 3.2535 & TRN & \\
\hline CHEMBL1369972 & 752319 & 3.262 & 3.2162 & TRN & \\
\hline CHEMBL1325192 & 752319 & 3.262 & 3.37399 & 99999999997 & TRN \\
\hline CHEMBL1586096 & 752319 & 3.262 & 3.3005 & TRN & \\
\hline CHEMBL1729450 & 752319 & 3.262 & 3.3055 & TRN & \\
\hline CHEMBL3195513 & 752319 & 3.2621 & 3.2484 & TRN & \\
\hline CHEMBL1418432 & 752319 & 3.262 & 3.304 & TRN & \\
\hline CHEMBL1302748 & 752319 & 3.2618 & 3.3205 & TRN & \\
\hline CHEMBL1591898 & 752319 & 4.4818 & 3.9576 & TRN & \\
\hline CHEMBL1318510 & 752319 & 3.2617 & 3.2345 & TRN & \\
\hline CHEMBL1966241 & 752319 & 3.2621 & 3.24600 & 00000000004 & TST \\
\hline CHEMBL1484277 & 752319 & 3.2621 & 3.236 & TRN & \\
\hline CHEMBL532160 & 752319 & 3.262 & 3.8004 & TRN & \\
\hline CHEMBL1472131 & 752319 & 3.2623 & 3.695 & TRN & \\
\hline CHEMBL1587031 & 752319 & 3.2618 & 3.2899 & TRN & \\
\hline CHEMBL1568474 & 752319 & 5.8804 & 4.8212 & TRN & \\
\hline CHEMBL1991601 & 752319 & 3.2622 & 3.3342 & TRN & \\
\hline CHEMBL1979061 & 752319 & 3.2624 & 3.2353 & TRN & \\
\hline CHEMBL1973159 & 752319 & 5.3375 & 3.75100 & 20000000003 & TST \\
\hline CHEMBL1733182 & 752319 & 3.2623 & 3.2952 & TST & \\
\hline CHEMBL1709883 & 752319 & 3.2621 & 3.3025 & TST & \\
\hline CHEMBL1995720 & 752319 & 5.0148 & 3.5485 & TST & \\
\hline CHEMBL86464 & 752319 & 3.2621 & 3.2457 & TRN & \\
\hline CHEMBL1497035 & 752319 & 3.2621 & 3.2602 & TRN & \\
\hline CHEMBL1726318 & 752319 & 3.262 & 3.2684 & TRN & \\
\hline CHEMBL1412077 & 752319 & 3.2623 & 3.6992 & TRN & \\
\hline CHEMBL1503093 & 752319 & 3.2621 & 3.2194 & TRN & \\
\hline CHEMBL1303641 & 752319 & 3.2621 & 3.2534 & TRN & \\
\hline CHEMBL1491847 & 752319 & 3.262 & 3.8476 & TRN & \\
\hline CHEMBL1454203 & 752319 & 3.2619 & 3.2335 & TRN & \\
\hline CHEMBL1575701 & 752319 & 3.2617 & 3.5714 & TST & \\
\hline CHEMBL3191688 & 752319 & 3.2617 & 3.7705 & TST & \\
\hline CHEMBL1553368 & 752319 & 3.2619 & 4.2342 & TRN & \\
\hline CHEMBL1527972 & 752319 & 5.1718 & 4.0449 & TRN & \\
\hline CHEMBL1331762 & 752319 & 3.262 & 3.2023 & TRN & \\
\hline CHEMBL1337599 & 752319 & 3.262 & 3.3591 & TRN & \\
\hline CHEMBL1880132 & 752319 & 3.262 & 3.3109 & TRN & \\
\hline
\end{tabular}




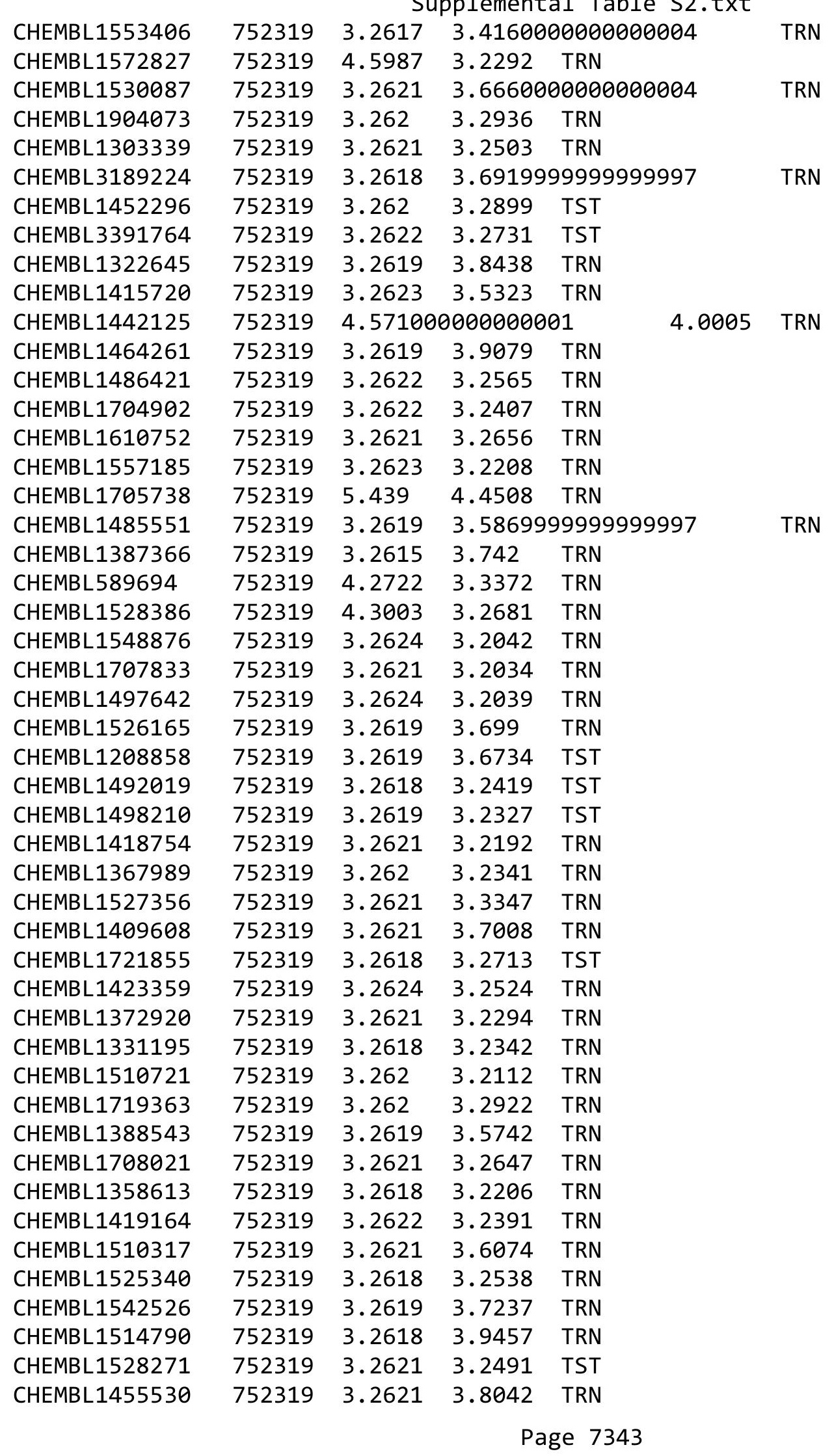


Supplemental Table S2.txt

\begin{tabular}{|c|c|c|c|c|}
\hline HEI & & 62 & & TR \\
\hline HEMPI 2102020 & 52319 & .262 & 3.2091 & \\
\hline$A E N$ & & 621 & & \\
\hline AEMBL & 2319 & 2621 & 39 & \\
\hline AEMBL1312403 & 52319 & 262 & & \\
\hline HEMBL1989158 & 52319 & .6278 & .7518 & \\
\hline HEMBL1 & 52319 & 262 & 5373 & \\
\hline IEMBL: & & & & \\
\hline AEMBL1 & 52319 & 2619 & 3.4399 & \\
\hline HEMBL136 & 52319 & .262 & 3.278 & \\
\hline AEMBL1 & 52319 & 262 & .7493 & \\
\hline AEMBL1 & 52319 & 2616 & 3347 & \\
\hline AEMBL & & & & \\
\hline HEMBL3 & 52319 & 851 & .2414 & \\
\hline AEMBL1 & 52319 & 623 & 65 & ST \\
\hline AEMBL1 & 52319 & 2616 & .2712 & \\
\hline AEMBL1 & 19 & 21 & 46 & \\
\hline HEMBL & & 24 & & \\
\hline AEMBL1 & 52319 & 621 & .2479 & \\
\hline AEMBL1 & & 22 & 85 & II \\
\hline AEMBL & 19 & 67 & 169 & RN \\
\hline HEMBL & 19 & 521 & 18 & \\
\hline HEMBL & 19 & & 81 & \\
\hline 06 & & & & DMe \\
\hline AEMBL1 & 19 & 21 & & KIV \\
\hline HEMBL & & & 27 & RN \\
\hline HEMBL & 19 & & & RN \\
\hline $\mathrm{AFMB}$ & 19 & 24 & 936 & RN \\
\hline HEMBL1 & & & & I KIV \\
\hline HEMBL198 & 19 & & 9045 & ISI \\
\hline AEMBL1 & & & 19 & ST \\
\hline AFMB & 9 & & 41 & RN \\
\hline 3 & & & 39 & ST \\
\hline HEMBL1 & & & 182 & TRN \\
\hline HEMBL1707076 & 19 & 621 & 3.2352 & ГRN \\
\hline HEMBL1 & 19 & & 186 & ST \\
\hline HFMRI - & & & & RN \\
\hline HEMBL1 & & & & $\mathrm{RN}$ \\
\hline HEMBL1996133 & 52319 & 622 & 3.5149 & TST \\
\hline IEMBL1 & 19 & & 3.27 & TST \\
\hline HEMBL1 & 19 & 617 & .2197 & RN \\
\hline HEMBL1 & & & & RN \\
\hline HEMBL1 & 52319 & 2621 & 3.361 & IST \\
\hline HEMBL160 & 52319 & 2623 & 3.2281 & TST \\
\hline MBL1 & & 621 & & TRN \\
\hline CHEMBL154 & & 3.2618 & 3.2417 & \\
\hline CHEMBL154 & 52319 & 3.2621 & 3.2178 & \\
\hline CHEMBL1360013 & 752319 & 3.262 & 3.2574 & ГRN \\
\hline
\end{tabular}


Supplemental Table S2.txt

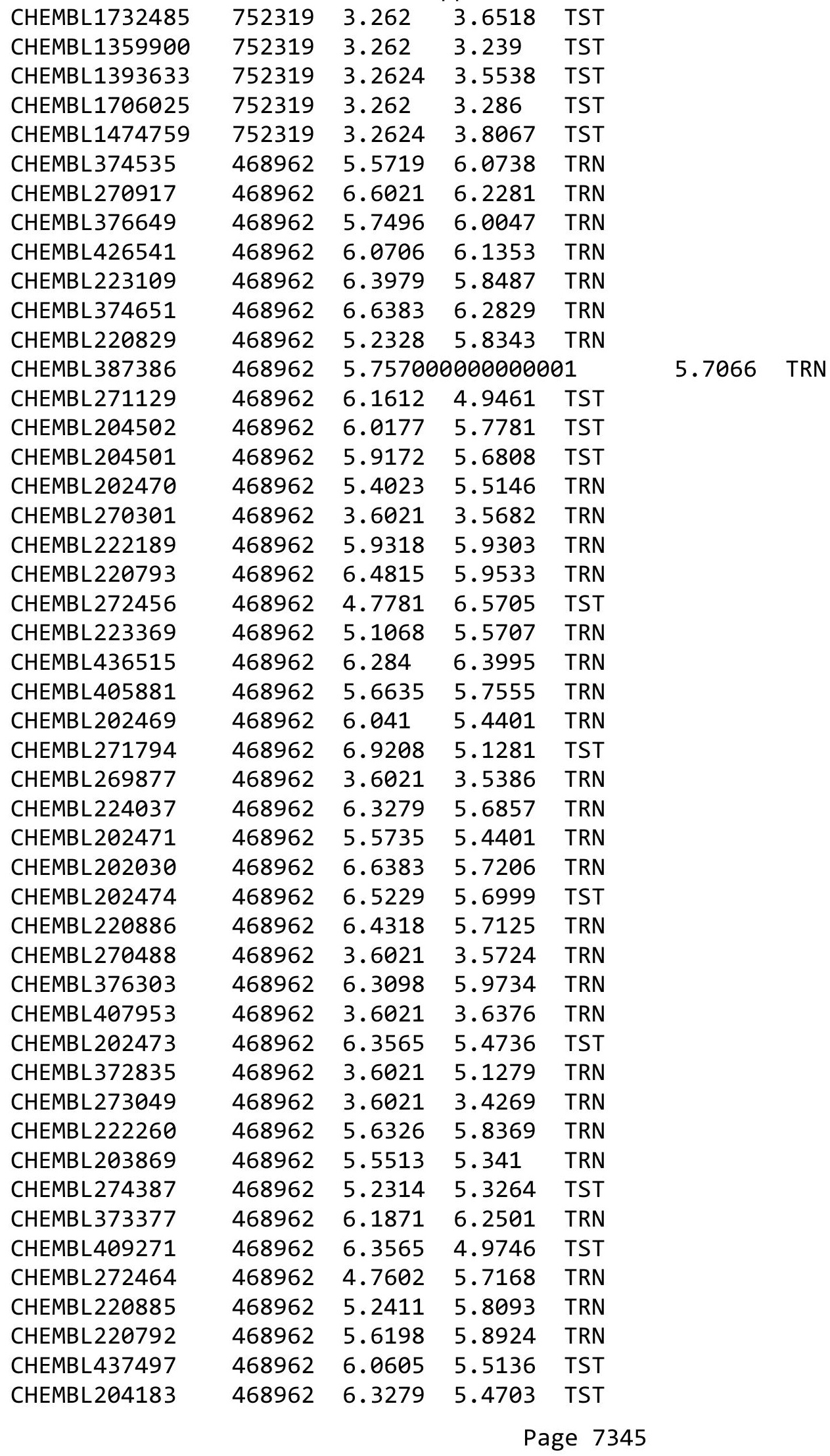




\begin{tabular}{|c|c|c|c|c|c|c|}
\hline \multicolumn{7}{|c|}{ Supplemental Table S2.txt } \\
\hline CHEMBL222250 & 468962 & 6.0915 & 6.3453 & TRN & & \\
\hline CHEMBL270283 & 468962 & 5.9706 & 5.0458 & TST & & \\
\hline CHEMBL204184 & 468962 & 5.6003 & 5.6265 & TRN & & \\
\hline CHEMBL404981 & 468962 & 5.9281 & 5.0841 & TRN & & \\
\hline CHEMBL223368 & 468962 & 6.4815 & 6.3461 & TRN & & \\
\hline CHEMBL407092 & 468962 & 3.6021 & 3.5277 & TRN & & \\
\hline CHEMBL272398 & 468962 & 5.9586 & 6.7813 & TST & & \\
\hline CHEMBL223162 & 468962 & 6.585 & 6.2659 & TRN & & \\
\hline CHEMBL220774 & 468962 & 6.5376 & 5.7656 & TRN & & \\
\hline CHEMBL270915 & 468962 & 6.1612 & 4.7808 & TST & & \\
\hline CHEMBL223421 & 468962 & 5.1278 & 5.6358 & TRN & & \\
\hline CHEMBL 7162 & 468962 & 6.1675 & 5.5117 & TST & & \\
\hline CHEMBL260955 & 468962 & 3.6021 & 4.7763 & TRN & & \\
\hline CHEMBL260098 & 468962 & 3.6021 & 3.438 & TRN & & \\
\hline CHEMBL443066 & 468962 & 5.75206 & 00000000 & 01 & 5.2258 & TST \\
\hline CHEMBL202452 & 468962 & 5.3478 & 5.5146 & TRN & & \\
\hline CHEMBL409448 & 468962 & 3.6021 & 3.5343 & TRN & & \\
\hline CHEMBL223161 & 468962 & 5.6635 & 5.9478 & TRN & & \\
\hline CHEMBL381883 & 468962 & 3.6021 & 5.2587 & TST & & \\
\hline CHEMBL373427 & 468962 & 6.2366 & 5.9587 & TRN & & \\
\hline CHEMBL223108 & 468962 & 5.6696 & 6.2122 & TRN & & \\
\hline CHEMBL382482 & 468962 & 6.1192 & 5.7057 & TRN & & \\
\hline CHEMBL96617 & 27571 & 4.0 & 3.986 & TRN & & \\
\hline CHEMBL103796 & 27571 & 4.0 & 4.1363 & TRN & & \\
\hline CHEMBL313864 & 27571 & 5.4089 & 5.6623 & TRN & & \\
\hline CHEMBL97687 & 27571 & 6.4437 & 6.7721 & TRN & & \\
\hline CHEMBL97904 & 27571 & 4.0 & 4.1694 & TRN & & \\
\hline CHEMBL97037 & 27571 & 5.8861 & 5.63 & TRN & & \\
\hline CHEMBL415697 & 27571 & 4.0 & 4.0044 & TST & & \\
\hline CHEMBL97344 & 27571 & 4.0 & 4.0433 & TRN & & \\
\hline CHEMBL102974 & 27571 & 4.0 & 4.3879 & TRN & & \\
\hline CHEMBL183 & 27571 & 8.1739 & 6.0669 & TST & & \\
\hline CHEMBL441815 & 27571 & 4.0 & 3.5044 & TRN & & \\
\hline CHEMBL321769 & 27571 & 5.6576 & 5.36700 & 0000000001 & & TRN \\
\hline CHEMBL319580 & 27571 & 4.0 & 3.6699 & TRN & & \\
\hline CHEMBL98227 & 27571 & 4.0 & 3.4692 & TST & & \\
\hline CHEMBL102753 & 27571 & 6.0315 & 4.2385 & TST & & \\
\hline CHEMBL97337 & 27571 & 5.699 & 5.4587 & TRN & & \\
\hline CHEMBL328214 & 27571 & 4.0 & 4.2336 & TST & & \\
\hline CHEMBL102491 & 27571 & 4.0 & 4.2489 & TRN & & \\
\hline CHEMBL104998 & 27571 & 5.699 & 5.4578 & TRN & & \\
\hline CHEMBL329294 & 27571 & 5.699 & 5.7454 & TRN & & \\
\hline CHEMBL103559 & 27571 & 6.0 & 5.6581 & TRN & & \\
\hline CHEMBL103150 & 27571 & 5.8239 & 5.9628 & TRN & & \\
\hline CHEMBL102429 & 27571 & 6.0088 & 6.0411 & TRN & & \\
\hline CHEMBL103588 & 27571 & 5.3872 & 5.3968 & TRN & & \\
\hline CHEMBL97549 & 27571 & 6.3665 & 5.9767 & TRN & & \\
\hline CHEMBL321330 & 27571 & 4.0 & 4.0417 & TRN & & \\
\hline
\end{tabular}




\begin{tabular}{|c|c|c|c|c|}
\hline & & & oplement & al Ta \\
\hline CHEMBL316630 & 27571 & 5.5086 & 5.4258 & TRN \\
\hline CHEMBL323288 & 27571 & 4.0 & 4.3077 & TST \\
\hline CHEMBL328334 & 27571 & 4.0 & 3.818 & TRN \\
\hline CHEMBL418797 & 27571 & 5.6576 & 6.0924 & TRN \\
\hline CHEMBL317411 & 27571 & 4.0 & 3.9961 & TRN \\
\hline CHEMBL102017 & 27571 & 4.0 & 4.2596 & TRN \\
\hline CHEMBL323303 & 27571 & 5.3979 & 5.6722 & TRN \\
\hline CHEMBL105000 & 27571 & 5.0 & 4.8934 & TRN \\
\hline CHEMBL97895 & 27571 & 5.585 & 5.5942 & TRN \\
\hline CHEMBL94538 & 27571 & 4.0 & 4.5277 & TRN \\
\hline CHEMBL103278 & 27571 & 4.0 & 3.9483 & TRN \\
\hline CHEMBL102430 & 27571 & 5.4685 & 5.5185 & TRN \\
\hline CHEMBL102178 & 27571 & 5.1249 & 5.2198 & TRN \\
\hline CHEMBL102126 & 27571 & 4.0 & 3.7327 & TST \\
\hline CHEMBL97665 & 27571 & 4.0 & 4.1854 & TRN \\
\hline CHEMBL 97760 & 27571 & 6.5229 & 6.3054 & TRN \\
\hline CHEMBL97757 & 27571 & 5.8539 & 5.8026 & TRN \\
\hline CHEMBL97778 & 27571 & 4.0 & 4.0769 & TRN \\
\hline CHEMBL329293 & 27571 & 5.699 & 5.3715 & TRN \\
\hline CHEMBL97624 & 27571 & 6.2518 & 6.1252 & TRN \\
\hline CHEMBL17127 & 27571 & 6.3344 & 5.0289 & TST \\
\hline CHEMBL103553 & 27571 & 4.0 & 4.4454 & TST \\
\hline CHEMBL96576 & 27571 & 5.0555 & 4.1503 & TST \\
\hline CHEMBL95384 & 27571 & 6.3098 & 5.7253 & TST \\
\hline CHEMBL104999 & 27571 & 6.041 & 6.0997 & TST \\
\hline CHEMBL97896 & 27571 & 4.0 & 5.3457 & TST \\
\hline CHEMBL100121 & 27571 & 4.0 & 3.8067 & TST \\
\hline CHEMBL451093 & 558984 & 6.699 & 6.6747 & TRN \\
\hline CHEMBL513102 & 558984 & 4.0 & 4.0144 & TRN \\
\hline CHEMBL468687 & 558984 & 6.6198 & 6.6267 & TRN \\
\hline CHEMBL467226 & 558984 & 5.9914 & 6.0229 & TRN \\
\hline CHEMBL446378 & 558984 & 4.0 & 3.9518 & TRN \\
\hline CHEMBL460375 & 558984 & 4.0 & 4.6408 & TST \\
\hline CHEMBL506753 & 558984 & 4.0 & 4.0195 & TRN \\
\hline CHEMBL517409 & 558984 & 4.0 & 4.0208 & TRN \\
\hline CHEMBL511590 & 558984 & 4.0 & 3.9805 & TRN \\
\hline CHEMBL454970 & 558984 & 4.0 & 4.1708 & TST \\
\hline CHEMBL465944 & 558984 & 5.2218 & 5.1923 & TRN \\
\hline CHEMBL460587 & 558984 & 4.0 & 4.0178 & TRN \\
\hline CHEMBL460376 & 558984 & 4.0 & 4.0089 & TRN \\
\hline CHEMBL468681 & 558984 & 4.0 & 4.0049 & TRN \\
\hline CHEMBL462500 & 558984 & 4.0 & 4.0252 & TRN \\
\hline CHEMBL466183 & 558984 & 4.0 & 4.0232 & TRN \\
\hline CHEMBL467034 & 558984 & 4.0 & 4.138 & TST \\
\hline CHEMBL468893 & 558984 & 4.0 & 4.01 & TRN \\
\hline CHEMBL460594 & 558984 & 4.0 & 3.9671 & TRN \\
\hline CHEMBL467225 & 558984 & 4.0 & 3.9913 & TRN \\
\hline CHEMBL466181 & 558984 & 4.0 & 3.9388 & TRN \\
\hline
\end{tabular}




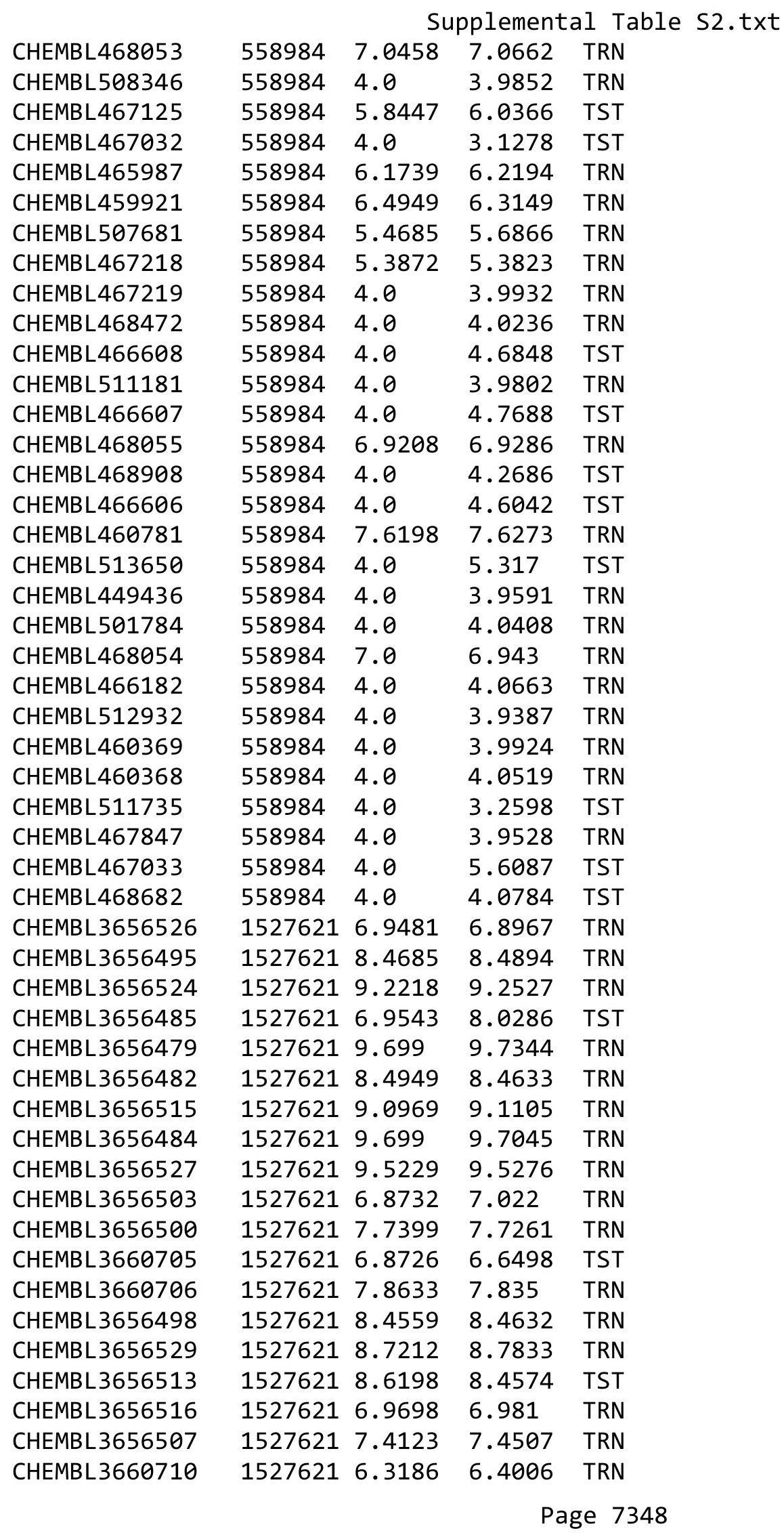


Supplemental Table S2.txt

\begin{tabular}{|c|c|c|c|c|c|}
\hline CHEMBL3656483 & 1527621 & 10.0 & 9.3056 & TST & \\
\hline CHEMBL3656525 & 1527621 & 8.3372 & 8.3118 & TST & \\
\hline CHEMBL3656501 & 1527621 & 9.0 & 9.0103 & TRN & \\
\hline CHEMBL3656493 & 1527621 & 7.6498 & 7.6401 & TRN & \\
\hline CHEMBL3656486 & 1527621 & 8.8861 & 8.8778 & TRN & \\
\hline CHEMBL3660709 & 1527621 & 7.3372 & 7.2899 & TRN & \\
\hline CHEMBL3656512 & 1527621 & 7.8928 & 7.8726 & TRN & \\
\hline CHEMBL3656534 & 1527621 & 9.1549 & 9.1446 & TRN & \\
\hline CHEMBL3656519 & 1527621 & 7.9788 & 7.936 & TRN & \\
\hline CHEMBL3656506 & 1527621 & 8.0177 & 7.9996 & TRN & \\
\hline CHEMBL3656508 & 1527621 & 7.2588 & 7.6223 & TST & \\
\hline CHEMBL3656518 & 1527621 & 8.1135 & 7.5839 & TST & \\
\hline CHEMBL3656521 & 1527621 & 7.7799 & 7.9681 & TST & \\
\hline CHEMBL3656533 & 1527621 & 9.5229 & 9.5264 & TRN & \\
\hline CHEMBL 3656478 & 1527621 & 7.5817 & 7.5923 & TRN & \\
\hline CHEMBL3656497 & 1527621 & 7.7399 & 7.694 & TRN & \\
\hline CHEMBL3656505 & 1527621 & 8.7212 & 8.7179 & TRN & \\
\hline CHEMBL3656487 & 1527621 & 9.0969 & 9.0671 & TRN & \\
\hline CHEMBL3656480 & 1527621 & 8.7696 & 8.7416 & TRN & \\
\hline CHEMBL3656523 & 1527621 & 7.6615 & 7.5983 & TRN & \\
\hline CHEMBL3656532 & 1527621 & 8.0969 & 8.1641 & TRN & \\
\hline CHEMBL3660708 & 1527621 & 7.699 & 7.6533 & TRN & \\
\hline CHEMBL3656509 & 1527621 & 8.3279 & 8.002 & TST & \\
\hline CHEMBL3656528 & 1527621 & 8.301 & 8.2755 & TRN & \\
\hline CHEMBL3656477 & 1527621 & 8.6778 & 8.7418 & TRN & \\
\hline CHEMBL3656535 & 1527621 & 7.2055 & 7.25 & TRN & \\
\hline CHEMBL3656517 & 1527621 & 9.0 & 8.6567 & TST & \\
\hline CHEMBL3656504 & 1527621 & 7.8761 & 7.8646 & TRN & \\
\hline CHEMBL3656489 & 1527621 & 8.8239 & 8.7423 & TRN & \\
\hline CHEMBL3656494 & 1527621 & 7.699 & 8.1858 & TST & \\
\hline CHEMBL3656492 & 1527621 & 9.699 & \multicolumn{2}{|c|}{9.716000000000001} & TRN \\
\hline CHEMBL3656511 & 1527621 & 8.1549 & 8.064 & TRN & \\
\hline CHEMBL3656530 & 1527621 & 9.301 & 9.3036 & TRN & \\
\hline CHEMBL3656475 & 1527621 & 8.6778 & 8.6558 & TRN & \\
\hline CHEMBL3660707 & 1527621 & 8.7212 & 8.7825 & TRN & \\
\hline CHEMBL3660701 & 1527621 & 7.6383 & 7.5803 & TRN & \\
\hline CHEMBL 3656488 & 1527621 & 9.301 & 9.3108 & TRN & \\
\hline CHEMBL3660702 & 1527621 & 7.3851 & 7.4013 & TRN & \\
\hline CHEMBL3656531 & 1527621 & 9.699 & 9.6946 & TRN & \\
\hline CHEMBL3656491 & 1527621 & 8.9208 & 8.9297 & TRN & \\
\hline CHEMBL3656496 & 1527621 & 9.5229 & 9.4779 & TRN & \\
\hline CHEMBL 3656520 & 1527621 & 7.7167 & 7.7678 & TRN & \\
\hline CHEMBL3656490 & 1527621 & 8.8861 & 8.9238 & TRN & \\
\hline CHEMBL3656474 & 1527621 & 8.4559 & 8.4729 & TRN & \\
\hline CHEMBL3656514 & 1527621 & 7.2269 & 8.2872 & TST & \\
\hline CHEMBL3660703 & 1527621 & 7.1864 & 7.1515 & TRN & \\
\hline CHEMBL3656522 & 1527621 & 9.1549 & 9.1437 & TRN & \\
\hline CHEMBL3656499 & 1527621 & 9.1549 & 9.0797 & TST & \\
\hline
\end{tabular}


Supplemental Table S2.txt

\begin{tabular}{|c|c|c|c|c|}
\hline 76 & 527621 & 8.6576 & 7.7106 & 8 \\
\hline CHEMBL 3656481 & 1527621 & 9.699 & 9.644 & ;T \\
\hline HEMBL3660704 & 527621 & 7.4498 & 7.5594 & \\
\hline IEMBL 3656510 & 27621 & 8.8861 & 397 & \\
\hline AEMBL 3656502 & 527621 & 7.5143 & 166 & \\
\hline HEMBL601348 & 369403 & 5.0 & 0821 & \\
\hline HEMBL470514 & 369403 & 5.0 & 4.8885 & \\
\hline HEMBL547488 & 369403 & & 297 & \\
\hline AEMBL 580580 & 369403 & 383 & 6.564 & \\
\hline AEMBL587083 & 369403 & & 7.6223 & \\
\hline HEMBL590674 & 369403 & 6.8239 & 7.0034 & \\
\hline HEMBL 524784 & L69403 & 6.3655 & 6.2435 & \\
\hline HEMBL2028055 & 1369403 & 6.5751 & 6.4247 & \\
\hline HEMBL 535079 & 369403 & & 5.0609 & \\
\hline HEMBL586344 & 1369403 & 5 & 5.2706 & \\
\hline AEMBL532987 & 369403 & & 6.7148 & \\
\hline HEMBL 547476 & 1369 & & 6.6596 & \\
\hline HEMBL494669 & 1369 & 94 & 87 & \\
\hline HEMBL 533017 & 1369 & & 117 & RN \\
\hline HEMBL598369 & 1369403 & 549 & 6.9864 & \\
\hline AEMBL587022 & 03 & 007 & & \\
\hline HEMBL 600305 & 1369 & & 193 & \\
\hline HEMBL106525 & 1369403 & 192 & 7. & KIV \\
\hline HEMBL 261693 & 136 & & 935 & RN \\
\hline HEMBL 586704 & 03 & 375 & 623 & $\mathrm{RN}$ \\
\hline HEMBL602413 & 33 & & 113 & RN \\
\hline HEMBL 604323 & 1369403 & & & RN \\
\hline HEMBL535514 & 1365 & & 427 & RIV \\
\hline HEMBL 2028053 & 33 & & 18 & RN \\
\hline HEMBL 527593 & 136 & & 5.1479 & RN \\
\hline AEMBL580353 & 33 & & & TRN \\
\hline HEMBL 317364 & 1369403 & 147 & 7.7913 & RN \\
\hline HEMBL 2028042 & 136 & & & RN \\
\hline 29773 & 33 & 11 & 45 & RN \\
\hline HEMBL 580381 & 136 & & 55 & RN \\
\hline HEMBL601957 & 369403 & 7.1871 & 867 & TR \\
\hline HEMBL 587410 & 369403 & & 136 & ST \\
\hline HEMB & 136 & & 275 & RN \\
\hline HEMBL549210 & 33 & 57 & 008 & RN \\
\hline HEMBL124006 & 1369403 & 7.2291 & 503 & $\mathrm{RN}$ \\
\hline HEMBL601771 & 369403 & 5.301 & 487 & TR \\
\hline CHEMBL605281 & 1369403 & 6.6757 & 934 & R \\
\hline CHEMBL206540 & 1369403 & & 5.0363 & $R$ \\
\hline CHEMBL529732 & 1369403 & 5.0 & 4.8605 & זRN \\
\hline CHEMBL525486 & 1369403 & 6.3036 & 6.1846 & TST \\
\hline CHEMBL590888 & 1369403 & & 4.9546 & rR \\
\hline CHEMBL530223 & 1369403 & & 6.8896 & R \\
\hline CHEMBL530973 & L369403 & 7.0706 & 6.8137 & \\
\hline
\end{tabular}

Page 7350 


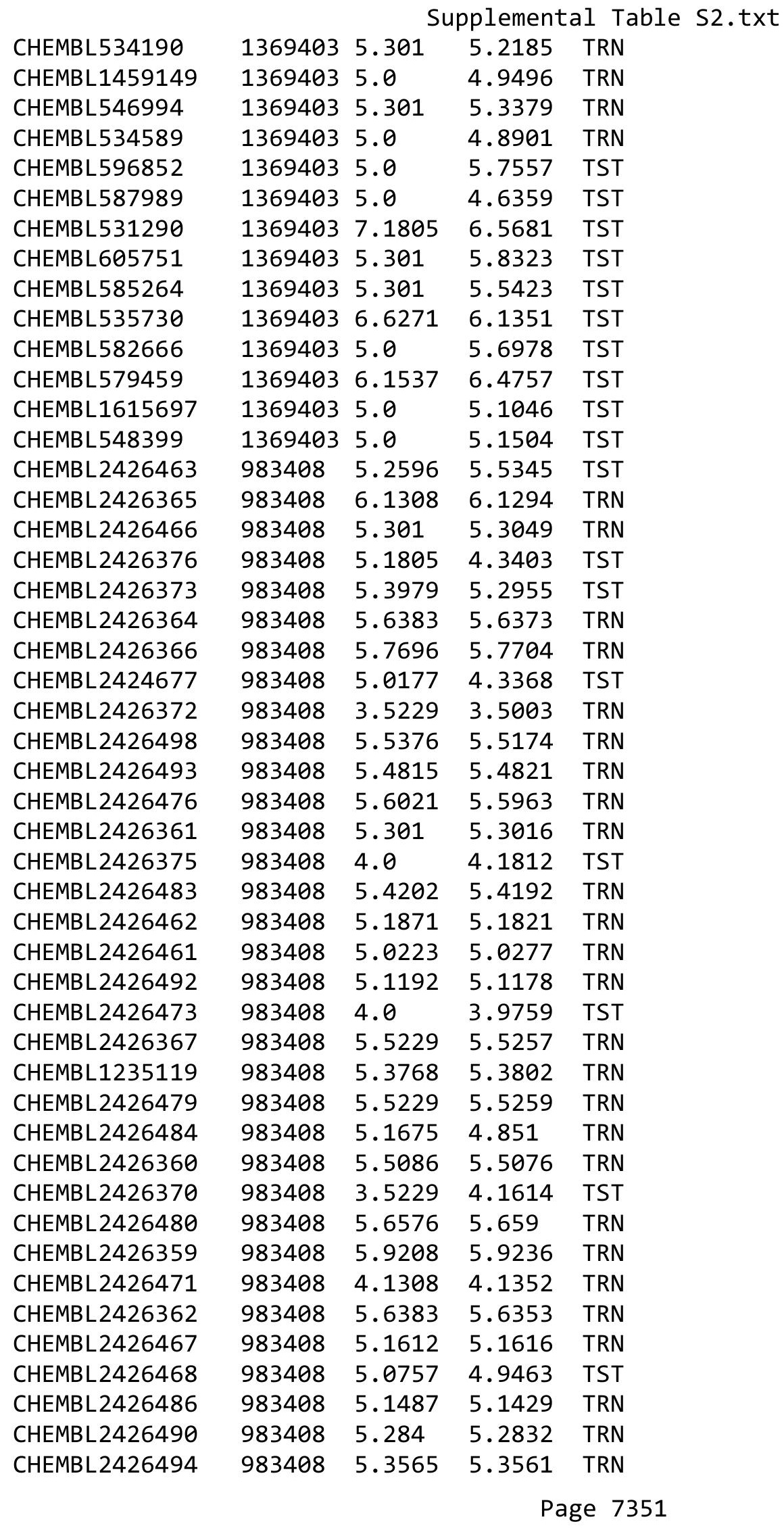




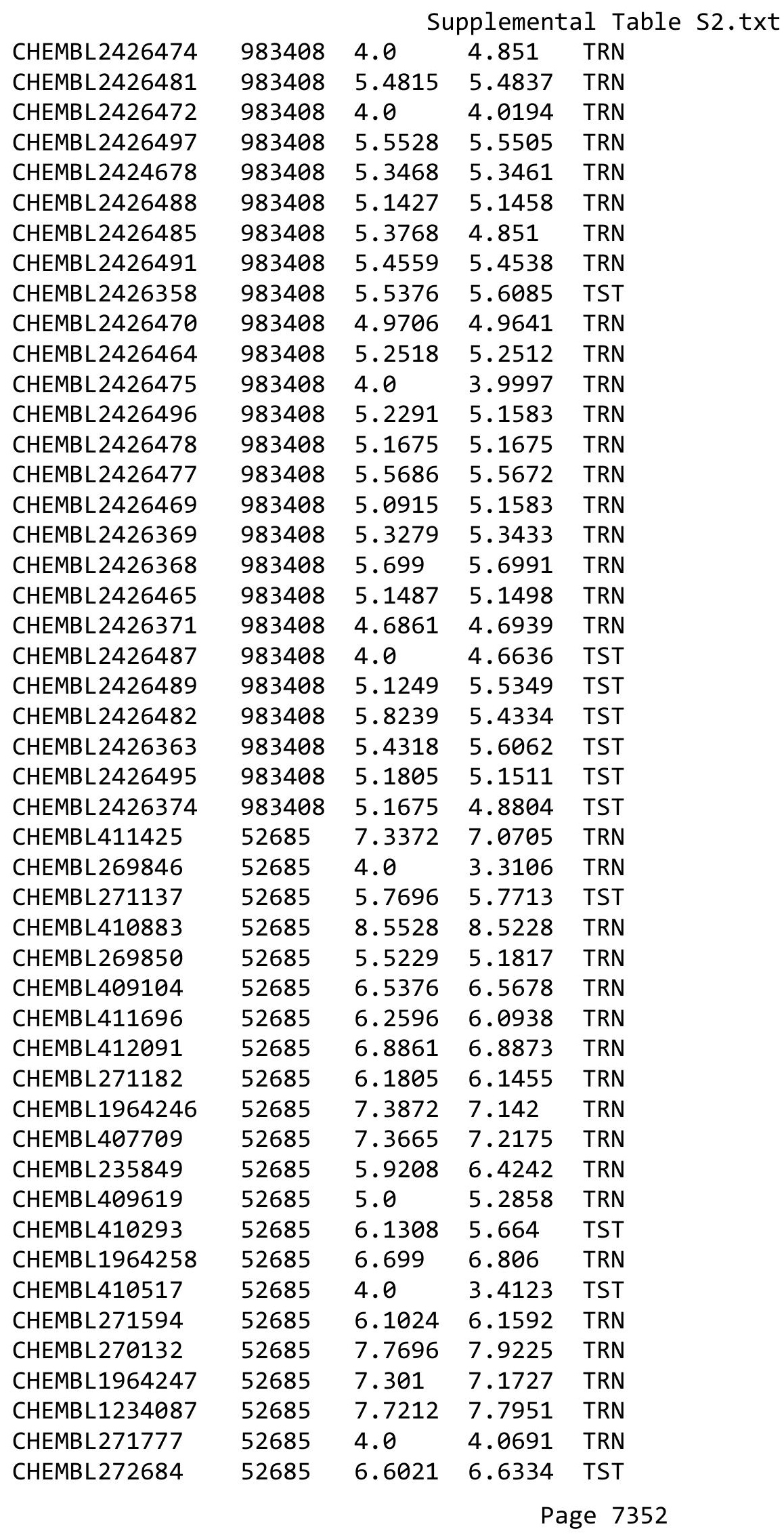




\begin{tabular}{|c|c|c|c|c|}
\hline & & & pplement & al $\mathrm{T}$ \\
\hline CHEMBL445945 & 52685 & 7.8239 & 7.7342 & TRN \\
\hline CHEMBL1964245 & 52685 & 7.1938 & 7.0018 & TRN \\
\hline CHEMBL1964242 & 52685 & 7.284 & 7.1424 & TRN \\
\hline CHEMBL1234089 & 52685 & 5.6021 & 5.2153 & TST \\
\hline CHEMBL272026 & 52685 & 6.6383 & 6.6546 & TRN \\
\hline CHEMBL271595 & 52685 & 7.5376 & 7.2348 & TRN \\
\hline CHEMBL273061 & 52685 & 6.5376 & 6.6852 & TRN \\
\hline CHEMBL1964249 & 52685 & 7.3468 & 7.6349 & TRN \\
\hline CHEMBL272028 & 52685 & 7.1612 & 7.058 & TRN \\
\hline CHEMBL272165 & 52685 & 7.1308 & 7.1732 & TRN \\
\hline CHEMBL271160 & 52685 & 7.3872 & 7.3682 & TRN \\
\hline CHEMBL438721 & 52685 & 5.8861 & 5.8856 & TRN \\
\hline CHEMBL272668 & 52685 & 6.8239 & 7.0658 & TST \\
\hline CHEMBL412097 & 52685 & 6.6576 & 6.4968 & TST \\
\hline CHEMBL271953 & 52685 & 7.2924 & 7.2961 & TRN \\
\hline CHEMBL1276446 & 52685 & 7.0 & 6.9207 & TRN \\
\hline CHEMBL 270054 & 52685 & 6.5229 & 6.6117 & TRN \\
\hline CHEMBL 272414 & 52685 & 5.5528 & 5.4834 & TST \\
\hline CHEMBL1964250 & 52685 & 7.1427 & 7.4064 & TRN \\
\hline CHEMBL429142 & 52685 & 7.7959 & 7.9439 & TST \\
\hline CHEMBL391229 & 52685 & 7.5086 & 6.9755 & TST \\
\hline CHEMBL 2112297 & 52685 & 7.3768 & 7.0898 & TRN \\
\hline CHEMBL411865 & 52685 & 6.8239 & 6.7383 & TRN \\
\hline CHEMBL411490 & 52685 & 6.6021 & 6.5867 & TST \\
\hline CHEMBL410072 & 52685 & 7.2218 & 7.0775 & TRN \\
\hline CHEMBL411224 & 52685 & 7.7212 & 7.8287 & TRN \\
\hline CHEMBL1964248 & 52685 & 5.2596 & 5.0766 & TST \\
\hline CHEMBL411426 & 52685 & 7.4318 & 7.5952 & TRN \\
\hline CHEMBL271952 & 52685 & 6.8239 & 6.9142 & TST \\
\hline CHEMBL409868 & 52685 & 6.8861 & 7.3211 & TRN \\
\hline CHEMBL260103 & 52685 & 6.6778 & 6.6636 & TRN \\
\hline CHEMBL272833 & 52685 & 6.9208 & 6.7362 & TST \\
\hline CHEMBL 272885 & 52685 & 4.0 & 4.1866 & TRN \\
\hline CHEMBL269883 & 52685 & 7.7212 & 7.9504 & TST \\
\hline CHEMBL411887 & 52685 & 8.1487 & 8.0473 & TRN \\
\hline CHEMBL1964257 & 52685 & 7.0 & 6.8952 & TRN \\
\hline CHEMBL 271778 & 52685 & 5.0 & 5.1594 & TRN \\
\hline CHEMBL 270544 & 52685 & 7.8239 & 7.7473 & TRN \\
\hline CHEMBL272387 & 52685 & 6.7696 & 6.7975 & TRN \\
\hline CHEMBL1964253 & 52685 & 7.1938 & 7.2498 & TRN \\
\hline CHEMBL 271822 & 52685 & 5.7696 & 6.0635 & TST \\
\hline CHEMBL409731 & 52685 & 7.9208 & 8.047 & TST \\
\hline CHEMBL411886 & 52685 & 6.1487 & 6.1051 & TRN \\
\hline CHEMBL269827 & 52685 & 8.0 & 8.1312 & TRN \\
\hline CHEMBL1964251 & 52685 & 7.4202 & 7.3338 & TRN \\
\hline CHEMBL271843 & 52685 & 6.4815 & 6.3815 & TRN \\
\hline CHEMBL1234085 & 52685 & 5.5376 & 5.058 & TST \\
\hline CHEMBL1964260 & 52685 & 7.4089 & 7.0915 & TRN \\
\hline
\end{tabular}




\begin{tabular}{|c|c|c|c|c|c|}
\hline \multirow[b]{2}{*}{ CHEMBL271842 } & \multicolumn{5}{|c|}{ Supplemental Table S2.txt } \\
\hline & 52685 & 5.8539 & 6.0668 & TRN & \\
\hline CHEMBL1794054 & 52685 & 6.5376 & 6.54200 & 0000000001 & TRN \\
\hline CHEMBL1964243 & 52685 & 6.041 & 6.2855 & TRN & \\
\hline CHEMBL1964255 & 52685 & 7.3468 & 7.1152 & TRN & \\
\hline CHEMBL408210 & 52685 & 6.8861 & 6.5057 & TST & \\
\hline CHEMBL272380 & 52685 & 6.7696 & 6.8529 & TRN & \\
\hline CHEMBL411491 & 52685 & 6.1079 & 6.4081 & TRN & \\
\hline CHEMBL409690 & 52685 & 7.1135 & 7.0853 & TRN & \\
\hline CHEMBL408131 & 52685 & 4.0 & 3.3467 & TST & \\
\hline CHEMBL405042 & 52685 & 5.6383 & 5.1818 & TST & \\
\hline CHEMBL1964259 & 52685 & 7.9208 & 7.7866 & TRN & \\
\hline CHEMBL 272667 & 52685 & 7.0605 & 6.7574 & TRN & \\
\hline CHEMBL1964244 & 52685 & 7.3872 & 7.1344 & TRN & \\
\hline CHEMBL314397 & 52685 & 6.9586 & 6.689 & TST & \\
\hline CHEMBL1234086 & 52685 & 7.2518 & 7.2983 & TRN & \\
\hline CHEMBL 271183 & 52685 & 6.284 & 6.2081 & TRN & \\
\hline CHEMBL1964256 & 52685 & 6.7696 & 6.7035 & TRN & \\
\hline CHEMBL272389 & 52685 & 6.4559 & 6.7243 & TRN & \\
\hline CHEMBL409892 & 52685 & 7.9208 & 7.8354 & TRN & \\
\hline CHEMBL269882 & 52685 & 7.0809 & 7.2706 & TST & \\
\hline CHEMBL273060 & 52685 & 7.0223 & 6.9324 & TRN & \\
\hline CHEMBL1234088 & 52685 & 5.4202 & 4.9722 & TST & \\
\hline CHEMBL271136 & 52685 & 8.0315 & 7.9667 & TRN & \\
\hline CHEMBL1964252 & 52685 & 4.8539 & 5.9673 & TRN & \\
\hline CHEMBL1585267 & 736957 & 3.4948 & 3.4824 & TRN & \\
\hline CHEMBL1565651 & 736957 & 3.4948 & 3.5333 & TRN & \\
\hline CHEMBL1716867 & 736957 & 3.4948 & 3.4593 & TRN & \\
\hline CHEMBL1493386 & 736957 & 3.4948 & 3.4556 & TRN & \\
\hline CHEMBL1430337 & 736957 & 5.8153 & 5.8195 & TRN & \\
\hline CHEMBL1403666 & 736957 & 3.4948 & 3.5406 & TRN & \\
\hline CHEMBL1602191 & 736957 & 3.4948 & 3.4963 & TRN & \\
\hline CHEMBL1706477 & 736957 & 3.4948 & 3.5181 & TRN & \\
\hline CHEMBL 3145240 & 736957 & 3.4948 & 4.4559 & TST & \\
\hline CHEMBL1359415 & 736957 & 3.4948 & 3.5139 & TRN & \\
\hline CHEMBL1388755 & 736957 & 3.4948 & 3.4928 & TRN & \\
\hline CHEMBL1371990 & 736957 & 3.4948 & 3.4917 & TRN & \\
\hline CHEMBL1508445 & 736957 & 3.4948 & 3.4759 & TRN & \\
\hline CHEMBL1445729 & 736957 & 3.4948 & 3.4852 & TRN & \\
\hline CHEMBL1524012 & 736957 & 3.4948 & 3.4993 & TRN & \\
\hline CHEMBL1710676 & 736957 & 5.7033 & 4.5588 & TST & \\
\hline CHEMBL1726168 & 736957 & 4.7545 & 3.6456 & TST & \\
\hline CHEMBL1723909 & 736957 & 3.4948 & 3.4602 & TRN & \\
\hline CHEMBL1564473 & 736957 & 3.4948 & 3.4786 & TRN & \\
\hline CHEMBL1493095 & 736957 & 3.4948 & 3.5072 & TRN & \\
\hline CHEMBL1731800 & 736957 & 4.6198 & 4.6139 & TRN & \\
\hline CHEMBL1405968 & 736957 & 6.2865 & 4.4652 & TST & \\
\hline CHEMBL1710618 & 736957 & 6.056 & 4.4343 & TST & \\
\hline CHEMBL1720217 & 736957 & 3.4948 & 4.0543 & TST & \\
\hline
\end{tabular}


Supplemental Table S2.txt

\begin{tabular}{|c|c|c|c|c|c|}
\hline CHEMBL1461661 & 736957 & 6.1308 & 4.3291 & TST & \\
\hline CHEMBL1732148 & 736957 & 3.4948 & 4.0622 & TST & \\
\hline CHEMBL1455762 & 736957 & 3.4948 & 3.4851 & TRN & \\
\hline CHEMBL1568059 & 736957 & 3.4948 & 3.4862 & TRN & \\
\hline CHEMBL1384726 & 736957 & 3.4948 & 3.5104 & TRN & \\
\hline CHEMBL1729385 & 736957 & 3.4948 & 3.5848 & TRN & \\
\hline CHEMBL1569631 & 736957 & 3.4948 & 3.5251 & TRN & \\
\hline CHEMBL1346675 & 736957 & 4.6882 & 4.6123 & TRN & \\
\hline CHEMBL1511139 & 736957 & 5.3251 & 5.3103 & TRN & \\
\hline CHEMBL1719035 & 736957 & 4.9245 & 3.792 & TST & \\
\hline CHEMBL1348399 & 736957 & 3.4948 & 3.49399 & 99999999998 & TRN \\
\hline CHEMBL1712643 & 736957 & 3.4948 & 3.5069 & TRN & \\
\hline CHEMBL1588996 & 736957 & 4.8153 & 4.6776 & TRN & \\
\hline CHEMBL3190555 & 736957 & 5.4413 & 4.5435 & TST & \\
\hline CHEMBL1490629 & 736957 & 3.4948 & 3.5044 & TRN & \\
\hline CHEMBL1342964 & 736957 & 3.4948 & 3.5238 & TRN & \\
\hline CHEMBL1311570 & 736957 & 3.4948 & 3.4627 & TRN & \\
\hline CHEMBL1333440 & 736957 & 3.4948 & 3.4949 & TRN & \\
\hline CHEMBL1455766 & 736957 & 5.8827 & 5.89 & TRN & \\
\hline CHEMBL1430524 & 736957 & 3.4948 & 3.4936 & TRN & \\
\hline CHEMBL1478375 & 736957 & 3.4948 & 3.5181 & TRN & \\
\hline CHEMBL3190827 & 736957 & 6.2733 & 3.8534 & TST & \\
\hline CHEMBL1505687 & 736957 & 3.4948 & 3.5354 & TRN & \\
\hline CHEMBL3193664 & 736957 & 4.6055 & 3.8644 & TST & \\
\hline CHEMBL1362498 & 736957 & 3.4948 & 3.4774 & TRN & \\
\hline CHEMBL1417841 & 736957 & 3.4948 & 3.4913 & TRN & \\
\hline CHEMBL1412822 & 736957 & 3.4948 & 3.4933 & TRN & \\
\hline CHEMBL1391476 & 736957 & 3.4948 & 3.4971 & TRN & \\
\hline CHEMBL1343080 & 736957 & 3.4948 & 3.4693 & TRN & \\
\hline CHEMBL1416769 & 736957 & 4.9101 & 3.8962 & TST & \\
\hline CHEMBL1440728 & 736957 & 3.4948 & 3.55899 & 99999999997 & TRN \\
\hline CHEMBL1724710 & 736957 & 3.4948 & 3.8543 & TST & \\
\hline CHEMBL1480657 & 736957 & 3.4948 & 3.5325 & TRN & \\
\hline CHEMBL1455045 & 736957 & \multicolumn{3}{|c|}{5.382999999999999} & TRN \\
\hline CHEMBL1707460 & 736957 & 3.4948 & 3.7779 & TST & \\
\hline CHEMBL1718305 & 736957 & 5.2204 & 2.9357 & TST & \\
\hline CHEMBL1726942 & 736957 & 3.4948 & 3.4337 & TRN & \\
\hline CHEMBL1705910 & 736957 & 4.8182 & 4.7003 & TRN & \\
\hline CHEMBL3940231 & 1641780 & 7.301 & 6.9749 & TRN & \\
\hline CHEMBL 2031021 & 1641780 & 7.2218 & 7.4471 & TRN & \\
\hline CHEMBL3954559 & 1641780 & 7.1549 & 6.7484 & TRN & \\
\hline CHEMBL3901575 & 1641780 & 8.0 & 7.8754 & TRN & \\
\hline CHEMBL3906577 & 1641780 & 8.0711 & 7.9865 & TRN & \\
\hline CHEMBL 2031018 & 1641780 & 7.3979 & 7.5441 & TRN & \\
\hline CHEMBL3904423 & 1641780 & 7.5229 & 7.5751 & TRN & \\
\hline CHEMBL 2031017 & 1641780 & 7.3979 & 7.7315 & TRN & \\
\hline CHEMBL 2030864 & 1641780 & 8.1959 & 8.1722 & TRN & \\
\hline CHEMBL3963735 & 1641780 & 8.0 & 7.3588 & TRN & \\
\hline
\end{tabular}


Supplemental Table S2.txt

\begin{tabular}{|c|c|c|c|c|}
\hline CHEMBL3928986 & 1641780 & 6.699 & 7.0284 & TRN \\
\hline CHEMBL3954188 & 1641780 & 7.699 & 7.4453 & TRN \\
\hline CHEMBL3917408 & 1641780 & 6.4089 & 6.4773 & TRN \\
\hline CHEMBL 3927598 & 1641780 & 6.6021 & 6.6087 & TRN \\
\hline CHEMBL 3982792 & 1641780 & 8.0899 & 7.0978 & TST \\
\hline CHEMBL 3962772 & 1641780 & 6.8539 & 7.0205 & TST \\
\hline CHEMBL3891889 & 1641780 & 6.0655 & 7.3731 & TST \\
\hline CHEMBL 2031009 & 1641780 & 8.0565 & 8.244 & TST \\
\hline CHEMBL 3898017 & 1641780 & \multicolumn{2}{|c|}{5.327000000000001} & 6.3681 \\
\hline CHEMBL 3912906 & 1641780 & 6.9586 & 6.5843 & TST \\
\hline CHEMBL 2031031 & 1641780 & 6.9208 & 7.3877 & TRN \\
\hline CHEMBL 2031026 & 1641780 & 8.0 & 7.8851 & TRN \\
\hline CHEMBL3912610 & 1641780 & 8.4449 & 8.4434 & TRN \\
\hline CHEMBL3981017 & 1641780 & 6.2924 & 6.2732 & TRN \\
\hline CHEMBL 2031027 & 1641780 & 8.0752 & 8.0913 & TRN \\
\hline CHEMBL 3931548 & 1641780 & 8.0386 & 8.25 & TRN \\
\hline CHEMBL 2031014 & 1641780 & 6.9586 & 6.9105 & TRN \\
\hline CHEMBL 3975289 & 1641780 & 7.301 & 7.4509 & TRN \\
\hline CHEMBL 2030859 & 1641780 & 8.0 & 8.0528 & TST \\
\hline CHEMBL 3890787 & 1641780 & 7.0458 & 6.6805 & TRN \\
\hline CHEMBL3912236 & 1641780 & 6.4685 & 6.4645 & TRN \\
\hline CHEMBL3917569 & 1641780 & 6.6383 & 6.7189 & TST \\
\hline CHEMBL3986056 & 1641780 & 7.0969 & 6.8133 & TRN \\
\hline CHEMBL3948491 & 1641780 & 7.301 & 6.8117 & TRN \\
\hline CHEMBL3952199 & 1641780 & 6.5376 & 6.074 & TRN \\
\hline CHEMBL3960836 & 1641780 & 6.9586 & 6.9181 & TRN \\
\hline CHEMBL 2031024 & 1641780 & 7.301 & 8.0702 & TRN \\
\hline CHEMBL 2031012 & 1641780 & 7.5229 & 7.29799 & 9999999999 \\
\hline CHEMBL 3966210 & 1641780 & 7.699 & 8.2321 & TST \\
\hline CHEMBL 3923567 & 1641780 & 6.0362 & 6.7444 & TRN \\
\hline CHEMBL2030852 & 1641780 & 7.699 & 7.8068 & TST \\
\hline CHEMBL 3918064 & 1641780 & 7.301 & 7.1904 & TRN \\
\hline CHEMBL3947141 & 1641780 & 8.1141 & 7.4502 & TRN \\
\hline CHEMBL3942482 & 1641780 & 7.5229 & 7.0366 & TRN \\
\hline CHEMBL3889549 & 1641780 & 7.1549 & 6.4426 & TRN \\
\hline CHEMBL3963540 & 1641780 & 6.3565 & 6.6857 & TRN \\
\hline CHEMBL 3965698 & 1641780 & 6.2218 & 6.5346 & TST \\
\hline CHEMBL3978452 & 1641780 & 6.5376 & 6.3042 & TRN \\
\hline CHEMBL 3955216 & 1641780 & 6.699 & 6.9806 & TRN \\
\hline CHEMBL 3938217 & 1641780 & 8.0 & 7.7707 & TRN \\
\hline CHEMBL3957469 & 1641780 & 6.3098 & 6.8419 & TRN \\
\hline CHEMBL 2031022 & 1641780 & 7.699 & 7.7027 & TRN \\
\hline CHEMBL 3936837 & 1641780 & 5.4225 & 6.2214 & TRN \\
\hline CHEMBL 2030850 & 1641780 & 7.0 & 7.3768 & TST \\
\hline CHEMBL 3897725 & 1641780 & 8.1568 & 7.81 & TST \\
\hline CHEMBL3899265 & 1641780 & 7.1549 & 7.5963 & TRN \\
\hline CHEMBL 3918855 & 1641780 & 6.8239 & 6.8354 & TRN \\
\hline CHEMBL3957861 & 1641780 & 7.2218 & 7.4311 & TST \\
\hline
\end{tabular}




$$
\text { Supplemental Table S2.txt }
$$

\begin{tabular}{|c|c|c|c|c|c|}
\hline CHEMBL 2030851 & 1641780 & 6.8861 & 7.4407 & TST & \\
\hline CHEMBL3921891 & 1641780 & 6.699 & 6.5233 & TST & \\
\hline CHEMBL3927294 & 1641780 & 7.699 & 7.2998 & TST & \\
\hline CHEMBL3936947 & 1641780 & 8.0531 & 7.97 & TRN & \\
\hline CHEMBL3968488 & 1641780 & 5.8356 & 6.6018 & TRN & \\
\hline CHEMBL3968982 & 1641780 & 7.3979 & 7.1077 & TRN & \\
\hline CHEMBL3893805 & 1641780 & 6.9208 & 6.7242 & TST & \\
\hline CHEMBL3890955 & 1641780 & 8.0 & 7.9379 & TRN & \\
\hline CHEMBL3962921 & 1641780 & 8.3778 & 8.0424 & TRN & \\
\hline CHEMBL3980078 & 1641780 & 8.4056 & 7.8422 & TRN & \\
\hline CHEMBL3893121 & 1641780 & 8.1397 & 7.3684 & TRN & \\
\hline CHEMBL3892056 & 1641780 & 7.0458 & 6.9663 & TRN & \\
\hline CHEMBL3927011 & 1641780 & 5.9957 & 6.8777 & TRN & \\
\hline CHEMBL3901024 & 1641780 & 7.5229 & 7.0597 & TRN & \\
\hline CHEMBL3960038 & 1641780 & 7.3979 & 7.5172 & TRN & \\
\hline CHEMBL3931099 & 1641780 & 7.2218 & 7.4271 & TRN & \\
\hline CHEMBL3986556 & 1641780 & 8.0 & 7.5995 & TST & \\
\hline CHEMBL3937806 & 1641780 & 7.0458 & 6.9207 & TRN & \\
\hline CHEMBL3984367 & 1641780 & 7.301 & 6.8756 & TRN & \\
\hline CHEMBL3945459 & 1641780 & 7.699 & 7.3426 & TRN & \\
\hline CHEMBL 2031008 & 1641780 & 8.2933 & 8.2812 & TST & \\
\hline CHEMBL3964186 & 1641780 & 6.585 & 6.6397 & TRN & \\
\hline CHEMBL3890311 & 1641780 & 6.3665 & 6.7127 & TST & \\
\hline CHEMBL2030856 & 1641780 & 7.699 & 7.6978 & TST & \\
\hline CHEMBL3912240 & 1641780 & 8.0 & 7.2714 & TST & \\
\hline CHEMBL3939961 & 1641780 & 6.2366 & 7.241006 & 00000000005 & TST \\
\hline CHEMBL3893154 & 1641780 & 7.301 & 7.2489 & TRN & \\
\hline CHEMBL3894163 & 1641780 & 7.5229 & 7.8097 & TRN & \\
\hline CHEMBL3914542 & 1641780 & 8.0 & 6.9948 & TRN & \\
\hline CHEMBL2031025 & 1641780 & 7.699 & 7.975 & TRN & \\
\hline CHEMBL3963300 & 1641780 & 7.699 & 7.3902 & TRN & \\
\hline CHEMBL3964058 & 1641780 & 7.0458 & 7.0707 & TRN & \\
\hline CHEMBL 2030853 & 1641780 & 8.1062 & 7.87299 & 9999999999 & TST \\
\hline CHEMBL 3927392 & 1641780 & 8.1057 & 8.4756 & TRN & \\
\hline CHEMBL3893974 & 1641780 & 5.7825 & 7.1468 & TRN & \\
\hline CHEMBL3233566 & 1335497 & 3.0 & 3.2021 & TRN & \\
\hline CHEMBL3233567 & 1335497 & 4.6576 & 4.2194 & TRN & \\
\hline CHEMBL 3233848 & 1335497 & 6.1079 & 6.9362 & TRN & \\
\hline CHEMBL 3233549 & 1335497 & 4.1739 & 3.6061 & TST & \\
\hline CHEMBL3233543 & 1335497 & 5.585 & $4.90600 t$ & 0000000001 & TRN \\
\hline CHEMBL3233847 & 1335497 & 7.9508 & 7.5846 & TRN & \\
\hline CHEMBL3233837 & 1335497 & 5.6925 & 5.7841 & TRN & \\
\hline CHEMBL3233834 & 1335497 & 6.301 & 6.5065 & TRN & \\
\hline CHEMBL3233542 & 1335497 & 4.6021 & 4.9839 & TRN & \\
\hline CHEMBL3233550 & 1335497 & 3.0 & 3.6133 & TST & \\
\hline CHEMBL3233557 & 1335497 & 4.4724 & 4.5533 & TRN & \\
\hline CHEMBL3233574 & 1335497 & 3.0 & 3.4716 & TRN & \\
\hline CHEMBL3233544 & 1335497 & 5.0458 & 5.041 & TRN & \\
\hline
\end{tabular}


Supplemental Table S2.txt

\begin{tabular}{|c|c|c|c|c|}
\hline CHEMBL3233560 & 1335497 & 4.5361 & 4.4884 & TRN \\
\hline CHEMBL3233553 & 1335497 & 5.0458 & 3.6018 & TST \\
\hline CHEMBL 2385300 & 1335497 & 3.301 & 4.0166 & TRN \\
\hline CHEMBL 3233845 & 1335497 & 4.7747 & 4.376 & TRN \\
\hline CHEMBL3233568 & 1335497 & 5.1427 & 4.6592 & TRN \\
\hline CHEMBL3233570 & 1335497 & 4.3188 & 4.2865 & TRN \\
\hline CHEMBL3233575 & 1335497 & 4.6198 & 4.4553 & TRN \\
\hline CHEMBL 2385281 & 1335497 & 6.0655 & 5.519 & TRN \\
\hline CHEMBL3233842 & 1335497 & 4.7447 & 5.0703 & TRN \\
\hline CHEMBL3233555 & 1335497 & 5.1675 & 5.2816 & TRN \\
\hline CHEMBL 3233835 & 1335497 & 5.041 & 5.3273 & TRN \\
\hline CHEMBL3233836 & 1335497 & 4.7122 & 5.1661 & TRN \\
\hline CHEMBL3233571 & 1335497 & 5.2518 & 4.9598 & TRN \\
\hline CHEMBL3233572 & 1335497 & 5.5686 & 5.0664 & TRN \\
\hline CHEMBL3233551 & 1335497 & 3.0 & 2.72 & TST \\
\hline CHEMBL3233552 & 1335497 & 3.0 & 3.7129 & TST \\
\hline CHEMBL3233558 & 1335497 & 4.8477 & 4.7989 & TRN \\
\hline CHEMBL3233538 & 1335497 & 3.0 & 3.3222 & TRN \\
\hline CHEMBL3233573 & 1335497 & 3.0 & 2.9364 & TRN \\
\hline CHEMBL 2333026 & 1335497 & 6.0044 & 6.0026 & TST \\
\hline CHEMBL3233554 & 1335497 & 4.9469 & 5.2919 & TRN \\
\hline CHEMBL3233548 & 1335497 & 3.6021 & 3.6661 & TRN \\
\hline CHEMBL3233546 & 1335497 & 5.699 & 5.0033 & TRN \\
\hline CHEMBL3233565 & 1335497 & 3.0 & \multicolumn{2}{|c|}{3.1430000000000002} \\
\hline CHEMBL3233561 & 1335497 & 5.699 & 5.2966 & TRN \\
\hline CHEMBL3233839 & 1335497 & 5.8928 & 5.4106 & TRN \\
\hline CHEMBL3233547 & 1335497 & 3.301 & 3.5741 & TRN \\
\hline CHEMBL3233556 & 1335497 & 5.1367 & 4.6513 & TRN \\
\hline CHEMBL1243153 & 1335497 & 3.0 & 2.7915 & TST \\
\hline CHEMBL3233569 & 1335497 & 4.8633 & 5.0278 & TRN \\
\hline CHEMBL3233833 & 1335497 & 5.4685 & 5.782 & TRN \\
\hline CHEMBL 3233564 & 1335497 & 5.1805 & 5.1849 & TRN \\
\hline CHEMBL3233559 & 1335497 & 4.9281 & 5.6488 & TRN \\
\hline CHEMBL3233541 & 1335497 & 4.3372 & 3.9632 & TRN \\
\hline CHEMBL3233562 & 1335497 & 5.2291 & 3.9616 & TST \\
\hline CHEMBL3233838 & 1335497 & 5.0605 & 4.4459 & TST \\
\hline CHEMBL3233545 & 1335497 & 5.2007 & 4.7815 & TST \\
\hline CHEMBL 3233844 & 1335497 & 5.0315 & 3.6307 & TST \\
\hline CHEMBL3233563 & 1335497 & 4.4089 & 4.6929 & TST \\
\hline CHEMBL3233843 & 1335497 & 5.0809 & 5.0706 & TST \\
\hline CHEMBL3233846 & 1335497 & 3.301 & 7.0887 & TST \\
\hline CHEMBL3186748 & 1301459 & 3.6615 & 5.5894 & TRN \\
\hline CHEMBL3182966 & 1301459 & 3.6615 & 3.5643 & TRN \\
\hline CHEMBL3187814 & 1301459 & 3.6615 & 3.3165 & TRN \\
\hline CHEMBL3184611 & 1301459 & 5.1884 & 4.8733 & TRN \\
\hline CHEMBL 3186476 & 1301459 & 3.6615 & 3.4129 & TRN \\
\hline CHEMBL3187241 & 1301459 & 3.6615 & 3.4099 & TRN \\
\hline CHEMBL3182177 & 1301459 & 3.6615 & 3.5347 & TRN \\
\hline
\end{tabular}

Page 7358 
Supplemental Table S2.txt

\begin{tabular}{|c|c|c|c|c|c|}
\hline CHEMBL3182201 & 1301459 & 3.6615 & 3.7328 & TRN & \\
\hline CHEMBL3183682 & 1301459 & 3.6615 & 3.8179 & TRN & \\
\hline CHEMBL3188146 & 1301459 & 3.6615 & 3.813 & TRN & \\
\hline CHEMBL 3182255 & 1301459 & 3.6615 & 3.5035 & TST & \\
\hline CHEMBL3187872 & 1301459 & 3.6615 & 4.0176 & TRN & \\
\hline CHEMBL 3182383 & 1301459 & 3.6615 & 3.4056 & TRN & \\
\hline CHEMBL3186429 & 1301459 & 3.6615 & \multicolumn{2}{|c|}{3.6630000000000003} & TRN \\
\hline CHEMBL 3182548 & 1301459 & 3.6615 & 3.5538 & TST & \\
\hline CHEMBL 3187493 & 1301459 & 3.6615 & 3.5553 & TRN & \\
\hline CHEMBL3189013 & 1301459 & 3.6615 & 3.6269 & TRN & \\
\hline CHEMBL 3184327 & 1301459 & 6.1574 & 6.3507 & TRN & \\
\hline CHEMBL1523428 & 1301459 & 3.6615 & 3.7338 & TST & \\
\hline CHEMBL3187538 & 1301459 & 3.6615 & 3.4281 & TRN & \\
\hline CHEMBL 3183804 & 1301459 & 3.6615 & 3.3572 & TRN & \\
\hline CHEMBL3185613 & 1301459 & 6.7645 & 6.4532 & TRN & \\
\hline CHEMBL 3187107 & 1301459 & 3.6615 & 3.1464 & TRN & \\
\hline CHEMBL3184277 & 1301459 & 3.6615 & 3.9939 & TRN & \\
\hline CHEMBL3185831 & 1301459 & 3.6615 & 3.8399 & TRN & \\
\hline CHEMBL 3188640 & 1301459 & 3.6615 & 3.8223 & TRN & \\
\hline CHEMBL 3187752 & 1301459 & 3.6615 & 3.6191 & TRN & \\
\hline CHEMBL3182557 & 1301459 & 3.6615 & 3.54699 & 99999999997 & TRN \\
\hline CHEMBL3187121 & 1301459 & 3.6615 & 3.0058 & TST & \\
\hline CHEMBL1393367 & 1301459 & 3.6615 & 4.0306 & TRN & \\
\hline CHEMBL1438842 & 1301459 & 3.6615 & 4.9123 & TST & \\
\hline CHEMBL 3182703 & 1301459 & 3.6615 & 3.4632 & TRN & \\
\hline CHEMBL3183962 & 1301459 & 3.6615 & 3.4024 & TST & \\
\hline CHEMBL 3187528 & 1301459 & 3.6615 & 4.01 & TST & \\
\hline CHEMBL 3183227 & 1301459 & 3.6615 & 2.8718 & TST & \\
\hline CHEMBL 3186610 & 1301459 & 3.6615 & 3.4109 & TRN & \\
\hline CHEMBL3183725 & 1301459 & 3.6615 & 3.66399 & Э99999999997 & TRN \\
\hline CHEMBL 3187517 & 1301459 & 3.6615 & 3.2525 & TST & \\
\hline CHEMBL 3186785 & 1301459 & 3.6615 & 3.5934 & TRN & \\
\hline CHEMBL 3185857 & 1301459 & 3.6615 & 3.198 & TST & \\
\hline CHEMBL 3184558 & 1301459 & 3.6615 & 3.8 & TRN & \\
\hline CHEMBL3188207 & 1301459 & 3.6615 & 3.9738 & TRN & \\
\hline CHEMBL3182163 & 1301459 & 3.6615 & 3.5113 & TRN & \\
\hline CHEMBL3183417 & 1301459 & 3.6615 & 3.8612 & TRN & \\
\hline CHEMBL3182280 & 1301459 & 3.6615 & 3.9454 & TRN & \\
\hline CHEMBL 3188524 & 1301459 & 3.6615 & 3.3419 & TST & \\
\hline CHEMBL1583316 & 1301459 & 3.6615 & 3.5571 & TRN & \\
\hline CHEMBL3183586 & 1301459 & 3.6615 & 3.9427 & TRN & \\
\hline CHEMBL 3184876 & 1301459 & 3.6615 & 4.0306 & TRN & \\
\hline CHEMBL3186180 & 1301459 & 3.6615 & 3.49 & TST & \\
\hline CHEMBL3183966 & 1301459 & 3.6615 & 3.5368 & TST & \\
\hline CHEMBL3188754 & 1301459 & 3.6615 & 3.5083 & TST & \\
\hline CHEMBL3187975 & 1301459 & 3.6615 & 3.7111 & TRN & \\
\hline CHEMBL3185694 & 1301459 & 3.6615 & 3.9305 & TRN & \\
\hline CHEMBL3188297 & 1301459 & 3.6615 & 3.0867 & TST & \\
\hline
\end{tabular}


Supplemental Table S2.txt

\begin{tabular}{|c|c|c|c|c|}
\hline 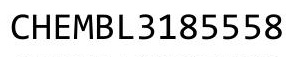 & & & & \\
\hline HEMBL 3185423 & 301459 & 8.3706 & 3024 & \\
\hline HEMBL3185202 & 301459 & 6615 & 6001 & \\
\hline 399 & 37739 & & & \\
\hline EMBL12 & 87739 & & 32 & N \\
\hline AEMBL1287975 & 87739 & 186 & 5882 & \\
\hline HEMBL1287974 & 87739 & .6021 & .5767 & \\
\hline HEMBL128 & 87739 & & 2572 & \\
\hline IEMBL] & 87739 & 09 & .0267 & \\
\hline IEMBL12 & 87739 & & .7228 & \\
\hline HEMBL1287859 & 87739 & 506 & 0414 & \\
\hline HEMBL1288932 & 87739 & .2007 & .1533 & \\
\hline HEMBL1288188 & 87739 & 79 & 353 & \\
\hline HEME & 37739 & & 3774 & \\
\hline AEMBL12 & 87739 & & 5398 & \\
\hline HEMBL128 & 87739 & & 6576 & \\
\hline HEMBL128 & 87739 & & 1187 & \\
\hline HEMBL $12 \varepsilon$ & 87739 & 7 & 2916 & \\
\hline HEMBL12 & 37739 & & 3874 & \\
\hline HEMBL12 & 87739 & & 5779 & \\
\hline HEMBL12 & 39 & & 2634 & \\
\hline HEMBL12 & 39 & & & \\
\hline HEMBL12 & 39 & 8 & 27 & NIV \\
\hline HEMBL12 & 39 & & 727 & RN \\
\hline HEM & 39 & & 1939 & RN \\
\hline HEMBL12 & 39 & & & N \\
\hline JEMBL12ع & 39 & & & II \\
\hline HEMBL12 & 39 & & 266 & RN \\
\hline HEM & 39 & & 06 & RN \\
\hline HEMBL12 & 39 & & .4094 & ST \\
\hline HEMBL128 & 39 & & & 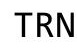 \\
\hline HEMBL128 & 87739 & & 46 & TRN \\
\hline HEMBL12 & 39 & & & ונכ \\
\hline 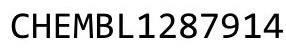 & 39 & & 77 & ST \\
\hline HEMBL12 & & & & RN \\
\hline HEMBL1287887 & 87739 & & & RN \\
\hline HEMBL1288037 & 87739 & & 3.2845 & RN \\
\hline 4 & & & 001 & ST \\
\hline 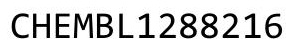 & 39 & & 45 & RN \\
\hline HEMBL 128 & 87739 & & & RN \\
\hline HEMBL128 & 87739 & & 919 & RN \\
\hline HEMBL $12 \varepsilon$ & 39 & & 823 & RN \\
\hline HEMBL128 & 87739 & & & \\
\hline HEMBL 128 & & & 5.5939 & ST \\
\hline HEMBL1288127 & & 696 & 5.7633 & RN \\
\hline HEMBL12ع & 87739 & & 5.9898 & RN \\
\hline HEMBL 128 & & & 184 & \\
\hline HFMBI 128893 & & & & \\
\hline
\end{tabular}

Page 7360 


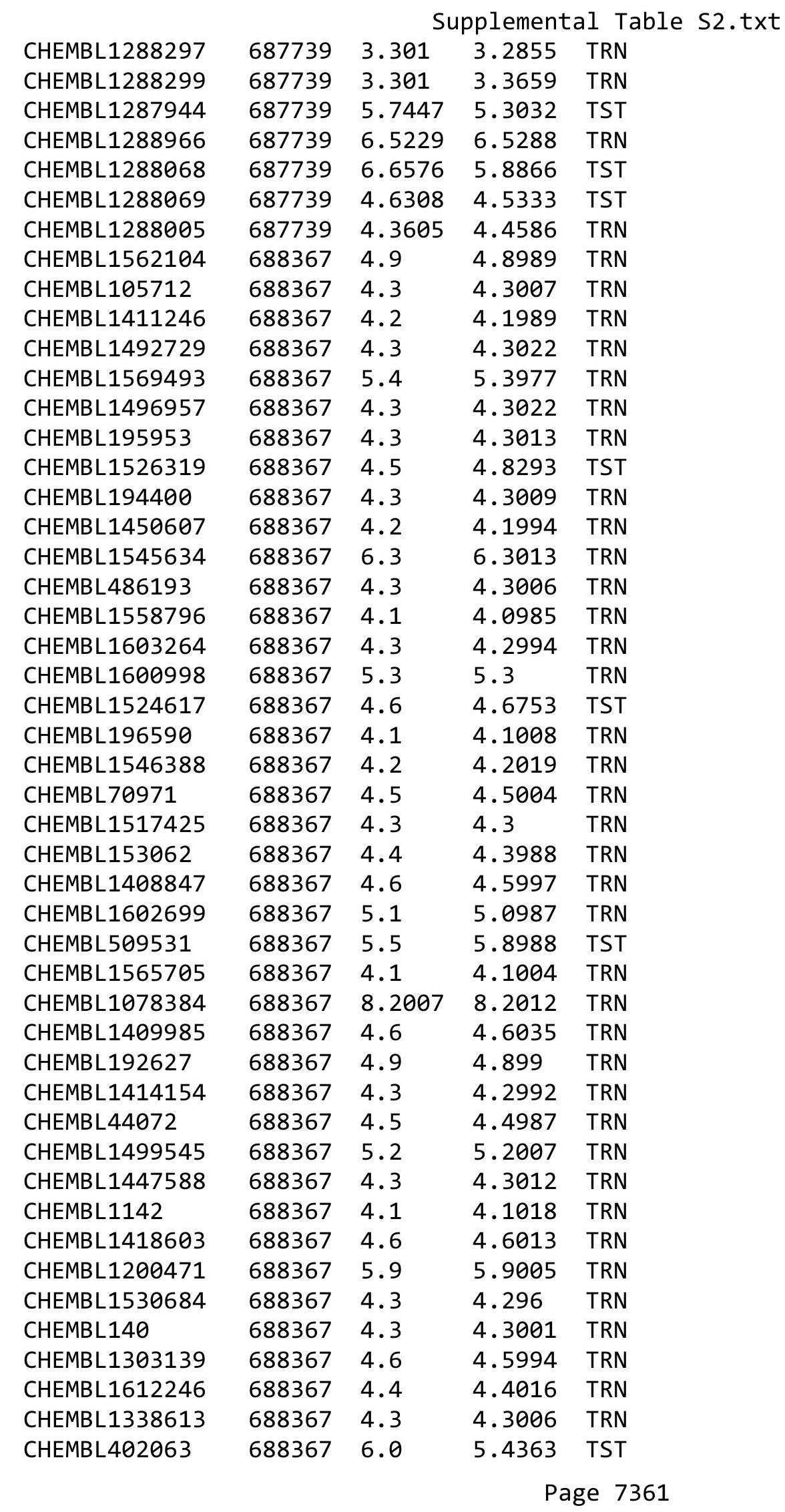




\begin{tabular}{|c|c|c|c|c|}
\hline & & & pplement & al $\mathrm{Ta}$ \\
\hline CHEMBL1522486 & 688367 & 4.8 & 4.7993 & TRN \\
\hline CHEMBL468759 & 688367 & 4.6 & 4.5982 & TRN \\
\hline CHEMBL454173 & 688367 & 4.4 & 4.3985 & TRN \\
\hline CHEMBL329673 & 688367 & 4.4 & 4.3994 & TRN \\
\hline CHEMBL388676 & 688367 & 5.0 & 4.6118 & TST \\
\hline CHEMBL1569226 & 688367 & 5.0 & 4.9988 & TRN \\
\hline CHEMBL1492884 & 688367 & 4.4 & 4.3995 & TRN \\
\hline CHEMBL1308088 & 688367 & 4.9 & 4.3754 & TST \\
\hline CHEMBL194399 & 688367 & 4.3 & 4.482 & TST \\
\hline CHEMBL1232240 & 688367 & 4.1 & 4.2997 & TST \\
\hline CHEMBL1449018 & 688367 & 5.4 & 4.4719 & TST \\
\hline CHEMBL1456906 & 688367 & 4.3 & 5.0534 & TST \\
\hline CHEMBL1519327 & 688367 & 4.7 & 5.1947 & TST \\
\hline CHEMBL1566504 & 688367 & 4.3 & 4.3794 & TST \\
\hline CHEMBL28 & 688367 & 4.1 & 3.9636 & TST \\
\hline CHEMBL1448387 & 688367 & 4.4 & 5.1436 & TST \\
\hline CHEMBL334255 & 688367 & 5.0 & 4.8561 & TST \\
\hline CHEMBL3951754 & 1613065 & 6.5452 & 6.9667 & TRN \\
\hline CHEMBL3904205 & 1613065 & 7.0862 & 7.1062 & TST \\
\hline CHEMBL3960911 & 1613065 & 6.289 & 6.9347 & TST \\
\hline CHEMBL3964581 & 1613065 & 6.3686 & 6.1908 & TRN \\
\hline CHEMBL3944572 & 1613065 & 7.0132 & 7.2153 & TRN \\
\hline CHEMBL3981041 & 1613065 & 7.2007 & 6.9246 & TRN \\
\hline CHEMBL3986103 & 1613065 & 8.5229 & 7.9108 & TRN \\
\hline CHEMBL3981551 & 1613065 & 8.5229 & 7.9461 & TST \\
\hline CHEMBL 3948084 & 1613065 & 7.7447 & 7.4017 & TRN \\
\hline CHEMBL3967962 & 1613065 & 8.3979 & 7.9038 & TRN \\
\hline CHEMBL3921129 & 1613065 & 8.3979 & 8.1896 & TRN \\
\hline CHEMBL3907533 & 1613065 & 8.2218 & 8.212 & TRN \\
\hline CHEMBL3890751 & 1613065 & 7.9586 & 8.1407 & TRN \\
\hline CHEMBL3972605 & 1613065 & 7.1079 & 6.9241 & TRN \\
\hline CHEMBL3925158 & 1613065 & 6.9666 & 6.5729 & TRN \\
\hline CHEMBL3896779 & 1613065 & 8.699 & 8.7165 & TRN \\
\hline CHEMBL 3916644 & 1613065 & 7.3979 & 7.3345 & TRN \\
\hline CHEMBL3921555 & 1613065 & 6.52 & 7.6971 & TST \\
\hline CHEMBL3899132 & 1613065 & 8.0 & 8.1779 & TRN \\
\hline CHEMBL3936505 & 1613065 & 7.5376 & 7.5603 & TRN \\
\hline CHEMBL3916141 & 1613065 & 6.1851 & 6.5347 & TRN \\
\hline CHEMBL 3970330 & 1613065 & 8.5229 & 8.5054 & TRN \\
\hline CHEMBL3950966 & 1613065 & 8.2218 & 8.251 & TRN \\
\hline CHEMBL3933895 & 1613065 & 7.5686 & 7.7835 & TRN \\
\hline CHEMBL 3942228 & 1613065 & 8.3979 & 8.6117 & TRN \\
\hline CHEMBL3958482 & 1613065 & 8.5229 & 8.5927 & TRN \\
\hline CHEMBL3930965 & 1613065 & 7.8861 & 7.7201 & TRN \\
\hline CHEMBL3904257 & 1613065 & 8.301 & 7.994 & TST \\
\hline CHEMBL3932176 & 1613065 & 8.5229 & 8.6244 & TRN \\
\hline CHEMBL3980622 & 1613065 & 6.1701 & 6.4897 & TRN \\
\hline CHEMBL3971413 & 1613065 & 8.3979 & 8.1664 & TRN \\
\hline
\end{tabular}


Supplemental Table S2.txt

\begin{tabular}{|c|c|c|c|c|c|}
\hline CHEMBL3939985 & 1613065 & 8.0 & 7.6283 & TST & \\
\hline CHEMBL3922441 & 1613065 & 6.6716 & 6.6315 & TRN & \\
\hline CHEMBL3923650 & 1613065 & 6.3125 & 6.54899 & 99999999995 & TRN \\
\hline CHEMBL3944095 & 1613065 & 7.1938 & 6.8193 & TRN & \\
\hline CHEMBL3919183 & 1613065 & 7.8239 & 7.2414 & TRN & \\
\hline CHEMBL3941175 & 1613065 & 6.2343 & 6.5055 & TRN & \\
\hline CHEMBL3977504 & 1613065 & 8.5229 & 8.6879 & TRN & \\
\hline CHEMBL3961532 & 1613065 & 6.1965 & 6.6939 & TST & \\
\hline CHEMBL3943512 & 1613065 & 7.3188 & 7.2563 & TRN & \\
\hline CHEMBL3914227 & 1613065 & 8.301 & 8.2282 & TRN & \\
\hline CHEMBL3968839 & 1613065 & 7.0223 & 7.0091 & TRN & \\
\hline CHEMBL3950549 & 1613065 & 7.0555 & 7.6741 & TST & \\
\hline CHEMBL3949347 & 1613065 & 8.5229 & 8.6267 & TRN & \\
\hline CHEMBL3969056 & 1613065 & 8.3979 & 7.9003 & TRN & \\
\hline CHEMBL 3948267 & 1613065 & 8.3979 & 8.6081 & TRN & \\
\hline CHEMBL3930506 & 1613065 & 8.1549 & 8.2328 & TST & \\
\hline CHEMBL3934034 & 1613065 & 6.3372 & 6.6362 & TRN & \\
\hline CHEMBL3941823 & 1613065 & 8.3979 & 8.3191 & TRN & \\
\hline CHEMBL3970738 & 1613065 & 6.3893 & 6.5926 & TRN & \\
\hline CHEMBL3957416 & 1613065 & 7.7447 & 7.6304 & TRN & \\
\hline CHEMBL3930316 & 1613065 & 6.4248 & 6.7257 & TST & \\
\hline CHEMBL3962365 & 1613065 & 8.3979 & 7.9767 & TST & \\
\hline CHEMBL3968417 & 1613065 & 7.5528 & 8.1497 & TST & \\
\hline CHEMBL3977926 & 1613065 & 7.3872 & 7.7122 & TRN & \\
\hline CHEMBL3939300 & 1613065 & 6.4841 & \multicolumn{2}{|c|}{6.8260000000000005} & TST \\
\hline CHEMBL3890186 & 1613065 & 8.699 & 8.8937 & TRN & \\
\hline CHEMBL3964380 & 1613065 & 7.6576 & 6.9989 & TST & \\
\hline CHEMBL3958006 & 1613065 & 7.3665 & 7.8514 & TST & \\
\hline CHEMBL3923228 & 1613065 & 8.3979 & 8.5614 & TRN & \\
\hline CHEMBL 3977326 & 1613065 & 7.4202 & 7.0917 & TST & \\
\hline CHEMBL3921446 & 1613065 & 7.0269 & 7.3373 & TRN & \\
\hline CHEMBL3959248 & 1613065 & 9.0 & 8.9509 & TRN & \\
\hline CHEMBL3922922 & 1613065 & 7.0269 & 7.2849 & TRN & \\
\hline CHEMBL1964290 & 809136 & 4.9 & 5.0868 & TRN & \\
\hline CHEMBL 2001398 & 809136 & 5.6 & 5.52 & TRN & \\
\hline CHEMBL202721 & 809136 & 4.5 & 5.5261 & TRN & \\
\hline CHEMBL1987034 & 809136 & 8.3 & \multicolumn{2}{|c|}{7.8020000000000005} & TRN \\
\hline CHEMBL1993941 & 809136 & 8.5 & 7.1014 & TRN & \\
\hline CHEMBL377383 & 809136 & 4.9 & 4.7718 & TST & \\
\hline CHEMBL 2005886 & 809136 & 8.5 & \multicolumn{2}{|c|}{7.5089999999999995} & TRN \\
\hline CHEMBL481491 & 809136 & 4.9 & 4.9982 & TST & \\
\hline CHEMBL1973142 & 809136 & 5.9 & 5.3237 & TRN & \\
\hline CHEMBL388311 & 809136 & 7.8 & 8.0508 & TRN & \\
\hline CHEMBL1973145 & 809136 & 6.3 & 6.1817 & TRN & \\
\hline CHEMBL1982924 & 809136 & 7.7 & 7.0585 & TRN & \\
\hline CHEMBL 2005936 & 809136 & 4.9 & 5.6864 & TRN & \\
\hline CHEMBL1807515 & 809136 & 7.0 & 6.2499 & TRN & \\
\hline CHEMBL1964948 & 809136 & 4.5 & 4.6995 & TRN & \\
\hline
\end{tabular}




\begin{tabular}{|c|c|c|c|c|c|}
\hline \\
\hline CHEMBL1971141 & 809136 & 4.9 & 5.8317 & TRN & \\
\hline CHEMBL1995813 & 809136 & 6.8 & 6.379 & TRN & \\
\hline CHEMBL206236 & 809136 & 4.9 & 4.672 & TRN & \\
\hline CHEMBL1989834 & 809136 & 3.7 & 4.1558 & TRN & \\
\hline CHEMBL 2003500 & 809136 & 6.0 & 5.1037 & TRN & \\
\hline CHEMBL1987430 & 809136 & 4.5 & 4.4738 & TRN & \\
\hline CHEMBL 244378 & 809136 & 4.9 & 5.5931 & TRN & \\
\hline CHEMBL2001957 & 809136 & 4.9 & 5.0218 & TRN & \\
\hline CHEMBL1969372 & 809136 & 4.9 & 4.5613 & TRN & \\
\hline CHEMBL1993413 & 809136 & 4.5 & 5.2386 & TRN & \\
\hline CHEMBL1986943 & 809136 & 7.1 & 6.8814 & TRN & \\
\hline CHEMBL 2006263 & 809136 & 4.9 & 4.9921 & TRN & \\
\hline CHEMBL1993584 & 809136 & 4.9 & 4.7168 & TRN & \\
\hline CHEMBL1986263 & 809136 & 6.3 & 5.7006 & TRN & \\
\hline CHEMBL2000114 & 809136 & 6.7 & 5.7319 & TRN & \\
\hline CHEMBL1986265 & 809136 & 4.5 & 4.5365 & TRN & \\
\hline CHEMBL1975647 & 809136 & 4.9 & 4.9417 & TRN & \\
\hline CHEMBL1968380 & 809136 & 4.9 & 4.664 & TRN & \\
\hline CHEMBL1964644 & 809136 & 4.9 & 5.0935 & TRN & \\
\hline CHEMBL1991734 & 809136 & 6.3 & 5.7923 & TST & \\
\hline CHEMBL1981782 & 809136 & 4.9 & 5.1304 & TRN & \\
\hline CHEMBL1977681 & 809136 & 6.4 & 6.1016 & TRN & \\
\hline CHEMBL1970142 & 809136 & 4.9 & 6.7351 & TRN & \\
\hline CHEMBL1991782 & 809136 & 3.2 & 3.6399 & TRN & \\
\hline CHEMBL1983348 & 809136 & 5.8 & 5.7416 & TRN & \\
\hline CHEMBL1988163 & 809136 & 7.0 & 6.9203 & TRN & \\
\hline CHEMBL1974480 & 809136 & 5.9 & 5.8522 & TRN & \\
\hline CHEMBL1986177 & 809136 & 4.5 & 4.8366 & TRN & \\
\hline CHEMBL1992323 & 809136 & 4.9 & 4.9564 & TRN & \\
\hline CHEMBL1969735 & 809136 & 4.9 & 5.0177 & TRN & \\
\hline CHEMBL2002649 & 809136 & 4.9 & 7.53799 & 9999999999 & TRN \\
\hline CHEMBL1985367 & 809136 & 5.6 & 4.8684 & TRN & \\
\hline CHEMBL1996510 & 809136 & 6.0 & 5.023 & TRN & \\
\hline CHEMBL1995172 & 809136 & 4.1 & 4.7952 & TST & \\
\hline CHEMBL 2001584 & 809136 & 4.5 & 5.1118 & TRN & \\
\hline CHEMBL1971227 & 809136 & 5.6 & 5.3772 & TST & \\
\hline CHEMBL1967998 & 809136 & 6.3 & 6.3742 & TRN & \\
\hline CHEMBL1978562 & 809136 & 6.1 & 5.9494 & TRN & \\
\hline CHEMBL1974875 & 809136 & 4.2 & 4.6578 & TST & \\
\hline CHEMBL1989471 & 809136 & 5.5 & 5.0818 & TST & \\
\hline CHEMBL2000508 & 809136 & 4.9 & 4.9304 & TRN & \\
\hline CHEMBL2001547 & 809136 & 4.9 & 4.8716 & TRN & \\
\hline CHEMBL210928 & 809136 & 4.9 & 4.8376 & TST & \\
\hline CHEMBL1978195 & 809136 & 4.5 & 4.2854 & TRN & \\
\hline CHEMBL1986603 & 809136 & 4.9 & 5.06800 & 00000000005 & TST \\
\hline CHEMBL1977148 & 809136 & 9.1 & 8.0204 & TRN & \\
\hline CHEMBL 2003286 & 809136 & 4.9 & 4.7673 & TRN & \\
\hline CHEMBL1992306 & 809136 & 7.8 & 6.6668 & TRN & \\
\hline
\end{tabular}




\begin{tabular}{|c|c|c|c|c|}
\hline \multicolumn{5}{|c|}{ Supplemental T } \\
\hline CHEMBL2002165 & 809136 & 8.4 & 7.2078 & TRN \\
\hline CHEMBL1998585 & 809136 & 8.6 & 8.565 & TRN \\
\hline CHEMBL519697 & 809136 & 4.9 & 5.9419 & TRN \\
\hline CHEMBL 2004934 & 809136 & 4.9 & 4.5995 & TRN \\
\hline CHEMBL1973516 & 809136 & 4.5 & 5.8174 & TRN \\
\hline CHEMBL1996345 & 809136 & 4.5 & 4.5057 & TST \\
\hline CHEMBL1975128 & 809136 & 4.9 & 5.2562 & TRN \\
\hline CHEMBL 2004025 & 809136 & 6.2 & 5.9639 & TRN \\
\hline CHEMBL1996048 & 809136 & 4.5 & 4.6221 & TST \\
\hline CHEMBL461876 & 809136 & 4.5 & 4.2576 & TRN \\
\hline CHEMBL2001485 & 809136 & 4.9 & 6.6974 & TRN \\
\hline CHEMBL1965033 & 809136 & 6.9 & 7.2162 & TRN \\
\hline CHEMBL1997335 & 809136 & 4.5 & 4.7946 & TRN \\
\hline CHEMBL1978099 & 809136 & 4.9 & 6.7289 & TRN \\
\hline CHEMBL1988608 & 809136 & 4.9 & 4.7936 & TRN \\
\hline CHEMBL184847 & 809136 & 6.2 & 6.053 & TRN \\
\hline CHEMBL1994808 & 809136 & 4.1 & 4.7493 & TRN \\
\hline CHEMBL1984367 & 809136 & 6.3 & 5.4449 & TRN \\
\hline CHEMBL226898 & 809136 & 4.9 & 5.8124 & TRN \\
\hline CHEMBL1982563 & 809136 & 4.9 & 4.833 & TRN \\
\hline CHEMBL539474 & 809136 & 5.9 & 5.6716 & TST \\
\hline CHEMBL575824 & 809136 & 4.9 & 4.9838 & TRN \\
\hline CHEMBL 1988387 & 809136 & 4.9 & 7.7786 & TRN \\
\hline CHEMBL1973868 & 809136 & 4.5 & 4.4597 & TRN \\
\hline CHEMBL1972462 & 809136 & 4.5 & 4.3027 & TRN \\
\hline CHEMBL1990288 & 809136 & 4.9 & 4.8224 & TRN \\
\hline CHEMBL1974803 & 809136 & 5.9 & 5.0735 & TRN \\
\hline CHEMBL1984500 & 809136 & 3.2 & 4.2953 & TRN \\
\hline CHEMBL1986970 & 809136 & 4.9 & 5.0936 & TRN \\
\hline CHEMBL1958401 & 809136 & 4.9 & 5.0586 & TRN \\
\hline CHEMBL 2003456 & 809136 & 4.9 & 5.2237 & TRN \\
\hline CHEMBL1966816 & 809136 & 4.9 & 5.3773 & TRN \\
\hline CHEMBL1972584 & 809136 & 7.1 & 6.3475 & TRN \\
\hline CHEMBL 2002992 & 809136 & 4.6 & 4.246 & TRN \\
\hline CHEMBL560813 & 809136 & 6.5 & 5.5462 & TRN \\
\hline CHEMBL1982700 & 809136 & 4.5 & 4.3413 & TST \\
\hline CHEMBL1968791 & 809136 & 4.9 & 5.5623 & TRN \\
\hline CHEMBL1977634 & 809136 & 4.5 & 4.4646 & TRN \\
\hline CHEMBL1971186 & 809136 & 4.9 & 4.5846 & TRN \\
\hline CHEMBL 2003482 & 809136 & 4.9 & 5.0084 & TRN \\
\hline CHEMBL1973211 & 809136 & 7.4 & 6.3164 & TRN \\
\hline CHEMBL1984700 & 809136 & 4.9 & 4.8741 & TRN \\
\hline CHEMBL1971606 & 809136 & 4.5 & 4.2736 & TRN \\
\hline CHEMBL1972125 & 809136 & 4.9 & 4.9157 & TRN \\
\hline CHEMBL1999120 & 809136 & 4.3 & 4.4989 & TST \\
\hline CHEMBL1976134 & 809136 & 6.5 & 6.6521 & TRN \\
\hline CHEMBL1965131 & 809136 & 4.9 & 5.2064 & TRN \\
\hline CHEMBL1972158 & 809136 & 6.2 & 5.4072 & TRN \\
\hline
\end{tabular}




\begin{tabular}{|c|c|c|c|c|c|}
\hline \\
\hline CHEMBL1981215 & 809136 & 4.5 & 4.6191 & TRN & \\
\hline CHEMBL1999414 & 809136 & 7.2 & 7.1159 & TRN & \\
\hline CHEMBL1967336 & 809136 & 4.5 & 4.683 & TRN & \\
\hline CHEMBL1970340 & 809136 & 3.5 & 3.7548 & TRN & \\
\hline CHEMBL1967992 & 809136 & 4.5 & 4.4926 & TRN & \\
\hline CHEMBL 2005186 & 809136 & 4.9 & 4.8076 & TRN & \\
\hline CHEMBL 2006450 & 809136 & 4.5 & 4.7767 & TRN & \\
\hline CHEMBL1975534 & 809136 & 4.9 & 5.33899 & 99999999995 & TRN \\
\hline CHEMBL1993424 & 809136 & 8.3 & 7.63 & TRN & \\
\hline CHEMBL1966703 & 809136 & 4.9 & 4.8846 & TST & \\
\hline CHEMBL2001987 & 809136 & 4.5 & 4.8398 & TRN & \\
\hline CHEMBL1969561 & 809136 & 4.9 & 5.0931 & TRN & \\
\hline CHEMBL1994555 & 809136 & 4.5 & 4.4306 & TRN & \\
\hline CHEMBL1975121 & 809136 & 4.6 & 4.3811 & TRN & \\
\hline CHEMBL1983640 & 809136 & 7.4 & 6.9634 & TRN & \\
\hline CHEMBL1997023 & 809136 & 4.9 & 4.9524 & TST & \\
\hline CHEMBL1964687 & 809136 & 7.5 & 6.8747 & TRN & \\
\hline CHEMBL1971943 & 809136 & 4.7 & 4.6216 & TRN & \\
\hline CHEMBL1974254 & 809136 & 8.6 & 7.5526 & TRN & \\
\hline CHEMBL1988537 & 809136 & 6.1 & 5.2078 & TST & \\
\hline CHEMBL1969049 & 809136 & 4.9 & 4.592 & TRN & \\
\hline CHEMBL 2005828 & 809136 & 6.8 & 6.1315 & TRN & \\
\hline CHEMBL1998611 & 809136 & 4.9 & 4.7717 & TRN & \\
\hline CHEMBL1975900 & 809136 & 4.9 & 4.5527 & TRN & \\
\hline CHEMBL 255822 & 809136 & 4.9 & 4.7785 & TRN & \\
\hline CHEMBL1972221 & 809136 & 4.9 & 4.7729 & TRN & \\
\hline CHEMBL378627 & 809136 & 4.9 & 4.8653 & TST & \\
\hline CHEMBL1996979 & 809136 & 7.5 & 7.7233 & TRN & \\
\hline CHEMBL1998545 & 809136 & 4.9 & 4.9416 & TRN & \\
\hline CHEMBL1986869 & 809136 & 4.9 & 4.9365 & TRN & \\
\hline CHEMBL1975923 & 809136 & 4.8 & 5.1947 & TST & \\
\hline CHEMBL 2005449 & 809136 & 6.1 & 6.0346 & TRN & \\
\hline CHEMBL1987998 & 809136 & 4.5 & 4.4377 & TRN & \\
\hline CHEMBL1682558 & 809136 & 4.9 & 4.7622 & TRN & \\
\hline CHEMBL1989259 & 809136 & 5.7 & 6.0017 & TRN & \\
\hline CHEMBL1990496 & 809136 & 4.6 & 4.6615 & TRN & \\
\hline CHEMBL 2002799 & 809136 & 6.0 & 5.3938 & TST & \\
\hline CHEMBL 242865 & 809136 & 4.5 & 4.7808 & TRN & \\
\hline CHEMBL 2002479 & 809136 & 4.9 & 5.6611 & TRN & \\
\hline CHEMBL1967094 & 809136 & 4.9 & 5.815 & TRN & \\
\hline CHEMBL2003341 & 809136 & 4.9 & 4.7745 & TRN & \\
\hline CHEMBL1982992 & 809136 & 4.9 & 5.4247 & TRN & \\
\hline CHEMBL1998110 & 809136 & 4.5 & 4.1581 & TRN & \\
\hline CHEMBL1999590 & 809136 & 4.9 & 5.2358 & TST & \\
\hline CHEMBL1981079 & 809136 & 4.9 & 4.8402 & TRN & \\
\hline CHEMBL1978166 & 809136 & 6.5 & 6.5348 & TRN & \\
\hline CHEMBL1980489 & 809136 & 4.9 & 4.5408 & TRN & \\
\hline CHEMBL2000832 & 809136 & 6.2 & 5.4855 & TRN & \\
\hline
\end{tabular}




\begin{tabular}{|c|c|c|c|c|c|}
\hline & & & & & \\
\hline CHEMBL1990590 & 809136 & 4.5 & 4.3198 & TRN & \\
\hline CHEMBL1977814 & 809136 & 6.6 & 4.6744 & TST & \\
\hline CHEMBL86755 & 809136 & 6.2 & 6.3212 & TRN & \\
\hline CHEMBL1970709 & 809136 & 4.9 & 5.0438 & TRN & \\
\hline CHEMBL1965660 & 809136 & 4.9 & 4.8580 & 00000000005 & TRN \\
\hline CHEMBL1992125 & 809136 & 6.2 & 5.642 & TRN & \\
\hline CHEMBL1998112 & 809136 & 4.9 & 5.0239 & TRN & \\
\hline CHEMBL1969126 & 809136 & 4.9 & 4.9799 & TRN & \\
\hline CHEMBL1980896 & 809136 & 6.1 & 6.2892 & TRN & \\
\hline CHEMBL1970104 & 809136 & 8.2 & 7.5325 & TRN & \\
\hline CHEMBL1991429 & 809136 & 4.9 & 5.6593 & TRN & \\
\hline CHEMBL1967612 & 809136 & 4.0 & 4.9515 & TRN & \\
\hline CHEMBL1971149 & 809136 & 4.9 & 4.8369 & TRN & \\
\hline CHEMBL1999714 & 809136 & 4.9 & 5.1661 & TRN & \\
\hline CHEMBL1994040 & 809136 & 4.9 & 4.7406 & TRN & \\
\hline CHEMBL388978 & 809136 & 8.7 & 8.2673 & TST & \\
\hline CHEMBL579246 & 809136 & 4.9 & 5.3398 & TRN & \\
\hline CHEMBL398951 & 809136 & 4.5 & 5.3785 & TRN & \\
\hline CHEMBL1982506 & 809136 & 4.9 & 4.6297 & TST & \\
\hline CHEMBL 2004716 & 809136 & 5.9 & 7.3972 & TRN & \\
\hline CHEMBL1968127 & 809136 & 4.9 & 4.8463 & TRN & \\
\hline CHEMBL1975233 & 809136 & 4.9 & 5.2366 & TRN & \\
\hline CHEMBL1985406 & 809136 & 4.9 & 5.1512 & TRN & \\
\hline CHEMBL207400 & 809136 & 7.3 & 4.9498 & TST & \\
\hline CHEMBL 2000894 & 809136 & 4.9 & 5.1306 & TST & \\
\hline CHEMBL1421720 & 809136 & 6.0 & 5.6105 & TRN & \\
\hline CHEMBL1976090 & 809136 & 4.9 & 4.7595 & TRN & \\
\hline CHEMBL1993243 & 809136 & 6.5 & 6.1638 & TRN & \\
\hline CHEMBL 2004771 & 809136 & 4.9 & 5.8478 & TRN & \\
\hline CHEMBL1997597 & 809136 & 4.9 & 4.9717 & TRN & \\
\hline CHEMBL1969537 & 809136 & 4.9 & 5.6616 & TST & \\
\hline CHEMBL1976093 & 809136 & 4.9 & 4.776 & TRN & \\
\hline CHEMBL1975256 & 809136 & 4.9 & 4.7379 & TST & \\
\hline CHEMBL508928 & 809136 & 8.3 & 7.7626 & TRN & \\
\hline CHEMBL1983309 & 809136 & 6.1 & 5.5945 & TRN & \\
\hline CHEMBL 2004892 & 809136 & 4.9 & 5.2289 & TRN & \\
\hline CHEMBL1949855 & 809136 & 4.6 & 4.9657 & TRN & \\
\hline CHEMBL116070 & 809136 & 4.9 & 4.8268 & TRN & \\
\hline CHEMBL1970314 & 809136 & 6.0 & 4.9247 & TRN & \\
\hline CHEMBL 2004871 & 809136 & 4.9 & 5.1084 & TRN & \\
\hline CHEMBL 2004872 & 809136 & 4.9 & 4.7861 & TRN & \\
\hline CHEMBL1990223 & 809136 & 4.5 & 4.3006 & TRN & \\
\hline CHEMBL1969879 & 809136 & 4.9 & 4.6831 & TRN & \\
\hline CHEMBL1964382 & 809136 & 4.5 & 4.7358 & TST & \\
\hline CHEMBL101311 & 809136 & 4.5 & 4.5804 & TRN & \\
\hline CHEMBL1981720 & 809136 & 4.9 & 5.0179 & TRN & \\
\hline CHEMBL419932 & 809136 & 4.9 & 4.8314 & TRN & \\
\hline CHEMBL 306380 & 809136 & 6.5 & 5.5853 & TRN & \\
\hline & & & & e 7367 & \\
\hline
\end{tabular}




\begin{tabular}{|c|c|c|c|c|c|}
\hline \\
\hline CHEMBL1966722 & 809136 & 4.9 & 5.5188 & TRN & \\
\hline CHEMBL1988581 & 809136 & 7.1 & 6.3987 & TST & \\
\hline CHEMBL2005699 & 809136 & 4.5 & 4.5459 & TRN & \\
\hline CHEMBL1975500 & 809136 & 6.6 & 5.5611 & TRN & \\
\hline CHEMBL394619 & 809136 & 7.1 & 6.5828 & TRN & \\
\hline CHEMBL 2006564 & 809136 & 6.0 & 6.0533 & TRN & \\
\hline CHEMBL1996831 & 809136 & 4.9 & 5.3084 & TST & \\
\hline CHEMBL1978167 & 809136 & 4.5 & 5.3364 & TRN & \\
\hline CHEMBL418203 & 809136 & 4.6 & 4.9282 & TST & \\
\hline CHEMBL1989646 & 809136 & 4.9 & 5.1717 & TRN & \\
\hline CHEMBL225519 & 809136 & 4.7 & 4.4422 & TRN & \\
\hline CHEMBL1978200 & 809136 & 4.9 & 4.7725 & TRN & \\
\hline CHEMBL1994159 & 809136 & 4.1 & 4.6813 & TRN & \\
\hline CHEMBL1970522 & 809136 & 4.9 & 5.3001 & TRN & \\
\hline CHEMBL402846 & 809136 & 6.8 & 6.32799 & 9999999999 & TRN \\
\hline CHEMBL1996931 & 809136 & 4.9 & 4.6468 & TRN & \\
\hline CHEMBL1973483 & 809136 & 4.9 & 5.1457 & TRN & \\
\hline CHEMBL1998470 & 809136 & 4.5 & 4.8038 & TRN & \\
\hline CHEMBL1975903 & 809136 & 4.5 & 5.0693 & TRN & \\
\hline CHEMBL1997340 & 809136 & 4.9 & 4.5927 & TRN & \\
\hline CHEMBL1522508 & 809136 & 4.9 & 4.83 & TRN & \\
\hline CHEMBL1989474 & 809136 & 4.9 & 4.9547 & TRN & \\
\hline CHEMBL1090360 & 809136 & 4.9 & 4.8106 & TRN & \\
\hline CHEMBL210887 & 809136 & 6.7 & 5.7502 & TRN & \\
\hline CHEMBL1988805 & 809136 & 4.5 & 4.1228 & TST & \\
\hline CHEMBL458997 & 809136 & 4.6 & 4.8788 & TRN & \\
\hline CHEMBL 227271 & 809136 & 6.0 & 5.8573 & TRN & \\
\hline CHEMBL1971021 & 809136 & 4.9 & 6.857 & TRN & \\
\hline CHEMBL583144 & 809136 & 6.1 & 5.295 & TRN & \\
\hline CHEMBL1974310 & 809136 & 4.9 & 5.0025 & TRN & \\
\hline CHEMBL1969942 & 809136 & 4.5 & 5.2176 & TRN & \\
\hline CHEMBL1978567 & 809136 & 4.5 & 4.1581 & TRN & \\
\hline CHEMBL1982660 & 809136 & 4.9 & 5.426 & TRN & \\
\hline CHEMBL1982957 & 809136 & 7.7 & 6.9563 & TRN & \\
\hline CHEMBL1725279 & 809136 & 8.1 & 5.8665 & TST & \\
\hline CHEMBL1975138 & 809136 & 4.9 & 5.5196 & TRN & \\
\hline CHEMBL1980704 & 809136 & 4.9 & 4.681 & TST & \\
\hline CHEMBL2003271 & 809136 & 4.9 & 5.1695 & TRN & \\
\hline CHEMBL1966808 & 809136 & 4.9 & 4.6708 & TRN & \\
\hline CHEMBL 2004447 & 809136 & 4.9 & 4.8723 & TST & \\
\hline CHEMBL1983111 & 809136 & 7.4 & 6.3291 & TRN & \\
\hline CHEMBL1973860 & 809136 & 4.9 & 4.9418 & TST & \\
\hline CHEMBL260135 & 809136 & 4.9 & 4.6524 & TRN & \\
\hline CHEMBL220241 & 809136 & 4.9 & 4.7459 & TRN & \\
\hline CHEMBL1988141 & 809136 & 6.9 & 6.3283 & TST & \\
\hline CHEMBL1982610 & 809136 & 4.9 & 5.41200 & 2000000001 & TST \\
\hline CHEMBL1977134 & 809136 & 7.8 & 7.9832 & TRN & \\
\hline CHEMBL1985206 & 809136 & 4.5 & 5.0097 & TRN & \\
\hline
\end{tabular}




\begin{tabular}{|c|c|c|c|c|c|}
\hline \\
\hline CHEMBL1988300 & 809136 & 6.7 & 6.4298 & TRN & \\
\hline CHEMBL1991078 & 809136 & 7.1 & 6.2179 & TRN & \\
\hline CHEMBL1987359 & 809136 & 4.9 & 4.7968 & TST & \\
\hline CHEMBL1977749 & 809136 & 4.5 & 4.5723 & TST & \\
\hline CHEMBL1975212 & 809136 & 4.7 & 4.8341 & TRN & \\
\hline CHEMBL 2001613 & 809136 & 4.3 & 4.6449 & TRN & \\
\hline CHEMBL1997275 & 809136 & 6.0 & 6.3282 & TRN & \\
\hline CHEMBL1993904 & 809136 & 5.8 & 5.2734 & TRN & \\
\hline CHEMBL1980376 & 809136 & 4.2 & 3.9267 & TRN & \\
\hline CHEMBL1967513 & 809136 & 4.5 & 4.6888 & TRN & \\
\hline CHEMBL 2000724 & 809136 & 4.5 & 4.5839 & TRN & \\
\hline CHEMBL1982413 & 809136 & 6.0 & 5.2829 & TRN & \\
\hline CHEMBL1969502 & 809136 & 6.0 & 5.7565 & TST & \\
\hline CHEMBL1682553 & 809136 & 4.9 & 4.4065 & TRN & \\
\hline CHEMBL1983963 & 809136 & 6.6 & 7.0238 & TRN & \\
\hline CHEMBL1997764 & 809136 & 7.1 & 7.0822 & TRN & \\
\hline CHEMBL1981792 & 809136 & 5.5 & 5.3267 & TRN & \\
\hline CHEMBL1987535 & 809136 & 4.5 & 4.67399 & 99999999995 & TRN \\
\hline CHEMBL1985092 & 809136 & 5.9 & 5.6795 & TRN & \\
\hline CHEMBL 2002586 & 809136 & 4.5 & 4.4671 & TRN & \\
\hline CHEMBL1981410 & 809136 & 7.5 & 7.305 & TRN & \\
\hline CHEMBL1987815 & 809136 & 4.2 & 4.5422 & TST & \\
\hline CHEMBL1996234 & 809136 & 4.9 & 4.5895 & TRN & \\
\hline CHEMBL383264 & 809136 & 4.5 & 5.0598 & TRN & \\
\hline CHEMBL 2007421 & 809136 & 8.8 & 7.8629 & TRN & \\
\hline CHEMBL1967544 & 809136 & 4.9 & 4.6905 & TRN & \\
\hline CHEMBL1973138 & 809136 & 4.5 & 5.0596 & TRN & \\
\hline CHEMBL340384 & 809136 & 6.5 & 4.9237 & TST & \\
\hline CHEMBL1969151 & 809136 & 5.7 & 5.8151 & TRN & \\
\hline CHEMBL1996587 & 809136 & 4.9 & 4.7284 & TRN & \\
\hline CHEMBL1981492 & 809136 & 4.2 & 4.7984 & TRN & \\
\hline CHEMBL1993335 & 809136 & 6.2 & 6.308 & TRN & \\
\hline CHEMBL1988692 & 809136 & 6.4 & 5.9174 & TRN & \\
\hline CHEMBL 2007574 & 809136 & 4.5 & 4.9062 & TRN & \\
\hline CHEMBL1964804 & 809136 & 4.9 & 4.7716 & TRN & \\
\hline CHEMBL 2000354 & 809136 & 4.9 & 5.1931 & TRN & \\
\hline CHEMBL1965507 & 809136 & 4.9 & 6.0592 & TRN & \\
\hline CHEMBL1998680 & 809136 & 4.5 & 4.4248 & TRN & \\
\hline CHEMBL1967564 & 809136 & 4.9 & 5.0465 & TRN & \\
\hline CHEMBL592030 & 809136 & 4.6 & 4.649 & TST & \\
\hline CHEMBL 2000071 & 809136 & 6.8 & 6.2196 & TRN & \\
\hline CHEMBL1979176 & 809136 & 4.9 & 5.3669 & TRN & \\
\hline CHEMBL2000408 & 809136 & 4.9 & 4.7605 & TRN & \\
\hline CHEMBL1978014 & 809136 & 4.9 & 4.9298 & TRN & \\
\hline CHEMBL1997007 & 809136 & 4.5 & 4.2477 & TRN & \\
\hline CHEMBL1994538 & 809136 & 4.9 & 5.1498 & TRN & \\
\hline CHEMBL1975490 & 809136 & 4.9 & 5.4633 & TRN & \\
\hline CHEMBL1964444 & 809136 & 4.9 & 5.0882 & TRN & \\
\hline
\end{tabular}




\begin{tabular}{|c|c|c|c|c|}
\hline & & & pplement & al Table S \\
\hline CHEMBL2002690 & 809136 & 4.5 & 5.2503 & TRN \\
\hline CHEMBL1986139 & 809136 & 4.9 & 5.0687 & TRN \\
\hline CHEMBL1980540 & 809136 & 4.9 & 5.2155 & TRN \\
\hline CHEMBL 278041 & 809136 & 5.6 & 4.9928 & TRN \\
\hline CHEMBL1979883 & 809136 & 7.7 & 7.0084 & TRN \\
\hline CHEMBL1984162 & 809136 & 8.0 & 6.8548 & TRN \\
\hline CHEMBL491758 & 809136 & 6.4 & 6.1047 & TRN \\
\hline CHEMBL1986590 & 809136 & 6.3 & 6.1439 & TRN \\
\hline CHEMBL549730 & 809136 & 4.9 & 4.5239 & TRN \\
\hline CHEMBL1870106 & 809136 & 4.5 & 4.1732 & TRN \\
\hline CHEMBL1996791 & 809136 & 6.0 & 4.8481 & TRN \\
\hline CHEMBL371206 & 809136 & 7.9 & 7.099 & TRN \\
\hline CHEMBL1974664 & 809136 & 4.9 & 5.6078 & TRN \\
\hline CHEMBL1998477 & 809136 & 5.5 & 5.2667 & TRN \\
\hline CHEMBL406845 & 809136 & 4.5 & 4.6066 & TRN \\
\hline CHEMBL482538 & 809136 & 4.0 & 4.7447 & TRN \\
\hline CHEMBL1974288 & 809136 & 4.9 & 4.8532 & TRN \\
\hline CHEMBL1984296 & 809136 & 5.6 & 5.1887 & TST \\
\hline CHEMBL196363 & 809136 & 8.0 & 7.3125 & TRN \\
\hline CHEMBL1190711 & 809136 & 4.9 & 5.0809 & TRN \\
\hline CHEMBL1968705 & 809136 & 4.6 & 4.9019 & TRN \\
\hline CHEMBL1964441 & 809136 & 7.2 & 6.5417 & TRN \\
\hline CHEMBL1991410 & 809136 & 4.5 & 4.8752 & TRN \\
\hline CHEMBL546797 & 809136 & 4.5 & 5.4826 & TST \\
\hline CHEMBL404367 & 809136 & 7.0 & 6.0207 & TRN \\
\hline CHEMBL1966343 & 809136 & 4.9 & 5.5958 & TRN \\
\hline CHEMBL1978271 & 809136 & 4.5 & 4.6173 & TRN \\
\hline CHEMBL1967887 & 809136 & 4.9 & 5.2879 & TRN \\
\hline CHEMBL 2007266 & 809136 & 6.5 & 5.7023 & TRN \\
\hline CHEMBL 2000568 & 809136 & 4.8 & 4.9278 & TRN \\
\hline CHEMBL1994308 & 809136 & 6.6 & 4.8303 & TST \\
\hline CHEMBL 2007097 & 809136 & 4.3 & 4.4226 & TRN \\
\hline CHEMBL1988717 & 809136 & 8.9 & 8.4961 & TRN \\
\hline CHEMBL1974328 & 809136 & 4.6 & 4.863 & TRN \\
\hline CHEMBL509032 & 809136 & 4.7 & 5.5906 & TRN \\
\hline CHEMBL1973808 & 809136 & 4.9 & 5.2814 & TRN \\
\hline CHEMBL 2000429 & 809136 & 4.9 & 4.8413 & TRN \\
\hline CHEMBL1972576 & 809136 & 4.9 & 5.2408 & TRN \\
\hline CHEMBL1992342 & 809136 & 4.9 & 4.9598 & TRN \\
\hline CHEMBL 2002202 & 809136 & 4.1 & 4.46899 & 9999999999 \\
\hline CHEMBL1988173 & 809136 & 4.9 & 5.7055 & TRN \\
\hline CHEMBL1973013 & 809136 & 4.5 & 4.9419 & TRN \\
\hline CHEMBL1965423 & 809136 & 4.9 & 4.6561 & TRN \\
\hline CHEMBL1975927 & 809136 & 4.5 & 5.6358 & TRN \\
\hline CHEMBL 205415 & 809136 & 4.6 & 5.0511 & TRN \\
\hline CHEMBL1977135 & 809136 & 4.9 & 5.1829 & TRN \\
\hline CHEMBL 2001920 & 809136 & 6.7 & 5.6343 & TRN \\
\hline CHEMBL1977138 & 809136 & 6.3 & 6.0052 & TST \\
\hline
\end{tabular}




\begin{tabular}{|c|c|c|c|c|c|}
\hline \\
\hline CHEMBL2000879 & 809136 & 4.1 & 5.1912 & TST & \\
\hline CHEMBL1978448 & 809136 & 4.7 & 4.8232 & TST & \\
\hline CHEMBL2001257 & 809136 & 7.3 & 6.2911 & TRN & \\
\hline CHEMBL1980329 & 809136 & 6.1 & 6.2935 & TRN & \\
\hline CHEMBL1992042 & 809136 & 5.7 & 5.7907 & TST & \\
\hline CHEMBL1992536 & 809136 & 4.9 & 4.9145 & TRN & \\
\hline CHEMBL 21156 & 809136 & 5.5 & 5.1159 & TST & \\
\hline CHEMBL1994724 & 809136 & 4.5 & 4.4884 & TRN & \\
\hline CHEMBL1989267 & 809136 & 5.8 & 5.7431 & TRN & \\
\hline CHEMBL439340 & 809136 & 4.9 & 4.8735 & TRN & \\
\hline CHEMBL2006188 & 809136 & 4.9 & 4.7916 & TRN & \\
\hline CHEMBL1970290 & 809136 & 6.0 & 5.8177 & TRN & \\
\hline CHEMBL1967531 & 809136 & 6.7 & 7.192 & TRN & \\
\hline CHEMBL1970913 & 809136 & 4.9 & 4.8984 & TRN & \\
\hline CHEMBL1973893 & 809136 & 4.9 & 4.8186 & TRN & \\
\hline CHEMBL1997534 & 809136 & 4.9 & 4.9752 & TRN & \\
\hline CHEMBL1993877 & 809136 & 5.6 & 5.2353 & TRN & \\
\hline CHEMBL1996500 & 809136 & 4.5 & 4.6228 & TRN & \\
\hline CHEMBL1985095 & 809136 & 4.9 & 4.9951 & TST & \\
\hline CHEMBL1973363 & 809136 & 5.5 & 5.4166 & TRN & \\
\hline CHEMBL1682540 & 809136 & 4.9 & 5.0216 & TRN & \\
\hline CHEMBL1976420 & 809136 & 4.6 & 4.7064 & TRN & \\
\hline CHEMBL1998253 & 809136 & 4.5 & 4.3653 & TST & \\
\hline CHEMBL1981744 & 809136 & 4.5 & 4.9602 & TRN & \\
\hline CHEMBL1994864 & 809136 & 4.9 & 4.4828 & TRN & \\
\hline CHEMBL497151 & 809136 & 4.9 & 4.9842 & TRN & \\
\hline CHEMBL 2000029 & 809136 & 4.5 & 4.5698 & TRN & \\
\hline CHEMBL1973961 & 809136 & 6.3 & 5.4009 & TRN & \\
\hline CHEMBL 246970 & 809136 & 4.9 & 4.9176 & TST & \\
\hline CHEMBL 340921 & 809136 & 5.9 & 4.7135 & TST & \\
\hline CHEMBL1994977 & 809136 & 4.5 & 4.4462 & TRN & \\
\hline CHEMBL1999718 & 809136 & 4.9 & 5.2349 & TRN & \\
\hline CHEMBL2001149 & 809136 & 4.5 & 4.07100 & 0000000001 & TRN \\
\hline CHEMBL 2005478 & 809136 & 6.2 & 6.392 & TRN & \\
\hline CHEMBL1276446 & 809136 & 4.9 & 7.8686 & TST & \\
\hline CHEMBL1996646 & 809136 & 7.4 & 6.5448 & TRN & \\
\hline CHEMBL1979773 & 809136 & 4.5 & 4.8406 & TRN & \\
\hline CHEMBL1977346 & 809136 & 6.9 & 5.5963 & TRN & \\
\hline CHEMBL1996702 & 809136 & 4.5 & 5.0515 & TRN & \\
\hline CHEMBL 2007124 & 809136 & 6.6 & 6.9659 & TRN & \\
\hline CHEMBL2006439 & 809136 & 6.8 & 6.447 & TRN & \\
\hline CHEMBL1985681 & 809136 & 4.5 & 5.4391 & TST & \\
\hline CHEMBL1973937 & 809136 & 7.3 & 6.845 & TRN & \\
\hline CHEMBL1991674 & 809136 & 6.4 & 4.9964 & TRN & \\
\hline CHEMBL1982711 & 809136 & 4.6 & 5.0325 & TRN & \\
\hline CHEMBL1984842 & 809136 & 4.5 & 4.5914 & TRN & \\
\hline CHEMBL 2004118 & 809136 & 4.5 & 4.5991 & TRN & \\
\hline CHEMBL1998829 & 809136 & 6.8 & 6.5336 & TRN & \\
\hline
\end{tabular}




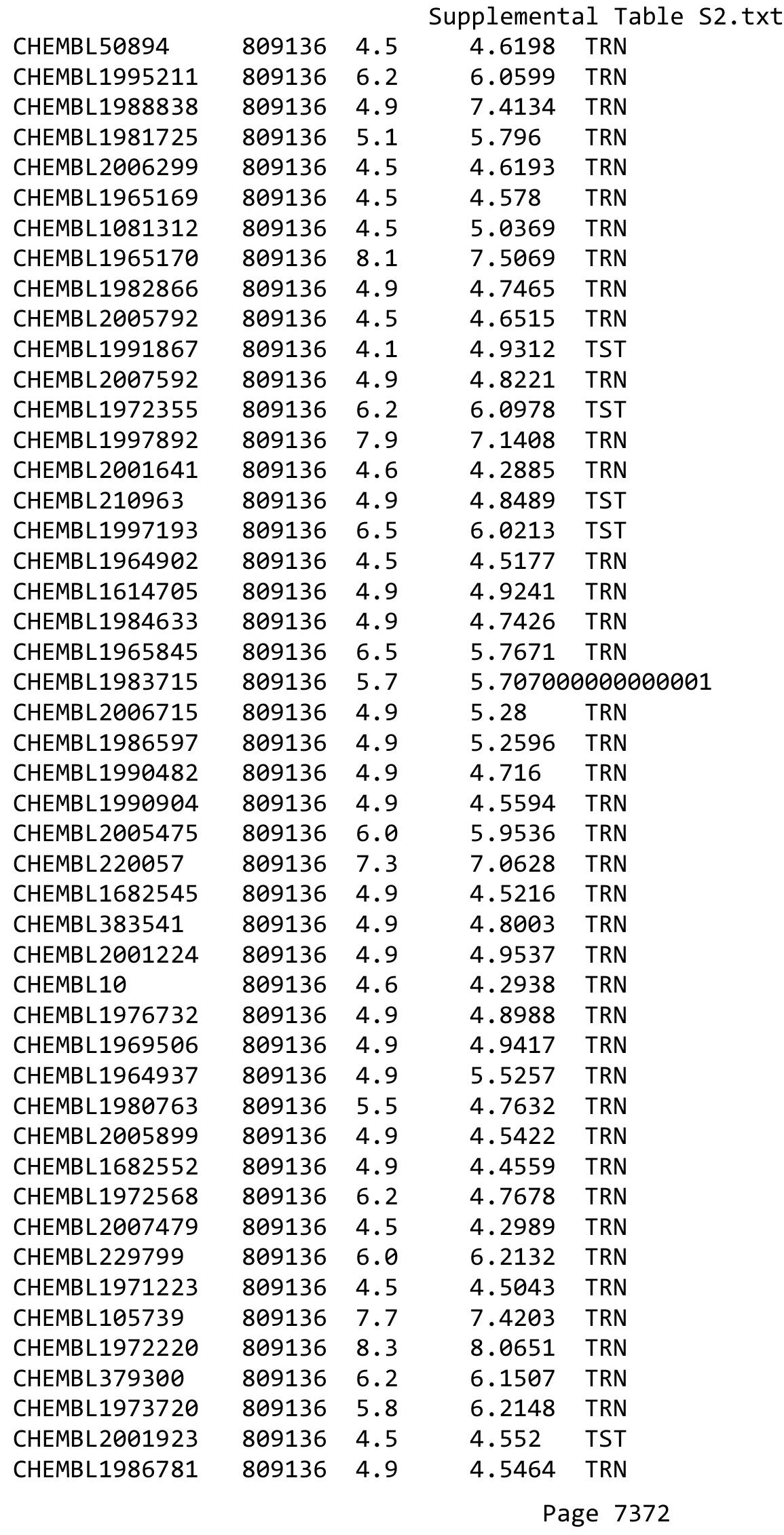

TRN 


\begin{tabular}{|c|c|c|c|c|}
\hline & & & lement & al Ta \\
\hline CHEMBL1983070 & 809136 & 4.5 & 4.5771 & TRN \\
\hline CHEMBL526133 & 809136 & 4.9 & 5.1669 & TRN \\
\hline CHEMBL 2003514 & 809136 & 4.5 & 4.2164 & TRN \\
\hline CHEMBL1989043 & 809136 & 4.5 & 4.0823 & TRN \\
\hline CHEMBL1979057 & 809136 & 6.1 & 5.2213 & TRN \\
\hline CHEMBL 387971 & 809136 & 6.3 & 5.7872 & TST \\
\hline CHEMBL1164180 & 809136 & 6.1 & 5.4399 & TST \\
\hline CHEMBL1999428 & 809136 & 4.9 & 5.1448 & TRN \\
\hline CHEMBL1967560 & 809136 & 4.9 & 4.7296 & TRN \\
\hline CHEMBL1997611 & 809136 & 4.5 & 4.6151 & TST \\
\hline CHEMBL 211378 & 809136 & 4.9 & 5.7965 & TRN \\
\hline CHEMBL1516890 & 809136 & 7.6 & 6.4705 & TRN \\
\hline CHEMBL 2001751 & 809136 & 7.9 & 7.6992 & TRN \\
\hline CHEMBL 2003420 & 809136 & 4.9 & 5.1267 & TRN \\
\hline CHEMBL1984586 & 809136 & 6.0 & 6.0755 & TRN \\
\hline CHEMBL1972659 & 809136 & 4.9 & 4.9526 & TST \\
\hline CHEMBL 2002723 & 809136 & 5.9 & 5.4289 & TST \\
\hline CHEMBL1970217 & 809136 & 4.9 & 4.6352 & TRN \\
\hline CHEMBL 2005528 & 809136 & 4.9 & 4.8929 & TRN \\
\hline CHEMBL1984686 & 809136 & 4.5 & 4.502 & TST \\
\hline CHEMBL185569 & 809136 & 7.0 & 7.2667 & TRN \\
\hline CHEMBL1969843 & 809136 & 4.9 & 4.5899 & TRN \\
\hline CHEMBL 2007002 & 809136 & 7.6 & 5.92 & TRN \\
\hline CHEMBL1987007 & 809136 & 4.9 & 5.5697 & TRN \\
\hline CHEMBL1973793 & 809136 & 4.5 & 4.6291 & TST \\
\hline CHEMBL1969588 & 809136 & 7.5 & 7.5531 & TRN \\
\hline CHEMBL1992073 & 809136 & 4.5 & 4.6516 & TRN \\
\hline CHEMBL484390 & 809136 & 4.9 & 5.7436 & TRN \\
\hline CHEMBL1986143 & 809136 & 4.5 & 4.5091 & TRN \\
\hline CHEMBL1979252 & 809136 & 4.9 & 4.9094 & TRN \\
\hline CHEMBL1972934 & 809136 & 4.6 & 4.3021 & TRN \\
\hline CHEMBL 2007559 & 809136 & 4.5 & 4.2496 & TRN \\
\hline CHEMBL1992581 & 809136 & 6.2 & 6.081 & TRN \\
\hline CHEMBL1986499 & 809136 & 4.9 & 5.6521 & TRN \\
\hline CHEMBL 2004290 & 809136 & 7.8 & 6.9325 & TRN \\
\hline CHEMBL1972937 & 809136 & 4.9 & 5.1473 & TRN \\
\hline CHEMBL 2000393 & 809136 & 7.1 & 6.5038 & TST \\
\hline CHEMBL 2004311 & 809136 & 4.9 & 6.8836 & TRN \\
\hline CHEMBL1983573 & 809136 & 5.0 & 4.6865 & TST \\
\hline CHEMBL1992634 & 809136 & 7.3 & 6.8834 & TRN \\
\hline CHEMBL1984847 & 809136 & 4.5 & 4.6813 & TST \\
\hline CHEMBL1988075 & 809136 & 6.4 & 6.7547 & TRN \\
\hline CHEMBL316264 & 809136 & 4.9 & 4.7815 & TRN \\
\hline CHEMBL1996576 & 809136 & 5.5 & 4.752 & TST \\
\hline CHEMBL1991678 & 809136 & 4.5 & 4.3952 & TRN \\
\hline CHEMBL 2001239 & 809136 & 4.9 & 4.8148 & TRN \\
\hline CHEMBL1988594 & 809136 & 5.9 & 5.8124 & TRN \\
\hline CHEMBL 2001288 & 809136 & 6.0 & 4.8006 & TRN \\
\hline
\end{tabular}




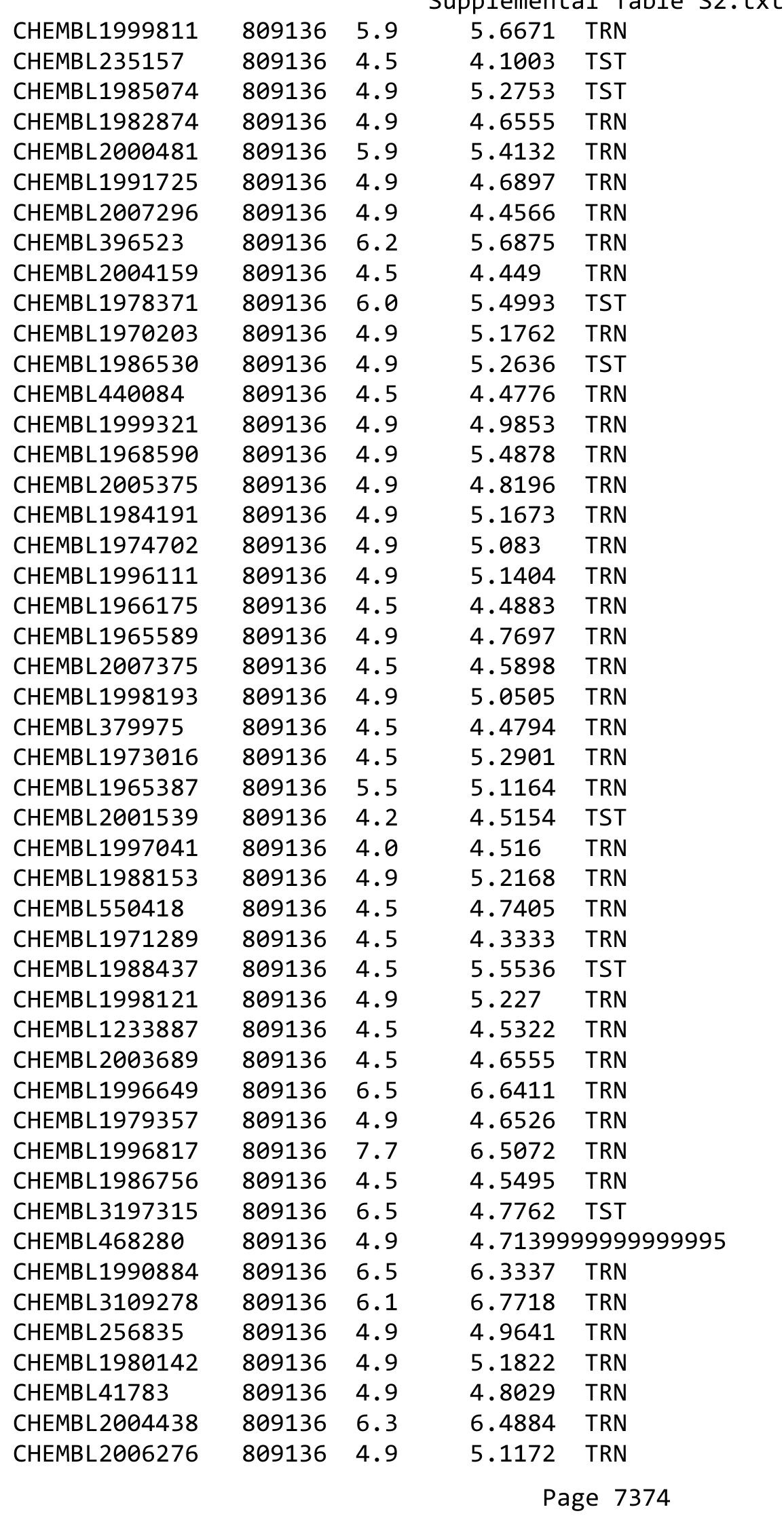




\begin{tabular}{|c|c|c|c|c|}
\hline & & & CI & al Ta \\
\hline CHEMBL191003 & 809136 & 4.5 & 4.9908 & TRN \\
\hline CHEMBL 271381 & 809136 & 8.3 & 7.6423 & TRN \\
\hline CHEMBL 2006785 & 809136 & 4.9 & 5.4938 & TRN \\
\hline CHEMBL1982466 & 809136 & 4.9 & 6.9424 & TRN \\
\hline CHEMBL1973359 & 809136 & 6.4 & 5.7388 & TST \\
\hline CHEMBL1995740 & 809136 & 4.9 & 5.1104 & TRN \\
\hline CHEMBL1979690 & 809136 & 6.2 & 6.4381 & TRN \\
\hline CHEMBL 234085 & 809136 & 4.5 & 4.5481 & TRN \\
\hline CHEMBL1995832 & 809136 & 4.9 & 4.9092 & TRN \\
\hline CHEMBL1998414 & 809136 & 6.2 & 4.9002 & TRN \\
\hline CHEMBL1969042 & 809136 & 6.0 & 6.2087 & TRN \\
\hline CHEMBL1999931 & 809136 & 6.8 & 6.5405 & TRN \\
\hline CHEMBL1976376 & 809136 & 5.6 & 5.8263 & TRN \\
\hline CHEMBL1983575 & 809136 & 6.7 & 6.0948 & TRN \\
\hline CHEMBL1968868 & 809136 & 4.5 & 4.8992 & TRN \\
\hline CHEMBL 2007064 & 809136 & 7.3 & 7.1382 & TRN \\
\hline CHEMBL1981047 & 809136 & 6.6 & 6.9315 & TRN \\
\hline CHEMBL229968 & 809136 & 5.9 & 5.9965 & TRN \\
\hline CHEMBL1976196 & 809136 & 4.5 & 4.5375 & TST \\
\hline CHEMBL1976240 & 809136 & 4.9 & 4.7664 & TRN \\
\hline CHEMBL1997197 & 809136 & 4.5 & 4.476 & TRN \\
\hline CHEMBL1983630 & 809136 & 4.2 & 4.3864 & TRN \\
\hline CHEMBL1968151 & 809136 & 4.9 & 4.8212 & TST \\
\hline CHEMBL1987009 & 809136 & 4.9 & 6.097 & TST \\
\hline CHEMBL 379218 & 809136 & 4.9 & 5.8719 & TST \\
\hline CHEMBL 2003817 & 809136 & 4.9 & 5.186 & TST \\
\hline CHEMBL1994830 & 809136 & 4.9 & 4.956 & TST \\
\hline CHEMBL226403 & 809136 & 4.9 & 4.7527 & TST \\
\hline CHEMBL1994938 & 809136 & 6.6 & 6.7678 & TST \\
\hline CHEMBL1995765 & 809136 & 4.6 & 4.3307 & TST \\
\hline CHEMBL1966279 & 809136 & 4.9 & 5.3756 & TST \\
\hline CHEMBL1984760 & 809136 & 4.5 & 4.7087 & TST \\
\hline CHEMBL1997846 & 809136 & 6.7 & 4.8237 & TST \\
\hline CHEMBL 2004419 & 809136 & 4.9 & 4.8021 & TST \\
\hline CHEMBL 360847 & 809136 & 4.5 & 4.444 & TST \\
\hline CHEMBL1995811 & 809136 & 4.5 & 5.3874 & TST \\
\hline CHEMBL1994074 & 809136 & 6.6 & 5.7571 & TST \\
\hline CHEMBL1992937 & 809136 & 4.5 & 4.505 & TST \\
\hline CHEMBL1972119 & 809136 & 4.9 & 4.9418 & TST \\
\hline CHEMBL 95692 & 809136 & 4.9 & 4.9448 & TST \\
\hline CHEMBL1090356 & 809136 & 4.9 & 5.2483 & TST \\
\hline CHEMBL1976455 & 809136 & 4.9 & 5.4739 & TST \\
\hline CHEMBL261849 & 809136 & 6.5 & 5.1451 & TST \\
\hline CHEMBL1983923 & 809136 & 7.1 & 6.5337 & TST \\
\hline CHEMBL1982361 & 809136 & 4.9 & 4.5116 & TST \\
\hline CHEMBL1983534 & 809136 & 4.9 & 5.1214 & TST \\
\hline CHEMBL1999112 & 809136 & 6.5 & 4.6939 & TST \\
\hline CHEMBL1982122 & 809136 & 4.9 & 4.7941 & TST \\
\hline
\end{tabular}




\begin{tabular}{|c|c|c|c|c|c|}
\hline \\
\hline CHEMBL2000801 & 809136 & 6.1 & 6.2839 & TST & \\
\hline CHEMBL1682546 & 809136 & 4.9 & 4.7281 & TST & \\
\hline CHEMBL1991395 & 809136 & 4.9 & 4.8065 & TST & \\
\hline CHEMBL1971245 & 809136 & 4.9 & 5.0609 & TST & \\
\hline CHEMBL1972142 & 809136 & 6.5 & 5.5787 & TST & \\
\hline CHEMBL2003638 & 809136 & 6.7 & 6.3838 & TST & \\
\hline CHEMBL1996066 & 809136 & 4.9 & 5.7353 & TST & \\
\hline CHEMBL1983393 & 809136 & 5.9 & 5.6773 & TST & \\
\hline CHEMBL 2006674 & 809136 & 4.5 & 4.4476 & TST & \\
\hline CHEMBL1984236 & 809136 & 4.5 & 4.6862 & TST & \\
\hline CHEMBL1992371 & 809136 & 5.5 & 5.1398 & TST & \\
\hline CHEMBL1375640 & 809136 & 4.9 & 4.7512 & TST & \\
\hline CHEMBL2002599 & 809136 & 4.5 & 4.5949 & TST & \\
\hline CHEMBL 2004637 & 809136 & 6.1 & 5.7329 & TST & \\
\hline CHEMBL1993374 & 809136 & 4.5 & 4.1784 & TST & \\
\hline CHEMBL1994318 & 809136 & 5.6 & 4.988 & TST & \\
\hline CHEMBL 2006237 & 809136 & 4.9 & 4.68199 & 99999999995 & TST \\
\hline CHEMBL1999506 & 809136 & 4.5 & 4.5475 & TST & \\
\hline CHEMBL1967720 & 809136 & 8.1 & 7.4055 & TST & \\
\hline CHEMBL1572266 & 809136 & 4.9 & 4.7785 & TST & \\
\hline CHEMBL1991138 & 809136 & 6.0 & 4.8375 & TST & \\
\hline CHEMBL1979516 & 809136 & 7.9 & 6.8439 & TST & \\
\hline CHEMBL1605605 & 809136 & 4.5 & 4.5118 & TST & \\
\hline CHEMBL1989029 & 809136 & 7.6 & 5.9988 & TST & \\
\hline CHEMBL392642 & 809136 & 4.9 & 4.9279 & TST & \\
\hline CHEMBL1970352 & 809136 & 4.5 & 5.2111 & TST & \\
\hline CHEMBL1980144 & 809136 & 4.9 & 5.2127 & TST & \\
\hline CHEMBL1991188 & 809136 & 4.9 & 4.8105 & TST & \\
\hline CHEMBL1980167 & 809136 & 5.7 & 5.3181 & TST & \\
\hline CHEMBL1972849 & 809136 & 4.9 & 4.7513 & TST & \\
\hline CHEMBL215152 & 809136 & 4.5 & 5.7008 & TST & \\
\hline CHEMBL2006765 & 809136 & 6.0 & 5.8095 & TST & \\
\hline CHEMBL 259922 & 809136 & 4.9 & 4.5645 & TST & \\
\hline CHEMBL1997617 & 809136 & 6.5 & 7.0427 & TST & \\
\hline CHEMBL1982383 & 809136 & 4.9 & 5.2008 & TST & \\
\hline CHEMBL1969301 & 809136 & 4.9 & 6.1365 & TST & \\
\hline CHEMBL17370 & 809136 & 4.9 & 4.6286 & TST & \\
\hline CHEMBL1987910 & 809136 & 4.9 & 6.6566 & TST & \\
\hline CHEMBL1983932 & 809136 & 4.9 & 5.8878 & TST & \\
\hline CHEMBL1980246 & 809136 & 4.5 & 4.2837 & TST & \\
\hline CHEMBL1983980 & 809136 & 5.8 & 5.8059 & TST & \\
\hline CHEMBL1999484 & 809136 & 4.5 & 5.6446 & TST & \\
\hline CHEMBL1986899 & 809136 & 5.5 & 5.034 & TST & \\
\hline CHEMBL1991285 & 809136 & 4.9 & 5.2735 & TST & \\
\hline CHEMBL1984038 & 809136 & 4.6 & 4.9253 & TST & \\
\hline CHEMBL243088 & 809136 & 5.9 & 5.6765 & TST & \\
\hline CHEMBL1968606 & 809136 & 6.0 & 5.7285 & TST & \\
\hline CHEMBL1993661 & 809136 & 7.0 & 6.9786 & TST & \\
\hline
\end{tabular}




\begin{tabular}{|c|c|c|c|c|}
\hline \multicolumn{5}{|c|}{ Supplemental Table S2.txt } \\
\hline CHEMBL1974416 & 809136 & 7.0 & 7.0294 & TST \\
\hline CHEMBL1997872 & 809136 & 6.1 & 5.2503 & TST \\
\hline CHEMBL98917 & 458939 & 5.4 & 5.6794 & TST \\
\hline CHEMBL 329298 & 458939 & 7.0 & 7.2604 & TST \\
\hline CHEMBL 98017 & 458939 & 6.1 & 6.2526 & TRN \\
\hline CHEMBL318716 & 458939 & 6.1 & 6.1545 & TRN \\
\hline CHEMBL99189 & 458939 & 6.4 & 6.4107 & TRN \\
\hline CHEMBL329313 & 458939 & 7.52 & 7.2726 & TST \\
\hline CHEMBL99981 & 458939 & 6.52 & 6.2205 & TRN \\
\hline CHEMBL318455 & 458939 & 5.16 & 5.7884 & TRN \\
\hline CHEMBL95614 & 458939 & 5.7 & 5.4586 & TRN \\
\hline CHEMBL 318023 & 458939 & 5.0 & 5.4774 & TRN \\
\hline CHEMBL329287 & 458939 & 5.22 & 5.6131 & TRN \\
\hline CHEMBL97936 & 458939 & 7.3 & 6.8363 & TST \\
\hline CHEMBL100100 & 458939 & 8.15 & 6.8721 & TST \\
\hline CHEMBL328162 & 458939 & 7.22 & 7.1907 & TST \\
\hline CHEMBL 99148 & 458939 & 6.4 & 6.3447 & TRN \\
\hline CHEMBL98044 & 458939 & 6.7 & 6.0726 & TRN \\
\hline CHEMBL 316954 & 458939 & 7.22 & 6.5682 & TST \\
\hline CHEMBL318190 & 458939 & 6.4 & 6.8821 & TST \\
\hline CHEMBL97382 & 458939 & 5.7 & 6.0259 & TST \\
\hline CHEMBL 3827433 & 458939 & 6.2 & 5.3355 & TRN \\
\hline CHEMBL 3828077 & 458939 & 5.0 & 5.1583 & TRN \\
\hline CHEMBL 3827238 & 458939 & 6.25 & 5.9721 & TRN \\
\hline CHEMBL 3827117 & 458939 & 5.47 & 5.9514 & TRN \\
\hline CHEMBL3828712 & 458939 & 6.56 & 6.3963 & TRN \\
\hline CHEMBL 3827120 & 458939 & 6.32 & 5.8042 & TRN \\
\hline CHEMBL3828398 & 458939 & 6.39 & 5.8607 & TRN \\
\hline CHEMBL 3828753 & 458939 & 6.24 & 6.8552 & TRN \\
\hline CHEMBL3828059 & 458939 & 7.32 & 7.1464 & TRN \\
\hline CHEMBL 3827768 & 458939 & 7.14 & 7.285 & TRN \\
\hline CHEMBL 3827627 & 458939 & 7.68 & 7.0997 & TRN \\
\hline CHEMBL 3828521 & 458939 & 7.72 & 7.8627 & TRN \\
\hline CHEMBL 3827566 & 458939 & 8.17 & 7.8505 & TRN \\
\hline CHEMBL3827831 & 458939 & 8.36 & 8.3039 & TRN \\
\hline CHEMBL 3827521 & 458939 & 7.89 & 7.7841 & TRN \\
\hline CHEMBL 3828455 & 458939 & 7.32 & 7.8665 & TRN \\
\hline CHEMBL3827934 & 458939 & 7.6 & 7.2684 & TRN \\
\hline CHEMBL356413 & 458939 & 7.4 & 7.5102 & TRN \\
\hline CHEMBL3828007 & 458939 & 9.3 & 8.9044 & TRN \\
\hline CHEMBL 3828582 & 458939 & 6.11 & 6.8913 & TRN \\
\hline CHEMBL 3827212 & 458939 & 6.96 & 7.6162 & TRN \\
\hline CHEMBL3827764 & 458939 & 6.35 & 7.5185 & TRN \\
\hline CHEMBL 3827694 & 458939 & 8.23 & 8.255 & TRN \\
\hline CHEMBL3827107 & 458939 & 7.89 & 8.0661 & TRN \\
\hline CHEMBL 3827703 & 458939 & 8.42 & 7.8011 & TRN \\
\hline CHEMBL 3828566 & 458939 & 8.0 & 7.814 & TRN \\
\hline CHEMBL3828216 & 458939 & 8.14 & 7.8274 & TRN \\
\hline
\end{tabular}




\begin{tabular}{|c|c|c|c|c|c|}
\hline \multicolumn{6}{|c|}{ Supplemental Table S2.txt } \\
\hline CHEMBL 3828314 & 458939 & 8.06 & 8.1167 & TRN & \\
\hline CHEMBL 3827249 & 458939 & 8.59 & 8.1465 & TRN & \\
\hline CHEMBL3828305 & 458939 & 6.92 & 7.2649 & TRN & \\
\hline CHEMBL 3828041 & 458939 & 7.59 & 7.8701 & TRN & \\
\hline CHEMBL140970 & 458939 & 9.15 & 8.5189 & TRN & \\
\hline CHEMBL140569 & 458939 & 7.96 & 7.8984 & TRN & \\
\hline CHEMBL344828 & 458939 & 7.77 & 8.0386 & TRN & \\
\hline CHEMBL343082 & 458939 & 7.6 & 7.7176 & TRN & \\
\hline CHEMBL140720 & 458939 & 7.34 & 7.7943 & TST & \\
\hline CHEMBL436205 & 458939 & 8.57 & 7.6629 & TST & \\
\hline CHEMBL139884 & 458939 & 8.18 & 7.8167 & TST & \\
\hline CHEMBL139886 & 458939 & 7.06 & 8.5093 & TST & \\
\hline CHEMBL334909 & 458939 & 7.05 & 7.9583 & TST & \\
\hline CHEMBL140511 & 458939 & 8.0 & 8.1407 & TST & \\
\hline CHEMBL342210 & 458939 & 8.16 & 8.3149 & TST & \\
\hline CHEMBL1683135 & 728289 & 5.5086 & 4.1535 & TST & \\
\hline CHEMBL1682982 & 728289 & 4.5528 & 4.553 & TRN & \\
\hline CHEMBL1683102 & 728289 & 4.1192 & 4.1187 & TRN & \\
\hline CHEMBL1682980 & 728289 & 3.0 & 3.0001 & TRN & \\
\hline CHEMBL1683130 & 728289 & 4.2291 & 4.2285 & TRN & \\
\hline CHEMBL1683128 & 728289 & 4.3665 & 4.3672 & TRN & \\
\hline CHEMBL25211 & 728289 & 5.8539 & 4.6703 & TST & \\
\hline CHEMBL1683087 & 728289 & 3.0 & 2.9997 & TRN & \\
\hline CHEMBL1683086 & 728289 & 3.0 & 2.9999 & TRN & \\
\hline CHEMBL1683139 & 728289 & 4.6198 & 4.6198 & TRN & \\
\hline CHEMBL1682979 & 728289 & 4.2147 & 4.2153 & TRN & \\
\hline CHEMBL1683136 & 728289 & 5.1427 & 5.1429 & TRN & \\
\hline CHEMBL1683105 & 728289 & 4.9208 & 4.921 & TRN & \\
\hline CHEMBL1683116 & 728289 & 6.0 & 4.6488 & TST & \\
\hline CHEMBL1683144 & 728289 & 4.6383 & 3.4553 & TST & \\
\hline CHEMBL1683122 & 728289 & 4.4437 & 3.5749 & TST & \\
\hline CHEMBL1683110 & 728289 & 3.0 & 3.0006 & TRN & \\
\hline CHEMBL1682976 & 728289 & 4.5686 & 4.5684 & TRN & \\
\hline CHEMBL1683089 & 728289 & 4.4089 & 3.9227 & TST & \\
\hline CHEMBL1683138 & 728289 & 4.5686 & 4.5682 & TRN & \\
\hline CHEMBL1683143 & 728289 & 4.5528 & 3.6536 & TST & \\
\hline CHEMBL1683090 & 728289 & 4.2441 & 4.2441 & TRN & \\
\hline CHEMBL1683097 & 728289 & 3.0 & 2.9999 & TRN & \\
\hline CHEMBL1683140 & 728289 & 4.7959 & 4.7954 & TRN & \\
\hline CHEMBL1683134 & 728289 & 4.7447 & 4.7448 & TRN & \\
\hline CHEMBL1683145 & 728289 & 4.7212 & 3.53800 & 00000000003 & TST \\
\hline CHEMBL1682975 & 728289 & 4.2076 & 4.2072 & TRN & \\
\hline CHEMBL1683095 & 728289 & 4.0706 & 4.0719 & TRN & \\
\hline CHEMBL1683101 & 728289 & 4.7959 & 4.7959 & TRN & \\
\hline CHEMBL1683109 & 728289 & 4.5229 & 4.5231 & TRN & \\
\hline CHEMBL1683093 & 728289 & 4.2924 & 4.2939 & TRN & \\
\hline CHEMBL1683123 & 728289 & 4.4318 & 4.1422 & TST & \\
\hline CHEMBL1683133 & 728289 & 5.3768 & 5.37700 & 3000000001 & TRN \\
\hline & & & & 737 & \\
\hline
\end{tabular}


Supplemental Table S2.txt

\begin{tabular}{|c|c|c|c|c|c|}
\hline CHEMBL1683096 & 728289 & 4.2596 & 4.2592 & TRN & \\
\hline CHEMBL1683141 & 728289 & 4.6383 & 4.6385 & TRN & \\
\hline CHEMBL1682981 & 728289 & 4.5086 & 4.50899 & 99999999995 & TRN \\
\hline CHEMBL1683092 & 728289 & 4.1938 & 4.1931 & TRN & \\
\hline CHEMBL1682978 & 728289 & 4.5229 & 4.5232 & TRN & \\
\hline CHEMBL1683125 & 728289 & 5.0 & 5.0005 & TRN & \\
\hline CHEMBL1682977 & 728289 & 4.3279 & 4.3273 & TRN & \\
\hline CHEMBL1683142 & 728289 & 4.9208 & 4.6111 & TST & \\
\hline CHEMBL1683103 & 728289 & 3.0 & 3.0 & TRN & \\
\hline CHEMBL1682974 & 728289 & 6.2441 & 4.2305 & TST & \\
\hline CHEMBL1683131 & 728289 & 4.7212 & 4.8398 & TST & \\
\hline CHEMBL1683091 & 728289 & 3.0 & 2.9995 & TRN & \\
\hline CHEMBL1683107 & 728289 & 4.4949 & 4.4487 & TST & \\
\hline CHEMBL1683132 & 728289 & 4.7959 & 4.8557 & TST & \\
\hline CHEMBL1683108 & 728289 & 4.8861 & 4.8859 & TRN & \\
\hline CHEMBL1683104 & 728289 & 4.2924 & 4.2926 & TRN & \\
\hline CHEMBL1683098 & 728289 & 6.0 & 5.9999 & TRN & \\
\hline CHEMBL1683137 & 728289 & 4.6021 & 4.09699 & 99999999995 & TST \\
\hline CHEMBL1682983 & 728289 & 4.4949 & 4.4952 & TRN & \\
\hline CHEMBL1683129 & 728289 & 3.0 & 3.0005 & TRN & \\
\hline CHEMBL1683088 & 728289 & 3.0 & 3.0003 & TRN & \\
\hline CHEMBL1683094 & 728289 & 3.0 & 2.9995 & TRN & \\
\hline CHEMBL1683100 & 728289 & 4.2757 & 4.2753 & TRN & \\
\hline CHEMBL1683112 & 728289 & 3.0 & 2.9999 & TRN & \\
\hline CHEMBL1683111 & 728289 & 4.0655 & 4.065 & TRN & \\
\hline CHEMBL1683106 & 728289 & 4.0915 & 4.0915 & TRN & \\
\hline CHEMBL1683124 & 728289 & 4.3468 & 4.4564 & TST & \\
\hline CHEMBL1683126 & 728289 & 4.8239 & 4.8236 & TRN & \\
\hline CHEMBL1682985 & 728289 & 4.7959 & 4.7954 & TRN & \\
\hline CHEMBL1683127 & 728289 & 4.7696 & 4.7688 & TRN & \\
\hline CHEMBL1682984 & 728289 & 4.6198 & 4.6197 & TRN & \\
\hline CHEMBL3932189 & 1637183 & 4.0 & 4.8517 & TRN & \\
\hline CHEMBL 3948746 & 1637183 & 7.0 & 6.1694 & TRN & \\
\hline CHEMBL3902748 & 1637183 & 4.0 & 5.9052 & TRN & \\
\hline CHEMBL3903845 & 1637183 & 7.0 & 7.8673 & TST & \\
\hline CHEMBL3900636 & 1637183 & 7.0 & 7.7514 & TRN & \\
\hline CHEMBL3902969 & 1637183 & 4.0 & 6.0945 & TST & \\
\hline CHEMBL3939431 & 1637183 & 6.0 & 6.2674 & TST & \\
\hline CHEMBL3970856 & 1637183 & 7.0 & 5.7088 & TRN & \\
\hline CHEMBL3900284 & 1637183 & 8.0 & 8.4019 & TRN & \\
\hline CHEMBL3977241 & 1637183 & 7.0 & 7.0834 & TRN & \\
\hline CHEMBL3940705 & 1637183 & 10.0 & 8.6602 & TRN & \\
\hline CHEMBL3902597 & 1637183 & 6.0 & 5.6304 & TST & \\
\hline CHEMBL3899006 & 1637183 & 4.0 & 5.0277 & TRN & \\
\hline CHEMBL3923718 & 1637183 & 7.0 & 6.7198 & TST & \\
\hline CHEMBL3966719 & 1637183 & 4.0 & 5.5469 & TRN & \\
\hline CHEMBL1923608 & 1637183 & 8.0 & 8.1164 & TRN & \\
\hline CHEMBL3977037 & 1637183 & 4.0 & 5.0039 & TST & \\
\hline
\end{tabular}




\begin{tabular}{|c|c|c|c|c|c|}
\hline & & & & & \\
\hline CHEMBL3967783 & 1637183 & 6.0 & 6.432 & TRN & \\
\hline CHEMBL1923631 & 1637183 & 6.0 & 5.8817 & TRN & \\
\hline CHEMBL3923324 & 1637183 & 7.0 & 7.1632 & TRN & \\
\hline CHEMBL3965516 & 1637183 & 7.0 & 7.5194 & TST & \\
\hline CHEMBL3905987 & 1637183 & 7.0 & 5.9091 & TRN & \\
\hline CHEMBL 3895776 & 1637183 & 10.0 & 8.1113 & TRN & \\
\hline CHEMBL3963523 & 1637183 & 7.0 & 5.7514 & TST & \\
\hline CHEMBL3935626 & 1637183 & 7.0 & 6.52 & TRN & \\
\hline CHEMBL3945280 & 1637183 & 5.0 & 6.1945 & TRN & \\
\hline CHEMBL3918046 & 1637183 & 10.0 & 7.9808 & TRN & \\
\hline CHEMBL 3942610 & 1637183 & 7.0 & 6.1088 & TRN & \\
\hline CHEMBL3934402 & 1637183 & 6.0 & 7.3287 & TRN & \\
\hline CHEMBL 2203623 & 1637183 & 6.0 & 6.5308 & TRN & \\
\hline CHEMBL3928367 & 1637183 & 7.0 & 7.6552 & TRN & \\
\hline CHEMBL3891657 & 1637183 & 7.0 & 6.5448 & TST & \\
\hline CHEMBL 3892517 & 1637183 & 7.0 & 5.4772 & TRN & \\
\hline CHEMBL3890339 & 1637183 & 4.0 & 6.0872 & TRN & \\
\hline CHEMBL3929852 & 1637183 & 8.0 & 8.0319 & TST & \\
\hline CHEMBL3900035 & 1637183 & 7.0 & 6.1694 & TRN & \\
\hline CHEMBL1923643 & 1637183 & 8.0 & 7.6569 & TRN & \\
\hline CHEMBL1923634 & 1637183 & 7.0 & 7.5183 & TRN & \\
\hline CHEMBL3935422 & 1637183 & 7.0 & 6.5202 & TRN & \\
\hline CHEMBL3890602 & 1637183 & 8.0 & 7.4905 & TRN & \\
\hline CHEMBL3979468 & 1637183 & 8.0 & 9.1492 & TST & \\
\hline CHEMBL3959346 & 1637183 & 6.0 & 6.3665 & TST & \\
\hline CHEMBL 3932144 & 1637183 & 4.0 & 5.5161 & TRN & \\
\hline CHEMBL1923609 & 1637183 & 10.0 & 8.5024 & TRN & \\
\hline CHEMBL1923509 & 1637183 & 4.0 & 6.1466 & TST & \\
\hline CHEMBL3935364 & 1637183 & 4.0 & 4.8203 & TST & \\
\hline CHEMBL 3932434 & 1637183 & 8.0 & 6.6848 & TRN & \\
\hline CHEMBL1923513 & 1637183 & 4.0 & 6.4315 & TST & \\
\hline CHEMBL 3942528 & 1637183 & 8.0 & 7.66299 & 9999999999 & TRN \\
\hline CHEMBL1923623 & 1637183 & 10.0 & 8.9377 & TRN & \\
\hline CHEMBL3937200 & 1637183 & 8.0 & 7.1416 & TRN & \\
\hline CHEMBL3913052 & 1637183 & 8.0 & 6.4 & TRN & \\
\hline CHEMBL 3898348 & 1637183 & 8.0 & 8.2083 & TRN & \\
\hline CHEMBL3986375 & 1637183 & 8.0 & 7.9543 & TRN & \\
\hline CHEMBL 3973940 & 1637183 & 7.0 & 6.5708 & TRN & \\
\hline CHEMBL 3983985 & 1637183 & 4.0 & 5.7942 & TST & \\
\hline CHEMBL3975170 & 1637183 & 4.0 & 6.062 & TRN & \\
\hline CHEMBL3973513 & 1637183 & 10.0 & 8.9552 & TRN & \\
\hline CHEMBL3943294 & 1637183 & 8.0 & 7.7204 & TRN & \\
\hline CHEMBL3905129 & 1637183 & 4.0 & 6.1027 & TRN & \\
\hline CHEMBL3967266 & 1637183 & 6.0 & 6.4935 & TRN & \\
\hline CHEMBL3931716 & 1637183 & 7.0 & 8.0968 & TRN & \\
\hline CHEMBL 3932408 & 1637183 & 8.0 & 7.6432 & TRN & \\
\hline CHEMBL1923612 & 1637183 & 7.8861 & 7.4392 & TRN & \\
\hline CHEMBL 3968175 & 1637183 & 8.0 & 8.1307 & TRN & \\
\hline
\end{tabular}




\begin{tabular}{|c|c|c|c|c|c|}
\hline \\
\hline CHEMBL3891381 & 1637183 & 8.0 & 8.9065 & & \\
\hline CHEMBL3970499 & 1637183 & 7.0 & 6.2394 & TRN & \\
\hline CHEMBL3910661 & 1637183 & 7.0 & 6.0646 & TRN & \\
\hline CHEMBL3923633 & 1637183 & 6.0 & 7.0824 & TRN & \\
\hline CHEMBL 3952596 & 1637183 & 6.0 & 6.6276 & TRN & \\
\hline CHEMBL3920711 & 1637183 & 6.0 & 6.5436 & TRN & \\
\hline CHEMBL1923636 & 1637183 & 8.0 & 6.6197 & TRN & \\
\hline CHEMBL 3912211 & 1637183 & 6.0 & 7.1179 & TST & \\
\hline CHEMBL 3970827 & 1637183 & 6.0 & 8.9844 & TST & \\
\hline CHEMBL3922810 & 1637183 & 8.0 & 8.0779 & TRN & \\
\hline CHEMBL3907497 & 1637183 & 10.0 & 9.5638 & TRN & \\
\hline CHEMBL3979911 & 1637183 & 8.0 & 8.4367 & TST & \\
\hline CHEMBL3909838 & 1637183 & 8.0 & 7.6174 & TRN & \\
\hline CHEMBL3918009 & 1637183 & 10.0 & 9.3752 & TRN & \\
\hline CHEMBL 3909834 & 1637183 & 8.0 & 8.1546 & TRN & \\
\hline CHEMBL3939872 & 1637183 & 10.0 & 8.317 & TRN & \\
\hline CHEMBL3921499 & 1637183 & 8.0 & 7.9065 & TRN & \\
\hline CHEMBL3912034 & 1637183 & 7.0 & 8.035 & TRN & \\
\hline CHEMBL 3943228 & 1637183 & 7.0 & 5.6194 & TRN & \\
\hline CHEMBL3954394 & 1637183 & 7.0 & 6.5654 & TRN & \\
\hline CHEMBL3976941 & 1637183 & 6.0 & 5.4644 & TST & \\
\hline CHEMBL 3918022 & 1637183 & 7.0 & 7.1747 & TRN & \\
\hline CHEMBL3930400 & 1637183 & 6.0 & 5.7435 & TRN & \\
\hline CHEMBL1923625 & 1637183 & 10.0 & 8.276 & TRN & \\
\hline CHEMBL3947758 & 1637183 & 7.0 & 8.1459 & TRN & \\
\hline CHEMBL3982825 & 1637183 & 8.0 & 7.7586 & TRN & \\
\hline CHEMBL 3892319 & 1637183 & 7.0 & 7.044 & TRN & \\
\hline CHEMBL3924192 & 1637183 & 8.0 & 7.8105 & TRN & \\
\hline CHEMBL3915269 & 1637183 & 10.0 & 8.2032 & TRN & \\
\hline CHEMBL3916659 & 1637183 & 6.0 & 7.2482 & TRN & \\
\hline CHEMBL3974802 & 1637183 & 4.0 & 5.9174 & TRN & \\
\hline CHEMBL 3970180 & 1637183 & 6.0 & 6.7083 & TRN & \\
\hline CHEMBL3974776 & 1637183 & 6.0 & 6.8233 & TST & \\
\hline CHEMBL3971837 & 1637183 & 4.0 & 5.322 & TRN & \\
\hline CHEMBL3977294 & 1637183 & 7.0 & 6.5218 & TRN & \\
\hline CHEMBL3947631 & 1637183 & 4.0 & 6.3521 & TRN & \\
\hline CHEMBL3931402 & 1637183 & 7.0 & 9.0304 & TRN & \\
\hline CHEMBL3953053 & 1637183 & 8.0 & 7.5274 & TRN & \\
\hline CHEMBL 3978661 & 1637183 & 7.0 & 8.0625 & TRN & \\
\hline CHEMBL3902856 & 1637183 & 8.0 & 6.329 & TRN & \\
\hline CHEMBL3970491 & 1637183 & 7.0 & 7.7086 & TRN & \\
\hline CHEMBL3961696 & 1637183 & 7.0 & 4.7763 & TRN & \\
\hline CHEMBL3981843 & 1637183 & 7.0 & $6.2070 e$ & 0000000001 & TRN \\
\hline CHEMBL 3958451 & 1637183 & 8.0 & 6.593 & TRN & \\
\hline CHEMBL3919021 & 1637183 & 8.0 & 8.7126 & TRN & \\
\hline CHEMBL3893850 & 1637183 & 7.0 & 7.0654 & TRN & \\
\hline CHEMBL3916727 & 1637183 & 4.0 & 6.3333 & TRN & \\
\hline CHEMBL3959108 & 1637183 & 8.0 & 7.7719 & TST & \\
\hline
\end{tabular}




\begin{tabular}{|c|c|c|c|c|c|}
\hline \multicolumn{6}{|c|}{ Supplemental Table S2.txt } \\
\hline CHEMBL3933573 & 1637183 & 4.0 & 5.5015 & TRN & \\
\hline CHEMBL3913855 & 1637183 & 10.0 & 8.0044 & TST & \\
\hline CHEMBL3934443 & 1637183 & 4.0 & 6.0359 & TRN & \\
\hline CHEMBL3905495 & 1637183 & 6.0 & 6.0549 & TRN & \\
\hline CHEMBL1923637 & 1637183 & 10.0 & 7.2286 & TRN & \\
\hline CHEMBL3922905 & 1637183 & 4.0 & 5.8044 & TST & \\
\hline CHEMBL3955064 & 1637183 & 4.0 & 5.1612 & TST & \\
\hline CHEMBL3979436 & 1637183 & 4.0 & 5.9077 & TRN & \\
\hline CHEMBL3957703 & 1637183 & 4.0 & 5.9313 & TST & \\
\hline CHEMBL3934854 & 1637183 & 4.0 & 5.7059 & TST & \\
\hline CHEMBL3940860 & 1637183 & 7.0 & 6.8653 & TRN & \\
\hline CHEMBL3985477 & 1637183 & 7.0 & 7.7229 & TRN & \\
\hline CHEMBL3908989 & 1637183 & 4.0 & 4.1956 & TRN & \\
\hline CHEMBL3912534 & 1637183 & 7.0 & 6.7122 & TRN & \\
\hline CHEMBL3918512 & 1637183 & 4.0 & 7.5917 & TST & \\
\hline CHEMBL3894559 & 1637183 & 4.0 & 5.3076 & TST & \\
\hline CHEMBL3918996 & 1637183 & 5.0 & 5.3768 & TRN & \\
\hline CHEMBL3977166 & 1637183 & 6.0 & 7.3644 & TRN & \\
\hline CHEMBL3931856 & 1637183 & $6.7520 e$ & 300000006 & 6.4021 & TRN \\
\hline CHEMBL3958460 & 1637183 & 8.0 & 8.2346 & TRN & \\
\hline CHEMBL3903118 & 1637183 & 10.0 & 10.3778 & TRN & \\
\hline CHEMBL3902231 & 1637183 & 6.0 & 6.3367 & TRN & \\
\hline CHEMBL3945310 & 1637183 & 5.0 & 6.1892 & TRN & \\
\hline CHEMBL3934901 & 1637183 & 7.0 & 5.5506 & TRN & \\
\hline CHEMBL 3898794 & 1637183 & 10.0 & 10.1155 & TRN & \\
\hline CHEMBL3914467 & 1637183 & 6.0 & 7.8328 & TRN & \\
\hline CHEMBL3939993 & 1637183 & 7.0 & 6.74100 & 00000000005 & TRN \\
\hline CHEMBL1923638 & 1637183 & 8.0 & 7.8397 & TRN & \\
\hline CHEMBL3974362 & 1637183 & 4.0 & 5.41 & TRN & \\
\hline CHEMBL 3910288 & 1637183 & 7.0 & 7.483 & TRN & \\
\hline CHEMBL3924187 & 1637183 & 6.0 & 7.8174 & TST & \\
\hline CHEMBL1923617 & 1637183 & 9.4685 & 9.9259 & TRN & \\
\hline CHEMBL1923642 & 1637183 & 10.0 & 7.7727 & TRN & \\
\hline CHEMBL3961641 & 1637183 & 7.0 & 6.4782 & TRN & \\
\hline CHEMBL3908583 & 1637183 & 7.0 & 6.5965 & TRN & \\
\hline CHEMBL3897510 & 1637183 & 8.0 & 7.5107 & TRN & \\
\hline CHEMBL3970414 & 1637183 & 6.0 & 6.5913 & TRN & \\
\hline CHEMBL3930905 & 1637183 & 4.0 & 6.6391 & TST & \\
\hline CHEMBL1923514 & 1637183 & 4.0 & 5.4558 & TST & \\
\hline CHEMBL3913763 & 1637183 & 8.0 & 7.9402 & TRN & \\
\hline CHEMBL1923511 & 1637183 & 7.0 & 6.5635 & TST & \\
\hline CHEMBL3961157 & 1637183 & 6.0 & 6.1694 & TRN & \\
\hline CHEMBL3917385 & 1637183 & 6.0 & 7.8713 & TRN & \\
\hline CHEMBL3984338 & 1637183 & 10.0 & 9.0694 & TRN & \\
\hline CHEMBL1923512 & 1637183 & 7.0 & 6.8521 & TST & \\
\hline CHEMBL3929656 & 1637183 & 7.0 & 7.3424 & TRN & \\
\hline CHEMBL1923610 & 1637183 & 10.0 & 9.0178 & TRN & \\
\hline CHEMBL3935670 & 1637183 & 10.0 & 8.1494 & TRN & \\
\hline
\end{tabular}




\begin{tabular}{|c|c|c|c|c|c|}
\hline & & & & & \\
\hline CHEMBL3974701 & 1637183 & 8.0 & 8.4984 & TRN & \\
\hline CHEMBL3986628 & 1637183 & 8.0 & 8.2928 & TRN & \\
\hline CHEMBL1923508 & 1637183 & 6.0 & 6.6632 & TST & \\
\hline CHEMBL3938683 & 1637183 & 8.0 & 7.688 & TRN & \\
\hline CHEMBL 3905791 & 1637183 & 10.0 & 10.3902 & TRN & \\
\hline CHEMBL3913130 & 1637183 & 4.0 & 7.2054 & TST & \\
\hline CHEMBL3893476 & 1637183 & 8.0 & 6.9394 & TRN & \\
\hline CHEMBL3979606 & 1637183 & 7.0 & 6.63299 & 9999999999 & TRN \\
\hline CHEMBL3934367 & 1637183 & 10.0 & 9.776 & TRN & \\
\hline CHEMBL3980873 & 1637183 & 7.0 & 6.1806 & TRN & \\
\hline CHEMBL1923507 & 1637183 & 4.0 & 7.0013 & TST & \\
\hline CHEMBL3980276 & 1637183 & 7.0 & 6.9305 & TRN & \\
\hline CHEMBL3971845 & 1637183 & 7.0 & 5.8567 & TRN & \\
\hline CHEMBL1923635 & 1637183 & 8.0 & 6.5194 & TRN & \\
\hline CHEMBL 3966251 & 1637183 & 7.0 & 7.7034 & TRN & \\
\hline CHEMBL3958739 & 1637183 & 7.0 & 7.3447 & TRN & \\
\hline CHEMBL3920479 & 1637183 & 6.0 & 5.5384 & TRN & \\
\hline CHEMBL3903351 & 1637183 & 7.0 & 6.3436 & TRN & \\
\hline CHEMBL3930882 & 1637183 & 4.0 & 6.6243 & TST & \\
\hline CHEMBL3983626 & 1637183 & 8.0 & 6.7269 & TST & \\
\hline CHEMBL3909702 & 1637183 & 4.0 & 6.5061 & TST & \\
\hline CHEMBL3952699 & 1637183 & 8.0 & 7.5656 & TRN & \\
\hline CHEMBL1923510 & 1637183 & 7.0 & 7.4472 & TST & \\
\hline CHEMBL3983297 & 1637183 & 5.0 & 5.9957 & TRN & \\
\hline CHEMBL3922056 & 1637183 & 10.0 & 7.8756 & TRN & \\
\hline CHEMBL3951110 & 1637183 & 7.0 & 6.2069 & TRN & \\
\hline CHEMBL3936957 & 1637183 & 7.0 & 6.3798 & TRN & \\
\hline CHEMBL3974323 & 1637183 & 6.0 & 5.5601 & TST & \\
\hline CHEMBL3955632 & 1637183 & 6.0 & 7.8445 & TRN & \\
\hline CHEMBL 3949023 & 1637183 & 7.0 & 8.1209 & TRN & \\
\hline CHEMBL3961160 & 1637183 & 7.0 & 7.516 & TRN & \\
\hline CHEMBL1923613 & 1637183 & 6.0 & 6.1468 & TRN & \\
\hline CHEMBL3937924 & 1637183 & 8.0 & 5.8503 & TRN & \\
\hline CHEMBL 3893048 & 1637183 & 10.0 & 9.5717 & TRN & \\
\hline CHEMBL 3918783 & 1637183 & 7.1739 & 6.7696 & TST & \\
\hline CHEMBL3963865 & 1637183 & 8.0 & 7.5534 & TRN & \\
\hline CHEMBL 3934561 & 1637183 & 6.9706 & 7.0046 & TST & \\
\hline CHEMBL3907891 & 1637183 & 6.0 & 7.4392 & TRN & \\
\hline CHEMBL1923624 & 1637183 & 8.0 & 8.9413 & TRN & \\
\hline CHEMBL3949653 & 1637183 & 6.0 & 6.2477 & TRN & \\
\hline CHEMBL3908156 & 1637183 & 7.0 & 6.5284 & TRN & \\
\hline CHEMBL3900193 & 1637183 & 6.0 & 7.4818 & TST & \\
\hline CHEMBL 3942543 & 1637183 & 7.0 & 6.0392 & TRN & \\
\hline CHEMBL3959816 & 1637183 & 10.0 & 9.709 & TRN & \\
\hline CHEMBL 3912375 & 1637183 & 8.0 & 8.1591 & TRN & \\
\hline CHEMBL 3907480 & 1637183 & 7.0 & 6.79 & TRN & \\
\hline CHEMBL 3923508 & 1637183 & 6.0 & 6.59399 & 9999999999 & TST \\
\hline CHEMBL 3955179 & 1637183 & 10.0 & 8.0763 & TRN & \\
\hline
\end{tabular}




\begin{tabular}{|c|c|c|c|c|}
\hline \multicolumn{5}{|c|}{ Supplemental Table S2.txt } \\
\hline CHEMBL3945918 & 1637183 & 7.0 & 5.8949 & TRN \\
\hline CHEMBL3900122 & 1637183 & 7.0 & 8.0161 & TRN \\
\hline CHEMBL3981235 & 1637183 & 6.0 & 5.9707 & TRN \\
\hline CHEMBL3965338 & 1637183 & 7.0 & 6.7994 & TST \\
\hline CHEMBL1923626 & 1637183 & 10.0 & 8.6588 & TRN \\
\hline CHEMBL1923633 & 1637183 & 7.0 & 6.4572 & TRN \\
\hline CHEMBL3951476 & 1637183 & 8.0 & 8.0167 & TRN \\
\hline CHEMBL3978864 & 1637183 & 7.0 & 7.8047 & TRN \\
\hline CHEMBL 3910300 & 1637183 & 10.0 & 9.4516 & TRN \\
\hline CHEMBL3930811 & 1637183 & 7.0 & 6.3947 & TRN \\
\hline CHEMBL3985913 & 1637183 & 6.0 & 6.0928 & TRN \\
\hline CHEMBL3942554 & 1637183 & 7.0 & 6.2112 & TRN \\
\hline CHEMBL3899825 & 1637183 & 6.0 & 5.5852 & TRN \\
\hline CHEMBL 3960463 & 1637183 & 5.301 & 6.1141 & TRN \\
\hline CHEMBL3889672 & 1637183 & 7.0 & 7.0306 & TRN \\
\hline CHEMBL3938104 & 1637183 & 8.0 & 7.6493 & TRN \\
\hline CHEMBL3969191 & 1637183 & 4.0 & 5.5004 & TST \\
\hline CHEMBL3934093 & 1637183 & 7.0 & 5.8984 & TST \\
\hline CHEMBL 3938452 & 1637183 & 8.0 & 6.7563 & TRN \\
\hline CHEMBL3939196 & 1637183 & 7.0 & 5.9944 & TST \\
\hline CHEMBL3942642 & 1637183 & 7.0 & 6.5522 & TRN \\
\hline CHEMBL3973085 & 1637183 & 6.0 & 8.1119 & TRN \\
\hline CHEMBL3963078 & 1637183 & 7.0 & 6.6627 & TRN \\
\hline CHEMBL3913335 & 1637183 & 8.0 & 6.7749 & TRN \\
\hline CHEMBL3921227 & 1637183 & 7.0 & 8.0271 & TRN \\
\hline CHEMBL3976294 & 1637183 & 8.0 & 8.698 & TRN \\
\hline CHEMBL3905641 & 1637183 & 4.0 & 5.9523 & TRN \\
\hline CHEMBL3923467 & 1637183 & 6.0 & 4.7522 & TRN \\
\hline CHEMBL3945984 & 1637183 & 7.0 & 6.5381 & TRN \\
\hline CHEMBL3938132 & 1637183 & 7.0 & 7.195 & TRN \\
\hline CHEMBL3936664 & 1637183 & 6.0 & 6.8329 & TRN \\
\hline CHEMBL3913486 & 1637183 & 7.0 & 6.1775 & TRN \\
\hline CHEMBL3951362 & 1637183 & 7.0 & 6.1694 & TRN \\
\hline CHEMBL 3928050 & 1637183 & 5.0 & 6.393 & TRN \\
\hline CHEMBL3891793 & 1637183 & 4.0 & 4.9037 & TST \\
\hline CHEMBL3921493 & 1637183 & 6.0 & 7.4647 & TRN \\
\hline CHEMBL3889512 & 1637183 & 8.0 & 7.7633 & TRN \\
\hline CHEMBL3920156 & 1637183 & 6.0 & 6.5155 & TST \\
\hline CHEMBL 3920049 & 1637183 & 10.0 & 10.2005 & TRN \\
\hline CHEMBL3917416 & 1637183 & 4.0 & 5.7872 & TRN \\
\hline CHEMBL3897387 & 1637183 & 7.0 & 7.6883 & TRN \\
\hline CHEMBL3981072 & 1637183 & 7.0 & 6.3657 & TRN \\
\hline CHEMBL3927481 & 1637183 & 8.0 & 6.6097 & TRN \\
\hline CHEMBL 3981238 & 1637183 & 8.0 & 8.4642 & TRN \\
\hline CHEMBL3897527 & 1637183 & 6.0 & 6.6043 & TRN \\
\hline CHEMBL3969506 & 1637183 & 6.0 & 6.3062 & TRN \\
\hline CHEMBL3940922 & 1637183 & 5.0 & 6.1703 & TRN \\
\hline CHEMBL3948472 & 1637183 & 6.0 & 6.3031 & TRN \\
\hline
\end{tabular}




\begin{tabular}{|c|c|c|c|c|c|}
\hline & & & & & \\
\hline CHEMBL3951593 & 1637183 & 7.0 & 6.4036 & TRN & \\
\hline CHEMBL3902804 & 1637183 & 7.0 & 6.3637 & TRN & \\
\hline CHEMBL3890889 & 1637183 & 8.0 & 6.4721 & TRN & \\
\hline CHEMBL3950904 & 1637183 & 6.0 & 6.403 & TST & \\
\hline CHEMBL3965402 & 1637183 & 6.0 & 7.67200 & 0000000001 & TST \\
\hline CHEMBL3926231 & 1637183 & 4.0 & 5.1281 & TST & \\
\hline CHEMBL3973254 & 1637183 & 7.0 & 6.3068 & TRN & \\
\hline CHEMBL3942846 & 1637183 & 5.0 & 6.2208 & TST & \\
\hline CHEMBL3975975 & 1637183 & 8.0 & 8.7451 & TRN & \\
\hline CHEMBL3919224 & 1637183 & 4.0 & 5.2431 & TST & \\
\hline CHEMBL3921750 & 1637183 & 8.0 & 9.1686 & TRN & \\
\hline CHEMBL3913981 & 1637183 & 7.0 & 7.4635 & TST & \\
\hline CHEMBL3916501 & 1637183 & 7.0 & 7.8198 & TRN & \\
\hline CHEMBL3908264 & 1637183 & 6.0 & 7.1662 & TRN & \\
\hline CHEMBL1923616 & 1637183 & 8.0 & 8.117 & TRN & \\
\hline CHEMBL1923607 & 1637183 & 4.0 & 6.2405 & TST & \\
\hline CHEMBL3961108 & 1637183 & 10.0 & 6.6849 & TST & \\
\hline CHEMBL3971540 & 1637183 & 8.0 & 5.9214 & TST & \\
\hline CHEMBL3966625 & 1637183 & 4.0 & 5.3588 & TST & \\
\hline CHEMBL3978455 & 1637183 & 6.0 & 7.8303 & TST & \\
\hline CHEMBL3896536 & 1637183 & 8.0 & 6.3644 & TST & \\
\hline CHEMBL3948268 & 1637183 & 8.0 & 7.0728 & TST & \\
\hline CHEMBL3909498 & 1637183 & 4.0 & 6.6003 & TST & \\
\hline CHEMBL3893697 & 1637183 & 8.0 & 7.4146 & TST & \\
\hline CHEMBL3953033 & 1637183 & 8.0 & 7.4677 & TST & \\
\hline CHEMBL3953467 & 1637183 & 4.0 & 4.8268 & TST & \\
\hline CHEMBL3937314 & 1637183 & 7.0 & 6.079 & TST & \\
\hline CHEMBL3934184 & 1637183 & 7.0 & 6.4181 & TST & \\
\hline CHEMBL3978207 & 1637183 & 8.0 & 6.3259 & TST & \\
\hline CHEMBL483397 & 537187 & 8.0458 & 8.64299 & 9999999999 & TRN \\
\hline CHEMBL458797 & 537187 & 7.2291 & 7.0395 & TRN & \\
\hline CHEMBL485232 & 537187 & 8.301 & 9.0554 & TRN & \\
\hline CHEMBL483764 & 537187 & 7.8539 & 7.5268 & TRN & \\
\hline CHEMBL485564 & 537187 & 7.3979 & 7.7409 & TRN & \\
\hline CHEMBL485607 & 537187 & 8.5229 & 7.2546 & TRN & \\
\hline CHEMBL521484 & 537187 & 5.3468 & 6.1403 & TRN & \\
\hline CHEMBL523633 & 537187 & 8.301 & 7.8348 & TRN & \\
\hline CHEMBL485399 & 537187 & 4.0 & 5.9991 & TRN & \\
\hline CHEMBL516958 & 537187 & 8.0969 & 7.2382 & TRN & \\
\hline CHEMBL489266 & 537187 & 6.1612 & 6.9963 & TRN & \\
\hline CHEMBL519183 & 537187 & 5.3468 & 6.7467 & TRN & \\
\hline CHEMBL485565 & 537187 & 8.0 & 7.9091 & TRN & \\
\hline CHEMBL461029 & 537187 & 7.1192 & 6.8803 & TST & \\
\hline CHEMBL483763 & 537187 & 8.0458 & 7.1914 & TRN & \\
\hline CHEMBL522085 & 537187 & 7.0506 & 7.0744 & TRN & \\
\hline CHEMBL460824 & 537187 & 7.699 & 7.7454 & TRN & \\
\hline CHEMBL519347 & 537187 & 8.2218 & 7.949 & TRN & \\
\hline CHEMBL484767 & 537187 & 7.7959 & 7.2367 & TRN & \\
\hline
\end{tabular}




\begin{tabular}{|c|c|c|c|c|c|}
\hline \multicolumn{6}{|c|}{ Supplemental Table S2.txt } \\
\hline CHEMBL516173 & 537187 & 6.8239 & 7.268 & TRN & \\
\hline CHEMBL483403 & 537187 & 8.3979 & 7.4976 & TRN & \\
\hline CHEMBL485390 & 537187 & 6.6021 & 6.1662 & TRN & \\
\hline CHEMBL485591 & 537187 & 8.5229 & 7.4158 & TST & \\
\hline CHEMBL485402 & 537187 & 7.6021 & 7.7782 & TRN & \\
\hline CHEMBL458787 & 537187 & 8.1549 & 7.6058 & TRN & \\
\hline CHEMBL458604 & 537187 & 3.699 & 7.4441 & TST & \\
\hline CHEMBL519697 & 537187 & 6.5686 & 7.1764 & TRN & \\
\hline CHEMBL521468 & 537187 & 7.4559 & 6.5771 & TRN & \\
\hline CHEMBL516012 & 537187 & 6.6576 & 6.6225 & TRN & \\
\hline CHEMBL491076 & 537187 & 8.301 & 7.8145 & TRN & \\
\hline CHEMBL520312 & 537187 & 8.0 & 7.9375 & TRN & \\
\hline CHEMBL460823 & 537187 & 7.3372 & 7.2484 & TRN & \\
\hline CHEMBL484390 & 537187 & 7.7959 & 7.1009 & TRN & \\
\hline CHEMBL484934 & 537187 & 7.1367 & 7.1224 & TRN & \\
\hline CHEMBL519698 & 537187 & 7.7959 & 7.4719 & TRN & \\
\hline CHEMBL484546 & 537187 & 6.284 & 6.3845 & TRN & \\
\hline CHEMBL485555 & 537187 & 8.3979 & 8.8218 & TRN & \\
\hline CHEMBL490872 & 537187 & 7.2147 & 7.6995 & TRN & \\
\hline CHEMBL484395 & 537187 & 7.4559 & 7.1388 & TRN & \\
\hline CHEMBL485031 & 537187 & 8.3979 & 9.043 & TRN & \\
\hline CHEMBL485556 & 537187 & 8.3979 & 7.1994 & TST & \\
\hline CHEMBL484940 & 537187 & 7.9208 & 6.0971 & TST & \\
\hline CHEMBL484941 & 537187 & 5.4815 & 7.5656 & TST & \\
\hline CHEMBL483602 & 537187 & 7.2518 & 8.1923 & TST & \\
\hline CHEMBL444151 & 537187 & 7.7447 & 7.63899 & 9999999999 & TST \\
\hline CHEMBL485378 & 537187 & 3.699 & 8.4453 & TST & \\
\hline CHEMBL485233 & 537187 & 8.0 & 7.9144 & TST & \\
\hline CHEMBL458798 & 537187 & 6.4949 & 7.0449 & TST & \\
\hline CHEMBL483181 & 537187 & 7.1675 & 6.5281 & TST & \\
\hline CHEMBL489460 & 537187 & 5.699 & 8.3828 & TST & \\
\hline CHEMBL 3655598 & 1527858 & 6.567 & 6.1332 & TRN & \\
\hline CHEMBL 3655623 & 1527858 & 6.0 & 6.0999 & TRN & \\
\hline CHEMBL3655631 & 1527858 & 4.0 & 5.0537 & TST & \\
\hline CHEMBL3655609 & 1527858 & 5.2449 & 4.6804 & TRN & \\
\hline CHEMBL 3655590 & 1527858 & 6.3372 & 6.416 & TRN & \\
\hline CHEMBL 3655641 & 1527858 & 5.7352 & 5.8784 & TRN & \\
\hline CHEMBL3655611 & 1527858 & 3.5229 & 4.1994 & TRN & \\
\hline CHEMBL 3655630 & 1527858 & 4.0 & 4.6928 & TST & \\
\hline CHEMBL 3655634 & 1527858 & 4.0 & 6.5551 & TST & \\
\hline CHEMBL3655648 & 1527858 & 6.7905 & 6.936 & TRN & \\
\hline CHEMBL3314815 & 1527858 & 6.0 & 5.8251 & TRN & \\
\hline CHEMBL3655646 & 1527858 & 6.9101 & 6.4193 & TRN & \\
\hline CHEMBL 3655595 & 1527858 & 3.5229 & 3.7015 & TRN & \\
\hline CHEMBL3655602 & 1527858 & 3.5229 & 3.3193 & TRN & \\
\hline CHEMBL3655614 & 1527858 & 4.0 & 3.9895 & TRN & \\
\hline CHEMBL3655654 & 1527858 & 6.6517 & 6.9454 & TRN & \\
\hline CHEMBL3655647 & 1527858 & 5.8827 & 6.2383 & TRN & \\
\hline
\end{tabular}


Supplemental Table S2.txt

\begin{tabular}{|c|c|c|c|c|c|}
\hline CHEMBL 3655616 & 1527858 & 4.0 & \multicolumn{2}{|c|}{4.361000000000001} & TRN \\
\hline CHEMBL 3655612 & 1527858 & 3.5229 & 3.4027 & TRN & \\
\hline CHEMBL3655605 & 1527858 & 6.5751 & 6.5917 & TRN & \\
\hline CHEMBL 3655603 & 1527858 & 3.5229 & 3.1729 & TRN & \\
\hline CHEMBL3314806 & 1527858 & 6.8416 & 6.985 & TRN & \\
\hline CHEMBL 3655604 & 1527858 & 6.8761 & 7.0819 & TRN & \\
\hline CHEMBL3314808 & 1527858 & 6.0 & 7.5753 & TST & \\
\hline CHEMBL3655589 & 1527858 & 6.7799 & 6.841 & TRN & \\
\hline CHEMBL3655639 & 1527858 & 6.0 & 4.0082 & TST & \\
\hline CHEMBL 3655617 & 1527858 & 3.5229 & 3.4404 & TRN & \\
\hline CHEMBL 3655607 & 1527858 & 5.1518 & 4.5519 & TRN & \\
\hline CHEMBL 3655613 & 1527858 & 3.5229 & 3.6582 & TRN & \\
\hline CHEMBL 3655625 & 1527858 & 5.1397 & 3.8246 & TST & \\
\hline CHEMBL 3655626 & 1527858 & 4.0 & 6.5616 & TST & \\
\hline CHEMBL 3655638 & 1527858 & 4.0 & 4.0362 & TST & \\
\hline CHEMBL 3655615 & 1527858 & 3.5229 & 4.1297 & TRN & \\
\hline CHEMBL3655608 & 1527858 & 4.8962 & 5.1369 & TRN & \\
\hline CHEMBL3655599 & 1527858 & 3.5229 & 4.0336 & TRN & \\
\hline CHEMBL 3655591 & 1527858 & 3.5229 & 4.3602 & TRN & \\
\hline CHEMBL 3655621 & 1527858 & 6.301 & 6.6164 & TRN & \\
\hline CHEMBL3655633 & 1527858 & 3.5229 & 3.54399 & 99999999996 & TST \\
\hline CHEMBL 3655645 & 1527858 & 5.6459 & 5.6698 & TRN & \\
\hline CHEMBL 3655588 & 1527858 & 6.0857 & 5.6314 & TRN & \\
\hline CHEMBL 3314814 & 1527858 & 6.0 & 6.2055 & TRN & \\
\hline CHEMBL 3655629 & 1527858 & 5.1226 & 3.8694 & TST & \\
\hline CHEMBL 3655661 & 1527858 & 6.9872 & 4.9081 & TST & \\
\hline CHEMBL 3655618 & 1527858 & 4.0 & 4.6318 & TRN & \\
\hline CHEMBL3655636 & 1527858 & 4.0 & 4.2528 & TST & \\
\hline CHEMBL3314805 & 1527858 & 5.9508 & 5.1668 & TRN & \\
\hline CHEMBL 3655592 & 1527858 & 4.0 & 3.7572 & TRN & \\
\hline CHEMBL 3655660 & 1527858 & 6.0 & 5.0598 & TST & \\
\hline CHEMBL 3655622 & 1527858 & 6.0 & 6.9521 & TST & \\
\hline CHEMBL3655606 & 1527858 & 5.6021 & 4.9452 & TRN & \\
\hline CHEMBL 3655640 & 1527858 & 4.0 & 4.2726 & TST & \\
\hline CHEMBL 3655653 & 1527858 & 4.0 & 3.7926 & TRN & \\
\hline CHEMBL3655597 & 1527858 & 7.0605 & 6.5973 & TRN & \\
\hline CHEMBL 3655643 & 1527858 & 5.2441 & 5.2474 & TRN & \\
\hline CHEMBL 3655627 & 1527858 & 6.0329 & 4.4774 & TST & \\
\hline CHEMBL 3655649 & 1527858 & 5.3439 & 5.4032 & TRN & \\
\hline CHEMBL 3655594 & 1527858 & 3.5229 & 3.4886 & TRN & \\
\hline CHEMBL3314810 & 1527858 & 4.0 & 3.7701 & TRN & \\
\hline CHEMBL 3655632 & 1527858 & 3.5229 & 3.9061 & TST & \\
\hline CHEMBL 3655656 & 1527858 & 6.585 & 6.7831 & TRN & \\
\hline CHEMBL 3655655 & 1527858 & 6.0 & 5.9936 & TRN & \\
\hline CHEMBL3655652 & 1527858 & 6.5243 & 6.4383 & TRN & \\
\hline CHEMBL3655619 & 1527858 & 4.0 & 3.8456 & TRN & \\
\hline CHEMBL 3314807 & 1527858 & 5.9872 & 5.7401 & TRN & \\
\hline CHEMBL 3655657 & 1527858 & 5.7471 & 5.4605 & TRN & \\
\hline
\end{tabular}




\begin{tabular}{|c|c|c|c|c|c|}
\hline \multicolumn{6}{|c|}{ Supplemental Table S2.txt } \\
\hline CHEMBL3639545 & 1527858 & 6.0 & 6.0334 & TRN & \\
\hline CHEMBL3655635 & 1527858 & 4.0 & 3.9222 & TRN & \\
\hline CHEMBL3655650 & 1527858 & 6.0079 & 6.0743 & TRN & \\
\hline CHEMBL3655659 & 1527858 & 6.9172 & 6.9223 & TRN & \\
\hline CHEMBL 3655628 & 1527858 & 6.0 & 6.8425 & TST & \\
\hline CHEMBL3655601 & 1527858 & 4.0 & 3.9899 & TRN & \\
\hline CHEMBL3314804 & 1527858 & 6.2381 & 6.6284 & TRN & \\
\hline CHEMBL 3655644 & 1527858 & 6.0348 & 5.9169 & TRN & \\
\hline CHEMBL 3655600 & 1527858 & 3.5229 & \multicolumn{2}{|c|}{3.6210000000000004} & TRN \\
\hline CHEMBL3314809 & 1527858 & 7.0 & 6.6961 & TRN & \\
\hline CHEMBL3655651 & 1527858 & 5.699 & 5.4465 & TRN & \\
\hline CHEMBL 3655637 & 1527858 & 3.5229 & 3.9752 & TST & \\
\hline CHEMBL3314811 & 1527858 & 6.0 & \multicolumn{2}{|c|}{5.837999999999999} & TRN \\
\hline CHEMBL3655620 & 1527858 & 6.8508 & 7.3217 & TST & \\
\hline CHEMBL3314848 & 1527858 & 3.5229 & 3.3432 & TRN & \\
\hline CHEMBL3655662 & 1527858 & 6.9431 & 4.1905 & TST & \\
\hline CHEMBL3655642 & 1527858 & 6.0 & 5.9066 & TRN & \\
\hline CHEMBL 3655610 & 1527858 & 3.5229 & 3.927 & TRN & \\
\hline CHEMBL3655593 & 1527858 & 4.0 & 4.5558 & TRN & \\
\hline CHEMBL3655624 & 1527858 & 3.5229 & 4.3832 & TST & \\
\hline CHEMBL426051 & 311896 & 6.5129 & 6.3291 & TRN & \\
\hline CHEMBL179969 & 311896 & 5.8254 & 5.4127 & TST & \\
\hline CHEMBL362824 & 311896 & 5.3865 & 6.1263 & TRN & \\
\hline CHEMBL180175 & 311896 & 5.9614 & 5.9495 & TRN & \\
\hline CHEMBL179577 & 311896 & 6.2381 & 6.2253 & TRN & \\
\hline CHEMBL179607 & 311896 & 6.3969 & 5.93 & TRN & \\
\hline CHEMBL175933 & 311896 & 5.8861 & 5.8286 & TRN & \\
\hline CHEMBL175840 & 311896 & 6.0031 & 6.0987 & TRN & \\
\hline CHEMBL362233 & 311896 & 5.8526 & \multicolumn{2}{|c|}{5.827000000000001} & TRN \\
\hline CHEMBL179923 & 311896 & 5.8321 & 6.0252 & TRN & \\
\hline CHEMBL 2112990 & 311896 & 4.6757 & 5.315 & TRN & \\
\hline CHEMBL178265 & 311896 & 4.0458 & 5.2313 & TRN & \\
\hline CHEMBL175492 & 311896 & 6.4437 & 5.7071 & TRN & \\
\hline CHEMBL178573 & 311896 & 6.1107 & 5.8268 & TRN & \\
\hline CHEMBL153763 & 311896 & 6.1824 & 5.7151 & TRN & \\
\hline CHEMBL368702 & 311896 & 6.0218 & 6.0626 & TRN & \\
\hline CHEMBL179052 & 311896 & 6.3363 & 5.9589 & TRN & \\
\hline CHEMBL362611 & 311896 & 6.1013 & 6.1825 & TRN & \\
\hline CHEMBL 367792 & 311896 & 4.5414 & 4.3724 & TRN & \\
\hline CHEMBL360979 & 311896 & 6.4841 & 6.0813 & TST & \\
\hline CHEMBL179726 & 311896 & 5.9508 & 6.2021 & TRN & \\
\hline CHEMBL179659 & 311896 & 6.4473 & 6.2952 & TRN & \\
\hline CHEMBL359630 & 311896 & 5.7627 & 5.4879 & TRN & \\
\hline CHEMBL179458 & 311896 & 5.5686 & 5.5563 & TST & \\
\hline CHEMBL175726 & 311896 & 6.3872 & 6.1694 & TRN & \\
\hline CHEMBL360028 & 311896 & 6.2604 & 6.0433 & TRN & \\
\hline CHEMBL424959 & 311896 & 5.9918 & 6.1169 & TRN & \\
\hline CHEMBL359629 & 311896 & 6.0119 & 5.7884 & TRN & \\
\hline
\end{tabular}




\begin{tabular}{|c|c|c|c|c|c|}
\hline & & \multicolumn{4}{|c|}{ Supplemental Table S2.txt } \\
\hline CHEMBL179527 & 311896 & 5.6536 & 6.2921 & TRN & \\
\hline CHEMBL368234 & 311896 & 4.0531 & 4.1524 & TRN & \\
\hline CHEMBL369299 & 311896 & 6.0343 & 6.11700 & 0000000001 & TRN \\
\hline CHEMBL360211 & 311896 & 6.5143 & 6.2274 & TRN & \\
\hline CHEMBL178958 & 311896 & 6.0931 & 5.9344 & TRN & \\
\hline CHEMBL179652 & 311896 & 6.1308 & 6.1897 & TST & \\
\hline CHEMBL178199 & 311896 & 6.301 & 6.0021 & TRN & \\
\hline CHEMBL179572 & 311896 & 5.7981 & 5.7759 & TRN & \\
\hline CHEMBL178654 & 311896 & 6.2916 & 6.1761 & TRN & \\
\hline CHEMBL180516 & 311896 & 6.2336 & 6.20200 & 0000000001 & TRN \\
\hline CHEMBL361343 & 311896 & 6.1884 & 6.2546 & TRN & \\
\hline CHEMBL179363 & 311896 & 6.0155 & 6.2229 & TRN & \\
\hline CHEMBL179310 & 311896 & 5.6778 & 5.9389 & TST & \\
\hline CHEMBL179074 & 311896 & 5.2612 & 5.4239 & TST & \\
\hline CHEMBL175557 & 311896 & 5.232 & 6.068 & TRN & \\
\hline CHEMBL434720 & 311896 & 6.3134 & 6.2007 & TRN & \\
\hline CHEMBL360780 & 311896 & 5.914 & 5.8302 & TRN & \\
\hline CHEMBL179123 & 311896 & 6.2588 & 6.2 & TRN & \\
\hline CHEMBL175621 & 311896 & 5.4866 & 5.7168 & TRN & \\
\hline CHEMBL360519 & 311896 & 6.0232 & 6.0919 & TRN & \\
\hline CHEMBL367754 & 311896 & 4.8096 & 4.8485 & TRN & \\
\hline CHEMBL359660 & 311896 & 5.6107 & 5.9629 & TRN & \\
\hline CHEMBL176199 & 311896 & 6.4365 & 6.2985 & TRN & \\
\hline CHEMBL179313 & 311896 & 6.7055 & 6.2733 & TRN & \\
\hline CHEMBL180018 & 311896 & 6.1656 & 6.1337 & TRN & \\
\hline CHEMBL179164 & 311896 & 5.9586 & 6.0354 & TST & \\
\hline CHEMBL367492 & 311896 & 6.0747 & 5.814 & TRN & \\
\hline CHEMBL427314 & 311896 & 5.8447 & 5.8559 & TRN & \\
\hline CHEMBL175513 & 311896 & 5.6682 & 5.67299 & 9999999999 & TRN \\
\hline CHEMBL179633 & 311896 & 5.5686 & 5.9644 & TRN & \\
\hline CHEMBL178922 & 311896 & 5.6778 & 5.9082 & TST & \\
\hline CHEMBL179521 & 311896 & 6.2076 & 5.6064 & TRN & \\
\hline CHEMBL179766 & 311896 & 6.0315 & 6.0083 & TRN & \\
\hline CHEMBL362232 & 311896 & 6.2366 & 6.0156 & TRN & \\
\hline CHEMBL175556 & 311896 & 5.5464 & 6.3796 & TRN & \\
\hline CHEMBL362618 & 311896 & 5.9208 & 5.7229 & TRN & \\
\hline CHEMBL180227 & 311896 & 6.0605 & 6.0904 & TST & \\
\hline CHEMBL440935 & 311896 & 6.2676 & 6.0039 & TRN & \\
\hline CHEMBL180415 & 311896 & 6.2269 & 6.2812 & TST & \\
\hline CHEMBL178290 & 311896 & 5.7688 & 6.0705 & TST & \\
\hline CHEMBL359705 & 311896 & 4.4836 & 4.5854 & TST & \\
\hline CHEMBL178096 & 311896 & 4.301 & 5.3244 & TST & \\
\hline CHEMBL369088 & 311896 & 5.7857 & 6.0817 & TST & \\
\hline CHEMBL360958 & 311896 & 6.4012 & 6.0142 & TST & \\
\hline CHEMBL178312 & 311896 & 6.51 & 6.1027 & TST & \\
\hline CHEMBL178144 & 311896 & 6.0878 & 6.33899 & 99999999995 & TST \\
\hline CHEMBL360933 & 311896 & 5.9348 & 6.0744 & TST & \\
\hline CHEMBL175558 & 311896 & 6.0173 & 5.6564 & TST & \\
\hline
\end{tabular}




\begin{tabular}{|c|c|c|c|c|c|c|}
\hline \multirow[b]{2}{*}{ CHEMBL 2408544} & & \multicolumn{5}{|c|}{ Supplemental Table S2.txt } \\
\hline & 972801 & 5.7212 & 5.5936 & TRN & & \\
\hline CHEMBL 2408541 & 972801 & 4.6702 & 4.6235 & TRN & & \\
\hline CHEMBL 2408546 & 972801 & 5.3116 & 5.1224 & TRN & & \\
\hline CHEMBL 2408555 & 972801 & \multicolumn{3}{|c|}{5.4510000000000005} & 5.3927 & TRN \\
\hline CHEMBL 2408362 & 972801 & 3.3979 & 4.0508 & TST & & \\
\hline CHEMBL 2408532 & 972801 & 4.9416 & 4.94 & TRN & & \\
\hline CHEMBL 2408553 & 972801 & 5.4202 & 5.2551 & TRN & & \\
\hline CHEMBL 2408359 & 972801 & 4.7404 & 3.9047 & TST & & \\
\hline CHEMBL 2408520 & 972801 & 4.8911 & 4.8977 & TRN & & \\
\hline CHEMBL 2408528 & 972801 & \multicolumn{3}{|c|}{5.4510000000000005} & 5.4063 & TRN \\
\hline CHEMBL 2408530 & 972801 & 4.8959 & 4.8511 & TRN & & \\
\hline CHEMBL 2408512 & 972801 & 4.862 & 4.9233 & TRN & & \\
\hline CHEMBL 2408551 & 972801 & 4.7518 & 4.8783 & TRN & & \\
\hline CHEMBL 2408549 & 972801 & 4.6639 & 4.5408 & TST & & \\
\hline CHEMBL 2408534 & 972801 & 4.753 & 4.7673 & TRN & & \\
\hline CHEMBL 2408548 & 972801 & 5.3363 & 5.3307 & TRN & & \\
\hline CHEMBL 2408540 & 972801 & 5.2321 & 5.2559 & TRN & & \\
\hline CHEMBL 2408550 & 972801 & 4.8671 & 4.8802 & TRN & & \\
\hline CHEMBL 2408523 & 972801 & \multicolumn{3}{|c|}{5.0680000000000005} & 5.1827 & TRN \\
\hline CHEMBL 2408517 & 972801 & 4.7474 & 4.7239 & TRN & & \\
\hline CHEMBL 2408554 & 972801 & 4.9169 & 5.0877 & TRN & & \\
\hline CHEMBL 2408543 & 972801 & 4.5815 & 4.7379 & TRN & & \\
\hline CHEMBL 2408364 & 972801 & 3.3979 & 3.406 & TRN & & \\
\hline CHEMBL 2408547 & 972801 & 5.4225 & 5.3979 & TRN & & \\
\hline CHEMBL 2408524 & 972801 & 4.4908 & 4.3786 & TST & & \\
\hline CHEMBL 2408525 & 972801 & 4.7423 & 4.7463 & TRN & & \\
\hline CHEMBL 2408516 & 972801 & 3.3979 & 3.4673 & TST & & \\
\hline CHEMBL 2408552 & 972801 & 5.4763 & 5.4211 & TRN & & \\
\hline CHEMBL 2408363 & 972801 & 4.5685 & 4.5953 & TRN & & \\
\hline CHEMBL 2408522 & 972801 & 5.4134 & 5.4503 & TRN & & \\
\hline CHEMBL 2408537 & 972801 & 5.1135 & 5.1945 & TRN & & \\
\hline CHEMBL 2408545 & 972801 & 5.0241 & 5.114 & TRN & & \\
\hline CHEMBL 2408531 & 972801 & 5.4609 & 5.3866 & TRN & & \\
\hline CHEMBL2408536 & 972801 & 5.1385 & 5.2224 & TRN & & \\
\hline CHEMBL 2408513 & 972801 & 4.6451 & 4.6489 & TRN & & \\
\hline CHEMBL2408556 & 972801 & 3.3979 & 3.0646 & TST & & \\
\hline CHEMBL 2408515 & 972801 & 4.8874 & 4.663 & TST & & \\
\hline CHEMBL 2408361 & 972801 & 4.8925 & 4.6563 & TST & & \\
\hline CHEMBL 2408535 & 972801 & 5.1675 & 4.9082 & TRN & & \\
\hline CHEMBL 2408514 & 972801 & 5.0726 & 5.1398 & TRN & & \\
\hline CHEMBL2408533 & 972801 & 4.5444 & 4.3712 & TST & & \\
\hline CHEMBL 2408538 & 972801 & 4.9935 & 4.9653 & TRN & & \\
\hline CHEMBL2408529 & 972801 & 4.8649 & 4.9935 & TRN & & \\
\hline CHEMBL 2408360 & 972801 & 4.631 & 3.8045 & TST & & \\
\hline CHEMBL 2408527 & 972801 & 5.2255 & 5.3167 & TRN & & \\
\hline CHEMBL 2408557 & 972801 & 4.7913 & 3.806 & TST & & \\
\hline CHEMBL 2408539 & 972801 & 5.426 & 5.4534 & TRN & & \\
\hline CHEMBL 2408521 & 972801 & 4.8122 & 4.794 & TRN & & \\
\hline
\end{tabular}


Supplemental Table S2.txt

\begin{tabular}{|c|c|c|c|c|}
\hline CHEMBL2408542 & 972801 & 3.3979 & 4.129 & TST \\
\hline CHEMBL 2408519 & 972801 & 5.52 & 5.5225 & TRN \\
\hline CHEMBL 2408518 & 972801 & 4.5439 & 4.3462 & TRN \\
\hline CHEMBL2408559 & 972801 & 4.6085 & 3.6315 & TST \\
\hline CHEMBL2408526 & 972801 & 4.6977 & 4.7105 & TRN \\
\hline CHEMBL2408365 & 972801 & 4.9133 & 4.9263 & TRN \\
\hline CHEMBL 2408558 & 972801 & 3.3979 & 3.1285 & TST \\
\hline CHEMBL108978 & 43999 & 5.9208 & 5.7763 & TRN \\
\hline CHEMBL109017 & 43999 & 6.9586 & 5.3695 & TST \\
\hline CHEMBL108452 & 43999 & 6.3565 & 6.3862 & TRN \\
\hline CHEMBL320961 & 43999 & 5.5376 & 5.7577 & TRN \\
\hline CHEMBL321216 & 43999 & 6.2757 & 6.2073 & TRN \\
\hline CHEMBL327078 & 43999 & 6.1367 & 6.0845 & TRN \\
\hline CHEMBL110876 & 43999 & 5.9586 & 5.2028 & TST \\
\hline CHEMBL46712 & 43999 & 7.0969 & 7.1514 & TRN \\
\hline CHEMBL321016 & 43999 & 5.8125 & 5.8093 & TRN \\
\hline CHEMBL419561 & 43999 & 5.38200 & 000000006 & 5.9711 \\
\hline CHEMBL321898 & 43999 & 4.2924 & 4.2888 & TRN \\
\hline CHEMBL323954 & 43999 & 5.9586 & 5.9528 & TRN \\
\hline CHEMBL110660 & 43999 & 6.3872 & 5.2771 & TST \\
\hline CHEMBL106151 & 43999 & 5.9208 & 6.0434 & TRN \\
\hline CHEMBL320330 & 43999 & 6.0223 & 6.0857 & TRN \\
\hline CHEMBL110145 & 43999 & 5.5528 & 5.3755 & TRN \\
\hline CHEMBL108936 & 43999 & 6.5376 & 6.507006 & 0000000001 \\
\hline CHEMBL321407 & 43999 & 5.7375 & 5.6005 & TRN \\
\hline CHEMBL322720 & 43999 & 4.684 & 4.8053 & TRN \\
\hline CHEMBL106192 & 43999 & 5.7696 & 5.7898 & TRN \\
\hline CHEMBL108961 & 43999 & 6.3565 & 6.3905 & TRN \\
\hline CHEMBL106023 & 43999 & 6.4685 & 6.6026 & TRN \\
\hline CHEMBL320926 & 43999 & 6.3665 & 6.5076 & TRN \\
\hline CHEMBL320118 & 43999 & 4.4248 & 3.8651 & TRN \\
\hline CHEMBL107600 & 43999 & 5.8239 & 5.9242 & TRN \\
\hline CHEMBL109143 & 43999 & 6.284 & 5.3636 & TST \\
\hline CHEMBL110331 & 43999 & 6.3768 & 6.2045 & TRN \\
\hline CHEMBL110446 & 43999 & 6.2007 & 6.2291 & TRN \\
\hline CHEMBL110448 & 43999 & 4.1024 & 4.0409 & TRN \\
\hline CHEMBL325755 & 43999 & 5.7721 & 5.6371 & TRN \\
\hline CHEMBL296447 & 43999 & 6.5528 & 6.414 & TRN \\
\hline CHEMBL321881 & 43999 & 5.8861 & 5.8853 & TRN \\
\hline CHEMBL326639 & 43999 & 6.0269 & 4.9103 & TST \\
\hline CHEMBL326005 & 43999 & 4.2924 & 4.3128 & TRN \\
\hline CHEMBL110462 & 43999 & 3.0297 & 3.1712 & TRN \\
\hline CHEMBL420479 & 43999 & 3.0 & 3.0058 & TRN \\
\hline CHEMBL110574 & 43999 & 5.0177 & 4.9598 & TRN \\
\hline CHEMBL325790 & 43999 & 5.7447 & 5.9394 & TRN \\
\hline CHEMBL320986 & 43999 & 4.2676 & 4.1084 & TRN \\
\hline CHEMBL321156 & 43999 & 7.1549 & 6.028 & TST \\
\hline CHEMBL322305 & 43999 & 3.0 & 3.4626 & TRN \\
\hline
\end{tabular}




\begin{tabular}{|c|c|c|c|c|c|}
\hline \multicolumn{6}{|c|}{ Supplemental Table S2.txt } \\
\hline CHEMBL421417 & 43999 & 6.3279 & 5.0072 & TST & \\
\hline CHEMBL42225 & 43999 & 6.8861 & 6.8497 & TRN & \\
\hline CHEMBL320318 & 43999 & 4.6126 & 4.6537 & TRN & \\
\hline CHEMBL110396 & 43999 & 3.0 & 2.8326 & TST & \\
\hline CHEMBL323277 & 43999 & 5.2366 & 5.3587 & TRN & \\
\hline CHEMBL42561 & 43999 & 6.7447 & 6.6766 & TRN & \\
\hline CHEMBL44466 & 43999 & 6.1024 & 6.0571 & TRN & \\
\hline CHEMBL320790 & 43999 & 6.3279 & 5.472 & TST & \\
\hline CHEMBL110382 & 43999 & 7.585 & 6.1087 & TST & \\
\hline CHEMBL322136 & 43999 & 5.7447 & 6.1329 & TST & \\
\hline CHEMBL105766 & 43999 & 6.2924 & 6.1186 & TST & \\
\hline CHEMBL3950726 & 1641659 & 4.0 & 4.737 & TRN & \\
\hline CHEMBL3938272 & 1641659 & 5.1367 & 6.2351 & TST & \\
\hline CHEMBL 3896729 & 1641659 & 6.699 & 6.7837 & TST & \\
\hline CHEMBL3907896 & 1641659 & 4.0 & 5.5051 & TST & \\
\hline CHEMBL3889826 & 1641659 & 5.1972 & 4.4237 & TRN & \\
\hline CHEMBL3986302 & 1641659 & 4.0 & 4.4402 & TRN & \\
\hline CHEMBL3920389 & 1641659 & 4.0 & 4.0547 & TRN & \\
\hline CHEMBL3936575 & 1641659 & 4.0 & 4.0159 & TRN & \\
\hline CHEMBL3982353 & 1641659 & 5.5045 & 5.6878 & TRN & \\
\hline CHEMBL3913408 & 1641659 & 5.0 & 4.3711 & TRN & \\
\hline CHEMBL3908633 & 1641659 & 4.0 & 4.1752 & TRN & \\
\hline CHEMBL3928303 & 1641659 & 4.0 & 4.0718 & TRN & \\
\hline CHEMBL3953582 & 1641659 & 5.8861 & 5.5407 & TRN & \\
\hline CHEMBL3977493 & 1641659 & 6.7212 & 6.6616 & TST & \\
\hline CHEMBL3982152 & 1641659 & 5.0 & 4.86600 & 00000000005 & TRN \\
\hline CHEMBL3922683 & 1641659 & 4.0 & 4.003 & TRN & \\
\hline CHEMBL3921694 & 1641659 & 6.8861 & 5.1308 & TRN & \\
\hline CHEMBL 3958461 & 1641659 & 4.1427 & 4.2389 & TRN & \\
\hline CHEMBL3969415 & 1641659 & 6.3468 & 5.8162 & TRN & \\
\hline CHEMBL3982606 & 1641659 & 6.3565 & 5.8432 & TRN & \\
\hline CHEMBL3946136 & 1641659 & 4.0 & 5.6504 & TST & \\
\hline CHEMBL3983038 & 1641659 & 5.3665 & 5.7221 & TRN & \\
\hline CHEMBL3961069 & 1641659 & 5.1805 & 4.7281 & TRN & \\
\hline CHEMBL3915977 & 1641659 & 6.0223 & 6.2424 & TST & \\
\hline CHEMBL3936556 & 1641659 & 4.0 & 4.0542 & TRN & \\
\hline CHEMBL 3892336 & 1641659 & 4.0 & 4.081 & TRN & \\
\hline CHEMBL3891925 & 1641659 & 5.1427 & 4.7843 & TRN & \\
\hline CHEMBL 3955782 & 1641659 & 4.0 & 4.1185 & TRN & \\
\hline CHEMBL3907243 & 1641659 & 4.0 & 4.4617 & TRN & \\
\hline CHEMBL3908647 & 1641659 & 4.0 & 5.4897 & TST & \\
\hline CHEMBL3954602 & 1641659 & 4.0 & 4.1192 & TRN & \\
\hline CHEMBL3937954 & 1641659 & 5.699 & 5.5077 & TST & \\
\hline CHEMBL 3922234 & 1641659 & 5.5376 & 5.8921 & TRN & \\
\hline CHEMBL3906878 & 1641659 & 4.0 & 4.0753 & TRN & \\
\hline CHEMBL3984258 & 1641659 & 5.0862 & 4.5401 & TRN & \\
\hline CHEMBL3928879 & 1641659 & 4.0 & 4.0434 & TRN & \\
\hline CHEMBL3931105 & 1641659 & 4.0 & 4.4513 & TRN & \\
\hline
\end{tabular}


Supplemental Table S2.txt

\begin{tabular}{|c|c|c|c|c|}
\hline HEMBL 39 & & 862 & 29 & TST \\
\hline HEMBL 3930637 & 641659 & 6.3468 & 6.2458 & \\
\hline HEMBL3967562 & & 8153 & 8489 & \\
\hline HEMBL3984410 & 641659 & 4.0 & .77 & \\
\hline HEMBL3951219 & 641659 & 5.983 & 7011 & \\
\hline HEMBL3893479 & 659 & 4.0 & 0801 & \\
\hline HEMBL 390 & & 6.13 & .2007 & \\
\hline HEMBL3923454 & 659 & 5.0 & 4.5264 & \\
\hline HEMBL3972647 & 559 & 5.6021 & .5098 & \\
\hline HEMBL3923497 & 559 & 4.0 & 4.2214 & \\
\hline HEMBL 389 & 59 & 5.7033 & .8433 & \\
\hline HEMBL 398 & & 5.3979 & .4259 & \\
\hline HEMBL 392 & 59 & 5.6126 & 4841 & \\
\hline HEMBL 392 & 59 & 4.0 & 4.4697 & \\
\hline HEMBL394 & 59 & 5.1079 & 5.4284 & \\
\hline HEMBL3 & 59 & 4. & 771 & \\
\hline HEMBL & & & 57 & \\
\hline HEMBL 390 & 59 & 4. & 2875 & \\
\hline HEMBL 39 & & & 5419 & \\
\hline HEMBL394C & 59 & 4. & 4.4312 & $I$ KIV \\
\hline HEMBL3 & 99 & 5 . & 761 & RN \\
\hline HEMBL: & & & 74 & RIV \\
\hline HEMBL & 59 & 5 . & 1633 & \\
\hline HEMBL3 & & 6 . & & \\
\hline HEMBL 389 & 59 & 6. & 743 & $\mathrm{RN}$ \\
\hline HEMBL3 & & 6 & 14 & ST \\
\hline HEMBL & & & 56 & $\mathrm{RN}$ \\
\hline HEMBL & & 4. & 4255 & RN \\
\hline HEMBL3 & & 4 & & RN \\
\hline HEMBL 397 & 99 & 6.42 & 5557 & ГST \\
\hline HEMBL3 & & 4 & 3949 & $\mathrm{RN}$ \\
\hline HEMBI & & 5 & 73 & RN \\
\hline & & 4. & & $\mathrm{RN}$ \\
\hline HEMBL 389 & & & 86 & 「RN \\
\hline HEMBL3933585 & 9 & 6. & 3334 & TST \\
\hline HEMBL3 & & & 756 & 「RN \\
\hline UIF & & & & ST \\
\hline HEMBL3\& & & 4.0 & 9077 & TRN \\
\hline HEMBL 390 & & 5.7959 & 176 & $\mathrm{TR}$ \\
\hline AEMBL3 & 59 & 5.431 & 526 & TST \\
\hline HEMBL39 & 6 & 4. & 4.4956 & TRN \\
\hline CHEMBL39 & & 6.08 & 6.7742 & ST \\
\hline HEMBL390 & & 4.0 & & TST \\
\hline HEMBL 389 & & 4 . & 06 & TR \\
\hline EMBL3 & & 4 & & RN \\
\hline CHEMBL3945465 & & 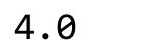 & 4.1128 & \\
\hline CHEMBL3977814 & & 4.0 & 4.381 & \\
\hline CHEMBL3959947 & 1641659 & 6.0 & 5.7658 & $\cdots$ \\
\hline
\end{tabular}




\begin{tabular}{|c|c|c|c|c|c|}
\hline \multicolumn{6}{|c|}{ Supplemental Table S2.txt } \\
\hline CHEMBL3936051 & 1641659 & 4.0 & 4.4105 & TRN & \\
\hline CHEMBL3938405 & 1641659 & 5.2388 & 4.4539 & TRN & \\
\hline CHEMBL3958871 & 1641659 & 4.0 & 4.7166 & TST & \\
\hline CHEMBL3914437 & 1641659 & 4.0 & 4.0351 & TRN & \\
\hline CHEMBL3936585 & 1641659 & 4.0 & 3.8872 & TRN & \\
\hline CHEMBL3950167 & 1641659 & 5.6459 & 5.5908 & TST & \\
\hline CHEMBL3977615 & 1641659 & 5.0 & 5.3265 & TRN & \\
\hline CHEMBL3949114 & 1641659 & 5.1427 & 5.5235 & TST & \\
\hline CHEMBL3969048 & 1641659 & 4.0 & 4.5571 & TRN & \\
\hline CHEMBL3952393 & 1641659 & 5.6198 & 6.2539 & TRN & \\
\hline CHEMBL3906101 & 1641659 & 6.1079 & 6.1784 & TRN & \\
\hline CHEMBL3931120 & 1641659 & 5.7212 & 5.7736 & TRN & \\
\hline CHEMBL3926239 & 1641659 & 4.0 & 4.3369 & TRN & \\
\hline CHEMBL3909743 & 1641659 & 4.0 & 5.7399 & TST & \\
\hline CHEMBL3935459 & 1641659 & 5.2403 & 5.4571 & TST & \\
\hline CHEMBL3982256 & 1641659 & 5.7959 & 6.1971 & TST & \\
\hline CHEMBL3894169 & 1641659 & 4.0 & 4.0278 & TRN & \\
\hline CHEMBL3983455 & 1641659 & 6.2291 & 5.0997 & TST & \\
\hline CHEMBL3954829 & 1641659 & 4.0 & 4.1935 & TRN & \\
\hline CHEMBL3921089 & 1641659 & 4.0 & 4.34399 & 9999999999 & TRN \\
\hline CHEMBL3976069 & 1641659 & 5.1007 & 4.51 & TRN & \\
\hline CHEMBL3944805 & 1641659 & 4.0 & 4.1096 & TRN & \\
\hline CHEMBL3908097 & 1641659 & 5.3768 & 4.9027 & TRN & \\
\hline CHEMBL3899586 & 1641659 & 4.0 & 4.4019 & TRN & \\
\hline CHEMBL 3941561 & 1641659 & 4.0 & 3.6176 & TRN & \\
\hline CHEMBL3914016 & 1641659 & 5.0 & 4.277 & TST & \\
\hline CHEMBL 3895504 & 1641659 & 4.1427 & 4.0648 & TRN & \\
\hline CHEMBL3955314 & 1641659 & 6.4815 & 5.8661 & TST & \\
\hline CHEMBL3944858 & 1641659 & 6.4685 & 6.4558 & TRN & \\
\hline CHEMBL3894179 & 1641659 & 5.6021 & 5.8356 & TRN & \\
\hline CHEMBL3915852 & 1641659 & 4.0 & 4.3246 & TRN & \\
\hline CHEMBL3929359 & 1641659 & 4.0 & 4.1106 & TRN & \\
\hline CHEMBL3908608 & 1641659 & 4.0 & 3.8489 & TRN & \\
\hline CHEMBL3952027 & 1641659 & 5.0706 & 5.722 & TRN & \\
\hline CHEMBL148517 & 66273 & 8.0458 & 7.3442 & TRN & \\
\hline CHEMBL321637 & 66273 & 7.7696 & 8.0737 & TRN & \\
\hline CHEMBL50871 & 66273 & 4.0 & 3.5476 & TRN & \\
\hline CHEMBL342115 & 66273 & 5.8292 & 6.3251 & TRN & \\
\hline CHEMBL49964 & 66273 & 6.6021 & 7.1459 & TRN & \\
\hline CHEMBL51710 & 66273 & 7.6198 & 7.5857 & TRN & \\
\hline CHEMBL51641 & 66273 & 5.8861 & 5.2578 & TRN & \\
\hline CHEMBL 6714 & 66273 & 6.1397 & 6.7804 & TRN & \\
\hline CHEMBL148555 & 66273 & 6.1296 & 6.2422 & TRN & \\
\hline CHEMBL151727 & 66273 & 9.301 & 9.0011 & TRN & \\
\hline CHEMBL146527 & 66273 & 6.3279 & 6.4293 & TST & \\
\hline CHEMBL 300040 & 66273 & 8.0809 & 7.362 & TRN & \\
\hline CHEMBL 357415 & 66273 & 6.6021 & 7.0695 & TRN & \\
\hline CHEMBL149373 & 66273 & 7.0862 & 7.1014 & TRN & \\
\hline
\end{tabular}




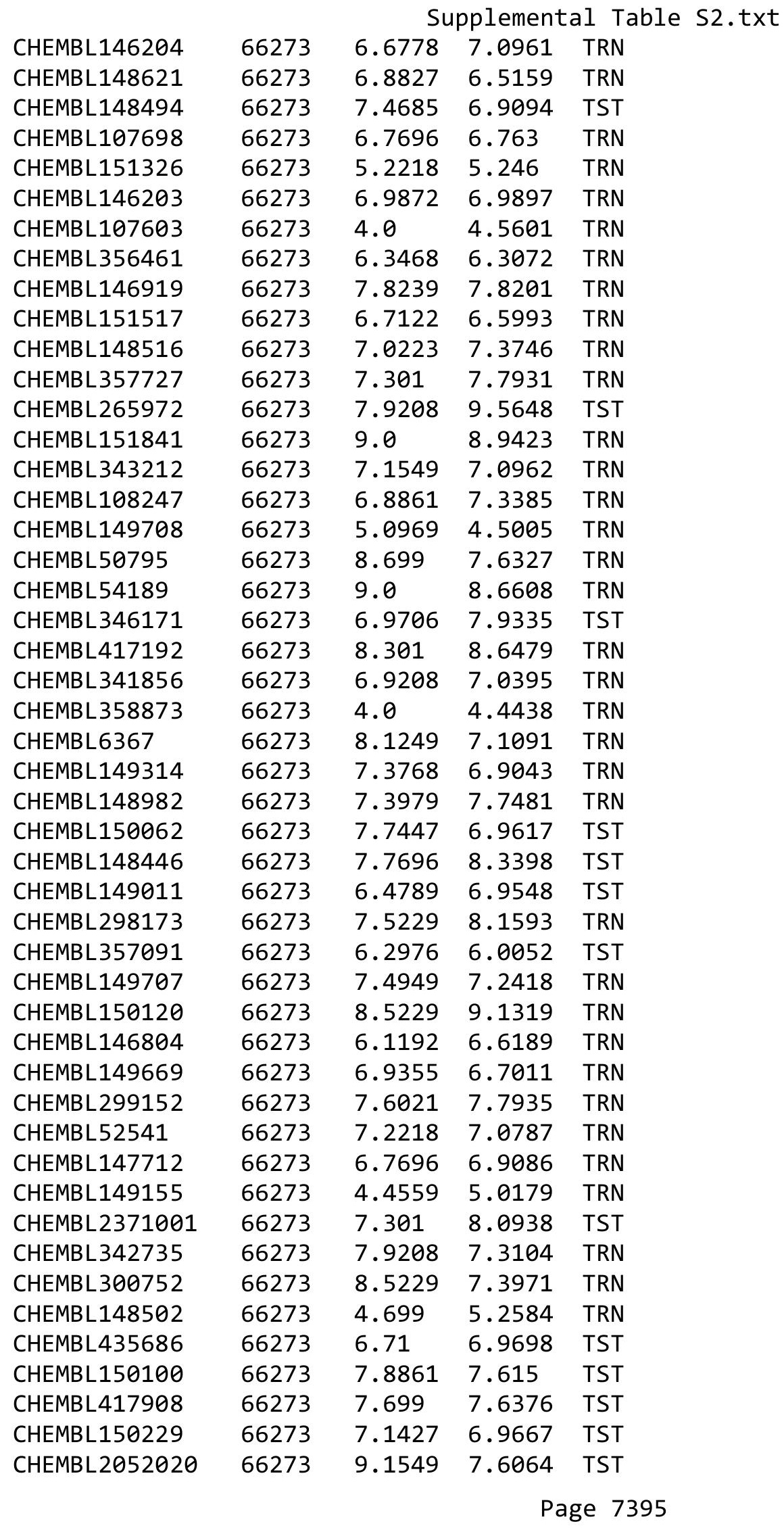




\begin{tabular}{|c|c|c|c|c|c|c|}
\hline \multicolumn{7}{|c|}{ Supplemental Table S2.txt } \\
\hline CHEMBL151327 & 66273 & 7.1079 & 6.0782 & TST & & \\
\hline CHEMBL423033 & 66273 & 8.5229 & 7.5734 & TST & & \\
\hline CHEMBL1301248 & 737093 & 3.1002 & 3.1691 & TRN & & \\
\hline CHEMBL1338178 & 737093 & 3.1002 & 3.0562 & TRN & & \\
\hline CHEMBL1491640 & 737093 & 3.1002 & 3.1207 & TST & & \\
\hline CHEMBL1471865 & 737093 & 5.2092 & 5.1039 & TRN & & \\
\hline CHEMBL3145282 & 737093 & 3.1002 & 3.1889 & TST & & \\
\hline CHEMBL1417070 & 737093 & 4.3025 & 4.4865 & TST & & \\
\hline CHEMBL3198585 & 737093 & 3.1002 & 3.0185 & TRN & & \\
\hline CHEMBL1320181 & 737093 & 5.6173 & 5.6168 & TRN & & \\
\hline CHEMBL1981200 & 737093 & 4.8259 & 4.8008 & TRN & & \\
\hline CHEMBL1385669 & 737093 & 3.1002 & 3.1531 & TRN & & \\
\hline CHEMBL1325945 & 737093 & 6.9066 & 6.789 & TRN & & \\
\hline CHEMBL578512 & 737093 & 6.9066 & 6.9321 & TRN & & \\
\hline CHEMBL1443048 & 737093 & 3.1002 & 3.1233 & TRN & & \\
\hline CHEMBL1426096 & 737093 & 5.37700 & 00000000 & $\partial 1$ & 5.242000000000001 & TRN \\
\hline CHEMBL601757 & 737093 & 6.9066 & 7.0505 & TRN & & \\
\hline CHEMBL1371816 & 737093 & 4.8355 & 4.8417 & TRN & & \\
\hline CHEMBL1438889 & 737093 & 5.4225 & 5.4515 & TRN & & \\
\hline CHEMBL1993612 & 737093 & 3.1002 & 3.207 & TRN & & \\
\hline CHEMBL1442148 & 737093 & 3.1002 & 3.1665 & TST & & \\
\hline CHEMBL3208035 & 737093 & 3.1002 & 3.2076 & TRN & & \\
\hline CHEMBL1508571 & 737093 & 3.1002 & 3.1142 & TRN & & \\
\hline CHEMBL1546449 & 737093 & 3.1002 & 2.9791 & TRN & & \\
\hline CHEMBL1488035 & 737093 & 5.05 & 5.0662 & TRN & & \\
\hline CHEMBL1444644 & 737093 & 3.1002 & 3.2314 & TRN & & \\
\hline CHEMBL3209512 & 737093 & 3.1002 & 3.0778 & TRN & & \\
\hline CHEMBL1307807 & 737093 & 3.1002 & 3.1356 & TRN & & \\
\hline CHEMBL1585090 & 737093 & 3.1002 & 3.0837 & TRN & & \\
\hline CHEMBL1343895 & 737093 & 3.1002 & 2.9553 & TRN & & \\
\hline CHEMBL1307336 & 737093 & 3.1002 & 3.0969 & TRN & & \\
\hline CHEMBL1465095 & 737093 & 3.1002 & 3.1702 & TRN & & \\
\hline CHEMBL570345 & 737093 & 5.3468 & 5.4101 & TRN & & \\
\hline CHEMBL1580949 & 737093 & 3.1002 & 3.1763 & TRN & & \\
\hline CHEMBL1576746 & 737093 & 4.2352 & 4.2584 & TST & & \\
\hline CHEMBL1464805 & 737093 & 4.3121 & 4.2593 & TRN & & \\
\hline CHEMBL1701224 & 737093 & 6.9066 & 6.7871 & TRN & & \\
\hline CHEMBL1340439 & 737093 & 3.1002 & 3.0721 & TRN & & \\
\hline CHEMBL1600686 & 737093 & 3.1002 & 3.1065 & TRN & & \\
\hline CHEMBL1344691 & 737093 & 3.1002 & 3.1323 & TRN & & \\
\hline CHEMBL1581837 & 737093 & 3.1002 & 3.1312 & TRN & & \\
\hline CHEMBL1444606 & 737093 & 3.1002 & 2.957 & TRN & & \\
\hline CHEMBL1493152 & 737093 & 3.1002 & 3.109 & TRN & & \\
\hline CHEMBL1359401 & 737093 & 3.1002 & 3.0956 & TRN & & \\
\hline CHEMBL1306172 & 737093 & 3.1002 & 3.0445 & TRN & & \\
\hline CHEMBL3211928 & 737093 & 3.1002 & 2.945 & TST & & \\
\hline CHEMBL1343286 & 737093 & 3.1002 & 3.3043 & TRN & & \\
\hline CHEMBL 3212510 & 737093 & 3.1002 & 3.0123 & TRN & & \\
\hline
\end{tabular}


Supplemental Table S2.txt

\begin{tabular}{|c|c|c|c|c|c|}
\hline CHEMBL1404195 & 737093 & 3.1002 & 3.1532 & TRN & \\
\hline CHEMBL1578734 & 737093 & 3.1002 & 3.1718 & TRN & \\
\hline CHEMBL1556336 & 737093 & 3.1002 & 3.15199 & 99999999997 & TRN \\
\hline CHEMBL1609158 & 737093 & 3.1002 & 3.11800 & 30000000003 & TRN \\
\hline CHEMBL1413468 & 737093 & 3.1002 & 3.0255 & TRN & \\
\hline CHEMBL1580263 & 737093 & 5.1646 & 4.8848 & TRN & \\
\hline CHEMBL1521466 & 737093 & 3.1002 & 3.0044 & TRN & \\
\hline CHEMBL1565650 & 737093 & 3.1002 & 3.2507 & TST & \\
\hline CHEMBL1492668 & 737093 & 3.1002 & 3.0246 & TRN & \\
\hline CHEMBL1445488 & 737093 & 6.9066 & 6.6594 & TRN & \\
\hline CHEMBL 2001743 & 737093 & 5.5988 & 5.789 & TRN & \\
\hline CHEMBL1527520 & 737093 & 4.9504 & 4.5614 & TST & \\
\hline CHEMBL1444510 & 737093 & 3.1002 & 3.096 & TRN & \\
\hline CHEMBL1586851 & 737093 & 3.1002 & 3.2712 & TRN & \\
\hline CHEMBL1583199 & 737093 & 4.1292 & 3.315 & TST & \\
\hline CHEMBL1492463 & 737093 & 3.1002 & 3.0377 & TRN & \\
\hline CHEMBL1536896 & 737093 & 5.7752 & 5.9807 & TRN & \\
\hline CHEMBL1533230 & 737093 & 4.7462 & 4.5323 & TST & \\
\hline CHEMBL1458847 & 737093 & 3.1002 & 3.0142 & TRN & \\
\hline CHEMBL 1445032 & 737093 & 3.1002 & 3.1099 & TRN & \\
\hline CHEMBL1416842 & 737093 & 3.1002 & 2.9532 & TRN & \\
\hline CHEMBL1492305 & 737093 & 4.9384 & 4.9143 & TRN & \\
\hline CHEMBL1479359 & 737093 & 3.1002 & 3.1285 & TRN & \\
\hline CHEMBL1535167 & 737093 & 3.1002 & 3.1574 & TRN & \\
\hline CHEMBL 1360572 & 737093 & 3.1002 & 3.0235 & TRN & \\
\hline CHEMBL3192388 & 737093 & 3.1002 & 3.1896 & TRN & \\
\hline CHEMBL1524972 & 737093 & 3.1002 & 3.1686 & TRN & \\
\hline CHEMBL1606761 & 737093 & 3.1002 & 3.0896 & TRN & \\
\hline CHEMBL1455026 & 737093 & 3.1002 & 3.0403 & TRN & \\
\hline CHEMBL1428328 & 737093 & 3.1002 & 3.0283 & TRN & \\
\hline CHEMBL1467425 & 737093 & 3.1002 & 3.1425 & TRN & \\
\hline CHEMBL1576652 & 737093 & 3.1002 & 3.0705 & TRN & \\
\hline CHEMBL1452770 & 737093 & 3.1002 & 3.1956 & TRN & \\
\hline CHEMBL3196559 & 737093 & 3.1002 & 2.9046 & TST & \\
\hline CHEMBL 1383176 & 737093 & 3.1002 & \multicolumn{2}{|c|}{3.2060000000000004} & TRN \\
\hline CHEMBL3190951 & 737093 & 5.1348 & \multicolumn{2}{|c|}{5.196000000000001} & TRN \\
\hline CHEMBL1549636 & 737093 & 3.1002 & \multicolumn{2}{|c|}{3.2430000000000003} & TRN \\
\hline CHEMBL599924 & 737093 & 4.9874 & 4.9331 & TRN & \\
\hline CHEMBL1543833 & 737093 & 3.1002 & 3.0317 & TRN & \\
\hline CHEMBL1330067 & 737093 & 3.1002 & 3.0937 & TRN & \\
\hline CHEMBL1448367 & 737093 & 3.1002 & 3.0792 & TRN & \\
\hline CHEMBL 1343390 & 737093 & 3.1002 & 3.0555 & TRN & \\
\hline CHEMBL1418466 & 737093 & 3.1002 & 3.1667 & TRN & \\
\hline CHEMBL1304417 & 737093 & 3.1002 & \multicolumn{2}{|c|}{3.0060000000000002} & TRN \\
\hline CHEMBL1529554 & 737093 & 4.9617 & 5.0428 & TRN & \\
\hline CHEMBL3193406 & 737093 & 3.1002 & 3.1764 & TRN & \\
\hline CHEMBL 3208812 & 737093 & 3.1002 & 3.1301 & TRN & \\
\hline CHEMBL1547129 & 737093 & 3.1002 & 3.0864 & TRN & \\
\hline
\end{tabular}


Supplemental Table S2.txt

\begin{tabular}{|c|c|c|c|c|}
\hline CHEMBL1484610 & 737093 & 3.1002 & 3.2642 & TRN \\
\hline CHEMBL1202929 & 737093 & 3.1002 & 3.0187 & TRN \\
\hline CHEMBL1371394 & 737093 & 3.1002 & 3.0549 & TRN \\
\hline CHEMBL1327743 & 737093 & 3.1002 & 3.0789 & TRN \\
\hline CHEMBL1337760 & 737093 & 3.1002 & 3.0782 & TST \\
\hline CHEMBL1574353 & 737093 & 3.1002 & 3.0476 & TRN \\
\hline CHEMBL1385167 & 737093 & 3.1002 & 3.0746 & TRN \\
\hline CHEMBL1557469 & 737093 & 3.1002 & 3.0238 & TRN \\
\hline CHEMBL1534728 & 737093 & 3.1002 & 3.1448 & TRN \\
\hline CHEMBL1335318 & 737093 & 3.1002 & 3.262 & TRN \\
\hline CHEMBL1393012 & 737093 & 3.1002 & 2.9682 & TRN \\
\hline CHEMBL1414751 & 737093 & 3.1002 & 3.21100 & 00000000003 \\
\hline CHEMBL1976414 & 737093 & 4.3085 & 4.3311 & TRN \\
\hline CHEMBL1499702 & 737093 & 3.1002 & 3.0112 & TRN \\
\hline CHEMBL1431216 & 737093 & 3.1002 & 3.1645 & TRN \\
\hline CHEMBL1424694 & 737093 & 5.3105 & 5.3351 & TRN \\
\hline CHEMBL1490435 & 737093 & 3.1002 & 3.0871 & TRN \\
\hline CHEMBL1443268 & 737093 & 4.8353 & 4.8964 & TRN \\
\hline CHEMBL1535241 & 737093 & 3.1002 & 3.0807 & TRN \\
\hline CHEMBL1499300 & 737093 & 3.1002 & 3.0629 & TRN \\
\hline CHEMBL1503817 & 737093 & 3.1002 & 3.033 & TRN \\
\hline CHEMBL1302136 & 737093 & 3.1002 & 3.1998 & TRN \\
\hline CHEMBL1412887 & 737093 & 3.1002 & 3.1186 & TRN \\
\hline CHEMBL1567100 & 737093 & 3.1002 & 3.0892 & TRN \\
\hline CHEMBL1341830 & 737093 & 3.1002 & 3.1093 & TST \\
\hline CHEMBL1568025 & 737093 & 3.1002 & 2.9065 & TST \\
\hline CHEMBL1486682 & 737093 & 3.1002 & 3.2023 & TST \\
\hline CHEMBL1326115 & 737093 & 3.1002 & 3.2176 & TST \\
\hline CHEMBL3209125 & 737093 & 3.1002 & 3.3539 & TST \\
\hline CHEMBL1321843 & 737093 & 3.1002 & 2.8831 & TST \\
\hline CHEMBL1439815 & 737093 & 4.914 & 5.0483 & TST \\
\hline CHEMBL1505659 & 737093 & 3.1002 & 3.0756 & TST \\
\hline CHEMBL1373137 & 737093 & 3.1002 & 2.8801 & TST \\
\hline CHEMBL1574873 & 737093 & 3.1002 & 3.4458 & TST \\
\hline CHEMBL 2000167 & 737093 & 5.4058 & 5.6625 & TST \\
\hline CHEMBL1448279 & 737093 & 3.1002 & 2.8019 & TST \\
\hline CHEMBL1340558 & 737093 & 3.1002 & 2.9749 & TST \\
\hline CHEMBL1584670 & 737093 & 3.1002 & 3.3864 & TST \\
\hline CHEMBL1441174 & 737093 & 3.1002 & 3.3146 & TST \\
\hline CHEMBL1548647 & 737093 & 3.1002 & 3.2745 & TST \\
\hline CHEMBL1429070 & 737093 & 3.1002 & 3.4609 & TST \\
\hline CHEMBL1439711 & 737093 & 3.1002 & 3.2571 & TST \\
\hline CHEMBL1458343 & 737093 & 3.1002 & 3.3833 & TST \\
\hline CHEMBL1323857 & 737093 & 3.1002 & 2.9299 & TST \\
\hline CHEMBL1309430 & 737093 & 4.1595 & 4.0101 & TST \\
\hline CHEMBL1442305 & 737093 & 3.1002 & 3.1321 & TST \\
\hline CHEMBL3195322 & 688125 & 4.9585 & 4.9861 & TRN \\
\hline CHEMBL1357072 & 688125 & 2.71 & 4.1201 & TRN \\
\hline
\end{tabular}




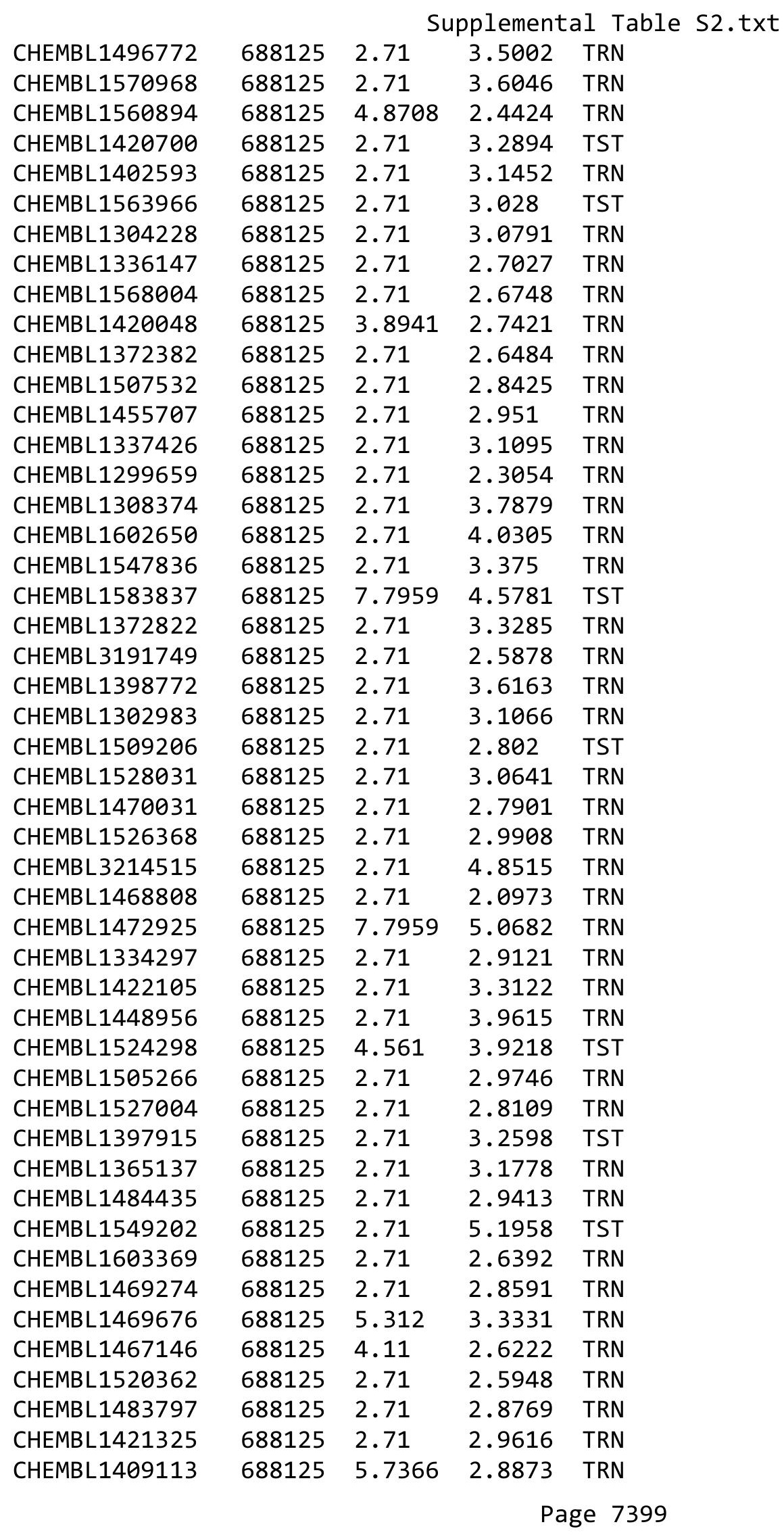




\begin{tabular}{|c|c|c|c|c|c|c|}
\hline \multicolumn{7}{|c|}{ Supplemental Table S2.txt } \\
\hline CHEMBL1479755 & 688125 & 2.71 & 2.9293 & TRN & & \\
\hline CHEMBL1378863 & 688125 & 2.71 & 5.5818 & TRN & & \\
\hline CHEMBL1487118 & 688125 & 2.71 & 3.4351 & TST & & \\
\hline CHEMBL1331586 & 688125 & 2.71 & 3.12399 & 99999999997 & TRN & \\
\hline CHEMBL 1450674 & 688125 & 2.71 & 3.4754 & TST & & \\
\hline CHEMBL1305809 & 688125 & 5.5967 & 4.4639 & TRN & & \\
\hline CHEMBL1538653 & 688125 & 2.71 & 3.2708 & TRN & & \\
\hline CHEMBL1546387 & 688125 & 2.71 & 3.1764 & TRN & & \\
\hline CHEMBL1425400 & 688125 & 2.71 & 2.4706 & TRN & & \\
\hline CHEMBL1467499 & 688125 & 2.71 & 2.4165 & TRN & & \\
\hline CHEMBL1359575 & 688125 & 5.6463 & 2.5908 & TRN & & \\
\hline CHEMBL1564136 & 688125 & 5.994 & 5.727 & TST & & \\
\hline CHEMBL1573902 & 688125 & 4.90300 & 00000000 & 005 & 00000000003 & TRN \\
\hline CHEMBL1969293 & 688125 & 2.71 & 4.1245 & TRN & & \\
\hline CHEMBL3190911 & 688125 & 6.7959 & 3.9743 & TRN & & \\
\hline CHEMBL1313917 & 688125 & 2.71 & 3.1519 & TRN & & \\
\hline CHEMBL1456627 & 688125 & 2.71 & 3.2979 & TST & & \\
\hline CHEMBL482116 & 688125 & 6.4895 & 4.1949 & TRN & & \\
\hline CHEMBL3197066 & 688125 & 2.71 & 3.2762 & TRN & & \\
\hline CHEMBL1466465 & 688125 & 2.71 & 3.2335 & TRN & & \\
\hline CHEMBL1321335 & 688125 & 6.6655 & 5.7018 & TST & & \\
\hline CHEMBL3196159 & 688125 & 2.71 & 4.0802 & TRN & & \\
\hline CHEMBL261681 & 688125 & 2.71 & 4.4239 & TRN & & \\
\hline CHEMBL1419210 & 688125 & 5.4567 & 4.23300 & 00000000005 & TRN & \\
\hline CHEMBL1320653 & 688125 & 2.71 & 3.5073 & TST & & \\
\hline CHEMBL1468663 & 688125 & 2.71 & 3.4859 & TRN & & \\
\hline CHEMBL1375594 & 688125 & 2.71 & 3.825 & TRN & & \\
\hline CHEMBL1339335 & 688125 & 2.71 & 2.8655 & TRN & & \\
\hline CHEMBL1387570 & 688125 & 2.71 & 2.7338 & TRN & & \\
\hline CHEMBL1579258 & 688125 & 7.7959 & 6.6311 & TRN & & \\
\hline CHEMBL1371445 & 688125 & 4.1078 & 3.2421 & TRN & & \\
\hline CHEMBL1324188 & 688125 & 7.7959 & 4.518 & TRN & & \\
\hline CHEMBL1372947 & 688125 & 5.5078 & 2.7119 & TRN & & \\
\hline CHEMBL1987894 & 688125 & 5.9348 & 4.6221 & TRN & & \\
\hline CHEMBL1523535 & 688125 & 2.71 & 3.6714 & TRN & & \\
\hline CHEMBL1363499 & 688125 & 2.71 & 2.8485 & TRN & & \\
\hline CHEMBL1472506 & 688125 & 2.71 & 2.5969 & TRN & & \\
\hline CHEMBL1345026 & 688125 & 2.71 & 3.4314 & TST & & \\
\hline CHEMBL1600875 & 688125 & 2.71 & 2.9218 & TRN & & \\
\hline CHEMBL1597487 & 688125 & 2.71 & 2.9351 & TRN & & \\
\hline CHEMBL1546561 & 688125 & 2.71 & 3.6294 & TRN & & \\
\hline CHEMBL1456366 & 688125 & 2.71 & 3.1106 & TRN & & \\
\hline CHEMBL1305472 & 688125 & 2.71 & 4.5109 & TRN & & \\
\hline CHEMBL1447328 & 688125 & 2.71 & 3.6037 & TRN & & \\
\hline CHEMBL1459144 & 688125 & 5.83 & 3.4852 & TRN & & \\
\hline CHEMBL1409086 & 688125 & 2.71 & 2.3501 & TRN & & \\
\hline CHEMBL1517813 & 688125 & 2.71 & 2.8297 & TRN & & \\
\hline CHEMBL1437545 & 688125 & 2.71 & 3.6962 & TRN & & \\
\hline
\end{tabular}




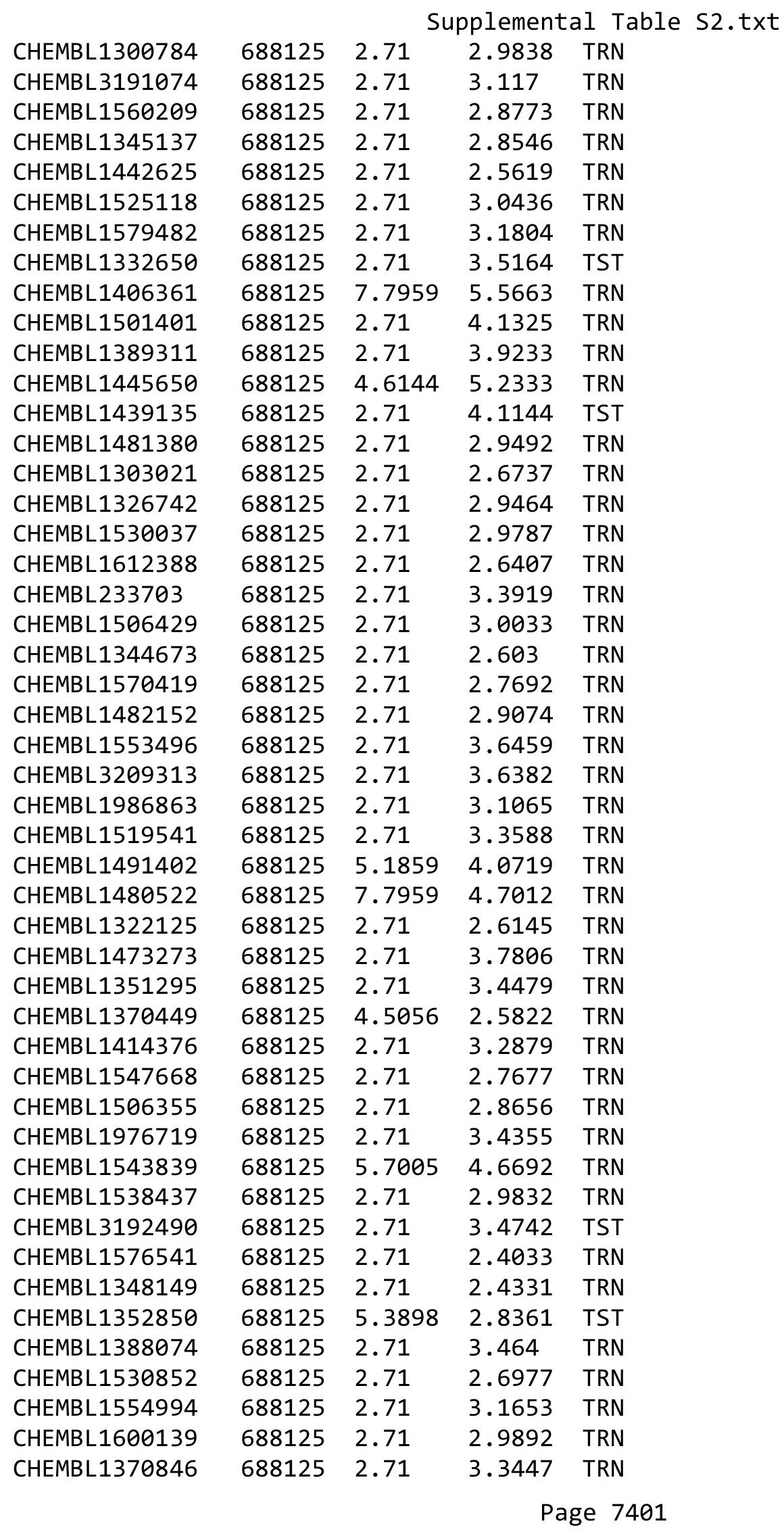




\begin{tabular}{|c|c|c|c|c|c|}
\hline \multicolumn{6}{|c|}{ Supplemental Table S2.txt } \\
\hline CHEMBL1338604 & 688125 & 2.71 & 3.1714 & TST & \\
\hline CHEMBL1304381 & 688125 & 2.71 & 2.7288 & TRN & \\
\hline CHEMBL1406454 & 688125 & 2.71 & 4.4023 & TRN & \\
\hline CHEMBL1305475 & 688125 & 6.4486 & 6.6442 & TRN & \\
\hline CHEMBL1466452 & 688125 & 2.71 & 3.8251 & TRN & \\
\hline CHEMBL1466116 & 688125 & 2.71 & 3.1176 & TST & \\
\hline CHEMBL1336413 & 688125 & 5.5945 & 3.1022 & TRN & \\
\hline CHEMBL1383312 & 688125 & 6.3675 & 5.273 & TRN & \\
\hline CHEMBL1308142 & 688125 & 2.71 & 3.1758 & TRN & \\
\hline CHEMBL3197380 & 688125 & 2.71 & 2.8664 & TRN & \\
\hline CHEMBL1495432 & 688125 & 2.71 & 3.4758 & TRN & \\
\hline CHEMBL1502976 & 688125 & 2.71 & 2.9844 & TRN & \\
\hline CHEMBL1453888 & 688125 & 2.71 & 2.73 & TRN & \\
\hline CHEMBL1612251 & 688125 & 2.71 & 3.3348 & TRN & \\
\hline CHEMBL1447558 & 688125 & 2.71 & 2.9666 & TRN & \\
\hline CHEMBL1326032 & 688125 & 2.71 & 3.2776 & TST & \\
\hline CHEMBL1567793 & 688125 & 6.6716 & 3.9567 & TRN & \\
\hline CHEMBL1583768 & 688125 & 7.7959 & 3.0605 & TRN & \\
\hline CHEMBL1399680 & 688125 & 2.71 & 3.5937 & TRN & \\
\hline CHEMBL1302231 & 688125 & 2.71 & 3.7755 & TRN & \\
\hline CHEMBL1407733 & 688125 & 2.71 & 3.8233 & TRN & \\
\hline CHEMBL1336354 & 688125 & 2.71 & 2.7367 & TRN & \\
\hline CHEMBL1560888 & 688125 & 2.71 & 3.3201 & TRN & \\
\hline CHEMBL1413239 & 688125 & 2.71 & 3.0133 & TRN & \\
\hline CHEMBL1609055 & 688125 & 2.71 & 2.60100 & 00000000004 & TRN \\
\hline CHEMBL1443946 & 688125 & 4.5379 & 3.866 & TRN & \\
\hline CHEMBL1450119 & 688125 & 5.183 & 5.614 & TRN & \\
\hline CHEMBL1348808 & 688125 & 6.6038 & 5.0566 & TRN & \\
\hline CHEMBL1462352 & 688125 & 5.5017 & 3.3801 & TST & \\
\hline CHEMBL1312515 & 688125 & 2.71 & 3.0752 & TRN & \\
\hline CHEMBL 3213844 & 688125 & 2.71 & 2.9308 & TRN & \\
\hline CHEMBL3192966 & 688125 & 2.71 & 2.9536 & TRN & \\
\hline CHEMBL 3194881 & 688125 & 2.71 & 3.5788 & TRN & \\
\hline CHEMBL175434 & 688125 & 2.71 & 3.6397 & TRN & \\
\hline CHEMBL1357281 & 688125 & 4.2989 & 3.10699 & 99999999998 & TRN \\
\hline CHEMBL1577233 & 688125 & 2.71 & 3.1158 & TRN & \\
\hline CHEMBL1587717 & 688125 & 2.71 & 3.0958 & TRN & \\
\hline CHEMBL3195883 & 688125 & 7.7959 & 4.9723 & TRN & \\
\hline CHEMBL1383664 & 688125 & 5.9439 & 2.8556 & TRN & \\
\hline CHEMBL1455289 & 688125 & 2.71 & 3.6394 & TRN & \\
\hline CHEMBL1529423 & 688125 & 2.71 & 2.75699 & 99999999997 & TRN \\
\hline CHEMBL1502300 & 688125 & 2.71 & 4.4423 & TRN & \\
\hline CHEMBL1582314 & 688125 & 4.5693 & 3.2578 & TRN & \\
\hline CHEMBL1360574 & 688125 & 2.71 & 3.8851 & TRN & \\
\hline CHEMBL3213177 & 688125 & 2.71 & 3.2488 & TST & \\
\hline CHEMBL1973921 & 688125 & 7.7959 & 5.3694 & TRN & \\
\hline CHEMBL1481697 & 688125 & 2.71 & 3.44 & TST & \\
\hline CHEMBL1501680 & 688125 & 5.1605 & 2.5396 & TRN & \\
\hline
\end{tabular}




\begin{tabular}{|c|c|c|c|c|c|}
\hline \multicolumn{6}{|c|}{ Supplemental Table S2.txt } \\
\hline CHEMBL1585892 & 688125 & 2.71 & 2.6269 & TRN & \\
\hline CHEMBL1323206 & 688125 & 4.1651 & 2.7891 & TRN & \\
\hline CHEMBL11860 & 688125 & 2.71 & 3.1394 & TST & \\
\hline CHEMBL1396600 & 688125 & 2.71 & 3.2424 & TST & \\
\hline CHEMBL1607455 & 688125 & 2.71 & 3.2509 & TRN & \\
\hline CHEMBL1417881 & 688125 & 2.71 & 2.9353 & TRN & \\
\hline CHEMBL1603901 & 688125 & 2.71 & 3.6086 & TRN & \\
\hline CHEMBL1611491 & 688125 & 2.71 & 2.7888 & TRN & \\
\hline CHEMBL1384904 & 688125 & 5.3661 & 3.6829 & TRN & \\
\hline CHEMBL3190612 & 688125 & 2.71 & 2.9356 & TRN & \\
\hline CHEMBL1320960 & 688125 & 2.71 & 3.0133 & TRN & \\
\hline CHEMBL1427868 & 688125 & 2.71 & 2.5593 & TRN & \\
\hline CHEMBL1532011 & 688125 & 2.71 & 3.5352 & TRN & \\
\hline CHEMBL1489160 & 688125 & 2.71 & 3.7498 & TRN & \\
\hline CHEMBL1385071 & 688125 & 2.71 & 3.9143 & TRN & \\
\hline CHEMBL1541150 & 688125 & 3.9195 & 3.0999 & TRN & \\
\hline CHEMBL1456180 & 688125 & 2.71 & 2.9163 & TRN & \\
\hline CHEMBL3210470 & 688125 & 2.71 & 3.2109 & TST & \\
\hline CHEMBL1331938 & 688125 & 2.71 & 2.6269 & TRN & \\
\hline CHEMBL1359577 & 688125 & 2.71 & 4.0204 & TRN & \\
\hline CHEMBL1506200 & 688125 & 2.71 & 3.0413 & TRN & \\
\hline CHEMBL580955 & 688125 & 5.7886 & 5.5113 & TRN & \\
\hline CHEMBL1345922 & 688125 & 2.71 & 2.7264 & TRN & \\
\hline CHEMBL1383630 & 688125 & 2.71 & 2.4122 & TRN & \\
\hline CHEMBL1335758 & 688125 & 2.71 & 3.0031 & TRN & \\
\hline CHEMBL1404192 & 688125 & 2.71 & 2.8196 & TRN & \\
\hline CHEMBL1578529 & 688125 & 2.71 & 2.3756 & TRN & \\
\hline CHEMBL1360097 & 688125 & 2.71 & 2.7843 & TRN & \\
\hline CHEMBL1391829 & 688125 & 2.71 & 3.0799 & TRN & \\
\hline CHEMBL1425247 & 688125 & 2.71 & 3.3627 & TST & \\
\hline CHEMBL3190218 & 688125 & 4.9911 & 3.0122 & TRN & \\
\hline CHEMBL1528362 & 688125 & 4.6434 & 3.8038 & TRN & \\
\hline CHEMBL1504155 & 688125 & 2.71 & 3.4585 & TRN & \\
\hline CHEMBL405317 & 688125 & 7.7959 & 6.5297 & TRN & \\
\hline CHEMBL1452338 & 688125 & 2.71 & 3.4489 & TRN & \\
\hline CHEMBL1391233 & 688125 & 2.71 & 3.9035 & TST & \\
\hline CHEMBL1506418 & 688125 & 2.71 & 3.6251 & TRN & \\
\hline CHEMBL1339049 & 688125 & 2.71 & 2.6994 & TRN & \\
\hline CHEMBL492468 & 688125 & 4.8704 & 3.2986 & TST & \\
\hline CHEMBL1352995 & 688125 & 2.71 & 2.3717 & TRN & \\
\hline CHEMBL1533283 & 688125 & 2.71 & 2.8989 & TRN & \\
\hline CHEMBL1587656 & 688125 & 2.71 & 3.1864 & TST & \\
\hline CHEMBL1454706 & 688125 & 5.364 & 3.24399 & 99999999998 & TRN \\
\hline CHEMBL1550315 & 688125 & 2.71 & 3.2958 & TRN & \\
\hline CHEMBL1526465 & 688125 & 2.71 & 3.4409 & TRN & \\
\hline CHEMBL1884996 & 688125 & 7.7959 & 6.8413 & TST & \\
\hline CHEMBL3198613 & 688125 & 2.71 & 3.7691 & TRN & \\
\hline CHEMBL1534737 & 688125 & 2.71 & 3.0796 & TRN & \\
\hline
\end{tabular}




\begin{tabular}{|c|c|c|c|c|c|}
\hline & & \multicolumn{4}{|c|}{ Supplemental Table S2.txt } \\
\hline CHEMBL1479637 & 688125 & 2.71 & 2.3725 & TRN & \\
\hline CHEMBL1549657 & 688125 & 5.2013 & 3.641 & TRN & \\
\hline CHEMBL1344136 & 688125 & 2.71 & 3.6276 & TRN & \\
\hline CHEMBL1361063 & 688125 & 2.71 & 2.8883 & TRN & \\
\hline CHEMBL1410226 & 688125 & 2.71 & 2.5332 & TRN & \\
\hline CHEMBL1480752 & 688125 & 2.71 & 3.0152 & TRN & \\
\hline CHEMBL1490624 & 688125 & 2.71 & 3.0347 & TRN & \\
\hline CHEMBL1516521 & 688125 & 2.71 & 2.8091 & TRN & \\
\hline CHEMBL2004141 & 688125 & 7.7959 & 7.0744 & TRN & \\
\hline CHEMBL1462339 & 688125 & 2.71 & 3.09 & TRN & \\
\hline CHEMBL1313171 & 688125 & 2.71 & 3.385 & TST & \\
\hline CHEMBL1367081 & 688125 & 2.71 & \multicolumn{2}{|c|}{3.2110000000000003} & TRN \\
\hline CHEMBL1464525 & 688125 & 5.1161 & 3.1613 & TST & \\
\hline CHEMBL1318266 & 688125 & 2.71 & 3.4853 & TRN & \\
\hline CHEMBL1457803 & 688125 & 5.3177 & 4.8675 & TRN & \\
\hline CHEMBL1492196 & 688125 & 2.71 & 2.6747 & TRN & \\
\hline CHEMBL1349671 & 688125 & 2.71 & 2.3866 & TRN & \\
\hline CHEMBL1549565 & 688125 & 2.71 & 3.2778 & TRN & \\
\hline CHEMBL1462745 & 688125 & 6.4776 & 4.3679 & TRN & \\
\hline CHEMBL1463422 & 688125 & 2.71 & 3.5877 & TRN & \\
\hline CHEMBL1380679 & 688125 & 2.71 & 3.1095 & TRN & \\
\hline CHEMBL1494025 & 688125 & 2.71 & 3.1166 & TRN & \\
\hline CHEMBL1374630 & 688125 & 2.71 & 2.7971 & TRN & \\
\hline CHEMBL1439146 & 688125 & 2.71 & 3.11 & TRN & \\
\hline CHEMBL1475426 & 688125 & 2.71 & 2.8223 & TRN & \\
\hline CHEMBL1335030 & 688125 & 5.64 & 5.3796 & TRN & \\
\hline CHEMBL1417851 & 688125 & 7.7959 & 7.9244 & TRN & \\
\hline CHEMBL1428445 & 688125 & 2.71 & 4.0617 & TRN & \\
\hline CHEMBL1452635 & 688125 & 2.71 & \multicolumn{2}{|c|}{2.8789999999999996} & TRN \\
\hline CHEMBL1341434 & 688125 & 2.71 & 3.2637 & TRN & \\
\hline CHEMBL1583698 & 688125 & 4.7661 & 3.2141 & TRN & \\
\hline CHEMBL1537268 & 688125 & 2.71 & 2.9586 & TRN & \\
\hline CHEMBL596847 & 688125 & 2.71 & \multicolumn{2}{|c|}{3.3819999999999997} & TRN \\
\hline CHEMBL3193153 & 688125 & 4.356 & 3.3186 & TRN & \\
\hline CHEMBL1422716 & 688125 & 2.71 & 3.7148 & TRN & \\
\hline CHEMBL1502321 & 688125 & 2.71 & 3.0526 & TRN & \\
\hline CHEMBL1400375 & 688125 & 4.9844 & 3.1689 & TRN & \\
\hline CHEMBL1502138 & 688125 & 2.71 & 2.4932 & TRN & \\
\hline CHEMBL1374517 & 688125 & 2.71 & 4.1304 & TRN & \\
\hline CHEMBL1517438 & 688125 & 2.71 & 3.5712 & TRN & \\
\hline CHEMBL1534209 & 688125 & 4.4454 & 3.8547 & TRN & \\
\hline CHEMBL1612880 & 688125 & 5.9169 & 3.4221 & TRN & \\
\hline CHEMBL1438225 & 688125 & 2.71 & 3.6843 & TRN & \\
\hline CHEMBL1454126 & 688125 & 2.71 & 2.7745 & TRN & \\
\hline CHEMBL1468348 & 688125 & 2.71 & 3.358 & TRN & \\
\hline CHEMBL1566610 & 688125 & 6.0088 & \multicolumn{2}{|c|}{5.9239999999999995} & TST \\
\hline CHEMBL1469594 & 688125 & 4.5109 & 3.5824 & TRN & \\
\hline CHEMBL1337869 & 688125 & 2.71 & 2.6801 & TRN & \\
\hline
\end{tabular}




\begin{tabular}{|c|c|c|c|c|c|}
\hline \multirow[b]{2}{*}{ CHEMBL1358722 } & \multicolumn{5}{|c|}{ Supplemental Table S2.txt } \\
\hline & 688125 & 6.1805 & 6.8719 & TST & \\
\hline CHEMBL1597141 & 688125 & 2.71 & 3.1043 & TRN & \\
\hline CHEMBL1344836 & 688125 & 2.71 & 2.9472 & TRN & \\
\hline CHEMBL1340946 & 688125 & 2.71 & 2.8946 & TRN & \\
\hline CHEMBL1360076 & 688125 & 2.71 & 3.0268 & TRN & \\
\hline CHEMBL1343822 & 688125 & 2.71 & 3.7295 & TRN & \\
\hline CHEMBL1312395 & 688125 & 2.71 & 3.8074 & TRN & \\
\hline CHEMBL1359305 & 688125 & 2.71 & 2.2282 & TRN & \\
\hline CHEMBL1447967 & 688125 & 2.71 & 2.9145 & TRN & \\
\hline CHEMBL1458120 & 688125 & 4.3318 & 2.79600 & 00000000003 & TRN \\
\hline CHEMBL1503545 & 688125 & 2.71 & 2.9724 & TRN & \\
\hline CHEMBL1373833 & 688125 & 2.71 & 2.2214 & TRN & \\
\hline CHEMBL1446426 & 688125 & 2.71 & 2.6563 & TRN & \\
\hline CHEMBL1530687 & 688125 & 2.71 & 4.4341 & TRN & \\
\hline CHEMBL1355100 & 688125 & 2.71 & 2.9597 & TRN & \\
\hline CHEMBL1353441 & 688125 & 2.71 & 2.7446 & TRN & \\
\hline CHEMBL3193019 & 688125 & 2.71 & 2.4287 & TRN & \\
\hline CHEMBL1420471 & 688125 & 2.71 & 2.6088 & TRN & \\
\hline CHEMBL1404783 & 688125 & 4.4917 & 2.688 & TRN & \\
\hline CHEMBL1611243 & 688125 & 2.71 & 3.1117 & TRN & \\
\hline CHEMBL1507154 & 688125 & 2.71 & 2.8502 & TRN & \\
\hline CHEMBL1600933 & 688125 & $4.0760 e$ & 00000000 & 3.3554 & TRN \\
\hline CHEMBL1445125 & 688125 & 2.71 & 3.0139 & TRN & \\
\hline CHEMBL1450355 & 688125 & 2.71 & 2.9592 & TRN & \\
\hline CHEMBL1460857 & 688125 & 2.71 & 3.2288 & TRN & \\
\hline CHEMBL1534261 & 688125 & 2.71 & 3.2467 & TST & \\
\hline CHEMBL1543842 & 688125 & 2.71 & 2.5068 & TRN & \\
\hline CHEMBL3193340 & 688125 & 2.71 & 4.4294 & TRN & \\
\hline CHEMBL3144894 & 688125 & 2.71 & 2.6808 & TRN & \\
\hline CHEMBL1578610 & 688125 & 2.71 & 2.303 & TRN & \\
\hline CHEMBL1426318 & 688125 & 4.471 & 3.8903 & TST & \\
\hline CHEMBL1491962 & 688125 & 2.71 & 3.4918 & TRN & \\
\hline CHEMBL1339283 & 688125 & 7.7959 & 4.5055 & TRN & \\
\hline CHEMBL1579278 & 688125 & 2.71 & 2.88100 & 00000000002 & TRN \\
\hline CHEMBL1490741 & 688125 & 2.71 & 2.5495 & TRN & \\
\hline CHEMBL1311940 & 688125 & 2.71 & 2.8091 & TRN & \\
\hline CHEMBL1557727 & 688125 & 2.71 & 3.7191 & TRN & \\
\hline CHEMBL1448474 & 688125 & 4.6871 & 3.8356 & TRN & \\
\hline CHEMBL1592545 & 688125 & 2.71 & 3.2726 & TRN & \\
\hline CHEMBL1339678 & 688125 & 7.7959 & 5.1625 & TRN & \\
\hline CHEMBL1314168 & 688125 & 2.71 & 2.7181 & TST & \\
\hline CHEMBL1546217 & 688125 & 2.71 & 3.455 & TST & \\
\hline CHEMBL1400758 & 688125 & 2.71 & 3.57800 & 00000000003 & TST \\
\hline CHEMBL1327231 & 688125 & 2.71 & 3.3961 & TST & \\
\hline CHEMBL1427700 & 688125 & 2.71 & 2.70600 & 00000000004 & TRN \\
\hline CHEMBL1328160 & 688125 & 4.511 & 3.2279 & TRN & \\
\hline CHEMBL1469656 & 688125 & 2.71 & 2.9572 & TRN & \\
\hline CHEMBL1574835 & 688125 & 2.71 & 2.884 & TRN & \\
\hline
\end{tabular}




\begin{tabular}{|c|c|c|c|c|c|}
\hline \multicolumn{6}{|c|}{ Supplemental Table S2.txt } \\
\hline CHEMBL1569296 & 688125 & 2.71 & 3.0692 & TRN & \\
\hline CHEMBL1545640 & 688125 & 2.71 & 3.7358 & TST & \\
\hline CHEMBL1563256 & 688125 & 2.71 & 2.6194 & TRN & \\
\hline CHEMBL535079 & 688125 & 2.71 & 3.93899 & 99999999996 & TRN \\
\hline CHEMBL1369520 & 688125 & 2.71 & 2.7328 & TRN & \\
\hline CHEMBL1392570 & 688125 & 5.9562 & 3.9143 & TRN & \\
\hline CHEMBL1313222 & 688125 & 2.71 & 3.1619 & TRN & \\
\hline CHEMBL598263 & 688125 & 6.6144 & 5.4332 & TRN & \\
\hline CHEMBL1381457 & 688125 & 2.71 & 3.073 & TST & \\
\hline CHEMBL1383150 & 688125 & 2.71 & 2.1662 & TRN & \\
\hline CHEMBL1555755 & 688125 & 2.71 & 3.1848 & TST & \\
\hline CHEMBL1364784 & 688125 & 2.71 & 3.4104 & TRN & \\
\hline CHEMBL1420030 & 688125 & 2.71 & 2.7158 & TRN & \\
\hline CHEMBL1490471 & 688125 & 2.71 & 3.4481 & TRN & \\
\hline CHEMBL1311847 & 688125 & 2.71 & 3.057 & TRN & \\
\hline CHEMBL1303841 & 688125 & 2.71 & 3.6964 & TRN & \\
\hline CHEMBL1432250 & 688125 & 2.71 & 2.9802 & TRN & \\
\hline CHEMBL1576734 & 688125 & 2.71 & 2.5154 & TRN & \\
\hline CHEMBL1556496 & 688125 & 2.71 & 3.1066 & TRN & \\
\hline CHEMBL1593070 & 688125 & 2.71 & 3.1772 & TRN & \\
\hline CHEMBL1569998 & 688125 & 2.71 & 3.1389 & TRN & \\
\hline CHEMBL1356935 & 688125 & 2.71 & 3.3128 & TST & \\
\hline CHEMBL1523524 & 688125 & 2.71 & 2.824 & TRN & \\
\hline CHEMBL1549506 & 688125 & 2.71 & 3.1567 & TRN & \\
\hline CHEMBL1346526 & 688125 & 2.71 & 2.825 & TRN & \\
\hline CHEMBL1508788 & 688125 & 2.71 & 4.2326 & TRN & \\
\hline CHEMBL1340742 & 688125 & 2.71 & 3.1775 & TRN & \\
\hline CHEMBL1543238 & 688125 & 5.3357 & 5.2287 & TRN & \\
\hline CHEMBL1351908 & 688125 & 7.7959 & 5.6981 & TRN & \\
\hline CHEMBL1321538 & 688125 & 5.8041 & 3.37399 & 99999999997 & TRN \\
\hline CHEMBL1534883 & 688125 & 2.71 & 3.8414 & TRN & \\
\hline CHEMBL1550735 & 688125 & 2.71 & 2.4187 & TRN & \\
\hline CHEMBL1362005 & 688125 & 2.71 & 3.1716 & TRN & \\
\hline CHEMBL1447468 & 688125 & 2.71 & 2.3463 & TRN & \\
\hline CHEMBL1319674 & 688125 & 2.71 & 2.82 & TRN & \\
\hline CHEMBL1352115 & 688125 & 2.71 & 3.0178 & TRN & \\
\hline CHEMBL1405663 & 688125 & 2.71 & 2.9099 & TRN & \\
\hline CHEMBL1411456 & 688125 & 2.71 & 4.4203 & TRN & \\
\hline CHEMBL3197813 & 688125 & 2.71 & 3.1229 & TRN & \\
\hline CHEMBL1375028 & 688125 & 2.71 & 2.8168 & TRN & \\
\hline CHEMBL1404435 & 688125 & 2.71 & 3.0887 & TRN & \\
\hline CHEMBL1584992 & 688125 & 2.71 & 3.2084 & TRN & \\
\hline CHEMBL1492648 & 688125 & 5.0534 & 4.1737 & TRN & \\
\hline CHEMBL1508309 & 688125 & 2.71 & 2.441 & TRN & \\
\hline CHEMBL1447868 & 688125 & 2.71 & 3.1175 & TST & \\
\hline CHEMBL1454901 & 688125 & 2.71 & 2.9446 & TRN & \\
\hline CHEMBL1359867 & 688125 & 2.71 & 3.2834 & TST & \\
\hline CHEMBL1392789 & 688125 & 2.71 & 2.2587 & TRN & \\
\hline
\end{tabular}




\begin{tabular}{|c|c|c|c|c|c|}
\hline \multirow[b]{2}{*}{ CHEMBL3193873 } & \multicolumn{5}{|c|}{ Supplemental Table S2.txt } \\
\hline & 688125 & 7.7959 & 5.5827 & TRN & \\
\hline CHEMBL1525368 & 688125 & 2.71 & 3.3095 & TRN & \\
\hline CHEMBL1480134 & 688125 & 2.71 & 3.2774 & TRN & \\
\hline CHEMBL1471341 & 688125 & 5.2859 & 4.4314 & TRN & \\
\hline CHEMBL1492586 & 688125 & 2.71 & 3.0004 & TRN & \\
\hline CHEMBL1399879 & 688125 & 2.71 & 2.6572 & TRN & \\
\hline CHEMBL1576748 & 688125 & 2.71 & 2.9411 & TRN & \\
\hline CHEMBL1439938 & 688125 & 2.71 & 4.4058 & TRN & \\
\hline CHEMBL1598220 & 688125 & 2.71 & 3.0972 & TRN & \\
\hline CHEMBL1422753 & 688125 & 2.71 & 3.2122 & TRN & \\
\hline CHEMBL3190926 & 688125 & 2.71 & 4.1221 & TST & \\
\hline CHEMBL3208468 & 688125 & 2.71 & 3.4562 & TST & \\
\hline CHEMBL1366042 & 688125 & 2.71 & 3.5962 & TRN & \\
\hline CHEMBL1479397 & 688125 & 2.71 & 2.1332 & TRN & \\
\hline CHEMBL1400757 & 688125 & 2.71 & 2.8665 & TRN & \\
\hline CHEMBL3190224 & 688125 & 2.71 & 4.5271 & TRN & \\
\hline CHEMBL1535731 & 688125 & 2.71 & 3.0266 & TRN & \\
\hline CHEMBL1337518 & 688125 & 5.2292 & 3.7464 & TRN & \\
\hline CHEMBL1402270 & 688125 & 2.71 & 2.8161 & TRN & \\
\hline CHEMBL 3190025 & 688125 & 2.71 & 3.2994 & TRN & \\
\hline CHEMBL 1386484 & 688125 & 2.71 & 3.9246 & TRN & \\
\hline CHEMBL1519120 & 688125 & 2.71 & 2.8104 & TRN & \\
\hline CHEMBL1352857 & 688125 & 2.71 & 3.2682 & TRN & \\
\hline CHEMBL1476596 & 688125 & 2.71 & 3.5047 & TRN & \\
\hline CHEMBL1561767 & 688125 & 5.9776 & 4.7825 & TRN & \\
\hline CHEMBL610198 & 688125 & 5.2638 & 4.2695 & TRN & \\
\hline CHEMBL1429343 & 688125 & 2.71 & 2.51 & TRN & \\
\hline CHEMBL1601639 & 688125 & 2.71 & 3.7525 & TRN & \\
\hline CHEMBL1597710 & 688125 & 2.71 & 3.1933 & TRN & \\
\hline CHEMBL1471633 & 688125 & 2.71 & 3.6126 & TRN & \\
\hline CHEMBL1384872 & 688125 & 2.71 & 3.1029 & TRN & \\
\hline CHEMBL1483643 & 688125 & 2.71 & 2.4988 & TRN & \\
\hline CHEMBL3196040 & 688125 & 2.71 & 2.6532 & TRN & \\
\hline CHEMBL1572900 & 688125 & 2.71 & 2.6486 & TST & \\
\hline CHEMBL 3214022 & 688125 & 2.71 & 4.0835 & TRN & \\
\hline CHEMBL1384838 & 688125 & 2.71 & 3.5593 & TST & \\
\hline CHEMBL1545507 & 688125 & 2.71 & 3.1903 & TRN & \\
\hline CHEMBL1507476 & 688125 & 2.71 & 3.0144 & TST & \\
\hline CHEMBL1412676 & 688125 & 2.71 & 2.8797 & TRN & \\
\hline CHEMBL1322078 & 688125 & 5.5293 & 3.8799 & TRN & \\
\hline CHEMBL191750 & 688125 & 5.1658 & 3.7398 & TRN & \\
\hline CHEMBL1349167 & 688125 & 2.71 & 2.6976 & TST & \\
\hline CHEMBL1525419 & 688125 & 2.71 & 3.9458 & TRN & \\
\hline CHEMBL1564451 & 688125 & 2.71 & 2.6817 & TRN & \\
\hline CHEMBL1311739 & 688125 & 4.7908 & 2.4356 & TRN & \\
\hline CHEMBL1391630 & 688125 & 6.3565 & 3.2414 & TRN & \\
\hline CHEMBL1576841 & 688125 & 2.71 & 3.6342 & TRN & \\
\hline CHEMBL1323442 & 688125 & 2.71 & 3.48100 & 00000000003 & TRN \\
\hline & & & & e 7407 & \\
\hline
\end{tabular}




\begin{tabular}{|c|c|c|c|c|c|}
\hline \multicolumn{6}{|c|}{ Supplemental Table S2.txt } \\
\hline CHEMBL1322580 & 688125 & 2.71 & 3.5189 & TST & \\
\hline CHEMBL1379074 & 688125 & 3.8467 & 2.6407 & TRN & \\
\hline CHEMBL1468545 & 688125 & 2.71 & 2.8952 & TRN & \\
\hline CHEMBL1448863 & 688125 & 2.71 & 3.2715 & TRN & \\
\hline CHEMBL1320422 & 688125 & 2.71 & 2.6324 & TRN & \\
\hline CHEMBL1448319 & 688125 & 4.4511 & 3.2181 & TST & \\
\hline CHEMBL 2002162 & 688125 & 5.0913 & 4.5279 & TST & \\
\hline CHEMBL1300687 & 688125 & 2.71 & 3.0714 & TST & \\
\hline CHEMBL 1325326 & 688125 & 2.71 & 3.2886 & TRN & \\
\hline CHEMBL1325943 & 688125 & 6.6778 & 5.4473 & TRN & \\
\hline CHEMBL1318363 & 688125 & 2.71 & 2.7014 & TRN & \\
\hline CHEMBL1454536 & 688125 & 2.71 & 3.0195 & TRN & \\
\hline CHEMBL1418996 & 688125 & 2.71 & 2.63100 & 00000000002 & TRN \\
\hline CHEMBL1995296 & 688125 & 2.71 & 3.2807 & TRN & \\
\hline CHEMBL1544131 & 688125 & 5.2538 & 4.9398 & TRN & \\
\hline CHEMBL3198633 & 688125 & 7.7959 & 5.3015 & TST & \\
\hline CHEMBL1566681 & 688125 & 2.71 & 2.5489 & TRN & \\
\hline CHEMBL1328336 & 688125 & 2.71 & 3.335 & TRN & \\
\hline CHEMBL 1467184 & 688125 & 6.5406 & 4.7748 & TRN & \\
\hline CHEMBL1337346 & 688125 & 2.71 & 3.1754 & TST & \\
\hline CHEMBL1419189 & 688125 & 2.71 & 4.2807 & TRN & \\
\hline CHEMBL1549938 & 688125 & 2.71 & 2.9304 & TRN & \\
\hline CHEMBL1456170 & 688125 & 2.71 & 2.98 & TRN & \\
\hline CHEMBL1345432 & 688125 & 2.71 & 3.2829 & TRN & \\
\hline CHEMBL3210058 & 688125 & 2.71 & 2.7747 & TST & \\
\hline CHEMBL1503466 & 688125 & 2.71 & 3.3095 & TRN & \\
\hline CHEMBL1492892 & 688125 & 2.71 & 2.5881 & TRN & \\
\hline CHEMBL1352938 & 688125 & 2.71 & 3.0674 & TRN & \\
\hline CHEMBL1552760 & 688125 & 2.71 & 3.1165 & TRN & \\
\hline CHEMBL1383420 & 688125 & 2.71 & 2.7112 & TRN & \\
\hline CHEMBL1983871 & 688125 & 2.71 & 3.7704 & TRN & \\
\hline CHEMBL1328401 & 688125 & 4.0249 & 2.7165 & TRN & \\
\hline CHEMBL1471943 & 688125 & 2.71 & 3.5523 & TST & \\
\hline CHEMBL1584730 & 688125 & 2.71 & 3.5553 & TRN & \\
\hline CHEMBL1321638 & 688125 & 5.1591 & 5.386 & TRN & \\
\hline CHEMBL1533635 & 688125 & 2.71 & 4.1114 & TRN & \\
\hline CHEMBL1491411 & 688125 & 2.71 & 2.1403 & TRN & \\
\hline CHEMBL1534546 & 688125 & 5.2452 & 4.5847 & TRN & \\
\hline CHEMBL1430727 & 688125 & 2.71 & 3.1587 & TRN & \\
\hline CHEMBL1412929 & 688125 & 4.0651 & 3.2713 & TRN & \\
\hline CHEMBL3194377 & 688125 & 2.71 & 3.0353 & TRN & \\
\hline CHEMBL1336545 & 688125 & 2.71 & 3.9172 & TST & \\
\hline CHEMBL1330034 & 688125 & 2.71 & 2.7166 & TRN & \\
\hline CHEMBL1313954 & 688125 & 4.8443 & 3.3827 & TRN & \\
\hline CHEMBL1514548 & 688125 & 2.71 & 3.678 & TRN & \\
\hline CHEMBL1319926 & 688125 & 2.71 & 2.9591 & TRN & \\
\hline CHEMBL1307366 & 688125 & 2.71 & 3.696 & TRN & \\
\hline CHEMBL1334530 & 688125 & 2.71 & 2.8793 & TRN & \\
\hline
\end{tabular}




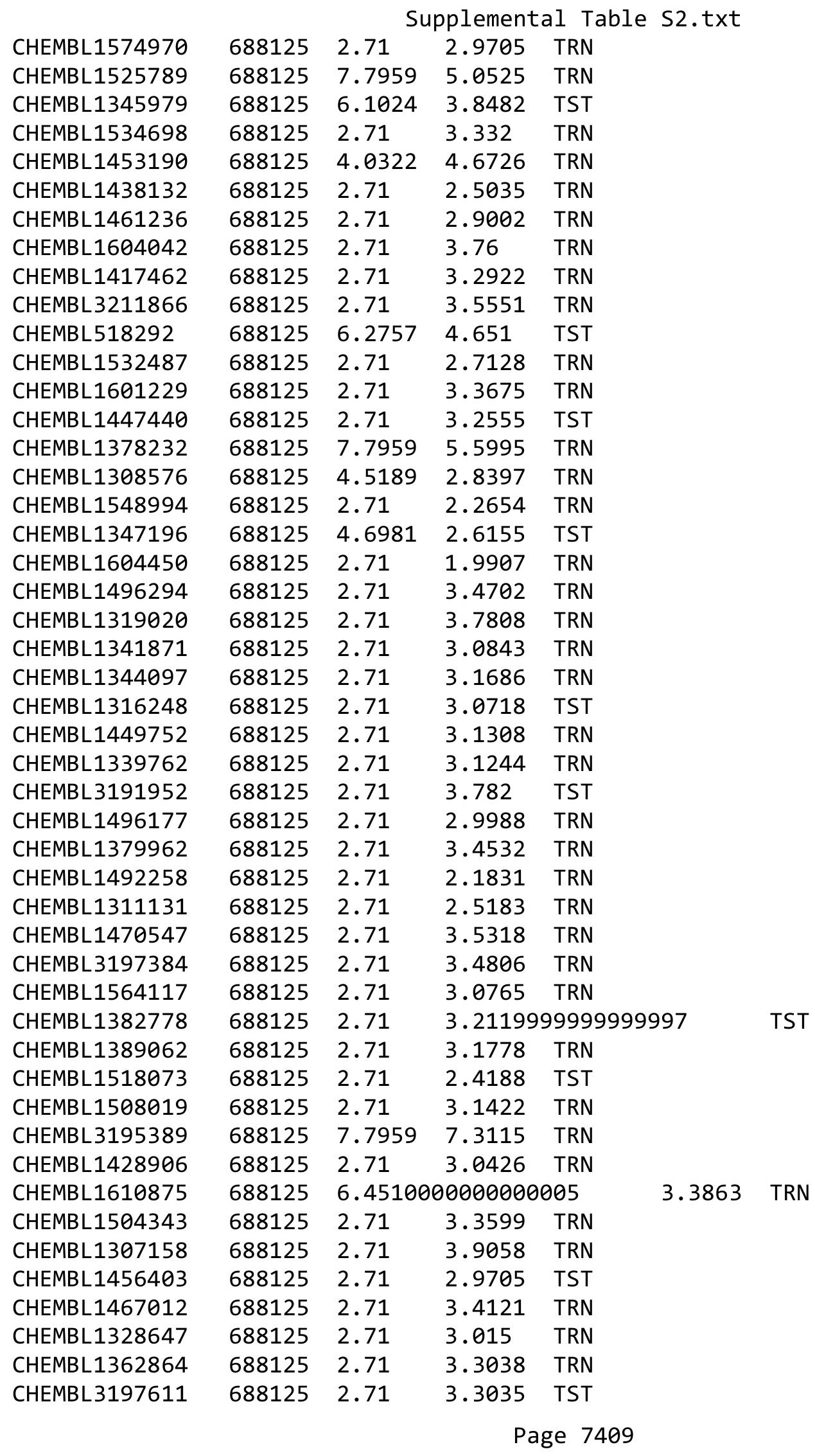




\begin{tabular}{|c|c|c|c|c|c|}
\hline & & \multicolumn{4}{|c|}{ Supplemental Table S2.txt } \\
\hline CHEMBL3208864 & 688125 & 2.71 & 2.5852 & TRN & \\
\hline CHEMBL1596909 & 688125 & 2.71 & 3.4734 & TRN & \\
\hline CHEMBL1601924 & 688125 & 2.71 & 2.6732 & TRN & \\
\hline CHEMBL1333070 & 688125 & 2.71 & 3.2257 & TST & \\
\hline CHEMBL1584171 & 688125 & 2.71 & 4.045 & TRN & \\
\hline CHEMBL1324674 & 688125 & 2.71 & 3.592 & TST & \\
\hline CHEMBL1335783 & 688125 & 2.71 & 3.3607 & TST & \\
\hline CHEMBL1372208 & 688125 & 2.71 & 2.113 & TRN & \\
\hline CHEMBL1521325 & 688125 & 2.71 & 2.762 & TST & \\
\hline CHEMBL1468610 & 688125 & 2.71 & 2.8727 & TRN & \\
\hline CHEMBL1433383 & 688125 & 2.71 & 2.7216 & TRN & \\
\hline CHEMBL1536289 & 688125 & 2.71 & 3.1725 & TRN & \\
\hline CHEMBL1484638 & 688125 & 2.71 & 2.662 & TRN & \\
\hline CHEMBL1301719 & 688125 & 2.71 & 2.6522 & TRN & \\
\hline CHEMBL1448374 & 688125 & 4.4217 & 3.5061 & TRN & \\
\hline CHEMBL1519531 & 688125 & 2.71 & 3.16600 & 00000000004 & TST \\
\hline CHEMBL1326986 & 688125 & 2.71 & 2.2594 & TRN & \\
\hline CHEMBL1416532 & 688125 & 2.71 & 2.5232 & TRN & \\
\hline CHEMBL1302130 & 688125 & 2.71 & 4.1324 & TRN & \\
\hline CHEMBL1541615 & 688125 & 2.71 & 3.0387 & TRN & \\
\hline CHEMBL1347039 & 688125 & 2.71 & 2.8653 & TRN & \\
\hline CHEMBL1603156 & 688125 & 2.71 & 2.7323 & TRN & \\
\hline CHEMBL3192873 & 688125 & 5.7506 & 5.6077 & TRN & \\
\hline CHEMBL1478850 & 688125 & 2.71 & 3.4201 & TRN & \\
\hline CHEMBL1461634 & 688125 & 2.71 & 2.9939 & TRN & \\
\hline CHEMBL3196722 & 688125 & 2.71 & 3.5048 & TST & \\
\hline CHEMBL1597561 & 688125 & 7.7959 & 6.4723 & TRN & \\
\hline CHEMBL1389672 & 688125 & 2.71 & 2.6242 & TRN & \\
\hline CHEMBL1534472 & 688125 & 2.71 & 3.38 & TST & \\
\hline CHEMBL1490222 & 688125 & 6.0405 & 5.768 & TRN & \\
\hline CHEMBL1559551 & 688125 & 2.71 & 3.0141 & TRN & \\
\hline CHEMBL1531245 & 688125 & 5.5385 & 3.931 & TRN & \\
\hline CHEMBL1408509 & 688125 & 2.71 & 2.4391 & TRN & \\
\hline CHEMBL1429542 & 688125 & 2.71 & 2.7479 & TRN & \\
\hline CHEMBL1488314 & 688125 & 2.71 & 2.9915 & TRN & \\
\hline CHEMBL3192102 & 688125 & 2.71 & 3.2891 & TRN & \\
\hline CHEMBL1326180 & 688125 & 2.71 & 2.8553 & TST & \\
\hline CHEMBL1327865 & 688125 & 2.71 & 2.9526 & TRN & \\
\hline CHEMBL273103 & 688125 & 2.71 & 3.9679 & TRN & \\
\hline CHEMBL1340084 & 688125 & 2.71 & 2.9767 & TRN & \\
\hline CHEMBL1517330 & 688125 & 2.71 & 3.6892 & TRN & \\
\hline CHEMBL1429372 & 688125 & 4.5854 & 3.0379 & TRN & \\
\hline CHEMBL1364999 & 688125 & 5.1971 & 3.7729 & TST & \\
\hline CHEMBL1309252 & 688125 & 2.71 & 2.0637 & TRN & \\
\hline CHEMBL1542627 & 688125 & 2.71 & 3.5562 & TRN & \\
\hline CHEMBL255067 & 688125 & 2.71 & 4.0279 & TRN & \\
\hline CHEMBL1431915 & 688125 & 4.8308 & 2.7435 & TRN & \\
\hline CHEMBL1508531 & 688125 & 2.71 & 2.988 & TRN & \\
\hline
\end{tabular}




\begin{tabular}{|c|c|c|c|c|c|c|}
\hline & & \multicolumn{5}{|c|}{ Supplemental Table S2.txt } \\
\hline CHEMBL1549331 & 688125 & 2.71 & 2.9276 & TRN & & \\
\hline CHEMBL 1482004 & 688125 & 4.3849 & 3.5729 & TST & & \\
\hline CHEMBL3198913 & 688125 & 2.71 & 3.2304 & TRN & & \\
\hline CHEMBL1426927 & 688125 & 2.71 & 3.2069 & TRN & & \\
\hline CHEMBL 3193487 & 688125 & 2.71 & 3.4177 & TRN & & \\
\hline CHEMBL1570517 & 688125 & 2.71 & 3.4185 & TST & & \\
\hline CHEMBL1320415 & 688125 & 2.71 & 3.165 & TRN & & \\
\hline CHEMBL1311632 & 688125 & 2.71 & 4.3568 & TST & & \\
\hline CHEMBL1504631 & 688125 & 2.71 & 3.33100 & 000000000 & 04 & TST \\
\hline CHEMBL1411322 & 688125 & 2.71 & 2.7881 & TRN & & \\
\hline CHEMBL1593768 & 688125 & 2.71 & 2.499 & TRN & & \\
\hline CHEMBL1596826 & 688125 & 2.71 & 3.2894 & TRN & & \\
\hline CHEMBL1448527 & 688125 & 2.71 & 3.0813 & TRN & & \\
\hline CHEMBL1399938 & 688125 & 5.5364 & 3.7669 & TRN & & \\
\hline CHEMBL1448357 & 688125 & 2.71 & 4.0434 & TRN & & \\
\hline CHEMBL1506696 & 688125 & 2.71 & 4.0139 & TRN & & \\
\hline CHEMBL3190832 & 688125 & 2.71 & 3.6403 & TRN & & \\
\hline CHEMBL1340981 & 688125 & 2.71 & 2.9031 & TRN & & \\
\hline CHEMBL1319810 & 688125 & 5.521 & 4.644 & TRN & & \\
\hline CHEMBL1439010 & 688125 & 2.71 & 2.8099 & TRN & & \\
\hline CHEMBL1365471 & 688125 & 5.8887 & 4.2151 & TRN & & \\
\hline CHEMBL1427279 & 688125 & 5.3223 & 4.978 & TRN & & \\
\hline CHEMBL1438842 & 688125 & \multicolumn{3}{|c|}{6.617999999999999} & 3.5341 & TRN \\
\hline CHEMBL1366262 & 688125 & 2.71 & 2.7766 & TRN & & \\
\hline CHEMBL3213574 & 688125 & 5.3723 & 4.8238 & TST & & \\
\hline CHEMBL1347868 & 688125 & 2.71 & 2.8381 & TRN & & \\
\hline CHEMBL 3197464 & 688125 & 2.71 & 3.2709 & TRN & & \\
\hline CHEMBL1522519 & 688125 & 2.71 & 2.8314 & TRN & & \\
\hline CHEMBL1427778 & 688125 & 2.71 & 3.2742 & TRN & & \\
\hline CHEMBL1438233 & 688125 & 2.71 & 3.1884 & TRN & & \\
\hline CHEMBL3191045 & 688125 & 2.71 & 4.1691 & TRN & & \\
\hline CHEMBL1357667 & 688125 & 2.71 & 3.7917 & TRN & & \\
\hline CHEMBL1550868 & 688125 & 2.71 & 2.9361 & TRN & & \\
\hline CHEMBL1580397 & 688125 & 2.71 & 3.549 & TRN & & \\
\hline CHEMBL1393082 & 688125 & 2.71 & 2.8851 & TRN & & \\
\hline CHEMBL1570045 & 688125 & 5.3702 & 3.1214 & TST & & \\
\hline CHEMBL1503911 & 688125 & 2.71 & 2.5492 & TRN & & \\
\hline CHEMBL1432554 & 688125 & 2.71 & 3.6362 & TRN & & \\
\hline CHEMBL1463969 & 688125 & 2.71 & 3.1935 & TRN & & \\
\hline CHEMBL1544067 & 688125 & 2.71 & 3.103 & TRN & & \\
\hline CHEMBL1424276 & 688125 & 4.7338 & 3.7054 & TST & & \\
\hline CHEMBL1482885 & 688125 & 2.71 & 3.4196 & TRN & & \\
\hline CHEMBL1570053 & 688125 & 2.71 & 2.7354 & TRN & & \\
\hline CHEMBL1441579 & 688125 & 2.71 & 3.2904 & TRN & & \\
\hline CHEMBL1334308 & 688125 & 2.71 & 2.7477 & TRN & & \\
\hline CHEMBL1571538 & 688125 & 5.6117 & 5.5811 & TRN & & \\
\hline CHEMBL1396588 & 688125 & 2.71 & 3.467 & TRN & & \\
\hline CHEMBL1496413 & 688125 & 7.7959 & 4.6629 & TRN & & \\
\hline
\end{tabular}

Page 7411 


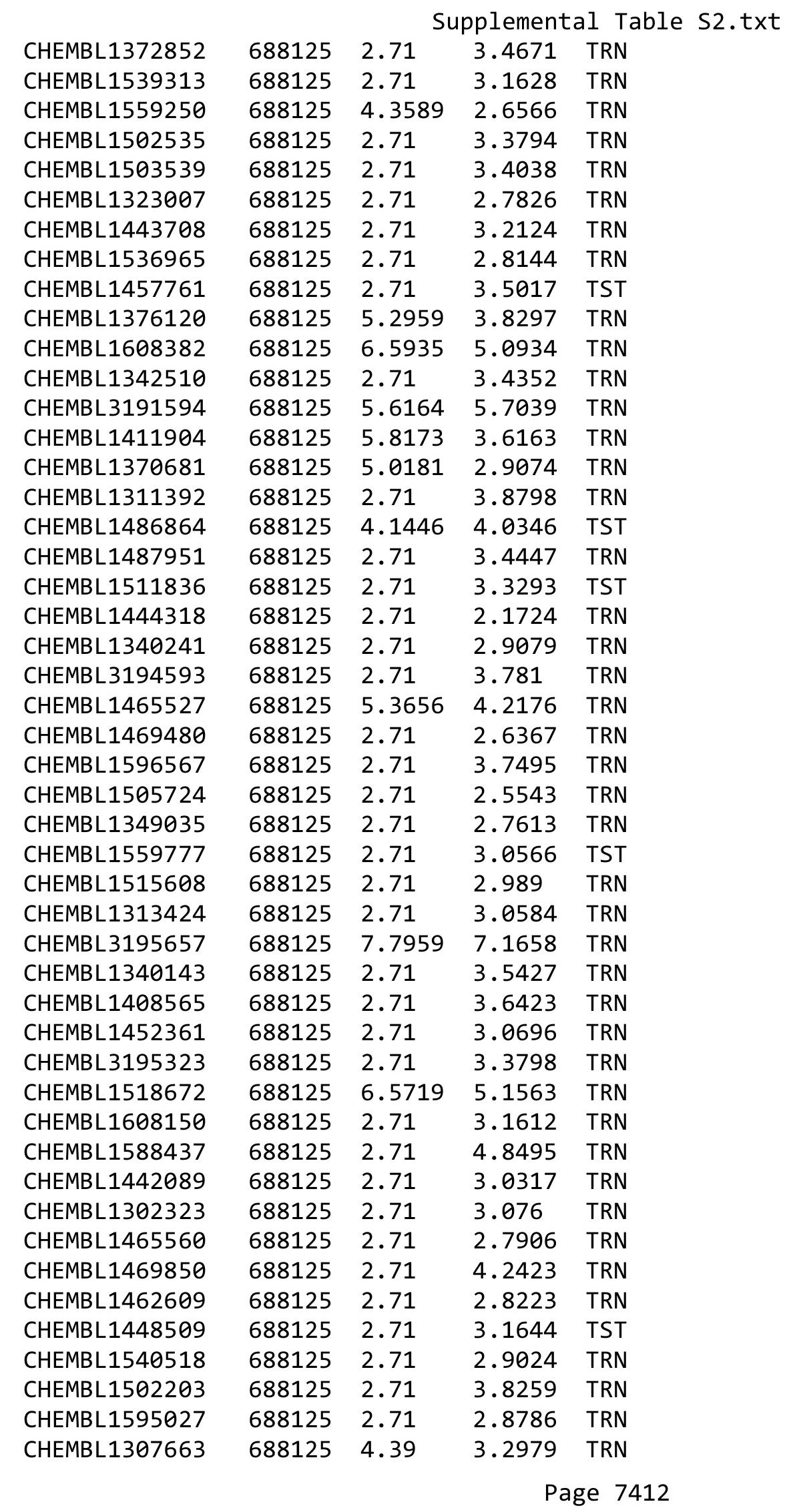




\begin{tabular}{|c|c|c|c|c|c|}
\hline & & \multicolumn{4}{|c|}{ Supplemental Table S2.txt } \\
\hline CHEMBL1547764 & 688125 & 2.71 & 2.227 & TRN & \\
\hline CHEMBL 3145301 & 688125 & 2.71 & 2.6829 & TST & \\
\hline CHEMBL1487375 & 688125 & 2.71 & 2.0596 & TRN & \\
\hline CHEMBL1562059 & 688125 & 2.71 & 2.8648 & TRN & \\
\hline CHEMBL1605728 & 688125 & 2.71 & 3.0663 & TRN & \\
\hline CHEMBL1608636 & 688125 & 4.4828 & 2.9663 & TRN & \\
\hline CHEMBL80094 & 688125 & 2.71 & 4.2796 & TRN & \\
\hline CHEMBL1418007 & 688125 & 2.71 & 3.0187 & TRN & \\
\hline CHEMBL1497165 & 688125 & 6.2984 & 3.7056 & TRN & \\
\hline CHEMBL3211332 & 688125 & 2.71 & 3.1253 & TST & \\
\hline CHEMBL81316 & 688125 & 2.71 & 2.4731 & TRN & \\
\hline CHEMBL1329798 & 688125 & 6.426 & 7.3028 & TRN & \\
\hline CHEMBL3195024 & 688125 & 2.71 & 2.9446 & TRN & \\
\hline CHEMBL1511404 & 688125 & 2.71 & 2.5415 & TRN & \\
\hline CHEMBL1350387 & 688125 & 3.767 & 3.3164 & TRN & \\
\hline CHEMBL1453516 & 688125 & 2.71 & 3.7159 & TST & \\
\hline CHEMBL1488585 & 688125 & 2.71 & 2.6755 & TRN & \\
\hline CHEMBL1611706 & 688125 & 2.71 & 2.1928 & TRN & \\
\hline CHEMBL1457961 & 688125 & 7.7959 & 4.395 & TRN & \\
\hline CHEMBL1452180 & 688125 & 2.71 & 3.5293 & TRN & \\
\hline CHEMBL1508458 & 688125 & 2.71 & 4.0816 & TRN & \\
\hline CHEMBL1580738 & 688125 & 2.71 & 2.3764 & TRN & \\
\hline CHEMBL1519316 & 688125 & 2.71 & 2.7313 & TRN & \\
\hline CHEMBL1491236 & 688125 & 2.71 & 2.8156 & TRN & \\
\hline CHEMBL1471839 & 688125 & 5.2435 & 3.6916 & TRN & \\
\hline CHEMBL1457790 & 688125 & 2.71 & 2.77699 & 99999999997 & TRN \\
\hline CHEMBL1546764 & 688125 & 2.71 & 3.1581 & TRN & \\
\hline CHEMBL3199915 & 688125 & 7.7959 & 3.1111 & TST & \\
\hline CHEMBL1605021 & 688125 & 7.7959 & 5.1211 & TRN & \\
\hline CHEMBL1424858 & 688125 & 2.71 & 4.1687 & TRN & \\
\hline CHEMBL1493442 & 688125 & 5.0507 & 3.5604 & TRN & \\
\hline CHEMBL3211911 & 688125 & 2.71 & 3.3636 & TRN & \\
\hline CHEMBL1430943 & 688125 & 2.71 & 2.4799 & TRN & \\
\hline CHEMBL3211647 & 688125 & 2.71 & 3.8122 & TST & \\
\hline CHEMBL1508947 & 688125 & 2.71 & 2.2986 & TRN & \\
\hline CHEMBL1549109 & 688125 & 2.71 & 2.6513 & TRN & \\
\hline CHEMBL1541037 & 688125 & 2.71 & 3.4999 & TRN & \\
\hline CHEMBL1428775 & 688125 & 2.71 & 3.3734 & TST & \\
\hline CHEMBL1468323 & 688125 & 6.4248 & 7.6817 & TRN & \\
\hline CHEMBL1382798 & 688125 & 4.8564 & 3.7779 & TRN & \\
\hline CHEMBL1376674 & 688125 & 7.7959 & 6.218 & TST & \\
\hline CHEMBL1344368 & 688125 & 2.71 & 2.8652 & TRN & \\
\hline CHEMBL1396012 & 688125 & 4.2582 & 2.6218 & TRN & \\
\hline CHEMBL1504879 & 688125 & 2.71 & 4.2289 & TST & \\
\hline CHEMBL171632 & 688125 & 2.71 & 3.6276 & TST & \\
\hline CHEMBL1549537 & 688125 & 2.71 & 2.7486 & TRN & \\
\hline CHEMBL1574038 & 688125 & 2.71 & 3.6195 & TRN & \\
\hline CHEMBL1389629 & 688125 & 2.71 & 3.6315 & TRN & \\
\hline
\end{tabular}




\begin{tabular}{|c|c|c|c|c|c|}
\hline & & \multicolumn{4}{|c|}{ Supplemental Table s2.txt } \\
\hline CHEMBL1338438 & 688125 & 2.71 & 2.5486 & TRN & \\
\hline CHEMBL1556034 & 688125 & 2.71 & 2.5744 & TRN & \\
\hline CHEMBL1457128 & 688125 & 2.71 & 3.967 & TRN & \\
\hline CHEMBL1360461 & 688125 & 2.71 & 2.9639 & TRN & \\
\hline CHEMBL1533064 & 688125 & 2.71 & 3.3548 & TST & \\
\hline CHEMBL1348921 & 688125 & 2.71 & 3.1733 & TRN & \\
\hline CHEMBL1527362 & 688125 & 2.71 & \multicolumn{2}{|c|}{2.8819999999999997} & TRN \\
\hline CHEMBL1408162 & 688125 & 2.71 & 3.1387 & TRN & \\
\hline CHEMBL1399287 & 688125 & 4.0796 & 3.6643 & TRN & \\
\hline CHEMBL1405979 & 688125 & 2.71 & 3.5743 & TRN & \\
\hline CHEMBL1363654 & 688125 & 2.71 & 3.1553 & TRN & \\
\hline CHEMBL 1448080 & 688125 & 3.0 & 3.1775 & TRN & \\
\hline CHEMBL1596771 & 688125 & 4.0429 & 3.4741 & TST & \\
\hline CHEMBL1477750 & 688125 & 2.71 & 2.908 & TRN & \\
\hline CHEMBL1595412 & 688125 & 4.817 & 3.7577 & TRN & \\
\hline CHEMBL1451195 & 688125 & 2.71 & 2.8941 & TRN & \\
\hline CHEMBL1545143 & 688125 & 2.71 & 2.6538 & TRN & \\
\hline CHEMBL1433127 & 688125 & 2.71 & 3.9441 & TRN & \\
\hline CHEMBL1373574 & 688125 & 4.263 & \multicolumn{2}{|c|}{ 2.4019999999999997 } & TRN \\
\hline CHEMBL1440696 & 688125 & 2.71 & 3.5781 & TRN & \\
\hline CHEMBL1503272 & 688125 & 2.71 & 2.9773 & TRN & \\
\hline CHEMBL1420215 & 688125 & 2.71 & 3.5574 & TRN & \\
\hline CHEMBL1476030 & 688125 & 2.71 & 2.9886 & TRN & \\
\hline CHEMBL1306823 & 688125 & 2.71 & 3.4143 & TRN & \\
\hline CHEMBL1426509 & 688125 & 2.71 & 3.0877 & TST & \\
\hline CHEMBL1337226 & 688125 & 5.4343 & 3.6413 & TRN & \\
\hline CHEMBL1558499 & 688125 & 2.71 & 3.5385 & TRN & \\
\hline CHEMBL1535599 & 688125 & 2.71 & 2.5297 & TRN & \\
\hline CHEMBL1464258 & 688125 & 2.71 & 3.3409 & TRN & \\
\hline CHEMBL82949 & 688125 & 2.71 & 3.615 & TRN & \\
\hline CHEMBL1558623 & 688125 & 2.71 & 3.3847 & TRN & \\
\hline CHEMBL1567331 & 688125 & 2.71 & 3.7355 & TRN & \\
\hline CHEMBL1359728 & 688125 & 2.71 & 3.4761 & TST & \\
\hline CHEMBL1568587 & 688125 & 2.71 & 3.2865 & TST & \\
\hline CHEMBL1526829 & 688125 & 2.71 & 3.1377 & TRN & \\
\hline CHEMBL1491690 & 688125 & 2.71 & 3.3283 & TRN & \\
\hline CHEMBL1586675 & 688125 & 2.71 & 3.5125 & TRN & \\
\hline CHEMBL1453723 & 688125 & 6.0731 & 5.1647 & TRN & \\
\hline CHEMBL1317001 & 688125 & 2.71 & 3.1833 & TRN & \\
\hline CHEMBL1311183 & 688125 & 2.71 & 3.2903 & TST & \\
\hline CHEMBL1407571 & 688125 & 2.71 & 3.5001 & TRN & \\
\hline CHEMBL1591316 & 688125 & 2.71 & 3.3897 & TRN & \\
\hline CHEMBL1526779 & 688125 & 2.71 & 3.0913 & TRN & \\
\hline CHEMBL1572671 & 688125 & 2.71 & 3.1633 & TRN & \\
\hline CHEMBL1312036 & 688125 & 2.71 & 2.8219 & TRN & \\
\hline CHEMBL1965654 & 688125 & 7.7959 & 7.4882 & TRN & \\
\hline CHEMBL1566307 & 688125 & 2.71 & 3.2545 & TST & \\
\hline CHEMBL1977063 & 688125 & 2.71 & 3.0724 & TST & \\
\hline
\end{tabular}




\begin{tabular}{|c|c|c|c|c|c|}
\hline \multicolumn{6}{|c|}{ Supplemental Table S2.txt } \\
\hline CHEMBL1559951 & 688125 & 2.71 & 3.0516 & TRN & \\
\hline CHEMBL1497029 & 688125 & 2.71 & 3.0804 & TRN & \\
\hline CHEMBL1362709 & 688125 & 2.71 & 2.97899 & 99999999996 & TST \\
\hline CHEMBL1317568 & 688125 & 2.71 & 2.7002 & TRN & \\
\hline CHEMBL1581516 & 688125 & 2.71 & 3.2445 & TRN & \\
\hline CHEMBL1520753 & 688125 & 5.2486 & 4.989 & TRN & \\
\hline CHEMBL1557867 & 688125 & 2.71 & 3.1458 & TRN & \\
\hline CHEMBL1339302 & 688125 & 2.71 & 2.9309 & TRN & \\
\hline CHEMBL1305480 & 688125 & 2.71 & 3.4055 & TST & \\
\hline CHEMBL1502781 & 688125 & 2.71 & 3.2456 & TST & \\
\hline CHEMBL3213886 & 688125 & 2.71 & 2.9322 & TRN & \\
\hline CHEMBL1304446 & 688125 & 2.71 & 2.7744 & TRN & \\
\hline CHEMBL1583576 & 688125 & 2.71 & 3.0889 & TST & \\
\hline CHEMBL1486651 & 688125 & 6.3354 & 5.7428 & TRN & \\
\hline CHEMBL1529718 & 688125 & 2.71 & 3.6455 & TRN & \\
\hline CHEMBL1573994 & 688125 & 7.7959 & 7.3798 & TRN & \\
\hline CHEMBL3192358 & 688125 & 2.71 & 3.054 & TRN & \\
\hline CHEMBL1309612 & 688125 & 2.71 & 3.3224 & TRN & \\
\hline CHEMBL1432743 & 688125 & 2.71 & 3.3513 & TRN & \\
\hline CHEMBL1563483 & 688125 & 5.5174 & 4.8497 & TST & \\
\hline CHEMBL1465392 & 688125 & 2.71 & 3.3942 & TRN & \\
\hline CHEMBL1477421 & 688125 & 2.71 & 2.6269 & TRN & \\
\hline CHEMBL1498275 & 688125 & 2.71 & 3.0637 & TRN & \\
\hline CHEMBL1344775 & 688125 & 2.71 & 3.5907 & TRN & \\
\hline CHEMBL3209507 & 688125 & 2.71 & 4.1931 & TRN & \\
\hline CHEMBL1412937 & 688125 & 2.71 & 3.3998 & TRN & \\
\hline CHEMBL1352208 & 688125 & 5.0619 & 2.8224 & TRN & \\
\hline CHEMBL1480098 & 688125 & 2.71 & 3.10600 & 00000000003 & TRN \\
\hline CHEMBL1446971 & 688125 & 5.2933 & 3.5974 & TRN & \\
\hline CHEMBL1352855 & 688125 & 2.71 & 3.5752 & TRN & \\
\hline CHEMBL1412026 & 688125 & 2.71 & 3.0791 & TRN & \\
\hline CHEMBL1404406 & 688125 & 2.71 & 2.1733 & TRN & \\
\hline CHEMBL1479756 & 688125 & 2.71 & 2.7045 & TRN & \\
\hline CHEMBL1400842 & 688125 & 2.71 & 3.1178 & TRN & \\
\hline CHEMBL1407664 & 688125 & 2.71 & 3.0677 & TRN & \\
\hline CHEMBL1517553 & 688125 & 4.6025 & 2.8544 & TRN & \\
\hline CHEMBL1441868 & 688125 & 4.7573 & 3.5078 & TST & \\
\hline CHEMBL1595790 & 688125 & 7.7959 & 6.2213 & TST & \\
\hline CHEMBL1363249 & 688125 & 2.71 & 3.8314 & TRN & \\
\hline CHEMBL1583923 & 688125 & 2.71 & 3.5732 & TST & \\
\hline CHEMBL1598940 & 688125 & 5.2172 & 3.14300 & 00000000002 & TRN \\
\hline CHEMBL1409703 & 688125 & 2.71 & 2.6169 & TRN & \\
\hline CHEMBL1424953 & 688125 & 2.71 & 3.8579 & TRN & \\
\hline CHEMBL1536406 & 688125 & 2.71 & 3.2354 & TST & \\
\hline CHEMBL287193 & 688125 & 2.71 & 3.3891 & TRN & \\
\hline CHEMBL1440920 & 688125 & 3.9006 & 3.6783 & TRN & \\
\hline CHEMBL1340119 & 688125 & 2.71 & 3.9786 & TST & \\
\hline CHEMBL473106 & 688125 & 2.71 & 4.7761 & TRN & \\
\hline
\end{tabular}




\begin{tabular}{|c|c|c|c|c|}
\hline \multicolumn{5}{|c|}{ Supplemental Table S2.txt } \\
\hline CHEMBL1586026 & 688125 & 2.71 & 3.7649 & TRN \\
\hline CHEMBL1373116 & 688125 & 4.2063 & 4.4 & TRN \\
\hline CHEMBL1602877 & 688125 & 2.71 & 2.7031 & TRN \\
\hline CHEMBL1501487 & 688125 & 2.71 & 3.1771 & TRN \\
\hline CHEMBL1307643 & 688125 & 4.9583 & 2.8255 & TRN \\
\hline CHEMBL1385771 & 688125 & 5.239 & 4.1132 & TRN \\
\hline CHEMBL1372417 & 688125 & 2.71 & 2.2592 & TRN \\
\hline CHEMBL1390859 & 688125 & 2.71 & 2.7317 & TST \\
\hline CHEMBL1347877 & 688125 & 2.71 & 4.3303 & TRN \\
\hline CHEMBL1332524 & 688125 & 4.8225 & 3.7133 & TRN \\
\hline CHEMBL1539980 & 688125 & 6.7423 & 4.6008 & TRN \\
\hline CHEMBL1607115 & 688125 & 2.71 & 3.5791 & TRN \\
\hline CHEMBL1523083 & 688125 & 2.71 & 2.6674 & TRN \\
\hline CHEMBL1509859 & 688125 & 2.71 & 2.7707 & TRN \\
\hline CHEMBL3207479 & 688125 & 2.71 & 3.0852 & TRN \\
\hline CHEMBL1308470 & 688125 & 2.71 & 2.6474 & TRN \\
\hline CHEMBL1543337 & 688125 & 5.3056 & 5.1347 & TRN \\
\hline CHEMBL1337359 & 688125 & 2.71 & 2.859 & TRN \\
\hline CHEMBL1534182 & 688125 & 2.71 & 3.3678 & TRN \\
\hline CHEMBL1403014 & 688125 & 7.7959 & 4.0905 & TRN \\
\hline CHEMBL1601279 & 688125 & 2.71 & 3.1602 & TRN \\
\hline CHEMBL1981685 & 688125 & 2.71 & 3.5895 & TRN \\
\hline CHEMBL3195447 & 688125 & 4.4502 & 3.4001 & TRN \\
\hline CHEMBL1497463 & 688125 & 5.0814 & 4.3382 & TRN \\
\hline CHEMBL1517267 & 688125 & 2.71 & 3.0795 & TRN \\
\hline CHEMBL1393542 & 688125 & 2.71 & 3.8676 & TRN \\
\hline CHEMBL1309548 & 688125 & 5.0796 & 3.3464 & TST \\
\hline CHEMBL 259072 & 688125 & 2.71 & 3.4049 & TRN \\
\hline CHEMBL1497098 & 688125 & 2.71 & 3.0868 & TRN \\
\hline CHEMBL1572869 & 688125 & 2.71 & 2.4475 & TRN \\
\hline CHEMBL1364385 & 688125 & 2.71 & 2.6949 & TRN \\
\hline CHEMBL1528002 & 688125 & 2.71 & 3.4444 & TRN \\
\hline CHEMBL1545077 & 688125 & 2.71 & 3.4124 & TST \\
\hline CHEMBL1325858 & 688125 & 2.71 & 3.6317 & TRN \\
\hline CHEMBL1519522 & 688125 & 2.71 & 2.6206 & TRN \\
\hline CHEMBL1531308 & 688125 & 5.1827 & 3.8017 & TRN \\
\hline CHEMBL1349642 & 688125 & 2.71 & 3.2605 & TRN \\
\hline CHEMBL570337 & 688125 & 2.71 & 3.3643 & TRN \\
\hline CHEMBL1366994 & 688125 & 2.71 & 2.8819 & TRN \\
\hline CHEMBL1379426 & 688125 & 2.71 & 3.0003 & TRN \\
\hline CHEMBL1599048 & 688125 & 2.71 & 2.5418 & TRN \\
\hline CHEMBL1493451 & 688125 & 2.71 & 3.1678 & TRN \\
\hline CHEMBL1390063 & 688125 & 2.71 & 3.3917 & TRN \\
\hline CHEMBL1551004 & 688125 & 2.71 & 3.4291 & TRN \\
\hline CHEMBL1511021 & 688125 & 2.71 & 2.3754 & TRN \\
\hline CHEMBL1345625 & 688125 & 5.0985 & 3.302 & TRN \\
\hline CHEMBL1587932 & 688125 & 5.0367 & 4.297 & TRN \\
\hline CHEMBL1561171 & 688125 & 6.06 & 4.5016 & TRN \\
\hline
\end{tabular}




\begin{tabular}{|c|c|c|c|c|}
\hline \multicolumn{5}{|c|}{ Supplemental Table S2.txt } \\
\hline CHEMBL1358066 & 688125 & 2.71 & 3.6709 & TRN \\
\hline CHEMBL1521164 & 688125 & 2.71 & 3.6516 & TRN \\
\hline CHEMBL1374232 & 688125 & 2.71 & 3.2955 & TRN \\
\hline CHEMBL1518027 & 688125 & 2.71 & 2.7493 & TRN \\
\hline CHEMBL1406832 & 688125 & 2.71 & 3.0331 & TRN \\
\hline CHEMBL1345630 & 688125 & 4.6779 & 4.0879 & TST \\
\hline CHEMBL1598036 & 688125 & 2.71 & 2.8243 & TRN \\
\hline CHEMBL1580149 & 688125 & 4.2208 & 2.2287 & TRN \\
\hline CHEMBL1446675 & 688125 & 2.71 & 2.6802 & TRN \\
\hline CHEMBL1564577 & 688125 & 4.0354 & 2.7857 & TRN \\
\hline CHEMBL1482069 & 688125 & 2.71 & 3.6709 & TST \\
\hline CHEMBL1365494 & 688125 & 2.71 & 2.5748 & TRN \\
\hline CHEMBL1310144 & 688125 & 7.7959 & 4.6447 & TRN \\
\hline CHEMBL1509068 & 688125 & 2.71 & 3.0147 & TRN \\
\hline CHEMBL1360795 & 688125 & 2.71 & 3.1849 & TRN \\
\hline CHEMBL1363766 & 688125 & 2.71 & 3.5983 & TRN \\
\hline CHEMBL1545274 & 688125 & 2.71 & 3.4606 & TRN \\
\hline CHEMBL1539005 & 688125 & 2.71 & 3.2483 & TRN \\
\hline CHEMBL1586149 & 688125 & 2.71 & 3.1801 & TRN \\
\hline CHEMBL1487975 & 688125 & 2.71 & 3.6392 & TRN \\
\hline CHEMBL1576977 & 688125 & 2.71 & 3.7628 & TRN \\
\hline CHEMBL1498711 & 688125 & 2.71 & 2.9649 & TRN \\
\hline CHEMBL 3190329 & 688125 & 2.71 & 2.8707 & TST \\
\hline CHEMBL1550372 & 688125 & 2.71 & 2.8934 & TRN \\
\hline CHEMBL1607126 & 688125 & 2.71 & 3.3932 & TST \\
\hline CHEMBL1513939 & 688125 & 2.71 & 3.6334 & TST \\
\hline CHEMBL1497864 & 688125 & 2.71 & 2.9092 & TRN \\
\hline CHEMBL1562575 & 688125 & 7.7959 & 8.258 & TRN \\
\hline CHEMBL 2001685 & 688125 & 2.71 & 3.1955 & TRN \\
\hline CHEMBL1405825 & 688125 & 2.71 & 2.6338 & TRN \\
\hline CHEMBL1452415 & 688125 & 5.4369 & 4.3101 & TRN \\
\hline CHEMBL1600296 & 688125 & 2.71 & 3.5047 & TRN \\
\hline CHEMBL1345222 & 688125 & 2.71 & 3.159 & TRN \\
\hline CHEMBL1307632 & 688125 & 2.71 & 3.5455 & TST \\
\hline CHEMBL1605319 & 688125 & 2.71 & 2.5031 & TRN \\
\hline CHEMBL1593146 & 688125 & 4.8337 & 3.1932 & TRN \\
\hline CHEMBL3212884 & 688125 & 2.71 & 3.725 & TRN \\
\hline CHEMBL1339961 & 688125 & 2.71 & 3.2452 & TRN \\
\hline CHEMBL1400991 & 688125 & 2.71 & 2.291 & TRN \\
\hline CHEMBL1350771 & 688125 & 2.71 & 3.9712 & TRN \\
\hline CHEMBL1428267 & 688125 & 2.71 & 3.1026 & TRN \\
\hline CHEMBL1368294 & 688125 & 2.71 & 3.2485 & TST \\
\hline CHEMBL1545660 & 688125 & 6.3224 & 4.353 & TRN \\
\hline CHEMBL1485676 & 688125 & 2.71 & 3.1502 & TRN \\
\hline CHEMBL1520570 & 688125 & 2.71 & 2.8366 & TRN \\
\hline CHEMBL1442558 & 688125 & 2.71 & 3.1023 & TST \\
\hline CHEMBL1427638 & 688125 & 2.71 & 3.4901 & TRN \\
\hline CHEMBL1445671 & 688125 & 2.71 & 2.7886 & TRN \\
\hline
\end{tabular}




\begin{tabular}{|c|c|c|c|c|}
\hline \multicolumn{5}{|c|}{ Supplemental Table S2.txt } \\
\hline CHEMBL153535 & 688125 & 2.71 & 5.0154 & TRN \\
\hline CHEMBL1427184 & 688125 & 2.71 & 4.0215 & TRN \\
\hline CHEMBL1416848 & 688125 & 6.1918 & 4.2785 & TRN \\
\hline CHEMBL1483049 & 688125 & 2.71 & 3.6637 & TRN \\
\hline CHEMBL1428874 & 688125 & 2.71 & 2.6918 & TRN \\
\hline CHEMBL1340102 & 688125 & 2.71 & 3.9377 & TRN \\
\hline CHEMBL1606807 & 688125 & 2.71 & 2.7764 & TRN \\
\hline CHEMBL1456650 & 688125 & 2.71 & 2.5337 & TRN \\
\hline CHEMBL1559179 & 688125 & 2.71 & 2.6394 & TST \\
\hline CHEMBL1446297 & 688125 & 2.71 & 2.7662 & TRN \\
\hline CHEMBL1563273 & 688125 & 2.71 & 3.0565 & TRN \\
\hline CHEMBL1600322 & 688125 & 2.71 & 2.4092 & TRN \\
\hline CHEMBL3213349 & 688125 & 2.71 & 3.3176 & TST \\
\hline CHEMBL1576783 & 688125 & 2.71 & 2.3673 & TRN \\
\hline CHEMBL1452795 & 688125 & 5.4393 & 5.5785 & TST \\
\hline CHEMBL1469415 & 688125 & 5.3672 & 3.7966 & TRN \\
\hline CHEMBL1596355 & 688125 & 2.71 & 2.6757 & TRN \\
\hline CHEMBL1437028 & 688125 & 2.71 & 3.2457 & TST \\
\hline CHEMBL1432017 & 688125 & 4.6749 & 3.4533 & TRN \\
\hline CHEMBL1326330 & 688125 & 2.71 & 3.0509 & TST \\
\hline CHEMBL1500818 & 688125 & 2.71 & 3.7831 & TRN \\
\hline CHEMBL1525816 & 688125 & 2.71 & 3.5666 & TRN \\
\hline CHEMBL1308020 & 688125 & 5.6955 & 2.9917 & TRN \\
\hline CHEMBL1385210 & 688125 & 2.71 & 3.7563 & TRN \\
\hline CHEMBL1390219 & 688125 & 2.71 & 3.4558 & TRN \\
\hline CHEMBL1561983 & 688125 & 2.71 & 2.7337 & TRN \\
\hline CHEMBL1337592 & 688125 & 6.1605 & 3.5899 & TRN \\
\hline CHEMBL1493545 & 688125 & 4.9102 & 2.8856 & TRN \\
\hline CHEMBL1540565 & 688125 & 4.4939 & 3.5038 & TRN \\
\hline CHEMBL1487959 & 688125 & 5.5877 & 4.0587 & TRN \\
\hline CHEMBL1426385 & 688125 & 2.71 & 4.0994 & TRN \\
\hline CHEMBL1326249 & 688125 & 4.7928 & 3.8558 & TRN \\
\hline CHEMBL1350133 & 688125 & 2.71 & 3.0158 & TRN \\
\hline CHEMBL1392508 & 688125 & 2.71 & 3.8773 & TRN \\
\hline CHEMBL1352125 & 688125 & 2.71 & 2.9459 & TRN \\
\hline CHEMBL1588665 & 688125 & 2.71 & 2.7666 & TRN \\
\hline CHEMBL1504204 & 688125 & 5.9144 & 3.3501 & TRN \\
\hline CHEMBL1078717 & 688125 & 2.71 & 3.5619 & TRN \\
\hline CHEMBL1343140 & 688125 & 2.71 & 3.5362 & TST \\
\hline CHEMBL1362846 & 688125 & 2.71 & 2.7363 & TRN \\
\hline CHEMBL1590949 & 688125 & 2.71 & 2.3086 & TRN \\
\hline CHEMBL1327644 & 688125 & 2.71 & 2.9369 & TRN \\
\hline CHEMBL1448444 & 688125 & 2.71 & 2.6055 & TRN \\
\hline CHEMBL1482663 & 688125 & 5.1308 & 4.6816 & TRN \\
\hline CHEMBL1373306 & 688125 & 4.5856 & 3.9616 & TRN \\
\hline CHEMBL1549985 & 688125 & 2.71 & 2.7099 & TRN \\
\hline CHEMBL 1448113 & 688125 & 2.71 & 2.3186 & TRN \\
\hline CHEMBL1311015 & 688125 & 2.71 & 4.0959 & TRN \\
\hline
\end{tabular}




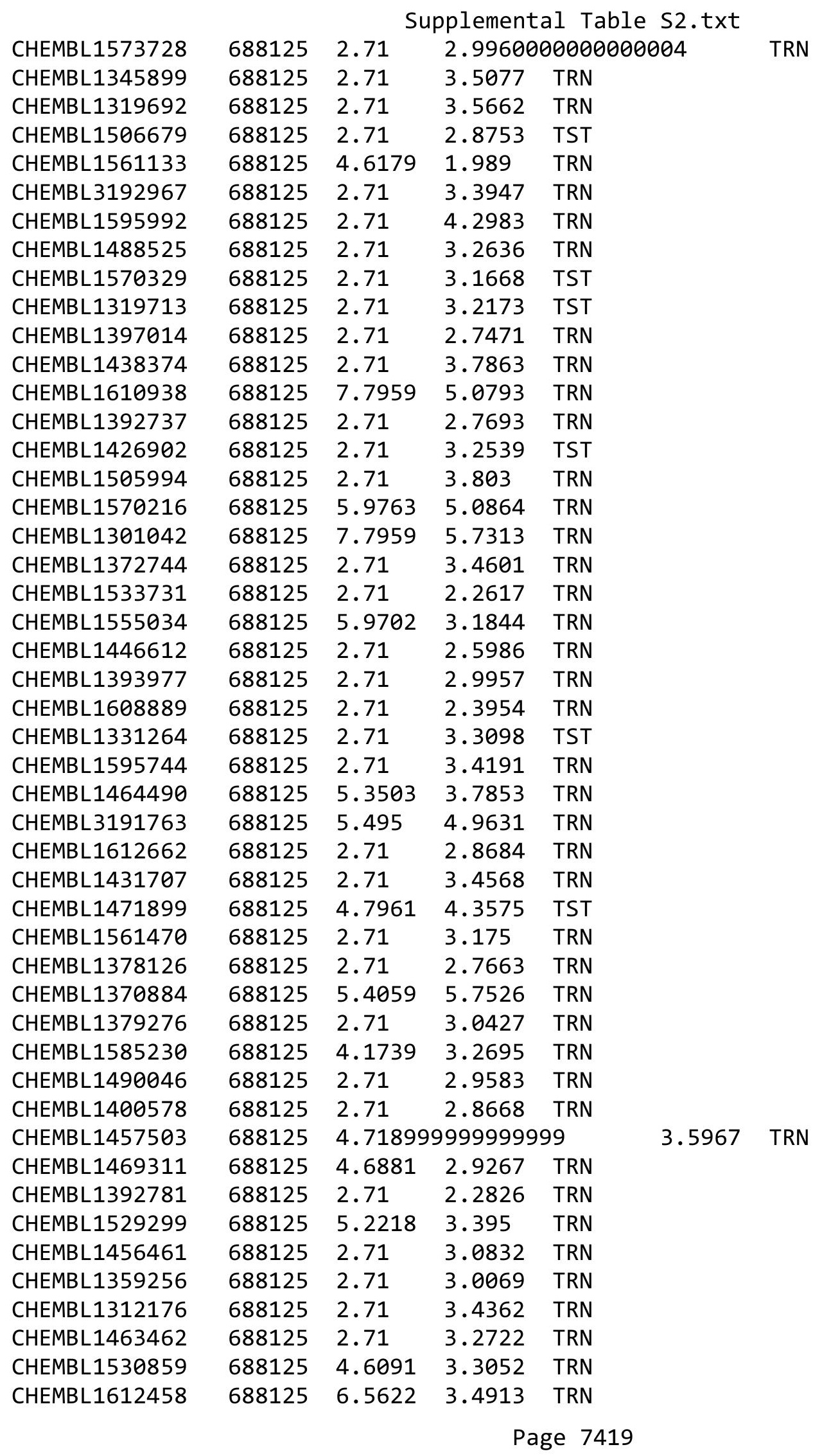




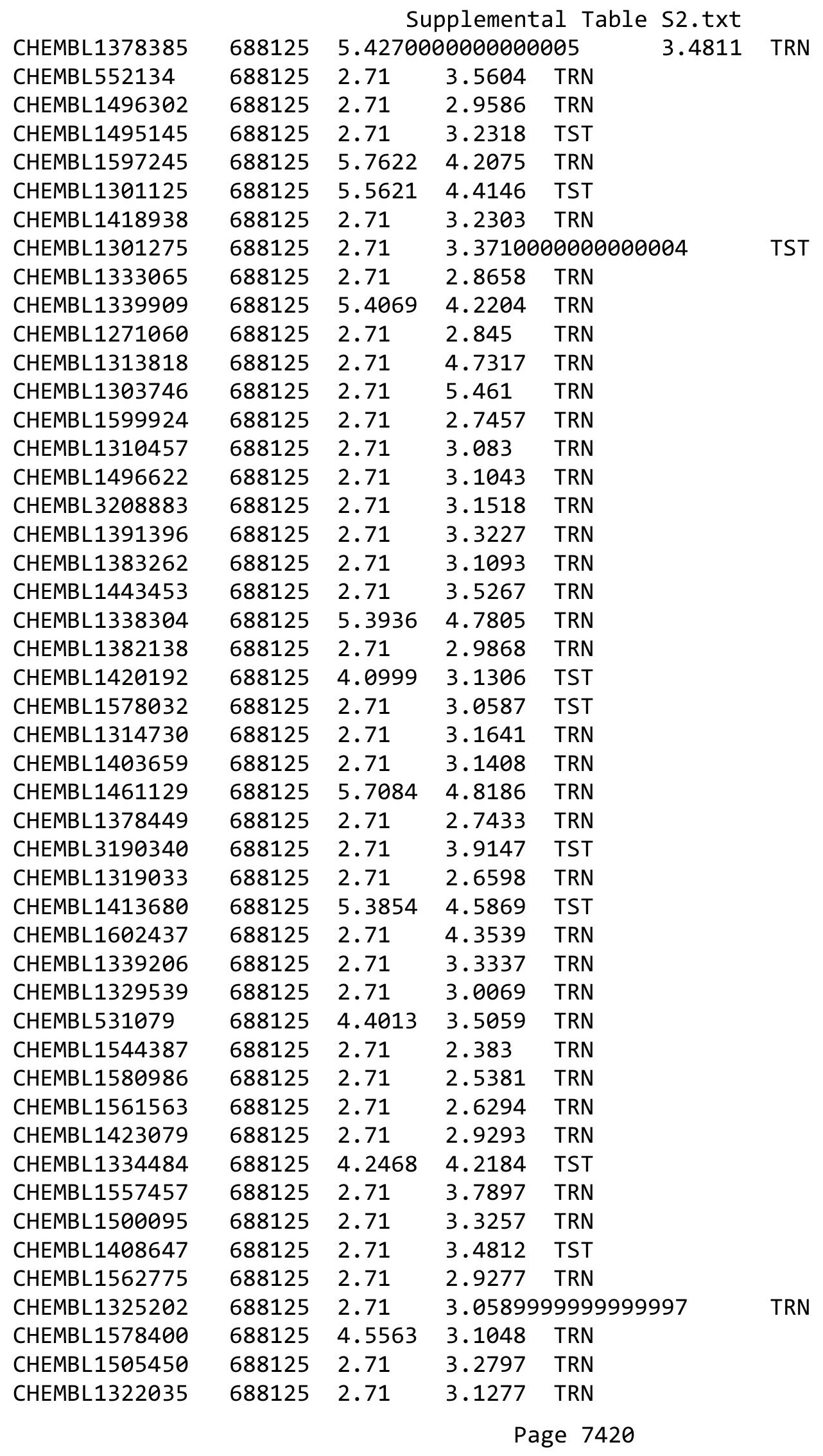




\begin{tabular}{|c|c|c|c|c|c|}
\hline \multirow[b]{2}{*}{ CHEMBL3196994 } & \multicolumn{5}{|c|}{ Supplemental Table S2.txt } \\
\hline & 688125 & 4.5279 & 3.6925 & TRN & \\
\hline CHEMBL1390074 & 688125 & 2.71 & 3.0958 & TRN & \\
\hline CHEMBL1438636 & 688125 & 4.905 & 4.2676 & TRN & \\
\hline CHEMBL1389474 & 688125 & 2.71 & 2.3237 & TRN & \\
\hline CHEMBL 3197258 & 688125 & 2.71 & 3.6608 & TST & \\
\hline CHEMBL3195889 & 688125 & 4.0568 & 4.2988 & TRN & \\
\hline CHEMBL1588375 & 688125 & 2.71 & 3.1944 & TRN & \\
\hline CHEMBL1595359 & 688125 & 2.71 & 2.6012 & TRN & \\
\hline CHEMBL1410323 & 688125 & 2.71 & 3.2954 & TRN & \\
\hline CHEMBL1468814 & 688125 & 2.71 & 2.9838 & TRN & \\
\hline CHEMBL1361091 & 688125 & 2.71 & 2.6546 & TRN & \\
\hline CHEMBL1366932 & 688125 & 2.71 & 4.6838 & TRN & \\
\hline CHEMBL1517987 & 688125 & 4.1556 & 3.6899 & TST & \\
\hline CHEMBL1976489 & 688125 & 2.71 & 4.2644 & TRN & \\
\hline CHEMBL1503220 & 688125 & 2.71 & 2.8939 & TRN & \\
\hline CHEMBL1402204 & 688125 & 2.71 & 3.5422 & TRN & \\
\hline CHEMBL1352521 & 688125 & 7.7959 & 5.0827 & TRN & \\
\hline CHEMBL1480181 & 688125 & 2.71 & 3.4 & TST & \\
\hline CHEMBL1363678 & 688125 & 2.71 & 2.9971 & TRN & \\
\hline CHEMBL1605795 & 688125 & 7.7959 & 4.3536 & TRN & \\
\hline CHEMBL1390620 & 688125 & 4.3375 & 2.5667 & TRN & \\
\hline CHEMBL1613451 & 688125 & 2.71 & 2.5977 & TRN & \\
\hline CHEMBL579318 & 688125 & 6.5171 & 4.5258 & TRN & \\
\hline CHEMBL1385024 & 688125 & 2.71 & 3.5588 & TRN & \\
\hline CHEMBL1521861 & 688125 & 6.1107 & 3.3657 & TRN & \\
\hline CHEMBL1469687 & 688125 & 2.71 & 3.0181 & TRN & \\
\hline CHEMBL1493508 & 688125 & 5.3436 & 2.7657 & TRN & \\
\hline CHEMBL3189708 & 688125 & 2.71 & 3.0683 & TRN & \\
\hline CHEMBL1540833 & 688125 & 2.71 & 2.971 & TRN & \\
\hline CHEMBL1442136 & 688125 & 5.8928 & 2.8822 & TRN & \\
\hline CHEMBL1427919 & 688125 & 2.71 & 2.8481 & TRN & \\
\hline CHEMBL1563184 & 688125 & 2.71 & 2.9679 & TRN & \\
\hline CHEMBL1312863 & 688125 & 2.71 & 4.0234 & TRN & \\
\hline CHEMBL1406841 & 688125 & 2.71 & 3.2042 & TST & \\
\hline CHEMBL1460499 & 688125 & 2.71 & 3.1333 & TRN & \\
\hline CHEMBL1598408 & 688125 & 2.71 & 3.0056 & TRN & \\
\hline CHEMBL1447248 & 688125 & 2.71 & 3.275 & TRN & \\
\hline CHEMBL1604457 & 688125 & 2.71 & 2.8761 & TST & \\
\hline CHEMBL1300791 & 688125 & 2.71 & 2.3999 & TRN & \\
\hline CHEMBL1456230 & 688125 & 2.71 & 3.10600 & 00000000003 & TRN \\
\hline CHEMBL1547557 & 688125 & 2.71 & 4.2111 & TRN & \\
\hline CHEMBL1343775 & 688125 & 2.71 & 4.2573 & TRN & \\
\hline CHEMBL1460740 & 688125 & 2.71 & 3.7495 & TRN & \\
\hline CHEMBL1492691 & 688125 & 2.71 & 3.6434 & TRN & \\
\hline CHEMBL1400908 & 688125 & 5.8008 & 3.6494 & TRN & \\
\hline CHEMBL1409487 & 688125 & 2.71 & 3.5995 & TRN & \\
\hline CHEMBL1499951 & 688125 & 5.3664 & 4.1763 & TRN & \\
\hline CHEMBL1410604 & 688125 & 2.71 & 2.6456 & TRN & \\
\hline
\end{tabular}




\begin{tabular}{|c|c|c|c|c|c|}
\hline & & \multicolumn{4}{|c|}{ Supplemental Table S2.txt } \\
\hline CHEMBL1571381 & 688125 & 2.71 & 2.6531 & TRN & \\
\hline CHEMBL1490478 & 688125 & 4.6487 & 5.4565 & TRN & \\
\hline CHEMBL1478246 & 688125 & 2.71 & 2.6251 & TRN & \\
\hline CHEMBL1548017 & 688125 & 2.71 & 3.0573 & TRN & \\
\hline CHEMBL1330717 & 688125 & 2.71 & 3.0205 & TRN & \\
\hline CHEMBL 3190744 & 688125 & 2.71 & 3.4337 & TRN & \\
\hline CHEMBL1365754 & 688125 & 2.71 & 3.022 & TRN & \\
\hline CHEMBL1602346 & 688125 & 2.71 & 3.4873 & TRN & \\
\hline CHEMBL1431204 & 688125 & 2.71 & 2.9068 & TRN & \\
\hline CHEMBL1572480 & 688125 & 4.8053 & 3.1021 & TRN & \\
\hline CHEMBL1596261 & 688125 & 2.71 & 2.9289 & TRN & \\
\hline CHEMBL1387674 & 688125 & 2.71 & 2.5166 & TRN & \\
\hline CHEMBL1466751 & 688125 & 2.71 & 2.4918 & TRN & \\
\hline CHEMBL1495325 & 688125 & 2.71 & 3.2581 & TRN & \\
\hline CHEMBL1607926 & 688125 & 2.71 & 3.6289 & TRN & \\
\hline CHEMBL1433270 & 688125 & 2.71 & 3.09899 & 99999999998 & TRN \\
\hline CHEMBL1303368 & 688125 & 2.71 & 3.5941 & TRN & \\
\hline CHEMBL1323746 & 688125 & 2.71 & 2.6964 & TRN & \\
\hline CHEMBL1570254 & 688125 & 2.71 & 2.9207 & TRN & \\
\hline CHEMBL1564965 & 688125 & 2.71 & 3.1472 & TRN & \\
\hline CHEMBL1332512 & 688125 & 7.7959 & 5.2416 & TRN & \\
\hline CHEMBL1419321 & 688125 & 2.71 & 2.7558 & TRN & \\
\hline CHEMBL1535784 & 688125 & 4.4758 & 3.4844 & TRN & \\
\hline CHEMBL1485677 & 688125 & 2.71 & 2.8164 & TST & \\
\hline CHEMBL1532909 & 688125 & 5.2779 & 3.5613 & TRN & \\
\hline CHEMBL1452159 & 688125 & \multicolumn{3}{|c|}{5.821000000000001} & TRN \\
\hline CHEMBL1582583 & 688125 & 2.71 & 3.2948 & TRN & \\
\hline CHEMBL1350908 & 688125 & 5.0311 & 2.8773 & TRN & \\
\hline CHEMBL1563973 & 688125 & 5.6968 & 3.54 & TRN & \\
\hline CHEMBL1519673 & 688125 & 2.71 & 2.5782 & TRN & \\
\hline CHEMBL3189716 & 688125 & 2.71 & 3.1591 & TRN & \\
\hline CHEMBL1587240 & 688125 & 4.4838 & 2.3315 & TRN & \\
\hline CHEMBL1576288 & 688125 & 2.71 & 3.2678 & TRN & \\
\hline CHEMBL1346419 & 688125 & 2.71 & 2.7192 & TRN & \\
\hline CHEMBL1300007 & 688125 & 2.71 & 3.4902 & TRN & \\
\hline CHEMBL1530727 & 688125 & 2.71 & 2.9339 & TRN & \\
\hline CHEMBL1415469 & 688125 & 2.71 & 2.96199 & 99999999997 & TRN \\
\hline CHEMBL1488970 & 688125 & 2.71 & 2.3926 & TRN & \\
\hline CHEMBL1595015 & 688125 & 4.8944 & 3.5088 & TRN & \\
\hline CHEMBL1611724 & 688125 & 2.71 & 3.2229 & TRN & \\
\hline CHEMBL1451228 & 688125 & 2.71 & 3.9905 & TRN & \\
\hline CHEMBL3207810 & 688125 & 4.5262 & 3.3686 & TRN & \\
\hline CHEMBL1510479 & 688125 & 2.71 & 3.0986 & TRN & \\
\hline CHEMBL1586322 & 688125 & 2.71 & 3.502 & TRN & \\
\hline CHEMBL1305488 & 688125 & 2.71 & 3.7861 & TRN & \\
\hline CHEMBL1573366 & 688125 & 7.7959 & 5.0792 & TRN & \\
\hline CHEMBL1613305 & 688125 & 2.71 & 2.9456 & TRN & \\
\hline CHEMBL1575324 & 688125 & 2.71 & 2.859 & TRN & \\
\hline
\end{tabular}




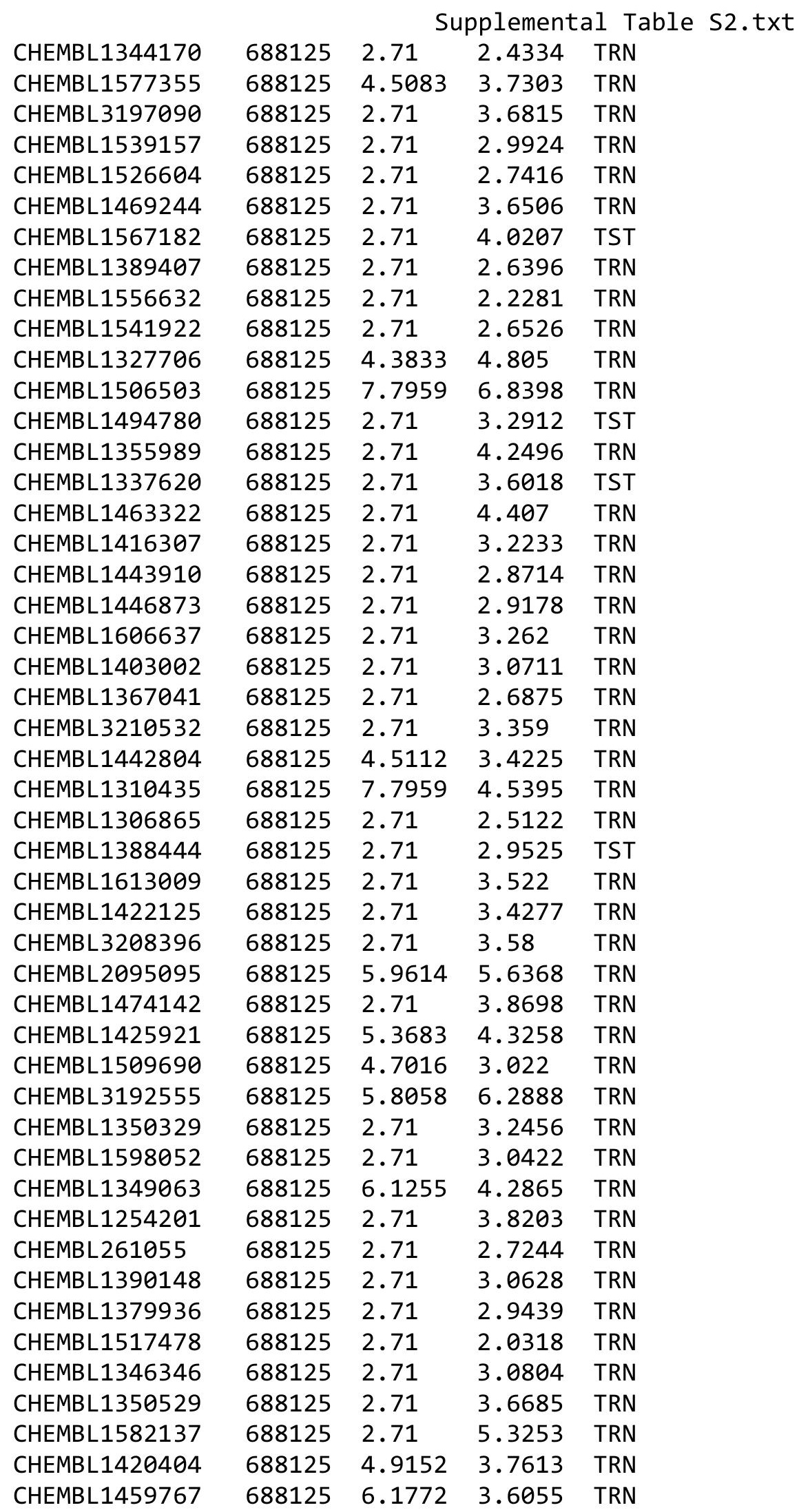

Page 7423 


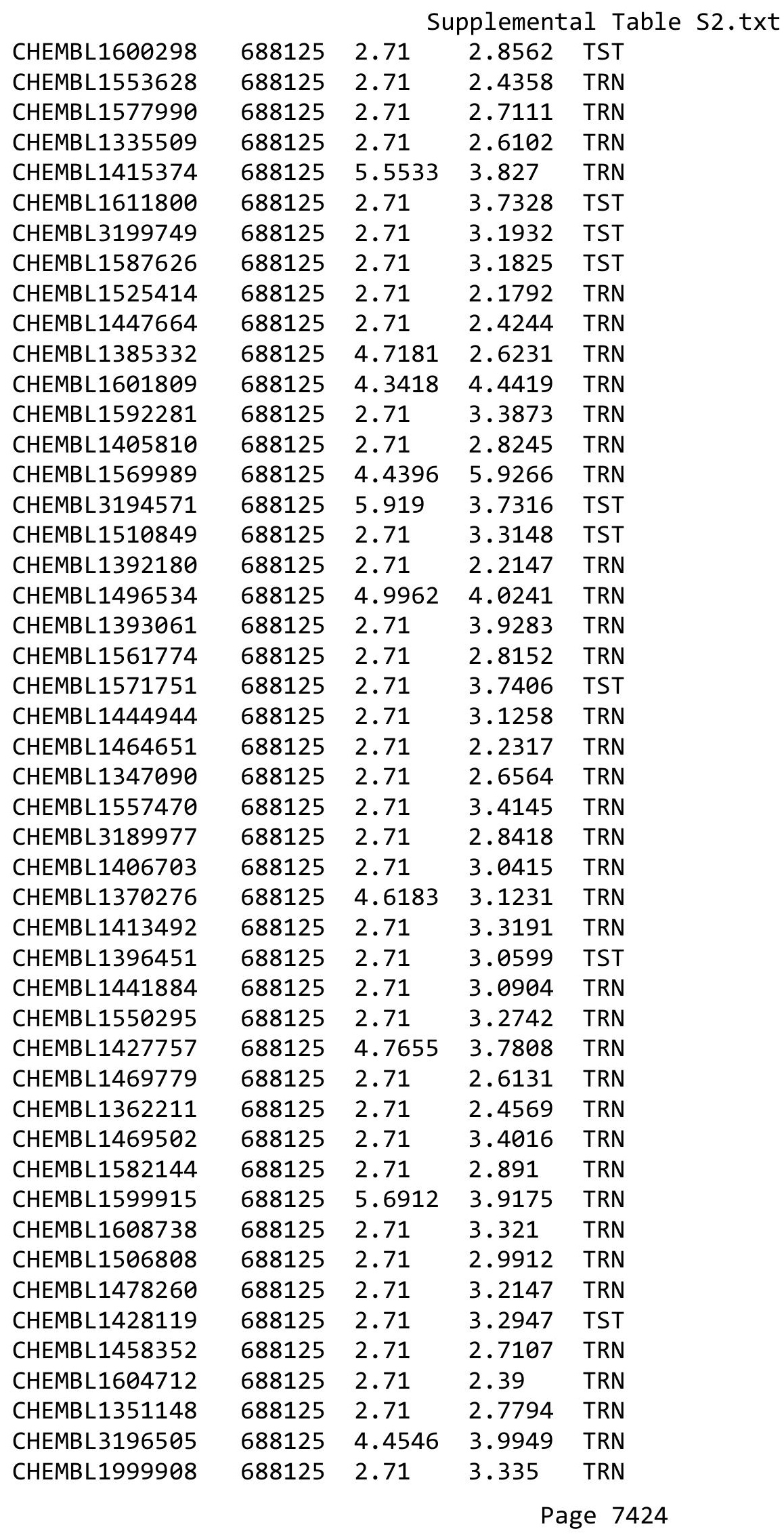




\begin{tabular}{|c|c|c|c|c|c|}
\hline \multirow[b]{2}{*}{ CHEMBL1480598 } & & \multicolumn{4}{|c|}{ Supplemental Table S2.txt } \\
\hline & 688125 & 2.71 & 2.9584 & TRN & \\
\hline CHEMBL1972014 & 688125 & 2.71 & 3.7186 & TRN & \\
\hline CHEMBL1519777 & 688125 & 2.71 & 3.2774 & TRN & \\
\hline CHEMBL1478026 & 688125 & 4.6385 & 2.6569 & TRN & \\
\hline CHEMBL1544285 & 688125 & 2.71 & 2.9201 & TRN & \\
\hline CHEMBL1473746 & 688125 & 3.8182 & 3.4117 & TRN & \\
\hline CHEMBL1347846 & 688125 & 4.4429 & 3.6282 & TRN & \\
\hline CHEMBL1346282 & 688125 & 2.71 & 3.14 & TRN & \\
\hline CHEMBL1565115 & 688125 & 2.71 & 3.7573 & TRN & \\
\hline CHEMBL1364395 & 688125 & 4.7223 & 3.0834 & TST & \\
\hline CHEMBL1460613 & 688125 & 2.71 & 3.0596 & TRN & \\
\hline CHEMBL1334982 & 688125 & 2.71 & 3.01800 & 00000000002 & TRN \\
\hline CHEMBL1542194 & 688125 & 2.71 & 3.483 & TST & \\
\hline CHEMBL1450564 & 688125 & 6.0691 & 3.4036 & TST & \\
\hline CHEMBL1562452 & 688125 & 2.71 & 2.6996 & TRN & \\
\hline CHEMBL1458414 & 688125 & 2.71 & 2.2838 & TRN & \\
\hline CHEMBL3207730 & 688125 & 2.71 & 2.9679 & TRN & \\
\hline CHEMBL1387441 & 688125 & 2.71 & 3.5166 & TRN & \\
\hline CHEMBL1610388 & 688125 & 2.71 & 4.8588 & TRN & \\
\hline CHEMBL1527061 & 688125 & 2.71 & 2.4621 & TRN & \\
\hline CHEMBL1498307 & 688125 & 5.1108 & 3.6884 & TRN & \\
\hline CHEMBL1364210 & 688125 & 2.71 & 3.1031 & TRN & \\
\hline CHEMBL1352531 & 688125 & 2.71 & 3.4035 & TRN & \\
\hline CHEMBL1564611 & 688125 & 2.71 & 2.5939 & TRN & \\
\hline CHEMBL1379842 & 688125 & 2.71 & 2.83600 & 00000000003 & TRN \\
\hline CHEMBL1320794 & 688125 & 6.7167 & 4.0431 & TRN & \\
\hline CHEMBL1383811 & 688125 & 2.71 & 2.7984 & TRN & \\
\hline CHEMBL1452937 & 688125 & 2.71 & 3.8292 & TRN & \\
\hline CHEMBL1423420 & 688125 & 2.71 & 2.7732 & TRN & \\
\hline CHEMBL1509507 & 688125 & 2.71 & 3.1348 & TRN & \\
\hline CHEMBL1430633 & 688125 & 2.71 & 2.3237 & TRN & \\
\hline CHEMBL3214105 & 688125 & 2.71 & 3.5827 & TST & \\
\hline CHEMBL1308016 & 688125 & 2.71 & 2.6434 & TST & \\
\hline CHEMBL3190653 & 688125 & 7.7959 & 5.5873 & TRN & \\
\hline CHEMBL1517291 & 688125 & 2.71 & 2.6438 & TRN & \\
\hline CHEMBL1403914 & 688125 & 2.71 & 2.7844 & TRN & \\
\hline CHEMBL1483466 & 688125 & 2.71 & 3.0394 & TRN & \\
\hline CHEMBL1584743 & 688125 & 2.71 & 3.5858 & TRN & \\
\hline CHEMBL1383510 & 688125 & 2.71 & 2.9741 & TST & \\
\hline CHEMBL1351975 & 688125 & 2.71 & 3.1729 & TRN & \\
\hline CHEMBL1543259 & 688125 & 2.71 & 2.85699 & 99999999998 & TRN \\
\hline CHEMBL 3212437 & 688125 & 2.71 & 3.6595 & TRN & \\
\hline CHEMBL1474942 & 688125 & 2.71 & 3.2235 & TRN & \\
\hline CHEMBL 3214000 & 688125 & 2.71 & 3.7175 & TRN & \\
\hline CHEMBL3192075 & 688125 & 2.71 & 2.6856 & TRN & \\
\hline CHEMBL1454237 & 688125 & $4.4460 €$ & 30000000 & 4.1118 & TRN \\
\hline CHEMBL1505598 & 688125 & 2.71 & 2.2514 & TRN & \\
\hline CHEMBL1426884 & 688125 & 2.71 & 2.7981 & TRN & \\
\hline
\end{tabular}




\begin{tabular}{|c|c|c|c|c|c|}
\hline \multicolumn{6}{|c|}{ Supplemental Table S2.txt } \\
\hline CHEMBL1540483 & 688125 & 2.71 & 3.3729 & TST & \\
\hline CHEMBL1524112 & 688125 & 2.71 & 3.5648 & TRN & \\
\hline CHEMBL1321540 & 688125 & 2.71 & 3.1705 & TST & \\
\hline CHEMBL1350547 & 688125 & 2.71 & 2.8606 & TRN & \\
\hline CHEMBL1595089 & 688125 & 2.71 & 2.7408 & TRN & \\
\hline CHEMBL1971760 & 688125 & 7.7959 & 5.433 & TST & \\
\hline CHEMBL1361679 & 688125 & 2.71 & 2.7277 & TRN & \\
\hline CHEMBL1610624 & 688125 & 2.71 & 2.2475 & TRN & \\
\hline CHEMBL1561205 & 688125 & 2.71 & 2.4893 & TRN & \\
\hline CHEMBL1585100 & 688125 & 2.71 & 2.1049 & TRN & \\
\hline CHEMBL1424504 & 688125 & 2.71 & 3.8697 & TRN & \\
\hline CHEMBL1488748 & 688125 & 2.71 & 2.2212 & TRN & \\
\hline CHEMBL3196698 & 688125 & 5.5196 & 2.8605 & TRN & \\
\hline CHEMBL1365106 & 688125 & 2.71 & 3.145 & TRN & \\
\hline CHEMBL1574683 & 688125 & 2.71 & 3.42100 & 00000000003 & TRN \\
\hline CHEMBL1573563 & 688125 & 5.7737 & 5.2237 & TRN & \\
\hline CHEMBL1414311 & 688125 & 5.0047 & 3.5779 & TRN & \\
\hline CHEMBL3209813 & 688125 & 2.71 & 3.2694 & TRN & \\
\hline CHEMBL1346901 & 688125 & 2.71 & 3.0749 & TRN & \\
\hline CHEMBL1571281 & 688125 & 2.71 & 2.7679 & TRN & \\
\hline CHEMBL3144830 & 688125 & 2.71 & 3.4469 & TRN & \\
\hline CHEMBL 1367770 & 688125 & 2.71 & 4.0256 & TRN & \\
\hline CHEMBL1483569 & 688125 & 2.71 & 2.9458 & TRN & \\
\hline CHEMBL1299565 & 688125 & 5.3123 & 5.0631 & TRN & \\
\hline CHEMBL1349554 & 688125 & 2.71 & 3.1437 & TST & \\
\hline CHEMBL1564120 & 688125 & 2.71 & 3.3753 & TRN & \\
\hline CHEMBL1581111 & 688125 & 2.71 & 2.7939 & TRN & \\
\hline CHEMBL1482289 & 688125 & 2.71 & 3.7545 & TRN & \\
\hline CHEMBL1524482 & 688125 & 7.7959 & 4.81800 & 00000000005 & TRN \\
\hline CHEMBL1316978 & 688125 & 5.3004 & 2.7013 & TRN & \\
\hline CHEMBL3145199 & 688125 & 2.71 & 4.018 & TRN & \\
\hline CHEMBL 1386852 & 688125 & 2.71 & 2.9494 & TRN & \\
\hline CHEMBL1500279 & 688125 & 2.71 & 2.8475 & TRN & \\
\hline CHEMBL1400921 & 688125 & 2.71 & 2.812 & TRN & \\
\hline CHEMBL1446551 & 688125 & 2.71 & 2.9521 & TRN & \\
\hline CHEMBL1305474 & 688125 & 2.71 & 2.7878 & TRN & \\
\hline CHEMBL1570497 & 688125 & 2.71 & 2.8843 & TRN & \\
\hline CHEMBL1580876 & 688125 & 2.71 & 2.4416 & TRN & \\
\hline CHEMBL3190941 & 688125 & 2.71 & 3.3794 & TST & \\
\hline CHEMBL 3211486 & 688125 & 2.71 & 2.819 & TRN & \\
\hline CHEMBL1426411 & 688125 & 4.7211 & 3.1343 & TRN & \\
\hline CHEMBL1569755 & 688125 & 2.71 & 4.5008 & TRN & \\
\hline CHEMBL1344192 & 688125 & 2.71 & 3.1214 & TRN & \\
\hline CHEMBL1405101 & 688125 & 2.71 & 3.4657 & TST & \\
\hline CHEMBL3210649 & 688125 & 2.71 & 3.3877 & TRN & \\
\hline CHEMBL3198716 & 688125 & 2.71 & 3.7259 & TRN & \\
\hline CHEMBL1427677 & 688125 & 2.71 & 2.6589 & TRN & \\
\hline CHEMBL1567944 & 688125 & 7.7959 & 7.5329 & TST & \\
\hline
\end{tabular}




\begin{tabular}{|c|c|c|c|c|c|}
\hline \multicolumn{6}{|c|}{ Supplemental Table S2.txt } \\
\hline CHEMBL1464703 & 688125 & 2.71 & 3.7114 & TRN & \\
\hline CHEMBL1405727 & 688125 & 2.71 & 3.5457 & TRN & \\
\hline CHEMBL1420453 & 688125 & 2.71 & 2.3667 & TRN & \\
\hline CHEMBL1479920 & 688125 & 2.71 & 2.9528 & TRN & \\
\hline CHEMBL1490033 & 688125 & 4.1588 & 3.3775 & TRN & \\
\hline CHEMBL1361624 & 688125 & 2.71 & 2.7974 & TRN & \\
\hline CHEMBL1503091 & 688125 & 2.71 & 2.7255 & TRN & \\
\hline CHEMBL1403432 & 688125 & 2.71 & 3.9395 & TRN & \\
\hline CHEMBL1458360 & 688125 & 2.71 & 2.8051 & TRN & \\
\hline CHEMBL1608477 & 688125 & 2.71 & 3.4861 & TST & \\
\hline CHEMBL1523387 & 688125 & 4.1324 & 3.8514 & TST & \\
\hline CHEMBL1463547 & 688125 & 2.71 & 2.4477 & TRN & \\
\hline CHEMBL1326371 & 688125 & 4.7686 & 3.2136 & TST & \\
\hline CHEMBL1466674 & 688125 & 4.4859 & 2.733 & TRN & \\
\hline CHEMBL1384069 & 688125 & 2.71 & 3.1972 & TRN & \\
\hline CHEMBL1409544 & 688125 & 2.71 & 2.8282 & TRN & \\
\hline CHEMBL1529810 & 688125 & 4.0486 & 3.0479 & TRN & \\
\hline CHEMBL1566115 & 688125 & 2.71 & 2.1998 & TRN & \\
\hline CHEMBL1336833 & 688125 & 4.7683 & 3.0157 & TST & \\
\hline CHEMBL1539803 & 688125 & 2.71 & 3.04399 & 99999999996 & TST \\
\hline CHEMBL1520132 & 688125 & 2.71 & 3.0906 & TRN & \\
\hline CHEMBL1413644 & 688125 & 2.71 & 2.8012 & TRN & \\
\hline CHEMBL1404962 & 688125 & 4.6189 & 2.5132 & TRN & \\
\hline CHEMBL1562470 & 688125 & 2.71 & 3.1501 & TRN & \\
\hline CHEMBL1461245 & 688125 & 2.71 & 2.6692 & TRN & \\
\hline CHEMBL1412042 & 688125 & 2.71 & 3.4875 & TRN & \\
\hline CHEMBL1402172 & 688125 & 2.71 & 2.7933 & TRN & \\
\hline CHEMBL1485782 & 688125 & 2.71 & 3.0606 & TRN & \\
\hline CHEMBL1601359 & 688125 & 2.71 & 2.6942 & TRN & \\
\hline CHEMBL1613427 & 688125 & 2.71 & 2.812 & TRN & \\
\hline CHEMBL1889837 & 688125 & 2.71 & 3.089 & TRN & \\
\hline CHEMBL1410443 & 688125 & 2.71 & 3.2789 & TRN & \\
\hline CHEMBL1489109 & 688125 & 4.216 & 3.2198 & TRN & \\
\hline CHEMBL1369482 & 688125 & 2.71 & 4.1101 & TST & \\
\hline CHEMBL1523189 & 688125 & 5.0414 & 3.4719 & TRN & \\
\hline CHEMBL1309004 & 688125 & 2.71 & 2.7769 & TRN & \\
\hline CHEMBL1531184 & 688125 & 6.4237 & 3.2925 & TRN & \\
\hline CHEMBL1339287 & 688125 & 2.71 & 3.3154 & TRN & \\
\hline CHEMBL1553065 & 688125 & 2.71 & 3.1255 & TRN & \\
\hline CHEMBL1525675 & 688125 & 2.71 & 2.9018 & TRN & \\
\hline CHEMBL1406978 & 688125 & 2.71 & 3.4215 & TRN & \\
\hline CHEMBL1426059 & 688125 & 2.71 & 2.9745 & TRN & \\
\hline CHEMBL1577373 & 688125 & 2.71 & 2.4397 & TRN & \\
\hline CHEMBL1312744 & 688125 & 4.5861 & 3.7404 & TRN & \\
\hline CHEMBL1392228 & 688125 & 5.7597 & 5.8708 & TRN & \\
\hline CHEMBL1610901 & 688125 & 2.71 & 2.5886 & TRN & \\
\hline CHEMBL1532390 & 688125 & 2.71 & 2.9687 & TRN & \\
\hline CHEMBL1363438 & 688125 & 4.7063 & 2.8877 & TRN & \\
\hline
\end{tabular}




\begin{tabular}{|c|c|c|c|c|c|}
\hline & & \multicolumn{4}{|c|}{ Supplemental Table S2.txt } \\
\hline CHEMBL604361 & 688125 & 4.9341 & 3.752 & TRN & \\
\hline CHEMBL1531746 & 688125 & 2.71 & 3.5819 & TRN & \\
\hline CHEMBL1309723 & 688125 & 2.71 & 3.1929 & TRN & \\
\hline CHEMBL1537098 & 688125 & 7.7959 & 7.8374 & TRN & \\
\hline CHEMBL1345717 & 688125 & 4.5962 & 4.2842 & TRN & \\
\hline CHEMBL1454883 & 688125 & 2.71 & 3.0633 & TRN & \\
\hline CHEMBL1412813 & 688125 & 2.71 & 3.0677 & TRN & \\
\hline CHEMBL1374713 & 688125 & 2.71 & 3.5393 & TRN & \\
\hline CHEMBL1325117 & 688125 & 2.71 & 2.986 & TRN & \\
\hline CHEMBL3194789 & 688125 & 2.71 & 2.8962 & TRN & \\
\hline CHEMBL1326874 & 688125 & 5.6146 & 4.7518 & TRN & \\
\hline CHEMBL17639 & 688125 & 4.0975 & 4.399 & TST & \\
\hline CHEMBL1455869 & 688125 & 2.71 & 2.7538 & TRN & \\
\hline CHEMBL1422115 & 688125 & 2.71 & 2.6723 & TRN & \\
\hline CHEMBL1493468 & 688125 & 2.71 & 3.3567 & TRN & \\
\hline CHEMBL1342224 & 688125 & 2.71 & 2.8047 & TRN & \\
\hline CHEMBL1359229 & 688125 & 2.71 & 3.0104 & TRN & \\
\hline CHEMBL1446475 & 688125 & 2.71 & 3.3404 & TRN & \\
\hline CHEMBL1494167 & 688125 & 2.71 & 3.1344 & TRN & \\
\hline CHEMBL 3192684 & 688125 & 2.71 & 3.8329 & TRN & \\
\hline CHEMBL1519374 & 688125 & 5.2659 & 4.395 & TRN & \\
\hline CHEMBL1527424 & 688125 & 2.71 & 2.9924 & TRN & \\
\hline CHEMBL1587117 & 688125 & 7.7959 & 6.8996 & TRN & \\
\hline CHEMBL3196867 & 688125 & 2.71 & 5.4385 & TRN & \\
\hline CHEMBL1499754 & 688125 & 2.71 & 3.61800 & 00000000003 & TRN \\
\hline CHEMBL1335969 & 688125 & 2.71 & 3.2247 & TRN & \\
\hline CHEMBL1541587 & 688125 & 2.71 & 2.6893 & TRN & \\
\hline CHEMBL1566796 & 688125 & 4.2727 & 3.0971 & TRN & \\
\hline CHEMBL1385111 & 688125 & 4.6635 & 3.4087 & TRN & \\
\hline CHEMBL1382637 & 688125 & 2.71 & 3.4941 & TRN & \\
\hline CHEMBL1495045 & 688125 & 2.71 & 2.7807 & TRN & \\
\hline CHEMBL1422749 & 688125 & 5.1005 & 2.7571 & TRN & \\
\hline CHEMBL1396030 & 688125 & 2.71 & 3.1234 & TST & \\
\hline CHEMBL1327959 & 688125 & 2.71 & 3.1626 & TRN & \\
\hline CHEMBL1548204 & 688125 & 4.40300 & 00000000 & 3.3086 & TRN \\
\hline CHEMBL1584852 & 688125 & 2.71 & 3.1362 & TRN & \\
\hline CHEMBL1497520 & 688125 & 2.71 & 2.8908 & TST & \\
\hline CHEMBL1313217 & 688125 & 4.4446 & 3.6742 & TST & \\
\hline CHEMBL1423501 & 688125 & 5.7765 & 3.9603 & TRN & \\
\hline CHEMBL1380189 & 688125 & 2.71 & 3.2421 & TST & \\
\hline CHEMBL1305023 & 688125 & 2.71 & 2.4617 & TRN & \\
\hline CHEMBL1500447 & 688125 & 7.7959 & 3.6118 & TRN & \\
\hline CHEMBL1420145 & 688125 & 2.71 & 3.4562 & TST & \\
\hline CHEMBL1485645 & 688125 & 2.71 & 3.4004 & TRN & \\
\hline CHEMBL1326905 & 688125 & 2.71 & 2.7512 & TRN & \\
\hline CHEMBL1335608 & 688125 & 2.71 & 3.2526 & TRN & \\
\hline CHEMBL1509478 & 688125 & 2.71 & 2.8504 & TRN & \\
\hline CHEMBL 3198084 & 688125 & 2.71 & 3.8562 & TRN & \\
\hline
\end{tabular}




\begin{tabular}{|c|c|c|c|c|c|}
\hline \multicolumn{6}{|c|}{ Supplemental Table S2.txt } \\
\hline CHEMBL1394357 & 688125 & 2.71 & 2.9603 & TRN & \\
\hline CHEMBL1391394 & 688125 & 2.71 & 2.4169 & TRN & \\
\hline CHEMBL1472133 & 688125 & 2.71 & 2.7437 & TRN & \\
\hline CHEMBL1465642 & 688125 & 2.71 & 2.9457 & TRN & \\
\hline CHEMBL1608296 & 688125 & 2.71 & 2.9704 & TRN & \\
\hline CHEMBL1442296 & 688125 & 2.71 & 3.6842 & TRN & \\
\hline CHEMBL1340165 & 688125 & 2.71 & 3.4076 & TRN & \\
\hline CHEMBL1613078 & 688125 & 2.71 & 3.45300 & 00000000003 & TRN \\
\hline CHEMBL1514691 & 688125 & 5.0711 & 3.7151 & TRN & \\
\hline CHEMBL1497190 & 688125 & 2.71 & 2.7973 & TRN & \\
\hline CHEMBL3194371 & 688125 & 2.71 & 2.7771 & TRN & \\
\hline CHEMBL1491773 & 688125 & 2.71 & 3.1938 & TRN & \\
\hline CHEMBL1498509 & 688125 & 5.7562 & 4.5441 & TST & \\
\hline CHEMBL1541441 & 688125 & 5.0852 & 3.6207 & TST & \\
\hline CHEMBL1496726 & 688125 & 4.4347 & 2.9934 & TST & \\
\hline CHEMBL1365888 & 688125 & 2.71 & 3.2994 & TRN & \\
\hline CHEMBL3192961 & 688125 & 2.71 & 3.4129 & TRN & \\
\hline CHEMBL1361876 & 688125 & 2.71 & 2.4031 & TRN & \\
\hline CHEMBL1579425 & 688125 & 2.71 & 2.9282 & TRN & \\
\hline CHEMBL1469204 & 688125 & 2.71 & 2.5292 & TRN & \\
\hline CHEMBL1465585 & 688125 & 2.71 & 3.0144 & TRN & \\
\hline CHEMBL1904348 & 688125 & 7.7959 & 4.7688 & TST & \\
\hline CHEMBL1319934 & 688125 & 2.71 & 3.1421 & TRN & \\
\hline CHEMBL1392142 & 688125 & 7.7959 & 7.06 & TRN & \\
\hline CHEMBL1529527 & 688125 & 2.71 & 2.8341 & TRN & \\
\hline CHEMBL1468129 & 688125 & 2.71 & 3.2553 & TRN & \\
\hline CHEMBL1483306 & 688125 & 2.71 & 2.8422 & TRN & \\
\hline CHEMBL1352897 & 688125 & 7.7959 & 4.5892 & TST & \\
\hline CHEMBL1508391 & 688125 & 2.71 & 2.2588 & TRN & \\
\hline CHEMBL1585829 & 688125 & 2.71 & 2.5699 & TRN & \\
\hline CHEMBL3192138 & 688125 & 7.7959 & 5.534 & TRN & \\
\hline CHEMBL1569682 & 688125 & 5.5168 & 3.0517 & TRN & \\
\hline CHEMBL1403385 & 688125 & 2.71 & 3.3526 & TRN & \\
\hline CHEMBL1595895 & 688125 & 2.71 & 2.7415 & TRN & \\
\hline CHEMBL1491071 & 688125 & 2.71 & 2.9174 & TRN & \\
\hline CHEMBL1535546 & 688125 & 5.3596 & 3.4781 & TRN & \\
\hline CHEMBL1522244 & 688125 & 2.71 & 2.6551 & TRN & \\
\hline CHEMBL1367551 & 688125 & 2.71 & 2.9081 & TRN & \\
\hline CHEMBL1491904 & 688125 & 2.71 & 2.9042 & TRN & \\
\hline CHEMBL1301700 & 688125 & 5.517 & 3.2344 & TRN & \\
\hline CHEMBL1533554 & 688125 & 2.71 & 3.3279 & TRN & \\
\hline CHEMBL1325455 & 688125 & 2.71 & 3.4561 & TST & \\
\hline CHEMBL1405757 & 688125 & 2.71 & 2.855 & TRN & \\
\hline CHEMBL1542304 & 688125 & 2.71 & 3.7085 & TST & \\
\hline CHEMBL1529089 & 688125 & 2.71 & 3.5409 & TRN & \\
\hline CHEMBL1356088 & 688125 & 2.71 & 2.8763 & TRN & \\
\hline CHEMBL1524433 & 688125 & 2.71 & 3.6283 & TRN & \\
\hline CHEMBL1307035 & 688125 & 2.71 & 2.8278 & TRN & \\
\hline
\end{tabular}




\begin{tabular}{|c|c|c|c|c|c|}
\hline \multicolumn{6}{|c|}{ Supplemental Table S2.txt } \\
\hline CHEMBL1324826 & 688125 & 4.95 & 3.4706 & TST & \\
\hline CHEMBL1361072 & 688125 & 4.8813 & 2.7532 & TRN & \\
\hline CHEMBL1452379 & 688125 & 5.1795 & 3.529 & TRN & \\
\hline CHEMBL1332724 & 688125 & 2.71 & 3.1008 & TRN & \\
\hline CHEMBL1468617 & 688125 & 2.71 & 2.3768 & TRN & \\
\hline CHEMBL1305519 & 688125 & 2.71 & 2.8481 & TRN & \\
\hline CHEMBL1353696 & 688125 & 2.71 & 2.9483 & TRN & \\
\hline CHEMBL1300136 & 688125 & 4.7813 & 3.8652 & TRN & \\
\hline CHEMBL1494893 & 688125 & 2.71 & 3.5971 & TRN & \\
\hline CHEMBL1415236 & 688125 & 2.71 & 3.6184 & TST & \\
\hline CHEMBL1300279 & 688125 & 2.71 & 2.7167 & TRN & \\
\hline CHEMBL1541326 & 688125 & 2.71 & 3.1879 & TRN & \\
\hline CHEMBL567529 & 688125 & 2.71 & 3.9534 & TRN & \\
\hline CHEMBL1505595 & 688125 & 2.71 & 2.2394 & TRN & \\
\hline CHEMBL1402605 & 688125 & 2.71 & 2.847 & TRN & \\
\hline CHEMBL131037 & 688125 & 5.3412 & 3.2423 & TST & \\
\hline CHEMBL1361720 & 688125 & 2.71 & 3.3338 & TST & \\
\hline CHEMBL1470904 & 688125 & 7.7959 & 5.1111 & TRN & \\
\hline CHEMBL1538510 & 688125 & 2.71 & 2.3774 & TRN & \\
\hline CHEMBL1566354 & 688125 & 3.9643 & 2.2219 & TRN & \\
\hline CHEMBL1527861 & 688125 & 5.0216 & 4.3231 & TRN & \\
\hline CHEMBL1402065 & 688125 & 2.71 & 3.4664 & TRN & \\
\hline CHEMBL1507250 & 688125 & 7.7959 & 6.8093 & TRN & \\
\hline CHEMBL1346431 & 688125 & 3.7715 & 4.0233 & TRN & \\
\hline CHEMBL1458216 & 688125 & 2.71 & 3.0812 & TRN & \\
\hline CHEMBL1543630 & 688125 & 2.71 & 3.4126 & TRN & \\
\hline CHEMBL1305426 & 688125 & 2.71 & 3.5648 & TRN & \\
\hline CHEMBL1386072 & 688125 & 2.71 & 2.7416 & TRN & \\
\hline CHEMBL1350077 & 688125 & 5.6119 & 3.4734 & TST & \\
\hline CHEMBL1432488 & 688125 & 2.71 & 2.4961 & TRN & \\
\hline CHEMBL1453996 & 688125 & 7.7959 & 6.4398 & TRN & \\
\hline CHEMBL1612238 & 688125 & 2.71 & 2.8985 & TRN & \\
\hline CHEMBL1471184 & 688125 & 2.71 & 2.7379 & TRN & \\
\hline CHEMBL1402144 & 688125 & 2.71 & 2.7137 & TST & \\
\hline CHEMBL1318945 & 688125 & 2.71 & 3.5546 & TRN & \\
\hline CHEMBL1356838 & 688125 & 6.4841 & 4.5264 & TRN & \\
\hline CHEMBL1466383 & 688125 & 2.71 & 2.1368 & TRN & \\
\hline CHEMBL1319041 & 688125 & 2.71 & 2.5974 & TRN & \\
\hline CHEMBL1573883 & 688125 & 4.7211 & 3.89899 & 99999999996 & TRN \\
\hline CHEMBL1339040 & 688125 & 2.71 & 4.2659 & TRN & \\
\hline CHEMBL1424606 & 688125 & 2.71 & 2.9657 & TRN & \\
\hline CHEMBL1592411 & 688125 & 2.71 & 2.4302 & TRN & \\
\hline CHEMBL1334333 & 688125 & 2.71 & 3.3683 & TST & \\
\hline CHEMBL1549929 & 688125 & 6.4295 & 2.7449 & TST & \\
\hline CHEMBL1608551 & 688125 & 2.71 & 4.8117 & TRN & \\
\hline CHEMBL1423727 & 688125 & 2.71 & 3.2577 & TRN & \\
\hline CHEMBL1547286 & 688125 & 2.71 & 3.2513 & TRN & \\
\hline CHEMBL1545625 & 688125 & 2.71 & 3.9015 & TRN & \\
\hline
\end{tabular}




\begin{tabular}{|c|c|c|c|c|c|}
\hline \multirow[b]{2}{*}{ CHEMBL1610429 } & \multicolumn{5}{|c|}{ Supplemental Table S2.txt } \\
\hline & 688125 & 6.5058 & 3.9633 & TRN & \\
\hline CHEMBL1428099 & 688125 & 2.71 & 2.8448 & TRN & \\
\hline CHEMBL1581490 & 688125 & 2.71 & 2.9818 & TRN & \\
\hline CHEMBL1311490 & 688125 & 2.71 & 3.0303 & TRN & \\
\hline CHEMBL1447884 & 688125 & 2.71 & 3.4792 & TRN & \\
\hline CHEMBL1974856 & 688125 & 2.71 & 3.6995 & TRN & \\
\hline CHEMBL1458302 & 688125 & 4.4281 & 2.9774 & TRN & \\
\hline CHEMBL1371387 & 688125 & 2.71 & 2.9474 & TRN & \\
\hline CHEMBL1530126 & 688125 & 2.71 & 2.698 & TRN & \\
\hline CHEMBL1387688 & 688125 & 5.3024 & 3.5251 & TRN & \\
\hline CHEMBL1519437 & 688125 & 2.71 & 3.1165 & TRN & \\
\hline CHEMBL1321408 & 688125 & 2.71 & 3.0473 & TST & \\
\hline CHEMBL1578490 & 688125 & 5.5357 & 3.0949 & TRN & \\
\hline CHEMBL1599516 & 688125 & 2.71 & 3.07800 & 00000000003 & TRN \\
\hline CHEMBL1351495 & 688125 & 2.71 & 2.8355 & TRN & \\
\hline CHEMBL1541925 & 688125 & 2.71 & 2.4374 & TRN & \\
\hline CHEMBL23507 & 688125 & 2.71 & 3.2819 & TST & \\
\hline CHEMBL1409646 & 688125 & 2.71 & 3.0379 & TRN & \\
\hline CHEMBL1381424 & 688125 & 2.71 & 3.3045 & TST & \\
\hline CHEMBL1527700 & 688125 & 2.71 & 3.42100 & 00000000003 & TRN \\
\hline CHEMBL1533394 & 688125 & 2.71 & 3.1847 & TRN & \\
\hline CHEMBL1453784 & 688125 & 2.71 & 2.0912 & TRN & \\
\hline CHEMBL1309878 & 688125 & 2.71 & 3.3355 & TRN & \\
\hline CHEMBL1361073 & 688125 & 2.71 & 3.1318 & TRN & \\
\hline CHEMBL 3194501 & 688125 & 2.71 & 2.8411 & TRN & \\
\hline CHEMBL1392925 & 688125 & 2.71 & 2.3932 & TRN & \\
\hline CHEMBL1500733 & 688125 & 2.71 & 3.23 & TST & \\
\hline CHEMBL1388645 & 688125 & 2.71 & 2.8575 & TRN & \\
\hline CHEMBL1346007 & 688125 & 2.71 & 2.9262 & TRN & \\
\hline CHEMBL1321840 & 688125 & 2.71 & 3.0175 & TST & \\
\hline CHEMBL1579922 & 688125 & 2.71 & 4.4332 & TRN & \\
\hline CHEMBL1549589 & 688125 & 2.71 & 3.2256 & TST & \\
\hline CHEMBL1313953 & 688125 & 2.71 & 2.3571 & TRN & \\
\hline CHEMBL1585086 & 688125 & 5.4646 & 3.1396 & TRN & \\
\hline CHEMBL1491448 & 688125 & 2.71 & 2.8293 & TRN & \\
\hline CHEMBL1423718 & 688125 & 2.71 & 2.8807 & TRN & \\
\hline CHEMBL1529495 & 688125 & 2.71 & 3.0378 & TRN & \\
\hline CHEMBL1461738 & 688125 & 2.71 & 4.1104 & TRN & \\
\hline CHEMBL1565662 & 688125 & 2.71 & 3.6039 & TRN & \\
\hline CHEMBL1421367 & 688125 & 2.71 & 3.0736 & TRN & \\
\hline CHEMBL1324485 & 688125 & 2.71 & 3.0256 & TRN & \\
\hline CHEMBL1370089 & 688125 & 2.71 & 2.68899 & 99999999996 & TRN \\
\hline CHEMBL1455906 & 688125 & 2.71 & 3.9887 & TST & \\
\hline CHEMBL1607086 & 688125 & 5.3079 & 6.0385 & TRN & \\
\hline CHEMBL1415958 & 688125 & 6.5702 & 3.8239 & TRN & \\
\hline CHEMBL1526284 & 688125 & 2.71 & 3.1054 & TRN & \\
\hline CHEMBL1330583 & 688125 & 7.7959 & 5.9904 & TRN & \\
\hline CHEMBL1545332 & 688125 & 2.71 & 3.3321 & TRN & \\
\hline
\end{tabular}




\begin{tabular}{|c|c|c|c|c|c|}
\hline \multicolumn{6}{|c|}{ Supplemental Table S2.txt } \\
\hline CHEMBL1560037 & 688125 & 2.71 & 2.6535 & TRN & \\
\hline CHEMBL1381241 & 688125 & 2.71 & 3.1539 & TST & \\
\hline CHEMBL1564891 & 688125 & 2.71 & 3.85399 & 99999999996 & TRN \\
\hline CHEMBL1437979 & 688125 & 4.3184 & 3.0533 & TRN & \\
\hline CHEMBL1398513 & 688125 & 2.71 & 2.7705 & TRN & \\
\hline CHEMBL1588363 & 688125 & 2.71 & 3.5645 & TRN & \\
\hline CHEMBL1331224 & 688125 & 2.71 & 3.1549 & TRN & \\
\hline CHEMBL1433114 & 688125 & 2.71 & 3.0154 & TRN & \\
\hline CHEMBL 3209422 & 688125 & 2.71 & 3.4276 & TST & \\
\hline CHEMBL1372211 & 688125 & 2.71 & 3.0774 & TRN & \\
\hline CHEMBL1496549 & 688125 & 4.4054 & 3.3447 & TRN & \\
\hline CHEMBL1588590 & 688125 & 2.71 & 2.5175 & TRN & \\
\hline CHEMBL1379613 & 688125 & 2.71 & 3.41399 & 99999999997 & TRN \\
\hline CHEMBL1556638 & 688125 & 2.71 & 3.0628 & TRN & \\
\hline CHEMBL1421491 & 688125 & 2.71 & 3.7661 & TST & \\
\hline CHEMBL1597822 & 688125 & 2.71 & 4.6668 & TRN & \\
\hline CHEMBL1576908 & 688125 & 2.71 & 2.3455 & TRN & \\
\hline CHEMBL1480112 & 688125 & 2.71 & 2.9077 & TRN & \\
\hline CHEMBL 1382488 & 688125 & 2.71 & 3.2779 & TRN & \\
\hline CHEMBL290077 & 688125 & 5.2625 & 4.7357 & TST & \\
\hline CHEMBL1486641 & 688125 & 2.71 & 3.1416 & TRN & \\
\hline CHEMBL1301506 & 688125 & 2.71 & 2.6289 & TRN & \\
\hline CHEMBL1431075 & 688125 & 5.4781 & 3.4173 & TRN & \\
\hline CHEMBL1361788 & 688125 & 2.71 & 2.9653 & TRN & \\
\hline CHEMBL1300781 & 688125 & 2.71 & 3.1191 & TRN & \\
\hline CHEMBL1359479 & 688125 & 2.71 & 3.0175 & TRN & \\
\hline CHEMBL1460747 & 688125 & 2.71 & 3.4501 & TRN & \\
\hline CHEMBL1547667 & 688125 & 2.71 & 2.8927 & TRN & \\
\hline CHEMBL1511279 & 688125 & 2.71 & 3.3039 & TST & \\
\hline CHEMBL1558065 & 688125 & 6.317 & 5.7293 & TRN & \\
\hline CHEMBL3210459 & 688125 & 4.2787 & 3.4635 & TRN & \\
\hline CHEMBL1479794 & 688125 & 2.71 & 3.514 & TRN & \\
\hline CHEMBL1609771 & 688125 & 2.71 & 3.68899 & 99999999996 & TRN \\
\hline CHEMBL1302194 & 688125 & 2.71 & 2.9587 & TRN & \\
\hline CHEMBL1544156 & 688125 & 2.71 & 2.5965 & TRN & \\
\hline CHEMBL1562952 & 688125 & 2.71 & 2.3381 & TRN & \\
\hline CHEMBL3197351 & 688125 & 4.0137 & 3.4959 & TRN & \\
\hline CHEMBL1539610 & 688125 & 2.71 & 3.0671 & TRN & \\
\hline CHEMBL1329504 & 688125 & 4.6685 & 2.8476 & TRN & \\
\hline CHEMBL1361821 & 688125 & 5.3944 & 2.9083 & TRN & \\
\hline CHEMBL1361526 & 688125 & 2.71 & 3.813 & TST & \\
\hline CHEMBL1368105 & 688125 & 2.71 & 3.3647 & TRN & \\
\hline CHEMBL1385668 & 688125 & 5.7093 & 2.9038 & TRN & \\
\hline CHEMBL1564501 & 688125 & 4.6519 & 3.8738 & TRN & \\
\hline CHEMBL1486932 & 688125 & 2.71 & 3.2904 & TRN & \\
\hline CHEMBL1446405 & 688125 & 4.6646 & 4.0097 & TRN & \\
\hline CHEMBL3210250 & 688125 & 4.6783 & 4.2507 & TST & \\
\hline CHEMBL1576840 & 688125 & 2.71 & 4.0899 & TRN & \\
\hline
\end{tabular}




\begin{tabular}{|c|c|c|c|c|c|}
\hline \multicolumn{6}{|c|}{ Supplemental Table S2.txt } \\
\hline CHEMBL1458410 & 688125 & 2.71 & 3.0669 & TRN & \\
\hline CHEMBL1532925 & 688125 & 2.71 & 4.2563 & TRN & \\
\hline CHEMBL1305321 & 688125 & 2.71 & 3.8451 & TRN & \\
\hline CHEMBL1475768 & 688125 & 2.71 & 3.6306 & TRN & \\
\hline CHEMBL1347464 & 688125 & 2.71 & 2.9308 & TRN & \\
\hline CHEMBL1371259 & 688125 & 2.71 & 2.9711 & TRN & \\
\hline CHEMBL1428966 & 688125 & 2.71 & 2.9482 & TRN & \\
\hline CHEMBL1413875 & 688125 & 2.71 & 2.4271 & TRN & \\
\hline CHEMBL1471123 & 688125 & 4.8078 & 3.4891 & TRN & \\
\hline CHEMBL1497167 & 688125 & 2.71 & 2.9175 & TRN & \\
\hline CHEMBL1567124 & 688125 & 2.71 & 2.8825 & TRN & \\
\hline CHEMBL1981533 & 688125 & 2.71 & 2.8717 & TRN & \\
\hline CHEMBL1496860 & 688125 & 2.71 & 2.68399 & 99999999997 & TST \\
\hline CHEMBL1374098 & 688125 & 2.71 & 3.1213 & TST & \\
\hline CHEMBL1380746 & 688125 & 4.8507 & 4.0208 & TRN & \\
\hline CHEMBL1419230 & 688125 & 2.71 & 2.9122 & TRN & \\
\hline CHEMBL1439218 & 688125 & 2.71 & 2.7635 & TRN & \\
\hline CHEMBL1489001 & 688125 & 2.71 & 3.7451 & TRN & \\
\hline CHEMBL1388740 & 688125 & 2.71 & 2.7944 & TRN & \\
\hline CHEMBL1347060 & 688125 & 2.71 & 2.8968 & TRN & \\
\hline CHEMBL1567901 & 688125 & 2.71 & 3.1596 & TRN & \\
\hline CHEMBL1585680 & 688125 & 2.71 & 2.8016 & TRN & \\
\hline CHEMBL1564047 & 688125 & 2.71 & 3.6543 & TST & \\
\hline CHEMBL1418790 & 688125 & 2.71 & 2.9107 & TRN & \\
\hline CHEMBL1328541 & 688125 & 2.71 & 2.9337 & TST & \\
\hline CHEMBL1405616 & 688125 & 2.71 & 2.8854 & TRN & \\
\hline CHEMBL1422335 & 688125 & 4.1526 & 5.8789 & TRN & \\
\hline CHEMBL3208974 & 688125 & 2.71 & 3.2839 & TRN & \\
\hline CHEMBL1581151 & 688125 & 4.6683 & 3.0471 & TRN & \\
\hline CHEMBL1351117 & 688125 & 2.71 & 3.3717 & TST & \\
\hline CHEMBL 3214254 & 688125 & 2.71 & 3.2544 & TST & \\
\hline CHEMBL1330345 & 688125 & 2.71 & 2.5533 & TRN & \\
\hline CHEMBL109772 & 688125 & 2.71 & 3.2168 & TST & \\
\hline CHEMBL1495977 & 688125 & 7.7959 & 5.6491 & TRN & \\
\hline CHEMBL1536187 & 688125 & 2.71 & 2.3114 & TRN & \\
\hline CHEMBL1452959 & 688125 & 2.71 & 3.1374 & TST & \\
\hline CHEMBL1529115 & 688125 & 5.2004 & 5.5263 & TRN & \\
\hline CHEMBL1370443 & 688125 & 2.71 & 2.8232 & TRN & \\
\hline CHEMBL1325900 & 688125 & 2.71 & 2.6442 & TRN & \\
\hline CHEMBL1326550 & 688125 & 2.71 & 3.2711 & TST & \\
\hline CHEMBL1359967 & 688125 & 2.71 & 2.6222 & TRN & \\
\hline CHEMBL1340664 & 688125 & 2.71 & 2.6894 & TRN & \\
\hline CHEMBL1427181 & 688125 & 2.71 & 3.8277 & TRN & \\
\hline CHEMBL1463136 & 688125 & 2.71 & 2.8809 & TRN & \\
\hline CHEMBL1584325 & 688125 & 2.71 & 2.9768 & TST & \\
\hline CHEMBL1440058 & 688125 & 4.5194 & 3.6408 & TRN & \\
\hline CHEMBL3193099 & 688125 & 2.71 & 3.0986 & TST & \\
\hline CHEMBL1339121 & 688125 & 5.7418 & 6.3178 & TRN & \\
\hline
\end{tabular}




\begin{tabular}{|c|c|c|c|c|c|}
\hline \multicolumn{6}{|c|}{ Supplemental Table S2.txt } \\
\hline CHEMBL1439144 & 688125 & 2.71 & 3.9039 & TST & \\
\hline CHEMBL1423731 & 688125 & 7.7959 & 3.6159 & TRN & \\
\hline CHEMBL1582217 & 688125 & 2.71 & 2.9956 & TRN & \\
\hline CHEMBL1541434 & 688125 & 2.71 & 3.7264 & TRN & \\
\hline CHEMBL1967184 & 688125 & 4.437 & 3.2856 & TST & \\
\hline CHEMBL1477985 & 688125 & 2.71 & 3.1401 & TRN & \\
\hline CHEMBL1510859 & 688125 & 2.71 & 3.0662 & TRN & \\
\hline CHEMBL1460181 & 688125 & 2.71 & 3.3906 & TRN & \\
\hline CHEMBL1606097 & 688125 & 5.5144 & 5.0305 & TRN & \\
\hline CHEMBL1455288 & 688125 & 2.71 & 2.5003 & TRN & \\
\hline CHEMBL1420168 & 688125 & 2.71 & 4.3238 & TRN & \\
\hline CHEMBL1500219 & 688125 & 2.71 & 3.6098 & TRN & \\
\hline CHEMBL1403367 & 688125 & 2.71 & 2.3345 & TRN & \\
\hline CHEMBL1578660 & 688125 & 2.71 & 2.7648 & TRN & \\
\hline CHEMBL1546843 & 688125 & 4.9861 & 3.7492 & TRN & \\
\hline CHEMBL1610049 & 688125 & 6.1599 & 3.4032 & TRN & \\
\hline CHEMBL1400298 & 688125 & 4.9442 & 5.7036 & TRN & \\
\hline CHEMBL1339546 & 688125 & 2.71 & 2.9386 & TRN & \\
\hline CHEMBL1469100 & 688125 & 2.71 & 3.0363 & TRN & \\
\hline CHEMBL1516927 & 688125 & 2.71 & 2.2914 & TRN & \\
\hline CHEMBL1450028 & 688125 & 2.71 & 3.9386 & TST & \\
\hline CHEMBL1971393 & 688125 & 2.71 & 3.8804 & TST & \\
\hline CHEMBL1578254 & 688125 & 2.71 & 2.4825 & TRN & \\
\hline CHEMBL1364655 & 688125 & 2.71 & 2.78899 & 99999999997 & TST \\
\hline CHEMBL1488622 & 688125 & 2.71 & 3.2083 & TST & \\
\hline CHEMBL1403980 & 688125 & 5.5103 & 3.0877 & TST & \\
\hline CHEMBL1322281 & 688125 & 2.71 & 3.0036 & TRN & \\
\hline CHEMBL1560958 & 688125 & 2.71 & 2.5915 & TRN & \\
\hline CHEMBL1536529 & 688125 & 2.71 & 3.2164 & TRN & \\
\hline CHEMBL1525536 & 688125 & 2.71 & 2.7327 & TRN & \\
\hline CHEMBL1456617 & 688125 & 2.71 & 3.6735 & TRN & \\
\hline CHEMBL1481069 & 688125 & 2.71 & 4.7515 & TRN & \\
\hline CHEMBL3191946 & 688125 & 7.7959 & 5.9652 & TRN & \\
\hline CHEMBL1481390 & 688125 & 2.71 & 3.3714 & TRN & \\
\hline CHEMBL1516115 & 688125 & 2.71 & 2.9889 & TRN & \\
\hline CHEMBL1494700 & 688125 & 2.71 & 3.6013 & TRN & \\
\hline CHEMBL1589268 & 688125 & 2.71 & 3.4032 & TRN & \\
\hline CHEMBL1342659 & 688125 & 2.71 & 3.0751 & TRN & \\
\hline CHEMBL325841 & 688125 & 3.9336 & 3.35100 & 00000000004 & TRN \\
\hline CHEMBL1364498 & 688125 & 4.6528 & 3.0062 & TST & \\
\hline CHEMBL1361684 & 688125 & 2.71 & 3.5134 & TST & \\
\hline CHEMBL1606031 & 688125 & 6.7773 & 4.1115 & TRN & \\
\hline CHEMBL1490601 & 688125 & 4.0278 & 2.7717 & TST & \\
\hline CHEMBL1605593 & 688125 & 2.71 & 2.3769 & TRN & \\
\hline CHEMBL1425100 & 688125 & 2.71 & 3.4217 & TRN & \\
\hline CHEMBL1472386 & 688125 & 2.71 & 3.2143 & TRN & \\
\hline CHEMBL1478765 & 688125 & 4.3772 & 3.2377 & TRN & \\
\hline CHEMBL3207619 & 688125 & 6.0655 & 4.587 & TRN & \\
\hline
\end{tabular}




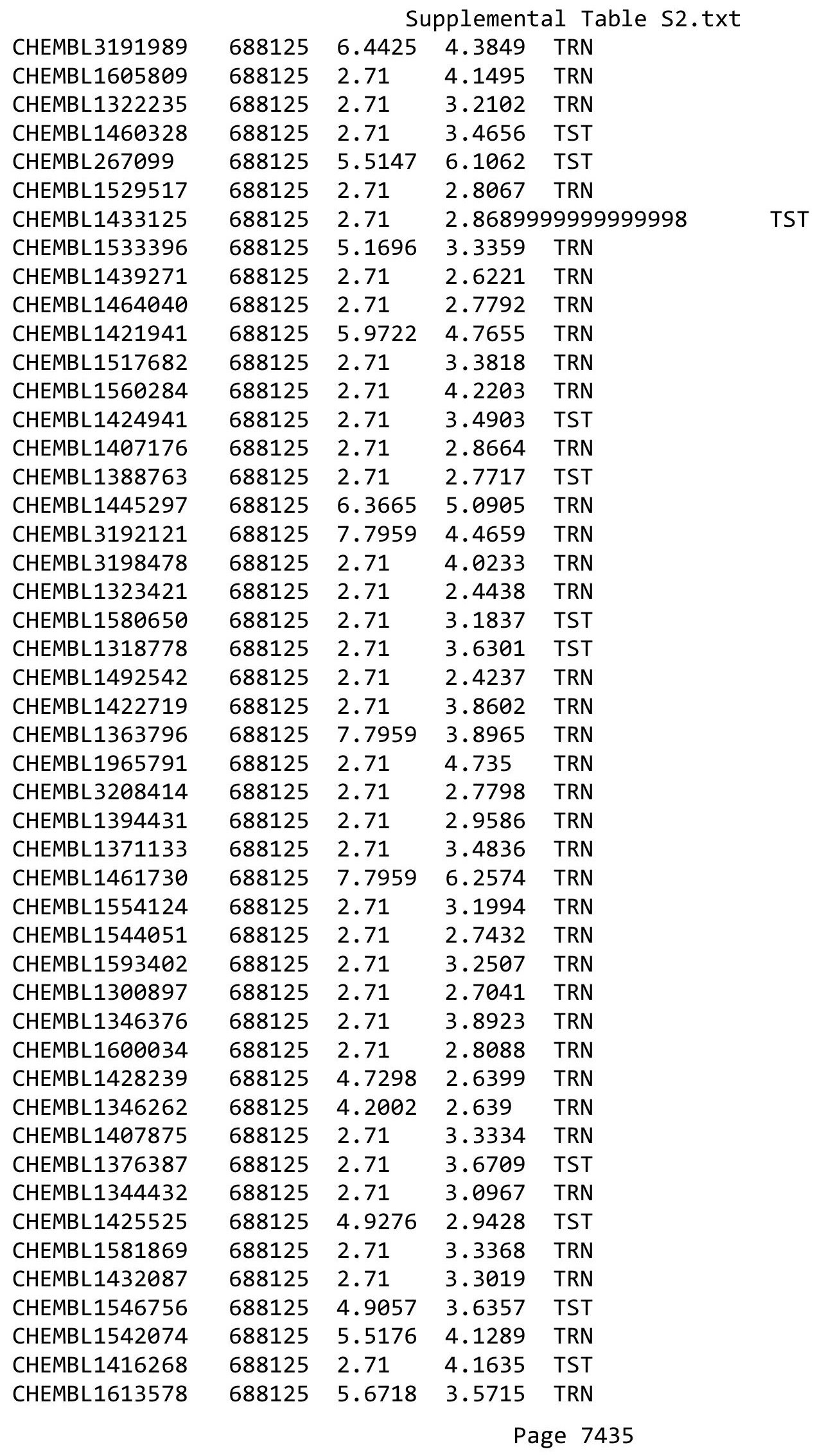




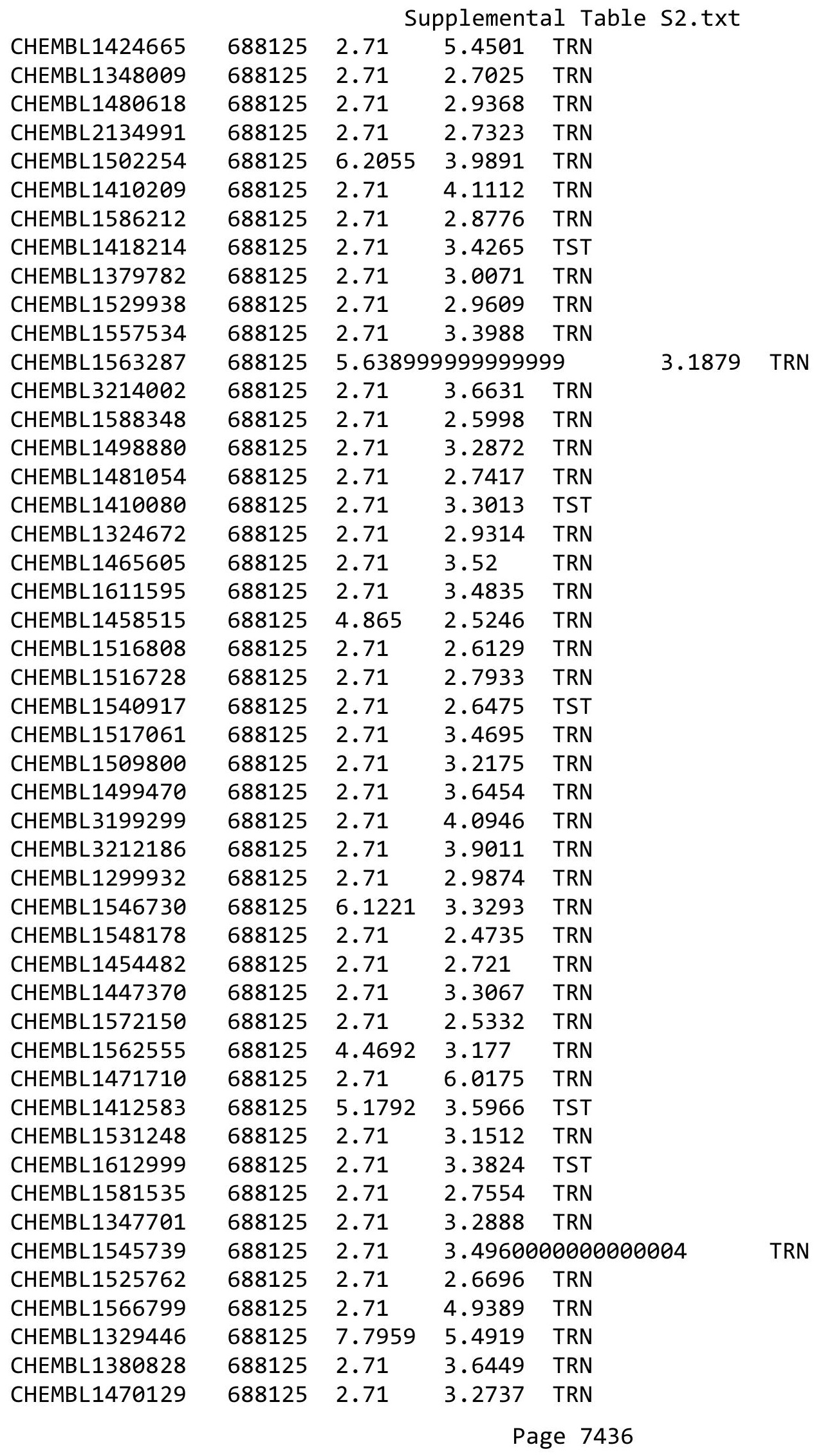




\begin{tabular}{|c|c|c|c|c|c|}
\hline & & \multicolumn{4}{|c|}{ Supplemental Table S2.txt } \\
\hline CHEMBL1340637 & 688125 & 2.71 & 2.6794 & TRN & \\
\hline CHEMBL1573720 & 688125 & 5.5006 & 2.8607 & TRN & \\
\hline CHEMBL1302575 & 688125 & 2.71 & 2.5247 & TRN & \\
\hline CHEMBL1449062 & 688125 & 2.71 & 2.9267 & TRN & \\
\hline CHEMBL1365146 & 688125 & 2.71 & 3.8968 & TST & \\
\hline CHEMBL1378649 & 688125 & 2.71 & 3.0205 & TRN & \\
\hline CHEMBL1597454 & 688125 & 2.71 & 3.26800 & 00000000002 & TRN \\
\hline CHEMBL1528157 & 688125 & 2.71 & 4.3449 & TRN & \\
\hline CHEMBL1564829 & 688125 & 2.71 & 2.9778 & TRN & \\
\hline CHEMBL1403959 & 688125 & 2.71 & 2.6536 & TRN & \\
\hline CHEMBL1588153 & 688125 & 2.71 & 3.4578 & TRN & \\
\hline CHEMBL1491104 & 688125 & 2.71 & 2.7816 & TRN & \\
\hline CHEMBL1437854 & 688125 & 2.71 & 3.3785 & TRN & \\
\hline CHEMBL1509200 & 688125 & 2.71 & 3.4651 & TRN & \\
\hline CHEMBL1352313 & 688125 & 5.4998 & 3.6717 & TRN & \\
\hline CHEMBL1582329 & 688125 & 2.71 & 2.8207 & TRN & \\
\hline CHEMBL3193530 & 688125 & 7.7959 & 6.7251 & TRN & \\
\hline CHEMBL1349172 & 688125 & 2.71 & 4.2941 & TST & \\
\hline CHEMBL1493620 & 688125 & 2.71 & 2.9052 & TRN & \\
\hline CHEMBL1459577 & 688125 & 2.71 & 3.8051 & TRN & \\
\hline CHEMBL1430917 & 688125 & 2.71 & 3.1649 & TRN & \\
\hline CHEMBL1310848 & 688125 & 2.71 & 3.5434 & TRN & \\
\hline CHEMBL1531448 & 688125 & 2.71 & 3.6072 & TST & \\
\hline CHEMBL1578690 & 688125 & 2.71 & 3.1919 & TRN & \\
\hline CHEMBL1484214 & 688125 & 2.71 & 3.1669 & TRN & \\
\hline CHEMBL1330617 & 688125 & 2.71 & 3.0893 & TST & \\
\hline CHEMBL1480999 & 688125 & 2.71 & 2.7455 & TRN & \\
\hline CHEMBL1353776 & 688125 & 2.71 & 3.6062 & TRN & \\
\hline CHEMBL1456359 & 688125 & 2.71 & 2.9752 & TRN & \\
\hline CHEMBL1311107 & 688125 & 2.71 & 2.8579 & TST & \\
\hline CHEMBL1496628 & 688125 & 2.71 & 3.1985 & TRN & \\
\hline CHEMBL1447526 & 688125 & 2.71 & 3.1166 & TST & \\
\hline CHEMBL1454455 & 688125 & 2.71 & 2.9659 & TRN & \\
\hline CHEMBL1449385 & 688125 & 2.71 & 3.5189 & TRN & \\
\hline CHEMBL1488886 & 688125 & 2.71 & 3.1201 & TRN & \\
\hline CHEMBL1421856 & 688125 & 2.71 & 2.9748 & TRN & \\
\hline CHEMBL1575525 & 688125 & 2.71 & 3.3841 & TRN & \\
\hline CHEMBL1300688 & 688125 & 2.71 & 4.4171 & TRN & \\
\hline CHEMBL1379670 & 688125 & 2.71 & 3.2173 & TRN & \\
\hline CHEMBL1400472 & 688125 & 2.71 & 2.5559 & TRN & \\
\hline CHEMBL1498955 & 688125 & 2.71 & 3.0425 & TRN & \\
\hline CHEMBL1414240 & 688125 & 2.71 & 2.8266 & TST & \\
\hline CHEMBL1412296 & 688125 & 2.71 & 3.0108 & TRN & \\
\hline CHEMBL1374437 & 688125 & 2.71 & 3.0091 & TRN & \\
\hline CHEMBL1591096 & 688125 & 4.7446 & 3.4497 & TRN & \\
\hline CHEMBL1548075 & 688125 & 4.6782 & 5.6872 & TRN & \\
\hline CHEMBL1343448 & 688125 & 5.5546 & 3.8249 & TRN & \\
\hline CHEMBL1595197 & 688125 & 2.71 & 2.8612 & TRN & \\
\hline
\end{tabular}




\begin{tabular}{|c|c|c|c|c|c|}
\hline \multicolumn{6}{|c|}{ Supplemental Table s2.txt } \\
\hline CHEMBL1319463 & 688125 & 2.71 & 3.1569 & TRN & \\
\hline CHEMBL1509122 & 688125 & 2.71 & 4.2203 & TST & \\
\hline CHEMBL1524431 & 688125 & 5.277 & 3.0871 & TRN & \\
\hline CHEMBL1464574 & 688125 & 2.71 & 3.5796 & TRN & \\
\hline CHEMBL1420349 & 688125 & 2.71 & 2.702 & TRN & \\
\hline CHEMBL1528529 & 688125 & 2.71 & 2.7771 & TRN & \\
\hline CHEMBL3199695 & 688125 & 2.71 & 3.04100 & 00000000004 & TRN \\
\hline CHEMBL3207745 & 688125 & 2.71 & 3.3535 & TRN & \\
\hline CHEMBL1542492 & 688125 & 5.2148 & 2.8915 & TRN & \\
\hline CHEMBL1321860 & 688125 & 2.71 & 3.5364 & TRN & \\
\hline CHEMBL1523924 & 688125 & 2.71 & 3.5891 & TST & \\
\hline CHEMBL1312747 & 688125 & 2.71 & 3.41 & TRN & \\
\hline CHEMBL1574775 & 688125 & 2.71 & 2.6706 & TRN & \\
\hline CHEMBL1405770 & 688125 & 2.71 & 3.0211 & TRN & \\
\hline CHEMBL1413816 & 688125 & 2.71 & 2.8972 & TRN & \\
\hline CHEMBL1584901 & 688125 & 2.71 & 2.795 & TRN & \\
\hline CHEMBL601400 & 688125 & 2.71 & 3.3506 & TST & \\
\hline CHEMBL1332976 & 688125 & 2.71 & 3.4398 & TRN & \\
\hline CHEMBL1409350 & 688125 & 2.71 & 3.8567 & TRN & \\
\hline CHEMBL1463299 & 688125 & 2.71 & 3.1273 & TRN & \\
\hline CHEMBL1406848 & 688125 & 2.71 & 3.6122 & TRN & \\
\hline CHEMBL1521323 & 688125 & 2.71 & 2.9772 & TRN & \\
\hline CHEMBL1609839 & 688125 & 2.71 & 3.1077 & TST & \\
\hline CHEMBL1470676 & 688125 & 7.7959 & 6.2361 & TRN & \\
\hline CHEMBL1502891 & 688125 & 6.5513 & 4.7915 & TRN & \\
\hline CHEMBL3192804 & 688125 & 2.71 & 3.5854 & TRN & \\
\hline CHEMBL1457306 & 688125 & 2.71 & 3.2952 & TST & \\
\hline CHEMBL1507181 & 688125 & 2.71 & 4.3801 & TRN & \\
\hline CHEMBL1569594 & 688125 & 2.71 & 3.0988 & TRN & \\
\hline CHEMBL1569581 & 688125 & 2.71 & 3.5362 & TST & \\
\hline CHEMBL1535205 & 688125 & 2.71 & 3.4016 & TRN & \\
\hline CHEMBL3213365 & 688125 & 2.71 & 3.3768 & TRN & \\
\hline CHEMBL1324265 & 688125 & 2.71 & 2.4316 & TST & \\
\hline CHEMBL1539357 & 688125 & 2.71 & 3.5375 & TRN & \\
\hline CHEMBL1329507 & 688125 & 2.71 & 3.9739 & TST & \\
\hline CHEMBL602632 & 688125 & 2.71 & 3.0081 & TRN & \\
\hline CHEMBL1426908 & 688125 & 2.71 & 2.8589 & TRN & \\
\hline CHEMBL1392611 & 688125 & 7.7959 & 6.4054 & TRN & \\
\hline CHEMBL1556915 & 688125 & 2.71 & 3.3688 & TST & \\
\hline CHEMBL1310529 & 688125 & 2.71 & 2.3436 & TRN & \\
\hline CHEMBL1528941 & 688125 & 2.71 & 3.637 & TRN & \\
\hline CHEMBL199925 & 688125 & 4.6343 & 4.635 & TRN & \\
\hline CHEMBL3198939 & 688125 & 7.7959 & 5.9505 & TRN & \\
\hline CHEMBL1404945 & 688125 & 2.71 & 2.7496 & TRN & \\
\hline CHEMBL1612633 & 688125 & 2.71 & 4.7295 & TRN & \\
\hline CHEMBL1603858 & 688125 & 2.71 & 3.6682 & TRN & \\
\hline CHEMBL1477594 & 688125 & 2.71 & 3.7037 & TRN & \\
\hline CHEMBL1469828 & 688125 & 2.71 & 2.2142 & TRN & \\
\hline
\end{tabular}




\begin{tabular}{|c|c|c|c|c|c|}
\hline \multicolumn{6}{|c|}{ Supplemental Table S2.txt } \\
\hline CHEMBL1406183 & 688125 & 2.71 & 2.5987 & TRN & \\
\hline CHEMBL1496145 & 688125 & 2.71 & 3.0857 & TRN & \\
\hline CHEMBL1312738 & 688125 & 7.7959 & 4.9874 & TRN & \\
\hline CHEMBL1405344 & 688125 & 5.6436 & 3.1865 & TST & \\
\hline CHEMBL1431844 & 688125 & 2.71 & 3.0752 & TRN & \\
\hline CHEMBL1327273 & 688125 & 2.71 & 2.7144 & TRN & \\
\hline CHEMBL1367166 & 688125 & 2.71 & 2.8074 & TRN & \\
\hline CHEMBL1374009 & 688125 & 4.9987 & 5.7474 & TRN & \\
\hline CHEMBL1561492 & 688125 & 2.71 & 2.832 & TRN & \\
\hline CHEMBL1351633 & 688125 & 2.71 & 2.6644 & TRN & \\
\hline CHEMBL1609514 & 688125 & 2.71 & 2.4563 & TRN & \\
\hline CHEMBL1392092 & 688125 & 2.71 & 3.3144 & TST & \\
\hline CHEMBL3190809 & 688125 & 2.71 & 4.0616 & TRN & \\
\hline CHEMBL1559518 & 688125 & 2.71 & 3.2822 & TRN & \\
\hline CHEMBL1299216 & 688125 & 2.71 & 3.3711 & TRN & \\
\hline CHEMBL1428228 & 688125 & 5.2768 & 2.9839 & TRN & \\
\hline CHEMBL1373951 & 688125 & 2.71 & 3.1138 & TRN & \\
\hline CHEMBL3210862 & 688125 & 2.71 & 3.3043 & TRN & \\
\hline CHEMBL3189260 & 688125 & 2.71 & 3.9752 & TRN & \\
\hline CHEMBL1427014 & 688125 & 2.71 & 3.633 & TRN & \\
\hline CHEMBL1526283 & 688125 & 2.71 & 2.7366 & TRN & \\
\hline CHEMBL1443525 & 688125 & 2.71 & 2.5673 & TRN & \\
\hline CHEMBL1575912 & 688125 & 2.71 & 4.2903 & TST & \\
\hline CHEMBL1224310 & 688125 & 3.9174 & 2.9011 & TRN & \\
\hline CHEMBL1544929 & 688125 & 5.4566 & 3.6782 & TRN & \\
\hline CHEMBL1574183 & 688125 & 2.71 & 3.617 & TRN & \\
\hline CHEMBL1491219 & 688125 & 2.71 & 2.42900 & 00000000003 & TRN \\
\hline CHEMBL1403329 & 688125 & 4.9283 & 3.3711 & TRN & \\
\hline CHEMBL3191218 & 688125 & 6.7773 & 6.4105 & TRN & \\
\hline CHEMBL1455847 & 688125 & 2.71 & 2.966 & TRN & \\
\hline CHEMBL1429902 & 688125 & 2.71 & 2.7609 & TST & \\
\hline CHEMBL1407904 & 688125 & 2.71 & 3.0537 & TRN & \\
\hline CHEMBL1483102 & 688125 & 2.71 & 2.6851 & TRN & \\
\hline CHEMBL1456355 & 688125 & 2.71 & 3.02600 & 00000000002 & TRN \\
\hline CHEMBL1508538 & 688125 & 2.71 & 2.8493 & TRN & \\
\hline CHEMBL1560991 & 688125 & 2.71 & 3.5121 & TST & \\
\hline CHEMBL1559538 & 688125 & 2.71 & 2.83399 & 99999999996 & TRN \\
\hline CHEMBL1342237 & 688125 & 2.71 & 2.5424 & TRN & \\
\hline CHEMBL1320532 & 688125 & 2.71 & 3.4009 & TST & \\
\hline CHEMBL1376548 & 688125 & 2.71 & 2.7036 & TRN & \\
\hline CHEMBL1411115 & 688125 & 2.71 & 3.2255 & TST & \\
\hline CHEMBL1395639 & 688125 & 2.71 & 2.7636 & TRN & \\
\hline CHEMBL1452062 & 688125 & 2.71 & 2.8967 & TST & \\
\hline CHEMBL1390339 & 688125 & 2.71 & 2.3489 & TRN & \\
\hline CHEMBL1481257 & 688125 & 2.71 & 3.2646 & TRN & \\
\hline CHEMBL1382714 & 688125 & 2.71 & 3.0124 & TRN & \\
\hline CHEMBL1335136 & 688125 & 2.71 & 3.1786 & TRN & \\
\hline CHEMBL1509683 & 688125 & 2.71 & 4.0532 & TRN & \\
\hline
\end{tabular}




\begin{tabular}{|c|c|c|c|c|c|}
\hline \multirow[b]{2}{*}{ CHEMBL1511037 } & \multicolumn{5}{|c|}{ Supplemental Table S2.txt } \\
\hline & 688125 & 5.803 & 4.7238 & TRN & \\
\hline CHEMBL1380810 & 688125 & 2.71 & 3.1822 & TST & \\
\hline CHEMBL3198239 & 688125 & 5.4309 & 3.6498 & TRN & \\
\hline CHEMBL1333350 & 688125 & 2.71 & 3.0637 & TRN & \\
\hline CHEMBL1599251 & 688125 & 2.71 & 2.9598 & TRN & \\
\hline CHEMBL1441359 & 688125 & 2.71 & 3.0231 & TRN & \\
\hline CHEMBL1497798 & 688125 & 2.71 & 2.6906 & TRN & \\
\hline CHEMBL1433245 & 688125 & 2.71 & 2.2941 & TRN & \\
\hline CHEMBL1400799 & 688125 & 2.71 & 2.9206 & TRN & \\
\hline CHEMBL1303404 & 688125 & 7.7959 & 3.8108 & TRN & \\
\hline CHEMBL1486523 & 688125 & 2.71 & 3.2412 & TRN & \\
\hline CHEMBL3209572 & 688125 & 2.71 & 2.5022 & TRN & \\
\hline CHEMBL298036 & 688125 & 2.71 & 3.4775 & TRN & \\
\hline CHEMBL1586314 & 688125 & 2.71 & 2.8226 & TRN & \\
\hline CHEMBL1503659 & 688125 & 7.7959 & 4.8084 & TRN & \\
\hline CHEMBL1320007 & 688125 & 6.7167 & 3.8923 & TRN & \\
\hline CHEMBL1351219 & 688125 & 2.71 & 2.3036 & TRN & \\
\hline CHEMBL1329292 & 688125 & 2.71 & 3.407 & TRN & \\
\hline CHEMBL1453299 & 688125 & 2.71 & 3.3838 & TRN & \\
\hline CHEMBL1467250 & 688125 & 2.71 & 2.572 & TRN & \\
\hline CHEMBL3193417 & 688125 & 2.71 & 3.6419 & TRN & \\
\hline CHEMBL1887153 & 688125 & 5.9055 & 4.7934 & TRN & \\
\hline CHEMBL 261123 & 688125 & 7.7959 & 6.2437 & TRN & \\
\hline CHEMBL1300237 & 688125 & 5.0965 & 4.8771 & TRN & \\
\hline CHEMBL1492735 & 688125 & 2.71 & 2.5385 & TRN & \\
\hline CHEMBL1549998 & 688125 & 2.71 & 2.9604 & TRN & \\
\hline CHEMBL1373570 & 688125 & 2.71 & 3.9096 & TRN & \\
\hline CHEMBL1463754 & 688125 & 2.71 & 2.7958 & TST & \\
\hline CHEMBL1524741 & 688125 & 4.2401 & 3.50600 & 00000000002 & TRN \\
\hline CHEMBL1480915 & 688125 & 2.71 & 3.6313 & TRN & \\
\hline CHEMBL1513972 & 688125 & 4.7333 & 2.5298 & TRN & \\
\hline CHEMBL1409543 & 688125 & 2.71 & 3.0098 & TRN & \\
\hline CHEMBL1299526 & 688125 & 5.3637 & 4.1392 & TRN & \\
\hline CHEMBL1396376 & 688125 & 2.71 & 3.5453 & TRN & \\
\hline CHEMBL1498363 & 688125 & 3.9671 & 2.9016 & TST & \\
\hline CHEMBL1471740 & 688125 & 4.8405 & 2.7641 & TRN & \\
\hline CHEMBL3208426 & 688125 & 2.71 & 2.4469 & TRN & \\
\hline CHEMBL1359459 & 688125 & 2.71 & 3.2445 & TRN & \\
\hline CHEMBL1346464 & 688125 & 6.0424 & 3.9501 & TRN & \\
\hline CHEMBL1429285 & 688125 & 2.71 & 3.0408 & TRN & \\
\hline CHEMBL1602964 & 688125 & 2.71 & 3.7129 & TRN & \\
\hline CHEMBL1431702 & 688125 & 2.71 & 3.2023 & TST & \\
\hline CHEMBL1599827 & 688125 & 2.71 & 2.8577 & TRN & \\
\hline CHEMBL1312906 & 688125 & 2.71 & 3.13100 & 00000000002 & TRN \\
\hline CHEMBL1543138 & 688125 & 2.71 & 2.8015 & TRN & \\
\hline CHEMBL1964909 & 688125 & 6.0101 & 3.6223 & TRN & \\
\hline CHEMBL1518471 & 688125 & 2.71 & 3.4853 & TRN & \\
\hline CHEMBL1582450 & 688125 & 2.71 & 4.4416 & TRN & \\
\hline
\end{tabular}




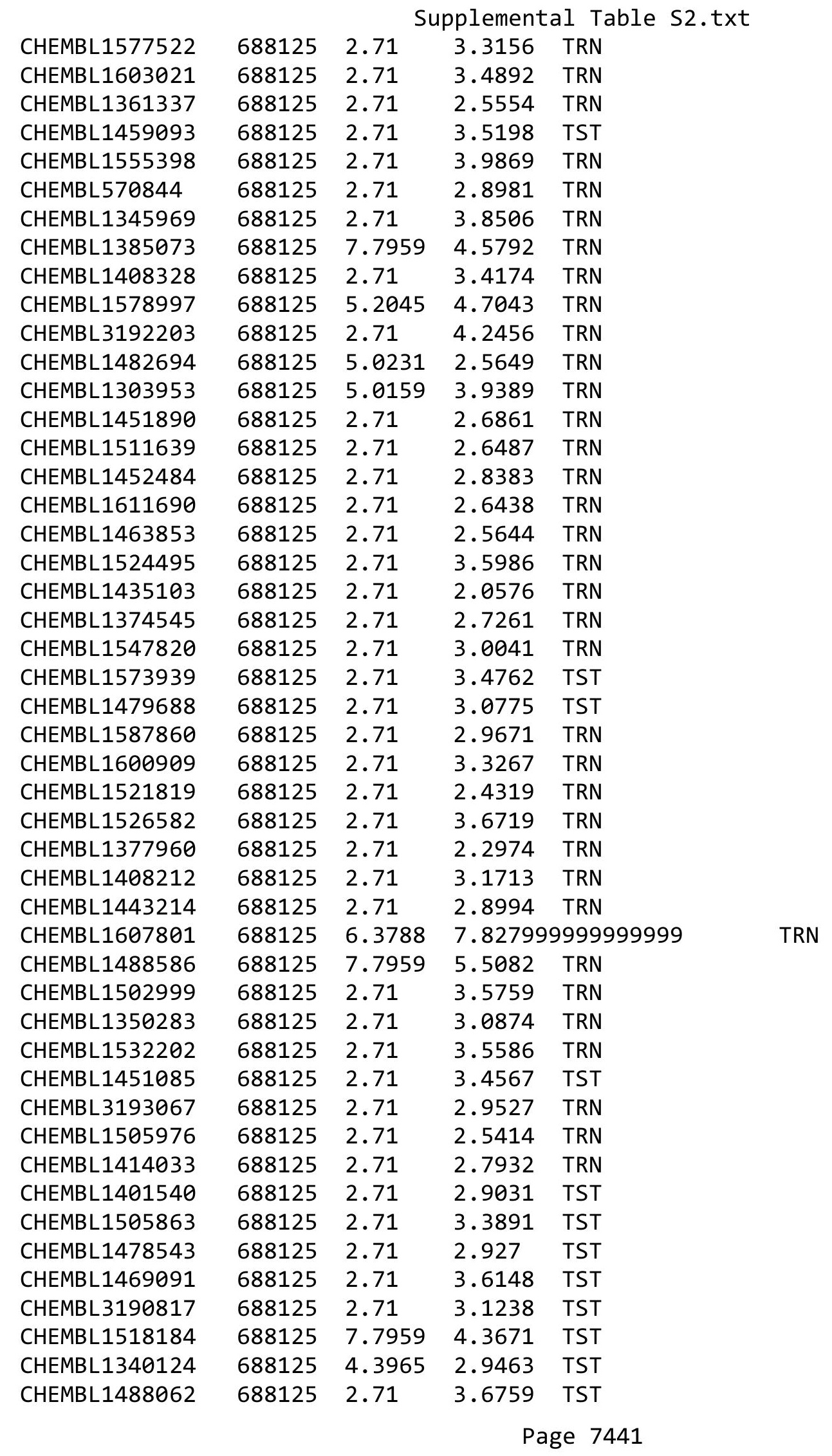




\begin{tabular}{|c|c|c|c|c|c|}
\hline \multicolumn{6}{|c|}{ Supplemental Table S2.txt } \\
\hline CHEMBL1406902 & 688125 & 2.71 & 2.9587 & TST & \\
\hline CHEMBL1341724 & 688125 & 2.71 & 2.9158 & TST & \\
\hline CHEMBL1517143 & 688125 & 2.71 & 3.8618 & TST & \\
\hline CHEMBL1446353 & 688125 & 5.1848 & 3.133 & TST & \\
\hline CHEMBL1606701 & 688125 & 2.71 & 2.8667 & TST & \\
\hline CHEMBL1529468 & 688125 & 2.71 & 3.2199 & TST & \\
\hline CHEMBL1388868 & 688125 & 3.9696 & 2.9375 & TST & \\
\hline CHEMBL 270472 & 688125 & 2.71 & 2.9242 & TST & \\
\hline CHEMBL1505420 & 688125 & 4.5202 & 3.5828 & TST & \\
\hline CHEMBL1484144 & 688125 & 2.71 & 3.3478 & TST & \\
\hline CHEMBL1585667 & 688125 & 2.71 & 4.2728 & TST & \\
\hline CHEMBL1590347 & 688125 & 2.71 & 2.9056 & TST & \\
\hline CHEMBL1563776 & 688125 & 2.71 & 2.9525 & TST & \\
\hline CHEMBL1347271 & 688125 & 2.71 & 2.9183 & TST & \\
\hline CHEMBL1562706 & 688125 & 2.71 & 3.0387 & TST & \\
\hline CHEMBL3212860 & 688125 & 4.4817 & 3.3392 & TST & \\
\hline CHEMBL1384702 & 688125 & 5.5727 & 3.6196 & TST & \\
\hline CHEMBL1468721 & 688125 & 2.71 & 3.6525 & TST & \\
\hline CHEMBL1450368 & 688125 & 2.71 & 2.8691 & TST & \\
\hline CHEMBL1472939 & 688125 & 2.71 & 3.5502 & TST & \\
\hline CHEMBL1478238 & 688125 & 2.71 & 3.9474 & TST & \\
\hline CHEMBL1301855 & 688125 & 6.51 & 3.2113 & TST & \\
\hline CHEMBL3197065 & 688125 & 5.4483 & 4.9449 & TST & \\
\hline CHEMBL1585907 & 688125 & 2.71 & 2.9378 & TST & \\
\hline CHEMBL1425891 & 688125 & 2.71 & 3.2322 & TST & \\
\hline CHEMBL1605794 & 688125 & 2.71 & 2.0511 & TST & \\
\hline CHEMBL1308545 & 688125 & 2.71 & 2.9159 & TST & \\
\hline CHEMBL 3209371 & 688125 & 2.71 & 3.3745 & TST & \\
\hline CHEMBL1307047 & 688125 & 2.71 & 2.662 & TST & \\
\hline CHEMBL1446603 & 688125 & 2.71 & 3.47600 & 00000000004 & TST \\
\hline CHEMBL1303557 & 688125 & 2.71 & 3.6591 & TST & \\
\hline CHEMBL3193922 & 688125 & 6.3605 & 3.5841 & TST & \\
\hline CHEMBL1449365 & 688125 & 2.71 & 2.5697 & TST & \\
\hline CHEMBL1381112 & 688125 & 2.71 & 2.7506 & TST & \\
\hline CHEMBL1345974 & 688125 & 2.71 & 3.4271 & TST & \\
\hline CHEMBL1397561 & 688125 & 2.71 & 3.1992 & TST & \\
\hline CHEMBL1335619 & 688125 & 2.71 & 2.4396 & TST & \\
\hline CHEMBL1352621 & 688125 & 5.7622 & 3.5726 & TST & \\
\hline CHEMBL1427265 & 688125 & 4.948 & 4.5858 & TST & \\
\hline CHEMBL1299439 & 688125 & 4.8607 & 3.661 & TST & \\
\hline CHEMBL1365572 & 688125 & 2.71 & 3.1644 & TST & \\
\hline CHEMBL3193237 & 688125 & 2.71 & 3.052 & TST & \\
\hline CHEMBL1486874 & 688125 & 7.7959 & 6.1179 & TST & \\
\hline CHEMBL1312401 & 688125 & 2.71 & 3.6301 & TST & \\
\hline CHEMBL1604502 & 688125 & 2.71 & 2.7993 & TST & \\
\hline CHEMBL1373488 & 688125 & 2.71 & 2.8512 & TST & \\
\hline CHEMBL1424968 & 688125 & 5.1243 & 3.3838 & TST & \\
\hline CHEMBL1464780 & 688125 & 2.71 & 3.4822 & TST & \\
\hline
\end{tabular}




\begin{tabular}{|c|c|c|c|c|c|}
\hline \multicolumn{6}{|c|}{ Supplemental Table S2.txt } \\
\hline CHEMBL 3211745 & 688125 & 2.71 & 2.5056 & TST & \\
\hline CHEMBL1326856 & 688125 & 2.71 & 3.3524 & TST & \\
\hline CHEMBL1577094 & 688125 & 2.71 & 3.0948 & TST & \\
\hline CHEMBL1301498 & 688125 & 2.71 & 3.1447 & TST & \\
\hline CHEMBL1363744 & 688125 & 2.71 & 3.8915 & TST & \\
\hline CHEMBL1381415 & 688125 & 2.71 & 3.3749 & TST & \\
\hline CHEMBL1544158 & 688125 & 4.487 & 3.5491 & TST & \\
\hline CHEMBL1489567 & 688125 & 4.728 & 4.7082 & TST & \\
\hline CHEMBL1544339 & 688125 & 2.71 & 3.6271 & TST & \\
\hline CHEMBL1579260 & 688125 & 2.71 & 3.2282 & TST & \\
\hline CHEMBL1481543 & 688125 & 7.7959 & 5.8972 & TST & \\
\hline CHEMBL1571541 & 688125 & 6.0721 & 3.6273 & TST & \\
\hline CHEMBL1420327 & 688125 & 2.71 & 3.5734 & TST & \\
\hline CHEMBL1446947 & 688125 & 4.947 & 2.8865 & TST & \\
\hline CHEMBL1996199 & 688125 & 5.0218 & 3.7295 & TST & \\
\hline CHEMBL1569034 & 688125 & 2.71 & 2.8775 & TST & \\
\hline CHEMBL1360869 & 688125 & 2.71 & 2.8184 & TST & \\
\hline CHEMBL1455230 & 688125 & 5.2337 & 5.5045 & TST & \\
\hline CHEMBL1313137 & 688125 & 2.71 & 2.1666 & TST & \\
\hline CHEMBL1368868 & 688125 & 2.71 & 2.8161 & TST & \\
\hline CHEMBL1085162 & 688125 & 2.71 & 2.8829 & TST & \\
\hline CHEMBL1384837 & 688125 & 2.71 & 3.0225 & TST & \\
\hline CHEMBL3212923 & 688125 & 4.9872 & 3.67199 & 99999999997 & TST \\
\hline CHEMBL1366602 & 688125 & 2.71 & 2.7345 & TST & \\
\hline CHEMBL1469916 & 688125 & 2.71 & 2.6128 & TST & \\
\hline CHEMBL1607590 & 688125 & 2.71 & 3.3278 & TST & \\
\hline CHEMBL1391078 & 688125 & 2.71 & 2.5352 & TST & \\
\hline CHEMBL1384253 & 688125 & 5.8047 & 4.9565 & TST & \\
\hline CHEMBL1452391 & 688125 & 5.6055 & 3.6135 & TST & \\
\hline CHEMBL3197091 & 688125 & 5.1722 & 4.6265 & TST & \\
\hline CHEMBL1425882 & 688125 & 2.71 & 3.4852 & TST & \\
\hline CHEMBL1446678 & 688125 & 5.2118 & 2.5968 & TST & \\
\hline CHEMBL1556964 & 688125 & 2.71 & 3.1853 & TST & \\
\hline CHEMBL1509640 & 688125 & 2.71 & 3.6703 & TST & \\
\hline CHEMBL1304458 & 688125 & 2.71 & 3.0944 & TST & \\
\hline CHEMBL3197873 & 688125 & 2.71 & 5.1779 & TST & \\
\hline CHEMBL1440300 & 688125 & 5.4488 & 4.9574 & TST & \\
\hline CHEMBL1497019 & 688125 & 5.6525 & 4.9386 & TST & \\
\hline CHEMBL1334296 & 688125 & 2.71 & 3.3908 & TST & \\
\hline CHEMBL1365352 & 688125 & 2.71 & 3.26899 & 99999999997 & TST \\
\hline CHEMBL3190392 & 688125 & 2.71 & 3.2403 & TST & \\
\hline CHEMBL1335299 & 688125 & 2.71 & 3.8696 & TST & \\
\hline CHEMBL1454366 & 688125 & 2.71 & 3.1385 & TST & \\
\hline CHEMBL1601191 & 688125 & 2.71 & 3.3861 & TST & \\
\hline CHEMBL1313238 & 688125 & 5.1087 & 4.851 & TST & \\
\hline CHEMBL1569988 & 688125 & 7.7959 & 4.8768 & TST & \\
\hline CHEMBL1448825 & 688125 & 2.71 & 3.4009 & TST & \\
\hline CHEMBL1444382 & 688125 & 2.71 & 2.5151 & TST & \\
\hline
\end{tabular}




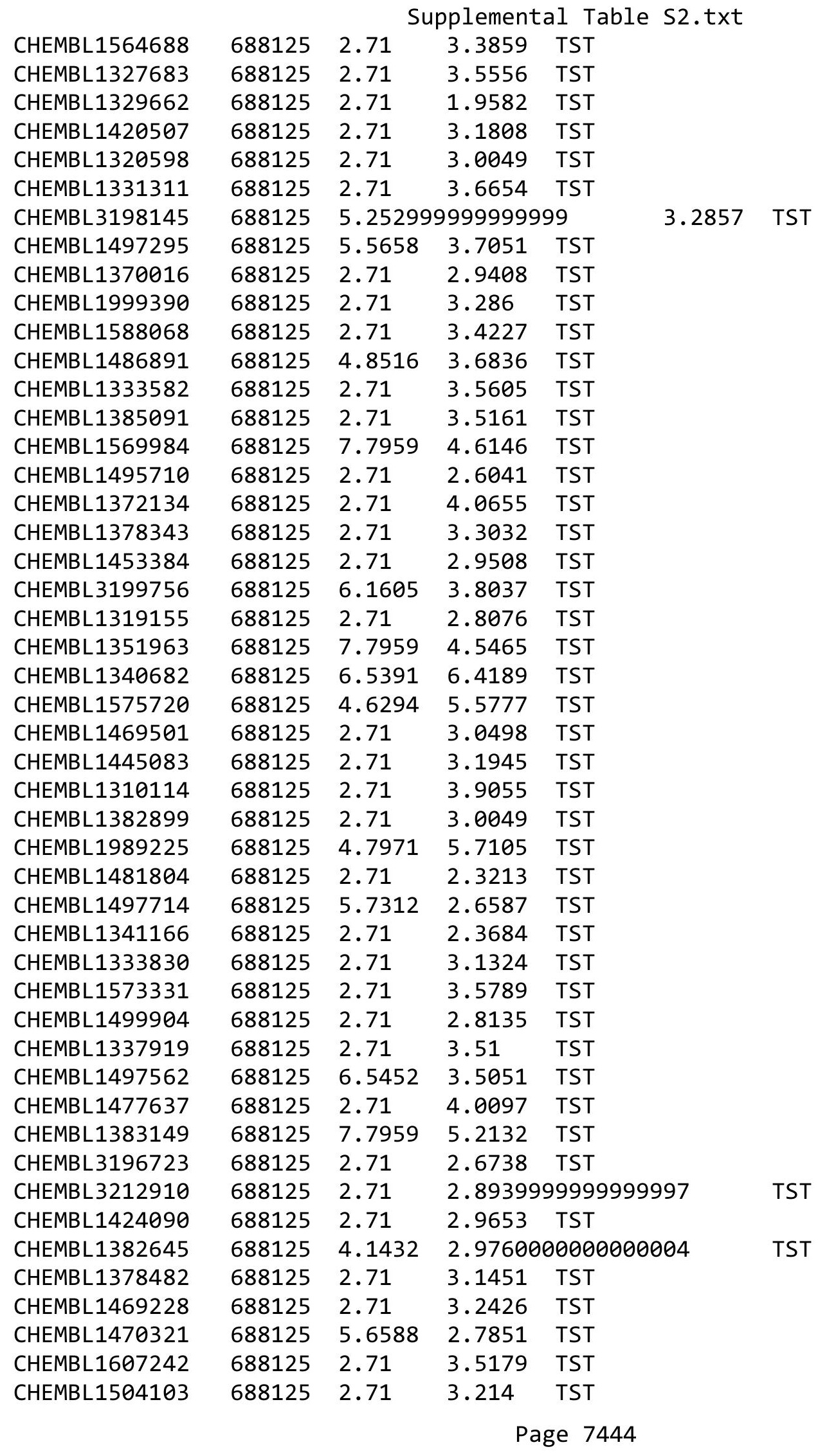





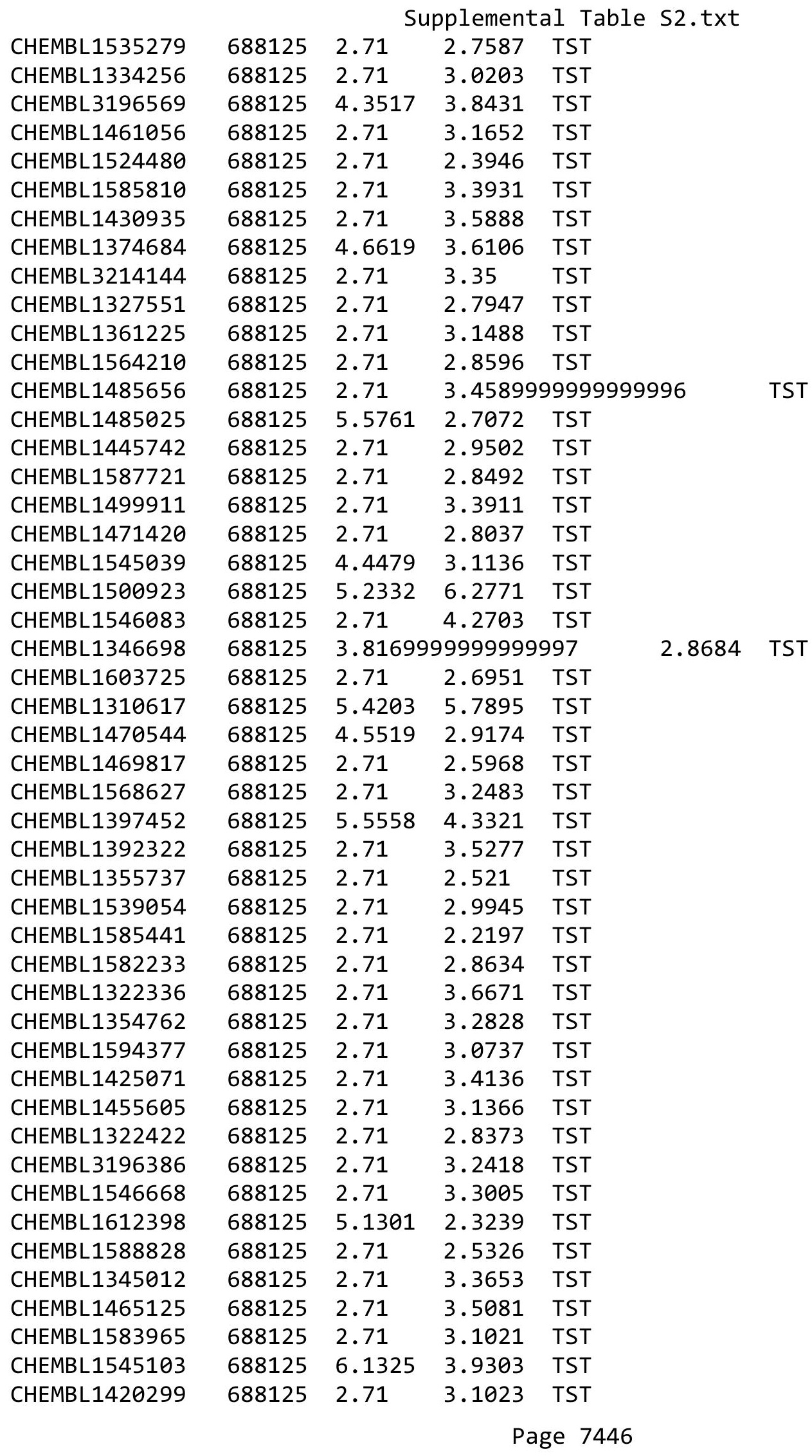





\begin{tabular}{|c|c|c|c|c|}
\hline & & & oplement & al Ta \\
\hline CHEMBL1365254 & 752467 & 3.0341 & 3.8553 & TRN \\
\hline CHEMBL1165197 & 752467 & 3.034 & 2.3554 & TRN \\
\hline CHEMBL1423609 & 752467 & 4.3578 & 3.5849 & TRN \\
\hline CHEMBL1604493 & 752467 & 3.9882 & 4.2767 & TRN \\
\hline CHEMBL1457803 & 752467 & 3.034 & 3.3522 & TST \\
\hline CHEMBL1730502 & 752467 & 3.0341 & 1.9374 & TST \\
\hline CHEMBL1385823 & 752467 & 4.7565 & 3.8028 & TRN \\
\hline CHEMBL1898753 & 752467 & 3.0337 & 2.3217 & TRN \\
\hline CHEMBL1208858 & 752467 & 3.0339 & 3.6043 & TST \\
\hline CHEMBL1714015 & 752467 & 3.034 & 3.6127 & TRN \\
\hline CHEMBL1512925 & 752467 & 3.034 & 2.6713 & TRN \\
\hline CHEMBL1458051 & 752467 & 4.1702 & 3.5017 & TRN \\
\hline CHEMBL1437975 & 752467 & 3.0337 & 3.9295 & TRN \\
\hline CHEMBL2003819 & 752467 & 3.034 & 3.5619 & TRN \\
\hline CHEMBL1700847 & 752467 & 5.4393 & 4.8075 & TRN \\
\hline CHEMBL1398707 & 752467 & 3.034 & 3.7758 & TRN \\
\hline CHEMBL1472987 & 752467 & 3.0341 & 3.7715 & TRN \\
\hline CHEMBL1412340 & 752467 & 4.5345 & 3.8544 & TST \\
\hline CHEMBL1607240 & 752467 & 3.0339 & 3.3072 & TRN \\
\hline CHEMBL1463894 & 752467 & 5.6167 & 5.1563 & TRN \\
\hline CHEMBL1332208 & 752467 & 3.034 & 3.9131 & TRN \\
\hline CHEMBL1613445 & 752467 & 3.034 & 4.069 & TRN \\
\hline CHEMBL1487650 & 752467 & 3.511 & 3.1812 & TRN \\
\hline CHEMBL1727052 & 752467 & 3.9886 & 3.6082 & TRN \\
\hline CHEMBL1985575 & 752467 & 3.0342 & 2.1096 & TRN \\
\hline CHEMBL1581275 & 752467 & 4.6063 & 3.6522 & TRN \\
\hline CHEMBL1169627 & 752467 & 3.0341 & 3.7928 & TST \\
\hline CHEMBL1706148 & 752467 & 3.0343 & 4.2315 & TRN \\
\hline CHEMBL1500489 & 752467 & 3.0337 & 3.1972 & TST \\
\hline CHEMBL1704769 & 752467 & 3.0339 & 3.1484 & TRN \\
\hline CHEMBL1332532 & 752467 & 3.0341 & 3.3548 & TRN \\
\hline CHEMBL1378322 & 752467 & 3.034 & 2.3038 & TRN \\
\hline CHEMBL1566963 & 752467 & 4.4756 & 4.3838 & TRN \\
\hline CHEMBL1448229 & 752467 & 4.7239 & 4.5641 & TRN \\
\hline CHEMBL1256750 & 752467 & 3.0337 & 3.4544 & TRN \\
\hline CHEMBL1581674 & 752467 & 5.4836 & 5.0628 & TRN \\
\hline CHEMBL1468190 & 752467 & 3.0341 & 2.8101 & TRN \\
\hline CHEMBL1426979 & 752467 & 4.9881 & 4.3524 & TRN \\
\hline CHEMBL1734003 & 752467 & 3.0336 & 3.8348 & TRN \\
\hline CHEMBL1392786 & 752467 & 3.034 & 3.0213 & TRN \\
\hline CHEMBL1898602 & 752467 & 3.0345 & 3.1191 & TRN \\
\hline CHEMBL1340264 & 752467 & 3.034 & 3.9215 & TRN \\
\hline CHEMBL1325945 & 752467 & 3.0339 & 2.5993 & TST \\
\hline CHEMBL1722114 & 752467 & 3.034 & 3.3301 & TRN \\
\hline CHEMBL3213958 & 752467 & 4.3684 & 3.7688 & TRN \\
\hline CHEMBL1722360 & 752467 & 3.034 & 3.4868 & TRN \\
\hline CHEMBL1256770 & 752467 & 3.034 & 3.5943 & TRN \\
\hline CHEMBL1700227 & 752467 & 3.0337 & 3.8513 & TRN \\
\hline
\end{tabular}




\begin{tabular}{|c|c|c|c|c|c|}
\hline & & \multicolumn{3}{|c|}{ Supplemental Table S2.txt } & \\
\hline CHEMBL1490069 & 752467 & 4.83899 & 99999999 & 3.6613 & $\mathrm{R}$ \\
\hline CHEMBL1540756 & 752467 & 3.0336 & 3.2938 & TRN & \\
\hline CHEMBL1708714 & 752467 & 3.0344 & 3.5466 & TST & \\
\hline CHEMBL1595735 & 752467 & 3.034 & 3.7067 & TRN & \\
\hline CHEMBL300117 & 752467 & 3.034 & 3.4268 & TRN & \\
\hline CHEMBL1719184 & 752467 & 4.8057 & 4.6194 & TRN & \\
\hline CHEMBL1579434 & 752467 & 3.034 & 3.2515 & TRN & \\
\hline CHEMBL1567143 & 752467 & 3.0342 & 3.8014 & TRN & \\
\hline CHEMBL1550356 & 752467 & 3.0339 & 3.3209 & TRN & \\
\hline CHEMBL1734772 & 752467 & 3.0344 & 3.6868 & TST & \\
\hline CHEMBL 3213181 & 752467 & 3.034 & 3.5961 & TRN & \\
\hline CHEMBL1427690 & 752467 & 3.034 & 3.5141 & TRN & \\
\hline CHEMBL1450071 & 752467 & 4.183 & 3.6244 & TRN & \\
\hline CHEMBL570399 & 752467 & 3.034 & 3.5576 & TST & \\
\hline CHEMBL1548948 & 752467 & 3.0341 & 3.3049 & TRN & \\
\hline CHEMBL1325297 & 752467 & 3.034 & 3.1872 & TRN & \\
\hline CHEMBL1447060 & 752467 & 3.034 & 3.6437 & TRN & \\
\hline CHEMBL1609119 & 752467 & 5.2924 & 4.928 & TRN & \\
\hline CHEMBL1707116 & 752467 & 3.0344 & 3.1749 & TRN & \\
\hline CHEMBL1378959 & 752467 & 3.0341 & 3.4332 & TRN & \\
\hline CHEMBL1437660 & 752467 & 4.2496 & 3.8635 & TRN & \\
\hline CHEMBL1419563 & 752467 & 3.034 & 2.4632 & TRN & \\
\hline CHEMBL1393837 & 752467 & 4.8098 & 4.1163 & TRN & \\
\hline CHEMBL1587149 & 752467 & 4.1283 & 4.0721 & TRN & \\
\hline CHEMBL1600293 & 752467 & 3.034 & 3.0077 & TRN & \\
\hline CHEMBL1356740 & 752467 & 4.5804 & 3.8676 & TRN & \\
\hline CHEMBL1882125 & 752467 & 3.034 & 3.8066 & TRN & \\
\hline CHEMBL1407554 & 752467 & 4.582 & 4.1397 & TRN & \\
\hline CHEMBL1365563 & 752467 & 3.034 & 3.7307 & TRN & \\
\hline CHEMBL1403842 & 752467 & 4.1517 & 3.9349 & TRN & \\
\hline CHEMBL1584594 & 752467 & 4.4348 & 3.6144 & TRN & \\
\hline CHEMBL1720091 & 752467 & 4.9195 & 3.8597 & TRN & \\
\hline CHEMBL1700880 & 752467 & 3.0345 & 3.7629 & TRN & \\
\hline CHEMBL1548019 & 752467 & 3.034 & 3.2639 & TRN & \\
\hline CHEMBL1494093 & 752467 & 3.034 & 3.2372 & TRN & \\
\hline CHEMBL1548987 & 752467 & 4.3173 & 3.9906 & TST & \\
\hline CHEMBL2001739 & 752467 & 3.0341 & 3.2116 & TST & \\
\hline CHEMBL1583291 & 752467 & 3.0341 & 3.3404 & TRN & \\
\hline CHEMBL1709988 & 752467 & 4.7321 & 4.0201 & TRN & \\
\hline CHEMBL1439686 & 752467 & 3.5112 & $3.5780 e$ & 00000000003 & \\
\hline CHEMBL1513567 & 752467 & 4.3911 & 3.5283 & TRN & \\
\hline CHEMBL1902708 & 752467 & 4.6814 & 4.0804 & TRN & \\
\hline CHEMBL1600506 & 752467 & 3.034 & 2.365 & TST & \\
\hline CHEMBL1422217 & 752467 & 4.4546 & 3.7313 & TRN & \\
\hline CHEMBL1597912 & 752467 & 3.0341 & 3.2263 & TRN & \\
\hline CHEMBL1705302 & 752467 & 4.9607 & 4.3302 & TRN & \\
\hline CHEMBL1703982 & 752467 & 4.2982 & 3.2974 & TRN & \\
\hline CHEMBL1429212 & 752467 & 4.7623 & 3.9432 & TRN & \\
\hline
\end{tabular}




\begin{tabular}{|c|c|c|c|c|c|}
\hline & & \multicolumn{4}{|c|}{ Supplemental Table S2.txt } \\
\hline CHEMBL1569933 & 752467 & 3.034 & 2.8929 & TRN & \\
\hline CHEMBL1558215 & 752467 & 4.2787 & 3.8497 & TRN & \\
\hline CHEMBL1732043 & 752467 & 3.034 & 3.4667 & TRN & \\
\hline CHEMBL1898779 & 752467 & 3.0342 & 3.3388 & TST & \\
\hline CHEMBL1713682 & 752467 & 3.0339 & 3.386 & TRN & \\
\hline CHEMBL1379878 & 752467 & 3.034 & 3.1379 & TRN & \\
\hline CHEMBL1509052 & 752467 & 3.034 & 3.3952 & TRN & \\
\hline CHEMBL1728422 & 752467 & 3.0338 & 2.2333 & TRN & \\
\hline CHEMBL1728200 & 752467 & 3.034 & 3.8029 & TST & \\
\hline CHEMBL1306479 & 752467 & 4.0659 & 3.4951 & TRN & \\
\hline CHEMBL1382321 & 752467 & 3.034 & 4.0826 & TRN & \\
\hline CHEMBL1473706 & 752467 & 4.6411 & 3.8083 & TRN & \\
\hline CHEMBL1460676 & 752467 & 4.9914 & 4.3996 & TRN & \\
\hline CHEMBL1522542 & 752467 & 5.3146 & 4.599 & TRN & \\
\hline CHEMBL1606743 & 752467 & 4.2254 & 3.2128 & TRN & \\
\hline CHEMBL1380599 & 752467 & 5.3815 & 4.8212 & TRN & \\
\hline CHEMBL1722228 & 752467 & 3.0345 & 3.5761 & TRN & \\
\hline CHEMBL1458967 & 752467 & 3.034 & 3.0511 & TRN & \\
\hline CHEMBL1717557 & 752467 & 5.8477 & 4.3079 & TRN & \\
\hline CHEMBL1968356 & 752467 & 3.034 & 3.15199 & 99999999997 & TRN \\
\hline CHEMBL1586285 & 752467 & 4.9666 & 4.2337 & TST & \\
\hline CHEMBL1387006 & 752467 & 3.0339 & 3.1584 & TRN & \\
\hline CHEMBL1720903 & 752467 & 3.0342 & 3.1161 & TRN & \\
\hline CHEMBL1588202 & 752467 & 4.8876 & 4.7259 & TRN & \\
\hline CHEMBL1387977 & 752467 & 3.034 & 3.2488 & TST & \\
\hline CHEMBL1612697 & 752467 & 4.6146 & 3.9867 & TRN & \\
\hline CHEMBL1699738 & 752467 & 3.0341 & 3.4294 & TRN & \\
\hline CHEMBL1699902 & 752467 & 3.0341 & 3.5129 & TRN & \\
\hline CHEMBL1531675 & 752467 & 4.9958 & 4.5086 & TRN & \\
\hline CHEMBL1721095 & 752467 & 3.0343 & 3.2747 & TST & \\
\hline CHEMBL1727246 & 752467 & 3.034 & 3.2571 & TRN & \\
\hline CHEMBL1345157 & 752467 & 3.034 & 3.2072 & TRN & \\
\hline CHEMBL1388222 & 752467 & 5.3307 & 4.3998 & TRN & \\
\hline CHEMBL67378 & 752467 & 3.034 & 4.1539 & TRN & \\
\hline CHEMBL1344909 & 752467 & 3.034 & 3.31399 & 99999999996 & TRN \\
\hline CHEMBL1732484 & 752467 & 6.2985 & 4.8019 & TRN & \\
\hline CHEMBL1506767 & 752467 & 3.0341 & 3.2779 & TRN & \\
\hline CHEMBL1493736 & 752467 & 3.0341 & 3.6542 & TRN & \\
\hline CHEMBL1587837 & 752467 & 3.0339 & 2.8255 & TRN & \\
\hline CHEMBL1423927 & 752467 & 4.3484 & 3.5724 & TRN & \\
\hline CHEMBL1561591 & 752467 & 3.034 & 3.5499 & TRN & \\
\hline CHEMBL1587604 & 752467 & 3.0342 & 3.505 & TRN & \\
\hline CHEMBL1416425 & 752467 & 5.3334 & 5.0031 & TRN & \\
\hline CHEMBL1331866 & 752467 & 5.5484 & 4.5044 & TST & \\
\hline CHEMBL1458515 & 752467 & 3.034 & 3.0758 & TRN & \\
\hline CHEMBL1720300 & 752467 & 3.0339 & 3.2425 & TRN & \\
\hline CHEMBL1599024 & 752467 & 3.034 & 3.7566 & TRN & \\
\hline CHEMBL1355165 & 752467 & 3.0341 & 3.7821 & TRN & \\
\hline
\end{tabular}




\begin{tabular}{|c|c|c|c|c|}
\hline \multicolumn{5}{|c|}{ Supplemental Table S2.txt } \\
\hline CHEMBL1507251 & 752467 & 3.0338 & 3.2882 & TST \\
\hline CHEMBL1334918 & 752467 & 3.0341 & 3.2878 & TRN \\
\hline CHEMBL1728158 & 752467 & 4.3199 & 3.9257 & TRN \\
\hline CHEMBL1544567 & 752467 & 3.034 & 3.8035 & TRN \\
\hline CHEMBL1986259 & 752467 & 3.0339 & 3.0647 & TST \\
\hline CHEMBL1198307 & 752467 & 4.3586 & 3.2538 & TRN \\
\hline CHEMBL1722730 & 752467 & 3.0344 & 3.0588 & TRN \\
\hline CHEMBL1524932 & 752467 & 3.034 & 3.6934 & TRN \\
\hline CHEMBL1722570 & 752467 & 3.034 & 4.1051 & TRN \\
\hline CHEMBL1727653 & 752467 & 3.034 & 2.5551 & TST \\
\hline CHEMBL1482107 & 752467 & 4.1721 & 3.7126 & TRN \\
\hline CHEMBL1444121 & 752467 & 3.0339 & 3.6059 & TRN \\
\hline CHEMBL1327306 & 752467 & 3.0341 & 3.0357 & TRN \\
\hline CHEMBL1607286 & 752467 & 3.0339 & 3.1241 & TRN \\
\hline CHEMBL1713166 & 752467 & 4.768 & 4.0829 & TRN \\
\hline CHEMBL1708311 & 752467 & 3.034 & 3.7349 & TRN \\
\hline CHEMBL1304909 & 752467 & 3.0342 & 2.5264 & TRN \\
\hline CHEMBL1533638 & 752467 & 4.3668 & 3.6655 & TRN \\
\hline CHEMBL1563669 & 752467 & 3.0342 & 3.551 & TRN \\
\hline CHEMBL1370471 & 752467 & 3.034 & 3.4434 & TRN \\
\hline CHEMBL1515502 & 752467 & 3.034 & 3.6559 & TRN \\
\hline CHEMBL1364960 & 752467 & 3.0341 & 3.3363 & TRN \\
\hline CHEMBL1563176 & 752467 & 3.034 & 3.4547 & TRN \\
\hline CHEMBL1698841 & 752467 & 5.1252 & 5.064 & TRN \\
\hline CHEMBL1464640 & 752467 & 3.0341 & 2.8213 & TRN \\
\hline CHEMBL1307021 & 752467 & 3.034 & 3.9149 & TST \\
\hline CHEMBL1353993 & 752467 & 3.034 & 3.7773 & TRN \\
\hline CHEMBL1345947 & 752467 & 4.283 & 3.4009 & TRN \\
\hline CHEMBL1872339 & 752467 & 3.0337 & 3.8645 & TRN \\
\hline CHEMBL1564646 & 752467 & 3.034 & 3.3966 & TRN \\
\hline CHEMBL1724267 & 752467 & 3.0339 & 3.8831 & TRN \\
\hline CHEMBL1486861 & 752467 & 3.034 & 2.986 & TRN \\
\hline CHEMBL1454070 & 752467 & 3.034 & 2.8995 & TRN \\
\hline CHEMBL1425453 & 752467 & 4.7272 & 4.1148 & TST \\
\hline CHEMBL1572068 & 752467 & 3.034 & 3.4678 & TRN \\
\hline CHEMBL1531172 & 752467 & 3.0341 & 3.4018 & TRN \\
\hline CHEMBL1603547 & 752467 & 3.034 & 2.4342 & TRN \\
\hline CHEMBL1430335 & 752467 & 3.034 & 3.4416 & TRN \\
\hline CHEMBL1596869 & 752467 & 3.0341 & 3.097 & TRN \\
\hline CHEMBL 2005743 & 752467 & 4.262 & 3.6504 & TST \\
\hline CHEMBL1390846 & 752467 & 3.0339 & 3.6205 & TRN \\
\hline CHEMBL1892729 & 752467 & 3.0341 & 3.2392 & TRN \\
\hline CHEMBL1545927 & 752467 & 3.0339 & 2.3494 & TRN \\
\hline CHEMBL1308389 & 752467 & 4.9035 & 4.5562 & TRN \\
\hline CHEMBL517986 & 752467 & 3.034 & 3.5416 & TST \\
\hline CHEMBL 1610756 & 752467 & 3.034 & 3.0555 & TST \\
\hline CHEMBL1445858 & 752467 & 3.0339 & 3.1329 & TST \\
\hline CHEMBL1463367 & 752467 & 3.034 & 2.4642 & TRN \\
\hline
\end{tabular}




\begin{tabular}{|c|c|c|c|c|c|}
\hline & & \multicolumn{4}{|c|}{ Supplemental Table S2.txt } \\
\hline CHEMBL1352185 & 752467 & 3.0341 & 3.3181 & TRN & \\
\hline CHEMBL1731939 & 752467 & 3.034 & 3.5528 & TST & \\
\hline CHEMBL1603928 & 752467 & 3.034 & 2.87600 & 00000000003 & TST \\
\hline CHEMBL1440652 & 752467 & 4.8039 & 3.9008 & TST & \\
\hline CHEMBL3189940 & 752467 & 3.0341 & 4.0419 & TST & \\
\hline CHEMBL1307063 & 752467 & 5.5608 & 4.7995 & TST & \\
\hline CHEMBL1550403 & 752467 & 3.0338 & 3.4817 & TST & \\
\hline CHEMBL1710136 & 752467 & 3.0342 & 3.4021 & TST & \\
\hline CHEMBL1587574 & 752467 & 4.3689 & 3.4051 & TST & \\
\hline CHEMBL1399743 & 752467 & 3.034 & 3.3337 & TST & \\
\hline CHEMBL1348719 & 752467 & 3.034 & 3.3797 & TST & \\
\hline CHEMBL1548542 & 752467 & 3.034 & 4.0242 & TST & \\
\hline CHEMBL1315401 & 752467 & 4.7448 & 3.5877 & TST & \\
\hline CHEMBL1361813 & 752467 & 3.034 & 3.2927 & TST & \\
\hline CHEMBL1582232 & 752467 & 3.0341 & 3.3074 & TST & \\
\hline CHEMBL3208729 & 752467 & 3.0341 & 3.4514 & TST & \\
\hline CHEMBL1419241 & 752467 & 3.034 & 3.5739 & TST & \\
\hline CHEMBL1488501 & 752467 & 3.0341 & 3.5774 & TST & \\
\hline CHEMBL1736138 & 752467 & 3.0341 & 3.4624 & TST & \\
\hline CHEMBL1437810 & 752467 & 3.034 & 3.8242 & TST & \\
\hline CHEMBL1708052 & 752467 & 3.034 & 3.4997 & TST & \\
\hline CHEMBL3191251 & 752467 & 3.034 & 2.5199 & TST & \\
\hline CHEMBL1440235 & 752467 & 4.4655 & 3.9782 & TST & \\
\hline CHEMBL1735778 & 752467 & 3.034 & 3.88100 & 00000000002 & TST \\
\hline CHEMBL1303361 & 752467 & 3.034 & 2.7817 & TST & \\
\hline CHEMBL1458770 & 752467 & 3.034 & 3.182 & TST & \\
\hline CHEMBL1566118 & 752467 & 3.034 & 3.5282 & TST & \\
\hline CHEMBL1893806 & 752467 & 3.0341 & 3.3327 & TST & \\
\hline CHEMBL435994 & 911390 & 7.9547 & 7.79 & TRN & \\
\hline CHEMBL125233 & 911390 & 6.9318 & 7.1854 & TRN & \\
\hline CHEMBL123671 & 911390 & 6.0 & 6.4756 & TRN & \\
\hline CHEMBL333722 & 911390 & 8.0809 & 8.3082 & TRN & \\
\hline CHEMBL125818 & 911390 & 6.0 & 5.0362 & TST & \\
\hline CHEMBL121718 & 911390 & 8.0088 & 8.1324 & TRN & \\
\hline CHEMBL419421 & 911390 & 8.3768 & 8.7506 & TRN & \\
\hline CHEMBL 2259780 & 911390 & 8.5229 & 8.6296 & TRN & \\
\hline CHEMBL123670 & 911390 & 7.7545 & 7.8153 & TRN & \\
\hline CHEMBL123091 & 911390 & 7.7799 & 7.7519 & TRN & \\
\hline CHEMBL126111 & 911390 & 6.0 & 6.3342 & TRN & \\
\hline CHEMBL122982 & 911390 & 8.3098 & 8.1688 & TRN & \\
\hline CHEMBL332766 & 911390 & 6.0 & 6.0972 & TST & \\
\hline CHEMBL125766 & 911390 & 6.0 & 5.9794 & TST & \\
\hline CHEMBL331121 & 911390 & 7.7496 & 7.8118 & TRN & \\
\hline CHEMBL126037 & 911390 & 6.0 & 6.4176 & TST & \\
\hline CHEMBL122494 & 911390 & 8.2366 & 8.4437 & TRN & \\
\hline CHEMBL331219 & 911390 & 7.7721 & 7.71 & TRN & \\
\hline CHEMBL122966 & 911390 & 8.8239 & 9.0038 & TRN & \\
\hline CHEMBL333126 & 911390 & 6.0 & 5.9252 & TST & \\
\hline
\end{tabular}




\begin{tabular}{|c|c|c|c|c|}
\hline & & & oplement & al Ta \\
\hline CHEMBL124144 & 911390 & 7.8356 & 8.5192 & TRN \\
\hline CHEMBL341131 & 911390 & 9.0458 & 8.1377 & TRN \\
\hline CHEMBL330942 & 911390 & 6.585 & 6.3426 & TRN \\
\hline CHEMBL124925 & 911390 & 9.2218 & 8.9945 & TRN \\
\hline CHEMBL121854 & 911390 & 8.4559 & 7.6016 & TST \\
\hline CHEMBL334326 & 911390 & 7.3799 & 7.4215 & TRN \\
\hline CHEMBL419058 & 911390 & 7.2636 & 7.2851 & TRN \\
\hline CHEMBL122443 & 911390 & 6.0 & 6.2376 & TRN \\
\hline CHEMBL2263317 & 911390 & 8.2147 & 7.9994 & TRN \\
\hline CHEMBL121990 & 911390 & 7.4473 & 7.4756 & TRN \\
\hline CHEMBL341151 & 911390 & 8.1938 & 7.4118 & TRN \\
\hline CHEMBL338514 & 911390 & 8.0706 & 7.5544 & TRN \\
\hline CHEMBL124141 & 911390 & 6.7033 & 6.5304 & TRN \\
\hline CHEMBL331081 & 911390 & 7.4609 & 7.6568 & TRN \\
\hline CHEMBL421629 & 911390 & 8.0458 & 8.0749 & TRN \\
\hline CHEMBL333411 & 911390 & 8.5229 & 6.2996 & TST \\
\hline CHEMBL331042 & 911390 & 6.0 & 5.9502 & TRN \\
\hline CHEMBL125533 & 911390 & 8.2757 & 8.0376 & TRN \\
\hline CHEMBL332323 & 911390 & 7.9066 & 8.1595 & TRN \\
\hline CHEMBL124913 & 911390 & 8.9208 & 8.0881 & TRN \\
\hline CHEMBL409136 & 911390 & 7.9547 & 8.0654 & TRN \\
\hline CHEMBL122490 & 911390 & 7.7328 & 7.888 & TRN \\
\hline CHEMBL 2263543 & 911390 & 8.0177 & 8.1616 & TRN \\
\hline CHEMBL 2259777 & 911390 & 7.5287 & 6.1477 & TST \\
\hline CHEMBL 338431 & 911390 & 7.1549 & 7.8659 & TRN \\
\hline CHEMBL331511 & 911390 & 8.4685 & 7.9474 & TRN \\
\hline CHEMBL331519 & 911390 & 8.4815 & 8.4331 & TRN \\
\hline CHEMBL 2259779 & 911390 & 8.6021 & 7.7776 & TST \\
\hline CHEMBL126170 & 911390 & 6.6108 & 6.7245 & TRN \\
\hline CHEMBL 2259778 & 911390 & 8.4815 & 6.1485 & TST \\
\hline CHEMBL122458 & 911390 & 8.0706 & 7.9197 & TRN \\
\hline CHEMBL 340882 & 911390 & 7.3197 & 7.3271 & TRN \\
\hline CHEMBL122638 & 911390 & 8.7212 & 8.1143 & TRN \\
\hline CHEMBL331546 & 911390 & 8.0969 & 8.4847 & TRN \\
\hline CHEMBL339544 & 911390 & 8.0969 & 8.2894 & TST \\
\hline CHEMBL338123 & 911390 & 7.6216 & 7.8153 & TRN \\
\hline CHEMBL125273 & 911390 & 7.9957 & 7.9389 & TRN \\
\hline CHEMBL125697 & 911390 & 7.6596 & 7.5002 & TRN \\
\hline CHEMBL121733 & 911390 & 7.8447 & 8.1211 & TRN \\
\hline CHEMBL 333058 & 911390 & 7.5086 & 7.2497 & TRN \\
\hline CHEMBL340605 & 911390 & 7.8386 & 7.9777 & TRN \\
\hline CHEMBL 2259781 & 911390 & 6.0535 & 6.1731 & TRN \\
\hline CHEMBL341456 & 911390 & 7.3958 & 7.5252 & TRN \\
\hline CHEMBL339709 & 911390 & 6.983 & 8.0912 & TST \\
\hline CHEMBL125958 & 911390 & 8.1487 & 8.0446 & TST \\
\hline CHEMBL 2263542 & 911390 & 7.5952 & 6.8246 & TST \\
\hline CHEMBL 339404 & 911390 & 8.3188 & 9.5029 & TST \\
\hline CHEMBL332152 & 911390 & 6.7986 & 6.9805 & TST \\
\hline
\end{tabular}




\begin{tabular}{|c|c|c|c|c|c|}
\hline \multicolumn{6}{|c|}{ Supplemental Table S2.txt } \\
\hline CHEMBL125835 & 911390 & 7.3206 & 8.9099 & TST & \\
\hline CHEMBL339480 & 911390 & 7.9547 & 7.2475 & TST & \\
\hline CHEMBL1411912 & 688494 & 5.4238 & 5.6048 & TRN & \\
\hline CHEMBL533602 & 688494 & 6.0353 & 5.7806 & TST & \\
\hline CHEMBL1404792 & 688494 & 5.5318 & 5.7801 & TST & \\
\hline CHEMBL1347469 & 688494 & 5.4405 & 5.3087 & TRN & \\
\hline CHEMBL1413625 & 688494 & 5.4349 & 5.4312 & TRN & \\
\hline CHEMBL1323894 & 688494 & 3.5229 & 3.4627 & TRN & \\
\hline CHEMBL1540682 & 688494 & 5.5546 & 5.4126 & TRN & \\
\hline CHEMBL1353442 & 688494 & 3.5229 & 3.7188 & TRN & \\
\hline CHEMBL1546374 & 688494 & 5.3688 & 5.3163 & TRN & \\
\hline CHEMBL3196976 & 688494 & 5.3639 & 5.335 & TRN & \\
\hline CHEMBL1333355 & 688494 & 3.5229 & 3.4854 & TRN & \\
\hline CHEMBL1481335 & 688494 & 5.0967 & 4.9521 & TRN & \\
\hline CHEMBL1316410 & 688494 & 3.5229 & 3.6032 & TRN & \\
\hline CHEMBL1985061 & 688494 & 4.3067 & 4.9223 & TRN & \\
\hline CHEMBL1376109 & 688494 & 3.5229 & 3.7938 & TRN & \\
\hline CHEMBL1986259 & 688494 & 5.4306 & 5.4253 & TRN & \\
\hline CHEMBL1572967 & 688494 & 5.4242 & 5.3628 & TRN & \\
\hline CHEMBL1566928 & 688494 & 5.5969 & 5.1707 & TST & \\
\hline CHEMBL1443201 & 688494 & 3.5229 & 3.4036 & TRN & \\
\hline CHEMBL1563483 & 688494 & 5.3469 & 5.7096 & TST & \\
\hline CHEMBL1607568 & 688494 & 5.3215 & 5.4511 & TRN & \\
\hline CHEMBL1488339 & 688494 & 3.5229 & 3.4514 & TRN & \\
\hline CHEMBL1197556 & 688494 & 5.5081 & 5.8463 & TST & \\
\hline CHEMBL1420175 & 688494 & 5.2841 & 4.8798 & TRN & \\
\hline CHEMBL1496004 & 688494 & 5.3964 & 5.4086 & TRN & \\
\hline CHEMBL1555086 & 688494 & 3.5229 & 3.6084 & TRN & \\
\hline CHEMBL601757 & 688494 & 5.8533 & 5.886 & TRN & \\
\hline CHEMBL1553842 & 688494 & 3.5229 & 3.5285 & TRN & \\
\hline CHEMBL1393783 & 688494 & 5.4628 & 5.2606 & TRN & \\
\hline CHEMBL1422386 & 688494 & 5.3572 & 5.5183 & TRN & \\
\hline CHEMBL 1356613 & 688494 & 3.5229 & 3.5256 & TRN & \\
\hline CHEMBL1459140 & 688494 & 5.4204 & 5.8904 & TRN & \\
\hline CHEMBL1503266 & 688494 & 3.5229 & 3.5486 & TRN & \\
\hline CHEMBL1543839 & 688494 & 5.5013 & 5.49299 & 9999999999 & TRN \\
\hline CHEMBL1467961 & 688494 & 5.3465 & 5.1246 & TRN & \\
\hline CHEMBL1535539 & 688494 & 5.3294 & 5.0566 & TRN & \\
\hline CHEMBL1596681 & 688494 & 5.0442 & 6.1189 & TST & \\
\hline CHEMBL1317987 & 688494 & 4.7354 & 4.3627 & TRN & \\
\hline CHEMBL1574879 & 688494 & 6.0259 & 5.9043 & TRN & \\
\hline CHEMBL1881714 & 688494 & 5.474 & 5.3069 & TRN & \\
\hline CHEMBL1417204 & 688494 & 5.4332 & 5.541 & TRN & \\
\hline CHEMBL1304582 & 688494 & 5.4084 & 5.2 & TRN & \\
\hline CHEMBL1393625 & 688494 & 5.1542 & 5.2823 & TRN & \\
\hline CHEMBL1334062 & 688494 & 6.0017 & 5.8323 & TRN & \\
\hline CHEMBL1519087 & 688494 & 4.8564 & 4.0466 & TRN & \\
\hline CHEMBL1570449 & 688494 & 3.5229 & 3.7407 & TRN & \\
\hline
\end{tabular}




\begin{tabular}{|c|c|c|c|c|c|}
\hline \multicolumn{6}{|c|}{ Supplemental Table s2.txt } \\
\hline CHEMBL1424968 & 688494 & 5.3303 & 5.2301 & TRN & \\
\hline CHEMBL1356269 & 688494 & 3.5229 & 3.4683 & TRN & \\
\hline CHEMBL1518905 & 688494 & 6.2314 & 6.05 & TST & \\
\hline CHEMBL1465527 & 688494 & 5.5126 & 5.2255 & TRN & \\
\hline CHEMBL1606330 & 688494 & 4.9412 & 4.8817 & TST & \\
\hline CHEMBL1309232 & 688494 & 5.8286 & 5.874 & TRN & \\
\hline CHEMBL1414715 & 688494 & 3.5229 & 3.61 & TRN & \\
\hline CHEMBL1395037 & 688494 & 3.5229 & 3.9516 & TRN & \\
\hline CHEMBL1470979 & 688494 & 5.6078 & 5.5419 & TRN & \\
\hline CHEMBL1309450 & 688494 & 6.0101 & 5.1292 & TST & \\
\hline CHEMBL1329973 & 688494 & 3.5229 & 3.6352 & TRN & \\
\hline CHEMBL1432251 & 688494 & 5.776 & 5.7666 & TRN & \\
\hline CHEMBL1504701 & 688494 & 6.1662 & 6.1059 & TRN & \\
\hline CHEMBL1508593 & 688494 & 5.1483 & 5.3231 & TRN & \\
\hline CHEMBL1565349 & 688494 & 5.4193 & 5.5872 & TRN & \\
\hline CHEMBL1440703 & 688494 & 5.2068 & 5.032 & TRN & \\
\hline CHEMBL1428153 & 688494 & 5.3591 & 5.1174 & TRN & \\
\hline CHEMBL3199050 & 688494 & 5.2237 & 5.319 & TRN & \\
\hline CHEMBL1355464 & 688494 & 3.5229 & 3.5391 & TRN & \\
\hline CHEMBL1518487 & 688494 & 3.5229 & 3.4906 & TRN & \\
\hline CHEMBL1563943 & 688494 & 5.9101 & 5.8991 & TRN & \\
\hline CHEMBL1343392 & 688494 & 5.5764 & 5.5544 & TRN & \\
\hline CHEMBL1307319 & 688494 & 4.077 & 5.1031 & TRN & \\
\hline CHEMBL1369655 & 688494 & 5.7547 & 5.7711 & TST & \\
\hline CHEMBL1533366 & 688494 & 3.301 & 5.2615 & TST & \\
\hline CHEMBL1531073 & 688494 & 5.4595 & 5.225 & TST & \\
\hline CHEMBL1344225 & 688494 & 6.0146 & 5.9904 & TST & \\
\hline CHEMBL1605274 & 688494 & 3.1219 & 5.1529 & TST & \\
\hline CHEMBL1341270 & 688494 & 5.4211 & 5.4539 & TST & \\
\hline CHEMBL1304169 & 688494 & 5.2935 & 5.2375 & TST & \\
\hline CHEMBL1531343 & 688494 & 3.5229 & 3.7906 & TST & \\
\hline CHEMBL1481347 & 688494 & 5.5312 & 6.1189 & TST & \\
\hline CHEMBL1322078 & 688494 & 5.4804 & 5.2362 & TST & \\
\hline CHEMBL1450007 & 688494 & 3.301 & 4.8062 & TST & \\
\hline CHEMBL225224 & 640075 & 7.7 & 7.3648 & TST & \\
\hline CHEMBL 225282 & 640075 & 6.59 & 7.6719 & TST & \\
\hline CHEMBL 225560 & 640075 & 7.07 & 7.3228 & TST & \\
\hline CHEMBL 224887 & 640075 & 6.66 & 7.0902 & TST & \\
\hline CHEMBL 224500 & 640075 & 6.62 & 6.57799 & 9999999999 & TRN \\
\hline CHEMBL386937 & 640075 & 7.49 & 7.6349 & TRN & \\
\hline CHEMBL 224885 & 640075 & 7.7 & 7.7191 & TRN & \\
\hline CHEMBL224076 & 640075 & 5.1 & 6.9484 & TST & \\
\hline CHEMBL427083 & 640075 & 6.87 & 6.7605 & TRN & \\
\hline CHEMBL223651 & 640075 & 6.27 & 6.2236 & TRN & \\
\hline CHEMBL415061 & 640075 & 7.74 & 7.7393 & TRN & \\
\hline CHEMBL 225434 & 640075 & 7.0 & 7.0136 & TRN & \\
\hline CHEMBL 225582 & 640075 & 8.0 & 8.0199 & TRN & \\
\hline CHEMBL 224558 & 640075 & 6.36 & 6.4104 & TRN & \\
\hline
\end{tabular}




\begin{tabular}{|c|c|c|c|c|c|}
\hline & & \multicolumn{4}{|c|}{ Supplemental Table s2.txt } \\
\hline CHEMBL224559 & 640075 & 6.54 & 6.5578 & TRN & \\
\hline CHEMBL225225 & 640075 & 6.54 & 6.5864 & TRN & \\
\hline CHEMBL388742 & 640075 & 7.35 & 7.4748 & TRN & \\
\hline CHEMBL390389 & 640075 & 7.7 & 7.6605 & TRN & \\
\hline CHEMBL427245 & 640075 & 7.62 & 7.70299 & 9999999999 & TRN \\
\hline CHEMBL390837 & 640075 & 7.89 & 7.5974 & TRN & \\
\hline CHEMBL389168 & 640075 & 7.72 & 7.7584 & TRN & \\
\hline CHEMBL 3689421 & 640075 & 7.96 & 7.8433 & TRN & \\
\hline CHEMBL 373487 & 640075 & 6.82 & 6.8956 & TRN & \\
\hline CHEMBL223553 & 640075 & 6.11 & 6.1223 & TRN & \\
\hline CHEMBL427085 & 640075 & 6.47 & 6.4927 & TRN & \\
\hline CHEMBL224509 & 640075 & 7.6 & 7.5938 & TRN & \\
\hline CHEMBL3689412 & 640075 & 8.0 & 8.057 & TRN & \\
\hline CHEMBL 3689418 & 640075 & 8.05 & 8.012 & TRN & \\
\hline CHEMBL 3689419 & 640075 & 7.8 & 7.8049 & TRN & \\
\hline CHEMBL389622 & 640075 & 7.1 & 7.0333 & TRN & \\
\hline CHEMBL427254 & 640075 & 7.07 & 7.1063 & TRN & \\
\hline CHEMBL390736 & 640075 & 7.46 & 7.4314 & TRN & \\
\hline CHEMBL224535 & 640075 & 8.0 & 8.0281 & TRN & \\
\hline CHEMBL224594 & 640075 & 8.52 & 8.5377 & TRN & \\
\hline CHEMBL389915 & 640075 & 7.06 & 7.0732 & TRN & \\
\hline CHEMBL224696 & 640075 & 6.62 & 6.6121 & TRN & \\
\hline CHEMBL224746 & 640075 & 7.14 & 7.1053 & TRN & \\
\hline CHEMBL224533 & 640075 & 6.72 & 6.7311 & TRN & \\
\hline CHEMBL224166 & 640075 & 7.96 & 7.9248 & TRN & \\
\hline CHEMBL373512 & 640075 & 8.3 & 8.3399 & TRN & \\
\hline CHEMBL225166 & 640075 & 8.52 & 8.5077 & TRN & \\
\hline CHEMBL225167 & 640075 & 6.74 & 6.8098 & TRN & \\
\hline CHEMBL224472 & 640075 & 6.46 & 6.482 & TRN & \\
\hline CHEMBL375882 & 640075 & 6.68 & 6.7525 & TRN & \\
\hline CHEMBL224505 & 640075 & 6.85 & 6.9018 & TRN & \\
\hline CHEMBL375736 & 640075 & 6.57 & 6.4919 & TRN & \\
\hline CHEMBL224508 & 640075 & 6.68 & 6.7385 & TRN & \\
\hline CHEMBL 389254 & 640075 & 6.58 & 6.7512 & TRN & \\
\hline CHEMBL225492 & 640075 & 6.73 & 6.7892 & TRN & \\
\hline CHEMBL389926 & 640075 & 7.0 & 6.9959 & TRN & \\
\hline CHEMBL223815 & 640075 & 7.19 & 7.0668 & TRN & \\
\hline CHEMBL 3689491 & 640075 & 7.19 & 7.0772 & TRN & \\
\hline CHEMBL 223336 & 640075 & 7.02 & 6.9523 & TRN & \\
\hline CHEMBL387954 & 640075 & 7.12 & 7.0812 & TRN & \\
\hline CHEMBL388285 & 640075 & 6.69 & 6.9754 & TST & \\
\hline CHEMBL373759 & 640075 & 6.56 & 7.1431 & TST & \\
\hline CHEMBL223907 & 640075 & 6.63 & 7.4418 & TST & \\
\hline CHEMBL1171888 & 640075 & 6.3 & 7.0183 & TST & \\
\hline CHEMBL1171889 & 640075 & 6.05 & 6.7104 & TST & \\
\hline CHEMBL1171890 & 640075 & 6.3 & 6.2694 & TST & \\
\hline CHEMBL1171704 & 640075 & 6.0 & 6.6758 & TST & \\
\hline CHEMBL1170714 & 640075 & 6.52 & 6.3862 & TST & \\
\hline
\end{tabular}




\begin{tabular}{|c|c|c|c|c|}
\hline \multicolumn{5}{|c|}{ Supplemental Table S2.txt } \\
\hline CHEMBL1171705 & 640075 & 6.15 & 6.1101 & TRN \\
\hline CHEMBL1172654 & 640075 & 7.0 & 6.6076 & TST \\
\hline CHEMBL1172655 & 640075 & 6.4 & 6.359 & TRN \\
\hline CHEMBL1170912 & 640075 & 6.7 & 6.8675 & TST \\
\hline CHEMBL1169749 & 640075 & 6.7 & 7.1095 & TST \\
\hline CHEMBL1169744 & 640075 & 7.0 & 6.5002 & TST \\
\hline CHEMBL3105681 & 1625734 & 7.0969 & 4.3952 & TST \\
\hline CHEMBL 3977048 & 1625734 & 7.3565 & 4.685 & TST \\
\hline CHEMBL 3929358 & 1625734 & 6.5086 & 6.8257 & TRN \\
\hline CHEMBL3913238 & 1625734 & 7.0555 & 7.1759 & TRN \\
\hline CHEMBL 3942787 & 1625734 & 5.6021 & 4.8163 & TRN \\
\hline CHEMBL3933686 & 1625734 & 5.585 & 5.1124 & TRN \\
\hline CHEMBL3920663 & 1625734 & 6.4318 & 4.8607 & TRN \\
\hline CHEMBL3956929 & 1625734 & 5.6778 & 5.7088 & TRN \\
\hline CHEMBL3931161 & 1625734 & 7.5086 & 6.4256 & TRN \\
\hline CHEMBL3896717 & 1625734 & 4.0 & 4.3479 & TRN \\
\hline CHEMBL3923672 & 1625734 & 5.1871 & 4.7322 & TRN \\
\hline CHEMBL3967961 & 1625734 & 5.9586 & 5.4736 & TRN \\
\hline CHEMBL 3972391 & 1625734 & 4.0 & 4.7121 & TRN \\
\hline CHEMBL3979349 & 1625734 & 6.1427 & 5.7723 & TRN \\
\hline CHEMBL3933815 & 1625734 & 5.2076 & 4.6567 & TRN \\
\hline CHEMBL3915908 & 1625734 & 5.4437 & 4.9833 & TRN \\
\hline CHEMBL 3922245 & 1625734 & 4.0 & 5.6691 & TRN \\
\hline CHEMBL 3938404 & 1625734 & 5.9208 & 5.8611 & TRN \\
\hline CHEMBL3912204 & 1625734 & 6.9208 & 5.4529 & TRN \\
\hline CHEMBL3940207 & 1625734 & 5.0362 & 4.9649 & TRN \\
\hline CHEMBL3924898 & 1625734 & 7.2676 & 4.9706 & TST \\
\hline CHEMBL3924764 & 1625734 & 4.0 & 4.4906 & TRN \\
\hline CHEMBL 3914641 & 1625734 & 5.3665 & 5.2735 & TRN \\
\hline CHEMBL3929577 & 1625734 & 6.5229 & 5.1867 & TRN \\
\hline CHEMBL3982499 & 1625734 & 4.0 & 4.9148 & TST \\
\hline CHEMBL3920454 & 1625734 & 5.4437 & 5.4928 & TRN \\
\hline CHEMBL3939711 & 1625734 & 5.301 & 6.4748 & TRN \\
\hline CHEMBL 3947182 & 1625734 & 4.0 & 4.7551 & TRN \\
\hline CHEMBL3983082 & 1625734 & 4.0 & 5.1583 & TRN \\
\hline CHEMBL3938602 & 1625734 & 4.0 & 4.3187 & TRN \\
\hline CHEMBL3911834 & 1625734 & 5.5686 & 4.8867 & TRN \\
\hline CHEMBL 3894222 & 1625734 & 6.585 & 7.0604 & TRN \\
\hline CHEMBL3951385 & 1625734 & 4.0 & 4.5478 & TRN \\
\hline CHEMBL3956564 & 1625734 & 4.0 & 4.6218 & TRN \\
\hline CHEMBL3218921 & 1625734 & 7.2218 & 5.0657 & TST \\
\hline CHEMBL 3977144 & 1625734 & 4.0 & 4.854 & TRN \\
\hline CHEMBL3911731 & 1625734 & 4.0 & 4.6298 & TRN \\
\hline CHEMBL3948265 & 1625734 & 6.6198 & 6.7479 & TRN \\
\hline CHEMBL 3957141 & 1625734 & 5.7447 & 5.2827 & TRN \\
\hline CHEMBL3947885 & 1625734 & 4.0 & 4.4418 & TRN \\
\hline CHEMBL3928131 & 1625734 & 6.0862 & 5.6319 & TRN \\
\hline CHEMBL3948459 & 1625734 & 4.0 & 4.265 & TRN \\
\hline
\end{tabular}


Supplemental Table S2.txt

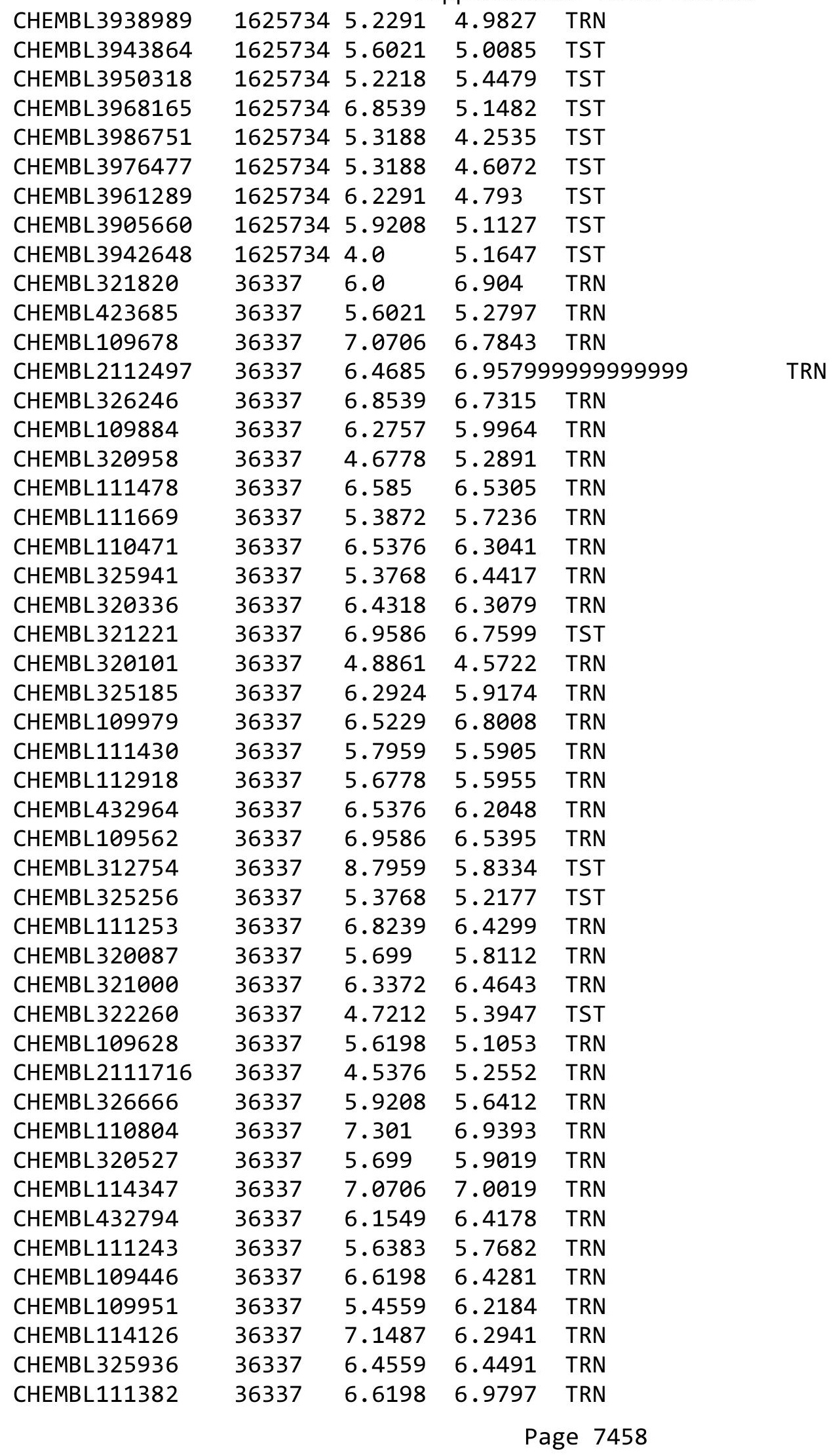




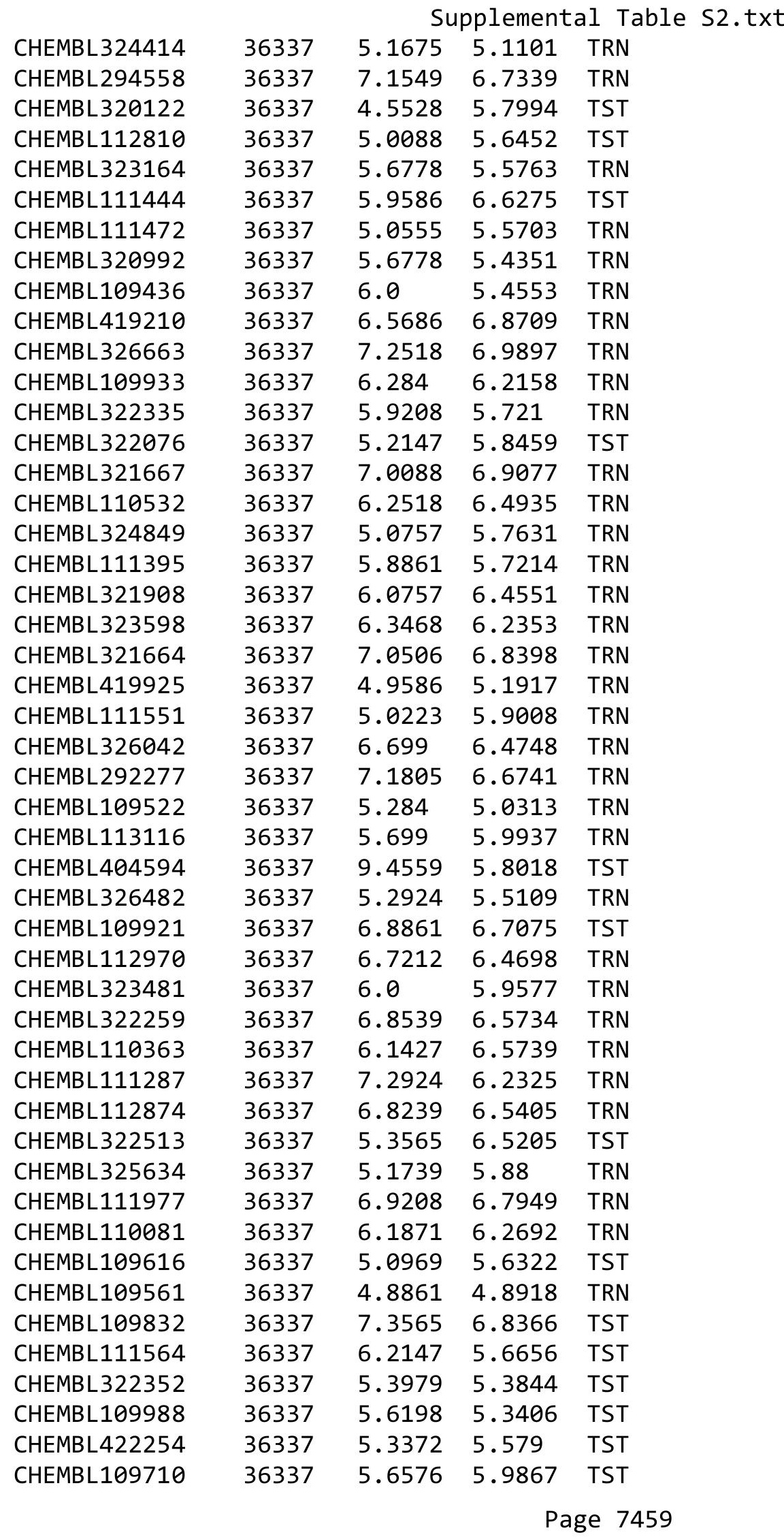




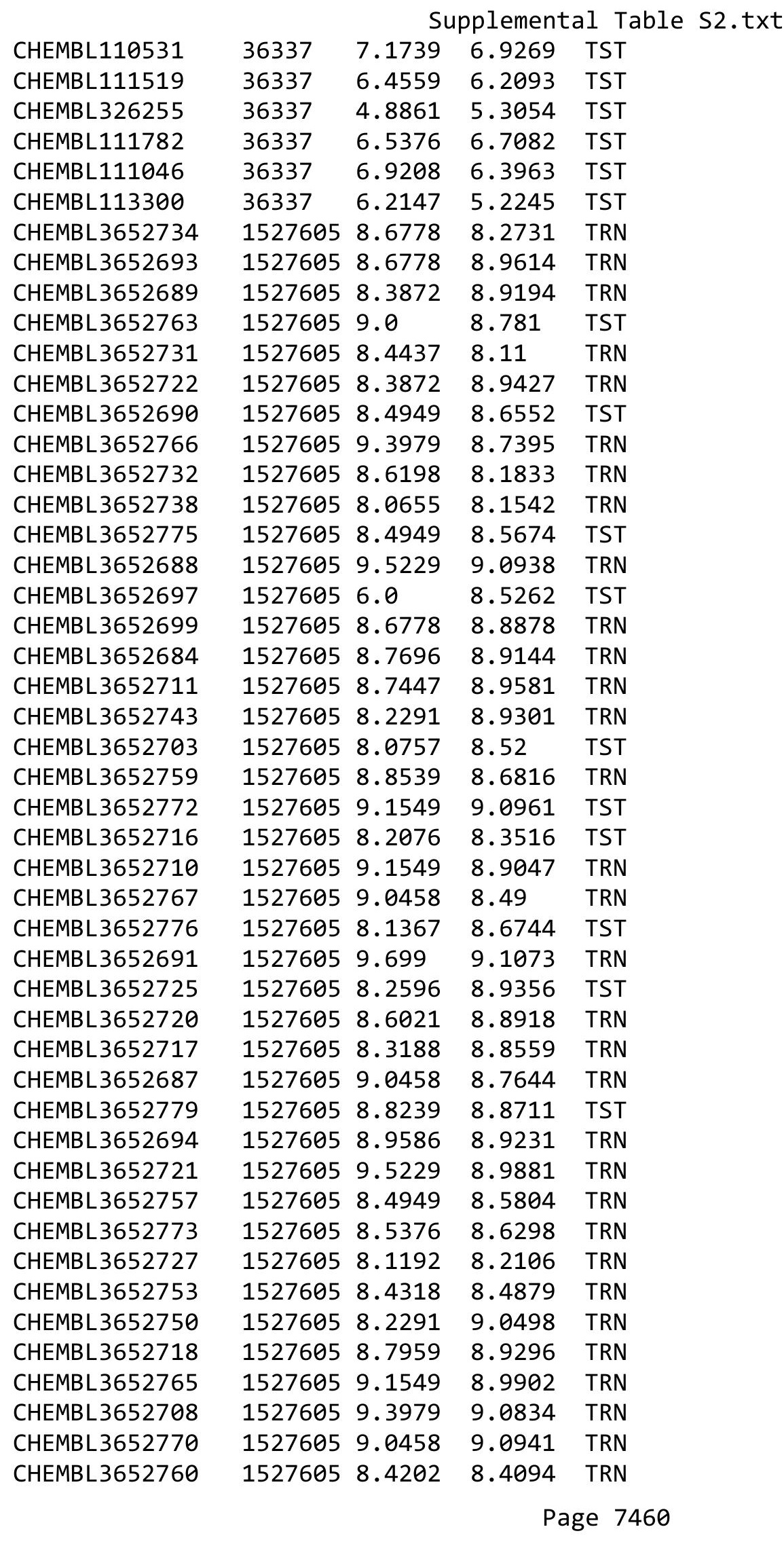


Supplemental Table S2.txt

\begin{tabular}{|c|c|c|c|c|}
\hline HEMB I & 527605 & & 8408 & \\
\hline & 527605 & 9.1549 & .5288 & \\
\hline 39 & 27605 & & & \\
\hline AEMBL & 27605 & 9 & & \\
\hline AEMBL3 & 527605 & 9.0 & 6974 & \\
\hline HEMBL3652724 & 527605 & 8.6021 & 9248 & \\
\hline HEMBL; & 605 & 6.0 & & \\
\hline IEMBL36 & car & 8 & & RN \\
\hline HEMBL 365 & 605 & 8.8861 & .565 & \\
\hline HEMBL 365 & 605 & 8.3188 & 5991 & \\
\hline AEMBL365 & 505 & 8.0969 & 1069 & \\
\hline IEMBL36 & כט & 28 & 131 & \\
\hline AEMBL36 & & & & \\
\hline HEMBL36 & 05 & 8.85 & 9623 & \\
\hline AEMBL 365 & 05 & 61 & 23 & \\
\hline AEMBL365 & כס & 089 & 15 & \\
\hline HEMBL36 & כנ & & 192 & \\
\hline HEMBL36 & & 212 & 876 & \\
\hline HEMBL36 & 05 & 01 & 8669 & \\
\hline IEMBL36 & & 528 & & \\
\hline HEMBLS & בל & 8 . & 38 & I RIV \\
\hline HEMBL3 & & 9. & 91 & RN \\
\hline HEMBL3 & & & 38 & \\
\hline 705 & & 9. & 3087 & \\
\hline JEMBL 36 & & & & $\Gamma \mathrm{RN}$ \\
\hline HEMBL3 & dל & & 167 & | \\
\hline HEMBL; & & & 358 & ST \\
\hline$H F M B I=$ & 5 & 8 & 155 & \\
\hline HEMBL 365 & & 8.9208 & 166 & I \\
\hline HEMBL 365 & & 8 . & 712 & IK \\
\hline HEMBL36 & & & 117 & SI \\
\hline HEMBL; & & & 955 & ST \\
\hline HEMBL & 5 & 8 & & 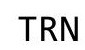 \\
\hline HEMBL365 & & 8. & & is \\
\hline HEMBL3652728 & 52 & 8.3372 & 301 & TST \\
\hline HEMBL36 & & & 739 & RN \\
\hline HFMRI 3 & 52 & & 49 & RN \\
\hline HEMBL3 & & 8 . & 652 & 「RN \\
\hline HEMBL3652696 & לS & 8.2518 & 5693 & TST \\
\hline AEMBL 365 & 52 & 9 . & 1363 & TST \\
\hline HEMBL36 & & 586 & & RN \\
\hline CHEMBL36 & & 8.7696 & 1895 & TRN \\
\hline HEMBL36 & 05 & 10.0 & 3.9644 & RN \\
\hline HEMBL365 & 05 & 8.8539 & 9402 & TR \\
\hline $\mathrm{MRI}=$ & $=0$ & 2 & 7213 & $\mathrm{~N}$ \\
\hline HEMBL 36 & & & 9036 & \\
\hline CHEMBL 365 & & 8.5229 & 8.6886 & \\
\hline CHEMBL3652777 & 1527605 & 8.9586 & 8.7056 & ГRN \\
\hline
\end{tabular}

Page 7461 


\begin{tabular}{|c|c|c|c|c|c|}
\hline \multicolumn{6}{|c|}{ Supplemental Table S2.txt } \\
\hline CHEMBL72701 & 37371 & 7.3665 & 7.3488 & TRN & \\
\hline CHEMBL308265 & 37371 & 8.5528 & 8.3895 & TRN & \\
\hline CHEMBL72390 & 37371 & 6.9208 & 7.1651 & TST & \\
\hline CHEMBL308035 & 37371 & 8.1938 & 8.2998 & TRN & \\
\hline CHEMBL 74427 & 37371 & 7.8539 & 7.9729 & TST & \\
\hline CHEMBL75104 & 37371 & 8.4089 & 8.4894 & TRN & \\
\hline CHEMBL73655 & 37371 & 7.8539 & 7.7951 & TRN & \\
\hline CHEMBL310708 & 37371 & 7.6021 & 7.4768 & TRN & \\
\hline CHEMBL75315 & 37371 & 7.5686 & 7.5939 & TRN & \\
\hline CHEMBL309330 & 37371 & 7.284 & 7.5944 & TRN & \\
\hline CHEMBL307489 & 37371 & 6.9788 & 7.1984 & TST & \\
\hline CHEMBL75216 & 37371 & 7.6576 & 7.4824 & TRN & \\
\hline CHEMBL307819 & 37371 & 8.0862 & 8.1097 & TRN & \\
\hline CHEMBL444051 & 37371 & 7.8239 & 7.7535 & TRN & \\
\hline CHEMBL431979 & 37371 & 7.1739 & 7.1148 & TST & \\
\hline CHEMBL307005 & 37371 & 8.0809 & 8.2712 & TRN & \\
\hline CHEMBL 309070 & 37371 & 7.7212 & 7.6966 & TRN & \\
\hline CHEMBL306342 & 37371 & 8.6198 & 8.5904 & TRN & \\
\hline CHEMBL73624 & 37371 & 7.699 & 7.8796 & TRN & \\
\hline CHEMBL 75513 & 37371 & 6.9788 & 7.1477 & TST & \\
\hline CHEMBL 74452 & 37371 & 8.8861 & 8.7281 & TRN & \\
\hline CHEMBL 75463 & 37371 & 8.1427 & 8.3223 & TRN & \\
\hline CHEMBL306816 & 37371 & 7.9208 & 8.0532 & TRN & \\
\hline CHEMBL 305842 & 37371 & 7.3468 & 7.3629 & TRN & \\
\hline CHEMBL 74266 & 37371 & 7.2757 & 7.2618 & TRN & \\
\hline CHEMBL54338 & 37371 & 8.3768 & 7.8597 & TST & \\
\hline CHEMBL75290 & 37371 & 7.4685 & 7.4996 & TRN & \\
\hline CHEMBL76465 & 37371 & 8.2757 & 8.2829 & TRN & \\
\hline CHEMBL 74879 & 37371 & 7.5086 & 7.4937 & TRN & \\
\hline CHEMBL308781 & 37371 & 8.4685 & 8.4697 & TRN & \\
\hline CHEMBL309090 & 37371 & 7.6198 & 7.63200 & 0000000001 & TST \\
\hline CHEMBL 307224 & 37371 & 6.7447 & 6.6861 & TRN & \\
\hline CHEMBL72321 & 37371 & 8.3872 & 8.2624 & TRN & \\
\hline CHEMBL309091 & 37371 & 7.9586 & 7.9752 & TRN & \\
\hline CHEMBL412356 & 37371 & 7.2924 & 7.1677 & TST & \\
\hline CHEMBL73203 & 37371 & 7.5086 & 7.4572 & TRN & \\
\hline CHEMBL307140 & 37371 & 7.0 & 7.2441 & TST & \\
\hline CHEMBL73292 & 37371 & 7.8861 & 7.9465 & TRN & \\
\hline CHEMBL432914 & 37371 & 7.2757 & 7.1907 & TRN & \\
\hline CHEMBL73443 & 37371 & 7.5686 & 7.6321 & TRN & \\
\hline CHEMBL307957 & 37371 & 8.4685 & 8.3525 & TRN & \\
\hline CHEMBL305704 & 37371 & 8.1739 & 8.0704 & TRN & \\
\hline CHEMBL308359 & 37371 & 8.1549 & 8.0308 & TRN & \\
\hline CHEMBL305830 & 37371 & 7.7447 & 7.7473 & TRN & \\
\hline CHEMBL75521 & 37371 & 7.7959 & 7.7684 & TRN & \\
\hline CHEMBL 72161 & 37371 & 7.3768 & 7.2275 & TST & \\
\hline CHEMBL 74443 & 37371 & 6.2218 & 6.6692 & TST & \\
\hline CHEMBL73070 & 37371 & 7.3665 & 7.46 & TRN & \\
\hline
\end{tabular}




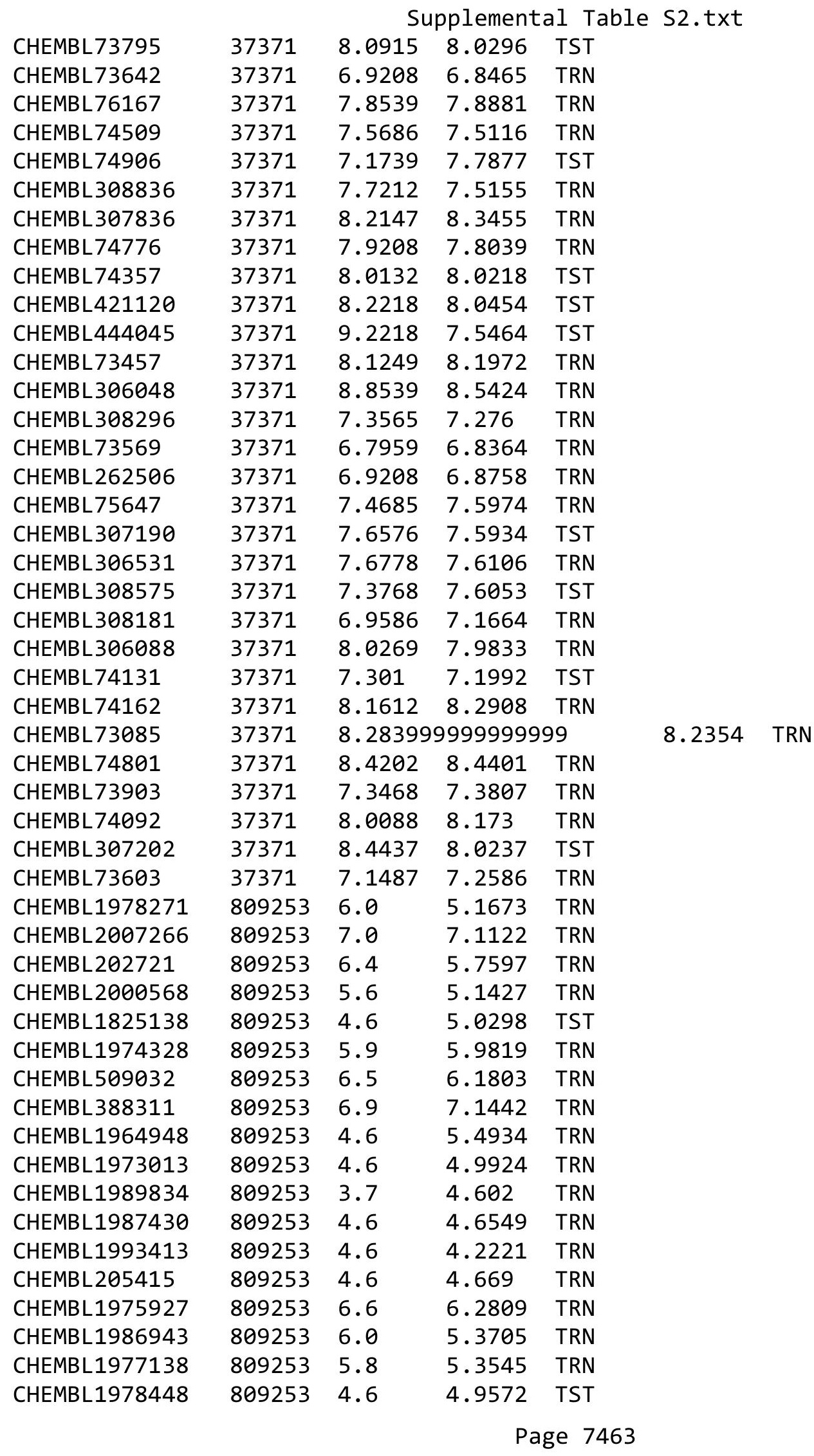




\begin{tabular}{|c|c|c|c|c|}
\hline & & & 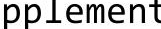 & al Ta \\
\hline CHEMBL1980329 & 809253 & 6.3 & 5.8918 & TRN \\
\hline CHEMBL 2001257 & 809253 & 6.6 & 7.5903 & TRN \\
\hline CHEMBL1971785 & 809253 & 4.2 & 4.6587 & TRN \\
\hline CHEMBL1992042 & 809253 & 4.6 & 5.4033 & TRN \\
\hline CHEMBL1986265 & 809253 & 6.0 & 5.0838 & TRN \\
\hline CHEMBL 2001704 & 809253 & 4.2 & 4.6338 & TRN \\
\hline CHEMBL1991734 & 809253 & 7.0 & 5.9134 & TST \\
\hline CHEMBL21156 & 809253 & 4.6 & 4.9313 & TRN \\
\hline CHEMBL1994724 & 809253 & 4.6 & 4.6308 & TRN \\
\hline CHEMBL1989267 & 809253 & 7.4 & 7.1802 & TRN \\
\hline CHEMBL1991782 & 809253 & 3.3 & 3.4395 & TRN \\
\hline CHEMBL 2002105 & 809253 & 4.1 & 4.2438 & TRN \\
\hline CHEMBL1983348 & 809253 & 5.6 & 5.5699 & TRN \\
\hline CHEMBL1970290 & 809253 & 6.6 & 6.0467 & TRN \\
\hline CHEMBL1993877 & 809253 & 4.6 & 5.0997 & TRN \\
\hline CHEMBL1996500 & 809253 & 4.6 & 4.9711 & TRN \\
\hline CHEMBL1980671 & 809253 & 4.4 & 4.8933 & TRN \\
\hline CHEMBL1973363 & 809253 & 5.8 & 5.443 & TRN \\
\hline CHEMBL1986177 & 809253 & 4.6 & 4.8503 & TRN \\
\hline CHEMBL1989708 & 809253 & 8.5 & 8.6745 & TRN \\
\hline CHEMBL1976420 & 809253 & 4.6 & 4.7349 & TRN \\
\hline CHEMBL1981744 & 809253 & 4.6 & 4.3329 & TRN \\
\hline CHEMBL1989423 & 809253 & 4.0 & 3.9536 & TRN \\
\hline CHEMBL1985367 & 809253 & 4.6 & 4.6713 & TRN \\
\hline CHEMBL1996510 & 809253 & 4.6 & 4.5823 & TRN \\
\hline CHEMBL 2000029 & 809253 & 4.6 & 4.8582 & TRN \\
\hline CHEMBL1995172 & 809253 & 4.6 & 4.4385 & TRN \\
\hline CHEMBL 2001584 & 809253 & 4.6 & 4.9379 & TRN \\
\hline CHEMBL1973961 & 809253 & 4.6 & 4.7056 & TRN \\
\hline CHEMBL1967998 & 809253 & 6.8 & 6.6963 & TRN \\
\hline CHEMBL1978562 & 809253 & 4.6 & 4.899 & TRN \\
\hline CHEMBL1994977 & 809253 & 4.6 & 5.1287 & TRN \\
\hline CHEMBL2001149 & 809253 & 5.7 & 5.1596 & TRN \\
\hline CHEMBL1974875 & 809253 & 4.3 & 4.2235 & TST \\
\hline CHEMBL 2005478 & 809253 & 4.6 & 4.8458 & TRN \\
\hline CHEMBL1996646 & 809253 & 7.1 & 6.599 & TRN \\
\hline CHEMBL1979773 & 809253 & 6.1 & 5.6218 & TRN \\
\hline CHEMBL1989471 & 809253 & 4.6 & 4.9845 & TST \\
\hline CHEMBL 2002099 & 809253 & 4.6 & 4.6179 & TRN \\
\hline CHEMBL1996702 & 809253 & 6.2 & 5.8718 & TRN \\
\hline CHEMBL 2007124 & 809253 & 4.6 & 5.3494 & TRN \\
\hline CHEMBL1994956 & 809253 & 5.6 & 4.5409 & TRN \\
\hline CHEMBL1978195 & 809253 & 4.6 & 4.7269 & TRN \\
\hline CHEMBL1985681 & 809253 & 4.6 & 5.5518 & TRN \\
\hline CHEMBL1991674 & 809253 & 4.8 & 5.0553 & TRN \\
\hline CHEMBL1982711 & 809253 & 4.6 & 4.4675 & TRN \\
\hline CHEMBL 262623 & 809253 & 4.6 & 4.5065 & TRN \\
\hline CHEMBL1984842 & 809253 & 4.6 & 4.9671 & TRN \\
\hline
\end{tabular}




\begin{tabular}{|c|c|c|c|c|}
\hline \multicolumn{5}{|c|}{ Supplemental Table S2.txt } \\
\hline CHEMBL 2004118 & 809253 & 4.6 & 4.7702 & TRN \\
\hline CHEMBL1996345 & 809253 & 4.6 & 4.647 & TRN \\
\hline CHEMBL 2004025 & 809253 & 4.6 & 5.1472 & TRN \\
\hline CHEMBL1996048 & 809253 & 5.8 & 5.8069 & TRN \\
\hline CHEMBL50894 & 809253 & 4.6 & 4.8841 & TRN \\
\hline CHEMBL1995211 & 809253 & 4.6 & 4.0959 & TRN \\
\hline CHEMBL1965033 & 809253 & 4.6 & 5.5054 & TRN \\
\hline CHEMBL461876 & 809253 & 4.6 & 4.7664 & TRN \\
\hline CHEMBL1982753 & 809253 & 4.8 & 5.0146 & TRN \\
\hline CHEMBL 2006299 & 809253 & 4.6 & 4.7108 & TRN \\
\hline CHEMBL1972346 & 809253 & 6.0 & 5.2152 & TST \\
\hline CHEMBL1997335 & 809253 & 6.7 & 5.9066 & TRN \\
\hline CHEMBL1965169 & 809253 & 4.6 & 4.7997 & TRN \\
\hline CHEMBL1991818 & 809253 & 5.9 & 5.2476 & TST \\
\hline CHEMBL1081312 & 809253 & 6.5 & 5.8955 & TRN \\
\hline CHEMBL1971132 & 809253 & 6.4 & 4.9881 & TRN \\
\hline CHEMBL1965170 & 809253 & 8.8 & 8.8036 & TRN \\
\hline CHEMBL1994808 & 809253 & 4.0 & 4.5543 & TRN \\
\hline CHEMBL 2005792 & 809253 & 4.6 & 4.9566 & TRN \\
\hline CHEMBL1991867 & 809253 & 4.3 & 4.1529 & TRN \\
\hline CHEMBL1972355 & 809253 & 6.2 & 5.8475 & TRN \\
\hline CHEMBL1997892 & 809253 & 6.7 & 5.4984 & TRN \\
\hline CHEMBL 2001641 & 809253 & 4.2 & 4.5534 & TRN \\
\hline CHEMBL1997193 & 809253 & 4.6 & 4.9446 & TST \\
\hline CHEMBL1964902 & 809253 & 4.6 & 4.6929 & TRN \\
\hline CHEMBL1973868 & 809253 & 4.6 & 4.7203 & TRN \\
\hline CHEMBL1998228 & 809253 & 4.8 & 4.7514 & TRN \\
\hline CHEMBL1983715 & 809253 & 6.6 & 6.8992 & TRN \\
\hline CHEMBL2002992 & 809253 & 4.6 & 4.5731 & TRN \\
\hline CHEMBL1982700 & 809253 & 4.6 & 4.8512 & TRN \\
\hline CHEMBL10 & 809253 & 4.5 & 4.598 & TRN \\
\hline CHEMBL1980763 & 809253 & 5.6 & 4.9013 & TRN \\
\hline CHEMBL1977634 & 809253 & 4.6 & 4.7437 & TRN \\
\hline CHEMBL1977931 & 809253 & 4.5 & 4.5533 & TRN \\
\hline CHEMBL1969156 & 809253 & 4.2 & 4.4536 & TRN \\
\hline CHEMBL 2007479 & 809253 & 4.6 & 4.6962 & TRN \\
\hline CHEMBL1998953 & 809253 & 4.7 & 4.34 & TRN \\
\hline CHEMBL1971606 & 809253 & 4.6 & 4.631 & TRN \\
\hline CHEMBL1986851 & 809253 & 7.6 & 8.3496 & TRN \\
\hline CHEMBL1999120 & 809253 & 4.2 & 4.0875 & TRN \\
\hline CHEMBL1972220 & 809253 & 8.6 & 8.9984 & TRN \\
\hline CHEMBL1981215 & 809253 & 4.6 & 4.3394 & TRN \\
\hline CHEMBL1973720 & 809253 & 5.9 & 5.4067 & TRN \\
\hline CHEMBL1999414 & 809253 & 8.9 & 8.6356 & TRN \\
\hline CHEMBL1967336 & 809253 & 4.6 & 4.7639 & TRN \\
\hline CHEMBL2001923 & 809253 & 4.6 & 5.1443 & TRN \\
\hline CHEMBL1983070 & 809253 & 4.6 & 5.1103 & TRN \\
\hline CHEMBL2003514 & 809253 & 4.6 & 4.4396 & TRN \\
\hline
\end{tabular}




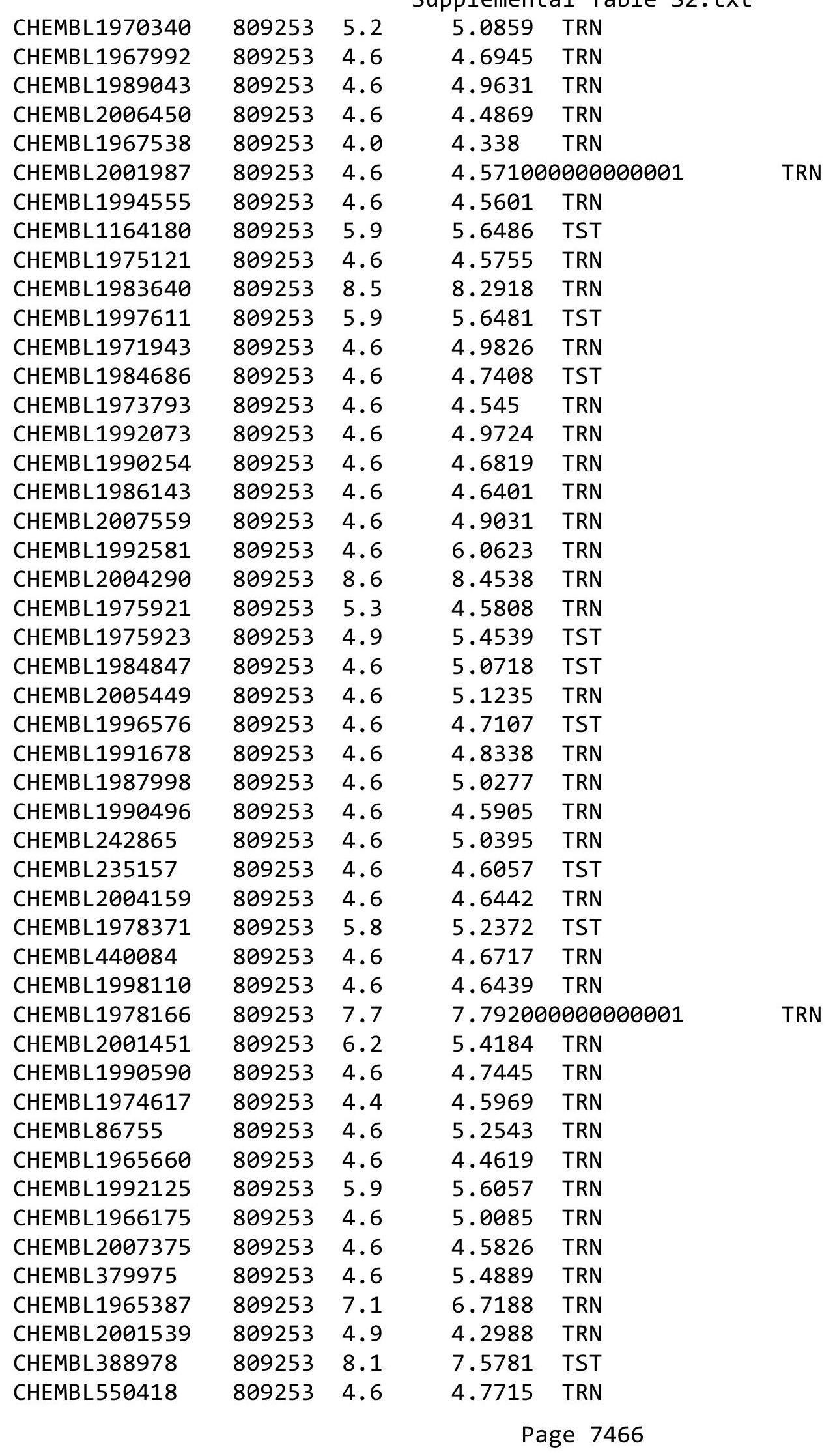




\begin{tabular}{|c|c|c|c|c|}
\hline & & & & al Ta \\
\hline CHEMBL398951 & 809253 & 5.9 & 5.1471 & TST \\
\hline CHEMBL 2004716 & 809253 & 7.9 & 7.9315 & TRN \\
\hline CHEMBL1971289 & 809253 & 4.6 & 4.8093 & TST \\
\hline CHEMBL1988437 & 809253 & 8.2 & 6.4452 & TRN \\
\hline CHEMBL1421720 & 809253 & 5.8 & 5.1674 & TRN \\
\hline CHEMBL1233887 & 809253 & 4.6 & 4.6543 & TRN \\
\hline CHEMBL1996649 & 809253 & 8.1 & 8.69 & TRN \\
\hline CHEMBL1986756 & 809253 & 4.6 & 4.2281 & TRN \\
\hline CHEMBL1949855 & 809253 & 6.0 & 4.6479 & TRN \\
\hline CHEMBL3109278 & 809253 & 5.1 & 6.3134 & TRN \\
\hline CHEMBL1727312 & 809253 & 4.4 & 4.0248 & TRN \\
\hline CHEMBL1990223 & 809253 & 6.7 & 4.9771 & TRN \\
\hline CHEMBL 2004438 & 809253 & 7.1 & 6.3525 & TRN \\
\hline CHEMBL1964382 & 809253 & 6.4 & 5.2709 & TST \\
\hline CHEMBL101311 & 809253 & 5.7 & 5.3734 & TRN \\
\hline CHEMBL191003 & 809253 & 4.7 & 4.9561 & TRN \\
\hline CHEMBL1973359 & 809253 & 6.7 & 6.1889 & TST \\
\hline CHEMBL1988581 & 809253 & 7.3 & 6.8418 & TST \\
\hline CHEMBL 2005699 & 809253 & 4.6 & 4.7283 & TRN \\
\hline CHEMBL 2006564 & 809253 & 6.8 & 6.1742 & TRN \\
\hline CHEMBL1979690 & 809253 & 6.7 & 6.6493 & TRN \\
\hline CHEMBL1991008 & 809253 & 4.3 & 4.6221 & TRN \\
\hline CHEMBL234085 & 809253 & 4.5 & 4.6505 & TRN \\
\hline CHEMBL1978167 & 809253 & 4.6 & 4.7392 & TRN \\
\hline CHEMBL418203 & 809253 & 4.6 & 4.9258 & TRN \\
\hline CHEMBL 225519 & 809253 & 4.6 & 4.4852 & TST \\
\hline CHEMBL1976376 & 809253 & 6.4 & 6.4203 & TRN \\
\hline CHEMBL1983575 & 809253 & 6.2 & 6.0217 & TRN \\
\hline CHEMBL1968868 & 809253 & 4.6 & 4.6018 & TRN \\
\hline CHEMBL1981047 & 809253 & 4.7 & 4.4614 & TRN \\
\hline CHEMBL1998470 & 809253 & 4.6 & 4.7233 & TRN \\
\hline CHEMBL1992354 & 809253 & 5.9 & 5.7675 & TRN \\
\hline CHEMBL1976196 & 809253 & 4.6 & 5.278 & TRN \\
\hline CHEMBL1997197 & 809253 & 4.6 & 4.9242 & TRN \\
\hline CHEMBL1975903 & 809253 & 4.6 & 4.7173 & TRN \\
\hline CHEMBL1983630 & 809253 & 4.4 & 4.5299 & TRN \\
\hline CHEMBL1522508 & 809253 & 4.3 & 3.7051 & TRN \\
\hline CHEMBL1988805 & 809253 & 4.6 & 4.6507 & TRN \\
\hline CHEMBL458997 & 809253 & 4.9 & 4.9782 & TRN \\
\hline CHEMBL1969942 & 809253 & 6.2 & 5.7098 & TRN \\
\hline CHEMBL1982660 & 809253 & 4.6 & 4.3705 & TRN \\
\hline CHEMBL1978567 & 809253 & 4.6 & 4.6439 & TRN \\
\hline CHEMBL1995765 & 809253 & 4.9 & 4.7827 & TRN \\
\hline CHEMBL1984760 & 809253 & 4.6 & 4.8781 & TRN \\
\hline CHEMBL424872 & 809253 & 4.5 & 4.7597 & TST \\
\hline CHEMBL 360847 & 809253 & 4.6 & 4.5037 & TRN \\
\hline CHEMBL1995811 & 809253 & 4.6 & 4.6342 & TRN \\
\hline CHEMBL1983111 & 809253 & 7.0 & 6.8702 & TRN \\
\hline
\end{tabular}




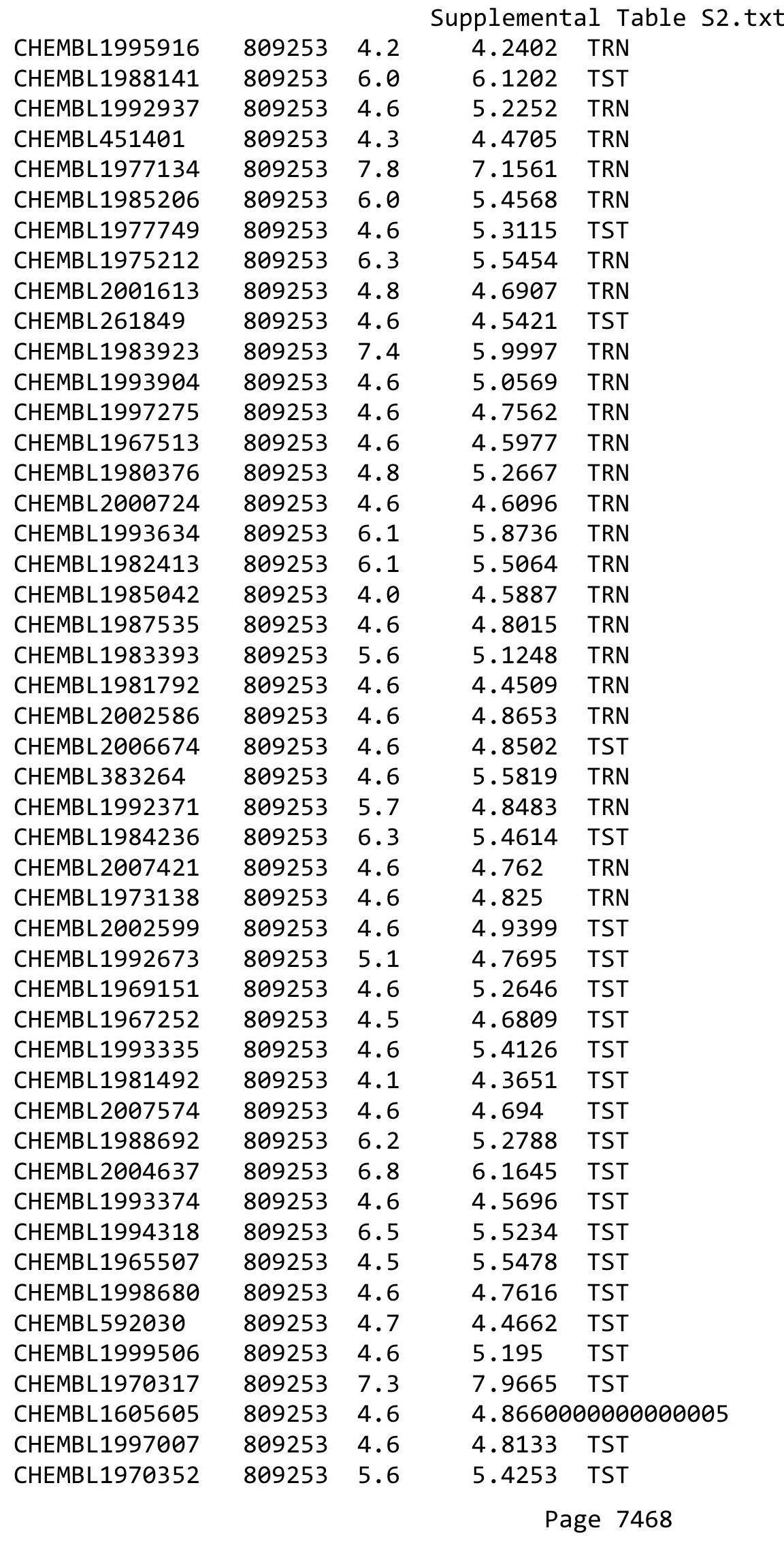




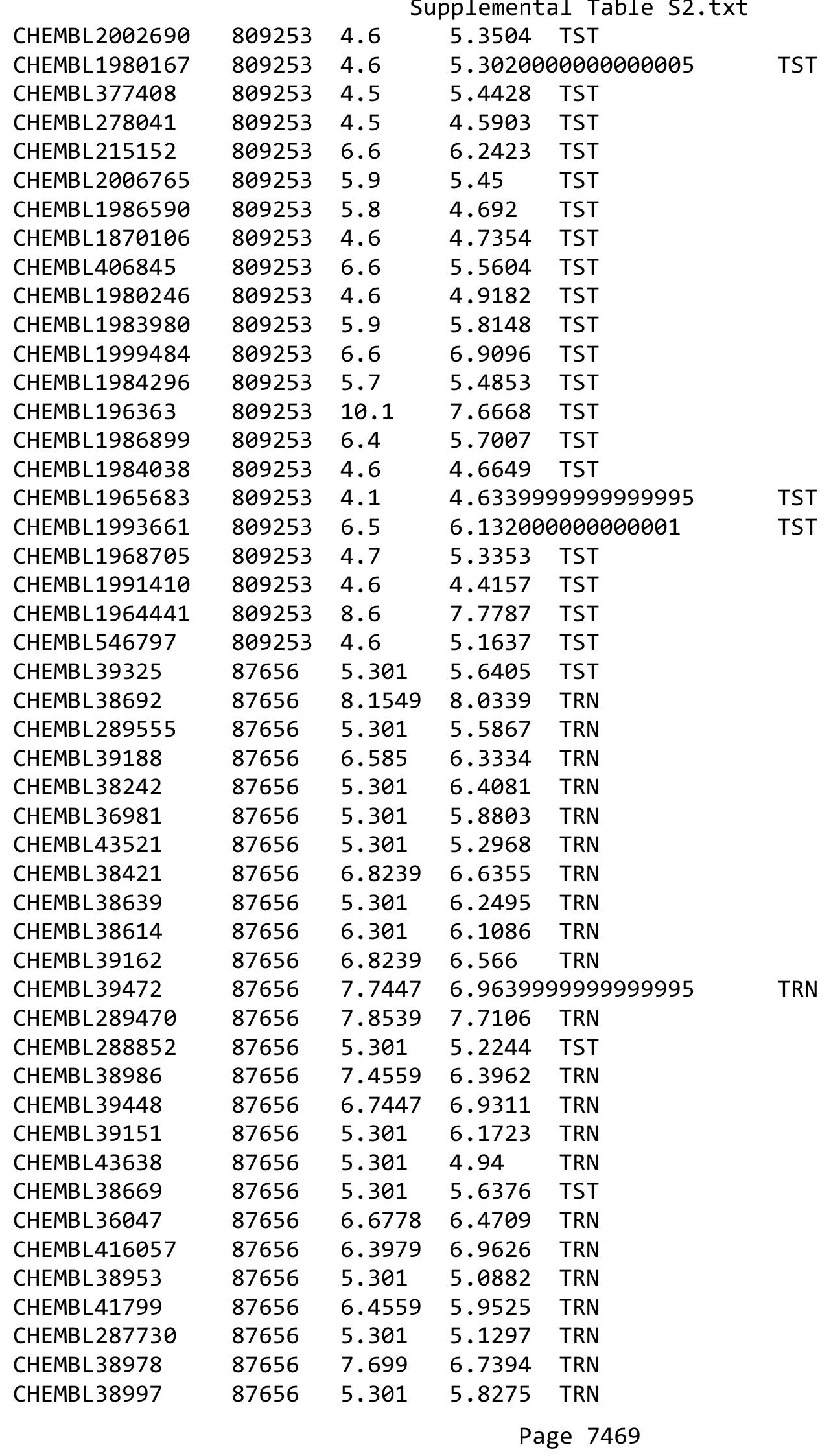




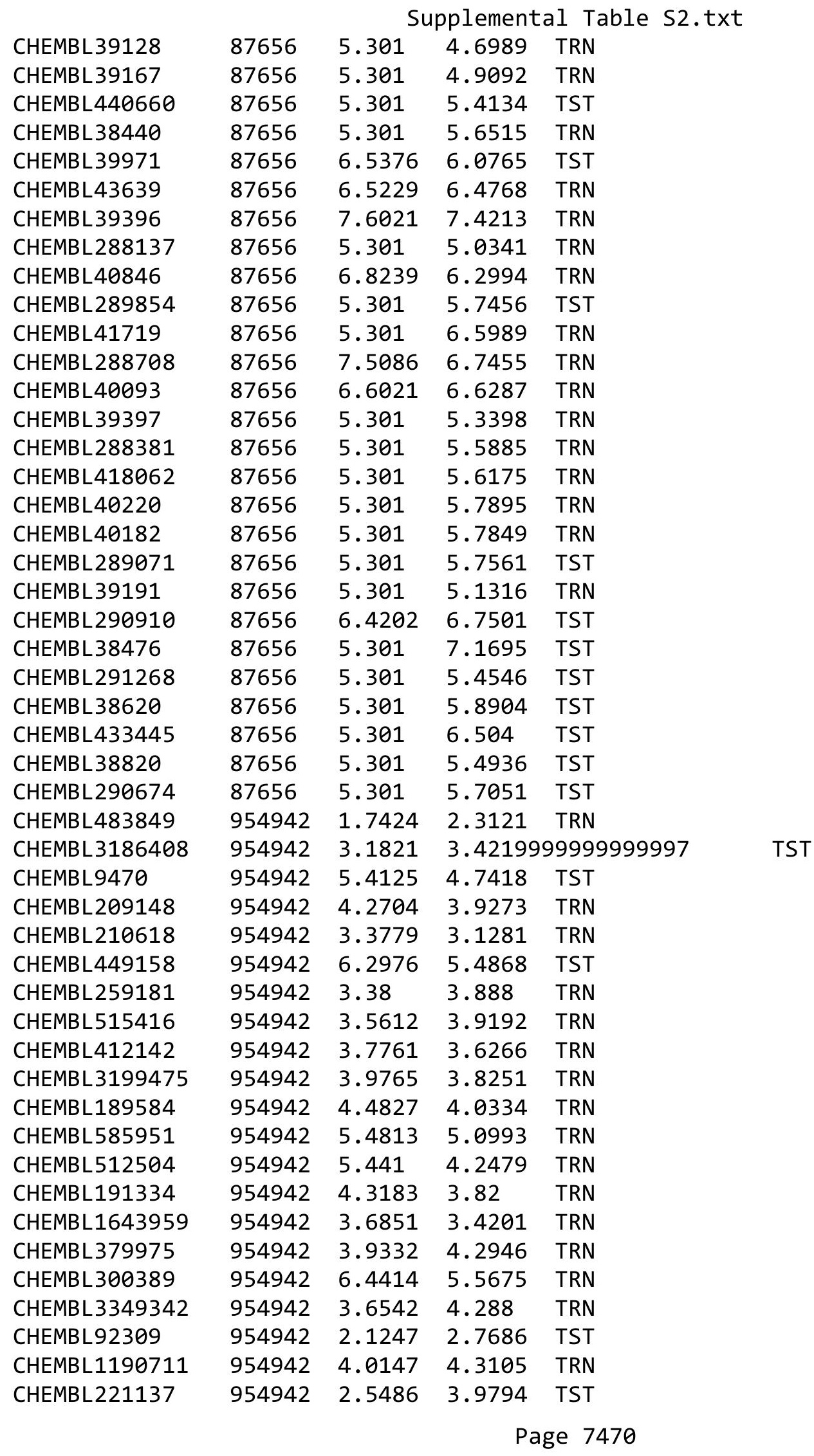


Supplemental Table S2.txt

\begin{tabular}{|c|c|c|c|c|c|}
\hline CHEMBL1404918 & 954942 & 3.4463 & 2.8011 & TRN & \\
\hline CHEMBL1230020 & 954942 & 3.9056 & 3.6089 & TRN & \\
\hline CHEMBL 258844 & 954942 & 3.8262 & 3.8416 & TRN & \\
\hline CHEMBL1242367 & 954942 & 3.5077 & 3.7067 & TRN & \\
\hline CHEMBL 202721 & 954942 & 4.4778 & 4.2429 & TRN & \\
\hline CHEMBL1970879 & 954942 & 4.5727 & 4.0453 & TRN & \\
\hline CHEMBL392695 & 954942 & 3.9773 & 4.2157 & TRN & \\
\hline CHEMBL 220241 & 954942 & 2.8756 & 4.0876 & TRN & \\
\hline CHEMBL 3392440 & 954942 & 3.7084 & 3.5109 & TRN & \\
\hline CHEMBL1673039 & 954942 & 3.3578 & 4.1346 & TRN & \\
\hline CHEMBL573107 & 954942 & 4.5984 & 4.354 & TRN & \\
\hline CHEMBL 2363137 & 954942 & 3.6046 & 4.053 & TRN & \\
\hline CHEMBL180127 & 954942 & 2.7253 & 3.6601 & TRN & \\
\hline CHEMBL483847 & 954942 & 3.6544 & 3.7242 & TRN & \\
\hline CHEMBL 240954 & 954942 & 3.3942 & 3.4126 & TST & \\
\hline CHEMBL1590308 & 954942 & 2.9896 & 3.185 & TST & \\
\hline CHEMBL472940 & 954942 & 2.4491 & 3.2522 & TRN & \\
\hline CHEMBL558642 & 954942 & 2.9118 & 3.6574 & TRN & \\
\hline CHEMBL1516890 & 954942 & 4.1342 & 3.6213 & TRN & \\
\hline CHEMBL102714 & 954942 & 3.5877 & 3.2917 & TRN & \\
\hline CHEMBL379300 & 954942 & 5.516 & \multicolumn{2}{|c|}{5.281000000000001} & TRN \\
\hline CHEMBL393929 & 954942 & 3.7662 & 3.5309 & TRN & \\
\hline CHEMBL 2005886 & 954942 & 4.9431 & 4.6016 & TRN & \\
\hline CHEMBL65 & 954942 & 5.5186 & 6.3176 & TRN & \\
\hline CHEMBL1357247 & 954942 & 3.2461 & 2.9023 & TRN & \\
\hline CHEMBL1788116 & 954942 & 3.5131 & 3.8214 & TRN & \\
\hline CHEMBL373751 & 954942 & 3.168 & 3.3476 & TRN & \\
\hline CHEMBL1909414 & 954942 & 4.4331 & 3.6418 & TRN & \\
\hline CHEMBL 213100 & 954942 & 4.7833 & 4.2537 & TST & \\
\hline CHEMBL 2144069 & 954942 & 4.7304 & 4.1927 & TST & \\
\hline CHEMBL192566 & 954942 & 4.7936 & 6.3124 & TST & \\
\hline CHEMBL1256459 & 954942 & 5.2463 & 5.606 & TST & \\
\hline CHEMBL509032 & 954942 & 4.0683 & 4.6974 & TST & \\
\hline CHEMBL135561 & 954942 & 4.4704 & 3.8358 & TST & \\
\hline CHEMBL514499 & 954942 & 5.3099 & \multicolumn{2}{|c|}{5.4879999999999995} & TST \\
\hline CHEMBL3965728 & 1641196 & 8.5229 & 8.6142 & TST & \\
\hline CHEMBL 3960541 & 1641196 & 8.301 & 8.5512 & TRN & \\
\hline CHEMBL 3976445 & 1641196 & 7.6383 & 7.8092 & TRN & \\
\hline CHEMBL3946614 & 1641196 & 8.1549 & 8.3731 & TST & \\
\hline CHEMBL 3966684 & 1641196 & 8.301 & 8.6986 & TST & \\
\hline CHEMBL3972567 & 1641196 & 8.3979 & 9.1674 & TST & \\
\hline CHEMBL 3905700 & 1641196 & 7.8239 & 7.9541 & TRN & \\
\hline CHEMBL 3899391 & 1641196 & 8.301 & 8.2149 & TRN & \\
\hline CHEMBL3695569 & 1641196 & 8.301 & 7.6968 & TST & \\
\hline CHEMBL3909641 & 1641196 & 8.0969 & 8.2606 & TRN & \\
\hline CHEMBL3936603 & 1641196 & 10.0 & 9.4672 & TRN & \\
\hline CHEMBL 3975927 & 1641196 & 6.9469 & 8.544 & TST & \\
\hline CHEMBL3973916 & 1641196 & 8.0 & 8.1548 & TRN & \\
\hline
\end{tabular}


Supplemental Table S2.txt

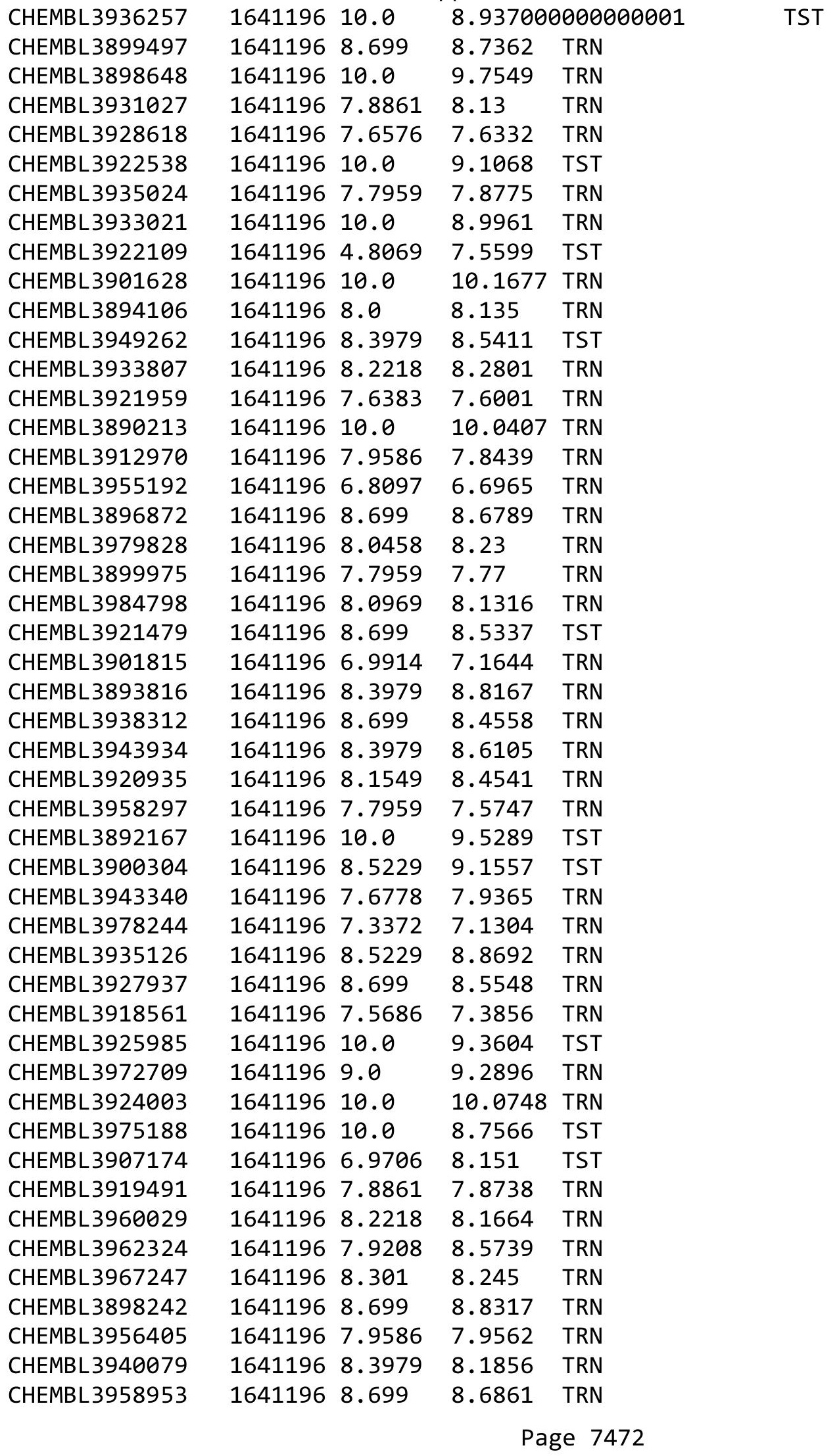


Supplemental Table S2.txt

\begin{tabular}{|c|c|c|c|c|}
\hline - & & & & \\
\hline HEMBL3907109 & 641196 & 7.9208 & 7.803 & \\
\hline & & 8.0 & & \\
\hline EMBL & 196 & 8.5229 & 9817 & \\
\hline JEMBL3921640 & 541196 & 8.699 & 339 & \\
\hline AEMBL3926692 & 641196 & 0969 & 1175 & \\
\hline HEMBL 389 & 196 & .6778 & 8447 & \\
\hline 5 & & 10.0 & 434 & \\
\hline HEMBL395 & 196 & 2218 & 9861 & \\
\hline AEMBL3915981 & 196 & 10.0 & 9712 & \\
\hline HEMBL3958095 & 196 & 6383 & 619 & \\
\hline AEMBL3986904 & 96 & 10.0 & .4542 & \\
\hline AEMBL3S & & 539 & 3296 & זו \\
\hline AEMBL3S & 196 & 7852 & 7066 & \\
\hline HEMBL396 & 196 & 10.0 & 3184 & \\
\hline HEMBL3958914 & & 7447 & 4021 & \\
\hline AEMBL38 & 196 & 229 & 844 & \\
\hline HEMBL3 & & & 382 & RN \\
\hline HEMBL 3 & & 3539 & 9348 & \\
\hline AEMBL397 & 96 & 5229 & 1792 & $\mathrm{RN}$ \\
\hline HEM L 39 & 96 & 0 & 024 & RN \\
\hline AEMBL3. & & 3539 & 813 & RN \\
\hline AEM & & & 434 & \\
\hline 42 & & 7696 & 844 & \\
\hline AEMBL3S & 96 & 212 & 34 & RIV \\
\hline 3 & & 29 & 56 & RN \\
\hline AEN & & $\partial 1$ & 01 & RN \\
\hline 8 & & & 03 & \\
\hline AEMBL3 & & 208 & 353 & TST \\
\hline AEMBL395 & 96 & 01 & 22 & SI \\
\hline AEMBL 398 & & 447 & 11 & ST \\
\hline $\mathrm{FM}$ & & 78 & & \\
\hline & & 55 & & ST \\
\hline HEMBL 2041 & & & & RN \\
\hline AEMBL 2041 & & 763 & 315 & RN \\
\hline AEMBL601 & & 55 & 177 & ST \\
\hline 5 & & 62 & $\partial 5$ & \\
\hline HEMBL2041808 & & & 591 & ST \\
\hline HEMBL601065 & & 2.9469 & 6903 & TRN \\
\hline fEMBL5967 & & & 266 & RN \\
\hline HEMBL 204 & & 647 & 385 & RA $>$ \\
\hline HEMBL2041 & & & & SI \\
\hline HEMBL2041814 & & 799 & 2145 & RN \\
\hline HEMBL601068 & 22 & 4.8539 & 8028 & RN \\
\hline$M P I 6017$ & & & 4927 & \\
\hline HEMBL 204 & & 605 & 899 & RN \\
\hline HEMBL 2041811 & & 4.3382 & 4.258 & N \\
\hline CHEMBL 2041806 & 823822 & 6.0159 & 6.285 & ГRN \\
\hline
\end{tabular}


Supplemental Table S2.txt

\begin{tabular}{|c|c|c|c|c|c|}
\hline CHEMBL 2041970 & 823822 & 5.1238 & 5.3145 & TRN & \\
\hline CHEMBL 2041810 & 823822 & 4.2916 & 4.2362 & TRN & \\
\hline CHEMBL 2041844 & 823822 & 5.5834 & 5.2105 & TRN & \\
\hline CHEMBL 2041827 & 823822 & 4.6576 & 4.8398 & TRN & \\
\hline CHEMBL 2041843 & 823822 & 6.58 & 6.2547 & TRN & \\
\hline CHEMBL 2041804 & 823822 & 2.8477 & 3.9265 & TRN & \\
\hline CHEMBL590266 & 823822 & 6.0 & 5.7713 & TRN & \\
\hline CHEMBL 2041971 & 823822 & 5.0031 & 5.2924 & TRN & \\
\hline CHEMBL 2041618 & 823822 & 5.9666 & 5.843 & TRN & \\
\hline CHEMBL 2041623 & 823822 & 5.1427 & 4.7986 & TRN & \\
\hline CHEMBL 2041821 & 823822 & 6.1904 & 6.0741 & TRN & \\
\hline CHEMBL 2041828 & 823822 & 4.6615 & 5.2265 & TST & \\
\hline CHEMBL 2041816 & 823822 & 2.5952 & 2.3647 & TRN & \\
\hline CHEMBL590504 & 823822 & 3.9359 & 3.4859 & TRN & \\
\hline CHEMBL 2041840 & 823822 & 6.0 & 5.1527 & TRN & \\
\hline CHEMBL 2041839 & 823822 & 5.4622 & 5.6492 & TRN & \\
\hline CHEMBL 2041817 & 823822 & 5.4012 & 5.1074 & TRN & \\
\hline CHEMBL 2041842 & 823822 & 5.8697 & 5.4386 & TRN & \\
\hline CHEMBL 2041807 & 823822 & 5.9547 & 5.7713 & TRN & \\
\hline CHEMBL 2041837 & 823822 & 5.3098 & 5.0167 & TRN & \\
\hline CHEMBL 2041829 & 823822 & 6.0273 & 5.8569 & TRN & \\
\hline CHEMBL 2041826 & 823822 & 5.6308 & 6.0564 & TRN & \\
\hline CHEMBL539632 & 823822 & 5.0605 & 5.3139 & TRN & \\
\hline CHEMBL 2041846 & 823822 & 4.6021 & 4.2685 & TRN & \\
\hline CHEMBL601066 & 823822 & 4.1349 & 4.4109 & TRN & \\
\hline CHEMBL605979 & 823822 & 2.8861 & 3.6185 & TRN & \\
\hline CHEMBL 2041805 & 823822 & 5.9872 & 6.2068 & TRN & \\
\hline CHEMBL 2041831 & 823822 & 4.7799 & 4.7659 & TST & \\
\hline CHEMBL 2041619 & 823822 & 5.0458 & 5.2429 & TRN & \\
\hline CHEMBL601067 & 823822 & 4.8356 & 4.6046 & TRN & \\
\hline CHEMBL 2041617 & 823822 & 5.6326 & 5.8062 & TRN & \\
\hline CHEMBL 2041795 & 823822 & 5.3497 & 5.4844 & TRN & \\
\hline CHEMBL 2041620 & 823822 & 5.1938 & 5.1235 & TRN & \\
\hline CHEMBL 2041796 & 823822 & 4.1818 & 4.3499 & TST & \\
\hline CHEMBL 2041802 & 823822 & 4.3134 & 3.9544 & TRN & \\
\hline CHEMBL 2041812 & 823822 & 3.9931 & 3.7134 & TRN & \\
\hline CHEMBL596744 & 823822 & 2.8268 & 2.5026 & TRN & \\
\hline CHEMBL 2041622 & 823822 & 4.1113 & 4.3613 & TRN & \\
\hline CHEMBL 2041815 & 823822 & 5.1124 & 5.20200 & 3000000001 & TRN \\
\hline CHEMBL 2041798 & 823822 & 5.4634 & 4.5541 & TRN & \\
\hline CHEMBL590385 & 823822 & 4.6402 & 4.4626 & TST & \\
\hline CHEMBL 2041809 & 823822 & 2.9547 & 3.2178 & TRN & \\
\hline CHEMBL601707 & 823822 & 2.9355 & 3.2885 & TRN & \\
\hline CHEMBL598801 & 823822 & 2.8861 & 3.0097 & TRN & \\
\hline CHEMBL601069 & 823822 & 4.0655 & 3.83 & TST & \\
\hline CHEMBL 2041799 & 823822 & 5.5376 & 5.0051 & TST & \\
\hline CHEMBL 2041801 & 823822 & 4.2255 & 4.173 & TRN & \\
\hline CHEMBL605561 & 823822 & 2.85699 & 9999999 & 2.9706 & TRN \\
\hline
\end{tabular}


Supplemental Table S2.txt

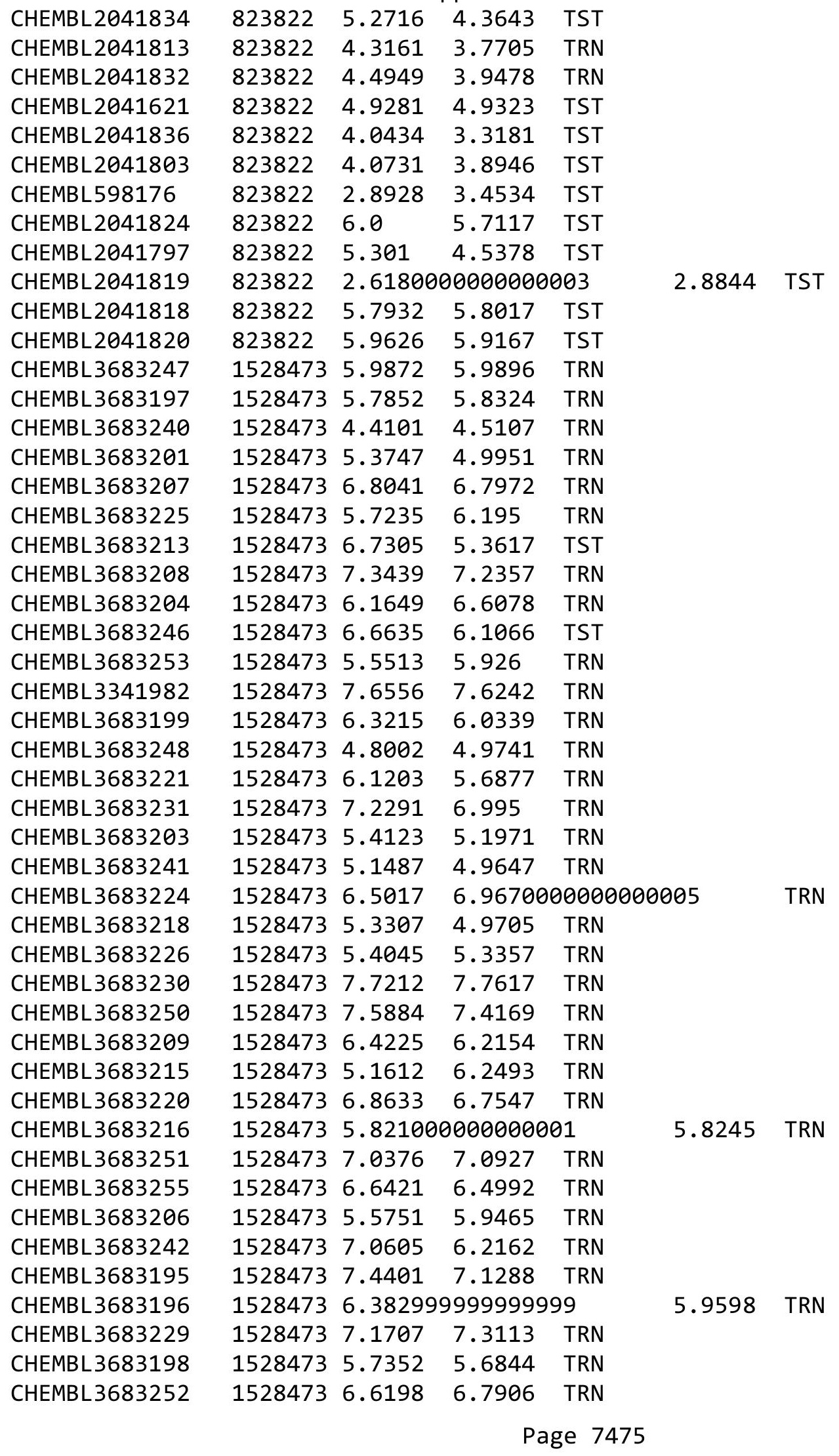


Supplemental Table S2.txt

\begin{tabular}{|c|c|c|c|c|c|c|}
\hline CHEMBL 3683234 & 1528473 & 5.1192 & 5.9409 & TST & & \\
\hline CHEMBL 3683239 & 1528473 & 5.025 & 6.1568 & TST & & \\
\hline CHEMBL 3683217 & 1528473 & 6.9031 & 6.2871 & TRN & & \\
\hline CHEMBL 3683233 & 1528473 & 4.8959 & 5.3294 & TRN & & \\
\hline CHEMBL 3683228 & 1528473 & 6.8697 & 7.1375 & TRN & & \\
\hline CHEMBL 3683238 & 1528473 & 4.8271 & 5.5406 & TRN & & \\
\hline CHEMBL 3683232 & 1528473 & 5.3872 & 5.9802 & TST & & \\
\hline CHEMBL 3683219 & 1528473 & \multicolumn{3}{|c|}{7.202000000000001} & 6.5984 & TRN \\
\hline CHEMBL 3683205 & 1528473 & 7.1062 & 6.9889 & TRN & & \\
\hline CHEMBL 3683235 & 1528473 & 4.7196 & 5.1238 & TRN & & \\
\hline CHEMBL 3683211 & 1528473 & 5.7447 & 6.6923 & TRN & & \\
\hline CHEMBL 3683212 & 1528473 & 7.0942 & 6.7394 & TRN & & \\
\hline CHEMBL 3683227 & 1528473 & 6.767 & 6.3123 & TRN & & \\
\hline CHEMBL 3683244 & 1528473 & 6.8508 & 6.6892 & TST & & \\
\hline CHEMBL 3683237 & 1528473 & 4.9792 & 6.1567 & TST & & \\
\hline CHEMBL 3683254 & 1528473 & 6.4034 & 6.2037 & TST & & \\
\hline CHEMBL 3683222 & 1528473 & 6.4547 & 7.1704 & TST & & \\
\hline CHEMBL 3683223 & 1528473 & 7.1904 & 7.3359 & TST & & \\
\hline CHEMBL 3683200 & 1528473 & \multicolumn{3}{|c|}{5.2620000000000005} & 5.2258 & TST \\
\hline CHEMBL 3683214 & 1528473 & 5.5719 & 4.9449 & TST & & \\
\hline CHEMBL 3683202 & 1528473 & \multicolumn{3}{|c|}{5.617999999999999} & 6.0067 & TST \\
\hline CHEMBL 3683243 & 1528473 & 6.0915 & 5.9719 & TST & & \\
\hline CHEMBL 3683210 & 1528473 & 5.2343 & 6.5914 & TST & & \\
\hline CHEMBL 2001398 & 809140 & 5.6 & 4.9825 & TRN & & \\
\hline CHEMBL1978271 & 809140 & 4.5 & 4.7428 & TRN & & \\
\hline CHEMBL 2007266 & 809140 & 4.5 & 4.3127 & TRN & & \\
\hline CHEMBL202721 & 809140 & 6.8 & 5.9874 & TRN & & \\
\hline CHEMBL 2000568 & 809140 & 4.5 & 4.5267 & TRN & & \\
\hline CHEMBL1994308 & 809140 & 4.5 & 4.6786 & TRN & & \\
\hline CHEMBL 2007097 & 809140 & 4.3 & 4.5286 & TRN & & \\
\hline CHEMBL1825138 & 809140 & 4.5 & 4.8959 & TST & & \\
\hline CHEMBL1974328 & 809140 & 6.3 & 6.2531 & TRN & & \\
\hline CHEMBL509032 & 809140 & 6.1 & 6.1855 & TRN & & \\
\hline CHEMBL388311 & 809140 & 6.5 & 7.1782 & TRN & & \\
\hline CHEMBL1964948 & 809140 & 4.5 & 4.5023 & TRN & & \\
\hline CHEMBL 2002202 & 809140 & 4.1 & 4.2458 & TRN & & \\
\hline CHEMBL 1973013 & 809140 & 4.5 & 4.8871 & TRN & & \\
\hline CHEMBL 1987430 & 809140 & 4.5 & 4.5142 & TRN & & \\
\hline CHEMBL1993413 & 809140 & 4.5 & 4.5256 & TRN & & \\
\hline CHEMBL 205415 & 809140 & 4.5 & 4.9054 & TRN & & \\
\hline CHEMBL1975927 & 809140 & 6.0 & 5.5934 & TRN & & \\
\hline CHEMBL 1986943 & 809140 & 7.5 & 7.657 & TRN & & \\
\hline CHEMBL289959 & 809140 & 4.2 & 5.3434 & TRN & & \\
\hline CHEMBL1997119 & 809140 & 4.5 & 4.3488 & TRN & & \\
\hline CHEMBL1977138 & 809140 & 5.7 & 5.11 & TRN & & \\
\hline CHEMBL 2000879 & 809140 & 4.4 & 4.6085 & TST & & \\
\hline CHEMBL 1978448 & 809140 & 4.5 & 4.4894 & TRN & & \\
\hline CHEMBL1980329 & 809140 & 5.9 & 5.4743 & TRN & & \\
\hline
\end{tabular}




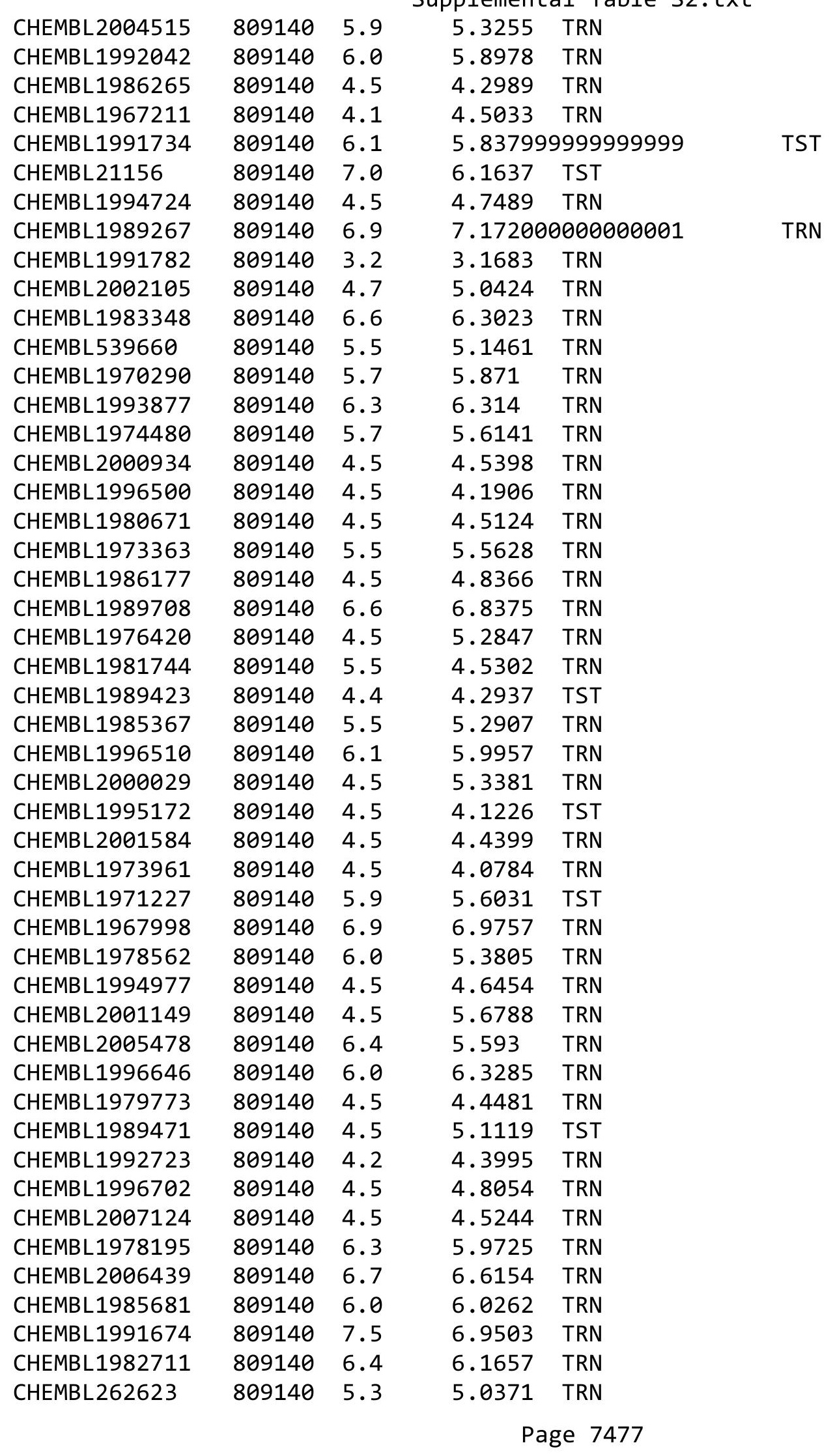




\begin{tabular}{|c|c|c|c|c|}
\hline & & & lement & al Ta \\
\hline CHEMBL1984842 & 809140 & 4.5 & 4.1992 & TRN \\
\hline CHEMBL 2004118 & 809140 & 5.6 & 5.8015 & TRN \\
\hline CHEMBL1996345 & 809140 & 4.5 & 4.8775 & TRN \\
\hline CHEMBL 2004025 & 809140 & 6.1 & 5.9584 & TRN \\
\hline CHEMBL1996048 & 809140 & 6.1 & 5.8198 & TRN \\
\hline CHEMBL50894 & 809140 & 4.5 & 5.2818 & TRN \\
\hline CHEMBL1995211 & 809140 & 6.0 & 6.1395 & TRN \\
\hline CHEMBL1965033 & 809140 & 4.5 & 4.3919 & TRN \\
\hline CHEMBL461876 & 809140 & 4.5 & 4.373 & TRN \\
\hline CHEMBL1982753 & 809140 & 6.0 & 5.8964 & TRN \\
\hline CHEMBL2006299 & 809140 & 4.5 & 4.5113 & TRN \\
\hline CHEMBL1972346 & 809140 & 4.5 & 5.0743 & TST \\
\hline CHEMBL1971519 & 809140 & 6.6 & 5.7671 & TRN \\
\hline CHEMBL1997335 & 809140 & 4.5 & 4.6241 & TRN \\
\hline CHEMBL1965169 & 809140 & 4.5 & 4.6735 & TRN \\
\hline CHEMBL1081312 & 809140 & 6.4 & 6.6309 & TRN \\
\hline CHEMBL1965170 & 809140 & 6.0 & 6.0886 & TRN \\
\hline CHEMBL1994808 & 809140 & 4.1 & 4.468 & TRN \\
\hline CHEMBL 2005792 & 809140 & 4.5 & 4.1043 & TRN \\
\hline CHEMBL1972355 & 809140 & 6.2 & 6.3446 & TRN \\
\hline CHEMBL1997892 & 809140 & 4.5 & 4.8685 & TRN \\
\hline CHEMBL 2001641 & 809140 & 4.7 & 4.5545 & TRN \\
\hline CHEMBL1997193 & 809140 & 4.5 & 5.9016 & TST \\
\hline CHEMBL1964902 & 809140 & 4.5 & 4.3519 & TRN \\
\hline CHEMBL1973868 & 809140 & 4.5 & 4.4976 & TRN \\
\hline CHEMBL1972462 & 809140 & 4.5 & 4.3292 & TRN \\
\hline CHEMBL1983715 & 809140 & 6.4 & 6.1993 & TRN \\
\hline CHEMBL1984500 & 809140 & 3.2 & 3.2205 & TRN \\
\hline CHEMBL 2002992 & 809140 & 4.6 & 4.9886 & TRN \\
\hline CHEMBL1982700 & 809140 & 4.5 & 4.3614 & TRN \\
\hline CHEMBL10 & 809140 & 4.5 & 4.4695 & TRN \\
\hline CHEMBL1980763 & 809140 & 5.7 & 5.9782 & TRN \\
\hline CHEMBL1977634 & 809140 & 4.5 & 4.3785 & TRN \\
\hline CHEMBL1977931 & 809140 & 4.1 & 5.03 & TRN \\
\hline CHEMBL1969156 & 809140 & 5.3 & 4.9787 & TRN \\
\hline CHEMBL 2007479 & 809140 & 4.5 & 4.4499 & TRN \\
\hline CHEMBL1998953 & 809140 & 6.5 & 5.9135 & TRN \\
\hline CHEMBL1971606 & 809140 & 4.5 & 4.5296 & TRN \\
\hline CHEMBL1999120 & 809140 & 4.0 & 4.6778 & TST \\
\hline CHEMBL1972220 & 809140 & 7.3 & 7.3452 & TRN \\
\hline CHEMBL1972583 & 809140 & 4.3 & 4.7967 & TRN \\
\hline CHEMBL1981215 & 809140 & 4.5 & 4.5257 & TRN \\
\hline CHEMBL 2003785 & 809140 & 5.0 & 4.8926 & TRN \\
\hline CHEMBL1973720 & 809140 & 7.7 & 7.8053 & TRN \\
\hline CHEMBL1999414 & 809140 & 6.0 & 6.2519 & TRN \\
\hline CHEMBL1967336 & 809140 & 4.5 & 4.5056 & TRN \\
\hline CHEMBL2001923 & 809140 & 4.5 & 4.2996 & TRN \\
\hline CHEMBL1994056 & 809140 & 4.1 & 4.5086 & TST \\
\hline
\end{tabular}




\begin{tabular}{|c|c|c|c|c|}
\hline & & & & al Ta \\
\hline CHEMBL1983070 & 809140 & 4.5 & 4.5995 & TRN \\
\hline CHEMBL 2003514 & 809140 & 4.5 & 4.7126 & TRN \\
\hline CHEMBL1970340 & 809140 & 5.8 & 5.2494 & TRN \\
\hline CHEMBL1967992 & 809140 & 4.5 & 4.5529 & TRN \\
\hline CHEMBL1989043 & 809140 & 4.5 & 4.3563 & TRN \\
\hline CHEMBL 2006450 & 809140 & 4.5 & 4.4504 & TRN \\
\hline CHEMBL1967538 & 809140 & 4.0 & 4.6649 & TRN \\
\hline CHEMBL 2001987 & 809140 & 4.5 & 4.5277 & TRN \\
\hline CHEMBL1994555 & 809140 & 4.5 & 4.8045 & TRN \\
\hline CHEMBL1164180 & 809140 & 4.5 & 4.371 & TST \\
\hline CHEMBL1975121 & 809140 & 4.5 & 4.546 & TRN \\
\hline CHEMBL1983640 & 809140 & 4.5 & 5.0268 & TRN \\
\hline CHEMBL1997611 & 809140 & 4.5 & 4.2542 & TRN \\
\hline CHEMBL1971943 & 809140 & 4.6 & 4.9651 & TRN \\
\hline CHEMBL 2002723 & 809140 & 5.6 & 5.3873 & TRN \\
\hline CHEMBL1984686 & 809140 & 4.5 & 4.5109 & TST \\
\hline CHEMBL1973793 & 809140 & 4.5 & 4.5239 & TRN \\
\hline CHEMBL1992073 & 809140 & 4.5 & 4.6102 & TRN \\
\hline CHEMBL1990254 & 809140 & 4.5 & 4.6231 & TRN \\
\hline CHEMBL1986143 & 809140 & 4.5 & 4.5808 & TRN \\
\hline CHEMBL1972934 & 809140 & 4.8 & 4.3511 & TRN \\
\hline CHEMBL 2007559 & 809140 & 4.5 & 5.2295 & TRN \\
\hline CHEMBL1992581 & 809140 & 6.3 & 5.5324 & TRN \\
\hline CHEMBL 2004290 & 809140 & 5.9 & 6.1092 & TRN \\
\hline CHEMBL1975921 & 809140 & 4.3 & 4.2479 & TRN \\
\hline CHEMBL1983573 & 809140 & 4.9 & 4.7453 & TRN \\
\hline CHEMBL 2004033 & 809140 & 5.6 & 5.4042 & TST \\
\hline CHEMBL1975923 & 809140 & 4.8 & 5.3655 & TST \\
\hline CHEMBL1984847 & 809140 & 4.5 & 4.8409 & TST \\
\hline CHEMBL 2005449 & 809140 & 4.5 & 4.5766 & TRN \\
\hline CHEMBL1996576 & 809140 & 4.5 & 4.8037 & TST \\
\hline CHEMBL1991678 & 809140 & 4.5 & 4.176 & TRN \\
\hline CHEMBL1987998 & 809140 & 4.5 & 4.2393 & TRN \\
\hline CHEMBL1971534 & 809140 & 5.0 & 5.1557 & TRN \\
\hline CHEMBL1990496 & 809140 & 4.5 & 4.2741 & TRN \\
\hline CHEMBL242865 & 809140 & 5.9 & 5.5579 & TRN \\
\hline CHEMBL 235157 & 809140 & 4.5 & 4.5865 & TST \\
\hline CHEMBL2004159 & 809140 & 4.5 & 4.5057 & TRN \\
\hline CHEMBL1978371 & 809140 & 6.0 & 5.6369 & TST \\
\hline CHEMBL440084 & 809140 & 4.5 & 4.7075 & TRN \\
\hline CHEMBL1998110 & 809140 & 4.5 & 4.4386 & TRN \\
\hline CHEMBL1978166 & 809140 & 6.3 & 6.2121 & TRN \\
\hline CHEMBL1990590 & 809140 & 4.5 & 4.4052 & TRN \\
\hline CHEMBL1977814 & 809140 & 5.5 & 4.7324 & TRN \\
\hline CHEMBL1974617 & 809140 & 5.0 & 4.669 & TRN \\
\hline CHEMBL1965660 & 809140 & 5.7 & 5.2685 & TRN \\
\hline CHEMBL1992125 & 809140 & 5.9 & 6.0281 & TRN \\
\hline CHEMBL1966175 & 809140 & 4.5 & 4.7257 & TRN \\
\hline
\end{tabular}




\begin{tabular}{|c|c|c|c|c|}
\hline & & & & $a \perp 1$ \\
\hline CHEMBL2007375 & 809140 & 4.5 & 5.1415 & TRN \\
\hline CHEMBL379975 & 809140 & 7.6 & 6.9913 & TST \\
\hline CHEMBL1973016 & 809140 & 4.5 & 4.6576 & TRN \\
\hline CHEMBL1965387 & 809140 & 4.5 & 4.5073 & TRN \\
\hline CHEMBL2001539 & 809140 & 4.5 & 4.707 & TST \\
\hline CHEMBL388978 & 809140 & 8.2 & 7.3437 & TST \\
\hline CHEMBL1997041 & 809140 & 5.9 & 5.53100 & 0000000001 \\
\hline CHEMBL550418 & 809140 & 4.5 & 4.5006 & TRN \\
\hline CHEMBL398951 & 809140 & 4.5 & 4.6883 & TST \\
\hline CHEMBL1971289 & 809140 & 4.5 & 4.5192 & TST \\
\hline CHEMBL1988437 & 809140 & 4.6 & 5.3675 & TST \\
\hline CHEMBL 2007603 & 809140 & 4.5 & 4.6826 & TRN \\
\hline CHEMBL1421720 & 809140 & 5.7 & 5.7469 & TRN \\
\hline CHEMBL1233887 & 809140 & 4.5 & 4.8218 & TRN \\
\hline CHEMBL1968130 & 809140 & 4.1 & 4.7969 & TRN \\
\hline CHEMBL 2003689 & 809140 & 4.5 & 4.338 & TRN \\
\hline CHEMBL1996649 & 809140 & 6.0 & 6.2616 & TRN \\
\hline CHEMBL1986756 & 809140 & 4.5 & 4.6731 & TRN \\
\hline CHEMBL1949855 & 809140 & 4.3 & 4.4301 & TRN \\
\hline CHEMBL 3109278 & 809140 & 7.4 & 6.7647 & TRN \\
\hline CHEMBL1990223 & 809140 & 4.5 & 4.2635 & TRN \\
\hline CHEMBL 2004438 & 809140 & 4.5 & 4.7621 & TRN \\
\hline CHEMBL1964382 & 809140 & 4.5 & 5.0557 & TST \\
\hline CHEMBL101311 & 809140 & 4.5 & 5.3249 & TRN \\
\hline CHEMBL191003 & 809140 & 5.7 & 5.6219 & TRN \\
\hline CHEMBL1973359 & 809140 & 5.8 & 6.0329 & TST \\
\hline CHEMBL1988581 & 809140 & 7.0 & 6.8063 & TST \\
\hline CHEMBL2005699 & 809140 & 4.5 & 4.348 & TRN \\
\hline CHEMBL 2006564 & 809140 & 7.1 & 6.994 & TRN \\
\hline CHEMBL1979690 & 809140 & 6.9 & 6.8842 & TRN \\
\hline CHEMBL 234085 & 809140 & 4.5 & 4.6865 & TRN \\
\hline CHEMBL1978167 & 809140 & 4.5 & 4.9479 & TRN \\
\hline CHEMBL418203 & 809140 & 4.5 & 4.6641 & TST \\
\hline CHEMBL225519 & 809140 & 4.5 & 4.5835 & TRN \\
\hline CHEMBL1994159 & 809140 & 4.4 & 4.2752 & TRN \\
\hline CHEMBL1976376 & 809140 & 8.3 & 7.2345 & TRN \\
\hline CHEMBL1983575 & 809140 & 8.0 & 5.5571 & TRN \\
\hline CHEMBL1968868 & 809140 & 4.5 & 4.8714 & TRN \\
\hline CHEMBL1981047 & 809140 & 4.5 & 4.6778 & TRN \\
\hline CHEMBL1998470 & 809140 & 4.5 & 4.3953 & TRN \\
\hline CHEMBL1976196 & 809140 & 4.5 & 4.8747 & TRN \\
\hline CHEMBL1997197 & 809140 & 4.5 & 4.5109 & TRN \\
\hline CHEMBL1975903 & 809140 & 4.5 & 4.6173 & TRN \\
\hline CHEMBL1983630 & 809140 & 4.1 & 4.335 & TRN \\
\hline CHEMBL1988805 & 809140 & 5.5 & 4.4341 & TRN \\
\hline CHEMBL458997 & 809140 & 4.5 & 4.8331 & TRN \\
\hline CHEMBL1969942 & 809140 & 4.5 & 4.2118 & TRN \\
\hline CHEMBL1982660 & 809140 & 4.5 & 4.7552 & TRN \\
\hline
\end{tabular}

TRN 


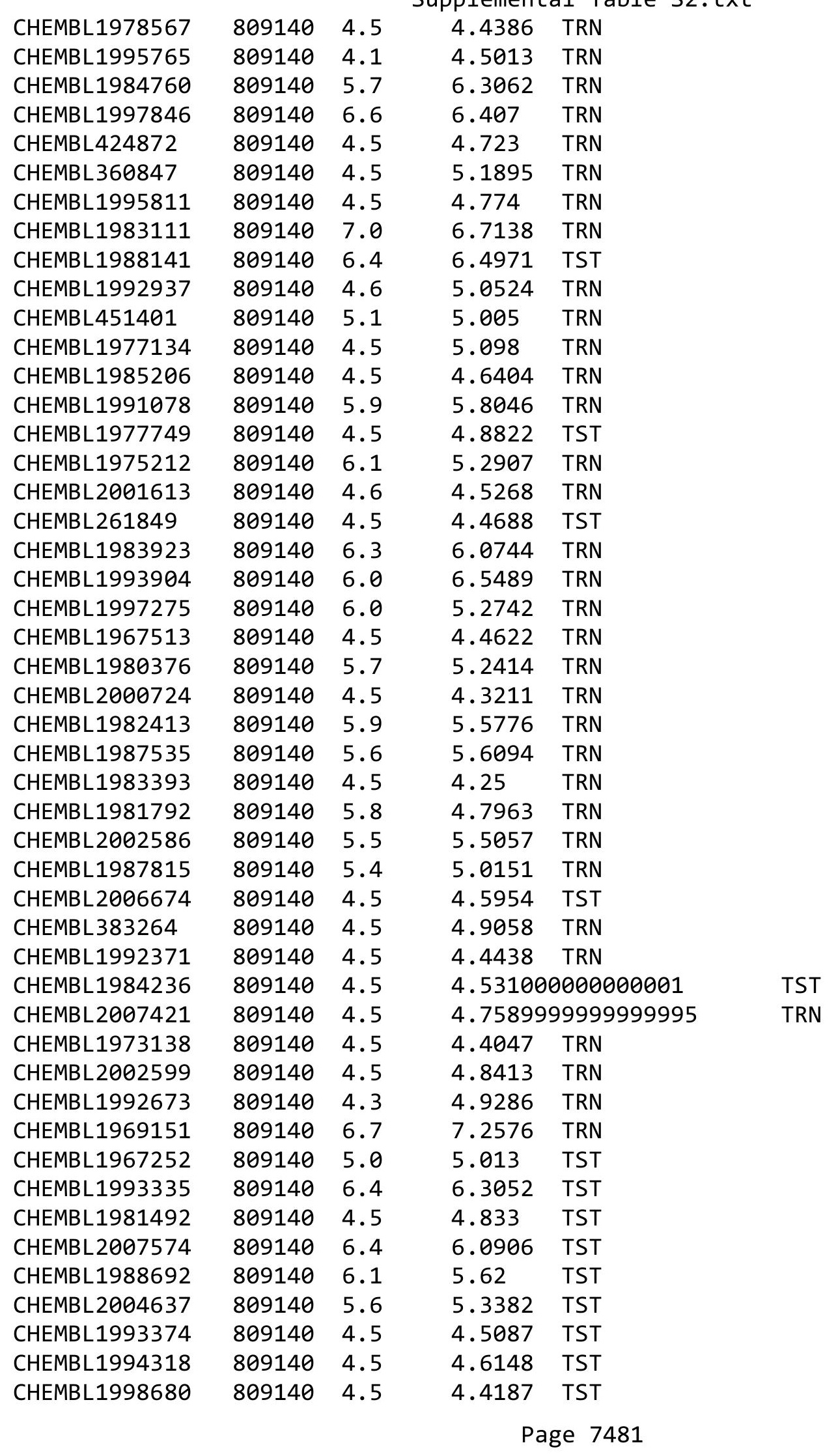




\begin{tabular}{|c|c|c|c|c|}
\hline & & & ent & al Ta \\
\hline CHEMBL592030 & 809140 & 4.5 & 4.6088 & TST \\
\hline CHEMBL1999506 & 809140 & 4.5 & 4.5382 & TST \\
\hline CHEMBL1970317 & 809140 & 5.9 & 6.3992 & TST \\
\hline CHEMBL1605605 & 809140 & 4.5 & 4.4793 & TST \\
\hline CHEMBL1997007 & 809140 & 5.6 & 6.2609 & TST \\
\hline CHEMBL1970352 & 809140 & 4.5 & 4.6244 & TST \\
\hline CHEMBL1964444 & 809140 & 4.5 & 4.5882 & TST \\
\hline CHEMBL 2002690 & 809140 & 4.5 & 4.7197 & TST \\
\hline CHEMBL1980167 & 809140 & 5.8 & 6.0495 & TST \\
\hline CHEMBL 377408 & 809140 & 4.5 & 5.1247 & TST \\
\hline CHEMBL 278041 & 809140 & 4.5 & 4.4753 & TST \\
\hline CHEMBL 215152 & 809140 & 4.7 & 4.7453 & TST \\
\hline CHEMBL 2006765 & 809140 & 7.2 & 7.2353 & TST \\
\hline CHEMBL1986590 & 809140 & 5.5 & 5.3878 & TST \\
\hline CHEMBL1870106 & 809140 & 4.6 & 5.0149 & TST \\
\hline CHEMBL406845 & 809140 & 6.6 & 6.216 & TST \\
\hline CHEMBL1980246 & 809140 & 4.5 & 4.6209 & TST \\
\hline CHEMBL1983980 & 809140 & 6.0 & 6.0866 & TST \\
\hline CHEMBL482538 & 809140 & 6.2 & 5.6221 & TST \\
\hline CHEMBL1999484 & 809140 & 6.1 & 5.9353 & TST \\
\hline CHEMBL1973399 & 809140 & 4.1 & 4.7195 & TST \\
\hline CHEMBL1984296 & 809140 & 4.5 & 5.4113 & TST \\
\hline CHEMBL1986899 & 809140 & 5.5 & 4.6983 & TST \\
\hline CHEMBL1996837 & 809140 & 5.0 & 4.9096 & TST \\
\hline CHEMBL1984038 & 809140 & 4.5 & 4.4081 & TST \\
\hline CHEMBL1993661 & 809140 & 7.2 & 7.2113 & TST \\
\hline CHEMBL1968705 & 809140 & 4.6 & 5.4168 & TST \\
\hline CHEMBL1964441 & 809140 & 4.5 & 5.3273 & TST \\
\hline CHEMBL1991410 & 809140 & 4.5 & 4.5464 & TST \\
\hline CHEMBL546797 & 809140 & 6.0 & 5.3244 & TST \\
\hline CHEMBL549020 & 1479002 & 6.35 & 6.2132 & TRN \\
\hline CHEMBL526199 & 1479002 & 5.0 & 5.4689 & TRN \\
\hline CHEMBL3430919 & 1479002 & 3.3 & 3.6238 & TRN \\
\hline CHEMBL528583 & 1479002 & 8.2 & 8.0951 & TRN \\
\hline CHEMBL530358 & 1479002 & 6.0 & 6.3355 & TRN \\
\hline CHEMBL534517 & 1479002 & 5.9 & 5.983 & TRN \\
\hline CHEMBL3430921 & 1479002 & 6.1 & 6.2556 & TST \\
\hline CHEMBL 3430922 & 1479002 & 6.1 & 5.9394 & TST \\
\hline CHEMBL 2098124 & 1479002 & 6.2 & 6.2499 & TRN \\
\hline CHEMBL 2098408 & 1479002 & 5.8 & 5.795 & TRN \\
\hline CHEMBL1578482 & 1479002 & 6.0 & 6.0578 & TRN \\
\hline CHEMBL 2098276 & 1479002 & 5.8 & 5.8616 & TRN \\
\hline CHEMBL3430923 & 1479002 & 6.5 & 5.97 & TST \\
\hline CHEMBL 3430924 & 1479002 & 6.0 & 5.7466 & TRN \\
\hline CHEMBL 3430925 & 1479002 & 6.6 & 5.9687 & TST \\
\hline CHEMBL3430926 & 1479002 & 6.6 & 6.479 & TST \\
\hline CHEMBL 2165401 & 1479002 & 4.6 & 4.6893 & TST \\
\hline CHEMBL3430928 & 1479002 & 5.8 & 5.6986 & TRN \\
\hline
\end{tabular}




\begin{tabular}{|c|c|c|c|c|}
\hline \multicolumn{5}{|c|}{ Supplemental Ta } \\
\hline CHEMBL3430929 & 1479002 & 5.3 & 5.2716 & TRN \\
\hline CHEMBL3430930 & 1479002 & 4.5 & 4.6461 & TRN \\
\hline CHEMBL305686 & 1479002 & 5.95 & 5.4234 & TST \\
\hline CHEMBL3430931 & 1479002 & 6.6 & 6.3127 & TST \\
\hline CHEMBL3430932 & 1479002 & 6.4 & 6.1577 & TST \\
\hline CHEMBL1232777 & 1479002 & 6.85 & 5.8778 & TST \\
\hline CHEMBL3430933 & 1479002 & 6.3 & 6.5855 & TRN \\
\hline CHEMBL3430913 & 1479002 & 5.9 & 5.5882 & TRN \\
\hline CHEMBL 3430934 & 1479002 & 6.0 & 5.0833 & TRN \\
\hline CHEMBL3430935 & 1479002 & 6.3 & 5.8515 & TST \\
\hline CHEMBL 3430936 & 1479002 & 5.9 & 6.0444 & TRN \\
\hline CHEMBL3430937 & 1479002 & 5.6 & 5.1841 & TRN \\
\hline CHEMBL3430938 & 1479002 & 5.3 & 5.1862 & TRN \\
\hline CHEMBL3430939 & 1479002 & 5.3 & 5.006 & TRN \\
\hline CHEMBL3430940 & 1479002 & 5.6 & 5.6042 & TRN \\
\hline CHEMBL 3430941 & 1479002 & 5.1 & 4.7911 & TRN \\
\hline CHEMBL3430942 & 1479002 & 5.4 & 5.3406 & TRN \\
\hline CHEMBL 3430943 & 1479002 & 5.4 & 5.5358 & TRN \\
\hline CHEMBL 3430944 & 1479002 & 5.4 & 5.2422 & TRN \\
\hline CHEMBL3430945 & 1479002 & 5.8 & 5.8371 & TRN \\
\hline CHEMBL 3430946 & 1479002 & 5.0 & 5.0735 & TRN \\
\hline CHEMBL 3430947 & 1479002 & 4.8 & 5.4546 & TRN \\
\hline CHEMBL 3430948 & 1479002 & 4.5 & 4.922 & TRN \\
\hline CHEMBL3430949 & 1479002 & 6.05 & 6.3393 & TRN \\
\hline CHEMBL1388922 & 1479002 & 5.45 & 5.3648 & TRN \\
\hline CHEMBL 3430950 & 1479002 & 5.6 & 5.6109 & TRN \\
\hline CHEMBL3430951 & 1479002 & 6.4 & 6.3978 & TST \\
\hline CHEMBL1321334 & 1479002 & 6.4 & 6.5101 & TRN \\
\hline CHEMBL3430953 & 1479002 & 4.5 & 4.7647 & TRN \\
\hline CHEMBL 3430954 & 1479002 & 6.1 & 5.8867 & TRN \\
\hline CHEMBL 3430955 & 1479002 & 5.8 & 5.7014 & TST \\
\hline CHEMBL3430956 & 1479002 & 5.75 & 5.9745 & TRN \\
\hline CHEMBL 3430957 & 1479002 & 5.5 & 5.4625 & TRN \\
\hline CHEMBL3430958 & 1479002 & 5.4 & 5.7027 & TRN \\
\hline CHEMBL3430959 & 1479002 & 5.7 & 5.5988 & TRN \\
\hline CHEMBL3430960 & 1479002 & 7.15 & 6.4811 & TRN \\
\hline CHEMBL3430961 & 1479002 & 5.6 & 5.7548 & TRN \\
\hline CHEMBL 3430962 & 1479002 & 3.3 & 4.5787 & TRN \\
\hline CHEMBL3430963 & 1479002 & 5.95 & 5.8216 & TRN \\
\hline CHEMBL 3430964 & 1479002 & 5.8 & 5.6173 & TRN \\
\hline CHEMBL3430965 & 1479002 & 4.7 & 4.7155 & TRN \\
\hline CHEMBL3430966 & 1479002 & 6.6 & 6.5445 & TRN \\
\hline CHEMBL3430967 & 1479002 & 5.3 & 5.3555 & TRN \\
\hline CHEMBL3430968 & 1479002 & 6.3 & 6.3826 & TRN \\
\hline CHEMBL3430969 & 1479002 & 5.9 & 6.2207 & TRN \\
\hline CHEMBL3430970 & 1479002 & 5.2 & 5.347 & TRN \\
\hline CHEMBL1482137 & 1479002 & 6.4 & 6.0424 & TRN \\
\hline CHEMBL3430971 & 1479002 & 6.6 & 6.6957 & TRN \\
\hline
\end{tabular}




\begin{tabular}{|c|c|c|c|c|c|}
\hline \multicolumn{6}{|c|}{ Supplemental Table S2.txt } \\
\hline CHEMBL3430972 & 1479002 & 6.05 & 6.0599 & TRN & \\
\hline CHEMBL3430973 & 1479002 & 5.55 & 5.6224 & TRN & \\
\hline CHEMBL3430974 & 1479002 & 3.3 & 3.7403 & TRN & \\
\hline CHEMBL3430975 & 1479002 & 5.55 & 5.4294 & TRN & \\
\hline CHEMBL3430976 & 1479002 & 5.45 & 5.3583 & TRN & \\
\hline CHEMBL3430977 & 1479002 & 4.4 & 4.9866 & TST & \\
\hline CHEMBL164422 & 1479002 & 6.2 & 6.343 & TRN & \\
\hline CHEMBL3430978 & 1479002 & 5.1 & 4.5795 & TRN & \\
\hline CHEMBL3430979 & 1479002 & 5.7 & 6.1806 & TRN & \\
\hline CHEMBL3430980 & 1479002 & 6.9 & \multicolumn{2}{|c|}{7.127999999999999} & TRN \\
\hline CHEMBL1487481 & 1479002 & 5.7 & 5.9656 & TRN & \\
\hline CHEMBL1487467 & 1479002 & 5.8 & 5.8152 & TRN & \\
\hline CHEMBL3430981 & 1479002 & 4.6 & 4.8368 & TRN & \\
\hline CHEMBL3430982 & 1479002 & 4.6 & 4.2811 & TRN & \\
\hline CHEMBL3430983 & 1479002 & 5.1 & 4.2747 & TRN & \\
\hline CHEMBL592827 & 1479002 & 6.3 & 6.5497 & TRN & \\
\hline CHEMBL3430984 & 1479002 & 5.6 & 5.7568 & TRN & \\
\hline CHEMBL3430985 & 1479002 & 5.2 & 5.6252 & TRN & \\
\hline CHEMBL1466712 & 1479002 & 5.2 & 5.4092 & TRN & \\
\hline CHEMBL3430986 & 1479002 & 5.0 & 4.7161 & TRN & \\
\hline CHEMBL3430987 & 1479002 & 5.2 & 5.5863 & TST & \\
\hline CHEMBL3430988 & 1479002 & 6.2 & 6.0929 & TRN & \\
\hline CHEMBL3430989 & 1479002 & 6.3 & \multicolumn{2}{|c|}{6.1370000000000005} & TRN \\
\hline CHEMBL3430990 & 1479002 & 6.2 & 6.3307 & TRN & \\
\hline CHEMBL3430991 & 1479002 & 6.6 & \multicolumn{2}{|c|}{6.577000000000001} & TRN \\
\hline CHEMBL3430992 & 1479002 & 6.7 & 6.4482 & TRN & \\
\hline CHEMBL3430993 & 1479002 & 6.0 & 5.54 & TRN & \\
\hline CHEMBL3430994 & 1479002 & 5.1 & 4.8988 & TRN & \\
\hline CHEMBL3430995 & 1479002 & 5.6 & 5.8525 & TST & \\
\hline CHEMBL3430996 & 1479002 & 6.8 & 6.4651 & TRN & \\
\hline CHEMBL3430997 & 1479002 & 5.7 & 5.7758 & TRN & \\
\hline CHEMBL3430998 & 1479002 & 6.15 & 5.9039 & TRN & \\
\hline CHEMBL3430999 & 1479002 & 6.6 & 6.8968 & TRN & \\
\hline CHEMBL 3431000 & 1479002 & 5.7 & 5.2383 & TRN & \\
\hline CHEMBL3431001 & 1479002 & 6.6 & \multicolumn{2}{|c|}{6.4910000000000005} & TRN \\
\hline CHEMBL3431002 & 1479002 & 6.0 & 6.1627 & TST & \\
\hline CHEMBL 3431003 & 1479002 & 7.15 & 6.816 & TRN & \\
\hline CHEMBL 3431004 & 1479002 & 6.9 & 6.9603 & TRN & \\
\hline CHEMBL 3431005 & 1479002 & 6.2 & 6.3615 & TRN & \\
\hline CHEMBL 3431006 & 1479002 & 6.6 & 6.6809 & TRN & \\
\hline CHEMBL 3431007 & 1479002 & 4.3 & 4.7199 & TRN & \\
\hline CHEMBL 3431008 & 1479002 & 6.0 & 5.4518 & TST & \\
\hline CHEMBL3431009 & 1479002 & 6.7 & 6.6183 & TRN & \\
\hline CHEMBL 2355685 & 1479002 & 5.65 & 5.9806 & TST & \\
\hline CHEMBL3431010 & 1479002 & 5.1 & 5.3313 & TRN & \\
\hline CHEMBL3431011 & 1479002 & 6.1 & 6.1017 & TRN & \\
\hline CHEMBL3431012 & 1479002 & 4.6 & 5.0196 & TST & \\
\hline CHEMBL1731664 & 1479002 & 5.1 & 4.9758 & TRN & \\
\hline
\end{tabular}




\begin{tabular}{|c|c|c|c|c|}
\hline & & & pplement & al $\mathrm{Ta}$ \\
\hline CHEMBL3431013 & 1479002 & 5.9 & 6.0194 & TRN \\
\hline CHEMBL3431014 & 1479002 & 5.7 & 5.2784 & TRN \\
\hline CHEMBL3431015 & 1479002 & 5.2 & 5.5189 & TRN \\
\hline CHEMBL3431016 & 1479002 & 6.4 & 6.5346 & TRN \\
\hline CHEMBL3431017 & 1479002 & 5.7 & 5.4959 & TRN \\
\hline CHEMBL3431018 & 1479002 & 6.2 & 5.9782 & TRN \\
\hline CHEMBL3431019 & 1479002 & 6.2 & 5.1273 & TRN \\
\hline CHEMBL3431020 & 1479002 & 6.2 & 6.4943 & TRN \\
\hline CHEMBL3431021 & 1479002 & 4.9 & 5.2317 & TRN \\
\hline CHEMBL3431022 & 1479002 & 5.45 & 5.5003 & TRN \\
\hline CHEMBL3431023 & 1479002 & 6.5 & 6.2268 & TST \\
\hline CHEMBL3431024 & 1479002 & 6.7 & 6.5766 & TRN \\
\hline CHEMBL3431025 & 1479002 & 7.7 & 7.5903 & TRN \\
\hline CHEMBL3431026 & 1479002 & 5.3 & 5.9053 & TST \\
\hline CHEMBL3431027 & 1479002 & 5.0 & 5.4058 & TRN \\
\hline CHEMBL3431028 & 1479002 & 6.95 & 7.0124 & TRN \\
\hline CHEMBL3431029 & 1479002 & 7.0 & 6.8696 & TRN \\
\hline CHEMBL3431030 & 1479002 & 5.2 & 5.774 & TRN \\
\hline CHEMBL3431031 & 1479002 & 5.8 & 5.4936 & TRN \\
\hline CHEMBL3431032 & 1479002 & 5.85 & 5.6808 & TRN \\
\hline CHEMBL1527364 & 1479002 & 3.3 & 4.4346 & TRN \\
\hline CHEMBL3430914 & 1479002 & 6.0 & 5.6692 & TRN \\
\hline CHEMBL3431033 & 1479002 & 6.65 & 6.2781 & TRN \\
\hline CHEMBL3431034 & 1479002 & 6.3 & 5.8842 & TRN \\
\hline CHEMBL3431035 & 1479002 & 5.4 & 5.8755 & TRN \\
\hline CHEMBL3431036 & 1479002 & 6.2 & 5.6483 & TRN \\
\hline CHEMBL3431037 & 1479002 & 5.4 & 5.3289 & TRN \\
\hline CHEMBL3431038 & 1479002 & 5.2 & 5.5831 & TRN \\
\hline CHEMBL3431039 & 1479002 & 6.55 & 6.6702 & TRN \\
\hline CHEMBL3431040 & 1479002 & 5.9 & 6.1001 & TRN \\
\hline CHEMBL1354075 & 1479002 & 5.7 & 5.8446 & TRN \\
\hline CHEMBL 3431041 & 1479002 & 5.1 & 4.7984 & TRN \\
\hline CHEMBL 3431042 & 1479002 & 6.7 & 6.5681 & TRN \\
\hline CHEMBL3431043 & 1479002 & 5.2 & 5.0705 & TST \\
\hline CHEMBL3431044 & 1479002 & 6.1 & 6.2742 & TST \\
\hline CHEMBL3431045 & 1479002 & 4.8 & 4.8308 & TRN \\
\hline CHEMBL3431046 & 1479002 & 5.7 & 5.0685 & TRN \\
\hline CHEMBL3431047 & 1479002 & 6.1 & 5.7972 & TRN \\
\hline CHEMBL3431048 & 1479002 & 6.15 & 5.817 & TRN \\
\hline CHEMBL3431049 & 1479002 & 6.1 & 5.8887 & TRN \\
\hline CHEMBL3431050 & 1479002 & 6.3 & 5.9797 & TRN \\
\hline CHEMBL3431051 & 1479002 & 6.2 & 5.7393 & TRN \\
\hline CHEMBL3431052 & 1479002 & 5.4 & 5.7981 & TRN \\
\hline CHEMBL3431053 & 1479002 & 6.3 & 6.0682 & TRN \\
\hline CHEMBL2356808 & 1479002 & 5.65 & 5.751 & TRN \\
\hline CHEMBL3431054 & 1479002 & 5.45 & 5.7541 & TRN \\
\hline CHEMBL3431055 & 1479002 & 6.4 & 6.3995 & TST \\
\hline CHEMBL3431056 & 1479002 & 6.8 & 6.954 & TRN \\
\hline
\end{tabular}




\begin{tabular}{|c|c|c|c|c|c|}
\hline \multirow{2}{*}{\multicolumn{6}{|c|}{ CHFMRI 3431957}} \\
\hline CHEMBL3431057 & 1479002 & 3.3 & & & \\
\hline CHEMBL 2093320 & 1479002 & 6.4 & 6.0895 & TRN & \\
\hline CHEMBL3431058 & 1479002 & 3.3 & 3.0912 & TRN & \\
\hline CHEMBL3431059 & 1479002 & 3.3 & 3.1014 & TRN & \\
\hline CHEMBL3431060 & 1479002 & 3.3 & 3.1379 & TRN & \\
\hline CHEMBL3431061 & 1479002 & 3.3 & 3.0791 & TRN & \\
\hline CHEMBL3431062 & 1479002 & 3.3 & 2.9966 & TRN & \\
\hline CHEMBL3431063 & 1479002 & 3.3 & 3.1244 & TRN & \\
\hline CHEMBL3431064 & 1479002 & 5.6 & 5.7082 & TRN & \\
\hline CHEMBL3431065 & 1479002 & 5.7 & 6.1878 & TST & \\
\hline CHEMBL3431066 & 1479002 & 5.9 & 5.9699 & TRN & \\
\hline CHEMBL3431067 & 1479002 & 5.0 & 5.2731 & TRN & \\
\hline CHEMBL3431068 & 1479002 & 6.4 & 6.565 & TRN & \\
\hline CHEMBL3431069 & 1479002 & 5.5 & 5.6547 & TRN & \\
\hline CHEMBL3431070 & 1479002 & 6.3 & 6.6036 & TRN & \\
\hline CHEMBL3431071 & 1479002 & 5.3 & 5.5486 & TST & \\
\hline CHEMBL3431072 & 1479002 & 5.6 & 5.7963 & TRN & \\
\hline CHEMBL3431073 & 1479002 & 3.3 & 4.4895 & TST & \\
\hline CHEMBL3431074 & 1479002 & 5.7 & 5.4193 & TRN & \\
\hline CHEMBL3431075 & 1479002 & 4.4 & 4.2623 & TST & \\
\hline CHEMBL3431076 & 1479002 & 6.5 & 6.319 & TRN & \\
\hline CHEMBL3431077 & 1479002 & 6.2 & 5.8409 & TRN & \\
\hline CHEMBL3431078 & 1479002 & 5.35 & 5.3426 & TRN & \\
\hline CHEMBL3431079 & 1479002 & 3.3 & 4.3884 & TRN & \\
\hline CHEMBL3431080 & 1479002 & 6.3 & 6.6382 & TRN & \\
\hline CHEMBL3431081 & 1479002 & 6.2 & 6.3244 & TRN & \\
\hline CHEMBL3431082 & 1479002 & 5.8 & 5.4883 & TRN & \\
\hline CHEMBL3431083 & 1479002 & 5.3 & 5.3622 & TRN & \\
\hline CHEMBL3431084 & 1479002 & 6.4 & 6.3031 & TST & \\
\hline CHEMBL1585368 & 1479002 & 4.7 & 4.9082 & TRN & \\
\hline CHEMBL3431085 & 1479002 & 6.4 & 6.3846 & TRN & \\
\hline CHEMBL3431086 & 1479002 & 5.1 & 5.4069 & TRN & \\
\hline CHEMBL3431087 & 1479002 & 5.5 & 5.7734 & TRN & \\
\hline CHEMBL 3431088 & 1479002 & 5.8 & 5.9346 & TRN & \\
\hline CHEMBL3431089 & 1479002 & 6.5 & $6.5120 e$ & 00000000005 & TRN \\
\hline CHEMBL3431090 & 1479002 & 6.2 & 6.1734 & TRN & \\
\hline CHEMBL3431091 & 1479002 & 5.0 & 5.1302 & TRN & \\
\hline CHEMBL3431092 & 1479002 & 5.0 & 5.2956 & TRN & \\
\hline CHEMBL3431093 & 1479002 & 5.5 & 5.4828 & TRN & \\
\hline CHEMBL 3431094 & 1479002 & 6.35 & 6.193 & TRN & \\
\hline CHEMBL3431095 & 1479002 & 5.8 & 6.1535 & TRN & \\
\hline CHEMBL3431096 & 1479002 & 3.3 & 4.1882 & TRN & \\
\hline CHEMBL3431097 & 1479002 & 5.8 & 5.8883 & TRN & \\
\hline CHEMBL3431098 & 1479002 & 5.2 & 5.4799 & TRN & \\
\hline CHEMBL3431099 & 1479002 & 3.3 & 4.7518 & TST & \\
\hline CHEMBL 3431100 & 1479002 & 5.5 & 5.3628 & TRN & \\
\hline CHEMBL3431101 & 1479002 & 5.4 & 5.4076 & TST & \\
\hline CHEMBL3431102 & 1479002 & 4.6 & 5.1672 & TST & \\
\hline
\end{tabular}




\begin{tabular}{|c|c|c|c|c|}
\hline \multicolumn{5}{|c|}{ 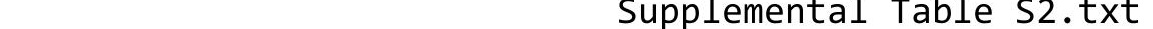 } \\
\hline CHEMBL3431103 & 1479002 & 4.6 & 5.0794 & TST \\
\hline CHEMBL3431104 & 1479002 & 6.5 & 6.5751 & TRN \\
\hline CHEMBL3431105 & 1479002 & 6.2 & 6.2321 & TRN \\
\hline CHEMBL3431106 & 1479002 & 6.65 & 6.6073 & TST \\
\hline CHEMBL3431107 & 1479002 & 6.85 & 6.8812 & TRN \\
\hline CHEMBL3431108 & 1479002 & 6.1 & 6.2652 & TRN \\
\hline CHEMBL3431109 & 1479002 & 5.3 & 5.4063 & TRN \\
\hline CHEMBL3431110 & 1479002 & 5.3 & 5.1702 & TRN \\
\hline CHEMBL3431111 & 1479002 & 6.2 & 5.5914 & TRN \\
\hline CHEMBL3431112 & 1479002 & 5.1 & 5.2208 & TRN \\
\hline CHEMBL3431113 & 1479002 & 6.0 & 5.7653 & TRN \\
\hline CHEMBL3431114 & 1479002 & 6.0 & 6.0129 & TRN \\
\hline CHEMBL3431115 & 1479002 & 5.3 & 5.0283 & TRN \\
\hline CHEMBL3431116 & 1479002 & 5.9 & 5.9255 & TRN \\
\hline CHEMBL3431117 & 1479002 & 7.8 & 7.7614 & TRN \\
\hline CHEMBL3431118 & 1479002 & 6.3 & 6.3168 & TRN \\
\hline CHEMBL3431119 & 1479002 & 6.2 & 5.9384 & TRN \\
\hline CHEMBL3431120 & 1479002 & 6.5 & 6.5528 & TRN \\
\hline CHEMBL3431121 & 1479002 & 6.0 & 5.9521 & TST \\
\hline CHEMBL3431122 & 1479002 & 6.3 & 6.4612 & TRN \\
\hline CHEMBL3431123 & 1479002 & 6.2 & 5.9757 & TRN \\
\hline CHEMBL3431124 & 1479002 & 6.0 & 6.0755 & TRN \\
\hline CHEMBL3431125 & 1479002 & 6.4 & 5.8209 & TST \\
\hline CHEMBL3431126 & 1479002 & 5.2 & 4.3495 & TRN \\
\hline CHEMBL3431128 & 1479002 & 7.5 & 7.0906 & TST \\
\hline CHEMBL3431129 & 1479002 & 7.2 & 7.8131 & TST \\
\hline CHEMBL3431130 & 1479002 & 7.1 & 7.1158 & TST \\
\hline CHEMBL3431131 & 1479002 & 6.1 & 6.3913 & TRN \\
\hline CHEMBL3430915 & 1479002 & 6.9 & 6.8422 & TRN \\
\hline CHEMBL3431132 & 1479002 & 6.4 & 6.4896 & TRN \\
\hline CHEMBL3431133 & 1479002 & 6.9 & 6.4521 & TRN \\
\hline CHEMBL3431134 & 1479002 & 5.9 & 5.7063 & TRN \\
\hline CHEMBL3431135 & 1479002 & 6.65 & 6.7253 & TRN \\
\hline CHEMBL3431136 & 1479002 & 5.45 & 5.7192 & TRN \\
\hline CHEMBL3431137 & 1479002 & 5.6 & 5.4553 & TRN \\
\hline CHEMBL3431138 & 1479002 & 4.8 & 5.2057 & TST \\
\hline CHEMBL3431139 & 1479002 & 6.3 & 6.1331 & TST \\
\hline CHEMBL3431140 & 1479002 & 7.3 & 7.1926 & TST \\
\hline CHEMBL 3431141 & 1479002 & 6.0 & 6.199 & TRN \\
\hline CHEMBL 3431142 & 1479002 & 5.8 & 5.1854 & TST \\
\hline CHEMBL3431143 & 1479002 & 6.1 & 5.5502 & TRN \\
\hline CHEMBL 3431144 & 1479002 & 5.7 & 5.5508 & TRN \\
\hline CHEMBL3431145 & 1479002 & 6.0 & 5.6843 & TRN \\
\hline CHEMBL3431146 & 1479002 & 6.5 & 6.3601 & TRN \\
\hline CHEMBL 3431147 & 1479002 & 5.3 & 4.9676 & TST \\
\hline CHEMBL 3431148 & 1479002 & 6.35 & 6.4675 & TRN \\
\hline CHEMBL3431149 & 1479002 & 5.1 & 5.2496 & TRN \\
\hline CHEMBL3431150 & 1479002 & 6.6 & 6.6272 & TRN \\
\hline
\end{tabular}




\begin{tabular}{|c|c|c|c|c|}
\hline & & & & \\
\hline CHEMBL 3431151 & 1479002 & 6.9 & 7.1555 & TRN \\
\hline CHEMBL3431152 & 1479002 & 6.5 & 6.4969 & TRN \\
\hline CHEMBL3431153 & 1479002 & 6.4 & 6.4284 & TRN \\
\hline CHEMBL 3431154 & 1479002 & 5.1 & 4.8676 & TST \\
\hline CHEMBL3431155 & 1479002 & 7.5 & 6.9049 & TRN \\
\hline CHEMBL3431156 & 1479002 & 6.65 & 6.7094 & TRN \\
\hline CHEMBL3431157 & 1479002 & 5.3 & 3.8416 & TST \\
\hline CHEMBL3431158 & 1479002 & 3.3 & 3.8099 & TST \\
\hline CHEMBL3431159 & 1479002 & 5.7 & 5.2347 & TST \\
\hline CHEMBL1593679 & 1479002 & 6.7 & 6.9024 & TRN \\
\hline CHEMBL3431160 & 1479002 & 5.3 & 5.3955 & TRN \\
\hline CHEMBL3431161 & 1479002 & 5.7 & 6.2245 & TST \\
\hline CHEMBL3431162 & 1479002 & 6.7 & 6.1102 & TST \\
\hline CHEMBL3431163 & 1479002 & 5.8 & 6.138 & TRN \\
\hline CHEMBL3431164 & 1479002 & 6.5 & 6.5071 & TRN \\
\hline CHEMBL3431165 & 1479002 & 4.7 & 4.9619 & TST \\
\hline CHEMBL1458931 & 1479002 & 7.0 & 6.8526 & TRN \\
\hline CHEMBL3431166 & 1479002 & 3.3 & 3.6188 & TRN \\
\hline CHEMBL3431167 & 1479002 & 5.6 & 5.2864 & TRN \\
\hline CHEMBL3431168 & 1479002 & 6.5 & 6.32 & TRN \\
\hline CHEMBL3431169 & 1479002 & 5.7 & 5.1823 & TRN \\
\hline CHEMBL3431170 & 1479002 & 6.4 & 6.093 & TRN \\
\hline CHEMBL3431171 & 1479002 & 4.6 & 4.9247 & TRN \\
\hline CHEMBL3431172 & 1479002 & 5.2 & 5.6184 & TRN \\
\hline CHEMBL3431173 & 1479002 & 5.3 & 5.4669 & TRN \\
\hline CHEMBL 3431174 & 1479002 & 5.55 & 5.7911 & TRN \\
\hline CHEMBL3431175 & 1479002 & 6.5 & 6.3057 & TST \\
\hline CHEMBL3431176 & 1479002 & 3.3 & 3.6858 & TRN \\
\hline CHEMBL3431177 & 1479002 & 5.2 & 5.916 & TRN \\
\hline CHEMBL3431178 & 1479002 & 5.8 & 5.7199 & TRN \\
\hline CHEMBL3431179 & 1479002 & 4.6 & 4.4644 & TRN \\
\hline CHEMBL3431180 & 1479002 & 5.3 & 4.6456 & TRN \\
\hline CHEMBL3431181 & 1479002 & 6.3 & 6.0442 & TRN \\
\hline CHEMBL3431182 & 1479002 & 5.2 & 5.1569 & TRN \\
\hline CHEMBL3431183 & 1479002 & 6.2 & 6.2692 & TRN \\
\hline CHEMBL3431184 & 1479002 & 4.6 & 4.1568 & TRN \\
\hline CHEMBL3431185 & 1479002 & 5.8 & 5.9337 & TRN \\
\hline CHEMBL3431186 & 1479002 & 5.5 & 5.8584 & TRN \\
\hline CHEMBL3431187 & 1479002 & 4.9 & 4.5065 & TRN \\
\hline CHEMBL3431188 & 1479002 & 6.4 & 6.7854 & TRN \\
\hline CHEMBL3431189 & 1479002 & 5.0 & 4.6312 & TST \\
\hline CHEMBL3431190 & 1479002 & 4.9 & 4.9605 & TRN \\
\hline CHEMBL3431191 & 1479002 & 6.0 & 5.7103 & TRN \\
\hline CHEMBL3431192 & 1479002 & 7.1 & 6.6014 & TRN \\
\hline CHEMBL3431193 & 1479002 & 6.9 & 6.8582 & TRN \\
\hline CHEMBL 3431194 & 1479002 & 6.5 & 6.1868 & TRN \\
\hline CHEMBL3431195 & 1479002 & 5.6 & 5.8366 & TRN \\
\hline CHEMBL3431196 & 1479002 & 5.6 & 6.1062 & TRN \\
\hline
\end{tabular}




\begin{tabular}{|c|c|c|c|c|c|}
\hline & & & & & \\
\hline CHEMBL3431197 & 1479002 & 5.4 & 5.5541 & TRN & \\
\hline CHEMBL3431198 & 1479002 & 5.4 & 5.7033 & TRN & \\
\hline CHEMBL3431199 & 1479002 & 5.2 & 5.3432 & TST & \\
\hline CHEMBL3431200 & 1479002 & 5.9 & 5.829 & TRN & \\
\hline CHEMBL 3431201 & 1479002 & 5.9 & 5.794 & TRN & \\
\hline CHEMBL3431202 & 1479002 & 5.4 & 5.9236 & TRN & \\
\hline CHEMBL3431203 & 1479002 & 5.8 & 5.7666 & TRN & \\
\hline CHEMBL3431204 & 1479002 & 5.5 & 5.3339 & TRN & \\
\hline CHEMBL3431205 & 1479002 & 6.0 & 5.7479 & TRN & \\
\hline CHEMBL3431206 & 1479002 & 7.1 & 6.8679 & TRN & \\
\hline CHEMBL3431207 & 1479002 & 5.1 & 5.4979 & TRN & \\
\hline CHEMBL3431208 & 1479002 & 6.55 & 6.1394 & TRN & \\
\hline CHEMBL3431209 & 1479002 & 6.2 & 5.9596 & TRN & \\
\hline CHEMBL3431210 & 1479002 & 6.2 & 6.1288 & TRN & \\
\hline CHEMBL3431211 & 1479002 & 5.75 & 6.1844 & TRN & \\
\hline CHEMBL3431212 & 1479002 & 5.7 & 6.3634 & TRN & \\
\hline CHEMBL3431213 & 1479002 & 6.4 & 6.3496 & TRN & \\
\hline CHEMBL3431214 & 1479002 & 6.2 & 6.3483 & TRN & \\
\hline CHEMBL3431215 & 1479002 & 5.2 & 5.3499 & TRN & \\
\hline CHEMBL3431216 & 1479002 & 6.5 & 6.5172 & TRN & \\
\hline CHEMBL3431217 & 1479002 & 5.3 & 5.2782 & TRN & \\
\hline CHEMBL3431218 & 1479002 & 6.3 & 6.5272 & TRN & \\
\hline CHEMBL3431219 & 1479002 & 3.3 & 3.6975 & TRN & \\
\hline CHEMBL3431220 & 1479002 & 6.9 & 6.6818 & TRN & \\
\hline CHEMBL3431221 & 1479002 & 6.5 & 6.1603 & TRN & \\
\hline CHEMBL3431222 & 1479002 & 4.5 & 4.4607 & TRN & \\
\hline CHEMBL 3431223 & 1479002 & 3.3 & 3.8854 & TST & \\
\hline CHEMBL3431224 & 1479002 & 4.6 & $4.3180 e$ & 20000000005 & TRN \\
\hline CHEMBL3431225 & 1479002 & 5.9 & 5.2427 & TRN & \\
\hline CHEMBL3431226 & 1479002 & 5.8 & 5.9795 & TRN & \\
\hline CHEMBL3431227 & 1479002 & 4.4 & 4.4063 & TRN & \\
\hline CHEMBL 3431228 & 1479002 & 3.3 & 4.3344 & TRN & \\
\hline CHEMBL3431229 & 1479002 & 6.4 & 6.3117 & TRN & \\
\hline CHEMBL3431230 & 1479002 & 6.4 & 6.249 & TRN & \\
\hline CHEMBL 2441267 & 1479002 & 6.9 & 6.6771 & TRN & \\
\hline CHEMBL3430916 & 1479002 & 5.9 & 5.942 & TRN & \\
\hline CHEMBL 3431231 & 1479002 & 5.6 & 5.6729 & TRN & \\
\hline CHEMBL3431232 & 1479002 & 6.85 & 6.5923 & TRN & \\
\hline CHEMBL3431233 & 1479002 & 5.7 & 5.7527 & TRN & \\
\hline CHEMBL 3431234 & 1479002 & 5.6 & 5.7525 & TRN & \\
\hline CHEMBL3431235 & 1479002 & 5.8 & 5.1119 & TST & \\
\hline CHEMBL 3431236 & 1479002 & 6.75 & 6.1781 & TST & \\
\hline CHEMBL3431237 & 1479002 & 6.1 & 6.3791 & TRN & \\
\hline CHEMBL3431238 & 1479002 & 7.0 & 6.6901 & TRN & \\
\hline CHEMBL3431239 & 1479002 & 3.3 & 3.3984 & TRN & \\
\hline CHEMBL3431240 & 1479002 & 5.9 & 5.5618 & TST & \\
\hline CHEMBL 3431241 & 1479002 & 6.6 & 6.6441 & TRN & \\
\hline CHEMBL 3431242 & 1479002 & 6.65 & 6.9339 & TRN & \\
\hline
\end{tabular}




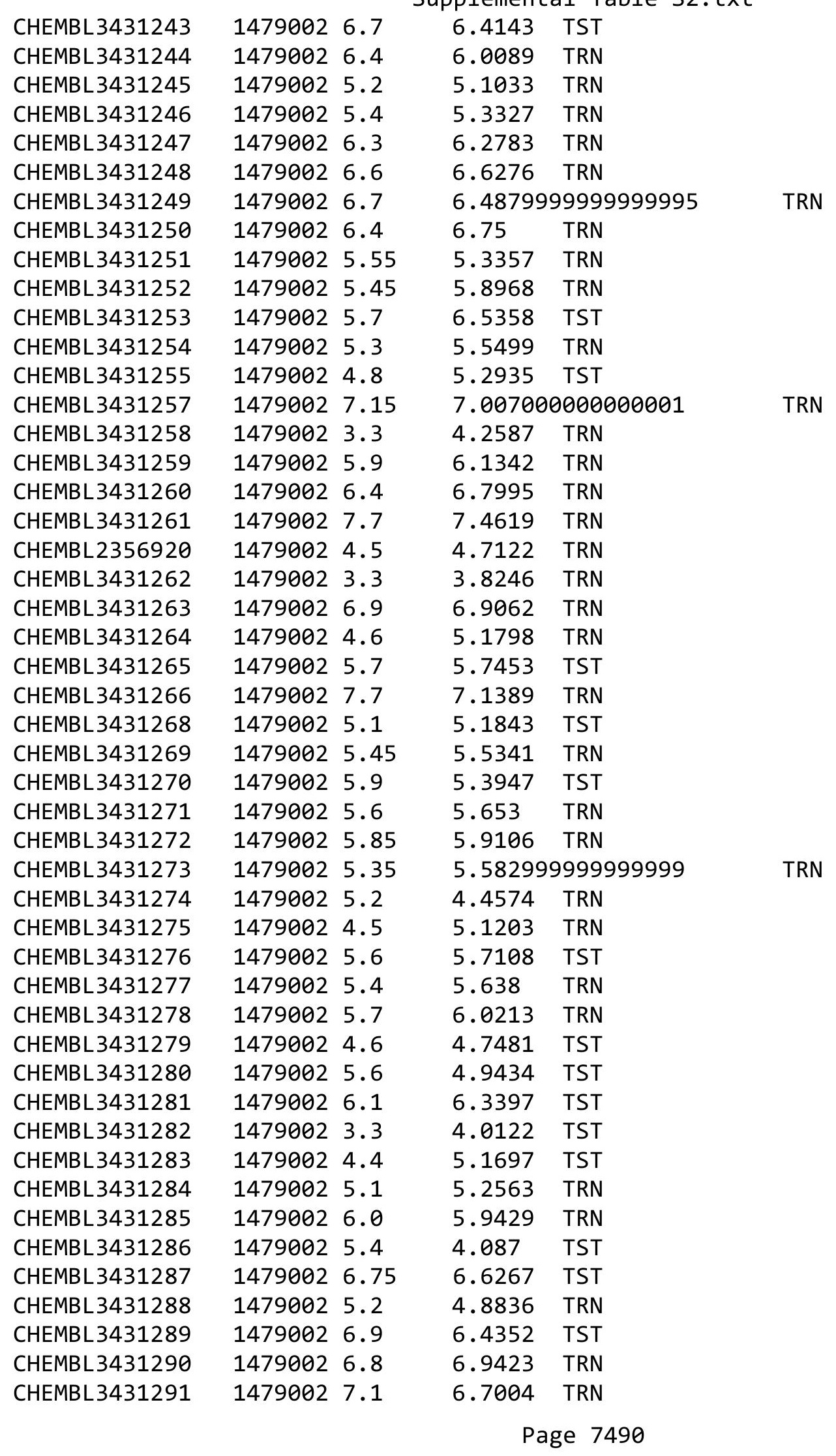




\begin{tabular}{|c|c|c|c|c|c|}
\hline \multicolumn{6}{|c|}{ Supplemental Table S2.txt } \\
\hline CHEMBL3431292 & 1479002 & 5.7 & 5.7414 & TRN & \\
\hline CHEMBL3431293 & 1479002 & 6.1 & 6.0163 & TRN & \\
\hline CHEMBL3431294 & 1479002 & 5.9 & 5.8272 & TRN & \\
\hline CHEMBL3431295 & 1479002 & 6.3 & 6.38200 & 0000000001 & TRN \\
\hline CHEMBL3431296 & 1479002 & 6.1 & 6.1177 & TRN & \\
\hline CHEMBL3431297 & 1479002 & 6.5 & 6.4574 & TRN & \\
\hline CHEMBL3431298 & 1479002 & 6.6 & 6.5136 & TRN & \\
\hline CHEMBL3431299 & 1479002 & 5.3 & 5.4775 & TRN & \\
\hline CHEMBL3431300 & 1479002 & 6.5 & 6.3844 & TRN & \\
\hline CHEMBL3431301 & 1479002 & 3.3 & 4.6041 & TST & \\
\hline CHEMBL3431302 & 1479002 & 6.15 & 6.3087 & TRN & \\
\hline CHEMBL3431303 & 1479002 & 6.75 & 6.6798 & TRN & \\
\hline CHEMBL3431304 & 1479002 & 5.5 & 5.232 & TRN & \\
\hline CHEMBL3431305 & 1479002 & 6.65 & 6.3124 & TRN & \\
\hline CHEMBL3431306 & 1479002 & 5.0 & 4.9836 & TRN & \\
\hline CHEMBL3431307 & 1479002 & 6.75 & 6.5898 & TRN & \\
\hline CHEMBL3431308 & 1479002 & 5.0 & 5.0999 & TRN & \\
\hline CHEMBL3431309 & 1479002 & 5.7 & 5.7316 & TRN & \\
\hline CHEMBL3431310 & 1479002 & 6.5 & 6.3835 & TRN & \\
\hline CHEMBL3431311 & 1479002 & 6.05 & 5.8643 & TRN & \\
\hline CHEMBL3431312 & 1479002 & 6.0 & 5.8862 & TRN & \\
\hline CHEMBL3431313 & 1479002 & 6.1 & 5.8362 & TRN & \\
\hline CHEMBL 3431314 & 1479002 & 6.2 & 5.69600 & 0000000001 & TRN \\
\hline CHEMBL3431315 & 1479002 & 5.2 & 5.3193 & TRN & \\
\hline CHEMBL3431316 & 1479002 & 5.6 & 5.8304 & TST & \\
\hline CHEMBL3431317 & 1479002 & 4.8 & 4.8729 & TRN & \\
\hline CHEMBL3431318 & 1479002 & 7.25 & 7.0848 & TST & \\
\hline CHEMBL3431319 & 1479002 & 4.5 & 4.2173 & TRN & \\
\hline CHEMBL3431320 & 1479002 & 5.9 & 5.5506 & TST & \\
\hline CHEMBL3431321 & 1479002 & 6.5 & 6.5521 & TRN & \\
\hline CHEMBL3431322 & 1479002 & 6.0 & 6.1013 & TRN & \\
\hline CHEMBL 3431323 & 1479002 & 6.3 & 6.3883 & TRN & \\
\hline CHEMBL3431324 & 1479002 & 6.2 & 6.1664 & TST & \\
\hline CHEMBL3431325 & 1479002 & 6.3 & 6.3853 & TRN & \\
\hline CHEMBL3431326 & 1479002 & 7.6 & 7.0436 & TRN & \\
\hline CHEMBL3431327 & 1479002 & 6.1 & 5.5295 & TST & \\
\hline CHEMBL3431328 & 1479002 & 6.5 & 6.5888 & TST & \\
\hline CHEMBL3431329 & 1479002 & 5.8 & 5.2445 & TST & \\
\hline CHEMBL3430917 & 1479002 & 6.8 & 6.6073 & TRN & \\
\hline CHEMBL3431330 & 1479002 & 6.4 & 6.2866 & TRN & \\
\hline CHEMBL3431331 & 1479002 & 6.85 & 6.3227 & TRN & \\
\hline CHEMBL3431332 & 1479002 & 6.8 & 6.5192 & TRN & \\
\hline CHEMBL1582997 & 1479002 & 5.8 & 5.5679 & TRN & \\
\hline CHEMBL 3431333 & 1479002 & 5.7 & 5.9115 & TRN & \\
\hline CHEMBL3431334 & 1479002 & 6.4 & 6.2494 & TRN & \\
\hline CHEMBL3431335 & 1479002 & 6.0 & 6.4219 & TRN & \\
\hline CHEMBL3431336 & 1479002 & 6.3 & 6.4695 & TRN & \\
\hline CHEMBL3431339 & 1479002 & 5.5 & 5.476 & TST & \\
\hline
\end{tabular}




\begin{tabular}{|c|c|c|c|c|}
\hline & & & & as labıe \\
\hline CHEMBL3431340 & 1479002 & 4.4 & 3.1875 & TRN \\
\hline CHEMBL3431341 & 1479002 & 6.8 & 6.6915 & TRN \\
\hline CHEMBL3431342 & 1479002 & 5.9 & 5.9264 & TRN \\
\hline CHEMBL 3431343 & 1479002 & 6.2 & 6.2459 & TRN \\
\hline CHEMBL3431344 & 1479002 & 5.8 & 6.0314 & TRN \\
\hline CHEMBL3431345 & 1479002 & 6.7 & 6.7696 & TRN \\
\hline CHEMBL3431346 & 1479002 & 6.8 & 6.6553 & TRN \\
\hline CHEMBL1430615 & 1479002 & 4.4 & 4.5504 & TRN \\
\hline CHEMBL3431347 & 1479002 & 6.1 & 6.2494 & TRN \\
\hline CHEMBL3431348 & 1479002 & 3.3 & 3.103 & TRN \\
\hline CHEMBL3431349 & 1479002 & 5.7 & 5.6135 & TRN \\
\hline CHEMBL3431350 & 1479002 & 6.6 & 6.4391 & TRN \\
\hline CHEMBL465227 & 1479002 & 6.1 & 6.1945 & TRN \\
\hline CHEMBL3431351 & 1479002 & 6.75 & 6.9199 & TRN \\
\hline CHEMBL1611993 & 1479002 & 6.3 & 6.1473 & TRN \\
\hline CHEMBL3431352 & 1479002 & 6.2 & 5.7886 & TRN \\
\hline CHEMBL3431353 & 1479002 & 5.6 & 5.8242 & TRN \\
\hline CHEMBL1393829 & 1479002 & 5.8 & 5.6604 & TST \\
\hline CHEMBL3431354 & 1479002 & 7.0 & 6.8908 & TRN \\
\hline CHEMBL3431355 & 1479002 & 6.7 & 6.5775 & TRN \\
\hline CHEMBL3431356 & 1479002 & 5.6 & 5.7201 & TRN \\
\hline CHEMBL 3431357 & 1479002 & 5.8 & 5.7261 & TRN \\
\hline CHEMBL3431358 & 1479002 & 6.8 & 6.999 & TRN \\
\hline CHEMBL3431359 & 1479002 & 6.3 & 6.5448 & TRN \\
\hline CHEMBL3431360 & 1479002 & 5.9 & 5.88299 & 9999999999 \\
\hline CHEMBL 3431361 & 1479002 & 6.7 & 6.5494 & TRN \\
\hline CHEMBL1535535 & 1479002 & 6.8 & 6.7186 & TRN \\
\hline CHEMBL3431362 & 1479002 & 5.8 & 6.1485 & TRN \\
\hline CHEMBL3431363 & 1479002 & 4.9 & 5.1326 & TRN \\
\hline CHEMBL3431364 & 1479002 & 5.6 & 5.9413 & TRN \\
\hline CHEMBL3431365 & 1479002 & 5.9 & 6.1077 & TRN \\
\hline CHEMBL3431366 & 1479002 & 4.6 & 4.5014 & TST \\
\hline CHEMBL3431367 & 1479002 & 6.1 & 6.2947 & TST \\
\hline CHEMBL3431368 & 1479002 & 7.4 & 6.3428 & TRN \\
\hline CHEMBL3431369 & 1479002 & 6.1 & 5.9773 & TRN \\
\hline CHEMBL1447267 & 1479002 & 5.8 & 5.8918 & TRN \\
\hline CHEMBL3431370 & 1479002 & 5.6 & 5.727 & TRN \\
\hline CHEMBL1325144 & 1479002 & 7.4 & 7.4031 & TRN \\
\hline CHEMBL1429841 & 1479002 & 5.1 & 5.1571 & TRN \\
\hline CHEMBL3431371 & 1479002 & 6.2 & 6.3627 & TRN \\
\hline CHEMBL1308225 & 1479002 & 5.8 & 5.5125 & TST \\
\hline CHEMBL 2441359 & 1479002 & 5.4 & 5.5384 & TRN \\
\hline CHEMBL1517284 & 1479002 & 6.2 & 5.9482 & TRN \\
\hline CHEMBL3431372 & 1479002 & 6.5 & 6.5261 & TRN \\
\hline CHEMBL 3431373 & 1479002 & 5.1 & 5.36 & TRN \\
\hline CHEMBL 3431374 & 1479002 & 6.2 & 5.9442 & TRN \\
\hline CHEMBL3431375 & 1479002 & 6.85 & 6.666 & TST \\
\hline CHEMBL3431376 & 1479002 & 7.0 & 7.0116 & TRN \\
\hline
\end{tabular}

TRN 


\begin{tabular}{|c|c|c|c|c|c|}
\hline \multicolumn{6}{|c|}{ Supplemental Table S2.txt } \\
\hline CHEMBL1365653 & 1479002 & 5.9 & 5.6312 & TRN & \\
\hline CHEMBL3431377 & 1479002 & 4.6 & 4.8465 & TRN & \\
\hline CHEMBL3431378 & 1479002 & 5.55 & 5.6673 & TRN & \\
\hline CHEMBL3431379 & 1479002 & 4.9 & 4.965 & TRN & \\
\hline CHEMBL1478826 & 1479002 & 5.9 & 6.0061 & TRN & \\
\hline CHEMBL1872842 & 1479002 & 6.25 & 6.1576 & TRN & \\
\hline CHEMBL3431380 & 1479002 & 6.4 & 6.4939 & TRN & \\
\hline CHEMBL3431381 & 1479002 & 7.1 & 6.6252 & TRN & \\
\hline CHEMBL3431382 & 1479002 & 5.5 & 5.5125 & TRN & \\
\hline CHEMBL3431383 & 1479002 & 5.1 & 4.949 & TRN & \\
\hline CHEMBL 3431384 & 1479002 & 4.85 & 5.1521 & TRN & \\
\hline CHEMBL3431385 & 1479002 & 3.3 & 3.6453 & TRN & \\
\hline CHEMBL3431386 & 1479002 & 5.2 & 5.3843 & TRN & \\
\hline CHEMBL1730515 & 1479002 & 6.7 & 6.6457 & TRN & \\
\hline CHEMBL3431387 & 1479002 & 6.6 & 6.845 & TRN & \\
\hline CHEMBL3431388 & 1479002 & 6.0 & 5.87799 & 9999999999 & TRN \\
\hline CHEMBL1566898 & 1479002 & 5.0 & 5.1026 & TRN & \\
\hline CHEMBL3431389 & 1479002 & 4.6 & 4.9679 & TRN & \\
\hline CHEMBL3431390 & 1479002 & 5.3 & 5.5122 & TST & \\
\hline CHEMBL3431391 & 1479002 & 4.4 & 3.8139 & TRN & \\
\hline CHEMBL1489081 & 1479002 & 6.2 & 6.2932 & TRN & \\
\hline CHEMBL3431392 & 1479002 & 3.3 & 3.7208 & TRN & \\
\hline CHEMBL3431393 & 1479002 & 5.9 & 5.7859 & TRN & \\
\hline CHEMBL3431394 & 1479002 & 5.3 & 5.3015 & TRN & \\
\hline CHEMBL3431395 & 1479002 & 5.6 & 4.9402 & TRN & \\
\hline CHEMBL3431396 & 1479002 & 5.5 & 4.9029 & TRN & \\
\hline CHEMBL3431397 & 1479002 & 6.2 & 6.697 & TRN & \\
\hline CHEMBL3431398 & 1479002 & 4.9 & 5.1703 & TRN & \\
\hline CHEMBL3431399 & 1479002 & 5.8 & 5.5462 & TST & \\
\hline CHEMBL3431400 & 1479002 & 7.0 & 6.9381 & TST & \\
\hline CHEMBL1418463 & 1479002 & 5.6 & 5.8447 & TST & \\
\hline CHEMBL 3431401 & 1479002 & 4.9 & 4.967 & TST & \\
\hline CHEMBL3431402 & 1479002 & 5.5 & 5.4476 & TST & \\
\hline CHEMBL3431403 & 1479002 & 5.7 & 5.1375 & TST & \\
\hline CHEMBL 3431404 & 1479002 & 5.8 & 5.8375 & TST & \\
\hline CHEMBL3431405 & 1479002 & 6.9 & 6.7045 & TST & \\
\hline CHEMBL3431406 & 1479002 & 5.7 & 6.0315 & TST & \\
\hline CHEMBL3431407 & 1479002 & 6.3 & 6.2262 & TST & \\
\hline CHEMBL 3431408 & 1479002 & 6.85 & 7.001 & TST & \\
\hline CHEMBL3431409 & 1479002 & 5.75 & 5.5652 & TST & \\
\hline CHEMBL3431410 & 1479002 & 6.6 & 6.2134 & TST & \\
\hline CHEMBL3431411 & 1479002 & 5.9 & 5.1164 & TST & \\
\hline CHEMBL3431412 & 1479002 & 6.45 & 6.1461 & TST & \\
\hline CHEMBL3431413 & 1479002 & 4.4 & 4.9282 & TST & \\
\hline CHEMBL3431414 & 1479002 & 6.5 & 6.4544 & TST & \\
\hline CHEMBL3431415 & 1479002 & 6.6 & 6.4765 & TST & \\
\hline CHEMBL3431416 & 1479002 & 6.75 & 6.6429 & TST & \\
\hline CHEMBL291721 & 1479002 & 5.9 & 5.3176 & TST & \\
\hline
\end{tabular}




\begin{tabular}{|c|c|c|c|c|c|}
\hline CHEMBL3431417 & 1479002 & 5.6 & 5.5546 & TST & \\
\hline CHEMBL3431418 & 1479002 & 6.6 & \multicolumn{2}{|c|}{6.957000000000001} & TST \\
\hline CHEMBL487186 & 1479002 & 6.9 & 6.7919 & TST & \\
\hline CHEMBL3431419 & 1479002 & 6.4 & 6.2413 & TST & \\
\hline CHEMBL3431420 & 1479002 & 6.6 & 6.1616 & TST & \\
\hline CHEMBL3431421 & 1479002 & 6.4 & 5.9728 & TST & \\
\hline CHEMBL3431422 & 1479002 & 4.5 & 5.4671 & TST & \\
\hline CHEMBL3431423 & 1479002 & 3.3 & 3.7985 & TST & \\
\hline CHEMBL3431424 & 1479002 & 6.4 & 6.4328 & TST & \\
\hline CHEMBL3431425 & 1479002 & 5.5 & 5.2678 & TST & \\
\hline CHEMBL3431426 & 1479002 & 6.2 & 6.2646 & TST & \\
\hline CHEMBL3431427 & 1479002 & 6.1 & 6.4608 & TST & \\
\hline CHEMBL3431428 & 1479002 & 4.6 & 4.9016 & TST & \\
\hline CHEMBL1725748 & 1479002 & 5.7 & 5.5881 & TST & \\
\hline CHEMBL3430918 & 1479002 & 6.4 & 6.3434 & TST & \\
\hline CHEMBL522630 & 1479002 & 6.8 & 6.0088 & TST & \\
\hline CHEMBL3431429 & 1479002 & 5.9 & 4.5301 & TST & \\
\hline CHEMBL523468 & 1479002 & 5.9 & 6.0367 & TST & \\
\hline CHEMBL3431430 & 1479002 & 6.7 & 6.3221 & TST & \\
\hline CHEMBL128672 & 1479002 & 6.45 & 5.8638 & TST & \\
\hline CHEMBL491149 & 1479002 & 6.7 & 6.4772 & TST & \\
\hline CHEMBL 3431431 & 1479002 & 5.6 & 5.8446 & TST & \\
\hline CHEMBL3431432 & 1479002 & 5.7 & 6.0087 & TST & \\
\hline CHEMBL3431433 & 1479002 & 7.3 & 6.6189 & TST & \\
\hline CHEMBL 3431434 & 1479002 & 7.4 & 7.0014 & TST & \\
\hline CHEMBL3431435 & 1479002 & 7.6 & 6.8702 & TST & \\
\hline CHEMBL3431436 & 1479002 & 5.6 & 5.7255 & TST & \\
\hline CHEMBL 3431437 & 1479002 & 3.3 & 4.332 & TST & \\
\hline CHEMBL3431438 & 1479002 & 6.2 & 5.7869 & TST & \\
\hline CHEMBL3431439 & 1479002 & 3.3 & 4.8544 & TST & \\
\hline CHEMBL 3431440 & 1479002 & 5.8 & 6.0268 & TST & \\
\hline CHEMBL 3431441 & 1479002 & 5.2 & 5.4455 & TST & \\
\hline CHEMBL 3431442 & 1479002 & 5.1 & 5.0667 & TST & \\
\hline CHEMBL3431443 & 1479002 & 6.6 & 6.3207 & TST & \\
\hline CHEMBL 3431444 & 1479002 & 5.6 & 5.0619 & TST & \\
\hline CHEMBL3431445 & 1479002 & 4.5 & 5.17899 & 9999999999 & TST \\
\hline CHEMBL543596 & 201266 & 6.5528 & 6.1882 & TRN & \\
\hline CHEMBL553817 & 201266 & 7.7447 & 8.0675 & TRN & \\
\hline CHEMBL280243 & 201266 & 7.1871 & 7.2813 & TRN & \\
\hline CHEMBL81773 & 201266 & 8.2218 & 8.2659 & TRN & \\
\hline CHEMBL543355 & 201266 & 6.9508 & 7.6699 & TRN & \\
\hline CHEMBL78928 & 201266 & 5.9208 & 6.2228 & TRN & \\
\hline CHEMBL77675 & 201266 & 6.4012 & 6.3814 & TRN & \\
\hline CHEMBL79164 & 201266 & 7.9208 & 7.8723 & TRN & \\
\hline CHEMBL 82247 & 201266 & 6.0362 & 5.8845 & TRN & \\
\hline CHEMBL543839 & 201266 & 6.6925 & 7.1633 & TRN & \\
\hline CHEMBL553896 & 201266 & 8.2218 & 8.3092 & TRN & \\
\hline CHEMBL79436 & 201266 & 7.4318 & 6.7521 & TRN & \\
\hline
\end{tabular}




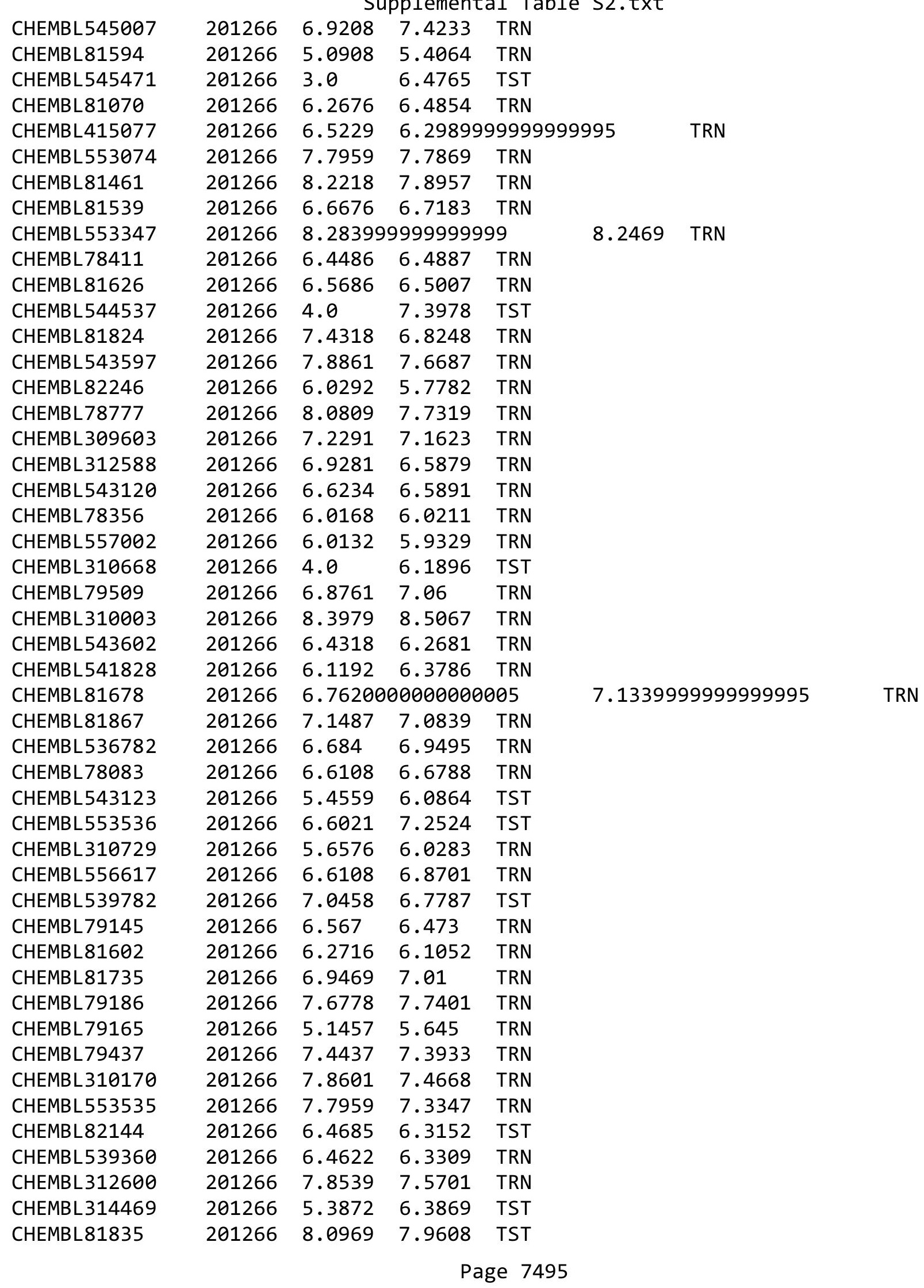




\begin{tabular}{|c|c|c|c|c|c|c|}
\hline & & \multicolumn{5}{|c|}{ Supplemental Table S2.txt } \\
\hline CHEMBL79665 & 201266 & 7.6021 & 7.8715 & TST & & \\
\hline CHEMBL78585 & 201266 & 6.3344 & 6.9054 & TST & & \\
\hline CHEMBL80081 & 201266 & 6.1249 & 6.7313 & TST & & \\
\hline CHEMBL 282433 & 201266 & 7.4949 & 7.0594 & TST & & \\
\hline CHEMBL 78488 & 201266 & 7.5229 & 7.2238 & TST & & \\
\hline CHEMBL540291 & 201266 & 7.8239 & 7.7611 & TST & & \\
\hline CHEMBL78306 & 201266 & 7.2306 & 7.1169 & TST & & \\
\hline CHEMBL82078 & 201266 & 7.1135 & 7.1184 & TST & & \\
\hline CHEMBL556021 & 201266 & 7.6757 & 7.2926 & TST & & \\
\hline CHEMBL65 & 954808 & 7.8027 & 7.8532 & TRN & & \\
\hline CHEMBL483849 & 954808 & 1.9914 & 2.9496 & TST & & \\
\hline CHEMBL188678 & 954808 & 3.9077 & 3.8985 & TRN & & \\
\hline CHEMBL393929 & 954808 & 4.34 & 4.4072 & TRN & & \\
\hline CHEMBL 222102 & 954808 & 3.1955 & 3.1886 & TRN & & \\
\hline CHEMBL210618 & 954808 & 4.117 & 4.0871 & TRN & & \\
\hline CHEMBL 258844 & 954808 & 6.0056 & 5.9621 & TRN & & \\
\hline CHEMBL1256459 & 954808 & 7.1443 & 7.0989 & TRN & & \\
\hline CHEMBL9470 & 954808 & 4.9753 & 5.3803 & TST & & \\
\hline CHEMBL1643959 & 954808 & 4.9733 & 5.0101 & TRN & & \\
\hline CHEMBL 300389 & 954808 & 5.9018 & 5.8726 & TRN & & \\
\hline CHEMBL512504 & 954808 & 4.1382 & 4.1256 & TRN & & \\
\hline CHEMBL3392440 & 954808 & 3.6843 & 3.5994 & TRN & & \\
\hline CHEMBL1788116 & 954808 & 4.9098 & 4.9117 & TRN & & \\
\hline CHEMBL577784 & 954808 & 4.9764 & 4.9263 & TRN & & \\
\hline CHEMBL240954 & 954808 & 3.6006 & 3.9874 & TST & & \\
\hline CHEMBL192566 & 954808 & 7.8573 & 6.6218 & TST & & \\
\hline CHEMBL514499 & 954808 & 4.9089 & 4.9058 & TRN & & \\
\hline CHEMBL102714 & 954808 & 4.1072 & 4.1774 & TRN & & \\
\hline CHEMBL1357247 & 954808 & 3.9613 & 3.9868 & TRN & & \\
\hline CHEMBL2134202 & 954808 & 4.9631 & 5.0033 & TRN & & \\
\hline CHEMBL 259181 & 954808 & 5.166 & 5.1291 & TRN & & \\
\hline CHEMBL 202721 & 954808 & 4.5263 & 4.5787 & TRN & & \\
\hline CHEMBL2363137 & 954808 & 6.0227 & 6.0185 & TRN & & \\
\hline CHEMBL1970879 & 954808 & 4.5386 & 4.5993 & TRN & & \\
\hline CHEMBL 209148 & 954808 & 3.5314 & 3.5161 & TRN & & \\
\hline CHEMBL472940 & 954808 & 2.8593 & 2.8425 & TRN & & \\
\hline CHEMBL392695 & 954808 & 5.2204 & 5.1952 & TRN & & \\
\hline CHEMBL1590308 & 954808 & 2.78899 & 99999999 & 997 & 4.2293 & TST \\
\hline CHEMBL1909414 & 954808 & 4.1764 & 4.1943 & TRN & & \\
\hline CHEMBL558642 & 954808 & 2.7148 & 2.7444 & TRN & & \\
\hline CHEMBL509032 & 954808 & 4.9831 & 4.9694 & TRN & & \\
\hline CHEMBL92309 & 954808 & 4.0167 & 3.3715 & TST & & \\
\hline CHEMBL 379300 & 954808 & 6.4426 & 6.4531 & TRN & & \\
\hline CHEMBL1404918 & 954808 & 3.1713 & 3.2323 & TRN & & \\
\hline CHEMBL1186585 & 954808 & 5.3003 & 5.1942 & TRN & & \\
\hline CHEMBL1230020 & 954808 & 3.8293 & 3.8315 & TRN & & \\
\hline CHEMBL135561 & 954808 & 4.4525 & 4.5096 & TRN & & \\
\hline CHEMBL585951 & 954808 & 6.1494 & 6.2226 & TRN & & \\
\hline
\end{tabular}


Supplemental Table S2.txt

\begin{tabular}{|c|c|c|c|c|}
\hline CHEMBL3349342 & 954808 & 4.9113 & 4.9008 & TRN \\
\hline CHEMBL221137 & 954808 & 3.1172 & 4.9406 & TST \\
\hline CHEMBL1242367 & 954808 & 4.3858 & 4.4291 & TRN \\
\hline CHEMBL255342 & 954808 & 3.9623 & 3.9234 & TRN \\
\hline CHEMBL573107 & 954808 & 4.6698 & 4.6765 & TRN \\
\hline CHEMBL220241 & 954808 & 5.0739 & 5.1188 & TRN \\
\hline CHEMBL1673039 & 954808 & 4.4693 & 4.4372 & TRN \\
\hline CHEMBL 2137530 & 954808 & 5.4891 & \multicolumn{2}{|c|}{5.4670000000000005} \\
\hline CHEMBL449158 & 954808 & 7.1109 & 6.651 & TST \\
\hline CHEMBL217354 & 954808 & 6.2868 & 6.3287 & TRN \\
\hline CHEMBL1516890 & 954808 & 4.998 & 4.8987 & TRN \\
\hline CHEMBL213100 & 954808 & 3.5845 & 3.5941 & TRN \\
\hline CHEMBL379975 & 954808 & 4.6262 & 4.6439 & TRN \\
\hline CHEMBL 2005886 & 954808 & 4.3839 & 4.2955 & TRN \\
\hline CHEMBL 3186408 & 954808 & 3.265 & 4.3035 & TST \\
\hline CHEMBL189584 & 954808 & 3.8247 & 3.8027 & TRN \\
\hline CHEMBL1190711 & 954808 & 3.2331 & 3.2748 & TRN \\
\hline CHEMBL412142 & 954808 & 4.8733 & 4.8566 & TRN \\
\hline CHEMBL3199475 & 954808 & 3.9186 & 4.7117 & TST \\
\hline CHEMBL515416 & 954808 & 3.6919 & 4.4574 & TST \\
\hline CHEMBL483847 & 954808 & 3.865 & 4.5968 & TST \\
\hline CHEMBL399530 & 954808 & 5.0536 & 4.8897 & TST \\
\hline CHEMBL180127 & 954808 & 3.7794 & 4.4838 & TST \\
\hline CHEMBL373751 & 954808 & 3.2859 & 4.1019 & TST \\
\hline CHEMBL 2144069 & 954808 & 4.6702 & 5.0816 & TST \\
\hline CHEMBL191334 & 954808 & 3.3602 & 4.341 & TST \\
\hline CHEMBL600074 & 613320 & 4.0706 & 3.8156 & TRN \\
\hline CHEMBL592179 & 613320 & 4.3468 & 4.2999 & TRN \\
\hline CHEMBL591001 & 613320 & 2.699 & 3.3919 & TRN \\
\hline CHEMBL600073 & 613320 & 3.8508 & 3.6758 & TRN \\
\hline CHEMBL591479 & 613320 & 2.699 & 3.4978 & TST \\
\hline CHEMBL601403 & 613320 & 2.699 & 3.5487 & TRN \\
\hline CHEMBL202173 & 613320 & 3.699 & 3.0827 & TRN \\
\hline CHEMBL591944 & 613320 & 3.8153 & 4.1769 & TRN \\
\hline CHEMBL589795 & 613320 & 4.3768 & 3.8954 & TRN \\
\hline CHEMBL506666 & 613320 & 3.8962 & 3.4382 & TRN \\
\hline CHEMBL589557 & 613320 & 4.0915 & 3.7613 & TRN \\
\hline CHEMBL592655 & 613320 & 2.699 & 3.0132 & TRN \\
\hline CHEMBL590996 & 613320 & 3.7122 & 3.9245 & TRN \\
\hline CHEMBL591006 & 613320 & 2.699 & 3.1045 & TRN \\
\hline CHEMBL600847 & 613320 & 4.1549 & 3.9795 & TRN \\
\hline CHEMBL589491 & 613320 & 2.699 & 3.1375 & TRN \\
\hline CHEMBL589075 & 613320 & 4.1079 & 4.1068 & TRN \\
\hline CHEMBL589796 & 613320 & 4.1871 & 4.3472 & TRN \\
\hline CHEMBL592444 & 613320 & 4.1367 & 3.9347 & TRN \\
\hline CHEMBL1989922 & 613320 & 4.5086 & 3.9257 & TST \\
\hline CHEMBL591735 & 613320 & 4.4815 & 4.4848 & TRN \\
\hline CHEMBL589798 & 613320 & 3.7986 & 3.9906 & TRN \\
\hline
\end{tabular}


Supplemental Table S2.txt

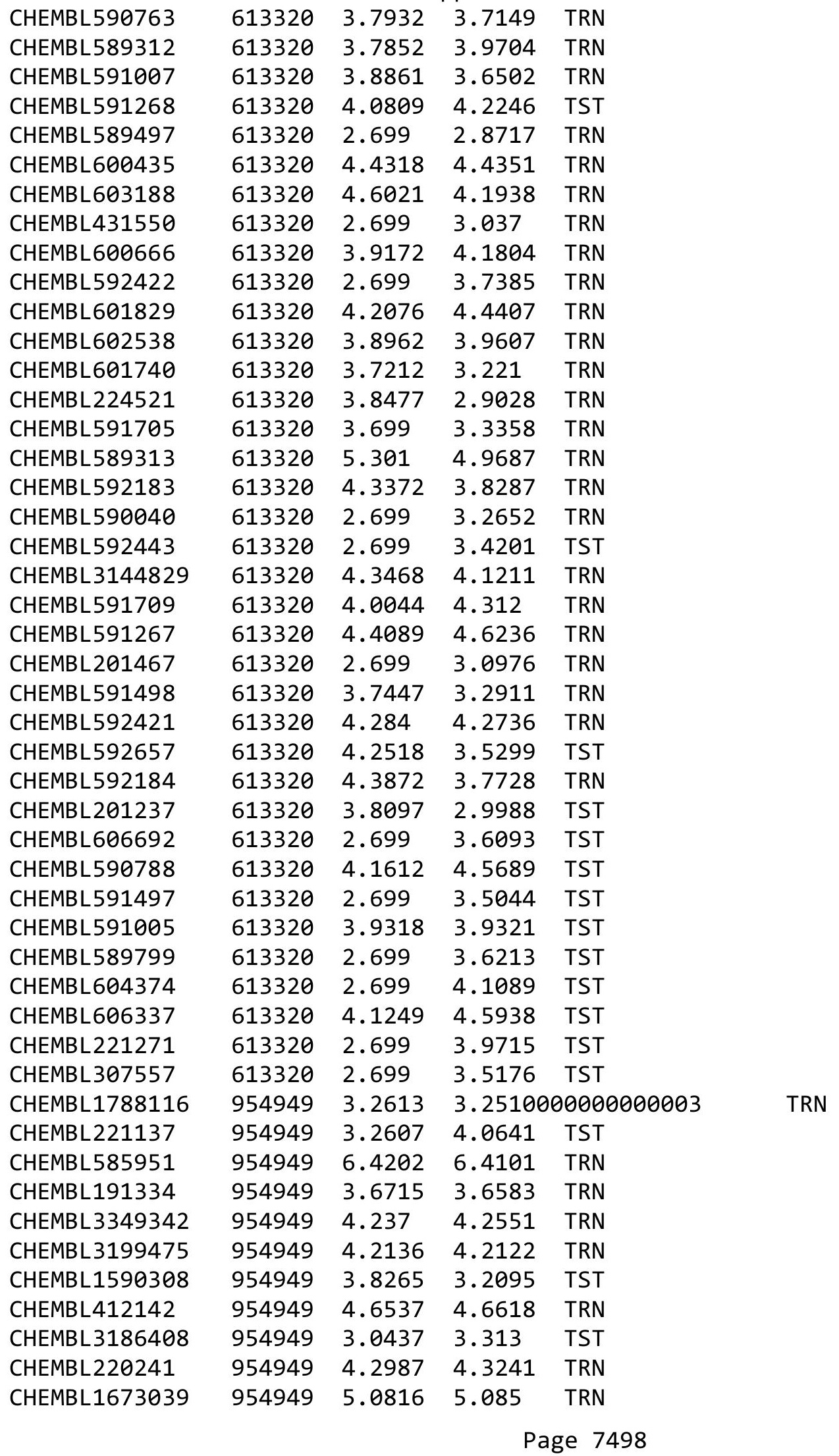




\begin{tabular}{|c|c|c|c|c|c|c|}
\hline & & \multicolumn{5}{|c|}{ Supplemental Table S2.txt } \\
\hline CHEMBL392695 & 954949 & 5.3783 & 5.3143 & TRN & & \\
\hline CHEMBL202721 & 954949 & 3.7696 & 3.7788 & TRN & & \\
\hline CHEMBL259181 & 954949 & 3.6691 & 3.6224 & TRN & & \\
\hline CHEMBL2363137 & 954949 & 3.3221 & 3.3216 & TRN & & \\
\hline CHEMBL1643959 & 954949 & 3.3148 & 3.3075 & TRN & & \\
\hline CHEMBL379975 & 954949 & 5.4126 & 5.41 & TRN & & \\
\hline CHEMBL189584 & 954949 & 4.667 & 4.6762 & TRN & & \\
\hline CHEMBL577784 & 954949 & 4.0731 & 4.055 & TRN & & \\
\hline CHEMBL558642 & 954949 & 2.8748 & 2.8527 & TRN & & \\
\hline CHEMBL3392440 & 954949 & 3.2672 & 3.2867 & TRN & & \\
\hline CHEMBL 209148 & 954949 & 4.5132 & 4.5232 & TRN & & \\
\hline CHEMBL1190711 & 954949 & 4.3298 & 4.3221 & TRN & & \\
\hline CHEMBL1909414 & 954949 & 3.8779 & 3.8914 & TRN & & \\
\hline CHEMBL515416 & 954949 & 3.6448 & 3.665 & TRN & & \\
\hline CHEMBL180127 & 954949 & 3.5064 & 3.5169 & TRN & & \\
\hline CHEMBL1230020 & 954949 & 4.3634 & 4.381 & TRN & & \\
\hline CHEMBL379300 & 954949 & 6.3254 & 6.3437 & TRN & & \\
\hline CHEMBL258844 & 954949 & 3.2614 & 3.2515 & TRN & & \\
\hline CHEMBL 373751 & 954949 & 3.1234 & 3.1373 & TRN & & \\
\hline CHEMBL512504 & 954949 & 6.0231 & 5.9985 & TRN & & \\
\hline CHEMBL240954 & 954949 & 4.8241 & 3.5271 & TST & & \\
\hline CHEMBL1970879 & 954949 & 3.303 & 3.2768 & TRN & & \\
\hline CHEMBL188678 & 954949 & 5.1351 & 5.1394 & TRN & & \\
\hline CHEMBL222102 & 954949 & 4.3339 & 4.3484 & TRN & & \\
\hline CHEMBL483847 & 954949 & 4.0803 & 4.1086 & TRN & & \\
\hline CHEMBL192566 & 954949 & 7.4481 & 6.4614 & TST & & \\
\hline CHEMBL135561 & 954949 & 3.9516 & 3.986 & TRN & & \\
\hline CHEMBL573107 & 954949 & 4.5611 & 4.5766 & TRN & & \\
\hline CHEMBL65 & 954949 & 5.5387 & 5.5709 & TRN & & \\
\hline CHEMBL 9470 & 954949 & 6.0972 & 5.1522 & TST & & \\
\hline CHEMBL 213100 & 954949 & 3.4032 & 3.3818 & TRN & & \\
\hline CHEMBL449158 & 954949 & 5.9286 & 6.0673 & TST & & \\
\hline CHEMBL472940 & 954949 & 2.8313 & 2.8437 & TRN & & \\
\hline CHEMBL92309 & 954949 & 4.00899 & 99999999 & 995 & 2.8198 & TST \\
\hline CHEMBL2005886 & 954949 & 5.4149 & 5.401 & TRN & & \\
\hline CHEMBL483849 & 954949 & 1.5019 & 1.4955 & TRN & & \\
\hline CHEMBL2144069 & 954949 & 3.2354 & 3.2287 & TRN & & \\
\hline CHEMBL393929 & 954949 & 3.6576 & 3.6391 & TRN & & \\
\hline CHEMBL1256459 & 954949 & 6.9125 & 6.9204 & TRN & & \\
\hline CHEMBL514499 & 954949 & 7.0254 & 7.0029 & TRN & & \\
\hline CHEMBL1516890 & 954949 & 4.2294 & 4.2373 & TRN & & \\
\hline CHEMBL210618 & 954949 & 4.3507 & 3.2903 & TST & & \\
\hline CHEMBL509032 & 954949 & 7.6227 & 4.9857 & TST & & \\
\hline CHEMBL1357247 & 954949 & 2.8493 & 2.5864 & TST & & \\
\hline CHEMBL1242367 & 954949 & 3.7782 & 3.5473 & TST & & \\
\hline CHEMBL 300389 & 954949 & 7.5352 & 6.1844 & TST & & \\
\hline CHEMBL1404918 & 954949 & 3.0006 & 2.2184 & TST & & \\
\hline CHEMBL102714 & 954949 & 4.0893 & 4.1394 & TST & & \\
\hline
\end{tabular}




\begin{tabular}{|c|c|c|c|c|c|}
\hline \multicolumn{6}{|c|}{ Supplemental Table S2.txt } \\
\hline CHEMBL 2234537 & 902584 & 6.22 & 5.2755 & TST & \\
\hline CHEMBL 2234536 & 902584 & 6.66 & 5.6368 & TST & \\
\hline CHEMBL 2234535 & 902584 & 6.64 & 5.3094 & TST & \\
\hline CHEMBL 2234534 & 902584 & 6.27 & 5.5913 & TST & \\
\hline CHEMBL 2234533 & 902584 & 6.49 & 5.3668 & TST & \\
\hline CHEMBL490359 & 902584 & 7.35 & 7.2624 & TRN & \\
\hline CHEMBL 2234532 & 902584 & 7.21 & 7.0944 & TRN & \\
\hline CHEMBL 2234531 & 902584 & 6.8 & 6.7757 & TRN & \\
\hline CHEMBL 2234530 & 902584 & 7.04 & 6.9865 & TRN & \\
\hline CHEMBL 2234529 & 902584 & 6.22 & 6.2591 & TRN & \\
\hline CHEMBL 2234528 & 902584 & 6.96 & 7.0698 & TRN & \\
\hline CHEMBL 2234527 & 902584 & 6.52 & 6.6203 & TST & \\
\hline CHEMBL 2234526 & 902584 & 7.28 & 7.3471 & TRN & \\
\hline CHEMBL 2234525 & 902584 & 7.1 & 7.1286 & TRN & \\
\hline CHEMBL 2234524 & 902584 & 4.39 & 4.4491 & TRN & \\
\hline CHEMBL 2234523 & 902584 & 4.67 & 3.9539 & TST & \\
\hline CHEMBL 2234522 & 902584 & 5.15 & 4.2436 & TST & \\
\hline CHEMBL 2234521 & 902584 & 4.29 & 4.2583 & TST & \\
\hline CHEMBL 2234520 & 902584 & 4.03 & 3.6997 & TST & \\
\hline CHEMBL 2234519 & 902584 & 4.92 & 4.0957 & TST & \\
\hline CHEMBL 2234518 & 902584 & 4.75 & 4.1221 & TST & \\
\hline CHEMBL 2234517 & 902584 & 4.16 & 4.7233 & TST & \\
\hline CHEMBL 2234516 & 902584 & 4.31 & 4.2344 & TST & \\
\hline CHEMBL 2234515 & 902584 & 5.67 & 5.70200 & 0000000001 & TRN \\
\hline CHEMBL 2234514 & 902584 & 5.73 & 5.7158 & TRN & \\
\hline CHEMBL 2234513 & 902584 & 5.41 & 5.3874 & TRN & \\
\hline CHEMBL 2234512 & 902584 & 5.41 & 5.1608 & TRN & \\
\hline CHEMBL 2234511 & 902584 & 5.72 & 5.5212 & TRN & \\
\hline CHEMBL 2234845 & 902584 & 5.46 & 5.4655 & TRN & \\
\hline CHEMBL 2234844 & 902584 & 5.71 & 5.8572 & TRN & \\
\hline CHEMBL 2234843 & 902584 & 5.74 & 5.7254 & TRN & \\
\hline CHEMBL 2234842 & 902584 & 5.81 & 5.9259 & TRN & \\
\hline CHEMBL 2234841 & 902584 & 4.48 & 4.5851 & TRN & \\
\hline CHEMBL 2234840 & 902584 & 4.68 & 4.7018 & TRN & \\
\hline CHEMBL2234839 & 902584 & 4.89 & 4.6955 & TRN & \\
\hline CHEMBL 2234838 & 902584 & 5.34 & 5.3064 & TRN & \\
\hline CHEMBL 2234837 & 902584 & 5.11 & 5.3927 & TRN & \\
\hline CHEMBL 2234836 & 902584 & 4.57 & 4.5968 & TRN & \\
\hline CHEMBL 2234835 & 902584 & 4.62 & 4.6971 & TRN & \\
\hline CHEMBL 2234834 & 902584 & 4.84 & 4.7205 & TST & \\
\hline CHEMBL 2234833 & 902584 & 4.49 & 4.4439 & TRN & \\
\hline CHEMBL 2234832 & 902584 & 5.07 & 5.046 & TRN & \\
\hline CHEMBL 2234831 & 902584 & 5.77 & 5.7744 & TRN & \\
\hline CHEMBL 2234830 & 902584 & 4.61 & 5.431 & TST & \\
\hline CHEMBL2234829 & 902584 & 5.15 & 5.1515 & TRN & \\
\hline CHEMBL 2234547 & 902584 & 5.52 & 5.7539 & TRN & \\
\hline CHEMBL 2234546 & 902584 & 6.06 & 5.9171 & TRN & \\
\hline CHEMBL 2234545 & 902584 & 4.56 & 4.7181 & TST & \\
\hline
\end{tabular}




\begin{tabular}{|c|c|c|c|c|c|}
\hline \multicolumn{6}{|c|}{ Supplemental Table S2.txt } \\
\hline CHEMBL 2234544 & 902584 & 5.18 & 5.0584 & TRN & \\
\hline CHEMBL252378 & 902584 & 5.87 & 5.0209 & TRN & \\
\hline CHEMBL253603 & 902584 & 5.05 & 5.7596 & TRN & \\
\hline CHEMBL398250 & 902584 & 4.86 & 5.0285 & TRN & \\
\hline CHEMBL253602 & 902584 & 4.68 & 4.8924 & TRN & \\
\hline CHEMBL398249 & 902584 & 4.92 & 4.8762 & TRN & \\
\hline CHEMBL252781 & 902584 & 5.92 & 5.9922 & TRN & \\
\hline CHEMBL 2234543 & 902584 & 4.77 & 5.0209 & TRN & \\
\hline CHEMBL 2234542 & 902584 & 4.77 & 4.8924 & TRN & \\
\hline CHEMBL 2234541 & 902584 & 4.85 & 5.0807 & TRN & \\
\hline CHEMBL 2234540 & 902584 & 4.72 & 4.8725 & TRN & \\
\hline CHEMBL252578 & 902584 & 5.27 & 5.38399 & 99999999995 & TRN \\
\hline CHEMBL252580 & 902584 & 5.19 & 5.1342 & TRN & \\
\hline CHEMBL 2234539 & 902584 & 4.66 & 5.178 & TST & \\
\hline CHEMBL 2234538 & 902584 & 4.89 & 4.8713 & TRN & \\
\hline CHEMBL400675 & 902584 & 6.03 & 5.8272 & TRN & \\
\hline CHEMBL252579 & 902584 & 5.89 & 5.5938 & TRN & \\
\hline CHEMBL252380 & 902584 & 6.15 & 6.0922 & TRN & \\
\hline CHEMBL252379 & 902584 & 5.89 & 5.8846 & TRN & \\
\hline CHEMBL399040 & 902584 & 5.92 & 5.891 & TRN & \\
\hline CHEMBL404407 & 902584 & 5.29 & 5.1456 & TRN & \\
\hline CHEMBL253783 & 902584 & 5.85 & 5.8758 & TRN & \\
\hline CHEMBL253782 & 902584 & 5.09 & 5.1685 & TRN & \\
\hline CHEMBL253386 & 902584 & 6.09 & 5.6414 & TRN & \\
\hline CHEMBL3716647 & 1536992 & 6.0 & 5.6332 & TRN & \\
\hline CHEMBL3716508 & 1536992 & 4.0 & 5.7784 & TRN & \\
\hline CHEMBL3717588 & 1536992 & 6.0 & 5.2355 & TRN & \\
\hline CHEMBL3714911 & 1536992 & 4.0 & 5.267 & TRN & \\
\hline CHEMBL3715305 & 1536992 & 6.0 & 5.3796 & TRN & \\
\hline CHEMBL3717392 & 1536992 & 4.0 & 5.4995 & TRN & \\
\hline CHEMBL3715749 & 1536992 & 6.0 & 5.9599 & TST & \\
\hline CHEMBL3718786 & 1536992 & 6.0 & 5.6896 & TRN & \\
\hline CHEMBL3715752 & 1536992 & 6.0 & 5.9395 & TRN & \\
\hline CHEMBL 3715144 & 1536992 & 4.0 & 4.8358 & TRN & \\
\hline CHEMBL 3717062 & 1536992 & 6.0 & 6.1934 & TRN & \\
\hline CHEMBL3715395 & 1536992 & 6.0 & 5.5924 & TRN & \\
\hline CHEMBL3719372 & 1536992 & 6.0 & 5.2828 & TRN & \\
\hline CHEMBL3718504 & 1536992 & 6.0 & 5.9668 & TST & \\
\hline CHEMBL3716838 & 1536992 & 6.0 & 5.9667 & TRN & \\
\hline CHEMBL3715306 & 1536992 & 6.0 & 5.9515 & TRN & \\
\hline CHEMBL3719350 & 1536992 & 6.0 & 5.9494 & TRN & \\
\hline CHEMBL3719303 & 1536992 & 6.0 & 5.76399 & 9999999999 & TRN \\
\hline CHEMBL3714786 & 1536992 & 6.0 & 5.9326 & TRN & \\
\hline CHEMBL 3717256 & 1536992 & 6.0 & 5.6865 & TRN & \\
\hline CHEMBL 3715245 & 1536992 & 6.0 & 5.75 & TRN & \\
\hline CHEMBL3716458 & 1536992 & 6.0 & 6.1762 & TRN & \\
\hline CHEMBL3716796 & 1536992 & 6.0 & 5.5928 & TRN & \\
\hline CHEMBL3718833 & 1536992 & 6.0 & 5.8838 & TRN & \\
\hline
\end{tabular}




\begin{tabular}{|c|c|c|c|c|}
\hline \\
\hline CHEMBL3719038 & 15369926.0 & 6.1536 & & \\
\hline CHEMBL3716034 & 15369926.0 & 5.7257 & TRN & \\
\hline CHEMBL3719132 & 15369926.0 & 6.0713 & TRN & \\
\hline CHEMBL 3717141 & 15369926.0 & 6.1931 & TRN & \\
\hline CHEMBL 3719324 & 15369924.0 & 5.1024 & TRN & \\
\hline CHEMBL3717372 & 15369926.0 & 5.8993 & TRN & \\
\hline CHEMBL3717072 & 15369926.0 & 5.8886 & TRN & \\
\hline CHEMBL3715012 & 15369926.0 & 5.7902 & TRN & \\
\hline CHEMBL 3717637 & 15369924.0 & 4.5023 & TRN & \\
\hline CHEMBL3717777 & 15369926.0 & 5.6997 & TRN & \\
\hline CHEMBL3716007 & 15369926.0 & 5.2933 & TRN & \\
\hline CHEMBL3716009 & 15369926.0 & 5.6362 & TRN & \\
\hline CHEMBL 3717400 & 15369926.0 & 5.7661 & TRN & \\
\hline CHEMBL 3715277 & 15369926.0 & 5.8515 & TST & \\
\hline CHEMBL3716004 & 15369926.0 & 6.0627 & TRN & \\
\hline CHEMBL3718072 & 15369926.0 & 5.1569 & TRN & \\
\hline CHEMBL3718184 & 15369926.0 & 5.6734 & TRN & \\
\hline CHEMBL 3717587 & 15369924.0 & 4.4328 & TRN & \\
\hline CHEMBL 3717800 & 15369926.0 & 5.8396 & TRN & \\
\hline CHEMBL 3717434 & 15369926.0 & 6.0538 & TRN & \\
\hline CHEMBL3716356 & 15369926.0 & 5.5079 & TRN & \\
\hline CHEMBL3714936 & 15369926.0 & 6.1842 & TRN & \\
\hline CHEMBL 3718721 & 15369926.0 & 5.6727 & TRN & \\
\hline CHEMBL3717687 & 15369926.0 & 5.6944 & TRN & \\
\hline CHEMBL3718202 & 15369926.0 & 5.6488 & TRN & \\
\hline CHEMBL3717873 & 15369926.0 & 6.1999 & TRN & \\
\hline CHEMBL3718933 & 15369924.0 & 5.8468 & TRN & \\
\hline CHEMBL3715727 & 15369926.0 & 6.0171 & TRN & \\
\hline CHEMBL3719218 & 15369924.0 & 5.21899 & 9999999999 & TRN \\
\hline CHEMBL3716608 & 15369926.0 & 5.7717 & TRN & \\
\hline CHEMBL3718311 & 15369926.0 & 5.8417 & TRN & \\
\hline CHEMBL 3717173 & 15369926.0 & 6.0841 & TRN & \\
\hline CHEMBL3715315 & 15369926.0 & 5.933 & TST & \\
\hline CHEMBL 3715384 & 15369926.0 & 5.3579 & TRN & \\
\hline CHEMBL3715630 & 15369926.0 & 5.7592 & TST & \\
\hline CHEMBL3714956 & 15369926.0 & 5.8888 & TRN & \\
\hline CHEMBL3716003 & 15369926.0 & 6.0895 & TRN & \\
\hline CHEMBL3716589 & 15369924.0 & 5.1163 & TST & \\
\hline CHEMBL 3715940 & 15369926.0 & 5.6149 & TST & \\
\hline CHEMBL3718477 & 15369924.0 & 4.5295 & TRN & \\
\hline CHEMBL3715232 & 15369926.0 & 5.7378 & TRN & \\
\hline CHEMBL 3716381 & 15369926.0 & 6.1024 & TRN & \\
\hline CHEMBL3719099 & 15369926.0 & 5.8119 & TRN & \\
\hline CHEMBL3718613 & 15369924.0 & 4.9334 & TST & \\
\hline CHEMBL3715111 & 15369926.0 & 6.2625 & TRN & \\
\hline CHEMBL3715094 & 15369926.0 & 5.7316 & TRN & \\
\hline CHEMBL3717739 & 15369926.0 & 5.9418 & TRN & \\
\hline CHEMBL 3717429 & 15369926.0 & 4.6742 & TRN & \\
\hline
\end{tabular}




\begin{tabular}{|c|c|c|c|c|}
\hline \multicolumn{5}{|c|}{ Supplemental Table S2.tx } \\
\hline CHEMBL 3715280 & 1536992 & 6.0 & 5.7945 & TRN \\
\hline CHEMBL3718475 & 1536992 & 6.0 & 5.8547 & TRN \\
\hline CHEMBL3719187 & 1536992 & 6.0 & 5.6136 & TST \\
\hline CHEMBL3716856 & 1536992 & 6.0 & 6.0704 & TRN \\
\hline CHEMBL3718915 & 1536992 & 4.0 & 5.3806 & TST \\
\hline CHEMBL3715461 & 1536992 & 4.0 & 5.8682 & TRN \\
\hline CHEMBL3714937 & 1536992 & 6.0 & 5.6197 & TRN \\
\hline CHEMBL3716831 & 1536992 & 6.0 & 6.025 & TRN \\
\hline CHEMBL3718928 & 1536992 & 6.0 & 5.6784 & TRN \\
\hline CHEMBL3715729 & 1536992 & 6.0 & 5.2903 & TRN \\
\hline CHEMBL 3715734 & 1536992 & 6.0 & 6.0799 & TRN \\
\hline CHEMBL3716739 & 1536992 & 6.0 & 5.5713 & TRN \\
\hline CHEMBL 3718262 & 1536992 & 4.0 & 4.4101 & TRN \\
\hline CHEMBL3716419 & 1536992 & 6.0 & 5.5469 & TST \\
\hline CHEMBL3715239 & 1536992 & 6.0 & 5.9125 & TST \\
\hline CHEMBL3717491 & 1536992 & 6.0 & 5.4682 & TST \\
\hline CHEMBL 3717516 & 1536992 & 4.0 & 5.1987 & TST \\
\hline CHEMBL3716797 & 1536992 & 4.0 & 5.5628 & TST \\
\hline CHEMBL 3718125 & 1536992 & 6.0 & 5.8294 & TST \\
\hline CHEMBL3715197 & 1536992 & 6.0 & 5.8705 & TST \\
\hline CHEMBL3718154 & 1536992 & 6.0 & 5.7336 & TST \\
\hline CHEMBL3715675 & 1536992 & 4.0 & 4.5806 & TST \\
\hline CHEMBL3716353 & 1536992 & 6.0 & $5.7120 e$ & 0000000001 \\
\hline CHEMBL3715534 & 1536992 & 6.0 & 6.0982 & TST \\
\hline CHEMBL3718717 & 1536992 & 6.0 & 5.0055 & TST \\
\hline CHEMBL3716028 & 1536992 & 6.0 & 5.2106 & TST \\
\hline CHEMBL 3718878 & 1536992 & 4.0 & 4.6289 & TST \\
\hline CHEMBL3715308 & 1536992 & 6.0 & 5.2561 & TST \\
\hline CHEMBL 3718461 & 1536992 & 6.0 & 5.8514 & TST \\
\hline CHEMBL1098389 & 629753 & 6.1805 & 6.1983 & TRN \\
\hline CHEMBL1097656 & 629753 & 5.4093 & 5.4131 & TRN \\
\hline CHEMBL1095702 & 629753 & 6.1024 & 6.0327 & TRN \\
\hline CHEMBL1096712 & 629753 & 6.4559 & 6.4618 & TRN \\
\hline CHEMBL1097053 & 629753 & 5.3516 & 5.3675 & TRN \\
\hline CHEMBL1098725 & 629753 & 3.5229 & 6.3096 & TST \\
\hline CHEMBL1094461 & 629753 & 5.8697 & 5.8686 & TRN \\
\hline CHEMBL1094430 & 629753 & 3.5229 & 5.3353 & TST \\
\hline CHEMBL1094146 & 629753 & 5.4815 & 5.483 & TRN \\
\hline CHEMBL1095750 & 629753 & 5.9318 & 5.919 & TRN \\
\hline CHEMBL1094125 & 629753 & 4.5229 & 5.5873 & TST \\
\hline CHEMBL1094462 & 629753 & 5.9136 & 5.9306 & TRN \\
\hline CHEMBL1097397 & 629753 & 3.5229 & 3.5095 & TRN \\
\hline CHEMBL1096052 & 629753 & 3.5229 & 5.2964 & TST \\
\hline CHEMBL1098388 & 629753 & 5.4634 & 5.465 & TRN \\
\hline CHEMBL1095704 & 629753 & 4.5998 & 5.8989 & TST \\
\hline CHEMBL1094734 & 629753 & 3.5229 & 3.5252 & TRN \\
\hline CHEMBL1097378 & 629753 & 6.2291 & 6.2322 & TRN \\
\hline CHEMBL1094460 & 629753 & 5.2314 & 5.27 & TRN \\
\hline
\end{tabular}


Supplemental Table S2.txt

\begin{tabular}{|c|c|c|c|c|}
\hline CHEMBL1094145 & 629753 & 4.5229 & 4.5117 & TRN \\
\hline CHEMBL1094429 & 629753 & 3.5229 & 5.2891 & TST \\
\hline CHEMBL1096079 & 629753 & 4.5229 & 4.506 & TRN \\
\hline CHEMBL1094733 & 629753 & 6.4437 & 6.4238 & TRN \\
\hline CHEMBL1095746 & 629753 & 6.1192 & 6.1359 & TRN \\
\hline CHEMBL1094124 & 629753 & 5.7144 & 5.7063 & TRN \\
\hline CHEMBL1094416 & 629753 & 5.6596 & 5.6606 & TRN \\
\hline CHEMBL1098390 & 629753 & 3.5229 & 3.5175 & TRN \\
\hline CHEMBL1095745 & 629753 & 6.6021 & 6.6063 & TRN \\
\hline CHEMBL1095705 & 629753 & 5.4559 & 5.4522 & TRN \\
\hline CHEMBL1096318 & 629753 & 5.1073 & 5.0888 & TRN \\
\hline CHEMBL1097051 & 629753 & 3.5229 & 3.5327 & TRN \\
\hline CHEMBL1094123 & 629753 & 4.5229 & 4.5222 & TRN \\
\hline CHEMBL1094415 & 629753 & 5.3862 & 5.3939 & TRN \\
\hline CHEMBL1096317 & 629753 & 4.5229 & 4.5294 & TRN \\
\hline CHEMBL1097044 & 629753 & 5.9281 & 5.9439 & TRN \\
\hline CHEMBL1096713 & 629753 & 6.6198 & 6.6021 & TRN \\
\hline CHEMBL1097984 & 629753 & 6.0757 & 6.0723 & TRN \\
\hline CHEMBL1097054 & 629753 & 5.7545 & 5.7488 & TRN \\
\hline CHEMBL1097052 & 629753 & 6.2291 & 6.2252 & TRN \\
\hline CHEMBL1098335 & 629753 & 3.5229 & 6.1976 & TST \\
\hline CHEMBL1095970 & 629753 & 6.1024 & 6.0818 & TRN \\
\hline CHEMBL1095703 & 629753 & 5.8861 & 5.8974 & TRN \\
\hline CHEMBL1096711 & 629753 & 6.4437 & 7.3273 & TST \\
\hline CHEMBL1097380 & 629753 & 6.2366 & 7.4706 & TST \\
\hline CHEMBL1098391 & 629753 & 6.4437 & 5.8478 & TST \\
\hline CHEMBL1095701 & 629753 & 5.9208 & 5.9859 & TRN \\
\hline CHEMBL1094134 & 629753 & 6.1938 & 6.1947 & TRN \\
\hline CHEMBL1096423 & 629753 & 6.1938 & 6.1765 & TRN \\
\hline CHEMBL1094133 & 629753 & 5.1457 & 5.166 & TRN \\
\hline CHEMBL1096081 & 629753 & 3.5229 & 3.532 & TRN \\
\hline CHEMBL1097379 & 629753 & 3.5229 & 5.6162 & TST \\
\hline CHEMBL1095749 & 629753 & 6.1938 & 6.1951 & TRN \\
\hline CHEMBL1096080 & 629753 & 5.5686 & 5.5765 & TRN \\
\hline CHEMBL1097396 & 629753 & 3.5229 & 5.2215 & TST \\
\hline CHEMBL1096663 & 629753 & 3.5229 & 3.5155 & TRN \\
\hline CHEMBL1098406 & 629753 & 6.1079 & 6.2866 & TST \\
\hline CHEMBL1095638 & 629753 & 5.4179 & 5.3904 & TRN \\
\hline CHEMBL1097398 & 629753 & 3.5229 & 4.9112 & TST \\
\hline CHEMBL1094414 & 629753 & 3.5229 & 3.93899 & و9999999996 \\
\hline CHEMBL 2017754 & 814588 & 6.8386 & 7.063 & TST \\
\hline CHEMBL 2017758 & 814588 & 6.9508 & 7.1051 & TST \\
\hline CHEMBL 2017746 & 814588 & 7.1308 & 7.3418 & TRN \\
\hline CHEMBL 2017764 & 814588 & 7.041 & 7.1638 & TRN \\
\hline CHEMBL 2017749 & 814588 & 7.0269 & 7.0561 & TRN \\
\hline CHEMBL 2017588 & 814588 & 7.2076 & 7.2017 & TRN \\
\hline CHEMBL 2017618 & 814588 & 7.699 & 7.6445 & TRN \\
\hline CHEMBL 2017742 & 814588 & 7.5229 & 7.55399 & 99999999999 \\
\hline
\end{tabular}

Page 7504 
Supplemental Table S2.txt

\begin{tabular}{|c|c|c|c|c|c|c|}
\hline CHEMBL 2017614 & 814588 & 6.7721 & 6.809 & TRN & & \\
\hline CHEMBL 2017597 & 814588 & 6.9136 & 6.9304 & TRN & & \\
\hline CHEMBL 2017745 & 814588 & 7.1612 & 7.2858 & TRN & & \\
\hline CHEMBL 2017602 & 814588 & 6.6861 & 6.6942 & TRN & & \\
\hline CHEMBL 2017598 & 814588 & 6.6968 & 6.7244 & TRN & & \\
\hline CHEMBL 2017600 & 814588 & 5.7447 & 5.7613 & TRN & & \\
\hline CHEMBL 2017760 & 814588 & 7.3468 & 7.3541 & TRN & & \\
\hline CHEMBL 2017603 & 814588 & 6.767 & 6.8176 & TRN & & \\
\hline CHEMBL 2017613 & 814588 & 6.5376 & 6.8164 & TST & & \\
\hline CHEMBL 2017753 & 814588 & 7.6778 & 7.7036 & TRN & & \\
\hline CHEMBL 2017608 & 814588 & 6.6108 & 6.6273 & TRN & & \\
\hline CHEMBL2017748 & 814588 & 8.3979 & 7.276 & TST & & \\
\hline CHEMBL 2017587 & 814588 & 6.2741 & 6.3225 & TST & & \\
\hline CHEMBL 2017761 & 814588 & 7.585 & 7.5594 & TRN & & \\
\hline CHEMBL 2017744 & 814588 & 7.9586 & 7.6286 & TRN & & \\
\hline CHEMBL 2017607 & 814588 & 6.6576 & 6.6264 & TRN & & \\
\hline CHEMBL 2017741 & 814588 & 8.0 & 7.9698 & TRN & & \\
\hline CHEMBL 2017615 & 814588 & 7.2676 & 7.0079 & TST & & \\
\hline CHEMBL 2017756 & 814588 & 6.6478 & 6.5762 & TRN & & \\
\hline CHEMBL 2017747 & 814588 & 7.0915 & 7.0264 & TRN & & \\
\hline CHEMBL2017599 & 814588 & 6.2076 & 6.171 & TRN & & \\
\hline CHEMBL 2017605 & 814588 & 6.5686 & 6.5497 & TRN & & \\
\hline CHEMBL 2017590 & 814588 & 6.1739 & 6.6626 & TST & & \\
\hline CHEMBL2017752 & 814588 & 7.1805 & 7.1479 & TRN & & \\
\hline CHEMBL 2017762 & 814588 & 7.4949 & 7.5503 & TRN & & \\
\hline CHEMBL2017750 & 814588 & 7.3872 & 7.3516 & TRN & & \\
\hline CHEMBL2017592 & 814588 & \multicolumn{3}{|c|}{6.4510000000000005} & 6.4776 & TS \\
\hline CHEMBL 2017755 & 814588 & 6.5528 & 7.3188 & TST & & \\
\hline CHEMBL2017596 & 814588 & 6.9355 & 6.9125 & TRN & & \\
\hline CHEMBL 2017589 & 814588 & 6.9706 & 7.0089 & TRN & & \\
\hline CHEMBL 2017765 & 814588 & 6.9788 & 7.0182 & TRN & & \\
\hline CHEMBL 2017594 & 814588 & 6.4634 & 6.4636 & TRN & & \\
\hline CHEMBL 2017763 & 814588 & 7.3468 & 7.2687 & TRN & & \\
\hline CHEMBL2017740 & 814588 & 7.7959 & 7.8713 & TRN & & \\
\hline CHEMBL 2017757 & 814588 & 7.5086 & 7.4291 & TRN & & \\
\hline CHEMBL2017595 & 814588 & 6.6345 & 6.523 & TRN & & \\
\hline CHEMBL 2017611 & 814588 & 6.2557 & 6.7657 & TST & & \\
\hline CHEMBL 2017612 & 814588 & 7.4437 & 7.2331 & TST & & \\
\hline CHEMBL2017593 & 814588 & 6.8268 & 6.768 & TRN & & \\
\hline CHEMBL 2017601 & 814588 & 5.9606 & 5.942 & TRN & & \\
\hline CHEMBL 2017743 & 814588 & 7.2924 & 7.4122 & TRN & & \\
\hline CHEMBL 2017751 & 814588 & 7.1675 & 7.1279 & TRN & & \\
\hline CHEMBL 2017759 & 814588 & 7.3872 & 7.3187 & TRN & & \\
\hline CHEMBL2017616 & 814588 & 7.2147 & 6.9705 & TST & & \\
\hline CHEMBL 2017617 & 814588 & 7.2007 & 7.0801 & TST & & \\
\hline CHEMBL2017606 & 814588 & 6.8239 & 6.8589 & TRN & & \\
\hline CHEMBL 2017610 & 814588 & 6.0706 & 6.4606 & TST & & \\
\hline CHEMBL2017604 & 814588 & 6.6108 & 6.6645 & TRN & & \\
\hline
\end{tabular}

Page 7505 


\begin{tabular}{|c|c|c|c|c|}
\hline \multicolumn{5}{|c|}{ Supplemental Table S2.txt } \\
\hline CHEMBL2017591 & 814588 & 6.6819 & 6.7552 & TRN \\
\hline CHEMBL 2017609 & 814588 & 6.399 & 6.902 & TST \\
\hline CHEMBL175886 & 303658 & 7.301 & 7.3104 & TRN \\
\hline CHEMBL175475 & 303658 & 7.8861 & 7.9971 & TRN \\
\hline CHEMBL360122 & 303658 & 8.4815 & 8.5405 & TRN \\
\hline CHEMBL180464 & 303658 & 7.4949 & 7.5312 & TRN \\
\hline CHEMBL178633 & 303658 & 5.0 & 5.1534 & TRN \\
\hline CHEMBL368905 & 303658 & 5.0 & 6.2089 & TRN \\
\hline CHEMBL179699 & 303658 & 7.0 & 6.8505 & TRN \\
\hline CHEMBL359650 & 303658 & 7.3665 & 7.194 & TRN \\
\hline CHEMBL178831 & 303658 & 7.5528 & 6.8767 & TRN \\
\hline CHEMBL179513 & 303658 & 6.8539 & 6.6538 & TRN \\
\hline CHEMBL359638 & 303658 & 5.301 & 5.4751 & TRN \\
\hline CHEMBL180224 & 303658 & 6.3565 & 6.3686 & TST \\
\hline CHEMBL366468 & 303658 & 7.5086 & 7.3848 & TRN \\
\hline CHEMBL 178830 & 303658 & 6.6383 & 6.4244 & TRN \\
\hline CHEMBL427313 & 303658 & 6.5086 & 6.4864 & TRN \\
\hline CHEMBL179430 & 303658 & 5.0 & 6.1816 & TRN \\
\hline CHEMBL179924 & 303658 & 7.1079 & 7.2744 & TRN \\
\hline CHEMBL359616 & 303658 & 5.0 & 6.0343 & TST \\
\hline CHEMBL 360966 & 303658 & 6.8861 & 6.3671 & TRN \\
\hline CHEMBL179810 & 303658 & 6.3188 & 6.2945 & TRN \\
\hline CHEMBL369093 & 303658 & 5.0 & 4.8558 & TST \\
\hline CHEMBL440558 & 303658 & 7.1079 & 7.3344 & TRN \\
\hline CHEMBL360113 & 303658 & 6.3098 & 6.3733 & TRN \\
\hline CHEMBL178242 & 303658 & 6.8539 & 6.9206 & TRN \\
\hline CHEMBL178303 & 303658 & 6.6383 & 6.4496 & TST \\
\hline CHEMBL179558 & 303658 & 8.1612 & 8.0069 & TRN \\
\hline CHEMBL359853 & 303658 & 5.301 & 5.0189 & TRN \\
\hline CHEMBL360311 & 303658 & 6.7959 & 7.0595 & TRN \\
\hline CHEMBL178508 & 303658 & 5.0 & 6.1338 & TRN \\
\hline CHEMBL179737 & 303658 & 6.284 & 6.2736 & TRN \\
\hline CHEMBL179509 & 303658 & 6.7212 & 6.8074 & TRN \\
\hline CHEMBL361786 & 303658 & 7.9586 & 8.2227 & TRN \\
\hline CHEMBL362421 & 303658 & 6.8239 & 6.6779 & TRN \\
\hline CHEMBL361200 & 303658 & 7.0862 & 6.9284 & TRN \\
\hline CHEMBL359545 & 303658 & 7.4559 & 7.4378 & TRN \\
\hline CHEMBL 179712 & 303658 & 7.9586 & 8.1293 & TRN \\
\hline CHEMBL178677 & 303658 & 8.4685 & 8.3656 & TRN \\
\hline CHEMBL180417 & 303658 & 7.1249 & 6.4397 & TRN \\
\hline CHEMBL179654 & 303658 & 5.301 & 5.1243 & TRN \\
\hline CHEMBL361754 & 303658 & 5.301 & 5.04 & TRN \\
\hline CHEMBL366471 & 303658 & 7.0969 & 7.3679 & TRN \\
\hline CHEMBL361561 & 303658 & 6.6778 & 6.4788 & TRN \\
\hline CHEMBL361129 & 303658 & 9.0458 & 8.4568 & TRN \\
\hline CHEMBL361597 & 303658 & 7.0605 & 6.8271 & TRN \\
\hline CHEMBL180416 & 303658 & 7.7696 & 8.0205 & TRN \\
\hline CHEMBL178956 & 303658 & 7.7959 & 7.6684 & TRN \\
\hline
\end{tabular}




\begin{tabular}{|c|c|c|c|c|c|}
\hline \multicolumn{6}{|c|}{ Supplemental Table S2.txt } \\
\hline CHEMBL360562 & 303658 & 5.0 & 4.995 & TRN & \\
\hline CHEMBL178670 & 303658 & 6.7212 & 6.5872 & TRN & \\
\hline CHEMBL179700 & 303658 & 6.8539 & 6.5338 & TRN & \\
\hline CHEMBL178710 & 303658 & 7.2518 & 7.3529 & TRN & \\
\hline CHEMBL179474 & 303658 & 8.0088 & 8.3842 & TRN & \\
\hline CHEMBL361015 & 303658 & 7.0706 & 7.4748 & TRN & \\
\hline CHEMBL360262 & 303658 & 5.301 & 5.3596 & TRN & \\
\hline CHEMBL179475 & 303658 & 7.8861 & 7.9905 & TRN & \\
\hline CHEMBL178856 & 303658 & 6.8861 & 7.0458 & TST & \\
\hline CHEMBL179000 & 303658 & 6.2441 & 6.3261 & TRN & \\
\hline CHEMBL178188 & 303658 & 6.3188 & 6.4612 & TRN & \\
\hline CHEMBL180215 & 303658 & 6.1249 & 6.0614 & TST & \\
\hline CHEMBL 361340 & 303658 & 7.2757 & 7.4521 & TRN & \\
\hline CHEMBL359906 & 303658 & 7.6778 & 7.6184 & TRN & \\
\hline CHEMBL180174 & 303658 & 7.4815 & 7.3752 & TRN & \\
\hline CHEMBL362014 & 303658 & 6.1367 & 6.0993 & TST & \\
\hline CHEMBL362282 & 303658 & 7.6383 & 7.6661 & TST & \\
\hline CHEMBL178942 & 303658 & 7.1487 & 6.9551 & TRN & \\
\hline CHEMBL179769 & 303658 & 6.5086 & 6.3692 & TRN & \\
\hline CHEMBL179555 & 303658 & 5.0 & 5.1699 & TST & \\
\hline CHEMBL179414 & 303658 & 8.4089 & 8.4353 & TRN & \\
\hline CHEMBL366537 & 303658 & 7.7212 & 7.8839 & TRN & \\
\hline CHEMBL361114 & 303658 & 9.0915 & 8.1456 & TRN & \\
\hline CHEMBL359474 & 303658 & 5.301 & 5.2764 & TRN & \\
\hline CHEMBL359613 & 303658 & 7.6778 & 6.8055 & TST & \\
\hline CHEMBL362409 & 303658 & 7.1367 & 7.1428 & TRN & \\
\hline CHEMBL178738 & 303658 & 6.8861 & 6.5344 & TRN & \\
\hline CHEMBL68712 & 303658 & 6.7959 & 7.0041 & TRN & \\
\hline CHEMBL179545 & 303658 & 6.1871 & 6.3995 & TRN & \\
\hline CHEMBL360036 & 303658 & 6.6576 & 6.5964 & TST & \\
\hline CHEMBL360733 & 303658 & 7.0315 & 7.2751 & TRN & \\
\hline CHEMBL360912 & 303658 & 7.1675 & 7.1683 & TRN & \\
\hline CHEMBL178783 & 303658 & 7.5376 & 7.7532 & TRN & \\
\hline CHEMBL426234 & 303658 & 6.5686 & 6.2368 & TRN & \\
\hline CHEMBL178632 & 303658 & 6.5686 & 6.7297 & TRN & \\
\hline CHEMBL178840 & 303658 & 7.0177 & 6.58700 & 0000000001 & TRN \\
\hline CHEMBL179048 & 303658 & 6.5086 & 6.2175 & TRN & \\
\hline CHEMBL180575 & 303658 & 5.0 & 5.2492 & TST & \\
\hline CHEMBL361105 & 303658 & 6.585 & 6.7579 & TST & \\
\hline CHEMBL178837 & 303658 & 6.5376 & 6.5935 & TST & \\
\hline CHEMBL178992 & 303658 & 7.1487 & 6.8948 & TST & \\
\hline CHEMBL369035 & 303658 & 7.5686 & 7.9022 & TST & \\
\hline CHEMBL179777 & 303658 & 7.6576 & 7.6236 & TST & \\
\hline CHEMBL 362620 & 303658 & 7.0 & 7.0531 & TST & \\
\hline CHEMBL360345 & 303658 & 5.0 & 5.9076 & TST & \\
\hline CHEMBL179664 & 303658 & 5.0 & 5.6742 & TST & \\
\hline CHEMBL362869 & 303658 & 6.8539 & 6.6021 & TST & \\
\hline CHEMBL434138 & 303658 & 5.0 & 6.2351 & TST & \\
\hline
\end{tabular}




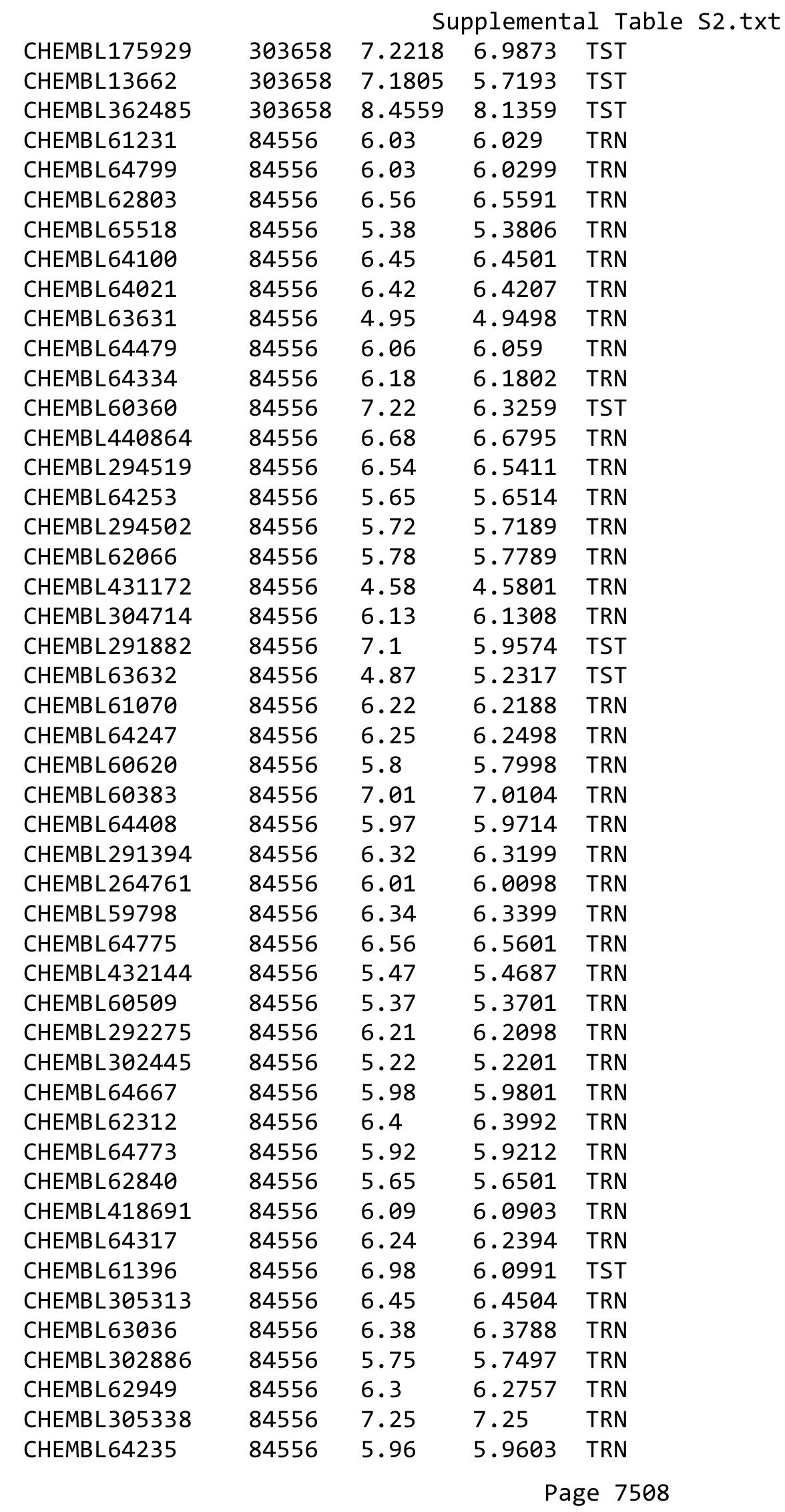




\begin{tabular}{|c|c|c|c|c|c|}
\hline \multicolumn{6}{|c|}{ Supplemental Table S2.txt } \\
\hline CHEMBL 304027 & 84556 & 5.99 & 6.5327 & TST & \\
\hline CHEMBL449040 & 84556 & 6.25 & 6.2757 & TRN & \\
\hline CHEMBL62948 & 84556 & 5.85 & 5.8511 & TRN & \\
\hline CHEMBL62726 & 84556 & 7.13 & 6.5681 & TST & \\
\hline CHEMBL62115 & 84556 & 5.69 & 5.7234 & TST & \\
\hline CHEMBL444307 & 84556 & 6.37 & 5.9683 & TST & \\
\hline CHEMBL64884 & 84556 & 7.25 & 6.29799 & 9999999999 & TST \\
\hline CHEMBL 2113738 & 84556 & 6.35 & 6.1557 & TST & \\
\hline CHEMBL 294349 & 84556 & 4.67 & 5.9218 & TST & \\
\hline CHEMBL418658 & 84556 & 6.14 & 5.9086 & TST & \\
\hline CHEMBL62527 & 84556 & 5.4 & 5.96200 & 0000000001 & TST \\
\hline CHEMBL59715 & 84556 & 6.28 & 6.1351 & TST & \\
\hline CHEMBL64259 & 84556 & 6.51 & 6.0659 & TST & \\
\hline CHEMBL3646830 & 1528641 & 6.7959 & 6.6448 & TRN & \\
\hline CHEMBL 3649636 & 1528641 & 6.5031 & 6.2136 & TRN & \\
\hline CHEMBL3649606 & 1528641 & 9.0 & 8.8688 & TRN & \\
\hline CHEMBL3646824 & 1528641 & 10.0 & 9.478 & TRN & \\
\hline CHEMBL 3649625 & 1528641 & 6.8477 & 6.3328 & TRN & \\
\hline CHEMBL3646817 & 1528641 & 6.7959 & 6.8744 & TRN & \\
\hline CHEMBL 3646849 & 1528641 & 8.1549 & 8.1673 & TRN & \\
\hline CHEMBL3649608 & 1528641 & 8.2218 & 8.4321 & TRN & \\
\hline CHEMBL3649626 & 1528641 & 6.5817 & 6.4131 & TRN & \\
\hline CHEMBL 3649621 & 1528641 & 8.2218 & 8.5383 & TRN & \\
\hline CHEMBL3646845 & 1528641 & 6.7696 & 7.0928 & TST & \\
\hline CHEMBL 3649642 & 1528641 & 6.0872 & 8.0758 & TST & \\
\hline CHEMBL3649627 & 1528641 & 6.1965 & 6.1385 & TRN & \\
\hline CHEMBL3649650 & 1528641 & 6.0531 & 7.3971 & TRN & \\
\hline CHEMBL 3649645 & 1528641 & 8.1549 & 8.1743 & TRN & \\
\hline CHEMBL3646827 & 1528641 & 5.9101 & 6.9933 & TST & \\
\hline CHEMBL3589169 & 1528641 & 9.0 & 8.7471 & TRN & \\
\hline CHEMBL 3646832 & 1528641 & 6.8239 & 7.1306 & TST & \\
\hline CHEMBL3649609 & 1528641 & 9.0 & 8.9727 & TRN & \\
\hline CHEMBL 3649623 & 1528641 & 6.9547 & 7.0156 & TRN & \\
\hline CHEMBL3649643 & 1528641 & 9.0 & 9.0029 & TRN & \\
\hline CHEMBL 3646813 & 1528641 & 8.2218 & 8.1854 & TRN & \\
\hline CHEMBL3646831 & 1528641 & 6.5376 & 6.5455 & TRN & \\
\hline CHEMBL 3649624 & 1528641 & 6.6576 & 6.2561 & TRN & \\
\hline CHEMBL 3646829 & 1528641 & 8.1549 & 8.0169 & TRN & \\
\hline CHEMBL3649640 & 1528641 & 6.8761 & 8.4984 & TST & \\
\hline CHEMBL 3646840 & 1528641 & 9.0 & 8.5795 & TRN & \\
\hline CHEMBL3649618 & 1528641 & 8.2218 & 8.1449 & TRN & \\
\hline CHEMBL3646838 & 1528641 & 9.0 & 8.8078 & TRN & \\
\hline CHEMBL3649628 & 1528641 & 9.0 & 6.9331 & TST & \\
\hline CHEMBL3649613 & 1528641 & 9.0 & 9.1322 & TRN & \\
\hline CHEMBL3649630 & 1528641 & 9.0 & 8.8948 & TRN & \\
\hline CHEMBL3649631 & 1528641 & 9.0 & 9.2757 & TRN & \\
\hline CHEMBL 3649614 & 1528641 & 9.0 & 9.0163 & TRN & \\
\hline CHEMBL 3646834 & 1528641 & 6.9586 & 7.2732 & TRN & \\
\hline
\end{tabular}




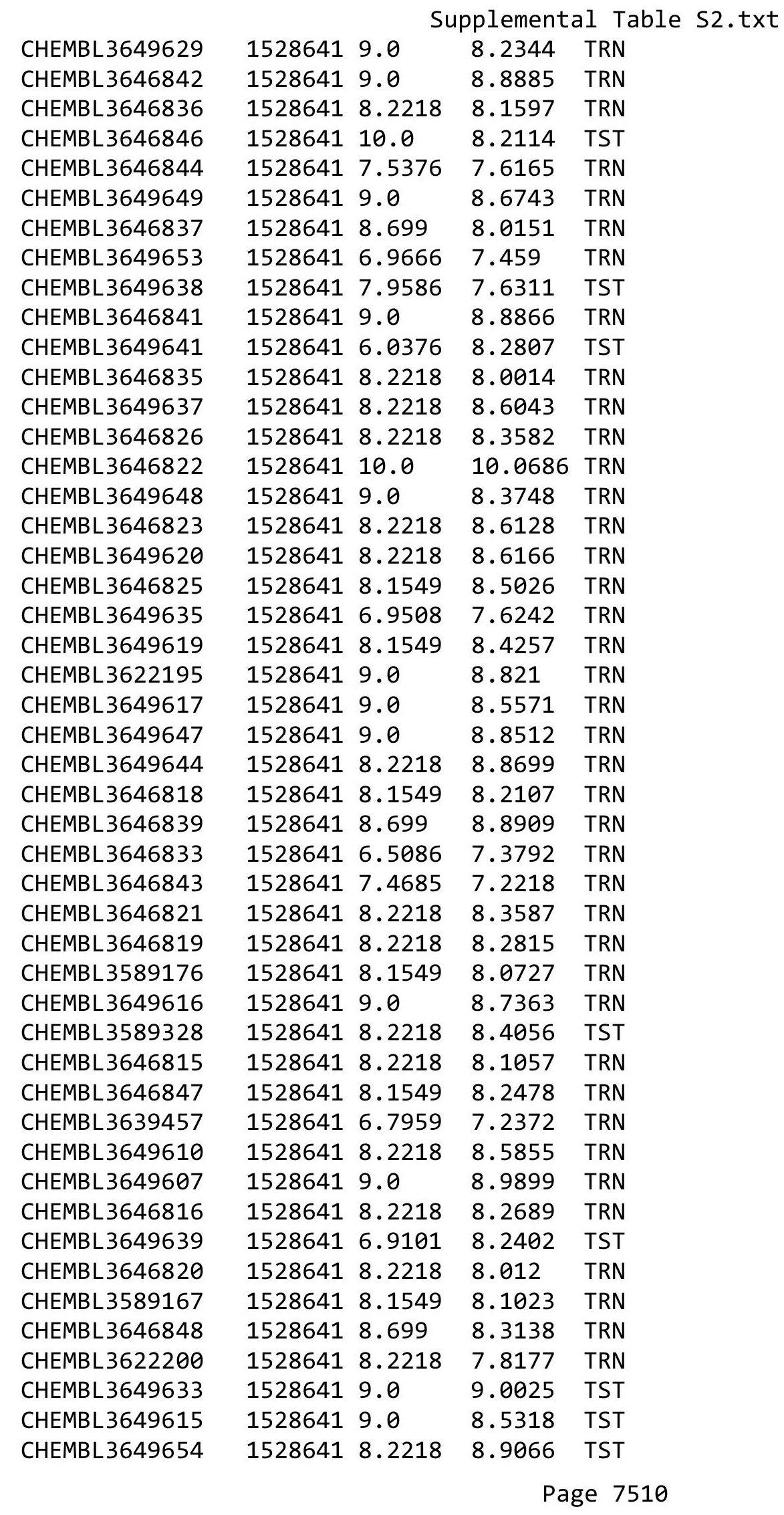


Supplemental Table S2.txt

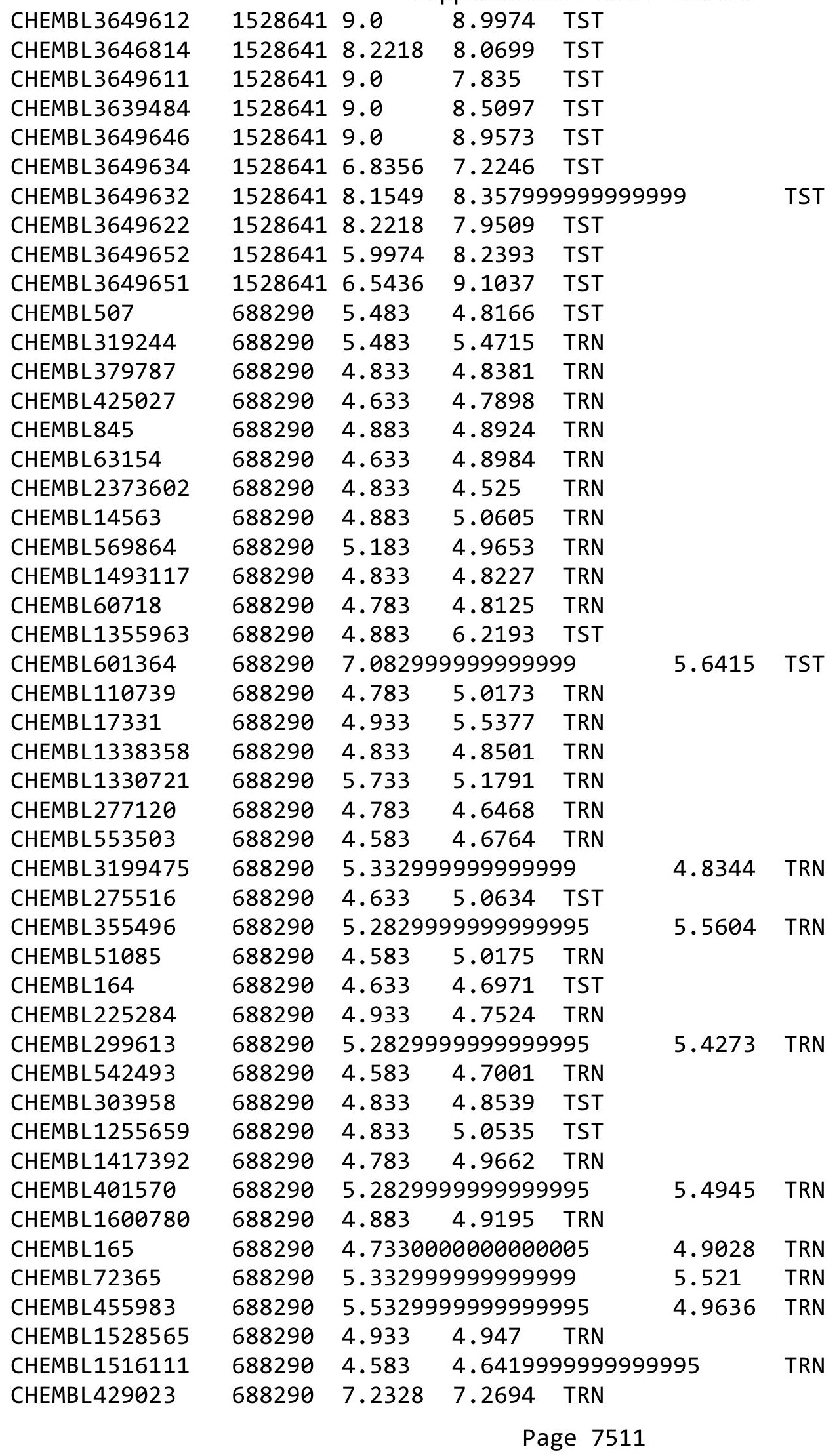




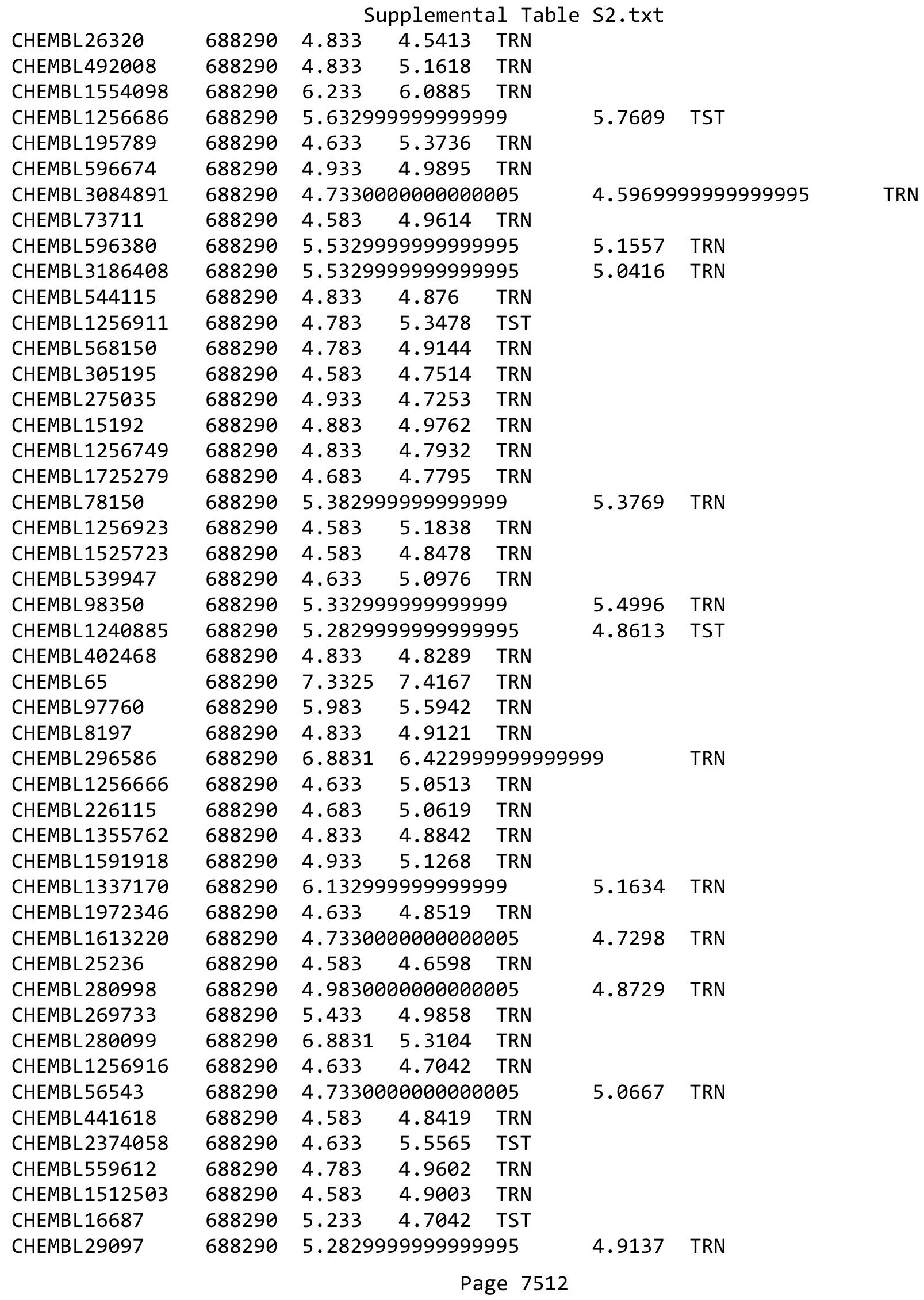




\begin{tabular}{|c|c|c|c|c|c|c|}
\hline \multirow[b]{2}{*}{ CHEMBL1256885 } & \multirow[b]{2}{*}{688290} & \multicolumn{5}{|c|}{ Supplemental Table S2.txt } \\
\hline & & \multicolumn{5}{|c|}{34.6802 TRN } \\
\hline CHEMBL 275311 & 688290 & \multicolumn{3}{|c|}{6.2829999999999995} & 4.7461 & TRN \\
\hline CHEMBL1256364 & 688290 & 5.233 & \multicolumn{3}{|c|}{5.0569999999999995} & TRN \\
\hline CHEMBL1517187 & 688290 & \multicolumn{3}{|c|}{4.7330000000000005} & 5.096 & TRN \\
\hline CHEMBL 375270 & 688290 & 4.833 & 5.2007 & TRN & & \\
\hline CHEMBL123 & 688290 & 4.883 & 5.2136 & TRN & & \\
\hline CHEMBL425294 & 688290 & \multicolumn{3}{|c|}{5.332999999999999} & 5.0778 & TRN \\
\hline CHEMBL85139 & 688290 & \multicolumn{3}{|c|}{4.7330000000000005} & 5.188 & TRN \\
\hline CHEMBL126077 & 688290 & 5.483 & 5.3126 & TRN & & \\
\hline CHEMBL1562420 & 688290 & \multicolumn{3}{|c|}{6.2829999999999995} & 5.1505 & TRN \\
\hline CHEMBL1256876 & 688290 & 4.783 & 4.8773 & TRN & & \\
\hline CHEMBL445102 & 688290 & 4.833 & 4.8217 & TRN & & \\
\hline CHEMBL243954 & 688290 & 4.633 & 4.8405 & TRN & & \\
\hline CHEMBL1513654 & 688290 & 5.183 & 4.9435 & TRN & & \\
\hline CHEMBL1628215 & 688290 & \multicolumn{3}{|c|}{5.332999999999999} & 5.1743 & TRN \\
\hline CHEMBL 293749 & 688290 & \multicolumn{3}{|c|}{4.9830000000000005} & 5.1385 & TRN \\
\hline CHEMBL21260 & 688290 & 7.3325 & 6.6365 & TRN & & \\
\hline CHEMBL1316314 & 688290 & 4.633 & 4.8267 & TRN & & \\
\hline CHEMBL1256698 & 688290 & 4.783 & 4.5004 & TRN & & \\
\hline CHEMBL288096 & 688290 & 4.833 & 4.55 & TRN & & \\
\hline CHEMBL494325 & 688290 & 4.633 & 5.0106 & TRN & & \\
\hline CHEMBL1256661 & 688290 & 4.633 & 4.6567 & TRN & & \\
\hline CHEMBL365739 & 688290 & 7.3325 & 5.7992 & TRN & & \\
\hline CHEMBL1435579 & 688290 & \multicolumn{3}{|c|}{4.7330000000000005} & 4.9638 & TRN \\
\hline CHEMBL34704 & 688290 & 4.783 & 4.8029 & TRN & & \\
\hline CHEMBL1208858 & 688290 & 4.633 & 4.7642 & TST & & \\
\hline CHEMBL76897 & 688290 & 5.683 & 4.8909 & TRN & & \\
\hline CHEMBL58033 & 688290 & 4.583 & 4.5317 & TRN & & \\
\hline CHEMBL328710 & 688290 & 4.833 & 6.0498 & TRN & & \\
\hline CHEMBL1407012 & 688290 & \multicolumn{3}{|c|}{4.7330000000000005} & 4.5636 & TRN \\
\hline CHEMBL129795 & 688290 & 4.583 & 5.1972 & TRN & & \\
\hline CHEMBL 29027 & 688290 & 4.583 & 4.9264 & TRN & & \\
\hline CHEMBL540848 & 688290 & \multicolumn{3}{|c|}{4.9830000000000005} & 4.6107 & TRN \\
\hline CHEMBL24983 & 688290 & 4.583 & 4.945 & TRN & & \\
\hline CHEMBL1256693 & 688290 & \multicolumn{3}{|c|}{4.7330000000000005} & 4.7351 & TRN \\
\hline CHEMBL2374027 & 688290 & 4.833 & 4.6083 & TRN & & \\
\hline CHEMBL338790 & 688290 & 4.833 & 4.9741 & TRN & & \\
\hline CHEMBL1241268 & 688290 & 4.633 & 4.8693 & TRN & & \\
\hline CHEMBL1256914 & 688290 & 4.783 & 5.2165 & TRN & & \\
\hline CHEMBL 288174 & 688290 & 4.783 & 5.0964 & TST & & \\
\hline CHEMBL448741 & 688290 & \multicolumn{3}{|c|}{4.7330000000000005} & 4.4997 & TRN \\
\hline CHEMBL 376505 & 688290 & 4.583 & 5.4691 & TST & & \\
\hline CHEMBL1322702 & 688290 & \multicolumn{3}{|c|}{4.7330000000000005} & 4.7273 & TRN \\
\hline CHEMBL1534566 & 688290 & 4.633 & \multicolumn{3}{|c|}{4.6530000000000005} & TRN \\
\hline CHEMBL192566 & 688290 & 8.0809 & 7.2646 & TST & & \\
\hline CHEMBL52 & 688290 & \multicolumn{3}{|c|}{4.7330000000000005} & 4.7731 & TRN \\
\hline CHEMBL1255867 & 688290 & 4.583 & 4.7317 & TRN & & \\
\hline CHEMBL30432 & 688290 & 4.583 & 5.1111 & TRN & & \\
\hline
\end{tabular}




\begin{tabular}{|c|c|c|c|c|c|c|c|}
\hline \multicolumn{7}{|c|}{ Supplemental Table S2.txt } & \\
\hline CHEMBL1516388 & 688290 & 4.583 & 4.8037 & TST & & & \\
\hline CHEMBL303579 & 688290 & 5.28299 & 99999999 & 995 & 5.2634 & TRN & \\
\hline CHEMBL 225230 & 688290 & 4.583 & 4.601 & TRN & & & \\
\hline CHEMBL1256659 & 688290 & 4.583 & 4.9148 & TRN & & & \\
\hline CHEMBL1437846 & 688290 & 6.03299 & 99999999 & 995 & 5.7852 & TRN & \\
\hline CHEMBL1357488 & 688290 & 5.28299 & 99999999 & 995 & 4.8659 & TST & \\
\hline CHEMBL68534 & 688290 & 4.73300 & 00000000 & 005 & 4.8241 & TRN & \\
\hline CHEMBL520992 & 688290 & 4.833 & 4.668 & TRN & & & \\
\hline CHEMBL1595524 & 688290 & 4.783 & 4.8036 & TRN & & & \\
\hline CHEMBL53898 & 688290 & 4.783 & 5.1403 & TRN & & & \\
\hline CHEMBL1256656 & 688290 & 5.233 & 5.0664 & TRN & & & \\
\hline CHEMBL1522486 & 688290 & 5.33299 & 99999999 & & 5.6999 & TST & \\
\hline CHEMBL1408519 & 688290 & 4.583 & 4.8983 & TST & & & \\
\hline CHEMBL605003 & 688290 & 5.233 & 5.6406 & TST & & & \\
\hline CHEMBL 250711 & 688290 & 5.433 & 5.2899 & TST & & & \\
\hline CHEMBL188 & 688290 & 4.783 & 4.8236 & TST & & & \\
\hline CHEMBL1590378 & 688290 & 4.783 & 4.7471 & TST & & & \\
\hline CHEMBL1324022 & 688290 & 4.833 & 4.8256 & TST & & & \\
\hline CHEMBL1257041 & 688290 & 4.833 & 4.6123 & TST & & & \\
\hline CHEMBL1553428 & 688290 & 4.583 & 4.6808 & TST & & & \\
\hline CHEMBL282489 & 688290 & 4.783 & 4.8702 & TST & & & \\
\hline CHEMBL1590980 & 688290 & 4.883 & 5.1647 & TST & & & \\
\hline CHEMBL602375 & 688290 & 4.98300 & 00000000 & 005 & 5.5682 & TST & \\
\hline CHEMBL567175 & 688290 & 4.633 & 4.6156 & TST & & & \\
\hline CHEMBL48449 & 688290 & 4.583 & 5.216 & TST & & & \\
\hline CHEMBL1554717 & 688290 & 4.783 & 4.645 & TST & & & \\
\hline CHEMBL1320902 & 688290 & 4.633 & 4.7122 & TST & & & \\
\hline CHEMBL1529009 & 688290 & 4.783 & 4.8762 & TST & & & \\
\hline CHEMBL179288 & 688290 & 4.583 & 5.1648 & TST & & & \\
\hline CHEMBL47940 & 688290 & 4.883 & 5.1917 & TST & & & \\
\hline CHEMBL153036 & 688290 & 4.633 & 5.3116 & TST & & & \\
\hline CHEMBL429095 & 688290 & 5.88299 & 99999999 & & 5.3621 & TST & \\
\hline CHEMBL1256647 & 688290 & 4.633 & 4.5653 & TST & & & \\
\hline CHEMBL1559663 & 688290 & 5.88299 & 99999999 & & 6.25200 & 0000000001 & TST \\
\hline CHEMBL399491 & 688290 & 5.33299 & 99999999 & & 5.1037 & TST & \\
\hline CHEMBL1440857 & 688290 & 5.33299 & 99999999 & & 6.7368 & TST & \\
\hline CHEMBL 301605 & 496983 & 8.4 & 8.4253 & TRN & & & \\
\hline CHEMBL78766 & 496983 & 8.4 & 8.2329 & TRN & & & \\
\hline CHEMBL 78524 & 496983 & 5.92 & 5.80399 & 999999999 & & TRN & \\
\hline CHEMBL 79887 & 496983 & 6.9 & 7.1876 & TRN & & & \\
\hline CHEMBL 78434 & 496983 & 7.36 & 7.5725 & TRN & & & \\
\hline CHEMBL 81512 & 496983 & 7.01 & 6.8436 & TRN & & & \\
\hline CHEMBL311776 & 496983 & 8.22 & 8.1816 & TRN & & & \\
\hline CHEMBL 78378 & 496983 & 6.51 & 6.5431 & TRN & & & \\
\hline CHEMBL310167 & 496983 & 8.22 & 7.6814 & TRN & & & \\
\hline CHEMBL 312333 & 496983 & 5.67 & 5.8788 & TRN & & & \\
\hline CHEMBL1195308 & 496983 & 6.12 & 6.2324 & TRN & & & \\
\hline CHEMBL304273 & 496983 & 6.65 & 6.6345 & TRN & & & \\
\hline
\end{tabular}




\begin{tabular}{|c|c|c|c|c|c|}
\hline \multicolumn{6}{|c|}{ Supplemental Table S2.txt } \\
\hline CHEMBL343107 & 496983 & 6.05 & 6.1742 & TRN & \\
\hline CHEMBL521542 & 496983 & 5.8 & 5.8039 & TRN & \\
\hline CHEMBL81479 & 496983 & 6.94 & 6.987 & TRN & \\
\hline CHEMBL311747 & 496983 & 7.92 & 8.0086 & TRN & \\
\hline CHEMBL78650 & 496983 & 7.1 & 7.0102 & TRN & \\
\hline CHEMBL1195609 & 496983 & 7.55 & 7.5995 & TRN & \\
\hline CHEMBL66274 & 496983 & 7.08 & 7.0443 & TRN & \\
\hline CHEMBL79945 & 496983 & 8.15 & 8.6203 & TRN & \\
\hline CHEMBL439945 & 496983 & 8.0 & 7.7523 & TRN & \\
\hline CHEMBL443010 & 496983 & 7.72 & 7.6805 & TRN & \\
\hline CHEMBL66273 & 496983 & 8.1 & 8.1675 & TRN & \\
\hline CHEMBL141039 & 496983 & 8.1 & 7.8034 & TRN & \\
\hline CHEMBL78400 & 496983 & 8.22 & 8.2818 & TRN & \\
\hline CHEMBL 302056 & 496983 & 6.15 & 6.0348 & TRN & \\
\hline CHEMBL67774 & 496983 & 6.6 & 6.6543 & TRN & \\
\hline CHEMBL312628 & 496983 & 6.24 & 6.3527 & TRN & \\
\hline CHEMBL76724 & 496983 & 6.6 & 6.6314 & TRN & \\
\hline CHEMBL299060 & 496983 & 5.94 & 5.8549 & TRN & \\
\hline CHEMBL69336 & 496983 & 6.8 & 6.8367 & TRN & \\
\hline CHEMBL69282 & 496983 & 5.71 & 5.7439 & TRN & \\
\hline CHEMBL523426 & 496983 & 5.72 & 5.6593 & TRN & \\
\hline CHEMBL19732 & 496983 & 9.51 & 7.1685 & TST & \\
\hline CHEMBL 20042 & 496983 & 8.94 & 6.6701 & TST & \\
\hline CHEMBL3144843 & 496983 & 9.35 & 9.3985 & TRN & \\
\hline CHEMBL3144755 & 496983 & 8.99 & 8.8878 & TRN & \\
\hline CHEMBL 3144746 & 496983 & 8.99 & 9.0195 & TRN & \\
\hline CHEMBL3144613 & 496983 & 8.96 & 8.2793 & TST & \\
\hline CHEMBL460381 & 496983 & 9.06 & 5.8588 & TST & \\
\hline CHEMBL 3144833 & 496983 & 9.05 & 9.2488 & TST & \\
\hline CHEMBL463928 & 496983 & 9.29 & 7.6987 & TST & \\
\hline CHEMBL 3144724 & 496983 & 8.87 & 8.834 & TST & \\
\hline CHEMBL463894 & 496983 & 9.27 & 6.9092 & TST & \\
\hline CHEMBL47625 & 496983 & 6.52 & 7.3104 & TST & \\
\hline CHEMBL 275224 & 496983 & 5.79 & 5.8482 & TRN & \\
\hline CHEMBL441986 & 496983 & 3.6 & 3.6152 & TRN & \\
\hline CHEMBL12014 & 496983 & 4.91 & 4.9214 & TRN & \\
\hline CHEMBL298561 & 496983 & 7.35 & 7.4561 & TRN & \\
\hline CHEMBL53229 & 496983 & 6.9 & 6.7378 & TRN & \\
\hline CHEMBL299662 & 496983 & 5.4 & 5.3881 & TRN & \\
\hline CHEMBL54228 & 496983 & 6.91 & 6.8682 & TRN & \\
\hline CHEMBL453066 & 496983 & 8.3 & 6.0 & TST & \\
\hline CHEMBL67772 & 496983 & 4.59 & 4.56800 & 00000000005 & TST \\
\hline CHEMBL 303932 & 496983 & 5.3 & 5.1554 & TST & \\
\hline CHEMBL70086 & 496983 & 5.04 & 4.7336 & TST & \\
\hline CHEMBL66487 & 496983 & 6.17 & 4.4417 & TST & \\
\hline CHEMBL55630 & 496983 & 5.77 & 4.7852 & TST & \\
\hline CHEMBL 3823673 & 1587724 & 9.699 & 9.6451 & TRN & \\
\hline CHEMBL 3824254 & 1587724 & 7.9208 & 7.8124 & TRN & \\
\hline
\end{tabular}


Supplemental Table S2.txt

\begin{tabular}{|c|c|c|c|c|}
\hline HEMBL & & 979 & & \\
\hline HFMRI 3824128 & 587724 & 7.585 & & \\
\hline HEMBL & 87724 & 301 & & \\
\hline AEMBL3823304 & 87724 & 5086 & 4325 & \\
\hline HEMBL3823406 & 587724 & 8.699 & .8727 & \\
\hline HEMBL; & 587724 & 7.8239 & .9666 & \\
\hline AEMBL & 87724 & 8.5229 & & \\
\hline HEMBL & 587724 & 8.3565 & 1738 & \\
\hline HEMBL3822738 & 587724 & 8.5229 & 4674 & \\
\hline HEMBL3822708 & 587724 & 6.9957 & .9983 & \\
\hline HEMBL3 & 587724 & 229 & & \\
\hline AEMBL & 87724 & & & \\
\hline HEMBL3 & 587724 & 99 & & \\
\hline AEMBL3 & 587724 & 458 & & \\
\hline HEMBL3823996 & 587724 & 7. & 84 & \\
\hline AEMBL & 24 & 01 & & \\
\hline AEMBL & & & & RN \\
\hline AEMBL & 724 & 208 & & RN \\
\hline AEMBL3 & 24 & 188 & & \\
\hline AEMBL3 & 24 & 356 & 56 & $\mathrm{NIN}$ \\
\hline IEMBL & 24 & & & RN \\
\hline HEME & & 79 & & RN \\
\hline HEMBL & 24 & 212 & & RN \\
\hline HEMBL & 24 & & & 「RN \\
\hline AEMBL 3 & 24 & 8. & 09 & $R N$ \\
\hline IEMBL & 24 & 823 & & ST \\
\hline AEM & & 8 & & RN \\
\hline 25 & & & & $-T$ \\
\hline IEMBL: & & & & SI \\
\hline AEMBL3 & 587724 & 9 . & & 「RN \\
\hline IEMBL & 24 & & & RN \\
\hline 3 & & & & ГRN \\
\hline & & & & $\mathrm{RN}$ \\
\hline AEMBL3 & 24 & & & 「RN \\
\hline HEMBL3 & 587724 & 383 & & 「RN \\
\hline AFMRI : & 24 & 99 & & 「RN \\
\hline & & & & \\
\hline AEMBL & & & & ГST \\
\hline AEMBL3 & 587724 & 8.5229 & & $\Gamma \mathrm{R}$ \\
\hline EMBL; & 24 & 218 & & TST \\
\hline HEMBL3 & 587724 & & & \\
\hline HEMBL3 & & & & $\mathrm{RN}$ \\
\hline HEMBL3 & 587724 & 8.2076 & & 「RN \\
\hline AEMBL3 & 2 & 7.9208 & & TR \\
\hline MBL: & & & & \\
\hline HEMBL3 & 587724 & עוצב. & & \\
\hline CHEMBL3 & .587724 & . 3979 & & \\
\hline CHEMBL3823339 & 1587724 & 7.1549 & 7.8456 & \\
\hline
\end{tabular}

Page 7516 
Supplemental Table S2.txt

\begin{tabular}{|c|c|c|c|c|c|}
\hline CHEMBL 3822820 & 1587724 & 9.699 & 8.5613 & TST & \\
\hline CHEMBL 3824145 & 1587724 & 7.9208 & 8.5646 & TST & \\
\hline CHEMBL 3823487 & 1587724 & 7.7212 & 7.8775 & TST & \\
\hline CHEMBL 3824167 & 1587724 & 8.0969 & 8.8867 & TST & \\
\hline CHEMBL3824211 & 1587724 & 8.1549 & 7.4952 & TST & \\
\hline CHEMBL 3824302 & 1587724 & 8.585 & 8.464 & TST & \\
\hline CHEMBL 3919854 & 1642149 & 6.7144 & 7.1148 & TRN & \\
\hline CHEMBL 3923837 & 1642149 & 7.8539 & 7.4451 & TST & \\
\hline CHEMBL 3890976 & 1642149 & 6.1315 & 6.0655 & TRN & \\
\hline CHEMBL3986369 & 1642149 & 7.2218 & 7.4659 & TST & \\
\hline CHEMBL 3890895 & 1642149 & 6.9485 & 7.3413 & TRN & \\
\hline CHEMBL 3958265 & 1642149 & 8.3979 & 8.0892 & TRN & \\
\hline CHEMBL 3917085 & 1642149 & 7.1675 & 7.3332 & TRN & \\
\hline CHEMBL 3931085 & 1642149 & 6.4711 & 7.0732 & TRN & \\
\hline CHEMBL3943647 & 1642149 & 8.1549 & 7.8563 & TRN & \\
\hline CHEMBL 3898613 & 1642149 & 7.3468 & 7.2628 & TRN & \\
\hline CHEMBL3973762 & 1642149 & 9.0 & 8.4608 & TRN & \\
\hline CHEMBL 3944619 & 1642149 & 6.767 & 7.2249 & TST & \\
\hline CHEMBL 3911705 & 1642149 & 7.8063 & 7.6438 & TRN & \\
\hline CHEMBL 3914403 & 1642149 & 7.54200 & 000000006 & 1 & 7.153 \\
\hline CHEMBL3921065 & 1642149 & 6.3 & 6.7183 & TST & \\
\hline CHEMBL 3967943 & 1642149 & 8.3979 & 7.7727 & TRN & \\
\hline CHEMBL 3959898 & 1642149 & 8.9547 & 8.5888 & TRN & \\
\hline CHEMBL 3905843 & 1642149 & 6.0 & 7.1394 & TRN & \\
\hline CHEMBL 3929617 & 1642149 & 7.0555 & 7.392 & TRN & \\
\hline CHEMBL 3922172 & 1642149 & 7.3188 & 7.6527 & TRN & \\
\hline CHEMBL 3933933 & 1642149 & 6.8111 & 7.3439 & TRN & \\
\hline CHEMBL 3914929 & 1642149 & 8.3979 & 8.1327 & TRN & \\
\hline CHEMBL 3980240 & 1642149 & 8.0 & 7.9338 & TRN & \\
\hline CHEMBL 3944060 & 1642149 & 7.9208 & 8.6187 & TRN & \\
\hline CHEMBL 3984533 & 1642149 & 5.9626 & 5.9926 & TRN & \\
\hline CHEMBL 3957192 & 1642149 & 8.1101 & 7.7187 & TRN & \\
\hline CHEMBL 3948120 & 1642149 & 8.3979 & 8.5646 & TRN & \\
\hline CHEMBL 3978709 & 1642149 & 7.3561 & 7.2687 & TRN & \\
\hline CHEMBL 3928432 & 1642149 & 9.0 & 8.5832 & TRN & \\
\hline CHEMBL3960095 & 1642149 & 8.5287 & 8.4107 & TRN & \\
\hline CHEMBL 3963203 & 1642149 & 5.9208 & 7.2881 & TST & \\
\hline CHEMBL 3901782 & 1642149 & 8.699 & 8.7045 & TST & \\
\hline CHEMBL 3897184 & 1642149 & 9.0 & 8.8977 & TRN & \\
\hline CHEMBL 3978789 & 1642149 & 7.6231 & 8.4669 & TST & \\
\hline CHEMBL 3949726 & 1642149 & 8.644 & 8.6307 & TRN & \\
\hline CHEMBL 3985650 & 1642149 & 6.7272 & 6.4914 & TRN & \\
\hline CHEMBL 3920775 & 1642149 & 8.0013 & 7.9744 & TST & \\
\hline CHEMBL 3973668 & 1642149 & 8.699 & 8.6224 & TRN & \\
\hline CHEMBL 3933516 & 1642149 & 8.8182 & 8.5632 & TRN & \\
\hline CHEMBL 3931849 & 1642149 & 8.5229 & 8.9094 & TST & \\
\hline CHEMBL 3946381 & 1642149 & 8.4881 & 8.2906 & TRN & \\
\hline CHEMBL 3958586 & 1642149 & 8.5229 & 8.9588 & TRN & \\
\hline
\end{tabular}


Supplemental Table S2.txt

\begin{tabular}{|c|c|c|c|c|}
\hline CHEMBL 3924765 & 1642149 & 8.699 & 8.6981 & TRN \\
\hline CHEMBL 3904844 & 1642149 & 6.7014 & 7.2378 & TST \\
\hline CHEMBL3936185 & 1642149 & 6.4547 & 6.8628 & TRN \\
\hline CHEMBL3941651 & 1642149 & 7.4437 & 6.86600 & 00000000005 \\
\hline CHEMBL 3942490 & 1642149 & 9.0 & 9.1946 & TST \\
\hline CHEMBL 3920712 & 1642149 & 7.6353 & 8.1949 & TST \\
\hline CHEMBL 3957815 & 1642149 & 6.9097 & 6.8586 & TRN \\
\hline CHEMBL3964200 & 1642149 & 8.5229 & 8.5147 & TST \\
\hline CHEMBL 3897054 & 1642149 & 7.5527 & 7.3832 & TRN \\
\hline CHEMBL3941032 & 1642149 & 7.2007 & 7.0866 & TRN \\
\hline CHEMBL 3902693 & 1642149 & 6.4411 & 6.7606 & TRN \\
\hline CHEMBL3973209 & 1642149 & 7.7212 & 7.5852 & TRN \\
\hline CHEMBL 3944483 & 1642149 & 6.5272 & 6.8827 & TRN \\
\hline CHEMBL3911065 & 1642149 & 8.7471 & 9.3351 & TRN \\
\hline CHEMBL 3890260 & 1642149 & 9.0 & 9.3406 & TRN \\
\hline CHEMBL 3947449 & 1642149 & 7.6972 & 7.9144 & TRN \\
\hline CHEMBL 3893241 & 1642149 & 8.0521 & 8.2178 & TST \\
\hline CHEMBL3939516 & 1642149 & 8.5229 & 8.4323 & TRN \\
\hline CHEMBL 3936195 & 1642149 & 8.0969 & 7.227 & TRN \\
\hline CHEMBL3927413 & 1642149 & 7.6144 & 6.7377 & TRN \\
\hline CHEMBL 3958053 & 1642149 & 7.1805 & 7.0213 & TRN \\
\hline CHEMBL3966036 & 1642149 & 9.0 & 8.1585 & TRN \\
\hline CHEMBL3964739 & 1642149 & 5.9606 & 6.7558 & TST \\
\hline CHEMBL3960366 & 1642149 & 7.1739 & 7.0234 & TRN \\
\hline CHEMBL 3892932 & 1642149 & 8.699 & 8.4955 & TRN \\
\hline CHEMBL 3922692 & 1642149 & 4.9626 & 5.8131 & TST \\
\hline CHEMBL 3931229 & 1642149 & 7.4989 & 7.1618 & TRN \\
\hline CHEMBL 3898485 & 1642149 & 7.3279 & 7.6966 & TRN \\
\hline CHEMBL 3928483 & 1642149 & 9.0 & 8.63 & TST \\
\hline CHEMBL3922030 & 1642149 & 8.6003 & 9.5817 & TRN \\
\hline CHEMBL 3912555 & 1642149 & 7.5769 & 7.8269 & TST \\
\hline CHEMBL 3893940 & 1642149 & 8.699 & 8.4745 & TRN \\
\hline CHEMBL 3945328 & 1642149 & 6.5186 & 6.2194 & TRN \\
\hline CHEMBL 3903266 & 1642149 & 5.2185 & 6.4542 & TRN \\
\hline CHEMBL3899364 & 1642149 & 6.0 & 6.3034 & TST \\
\hline CHEMBL3900349 & 1642149 & 7.3001 & 7.2799 & TRN \\
\hline CHEMBL3949751 & 1642149 & 6.9431 & 6.6409 & TRN \\
\hline CHEMBL3940739 & 1642149 & 7.0537 & 7.3294 & TST \\
\hline CHEMBL 3928560 & 1642149 & 6.4535 & 6.1512 & TRN \\
\hline CHEMBL3913707 & 1642149 & 5.4883 & 5.4624 & TRN \\
\hline CHEMBL3929758 & 1642149 & 6.7077 & 5.9834 & TRN \\
\hline CHEMBL3923005 & 1642149 & 7.7959 & 7.9687 & TRN \\
\hline CHEMBL3943839 & 1642149 & 7.0396 & 7.0006 & TRN \\
\hline CHEMBL3978918 & 1642149 & 7.7156 & 8.4147 & TST \\
\hline CHEMBL3897906 & 1642149 & 3.8854 & 4.981 & TRN \\
\hline CHEMBL3982389 & 1642149 & 7.585 & 7.2158 & TRN \\
\hline CHEMBL 3894288 & 1642149 & 7.8993 & 7.9139 & TST \\
\hline CHEMBL3955015 & 1642149 & 7.284 & 7.5026 & TRN \\
\hline
\end{tabular}


Supplemental Table S2.txt

\begin{tabular}{|c|c|c|c|c|c|c|}
\hline CHEMBL 3960524 & 1642149 & 7.6662 & 8.5252 & TST & & \\
\hline CHEMBL 3936243 & 1642149 & 7.2996 & 7.5631 & TST & & \\
\hline CHEMBL3935215 & 1642149 & 9.0 & 9.0211 & TRN & & \\
\hline CHEMBL 3968405 & 1642149 & 9.0 & 8.2592 & TRN & & \\
\hline CHEMBL3939754 & 1642149 & 8.4078 & 7.9796 & TRN & & \\
\hline CHEMBL3974516 & 1642149 & 7.5376 & 7.4193 & TRN & & \\
\hline CHEMBL 3984222 & 1642149 & 6.9788 & 7.0876 & TRN & & \\
\hline CHEMBL 3948542 & 1642149 & 7.1135 & 7.1387 & TRN & & \\
\hline CHEMBL3910869 & 1642149 & 9.0 & 8.5971 & TRN & & \\
\hline CHEMBL3955175 & 1642149 & 6.8861 & 7.4094 & TRN & & \\
\hline CHEMBL3920016 & 1642149 & 8.4078 & 8.6714 & TST & & \\
\hline CHEMBL 3950625 & 1642149 & 6.76200 & $0000000 t$ & 205 & 6.2219 & TRN \\
\hline CHEMBL3958935 & 1642149 & 8.2218 & 8.7958 & TRN & & \\
\hline CHEMBL 3931867 & 1642149 & 7.4057 & 7.3193 & TRN & & \\
\hline CHEMBL 3978707 & 1642149 & 8.0 & 8.0891 & TRN & & \\
\hline CHEMBL3964476 & 1642149 & 8.0969 & 8.4372 & TRN & & \\
\hline CHEMBL3935214 & 1642149 & 8.2366 & 8.3278 & TRN & & \\
\hline CHEMBL 3974538 & 1642149 & 7.6021 & 7.3986 & TRN & & \\
\hline CHEMBL 3897046 & 1642149 & 6.0 & 6.9019 & TRN & & \\
\hline CHEMBL3958467 & 1642149 & 7.76 & 7.5457 & TRN & & \\
\hline CHEMBL 3923576 & 1642149 & 8.3979 & 8.6853 & TRN & & \\
\hline CHEMBL 3905502 & 1642149 & 6.0 & 6.4913 & TRN & & \\
\hline CHEMBL3980772 & 1642149 & 7.6469 & 7.4341 & TRN & & \\
\hline CHEMBL 3897573 & 1642149 & 6.9034 & 7.0081 & TRN & & \\
\hline CHEMBL3958750 & 1642149 & 8.1118 & 7.0926 & TRN & & \\
\hline CHEMBL3970496 & 1642149 & 8.1549 & 7.8202 & TRN & & \\
\hline CHEMBL 3957332 & 1642149 & 8.5229 & 7.9994 & TRN & & \\
\hline CHEMBL3905504 & 1642149 & 8.3161 & 7.7986 & TST & & \\
\hline CHEMBL 3950501 & 1642149 & 6.1746 & 7.0744 & TRN & & \\
\hline CHEMBL3905352 & 1642149 & 6.5674 & 6.4253 & TST & & \\
\hline CHEMBL 3916701 & 1642149 & 7.2757 & 7.0401 & TST & & \\
\hline CHEMBL 3934284 & 1642149 & 5.0307 & 5.5906 & TRN & & \\
\hline CHEMBL3948880 & 1642149 & 6.8345 & 6.7155 & TST & & \\
\hline CHEMBL3931901 & 1642149 & 8.6162 & 8.1658 & TRN & & \\
\hline CHEMBL3938650 & 1642149 & 7.8239 & 7.8712 & TRN & & \\
\hline CHEMBL 3951134 & 1642149 & 7.4202 & 7.4642 & TRN & & \\
\hline CHEMBL3943987 & 1642149 & 6.5433 & 7.0117 & TST & & \\
\hline CHEMBL 3972874 & 1642149 & 7.2483 & 7.3275 & TRN & & \\
\hline CHEMBL3953049 & 1642149 & 7.5213 & 7.7318 & TRN & & \\
\hline CHEMBL3986590 & 1642149 & 9.2518 & 9.1125 & TST & & \\
\hline CHEMBL 3940340 & 1642149 & 8.2218 & 7.9947 & TRN & & \\
\hline CHEMBL3978860 & 1642149 & 8.301 & 8.2369 & TRN & & \\
\hline CHEMBL3982731 & 1642149 & 7.3372 & 7.1909 & TRN & & \\
\hline CHEMBL3932418 & 1642149 & 9.0 & 8.4064 & TRN & & \\
\hline CHEMBL3983718 & 1642149 & 7.6576 & 7.3044 & TST & & \\
\hline CHEMBL 3935027 & 1642149 & 3.8854 & 5.5058 & TRN & & \\
\hline CHEMBL 3898246 & 1642149 & 8.5086 & 8.3402 & TRN & & \\
\hline CHEMBL3960611 & 1642149 & 6.0506 & 5.8331 & TRN & & \\
\hline
\end{tabular}


Supplemental Table S2.txt

\begin{tabular}{|c|c|c|c|c|c|c|}
\hline CHEMBL3942702 & 1642149 & 8.5229 & 8.0411 & TRN & & \\
\hline CHEMBL3895836 & 1642149 & 9.0 & 8.0989 & TRN & & \\
\hline CHEMBL3916100 & 1642149 & 6.6696 & 6.3544 & TRN & & \\
\hline CHEMBL3961705 & 1642149 & 8.5229 & 8.3317 & TRN & & \\
\hline CHEMBL3938387 & 1642149 & 6.6234 & 6.97 & TST & & \\
\hline CHEMBL3986853 & 1642149 & 5.6931 & 5.5589 & TRN & & \\
\hline CHEMBL3959324 & 1642149 & 8.301 & 8.6307 & TRN & & \\
\hline CHEMBL3972269 & 1642149 & 8.5229 & 8.3522 & TST & & \\
\hline CHEMBL3973665 & 1642149 & 6.8441 & 6.747999 & 99999999 & & TRN \\
\hline CHEMBL3947813 & 1642149 & 6.7409 & 7.3168 & TRN & & \\
\hline CHEMBL 3908281 & 1642149 & 6.93 & 6.9624 & TRN & & \\
\hline CHEMBL3930953 & 1642149 & 7.2185 & 6.6637 & TRN & & \\
\hline CHEMBL3899207 & 1642149 & 8.5229 & 7.8792 & TRN & & \\
\hline CHEMBL3963118 & 1642149 & 6.0 & 6.3776 & TRN & & \\
\hline CHEMBL3955069 & 1642149 & 8.1549 & 8.477 & TST & & \\
\hline CHEMBL3964855 & 1642149 & 7.8239 & 7.5094 & TRN & & \\
\hline CHEMBL3925857 & 1642149 & 7.7615 & 7.7679 & TST & & \\
\hline CHEMBL3916545 & 1642149 & 7.8444 & 8.533 & TRN & & \\
\hline CHEMBL3977845 & 1642149 & 6.9278 & 6.9549 & TRN & & \\
\hline CHEMBL3967753 & 1642149 & 5.6194 & 6.0426 & TRN & & \\
\hline CHEMBL3938635 & 1642149 & 5.4067 & 5.854 & TRN & & \\
\hline CHEMBL3906434 & 1642149 & 6.1144 & 5.8894 & TRN & & \\
\hline CHEMBL3978591 & 1642149 & 8.1911 & 7.6619 & TRN & & \\
\hline CHEMBL3964815 & 1642149 & 7.6641 & 7.7292 & TST & & \\
\hline CHEMBL3916367 & 1642149 & 8.301 & 8.0047 & TST & & \\
\hline CHEMBL3969517 & 1642149 & 7.3934 & 7.6498 & TST & & \\
\hline CHEMBL3946379 & 1642149 & 8.301 & 8.3027 & TRN & & \\
\hline CHEMBL3903733 & 1642149 & 7.5613 & 7.8281 & TST & & \\
\hline CHEMBL3952811 & 1642149 & 7.3979 & 6.7825 & TRN & & \\
\hline CHEMBL 3892283 & 1642149 & 7.54200 & 200000000 & 11 & 7.6763 & I n \\
\hline CHEMBL3930228 & 1642149 & 5.4724 & 5.2936 & TRN & & \\
\hline CHEMBL3904738 & 1642149 & 5.8804 & 6.2004 & TST & & \\
\hline CHEMBL3921526 & 1642149 & 8.1643 & 7.5354 & TRN & & \\
\hline CHEMBL3929340 & 1642149 & 7.8239 & 7.7727 & TRN & & \\
\hline CHEMBL3920143 & 1642149 & 7.7447 & 8.1381 & TST & & \\
\hline CHEMBL3920224 & 1642149 & 5.9884 & 6.0784 & TRN & & \\
\hline CHEMBL3914701 & 1642149 & 8.5229 & 8.4947 & TST & & \\
\hline CHEMBL3971744 & 1642149 & 6.96700 & 000000000 & 305 & 6.3665 & T \\
\hline CHEMBL3985861 & 1642149 & 8.4711 & 8.4284 & TST & & \\
\hline CHEMBL3916145 & 1642149 & 8.1898 & 8.4005 & TST & & \\
\hline CHEMBL3916853 & 1642149 & 6.7158 & 7.1195 & TST & & \\
\hline CHEMBL3914778 & 1642149 & 8.4828 & 9.0187 & TRN & & \\
\hline CHEMBL3912747 & 1642149 & 7.7964 & 7.8131 & TRN & & \\
\hline CHEMBL3929551 & 1642149 & 7.5941 & 7.4248 & TST & & \\
\hline CHEMBL3920856 & 1642149 & 8.5229 & 9.1965 & TRN & & \\
\hline CHEMBL3985285 & 1642149 & 6.5086 & 5.9458 & TRN & & \\
\hline CHEMBL3917345 & 1642149 & 7.4202 & 7.2228 & TRN & & \\
\hline CHEMBL3983517 & 1642149 & 6.9666 & 6.4786 & TRN & & \\
\hline
\end{tabular}


Supplemental Table S2.txt

\begin{tabular}{|c|c|c|c|c|c|c|}
\hline CHEMBL 3907945 & 1642149 & 6.3398 & 7.1311 & TRN & & \\
\hline CHEMBL3901809 & 1642149 & 8.1244 & 8.0734 & TRN & & \\
\hline CHEMBL3931467 & 1642149 & 7.7212 & 7.5598 & TRN & & \\
\hline CHEMBL 3908247 & 1642149 & 6.8633 & 7.0959 & TRN & & \\
\hline CHEMBL3977086 & 1642149 & 5.7176 & 6.2989 & TRN & & \\
\hline CHEMBL 3906303 & 1642149 & 6.0 & 6.4675 & TRN & & \\
\hline CHEMBL 3956048 & 1642149 & 6.0119 & 7.4758 & TRN & & \\
\hline CHEMBL3906605 & 1642149 & 8.4089 & 7.2275 & TST & & \\
\hline CHEMBL 3907069 & 1642149 & 8.4425 & 9.1558 & TST & & \\
\hline CHEMBL3986929 & 1642149 & 7.3098 & 7.2862 & TRN & & \\
\hline CHEMBL 3957981 & 1642149 & 6.67299 & 999999999 & 99 & 6.0567 & TRN \\
\hline CHEMBL 3909421 & 1642149 & 6.7471 & 7.115 & TRN & & \\
\hline CHEMBL 3917115 & 1642149 & 6.2721 & 5.2456 & TRN & & \\
\hline CHEMBL 3950860 & 1642149 & 7.8861 & 8.0894 & TRN & & \\
\hline CHEMBL3969958 & 1642149 & 6.9285 & 7.1751 & TRN & & \\
\hline CHEMBL 217354 & 954562 & 6.6844 & 5.5371 & TRN & & \\
\hline CHEMBL102714 & 954562 & 3.5157 & 3.7456 & TRN & & \\
\hline CHEMBL 255342 & 954562 & 4.3173 & 4.0513 & TRN & & \\
\hline CHEMBL1357247 & 954562 & 4.5187 & 3.3435 & TRN & & \\
\hline CHEMBL514499 & 954562 & 7.4267 & 6.7792 & TRN & & \\
\hline CHEMBL 2363137 & 954562 & 4.1974 & 4.6209 & TRN & & \\
\hline CHEMBL1186585 & 954562 & 4.4746 & 4.8305 & TRN & & \\
\hline CHEMBL 220241 & 954562 & 5.023 & 4.4981 & TRN & & \\
\hline CHEMBL 2144069 & 954562 & 4.1106 & 4.0298 & TRN & & \\
\hline CHEMBL 3392440 & 954562 & 4.6734 & 3.8949 & TRN & & \\
\hline CHEMBL1673039 & 954562 & 4.4866 & 4.4933 & TRN & & \\
\hline CHEMBL483849 & 954562 & 2.9931 & 2.5843 & TST & & \\
\hline CHEMBL65 & 954562 & 7.6637 & 8.0481 & TRN & & \\
\hline CHEMBL1190711 & 954562 & 4.8482 & 5.1572 & TRN & & \\
\hline CHEMBL515416 & 954562 & 4.1898 & 4.3481 & TRN & & \\
\hline CHEMBL 3349342 & 954562 & 4.0355 & 4.1399 & TRN & & \\
\hline CHEMBL1643959 & 954562 & 2.8865 & 3.3145 & TRN & & \\
\hline CHEMBL472940 & 954562 & \multicolumn{3}{|c|}{5.0360000000000005} & 4.3658 & TRN \\
\hline CHEMBL 209148 & 954562 & 3.6683 & 4.1599 & TRN & & \\
\hline CHEMBL135561 & 954562 & 4.0627 & 4.2089 & TRN & & \\
\hline CHEMBL1230020 & 954562 & 3.0496 & 3.8499 & TRN & & \\
\hline CHEMBL449158 & 954562 & 6.9432 & 6.4691 & TST & & \\
\hline CHEMBL379975 & 954562 & 4.9375 & 5.3539 & TRN & & \\
\hline CHEMBL573107 & 954562 & 4.6005 & 5.0407 & TRN & & \\
\hline CHEMBL 2134202 & 954562 & 4.3832 & 4.7519 & TRN & & \\
\hline CHEMBL 210618 & 954562 & 3.9458 & 3.7646 & TRN & & \\
\hline CHEMBL1788116 & 954562 & 3.8435 & 4.1512 & TRN & & \\
\hline CHEMBL577784 & 954562 & 4.0346 & 5.1063 & TRN & & \\
\hline CHEMBL392695 & 954562 & 5.5024 & 5.0523 & TRN & & \\
\hline CHEMBL 221137 & 954562 & 4.2155 & 4.7692 & TST & & \\
\hline CHEMBL 2005886 & 954562 & 5.6757 & 4.8224 & TRN & & \\
\hline CHEMBL1516890 & 954562 & 3.7856 & 4.1051 & TRN & & \\
\hline CHEMBL 3186408 & 954562 & 5.3324 & 3.8977 & TST & & \\
\hline
\end{tabular}




\begin{tabular}{|c|c|c|c|c|c|}
\hline \multirow[b]{2}{*}{ CHEMBL1242367 } & \multicolumn{5}{|c|}{ Supplemental Table S2.txt } \\
\hline & 954562 & 4.5441 & 4.0407 & TRN & \\
\hline CHEMBL1256459 & 954562 & 6.8321 & 6.654 & TRN & \\
\hline CHEMBL259181 & 954562 & 5.6524 & 4.6949 & TRN & \\
\hline CHEMBL512504 & 954562 & 6.0957 & 6.0087 & TRN & \\
\hline CHEMBL258844 & 954562 & 3.4585 & 4.1237 & TRN & \\
\hline CHEMBL180127 & 954562 & 3.4075 & 4.2024 & TRN & \\
\hline CHEMBL3199475 & 954562 & 4.3683 & 4.6978 & TRN & \\
\hline CHEMBL1970879 & 954562 & 4.4169 & 4.0608 & TRN & \\
\hline CHEMBL585951 & 954562 & 5.7312 & 6.0625 & TRN & \\
\hline CHEMBL373751 & 954562 & 3.14 & 3.6674 & TRN & \\
\hline CHEMBL 2137530 & 954562 & 5.4406 & 4.8566 & TRN & \\
\hline CHEMBL191334 & 954562 & 3.8346 & 4.0935 & TRN & \\
\hline CHEMBL1590308 & 954562 & 2.7206 & 3.4321 & TST & \\
\hline CHEMBL 213100 & 954562 & 4.8404 & 4.0814 & TRN & \\
\hline CHEMBL483847 & 954562 & 3.8058 & 3.9767 & TRN & \\
\hline CHEMBL240954 & 954562 & 4.9316 & 3.993000 & 00000000003 & TST \\
\hline CHEMBL189584 & 954562 & 4.7976 & 4.7121 & TRN & \\
\hline CHEMBL 379300 & 954562 & 5.1925 & 5.9437 & TRN & \\
\hline CHEMBL192566 & 954562 & 7.3646 & 7.7169 & TST & \\
\hline CHEMBL393929 & 954562 & 5.6949 & 4.359 & TRN & \\
\hline CHEMBL188678 & 954562 & 4.2161 & 4.5693 & TRN & \\
\hline CHEMBL1404918 & 954562 & 2.4567 & 3.1335 & TRN & \\
\hline CHEMBL 222102 & 954562 & 4.3006 & 3.9045 & TST & \\
\hline CHEMBL300389 & 954562 & 6.3508 & 6.462000 & 0000000001 & TST \\
\hline CHEMBL399530 & 954562 & 5.1187 & 4.8118 & TST & \\
\hline CHEMBL558642 & 954562 & 3.8665 & 4.173 & TST & \\
\hline CHEMBL9470 & 954562 & 5.744 & 5.71 & TST & \\
\hline CHEMBL92309 & 954562 & 2.5093 & 3.1758 & TST & \\
\hline CHEMBL509032 & 954562 & 5.7488 & 5.2431 & TST & \\
\hline CHEMBL412142 & 954562 & 5.0151 & 3.8322 & TST & \\
\hline CHEMBL1909414 & 954562 & 3.6799 & 4.0339 & TST & \\
\hline CHEMBL202721 & 954562 & 3.5188 & 4.9163 & TST & \\
\hline CHEMBL3933497 & 1641129 & 10.0 & 10.2092 & TRN & \\
\hline CHEMBL3905909 & 1641129 & 9.0 & 9.1713 & TRN & \\
\hline CHEMBL 3949084 & 1641129 & 11.0 & 10.6531 & TRN & \\
\hline CHEMBL3905418 & 1641129 & 11.0 & 10.7079 & TRN & \\
\hline CHEMBL3899990 & 1641129 & 10.0 & 10.0251 & TRN & \\
\hline CHEMBL 3905260 & 1641129 & 11.0 & 10.9397 & TRN & \\
\hline CHEMBL 3897585 & 1641129 & 11.0 & 10.4618 & TRN & \\
\hline CHEMBL 3971077 & 1641129 & 10.0 & 9.7988 & TRN & \\
\hline CHEMBL3906083 & 1641129 & 9.0 & 9.477 & TST & \\
\hline CHEMBL3933419 & 1641129 & 10.0 & 9.981 & TST & \\
\hline CHEMBL3965993 & 1641129 & 11.0 & 11.043 & TRN & \\
\hline CHEMBL3976633 & 1641129 & 9.0 & 10.08 & TST & \\
\hline CHEMBL 3940213 & 1641129 & 11.0 & 11.0318 & TRN & \\
\hline CHEMBL 3974489 & 1641129 & 11.0 & 10.887 & TRN & \\
\hline CHEMBL3920263 & 1641129 & 9.0 & 8.9587 & TRN & \\
\hline CHEMBL3915372 & 1641129 & 10.0 & 9.9718 & TRN & \\
\hline
\end{tabular}


Supplemental Table S2.txt

\begin{tabular}{|c|c|c|c|c|c|}
\hline CHEMBL3945946 & 1641129 & 10.0 & 9.7953 & TRN & \\
\hline CHEMBL3957700 & 1641129 & 10.0 & 9.7924 & TRN & \\
\hline CHEMBL3945768 & 1641129 & 9.0 & 9.6845 & TST & \\
\hline CHEMBL3950915 & 1641129 & 9.0 & 9.4179 & TST & \\
\hline CHEMBL 3938130 & 1641129 & 10.0 & 9.8614 & TRN & \\
\hline CHEMBL3969479 & 1641129 & 11.0 & 11.1216 & TRN & \\
\hline CHEMBL3955682 & 1641129 & 11.0 & 10.9701 & TRN & \\
\hline CHEMBL 3925754 & 1641129 & 11.0 & 11.0082 & TRN & \\
\hline CHEMBL 3898079 & 1641129 & 11.0 & 11.0729 & TRN & \\
\hline CHEMBL 3970490 & 1641129 & 9.0 & 8.8886 & TRN & \\
\hline CHEMBL3958766 & 1641129 & 10.0 & 9.9992 & TRN & \\
\hline CHEMBL3943526 & 1641129 & 10.0 & 9.6924 & TRN & \\
\hline CHEMBL3934076 & 1641129 & 9.0 & 9.4571 & TST & \\
\hline CHEMBL 3924588 & 1641129 & 11.0 & 10.86900 & 00000000002 & TRN \\
\hline CHEMBL 3946961 & 1641129 & 11.0 & 10.6104 & TST & \\
\hline CHEMBL3911645 & 1641129 & 9.0 & 9.7589 & TST & \\
\hline CHEMBL3976171 & 1641129 & 11.0 & 10.9159 & TRN & \\
\hline CHEMBL3973259 & 1641129 & 11.0 & 10.7767 & TRN & \\
\hline CHEMBL3979819 & 1641129 & 11.0 & 10.8422 & TRN & \\
\hline CHEMBL 3950091 & 1641129 & 11.0 & 11.2006 & TRN & \\
\hline CHEMBL3967662 & 1641129 & 11.0 & 11.075 & TRN & \\
\hline CHEMBL3948711 & 1641129 & 9.0 & 9.3945 & TST & \\
\hline CHEMBL3897369 & 1641129 & 10.0 & 10.2225 & TRN & \\
\hline CHEMBL3961389 & 1641129 & 10.0 & 10.1811 & TRN & \\
\hline CHEMBL3958198 & 1641129 & 11.0 & 10.9236 & TRN & \\
\hline CHEMBL 3972091 & 1641129 & 9.0 & 9.3333 & TST & \\
\hline CHEMBL 3972278 & 1641129 & 10.0 & 10.1515 & TRN & \\
\hline CHEMBL3960089 & 1641129 & 10.0 & 10.1019 & TRN & \\
\hline CHEMBL 3904082 & 1641129 & 10.0 & 9.9623 & TRN & \\
\hline CHEMBL 3895846 & 1641129 & 10.0 & 10.0626 & TRN & \\
\hline CHEMBL 3985832 & 1641129 & 10.0 & 10.0631 & TRN & \\
\hline CHEMBL3941470 & 1641129 & 11.0 & 10.9285 & TRN & \\
\hline CHEMBL3955279 & 1641129 & 8.0 & 8.8168 & TST & \\
\hline CHEMBL 3945708 & 1641129 & 9.0 & 9.4384 & TST & \\
\hline CHEMBL 3986426 & 1641129 & 9.0 & 9.4308 & TRN & \\
\hline CHEMBL3905417 & 1641129 & 11.0 & 10.3547 & TST & \\
\hline CHEMBL 3981259 & 1641129 & 9.0 & 9.3833 & TST & \\
\hline CHEMBL 3980264 & 1641129 & 9.0 & 10.5637 & TST & \\
\hline CHEMBL 3903563 & 1641129 & 11.0 & 10.8406 & TRN & \\
\hline CHEMBL 3895837 & 1641129 & 9.0 & 8.9091 & TRN & \\
\hline CHEMBL3986911 & 1641129 & 11.0 & 10.8009 & TRN & \\
\hline CHEMBL 3943744 & 1641129 & 10.0 & 10.5859 & TRN & \\
\hline CHEMBL 3973811 & 1641129 & 10.0 & 10.6705 & TRN & \\
\hline CHEMBL 3898732 & 1641129 & 10.0 & 9.6616 & TST & \\
\hline CHEMBL 3934775 & 1641129 & 10.0 & 10.2853 & TRN & \\
\hline CHEMBL 3895114 & 1641129 & 11.0 & 10.9881 & TRN & \\
\hline CHEMBL 3915281 & 1641129 & 10.0 & 10.1509 & TRN & \\
\hline CHEMBL3931533 & 1637323 & 8.11 & 8.3277 & TRN & \\
\hline
\end{tabular}

Page 7523 


\begin{tabular}{|c|c|c|c|c|c|}
\hline \multirow[b]{2}{*}{ CHEMBL 3947740} & \\
\hline & 1637323 & 7.91 & 8.1889 & TRN & \\
\hline CHEMBL3963816 & 1637323 & 7.71 & 7.1644 & TRN & \\
\hline CHEMBL3909951 & 1637323 & 7.48 & 7.7015 & TST & \\
\hline CHEMBL 3912630 & 1637323 & 7.19 & 7.5623 & TRN & \\
\hline CHEMBL3933449 & 1637323 & 7.93 & 8.1707 & TRN & \\
\hline CHEMBL3898908 & 1637323 & 8.46 & 8.5141 & TST & \\
\hline CHEMBL3986163 & 1637323 & 7.91 & 8.0531 & TRN & \\
\hline CHEMBL 3898120 & 1637323 & 8.32 & 8.3173 & TRN & \\
\hline CHEMBL3955288 & 1637323 & 8.09 & \multicolumn{2}{|c|}{8.142000000000001} & TRN \\
\hline CHEMBL3957914 & 1637323 & 7.21 & 7.2871 & TRN & \\
\hline CHEMBL3908978 & 1637323 & 6.07 & 5.8894 & TRN & \\
\hline CHEMBL3906155 & 1637323 & 8.03 & 8.2174 & TRN & \\
\hline CHEMBL 3940334 & 1637323 & 7.88 & 8.0676 & TRN & \\
\hline CHEMBL3958153 & 1637323 & 8.41 & 8.5752 & TRN & \\
\hline CHEMBL 3925254 & 1637323 & 8.15 & 8.2199 & TRN & \\
\hline CHEMBL3907600 & 1637323 & 8.09 & 8.2084 & TRN & \\
\hline CHEMBL3954368 & 1637323 & 7.0 & 7.1517 & TRN & \\
\hline CHEMBL3951714 & 1637323 & 8.28 & 8.3304 & TRN & \\
\hline CHEMBL3965364 & 1637323 & 6.07 & \multicolumn{2}{|c|}{5.9079999999999995} & TRN \\
\hline CHEMBL3969446 & 1637323 & 8.42 & 8.4998 & TRN & \\
\hline CHEMBL3951126 & 1637323 & 8.49 & 8.5841 & TRN & \\
\hline CHEMBL 3933015 & 1637323 & 6.39 & 6.642 & TRN & \\
\hline CHEMBL3898881 & 1637323 & 8.49 & 8.6396 & TRN & \\
\hline CHEMBL3901644 & 1637323 & 8.05 & 8.1614 & TRN & \\
\hline CHEMBL 3944665 & 1637323 & 6.92 & 7.0877 & TST & \\
\hline CHEMBL 3947293 & 1637323 & 7.01 & 7.3096 & TRN & \\
\hline CHEMBL3947826 & 1637323 & 6.62 & 6.7448 & TST & \\
\hline CHEMBL 3985692 & 1637323 & 8.44 & 8.5638 & TST & \\
\hline CHEMBL3947990 & 1637323 & 7.83 & 7.8076 & TST & \\
\hline CHEMBL 3925306 & 1637323 & 8.45 & 8.5483 & TRN & \\
\hline CHEMBL3951245 & 1637323 & 8.54 & 8.6227 & TST & \\
\hline CHEMBL3948623 & 1637323 & 8.07 & 8.0309 & TRN & \\
\hline CHEMBL 3892018 & 1637323 & 8.48 & 8.4106 & TRN & \\
\hline CHEMBL3987037 & 1637323 & 8.4 & 8.3552 & TRN & \\
\hline CHEMBL3921313 & 1637323 & 8.19 & 8.0057 & TRN & \\
\hline CHEMBL3927327 & 1637323 & 8.14 & 8.3414 & TRN & \\
\hline CHEMBL3976280 & 1637323 & 8.53 & 8.4607 & TRN & \\
\hline CHEMBL3973820 & 1637323 & 8.29 & \multicolumn{2}{|c|}{8.097999999999999} & TRN \\
\hline CHEMBL3918011 & 1637323 & 7.95 & 7.7985 & TRN & \\
\hline CHEMBL 3915235 & 1637323 & 7.82 & 7.9851 & TRN & \\
\hline CHEMBL3965673 & 1637323 & 5.0 & 5.5464 & TRN & \\
\hline CHEMBL3968094 & 1637323 & 7.39 & 7.4685 & TRN & \\
\hline CHEMBL3918751 & 1637323 & 8.57 & 8.622 & TRN & \\
\hline CHEMBL3956164 & 1637323 & 8.01 & 7.9565 & TRN & \\
\hline CHEMBL 3908829 & 1637323 & 8.19 & 8.294 & TRN & \\
\hline CHEMBL3911573 & 1637323 & 8.53 & 8.4379 & TRN & \\
\hline CHEMBL3969879 & 1637323 & 7.33 & 7.646 & TRN & \\
\hline \multirow[t]{2}{*}{ CHEMBL3972564 } & 1637323 & 6.99 & \multicolumn{2}{|c|}{6.917999999999999} & TRN \\
\hline & & & & 7524 & \\
\hline
\end{tabular}




\begin{tabular}{|c|c|c|c|c|}
\hline \multicolumn{5}{|c|}{ Supplemental Table S2.txt } \\
\hline CHEMBL 3927875 & 1637323 & 8.57 & 8.6913 & TRN \\
\hline CHEMBL 3930634 & 1637323 & 6.96 & 6.6598 & TRN \\
\hline CHEMBL 3901627 & 1637323 & 8.33 & 8.4091 & TST \\
\hline CHEMBL 3904329 & 1637323 & 8.18 & 8.3396 & TRN \\
\hline CHEMBL 3969408 & 1637323 & 5.99 & 6.0562 & TRN \\
\hline CHEMBL 3985853 & 1637323 & 8.5 & 8.4203 & TRN \\
\hline CHEMBL 3908326 & 1637323 & 8.26 & 8.395 & TRN \\
\hline CHEMBL 3918092 & 1637323 & 8.78 & 8.8564 & TRN \\
\hline CHEMBL 3964675 & 1637323 & 8.52 & 8.2758 & TRN \\
\hline CHEMBL3955706 & 1637323 & 8.61 & 8.5774 & TRN \\
\hline CHEMBL 3937533 & 1637323 & 8.36 & 8.3769 & TRN \\
\hline CHEMBL 3962814 & 1637323 & 8.29 & 8.17 & TRN \\
\hline CHEMBL3931674 & 1637323 & 8.02 & 8.1218 & TRN \\
\hline CHEMBL 3976219 & 1637323 & 8.09 & 8.1181 & TRN \\
\hline CHEMBL 3924872 & 1637323 & 7.94 & 7.6766 & TRN \\
\hline CHEMBL3908529 & 1637323 & 8.31 & 8.3219 & TRN \\
\hline CHEMBL 3962805 & 1637323 & 8.08 & 8.116 & TRN \\
\hline CHEMBL3960128 & 1637323 & 7.73 & 7.7453 & TST \\
\hline CHEMBL 3909565 & 1637323 & 8.48 & 8.6165 & TRN \\
\hline CHEMBL 3948321 & 1637323 & 8.5 & 8.3909 & TRN \\
\hline CHEMBL3985750 & 1637323 & 8.33 & 8.2909 & TRN \\
\hline CHEMBL 3983115 & 1637323 & 8.19 & 8.1989 & TRN \\
\hline CHEMBL3926311 & 1637323 & 7.9 & 7.6163 & TRN \\
\hline CHEMBL 3926406 & 1637323 & 8.52 & 8.1455 & TRN \\
\hline CHEMBL 3979490 & 1637323 & 8.54 & 8.6016 & TST \\
\hline CHEMBL3898355 & 1637323 & 8.47 & 8.6001 & TST \\
\hline CHEMBL 3940725 & 1637323 & 7.58 & 7.6924 & TRN \\
\hline CHEMBL3973531 & 1637323 & 8.17 & 8.1985 & TRN \\
\hline CHEMBL 3913757 & 1637323 & 8.63 & 8.6908 & TRN \\
\hline CHEMBL 3961210 & 1637323 & 8.51 & 8.669 & TRN \\
\hline CHEMBL 3936765 & 1637323 & 6.56 & 6.1455 & TRN \\
\hline CHEMBL3951156 & 1637323 & 7.93 & 8.0647 & TRN \\
\hline CHEMBL3979170 & 1637323 & 8.5 & 8.338 & TST \\
\hline CHEMBL 3969815 & 1637323 & 8.61 & 8.5315 & TRN \\
\hline CHEMBL3961872 & 1637323 & 8.52 & 8.4897 & TST \\
\hline CHEMBL 3985222 & 1637323 & 8.75 & 8.6335 & TRN \\
\hline CHEMBL 3974664 & 1637323 & 8.19 & 8.2529 & TRN \\
\hline CHEMBL3972173 & 1637323 & 7.7 & 7.7762 & TRN \\
\hline CHEMBL 3919173 & 1637323 & 8.74 & 8.9773 & TRN \\
\hline CHEMBL 3956737 & 1637323 & 6.44 & 6.4809 & TRN \\
\hline CHEMBL 3966022 & 1637323 & 7.87 & 8.0801 & TRN \\
\hline CHEMBL3968499 & 1637323 & 8.75 & 8.6816 & TRN \\
\hline CHEMBL 3912505 & 1637323 & 7.09 & 6.9378 & TRN \\
\hline CHEMBL 3915158 & 1637323 & 6.27 & 6.4231 & TRN \\
\hline CHEMBL3950262 & 1637323 & 7.86 & 7.9189 & TRN \\
\hline CHEMBL 3949470 & 1637323 & 8.46 & 8.6247 & TRN \\
\hline CHEMBL 3893008 & 1637323 & 8.47 & 8.5905 & TRN \\
\hline CHEMBL3889493 & 1637323 & 7.99 & 8.0672 & TRN \\
\hline
\end{tabular}




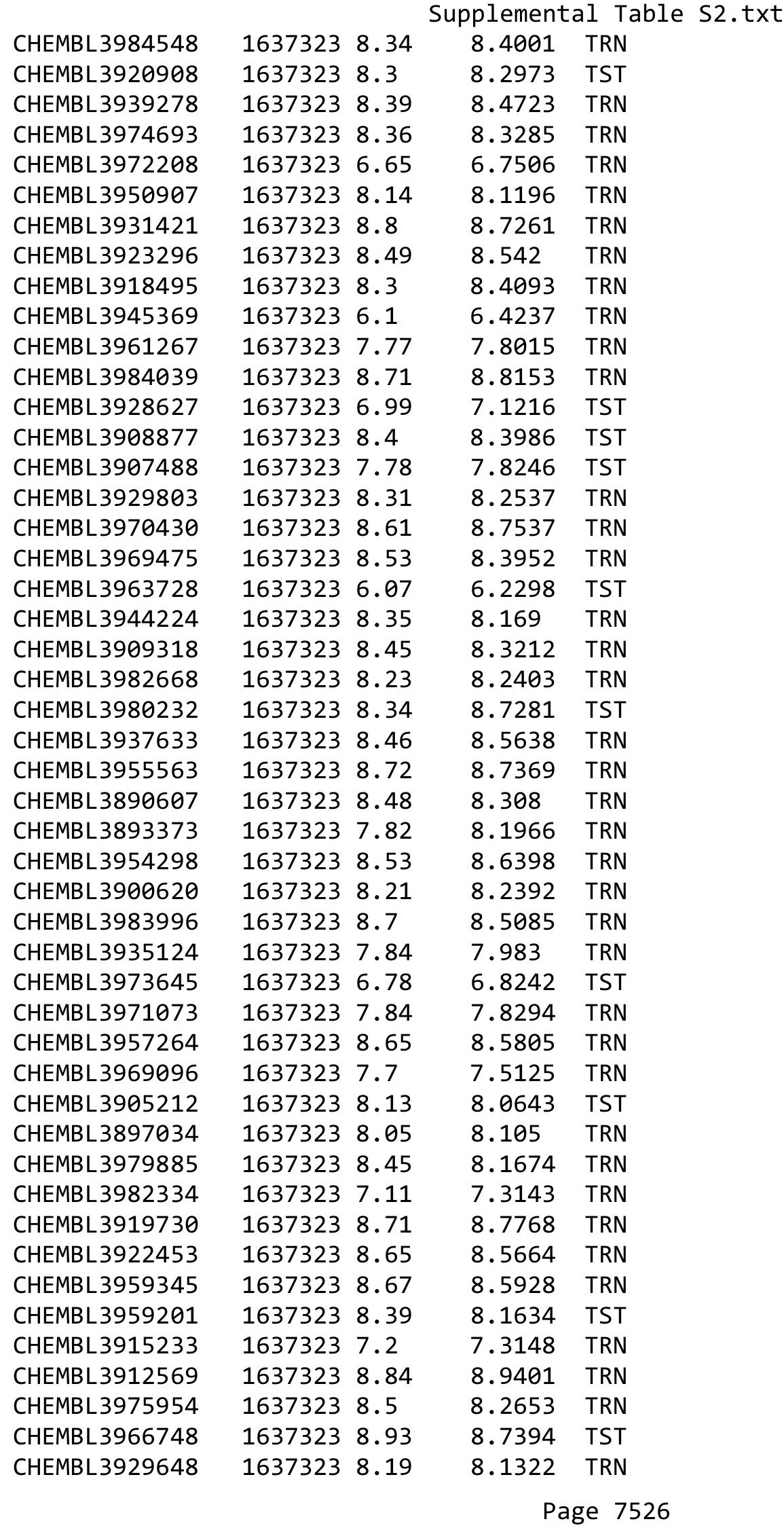




\begin{tabular}{|c|c|c|c|c|}
\hline \multicolumn{5}{|c|}{ Supplemental Table S2.txt } \\
\hline CHEMBL3926964 & 1637323 & 6.4 & 6.5797 & TRN \\
\hline CHEMBL3891619 & 1637323 & 8.01 & 8.019 & TRN \\
\hline CHEMBL3986661 & 1637323 & 8.05 & 7.9086 & TRN \\
\hline CHEMBL 3943043 & 1637323 & 8.6 & 8.5542 & TRN \\
\hline CHEMBL3904745 & 1637323 & 8.47 & 8.244 & TRN \\
\hline CHEMBL3965614 & 1637323 & 8.47 & 8.2972 & TRN \\
\hline CHEMBL3968009 & 1637323 & 8.51 & 8.5423 & TST \\
\hline CHEMBL3906122 & 1637323 & 8.41 & 8.1726 & TST \\
\hline CHEMBL 3900268 & 1637323 & 6.55 & 7.0385 & TRN \\
\hline CHEMBL3951728 & 1637323 & 7.91 & 8.0473 & TRN \\
\hline CHEMBL 3962554 & 1637323 & 8.29 & 8.081 & TRN \\
\hline CHEMBL3913970 & 1637323 & 8.35 & 8.1974 & TST \\
\hline CHEMBL3972979 & 1637323 & 8.54 & 8.704 & TRN \\
\hline CHEMBL3975447 & 1637323 & 8.73 & 8.7919 & TRN \\
\hline CHEMBL3911516 & 1637323 & 8.08 & 8.0905 & TRN \\
\hline CHEMBL3958756 & 1637323 & 7.21 & 7.4052 & TRN \\
\hline CHEMBL3956120 & 1637323 & 8.06 & 7.8011 & TRN \\
\hline CHEMBL3907551 & 1637323 & 6.47 & 6.2333 & TRN \\
\hline CHEMBL 3904777 & 1637323 & 7.71 & 7.8725 & TST \\
\hline CHEMBL3975007 & 1637323 & 6.9 & 7.0355 & TRN \\
\hline CHEMBL3972517 & 1637323 & 8.37 & 8.5013 & TRN \\
\hline CHEMBL3928956 & 1637323 & 7.01 & 7.067 & TRN \\
\hline CHEMBL3919270 & 1637323 & 7.57 & 7.5376 & TRN \\
\hline CHEMBL3941705 & 1637323 & 7.67 & 7.6525 & TRN \\
\hline CHEMBL3982570 & 1637323 & 7.42 & 7.2466 & TRN \\
\hline CHEMBL3920007 & 1637323 & 8.26 & 8.3742 & TRN \\
\hline CHEMBL3922698 & 1637323 & 8.71 & 8.6625 & TRN \\
\hline CHEMBL3957533 & 1637323 & 8.19 & 8.2813 & TRN \\
\hline CHEMBL3969373 & 1637323 & 8.41 & 8.4545 & TRN \\
\hline CHEMBL3905485 & 1637323 & 8.6 & 8.6509 & TRN \\
\hline CHEMBL 3904674 & 1637323 & 8.86 & 8.9137 & TRN \\
\hline CHEMBL 3945845 & 1637323 & 7.99 & 7.9816 & TRN \\
\hline CHEMBL3951694 & 1637323 & 8.7 & 8.6211 & TRN \\
\hline CHEMBL3929914 & 1637323 & 8.57 & 8.2661 & TST \\
\hline CHEMBL3971277 & 1637323 & 8.68 & 8.5455 & TRN \\
\hline CHEMBL3891892 & 1637323 & 8.45 & 8.7774 & TRN \\
\hline CHEMBL3985498 & 1637323 & 7.97 & 7.8713 & TRN \\
\hline CHEMBL3912831 & 1637323 & 8.59 & 8.6225 & TRN \\
\hline CHEMBL3931154 & 1637323 & 8.41 & 8.2882 & TRN \\
\hline CHEMBL3893718 & 1637323 & 8.52 & 8.2295 & TRN \\
\hline CHEMBL3973321 & 1637323 & 8.54 & 8.146 & TRN \\
\hline CHEMBL3960327 & 1637323 & 8.28 & 8.4084 & TRN \\
\hline CHEMBL3956571 & 1637323 & 7.77 & 7.8025 & TRN \\
\hline CHEMBL 3907314 & 1637323 & 8.81 & 8.8594 & TRN \\
\hline CHEMBL3904561 & 1637323 & 8.29 & 8.381 & TST \\
\hline CHEMBL3945264 & 1637323 & 8.45 & 8.4208 & TRN \\
\hline CHEMBL3942594 & 1637323 & 8.36 & 8.3752 & TRN \\
\hline CHEMBL3915268 & 1637323 & 8.59 & 8.5574 & TRN \\
\hline
\end{tabular}




\begin{tabular}{|c|c|c|c|c|}
\hline \multicolumn{5}{|c|}{ Supplemental Table S2.txt } \\
\hline CHEMBL3925081 & 1637323 & 8.37 & 8.5752 & TRN \\
\hline CHEMBL3959849 & 1637323 & 8.46 & 8.4329 & TST \\
\hline CHEMBL 3962549 & 1637323 & 7.78 & 7.8525 & TRN \\
\hline CHEMBL 3966626 & 1637323 & 6.89 & 7.0682 & TRN \\
\hline CHEMBL 3969192 & 1637323 & 6.84 & 6.937 & TRN \\
\hline CHEMBL3975986 & 1637323 & 6.74 & 6.4065 & TRN \\
\hline CHEMBL3979996 & 1637323 & 6.75 & 6.6327 & TRN \\
\hline CHEMBL 3891474 & 1637323 & 8.36 & 8.0471 & TST \\
\hline CHEMBL 3892135 & 1637323 & 8.5 & 8.4698 & TRN \\
\hline CHEMBL 3969824 & 1637323 & 8.43 & 8.1194 & TRN \\
\hline CHEMBL 3932285 & 1637323 & 8.42 & 8.4919 & TRN \\
\hline CHEMBL 3922586 & 1637323 & 8.46 & 8.5563 & TRN \\
\hline CHEMBL3901682 & 1637323 & 6.8 & 6.9435 & TRN \\
\hline CHEMBL 3927733 & 1637323 & 8.46 & 8.1842 & TRN \\
\hline CHEMBL3976053 & 1637323 & 8.4 & 8.3725 & TST \\
\hline CHEMBL3973587 & 1637323 & 8.0 & 8.2032 & TRN \\
\hline CHEMBL3936828 & 1637323 & 8.31 & 8.2923 & TRN \\
\hline CHEMBL3934039 & 1637323 & 7.83 & 7.9616 & TRN \\
\hline CHEMBL3981418 & 1637323 & 8.55 & 8.5773 & TST \\
\hline CHEMBL3972694 & 1637323 & 7.78 & 7.7983 & TST \\
\hline CHEMBL3921457 & 1637323 & 8.4 & 8.427 & TST \\
\hline CHEMBL3918739 & 1637323 & 8.73 & 8.5054 & TRN \\
\hline CHEMBL3968793 & 1637323 & 7.89 & 7.909 & TRN \\
\hline CHEMBL3966305 & 1637323 & 8.68 & 8.629 & TST \\
\hline CHEMBL3891115 & 1637323 & 6.87 & 6.8646 & TST \\
\hline CHEMBL3979662 & 1637323 & 6.71 & 6.6895 & TST \\
\hline CHEMBL 3983387 & 1637323 & 8.32 & 8.0685 & TST \\
\hline CHEMBL3986068 & 1637323 & 8.46 & 8.5047 & TRN \\
\hline CHEMBL3916975 & 1637323 & 8.52 & 8.3767 & TRN \\
\hline CHEMBL3919709 & 1637323 & 8.64 & 8.2906 & TRN \\
\hline CHEMBL3975791 & 1637323 & 8.5 & 8.2906 & TRN \\
\hline CHEMBL 3963323 & 1637323 & 8.32 & 8.4483 & TRN \\
\hline CHEMBL3945373 & 1637323 & 8.33 & 8.5862 & TRN \\
\hline CHEMBL 3893344 & 1637323 & 8.45 & 8.4086 & TRN \\
\hline CHEMBL3896052 & 1637323 & 8.54 & 8.4928 & TRN \\
\hline CHEMBL3947361 & 1637323 & 8.19 & 8.3335 & TRN \\
\hline CHEMBL 3944739 & 1637323 & 7.74 & 7.7415 & TST \\
\hline CHEMBL3909551 & 1637323 & 8.47 & 8.543 & TRN \\
\hline CHEMBL 3899692 & 1637323 & 8.43 & 8.5435 & TRN \\
\hline CHEMBL3961400 & 1637323 & 8.34 & 8.3514 & TRN \\
\hline CHEMBL3958708 & 1637323 & 8.47 & 8.4124 & TRN \\
\hline CHEMBL 3974080 & 1637323 & 7.7 & 7.445 & TRN \\
\hline CHEMBL3921197 & 1637323 & 8.58 & 8.6255 & TST \\
\hline CHEMBL 3898568 & 1637323 & 8.31 & 8.3535 & TRN \\
\hline CHEMBL3924422 & 1637323 & 8.06 & 8.1655 & TRN \\
\hline CHEMBL3959193 & 1637323 & 8.04 & 7.9826 & TRN \\
\hline CHEMBL 3936087 & 1637323 & 8.65 & 8.5164 & TRN \\
\hline CHEMBL3893070 & 1637323 & 8.36 & 7.9053 & TRN \\
\hline
\end{tabular}




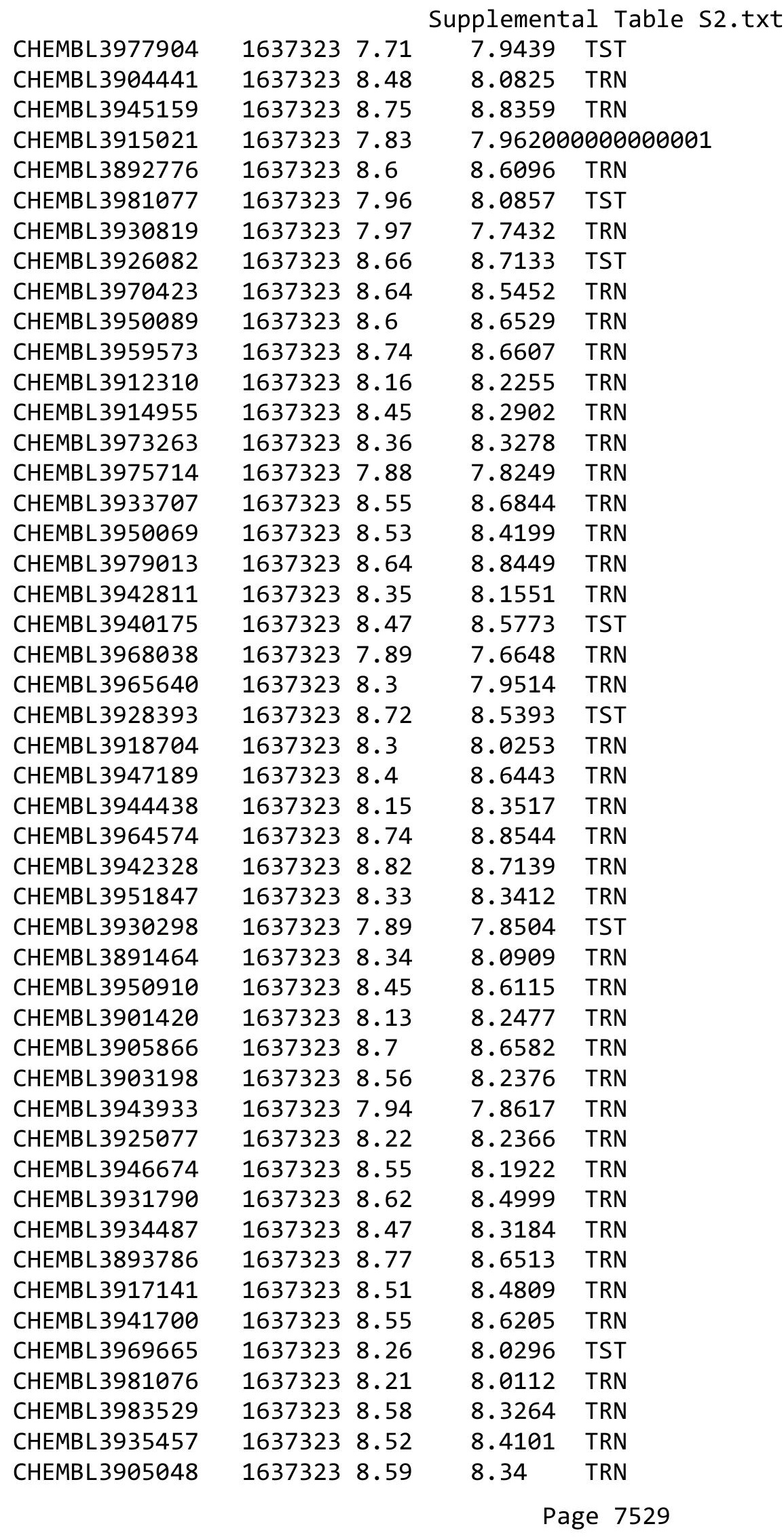




\begin{tabular}{|c|c|c|c|c|c|}
\hline \multicolumn{6}{|c|}{ Supplemental Table S2.txt } \\
\hline CHEMBL 3925610 & 1637323 & 8.12 & 7.9147 & TST & \\
\hline CHEMBL 3928261 & 1637323 & 8.67 & 8.5167 & TRN & \\
\hline CHEMBL3985259 & 1637323 & 8.29 & 8.0576 & TST & \\
\hline CHEMBL 3890205 & 1637323 & 7.36 & 7.3607 & TST & \\
\hline CHEMBL 3944610 & 1637323 & 8.65 & 8.455 & TRN & \\
\hline CHEMBL 3944320 & 1637323 & 8.66 & 8.3595 & TRN & \\
\hline CHEMBL3979908 & 1637323 & 7.52 & 7.5034 & TRN & \\
\hline CHEMBL3934355 & 1637323 & 8.31 & 7.9621 & TRN & \\
\hline CHEMBL 3919750 & 1637323 & 8.1 & 7.71 & TRN & \\
\hline CHEMBL3969112 & 1637323 & 8.56 & 8.3597 & TRN & \\
\hline CHEMBL 3966560 & 1637323 & 8.28 & 8.2687 & TRN & \\
\hline CHEMBL 3910444 & 1637323 & 8.81 & 8.6256 & TRN & \\
\hline CHEMBL3907642 & 1637323 & 8.5 & 8.1107 & TRN & \\
\hline CHEMBL 3973929 & 1637323 & 8.54 & 8.4686 & TRN & \\
\hline CHEMBL3972617 & 1637323 & 8.11 & 7.9912 & TRN & \\
\hline CHEMBL3908149 & 1637323 & 8.78 & 8.5204 & TRN & \\
\hline CHEMBL3943080 & 1637323 & 7.62 & 7.7731 & TRN & \\
\hline CHEMBL3904294 & 1637323 & 8.51 & 8.3673 & TRN & \\
\hline CHEMBL 3907063 & 1637323 & 8.4 & 8.094 & TRN & \\
\hline CHEMBL 3896623 & 1637323 & 8.36 & 8.2807 & TRN & \\
\hline CHEMBL3893950 & 1637323 & 8.32 & 8.2034 & TRN & \\
\hline CHEMBL 3955745 & 1637323 & 8.15 & 7.8249 & TRN & \\
\hline CHEMBL3953117 & 1637323 & 8.12 & 7.87299 & 7999999999 & TST \\
\hline CHEMBL 3951360 & 1637323 & 8.56 & 8.26799 & 7999999999 & TRN \\
\hline CHEMBL 3930158 & 1637323 & 7.9 & 7.8199 & TRN & \\
\hline CHEMBL3911746 & 1637323 & 8.35 & 7.9631 & TST & \\
\hline CHEMBL3917295 & 1637323 & 8.51 & 8.3472 & TRN & \\
\hline CHEMBL3902110 & 1637323 & 8.28 & 8.1089 & TRN & \\
\hline CHEMBL 3904814 & 1637323 & 7.22 & 7.2635 & TST & \\
\hline CHEMBL3911948 & 1637323 & 7.23 & 7.4356 & TST & \\
\hline CHEMBL 3928239 & 1637323 & 8.65 & 8.2029 & TRN & \\
\hline CHEMBL 3979028 & 1637323 & 7.81 & 7.7793 & TRN & \\
\hline CHEMBL 3890378 & 1637323 & 8.67 & 8.3317 & TRN & \\
\hline CHEMBL 3932363 & 1637323 & 8.19 & 8.3169 & TST & \\
\hline CHEMBL 3932756 & 1637323 & 8.42 & 8.3301 & TRN & \\
\hline CHEMBL 3919479 & 1637323 & 8.9 & 8.6117 & TRN & \\
\hline CHEMBL3968818 & 1637323 & 8.72 & 8.3711 & TRN & \\
\hline CHEMBL3966316 & 1637323 & 7.68 & 7.5801 & TRN & \\
\hline CHEMBL3940940 & 1637323 & 8.08 & 7.7689 & TST & \\
\hline CHEMBL3982107 & 1637323 & 8.36 & 8.2797 & TRN & \\
\hline CHEMBL 3979670 & 1637323 & 8.67 & 8.4605 & TRN & \\
\hline CHEMBL3911738 & 1637323 & 8.2 & 8.0881 & TRN & \\
\hline CHEMBL3951090 & 1637323 & 7.95 & 7.9098 & TRN & \\
\hline CHEMBL3960571 & 1637323 & 8.34 & 8.4502 & TRN & \\
\hline CHEMBL3949508 & 1637323 & 7.91 & 7.8183 & TRN & \\
\hline CHEMBL3901612 & 1637323 & 8.5 & 8.3817 & TRN & \\
\hline CHEMBL 3974206 & 1637323 & 8.68 & 8.4862 & TST & \\
\hline CHEMBL3889711 & 1637323 & 8.21 & 8.2056 & TRN & \\
\hline
\end{tabular}




\begin{tabular}{|c|c|c|c|c|}
\hline \multicolumn{5}{|c|}{ Supplemental Table S2.txt } \\
\hline CHEMBL3927585 & 1637323 & 7.69 & 7.9338 & TRN \\
\hline CHEMBL3946103 & 1637323 & 8.29 & 8.3243 & TRN \\
\hline CHEMBL3936421 & 1637323 & 7.55 & 7.7139 & TRN \\
\hline CHEMBL3901119 & 1637323 & 8.47 & 8.5994 & TST \\
\hline CHEMBL 3919884 & 1637323 & 8.37 & 8.4349 & TST \\
\hline CHEMBL3942606 & 1637323 & 8.31 & 8.2644 & TST \\
\hline CHEMBL 3945277 & 1637323 & 8.36 & 8.4468 & TRN \\
\hline CHEMBL 3897523 & 1637323 & 8.09 & 7.8927 & TRN \\
\hline CHEMBL3907327 & 1637323 & 7.91 & 7.7772 & TRN \\
\hline CHEMBL3956579 & 1637323 & 8.0 & 8.0103 & TST \\
\hline CHEMBL3959260 & 1637323 & 7.94 & 8.1185 & TRN \\
\hline CHEMBL 3890852 & 1637323 & 8.03 & 8.2354 & TST \\
\hline CHEMBL3893642 & 1637323 & 8.28 & 8.4634 & TRN \\
\hline CHEMBL3950156 & 1637323 & 8.07 & 8.2329 & TRN \\
\hline CHEMBL3952866 & 1637323 & 7.92 & 8.0698 & TST \\
\hline CHEMBL3925114 & 1637323 & 8.56 & 8.5755 & TRN \\
\hline CHEMBL3897155 & 1637323 & 8.37 & 8.4457 & TST \\
\hline CHEMBL3937972 & 1637323 & 8.69 & 8.6776 & TRN \\
\hline CHEMBL3935177 & 1637323 & 7.92 & 7.9193 & TRN \\
\hline CHEMBL3962492 & 1637323 & 8.41 & 8.4879 & TRN \\
\hline CHEMBL3903823 & 1637323 & 7.63 & 8.1142 & TRN \\
\hline CHEMBL3964096 & 1637323 & 8.61 & 8.6957 & TST \\
\hline CHEMBL3948755 & 1637323 & 7.85 & 7.9705 & TST \\
\hline CHEMBL3892155 & 1637323 & 8.24 & 8.2966 & TRN \\
\hline CHEMBL3987162 & 1637323 & 7.48 & 7.5409 & TRN \\
\hline CHEMBL3921441 & 1637323 & 8.43 & 8.6396 & TRN \\
\hline CHEMBL3905015 & 1637323 & 7.41 & 7.5358 & TRN \\
\hline CHEMBL3921817 & 1637323 & 8.24 & 8.6073 & TRN \\
\hline CHEMBL 3927219 & 1637323 & 8.01 & 7.909 & TRN \\
\hline CHEMBL3902434 & 1637323 & 8.3 & 8.2511 & TRN \\
\hline CHEMBL3927158 & 1637323 & 7.38 & 7.1196 & TRN \\
\hline CHEMBL3985182 & 1637323 & 7.89 & 7.6401 & TRN \\
\hline CHEMBL3933442 & 1637323 & 8.14 & 7.9312 & TRN \\
\hline CHEMBL3934080 & 1637323 & 8.36 & 8.6145 & TRN \\
\hline CHEMBL3895443 & 1637323 & 8.09 & 8.1555 & TRN \\
\hline CHEMBL3904736 & 1637323 & 6.36 & 6.7182 & TRN \\
\hline CHEMBL3914473 & 1637323 & 6.99 & 6.9404 & TRN \\
\hline CHEMBL3898926 & 1637323 & 7.92 & 7.6675 & TRN \\
\hline CHEMBL 3952277 & 1637323 & 8.2 & 8.4761 & TRN \\
\hline CHEMBL3926245 & 1637323 & 7.5 & 7.7931 & TST \\
\hline CHEMBL3978617 & 1637323 & 8.18 & 8.4535 & TRN \\
\hline CHEMBL3966071 & 1637323 & 8.33 & 8.373 & TST \\
\hline CHEMBL3966200 & 1637323 & 8.42 & 8.2957 & TRN \\
\hline CHEMBL 3940672 & 1637323 & 8.22 & 8.2267 & TST \\
\hline CHEMBL3979328 & 1637323 & 8.04 & 8.4195 & TRN \\
\hline CHEMBL3983918 & 1637323 & 8.53 & 8.8207 & TST \\
\hline CHEMBL3975193 & 1637323 & 7.8 & 7.8543 & TRN \\
\hline CHEMBL3924172 & 1637323 & 8.38 & 8.2961 & TRN \\
\hline
\end{tabular}




\begin{tabular}{|c|c|c|c|c|c|}
\hline \multicolumn{6}{|c|}{ Supplemental Table S2.txt } \\
\hline CHEMBL3921469 & 1637323 & 8.47 & 8.5986 & TRN & \\
\hline CHEMBL 3900551 & 1637323 & 6.36 & 6.9219 & TRN & \\
\hline CHEMBL 3897783 & 1637323 & 8.2 & 8.6129 & TRN & \\
\hline CHEMBL 3891525 & 1637323 & 8.18 & 8.4457 & TRN & \\
\hline CHEMBL 3935838 & 1637323 & 7.75 & 8.0635 & TST & \\
\hline CHEMBL 3977010 & 1637323 & 8.12 & 8.4127 & TRN & \\
\hline CHEMBL 3967761 & 1637323 & 8.19 & 8.6023 & TRN & \\
\hline CHEMBL 3893556 & 1637323 & 7.31 & 7.4383 & TRN & \\
\hline CHEMBL 3896249 & 1637323 & 8.43 & 8.6331 & TRN & \\
\hline CHEMBL3952789 & 1637323 & 7.91 & 7.83200 & 0000000001 & TRN \\
\hline CHEMBL 3955385 & 1637323 & 7.47 & 7.4143 & TRN & \\
\hline CHEMBL 3977708 & 1637323 & 7.99 & 7.9525 & TRN & \\
\hline CHEMBL3980069 & 1637323 & 8.54 & 8.8645 & TRN & \\
\hline CHEMBL 3946938 & 1637323 & 8.25 & 8.5752 & TRN & \\
\hline CHEMBL3941337 & 1637323 & 6.39 & 6.7267 & TRN & \\
\hline CHEMBL3983585 & 1637323 & 6.51 & 6.9262 & TRN & \\
\hline CHEMBL 3918638 & 1637323 & 8.76 & 8.2906 & TRN & \\
\hline CHEMBL3920637 & 1637323 & 8.14 & 8.1855 & TRN & \\
\hline CHEMBL 3917908 & 1637323 & 8.53 & 8.599 & TRN & \\
\hline CHEMBL 3980712 & 1637323 & 6.4 & 6.5618 & TRN & \\
\hline CHEMBL3978349 & 1637323 & 7.98 & 8.106 & TST & \\
\hline CHEMBL 3976721 & 1637323 & 7.33 & 7.4349 & TRN & \\
\hline CHEMBL3974273 & 1637323 & 7.37 & 7.271 & TRN & \\
\hline CHEMBL 3898255 & 1637323 & 7.35 & 7.4176 & TST & \\
\hline CHEMBL 3927794 & 1637323 & 7.11 & 7.3469 & TST & \\
\hline CHEMBL3953833 & 1637323 & 8.13 & 7.984 & TRN & \\
\hline CHEMBL 3964043 & 1637323 & 8.26 & 8.1865 & TRN & \\
\hline CHEMBL 3945658 & 1637323 & 6.64 & 7.1365 & TRN & \\
\hline CHEMBL 3948306 & 1637323 & 6.49 & 6.6952 & TRN & \\
\hline CHEMBL 3984035 & 1637323 & 8.15 & 7.8427 & TST & \\
\hline CHEMBL 3986725 & 1637323 & 7.77 & 7.8909 & TST & \\
\hline CHEMBL 3896142 & 1637323 & 8.54 & 8.4229 & TST & \\
\hline CHEMBL3908707 & 1637323 & 8.41 & 8.4921 & TRN & \\
\hline CHEMBL 3941227 & 1637323 & 8.14 & 7.7662 & TST & \\
\hline CHEMBL3943917 & 1637323 & 8.02 & 7.9646 & TRN & \\
\hline CHEMBL 3979972 & 1637323 & 8.07 & 7.652 & TRN & \\
\hline CHEMBL 3982399 & 1637323 & 8.35 & 7.8234 & TRN & \\
\hline CHEMBL3932817 & 1637323 & 7.97 & 7.8548 & TST & \\
\hline CHEMBL 3930088 & 1637323 & 7.75 & 7.8625 & TST & \\
\hline CHEMBL 3972445 & 1637323 & 6.54 & 6.7986 & TRN & \\
\hline CHEMBL3969747 & 1637323 & 7.14 & 7.4645 & TST & \\
\hline CHEMBL3918426 & 1637323 & 8.47 & 8.167 & TST & \\
\hline CHEMBL3906938 & 1637323 & 8.01 & 7.8921 & TRN & \\
\hline CHEMBL 3956028 & 1637323 & 6.64 & 6.6894 & TRN & \\
\hline CHEMBL3964762 & 1637323 & 7.79 & 7.8355 & TRN & \\
\hline CHEMBL 3948234 & 1637323 & 8.16 & 8.0598 & TST & \\
\hline CHEMBL 3932022 & 1637323 & 8.48 & 8.3275 & TST & \\
\hline CHEMBL3957473 & 1637323 & 8.29 & 8.4143 & TRN & \\
\hline
\end{tabular}




\begin{tabular}{|c|c|c|c|c|c|}
\hline \multicolumn{6}{|c|}{ plemental } \\
\hline CHEMBL3950496 & 1637323 & 8.23 & 8.1189 & TRN & \\
\hline CHEMBL3902961 & 1637323 & 8.53 & 8.2311 & TRN & \\
\hline CHEMBL3905633 & 1637323 & 7.89 & 7.9074 & TST & \\
\hline CHEMBL 3937212 & 1637323 & 7.82 & 7.74100 & 00000000005 & TST \\
\hline CHEMBL3966929 & 1637323 & 8.12 & 7.909 & TRN & \\
\hline CHEMBL3922100 & 1637323 & 8.43 & 7.9799 & TST & \\
\hline CHEMBL3906284 & 1637323 & 8.47 & 8.6396 & TRN & \\
\hline CHEMBL3921787 & 1637323 & 7.36 & 7.4832 & TRN & \\
\hline CHEMBL3951171 & 1637323 & 8.38 & 8.4589 & TRN & \\
\hline CHEMBL3983694 & 1637323 & 7.82 & 7.8099 & TRN & \\
\hline CHEMBL3981207 & 1637323 & 7.67 & 7.904 & TRN & \\
\hline CHEMBL3986631 & 1637323 & 7.15 & 7.1394 & TRN & \\
\hline CHEMBL3969667 & 1637323 & 7.91 & 8.1295 & TRN & \\
\hline CHEMBL3933908 & 1637323 & 7.79 & 7.8836 & TRN & \\
\hline CHEMBL3936673 & 1637323 & 7.36 & 7.652 & TRN & \\
\hline CHEMBL3980417 & 1637323 & 8.34 & 8.3079 & TRN & \\
\hline CHEMBL3921190 & 1637323 & 8.23 & 8.3606 & TRN & \\
\hline CHEMBL3920274 & 1637323 & 6.59 & 6.5724 & TST & \\
\hline CHEMBL3953771 & 1637323 & 7.77 & 8.0417 & TST & \\
\hline CHEMBL3950292 & 1637323 & 7.69 & 7.7404 & TRN & \\
\hline CHEMBL3959787 & 1637323 & 7.05 & 7.0052 & TRN & \\
\hline CHEMBL3986861 & 1637323 & 8.24 & 7.5729 & TST & \\
\hline CHEMBL3891816 & 1637323 & 7.85 & 7.5423 & TST & \\
\hline CHEMBL3927140 & 1637323 & 8.15 & 8.1195 & TRN & \\
\hline CHEMBL3929849 & 1637323 & 7.05 & 7.3936 & TRN & \\
\hline CHEMBL3966941 & 1637323 & 7.66 & 7.5206 & TST & \\
\hline CHEMBL3939018 & 1637323 & 8.11 & 8.2751 & TST & \\
\hline CHEMBL3912757 & 1637323 & 7.69 & 7.642 & TRN & \\
\hline CHEMBL 3915450 & 1637323 & 7.6 & 7.5535 & TRN & \\
\hline CHEMBL3956493 & 1637323 & 8.37 & 8.2439 & TRN & \\
\hline CHEMBL3964931 & 1637323 & 7.8 & 7.6866 & TRN & \\
\hline CHEMBL3918956 & 1637323 & 7.55 & 7.5385 & TRN & \\
\hline CHEMBL3894754 & 1637323 & 8.02 & 7.8805 & TRN & \\
\hline CHEMBL3963296 & 1637323 & 7.63 & 7.5685 & TRN & \\
\hline CHEMBL 3890187 & 1637323 & 6.75 & 7.0478 & TST & \\
\hline CHEMBL3978313 & 1637323 & 7.49 & 7.7099 & TRN & \\
\hline CHEMBL3889604 & 1637323 & 7.67 & 7.7413 & TRN & \\
\hline CHEMBL3939332 & 1637323 & 7.97 & 7.916 & TRN & \\
\hline CHEMBL3912250 & 1637323 & 7.47 & 7.6179 & TRN & \\
\hline CHEMBL3901265 & 1637323 & 8.09 & 7.96899 & 9999999999 & TRN \\
\hline CHEMBL3903973 & 1637323 & 8.59 & 8.8213 & TRN & \\
\hline CHEMBL3957928 & 1637323 & 7.47 & 7.4053 & TRN & \\
\hline CHEMBL3960591 & 1637323 & 7.62 & 7.5614 & TST & \\
\hline CHEMBL3899721 & 1637323 & 7.09 & 7.2221 & TRN & \\
\hline CHEMBL3934772 & 1637323 & 7.59 & 7.625 & TRN & \\
\hline CHEMBL 3909752 & 1637323 & 7.64 & 7.52 & TRN & \\
\hline CHEMBL3906945 & 1637323 & 7.78 & 7.7903 & TRN & \\
\hline CHEMBL3954396 & 1637323 & 8.45 & 8.6824 & TRN & \\
\hline
\end{tabular}




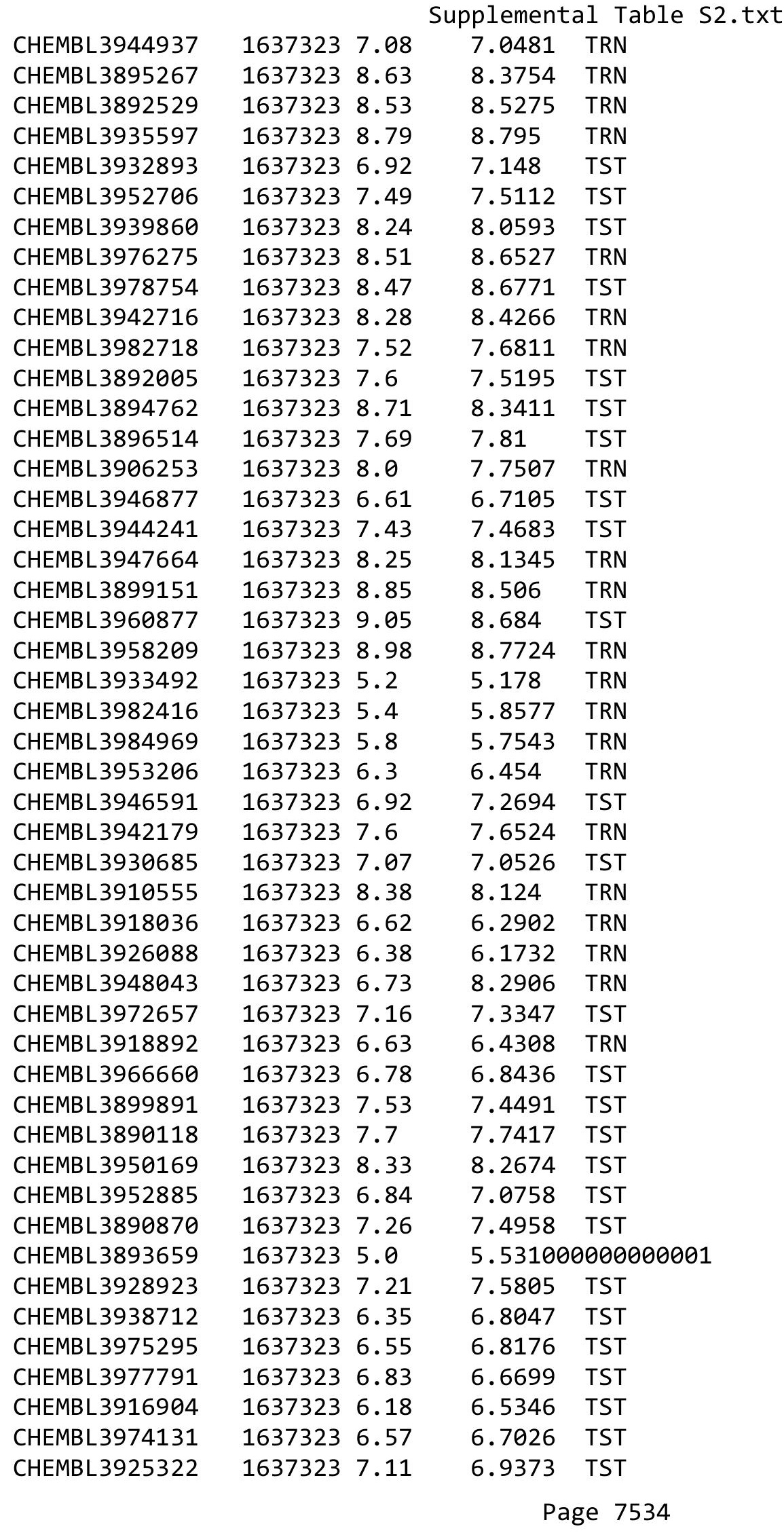


Supplemental Table S2.txt

\begin{tabular}{|c|c|c|c|c|}
\hline CHEMBL 3922592 & 1637323 & 6.0 & 5.8464 & TST \\
\hline CHEMBL 3985007 & 1637323 & 6.72 & 6.6837 & TST \\
\hline CHEMBL3982466 & 1637323 & 5.0 & 5.6931 & TST \\
\hline CHEMBL 3910921 & 1637323 & 7.69 & 7.5569 & TST \\
\hline CHEMBL3908141 & 1637323 & 5.0 & 5.735 & TST \\
\hline CHEMBL3971947 & 1637323 & 6.99 & 7.2477 & TST \\
\hline CHEMBL 3960102 & 1637323 & 6.53 & 6.7103 & TST \\
\hline CHEMBL3891736 & 1637323 & 7.15 & 7.4066 & TST \\
\hline CHEMBL3975903 & 1637323 & 7.21 & 7.518 & TST \\
\hline CHEMBL 3932123 & 1637323 & 6.73 & 7.2163 & TST \\
\hline CHEMBL3952488 & 1637323 & 7.93 & 7.4905 & TST \\
\hline CHEMBL3416719 & 1473486 & 5.4685 & 5.6849 & TRN \\
\hline CHEMBL 3416714 & 1473486 & 5.5376 & 5.4775 & TRN \\
\hline CHEMBL 3416730 & 1473486 & 5.1192 & 5.1781 & TRN \\
\hline CHEMBL3416691 & 1473486 & 5.9208 & 5.3048 & TRN \\
\hline CHEMBL 3416580 & 1473486 & 5.2441 & 5.3324 & TRN \\
\hline CHEMBL3416693 & 1473486 & 6.5287 & 6.5518 & TRN \\
\hline CHEMBL 3416577 & 1473486 & 5.4202 & 5.3073 & TRN \\
\hline CHEMBL 3416704 & 1473486 & 5.0044 & 4.7538 & TST \\
\hline CHEMBL 3416725 & 1473486 & 5.4437 & 5.2998 & TRN \\
\hline CHEMBL3416690 & 1473486 & 3.0 & 3.3036 & TRN \\
\hline CHEMBL 3416727 & 1473486 & 5.7696 & 6.0954 & TRN \\
\hline CHEMBL 3416586 & 1473486 & 4.9208 & 4.6206 & TRN \\
\hline CHEMBL 3416688 & 1473486 & 5.3565 & 5.5938 & TRN \\
\hline CHEMBL 3416705 & 1473486 & 4.6478 & 4.3906 & TRN \\
\hline CHEMBL3416566 & 1473486 & 4.2441 & 4.4657 & TRN \\
\hline CHEMBL3416685 & 1473486 & 5.1487 & 5.0992 & TRN \\
\hline CHEMBL 3416703 & 1473486 & 3.0 & 3.2982 & TST \\
\hline CHEMBL 3416579 & 1473486 & 4.9706 & 4.5702 & TRN \\
\hline CHEMBL 3416733 & 1473486 & 7.5229 & 5.6168 & TST \\
\hline CHEMBL 3416574 & 1473486 & 4.4685 & 5.4299 & TST \\
\hline CHEMBL 3416713 & 1473486 & 5.3279 & 5.185 & TRN \\
\hline CHEMBL3416589 & 1473486 & 3.0 & 2.5722 & TRN \\
\hline CHEMBL3416569 & 1473486 & 4.9208 & 4.9851 & TRN \\
\hline CHEMBL 3416726 & 1473486 & 6.3585 & 6.5042 & TRN \\
\hline CHEMBL3416718 & 1473486 & 4.1549 & 4.626 & TRN \\
\hline CHEMBL3416729 & 1473486 & 5.6576 & 6.0608 & TRN \\
\hline CHEMBL3416584 & 1473486 & 3.0 & 3.6077 & TRN \\
\hline CHEMBL 3416715 & 1473486 & 5.4318 & 5.2196 & TRN \\
\hline CHEMBL3416696 & 1473486 & 6.015 & 6.2041 & TRN \\
\hline CHEMBL3416699 & 1473486 & 5.0809 & 4.7492 & TRN \\
\hline CHEMBL3416687 & 1473486 & 6.0301 & 5.8214 & TRN \\
\hline CHEMBL3416578 & 1473486 & 5.3188 & 5.3393 & TRN \\
\hline CHEMBL3416698 & 1473486 & 5.7696 & 5.4462 & TRN \\
\hline CHEMBL3416711 & 1473486 & 5.8861 & 5.8227 & TRN \\
\hline CHEMBL3416716 & 1473486 & 5.4202 & 5.3988 & TRN \\
\hline CHEMBL3416709 & 1473486 & 4.8416 & 5.3216 & TRN \\
\hline CHEMBL3416717 & 1473486 & 5.8861 & 5.54899 & 99999999995 \\
\hline
\end{tabular}

Page 7535 
Supplemental Table S2.txt

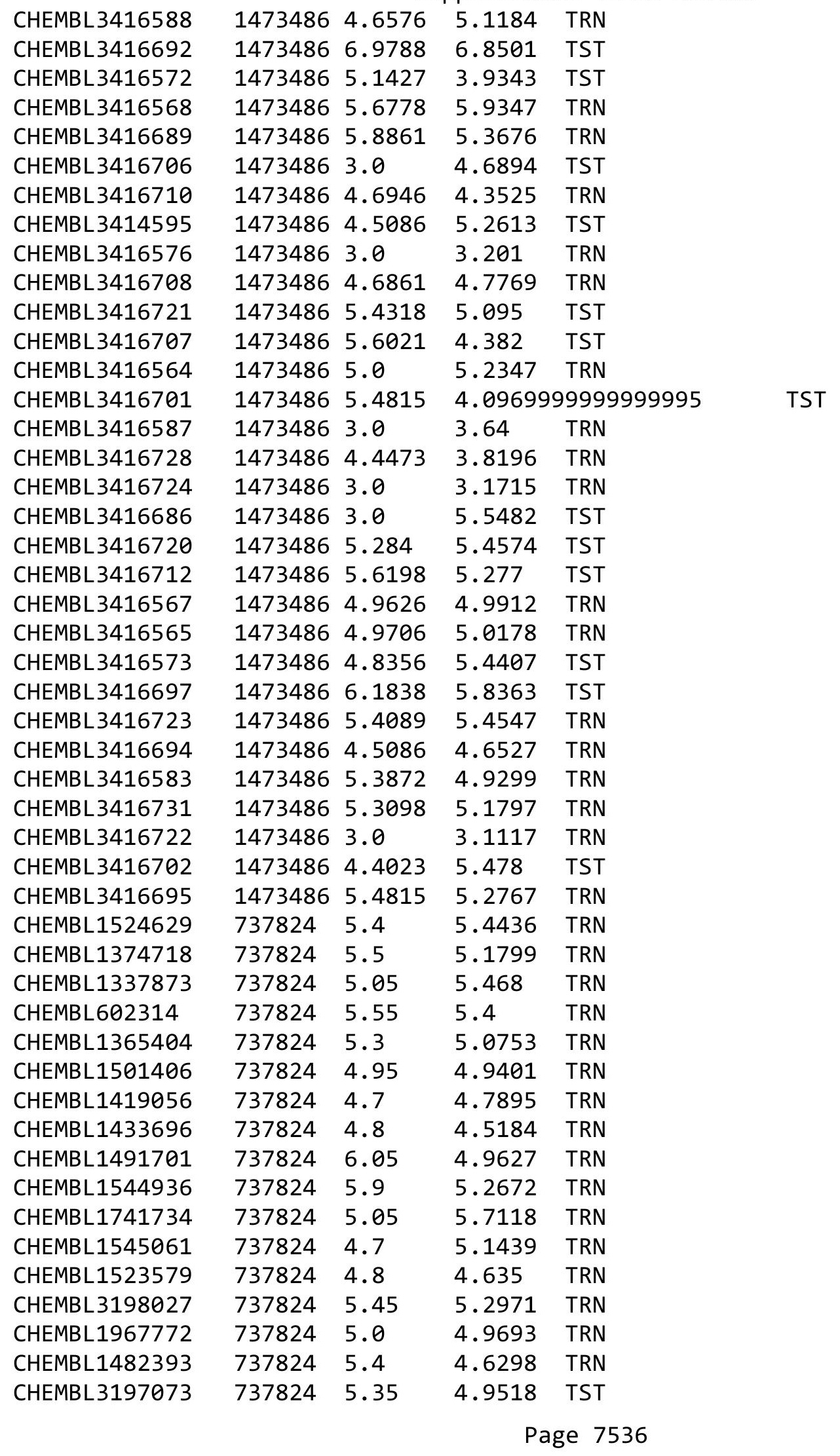




\begin{tabular}{|c|c|c|c|c|c|}
\hline \multirow{2}{*}{ CHEMBL1337409 } & \multirow[b]{2}{*}{737824} & \\
\hline & & 6.15 & \multicolumn{2}{|c|}{5.242999999999999} & TRN \\
\hline CHEMBL1331888 & 737824 & 4.5 & 5.1339 & TST & \\
\hline CHEMBL1613160 & 737824 & 5.45 & 5.3438 & TST & \\
\hline CHEMBL3207984 & 737824 & 5.35 & 5.4397 & TST & \\
\hline CHEMBL1459455 & 737824 & 6.2 & 5.8174 & TRN & \\
\hline CHEMBL3193339 & 737824 & 5.45 & 5.5866 & TRN & \\
\hline CHEMBL2373651 & 737824 & 6.8 & 5.9806 & TST & \\
\hline CHEMBL1201074 & 737824 & 5.5 & 5.3307 & TRN & \\
\hline CHEMBL1453970 & 737824 & 5.3 & 4.8698 & TRN & \\
\hline CHEMBL1486778 & 737824 & 4.7 & 5.0784 & TRN & \\
\hline CHEMBL1443703 & 737824 & 5.3 & 5.3129 & TRN & \\
\hline CHEMBL3192856 & 737824 & 4.9 & 5.0212 & TRN & \\
\hline CHEMBL1482790 & 737824 & 4.9 & 4.9495 & TRN & \\
\hline CHEMBL1414232 & 737824 & 6.6 & 6.3626 & TRN & \\
\hline CHEMBL3192650 & 737824 & 5.4 & 5.1692 & TRN & \\
\hline CHEMBL1492815 & 737824 & 7.05 & 4.9163 & TRN & \\
\hline CHEMBL1421103 & 737824 & 5.6 & 5.5776 & TRN & \\
\hline CHEMBL1455438 & 737824 & 4.4 & 4.1435 & TRN & \\
\hline CHEMBL3211761 & 737824 & 7.1 & 5.2253 & TST & \\
\hline CHEMBL1436540 & 737824 & 4.5 & 4.6192 & TRN & \\
\hline CHEMBL1500786 & 737824 & 6.3 & 5.7805 & TRN & \\
\hline CHEMBL1381203 & 737824 & 4.9 & 5.1814 & TRN & \\
\hline CHEMBL1498788 & 737824 & 5.6 & 5.6541 & TRN & \\
\hline CHEMBL1566214 & 737824 & 5.65 & 5.0888 & TRN & \\
\hline CHEMBL1451875 & 737824 & 4.85 & 5.2426 & TRN & \\
\hline CHEMBL1445647 & 737824 & 5.75 & 5.2084 & TRN & \\
\hline CHEMBL1331443 & 737824 & 6.0 & 5.1925 & TST & \\
\hline CHEMBL587849 & 737824 & 5.5 & 5.6675 & TRN & \\
\hline CHEMBL1572834 & 737824 & 4.4 & 4.3536 & TRN & \\
\hline CHEMBL1400456 & 737824 & 4.6 & 5.1987 & TST & \\
\hline CHEMBL1504724 & 737824 & 6.2 & 5.505 & TST & \\
\hline CHEMBL1573688 & 737824 & 5.6 & 5.4144 & TRN & \\
\hline CHEMBL3190214 & 737824 & 5.6 & 5.6168 & TRN & \\
\hline CHEMBL3198125 & 737824 & 4.8 & 5.1742 & TRN & \\
\hline CHEMBL1380712 & 737824 & 5.05 & 5.2359 & TST & \\
\hline CHEMBL1450716 & 737824 & 5.1 & 4.9731 & TRN & \\
\hline CHEMBL1559990 & 737824 & 4.6 & 5.3744 & TRN & \\
\hline CHEMBL1343084 & 737824 & 5.4 & 5.4987 & TRN & \\
\hline CHEMBL1403781 & 737824 & 5.25 & 5.6879 & TRN & \\
\hline CHEMBL1711658 & 737824 & 4.55 & 5.20299 & 9999999999 & TST \\
\hline CHEMBL1466220 & 737824 & 5.0 & 5.3096 & TRN & \\
\hline CHEMBL1530558 & 737824 & 5.8 & 5.737 & TRN & \\
\hline CHEMBL1512444 & 737824 & 4.5 & 4.4492 & TRN & \\
\hline CHEMBL1566017 & 737824 & 5.2 & 5.1788 & TRN & \\
\hline CHEMBL1349786 & 737824 & 4.85 & 5.043 & TRN & \\
\hline CHEMBL1465287 & 737824 & 4.95 & 5.4605 & TRN & \\
\hline CHEMBL1376629 & 737824 & 5.8 & 5.5668 & TRN & \\
\hline CHEMBL1496972 & 737824 & 5.35 & 5.271 & TRN & \\
\hline
\end{tabular}




\begin{tabular}{|c|c|c|c|c|}
\hline & & & pplement & $\mathrm{a} \perp \mathrm{Ta}$ \\
\hline CHEMBL1315083 & 737824 & 5.4 & 5.4576 & TRN \\
\hline CHEMBL1309557 & 737824 & 5.2 & 5.3219 & TRN \\
\hline CHEMBL1374784 & 737824 & 5.4 & 5.2572 & TRN \\
\hline CHEMBL 3193500 & 737824 & 4.85 & 5.2801 & TRN \\
\hline CHEMBL1420741 & 737824 & 5.3 & 5.4035 & TRN \\
\hline CHEMBL1342908 & 737824 & 4.5 & 5.398 & TRN \\
\hline CHEMBL1603186 & 737824 & 5.9 & 6.3296 & TRN \\
\hline CHEMBL1513876 & 737824 & 5.0 & 4.7474 & TRN \\
\hline CHEMBL1728158 & 737824 & 5.3 & 5.6485 & TRN \\
\hline CHEMBL1458047 & 737824 & 4.6 & 5.3512 & TRN \\
\hline CHEMBL492193 & 737824 & 6.0 & 5.6098 & TST \\
\hline CHEMBL1714628 & 737824 & 4.55 & 4.9423 & TRN \\
\hline CHEMBL1604631 & 737824 & 4.6 & 5.0465 & TRN \\
\hline CHEMBL1565409 & 737824 & 4.9 & 4.8703 & TRN \\
\hline CHEMBL1516787 & 737824 & 5.1 & 5.2066 & TRN \\
\hline CHEMBL1301716 & 737824 & 5.1 & 5.2288 & TRN \\
\hline CHEMBL1432354 & 737824 & 5.85 & 5.4854 & TRN \\
\hline CHEMBL1433559 & 737824 & 4.8 & 4.6922 & TRN \\
\hline CHEMBL1375382 & 737824 & 5.05 & 5.2336 & TRN \\
\hline CHEMBL1588312 & 737824 & 5.25 & 5.6224 & TRN \\
\hline CHEMBL1332362 & 737824 & 5.4 & 4.8935 & TRN \\
\hline CHEMBL1423078 & 737824 & 4.5 & 5.8461 & TST \\
\hline CHEMBL1605814 & 737824 & 4.95 & 5.3355 & TRN \\
\hline CHEMBL1567020 & 737824 & 6.2 & 5.1596 & TST \\
\hline CHEMBL1741342 & 737824 & 4.75 & 5.0491 & TRN \\
\hline CHEMBL1451411 & 737824 & 4.4 & 4.5461 & TRN \\
\hline CHEMBL1989683 & 737824 & 6.1 & 6.1151 & TRN \\
\hline CHEMBL1333056 & 737824 & 6.0 & 5.2978 & TST \\
\hline CHEMBL1584932 & 737824 & 4.55 & 5.3849 & TRN \\
\hline CHEMBL1422368 & 737824 & 5.2 & 5.3691 & TRN \\
\hline CHEMBL3211021 & 737824 & 5.2 & 5.5405 & TRN \\
\hline CHEMBL1350810 & 737824 & 5.55 & 5.6685 & TRN \\
\hline CHEMBL1486831 & 737824 & 4.7 & 5.1445 & TRN \\
\hline CHEMBL1302009 & 737824 & 4.65 & 4.9886 & TRN \\
\hline CHEMBL1741947 & 737824 & 4.65 & 5.1241 & TRN \\
\hline CHEMBL1503678 & 737824 & 5.65 & 5.2239 & TRN \\
\hline CHEMBL1594086 & 737824 & -0.0 & 4.2219 & TRN \\
\hline CHEMBL1325662 & 737824 & 4.9 & 5.4015 & TRN \\
\hline CHEMBL1551133 & 737824 & 6.2 & 6.4244 & TRN \\
\hline CHEMBL1490079 & 737824 & 4.9 & 5.2432 & TRN \\
\hline CHEMBL1362305 & 737824 & 6.0 & 5.0626 & TRN \\
\hline CHEMBL1471600 & 737824 & 5.25 & 4.9749 & TST \\
\hline CHEMBL3208021 & 737824 & 5.8 & 5.0817 & TRN \\
\hline CHEMBL1369438 & 737824 & 4.4 & 4.7014 & TRN \\
\hline CHEMBL3210333 & 737824 & 5.0 & 5.3072 & TRN \\
\hline CHEMBL299613 & 737824 & 4.4 & 4.5046 & TST \\
\hline CHEMBL1457414 & 737824 & 5.3 & 4.9969 & TRN \\
\hline CHEMBL1422219 & 737824 & 5.7 & 5.5458 & TRN \\
\hline
\end{tabular}




\begin{tabular}{|c|c|c|c|c|c|}
\hline \\
\hline CHEMBL1332990 & 737824 & 4.9 & 5.1252 & TRN & \\
\hline CHEMBL1357982 & 737824 & 5.3 & 5.4063 & TRN & \\
\hline CHEMBL1596698 & 737824 & 6.6 & 5.7351 & TRN & \\
\hline CHEMBL1587109 & 737824 & 4.75 & 5.1405 & TRN & \\
\hline CHEMBL1594242 & 737824 & 5.45 & 5.6945 & TRN & \\
\hline CHEMBL1354281 & 737824 & 4.9 & 4.9551 & TRN & \\
\hline CHEMBL1378246 & 737824 & 4.4 & 5.3626 & TRN & \\
\hline CHEMBL123433 & 737824 & 4.8 & 4.3784 & TST & \\
\hline CHEMBL3197506 & 737824 & 4.55 & 4.9264 & TRN & \\
\hline CHEMBL1333637 & 737824 & 6.2 & 5.4377 & TRN & \\
\hline CHEMBL596674 & 737824 & 4.5 & 4.8743 & TRN & \\
\hline CHEMBL1403937 & 737824 & 5.45 & 5.6051 & TRN & \\
\hline CHEMBL3211454 & 737824 & 5.5 & 5.40799 & 99999999995 & TRN \\
\hline CHEMBL1476021 & 737824 & 5.6 & 5.9045 & TRN & \\
\hline CHEMBL1577673 & 737824 & 5.1 & 5.0778 & TRN & \\
\hline CHEMBL1312757 & 737824 & 7.05 & 6.0774 & TRN & \\
\hline CHEMBL1583793 & 737824 & 4.75 & 4.9544 & TRN & \\
\hline CHEMBL1496194 & 737824 & 5.3 & 4.8745 & TRN & \\
\hline CHEMBL1527006 & 737824 & 5.45 & 5.3261 & TRN & \\
\hline CHEMBL1337617 & 737824 & 4.75 & 4.8652 & TRN & \\
\hline CHEMBL1511350 & 737824 & 5.45 & 5.4542 & TRN & \\
\hline CHEMBL1299933 & 737824 & 6.55 & 5.6151 & TRN & \\
\hline CHEMBL1567305 & 737824 & 4.4 & 5.0469 & TRN & \\
\hline CHEMBL1463002 & 737824 & 4.85 & 5.4159 & TRN & \\
\hline CHEMBL1508532 & 737824 & 4.6 & 4.3509 & TRN & \\
\hline CHEMBL1301709 & 737824 & 5.4 & 5.3606 & TRN & \\
\hline CHEMBL1540313 & 737824 & 7.0 & 6.4898 & TST & \\
\hline CHEMBL258767 & 737824 & 6.0 & 5.8676 & TRN & \\
\hline CHEMBL1578011 & 737824 & 6.25 & 5.4703 & TRN & \\
\hline CHEMBL1548380 & 737824 & 5.5 & 5.1341 & TRN & \\
\hline CHEMBL1607997 & 737824 & 4.75 & 5.2089 & TST & \\
\hline CHEMBL1475338 & 737824 & 6.3 & 6.29200 & 0000000001 & TRN \\
\hline CHEMBL1446628 & 737824 & 4.6 & 4.9213 & TRN & \\
\hline CHEMBL1565060 & 737824 & 4.9 & 4.6487 & TRN & \\
\hline CHEMBL1344002 & 737824 & 5.3 & 5.2843 & TST & \\
\hline CHEMBL1434098 & 737824 & 4.7 & 5.0037 & TRN & \\
\hline CHEMBL1356772 & 737824 & 5.4 & 5.1904 & TST & \\
\hline CHEMBL1517935 & 737824 & 4.9 & 4.8024 & TRN & \\
\hline CHEMBL1424481 & 737824 & 5.55 & 5.7196 & TRN & \\
\hline CHEMBL3192271 & 737824 & 4.9 & 5.17200 & 0000000001 & TRN \\
\hline CHEMBL1413443 & 737824 & 4.55 & 5.1357 & TRN & \\
\hline CHEMBL1387889 & 737824 & 4.9 & 5.1544 & TRN & \\
\hline CHEMBL3196358 & 737824 & 4.45 & 5.2024 & TRN & \\
\hline CHEMBL1483693 & 737824 & 5.4 & 5.4738 & TRN & \\
\hline CHEMBL 1587783 & 737824 & 5.05 & 5.2231 & TRN & \\
\hline CHEMBL1741689 & 737824 & 5.5 & 4.7161 & TRN & \\
\hline CHEMBL1446335 & 737824 & 4.4 & 4.5196 & TRN & \\
\hline CHEMBL1473875 & 737824 & 5.4 & 5.3995 & TRN & \\
\hline
\end{tabular}




\begin{tabular}{|c|c|c|c|c|c|}
\hline \multicolumn{6}{|c|}{ Supplemental Table S2.txt } \\
\hline CHEMBL1609754 & 737824 & 5.0 & 4.9353 & TRN & \\
\hline CHEMBL1612133 & 737824 & 6.35 & 5.4206 & TRN & \\
\hline CHEMBL1416727 & 737824 & 5.2 & 5.32 & TRN & \\
\hline CHEMBL1451363 & 737824 & 5.95 & 5.5356 & TRN & \\
\hline CHEMBL1374605 & 737824 & 5.45 & 5.395 & TRN & \\
\hline CHEMBL1570435 & 737824 & 4.8 & 4.8923 & TRN & \\
\hline CHEMBL1522815 & 737824 & 5.05 & 5.1053 & TRN & \\
\hline CHEMBL1721668 & 737824 & 5.25 & 5.2741 & TRN & \\
\hline CHEMBL1452742 & 737824 & 5.4 & 5.4729 & TRN & \\
\hline CHEMBL1402799 & 737824 & 4.6 & 4.3017 & TRN & \\
\hline CHEMBL1524128 & 737824 & 5.1 & 5.0338 & TST & \\
\hline CHEMBL1540150 & 737824 & 5.45 & 5.46399 & 99999999995 & TRN \\
\hline CHEMBL1444789 & 737824 & 4.8 & 4.9191 & TRN & \\
\hline CHEMBL1256995 & 737824 & 5.6 & 5.4278 & TST & \\
\hline CHEMBL1517248 & 737824 & 4.5 & 4.9649 & TRN & \\
\hline CHEMBL1397283 & 737824 & 5.5 & 5.8073 & TST & \\
\hline CHEMBL1376289 & 737824 & 6.55 & 5.4481 & TRN & \\
\hline CHEMBL1318495 & 737824 & 7.1 & 7.2536 & TRN & \\
\hline CHEMBL1567887 & 737824 & 6.0 & 5.4772 & TRN & \\
\hline CHEMBL1509329 & 737824 & 5.35 & 5.6115 & TRN & \\
\hline CHEMBL1302827 & 737824 & 4.8 & 5.6524 & TST & \\
\hline CHEMBL1718851 & 737824 & 5.15 & 5.7153 & TRN & \\
\hline CHEMBL1406495 & 737824 & 4.4 & 5.2332 & TRN & \\
\hline CHEMBL1580116 & 737824 & 5.9 & 5.8262 & TRN & \\
\hline CHEMBL1319038 & 737824 & 4.85 & 5.5324 & TST & \\
\hline CHEMBL1569352 & 737824 & 6.65 & 5.8274 & TRN & \\
\hline CHEMBL1409782 & 737824 & 4.75 & 5.2577 & TRN & \\
\hline CHEMBL1572118 & 737824 & 5.3 & 5.6767 & TRN & \\
\hline CHEMBL1331726 & 737824 & 5.1 & 5.1073 & TRN & \\
\hline CHEMBL1579424 & 737824 & 4.95 & 5.8303 & TRN & \\
\hline CHEMBL3211591 & 737824 & 4.65 & 5.4016 & TST & \\
\hline CHEMBL1741429 & 737824 & 4.65 & 4.9886 & TRN & \\
\hline CHEMBL406845 & 737824 & 5.7 & 4.948 & TST & \\
\hline CHEMBL1371824 & 737824 & 5.95 & 5.3069 & TRN & \\
\hline CHEMBL1741512 & 737824 & 5.1 & 5.2378 & TRN & \\
\hline CHEMBL1552707 & 737824 & 5.1 & 5.0477 & TRN & \\
\hline CHEMBL3213479 & 737824 & 4.9 & 5.3281 & TRN & \\
\hline CHEMBL1430379 & 737824 & 5.55 & 5.4772 & TRN & \\
\hline CHEMBL1545634 & 737824 & 5.9 & 5.8594 & TST & \\
\hline CHEMBL3210437 & 737824 & 4.85 & 5.0223 & TST & \\
\hline CHEMBL3193076 & 737824 & 6.45 & 5.5185 & TRN & \\
\hline CHEMBL1436059 & 737824 & 5.4 & 5.58200 & $\partial 000000001$ & TRN \\
\hline CHEMBL1438677 & 737824 & 5.0 & 5.1275 & TRN & \\
\hline CHEMBL1603871 & 737824 & 5.7 & 5.7894 & TRN & \\
\hline CHEMBL1546411 & 737824 & 4.95 & 5.1908 & TRN & \\
\hline CHEMBL1504272 & 737824 & 5.45 & 5.2037 & TRN & \\
\hline CHEMBL1563722 & 737824 & 5.4 & 5.0295 & TRN & \\
\hline CHEMBL1340676 & 737824 & 5.3 & 5.2285 & TRN & \\
\hline
\end{tabular}




\begin{tabular}{|c|c|c|c|c|c|}
\hline \\
\hline CHEMBL1512708 & 737824 & 6.6 & 6.2272 & TRN & \\
\hline CHEMBL1460907 & 737824 & 5.1 & 5.2225 & TRN & \\
\hline CHEMBL1581575 & 737824 & 5.3 & 4.9681 & TRN & \\
\hline CHEMBL1445889 & 737824 & 6.25 & 5.4802 & TRN & \\
\hline CHEMBL1479792 & 737824 & 5.4 & 5.3021 & TRN & \\
\hline CHEMBL1439336 & 737824 & 5.05 & 5.0598 & TRN & \\
\hline CHEMBL1366479 & 737824 & 5.0 & 5.2387 & TRN & \\
\hline CHEMBL1332929 & 737824 & 5.0 & 4.914 & TRN & \\
\hline CHEMBL1321459 & 737824 & 5.4 & 5.182 & TRN & \\
\hline CHEMBL104554 & 737824 & 4.9 & 5.2396 & TRN & \\
\hline CHEMBL1359184 & 737824 & 5.05 & 5.4155 & TRN & \\
\hline CHEMBL1327004 & 737824 & 5.0 & 5.2462 & TRN & \\
\hline CHEMBL1511986 & 737824 & 5.7 & 5.7088 & TRN & \\
\hline CHEMBL1741329 & 737824 & 4.75 & 5.0352 & TRN & \\
\hline CHEMBL1565724 & 737824 & 8.1 & 7.1697 & TRN & \\
\hline CHEMBL1430657 & 737824 & 5.0 & 5.1578 & TRN & \\
\hline CHEMBL1741344 & 737824 & 4.8 & 5.6498 & TST & \\
\hline CHEMBL1301059 & 737824 & 5.1 & 5.1751 & TST & \\
\hline CHEMBL1576560 & 737824 & 4.95 & 4.8871 & TRN & \\
\hline CHEMBL1424761 & 737824 & 5.9 & 5.6094 & TRN & \\
\hline CHEMBL1328369 & 737824 & 5.9 & 5.7073 & TST & \\
\hline CHEMBL1533099 & 737824 & 5.85 & 5.28299 & 99999999995 & TRN \\
\hline CHEMBL1343666 & 737824 & 6.25 & 5.3276 & TRN & \\
\hline CHEMBL1447248 & 737824 & 4.95 & 5.5471 & TRN & \\
\hline CHEMBL1330272 & 737824 & -0.0 & 4.9385 & TRN & \\
\hline CHEMBL1431432 & 737824 & 5.15 & 5.0642 & TST & \\
\hline CHEMBL1516054 & 737824 & 5.5 & 5.3628 & TRN & \\
\hline CHEMBL1551066 & 737824 & 4.8 & 4.5389 & TRN & \\
\hline CHEMBL1330422 & 737824 & 4.4 & 4.7911 & TRN & \\
\hline CHEMBL1412842 & 737824 & 6.0 & 5.9202 & TRN & \\
\hline CHEMBL1600497 & 737824 & 5.3 & 5.2392 & TRN & \\
\hline CHEMBL1429698 & 737824 & 6.55 & 5.5457 & TRN & \\
\hline CHEMBL1327203 & 737824 & 7.1 & 7.7881 & TST & \\
\hline CHEMBL1463367 & 737824 & 5.0 & 5.4039 & TRN & \\
\hline CHEMBL1585720 & 737824 & 4.6 & 5.0171 & TRN & \\
\hline CHEMBL1510918 & 737824 & 5.65 & 5.4896 & TST & \\
\hline CHEMBL1316408 & 737824 & 5.6 & 5.7093 & TRN & \\
\hline CHEMBL1426283 & 737824 & 5.5 & 5.2958 & TRN & \\
\hline CHEMBL1458544 & 737824 & 5.9 & 5.4773 & TRN & \\
\hline CHEMBL1397517 & 737824 & 4.6 & 4.7959 & TRN & \\
\hline CHEMBL1441222 & 737824 & 5.8 & 5.8985 & TRN & \\
\hline CHEMBL1334512 & 737824 & 4.95 & 5.039 & TST & \\
\hline CHEMBL1594058 & 737824 & 4.4 & 4.4253 & TRN & \\
\hline CHEMBL1400667 & 737824 & 4.5 & 4.3665 & TST & \\
\hline CHEMBL1370314 & 737824 & 4.9 & 5.4973 & TRN & \\
\hline CHEMBL1543685 & 737824 & 4.85 & 5.0286 & TST & \\
\hline CHEMBL1501924 & 737824 & 5.75 & 5.4814 & TRN & \\
\hline CHEMBL1600019 & 737824 & 4.7 & 4.9786 & TST & \\
\hline
\end{tabular}




\begin{tabular}{|c|c|c|c|c|}
\hline & & & pplement & al $\mathrm{Ta}$ \\
\hline CHEMBL 3213210 & 737824 & 5.5 & 5.2131 & TRN \\
\hline CHEMBL1324273 & 737824 & 4.8 & 4.8579 & TRN \\
\hline CHEMBL1387271 & 737824 & 5.25 & 5.5555 & TRN \\
\hline CHEMBL1435409 & 737824 & 5.7 & 5.7744 & TRN \\
\hline CHEMBL491771 & 737824 & 5.1 & 5.2184 & TRN \\
\hline CHEMBL1394956 & 737824 & 5.5 & 5.2181 & TRN \\
\hline CHEMBL1470395 & 737824 & 5.0 & 4.7435 & TRN \\
\hline CHEMBL1423034 & 737824 & 5.5 & 5.3351 & TRN \\
\hline CHEMBL1569058 & 737824 & 6.85 & 6.1702 & TRN \\
\hline CHEMBL1593071 & 737824 & 4.5 & 4.2199 & TRN \\
\hline CHEMBL 3192578 & 737824 & 5.45 & 5.2239 & TST \\
\hline CHEMBL1603471 & 737824 & 4.9 & 5.269 & TRN \\
\hline CHEMBL1545862 & 737824 & 5.85 & 5.1479 & TST \\
\hline CHEMBL1708664 & 737824 & 6.15 & 5.2503 & TST \\
\hline CHEMBL1341978 & 737824 & 4.9 & 4.8796 & TRN \\
\hline CHEMBL3213929 & 737824 & 5.3 & 5.5081 & TRN \\
\hline CHEMBL1509171 & 737824 & 4.4 & 5.1853 & TRN \\
\hline CHEMBL1339319 & 737824 & 5.0 & 5.3079 & TRN \\
\hline CHEMBL1302224 & 737824 & 4.7 & 4.862 & TRN \\
\hline CHEMBL1357167 & 737824 & 6.3 & 6.165 & TRN \\
\hline CHEMBL1436661 & 737824 & 5.3 & 5.0694 & TRN \\
\hline CHEMBL1467331 & 737824 & 6.0 & 5.8399 & TRN \\
\hline CHEMBL1411662 & 737824 & 5.95 & 5.6352 & TST \\
\hline CHEMBL1503232 & 737824 & 4.55 & 5.0475 & TRN \\
\hline CHEMBL1410725 & 737824 & 5.3 & 5.1867 & TRN \\
\hline CHEMBL1983345 & 737824 & 5.75 & 5.3582 & TRN \\
\hline CHEMBL1208858 & 737824 & 4.6 & 4.9142 & TST \\
\hline CHEMBL1497898 & 737824 & 4.4 & 5.3939 & TRN \\
\hline CHEMBL1523773 & 737824 & 4.85 & 5.1145 & TRN \\
\hline CHEMBL1480431 & 737824 & 6.05 & 5.2899 & TRN \\
\hline CHEMBL1500582 & 737824 & 4.8 & 5.0926 & TRN \\
\hline CHEMBL1459103 & 737824 & 4.6 & 4.9839 & TRN \\
\hline CHEMBL1355701 & 737824 & 5.9 & 5.4541 & TRN \\
\hline CHEMBL1400520 & 737824 & 4.9 & 4.9974 & TRN \\
\hline CHEMBL1412390 & 737824 & 6.1 & 6.0387 & TRN \\
\hline CHEMBL1363364 & 737824 & 4.75 & 5.2753 & TST \\
\hline CHEMBL1304396 & 737824 & 4.9 & 5.4901 & TST \\
\hline CHEMBL1982071 & 737824 & 4.55 & 4.8183 & TRN \\
\hline CHEMBL1567251 & 737824 & 4.7 & 4.6964 & TRN \\
\hline CHEMBL1488504 & 737824 & 5.35 & 4.8644 & TRN \\
\hline CHEMBL1534566 & 737824 & 4.9 & 5.0271 & TRN \\
\hline CHEMBL1498778 & 737824 & 6.5 & 5.5789 & TRN \\
\hline CHEMBL1570633 & 737824 & 5.0 & 5.2364 & TRN \\
\hline CHEMBL1525602 & 737824 & 5.1 & 5.0498 & TRN \\
\hline CHEMBL1570083 & 737824 & 5.65 & 5.9339 & TRN \\
\hline CHEMBL1417583 & 737824 & 4.85 & 5.2761 & TRN \\
\hline CHEMBL1377566 & 737824 & 4.8 & 5.1427 & TST \\
\hline CHEMBL1578522 & 737824 & 5.2 & 5.6367 & TRN \\
\hline
\end{tabular}




\begin{tabular}{|c|c|c|c|c|c|}
\hline \\
\hline CHEMBL1382013 & 737824 & 4.85 & 5.2187 & TRN & \\
\hline CHEMBL1301997 & 737824 & 6.0 & 5.3318 & TRN & \\
\hline CHEMBL1305416 & 737824 & 4.4 & 4.9038 & TST & \\
\hline CHEMBL1424384 & 737824 & 5.5 & 5.941 & TRN & \\
\hline CHEMBL1442987 & 737824 & 6.0 & 6.0921 & TRN & \\
\hline CHEMBL1468288 & 737824 & 5.0 & 5.1476 & TRN & \\
\hline CHEMBL1530982 & 737824 & 4.9 & 4.67399 & 99999999995 & TRN \\
\hline CHEMBL1555896 & 737824 & 5.15 & 5.7817 & TRN & \\
\hline CHEMBL1400309 & 737824 & 4.9 & 4.8079 & TRN & \\
\hline CHEMBL1406677 & 737824 & 4.95 & 4.9248 & TRN & \\
\hline CHEMBL1382811 & 737824 & 5.65 & 5.3984 & TST & \\
\hline CHEMBL1424596 & 737824 & 5.65 & 5.2121 & TST & \\
\hline CHEMBL1447637 & 737824 & 5.55 & 5.3808 & TRN & \\
\hline CHEMBL1416213 & 737824 & 5.05 & 5.553 & TRN & \\
\hline CHEMBL1523892 & 737824 & 5.3 & 5.4559 & TRN & \\
\hline CHEMBL1452111 & 737824 & 6.0 & 5.778 & TRN & \\
\hline CHEMBL1482582 & 737824 & 5.5 & 5.7206 & TRN & \\
\hline CHEMBL1403388 & 737824 & 6.7 & 6.6725 & TST & \\
\hline CHEMBL1318708 & 737824 & 5.4 & 4.5821 & TST & \\
\hline CHEMBL1502796 & 737824 & 4.9 & 5.1765 & TRN & \\
\hline CHEMBL1331913 & 737824 & 5.5 & 5.0472 & TRN & \\
\hline CHEMBL1369796 & 737824 & 5.3 & 5.1659 & TRN & \\
\hline CHEMBL1415221 & 737824 & 4.9 & 5.4115 & TRN & \\
\hline CHEMBL1434006 & 737824 & 4.9 & 4.6887 & TRN & \\
\hline CHEMBL3198273 & 737824 & 8.3 & 8.0198 & TRN & \\
\hline CHEMBL1568575 & 737824 & 4.5 & 4.6005 & TRN & \\
\hline CHEMBL1741849 & 737824 & 4.4 & 5.147 & TRN & \\
\hline CHEMBL1711464 & 737824 & 5.55 & 5.4288 & TRN & \\
\hline CHEMBL1427572 & 737824 & 4.9 & 5.6404 & TRN & \\
\hline CHEMBL1488294 & 737824 & 4.8 & 5.3425 & TRN & \\
\hline CHEMBL1330067 & 737824 & 4.9 & 5.2818 & TRN & \\
\hline CHEMBL1404737 & 737824 & 4.6 & 5.0272 & TRN & \\
\hline CHEMBL3208462 & 737824 & 6.2 & 5.3808 & TRN & \\
\hline CHEMBL1436228 & 737824 & 4.9 & 4.7476 & TRN & \\
\hline CHEMBL1452894 & 737824 & 4.8 & 4.5629 & TRN & \\
\hline CHEMBL1590550 & 737824 & 5.1 & 4.8967 & TRN & \\
\hline CHEMBL1489961 & 737824 & 5.35 & 5.178 & TRN & \\
\hline CHEMBL1538552 & 737824 & 4.4 & 5.0747 & TRN & \\
\hline CHEMBL1440921 & 737824 & 6.65 & 5.6077 & TRN & \\
\hline CHEMBL1332225 & 737824 & 7.8 & 5.979 & TRN & \\
\hline CHEMBL1545573 & 737824 & 4.55 & 5.0179 & TRN & \\
\hline CHEMBL1369223 & 737824 & 6.5 & 5.6122 & TRN & \\
\hline CHEMBL1398137 & 737824 & 4.6 & 4.5466 & TRN & \\
\hline CHEMBL3209589 & 737824 & 4.85 & 5.102 & TRN & \\
\hline CHEMBL1486160 & 737824 & 5.65 & 5.0573 & TRN & \\
\hline CHEMBL1495397 & 737824 & 5.4 & 5.6038 & TRN & \\
\hline CHEMBL143360 & 737824 & 5.0 & 5.0386 & TRN & \\
\hline CHEMBL1391888 & 737824 & 4.8 & 5.1755 & TST & \\
\hline
\end{tabular}




\begin{tabular}{|c|c|c|c|c|}
\hline \multicolumn{5}{|c|}{ Supplemental Tabl } \\
\hline CHEMBL1733552 & 737824 & 4.4 & 5.0353 & TRN \\
\hline CHEMBL3194166 & 737824 & 4.55 & 5.3316 & TST \\
\hline CHEMBL3199876 & 737824 & 6.25 & 5.7386 & TRN \\
\hline CHEMBL1742239 & 737824 & 4.7 & 5.305 & TRN \\
\hline CHEMBL1368855 & 737824 & 5.85 & 5.4848 & TRN \\
\hline CHEMBL1463322 & 737824 & 4.4 & 5.354 & TRN \\
\hline CHEMBL1407572 & 737824 & 5.45 & 5.6309 & TRN \\
\hline CHEMBL1373930 & 737824 & 4.9 & 5.1969 & TRN \\
\hline CHEMBL1328979 & 737824 & 4.8 & 4.5615 & TRN \\
\hline CHEMBL1741558 & 737824 & 5.4 & 5.0676 & TRN \\
\hline CHEMBL1567431 & 737824 & 4.85 & 4.928 & TRN \\
\hline CHEMBL1369008 & 737824 & 4.4 & 4.2171 & TRN \\
\hline CHEMBL1385130 & 737824 & 5.9 & 5.3175 & TRN \\
\hline CHEMBL1353174 & 737824 & 5.3 & 5.2319 & TRN \\
\hline CHEMBL1406121 & 737824 & 4.85 & 5.4544 & TST \\
\hline CHEMBL3212934 & 737824 & 5.7 & 5.562 & TRN \\
\hline CHEMBL3191786 & 737824 & 4.75 & 5.1133 & TST \\
\hline CHEMBL1563819 & 737824 & 5.75 & 5.3019 & TST \\
\hline CHEMBL1557567 & 737824 & 5.4 & 4.625 & TRN \\
\hline CHEMBL1323905 & 737824 & 5.5 & 5.2546 & TRN \\
\hline CHEMBL1456755 & 737824 & 5.3 & 5.0513 & TRN \\
\hline CHEMBL1610758 & 737824 & 5.05 & 5.0459 & TST \\
\hline CHEMBL1406644 & 737824 & 5.45 & 5.5719 & TRN \\
\hline CHEMBL3196953 & 737824 & 6.45 & 6.0179 & TRN \\
\hline CHEMBL1450537 & 737824 & 5.75 & 5.6128 & TST \\
\hline CHEMBL1600294 & 737824 & 5.75 & 5.8633 & TRN \\
\hline CHEMBL1570079 & 737824 & 4.75 & 5.1679 & TRN \\
\hline CHEMBL1336155 & 737824 & 5.6 & 5.1425 & TST \\
\hline CHEMBL1611388 & 737824 & 5.3 & 5.1843 & TRN \\
\hline CHEMBL 2373630 & 737824 & 5.8 & 4.9829 & TST \\
\hline CHEMBL1720191 & 737824 & 4.4 & 5.3017 & TRN \\
\hline CHEMBL1590763 & 737824 & 5.0 & 4.9129 & TRN \\
\hline CHEMBL1311461 & 737824 & 7.05 & 5.2538 & TRN \\
\hline CHEMBL1525540 & 737824 & 4.85 & 5.1684 & TRN \\
\hline CHEMBL1443979 & 737824 & 5.9 & 5.5221 & TRN \\
\hline CHEMBL1409262 & 737824 & 5.0 & 5.0569 & TRN \\
\hline CHEMBL1328307 & 737824 & 4.9 & 5.6091 & TRN \\
\hline CHEMBL1489981 & 737824 & 5.35 & 5.4311 & TRN \\
\hline CHEMBL1498977 & 737824 & 5.1 & 5.032 & TRN \\
\hline CHEMBL1386418 & 737824 & 5.3 & 5.3187 & TRN \\
\hline CHEMBL1395219 & 737824 & 4.4 & 4.1335 & TRN \\
\hline CHEMBL1492205 & 737824 & 5.3 & 5.1285 & TRN \\
\hline CHEMBL1346997 & 737824 & 5.8 & 5.0258 & TRN \\
\hline CHEMBL1411123 & 737824 & 4.95 & 5.1666 & TRN \\
\hline CHEMBL1391737 & 737824 & 4.95 & 5.2276 & TRN \\
\hline CHEMBL1457419 & 737824 & 5.65 & 5.6619 & TST \\
\hline CHEMBL1572589 & 737824 & 5.3 & 5.2303 & TRN \\
\hline CHEMBL1363953 & 737824 & 4.55 & 4.6961 & TST \\
\hline
\end{tabular}




\begin{tabular}{|c|c|c|c|c|c|}
\hline CHEMBL1425715 & 737824 & 5.45 & \multicolumn{2}{|c|}{5.207999999999999} & TRN \\
\hline CHEMBL1464821 & 737824 & 4.8 & 5.0653 & TRN & \\
\hline CHEMBL1355408 & 737824 & 5.0 & 5.0577 & TRN & \\
\hline CHEMBL1374205 & 737824 & 5.4 & 5.6995 & TRN & \\
\hline CHEMBL1304794 & 737824 & 5.5 & 5.313 & TRN & \\
\hline CHEMBL1384330 & 737824 & 5.15 & 5.5014 & TRN & \\
\hline CHEMBL1462914 & 737824 & 5.7 & 5.6553 & TRN & \\
\hline CHEMBL1306798 & 737824 & 5.3 & 5.3658 & TRN & \\
\hline CHEMBL1371661 & 737824 & 4.8 & 5.4421 & TST & \\
\hline CHEMBL1432466 & 737824 & 5.55 & 5.481 & TRN & \\
\hline CHEMBL3213131 & 737824 & 5.55 & 5.5328 & TST & \\
\hline CHEMBL1469212 & 737824 & 4.85 & 5.4733 & TRN & \\
\hline CHEMBL3198312 & 737824 & 5.95 & 5.4838 & TRN & \\
\hline CHEMBL1303217 & 737824 & 5.55 & 5.1743 & TRN & \\
\hline CHEMBL 2094549 & 737824 & 5.55 & 5.7667 & TRN & \\
\hline CHEMBL1352082 & 737824 & 4.9 & 5.5279 & TRN & \\
\hline CHEMBL1594612 & 737824 & 5.7 & 5.7559 & TRN & \\
\hline CHEMBL1314486 & 737824 & 6.2 & 6.0788 & TRN & \\
\hline CHEMBL1372850 & 737824 & 5.5 & 5.2529 & TRN & \\
\hline CHEMBL409024 & 737824 & 5.1 & 4.9855 & TST & \\
\hline CHEMBL1451307 & 737824 & 5.2 & 5.2514 & TRN & \\
\hline CHEMBL1306197 & 737824 & 4.8 & 5.2036 & TST & \\
\hline CHEMBL1580257 & 737824 & 5.3 & 5.0488 & TRN & \\
\hline CHEMBL1403905 & 737824 & 5.0 & 5.124 & TRN & \\
\hline CHEMBL1544016 & 737824 & 6.4 & 5.7296 & TRN & \\
\hline CHEMBL1529665 & 737824 & 6.2 & 5.239 & TST & \\
\hline CHEMBL34450 & 737824 & 4.9 & 4.9687 & TST & \\
\hline CHEMBL1386540 & 737824 & 5.1 & 5.043 & TRN & \\
\hline CHEMBL1403982 & 737824 & 6.0 & 6.0012 & TRN & \\
\hline CHEMBL 3213001 & 737824 & 7.1 & 5.896 & TRN & \\
\hline CHEMBL1422230 & 737824 & 6.75 & 5.8952 & TST & \\
\hline CHEMBL1355227 & 737824 & 4.9 & 5.0345 & TRN & \\
\hline CHEMBL1410496 & 737824 & 5.0 & 4.9534 & TRN & \\
\hline CHEMBL1705400 & 737824 & 5.15 & 5.2894 & TRN & \\
\hline CHEMBL1530613 & 737824 & 6.8 & 6.9316 & TST & \\
\hline CHEMBL1351838 & 737824 & 4.85 & 4.7288 & TST & \\
\hline CHEMBL1409713 & 737824 & 5.5 & 5.15799 & 99999999995 & TST \\
\hline CHEMBL1376134 & 737824 & 5.6 & 5.1104 & TRN & \\
\hline CHEMBL1432284 & 737824 & 4.8 & 5.084 & TRN & \\
\hline CHEMBL1574233 & 737824 & 4.4 & 4.9224 & TRN & \\
\hline CHEMBL1334106 & 737824 & 5.0 & 4.9328 & TRN & \\
\hline CHEMBL1542262 & 737824 & 5.3 & 5.1586 & TRN & \\
\hline CHEMBL1499314 & 737824 & 4.85 & 5.2538 & TST & \\
\hline CHEMBL1431735 & 737824 & 6.15 & 6.0723 & TRN & \\
\hline CHEMBL1610944 & 737824 & 6.3 & 5.9824 & TRN & \\
\hline CHEMBL1409815 & 737824 & 4.6 & 4.9713 & TRN & \\
\hline CHEMBL1355387 & 737824 & 5.1 & 5.1493 & TRN & \\
\hline CHEMBL1571361 & 737824 & 4.8 & 5.4268 & TRN & \\
\hline
\end{tabular}




\begin{tabular}{|c|c|c|c|c|c|}
\hline \multirow{2}{*}{\multicolumn{2}{|c|}{ CHEMBL1476078 }} & \\
\hline & & 4.4 & 4.4719 & TRN & \\
\hline CHEMBL1320904 & 737824 & 5.0 & 5.2383 & TRN & \\
\hline CHEMBL3189630 & 737824 & 4.55 & 5.2373 & TST & \\
\hline CHEMBL1322219 & 737824 & 5.3 & 5.5485 & TRN & \\
\hline CHEMBL1552478 & 737824 & 4.5 & 4.1897 & TRN & \\
\hline CHEMBL1741952 & 737824 & 5.05 & 5.4764 & TRN & \\
\hline CHEMBL1325766 & 737824 & 5.7 & 5.9113 & TRN & \\
\hline CHEMBL1507026 & 737824 & 5.2 & 5.3694 & TRN & \\
\hline CHEMBL1438674 & 737824 & 4.4 & 4.2577 & TRN & \\
\hline CHEMBL1578958 & 737824 & 5.25 & 5.7517 & TRN & \\
\hline CHEMBL1315072 & 737824 & 4.4 & 4.6099 & TRN & \\
\hline CHEMBL479014 & 737824 & 6.6 & 6.0557 & TST & \\
\hline CHEMBL1256910 & 737824 & 4.5 & 4.8436 & TST & \\
\hline CHEMBL1358137 & 737824 & 5.4 & 5.8195 & TRN & \\
\hline CHEMBL1450125 & 737824 & 4.45 & 4.7719 & TRN & \\
\hline CHEMBL42485 & 737824 & 5.3 & 5.3538 & TST & \\
\hline CHEMBL1334687 & 737824 & 5.4 & 5.2889 & TRN & \\
\hline CHEMBL1439808 & 737824 & 6.35 & 5.3823 & TST & \\
\hline CHEMBL1343368 & 737824 & 5.45 & 5.2936 & TRN & \\
\hline CHEMBL1409320 & 737824 & 4.8 & 4.8846 & TRN & \\
\hline CHEMBL1456034 & 737824 & 4.9 & 5.073 & TST & \\
\hline CHEMBL1508636 & 737824 & 4.9 & 4.9303 & TST & \\
\hline CHEMBL1437158 & 737824 & 4.6 & 4.55 & TRN & \\
\hline CHEMBL1601163 & 737824 & 5.4 & 5.5066 & TRN & \\
\hline CHEMBL1326546 & 737824 & 6.45 & 5.7384 & TRN & \\
\hline CHEMBL1699997 & 737824 & 4.4 & 4.8441 & TRN & \\
\hline CHEMBL1485598 & 737824 & 5.9 & 5.9314 & TRN & \\
\hline CHEMBL1432402 & 737824 & 4.9 & 5.0621 & TST & \\
\hline CHEMBL1534919 & 737824 & 6.05 & 5.5708 & TRN & \\
\hline CHEMBL1439893 & 737824 & 5.1 & 5.1899 & TRN & \\
\hline CHEMBL1366635 & 737824 & 4.8 & 5.2847 & TST & \\
\hline CHEMBL1348845 & 737824 & 5.25 & 5.045 & TRN & \\
\hline CHEMBL1415053 & 737824 & 5.8 & 5.5411 & TST & \\
\hline CHEMBL1368942 & 737824 & 5.6 & 5.6929 & TRN & \\
\hline CHEMBL1485287 & 737824 & 4.6 & 5.3567 & TRN & \\
\hline CHEMBL1500518 & 737824 & 5.65 & 4.9736 & TRN & \\
\hline CHEMBL1410759 & 737824 & 5.2 & 5.0279 & TST & \\
\hline CHEMBL1550134 & 737824 & 4.85 & 5.0312 & TRN & \\
\hline CHEMBL1391169 & 737824 & 5.35 & 4.8098 & TRN & \\
\hline CHEMBL1488362 & 737824 & 5.05 & 5.0713 & TRN & \\
\hline CHEMBL1596477 & 737824 & 6.0 & 5.1088 & TRN & \\
\hline CHEMBL 23194 & 737824 & 5.1 & 5.0425 & TST & \\
\hline CHEMBL1304655 & 737824 & 5.2 & 5.2927 & TRN & \\
\hline CHEMBL1393933 & 737824 & 5.75 & $5.5710 e$ & 2000000001 & TRN \\
\hline CHEMBL1450317 & 737824 & 6.1 & 5.5246 & TRN & \\
\hline CHEMBL1335690 & 737824 & 5.6 & 5.9192 & TRN & \\
\hline CHEMBL1368965 & 737824 & 4.4 & 4.2992 & TRN & \\
\hline CHEMBL1605085 & 737824 & 6.65 & $5.9220 e$ & 2000000001 & TRN \\
\hline & & & & e 7546 & \\
\hline
\end{tabular}




\begin{tabular}{|c|c|c|c|c|}
\hline \multicolumn{5}{|c|}{ Supplemental Table S2.txt } \\
\hline CHEMBL221733 & 737824 & 5.5 & 5.2256 & TRN \\
\hline CHEMBL1545514 & 737824 & 5.25 & 5.1877 & TRN \\
\hline CHEMBL1409996 & 737824 & 4.6 & 4.1109 & TRN \\
\hline CHEMBL1356505 & 737824 & 5.3 & 5.254 & TRN \\
\hline CHEMBL1505738 & 737824 & 4.85 & 5.1299 & TRN \\
\hline CHEMBL1432821 & 737824 & 4.75 & 4.948 & TRN \\
\hline CHEMBL1394533 & 737824 & 4.4 & 4.5464 & TRN \\
\hline CHEMBL1354693 & 737824 & 4.4 & 4.3859 & TRN \\
\hline CHEMBL1564813 & 737824 & 4.7 & 4.3424 & TRN \\
\hline CHEMBL1446286 & 737824 & 5.55 & 5.1529 & TRN \\
\hline CHEMBL1586735 & 737824 & 5.45 & 5.6085 & TRN \\
\hline CHEMBL1579956 & 737824 & 4.8 & 4.8538 & TRN \\
\hline CHEMBL1360952 & 737824 & 5.45 & 5.2207 & TST \\
\hline CHEMBL1401859 & 737824 & 5.5 & 5.5034 & TRN \\
\hline CHEMBL1605138 & 737824 & 5.1 & 5.1234 & TRN \\
\hline CHEMBL1370891 & 737824 & 5.2 & 5.0762 & TST \\
\hline CHEMBL1348374 & 737824 & 5.45 & 5.0031 & TRN \\
\hline CHEMBL1571457 & 737824 & 4.5 & 5.0038 & TRN \\
\hline CHEMBL1328887 & 737824 & 5.65 & 4.9335 & TRN \\
\hline CHEMBL1454224 & 737824 & 4.7 & 4.7495 & TRN \\
\hline CHEMBL1528708 & 737824 & 5.6 & 5.4416 & TRN \\
\hline CHEMBL1449517 & 737824 & 5.7 & 5.715 & TRN \\
\hline CHEMBL1967859 & 737824 & 5.9 & 5.5354 & TRN \\
\hline CHEMBL1303941 & 737824 & 4.8 & 4.9998 & TRN \\
\hline CHEMBL1464371 & 737824 & 5.4 & 5.3947 & TST \\
\hline CHEMBL3199688 & 737824 & 5.5 & 5.1982 & TST \\
\hline CHEMBL471225 & 737824 & 5.4 & 5.5075 & TST \\
\hline CHEMBL1448291 & 737824 & 6.1 & 5.2954 & TRN \\
\hline CHEMBL1362544 & 737824 & 4.55 & 4.7306 & TRN \\
\hline CHEMBL1318411 & 737824 & 4.4 & 4.7745 & TRN \\
\hline CHEMBL1390261 & 737824 & 7.6 & 7.2558 & TRN \\
\hline CHEMBL1448974 & 737824 & 6.1 & 5.2199 & TRN \\
\hline CHEMBL1409605 & 737824 & 5.5 & 5.2333 & TRN \\
\hline CHEMBL1544856 & 737824 & 5.1 & 5.1065 & TRN \\
\hline CHEMBL1406530 & 737824 & 5.15 & 5.2005 & TRN \\
\hline CHEMBL13791 & 737824 & 6.0 & 5.4382 & TRN \\
\hline CHEMBL1721237 & 737824 & 6.65 & 5.4565 & TRN \\
\hline CHEMBL3209592 & 737824 & 4.7 & 4.9992 & TRN \\
\hline CHEMBL1544319 & 737824 & 5.9 & 5.3654 & TRN \\
\hline CHEMBL31599 & 737824 & 4.5 & 4.439 & TRN \\
\hline CHEMBL1540288 & 737824 & 4.55 & 4.957 & TRN \\
\hline CHEMBL1508832 & 737824 & 5.85 & 5.2303 & TRN \\
\hline CHEMBL276727 & 737824 & 4.4 & 4.1146 & TST \\
\hline CHEMBL1511181 & 737824 & 6.25 & 5.6177 & TRN \\
\hline CHEMBL1453992 & 737824 & 5.6 & 5.5839 & TRN \\
\hline CHEMBL1432791 & 737824 & 5.4 & 5.1194 & TST \\
\hline CHEMBL1703799 & 737824 & 5.55 & 5.1521 & TRN \\
\hline CHEMBL1706840 & 737824 & 4.4 & 4.6868 & TRN \\
\hline
\end{tabular}




\begin{tabular}{|c|c|c|c|c|c|}
\hline \multicolumn{6}{|c|}{ tementents } \\
\hline CHEMBL1369966 & 737824 & 5.0 & 4.6718 & TRN & \\
\hline CHEMBL1391756 & 737824 & 6.2 & 5.7002 & TRN & \\
\hline CHEMBL1555014 & 737824 & 5.7 & 5.7192 & TRN & \\
\hline CHEMBL1603803 & 737824 & 5.8 & 5.91299 & 9999999999 & TRN \\
\hline CHEMBL1569655 & 737824 & 4.95 & 5.1201 & TRN & \\
\hline CHEMBL1484079 & 737824 & 4.85 & 4.9743 & TRN & \\
\hline CHEMBL475376 & 737824 & 5.5 & 5.5679 & TRN & \\
\hline CHEMBL1332984 & 737824 & 4.4 & 5.2284 & TRN & \\
\hline CHEMBL1473754 & 737824 & 5.2 & 5.4112 & TRN & \\
\hline CHEMBL1414083 & 737824 & 5.15 & 5.1249 & TRN & \\
\hline CHEMBL1446314 & 737824 & 6.65 & 5.2073 & TST & \\
\hline CHEMBL1329720 & 737824 & 4.9 & 5.104 & TRN & \\
\hline CHEMBL1382242 & 737824 & 4.85 & 5.0031 & TRN & \\
\hline CHEMBL1306927 & 737824 & 5.6 & 5.4049 & TRN & \\
\hline CHEMBL1430383 & 737824 & 5.05 & 5.2719 & TRN & \\
\hline CHEMBL1727670 & 737824 & 4.9 & 5.0773 & TRN & \\
\hline CHEMBL1342562 & 737824 & 5.5 & 5.3564 & TRN & \\
\hline CHEMBL1256660 & 737824 & 4.6 & 4.6524 & TRN & \\
\hline CHEMBL1731436 & 737824 & 4.65 & 5.0527 & TRN & \\
\hline CHEMBL1308621 & 737824 & 4.95 & 5.2138 & TST & \\
\hline CHEMBL1422270 & 737824 & 6.1 & 4.81800 & 00000000005 & TST \\
\hline CHEMBL1299692 & 737824 & 5.6 & 5.5694 & TRN & \\
\hline CHEMBL1372952 & 737824 & 5.0 & 5.191 & TRN & \\
\hline CHEMBL3189813 & 737824 & 4.4 & 4.7274 & TRN & \\
\hline CHEMBL1437442 & 737824 & 5.4 & 5.4903 & TRN & \\
\hline CHEMBL1547764 & 737824 & 5.45 & 5.3924 & TRN & \\
\hline CHEMBL1579360 & 737824 & 5.35 & 5.4062 & TRN & \\
\hline CHEMBL1551445 & 737824 & 4.5 & 4.1263 & TRN & \\
\hline CHEMBL1429357 & 737824 & 4.6 & 5.2665 & TRN & \\
\hline CHEMBL1561190 & 737824 & 5.3 & 5.1643 & TRN & \\
\hline CHEMBL1566015 & 737824 & 5.55 & 5.01699 & 99999999995 & TRN \\
\hline CHEMBL1606193 & 737824 & 5.8 & 5.4017 & TRN & \\
\hline CHEMBL1568870 & 737824 & 5.05 & 4.8783 & TRN & \\
\hline CHEMBL1376212 & 737824 & 6.0 & 5.9172 & TRN & \\
\hline CHEMBL1443281 & 737824 & 4.9 & 5.1157 & TRN & \\
\hline CHEMBL1532921 & 737824 & 5.6 & 5.897 & TRN & \\
\hline CHEMBL565359 & 737824 & 5.05 & 5.6642 & TRN & \\
\hline CHEMBL491943 & 737824 & 4.8 & 4.4955 & TRN & \\
\hline CHEMBL1331064 & 737824 & 5.2 & 5.1594 & TRN & \\
\hline CHEMBL1520347 & 737824 & 4.7 & 4.6601 & TRN & \\
\hline CHEMBL1522654 & 737824 & 4.9 & 4.8198 & TRN & \\
\hline CHEMBL1333030 & 737824 & 4.55 & 4.8944 & TRN & \\
\hline CHEMBL1439183 & 737824 & 4.9 & 4.9551 & TRN & \\
\hline CHEMBL94734 & 737824 & 4.9 & 4.1439 & TRN & \\
\hline CHEMBL1511129 & 737824 & 6.05 & 5.6842 & TRN & \\
\hline CHEMBL1488264 & 737824 & 5.15 & 5.0274 & TRN & \\
\hline CHEMBL1560502 & 737824 & 5.1 & 5.0185 & TRN & \\
\hline CHEMBL909 & 737824 & 6.1 & 5.9651 & TRN & \\
\hline
\end{tabular}




\begin{tabular}{|c|c|c|c|c|c|}
\hline \multicolumn{6}{|c|}{ Supplemental Table S2.txt } \\
\hline CHEMBL3190889 & 737824 & 5.95 & 5.931 & TRN & \\
\hline CHEMBL3189672 & 737824 & 5.55 & 5.2347 & TRN & \\
\hline CHEMBL1430600 & 737824 & 4.65 & 5.0724 & TRN & \\
\hline CHEMBL1530445 & 737824 & 6.0 & 5.7191 & TST & \\
\hline CHEMBL1482196 & 737824 & 6.5 & 5.8222 & TRN & \\
\hline CHEMBL1383601 & 737824 & 4.7 & 5.6995 & TRN & \\
\hline CHEMBL1606415 & 737824 & 4.5 & 5.0842 & TRN & \\
\hline CHEMBL3199868 & 737824 & 5.65 & 5.2309 & TRN & \\
\hline CHEMBL1436125 & 737824 & 5.7 & 5.4425 & TRN & \\
\hline CHEMBL1602780 & 737824 & 5.0 & 5.2024 & TRN & \\
\hline CHEMBL1332346 & 737824 & 4.9 & 4.8328 & TRN & \\
\hline CHEMBL1510930 & 737824 & 5.2 & 5.4296 & TRN & \\
\hline CHEMBL1387098 & 737824 & 4.85 & 5.3243 & TST & \\
\hline CHEMBL1484896 & 737824 & 5.4 & 5.3188 & TRN & \\
\hline CHEMBL1487318 & 737824 & 6.0 & 6.0807 & TRN & \\
\hline CHEMBL1389823 & 737824 & 5.8 & 5.29899 & 99999999995 & TST \\
\hline CHEMBL1507424 & 737824 & 5.55 & 4.9636 & TRN & \\
\hline CHEMBL1482184 & 737824 & 5.5 & 5.8159 & TST & \\
\hline CHEMBL1490330 & 737824 & 5.55 & 5.5587 & TRN & \\
\hline CHEMBL1505565 & 737824 & 5.5 & 5.5116 & TRN & \\
\hline CHEMBL76904 & 737824 & 4.8 & 4.6715 & TRN & \\
\hline CHEMBL1554243 & 737824 & 4.7 & 4.3141 & TRN & \\
\hline CHEMBL1368681 & 737824 & 6.35 & 5.8648 & TRN & \\
\hline CHEMBL1487735 & 737824 & 5.5 & 5.3041 & TRN & \\
\hline CHEMBL1482158 & 737824 & 4.4 & 4.9291 & TST & \\
\hline CHEMBL1555368 & 737824 & 4.9 & 4.707 & TRN & \\
\hline CHEMBL1320471 & 737824 & 4.5 & 5.2637 & TRN & \\
\hline CHEMBL1448533 & 737824 & 4.85 & 5.0101 & TRN & \\
\hline CHEMBL1454951 & 737824 & 5.5 & 5.7157 & TRN & \\
\hline CHEMBL1595551 & 737824 & 4.7 & 5.0172 & TRN & \\
\hline CHEMBL1709072 & 737824 & 4.7 & 5.1944 & TRN & \\
\hline CHEMBL1562053 & 737824 & 4.6 & 5.4127 & TRN & \\
\hline CHEMBL3213672 & 737824 & 5.45 & 5.2246 & TRN & \\
\hline CHEMBL1425640 & 737824 & 5.85 & 5.3958 & TRN & \\
\hline CHEMBL1599118 & 737824 & 5.0 & 4.9256 & TRN & \\
\hline CHEMBL3211406 & 737824 & 4.7 & 5.115 & TRN & \\
\hline CHEMBL1548495 & 737824 & 5.0 & 5.1265 & TRN & \\
\hline CHEMBL1578193 & 737824 & 4.55 & 4.9648 & TST & \\
\hline CHEMBL3190830 & 737824 & 4.85 & 4.961 & TRN & \\
\hline CHEMBL1498258 & 737824 & 5.6 & 5.7211 & TRN & \\
\hline CHEMBL1425688 & 737824 & 4.9 & 5.0912 & TRN & \\
\hline CHEMBL1583020 & 737824 & 4.7 & 4.8885 & TRN & \\
\hline CHEMBL1543421 & 737824 & 4.95 & 5.3403 & TST & \\
\hline CHEMBL1505201 & 737824 & 4.6 & 5.2038 & TRN & \\
\hline CHEMBL1979849 & 737824 & 4.8 & 5.18 & TRN & \\
\hline CHEMBL1355370 & 737824 & 5.0 & 4.9473 & TRN & \\
\hline CHEMBL1502052 & 737824 & 5.9 & 6.3841 & TRN & \\
\hline CHEMBL1368895 & 737824 & 5.2 & 4.7841 & TST & \\
\hline
\end{tabular}




\begin{tabular}{|c|c|c|c|c|}
\hline & & & pplement & $\mathrm{a} \perp \mathrm{Ta}$ \\
\hline CHEMBL1514153 & 737824 & 5.0 & 5.0181 & TRN \\
\hline CHEMBL1458916 & 737824 & 5.35 & 5.3201 & TRN \\
\hline CHEMBL1433730 & 737824 & 4.9 & 4.9957 & TRN \\
\hline CHEMBL1565525 & 737824 & 7.5 & 7.2992 & TRN \\
\hline CHEMBL1582789 & 737824 & 4.85 & 4.7808 & TRN \\
\hline CHEMBL1411832 & 737824 & 5.2 & 5.1712 & TRN \\
\hline CHEMBL1507098 & 737824 & 5.15 & 5.0082 & TST \\
\hline CHEMBL1407289 & 737824 & 5.65 & 5.723 & TRN \\
\hline CHEMBL1378758 & 737824 & 6.2 & 5.8281 & TRN \\
\hline CHEMBL1382870 & 737824 & 4.95 & 5.3736 & TRN \\
\hline CHEMBL1476939 & 737824 & 5.4 & 5.5166 & TST \\
\hline CHEMBL1480141 & 737824 & 4.6 & 5.1215 & TRN \\
\hline CHEMBL1480885 & 737824 & 5.5 & 4.987 & TST \\
\hline CHEMBL1720599 & 737824 & 4.4 & 5.0524 & TRN \\
\hline CHEMBL1305846 & 737824 & 5.15 & 5.5421 & TST \\
\hline CHEMBL1516468 & 737824 & 6.0 & 5.9174 & TRN \\
\hline CHEMBL1488931 & 737824 & 5.85 & 5.5892 & TST \\
\hline CHEMBL1523946 & 737824 & 5.15 & 5.3528 & TRN \\
\hline CHEMBL1578457 & 737824 & 5.65 & 4.8852 & TRN \\
\hline CHEMBL1507984 & 737824 & 4.55 & 4.9625 & TST \\
\hline CHEMBL1605449 & 737824 & 5.65 & 5.5149 & TRN \\
\hline CHEMBL1594284 & 737824 & 4.5 & 4.9269 & TRN \\
\hline CHEMBL1407304 & 737824 & 4.5 & 5.0589 & TRN \\
\hline CHEMBL1496350 & 737824 & 5.2 & 5.1354 & TRN \\
\hline CHEMBL 3198283 & 737824 & 4.6 & 4.9215 & TST \\
\hline CHEMBL1441823 & 737824 & 7.4 & 5.7403 & TRN \\
\hline CHEMBL1741716 & 737824 & 4.55 & 5.4715 & TRN \\
\hline CHEMBL1490820 & 737824 & 4.95 & 5.6377 & TRN \\
\hline CHEMBL1344026 & 737824 & 4.55 & 5.1066 & TRN \\
\hline CHEMBL1373326 & 737824 & 6.2 & 5.8128 & TRN \\
\hline CHEMBL1527872 & 737824 & 5.75 & 5.2211 & TRN \\
\hline CHEMBL1590081 & 737824 & 5.0 & 5.2708 & TRN \\
\hline CHEMBL1527436 & 737824 & 4.9 & 4.559 & TRN \\
\hline CHEMBL1500967 & 737824 & 4.85 & 4.6286 & TRN \\
\hline CHEMBL450493 & 737824 & 5.7 & 5.7143 & TRN \\
\hline CHEMBL1602161 & 737824 & 5.1 & 4.8263 & TRN \\
\hline CHEMBL1441148 & 737824 & 4.8 & 4.8005 & TRN \\
\hline CHEMBL1537367 & 737824 & 5.35 & 5.5217 & TRN \\
\hline CHEMBL1385596 & 737824 & 5.75 & 5.1089 & TRN \\
\hline CHEMBL1421262 & 737824 & 5.5 & 5.4534 & TRN \\
\hline CHEMBL1429121 & 737824 & 4.65 & 5.0175 & TRN \\
\hline CHEMBL1449669 & 737824 & 5.05 & 5.5064 & TRN \\
\hline CHEMBL1463329 & 737824 & 5.45 & 5.3218 & TST \\
\hline CHEMBL1425687 & 737824 & 4.75 & 4.9572 & TRN \\
\hline CHEMBL1322026 & 737824 & 6.5 & 7.0621 & TST \\
\hline CHEMBL1496344 & 737824 & 5.05 & 4.9879 & TRN \\
\hline CHEMBL1465834 & 737824 & 4.95 & 4.9158 & TRN \\
\hline CHEMBL1560706 & 737824 & 5.2 & 5.2513 & TRN \\
\hline
\end{tabular}




\begin{tabular}{|c|c|c|c|c|c|}
\hline \\
\hline CHEMBL1450373 & 737824 & 5.5 & 5.3222 & TRN & \\
\hline CHEMBL1613702 & 737824 & 4.5 & 4.7964 & TRN & \\
\hline CHEMBL3192471 & 737824 & 4.5 & 4.8723 & TRN & \\
\hline CHEMBL1705301 & 737824 & 4.8 & 5.4341 & TRN & \\
\hline CHEMBL1340722 & 737824 & 5.65 & 4.7931 & TRN & \\
\hline CHEMBL1389059 & 737824 & 5.6 & 5.8924 & TRN & \\
\hline CHEMBL1396230 & 737824 & 4.9 & 4.5711 & TRN & \\
\hline CHEMBL1482233 & 737824 & 4.85 & 4.8999 & TRN & \\
\hline CHEMBL1310885 & 737824 & 4.55 & 5.1436 & TRN & \\
\hline CHEMBL1308139 & 737824 & 5.8 & 5.3932 & TRN & \\
\hline CHEMBL1395137 & 737824 & 5.7 & 5.2222 & TRN & \\
\hline CHEMBL1372413 & 737824 & 5.05 & 5.153 & TRN & \\
\hline CHEMBL1580474 & 737824 & 4.55 & 5.0332 & TRN & \\
\hline CHEMBL1413489 & 737824 & 6.0 & 5.7397 & TRN & \\
\hline CHEMBL1339949 & 737824 & 5.55 & 5.2493 & TRN & \\
\hline CHEMBL1604519 & 737824 & 5.95 & 5.7708 & TRN & \\
\hline CHEMBL1317451 & 737824 & 4.4 & 4.08899 & 79999999995 & TRN \\
\hline CHEMBL1494182 & 737824 & 5.1 & 5.2134 & TST & \\
\hline CHEMBL1458869 & 737824 & 5.8 & 5.5467 & TRN & \\
\hline CHEMBL1447425 & 737824 & 5.35 & 5.7934 & TRN & \\
\hline CHEMBL3214365 & 737824 & 5.05 & 5.2462 & TRN & \\
\hline CHEMBL1311139 & 737824 & 5.05 & 4.7681 & TRN & \\
\hline CHEMBL1510139 & 737824 & 4.65 & 5.0759 & TRN & \\
\hline CHEMBL1605356 & 737824 & 4.8 & 4.9588 & TRN & \\
\hline CHEMBL1522755 & 737824 & 5.85 & 5.7077 & TRN & \\
\hline CHEMBL1557811 & 737824 & 5.7 & 5.3225 & TRN & \\
\hline CHEMBL1255837 & 737824 & 6.0 & 5.5895 & TST & \\
\hline CHEMBL1443124 & 737824 & 4.95 & 4.7388 & TRN & \\
\hline CHEMBL1466277 & 737824 & 6.45 & 5.5051 & TST & \\
\hline CHEMBL1381498 & 737824 & 5.3 & 5.5236 & TST & \\
\hline CHEMBL1516521 & 737824 & 4.85 & 5.3747 & TRN & \\
\hline CHEMBL1351153 & 737824 & 5.15 & 5.266 & TRN & \\
\hline CHEMBL1594405 & 737824 & 5.6 & 5.5449 & TRN & \\
\hline CHEMBL1418280 & 737824 & 5.65 & 5.5991 & TRN & \\
\hline CHEMBL1570405 & 737824 & 4.85 & 5.2391 & TST & \\
\hline CHEMBL1556027 & 737824 & 6.95 & 5.6965 & TRN & \\
\hline CHEMBL1582666 & 737824 & 4.65 & 5.1325 & TRN & \\
\hline CHEMBL3196233 & 737824 & 5.25 & 5.0616 & TRN & \\
\hline CHEMBL3213403 & 737824 & 5.5 & 5.0602 & TRN & \\
\hline CHEMBL1447392 & 737824 & 5.0 & 5.25 & TRN & \\
\hline CHEMBL1411201 & 737824 & 4.8 & 4.7079 & TRN & \\
\hline CHEMBL1334292 & 737824 & 5.0 & 5.1159 & TRN & \\
\hline CHEMBL1379350 & 737824 & 5.45 & 5.2604 & TST & \\
\hline CHEMBL1477786 & 737824 & 6.15 & 5.1575 & TRN & \\
\hline CHEMBL1437825 & 737824 & 5.45 & 4.9889 & TRN & \\
\hline CHEMBL1369444 & 737824 & 4.5 & 4.902 & TRN & \\
\hline CHEMBL1603724 & 737824 & 5.2 & 5.2368 & TRN & \\
\hline CHEMBL1299232 & 737824 & 4.95 & 5.1484 & TRN & \\
\hline
\end{tabular}




\begin{tabular}{|c|c|c|c|c|}
\hline \multicolumn{5}{|c|}{ lemental Table s } \\
\hline CHEMBL1552329 & 737824 & 5.0 & 4.8783 & TRN \\
\hline CHEMBL1567569 & 737824 & 5.2 & 5.1418 & TRN \\
\hline CHEMBL1460774 & 737824 & 6.7 & 5.2385 & TST \\
\hline CHEMBL1452708 & 737824 & 5.35 & 5.4818 & TRN \\
\hline CHEMBL1397634 & 737824 & 6.3 & 6.0979 & TRN \\
\hline CHEMBL1536254 & 737824 & 5.0 & 5.0678 & TRN \\
\hline CHEMBL1487692 & 737824 & 5.05 & 4.6622 & TST \\
\hline CHEMBL1577571 & 737824 & 5.65 & 5.5888 & TRN \\
\hline CHEMBL22075 & 737824 & 6.3 & 6.0874 & TRN \\
\hline CHEMBL1433785 & 737824 & 4.8 & 4.6415 & TRN \\
\hline CHEMBL1495011 & 737824 & 5.05 & 5.3015 & TRN \\
\hline CHEMBL1575261 & 737824 & 6.05 & 5.6143 & TRN \\
\hline CHEMBL1537501 & 737824 & 5.55 & 5.4817 & TRN \\
\hline CHEMBL1544437 & 737824 & 5.4 & 5.2478 & TRN \\
\hline CHEMBL1575273 & 737824 & 5.0 & 5.3704 & TRN \\
\hline CHEMBL1339404 & 737824 & 6.15 & 5.3689 & TRN \\
\hline CHEMBL1302930 & 737824 & 5.8 & 5.8041 & TRN \\
\hline CHEMBL1434801 & 737824 & 5.5 & 4.9229 & TRN \\
\hline CHEMBL1381655 & 737824 & 4.8 & 5.016 & TRN \\
\hline CHEMBL1349496 & 737824 & 5.75 & 5.58799 & 9999999999 \\
\hline CHEMBL1408128 & 737824 & 4.9 & 5.4316 & TRN \\
\hline CHEMBL1330032 & 737824 & 5.05 & 5.2067 & TRN \\
\hline CHEMBL1363272 & 737824 & 4.9 & 5.7224 & TRN \\
\hline CHEMBL1547055 & 737824 & 5.1 & 5.0634 & TRN \\
\hline CHEMBL1496663 & 737824 & 5.0 & 5.1274 & TST \\
\hline CHEMBL1587410 & 737824 & 4.65 & 5.0669 & TRN \\
\hline CHEMBL1543028 & 737824 & 4.9 & 5.2276 & TRN \\
\hline CHEMBL1558538 & 737824 & 4.45 & 5.1616 & TRN \\
\hline CHEMBL1577056 & 737824 & 5.6 & 5.3107 & TRN \\
\hline CHEMBL1392330 & 737824 & 4.7 & 5.2607 & TRN \\
\hline CHEMBL3196561 & 737824 & 4.9 & 5.2539 & TRN \\
\hline CHEMBL1309678 & 737824 & 4.9 & 5.187 & TST \\
\hline CHEMBL1372491 & 737824 & 5.95 & 5.6206 & TRN \\
\hline CHEMBL1364047 & 737824 & 4.55 & 5.3862 & TRN \\
\hline CHEMBL1338480 & 737824 & 4.9 & 5.1601 & TRN \\
\hline CHEMBL1415728 & 737824 & 4.9 & 5.0789 & TRN \\
\hline CHEMBL1302204 & 737824 & 5.15 & 4.835 & TRN \\
\hline CHEMBL1432433 & 737824 & 4.75 & 4.7 & TRN \\
\hline CHEMBL1477964 & 737824 & 5.2 & 5.1552 & TRN \\
\hline CHEMBL1419233 & 737824 & 5.0 & 4.9188 & TRN \\
\hline CHEMBL1429067 & 737824 & 5.1 & 5.3229 & TRN \\
\hline CHEMBL1505597 & 737824 & 5.55 & 5.2092 & TRN \\
\hline CHEMBL1331137 & 737824 & 5.2 & 5.2317 & TRN \\
\hline CHEMBL1742231 & 737824 & 5.4 & 5.385 & TRN \\
\hline CHEMBL1573743 & 737824 & 5.2 & 5.0754 & TRN \\
\hline CHEMBL1326204 & 737824 & 5.5 & 5.4105 & TST \\
\hline CHEMBL1476712 & 737824 & 4.8 & 4.9983 & TRN \\
\hline CHEMBL1528538 & 737824 & 5.55 & 5.2258 & TRN \\
\hline
\end{tabular}

TRN 


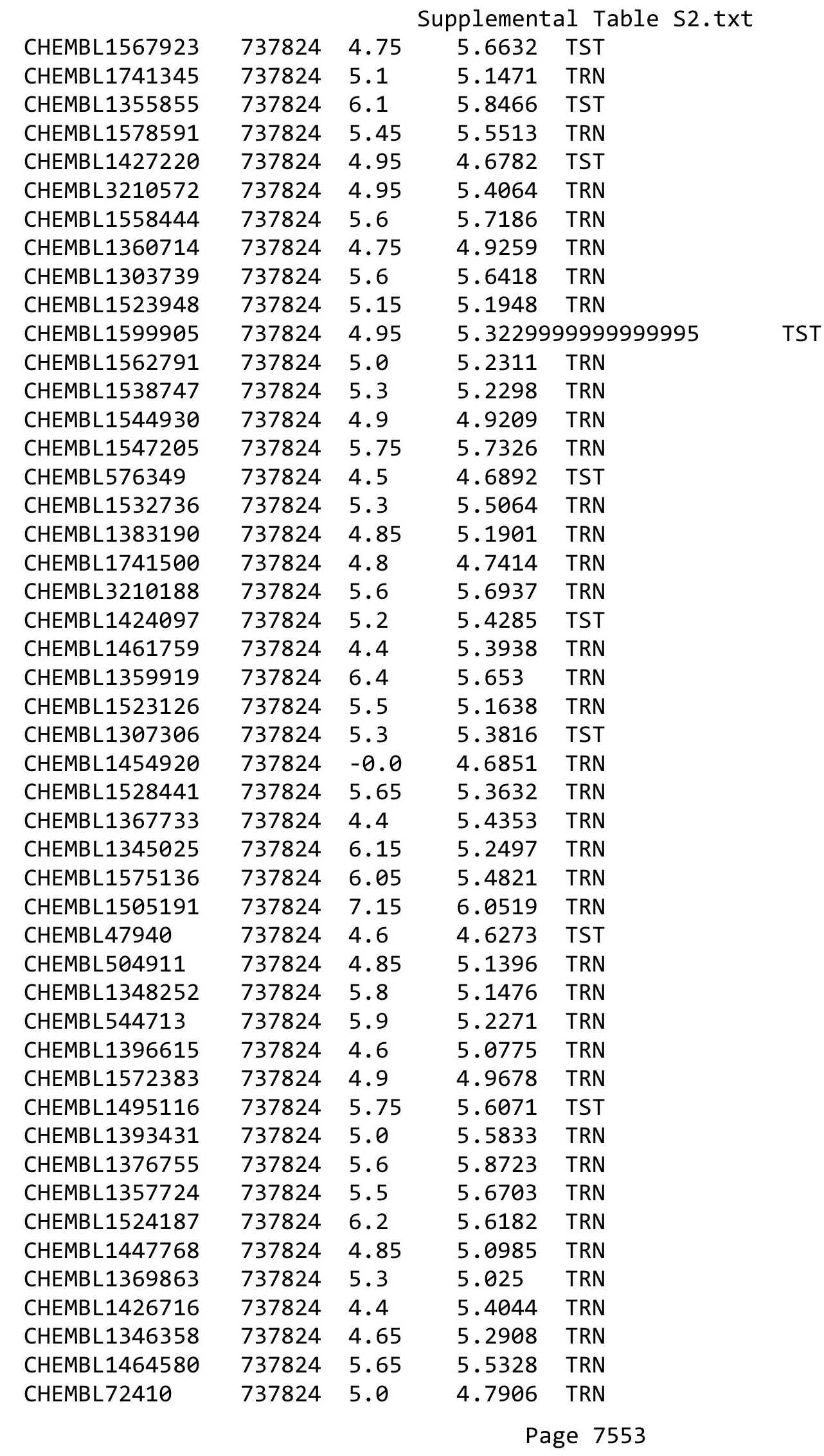




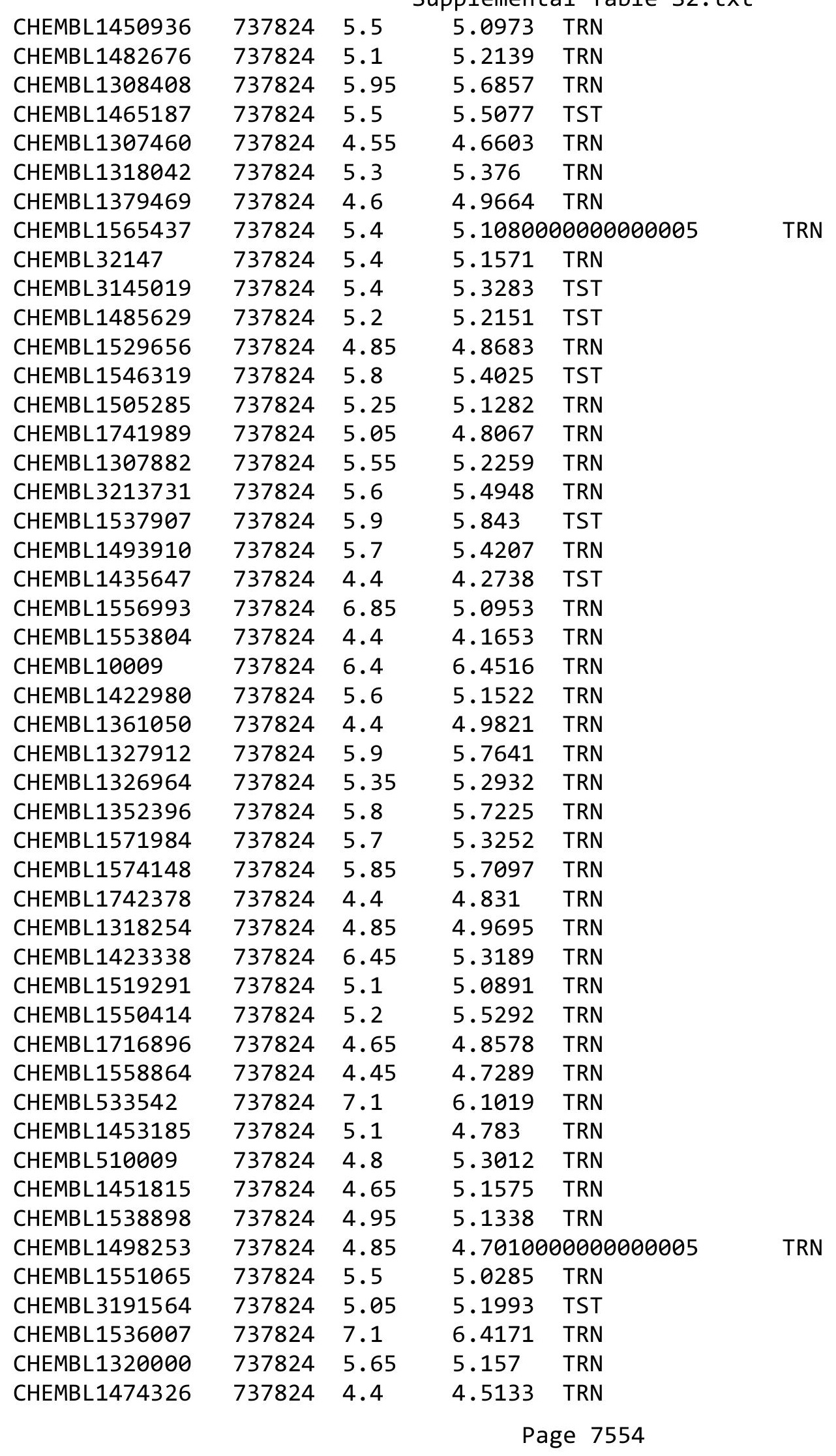




\begin{tabular}{|c|c|c|c|c|}
\hline \multicolumn{5}{|c|}{ Supplemental Table S2.txt } \\
\hline CHEMBL1312573 & 737824 & 4.95 & 5.1667 & TRN \\
\hline CHEMBL1371959 & 737824 & 5.45 & 5.3829 & TRN \\
\hline CHEMBL1305585 & 737824 & 4.8 & 4.8891 & TRN \\
\hline CHEMBL1328527 & 737824 & 5.3 & 4.8366 & TRN \\
\hline CHEMBL1396384 & 737824 & 5.5 & 5.3621 & TRN \\
\hline CHEMBL409902 & 737824 & 4.4 & 3.9992 & TRN \\
\hline CHEMBL522600 & 737824 & 5.9 & 5.7897 & TRN \\
\hline CHEMBL1515355 & 737824 & 6.5 & 6.1585 & TRN \\
\hline CHEMBL1536188 & 737824 & 4.6 & 4.6502 & TST \\
\hline CHEMBL1968402 & 737824 & 6.35 & 5.5595 & TRN \\
\hline CHEMBL1501526 & 737824 & 5.8 & 5.3029 & TRN \\
\hline CHEMBL1347770 & 737824 & 4.95 & 5.1033 & TRN \\
\hline CHEMBL1980198 & 737824 & 5.15 & 5.5449 & TRN \\
\hline CHEMBL1449707 & 737824 & 5.55 & 5.2117 & TRN \\
\hline CHEMBL1403034 & 737824 & 4.6 & 5.3024 & TRN \\
\hline CHEMBL1511408 & 737824 & 5.1 & 5.8456 & TRN \\
\hline CHEMBL1499721 & 737824 & 6.05 & 5.2379 & TRN \\
\hline CHEMBL1388305 & 737824 & 4.85 & 4.9366 & TRN \\
\hline CHEMBL1383867 & 737824 & 5.65 & 4.8797 & TRN \\
\hline CHEMBL1416252 & 737824 & 5.2 & 5.4975 & TRN \\
\hline CHEMBL1334122 & 737824 & 5.1 & 5.3176 & TRN \\
\hline CHEMBL1409613 & 737824 & 4.5 & 4.6791 & TRN \\
\hline CHEMBL1515417 & 737824 & 6.0 & 6.0725 & TRN \\
\hline CHEMBL1335220 & 737824 & 5.5 & 5.1166 & TRN \\
\hline CHEMBL1357018 & 737824 & 5.3 & 5.2448 & TRN \\
\hline CHEMBL1320206 & 737824 & 4.4 & 4.4022 & TRN \\
\hline CHEMBL1534714 & 737824 & 4.95 & 5.3334 & TRN \\
\hline CHEMBL1542169 & 737824 & 4.85 & 5.3752 & TST \\
\hline CHEMBL3199177 & 737824 & 5.85 & 5.6132 & TRN \\
\hline CHEMBL1492063 & 737824 & 5.9 & 5.2095 & TRN \\
\hline CHEMBL1478808 & 737824 & 5.1 & 5.0416 & TRN \\
\hline CHEMBL1414240 & 737824 & 6.55 & 5.2766 & TST \\
\hline CHEMBL1436882 & 737824 & 6.2 & 5.4316 & TST \\
\hline CHEMBL1483110 & 737824 & 5.6 & 5.4689 & TRN \\
\hline CHEMBL1448354 & 737824 & 5.5 & 5.4864 & TRN \\
\hline CHEMBL1483550 & 737824 & 5.7 & 5.7017 & TRN \\
\hline CHEMBL1326935 & 737824 & 4.65 & 4.8881 & TRN \\
\hline CHEMBL1457730 & 737824 & 5.55 & 5.5007 & TRN \\
\hline CHEMBL1438199 & 737824 & 5.05 & 4.7109 & TRN \\
\hline CHEMBL1588349 & 737824 & 5.5 & 5.629 & TRN \\
\hline CHEMBL1562937 & 737824 & 5.0 & 5.2441 & TRN \\
\hline CHEMBL1554622 & 737824 & 4.9 & 4.8924 & TRN \\
\hline CHEMBL1549020 & 737824 & 4.85 & 4.6063 & TRN \\
\hline CHEMBL1511729 & 737824 & 5.4 & 4.7843 & TRN \\
\hline CHEMBL1323465 & 737824 & 5.2 & 5.1048 & TRN \\
\hline CHEMBL1343091 & 737824 & 4.4 & 4.8946 & TRN \\
\hline CHEMBL1437325 & 737824 & 4.9 & 5.0572 & TRN \\
\hline CHEMBL1578653 & 737824 & 4.4 & 4.6727 & TST \\
\hline
\end{tabular}




\begin{tabular}{|c|c|c|c|c|c|}
\hline \multicolumn{6}{|c|}{ Supplemental Table S2.txt } \\
\hline CHEMBL1336932 & 737824 & 5.0 & 4.846 & TRN & \\
\hline CHEMBL1500145 & 737824 & 4.75 & 5.0369 & TRN & \\
\hline CHEMBL321820 & 737824 & 5.8 & 5.7469 & TST & \\
\hline CHEMBL1424815 & 737824 & 6.45 & 5.7024 & TRN & \\
\hline CHEMBL1595377 & 737824 & 4.7 & 4.5406 & TRN & \\
\hline CHEMBL44 & 737824 & 5.0 & 5.6941 & TRN & \\
\hline CHEMBL1433052 & 737824 & 5.55 & 4.9442 & TST & \\
\hline CHEMBL1318544 & 737824 & 4.5 & 4.6036 & TRN & \\
\hline CHEMBL1579818 & 737824 & 5.15 & 5.3829 & TRN & \\
\hline CHEMBL1423810 & 737824 & 4.95 & 5.2033 & TRN & \\
\hline CHEMBL1469541 & 737824 & 4.85 & 4.7483 & TRN & \\
\hline CHEMBL1497805 & 737824 & 5.45 & 5.2908 & TRN & \\
\hline CHEMBL1601285 & 737824 & 5.5 & 5.3782 & TRN & \\
\hline CHEMBL1462878 & 737824 & 6.4 & 5.9376 & TRN & \\
\hline CHEMBL1397443 & 737824 & 5.4 & 5.2537 & TST & \\
\hline CHEMBL1524183 & 737824 & 5.2 & 5.4072 & TRN & \\
\hline CHEMBL1363594 & 737824 & 4.8 & 4.8968 & TRN & \\
\hline CHEMBL1489392 & 737824 & 4.4 & 4.427 & TST & \\
\hline CHEMBL1415310 & 737824 & 5.35 & 5.2191 & TRN & \\
\hline CHEMBL1230276 & 737824 & 5.5 & 5.1595 & TRN & \\
\hline CHEMBL1580894 & 737824 & 4.5 & 4.7055 & TRN & \\
\hline CHEMBL 3193784 & 737824 & 5.45 & 5.6528 & TRN & \\
\hline CHEMBL1556272 & 737824 & 5.75 & 6.7131 & TRN & \\
\hline CHEMBL1394499 & 737824 & 4.9 & 5.0441 & TRN & \\
\hline CHEMBL1451747 & 737824 & 4.5 & 4.981 & TRN & \\
\hline CHEMBL1391592 & 737824 & 5.05 & 5.1714 & TRN & \\
\hline CHEMBL1340374 & 737824 & 4.4 & 5.5502 & TST & \\
\hline CHEMBL1476526 & 737824 & 5.1 & 5.1765 & TRN & \\
\hline CHEMBL1357968 & 737824 & 4.7 & 4.4261 & TRN & \\
\hline CHEMBL1387379 & 737824 & 4.45 & 5.0772 & TRN & \\
\hline CHEMBL1598230 & 737824 & 4.4 & 5.1543 & TST & \\
\hline CHEMBL1487537 & 737824 & 4.65 & 5.4328 & TRN & \\
\hline CHEMBL1318448 & 737824 & 4.4 & 4.4424 & TRN & \\
\hline CHEMBL1484261 & 737824 & 6.5 & 6.4509 & TRN & \\
\hline CHEMBL1329102 & 737824 & 7.7001 & 6.4808 & TST & \\
\hline CHEMBL1334104 & 737824 & 5.6 & 5.3759 & TRN & \\
\hline CHEMBL1516905 & 737824 & 5.1 & 5.1931 & TRN & \\
\hline CHEMBL1476711 & 737824 & 4.4 & 4.0418 & TRN & \\
\hline CHEMBL1422629 & 737824 & 4.8 & 5.2486 & TRN & \\
\hline CHEMBL1611508 & 737824 & 5.75 & 5.402 & TRN & \\
\hline CHEMBL1572275 & 737824 & 5.0 & 5.002 & TRN & \\
\hline CHEMBL1487092 & 737824 & 5.95 & 5.2632 & TRN & \\
\hline CHEMBL1393189 & 737824 & 5.7 & 5.5787 & TRN & \\
\hline CHEMBL1350079 & 737824 & 5.2 & 5.4541 & TRN & \\
\hline CHEMBL1496571 & 737824 & 5.3 & 5.6094 & TRN & \\
\hline CHEMBL1601630 & 737824 & 5.0 & 4.3548 & TRN & \\
\hline CHEMBL1421758 & 737824 & 7.45 & 5.36600 & 00000000005 & TRN \\
\hline CHEMBL1472129 & 737824 & 5.55 & 5.6683 & TRN & \\
\hline
\end{tabular}




\begin{tabular}{|c|c|c|c|c|c|}
\hline \multirow[b]{2}{*}{ CHEMBL1525916 } & \multicolumn{5}{|c|}{ Supplemental Table S2.txt } \\
\hline & 737824 & 4.85 & 5.5007 & TRN & \\
\hline CHEMBL1433687 & 737824 & 6.6 & \multicolumn{2}{|c|}{6.537000000000001} & TRN \\
\hline CHEMBL1357294 & 737824 & 4.9 & 4.7083 & TRN & \\
\hline CHEMBL1563331 & 737824 & 4.75 & 5.205 & TRN & \\
\hline CHEMBL1479218 & 737824 & 6.3 & 6.0986 & TRN & \\
\hline CHEMBL1585650 & 737824 & 5.35 & 5.0988 & TRN & \\
\hline CHEMBL1555369 & 737824 & 5.8 & 5.7314 & TRN & \\
\hline CHEMBL1424582 & 737824 & 5.65 & 5.5946 & TRN & \\
\hline CHEMBL1410999 & 737824 & 6.25 & 5.6791 & TRN & \\
\hline CHEMBL1425931 & 737824 & 4.9 & 4.8849 & TRN & \\
\hline CHEMBL 3210057 & 737824 & 5.5 & 5.4726 & TRN & \\
\hline CHEMBL1374426 & 737824 & 8.7001 & 7.3133 & TST & \\
\hline CHEMBL1613268 & 737824 & 8.0 & 6.0442 & TRN & \\
\hline CHEMBL1306504 & 737824 & 5.1 & 5.311 & TRN & \\
\hline CHEMBL1891843 & 737824 & 4.95 & 4.8008 & TST & \\
\hline CHEMBL1519330 & 737824 & 4.85 & 4.9877 & TRN & \\
\hline CHEMBL1598228 & 737824 & 6.6 & 6.096 & TST & \\
\hline CHEMBL1335882 & 737824 & 4.6 & 4.8466 & TRN & \\
\hline CHEMBL1349158 & 737824 & 5.7 & 5.6276 & TRN & \\
\hline CHEMBL3209931 & 737824 & 5.35 & 5.46200 & 0000000001 & TRN \\
\hline CHEMBL1360310 & 737824 & 4.8 & 4.6526 & TRN & \\
\hline CHEMBL1519110 & 737824 & 4.8 & 5.2579 & TST & \\
\hline CHEMBL1516388 & 737824 & 5.2 & 5.1379 & TST & \\
\hline CHEMBL1420898 & 737824 & 4.95 & 5.4514 & TRN & \\
\hline CHEMBL3190658 & 737824 & 4.9 & 5.2237 & TRN & \\
\hline CHEMBL1438058 & 737824 & 4.55 & 5.30399 & 9999999999 & TRN \\
\hline CHEMBL1442425 & 737824 & 4.6 & 4.7218 & TRN & \\
\hline CHEMBL1371726 & 737824 & 5.3 & 4.8787 & TRN & \\
\hline CHEMBL1305545 & 737824 & 4.9 & 4.9414 & TRN & \\
\hline CHEMBL1542296 & 737824 & 4.6 & 5.3031 & TST & \\
\hline CHEMBL1609270 & 737824 & 5.25 & 5.5499 & TRN & \\
\hline CHEMBL1591971 & 737824 & 5.7 & 5.4936 & TRN & \\
\hline CHEMBL1490894 & 737824 & 5.05 & 5.3868 & TRN & \\
\hline CHEMBL1723995 & 737824 & 4.8 & 5.3182 & TRN & \\
\hline CHEMBL1318937 & 737824 & 5.2 & 5.2549 & TRN & \\
\hline CHEMBL1506130 & 737824 & 4.95 & 5.4897 & TRN & \\
\hline CHEMBL1372798 & 737824 & 5.0 & 4.8478 & TST & \\
\hline CHEMBL1540172 & 737824 & 5.7 & 5.4806 & TST & \\
\hline CHEMBL3195730 & 737824 & 5.8 & 5.2428 & TRN & \\
\hline CHEMBL1315725 & 737824 & 6.1 & 5.6403 & TST & \\
\hline CHEMBL1501536 & 737824 & 5.05 & 5.2814 & TRN & \\
\hline CHEMBL1582268 & 737824 & 4.5 & 5.48600 & 0000000001 & TRN \\
\hline CHEMBL153036 & 737824 & 6.0 & 5.9573 & TRN & \\
\hline CHEMBL1419019 & 737824 & 5.05 & 5.3339 & TRN & \\
\hline CHEMBL1352931 & 737824 & 5.15 & 4.6968 & TRN & \\
\hline CHEMBL1435028 & 737824 & 4.9 & 4.8101 & TRN & \\
\hline CHEMBL1466017 & 737824 & 6.2 & 5.6379 & TRN & \\
\hline CHEMBL1329927 & 737824 & 4.8 & 4.7427 & TRN & \\
\hline
\end{tabular}




\begin{tabular}{|c|c|c|c|c|c|}
\hline \\
\hline CHEMBL1520177 & 737824 & 4.9 & 4.4744 & TRN & \\
\hline CHEMBL1383401 & 737824 & 4.75 & 4.7683 & TRN & \\
\hline CHEMBL1593827 & 737824 & 5.1 & 5.1334 & TRN & \\
\hline CHEMBL 1479074 & 737824 & 4.45 & 5.0343 & TRN & \\
\hline CHEMBL539947 & 737824 & 5.0 & 4.9542 & TRN & \\
\hline CHEMBL1516953 & 737824 & 4.9 & 4.9887 & TRN & \\
\hline CHEMBL1413132 & 737824 & 5.7 & 5.9407 & TRN & \\
\hline CHEMBL1426500 & 737824 & 4.8 & 5.0712 & TRN & \\
\hline CHEMBL566899 & 737824 & 7.9 & 8.2777 & TRN & \\
\hline CHEMBL3196654 & 737824 & 5.45 & 5.5068 & TRN & \\
\hline CHEMBL1403902 & 737824 & 5.55 & 5.4867 & TRN & \\
\hline CHEMBL1564734 & 737824 & 5.4 & 5.4874 & TRN & \\
\hline CHEMBL1742309 & 737824 & 4.5 & 5.4983 & TRN & \\
\hline CHEMBL1313647 & 737824 & 4.85 & 4.9607 & TRN & \\
\hline CHEMBL 305881 & 737824 & 6.0 & 5.7061 & TRN & \\
\hline CHEMBL447347 & 737824 & 6.5 & 6.4333 & TRN & \\
\hline CHEMBL1359661 & 737824 & 5.0 & 5.4126 & TRN & \\
\hline CHEMBL1490024 & 737824 & 5.2 & 5.7067 & TRN & \\
\hline CHEMBL1369871 & 737824 & 4.4 & 4.2007 & TRN & \\
\hline CHEMBL 1408604 & 737824 & 5.6 & 5.4541 & TST & \\
\hline CHEMBL1741640 & 737824 & 5.3 & 5.3407 & TRN & \\
\hline CHEMBL1447970 & 737824 & 4.5 & 5.3297 & TRN & \\
\hline CHEMBL1301027 & 737824 & 4.8 & 5.4032 & TRN & \\
\hline CHEMBL1973886 & 737824 & 5.45 & 5.6846 & TRN & \\
\hline CHEMBL1492541 & 737824 & 5.45 & 5.0881 & TST & \\
\hline CHEMBL1524768 & 737824 & 4.4 & 4.9896 & TRN & \\
\hline CHEMBL1334179 & 737824 & 5.45 & 5.3818 & TRN & \\
\hline CHEMBL1256693 & 737824 & 5.1 & 4.5741 & TRN & \\
\hline CHEMBL1414251 & 737824 & 4.7 & 4.7382 & TRN & \\
\hline CHEMBL1553694 & 737824 & 6.3 & 6.0545 & TRN & \\
\hline CHEMBL1338311 & 737824 & 4.4 & 4.2931 & TRN & \\
\hline CHEMBL1308401 & 737824 & 6.25 & 5.1599 & TST & \\
\hline CHEMBL1484422 & 737824 & 5.9 & 5.9448 & TRN & \\
\hline CHEMBL1502803 & 737824 & 5.2 & 5.29200 & 0000000001 & TRN \\
\hline CHEMBL1399905 & 737824 & 4.8 & 4.927 & TRN & \\
\hline CHEMBL1476741 & 737824 & 4.4 & 5.398 & TRN & \\
\hline CHEMBL1480190 & 737824 & 4.55 & 4.9008 & TRN & \\
\hline CHEMBL899 & 737824 & 5.8 & 5.2673 & TST & \\
\hline CHEMBL516075 & 737824 & 5.5 & 5.8219 & TRN & \\
\hline CHEMBL1471858 & 737824 & 5.2 & 5.5029 & TRN & \\
\hline CHEMBL1471206 & 737824 & 4.85 & 5.0697 & TRN & \\
\hline CHEMBL1545995 & 737824 & 6.1 & 5.5658 & TRN & \\
\hline CHEMBL1490414 & 737824 & 4.6 & 5.3474 & TRN & \\
\hline CHEMBL416657 & 737824 & 4.4 & 4.7021 & TST & \\
\hline CHEMBL1436811 & 737824 & 4.4 & 4.6229 & TRN & \\
\hline CHEMBL1567516 & 737824 & 5.9 & 5.8785 & TST & \\
\hline CHEMBL1334882 & 737824 & 5.1 & 4.9038 & TRN & \\
\hline CHEMBL1572174 & 737824 & 7.45 & 5.2421 & TRN & \\
\hline & & & & 7558 & \\
\hline
\end{tabular}




\begin{tabular}{|c|c|c|c|c|c|}
\hline \multicolumn{6}{|c|}{ plemental } \\
\hline CHEMBL39317 & 737824 & 4.8 & 4.752 & TRN & \\
\hline CHEMBL1303722 & 737824 & 4.95 & 5.3863 & TRN & \\
\hline CHEMBL1470037 & 737824 & 5.75 & 5.4227 & TST & \\
\hline CHEMBL1557015 & 737824 & 5.7 & 5.61600 & 00000000005 & TRN \\
\hline CHEMBL1591190 & 737824 & 5.0 & 4.7993 & TRN & \\
\hline CHEMBL1593765 & 737824 & 6.0 & 5.7048 & TRN & \\
\hline CHEMBL1436715 & 737824 & 5.4 & 5.2352 & TRN & \\
\hline CHEMBL1477140 & 737824 & 4.8 & 4.9803 & TRN & \\
\hline CHEMBL1507825 & 737824 & 5.55 & 5.2317 & TRN & \\
\hline CHEMBL1345410 & 737824 & 5.85 & 5.1367 & TRN & \\
\hline CHEMBL1415115 & 737824 & 5.05 & 5.3025 & TRN & \\
\hline CHEMBL1396090 & 737824 & 4.9 & 5.3276 & TRN & \\
\hline CHEMBL1563513 & 737824 & 5.35 & 5.1341 & TRN & \\
\hline CHEMBL1379083 & 737824 & 4.85 & 5.1099 & TRN & \\
\hline CHEMBL1488395 & 737824 & 4.6 & 5.5523 & TST & \\
\hline CHEMBL1530895 & 737824 & 4.6 & 4.7838 & TRN & \\
\hline CHEMBL1553926 & 737824 & 5.9 & 5.5783 & TRN & \\
\hline CHEMBL1318307 & 737824 & 5.1 & 4.5897 & TST & \\
\hline CHEMBL1742209 & 737824 & 4.6 & 5.5297 & TRN & \\
\hline CHEMBL1602382 & 737824 & 4.65 & 5.2655 & TST & \\
\hline CHEMBL 270299 & 737824 & 4.9 & 5.6531 & TRN & \\
\hline CHEMBL1567915 & 737824 & 4.85 & 4.9296 & TRN & \\
\hline CHEMBL1972348 & 737824 & 5.1 & 5.1505 & TRN & \\
\hline CHEMBL 285843 & 737824 & 7.9 & 6.8811 & TST & \\
\hline CHEMBL1509370 & 737824 & 5.8 & 5.5295 & TRN & \\
\hline CHEMBL3209977 & 737824 & 4.85 & 4.6051 & TRN & \\
\hline CHEMBL1410635 & 737824 & 4.9 & 4.8061 & TRN & \\
\hline CHEMBL1407677 & 737824 & 6.1 & 6.1609 & TRN & \\
\hline CHEMBL1372883 & 737824 & 4.7 & 4.7817 & TRN & \\
\hline CHEMBL1325335 & 737824 & 4.4 & 4.0641 & TRN & \\
\hline CHEMBL1384157 & 737824 & 4.85 & 5.1322 & TRN & \\
\hline CHEMBL1722649 & 737824 & 5.3 & 5.3397 & TRN & \\
\hline CHEMBL3213666 & 737824 & 5.7 & 5.6384 & TRN & \\
\hline CHEMBL1557089 & 737824 & 4.85 & 4.8493 & TRN & \\
\hline CHEMBL1374050 & 737824 & 4.95 & 4.9958 & TRN & \\
\hline CHEMBL1583067 & 737824 & 6.0 & 5.6776 & TRN & \\
\hline CHEMBL1589340 & 737824 & 5.6 & 5.4292 & TRN & \\
\hline CHEMBL1381200 & 737824 & 6.45 & 5.3275 & TRN & \\
\hline CHEMBL1363499 & 737824 & 4.4 & 4.7383 & TRN & \\
\hline CHEMBL1600421 & 737824 & 5.35 & 5.434 & TST & \\
\hline CHEMBL1505375 & 737824 & 5.3 & 5.4856 & TRN & \\
\hline CHEMBL1328319 & 737824 & 4.5 & 4.2953 & TRN & \\
\hline CHEMBL1531688 & 737824 & 5.5 & 5.0681 & TRN & \\
\hline CHEMBL1317056 & 737824 & 4.4 & 4.2713 & TRN & \\
\hline CHEMBL1505265 & 737824 & 6.1 & 5.4566 & TRN & \\
\hline CHEMBL180966 & 737824 & 5.2 & 5.1114 & TRN & \\
\hline CHEMBL1394353 & 737824 & 5.5 & 5.1995 & TRN & \\
\hline CHEMBL1538381 & 737824 & 4.95 & 4.7051 & TRN & \\
\hline
\end{tabular}




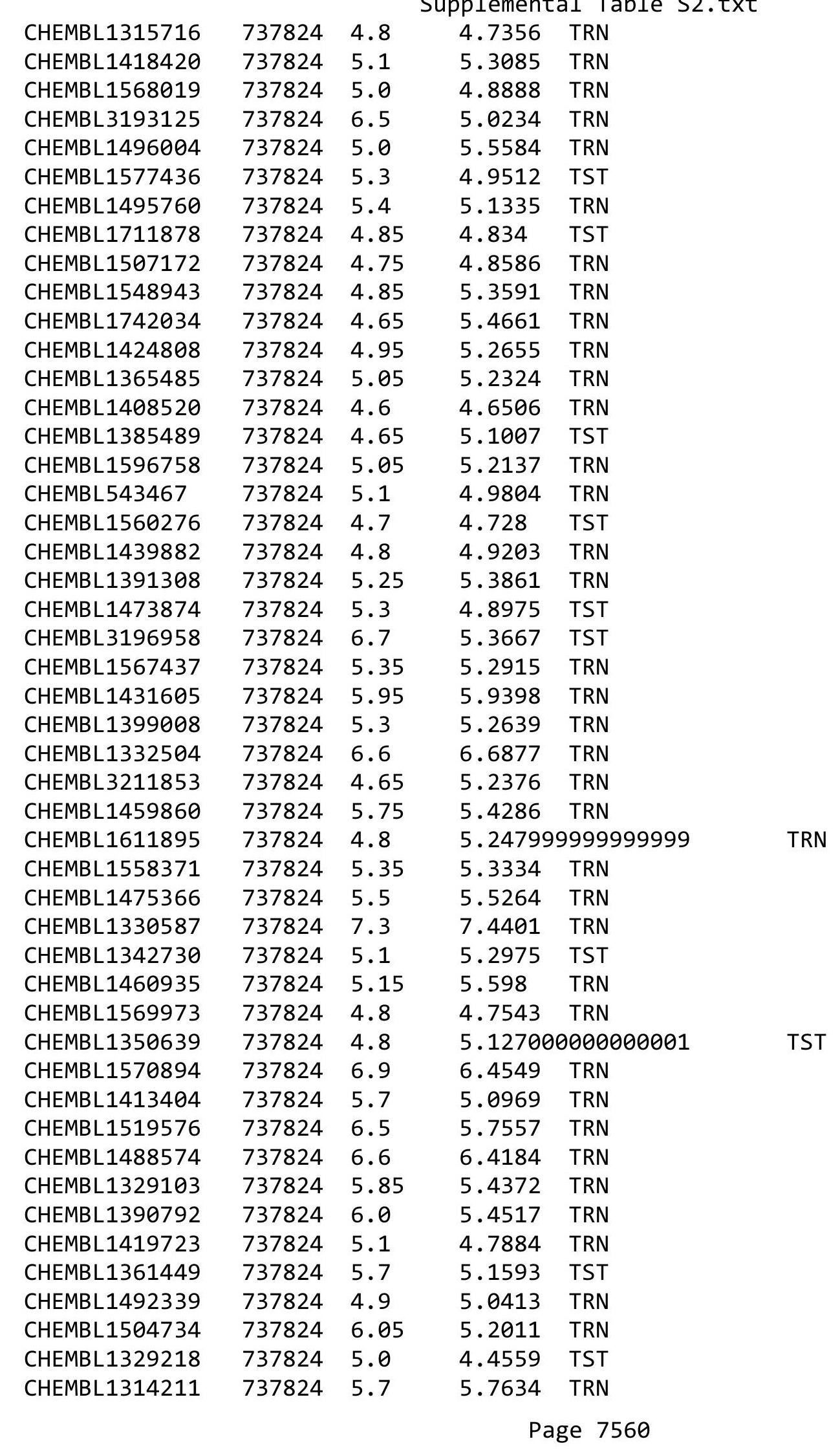




\begin{tabular}{|c|c|c|c|c|c|}
\hline \\
\hline CHEMBL1399944 & 737824 & 5.65 & 5.4439 & TRN & \\
\hline CHEMBL1480632 & 737824 & 4.5 & 4.731 & TRN & \\
\hline CHEMBL1320750 & 737824 & 6.9 & 5.2282 & TRN & \\
\hline CHEMBL1424121 & 737824 & 4.8 & 4.5653 & TRN & \\
\hline CHEMBL1584828 & 737824 & 4.4 & 5.4648 & TRN & \\
\hline CHEMBL1408323 & 737824 & 5.35 & 5.2159 & TRN & \\
\hline CHEMBL1567410 & 737824 & 6.35 & 6.5463 & TRN & \\
\hline CHEMBL467706 & 737824 & 5.2 & 5.4134 & TST & \\
\hline CHEMBL1586365 & 737824 & 4.6 & 5.3298 & TRN & \\
\hline CHEMBL1370855 & 737824 & 6.25 & 5.9598 & TRN & \\
\hline CHEMBL1361837 & 737824 & 5.05 & 5.1901 & TRN & \\
\hline CHEMBL362863 & 737824 & 8.1 & 7.3054 & TST & \\
\hline CHEMBL1332569 & 737824 & 5.0 & 5.1976 & TRN & \\
\hline CHEMBL1442011 & 737824 & 5.0 & 4.6371 & TRN & \\
\hline CHEMBL1366361 & 737824 & 5.4 & 5.4194 & TRN & \\
\hline CHEMBL1414849 & 737824 & 5.4 & 4.8286 & TRN & \\
\hline CHEMBL1593432 & 737824 & 5.3 & 5.0801 & TRN & \\
\hline CHEMBL1425511 & 737824 & 4.85 & 5.2269 & TST & \\
\hline CHEMBL1539358 & 737824 & 4.9 & 4.872 & TRN & \\
\hline CHEMBL41680 & 737824 & 4.6 & 4.0714 & TST & \\
\hline CHEMBL1495604 & 737824 & 5.45 & 5.41100 & 20000000005 & TRN \\
\hline CHEMBL 222993 & 737824 & 5.4 & 5.3476 & TRN & \\
\hline CHEMBL1484861 & 737824 & 6.3 & 6.2576 & TRN & \\
\hline CHEMBL541847 & 737824 & 5.3 & 5.119 & TRN & \\
\hline CHEMBL1567159 & 737824 & 4.95 & 5.6548 & TRN & \\
\hline CHEMBL1385309 & 737824 & 5.45 & 5.2995 & TRN & \\
\hline CHEMBL 68423 & 737824 & 4.5 & 4.9812 & TST & \\
\hline CHEMBL1520374 & 737824 & 4.4 & 5.11600 & 00000000005 & TRN \\
\hline CHEMBL425403 & 737824 & 5.4 & 4.9802 & TST & \\
\hline CHEMBL1323204 & 737824 & 5.9 & 5.8228 & TRN & \\
\hline CHEMBL1531021 & 737824 & 5.0 & 5.026 & TRN & \\
\hline CHEMBL 3199708 & 737824 & 4.95 & 5.4947 & TRN & \\
\hline CHEMBL1527221 & 737824 & 4.8 & 4.7254 & TRN & \\
\hline CHEMBL1592964 & 737824 & 5.2 & 5.1555 & TRN & \\
\hline CHEMBL464433 & 737824 & 4.6 & 5.1429 & TRN & \\
\hline CHEMBL1502064 & 737824 & 4.55 & 5.8738 & TRN & \\
\hline CHEMBL1605237 & 737824 & 5.1 & 5.1008 & TRN & \\
\hline CHEMBL1256865 & 737824 & 4.6 & 4.4912 & TRN & \\
\hline CHEMBL1560567 & 737824 & -0.0 & 4.3778 & TRN & \\
\hline CHEMBL1591272 & 737824 & 5.8 & 5.6493 & TRN & \\
\hline CHEMBL1481724 & 737824 & 5.15 & 4.4803 & TRN & \\
\hline CHEMBL1402633 & 737824 & 5.45 & 6.0516 & TRN & \\
\hline CHEMBL1522803 & 737824 & 4.65 & 4.6447 & TST & \\
\hline CHEMBL1579981 & 737824 & 5.0 & 5.374 & TRN & \\
\hline CHEMBL1543570 & 737824 & 5.35 & 5.7097 & TRN & \\
\hline CHEMBL1460531 & 737824 & 6.0 & 5.8393 & TRN & \\
\hline CHEMBL1566470 & 737824 & 5.1 & 4.776 & TRN & \\
\hline CHEMBL1442126 & 737824 & 5.35 & 5.6994 & TST & \\
\hline
\end{tabular}




\begin{tabular}{|c|c|c|c|c|}
\hline \multicolumn{5}{|c|}{ Supplemental Table S2.txt } \\
\hline CHEMBL1313459 & 737824 & 6.05 & 5.3481 & TRN \\
\hline CHEMBL1323124 & 737824 & 4.6 & 4.291 & TRN \\
\hline CHEMBL1456076 & 737824 & 5.4 & 5.4984 & TRN \\
\hline CHEMBL1413367 & 737824 & 5.45 & 6.3344 & TRN \\
\hline CHEMBL1604505 & 737824 & 4.65 & 5.1242 & TRN \\
\hline CHEMBL1559333 & 737824 & 5.3 & 5.24700 & 0000000001 \\
\hline CHEMBL 3208295 & 737824 & 4.75 & 5.0714 & TST \\
\hline CHEMBL1553322 & 737824 & 4.4 & 4.419 & TRN \\
\hline CHEMBL1309266 & 737824 & 5.8 & 5.4337 & TRN \\
\hline CHEMBL1538866 & 737824 & 5.3 & 4.6079 & TRN \\
\hline CHEMBL1408908 & 737824 & 6.15 & 5.4849 & TST \\
\hline CHEMBL 3213318 & 737824 & 5.2 & 5.0163 & TRN \\
\hline CHEMBL1548218 & 737824 & 5.9 & 5.7468 & TRN \\
\hline CHEMBL1440867 & 737824 & 5.3 & 5.311 & TRN \\
\hline CHEMBL1503340 & 737824 & 5.4 & 5.5409 & TRN \\
\hline CHEMBL1607586 & 737824 & 5.4 & 5.4141 & TRN \\
\hline CHEMBL1337584 & 737824 & 6.1 & 5.3369 & TRN \\
\hline CHEMBL590670 & 737824 & 5.55 & 5.1438 & TRN \\
\hline CHEMBL1741541 & 737824 & 5.05 & 4.8048 & TST \\
\hline CHEMBL1516249 & 737824 & 4.4 & 4.6499 & TRN \\
\hline CHEMBL1366995 & 737824 & 4.8 & 5.2898 & TRN \\
\hline CHEMBL1703162 & 737824 & 4.4 & 4.973 & TST \\
\hline CHEMBL1308218 & 737824 & 4.8 & 5.1539 & TRN \\
\hline CHEMBL1593269 & 737824 & 5.2 & 5.239 & TRN \\
\hline CHEMBL1378306 & 737824 & 4.85 & 4.9158 & TRN \\
\hline CHEMBL1531779 & 737824 & 5.45 & 5.3967 & TRN \\
\hline CHEMBL1531672 & 737824 & 5.5 & 5.8473 & TRN \\
\hline CHEMBL1414438 & 737824 & 5.25 & 5.584 & TRN \\
\hline CHEMBL1372406 & 737824 & 4.8 & 5.0948 & TRN \\
\hline CHEMBL1329094 & 737824 & 5.6 & 5.2235 & TRN \\
\hline CHEMBL1448655 & 737824 & 5.1 & 5.3416 & TRN \\
\hline CHEMBL1505026 & 737824 & 4.9 & 5.4588 & TRN \\
\hline CHEMBL1320225 & 737824 & 4.9 & 5.0552 & TRN \\
\hline CHEMBL1499116 & 737824 & 5.1 & 4.9665 & TRN \\
\hline CHEMBL1453872 & 737824 & 5.6 & 5.3931 & TST \\
\hline CHEMBL1604846 & 737824 & 5.75 & 4.938 & TRN \\
\hline CHEMBL15192 & 737824 & 5.4 & 4.9534 & TST \\
\hline CHEMBL1452722 & 737824 & 5.8 & 5.7322 & TRN \\
\hline CHEMBL1529490 & 737824 & 4.9 & 5.5199 & TRN \\
\hline CHEMBL1311630 & 737824 & 5.8 & 5.5298 & TRN \\
\hline CHEMBL1443859 & 737824 & 6.0 & 5.5588 & TRN \\
\hline CHEMBL1334327 & 737824 & 6.0 & 5.7254 & TRN \\
\hline CHEMBL1379706 & 737824 & 5.6 & 5.2593 & TRN \\
\hline CHEMBL1539796 & 737824 & 4.9 & 4.9979 & TRN \\
\hline CHEMBL1568715 & 737824 & 4.9 & 5.1571 & TRN \\
\hline CHEMBL1308897 & 737824 & 4.8 & 5.082 & TST \\
\hline CHEMBL1533923 & 737824 & 7.1 & 7.1501 & TRN \\
\hline CHEMBL1318454 & 737824 & 4.7 & 4.4093 & TRN \\
\hline
\end{tabular}




\begin{tabular}{|c|c|c|c|c|}
\hline \\
\hline CHEMBL1490386 & 737824 & 4.9 & 4.5825 & TRN \\
\hline CHEMBL1530832 & 737824 & 5.5 & 5.4233 & TRN \\
\hline CHEMBL1466684 & 737824 & 4.85 & 4.85 & TRN \\
\hline CHEMBL1546843 & 737824 & 5.65 & 5.2355 & TRN \\
\hline CHEMBL1469707 & 737824 & 4.95 & 5.0086 & TST \\
\hline CHEMBL1432016 & 737824 & 4.6 & 5.2282 & TST \\
\hline CHEMBL1412520 & 737824 & 5.7 & 5.6199 & TRN \\
\hline CHEMBL1402552 & 737824 & 7.6499 & 5.4608 & TST \\
\hline CHEMBL1328536 & 737824 & 6.0 & 6.0436 & TRN \\
\hline CHEMBL1502523 & 737824 & 5.55 & 5.2706 & TRN \\
\hline CHEMBL1354355 & 737824 & 4.5 & 4.6126 & TRN \\
\hline CHEMBL1303450 & 737824 & 6.25 & 5.2173 & TRN \\
\hline CHEMBL1555132 & 737824 & 4.7 & 4.6077 & TRN \\
\hline CHEMBL1544694 & 737824 & 5.65 & 5.0401 & TST \\
\hline CHEMBL1492282 & 737824 & 4.4 & 5.4413 & TRN \\
\hline CHEMBL1323499 & 737824 & 4.9 & 5.2743 & TST \\
\hline CHEMBL1574393 & 737824 & 4.8 & 5.176 & TRN \\
\hline CHEMBL1412429 & 737824 & 4.85 & 5.2718 & TRN \\
\hline CHEMBL1552953 & 737824 & 5.5 & 5.5033 & TRN \\
\hline CHEMBL1422116 & 737824 & 5.1 & 5.0331 & TRN \\
\hline CHEMBL1543808 & 737824 & 4.85 & 5.5203 & TRN \\
\hline CHEMBL1561910 & 737824 & 4.55 & 4.7432 & TRN \\
\hline CHEMBL1404928 & 737824 & 4.4 & 5.376 & TRN \\
\hline CHEMBL1358462 & 737824 & 5.2 & 4.6823 & TST \\
\hline CHEMBL1457785 & 737824 & 4.95 & 5.1522 & TST \\
\hline CHEMBL1598359 & 737824 & 4.55 & 5.3387 & TRN \\
\hline CHEMBL1493118 & 737824 & 4.9 & 5.2058 & TRN \\
\hline CHEMBL1512222 & 737824 & 5.0 & 4.6602 & TRN \\
\hline CHEMBL1467171 & 737824 & 5.0 & 5.3184 & TST \\
\hline CHEMBL1493566 & 737824 & 4.95 & 5.3879 & TST \\
\hline CHEMBL1552277 & 737824 & 4.8 & 4.687 & TRN \\
\hline CHEMBL1326272 & 737824 & 5.15 & 5.6512 & TRN \\
\hline CHEMBL1489204 & 737824 & 7.4 & 6.5445 & TRN \\
\hline CHEMBL1742060 & 737824 & 4.4 & 4.7431 & TRN \\
\hline CHEMBL1463543 & 737824 & 6.25 & 5.5832 & TRN \\
\hline CHEMBL1361500 & 737824 & 5.55 & 5.3341 & TRN \\
\hline CHEMBL1441394 & 737824 & 5.05 & 4.9392 & TRN \\
\hline CHEMBL1466129 & 737824 & 5.15 & 5.5886 & TRN \\
\hline CHEMBL1603539 & 737824 & 5.0 & 5.1504 & TRN \\
\hline CHEMBL1453840 & 737824 & 5.3 & 5.2818 & TST \\
\hline CHEMBL1317335 & 737824 & 5.4 & 5.3856 & TRN \\
\hline CHEMBL1351200 & 737824 & 5.1 & 5.2579 & TRN \\
\hline CHEMBL1529265 & 737824 & 5.1 & 5.0902 & TST \\
\hline CHEMBL 28140 & 737824 & 5.2 & 5.131 & TRN \\
\hline CHEMBL1345906 & 737824 & 4.85 & 4.8978 & TRN \\
\hline CHEMBL1438434 & 737824 & 5.45 & 5.5139 & TST \\
\hline CHEMBL1417002 & 737824 & 4.95 & 4.9909 & TST \\
\hline CHEMBL1591673 & 737824 & 6.0 & 5.9502 & TRN \\
\hline
\end{tabular}




\begin{tabular}{|c|c|c|c|c|c|}
\hline CHEMBL1382099 & 737824 & 4.4 & \multicolumn{2}{|c|}{5.0489999999999995} & TST \\
\hline CHEMBL1522897 & 737824 & 7.4 & 6.2539 & TRN & \\
\hline CHEMBL9352 & 737824 & 5.4 & 5.6366 & TST & \\
\hline CHEMBL1381730 & 737824 & 6.1 & 5.7215 & TRN & \\
\hline CHEMBL1391936 & 737824 & 5.8 & 5.7932 & TRN & \\
\hline CHEMBL1350587 & 737824 & 4.75 & 5.4138 & TRN & \\
\hline CHEMBL1587094 & 737824 & 5.8 & 4.8148 & TRN & \\
\hline CHEMBL1356106 & 737824 & 5.4 & 5.1465 & TST & \\
\hline CHEMBL1256876 & 737824 & 5.1 & 5.0843 & TST & \\
\hline CHEMBL1320019 & 737824 & 6.9 & 6.1779 & TRN & \\
\hline CHEMBL1523400 & 737824 & 4.55 & 5.3275 & TRN & \\
\hline CHEMBL1471635 & 737824 & 4.85 & 5.1436 & TRN & \\
\hline CHEMBL 3210042 & 737824 & 4.6 & 5.0399 & TRN & \\
\hline CHEMBL3196691 & 737824 & 5.35 & 5.1093 & TRN & \\
\hline CHEMBL1478761 & 737824 & 4.9 & 5.1742 & TRN & \\
\hline CHEMBL1375753 & 737824 & 5.4 & 4.8809 & TRN & \\
\hline CHEMBL1438771 & 737824 & 4.95 & 5.2388 & TRN & \\
\hline CHEMBL1481510 & 737824 & 4.4 & 4.5317 & TRN & \\
\hline CHEMBL1482035 & 737824 & 5.35 & 5.3625 & TRN & \\
\hline CHEMBL1307004 & 737824 & 5.0 & 5.4155 & TRN & \\
\hline CHEMBL1300301 & 737824 & 4.9 & 5.1125 & TST & \\
\hline CHEMBL1587957 & 737824 & 4.4 & 5.0848 & TRN & \\
\hline CHEMBL1580880 & 737824 & 5.45 & 5.0789 & TRN & \\
\hline CHEMBL1735112 & 737824 & 4.65 & 5.2264 & TST & \\
\hline CHEMBL1372099 & 737824 & 5.4 & 5.0922 & TRN & \\
\hline CHEMBL1352525 & 737824 & 4.75 & 4.9484 & TRN & \\
\hline CHEMBL1572734 & 737824 & 5.85 & 5.5329 & TRN & \\
\hline CHEMBL1499501 & 737824 & 4.8 & 5.8044 & TRN & \\
\hline CHEMBL1457798 & 737824 & 5.35 & 5.0324 & TRN & \\
\hline CHEMBL1424441 & 737824 & 4.9 & \multicolumn{2}{|c|}{5.6370000000000005} & TRN \\
\hline CHEMBL1401933 & 737824 & 5.65 & 5.5028 & TRN & \\
\hline CHEMBL1589942 & 737824 & 5.6 & 4.9663 & TST & \\
\hline CHEMBL1493869 & 737824 & 5.5 & 5.6562 & TRN & \\
\hline CHEMBL1409568 & 737824 & 5.55 & 4.8125 & TRN & \\
\hline CHEMBL1997370 & 737824 & 4.85 & 4.9546 & TRN & \\
\hline CHEMBL1307309 & 737824 & 5.05 & 5.129 & TRN & \\
\hline CHEMBL1372102 & 737824 & 5.4 & 5.5942 & TST & \\
\hline CHEMBL1389304 & 737824 & 4.8 & 4.8722 & TRN & \\
\hline CHEMBL1408484 & 737824 & 5.15 & 5.5484 & TRN & \\
\hline CHEMBL1457224 & 737824 & 5.0 & 5.1726 & TRN & \\
\hline CHEMBL3196157 & 737824 & 4.55 & 5.0141 & TRN & \\
\hline CHEMBL 26915 & 737824 & 5.1 & 5.3427 & TST & \\
\hline CHEMBL1418178 & 737824 & 5.6 & 5.4425 & TRN & \\
\hline CHEMBL1600921 & 737824 & 4.75 & 5.5638 & TRN & \\
\hline CHEMBL1606199 & 737824 & 5.4 & 5.2897 & TRN & \\
\hline CHEMBL1414185 & 737824 & 5.8 & 5.9952 & TST & \\
\hline CHEMBL1490078 & 737824 & 4.85 & 5.3038 & TRN & \\
\hline CHEMBL1430823 & 737824 & 5.7 & 5.4379 & TRN & \\
\hline
\end{tabular}




\begin{tabular}{|c|c|c|c|c|c|}
\hline \multirow[b]{2}{*}{ CHEMBL1491709 } & \multirow[b]{2}{*}{737824} & \\
\hline & & 5.25 & 5.4717 & TRN & \\
\hline CHEMBL1305982 & 737824 & 5.65 & 5.5849 & TRN & \\
\hline CHEMBL1588453 & 737824 & 4.9 & 5.1848 & TRN & \\
\hline CHEMBL1507015 & 737824 & 4.7 & 5.3031 & TRN & \\
\hline CHEMBL1484990 & 737824 & 4.6 & 5.4362 & TST & \\
\hline CHEMBL1460769 & 737824 & 5.0 & 4.9105 & TST & \\
\hline CHEMBL1531070 & 737824 & 6.4 & 6.04 & TRN & \\
\hline CHEMBL1235001 & 737824 & 4.8 & 5.2391 & TRN & \\
\hline CHEMBL1308052 & 737824 & 4.55 & 5.1643 & TRN & \\
\hline CHEMBL1371869 & 737824 & 4.45 & 5.2648 & TST & \\
\hline CHEMBL1707407 & 737824 & 5.05 & 5.5124 & TRN & \\
\hline CHEMBL1446270 & 737824 & 5.7 & 5.26399 & 9999999999 & TRN \\
\hline CHEMBL1711825 & 737824 & 4.55 & 5.1799 & TRN & \\
\hline CHEMBL1446815 & 737824 & 4.6 & 4.5497 & TRN & \\
\hline CHEMBL3214169 & 737824 & 6.0 & 5.5635 & TRN & \\
\hline CHEMBL1608337 & 737824 & 5.7 & 5.9783 & TRN & \\
\hline CHEMBL3213228 & 737824 & 4.95 & 4.6353 & TST & \\
\hline CHEMBL1742228 & 737824 & 6.0 & 5.5202 & TRN & \\
\hline CHEMBL1742059 & 737824 & 4.4 & 5.2456 & TRN & \\
\hline CHEMBL3212297 & 737824 & 4.65 & 5.1758 & TRN & \\
\hline CHEMBL1741436 & 737824 & 4.9 & 4.6212 & TRN & \\
\hline CHEMBL1526524 & 737824 & 5.75 & 5.7245 & TRN & \\
\hline CHEMBL1525487 & 737824 & 5.1 & 5.394 & TRN & \\
\hline CHEMBL1427330 & 737824 & 4.4 & 5.2139 & TST & \\
\hline CHEMBL1404954 & 737824 & 5.0 & 4.3398 & TRN & \\
\hline CHEMBL1559556 & 737824 & 4.45 & 4.9898 & TRN & \\
\hline CHEMBL1403831 & 737824 & 5.5 & 5.441 & TRN & \\
\hline CHEMBL1432275 & 737824 & 4.8 & 4.9275 & TRN & \\
\hline CHEMBL1401324 & 737824 & 5.3 & 5.3208 & TST & \\
\hline CHEMBL1494832 & 737824 & 4.4 & 4.1028 & TRN & \\
\hline CHEMBL1510205 & 737824 & 5.1 & 5.0187 & TRN & \\
\hline CHEMBL1505836 & 737824 & 5.95 & 5.2665 & TRN & \\
\hline CHEMBL1322078 & 737824 & 5.55 & 5.2745 & TRN & \\
\hline CHEMBL1591860 & 737824 & 6.3 & 5.9469 & TRN & \\
\hline CHEMBL1544733 & 737824 & 5.65 & 5.2518 & TRN & \\
\hline CHEMBL1457723 & 737824 & 4.9 & 5.131 & TRN & \\
\hline CHEMBL1538297 & 737824 & 5.35 & 5.4284 & TRN & \\
\hline CHEMBL1387472 & 737824 & 5.4 & 5.1166 & TST & \\
\hline CHEMBL1564261 & 737824 & 5.5 & 5.1122 & TRN & \\
\hline CHEMBL1396809 & 737824 & 4.6 & 4.5341 & TRN & \\
\hline CHEMBL1742156 & 737824 & 4.9 & 4.9989 & TRN & \\
\hline CHEMBL1404598 & 737824 & 7.3 & 7.7736 & TRN & \\
\hline CHEMBL1400535 & 737824 & 5.7 & 5.8207 & TRN & \\
\hline CHEMBL1556436 & 737824 & 4.95 & 5.3071 & TRN & \\
\hline CHEMBL1516232 & 737824 & 6.4 & 6.6559 & TRN & \\
\hline CHEMBL1393918 & 737824 & 5.05 & 4.7225 & TRN & \\
\hline CHEMBL1476958 & 737824 & 5.4 & 4.9654 & TRN & \\
\hline CHEMBL1446112 & 737824 & 5.7 & 5.95200 & 0000000001 & TRN \\
\hline & & & & 7565 & \\
\hline
\end{tabular}




\begin{tabular}{|c|c|c|c|c|c|}
\hline \\
\hline CHEMBL1416402 & 737824 & 4.9 & 5.3868 & TST & \\
\hline CHEMBL1433259 & 737824 & 5.45 & 4.8252 & TRN & \\
\hline CHEMBL1726451 & 737824 & 5.05 & 4.8091 & TRN & \\
\hline CHEMBL1516701 & 737824 & 4.6 & 4.3223 & TRN & \\
\hline CHEMBL1347492 & 737824 & 4.95 & 5.1267 & TRN & \\
\hline CHEMBL1446743 & 737824 & 5.3 & 4.9832 & TST & \\
\hline CHEMBL1240673 & 737824 & 5.4 & 5.63 & TRN & \\
\hline CHEMBL1551274 & 737824 & 6.0 & 5.5816 & TRN & \\
\hline CHEMBL1552095 & 737824 & 6.0 & 5.5869 & TST & \\
\hline CHEMBL1496623 & 737824 & 6.45 & 5.8552 & TRN & \\
\hline CHEMBL1308019 & 737824 & 5.7 & 5.4164 & TRN & \\
\hline CHEMBL1524985 & 737824 & 5.6 & 5.4447 & TRN & \\
\hline CHEMBL1446523 & 737824 & 5.4 & 5.2939 & TRN & \\
\hline CHEMBL521971 & 737824 & 4.6 & 4.5643 & TRN & \\
\hline CHEMBL1500686 & 737824 & 4.7 & 5.1916 & TRN & \\
\hline CHEMBL1592388 & 737824 & 4.8 & 4.6515 & TRN & \\
\hline CHEMBL 21260 & 737824 & 6.0 & 6.2496 & TST & \\
\hline CHEMBL1727631 & 737824 & 5.15 & 4.8152 & TRN & \\
\hline CHEMBL1977734 & 737824 & 4.85 & 5.3512 & TRN & \\
\hline CHEMBL1601536 & 737824 & 4.85 & 4.829 & TRN & \\
\hline CHEMBL1527173 & 737824 & 5.3 & 5.0854 & TRN & \\
\hline CHEMBL1607419 & 737824 & 4.75 & 5.0788 & TRN & \\
\hline CHEMBL1709586 & 737824 & 5.15 & 5.0111 & TRN & \\
\hline CHEMBL1312952 & 737824 & 4.85 & 5.1986 & TRN & \\
\hline CHEMBL1466162 & 737824 & 4.4 & 4.9942 & TRN & \\
\hline CHEMBL3194935 & 737824 & 6.15 & 5.2574 & TRN & \\
\hline CHEMBL1366777 & 737824 & 4.45 & 4.7151 & TRN & \\
\hline CHEMBL1320042 & 737824 & 5.5 & 5.0644 & TRN & \\
\hline CHEMBL1611423 & 737824 & 5.65 & 5.4717 & TRN & \\
\hline CHEMBL1355139 & 737824 & 6.3 & 6.4895 & TRN & \\
\hline CHEMBL1354145 & 737824 & 4.8 & $4.3660 e$ & 20000000005 & TRN \\
\hline CHEMBL1352421 & 737824 & 7.25 & 5.1255 & TRN & \\
\hline CHEMBL1578596 & 737824 & 5.2 & 4.8026 & TRN & \\
\hline CHEMBL1420206 & 737824 & 6.25 & 5.8406 & TRN & \\
\hline CHEMBL3210631 & 737824 & 6.3 & 5.4325 & TRN & \\
\hline CHEMBL1592227 & 737824 & 4.7 & 4.9199 & TRN & \\
\hline CHEMBL1993145 & 737824 & 5.15 & 4.8122 & TRN & \\
\hline CHEMBL1350935 & 737824 & 5.0 & 5.2185 & TRN & \\
\hline CHEMBL 304008 & 737824 & 6.9 & 5.9711 & TST & \\
\hline CHEMBL1393076 & 737824 & 5.6 & 5.38899 & 9999999999 & TST \\
\hline CHEMBL1079460 & 737824 & 5.2 & 4.833 & TST & \\
\hline CHEMBL1420090 & 737824 & 4.65 & 4.9134 & TRN & \\
\hline CHEMBL1441359 & 737824 & 4.75 & 5.2023 & TRN & \\
\hline CHEMBL1447964 & 737824 & 5.45 & 5.5464 & TRN & \\
\hline CHEMBL1457902 & 737824 & 5.65 & 5.5781 & TRN & \\
\hline CHEMBL1438323 & 737824 & 4.9 & 5.0382 & TRN & \\
\hline CHEMBL1514431 & 737824 & 4.5 & 4.4016 & TRN & \\
\hline CHEMBL1742044 & 737824 & 4.7 & 4.7039 & TRN & \\
\hline
\end{tabular}




\begin{tabular}{|c|c|c|c|c|c|}
\hline \\
\hline CHEMBL1579133 & 737824 & 4.9 & 5.1146 & TRN & \\
\hline CHEMBL1415521 & 737824 & 5.4 & 5.4964 & TRN & \\
\hline CHEMBL1591460 & 737824 & 6.8 & 6.6332 & TRN & \\
\hline CHEMBL1552985 & 737824 & 6.5 & 6.07 & TRN & \\
\hline CHEMBL1573063 & 737824 & 5.1 & 5.0154 & TRN & \\
\hline CHEMBL1533962 & 737824 & 5.0 & 5.3504 & TRN & \\
\hline CHEMBL1562643 & 737824 & 6.0 & 5.2896 & TRN & \\
\hline CHEMBL598270 & 737824 & 4.9 & 5.0416 & TST & \\
\hline CHEMBL1353281 & 737824 & 4.8 & 5.2237 & TRN & \\
\hline CHEMBL1395850 & 737824 & 4.7 & 4.8564 & TRN & \\
\hline CHEMBL1568009 & 737824 & 4.85 & 5.7335 & TRN & \\
\hline CHEMBL1741596 & 737824 & 4.75 & 5.4935 & TRN & \\
\hline CHEMBL1388530 & 737824 & 5.6 & 5.1709 & TRN & \\
\hline CHEMBL1563992 & 737824 & 6.2 & 5.1061 & TST & \\
\hline CHEMBL269521 & 737824 & 5.2 & 4.811 & TST & \\
\hline CHEMBL1477383 & 737824 & 5.3 & 5.11600 & 00000000005 & TRN \\
\hline CHEMBL1372132 & 737824 & 4.75 & 5.2049 & TRN & \\
\hline CHEMBL1431953 & 737824 & 5.3 & 5.5105 & TST & \\
\hline CHEMBL1375424 & 737824 & 4.95 & 5.6347 & TRN & \\
\hline CHEMBL1486808 & 737824 & 4.7 & 4.6575 & TRN & \\
\hline CHEMBL1511687 & 737824 & 4.85 & 5.0176 & TRN & \\
\hline CHEMBL1320841 & 737824 & 4.9 & 5.1725 & TRN & \\
\hline CHEMBL1380994 & 737824 & 6.5 & 6.0172 & TRN & \\
\hline CHEMBL1741439 & 737824 & 5.0 & 5.2122 & TRN & \\
\hline CHEMBL1598297 & 737824 & 6.45 & 5.5168 & TRN & \\
\hline CHEMBL1420257 & 737824 & 5.8 & 5.6971 & TRN & \\
\hline CHEMBL1603906 & 737824 & 6.2 & 5.9259 & TRN & \\
\hline CHEMBL1514071 & 737824 & 4.7 & 4.7501 & TRN & \\
\hline CHEMBL1426718 & 737824 & 5.35 & 4.6961 & TRN & \\
\hline CHEMBL1423313 & 737824 & 6.8 & 5.0083 & TRN & \\
\hline CHEMBL1561515 & 737824 & 4.85 & 4.9702 & TST & \\
\hline CHEMBL1348987 & 737824 & 5.65 & 5.3791 & TST & \\
\hline CHEMBL1323391 & 737824 & 4.9 & 4.8579 & TRN & \\
\hline CHEMBL1482119 & 737824 & 5.1 & 5.2207 & TRN & \\
\hline CHEMBL1599391 & 737824 & 5.3 & 5.6477 & TRN & \\
\hline CHEMBL1308726 & 737824 & 4.65 & 5.29899 & 99999999995 & TRN \\
\hline CHEMBL1718206 & 737824 & 5.1 & 5.2005 & TRN & \\
\hline CHEMBL1597015 & 737824 & 4.9 & 4.9183 & TRN & \\
\hline CHEMBL1317932 & 737824 & 6.9 & 6.8268 & TRN & \\
\hline CHEMBL1459485 & 737824 & 5.05 & 5.3004 & TRN & \\
\hline CHEMBL1352616 & 737824 & 5.75 & 5.2743 & TRN & \\
\hline CHEMBL3197594 & 737824 & 4.55 & 5.0428 & TRN & \\
\hline CHEMBL1723188 & 737824 & 4.4 & 4.6896 & TRN & \\
\hline CHEMBL1341270 & 737824 & 5.55 & 4.9397 & TST & \\
\hline CHEMBL1365504 & 737824 & 5.2 & 5.2879 & TRN & \\
\hline CHEMBL1471064 & 737824 & 5.7 & 5.6741 & TRN & \\
\hline CHEMBL1741449 & 737824 & 4.4 & 4.8582 & TST & \\
\hline CHEMBL1486217 & 737824 & 4.55 & 5.3077 & TRN & \\
\hline
\end{tabular}




\begin{tabular}{|c|c|c|c|c|}
\hline & & & pplement & $\mathrm{a} \perp \mathrm{Ta}$ \\
\hline CHEMBL1604879 & 737824 & 5.2 & 4.9712 & TRN \\
\hline CHEMBL1520442 & 737824 & 8.2 & 7.2218 & TRN \\
\hline CHEMBL3189243 & 737824 & 5.05 & 4.6419 & TRN \\
\hline CHEMBL1339544 & 737824 & 6.0 & 5.3541 & TRN \\
\hline CHEMBL1514016 & 737824 & 4.7 & 4.615 & TRN \\
\hline CHEMBL1437650 & 737824 & 4.4 & 4.5179 & TRN \\
\hline CHEMBL1547257 & 737824 & 5.15 & 5.5467 & TRN \\
\hline CHEMBL1410547 & 737824 & 4.4 & 4.7156 & TRN \\
\hline CHEMBL1324982 & 737824 & 4.95 & 5.3159 & TRN \\
\hline CHEMBL1299891 & 737824 & 4.95 & 4.9891 & TRN \\
\hline CHEMBL1352766 & 737824 & 4.7 & 5.1085 & TRN \\
\hline CHEMBL1494717 & 737824 & 5.1 & 5.4566 & TRN \\
\hline CHEMBL1348993 & 737824 & 5.3 & 5.3811 & TRN \\
\hline CHEMBL1435210 & 737824 & 7.2 & 5.8359 & TRN \\
\hline CHEMBL1545142 & 737824 & 4.6 & 4.4275 & TST \\
\hline CHEMBL1468225 & 737824 & 5.25 & 5.5118 & TRN \\
\hline CHEMBL1349227 & 737824 & 5.6 & 5.3797 & TRN \\
\hline CHEMBL1973707 & 737824 & 5.35 & 5.1211 & TRN \\
\hline CHEMBL1447719 & 737824 & 6.45 & 5.4324 & TRN \\
\hline CHEMBL1330449 & 737824 & 5.35 & 5.6841 & TRN \\
\hline CHEMBL1353342 & 737824 & 6.0 & 5.1711 & TRN \\
\hline CHEMBL1534263 & 737824 & 5.45 & 5.3028 & TRN \\
\hline CHEMBL1340705 & 737824 & 5.35 & 5.0741 & TRN \\
\hline CHEMBL1350120 & 737824 & 4.8 & 5.3632 & TRN \\
\hline CHEMBL1429896 & 737824 & 4.6 & 5.0258 & TRN \\
\hline CHEMBL1418916 & 737824 & 5.6 & 5.7243 & TRN \\
\hline CHEMBL1399481 & 737824 & 4.9 & 4.5569 & TRN \\
\hline CHEMBL1428519 & 737824 & 5.45 & 5.0499 & TRN \\
\hline CHEMBL1529694 & 737824 & 5.05 & 4.9583 & TRN \\
\hline CHEMBL1430016 & 737824 & 5.45 & 5.7474 & TRN \\
\hline CHEMBL1384720 & 737824 & 5.35 & 5.1301 & TRN \\
\hline CHEMBL1413858 & 737824 & 5.1 & 4.8393 & TRN \\
\hline CHEMBL1431797 & 737824 & 4.75 & 4.8615 & TRN \\
\hline CHEMBL1537215 & 737824 & 5.45 & 5.1603 & TRN \\
\hline CHEMBL1500692 & 737824 & 5.6 & 5.5583 & TRN \\
\hline CHEMBL1454178 & 737824 & 4.75 & 5.2853 & TRN \\
\hline CHEMBL1523188 & 737824 & 5.1 & 4.8689 & TRN \\
\hline CHEMBL1500134 & 737824 & 4.95 & 5.051 & TRN \\
\hline CHEMBL1596801 & 737824 & 5.2 & 5.126 & TRN \\
\hline CHEMBL1305037 & 737824 & 5.0 & 5.3445 & TRN \\
\hline CHEMBL1461253 & 737824 & 4.95 & 4.9737 & TRN \\
\hline CHEMBL1424307 & 737824 & 5.0 & 5.1993 & TRN \\
\hline CHEMBL490742 & 737824 & 5.1 & 5.0641 & TRN \\
\hline CHEMBL1421016 & 737824 & 4.9 & 4.6347 & TST \\
\hline CHEMBL 259073 & 737824 & 4.4 & 4.0435 & TRN \\
\hline CHEMBL1532386 & 737824 & 5.3 & 5.7599 & TRN \\
\hline CHEMBL1545653 & 737824 & 5.45 & 5.9911 & TRN \\
\hline CHEMBL1494817 & 737824 & 4.85 & 5.0918 & TRN \\
\hline
\end{tabular}




\begin{tabular}{|c|c|c|c|c|c|}
\hline \\
\hline CHEMBL1729853 & 737824 & 4.9 & 4.9626 & TRN & \\
\hline CHEMBL331372 & 737824 & 4.9 & 4.1527 & TST & \\
\hline CHEMBL1559127 & 737824 & 5.0 & 5.0683 & TRN & \\
\hline CHEMBL1610687 & 737824 & 5.0 & 5.3517 & TRN & \\
\hline CHEMBL1715711 & 737824 & 4.75 & 4.8474 & TRN & \\
\hline CHEMBL1396261 & 737824 & 7.1 & 7.6036 & TRN & \\
\hline CHEMBL1409148 & 737824 & 6.0 & 5.9926 & TRN & \\
\hline CHEMBL1317076 & 737824 & 4.8 & 4.5055 & TRN & \\
\hline CHEMBL1417999 & 737824 & 5.35 & 5.3638 & TRN & \\
\hline CHEMBL1521067 & 737824 & 5.75 & 5.5532 & TRN & \\
\hline CHEMBL1611048 & 737824 & 7.2 & 6.0991 & TRN & \\
\hline CHEMBL1448803 & 737824 & 4.6 & 4.7632 & TRN & \\
\hline CHEMBL1477725 & 737824 & 6.0 & 5.6907 & TRN & \\
\hline CHEMBL1371022 & 737824 & 4.85 & 4.8149 & TRN & \\
\hline CHEMBL1334821 & 737824 & 5.0 & 5.1917 & TRN & \\
\hline CHEMBL1443163 & 737824 & 7.0 & 6.9506 & TRN & \\
\hline CHEMBL1478772 & 737824 & 4.7 & 4.5485 & TRN & \\
\hline CHEMBL1570792 & 737824 & 5.0 & 4.7923 & TRN & \\
\hline CHEMBL1335680 & 737824 & 6.05 & 5.1915 & TRN & \\
\hline CHEMBL1741881 & 737824 & 5.1 & 5.2847 & TRN & \\
\hline CHEMBL1577515 & 737824 & 5.75 & 5.6466 & TRN & \\
\hline CHEMBL1300958 & 737824 & 5.25 & 5.0653 & TRN & \\
\hline CHEMBL1422234 & 737824 & 4.8 & 4.9583 & TRN & \\
\hline CHEMBL1479036 & 737824 & 5.9 & 5.5843 & TRN & \\
\hline CHEMBL1527840 & 737824 & 5.1 & 5.4336 & TRN & \\
\hline CHEMBL1544662 & 737824 & 5.0 & 5.3022 & TRN & \\
\hline CHEMBL1564907 & 737824 & 5.3 & 5.2704 & TRN & \\
\hline CHEMBL1532016 & 737824 & 5.4 & 5.2397 & TRN & \\
\hline CHEMBL1604887 & 737824 & 6.75 & 5.3322 & TRN & \\
\hline CHEMBL1605699 & 737824 & 4.95 & 5.0816 & TRN & \\
\hline CHEMBL1417412 & 737824 & 5.15 & 4.9762 & TST & \\
\hline CHEMBL1324882 & 737824 & 5.6 & 5.6568 & TRN & \\
\hline CHEMBL1470386 & 737824 & 4.95 & 5.5208 & TST & \\
\hline CHEMBL1397221 & 737824 & 5.3 & 5.25899 & 99999999995 & TRN \\
\hline CHEMBL1356630 & 737824 & 5.5 & 5.3044 & TRN & \\
\hline CHEMBL1364168 & 737824 & 4.6 & 4.4859 & TRN & \\
\hline CHEMBL1599821 & 737824 & 4.85 & 5.1263 & TRN & \\
\hline CHEMBL1329384 & 737824 & 4.85 & 4.7989 & TRN & \\
\hline CHEMBL1698554 & 737824 & 4.55 & 4.6624 & TRN & \\
\hline CHEMBL1412639 & 737824 & 5.5 & 4.873 & TRN & \\
\hline CHEMBL1399621 & 737824 & 4.85 & 5.1499 & TRN & \\
\hline CHEMBL1363185 & 737824 & 5.0 & 5.5501 & TST & \\
\hline CHEMBL1445893 & 737824 & 4.8 & 4.5347 & TRN & \\
\hline CHEMBL1323529 & 737824 & 4.6 & 4.0265 & TRN & \\
\hline CHEMBL1475574 & 737824 & 7.5 & 6.6461 & TRN & \\
\hline CHEMBL1515559 & 737824 & 4.6 & 5.16 & TRN & \\
\hline CHEMBL1470174 & 737824 & 6.5 & 5.3245 & TRN & \\
\hline CHEMBL1495801 & 737824 & 5.05 & 5.1584 & TRN & \\
\hline
\end{tabular}




\begin{tabular}{|c|c|c|c|c|c|}
\hline \\
\hline CHEMBL1500174 & 737824 & 6.2 & 5.14 & TRN & \\
\hline CHEMBL1321695 & 737824 & 5.55 & 4.9538 & TRN & \\
\hline CHEMBL1589925 & 737824 & 5.1 & 5.5377 & TRN & \\
\hline CHEMBL1741919 & 737824 & 4.65 & 5.0012 & TRN & \\
\hline CHEMBL1585305 & 737824 & 4.95 & 5.1783 & TRN & \\
\hline CHEMBL1435235 & 737824 & 4.8 & 4.6726 & TRN & \\
\hline CHEMBL1316219 & 737824 & 5.4 & 5.1947 & TST & \\
\hline CHEMBL1479296 & 737824 & 5.1 & 5.5026 & TRN & \\
\hline CHEMBL1416438 & 737824 & 5.5 & 6.1692 & TRN & \\
\hline CHEMBL1364955 & 737824 & 5.35 & 5.3034 & TRN & \\
\hline CHEMBL1472926 & 737824 & 5.9 & 5.66200 & 0000000001 & TRN \\
\hline CHEMBL1560445 & 737824 & 6.8 & 6.1789 & TRN & \\
\hline CHEMBL1397334 & 737824 & 8.4 & 7.2055 & TST & \\
\hline CHEMBL1436488 & 737824 & -0.0 & 4.3029 & TRN & \\
\hline CHEMBL1583617 & 737824 & 4.8 & 5.2297 & TST & \\
\hline CHEMBL1325580 & 737824 & 4.6 & 4.8653 & TRN & \\
\hline CHEMBL1565564 & 737824 & 5.6 & 5.3885 & TRN & \\
\hline CHEMBL1338333 & 737824 & 4.55 & 4.9837 & TRN & \\
\hline CHEMBL491978 & 737824 & 4.8 & 4.6489 & TRN & \\
\hline CHEMBL1539817 & 737824 & 6.75 & 5.3298 & TRN & \\
\hline CHEMBL3208086 & 737824 & 5.0 & 4.8146 & TRN & \\
\hline CHEMBL1591731 & 737824 & 6.6 & 5.7076 & TST & \\
\hline CHEMBL1566751 & 737824 & 4.6 & 4.9741 & TST & \\
\hline CHEMBL1408386 & 737824 & 5.7 & 5.871 & TRN & \\
\hline CHEMBL1558135 & 737824 & 4.7 & 4.8325 & TRN & \\
\hline CHEMBL1489162 & 737824 & 4.7 & 4.6819 & TRN & \\
\hline CHEMBL1303935 & 737824 & 5.95 & 5.4818 & TRN & \\
\hline CHEMBL1593547 & 737824 & 5.0 & 4.9647 & TRN & \\
\hline CHEMBL1470330 & 737824 & 4.95 & 5.2724 & TRN & \\
\hline CHEMBL1420830 & 737824 & 5.65 & 5.5489 & TST & \\
\hline CHEMBL1688558 & 737824 & 5.4 & 5.5398 & TRN & \\
\hline CHEMBL1579947 & 737824 & 4.9 & 5.0157 & TRN & \\
\hline CHEMBL1308249 & 737824 & 4.9 & 4.8404 & TST & \\
\hline CHEMBL1515246 & 737824 & 5.4 & 5.3397 & TRN & \\
\hline CHEMBL1344533 & 737824 & 5.55 & 5.76 & TRN & \\
\hline CHEMBL1310444 & 737824 & 5.4 & 5.0646 & TRN & \\
\hline CHEMBL1724774 & 737824 & 4.9 & 4.8853 & TRN & \\
\hline CHEMBL1319049 & 737824 & 6.0 & 5.8935 & TRN & \\
\hline CHEMBL1558303 & 737824 & 7.0 & 6.3718 & TRN & \\
\hline CHEMBL1349241 & 737824 & 4.5 & 4.6693 & TRN & \\
\hline CHEMBL1378237 & 737824 & 4.8 & 4.7501 & TRN & \\
\hline CHEMBL1559387 & 737824 & 4.85 & 5.1912 & TST & \\
\hline CHEMBL1605000 & 737824 & 5.25 & 5.8924 & TRN & \\
\hline CHEMBL1548624 & 737824 & 5.35 & 5.2827 & TRN & \\
\hline CHEMBL1404529 & 737824 & 5.55 & 5.0754 & TRN & \\
\hline CHEMBL1973500 & 737824 & 4.6 & 4.9781 & TST & \\
\hline CHEMBL1595037 & 737824 & 4.65 & 5.4861 & TST & \\
\hline CHEMBL1480903 & 737824 & 5.5 & 5.046 & TST & \\
\hline
\end{tabular}




\begin{tabular}{|c|c|c|c|c|c|}
\hline \multirow[b]{2}{*}{ CHEMBL1450617 } & \multirow[b]{2}{*}{737824} & \multicolumn{4}{|c|}{ Supplemental Table s2.txt } \\
\hline & & 5.45 & 5.4586 & TRN & \\
\hline CHEMBL1573532 & 737824 & 7.2 & 7.1225 & TRN & \\
\hline CHEMBL3210890 & 737824 & 5.3 & \multicolumn{2}{|c|}{5.2379999999999995} & TRN \\
\hline CHEMBL1401813 & 737824 & 5.7 & 5.2956 & TRN & \\
\hline CHEMBL1597843 & 737824 & 5.05 & 5.4573 & TRN & \\
\hline CHEMBL1452436 & 737824 & 6.05 & 5.5632 & TST & \\
\hline CHEMBL1716644 & 737824 & 5.15 & 5.1367 & TRN & \\
\hline CHEMBL1552720 & 737824 & 6.2 & 6.2323 & TRN & \\
\hline CHEMBL1511648 & 737824 & 4.9 & 4.8431 & TRN & \\
\hline CHEMBL1343385 & 737824 & 4.65 & 4.8933 & TRN & \\
\hline CHEMBL1311432 & 737824 & 5.55 & 5.2328 & TRN & \\
\hline CHEMBL1441964 & 737824 & 5.55 & 4.8742 & TRN & \\
\hline CHEMBL1567236 & 737824 & 4.8 & 4.6498 & TRN & \\
\hline CHEMBL 3192412 & 737824 & 4.95 & 4.8918 & TRN & \\
\hline CHEMBL1389235 & 737824 & 4.8 & 5.256 & TRN & \\
\hline CHEMBL1611463 & 737824 & 5.65 & \multicolumn{2}{|c|}{5.446000000000001} & TRN \\
\hline CHEMBL1460842 & 737824 & 6.05 & 6.0438 & TRN & \\
\hline CHEMBL1607512 & 737824 & 5.25 & 5.3414 & TRN & \\
\hline CHEMBL1609324 & 737824 & 4.8 & 4.9921 & TRN & \\
\hline CHEMBL1741421 & 737824 & 5.45 & 5.0748 & TRN & \\
\hline CHEMBL1611188 & 737824 & 8.25 & \multicolumn{2}{|c|}{5.827999999999999} & TRN \\
\hline CHEMBL1520405 & 737824 & 4.9 & 5.4767 & TRN & \\
\hline CHEMBL523167 & 737824 & 5.7 & 5.6316 & TRN & \\
\hline CHEMBL1971532 & 737824 & 5.2 & 5.2165 & TRN & \\
\hline CHEMBL1475375 & 737824 & 5.4 & 5.237 & TST & \\
\hline CHEMBL1373621 & 737824 & 7.0 & 6.5717 & TRN & \\
\hline CHEMBL1325411 & 737824 & 4.4 & 4.7878 & TRN & \\
\hline CHEMBL1549240 & 737824 & 5.7 & 5.0107 & TRN & \\
\hline CHEMBL10 & 737824 & 7.4 & 6.8226 & TRN & \\
\hline CHEMBL1441981 & 737824 & 4.9 & 5.0237 & TRN & \\
\hline CHEMBL1324418 & 737824 & 4.6 & 4.4346 & TRN & \\
\hline CHEMBL1381787 & 737824 & 5.3 & 5.3166 & TRN & \\
\hline CHEMBL1397009 & 737824 & 4.5 & 4.702 & TRN & \\
\hline CHEMBL1436957 & 737824 & 4.9 & 4.9147 & TRN & \\
\hline CHEMBL1411609 & 737824 & 7.1 & 6.4323 & TST & \\
\hline CHEMBL1596241 & 737824 & 4.5 & 4.4284 & TRN & \\
\hline CHEMBL1391723 & 737824 & 5.15 & 4.7764 & TRN & \\
\hline CHEMBL83899 & 737824 & 5.0 & 4.9208 & TST & \\
\hline CHEMBL 1445840 & 737824 & 6.1 & 5.6992 & TRN & \\
\hline CHEMBL1304670 & 737824 & 5.45 & 5.2637 & TRN & \\
\hline CHEMBL1741978 & 737824 & 6.65 & 4.837 & TRN & \\
\hline CHEMBL1378322 & 737824 & 5.25 & 5.38299 & 9999999999 & TRN \\
\hline CHEMBL1514129 & 737824 & 5.3 & 4.84399 & 9999999999 & TRN \\
\hline CHEMBL1363413 & 737824 & 5.1 & 4.9915 & TRN & \\
\hline CHEMBL1299690 & 737824 & 5.35 & 5.3981 & TRN & \\
\hline CHEMBL 74121 & 737824 & 5.3 & 4.6992 & TST & \\
\hline CHEMBL1517696 & 737824 & 5.7 & 5.5168 & TRN & \\
\hline \multirow[t]{2}{*}{ CHEMBL1593365 } & 737824 & 5.2 & 5.0872 & TRN & \\
\hline & & \multicolumn{4}{|c|}{ Page 7571} \\
\hline
\end{tabular}




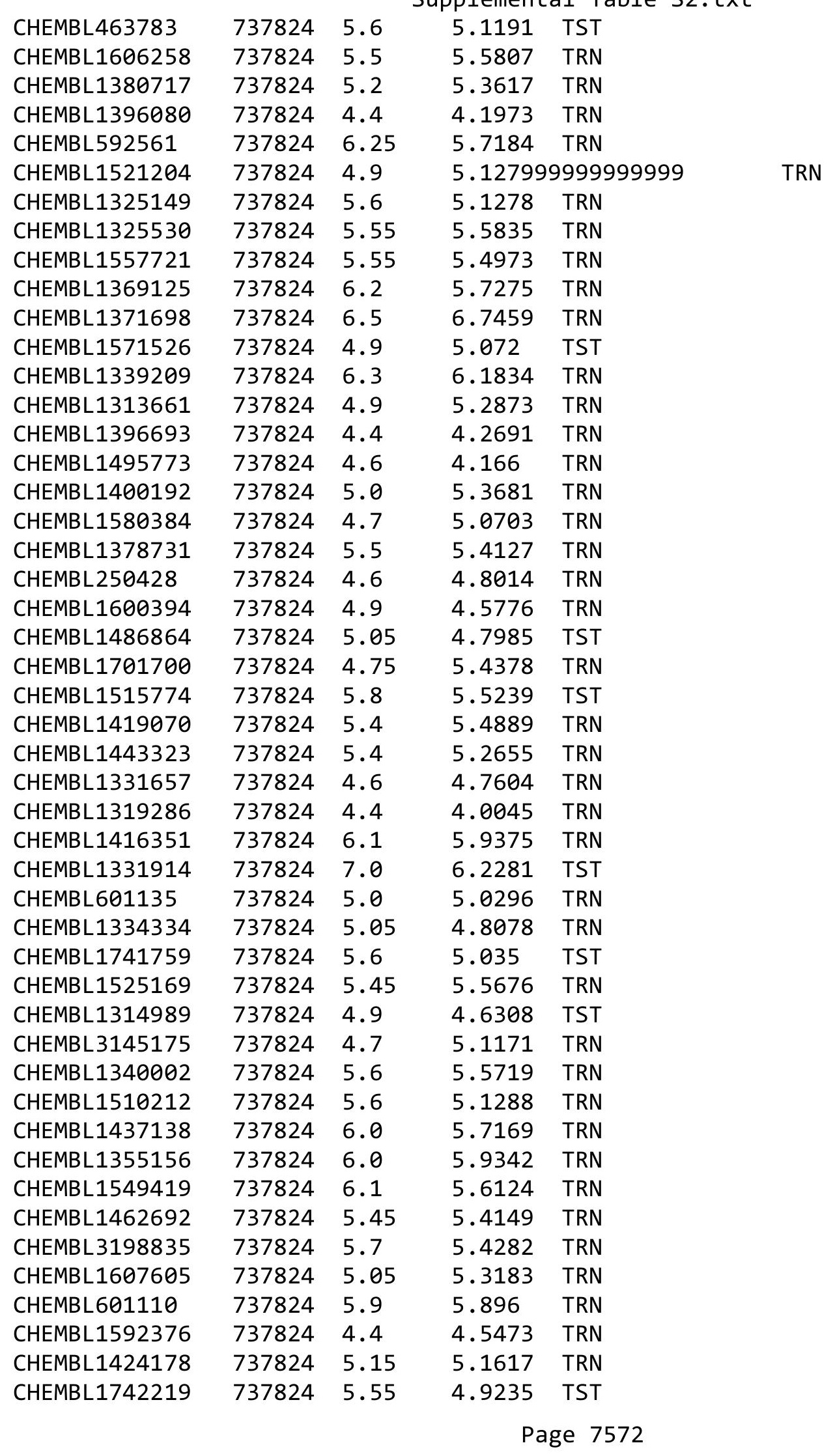




\begin{tabular}{|c|c|c|c|c|}
\hline \multicolumn{5}{|c|}{ Supplemental Table S2.txt } \\
\hline CHEMBL1571531 & 737824 & 4.75 & 5.325 & TST \\
\hline CHEMBL1742011 & 737824 & 6.1 & 5.5073 & TRN \\
\hline CHEMBL1306864 & 737824 & 4.8 & 4.8366 & TRN \\
\hline CHEMBL1413831 & 737824 & 5.15 & 5.0986 & TRN \\
\hline CHEMBL1420061 & 737824 & 4.95 & 5.0528 & TRN \\
\hline CHEMBL1612410 & 737824 & 4.6 & 4.3151 & TRN \\
\hline CHEMBL1742253 & 737824 & 5.6 & 5.3152 & TRN \\
\hline CHEMBL1396010 & 737824 & 4.9 & 4.6264 & TRN \\
\hline CHEMBL1412697 & 737824 & 5.45 & 5.3465 & TRN \\
\hline CHEMBL1506550 & 737824 & 5.2 & 5.2691 & TRN \\
\hline CHEMBL1532720 & 737824 & 7.5 & 6.9374 & TRN \\
\hline CHEMBL1378110 & 737824 & 5.45 & 5.3309 & TRN \\
\hline CHEMBL3191520 & 737824 & 5.15 & 5.6273 & TRN \\
\hline CHEMBL1425861 & 737824 & 8.2 & 5.0837 & TRN \\
\hline CHEMBL1569972 & 737824 & 4.7 & 4.7058 & TRN \\
\hline CHEMBL3145111 & 737824 & 5.05 & 5.3786 & TRN \\
\hline CHEMBL1742365 & 737824 & -0.0 & 5.311 & TRN \\
\hline CHEMBL1340013 & 737824 & 5.75 & 5.4053 & TRN \\
\hline CHEMBL1609808 & 737824 & 5.6 & 5.3934 & TRN \\
\hline CHEMBL1338229 & 737824 & 5.0 & 4.726 & TRN \\
\hline CHEMBL159096 & 737824 & 5.3 & 4.8409 & TST \\
\hline CHEMBL1577205 & 737824 & 4.85 & 5.1091 & TRN \\
\hline CHEMBL1509858 & 737824 & 4.85 & 4.872 & TRN \\
\hline CHEMBL1496056 & 737824 & 5.75 & 5.4946 & TRN \\
\hline CHEMBL1505516 & 737824 & 4.5 & 5.3321 & TRN \\
\hline CHEMBL1424276 & 737824 & 5.1 & 5.5337 & TST \\
\hline CHEMBL1379383 & 737824 & 4.8 & 5.1849 & TRN \\
\hline CHEMBL1468477 & 737824 & 4.65 & 5.3457 & TRN \\
\hline CHEMBL1540244 & 737824 & 5.7 & 5.1904 & TRN \\
\hline CHEMBL1333076 & 737824 & 5.4 & 5.2844 & TRN \\
\hline CHEMBL1307848 & 737824 & 5.05 & 5.4541 & TRN \\
\hline CHEMBL1420757 & 737824 & 4.95 & 5.1837 & TRN \\
\hline CHEMBL1612722 & 737824 & 5.5 & 5.2866 & TRN \\
\hline CHEMBL1256749 & 737824 & 6.0 & 5.7152 & TST \\
\hline CHEMBL1337128 & 737824 & 6.0 & 5.5616 & TST \\
\hline CHEMBL1579455 & 737824 & 5.4 & 5.1863 & TST \\
\hline CHEMBL3190392 & 737824 & 4.85 & 4.8233 & TRN \\
\hline CHEMBL1579324 & 737824 & 4.65 & 5.3333 & TRN \\
\hline CHEMBL608109 & 737824 & 6.0 & 6.0443 & TRN \\
\hline CHEMBL1469402 & 737824 & 5.0 & 4.9283 & TRN \\
\hline CHEMBL1330954 & 737824 & 5.55 & 5.2608 & TRN \\
\hline CHEMBL1404408 & 737824 & 4.8 & 4.8651 & TRN \\
\hline CHEMBL3190938 & 737824 & 5.9 & 5.7597 & TRN \\
\hline CHEMBL1468692 & 737824 & 5.05 & 5.6929 & TST \\
\hline CHEMBL1497925 & 737824 & 4.75 & 5.3997 & TRN \\
\hline CHEMBL1449000 & 737824 & 4.8 & 5.1563 & TST \\
\hline CHEMBL1604670 & 737824 & 5.5 & 5.347 & TRN \\
\hline CHEMBL1492669 & 737824 & 5.4 & 5.0772 & TST \\
\hline
\end{tabular}




\begin{tabular}{|c|c|c|c|c|c|}
\hline \\
\hline CHEMBL1602568 & 737824 & 4.4 & 4.7403 & TRN & \\
\hline CHEMBL1325673 & 737824 & 5.45 & 5.0254 & TRN & \\
\hline CHEMBL1573944 & 737824 & 5.7 & 5.519 & TST & \\
\hline CHEMBL18879 & 737824 & 5.9 & 5.1877 & TST & \\
\hline CHEMBL3198365 & 737824 & 5.55 & 5.4077 & TRN & \\
\hline CHEMBL1741625 & 737824 & 4.5 & 5.294 & TST & \\
\hline CHEMBL1725507 & 737824 & 5.0 & 4.8021 & TRN & \\
\hline CHEMBL1475395 & 737824 & 5.8 & 5.2441 & TST & \\
\hline CHEMBL1544764 & 737824 & 4.55 & 4.7822 & TRN & \\
\hline CHEMBL1550463 & 737824 & 5.3 & 5.36 & TRN & \\
\hline CHEMBL1400050 & 737824 & 6.0 & 6.2209 & TRN & \\
\hline CHEMBL1339054 & 737824 & 5.55 & 5.2688 & TRN & \\
\hline CHEMBL1474695 & 737824 & 4.6 & 4.8811 & TRN & \\
\hline CHEMBL1485397 & 737824 & 5.6 & 5.3227 & TRN & \\
\hline CHEMBL1455783 & 737824 & 5.5 & 4.8181 & TRN & \\
\hline CHEMBL1331280 & 737824 & 4.9 & 5.2689 & TST & \\
\hline CHEMBL1344685 & 737824 & 4.55 & 4.78100 & 0000000001 & TRN \\
\hline CHEMBL1326282 & 737824 & 4.4 & 4.6617 & TRN & \\
\hline CHEMBL1365902 & 737824 & 5.65 & 5.4163 & TRN & \\
\hline CHEMBL1493402 & 737824 & 6.1 & 6.0976 & TRN & \\
\hline CHEMBL1313698 & 737824 & 5.1 & 5.1327 & TRN & \\
\hline CHEMBL292477 & 737824 & 5.6 & 5.2345 & TRN & \\
\hline CHEMBL1498884 & 737824 & 5.65 & 5.8943 & TRN & \\
\hline CHEMBL1428944 & 737824 & 4.75 & 5.088 & TRN & \\
\hline CHEMBL3193547 & 737824 & 5.45 & 5.4649 & TRN & \\
\hline CHEMBL1522087 & 737824 & 5.85 & 5.16100 & 00000000005 & TST \\
\hline CHEMBL1320453 & 737824 & 4.8 & 5.0898 & TST & \\
\hline CHEMBL1412450 & 737824 & 5.55 & 5.3567 & TRN & \\
\hline CHEMBL1510451 & 737824 & 6.0 & 5.5523 & TST & \\
\hline CHEMBL1491037 & 737824 & 5.25 & 4.8013 & TRN & \\
\hline CHEMBL1400312 & 737824 & 5.0 & 5.1575 & TRN & \\
\hline CHEMBL1308361 & 737824 & 4.55 & 5.0316 & TRN & \\
\hline CHEMBL1471318 & 737824 & 5.45 & 5.4435 & TRN & \\
\hline CHEMBL3212051 & 737824 & 5.15 & 4.9563 & TST & \\
\hline CHEMBL1491193 & 737824 & 5.2 & 4.9814 & TRN & \\
\hline CHEMBL1989847 & 737824 & 5.2 & 5.36100 & 2000000001 & TRN \\
\hline CHEMBL1320485 & 737824 & 5.0 & 5.083 & TRN & \\
\hline CHEMBL1371311 & 737824 & 5.3 & 5.145 & TST & \\
\hline CHEMBL1404858 & 737824 & 4.7 & 4.9476 & TRN & \\
\hline CHEMBL1536139 & 737824 & 5.6 & 5.3607 & TRN & \\
\hline CHEMBL1330317 & 737824 & 5.5 & 5.7568 & TRN & \\
\hline CHEMBL1465378 & 737824 & 4.45 & 4.8627 & TRN & \\
\hline CHEMBL3199347 & 737824 & 5.25 & 5.0405 & TRN & \\
\hline CHEMBL1706489 & 737824 & 4.4 & 4.5102 & TRN & \\
\hline CHEMBL3211476 & 737824 & 5.65 & 5.4909 & TST & \\
\hline CHEMBL1334589 & 737824 & 5.05 & 5.2762 & TRN & \\
\hline CHEMBL1394456 & 737824 & 5.4 & 5.5128 & TRN & \\
\hline CHEMBL1481747 & 737824 & 5.0 & 4.8484 & TRN & \\
\hline
\end{tabular}




\begin{tabular}{|c|c|c|c|c|c|}
\hline \\
\hline CHEMBL1397177 & 737824 & 5.5 & 5.4381 & TRN & \\
\hline CHEMBL1514748 & 737824 & 5.8 & 5.8069 & TRN & \\
\hline CHEMBL1307249 & 737824 & 4.7 & 4.9078 & TST & \\
\hline CHEMBL513116 & 737824 & 6.0 & 7.1566 & TRN & \\
\hline CHEMBL1371238 & 737824 & 5.3 & 5.5882 & TRN & \\
\hline CHEMBL1337087 & 737824 & 4.8 & 5.1639 & TRN & \\
\hline CHEMBL1420145 & 737824 & 5.5 & 5.7034 & TRN & \\
\hline CHEMBL1473430 & 737824 & 5.6 & 5.5528 & TRN & \\
\hline CHEMBL1494196 & 737824 & 5.2 & 4.8808 & TRN & \\
\hline CHEMBL119841 & 737824 & 4.8 & 4.6879 & TRN & \\
\hline CHEMBL1348158 & 737824 & 5.35 & 5.2633 & TRN & \\
\hline CHEMBL1303348 & 737824 & 5.4 & 5.478 & TST & \\
\hline CHEMBL1544517 & 737824 & 4.85 & 5.5367 & TRN & \\
\hline CHEMBL1741364 & 737824 & 5.5 & 4.8236 & TST & \\
\hline CHEMBL1579444 & 737824 & 6.05 & 5.4628 & TRN & \\
\hline CHEMBL1510667 & 737824 & 5.2 & 4.9889 & TRN & \\
\hline CHEMBL1405262 & 737824 & 4.85 & 5.0473 & TRN & \\
\hline CHEMBL518923 & 737824 & 4.95 & 5.7165 & TRN & \\
\hline CHEMBL1583973 & 737824 & 4.4 & 5.1155 & TST & \\
\hline CHEMBL1418074 & 737824 & 5.25 & 5.2569 & TRN & \\
\hline CHEMBL1305322 & 737824 & 5.6 & 5.4337 & TRN & \\
\hline CHEMBL3189154 & 737824 & 5.0 & 4.7747 & TRN & \\
\hline CHEMBL1571290 & 737824 & 4.9 & 5.4265 & TRN & \\
\hline CHEMBL1395009 & 737824 & 6.2 & 5.9156 & TRN & \\
\hline CHEMBL1561457 & 737824 & 6.0 & 5.33799 & 9999999999 & TRN \\
\hline CHEMBL3199510 & 737824 & 4.8 & 4.7845 & TRN & \\
\hline CHEMBL1586705 & 737824 & 7.1 & 7.2106 & TRN & \\
\hline CHEMBL1558951 & 737824 & 5.4 & 5.4102 & TRN & \\
\hline CHEMBL3211758 & 737824 & 5.45 & 5.0425 & TRN & \\
\hline CHEMBL1494865 & 737824 & 4.6 & 4.9554 & TRN & \\
\hline CHEMBL1319632 & 737824 & 5.65 & 5.7882 & TRN & \\
\hline CHEMBL1433336 & 737824 & 5.1 & 4.9241 & TRN & \\
\hline CHEMBL 3214072 & 737824 & 4.95 & 5.3558 & TRN & \\
\hline CHEMBL1302767 & 737824 & 5.1 & 5.3915 & TST & \\
\hline CHEMBL1544332 & 737824 & 5.0 & 5.4265 & TRN & \\
\hline CHEMBL1472223 & 737824 & 4.9 & 5.1035 & TRN & \\
\hline CHEMBL1553902 & 737824 & 4.7 & 4.4399 & TRN & \\
\hline CHEMBL1581163 & 737824 & 5.1 & 5.1759 & TRN & \\
\hline CHEMBL1435638 & 737824 & 5.8 & 5.9622 & TRN & \\
\hline CHEMBL1331952 & 737824 & 4.8 & 5.1681 & TRN & \\
\hline CHEMBL119264 & 737824 & 4.5 & 4.511 & TRN & \\
\hline CHEMBL1328943 & 737824 & 5.8 & 5.8154 & TRN & \\
\hline CHEMBL1523996 & 737824 & 4.9 & 4.9024 & TRN & \\
\hline CHEMBL1438173 & 737824 & 4.75 & 4.7988 & TRN & \\
\hline CHEMBL405912 & 737824 & 5.6 & 5.6858 & TRN & \\
\hline CHEMBL1592651 & 737824 & 4.9 & 4.8853 & TRN & \\
\hline CHEMBL1422800 & 737824 & 4.95 & 5.2056 & TRN & \\
\hline CHEMBL1370525 & 737824 & 4.8 & 5.0627 & TRN & \\
\hline
\end{tabular}




\begin{tabular}{|c|c|c|c|c|}
\hline & & & pplement & \\
\hline CHEMBL1448646 & 737824 & 6.2 & 5.6651 & TRN \\
\hline CHEMBL1575560 & 737824 & 4.75 & 4.8938 & TRN \\
\hline CHEMBL1420945 & 737824 & 5.05 & 5.5472 & TRN \\
\hline CHEMBL1214274 & 737824 & 6.1 & 5.9394 & TST \\
\hline CHEMBL1572430 & 737824 & 4.95 & 5.2292 & TRN \\
\hline CHEMBL1361909 & 737824 & 4.85 & 4.9239 & TRN \\
\hline CHEMBL1544968 & 737824 & 5.2 & 5.1717 & TRN \\
\hline CHEMBL1348828 & 737824 & 5.1 & 5.4736 & TRN \\
\hline CHEMBL1527392 & 737824 & 5.25 & 4.9461 & TRN \\
\hline CHEMBL3207783 & 737824 & 5.6 & 5.5583 & TRN \\
\hline CHEMBL3211795 & 737824 & 5.6 & 5.4127 & TRN \\
\hline CHEMBL489943 & 737824 & 5.8 & 5.6839 & TRN \\
\hline CHEMBL1364366 & 737824 & 4.8 & 4.6721 & TRN \\
\hline CHEMBL1579683 & 737824 & 4.9 & 5.3422 & TRN \\
\hline CHEMBL3208514 & 737824 & 5.1 & 4.6983 & TRN \\
\hline CHEMBL1388158 & 737824 & 5.8 & 5.1989 & TST \\
\hline CHEMBL1324494 & 737824 & 5.0 & 4.9025 & TRN \\
\hline CHEMBL1389497 & 737824 & 5.95 & 5.1968 & TRN \\
\hline CHEMBL3199340 & 737824 & 5.2 & 5.1961 & TRN \\
\hline CHEMBL3212049 & 737824 & 5.3 & 5.5421 & TRN \\
\hline CHEMBL1387144 & 737824 & 4.6 & 5.3992 & TRN \\
\hline CHEMBL1302253 & 737824 & 4.95 & 4.9988 & TRN \\
\hline CHEMBL1581512 & 737824 & 5.05 & 5.1793 & TRN \\
\hline CHEMBL1426905 & 737824 & 4.5 & 5.0647 & TRN \\
\hline CHEMBL1346217 & 737824 & 5.3 & 5.1058 & TRN \\
\hline CHEMBL1417263 & 737824 & 4.55 & 4.7323 & TRN \\
\hline CHEMBL1981770 & 737824 & 5.05 & 5.3739 & TRN \\
\hline CHEMBL1367656 & 737824 & 6.1 & 6.0698 & TRN \\
\hline CHEMBL1358560 & 737824 & 4.9 & 4.6815 & TRN \\
\hline CHEMBL1557355 & 737824 & 5.45 & 5.8062 & TRN \\
\hline CHEMBL1485727 & 737824 & 8.15 & 5.2937 & TST \\
\hline CHEMBL1481378 & 737824 & 5.8 & 5.369 & TRN \\
\hline CHEMBL1417610 & 737824 & 5.25 & 5.1819 & TRN \\
\hline CHEMBL1343900 & 737824 & 5.35 & 5.3952 & TRN \\
\hline CHEMBL1476298 & 737824 & 4.4 & 4.0998 & TRN \\
\hline CHEMBL1706828 & 737824 & 4.95 & 5.1672 & TRN \\
\hline CHEMBL1552643 & 737824 & 4.4 & 4.3114 & TRN \\
\hline CHEMBL1605940 & 737824 & 4.8 & 4.7769 & TRN \\
\hline CHEMBL1378764 & 737824 & 5.0 & 5.0625 & TRN \\
\hline CHEMBL1386168 & 737824 & 4.95 & 5.0976 & TRN \\
\hline CHEMBL1319120 & 737824 & 4.6 & 4.8079 & TRN \\
\hline CHEMBL1485494 & 737824 & 6.5 & 5.7705 & TRN \\
\hline CHEMBL1373907 & 737824 & 5.0 & 4.7244 & TRN \\
\hline CHEMBL1321686 & 737824 & 5.1 & 5.4734 & TRN \\
\hline CHEMBL1339696 & 737824 & 5.4 & 5.143 & TRN \\
\hline CHEMBL1306134 & 737824 & 6.05 & 5.322 & TRN \\
\hline CHEMBL1302924 & 737824 & 4.75 & 4.9611 & TRN \\
\hline CHEMBL1418094 & 737824 & 5.5 & 4.997 & TST \\
\hline
\end{tabular}




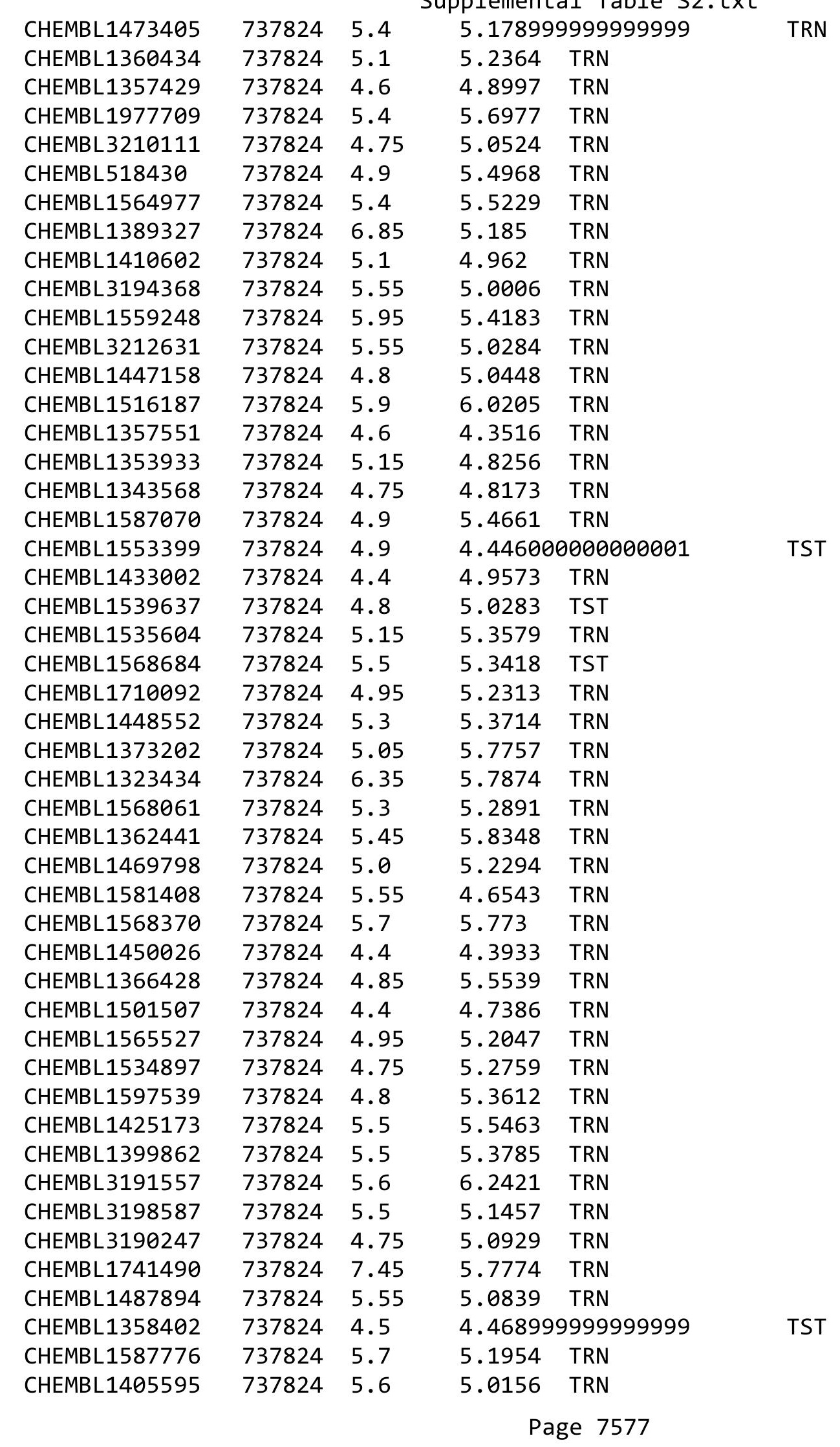




\begin{tabular}{|c|c|c|c|c|c|}
\hline & & & & & \\
\hline CHEMBL1480192 & 737824 & 5.1 & 5.039 & TRN & \\
\hline CHEMBL1413165 & 737824 & 5.6 & 5.7411 & TRN & \\
\hline CHEMBL1393658 & 737824 & 4.7 & 4.8167 & TRN & \\
\hline CHEMBL1566984 & 737824 & 4.4 & 4.942 & TRN & \\
\hline CHEMBL1452192 & 737824 & 4.85 & 4.6209 & TRN & \\
\hline CHEMBL1310531 & 737824 & 6.55 & 5.4602 & TST & \\
\hline CHEMBL1581594 & 737824 & 4.95 & 5.9778 & TRN & \\
\hline CHEMBL1414954 & 737824 & 4.85 & 4.8021 & TRN & \\
\hline CHEMBL 3209087 & 737824 & 5.3 & 4.6742 & TRN & \\
\hline CHEMBL1449268 & 737824 & 5.3 & 5.3437 & TRN & \\
\hline CHEMBL1462072 & 737824 & 5.5 & 5.46299 & 9999999999 & TRN \\
\hline CHEMBL1307904 & 737824 & 5.1 & 5.33899 & 99999999995 & TST \\
\hline CHEMBL1415777 & 737824 & 4.7 & 4.0857 & TST & \\
\hline CHEMBL1365033 & 737824 & 5.8 & 5.729 & TRN & \\
\hline CHEMBL1367845 & 737824 & 5.5 & 5.2667 & TRN & \\
\hline CHEMBL1971875 & 737824 & 5.55 & 5.4149 & TRN & \\
\hline CHEMBL1412519 & 737824 & 5.4 & 5.2834 & TRN & \\
\hline CHEMBL1324697 & 737824 & 4.7 & 4.1617 & TST & \\
\hline CHEMBL1439148 & 737824 & 6.25 & 5.692 & TRN & \\
\hline CHEMBL1573692 & 737824 & 5.65 & 5.2878 & TRN & \\
\hline CHEMBL1400835 & 737824 & 5.15 & 5.3431 & TRN & \\
\hline CHEMBL1374373 & 737824 & 7.25 & 5.3906 & TST & \\
\hline CHEMBL1573867 & 737824 & 4.5 & 4.9724 & TRN & \\
\hline CHEMBL1582125 & 737824 & 6.15 & 6.0284 & TRN & \\
\hline CHEMBL1506416 & 737824 & 5.7 & 5.1967 & TRN & \\
\hline CHEMBL1411055 & 737824 & 5.8 & 5.5517 & TST & \\
\hline CHEMBL3194362 & 737824 & 4.95 & 5.289 & TRN & \\
\hline CHEMBL1547832 & 737824 & 5.35 & 5.1791 & TRN & \\
\hline CHEMBL1501511 & 737824 & 4.85 & 4.7906 & TRN & \\
\hline CHEMBL1469018 & 737824 & 4.95 & 5.7482 & TRN & \\
\hline CHEMBL1524707 & 737824 & 4.65 & 4.8075 & TRN & \\
\hline CHEMBL1603542 & 737824 & 5.65 & 5.0185 & TRN & \\
\hline CHEMBL1470084 & 737824 & 5.0 & 4.8697 & TRN & \\
\hline CHEMBL1324640 & 737824 & 5.55 & 5.0867 & TST & \\
\hline CHEMBL1435919 & 737824 & 4.9 & 4.7963 & TRN & \\
\hline CHEMBL1451986 & 737824 & 5.7 & 5.5424 & TST & \\
\hline CHEMBL591613 & 737824 & 4.9 & 4.88399 & 99999999995 & TRN \\
\hline CHEMBL1435698 & 737824 & 4.9 & 4.3801 & TRN & \\
\hline CHEMBL1369822 & 737824 & 4.7 & 4.6213 & TRN & \\
\hline CHEMBL1502201 & 737824 & 5.0 & 5.5612 & TST & \\
\hline CHEMBL1444745 & 737824 & 4.85 & 5.0193 & TRN & \\
\hline CHEMBL 1725130 & 737824 & 4.95 & 5.06 & TRN & \\
\hline CHEMBL1431037 & 737824 & 4.75 & 5.0401 & TRN & \\
\hline CHEMBL1579887 & 737824 & 5.2 & 5.0868 & TRN & \\
\hline CHEMBL1736254 & 737824 & 6.3 & 6.148 & TST & \\
\hline CHEMBL3210395 & 737824 & 5.5 & 5.4402 & TRN & \\
\hline CHEMBL1420531 & 737824 & 5.45 & 5.1942 & TRN & \\
\hline CHEMBL1453519 & 737824 & 5.75 & 5.5868 & TRN & \\
\hline
\end{tabular}




\begin{tabular}{|c|c|c|c|c|}
\hline \multicolumn{5}{|c|}{ lemental T } \\
\hline CHEMBL1483498 & 737824 & 5.1 & 5.0694 & TRN \\
\hline CHEMBL1612691 & 737824 & 4.7 & 4.593 & TRN \\
\hline CHEMBL1611496 & 737824 & 5.2 & 5.301 & TRN \\
\hline CHEMBL1511512 & 737824 & 5.2 & 5.23 & TRN \\
\hline CHEMBL1429119 & 737824 & 4.85 & 4.7352 & TRN \\
\hline CHEMBL1516817 & 737824 & 4.95 & 5.0476 & TRN \\
\hline CHEMBL1358758 & 737824 & 5.0 & 5.2244 & TRN \\
\hline CHEMBL 3189742 & 737824 & 4.85 & 5.1827 & TRN \\
\hline CHEMBL1306897 & 737824 & 4.95 & 5.0928 & TRN \\
\hline CHEMBL1408140 & 737824 & 4.55 & 4.796 & TRN \\
\hline CHEMBL3211347 & 737824 & 5.3 & 5.324 & TRN \\
\hline CHEMBL1324806 & 737824 & 4.4 & 4.8684 & TRN \\
\hline CHEMBL1305433 & 737824 & 4.4 & 4.7454 & TRN \\
\hline CHEMBL1526613 & 737824 & 5.85 & 5.4854 & TRN \\
\hline CHEMBL1356733 & 737824 & 5.1 & 4.6765 & TRN \\
\hline CHEMBL1372997 & 737824 & 5.0 & 4.164 & TST \\
\hline CHEMBL1510548 & 737824 & 5.1 & 5.2024 & TRN \\
\hline CHEMBL441618 & 737824 & 5.4 & 5.6154 & TST \\
\hline CHEMBL1511555 & 737824 & 4.95 & 5.3413 & TRN \\
\hline CHEMBL1326533 & 737824 & 5.5 & 5.7628 & TRN \\
\hline CHEMBL1493369 & 737824 & 5.6 & 5.4866 & TRN \\
\hline CHEMBL1488845 & 737824 & 5.1 & 4.6033 & TST \\
\hline CHEMBL1600871 & 737824 & 5.55 & 5.6507 & TST \\
\hline CHEMBL1370553 & 737824 & 4.6 & 4.3141 & TRN \\
\hline CHEMBL1399879 & 737824 & 6.7 & 5.3979 & TRN \\
\hline CHEMBL1303309 & 737824 & 4.8 & 5.0347 & TRN \\
\hline CHEMBL1589352 & 737824 & 4.7 & 5.1625 & TRN \\
\hline CHEMBL1577686 & 737824 & 4.85 & 5.2917 & TRN \\
\hline CHEMBL3208933 & 737824 & 4.95 & 4.9471 & TST \\
\hline CHEMBL 3214586 & 737824 & 4.85 & 5.3276 & TRN \\
\hline CHEMBL1310248 & 737824 & 6.15 & 5.5211 & TRN \\
\hline CHEMBL1522582 & 737824 & 5.45 & 5.2185 & TRN \\
\hline CHEMBL 3190572 & 737824 & 5.5 & 5.5269 & TRN \\
\hline CHEMBL1378440 & 737824 & 4.9 & 4.995 & TRN \\
\hline CHEMBL18794 & 737824 & 4.9 & 4.5528 & TST \\
\hline CHEMBL1472233 & 737824 & 5.0 & 5.272 & TRN \\
\hline CHEMBL1477222 & 737824 & 5.65 & 5.4055 & TRN \\
\hline CHEMBL1309305 & 737824 & 4.5 & 4.9782 & TRN \\
\hline CHEMBL1518532 & 737824 & 4.4 & 4.7975 & TRN \\
\hline CHEMBL1331148 & 737824 & 7.1 & 7.1566 & TRN \\
\hline CHEMBL311158 & 737824 & 5.0 & 4.4966 & TRN \\
\hline CHEMBL1541553 & 737824 & 5.25 & 5.2866 & TRN \\
\hline CHEMBL1420930 & 737824 & 4.4 & 5.1563 & TRN \\
\hline CHEMBL1365932 & 737824 & 4.4 & 4.988 & TRN \\
\hline CHEMBL3208361 & 737824 & 4.9 & 5.3005 & TRN \\
\hline CHEMBL1429612 & 737824 & 6.45 & 5.2031 & TRN \\
\hline CHEMBL1447313 & 737824 & 5.5 & 5.7068 & TRN \\
\hline CHEMBL1335332 & 737824 & 4.9 & 4.9966 & TRN \\
\hline
\end{tabular}




\begin{tabular}{|c|c|c|c|c|}
\hline \multicolumn{5}{|c|}{ Supplemental Table S2.txt } \\
\hline CHEMBL1374585 & 737824 & 5.6 & 5.6951 & TRN \\
\hline CHEMBL1523040 & 737824 & 4.95 & 5.2425 & TRN \\
\hline CHEMBL1301015 & 737824 & 5.4 & 5.2309 & TRN \\
\hline CHEMBL1395337 & 737824 & 5.6 & 5.1185 & TRN \\
\hline CHEMBL1314971 & 737824 & 4.4 & 4.4628 & TRN \\
\hline CHEMBL1331112 & 737824 & 4.6 & 4.4779 & TST \\
\hline CHEMBL3213467 & 737824 & 4.5 & 4.9754 & TRN \\
\hline CHEMBL1381972 & 737824 & 5.15 & 5.4525 & TRN \\
\hline CHEMBL1376952 & 737824 & 5.5 & 5.7229 & TRN \\
\hline CHEMBL52460 & 737824 & 4.4 & 5.47 & TRN \\
\hline CHEMBL1579521 & 737824 & 6.25 & 5.8433 & TRN \\
\hline CHEMBL1535022 & 737824 & 4.95 & 5.2383 & TRN \\
\hline CHEMBL1398622 & 737824 & 4.8 & 5.1432 & TRN \\
\hline CHEMBL1579761 & 737824 & 4.95 & 5.0162 & TRN \\
\hline CHEMBL1742155 & 737824 & 4.95 & 5.2869 & TRN \\
\hline CHEMBL1406703 & 737824 & 4.95 & 5.2014 & TST \\
\hline CHEMBL1316828 & 737824 & 4.8 & 4.5782 & TST \\
\hline CHEMBL1444914 & 737824 & 5.5 & 5.3217 & TRN \\
\hline CHEMBL1315417 & 737824 & 4.9 & 4.2088 & TST \\
\hline CHEMBL1474302 & 737824 & 5.2 & 5.1409 & TRN \\
\hline CHEMBL1466103 & 737824 & 4.95 & 4.9803 & TRN \\
\hline CHEMBL491977 & 737824 & 4.9 & 4.6981 & TRN \\
\hline CHEMBL1340383 & 737824 & 6.05 & 5.2481 & TRN \\
\hline CHEMBL1597366 & 737824 & 4.6 & 4.3562 & TRN \\
\hline CHEMBL1569979 & 737824 & 4.65 & 5.1562 & TST \\
\hline CHEMBL1381005 & 737824 & 7.05 & 5.8277 & TRN \\
\hline CHEMBL1572530 & 737824 & 5.4 & 5.2339 & TRN \\
\hline CHEMBL1329312 & 737824 & 5.5 & 5.2913 & TST \\
\hline CHEMBL1433155 & 737824 & 5.6 & 5.2701 & TST \\
\hline CHEMBL3191940 & 737824 & 5.6 & 5.3403 & TST \\
\hline CHEMBL68534 & 737824 & 4.5 & 4.3586 & TRN \\
\hline CHEMBL1309131 & 737824 & 5.05 & 5.4061 & TRN \\
\hline CHEMBL1551477 & 737824 & 5.4 & 5.4871 & TRN \\
\hline CHEMBL 255027 & 737824 & 5.2 & 4.9511 & TRN \\
\hline CHEMBL1414061 & 737824 & 4.9 & 4.6574 & TRN \\
\hline CHEMBL1497392 & 737824 & 4.5 & 5.4542 & TRN \\
\hline CHEMBL 1475860 & 737824 & 6.5 & 6.3423 & TRN \\
\hline CHEMBL1368493 & 737824 & 5.85 & 5.3833 & TRN \\
\hline CHEMBL1431981 & 737824 & 4.55 & 4.6405 & TRN \\
\hline CHEMBL 9225 & 737824 & 5.5 & 5.1018 & TRN \\
\hline CHEMBL1865547 & 737824 & 5.6 & 5.6845 & TRN \\
\hline CHEMBL 1457317 & 737824 & 4.7 & 4.7315 & TRN \\
\hline CHEMBL1324402 & 737824 & 5.75 & 5.5742 & TRN \\
\hline CHEMBL1303328 & 737824 & 5.9 & 5.1507 & TRN \\
\hline CHEMBL1542604 & 737824 & 5.6 & 5.6018 & TST \\
\hline CHEMBL1322091 & 737824 & 5.55 & 5.7559 & TRN \\
\hline CHEMBL1480293 & 737824 & 4.4 & 4.3585 & TRN \\
\hline CHEMBL1512359 & 737824 & 5.6 & 5.5048 & TRN \\
\hline
\end{tabular}




\begin{tabular}{|c|c|c|c|c|}
\hline \multicolumn{5}{|c|}{ Supplemental Table S2.txt } \\
\hline CHEMBL1375469 & 737824 & 6.0 & 6.1104 & TRN \\
\hline CHEMBL1369948 & 737824 & 6.25 & 4.9131 & TST \\
\hline CHEMBL1319243 & 737824 & 4.95 & 5.2427 & TRN \\
\hline CHEMBL1443628 & 737824 & 6.4 & 6.3928 & TRN \\
\hline CHEMBL1536844 & 737824 & 4.85 & 5.4071 & TST \\
\hline CHEMBL 3195251 & 737824 & 4.95 & 5.0997 & TRN \\
\hline CHEMBL1507654 & 737824 & 4.45 & 5.5517 & TST \\
\hline CHEMBL1533232 & 737824 & 5.4 & 5.0037 & TRN \\
\hline CHEMBL1302425 & 737824 & 4.6 & 5.2564 & TST \\
\hline CHEMBL1435080 & 737824 & 6.1 & 6.0219 & TRN \\
\hline CHEMBL1512385 & 737824 & 4.9 & 4.9973 & TRN \\
\hline CHEMBL1434369 & 737824 & 5.4 & 5.5155 & TRN \\
\hline CHEMBL1422579 & 737824 & 5.15 & 5.403 & TST \\
\hline CHEMBL 3213904 & 737824 & 6.15 & 5.4273 & TST \\
\hline CHEMBL1525168 & 737824 & 4.55 & 5.0549 & TRN \\
\hline CHEMBL1453899 & 737824 & 4.7 & 5.197 & TRN \\
\hline CHEMBL1717341 & 737824 & 4.55 & 4.8916 & TRN \\
\hline CHEMBL1554194 & 737824 & 5.1 & 5.2967 & TRN \\
\hline CHEMBL1449528 & 737824 & 5.9 & 5.5432 & TRN \\
\hline CHEMBL1522524 & 737824 & 5.55 & 4.9619 & TRN \\
\hline CHEMBL1414668 & 737824 & 5.05 & 5.2207 & TST \\
\hline CHEMBL1411164 & 737824 & 5.0 & 5.0195 & TRN \\
\hline CHEMBL1442091 & 737824 & 5.45 & 5.2469 & TRN \\
\hline CHEMBL1516005 & 737824 & 6.0 & 5.8034 & TRN \\
\hline CHEMBL1310409 & 737824 & 4.9 & 4.8296 & TRN \\
\hline CHEMBL1550597 & 737824 & 5.15 & 5.2513 & TRN \\
\hline CHEMBL1742070 & 737824 & 4.7 & 4.8913 & TRN \\
\hline CHEMBL1425367 & 737824 & 5.95 & 5.8189 & TRN \\
\hline CHEMBL1524497 & 737824 & 5.2 & 5.2 & TRN \\
\hline CHEMBL1466628 & 737824 & 5.05 & 5.2971 & TRN \\
\hline CHEMBL 3198264 & 737824 & 4.85 & 5.0853 & TST \\
\hline CHEMBL1438061 & 737824 & 4.75 & 5.6805 & TRN \\
\hline CHEMBL1474410 & 737824 & 5.2 & 5.1537 & TRN \\
\hline CHEMBL1370622 & 737824 & 5.9 & 6.0955 & TRN \\
\hline CHEMBL1555348 & 737824 & 4.8 & 4.9151 & TRN \\
\hline CHEMBL1413611 & 737824 & 4.75 & 5.4016 & TRN \\
\hline CHEMBL1609103 & 737824 & 4.8 & 5.2021 & TRN \\
\hline CHEMBL1516170 & 737824 & 5.3 & 5.1128 & TRN \\
\hline CHEMBL1594421 & 737824 & 5.2 & 5.4822 & TRN \\
\hline CHEMBL 3198793 & 737824 & 4.85 & 4.9922 & TRN \\
\hline CHEMBL1425899 & 737824 & 5.4 & 5.6136 & TRN \\
\hline CHEMBL1474114 & 737824 & 5.0 & 4.8748 & TRN \\
\hline CHEMBL1434072 & 737824 & 6.0 & 5.6293 & TRN \\
\hline CHEMBL1431706 & 737824 & 4.4 & 4.7415 & TRN \\
\hline CHEMBL1335654 & 737824 & 4.5 & 4.7269 & TRN \\
\hline CHEMBL1304718 & 737824 & 5.35 & 5.3783 & TST \\
\hline CHEMBL1312826 & 737824 & 5.9 & 5.3126 & TRN \\
\hline CHEMBL3210605 & 737824 & 4.4 & 5.6746 & TRN \\
\hline
\end{tabular}




\begin{tabular}{|c|c|c|c|c|c|}
\hline \\
\hline CHEMBL1981657 & 737824 & 4.4 & 4.6065 & TST & \\
\hline CHEMBL1598705 & 737824 & 5.45 & 5.1603 & TRN & \\
\hline CHEMBL1527745 & 737824 & 5.45 & 5.0679 & TRN & \\
\hline CHEMBL1467157 & 737824 & 5.2 & 5.5628 & TRN & \\
\hline CHEMBL1330929 & 737824 & 4.6 & 5.3152 & TRN & \\
\hline CHEMBL1383076 & 737824 & 4.75 & 4.7652 & TST & \\
\hline CHEMBL1540834 & 737824 & 5.45 & 5.4548 & TST & \\
\hline CHEMBL1371821 & 737824 & 6.2 & 5.5751 & TRN & \\
\hline CHEMBL1317795 & 737824 & 5.0 & 4.9667 & TRN & \\
\hline CHEMBL1505006 & 737824 & 5.4 & 5.1024 & TRN & \\
\hline CHEMBL1546136 & 737824 & 5.65 & 5.3013 & TRN & \\
\hline CHEMBL1541166 & 737824 & 4.55 & 5.1212 & TRN & \\
\hline CHEMBL1397353 & 737824 & 4.7 & 4.5113 & TRN & \\
\hline CHEMBL1399844 & 737824 & 5.95 & 5.5995 & TST & \\
\hline CHEMBL1592438 & 737824 & 5.1 & 5.1143 & TRN & \\
\hline CHEMBL1348021 & 737824 & 5.0 & 4.8926 & TRN & \\
\hline CHEMBL1568026 & 737824 & 4.85 & 4.881 & TST & \\
\hline CHEMBL1609896 & 737824 & 4.9 & 4.7415 & TRN & \\
\hline CHEMBL1741579 & 737824 & 5.45 & 5.1654 & TRN & \\
\hline CHEMBL1600210 & 737824 & 5.5 & 5.4085 & TRN & \\
\hline CHEMBL 7162 & 737824 & 7.1 & 6.2467 & TST & \\
\hline CHEMBL1417491 & 737824 & 4.4 & 4.8747 & TST & \\
\hline CHEMBL3212789 & 737824 & 5.25 & 5.09399 & 9999999999 & TRN \\
\hline CHEMBL153648 & 737824 & 7.2 & 6.3948 & TST & \\
\hline CHEMBL1607885 & 737824 & 5.1 & 5.1947 & TRN & \\
\hline CHEMBL1460723 & 737824 & 5.5 & 5.5857 & TRN & \\
\hline CHEMBL1461188 & 737824 & 5.65 & 5.4011 & TRN & \\
\hline CHEMBL1397913 & 737824 & 6.9 & 6.7859 & TRN & \\
\hline CHEMBL1490809 & 737824 & 4.85 & 5.24200 & 0000000001 & TRN \\
\hline CHEMBL1545141 & 737824 & 5.4 & 5.5503 & TRN & \\
\hline CHEMBL1720126 & 737824 & 5.65 & 5.4654 & TRN & \\
\hline CHEMBL3195611 & 737824 & 5.05 & 5.5657 & TRN & \\
\hline CHEMBL1598974 & 737824 & 6.7 & 5.75200 & 2000000001 & TRN \\
\hline CHEMBL1418358 & 737824 & 5.2 & 4.7182 & TRN & \\
\hline CHEMBL1357338 & 737824 & 5.0 & 4.8033 & TRN & \\
\hline CHEMBL1463479 & 737824 & 4.45 & 5.2613 & TRN & \\
\hline CHEMBL1444632 & 737824 & 4.65 & 5.0023 & TST & \\
\hline CHEMBL1356485 & 737824 & 4.8 & 4.9265 & TRN & \\
\hline CHEMBL1450115 & 737824 & 5.45 & 5.2693 & TRN & \\
\hline CHEMBL1574218 & 737824 & 4.8 & 4.8709 & TRN & \\
\hline CHEMBL1707011 & 737824 & 5.55 & 5.3438 & TRN & \\
\hline CHEMBL1474989 & 737824 & 5.1 & 5.0687 & TRN & \\
\hline CHEMBL1723390 & 737824 & 5.3 & 5.2391 & TRN & \\
\hline CHEMBL1595190 & 737824 & 5.65 & 5.4989 & TRN & \\
\hline CHEMBL 1465782 & 737824 & 5.05 & 5.4096 & TST & \\
\hline CHEMBL1465094 & 737824 & 5.05 & 5.1643 & TRN & \\
\hline CHEMBL1338985 & 737824 & 5.0 & 4.7622 & TRN & \\
\hline CHEMBL1345528 & 737824 & 6.3 & 5.9188 & TRN & \\
\hline
\end{tabular}




\begin{tabular}{|c|c|c|c|c|c|}
\hline \\
\hline CHEMBL1555314 & 737824 & 4.6 & 4.3356 & TRN & \\
\hline CHEMBL1429153 & 737824 & 5.0 & 4.5299 & TRN & \\
\hline CHEMBL1727976 & 737824 & 4.9 & 4.7459 & TRN & \\
\hline CHEMBL1477299 & 737824 & 5.65 & 5.4315 & TRN & \\
\hline CHEMBL1590378 & 737824 & 6.0 & 5.9853 & TST & \\
\hline CHEMBL1561738 & 737824 & 6.55 & 5.3699 & TRN & \\
\hline CHEMBL1299856 & 737824 & 6.2 & 5.3005 & TRN & \\
\hline CHEMBL527271 & 737824 & 5.25 & 5.37700 & 0000000001 & TRN \\
\hline CHEMBL1308013 & 737824 & 5.7 & 5.5413 & TRN & \\
\hline CHEMBL1255659 & 737824 & 5.0 & 4.1822 & TST & \\
\hline CHEMBL1508024 & 737824 & 4.8 & 5.0337 & TRN & \\
\hline CHEMBL1494351 & 737824 & 5.6 & 5.191 & TRN & \\
\hline CHEMBL1604088 & 737824 & 4.45 & 4.9251 & TRN & \\
\hline CHEMBL478 & 737824 & 4.6 & 4.7025 & TRN & \\
\hline CHEMBL1729658 & 737824 & 4.7 & 4.8596 & TST & \\
\hline CHEMBL1584523 & 737824 & 5.7 & 5.5005 & TRN & \\
\hline CHEMBL1508431 & 737824 & 5.45 & 5.5026 & TRN & \\
\hline CHEMBL1531038 & 737824 & 4.85 & 4.8251 & TRN & \\
\hline CHEMBL1410859 & 737824 & 5.2 & 5.0901 & TRN & \\
\hline CHEMBL1463617 & 737824 & 5.3 & 5.0597 & TRN & \\
\hline CHEMBL1365269 & 737824 & 4.7 & 4.7027 & TRN & \\
\hline CHEMBL1596831 & 737824 & 6.5 & 5.8506 & TST & \\
\hline CHEMBL3194463 & 737824 & 5.85 & 5.0515 & TST & \\
\hline CHEMBL1331231 & 737824 & 4.95 & 5.3157 & TST & \\
\hline CHEMBL1354190 & 737824 & 7.2 & 6.6615 & TST & \\
\hline CHEMBL1551962 & 737824 & 6.1 & 6.0892 & TRN & \\
\hline CHEMBL1572595 & 737824 & 5.0 & 5.0506 & TRN & \\
\hline CHEMBL1301953 & 737824 & 4.8 & 4.6794 & TRN & \\
\hline CHEMBL1353336 & 737824 & 5.25 & 5.2635 & TRN & \\
\hline CHEMBL1742267 & 737824 & 5.3 & 5.2105 & TRN & \\
\hline CHEMBL1741841 & 737824 & 4.5 & 5.1099 & TRN & \\
\hline CHEMBL1574017 & 737824 & 4.5 & 5.228 & TRN & \\
\hline CHEMBL1317039 & 737824 & 5.1 & 5.067 & TRN & \\
\hline CHEMBL1562229 & 737824 & 6.15 & 5.2078 & TRN & \\
\hline CHEMBL1501702 & 737824 & 5.35 & 4.908 & TST & \\
\hline CHEMBL489738 & 737824 & 7.2 & 6.8501 & TRN & \\
\hline CHEMBL1256695 & 737824 & 4.6 & 4.7248 & TRN & \\
\hline CHEMBL1571705 & 737824 & 4.8 & 4.7341 & TRN & \\
\hline CHEMBL1532426 & 737824 & 4.4 & 4.0529 & TRN & \\
\hline CHEMBL1335865 & 737824 & 5.45 & 5.5235 & TRN & \\
\hline CHEMBL1612492 & 737824 & 5.45 & 5.4926 & TRN & \\
\hline CHEMBL1392549 & 737824 & 4.8 & 4.9626 & TST & \\
\hline CHEMBL1388771 & 737824 & 5.0 & 5.12299 & 9999999999 & TRN \\
\hline CHEMBL1561402 & 737824 & 5.5 & 5.3797 & TRN & \\
\hline CHEMBL1312725 & 737824 & 4.85 & 5.0773 & TRN & \\
\hline CHEMBL1525957 & 737824 & 5.45 & 5.2673 & TRN & \\
\hline CHEMBL1524127 & 737824 & 4.75 & 4.6283 & TRN & \\
\hline CHEMBL1529327 & 737824 & 5.1 & 5.6752 & TRN & \\
\hline
\end{tabular}




\begin{tabular}{|c|c|c|c|c|}
\hline \multicolumn{5}{|c|}{ pplemental T } \\
\hline CHEMBL1309472 & 737824 & 4.85 & 4.9845 & TST \\
\hline CHEMBL1490143 & 737824 & 5.05 & 5.5721 & TRN \\
\hline CHEMBL1445337 & 737824 & 4.85 & 4.336 & TST \\
\hline CHEMBL1332759 & 737824 & 4.4 & 4.4952 & TRN \\
\hline CHEMBL1610605 & 737824 & 5.1 & 5.3698 & TRN \\
\hline CHEMBL1537962 & 737824 & 4.65 & 4.7972 & TRN \\
\hline CHEMBL1455816 & 737824 & 4.95 & 5.0761 & TST \\
\hline CHEMBL1717461 & 737824 & 4.95 & 5.5092 & TST \\
\hline CHEMBL1548480 & 737824 & 5.9 & 5.5469 & TRN \\
\hline CHEMBL1310701 & 737824 & 5.05 & 4.8725 & TRN \\
\hline CHEMBL1446716 & 737824 & 8.0 & 8.2827 & TST \\
\hline CHEMBL1371510 & 737824 & 5.6 & 5.2188 & TST \\
\hline CHEMBL1427932 & 737824 & 4.85 & 5.6041 & TRN \\
\hline CHEMBL1480742 & 737824 & 4.7 & 4.4089 & TRN \\
\hline CHEMBL1600685 & 737824 & 5.4 & 5.4827 & TRN \\
\hline CHEMBL1596170 & 737824 & 4.8 & 4.592 & TRN \\
\hline CHEMBL2369279 & 737824 & 4.75 & 5.1606 & TRN \\
\hline CHEMBL3193466 & 737824 & 5.7 & 5.3184 & TRN \\
\hline CHEMBL1334847 & 737824 & 4.9 & 4.7747 & TRN \\
\hline CHEMBL1603700 & 737824 & 5.65 & 4.9249 & TRN \\
\hline CHEMBL3196672 & 737824 & 4.7 & 5.3106 & TRN \\
\hline CHEMBL1316557 & 737824 & 4.6 & 4.4525 & TRN \\
\hline CHEMBL1321118 & 737824 & 4.9 & 4.6118 & TRN \\
\hline CHEMBL1363193 & 737824 & 5.15 & 4.8219 & TST \\
\hline CHEMBL1416414 & 737824 & 4.6 & 5.0883 & TRN \\
\hline CHEMBL1329460 & 737824 & 5.05 & 4.9511 & TRN \\
\hline CHEMBL1302342 & 737824 & 4.85 & 5.0321 & TRN \\
\hline CHEMBL1302086 & 737824 & 5.3 & 4.8403 & TST \\
\hline CHEMBL1409078 & 737824 & 4.9 & 5.5515 & TRN \\
\hline CHEMBL1494695 & 737824 & 5.5 & 5.3163 & TRN \\
\hline CHEMBL1710426 & 737824 & 4.7 & 5.0643 & TRN \\
\hline CHEMBL1573244 & 737824 & 4.5 & 5.4111 & TST \\
\hline CHEMBL1463140 & 737824 & 5.0 & 5.3392 & TRN \\
\hline CHEMBL1588072 & 737824 & 4.9 & 5.0264 & TRN \\
\hline CHEMBL1414317 & 737824 & 5.25 & 5.2737 & TST \\
\hline CHEMBL1327247 & 737824 & 4.7 & 4.4157 & TRN \\
\hline CHEMBL1341727 & 737824 & 4.85 & 4.6864 & TRN \\
\hline CHEMBL1306550 & 737824 & 4.9 & 5.1938 & TRN \\
\hline CHEMBL1741905 & 737824 & 5.5 & 5.1136 & TRN \\
\hline CHEMBL1587575 & 737824 & 5.3 & 4.7206 & TRN \\
\hline CHEMBL1397825 & 737824 & 5.3 & 5.2993 & TRN \\
\hline CHEMBL601616 & 737824 & 5.75 & 5.5599 & TRN \\
\hline CHEMBL1403482 & 737824 & 6.6 & 5.8572 & TRN \\
\hline CHEMBL1609497 & 737824 & 5.1 & 5.4859 & TST \\
\hline CHEMBL1543793 & 737824 & 5.4 & 5.096 & TRN \\
\hline CHEMBL1511207 & 737824 & 5.1 & 5.0673 & TRN \\
\hline CHEMBL1555519 & 737824 & 5.5 & 5.6117 & TRN \\
\hline CHEMBL1554826 & 737824 & 4.4 & 4.084 & TRN \\
\hline
\end{tabular}




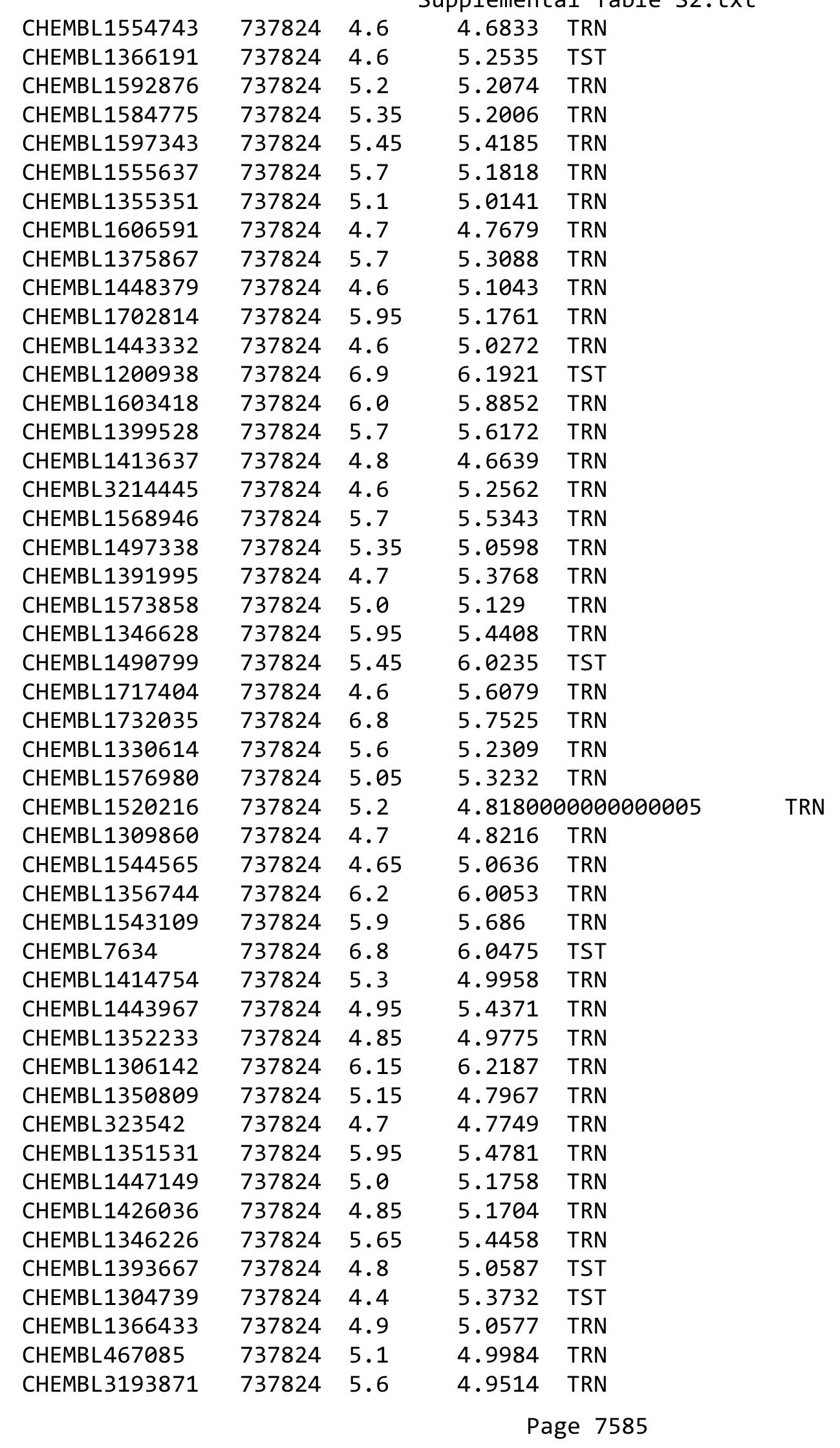




\begin{tabular}{|c|c|c|c|c|c|}
\hline \multirow{2}{*}{ CHEMBL1561346 } & \multirow{2}{*}{737824} & \\
\hline & & 4.8 & 5.1005 & TRN & \\
\hline CHEMBL1571550 & 737824 & 4.7 & 5.1481 & TST & \\
\hline CHEMBL1399898 & 737824 & 5.75 & 5.7845 & TRN & \\
\hline CHEMBL1372210 & 737824 & 5.45 & 5.6412 & TRN & \\
\hline CHEMBL1366296 & 737824 & 4.4 & 4.3487 & TRN & \\
\hline CHEMBL1495875 & 737824 & 4.9 & 4.4099 & TRN & \\
\hline CHEMBL198159 & 737824 & 5.7 & 5.4927 & TRN & \\
\hline CHEMBL1340140 & 737824 & 8.25 & 5.6842 & TRN & \\
\hline CHEMBL1397902 & 737824 & 5.6 & 5.5556 & TRN & \\
\hline CHEMBL1388862 & 737824 & 4.4 & 5.1733 & TRN & \\
\hline CHEMBL1470632 & 737824 & 4.75 & 4.9065 & TRN & \\
\hline CHEMBL1481746 & 737824 & 5.75 & 5.3468 & TST & \\
\hline CHEMBL1316055 & 737824 & 5.4 & 5.3413 & TRN & \\
\hline CHEMBL1496074 & 737824 & 5.0 & 5.4584 & TRN & \\
\hline CHEMBL1603268 & 737824 & 6.0 & 4.8524 & TST & \\
\hline CHEMBL1437985 & 737824 & 4.85 & 4.7472 & TST & \\
\hline CHEMBL1490181 & 737824 & 5.3 & 5.6079 & TRN & \\
\hline CHEMBL1718033 & 737824 & 4.75 & 5.2371 & TRN & \\
\hline CHEMBL1333454 & 737824 & 5.3 & 5.1363 & TRN & \\
\hline CHEMBL410873 & 737824 & 4.4 & 4.0162 & TST & \\
\hline CHEMBL1335726 & 737824 & 6.2 & 5.66100 & 00000000005 & TRN \\
\hline CHEMBL1591374 & 737824 & 4.7 & 4.7973 & TRN & \\
\hline CHEMBL1565361 & 737824 & 5.45 & 5.3909 & TRN & \\
\hline CHEMBL1471920 & 737824 & 5.7 & 5.5481 & TRN & \\
\hline CHEMBL1301725 & 737824 & 6.05 & 5.6376 & TRN & \\
\hline CHEMBL1599025 & 737824 & 4.85 & 4.9331 & TRN & \\
\hline CHEMBL1503501 & 737824 & 4.85 & 4.9298 & TRN & \\
\hline CHEMBL1521830 & 737824 & 5.35 & 5.7505 & TRN & \\
\hline CHEMBL1406640 & 737824 & 4.85 & 5.0996 & TRN & \\
\hline CHEMBL1561156 & 737824 & 4.75 & 5.7011 & TRN & \\
\hline CHEMBL3192627 & 737824 & 5.9 & 4.8552 & TRN & \\
\hline CHEMBL 1481348 & 737824 & 5.15 & 5.4515 & TRN & \\
\hline CHEMBL1343240 & 737824 & 5.3 & 5.2055 & TRN & \\
\hline CHEMBL1564032 & 737824 & 4.9 & 5.1113 & TRN & \\
\hline CHEMBL1571395 & 737824 & 4.7 & 5.5699 & TRN & \\
\hline CHEMBL1465250 & 737824 & 4.9 & 5.1633 & TRN & \\
\hline CHEMBL1349061 & 737824 & 5.05 & 5.4082 & TST & \\
\hline CHEMBL1434460 & 737824 & -0.0 & 4.5288 & TRN & \\
\hline CHEMBL1563546 & 737824 & 5.55 & 5.3837 & TRN & \\
\hline CHEMBL1980826 & 737824 & 5.05 & 5.3482 & TRN & \\
\hline CHEMBL1586835 & 737824 & 4.9 & 5.2649 & TRN & \\
\hline CHEMBL1566202 & 737824 & 4.4 & 4.955 & TRN & \\
\hline CHEMBL1255940 & 737824 & 4.9 & 4.9628 & TST & \\
\hline CHEMBL1483972 & 737824 & 4.4 & 5.6361 & TRN & \\
\hline CHEMBL1416055 & 737824 & 6.1 & 6.034 & TST & \\
\hline CHEMBL1462161 & 737824 & 5.55 & 5.2086 & TRN & \\
\hline CHEMBL1399994 & 737824 & 7.7001 & 7.2825 & TRN & \\
\hline CHEMBL1501395 & 737824 & 5.5 & 5.52 & TST & \\
\hline & & & & 7586 & \\
\hline
\end{tabular}




\begin{tabular}{|c|c|c|c|c|}
\hline \multicolumn{5}{|c|}{ lemental T } \\
\hline CHEMBL1305594 & 737824 & 4.5 & 5.0078 & TRN \\
\hline CHEMBL1514440 & 737824 & 6.0 & 5.9853 & TRN \\
\hline CHEMBL1403488 & 737824 & 5.3 & 4.7467 & TRN \\
\hline CHEMBL1447745 & 737824 & 5.3 & 5.1649 & TRN \\
\hline CHEMBL1524866 & 737824 & 5.15 & 5.0526 & TST \\
\hline CHEMBL 313833 & 737824 & 6.0 & 5.874 & TST \\
\hline CHEMBL1562895 & 737824 & 5.6 & 5.4961 & TRN \\
\hline CHEMBL1419672 & 737824 & 5.2 & 5.5955 & TRN \\
\hline CHEMBL1454463 & 737824 & 5.0 & 5.0925 & TRN \\
\hline CHEMBL1370601 & 737824 & 5.3 & 5.3706 & TRN \\
\hline CHEMBL1354272 & 737824 & 4.4 & 4.5476 & TRN \\
\hline CHEMBL1513985 & 737824 & 4.6 & 4.7526 & TRN \\
\hline CHEMBL247129 & 737824 & 5.05 & 5.1531 & TST \\
\hline CHEMBL1515449 & 737824 & 8.0 & 8.0729 & TRN \\
\hline CHEMBL1368357 & 737824 & 5.5 & 5.3849 & TRN \\
\hline CHEMBL1310757 & 737824 & 4.45 & 4.7622 & TRN \\
\hline CHEMBL1489551 & 737824 & 5.8 & 5.6636 & TRN \\
\hline CHEMBL1426944 & 737824 & 4.55 & 4.8306 & TRN \\
\hline CHEMBL1303347 & 737824 & 4.5 & 4.8411 & TRN \\
\hline CHEMBL1501014 & 737824 & 4.9 & 5.0018 & TRN \\
\hline CHEMBL1256646 & 737824 & 4.5 & 4.5433 & TST \\
\hline CHEMBL1559023 & 737824 & 5.1 & 4.6028 & TRN \\
\hline CHEMBL1526421 & 737824 & 5.55 & 5.3278 & TRN \\
\hline CHEMBL411502 & 737824 & 4.4 & 3.7856 & TRN \\
\hline CHEMBL1373151 & 737824 & 4.9 & 4.8092 & TRN \\
\hline CHEMBL1355537 & 737824 & 5.1 & 4.5718 & TST \\
\hline CHEMBL1598994 & 737824 & 4.8 & 4.859 & TRN \\
\hline CHEMBL1416681 & 737824 & 4.95 & 4.6487 & TST \\
\hline CHEMBL1601908 & 737824 & 4.9 & 4.706 & TRN \\
\hline CHEMBL1514953 & 737824 & 5.4 & 5.1275 & TRN \\
\hline CHEMBL1403023 & 737824 & 4.85 & 5.0198 & TRN \\
\hline CHEMBL1599132 & 737824 & 5.15 & 5.2424 & TRN \\
\hline CHEMBL1304201 & 737824 & 5.2 & 5.2431 & TRN \\
\hline CHEMBL1590259 & 737824 & 4.9 & 4.7673 & TRN \\
\hline CHEMBL582444 & 737824 & 5.0 & 5.489 & TST \\
\hline CHEMBL1360327 & 737824 & 5.55 & 5.0687 & TST \\
\hline CHEMBL1538763 & 737824 & 4.85 & 5.2835 & TRN \\
\hline CHEMBL1423092 & 737824 & 4.65 & 5.7303 & TRN \\
\hline CHEMBL1381111 & 737824 & 5.2 & 5.4135 & TRN \\
\hline CHEMBL1448473 & 737824 & 4.9 & 5.6143 & TRN \\
\hline CHEMBL1301014 & 737824 & 4.65 & 5.1463 & TRN \\
\hline CHEMBL1741816 & 737824 & 5.75 & 5.072 & TST \\
\hline CHEMBL489737 & 737824 & 5.8 & 5.9635 & TRN \\
\hline CHEMBL1741539 & 737824 & 4.7 & 4.8749 & TST \\
\hline CHEMBL1612346 & 737824 & 5.4 & 5.1475 & TRN \\
\hline CHEMBL1386277 & 737824 & 5.6 & 5.2561 & TRN \\
\hline CHEMBL1360601 & 737824 & 5.7 & 5.4528 & TRN \\
\hline CHEMBL1306540 & 737824 & 5.0 & 5.6111 & TRN \\
\hline
\end{tabular}




\begin{tabular}{|c|c|c|c|c|}
\hline \multicolumn{5}{|c|}{ Supplemental Table S2.txt } \\
\hline CHEMBL1408735 & 737824 & 5.5 & 5.4689 & TRN \\
\hline CHEMBL1508044 & 737824 & 4.7 & 4.9699 & TRN \\
\hline CHEMBL1598317 & 737824 & 5.65 & 5.0086 & TRN \\
\hline CHEMBL1593663 & 737824 & 4.4 & 4.5958 & TRN \\
\hline CHEMBL1590909 & 737824 & 5.8 & 5.8739 & TRN \\
\hline CHEMBL1529777 & 737824 & 4.55 & 4.7615 & TRN \\
\hline CHEMBL1582272 & 737824 & 5.95 & 5.1887 & TST \\
\hline CHEMBL1345648 & 737824 & 4.85 & 5.5899 & TRN \\
\hline CHEMBL1456688 & 737824 & 5.6 & 5.4228 & TRN \\
\hline CHEMBL3198037 & 737824 & 4.6 & 5.518 & TRN \\
\hline CHEMBL1365236 & 737824 & 4.7 & 4.6744 & TRN \\
\hline CHEMBL1327505 & 737824 & 5.9 & 5.2454 & TRN \\
\hline CHEMBL1468831 & 737824 & 4.4 & 5.0352 & TRN \\
\hline CHEMBL1400427 & 737824 & 5.7 & 5.693 & TRN \\
\hline CHEMBL1547186 & 737824 & 4.75 & 5.1409 & TST \\
\hline CHEMBL1741327 & 737824 & 4.9 & 5.4534 & TRN \\
\hline CHEMBL1343639 & 737824 & 6.2 & 5.6803 & TRN \\
\hline CHEMBL1518970 & 737824 & 5.25 & 5.3183 & TRN \\
\hline CHEMBL1328339 & 737824 & 4.4 & 4.5378 & TRN \\
\hline CHEMBL1966657 & 737824 & 6.1 & 4.9929 & TRN \\
\hline CHEMBL1537609 & 737824 & 5.45 & 5.1372 & TRN \\
\hline CHEMBL1564579 & 737824 & 5.55 & 5.4326 & TRN \\
\hline CHEMBL491547 & 737824 & 5.6 & 5.4975 & TRN \\
\hline CHEMBL1543168 & 737824 & 5.35 & 5.4592 & TRN \\
\hline CHEMBL 3212521 & 737824 & 5.5 & 5.8939 & TRN \\
\hline CHEMBL1478806 & 737824 & 6.1 & 5.2384 & TRN \\
\hline CHEMBL1401483 & 737824 & 4.5 & 4.2279 & TRN \\
\hline CHEMBL1703723 & 737824 & 6.95 & 5.7345 & TRN \\
\hline CHEMBL1560487 & 737824 & 6.95 & 5.3672 & TRN \\
\hline CHEMBL1728635 & 737824 & 5.45 & 5.0607 & TRN \\
\hline CHEMBL1742103 & 737824 & 4.4 & 5.4146 & TST \\
\hline CHEMBL1345927 & 737824 & 4.85 & 4.978 & TRN \\
\hline CHEMBL1595524 & 737824 & 4.6 & 4.5065 & TST \\
\hline CHEMBL3196775 & 737824 & 5.05 & 5.5741 & TRN \\
\hline CHEMBL1471546 & 737824 & 5.1 & 5.5932 & TST \\
\hline CHEMBL1552551 & 737824 & 6.0 & 6.3038 & TRN \\
\hline CHEMBL1484181 & 737824 & 4.5 & 5.006 & TRN \\
\hline CHEMBL1452221 & 737824 & 5.6 & 5.7143 & TRN \\
\hline CHEMBL1537183 & 737824 & 4.8 & 4.9285 & TRN \\
\hline CHEMBL1530194 & 737824 & 5.2 & 5.58 & TRN \\
\hline CHEMBL1385495 & 737824 & 4.8 & 5.3252 & TRN \\
\hline CHEMBL1533144 & 737824 & 5.4 & 5.3794 & TRN \\
\hline CHEMBL1570851 & 737824 & 5.7 & 5.6811 & TRN \\
\hline CHEMBL1601844 & 737824 & 4.8 & 4.9881 & TRN \\
\hline CHEMBL1428001 & 737824 & 4.6 & 4.7475 & TRN \\
\hline CHEMBL1537075 & 737824 & 4.75 & 5.1185 & TRN \\
\hline CHEMBL1409446 & 737824 & 5.3 & 5.3779 & TRN \\
\hline CHEMBL1543887 & 737824 & 6.55 & 5.4619 & TRN \\
\hline
\end{tabular}




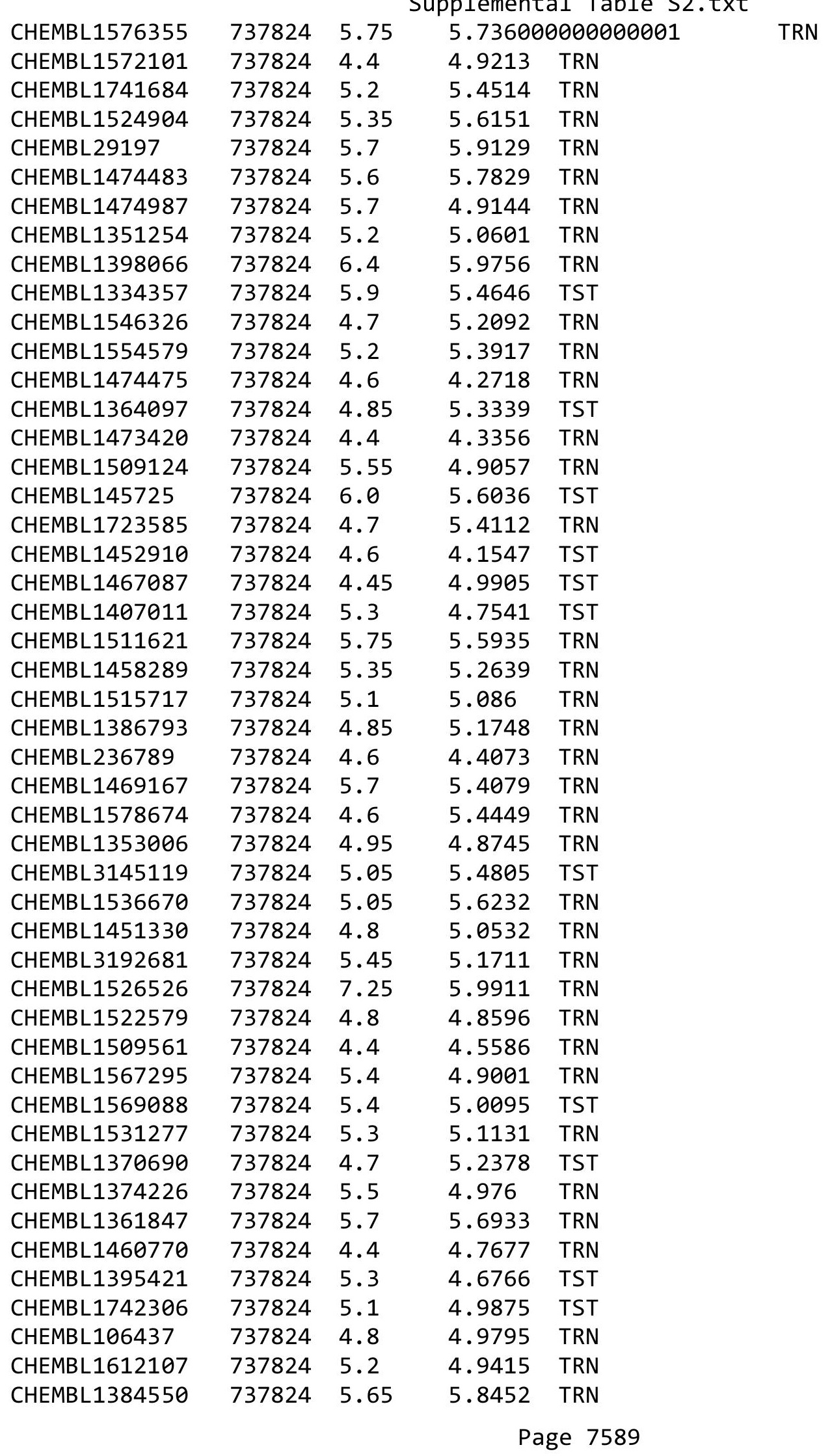




\begin{tabular}{|c|c|c|c|c|c|}
\hline \\
\hline CHEMBL1387587 & 737824 & 4.6 & 5.1566 & TST & \\
\hline CHEMBL1439631 & 737824 & 5.1 & \multicolumn{2}{|c|}{5.361000000000001} & TRN \\
\hline CHEMBL1458660 & 737824 & 5.85 & 5.7856 & TRN & \\
\hline CHEMBL1315268 & 737824 & 5.4 & 4.8684 & TRN & \\
\hline CHEMBL1331690 & 737824 & 4.6 & 4.8002 & TRN & \\
\hline CHEMBL1333968 & 737824 & 4.7 & 4.6928 & TRN & \\
\hline CHEMBL1449916 & 737824 & 7.6 & 5.6102 & TRN & \\
\hline CHEMBL1416009 & 737824 & 6.2 & 5.816 & TST & \\
\hline CHEMBL1371014 & 737824 & 4.9 & 5.0564 & TRN & \\
\hline CHEMBL1376097 & 737824 & 4.55 & 4.8878 & TRN & \\
\hline CHEMBL1383532 & 737824 & 4.95 & 5.226 & TST & \\
\hline CHEMBL1461075 & 737824 & 4.85 & 4.9894 & TRN & \\
\hline CHEMBL1428167 & 737824 & 4.55 & 4.6329 & TRN & \\
\hline CHEMBL1551051 & 737824 & 4.5 & 4.8611 & TRN & \\
\hline CHEMBL1329507 & 737824 & 4.85 & 5.2389 & TRN & \\
\hline CHEMBL1741917 & 737824 & 4.65 & 4.9472 & TRN & \\
\hline CHEMBL1311749 & 737824 & 5.3 & 5.0441 & TST & \\
\hline CHEMBL1436832 & 737824 & 4.5 & 4.6794 & TRN & \\
\hline CHEMBL3213185 & 737824 & 5.2 & 4.8185 & TRN & \\
\hline CHEMBL1491104 & 737824 & 6.5 & 6.5099 & TRN & \\
\hline CHEMBL1330751 & 737824 & 5.7 & 5.7777 & TRN & \\
\hline CHEMBL1470136 & 737824 & 5.7 & 5.254 & TRN & \\
\hline CHEMBL1414719 & 737824 & 5.85 & 5.4495 & TRN & \\
\hline CHEMBL1602964 & 737824 & 4.8 & 5.4157 & TST & \\
\hline CHEMBL1590123 & 737824 & 4.4 & 4.8985 & TRN & \\
\hline CHEMBL1419252 & 737824 & 4.4 & 5.4125 & TST & \\
\hline CHEMBL1512740 & 737824 & 4.4 & 4.4836 & TRN & \\
\hline CHEMBL1741551 & 737824 & 5.3 & 5.1572 & TRN & \\
\hline CHEMBL1612774 & 737824 & 5.3 & 5.4234 & TRN & \\
\hline CHEMBL1741768 & 737824 & 4.4 & 5.1424 & TRN & \\
\hline CHEMBL1546667 & 737824 & 6.2 & 5.3172 & TRN & \\
\hline CHEMBL1371975 & 737824 & 4.7 & 5.1508 & TST & \\
\hline CHEMBL479219 & 737824 & 4.8 & 4.7955 & TRN & \\
\hline CHEMBL1392767 & 737824 & 5.05 & 5.2939 & TRN & \\
\hline CHEMBL1566670 & 737824 & 4.4 & 4.3747 & TRN & \\
\hline CHEMBL1537750 & 737824 & 5.1 & 5.1846 & TRN & \\
\hline CHEMBL1502553 & 737824 & 4.95 & 4.9922 & TRN & \\
\hline CHEMBL1451387 & 737824 & 4.8 & 5.2828 & TST & \\
\hline CHEMBL1529478 & 737824 & 5.1 & 5.1724 & TRN & \\
\hline CHEMBL1517085 & 737824 & 5.55 & 5.5832 & TRN & \\
\hline CHEMBL1349528 & 737824 & 5.0 & 4.9572 & TRN & \\
\hline CHEMBL3191244 & 737824 & 5.0 & 5.0502 & TRN & \\
\hline CHEMBL1541799 & 737824 & 4.95 & 5.2285 & TRN & \\
\hline CHEMBL1310481 & 737824 & 4.45 & 5.0976 & TRN & \\
\hline CHEMBL1447244 & 737824 & 5.25 & 4.7541 & TRN & \\
\hline CHEMBL1521352 & 737824 & 4.7 & 5.2617 & TRN & \\
\hline CHEMBL1411148 & 737824 & 4.9 & 5.2031 & TST & \\
\hline CHEMBL1322757 & 737824 & 5.7 & 5.8678 & TRN & \\
\hline
\end{tabular}




\begin{tabular}{|c|c|c|c|c|c|}
\hline \multicolumn{6}{|c|}{ Supplemental Table S2.txt } \\
\hline CHEMBL1586326 & 737824 & 5.35 & 5.282 & TRN & \\
\hline CHEMBL1392952 & 737824 & 5.35 & 5.1948 & TRN & \\
\hline CHEMBL490717 & 737824 & 4.9 & 4.7171 & TRN & \\
\hline CHEMBL1526673 & 737824 & 5.2 & 5.2562 & TRN & \\
\hline CHEMBL1729474 & 737824 & 5.35 & 5.7462 & TRN & \\
\hline CHEMBL490749 & 737824 & 6.0 & 5.8953 & TRN & \\
\hline CHEMBL1370701 & 737824 & 4.95 & 5.2369 & TRN & \\
\hline CHEMBL 3208805 & 737824 & 4.9 & 5.1697 & TRN & \\
\hline CHEMBL1741665 & 737824 & 4.6 & 5.0828 & TRN & \\
\hline CHEMBL1400015 & 737824 & 5.1 & 4.9992 & TRN & \\
\hline CHEMBL1452932 & 737824 & 5.95 & 5.1937 & TRN & \\
\hline CHEMBL1422796 & 737824 & 5.35 & 4.9609 & TRN & \\
\hline CHEMBL1306988 & 737824 & 4.7 & 5.0097 & TRN & \\
\hline CHEMBL1381224 & 737824 & 5.6 & 5.1978 & TRN & \\
\hline CHEMBL1575849 & 737824 & 5.0 & 4.8095 & TRN & \\
\hline CHEMBL1544821 & 737824 & 5.35 & 5.9731 & TRN & \\
\hline CHEMBL1363275 & 737824 & 5.9 & 5.6782 & TRN & \\
\hline CHEMBL1343750 & 737824 & 5.1 & 5.2667 & TRN & \\
\hline CHEMBL1605334 & 737824 & 5.4 & 5.2245 & TRN & \\
\hline CHEMBL1417140 & 737824 & 4.9 & 4.6719 & TRN & \\
\hline CHEMBL1392868 & 737824 & 4.9 & 5.0014 & TRN & \\
\hline CHEMBL1455919 & 737824 & 4.55 & 4.8433 & TRN & \\
\hline CHEMBL1706244 & 737824 & 5.1 & 5.3307 & TRN & \\
\hline CHEMBL1724748 & 737824 & 5.5 & 5.4232 & TRN & \\
\hline CHEMBL1451149 & 737824 & 5.5 & 5.381 & TRN & \\
\hline CHEMBL256835 & 737824 & 5.1 & 4.8121 & TRN & \\
\hline CHEMBL1367951 & 737824 & 4.8 & 5.1195 & TRN & \\
\hline CHEMBL1326466 & 737824 & 5.1 & 5.1318 & TRN & \\
\hline CHEMBL1469862 & 737824 & 6.6 & 5.8995 & TRN & \\
\hline CHEMBL1589130 & 737824 & 5.5 & 5.2673 & TRN & \\
\hline CHEMBL1728559 & 737824 & 4.65 & 5.0717 & TRN & \\
\hline CHEMBL1361022 & 737824 & 5.65 & 5.5281 & TRN & \\
\hline CHEMBL1503434 & 737824 & 4.75 & 5.3055 & TRN & \\
\hline CHEMBL1396463 & 737824 & 4.6 & 4.9051 & TST & \\
\hline CHEMBL1317805 & 737824 & 6.5 & 6.46299 & 9999999999 & TRN \\
\hline CHEMBL1314273 & 737824 & 7.2 & 6.8137 & TRN & \\
\hline CHEMBL1427943 & 737824 & 5.0 & 5.2241 & TRN & \\
\hline CHEMBL1442060 & 737824 & 5.15 & 5.2198 & TRN & \\
\hline CHEMBL1488477 & 737824 & 4.9 & 4.9981 & TRN & \\
\hline CHEMBL1490500 & 737824 & 5.1 & 5.3435 & TST & \\
\hline CHEMBL1349875 & 737824 & 5.0 & 4.7793 & TRN & \\
\hline CHEMBL3191489 & 737824 & 6.1 & 5.3507 & TRN & \\
\hline CHEMBL1479479 & 737824 & 4.75 & 4.8588 & TRN & \\
\hline CHEMBL1508837 & 737824 & 7.8 & 5.119 & TRN & \\
\hline CHEMBL1613049 & 737824 & 4.85 & 5.5276 & TRN & \\
\hline CHEMBL1519435 & 737824 & 5.8 & 5.7553 & TRN & \\
\hline CHEMBL1457262 & 737824 & 5.0 & 4.5529 & TRN & \\
\hline CHEMBL1463991 & 737824 & 4.6 & 5.0213 & TRN & \\
\hline
\end{tabular}




\begin{tabular}{|c|c|c|c|c|}
\hline \multicolumn{5}{|c|}{ Supplemental Table S2.txt } \\
\hline CHEMBL1312105 & 737824 & 5.65 & 5.2883 & TRN \\
\hline CHEMBL1472118 & 737824 & 4.85 & 4.8896 & TRN \\
\hline CHEMBL1314625 & 737824 & 5.1 & 5.3093 & TRN \\
\hline CHEMBL1529330 & 737824 & 4.8 & 4.832 & TRN \\
\hline CHEMBL1482968 & 737824 & 4.4 & 4.0862 & TRN \\
\hline CHEMBL1311791 & 737824 & 4.4 & 5.2734 & TRN \\
\hline CHEMBL1362464 & 737824 & 5.15 & 5.2891 & TRN \\
\hline CHEMBL1323894 & 737824 & 4.4 & 5.1487 & TST \\
\hline CHEMBL1501140 & 737824 & 5.65 & 5.8021 & TRN \\
\hline CHEMBL1607187 & 737824 & 5.1 & 4.999 & TRN \\
\hline CHEMBL1539526 & 737824 & 5.9 & 5.6392 & TST \\
\hline CHEMBL1534082 & 737824 & 4.9 & 5.0079 & TRN \\
\hline CHEMBL1563772 & 737824 & 6.45 & 5.6685 & TRN \\
\hline CHEMBL1591745 & 737824 & 6.4 & 5.9855 & TST \\
\hline CHEMBL1580265 & 737824 & 4.9 & 5.6145 & TRN \\
\hline CHEMBL1492266 & 737824 & 5.35 & 5.2305 & TST \\
\hline CHEMBL1575899 & 737824 & 5.4 & 5.2225 & TRN \\
\hline CHEMBL1395098 & 737824 & 4.8 & 4.9391 & TRN \\
\hline CHEMBL1547372 & 737824 & 4.95 & 4.9514 & TRN \\
\hline CHEMBL1717970 & 737824 & 5.4 & 4.683 & TRN \\
\hline CHEMBL1544265 & 737824 & 5.5 & 5.4642 & TRN \\
\hline CHEMBL1540956 & 737824 & 5.15 & 5.4562 & TRN \\
\hline CHEMBL1454954 & 737824 & 4.9 & 5.0983 & TRN \\
\hline CHEMBL420539 & 737824 & 4.9 & 4.8216 & TRN \\
\hline CHEMBL3212657 & 737824 & 5.7 & 5.4022 & TRN \\
\hline CHEMBL1412756 & 737824 & 5.4 & 5.5031 & TRN \\
\hline CHEMBL1349620 & 737824 & 4.85 & 4.9469 & TRN \\
\hline CHEMBL1408422 & 737824 & 5.0 & 4.8302 & TRN \\
\hline CHEMBL1487316 & 737824 & 6.3 & 5.4336 & TRN \\
\hline CHEMBL1518620 & 737824 & 4.8 & 5.3536 & TST \\
\hline CHEMBL1481608 & 737824 & 5.2 & 5.3804 & TRN \\
\hline CHEMBL1372282 & 737824 & 6.3 & 5.956 & TST \\
\hline CHEMBL1512780 & 737824 & 5.1 & 4.8002 & TRN \\
\hline CHEMBL1346159 & 737824 & 5.65 & 5.7213 & TST \\
\hline CHEMBL1517176 & 737824 & 5.3 & 5.353 & TRN \\
\hline CHEMBL1300098 & 737824 & 4.85 & 5.597 & TRN \\
\hline CHEMBL543557 & 737824 & 5.1 & 4.5818 & TRN \\
\hline CHEMBL1471304 & 737824 & 4.85 & 5.3907 & TRN \\
\hline CHEMBL1561570 & 737824 & 5.35 & 5.7666 & TRN \\
\hline CHEMBL1464066 & 737824 & 4.95 & 5.6062 & TRN \\
\hline CHEMBL1313701 & 737824 & 5.1 & 5.2706 & TRN \\
\hline CHEMBL1439518 & 737824 & 5.6 & 5.3842 & TRN \\
\hline CHEMBL1505689 & 737824 & 5.55 & 5.3431 & TRN \\
\hline CHEMBL1382735 & 737824 & 4.9 & 5.1274 & TRN \\
\hline CHEMBL1438371 & 737824 & 4.9 & 4.9747 & TRN \\
\hline CHEMBL1719114 & 737824 & 4.95 & 4.9984 & TRN \\
\hline CHEMBL1453369 & 737824 & 4.95 & 5.1938 & TRN \\
\hline CHEMBL1491786 & 737824 & 5.9 & 5.3935 & TRN \\
\hline
\end{tabular}




\begin{tabular}{|c|c|c|c|c|c|}
\hline \multicolumn{6}{|c|}{ Supplemental Table S2.txt } \\
\hline CHEMBL1333519 & 737824 & 6.75 & 6.0313 & TRN & \\
\hline CHEMBL1351404 & 737824 & 4.9 & 5.3253 & TST & \\
\hline CHEMBL1363142 & 737824 & 5.5 & 5.4972 & TRN & \\
\hline CHEMBL31741 & 737824 & 4.5 & 4.71399 & 99999999995 & TST \\
\hline CHEMBL1340517 & 737824 & 8.8499 & 5.4527 & TRN & \\
\hline CHEMBL1330483 & 737824 & 4.4 & 4.8617 & TRN & \\
\hline CHEMBL1337096 & 737824 & 5.85 & 5.2711 & TRN & \\
\hline CHEMBL3197456 & 737824 & 4.95 & 5.2513 & TRN & \\
\hline CHEMBL1403121 & 737824 & 4.9 & 5.0548 & TRN & \\
\hline CHEMBL1410599 & 737824 & 5.45 & 5.4217 & TRN & \\
\hline CHEMBL1497637 & 737824 & 6.5 & 5.7944 & TRN & \\
\hline CHEMBL475375 & 737824 & 5.4 & 5.3628 & TRN & \\
\hline CHEMBL1436323 & 737824 & 5.9 & 5.7371 & TRN & \\
\hline CHEMBL1997220 & 737824 & 5.1 & 5.3986 & TRN & \\
\hline CHEMBL28 & 737824 & 5.1 & 5.7442 & TRN & \\
\hline CHEMBL1392169 & 737824 & 5.6 & 5.3275 & TRN & \\
\hline CHEMBL1602710 & 737824 & 4.4 & 3.8479 & TRN & \\
\hline CHEMBL1504240 & 737824 & 5.2 & 5.1449 & TRN & \\
\hline CHEMBL1591956 & 737824 & 4.9 & 5.2025 & TRN & \\
\hline CHEMBL1375365 & 737824 & 4.9 & 4.9633 & TRN & \\
\hline CHEMBL1576517 & 737824 & 6.0 & 4.9084 & TST & \\
\hline CHEMBL1464417 & 737824 & 7.05 & 6.0005 & TRN & \\
\hline CHEMBL1502327 & 737824 & 4.95 & 5.2134 & TST & \\
\hline CHEMBL1331031 & 737824 & 5.0 & 4.9074 & TRN & \\
\hline CHEMBL1415406 & 737824 & 5.2 & 5.0303 & TRN & \\
\hline CHEMBL1533607 & 737824 & 4.45 & 5.5258 & TRN & \\
\hline CHEMBL1482510 & 737824 & 5.6 & 5.4126 & TRN & \\
\hline CHEMBL1311780 & 737824 & 4.9 & 5.25799 & 9999999999 & TRN \\
\hline CHEMBL1559828 & 737824 & 5.65 & 5.405 & TRN & \\
\hline CHEMBL1482677 & 737824 & 4.4 & 4.8192 & TRN & \\
\hline CHEMBL1398050 & 737824 & 4.7 & 4.6928 & TRN & \\
\hline CHEMBL1372037 & 737824 & 5.5 & 5.5744 & TRN & \\
\hline CHEMBL1599748 & 737824 & 6.0 & 5.55 & TRN & \\
\hline CHEMBL1487819 & 737824 & 5.2 & 5.46399 & 99999999995 & TRN \\
\hline CHEMBL1558201 & 737824 & 6.3 & 6.2069 & TRN & \\
\hline CHEMBL1409686 & 737824 & 5.9 & 5.4097 & TRN & \\
\hline CHEMBL1385943 & 737824 & 4.95 & 5.1042 & TRN & \\
\hline CHEMBL1526199 & 737824 & 7.15 & 5.8277 & TRN & \\
\hline CHEMBL1370244 & 737824 & 5.55 & 5.21200 & 0000000001 & TRN \\
\hline CHEMBL1343632 & 737824 & 4.95 & 5.0304 & TRN & \\
\hline CHEMBL1530472 & 737824 & 4.55 & 5.1272 & TRN & \\
\hline CHEMBL1592213 & 737824 & 4.4 & 4.1966 & TRN & \\
\hline CHEMBL1424953 & 737824 & 5.5 & 5.641 & TRN & \\
\hline CHEMBL1483302 & 737824 & 5.55 & 5.6683 & TRN & \\
\hline CHEMBL1448726 & 737824 & 4.4 & 4.2202 & TRN & \\
\hline CHEMBL1560296 & 737824 & 5.05 & 5.2118 & TRN & \\
\hline CHEMBL1491778 & 737824 & 4.6 & 5.1456 & TRN & \\
\hline CHEMBL1391390 & 737824 & 5.05 & 5.2849 & TRN & \\
\hline
\end{tabular}




\begin{tabular}{|c|c|c|c|c|c|}
\hline \multicolumn{6}{|c|}{ Supplemental Table S2.txt } \\
\hline CHEMBL3192647 & 737824 & 6.35 & 5.81 & TRN & \\
\hline CHEMBL1598666 & 737824 & 5.45 & 5.3795 & TRN & \\
\hline CHEMBL1554717 & 737824 & 6.3 & 5.7659 & TRN & \\
\hline CHEMBL1719583 & 737824 & 5.25 & 4.8493 & TST & \\
\hline CHEMBL1497812 & 737824 & 4.8 & 5.0919 & TRN & \\
\hline CHEMBL1565597 & 737824 & 4.55 & 5.0529 & TRN & \\
\hline CHEMBL1532597 & 737824 & 6.3 & 6.1186 & TRN & \\
\hline CHEMBL1513740 & 737824 & 5.2 & 5.0586 & TRN & \\
\hline CHEMBL1389815 & 737824 & 4.9 & 5.4168 & TRN & \\
\hline CHEMBL1565842 & 737824 & 4.4 & 4.4261 & TST & \\
\hline CHEMBL1480575 & 737824 & 5.55 & 5.7564 & TRN & \\
\hline CHEMBL1442106 & 737824 & 5.0 & 4.6668 & TRN & \\
\hline CHEMBL1416235 & 737824 & 5.25 & 5.8442 & TRN & \\
\hline CHEMBL1468982 & 737824 & 4.9 & 5.5582 & TST & \\
\hline CHEMBL457665 & 737824 & 5.1 & 5.0238 & TST & \\
\hline CHEMBL1435885 & 737824 & 5.9 & 5.7229 & TST & \\
\hline CHEMBL1517886 & 737824 & 4.75 & 5.2026 & TRN & \\
\hline CHEMBL1338917 & 737824 & 5.05 & 5.1085 & TRN & \\
\hline CHEMBL1388668 & 737824 & 6.2 & 5.5648 & TRN & \\
\hline CHEMBL1608233 & 737824 & 4.85 & 5.2609 & TRN & \\
\hline CHEMBL1525767 & 737824 & 5.3 & 4.7885 & TRN & \\
\hline CHEMBL1439231 & 737824 & 5.05 & 5.596 & TRN & \\
\hline CHEMBL1568109 & 737824 & 4.85 & 5.2567 & TST & \\
\hline CHEMBL1741648 & 737824 & 5.05 & 4.5979 & TRN & \\
\hline CHEMBL1313121 & 737824 & 5.15 & 5.2311 & TRN & \\
\hline CHEMBL1458191 & 737824 & 5.15 & 5.5436 & TRN & \\
\hline CHEMBL1430749 & 737824 & 5.1 & 5.847 & TRN & \\
\hline CHEMBL1524598 & 737824 & 4.6 & 5.2895 & TRN & \\
\hline CHEMBL1724116 & 737824 & 4.7 & 4.8623 & TRN & \\
\hline CHEMBL1518920 & 737824 & 5.25 & 5.7746 & TRN & \\
\hline CHEMBL1388465 & 737824 & 4.8 & 5.018 & TRN & \\
\hline CHEMBL1504000 & 737824 & 5.5 & 5.539 & TRN & \\
\hline CHEMBL1528911 & 737824 & 6.45 & 5.8963 & TRN & \\
\hline CHEMBL1718203 & 737824 & 5.35 & 5.0525 & TRN & \\
\hline CHEMBL1366061 & 737824 & 6.3 & 5.9823 & TRN & \\
\hline CHEMBL1734883 & 737824 & 4.4 & 4.5872 & TRN & \\
\hline CHEMBL1587603 & 737824 & 4.4 & 4.8929 & TRN & \\
\hline CHEMBL1309272 & 737824 & 5.0 & 5.2374 & TRN & \\
\hline CHEMBL1500383 & 737824 & 5.65 & 5.36799 & 9999999999 & TRN \\
\hline CHEMBL1988621 & 737824 & 5.7 & 5.3225 & TRN & \\
\hline CHEMBL521970 & 737824 & 5.0 & 5.1795 & TRN & \\
\hline CHEMBL1365701 & 737824 & 6.0 & 6.7063 & TRN & \\
\hline CHEMBL3190602 & 737824 & 5.05 & 5.3938 & TRN & \\
\hline CHEMBL1729994 & 737824 & 4.4 & 5.2846 & TRN & \\
\hline CHEMBL1562420 & 737824 & 5.3 & 4.9998 & TRN & \\
\hline CHEMBL1462816 & 737824 & 5.45 & 5.5349 & TRN & \\
\hline CHEMBL1447946 & 737824 & 5.0 & 4.8107 & TRN & \\
\hline CHEMBL1401243 & 737824 & 4.4 & 4.3831 & TRN & \\
\hline
\end{tabular}




\begin{tabular}{|c|c|c|c|c|c|}
\hline & & & & & \\
\hline CHEMBL1419743 & 737824 & 4.6 & 4.6146 & TST & \\
\hline CHEMBL 3207538 & 737824 & 4.45 & 5.2716 & TRN & \\
\hline CHEMBL1611718 & 737824 & 5.0 & 4.9606 & TRN & \\
\hline CHEMBL1551139 & 737824 & 5.7 & 5.7949 & TRN & \\
\hline CHEMBL1461496 & 737824 & 4.4 & 5.0132 & TRN & \\
\hline CHEMBL1301881 & 737824 & 5.55 & 5.3274 & TRN & \\
\hline CHEMBL1373428 & 737824 & 5.8 & 5.3327 & TRN & \\
\hline CHEMBL3194069 & 737824 & 4.85 & 5.2436 & TRN & \\
\hline CHEMBL1599059 & 737824 & 5.15 & 5.0877 & TRN & \\
\hline CHEMBL1306752 & 737824 & 5.8 & 5.61299 & 99999999995 & TRN \\
\hline CHEMBL1496054 & 737824 & 5.15 & 5.1313 & TRN & \\
\hline CHEMBL1544773 & 737824 & 5.15 & 5.2418 & TST & \\
\hline CHEMBL1307282 & 737824 & 5.45 & 5.4383 & TRN & \\
\hline CHEMBL399121 & 737824 & 5.3 & 5.5318 & TST & \\
\hline CHEMBL1725383 & 737824 & 5.4 & 5.3564 & TST & \\
\hline CHEMBL1484447 & 737824 & 4.7 & 4.4255 & TST & \\
\hline CHEMBL3214385 & 737824 & 4.6 & 4.7255 & TRN & \\
\hline CHEMBL1404595 & 737824 & 5.25 & 5.4142 & TRN & \\
\hline CHEMBL1991234 & 737824 & 5.1 & 5.5798 & TST & \\
\hline CHEMBL1449417 & 737824 & 5.4 & 5.39 & TRN & \\
\hline CHEMBL1409830 & 737824 & 5.0 & 4.9009 & TRN & \\
\hline CHEMBL1414666 & 737824 & 4.75 & 5.0476 & TRN & \\
\hline CHEMBL1453354 & 737824 & 5.55 & 5.3649 & TRN & \\
\hline CHEMBL1701677 & 737824 & 4.65 & 5.3678 & TRN & \\
\hline CHEMBL1403483 & 737824 & 5.1 & 5.5516 & TRN & \\
\hline CHEMBL1441347 & 737824 & 4.8 & 5.0666 & TST & \\
\hline CHEMBL1409689 & 737824 & 5.1 & 5.3085 & TRN & \\
\hline CHEMBL 2141452 & 737824 & 5.5 & 4.8108 & TRN & \\
\hline CHEMBL3208526 & 737824 & 4.55 & 5.1002 & TRN & \\
\hline CHEMBL1436976 & 737824 & 4.4 & 4.4204 & TRN & \\
\hline CHEMBL1497777 & 737824 & 4.95 & 4.9417 & TRN & \\
\hline CHEMBL1308948 & 737824 & 6.15 & 5.8621 & TST & \\
\hline CHEMBL1378064 & 737824 & 6.1 & 5.78799 & 9999999999 & TRN \\
\hline CHEMBL1571840 & 737824 & 5.1 & 5.2085 & TRN & \\
\hline CHEMBL3213165 & 737824 & 6.55 & 5.9566 & TRN & \\
\hline CHEMBL1437597 & 737824 & 5.6 & 4.9597 & TRN & \\
\hline CHEMBL1742064 & 737824 & 4.65 & 5.2564 & TRN & \\
\hline CHEMBL1410865 & 737824 & 6.0 & 6.0321 & TRN & \\
\hline CHEMBL1344709 & 737824 & 5.55 & 5.5626 & TST & \\
\hline CHEMBL1470721 & 737824 & 6.4 & 5.6658 & TRN & \\
\hline CHEMBL3209598 & 737824 & 5.3 & 5.2984 & TRN & \\
\hline CHEMBL1561718 & 737824 & 5.7 & 5.3924 & TRN & \\
\hline CHEMBL3196220 & 737824 & 5.45 & 5.5703 & TRN & \\
\hline CHEMBL 88272 & 737824 & 5.7 & 5.2279 & TST & \\
\hline CHEMBL1403270 & 737824 & 5.55 & 5.3067 & TST & \\
\hline CHEMBL1452057 & 737824 & 4.4 & 4.0566 & TRN & \\
\hline CHEMBL1448849 & 737824 & 5.8 & 5.3193 & TRN & \\
\hline CHEMBL1532949 & 737824 & 4.8 & 5.0051 & TRN & \\
\hline & & & & 7595 & \\
\hline
\end{tabular}




\begin{tabular}{|c|c|c|c|c|c|}
\hline \\
\hline CHEMBL1409825 & 737824 & 5.1 & 5.211 & TRN & \\
\hline CHEMBL1514149 & 737824 & 5.3 & 5.5426 & TRN & \\
\hline CHEMBL1364466 & 737824 & 4.6 & 4.7775 & TRN & \\
\hline CHEMBL1373941 & 737824 & 4.65 & 4.99100 & 20000000005 & TRN \\
\hline CHEMBL1310193 & 737824 & 5.15 & 5.1117 & TRN & \\
\hline CHEMBL1742246 & 737824 & 5.2 & 4.8782 & TRN & \\
\hline CHEMBL171064 & 737824 & 5.2 & 5.0586 & TRN & \\
\hline CHEMBL1383931 & 737824 & 4.95 & 5.5757 & TRN & \\
\hline CHEMBL1454035 & 737824 & 5.95 & 5.3243 & TRN & \\
\hline CHEMBL1425476 & 737824 & 4.5 & 4.9444 & TRN & \\
\hline CHEMBL379350 & 737824 & 5.8 & 5.1557 & TRN & \\
\hline CHEMBL1392170 & 737824 & 7.8 & 5.6668 & TRN & \\
\hline CHEMBL1581616 & 737824 & 5.25 & 5.4539 & TRN & \\
\hline CHEMBL1566978 & 737824 & 5.0 & 5.117 & TRN & \\
\hline CHEMBL1498694 & 737824 & 5.7 & 6.0334 & TST & \\
\hline CHEMBL1555510 & 737824 & 4.95 & 4.9292 & TRN & \\
\hline CHEMBL528080 & 737824 & 4.9 & 5.2461 & TRN & \\
\hline CHEMBL1500365 & 737824 & 4.9 & 5.142 & TRN & \\
\hline CHEMBL1598704 & 737824 & 5.45 & 5.6063 & TRN & \\
\hline CHEMBL113180 & 737824 & 4.9 & 4.6337 & TST & \\
\hline CHEMBL540294 & 737824 & 4.4 & 4.9123 & TST & \\
\hline CHEMBL1512802 & 737824 & 5.2 & 5.0504 & TRN & \\
\hline CHEMBL1394113 & 737824 & 5.1 & 5.1157 & TRN & \\
\hline CHEMBL1324667 & 737824 & 5.8 & 5.7762 & TRN & \\
\hline CHEMBL1540034 & 737824 & 5.0 & 5.1915 & TRN & \\
\hline CHEMBL1585369 & 737824 & 4.75 & 5.2769 & TRN & \\
\hline CHEMBL1415854 & 737824 & 4.95 & 5.2924 & TST & \\
\hline CHEMBL1407857 & 737824 & 5.3 & 5.4516 & TRN & \\
\hline CHEMBL585045 & 737824 & 5.15 & 5.3938 & TRN & \\
\hline CHEMBL1701329 & 737824 & 5.85 & 4.5804 & TRN & \\
\hline CHEMBL1451057 & 737824 & 7.0 & 6.6911 & TRN & \\
\hline CHEMBL1602966 & 737824 & 4.85 & 5.2862 & TST & \\
\hline CHEMBL1476108 & 737824 & 5.0 & 4.5306 & TST & \\
\hline CHEMBL3208773 & 737824 & 5.95 & 5.3715 & TST & \\
\hline CHEMBL1445685 & 737824 & 5.5 & 5.2474 & TRN & \\
\hline CHEMBL1537864 & 737824 & 5.6 & 5.2092 & TRN & \\
\hline CHEMBL1538531 & 737824 & 5.5 & 5.2213 & TRN & \\
\hline CHEMBL1395997 & 737824 & 6.5 & 6.6368 & TRN & \\
\hline CHEMBL398673 & 737824 & 5.5 & 5.1645 & TRN & \\
\hline CHEMBL1483214 & 737824 & 6.15 & 5.5728 & TRN & \\
\hline CHEMBL568379 & 737824 & 5.9 & 5.4569 & TRN & \\
\hline CHEMBL1447089 & 737824 & 5.5 & 5.2344 & TRN & \\
\hline CHEMBL1391974 & 737824 & 6.35 & 5.35 & TST & \\
\hline CHEMBL1741755 & 737824 & 5.35 & 4.7359 & TRN & \\
\hline CHEMBL1448691 & 737824 & 4.8 & 4.9679 & TRN & \\
\hline CHEMBL1499610 & 737824 & 4.4 & 4.9014 & TST & \\
\hline CHEMBL1496528 & 737824 & 4.65 & 5.1882 & TRN & \\
\hline CHEMBL1411967 & 737824 & 5.15 & 5.0082 & TRN & \\
\hline
\end{tabular}




\begin{tabular}{|c|c|c|c|c|}
\hline \multicolumn{5}{|c|}{ lemental T } \\
\hline CHEMBL1363551 & 737824 & 5.6 & 5.3243 & TST \\
\hline CHEMBL1604036 & 737824 & 5.5 & 5.3163 & TST \\
\hline CHEMBL1742204 & 737824 & 4.85 & 5.0963 & TRN \\
\hline CHEMBL1413605 & 737824 & 5.85 & 5.0502 & TRN \\
\hline CHEMBL1742104 & 737824 & 5.5 & 5.0669 & TRN \\
\hline CHEMBL1494332 & 737824 & 5.05 & 4.9878 & TRN \\
\hline CHEMBL1626013 & 737824 & 5.3 & 5.2835 & TRN \\
\hline CHEMBL117 & 737824 & 6.1 & 6.1125 & TRN \\
\hline CHEMBL1371423 & 737824 & 4.6 & 5.1926 & TRN \\
\hline CHEMBL1397636 & 737824 & 4.9 & 5.004 & TRN \\
\hline CHEMBL 1487063 & 737824 & 6.1 & 5.8093 & TRN \\
\hline CHEMBL3190254 & 737824 & 5.15 & 4.9878 & TRN \\
\hline CHEMBL1354596 & 737824 & 5.0 & 4.8564 & TRN \\
\hline CHEMBL1611549 & 737824 & 6.2 & 6.0317 & TRN \\
\hline CHEMBL1443307 & 737824 & 6.5 & 5.8239 & TRN \\
\hline CHEMBL 1333810 & 737824 & 5.8 & 5.4095 & TRN \\
\hline CHEMBL1416531 & 737824 & 5.3 & 5.5041 & TRN \\
\hline CHEMBL1350039 & 737824 & 5.25 & 5.4144 & TRN \\
\hline CHEMBL1552680 & 737824 & 5.3 & 4.783 & TRN \\
\hline CHEMBL1372302 & 737824 & -0.0 & 5.3521 & TST \\
\hline CHEMBL 1557159 & 737824 & 5.4 & 5.2651 & TRN \\
\hline CHEMBL3197893 & 737824 & 5.5 & 5.1958 & TRN \\
\hline CHEMBL1372404 & 737824 & 5.0 & 5.5037 & TRN \\
\hline CHEMBL1437776 & 737824 & 4.9 & 4.9567 & TRN \\
\hline CHEMBL1518718 & 737824 & 6.2 & 5.919 & TRN \\
\hline CHEMBL1600653 & 737824 & 4.6 & 5.0953 & TST \\
\hline CHEMBL1562786 & 737824 & 4.6 & 4.6139 & TRN \\
\hline CHEMBL1454949 & 737824 & 5.6 & 5.6336 & TST \\
\hline CHEMBL1396109 & 737824 & 5.4 & 5.294 & TRN \\
\hline CHEMBL1611902 & 737824 & 5.95 & 5.4963 & TST \\
\hline CHEMBL580421 & 737824 & 4.5 & 4.2462 & TST \\
\hline CHEMBL1454735 & 737824 & 4.9 & 5.2473 & TRN \\
\hline CHEMBL1363345 & 737824 & 4.85 & 4.8155 & TRN \\
\hline CHEMBL1393246 & 737824 & 4.6 & 5.4404 & TRN \\
\hline CHEMBL1602926 & 737824 & 7.5 & 7.1664 & TRN \\
\hline CHEMBL1420088 & 737824 & 5.45 & 5.2899 & TRN \\
\hline CHEMBL1541004 & 737824 & 5.25 & 5.3484 & TRN \\
\hline CHEMBL492122 & 737824 & 4.9 & 4.8393 & TRN \\
\hline CHEMBL1590261 & 737824 & 5.2 & 5.1303 & TRN \\
\hline CHEMBL1461461 & 737824 & 5.4 & 5.7358 & TRN \\
\hline CHEMBL1457332 & 737824 & 4.9 & 4.9774 & TRN \\
\hline CHEMBL572203 & 737824 & 5.0 & 5.3275 & TRN \\
\hline CHEMBL1611691 & 737824 & 4.95 & 4.55 & TRN \\
\hline CHEMBL1405461 & 737824 & 5.6 & 5.3771 & TRN \\
\hline CHEMBL1467429 & 737824 & 4.6 & 5.091 & TRN \\
\hline CHEMBL1333773 & 737824 & 5.35 & 5.4206 & TRN \\
\hline CHEMBL1595944 & 737824 & 4.4 & 5.0641 & TRN \\
\hline CHEMBL1576353 & 737824 & 5.5 & 5.591 & TST \\
\hline
\end{tabular}




\begin{tabular}{|c|c|c|c|c|c|}
\hline \\
\hline CHEMBL1582671 & 737824 & 4.6 & 5.2654 & TRN & \\
\hline CHEMBL1556619 & 737824 & 5.85 & 5.44 & TST & \\
\hline CHEMBL1421390 & 737824 & 6.1 & 5.4051 & TRN & \\
\hline CHEMBL1313894 & 737824 & 4.8 & 5.2657 & TRN & \\
\hline CHEMBL584860 & 737824 & 5.8 & 5.5354 & TRN & \\
\hline CHEMBL1311806 & 737824 & 5.2 & 5.1909 & TRN & \\
\hline CHEMBL3207894 & 737824 & 6.0 & 6.2614 & TRN & \\
\hline CHEMBL1527574 & 737824 & 5.0 & 5.0209 & TRN & \\
\hline CHEMBL1535118 & 737824 & 5.1 & 5.2078 & TRN & \\
\hline CHEMBL1334959 & 737824 & 6.6 & 6.9845 & TRN & \\
\hline CHEMBL1482789 & 737824 & 4.6 & 5.1995 & TST & \\
\hline CHEMBL1588553 & 737824 & 4.85 & 4.8826 & TRN & \\
\hline CHEMBL1329761 & 737824 & 4.4 & 4.9863 & TRN & \\
\hline CHEMBL1466831 & 737824 & 4.9 & 4.5527 & TRN & \\
\hline CHEMBL1246 & 737824 & 4.8 & 5.0144 & TRN & \\
\hline CHEMBL1441218 & 737824 & 5.25 & 5.3564 & TRN & \\
\hline CHEMBL1415482 & 737824 & 4.9 & 5.16 & TRN & \\
\hline CHEMBL1344541 & 737824 & 5.45 & 5.09 & TRN & \\
\hline CHEMBL3207490 & 737824 & 4.7 & 5.4092 & TRN & \\
\hline CHEMBL1520792 & 737824 & 5.3 & 5.1288 & TRN & \\
\hline CHEMBL1318758 & 737824 & 5.2 & 5.3632 & TRN & \\
\hline CHEMBL1517195 & 737824 & 5.65 & 5.3546 & TRN & \\
\hline CHEMBL1363622 & 737824 & 4.4 & 4.3002 & TRN & \\
\hline CHEMBL1557599 & 737824 & 5.35 & 5.3127 & TRN & \\
\hline CHEMBL1741724 & 737824 & 5.0 & 4.9275 & TST & \\
\hline CHEMBL1325408 & 737824 & 5.6 & 5.5482 & TRN & \\
\hline CHEMBL1554593 & 737824 & 6.4 & 6.2232 & TST & \\
\hline CHEMBL1605436 & 737824 & 4.4 & 4.876 & TRN & \\
\hline CHEMBL1714794 & 737824 & 6.1 & 5.2896 & TST & \\
\hline CHEMBL1408031 & 737824 & 5.5 & 4.9618 & TST & \\
\hline CHEMBL1604924 & 737824 & 4.5 & 5.0306 & TRN & \\
\hline CHEMBL1705167 & 737824 & 4.85 & 5.0195 & TRN & \\
\hline CHEMBL1432751 & 737824 & 5.15 & 5.4339 & TRN & \\
\hline CHEMBL1546034 & 737824 & 5.4 & 5.4362 & TST & \\
\hline CHEMBL1329855 & 737824 & 4.55 & 4.5979 & TRN & \\
\hline CHEMBL1403931 & 737824 & -0.0 & 5.3923 & TST & \\
\hline CHEMBL1366680 & 737824 & 4.8 & 5.13700 & 00000000005 & TST \\
\hline CHEMBL1256656 & 737824 & 4.9 & 5.03600 & 20000000005 & TRN \\
\hline CHEMBL1528170 & 737824 & 4.8 & 4.7399 & TRN & \\
\hline CHEMBL1437007 & 737824 & 4.5 & 4.4793 & TRN & \\
\hline CHEMBL1521453 & 737824 & 6.0 & 5.7124 & TST & \\
\hline CHEMBL1987087 & 737824 & 5.0 & 5.4161 & TST & \\
\hline CHEMBL1334145 & 737824 & 5.35 & 5.1756 & TRN & \\
\hline CHEMBL1515802 & 737824 & 4.8 & 4.8994 & TST & \\
\hline CHEMBL1528688 & 737824 & 5.4 & 5.3231 & TST & \\
\hline CHEMBL1328830 & 737824 & 4.85 & 5.109 & TST & \\
\hline CHEMBL1742190 & 737824 & 5.35 & 4.8625 & TRN & \\
\hline CHEMBL1581320 & 737824 & 4.4 & 5.3426 & TST & \\
\hline
\end{tabular}




\begin{tabular}{|c|c|c|c|c|c|}
\hline \multicolumn{6}{|c|}{ Supplemental Table S2.txt } \\
\hline CHEMBL145346 & 737824 & 5.35 & 5.7536 & TRN & \\
\hline CHEMBL1574160 & 737824 & 4.9 & 4.7427 & TRN & \\
\hline CHEMBL1542592 & 737824 & 5.45 & 5.3649 & TST & \\
\hline CHEMBL1497639 & 737824 & 5.0 & 5.1785 & TRN & \\
\hline CHEMBL1598896 & 737824 & 5.4 & 5.1972 & TRN & \\
\hline CHEMBL448602 & 737824 & 6.5 & 6.4852 & TRN & \\
\hline CHEMBL1567704 & 737824 & 4.45 & 4.9866 & TRN & \\
\hline CHEMBL1364931 & 737824 & 5.95 & 6.3342 & TRN & \\
\hline CHEMBL1510723 & 737824 & 6.3 & 5.0592 & TRN & \\
\hline CHEMBL1504668 & 737824 & 4.5 & 5.0595 & TRN & \\
\hline CHEMBL1403168 & 737824 & 5.45 & 5.2863 & TRN & \\
\hline CHEMBL1442300 & 737824 & 5.2 & 5.124 & TRN & \\
\hline CHEMBL1491744 & 737824 & 6.6 & 6.5465 & TRN & \\
\hline CHEMBL1386373 & 737824 & 5.75 & 5.2105 & TRN & \\
\hline CHEMBL1534630 & 737824 & 4.4 & 4.1289 & TST & \\
\hline CHEMBL1405203 & 737824 & 5.1 & 5.1752 & TRN & \\
\hline CHEMBL1484196 & 737824 & 4.4 & 4.1894 & TRN & \\
\hline CHEMBL1541286 & 737824 & 4.85 & 5.2647 & TRN & \\
\hline CHEMBL1337320 & 737824 & 5.4 & 5.16700 & 0000000001 & TRN \\
\hline CHEMBL1454402 & 737824 & 5.05 & 5.1931 & TRN & \\
\hline CHEMBL1555610 & 737824 & 4.6 & 4.36600 & 00000000005 & TRN \\
\hline CHEMBL1449589 & 737824 & 4.9 & 5.0731 & TRN & \\
\hline CHEMBL 2369256 & 737824 & 5.2 & 5.0538 & TRN & \\
\hline CHEMBL1454368 & 737824 & 5.65 & 4.8546 & TRN & \\
\hline CHEMBL1371243 & 737824 & 6.05 & 5.4444 & TRN & \\
\hline CHEMBL1344331 & 737824 & 4.95 & 5.3141 & TRN & \\
\hline CHEMBL1320989 & 737824 & 4.4 & 4.1853 & TRN & \\
\hline CHEMBL1368887 & 737824 & 6.0 & 5.8286 & TRN & \\
\hline CHEMBL1348883 & 737824 & 5.9 & 5.3594 & TRN & \\
\hline CHEMBL1512683 & 737824 & 4.8 & 4.1822 & TST & \\
\hline CHEMBL1310796 & 737824 & 5.2 & 5.2108 & TRN & \\
\hline CHEMBL1500641 & 737824 & 4.8 & 4.7795 & TRN & \\
\hline CHEMBL216973 & 737824 & 4.7 & 4.9228 & TRN & \\
\hline CHEMBL1596258 & 737824 & 5.25 & 4.5979 & TRN & \\
\hline CHEMBL1568588 & 737824 & 5.3 & 5.3596 & TRN & \\
\hline CHEMBL1485361 & 737824 & 4.4 & 3.9363 & TRN & \\
\hline CHEMBL 276140 & 737824 & 5.0 & 5.6071 & TRN & \\
\hline CHEMBL1605713 & 737824 & 5.25 & 5.4817 & TRN & \\
\hline CHEMBL1516500 & 737824 & 5.05 & 5.1976 & TRN & \\
\hline CHEMBL1542112 & 737824 & 5.55 & 5.6749 & TRN & \\
\hline CHEMBL1394187 & 737824 & 4.9 & 4.9406 & TRN & \\
\hline CHEMBL1496315 & 737824 & 5.8 & 6.3008 & TRN & \\
\hline CHEMBL1392564 & 737824 & 5.4 & 5.5077 & TRN & \\
\hline CHEMBL1742323 & 737824 & 5.45 & 5.0767 & TRN & \\
\hline CHEMBL1365347 & 737824 & 5.8 & 5.3265 & TRN & \\
\hline CHEMBL1427101 & 737824 & 4.9 & 4.8396 & TRN & \\
\hline CHEMBL1492095 & 737824 & 4.95 & 4.9531 & TRN & \\
\hline CHEMBL1553751 & 737824 & 4.7 & 4.88 & TRN & \\
\hline
\end{tabular}




\begin{tabular}{|c|c|c|c|c|c|}
\hline \\
\hline CHEMBL1540031 & 737824 & 4.5 & 4.8981 & TRN & \\
\hline CHEMBL1463609 & 737824 & 4.8 & 5.2264 & TRN & \\
\hline CHEMBL1421692 & 737824 & 4.4 & 5.4493 & TRN & \\
\hline CHEMBL1492616 & 737824 & 4.9 & 5.5495 & TRN & \\
\hline CHEMBL1441737 & 737824 & 4.9 & 4.8087 & TRN & \\
\hline CHEMBL1423135 & 737824 & 5.1 & 5.2125 & TRN & \\
\hline CHEMBL1982308 & 737824 & 5.95 & 4.9862 & TRN & \\
\hline CHEMBL1432807 & 737824 & 4.8 & 5.0643 & TST & \\
\hline CHEMBL1412557 & 737824 & 4.4 & 4.845 & TRN & \\
\hline CHEMBL1485450 & 737824 & 5.35 & 5.2198 & TRN & \\
\hline CHEMBL3145078 & 737824 & 4.9 & 5.3058 & TST & \\
\hline CHEMBL1599266 & 737824 & 6.3 & 5.5558 & TST & \\
\hline CHEMBL1597569 & 737824 & 4.9 & 5.5501 & TRN & \\
\hline CHEMBL1547276 & 737824 & 5.1 & 5.0028 & TRN & \\
\hline CHEMBL1545055 & 737824 & 4.95 & 4.8647 & TRN & \\
\hline CHEMBL1444164 & 737824 & 4.95 & 5.3041 & TRN & \\
\hline CHEMBL1563304 & 737824 & 6.4 & 6.0218 & TRN & \\
\hline CHEMBL1358033 & 737824 & 5.0 & 4.8871 & TRN & \\
\hline CHEMBL1405892 & 737824 & 4.4 & 5.28600 & 00000000005 & TRN \\
\hline CHEMBL1358983 & 737824 & 5.0 & 4.9722 & TRN & \\
\hline CHEMBL492610 & 737824 & 5.1 & 5.3447 & TRN & \\
\hline CHEMBL3209279 & 737824 & 4.5 & 5.1914 & TRN & \\
\hline CHEMBL1709177 & 737824 & 4.4 & 4.9603 & TST & \\
\hline CHEMBL1362892 & 737824 & 5.3 & 5.047 & TRN & \\
\hline CHEMBL1609404 & 737824 & 5.75 & 5.2983 & TRN & \\
\hline CHEMBL1581350 & 737824 & 4.85 & 5.4405 & TRN & \\
\hline CHEMBL1392232 & 737824 & 6.05 & 5.381 & TRN & \\
\hline CHEMBL1323101 & 737824 & 5.35 & 5.4123 & TRN & \\
\hline CHEMBL1541936 & 737824 & 4.7 & 5.2151 & TRN & \\
\hline CHEMBL1562612 & 737824 & 6.0 & 5.6889 & TRN & \\
\hline CHEMBL1353190 & 737824 & 5.75 & 5.6676 & TRN & \\
\hline CHEMBL1446731 & 737824 & 5.7 & 5.75700 & 0000000001 & TRN \\
\hline CHEMBL1345724 & 737824 & 4.9 & 5.0723 & TRN & \\
\hline CHEMBL3210325 & 737824 & 5.4 & 5.2099 & TRN & \\
\hline CHEMBL1530700 & 737824 & 4.4 & 5.3153 & TRN & \\
\hline CHEMBL1742026 & 737824 & 4.6 & 5.0251 & TRN & \\
\hline CHEMBL584854 & 737824 & 6.9 & 5.8373 & TRN & \\
\hline CHEMBL1362959 & 737824 & 5.95 & 5.73799 & 99999999995 & TST \\
\hline CHEMBL1560912 & 737824 & 5.55 & 5.3132 & TST & \\
\hline CHEMBL1351829 & 737824 & 5.05 & 5.6681 & TRN & \\
\hline CHEMBL1414269 & 737824 & 4.6 & 4.7611 & TRN & \\
\hline CHEMBL1559560 & 737824 & 5.2 & 5.0335 & TRN & \\
\hline CHEMBL3191804 & 737824 & 4.45 & 4.6559 & TRN & \\
\hline CHEMBL1364220 & 737824 & 4.55 & 4.748 & TRN & \\
\hline CHEMBL1436644 & 737824 & 5.0 & 5.5687 & TRN & \\
\hline CHEMBL1453834 & 737824 & 6.45 & 5.4793 & TRN & \\
\hline CHEMBL1516503 & 737824 & 5.95 & 5.4635 & TRN & \\
\hline CHEMBL1480371 & 737824 & 4.6 & 5.0361 & TRN & \\
\hline
\end{tabular}




\begin{tabular}{|c|c|c|c|c|c|}
\hline \multirow{2}{*}{ CHEMBL1437408 } & \multirow{2}{*}{737824} & \\
\hline & & 4.6 & 4.4795 & \multicolumn{2}{|l|}{ TRN } \\
\hline CHEMBL1320947 & 737824 & 5.6 & 5.4794 & \multicolumn{2}{|l|}{ TRN } \\
\hline CHEMBL1382385 & 737824 & 5.15 & 5.5043 & \multicolumn{2}{|l|}{ TRN } \\
\hline CHEMBL1714323 & 737824 & 4.7 & 5.6482 & \multicolumn{2}{|l|}{ TRN } \\
\hline CHEMBL552439 & 737824 & 5.5 & 5.2685 & \multicolumn{2}{|l|}{ TST } \\
\hline CHEMBL1331572 & 737824 & 5.95 & 6.0116 & \multicolumn{2}{|l|}{ TRN } \\
\hline CHEMBL1315504 & 737824 & 4.9 & 4.7144 & \multicolumn{2}{|l|}{ TRN } \\
\hline CHEMBL1496891 & 737824 & 4.4 & 5.6346 & \multicolumn{2}{|l|}{ TRN } \\
\hline CHEMBL1310284 & 737824 & 5.8 & 5.58 & \multicolumn{2}{|l|}{ TRN } \\
\hline CHEMBL1384608 & 737824 & 5.5 & 5.5018 & \multicolumn{2}{|l|}{ TRN } \\
\hline CHEMBL303516 & 737824 & 5.9 & 5.8276 & \multicolumn{2}{|l|}{ TST } \\
\hline CHEMBL1462462 & 737824 & 5.0 & 5.5149 & \multicolumn{2}{|l|}{ TST } \\
\hline CHEMBL1705804 & 737824 & 5.0 & 5.2948 & \multicolumn{2}{|l|}{ TRN } \\
\hline CHEMBL1320662 & 737824 & 4.7 & 4.5798 & \multicolumn{2}{|l|}{ TRN } \\
\hline CHEMBL1320315 & 737824 & 6.2 & 5.4908 & \multicolumn{2}{|l|}{ TST } \\
\hline CHEMBL1452643 & 737824 & 4.9 & 5.1038 & \multicolumn{2}{|l|}{ TRN } \\
\hline CHEMBL1491858 & 737824 & 5.35 & 5.3477 & \multicolumn{2}{|l|}{ TST } \\
\hline CHEMBL1551321 & 737824 & 4.7 & 4.7651 & \multicolumn{2}{|l|}{ TRN } \\
\hline CHEMBL1366562 & 737824 & 5.35 & 5.1872 & TRN & \\
\hline CHEMBL1559654 & 737824 & 5.1 & 5.1738 & TRN & \\
\hline CHEMBL1546475 & 737824 & 4.75 & 5.2086 & TRN & \\
\hline CHEMBL1357157 & 737824 & 5.1 & 5.2162 & TRN & \\
\hline CHEMBL 279841 & 737824 & 5.0 & 4.5789 & TRN & \\
\hline CHEMBL15927 & 737824 & 4.5 & 3.8867 & TRN & \\
\hline CHEMBL491960 & 737824 & 7.1 & 6.7313 & TRN & \\
\hline CHEMBL602418 & 737824 & 4.55 & 4.9723 & TRN & \\
\hline CHEMBL1410399 & 737824 & 5.5 & 5.2161 & TRN & \\
\hline CHEMBL1413306 & 737824 & 5.6 & 5.7223 & TRN & \\
\hline CHEMBL1368286 & 737824 & 5.2 & 5.7555 & TRN & \\
\hline CHEMBL1554745 & 737824 & 6.2 & 5.8492 & TRN & \\
\hline CHEMBL1565164 & 737824 & 5.75 & 5.1657 & TST & \\
\hline CHEMBL1408343 & 737824 & 5.4 & 5.4476 & TRN & \\
\hline CHEMBL1461827 & 737824 & 6.05 & 5.0133 & TRN & \\
\hline CHEMBL1333783 & 737824 & 4.8 & 4.9101 & TRN & \\
\hline CHEMBL1308151 & 737824 & 5.25 & 4.8673 & TRN & \\
\hline CHEMBL1984764 & 737824 & 6.3 & 5.2866 & TRN & \\
\hline CHEMBL1434082 & 737824 & 5.3 & 5.0344 & TRN & \\
\hline CHEMBL1519978 & 737824 & 5.0 & $4.7810 €$ & 2000000001 & TRN \\
\hline CHEMBL372797 & 737824 & 7.0 & 6.2539 & TST & \\
\hline CHEMBL1182777 & 737824 & 5.4 & 5.5236 & TST & \\
\hline CHEMBL1329240 & 737824 & 5.25 & 5.1232 & TRN & \\
\hline CHEMBL1573949 & 737824 & 4.95 & 5.2265 & TRN & \\
\hline CHEMBL3199416 & 737824 & 5.3 & 5.1622 & TRN & \\
\hline CHEMBL1601121 & 737824 & 4.8 & 4.7895 & TRN & \\
\hline CHEMBL1403154 & 737824 & 5.9 & 5.7868 & TST & \\
\hline CHEMBL1415100 & 737824 & 5.5 & 5.5921 & TRN & \\
\hline CHEMBL1312235 & 737824 & 4.5 & 5.09399 & 9999999999 & TRN \\
\hline CHEMBL192566 & 737824 & 4.9 & 4.2312 & TST & \\
\hline & & & & e 7601 & \\
\hline
\end{tabular}




\begin{tabular}{|c|c|c|c|c|c|}
\hline & & & & & \\
\hline CHEMBL1377526 & 737824 & 4.7 & 4.6394 & TRN & \\
\hline CHEMBL522311 & 737824 & 6.4 & 5.9389 & TRN & \\
\hline CHEMBL1553404 & 737824 & 4.8 & 4.6729 & TRN & \\
\hline CHEMBL1395415 & 737824 & 4.9 & 4.9807 & TRN & \\
\hline CHEMBL1706387 & 737824 & 4.4 & 4.8973 & TRN & \\
\hline CHEMBL1521460 & 737824 & 6.2 & 5.58299 & 9999999999 & TRN \\
\hline CHEMBL238624 & 737824 & 5.6 & 5.9256 & TST & \\
\hline CHEMBL1322207 & 737824 & 6.5 & 6.066 & TST & \\
\hline CHEMBL1523143 & 737824 & 4.75 & 4.9028 & TRN & \\
\hline CHEMBL1536773 & 737824 & 4.6 & 5.0853 & TST & \\
\hline CHEMBL1359193 & 737824 & 5.1 & 4.855 & TRN & \\
\hline CHEMBL1567499 & 737824 & 5.0 & 5.24100 & 00000000005 & TST \\
\hline CHEMBL3189455 & 737824 & 4.95 & 5.1232 & TST & \\
\hline CHEMBL1542591 & 737824 & 4.8 & 5.4975 & TRN & \\
\hline CHEMBL1587753 & 737824 & 4.4 & 5.53100 & 0000000001 & TST \\
\hline CHEMBL1598112 & 737824 & 4.6 & 4.7487 & TRN & \\
\hline CHEMBL1498572 & 737824 & 5.05 & 5.36100 & 0000000001 & TRN \\
\hline CHEMBL1443975 & 737824 & 5.35 & 5.2085 & TRN & \\
\hline CHEMBL3196379 & 737824 & 5.9 & 5.88200 & 0000000001 & TRN \\
\hline CHEMBL1328265 & 737824 & 5.7 & 5.4946 & TST & \\
\hline CHEMBL1465552 & 737824 & 4.85 & 4.9196 & TRN & \\
\hline CHEMBL1417125 & 737824 & 4.55 & 5.3126 & TRN & \\
\hline CHEMBL1383786 & 737824 & 4.9 & 5.7624 & TRN & \\
\hline CHEMBL1329895 & 737824 & 5.7 & 5.478 & TRN & \\
\hline CHEMBL1316317 & 737824 & 4.8 & 5.1645 & TRN & \\
\hline CHEMBL1496934 & 737824 & 5.5 & 5.2301 & TRN & \\
\hline CHEMBL1545539 & 737824 & 5.45 & 5.0964 & TST & \\
\hline CHEMBL1522566 & 737824 & 5.5 & 5.5559 & TRN & \\
\hline CHEMBL1376005 & 737824 & 5.3 & 5.2657 & TST & \\
\hline CHEMBL1704202 & 737824 & 4.6 & 4.7868 & TRN & \\
\hline CHEMBL1328880 & 737824 & 5.7 & 5.3969 & TRN & \\
\hline CHEMBL1499774 & 737824 & 4.8 & 5.1405 & TRN & \\
\hline CHEMBL1443340 & 737824 & 5.3 & 5.2288 & TST & \\
\hline CHEMBL1550234 & 737824 & 8.25 & 5.5094 & TRN & \\
\hline CHEMBL1525437 & 737824 & 6.3 & 5.836 & TRN & \\
\hline CHEMBL1325709 & 737824 & 6.1 & 5.5924 & TRN & \\
\hline CHEMBL1482381 & 737824 & 4.95 & 5.4311 & TST & \\
\hline CHEMBL1397257 & 737824 & 5.3 & 5.3124 & TRN & \\
\hline CHEMBL1325634 & 737824 & 5.25 & 5.5028 & TRN & \\
\hline CHEMBL1557234 & 737824 & 4.9 & 4.426 & TRN & \\
\hline CHEMBL1595491 & 737824 & 4.8 & 5.6993 & TRN & \\
\hline CHEMBL1393011 & 737824 & 5.15 & 4.9239 & TRN & \\
\hline CHEMBL1367220 & 737824 & 6.45 & 5.5891 & TRN & \\
\hline CHEMBL1606094 & 737824 & 5.7 & 5.4452 & TST & \\
\hline CHEMBL1490634 & 737824 & 5.0 & 4.99100 & 00000000005 & TRN \\
\hline CHEMBL1309244 & 737824 & 5.9 & 5.8182 & TRN & \\
\hline CHEMBL1427186 & 737824 & 4.85 & 5.0295 & TRN & \\
\hline CHEMBL1531294 & 737824 & 6.0 & 6.0858 & TRN & \\
\hline & & & & e 7602 & \\
\hline
\end{tabular}




\begin{tabular}{|c|c|c|c|c|c|}
\hline \multicolumn{6}{|c|}{ Supplemental Table S2.txt } \\
\hline CHEMBL3192006 & 737824 & 5.9 & 4.7783 & TST & \\
\hline CHEMBL3193407 & 737824 & 5.35 & 5.2067 & TST & \\
\hline CHEMBL1418917 & 737824 & 4.95 & 5.2102 & TRN & \\
\hline CHEMBL1714198 & 737824 & 4.6 & 4.7661 & TRN & \\
\hline CHEMBL1348303 & 737824 & 6.0 & 5.398 & TRN & \\
\hline CHEMBL1308386 & 737824 & 5.35 & 4.9541 & TRN & \\
\hline CHEMBL1327403 & 737824 & 4.9 & 4.7443 & TRN & \\
\hline CHEMBL1578474 & 737824 & 5.1 & 4.8669 & TRN & \\
\hline CHEMBL1305215 & 737824 & 5.6 & 5.2964 & TRN & \\
\hline CHEMBL1315292 & 737824 & 4.8 & 5.0521 & TRN & \\
\hline CHEMBL1724190 & 737824 & 4.85 & \multicolumn{2}{|c|}{5.0680000000000005} & TRN \\
\hline CHEMBL1367222 & 737824 & 5.0 & 5.1469 & TRN & \\
\hline CHEMBL1380069 & 737824 & 5.4 & 5.9249 & TRN & \\
\hline CHEMBL1406491 & 737824 & 4.8 & 5.2806 & TST & \\
\hline CHEMBL1443952 & 737824 & 6.35 & 5.6455 & TRN & \\
\hline CHEMBL1604278 & 737824 & 5.65 & 5.0058 & TRN & \\
\hline CHEMBL1417599 & 737824 & 4.85 & 4.9308 & TRN & \\
\hline CHEMBL1461873 & 737824 & 5.4 & 5.6214 & TRN & \\
\hline CHEMBL1509341 & 737824 & 4.85 & 5.2175 & TRN & \\
\hline CHEMBL1577130 & 737824 & 4.95 & 5.2117 & TRN & \\
\hline CHEMBL1522136 & 737824 & 5.4 & 5.3534 & TRN & \\
\hline CHEMBL1330580 & 737824 & 5.75 & 5.5286 & TRN & \\
\hline CHEMBL68230 & 737824 & 4.5 & 5.0386 & TRN & \\
\hline CHEMBL1441088 & 737824 & 5.95 & 6.0657 & TRN & \\
\hline CHEMBL1568086 & 737824 & 5.6 & 5.8488 & TRN & \\
\hline CHEMBL1395344 & 737824 & 4.7 & 4.7923 & TRN & \\
\hline CHEMBL1379391 & 737824 & 5.7 & 5.5277 & TRN & \\
\hline CHEMBL1566900 & 737824 & 4.4 & 4.6478 & TRN & \\
\hline CHEMBL1557983 & 737824 & 5.65 & 5.1835 & TST & \\
\hline CHEMBL3190824 & 737824 & 5.7 & 5.3386 & TRN & \\
\hline CHEMBL1540475 & 737824 & 4.65 & 5.1107 & TRN & \\
\hline CHEMBL1465060 & 737824 & 5.0 & 4.8029 & TST & \\
\hline CHEMBL266500 & 737824 & 5.3 & 5.2405 & TRN & \\
\hline CHEMBL1522017 & 737824 & 5.45 & 4.6858 & TST & \\
\hline CHEMBL1542458 & 737824 & 4.85 & 5.4167 & TST & \\
\hline CHEMBL1554851 & 737824 & 5.3 & 5.1143 & TRN & \\
\hline CHEMBL1359691 & 737824 & 5.1 & 5.4765 & TRN & \\
\hline CHEMBL1439338 & 737824 & 5.65 & 5.489 & TRN & \\
\hline CHEMBL1449042 & 737824 & 4.9 & 5.0304 & TRN & \\
\hline CHEMBL1593466 & 737824 & 6.1 & \multicolumn{2}{|c|}{5.587000000000001} & TRN \\
\hline CHEMBL1555483 & 737824 & 5.3 & 5.345 & TRN & \\
\hline CHEMBL1395277 & 737824 & 5.6 & 5.9463 & TRN & \\
\hline CHEMBL1331618 & 737824 & 6.2 & 6.3772 & TRN & \\
\hline CHEMBL1515804 & 737824 & 4.9 & 4.4181 & TRN & \\
\hline CHEMBL1741701 & 737824 & 5.5 & 5.4342 & TRN & \\
\hline CHEMBL1584779 & 737824 & 5.65 & 5.761 & TRN & \\
\hline CHEMBL1479994 & 737824 & 4.75 & 5.1818 & TRN & \\
\hline CHEMBL3208450 & 737824 & 5.55 & 5.3689 & TRN & \\
\hline
\end{tabular}




\begin{tabular}{|c|c|c|c|c|c|}
\hline \\
\hline CHEMBL3213435 & 737824 & 4.7 & 5.2018 & TRN & \\
\hline CHEMBL1426826 & 737824 & 5.65 & 5.6311 & TRN & \\
\hline CHEMBL1515777 & 737824 & 5.1 & 4.9775 & TRN & \\
\hline CHEMBL1532175 & 737824 & 4.6 & 4.9199 & TST & \\
\hline CHEMBL1515194 & 737824 & 4.9 & 4.6353 & TRN & \\
\hline CHEMBL1538161 & 737824 & 5.15 & 4.7117 & TRN & \\
\hline CHEMBL1407527 & 737824 & 4.9 & 4.7547 & TRN & \\
\hline CHEMBL1340538 & 737824 & 4.9 & 5.3327 & TRN & \\
\hline CHEMBL1511739 & 737824 & 5.35 & 5.3302 & TRN & \\
\hline CHEMBL1461327 & 737824 & 5.45 & 5.204 & TRN & \\
\hline CHEMBL1571716 & 737824 & 6.05 & 5.22 & TRN & \\
\hline CHEMBL3199356 & 737824 & 4.4 & 5.0575 & TST & \\
\hline CHEMBL1490442 & 737824 & 4.4 & 5.2788 & TST & \\
\hline CHEMBL1304606 & 737824 & 4.9 & 4.8567 & TRN & \\
\hline CHEMBL1522222 & 737824 & 4.9 & 4.857 & TRN & \\
\hline CHEMBL 269550 & 737824 & 4.8 & 4.744 & TRN & \\
\hline CHEMBL1366070 & 737824 & 4.8 & 5.3688 & TRN & \\
\hline CHEMBL1530213 & 737824 & 5.4 & 5.2143 & TRN & \\
\hline CHEMBL1314247 & 737824 & 5.0 & 4.7832 & TRN & \\
\hline CHEMBL1517765 & 737824 & 4.8 & 4.7167 & TRN & \\
\hline CHEMBL1371397 & 737824 & 4.4 & 4.2428 & TST & \\
\hline CHEMBL1708264 & 737824 & 5.05 & 5.0858 & TRN & \\
\hline CHEMBL1473133 & 737824 & 5.2 & 5.0593 & TRN & \\
\hline CHEMBL1352779 & 737824 & 5.4 & 5.4908 & TRN & \\
\hline CHEMBL1474927 & 737824 & 4.6 & 4.98600 & 0000000001 & TRN \\
\hline CHEMBL1975888 & 737824 & 5.7 & 5.5009 & TRN & \\
\hline CHEMBL1519953 & 737824 & 5.2 & 5.4995 & TRN & \\
\hline CHEMBL1345940 & 737824 & 4.95 & 4.9548 & TRN & \\
\hline CHEMBL1422472 & 737824 & 5.55 & 5.2214 & TRN & \\
\hline CHEMBL1567933 & 737824 & 5.5 & 5.1958 & TRN & \\
\hline CHEMBL3209384 & 737824 & 4.95 & 4.6151 & TRN & \\
\hline CHEMBL1596063 & 737824 & 5.1 & 5.5209 & TST & \\
\hline CHEMBL1492898 & 737824 & 5.15 & 5.1751 & TST & \\
\hline CHEMBL3197274 & 737824 & 5.0 & 5.07600 & 00000000005 & TRN \\
\hline CHEMBL1529093 & 737824 & 5.6 & 5.0067 & TST & \\
\hline CHEMBL1370189 & 737824 & 5.4 & 5.3337 & TRN & \\
\hline CHEMBL1375723 & 737824 & 5.7 & 5.481 & TRN & \\
\hline CHEMBL1527209 & 737824 & 4.4 & 4.2998 & TRN & \\
\hline CHEMBL1571756 & 737824 & 6.45 & 5.78700 & 0000000001 & TRN \\
\hline CHEMBL1494408 & 737824 & 4.9 & 4.7866 & TRN & \\
\hline CHEMBL1517099 & 737824 & 4.7 & 4.5084 & TRN & \\
\hline CHEMBL1741388 & 737824 & 5.5 & 5.4003 & TRN & \\
\hline CHEMBL1377552 & 737824 & 5.9 & 5.7245 & TRN & \\
\hline CHEMBL1256735 & 737824 & 5.1 & 5.04899 & 99999999995 & TRN \\
\hline CHEMBL1444135 & 737824 & 4.85 & 4.2987 & TRN & \\
\hline CHEMBL1534872 & 737824 & 4.8 & 4.5662 & TST & \\
\hline CHEMBL3190163 & 737824 & 6.65 & 5.4353 & TRN & \\
\hline CHEMBL1305410 & 737824 & 5.25 & 5.4852 & TRN & \\
\hline
\end{tabular}




\begin{tabular}{|c|c|c|c|c|}
\hline \multicolumn{5}{|c|}{ lemental T } \\
\hline CHEMBL1710203 & 737824 & 5.0 & 5.3947 & TRN \\
\hline CHEMBL1594648 & 737824 & 7.0 & 6.7577 & TRN \\
\hline CHEMBL1375115 & 737824 & 4.5 & 5.2542 & TST \\
\hline CHEMBL1335806 & 737824 & 4.4 & 5.1966 & TRN \\
\hline CHEMBL1486638 & 737824 & 5.1 & 4.7624 & TST \\
\hline CHEMBL3211748 & 737824 & 4.6 & 4.9807 & TRN \\
\hline CHEMBL1367355 & 737824 & 7.8 & 5.1473 & TRN \\
\hline CHEMBL1507058 & 737824 & 5.5 & 5.3695 & TRN \\
\hline CHEMBL1410367 & 737824 & 6.1 & 5.9646 & TRN \\
\hline CHEMBL1364963 & 737824 & 5.4 & 5.1646 & TRN \\
\hline CHEMBL1468251 & 737824 & 6.1 & 5.2808 & TRN \\
\hline CHEMBL1538611 & 737824 & 4.65 & 5.1291 & TRN \\
\hline CHEMBL1299810 & 737824 & 5.8 & 5.6654 & TRN \\
\hline CHEMBL1439839 & 737824 & 4.9 & 4.7361 & TRN \\
\hline CHEMBL1594030 & 737824 & 5.0 & 4.7201 & TRN \\
\hline CHEMBL1472753 & 737824 & 4.4 & 4.3284 & TRN \\
\hline CHEMBL1522767 & 737824 & 5.55 & 4.8265 & TRN \\
\hline CHEMBL1393830 & 737824 & 5.1 & 5.2329 & TST \\
\hline CHEMBL1566928 & 737824 & 4.9 & 5.3715 & TRN \\
\hline CHEMBL1507864 & 737824 & 5.3 & 4.7916 & TST \\
\hline CHEMBL1314222 & 737824 & 4.8 & 5.1298 & TRN \\
\hline CHEMBL1557318 & 737824 & 4.65 & 4.9878 & TRN \\
\hline CHEMBL1451346 & 737824 & 5.1 & 5.2193 & TRN \\
\hline CHEMBL1548190 & 737824 & 5.0 & 4.8248 & TRN \\
\hline CHEMBL1299899 & 737824 & 6.1 & 5.2709 & TRN \\
\hline CHEMBL1525024 & 737824 & 5.5 & 5.3056 & TRN \\
\hline CHEMBL1556561 & 737824 & 5.15 & 5.2332 & TRN \\
\hline CHEMBL3197180 & 737824 & 4.95 & 5.3522 & TRN \\
\hline CHEMBL1489263 & 737824 & 5.4 & 5.2531 & TRN \\
\hline CHEMBL1563507 & 737824 & 5.1 & 5.3517 & TRN \\
\hline CHEMBL1532023 & 737824 & 5.8 & 5.7769 & TRN \\
\hline CHEMBL1315609 & 737824 & 5.1 & 5.1792 & TRN \\
\hline CHEMBL1741481 & 737824 & 5.05 & 5.0562 & TRN \\
\hline CHEMBL1310196 & 737824 & 4.7 & 5.1708 & TRN \\
\hline CHEMBL1591209 & 737824 & 7.4 & 7.746 & TRN \\
\hline CHEMBL1569337 & 737824 & 4.9 & 5.1799 & TRN \\
\hline CHEMBL1579328 & 737824 & 5.85 & 5.1587 & TST \\
\hline CHEMBL1708951 & 737824 & 5.1 & 5.3081 & TRN \\
\hline CHEMBL1495077 & 737824 & 4.8 & 4.3958 & TRN \\
\hline CHEMBL1741897 & 737824 & 5.0 & 4.9112 & TRN \\
\hline CHEMBL1335617 & 737824 & 4.9 & 4.691 & TST \\
\hline CHEMBL1554411 & 737824 & 6.4 & 6.1589 & TRN \\
\hline CHEMBL1374204 & 737824 & 4.85 & 5.0206 & TRN \\
\hline CHEMBL1412128 & 737824 & 5.0 & 5.631 & TRN \\
\hline CHEMBL1484371 & 737824 & 4.55 & 4.7744 & TST \\
\hline CHEMBL1338095 & 737824 & 4.8 & 4.9394 & TRN \\
\hline CHEMBL1315820 & 737824 & 7.6 & 7.3194 & TRN \\
\hline CHEMBL1302946 & 737824 & 4.4 & 5.1456 & TST \\
\hline
\end{tabular}




\begin{tabular}{|c|c|c|c|c|c|}
\hline \multicolumn{6}{|c|}{ dule } \\
\hline CHEMBL1397782 & 737824 & 5.1 & 4.6455 & TST & \\
\hline CHEMBL1324178 & 737824 & 5.9 & 5.7544 & TRN & \\
\hline CHEMBL1506245 & 737824 & 5.55 & 5.0909 & TRN & \\
\hline CHEMBL1405696 & 737824 & 4.85 & 5.6873 & TRN & \\
\hline CHEMBL1487111 & 737824 & 4.5 & 4.5359 & TRN & \\
\hline CHEMBL1436049 & 737824 & 5.0 & 5.2033 & TRN & \\
\hline CHEMBL1447481 & 737824 & 5.7 & 5.1323 & TRN & \\
\hline CHEMBL1733899 & 737824 & 5.9 & 5.4616 & TRN & \\
\hline CHEMBL1407160 & 737824 & 6.6 & 5.7033 & TRN & \\
\hline CHEMBL1581696 & 737824 & 5.35 & 5.3452 & TRN & \\
\hline CHEMBL1475381 & 737824 & 4.4 & 4.4803 & TRN & \\
\hline CHEMBL1601111 & 737824 & 4.95 & 5.5821 & TST & \\
\hline CHEMBL1432651 & 737824 & 5.8 & 5.3425 & TRN & \\
\hline CHEMBL1350235 & 737824 & 4.8 & 4.8943 & TRN & \\
\hline CHEMBL1568178 & 737824 & 5.4 & 5.2193 & TRN & \\
\hline CHEMBL1741531 & 737824 & 5.5 & 5.1764 & TST & \\
\hline CHEMBL1533276 & 737824 & 4.8 & 5.183 & TRN & \\
\hline CHEMBL1406457 & 737824 & 5.85 & 5.6229 & TRN & \\
\hline CHEMBL1405581 & 737824 & 4.65 & 5.0421 & TRN & \\
\hline CHEMBL1561667 & 737824 & 5.85 & 5.3835 & TRN & \\
\hline CHEMBL1331253 & 737824 & 5.45 & 5.0957 & TRN & \\
\hline CHEMBL1359613 & 737824 & 4.9 & 4.7499 & TRN & \\
\hline CHEMBL1577187 & 737824 & 5.0 & 5.0616 & TRN & \\
\hline CHEMBL1362108 & 737824 & 6.05 & 5.5342 & TRN & \\
\hline CHEMBL3145025 & 737824 & 5.45 & 5.29299 & 9999999999 & TRN \\
\hline CHEMBL489934 & 737824 & 5.8 & 6.0018 & TRN & \\
\hline CHEMBL1498835 & 737824 & 4.95 & 5.2683 & TRN & \\
\hline CHEMBL1322537 & 737824 & 5.15 & 5.3474 & TRN & \\
\hline CHEMBL1337725 & 737824 & 5.45 & 5.715 & TRN & \\
\hline CHEMBL3195405 & 737824 & 4.9 & 5.1656 & TRN & \\
\hline CHEMBL1533572 & 737824 & 4.9 & 4.9792 & TRN & \\
\hline CHEMBL1403145 & 737824 & 4.95 & 5.1656 & TRN & \\
\hline CHEMBL1514098 & 737824 & 7.5 & 6.8067 & TST & \\
\hline CHEMBL1468024 & 737824 & 5.15 & 5.2228 & TRN & \\
\hline CHEMBL1571005 & 737824 & 4.8 & 5.1208 & TRN & \\
\hline CHEMBL1363168 & 737824 & 4.5 & 4.7444 & TRN & \\
\hline CHEMBL1380304 & 737824 & 4.95 & 4.9809 & TRN & \\
\hline CHEMBL1375285 & 737824 & 6.0 & 5.3945 & TRN & \\
\hline CHEMBL1436507 & 737824 & 4.9 & 4.8889 & TRN & \\
\hline CHEMBL1344112 & 737824 & 5.05 & 5.4909 & TRN & \\
\hline CHEMBL1600504 & 737824 & 5.95 & 5.1295 & TST & \\
\hline CHEMBL1557821 & 737824 & 5.0 & 5.5634 & TRN & \\
\hline CHEMBL1514272 & 737824 & 4.6 & 4.1511 & TRN & \\
\hline CHEMBL1606345 & 737824 & 5.3 & 5.3708 & TRN & \\
\hline CHEMBL1413343 & 737824 & 5.2 & 4.876 & TRN & \\
\hline CHEMBL1742296 & 737824 & 5.7 & 5.2663 & TRN & \\
\hline CHEMBL1425720 & 737824 & 5.45 & 5.2039 & TRN & \\
\hline CHEMBL1391744 & 737824 & 5.05 & 5.3461 & TST & \\
\hline & & & & e 7606 & \\
\hline
\end{tabular}




\begin{tabular}{|c|c|c|c|c|}
\hline & & & & al lable s \\
\hline CHEMBL1347768 & 737824 & 5.0 & 5.4419 & TRN \\
\hline CHEMBL1370903 & 737824 & 7.1 & 6.8367 & TRN \\
\hline CHEMBL1333414 & 737824 & 4.6 & 4.8207 & TRN \\
\hline CHEMBL1496349 & 737824 & 4.95 & 4.97 & TST \\
\hline CHEMBL1551090 & 737824 & 4.8 & 4.9384 & TRN \\
\hline CHEMBL1393508 & 737824 & 4.55 & 5.2631 & TRN \\
\hline CHEMBL1448411 & 737824 & 4.75 & 4.9059 & TRN \\
\hline CHEMBL1367149 & 737824 & 5.25 & 4.9029 & TRN \\
\hline CHEMBL1417646 & 737824 & 4.4 & 4.2145 & TRN \\
\hline CHEMBL1507494 & 737824 & 4.4 & 4.7237 & TST \\
\hline CHEMBL1372028 & 737824 & 6.5 & 5.4805 & TST \\
\hline CHEMBL1332636 & 737824 & 5.6 & 5.55 & TRN \\
\hline CHEMBL1450677 & 737824 & 4.85 & 4.9719 & TRN \\
\hline CHEMBL1490544 & 737824 & 5.2 & 4.8728 & TRN \\
\hline CHEMBL1162107 & 737824 & 5.6 & 5.0082 & TST \\
\hline CHEMBL1538191 & 737824 & 4.4 & 4.7305 & TST \\
\hline CHEMBL1375127 & 737824 & 7.0 & 6.5456 & TRN \\
\hline CHEMBL1485587 & 737824 & 5.55 & 5.3846 & TRN \\
\hline CHEMBL1402562 & 737824 & 4.95 & 5.2866 & TRN \\
\hline CHEMBL1574106 & 737824 & 4.7 & 4.67 & TRN \\
\hline CHEMBL1357872 & 737824 & 4.8 & 4.6258 & TRN \\
\hline CHEMBL1474185 & 737824 & 4.5 & 4.5761 & TRN \\
\hline CHEMBL1611856 & 737824 & 6.4 & 6.26399 & 9999999999 \\
\hline CHEMBL1311305 & 737824 & 5.6 & 5.3209 & TRN \\
\hline CHEMBL1299384 & 737824 & 4.65 & 4.9171 & TST \\
\hline CHEMBL1399619 & 737824 & 5.6 & 5.5332 & TRN \\
\hline CHEMBL3207650 & 737824 & 5.75 & 5.3674 & TST \\
\hline CHEMBL1486659 & 737824 & 5.6 & 5.1649 & TST \\
\hline CHEMBL69234 & 737824 & 7.9 & 6.562 & TST \\
\hline CHEMBL1531681 & 737824 & 5.35 & 5.4739 & TRN \\
\hline CHEMBL1531299 & 737824 & 6.6 & 6.3589 & TRN \\
\hline CHEMBL3211571 & 737824 & 4.6 & 4.9786 & TRN \\
\hline CHEMBL1408647 & 737824 & 4.8 & 5.0102 & TRN \\
\hline CHEMBL1435823 & 737824 & 4.9 & 5.1537 & TRN \\
\hline CHEMBL1349604 & 737824 & 5.3 & 5.1913 & TRN \\
\hline CHEMBL1532067 & 737824 & 6.2 & 4.9253 & TRN \\
\hline CHEMBL1344309 & 737824 & 5.15 & 5.086 & TRN \\
\hline CHEMBL1525560 & 737824 & 4.7 & 4.9555 & TRN \\
\hline CHEMBL1439936 & 737824 & 4.8 & 5.1603 & TST \\
\hline CHEMBL1567447 & 737824 & 6.3 & 5.6586 & TRN \\
\hline CHEMBL 2006154 & 737824 & 5.7 & 5.9847 & TRN \\
\hline CHEMBL3199291 & 737824 & 5.4 & 5.7075 & TRN \\
\hline CHEMBL1708371 & 737824 & 4.45 & 5.1003 & TRN \\
\hline CHEMBL1519173 & 737824 & 5.1 & 5.1565 & TST \\
\hline CHEMBL1315920 & 737824 & 5.5 & 5.2592 & TRN \\
\hline CHEMBL1340272 & 737824 & 5.45 & 5.3634 & TRN \\
\hline CHEMBL1341335 & 737824 & 4.9 & 4.7516 & TRN \\
\hline CHEMBL1422586 & 737824 & 4.6 & 4.8757 & TRN \\
\hline
\end{tabular}

TRN 


\begin{tabular}{|c|c|c|c|c|c|}
\hline & & \multicolumn{4}{|c|}{ Supplemental Table S2.txt } \\
\hline CHEMBL1587637 & 737824 & 5.15 & 4.9752 & TRN & \\
\hline CHEMBL1500226 & 737824 & 5.1 & 5.6912 & TST & \\
\hline CHEMBL1411094 & 737824 & 4.5 & 4.6278 & TRN & \\
\hline CHEMBL1361675 & 737824 & 5.95 & 6.0717 & TRN & \\
\hline CHEMBL1373075 & 737824 & 5.0 & 5.2247 & TRN & \\
\hline CHEMBL1433724 & 737824 & 5.6 & 5.6988 & TRN & \\
\hline CHEMBL1412209 & 737824 & 5.15 & 5.5971 & TRN & \\
\hline CHEMBL1581055 & 737824 & 5.7 & 5.6535 & TRN & \\
\hline CHEMBL1328118 & 737824 & 5.65 & 5.7119 & TRN & \\
\hline CHEMBL1339670 & 737824 & 4.6 & 4.9654 & TST & \\
\hline CHEMBL1317537 & 737824 & 4.7 & 4.7433 & TRN & \\
\hline CHEMBL1570465 & 737824 & 5.6 & 5.2398 & TRN & \\
\hline CHEMBL 2000120 & 737824 & 5.4 & 5.8593 & TRN & \\
\hline CHEMBL1359094 & 737824 & 4.85 & 4.6494 & TRN & \\
\hline CHEMBL1403311 & 737824 & 7.05 & 4.8553 & TST & \\
\hline CHEMBL1451768 & 737824 & 5.6 & 5.6358 & TRN & \\
\hline CHEMBL1575726 & 737824 & 5.3 & $5.8770 e$ & 0000000001 & TRN \\
\hline CHEMBL1362390 & 737824 & 5.45 & 5.29299 & 9999999999 & TRN \\
\hline CHEMBL1430258 & 737824 & 4.95 & 5.3491 & TRN & \\
\hline CHEMBL1426147 & 737824 & 4.95 & 5.1405 & TRN & \\
\hline CHEMBL1429762 & 737824 & 4.8 & 5.4981 & TRN & \\
\hline CHEMBL1467940 & 737824 & 6.6 & 5.3906 & TST & \\
\hline CHEMBL1578254 & 737824 & 6.1 & 5.0495 & TRN & \\
\hline CHEMBL1736877 & 737824 & 4.4 & 5.2475 & TRN & \\
\hline CHEMBL1545452 & 737824 & 4.85 & 4.9155 & TRN & \\
\hline CHEMBL3195972 & 737824 & 4.85 & 5.1165 & TRN & \\
\hline CHEMBL1567589 & 737824 & 5.45 & 5.3243 & TRN & \\
\hline CHEMBL1443741 & 737824 & 4.4 & 4.0706 & TRN & \\
\hline CHEMBL66105 & 737824 & 6.0 & 5.4674 & TST & \\
\hline CHEMBL1538879 & 737824 & 5.7 & 5.37 & TST & \\
\hline CHEMBL1351344 & 737824 & 5.5 & 5.6671 & TRN & \\
\hline CHEMBL1478530 & 737824 & 4.9 & 4.6092 & TST & \\
\hline CHEMBL1565333 & 737824 & 5.7 & 5.4977 & TST & \\
\hline CHEMBL1524401 & 737824 & 4.95 & 5.4816 & TRN & \\
\hline CHEMBL1611062 & 737824 & 4.6 & 4.4661 & TRN & \\
\hline CHEMBL1560068 & 737824 & 4.6 & 4.987 & TRN & \\
\hline CHEMBL1491574 & 737824 & 4.4 & 4.0698 & TRN & \\
\hline CHEMBL1580216 & 737824 & 4.85 & 5.1906 & TRN & \\
\hline CHEMBL1472029 & 737824 & 4.95 & 5.0874 & TRN & \\
\hline CHEMBL1377727 & 737824 & 4.8 & 4.8117 & TRN & \\
\hline CHEMBL40004 & 737824 & 6.9 & 6.0921 & TRN & \\
\hline CHEMBL1493496 & 737824 & 5.7 & 6.0268 & TRN & \\
\hline CHEMBL1606541 & 737824 & 5.4 & 5.0795 & TST & \\
\hline CHEMBL1374863 & 737824 & 6.4 & 6.2086 & TRN & \\
\hline CHEMBL1496596 & 737824 & 4.6 & 4.6325 & TRN & \\
\hline CHEMBL1340458 & 737824 & 5.45 & 5.9146 & TRN & \\
\hline CHEMBL3213163 & 737824 & 5.9 & 5.6959 & TRN & \\
\hline CHEMBL1379991 & 737824 & 4.6 & 5.1756 & TST & \\
\hline
\end{tabular}




\begin{tabular}{|c|c|c|c|c|c|}
\hline \multicolumn{6}{|c|}{ Supplemental Table S2.txt } \\
\hline CHEMBL1501724 & 737824 & 5.35 & 5.4904 & TRN & \\
\hline CHEMBL1553990 & 737824 & 4.4 & 4.3677 & TRN & \\
\hline CHEMBL407874 & 737824 & 5.2 & 5.0685 & TRN & \\
\hline CHEMBL1489765 & 737824 & 5.0 & 5.4334 & TRN & \\
\hline CHEMBL1369212 & 737824 & 6.0 & 6.2039 & TRN & \\
\hline CHEMBL1558771 & 737824 & 6.2 & 5.9718 & TRN & \\
\hline CHEMBL1374501 & 737824 & 5.6 & 5.4572 & TRN & \\
\hline CHEMBL1347400 & 737824 & 5.15 & 4.9981 & TRN & \\
\hline CHEMBL1489708 & 737824 & 4.9 & 4.5802 & TRN & \\
\hline CHEMBL1441404 & 737824 & 5.2 & 5.2096 & TRN & \\
\hline CHEMBL1538999 & 737824 & 5.1 & 5.3272 & TRN & \\
\hline CHEMBL1410926 & 737824 & 4.8 & 5.06 & TRN & \\
\hline CHEMBL1378339 & 737824 & 4.9 & 4.8164 & TST & \\
\hline CHEMBL3192752 & 737824 & 4.85 & 5.0843 & TRN & \\
\hline CHEMBL1492177 & 737824 & 5.65 & 5.50299 & 7999999999 & TRN \\
\hline CHEMBL1515874 & 737824 & 4.9 & 5.2532 & TRN & \\
\hline CHEMBL1454660 & 737824 & 6.05 & 5.4308 & TRN & \\
\hline CHEMBL1516015 & 737824 & 4.8 & 4.8711 & TST & \\
\hline CHEMBL1741623 & 737824 & 5.8 & 5.291 & TRN & \\
\hline CHEMBL3193508 & 737824 & 5.5 & 5.3307 & TRN & \\
\hline CHEMBL1573171 & 737824 & 7.15 & 5.8183 & TRN & \\
\hline CHEMBL1371017 & 737824 & 5.35 & 5.3988 & TRN & \\
\hline CHEMBL1416194 & 737824 & 4.65 & 5.1742 & TRN & \\
\hline CHEMBL1475255 & 737824 & 5.6 & 5.4827 & TRN & \\
\hline CHEMBL1518415 & 737824 & 5.0 & 5.0649 & TRN & \\
\hline CHEMBL1574196 & 737824 & 4.8 & 4.544 & TRN & \\
\hline CHEMBL1367548 & 737824 & 4.65 & 5.1465 & TRN & \\
\hline CHEMBL1544498 & 737824 & 4.9 & 5.4287 & TRN & \\
\hline CHEMBL1522232 & 737824 & 5.65 & 5.1021 & TRN & \\
\hline CHEMBL1707644 & 737824 & 5.05 & 5.1353 & TRN & \\
\hline CHEMBL1406879 & 737824 & 5.1 & 4.7529 & TRN & \\
\hline CHEMBL1547886 & 737824 & 5.8 & 5.4723 & TRN & \\
\hline CHEMBL1461936 & 737824 & 4.6 & 4.6338 & TRN & \\
\hline CHEMBL3196035 & 737824 & 4.55 & 4.8938 & TRN & \\
\hline CHEMBL3208849 & 737824 & 4.85 & 4.6909 & TRN & \\
\hline CHEMBL1342336 & 737824 & 4.9 & 5.3887 & TRN & \\
\hline CHEMBL1987784 & 737824 & 6.15 & 5.6213 & TRN & \\
\hline CHEMBL1318509 & 737824 & 5.0 & 5.0654 & TRN & \\
\hline CHEMBL3191366 & 737824 & 5.0 & 5.1774 & TRN & \\
\hline CHEMBL1361797 & 737824 & 5.8 & 5.5293 & TRN & \\
\hline CHEMBL1459858 & 737824 & 5.7 & 5.0683 & TRN & \\
\hline CHEMBL3196744 & 737824 & 4.75 & 5.0135 & TRN & \\
\hline CHEMBL1436817 & 737824 & 4.8 & 4.4083 & TRN & \\
\hline CHEMBL1494979 & 737824 & 5.25 & 5.1069 & TRN & \\
\hline CHEMBL3213793 & 737824 & 5.1 & 4.8174 & TRN & \\
\hline CHEMBL1428926 & 737824 & 5.15 & 4.9532 & TRN & \\
\hline CHEMBL1526761 & 737824 & 4.5 & 5.0073 & TST & \\
\hline CHEMBL1741965 & 737824 & 5.2 & 5.4437 & TST & \\
\hline
\end{tabular}




\begin{tabular}{|c|c|c|c|c|}
\hline \multicolumn{5}{|c|}{ Supplemental Table } \\
\hline CHEMBL1491137 & 737824 & 4.75 & 5.3908 & TRN \\
\hline CHEMBL1574831 & 737824 & 5.6 & 5.3805 & TRN \\
\hline CHEMBL1431794 & 737824 & 4.85 & 5.1599 & TRN \\
\hline CHEMBL1335890 & 737824 & 6.0 & 6.1366 & TRN \\
\hline CHEMBL1557851 & 737824 & 4.9 & 5.4581 & TST \\
\hline CHEMBL1574576 & 737824 & 6.75 & 6.0804 & TRN \\
\hline CHEMBL1433950 & 737824 & 4.5 & 4.5014 & TRN \\
\hline CHEMBL1610581 & 737824 & 4.9 & 5.1949 & TRN \\
\hline CHEMBL1494100 & 737824 & 5.4 & 5.1406 & TRN \\
\hline CHEMBL1567472 & 737824 & 4.4 & 4.3955 & TRN \\
\hline CHEMBL399491 & 737824 & 6.0 & 5.7675 & TRN \\
\hline CHEMBL1360980 & 737824 & 4.9 & 5.0519 & TST \\
\hline CHEMBL1409961 & 737824 & 6.4 & 6.2435 & TRN \\
\hline CHEMBL1346774 & 737824 & 5.3 & 5.4857 & TRN \\
\hline CHEMBL1588249 & 737824 & 4.85 & 4.8257 & TRN \\
\hline CHEMBL1506666 & 737824 & 5.1 & 5.221 & TRN \\
\hline CHEMBL1584452 & 737824 & 4.7 & 5.4866 & TRN \\
\hline CHEMBL1404882 & 737824 & 5.2 & 5.8877 & TRN \\
\hline CHEMBL1509383 & 737824 & 4.95 & 4.7796 & TRN \\
\hline CHEMBL1460984 & 737824 & 5.35 & 5.6798 & TRN \\
\hline CHEMBL1352225 & 737824 & 5.7 & 5.5557 & TRN \\
\hline CHEMBL1347205 & 737824 & 5.95 & 5.2574 & TRN \\
\hline CHEMBL1719399 & 737824 & 4.9 & 5.0476 & TRN \\
\hline CHEMBL1513392 & 737824 & 6.1 & 5.8035 & TRN \\
\hline CHEMBL3199738 & 737824 & 5.35 & 4.9627 & TRN \\
\hline CHEMBL1714814 & 737824 & 4.9 & 4.7975 & TST \\
\hline CHEMBL1456743 & 737824 & 6.6 & 6.0014 & TRN \\
\hline CHEMBL1514219 & 737824 & 4.7 & 4.4202 & TST \\
\hline CHEMBL1587532 & 737824 & 4.7 & 4.9459 & TRN \\
\hline CHEMBL1424229 & 737824 & 4.8 & 5.3149 & TST \\
\hline CHEMBL1554569 & 737824 & 5.3 & 5.0618 & TRN \\
\hline CHEMBL1096411 & 737824 & 5.0 & 4.9855 & TRN \\
\hline CHEMBL1591908 & 737824 & 4.8 & 4.9629 & TRN \\
\hline CHEMBL1404940 & 737824 & 4.95 & 4.9866 & TRN \\
\hline CHEMBL1343101 & 737824 & 5.65 & 5.3054 & TST \\
\hline CHEMBL1741818 & 737824 & 4.65 & 4.8487 & TRN \\
\hline CHEMBL3199680 & 737824 & 4.85 & 5.0899 & TRN \\
\hline CHEMBL1370889 & 737824 & 4.55 & 4.8244 & TRN \\
\hline CHEMBL1568113 & 737824 & 6.35 & 5.7937 & TRN \\
\hline CHEMBL1742217 & 737824 & 4.95 & 4.8424 & TST \\
\hline CHEMBL1354626 & 737824 & 5.6 & 5.6024 & TRN \\
\hline CHEMBL1436045 & 737824 & 6.6 & 6.2201 & TRN \\
\hline CHEMBL3192865 & 737824 & 5.5 & 5.1816 & TRN \\
\hline CHEMBL129795 & 737824 & 4.9 & 5.5568 & TRN \\
\hline CHEMBL1427131 & 737824 & 4.85 & 5.3277 & TRN \\
\hline CHEMBL1390531 & 737824 & 4.4 & 4.8755 & TRN \\
\hline CHEMBL1610409 & 737824 & 5.2 & 5.3479 & TRN \\
\hline CHEMBL1425971 & 737824 & 4.8 & 5.0561 & TRN \\
\hline
\end{tabular}




\begin{tabular}{|c|c|c|c|c|}
\hline \multicolumn{5}{|c|}{ Supplemental Table S2.txt } \\
\hline CHEMBL1501701 & 737824 & 4.9 & 5.2313 & TRN \\
\hline CHEMBL1604492 & 737824 & 4.6 & 5.2879 & TRN \\
\hline CHEMBL1742020 & 737824 & 4.65 & 5.053 & TRN \\
\hline CHEMBL1436324 & 737824 & 5.4 & 5.1167 & TST \\
\hline CHEMBL1584983 & 737824 & 6.65 & 5.9429 & TST \\
\hline CHEMBL1590974 & 737824 & 4.5 & 4.7415 & TRN \\
\hline CHEMBL1456015 & 737824 & 5.3 & 5.1313 & TRN \\
\hline CHEMBL1319426 & 737824 & 6.2 & 5.5936 & TRN \\
\hline CHEMBL 3210367 & 737824 & 6.4 & 5.3112 & TRN \\
\hline CHEMBL1479131 & 737824 & 5.15 & 5.086 & TRN \\
\hline CHEMBL1594799 & 737824 & 5.05 & 5.1603 & TRN \\
\hline CHEMBL241657 & 737824 & 4.9 & 5.0603 & TRN \\
\hline CHEMBL1448138 & 737824 & 4.6 & 4.638 & TRN \\
\hline CHEMBL1546480 & 737824 & 4.95 & 5.085 & TRN \\
\hline CHEMBL18132 & 737824 & 5.3 & 5.0726 & TST \\
\hline CHEMBL1539830 & 737824 & 5.8 & 5.6732 & TRN \\
\hline CHEMBL1332286 & 737824 & 5.45 & 5.1033 & TRN \\
\hline CHEMBL1354093 & 737824 & 5.65 & 5.4554 & TRN \\
\hline CHEMBL1525473 & 737824 & 5.9 & 5.3274 & TST \\
\hline CHEMBL1533139 & 737824 & 5.2 & 5.2754 & TRN \\
\hline CHEMBL1337622 & 737824 & 5.15 & 5.3435 & TRN \\
\hline CHEMBL1514045 & 737824 & 4.8 & 4.5634 & TRN \\
\hline CHEMBL1417375 & 737824 & 5.4 & 5.2469 & TRN \\
\hline CHEMBL1302114 & 737824 & 5.55 & 4.883 & TRN \\
\hline CHEMBL1326093 & 737824 & 5.35 & 5.1619 & TRN \\
\hline CHEMBL3189288 & 737824 & 5.3 & 5.6236 & TRN \\
\hline CHEMBL1438357 & 737824 & 4.55 & 5.0648 & TRN \\
\hline CHEMBL3195544 & 737824 & 5.4 & 5.1944 & TRN \\
\hline CHEMBL1611820 & 737824 & 4.4 & 4.283 & TRN \\
\hline CHEMBL329872 & 737824 & 5.6 & 4.6982 & TRN \\
\hline CHEMBL3212989 & 737824 & 5.35 & 5.5704 & TRN \\
\hline CHEMBL1399207 & 737824 & 4.85 & 5.4585 & TRN \\
\hline CHEMBL1741361 & 737824 & 5.05 & 5.0795 & TRN \\
\hline CHEMBL1495091 & 737824 & 5.6 & 5.5396 & TRN \\
\hline CHEMBL1741605 & 737824 & 5.3 & 4.9894 & TRN \\
\hline CHEMBL1513347 & 737824 & 5.2 & 5.3437 & TRN \\
\hline CHEMBL1478703 & 737824 & 4.8 & 4.9923 & TRN \\
\hline CHEMBL1345354 & 737824 & 5.55 & 5.2935 & TRN \\
\hline CHEMBL1333338 & 737824 & 5.8 & 5.4589 & TRN \\
\hline CHEMBL1611715 & 737824 & 4.7 & 4.9831 & TRN \\
\hline CHEMBL1596762 & 737824 & 4.9 & 5.1732 & TRN \\
\hline CHEMBL3209915 & 737824 & 4.6 & 4.9431 & TRN \\
\hline CHEMBL1558087 & 737824 & 5.5 & 5.19 & TRN \\
\hline CHEMBL3197876 & 737824 & 5.5 & 5.5627 & TRN \\
\hline CHEMBL1345174 & 737824 & 4.85 & 5.1074 & TRN \\
\hline CHEMBL1514819 & 737824 & 8.2 & 7.8025 & TRN \\
\hline CHEMBL1307577 & 737824 & 4.95 & 5.2203 & TRN \\
\hline CHEMBL1700721 & 737824 & 5.85 & 5.4309 & TRN \\
\hline
\end{tabular}




\begin{tabular}{|c|c|c|c|c|c|}
\hline \\
\hline CHEMBL1309304 & 737824 & 5.4 & 5.8059 & TRN & \\
\hline CHEMBL539676 & 737824 & 4.4 & 5.3253 & TRN & \\
\hline CHEMBL1550240 & 737824 & 5.0 & 4.9235 & TST & \\
\hline CHEMBL1561905 & 737824 & 5.25 & 5.6143 & TRN & \\
\hline CHEMBL1576361 & 737824 & 4.4 & 5.1731 & TRN & \\
\hline CHEMBL150 & 737824 & 5.2 & 6.5564 & TRN & \\
\hline CHEMBL1580282 & 737824 & 5.0 & 5.0669 & TRN & \\
\hline CHEMBL1613081 & 737824 & 4.95 & 4.9322 & TRN & \\
\hline CHEMBL1501081 & 737824 & 4.75 & 4.7316 & TRN & \\
\hline CHEMBL1567530 & 737824 & 5.7 & 5.6052 & TST & \\
\hline CHEMBL1595145 & 737824 & 5.05 & 4.8228 & TST & \\
\hline CHEMBL1602892 & 737824 & 4.95 & 5.4403 & TRN & \\
\hline CHEMBL1526964 & 737824 & 6.0 & 5.648 & TST & \\
\hline CHEMBL1575404 & 737824 & 5.3 & 4.8106 & TRN & \\
\hline CHEMBL1973729 & 737824 & 4.6 & 5.09399 & 9999999999 & TRN \\
\hline CHEMBL1488466 & 737824 & 5.0 & 5.4751 & TRN & \\
\hline CHEMBL1717253 & 737824 & 5.4 & 5.3096 & TRN & \\
\hline CHEMBL3192117 & 737824 & 5.0 & 5.3912 & TRN & \\
\hline CHEMBL3207394 & 737824 & 5.4 & 5.4592 & TRN & \\
\hline CHEMBL3189190 & 737824 & 5.3 & 5.4328 & TRN & \\
\hline CHEMBL1532941 & 737824 & 5.5 & 4.7929 & TRN & \\
\hline CHEMBL1502348 & 737824 & 5.15 & 5.1926 & TRN & \\
\hline CHEMBL1454730 & 737824 & 5.5 & 5.3337 & TRN & \\
\hline CHEMBL1530209 & 737824 & 4.95 & 4.9845 & TRN & \\
\hline CHEMBL1558867 & 737824 & 8.25 & 5.0442 & TST & \\
\hline CHEMBL1322864 & 737824 & 5.8 & 5.6578 & TRN & \\
\hline CHEMBL1580660 & 737824 & 6.7 & 6.1176 & TRN & \\
\hline CHEMBL1361757 & 737824 & 5.2 & 5.3395 & TRN & \\
\hline CHEMBL1459301 & 737824 & 4.9 & 5.0686 & TRN & \\
\hline CHEMBL1530672 & 737824 & 5.4 & 5.1536 & TRN & \\
\hline CHEMBL1525376 & 737824 & 4.95 & 5.1317 & TRN & \\
\hline CHEMBL 247378 & 737824 & 5.8 & 5.6453 & TST & \\
\hline CHEMBL1551841 & 737824 & 5.0 & 4.9746 & TRN & \\
\hline CHEMBL1584624 & 737824 & 4.95 & 5.394 & TRN & \\
\hline CHEMBL1720109 & 737824 & 5.0 & 5.6245 & TRN & \\
\hline CHEMBL1406391 & 737824 & 5.2 & 4.99 & TRN & \\
\hline CHEMBL1353871 & 737824 & 5.95 & 5.8148 & TRN & \\
\hline CHEMBL1353322 & 737824 & 5.4 & 5.5373 & TRN & \\
\hline CHEMBL1741578 & 737824 & 5.75 & 5.0969 & TRN & \\
\hline CHEMBL472994 & 737824 & 5.8 & 5.8428 & TST & \\
\hline CHEMBL994 & 737824 & 5.4 & 5.3146 & TST & \\
\hline CHEMBL1483874 & 737824 & 4.85 & 4.9243 & TRN & \\
\hline CHEMBL1533672 & 737824 & 5.6 & 5.1351 & TRN & \\
\hline CHEMBL1385746 & 737824 & 4.4 & 5.2392 & TRN & \\
\hline CHEMBL1394258 & 737824 & 5.0 & 5.0289 & TRN & \\
\hline CHEMBL1372401 & 737824 & 4.95 & 5.4953 & TRN & \\
\hline CHEMBL434119 & 737824 & 4.6 & 4.4441 & TRN & \\
\hline CHEMBL1337387 & 737824 & 4.4 & 5.0133 & TRN & \\
\hline & & & & 7612 & \\
\hline
\end{tabular}




\begin{tabular}{|c|c|c|c|c|c|}
\hline \multirow[b]{2}{*}{ CHEMBL3191464 } & \multirow[b]{2}{*}{737824} & \multicolumn{4}{|c|}{ Supplemental Table S2.txt } \\
\hline & & 5.35 & 4.8448 & TST & \\
\hline CHEMBL1435384 & 737824 & 4.6 & 4.5044 & TRN & \\
\hline CHEMBL1419356 & 737824 & 5.0 & 5.7262 & TRN & \\
\hline CHEMBL1362642 & 737824 & 4.85 & 4.8674 & TRN & \\
\hline CHEMBL1390616 & 737824 & 5.7 & 5.2562 & TRN & \\
\hline CHEMBL1386361 & 737824 & 6.25 & 5.6092 & TRN & \\
\hline CHEMBL1595376 & 737824 & 4.75 & 4.9858 & TST & \\
\hline CHEMBL1361406 & 737824 & 5.0 & 4.8333 & TRN & \\
\hline CHEMBL1332033 & 737824 & 5.3 & 5.312 & TRN & \\
\hline CHEMBL1384961 & 737824 & 4.65 & 4.7943 & TRN & \\
\hline CHEMBL1583260 & 737824 & 5.05 & 5.9682 & TST & \\
\hline CHEMBL452153 & 737824 & 5.45 & 5.5033 & TST & \\
\hline CHEMBL1539897 & 737824 & 5.95 & 4.9735 & TST & \\
\hline CHEMBL1449420 & 737824 & 4.4 & 5.3539 & TRN & \\
\hline CHEMBL1411115 & 737824 & 5.9 & 5.62200 & 0000000001 & TRN \\
\hline CHEMBL1441290 & 737824 & 5.6 & 5.4514 & TRN & \\
\hline CHEMBL1546060 & 737824 & 4.9 & 4.8773 & TRN & \\
\hline CHEMBL1361905 & 737824 & 5.0 & 5.3131 & TRN & \\
\hline CHEMBL78150 & 737824 & 5.1 & 5.1775 & TRN & \\
\hline CHEMBL1346239 & 737824 & 5.7 & 5.336 & TRN & \\
\hline CHEMBL1557947 & 737824 & 5.1 & 5.7536 & TRN & \\
\hline CHEMBL1447809 & 737824 & 4.9 & 5.0639 & TRN & \\
\hline CHEMBL1418803 & 737824 & 5.45 & 5.468 & TRN & \\
\hline CHEMBL1310213 & 737824 & 4.85 & 5.0485 & TRN & \\
\hline CHEMBL1564094 & 737824 & 4.4 & 5.2738 & TRN & \\
\hline CHEMBL1459899 & 737824 & 5.9 & 5.2242 & TRN & \\
\hline CHEMBL1595998 & 737824 & 4.8 & 5.5031 & TRN & \\
\hline CHEMBL1535457 & 737824 & 5.2 & 5.0848 & TRN & \\
\hline CHEMBL1488679 & 737824 & 5.5 & 5.4107 & TST & \\
\hline CHEMBL1486583 & 737824 & 4.55 & 5.4724 & TRN & \\
\hline CHEMBL1470528 & 737824 & 4.8 & 5.3233 & TST & \\
\hline CHEMBL1305513 & 737824 & 5.0 & 5.1237 & TRN & \\
\hline CHEMBL1501400 & 737824 & 5.35 & 4.8808 & TRN & \\
\hline CHEMBL1376622 & 737824 & 4.55 & 5.2847 & TST & \\
\hline CHEMBL1489659 & 737824 & 5.1 & 5.1302 & TRN & \\
\hline CHEMBL1558384 & 737824 & 4.5 & 4.2957 & TRN & \\
\hline CHEMBL3198484 & 737824 & 5.15 & 5.8445 & TRN & \\
\hline CHEMBL1495854 & 737824 & 4.5 & 4.4505 & TRN & \\
\hline CHEMBL1476049 & 737824 & 4.9 & 4.8848 & TRN & \\
\hline CHEMBL1569985 & 737824 & 6.3 & 6.2082 & TRN & \\
\hline CHEMBL1558480 & 737824 & 4.7 & 4.8753 & TRN & \\
\hline CHEMBL1416452 & 737824 & -0.0 & 4.1604 & TRN & \\
\hline CHEMBL3210244 & 737824 & 6.1 & 6.0816 & TRN & \\
\hline CHEMBL3193293 & 737824 & 4.85 & 5.0063 & TST & \\
\hline CHEMBL1603577 & 737824 & 5.4 & 4.9935 & TRN & \\
\hline CHEMBL1578021 & 737824 & 5.4 & 5.7375 & TRN & \\
\hline CHEMBL1443362 & 737824 & 5.05 & 4.9524 & TRN & \\
\hline CHEMBL1354231 & 737824 & 5.25 & 5.2938 & TRN & \\
\hline
\end{tabular}




\begin{tabular}{|c|c|c|c|c|c|}
\hline \multicolumn{6}{|c|}{ pıemental } \\
\hline CHEMBL3196221 & 737824 & 4.95 & 5.3921 & TST & \\
\hline CHEMBL1570763 & 737824 & 4.8 & 5.7478 & TRN & \\
\hline CHEMBL1585542 & 737824 & 5.05 & 5.6034 & TRN & \\
\hline CHEMBL1742147 & 737824 & 5.3 & 5.3802 & TRN & \\
\hline CHEMBL1488990 & 737824 & 4.8 & 4.7447 & TRN & \\
\hline CHEMBL1521414 & 737824 & 5.6 & 5.3352 & TRN & \\
\hline CHEMBL1390122 & 737824 & 6.0 & 5.5228 & TRN & \\
\hline CHEMBL1471931 & 737824 & 5.65 & 5.2582 & TRN & \\
\hline CHEMBL1382261 & 737824 & 5.9 & 5.1166 & TRN & \\
\hline CHEMBL1390555 & 737824 & 5.9 & 6.11700 & 0000000001 & TRN \\
\hline CHEMBL1466200 & 737824 & 4.5 & 5.2462 & TRN & \\
\hline CHEMBL1357722 & 737824 & 4.4 & 4.029 & TRN & \\
\hline CHEMBL1377201 & 737824 & 5.2 & 5.3492 & TRN & \\
\hline CHEMBL1742255 & 737824 & 5.65 & 5.3821 & TRN & \\
\hline CHEMBL1590663 & 737824 & 4.8 & 4.614 & TRN & \\
\hline CHEMBL1326815 & 737824 & 5.8 & 5.5825 & TRN & \\
\hline CHEMBL1391091 & 737824 & 4.9 & 5.0663 & TRN & \\
\hline CHEMBL 3210081 & 737824 & 4.9 & 5.5822 & TRN & \\
\hline CHEMBL1478660 & 737824 & 4.4 & 5.1276 & TRN & \\
\hline CHEMBL3192255 & 737824 & 5.0 & 4.8193 & TRN & \\
\hline CHEMBL1432973 & 737824 & 5.65 & 5.1629 & TRN & \\
\hline CHEMBL63154 & 737824 & 5.4 & 5.7987 & TRN & \\
\hline CHEMBL1587843 & 737824 & 5.15 & 5.2086 & TRN & \\
\hline CHEMBL1559279 & 737824 & 4.8 & 4.625 & TRN & \\
\hline CHEMBL1508113 & 737824 & 5.2 & 5.12299 & 9999999999 & TRN \\
\hline CHEMBL1336412 & 737824 & 4.6 & 5.2596 & TST & \\
\hline CHEMBL1453758 & 737824 & 4.9 & 5.3012 & TRN & \\
\hline CHEMBL1367499 & 737824 & 5.2 & 5.1603 & TRN & \\
\hline CHEMBL1378353 & 737824 & 4.7 & 5.44799 & 99999999995 & TRN \\
\hline CHEMBL1597203 & 737824 & 5.55 & 5.7115 & TRN & \\
\hline CHEMBL1742135 & 737824 & 4.9 & 4.9767 & TST & \\
\hline CHEMBL1557696 & 737824 & 5.4 & 5.0809 & TRN & \\
\hline CHEMBL90769 & 737824 & 6.0 & 5.8019 & TRN & \\
\hline CHEMBL1478640 & 737824 & 5.65 & 5.7375 & TRN & \\
\hline CHEMBL1458143 & 737824 & 5.9 & 5.6882 & TRN & \\
\hline CHEMBL1411651 & 737824 & 4.55 & 5.2793 & TRN & \\
\hline CHEMBL1393435 & 737824 & 5.4 & 5.4315 & TST & \\
\hline CHEMBL1603852 & 737824 & 7.3 & 7.5828 & TRN & \\
\hline CHEMBL1562974 & 737824 & 6.0 & 5.5226 & TRN & \\
\hline CHEMBL1366020 & 737824 & 5.8 & 5.8207 & TRN & \\
\hline CHEMBL3199351 & 737824 & 5.6 & 5.5184 & TRN & \\
\hline CHEMBL1376554 & 737824 & 4.6 & 5.0053 & TRN & \\
\hline CHEMBL 258405 & 737824 & 5.2 & 5.0727 & TST & \\
\hline CHEMBL1733088 & 737824 & 5.65 & 5.3112 & TRN & \\
\hline CHEMBL 3212802 & 737824 & 5.15 & 5.2338 & TRN & \\
\hline CHEMBL1715395 & 737824 & 4.4 & 4.8068 & TRN & \\
\hline CHEMBL1482575 & 737824 & 4.8 & 4.8082 & TRN & \\
\hline CHEMBL1588990 & 737824 & 6.15 & 5.8275 & TRN & \\
\hline
\end{tabular}




\begin{tabular}{|c|c|c|c|c|c|}
\hline & & & & & \\
\hline CHEMBL1330626 & 737824 & 4.9 & 5.2558 & TRN & \\
\hline CHEMBL1552623 & 737824 & 5.8 & 5.8143 & TRN & \\
\hline CHEMBL1560095 & 737824 & 4.9 & 4.6366 & TRN & \\
\hline CHEMBL1436743 & 737824 & 5.3 & 5.8586 & TRN & \\
\hline CHEMBL1376767 & 737824 & 5.0 & 5.6069 & TRN & \\
\hline CHEMBL1560551 & 737824 & 5.7 & 5.046 & TST & \\
\hline CHEMBL1711849 & 737824 & 4.55 & 5.0521 & TRN & \\
\hline CHEMBL1595731 & 737824 & 4.6 & 5.2516 & TRN & \\
\hline CHEMBL1558802 & 737824 & 4.85 & 4.66100 & 00000000005 & TRN \\
\hline CHEMBL1408922 & 737824 & 5.1 & 4.4566 & TST & \\
\hline CHEMBL1485568 & 737824 & 5.8 & 5.2411 & TRN & \\
\hline CHEMBL1460094 & 737824 & 5.75 & 5.2388 & TST & \\
\hline CHEMBL1327910 & 737824 & 4.4 & 4.6406 & TRN & \\
\hline CHEMBL1368866 & 737824 & 5.35 & 4.9984 & TRN & \\
\hline CHEMBL3196253 & 737824 & 5.1 & 5.0422 & TST & \\
\hline CHEMBL1316760 & 737824 & 4.6 & 4.4934 & TRN & \\
\hline CHEMBL3208715 & 737824 & 4.4 & 4.5223 & TRN & \\
\hline CHEMBL1331351 & 737824 & 4.7 & 4.3011 & TRN & \\
\hline CHEMBL1378715 & 737824 & 4.5 & 4.9268 & TRN & \\
\hline CHEMBL1582787 & 737824 & 4.5 & 5.4777 & TRN & \\
\hline CHEMBL1613725 & 737824 & 4.8 & 4.6619 & TRN & \\
\hline CHEMBL1562915 & 737824 & 4.45 & 5.2785 & TRN & \\
\hline CHEMBL1562832 & 737824 & 5.6 & 5.4714 & TRN & \\
\hline CHEMBL1467491 & 737824 & 7.5 & 6.022 & TRN & \\
\hline CHEMBL1441415 & 737824 & 5.0 & 5.1088 & TRN & \\
\hline CHEMBL1481465 & 737824 & 5.0 & 4.533 & TRN & \\
\hline CHEMBL1319381 & 737824 & 5.05 & 5.6317 & TRN & \\
\hline CHEMBL1449293 & 737824 & 7.0 & 5.5494 & TRN & \\
\hline CHEMBL1504596 & 737824 & 4.4 & 4.6906 & TST & \\
\hline CHEMBL1450275 & 737824 & 4.85 & 4.93 & TRN & \\
\hline CHEMBL1543676 & 737824 & 4.85 & 5.1675 & TRN & \\
\hline CHEMBL1551122 & 737824 & 4.4 & 4.1023 & TRN & \\
\hline CHEMBL1353404 & 737824 & 5.95 & 5.5033 & TRN & \\
\hline CHEMBL1592760 & 737824 & 4.4 & 4.1961 & TRN & \\
\hline CHEMBL1371160 & 737824 & 5.4 & 5.3516 & TRN & \\
\hline CHEMBL1366390 & 737824 & 6.25 & 5.7848 & TRN & \\
\hline CHEMBL1480350 & 737824 & 4.9 & 4.7037 & TRN & \\
\hline CHEMBL1518285 & 737824 & 4.9 & 5.6672 & TST & \\
\hline CHEMBL1477071 & 737824 & 5.6 & 5.3151 & TRN & \\
\hline CHEMBL1305576 & 737824 & 5.6 & 5.4994 & TRN & \\
\hline CHEMBL1559877 & 737824 & 5.15 & 5.3852 & TRN & \\
\hline CHEMBL1385123 & 737824 & 5.05 & 5.4632 & TST & \\
\hline CHEMBL1892270 & 737824 & 5.0 & 5.0318 & TRN & \\
\hline CHEMBL1468272 & 737824 & 6.15 & 5.3325 & TRN & \\
\hline CHEMBL3199785 & 737824 & 4.4 & 4.7707 & TRN & \\
\hline CHEMBL1576372 & 737824 & 4.9 & 5.1651 & TRN & \\
\hline CHEMBL1380396 & 737824 & 6.2 & 6.0828 & TRN & \\
\hline CHEMBL1378629 & 737824 & 4.85 & 5.3091 & TRN & \\
\hline & & & & 7615 & \\
\hline
\end{tabular}




\begin{tabular}{|c|c|c|c|c|}
\hline \multicolumn{5}{|c|}{ Supplemental Table S2.txt } \\
\hline CHEMBL1327243 & 737824 & 4.9 & 4.7383 & TST \\
\hline CHEMBL1411543 & 737824 & 5.8 & 5.9159 & TRN \\
\hline CHEMBL1321660 & 737824 & 6.0 & 5.8091 & TRN \\
\hline CHEMBL1369062 & 737824 & 4.6 & 4.2955 & TRN \\
\hline CHEMBL1480847 & 737824 & 5.45 & 5.1022 & TRN \\
\hline CHEMBL1421107 & 737824 & 5.1 & 5.4135 & TRN \\
\hline CHEMBL1444406 & 737824 & 6.2 & 5.2707 & TRN \\
\hline CHEMBL1312648 & 737824 & 6.25 & 5.9362 & TRN \\
\hline CHEMBL1446172 & 737824 & 4.4 & 4.7091 & TRN \\
\hline CHEMBL1433013 & 737824 & 5.2 & 5.2959 & TRN \\
\hline CHEMBL1366926 & 737824 & 5.0 & 5.0227 & TRN \\
\hline CHEMBL 3194051 & 737824 & 5.95 & 5.1371 & TST \\
\hline CHEMBL1390396 & 737824 & 7.1 & 5.8581 & TRN \\
\hline CHEMBL1466551 & 737824 & 5.35 & 5.2486 & TRN \\
\hline CHEMBL1576446 & 737824 & 5.3 & 5.1334 & TRN \\
\hline CHEMBL1418523 & 737824 & 4.5 & 4.4956 & TRN \\
\hline CHEMBL1486163 & 737824 & 4.8 & 5.3855 & TST \\
\hline CHEMBL1543760 & 737824 & 5.2 & 5.3327 & TRN \\
\hline CHEMBL3348998 & 737824 & 6.0 & 5.2233 & TST \\
\hline CHEMBL1538764 & 737824 & 5.4 & 5.4403 & TRN \\
\hline CHEMBL1386397 & 737824 & 4.95 & 5.0757 & TRN \\
\hline CHEMBL1877767 & 737824 & 5.4 & 5.7357 & TST \\
\hline CHEMBL1300546 & 737824 & 4.4 & 5.2113 & TRN \\
\hline CHEMBL 277127 & 737824 & 4.8 & 4.7094 & TRN \\
\hline CHEMBL1601019 & 737824 & 5.1 & 5.3418 & TRN \\
\hline CHEMBL1553741 & 737824 & 4.5 & 4.617 & TRN \\
\hline CHEMBL1698533 & 737824 & 4.95 & 5.1385 & TRN \\
\hline CHEMBL1423348 & 737824 & 4.8 & 4.9292 & TRN \\
\hline CHEMBL1369939 & 737824 & 5.05 & 5.2469 & TST \\
\hline CHEMBL1389687 & 737824 & 6.15 & 5.5937 & TRN \\
\hline CHEMBL1518168 & 737824 & 5.5 & 5.1411 & TRN \\
\hline CHEMBL1554982 & 737824 & 6.0 & 5.5778 & TRN \\
\hline CHEMBL1499214 & 737824 & 5.8 & 5.5758 & TRN \\
\hline CHEMBL1392986 & 737824 & 5.55 & 4.9095 & TST \\
\hline CHEMBL1312830 & 737824 & 5.75 & 4.7969 & TRN \\
\hline CHEMBL1453208 & 737824 & 4.6 & 4.7727 & TRN \\
\hline CHEMBL1418130 & 737824 & 4.65 & 5.2135 & TRN \\
\hline CHEMBL1701728 & 737824 & 4.9 & 4.8564 & TRN \\
\hline CHEMBL1363782 & 737824 & 4.95 & 4.7486 & TST \\
\hline CHEMBL1539225 & 737824 & 4.4 & 5.3019 & TRN \\
\hline CHEMBL1417025 & 737824 & 4.8 & 4.9524 & TRN \\
\hline CHEMBL1453450 & 737824 & 4.4 & 4.52 & TRN \\
\hline CHEMBL1370805 & 737824 & 5.6 & 5.4547 & TRN \\
\hline CHEMBL1454249 & 737824 & 5.05 & 5.3681 & TRN \\
\hline CHEMBL1335760 & 737824 & 5.35 & 5.2649 & TRN \\
\hline CHEMBL1466128 & 737824 & 5.45 & 5.4863 & TRN \\
\hline CHEMBL1306942 & 737824 & 4.8 & 4.8801 & TRN \\
\hline CHEMBL1443520 & 737824 & 5.3 & 5.436 & TRN \\
\hline
\end{tabular}




\begin{tabular}{|c|c|c|c|c|c|}
\hline & & \multicolumn{4}{|c|}{ Supplemental Table s2.txt } \\
\hline CHEMBL1378030 & 737824 & 6.25 & 5.518 & TRN & \\
\hline CHEMBL1416207 & 737824 & 5.5 & 5.19 & TRN & \\
\hline CHEMBL1413340 & 737824 & 5.1 & \multicolumn{2}{|c|}{5.093999999999999} & TRN \\
\hline CHEMBL1591543 & 737824 & 5.9 & 5.8207 & TRN & \\
\hline CHEMBL1371564 & 737824 & 4.5 & 5.098 & TRN & \\
\hline CHEMBL1511066 & 737824 & 4.65 & 5.1814 & TRN & \\
\hline CHEMBL1331921 & 737824 & 4.85 & 5.2765 & TRN & \\
\hline CHEMBL1478570 & 737824 & 4.55 & 4.5931 & TRN & \\
\hline CHEMBL1391282 & 737824 & 5.0 & 5.0304 & TRN & \\
\hline CHEMBL1404945 & 737824 & 5.1 & 5.7944 & TST & \\
\hline CHEMBL1361808 & 737824 & 6.15 & 5.606 & TRN & \\
\hline CHEMBL1332696 & 737824 & 4.75 & 5.3607 & TRN & \\
\hline CHEMBL1467606 & 737824 & 4.9 & 5.0861 & TRN & \\
\hline CHEMBL1380899 & 737824 & 4.95 & 4.9593 & TRN & \\
\hline CHEMBL1519261 & 737824 & 5.5 & 5.3837 & TRN & \\
\hline CHEMBL1540663 & 737824 & 6.85 & 5.8631 & TRN & \\
\hline CHEMBL1555118 & 737824 & 5.2 & 5.1282 & TRN & \\
\hline CHEMBL1323438 & 737824 & 4.8 & 4.723 & TRN & \\
\hline CHEMBL1324891 & 737824 & 4.85 & 4.8694 & TRN & \\
\hline CHEMBL509150 & 737824 & 5.4 & 5.2915 & TRN & \\
\hline CHEMBL1523520 & 737824 & 4.9 & 5.2432 & TST & \\
\hline CHEMBL3198788 & 737824 & 4.4 & 4.7722 & TRN & \\
\hline CHEMBL1565236 & 737824 & 5.55 & 5.2709 & TRN & \\
\hline CHEMBL1483608 & 737824 & 5.05 & 5.3473 & TST & \\
\hline CHEMBL1313043 & 737824 & 5.9 & 5.6952 & TRN & \\
\hline CHEMBL1467630 & 737824 & 5.55 & 5.4281 & TRN & \\
\hline CHEMBL1451274 & 737824 & 4.55 & 5.4105 & TRN & \\
\hline CHEMBL1455524 & 737824 & 4.55 & 5.2264 & TRN & \\
\hline CHEMBL1741347 & 737824 & 4.95 & 5.5159 & TRN & \\
\hline CHEMBL490577 & 737824 & 5.3 & 5.3056 & TRN & \\
\hline CHEMBL1306727 & 737824 & 4.55 & 4.9314 & TRN & \\
\hline CHEMBL1526262 & 737824 & 6.5 & 5.8657 & TRN & \\
\hline CHEMBL1565278 & 737824 & 5.55 & 4.7351 & TRN & \\
\hline CHEMBL1378755 & 737824 & 6.3 & 6.1909 & TRN & \\
\hline CHEMBL1440585 & 737824 & 5.45 & 4.7622 & TRN & \\
\hline CHEMBL1440067 & 737824 & 6.1 & 5.5312 & TRN & \\
\hline CHEMBL1459535 & 737824 & 4.95 & 5.5314 & TRN & \\
\hline CHEMBL1354913 & 737824 & 5.1 & 5.5405 & TST & \\
\hline CHEMBL1438327 & 737824 & 5.15 & 5.3666 & TRN & \\
\hline CHEMBL1338432 & 737824 & 4.6 & 4.8196 & TRN & \\
\hline CHEMBL1742100 & 737824 & 5.35 & 5.0797 & TRN & \\
\hline CHEMBL1699046 & 737824 & 4.55 & 5.0589 & TST & \\
\hline CHEMBL1366732 & 737824 & 6.2 & 6.0431 & TRN & \\
\hline CHEMBL1392932 & 737824 & 4.75 & 4.7231 & TST & \\
\hline CHEMBL1421029 & 737824 & 4.95 & 5.41799 & 9999999999 & TRN \\
\hline CHEMBL1531727 & 737824 & 6.3 & 5.9595 & TST & \\
\hline CHEMBL1448689 & 737824 & 4.4 & 5.24700 & 0000000001 & TRN \\
\hline CHEMBL1463453 & 737824 & 4.95 & 4.6559 & TRN & \\
\hline
\end{tabular}




\begin{tabular}{|c|c|c|c|c|c|}
\hline \\
\hline CHEMBL3189663 & 737824 & 6.0 & 5.584 & TRN & \\
\hline CHEMBL1506391 & 737824 & 4.55 & 5.6642 & TST & \\
\hline CHEMBL536950 & 737824 & 5.5 & 5.517 & TST & \\
\hline CHEMBL1319672 & 737824 & 5.9 & 6.056 & TRN & \\
\hline CHEMBL1416508 & 737824 & 4.4 & 5.0719 & TRN & \\
\hline CHEMBL1578418 & 737824 & 5.5 & 5.4531 & TRN & \\
\hline CHEMBL1303518 & 737824 & 4.8 & 4.859 & TST & \\
\hline CHEMBL1373818 & 737824 & 5.1 & 4.7094 & TST & \\
\hline CHEMBL1477076 & 737824 & 4.5 & 4.9722 & TRN & \\
\hline CHEMBL1470840 & 737824 & 5.55 & 5.4061 & TRN & \\
\hline CHEMBL599705 & 737824 & 6.15 & 5.0134 & TRN & \\
\hline CHEMBL1437364 & 737824 & 5.7 & 5.7756 & TRN & \\
\hline CHEMBL1548924 & 737824 & 6.2 & 5.71299 & 9999999999 & TRN \\
\hline CHEMBL1584906 & 737824 & 4.95 & 5.2845 & TST & \\
\hline CHEMBL1307486 & 737824 & 5.1 & 5.3822 & TRN & \\
\hline CHEMBL1741737 & 737824 & 4.95 & 4.9119 & TRN & \\
\hline CHEMBL1591275 & 737824 & 4.6 & 3.9287 & TRN & \\
\hline CHEMBL1513511 & 737824 & 5.4 & 5.4662 & TRN & \\
\hline CHEMBL1358449 & 737824 & 6.8 & 6.5472 & TST & \\
\hline CHEMBL1302643 & 737824 & 5.55 & 5.4355 & TRN & \\
\hline CHEMBL1374456 & 737824 & 5.55 & 5.3827 & TRN & \\
\hline CHEMBL1472322 & 737824 & 5.5 & 5.1416 & TRN & \\
\hline CHEMBL1517040 & 737824 & 4.85 & 5.0873 & TRN & \\
\hline CHEMBL1525558 & 737824 & 4.8 & 4.9541 & TRN & \\
\hline CHEMBL1721518 & 737824 & 4.6 & 4.9758 & TRN & \\
\hline CHEMBL1562987 & 737824 & 5.3 & 5.16 & TRN & \\
\hline CHEMBL1536389 & 737824 & 4.85 & 4.9681 & TRN & \\
\hline CHEMBL1368892 & 737824 & 6.2 & 6.3905 & TRN & \\
\hline CHEMBL1741375 & 737824 & 4.6 & 5.2649 & TST & \\
\hline CHEMBL1311526 & 737824 & 5.1 & 5.3251 & TRN & \\
\hline CHEMBL1567365 & 737824 & 5.7 & 5.1022 & TRN & \\
\hline CHEMBL3194933 & 737824 & 5.7 & 4.8116 & TST & \\
\hline CHEMBL1464103 & 737824 & 4.95 & 5.106 & TST & \\
\hline CHEMBL315268 & 737824 & 4.9 & 4.5246 & TST & \\
\hline CHEMBL1417861 & 737824 & 5.65 & 5.0532 & TRN & \\
\hline CHEMBL1485000 & 737824 & 6.0 & 5.4198 & TRN & \\
\hline CHEMBL1320922 & 737824 & 5.5 & 5.6763 & TST & \\
\hline CHEMBL1380474 & 737824 & 4.65 & 5.7508 & TST & \\
\hline CHEMBL275097 & 737824 & 5.9 & 5.6943 & TRN & \\
\hline CHEMBL1506343 & 737824 & 4.95 & 5.3395 & TRN & \\
\hline CHEMBL1350756 & 737824 & 5.45 & 6.1866 & TRN & \\
\hline CHEMBL3209203 & 737824 & 5.15 & 5.5873 & TRN & \\
\hline CHEMBL1382075 & 737824 & 4.85 & 5.3438 & TRN & \\
\hline CHEMBL1361855 & 737824 & 5.8 & 5.398 & TST & \\
\hline CHEMBL1573964 & 737824 & 4.6 & 4.6018 & TRN & \\
\hline CHEMBL1544379 & 737824 & 5.3 & 5.2392 & TST & \\
\hline CHEMBL1565342 & 737824 & 6.0 & 6.0845 & TRN & \\
\hline CHEMBL1301326 & 737824 & 5.7 & 5.7364 & TRN & \\
\hline
\end{tabular}




\begin{tabular}{|c|c|c|c|c|}
\hline \multicolumn{5}{|c|}{ Supplemental Table } \\
\hline CHEMBL1470904 & 737824 & 5.35 & 5.4252 & TST \\
\hline CHEMBL491910 & 737824 & 5.8 & 5.7464 & TRN \\
\hline CHEMBL1741417 & 737824 & 4.9 & 5.0419 & TRN \\
\hline CHEMBL1598878 & 737824 & 5.35 & 4.9022 & TST \\
\hline CHEMBL1987514 & 737824 & 5.55 & 5.272 & TRN \\
\hline CHEMBL158507 & 737824 & 5.0 & 5.4361 & TRN \\
\hline CHEMBL1365367 & 737824 & 5.6 & 5.8341 & TRN \\
\hline CHEMBL1468198 & 737824 & 5.25 & 4.9984 & TRN \\
\hline CHEMBL1479420 & 737824 & 5.05 & 4.9356 & TRN \\
\hline CHEMBL1572935 & 737824 & 5.65 & 5.6126 & TRN \\
\hline CHEMBL1362547 & 737824 & 4.85 & 5.3623 & TRN \\
\hline CHEMBL1492493 & 737824 & 6.15 & 5.3016 & TRN \\
\hline CHEMBL1544155 & 737824 & 5.65 & 5.2893 & TRN \\
\hline CHEMBL1346850 & 737824 & 5.1 & 5.1361 & TRN \\
\hline CHEMBL1725270 & 737824 & 6.5 & 5.1738 & TRN \\
\hline CHEMBL1345307 & 737824 & 5.45 & 5.2437 & TRN \\
\hline CHEMBL1434199 & 737824 & 6.6 & 6.2851 & TRN \\
\hline CHEMBL1595826 & 737824 & 4.9 & 4.8592 & TRN \\
\hline CHEMBL469309 & 737824 & 5.5 & 5.392 & TRN \\
\hline CHEMBL1380022 & 737824 & 5.15 & 4.9104 & TRN \\
\hline CHEMBL1455106 & 737824 & 5.45 & 5.3259 & TRN \\
\hline CHEMBL1448350 & 737824 & 4.85 & 5.4032 & TST \\
\hline CHEMBL1535980 & 737824 & 4.85 & 4.8417 & TRN \\
\hline CHEMBL3212851 & 737824 & 4.5 & 4.9884 & TST \\
\hline CHEMBL1302696 & 737824 & 5.35 & 5.4928 & TRN \\
\hline CHEMBL1393461 & 737824 & 5.15 & 5.3088 & TRN \\
\hline CHEMBL1418866 & 737824 & 6.5 & 5.7274 & TST \\
\hline CHEMBL1469083 & 737824 & 5.1 & 5.1112 & TRN \\
\hline CHEMBL1322352 & 737824 & 4.95 & 5.3936 & TRN \\
\hline CHEMBL1592211 & 737824 & 6.4 & 6.1285 & TRN \\
\hline CHEMBL1310477 & 737824 & 5.4 & 5.0544 & TRN \\
\hline CHEMBL1455353 & 737824 & 5.7 & 5.5869 & TRN \\
\hline CHEMBL1399438 & 737824 & 4.9 & 5.3805 & TST \\
\hline CHEMBL1363474 & 737824 & 4.7 & 5.2685 & TRN \\
\hline CHEMBL1732053 & 737824 & 4.55 & 4.887 & TRN \\
\hline CHEMBL434063 & 737824 & 5.4 & 5.1999 & TST \\
\hline CHEMBL3208062 & 737824 & 4.4 & 4.708 & TRN \\
\hline CHEMBL1544545 & 737824 & 4.8 & 5.0092 & TRN \\
\hline CHEMBL1981840 & 737824 & 5.3 & 5.2447 & TST \\
\hline CHEMBL1537880 & 737824 & 4.75 & 5.0357 & TRN \\
\hline CHEMBL1516856 & 737824 & 4.75 & 5.2507 & TRN \\
\hline CHEMBL1705664 & 737824 & 4.75 & 4.9374 & TST \\
\hline CHEMBL1605341 & 737824 & 5.45 & 5.4681 & TRN \\
\hline CHEMBL1506687 & 737824 & 4.9 & 4.8073 & TRN \\
\hline CHEMBL1554976 & 737824 & 5.7 & 5.5156 & TRN \\
\hline CHEMBL1533843 & 737824 & 5.5 & 5.1011 & TRN \\
\hline CHEMBL3192875 & 737824 & 4.95 & 5.4281 & TRN \\
\hline CHEMBL1594350 & 737824 & 5.4 & 5.3047 & TRN \\
\hline
\end{tabular}




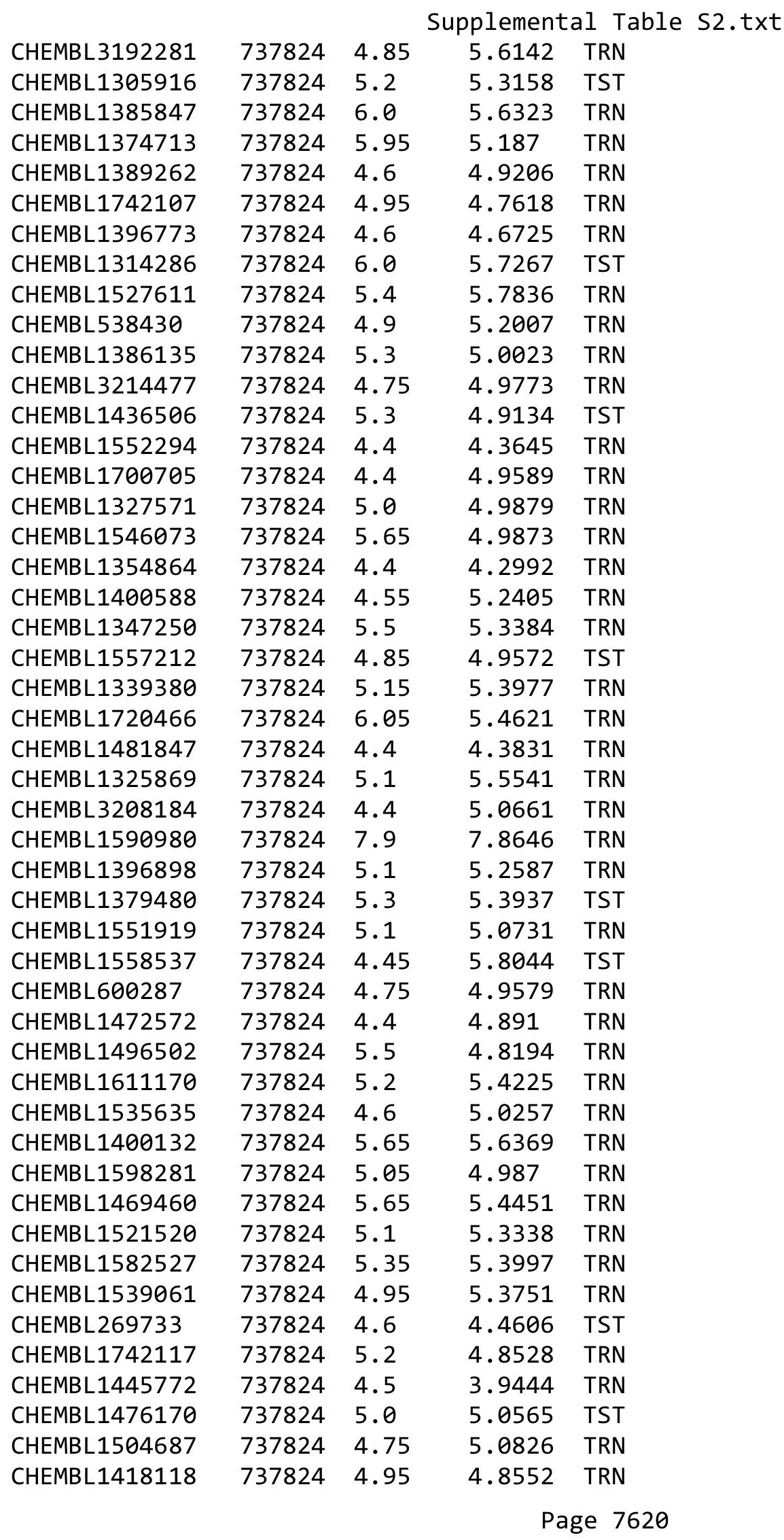




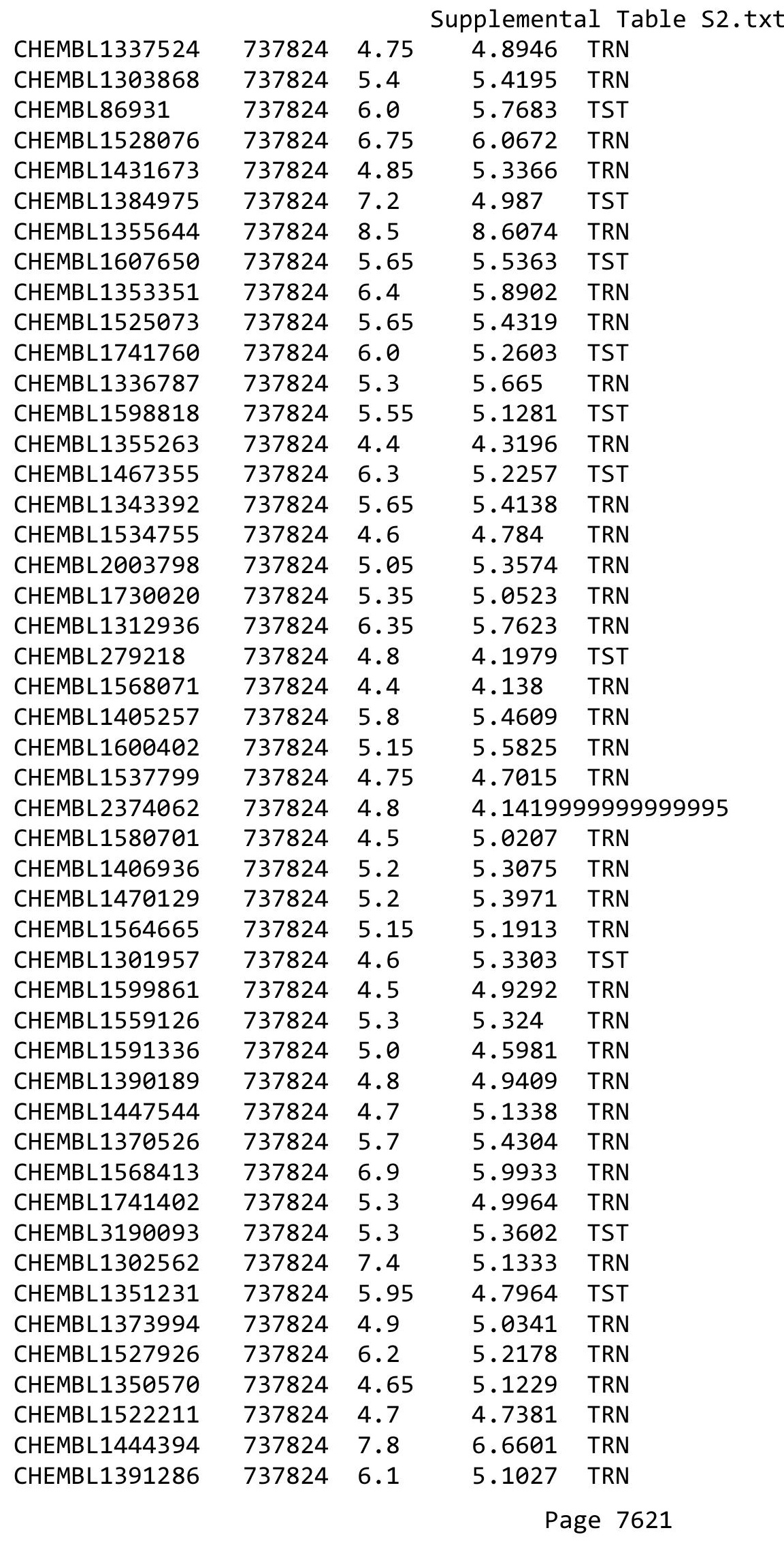




\begin{tabular}{|c|c|c|c|c|c|}
\hline & & & & & \\
\hline CHEMBL1488127 & 737824 & 4.65 & 4.8695 & TRN & \\
\hline CHEMBL1331674 & 737824 & 5.05 & 5.6603 & TRN & \\
\hline CHEMBL1382427 & 737824 & 4.45 & 5.0605 & TRN & \\
\hline CHEMBL1742157 & 737824 & 4.4 & 4.8703 & TRN & \\
\hline CHEMBL1393480 & 737824 & 4.9 & 5.1973 & TRN & \\
\hline CHEMBL1319718 & 737824 & 4.95 & 5.1867 & TRN & \\
\hline CHEMBL1322285 & 737824 & 4.9 & 5.0252 & TRN & \\
\hline CHEMBL1498886 & 737824 & 5.8 & 5.5756 & TRN & \\
\hline CHEMBL1323166 & 737824 & 5.15 & 5.3047 & TRN & \\
\hline CHEMBL1521391 & 737824 & 4.4 & 4.32100 & 0000000001 & TRN \\
\hline CHEMBL3199536 & 737824 & 5.55 & 5.1808 & TRN & \\
\hline CHEMBL1529578 & 737824 & 5.6 & 5.7289 & TRN & \\
\hline CHEMBL200309 & 737824 & 4.4 & 4.1059 & TST & \\
\hline CHEMBL1567584 & 737824 & 4.7 & 5.2122 & TRN & \\
\hline CHEMBL1594232 & 737824 & 5.1 & 5.1242 & TRN & \\
\hline CHEMBL1578496 & 737824 & 5.5 & 5.574 & TRN & \\
\hline CHEMBL1433173 & 737824 & 5.1 & 5.37200 & 2000000001 & TRN \\
\hline CHEMBL1742292 & 737824 & 6.1 & 5.2832 & TRN & \\
\hline CHEMBL1564477 & 737824 & 4.5 & 4.1224 & TRN & \\
\hline CHEMBL1555713 & 737824 & 4.8 & 4.5638 & TRN & \\
\hline CHEMBL1353756 & 737824 & 4.55 & 5.2972 & TRN & \\
\hline CHEMBL1438661 & 737824 & 4.9 & 5.2195 & TRN & \\
\hline CHEMBL1317461 & 737824 & 5.6 & 5.6097 & TRN & \\
\hline CHEMBL1574626 & 737824 & 5.6 & 5.5851 & TRN & \\
\hline CHEMBL1570196 & 737824 & 4.9 & 4.8739 & TST & \\
\hline CHEMBL1329940 & 737824 & 6.6 & 6.3738 & TST & \\
\hline CHEMBL1310938 & 737824 & 5.7 & 5.6714 & TRN & \\
\hline CHEMBL1555944 & 737824 & 6.05 & 5.4345 & TRN & \\
\hline CHEMBL1722356 & 737824 & 4.55 & 5.4188 & TST & \\
\hline CHEMBL3193830 & 737824 & 4.85 & 5.3126 & TRN & \\
\hline CHEMBL1377301 & 737824 & 6.4 & 6.4903 & TRN & \\
\hline CHEMBL1465985 & 737824 & 5.65 & 5.7136 & TRN & \\
\hline CHEMBL1553700 & 737824 & 6.3 & 5.8201 & TRN & \\
\hline CHEMBL1362021 & 737824 & 4.55 & 5.6108 & TRN & \\
\hline CHEMBL1389765 & 737824 & 6.0 & 6.0227 & TRN & \\
\hline CHEMBL1496576 & 737824 & 4.4 & 4.3356 & TRN & \\
\hline CHEMBL1742363 & 737824 & 4.95 & 5.4868 & TRN & \\
\hline CHEMBL1435912 & 737824 & 6.1 & 5.4652 & TRN & \\
\hline CHEMBL1496418 & 737824 & 6.1 & 5.5668 & TRN & \\
\hline CHEMBL1566217 & 737824 & 5.0 & 5.1478 & TRN & \\
\hline CHEMBL1313104 & 737824 & 4.4 & 5.1726 & TRN & \\
\hline CHEMBL1558388 & 737824 & 4.85 & 4.8605 & TRN & \\
\hline CHEMBL1348869 & 737824 & 5.2 & 5.614 & TST & \\
\hline CHEMBL1329119 & 737824 & 4.85 & 4.8169 & TRN & \\
\hline CHEMBL1453817 & 737824 & 6.0 & 5.3358 & TRN & \\
\hline CHEMBL1584418 & 737824 & 5.9 & 5.4923 & TRN & \\
\hline CHEMBL1407440 & 737824 & 4.4 & 4.4101 & TRN & \\
\hline CHEMBL1412847 & 737824 & 5.2 & 5.1306 & TRN & \\
\hline & & & & 7622 & \\
\hline
\end{tabular}




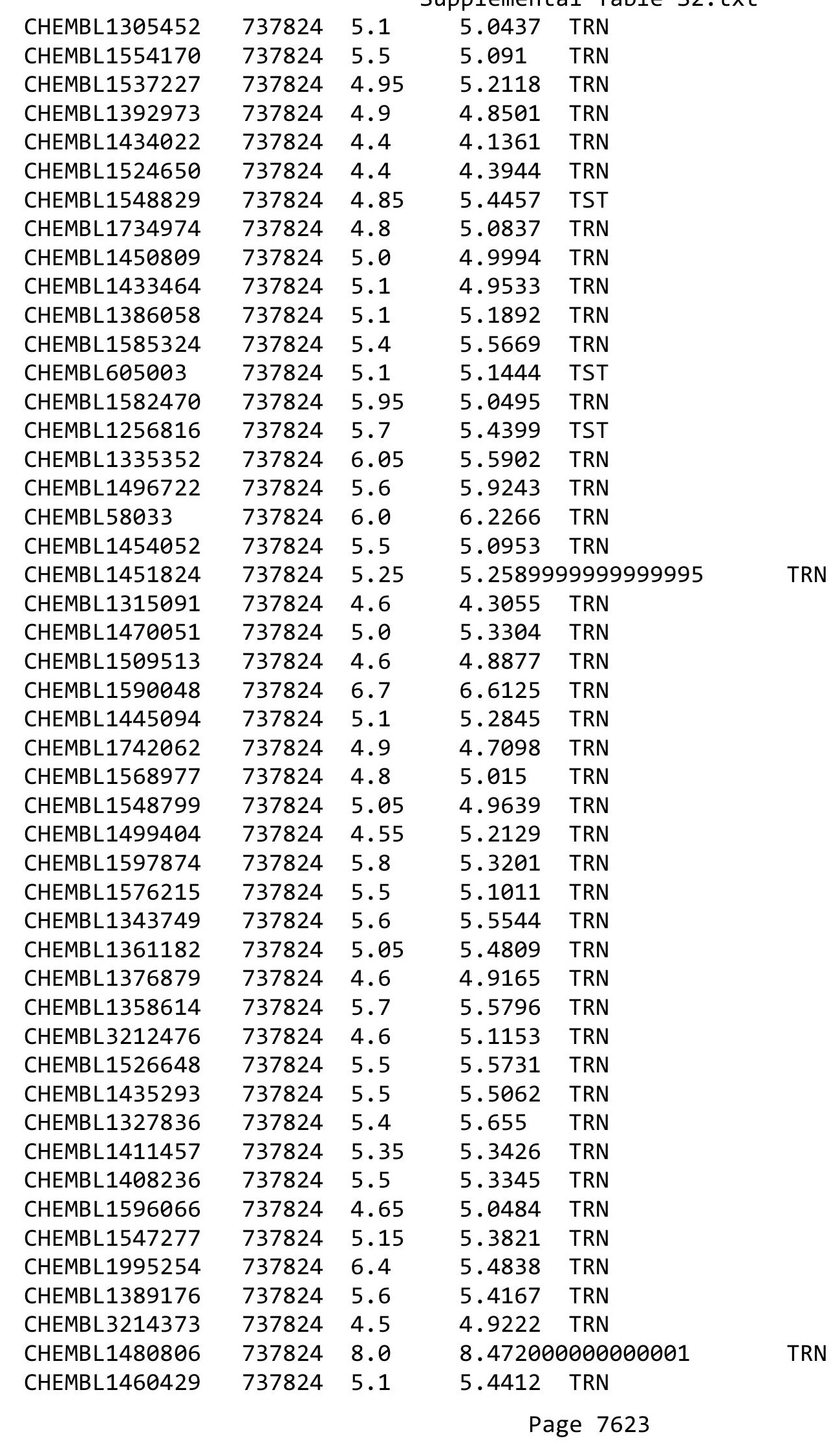




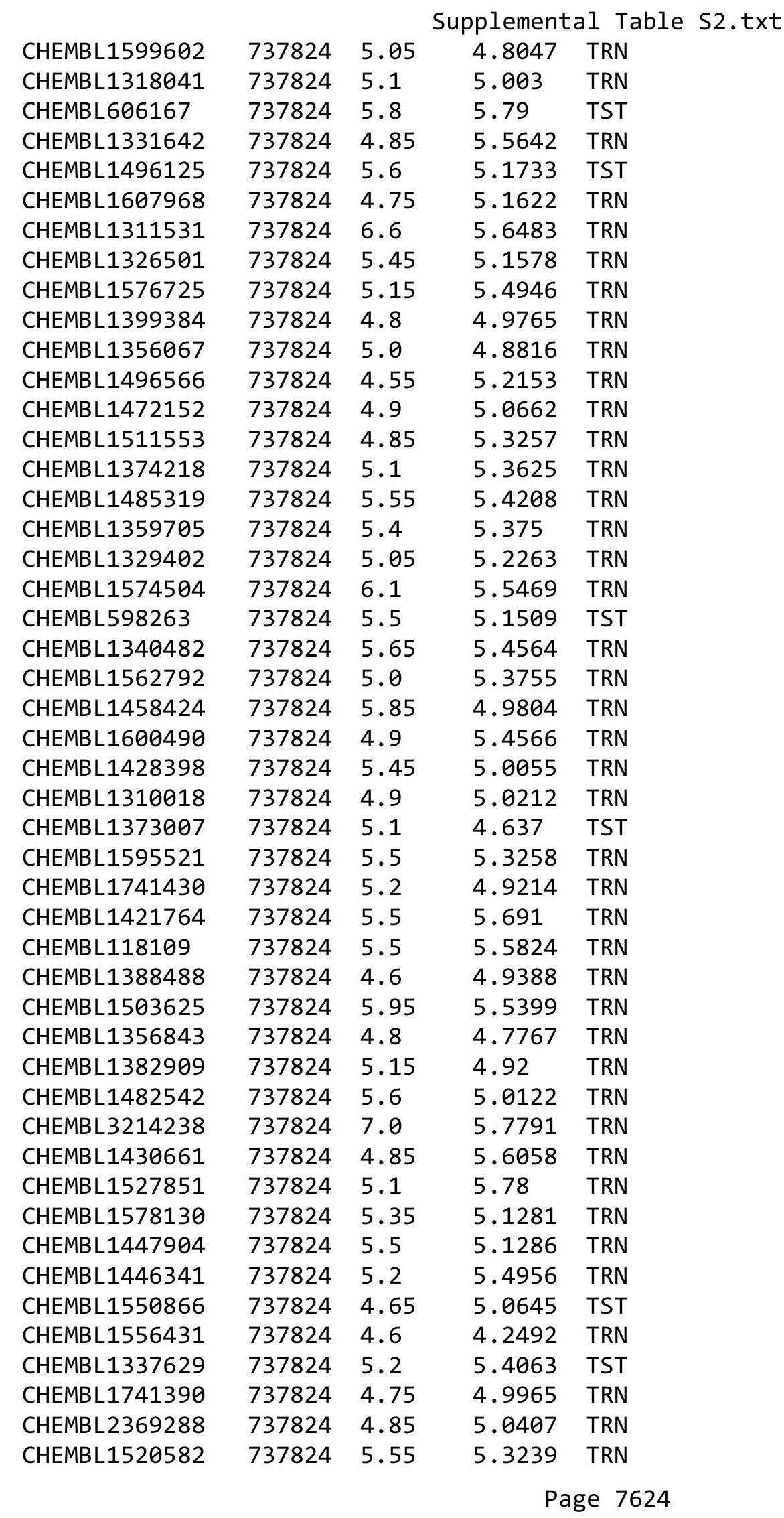




\begin{tabular}{|c|c|c|c|c|c|}
\hline \multicolumn{6}{|c|}{ Jie } \\
\hline CHEMBL1333156 & 737824 & 6.1 & 6.0531 & TRN & \\
\hline CHEMBL1375474 & 737824 & 4.5 & 4.3054 & TRN & \\
\hline CHEMBL1372696 & 737824 & 5.55 & 5.2599 & TRN & \\
\hline CHEMBL260374 & 737824 & 6.0 & 5.9003 & TST & \\
\hline CHEMBL1571970 & 737824 & 6.6 & 5.4425 & TST & \\
\hline CHEMBL1359713 & 737824 & 8.0 & 8.2064 & TST & \\
\hline CHEMBL1519453 & 737824 & 5.7 & 5.3084 & TST & \\
\hline CHEMBL1714329 & 737824 & 5.55 & 5.3565 & TRN & \\
\hline CHEMBL444810 & 737824 & 4.8 & 5.3003 & TST & \\
\hline CHEMBL1413915 & 737824 & 5.05 & \multicolumn{2}{|c|}{5.218999999999999} & TRN \\
\hline CHEMBL1505382 & 737824 & 4.7 & 4.7366 & TST & \\
\hline CHEMBL1503919 & 737824 & 5.0 & 5.1721 & TRN & \\
\hline CHEMBL1489528 & 737824 & 5.1 & 5.1523 & TRN & \\
\hline CHEMBL1312233 & 737824 & 6.9 & 5.1584 & TST & \\
\hline CHEMBL1093717 & 737824 & 4.45 & 4.882 & TRN & \\
\hline CHEMBL1366030 & 737824 & 5.8 & 5.5741 & TRN & \\
\hline CHEMBL1466642 & 737824 & 5.15 & 4.6849 & TRN & \\
\hline CHEMBL1741479 & 737824 & 5.4 & 5.4315 & TST & \\
\hline CHEMBL1742342 & 737824 & 4.9 & 5.4034 & TRN & \\
\hline CHEMBL1428990 & 737824 & 4.5 & 5.2935 & TRN & \\
\hline CHEMBL1455565 & 737824 & 5.5 & 5.2145 & TRN & \\
\hline CHEMBL1439063 & 737824 & 5.65 & 5.1854 & TRN & \\
\hline CHEMBL1330718 & 737824 & 6.4 & 6.2179 & TRN & \\
\hline CHEMBL3190580 & 737824 & 5.75 & 5.6394 & TRN & \\
\hline CHEMBL1594862 & 737824 & 6.05 & 5.0267 & TRN & \\
\hline CHEMBL1345517 & 737824 & 5.2 & 4.999 & TRN & \\
\hline CHEMBL1350723 & 737824 & 5.15 & 5.6026 & TRN & \\
\hline CHEMBL1462156 & 737824 & 4.8 & 4.824 & TRN & \\
\hline CHEMBL 3198104 & 737824 & 4.9 & 4.9116 & TRN & \\
\hline CHEMBL1371604 & 737824 & 5.4 & 4.9449 & TRN & \\
\hline CHEMBL1580037 & 737824 & 5.05 & 5.0247 & TRN & \\
\hline CHEMBL1590886 & 737824 & 4.9 & 4.6594 & TRN & \\
\hline CHEMBL1501374 & 737824 & 5.95 & 5.0605 & TRN & \\
\hline CHEMBL1380424 & 737824 & 5.1 & 5.4843 & TRN & \\
\hline CHEMBL1613481 & 737824 & 4.4 & 5.2172 & TRN & \\
\hline CHEMBL1311840 & 737824 & 4.85 & 5.1002 & TRN & \\
\hline CHEMBL1576777 & 737824 & 5.95 & 5.8452 & TRN & \\
\hline CHEMBL1368786 & 737824 & 5.35 & 5.1531 & TRN & \\
\hline CHEMBL1336516 & 737824 & 4.4 & 5.1791 & TRN & \\
\hline CHEMBL1509602 & 737824 & 5.15 & 5.1831 & TRN & \\
\hline CHEMBL1473760 & 737824 & 4.4 & 4.4278 & TRN & \\
\hline CHEMBL1458392 & 737824 & 5.75 & 5.7496 & TRN & \\
\hline CHEMBL1316956 & 737824 & 7.1 & 7.0326 & TRN & \\
\hline CHEMBL1319109 & 737824 & 4.9 & 5.0341 & TRN & \\
\hline CHEMBL1367399 & 737824 & 4.9 & 5.4098 & TST & \\
\hline CHEMBL 34704 & 737824 & 4.6 & 4.5114 & TST & \\
\hline CHEMBL1475617 & 737824 & 4.6 & 4.5394 & TRN & \\
\hline CHEMBL1335037 & 737824 & 5.3 & 5.5553 & TRN & \\
\hline & & & & 7625 & \\
\hline
\end{tabular}




\begin{tabular}{|c|c|c|c|c|c|}
\hline \\
\hline CHEMBL1483152 & 737824 & 5.0 & 5.1588 & TRN & \\
\hline CHEMBL1365092 & 737824 & 5.2 & 4.9599 & TRN & \\
\hline CHEMBL1330730 & 737824 & 5.3 & 5.5518 & TRN & \\
\hline CHEMBL1568250 & 737824 & 5.4 & 5.1892 & TRN & \\
\hline CHEMBL3211009 & 737824 & 5.85 & 5.4345 & TRN & \\
\hline CHEMBL1741584 & 737824 & 4.4 & 5.0772 & TRN & \\
\hline CHEMBL 3198545 & 737824 & 7.15 & 5.5467 & TST & \\
\hline CHEMBL1533643 & 737824 & 6.4 & 5.6366 & TRN & \\
\hline CHEMBL1389843 & 737824 & 6.2 & 5.6281 & TRN & \\
\hline CHEMBL1389097 & 737824 & 4.85 & 5.0857 & TRN & \\
\hline CHEMBL455185 & 737824 & 4.9 & 4.6703 & TRN & \\
\hline CHEMBL1577306 & 737824 & 4.85 & 5.0602 & TRN & \\
\hline CHEMBL1359298 & 737824 & 5.55 & 5.5343 & TRN & \\
\hline CHEMBL1405922 & 737824 & 5.3 & 5.1541 & TRN & \\
\hline CHEMBL1602770 & 737824 & 4.4 & 5.0204 & TRN & \\
\hline CHEMBL1342813 & 737824 & 5.0 & 4.9687 & TRN & \\
\hline CHEMBL1594227 & 737824 & 5.3 & 5.3007 & TRN & \\
\hline CHEMBL345124 & 737824 & 5.8 & 4.9744 & TST & \\
\hline CHEMBL1451317 & 737824 & 5.55 & 5.6041 & TRN & \\
\hline CHEMBL1331778 & 737824 & 5.7 & 5.8306 & TRN & \\
\hline CHEMBL1605619 & 737824 & 6.15 & 5.4988 & TRN & \\
\hline CHEMBL1741610 & 737824 & 4.9 & 5.2067 & TRN & \\
\hline CHEMBL1607752 & 737824 & 5.05 & 5.115 & TST & \\
\hline CHEMBL3199540 & 737824 & 5.8 & 5.3368 & TRN & \\
\hline CHEMBL 3213016 & 737824 & 5.0 & 5.2855 & TRN & \\
\hline CHEMBL1558076 & 737824 & 6.5 & 5.5454 & TRN & \\
\hline CHEMBL1388651 & 737824 & 5.9 & 5.943 & TRN & \\
\hline CHEMBL1362111 & 737824 & 4.9 & 5.226 & TRN & \\
\hline CHEMBL1511120 & 737824 & 4.95 & 5.4056 & TRN & \\
\hline CHEMBL1256869 & 737824 & 5.4 & 5.3414 & TRN & \\
\hline CHEMBL1440943 & 737824 & 5.1 & 4.6929 & TRN & \\
\hline CHEMBL1491554 & 737824 & 6.2 & 5.6822 & TRN & \\
\hline CHEMBL1520507 & 737824 & 5.7 & 5.4462 & TST & \\
\hline CHEMBL1591635 & 737824 & 5.2 & 4.8945 & TRN & \\
\hline CHEMBL36121 & 737824 & 4.7 & 5.5068 & TST & \\
\hline CHEMBL1422181 & 737824 & 4.85 & 5.0383 & TRN & \\
\hline CHEMBL482116 & 737824 & 4.4 & 4.89199 & 99999999995 & TRN \\
\hline CHEMBL1722610 & 737824 & 4.65 & 5.1041 & TRN & \\
\hline CHEMBL 3197330 & 737824 & 5.6 & 5.2423 & TST & \\
\hline CHEMBL1340539 & 737824 & 4.55 & 5.044 & TRN & \\
\hline CHEMBL1445026 & 737824 & 5.6 & 5.5054 & TRN & \\
\hline CHEMBL1719945 & 737824 & 4.8 & 4.8962 & TRN & \\
\hline CHEMBL1437783 & 737824 & 6.5 & 6.4726 & TRN & \\
\hline CHEMBL1552172 & 737824 & 4.4 & 4.2693 & TRN & \\
\hline CHEMBL1411045 & 737824 & 5.8 & 6.0725 & TST & \\
\hline CHEMBL1733514 & 737824 & 4.6 & 4.9634 & TRN & \\
\hline CHEMBL1533680 & 737824 & 6.0 & 5.7576 & TRN & \\
\hline CHEMBL1320272 & 737824 & 6.0 & 5.306 & TRN & \\
\hline
\end{tabular}




\begin{tabular}{|c|c|c|c|c|c|}
\hline \\
\hline CHEMBL1404451 & 737824 & 6.0 & 6.0067 & TRN & \\
\hline CHEMBL 275311 & 737824 & 5.4 & 4.8737 & TRN & \\
\hline CHEMBL1525261 & 737824 & 5.55 & 4.9951 & TRN & \\
\hline CHEMBL1350113 & 737824 & 6.2 & 5.8243 & TRN & \\
\hline CHEMBL1493037 & 737824 & 6.0 & 5.375 & TST & \\
\hline CHEMBL1612335 & 737824 & 4.45 & 4.8822 & TRN & \\
\hline CHEMBL1440329 & 737824 & 4.65 & 5.0325 & TRN & \\
\hline CHEMBL1488420 & 737824 & 6.1 & 5.8048 & TRN & \\
\hline CHEMBL1610945 & 737824 & 5.4 & 5.1023 & TST & \\
\hline CHEMBL1531174 & 737824 & 5.15 & 5.3628 & TST & \\
\hline CHEMBL1334840 & 737824 & 4.4 & 5.2078 & TRN & \\
\hline CHEMBL3212090 & 737824 & 4.9 & 4.9605 & TRN & \\
\hline CHEMBL56543 & 737824 & 4.6 & 4.7601 & TRN & \\
\hline CHEMBL1491258 & 737824 & 5.1 & 4.8315 & TRN & \\
\hline CHEMBL1318553 & 737824 & 5.0 & 5.4272 & TST & \\
\hline CHEMBL1467911 & 737824 & 6.35 & 5.3862 & TRN & \\
\hline CHEMBL1407646 & 737824 & 5.15 & 5.3661 & TRN & \\
\hline CHEMBL164 & 737824 & 6.0 & 6.2139 & TRN & \\
\hline CHEMBL1602633 & 737824 & 4.7 & 4.6551 & TRN & \\
\hline CHEMBL1520727 & 737824 & 5.0 & 4.7883 & TRN & \\
\hline CHEMBL3207405 & 737824 & 5.05 & 5.032 & TRN & \\
\hline CHEMBL1569277 & 737824 & 6.7 & 5.6659 & TST & \\
\hline CHEMBL1377767 & 737824 & 5.1 & 5.2487 & TRN & \\
\hline CHEMBL1574915 & 737824 & 5.55 & 6.03799 & 9999999999 & TRN \\
\hline CHEMBL1514027 & 737824 & 5.2 & 5.3565 & TRN & \\
\hline CHEMBL1394137 & 737824 & 5.7 & 5.8183 & TRN & \\
\hline CHEMBL1588523 & 737824 & 5.4 & 5.2803 & TRN & \\
\hline CHEMBL1352188 & 737824 & 4.95 & 5.183 & TST & \\
\hline CHEMBL1554693 & 737824 & 4.7 & 5.1147 & TRN & \\
\hline CHEMBL1529948 & 737824 & 5.35 & 5.2747 & TRN & \\
\hline CHEMBL1253351 & 737824 & 4.9 & 4.8163 & TST & \\
\hline CHEMBL1517550 & 737824 & 4.5 & 5.5266 & TST & \\
\hline CHEMBL1321338 & 737824 & 4.4 & 3.9334 & TRN & \\
\hline CHEMBL3192331 & 737824 & 4.95 & 5.0431 & TRN & \\
\hline CHEMBL1562337 & 737824 & 5.8 & 5.5691 & TRN & \\
\hline CHEMBL1742376 & 737824 & 4.85 & 5.0723 & TRN & \\
\hline CHEMBL1467631 & 737824 & 4.7 & 5.0299 & TRN & \\
\hline CHEMBL1408303 & 737824 & 6.5 & 5.7246 & TRN & \\
\hline CHEMBL1432279 & 737824 & 4.6 & 4.7445 & TRN & \\
\hline CHEMBL1556701 & 737824 & 4.7 & 4.2865 & TRN & \\
\hline CHEMBL1385273 & 737824 & 4.4 & 4.7472 & TRN & \\
\hline CHEMBL1741573 & 737824 & 4.4 & 5.2793 & TRN & \\
\hline CHEMBL3211431 & 737824 & 5.5 & 5.3794 & TRN & \\
\hline CHEMBL1517187 & 737824 & 4.6 & 3.7055 & TST & \\
\hline CHEMBL1725938 & 737824 & 4.95 & 5.5603 & TST & \\
\hline CHEMBL1362931 & 737824 & 4.8 & 5.3904 & TRN & \\
\hline CHEMBL1586264 & 737824 & 4.6 & 5.2479 & TRN & \\
\hline CHEMBL1541180 & 737824 & 5.4 & 5.5244 & TRN & \\
\hline & & & & 7627 & \\
\hline
\end{tabular}




\begin{tabular}{|c|c|c|c|c|c|}
\hline \\
\hline CHEMBL1741971 & 737824 & 4.4 & 4.9914 & TRN & \\
\hline CHEMBL1499209 & 737824 & 5.65 & 5.0493 & TST & \\
\hline CHEMBL1305631 & 737824 & 5.4 & 5.5933 & TRN & \\
\hline CHEMBL1576499 & 737824 & 6.2 & 5.6052 & TRN & \\
\hline CHEMBL1424424 & 737824 & 4.8 & 4.9817 & TRN & \\
\hline CHEMBL1507282 & 737824 & 5.0 & 4.9672 & TRN & \\
\hline CHEMBL1561209 & 737824 & 5.9 & 5.1628 & TRN & \\
\hline CHEMBL1435544 & 737824 & 4.7 & 4.7721 & TRN & \\
\hline CHEMBL1390056 & 737824 & 4.9 & 4.9443 & TRN & \\
\hline CHEMBL1590106 & 737824 & 4.6 & 4.42399 & 99999999995 & TRN \\
\hline CHEMBL1461573 & 737824 & 4.4 & 4.8862 & TST & \\
\hline CHEMBL1333449 & 737824 & 5.9 & 5.9557 & TRN & \\
\hline CHEMBL1413296 & 737824 & 5.0 & 4.9628 & TRN & \\
\hline CHEMBL 258893 & 737824 & 5.0 & 4.7021 & TST & \\
\hline CHEMBL1524366 & 737824 & 6.6 & 5.228 & TST & \\
\hline CHEMBL1480087 & 737824 & 5.75 & 5.2361 & TRN & \\
\hline CHEMBL1555823 & 737824 & 5.4 & 5.3297 & TRN & \\
\hline CHEMBL1611220 & 737824 & 6.0 & 5.6369 & TST & \\
\hline CHEMBL1497504 & 737824 & 7.0 & 6.1696 & TRN & \\
\hline CHEMBL1331120 & 737824 & 5.8 & 5.3881 & TRN & \\
\hline CHEMBL1574720 & 737824 & 4.55 & 4.9417 & TRN & \\
\hline CHEMBL1437905 & 737824 & 5.1 & 5.2081 & TRN & \\
\hline CHEMBL1300933 & 737824 & 5.05 & 5.2476 & TRN & \\
\hline CHEMBL1357850 & 737824 & 5.0 & 5.2075 & TRN & \\
\hline CHEMBL32503 & 737824 & 6.8 & 5.726 & TST & \\
\hline CHEMBL1431290 & 737824 & 4.8 & 5.1548 & TRN & \\
\hline CHEMBL3208389 & 737824 & 5.1 & 5.0715 & TRN & \\
\hline CHEMBL1452116 & 737824 & 4.6 & 4.8764 & TRN & \\
\hline CHEMBL1092376 & 737824 & 4.75 & 4.769 & TRN & \\
\hline CHEMBL1741644 & 737824 & 5.05 & 5.4831 & TST & \\
\hline CHEMBL1578454 & 737824 & 4.75 & 5.4558 & TRN & \\
\hline CHEMBL1475079 & 737824 & 4.7 & 4.8112 & TRN & \\
\hline CHEMBL1586050 & 737824 & 5.05 & 5.0366 & TRN & \\
\hline CHEMBL3196138 & 737824 & 5.45 & 5.1529 & TST & \\
\hline CHEMBL3194024 & 737824 & 4.7 & 5.2292 & TST & \\
\hline CHEMBL1322942 & 737824 & 5.05 & 5.2249 & TRN & \\
\hline CHEMBL1560272 & 737824 & 4.95 & 5.2859 & TRN & \\
\hline CHEMBL1347362 & 737824 & 4.6 & 4.8757 & TRN & \\
\hline CHEMBL1450556 & 737824 & 4.6 & 5.3341 & TRN & \\
\hline CHEMBL1408315 & 737824 & 5.1 & 5.2122 & TRN & \\
\hline CHEMBL1741337 & 737824 & 4.4 & 4.8329 & TRN & \\
\hline CHEMBL1588068 & 737824 & 4.75 & 4.9137 & TST & \\
\hline CHEMBL1605581 & 737824 & 4.6 & 5.0823 & TRN & \\
\hline CHEMBL1585833 & 737824 & 4.9 & 5.2763 & TRN & \\
\hline CHEMBL1569592 & 737824 & 5.1 & 4.8079 & TRN & \\
\hline CHEMBL1472922 & 737824 & 4.9 & 4.8008 & TRN & \\
\hline CHEMBL1395869 & 737824 & 5.9 & 5.96899 & 9999999999 & TRN \\
\hline CHEMBL1315373 & 737824 & 5.0 & 5.125 & TRN & \\
\hline
\end{tabular}




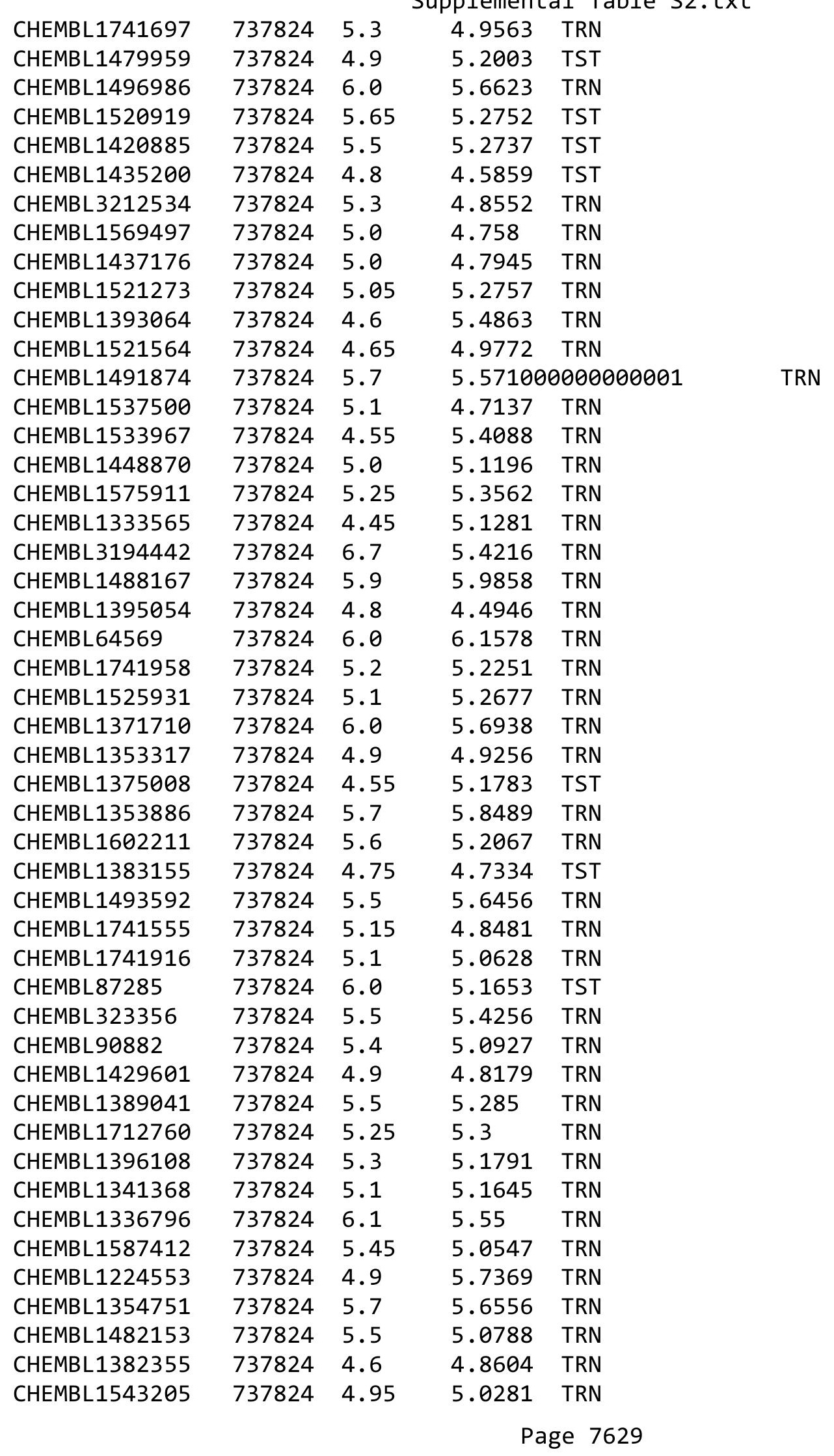




\begin{tabular}{|c|c|c|c|c|c|}
\hline & & & & & \\
\hline CHEMBL1601104 & 737824 & 5.0 & 5.0033 & TST & \\
\hline CHEMBL1351420 & 737824 & 4.6 & 4.9191 & TRN & \\
\hline CHEMBL1389326 & 737824 & 6.9 & 6.1448 & TRN & \\
\hline CHEMBL1429056 & 737824 & 4.6 & 5.8353 & TST & \\
\hline CHEMBL1565215 & 737824 & 5.5 & 5.3418 & TRN & \\
\hline CHEMBL1516068 & 737824 & 5.2 & 4.7133 & TRN & \\
\hline CHEMBL1288013 & 737824 & 6.1 & 5.7767 & TRN & \\
\hline CHEMBL1466047 & 737824 & 4.8 & 5.0462 & TRN & \\
\hline CHEMBL3197064 & 737824 & 4.6 & 4.965 & TRN & \\
\hline CHEMBL1509960 & 737824 & 4.8 & 5.07100 & 0000000001 & TRN \\
\hline CHEMBL 1610320 & 737824 & 5.0 & 5.0553 & TRN & \\
\hline CHEMBL1331363 & 737824 & 5.1 & 5.4726 & TRN & \\
\hline CHEMBL1372708 & 737824 & 5.55 & 5.2983 & TRN & \\
\hline CHEMBL1742029 & 737824 & 4.95 & 5.7184 & TRN & \\
\hline CHEMBL1543262 & 737824 & 4.6 & 5.3735 & TRN & \\
\hline CHEMBL 1455802 & 737824 & 5.1 & 5.2608 & TRN & \\
\hline CHEMBL1526824 & 737824 & 4.85 & 5.2829 & TRN & \\
\hline CHEMBL1452079 & 737824 & 4.65 & 4.9607 & TRN & \\
\hline CHEMBL1437075 & 737824 & 5.0 & 4.8342 & TRN & \\
\hline CHEMBL1438615 & 737824 & 5.1 & 5.3392 & TRN & \\
\hline CHEMBL1369940 & 737824 & 5.9 & 5.9207 & TRN & \\
\hline CHEMBL1433726 & 737824 & 4.9 & 4.7636 & TST & \\
\hline CHEMBL1607868 & 737824 & 4.9 & 4.727 & TRN & \\
\hline CHEMBL258465 & 737824 & 6.9 & 6.4486 & TST & \\
\hline CHEMBL1607611 & 737824 & 5.05 & 5.5629 & TRN & \\
\hline CHEMBL402063 & 737824 & 4.9 & 4.9083 & TST & \\
\hline CHEMBL1301031 & 737824 & 4.9 & 5.3909 & TST & \\
\hline CHEMBL1313549 & 737824 & 5.7 & 5.8234 & TRN & \\
\hline CHEMBL1431523 & 737824 & 5.85 & 5.3701 & TRN & \\
\hline CHEMBL1607234 & 737824 & 4.4 & 4.9305 & TRN & \\
\hline CHEMBL1965376 & 737824 & 4.9 & 5.2345 & TRN & \\
\hline CHEMBL1477727 & 737824 & 5.1 & 4.7534 & TRN & \\
\hline CHEMBL1335329 & 737824 & 6.35 & 5.6154 & TRN & \\
\hline CHEMBL1311981 & 737824 & 5.7 & 5.3569 & TRN & \\
\hline CHEMBL3210667 & 737824 & 5.05 & 5.4789 & TRN & \\
\hline CHEMBL1539107 & 737824 & 5.95 & 5.4236 & TRN & \\
\hline CHEMBL1430137 & 737824 & 4.85 & 5.1365 & TST & \\
\hline CHEMBL1314011 & 737824 & 5.95 & 6.0414 & TRN & \\
\hline CHEMBL1452389 & 737824 & 6.9 & 6.4316 & TRN & \\
\hline CHEMBL1605922 & 737824 & 4.65 & 4.8833 & TRN & \\
\hline CHEMBL1395429 & 737824 & 4.4 & 4.5226 & TRN & \\
\hline CHEMBL1549510 & 737824 & 5.85 & 5.8402 & TRN & \\
\hline CHEMBL1358266 & 737824 & 5.1 & 5.0038 & TRN & \\
\hline CHEMBL1365665 & 737824 & 5.8 & 5.8524 & TRN & \\
\hline CHEMBL1586704 & 737824 & 4.4 & 5.2747 & TRN & \\
\hline CHEMBL1356372 & 737824 & 4.8 & 4.7887 & TRN & \\
\hline CHEMBL1594359 & 737824 & 6.8 & 6.0559 & TRN & \\
\hline CHEMBL1545002 & 737824 & 5.1 & 5.3237 & TRN & \\
\hline
\end{tabular}




\begin{tabular}{|c|c|c|c|c|c|}
\hline \\
\hline CHEMBL1382389 & 737824 & 5.9 & 5.1984 & TRN & \\
\hline CHEMBL1596110 & 737824 & 4.8 & 5.2695 & TRN & \\
\hline CHEMBL1466055 & 737824 & 5.55 & 5.6477 & TRN & \\
\hline CHEMBL1367030 & 737824 & 6.0 & 5.9573 & TRN & \\
\hline CHEMBL3351080 & 737824 & 6.0 & 5.8865 & TST & \\
\hline CHEMBL1992166 & 737824 & 4.85 & 5.6066 & TRN & \\
\hline CHEMBL 1454530 & 737824 & 5.05 & 4.8153 & TRN & \\
\hline CHEMBL1600340 & 737824 & 4.7 & 4.6261 & TRN & \\
\hline CHEMBL1321476 & 737824 & 5.55 & 5.8053 & TRN & \\
\hline CHEMBL1519172 & 737824 & 5.3 & 5.2165 & TRN & \\
\hline CHEMBL28992 & 737824 & 4.8 & 4.5475 & TST & \\
\hline CHEMBL1435604 & 737824 & 5.0 & 4.8161 & TRN & \\
\hline CHEMBL1422718 & 737824 & 6.1 & 5.2877 & TRN & \\
\hline CHEMBL3145061 & 737824 & 5.4 & 5.4747 & TRN & \\
\hline CHEMBL1444973 & 737824 & -0.0 & 4.2519 & TRN & \\
\hline CHEMBL1474875 & 737824 & 5.1 & 5.0041 & TRN & \\
\hline CHEMBL1403307 & 737824 & 5.3 & 5.8437 & TRN & \\
\hline CHEMBL1256851 & 737824 & 7.2 & 7.138 & TST & \\
\hline CHEMBL1430479 & 737824 & 6.0 & 5.5318 & TRN & \\
\hline CHEMBL3193223 & 737824 & 5.05 & 5.33799 & 9999999999 & TRN \\
\hline CHEMBL1593511 & 737824 & 5.1 & 5.2327 & TRN & \\
\hline CHEMBL1410676 & 737824 & 6.0 & 6.0647 & TRN & \\
\hline CHEMBL1473753 & 737824 & 5.5 & 6.0047 & TRN & \\
\hline CHEMBL1392755 & 737824 & 5.55 & 5.0409 & TRN & \\
\hline CHEMBL1592558 & 737824 & 4.8 & 4.3594 & TST & \\
\hline CHEMBL1347463 & 737824 & 5.65 & 5.3309 & TRN & \\
\hline CHEMBL1507167 & 737824 & 5.1 & 5.3449 & TRN & \\
\hline CHEMBL1742180 & 737824 & 5.15 & 5.2682 & TRN & \\
\hline CHEMBL1713713 & 737824 & 5.95 & 5.7086 & TRN & \\
\hline CHEMBL1302993 & 737824 & 5.2 & 5.2267 & TRN & \\
\hline CHEMBL1313506 & 737824 & 4.8 & 5.2146 & TRN & \\
\hline CHEMBL1408459 & 737824 & 4.8 & 4.5405 & TRN & \\
\hline CHEMBL1557048 & 737824 & 6.1 & 6.3013 & TRN & \\
\hline CHEMBL1487801 & 737824 & 5.5 & 4.7954 & TST & \\
\hline CHEMBL1461418 & 737824 & 4.9 & 4.9868 & TRN & \\
\hline CHEMBL1595002 & 737824 & 5.1 & 5.2209 & TRN & \\
\hline CHEMBL1552028 & 737824 & 5.5 & 4.7801 & TRN & \\
\hline CHEMBL1347066 & 737824 & 5.0 & 5.1511 & TRN & \\
\hline CHEMBL3207899 & 737824 & 5.8 & 5.6661 & TRN & \\
\hline CHEMBL1527565 & 737824 & 6.1 & 6.2363 & TST & \\
\hline CHEMBL1515221 & 737824 & 4.9 & 4.6735 & TRN & \\
\hline CHEMBL1304478 & 737824 & 4.95 & 5.2465 & TRN & \\
\hline CHEMBL1518270 & 737824 & 4.6 & 5.166 & TRN & \\
\hline CHEMBL1582625 & 737824 & 5.05 & 5.3784 & TST & \\
\hline CHEMBL1422254 & 737824 & 4.9 & 5.295 & TRN & \\
\hline CHEMBL56331 & 737824 & 4.5 & 4.2572 & TRN & \\
\hline CHEMBL1589809 & 737824 & 5.5 & 5.1138 & TRN & \\
\hline CHEMBL1441508 & 737824 & 5.95 & 6.1304 & TST & \\
\hline
\end{tabular}




\begin{tabular}{|c|c|c|c|c|c|}
\hline CHEMBL1316463 & 737824 & 5.1 & \multicolumn{2}{|c|}{5.3870000000000005} & TRN \\
\hline CHEMBL1565961 & 737824 & 4.55 & 4.7597 & TRN & \\
\hline CHEMBL1544472 & 737824 & 4.55 & 5.0826 & TST & \\
\hline CHEMBL1301444 & 737824 & 5.0 & 5.039 & TRN & \\
\hline CHEMBL1449160 & 737824 & 4.8 & 5.0212 & TRN & \\
\hline CHEMBL1380844 & 737824 & 5.9 & 5.5222 & TRN & \\
\hline CHEMBL3213530 & 737824 & 5.05 & 5.1158 & TRN & \\
\hline CHEMBL1471244 & 737824 & 4.55 & 4.6161 & TRN & \\
\hline CHEMBL1515401 & 737824 & 6.5 & 6.4348 & TRN & \\
\hline CHEMBL1307620 & 737824 & 4.85 & 5.1952 & TRN & \\
\hline CHEMBL1352528 & 737824 & 5.4 & 5.3008 & TRN & \\
\hline CHEMBL1356113 & 737824 & 5.6 & 5.2595 & TRN & \\
\hline CHEMBL1348609 & 737824 & 5.35 & 5.6722 & TRN & \\
\hline CHEMBL1335862 & 737824 & 5.8 & 5.2142 & TST & \\
\hline CHEMBL1565366 & 737824 & 5.45 & 5.5611 & TRN & \\
\hline CHEMBL1529543 & 737824 & 4.8 & 4.9056 & TRN & \\
\hline CHEMBL3197818 & 737824 & 4.6 & 5.0302 & TRN & \\
\hline CHEMBL1436361 & 737824 & 4.5 & 4.2994 & TRN & \\
\hline CHEMBL1398540 & 737824 & 6.1 & 6.1301 & TRN & \\
\hline CHEMBL1481781 & 737824 & 5.0 & 4.5783 & TRN & \\
\hline CHEMBL1533661 & 737824 & 5.85 & 5.8243 & TRN & \\
\hline CHEMBL1729717 & 737824 & 4.85 & 5.2483 & TRN & \\
\hline CHEMBL1370377 & 737824 & 4.85 & 5.099 & TRN & \\
\hline CHEMBL1344769 & 737824 & 5.3 & 5.1878 & TST & \\
\hline CHEMBL1454748 & 737824 & 5.55 & 5.9833 & TRN & \\
\hline CHEMBL1436992 & 737824 & 4.4 & 4.0787 & TST & \\
\hline CHEMBL1477545 & 737824 & 5.25 & \multicolumn{2}{|c|}{5.0489999999999995} & TRN \\
\hline CHEMBL1553001 & 737824 & 4.5 & 4.352 & TRN & \\
\hline CHEMBL1583279 & 737824 & 5.05 & 5.311 & TRN & \\
\hline CHEMBL1256776 & 737824 & 5.3 & 5.4134 & TRN & \\
\hline CHEMBL1393740 & 737824 & 5.2 & 5.3254 & TRN & \\
\hline CHEMBL1333759 & 737824 & 5.95 & 5.5708 & TRN & \\
\hline CHEMBL1457143 & 737824 & 5.6 & 5.5152 & TRN & \\
\hline CHEMBL1742109 & 737824 & 4.4 & \multicolumn{2}{|c|}{4.8260000000000005} & TRN \\
\hline CHEMBL1592220 & 737824 & 4.9 & 4.8201 & TRN & \\
\hline CHEMBL1602258 & 737824 & 5.05 & 5.0146 & TRN & \\
\hline CHEMBL1340572 & 737824 & 4.95 & 5.0699 & TRN & \\
\hline CHEMBL1374355 & 737824 & 4.4 & 4.5415 & TRN & \\
\hline CHEMBL1350128 & 737824 & 5.45 & 5.2355 & TRN & \\
\hline CHEMBL1357180 & 737824 & 4.6 & 4.5537 & TRN & \\
\hline CHEMBL1383851 & 737824 & 4.85 & \multicolumn{2}{|c|}{5.207999999999999} & TRN \\
\hline CHEMBL1741744 & 737824 & 5.6 & 4.9716 & TRN & \\
\hline CHEMBL1412900 & 737824 & 4.4 & 4.3924 & TRN & \\
\hline CHEMBL1526369 & 737824 & 5.3 & 5.4727 & TRN & \\
\hline CHEMBL1361427 & 737824 & 4.85 & 5.3954 & TRN & \\
\hline CHEMBL1435450 & 737824 & 5.5 & 5.3633 & TRN & \\
\hline CHEMBL126077 & 737824 & 4.4 & 5.5729 & TST & \\
\hline CHEMBL1471761 & 737824 & 4.5 & 4.4893 & TRN & \\
\hline
\end{tabular}




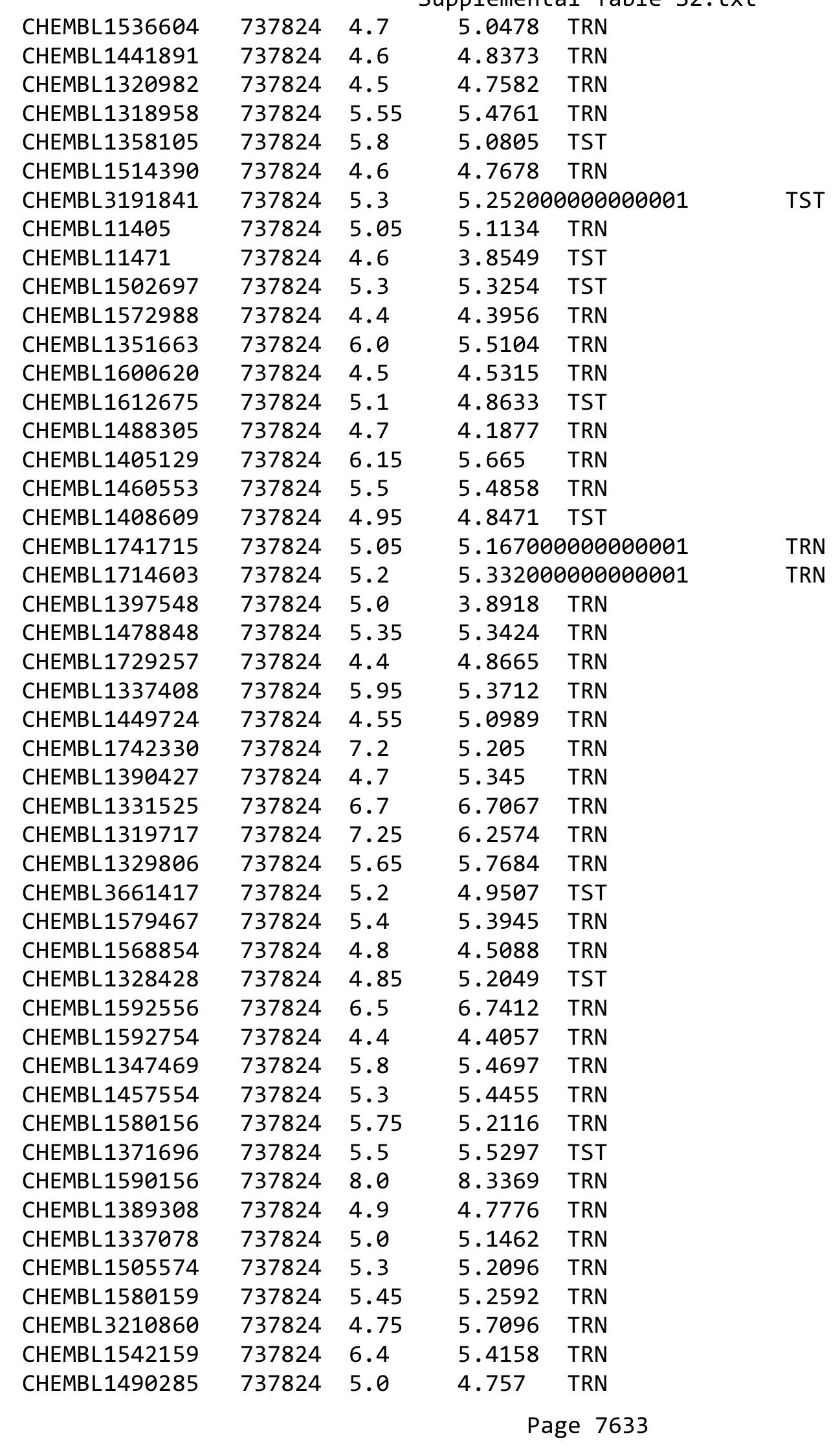




\begin{tabular}{|c|c|c|c|c|}
\hline \multicolumn{5}{|c|}{ lemental T } \\
\hline CHEMBL1356657 & 737824 & 4.4 & 4.1885 & TRN \\
\hline CHEMBL1433752 & 737824 & 5.1 & 5.1711 & TRN \\
\hline CHEMBL1307175 & 737824 & 5.2 & 4.9786 & TRN \\
\hline CHEMBL1356652 & 737824 & 5.0 & 5.0009 & TRN \\
\hline CHEMBL1380635 & 737824 & 4.6 & 5.2134 & TRN \\
\hline CHEMBL1547490 & 737824 & 5.45 & 5.1283 & TRN \\
\hline CHEMBL3196162 & 737824 & 4.4 & 5.0333 & TRN \\
\hline CHEMBL1447333 & 737824 & 5.7 & 5.8218 & TST \\
\hline CHEMBL1377908 & 737824 & 5.9 & 5.48 & TRN \\
\hline CHEMBL86537 & 737824 & 7.1 & 6.5775 & TST \\
\hline CHEMBL1365537 & 737824 & 6.4 & 6.6384 & TRN \\
\hline CHEMBL1478762 & 737824 & 6.35 & 5.6414 & TRN \\
\hline CHEMBL1384971 & 737824 & 4.8 & 5.2612 & TRN \\
\hline CHEMBL1506056 & 737824 & 5.75 & 5.6099 & TRN \\
\hline CHEMBL1493944 & 737824 & 4.85 & 5.4068 & TRN \\
\hline CHEMBL 319244 & 737824 & 4.9 & 4.7355 & TRN \\
\hline CHEMBL1489424 & 737824 & 5.7 & 5.6651 & TRN \\
\hline CHEMBL1519083 & 737824 & 4.95 & 5.1085 & TRN \\
\hline CHEMBL 2002680 & 737824 & 4.95 & 5.564 & TRN \\
\hline CHEMBL1430579 & 737824 & 4.65 & 5.5309 & TRN \\
\hline CHEMBL1565378 & 737824 & 4.85 & 5.0824 & TRN \\
\hline CHEMBL1407848 & 737824 & 5.55 & 5.572 & TRN \\
\hline CHEMBL1457123 & 737824 & 7.3 & 6.5186 & TRN \\
\hline CHEMBL1465393 & 737824 & 6.05 & 5.8591 & TRN \\
\hline CHEMBL1707752 & 737824 & 4.5 & 5.0164 & TRN \\
\hline CHEMBL1715733 & 737824 & 4.4 & 4.8818 & TRN \\
\hline CHEMBL1524331 & 737824 & 4.7 & 4.5219 & TRN \\
\hline CHEMBL1741636 & 737824 & 4.5 & 5.1638 & TRN \\
\hline CHEMBL1588818 & 737824 & 5.25 & 5.4229 & TRN \\
\hline CHEMBL1304517 & 737824 & 4.7 & 5.1537 & TRN \\
\hline CHEMBL1463720 & 737824 & 4.4 & 5.1231 & TRN \\
\hline CHEMBL1313465 & 737824 & 5.85 & 5.4633 & TRN \\
\hline CHEMBL 21241 & 737824 & 4.6 & 4.7919 & TRN \\
\hline CHEMBL1570769 & 737824 & 6.2 & 5.7781 & TRN \\
\hline CHEMBL1380667 & 737824 & 5.1 & 5.3069 & TST \\
\hline CHEMBL1567176 & 737824 & 4.8 & 4.3417 & TRN \\
\hline CHEMBL1349639 & 737824 & 5.85 & 5.3038 & TRN \\
\hline CHEMBL1365616 & 737824 & 4.7 & 4.7443 & TRN \\
\hline CHEMBL1516629 & 737824 & 4.9 & 5.7139 & TRN \\
\hline CHEMBL1405364 & 737824 & 5.25 & 5.4488 & TRN \\
\hline CHEMBL1319346 & 737824 & 4.8 & 4.8845 & TRN \\
\hline CHEMBL1481014 & 737824 & 4.7 & 4.5151 & TST \\
\hline CHEMBL1327355 & 737824 & 5.9 & 5.9163 & TRN \\
\hline CHEMBL1552181 & 737824 & 4.4 & 4.2733 & TRN \\
\hline CHEMBL1397079 & 737824 & 4.9 & 4.7781 & TRN \\
\hline CHEMBL1464044 & 737824 & 4.55 & 4.7786 & TRN \\
\hline CHEMBL37081 & 737824 & 5.2 & 5.2596 & TRN \\
\hline CHEMBL1334477 & 737824 & 5.4 & 5.1867 & TRN \\
\hline
\end{tabular}




\begin{tabular}{|c|c|c|c|c|}
\hline & & & & al lable s \\
\hline CHEMBL1608678 & 737824 & 4.6 & 5.0668 & TRN \\
\hline CHEMBL1314674 & 737824 & 4.5 & 4.4792 & TRN \\
\hline CHEMBL1313827 & 737824 & 5.2 & 5.6201 & TST \\
\hline CHEMBL1491168 & 737824 & 4.8 & 5.005 & TRN \\
\hline CHEMBL1509477 & 737824 & 5.65 & 5.4837 & TRN \\
\hline CHEMBL1608811 & 737824 & 5.65 & 5.6204 & TRN \\
\hline CHEMBL1378653 & 737824 & 5.95 & 6.0735 & TRN \\
\hline CHEMBL1374288 & 737824 & 5.1 & 4.6738 & TRN \\
\hline CHEMBL188 & 737824 & 5.0 & 4.7659 & TRN \\
\hline CHEMBL1475620 & 737824 & 4.6 & 4.5555 & TRN \\
\hline CHEMBL1587369 & 737824 & 4.6 & 4.9243 & TRN \\
\hline CHEMBL1981379 & 737824 & 6.25 & 5.1947 & TST \\
\hline CHEMBL1489512 & 737824 & 5.35 & 5.5753 & TRN \\
\hline CHEMBL1288014 & 737824 & 5.9 & 5.9114 & TRN \\
\hline CHEMBL1367474 & 737824 & 4.95 & 5.3538 & TRN \\
\hline CHEMBL1417581 & 737824 & 5.95 & 4.9403 & TRN \\
\hline CHEMBL1441676 & 737824 & 7.45 & 5.0302 & TRN \\
\hline CHEMBL1485152 & 737824 & 4.75 & 4.9214 & TRN \\
\hline CHEMBL554041 & 737824 & 5.4 & 5.0592 & TST \\
\hline CHEMBL1387681 & 737824 & 6.05 & 5.4733 & TRN \\
\hline CHEMBL1467219 & 737824 & 4.5 & 5.3888 & TRN \\
\hline CHEMBL1335967 & 737824 & 4.5 & 4.782 & TRN \\
\hline CHEMBL1409547 & 737824 & 4.6 & 4.46899 & 9999999999 \\
\hline CHEMBL1437448 & 737824 & 4.8 & 4.3583 & TST \\
\hline CHEMBL1589098 & 737824 & 5.1 & 5.7173 & TRN \\
\hline CHEMBL1487641 & 737824 & 4.65 & 5.1539 & TRN \\
\hline CHEMBL1526429 & 737824 & 5.6 & 5.438 & TST \\
\hline CHEMBL3196296 & 737824 & 4.9 & 5.1609 & TST \\
\hline CHEMBL1327697 & 737824 & 4.4 & 4.305 & TRN \\
\hline CHEMBL1741912 & 737824 & 6.0 & 5.0892 & TRN \\
\hline CHEMBL1527622 & 737824 & 5.6 & 5.5427 & TRN \\
\hline CHEMBL1408614 & 737824 & 4.85 & 5.6544 & TRN \\
\hline CHEMBL1418437 & 737824 & 4.7 & 5.5726 & TRN \\
\hline CHEMBL1342661 & 737824 & 5.55 & 5.0766 & TRN \\
\hline CHEMBL1555677 & 737824 & 5.05 & 4.9458 & TRN \\
\hline CHEMBL1602940 & 737824 & 5.1 & 4.8789 & TRN \\
\hline CHEMBL1304993 & 737824 & 4.8 & 5.0824 & TRN \\
\hline CHEMBL1361214 & 737824 & 5.15 & 5.2218 & TRN \\
\hline CHEMBL1553941 & 737824 & 5.9 & 5.2937 & TRN \\
\hline CHEMBL1539317 & 737824 & 5.2 & 5.2179 & TRN \\
\hline CHEMBL3208230 & 737824 & 5.05 & 5.1431 & TRN \\
\hline CHEMBL1407215 & 737824 & 4.85 & 5.3831 & TRN \\
\hline CHEMBL1527466 & 737824 & 6.0 & 6.1642 & TRN \\
\hline CHEMBL1403793 & 737824 & 4.4 & 4.1898 & TRN \\
\hline CHEMBL1473755 & 737824 & 5.8 & 6.0186 & TRN \\
\hline CHEMBL1317009 & 737824 & 4.7 & 4.775 & TRN \\
\hline CHEMBL1490573 & 737824 & 5.55 & 5.6996 & TRN \\
\hline CHEMBL1588074 & 737824 & 5.0 & 5.2571 & TST \\
\hline
\end{tabular}




\begin{tabular}{|c|c|c|c|c|c|}
\hline \\
\hline CHEMBL1523565 & 737824 & 4.65 & 5.0942 & TRN & \\
\hline CHEMBL1741663 & 737824 & 4.75 & 5.2654 & TRN & \\
\hline CHEMBL1300309 & 737824 & 4.85 & 4.8385 & TRN & \\
\hline CHEMBL1531837 & 737824 & 4.9 & 4.6079 & TRN & \\
\hline CHEMBL1389499 & 737824 & 4.4 & 5.3891 & TRN & \\
\hline CHEMBL3213218 & 737824 & 4.5 & 4.8146 & TST & \\
\hline CHEMBL1464956 & 737824 & 4.8 & 5.0056 & TRN & \\
\hline CHEMBL1413701 & 737824 & 5.5 & 5.4684 & TRN & \\
\hline CHEMBL1356135 & 737824 & 4.8 & 4.8109 & TRN & \\
\hline CHEMBL249669 & 737824 & 6.0 & 5.5454 & TRN & \\
\hline CHEMBL1572173 & 737824 & 6.2 & 6.2742 & TRN & \\
\hline CHEMBL1302626 & 737824 & 5.2 & 5.2049 & TRN & \\
\hline CHEMBL1519293 & 737824 & 5.5 & 5.5602 & TRN & \\
\hline CHEMBL1322760 & 737824 & 6.5 & 5.7003 & TST & \\
\hline CHEMBL1331054 & 737824 & 4.5 & 4.9664 & TRN & \\
\hline CHEMBL1391721 & 737824 & 6.3 & 5.1371 & TRN & \\
\hline CHEMBL1351822 & 737824 & 4.85 & 5.0429 & TRN & \\
\hline CHEMBL3207362 & 737824 & 4.6 & 5.2291 & TST & \\
\hline CHEMBL1545870 & 737824 & 4.7 & 5.3275 & TRN & \\
\hline CHEMBL1510646 & 737824 & 5.35 & 4.8419 & TRN & \\
\hline CHEMBL1367020 & 737824 & 4.4 & 4.2988 & TRN & \\
\hline CHEMBL1530252 & 737824 & 5.05 & 5.2901 & TRN & \\
\hline CHEMBL414400 & 737824 & 5.0 & 4.6338 & TRN & \\
\hline CHEMBL1587168 & 737824 & 6.6 & 5.3932 & TRN & \\
\hline CHEMBL1347071 & 737824 & 4.7 & 5.2159 & TST & \\
\hline CHEMBL1441039 & 737824 & 5.35 & 5.0466 & TRN & \\
\hline CHEMBL 3214452 & 737824 & 5.95 & 5.157 & TRN & \\
\hline CHEMBL1560716 & 737824 & 5.9 & 5.5728 & TRN & \\
\hline CHEMBL1601955 & 737824 & 4.75 & 4.8877 & TRN & \\
\hline CHEMBL1329418 & 737824 & 7.1 & 5.8299 & TRN & \\
\hline CHEMBL1318447 & 737824 & 4.5 & 4.49100 & 30000000005 & TRN \\
\hline CHEMBL1522517 & 737824 & 5.3 & 5.2964 & TRN & \\
\hline CHEMBL1515295 & 737824 & 4.6 & 4.303 & TRN & \\
\hline CHEMBL1530272 & 737824 & 5.2 & 5.8127 & TST & \\
\hline CHEMBL 26320 & 737824 & 6.0 & 5.2332 & TRN & \\
\hline CHEMBL1502330 & 737824 & 4.4 & 4.6652 & TRN & \\
\hline CHEMBL1449838 & 737824 & 5.5 & 5.5099 & TRN & \\
\hline CHEMBL1475689 & 737824 & 4.6 & 4.6643 & TRN & \\
\hline CHEMBL1609251 & 737824 & 4.85 & 5.2748 & TRN & \\
\hline CHEMBL1353815 & 737824 & 5.7 & 5.3741 & TRN & \\
\hline CHEMBL1344123 & 737824 & 5.4 & 5.0839 & TRN & \\
\hline CHEMBL1592663 & 737824 & 5.4 & 5.2106 & TST & \\
\hline CHEMBL1460606 & 737824 & 4.7 & 4.3124 & TRN & \\
\hline CHEMBL1562685 & 737824 & 4.5 & 5.0363 & TRN & \\
\hline CHEMBL1606259 & 737824 & 5.75 & 5.6915 & TRN & \\
\hline CHEMBL1473099 & 737824 & 6.4 & 6.1289 & TRN & \\
\hline CHEMBL1428339 & 737824 & 4.85 & 4.8475 & TRN & \\
\hline CHEMBL1422001 & 737824 & 6.05 & 5.428 & TRN & \\
\hline
\end{tabular}




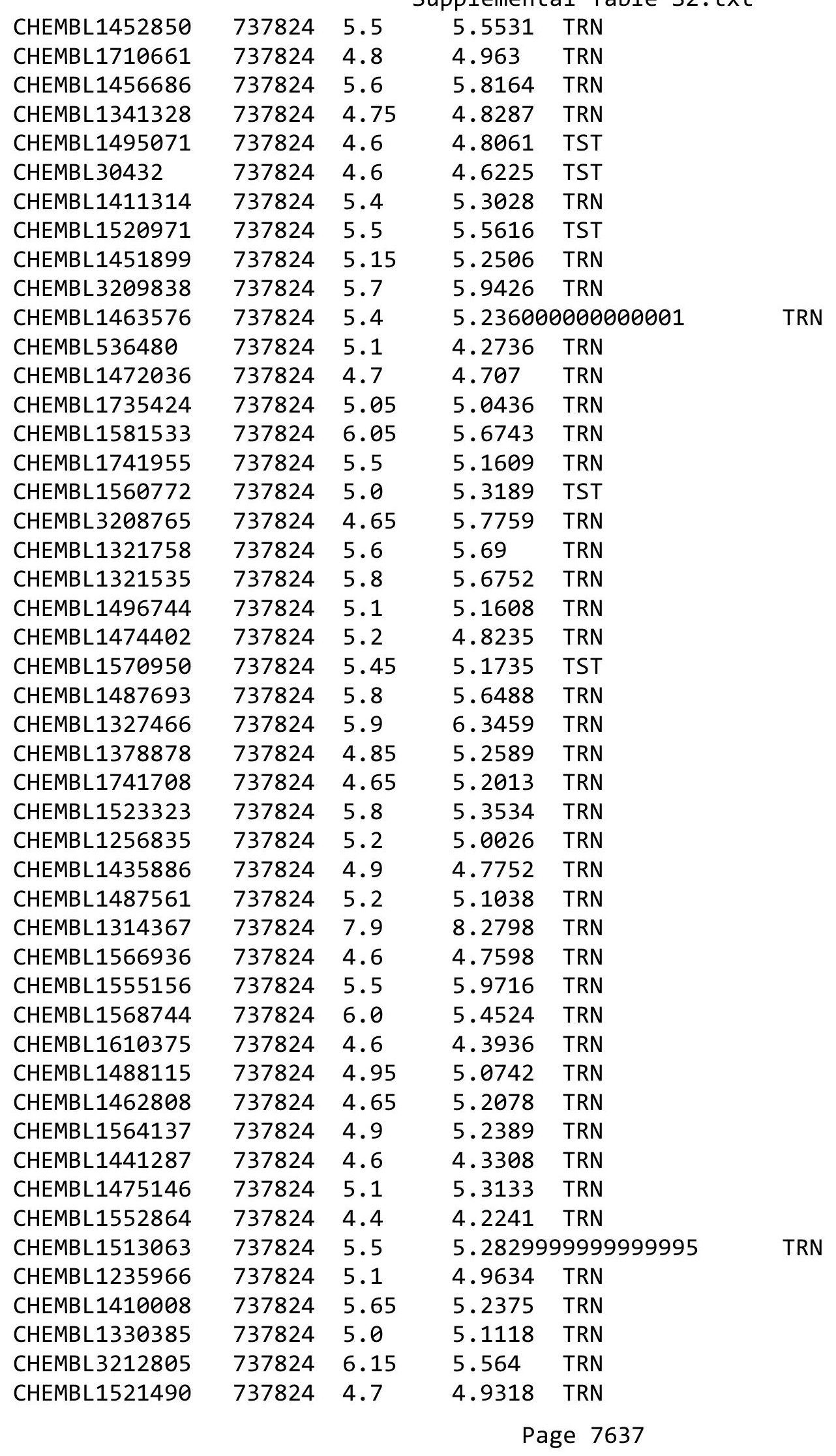




\begin{tabular}{|c|c|c|c|c|c|}
\hline \multirow{3}{*}{$\begin{array}{l}\text { CHEMBL1326406 } \\
\text { CHEMBL1459503 }\end{array}$} & \multirow{3}{*}{$\begin{array}{l}737824 \\
737824\end{array}$} & \multicolumn{4}{|c|}{ Supplemental Table S2.txt } \\
\hline & & 5.15 & \multicolumn{2}{|c|}{5.257000000000001} & TRN \\
\hline & & 4.4 & 4.9047 & TRN & \\
\hline CHEMBL1357293 & 737824 & 5.0 & 4.7591 & TRN & \\
\hline CHEMBL1474468 & 737824 & 5.0 & 5.1102 & TRN & \\
\hline CHEMBL1590270 & 737824 & 4.8 & 4.8255 & TRN & \\
\hline CHEMBL1499485 & 737824 & 5.15 & 5.3742 & TRN & \\
\hline CHEMBL1385038 & 737824 & 4.9 & 5.2077 & TRN & \\
\hline CHEMBL1320469 & 737824 & 5.3 & 5.5254 & TRN & \\
\hline CHEMBL1442087 & 737824 & 5.6 & 5.6775 & TRN & \\
\hline CHEMBL1567265 & 737824 & 5.1 & 5.2947 & TRN & \\
\hline CHEMBL1330087 & 737824 & 6.0 & 5.7983 & TRN & \\
\hline CHEMBL 20562 & 737824 & 4.6 & 4.3206 & TST & \\
\hline CHEMBL1488727 & 737824 & 4.65 & 5.5155 & TRN & \\
\hline CHEMBL1592202 & 737824 & 4.4 & 4.3745 & TRN & \\
\hline CHEMBL1404031 & 737824 & 5.45 & 5.638 & TRN & \\
\hline CHEMBL1557870 & 737824 & 5.2 & 5.4411 & TRN & \\
\hline CHEMBL1581951 & 737824 & 4.95 & 5.5407 & TRN & \\
\hline CHEMBL1551639 & 737824 & 4.6 & 4.6378 & TRN & \\
\hline CHEMBL1478769 & 737824 & 5.65 & 5.3802 & TRN & \\
\hline CHEMBL556001 & 737824 & 6.1 & 5.4865 & TRN & \\
\hline CHEMBL1372773 & 737824 & 4.85 & 5.1584 & TRN & \\
\hline CHEMBL1333755 & 737824 & 4.7 & 5.2959 & TST & \\
\hline CHEMBL1373723 & 737824 & 4.8 & 4.9857 & TRN & \\
\hline CHEMBL1514604 & 737824 & 7.9 & 7.0218 & TRN & \\
\hline CHEMBL1368337 & 737824 & 5.05 & 4.9827 & TRN & \\
\hline CHEMBL1461894 & 737824 & 4.9 & 5.5288 & TST & \\
\hline CHEMBL1512562 & 737824 & 4.7 & 4.6989 & TRN & \\
\hline CHEMBL 3209784 & 737824 & 4.75 & 5.0968 & TST & \\
\hline CHEMBL1463200 & 737824 & 4.85 & 5.0164 & TRN & \\
\hline CHEMBL1522972 & 737824 & 4.85 & 5.25 & TRN & \\
\hline CHEMBL1536326 & 737824 & 7.5501 & 5.4917 & TRN & \\
\hline CHEMBL3198813 & 737824 & 5.65 & 5.2495 & TRN & \\
\hline CHEMBL1427154 & 737824 & 5.25 & 5.7901 & TRN & \\
\hline CHEMBL1333382 & 737824 & 6.25 & 5.6712 & TRN & \\
\hline CHEMBL1454049 & 737824 & 5.4 & 5.3271 & TRN & \\
\hline CHEMBL1526486 & 737824 & 4.4 & 4.1971 & TST & \\
\hline CHEMBL1444310 & 737824 & 5.0 & 5.0096 & TRN & \\
\hline CHEMBL1407688 & 737824 & 6.3 & 5.4469 & TRN & \\
\hline CHEMBL1422932 & 737824 & 5.4 & 4.8385 & TRN & \\
\hline CHEMBL15134 & 737824 & 6.3 & 5.8404 & TST & \\
\hline CHEMBL1588025 & 737824 & 5.5 & 4.7325 & TST & \\
\hline CHEMBL1484866 & 737824 & 7.3 & 6.0456 & TRN & \\
\hline CHEMBL27403 & 737824 & 4.9 & 4.7892 & TRN & \\
\hline CHEMBL3195142 & 737824 & 5.75 & 5.1089 & TRN & \\
\hline CHEMBL1360848 & 737824 & 4.4 & 5.1535 & TRN & \\
\hline CHEMBL1596455 & 737824 & 5.4 & 5.21399 & 99999999995 & TRN \\
\hline CHEMBL1389781 & 737824 & 4.65 & 4.7111 & TRN & \\
\hline CHEMBL1348253 & 737824 & 4.75 & 4.8408 & TRN & \\
\hline
\end{tabular}




\begin{tabular}{|c|c|c|c|c|c|}
\hline \multicolumn{6}{|c|}{ Supplemental Table S2.txt } \\
\hline CHEMBL1341152 & 737824 & 6.55 & 5.5824 & TRN & \\
\hline CHEMBL1328166 & 737824 & 5.6 & 5.2617 & TRN & \\
\hline CHEMBL1366323 & 737824 & 4.8 & 4.8536 & TRN & \\
\hline CHEMBL1421737 & 737824 & 4.75 & 5.2241 & TRN & \\
\hline CHEMBL1396203 & 737824 & 5.0 & 5.1273 & TRN & \\
\hline CHEMBL1440487 & 737824 & 5.1 & 5.1523 & TRN & \\
\hline CHEMBL1569009 & 737824 & 4.6 & 5.2574 & TRN & \\
\hline CHEMBL1600239 & 737824 & 5.4 & 5.7892 & TRN & \\
\hline CHEMBL1605255 & 737824 & 4.9 & 5.0095 & TRN & \\
\hline CHEMBL1375812 & 737824 & 5.85 & 5.5665 & TRN & \\
\hline CHEMBL1367772 & 737824 & 5.9 & 5.0667 & TRN & \\
\hline CHEMBL1450395 & 737824 & 5.5 & 5.3225 & TST & \\
\hline CHEMBL1330692 & 737824 & 6.5 & 6.5441 & TRN & \\
\hline CHEMBL1402965 & 737824 & 4.85 & 5.4359 & TRN & \\
\hline CHEMBL1437690 & 737824 & 4.9 & 4.7352 & TRN & \\
\hline CHEMBL1741956 & 737824 & 4.85 & 4.8615 & TRN & \\
\hline CHEMBL1363897 & 737824 & 4.7 & 5.1258 & TRN & \\
\hline CHEMBL1518546 & 737824 & 5.1 & 5.0051 & TRN & \\
\hline CHEMBL3191056 & 737824 & 5.45 & 5.0274 & TST & \\
\hline CHEMBL1717653 & 737824 & 5.7 & 5.1679 & TRN & \\
\hline CHEMBL1532015 & 737824 & 5.4 & 5.4023 & TRN & \\
\hline CHEMBL1362159 & 737824 & 5.0 & 5.2488 & TRN & \\
\hline CHEMBL1446774 & 737824 & 5.1 & 5.063 & TRN & \\
\hline CHEMBL3209943 & 737824 & 5.5 & 5.7062 & TRN & \\
\hline CHEMBL1482566 & 737824 & 5.75 & 5.6793 & TRN & \\
\hline CHEMBL1334465 & 737824 & 4.8 & 4.874 & TRN & \\
\hline CHEMBL1356834 & 737824 & 4.6 & 4.4645 & TRN & \\
\hline CHEMBL1495580 & 737824 & 5.55 & 5.1507 & TST & \\
\hline CHEMBL1373610 & 737824 & -0.0 & 4.487 & TRN & \\
\hline CHEMBL1324405 & 737824 & 6.0 & 5.8231 & TRN & \\
\hline CHEMBL1533010 & 737824 & 4.8 & 4.8731 & TRN & \\
\hline CHEMBL1567121 & 737824 & 5.4 & 4.5401 & TRN & \\
\hline CHEMBL1393270 & 737824 & 4.7 & 5.3154 & TRN & \\
\hline CHEMBL1587623 & 737824 & 4.7 & 5.2691 & TRN & \\
\hline CHEMBL1995904 & 737824 & 5.4 & 5.3439 & TRN & \\
\hline CHEMBL1435509 & 737824 & 5.8 & 6.0261 & TRN & \\
\hline CHEMBL507112 & 737824 & 6.6 & 6.483 & TRN & \\
\hline CHEMBL1301792 & 737824 & 5.1 & 4.9247 & TST & \\
\hline CHEMBL1351832 & 737824 & 4.85 & 5.2973 & TRN & \\
\hline CHEMBL1368962 & 737824 & 5.4 & 5.3501 & TRN & \\
\hline CHEMBL1533024 & 737824 & 5.65 & 5.3443 & TRN & \\
\hline CHEMBL1300519 & 737824 & 5.5 & 5.3378 & TRN & \\
\hline CHEMBL3213682 & 737824 & 4.75 & 4.96399 & 99999999995 & TRN \\
\hline CHEMBL1427884 & 737824 & 5.3 & 5.4002 & TST & \\
\hline CHEMBL1609519 & 737824 & 4.85 & 4.9395 & TST & \\
\hline CHEMBL1401455 & 737824 & 5.6 & 5.2926 & TRN & \\
\hline CHEMBL1517172 & 737824 & 5.1 & 4.6463 & TRN & \\
\hline CHEMBL1413058 & 737824 & 6.05 & 5.7397 & TRN & \\
\hline
\end{tabular}




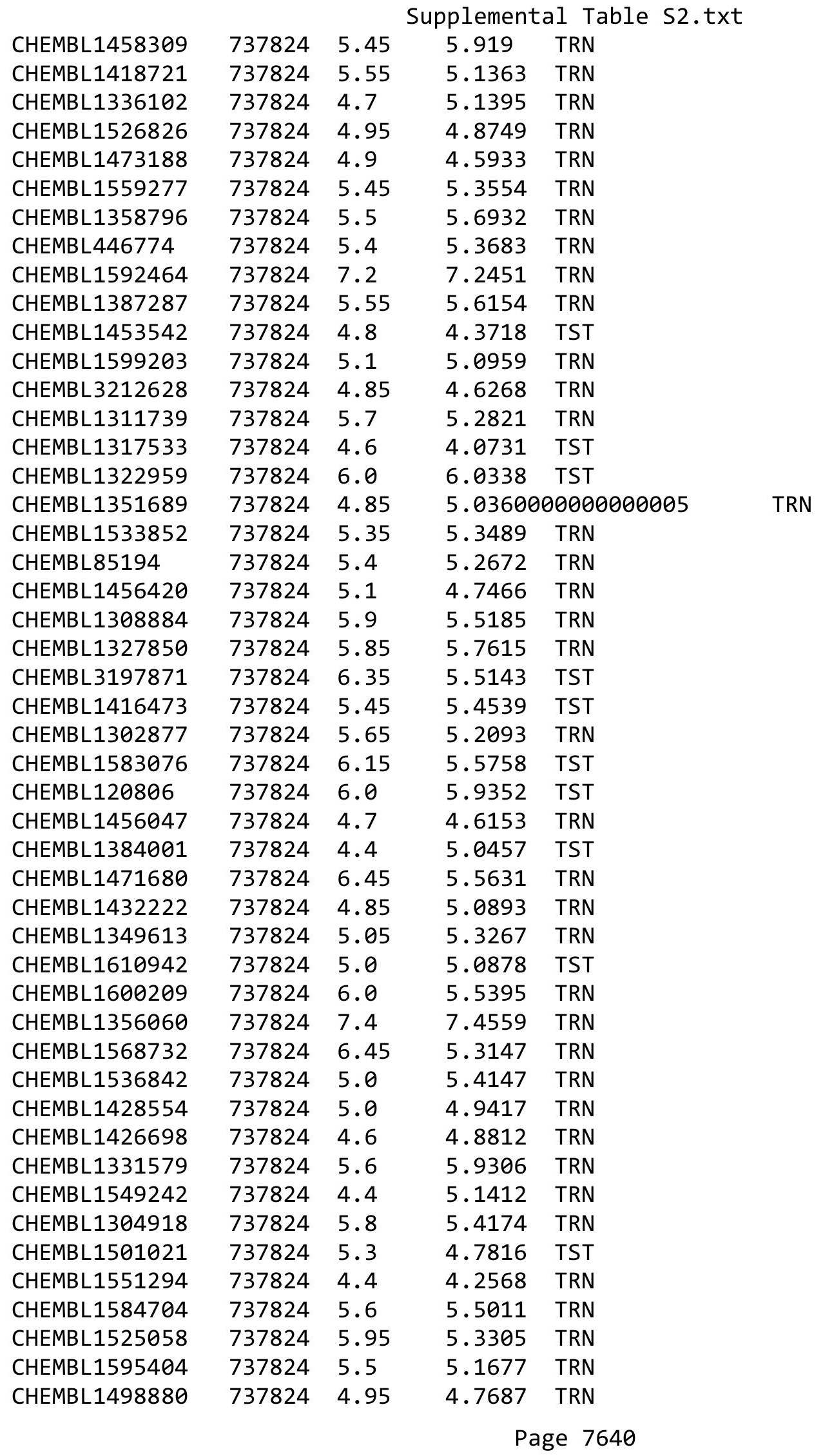




\begin{tabular}{|c|c|c|c|c|c|}
\hline \\
\hline CHEMBL1604396 & 737824 & 6.1 & 5.3826 & TRN & \\
\hline CHEMBL1607106 & 737824 & 5.5 & 5.4808 & TRN & \\
\hline CHEMBL1547349 & 737824 & 4.75 & 5.3226 & TRN & \\
\hline CHEMBL1372366 & 737824 & 4.65 & 5.3192 & TRN & \\
\hline CHEMBL1476348 & 737824 & 4.4 & 4.2398 & TRN & \\
\hline CHEMBL1449255 & 737824 & 4.4 & 5.0893 & TRN & \\
\hline CHEMBL1365175 & 737824 & 5.7 & 5.1674 & TRN & \\
\hline CHEMBL1316165 & 737824 & 4.4 & 4.5243 & TRN & \\
\hline CHEMBL1434550 & 737824 & 4.9 & 4.9374 & TRN & \\
\hline CHEMBL1487164 & 737824 & 5.7 & 5.3818 & TRN & \\
\hline CHEMBL1329408 & 737824 & 5.0 & 5.7548 & TRN & \\
\hline CHEMBL3194219 & 737824 & 4.85 & 5.1784 & TRN & \\
\hline CHEMBL1333658 & 737824 & 5.4 & 5.1053 & TST & \\
\hline CHEMBL1423337 & 737824 & 5.5 & 5.4047 & TRN & \\
\hline CHEMBL1561829 & 737824 & 6.5 & 6.5316 & TST & \\
\hline CHEMBL1476266 & 737824 & 4.4 & 4.5142 & TRN & \\
\hline CHEMBL1972824 & 737824 & 4.7 & 5.6641 & TRN & \\
\hline CHEMBL1519165 & 737824 & 4.8 & 5.5427 & TRN & \\
\hline CHEMBL1478545 & 737824 & 4.8 & 5.7214 & TRN & \\
\hline CHEMBL186872 & 737824 & 6.2 & 5.8414 & TST & \\
\hline CHEMBL1339516 & 737824 & 5.15 & 5.396 & TRN & \\
\hline CHEMBL1385137 & 737824 & 5.65 & 5.4382 & TST & \\
\hline CHEMBL1484398 & 737824 & 6.15 & 5.4723 & TRN & \\
\hline CHEMBL1491888 & 737824 & 4.8 & 5.4372 & TST & \\
\hline CHEMBL1334283 & 737824 & 4.6 & 4.6447 & TRN & \\
\hline CHEMBL1480917 & 737824 & 4.5 & 4.9558 & TRN & \\
\hline CHEMBL 2369218 & 737824 & 4.9 & 5.4589 & TST & \\
\hline CHEMBL1528565 & 737824 & 4.4 & 3.6396 & TST & \\
\hline CHEMBL1477447 & 737824 & 8.3 & 5.0248 & TRN & \\
\hline CHEMBL1544494 & 737824 & 5.0 & 5.1882 & TRN & \\
\hline CHEMBL1356336 & 737824 & 8.1 & 8.5965 & TRN & \\
\hline CHEMBL1437906 & 737824 & 4.8 & 4.8317 & TRN & \\
\hline CHEMBL1529954 & 737824 & 5.2 & 4.5666 & TRN & \\
\hline CHEMBL1402822 & 737824 & 5.7 & 5.6076 & TRN & \\
\hline CHEMBL1366112 & 737824 & 5.35 & 5.2431 & TRN & \\
\hline CHEMBL1517121 & 737824 & 4.9 & 5.1905 & TST & \\
\hline CHEMBL1364871 & 737824 & 4.6 & 4.5416 & TRN & \\
\hline CHEMBL1440157 & 737824 & 6.4 & 6.3412 & TRN & \\
\hline CHEMBL1480788 & 737824 & 5.0 & 5.4486 & TRN & \\
\hline CHEMBL365739 & 737824 & 6.0 & 5.9925 & TST & \\
\hline CHEMBL1299867 & 737824 & 4.95 & 5.4212 & TRN & \\
\hline CHEMBL1343620 & 737824 & 4.95 & 5.0311 & TRN & \\
\hline CHEMBL3195098 & 737824 & 4.65 & 4.9423 & TRN & \\
\hline CHEMBL1326359 & 737824 & 5.6 & 5.50899 & 99999999995 & TRN \\
\hline CHEMBL1462730 & 737824 & 6.6 & 5.6726 & TST & \\
\hline CHEMBL1445702 & 737824 & 4.95 & 5.4952 & TRN & \\
\hline CHEMBL1528942 & 737824 & 4.95 & 5.2716 & TRN & \\
\hline CHEMBL1524907 & 737824 & 5.45 & 5.1187 & TRN & \\
\hline
\end{tabular}




\begin{tabular}{|c|c|c|c|c|}
\hline \multicolumn{5}{|c|}{ lemental T } \\
\hline CHEMBL1437226 & 737824 & 4.9 & 4.8044 & TRN \\
\hline CHEMBL1604421 & 737824 & 5.0 & 4.8162 & TRN \\
\hline CHEMBL1584359 & 737824 & 5.45 & 4.8724 & TRN \\
\hline CHEMBL1421108 & 737824 & 5.0 & 5.1246 & TRN \\
\hline CHEMBL1536759 & 737824 & 4.75 & 5.0119 & TRN \\
\hline CHEMBL545523 & 737824 & 4.4 & 4.6232 & TRN \\
\hline CHEMBL1533645 & 737824 & 7.15 & 5.716 & TST \\
\hline CHEMBL1372577 & 737824 & 5.6 & 5.0572 & TRN \\
\hline CHEMBL1606693 & 737824 & 5.0 & 5.2255 & TRN \\
\hline CHEMBL1999906 & 737824 & 7.1 & 5.5209 & TST \\
\hline CHEMBL1414493 & 737824 & 4.75 & 5.6475 & TRN \\
\hline CHEMBL1544254 & 737824 & 4.95 & 5.0787 & TRN \\
\hline CHEMBL1423586 & 737824 & 5.8 & 5.3351 & TRN \\
\hline CHEMBL1562730 & 737824 & 5.65 & 5.4411 & TRN \\
\hline CHEMBL1481185 & 737824 & 5.25 & 4.8812 & TRN \\
\hline CHEMBL1335655 & 737824 & 4.85 & 5.1308 & TRN \\
\hline CHEMBL1388234 & 737824 & 4.9 & 5.1279 & TRN \\
\hline CHEMBL1476687 & 737824 & 5.2 & 4.5951 & TRN \\
\hline CHEMBL1526229 & 737824 & 5.7 & 5.4391 & TRN \\
\hline CHEMBL1324022 & 737824 & 5.1 & 4.8306 & TST \\
\hline CHEMBL1595500 & 737824 & 5.3 & 5.2728 & TRN \\
\hline CHEMBL1601662 & 737824 & 5.0 & 5.1896 & TRN \\
\hline CHEMBL3211887 & 737824 & 5.55 & 4.9984 & TST \\
\hline CHEMBL587259 & 737824 & 5.4 & 4.8223 & TRN \\
\hline CHEMBL1400788 & 737824 & 6.4 & 5.9318 & TST \\
\hline CHEMBL1360221 & 737824 & 5.35 & 5.18 & TRN \\
\hline CHEMBL1592803 & 737824 & 5.0 & 5.0705 & TRN \\
\hline CHEMBL1365979 & 737824 & -0.0 & 4.4551 & TRN \\
\hline CHEMBL45068 & 737824 & 4.7 & 5.4249 & TST \\
\hline CHEMBL1429193 & 737824 & 4.85 & 5.3275 & TST \\
\hline CHEMBL1501836 & 737824 & 6.6 & 5.9228 & TST \\
\hline CHEMBL1457808 & 737824 & 5.5 & 5.5177 & TST \\
\hline CHEMBL1606137 & 737824 & 5.45 & 5.7254 & TRN \\
\hline CHEMBL1519490 & 737824 & 5.5 & 5.6412 & TRN \\
\hline CHEMBL1605666 & 737824 & 5.0 & 5.6157 & TST \\
\hline CHEMBL1475789 & 737824 & 5.5 & 5.0199 & TRN \\
\hline CHEMBL1383268 & 737824 & 4.4 & 4.9455 & TST \\
\hline CHEMBL1436169 & 737824 & 8.1 & 8.4696 & TRN \\
\hline CHEMBL1352269 & 737824 & 5.55 & 5.1389 & TRN \\
\hline CHEMBL1741984 & 737824 & 4.7 & 5.1546 & TRN \\
\hline CHEMBL1502711 & 737824 & 5.8 & 5.7577 & TRN \\
\hline CHEMBL1392359 & 737824 & 5.95 & 5.4932 & TRN \\
\hline CHEMBL1323488 & 737824 & 4.9 & 4.5386 & TRN \\
\hline CHEMBL1432327 & 737824 & 5.75 & 5.4646 & TRN \\
\hline CHEMBL1490045 & 737824 & 5.1 & 5.5348 & TST \\
\hline CHEMBL1742096 & 737824 & 5.6 & 5.0793 & TRN \\
\hline CHEMBL1466281 & 737824 & 5.45 & 4.6777 & TRN \\
\hline CHEMBL1388133 & 737824 & 4.85 & 4.9864 & TRN \\
\hline
\end{tabular}




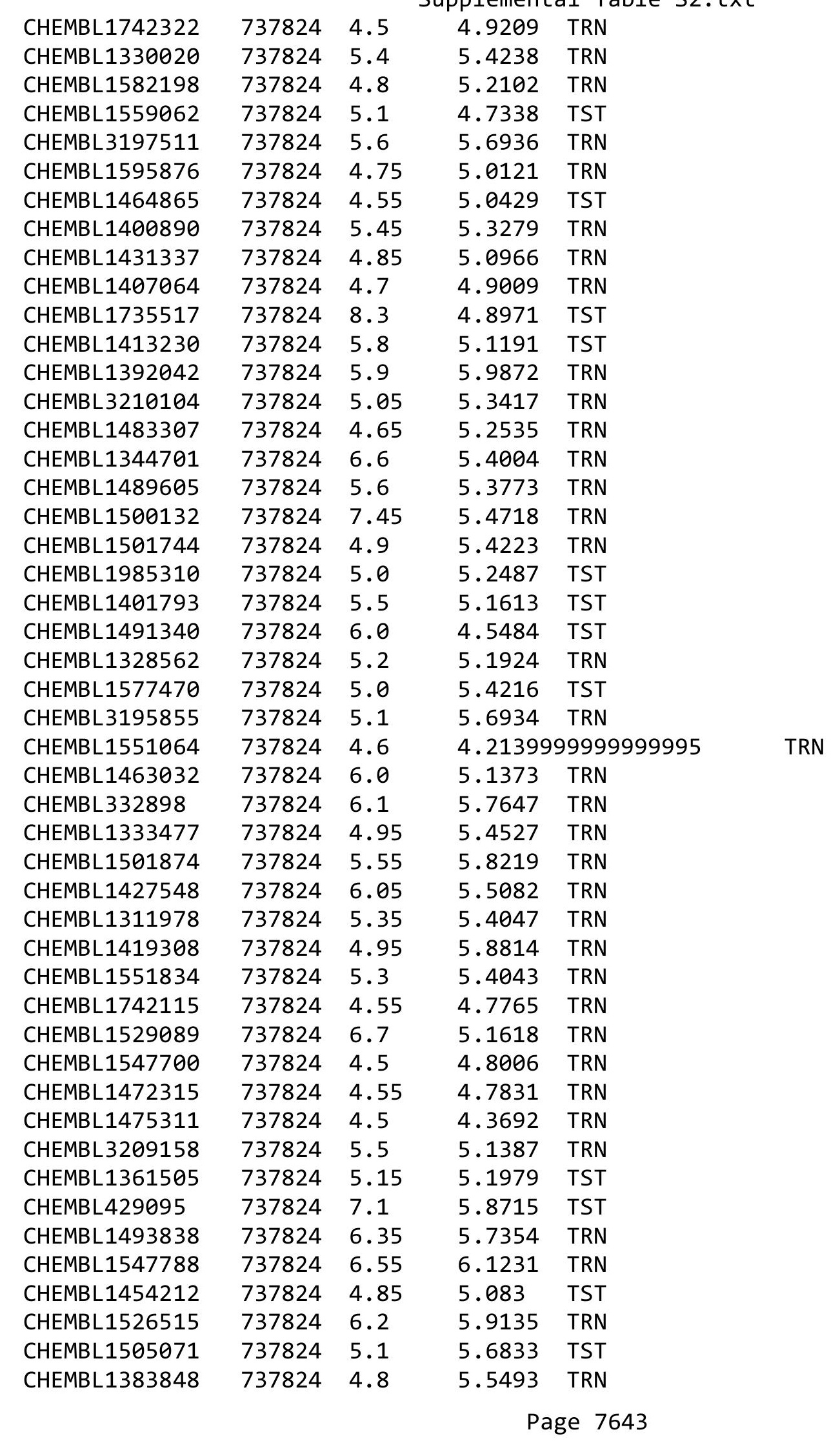




\begin{tabular}{|c|c|c|c|c|}
\hline \multicolumn{5}{|c|}{ Supplemental Table S2.txt } \\
\hline CHEMBL1380806 & 737824 & 4.8 & 5.1377 & TRN \\
\hline CHEMBL1350071 & 737824 & 5.65 & 5.2718 & TRN \\
\hline CHEMBL1590919 & 737824 & 4.8 & 4.9473 & TRN \\
\hline CHEMBL1450860 & 737824 & 7.7001 & 6.3613 & TRN \\
\hline CHEMBL1396142 & 737824 & 4.4 & 4.1001 & TRN \\
\hline CHEMBL1982520 & 737824 & 5.35 & 5.4511 & TST \\
\hline CHEMBL1358197 & 737824 & 4.8 & 4.9787 & TRN \\
\hline CHEMBL501701 & 737824 & 5.3 & 4.9108 & TST \\
\hline CHEMBL1328533 & 737824 & 5.0 & 5.2525 & TRN \\
\hline CHEMBL1406437 & 737824 & 6.1 & 5.234 & TRN \\
\hline CHEMBL1365779 & 737824 & 4.9 & 4.916 & TRN \\
\hline CHEMBL1501813 & 737824 & 5.15 & 5.1879 & TRN \\
\hline CHEMBL3211462 & 737824 & 4.85 & 5.2336 & TST \\
\hline CHEMBL1561791 & 737824 & 5.6 & 5.2103 & TRN \\
\hline CHEMBL1432306 & 737824 & 5.55 & 5.3283 & TRN \\
\hline CHEMBL3196565 & 737824 & 6.1 & 5.6969 & TRN \\
\hline CHEMBL1463060 & 737824 & 4.6 & 5.1938 & TRN \\
\hline CHEMBL3210522 & 737824 & 4.6 & 5.0305 & TST \\
\hline CHEMBL1405758 & 737824 & 5.0 & 5.3367 & TRN \\
\hline CHEMBL1531607 & 737824 & 5.7 & 5.2874 & TRN \\
\hline CHEMBL1468406 & 737824 & 4.55 & 4.9591 & TRN \\
\hline CHEMBL1577007 & 737824 & 5.35 & 5.1959 & TRN \\
\hline CHEMBL1406631 & 737824 & 4.8 & 5.1937 & TRN \\
\hline CHEMBL3195528 & 737824 & 5.95 & 5.5911 & TRN \\
\hline CHEMBL3195443 & 737824 & 5.65 & 5.0428 & TRN \\
\hline CHEMBL1435077 & 737824 & 4.9 & 5.1708 & TRN \\
\hline CHEMBL474415 & 737824 & 4.8 & 4.7241 & TRN \\
\hline CHEMBL1336532 & 737824 & 6.2 & 5.3832 & TST \\
\hline CHEMBL1326322 & 737824 & 4.7 & 4.7954 & TRN \\
\hline CHEMBL1372528 & 737824 & 4.95 & 5.3062 & TRN \\
\hline CHEMBL1479372 & 737824 & 5.6 & 5.4327 & TRN \\
\hline CHEMBL1397833 & 737824 & 5.2 & 5.6021 & TST \\
\hline CHEMBL3192742 & 737824 & 6.2 & 6.1201 & TRN \\
\hline CHEMBL1466883 & 737824 & 4.65 & 4.9707 & TRN \\
\hline CHEMBL1340104 & 737824 & 5.1 & 5.3643 & TST \\
\hline CHEMBL1333615 & 737824 & 4.6 & 4.905 & TRN \\
\hline CHEMBL1528376 & 737824 & 4.55 & 4.8611 & TRN \\
\hline CHEMBL1371127 & 737824 & 5.9 & 5.5944 & TST \\
\hline CHEMBL1548421 & 737824 & 4.4 & 4.5337 & TRN \\
\hline CHEMBL1538039 & 737824 & 6.4 & 5.3576 & TRN \\
\hline CHEMBL1491288 & 737824 & 5.5 & 5.3731 & TRN \\
\hline CHEMBL1355256 & 737824 & 5.4 & 5.3489 & TRN \\
\hline CHEMBL1256243 & 737824 & 4.5 & 4.3702 & TST \\
\hline CHEMBL565856 & 737824 & 5.3 & 5.3358 & TRN \\
\hline CHEMBL1741419 & 737824 & 4.55 & 5.3181 & TST \\
\hline CHEMBL1390207 & 737824 & 4.95 & 4.9276 & TRN \\
\hline CHEMBL1469557 & 737824 & 5.4 & 5.3953 & TRN \\
\hline CHEMBL1538789 & 737824 & 5.2 & 5.6082 & TRN \\
\hline
\end{tabular}




\begin{tabular}{|c|c|c|c|c|}
\hline & & & pplement & al $\mathrm{Ta}$ \\
\hline CHEMBL1318228 & 737824 & 4.6 & 4.6177 & TRN \\
\hline CHEMBL1395241 & 737824 & 5.1 & 4.5742 & TRN \\
\hline CHEMBL1587518 & 737824 & 5.3 & 5.6977 & TST \\
\hline CHEMBL1359379 & 737824 & 4.9 & 5.1226 & TRN \\
\hline CHEMBL1540401 & 737824 & 5.45 & 5.3857 & TST \\
\hline CHEMBL1415569 & 737824 & 4.8 & 4.5826 & TRN \\
\hline CHEMBL1398319 & 737824 & 5.4 & 4.7359 & TST \\
\hline CHEMBL1530523 & 737824 & 4.95 & 4.9649 & TRN \\
\hline CHEMBL428814 & 737824 & 5.0 & 5.2909 & TRN \\
\hline CHEMBL1341400 & 737824 & 5.3 & 5.4308 & TRN \\
\hline CHEMBL1594372 & 737824 & 6.9 & 6.2425 & TRN \\
\hline CHEMBL1446854 & 737824 & 5.3 & 4.7263 & TRN \\
\hline CHEMBL1431119 & 737824 & 5.7 & 4.9712 & TRN \\
\hline CHEMBL1518362 & 737824 & 5.2 & 5.3407 & TRN \\
\hline CHEMBL1585731 & 737824 & 4.5 & 5.2807 & TRN \\
\hline CHEMBL1400637 & 737824 & -0.0 & 4.3077 & TRN \\
\hline CHEMBL1438458 & 737824 & 5.5 & 5.0722 & TRN \\
\hline CHEMBL1445737 & 737824 & 5.65 & 5.6434 & TST \\
\hline CHEMBL1542230 & 737824 & 4.9 & 5.0698 & TRN \\
\hline CHEMBL1332781 & 737824 & 5.6 & 5.2878 & TST \\
\hline CHEMBL3195732 & 737824 & 4.55 & 4.9969 & TRN \\
\hline CHEMBL1518719 & 737824 & 6.55 & 4.8877 & TST \\
\hline CHEMBL1594883 & 737824 & 6.95 & 5.9627 & TRN \\
\hline CHEMBL1370255 & 737824 & 4.85 & 4.6907 & TRN \\
\hline CHEMBL1483672 & 737824 & 5.4 & 5.6728 & TRN \\
\hline CHEMBL1304405 & 737824 & 4.95 & 5.2162 & TRN \\
\hline CHEMBL1324528 & 737824 & 5.55 & 5.6723 & TRN \\
\hline CHEMBL1318400 & 737824 & 6.0 & 6.0021 & TRN \\
\hline CHEMBL1382296 & 737824 & 6.65 & 5.3461 & TST \\
\hline CHEMBL1437011 & 737824 & 4.5 & 4.6225 & TRN \\
\hline CHEMBL3193687 & 737824 & 4.8 & 5.1799 & TRN \\
\hline CHEMBL1502425 & 737824 & 4.85 & 5.2336 & TRN \\
\hline CHEMBL1547685 & 737824 & 5.2 & 5.1557 & TRN \\
\hline CHEMBL1342069 & 737824 & 5.4 & 5.5913 & TST \\
\hline CHEMBL1612050 & 737824 & 7.3 & 7.1224 & TRN \\
\hline CHEMBL1403448 & 737824 & 5.7 & 5.0295 & TRN \\
\hline CHEMBL1422591 & 737824 & 5.35 & 5.6247 & TRN \\
\hline CHEMBL1443086 & 737824 & 4.7 & 4.9606 & TRN \\
\hline CHEMBL1524520 & 737824 & 6.6 & 6.4058 & TRN \\
\hline CHEMBL1399058 & 737824 & 5.3 & 5.5568 & TRN \\
\hline CHEMBL1358276 & 737824 & 4.8 & 4.434 & TRN \\
\hline CHEMBL1604063 & 737824 & 5.4 & 5.2386 & TST \\
\hline CHEMBL1362249 & 737824 & 4.85 & 5.0654 & TST \\
\hline CHEMBL1419618 & 737824 & 4.9 & 5.0286 & TRN \\
\hline CHEMBL271165 & 737824 & 6.4 & 6.218 & TST \\
\hline CHEMBL1516477 & 737824 & 5.1 & 4.8954 & TST \\
\hline CHEMBL1417341 & 737824 & 4.75 & 5.3384 & TRN \\
\hline CHEMBL1360821 & 737824 & 4.4 & 4.7515 & TRN \\
\hline
\end{tabular}




\begin{tabular}{|c|c|c|c|c|}
\hline \multicolumn{5}{|c|}{ Supplemental Table S2.txt } \\
\hline CHEMBL1569975 & 737824 & 5.1 & 4.9675 & TRN \\
\hline CHEMBL1970734 & 737824 & 6.45 & 5.7582 & TRN \\
\hline CHEMBL1374334 & 737824 & 6.1 & 5.7138 & TST \\
\hline CHEMBL1494802 & 737824 & 5.65 & 5.0714 & TRN \\
\hline CHEMBL1360622 & 737824 & 5.2 & 5.4824 & TRN \\
\hline CHEMBL1568643 & 737824 & 5.35 & 5.2071 & TST \\
\hline CHEMBL1378208 & 737824 & 4.8 & 4.9937 & TRN \\
\hline CHEMBL1557784 & 737824 & 4.55 & 5.1738 & TST \\
\hline CHEMBL1602002 & 737824 & 5.75 & 5.0383 & TRN \\
\hline CHEMBL1483978 & 737824 & 5.05 & 5.0774 & TRN \\
\hline CHEMBL1371655 & 737824 & 4.85 & 4.8342 & TRN \\
\hline CHEMBL1387625 & 737824 & 4.95 & 5.0768 & TRN \\
\hline CHEMBL1317066 & 737824 & 5.0 & 4.8878 & TRN \\
\hline CHEMBL1595282 & 737824 & 5.5 & 5.1563 & TRN \\
\hline CHEMBL1480840 & 737824 & 5.05 & 5.2911 & TRN \\
\hline CHEMBL1722621 & 737824 & 5.25 & 5.3684 & TRN \\
\hline CHEMBL1499919 & 737824 & 5.7 & 5.1383 & TRN \\
\hline CHEMBL1316749 & 737824 & 5.9 & 5.9672 & TRN \\
\hline CHEMBL1583568 & 737824 & 5.35 & 5.244 & TRN \\
\hline CHEMBL1488084 & 737824 & 5.1 & 5.403 & TRN \\
\hline CHEMBL1501148 & 737824 & 5.15 & 5.0475 & TRN \\
\hline CHEMBL1256392 & 737824 & 8.6 & 8.3489 & TRN \\
\hline CHEMBL1358807 & 737824 & 4.8 & 4.8738 & TRN \\
\hline CHEMBL1599163 & 737824 & 4.9 & 5.1385 & TRN \\
\hline CHEMBL1340186 & 737824 & 5.55 & 5.7739 & TRN \\
\hline CHEMBL1503191 & 737824 & 5.1 & 5.3313 & TRN \\
\hline CHEMBL1453244 & 737824 & 4.8 & 5.1282 & TRN \\
\hline CHEMBL1530269 & 737824 & 4.65 & 5.1451 & TST \\
\hline CHEMBL1461862 & 737824 & 4.85 & 4.7197 & TRN \\
\hline CHEMBL1421523 & 737824 & 6.25 & 5.2664 & TST \\
\hline CHEMBL3211592 & 737824 & 5.7 & 5.3363 & TRN \\
\hline CHEMBL1492056 & 737824 & 5.15 & 5.0754 & TRN \\
\hline CHEMBL1419811 & 737824 & 5.1 & 5.3244 & TST \\
\hline CHEMBL1475924 & 737824 & 4.4 & 4.3957 & TRN \\
\hline CHEMBL1483257 & 737824 & 4.6 & 4.9924 & TRN \\
\hline CHEMBL1358122 & 737824 & 5.3 & 5.8821 & TRN \\
\hline CHEMBL1545534 & 737824 & 5.05 & 5.4111 & TST \\
\hline CHEMBL1602490 & 737824 & 4.65 & 4.8718 & TRN \\
\hline CHEMBL1335233 & 737824 & 4.9 & 4.7845 & TRN \\
\hline CHEMBL1458493 & 737824 & 4.9 & 4.9859 & TRN \\
\hline CHEMBL1270410 & 737824 & 5.5 & 5.8906 & TRN \\
\hline CHEMBL1433783 & 737824 & 4.9 & 4.6527 & TRN \\
\hline CHEMBL1505390 & 737824 & 5.65 & 5.4303 & TRN \\
\hline CHEMBL1333556 & 737824 & 5.1 & 5.0898 & TST \\
\hline CHEMBL1523363 & 737824 & 6.3 & 5.5287 & TRN \\
\hline CHEMBL1741780 & 737824 & 4.95 & 5.0086 & TRN \\
\hline CHEMBL1372371 & 737824 & 5.5 & 5.1789 & TRN \\
\hline CHEMBL1442380 & 737824 & 6.0 & 5.5312 & TRN \\
\hline
\end{tabular}




\begin{tabular}{|c|c|c|c|c|c|}
\hline & & & & & \\
\hline CHEMBL1322136 & 737824 & 5.2 & 5.6191 & TRN & \\
\hline CHEMBL 279556 & 737824 & 5.1 & 5.0345 & TST & \\
\hline CHEMBL3194238 & 737824 & 5.0 & 4.7951 & TRN & \\
\hline CHEMBL1452961 & 737824 & 5.7 & 5.1922 & TRN & \\
\hline CHEMBL1604172 & 737824 & 4.9 & 5.3368 & TST & \\
\hline CHEMBL1451119 & 737824 & 5.6 & 5.3033 & TRN & \\
\hline CHEMBL1964464 & 737824 & 5.3 & 5.2505 & TRN & \\
\hline CHEMBL1362562 & 737824 & 5.5 & 5.7224 & TRN & \\
\hline CHEMBL1301722 & 737824 & 4.9 & 4.9485 & TST & \\
\hline CHEMBL1466372 & 737824 & 4.9 & 4.9896 & TST & \\
\hline CHEMBL1549118 & 737824 & 5.1 & 5.4761 & TRN & \\
\hline CHEMBL1435381 & 737824 & 4.4 & 3.7055 & TST & \\
\hline CHEMBL1496611 & 737824 & 5.4 & 5.2663 & TRN & \\
\hline CHEMBL1393776 & 737824 & 4.55 & 5.32100 & $\partial 000000001$ & TST \\
\hline CHEMBL1608975 & 737824 & 4.9 & 4.7534 & TRN & \\
\hline CHEMBL3209485 & 737824 & 4.75 & 5.0179 & TRN & \\
\hline CHEMBL1373772 & 737824 & 4.55 & 5.1121 & TRN & \\
\hline CHEMBL1490528 & 737824 & 4.6 & 4.385 & TRN & \\
\hline CHEMBL1568555 & 737824 & 5.5 & 5.7004 & TST & \\
\hline CHEMBL1545407 & 737824 & 5.8 & 5.51399 & 9999999999 & TRN \\
\hline CHEMBL1483625 & 737824 & 4.7 & 4.9706 & TRN & \\
\hline CHEMBL1532466 & 737824 & 4.5 & 4.8524 & TRN & \\
\hline CHEMBL1501500 & 737824 & 5.25 & 5.2621 & TRN & \\
\hline CHEMBL1399291 & 737824 & 5.3 & 5.7147 & TRN & \\
\hline CHEMBL1336082 & 737824 & 5.65 & 5.5678 & TRN & \\
\hline CHEMBL1595363 & 737824 & 5.45 & 5.0443 & TRN & \\
\hline CHEMBL1425063 & 737824 & 5.8 & 5.1377 & TST & \\
\hline CHEMBL1352133 & 737824 & 4.65 & 5.3123 & TRN & \\
\hline CHEMBL1728908 & 737824 & 4.75 & 5.199 & TRN & \\
\hline CHEMBL 3208267 & 737824 & 4.9 & 5.4761 & TRN & \\
\hline CHEMBL1533413 & 737824 & 5.4 & 4.6731 & TST & \\
\hline CHEMBL1514923 & 737824 & 4.8 & 4.5843 & TRN & \\
\hline CHEMBL1481029 & 737824 & 5.5 & 5.6898 & TRN & \\
\hline CHEMBL 278041 & 737824 & 5.0 & 5.7372 & TRN & \\
\hline CHEMBL1338430 & 737824 & 5.0 & 5.0532 & TST & \\
\hline CHEMBL1558934 & 737824 & 5.5 & 5.2833 & TRN & \\
\hline CHEMBL1322137 & 737824 & 5.4 & 5.3724 & TRN & \\
\hline CHEMBL1490108 & 737824 & 4.65 & 4.6354 & TRN & \\
\hline CHEMBL1431724 & 737824 & 5.35 & 5.9695 & TRN & \\
\hline CHEMBL1718423 & 737824 & 5.8 & 5.5447 & TRN & \\
\hline CHEMBL1383364 & 737824 & 4.6 & 5.1365 & TRN & \\
\hline CHEMBL1482437 & 737824 & 4.45 & 4.6635 & TRN & \\
\hline CHEMBL1390028 & 737824 & 5.55 & 5.6874 & TRN & \\
\hline CHEMBL1317010 & 737824 & 5.9 & 6.4015 & TRN & \\
\hline CHEMBL1580610 & 737824 & 5.05 & 4.8978 & TST & \\
\hline CHEMBL1510192 & 737824 & 6.5 & 6.0394 & TRN & \\
\hline CHEMBL1435947 & 737824 & 4.9 & 4.8059 & TRN & \\
\hline CHEMBL1449082 & 737824 & 4.4 & 4.2792 & TRN & \\
\hline
\end{tabular}




\begin{tabular}{|c|c|c|c|c|c|}
\hline \multicolumn{6}{|c|}{ Supplemental Table S2.txt } \\
\hline CHEMBL1337713 & 737824 & 5.1 & 5.0523 & TRN & \\
\hline CHEMBL1408904 & 737824 & 4.85 & 5.2829 & TRN & \\
\hline CHEMBL1376143 & 737824 & 4.4 & 4.4515 & TRN & \\
\hline CHEMBL1361226 & 737824 & 8.2 & 7.6031 & TRN & \\
\hline CHEMBL1515287 & 737824 & 5.0 & 4.5925 & TRN & \\
\hline CHEMBL1361000 & 737824 & 5.4 & 5.002 & TST & \\
\hline CHEMBL1308450 & 737824 & 4.85 & 5.3249 & TRN & \\
\hline CHEMBL1374931 & 737824 & 5.15 & 5.0343 & TRN & \\
\hline CHEMBL1586937 & 737824 & 4.4 & 5.4362 & TRN & \\
\hline CHEMBL1326753 & 737824 & 5.0 & 4.8564 & TRN & \\
\hline CHEMBL1347829 & 737824 & 5.35 & 5.3701 & TRN & \\
\hline CHEMBL1439144 & 737824 & 4.85 & 4.6678 & TST & \\
\hline CHEMBL3189237 & 737824 & 4.7 & 5.1057 & TST & \\
\hline CHEMBL1365082 & 737824 & 5.8 & 5.62700 & 0000000001 & TST \\
\hline CHEMBL3193903 & 737824 & 4.65 & 4.94 & TRN & \\
\hline CHEMBL1421334 & 737824 & 4.8 & 5.0217 & TST & \\
\hline CHEMBL1332143 & 737824 & 5.1 & 5.5827 & TST & \\
\hline CHEMBL1606727 & 737824 & 5.1 & 5.3553 & TRN & \\
\hline CHEMBL1566244 & 737824 & 4.95 & 5.1604 & TRN & \\
\hline CHEMBL1312422 & 737824 & 4.85 & 5.3195 & TRN & \\
\hline CHEMBL1515540 & 737824 & 4.7 & 4.5904 & TRN & \\
\hline CHEMBL1741463 & 737824 & 4.9 & 5.776 & TRN & \\
\hline CHEMBL1335471 & 737824 & 4.4 & 4.0051 & TST & \\
\hline CHEMBL1364243 & 737824 & 6.0 & 5.9812 & TRN & \\
\hline CHEMBL1442506 & 737824 & 5.4 & 5.046 & TRN & \\
\hline CHEMBL1424256 & 737824 & 5.35 & 5.2796 & TRN & \\
\hline CHEMBL1330299 & 737824 & 7.6499 & 7.0751 & TRN & \\
\hline CHEMBL1379839 & 737824 & 4.7 & 4.8652 & TRN & \\
\hline CHEMBL1452827 & 737824 & 5.45 & 5.6077 & TRN & \\
\hline CHEMBL1525975 & 737824 & 4.85 & 4.8962 & TST & \\
\hline CHEMBL 3213748 & 737824 & 5.2 & 5.9727 & TRN & \\
\hline CHEMBL1407910 & 737824 & 6.65 & 6.3176 & TRN & \\
\hline CHEMBL1464193 & 737824 & 5.55 & 5.3651 & TST & \\
\hline CHEMBL286615 & 737824 & 4.6 & 4.4115 & TRN & \\
\hline CHEMBL1570881 & 737824 & 5.05 & 5.2156 & TRN & \\
\hline CHEMBL1317344 & 737824 & 5.3 & 5.4148 & TRN & \\
\hline CHEMBL1742187 & 737824 & 5.15 & 4.997 & TRN & \\
\hline CHEMBL1344743 & 737824 & 5.35 & 5.145 & TRN & \\
\hline CHEMBL1527813 & 737824 & 4.8 & 4.8586 & TRN & \\
\hline CHEMBL447507 & 737824 & 6.1 & 6.1398 & TRN & \\
\hline CHEMBL1559538 & 737824 & 5.45 & 5.4207 & TRN & \\
\hline CHEMBL1456931 & 737824 & 6.4 & 5.9365 & TRN & \\
\hline CHEMBL1469742 & 737824 & 4.9 & 4.6096 & TRN & \\
\hline CHEMBL1546137 & 737824 & 5.05 & 5.1826 & TRN & \\
\hline CHEMBL1571749 & 737824 & 4.8 & 5.2564 & TRN & \\
\hline CHEMBL1726083 & 737824 & 4.9 & 5.3139 & TRN & \\
\hline CHEMBL1732228 & 737824 & 5.8 & 5.5275 & TRN & \\
\hline CHEMBL1369642 & 737824 & 4.9 & 5.0604 & TRN & \\
\hline
\end{tabular}




\begin{tabular}{|c|c|c|c|c|c|}
\hline \multicolumn{6}{|c|}{ p temer } \\
\hline CHEMBL1441066 & 737824 & 5.5 & 5.2351 & TST & \\
\hline CHEMBL1430994 & 737824 & 6.25 & 5.2708 & TRN & \\
\hline CHEMBL1333002 & 737824 & 5.35 & 5.1522 & TRN & \\
\hline CHEMBL1332630 & 737824 & 5.5 & 5.2901 & TRN & \\
\hline CHEMBL1353420 & 737824 & 5.05 & 5.4317 & TRN & \\
\hline CHEMBL1741766 & 737824 & 4.4 & 4.9511 & TRN & \\
\hline CHEMBL1371337 & 737824 & 5.35 & 5.1645 & TST & \\
\hline CHEMBL395446 & 737824 & 4.9 & 5.1059 & TRN & \\
\hline CHEMBL3207808 & 737824 & 5.7 & 5.7278 & TRN & \\
\hline CHEMBL1314799 & 737824 & 5.3 & 5.4928 & TRN & \\
\hline CHEMBL1409299 & 737824 & 5.05 & 4.752 & TRN & \\
\hline CHEMBL1461234 & 737824 & 4.85 & 4.8694 & TRN & \\
\hline CHEMBL1518560 & 737824 & 4.85 & 4.8016 & TRN & \\
\hline CHEMBL1404295 & 737824 & 5.35 & 5.2492 & TRN & \\
\hline CHEMBL1501275 & 737824 & 5.75 & 5.6227 & TRN & \\
\hline CHEMBL1434747 & 737824 & 5.0 & 4.7708 & TRN & \\
\hline CHEMBL1965559 & 737824 & 5.7 & 5.2135 & TRN & \\
\hline CHEMBL1566684 & 737824 & 5.0 & 5.6305 & TST & \\
\hline CHEMBL1336557 & 737824 & 6.0 & 5.4737 & TRN & \\
\hline CHEMBL1459871 & 737824 & 4.4 & 4.8629 & TRN & \\
\hline CHEMBL1378710 & 737824 & 5.2 & 5.32600 & 00000000005 & TST \\
\hline CHEMBL1506693 & 737824 & 5.35 & 5.5961 & TRN & \\
\hline CHEMBL1505957 & 737824 & 6.15 & 5.8519 & TRN & \\
\hline CHEMBL1555862 & 737824 & 5.65 & 5.2251 & TRN & \\
\hline CHEMBL1384353 & 737824 & 6.0 & 5.5376 & TRN & \\
\hline CHEMBL1308605 & 737824 & 5.3 & 5.3408 & TRN & \\
\hline CHEMBL1586621 & 737824 & 5.45 & 5.3346 & TRN & \\
\hline CHEMBL1332471 & 737824 & 4.8 & 4.768 & TRN & \\
\hline CHEMBL1313335 & 737824 & 5.2 & 6.0868 & TRN & \\
\hline CHEMBL1521909 & 737824 & 5.8 & 5.27 & TRN & \\
\hline CHEMBL1741471 & 737824 & 5.3 & 5.0124 & TRN & \\
\hline CHEMBL1437259 & 737824 & 5.0 & 4.8804 & TRN & \\
\hline CHEMBL1542131 & 737824 & 6.3 & 5.4765 & TRN & \\
\hline CHEMBL1374614 & 737824 & 4.9 & 5.0401 & TRN & \\
\hline CHEMBL1450942 & 737824 & 5.05 & 5.1492 & TRN & \\
\hline CHEMBL1333742 & 737824 & 5.9 & 5.7198 & TRN & \\
\hline CHEMBL1415759 & 737824 & 5.85 & 5.1465 & TRN & \\
\hline CHEMBL1441572 & 737824 & 5.5 & 5.1622 & TRN & \\
\hline CHEMBL1309646 & 737824 & 5.05 & 4.8306 & TRN & \\
\hline CHEMBL1407530 & 737824 & 5.25 & 4.9105 & TRN & \\
\hline CHEMBL311226 & 737824 & 4.4 & 4.0413 & TST & \\
\hline CHEMBL1734210 & 737824 & 4.8 & 5.2766 & TRN & \\
\hline CHEMBL1359917 & 737824 & 5.5 & 5.6168 & TRN & \\
\hline CHEMBL105739 & 737824 & 5.1 & 5.4309 & TST & \\
\hline CHEMBL1335761 & 737824 & 4.4 & 5.2519 & TST & \\
\hline CHEMBL1497138 & 737824 & 5.6 & 5.112 & TRN & \\
\hline CHEMBL1301385 & 737824 & 5.45 & 5.4831 & TRN & \\
\hline CHEMBL1437713 & 737824 & 4.9 & 4.8045 & TRN & \\
\hline
\end{tabular}




\begin{tabular}{|c|c|c|c|c|c|}
\hline \\
\hline CHEMBL1232596 & 737824 & 5.0 & 5.3973 & TRN & \\
\hline CHEMBL3214519 & 737824 & 4.6 & 5.0813 & TST & \\
\hline CHEMBL1256916 & 737824 & 5.0 & 5.0017 & TRN & \\
\hline CHEMBL1542520 & 737824 & 5.85 & 5.0089 & TRN & \\
\hline CHEMBL1486716 & 737824 & 5.0 & 5.1343 & TRN & \\
\hline CHEMBL1453217 & 737824 & 5.15 & 5.5979 & TRN & \\
\hline CHEMBL1318056 & 737824 & 5.6 & 5.3044 & TRN & \\
\hline CHEMBL1570869 & 737824 & 5.5 & 5.0912 & TRN & \\
\hline CHEMBL1510347 & 737824 & 4.8 & 4.7335 & TST & \\
\hline CHEMBL1360026 & 737824 & 7.15 & 5.6749 & TRN & \\
\hline CHEMBL1337991 & 737824 & 6.15 & 5.7071 & TST & \\
\hline CHEMBL1460356 & 737824 & 4.55 & 5.1357 & TRN & \\
\hline CHEMBL1461660 & 737824 & 5.45 & 5.9039 & TRN & \\
\hline CHEMBL1511393 & 737824 & 6.35 & 5.1403 & TST & \\
\hline CHEMBL1489663 & 737824 & 5.5 & 5.4709 & TRN & \\
\hline CHEMBL45891 & 737824 & 7.6 & 6.2704 & TST & \\
\hline CHEMBL1360744 & 737824 & 5.05 & 5.2601 & TRN & \\
\hline CHEMBL1554637 & 737824 & 4.7 & 4.4113 & TRN & \\
\hline CHEMBL1472955 & 737824 & 5.3 & 5.2682 & TRN & \\
\hline CHEMBL1530805 & 737824 & 5.45 & 5.5838 & TRN & \\
\hline CHEMBL1366197 & 737824 & 4.95 & 4.7569 & TRN & \\
\hline CHEMBL137648 & 737824 & 5.1 & 4.6196 & TST & \\
\hline CHEMBL1582278 & 737824 & 5.8 & 5.3744 & TRN & \\
\hline CHEMBL98350 & 737824 & 5.0 & 4.7996 & TST & \\
\hline CHEMBL3208809 & 737824 & 4.7 & 5.1115 & TRN & \\
\hline CHEMBL1450241 & 737824 & 5.55 & 5.7094 & TRN & \\
\hline CHEMBL1400398 & 737824 & 6.7 & 5.4103 & TRN & \\
\hline CHEMBL1508906 & 737824 & 5.8 & 5.4999 & TRN & \\
\hline CHEMBL1424948 & 737824 & 4.85 & 5.1305 & TRN & \\
\hline CHEMBL1309312 & 737824 & 5.3 & 5.7567 & TRN & \\
\hline CHEMBL1507021 & 737824 & 5.0 & 5.0811 & TRN & \\
\hline CHEMBL1741986 & 737824 & 4.7 & 4.8479 & TRN & \\
\hline CHEMBL1312265 & 737824 & 5.3 & 5.2992 & TRN & \\
\hline CHEMBL 2003072 & 737824 & 5.2 & 5.46899 & 9999999999 & TRN \\
\hline CHEMBL1339267 & 737824 & 4.55 & 4.9946 & TRN & \\
\hline CHEMBL1601191 & 737824 & 4.4 & 4.8505 & TRN & \\
\hline CHEMBL1389838 & 737824 & 5.3 & 5.0901 & TRN & \\
\hline CHEMBL1350835 & 737824 & 5.5 & 5.1073 & TRN & \\
\hline CHEMBL476833 & 737824 & 5.1 & 4.6126 & TST & \\
\hline CHEMBL1335644 & 737824 & 5.55 & 5.5533 & TRN & \\
\hline CHEMBL1604261 & 737824 & 4.95 & 5.5159 & TST & \\
\hline CHEMBL546597 & 737824 & 5.15 & 5.1282 & TRN & \\
\hline CHEMBL1414577 & 737824 & 4.85 & 5.255 & TRN & \\
\hline CHEMBL429773 & 737824 & 4.8 & 5.1039 & TRN & \\
\hline CHEMBL1536509 & 737824 & 5.95 & 4.8416 & TST & \\
\hline CHEMBL1330569 & 737824 & 4.85 & 5.1963 & TST & \\
\hline CHEMBL1447758 & 737824 & 6.3 & 5.9645 & TST & \\
\hline CHEMBL1495886 & 737824 & 4.65 & 5.0882 & TST & \\
\hline
\end{tabular}




\begin{tabular}{|c|c|c|c|c|}
\hline \multicolumn{5}{|c|}{ lemental T } \\
\hline CHEMBL1444545 & 737824 & 5.1 & 5.4853 & TRN \\
\hline CHEMBL 8145 & 737824 & 5.0 & 4.5103 & TRN \\
\hline CHEMBL1302444 & 737824 & 4.9 & 4.8521 & TRN \\
\hline CHEMBL1323270 & 737824 & 4.4 & 4.5222 & TRN \\
\hline CHEMBL1381238 & 737824 & 5.6 & 5.5278 & TST \\
\hline CHEMBL1571995 & 737824 & 5.4 & 5.096 & TRN \\
\hline CHEMBL1570658 & 737824 & 6.65 & 6.2263 & TRN \\
\hline CHEMBL1741745 & 737824 & 5.45 & 5.4665 & TRN \\
\hline CHEMBL1507419 & 737824 & 4.55 & 4.8256 & TST \\
\hline CHEMBL1595703 & 737824 & 4.95 & 4.8763 & TRN \\
\hline CHEMBL1319691 & 737824 & 5.0 & 5.3313 & TRN \\
\hline CHEMBL1488179 & 737824 & 5.1 & 5.1289 & TRN \\
\hline CHEMBL1343012 & 737824 & 4.75 & 5.0877 & TRN \\
\hline CHEMBL1429370 & 737824 & 5.65 & 5.1215 & TRN \\
\hline CHEMBL1474317 & 737824 & 4.8 & 4.5858 & TRN \\
\hline CHEMBL1443898 & 737824 & 5.35 & 5.2816 & TST \\
\hline CHEMBL1473448 & 737824 & 5.0 & 4.2855 & TRN \\
\hline CHEMBL1256697 & 737824 & 4.6 & 4.6833 & TRN \\
\hline CHEMBL1542047 & 737824 & 5.95 & 5.4078 & TRN \\
\hline CHEMBL1588064 & 737824 & 4.9 & 4.8218 & TRN \\
\hline CHEMBL1401085 & 737824 & 5.3 & 5.4176 & TRN \\
\hline CHEMBL1368572 & 737824 & 5.8 & 5.6205 & TRN \\
\hline CHEMBL1565160 & 737824 & 6.1 & 5.6918 & TRN \\
\hline CHEMBL1255650 & 737824 & 4.4 & 4.3787 & TST \\
\hline CHEMBL1576417 & 737824 & 4.95 & 5.5483 & TRN \\
\hline CHEMBL1375098 & 737824 & 5.45 & 5.1267 & TRN \\
\hline CHEMBL1552194 & 737824 & 5.5 & 5.3891 & TRN \\
\hline CHEMBL1506402 & 737824 & 4.75 & 5.0047 & TRN \\
\hline CHEMBL1421353 & 737824 & 5.15 & 5.4729 & TRN \\
\hline CHEMBL1580242 & 737824 & 4.65 & 4.8906 & TRN \\
\hline CHEMBL1325353 & 737824 & 4.4 & 4.8059 & TRN \\
\hline CHEMBL1551981 & 737824 & 5.3 & 5.3299 & TRN \\
\hline CHEMBL1315318 & 737824 & 4.8 & 4.591 & TRN \\
\hline CHEMBL 243664 & 737824 & 6.0 & 5.6584 & TRN \\
\hline CHEMBL1442761 & 737824 & 4.65 & 5.4886 & TRN \\
\hline CHEMBL1460922 & 737824 & 5.15 & 5.4748 & TRN \\
\hline CHEMBL1452675 & 737824 & 4.4 & 5.2918 & TRN \\
\hline CHEMBL1373767 & 737824 & 4.7 & 4.453 & TRN \\
\hline CHEMBL1411049 & 737824 & 4.5 & 4.5188 & TRN \\
\hline CHEMBL1519178 & 737824 & 4.55 & 5.0623 & TRN \\
\hline CHEMBL1491710 & 737824 & 5.4 & 5.5878 & TST \\
\hline CHEMBL1571734 & 737824 & 4.8 & 5.1185 & TRN \\
\hline CHEMBL1609585 & 737824 & 5.05 & 4.8801 & TRN \\
\hline CHEMBL1462862 & 737824 & 5.8 & 5.7357 & TST \\
\hline CHEMBL1338094 & 737824 & 4.85 & 4.9563 & TRN \\
\hline CHEMBL1495971 & 737824 & 5.5 & 5.6177 & TRN \\
\hline CHEMBL1550593 & 737824 & 5.5 & 5.3859 & TRN \\
\hline CHEMBL1536129 & 737824 & 5.45 & 5.3406 & TRN \\
\hline
\end{tabular}




\begin{tabular}{|c|c|c|c|c|}
\hline \multicolumn{5}{|c|}{ Supplemental Table s2.txt } \\
\hline CHEMBL1358092 & 737824 & 5.5 & 5.3539 & TRN \\
\hline CHEMBL1583222 & 737824 & 4.95 & 4.9137 & TRN \\
\hline CHEMBL1507862 & 737824 & 5.6 & 5.5115 & TST \\
\hline CHEMBL1332726 & 737824 & 4.9 & 4.5079 & TST \\
\hline CHEMBL529675 & 737824 & 5.4 & 5.6523 & TST \\
\hline CHEMBL1607115 & 737824 & 5.4 & 5.8098 & TRN \\
\hline CHEMBL3207962 & 737824 & 5.7 & 4.9451 & TRN \\
\hline CHEMBL1404071 & 737824 & 5.9 & 5.6258 & TRN \\
\hline CHEMBL1564194 & 737824 & 4.7 & 4.7196 & TRN \\
\hline CHEMBL1552249 & 737824 & 6.0 & 5.4959 & TST \\
\hline CHEMBL1587133 & 737824 & 4.4 & 4.7976 & TRN \\
\hline CHEMBL1514804 & 737824 & 4.8 & 4.8034 & TRN \\
\hline CHEMBL257359 & 737824 & 5.0 & 4.9426 & TST \\
\hline CHEMBL1338571 & 737824 & 6.15 & 5.5906 & TRN \\
\hline CHEMBL1461795 & 737824 & 5.05 & 5.2017 & TRN \\
\hline CHEMBL1342476 & 737824 & 5.1 & 5.0626 & TRN \\
\hline CHEMBL1402435 & 737824 & 5.1 & 4.6375 & TST \\
\hline CHEMBL1473191 & 737824 & 5.2 & 5.2868 & TST \\
\hline CHEMBL1322527 & 737824 & 5.35 & 5.399 & TST \\
\hline CHEMBL1468283 & 737824 & 5.75 & 5.8188 & TRN \\
\hline CHEMBL1331118 & 737824 & 4.4 & 4.2397 & TRN \\
\hline CHEMBL1422113 & 737824 & 5.4 & 5.1697 & TRN \\
\hline CHEMBL1393682 & 737824 & 5.45 & 5.0435 & TST \\
\hline CHEMBL1504600 & 737824 & 5.6 & 5.4672 & TST \\
\hline CHEMBL1422120 & 737824 & 5.25 & 4.8299 & TRN \\
\hline CHEMBL1409809 & 737824 & 6.45 & 5.6022 & TRN \\
\hline CHEMBL1594149 & 737824 & 4.6 & 4.3848 & TST \\
\hline CHEMBL1415861 & 737824 & 5.5 & 5.3217 & TST \\
\hline CHEMBL1489353 & 737824 & 5.0 & 4.878 & TRN \\
\hline CHEMBL1527086 & 737824 & 6.0 & 5.346 & TRN \\
\hline CHEMBL1607888 & 737824 & 5.05 & 4.9347 & TST \\
\hline CHEMBL1357553 & 737824 & 4.9 & 4.8935 & TRN \\
\hline CHEMBL1351562 & 737824 & 5.85 & 5.4827 & TRN \\
\hline CHEMBL1437263 & 737824 & 4.7 & 4.4093 & TRN \\
\hline CHEMBL1459145 & 737824 & 6.1 & 5.4264 & TRN \\
\hline CHEMBL1528906 & 737824 & 5.55 & 5.4865 & TRN \\
\hline CHEMBL1360125 & 737824 & 4.95 & 5.4224 & TRN \\
\hline CHEMBL1506638 & 737824 & 6.55 & 6.5624 & TRN \\
\hline CHEMBL1438688 & 737824 & 5.0 & 4.7838 & TRN \\
\hline CHEMBL1487396 & 737824 & 5.05 & 5.2954 & TRN \\
\hline CHEMBL1548344 & 737824 & 4.65 & 5.7322 & TRN \\
\hline CHEMBL491909 & 737824 & 5.1 & 5.0606 & TRN \\
\hline CHEMBL1542385 & 737824 & 5.1 & 5.1128 & TRN \\
\hline CHEMBL1519980 & 737824 & 4.4 & 4.8135 & TRN \\
\hline CHEMBL1555567 & 737824 & 6.1 & 6.0201 & TRN \\
\hline CHEMBL 3214526 & 737824 & 4.6 & 5.1892 & TRN \\
\hline CHEMBL1591896 & 737824 & 6.5 & 6.3863 & TRN \\
\hline CHEMBL1549864 & 737824 & 5.7 & 5.0194 & TST \\
\hline
\end{tabular}




\begin{tabular}{|c|c|c|c|c|c|}
\hline & & & & & \\
\hline CHEMBL1523570 & 737824 & 5.3 & 5.0868 & TRN & \\
\hline CHEMBL1459170 & 737824 & 5.0 & 5.5166 & TRN & \\
\hline CHEMBL1438867 & 737824 & 5.7 & 5.4281 & TST & \\
\hline CHEMBL 235453 & 737824 & 5.0 & 5.29700 & 0000000001 & TRN \\
\hline CHEMBL1324981 & 737824 & 4.7 & 4.7922 & TRN & \\
\hline CHEMBL1346999 & 737824 & 4.55 & 5.3752 & TRN & \\
\hline CHEMBL1982203 & 737824 & 5.6 & 5.5044 & TRN & \\
\hline CHEMBL3191906 & 737824 & 4.9 & 5.1998 & TRN & \\
\hline CHEMBL1415488 & 737824 & 5.6 & 5.3855 & TRN & \\
\hline CHEMBL3198070 & 737824 & 4.9 & 4.9927 & TRN & \\
\hline CHEMBL1716417 & 737824 & 4.9 & 4.7722 & TRN & \\
\hline CHEMBL1472765 & 737824 & 4.7 & 4.7002 & TRN & \\
\hline CHEMBL1503135 & 737824 & 4.6 & 4.9773 & TRN & \\
\hline CHEMBL1480796 & 737824 & 6.45 & 5.1828 & TRN & \\
\hline CHEMBL1598462 & 737824 & 5.15 & 5.269 & TRN & \\
\hline CHEMBL1489980 & 737824 & 4.4 & 5.10800 & 00000000005 & TRN \\
\hline CHEMBL1481573 & 737824 & 5.15 & 5.2291 & TST & \\
\hline CHEMBL429023 & 737824 & 5.6 & 5.3924 & TST & \\
\hline CHEMBL1488335 & 737824 & 5.0 & 4.8554 & TRN & \\
\hline CHEMBL1574548 & 737824 & 5.7 & 5.3794 & TST & \\
\hline CHEMBL1531899 & 737824 & -0.0 & 4.4861 & TRN & \\
\hline CHEMBL1732802 & 737824 & 4.55 & 5.3421 & TRN & \\
\hline CHEMBL1560555 & 737824 & 4.85 & 5.1045 & TRN & \\
\hline CHEMBL3197859 & 737824 & 4.6 & 4.9105 & TST & \\
\hline CHEMBL3195166 & 737824 & 5.45 & 5.6101 & TRN & \\
\hline CHEMBL1557373 & 737824 & 5.3 & 5.5454 & TRN & \\
\hline CHEMBL1434111 & 737824 & 4.7 & 4.6134 & TRN & \\
\hline CHEMBL1523038 & 737824 & 5.05 & 5.3526 & TRN & \\
\hline CHEMBL1314388 & 737824 & 5.5 & 5.5165 & TRN & \\
\hline CHEMBL1321511 & 737824 & 5.5 & 5.5595 & TRN & \\
\hline CHEMBL1314453 & 737824 & 4.8 & 4.6854 & TRN & \\
\hline CHEMBL1352043 & 737824 & 5.0 & 4.8243 & TRN & \\
\hline CHEMBL1511286 & 737824 & 4.85 & 5.2176 & TRN & \\
\hline CHEMBL1439866 & 737824 & 7.2 & 6.5989 & TST & \\
\hline CHEMBL1741376 & 737824 & 6.6 & 5.166 & TST & \\
\hline CHEMBL1409938 & 737824 & 4.4 & 4.503 & TRN & \\
\hline CHEMBL1416272 & 737824 & 5.45 & 5.4608 & TRN & \\
\hline CHEMBL1454793 & 737824 & 5.1 & 5.3658 & TRN & \\
\hline CHEMBL1331489 & 737824 & 7.25 & 6.3412 & TRN & \\
\hline CHEMBL3193129 & 737824 & 4.7 & 5.5404 & TRN & \\
\hline CHEMBL1557564 & 737824 & 5.7 & 5.5459 & TRN & \\
\hline CHEMBL1723545 & 737824 & 4.4 & 5.0446 & TRN & \\
\hline CHEMBL1404209 & 737824 & 6.3 & 5.93 & TRN & \\
\hline CHEMBL1508362 & 737824 & 6.1 & 5.3084 & TRN & \\
\hline CHEMBL1600612 & 737824 & 4.9 & 5.0575 & TRN & \\
\hline CHEMBL1319275 & 737824 & 5.55 & 5.4648 & TRN & \\
\hline CHEMBL1389463 & 737824 & 4.7 & 4.8246 & TRN & \\
\hline CHEMBL1481347 & 737824 & 4.55 & 4.6675 & TST & \\
\hline & & & & e 7653 & \\
\hline
\end{tabular}




\begin{tabular}{|c|c|c|c|c|c|}
\hline \multirow{2}{*}{ CHEMBL1350243 } & \multirow{2}{*}{737824} & \\
\hline & & 5.1 & 5.1513 & TRN & \\
\hline CHEMBL1356138 & 737824 & 4.6 & 4.5445 & TRN & \\
\hline CHEMBL3198645 & 737824 & 4.9 & 5.1108 & TRN & \\
\hline CHEMBL1441353 & 737824 & 5.4 & 5.54200 & 2000000001 & TRN \\
\hline CHEMBL1322545 & 737824 & 4.8 & 4.3689 & TRN & \\
\hline CHEMBL1494771 & 737824 & 5.45 & 5.1317 & TST & \\
\hline CHEMBL148124 & 737824 & 7.8 & 5.4598 & TRN & \\
\hline CHEMBL1396595 & 737824 & 5.0 & 5.0886 & TRN & \\
\hline CHEMBL1441408 & 737824 & 4.8 & 4.9198 & TST & \\
\hline CHEMBL1378037 & 737824 & 5.0 & 5.04 & TST & \\
\hline CHEMBL1329026 & 737824 & 6.0 & 6.159 & TST & \\
\hline CHEMBL3209398 & 737824 & 5.65 & 5.32700 & 0000000001 & TRN \\
\hline CHEMBL1483700 & 737824 & 5.0 & 5.1006 & TRN & \\
\hline CHEMBL1484949 & 737824 & 4.95 & 5.7071 & TRN & \\
\hline CHEMBL1480880 & 737824 & 5.8 & 5.2431 & TST & \\
\hline CHEMBL1741628 & 737824 & 5.2 & 5.3055 & TRN & \\
\hline CHEMBL1456464 & 737824 & 5.6 & 5.4521 & TRN & \\
\hline CHEMBL106780 & 737824 & 4.6 & 5.0749 & TRN & \\
\hline CHEMBL1518570 & 737824 & 4.8 & 5.2745 & TRN & \\
\hline CHEMBL1363367 & 737824 & 6.0 & 5.9004 & TST & \\
\hline CHEMBL1371031 & 737824 & 5.0 & 5.1003 & TRN & \\
\hline CHEMBL1404456 & 737824 & 4.7 & 4.9736 & TRN & \\
\hline CHEMBL1336347 & 737824 & 5.5 & 4.9968 & TRN & \\
\hline CHEMBL1363376 & 737824 & 6.2 & 5.8746 & TRN & \\
\hline CHEMBL1395605 & 737824 & 4.5 & 4.2078 & TRN & \\
\hline CHEMBL1462826 & 737824 & 5.4 & 4.9982 & TST & \\
\hline CHEMBL1509337 & 737824 & 5.6 & 5.4064 & TRN & \\
\hline CHEMBL1490223 & 737824 & 5.05 & 4.9879 & TRN & \\
\hline CHEMBL1375428 & 737824 & 4.85 & 5.6312 & TRN & \\
\hline CHEMBL1430976 & 737824 & 4.7 & 5.1373 & TRN & \\
\hline CHEMBL1326308 & 737824 & 4.95 & 4.9032 & TRN & \\
\hline CHEMBL376103 & 737824 & 5.3 & 4.7757 & TRN & \\
\hline CHEMBL1576865 & 737824 & 5.65 & 4.9943 & TRN & \\
\hline CHEMBL1357759 & 737824 & 5.1 & 5.2826 & TRN & \\
\hline CHEMBL1437013 & 737824 & 5.3 & 5.3306 & TRN & \\
\hline CHEMBL1418522 & 737824 & 6.5 & 5.3772 & TST & \\
\hline CHEMBL1741802 & 737824 & 5.6 & 5.6449 & TRN & \\
\hline CHEMBL1466350 & 737824 & 4.4 & 5.1067 & TRN & \\
\hline CHEMBL1371572 & 737824 & 5.9 & 5.7852 & TRN & \\
\hline CHEMBL1482653 & 737824 & 6.45 & 5.2198 & TRN & \\
\hline CHEMBL1471962 & 737824 & 6.05 & 5.6608 & TRN & \\
\hline CHEMBL1305738 & 737824 & 4.65 & 5.3675 & TRN & \\
\hline CHEMBL1571883 & 737824 & 6.2 & 5.8216 & TRN & \\
\hline CHEMBL63426 & 737824 & 4.5 & 4.5414 & TST & \\
\hline CHEMBL1312774 & 737824 & 4.85 & 4.9108 & TRN & \\
\hline CHEMBL1741695 & 737824 & 5.7 & 5.0549 & TRN & \\
\hline CHEMBL1440108 & 737824 & 5.35 & 5.1017 & TRN & \\
\hline CHEMBL1589879 & 737824 & 5.9 & 6.1044 & TRN & \\
\hline
\end{tabular}




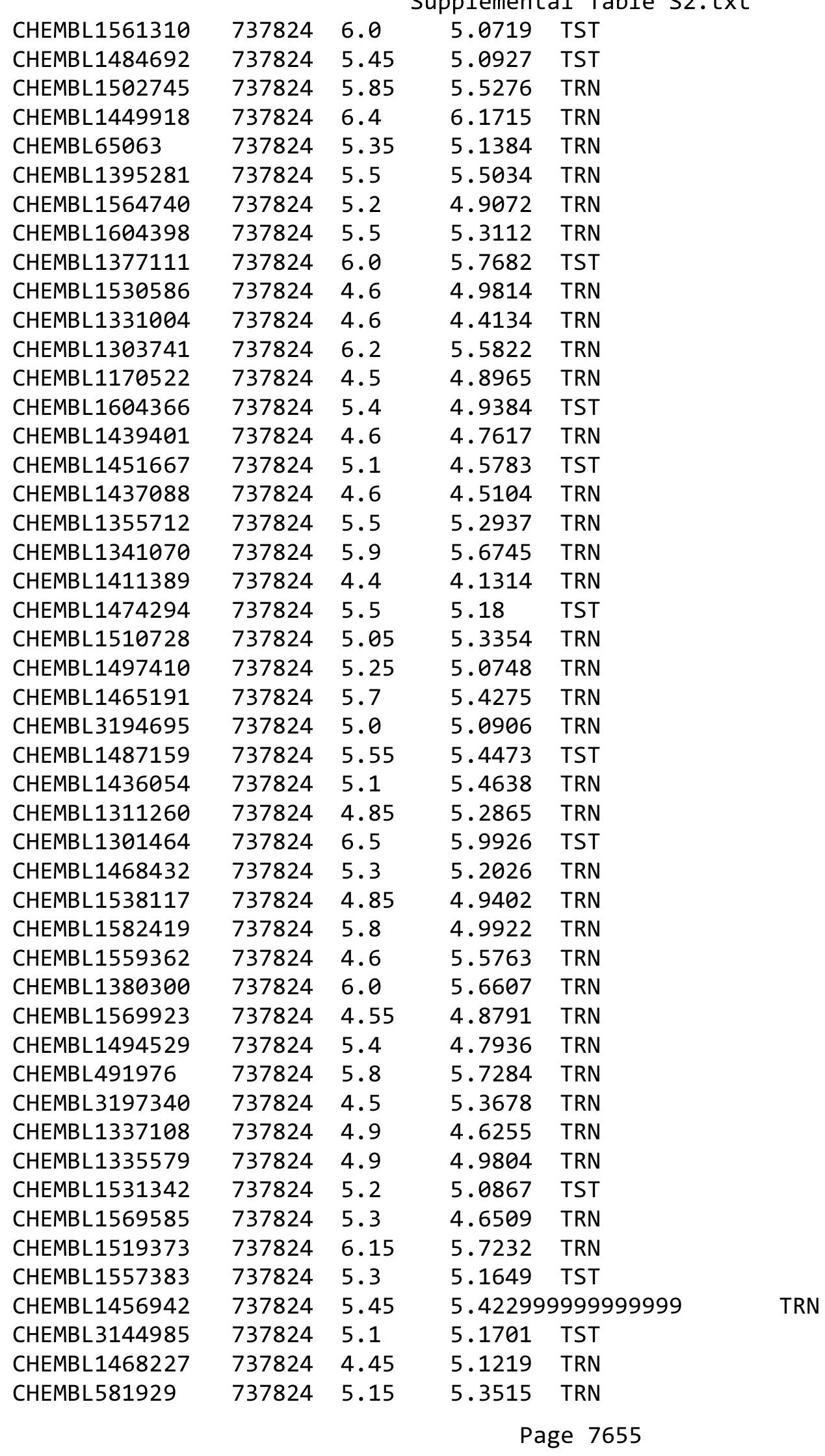




\begin{tabular}{|c|c|c|c|c|}
\hline & & & & \\
\hline CHEMBL1606337 & 737824 & 5.7 & 5.3622 & TST \\
\hline CHEMBL1605309 & 737824 & 4.6 & 5.2312 & TRN \\
\hline CHEMBL112816 & 737824 & 5.3 & 4.9148 & TRN \\
\hline CHEMBL1554158 & 737824 & 4.9 & 4.7638 & TRN \\
\hline CHEMBL1416476 & 737824 & 5.8 & 5.7412 & TRN \\
\hline CHEMBL1525822 & 737824 & 6.0 & 5.7704 & TRN \\
\hline CHEMBL1579482 & 737824 & 5.05 & 4.9195 & TRN \\
\hline CHEMBL1597107 & 737824 & 4.6 & 4.2689 & TRN \\
\hline CHEMBL1354941 & 737824 & 4.8 & 5.2988 & TRN \\
\hline CHEMBL1471612 & 737824 & 5.85 & 5.6071 & TRN \\
\hline CHEMBL1344032 & 737824 & 5.65 & 5.0899 & TRN \\
\hline CHEMBL1434643 & 737824 & 5.0 & 5.0032 & TRN \\
\hline CHEMBL1331026 & 737824 & 4.75 & 5.3731 & TRN \\
\hline CHEMBL1420680 & 737824 & 5.55 & 5.5369 & TRN \\
\hline CHEMBL1558777 & 737824 & 5.1 & 5.2716 & TRN \\
\hline CHEMBL1412564 & 737824 & 4.55 & 4.9116 & TRN \\
\hline CHEMBL1305256 & 737824 & 4.85 & 5.1502 & TRN \\
\hline CHEMBL1333410 & 737824 & 5.75 & 5.4086 & TRN \\
\hline CHEMBL1337691 & 737824 & 5.9 & 5.9921 & TRN \\
\hline CHEMBL10347 & 737824 & 6.0 & 5.862 & TRN \\
\hline CHEMBL1424763 & 737824 & 5.1 & 5.3428 & TRN \\
\hline CHEMBL1576783 & 737824 & 4.95 & 5.0129 & TRN \\
\hline CHEMBL1391209 & 737824 & 4.85 & 5.3548 & TRN \\
\hline CHEMBL1387431 & 737824 & 5.2 & 4.9097 & TRN \\
\hline CHEMBL1465487 & 737824 & 5.6 & 4.5939 & TRN \\
\hline CHEMBL1346685 & 737824 & 4.8 & 5.1208 & TRN \\
\hline CHEMBL1584092 & 737824 & 4.85 & 5.0266 & TRN \\
\hline CHEMBL1518462 & 737824 & 5.55 & 5.0263 & TRN \\
\hline CHEMBL1493707 & 737824 & 5.6 & 5.5728 & TRN \\
\hline CHEMBL1402493 & 737824 & 5.3 & 5.4008 & TRN \\
\hline CHEMBL1525465 & 737824 & 5.75 & 5.4499 & TRN \\
\hline CHEMBL1352887 & 737824 & 5.0 & 4.7573 & TRN \\
\hline CHEMBL1485991 & 737824 & 4.8 & 5.227 & TRN \\
\hline CHEMBL 282489 & 737824 & 4.8 & 4.9597 & TST \\
\hline CHEMBL1553070 & 737824 & 5.1 & 5.4679 & TRN \\
\hline CHEMBL1447410 & 737824 & 4.4 & 4.9273 & TRN \\
\hline CHEMBL1442537 & 737824 & 6.3 & 5.4177 & TRN \\
\hline CHEMBL1969457 & 737824 & 5.1 & 5.0458 & TRN \\
\hline CHEMBL1323759 & 737824 & 4.5 & 4.3153 & TRN \\
\hline CHEMBL1367387 & 737824 & 5.05 & 5.155 & TRN \\
\hline CHEMBL1581905 & 737824 & 5.0 & 4.9407 & TRN \\
\hline CHEMBL1598543 & 737824 & 5.35 & 5.205 & TRN \\
\hline CHEMBL1320141 & 737824 & 5.4 & 5.4451 & TRN \\
\hline CHEMBL1382253 & 737824 & 4.45 & 5.0843 & TRN \\
\hline CHEMBL1379079 & 737824 & 4.95 & 4.88399 & 99999999995 \\
\hline CHEMBL1392763 & 737824 & 4.95 & 5.2134 & TST \\
\hline CHEMBL1510298 & 737824 & 4.55 & 4.7639 & TRN \\
\hline \multirow[t]{2}{*}{ CHEMBL1308538 } & 737824 & 5.0 & 4.8419 & TRN \\
\hline & & & \multicolumn{2}{|c|}{ Page 7656} \\
\hline
\end{tabular}




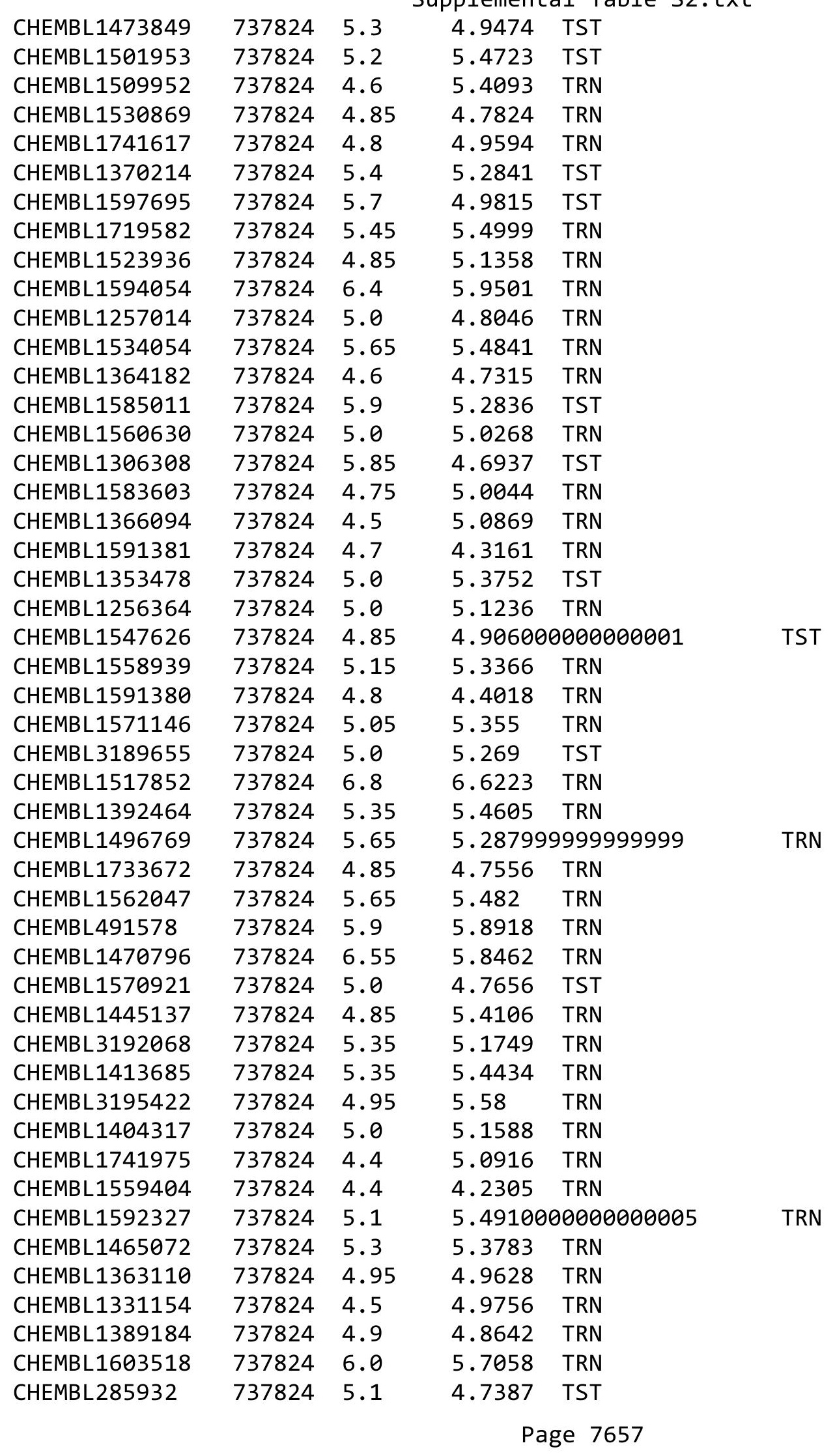




\begin{tabular}{|c|c|c|c|c|}
\hline & & & pplement & $\mathrm{a} \perp \mathrm{Ta}$ \\
\hline CHEMBL1445399 & 737824 & 5.0 & 4.5106 & TST \\
\hline CHEMBL1406851 & 737824 & 5.3 & 5.1295 & TRN \\
\hline CHEMBL1591368 & 737824 & 5.3 & 5.3752 & TRN \\
\hline CHEMBL1335052 & 737824 & 6.25 & 5.2349 & TRN \\
\hline CHEMBL1303855 & 737824 & 4.9 & 4.873 & TRN \\
\hline CHEMBL1424521 & 737824 & 4.55 & 5.1175 & TRN \\
\hline CHEMBL1460036 & 737824 & 4.85 & 5.3507 & TRN \\
\hline CHEMBL1464341 & 737824 & 4.55 & 5.1403 & TRN \\
\hline CHEMBL1558437 & 737824 & 4.6 & 4.6855 & TRN \\
\hline CHEMBL1319393 & 737824 & 4.75 & 4.8853 & TRN \\
\hline CHEMBL1411496 & 737824 & 5.65 & 5.6439 & TST \\
\hline CHEMBL1540051 & 737824 & 6.0 & 5.6361 & TRN \\
\hline CHEMBL1502195 & 737824 & 5.8 & 5.3181 & TRN \\
\hline CHEMBL1396559 & 737824 & 5.6 & 5.2306 & TRN \\
\hline CHEMBL1568786 & 737824 & 5.15 & 5.6292 & TRN \\
\hline CHEMBL1398138 & 737824 & 6.1 & 6.2529 & TST \\
\hline CHEMBL1450653 & 737824 & 5.85 & 5.5003 & TRN \\
\hline CHEMBL1361656 & 737824 & 4.9 & 5.3564 & TRN \\
\hline CHEMBL1403583 & 737824 & 4.4 & 4.8062 & TRN \\
\hline CHEMBL1565610 & 737824 & 4.8 & 5.0645 & TRN \\
\hline CHEMBL1421060 & 737824 & 5.45 & 5.2437 & TRN \\
\hline CHEMBL1447550 & 737824 & 5.6 & 5.1165 & TRN \\
\hline CHEMBL1965069 & 737824 & 4.55 & 4.988 & TRN \\
\hline CHEMBL1376927 & 737824 & 5.95 & 5.7565 & TRN \\
\hline CHEMBL1607837 & 737824 & 5.65 & 5.6971 & TRN \\
\hline CHEMBL 288174 & 737824 & 4.8 & 4.6386 & TST \\
\hline CHEMBL1727680 & 737824 & 6.3 & 5.8966 & TRN \\
\hline CHEMBL1316213 & 737824 & 7.1 & 7.0048 & TRN \\
\hline CHEMBL3196632 & 737824 & 6.05 & 5.7804 & TRN \\
\hline CHEMBL1403078 & 737824 & 5.3 & 5.1873 & TST \\
\hline CHEMBL1728383 & 737824 & 5.55 & 5.0851 & TRN \\
\hline CHEMBL1579123 & 737824 & 4.9 & 5.1582 & TRN \\
\hline CHEMBL1729447 & 737824 & 4.7 & 4.8283 & TRN \\
\hline CHEMBL1338884 & 737824 & 4.65 & 4.7214 & TRN \\
\hline CHEMBL1521440 & 737824 & 5.1 & 4.9198 & TRN \\
\hline CHEMBL1485384 & 737824 & 6.4 & 5.2291 & TRN \\
\hline CHEMBL1478734 & 737824 & 5.7 & 5.3012 & TRN \\
\hline CHEMBL1529705 & 737824 & 4.75 & 5.2782 & TST \\
\hline CHEMBL1474625 & 737824 & 5.0 & 4.96 & TRN \\
\hline CHEMBL1328340 & 737824 & 5.4 & 5.7457 & TRN \\
\hline CHEMBL1329630 & 737824 & 4.75 & 5.1569 & TST \\
\hline CHEMBL1471561 & 737824 & 5.5 & 5.6145 & TRN \\
\hline CHEMBL1373948 & 737824 & 5.55 & 5.5931 & TRN \\
\hline CHEMBL1454931 & 737824 & 5.65 & 4.9636 & TRN \\
\hline CHEMBL1304907 & 737824 & 5.15 & 4.6843 & TRN \\
\hline CHEMBL1495763 & 737824 & 5.55 & 5.4242 & TRN \\
\hline CHEMBL1447127 & 737824 & 4.85 & 4.8994 & TRN \\
\hline CHEMBL1536762 & 737824 & 5.4 & 5.4592 & TRN \\
\hline
\end{tabular}




\begin{tabular}{|c|c|c|c|c|c|}
\hline & & & & & \\
\hline CHEMBL1307715 & 737824 & 5.0 & 5.5801 & TRN & \\
\hline CHEMBL1588802 & 737824 & 4.6 & 5.2818 & TRN & \\
\hline CHEMBL1353037 & 737824 & 5.7 & 5.2596 & TRN & \\
\hline CHEMBL1699304 & 737824 & 4.95 & 5.001 & TRN & \\
\hline CHEMBL1440145 & 737824 & 6.0 & 6.1718 & TRN & \\
\hline CHEMBL1532230 & 737824 & 5.1 & 5.0776 & TRN & \\
\hline CHEMBL1358631 & 737824 & 5.1 & 5.15600 & 0000000001 & TRN \\
\hline CHEMBL1496965 & 737824 & 5.6 & 5.5724 & TST & \\
\hline CHEMBL1517335 & 737824 & 5.0 & 4.9 & TRN & \\
\hline CHEMBL1318066 & 737824 & 5.5 & 5.0523 & TRN & \\
\hline CHEMBL1527955 & 737824 & 5.1 & 5.3391 & TST & \\
\hline CHEMBL1703266 & 737824 & 5.6 & 5.5436 & TRN & \\
\hline CHEMBL3194986 & 737824 & 5.25 & 4.9642 & TST & \\
\hline CHEMBL1355935 & 737824 & 4.6 & 4.8432 & TRN & \\
\hline CHEMBL1404660 & 737824 & 4.9 & 5.3611 & TRN & \\
\hline CHEMBL1571264 & 737824 & 4.9 & 4.9898 & TRN & \\
\hline CHEMBL490913 & 737824 & 5.2 & 4.7813 & TRN & \\
\hline CHEMBL1592982 & 737824 & 5.8 & 5.5484 & TRN & \\
\hline CHEMBL1741340 & 737824 & 4.85 & 4.8595 & TST & \\
\hline CHEMBL1452398 & 737824 & 5.1 & 5.7301 & TRN & \\
\hline CHEMBL1476897 & 737824 & 5.7 & 5.7236 & TST & \\
\hline CHEMBL1505717 & 737824 & 4.6 & 4.7448 & TRN & \\
\hline CHEMBL1513077 & 737824 & 4.8 & 4.6121 & TRN & \\
\hline CHEMBL1607455 & 737824 & 7.25 & 5.928 & TRN & \\
\hline CHEMBL1356242 & 737824 & 5.1 & 4.5174 & TST & \\
\hline CHEMBL1368670 & 737824 & 5.0 & 5.3596 & TRN & \\
\hline CHEMBL1328784 & 737824 & 5.3 & 5.6537 & TRN & \\
\hline CHEMBL1436195 & 737824 & 4.9 & 4.6914 & TRN & \\
\hline CHEMBL1425077 & 737824 & 5.35 & 5.1129 & TRN & \\
\hline CHEMBL1307390 & 737824 & 5.5 & 5.2521 & TRN & \\
\hline CHEMBL1533932 & 737824 & 4.6 & 4.1368 & TRN & \\
\hline CHEMBL1722019 & 737824 & 8.25 & 5.7211 & TRN & \\
\hline CHEMBL1580790 & 737824 & 5.6 & 5.6196 & TRN & \\
\hline CHEMBL1592958 & 737824 & 5.0 & 4.4917 & TRN & \\
\hline CHEMBL1547568 & 737824 & 4.9 & 5.1946 & TRN & \\
\hline CHEMBL1564353 & 737824 & 5.25 & 5.5423 & TST & \\
\hline CHEMBL1599585 & 737824 & 5.0 & 5.2574 & TRN & \\
\hline CHEMBL1525226 & 737824 & 5.65 & 4.8645 & TRN & \\
\hline CHEMBL1741671 & 737824 & 5.4 & 4.5531 & TRN & \\
\hline CHEMBL1307989 & 737824 & 4.55 & 4.9709 & TST & \\
\hline CHEMBL1479771 & 737824 & 4.9 & 4.7288 & TRN & \\
\hline CHEMBL1505844 & 737824 & 5.6 & 5.0142 & TRN & \\
\hline CHEMBL1610924 & 737824 & 4.75 & 5.0108 & TRN & \\
\hline CHEMBL172064 & 737824 & 7.3 & 7.1111 & TST & \\
\hline CHEMBL1376258 & 737824 & 5.1 & 5.2067 & TRN & \\
\hline CHEMBL234978 & 737824 & 5.85 & 5.4333 & TRN & \\
\hline CHEMBL1733817 & 737824 & 5.15 & 4.9956 & TRN & \\
\hline CHEMBL1547410 & 737824 & 5.3 & 5.0982 & TRN & \\
\hline & & & & e 7659 & \\
\hline
\end{tabular}




\begin{tabular}{|c|c|c|c|c|}
\hline \\
\hline CHEMBL1342700 & 737824 & 4.55 & 4.8946 & TRN \\
\hline CHEMBL471005 & 737824 & 5.3 & 5.1611 & TST \\
\hline CHEMBL1531466 & 737824 & 5.05 & 5.2104 & TRN \\
\hline CHEMBL1529571 & 737824 & 5.65 & 5.1534 & TRN \\
\hline CHEMBL14276 & 737824 & 5.0 & 5.7937 & TRN \\
\hline CHEMBL1598909 & 737824 & 5.15 & 5.1047 & TRN \\
\hline CHEMBL1507676 & 737824 & 4.85 & 5.0789 & TRN \\
\hline CHEMBL1560839 & 737824 & 5.0 & 4.8234 & TRN \\
\hline CHEMBL1346800 & 737824 & 5.6 & 4.8733 & TRN \\
\hline CHEMBL97797 & 737824 & 4.5 & 5.2199 & TRN \\
\hline CHEMBL1443713 & 737824 & 5.1 & 4.5697 & TRN \\
\hline CHEMBL1313409 & 737824 & 6.0 & 5.24299 & 9999999999 \\
\hline CHEMBL1500398 & 737824 & 5.15 & 5.4349 & TRN \\
\hline CHEMBL1450096 & 737824 & 7.8499 & 6.1417 & TRN \\
\hline CHEMBL1497621 & 737824 & 4.9 & 5.2101 & TST \\
\hline CHEMBL1518182 & 737824 & 4.4 & 4.5937 & TRN \\
\hline CHEMBL1323273 & 737824 & 4.5 & 5.0151 & TRN \\
\hline CHEMBL1425944 & 737824 & 5.0 & 5.2391 & TRN \\
\hline CHEMBL1411438 & 737824 & 5.4 & 5.5003 & TRN \\
\hline CHEMBL1515324 & 737824 & 4.7 & 4.5572 & TRN \\
\hline CHEMBL1306015 & 737824 & 6.75 & 6.1312 & TRN \\
\hline CHEMBL1503769 & 737824 & 4.85 & 5.0605 & TRN \\
\hline CHEMBL1414073 & 737824 & 4.4 & 4.4979 & TRN \\
\hline CHEMBL1741914 & 737824 & 4.9 & 5.0787 & TRN \\
\hline CHEMBL1428217 & 737824 & 5.7 & 5.4745 & TRN \\
\hline CHEMBL1414213 & 737824 & 5.15 & 4.9264 & TRN \\
\hline CHEMBL1509598 & 737824 & 4.75 & 4.8763 & TRN \\
\hline CHEMBL 1485850 & 737824 & 4.4 & 4.6359 & TRN \\
\hline CHEMBL1468265 & 737824 & 6.2 & 5.7519 & TRN \\
\hline CHEMBL1565311 & 737824 & 7.0 & 7.7125 & TRN \\
\hline CHEMBL1513121 & 737824 & 4.9 & 4.6814 & TRN \\
\hline CHEMBL1553173 & 737824 & 5.8 & 5.7669 & TRN \\
\hline CHEMBL1458985 & 737824 & 5.0 & 4.9557 & TRN \\
\hline CHEMBL1565577 & 737824 & 5.15 & 5.4736 & TST \\
\hline CHEMBL1528993 & 737824 & 5.7 & 4.9373 & TRN \\
\hline CHEMBL1469597 & 737824 & 4.85 & 5.1089 & TRN \\
\hline CHEMBL1609624 & 737824 & 4.4 & 4.7093 & TRN \\
\hline CHEMBL1380794 & 737824 & 5.35 & 5.0238 & TRN \\
\hline CHEMBL1385673 & 737824 & 5.0 & 4.8714 & TST \\
\hline CHEMBL1574158 & 737824 & 5.35 & 5.5125 & TRN \\
\hline CHEMBL1301598 & 737824 & 5.45 & 5.1687 & TRN \\
\hline CHEMBL1325701 & 737824 & 5.3 & 5.5719 & TRN \\
\hline CHEMBL1422909 & 737824 & 4.75 & 4.7909 & TRN \\
\hline CHEMBL1612234 & 737824 & 4.95 & 5.7222 & TRN \\
\hline CHEMBL1486380 & 737824 & 5.05 & 5.3111 & TRN \\
\hline CHEMBL1482426 & 737824 & 4.9 & 4.6648 & TRN \\
\hline CHEMBL1565536 & 737824 & 4.9 & 5.1233 & TRN \\
\hline CHEMBL 3195867 & 737824 & 5.35 & 5.4552 & TRN \\
\hline
\end{tabular}




\begin{tabular}{|c|c|c|c|c|}
\hline & & & pplement & \\
\hline CHEMBL392394 & 737824 & 5.3 & 5.1967 & TST \\
\hline CHEMBL1584987 & 737824 & 4.85 & 5.1801 & TRN \\
\hline CHEMBL1333144 & 737824 & 4.85 & 5.3342 & TRN \\
\hline CHEMBL1363569 & 737824 & 5.55 & 5.6203 & TRN \\
\hline CHEMBL1376224 & 737824 & 5.85 & 5.2653 & TRN \\
\hline CHEMBL1479936 & 737824 & 6.1 & 5.2946 & TRN \\
\hline CHEMBL1317172 & 737824 & -0.0 & 4.7167 & TRN \\
\hline CHEMBL1320948 & 737824 & 4.85 & 5.0452 & TRN \\
\hline CHEMBL1362189 & 737824 & 6.1 & 5.6339 & TRN \\
\hline CHEMBL1585320 & 737824 & 5.2 & 4.9107 & TRN \\
\hline CHEMBL1495867 & 737824 & 5.5 & 5.0738 & TRN \\
\hline CHEMBL1490195 & 737824 & 5.0 & 4.9987 & TRN \\
\hline CHEMBL1600552 & 737824 & 5.55 & 5.6762 & TRN \\
\hline CHEMBL1356391 & 737824 & 5.5 & 5.0369 & TRN \\
\hline CHEMBL1316353 & 737824 & 6.5 & 6.5473 & TRN \\
\hline CHEMBL1570716 & 737824 & 6.0 & 5.9512 & TRN \\
\hline CHEMBL1407089 & 737824 & 5.45 & 5.2251 & TRN \\
\hline CHEMBL424414 & 737824 & 4.7 & 5.2624 & TST \\
\hline CHEMBL1490740 & 737824 & 4.4 & 4.4345 & TRN \\
\hline CHEMBL1307158 & 737824 & 5.0 & 4.9845 & TRN \\
\hline CHEMBL1592571 & 737824 & 4.9 & 4.8132 & TRN \\
\hline CHEMBL1302492 & 737824 & 5.9 & 5.4166 & TRN \\
\hline CHEMBL1400921 & 737824 & 4.85 & 5.5584 & TRN \\
\hline CHEMBL3197815 & 737824 & 5.7 & 5.5107 & TRN \\
\hline CHEMBL1563047 & 737824 & 4.4 & 4.2168 & TRN \\
\hline CHEMBL1565411 & 737824 & 4.5 & 5.0615 & TRN \\
\hline CHEMBL1437128 & 737824 & 5.5 & 5.3531 & TRN \\
\hline CHEMBL1503178 & 737824 & 5.3 & 5.1598 & TRN \\
\hline CHEMBL1347738 & 737824 & 4.8 & 5.1173 & TST \\
\hline CHEMBL1357558 & 737824 & 6.0 & 5.7608 & TRN \\
\hline CHEMBL1307320 & 737824 & 6.5 & 5.7313 & TRN \\
\hline CHEMBL1325392 & 737824 & 5.5 & 4.8357 & TRN \\
\hline CHEMBL1538008 & 737824 & 4.85 & 4.9049 & TRN \\
\hline CHEMBL1387125 & 737824 & 5.45 & 5.0702 & TST \\
\hline CHEMBL1591158 & 737824 & 7.6 & 6.7464 & TST \\
\hline CHEMBL3209359 & 737824 & 4.9 & 5.2737 & TRN \\
\hline CHEMBL1596952 & 737824 & 4.6 & 4.7522 & TRN \\
\hline CHEMBL1321892 & 737824 & 6.1 & 5.4665 & TRN \\
\hline CHEMBL1588389 & 737824 & 5.85 & 5.8874 & TRN \\
\hline CHEMBL1411578 & 737824 & 4.4 & 3.9462 & TST \\
\hline CHEMBL1448896 & 737824 & 5.7 & 5.7239 & TRN \\
\hline CHEMBL1443681 & 737824 & 5.9 & 5.3706 & TRN \\
\hline CHEMBL1602084 & 737824 & 5.05 & 5.6921 & TRN \\
\hline CHEMBL1341772 & 737824 & 5.5 & 5.4219 & TRN \\
\hline CHEMBL1494296 & 737824 & 5.9 & 5.6687 & TRN \\
\hline CHEMBL1588028 & 737824 & 5.0 & 5.119 & TRN \\
\hline CHEMBL1368186 & 737824 & 4.9 & 5.0952 & TRN \\
\hline CHEMBL1438358 & 737824 & 5.35 & 5.5147 & TRN \\
\hline
\end{tabular}




\begin{tabular}{|c|c|c|c|c|c|}
\hline \multicolumn{6}{|c|}{ Supplemental Table S2.txt } \\
\hline CHEMBL1530352 & 737824 & 5.35 & 5.1695 & TST & \\
\hline CHEMBL1492136 & 737824 & 4.45 & 5.5088 & TRN & \\
\hline CHEMBL3214295 & 737824 & 5.35 & 5.2113 & TRN & \\
\hline CHEMBL1601015 & 737824 & 4.85 & 5.0309 & TRN & \\
\hline CHEMBL1724475 & 737824 & 4.4 & 4.6318 & TRN & \\
\hline CHEMBL1600150 & 737824 & 5.1 & 4.9908 & TRN & \\
\hline CHEMBL1577699 & 737824 & 5.2 & 5.6116 & TRN & \\
\hline CHEMBL1062 & 737824 & 5.3 & 4.9081 & TST & \\
\hline CHEMBL1465936 & 737824 & 6.0 & 5.1166 & TRN & \\
\hline CHEMBL1510151 & 737824 & 6.5 & 5.7504 & TRN & \\
\hline CHEMBL1461239 & 737824 & 5.3 & 5.5237 & TRN & \\
\hline CHEMBL39878 & 737824 & 5.3 & 4.9902 & TRN & \\
\hline CHEMBL1347208 & 737824 & 4.65 & 5.5677 & TST & \\
\hline CHEMBL1344974 & 737824 & 5.2 & 5.2331 & TRN & \\
\hline CHEMBL1544250 & 737824 & 6.2 & 5.1894 & TRN & \\
\hline CHEMBL1388783 & 737824 & 5.55 & 5.2453 & TRN & \\
\hline CHEMBL1563219 & 737824 & 4.65 & 4.8893 & TRN & \\
\hline CHEMBL1377637 & 737824 & 5.65 & 5.0955 & TRN & \\
\hline CHEMBL1526170 & 737824 & 4.6 & 4.4355 & TRN & \\
\hline CHEMBL1515829 & 737824 & 4.6 & 4.409 & TRN & \\
\hline CHEMBL1540570 & 737824 & 5.2 & 5.54899 & 99999999995 & TST \\
\hline CHEMBL1491853 & 737824 & 5.9 & 5.3653 & TRN & \\
\hline CHEMBL1399489 & 737824 & 5.3 & 5.3805 & TRN & \\
\hline CHEMBL3211292 & 737824 & 5.15 & 5.04 & TRN & \\
\hline CHEMBL1544377 & 737824 & 4.85 & 5.3099 & TRN & \\
\hline CHEMBL1433232 & 737824 & 5.1 & 5.8005 & TRN & \\
\hline CHEMBL1536680 & 737824 & 5.4 & 5.4975 & TRN & \\
\hline CHEMBL1470566 & 737824 & 5.8 & 5.5431 & TRN & \\
\hline CHEMBL1314288 & 737824 & 4.4 & 4.6144 & TRN & \\
\hline CHEMBL1341809 & 737824 & 5.6 & 5.3097 & TST & \\
\hline CHEMBL3190415 & 737824 & 5.0 & 5.4483 & TRN & \\
\hline CHEMBL1551200 & 737824 & 5.4 & 5.2963 & TRN & \\
\hline CHEMBL1741477 & 737824 & 4.6 & 5.2253 & TRN & \\
\hline CHEMBL1548666 & 737824 & 5.15 & 4.8808 & TRN & \\
\hline CHEMBL1478612 & 737824 & 5.4 & 5.1421 & TRN & \\
\hline CHEMBL1364135 & 737824 & 6.1 & 5.5702 & TRN & \\
\hline CHEMBL1486796 & 737824 & 4.4 & 4.9469 & TRN & \\
\hline CHEMBL1322233 & 737824 & 5.3 & 5.1658 & TRN & \\
\hline CHEMBL1349372 & 737824 & 4.4 & 4.8679 & TRN & \\
\hline CHEMBL 3214277 & 737824 & 6.15 & 5.2486 & TRN & \\
\hline CHEMBL1596743 & 737824 & 4.4 & 4.5881 & TRN & \\
\hline CHEMBL1572789 & 737824 & 5.2 & 5.227 & TRN & \\
\hline CHEMBL1343857 & 737824 & 6.15 & 5.9989 & TRN & \\
\hline CHEMBL289233 & 737824 & 5.1 & 4.4183 & TRN & \\
\hline CHEMBL1438722 & 737824 & 5.3 & 5.1758 & TRN & \\
\hline CHEMBL1485338 & 737824 & 5.65 & 5.4948 & TRN & \\
\hline CHEMBL1356690 & 737824 & 4.6 & 4.1545 & TRN & \\
\hline CHEMBL1455200 & 737824 & 4.7 & 4.537 & TRN & \\
\hline
\end{tabular}




\begin{tabular}{|c|c|c|c|c|}
\hline & & & & $a \perp 1$ \\
\hline CHEMBL1322901 & 737824 & 5.4 & 4.9861 & TST \\
\hline CHEMBL1478198 & 737824 & 4.85 & 5.1318 & TRN \\
\hline CHEMBL1537303 & 737824 & 4.95 & 5.2345 & TST \\
\hline CHEMBL1555480 & 737824 & 4.6 & 4.5329 & TRN \\
\hline CHEMBL1338163 & 737824 & 5.6 & 5.4737 & TRN \\
\hline CHEMBL1364611 & 737824 & 4.7 & 4.8303 & TRN \\
\hline CHEMBL1350410 & 737824 & 5.15 & 5.4815 & TRN \\
\hline CHEMBL306764 & 737824 & 5.0 & 4.9062 & TRN \\
\hline CHEMBL3213468 & 737824 & 4.9 & 4.9896 & TRN \\
\hline CHEMBL1397860 & 737824 & 4.7 & 4.9249 & TRN \\
\hline CHEMBL250711 & 737824 & 4.9 & 4.8064 & TRN \\
\hline CHEMBL1573134 & 737824 & 5.9 & 5.4401 & TRN \\
\hline CHEMBL1329327 & 737824 & 5.3 & 5.0204 & TRN \\
\hline CHEMBL1323563 & 737824 & 6.4 & 6.4838 & TRN \\
\hline CHEMBL1538593 & 737824 & 4.6 & 4.7433 & TRN \\
\hline CHEMBL1472898 & 737824 & 4.5 & 4.5027 & TRN \\
\hline CHEMBL1490333 & 737824 & 4.75 & 5.1917 & TRN \\
\hline CHEMBL 75913 & 737824 & 5.95 & 5.3885 & TST \\
\hline CHEMBL1376394 & 737824 & 4.85 & 5.5587 & TRN \\
\hline CHEMBL1605586 & 737824 & 5.45 & 5.755 & TRN \\
\hline CHEMBL1742382 & 737824 & 4.65 & 5.0911 & TRN \\
\hline CHEMBL1526543 & 737824 & 6.2 & 5.5336 & TST \\
\hline CHEMBL1536942 & 737824 & 5.05 & 4.8081 & TRN \\
\hline CHEMBL1480273 & 737824 & 5.25 & 5.2237 & TRN \\
\hline CHEMBL1485865 & 737824 & 5.05 & 4.8632 & TST \\
\hline CHEMBL251647 & 737824 & 5.4 & 5.9621 & TST \\
\hline CHEMBL1467364 & 737824 & 4.65 & 5.0815 & TRN \\
\hline CHEMBL1581598 & 737824 & 5.35 & 5.2862 & TRN \\
\hline CHEMBL1302090 & 737824 & 4.75 & 4.8317 & TRN \\
\hline CHEMBL1425746 & 737824 & 5.85 & 5.6167 & TRN \\
\hline CHEMBL3189794 & 737824 & 4.7 & 4.905 & TRN \\
\hline CHEMBL1390992 & 737824 & 4.7 & 4.9152 & TRN \\
\hline CHEMBL1461491 & 737824 & 4.9 & 4.8764 & TST \\
\hline CHEMBL1542902 & 737824 & 5.65 & 5.765 & TRN \\
\hline CHEMBL1532991 & 737824 & 6.65 & 5.6538 & TRN \\
\hline CHEMBL1309281 & 737824 & 5.0 & 4.9458 & TRN \\
\hline CHEMBL 259355 & 737824 & 4.65 & 5.3099 & TRN \\
\hline CHEMBL3197172 & 737824 & 4.8 & 5.1475 & TRN \\
\hline CHEMBL 2028181 & 737824 & 5.7 & 5.51200 & 00000000005 \\
\hline CHEMBL1502413 & 737824 & 6.1 & 5.8797 & TRN \\
\hline CHEMBL1567229 & 737824 & 5.1 & 5.2852 & TRN \\
\hline CHEMBL1578210 & 737824 & 5.85 & 5.4403 & TRN \\
\hline CHEMBL1544757 & 737824 & 5.0 & 5.2261 & TRN \\
\hline CHEMBL1369078 & 737824 & 5.25 & 5.1195 & TRN \\
\hline CHEMBL1408259 & 737824 & 6.0 & 6.0594 & TRN \\
\hline CHEMBL1586504 & 737824 & 4.4 & 4.7617 & TRN \\
\hline CHEMBL1588525 & 737824 & 5.35 & 5.2192 & TRN \\
\hline CHEMBL1458036 & 737824 & 4.95 & 5.0183 & TRN \\
\hline
\end{tabular}




\begin{tabular}{|c|c|c|c|c|}
\hline & & & pplement & $\mathrm{dI}$ \\
\hline CHEMBL3190499 & 737824 & 4.85 & 5.1822 & TST \\
\hline CHEMBL1379783 & 737824 & 5.05 & 5.4801 & TRN \\
\hline CHEMBL1720268 & 737824 & 5.0 & 5.2956 & TRN \\
\hline CHEMBL1442986 & 737824 & 4.6 & 5.0233 & TRN \\
\hline CHEMBL1407670 & 737824 & 7.3 & 7.2003 & TRN \\
\hline CHEMBL1425091 & 737824 & 4.9 & 5.2577 & TRN \\
\hline CHEMBL3192219 & 737824 & 4.75 & 5.3025 & TRN \\
\hline CHEMBL1527251 & 737824 & 4.85 & 5.4856 & TRN \\
\hline CHEMBL1511940 & 737824 & 5.15 & 5.6219 & TRN \\
\hline CHEMBL1520153 & 737824 & 5.6 & 5.8608 & TRN \\
\hline CHEMBL1565645 & 737824 & 5.65 & 4.8263 & TRN \\
\hline CHEMBL1534202 & 737824 & 4.95 & 5.2129 & TST \\
\hline CHEMBL1329046 & 737824 & 6.4 & 5.8306 & TRN \\
\hline CHEMBL1446467 & 737824 & 5.5 & 5.4749 & TST \\
\hline CHEMBL1398580 & 737824 & 4.9 & 5.3833 & TRN \\
\hline CHEMBL1742244 & 737824 & 4.85 & 5.4827 & TRN \\
\hline CHEMBL1378545 & 737824 & 4.85 & 5.4424 & TRN \\
\hline CHEMBL1478350 & 737824 & 5.15 & 5.2477 & TRN \\
\hline CHEMBL1395226 & 737824 & 4.4 & 3.9394 & TRN \\
\hline CHEMBL1327351 & 737824 & 5.4 & 5.5574 & TRN \\
\hline CHEMBL1601898 & 737824 & 5.45 & 5.6966 & TRN \\
\hline CHEMBL1490012 & 737824 & 5.1 & 5.4673 & TRN \\
\hline CHEMBL1568723 & 737824 & 5.45 & 4.8591 & TRN \\
\hline CHEMBL545050 & 737824 & 5.0 & 5.3 & TST \\
\hline CHEMBL45281 & 737824 & 4.5 & 5.5663 & TST \\
\hline CHEMBL1413137 & 737824 & 5.0 & 5.2938 & TRN \\
\hline CHEMBL1492946 & 737824 & 4.8 & 5.2297 & TRN \\
\hline CHEMBL1396792 & 737824 & 5.5 & 5.3679 & TRN \\
\hline CHEMBL1526751 & 737824 & 5.2 & 5.2046 & TST \\
\hline CHEMBL1398669 & 737824 & 5.9 & 5.5704 & TRN \\
\hline CHEMBL3189338 & 737824 & 4.5 & 5.1976 & TRN \\
\hline CHEMBL1597397 & 737824 & 4.4 & 4.2356 & TRN \\
\hline CHEMBL1595253 & 737824 & 5.95 & 5.601 & TRN \\
\hline CHEMBL1309630 & 737824 & 5.1 & 5.0338 & TST \\
\hline CHEMBL1374527 & 737824 & 7.5 & 5.8891 & TRN \\
\hline CHEMBL1598771 & 737824 & 4.35 & 4.9208 & TST \\
\hline CHEMBL1709061 & 737824 & 4.4 & 5.0207 & TST \\
\hline CHEMBL1310543 & 737824 & 5.6 & 5.3426 & TRN \\
\hline CHEMBL1513990 & 737824 & 7.1 & 7.6879 & TRN \\
\hline CHEMBL1605152 & 737824 & 6.6 & 6.9121 & TRN \\
\hline CHEMBL3194276 & 737824 & 5.4 & 4.9554 & TRN \\
\hline CHEMBL2002517 & 737824 & 7.7501 & 5.7138 & TRN \\
\hline CHEMBL1467643 & 737824 & 5.3 & 5.4967 & TRN \\
\hline CHEMBL1531376 & 737824 & 5.5 & 5.3893 & TRN \\
\hline CHEMBL1361876 & 737824 & 5.1 & 5.4884 & TRN \\
\hline CHEMBL1507563 & 737824 & 5.45 & 5.1974 & TRN \\
\hline CHEMBL1602329 & 737824 & 4.6 & 4.6397 & TRN \\
\hline CHEMBL1410009 & 737824 & 5.45 & 5.5277 & TRN \\
\hline
\end{tabular}




\begin{tabular}{|c|c|c|c|c|c|}
\hline \\
\hline CHEMBL1527195 & 737824 & 4.9 & 4.4679 & TRN & \\
\hline CHEMBL1484214 & 737824 & 5.7 & 5.5364 & TRN & \\
\hline CHEMBL3193950 & 737824 & 6.0 & 4.7222 & TRN & \\
\hline CHEMBL1587716 & 737824 & 4.55 & 5.0241 & TRN & \\
\hline CHEMBL1345018 & 737824 & 5.35 & 5.0265 & TRN & \\
\hline CHEMBL1327793 & 737824 & 5.6 & 5.5748 & TST & \\
\hline CHEMBL1361813 & 737824 & 5.0 & 5.4468 & TRN & \\
\hline CHEMBL1505211 & 737824 & 5.4 & 5.6846 & TRN & \\
\hline CHEMBL1612048 & 737824 & 4.4 & 4.9248 & TST & \\
\hline CHEMBL 294747 & 737824 & 4.8 & 4.2737 & TRN & \\
\hline CHEMBL1461359 & 737824 & 4.4 & 5.0781 & TRN & \\
\hline CHEMBL1593199 & 737824 & 4.4 & 4.68199 & 99999999995 & TRN \\
\hline CHEMBL1351579 & 737824 & 4.4 & 4.9698 & TRN & \\
\hline CHEMBL1724554 & 737824 & 4.95 & 5.1577 & TRN & \\
\hline CHEMBL1699708 & 737824 & 5.6 & 5.4249 & TRN & \\
\hline CHEMBL1468324 & 737824 & 5.6 & 5.4582 & TRN & \\
\hline CHEMBL1524211 & 737824 & 4.8 & 4.75899 & 99999999995 & TRN \\
\hline CHEMBL1367958 & 737824 & 4.8 & 4.5512 & TST & \\
\hline CHEMBL1441667 & 737824 & 5.2 & 4.9271 & TRN & \\
\hline CHEMBL3211162 & 737824 & 4.85 & 4.9576 & TRN & \\
\hline CHEMBL1603549 & 737824 & 5.15 & 5.5536 & TST & \\
\hline CHEMBL3212828 & 737824 & 4.95 & 4.9767 & TRN & \\
\hline CHEMBL1597410 & 737824 & 4.9 & 4.9118 & TRN & \\
\hline CHEMBL591126 & 737824 & 4.4 & 5.1675 & TRN & \\
\hline CHEMBL1626274 & 737824 & 5.0 & 5.6987 & TST & \\
\hline CHEMBL1589070 & 737824 & 4.5 & 5.1042 & TRN & \\
\hline CHEMBL1356497 & 737824 & 4.9 & 4.9898 & TRN & \\
\hline CHEMBL1369322 & 737824 & 5.3 & 5.7022 & TRN & \\
\hline CHEMBL 3211776 & 737824 & 5.85 & 5.3495 & TRN & \\
\hline CHEMBL1523982 & 737824 & 5.3 & 5.3264 & TRN & \\
\hline CHEMBL1396377 & 737824 & 5.0 & 4.9106 & TRN & \\
\hline CHEMBL1564816 & 737824 & 4.9 & 5.0792 & TRN & \\
\hline CHEMBL1342307 & 737824 & 4.8 & 4.8515 & TRN & \\
\hline CHEMBL1472481 & 737824 & 5.9 & 5.6556 & TRN & \\
\hline CHEMBL 317757 & 737824 & 5.0 & 4.584 & TST & \\
\hline CHEMBL1376749 & 737824 & 5.6 & 5.1543 & TRN & \\
\hline CHEMBL1507467 & 737824 & 4.8 & 4.8075 & TRN & \\
\hline CHEMBL1379007 & 737824 & 5.85 & 5.2374 & TRN & \\
\hline CHEMBL1369693 & 737824 & 5.65 & 5.6533 & TRN & \\
\hline CHEMBL1304114 & 737824 & 5.05 & 6.0363 & TRN & \\
\hline CHEMBL1307887 & 737824 & 4.75 & 5.0904 & TRN & \\
\hline CHEMBL3191893 & 737824 & 5.6 & 5.3195 & TRN & \\
\hline CHEMBL1493064 & 737824 & 5.65 & 5.0178 & TRN & \\
\hline CHEMBL1599378 & 737824 & 5.0 & 5.0356 & TRN & \\
\hline CHEMBL1411360 & 737824 & 5.6 & 5.6004 & TST & \\
\hline CHEMBL1484006 & 737824 & 6.0 & 6.1008 & TRN & \\
\hline CHEMBL1379187 & 737824 & 5.45 & 5.7443 & TRN & \\
\hline CHEMBL1523557 & 737824 & 4.8 & 5.3852 & TRN & \\
\hline
\end{tabular}




\begin{tabular}{|c|c|c|c|c|}
\hline & & & pplement & al $\mathrm{Ta}$ \\
\hline CHEMBL1411210 & 737824 & 6.4 & 5.5769 & TRN \\
\hline CHEMBL1603445 & 737824 & 6.05 & 5.3059 & TRN \\
\hline CHEMBL1582548 & 737824 & 6.4 & 5.3756 & TRN \\
\hline CHEMBL1302442 & 737824 & 5.45 & 5.3047 & TRN \\
\hline CHEMBL1329622 & 737824 & 4.4 & 5.1278 & TST \\
\hline CHEMBL1344451 & 737824 & 5.5 & 5.4839 & TRN \\
\hline CHEMBL1411396 & 737824 & 5.15 & 5.1629 & TST \\
\hline CHEMBL1735134 & 737824 & 6.2 & 6.0645 & TRN \\
\hline CHEMBL1487070 & 737824 & 5.6 & 4.7697 & TRN \\
\hline CHEMBL1587447 & 737824 & 5.5 & 5.0219 & TRN \\
\hline CHEMBL1570292 & 737824 & 5.6 & 5.1691 & TST \\
\hline CHEMBL1395992 & 737824 & 5.5 & 5.7507 & TRN \\
\hline CHEMBL1446687 & 737824 & 5.75 & 5.5857 & TRN \\
\hline CHEMBL1544981 & 737824 & 4.4 & 5.0463 & TRN \\
\hline CHEMBL1421568 & 737824 & 4.4 & 4.9407 & TRN \\
\hline CHEMBL3190560 & 737824 & 5.5 & 5.4363 & TRN \\
\hline CHEMBL1475541 & 737824 & 4.7 & 4.4282 & TRN \\
\hline CHEMBL1437991 & 737824 & 7.0 & 5.4346 & TRN \\
\hline CHEMBL77971 & 737824 & 5.0 & 5.0559 & TST \\
\hline CHEMBL1532107 & 737824 & 4.75 & 5.0156 & TST \\
\hline CHEMBL1464437 & 737824 & 4.75 & 5.5281 & TST \\
\hline CHEMBL1720911 & 737824 & 5.1 & 5.1606 & TRN \\
\hline CHEMBL1560435 & 737824 & 5.6 & 5.1543 & TRN \\
\hline CHEMBL1490857 & 737824 & 6.3 & 5.5786 & TRN \\
\hline CHEMBL1350339 & 737824 & 4.85 & 4.8483 & TRN \\
\hline CHEMBL1355909 & 737824 & 4.6 & 4.5734 & TRN \\
\hline CHEMBL1599844 & 737824 & 4.85 & 5.0919 & TRN \\
\hline CHEMBL1384414 & 737824 & 6.3 & 5.4582 & TRN \\
\hline CHEMBL1435654 & 737824 & 6.5 & 6.3812 & TRN \\
\hline CHEMBL1607962 & 737824 & 4.4 & 5.1278 & TRN \\
\hline CHEMBL1417604 & 737824 & 5.3 & 5.3899 & TST \\
\hline CHEMBL1366260 & 737824 & 6.15 & 5.404 & TRN \\
\hline CHEMBL1332456 & 737824 & 4.9 & 5.3466 & TRN \\
\hline CHEMBL 275938 & 737824 & 4.6 & 4.7231 & TST \\
\hline CHEMBL1524295 & 737824 & 4.8 & 5.2321 & TRN \\
\hline CHEMBL1382247 & 737824 & 5.15 & 5.2748 & TRN \\
\hline CHEMBL1574219 & 737824 & 4.85 & 5.1677 & TST \\
\hline CHEMBL1270168 & 737824 & 5.6 & 5.8448 & TRN \\
\hline CHEMBL1322506 & 737824 & 5.15 & 5.6256 & TRN \\
\hline CHEMBL1453591 & 737824 & 5.95 & 5.6303 & TRN \\
\hline CHEMBL1388353 & 737824 & 5.5 & 5.2456 & TRN \\
\hline CHEMBL1395029 & 737824 & 4.8 & 4.5609 & TRN \\
\hline CHEMBL1481810 & 737824 & 6.1 & 5.3545 & TRN \\
\hline CHEMBL3191729 & 737824 & 4.95 & 5.1301 & TRN \\
\hline CHEMBL1554935 & 737824 & 4.7 & 4.7004 & TRN \\
\hline CHEMBL1460680 & 737824 & 4.55 & 4.9188 & TRN \\
\hline CHEMBL1710090 & 737824 & 4.55 & 4.8811 & TRN \\
\hline CHEMBL1306585 & 737824 & 6.05 & 4.9853 & TST \\
\hline
\end{tabular}




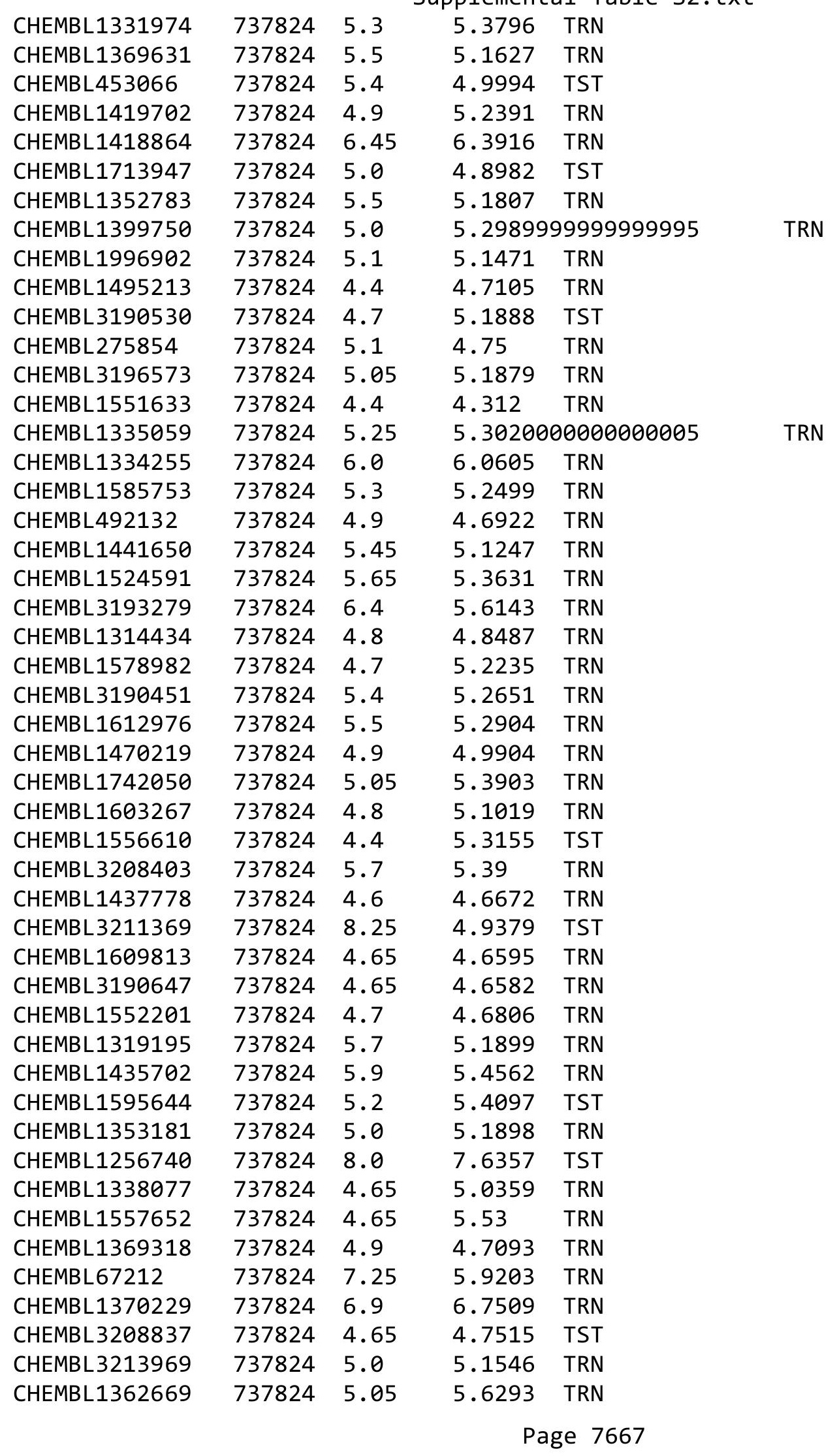




\begin{tabular}{|c|c|c|c|c|}
\hline & & & pplement & al $\mathrm{Ta}$ \\
\hline CHEMBL1378863 & 737824 & 4.65 & 5.2116 & TRN \\
\hline CHEMBL1561506 & 737824 & 5.0 & 4.9886 & TRN \\
\hline CHEMBL1488301 & 737824 & 4.5 & 5.1193 & TRN \\
\hline CHEMBL1428232 & 737824 & 4.85 & 5.1133 & TRN \\
\hline CHEMBL1712981 & 737824 & 5.1 & 5.2695 & TRN \\
\hline CHEMBL1408954 & 737824 & 5.8 & 5.6434 & TRN \\
\hline CHEMBL1361984 & 737824 & 5.65 & 5.551 & TRN \\
\hline CHEMBL1461802 & 737824 & 4.8 & 5.0548 & TRN \\
\hline CHEMBL1460449 & 737824 & 4.9 & 4.9413 & TRN \\
\hline CHEMBL1565139 & 737824 & 5.3 & 5.5476 & TRN \\
\hline CHEMBL1312169 & 737824 & 4.7 & 4.6852 & TRN \\
\hline CHEMBL 3207571 & 737824 & 5.2 & 5.3903 & TRN \\
\hline CHEMBL1500880 & 737824 & 5.45 & 5.6172 & TRN \\
\hline CHEMBL596728 & 737824 & 4.85 & 5.3502 & TRN \\
\hline CHEMBL1584783 & 737824 & 5.85 & 5.6327 & TST \\
\hline CHEMBL3212026 & 737824 & 5.6 & 5.3811 & TRN \\
\hline CHEMBL1383753 & 737824 & 5.3 & 5.3105 & TRN \\
\hline CHEMBL1309259 & 737824 & 5.6 & 5.2296 & TRN \\
\hline CHEMBL1355262 & 737824 & 5.0 & 4.8156 & TRN \\
\hline CHEMBL1322756 & 737824 & 5.7 & 5.6376 & TRN \\
\hline CHEMBL1256180 & 737824 & 4.5 & 4.2783 & TST \\
\hline CHEMBL3196906 & 737824 & 5.4 & 5.3152 & TRN \\
\hline CHEMBL1348445 & 737824 & 4.65 & 5.0847 & TRN \\
\hline CHEMBL1524503 & 737824 & 4.8 & 5.3308 & TRN \\
\hline CHEMBL1434149 & 737824 & 5.5 & 5.5715 & TRN \\
\hline CHEMBL1400491 & 737824 & 4.6 & 4.5528 & TRN \\
\hline CHEMBL1340837 & 737824 & 5.5 & 5.0301 & TRN \\
\hline CHEMBL3392074 & 737824 & 4.9 & 4.4521 & TST \\
\hline CHEMBL1450934 & 737824 & 5.6 & 5.1981 & TRN \\
\hline CHEMBL1352096 & 737824 & 5.25 & 5.2478 & TRN \\
\hline CHEMBL1451037 & 737824 & 5.0 & 5.0916 & TST \\
\hline CHEMBL1502107 & 737824 & 5.5 & 5.364 & TRN \\
\hline CHEMBL3211898 & 737824 & 4.95 & 5.2605 & TRN \\
\hline CHEMBL1610312 & 737824 & 5.2 & 5.1464 & TST \\
\hline CHEMBL1352270 & 737824 & 5.05 & 5.6008 & TRN \\
\hline CHEMBL3213624 & 737824 & 4.75 & 5.3134 & TRN \\
\hline CHEMBL1532380 & 737824 & 5.65 & 5.2336 & TRN \\
\hline CHEMBL1419997 & 737824 & 4.9 & 4.8983 & TRN \\
\hline CHEMBL1494697 & 737824 & 5.8 & 5.5759 & TRN \\
\hline CHEMBL1547564 & 737824 & 5.1 & 5.0443 & TRN \\
\hline CHEMBL1341789 & 737824 & 5.5 & 4.8082 & TRN \\
\hline CHEMBL1607167 & 737824 & 5.4 & 5.0615 & TST \\
\hline CHEMBL1477826 & 737824 & 4.75 & 5.2537 & TRN \\
\hline CHEMBL1301918 & 737824 & 5.0 & 4.9459 & TRN \\
\hline CHEMBL1734683 & 737824 & 5.0 & 4.5934 & TST \\
\hline CHEMBL1554936 & 737824 & 6.3 & 6.1649 & TRN \\
\hline CHEMBL1306278 & 737824 & 4.4 & 4.8102 & TRN \\
\hline CHEMBL1456330 & 737824 & 4.95 & 5.1498 & TST \\
\hline
\end{tabular}




\begin{tabular}{|c|c|c|c|c|c|}
\hline \multicolumn{6}{|c|}{ Supplemental Table S2.txt } \\
\hline CHEMBL1307909 & 737824 & 5.75 & 5.2716 & TST & \\
\hline CHEMBL1161936 & 737824 & 5.6 & 5.227 & TST & \\
\hline CHEMBL1492604 & 737824 & 4.8 & 4.8819 & TST & \\
\hline CHEMBL1532878 & 737824 & 6.6 & 5.66 & TRN & \\
\hline CHEMBL1494444 & 737824 & 5.0 & 4.9463 & TST & \\
\hline CHEMBL1529625 & 737824 & 4.4 & 4.0363 & TST & \\
\hline CHEMBL1605148 & 737824 & 5.1 & 5.1467 & TRN & \\
\hline CHEMBL1361725 & 737824 & 4.8 & 4.155 & TRN & \\
\hline CHEMBL3211338 & 737824 & 6.0 & 6.2274 & TRN & \\
\hline CHEMBL1574886 & 737824 & 4.7 & 5.0945 & TRN & \\
\hline CHEMBL1309858 & 737824 & 5.4 & 5.0039 & TRN & \\
\hline CHEMBL1603884 & 737824 & 5.4 & 4.9635 & TRN & \\
\hline CHEMBL1520238 & 737824 & 6.5 & 5.8244 & TRN & \\
\hline CHEMBL1358939 & 737824 & 6.0 & 5.4828 & TRN & \\
\hline CHEMBL1741647 & 737824 & 4.6 & 4.9928 & TRN & \\
\hline CHEMBL565654 & 737824 & 5.0 & 5.1084 & TRN & \\
\hline CHEMBL1353889 & 737824 & 5.6 & 5.7255 & TRN & \\
\hline CHEMBL1483344 & 737824 & 4.9 & 4.6404 & TRN & \\
\hline CHEMBL1395089 & 737824 & 5.0 & 4.7803 & TRN & \\
\hline CHEMBL1337787 & 737824 & 5.85 & 5.307 & TRN & \\
\hline CHEMBL1588011 & 737824 & 6.4 & 5.4136 & TRN & \\
\hline CHEMBL1428264 & 737824 & 5.6 & 6.046 & TRN & \\
\hline CHEMBL1472703 & 737824 & 5.1 & 5.1109 & TST & \\
\hline CHEMBL1473472 & 737824 & 4.8 & 4.6601 & TRN & \\
\hline CHEMBL1515131 & 737824 & 5.4 & 5.0434 & TRN & \\
\hline CHEMBL1555164 & 737824 & 7.9 & 7.5889 & TRN & \\
\hline CHEMBL1350707 & 737824 & 5.45 & 5.7366 & TRN & \\
\hline CHEMBL1574071 & 737824 & 4.95 & 4.8323 & TST & \\
\hline CHEMBL1374696 & 737824 & 5.5 & 5.1688 & TRN & \\
\hline CHEMBL1450864 & 737824 & 4.75 & 4.9483 & TRN & \\
\hline CHEMBL1437428 & 737824 & 5.4 & 5.6838 & TST & \\
\hline CHEMBL1502536 & 737824 & 5.6 & 5.3778 & TRN & \\
\hline CHEMBL1321655 & 737824 & 7.7001 & 6.5187 & TRN & \\
\hline CHEMBL1488236 & 737824 & 5.15 & 5.0326 & TRN & \\
\hline CHEMBL1583920 & 737824 & 6.2 & 5.61100 & $\partial 000000001$ & TRN \\
\hline CHEMBL1520998 & 737824 & 4.75 & 5.3688 & TRN & \\
\hline CHEMBL1576119 & 737824 & 4.75 & 5.2025 & TST & \\
\hline CHEMBL1404656 & 737824 & 5.5 & 5.308 & TRN & \\
\hline CHEMBL1461511 & 737824 & 5.05 & 5.20100 & 20000000005 & TRN \\
\hline CHEMBL1605632 & 737824 & 4.5 & 4.5769 & TRN & \\
\hline CHEMBL3210612 & 737824 & 5.3 & 5.0393 & TRN & \\
\hline CHEMBL1442612 & 737824 & 6.15 & 6.0184 & TRN & \\
\hline CHEMBL1388994 & 737824 & 4.65 & 5.1467 & TRN & \\
\hline CHEMBL1306620 & 737824 & 4.85 & 4.6575 & TRN & \\
\hline CHEMBL1605992 & 737824 & 5.2 & 5.0332 & TST & \\
\hline CHEMBL1549097 & 737824 & 4.65 & 5.4145 & TRN & \\
\hline CHEMBL1448403 & 737824 & 4.85 & 5.3442 & TRN & \\
\hline CHEMBL1545790 & 737824 & 5.2 & 5.4642 & TRN & \\
\hline
\end{tabular}




\begin{tabular}{|c|c|c|c|c|}
\hline \multicolumn{5}{|c|}{ Supplemental Table S2.txt } \\
\hline CHEMBL1569019 & 737824 & 4.45 & 4.7714 & TRN \\
\hline CHEMBL1715023 & 737824 & 6.0 & 5.0656 & TRN \\
\hline CHEMBL1608125 & 737824 & 5.5 & 5.5675 & TRN \\
\hline CHEMBL1444269 & 737824 & 5.15 & 5.0657 & TRN \\
\hline CHEMBL1742131 & 737824 & 5.15 & 4.6924 & TST \\
\hline CHEMBL1424426 & 737824 & 4.8 & 5.0635 & TRN \\
\hline CHEMBL1554723 & 737824 & 5.0 & 4.896 & TRN \\
\hline CHEMBL1503270 & 737824 & 4.45 & 4.8164 & TRN \\
\hline CHEMBL574181 & 737824 & 4.8 & 4.1036 & TST \\
\hline CHEMBL1517652 & 737824 & 5.45 & 5.7488 & TRN \\
\hline CHEMBL1342890 & 737824 & 7.7001 & 5.7799 & TRN \\
\hline CHEMBL1301521 & 737824 & 5.6 & 5.088 & TRN \\
\hline CHEMBL1742258 & 737824 & 4.85 & 5.2951 & TRN \\
\hline CHEMBL1366453 & 737824 & 4.85 & 5.2158 & TST \\
\hline CHEMBL1432368 & 737824 & 5.35 & 5.1131 & TRN \\
\hline CHEMBL1539794 & 737824 & 4.85 & 5.1599 & TRN \\
\hline CHEMBL 92708 & 737824 & 5.0 & 5.0065 & TRN \\
\hline CHEMBL1600038 & 737824 & 7.7501 & 5.4966 & TRN \\
\hline CHEMBL606675 & 737824 & 5.5 & 5.7159 & TST \\
\hline CHEMBL1388541 & 737824 & 5.45 & 5.0333 & TRN \\
\hline CHEMBL1583320 & 737824 & 4.75 & 5.1034 & TRN \\
\hline CHEMBL1741622 & 737824 & 5.5 & 5.3859 & TRN \\
\hline CHEMBL1578191 & 737824 & 4.45 & 4.1338 & TRN \\
\hline CHEMBL1552150 & 737824 & 5.0 & 5.2116 & TRN \\
\hline CHEMBL1359326 & 737824 & 4.55 & 5.5514 & TRN \\
\hline CHEMBL123904 & 737824 & 6.4 & 5.7616 & TST \\
\hline CHEMBL515505 & 737824 & 5.8 & 5.7183 & TRN \\
\hline CHEMBL1554914 & 737824 & 5.9 & 5.7296 & TRN \\
\hline CHEMBL1513665 & 737824 & 4.6 & 4.1632 & TRN \\
\hline CHEMBL1496761 & 737824 & 5.5 & 6.0116 & TRN \\
\hline CHEMBL1581282 & 737824 & 5.55 & 5.095 & TRN \\
\hline CHEMBL165 & 737824 & 8.6 & 6.0057 & TRN \\
\hline CHEMBL1495099 & 737824 & 5.0 & 5.3178 & TRN \\
\hline CHEMBL1583562 & 737824 & 5.35 & 5.1364 & TRN \\
\hline CHEMBL1318799 & 737824 & 4.9 & 5.1776 & TRN \\
\hline CHEMBL3191740 & 737824 & 5.0 & 5.6174 & TRN \\
\hline CHEMBL1607830 & 737824 & 5.6 & 5.405 & TST \\
\hline CHEMBL1727118 & 737824 & 4.95 & 4.9086 & TRN \\
\hline CHEMBL1551503 & 737824 & 5.5 & 5.3629 & TRN \\
\hline CHEMBL1579705 & 737824 & 4.9 & 5.1605 & TRN \\
\hline CHEMBL1409756 & 737824 & 6.2 & 5.689 & TRN \\
\hline CHEMBL1603124 & 737824 & 4.55 & 4.9152 & TST \\
\hline CHEMBL1563497 & 737824 & 4.8 & 5.0984 & TRN \\
\hline CHEMBL1568990 & 737824 & 4.6 & 5.0386 & TRN \\
\hline CHEMBL1331780 & 737824 & 4.85 & 4.9776 & TRN \\
\hline CHEMBL1440032 & 737824 & 5.45 & 5.0439 & TRN \\
\hline CHEMBL1508952 & 737824 & 6.7 & 5.355 & TRN \\
\hline CHEMBL1420689 & 737824 & 6.25 & 5.7428 & TRN \\
\hline
\end{tabular}




\begin{tabular}{|c|c|c|c|c|}
\hline CHEMBL567332 & 737824 & 5.3 & 4.9532 & TRN \\
\hline CHEMBL1543285 & 737824 & 5.5 & 5.5092 & TRN \\
\hline CHEMBL1308838 & 737824 & 4.9 & 5.0931 & TRN \\
\hline CHEMBL1467227 & 737824 & 5.3 & 4.9158 & TST \\
\hline CHEMBL1377321 & 737824 & 5.4 & 5.5084 & TRN \\
\hline CHEMBL1580804 & 737824 & 4.85 & 4.8778 & TRN \\
\hline CHEMBL1567101 & 737824 & 5.0 & 5.0385 & TRN \\
\hline CHEMBL1387828 & 737824 & 4.75 & \multicolumn{2}{|c|}{5.332000000000001} \\
\hline CHEMBL1517418 & 737824 & 5.35 & 5.0615 & TRN \\
\hline CHEMBL1392865 & 737824 & 6.4 & 5.7429 & TRN \\
\hline CHEMBL1316056 & 737824 & 5.5 & 5.3937 & TRN \\
\hline CHEMBL1475131 & 737824 & 6.8 & 6.5897 & TRN \\
\hline CHEMBL1389090 & 737824 & 4.75 & 4.7345 & TRN \\
\hline CHEMBL1542526 & 737824 & 4.65 & 4.8763 & TRN \\
\hline CHEMBL1350293 & 737824 & 5.6 & 5.3514 & TRN \\
\hline CHEMBL1501668 & 737824 & 4.7 & 4.7865 & TRN \\
\hline CHEMBL1412815 & 737824 & 4.9 & 4.975 & TRN \\
\hline CHEMBL1377668 & 737824 & 4.4 & 4.2494 & TRN \\
\hline CHEMBL1343329 & 737824 & 5.3 & 5.3788 & TST \\
\hline CHEMBL1512023 & 737824 & 4.8 & 4.869 & TRN \\
\hline CHEMBL1455604 & 737824 & 6.5 & 5.9449 & TRN \\
\hline CHEMBL1570285 & 737824 & 4.6 & 4.8914 & TRN \\
\hline CHEMBL291536 & 737824 & 5.0 & 3.9928 & TST \\
\hline CHEMBL1533537 & 737824 & 4.9 & 5.0942 & TRN \\
\hline CHEMBL1377868 & 737824 & 5.6 & 5.3794 & TRN \\
\hline CHEMBL1386571 & 737824 & 5.1 & 5.3526 & TRN \\
\hline CHEMBL1392154 & 737824 & 4.8 & 5.1322 & TRN \\
\hline CHEMBL1395252 & 737824 & -0.0 & 5.1097 & TST \\
\hline CHEMBL1332450 & 737824 & 5.4 & 5.3469 & TRN \\
\hline CHEMBL1706307 & 737824 & 4.7 & 4.9532 & TRN \\
\hline CHEMBL1470199 & 737824 & 4.8 & 5.2408 & TRN \\
\hline CHEMBL1600753 & 737824 & 5.1 & 4.909 & TRN \\
\hline CHEMBL1385992 & 737824 & 4.75 & 4.6002 & TST \\
\hline CHEMBL1533853 & 737824 & 6.1 & 6.1052 & TRN \\
\hline CHEMBL1498179 & 737824 & 5.8 & 5.6369 & TRN \\
\hline CHEMBL1742202 & 737824 & 5.25 & 5.2123 & TST \\
\hline CHEMBL1375321 & 737824 & 5.25 & 5.3252 & TRN \\
\hline CHEMBL1554612 & 737824 & 7.0 & 6.6909 & TRN \\
\hline CHEMBL1484898 & 737824 & 5.0 & 4.8903 & TST \\
\hline CHEMBL1584442 & 737824 & 4.55 & 4.8773 & TRN \\
\hline CHEMBL1348385 & 737824 & 5.4 & 5.4266 & TRN \\
\hline CHEMBL1548959 & 737824 & 4.65 & 4.8057 & TRN \\
\hline CHEMBL1575531 & 737824 & 5.1 & 5.3015 & TRN \\
\hline CHEMBL1310810 & 737824 & 5.5 & 5.4527 & TRN \\
\hline CHEMBL1340207 & 737824 & 4.6 & 4.9961 & TRN \\
\hline CHEMBL1564927 & 737824 & 5.4 & 5.3171 & TST \\
\hline CHEMBL1742326 & 737824 & 6.1 & 5.6652 & TRN \\
\hline CHEMBL1490786 & 737824 & 4.6 & 4.5299 & TRN \\
\hline
\end{tabular}




\begin{tabular}{|c|c|c|c|c|c|}
\hline & & & & & \\
\hline CHEMBL1499071 & 737824 & 4.9 & 4.795 & TRN & \\
\hline CHEMBL1362630 & 737824 & 5.4 & 5.0737 & TST & \\
\hline CHEMBL1314291 & 737824 & 4.6 & 4.7131 & TRN & \\
\hline CHEMBL1429162 & 737824 & 5.1 & 5.5834 & TRN & \\
\hline CHEMBL1434895 & 737824 & 5.6 & 5.4174 & TRN & \\
\hline CHEMBL1507611 & 737824 & 6.1 & 5.6057 & TRN & \\
\hline CHEMBL3195510 & 737824 & 5.4 & 4.9717 & TRN & \\
\hline CHEMBL1507704 & 737824 & 5.4 & 5.0232 & TRN & \\
\hline CHEMBL1356132 & 737824 & 4.6 & 4.5677 & TRN & \\
\hline CHEMBL1317494 & 737824 & 5.4 & 5.1848 & TRN & \\
\hline CHEMBL1526768 & 737824 & 6.2 & 6.0876 & TST & \\
\hline CHEMBL1585273 & 737824 & 5.3 & 5.0789 & TST & \\
\hline CHEMBL1453311 & 737824 & 4.95 & 5.3353 & TRN & \\
\hline CHEMBL 3209835 & 737824 & 4.45 & 4.9838 & TRN & \\
\hline CHEMBL1492299 & 737824 & 7.45 & 5.4622 & TRN & \\
\hline CHEMBL1328324 & 737824 & 5.1 & 4.7733 & TST & \\
\hline CHEMBL1379160 & 737824 & 5.1 & 5.3554 & TRN & \\
\hline CHEMBL1466675 & 737824 & 5.5 & 5.1188 & TRN & \\
\hline CHEMBL1487013 & 737824 & 5.85 & 5.4649 & TRN & \\
\hline CHEMBL1442770 & 737824 & 4.4 & 4.3137 & TST & \\
\hline CHEMBL1450157 & 737824 & 5.5 & 5.5783 & TRN & \\
\hline CHEMBL1463649 & 737824 & 6.0 & 5.5975 & TRN & \\
\hline CHEMBL1526390 & 737824 & 5.35 & 5.3601 & TRN & \\
\hline CHEMBL1547711 & 737824 & 4.8 & 5.114 & TRN & \\
\hline CHEMBL1399922 & 737824 & 4.7 & 4.6515 & TST & \\
\hline CHEMBL1406460 & 737824 & 5.2 & 5.1577 & TST & \\
\hline CHEMBL1575087 & 737824 & 4.95 & 4.9602 & TRN & \\
\hline CHEMBL1326360 & 737824 & 4.8 & 5.0075 & TRN & \\
\hline CHEMBL1414662 & 737824 & 5.2 & 5.4859 & TRN & \\
\hline CHEMBL1611066 & 737824 & 4.8 & 4.7908 & TRN & \\
\hline CHEMBL1498995 & 737824 & 5.65 & 5.2625 & TST & \\
\hline CHEMBL1504481 & 737824 & 5.6 & 5.1989 & TRN & \\
\hline CHEMBL1256984 & 737824 & 5.7 & 5.4499 & TST & \\
\hline CHEMBL1257078 & 737824 & 5.3 & 5.48600 & 2000000001 & TST \\
\hline CHEMBL1610082 & 737824 & 5.1 & 5.4383 & TRN & \\
\hline CHEMBL3198450 & 737824 & 5.9 & 5.0392 & TST & \\
\hline CHEMBL1372657 & 737824 & 5.2 & 5.1063 & TST & \\
\hline CHEMBL1421520 & 737824 & 5.4 & 5.6772 & TRN & \\
\hline CHEMBL1528428 & 737824 & 4.85 & 4.8033 & TST & \\
\hline CHEMBL1450903 & 737824 & 4.6 & 4.1867 & TRN & \\
\hline CHEMBL1566101 & 737824 & 4.9 & 4.6127 & TRN & \\
\hline CHEMBL1441593 & 737824 & 5.8 & 5.9101 & TRN & \\
\hline CHEMBL1580932 & 737824 & 5.85 & 5.72 & TRN & \\
\hline CHEMBL1384675 & 737824 & 5.65 & 5.53 & TRN & \\
\hline CHEMBL1425311 & 737824 & 5.3 & 5.15799 & 99999999995 & TRN \\
\hline CHEMBL1572371 & 737824 & 5.75 & 5.7146 & TRN & \\
\hline CHEMBL1538333 & 737824 & 5.1 & 5.3654 & TRN & \\
\hline CHEMBL1544965 & 737824 & 5.05 & 5.3179 & TRN & \\
\hline & & & & 7672 & \\
\hline
\end{tabular}




\begin{tabular}{|c|c|c|c|c|c|}
\hline \\
\hline CHEMBL1473055 & 737824 & 4.8 & 4.5998 & TRN & \\
\hline CHEMBL3198385 & 737824 & 4.8 & 5.2728 & TRN & \\
\hline CHEMBL1408427 & 737824 & 7.6 & 7.9252 & TRN & \\
\hline CHEMBL1493411 & 737824 & 5.3 & 5.3411 & TST & \\
\hline CHEMBL1405860 & 737824 & 4.5 & 5.3072 & TRN & \\
\hline CHEMBL60718 & 737824 & 5.0 & 4.8557 & TRN & \\
\hline CHEMBL1300567 & 737824 & 5.85 & 5.1089 & TST & \\
\hline CHEMBL3210945 & 737824 & 5.6 & 5.4166 & TRN & \\
\hline CHEMBL1357130 & 737824 & 5.1 & 4.9576 & TST & \\
\hline CHEMBL1506736 & 737824 & 4.95 & 5.1792 & TRN & \\
\hline CHEMBL1598049 & 737824 & 4.85 & 5.2502 & TRN & \\
\hline CHEMBL1307447 & 737824 & 5.4 & 5.2426 & TRN & \\
\hline CHEMBL1355135 & 737824 & 4.8 & 4.9282 & TRN & \\
\hline CHEMBL279731 & 737824 & 5.1 & 4.2363 & TST & \\
\hline CHEMBL1603802 & 737824 & 5.5 & 5.1334 & TST & \\
\hline CHEMBL3195378 & 737824 & 5.0 & 4.7402 & TST & \\
\hline CHEMBL1435809 & 737824 & 4.9 & 5.0089 & TRN & \\
\hline CHEMBL1451562 & 737824 & 4.5 & 4.1603 & TRN & \\
\hline CHEMBL1491271 & 737824 & 6.15 & 5.7788 & TRN & \\
\hline CHEMBL73310 & 737824 & 4.8 & 4.48 & TRN & \\
\hline CHEMBL1562101 & 737824 & 4.8 & 5.2448 & TRN & \\
\hline CHEMBL1579814 & 737824 & 6.15 & 5.4819 & TRN & \\
\hline CHEMBL1534143 & 737824 & 4.6 & 5.0304 & TRN & \\
\hline CHEMBL1384711 & 737824 & 5.4 & 5.26200 & 0000000005 & TRN \\
\hline CHEMBL1415219 & 737824 & 5.05 & 4.953 & TRN & \\
\hline CHEMBL1610514 & 737824 & 5.0 & 4.8509 & TRN & \\
\hline CHEMBL1314451 & 737824 & 6.2 & 5.9054 & TRN & \\
\hline CHEMBL3210074 & 737824 & 5.45 & 5.3164 & TRN & \\
\hline CHEMBL1437990 & 737824 & 6.2 & 6.2574 & TRN & \\
\hline CHEMBL1454855 & 737824 & 5.5 & 5.8819 & TRN & \\
\hline CHEMBL1971420 & 737824 & 4.45 & 4.8271 & TRN & \\
\hline CHEMBL1352069 & 737824 & 5.25 & 5.1174 & TST & \\
\hline CHEMBL1415500 & 737824 & 5.0 & 5.4483 & TRN & \\
\hline CHEMBL1407398 & 737824 & 5.45 & 5.141 & TRN & \\
\hline CHEMBL1309130 & 737824 & 4.85 & 4.6075 & TRN & \\
\hline CHEMBL1358722 & 737824 & 4.8 & 4.1831 & TST & \\
\hline CHEMBL1497592 & 737824 & 4.65 & 5.0436 & TRN & \\
\hline CHEMBL1546161 & 737824 & 6.55 & 5.7899 & TST & \\
\hline CHEMBL1375985 & 737824 & 5.65 & 5.6694 & TST & \\
\hline CHEMBL1580710 & 737824 & 6.25 & 5.5077 & TRN & \\
\hline CHEMBL1398600 & 737824 & 5.8 & 5.7474 & TST & \\
\hline CHEMBL1256359 & 737824 & 5.4 & 5.1401 & TRN & \\
\hline CHEMBL1573735 & 737824 & 4.8 & 5.3165 & TST & \\
\hline CHEMBL1364717 & 737824 & 6.9 & 5.9839 & TRN & \\
\hline CHEMBL1609160 & 737824 & 5.1 & 5.6563 & TST & \\
\hline CHEMBL1574531 & 737824 & 5.05 & 5.3288 & TRN & \\
\hline CHEMBL1610350 & 737824 & 6.5 & 6.303 & TRN & \\
\hline CHEMBL1356844 & 737824 & 6.5 & 5.61 & TRN & \\
\hline & & & & 7673 & \\
\hline
\end{tabular}




\begin{tabular}{|c|c|c|c|c|}
\hline \multicolumn{5}{|c|}{ lemental I } \\
\hline CHEMBL1456454 & 737824 & 4.6 & 4.8494 & TRN \\
\hline CHEMBL1547900 & 737824 & 4.4 & 4.8575 & TRN \\
\hline CHEMBL1499297 & 737824 & 5.85 & 5.2493 & TST \\
\hline CHEMBL1481361 & 737824 & 5.1 & 4.9741 & TRN \\
\hline CHEMBL1386546 & 737824 & 5.4 & 5.5755 & TRN \\
\hline CHEMBL1299593 & 737824 & 4.4 & 5.295 & TRN \\
\hline CHEMBL547407 & 737824 & 4.95 & 5.1081 & TRN \\
\hline CHEMBL1527332 & 737824 & 4.9 & 4.8607 & TRN \\
\hline CHEMBL1612586 & 737824 & 5.65 & 5.2679 & TRN \\
\hline CHEMBL1569147 & 737824 & 4.5 & 4.9529 & TST \\
\hline CHEMBL321691 & 737824 & 4.8 & 4.1708 & TST \\
\hline CHEMBL1460951 & 737824 & 5.0 & 5.0758 & TRN \\
\hline CHEMBL1318622 & 737824 & 6.5 & 6.4985 & TRN \\
\hline CHEMBL1589133 & 737824 & 4.95 & 5.1535 & TRN \\
\hline CHEMBL1398790 & 737824 & 5.35 & 5.1111 & TRN \\
\hline CHEMBL1334543 & 737824 & 4.4 & 4.8086 & TRN \\
\hline CHEMBL1575145 & 737824 & 5.15 & 5.2766 & TRN \\
\hline CHEMBL1356628 & 737824 & 4.6 & 4.213 & TST \\
\hline CHEMBL1364298 & 737824 & 5.95 & 6.1273 & TRN \\
\hline CHEMBL1448223 & 737824 & 4.85 & 5.2334 & TRN \\
\hline CHEMBL1416184 & 737824 & 5.6 & 5.9623 & TRN \\
\hline CHEMBL1356943 & 737824 & 4.4 & 4.4081 & TRN \\
\hline CHEMBL3195361 & 737824 & 5.65 & 5.2114 & TRN \\
\hline CHEMBL1413647 & 737824 & 4.35 & 4.834 & TST \\
\hline CHEMBL1522372 & 737824 & 4.95 & 5.4374 & TRN \\
\hline CHEMBL1525571 & 737824 & 5.85 & 5.2015 & TRN \\
\hline CHEMBL1322979 & 737824 & 5.4 & 5.3193 & TRN \\
\hline CHEMBL1332937 & 737824 & 4.6 & 4.6164 & TRN \\
\hline CHEMBL1411467 & 737824 & 5.0 & 5.6882 & TRN \\
\hline CHEMBL1451128 & 737824 & 4.9 & 5.2513 & TRN \\
\hline CHEMBL87385 & 737824 & 5.6 & 5.21899 & 9999999999 \\
\hline CHEMBL1470578 & 737824 & 4.85 & 5.0406 & TRN \\
\hline CHEMBL1596186 & 737824 & 5.5 & 6.0008 & TST \\
\hline CHEMBL1345104 & 737824 & 5.35 & 5.2903 & TRN \\
\hline CHEMBL1447682 & 737824 & 5.9 & 5.8778 & TRN \\
\hline CHEMBL1604095 & 737824 & 4.9 & 4.8732 & TRN \\
\hline CHEMBL1531754 & 737824 & 6.0 & 5.9992 & TRN \\
\hline CHEMBL1406800 & 737824 & 4.8 & 5.1031 & TRN \\
\hline CHEMBL1503387 & 737824 & 5.8 & 5.8931 & TRN \\
\hline CHEMBL1497087 & 737824 & 4.5 & 5.3317 & TRN \\
\hline CHEMBL1548428 & 737824 & 5.4 & 5.1579 & TRN \\
\hline CHEMBL1554721 & 737824 & 7.9 & 8.3681 & TRN \\
\hline CHEMBL1374913 & 737824 & 5.3 & 5.0843 & TRN \\
\hline CHEMBL1410388 & 737824 & 4.6 & 4.957 & TRN \\
\hline CHEMBL1461462 & 737824 & 5.6 & 5.1909 & TRN \\
\hline CHEMBL3197177 & 737824 & 5.05 & 4.6389 & TRN \\
\hline CHEMBL1472356 & 737824 & 5.85 & 5.4788 & TRN \\
\hline CHEMBL1409720 & 737824 & 5.5 & 5.705 & TRN \\
\hline
\end{tabular}




\begin{tabular}{|c|c|c|c|c|c|}
\hline & & & & & \\
\hline CHEMBL1514765 & 737824 & 5.5 & 5.0799 & TST & \\
\hline CHEMBL1509145 & 737824 & 5.6 & 5.4898 & TRN & \\
\hline CHEMBL1604264 & 737824 & 5.8 & 5.7853 & TRN & \\
\hline CHEMBL1512190 & 737824 & 4.9 & 4.6814 & TRN & \\
\hline CHEMBL1384381 & 737824 & 4.65 & 5.18 & TRN & \\
\hline CHEMBL1514639 & 737824 & 4.8 & 4.6654 & TST & \\
\hline CHEMBL1607620 & 737824 & 5.05 & 4.8946 & TRN & \\
\hline CHEMBL1602050 & 737824 & 5.3 & 5.4138 & TRN & \\
\hline CHEMBL1520292 & 737824 & 4.5 & 4.2559 & TRN & \\
\hline CHEMBL1371202 & 737824 & 5.4 & 5.74799 & 9999999999 & TRN \\
\hline CHEMBL1469385 & 737824 & 5.95 & 5.3415 & TST & \\
\hline CHEMBL1383897 & 737824 & 4.6 & 4.6401 & TRN & \\
\hline CHEMBL1476604 & 737824 & 5.0 & 4.7886 & TRN & \\
\hline CHEMBL1466677 & 737824 & 6.3 & 6.1924 & TRN & \\
\hline CHEMBL1590968 & 737824 & 5.0 & 5.0781 & TRN & \\
\hline CHEMBL1411555 & 737824 & 5.45 & 5.5729 & TRN & \\
\hline CHEMBL1303031 & 737824 & 6.05 & 5.9064 & TRN & \\
\hline CHEMBL1364517 & 737824 & 4.85 & 5.4853 & TRN & \\
\hline CHEMBL1477644 & 737824 & 5.4 & 5.5102 & TST & \\
\hline CHEMBL1344080 & 737824 & 5.75 & 5.0776 & TRN & \\
\hline CHEMBL1447487 & 737824 & 5.3 & 5.2466 & TRN & \\
\hline CHEMBL1741977 & 737824 & 5.0 & 5.0449 & TRN & \\
\hline CHEMBL1495840 & 737824 & 4.9 & 4.7386 & TRN & \\
\hline CHEMBL1522198 & 737824 & 4.95 & 5.0433 & TST & \\
\hline CHEMBL1562277 & 737824 & 5.4 & 5.5774 & TRN & \\
\hline CHEMBL1498966 & 737824 & 4.55 & 5.0713 & TRN & \\
\hline CHEMBL1529700 & 737824 & 5.05 & 5.1347 & TRN & \\
\hline CHEMBL1448819 & 737824 & 5.7 & 6.0042 & TRN & \\
\hline CHEMBL1604074 & 737824 & 4.9 & 4.75 & TRN & \\
\hline CHEMBL1572599 & 737824 & 5.9 & 5.1136 & TRN & \\
\hline CHEMBL1476871 & 737824 & 4.4 & 4.521 & TST & \\
\hline CHEMBL1306491 & 737824 & 5.5 & 5.4394 & TRN & \\
\hline CHEMBL56731 & 737824 & 4.9 & 5.0948 & TRN & \\
\hline CHEMBL1726685 & 737824 & 4.85 & 5.2972 & TST & \\
\hline CHEMBL1537099 & 737824 & 5.35 & 5.879 & TST & \\
\hline CHEMBL1364980 & 737824 & 4.7 & 4.3611 & TRN & \\
\hline CHEMBL1316075 & 737824 & 5.1 & 5.3103 & TRN & \\
\hline CHEMBL1362300 & 737824 & 4.4 & 4.8474 & TRN & \\
\hline CHEMBL1577593 & 737824 & 4.95 & 5.2471 & TRN & \\
\hline CHEMBL1406556 & 737824 & 5.5 & 5.185 & TRN & \\
\hline CHEMBL1551308 & 737824 & 7.1 & 6.7404 & TRN & \\
\hline CHEMBL1479195 & 737824 & 4.4 & 5.2094 & TST & \\
\hline CHEMBL1487191 & 737824 & 7.6 & 6.7068 & TRN & \\
\hline CHEMBL1440293 & 737824 & 5.85 & 5.79299 & 9999999999 & TST \\
\hline CHEMBL1470690 & 737824 & 4.75 & 4.7991 & TRN & \\
\hline CHEMBL1602812 & 737824 & 4.6 & 4.4571 & TRN & \\
\hline CHEMBL1492687 & 737824 & 6.65 & 5.6349 & TRN & \\
\hline CHEMBL1546010 & 737824 & 4.85 & 5.5859 & TST & \\
\hline & & & & 7675 & \\
\hline
\end{tabular}




\begin{tabular}{|c|c|c|c|c|}
\hline \multicolumn{5}{|c|}{ Supplemental Table S2.txt } \\
\hline CHEMBL421215 & 737824 & 5.8 & 5.8026 & TST \\
\hline CHEMBL402468 & 737824 & 4.5 & 4.5881 & TRN \\
\hline CHEMBL1437488 & 737824 & 7.3 & 5.803 & TRN \\
\hline CHEMBL1552540 & 737824 & 5.0 & 5.1352 & TRN \\
\hline CHEMBL50112 & 737824 & 4.8 & 4.2141 & TRN \\
\hline CHEMBL1551749 & 737824 & 4.9 & 4.4643 & TRN \\
\hline CHEMBL1443798 & 737824 & 5.5 & 5.7672 & TST \\
\hline CHEMBL1486554 & 737824 & 5.3 & 5.1051 & TRN \\
\hline CHEMBL1423713 & 737824 & 5.6 & 5.0557 & TRN \\
\hline CHEMBL440084 & 737824 & 5.6 & 5.0987 & TRN \\
\hline CHEMBL1512250 & 737824 & 5.0 & 4.9202 & TRN \\
\hline CHEMBL1400043 & 737824 & 5.7 & 5.5914 & TRN \\
\hline CHEMBL1352808 & 737824 & 6.1 & 6.0766 & TRN \\
\hline CHEMBL1598717 & 737824 & 4.7 & 5.0528 & TRN \\
\hline CHEMBL1446078 & 737824 & 4.45 & 5.0891 & TRN \\
\hline CHEMBL1522187 & 737824 & 4.55 & 4.8073 & TRN \\
\hline CHEMBL523283 & 737824 & 6.0 & 5.836 & TRN \\
\hline CHEMBL1312586 & 737824 & 5.85 & 5.8412 & TRN \\
\hline CHEMBL1572029 & 737824 & 5.1 & 5.8145 & TRN \\
\hline CHEMBL1446324 & 737824 & 4.4 & 4.1798 & TRN \\
\hline CHEMBL1301960 & 737824 & 5.05 & 5.2486 & TRN \\
\hline CHEMBL1451167 & 737824 & 4.6 & 5.2756 & TRN \\
\hline CHEMBL3196704 & 737824 & 5.65 & 5.3816 & TRN \\
\hline CHEMBL1471411 & 737824 & 5.1 & 5.7358 & TRN \\
\hline CHEMBL1699614 & 737824 & 4.9 & 5.0945 & TRN \\
\hline CHEMBL1408856 & 737824 & 6.3 & 6.1112 & TRN \\
\hline CHEMBL1358012 & 737824 & 5.1 & 4.7239 & TST \\
\hline CHEMBL1498627 & 737824 & 5.65 & 5.6256 & TRN \\
\hline CHEMBL1395088 & 737824 & 6.4 & 6.2913 & TRN \\
\hline CHEMBL1600131 & 737824 & 5.15 & 4.9156 & TRN \\
\hline CHEMBL1742280 & 737824 & 5.3 & 5.1741 & TRN \\
\hline CHEMBL1416225 & 737824 & 4.85 & 5.0763 & TRN \\
\hline CHEMBL1436761 & 737824 & -0.0 & 4.2074 & TRN \\
\hline CHEMBL1541487 & 737824 & 4.6 & 4.9459 & TRN \\
\hline CHEMBL1589897 & 737824 & 4.4 & 4.3035 & TRN \\
\hline CHEMBL1585681 & 737824 & 4.55 & 4.9281 & TRN \\
\hline CHEMBL1421344 & 737824 & 5.55 & 5.1952 & TRN \\
\hline CHEMBL1396862 & 737824 & 6.5 & 6.2125 & TRN \\
\hline CHEMBL 3189280 & 737824 & 5.1 & 5.5652 & TRN \\
\hline CHEMBL1384477 & 737824 & 5.1 & 5.3312 & TRN \\
\hline CHEMBL1405464 & 737824 & 5.3 & 5.653 & TRN \\
\hline CHEMBL2369181 & 737824 & 5.15 & 5.1252 & TRN \\
\hline CHEMBL1360337 & 737824 & 5.05 & 5.4098 & TRN \\
\hline CHEMBL1361114 & 737824 & 5.55 & 5.3079 & TST \\
\hline CHEMBL1516265 & 737824 & 4.9 & 4.9196 & TRN \\
\hline CHEMBL1477503 & 737824 & 4.9 & 4.9571 & TRN \\
\hline CHEMBL1465935 & 737824 & 5.5 & 5.2855 & TRN \\
\hline CHEMBL1415331 & 737824 & 6.15 & 5.4704 & TRN \\
\hline
\end{tabular}




\begin{tabular}{|c|c|c|c|c|c|}
\hline \\
\hline CHEMBL188641 & 737824 & 5.8 & 5.9509 & TST & \\
\hline CHEMBL1361839 & 737824 & 4.6 & 4.1132 & TRN & \\
\hline CHEMBL1312373 & 737824 & 4.55 & 5.2103 & TRN & \\
\hline CHEMBL1581737 & 737824 & 4.9 & 5.3887 & TRN & \\
\hline CHEMBL1566442 & 737824 & 6.1 & 5.9484 & TRN & \\
\hline CHEMBL1335382 & 737824 & 5.45 & 5.4134 & TRN & \\
\hline CHEMBL1324889 & 737824 & 5.4 & 5.3876 & TRN & \\
\hline CHEMBL1458255 & 737824 & 5.0 & 5.12 & TRN & \\
\hline CHEMBL1741487 & 737824 & 5.75 & 5.1694 & TRN & \\
\hline CHEMBL1400546 & 737824 & 5.0 & 4.9853 & TST & \\
\hline CHEMBL1365848 & 737824 & 6.75 & 5.415 & TRN & \\
\hline CHEMBL3212912 & 737824 & 6.35 & 5.004 & TST & \\
\hline CHEMBL1315700 & 737824 & 6.0 & 5.848 & TRN & \\
\hline CHEMBL1359611 & 737824 & 4.55 & 5.0421 & TRN & \\
\hline CHEMBL1521784 & 737824 & 5.3 & 5.1807 & TRN & \\
\hline CHEMBL1593589 & 737824 & 7.4 & 6.9582 & TRN & \\
\hline CHEMBL1323241 & 737824 & 4.85 & 4.6192 & TRN & \\
\hline CHEMBL1544357 & 737824 & 4.55 & 4.6508 & TST & \\
\hline CHEMBL1593134 & 737824 & 4.4 & 4.2886 & TRN & \\
\hline CHEMBL490718 & 737824 & 4.9 & 4.636 & TRN & \\
\hline CHEMBL3194740 & 737824 & 5.3 & 5.1881 & TRN & \\
\hline CHEMBL1424743 & 737824 & 5.0 & 5.0366 & TRN & \\
\hline CHEMBL1489182 & 737824 & 5.0 & 5.58799 & 9999999999 & TRN \\
\hline CHEMBL1565546 & 737824 & 5.05 & 5.0815 & TRN & \\
\hline CHEMBL1357956 & 737824 & 4.9 & 4.9767 & TRN & \\
\hline CHEMBL1573862 & 737824 & 4.7 & 4.7693 & TRN & \\
\hline CHEMBL567175 & 737824 & 6.0 & 5.8494 & TST & \\
\hline CHEMBL1415013 & 737824 & 4.4 & 5.004 & TRN & \\
\hline CHEMBL1595576 & 737824 & 5.7 & 5.6967 & TRN & \\
\hline CHEMBL1550716 & 737824 & 4.5 & 5.3723 & TRN & \\
\hline CHEMBL1488095 & 737824 & 5.4 & 5.1982 & TRN & \\
\hline CHEMBL1558519 & 737824 & 4.75 & 5.0984 & TRN & \\
\hline CHEMBL1596221 & 737824 & 6.2 & 5.6241 & TRN & \\
\hline CHEMBL1435216 & 737824 & 4.9 & 4.5134 & TRN & \\
\hline CHEMBL1438456 & 737824 & 5.0 & 5.1331 & TRN & \\
\hline CHEMBL1717575 & 737824 & 4.75 & 4.9683 & TRN & \\
\hline CHEMBL1742327 & 737824 & 5.1 & 5.1711 & TRN & \\
\hline CHEMBL3210161 & 737824 & 7.0 & 6.7616 & TRN & \\
\hline CHEMBL1356041 & 737824 & 5.1 & 5.0261 & TRN & \\
\hline CHEMBL1417552 & 737824 & 5.2 & 4.9768 & TRN & \\
\hline CHEMBL1392213 & 737824 & 5.35 & 5.1194 & TRN & \\
\hline CHEMBL 3212240 & 737824 & 4.4 & 5.3347 & TRN & \\
\hline CHEMBL1317358 & 737824 & 4.9 & 5.0205 & TRN & \\
\hline CHEMBL1323549 & 737824 & 7.4 & 7.3054 & TRN & \\
\hline CHEMBL1486915 & 737824 & 4.8 & 4.4125 & TRN & \\
\hline CHEMBL1444983 & 737824 & 5.15 & 5.042 & TRN & \\
\hline CHEMBL1382161 & 737824 & 5.45 & 4.7429 & TST & \\
\hline CHEMBL1506831 & 737824 & 5.15 & 5.3319 & TRN & \\
\hline
\end{tabular}




\begin{tabular}{|c|c|c|c|c|c|}
\hline & & \multicolumn{4}{|c|}{ Supplemental Table S2.txt } \\
\hline CHEMBL1573306 & 737824 & 4.75 & 5.3489 & TRN & \\
\hline CHEMBL1352255 & 737824 & 4.4 & 4.878 & TRN & \\
\hline CHEMBL1324352 & 737824 & 5.55 & 5.2841 & TRN & \\
\hline CHEMBL1322414 & 737824 & 7.0 & 6.5923 & TRN & \\
\hline CHEMBL1568111 & 737824 & 4.9 & 4.8508 & TRN & \\
\hline CHEMBL1437054 & 737824 & 8.5 & 7.4528 & TST & \\
\hline CHEMBL1453364 & 737824 & 4.8 & 5.2922 & TRN & \\
\hline CHEMBL1308391 & 737824 & 5.55 & 5.5954 & TRN & \\
\hline CHEMBL1437012 & 737824 & 5.7 & 5.6339 & TST & \\
\hline CHEMBL3208477 & 737824 & 4.9 & 5.0489 & TRN & \\
\hline CHEMBL1340864 & 737824 & 4.6 & 5.2801 & TRN & \\
\hline CHEMBL1464487 & 737824 & 7.15 & 5.4909 & TST & \\
\hline CHEMBL3192460 & 737824 & 5.15 & 5.6696 & TRN & \\
\hline CHEMBL1405627 & 737824 & 4.7 & 4.6017 & TRN & \\
\hline CHEMBL1478504 & 737824 & 5.9 & 5.7383 & TRN & \\
\hline CHEMBL1549831 & 737824 & 6.7 & 5.8983 & TRN & \\
\hline CHEMBL1566105 & 737824 & 6.0 & 5.854 & TST & \\
\hline CHEMBL1304054 & 737824 & 5.6 & 5.4536 & TRN & \\
\hline CHEMBL473136 & 737824 & 5.5 & 4.7875 & TST & \\
\hline CHEMBL419815 & 737824 & 4.6 & 4.8746 & TST & \\
\hline CHEMBL1570347 & 737824 & 5.35 & 5.4619 & TRN & \\
\hline CHEMBL1450521 & 737824 & 6.6 & 6.6628 & TRN & \\
\hline CHEMBL1583978 & 737824 & 5.0 & 5.3532 & TRN & \\
\hline CHEMBL1551557 & 737824 & 5.8 & 5.7958 & TRN & \\
\hline CHEMBL3192160 & 737824 & 4.85 & 5.0181 & TRN & \\
\hline CHEMBL1514740 & 737824 & 4.4 & 4.0393 & TRN & \\
\hline CHEMBL1304319 & 737824 & 5.8 & 5.3429 & TRN & \\
\hline CHEMBL1573739 & 737824 & 4.95 & 5.3455 & TRN & \\
\hline CHEMBL88147 & 737824 & 5.8 & 5.9736 & TRN & \\
\hline CHEMBL1376543 & 737824 & 4.7 & 3.9771 & TST & \\
\hline CHEMBL1498144 & 737824 & 5.95 & $5.3210 e$ & 0000000001 & TRN \\
\hline CHEMBL1340514 & 737824 & 5.4 & 5.7382 & TRN & \\
\hline CHEMBL1483207 & 737824 & 5.05 & 4.6499 & TRN & \\
\hline CHEMBL1590855 & 737824 & 5.5 & 5.4184 & TRN & \\
\hline CHEMBL3145189 & 737824 & 5.35 & 5.1653 & TRN & \\
\hline CHEMBL1598680 & 737824 & 6.0 & 5.9691 & TRN & \\
\hline CHEMBL1447438 & 737824 & 4.4 & 4.044 & TRN & \\
\hline CHEMBL1725604 & 737824 & 4.75 & 5.5563 & TRN & \\
\hline CHEMBL1502591 & 737824 & 5.35 & 5.5079 & TRN & \\
\hline CHEMBL1427581 & 737824 & 4.9 & 4.8466 & TRN & \\
\hline CHEMBL1528626 & 737824 & 5.45 & 5.3867 & TRN & \\
\hline CHEMBL1303074 & 737824 & 4.75 & 5.0916 & TST & \\
\hline CHEMBL1523691 & 737824 & 5.1 & 5.2186 & TST & \\
\hline CHEMBL1375759 & 737824 & 5.35 & 5.4281 & TRN & \\
\hline CHEMBL1966867 & 737824 & 4.8 & 4.6852 & TRN & \\
\hline CHEMBL432527 & 737824 & 8.0 & 7.1169 & TRN & \\
\hline CHEMBL1561927 & 737824 & 6.0 & 5.4693 & TRN & \\
\hline CHEMBL1518559 & 737824 & 4.9 & 4.9774 & TRN & \\
\hline
\end{tabular}




\begin{tabular}{|c|c|c|c|c|c|}
\hline \\
\hline CHEMBL1370053 & 737824 & 4.8 & 5.4271 & TRN & \\
\hline CHEMBL1514398 & 737824 & 8.6 & 7.6009 & TST & \\
\hline CHEMBL3145176 & 737824 & 4.75 & 5.3451 & TST & \\
\hline CHEMBL1547922 & 737824 & 4.9 & 4.7816 & TRN & \\
\hline CHEMBL3192674 & 737824 & 6.4 & 6.0609 & TRN & \\
\hline CHEMBL512832 & 737824 & 5.9 & 5.9369 & TRN & \\
\hline CHEMBL1428605 & 737824 & 5.4 & 4.8535 & TRN & \\
\hline CHEMBL1555067 & 737824 & 4.5 & 4.5596 & TST & \\
\hline CHEMBL 269366 & 737824 & 5.9 & 5.5858 & TST & \\
\hline CHEMBL1309731 & 737824 & 4.8 & 5.4848 & TRN & \\
\hline CHEMBL1521286 & 737824 & 4.65 & 5.1559 & TST & \\
\hline CHEMBL1323029 & 737824 & 5.05 & 5.1863 & TRN & \\
\hline CHEMBL1415809 & 737824 & 7.15 & 4.9366 & TST & \\
\hline CHEMBL1410452 & 737824 & 4.9 & 4.8285 & TRN & \\
\hline CHEMBL1698558 & 737824 & 5.0 & 5.0196 & TRN & \\
\hline CHEMBL1405762 & 737824 & 7.1 & 6.44799 & 99999999995 & TST \\
\hline CHEMBL1407743 & 737824 & 4.7 & 5.0049 & TRN & \\
\hline CHEMBL1316337 & 737824 & 5.8 & 5.4803 & TRN & \\
\hline CHEMBL1602849 & 737824 & 6.25 & 5.6714 & TRN & \\
\hline CHEMBL1587080 & 737824 & 5.35 & 4.9552 & TST & \\
\hline CHEMBL1351222 & 737824 & 6.2 & 5.5864 & TST & \\
\hline CHEMBL1538975 & 737824 & 5.85 & 5.6184 & TRN & \\
\hline CHEMBL1419479 & 737824 & 4.9 & 4.6035 & TST & \\
\hline CHEMBL1529652 & 737824 & 5.15 & 5.266 & TRN & \\
\hline CHEMBL1338276 & 737824 & 6.5 & 5.8359 & TRN & \\
\hline CHEMBL1407667 & 737824 & 5.9 & 5.3528 & TRN & \\
\hline CHEMBL1484108 & 737824 & 5.85 & 5.3314 & TRN & \\
\hline CHEMBL611494 & 737824 & 5.1 & 5.2033 & TST & \\
\hline CHEMBL1322311 & 737824 & 5.2 & 5.4188 & TRN & \\
\hline CHEMBL1537212 & 737824 & 4.75 & 4.9095 & TST & \\
\hline CHEMBL1442458 & 737824 & 4.5 & 4.5446 & TRN & \\
\hline CHEMBL1327681 & 737824 & 5.2 & 5.131 & TRN & \\
\hline CHEMBL1463824 & 737824 & 5.2 & 5.3812 & TRN & \\
\hline CHEMBL1970527 & 737824 & 5.8 & 5.5115 & TRN & \\
\hline CHEMBL1701090 & 737824 & 4.55 & 5.1802 & TRN & \\
\hline CHEMBL1593774 & 737824 & 5.9 & 5.9768 & TRN & \\
\hline CHEMBL1732963 & 737824 & 5.2 & 5.7328 & TRN & \\
\hline CHEMBL1539263 & 737824 & 5.55 & 5.9031 & TRN & \\
\hline CHEMBL1601970 & 737824 & 5.1 & 5.4804 & TST & \\
\hline CHEMBL 1256667 & 737824 & 4.6 & 4.8419 & TST & \\
\hline CHEMBL1514719 & 737824 & 6.4 & 5.9165 & TRN & \\
\hline CHEMBL1412769 & 737824 & 5.0 & 4.7393 & TRN & \\
\hline CHEMBL1475951 & 737824 & 6.5 & 6.5177 & TRN & \\
\hline CHEMBL1311026 & 737824 & 5.9 & 5.3804 & TST & \\
\hline CHEMBL1317885 & 737824 & 4.9 & 4.8917 & TRN & \\
\hline CHEMBL1377215 & 737824 & 5.35 & 5.5524 & TRN & \\
\hline CHEMBL1448161 & 737824 & 6.25 & 5.2005 & TST & \\
\hline CHEMBL1607228 & 737824 & 6.0 & 6.1277 & TRN & \\
\hline
\end{tabular}




\begin{tabular}{|c|c|c|c|c|}
\hline \multicolumn{5}{|c|}{ Supplemental Table S2.txt } \\
\hline CHEMBL1550370 & 737824 & 4.85 & 5.3073 & TRN \\
\hline CHEMBL1606723 & 737824 & 4.65 & 5.2994 & TRN \\
\hline CHEMBL1429915 & 737824 & 5.65 & 5.4823 & TRN \\
\hline CHEMBL1578181 & 737824 & 5.15 & 5.6497 & TRN \\
\hline CHEMBL1435276 & 737824 & 4.6 & 4.415 & TRN \\
\hline CHEMBL1430918 & 737824 & 5.4 & 5.2668 & TRN \\
\hline CHEMBL1606673 & 737824 & 4.6 & 5.1179 & TRN \\
\hline CHEMBL1398931 & 737824 & 5.1 & 5.0851 & TRN \\
\hline CHEMBL1310646 & 737824 & 4.65 & 4.8095 & TRN \\
\hline CHEMBL1192187 & 737824 & 4.8 & 4.2158 & TRN \\
\hline CHEMBL1990383 & 737824 & 5.05 & 5.3736 & TRN \\
\hline CHEMBL1484337 & 737824 & 4.6 & 4.4962 & TRN \\
\hline CHEMBL1487874 & 737824 & 4.95 & 5.0662 & TRN \\
\hline CHEMBL1414913 & 737824 & 4.6 & 5.2845 & TRN \\
\hline CHEMBL1366778 & 737824 & 4.6 & 4.9225 & TRN \\
\hline CHEMBL1504577 & 737824 & 5.55 & 4.9467 & TRN \\
\hline CHEMBL77030 & 737824 & 4.6 & 4.5106 & TRN \\
\hline CHEMBL 3210166 & 737824 & 4.8 & 4.7838 & TRN \\
\hline CHEMBL1493054 & 737824 & 6.05 & 5.9298 & TRN \\
\hline CHEMBL1499633 & 737824 & 4.55 & 5.2521 & TRN \\
\hline CHEMBL1610961 & 737824 & 4.9 & 5.039 & TRN \\
\hline CHEMBL1432644 & 737824 & 4.65 & 4.959 & TRN \\
\hline CHEMBL1516706 & 737824 & 5.15 & 5.0347 & TRN \\
\hline CHEMBL1322549 & 737824 & 5.3 & 4.6724 & TST \\
\hline CHEMBL1366383 & 737824 & 5.55 & 5.2253 & TRN \\
\hline CHEMBL1551777 & 737824 & 4.9 & 4.805 & TRN \\
\hline CHEMBL1730298 & 737824 & 4.4 & 4.7544 & TRN \\
\hline CHEMBL1331745 & 737824 & 4.8 & 5.0094 & TRN \\
\hline CHEMBL1564361 & 737824 & 5.55 & 5.066 & TRN \\
\hline CHEMBL 1479340 & 737824 & 5.75 & 5.7727 & TRN \\
\hline CHEMBL1325735 & 737824 & 5.4 & 5.4884 & TRN \\
\hline CHEMBL1504999 & 737824 & 4.8 & 4.9009 & TST \\
\hline CHEMBL1505091 & 737824 & 5.0 & 5.223 & TST \\
\hline CHEMBL 3211687 & 737824 & 5.15 & 5.1637 & TRN \\
\hline CHEMBL 3212941 & 737824 & 4.5 & 5.0934 & TRN \\
\hline CHEMBL1462380 & 737824 & 4.95 & 4.8434 & TRN \\
\hline CHEMBL1467717 & 737824 & 5.45 & 5.2856 & TRN \\
\hline CHEMBL1584758 & 737824 & 5.45 & 5.0527 & TRN \\
\hline CHEMBL1551567 & 737824 & 7.4 & 6.0945 & TRN \\
\hline CHEMBL1401539 & 737824 & 5.0 & 5.2168 & TRN \\
\hline CHEMBL1603589 & 737824 & 4.55 & 4.9939 & TRN \\
\hline CHEMBL1533616 & 737824 & 5.45 & 5.5482 & TRN \\
\hline CHEMBL3207333 & 737824 & 6.05 & 5.1134 & TRN \\
\hline CHEMBL1536299 & 737824 & 4.9 & 5.4115 & TRN \\
\hline CHEMBL1460432 & 737824 & 4.85 & 5.1931 & TRN \\
\hline CHEMBL1590059 & 737824 & 4.4 & 4.4174 & TRN \\
\hline CHEMBL1340893 & 737824 & 5.45 & 5.1073 & TRN \\
\hline CHEMBL3213913 & 737824 & 6.45 & 5.5836 & TRN \\
\hline
\end{tabular}




\begin{tabular}{|c|c|c|c|c|c|}
\hline & & \multicolumn{4}{|c|}{ Supplemental Table S2.txt } \\
\hline CHEMBL1410101 & 737824 & 5.7 & 5.3864 & TRN & \\
\hline CHEMBL1371490 & 737824 & 6.35 & 5.4801 & TRN & \\
\hline CHEMBL1310415 & 737824 & 4.75 & 4.9507 & TRN & \\
\hline CHEMBL1568982 & 737824 & 5.5 & 5.3818 & TRN & \\
\hline CHEMBL1552752 & 737824 & 5.8 & 5.6493 & TRN & \\
\hline CHEMBL1338825 & 737824 & 4.9 & 4.8939 & TRN & \\
\hline CHEMBL1612127 & 737824 & 4.85 & 5.055 & TRN & \\
\hline CHEMBL1346080 & 737824 & 5.05 & 5.5048 & TRN & \\
\hline CHEMBL1568012 & 737824 & 5.8 & 5.63700 & 00000000005 & TRN \\
\hline CHEMBL1522433 & 737824 & 5.7 & 5.5383 & TST & \\
\hline CHEMBL1406406 & 737824 & 5.0 & 5.5699 & TRN & \\
\hline CHEMBL1465301 & 737824 & 4.45 & 4.7851 & TRN & \\
\hline CHEMBL1597434 & 737824 & 4.6 & 4.4131 & TRN & \\
\hline CHEMBL1704069 & 737824 & 5.85 & 5.3332 & TST & \\
\hline CHEMBL1611022 & 737824 & 5.65 & 5.2085 & TST & \\
\hline CHEMBL 3189564 & 737824 & 4.65 & 4.8359 & TRN & \\
\hline CHEMBL1429076 & 737824 & 4.75 & 5.0853 & TST & \\
\hline CHEMBL1456646 & 737824 & 4.45 & 5.2291 & TRN & \\
\hline CHEMBL428901 & 737824 & 5.7 & 5.7489 & TST & \\
\hline CHEMBL1380910 & 737824 & 4.85 & 5.234 & TRN & \\
\hline CHEMBL1348414 & 737824 & 4.75 & 5.2772 & TST & \\
\hline CHEMBL1444936 & 737824 & 8.1 & 5.7238 & TRN & \\
\hline CHEMBL1465342 & 737824 & 5.45 & 5.5679 & TRN & \\
\hline CHEMBL1342006 & 737824 & 5.8 & 5.8301 & TRN & \\
\hline CHEMBL1607133 & 737824 & 4.6 & 4.4772 & TRN & \\
\hline CHEMBL1510699 & 737824 & 5.75 & 5.5007 & TRN & \\
\hline CHEMBL1509804 & 737824 & 5.7 & 5.4746 & TRN & \\
\hline CHEMBL1600243 & 737824 & 4.95 & 5.5803 & TRN & \\
\hline CHEMBL1582663 & 737824 & 5.45 & 5.2667 & TRN & \\
\hline CHEMBL1333616 & 737824 & 5.45 & 5.1459 & TRN & \\
\hline CHEMBL1320242 & 737824 & 4.95 & 5.3946 & TRN & \\
\hline CHEMBL1564800 & 737824 & 5.05 & 5.1757 & TRN & \\
\hline CHEMBL1478226 & 737824 & 5.2 & 4.9293 & TRN & \\
\hline CHEMBL1591107 & 737824 & 5.1 & 5.3894 & TRN & \\
\hline CHEMBL1521468 & 737824 & 4.55 & 4.7392 & TRN & \\
\hline CHEMBL1399273 & 737824 & 5.05 & 5.1556 & TRN & \\
\hline CHEMBL1561188 & 737824 & 5.65 & 5.5529 & TRN & \\
\hline CHEMBL1316402 & 737824 & 4.4 & 4.9009 & TRN & \\
\hline CHEMBL1532774 & 737824 & 4.55 & 4.4798 & TRN & \\
\hline CHEMBL1571929 & 737824 & 7.1 & 5.9784 & TST & \\
\hline CHEMBL1562715 & 737824 & 5.35 & 5.0944 & TRN & \\
\hline CHEMBL577455 & 737824 & 4.9 & 4.5938 & TST & \\
\hline CHEMBL1569843 & 737824 & 7.4 & 6.2005 & TRN & \\
\hline CHEMBL1530789 & 737824 & 5.95 & 5.0595 & TRN & \\
\hline CHEMBL1612486 & 737824 & 4.95 & 4.7974 & TRN & \\
\hline CHEMBL1401672 & 737824 & 5.5 & 5.3592 & TRN & \\
\hline CHEMBL1505628 & 737824 & 5.55 & 5.6124 & TST & \\
\hline CHEMBL250053 & 737824 & 4.8 & 4.4703 & TST & \\
\hline
\end{tabular}




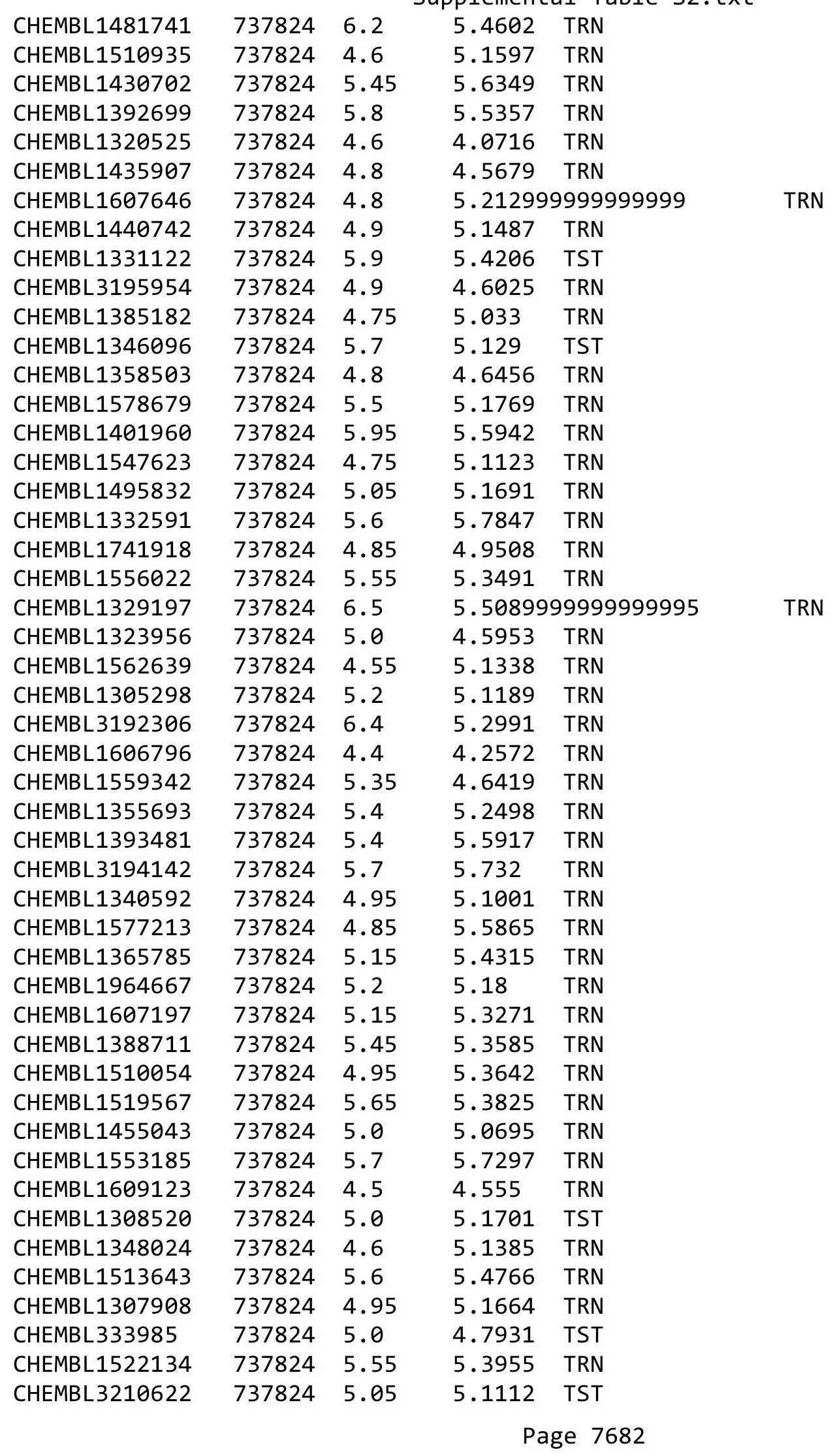




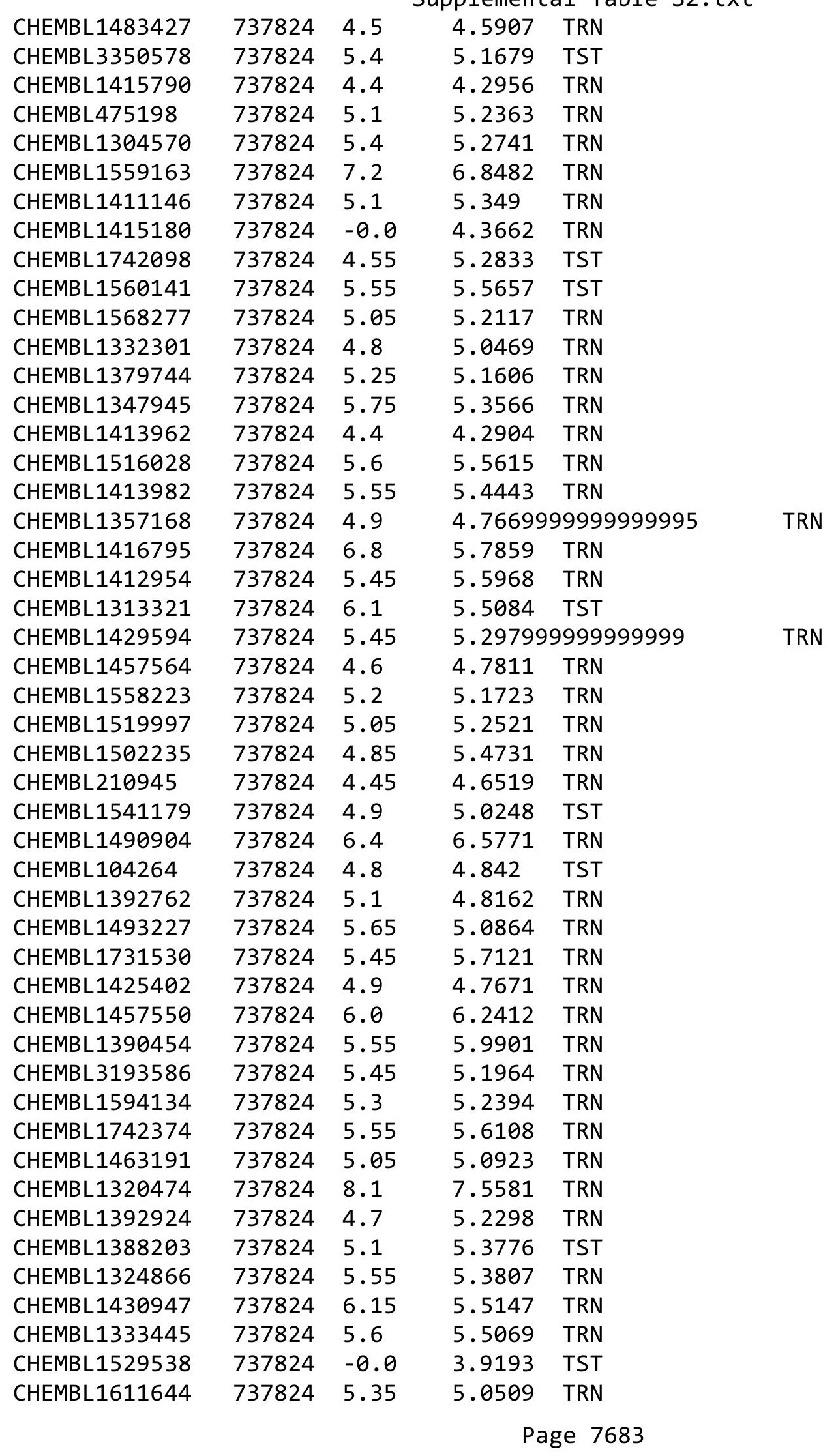




\begin{tabular}{|c|c|c|c|c|c|}
\hline \multicolumn{6}{|c|}{ plementim } \\
\hline CHEMBL1565125 & 737824 & 4.4 & 4.0864 & TST & \\
\hline CHEMBL1401499 & 737824 & 4.4 & 4.8834 & TRN & \\
\hline CHEMBL1591677 & 737824 & 4.4 & 4.442 & TRN & \\
\hline CHEMBL1589230 & 737824 & 5.35 & 5.1085 & TRN & \\
\hline CHEMBL1492293 & 737824 & 5.5 & 5.0558 & TRN & \\
\hline CHEMBL1462421 & 737824 & 5.45 & 5.1625 & TRN & \\
\hline CHEMBL1370467 & 737824 & 6.0 & 6.21299 & 9999999999 & TRN \\
\hline CHEMBL1563254 & 737824 & 5.6 & 5.5991 & TST & \\
\hline CHEMBL1485948 & 737824 & 5.05 & 5.3824 & TRN & \\
\hline CHEMBL1401073 & 737824 & 4.9 & 5.6215 & TRN & \\
\hline CHEMBL1359473 & 737824 & 5.2 & 5.4358 & TRN & \\
\hline CHEMBL1519109 & 737824 & 5.45 & 4.9703 & TRN & \\
\hline CHEMBL1571639 & 737824 & 5.45 & 5.4623 & TRN & \\
\hline CHEMBL1409258 & 737824 & 5.75 & 5.7342 & TRN & \\
\hline CHEMBL1516622 & 737824 & 5.5 & 5.83 & TRN & \\
\hline CHEMBL1492504 & 737824 & 5.6 & 5.2334 & TRN & \\
\hline CHEMBL1742168 & 737824 & 4.9 & 5.3125 & TRN & \\
\hline CHEMBL1381896 & 737824 & 5.0 & 5.2733 & TRN & \\
\hline CHEMBL1335401 & 737824 & 4.95 & 5.6551 & TST & \\
\hline CHEMBL3208377 & 737824 & 4.6 & 5.231 & TST & \\
\hline CHEMBL313163 & 737824 & 4.75 & 5.1906 & TRN & \\
\hline CHEMBL1478249 & 737824 & 5.8 & 5.6829 & TRN & \\
\hline CHEMBL1329939 & 737824 & 5.8 & 5.1806 & TST & \\
\hline CHEMBL1525292 & 737824 & 5.65 & 5.8692 & TST & \\
\hline CHEMBL1590077 & 737824 & 5.3 & 5.3777 & TRN & \\
\hline CHEMBL1365235 & 737824 & 5.0 & 4.9482 & TRN & \\
\hline CHEMBL1596756 & 737824 & 5.3 & 5.1434 & TRN & \\
\hline CHEMBL1519603 & 737824 & 6.4 & 5.6534 & TRN & \\
\hline CHEMBL1339710 & 737824 & 5.1 & 5.0909 & TRN & \\
\hline CHEMBL1359531 & 737824 & 4.7 & 4.9122 & TRN & \\
\hline CHEMBL1359181 & 737824 & 5.0 & 5.2263 & TRN & \\
\hline CHEMBL1569400 & 737824 & 4.4 & 4.3889 & TRN & \\
\hline CHEMBL1719321 & 737824 & 4.4 & 4.4229 & TST & \\
\hline CHEMBL1569491 & 737824 & 4.75 & 5.0664 & TRN & \\
\hline CHEMBL491555 & 737824 & 5.9 & 5.8459 & TRN & \\
\hline CHEMBL1706520 & 737824 & 4.7 & 4.9493 & TRN & \\
\hline CHEMBL1256814 & 737824 & 5.0 & 4.7706 & TRN & \\
\hline CHEMBL1303042 & 737824 & 5.15 & 5.7185 & TRN & \\
\hline CHEMBL3211211 & 737824 & 4.85 & 5.1803 & TRN & \\
\hline CHEMBL1741821 & 737824 & 4.4 & 4.6378 & TRN & \\
\hline CHEMBL1391420 & 737824 & 4.8 & 5.4605 & TRN & \\
\hline CHEMBL1304296 & 737824 & 4.6 & 5.0766 & TST & \\
\hline CHEMBL1742335 & 737824 & 7.95 & 5.2605 & TRN & \\
\hline CHEMBL1361133 & 737824 & 6.3 & 5.6137 & TST & \\
\hline CHEMBL1304386 & 737824 & 4.85 & 5.0975 & TRN & \\
\hline CHEMBL1383496 & 737824 & 6.4 & 5.5674 & TRN & \\
\hline CHEMBL1395899 & 737824 & 4.6 & 4.8169 & TRN & \\
\hline CHEMBL1330251 & 737824 & 4.4 & 3.9357 & TRN & \\
\hline
\end{tabular}




\begin{tabular}{|c|c|c|c|c|c|}
\hline \\
\hline CHEMBL1312003 & 737824 & 4.85 & 5.1789 & TST & \\
\hline CHEMBL1546772 & 737824 & 4.8 & 4.6311 & TRN & \\
\hline CHEMBL1442542 & 737824 & 4.7 & 5.5162 & TST & \\
\hline CHEMBL1559187 & 737824 & 4.8 & 5.0587 & TRN & \\
\hline CHEMBL1324334 & 737824 & 5.4 & 5.6128 & TRN & \\
\hline CHEMBL1386704 & 737824 & 5.55 & 5.1687 & TRN & \\
\hline CHEMBL1508888 & 737824 & 4.45 & 5.1111 & TRN & \\
\hline CHEMBL1463847 & 737824 & 5.5 & 5.4713 & TST & \\
\hline CHEMBL1366573 & 737824 & 5.6 & 5.7942 & TRN & \\
\hline CHEMBL3392050 & 737824 & 4.4 & 4.0188 & TST & \\
\hline CHEMBL1413001 & 737824 & 4.4 & 5.0126 & TST & \\
\hline CHEMBL1493183 & 737824 & 6.1 & 5.2121 & TRN & \\
\hline CHEMBL1566556 & 737824 & 5.1 & 4.7013 & TRN & \\
\hline CHEMBL1449103 & 737824 & 5.15 & 5.3597 & TRN & \\
\hline CHEMBL1388860 & 737824 & 5.35 & 5.591 & TRN & \\
\hline CHEMBL1607623 & 737824 & 6.0 & 5.8758 & TRN & \\
\hline CHEMBL1523486 & 737824 & 4.4 & 4.8438 & TRN & \\
\hline CHEMBL 2000196 & 737824 & 5.35 & 5.25200 & 3000000001 & TRN \\
\hline CHEMBL1455570 & 737824 & 5.7 & 5.5714 & TRN & \\
\hline CHEMBL1451548 & 737824 & 5.45 & 5.5414 & TRN & \\
\hline CHEMBL1395297 & 737824 & 4.5 & 4.252 & TRN & \\
\hline CHEMBL1329104 & 737824 & 5.4 & 5.6696 & TRN & \\
\hline CHEMBL1457305 & 737824 & 4.9 & 5.4145 & TRN & \\
\hline CHEMBL1544991 & 737824 & 5.0 & 4.9678 & TRN & \\
\hline CHEMBL1394640 & 737824 & 6.0 & 6.0204 & TRN & \\
\hline CHEMBL1368566 & 737824 & 4.4 & 4.5785 & TRN & \\
\hline CHEMBL1545958 & 737824 & 4.8 & 5.0787 & TRN & \\
\hline CHEMBL1302141 & 737824 & 5.45 & 5.403 & TRN & \\
\hline CHEMBL1479112 & 737824 & 5.25 & 5.4202 & TRN & \\
\hline CHEMBL1319554 & 737824 & 5.05 & 5.1752 & TRN & \\
\hline CHEMBL1593337 & 737824 & -0.0 & 4.3227 & TRN & \\
\hline CHEMBL1552973 & 737824 & 4.8 & 4.7843 & TRN & \\
\hline CHEMBL1495251 & 737824 & 4.7 & 4.5941 & TRN & \\
\hline CHEMBL1404831 & 737824 & 4.75 & 5.3219 & TRN & \\
\hline CHEMBL1362616 & 737824 & 4.85 & 4.6568 & TRN & \\
\hline CHEMBL1300710 & 737824 & 4.5 & 4.8896 & TRN & \\
\hline CHEMBL1742383 & 737824 & 4.6 & 5.0307 & TRN & \\
\hline CHEMBL1374729 & 737824 & 5.3 & 5.0888 & TST & \\
\hline CHEMBL492611 & 737824 & 4.8 & 4.82100 & 0000000001 & TRN \\
\hline CHEMBL1479506 & 737824 & 4.8 & 4.5685 & TRN & \\
\hline CHEMBL1316893 & 737824 & 4.6 & 4.5526 & TRN & \\
\hline CHEMBL1501211 & 737824 & 6.25 & 4.9308 & TRN & \\
\hline CHEMBL1608397 & 737824 & 5.95 & 5.6431 & TRN & \\
\hline CHEMBL1490139 & 737824 & 5.2 & 4.9338 & TRN & \\
\hline CHEMBL1440842 & 737824 & 5.9 & 6.1079 & TST & \\
\hline CHEMBL1382877 & 737824 & 6.0 & 5.3652 & TRN & \\
\hline CHEMBL1527363 & 737824 & 4.85 & 5.0189 & TRN & \\
\hline CHEMBL1395882 & 737824 & 6.2 & 6.3572 & TRN & \\
\hline
\end{tabular}




\begin{tabular}{|c|c|c|c|c|c|}
\hline \multicolumn{6}{|c|}{ Supplemental Table S2.txt } \\
\hline CHEMBL1526697 & 737824 & 5.1 & 5.1182 & TRN & \\
\hline CHEMBL1498141 & 737824 & 5.45 & 5.4084 & TRN & \\
\hline CHEMBL1498420 & 737824 & 4.55 & 5.396 & TRN & \\
\hline CHEMBL1432283 & 737824 & 5.15 & 4.8127 & TRN & \\
\hline CHEMBL1361731 & 737824 & 4.6 & 4.5817 & TRN & \\
\hline CHEMBL1440290 & 737824 & 6.0 & 4.4699 & TRN & \\
\hline CHEMBL1596260 & 737824 & 5.65 & 5.5582 & TRN & \\
\hline CHEMBL1530695 & 737824 & 4.6 & 4.9971 & TRN & \\
\hline CHEMBL1449870 & 737824 & 4.95 & 4.9418 & TRN & \\
\hline CHEMBL1461732 & 737824 & 6.4 & 5.1725 & TRN & \\
\hline CHEMBL1397293 & 737824 & 4.8 & 4.5865 & TRN & \\
\hline CHEMBL1602549 & 737824 & 5.6 & 5.1526 & TST & \\
\hline CHEMBL1344860 & 737824 & 5.55 & 5.4064 & TST & \\
\hline CHEMBL1558574 & 737824 & 5.0 & 5.1162 & TRN & \\
\hline CHEMBL1558569 & 737824 & 6.1 & 5.9511 & TRN & \\
\hline CHEMBL1553498 & 737824 & 7.8 & 7.2595 & TST & \\
\hline CHEMBL1336521 & 737824 & 4.8 & 5.2048 & TRN & \\
\hline CHEMBL1605426 & 737824 & 4.6 & 4.1568 & TST & \\
\hline CHEMBL1742208 & 737824 & 4.6 & 5.4481 & TRN & \\
\hline CHEMBL3194967 & 737824 & 5.6 & 5.4692 & TRN & \\
\hline CHEMBL1337830 & 737824 & 5.35 & 5.5742 & TST & \\
\hline CHEMBL1452159 & 737824 & 5.0 & 4.868 & TRN & \\
\hline CHEMBL1456872 & 737824 & 4.9 & 4.7281 & TRN & \\
\hline CHEMBL1742325 & 737824 & 4.55 & 4.8618 & TRN & \\
\hline CHEMBL3208441 & 737824 & 4.75 & 4.5511 & TRN & \\
\hline CHEMBL1380975 & 737824 & 4.8 & 4.8658 & TRN & \\
\hline CHEMBL1391435 & 737824 & 5.1 & 5.16 & TRN & \\
\hline CHEMBL1541564 & 737824 & 5.05 & 5.37700 & 0000000001 & TRN \\
\hline CHEMBL1575580 & 737824 & 4.8 & 4.9269 & TRN & \\
\hline CHEMBL1741496 & 737824 & 5.15 & 5.7129 & TRN & \\
\hline CHEMBL1596872 & 737824 & 4.9 & 4.8779 & TRN & \\
\hline CHEMBL1403809 & 737824 & 4.85 & 5.0097 & TRN & \\
\hline CHEMBL1531620 & 737824 & 5.55 & 5.1411 & TST & \\
\hline CHEMBL1411608 & 737824 & 5.6 & 5.2866 & TST & \\
\hline CHEMBL1412499 & 737824 & 5.6 & 5.6008 & TRN & \\
\hline CHEMBL1469165 & 737824 & 4.9 & 4.987 & TRN & \\
\hline CHEMBL103469 & 737824 & 4.9 & 4.69 & TRN & \\
\hline CHEMBL1741698 & 737824 & 5.1 & 5.5101 & TRN & \\
\hline CHEMBL1309874 & 737824 & 5.4 & 5.6319 & TRN & \\
\hline CHEMBL1381829 & 737824 & 6.45 & 5.8512 & TRN & \\
\hline CHEMBL1448562 & 737824 & 5.3 & 4.9987 & TRN & \\
\hline CHEMBL1335686 & 737824 & 4.4 & 4.9402 & TRN & \\
\hline CHEMBL1380096 & 737824 & 5.05 & 5.2522 & TRN & \\
\hline CHEMBL1371346 & 737824 & 5.2 & 5.5251 & TST & \\
\hline CHEMBL3193196 & 737824 & 5.8 & 5.5522 & TRN & \\
\hline CHEMBL1332357 & 737824 & 4.5 & 5.0866 & TRN & \\
\hline CHEMBL1521744 & 737824 & 5.0 & 5.0352 & TRN & \\
\hline CHEMBL1451788 & 737824 & 4.7 & 4.5294 & TRN & \\
\hline
\end{tabular}




\begin{tabular}{|c|c|c|c|c|c|}
\hline \multicolumn{6}{|c|}{ Supplemental Table S2.txt } \\
\hline CHEMBL1461321 & 737824 & 5.6 & 5.3434 & TRN & \\
\hline CHEMBL1575680 & 737824 & 5.05 & 4.70100 & 00000000005 & TRN \\
\hline CHEMBL1310678 & 737824 & 4.4 & 5.3007 & TRN & \\
\hline CHEMBL1441920 & 737824 & 4.4 & 5.895 & TST & \\
\hline CHEMBL1489212 & 737824 & 4.6 & 4.3362 & TST & \\
\hline CHEMBL1421887 & 737824 & 4.9 & 5.0 & TRN & \\
\hline CHEMBL1490567 & 737824 & 4.75 & 4.7498 & TRN & \\
\hline CHEMBL1385652 & 737824 & 5.4 & 5.396 & TRN & \\
\hline CHEMBL1327087 & 737824 & 7.5 & 5.088 & TRN & \\
\hline CHEMBL1369854 & 737824 & 4.5 & 4.9132 & TRN & \\
\hline CHEMBL1377369 & 737824 & 5.15 & 5.4135 & TRN & \\
\hline CHEMBL1599607 & 737824 & 5.55 & 5.8145 & TRN & \\
\hline CHEMBL1541518 & 737824 & 5.65 & 5.3745 & TRN & \\
\hline CHEMBL1611225 & 737824 & 5.9 & 6.1176 & TRN & \\
\hline CHEMBL1596230 & 737824 & 4.4 & 4.9928 & TRN & \\
\hline CHEMBL1729999 & 737824 & 4.65 & 5.2607 & TST & \\
\hline CHEMBL1591238 & 737824 & 5.4 & 5.3707 & TRN & \\
\hline CHEMBL1552854 & 737824 & 5.1 & 4.9168 & TRN & \\
\hline CHEMBL1380944 & 737824 & 4.55 & 4.7829 & TRN & \\
\hline CHEMBL1085765 & 737824 & 5.6 & 5.7521 & TRN & \\
\hline CHEMBL3199652 & 737824 & 5.35 & 5.5538 & TRN & \\
\hline CHEMBL1396907 & 737824 & 4.4 & 4.1449 & TRN & \\
\hline CHEMBL1364880 & 737824 & 5.0 & 4.8531 & TRN & \\
\hline CHEMBL1403617 & 737824 & 5.45 & 5.6684 & TRN & \\
\hline CHEMBL1475788 & 737824 & 4.6 & 4.8647 & TRN & \\
\hline CHEMBL1571483 & 737824 & 5.55 & 5.1399 & TRN & \\
\hline CHEMBL1466869 & 737824 & 5.5 & 5.4974 & TRN & \\
\hline CHEMBL1542248 & 737824 & 5.65 & 5.4687 & TRN & \\
\hline CHEMBL1527722 & 737824 & 6.0 & 5.66100 & 00000000005 & TST \\
\hline CHEMBL1741782 & 737824 & 4.85 & 4.6055 & TRN & \\
\hline CHEMBL586946 & 737824 & 4.8 & 4.8793 & TST & \\
\hline CHEMBL1529076 & 737824 & 6.1 & 5.8854 & TRN & \\
\hline CHEMBL1968162 & 737824 & 4.75 & 5.2803 & TRN & \\
\hline CHEMBL1372199 & 737824 & 5.55 & 5.4075 & TRN & \\
\hline CHEMBL1489033 & 737824 & 5.5 & 5.1609 & TST & \\
\hline CHEMBL1487502 & 737824 & 4.8 & 5.1788 & TRN & \\
\hline CHEMBL1353128 & 737824 & 4.75 & 5.1638 & TRN & \\
\hline CHEMBL3212375 & 737824 & 4.4 & 5.0515 & TST & \\
\hline CHEMBL1377580 & 737824 & 5.05 & 5.2135 & TRN & \\
\hline CHEMBL1538146 & 737824 & 5.6 & 5.2074 & TRN & \\
\hline CHEMBL1355835 & 737824 & 4.8 & 4.748 & TRN & \\
\hline CHEMBL1511690 & 737824 & 4.85 & 5.4417 & TST & \\
\hline CHEMBL608555 & 737824 & 5.6 & 5.105 & TST & \\
\hline CHEMBL1379830 & 737824 & 5.3 & 5.5236 & TRN & \\
\hline CHEMBL1554888 & 737824 & 5.0 & 5.1281 & TRN & \\
\hline CHEMBL1333080 & 737824 & 5.6 & 5.1347 & TRN & \\
\hline CHEMBL1444331 & 737824 & 5.6 & 5.231 & TRN & \\
\hline CHEMBL1501882 & 737824 & 5.4 & 5.4824 & TRN & \\
\hline
\end{tabular}




\begin{tabular}{|c|c|c|c|c|}
\hline \multicolumn{5}{|c|}{ pplemental } \\
\hline CHEMBL1534214 & 737824 & 6.1 & 5.4939 & TRN \\
\hline CHEMBL1326132 & 737824 & 5.5 & 5.7276 & TRN \\
\hline CHEMBL1386709 & 737824 & 5.1 & 5.2763 & TRN \\
\hline CHEMBL1515209 & 737824 & 5.7 & 5.3746 & TST \\
\hline CHEMBL265177 & 737824 & 5.5 & 5.59399 & 9999999999 \\
\hline CHEMBL1432440 & 737824 & 4.9 & 4.7682 & TRN \\
\hline CHEMBL1996020 & 737824 & 4.9 & 5.1091 & TRN \\
\hline CHEMBL1421567 & 737824 & 6.5 & 5.0354 & TST \\
\hline CHEMBL1373797 & 737824 & 4.6 & 4.899 & TRN \\
\hline CHEMBL1257002 & 737824 & 4.6 & 5.7564 & TRN \\
\hline CHEMBL3214056 & 737824 & 5.05 & 6.0838 & TRN \\
\hline CHEMBL1357231 & 737824 & 5.9 & 5.8363 & TRN \\
\hline CHEMBL1420699 & 737824 & 5.0 & 5.2995 & TRN \\
\hline CHEMBL1566120 & 737824 & 5.75 & 5.0175 & TRN \\
\hline CHEMBL1479912 & 737824 & 4.9 & 4.5227 & TRN \\
\hline CHEMBL1419890 & 737824 & 6.15 & 5.511 & TRN \\
\hline CHEMBL1566987 & 737824 & 7.3 & 7.3874 & TRN \\
\hline CHEMBL3193309 & 737824 & 4.85 & 4.8692 & TRN \\
\hline CHEMBL3208065 & 737824 & 5.65 & 5.1558 & TRN \\
\hline CHEMBL1511721 & 737824 & 4.65 & 5.181 & TST \\
\hline CHEMBL1358738 & 737824 & 6.2 & 5.7317 & TRN \\
\hline CHEMBL1543084 & 737824 & 5.3 & 5.4378 & TRN \\
\hline CHEMBL1388180 & 737824 & 4.95 & 5.3095 & TST \\
\hline CHEMBL1331980 & 737824 & 5.6 & 5.1863 & TST \\
\hline CHEMBL1441608 & 737824 & -0.0 & 3.7487 & TRN \\
\hline CHEMBL1426357 & 737824 & 6.25 & 5.8552 & TRN \\
\hline CHEMBL358326 & 737824 & 5.4 & 5.5112 & TRN \\
\hline CHEMBL1472971 & 737824 & 4.8 & 4.641 & TRN \\
\hline CHEMBL1704851 & 737824 & 5.3 & 5.2332 & TRN \\
\hline CHEMBL1453216 & 737824 & 5.2 & 5.2904 & TRN \\
\hline CHEMBL1353921 & 737824 & 5.5 & 5.1432 & TRN \\
\hline CHEMBL24909 & 737824 & 6.2 & 6.0884 & TRN \\
\hline CHEMBL1741523 & 737824 & 4.45 & 4.9642 & TRN \\
\hline CHEMBL1418947 & 737824 & 4.8 & 5.1742 & TRN \\
\hline CHEMBL1371329 & 737824 & 4.8 & 4.8614 & TRN \\
\hline CHEMBL1475990 & 737824 & 4.7 & 4.8126 & TRN \\
\hline CHEMBL1361742 & 737824 & 5.55 & 5.1662 & TRN \\
\hline CHEMBL1575920 & 737824 & 5.95 & 5.6299 & TRN \\
\hline CHEMBL1601626 & 737824 & 7.5 & 5.1459 & TRN \\
\hline CHEMBL1358272 & 737824 & 5.8 & 5.5866 & TRN \\
\hline CHEMBL1404647 & 737824 & 4.85 & 4.9792 & TRN \\
\hline CHEMBL1506622 & 737824 & 5.45 & 5.2376 & TRN \\
\hline CHEMBL1731285 & 737824 & 4.65 & 5.1193 & TRN \\
\hline CHEMBL1433762 & 737824 & 5.2 & 5.0686 & TRN \\
\hline CHEMBL1439210 & 737824 & 4.85 & 4.6782 & TRN \\
\hline CHEMBL1404788 & 737824 & 5.5 & 5.0987 & TRN \\
\hline CHEMBL1741458 & 737824 & 5.55 & 5.4642 & TRN \\
\hline CHEMBL1442243 & 737824 & 5.45 & 5.2352 & TRN \\
\hline
\end{tabular}




\begin{tabular}{|c|c|c|c|c|}
\hline \multicolumn{5}{|c|}{ Supplemental Table s2.txt } \\
\hline CHEMBL1431111 & 737824 & 5.5 & 4.987 & TST \\
\hline CHEMBL1561206 & 737824 & 7.0 & 5.7898 & TRN \\
\hline CHEMBL1613397 & 737824 & 4.8 & 4.7582 & TRN \\
\hline CHEMBL3211920 & 737824 & 4.9 & 4.84 & TST \\
\hline CHEMBL3209417 & 737824 & 4.85 & 4.9773 & TST \\
\hline CHEMBL1363513 & 737824 & 4.4 & 4.3854 & TRN \\
\hline CHEMBL1584461 & 737824 & 5.85 & 5.4618 & TRN \\
\hline CHEMBL1345892 & 737824 & 5.3 & 5.225 & TRN \\
\hline CHEMBL281622 & 737824 & 6.6 & 6.3374 & TST \\
\hline CHEMBL1519647 & 737824 & 5.35 & 5.3248 & TRN \\
\hline CHEMBL3195449 & 737824 & 4.5 & 5.4052 & TRN \\
\hline CHEMBL1741926 & 737824 & 4.65 & 4.9736 & TST \\
\hline CHEMBL1514143 & 737824 & 5.3 & 5.1411 & TRN \\
\hline CHEMBL1412937 & 737824 & 5.55 & 5.603 & TRN \\
\hline CHEMBL1565258 & 737824 & 4.8 & 5.6633 & TRN \\
\hline CHEMBL1596387 & 737824 & 6.2 & 5.5515 & TRN \\
\hline CHEMBL1415957 & 737824 & 4.4 & 4.3043 & TRN \\
\hline CHEMBL1368788 & 737824 & 4.7 & 5.006 & TRN \\
\hline CHEMBL3191409 & 737824 & 4.85 & 4.8855 & TST \\
\hline CHEMBL111545 & 737824 & 4.4 & 4.1659 & TST \\
\hline CHEMBL1438331 & 737824 & 4.65 & 4.7215 & TRN \\
\hline CHEMBL3193269 & 737824 & 5.0 & 4.7892 & TRN \\
\hline CHEMBL1353672 & 737824 & 5.1 & 5.007 & TRN \\
\hline CHEMBL1374763 & 737824 & 5.4 & 3.9445 & TST \\
\hline CHEMBL1317458 & 737824 & 6.7 & 6.246 & TST \\
\hline CHEMBL1585900 & 737824 & 5.0 & 4.829 & TRN \\
\hline CHEMBL1325554 & 737824 & 4.85 & 5.1936 & TRN \\
\hline CHEMBL1330781 & 737824 & 5.9 & 5.1689 & TRN \\
\hline CHEMBL1530189 & 737824 & 5.0 & 5.2563 & TST \\
\hline CHEMBL1484738 & 737824 & 5.3 & 4.5019 & TST \\
\hline CHEMBL1526113 & 737824 & 5.5 & 5.3361 & TRN \\
\hline CHEMBL1447245 & 737824 & 5.0 & 5.4629 & TRN \\
\hline CHEMBL1595862 & 737824 & 4.65 & 4.8645 & TST \\
\hline CHEMBL3192906 & 737824 & 4.9 & 5.2026 & TRN \\
\hline CHEMBL1328375 & 737824 & 4.8 & 5.3806 & TRN \\
\hline CHEMBL1341313 & 737824 & 5.8 & 5.2986 & TRN \\
\hline CHEMBL1458664 & 737824 & 5.4 & 5.1724 & TRN \\
\hline CHEMBL1335595 & 737824 & 5.8 & 4.8494 & TRN \\
\hline CHEMBL1465428 & 737824 & 4.45 & 4.8292 & TRN \\
\hline CHEMBL1706086 & 737824 & 4.6 & 5.0242 & TRN \\
\hline CHEMBL1454544 & 737824 & 5.1 & 5.4226 & TRN \\
\hline CHEMBL1407257 & 737824 & 5.0 & 5.0252 & TRN \\
\hline CHEMBL1465534 & 737824 & 4.7 & 5.2034 & TST \\
\hline CHEMBL3193750 & 737824 & 5.35 & 5.0484 & TST \\
\hline CHEMBL1425523 & 737824 & 4.75 & 5.0839 & TRN \\
\hline CHEMBL1372330 & 737824 & 6.0 & 6.1366 & TRN \\
\hline CHEMBL1358297 & 737824 & 4.5 & 3.9912 & TST \\
\hline CHEMBL1299525 & 737824 & 7.6499 & 7.2589 & TRN \\
\hline
\end{tabular}




\begin{tabular}{|c|c|c|c|c|}
\hline \multicolumn{5}{|c|}{ Supplemental Table } \\
\hline CHEMBL1493861 & 737824 & 5.05 & 5.2558 & TRN \\
\hline CHEMBL1603926 & 737824 & 4.85 & 5.4999 & TRN \\
\hline CHEMBL1371898 & 737824 & 4.75 & 5.385 & TRN \\
\hline CHEMBL1716185 & 737824 & 5.15 & 5.3535 & TST \\
\hline CHEMBL1400744 & 737824 & 5.6 & 5.5434 & TRN \\
\hline CHEMBL1590397 & 737824 & 6.0 & 6.6042 & TRN \\
\hline CHEMBL1318316 & 737824 & 6.3 & 6.3699 & TRN \\
\hline CHEMBL1490198 & 737824 & 4.9 & 5.2812 & TRN \\
\hline CHEMBL1576649 & 737824 & 5.25 & 5.8282 & TRN \\
\hline CHEMBL1303356 & 737824 & 5.7 & 5.5509 & TRN \\
\hline CHEMBL1473996 & 737824 & 5.1 & 5.3152 & TRN \\
\hline CHEMBL1423250 & 737824 & 4.85 & 5.023 & TRN \\
\hline CHEMBL1599122 & 737824 & 4.85 & 5.0304 & TRN \\
\hline CHEMBL1507893 & 737824 & 4.65 & 4.9649 & TRN \\
\hline CHEMBL1453438 & 737824 & 5.45 & 5.1306 & TRN \\
\hline CHEMBL24983 & 737824 & 4.6 & 4.8538 & TST \\
\hline CHEMBL1437046 & 737824 & 5.1 & 5.1139 & TRN \\
\hline CHEMBL1326159 & 737824 & 4.9 & 5.3606 & TRN \\
\hline CHEMBL1470016 & 737824 & 5.05 & 5.2482 & TRN \\
\hline CHEMBL1548739 & 737824 & 5.55 & 5.5375 & TRN \\
\hline CHEMBL1366766 & 737824 & 5.8 & 5.7645 & TRN \\
\hline CHEMBL1326346 & 737824 & 5.5 & 5.0293 & TRN \\
\hline CHEMBL1392360 & 737824 & 5.55 & 5.5076 & TRN \\
\hline CHEMBL 3189225 & 737824 & 5.0 & 4.9292 & TRN \\
\hline CHEMBL1437447 & 737824 & 7.2 & 6.7093 & TRN \\
\hline CHEMBL1306964 & 737824 & 4.9 & 4.8563 & TRN \\
\hline CHEMBL1432676 & 737824 & 6.35 & 4.7189 & TST \\
\hline CHEMBL1434817 & 737824 & 5.0 & 4.867 & TRN \\
\hline CHEMBL1543489 & 737824 & 5.0 & 5.0619 & TRN \\
\hline CHEMBL1443508 & 737824 & 5.5 & 5.4657 & TRN \\
\hline CHEMBL1536766 & 737824 & 4.55 & 5.012 & TRN \\
\hline CHEMBL1356808 & 737824 & 4.9 & 5.0694 & TRN \\
\hline CHEMBL1585809 & 737824 & 5.45 & 5.4182 & TRN \\
\hline CHEMBL1721191 & 737824 & 4.8 & 4.9912 & TRN \\
\hline CHEMBL1302300 & 737824 & 4.85 & 5.4291 & TST \\
\hline CHEMBL1383348 & 737824 & 4.7 & 5.5573 & TRN \\
\hline CHEMBL1517817 & 737824 & 5.1 & 5.0886 & TRN \\
\hline CHEMBL1447520 & 737824 & 7.15 & 5.4506 & TST \\
\hline CHEMBL1518301 & 737824 & 5.5 & 5.1196 & TRN \\
\hline CHEMBL1579870 & 737824 & 4.5 & 4.8899 & TRN \\
\hline CHEMBL1565888 & 737824 & 5.6 & 5.2467 & TRN \\
\hline CHEMBL1464306 & 737824 & 5.65 & 5.6788 & TRN \\
\hline CHEMBL1546249 & 737824 & 6.6 & 5.5435 & TST \\
\hline CHEMBL1357444 & 737824 & 5.7 & 5.3499 & TRN \\
\hline CHEMBL1603394 & 737824 & 5.2 & 5.3278 & TRN \\
\hline CHEMBL1972133 & 737824 & 4.9 & 5.1063 & TRN \\
\hline CHEMBL3197786 & 737824 & 5.15 & 5.5292 & TRN \\
\hline CHEMBL1562088 & 737824 & 5.8 & 5.3711 & TST \\
\hline
\end{tabular}




\begin{tabular}{|c|c|c|c|c|}
\hline & & & & \\
\hline CHEMBL 35482 & 737824 & 5.2 & 5.2043 & TRN \\
\hline CHEMBL 3208819 & 737824 & 4.85 & 5.1883 & TRN \\
\hline CHEMBL1531701 & 737824 & 5.15 & 4.7957 & TRN \\
\hline CHEMBL1741829 & 737824 & 5.05 & 5.2162 & TRN \\
\hline CHEMBL1318616 & 737824 & 4.4 & 4.36600 & 00000000005 \\
\hline CHEMBL1363773 & 737824 & 5.2 & 5.2425 & TRN \\
\hline CHEMBL1489778 & 737824 & 5.65 & 5.0531 & TRN \\
\hline CHEMBL1404254 & 737824 & 4.65 & 5.1143 & TRN \\
\hline CHEMBL1463219 & 737824 & 4.6 & 5.1626 & TRN \\
\hline CHEMBL1582729 & 737824 & 4.4 & 4.9612 & TRN \\
\hline CHEMBL1556705 & 737824 & 5.55 & 5.5723 & TRN \\
\hline CHEMBL1350038 & 737824 & 5.55 & 5.0017 & TRN \\
\hline CHEMBL1558526 & 737824 & 4.8 & 4.8932 & TRN \\
\hline CHEMBL1496811 & 737824 & 4.8 & 4.7938 & TRN \\
\hline CHEMBL1407380 & 737824 & 4.4 & 5.0363 & TRN \\
\hline CHEMBL1398528 & 737824 & 5.0 & 4.8753 & TRN \\
\hline CHEMBL1307437 & 737824 & 6.0 & 5.9813 & TRN \\
\hline CHEMBL1522556 & 737824 & 5.25 & 5.1832 & TRN \\
\hline CHEMBL1499837 & 737824 & 4.65 & 4.8495 & TRN \\
\hline CHEMBL1572635 & 737824 & 4.95 & 5.8394 & TRN \\
\hline CHEMBL 3196390 & 737824 & 5.45 & 5.2255 & TRN \\
\hline CHEMBL1596030 & 737824 & 4.55 & 5.3561 & TRN \\
\hline CHEMBL1527443 & 737824 & 5.1 & 5.0959 & TRN \\
\hline CHEMBL1590975 & 737824 & 4.6 & 5.2005 & TRN \\
\hline CHEMBL1557762 & 737824 & 4.55 & 4.9803 & TRN \\
\hline CHEMBL1591140 & 737824 & 4.9 & 5.0664 & TRN \\
\hline CHEMBL1331751 & 737824 & 4.85 & 5.0611 & TRN \\
\hline CHEMBL1568080 & 737824 & 5.6 & 5.2246 & TRN \\
\hline CHEMBL 3212838 & 737824 & 4.65 & 5.1281 & TRN \\
\hline CHEMBL1588849 & 737824 & 4.8 & 5.0896 & TST \\
\hline CHEMBL1329392 & 737824 & 4.4 & 5.195 & TRN \\
\hline CHEMBL1330468 & 737824 & 5.5 & 5.6654 & TRN \\
\hline CHEMBL1466170 & 737824 & 4.6 & 5.1993 & TRN \\
\hline CHEMBL1573125 & 737824 & 4.85 & 5.0325 & TRN \\
\hline CHEMBL1425995 & 737824 & 5.9 & 5.3644 & TRN \\
\hline CHEMBL3195612 & 737824 & 4.65 & 5.0296 & TRN \\
\hline CHEMBL 3198738 & 737824 & 5.15 & 5.6092 & TRN \\
\hline CHEMBL1475075 & 737824 & 5.8 & 5.9296 & TRN \\
\hline CHEMBL1342116 & 737824 & 5.35 & 4.9106 & TRN \\
\hline CHEMBL 1405744 & 737824 & 6.0 & 5.6933 & TRN \\
\hline CHEMBL1544180 & 737824 & 4.9 & 5.1716 & TRN \\
\hline CHEMBL 1442250 & 737824 & 5.6 & 5.6887 & TRN \\
\hline CHEMBL122270 & 737824 & -0.0 & 4.6243 & TRN \\
\hline CHEMBL1741783 & 737824 & 5.1 & 5.5287 & TRN \\
\hline CHEMBL1487101 & 737824 & 5.35 & 5.199 & TRN \\
\hline CHEMBL1390934 & 737824 & 5.3 & 5.532 & TRN \\
\hline CHEMBL 1425169 & 737824 & 4.95 & 4.9103 & TRN \\
\hline CHEMBL1400113 & 737824 & 4.55 & 5.46200 & 3000000001 \\
\hline & & & & e 7691 \\
\hline
\end{tabular}




\begin{tabular}{|c|c|c|c|c|c|}
\hline & & & & & \\
\hline CHEMBL1446244 & 737824 & 4.8 & 5.1828 & TRN & \\
\hline CHEMBL1351212 & 737824 & 4.7 & 5.1401 & TRN & \\
\hline CHEMBL1602394 & 737824 & 5.9 & 6.4341 & TRN & \\
\hline CHEMBL1706994 & 737824 & 6.2 & 5.6872 & TRN & \\
\hline CHEMBL491548 & 737824 & 4.4 & 4.438 & TRN & \\
\hline CHEMBL1608175 & 737824 & 5.5 & 5.3767 & TST & \\
\hline CHEMBL1481127 & 737824 & 4.8 & 4.6197 & TRN & \\
\hline CHEMBL1319232 & 737824 & 4.6 & 5.2198 & TRN & \\
\hline CHEMBL3208355 & 737824 & 4.95 & 5.2676 & TRN & \\
\hline CHEMBL1520928 & 737824 & 5.95 & 5.4769 & TRN & \\
\hline CHEMBL1309540 & 737824 & 5.6 & 5.1756 & TRN & \\
\hline CHEMBL1342892 & 737824 & 4.75 & 5.37200 & 000000001 & TRN \\
\hline CHEMBL1311695 & 737824 & 5.3 & 5.2187 & TRN & \\
\hline CHEMBL1471648 & 737824 & 5.45 & 5.3955 & TRN & \\
\hline CHEMBL1349246 & 737824 & 5.9 & 5.0298 & TST & \\
\hline CHEMBL3207544 & 737824 & 5.0 & 5.2346 & TRN & \\
\hline CHEMBL1374962 & 737824 & 6.1 & 6.69 & TRN & \\
\hline CHEMBL1476084 & 737824 & 8.2 & 7.3619 & TRN & \\
\hline CHEMBL1533148 & 737824 & 4.55 & 5.2818 & TST & \\
\hline CHEMBL1599014 & 737824 & 4.6 & 4.3034 & TRN & \\
\hline CHEMBL1583365 & 737824 & 5.7 & 5.3621 & TRN & \\
\hline CHEMBL1451031 & 737824 & 4.95 & 4.7971 & TRN & \\
\hline CHEMBL 375270 & 737824 & 6.1 & 5.8163 & TRN & \\
\hline CHEMBL1604087 & 737824 & 5.15 & 5.4129 & TRN & \\
\hline CHEMBL1424275 & 737824 & 4.7 & 5.4032 & TRN & \\
\hline CHEMBL1518901 & 737824 & 4.8 & 4.9703 & TRN & \\
\hline CHEMBL1446649 & 737824 & 4.9 & 4.8501 & TRN & \\
\hline CHEMBL1233960 & 737824 & 5.7 & 5.3292 & TRN & \\
\hline CHEMBL1586684 & 737824 & 7.3 & 5.5412 & TRN & \\
\hline CHEMBL1582783 & 737824 & 7.15 & 5.4063 & TRN & \\
\hline CHEMBL1445999 & 737824 & 4.8 & 4.7987 & TST & \\
\hline CHEMBL1965223 & 737824 & 5.3 & 5.6668 & TRN & \\
\hline CHEMBL1397225 & 737824 & 4.7 & 4.8452 & TRN & \\
\hline CHEMBL1612230 & 737824 & 5.5 & 5.5368 & TST & \\
\hline CHEMBL1742215 & 737824 & 4.6 & 5.1024 & TRN & \\
\hline CHEMBL1436925 & 737824 & 5.1 & 5.0816 & TRN & \\
\hline CHEMBL1445795 & 737824 & 5.5 & 5.5737 & TRN & \\
\hline CHEMBL1509009 & 737824 & 4.85 & 5.7453 & TRN & \\
\hline CHEMBL3214392 & 737824 & 4.95 & 5.3089 & TRN & \\
\hline CHEMBL3195211 & 737824 & 4.9 & 5.2353 & TRN & \\
\hline CHEMBL1414683 & 737824 & 5.5 & 5.0888 & TRN & \\
\hline CHEMBL1396577 & 737824 & 5.1 & 5.3535 & TRN & \\
\hline CHEMBL1371221 & 737824 & 5.4 & 5.3696 & TRN & \\
\hline CHEMBL1487236 & 737824 & 4.4 & 5.0443 & TRN & \\
\hline CHEMBL3195205 & 737824 & 4.85 & 5.1186 & TRN & \\
\hline CHEMBL3211122 & 737824 & 4.85 & 5.2341 & TST & \\
\hline CHEMBL3214406 & 737824 & 5.65 & 5.6338 & TST & \\
\hline CHEMBL1358708 & 737824 & 7.0 & 5.98799 & 99999999995 & TST \\
\hline & & & & e 7692 & \\
\hline
\end{tabular}




\begin{tabular}{|c|c|c|c|c|c|}
\hline \\
\hline CHEMBL1701169 & 737824 & 4.9 & 5.8232 & TRN & \\
\hline CHEMBL1448288 & 737824 & 5.0 & 5.1388 & TRN & \\
\hline CHEMBL1312970 & 737824 & 4.85 & 5.1238 & TRN & \\
\hline CHEMBL3194665 & 737824 & 4.75 & 4.747 & TST & \\
\hline CHEMBL1477833 & 737824 & 4.5 & 4.3075 & TRN & \\
\hline CHEMBL1357676 & 737824 & 5.1 & 4.9157 & TRN & \\
\hline CHEMBL1311969 & 737824 & 4.95 & 4.7752 & TRN & \\
\hline CHEMBL1547530 & 737824 & 4.65 & 4.9108 & TRN & \\
\hline CHEMBL3195554 & 737824 & 5.45 & 5.1496 & TRN & \\
\hline CHEMBL1393664 & 737824 & 5.2 & 5.239 & TRN & \\
\hline CHEMBL490706 & 737824 & 5.1 & 5.6273 & TRN & \\
\hline CHEMBL1521167 & 737824 & 5.1 & 4.7371 & TST & \\
\hline CHEMBL123 & 737824 & 5.5 & 4.7696 & TST & \\
\hline CHEMBL1330811 & 737824 & 4.8 & 5.26200 & 00000000005 & TRN \\
\hline CHEMBL1358570 & 737824 & 5.5 & 5.3649 & TST & \\
\hline CHEMBL3210053 & 737824 & 5.7 & 5.4794 & TRN & \\
\hline CHEMBL1563936 & 737824 & 5.65 & 4.7877 & TRN & \\
\hline CHEMBL1357574 & 737824 & 5.6 & 5.48600 & $\partial 000000001$ & TRN \\
\hline CHEMBL1565302 & 737824 & 4.8 & 4.2233 & TRN & \\
\hline CHEMBL1364637 & 737824 & 4.55 & 5.2332 & TRN & \\
\hline CHEMBL1395769 & 737824 & 5.5 & 4.9148 & TST & \\
\hline CHEMBL3212699 & 737824 & 5.05 & 5.4438 & TRN & \\
\hline CHEMBL1527775 & 737824 & 6.25 & 5.4885 & TRN & \\
\hline CHEMBL1603627 & 737824 & 5.0 & 5.0115 & TRN & \\
\hline CHEMBL 325238 & 737824 & 4.8 & 4.7739 & TRN & \\
\hline CHEMBL1379690 & 737824 & 5.1 & 4.6459 & TRN & \\
\hline CHEMBL1576662 & 737824 & 6.05 & 5.816 & TST & \\
\hline CHEMBL1347390 & 737824 & 6.25 & 5.8724 & TRN & \\
\hline CHEMBL1551979 & 737824 & 5.0 & 5.0511 & TRN & \\
\hline CHEMBL1352020 & 737824 & 5.8 & 5.5622 & TRN & \\
\hline CHEMBL1343075 & 737824 & 4.85 & 4.9516 & TRN & \\
\hline CHEMBL1361461 & 737824 & 4.85 & 5.1124 & TRN & \\
\hline CHEMBL1487219 & 737824 & 4.9 & 4.7686 & TST & \\
\hline CHEMBL1716016 & 737824 & 4.85 & 5.1674 & TRN & \\
\hline CHEMBL1357909 & 737824 & 4.4 & 4.2876 & TRN & \\
\hline CHEMBL1323183 & 737824 & 6.65 & 5.3652 & TRN & \\
\hline CHEMBL1564379 & 737824 & 5.1 & 5.3866 & TRN & \\
\hline CHEMBL1364804 & 737824 & 5.0 & 5.2507 & TRN & \\
\hline CHEMBL1317373 & 737824 & 5.3 & 5.3668 & TRN & \\
\hline CHEMBL1531291 & 737824 & 5.95 & 5.357 & TRN & \\
\hline CHEMBL3209936 & 737824 & 4.8 & 5.0509 & TRN & \\
\hline CHEMBL1439665 & 737824 & 4.4 & 4.2957 & TRN & \\
\hline CHEMBL1583276 & 737824 & 5.3 & 4.9397 & TRN & \\
\hline CHEMBL1519709 & 737824 & 5.6 & 4.9068 & TRN & \\
\hline CHEMBL1476791 & 737824 & 4.4 & 4.6342 & TRN & \\
\hline CHEMBL1350898 & 737824 & 5.05 & 4.9329 & TRN & \\
\hline CHEMBL1327171 & 737824 & 5.8 & 5.5311 & TRN & \\
\hline CHEMBL1488918 & 737824 & 5.2 & 5.1318 & TRN & \\
\hline
\end{tabular}




\begin{tabular}{|c|c|c|c|c|c|}
\hline \\
\hline CHEMBL1422725 & 737824 & 4.9 & 5.0466 & TRN & \\
\hline CHEMBL1313170 & 737824 & 5.65 & 5.3677 & TRN & \\
\hline CHEMBL1566184 & 737824 & 4.9 & 5.2234 & TRN & \\
\hline CHEMBL1589282 & 737824 & 6.25 & 5.8195 & TST & \\
\hline CHEMBL1396791 & 737824 & 5.5 & 5.3532 & TRN & \\
\hline CHEMBL1370100 & 737824 & 5.15 & 5.3876 & TRN & \\
\hline CHEMBL1327945 & 737824 & 4.9 & 4.8662 & TRN & \\
\hline CHEMBL1427178 & 737824 & 4.45 & 4.9387 & TRN & \\
\hline CHEMBL1427095 & 737824 & 4.55 & 5.0142 & TRN & \\
\hline CHEMBL1587519 & 737824 & 5.3 & 5.1061 & TRN & \\
\hline CHEMBL3211204 & 737824 & 7.6 & 5.5583 & TRN & \\
\hline CHEMBL1612582 & 737824 & 4.8 & 4.5681 & TRN & \\
\hline CHEMBL1398707 & 737824 & 4.6 & 5.2041 & TRN & \\
\hline CHEMBL1413654 & 737824 & 4.9 & 4.9662 & TRN & \\
\hline CHEMBL1415702 & 737824 & 4.4 & 5.2019 & TRN & \\
\hline CHEMBL1331702 & 737824 & 5.25 & 4.8977 & TRN & \\
\hline CHEMBL1575476 & 737824 & 5.55 & 5.2194 & TST & \\
\hline CHEMBL3192246 & 737824 & 5.55 & 5.4944 & TRN & \\
\hline CHEMBL1605811 & 737824 & 5.4 & 5.1463 & TST & \\
\hline CHEMBL1434882 & 737824 & 5.0 & 4.8254 & TRN & \\
\hline CHEMBL1438690 & 737824 & 5.8 & 5.7697 & TRN & \\
\hline CHEMBL1331288 & 737824 & 4.8 & 4.7656 & TRN & \\
\hline CHEMBL1447538 & 737824 & 7.2 & 7.1464 & TRN & \\
\hline CHEMBL1456312 & 737824 & 5.3 & 4.8407 & TRN & \\
\hline CHEMBL1577148 & 737824 & 5.55 & 5.4126 & TRN & \\
\hline CHEMBL303579 & 737824 & 5.3 & 5.5673 & TRN & \\
\hline CHEMBL1538481 & 737824 & 5.7 & 5.4312 & TRN & \\
\hline CHEMBL1393348 & 737824 & 5.45 & 4.9382 & TRN & \\
\hline CHEMBL1499237 & 737824 & 5.05 & 5.23600 & 0000000001 & TRN \\
\hline CHEMBL1595178 & 737824 & 4.7 & 5.2635 & TRN & \\
\hline CHEMBL3213029 & 737824 & 5.0 & 4.9954 & TRN & \\
\hline CHEMBL1332594 & 737824 & 5.0 & 5.3425 & TRN & \\
\hline CHEMBL1366393 & 737824 & 5.4 & 5.1535 & TRN & \\
\hline CHEMBL1338596 & 737824 & 5.55 & 5.5949 & TRN & \\
\hline CHEMBL1488197 & 737824 & 4.8 & 4.9735 & TRN & \\
\hline CHEMBL1429416 & 737824 & 5.0 & 4.9732 & TRN & \\
\hline CHEMBL1557752 & 737824 & 5.25 & 4.5161 & TRN & \\
\hline CHEMBL1579698 & 737824 & 5.4 & 5.1868 & TRN & \\
\hline CHEMBL1572747 & 737824 & 6.1 & 5.8022 & TRN & \\
\hline CHEMBL1322349 & 737824 & 6.8 & 5.5433 & TRN & \\
\hline CHEMBL3196667 & 737824 & 6.2 & 5.8041 & TRN & \\
\hline CHEMBL1339074 & 737824 & 4.6 & 5.45299 & 9999999999 & TRN \\
\hline CHEMBL1369874 & 737824 & 6.4 & 5.0017 & TRN & \\
\hline CHEMBL1518558 & 737824 & 5.65 & 5.4916 & TRN & \\
\hline CHEMBL1437064 & 737824 & 5.0 & 4.6742 & TRN & \\
\hline CHEMBL1318310 & 737824 & 5.2 & 5.2681 & TRN & \\
\hline CHEMBL1351886 & 737824 & 4.6 & 5.2123 & TST & \\
\hline CHEMBL3194842 & 737824 & 5.05 & 4.9425 & TRN & \\
\hline
\end{tabular}




\begin{tabular}{|c|c|c|c|c|}
\hline \multicolumn{5}{|c|}{ pplemental T } \\
\hline CHEMBL1556742 & 737824 & 5.4 & 5.2293 & TST \\
\hline CHEMBL1741451 & 737824 & 5.0 & 5.0326 & TRN \\
\hline CHEMBL1362918 & 737824 & 6.35 & 5.7055 & TRN \\
\hline CHEMBL400875 & 737824 & 5.8 & 5.6203 & TRN \\
\hline CHEMBL1369964 & 737824 & 5.35 & 5.4069 & TRN \\
\hline CHEMBL1704176 & 737824 & 4.85 & 5.5077 & TRN \\
\hline CHEMBL1546374 & 737824 & 4.55 & 5.7192 & TST \\
\hline CHEMBL1529232 & 737824 & 4.9 & 5.6251 & TRN \\
\hline CHEMBL1402908 & 737824 & 4.6 & 5.1607 & TRN \\
\hline CHEMBL1333833 & 737824 & 4.95 & 5.1384 & TRN \\
\hline CHEMBL1396358 & 737824 & 4.8 & 4.5064 & TRN \\
\hline CHEMBL1256737 & 737824 & 6.0 & 5.6455 & TRN \\
\hline CHEMBL1536459 & 737824 & 5.25 & 5.3407 & TRN \\
\hline CHEMBL1352774 & 737824 & 6.25 & 5.4613 & TST \\
\hline CHEMBL1724565 & 737824 & 5.45 & 5.0599 & TRN \\
\hline CHEMBL1601508 & 737824 & 5.0 & 5.1912 & TRN \\
\hline CHEMBL1567160 & 737824 & 5.6 & 5.3582 & TRN \\
\hline CHEMBL1580127 & 737824 & 5.35 & 5.1213 & TRN \\
\hline CHEMBL1564066 & 737824 & 5.75 & 5.8825 & TRN \\
\hline CHEMBL1578122 & 737824 & 5.7 & 5.5327 & TRN \\
\hline CHEMBL1591874 & 737824 & 4.4 & 3.6442 & TRN \\
\hline CHEMBL1607206 & 737824 & 5.05 & 5.8067 & TRN \\
\hline CHEMBL1494099 & 737824 & 5.8 & 5.9372 & TRN \\
\hline CHEMBL1316456 & 737824 & 6.9 & 6.2357 & TRN \\
\hline CHEMBL1437095 & 737824 & 5.7 & 5.7613 & TRN \\
\hline CHEMBL1401126 & 737824 & 6.45 & 5.6002 & TRN \\
\hline CHEMBL1490477 & 737824 & 4.5 & 4.5335 & TRN \\
\hline CHEMBL1590197 & 737824 & 4.5 & 4.4899 & TRN \\
\hline CHEMBL1546114 & 737824 & 4.75 & 5.3717 & TRN \\
\hline CHEMBL1393997 & 737824 & 4.85 & 5.5841 & TRN \\
\hline CHEMBL1601589 & 737824 & 5.45 & 5.3019 & TRN \\
\hline CHEMBL1313575 & 737824 & 5.0 & 5.2056 & TRN \\
\hline CHEMBL476513 & 737824 & 5.05 & 5.2676 & TRN \\
\hline CHEMBL1562589 & 737824 & 6.5 & 6.325 & TRN \\
\hline CHEMBL1572006 & 737824 & 5.1 & 5.1258 & TRN \\
\hline CHEMBL1445828 & 737824 & 6.6 & 5.3889 & TRN \\
\hline CHEMBL1544037 & 737824 & 5.3 & 5.5118 & TRN \\
\hline CHEMBL1454709 & 737824 & 4.5 & 5.3366 & TRN \\
\hline CHEMBL1489737 & 737824 & 4.95 & 5.2563 & TRN \\
\hline CHEMBL2369261 & 737824 & 5.3 & 5.3467 & TST \\
\hline CHEMBL1374947 & 737824 & 5.8 & 5.3058 & TRN \\
\hline CHEMBL1447162 & 737824 & 4.9 & 5.1375 & TST \\
\hline CHEMBL1427738 & 737824 & 4.55 & 5.2425 & TRN \\
\hline CHEMBL1511006 & 737824 & 6.2 & 5.1675 & TRN \\
\hline CHEMBL1355896 & 737824 & 6.0 & 5.8106 & TRN \\
\hline CHEMBL1316265 & 737824 & 4.5 & 4.1962 & TRN \\
\hline CHEMBL1412723 & 737824 & 4.85 & 5.2227 & TRN \\
\hline CHEMBL1553056 & 737824 & 5.9 & 6.0063 & TRN \\
\hline
\end{tabular}




\begin{tabular}{|c|c|c|c|c|c|}
\hline \multicolumn{6}{|c|}{ Supplemental Table S2.txt } \\
\hline CHEMBL 2001481 & 737824 & 5.75 & 5.1468 & TRN & \\
\hline CHEMBL1599663 & 737824 & 5.15 & 5.118 & TRN & \\
\hline CHEMBL1612814 & 737824 & 5.15 & 5.0239 & TST & \\
\hline CHEMBL1319962 & 737824 & 5.15 & 5.2443 & TRN & \\
\hline CHEMBL1422148 & 737824 & 5.3 & 5.3051 & TRN & \\
\hline CHEMBL1348933 & 737824 & 5.15 & 5.3981 & TRN & \\
\hline CHEMBL1299997 & 737824 & 4.85 & 5.0879 & TST & \\
\hline CHEMBL1563190 & 737824 & 5.05 & 5.6437 & TRN & \\
\hline CHEMBL1550048 & 737824 & 7.2 & 5.9588 & TRN & \\
\hline CHEMBL1523175 & 737824 & 5.5 & 5.066 & TRN & \\
\hline CHEMBL1348638 & 737824 & 5.95 & 4.9606 & TST & \\
\hline CHEMBL1311520 & 737824 & 5.5 & 5.4587 & TRN & \\
\hline CHEMBL1708288 & 737824 & 6.55 & 5.2311 & TRN & \\
\hline CHEMBL1585534 & 737824 & 5.55 & 5.2303 & TRN & \\
\hline CHEMBL1315457 & 737824 & 4.5 & 4.09699 & 99999999995 & TST \\
\hline CHEMBL1606729 & 737824 & 6.15 & 5.2385 & TRN & \\
\hline CHEMBL1446260 & 737824 & 5.55 & 5.8149 & TRN & \\
\hline CHEMBL1353502 & 737824 & 5.1 & 5.2879 & TRN & \\
\hline CHEMBL1565585 & 737824 & 4.55 & 4.9242 & TST & \\
\hline CHEMBL1435079 & 737824 & 5.5 & 5.083 & TRN & \\
\hline CHEMBL287327 & 737824 & 4.6 & 4.2078 & TST & \\
\hline CHEMBL1572239 & 737824 & 7.5 & 6.8499 & TRN & \\
\hline CHEMBL1509922 & 737824 & 4.7 & 4.7787 & TRN & \\
\hline CHEMBL1532513 & 737824 & 4.6 & 4.9399 & TRN & \\
\hline CHEMBL1499077 & 737824 & 7.0 & 7.45299 & & TRN \\
\hline CHEMBL1352745 & 737824 & 5.1 & 4.9713 & TST & \\
\hline CHEMBL3213877 & 737824 & 4.7 & 5.0753 & TRN & \\
\hline CHEMBL1460996 & 737824 & 4.85 & 4.8597 & TRN & \\
\hline CHEMBL1479144 & 737824 & 5.4 & 5.7665 & TRN & \\
\hline CHEMBL1371547 & 737824 & 5.3 & 4.8815 & TRN & \\
\hline CHEMBL1571238 & 737824 & 5.9 & 5.8512 & TRN & \\
\hline CHEMBL1733013 & 737824 & 5.15 & 5.2214 & TRN & \\
\hline CHEMBL1374043 & 737824 & 4.95 & 4.6835 & TST & \\
\hline CHEMBL1349872 & 737824 & 4.9 & 5.0452 & TRN & \\
\hline CHEMBL3196801 & 737824 & 4.75 & 5.2437 & TRN & \\
\hline CHEMBL1485323 & 737824 & 4.6 & 5.6614 & TRN & \\
\hline CHEMBL1499893 & 737824 & 5.65 & 5.5003 & TRN & \\
\hline CHEMBL1741657 & 737824 & 4.4 & 5.0672 & TRN & \\
\hline CHEMBL1400385 & 737824 & 5.4 & 5.7434 & TRN & \\
\hline CHEMBL1521039 & 737824 & 4.8 & 5.081 & TRN & \\
\hline CHEMBL3212319 & 737824 & 4.85 & 5.1934 & TRN & \\
\hline CHEMBL1574026 & 737824 & 4.65 & 4.6134 & TRN & \\
\hline CHEMBL1522909 & 737824 & 4.85 & 5.3035 & TST & \\
\hline CHEMBL1742195 & 737824 & 5.35 & 5.2925 & TRN & \\
\hline CHEMBL1408238 & 737824 & 5.4 & 5.0248 & TRN & \\
\hline CHEMBL1403626 & 737824 & 6.2 & 6.3764 & TRN & \\
\hline CHEMBL3193992 & 737824 & 5.65 & 5.2638 & TRN & \\
\hline CHEMBL313938 & 737824 & 4.8 & 4.9718 & TRN & \\
\hline
\end{tabular}




\begin{tabular}{|c|c|c|c|c|c|}
\hline \multirow{2}{*}{ CHEMBL1489549 } & \multirow{2}{*}{737824} & \\
\hline & & 5.1 & 5.2799 & TRN & \\
\hline CHEMBL1730483 & 737824 & 5.35 & 5.1543 & TRN & \\
\hline CHEMBL1592209 & 737824 & 5.4 & 5.2646 & TRN & \\
\hline CHEMBL1415465 & 737824 & 4.4 & 4.2375 & TRN & \\
\hline CHEMBL1405546 & 737824 & 4.4 & 4.5259 & TRN & \\
\hline CHEMBL1517241 & 737824 & 4.9 & 4.9204 & TRN & \\
\hline CHEMBL1579244 & 737824 & 4.85 & 4.8077 & TRN & \\
\hline CHEMBL1421734 & 737824 & 5.0 & 5.3415 & TRN & \\
\hline CHEMBL1349535 & 737824 & 6.05 & \multicolumn{2}{|c|}{5.577000000000001} & TRN \\
\hline CHEMBL1455018 & 737824 & 4.6 & 4.7287 & TRN & \\
\hline CHEMBL1374544 & 737824 & 6.2 & 6.0519 & TRN & \\
\hline CHEMBL1303933 & 737824 & 5.45 & 5.1754 & TRN & \\
\hline CHEMBL1539239 & 737824 & 4.85 & 5.02 & TRN & \\
\hline CHEMBL1403372 & 737824 & 6.8 & 5.4001 & TRN & \\
\hline CHEMBL1434833 & 737824 & 5.6 & 5.9496 & TRN & \\
\hline CHEMBL1321719 & 737824 & 5.1 & 5.4597 & TRN & \\
\hline CHEMBL1305253 & 737824 & 5.35 & 5.3364 & TRN & \\
\hline CHEMBL1530280 & 737824 & 5.8 & 5.3227 & TRN & \\
\hline CHEMBL1472880 & 737824 & 5.1 & 5.3216 & TRN & \\
\hline CHEMBL65 & 737824 & 4.7 & 4.9105 & TST & \\
\hline CHEMBL1451979 & 737824 & 5.4 & 4.7875 & TRN & \\
\hline CHEMBL1516211 & 737824 & 5.1 & 5.0999 & TRN & \\
\hline CHEMBL 1456334 & 737824 & 5.25 & 5.0876 & TRN & \\
\hline CHEMBL1554817 & 737824 & 6.9 & 6.8655 & TRN & \\
\hline CHEMBL1496101 & 737824 & 5.8 & 5.9893 & TRN & \\
\hline CHEMBL1600524 & 737824 & 5.45 & 5.7094 & TRN & \\
\hline CHEMBL1560603 & 737824 & 4.9 & 4.9072 & TRN & \\
\hline CHEMBL1993788 & 737824 & 5.95 & 5.4457 & TRN & \\
\hline CHEMBL1479862 & 737824 & 4.85 & 4.8636 & TRN & \\
\hline CHEMBL1388315 & 737824 & 5.85 & 5.9978 & TRN & \\
\hline CHEMBL1407012 & 737824 & 4.9 & 4.3819 & TRN & \\
\hline CHEMBL1363867 & 737824 & 5.1 & 5.3654 & TRN & \\
\hline CHEMBL1316656 & 737824 & 5.3 & 5.807 & TRN & \\
\hline CHEMBL1439483 & 737824 & 5.05 & 5.4892 & TRN & \\
\hline CHEMBL1535905 & 737824 & 4.5 & 5.3333 & TRN & \\
\hline CHEMBL1416634 & 737824 & 4.75 & 5.1172 & TRN & \\
\hline CHEMBL1510521 & 737824 & 5.05 & 5.0048 & TST & \\
\hline CHEMBL1472214 & 737824 & 4.75 & 4.8576 & TST & \\
\hline CHEMBL136906 & 737824 & 5.9 & 5.4494 & TRN & \\
\hline CHEMBL1398488 & 737824 & 4.4 & 4.1547 & TRN & \\
\hline CHEMBL1533768 & 737824 & 4.95 & 5.3473 & TRN & \\
\hline CHEMBL1558413 & 737824 & 5.05 & 5.1194 & TRN & \\
\hline CHEMBL1333749 & 737824 & 4.8 & 5.2946 & TRN & \\
\hline CHEMBL1609178 & 737824 & 5.4 & 5.3974 & TRN & \\
\hline CHEMBL1255867 & 737824 & 5.2 & 5.2914 & TRN & \\
\hline CHEMBL 3192267 & 737824 & 4.85 & 5.0905 & TRN & \\
\hline CHEMBL1319093 & 737824 & 6.1 & 6.00799 & 9999999999 & TRN \\
\hline CHEMBL1597037 & 737824 & 5.9 & 5.9542 & TRN & \\
\hline
\end{tabular}




\begin{tabular}{|c|c|c|c|c|c|}
\hline & & \multicolumn{4}{|c|}{ Supplemental Table S2.txt } \\
\hline CHEMBL1352445 & 737824 & 4.85 & 4.8852 & TRN & \\
\hline CHEMBL1470888 & 737824 & 4.7 & 5.3786 & TRN & \\
\hline CHEMBL1380684 & 737824 & 4.8 & 5.6658 & TRN & \\
\hline CHEMBL3191606 & 737824 & 5.65 & 4.896 & TST & \\
\hline CHEMBL1420370 & 737824 & 5.45 & 4.9018 & TRN & \\
\hline CHEMBL1341999 & 737824 & 4.75 & 5.3865 & TRN & \\
\hline CHEMBL3197789 & 737824 & 5.6 & 5.3421 & TRN & \\
\hline CHEMBL1470727 & 737824 & 5.2 & 5.2549 & TRN & \\
\hline CHEMBL1529853 & 737824 & 5.3 & 5.1884 & TRN & \\
\hline CHEMBL1430842 & 737824 & 4.95 & 5.7693 & TRN & \\
\hline CHEMBL1491674 & 737824 & 5.0 & 5.1604 & TRN & \\
\hline CHEMBL1307366 & 737824 & 5.25 & 5.5363 & TRN & \\
\hline CHEMBL1576072 & 737824 & 5.3 & 5.3838 & TRN & \\
\hline CHEMBL1373903 & 737824 & 5.25 & 5.4585 & TRN & \\
\hline CHEMBL1564756 & 737824 & 5.2 & 4.6508 & TRN & \\
\hline CHEMBL3212510 & 737824 & 4.85 & 5.1088 & TRN & \\
\hline CHEMBL1403852 & 737824 & 5.85 & 4.85 & TRN & \\
\hline CHEMBL1406944 & 737824 & 5.05 & 5.3226 & TRN & \\
\hline CHEMBL1702111 & 737824 & 5.6 & 5.5597 & TRN & \\
\hline CHEMBL1561692 & 737824 & 5.5 & 5.7733 & TRN & \\
\hline CHEMBL 275006 & 737824 & 5.1 & 5.0559 & TST & \\
\hline CHEMBL1418881 & 737824 & 5.0 & 5.2685 & TST & \\
\hline CHEMBL1368843 & 737824 & 4.9 & 4.8396 & TRN & \\
\hline CHEMBL1388293 & 737824 & 4.7 & 5.0394 & TRN & \\
\hline CHEMBL1433093 & 737824 & 5.0 & 5.30200 & 00000000005 & TST \\
\hline CHEMBL1578807 & 737824 & 4.6 & 5.0084 & TRN & \\
\hline CHEMBL1429733 & 737824 & 4.9 & 5.3192 & TRN & \\
\hline CHEMBL1330388 & 737824 & 5.9 & 5.3819 & TRN & \\
\hline CHEMBL1535796 & 737824 & 5.3 & 5.1718 & TRN & \\
\hline CHEMBL1595929 & 737824 & 5.85 & 4.8551 & TST & \\
\hline CHEMBL1561366 & 737824 & 6.3 & 6.3001 & TRN & \\
\hline CHEMBL1403214 & 737824 & 5.1 & 5.1669 & TRN & \\
\hline CHEMBL1541719 & 737824 & 4.95 & 4.7642 & TRN & \\
\hline CHEMBL3207696 & 737824 & 4.75 & 5.4054 & TRN & \\
\hline CHEMBL1606547 & 737824 & 5.2 & 5.5518 & TRN & \\
\hline CHEMBL1395417 & 737824 & 5.4 & 5.3046 & TRN & \\
\hline CHEMBL1499015 & 737824 & 5.3 & 5.4034 & TRN & \\
\hline CHEMBL3209319 & 737824 & 5.45 & 5.2663 & TRN & \\
\hline CHEMBL1475200 & 737824 & 8.0 & 7.6045 & TRN & \\
\hline CHEMBL1362504 & 737824 & 5.5 & 5.5516 & TRN & \\
\hline CHEMBL1382729 & 737824 & 5.15 & 4.9811 & TRN & \\
\hline CHEMBL1601482 & 737824 & 4.9 & 5.2083 & TRN & \\
\hline CHEMBL1516103 & 737824 & 4.6 & 4.6871 & TRN & \\
\hline CHEMBL1316979 & 737824 & 5.5 & 5.3419 & TRN & \\
\hline CHEMBL1305989 & 737824 & 4.85 & 5.12200 & 0000000001 & TRN \\
\hline CHEMBL1445233 & 737824 & 5.6 & 5.2146 & TRN & \\
\hline CHEMBL1306717 & 737824 & 7.5501 & 6.1668 & TRN & \\
\hline CHEMBL1398543 & 737824 & 4.7 & 4.8215 & TRN & \\
\hline
\end{tabular}




\begin{tabular}{|c|c|c|c|c|}
\hline & & & & \\
\hline CHEMBL1356094 & 737824 & 5.4 & 5.2693 & TST \\
\hline CHEMBL1603393 & 737824 & 4.9 & 4.9101 & TRN \\
\hline CHEMBL1445850 & 737824 & 5.6 & 4.88899 & 9999999999 \\
\hline CHEMBL1600813 & 737824 & 5.05 & 5.1318 & TRN \\
\hline CHEMBL1526455 & 737824 & 7.0 & 6.9321 & TRN \\
\hline CHEMBL1562333 & 737824 & 5.55 & 5.6675 & TRN \\
\hline CHEMBL3197094 & 737824 & 5.3 & 5.4615 & TRN \\
\hline CHEMBL1555581 & 737824 & 5.2 & 5.2812 & TRN \\
\hline CHEMBL1396407 & 737824 & 4.5 & 4.7216 & TRN \\
\hline CHEMBL1518689 & 737824 & 5.3 & 5.018 & TRN \\
\hline CHEMBL1474471 & 737824 & 6.0 & 6.2229 & TRN \\
\hline CHEMBL1398608 & 737824 & 6.4 & 6.2529 & TRN \\
\hline CHEMBL1707095 & 737824 & 4.6 & 5.2998 & TST \\
\hline CHEMBL1338714 & 737824 & 5.5 & 5.3053 & TST \\
\hline CHEMBL1345777 & 737824 & 5.0 & 5.2271 & TST \\
\hline CHEMBL1450689 & 737824 & 5.5 & 5.5921 & TST \\
\hline CHEMBL14690 & 737824 & 4.8 & 4.7103 & TST \\
\hline CHEMBL1307425 & 737824 & 5.9 & 5.3559 & TST \\
\hline CHEMBL1561151 & 737824 & 6.25 & 5.5117 & TST \\
\hline CHEMBL1462936 & 737824 & 4.5 & 5.1564 & TST \\
\hline CHEMBL1570922 & 737824 & 5.1 & 5.2282 & TST \\
\hline CHEMBL1466951 & 737824 & 4.8 & 5.2583 & TST \\
\hline CHEMBL1518419 & 737824 & 5.1 & 5.2514 & TST \\
\hline CHEMBL1371756 & 737824 & 5.7 & 5.1385 & TST \\
\hline CHEMBL1371689 & 737824 & 4.4 & 5.5612 & TST \\
\hline CHEMBL3209355 & 737824 & 5.5 & 5.2612 & TST \\
\hline CHEMBL1359620 & 737824 & 4.85 & 5.0005 & TST \\
\hline CHEMBL1318480 & 737824 & -0.0 & 4.9436 & TST \\
\hline CHEMBL1451176 & 737824 & 5.3 & 5.5219 & TST \\
\hline CHEMBL1567886 & 737824 & 5.3 & 5.2 & TST \\
\hline CHEMBL1556569 & 737824 & 5.0 & 5.0171 & TST \\
\hline CHEMBL1506208 & 737824 & 5.7 & 4.7478 & TST \\
\hline CHEMBL1608942 & 737824 & 5.8 & 5.8738 & TST \\
\hline CHEMBL1609472 & 737824 & 4.95 & 5.6484 & TST \\
\hline CHEMBL1594947 & 737824 & 6.5 & 6.3389 & TST \\
\hline CHEMBL1454305 & 737824 & 4.65 & 4.7931 & TST \\
\hline CHEMBL1473990 & 737824 & 5.0 & 5.2793 & TST \\
\hline CHEMBL1352502 & 737824 & 4.7 & 4.5133 & TST \\
\hline CHEMBL1405101 & 737824 & 4.55 & 4.8596 & TST \\
\hline CHEMBL1479817 & 737824 & 4.9 & 5.0828 & TST \\
\hline CHEMBL1502952 & 737824 & 5.75 & 5.6045 & TST \\
\hline CHEMBL1534591 & 737824 & 4.7 & 4.5075 & TST \\
\hline CHEMBL1606292 & 737824 & 4.9 & 5.2854 & TST \\
\hline CHEMBL1441254 & 737824 & 5.65 & 5.3083 & TST \\
\hline CHEMBL1463376 & 737824 & 5.2 & 5.2669 & TST \\
\hline CHEMBL1563094 & 737824 & 4.4 & 5.0605 & TST \\
\hline CHEMBL1306881 & 737824 & 5.25 & 5.1865 & TST \\
\hline CHEMBL1450153 & 737824 & 4.45 & 4.9495 & TST \\
\hline
\end{tabular}

TRN 


\begin{tabular}{|c|c|c|c|c|}
\hline \multirow[b]{2}{*}{ CHEMBL1301162 } & \multicolumn{4}{|c|}{ Supplemental Table s2.txt } \\
\hline & 737824 & 4.95 & 4.977 & TST \\
\hline CHEMBL1359027 & 737824 & 5.75 & 5.6995 & TST \\
\hline CHEMBL1411881 & 737824 & 5.0 & 5.6942 & TST \\
\hline CHEMBL1390245 & 737824 & 5.65 & 5.2074 & TST \\
\hline CHEMBL1473317 & 737824 & 5.2 & 5.1895 & TST \\
\hline CHEMBL1330951 & 737824 & 5.4 & 5.5147 & TST \\
\hline CHEMBL1484573 & 737824 & 4.4 & 4.9584 & TST \\
\hline CHEMBL1491976 & 737824 & 5.55 & 5.4585 & TST \\
\hline CHEMBL1502534 & 737824 & 4.6 & 5.1197 & TST \\
\hline CHEMBL3208032 & 737824 & 4.85 & 5.4966 & TST \\
\hline CHEMBL 1484400 & 737824 & 5.0 & 5.5324 & TST \\
\hline CHEMBL44297 & 737824 & 5.0 & 4.8047 & TST \\
\hline CHEMBL1301415 & 737824 & 4.6 & 5.1126 & TST \\
\hline CHEMBL1572157 & 737824 & 4.75 & 5.3389 & TST \\
\hline CHEMBL1366106 & 737824 & 4.7 & 4.6701 & TST \\
\hline CHEMBL1603446 & 737824 & 5.5 & 5.5775 & TST \\
\hline CHEMBL1552314 & 737824 & 8.2 & 7.2497 & TST \\
\hline CHEMBL523464 & 737824 & 4.5 & 4.1854 & TST \\
\hline CHEMBL1609561 & 737824 & 4.4 & 4.8787 & TST \\
\hline CHEMBL1593001 & 737824 & 5.5 & 5.5185 & TST \\
\hline CHEMBL1421286 & 737824 & 5.45 & 5.3526 & TST \\
\hline CHEMBL1379481 & 737824 & 6.2 & 5.3139 & TST \\
\hline CHEMBL1400275 & 737824 & 6.6 & 5.3633 & TST \\
\hline CHEMBL1391059 & 737824 & 5.1 & 5.1477 & TST \\
\hline CHEMBL1372635 & 737824 & 4.9 & 4.8066 & TST \\
\hline CHEMBL1380031 & 737824 & 4.6 & 5.075 & TST \\
\hline CHEMBL1498873 & 737824 & 5.9 & 5.3948 & TST \\
\hline CHEMBL1301946 & 737824 & 4.65 & 4.9783 & TST \\
\hline CHEMBL492127 & 737824 & 5.7 & 5.6159 & TST \\
\hline CHEMBL1321899 & 737824 & 4.6 & 4.6589 & TST \\
\hline CHEMBL1312751 & 737824 & 5.1 & 5.1199 & TST \\
\hline CHEMBL1717521 & 737824 & 4.6 & 4.8792 & TST \\
\hline CHEMBL1398321 & 737824 & 5.2 & 5.1061 & TST \\
\hline CHEMBL1466137 & 737824 & 7.6499 & 5.1342 & TST \\
\hline CHEMBL1595643 & 737824 & 6.45 & 5.2197 & TST \\
\hline CHEMBL1577959 & 737824 & 4.85 & 5.1765 & TST \\
\hline CHEMBL1428510 & 737824 & 5.65 & 5.2401 & TST \\
\hline CHEMBL1508815 & 737824 & 5.15 & 5.3503 & TST \\
\hline CHEMBL1314100 & 737824 & 5.65 & 5.3433 & TST \\
\hline CHEMBL1593997 & 737824 & 4.4 & 4.2486 & TST \\
\hline CHEMBL1353749 & 737824 & 5.65 & 5.2106 & TST \\
\hline CHEMBL1522673 & 737824 & 7.35 & 5.7544 & TST \\
\hline CHEMBL1573783 & 737824 & 5.05 & 4.9982 & TST \\
\hline CHEMBL1459527 & 737824 & 6.45 & 5.0029 & TST \\
\hline CHEMBL1331419 & 737824 & 5.55 & 5.7163 & TST \\
\hline CHEMBL1723524 & 737824 & 5.25 & 5.7696 & TST \\
\hline CHEMBL489935 & 737824 & 5.3 & 5.3875 & TST \\
\hline CHEMBL1464912 & 737824 & 5.5 & 5.2422 & TST \\
\hline
\end{tabular}




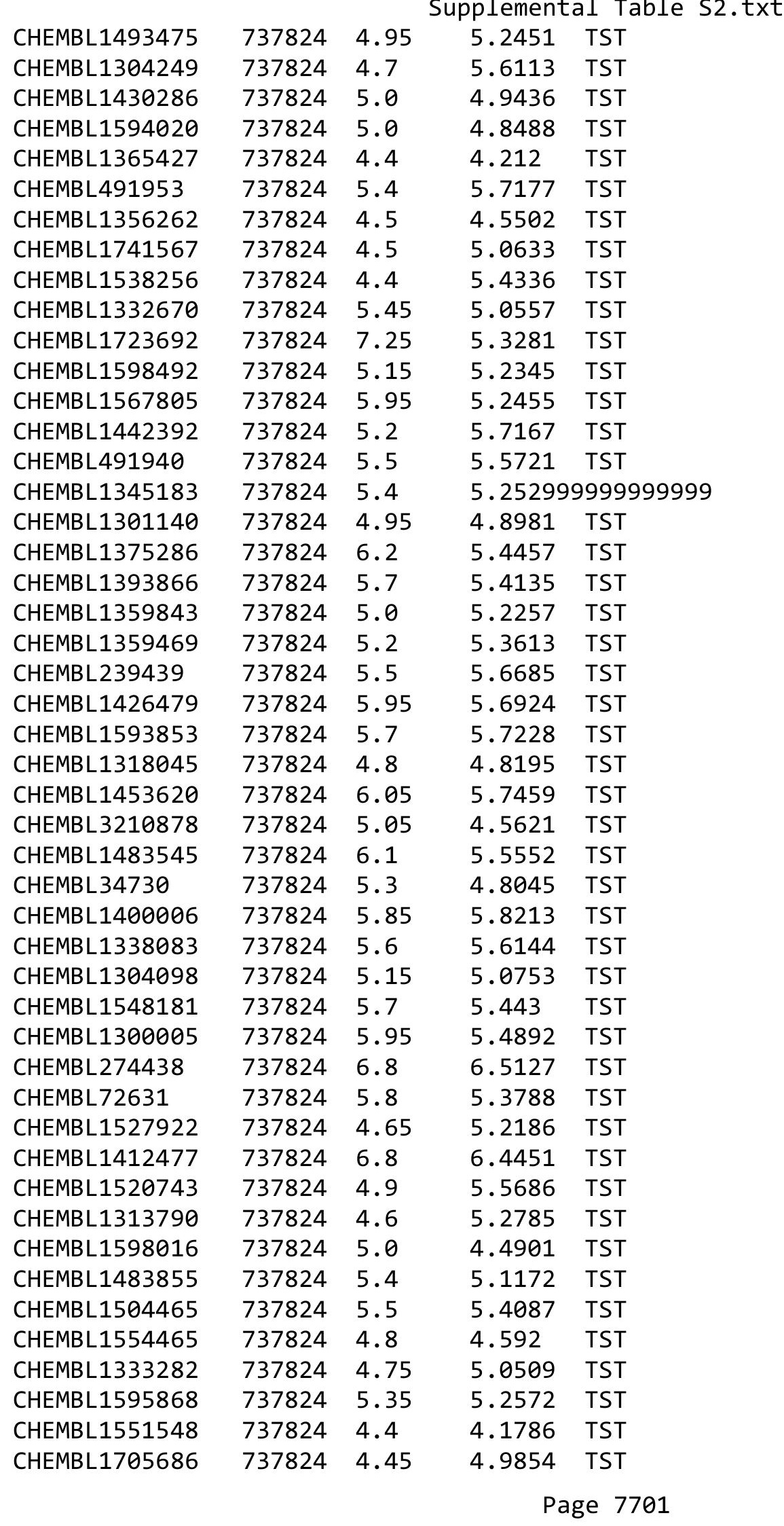




\begin{tabular}{|c|c|c|c|c|}
\hline & & & pplement & le $\mathrm{s}$ \\
\hline CHEMBL1159900 & 737824 & 4.6 & 4.0316 & TST \\
\hline CHEMBL1500199 & 737824 & 6.55 & 5.4772 & TST \\
\hline CHEMBL1340051 & 737824 & 5.55 & 4.9891 & TST \\
\hline CHEMBL1378443 & 737824 & 6.35 & 5.4441 & TST \\
\hline CHEMBL1314906 & 737824 & 5.1 & 4.7718 & TST \\
\hline CHEMBL1439658 & 737824 & 8.25 & 5.3129 & TST \\
\hline CHEMBL1337781 & 737824 & 5.9 & 6.1115 & TST \\
\hline CHEMBL1472011 & 737824 & 5.25 & 5.5079 & TST \\
\hline CHEMBL1370480 & 737824 & 5.6 & 5.3499 & TST \\
\hline CHEMBL1305666 & 737824 & 4.5 & 4.9744 & TST \\
\hline CHEMBL1592371 & 737824 & 5.0 & 5.1799 & TST \\
\hline CHEMBL1560365 & 737824 & 4.95 & 5.6177 & TST \\
\hline CHEMBL1381161 & 737824 & 5.05 & 5.4405 & TST \\
\hline CHEMBL1599388 & 737824 & 5.8 & 5.4458 & TST \\
\hline CHEMBL1716715 & 737824 & 5.4 & 5.2235 & TST \\
\hline CHEMBL1369886 & 737824 & 5.15 & 5.2254 & TST \\
\hline CHEMBL478501 & 737824 & 5.1 & 4.7663 & TST \\
\hline CHEMBL1334293 & 737824 & 4.85 & 5.115 & TST \\
\hline CHEMBL1354563 & 737824 & 5.1 & 5.2613 & TST \\
\hline CHEMBL1728281 & 737824 & 4.65 & 4.7678 & TST \\
\hline CHEMBL1478520 & 737824 & 5.35 & 5.5041 & TST \\
\hline CHEMBL1568735 & 737824 & 5.3 & 5.2982 & TST \\
\hline CHEMBL1600985 & 737824 & 4.7 & 5.0142 & TST \\
\hline CHEMBL1700160 & 737824 & 4.95 & 4.8087 & TST \\
\hline CHEMBL1491966 & 737824 & 5.0 & 4.9922 & TST \\
\hline CHEMBL1711461 & 737824 & 5.55 & 5.5221 & TST \\
\hline CHEMBL1465401 & 737824 & 5.0 & 4.89199 & 99999999995 \\
\hline CHEMBL1989625 & 737824 & 4.8 & 5.6622 & TST \\
\hline CHEMBL1357199 & 737824 & 4.5 & 4.7004 & TST \\
\hline CHEMBL1347262 & 737824 & 5.1 & 5.1679 & TST \\
\hline CHEMBL1525907 & 737824 & 4.55 & 4.9426 & TST \\
\hline CHEMBL1200766 & 737824 & 5.9 & 5.7211 & TST \\
\hline CHEMBL1742042 & 737824 & 5.6 & 5.3367 & TST \\
\hline CHEMBL1423999 & 737824 & 4.9 & 4.7688 & TST \\
\hline CHEMBL1433153 & 737824 & 6.1 & 5.4975 & TST \\
\hline CHEMBL3213457 & 737824 & 4.9 & 5.4719 & TST \\
\hline CHEMBL1344162 & 737824 & 8.25 & 5.2202 & TST \\
\hline CHEMBL1606968 & 737824 & 5.35 & 5.1035 & TST \\
\hline CHEMBL1467618 & 737824 & 4.85 & 5.1603 & TST \\
\hline CHEMBL1613529 & 737824 & 4.65 & 4.7486 & TST \\
\hline CHEMBL1433021 & 737824 & 5.75 & 5.7073 & TST \\
\hline CHEMBL1382823 & 737824 & 5.55 & 5.2979 & TST \\
\hline CHEMBL1591459 & 737824 & 6.4 & 6.4977 & TST \\
\hline CHEMBL1388665 & 737824 & 5.65 & 5.8763 & TST \\
\hline CHEMBL1606892 & 737824 & 4.9 & 4.5887 & TST \\
\hline CHEMBL1593815 & 737824 & 7.5 & 6.2326 & TST \\
\hline CHEMBL1467110 & 737824 & 5.05 & 5.3972 & TST \\
\hline CHEMBL1490656 & 737824 & 4.95 & 5.0433 & TST \\
\hline
\end{tabular}




\begin{tabular}{|c|c|c|c|c|c|}
\hline \\
\hline CHEMBL1373998 & 737824 & 6.3 & 6.1817 & TST & \\
\hline CHEMBL1713677 & 737824 & 6.05 & 4.9204 & TST & \\
\hline CHEMBL1507109 & 737824 & 5.8 & 5.4047 & TST & \\
\hline CHEMBL1590821 & 737824 & 4.9 & 4.6039 & TST & \\
\hline CHEMBL1361455 & 737824 & 5.4 & 5.2587 & TST & \\
\hline CHEMBL1398067 & 737824 & 6.4 & 6.3112 & TST & \\
\hline CHEMBL 3211478 & 737824 & 5.05 & 4.9106 & TST & \\
\hline CHEMBL1416491 & 737824 & 5.0 & 5.4768 & TST & \\
\hline CHEMBL1609078 & 737824 & 4.7 & 5.53100 & 0000000001 & TST \\
\hline CHEMBL1356346 & 737824 & 4.5 & 4.5848 & TST & \\
\hline CHEMBL1313693 & 737824 & 4.5 & 4.937 & TST & \\
\hline CHEMBL1527958 & 737824 & 5.8 & 5.9247 & TST & \\
\hline CHEMBL1524388 & 737824 & 5.55 & 5.499 & TST & \\
\hline CHEMBL1255578 & 737824 & 5.1 & 4.4168 & TST & \\
\hline CHEMBL3197350 & 737824 & 6.05 & 5.0383 & TST & \\
\hline CHEMBL1335370 & 737824 & 4.4 & 5.8324 & TST & \\
\hline CHEMBL1435254 & 737824 & 4.4 & 4.4497 & TST & \\
\hline CHEMBL1407287 & 737824 & 7.4 & 4.5671 & TST & \\
\hline CHEMBL1547352 & 737824 & 4.8 & 5.1154 & TST & \\
\hline CHEMBL8747 & 737824 & 5.2 & 5.1293 & TST & \\
\hline CHEMBL1741773 & 737824 & 5.0 & 5.1958 & TST & \\
\hline CHEMBL1714369 & 737824 & 5.3 & 5.4605 & TST & \\
\hline CHEMBL1594320 & 737824 & 4.7 & 5.2849 & TST & \\
\hline CHEMBL1335102 & 737824 & 4.8 & 4.852 & TST & \\
\hline CHEMBL1319626 & 737824 & 5.4 & 5.1373 & TST & \\
\hline CHEMBL1333384 & 737824 & 6.2 & 5.4707 & TST & \\
\hline CHEMBL1571807 & 737824 & 5.5 & 5.5492 & TST & \\
\hline CHEMBL1300494 & 737824 & 5.0 & 5.3452 & TST & \\
\hline CHEMBL1532441 & 737824 & 4.9 & 5.0791 & TST & \\
\hline CHEMBL1395564 & 737824 & 4.4 & 4.4589 & TST & \\
\hline CHEMBL1476632 & 737824 & 7.4 & 6.6414 & TST & \\
\hline CHEMBL1556106 & 737824 & 4.9 & 5.0854 & TST & \\
\hline CHEMBL1313226 & 737824 & 5.4 & 5.4777 & TST & \\
\hline CHEMBL1526260 & 737824 & 4.55 & 4.8927 & TST & \\
\hline CHEMBL491742 & 737824 & 5.1 & 5.144 & TST & \\
\hline CHEMBL1433805 & 737824 & 5.4 & 5.8569 & TST & \\
\hline CHEMBL1487748 & 737824 & 6.0 & 6.1338 & TST & \\
\hline CHEMBL1742347 & 737824 & 5.2 & 5.1557 & TST & \\
\hline CHEMBL1717360 & 737824 & 4.55 & 5.17700 & 00000000005 & TST \\
\hline CHEMBL1304990 & 737824 & 5.1 & 4.8262 & TST & \\
\hline CHEMBL3198953 & 737824 & 4.95 & 5.6585 & TST & \\
\hline CHEMBL1726069 & 737824 & 4.95 & 5.6785 & TST & \\
\hline CHEMBL1506462 & 737824 & 5.1 & 5.1508 & TST & \\
\hline CHEMBL1475562 & 737824 & 4.4 & 4.5115 & TST & \\
\hline CHEMBL 3214400 & 737824 & 5.35 & 5.1588 & TST & \\
\hline CHEMBL1565927 & 737824 & 4.9 & 4.9414 & TST & \\
\hline CHEMBL1381863 & 737824 & 5.05 & 5.2812 & TST & \\
\hline CHEMBL1555396 & 737824 & 5.0 & 4.9986 & TST & \\
\hline
\end{tabular}




\begin{tabular}{|c|c|c|c|c|}
\hline & & & upplement & al $\mathrm{T}$ \\
\hline CHEMBL1355708 & 737824 & 4.7 & 4.796 & TST \\
\hline CHEMBL1532443 & 737824 & 4.7 & 5.1385 & TST \\
\hline CHEMBL1587759 & 737824 & 4.6 & 4.8061 & TST \\
\hline CHEMBL1543038 & 737824 & 5.1 & 5.4928 & TST \\
\hline CHEMBL1507792 & 737824 & 4.8 & 5.1303 & TST \\
\hline CHEMBL1359761 & 737824 & 4.7 & 4.9284 & TST \\
\hline CHEMBL1451950 & 737824 & 5.85 & 5.6087 & TST \\
\hline CHEMBL1541405 & 737824 & 8.45 & 5.8818 & TST \\
\hline CHEMBL1429297 & 737824 & 5.15 & 4.9816 & TST \\
\hline CHEMBL1320051 & 737824 & 4.7 & 4.8912 & TST \\
\hline CHEMBL1549980 & 737824 & 6.3 & 5.4031 & TST \\
\hline CHEMBL1516851 & 737824 & 5.8 & 5.6463 & TST \\
\hline CHEMBL1450507 & 737824 & 4.9 & 4.7105 & TST \\
\hline CHEMBL1411912 & 737824 & 4.9 & 5.0172 & TST \\
\hline CHEMBL1371944 & 737824 & 4.9 & 4.9064 & TST \\
\hline CHEMBL1370296 & 737824 & 5.1 & 5.0538 & TST \\
\hline CHEMBL1486506 & 737824 & 5.35 & 5.5198 & TST \\
\hline CHEMBL1985350 & 737824 & 5.0 & 5.5428 & TST \\
\hline CHEMBL1347451 & 737824 & 5.75 & 5.2781 & TST \\
\hline CHEMBL1422487 & 737824 & 5.05 & 5.1491 & TST \\
\hline CHEMBL1528262 & 737824 & 4.65 & 5.4028 & TST \\
\hline CHEMBL1459758 & 737824 & 4.9 & 4.9519 & TST \\
\hline CHEMBL1369376 & 737824 & 5.4 & 5.5356 & TST \\
\hline CHEMBL1256687 & 737824 & 8.4 & 7.6371 & TST \\
\hline CHEMBL1393271 & 737824 & 5.05 & 4.9114 & TST \\
\hline CHEMBL1712617 & 737824 & 4.85 & 4.9531 & TST \\
\hline CHEMBL1547741 & 737824 & 4.85 & 5.2557 & TST \\
\hline CHEMBL1529570 & 737824 & 5.7 & 5.3919 & TST \\
\hline CHEMBL1485231 & 737824 & 4.9 & 5.0362 & TST \\
\hline CHEMBL1530995 & 737824 & 5.25 & 5.4312 & TST \\
\hline CHEMBL1484231 & 737824 & 5.35 & 5.2069 & TST \\
\hline CHEMBL1493099 & 737824 & 4.9 & 5.4815 & TST \\
\hline CHEMBL1453108 & 737824 & 5.1 & 5.0467 & TST \\
\hline CHEMBL 222519 & 737824 & 4.6 & 3.9158 & TST \\
\hline CHEMBL1425423 & 737824 & 4.5 & 5.2215 & TST \\
\hline CHEMBL476135 & 737824 & 6.3 & 6.1097 & TST \\
\hline CHEMBL1383143 & 737824 & 5.1 & 5.586 & TST \\
\hline CHEMBL1488997 & 737824 & 5.3 & 5.5831 & TST \\
\hline CHEMBL1512540 & 737824 & 5.4 & 5.6735 & TST \\
\hline CHEMBL1474890 & 737824 & 5.1 & 5.124 & TST \\
\hline CHEMBL1582074 & 737824 & 4.95 & 5.1904 & TST \\
\hline CHEMBL1416829 & 737824 & 4.6 & 4.4841 & TST \\
\hline CHEMBL1426599 & 737824 & 5.1 & 5.0617 & TST \\
\hline CHEMBL1323317 & 737824 & 5.25 & 5.6802 & TST \\
\hline CHEMBL1432632 & 737824 & 5.05 & 5.033 & TST \\
\hline CHEMBL1569846 & 737824 & 4.9 & 5.0726 & TST \\
\hline CHEMBL1235551 & 737824 & 5.3 & 5.2511 & TST \\
\hline CHEMBL1188431 & 737824 & 6.0 & 6.4197 & TST \\
\hline
\end{tabular}




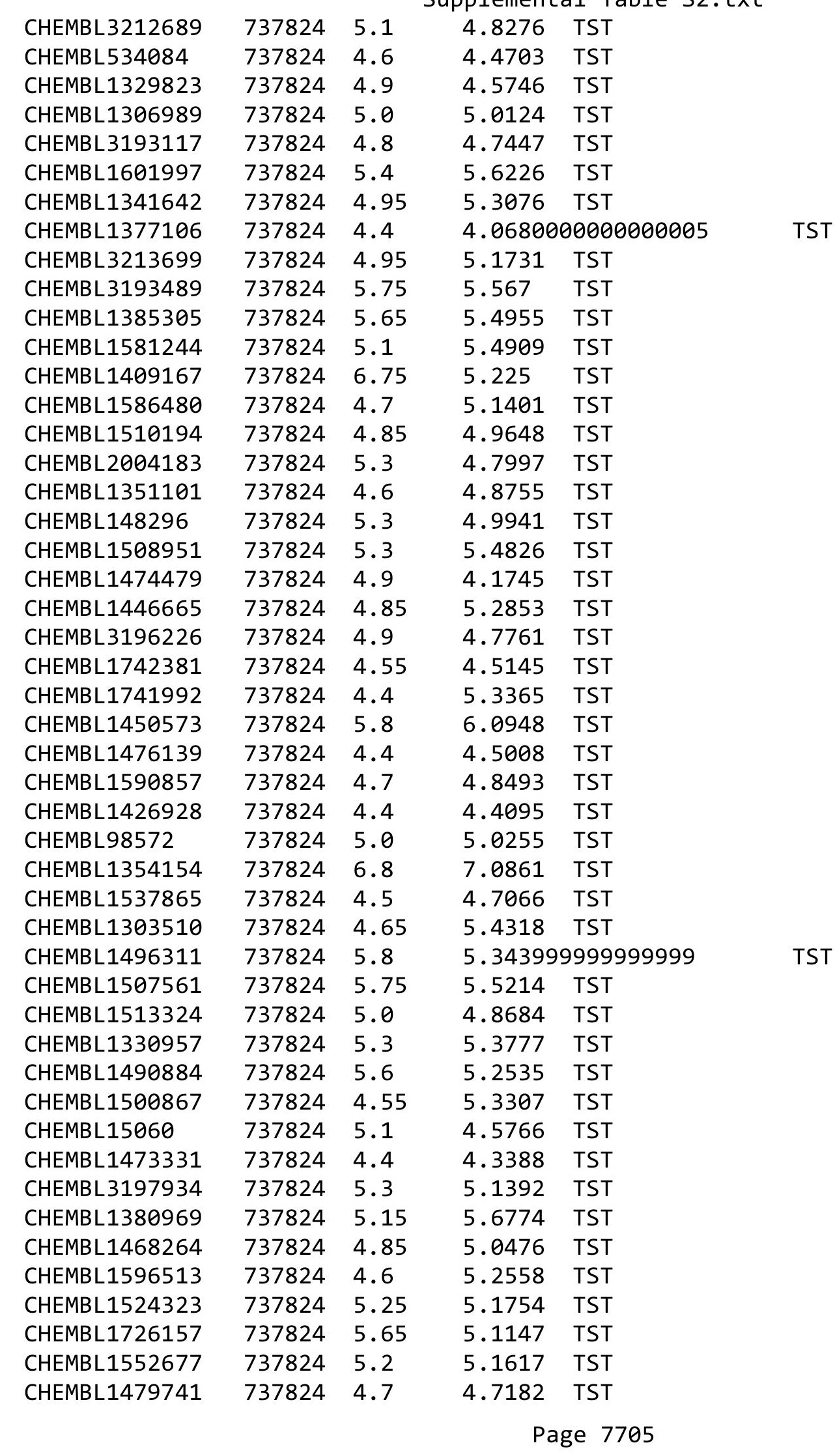




\begin{tabular}{|c|c|c|c|c|c|}
\hline \multicolumn{6}{|c|}{ Supplemental Table S2.txt } \\
\hline CHEMBL1403294 & 737824 & 5.05 & 5.1091 & TST & \\
\hline CHEMBL1595328 & 737824 & 4.4 & 4.2652 & TST & \\
\hline CHEMBL1508610 & 737824 & 5.1 & 5.419 & TST & \\
\hline CHEMBL242363 & 737824 & 4.6 & 5.1181 & TST & \\
\hline CHEMBL1573813 & 737824 & 4.55 & 5.2699 & TST & \\
\hline CHEMBL1454711 & 737824 & 4.9 & 5.7528 & TST & \\
\hline CHEMBL52 & 737824 & 4.8 & 5.744 & TST & \\
\hline CHEMBL1412997 & 737824 & 4.85 & 5.0131 & TST & \\
\hline CHEMBL1527911 & 737824 & 7.2 & 5.2111 & TST & \\
\hline CHEMBL1329928 & 737824 & 4.85 & 4.8155 & TST & \\
\hline CHEMBL1576031 & 737824 & 7.5501 & 5.2993 & TST & \\
\hline CHEMBL1980031 & 737824 & 5.9 & 4.8837 & TST & \\
\hline CHEMBL1602661 & 737824 & 5.6 & 6.0377 & TST & \\
\hline CHEMBL1435227 & 737824 & 4.6 & 4.5372 & TST & \\
\hline CHEMBL1597812 & 737824 & 4.9 & 5.01399 & 9999999999 & TST \\
\hline CHEMBL1356879 & 737824 & 5.5 & 4.9212 & TST & \\
\hline CHEMBL1552066 & 737824 & 5.9 & 5.8264 & TST & \\
\hline CHEMBL1446990 & 737824 & 6.0 & 5.6816 & TST & \\
\hline CHEMBL1545903 & 737824 & 4.4 & 4.6729 & TST & \\
\hline CHEMBL1741612 & 737824 & 5.3 & 5.1922 & TST & \\
\hline CHEMBL1414633 & 737824 & 6.0 & 5.621 & TST & \\
\hline CHEMBL1508220 & 737824 & 6.8 & 5.8743 & TST & \\
\hline CHEMBL1538954 & 737824 & 5.5 & 5.231 & TST & \\
\hline CHEMBL1342791 & 737824 & 5.35 & 5.6102 & TST & \\
\hline CHEMBL1529359 & 737824 & 5.9 & 5.432 & TST & \\
\hline CHEMBL3190650 & 737824 & 4.55 & 5.1787 & TST & \\
\hline CHEMBL3212613 & 737824 & 4.4 & 5.0533 & TST & \\
\hline CHEMBL1358583 & 737824 & 4.4 & 4.36 & TST & \\
\hline CHEMBL1335409 & 737824 & 5.6 & 5.3699 & TST & \\
\hline CHEMBL1360942 & 737824 & 5.5 & 5.3052 & TST & \\
\hline CHEMBL1386703 & 737824 & 4.55 & 5.0762 & TST & \\
\hline CHEMBL1570733 & 737824 & 4.55 & 5.4768 & TST & \\
\hline CHEMBL1561907 & 737824 & 5.15 & 5.7013 & TST & \\
\hline CHEMBL1425631 & 737824 & 5.3 & 4.7174 & TST & \\
\hline CHEMBL1389433 & 737824 & 4.95 & 5.3378 & TST & \\
\hline CHEMBL1476430 & 737824 & 5.6 & 5.3591 & TST & \\
\hline CHEMBL1373773 & 737824 & 5.1 & 5.059 & TST & \\
\hline CHEMBL1532985 & 737824 & 5.2 & 5.2541 & TST & \\
\hline CHEMBL1569502 & 737824 & 4.6 & 5.0709 & TST & \\
\hline CHEMBL1452250 & 737824 & 6.9 & 6.7761 & TST & \\
\hline CHEMBL1363130 & 737824 & 4.8 & 5.2732 & TST & \\
\hline CHEMBL 1350415 & 737824 & 5.6 & 5.369 & TST & \\
\hline CHEMBL1519798 & 737824 & 5.6 & 5.5581 & TST & \\
\hline CHEMBL1450602 & 737824 & 5.3 & 5.0824 & TST & \\
\hline CHEMBL1423903 & 737824 & 5.6 & 5.6474 & TST & \\
\hline CHEMBL1733541 & 737824 & 4.55 & 4.8287 & TST & \\
\hline CHEMBL1530645 & 737824 & 5.5 & 5.6073 & TST & \\
\hline CHEMBL1436024 & 737824 & 5.1 & 5.2391 & TST & \\
\hline
\end{tabular}




\begin{tabular}{|c|c|c|c|c|}
\hline \multirow[b]{2}{*}{ CHEMBL1485060 } & \multicolumn{4}{|c|}{ Supplemental Table S2.txt } \\
\hline & 737824 & 5.4 & 5.4487 & TST \\
\hline CHEMBL1719804 & 737824 & 5.75 & 5.6245 & TST \\
\hline CHEMBL3192809 & 737824 & 4.85 & 5.4282 & TST \\
\hline CHEMBL1587995 & 737824 & 4.9 & 4.9095 & TST \\
\hline CHEMBL1348181 & 737824 & 5.4 & 5.1256 & TST \\
\hline CHEMBL1319783 & 737824 & 5.3 & 5.0203 & TST \\
\hline CHEMBL1444270 & 737824 & 5.3 & 5.4546 & TST \\
\hline CHEMBL1480116 & 737824 & 5.45 & 5.5859 & TST \\
\hline CHEMBL601123 & 737824 & 4.5 & 4.7962 & TST \\
\hline CHEMBL1309621 & 737824 & 5.45 & 5.061 & TST \\
\hline CHEMBL1436536 & 737824 & 5.5 & 5.9832 & TST \\
\hline CHEMBL1560252 & 737824 & 5.55 & 5.1851 & TST \\
\hline CHEMBL1477492 & 737824 & 5.1 & 5.044 & TST \\
\hline CHEMBL79140 & 737824 & 4.9 & 4.773 & TST \\
\hline CHEMBL1599555 & 737824 & 5.7 & 5.6126 & TST \\
\hline CHEMBL1592470 & 737824 & 5.7 & 5.2435 & TST \\
\hline CHEMBL1464257 & 737824 & 4.9 & 5.2069 & TST \\
\hline CHEMBL1483801 & 737824 & 5.5 & 5.1941 & TST \\
\hline CHEMBL1510920 & 737824 & 5.7 & 5.1049 & TST \\
\hline CHEMBL16671 & 737824 & 5.8 & 5.3345 & TST \\
\hline CHEMBL1405151 & 737824 & 5.4 & 5.5348 & TST \\
\hline CHEMBL1512702 & 737824 & 6.8 & 6.0817 & TST \\
\hline CHEMBL1599438 & 737824 & 6.3 & 5.9264 & TST \\
\hline CHEMBL1509992 & 737824 & 4.95 & 5.0743 & TST \\
\hline CHEMBL1312956 & 737824 & 4.85 & 4.9529 & TST \\
\hline CHEMBL1348996 & 737824 & 5.6 & 5.1001 & TST \\
\hline CHEMBL1371781 & 737824 & 4.4 & 3.6568 & TST \\
\hline CHEMBL3197636 & 737824 & 4.95 & 5.0832 & TST \\
\hline CHEMBL1549333 & 737824 & 6.45 & 5.5167 & TST \\
\hline CHEMBL1324194 & 737824 & 5.0 & 5.223 & TST \\
\hline CHEMBL1480104 & 737824 & 4.95 & 5.2252 & TST \\
\hline CHEMBL1706736 & 737824 & 8.25 & 4.7784 & TST \\
\hline CHEMBL1343285 & 737824 & 6.15 & 5.7505 & TST \\
\hline CHEMBL1339917 & 737824 & 4.6 & 5.1661 & TST \\
\hline CHEMBL1492374 & 737824 & 4.85 & 5.4386 & TST \\
\hline CHEMBL1402827 & 737824 & 4.5 & 4.4552 & TST \\
\hline CHEMBL1522155 & 737824 & 5.2 & 4.4113 & TST \\
\hline CHEMBL3199344 & 737824 & 4.85 & 5.1105 & TST \\
\hline CHEMBL1452408 & 737824 & 4.9 & 4.6183 & TST \\
\hline CHEMBL1314182 & 737824 & 4.9 & 4.5518 & TST \\
\hline CHEMBL1992293 & 737824 & 4.55 & 5.1034 & TST \\
\hline CHEMBL3189451 & 737824 & 4.8 & 5.1483 & TST \\
\hline CHEMBL1318104 & 737824 & 5.8 & 5.8449 & TST \\
\hline CHEMBL1452391 & 737824 & 5.8 & 5.6999 & TST \\
\hline CHEMBL1517752 & 737824 & 5.55 & 5.0177 & TST \\
\hline CHEMBL1576710 & 737824 & 6.45 & 5.4521 & TST \\
\hline CHEMBL1486231 & 737824 & 5.45 & 5.6533 & TST \\
\hline CHEMBL1559650 & 737824 & 4.75 & 5.2176 & TST \\
\hline
\end{tabular}




\begin{tabular}{|c|c|c|c|c|c|}
\hline \multicolumn{6}{|c|}{ Supplemental Table s2.txt } \\
\hline CHEMBL1306876 & 737824 & 5.35 & 5.0969 & TST & \\
\hline CHEMBL1741725 & 737824 & 4.55 & 5.3702 & TST & \\
\hline CHEMBL1394135 & 737824 & 5.5 & 6.0382 & TST & \\
\hline CHEMBL1459487 & 737824 & 4.95 & 5.3299 & TST & \\
\hline CHEMBL1331410 & 737824 & 4.4 & 4.3059 & TST & \\
\hline CHEMBL1366446 & 737824 & 4.75 & 5.4132 & TST & \\
\hline CHEMBL1395620 & 737824 & 4.7 & 4.7214 & TST & \\
\hline CHEMBL1417636 & 737824 & 5.6 & 5.8115 & TST & \\
\hline CHEMBL1452750 & 737824 & 5.1 & 5.6968 & TST & \\
\hline CHEMBL1375243 & 737824 & 6.3 & 5.8169 & TST & \\
\hline CHEMBL512908 & 737824 & 6.4 & 6.3972 & TST & \\
\hline CHEMBL1587524 & 737824 & 5.45 & 5.6159 & TST & \\
\hline CHEMBL369142 & 737824 & 8.6 & 6.9269 & TST & \\
\hline CHEMBL428768 & 737824 & 6.0 & 6.1389 & TST & \\
\hline CHEMBL1387012 & 737824 & 4.6 & 4.9499 & TST & \\
\hline CHEMBL1329846 & 737824 & 6.45 & 5.5147 & TST & \\
\hline CHEMBL1597288 & 737824 & 5.3 & 4.9418 & TST & \\
\hline CHEMBL585861 & 737824 & 7.7001 & 7.5419 & TST & \\
\hline CHEMBL1604427 & 737824 & 4.8 & 5.1174 & TST & \\
\hline CHEMBL1328726 & 737824 & 4.95 & 5.245 & TST & \\
\hline CHEMBL1475010 & 737824 & 4.4 & 4.6823 & TST & \\
\hline CHEMBL1338358 & 737824 & 5.7 & 4.8504 & TST & \\
\hline CHEMBL1591876 & 737824 & 7.6 & 7.2024 & TST & \\
\hline CHEMBL1374335 & 737824 & 5.9 & 5.8685 & TST & \\
\hline CHEMBL1538177 & 737824 & 4.95 & 5.4571 & TST & \\
\hline CHEMBL1428733 & 737824 & 5.25 & 5.2369 & TST & \\
\hline CHEMBL1566780 & 737824 & 5.2 & 5.2656 & TST & \\
\hline CHEMBL1390135 & 737824 & 5.0 & 5.6347 & TST & \\
\hline CHEMBL1351426 & 737824 & 5.45 & 5.0873 & TST & \\
\hline CHEMBL1428357 & 737824 & 4.65 & 4.6396 & TST & \\
\hline CHEMBL1742307 & 737824 & 6.55 & 4.8071 & TST & \\
\hline CHEMBL1526635 & 737824 & 5.85 & 5.7104 & TST & \\
\hline CHEMBL3195193 & 737824 & 5.9 & 4.9961 & TST & \\
\hline CHEMBL1392275 & 737824 & 4.85 & 4.7853 & TST & \\
\hline CHEMBL1429565 & 737824 & 6.4 & 5.0692 & TST & \\
\hline CHEMBL1374796 & 737824 & 6.75 & 6.5904 & TST & \\
\hline CHEMBL1579407 & 737824 & 6.0 & 5.37299 & 9999999999 & TST \\
\hline CHEMBL1408138 & 737824 & 6.0 & 5.8755 & TST & \\
\hline CHEMBL1525813 & 737824 & 5.4 & 5.7019 & TST & \\
\hline CHEMBL1335777 & 737824 & 4.6 & 5.2708 & TST & \\
\hline CHEMBL1482482 & 737824 & 5.45 & 5.6971 & TST & \\
\hline CHEMBL1540708 & 737824 & 5.9 & 5.4938 & TST & \\
\hline CHEMBL1356439 & 737824 & 5.5 & 5.6033 & TST & \\
\hline CHEMBL1741613 & 737824 & 4.8 & 5.1761 & TST & \\
\hline CHEMBL1591508 & 737824 & 4.9 & 4.2502 & TST & \\
\hline CHEMBL1315316 & 737824 & 5.8 & 5.4272 & TST & \\
\hline CHEMBL1385365 & 737824 & 4.45 & 4.59 & TST & \\
\hline CHEMBL1529795 & 737824 & 4.85 & 5.0828 & TST & \\
\hline
\end{tabular}




\begin{tabular}{|c|c|c|c|c|c|}
\hline \\
\hline CHEMBL1430113 & 737824 & 4.6 & 4.6489 & TST & \\
\hline CHEMBL1582760 & 737824 & 6.05 & 5.2577 & TST & \\
\hline CHEMBL1527132 & 737824 & 6.5 & 5.6719 & TST & \\
\hline CHEMBL1576205 & 737824 & 5.6 & 5.0675 & TST & \\
\hline CHEMBL1315184 & 737824 & 6.3 & 6.0474 & TST & \\
\hline CHEMBL1314185 & 737824 & 4.4 & 4.4236 & TST & \\
\hline CHEMBL1741907 & 737824 & 5.0 & 5.3722 & TST & \\
\hline CHEMBL 3212645 & 737824 & 5.9 & 6.0946 & TST & \\
\hline CHEMBL1379319 & 737824 & 4.4 & 4.7391 & TST & \\
\hline CHEMBL3189715 & 737824 & 4.9 & 5.2863 & TST & \\
\hline CHEMBL1359716 & 737824 & 5.65 & 5.4281 & TST & \\
\hline CHEMBL1552517 & 737824 & 5.0 & 4.7477 & TST & \\
\hline CHEMBL1313588 & 737824 & 5.35 & 5.32299 & 99999999995 & TST \\
\hline CHEMBL1588059 & 737824 & 5.0 & 5.28799 & 9999999999 & TST \\
\hline CHEMBL 3190590 & 737824 & 5.7 & 5.2033 & TST & \\
\hline CHEMBL1518057 & 737824 & 6.05 & 5.7592 & TST & \\
\hline CHEMBL1398691 & 737824 & 5.4 & 5.1953 & TST & \\
\hline CHEMBL1232474 & 737824 & 7.2 & 7.9036 & TST & \\
\hline CHEMBL 3196345 & 737824 & 5.5 & 5.1186 & TST & \\
\hline CHEMBL1354262 & 737824 & 4.4 & 4.0555 & TST & \\
\hline CHEMBL1360767 & 737824 & 5.85 & 5.3959 & TST & \\
\hline CHEMBL1497183 & 737824 & 5.65 & 5.3911 & TST & \\
\hline CHEMBL1379149 & 737824 & 4.9 & 5.4811 & TST & \\
\hline CHEMBL1533335 & 737824 & 5.4 & 5.4141 & TST & \\
\hline CHEMBL1428349 & 737824 & 4.6 & 5.0032 & TST & \\
\hline CHEMBL1324162 & 737824 & 4.55 & 4.8355 & TST & \\
\hline CHEMBL1543213 & 737824 & 4.85 & 5.322 & TST & \\
\hline CHEMBL1370698 & 737824 & 5.4 & 5.1166 & TST & \\
\hline CHEMBL1722408 & 737824 & 5.5 & 5.3162 & TST & \\
\hline CHEMBL1305118 & 737824 & 6.05 & 5.3514 & TST & \\
\hline CHEMBL1702153 & 737824 & 4.9 & 5.1219 & TST & \\
\hline CHEMBL1463577 & 737824 & 5.1 & 5.3139 & TST & \\
\hline CHEMBL1514307 & 737824 & 5.0 & 5.0895 & TST & \\
\hline CHEMBL1331020 & 737824 & 4.45 & 5.6114 & TST & \\
\hline CHEMBL1457544 & 737824 & 4.4 & 3.6905 & TST & \\
\hline CHEMBL1608425 & 737824 & 5.5 & 5.3217 & TST & \\
\hline CHEMBL1493039 & 737824 & 5.5 & 5.4008 & TST & \\
\hline CHEMBL1079374 & 737824 & 5.3 & 5.6403 & TST & \\
\hline CHEMBL1502739 & 737824 & 5.1 & 5.561 & TST & \\
\hline CHEMBL1531676 & 737824 & 4.7 & 5.4344 & TST & \\
\hline CHEMBL1367708 & 737824 & 5.45 & 5.2305 & TST & \\
\hline CHEMBL1502072 & 737824 & 5.05 & 5.6099 & TST & \\
\hline CHEMBL1533516 & 737824 & 4.4 & 4.3607 & TST & \\
\hline CHEMBL1410910 & 737824 & 6.0 & 5.6563 & TST & \\
\hline CHEMBL1741681 & 737824 & 4.75 & 5.2749 & TST & \\
\hline CHEMBL1441795 & 737824 & 4.55 & 5.229 & TST & \\
\hline CHEMBL1612602 & 737824 & 5.1 & 5.1488 & TST & \\
\hline CHEMBL1539506 & 737824 & 4.9 & 5.3683 & TST & \\
\hline
\end{tabular}




\begin{tabular}{|c|c|c|c|c|}
\hline \multicolumn{5}{|c|}{ lemental Table s } \\
\hline CHEMBL3207645 & 737824 & 5.7 & 5.3601 & TST \\
\hline CHEMBL1593981 & 737824 & 5.6 & 5.4713 & TST \\
\hline CHEMBL1436042 & 737824 & 5.0 & 4.7343 & TST \\
\hline CHEMBL1386594 & 737824 & 5.75 & 5.2854 & TST \\
\hline CHEMBL 86676 & 737824 & 5.4 & 5.4916 & TST \\
\hline CHEMBL1741728 & 737824 & 5.15 & 5.5268 & TST \\
\hline CHEMBL1375216 & 737824 & 5.55 & 5.7655 & TST \\
\hline CHEMBL1511135 & 737824 & 4.85 & 4.9239 & TST \\
\hline CHEMBL1357770 & 737824 & 7.2 & 7.169 & TST \\
\hline CHEMBL1378642 & 737824 & 4.9 & 5.1095 & TST \\
\hline CHEMBL 1577237 & 737824 & 5.35 & 5.2865 & TST \\
\hline CHEMBL1701206 & 737824 & 5.05 & 4.7145 & TST \\
\hline CHEMBL1530692 & 737824 & 4.75 & 5.1327 & TST \\
\hline CHEMBL540848 & 737824 & 4.5 & 4.3074 & TST \\
\hline CHEMBL33171 & 737824 & 5.0 & 4.7397 & TST \\
\hline CHEMBL 1317913 & 737824 & 4.9 & 4.8869 & TST \\
\hline CHEMBL3208106 & 737824 & 4.9 & 5.20200 & 0000000001 \\
\hline CHEMBL1526213 & 737824 & 6.1 & 6.045 & TST \\
\hline CHEMBL1538244 & 737824 & 5.05 & 5.5952 & TST \\
\hline CHEMBL1741492 & 737824 & 5.35 & 5.3841 & TST \\
\hline CHEMBL1502885 & 737824 & 5.25 & 4.9135 & TST \\
\hline CHEMBL1561341 & 737824 & 5.6 & 5.7621 & TST \\
\hline CHEMBL75773 & 737824 & 5.0 & 4.34 & TST \\
\hline CHEMBL1552922 & 737824 & 4.7 & 4.0965 & TST \\
\hline CHEMBL1394031 & 737824 & 5.9 & 5.7257 & TST \\
\hline CHEMBL1503381 & 737824 & 6.2 & 5.7894 & TST \\
\hline CHEMBL1390229 & 737824 & 4.85 & 5.254 & TST \\
\hline CHEMBL1438164 & 737824 & 4.9 & 4.9557 & TST \\
\hline CHEMBL1390586 & 737824 & 5.4 & 5.4168 & TST \\
\hline CHEMBL1392455 & 737824 & 4.9 & 5.4697 & TST \\
\hline CHEMBL1379308 & 737824 & 5.4 & 4.5401 & TST \\
\hline CHEMBL1566014 & 737824 & 4.55 & 4.7846 & TST \\
\hline CHEMBL1317986 & 737824 & 5.8 & 5.9111 & TST \\
\hline CHEMBL1568519 & 737824 & 4.7 & 5.541 & TST \\
\hline CHEMBL1553114 & 737824 & 5.8 & 5.9325 & TST \\
\hline CHEMBL1320326 & 737824 & 5.8 & 5.4085 & TST \\
\hline CHEMBL1399842 & 737824 & 4.75 & 5.0252 & TST \\
\hline CHEMBL1601416 & 737824 & 4.8 & 4.581 & TST \\
\hline CHEMBL1356771 & 737824 & 5.9 & 5.4061 & TST \\
\hline CHEMBL1569891 & 737824 & 5.1 & 5.4902 & TST \\
\hline CHEMBL1318114 & 737824 & 6.3 & 6.2697 & TST \\
\hline CHEMBL1403333 & 737824 & 5.1 & 5.2887 & TST \\
\hline CHEMBL1437667 & 737824 & 5.7 & 5.8633 & TST \\
\hline CHEMBL1409866 & 737824 & 5.7 & 5.5928 & TST \\
\hline CHEMBL1575007 & 737824 & 5.15 & 4.8978 & TST \\
\hline CHEMBL1442105 & 737824 & 5.0 & 5.05 & TST \\
\hline CHEMBL1361585 & 737824 & 4.95 & 5.3188 & TST \\
\hline CHEMBL1478351 & 737824 & 5.05 & 5.2214 & TST \\
\hline
\end{tabular}




\begin{tabular}{|c|c|c|c|c|}
\hline \multicolumn{5}{|c|}{ Supplemental Table S2.txt } \\
\hline CHEMBL1336865 & 737824 & 5.0 & 4.7166 & TST \\
\hline CHEMBL1337292 & 737824 & 5.0 & 5.2196 & TST \\
\hline CHEMBL1426303 & 737824 & 5.5 & 4.7835 & TST \\
\hline CHEMBL1550126 & 737824 & 4.4 & 5.1894 & TST \\
\hline CHEMBL259389 & 737824 & 6.2 & 5.9628 & TST \\
\hline CHEMBL1590038 & 737824 & 4.9 & 4.6215 & TST \\
\hline CHEMBL1320273 & 737824 & 4.75 & 5.6606 & TST \\
\hline CHEMBL1544520 & 737824 & 4.9 & 4.958 & TST \\
\hline CHEMBL1398456 & 737824 & 5.0 & 4.9123 & TST \\
\hline CHEMBL1602083 & 737824 & 4.9 & 5.2571 & TST \\
\hline CHEMBL 3194874 & 737824 & 6.0 & 5.1188 & TST \\
\hline CHEMBL1323320 & 737824 & 4.8 & 5.1983 & TST \\
\hline CHEMBL3195739 & 737824 & 4.65 & 4.9072 & TST \\
\hline CHEMBL 3197425 & 737824 & 5.7 & 5.2689 & TST \\
\hline CHEMBL1458881 & 737824 & 5.45 & 5.4534 & TST \\
\hline CHEMBL1451315 & 737824 & 6.0 & 6.0069 & TST \\
\hline CHEMBL 2007212 & 737824 & 4.95 & 5.072 & TST \\
\hline CHEMBL1543356 & 737824 & 5.6 & 5.3787 & TST \\
\hline CHEMBL1964690 & 737824 & 5.4 & 5.4474 & TST \\
\hline CHEMBL1537220 & 737824 & 4.75 & 5.1745 & TST \\
\hline CHEMBL1559618 & 737824 & 5.4 & 5.7367 & TST \\
\hline CHEMBL1347827 & 737824 & 4.8 & 4.8694 & TST \\
\hline CHEMBL1505411 & 737824 & 5.95 & 5.5497 & TST \\
\hline CHEMBL3194920 & 737824 & 6.6 & 5.1148 & TST \\
\hline CHEMBL1603100 & 737824 & 5.7 & 5.614 & TST \\
\hline CHEMBL1575432 & 737824 & 5.7 & 5.7028 & TST \\
\hline CHEMBL1334323 & 737824 & 5.35 & 5.0438 & TST \\
\hline CHEMBL489534 & 737824 & 5.7 & 5.7243 & TST \\
\hline CHEMBL1505786 & 737824 & 4.4 & 5.4987 & TST \\
\hline CHEMBL1374260 & 737824 & 5.45 & 5.0945 & TST \\
\hline CHEMBL1574956 & 737824 & 4.4 & 4.188 & TST \\
\hline CHEMBL1391234 & 737824 & 5.25 & 4.8926 & TST \\
\hline CHEMBL1466490 & 737824 & 4.4 & 5.0983 & TST \\
\hline CHEMBL107528 & 737824 & 5.7 & 4.9286 & TST \\
\hline CHEMBL1597474 & 737824 & 4.6 & 4.5138 & TST \\
\hline CHEMBL1425061 & 737824 & 4.9 & 5.0326 & TST \\
\hline CHEMBL1542082 & 737824 & 5.9 & 4.927 & TST \\
\hline CHEMBL1317148 & 737824 & 4.5 & 4.3017 & TST \\
\hline CHEMBL1301305 & 737824 & 4.5 & 5.1806 & TST \\
\hline CHEMBL1306724 & 737824 & 4.5 & 5.2745 & TST \\
\hline CHEMBL1381739 & 737824 & 4.8 & 5.4069 & TST \\
\hline CHEMBL1331634 & 737824 & 6.0 & 5.9927 & TST \\
\hline CHEMBL1358628 & 737824 & 6.1 & 5.501 & TST \\
\hline CHEMBL1360650 & 737824 & 4.9 & 5.0114 & TST \\
\hline CHEMBL1430904 & 737824 & 4.6 & 5.2289 & TST \\
\hline CHEMBL1382955 & 737824 & 5.65 & 5.6371 & TST \\
\hline CHEMBL1416703 & 737824 & 4.95 & 4.8348 & TST \\
\hline CHEMBL1503273 & 737824 & 5.6 & 5.0996 & TST \\
\hline
\end{tabular}




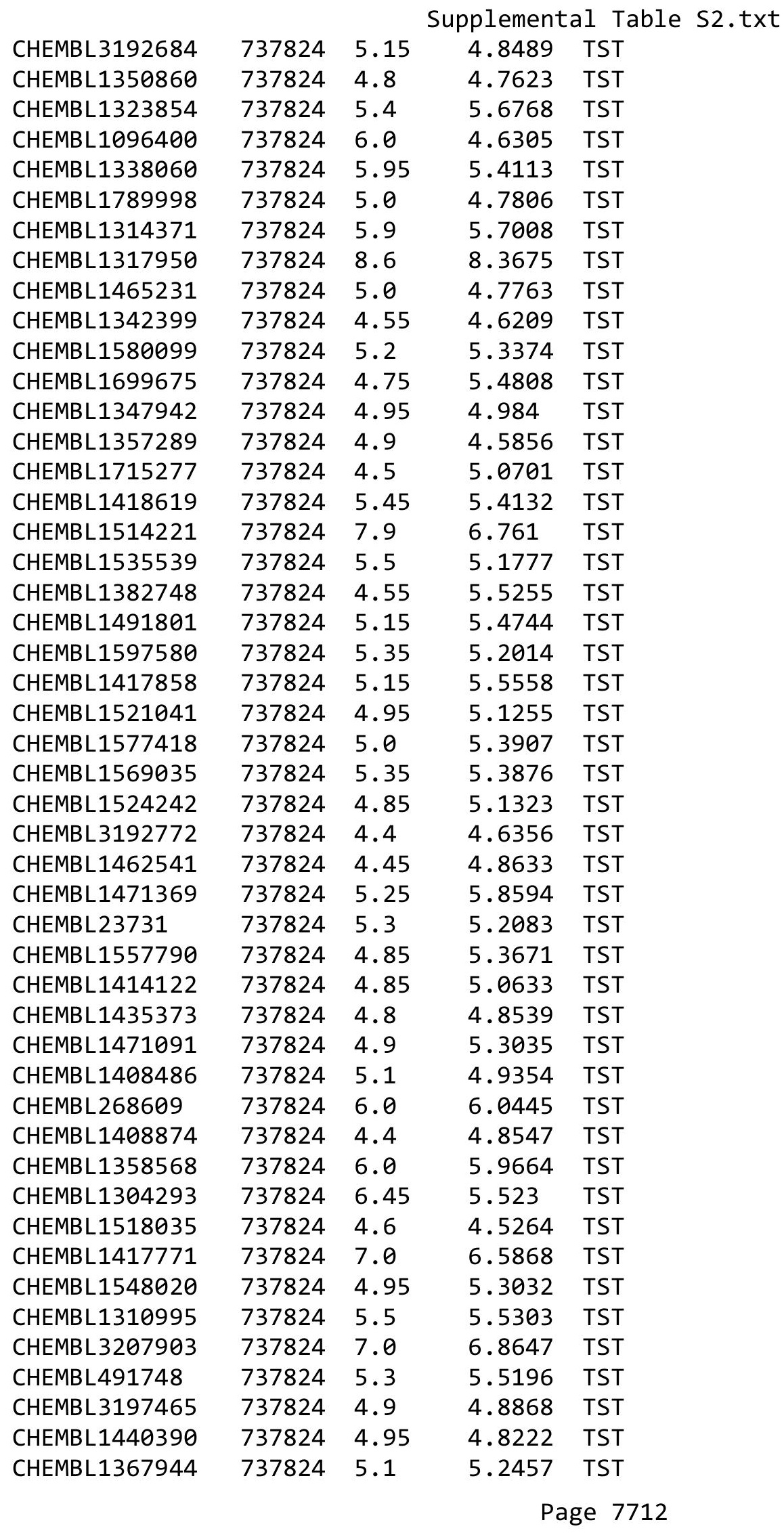




\begin{tabular}{|c|c|c|c|c|}
\hline \multicolumn{5}{|c|}{ Supplemental Table S2.txt } \\
\hline CHEMBL1382292 & 737824 & 4.9 & 4.8777 & TST \\
\hline CHEMBL1396374 & 737824 & 5.5 & 5.3434 & TST \\
\hline CHEMBL1549003 & 737824 & 5.1 & 5.4108 & TST \\
\hline CHEMBL1536954 & 737824 & 5.15 & 4.8082 & TST \\
\hline CHEMBL1372627 & 737824 & 5.8 & 5.601 & TST \\
\hline CHEMBL17002 & 737824 & 5.1 & 5.0277 & TST \\
\hline CHEMBL1548101 & 737824 & 6.45 & 5.3718 & TST \\
\hline CHEMBL1524363 & 737824 & 4.55 & 5.1402 & TST \\
\hline CHEMBL1741831 & 737824 & 6.15 & 5.3635 & TST \\
\hline CHEMBL1358263 & 737824 & 4.7 & 4.8283 & TST \\
\hline CHEMBL1354363 & 737824 & 5.0 & 4.8339 & TST \\
\hline CHEMBL3209650 & 737824 & 4.85 & 4.6969 & TST \\
\hline CHEMBL182310 & 737824 & 4.6 & 4.1229 & TST \\
\hline CHEMBL53898 & 737824 & 5.0 & 5.5194 & TST \\
\hline CHEMBL1497610 & 737824 & 5.2 & 5.4869 & TST \\
\hline CHEMBL1512701 & 737824 & 5.3 & 5.4519 & TST \\
\hline CHEMBL1426363 & 737824 & 4.7 & 4.7721 & TST \\
\hline CHEMBL1458583 & 737824 & 4.55 & 4.8275 & TST \\
\hline CHEMBL1587467 & 737824 & 6.75 & 5.9763 & TST \\
\hline CHEMBL1447663 & 737824 & 5.0 & 5.1712 & TST \\
\hline CHEMBL1467857 & 737824 & 5.35 & 5.8292 & TST \\
\hline CHEMBL1597735 & 737824 & 5.85 & 4.9657 & TST \\
\hline CHEMBL1575193 & 737824 & 5.0 & 5.4761 & TST \\
\hline CHEMBL1368479 & 737824 & 4.7 & 4.8822 & TST \\
\hline CHEMBL1534376 & 737824 & 5.4 & 5.0227 & TST \\
\hline CHEMBL1554664 & 737824 & 5.0 & 5.0994 & TST \\
\hline CHEMBL1396949 & 737824 & 5.3 & 5.0951 & TST \\
\hline CHEMBL1353775 & 737824 & 4.9 & 5.3215 & TST \\
\hline CHEMBL1454533 & 737824 & 4.8 & 5.1493 & TST \\
\hline CHEMBL1522864 & 737824 & 4.95 & 5.2674 & TST \\
\hline CHEMBL1593371 & 737824 & 5.0 & 5.0151 & TST \\
\hline CHEMBL1428282 & 737824 & 5.05 & 5.0832 & TST \\
\hline CHEMBL1429320 & 737824 & 5.0 & 5.1552 & TST \\
\hline CHEMBL495068 & 737824 & 4.8 & 4.94600 & 0000000001 \\
\hline CHEMBL1490268 & 737824 & 4.4 & 4.1397 & TST \\
\hline CHEMBL391997 & 737824 & 6.5 & 6.1953 & TST \\
\hline CHEMBL1347641 & 737824 & 5.55 & 5.4781 & TST \\
\hline CHEMBL1359407 & 737824 & 5.75 & 5.3768 & TST \\
\hline CHEMBL1322376 & 737824 & 4.95 & 4.9765 & TST \\
\hline CHEMBL1566407 & 737824 & 6.0 & 5.8421 & TST \\
\hline CHEMBL1496370 & 737824 & 4.7 & 5.6548 & TST \\
\hline CHEMBL1593707 & 737824 & 4.7 & 4.5671 & TST \\
\hline CHEMBL1400995 & 737824 & 4.8 & 5.3245 & TST \\
\hline CHEMBL1269022 & 737824 & 6.0 & 6.3187 & TST \\
\hline CHEMBL1310057 & 737824 & 4.95 & 5.0974 & TST \\
\hline CHEMBL1610132 & 737824 & 6.75 & 5.5457 & TST \\
\hline CHEMBL1323732 & 737824 & 5.65 & 5.2885 & TST \\
\hline CHEMBL3214362 & 737824 & 4.8 & 5.1071 & TST \\
\hline
\end{tabular}




\begin{tabular}{|c|c|c|c|c|}
\hline & & & pplement & al Table S \\
\hline CHEMBL1594329 & 737824 & 5.0 & 5.005 & TST \\
\hline CHEMBL1742148 & 737824 & -0.0 & 5.3612 & TST \\
\hline CHEMBL1399815 & 737824 & 5.2 & 5.5545 & TST \\
\hline CHEMBL1504955 & 737824 & 4.9 & 5.3013 & TST \\
\hline CHEMBL1328109 & 737824 & 6.3 & 6.0747 & TST \\
\hline CHEMBL1522752 & 737824 & 5.7 & 5.3843 & TST \\
\hline CHEMBL38576 & 737824 & 6.5 & 5.8912 & TST \\
\hline CHEMBL1381586 & 737824 & 4.9 & 4.731 & TST \\
\hline CHEMBL1554577 & 737824 & 7.3 & 7.1751 & TST \\
\hline CHEMBL1492346 & 737824 & 5.0 & 5.2256 & TST \\
\hline CHEMBL546257 & 737824 & 5.0 & 4.5274 & TST \\
\hline CHEMBL1593889 & 737824 & 6.2 & 5.9249 & TST \\
\hline CHEMBL1588356 & 737824 & 6.55 & 5.4151 & TST \\
\hline CHEMBL1558029 & 737824 & 4.95 & 4.8048 & TST \\
\hline CHEMBL1544132 & 737824 & 5.9 & 5.8335 & TST \\
\hline CHEMBL1741807 & 737824 & 4.6 & 5.209 & TST \\
\hline CHEMBL1472456 & 737824 & 5.0 & 5.5022 & TST \\
\hline CHEMBL1514090 & 737824 & 5.6 & 4.458 & TST \\
\hline CHEMBL1412594 & 737824 & 5.75 & 5.6992 & TST \\
\hline CHEMBL1485605 & 737824 & 4.9 & 5.4997 & TST \\
\hline CHEMBL1530955 & 737824 & 4.8 & 4.6275 & TST \\
\hline CHEMBL1375478 & 737824 & 4.85 & 5.6591 & TST \\
\hline CHEMBL1342397 & 737824 & 5.75 & 4.6984 & TST \\
\hline CHEMBL1359378 & 737824 & 4.75 & 5.8287 & TST \\
\hline CHEMBL3207422 & 737824 & 5.6 & 4.8273 & TST \\
\hline CHEMBL1385649 & 737824 & 6.35 & 5.2799 & TST \\
\hline CHEMBL313339 & 737824 & 5.35 & 5.6259 & TST \\
\hline CHEMBL1347660 & 737824 & 5.45 & 5.1952 & TST \\
\hline CHEMBL 384903 & 737824 & 6.9 & 6.4955 & TST \\
\hline CHEMBL1741922 & 737824 & 5.35 & 4.6861 & TST \\
\hline CHEMBL1709113 & 737824 & 4.4 & 5.124 & TST \\
\hline CHEMBL1594473 & 737824 & 5.0 & 5.0608 & TST \\
\hline CHEMBL1601300 & 737824 & 4.95 & 4.9248 & TST \\
\hline CHEMBL1318340 & 737824 & 4.9 & 4.9015 & TST \\
\hline CHEMBL1611218 & 737824 & 5.0 & 4.3892 & TST \\
\hline CHEMBL1433039 & 737824 & 5.55 & 5.7965 & TST \\
\hline CHEMBL1356395 & 737824 & 5.2 & 4.8445 & TST \\
\hline CHEMBL1329562 & 737824 & 6.0 & $5.6960 e$ & 0000000001 \\
\hline CHEMBL1546037 & 737824 & 4.75 & 5.2393 & TST \\
\hline CHEMBL1330763 & 737824 & 7.3 & 6.4013 & TST \\
\hline CHEMBL1612296 & 737824 & 4.55 & 5.3367 & TST \\
\hline CHEMBL1411982 & 737824 & 4.45 & 5.0818 & TST \\
\hline CHEMBL1589124 & 737824 & 5.65 & 5.8721 & TST \\
\hline CHEMBL1549000 & 737824 & 5.0 & 4.8514 & TST \\
\hline CHEMBL1474681 & 737824 & 5.8 & 5.7521 & TST \\
\hline CHEMBL1479727 & 737824 & 5.5 & 5.2385 & TST \\
\hline CHEMBL1519456 & 737824 & 4.85 & 5.2531 & TST \\
\hline CHEMBL1534554 & 737824 & 8.0 & 5.1146 & TST \\
\hline
\end{tabular}




\begin{tabular}{|c|c|c|c|c|c|}
\hline CHEMBL1465707 & 737824 & 5.6 & \multicolumn{2}{|c|}{5.4670000000000005} & TST \\
\hline CHEMBL1429809 & 737824 & 5.2 & 5.5412 & TST & \\
\hline CHEMBL69367 & 737824 & 4.5 & 3.9947 & TST & \\
\hline CHEMBL1588955 & 737824 & 4.8 & 5.2648 & TST & \\
\hline CHEMBL3213443 & 737824 & 4.65 & 5.2545 & TST & \\
\hline CHEMBL1527837 & 737824 & 4.8 & 5.0072 & TST & \\
\hline CHEMBL3213021 & 737824 & 7.3 & 5.4564 & TST & \\
\hline CHEMBL1742358 & 737824 & 4.6 & 4.9982 & TST & \\
\hline CHEMBL1489354 & 737824 & 5.4 & 4.9824 & TST & \\
\hline CHEMBL1568465 & 737824 & 4.9 & 4.7085 & TST & \\
\hline CHEMBL1583992 & 737824 & 5.0 & 4.881 & TST & \\
\hline CHEMBL1458453 & 737824 & 4.9 & 5.2012 & TST & \\
\hline CHEMBL1593440 & 737824 & 5.6 & 5.2843 & TST & \\
\hline CHEMBL1703300 & 737824 & 4.7 & 5.0495 & TST & \\
\hline CHEMBL1314935 & 737824 & 5.4 & 5.2196 & TST & \\
\hline CHEMBL1585050 & 737824 & 6.0 & \multicolumn{2}{|c|}{5.7010000000000005} & TST \\
\hline CHEMBL3213815 & 737824 & 4.55 & 4.9393 & TST & \\
\hline CHEMBL1492641 & 737824 & 4.75 & 4.6805 & TST & \\
\hline CHEMBL1332463 & 737824 & 4.4 & 4.9529 & TST & \\
\hline CHEMBL1486399 & 737824 & 5.9 & \multicolumn{2}{|c|}{5.542000000000001} & TST \\
\hline CHEMBL1447959 & 737824 & 5.4 & 5.4724 & TST & \\
\hline CHEMBL 3199224 & 737824 & 5.15 & 5.41 & TST & \\
\hline CHEMBL 287689 & 737824 & 5.4 & 5.5086 & TST & \\
\hline CHEMBL1376736 & 737824 & 4.7 & 4.288 & TST & \\
\hline CHEMBL1476206 & 737824 & 4.6 & 4.3571 & TST & \\
\hline CHEMBL1421648 & 737824 & 5.0 & 5.3013 & TST & \\
\hline CHEMBL1382227 & 737824 & 5.25 & 5.3842 & TST & \\
\hline CHEMBL1542467 & 737824 & 5.35 & 5.0672 & TST & \\
\hline CHEMBL1388814 & 737824 & 5.45 & 4.891 & TST & \\
\hline CHEMBL1511199 & 737824 & 4.7 & 4.6026 & TST & \\
\hline CHEMBL1464331 & 737824 & 4.75 & 4.8428 & TST & \\
\hline CHEMBL1495506 & 737824 & 4.85 & 4.7458 & TST & \\
\hline CHEMBL1603192 & 737824 & 5.85 & 5.9005 & TST & \\
\hline CHEMBL1487790 & 737824 & 5.3 & 5.0272 & TST & \\
\hline CHEMBL1446009 & 737824 & 5.4 & 5.4717 & TST & \\
\hline CHEMBL3195945 & 737824 & 5.1 & 5.0933 & TST & \\
\hline CHEMBL1462483 & 737824 & 5.0 & 5.1628 & TST & \\
\hline CHEMBL1385440 & 737824 & 4.65 & 4.8607 & TST & \\
\hline CHEMBL1475036 & 737824 & 4.6 & 4.1997 & TST & \\
\hline CHEMBL1356923 & 737824 & 5.7 & 5.2468 & TST & \\
\hline CHEMBL1396211 & 737824 & 5.6 & 5.2224 & TST & \\
\hline CHEMBL1569485 & 737824 & 4.9 & 4.6976 & TST & \\
\hline CHEMBL1409396 & 737824 & 5.6 & 5.6441 & TST & \\
\hline CHEMBL1364185 & 737824 & 5.0 & 4.7207 & TST & \\
\hline CHEMBL1409436 & 737824 & 4.95 & 4.8268 & TST & \\
\hline CHEMBL1982394 & 737824 & 5.35 & 5.3956 & TST & \\
\hline CHEMBL1432053 & 737824 & 4.9 & 4.9252 & TST & \\
\hline CHEMBL1466584 & 737824 & 8.25 & 4.8356 & TST & \\
\hline
\end{tabular}




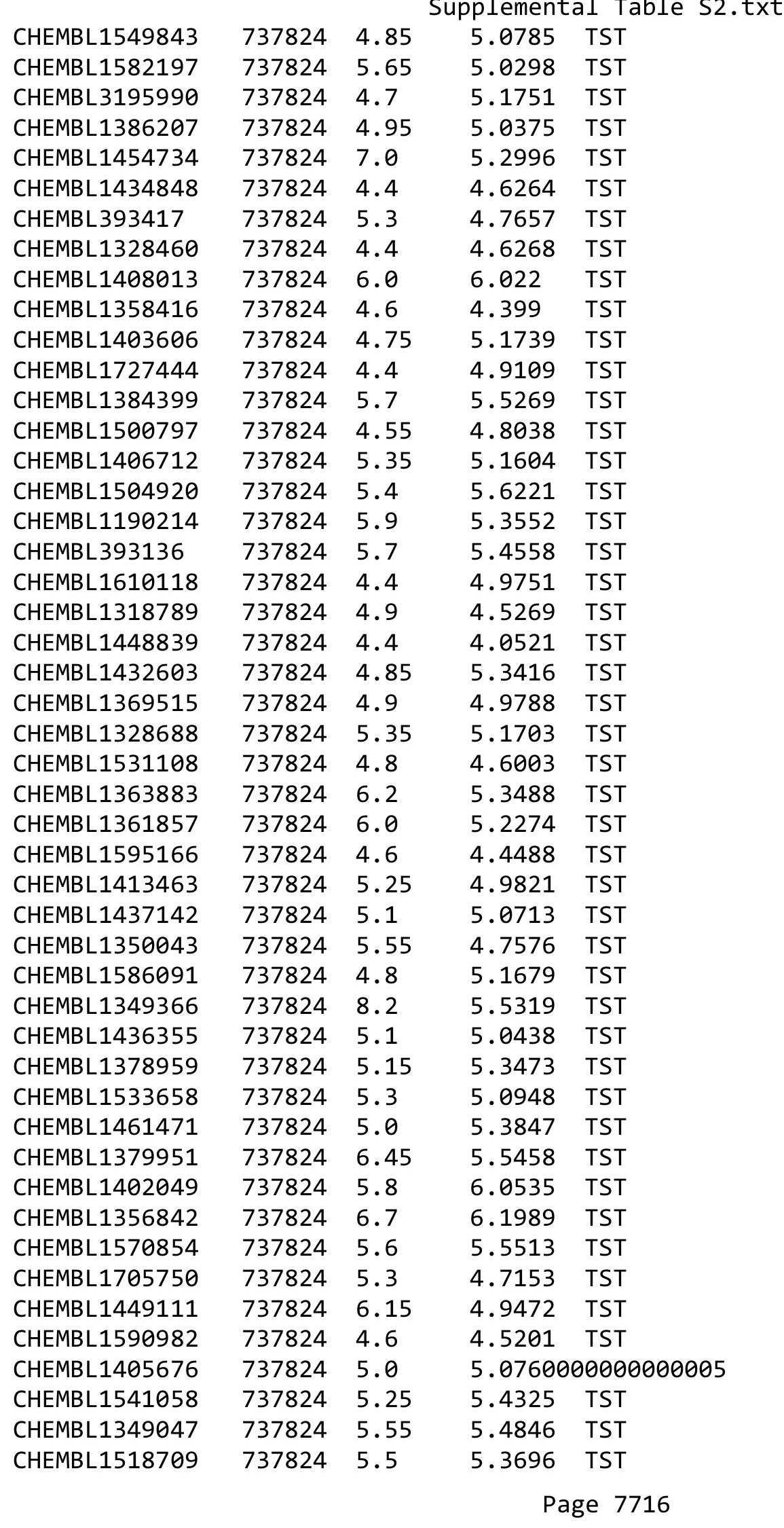




\begin{tabular}{|c|c|c|c|c|}
\hline \multicolumn{5}{|c|}{ Supplemental Table S2.txt } \\
\hline CHEMBL 3211113 & 737824 & 6.1 & 5.6395 & TST \\
\hline CHEMBL1413524 & 737824 & 4.7 & 5.2165 & TST \\
\hline CHEMBL491952 & 737824 & 4.7 & 4.6811 & TST \\
\hline CHEMBL1339210 & 737824 & 4.7 & 5.3007 & TST \\
\hline CHEMBL1313704 & 737824 & 6.4 & 5.6606 & TST \\
\hline CHEMBL1569345 & 737824 & 5.8 & 5.0763 & TST \\
\hline CHEMBL1383146 & 737824 & 5.55 & 5.5987 & TST \\
\hline CHEMBL1536220 & 737824 & 4.7 & 5.2879 & TST \\
\hline CHEMBL1513800 & 737824 & 4.5 & 4.2711 & TST \\
\hline CHEMBL1396546 & 737824 & 5.3 & 5.0291 & TST \\
\hline CHEMBL1554567 & 737824 & 4.8 & 4.6877 & TST \\
\hline CHEMBL1553930 & 737824 & 4.9 & 4.8941 & TST \\
\hline CHEMBL1480944 & 737824 & 4.8 & 4.8915 & TST \\
\hline CHEMBL1523995 & 737824 & 5.4 & 5.1723 & TST \\
\hline CHEMBL1491098 & 737824 & 4.8 & 5.065 & TST \\
\hline CHEMBL1450977 & 737824 & 5.7 & 4.9672 & TST \\
\hline CHEMBL1382819 & 737824 & 5.5 & 4.873 & TST \\
\hline CHEMBL1462988 & 737824 & 4.4 & 5.2188 & TST \\
\hline CHEMBL1716960 & 737824 & 4.7 & 5.0348 & TST \\
\hline CHEMBL1422891 & 737824 & 4.8 & 5.2191 & TST \\
\hline CHEMBL1369388 & 737824 & 4.8 & 4.8261 & TST \\
\hline CHEMBL1440255 & 737824 & 5.4 & 5.2037 & TST \\
\hline CHEMBL1362365 & 737824 & 5.4 & 5.4489 & TST \\
\hline CHEMBL1493877 & 737824 & 5.3 & 5.3288 & TST \\
\hline CHEMBL1336961 & 737824 & 4.45 & 5.0644 & TST \\
\hline CHEMBL1366979 & 737824 & 6.1 & 5.7572 & TST \\
\hline CHEMBL1431665 & 737824 & 4.4 & 5.0533 & TST \\
\hline CHEMBL1471467 & 737824 & 4.85 & 4.5629 & TST \\
\hline CHEMBL1546816 & 737824 & 4.7 & 4.8532 & TST \\
\hline CHEMBL3199657 & 737824 & 4.55 & 5.1694 & TST \\
\hline CHEMBL1317802 & 737824 & -0.0 & 4.2846 & TST \\
\hline CHEMBL1446323 & 737824 & 5.0 & 4.9615 & TST \\
\hline CHEMBL1588323 & 737824 & 4.95 & 5.272 & TST \\
\hline CHEMBL1406274 & 737824 & 4.8 & 4.4885 & TST \\
\hline CHEMBL1486304 & 737824 & 5.6 & 6.0989 & TST \\
\hline CHEMBL1423533 & 737824 & 5.0 & 5.2288 & TST \\
\hline CHEMBL1460362 & 737824 & 5.45 & 5.6831 & TST \\
\hline CHEMBL1558843 & 737824 & 5.3 & 5.1913 & TST \\
\hline CHEMBL1395974 & 737824 & 4.5 & 4.4543 & TST \\
\hline CHEMBL1476280 & 737824 & 5.9 & 5.6339 & TST \\
\hline CHEMBL1534816 & 737824 & 6.05 & 5.5136 & TST \\
\hline CHEMBL1728280 & 1301616 & 5.0227 & 4.8575 & TST \\
\hline CHEMBL2360358 & 1301616 & 4.1961 & 4.6517 & TRN \\
\hline CHEMBL1578386 & 1301616 & 4.6373 & 4.479 & TRN \\
\hline CHEMBL1469676 & 1301616 & 5.0146 & 5.2504 & TRN \\
\hline CHEMBL1361883 & 1301616 & 4.4349 & 4.7701 & TRN \\
\hline CHEMBL1988829 & 1301616 & 4.4162 & 4.7221 & TRN \\
\hline CHEMBL2356209 & 1301616 & 4.93 & 4.7013 & TRN \\
\hline
\end{tabular}


Supplemental Table S2.txt

\begin{tabular}{|c|c|c|c|c|c|c|}
\hline CHEMBL1337592 & 1301616 & 5.9914 & 5.9763 & TRN & & \\
\hline CHEMBL1366838 & 1301616 & 6.0205 & 5.327999 & 99999999 & & TRN \\
\hline CHEMBL1235676 & 1301616 & 4.8286 & 5.0172 & TST & & \\
\hline CHEMBL1479393 & 1301616 & 5.4283 & 4.687 & TRN & & \\
\hline CHEMBL 2360775 & 1301616 & 4.3796 & 4.4894 & TRN & & \\
\hline CHEMBL1612044 & 1301616 & 5.4698 & 4.9082 & TRN & & \\
\hline CHEMBL1320274 & 1301616 & 4.9462 & 5.2633 & TRN & & \\
\hline CHEMBL 2355085 & 1301616 & 4.2598 & 4.6017 & TRN & & \\
\hline CHEMBL 2356442 & 1301616 & 4.1552 & 4.5397 & TRN & & \\
\hline CHEMBL 2360650 & 1301616 & 4.2887 & 4.5303 & TRN & & \\
\hline CHEMBL1879111 & 1301616 & 4.4305 & 4.6073 & TRN & & \\
\hline CHEMBL1971727 & 1301616 & 4.2966 & 4.6165 & TRN & & \\
\hline CHEMBL 2354924 & 1301616 & 4.335 & 4.3995 & TRN & & \\
\hline CHEMBL 1341816 & 1301616 & 4.5227 & 4.6351 & TRN & & \\
\hline CHEMBL 2356010 & 1301616 & 4.4603 & 4.6141 & TRN & & \\
\hline CHEMBL599924 & 1301616 & 4.8969 & 5.2127 & TRN & & \\
\hline CHEMBL1512775 & 1301616 & 4.504 & 4.6828 & TST & & \\
\hline CHEMBL1463884 & 1301616 & 4.2862 & 4.6496 & TRN & & \\
\hline CHEMBL 1465040 & 1301616 & 4.8294 & 4.9676 & TRN & & \\
\hline CHEMBL 1895744 & 1301616 & 4.6108 & 4.6648 & TRN & & \\
\hline CHEMBL 2357993 & 1301616 & 4.4226 & 4.7301 & TST & & \\
\hline CHEMBL 2357642 & 1301616 & 4.1734 & 4.6335 & TRN & & \\
\hline CHEMBL1727997 & 1301616 & 4.5847 & 4.532 & TST & & \\
\hline CHEMBL 2354812 & 1301616 & 4.3796 & 4.5099 & TRN & & \\
\hline CHEMBL1450797 & 1301616 & 4.4568 & 4.625 & TRN & & \\
\hline CHEMBL 2133790 & 1301616 & 4.7181 & 4.8038 & TRN & & \\
\hline CHEMBL 2357765 & 1301616 & 4.4016 & 4.6896 & TRN & & \\
\hline CHEMBL 1444103 & 1301616 & 4.9987 & 4.6057 & TST & & \\
\hline CHEMBL1351908 & 1301616 & 5.104 & 4.9163 & TRN & & \\
\hline CHEMBL 283078 & 1301616 & 5.6556 & 4.838 & TST & & \\
\hline CHEMBL1893035 & 1301616 & 4.2076 & 4.6283 & TRN & & \\
\hline CHEMBL1383534 & 1301616 & 4.76699 & 999999999 & 995 & 4.4237 & TRN \\
\hline CHEMBL1704261 & 1301616 & 4.5479 & 4.9741 & TRN & & \\
\hline CHEMBL 2356002 & 1301616 & 4.6119 & 4.5655 & TRN & & \\
\hline CHEMBL 2354319 & 1301616 & 4.3891 & 4.5477 & TRN & & \\
\hline CHEMBL1462900 & 1301616 & 6.1688 & 5.4588 & TRN & & \\
\hline CHEMBL 1888815 & 1301616 & 4.7064 & 4.5304 & TST & & \\
\hline CHEMBL1517888 & 1301616 & 4.3781 & 4.5497 & TRN & & \\
\hline CHEMBL 2355817 & 1301616 & 4.3188 & 4.485 & TRN & & \\
\hline CHEMBL 2359541 & 1301616 & 6.0 & 4.6605 & TRN & & \\
\hline CHEMBL 2359026 & 1301616 & 4.6405 & 4.5839 & TRN & & \\
\hline CHEMBL 1438983 & 1301616 & 4.4175 & 4.768 & TST & & \\
\hline CHEMBL 2009682 & 1301616 & 4.3992 & 4.7212 & TRN & & \\
\hline CHEMBL1701527 & 1301616 & 4.4769 & 4.4965 & TST & & \\
\hline CHEMBL515505 & 1301616 & 5.9318 & 4.8189 & TST & & \\
\hline CHEMBL1428095 & 1301616 & 4.684 & 4.4697 & TRN & & \\
\hline CHEMBL1412396 & 1301616 & 4.6755 & 4.6056 & TRN & & \\
\hline CHEMBL 309474 & 1301616 & 4.2548 & 4.6034 & TST & & \\
\hline
\end{tabular}


Supplemental Table S2.txt

\begin{tabular}{|c|c|c|}
\hline 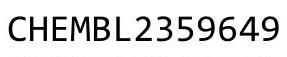 & & \\
\hline & & 2379 \\
\hline CMDI 1 & & \\
\hline IEMBL 2362033 & & \\
\hline HEMBL154 & 301016 & ( \\
\hline AEMBL2357535 & 301616 & 6.0 \\
\hline IEMBL] & $a_{1}$ & 4.663 \\
\hline EMBL & 20 & $68+2+2+3$ \\
\hline IEMBL1428437 & 301616 & 112 \\
\hline AEMBL1973122 & 301616 & 5.779 \\
\hline AEMBL1735482 & 301616 & 99 \\
\hline IEMBL] & 30 & 5.315 \\
\hline EMBL & & \\
\hline HEMBL1563669 & 301616 & 4.311 \\
\hline AEMBL1900870 & 16 & 5.303 \\
\hline 44836 & . & $20+2+2$ \\
\hline AEMBL & 30 & 5.0297 \\
\hline AEMBL & 16 & 4.3734 \\
\hline 387688 & 616 & 4.972 \\
\hline EMBL & 36 & 4.387 \\
\hline AEMBL: & 30. & 5.333 \\
\hline IEMBL & 36 & 4.283 \\
\hline IEMBL & 10 & 4.19 \\
\hline EMBL: & & 4.64 \\
\hline IEMBL 2355635 & 36 & $4.70<$ \\
\hline 86255 & 36 & 5.481 \\
\hline IEMBL & 30 & 4 . \\
\hline 2873 & 30 & 4.5916 \\
\hline IEMBL: & $391+2+3$ & 4.365 \\
\hline IEMBL1350432 & 00 & 4.217 \\
\hline AEMBL: & 30 & 4.390 \\
\hline IEMBL & 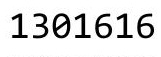 & 4.277 \\
\hline 99 & 36 & 4.477 \\
\hline 49063 & 301 & 5.823 \\
\hline HEMBL2356602 & 301 & 4.364 \\
\hline IEMBL & 36 & 5.154 \\
\hline AEMBL & $20+2-2+1$ & 4.351 \\
\hline HEMBL & 301 & 4.182 \\
\hline AEMBL2356655 & 301 & 4.487 \\
\hline AEMBL2359438 & 3016 & 4.556 \\
\hline CHEMBL & 301 & 4. \\
\hline CHEMBL & 30161 & 4.685 \\
\hline 57286 & 301 & 4.353 \\
\hline AEMBL3199673 & 30161 & 4.664 \\
\hline 712082 & 30161 & 4587 \\
\hline CHEMBL & 13016 & 5.59 \\
\hline CHEMBL & 3016 & $4.6 \varepsilon$ \\
\hline (1) 1 & & \\
\hline
\end{tabular}

.

4.5784 TRN

4.5883 TRN

4.6488 TRN

4.4744 TRN

4.6288 TRN

4.6814 TRN

4.5776 TRN

4.5213 TRN

4.5011 TST

5.2078 TRN

4.9227 TRN

5.4713 TRN

4.566 TRN

4.7087 TRN

4.6838 TST

4.5284 TRN

5.3867 TRN

4.8094 TRN

5.3183 TRN

4.5717 TRN

5.6196 TRN

4.7147 TRN

4.8041 TRN

4.4898 TST

4.7079 TRN

4.8049 TRN

4.6499 TRN

4.5479 TRN

4.4511 TRN

4.7872 TRN

4.6703 TST

4.5591 TST

4.4867 TRN

5.104 TRN

4.6836 TRN

5.3419 TRN

4.784 TRN

4.6399 TRN

4.6039 TRN

4.6809 TRN

4.9623 TRN

5.0793 TRN

4.4773 TRN

4.6752 TRN

4.7535 TST

4.5898 TRN

4.6963 TRN

5.2170000000000005 TRN

Page 7719 
Supplemental Table S2.txt

\begin{tabular}{|c|c|c|c|c|c|}
\hline CHEMBL2355923 & 1301616 & 4.2797 & 4.7861 & TRN & \\
\hline CHEMBL1468011 & 1301616 & 4.5177 & 4.7432 & TRN & \\
\hline CHEMBL1338304 & 1301616 & 4.5331 & 4.7307 & TRN & \\
\hline CHEMBL2354739 & 1301616 & 4.3668 & 4.7037 & TRN & \\
\hline CHEMBL3392492 & 1301616 & 4.6457 & 4.6386 & TST & \\
\hline CHEMBL 2358064 & 1301616 & 4.377 & 4.5508 & TRN & \\
\hline CHEMBL1402010 & 1301616 & 5.1013 & 4.827 & TRN & \\
\hline CHEMBL2355651 & 1301616 & 4.5518 & 4.6625 & TRN & \\
\hline CHEMBL 2134529 & 1301616 & 4.3399 & 4.4911 & TRN & \\
\hline CHEMBL2357399 & 1301616 & 4.8536 & 4.654 & TRN & \\
\hline CHEMBL3199324 & 1301616 & 4.6807 & 4.5282 & TRN & \\
\hline CHEMBL1875746 & 1301616 & 4.4165 & 4.645 & TST & \\
\hline CHEMBL2358924 & 1301616 & 4.3141 & 4.6396 & TRN & \\
\hline CHEMBL1903878 & 1301616 & 4.2611 & 4.4487 & TRN & \\
\hline CHEMBL1889837 & 1301616 & 4.3171 & 4.4014 & TRN & \\
\hline CHEMBL1503659 & 1301616 & 4.4949 & 4.5566 & TRN & \\
\hline CHEMBL18115 & 1301616 & 5.8601 & 4.7054 & TST & \\
\hline CHEMBL1438038 & 1301616 & 4.575 & 4.7389 & TRN & \\
\hline CHEMBL1486332 & 1301616 & 5.1325 & 5.4808 & TRN & \\
\hline CHEMBL1526855 & 1301616 & 4.6668 & 5.1701 & TRN & \\
\hline CHEMBL2358490 & 1301616 & 5.4342 & 4.7015 & TRN & \\
\hline CHEMBL1967856 & 1301616 & 4.56800 & 20000000 & 4.4855 & TST \\
\hline CHEMBL 2360588 & 1301616 & 4.6304 & 4.4905 & TRN & \\
\hline CHEMBL1524929 & 1301616 & 4.9792 & 4.8657 & TRN & \\
\hline CHEMBL1515610 & 1301616 & 4.4695 & 4.7789 & TRN & \\
\hline CHEMBL1440503 & 1301616 & 4.2556 & 4.6878 & TST & \\
\hline CHEMBL1444020 & 1301616 & 6.0825 & 5.8277 & TRN & \\
\hline CHEMBL1299925 & 1301616 & 6.0114 & 4.5537 & TRN & \\
\hline CHEMBL2361778 & 1301616 & 4.2823 & 4.5187 & TRN & \\
\hline CHEMBL1904760 & 1301616 & 4.9674 & 4.6099 & TRN & \\
\hline CHEMBL3183012 & 1301616 & 4.8798 & 4.7723 & TRN & \\
\hline CHEMBL1735961 & 1301616 & 4.1709 & 4.4785 & TST & \\
\hline CHEMBL1971142 & 1301616 & 4.558 & 4.4974 & TRN & \\
\hline CHEMBL1514790 & 1301616 & 4.5608 & 4.753 & TST & \\
\hline CHEMBL1883124 & 1301616 & 4.1882 & 4.8462 & TST & \\
\hline CHEMBL2355340 & 1301616 & 4.3188 & 4.4275 & TRN & \\
\hline CHEMBL 2358498 & 1301616 & 4.2415 & 4.5079 & TRN & \\
\hline CHEMBL3191107 & 1301616 & 4.2264 & 4.7078 & TRN & \\
\hline CHEMBL1980982 & 1301616 & 5.4283 & 5.1773 & TRN & \\
\hline CHEMBL3193725 & 1301616 & 4.3141 & 4.7459 & TRN & \\
\hline CHEMBL1979106 & 1301616 & 4.5717 & 4.707 & TRN & \\
\hline CHEMBL1393529 & 1301616 & 4.1792 & 4.4212 & TRN & \\
\hline CHEMBL2355203 & 1301616 & 4.2552 & 4.52800 & 00000000005 & TRN \\
\hline CHEMBL 2359710 & 1301616 & 4.1826 & 4.4968 & TRN & \\
\hline CHEMBL 2360968 & 1301616 & 4.2282 & 4.4958 & TRN & \\
\hline CHEMBL1867894 & 1301616 & 4.2658 & 4.6783 & TRN & \\
\hline CHEMBL3198763 & 1301616 & 5.063 & 4.762 & TST & \\
\hline CHEMBL2355758 & 1301616 & 4.2818 & 4.5969 & TRN & \\
\hline
\end{tabular}

Page 7720 
Supplemental Table S2.txt

$\begin{array}{lllll}\text { CHEMBL3184851 } & 1301616 & 4.2458 & 4.6494 & \text { TRN } \\ \text { CHEMBL2360341 } & 1301616 & 6.0 & 4.6794 & \text { TRN } \\ \text { CHEMBL2355890 } & 1301616 & 4.3345 & 4.6428 & \text { TRN } \\ \text { CHEMBL1561133 } & 1301616 & 4.2132 & 4.6637 & \text { TST } \\ \text { CHEMBL3191855 } & 1301616 & 5.1308 & 5.043 & \text { TRN } \\ \text { CHEMBL1342336 } & 1301616 & 4.2009 & 5.0562 & \text { TRN } \\ \text { CHEMBL1352850 } & 1301616 & 5.4855 & 5.1362 & \text { TRN } \\ \text { CHEMBL2359502 } & 1301616 & 4.1997 & 4.5397 & \text { TRN } \\ \text { CHEMBL1488060 } & 1301616 & 5.5306 & 4.6196 & \text { TRN } \\ \text { CHEMBL1417929 } & 1301616 & 4.4378 & 5.0331 & \text { TRN } \\ \text { CHEMBL2359591 } & 1301616 & 4.3935 & 4.4817 & \text { TRN } \\ \text { CHEMBL1880661 } & 1301616 & 5.3536 & 4.5741 & \text { TRN } \\ \text { CHEMBL1720389 } & 1301616 & 5.7721 & 4.8427 & \text { TRN } \\ \text { CHEMBL2356947 } & 1301616 & 4.2437 & 4.5621 & \text { TRN } \\ \text { CHEMBL1561089 } & 1301616 & 4.8687 & 4.7568 & \text { TRN } \\ \text { CHEMBL1971760 } & 1301616 & 4.3538 & 4.974 & \text { TST } \\ \text { CHEMBL2356688 } & 1301616 & 4.2617 & 4.5704 & \text { TRN } \\ \text { CHEMBL2354318 } & 1301616 & 6.52 & 4.7247 & \text { TRN } \\ \text { CHEMBL1882125 } & 1301616 & 4.5809 & 4.3565 & \text { TRN } \\ \text { CHEMBL328834 } & 1301616 & 6.2284 & 5.0123 & \text { TST } \\ \text { CHEMBL2361049 } & 1301616 & 4.5552 & 4.5528 & \text { TRN } \\ \text { CHEMBL2359863 } & 1301616 & 6.0 & 4.734 & \text { TRN } \\ \text { CHEMBL1430096 } & 1301616 & 4.9176 & 4.9561 & \text { TRN } \\ \text { CHEMBL1622981 } & 1301616 & 4.9344 & 4.6407 & \text { TST } \\ \text { CHEMBL2354903 } & 1301616 & 4.2849 & 4.4223 & \text { TRN } \\ \text { CHEMBL1459468 } & 1301616 & 5.7471 & 4.9339 & \text { TRN } \\ \text { CHEMEMBL } 362538 & 1301616 & 4.2847 & 4.6824 & \text { TRN } \\ \text { CHEMBL1607086 } & 1301616 & 4.9948 & 4.6934 & \text { TRN } \\ \text { CHEMBL461193 } & 1301616 & 4.6921 & 4.7082 & \text { TRN } \\ \text { CHEMBL1976507 } & 1301616 & 4.5153 & 4.5412 & \text { TRN } \\ \text { CHEMBL1499544 } & 1301616 & 5.6655 & 5.6313 & \text { TRN } \\ \text { CHEMEMBEM } & & & \end{array}$

Page 7721 
Supplemental Table S2.txt

\begin{tabular}{|c|c|c|c|c|}
\hline HEN & 301616 & & & \\
\hline HEMBL56897 & & 5.4737 & & \\
\hline 63 & & & & \\
\hline HEMBL2 & & & 5738 & \\
\hline HEMBL1423192 & 301616 & 233 & 5401 & \\
\hline HEMBL1489769 & 301616 & 4.3907 & 6886 & \\
\hline HEMBL2 & 16 & 104 & 575 & \\
\hline |FMRI & & & & \\
\hline HEMBL 235534 & 301616 & & 4.38 & \\
\hline HEMBL 225903 & 301616 & 5.2255 & 7555 & \\
\hline HEMBL 2136180 & 616 & 6.0 & 133 & \\
\hline AEMBL2 & 16 & 94 & 05 & \\
\hline AEMBL 2 & & & & \\
\hline HEMBL14031 & 301616 & & 992 & \\
\hline AEMBL1 & 16 & & & \\
\hline HEMBL2 & 16 & 96 & 5682 & \\
\hline HEMBL2 & 0 & & 562 & \\
\hline HEMBL1 & 6 & & & \\
\hline HEMBL1 & 16 & & 7044 & \\
\hline AEMBL2 & 6 & & 333 & \\
\hline AEMBL1 & 16 & & 17 & Niv \\
\hline HEMBL: & 6 & & 92 & 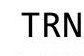 \\
\hline HEMBL & 6 & 79 & & \\
\hline AFMRI & & & & \\
\hline AEMBL1 & & & & 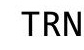 \\
\hline HEMBL 2 & 6 & & 175 & 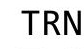 \\
\hline HEMBL & 0 & & 66 & 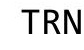 \\
\hline HFMBI 2 & 16 & & 21 & \\
\hline HEMBL 2 & & & & TIV \\
\hline HEMBL1403e & & & & 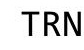 \\
\hline HEMBL 2 & 6 & & 346 & RIV \\
\hline HEMBL & 0 & & 43 & ST \\
\hline HEMPI & 16 & & 87 & $\mathrm{~N}$ \\
\hline HEMBL1471 & & & 362 & IRN \\
\hline HEMBL1399938 & 30 & & 134 & TRN \\
\hline HEMBL 2 & 6 & 78 & 32 & \\
\hline HᄃMP - & & 4 & & RIV \\
\hline HEMBL1 & & & 356 & RN \\
\hline HEMBL 23618 & 16 & 94 & 344 & TRN \\
\hline AEMBL1 & ח & & 867 & TRN \\
\hline HEMBL186 & 6 & & 074 & \\
\hline CHEMBL1: & & & & Niv \\
\hline HEMBL1490308 & 16 & & 7826 & IST \\
\hline HEMBL31982 & 16 & 4.8511 & & ГRN \\
\hline $\mathrm{MRI}$ & & & & \\
\hline HEMBL1. & & & & \\
\hline CHEMBL170 & 20 & 4.3011 & .7297 & \\
\hline SHEMBL318466e & 1301616 & 5.767 & 4.7277 & RN \\
\hline
\end{tabular}

Page 7722 
Supplemental Table S2.txt

\begin{tabular}{|c|c|c|c|c|}
\hline CHEMBL1212972 & 1301616 & 5.4622 & 4.9232 & TST \\
\hline CHEMBL1311838 & 1301616 & 4.2224 & 4.6576 & TRN \\
\hline CHEMBL2360927 & 1301616 & 5.4789 & 4.7176 & TRN \\
\hline CHEMBL1736490 & 1301616 & 4.6388 & 4.7646 & TRN \\
\hline CHEMBL1418818 & 1301616 & 4.7562 & 4.6214 & TRN \\
\hline CHEMBL1897634 & 1301616 & 4.4181 & 4.8345 & TST \\
\hline CHEMBL1531308 & 1301616 & 4.6247 & 4.7132 & TRN \\
\hline CHEMBL 2143863 & 1301616 & 4.6609 & 4.6452 & TRN \\
\hline CHEMBL 2362712 & 1301616 & 5.6655 & 4.6271 & TRN \\
\hline CHEMBL1321754 & 1301616 & 4.3563 & 4.7972 & TST \\
\hline CHEMBL1613147 & 1301616 & 4.9337 & 4.6232 & TRN \\
\hline CHEMBL 2357983 & 1301616 & 4.6799 & 4.5461 & TRN \\
\hline CHEMBL 2354467 & 1301616 & 4.3667 & 4.572 & TRN \\
\hline CHEMBL1598445 & 1301616 & 4.3571 & 4.5576 & TRN \\
\hline CHEMBL 2359448 & 1301616 & 4.6819 & 4.4494 & TRN \\
\hline CHEMBL 2135896 & 1301616 & 4.6142 & 4.5713 & TRN \\
\hline CHEMBL78765 & 1301616 & 4.6087 & 4.79899 & 99999999995 \\
\hline CHEMBL1301855 & 1301616 & 4.3089 & 4.6641 & TRN \\
\hline CHEMBL1602687 & 1301616 & 4.2929 & 4.4461 & TST \\
\hline CHEMBL1546172 & 1301616 & 4.7645 & 5.0056 & TRN \\
\hline CHEMBL 2140530 & 1301616 & 4.2922 & 4.5033 & TRN \\
\hline CHEMBL 2362415 & 1301616 & 4.4717 & 4.6465 & TRN \\
\hline CHEMBL1903021 & 1301616 & 4.7217 & 4.5777 & TRN \\
\hline CHEMBL1328504 & 1301616 & 4.9048 & 4.6857 & TRN \\
\hline CHEMBL 2358823 & 1301616 & 5.5751 & 4.6057 & TRN \\
\hline CHEMBL3188797 & 1301616 & 4.3672 & 4.583 & TRN \\
\hline CHEMBL1384253 & 1301616 & 5.3072 & 5.232 & TRN \\
\hline CHEMBL 2359612 & 1301616 & 4.3426 & 4.6483 & TRN \\
\hline CHEMBL 2356480 & 1301616 & 4.354 & 4.5589 & TRN \\
\hline CHEMBL 2354757 & 1301616 & 4.263 & 4.7123 & TRN \\
\hline CHEMBL 2006840 & 1301616 & 4.7891 & 4.5518 & TRN \\
\hline CHEMBL2359417 & 1301616 & 4.2131 & 4.6482 & TRN \\
\hline CHEMBL3182010 & 1301616 & 4.1863 & 4.3316 & TRN \\
\hline CHEMBL1876267 & 1301616 & 4.9431 & 4.7358 & TRN \\
\hline CHEMBL1717890 & 1301616 & 4.6167 & 4.8623 & TRN \\
\hline CHEMBL1573994 & 1301616 & 5.0931 & 4.8866 & TRN \\
\hline CHEMBL 2361222 & 1301616 & 4.4504 & 4.6173 & TRN \\
\hline CHEMBL1520312 & 1301616 & 4.2996 & 4.6652 & TRN \\
\hline CHEMBL 26260 & 1301616 & 4.5343 & 4.7636 & TST \\
\hline CHEMBL1698341 & 1301616 & 5.3197 & 4.758 & TST \\
\hline CHEMBL1404301 & 1301616 & 4.3479 & 4.6277 & TRN \\
\hline CHEMBL 235504 & 1301616 & 5.0691 & 4.9083 & TRN \\
\hline CHEMBL2355418 & 1301616 & 4.4721 & 4.6649 & TST \\
\hline CHEMBL1487345 & 1301616 & 4.9488 & 5.2391 & TST \\
\hline CHEMBL1396619 & 1301616 & 4.2815 & 4.5724 & TST \\
\hline CHEMBL1729132 & 1301616 & 4.3976 & 4.687 & TST \\
\hline CHEMBL1416089 & 1301616 & 4.673 & 4.9187 & TST \\
\hline CHEMBL2355430 & 1301616 & 5.7352 & 4.5431 & TST \\
\hline
\end{tabular}


Supplemental Table S2.txt

\begin{tabular}{|c|c|c|c|c|}
\hline HEMBL14 & & & 24 & TS \\
\hline HFMRI 1442136 & 301616 & 5.2125 & 5.5841 & \\
\hline HEMBL1733422 & & 8035 & & \\
\hline AEMBL1448905 & 301616 & 9115 & & \\
\hline HEMBL1879116 & 301616 & 4.7254 & .6081 & \\
\hline HEMBL1321538 & 16 & 5.1612 & 398 & \\
\hline AEMBL21 & & & & \\
\hline HEMBL15 & 16 & 5.0367 & & \\
\hline HEMBL3193058 & 301616 & 5.5622 & 2344 & \\
\hline HEMBL3186447 & 516 & 4.3143 & 63 & \\
\hline HEMBL 235 & 16 & 18 & 71 & \\
\hline AEMBL136 & & 077 & & \\
\hline HEMBL235 & 16 & 6 . & & \\
\hline HEMBL159 & 16 & 038 & 79 & \\
\hline HEMBL1967 & 16 & 4.4889 & 45 & \\
\hline AEMBL23 & 16 & 234 & & \\
\hline AEMBL31 & & & & \\
\hline HEMBL16 & 16 & 467 & & \\
\hline HEMBL14 & & & & \\
\hline HEMBL133 & 16 & 78 & 04 & \\
\hline AEMBL17 & 16 & $\partial 4$ & & \\
\hline AEMBL2 & & 54 & & \\
\hline HEMBL21 & & 674 & & \\
\hline AEMBL15 & & & & \\
\hline AEMBL135 & 6 & 08 & 53 & $\mid$ \\
\hline IEMBL19 & 6 & 67 & & \\
\hline AEMBL15 & & 26 & & \\
\hline 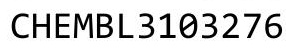 & & 979 & & \\
\hline IEMBL 31 & & & & \\
\hline AEMBL 222 & 09 & 4 & 388 & IST \\
\hline IEMBL11 & 39 & 4 & & \\
\hline AFM & & 29 & & \\
\hline & & & & \\
\hline HEMBL 310 & & & & IRN \\
\hline HEMBL3103279 & 09 & 559 & & $\mathrm{RN}$ \\
\hline AFMRI 310 & 99 & 03 & & \\
\hline & & & & RN \\
\hline HEMBL 327 & & 4.0 & & ST \\
\hline HEMBL 310 & 109 & 6 . & & $\mathrm{BN}$ \\
\hline EMBL31 & $\partial 9$ & 7.3979 & & ГRN \\
\hline HEMBL326 & 09 & 4 & 84 & \\
\hline HEMBL310 & & 7. & & $\mathrm{RN}$ \\
\hline HEMBL310 & & 7.3979 & 7.2369 & RN \\
\hline HEMBL 310 & 09 & 7.2218 & 59 & RN \\
\hline r. & & 7.3979 & & \\
\hline HEMBL116040 & & 4.0 & & \\
\hline CHEMBL 310328 & 285709 & 7.301 & 7.2226 & \\
\hline CHEMBL118883 & 1285709 & 4.0 & 2.8983 & TT \\
\hline
\end{tabular}

Page 7724 
Supplemental Table S2.txt

\begin{tabular}{|c|c|c|c|c|c|}
\hline CHEMBL3103270 & 1285709 & 8.5229 & 8.429 & TRN & \\
\hline CHEMBL3103261 & 1285709 & 4.0 & 2.9408 & TST & \\
\hline CHEMBL3103272 & 1285709 & 7.2218 & 7.2048 & TRN & \\
\hline CHEMBL 3103271 & 1285709 & 7.5229 & 7.6097 & TRN & \\
\hline CHEMBL3103287 & 1285709 & 6.5376 & 6.6359 & TRN & \\
\hline CHEMBL3103291 & 1285709 & 6.699 & 6.9316 & TRN & \\
\hline CHEMBL3103285 & 1285709 & 6.8239 & 6.83899 & 99999999995 & TRN \\
\hline CHEMBL3103295 & 1285709 & 6.3372 & 6.2321 & TRN & \\
\hline CHEMBL3103262 & 1285709 & 6.6576 & 5.7475 & TST & \\
\hline CHEMBL3103280 & 1285709 & 5.3134 & 5.3075 & TRN & \\
\hline CHEMBL3103299 & 1285709 & 5.6757 & 5.6799 & TRN & \\
\hline CHEMBL3103297 & 1285709 & 7.5229 & 7.3135 & TRN & \\
\hline CHEMBL3103292 & 1285709 & 6.5229 & 6.3134 & TRN & \\
\hline CHEMBL3103296 & 1285709 & 5.767 & 5.9441 & TRN & \\
\hline CHEMBL3103281 & 1285709 & 5.38399 & 99999999 & 5.2666 & TRN \\
\hline CHEMBL3103303 & 1285709 & 5.3107 & 5.2969 & TRN & \\
\hline CHEMBL3103264 & 1285709 & 6.7696 & 6.7464 & TRN & \\
\hline CHEMBL3103273 & 1285709 & 8.2218 & 8.1459 & TRN & \\
\hline CHEMBL3103288 & 1285709 & 7.3979 & 7.5777 & TRN & \\
\hline CHEMBL3103300 & 1285709 & 5.5346 & 5.4694 & TRN & \\
\hline CHEMBL3103274 & 1285709 & 7.5229 & 7.5562 & TRN & \\
\hline CHEMBL3103275 & 1285709 & 7.1549 & 7.1282 & TRN & \\
\hline CHEMBL3103282 & 1285709 & 8.0 & 8.0638 & TRN & \\
\hline CHEMBL3103293 & 1285709 & 6.1427 & 6.2363 & TRN & \\
\hline CHEMBL3103289 & 1285709 & 7.301 & 7.211 & TRN & \\
\hline CHEMBL3103269 & 1285709 & 7.3979 & 7.9465 & TST & \\
\hline CHEMBL3103290 & 1285709 & 4.0 & 5.5522 & TST & \\
\hline CHEMBL65 & 1285709 & 7.3979 & 7.3044 & TST & \\
\hline CHEMBL3103283 & 1285709 & 7.5229 & 7.6246 & TST & \\
\hline CHEMBL3103294 & 1285709 & 5.8601 & 6.1007 & TST & \\
\hline CHEMBL3942863 & 1639959 & 4.2358 & 5.1146 & TRN & \\
\hline CHEMBL3927767 & 1639959 & 4.6021 & 5.20299 & 9999999999 & TST \\
\hline CHEMBL3919188 & 1639959 & 6.0044 & 5.0445 & TRN & \\
\hline CHEMBL3914014 & 1639959 & 4.6021 & 4.9308 & TRN & \\
\hline CHEMBL3928702 & 1639959 & 5.6757 & 5.5542 & TRN & \\
\hline CHEMBL1321754 & 1639959 & 4.0 & 4.69600 & 2000000001 & TST \\
\hline CHEMBL3942046 & 1639959 & 5.8861 & 5.0658 & TRN & \\
\hline CHEMBL3928163 & 1639959 & 5.3958 & 5.5525 & TRN & \\
\hline CHEMBL258314 & 1639959 & 4.0 & 4.6083 & TRN & \\
\hline CHEMBL270799 & 1639959 & 5.8069 & 5.84200 & 00000000005 & TRN \\
\hline CHEMBL3943490 & 1639959 & 6.0177 & 5.3311 & TRN & \\
\hline CHEMBL3897782 & 1639959 & 4.6021 & 4.6883 & TST & \\
\hline CHEMBL3899679 & 1639959 & 5.585 & 5.3291 & TRN & \\
\hline CHEMBL3926230 & 1639959 & 5.7773 & 4.8936 & TRN & \\
\hline CHEMBL3977127 & 1639959 & 5.9586 & 4.9035 & TRN & \\
\hline CHEMBL3918870 & 1639959 & 4.6021 & 5.8122 & TRN & \\
\hline CHEMBL3945570 & 1639959 & 5.9208 & 5.5824 & TRN & \\
\hline CHEMBL3902124 & 1639959 & 5.71899 & 99999999 & 5.5051 & TRN \\
\hline
\end{tabular}


Supplemental Table S2.txt

\begin{tabular}{|c|c|c|c|c|c|}
\hline CHEMBL3392552 & 1639959 & 4.0 & \multicolumn{2}{|c|}{5.242999999999999} & TRN \\
\hline CHEMBL3956062 & 1639959 & 5.1494 & 5.2123 & TRN & \\
\hline CHEMBL3940785 & 1639959 & 5.2048 & 4.6157 & TST & \\
\hline CHEMBL3909921 & 1639959 & 4.6091 & 5.0946 & TRN & \\
\hline CHEMBL3951683 & 1639959 & 5.5229 & 5.025 & TRN & \\
\hline CHEMBL3903574 & 1639959 & 5.5622 & 5.1186 & TST & \\
\hline CHEMBL3958707 & 1639959 & 5.7496 & 5.231 & TRN & \\
\hline CHEMBL3965637 & 1639959 & 4.0 & 5.1484 & TRN & \\
\hline CHEMBL3894587 & 1639959 & 6.4949 & 5.0279 & TRN & \\
\hline CHEMBL428064 & 1639959 & 5.5376 & 5.4779 & TRN & \\
\hline CHEMBL3940198 & 1639959 & 5.857 & 5.2962 & TRN & \\
\hline CHEMBL3955081 & 1639959 & 5.0701 & 5.3495 & TRN & \\
\hline CHEMBL3899965 & 1639959 & 5.1273 & 5.8253 & TRN & \\
\hline CHEMBL3936153 & 1639959 & 4.1024 & 5.1342 & TST & \\
\hline CHEMBL3957929 & 1639959 & 5.6536 & 5.6381 & TRN & \\
\hline CHEMBL3928412 & 1639959 & 4.6021 & 5.0889 & TRN & \\
\hline CHEMBL3892051 & 1639959 & 4.0 & 4.9559 & TRN & \\
\hline CHEMBL3936238 & 1639959 & 5.3288 & 5.7373 & TRN & \\
\hline CHEMBL3954885 & 1639959 & 5.301 & 5.1216 & TRN & \\
\hline CHEMBL3983184 & 1639959 & 4.6021 & 4.7411 & TRN & \\
\hline CHEMBL3896934 & 1639959 & 4.0 & 4.8608 & TRN & \\
\hline CHEMBL3904725 & 1639959 & 5.6308 & 5.7815 & TRN & \\
\hline CHEMBL3964091 & 1639959 & 4.0 & 5.1605 & TRN & \\
\hline CHEMBL3902067 & 1639959 & 5.0969 & 5.2062 & TRN & \\
\hline CHEMBL3980717 & 1639959 & 5.1302 & 5.8649 & TRN & \\
\hline CHEMBL3914817 & 1639959 & 6.2596 & 5.1116 & TRN & \\
\hline CHEMBL3896354 & 1639959 & 4.6021 & 5.3054 & TRN & \\
\hline CHEMBL3954246 & 1639959 & 4.9031 & 5.5236 & TRN & \\
\hline CHEMBL3934171 & 1639959 & 4.0 & 4.6269 & TRN & \\
\hline CHEMBL3943167 & 1639959 & 5.4473 & 5.1285 & TRN & \\
\hline CHEMBL3907842 & 1639959 & 4.6021 & 5.0135 & TST & \\
\hline CHEMBL271669 & 1639959 & 5.4949 & 5.6653 & TRN & \\
\hline CHEMBL3890175 & 1639959 & 5.8297 & 5.9077 & TRN & \\
\hline CHEMBL3979691 & 1639959 & 6.1192 & 5.4497 & TRN & \\
\hline CHEMBL3894576 & 1639959 & 4.0 & 5.1489 & TST & \\
\hline CHEMBL3970065 & 1639959 & 6.041 & 5.6858 & TRN & \\
\hline CHEMBL3945701 & 1639959 & 5.4522 & 4.8306 & TST & \\
\hline CHEMBL3940455 & 1639959 & 4.8729 & 5.0951 & TRN & \\
\hline CHEMBL3919322 & 1639959 & 6.4202 & 5.5395 & TRN & \\
\hline CHEMBL3902024 & 1639959 & 5.9318 & 5.7418 & TRN & \\
\hline CHEMBL3895525 & 1639959 & 4.4034 & 5.5685 & TST & \\
\hline CHEMBL3901591 & 1639959 & 4.0 & 5.2788 & TST & \\
\hline CHEMBL3949182 & 1639959 & 5.2111 & 5.567 & TRN & \\
\hline CHEMBL3951122 & 1639959 & 5.4089 & 5.0105 & TRN & \\
\hline CHEMBL3925149 & 1639959 & 5.8041 & 5.932 & TRN & \\
\hline CHEMBL3904197 & 1639959 & 4.0 & 5.0408 & TRN & \\
\hline CHEMBL3924313 & 1639959 & 4.6021 & 5.46299 & 9999999999 & TRN \\
\hline CHEMBL3911365 & 1639959 & 5.9586 & 5.3306 & TST & \\
\hline
\end{tabular}


Supplemental Table S2.txt

\begin{tabular}{|c|c|c|c|c|c|}
\hline CHEMBL3918343 & 1639959 & 4.6021 & 4.7817 & TRN & \\
\hline CHEMBL3901927 & 1639959 & 4.6021 & 5.1218 & TST & \\
\hline CHEMBL3927455 & 1639959 & 4.0 & 4.6621 & TST & \\
\hline CHEMBL3948191 & 1639959 & 5.4949 & 5.318 & TRN & \\
\hline CHEMBL3956123 & 1639959 & 5.3706 & 5.4666 & TRN & \\
\hline CHEMBL3898092 & 1639959 & 4.0 & 5.1271 & TRN & \\
\hline CHEMBL3917943 & 1639959 & 5.7959 & 6.0263 & TRN & \\
\hline CHEMBL3980814 & 1639959 & 5.7905 & 5.3126 & TST & \\
\hline CHEMBL1876714 & 1639959 & 5.1938 & 5.1568 & TRN & \\
\hline CHEMBL3968671 & 1639959 & 4.8996 & 5.1735 & TRN & \\
\hline CHEMBL3951370 & 1639959 & 5.4318 & 5.8662 & TRN & \\
\hline CHEMBL3956684 & 1639959 & 4.0 & 5.1928 & TRN & \\
\hline CHEMBL3983557 & 1639959 & 5.3215 & 4.7233 & TRN & \\
\hline CHEMBL1487635 & 1639959 & 4.3019 & 5.4313 & TRN & \\
\hline CHEMBL3949086 & 1639959 & 5.857 & 5.3918 & TRN & \\
\hline CHEMBL3916835 & 1639959 & 6.0052 & 5.1689 & TRN & \\
\hline CHEMBL3985825 & 1639959 & 4.6021 & 4.7213 & TRN & \\
\hline CHEMBL3950478 & 1639959 & 5.0009 & 5.0848 & TRN & \\
\hline CHEMBL 256062 & 1639959 & 4.6819 & 5.1559 & TRN & \\
\hline CHEMBL3912604 & 1639959 & 6.5129 & 5.3206 & TRN & \\
\hline CHEMBL3914642 & 1639959 & 6.2218 & 5.8366 & TRN & \\
\hline CHEMBL3897526 & 1639959 & 5.3478 & 5.8664 & TRN & \\
\hline CHEMBL3956180 & 1639959 & 4.6021 & 4.9913 & TRN & \\
\hline CHEMBL3902951 & 1639959 & 5.9431 & 5.269 & TST & \\
\hline CHEMBL3939145 & 1639959 & 5.6383 & 5.2607 & TST & \\
\hline CHEMBL3952234 & 1639959 & 5.3605 & 5.3069 & TST & \\
\hline CHEMBL3975768 & 1639959 & 5.7282 & 5.6005 & TRN & \\
\hline CHEMBL3917036 & 1639959 & 5.6799 & 5.4506 & TRN & \\
\hline CHEMBL3956703 & 1639959 & 4.0 & 5.3 & TST & \\
\hline CHEMBL3923103 & 1639959 & 4.6021 & 5.5634 & TST & \\
\hline CHEMBL3914030 & 1639959 & 5.6596 & 5.1913 & TRN & \\
\hline CHEMBL3892621 & 1639959 & 5.7033 & 5.15 & TRN & \\
\hline CHEMBL3392504 & 1639959 & 4.0 & 5.1342 & TRN & \\
\hline CHEMBL3895353 & 1639959 & 5.6968 & 5.7318 & TST & \\
\hline CHEMBL3907733 & 1639959 & 4.6021 & 4.7325 & TST & \\
\hline CHEMBL3911568 & 1639959 & 5.9626 & 5.4843 & TRN & \\
\hline CHEMBL3957827 & 1639959 & 5.8633 & 5.1207 & TRN & \\
\hline CHEMBL3952348 & 1639959 & 4.0 & 5.1899 & TRN & \\
\hline CHEMBL3909460 & 1639959 & 6.0605 & 5.63700 & 00000000005 & TRN \\
\hline CHEMBL3911473 & 1639959 & 4.0 & 5.2413 & TRN & \\
\hline CHEMBL3986484 & 1639959 & 4.0 & 5.0017 & TRN & \\
\hline CHEMBL3968736 & 1639959 & 4.6021 & 4.9265 & TRN & \\
\hline CHEMBL272552 & 1639959 & 6.8861 & 5.8028 & TRN & \\
\hline CHEMBL3979514 & 1639959 & 5.4001 & 5.7418 & TRN & \\
\hline CHEMBL3958839 & 1639959 & 6.3768 & 5.2467 & TRN & \\
\hline CHEMBL3903239 & 1639959 & 5.9788 & 5.1223 & TRN & \\
\hline CHEMBL3953777 & 1639959 & 4.301 & 4.5666 & TST & \\
\hline CHEMBL3977156 & 1639959 & 4.8125 & 5.3681 & TRN & \\
\hline
\end{tabular}


Supplemental Table S2.txt

\begin{tabular}{|c|c|c|c|c|c|}
\hline CHEMBL 3927819 & 1639959 & 6.1427 & 5.9964 & TRN & \\
\hline CHEMBL 3986143 & 1639959 & 4.0 & 5.0842 & TST & \\
\hline CHEMBL 3908374 & 1639959 & 4.6021 & 5.0577 & TRN & \\
\hline CHEMBL 3965000 & 1639959 & 6.2226 & 5.0685 & TRN & \\
\hline CHEMBL 3930418 & 1639959 & 6.0177 & 5.9302 & TRN & \\
\hline CHEMBL 3929388 & 1639959 & 6.0 & 5.6481 & TRN & \\
\hline CHEMBL 3953717 & 1639959 & 4.0 & 5.322999 & 99999999995 & TST \\
\hline CHEMBL 3893426 & 1639959 & 4.0 & 4.758999 & 99999999995 & \\
\hline CHEMBL 3942756 & 1639959 & 5.7905 & 5.8213 & TRN & \\
\hline CHEMBL 3893035 & 1639959 & 5.8069 & 5.3202 & TST & \\
\hline CHEMBL 3978323 & 1639959 & 6.0044 & 5.1407 & TRN & \\
\hline CHEMBL 3965422 & 1639959 & 4.0 & 4.98 & TST & \\
\hline CHEMBL 3930846 & 1639959 & 6.3372 & 5.5775 & TST & \\
\hline CHEMBL429599 & 1639959 & 6.1135 & 5.5811 & TRN & \\
\hline CHEMBL 3933701 & 1639959 & 6.2147 & 4.8436 & TRN & \\
\hline CHEMBL 3916416 & 1639959 & 5.6861 & 5.5768 & TRN & \\
\hline CHEMBL3969259 & 1639959 & 6.6021 & 5.9874 & TRN & \\
\hline CHEMBL 3891388 & 1639959 & 5.6615 & 5.2839 & TRN & \\
\hline CHEMBL 3922079 & 1639959 & 4.6021 & 5.1316 & TRN & \\
\hline CHEMBL 3986202 & 1639959 & 4.0 & 5.3135 & TST & \\
\hline CHEMBL 3928331 & 1639959 & 5.6757 & 5.4937 & TRN & \\
\hline CHEMBL 3965273 & 1639959 & 6.0092 & 5.1017 & TRN & \\
\hline CHEMBL 3934992 & 1639959 & 5.426 & 5.6436 & TRN & \\
\hline CHEMBL 3926407 & 1639959 & 4.0 & 5.1917 & TST & \\
\hline CHEMBL 3947858 & 1639959 & 4.6576 & 5.1562 & TST & \\
\hline CHEMBL 3964462 & 1639959 & 4.6021 & 4.7437 & TRN & \\
\hline CHEMBL 3941683 & 1639959 & 5.9706 & 5.6602 & TRN & \\
\hline CHEMBL 3907573 & 1639959 & 4.0 & 5.2568 & TST & \\
\hline CHEMBL 3965168 & 1639959 & 4.8508 & 5.2571 & TRN & \\
\hline CHEMBL3959566 & 1639959 & 6.059 & 5.5163 & TRN & \\
\hline CHEMBL3917008 & 1639959 & 4.6021 & 4.6918 & TST & \\
\hline CHEMBL 3961534 & 1639959 & 6.0 & 5.5471 & TRN & \\
\hline CHEMBL 3950857 & 1639959 & 6.0066 & 5.381 & TRN & \\
\hline CHEMBL3971981 & 1639959 & 4.9031 & 4.6901 & TRN & \\
\hline CHEMBL3966697 & 1639959 & 4.9031 & 5.4836 & TRN & \\
\hline CHEMBL3905512 & 1639959 & 5.0969 & 5.1504 & TRN & \\
\hline CHEMBL3969674 & 1639959 & 6.0048 & 5.3032 & TRN & \\
\hline CHEMBL 3943449 & 1639959 & 4.98300 & 000000000 & 4.5596 & ונ \\
\hline CHEMBL3963591 & 1639959 & 4.6021 & 5.3072 & TRN & \\
\hline CHEMBL3976830 & 1639959 & 6.2076 & 5.2542 & TST & \\
\hline CHEMBL3950686 & 1639959 & 5.9136 & 4.9661 & TRN & \\
\hline CHEMBL270605 & 1639959 & 5.5376 & 5.3419 & TRN & \\
\hline CHEMBL 3905388 & 1639959 & 5.6253 & 5.5007 & TST & \\
\hline CHEMBL3928897 & 1639959 & 4.0 & 4.7179 & TST & \\
\hline CHEMBL 3934043 & 1639959 & 5.1871 & 5.6634 & TST & \\
\hline CHEMBL3957889 & 1639959 & 4.6021 & 5.4648 & TRN & \\
\hline CHEMBL3926321 & 1639959 & 4.0 & 5.1053 & TRN & \\
\hline CHEMBL3960957 & 1639959 & 5.4112 & 5.5558 & TST & \\
\hline
\end{tabular}


Supplemental Table S2.txt

\begin{tabular}{|c|c|c|c|c|}
\hline 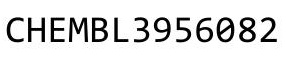 & & 5.0 & & $\cdot$ \\
\hline HEMBL 3921624 & 539959 & 4.60 & 848 & \\
\hline MBL3904127 & & & & \\
\hline 3438 & 59 & 1 & & \\
\hline IEMBL3949160 & 539959 & & 271 & \\
\hline IEMBL3950354 & 639959 & 6.067 & 158 & \\
\hline AEMBL 257286 & 639959 & 5.3382 & 584 & \\
\hline EMBL 3981698 & 539959 & & 926 & \\
\hline EMBL 3979305 & 639959 & & \multicolumn{2}{|c|}{5.1720000000} \\
\hline HEMBL3961348 & 639959 & 5.6253 & 5.5647 & \\
\hline AEMBL3906499 & 639959 & 5.699 & 296 & \\
\hline IEMBL3895690 & 639959 & $\partial 21$ & & \\
\hline 30 & 639959 & 5.8633 & 79 & \\
\hline EMBL 394 & 639959 & 5.4895 & 165 & \\
\hline IEMBL3919719 & 639959 & 6.1612 & 948 & \\
\hline IEMBL 3904222 & 639959 & 4.6021 & & \\
\hline IEMBL396 & 1639959 & 5.5528 & 558 & \\
\hline EME & 639959 & 4. & 04 & 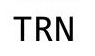 \\
\hline EMBL39 & 639959 & 4.6021 & 253 & \\
\hline IEMBL3935005 & 639959 & 6.0 & 774 & \\
\hline IEMBL 3904731 & 639959 & 5 . & & \\
\hline EMBL 3964340 & 1639959 & $5.2-2.0$ & & $\mathrm{~K}$ \\
\hline 84 & 639 & 5 . & & 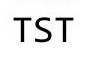 \\
\hline 46 & 639 & 5. & & \\
\hline 826 & 639959 & 372 & & $1 \pi$ \\
\hline EMBL 3985021 & 639959 & & & TS \\
\hline IEMBL3392550 & 1639959 & $5.7-7$ & & Th \\
\hline 0 & 59 & 4. & & $\pi$ \\
\hline 58 & 59 & & & \\
\hline 528 & 639959 & & & $\mathrm{TR}$ \\
\hline IEMBL 3904828 & 639959 & & & $\mathrm{~T}$ \\
\hline MBL256061 & 639959 & 6. & & TR \\
\hline 91 & 59 & 5 . & & $1 \mathrm{~K}$ \\
\hline 78 & 59 & & & TS \\
\hline IEMBL3918106 & 639959 & $5 . \varepsilon$ & & TR \\
\hline EMBL 3929579 & 639959 & & & TS \\
\hline 964781 & 639959 & 4. & & TS \\
\hline 327 & 639959 & 4. & & $\mathrm{IR}$ \\
\hline 62 & 59 & 4.6 & & \\
\hline EMBL 3906454 & 639959 & 5.2314 & & $\mathrm{TR}$ \\
\hline EMBL3956864 & 639959 & 6. & & $\mathrm{TR}$ \\
\hline ABL3896154 & 639959 & & & K \\
\hline HEMBL3948474 & 639959 & & & $\mathrm{TR}$ \\
\hline HEMBL 3897801 & 539959 & 6.0888 & 986 & TS \\
\hline EMBL401504 & 639959 & 5.1675 & 5.3779 & TS \\
\hline IEMBL 3967472 & 639959 & 5.5591 & 028 & $\mathrm{TR}$ \\
\hline & & 5.4389 & 5.5823 & TR \\
\hline & & & & \\
\hline
\end{tabular}

TRN 
Supplemental Table S2.txt

\begin{tabular}{|c|c|c|c|c|c|}
\hline CHEMBL3927184 & 1639959 & 4.6021 & 5.0859 & TRN & \\
\hline CHEMBL3948213 & 1639959 & 5.8239 & 5.3432 & TRN & \\
\hline CHEMBL3986262 & 1639959 & 4.6021 & 4.6631 & TRN & \\
\hline CHEMBL 3893468 & 1639959 & 4.0 & 5.2317 & TST & \\
\hline CHEMBL3904075 & 1639959 & 6.6021 & 5.4605 & TST & \\
\hline CHEMBL3959790 & 1639959 & 5.8477 & 5.3264 & TRN & \\
\hline CHEMBL3900875 & 1639959 & 6.0362 & 5.6363 & TRN & \\
\hline CHEMBL3968061 & 1639959 & 5.426 & 5.5736 & TST & \\
\hline CHEMBL3951787 & 1639959 & 5.5317 & 4.6699 & TRN & \\
\hline CHEMBL3892143 & 1639959 & 5.0458 & 5.364 & TRN & \\
\hline CHEMBL3975758 & 1639959 & 4.0 & 4.8523 & TRN & \\
\hline CHEMBL3895761 & 1639959 & 4.6021 & 5.3404 & TST & \\
\hline CHEMBL3892473 & 1639959 & 6.1079 & 5.4467 & TRN & \\
\hline CHEMBL3974353 & 1639959 & 4.6021 & 4.7572 & TRN & \\
\hline CHEMBL3904963 & 1639959 & 5.5482 & 5.0478 & TRN & \\
\hline CHEMBL3933528 & 1639959 & 4.0 & 5.4809 & TST & \\
\hline CHEMBL3973932 & 1639959 & 5.433 & 5.5617 & TRN & \\
\hline CHEMBL3896336 & 1639959 & 5.8601 & 5.2352 & TRN & \\
\hline CHEMBL3894856 & 1639959 & 5.0675 & 5.8299 & TST & \\
\hline CHEMBL3980701 & 1639959 & 5.4157 & 5.6565 & TRN & \\
\hline CHEMBL3913079 & 1639959 & 4.0 & 4.7166 & TRN & \\
\hline CHEMBL3947829 & 1639959 & 4.6778 & 4.6845 & TRN & \\
\hline CHEMBL3966573 & 1639959 & 6.38399 & 999999995 & 995 & 5.5427 \\
\hline CHEMBL3932263 & 1639959 & 5.3788 & 5.4429 & TRN & \\
\hline CHEMBL 3894606 & 1639959 & 4.0 & 4.9974 & TRN & \\
\hline CHEMBL3925082 & 1639959 & 4.8239 & 5.2475 & TST & \\
\hline CHEMBL3933529 & 1639959 & 6.4437 & 5.6483 & TRN & \\
\hline CHEMBL3912172 & 1639959 & 4.6021 & 5.1235 & TST & \\
\hline CHEMBL3946433 & 1639959 & 5.2041 & 5.3349 & TRN & \\
\hline CHEMBL404128 & 1639959 & 5.8013 & 5.5008 & TRN & \\
\hline CHEMBL3971475 & 1639959 & 5.5482 & 5.7259 & TRN & \\
\hline CHEMBL3939556 & 1639959 & 4.6021 & 5.1169 & TRN & \\
\hline CHEMBL3931812 & 1639959 & 4.6021 & 5.2694 & TRN & \\
\hline CHEMBL404588 & 1639959 & 4.0 & 5.5944 & TRN & \\
\hline CHEMBL3907605 & 1639959 & 5.6021 & 5.3401 & TRN & \\
\hline CHEMBL3947100 & 1639959 & 6.1427 & 5.6066 & TRN & \\
\hline CHEMBL3910392 & 1639959 & 4.0 & 5.4775 & TST & \\
\hline CHEMBL3959067 & 1639959 & 6.4685 & 5.9222 & TST & \\
\hline CHEMBL3905166 & 1639959 & 5.3915 & 4.9847 & TRN & \\
\hline CHEMBL3983154 & 1639959 & 5.2652 & 5.8673 & TST & \\
\hline CHEMBL141831 & 7296 & 6.699 & 6.9177 & TRN & \\
\hline CHEMBL142900 & 7296 & 5.7212 & 5.7505 & TRN & \\
\hline CHEMBL144219 & 7296 & 6.2218 & 6.4492 & TRN & \\
\hline CHEMBL145311 & 7296 & 6.2596 & 6.1864 & TRN & \\
\hline CHEMBL107707 & 7296 & 7.0 & 6.1871 & TST & \\
\hline CHEMBL322704 & 7296 & 6.1192 & 5.9998 & TRN & \\
\hline CHEMBL444340 & 7296 & 6.5302 & 6.5787 & TRN & \\
\hline CHEMBL344072 & 7296 & 5.6576 & 5.8125 & TRN & \\
\hline
\end{tabular}




\begin{tabular}{|c|c|c|c|c|c|c|}
\hline \multicolumn{7}{|c|}{ Supplemental } \\
\hline CHEMBL144617 & 7296 & 6.2924 & 6.3026 & TRN & & \\
\hline CHEMBL144411 & 7296 & 3.6021 & 3.3019 & TRN & & \\
\hline CHEMBL144999 & 7296 & 6.284 & 5.9341 & TST & & \\
\hline CHEMBL91898 & 7296 & 5.2757 & 3.793 & TST & & \\
\hline CHEMBL109890 & 7296 & 5.75700 & 00000000 & 01 & 5.5649 & TRN \\
\hline CHEMBL144386 & 7296 & 6.2676 & 6.0671 & TRN & & \\
\hline CHEMBL14832 & 7296 & 6.7447 & 6.1871 & TST & & \\
\hline CHEMBL34683 & 7296 & 5.6289 & 5.5584 & TRN & & \\
\hline CHEMBL144208 & 7296 & 3.6021 & 3.9708 & TRN & & \\
\hline CHEMBL144334 & 7296 & 5.699 & 5.5991 & TRN & & \\
\hline CHEMBL111417 & 7296 & 5.6676 & 5.9721 & TRN & & \\
\hline CHEMBL144984 & 7296 & 6.4815 & 6.5564 & TRN & & \\
\hline CHEMBL144303 & 7296 & 5.3716 & 5.3347 & TRN & & \\
\hline CHEMBL33618 & 7296 & 5.8861 & 5.4071 & TST & & \\
\hline CHEMBL144134 & 7296 & 6.2518 & 6.364 & TST & & \\
\hline CHEMBL144088 & 7296 & 6.4949 & 6.77 & TRN & & \\
\hline CHEMBL109617 & 7296 & 5.6478 & 5.9162 & TRN & & \\
\hline CHEMBL343238 & 7296 & 6.284 & 6.2508 & TRN & & \\
\hline CHEMBL 33505 & 7296 & 3.6021 & 3.793 & TST & & \\
\hline CHEMBL356077 & 7296 & 6.4559 & 6.6319 & TRN & & \\
\hline CHEMBL145575 & 7296 & 6.1938 & 6.0478 & TRN & & \\
\hline CHEMBL144756 & 7296 & 6.3565 & 5.9162 & TRN & & \\
\hline CHEMBL91163 & 7296 & 5.6778 & 5.5584 & TRN & & \\
\hline CHEMBL146111 & 7296 & 5.6778 & 5.9128 & TRN & & \\
\hline CHEMBL144664 & 7296 & 6.4949 & 6.45 & TRN & & \\
\hline CHEMBL89250 & 7296 & 6.3188 & 5.4071 & TST & & \\
\hline CHEMBL145490 & 7296 & 5.7696 & 5.7315 & TRN & & \\
\hline CHEMBL 300584 & 7296 & 7.7959 & 7.5358 & TRN & & \\
\hline CHEMBL144757 & 7296 & 5.9208 & 5.3657 & TST & & \\
\hline CHEMBL144848 & 7296 & 6.3615 & 6.2709 & TRN & & \\
\hline CHEMBL359443 & 7296 & 6.5376 & 7.1137 & TRN & & \\
\hline CHEMBL146602 & 7296 & 6.3188 & 6.364 & TST & & \\
\hline CHEMBL143452 & 7296 & 5.8239 & 5.7911 & TRN & & \\
\hline CHEMBL444347 & 7296 & 5.5935 & 5.6607 & TRN & & \\
\hline CHEMBL144827 & 7296 & 5.4318 & 5.3786 & TRN & & \\
\hline CHEMBL110044 & 7296 & 5.7212 & 5.9341 & TST & & \\
\hline CHEMBL343445 & 7296 & 4.4089 & 5.3657 & TST & & \\
\hline CHEMBL422120 & 7296 & 6.2757 & 6.3225 & TRN & & \\
\hline CHEMBL 345004 & 7296 & 8.6021 & 8.0085 & TRN & & \\
\hline CHEMBL344274 & 7296 & 5.7212 & 5.6016 & TRN & & \\
\hline CHEMBL89977 & 7296 & 5.6778 & 5.6607 & TRN & & \\
\hline CHEMBL423017 & 7296 & 6.4815 & 5.9128 & TST & & \\
\hline CHEMBL1974713 & 752327 & 4.9121 & 3.971 & TRN & & \\
\hline CHEMBL1303540 & 752327 & 5.1669 & 3.3171 & TRN & & \\
\hline CHEMBL1726149 & 752327 & 3.1024 & 3.6132 & TRN & & \\
\hline CHEMBL1382123 & 752327 & 4.8977 & 3.8074 & TRN & & \\
\hline CHEMBL1481069 & 752327 & 3.1024 & 3.525 & TRN & & \\
\hline CHEMBL1710294 & 752327 & 3.1024 & 3.9834 & TRN & & \\
\hline
\end{tabular}


Supplemental Table S2.txt

\begin{tabular}{|c|c|c|c|c|}
\hline CHEMBL1373079 & 752327 & 4.1871 & 3.5952 & TRN \\
\hline CHEMBL1901063 & 752327 & 3.1024 & 3.6589 & TST \\
\hline CHEMBL1730810 & 752327 & 4.4438 & 3.7113 & TST \\
\hline CHEMBL1532085 & 752327 & 3.1024 & 3.5345 & TRN \\
\hline CHEMBL1993796 & 752327 & 3.1024 & 3.8948 & TRN \\
\hline CHEMBL1555499 & 752327 & 5.0185 & 3.8948 & TRN \\
\hline CHEMBL1456803 & 752327 & 3.1024 & 3.5987 & TRN \\
\hline CHEMBL1402898 & 752327 & 4.9571 & 3.8231 & TRN \\
\hline CHEMBL1550273 & 752327 & 4.8715 & 3.7176 & TRN \\
\hline CHEMBL1973705 & 752327 & 3.1024 & 3.5849 & TST \\
\hline CHEMBL1340393 & 752327 & 3.1024 & 3.8853 & TRN \\
\hline CHEMBL1418287 & 752327 & 3.1024 & 3.9975 & TRN \\
\hline CHEMBL1566066 & 752327 & 3.1024 & 3.2262 & TRN \\
\hline CHEMBL1571998 & 752327 & 3.1024 & 3.8882 & TRN \\
\hline CHEMBL1879649 & 752327 & 4.5099 & 3.6778 & TRN \\
\hline CHEMBL1376580 & 752327 & 4.6909 & 3.657 & TRN \\
\hline CHEMBL1339699 & 752327 & 3.1024 & 3.6417 & TRN \\
\hline CHEMBL1997195 & 752327 & 4.4732 & 3.7994 & TRN \\
\hline CHEMBL 2000633 & 752327 & 3.1024 & 3.4088 & TRN \\
\hline CHEMBL1355118 & 752327 & 3.1024 & 3.3152 & TRN \\
\hline CHEMBL1734249 & 752327 & 4.1163 & 3.2931 & TRN \\
\hline CHEMBL1385083 & 752327 & 4.5595 & 3.2424 & TRN \\
\hline CHEMBL1724206 & 752327 & 3.1024 & 3.5115 & TRN \\
\hline CHEMBL1480223 & 752327 & 3.1024 & 3.6906 & TRN \\
\hline CHEMBL1534849 & 752327 & 3.1024 & 3.8049 & TST \\
\hline CHEMBL1447730 & 752327 & 3.1024 & 3.9009 & TRN \\
\hline CHEMBL1563287 & 752327 & 3.1024 & 3.7849 & TST \\
\hline CHEMBL1387231 & 752327 & 4.3422 & 3.7286 & TRN \\
\hline CHEMBL1440892 & 752327 & 3.1024 & 3.6712 & TRN \\
\hline CHEMBL1308563 & 752327 & 4.7981 & 3.8024 & TRN \\
\hline CHEMBL1305963 & 752327 & 3.1024 & 3.7509 & TRN \\
\hline CHEMBL1484274 & 752327 & 3.1024 & 3.6793 & TRN \\
\hline CHEMBL1485381 & 752327 & 3.1024 & 3.7793 & TRN \\
\hline CHEMBL1525606 & 752327 & 3.1024 & 3.6901 & TRN \\
\hline CHEMBL1893298 & 752327 & 3.1024 & 3.856999 & \\
\hline CHEMBL1534665 & 752327 & 3.1024 & 3.4524 & TRN \\
\hline CHEMBL1880451 & 752327 & 3.1024 & 3.5464 & TST \\
\hline CHEMBL1421091 & 752327 & 4.6869 & 3.9068 & TRN \\
\hline CHEMBL1879283 & 752327 & 3.1024 & 3.5092 & TRN \\
\hline CHEMBL1991440 & 752327 & 3.1024 & 3.6836 & TRN \\
\hline CHEMBL1880550 & 752327 & 4.9218 & 3.9519 & TRN \\
\hline CHEMBL1406133 & 752327 & 3.1024 & 3.9217 & TRN \\
\hline CHEMBL1432772 & 752327 & 3.1024 & 3.973999 & 99999999998 \\
\hline CHEMBL1975051 & 752327 & 5.0392 & 3.873 & TRN \\
\hline CHEMBL1970636 & 752327 & 3.1024 & 3.6369 & TRN \\
\hline CHEMBL1417160 & 752327 & 3.1024 & 3.9061 & TRN \\
\hline CHEMBL1372492 & 752327 & 4.74 & 3.7907 & TRN \\
\hline CHEMBL1380024 & 752327 & 4.9283 & 3.8368 & TRN \\
\hline
\end{tabular}


Supplemental Table S2.txt

\begin{tabular}{|c|c|c|c|c|c|}
\hline CHEMBL1489749 & 752327 & 3.1024 & 3.3731 & TRN & \\
\hline CHEMBL1470565 & 752327 & 3.1024 & 3.5572 & TST & \\
\hline CHEMBL1511397 & 752327 & 3.1024 & 3.7874 & TST & \\
\hline CHEMBL1526033 & 752327 & 4.8815 & 3.7967 & TRN & \\
\hline CHEMBL1605713 & 752327 & 3.1024 & 3.7937 & TST & \\
\hline CHEMBL1463401 & 752327 & 3.1024 & 3.5605 & TRN & \\
\hline CHEMBL1604372 & 752327 & 3.1024 & 3.6641 & TRN & \\
\hline CHEMBL1490367 & 752327 & 3.1024 & 3.8582 & TRN & \\
\hline CHEMBL1390768 & 752327 & 3.1024 & 3.6071 & TST & \\
\hline CHEMBL 2006274 & 752327 & 4.7182 & 3.705 & TRN & \\
\hline CHEMBL1969034 & 752327 & 4.8526 & 3.6939 & TRN & \\
\hline CHEMBL1733261 & 752327 & 3.1024 & 3.4362 & TRN & \\
\hline CHEMBL1581175 & 752327 & 3.1024 & 3.6805 & TRN & \\
\hline CHEMBL1456075 & 752327 & 3.1024 & 3.7819 & TRN & \\
\hline CHEMBL1338641 & 752327 & 3.1024 & 3.4978 & TRN & \\
\hline CHEMBL1420497 & 752327 & 5.0147 & 3.653 & TRN & \\
\hline CHEMBL1518907 & 752327 & 3.1024 & 3.8092 & TRN & \\
\hline CHEMBL1433386 & 752327 & 3.1024 & 3.7489 & TRN & \\
\hline CHEMBL1867718 & 752327 & 3.1024 & 3.8486 & TRN & \\
\hline CHEMBL1354360 & 752327 & 3.1024 & 3.7886 & TRN & \\
\hline CHEMBL1996299 & 752327 & 5.0315 & 3.7056 & TRN & \\
\hline CHEMBL1338315 & 752327 & 3.1024 & 3.5639 & TRN & \\
\hline CHEMBL1572279 & 752327 & 3.1024 & 3.4764 & TRN & \\
\hline CHEMBL1515432 & 752327 & 5.2198 & 3.7157 & TST & \\
\hline CHEMBL1304960 & 752327 & 4.6312 & 3.6595 & TRN & \\
\hline CHEMBL1439288 & 752327 & 3.1024 & 3.4874 & TRN & \\
\hline CHEMBL1395284 & 752327 & 3.1024 & 3.7465 & TRN & \\
\hline CHEMBL1575370 & 752327 & 3.1024 & 3.6941 & TST & \\
\hline CHEMBL1322873 & 752327 & 3.1024 & 3.2948 & TRN & \\
\hline CHEMBL1309134 & 752327 & 3.1024 & 3.7492 & TST & \\
\hline CHEMBL1736890 & 752327 & 3.1024 & 3.7293 & TRN & \\
\hline CHEMBL1906351 & 752327 & 3.1024 & 3.8842 & TRN & \\
\hline CHEMBL1869519 & 752327 & 3.1024 & 3.3664 & TRN & \\
\hline CHEMBL1606890 & 752327 & 3.1024 & 3.75600 & 00000000002 & TRN \\
\hline CHEMBL1606973 & 752327 & 3.1024 & 3.335 & TRN & \\
\hline CHEMBL1870697 & 752327 & 3.1024 & 3.5773 & TRN & \\
\hline CHEMBL1722673 & 752327 & 4.7568 & 3.9146 & TST & \\
\hline CHEMBL1599416 & 752327 & 3.1024 & 3.4768 & TRN & \\
\hline CHEMBL1899834 & 752327 & 3.1024 & 3.4849 & TRN & \\
\hline CHEMBL1881477 & 752327 & 3.1024 & 3.8558 & TRN & \\
\hline CHEMBL1482332 & 752327 & 3.1024 & 3.8152 & TRN & \\
\hline CHEMBL1365676 & 752327 & 3.1024 & 3.4334 & TRN & \\
\hline CHEMBL1391456 & 752327 & 4.1504 & 3.6675 & TRN & \\
\hline CHEMBL1502371 & 752327 & 4.6492 & 4.0362 & TRN & \\
\hline CHEMBL1714561 & 752327 & 3.1024 & 3.5556 & TRN & \\
\hline CHEMBL1504419 & 752327 & 3.1024 & 3.7852 & TRN & \\
\hline CHEMBL1565318 & 752327 & 4.5315 & 3.488 & TRN & \\
\hline CHEMBL1901020 & 752327 & 3.1024 & 3.5922 & TST & \\
\hline
\end{tabular}

Page 7733 
Supplemental Table S2.txt

\begin{tabular}{|c|c|c|c|c|}
\hline CHEMBL1535344 & 752327 & 4.8053 & 3.5903 & TRN \\
\hline CHEMBL1487042 & 752327 & 3.1024 & 3.8402 & TRN \\
\hline CHEMBL1376108 & 752327 & 3.1024 & 3.3294 & TRN \\
\hline CHEMBL1300822 & 752327 & 3.1024 & 4.0418 & TRN \\
\hline CHEMBL1374384 & 752327 & 3.1024 & 3.6895 & TRN \\
\hline CHEMBL1984130 & 752327 & 3.1024 & 3.6495 & TRN \\
\hline CHEMBL1439268 & 752327 & 3.1024 & 3.6392 & TST \\
\hline CHEMBL1887146 & 752327 & 4.9185 & 3.8758 & TRN \\
\hline CHEMBL1319484 & 752327 & 3.1024 & 3.8128 & TRN \\
\hline CHEMBL1491734 & 752327 & 3.1024 & 3.6627 & TST \\
\hline CHEMBL1448074 & 752327 & 4.8493 & 3.7102 & TRN \\
\hline CHEMBL1705033 & 752327 & 3.1024 & 3.5102 & TRN \\
\hline CHEMBL1307075 & 752327 & 3.1024 & 3.6264 & TST \\
\hline CHEMBL1999513 & 752327 & 3.1024 & 3.7309 & TRN \\
\hline CHEMBL1560092 & 752327 & 3.1024 & 3.6758 & TRN \\
\hline CHEMBL1589418 & 752327 & 4.7443 & 3.9561 & TRN \\
\hline CHEMBL1468409 & 752327 & 3.1024 & 3.6115 & TRN \\
\hline CHEMBL1423034 & 752327 & 3.1024 & 3.7531 & TRN \\
\hline CHEMBL1473428 & 752327 & 4.6056 & 3.6265 & TRN \\
\hline CHEMBL1993978 & 752327 & 3.1024 & 3.8819 & TRN \\
\hline CHEMBL1491564 & 752327 & 3.1024 & 3.4995 & TRN \\
\hline CHEMBL1978995 & 752327 & 3.1024 & 3.4657 & TST \\
\hline CHEMBL1384754 & 752327 & 3.1024 & 3.546999 & 9999999997 \\
\hline CHEMBL1598403 & 752327 & 3.1024 & 3.4653 & TRN \\
\hline CHEMBL1892123 & 752327 & 3.1024 & 3.4776 & TRN \\
\hline CHEMBL1468550 & 752327 & 4.3558 & 3.8183 & TRN \\
\hline CHEMBL1602141 & 752327 & 3.1024 & 3.6087 & TST \\
\hline CHEMBL1314090 & 752327 & 3.1024 & 3.8235 & TRN \\
\hline CHEMBL1373868 & 752327 & 3.1024 & 3.7495 & TRN \\
\hline CHEMBL1897854 & 752327 & 4.6491 & 3.8433 & TST \\
\hline CHEMBL1500200 & 752327 & 4.3625 & 3.9037 & TRN \\
\hline CHEMBL1402745 & 752327 & 4.5381 & 3.7156 & TRN \\
\hline CHEMBL210276 & 752327 & 3.1024 & 3.3957 & TRN \\
\hline CHEMBL1387165 & 752327 & 3.1024 & 3.5763 & TRN \\
\hline CHEMBL1311027 & 752327 & 4.5458 & 3.8163 & TRN \\
\hline CHEMBL1420862 & 752327 & 3.1024 & 3.7592 & TRN \\
\hline CHEMBL1610731 & 752327 & 3.1024 & 3.5776 & TRN \\
\hline CHEMBL1544447 & 752327 & 4.4832 & 3.7396 & TRN \\
\hline CHEMBL1554786 & 752327 & 4.7144 & 3.5914 & TRN \\
\hline CHEMBL1360390 & 752327 & 3.1024 & 3.7634 & TRN \\
\hline CHEMBL1579824 & 752327 & 3.1024 & 3.6448 & TRN \\
\hline CHEMBL1735066 & 752327 & 3.1024 & 3.2529 & TRN \\
\hline CHEMBL1377309 & 752327 & 3.1024 & 3.6051 & TRN \\
\hline CHEMBL1711523 & 752327 & 3.1024 & 3.4021 & TRN \\
\hline CHEMBL 2005850 & 752327 & 3.1024 & \multicolumn{2}{|c|}{3.8289999999999997} \\
\hline CHEMBL1998234 & 752327 & 3.1024 & 3.7396 & TRN \\
\hline CHEMBL1490537 & 752327 & 3.1024 & 3.7322 & TRN \\
\hline CHEMBL1302624 & 752327 & 3.1024 & 3.7912 & TRN \\
\hline
\end{tabular}

Page 7734 
Supplemental Table S2.txt

\begin{tabular}{|c|c|c|c|c|}
\hline CHEMBL1900518 & 752327 & 3.1024 & 4.0561 & TRN \\
\hline CHEMBL1367230 & 752327 & 3.1024 & 3.9465 & TRN \\
\hline CHEMBL1719681 & 752327 & 3.1024 & 3.6443 & TRN \\
\hline CHEMBL1710984 & 752327 & 3.1024 & 3.6983 & TRN \\
\hline CHEMBL1707958 & 752327 & 3.1024 & 3.3733 & TRN \\
\hline CHEMBL1714156 & 752327 & 3.1024 & 3.3455 & TRN \\
\hline CHEMBL1524727 & 752327 & 3.1024 & 3.3964 & TRN \\
\hline CHEMBL1317012 & 752327 & 4.7394 & 3.792 & TST \\
\hline CHEMBL1336970 & 752327 & 4.7172 & 3.5933 & TRN \\
\hline CHEMBL1446935 & 752327 & 4.7624 & 3.596 & TRN \\
\hline CHEMBL1594835 & 752327 & 3.1024 & 3.6143 & TRN \\
\hline CHEMBL551657 & 752327 & 3.1024 & 3.4115 & TRN \\
\hline CHEMBL1985142 & 752327 & 3.1024 & 3.7501 & TST \\
\hline CHEMBL1343368 & 752327 & 4.621 & 3.7326 & TRN \\
\hline CHEMBL1475057 & 752327 & 3.1024 & 3.5726 & TRN \\
\hline CHEMBL1576457 & 752327 & 4.3577 & 3.7896 & TRN \\
\hline CHEMBL1470342 & 752327 & 3.1024 & 3.6841 & TRN \\
\hline CHEMBL1700891 & 752327 & 3.1024 & 3.38100 & 00000000002 \\
\hline CHEMBL1895133 & 752327 & 3.1024 & 3.6287 & TST \\
\hline CHEMBL1490436 & 752327 & 4.6708 & 3.573 & TRN \\
\hline CHEMBL1981303 & 752327 & 3.1024 & 3.588 & TST \\
\hline CHEMBL1877015 & 752327 & 5.0171 & 4.0994 & TST \\
\hline CHEMBL1429848 & 752327 & 3.1024 & 3.5235 & TRN \\
\hline CHEMBL1461413 & 752327 & 3.1024 & 3.4596 & TST \\
\hline CHEMBL1308945 & 752327 & 4.5904 & 3.6123 & TRN \\
\hline CHEMBL1893210 & 752327 & 4.8423 & 3.9824 & TRN \\
\hline CHEMBL1511370 & 752327 & 3.1024 & 3.4119 & TRN \\
\hline CHEMBL1719240 & 752327 & 3.1024 & 3.8461 & TRN \\
\hline CHEMBL1425581 & 752327 & 3.1024 & 3.5155 & TRN \\
\hline CHEMBL1414773 & 752327 & 3.1024 & 3.6044 & TRN \\
\hline CHEMBL1408484 & 752327 & 4.7944 & 3.9428 & TRN \\
\hline CHEMBL1302642 & 752327 & 3.1024 & 3.7418 & TRN \\
\hline CHEMBL1443589 & 752327 & 4.7584 & 3.5497 & TRN \\
\hline CHEMBL1547685 & 752327 & 3.1024 & 3.8511 & TRN \\
\hline CHEMBL1314124 & 752327 & 4.4505 & 3.6743 & TRN \\
\hline CHEMBL1404897 & 752327 & 3.1024 & 3.5001 & TRN \\
\hline CHEMBL1603166 & 752327 & 4.9598 & 3.9775 & TRN \\
\hline CHEMBL1702908 & 752327 & 4.4998 & 3.4984 & TRN \\
\hline CHEMBL1497333 & 752327 & 5.0392 & 3.638 & TRN \\
\hline CHEMBL1354874 & 752327 & 3.1024 & 3.7154 & TRN \\
\hline CHEMBL1496105 & 752327 & 4.8725 & 3.7199 & TRN \\
\hline CHEMBL1601691 & 752327 & 4.4502 & 3.8691 & TST \\
\hline CHEMBL1511879 & 752327 & 4.5462 & 3.7628 & TRN \\
\hline CHEMBL1984924 & 752327 & 3.1024 & 3.6671 & TRN \\
\hline CHEMBL1872827 & 752327 & 3.1024 & 3.8694 & TRN \\
\hline CHEMBL1477569 & 752327 & 3.1024 & 3.5307 & TST \\
\hline CHEMBL1992858 & 752327 & 3.1024 & 3.8262 & TRN \\
\hline CHEMBL1717811 & 752327 & 3.1024 & 3.2452 & TRN \\
\hline
\end{tabular}


Supplemental Table S2.txt

\begin{tabular}{|c|c|c|c|c|}
\hline CHEMBL1322215 & 752327 & 3.1024 & 3.6902 & TRN \\
\hline CHEMBL1900738 & 752327 & 4.8971 & 3.9631 & TST \\
\hline CHEMBL1583576 & 752327 & 3.1024 & 3.6246 & TST \\
\hline CHEMBL1484629 & 752327 & 5.0027 & 3.6069 & TRN \\
\hline CHEMBL 2003436 & 752327 & 3.1024 & 3.5735 & TRN \\
\hline CHEMBL1489244 & 752327 & 4.9492 & 3.7236 & TRN \\
\hline CHEMBL1417717 & 752327 & 3.1024 & 3.8941 & TST \\
\hline CHEMBL 2003869 & 752327 & 3.1024 & 3.7395 & TRN \\
\hline CHEMBL1460061 & 752327 & 3.1024 & 3.5842 & TRN \\
\hline CHEMBL1731300 & 752327 & 3.1024 & 3.8786 & TST \\
\hline CHEMBL1311279 & 752327 & 4.909 & 3.7152 & TST \\
\hline CHEMBL1891270 & 752327 & 3.1024 & 3.8384 & TRN \\
\hline CHEMBL1879295 & 752327 & 3.1024 & 3.6381 & TRN \\
\hline CHEMBL1904694 & 752327 & 3.1024 & 3.7182 & TRN \\
\hline CHEMBL1443753 & 752327 & 3.1024 & 3.7478 & TST \\
\hline CHEMBL1558372 & 752327 & 4.6214 & 3.878 & TRN \\
\hline CHEMBL1720199 & 752327 & 3.1024 & 3.5235 & TRN \\
\hline CHEMBL1984554 & 752327 & 3.1024 & 3.8047 & TRN \\
\hline CHEMBL1982363 & 752327 & 4.5431 & 3.8564 & TRN \\
\hline CHEMBL1392113 & 752327 & 4.5881 & 3.663006 & 00000000003 \\
\hline CHEMBL1601471 & 752327 & 4.6161 & 3.9053 & TRN \\
\hline CHEMBL1330139 & 752327 & 3.1024 & 3.5581 & TST \\
\hline CHEMBL1448654 & 752327 & 3.1024 & 3.9225 & TST \\
\hline CHEMBL1443013 & 752327 & 3.1024 & 3.5149 & TST \\
\hline CHEMBL1505705 & 752327 & 3.1024 & 3.8269 & TRN \\
\hline CHEMBL1304801 & 752327 & 4.17399 & 99999999 & 3.8122 \\
\hline CHEMBL1735129 & 752327 & 3.1024 & 3.6111 & TRN \\
\hline CHEMBL1525257 & 752327 & 4.9974 & 3.5759 & TRN \\
\hline CHEMBL1472228 & 752327 & 3.1024 & 3.7416 & TRN \\
\hline CHEMBL1498553 & 752327 & 3.1024 & 3.8214 & TRN \\
\hline CHEMBL1439554 & 752327 & 3.1024 & 3.4701 & TRN \\
\hline CHEMBL1544440 & 752327 & 5.1842 & 3.9214 & TRN \\
\hline CHEMBL1884406 & 752327 & 3.1024 & 3.3337 & TRN \\
\hline CHEMBL1599059 & 752327 & 3.1024 & 3.7229 & TST \\
\hline CHEMBL1457432 & 752327 & 4.8221 & 3.782 & TRN \\
\hline CHEMBL1365739 & 752327 & 3.1024 & 3.5899 & TRN \\
\hline CHEMBL1374694 & 752327 & 4.2799 & 3.5867 & TST \\
\hline CHEMBL1506609 & 752327 & 3.1024 & 3.6341 & TRN \\
\hline CHEMBL1723920 & 752327 & 3.1024 & 3.7839 & TST \\
\hline CHEMBL1397451 & 752327 & 3.1024 & 3.4665 & TRN \\
\hline CHEMBL1880439 & 752327 & 3.1024 & 3.1924 & TRN \\
\hline CHEMBL1965579 & 752327 & 4.8916 & 3.8347 & TRN \\
\hline CHEMBL1374012 & 752327 & 3.1024 & 3.4978 & TRN \\
\hline CHEMBL1510924 & 752327 & 3.1024 & 3.7576 & TRN \\
\hline CHEMBL1966728 & 752327 & 3.1024 & 3.6663 & TRN \\
\hline CHEMBL1987709 & 752327 & 4.5005 & 3.3298 & TRN \\
\hline CHEMBL1365163 & 752327 & 3.1024 & 3.688 & TRN \\
\hline CHEMBL1878680 & 752327 & 4.9835 & 3.8148 & TRN \\
\hline
\end{tabular}


Supplemental Table S2.txt

\begin{tabular}{|c|c|c|c|c|}
\hline CHEMBL1993199 & 752327 & 3.1024 & 3.4031 & TRN \\
\hline CHEMBL1423764 & 752327 & 3.1024 & 3.6601 & TRN \\
\hline CHEMBL1535190 & 752327 & 4.6631 & 3.7102 & TST \\
\hline CHEMBL1890888 & 752327 & 3.1024 & 3.9308 & TRN \\
\hline CHEMBL1547410 & 752327 & 3.1024 & 3.5224 & TRN \\
\hline CHEMBL1728503 & 752327 & 3.1024 & 3.7591 & TRN \\
\hline CHEMBL1311274 & 752327 & 3.1024 & 3.9596 & TRN \\
\hline CHEMBL1531038 & 752327 & 4.4923 & 3.8196 & TRN \\
\hline CHEMBL1968465 & 752327 & 4.8817 & 3.827 & TRN \\
\hline CHEMBL1890494 & 752327 & 3.1024 & 3.6434 & TRN \\
\hline CHEMBL1584639 & 752327 & 3.1024 & 3.7909 & TRN \\
\hline CHEMBL1352504 & 752327 & 4.6489 & 3.8076 & TRN \\
\hline CHEMBL1726798 & 752327 & 3.1024 & 3.481999 & 99999999998 \\
\hline CHEMBL1329434 & 752327 & 3.1024 & 3.4227 & TRN \\
\hline CHEMBL1393543 & 752327 & 3.1024 & 3.7644 & TRN \\
\hline CHEMBL1416321 & 752327 & 3.1024 & 3.8758 & TRN \\
\hline CHEMBL1731566 & 752327 & 4.2639 & 3.7438 & TRN \\
\hline CHEMBL1894140 & 752327 & 3.1024 & 3.3727 & TRN \\
\hline CHEMBL1365106 & 752327 & 3.1024 & 3.2925 & TRN \\
\hline CHEMBL1395025 & 752327 & 3.1024 & 3.3063 & TRN \\
\hline CHEMBL1417523 & 752327 & 4.3085 & 3.3811 & TRN \\
\hline CHEMBL1553358 & 752327 & 3.1024 & 3.2856 & TRN \\
\hline CHEMBL1906558 & 752327 & 3.1024 & 3.6848 & TST \\
\hline CHEMBL1905319 & 752327 & 3.1024 & 3.336999 & 99999999997 \\
\hline CHEMBL1528882 & 752327 & 3.1024 & 3.6909 & TRN \\
\hline CHEMBL1896831 & 752327 & 3.1024 & 3.7351 & TRN \\
\hline CHEMBL1498273 & 752327 & 3.1024 & 3.7258 & TRN \\
\hline CHEMBL1700439 & 752327 & 3.1024 & 3.4896 & TRN \\
\hline CHEMBL1450838 & 752327 & 4.9168 & 3.8025 & TRN \\
\hline CHEMBL 2002824 & 752327 & 3.1024 & 3.5093 & TRN \\
\hline CHEMBL1866108 & 752327 & 4.3667 & 3.4455 & TRN \\
\hline CHEMBL1590788 & 752327 & 3.1024 & 3.4227 & TRN \\
\hline CHEMBL1345381 & 752327 & 3.1024 & 3.7032 & TRN \\
\hline CHEMBL1313565 & 752327 & 3.1024 & 3.8232 & TRN \\
\hline CHEMBL1580219 & 752327 & 4.7673 & 3.6354 & TRN \\
\hline CHEMBL1887295 & 752327 & 3.1024 & 3.9232 & TRN \\
\hline CHEMBL1395840 & 752327 & 3.1024 & 3.7314 & TRN \\
\hline CHEMBL1365331 & 752327 & 5.0959 & 3.5505 & TRN \\
\hline CHEMBL1311198 & 752327 & 3.1024 & 3.7907 & TRN \\
\hline CHEMBL1603373 & 752327 & 3.1024 & 3.8112 & TRN \\
\hline CHEMBL1475768 & 752327 & 3.1024 & 3.3617 & TRN \\
\hline CHEMBL1970371 & 752327 & 3.1024 & 3.2989 & TRN \\
\hline CHEMBL1404516 & 752327 & 3.1024 & 3.5242 & TRN \\
\hline CHEMBL1333734 & 752327 & 3.1024 & 3.5047 & TST \\
\hline CHEMBL1438732 & 752327 & 4.9582 & 3.7463 & TRN \\
\hline CHEMBL1475242 & 752327 & 3.1024 & 3.7954 & TRN \\
\hline CHEMBL1598069 & 752327 & 3.1024 & \multicolumn{2}{|c|}{3.7960000000000003} \\
\hline CHEMBL1470504 & 752327 & 3.1024 & 3.79 & TRN \\
\hline
\end{tabular}


Supplemental Table S2.txt

\begin{tabular}{|c|c|c|c|c|c|c|}
\hline CHEMBL1967640 & 752327 & 4.9044 & 3.9471 & TRN & & \\
\hline CHEMBL1986541 & 752327 & 3.1024 & 3.7327 & TRN & & \\
\hline CHEMBL1329077 & 752327 & 3.1024 & 3.4671 & TRN & & \\
\hline CHEMBL1595428 & 752327 & 4.3696 & 3.8904 & TRN & & \\
\hline CHEMBL1988621 & 752327 & 3.1024 & 3.6935 & TRN & & \\
\hline CHEMBL1721546 & 752327 & 4.8004 & 3.6851 & TST & & \\
\hline CHEMBL1893542 & 752327 & 3.1024 & 3.8222 & TST & & \\
\hline CHEMBL1429867 & 752327 & 4.2416 & 3.5494 & TRN & & \\
\hline CHEMBL1358434 & 752327 & 3.1024 & 3.7309 & TRN & & \\
\hline CHEMBL1999648 & 752327 & 3.1024 & 3.6017 & TST & & \\
\hline CHEMBL1371305 & 752327 & 3.1024 & 3.5407 & TRN & & \\
\hline CHEMBL1516650 & 752327 & 4.5042 & 3.3459 & TRN & & \\
\hline CHEMBL1611912 & 752327 & 4.1702 & 3.6747 & TRN & & \\
\hline CHEMBL1964556 & 752327 & 3.1024 & 3.9527 & TRN & & \\
\hline CHEMBL1372308 & 752327 & 4.6102 & 3.4802 & TRN & & \\
\hline CHEMBL1970160 & 752327 & 3.1024 & 3.585 & TRN & & \\
\hline CHEMBL1707119 & 752327 & 4.1334 & 3.2512 & TRN & & \\
\hline CHEMBL1394222 & 752327 & 3.1024 & 3.9214 & TST & & \\
\hline CHEMBL1989527 & 752327 & 3.1024 & 3.8515 & TRN & & \\
\hline CHEMBL1344755 & 752327 & 3.1024 & 3.9055 & TRN & & \\
\hline CHEMBL1902880 & 752327 & 3.1024 & 3.5779 & TRN & & \\
\hline CHEMBL1463620 & 752327 & 3.1024 & 3.4413 & TRN & & \\
\hline CHEMBL1891615 & 752327 & 3.1024 & 3.6158 & TST & & \\
\hline CHEMBL1534949 & 752327 & 3.1024 & 3.6437 & TRN & & \\
\hline CHEMBL1390449 & 752327 & 3.1024 & 3.4005 & TRN & & \\
\hline CHEMBL1420974 & 752327 & 3.1024 & 3.5954 & TRN & & \\
\hline CHEMBL1460751 & 752327 & 4.5248 & 3.9055 & TST & & \\
\hline CHEMBL1374627 & 752327 & 3.1024 & 3.4506 & TRN & & \\
\hline CHEMBL1478646 & 752327 & 3.1024 & 3.8155 & TRN & & \\
\hline CHEMBL1582880 & 752327 & \multicolumn{3}{|c|}{4.8069999999999995} & 3.8497 & TRN \\
\hline CHEMBL1390527 & 752327 & 4.5966 & 3.6464 & TRN & & \\
\hline CHEMBL1335734 & 752327 & 3.1024 & 3.6639 & TRN & & \\
\hline CHEMBL1425097 & 752327 & 3.1024 & 3.553 & TRN & & \\
\hline CHEMBL1886490 & 752327 & 4.8624 & 4.1015 & TRN & & \\
\hline CHEMBL1707646 & 752327 & 3.1024 & 3.5021 & TRN & & \\
\hline CHEMBL1523527 & 752327 & 3.1024 & 3.9014 & TRN & & \\
\hline CHEMBL1988660 & 752327 & 3.1024 & 3.6523 & TRN & & \\
\hline CHEMBL1548173 & 752327 & 5.2394 & 3.7563 & TST & & \\
\hline CHEMBL1365411 & 752327 & 3.1024 & 3.5334 & TRN & & \\
\hline CHEMBL1986459 & 752327 & 4.4941 & 3.6492 & TRN & & \\
\hline CHEMBL1871592 & 752327 & 3.1024 & 3.8622 & TRN & & \\
\hline CHEMBL1877761 & 752327 & 3.1024 & 3.6459 & TRN & & \\
\hline CHEMBL1441918 & 752327 & 4.4986 & 3.4108 & TST & & \\
\hline CHEMBL1880327 & 752327 & 3.1024 & 3.7466 & TRN & & \\
\hline CHEMBL1897884 & 752327 & 3.1024 & 3.6431 & TRN & & \\
\hline CHEMBL1335812 & 752327 & 4.6308 & 3.6384 & TRN & & \\
\hline CHEMBL1701254 & 752327 & 3.1024 & 3.4407 & TRN & & \\
\hline CHEMBL1731481 & 752327 & 3.1024 & 3.5896 & TRN & & \\
\hline
\end{tabular}


Supplemental Table S2.txt

\begin{tabular}{|c|c|c|c|c|}
\hline CHEMBL1555593 & 752327 & 3.1024 & 3.4561 & TRN \\
\hline CHEMBL1725294 & 752327 & 3.1024 & 3.7955 & TRN \\
\hline CHEMBL1893675 & 752327 & 3.1024 & 4.0824 & TRN \\
\hline CHEMBL1598649 & 752327 & 3.1024 & 3.4607 & TRN \\
\hline CHEMBL1517909 & 752327 & 4.8652 & 3.8946 & TRN \\
\hline CHEMBL1404915 & 752327 & 4.7063 & 3.5006 & TST \\
\hline CHEMBL 2001262 & 752327 & 3.1024 & 3.9085 & TRN \\
\hline CHEMBL1971553 & 752327 & 4.4434 & 3.5487 & TRN \\
\hline CHEMBL1968168 & 752327 & 3.1024 & 3.248999 & 99999999997 \\
\hline CHEMBL1582714 & 752327 & 3.1024 & 3.532 & TRN \\
\hline CHEMBL1966108 & 752327 & 3.1024 & 3.6771 & TRN \\
\hline CHEMBL1340831 & 752327 & 3.1024 & 3.4436 & TRN \\
\hline CHEMBL1409324 & 752327 & 3.1024 & 3.4039 & TRN \\
\hline CHEMBL1704199 & 752327 & 3.1024 & 3.3626 & TRN \\
\hline CHEMBL1714606 & 752327 & 3.1024 & 3.563999 & \\
\hline CHEMBL1507539 & 752327 & 3.1024 & 3.496006 & 00000000004 \\
\hline CHEMBL1863958 & 752327 & 3.1024 & 3.9146 & TRN \\
\hline CHEMBL1972014 & 752327 & 3.1024 & 3.5371 & TRN \\
\hline CHEMBL1384547 & 752327 & 3.1024 & 3.753 & TRN \\
\hline CHEMBL1976625 & 752327 & 4.4232 & 3.6647 & TRN \\
\hline CHEMBL1381711 & 752327 & 4.5609 & 3.7946 & TRN \\
\hline CHEMBL1992977 & 752327 & 5.0519 & 3.6755 & TRN \\
\hline CHEMBL1966657 & 752327 & 3.1024 & 3.762 & TRN \\
\hline CHEMBL1880887 & 752327 & 3.1024 & 3.8056 & TRN \\
\hline CHEMBL1904358 & 752327 & 3.1024 & 3.2884 & TRN \\
\hline CHEMBL1368699 & 752327 & 3.1024 & 3.6665 & TRN \\
\hline CHEMBL1307671 & 752327 & 4.8558 & 3.3713 & TRN \\
\hline CHEMBL1477594 & 752327 & 3.1024 & 3.3998 & TRN \\
\hline CHEMBL1427949 & 752327 & 3.1024 & 3.9584 & TST \\
\hline CHEMBL1565006 & 752327 & 3.1024 & 3.3445 & TRN \\
\hline CHEMBL1475748 & 752327 & 4.7855 & 3.7187 & TRN \\
\hline CHEMBL1587680 & 752327 & 3.1024 & 3.6135 & TRN \\
\hline CHEMBL1537709 & 752327 & 3.1024 & 3.68 & TRN \\
\hline CHEMBL1385597 & 752327 & 4.7551 & 3.7738 & TRN \\
\hline CHEMBL1318666 & 752327 & 4.5537 & 3.5131 & TRN \\
\hline CHEMBL1727505 & 752327 & 3.1024 & 3.4325 & TRN \\
\hline CHEMBL1366561 & 752327 & 3.1024 & 3.5155 & TRN \\
\hline CHEMBL1714012 & 752327 & 4.8218 & 3.6626 & TST \\
\hline CHEMBL1364424 & 752327 & 3.1024 & 3.6693 & TST \\
\hline CHEMBL590457 & 752327 & 4.5482 & 3.7302 & TRN \\
\hline CHEMBL1486149 & 752327 & 4.6059 & 3.5111 & TRN \\
\hline CHEMBL1494138 & 752327 & 3.1024 & $3.43600 e$ & 00000000004 \\
\hline CHEMBL1882042 & 752327 & 3.1024 & 3.5024 & TRN \\
\hline CHEMBL1458710 & 752327 & 3.1024 & 3.741 & TRN \\
\hline CHEMBL1587526 & 752327 & 3.1024 & 3.5647 & TRN \\
\hline CHEMBL1400446 & 752327 & 3.1024 & 3.5672 & TRN \\
\hline CHEMBL1867569 & 752327 & 5.1946 & 4.0606 & TRN \\
\hline CHEMBL1698139 & 752327 & 4.5503 & 3.8428 & TST \\
\hline
\end{tabular}


Supplemental Table S2.txt

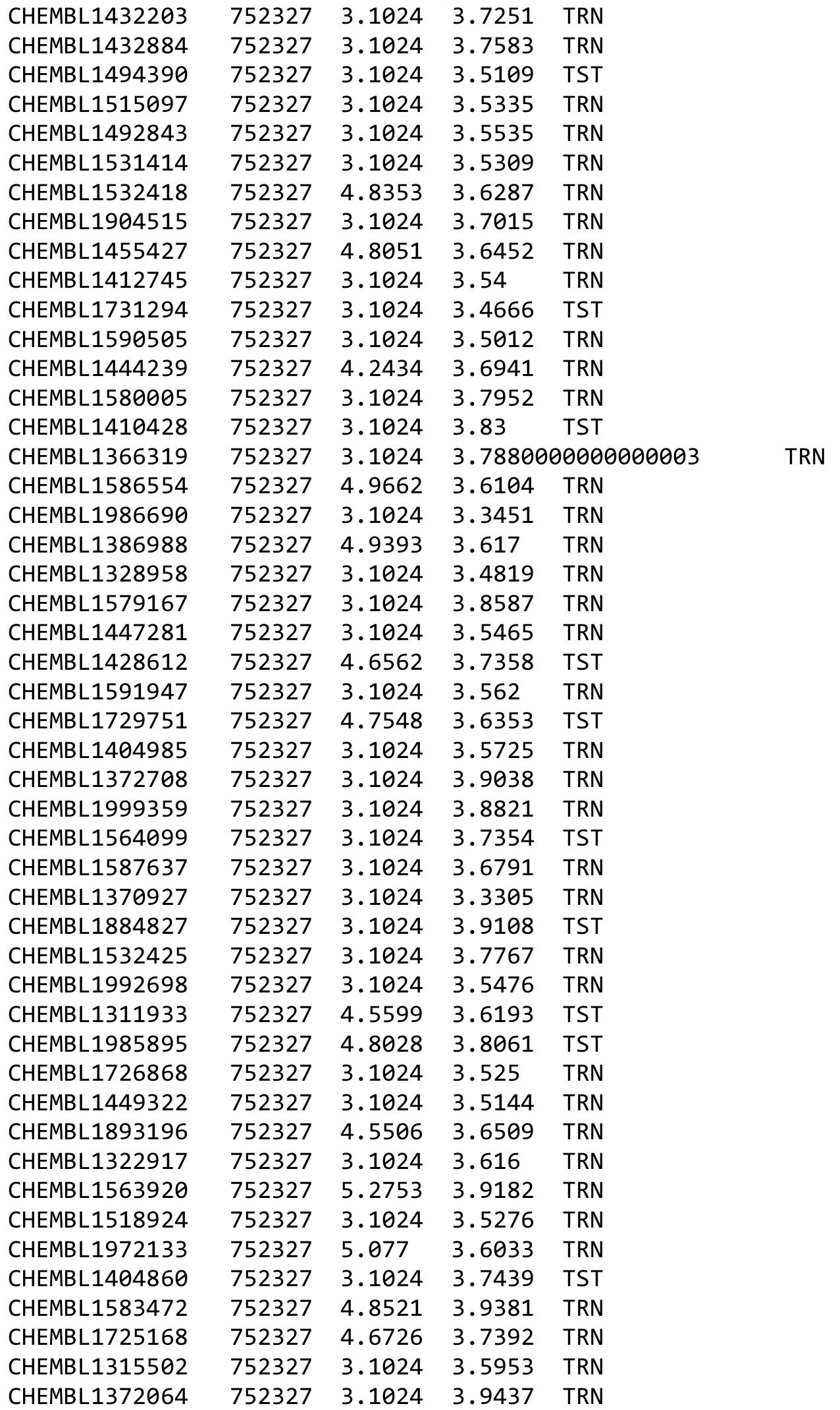




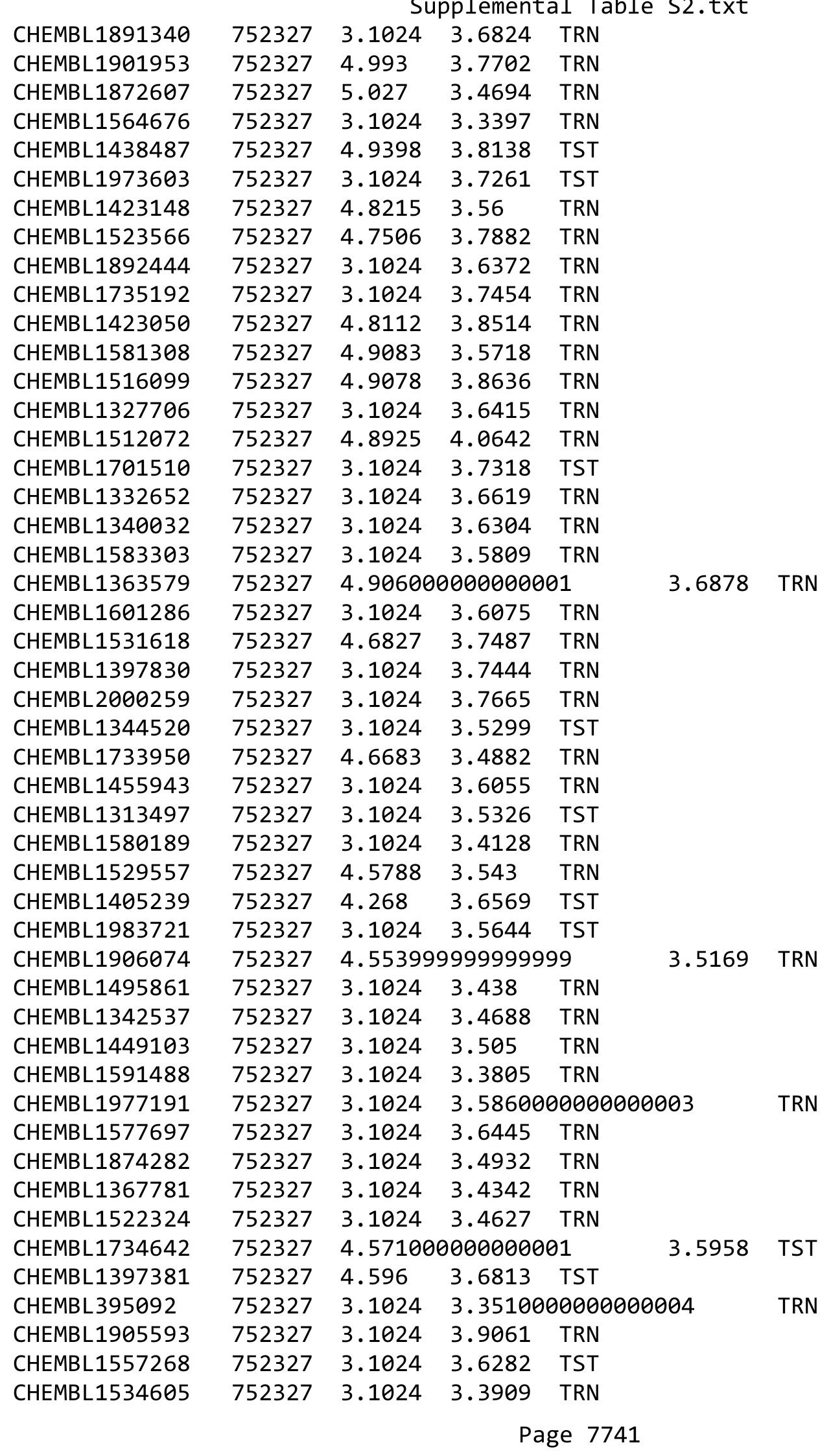


Supplemental Table S2.txt

\begin{tabular}{|c|c|c|c|c|}
\hline CHEMBL1728741 & 752327 & 3.1024 & 3.5343 & TRN \\
\hline CHEMBL3145300 & 752327 & 3.1024 & 3.7857 & TST \\
\hline CHEMBL1703352 & 752327 & 3.1024 & 3.3569 & TST \\
\hline CHEMBL1968095 & 752327 & 3.1024 & 3.7194 & TRN \\
\hline CHEMBL1373819 & 752327 & 3.1024 & 3.5418 & TST \\
\hline CHEMBL1519711 & 752327 & 4.5954 & 3.5815 & TRN \\
\hline CHEMBL1529401 & 752327 & 4.8351 & 3.5574 & TRN \\
\hline CHEMBL1447305 & 752327 & 3.1024 & 3.5943 & TRN \\
\hline CHEMBL1550518 & 752327 & 3.1024 & 3.8682 & TRN \\
\hline CHEMBL1383503 & 752327 & 3.1024 & 3.4716 & TRN \\
\hline CHEMBL1328045 & 752327 & 4.8984 & 3.6866 & TRN \\
\hline CHEMBL1730403 & 752327 & 4.2209 & 3.9483 & TRN \\
\hline CHEMBL1892639 & 752327 & 3.1024 & 3.9059 & TRN \\
\hline CHEMBL1379420 & 752327 & 4.272 & 3.895 & TRN \\
\hline CHEMBL1982632 & 752327 & 3.1024 & 3.6851 & TST \\
\hline CHEMBL 2006310 & 752327 & 3.1024 & $3.80800 €$ & 0000000003 \\
\hline CHEMBL1579798 & 752327 & 4.353 & 3.4216 & TRN \\
\hline CHEMBL1534836 & 752327 & 4.4383 & 3.9584 & TRN \\
\hline CHEMBL1464468 & 752327 & 3.1024 & 3.4946 & TRN \\
\hline CHEMBL1975975 & 752327 & 4.6527 & 3.9123 & TRN \\
\hline CHEMBL1336062 & 752327 & 3.1024 & 3.3948 & TRN \\
\hline CHEMBL1700311 & 752327 & 4.7993 & 3.7914 & TRN \\
\hline CHEMBL1538790 & 752327 & 3.1024 & 3.7472 & TRN \\
\hline CHEMBL1300649 & 752327 & 5.1825 & 3.8072 & TRN \\
\hline CHEMBL1965758 & 752327 & 5.0448 & 3.7492 & TRN \\
\hline CHEMBL 2004144 & 752327 & 3.1024 & 3.8328 & TRN \\
\hline CHEMBL1504144 & 752327 & 3.1024 & 3.5023 & TRN \\
\hline CHEMBL1496400 & 752327 & 3.1024 & 3.4157 & TRN \\
\hline CHEMBL1971117 & 752327 & 3.1024 & 3.7133 & TRN \\
\hline CHEMBL1532599 & 752327 & 3.1024 & 3.5225 & TRN \\
\hline CHEMBL1331249 & 752327 & 3.1024 & 3.5239 & TST \\
\hline CHEMBL1971872 & 752327 & 3.1024 & 3.5669 & TRN \\
\hline CHEMBL1432015 & 752327 & 5.0881 & 3.4802 & TRN \\
\hline CHEMBL1521120 & 752327 & 4.7521 & 3.6151 & TST \\
\hline CHEMBL1509007 & 752327 & 5.0051 & 3.6762 & TRN \\
\hline CHEMBL1891356 & 752327 & 3.1024 & 3.9579 & TRN \\
\hline CHEMBL1705527 & 752327 & 3.1024 & 3.6652 & TST \\
\hline CHEMBL1329044 & 752327 & 3.1024 & 3.5021 & TST \\
\hline CHEMBL1495078 & 752327 & 3.1024 & 3.6267 & TST \\
\hline CHEMBL1983587 & 752327 & 3.1024 & 3.6188 & TRN \\
\hline CHEMBL1465741 & 752327 & 3.1024 & 3.5771 & TRN \\
\hline CHEMBL1346584 & 752327 & 4.4645 & 3.9114 & TST \\
\hline CHEMBL1708448 & 752327 & 3.1024 & 3.3005 & TRN \\
\hline CHEMBL1339637 & 752327 & 3.1024 & 3.4457 & TRN \\
\hline CHEMBL1314845 & 752327 & 3.1024 & 3.3907 & TRN \\
\hline CHEMBL591834 & 752327 & 3.1024 & 3.312 & TST \\
\hline CHEMBL 2002274 & 752327 & 4.3953 & 3.5156 & TRN \\
\hline CHEMBL1302865 & 752327 & 3.1024 & 3.3764 & TRN \\
\hline
\end{tabular}




\begin{tabular}{|c|c|c|c|c|c|}
\hline \multirow{2}{*}{ CHEMBL1337016 } & \multirow{2}{*}{752327} & \\
\hline & & 4.5617 & \multicolumn{2}{|c|}{3.7680000000000002} & TRN \\
\hline CHEMBL1966886 & 752327 & 4.7917 & 3.6042 & TRN & \\
\hline CHEMBL1381720 & 752327 & 3.1024 & 3.5039 & TRN & \\
\hline CHEMBL1477801 & 752327 & 4.4048 & 3.6826 & TRN & \\
\hline CHEMBL1981305 & 752327 & 4.8802 & 3.6585 & TRN & \\
\hline CHEMBL1409280 & 752327 & 3.1024 & 3.7287 & TRN & \\
\hline CHEMBL1540730 & 752327 & 3.1024 & 3.5127 & TRN & \\
\hline CHEMBL1990091 & 752327 & 3.1024 & 3.8525 & TRN & \\
\hline CHEMBL1552521 & 752327 & 3.1024 & 3.2873 & TRN & \\
\hline CHEMBL1457134 & 752327 & 4.977 & 3.8102 & TRN & \\
\hline CHEMBL1868417 & 752327 & 3.1024 & 3.4277 & TRN & \\
\hline CHEMBL1704644 & 752327 & 4.7923 & 3.8699 & TRN & \\
\hline CHEMBL1317513 & 752327 & 3.1024 & 3.6838 & TRN & \\
\hline CHEMBL1402530 & 752327 & 3.1024 & 3.7799 & TST & \\
\hline CHEMBL1896941 & 752327 & 3.1024 & 3.4355 & TRN & \\
\hline CHEMBL1535801 & 752327 & 4.4551 & 3.6653 & TRN & \\
\hline CHEMBL1507647 & 752327 & 4.863 & 3.7999 & TST & \\
\hline CHEMBL1601300 & 752327 & 4.8789 & 3.8674 & TST & \\
\hline CHEMBL1571973 & 752327 & 4.5509 & 3.4979 & TST & \\
\hline CHEMBL1459757 & 752327 & 5.1197 & 3.8071 & TRN & \\
\hline CHEMBL1382113 & 752327 & 3.1024 & 3.4838 & TRN & \\
\hline CHEMBL1459641 & 752327 & 3.1024 & 3.5462 & TRN & \\
\hline CHEMBL1902329 & 752327 & 3.1024 & 3.4651 & TRN & \\
\hline CHEMBL1408533 & 752327 & 4.9603 & 3.4481 & TRN & \\
\hline CHEMBL1586992 & 752327 & 3.1024 & 3.8023 & TRN & \\
\hline CHEMBL1975458 & 752327 & 3.1024 & 3.8354 & TRN & \\
\hline CHEMBL1412725 & 752327 & 3.1024 & 3.6978 & TRN & \\
\hline CHEMBL1985765 & 752327 & 4.6021 & 3.8021 & TRN & \\
\hline CHEMBL1731988 & 752327 & 3.1024 & 3.46199 & 99999999997 & TRN \\
\hline CHEMBL273807 & 752327 & 3.1024 & 3.6614 & TRN & \\
\hline CHEMBL1365585 & 752327 & 4.4297 & 3.5954 & TRN & \\
\hline CHEMBL1400525 & 752327 & 3.1024 & 3.24 & TRN & \\
\hline CHEMBL1577620 & 752327 & 3.1024 & 3.525 & TRN & \\
\hline CHEMBL1312383 & 752327 & 3.1024 & 3.5421 & TRN & \\
\hline CHEMBL1727996 & 752327 & 4.6355 & 3.3272 & TRN & \\
\hline CHEMBL1432550 & 752327 & 3.1024 & 3.8125 & TRN & \\
\hline CHEMBL1570765 & 752327 & 3.1024 & 3.6513 & TST & \\
\hline CHEMBL1985660 & 752327 & 3.1024 & 3.3627 & TRN & \\
\hline CHEMBL1432762 & 752327 & 3.1024 & 3.5725 & TST & \\
\hline CHEMBL1725784 & 752327 & 4.9784 & 3.483 & TRN & \\
\hline CHEMBL1698095 & 752327 & 3.1024 & 3.6117 & TRN & \\
\hline CHEMBL1881977 & 752327 & 3.1024 & 3.4607 & TST & \\
\hline CHEMBL1699788 & 752327 & 3.1024 & 3.5537 & TRN & \\
\hline CHEMBL1444339 & 752327 & 3.1024 & 3.6049 & TRN & \\
\hline CHEMBL1460823 & 752327 & 3.1024 & 3.4578 & TRN & \\
\hline CHEMBL1557601 & 752327 & 4.9725 & 3.7466 & TRN & \\
\hline CHEMBL1888044 & 752327 & 3.1024 & 3.6151 & TST & \\
\hline CHEMBL1482960 & 752327 & 3.1024 & 3.6405 & TRN & \\
\hline
\end{tabular}


Supplemental Table S2.txt

\begin{tabular}{|c|c|c|c|c|}
\hline & & & & \\
\hline AEMBL1895020 & 327 & 5967 & & \\
\hline IEMBL1603609 & 2327 & 5093 & 5654 & \\
\hline AEMBL1873279 & 52327 & 024 & 121 & \\
\hline 599 & & & & \\
\hline AEMBL1979539 & 2327 & & 5361 & \\
\hline AEMBL1385111 & 52327 & 536 & 9242 & \\
\hline AEMBL1452652 & 52327 & 4.8959 & 8396 & \\
\hline AEMBL142 & 52327 & 4.9879 & 755 & \\
\hline IEMBL198 & 52327 & 024 & 3272 & \\
\hline AEMBL198 & 52327 & 495 & 3322 & \\
\hline AEMBL1345625 & 52327 & 3.1024 & 609 & \\
\hline AEMBL1410544 & 52327 & 024 & 5123 & \\
\hline IEMBL170 & 52 & 024 & 1486 & \\
\hline EMBL14 & 2327 & 024 & 253 & \\
\hline AEMBL 155 & & 024 & 116 & \\
\hline AEMBL1305255 & 52327 & 024 & 155 & RN \\
\hline AEMBL1410653 & & 24 & 878 & \\
\hline IEMBLIS & 7 & 24 & 402 & \\
\hline IEMBL18 & 7 & 24 & 012 & \\
\hline IEMBL15 & 27 & $\partial 24$ & 27 & \\
\hline AEMBL1732290 & 27 & 024 & 287 & RN \\
\hline IEMBL1868131 & & & 93 & \\
\hline EMBL17e & 7 & 46 & 924 & \\
\hline HEMBL19 & 7 & 19 & 426 & $\mathrm{RN}$ \\
\hline AFMRI 12 & 27 & 3. & 085 & ST \\
\hline AEMBL1714625 & & & 764 & RN \\
\hline IEMBL 2005602 & & & & \\
\hline AEMBL139 & 7 & 24 & 028 & $\mathrm{RN}$ \\
\hline 02 & 7 & 99 & 201 & 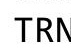 \\
\hline 969 & 7 & 36 & 673 & $\mathrm{RN}$ \\
\hline IEMBL1868465 & & & 725 & RN \\
\hline AEMBL1529402 & & & & $\mathrm{RI}$ \\
\hline EMBL1586524 & 7 & 25 & 079 & RI \\
\hline 351 & 7 & 24 & 917 & ועל \\
\hline 28 & & & 53 & $\mathrm{RN}$ \\
\hline AEMBL1885362 & 52 & & 576 & RN \\
\hline AEMBL1416156 & 7 & & 558 & $\mathrm{RI}$ \\
\hline IEMBL144 & 7 & & 132 & RI \\
\hline בסים & & 3. & 293 & \\
\hline 410 & & 3. & 981 & RN \\
\hline AEMBL1545924 & 52 & 3.1024 & 2602 & $S T$ \\
\hline AEMBL 172 & 7 & & 954 & TS \\
\hline HEMBL189 & & & & $T R$ \\
\hline & & & & \\
\hline CHEMBL1718652 & & 3.1024 & 526 & RI \\
\hline AEMBL1334334 & 52327 & 4.8166 & 3.6494 & $\Gamma R$ \\
\hline HFMRI 1507320 & 52327 & 3.1024 & 3.5335 & \\
\hline
\end{tabular}


Supplemental Table S2.txt

\begin{tabular}{|c|c|c|c|c|}
\hline CHEMBL1493328 & 752327 & 3.1024 & 3.7387 & TRN \\
\hline CHEMBL1891639 & 752327 & 4.9104 & 3.9486 & TRN \\
\hline CHEMBL1324722 & 752327 & 4.7925 & 4.1238 & TRN \\
\hline CHEMBL1440686 & 752327 & 3.1024 & 3.8418 & TRN \\
\hline CHEMBL1729505 & 752327 & 3.1024 & 3.6921 & TRN \\
\hline CHEMBL1511158 & 752327 & 3.1024 & 3.6183 & TRN \\
\hline CHEMBL1729086 & 752327 & 4.9086 & 3.8397 & TRN \\
\hline CHEMBL1904672 & 752327 & 3.1024 & 3.8283 & TRN \\
\hline CHEMBL1520122 & 752327 & 3.1024 & 3.8068 & TRN \\
\hline CHEMBL1337268 & 752327 & 3.1024 & 3.6847 & TRN \\
\hline CHEMBL 3145254 & 752327 & 3.1024 & 3.5464 & TST \\
\hline CHEMBL1417515 & 752327 & 3.1024 & 3.4532 & TST \\
\hline CHEMBL1538636 & 752327 & 4.8204 & 3.293999 & 99999999996 \\
\hline CHEMBL1319264 & 752327 & 4.5976 & 3.7236 & TRN \\
\hline CHEMBL1555186 & 752327 & 3.1024 & 3.7346 & TST \\
\hline CHEMBL1984056 & 752327 & 3.1024 & 3.6953 & TRN \\
\hline CHEMBL1450084 & 752327 & 4.577 & 3.4305 & TST \\
\hline CHEMBL1547457 & 752327 & 4.7396 & 3.6525 & TRN \\
\hline CHEMBL1371971 & 752327 & 3.1024 & 3.9086 & TRN \\
\hline CHEMBL1879029 & 752327 & 4.709 & 3.8246 & TRN \\
\hline CHEMBL1372519 & 752327 & 3.1024 & 3.6914 & TST \\
\hline CHEMBL1564425 & 752327 & 3.1024 & 3.718 & TRN \\
\hline CHEMBL1990081 & 752327 & 3.1024 & 3.5163 & TRN \\
\hline CHEMBL1311025 & 752327 & 3.1024 & 3.5928 & TRN \\
\hline CHEMBL 249301 & 752327 & 4.6861 & 3.6399 & TRN \\
\hline CHEMBL1398174 & 752327 & 3.1024 & 3.5303 & TRN \\
\hline CHEMBL1373183 & 752327 & 4.8844 & 3.6549 & TRN \\
\hline CHEMBL1173522 & 752327 & 4.6343 & 3.7889 & TST \\
\hline CHEMBL1507497 & 752327 & 3.1024 & 3.6058 & TST \\
\hline CHEMBL1992540 & 752327 & 3.1024 & 3.9052 & TRN \\
\hline CHEMBL1506903 & 752327 & 4.7753 & 3.6026 & TRN \\
\hline CHEMBL1867143 & 752327 & 3.1024 & 3.8699 & TRN \\
\hline CHEMBL1367309 & 752327 & 3.1024 & 3.7726 & TRN \\
\hline CHEMBL 1875387 & 752327 & 3.1024 & 3.3867 & TRN \\
\hline CHEMBL1707466 & 752327 & 3.1024 & 3.7288 & TRN \\
\hline CHEMBL1990796 & 752327 & 4.4462 & 3.6828 & TRN \\
\hline CHEMBL1557763 & 752327 & 4.8592 & 3.7597 & TRN \\
\hline CHEMBL1578975 & 752327 & 3.1024 & 3.5995 & TRN \\
\hline CHEMBL1699180 & 752327 & 4.6169 & 3.7456 & TST \\
\hline CHEMBL1475477 & 752327 & 3.1024 & 3.4477 & TRN \\
\hline CHEMBL1878724 & 752327 & 3.1024 & 3.6431 & TRN \\
\hline CHEMBL1884334 & 752327 & 5.2772 & 3.7818 & TRN \\
\hline CHEMBL1602934 & 752327 & 3.1024 & 3.5594 & TRN \\
\hline CHEMBL1321016 & 752327 & 3.1024 & 3.8398 & TRN \\
\hline CHEMBL1698435 & 752327 & 3.1024 & 3.4608 & TRN \\
\hline CHEMBL1898660 & 752327 & 3.1024 & 3.3098 & TRN \\
\hline CHEMBL1513925 & 752327 & 4.8947 & 3.7237 & TST \\
\hline CHEMBL1982577 & 752327 & 3.1024 & 3.56 & TST \\
\hline
\end{tabular}


Supplemental Table S2.txt

\begin{tabular}{|c|c|c|c|c|}
\hline CHEMBL1558819 & 752327 & 4.6569 & 3.924 & TRN \\
\hline CHEMBL1880968 & 752327 & 4.7463 & 3.7993 & TRN \\
\hline CHEMBL1969457 & 752327 & 3.1024 & 3.7003 & TST \\
\hline CHEMBL1987344 & 752327 & 3.1024 & 3.7268 & TST \\
\hline CHEMBL1865197 & 752327 & 3.1024 & 3.7492 & TRN \\
\hline CHEMBL1503062 & 752327 & 4.4737 & 3.5456 & TRN \\
\hline CHEMBL1300729 & 752327 & 3.1024 & 3.7549 & TRN \\
\hline CHEMBL1989704 & 752327 & 3.1024 & 3.3765 & TST \\
\hline CHEMBL1895933 & 752327 & 3.1024 & 3.8254 & TST \\
\hline CHEMBL1344247 & 752327 & 3.1024 & 3.6783 & TST \\
\hline CHEMBL1712358 & 752327 & 5.2208 & 3.656 & TST \\
\hline CHEMBL1414448 & 752327 & 4.2775 & 3.7253 & TRN \\
\hline CHEMBL1416039 & 752327 & 4.5955 & 3.9269 & TRN \\
\hline CHEMBL1456690 & 752327 & 4.8836 & 3.6087 & TRN \\
\hline CHEMBL1338736 & 752327 & 4.7918 & 3.6432 & TRN \\
\hline CHEMBL45245 & 752327 & 3.1024 & 3.2853 & TRN \\
\hline CHEMBL1328052 & 752327 & 4.775 & 3.6213 & TRN \\
\hline CHEMBL1430507 & 752327 & 3.1024 & 3.783 & TRN \\
\hline CHEMBL1478438 & 752327 & 3.1024 & 3.4862 & TRN \\
\hline CHEMBL1903425 & 752327 & 4.4286 & 3.9466 & TRN \\
\hline CHEMBL1534716 & 752327 & 4.8337 & 3.5886 & TRN \\
\hline CHEMBL1427466 & 752327 & 4.8004 & 3.5814 & TRN \\
\hline CHEMBL1453306 & 752327 & 4.7239 & 3.5417 & TRN \\
\hline CHEMBL1379359 & 752327 & 4.7891 & 3.7939 & TRN \\
\hline CHEMBL1883315 & 752327 & 4.9286 & 3.6117 & TST \\
\hline CHEMBL1400996 & 752327 & 4.8273 & 3.7606 & TRN \\
\hline CHEMBL1376482 & 752327 & 3.1024 & 3.6128 & TST \\
\hline CHEMBL1392137 & 752327 & 3.1024 & 3.6941 & TRN \\
\hline CHEMBL1536692 & 752327 & 3.1024 & 3.8697 & TRN \\
\hline CHEMBL1313574 & 752327 & 3.1024 & 3.9118 & TRN \\
\hline CHEMBL1557445 & 752327 & 3.1024 & 3.6892 & TRN \\
\hline CHEMBL1418124 & 752327 & 3.1024 & 3.5417 & TRN \\
\hline CHEMBL1277891 & 752327 & 4.8861 & 3.8827 & TRN \\
\hline CHEMBL1403868 & 752327 & 3.1024 & 3.4732 & TRN \\
\hline CHEMBL1894129 & 752327 & 3.1024 & 4.0788 & TRN \\
\hline CHEMBL1974112 & 752327 & 4.3866 & 3.7274 & TST \\
\hline CHEMBL1422295 & 752327 & 3.1024 & 3.4416 & TRN \\
\hline CHEMBL1470755 & 752327 & 4.828 & 3.9296 & TRN \\
\hline CHEMBL1486272 & 752327 & 4.4905 & 3.6857 & TRN \\
\hline CHEMBL1570792 & 752327 & 5.1132 & 3.8502 & TRN \\
\hline CHEMBL1470112 & 752327 & 3.1024 & 3.7004 & TST \\
\hline CHEMBL1553364 & 752327 & 3.1024 & 3.7603 & TRN \\
\hline CHEMBL1708772 & 752327 & 4.4207 & 3.3232 & TRN \\
\hline CHEMBL1466799 & 752327 & 3.1024 & 3.5908 & TRN \\
\hline CHEMBL1580522 & 752327 & 4.9742 & \multicolumn{2}{|c|}{3.7560000000000002} \\
\hline CHEMBL1475718 & 752327 & 3.1024 & 3.4538 & TRN \\
\hline CHEMBL1494087 & 752327 & 4.3949 & 3.5492 & TRN \\
\hline CHEMBL1397022 & 752327 & 3.1024 & 3.6952 & TRN \\
\hline
\end{tabular}


Supplemental Table S2.txt

\begin{tabular}{|c|c|c|c|c|c|}
\hline CHEMBL1589231 & 752327 & 3.1024 & 3.7489 & TRN & \\
\hline CHEMBL1336537 & 752327 & 3.1024 & 3.715 & TST & \\
\hline CHEMBL2006998 & 752327 & 4.5012 & 3.5388 & TRN & \\
\hline CHEMBL1982852 & 752327 & 3.1024 & 3.7221 & TRN & \\
\hline CHEMBL1718951 & 752327 & 3.1024 & 3.7256 & TST & \\
\hline CHEMBL1558744 & 752327 & 3.1024 & 3.7919 & TRN & \\
\hline CHEMBL1467701 & 752327 & 4.842 & 3.9968 & TRN & \\
\hline CHEMBL1330677 & 752327 & 3.1024 & 3.8354 & TRN & \\
\hline CHEMBL1967479 & 752327 & 4.5632 & 3.4494 & TRN & \\
\hline CHEMBL1572585 & 752327 & 3.1024 & 3.6369 & TST & \\
\hline CHEMBL1986898 & 752327 & 4.9031 & 3.6954 & TRN & \\
\hline CHEMBL1343685 & 752327 & 3.1024 & 3.9368 & TRN & \\
\hline CHEMBL1321728 & 752327 & 4.8361 & 3.7676 & TRN & \\
\hline CHEMBL1875686 & 752327 & 3.1024 & 3.5831 & TST & \\
\hline CHEMBL1310005 & 752327 & 4.8591 & 3.699 & TRN & \\
\hline CHEMBL1887390 & 752327 & 4.8701 & 3.9403 & TRN & \\
\hline CHEMBL1584490 & 752327 & 3.1024 & 3.2104 & TRN & \\
\hline CHEMBL1559375 & 752327 & 4.9159 & 3.9148 & TRN & \\
\hline CHEMBL1364009 & 752327 & 3.1024 & 3.7319 & TRN & \\
\hline CHEMBL2361002 & 752327 & 3.1024 & 3.7783 & TST & \\
\hline CHEMBL1990248 & 752327 & 4.9933 & 3.5717 & TST & \\
\hline CHEMBL1563074 & 752327 & 3.1024 & 3.6205 & TRN & \\
\hline CHEMBL1463514 & 752327 & 3.1024 & 3.9113 & TRN & \\
\hline CHEMBL1427663 & 752327 & 3.1024 & 3.515 & TRN & \\
\hline CHEMBL 338314 & 752327 & 3.1024 & 3.2723 & TST & \\
\hline CHEMBL1507325 & 752327 & 3.1024 & 3.8029 & TRN & \\
\hline CHEMBL1364817 & 752327 & 4.8316 & 3.9359 & TRN & \\
\hline CHEMBL 2004928 & 752327 & 3.1024 & 3.8487 & TRN & \\
\hline CHEMBL492886 & 752327 & 3.1024 & 3.5223 & TRN & \\
\hline CHEMBL1730650 & 752327 & 3.1024 & 3.4968 & TRN & \\
\hline CHEMBL1580363 & 752327 & 3.1024 & 3.4137 & TRN & \\
\hline CHEMBL1452189 & 752327 & 3.1024 & 3.5371 & TST & \\
\hline CHEMBL1410989 & 752327 & 3.1024 & 3.9163 & TRN & \\
\hline CHEMBL1982071 & 752327 & 3.1024 & 3.8935 & TRN & \\
\hline CHEMBL1432607 & 752327 & 3.1024 & 3.7543 & TRN & \\
\hline CHEMBL1905395 & 752327 & 3.1024 & 3.4533 & TRN & \\
\hline CHEMBL1965966 & 752327 & 4.9712 & 3.9175 & TRN & \\
\hline CHEMBL1882187 & 752327 & 3.1024 & 3.3419 & TRN & \\
\hline CHEMBL1977538 & 752327 & 3.1024 & 3.87100 & 00000000004 & TRN \\
\hline CHEMBL1880468 & 752327 & 3.1024 & 3.7581 & TRN & \\
\hline CHEMBL1728949 & 752327 & 4.9672 & 3.63199 & 99999999997 & TRN \\
\hline CHEMBL1712090 & 752327 & 4.9759 & 4.0181 & TRN & \\
\hline CHEMBL1421246 & 752327 & 3.1024 & 3.7519 & TRN & \\
\hline CHEMBL1979976 & 752327 & 3.1024 & 3.7674 & TRN & \\
\hline CHEMBL1460101 & 752327 & 3.1024 & 3.5445 & TRN & \\
\hline CHEMBL1551558 & 752327 & 4.5522 & 3.5991 & TRN & \\
\hline CHEMBL1387802 & 752327 & 3.1024 & 3.6214 & TRN & \\
\hline CHEMBL1968162 & 752327 & 4.812 & 3.804 & TRN & \\
\hline
\end{tabular}


Supplemental Table S2.txt

\begin{tabular}{|c|c|c|c|c|c|}
\hline CHEMBL1719740 & 752327 & 3.1024 & 3.6383 & TRN & \\
\hline CHEMBL1461430 & 752327 & 4.4264 & 3.8034 & TRN & \\
\hline CHEMBL1870332 & 752327 & 4.8563 & 3.9171 & TRN & \\
\hline CHEMBL1906483 & 752327 & 3.1024 & 3.7297 & TRN & \\
\hline CHEMBL1342238 & 752327 & 3.1024 & 3.5443 & TRN & \\
\hline CHEMBL1509053 & 752327 & 4.3062 & 3.5124 & TRN & \\
\hline CHEMBL1474877 & 752327 & 5.152 & 3.8455 & TRN & \\
\hline CHEMBL1428783 & 752327 & 3.1024 & 3.8072 & TRN & \\
\hline CHEMBL1471101 & 752327 & 4.6502 & 3.7925 & TRN & \\
\hline CHEMBL1588886 & 752327 & 3.1024 & 3.549 & TST & \\
\hline CHEMBL1371967 & 752327 & 4.4005 & 3.4394 & TRN & \\
\hline CHEMBL1512150 & 752327 & 3.1024 & 3.4111 & TRN & \\
\hline CHEMBL422237 & 752327 & 3.1024 & 3.6891 & TRN & \\
\hline CHEMBL1346278 & 752327 & 3.1024 & 3.5859 & TRN & \\
\hline CHEMBL1548262 & 752327 & 3.1024 & 3.6968 & TRN & \\
\hline CHEMBL1537317 & 752327 & 3.1024 & 3.5673 & TRN & \\
\hline CHEMBL1503376 & 752327 & 3.1024 & 3.9237 & TRN & \\
\hline CHEMBL1400225 & 752327 & 4.7969 & 3.65 & TST & \\
\hline CHEMBL1562838 & 752327 & 3.1024 & 3.5627 & TRN & \\
\hline CHEMBL597888 & 752327 & 3.1024 & 3.549 & TST & \\
\hline CHEMBL1879349 & 752327 & 3.1024 & 3.7817 & TRN & \\
\hline CHEMBL1586943 & 752327 & 3.1024 & 3.3284 & TRN & \\
\hline CHEMBL1524990 & 752327 & 4.9034 & 3.6959 & TST & \\
\hline CHEMBL1431520 & 752327 & 3.1024 & 3.7208 & TRN & \\
\hline CHEMBL1302703 & 752327 & 4.5252 & 3.5222 & TRN & \\
\hline CHEMBL1704710 & 752327 & 4.6107 & 3.5336 & TRN & \\
\hline CHEMBL1329368 & 752327 & 3.1024 & 3.3496 & TRN & \\
\hline CHEMBL1894456 & 752327 & 3.1024 & 3.8872 & TRN & \\
\hline CHEMBL1460875 & 752327 & 4.7028 & 3.5122 & TRN & \\
\hline CHEMBL1495663 & 752327 & 3.1024 & 3.8432 & TRN & \\
\hline CHEMBL1419579 & 752327 & 4.9716 & 3.7502 & TRN & \\
\hline CHEMBL1996360 & 752327 & 5.1623 & 3.7998 & TRN & \\
\hline CHEMBL1548803 & 752327 & 3.1024 & 3.7047 & TRN & \\
\hline CHEMBL1517184 & 752327 & 3.1024 & 3.7957 & TRN & \\
\hline CHEMBL1568800 & 752327 & 4.3024 & 3.5508 & TRN & \\
\hline CHEMBL1376406 & 752327 & 3.1024 & 3.4007 & TRN & \\
\hline CHEMBL1485471 & 752327 & 3.1024 & 3.9286 & TRN & \\
\hline CHEMBL1596782 & 752327 & 3.1024 & 3.87100 & 00000000004 & TRN \\
\hline CHEMBL1723903 & 752327 & 4.1464 & 3.4869 & TRN & \\
\hline CHEMBL1405103 & 752327 & 3.1024 & 3.6222 & TRN & \\
\hline CHEMBL1328779 & 752327 & 5.1407 & 3.2456 & TRN & \\
\hline CHEMBL1414396 & 752327 & 3.1024 & 3.2833 & TRN & \\
\hline CHEMBL1901008 & 752327 & 3.1024 & 3.5826 & TST & \\
\hline CHEMBL1454154 & 752327 & 4.2472 & 3.5811 & TRN & \\
\hline CHEMBL 2005653 & 752327 & 4.3839 & 3.593 & TST & \\
\hline CHEMBL1555363 & 752327 & 4.4033 & 3.5423 & TRN & \\
\hline CHEMBL1699961 & 752327 & 3.1024 & 3.9222 & TRN & \\
\hline CHEMBL1898099 & 752327 & 4.3503 & 3.4765 & TST & \\
\hline
\end{tabular}


Supplemental Table S2.txt

\begin{tabular}{|c|c|c|c|c|}
\hline CHEMBL1498350 & 752327 & 3.1024 & 3.6106 & TRN \\
\hline CHEMBL1868168 & 752327 & 3.1024 & 3.8542 & TRN \\
\hline CHEMBL1556578 & 752327 & 4.8377 & 3.5732 & TRN \\
\hline CHEMBL1868534 & 752327 & 4.9068 & 3.5153 & TST \\
\hline CHEMBL1357542 & 752327 & 3.1024 & 3.4673 & TRN \\
\hline CHEMBL1476695 & 752327 & 4.4022 & 3.7312 & TRN \\
\hline CHEMBL1885240 & 752327 & 3.1024 & 3.6886 & TST \\
\hline CHEMBL1374250 & 752327 & 3.1024 & 3.7672 & TRN \\
\hline CHEMBL1390428 & 752327 & 3.1024 & 3.5102 & TRN \\
\hline CHEMBL1893549 & 752327 & 4.9276 & \multicolumn{2}{|c|}{3.8339999999999996} \\
\hline CHEMBL1539016 & 752327 & 3.1024 & 3.5803 & TST \\
\hline CHEMBL1570212 & 752327 & 3.1024 & 3.7668 & TRN \\
\hline CHEMBL1531521 & 752327 & 4.7714 & 3.667 & TRN \\
\hline CHEMBL1728704 & 752327 & 3.1024 & 3.5282 & TRN \\
\hline CHEMBL1340521 & 752327 & 4.9485 & 3.7655 & TRN \\
\hline CHEMBL1323843 & 752327 & 4.2324 & 3.7492 & TRN \\
\hline CHEMBL1304998 & 752327 & 4.4941 & 3.7524 & TRN \\
\hline CHEMBL1456036 & 752327 & 3.1024 & 3.9335 & TRN \\
\hline CHEMBL1599015 & 752327 & 4.5266 & 3.6619 & TRN \\
\hline CHEMBL1868091 & 752327 & 3.1024 & 3.5413 & TRN \\
\hline CHEMBL1565437 & 752327 & 3.1024 & 3.8065 & TST \\
\hline CHEMBL1359239 & 752327 & 3.1024 & 3.5636 & TRN \\
\hline CHEMBL1878613 & 752327 & 3.1024 & 3.7715 & TRN \\
\hline CHEMBL1343805 & 752327 & 3.1024 & 3.7463 & TRN \\
\hline CHEMBL1408518 & 752327 & 4.877 & 3.8436 & TRN \\
\hline CHEMBL1564224 & 752327 & 4.8417 & 3.5421 & TRN \\
\hline CHEMBL1552846 & 752327 & 3.1024 & 3.4965 & TRN \\
\hline CHEMBL1708119 & 752327 & 3.1024 & 3.4737 & TRN \\
\hline CHEMBL1319627 & 752327 & 5.2588 & 3.3317 & TRN \\
\hline CHEMBL578177 & 752327 & 3.1024 & \multicolumn{2}{|c|}{3.5780000000000003} \\
\hline CHEMBL1982896 & 752327 & 4.9409 & 3.5977 & TRN \\
\hline CHEMBL1396993 & 752327 & 3.1024 & 3.4401 & TRN \\
\hline CHEMBL1526184 & 752327 & 3.1024 & 3.7726 & TST \\
\hline CHEMBL1967734 & 752327 & 3.1024 & 3.6795 & TST \\
\hline CHEMBL1368173 & 752327 & 4.5467 & 3.9416 & TRN \\
\hline CHEMBL1518972 & 752327 & 4.7683 & 3.6632 & TST \\
\hline CHEMBL1495112 & 752327 & 5.1096 & 3.5906 & TRN \\
\hline CHEMBL1900199 & 752327 & 3.1024 & 3.8313 & TRN \\
\hline CHEMBL1368844 & 752327 & 3.1024 & 3.4608 & TRN \\
\hline CHEMBL1434073 & 752327 & 3.1024 & 3.6869 & TRN \\
\hline CHEMBL1491750 & 752327 & 4.6864 & 3.4532 & TRN \\
\hline CHEMBL1416770 & 752327 & 3.1024 & 3.4042 & TRN \\
\hline CHEMBL1879776 & 752327 & 3.1024 & 3.9444 & TRN \\
\hline CHEMBL1985883 & 752327 & 3.1024 & 3.7547 & TRN \\
\hline CHEMBL1412113 & 752327 & 4.5039 & 3.6237 & TRN \\
\hline CHEMBL1474128 & 752327 & 3.1024 & 3.4094 & TRN \\
\hline CHEMBL 140 & 752327 & 3.1024 & 3.5021 & TRN \\
\hline CHEMBL1583670 & 752327 & 3.1024 & 3.7095 & TRN \\
\hline
\end{tabular}


Supplemental Table S2.txt

\begin{tabular}{|c|c|c|c|c|}
\hline 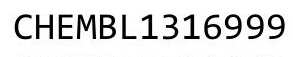 & & & 19 & \\
\hline HEMBL1711809 & 52327 & 3.1024 & 0377 & \\
\hline AEMBL1574224 & 2327 & 1024 & 082 & \\
\hline 458 & 2327 & 1024 & & \\
\hline EMMBL1882358 & 52327 & 1024 & & \\
\hline AEMBL1462924 & 52327 & 7448 & 7514 & \\
\hline AEMBL1435025 & 52327 & 3.1024 & .8461 & \\
\hline AEMBL1471664 & & 024 & & \\
\hline AEMBL187 & 52327 & .1024 & & \\
\hline IEMBL158 & 52327 & 357 & & \\
\hline AEMBL1879313 & 52327 & 3.1024 & & \\
\hline AEMBL1348954 & 52327 & 3.1024 & & \\
\hline AEMBL1993203 & 27 & 024 & 3926 & \\
\hline AEMBL66 & 27 & 024 & 68 & \\
\hline AEMBL14 & 27 & 024 & & \\
\hline AEMBL1897646 & 27 & 22 & 534 & \\
\hline AEMBL1500468 & 27 & 024 & & \\
\hline HEMBL151 & 27 & 206 & & \\
\hline HEMBL141 & 27 & 24 & & \\
\hline HEMBL 15 & & 94 & & \\
\hline AEMBL1318639 & 27 & 024 & & \\
\hline AEMBL1703276 & & 25 & & \\
\hline AEMBL199 & 7 & 24 & & \\
\hline AEMBL 136 & & 44 & & \\
\hline AFMBI 14 & & 24 & & \\
\hline AEMBL 14 & & 94 & & \\
\hline HEMBL1699386 & & & & \\
\hline IEMBL14 & 7 & & & \\
\hline AFMBI 13 & 27 & & & \\
\hline 27 & & 4 & & \\
\hline AEMBL1611803 & & & & \\
\hline AEMBL1343321 & 27 & & & \\
\hline 314 & & & & \\
\hline 301 & 7 & & 89 & \\
\hline 17 & & 8 & 67 & $=0$ \\
\hline AEMBL1883673 & 27 & & 314 & $\mathrm{R}$ \\
\hline AEMBL1346308 & 52 & 3. & 211 & \\
\hline 884 & 7 & 4 & 67 & \\
\hline 80 & 7 & 24 & 52 & Nor \\
\hline HEMBL1731097 & & & 509 & ST \\
\hline AEMBL1716060 & 27 & 4. & 756 & $\mathrm{R}$ \\
\hline HEMBL145 & 7 & & & \\
\hline HEMBL1534602 & & 3. & 792 & \\
\hline CHEMBL1526124 & & & 3.7165 & \\
\hline HEMBL1384484 & & 4.6975 & .5827 & RN \\
\hline AEMBL1538976 & 7 & 3.1024 & & \\
\hline & & & & \\
\hline 12 & & & & \\
\hline
\end{tabular}


Supplemental Table S2.txt

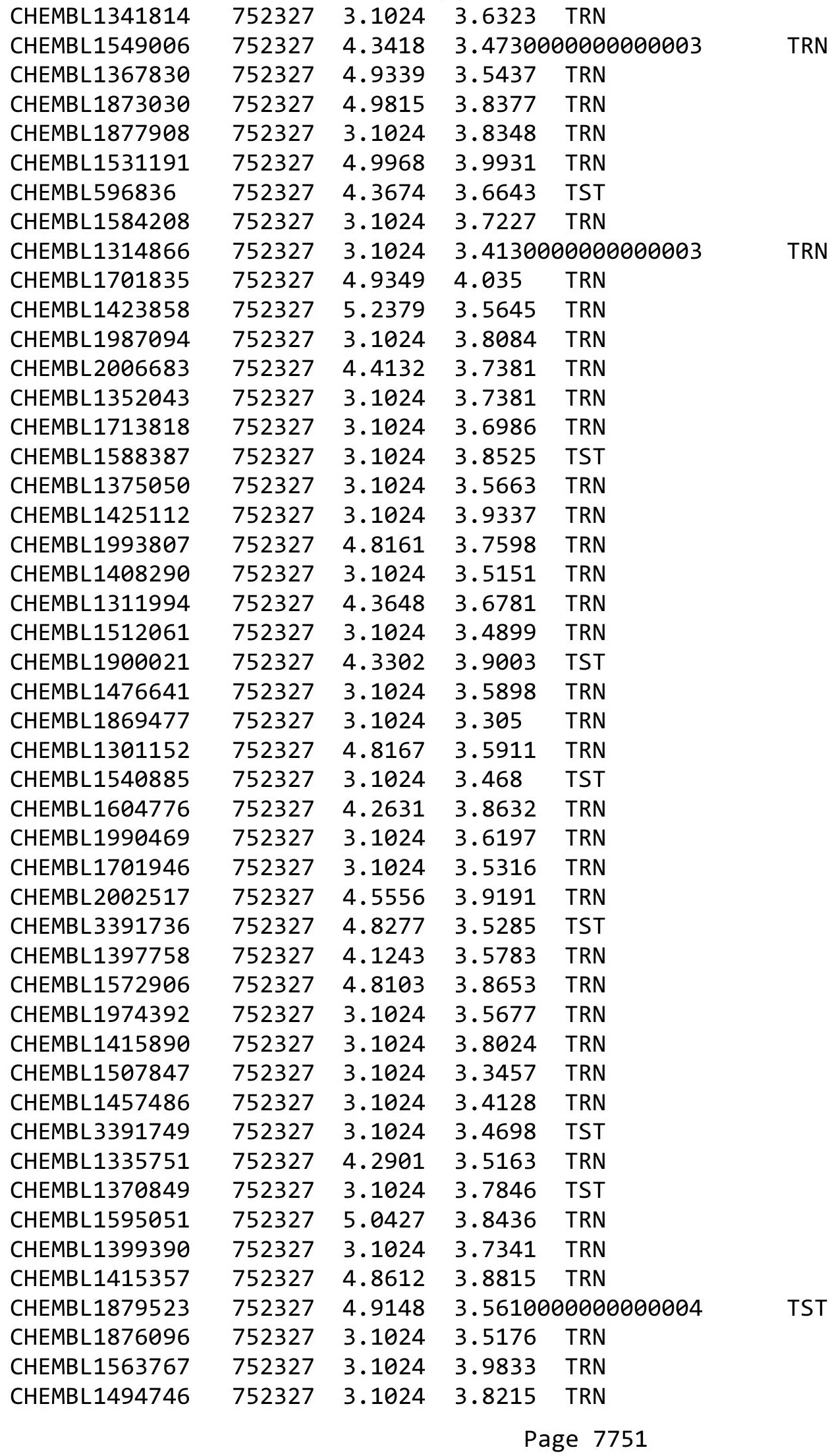


Supplemental Table S2.txt

\begin{tabular}{|c|c|c|c|c|c|}
\hline CHEMBL1989262 & 752327 & 4.5717 & 3.7628 & TRN & \\
\hline CHEMBL1417610 & 752327 & 4.4565 & 3.4808 & TRN & \\
\hline CHEMBL1863599 & 752327 & 4.6783 & 3.6645 & TST & \\
\hline CHEMBL1611135 & 752327 & 4.4402 & 3.5179 & TRN & \\
\hline CHEMBL1410280 & 752327 & 4.4119 & 3.7381 & TRN & \\
\hline CHEMBL1731522 & 752327 & 3.1024 & 3.5293 & TRN & \\
\hline CHEMBL1338135 & 752327 & 3.1024 & 3.3266 & TRN & \\
\hline CHEMBL1994259 & 752327 & 3.1024 & 3.7064 & TRN & \\
\hline CHEMBL1299662 & 752327 & 3.1024 & 3.5134 & TRN & \\
\hline CHEMBL1507163 & 752327 & 3.1024 & 3.7085 & TST & \\
\hline CHEMBL1865860 & 752327 & 4.2616 & 3.7648 & TST & \\
\hline CHEMBL1719590 & 752327 & 4.428999 & 99999999 & 3.8268 & TST \\
\hline CHEMBL1385793 & 752327 & 3.1024 & 3.6588 & TRN & \\
\hline CHEMBL1418825 & 752327 & 3.1024 & 3.4238 & TRN & \\
\hline CHEMBL1534172 & 752327 & 3.1024 & 3.8424 & TRN & \\
\hline CHEMBL1545703 & 752327 & 3.1024 & $3.43300 e$ & 30000000003 & TRN \\
\hline CHEMBL1375247 & 752327 & 4.9104 & 3.7588 & TRN & \\
\hline CHEMBL1707221 & 752327 & 4.5046 & 3.6434 & TST & \\
\hline CHEMBL1443499 & 752327 & 3.1024 & 3.7283 & TRN & \\
\hline CHEMBL1997895 & 752327 & 3.1024 & 3.7616 & TRN & \\
\hline CHEMBL1890952 & 752327 & 4.8112 & 3.4273 & TRN & \\
\hline CHEMBL1479362 & 752327 & 4.9441 & 3.9183 & TRN & \\
\hline CHEMBL1344538 & 752327 & 3.1024 & 3.9123 & TRN & \\
\hline CHEMBL1598940 & 752327 & 3.1024 & 3.7589 & TRN & \\
\hline CHEMBL1512041 & 752327 & 3.1024 & 3.4105 & TRN & \\
\hline CHEMBL1584577 & 752327 & 3.1024 & 3.799 & TRN & \\
\hline CHEMBL1324351 & 752327 & 3.1024 & 3.4503 & TRN & \\
\hline CHEMBL1500229 & 752327 & 3.1024 & 3.7717 & TST & \\
\hline CHEMBL1334204 & 752327 & 4.4565 & 3.7566 & TRN & \\
\hline CHEMBL1584903 & 752327 & 3.1024 & 3.758 & TRN & \\
\hline CHEMBL68230 & 752327 & 3.1024 & 3.4916 & TRN & \\
\hline CHEMBL1550633 & 752327 & 5.2417 & 3.8337 & TST & \\
\hline CHEMBL1539384 & 752327 & 3.1024 & 3.1528 & TRN & \\
\hline CHEMBL1538169 & 752327 & 4.1756 & 3.5574 & TST & \\
\hline CHEMBL1719814 & 752327 & 3.1024 & 3.3395 & TRN & \\
\hline CHEMBL1603318 & 752327 & 3.1024 & $3.87600 e$ & 30000000003 & In \\
\hline CHEMBL1301126 & 752327 & 3.1024 & 3.5155 & TST & \\
\hline CHEMBL2000316 & 752327 & 3.1024 & 3.9836 & TRN & \\
\hline CHEMBL1347750 & 752327 & 3.1024 & 3.6297 & TRN & \\
\hline CHEMBL1596732 & 752327 & 3.1024 & 3.7796 & TST & \\
\hline CHEMBL1557027 & 752327 & 4.9647 & 3.6261 & TST & \\
\hline CHEMBL1348996 & 752327 & 3.1024 & 3.8039 & TRN & \\
\hline CHEMBL1379578 & 752327 & 4.4152 & 3.7477 & TRN & \\
\hline CHEMBL 2006569 & 752327 & 4.9388 & 3.7216 & TRN & \\
\hline CHEMBL1699437 & 752327 & 3.1024 & 3.3704 & TRN & \\
\hline CHEMBL1529254 & 752327 & 3.1024 & 3.3418 & TRN & \\
\hline CHEMBL1503702 & 752327 & 3.1024 & 3.7243 & TRN & \\
\hline CHEMBL1992394 & 752327 & 3.1024 & 3.6098 & TRN & \\
\hline
\end{tabular}


Supplemental Table S2.txt

\begin{tabular}{|c|c|c|c|c|}
\hline CHEMBL1429099 & 752327 & 3.1024 & 3.5289 & TRN \\
\hline CHEMBL1567858 & 752327 & 3.1024 & 3.4686 & TRN \\
\hline CHEMBL1881686 & 752327 & 3.1024 & 3.6327 & TST \\
\hline CHEMBL1880985 & 752327 & 3.1024 & 3.47399 & 99999999998 \\
\hline CHEMBL1490680 & 752327 & 3.1024 & 3.3454 & TRN \\
\hline CHEMBL1717744 & 752327 & 3.1024 & 3.5116 & TRN \\
\hline CHEMBL1995870 & 752327 & 3.1024 & 3.5163 & TRN \\
\hline CHEMBL1529638 & 752327 & 4.8339 & 3.6816 & TRN \\
\hline CHEMBL 2001029 & 752327 & 4.5095 & 3.7167 & TRN \\
\hline CHEMBL1383027 & 752327 & 4.4568 & 3.8879 & TRN \\
\hline CHEMBL1972651 & 752327 & 4.5737 & 3.6857 & TRN \\
\hline CHEMBL1999984 & 752327 & 3.1024 & 3.8038 & TRN \\
\hline CHEMBL1452604 & 752327 & 3.1024 & 3.5685 & TST \\
\hline CHEMBL1735853 & 752327 & 3.1024 & 3.3105 & TRN \\
\hline CHEMBL1328957 & 752327 & 3.1024 & 3.4624 & TRN \\
\hline CHEMBL1880473 & 752327 & 4.8543 & 3.8698 & TRN \\
\hline CHEMBL1081637 & 752327 & 3.1024 & 3.5762 & TST \\
\hline CHEMBL1324195 & 752327 & 3.1024 & 3.4968 & TRN \\
\hline CHEMBL1586662 & 752327 & 3.1024 & 3.5502 & TRN \\
\hline CHEMBL1525055 & 752327 & 3.1024 & 3.9859 & TRN \\
\hline CHEMBL1468807 & 752327 & 3.1024 & 3.6142 & TRN \\
\hline CHEMBL489696 & 752327 & 3.1024 & 3.5917 & TRN \\
\hline CHEMBL1969761 & 752327 & 3.1024 & 3.7057 & TRN \\
\hline CHEMBL1450098 & 752327 & 3.1024 & 3.6791 & TST \\
\hline CHEMBL1729028 & 752327 & 3.1024 & 3.8172 & TRN \\
\hline CHEMBL1879553 & 752327 & 4.5229 & 3.9643 & TRN \\
\hline CHEMBL1888498 & 752327 & 3.1024 & 3.5402 & TRN \\
\hline CHEMBL1543078 & 752327 & 4.8371 & 3.6977 & TRN \\
\hline CHEMBL65892 & 752327 & 4.308 & 3.6817 & TST \\
\hline CHEMBL1369130 & 752327 & 3.1024 & 3.6977 & TRN \\
\hline CHEMBL1300874 & 752327 & 3.1024 & 3.5863 & TST \\
\hline CHEMBL1530972 & 752327 & 5.1655 & 3.8499 & TRN \\
\hline CHEMBL1510105 & 752327 & 3.1024 & 3.6314 & TRN \\
\hline CHEMBL1901671 & 752327 & 3.1024 & 3.8666 & TRN \\
\hline CHEMBL1440301 & 752327 & 3.1024 & 3.5814 & TST \\
\hline CHEMBL1721465 & 752327 & 3.1024 & 3.5187 & TRN \\
\hline CHEMBL1439140 & 752327 & 4.6873 & 3.6709 & TRN \\
\hline CHEMBL1565164 & 752327 & 3.1024 & 3.4144 & TST \\
\hline CHEMBL1699667 & 752327 & 3.1024 & 3.5202 & TRN \\
\hline CHEMBL1978228 & 752327 & 3.1024 & 3.6353 & TST \\
\hline CHEMBL1416662 & 752327 & 4.7852 & 3.6875 & TRN \\
\hline CHEMBL1591182 & 752327 & 4.3014 & 3.7098 & TRN \\
\hline CHEMBL1906365 & 752327 & 3.1024 & 3.1843 & TRN \\
\hline CHEMBL1995218 & 752327 & 3.1024 & 3.5251 & TRN \\
\hline CHEMBL1429513 & 752327 & 3.1024 & 3.8656 & TRN \\
\hline CHEMBL1724709 & 752327 & 3.1024 & 3.4575 & TRN \\
\hline CHEMBL1361392 & 752327 & 3.1024 & 3.4649 & TRN \\
\hline CHEMBL1902783 & 752327 & 3.1024 & 3.78899 & 99999999997 \\
\hline
\end{tabular}

Page 7753 
Supplemental Table S2.txt

\begin{tabular}{|c|c|c|c|c|}
\hline CHEMBL1353965 & 752327 & 4.5306 & 3.2867 & TRN \\
\hline CHEMBL1471867 & 752327 & 3.1024 & 3.8775 & TRN \\
\hline CHEMBL1479872 & 752327 & 4.9569 & 3.7648 & TRN \\
\hline CHEMBL1386200 & 752327 & 3.1024 & 3.7653 & TRN \\
\hline CHEMBL1713021 & 752327 & 4.9702 & 3.8106 & TRN \\
\hline CHEMBL1708251 & 752327 & 3.1024 & 3.5588 & TRN \\
\hline CHEMBL1888464 & 752327 & 3.1024 & 3.7231 & TRN \\
\hline CHEMBL1581335 & 752327 & 3.1024 & 3.8639 & TST \\
\hline CHEMBL1473172 & 752327 & 3.1024 & 3.7305 & TST \\
\hline CHEMBL1875011 & 752327 & 3.1024 & 3.5483 & TRN \\
\hline CHEMBL1470073 & 752327 & 4.6425 & 3.8268 & TST \\
\hline CHEMBL 2004942 & 752327 & 3.1024 & 3.656 & TST \\
\hline CHEMBL1566084 & 752327 & 3.1024 & 3.8277 & TRN \\
\hline CHEMBL1892433 & 752327 & 3.1024 & 3.4668 & TRN \\
\hline CHEMBL12019 & 752327 & 3.1024 & 3.5098 & TRN \\
\hline CHEMBL1350682 & 752327 & 4.8614 & 3.6019 & TRN \\
\hline CHEMBL1577144 & 752327 & 3.1024 & 3.6859 & TST \\
\hline CHEMBL1985708 & 752327 & 4.8283 & 3.8834 & TRN \\
\hline CHEMBL1987417 & 752327 & 3.1024 & 3.4745 & TRN \\
\hline CHEMBL1732062 & 752327 & 3.1024 & 3.6151 & TRN \\
\hline CHEMBL1352633 & 752327 & 4.6441 & 3.7343 & TRN \\
\hline CHEMBL 2002773 & 752327 & 3.1024 & 3.5615 & TST \\
\hline CHEMBL1513847 & 752327 & 4.5663 & 3.7749 & TST \\
\hline CHEMBL1497792 & 752327 & 3.1024 & 3.3451 & TST \\
\hline CHEMBL1472051 & 752327 & 3.1024 & 3.4886 & TRN \\
\hline CHEMBL1313961 & 752327 & 3.1024 & 3.9081 & TRN \\
\hline CHEMBL1463672 & 752327 & 3.1024 & 3.6391 & TRN \\
\hline CHEMBL1351484 & 752327 & 5.0252 & 3.9043 & TRN \\
\hline CHEMBL1575293 & 752327 & 4.5871 & 3.9398 & TRN \\
\hline CHEMBL1731866 & 752327 & 3.1024 & 3.5049 & TRN \\
\hline CHEMBL1717627 & 752327 & 3.1024 & 3.4476 & TRN \\
\hline CHEMBL 2001685 & 752327 & 3.1024 & 3.9789 & TRN \\
\hline CHEMBL1453981 & 752327 & 4.2845 & 3.5192 & TRN \\
\hline CHEMBL1732612 & 752327 & 3.1024 & 3.4332 & TRN \\
\hline CHEMBL1497342 & 752327 & 4.9349 & 3.7204 & TRN \\
\hline CHEMBL1708696 & 752327 & 3.1024 & 3.6039 & TRN \\
\hline CHEMBL1323071 & 752327 & 5.0719 & 3.8948 & TRN \\
\hline CHEMBL1364216 & 752327 & 3.1024 & 3.3621 & TRN \\
\hline CHEMBL1969010 & 752327 & 4.5881 & 4.0549 & TRN \\
\hline CHEMBL1973722 & 752327 & 3.1024 & 3.7595 & TRN \\
\hline CHEMBL1599759 & 752327 & 3.1024 & 3.4215 & TRN \\
\hline CHEMBL1877984 & 752327 & 3.1024 & 3.5516 & TST \\
\hline CHEMBL1479277 & 752327 & 3.1024 & 3.4584 & TRN \\
\hline CHEMBL1545864 & 752327 & 5.0306 & 3.8609 & TRN \\
\hline CHEMBL1592387 & 752327 & 3.1024 & 3.5824 & TRN \\
\hline CHEMBL1450049 & 752327 & 3.1024 & 3.421999 & 99999999997 \\
\hline CHEMBL1549839 & 752327 & 3.1024 & 3.6688 & TST \\
\hline CHEMBL1430145 & 752327 & 4.8544 & 3.6865 & TRN \\
\hline
\end{tabular}

Page 7754 
Supplemental Table S2.txt

\begin{tabular}{|c|c|c|c|c|}
\hline CHEMBL1886747 & 752327 & 3.1024 & 3.6686 & TST \\
\hline CHEMBL1495927 & 752327 & 5.0944 & 3.3414 & TST \\
\hline CHEMBL1315817 & 752327 & 3.1024 & 3.8404 & TRN \\
\hline CHEMBL1885453 & 752327 & 3.1024 & 3.7437 & TRN \\
\hline CHEMBL1999454 & 752327 & 4.2339 & 3.5936 & TRN \\
\hline CHEMBL1383421 & 752327 & 3.1024 & 3.6946 & TRN \\
\hline CHEMBL1966961 & 752327 & 5.0552 & 3.6475 & TRN \\
\hline CHEMBL1322362 & 752327 & 4.5704 & 3.798 & TRN \\
\hline CHEMBL1591509 & 752327 & 3.1024 & 3.9112 & TRN \\
\hline CHEMBL1306971 & 752327 & 4.4397 & 3.6384 & TRN \\
\hline CHEMBL1983581 & 752327 & 4.5775 & 3.538999 & 99999999997 \\
\hline CHEMBL1524367 & 752327 & 4.6779 & 3.5624 & TRN \\
\hline CHEMBL1336927 & 752327 & 4.6991 & 3.679 & TRN \\
\hline CHEMBL1377648 & 752327 & 3.1024 & 3.6286 & TRN \\
\hline CHEMBL1558069 & 752327 & 4.9092 & 3.7132 & TRN \\
\hline CHEMBL1453916 & 752327 & 3.1024 & 3.8476 & TRN \\
\hline CHEMBL1892448 & 752327 & 5.2821 & 3.8146 & TRN \\
\hline CHEMBL1733606 & 752327 & 3.1024 & 3.7254 & TRN \\
\hline CHEMBL1465951 & 752327 & 3.1024 & 3.5972 & TST \\
\hline CHEMBL1546779 & 752327 & 3.1024 & 3.7076 & TRN \\
\hline CHEMBL1882724 & 752327 & 4.8458 & 3.8021 & TST \\
\hline CHEMBL1323249 & 752327 & 3.1024 & 3.8598 & TRN \\
\hline CHEMBL1864299 & 752327 & 3.1024 & 3.5061 & TRN \\
\hline CHEMBL1992359 & 752327 & 4.7867 & 3.8478 & TRN \\
\hline CHEMBL1309416 & 752327 & 3.1024 & 3.5453 & TRN \\
\hline CHEMBL1873978 & 752327 & 3.1024 & 3.4976 & TRN \\
\hline CHEMBL1882485 & 752327 & 5.1213 & 3.9887 & TRN \\
\hline CHEMBL1468925 & 752327 & 3.1024 & 3.589 & TST \\
\hline CHEMBL 3208718 & 752327 & 3.1024 & 3.6344 & TRN \\
\hline CHEMBL1874267 & 752327 & 3.1024 & 3.2178 & TRN \\
\hline CHEMBL 2002995 & 752327 & 4.6079 & 3.8336 & TRN \\
\hline CHEMBL1580989 & 752327 & 3.1024 & 3.8856 & TRN \\
\hline CHEMBL1502259 & 752327 & 3.1024 & 3.7501 & TRN \\
\hline CHEMBL1605077 & 752327 & 4.5697 & 3.7297 & TST \\
\hline CHEMBL1358058 & 752327 & 3.1024 & 3.7765 & TRN \\
\hline CHEMBL1741489 & 752327 & 3.1024 & 3.5029 & TRN \\
\hline CHEMBL1405690 & 752327 & 3.1024 & 3.6373 & TRN \\
\hline CHEMBL1494256 & 752327 & 3.1024 & 3.7605 & TRN \\
\hline CHEMBL1881568 & 752327 & 3.1024 & 3.9309 & TRN \\
\hline CHEMBL1447596 & 752327 & 3.1024 & 3.6974 & TRN \\
\hline CHEMBL1712645 & 752327 & 3.1024 & 3.7691 & TRN \\
\hline CHEMBL1388119 & 752327 & 3.1024 & 3.5357 & TRN \\
\hline CHEMBL1355497 & 752327 & 3.1024 & 3.5059 & TRN \\
\hline CHEMBL1562798 & 752327 & 3.1024 & 3.6238 & TST \\
\hline CHEMBL1557060 & 752327 & 4.6818 & 3.8347 & TRN \\
\hline CHEMBL1408059 & 752327 & 3.1024 & 3.5251 & TRN \\
\hline CHEMBL1986047 & 752327 & 3.1024 & 3.4721 & TST \\
\hline CHEMBL1602676 & 752327 & 3.1024 & 3.7636 & TRN \\
\hline
\end{tabular}


Supplemental Table S2.txt

\begin{tabular}{|c|c|c|c|c|}
\hline CHEMBL1500702 & 752327 & 3.1024 & 3.8216 & TST \\
\hline CHEMBL1484346 & 752327 & 3.1024 & 3.4947 & TRN \\
\hline CHEMBL1530859 & 752327 & 3.1024 & 3.5917 & TRN \\
\hline CHEMBL1594018 & 752327 & 3.1024 & 3.4249 & TRN \\
\hline CHEMBL1467641 & 752327 & 5.2306 & 3.9013 & TRN \\
\hline CHEMBL1337433 & 752327 & 3.1024 & 3.5488 & TRN \\
\hline CHEMBL1484491 & 752327 & 4.5162 & 3.6889 & TRN \\
\hline CHEMBL1545153 & 752327 & 3.1024 & 3.7076 & TRN \\
\hline CHEMBL1599711 & 752327 & 3.1024 & 3.6413 & TRN \\
\hline CHEMBL1438811 & 752327 & 3.1024 & 3.4342 & TRN \\
\hline CHEMBL1699258 & 752327 & 3.1024 & 3.4578 & TRN \\
\hline CHEMBL1587670 & 752327 & 3.1024 & 3.6061 & TRN \\
\hline CHEMBL601822 & 752327 & 4.5853 & 3.7426 & TRN \\
\hline CHEMBL1992883 & 752327 & 5.2072 & 3.8252 & TRN \\
\hline CHEMBL1489418 & 752327 & 3.1024 & 3.7973 & TST \\
\hline CHEMBL 2005247 & 752327 & 4.497 & 3.8532 & TRN \\
\hline CHEMBL1457087 & 752327 & 4.3982 & 3.7284 & TRN \\
\hline CHEMBL1347165 & 752327 & 3.1024 & 3.5185 & TRN \\
\hline CHEMBL1892780 & 752327 & 3.1024 & 3.7798 & TRN \\
\hline CHEMBL1530586 & 752327 & 3.1024 & 3.9172 & TRN \\
\hline CHEMBL1445873 & 752327 & 4.4669 & 3.7327 & TRN \\
\hline CHEMBL1994068 & 752327 & 3.1024 & 3.8481 & TRN \\
\hline CHEMBL1495295 & 752327 & 4.3977 & 3.7688 & TST \\
\hline CHEMBL1401564 & 752327 & 3.1024 & 3.8575 & TRN \\
\hline CHEMBL1299313 & 752327 & 4.452 & 3.5932 & TRN \\
\hline CHEMBL1346748 & 752327 & 4.7025 & 3.4545 & TRN \\
\hline CHEMBL1588014 & 752327 & 3.1024 & 3.8523 & TST \\
\hline CHEMBL1432276 & 752327 & 3.1024 & 3.7387 & TRN \\
\hline CHEMBL1578365 & 752327 & 4.4708 & 3.9627 & TRN \\
\hline CHEMBL1728872 & 752327 & 4.3678 & 3.7864 & TRN \\
\hline CHEMBL1506684 & 752327 & 3.1024 & 3.432 & TRN \\
\hline CHEMBL1984114 & 752327 & 4.3084 & 3.7939 & TRN \\
\hline CHEMBL1330873 & 752327 & 4.8608 & 3.6827 & TRN \\
\hline CHEMBL1729533 & 752327 & 3.1024 & 3.4871 & TRN \\
\hline CHEMBL1905929 & 752327 & 3.1024 & 3.6318 & TST \\
\hline CHEMBL1863528 & 752327 & 3.1024 & 3.6862 & TRN \\
\hline CHEMBL1568225 & 752327 & 3.1024 & 3.7741 & TRN \\
\hline CHEMBL1320932 & 752327 & 3.1024 & 3.4936 & TRN \\
\hline CHEMBL1975660 & 752327 & 3.1024 & 3.603999 & 99999999996 \\
\hline CHEMBL 2005961 & 752327 & 3.1024 & 3.6778 & TRN \\
\hline CHEMBL1383978 & 752327 & 4.7712 & 3.5837 & TRN \\
\hline CHEMBL1475866 & 752327 & 4.7216 & 3.6299 & TRN \\
\hline CHEMBL1463893 & 752327 & 3.1024 & 3.8252 & TRN \\
\hline CHEMBL1536722 & 752327 & 3.1024 & 3.6266 & TRN \\
\hline CHEMBL1439208 & 752327 & 4.8723 & 3.8594 & TRN \\
\hline CHEMBL1499592 & 752327 & 3.1024 & 3.8443 & TRN \\
\hline CHEMBL1888908 & 752327 & 3.1024 & 3.8913 & TRN \\
\hline CHEMBL1355133 & 752327 & 3.1024 & 3.6214 & TRN \\
\hline
\end{tabular}


Supplemental Table S2.txt

\begin{tabular}{|c|c|c|c|c|c|}
\hline CHEMBL 250574 & 752327 & 3.1024 & 3.5246 & TRN & \\
\hline CHEMBL1422178 & 752327 & 3.1024 & 3.7359 & TST & \\
\hline CHEMBL1989592 & 752327 & 3.1024 & 3.7319 & TRN & \\
\hline CHEMBL1966848 & 752327 & 3.1024 & 3.6904 & TRN & \\
\hline CHEMBL1388708 & 752327 & 3.1024 & 3.6637 & TRN & \\
\hline CHEMBL1392487 & 752327 & 3.1024 & 3.6759 & TRN & \\
\hline CHEMBL1438663 & 752327 & 4.8503 & 3.6878 & TRN & \\
\hline CHEMBL1341841 & 752327 & 3.1024 & 3.6795 & TRN & \\
\hline CHEMBL1498596 & 752327 & 4.4677 & 3.8001 & TST & \\
\hline CHEMBL1528726 & 752327 & 4.7543 & 4.0783 & TRN & \\
\hline CHEMBL1396056 & 752327 & 3.1024 & 3.3906 & TRN & \\
\hline CHEMBL1419223 & 752327 & 3.1024 & 3.6498 & TRN & \\
\hline CHEMBL1723019 & 752327 & 3.1024 & 3.6986 & TST & \\
\hline CHEMBL1427061 & 752327 & 3.1024 & 3.7405 & TST & \\
\hline CHEMBL1987906 & 752327 & 4.489 & 3.5673 & TST & \\
\hline CHEMBL1460775 & 752327 & 3.1024 & 3.7308 & TRN & \\
\hline CHEMBL1735332 & 752327 & 4.7792 & 3.87 & TRN & \\
\hline CHEMBL1574132 & 752327 & 4.6329 & 3.7426 & TRN & \\
\hline CHEMBL1447188 & 752327 & 3.1024 & 3.7969 & TRN & \\
\hline CHEMBL1443198 & 752327 & 3.1024 & 3.6082 & TRN & \\
\hline CHEMBL1392751 & 752327 & 3.1024 & 3.7008 & TST & \\
\hline CHEMBL1542574 & 752327 & 3.1024 & 3.4863 & TST & \\
\hline CHEMBL1878991 & 752327 & 3.1024 & 3.9323 & TRN & \\
\hline CHEMBL1426855 & 752327 & 5.0701 & 3.8035 & TRN & \\
\hline CHEMBL1550407 & 752327 & 3.1024 & 3.8553 & TRN & \\
\hline CHEMBL1971316 & 752327 & 3.1024 & 3.3878 & TRN & \\
\hline CHEMBL1701636 & 752327 & 4.9727 & 3.6703 & TRN & \\
\hline CHEMBL1892438 & 752327 & 3.1024 & 3.3581 & TRN & \\
\hline CHEMBL1307821 & 752327 & 4.5604 & 3.8396 & TRN & \\
\hline CHEMBL1356354 & 752327 & 3.1024 & 3.5897 & TRN & \\
\hline CHEMBL1309409 & 752327 & 3.1024 & 3.6038 & TST & \\
\hline CHEMBL1528644 & 752327 & 3.1024 & 3.4271 & TRN & \\
\hline CHEMBL1512087 & 752327 & 3.1024 & 3.525 & TRN & \\
\hline CHEMBL1870365 & 752327 & 3.1024 & 3.6867 & TRN & \\
\hline CHEMBL1476931 & 752327 & 3.1024 & 3.3261 & TRN & \\
\hline CHEMBL1530211 & 752327 & 4.2626 & 3.7936 & TRN & \\
\hline CHEMBL1699659 & 752327 & 3.1024 & 3.8318 & TST & \\
\hline CHEMBL1329148 & 752327 & 3.1024 & 3.6501 & TST & \\
\hline CHEMBL598477 & 752327 & 3.1024 & 3.6059 & TRN & \\
\hline CHEMBL1534533 & 752327 & 4.6326 & 3.9218 & TRN & \\
\hline CHEMBL1497853 & 752327 & 3.1024 & 3.6972 & TRN & \\
\hline CHEMBL1599708 & 752327 & 3.1024 & \multicolumn{2}{|c|}{3.6910000000000003} & TRN \\
\hline CHEMBL1612775 & 752327 & 4.6404 & 3.8218 & TRN & \\
\hline CHEMBL1723414 & 752327 & 4.3499 & 3.9603 & TRN & \\
\hline CHEMBL1442453 & 752327 & 4.852 & 3.8231 & TRN & \\
\hline CHEMBL1538754 & 752327 & 3.1024 & \multicolumn{2}{|c|}{ 3.7039999999999997 } & TST \\
\hline CHEMBL2004900 & 752327 & 4.6238 & 3.5697 & TRN & \\
\hline CHEMBL1467354 & 752327 & 4.7036 & 3.7557 & TRN & \\
\hline
\end{tabular}

Page 7757 
Supplemental Table S2.txt

\begin{tabular}{|c|c|c|c|c|c|}
\hline CHEMBL1723826 & 752327 & 3.1024 & 3.359 & TRN & \\
\hline CHEMBL1309310 & 752327 & 4.8126 & 3.7142 & TRN & \\
\hline CHEMBL1516113 & 752327 & 3.1024 & 3.3937 & TRN & \\
\hline CHEMBL1574359 & 752327 & 4.4947 & 3.9484 & TRN & \\
\hline CHEMBL1532449 & 752327 & 3.1024 & 3.5371 & TRN & \\
\hline CHEMBL1307703 & 752327 & 3.1024 & 3.8428 & TRN & \\
\hline CHEMBL1364493 & 752327 & 3.1024 & 3.5508 & TRN & \\
\hline CHEMBL1314964 & 752327 & 3.1024 & 3.5521 & TRN & \\
\hline CHEMBL1560709 & 752327 & 3.1024 & 3.6589 & TRN & \\
\hline CHEMBL1560069 & 752327 & 3.1024 & 3.9133 & TRN & \\
\hline CHEMBL1888730 & 752327 & 4.8002 & 3.8866 & TRN & \\
\hline CHEMBL1607222 & 752327 & 3.1024 & 3.7521 & TRN & \\
\hline CHEMBL1712296 & 752327 & 4.3976 & 3.3317 & TRN & \\
\hline CHEMBL1487964 & 752327 & 3.1024 & 3.7089 & TRN & \\
\hline CHEMBL1564259 & 752327 & 3.1024 & 3.2986 & TRN & \\
\hline CHEMBL1599749 & 752327 & 3.1024 & 3.7395 & TST & \\
\hline CHEMBL1587395 & 752327 & 3.1024 & 3.5805 & TST & \\
\hline CHEMBL1899974 & 752327 & 3.1024 & 3.9239 & TRN & \\
\hline CHEMBL1362217 & 752327 & 4.6637 & 3.9219 & TRN & \\
\hline CHEMBL1971072 & 752327 & 3.1024 & 3.417 & TRN & \\
\hline CHEMBL1302020 & 752327 & 3.1024 & 3.5415 & TRN & \\
\hline CHEMBL1414819 & 752327 & 4.6348 & 3.6583 & TRN & \\
\hline CHEMBL1486891 & 752327 & 3.1024 & 3.8384 & TRN & \\
\hline CHEMBL1410575 & 752327 & 3.1024 & 3.5432 & TST & \\
\hline CHEMBL1701321 & 752327 & 3.1024 & 3.4554 & TRN & \\
\hline CHEMBL1865969 & 752327 & 4.9115 & 3.5249 & TST & \\
\hline CHEMBL1895513 & 752327 & 3.1024 & 3.3962 & TRN & \\
\hline CHEMBL1325432 & 752327 & 4.2365 & 4.0474 & TRN & \\
\hline CHEMBL1309516 & 752327 & 4.3602 & 3.5783 & TST & \\
\hline CHEMBL1351653 & 752327 & 3.1024 & 3.778 & TRN & \\
\hline CHEMBL1991618 & 752327 & 3.1024 & 3.9378 & TRN & \\
\hline CHEMBL1869583 & 752327 & 3.1024 & 3.5816 & TRN & \\
\hline CHEMBL1566701 & 752327 & 4.5043 & 3.6152 & TST & \\
\hline CHEMBL1726305 & 752327 & 4.9957 & 3.8752 & TST & \\
\hline CHEMBL1387484 & 752327 & 4.9421 & 3.6909 & TST & \\
\hline CHEMBL1568409 & 752327 & 4.5982 & 3.6628 & TRN & \\
\hline CHEMBL1396713 & 752327 & 3.1024 & 3.923 & TST & \\
\hline CHEMBL1370932 & 752327 & 3.1024 & \multicolumn{2}{|c|}{3.5260000000000002} & TRN \\
\hline CHEMBL1904959 & 752327 & 3.1024 & 3.7536 & TRN & \\
\hline CHEMBL1588045 & 752327 & 4.5214 & 3.8289 & TRN & \\
\hline CHEMBL1380392 & 752327 & 3.1024 & 3.6576 & TST & \\
\hline CHEMBL1521813 & 752327 & 3.1024 & 3.4647 & TST & \\
\hline CHEMBL1404434 & 752327 & 4.4983 & 3.7313 & TRN & \\
\hline CHEMBL1474526 & 752327 & 3.1024 & 3.5691 & TRN & \\
\hline CHEMBL1503607 & 752327 & 3.1024 & 3.5861 & TST & \\
\hline CHEMBL1549308 & 752327 & 4.7217 & 3.6618 & TRN & \\
\hline CHEMBL1609488 & 752327 & 3.1024 & 3.563 & TRN & \\
\hline CHEMBL1468363 & 752327 & 3.1024 & 3.7964 & TRN & \\
\hline
\end{tabular}


Supplemental Table S2.txt

\begin{tabular}{|c|c|c|c|c|c|}
\hline CHEMBL1883523 & 752327 & 3.1024 & 3.7363 & TRN & \\
\hline CHEMBL1466281 & 752327 & \multicolumn{3}{|c|}{4.468999999999999} & TRN \\
\hline CHEMBL 2002972 & 752327 & 3.1024 & 3.603 & TRN & \\
\hline CHEMBL1315337 & 752327 & 3.1024 & 3.7902 & TRN & \\
\hline CHEMBL1873948 & 752327 & 3.1024 & 3.625 & TRN & \\
\hline CHEMBL1736367 & 752327 & 3.1024 & 3.6441 & TRN & \\
\hline CHEMBL1708985 & 752327 & 4.9003 & 3.5384 & TST & \\
\hline CHEMBL1364287 & 752327 & 3.1024 & 4.0728 & TRN & \\
\hline CHEMBL1403619 & 752327 & 3.1024 & 3.79600 & 00000000003 & TRN \\
\hline CHEMBL1305936 & 752327 & 3.1024 & 3.6508 & TRN & \\
\hline CHEMBL1524400 & 752327 & 4.5285 & 3.4182 & TRN & \\
\hline CHEMBL1585428 & 752327 & 3.1024 & 3.68899 & 99999999996 & TRN \\
\hline CHEMBL1324820 & 752327 & 3.1024 & 3.3869 & TRN & \\
\hline CHEMBL1609737 & 752327 & 3.1024 & 3.6119 & TRN & \\
\hline CHEMBL1341668 & 752327 & 4.6271 & 3.8119 & TRN & \\
\hline CHEMBL1875031 & 752327 & 3.1024 & 3.4163 & TRN & \\
\hline CHEMBL1505157 & 752327 & 4.7049 & 3.5472 & TST & \\
\hline CHEMBL1369225 & 752327 & 4.7391 & 3.5943 & TST & \\
\hline CHEMBL1393529 & 752327 & 3.1024 & 3.5882 & TRN & \\
\hline CHEMBL1734079 & 752327 & 3.1024 & 3.7302 & TRN & \\
\hline CHEMBL1373988 & 752327 & 4.645 & 3.8485 & TRN & \\
\hline CHEMBL1383269 & 752327 & 4.7985 & 3.4676 & TRN & \\
\hline CHEMBL1972739 & 752327 & 4.4018 & 3.3924 & TRN & \\
\hline CHEMBL1880661 & 752327 & 3.1024 & 3.8431 & TRN & \\
\hline CHEMBL1967814 & 752327 & 3.1024 & 3.6541 & TRN & \\
\hline CHEMBL1583801 & 752327 & 3.1024 & 3.6852 & TRN & \\
\hline CHEMBL1490861 & 752327 & 4.5859 & 3.7649 & TRN & \\
\hline CHEMBL1550676 & 752327 & 4.2 & 3.5829 & TRN & \\
\hline CHEMBL1299658 & 752327 & 3.1024 & 3.4468 & TRN & \\
\hline CHEMBL1611223 & 752327 & 4.4263 & 3.6986 & TRN & \\
\hline CHEMBL1865363 & 752327 & 4.7139 & 3.9374 & TRN & \\
\hline CHEMBL1975888 & 752327 & 3.1024 & 3.5721 & TRN & \\
\hline CHEMBL1329418 & 752327 & 4.533 & 3.5704 & TST & \\
\hline CHEMBL1301826 & 752327 & 4.9019 & 3.7018 & TRN & \\
\hline CHEMBL1732017 & 752327 & 3.1024 & 3.7503 & TRN & \\
\hline CHEMBL1496543 & 752327 & 3.1024 & 3.2619 & TRN & \\
\hline CHEMBL1502001 & 752327 & 4.4995 & 3.8153 & TRN & \\
\hline CHEMBL1510326 & 752327 & 4.5732 & 3.449 & TRN & \\
\hline CHEMBL1709418 & 752327 & 3.1024 & 3.4764 & TRN & \\
\hline CHEMBL1722488 & 752327 & 3.1024 & 3.6038 & TRN & \\
\hline CHEMBL1896933 & 752327 & 3.1024 & 3.7782 & TRN & \\
\hline CHEMBL1355706 & 752327 & 3.1024 & 3.4122 & TRN & \\
\hline CHEMBL1579612 & 752327 & 3.1024 & 3.622 & TRN & \\
\hline CHEMBL1347142 & 752327 & 3.1024 & 3.62399 & 99999999997 & KIV \\
\hline CHEMBL1416187 & 752327 & 3.1024 & 3.7735 & TST & \\
\hline CHEMBL1363855 & 752327 & 4.8562 & 3.4119 & TRN & \\
\hline CHEMBL1312157 & 752327 & 4.7329 & 3.8666 & TRN & \\
\hline CHEMBL1996181 & 752327 & 3.1024 & 3.6013 & TST & \\
\hline
\end{tabular}


Supplemental Table S2.txt

\begin{tabular}{|c|c|c|c|c|}
\hline CHEMBL1500721 & 752327 & 3.1024 & 3.6035 & TST \\
\hline CHEMBL1703524 & 752327 & 3.1024 & 3.4408 & TST \\
\hline CHEMBL1474285 & 752327 & 4.6674 & 3.7047 & TST \\
\hline CHEMBL1372415 & 752327 & 3.1024 & 3.7572 & TST \\
\hline CHEMBL1336677 & 752327 & 3.1024 & 3.8136 & TST \\
\hline CHEMBL1974800 & 752327 & 3.1024 & \multicolumn{2}{|c|}{3.6630000000000003} \\
\hline CHEMBL1990418 & 752327 & 4.9019 & 3.5999 & TST \\
\hline CHEMBL1445287 & 752327 & 4.5338 & 4.0355 & TST \\
\hline CHEMBL1894258 & 752327 & 3.1024 & 3.8617 & TST \\
\hline CHEMBL572180 & 752327 & 3.1024 & 3.3785 & TST \\
\hline CHEMBL1400208 & 752327 & 3.1024 & 3.6069 & TST \\
\hline CHEMBL1501584 & 752327 & 4.9048 & \multicolumn{2}{|c|}{3.9419999999999997} \\
\hline CHEMBL1368128 & 752327 & 3.1024 & 3.4441 & TST \\
\hline CHEMBL1504525 & 752327 & 3.1024 & 3.8081 & TST \\
\hline CHEMBL1894537 & 752327 & 3.1024 & 3.7816 & TST \\
\hline CHEMBL1482672 & 752327 & 3.1024 & 3.3442 & TST \\
\hline CHEMBL1711830 & 752327 & 3.1024 & 3.9929 & TST \\
\hline CHEMBL1383743 & 752327 & 3.1024 & 3.6457 & TST \\
\hline CHEMBL1598158 & 752327 & 3.1024 & 3.4775 & TST \\
\hline CHEMBL1607534 & 752327 & 4.6432 & 3.3079 & TST \\
\hline CHEMBL1709171 & 752327 & 3.1024 & 3.6559 & TST \\
\hline CHEMBL1569668 & 752327 & 3.1024 & 3.8617 & TST \\
\hline CHEMBL1972500 & 752327 & 4.5341 & 3.6829 & TST \\
\hline CHEMBL1608653 & 752327 & 3.1024 & \multicolumn{2}{|c|}{3.7119999999999997} \\
\hline CHEMBL1393504 & 752327 & 4.9313 & 3.6871 & TST \\
\hline CHEMBL1890768 & 752327 & 3.1024 & 3.7161 & TST \\
\hline CHEMBL 2001071 & 752327 & 3.1024 & 3.8982 & TST \\
\hline CHEMBL1714180 & 752327 & 4.7568 & 3.5965 & TST \\
\hline CHEMBL1480000 & 752327 & 3.1024 & 3.3465 & TST \\
\hline CHEMBL1705568 & 752327 & 3.1024 & 3.4615 & TST \\
\hline CHEMBL1436557 & 752327 & 4.3523 & 3.7067 & TST \\
\hline CHEMBL1495281 & 752327 & 4.8591 & 3.7689 & TST \\
\hline CHEMBL1584950 & 752327 & 5.0423 & 3.5591 & TST \\
\hline CHEMBL329706 & 752327 & 3.1024 & 3.5019 & TST \\
\hline CHEMBL1731749 & 752327 & 3.1024 & 3.8053 & TST \\
\hline CHEMBL1464128 & 752327 & 3.1024 & 3.5844 & TST \\
\hline CHEMBL1493942 & 752327 & 3.1024 & 3.7006 & TST \\
\hline CHEMBL1408688 & 752327 & 3.1024 & 3.6229 & TST \\
\hline CHEMBL1352434 & 752327 & 3.1024 & 3.8628 & TST \\
\hline CHEMBL1345140 & 752327 & 3.1024 & 3.6299 & TST \\
\hline CHEMBL1884846 & 752327 & 3.1024 & 3.8738 & TST \\
\hline CHEMBL1381625 & 752327 & 3.1024 & 3.7417 & TST \\
\hline CHEMBL1716393 & 752327 & 5.0938 & 3.5615 & TST \\
\hline CHEMBL1894626 & 752327 & 3.1024 & 3.489 & TST \\
\hline CHEMBL1448982 & 752327 & 3.1024 & 3.6424 & TST \\
\hline CHEMBL1369169 & 752327 & 3.1024 & 3.3098 & TST \\
\hline CHEMBL1563019 & 752327 & 3.1024 & 3.5289 & TST \\
\hline CHEMBL1321703 & 752327 & 3.1024 & 3.8847 & TST \\
\hline
\end{tabular}




\begin{tabular}{|c|c|c|c|c|c|}
\hline \multicolumn{6}{|c|}{ Supplemental Table s2.txt } \\
\hline CHEMBL1721561 & 752327 & 4.68 & 3.9352 & TST & \\
\hline CHEMBL1400198 & 752327 & 3.1024 & 3.4724 & TST & \\
\hline CHEMBL1441149 & 752327 & 5.1348 & 3.7502 & TST & \\
\hline CHEMBL1547898 & 752327 & 3.1024 & 3.7378 & TST & \\
\hline CHEMBL1494757 & 752327 & 3.1024 & 3.7182 & TST & \\
\hline CHEMBL1342377 & 752327 & 3.1024 & 3.5118 & TST & \\
\hline CHEMBL177938 & 752327 & 4.901 & 3.6596 & TST & \\
\hline CHEMBL1411635 & 752327 & 3.1024 & 3.7276 & TST & \\
\hline CHEMBL1421022 & 752327 & 3.1024 & 3.3955 & TST & \\
\hline CHEMBL1612781 & 752327 & 4.6861 & 3.2536 & TST & \\
\hline CHEMBL1535237 & 752327 & 3.1024 & 3.6075 & TST & \\
\hline CHEMBL1704990 & 752327 & 3.1024 & 3.6041 & TST & \\
\hline CHEMBL2004919 & 752327 & 3.1024 & 3.7342 & TST & \\
\hline CHEMBL1497909 & 752327 & 3.1024 & 3.77399 & 99999999996 & TST \\
\hline CHEMBL1729491 & 752327 & 3.1024 & 3.6143 & TST & \\
\hline CHEMBL1339743 & 752327 & 3.1024 & 3.8847 & TST & \\
\hline CHEMBL1980827 & 752327 & 4.9333 & 3.6694 & TST & \\
\hline CHEMBL1595618 & 752327 & 3.1024 & 3.6002 & TST & \\
\hline CHEMBL1571607 & 752327 & 3.1024 & 3.3449 & TST & \\
\hline CHEMBL1996203 & 752327 & 4.2284 & 3.3365 & TST & \\
\hline CHEMBL1605288 & 752327 & 3.1024 & 3.8713 & TST & \\
\hline CHEMBL1714762 & 752327 & 3.1024 & 3.4838 & TST & \\
\hline CHEMBL1468500 & 752327 & 4.8869 & 3.67100 & 00000000003 & TST \\
\hline CHEMBL1977369 & 752327 & 3.1024 & 3.713 & TST & \\
\hline CHEMBL1476335 & 752327 & 3.1024 & 3.5101 & TST & \\
\hline CHEMBL1430891 & 752327 & 3.1024 & 3.7869 & TST & \\
\hline CHEMBL1496932 & 752327 & 4.5586 & 3.7001 & TST & \\
\hline CHEMBL1380037 & 752327 & 3.1024 & 3.7728 & TST & \\
\hline CHEMBL1567432 & 752327 & 3.1024 & 3.66899 & 99999999996 & TST \\
\hline CHEMBL1519842 & 752327 & 3.1024 & 3.4586 & TST & \\
\hline CHEMBL1726644 & 752327 & 5.043 & 3.5037 & TST & \\
\hline CHEMBL56897 & 752327 & 3.1024 & 3.6896 & TST & \\
\hline CHEMBL1388922 & 752327 & 3.1024 & 3.7677 & TST & \\
\hline CHEMBL1527149 & 752327 & 3.1024 & 3.5324 & TST & \\
\hline CHEMBL1313763 & 752327 & 5.0254 & 3.4655 & TST & \\
\hline CHEMBL1332261 & 752327 & 4.8153 & 3.8562 & TST & \\
\hline CHEMBL1431668 & 752327 & 4.8963 & 3.7179 & TST & \\
\hline CHEMBL1575354 & 752327 & 4.4481 & 3.6559 & TST & \\
\hline CHEMBL1524703 & 752327 & 4.7564 & 3.3516 & TST & \\
\hline CHEMBL1533431 & 752327 & 3.1024 & 3.5772 & TST & \\
\hline CHEMBL1714949 & 752327 & 4.6892 & 3.6993 & TST & \\
\hline CHEMBL1540513 & 752327 & 5.1427 & 3.9207 & TST & \\
\hline CHEMBL1336535 & 752327 & 3.1024 & 3.74600 & 00000000004 & TST \\
\hline CHEMBL1557566 & 752327 & 3.1024 & 3.5658 & TST & \\
\hline CHEMBL1901090 & 752327 & 4.2862 & 3.9834 & TST & \\
\hline CHEMBL1435228 & 752327 & 3.1024 & 3.7659 & TST & \\
\hline CHEMBL1727940 & 752327 & 4.1305 & 3.6307 & TST & \\
\hline CHEMBL1542157 & 752327 & 3.1024 & 3.4074 & TST & \\
\hline
\end{tabular}


Supplemental Table S2.txt

\begin{tabular}{|c|c|c|c|c|c|}
\hline CHEMBL1496529 & 752327 & 3.1024 & 3.6578 & TST & \\
\hline CHEMBL1501213 & 752327 & 4.8237 & 3.7422 & TST & \\
\hline CHEMBL1309926 & 752327 & 3.1024 & 3.56600 & 00000000003 & TST \\
\hline CHEMBL1420733 & 752327 & 4.4797 & 3.319 & TST & \\
\hline CHEMBL1516127 & 752327 & 4.3816 & 3.9241 & TST & \\
\hline CHEMBL2003599 & 752327 & 3.1024 & 3.6998 & TST & \\
\hline CHEMBL1604988 & 752327 & 4.9431 & 3.6087 & TST & \\
\hline CHEMBL1492744 & 752327 & 4.4121 & 3.7314 & TST & \\
\hline CHEMBL1609946 & 752327 & 5.0427 & 3.8176 & TST & \\
\hline CHEMBL1538188 & 752327 & 4.3409 & 3.7856 & TST & \\
\hline CHEMBL1880018 & 752327 & 3.1024 & 3.8497 & TST & \\
\hline CHEMBL1608656 & 752327 & 3.1024 & 3.4375 & TST & \\
\hline CHEMBL1975487 & 752327 & 3.1024 & 3.6417 & TST & \\
\hline CHEMBL1728156 & 752327 & 3.1024 & 3.4188 & TST & \\
\hline CHEMBL1553004 & 752327 & 4.8831 & 3.7096 & TST & \\
\hline CHEMBL1574687 & 752327 & 3.1024 & 3.613 & TST & \\
\hline CHEMBL1331666 & 752327 & 4.5459 & 3.7102 & TST & \\
\hline CHEMBL1448193 & 752327 & 4.6654 & 3.7921 & TST & \\
\hline CHEMBL1699029 & 752327 & 3.1024 & 3.3575 & TST & \\
\hline CHEMBL1599400 & 752327 & 4.6394 & 3.6978 & TST & \\
\hline CHEMBL1384619 & 752327 & 3.1024 & 3.7143 & TST & \\
\hline CHEMBL1323293 & 752327 & 3.1024 & 3.4123 & TST & \\
\hline CHEMBL1370934 & 752327 & 3.1024 & 3.7397 & TST & \\
\hline CHEMBL1390816 & 752327 & 3.1024 & 3.605 & TST & \\
\hline CHEMBL1723682 & 752327 & 4.9629 & 3.7594 & TST & \\
\hline CHEMBL1725217 & 752327 & 3.1024 & 3.4661 & TST & \\
\hline CHEMBL1366381 & 752327 & 3.1024 & 3.5352 & TST & \\
\hline CHEMBL1413178 & 752327 & 4.9935 & 3.5141 & TST & \\
\hline CHEMBL1333594 & 752327 & 3.1024 & 3.4457 & TST & \\
\hline CHEMBL1510895 & 752327 & 3.1024 & 3.7125 & TST & \\
\hline CHEMBL1994456 & 752327 & 3.1024 & 3.6184 & TST & \\
\hline CHEMBL1419693 & 752327 & 4.4092 & 3.6366 & TST & \\
\hline CHEMBL1507187 & 752327 & 4.5356 & 3.7451 & TST & \\
\hline CHEMBL1341199 & 752327 & 5.0052 & 3.6906 & TST & \\
\hline CHEMBL129888 & 140713 & 8.4815 & \multicolumn{2}{|c|}{ 7.912999999999999 } & TRN \\
\hline CHEMBL130951 & 140713 & 7.4868 & 7.9962 & TRN & \\
\hline CHEMBL335840 & 140713 & 7.3696 & 8.0666 & TRN & \\
\hline CHEMBL133396 & 140713 & 8.1079 & 8.3862 & TRN & \\
\hline CHEMBL131385 & 140713 & 7.9136 & 8.4207 & TRN & \\
\hline CHEMBL434620 & 140713 & 6.8041 & 6.4706 & TRN & \\
\hline CHEMBL129925 & 140713 & 7.9318 & 7.8771 & TRN & \\
\hline CHEMBL335059 & 140713 & 8.4437 & 8.3855 & TRN & \\
\hline CHEMBL131315 & 140713 & 8.0177 & 8.0598 & TRN & \\
\hline CHEMBL133380 & 140713 & 5.5186 & 7.0421 & TST & \\
\hline CHEMBL130399 & 140713 & 7.6421 & 7.7275 & TRN & \\
\hline CHEMBL131076 & 140713 & 6.9066 & 7.5446 & TRN & \\
\hline CHEMBL114365 & 140713 & 5.1925 & 5.1283 & TRN & \\
\hline CHEMBL311389 & 140713 & 6.4949 & 6.6259 & TRN & \\
\hline
\end{tabular}




\begin{tabular}{|c|c|c|c|c|c|c|}
\hline & & \multicolumn{5}{|l|}{3} \\
\hline CHEMBL338286 & 140713 & 6.2495 & 6.2316 & TRN & & \\
\hline CHEMBL115077 & 140713 & 6.0306 & 6.4452 & TRN & & \\
\hline CHEMBL32240 & 140713 & 8.3979 & 8.013 & TRN & & \\
\hline CHEMBL132851 & 140713 & 5.8182 & 5.9885 & TRN & & \\
\hline CHEMBL130735 & 140713 & 6.4078 & 6.1877 & TRN & & \\
\hline CHEMBL131592 & 140713 & 6.0205 & 5.9563 & TRN & & \\
\hline CHEMBL130144 & 140713 & 8.2218 & 7.9947 & TRN & & \\
\hline CHEMBL131832 & 140713 & 8.0458 & 7.9891 & TRN & & \\
\hline CHEMBL131569 & 140713 & 8.0969 & 7.9609 & TRN & & \\
\hline CHEMBL104297 & 140713 & 5.1904 & 5.4743 & TRN & & \\
\hline CHEMBL133796 & 140713 & 8.3979 & 8.1179 & TST & & \\
\hline CHEMBL32076 & 140713 & 8.8539 & 8.314 & TRN & & \\
\hline CHEMBL132903 & 140713 & 6.4535 & 6.2314 & TRN & & \\
\hline CHEMBL130454 & 140713 & 4.7773 & 4.9243 & TRN & & \\
\hline CHEMBL115447 & 140713 & 5.6216 & 5.7782 & TRN & & \\
\hline CHEMBL335157 & 140713 & 4.5229 & 4.1105 & TRN & & \\
\hline CHEMBL336068 & 140713 & 8.4437 & 8.3046 & TRN & & \\
\hline CHEMBL132660 & 140713 & 8.8861 & 8.456 & TRN & & \\
\hline CHEMBL324697 & 140713 & 5.5229 & 5.2719 & TRN & & \\
\hline CHEMBL102574 & 140713 & 6.38299 & 99999999 & 99 & 6.454 & TST \\
\hline CHEMBL340946 & 140713 & 7.5544 & 7.64 & TRN & & \\
\hline CHEMBL31661 & 140713 & 6.7645 & 6.8626 & TRN & & \\
\hline CHEMBL31049 & 140713 & 8.3468 & 7.8666 & TRN & & \\
\hline CHEMBL131504 & 140713 & 8.71 & 9.1818 & TRN & & \\
\hline CHEMBL 336720 & 140713 & 5.5229 & 6.0508 & TRN & & \\
\hline CHEMBL434801 & 140713 & 6.1649 & 7.5896 & TST & & \\
\hline CHEMBL129974 & 140713 & 8.6198 & 8.0288 & TRN & & \\
\hline CHEMBL130778 & 140713 & 8.0506 & 7.6739 & TRN & & \\
\hline CHEMBL338907 & 140713 & 6.1267 & 5.7914 & TRN & & \\
\hline CHEMBL 280062 & 140713 & 6.2636 & 5.9473 & TST & & \\
\hline CHEMBL130879 & 140713 & 7.9626 & 7.801 & TRN & & \\
\hline CHEMBL324519 & 140713 & 5.1249 & 5.2701 & TRN & & \\
\hline CHEMBL31718 & 140713 & 8.6576 & 8.1399 & TRN & & \\
\hline CHEMBL131418 & 140713 & 5.5229 & 5.7942 & TRN & & \\
\hline CHEMBL341030 & 140713 & 5.0788 & 5.3873 & TRN & & \\
\hline CHEMBL113660 & 140713 & 6.75700 & 000000006 & $\partial 1$ & 6.6722 & TRN \\
\hline CHEMBL115225 & 140713 & 6.3778 & 6.3251 & TRN & & \\
\hline CHEMBL335431 & 140713 & 5.1707 & 5.8953 & TRN & & \\
\hline CHEMBL322420 & 140713 & 8.1612 & 7.6757 & TRN & & \\
\hline CHEMBL43372 & 140713 & 7.4389 & 7.6733 & TST & & \\
\hline CHEMBL339502 & 140713 & 6.3179 & 5.8935 & TRN & & \\
\hline CHEMBL334378 & 140713 & 7.9172 & 7.8268 & TRN & & \\
\hline CHEMBL50267 & 140713 & 7.1938 & 7.6351 & TRN & & \\
\hline CHEMBL131505 & 140713 & 6.0872 & 6.4231 & TRN & & \\
\hline CHEMBL112353 & 140713 & 4.5952 & 4.0491 & TRN & & \\
\hline CHEMBL336729 & 140713 & 7.0757 & 7.3449 & TRN & & \\
\hline CHEMBL336156 & 140713 & 6.6904 & 7.2768 & TRN & & \\
\hline CHEMBL133526 & 140713 & 5.6517 & 5.9867 & TST & & \\
\hline
\end{tabular}


Supplemental Table S2.txt

\begin{tabular}{|c|c|c|c|c|c|}
\hline CHEMBL 31741 & 140713 & 8.699 & 8.4018 & TST & \\
\hline CHEMBL15449 & 140713 & 6.3706 & 5.6348 & TST & \\
\hline CHEMBL129996 & 140713 & 7.4225 & 8.1433 & TST & \\
\hline CHEMBL130575 & 140713 & 7.9914 & 7.9163 & TST & \\
\hline CHEMBL130535 & 140713 & 7.4647 & 7.7689 & TST & \\
\hline CHEMBL132062 & 140713 & 7.1215 & 8.3803 & TST & \\
\hline CHEMBL 323335 & 140713 & 6.7696 & 4.9206 & TST & \\
\hline CHEMBL 290738 & 140713 & 7.6198 & 6.9407 & TST & \\
\hline CHEMBL130895 & 140713 & 6.3757 & 6.2651 & TST & \\
\hline CHEMBL133163 & 140713 & 7.4145 & 7.9456 & TST & \\
\hline CHEMBL131126 & 140713 & 5.9626 & 5.9472 & TST & \\
\hline CHEMBL 340980 & 140713 & 6.1818 & 6.5 & TST & \\
\hline CHEMBL56983 & 152457 & 6.3468 & 6.3505 & TRN & \\
\hline CHEMBL 292701 & 152457 & 3.301 & 3.3066 & TRN & \\
\hline CHEMBL57323 & 152457 & 6.4685 & 6.2297 & TST & \\
\hline CHEMBL432708 & 152457 & 6.0757 & 6.0622 & TRN & \\
\hline CHEMBL299687 & 152457 & 5.301 & 5.2996 & TRN & \\
\hline CHEMBL57347 & 152457 & 6.3279 & 6.3368 & TRN & \\
\hline CHEMBL57451 & 152457 & 5.3768 & 5.3882 & TRN & \\
\hline CHEMBL301641 & 152457 & 6.1805 & 6.1742 & TRN & \\
\hline CHEMBL417961 & 152457 & 5.6198 & 5.6277 & TRN & \\
\hline CHEMBL58627 & 152457 & 4.7959 & 4.8179 & TST & \\
\hline CHEMBL431942 & 152457 & 6.5528 & 6.5356 & TRN & \\
\hline CHEMBL56236 & 152457 & 3.301 & 4.5276 & TST & \\
\hline CHEMBL56380 & 152457 & 4.7959 & 4.8069 & TRN & \\
\hline CHEMBL417208 & 152457 & 5.6576 & 5.6384 & TRN & \\
\hline CHEMBL301273 & 152457 & 5.8861 & 5.9212 & TRN & \\
\hline CHEMBL300784 & 152457 & 4.3372 & 4.4866 & TST & \\
\hline CHEMBL298679 & 152457 & 6.1675 & 6.1621 & TRN & \\
\hline CHEMBL 300992 & 152457 & 3.301 & 3.3089 & TRN & \\
\hline CHEMBL58937 & 152457 & 3.301 & 3.2907 & TRN & \\
\hline CHEMBL299270 & 152457 & 3.301 & 3.2838 & TRN & \\
\hline CHEMBL57585 & 152457 & 5.5528 & 5.562 & TRN & \\
\hline CHEMBL60635 & 152457 & 3.301 & 3.3393 & TRN & \\
\hline CHEMBL57035 & 152457 & 3.301 & 4.0683 & TST & \\
\hline CHEMBL300335 & 152457 & 4.4318 & 4.4599 & TRN & \\
\hline CHEMBL416501 & 152457 & 5.2076 & 5.2071 & TRN & \\
\hline CHEMBL293592 & 152457 & 3.301 & 3.1066 & TST & \\
\hline CHEMBL58684 & 152457 & 5.4949 & 5.49299 & 9999999999 & TRN \\
\hline CHEMBL291777 & 152457 & 6.0969 & 6.0979 & TRN & \\
\hline CHEMBL 294711 & 152457 & 5.2596 & 5.2599 & TRN & \\
\hline CHEMBL56958 & 152457 & 3.301 & 4.5277 & TST & \\
\hline CHEMBL57761 & 152457 & 4.9208 & 4.9053 & TRN & \\
\hline CHEMBL 299026 & 152457 & 6.1805 & 6.1642 & TRN & \\
\hline CHEMBL293322 & 152457 & 6.0757 & 6.0747 & TRN & \\
\hline CHEMBL443262 & 152457 & 5.585 & 5.5819 & TRN & \\
\hline CHEMBL51485 & 152457 & 5.6021 & 5.5898 & TRN & \\
\hline CHEMBL57229 & 152457 & 4.6021 & 4.6466 & TST & \\
\hline
\end{tabular}




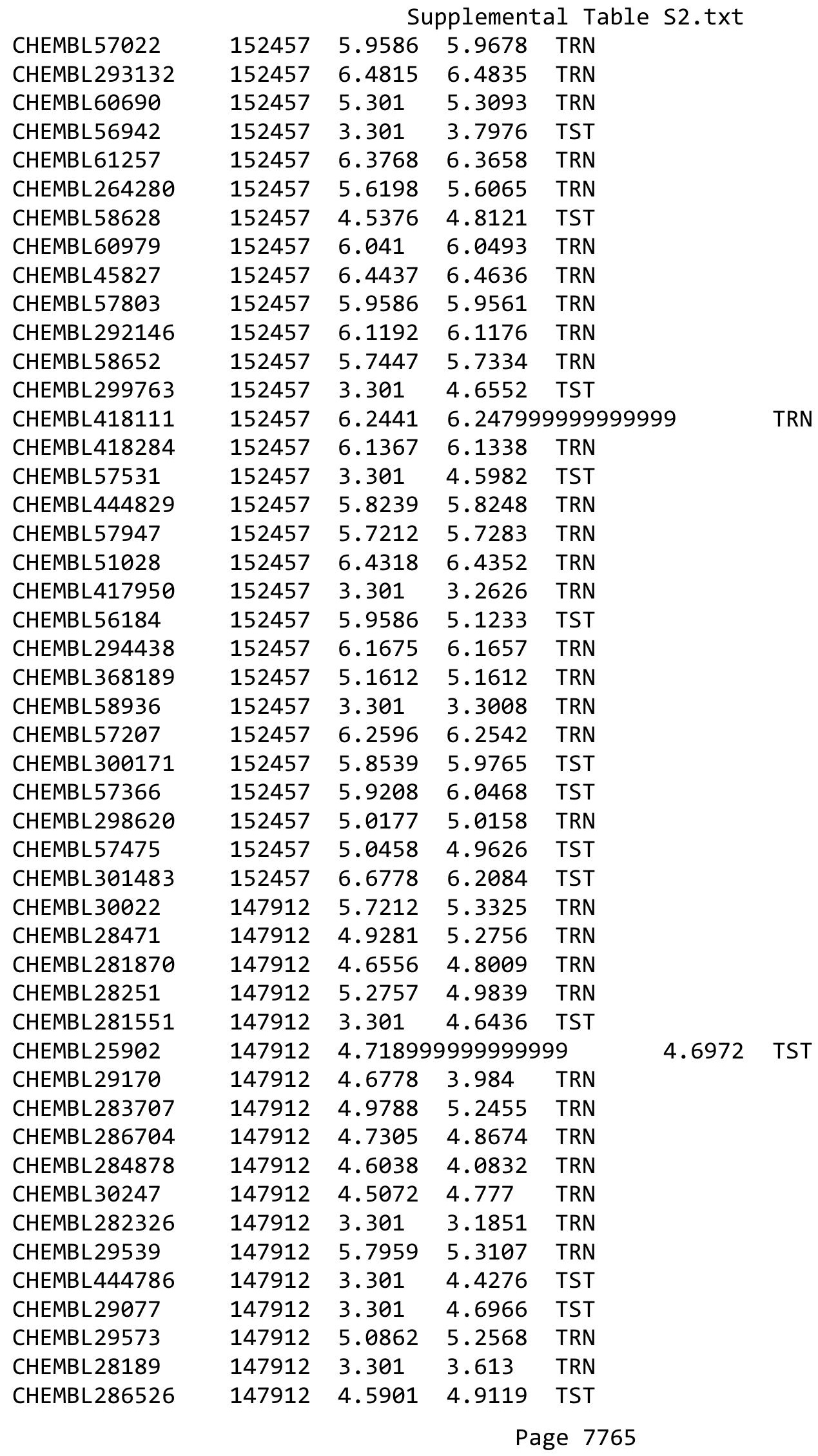




\begin{tabular}{|c|c|c|c|c|c|}
\hline \multirow[b]{2}{*}{ CHEMBL30096 } & \multicolumn{5}{|c|}{ Supplemental Table s2.txt } \\
\hline & 147912 & 4.618 & 4.864 & TST & \\
\hline CHEMBL29787 & 147912 & 4.7011 & 5.29200 & 0000000001 & TRN \\
\hline CHEMBL28855 & 147912 & 3.301 & 3.9402 & TRN & \\
\hline CHEMBL 29542 & 147912 & 4.7545 & 4.7364 & TRN & \\
\hline CHEMBL29701 & 147912 & 3.301 & 4.3275 & TST & \\
\hline CHEMBL28755 & 147912 & 4.7986 & 4.4706 & TRN & \\
\hline CHEMBL 28613 & 147912 & 4.301 & 4.6439 & TST & \\
\hline CHEMBL282831 & 147912 & 4.6271 & 4.6676 & TST & \\
\hline CHEMBL 28614 & 147912 & 3.301 & 4.7536 & TST & \\
\hline CHEMBL413538 & 147912 & 4.58 & 4.046 & TRN & \\
\hline CHEMBL280639 & 147912 & 3.301 & 3.6087 & TRN & \\
\hline CHEMBL 28667 & 147912 & 4.7747 & 4.599 & TST & \\
\hline CHEMBL29251 & 147912 & 4.7878 & 4.9857 & TRN & \\
\hline CHEMBL287179 & 147912 & 4.6904 & 4.3229 & TRN & \\
\hline CHEMBL28591 & 147912 & 3.301 & 3.4639 & TRN & \\
\hline CHEMBL281980 & 147912 & 3.301 & 4.0196 & TRN & \\
\hline CHEMBL282962 & 147912 & 4.3979 & 3.8457 & TRN & \\
\hline CHEMBL 30145 & 147912 & 3.301 & 3.7991 & TRN & \\
\hline CHEMBL282399 & 147912 & 4.8013 & 4.9633 & TRN & \\
\hline CHEMBL30095 & 147912 & 4.9208 & 4.6525 & TRN & \\
\hline CHEMBL28190 & 147912 & 4.4134 & 3.8951 & TRN & \\
\hline CHEMBL30098 & 147912 & 3.301 & 3.5408 & TRN & \\
\hline CHEMBL29563 & 147912 & 4.7799 & 4.9085 & TRN & \\
\hline CHEMBL417294 & 147912 & 4.8962 & 4.7598 & TRN & \\
\hline CHEMBL 29042 & 147912 & 3.301 & 3.6193 & TRN & \\
\hline CHEMBL27535 & 147912 & 4.9547 & 4.8174 & TRN & \\
\hline CHEMBL282171 & 147912 & 4.9626 & 5.0527 & TRN & \\
\hline CHEMBL 29351 & 147912 & 4.7747 & 4.9361 & TRN & \\
\hline CHEMBL 29845 & 147912 & 4.6799 & 4.53 & TRN & \\
\hline CHEMBL29493 & 147912 & 4.5986 & 4.398 & TST & \\
\hline CHEMBL281704 & 147912 & 4.5258 & 4.9093 & TST & \\
\hline CHEMBL 29737 & 147912 & 4.7258 & 4.9307 & TST & \\
\hline CHEMBL284405 & 147912 & 5.0223 & 4.993 & TRN & \\
\hline CHEMBL 28689 & 147912 & 4.52 & 4.4342 & TRN & \\
\hline CHEMBL282370 & 147912 & 3.301 & 3.4691 & TRN & \\
\hline CHEMBL 28861 & 147912 & 4.9626 & 4.3872 & TRN & \\
\hline CHEMBL29733 & 147912 & 4.752 & 4.7461 & TRN & \\
\hline CHEMBL417299 & 147912 & 4.857 & 5.0276 & TRN & \\
\hline CHEMBL501496 & 493931 & 6.7447 & 6.2132 & TRN & \\
\hline CHEMBL507864 & 493931 & 7.699 & 7.7911 & TRN & \\
\hline CHEMBL502458 & 493931 & 6.4949 & 6.2112 & TRN & \\
\hline CHEMBL455572 & 493931 & 6.3979 & 6.46200 & 2000000001 & TST \\
\hline CHEMBL508618 & 493931 & 6.699 & 6.71899 & 9999999999 & TRN \\
\hline CHEMBL499284 & 493931 & 6.3188 & 6.17 & TRN & \\
\hline CHEMBL455363 & 493931 & 7.5229 & 7.7212 & TRN & \\
\hline CHEMBL447045 & 493931 & 6.699 & 6.3908 & TRN & \\
\hline CHEMBL504912 & 493931 & 6.7959 & 6.6641 & TRN & \\
\hline CHEMBL474478 & 493931 & 6.699 & 6.1458 & TRN & \\
\hline
\end{tabular}


Supplemental Table S2.txt

\begin{tabular}{|c|c|c|c|c|}
\hline CHEMBL504084 & 493931 & 6.9586 & 6.7923 & TST \\
\hline CHEMBL448664 & 493931 & 7.0969 & 6.9563 & TRN \\
\hline CHEMBL501774 & 493931 & 6.6778 & 6.2203 & TRN \\
\hline CHEMBL504617 & 493931 & 6.7696 & 6.9115 & TRN \\
\hline CHEMBL466695 & 493931 & 6.5086 & 5.9494 & TRN \\
\hline CHEMBL376633 & 493931 & 6.2007 & 6.442 & TRN \\
\hline CHEMBL448722 & 493931 & 5.8239 & 6.6831 & TST \\
\hline CHEMBL510044 & 493931 & 6.2518 & 6.3892 & TRN \\
\hline CHEMBL509739 & 493931 & 5.2518 & 6.4277 & TST \\
\hline CHEMBL486472 & 493931 & 4.9031 & 5.249 & TRN \\
\hline CHEMBL510417 & 493931 & 6.699 & 6.4049 & TST \\
\hline CHEMBL502901 & 493931 & 6.5229 & 6.3674 & TRN \\
\hline CHEMBL504730 & 493931 & 7.1135 & 6.8467 & TRN \\
\hline CHEMBL503141 & 493931 & 7.1549 & 7.2997 & TRN \\
\hline CHEMBL501336 & 493931 & 6.8539 & 6.4953 & TRN \\
\hline CHEMBL408261 & 493931 & 6.699 & 6.8972 & TST \\
\hline CHEMBL443645 & 493931 & 5.9208 & 5.9501 & TRN \\
\hline CHEMBL449113 & 493931 & 7.0458 & 7.3181 & TRN \\
\hline CHEMBL451024 & 493931 & 4.0 & 5.058 & TRN \\
\hline CHEMBL502964 & 493931 & 6.6198 & 6.6962 & TRN \\
\hline CHEMBL373778 & 493931 & 6.9208 & 6.6225 & TRN \\
\hline CHEMBL503626 & 493931 & 7.301 & 7.195 & TRN \\
\hline CHEMBL504281 & 493931 & 6.7959 & 6.6208 & TRN \\
\hline CHEMBL448596 & 493931 & 6.3188 & 5.9521 & TRN \\
\hline CHEMBL504199 & 493931 & 6.8539 & 6.6719 & TRN \\
\hline CHEMBL506138 & 493931 & 6.4815 & 6.6485 & TRN \\
\hline CHEMBL404529 & 493931 & 7.5229 & 6.96399 & 99999999995 \\
\hline CHEMBL510461 & 493931 & 6.3468 & 6.2769 & TST \\
\hline CHEMBL501852 & 493931 & 7.2441 & 7.1748 & TRN \\
\hline CHEMBL504728 & 493931 & 7.1308 & 6.6784 & TRN \\
\hline CHEMBL488320 & 493931 & 6.4815 & 6.5057 & TRN \\
\hline CHEMBL453714 & 493931 & 7.1249 & 6.4832 & TRN \\
\hline CHEMBL442623 & 493931 & 6.5528 & 6.7957 & TST \\
\hline CHEMBL452094 & 493931 & 6.4685 & 7.0723 & TRN \\
\hline CHEMBL506097 & 493931 & 7.5528 & 7.08700 & $\partial 000000001$ \\
\hline CHEMBL509488 & 493931 & 5.8861 & 6.2036 & TRN \\
\hline CHEMBL444909 & 493931 & 7.0 & 6.8415 & TRN \\
\hline CHEMBL504746 & 493931 & 7.4318 & 6.8882 & TST \\
\hline CHEMBL505164 & 493931 & 7.6021 & 7.2827 & TST \\
\hline CHEMBL508499 & 493931 & 5.301 & 5.9822 & TRN \\
\hline CHEMBL451642 & 493931 & 7.4685 & 7.6358 & TRN \\
\hline CHEMBL504280 & 493931 & 7.301 & 6.9919 & TST \\
\hline CHEMBL449829 & 493931 & 6.8539 & 6.6615 & TRN \\
\hline CHEMBL451133 & 493931 & 6.2757 & 6.9096 & TRN \\
\hline CHEMBL468442 & 493931 & 6.5229 & 6.7169 & TRN \\
\hline CHEMBL448639 & 493931 & 5.4949 & 6.2897 & TRN \\
\hline CHEMBL505593 & 493931 & 7.0969 & 7.3736 & TRN \\
\hline CHEMBL503263 & 493931 & 6.2676 & 6.3907 & TST \\
\hline
\end{tabular}


Supplemental Table S2.txt

\begin{tabular}{|c|c|c|c|c|}
\hline CHEMBL510703 & 493931 & 6.8239 & 6.9892 & TST \\
\hline CHEMBL503893 & 493931 & 7.0969 & 7.0834 & TRN \\
\hline CHEMBL463857 & 493931 & 5.2366 & 6.7155 & TST \\
\hline CHEMBL468377 & 493931 & 6.8539 & 7.0732 & TRN \\
\hline CHEMBL449856 & 493931 & 6.8239 & 6.5373 & TRN \\
\hline CHEMBL133511 & 217761 & 4.1427 & 4.3257 & TRN \\
\hline CHEMBL335628 & 217761 & 5.301 & 5.5961 & TRN \\
\hline CHEMBL407143 & 217761 & 5.5229 & 5.46 & TRN \\
\hline CHEMBL423330 & 217761 & 4.0269 & 4.1622 & TRN \\
\hline CHEMBL337737 & 217761 & 5.5229 & 5.5889 & TRN \\
\hline CHEMBL430059 & 217761 & 3.3747 & 3.9546 & TST \\
\hline CHEMBL130106 & 217761 & 4.0177 & 4.6008 & TRN \\
\hline CHEMBL 318300 & 217761 & 5.2218 & 5.4148 & TRN \\
\hline CHEMBL130401 & 217761 & 4.1871 & 3.9211 & TRN \\
\hline CHEMBL336949 & 217761 & 5.699 & 5.3554 & TRN \\
\hline CHEMBL130931 & 217761 & 5.5229 & 5.3923 & TRN \\
\hline CHEMBL133929 & 217761 & 5.301 & 4.7844 & TRN \\
\hline CHEMBL131768 & 217761 & 3.6421 & 4.1265 & TRN \\
\hline CHEMBL131361 & 217761 & 5.301 & 5.3989 & TRN \\
\hline CHEMBL336958 & 217761 & 6.0 & 6.1797 & TRN \\
\hline CHEMBL337459 & 217761 & 4.8539 & 4.7707 & TRN \\
\hline CHEMBL340977 & 217761 & 5.5229 & 5.3332 & TRN \\
\hline CHEMBL336864 & 217761 & 5.5229 & 5.7913 & TRN \\
\hline CHEMBL134004 & 217761 & 5.2218 & 5.1899 & TRN \\
\hline CHEMBL336644 & 217761 & 5.5229 & 5.4816 & TRN \\
\hline CHEMBL334979 & 217761 & 5.3979 & 4.8298 & TRN \\
\hline CHEMBL311937 & 217761 & 3.2757 & 3.9177 & TST \\
\hline CHEMBL133644 & 217761 & 5.301 & 5.3385 & TRN \\
\hline CHEMBL334891 & 217761 & 4.8539 & 4.6913 & TRN \\
\hline CHEMBL77067 & 217761 & 2.301 & 3.98100 & 30000000003 \\
\hline CHEMBL424449 & 217761 & 5.3979 & 5.2241 & TRN \\
\hline CHEMBL129842 & 217761 & 4.2147 & 4.7991 & TRN \\
\hline CHEMBL132963 & 217761 & 4.3665 & 4.3758 & TRN \\
\hline CHEMBL103838 & 217761 & 5.1549 & 4.6732 & TRN \\
\hline CHEMBL336978 & 217761 & 4.585 & 4.0715 & TRN \\
\hline CHEMBL130871 & 217761 & 4.4437 & 4.1705 & TRN \\
\hline CHEMBL134243 & 217761 & 5.0969 & 4.9335 & TRN \\
\hline CHEMBL335284 & 217761 & 4.4815 & 4.5243 & TRN \\
\hline CHEMBL132007 & 217761 & 5.1549 & 4.9481 & TRN \\
\hline CHEMBL339077 & 217761 & 5.1549 & 4.792 & TRN \\
\hline CHEMBL336314 & 217761 & 5.699 & 5.7544 & TRN \\
\hline CHEMBL134030 & 217761 & 4.5086 & 4.4852 & TRN \\
\hline CHEMBL337253 & 217761 & 5.301 & 4.6123 & TRN \\
\hline CHEMBL133185 & 217761 & 4.9586 & 4.8412 & TRN \\
\hline CHEMBL134191 & 217761 & 2.301 & 3.9797 & TST \\
\hline CHEMBL337451 & 217761 & 5.699 & 6.0459 & TRN \\
\hline CHEMBL316967 & 217761 & 5.3979 & 5.5533 & TRN \\
\hline CHEMBL310313 & 217761 & 4.2596 & 4.2637 & TRN \\
\hline
\end{tabular}

Page 7768 


\begin{tabular}{|c|c|c|c|c|c|}
\hline \multicolumn{6}{|c|}{ Supplemental Table S2.txt } \\
\hline CHEMBL76963 & 217761 & 2.301 & 4.1884 & TST & \\
\hline CHEMBL411163 & 217761 & 7.4202 & 4.3876 & TST & \\
\hline CHEMBL334539 & 217761 & 4.4949 & 4.8658 & TST & \\
\hline CHEMBL132006 & 217761 & 5.3979 & 4.9498 & TST & \\
\hline CHEMBL132014 & 217761 & 3.8928 & 4.3531 & TST & \\
\hline CHEMBL134042 & 217761 & 4.8539 & 4.6494 & TST & \\
\hline CHEMBL336957 & 217761 & 3.4841 & 4.026 & TST & \\
\hline CHEMBL131229 & 217761 & 5.301 & 5.47 & TST & \\
\hline CHEMBL341314 & 217761 & 3.7352 & 4.5061 & TST & \\
\hline CHEMBL130751 & 217761 & 2.301 & 4.4933 & TST & \\
\hline CHEMBL131944 & 217761 & 5.2218 & 5.2075 & TST & \\
\hline CHEMBL310267 & 34948 & 8.8861 & 8.927999 & 9999999999 & TRN \\
\hline CHEMBL311312 & 34948 & 10.0 & 9.9912 & TRN & \\
\hline CHEMBL77360 & 34948 & 9.0969 & 9.1291 & TRN & \\
\hline CHEMBL 76870 & 34948 & 10.0458 & 10.0635 & TRN & \\
\hline CHEMBL311031 & 34948 & 7.1079 & 7.4507 & TST & \\
\hline CHEMBL77138 & 34948 & 9.0969 & 9.1001 & TRN & \\
\hline CHEMBL80181 & 34948 & 8.7447 & 8.7186 & TRN & \\
\hline CHEMBL80370 & 34948 & 9.3188 & 9.307 & TRN & \\
\hline CHEMBL79106 & 34948 & 8.3468 & 8.3593 & TRN & \\
\hline CHEMBL76760 & 34948 & 8.585 & 8.1302 & TST & \\
\hline CHEMBL 2114159 & 34948 & 6.9872 & 8.5277 & TST & \\
\hline CHEMBL63998 & 34948 & 9.699 & 9.6459 & TRN & \\
\hline CHEMBL76799 & 34948 & 9.0969 & 9.0834 & TRN & \\
\hline CHEMBL79108 & 34948 & 7.4437 & 7.4362 & TRN & \\
\hline CHEMBL 309602 & 34948 & 9.699 & 9.716000 & 0000000001 & TRN \\
\hline CHEMBL311847 & 34948 & 9.0458 & 9.0747 & TRN & \\
\hline CHEMBL80901 & 34948 & 8.3279 & 8.3135 & TRN & \\
\hline CHEMBL 309845 & 34948 & 9.5229 & 9.5358 & TRN & \\
\hline CHEMBL 306180 & 34948 & 8.5086 & 8.5309 & TRN & \\
\hline CHEMBL76948 & 34948 & 9.3979 & 9.3825 & TRN & \\
\hline CHEMBL309313 & 34948 & 10.0 & 9.9795 & TRN & \\
\hline CHEMBL80239 & 34948 & 6.9431 & 8.86 & TST & \\
\hline CHEMBL306157 & 34948 & 9.301 & 9.3024 & TRN & \\
\hline CHEMBL311827 & 34948 & 9.699 & 9.6902 & TRN & \\
\hline CHEMBL80971 & 34948 & 9.3979 & 9.4014 & TRN & \\
\hline CHEMBL 80908 & 34948 & 8.9586 & 8.9723 & TRN & \\
\hline CHEMBL 80212 & 34948 & 8.4949 & 8.4907 & TRN & \\
\hline CHEMBL 76538 & 34948 & 9.5229 & 9.5171 & TRN & \\
\hline CHEMBL 78169 & 34948 & 8.8239 & 8.8258 & TRN & \\
\hline CHEMBL443069 & 34948 & 8.9586 & 8.9329 & TRN & \\
\hline CHEMBL 78445 & 34948 & 8.6778 & 8.6869 & TRN & \\
\hline CHEMBL 80900 & 34948 & 9.0458 & 9.0564 & TRN & \\
\hline CHEMBL 306085 & 34948 & 9.0 & 9.0135 & TRN & \\
\hline CHEMBL 76675 & 34948 & 7.8239 & 7.8141 & TRN & \\
\hline CHEMBL 78866 & 34948 & 9.699 & 9.6734 & TRN & \\
\hline CHEMBL312386 & 34948 & 9.5229 & 9.5372 & TRN & \\
\hline CHEMBL 306778 & 34948 & 9.0 & 8.997 & TRN & \\
\hline
\end{tabular}




\begin{tabular}{|c|c|c|c|c|c|}
\hline \multicolumn{6}{|c|}{ Supplemental Table S2.txt } \\
\hline CHEMBL308135 & 34948 & 9.699 & 9.6779 & TRN & \\
\hline CHEMBL445365 & 34948 & 9.699 & 9.6995 & TRN & \\
\hline CHEMBL413491 & 34948 & 8.7696 & 8.7241 & TRN & \\
\hline CHEMBL 76613 & 34948 & 9.0 & 8.9897 & TRN & \\
\hline CHEMBL80622 & 34948 & 9.2218 & 9.2693 & TRN & \\
\hline CHEMBL305638 & 34948 & 9.5229 & 9.5489 & TRN & \\
\hline CHEMBL80177 & 34948 & 10.0969 & 9.2856 & TST & \\
\hline CHEMBL432158 & 34948 & 9.0969 & 9.2851 & TST & \\
\hline CHEMBL305604 & 34948 & 9.2218 & 9.4846 & TST & \\
\hline CHEMBL310610 & 34948 & 8.7212 & 9.176 & TST & \\
\hline CHEMBL75921 & 34948 & 8.1135 & 8.2872 & TST & \\
\hline CHEMBL311189 & 34948 & 9.0458 & 9.3709 & TST & \\
\hline CHEMBL77308 & 34948 & 9.699 & 9.1644 & TST & \\
\hline CHEMBL441990 & 34948 & 8.6778 & 9.0382 & TST & \\
\hline CHEMBL 80700 & 34948 & 9.699 & 9.4769 & TST & \\
\hline CHEMBL76525 & 34948 & 9.5229 & 9.4088 & TST & \\
\hline CHEMBL33952 & 224214 & 3.301 & 4.9862 & TRN & \\
\hline CHEMBL36371 & 224214 & 5.699 & 5.4854 & TRN & \\
\hline CHEMBL36155 & 224214 & 5.3979 & 4.1248 & TST & \\
\hline CHEMBL40003 & 224214 & 5.5229 & 5.3527 & TRN & \\
\hline CHEMBL290710 & 224214 & 5.3979 & 5.0948 & TST & \\
\hline CHEMBL288726 & 224214 & 3.301 & 4.6199 & TRN & \\
\hline CHEMBL38119 & 224214 & 5.0458 & 4.3707 & TRN & \\
\hline CHEMBL40731 & 224214 & 5.699 & 5.0963 & TST & \\
\hline CHEMBL39798 & 224214 & 6.0 & 5.5056 & TRN & \\
\hline CHEMBL39751 & 224214 & 5.3979 & 5.2559 & TST & \\
\hline CHEMBL405035 & 224214 & 5.699 & 5.5665 & TRN & \\
\hline CHEMBL37200 & 224214 & 5.699 & 5.7173 & TRN & \\
\hline CHEMBL39896 & 224214 & 6.0 & 5.8523 & TRN & \\
\hline CHEMBL36538 & 224214 & 4.9586 & 5.3164 & TRN & \\
\hline CHEMBL32880 & 224214 & 5.0969 & 5.2141 & TRN & \\
\hline CHEMBL 284503 & 224214 & 5.3979 & 5.1335 & TRN & \\
\hline CHEMBL38233 & 224214 & 5.699 & 5.4153 & TRN & \\
\hline CHEMBL32353 & 224214 & 5.2218 & 5.3536 & TRN & \\
\hline CHEMBL39783 & 224214 & 5.5229 & 5.3631 & TRN & \\
\hline CHEMBL36742 & 224214 & 5.699 & 5.6008 & TRN & \\
\hline CHEMBL35999 & 224214 & 5.3979 & 5.3763 & TRN & \\
\hline CHEMBL39561 & 224214 & 5.1549 & 5.152 & TRN & \\
\hline CHEMBL39850 & 224214 & 5.1549 & 4.9144 & TRN & \\
\hline CHEMBL38350 & 224214 & 5.2218 & 5.0253 & TRN & \\
\hline CHEMBL416415 & 224214 & 5.2218 & 5.3888 & TRN & \\
\hline CHEMBL284100 & 224214 & 4.9208 & 5.28299 & 99999999995 & TRN \\
\hline CHEMBL263418 & 224214 & 6.0 & 5.0499 & TRN & \\
\hline CHEMBL 288650 & 224214 & 5.3979 & 5.1458 & TRN & \\
\hline CHEMBL36829 & 224214 & 5.301 & 5.6809 & TRN & \\
\hline CHEMBL290392 & 224214 & 5.699 & 5.7278 & TRN & \\
\hline CHEMBL 285700 & 224214 & 5.0969 & 5.5809 & TRN & \\
\hline CHEMBL39857 & 224214 & 3.301 & 5.8582 & TST & \\
\hline
\end{tabular}




\begin{tabular}{|c|c|c|c|c|c|}
\hline \multicolumn{6}{|c|}{ Supplemental Table S2.txt } \\
\hline CHEMBL34980 & 224214 & 5.5229 & 5.4962 & TRN & \\
\hline CHEMBL39359 & 224214 & 5.301 & 5.4666 & TRN & \\
\hline CHEMBL37677 & 224214 & 5.5229 & 5.0773 & TRN & \\
\hline CHEMBL289427 & 224214 & 6.0 & 5.8101 & TRN & \\
\hline CHEMBL39401 & 224214 & 5.301 & 5.3356 & TRN & \\
\hline CHEMBL290167 & 224214 & 6.0 & 5.3268 & TRN & \\
\hline CHEMBL261943 & 224214 & 5.5229 & 5.6306 & TST & \\
\hline CHEMBL40331 & 224214 & 5.5229 & 5.7041 & TRN & \\
\hline CHEMBL435770 & 224214 & 5.5229 & 5.5121 & TST & \\
\hline CHEMBL435370 & 224214 & 4.7696 & 4.462 & TRN & \\
\hline CHEMBL288927 & 224214 & 4.7696 & 4.8548 & TRN & \\
\hline CHEMBL39624 & 224214 & 5.3979 & 5.4771 & TST & \\
\hline CHEMBL418246 & 224214 & 4.5376 & 5.3756 & TRN & \\
\hline CHEMBL34398 & 224214 & 4.8539 & 4.4107 & TRN & \\
\hline CHEMBL36619 & 224214 & 5.2218 & 5.3137 & TRN & \\
\hline CHEMBL287939 & 224214 & 5.5229 & 5.4978 & TRN & \\
\hline CHEMBL449083 & 224214 & 5.699 & 5.4569 & TRN & \\
\hline CHEMBL285544 & 224214 & 5.699 & 5.6587 & TRN & \\
\hline CHEMBL35981 & 224214 & 5.699 & 5.6117 & TRN & \\
\hline CHEMBL39549 & 224214 & 5.5229 & 5.4764 & TRN & \\
\hline CHEMBL37331 & 224214 & 5.5229 & 5.2359 & TRN & \\
\hline CHEMBL36606 & 224214 & 4.8239 & 5.4042 & TRN & \\
\hline CHEMBL287786 & 224214 & 5.301 & 5.2623 & TRN & \\
\hline CHEMBL 36000 & 224214 & 3.301 & 4.7912 & TRN & \\
\hline CHEMBL 37662 & 224214 & 6.0 & 5.5361 & TRN & \\
\hline CHEMBL39558 & 224214 & 5.3979 & 5.3895 & TRN & \\
\hline CHEMBL39400 & 224214 & 5.699 & 5.2777 & TRN & \\
\hline CHEMBL40330 & 224214 & 5.5229 & 5.3662 & TRN & \\
\hline CHEMBL39656 & 224214 & 6.0 & 5.8495 & TRN & \\
\hline CHEMBL7976 & 224214 & 4.6383 & 4.1648 & TRN & \\
\hline CHEMBL 37327 & 224214 & 4.3279 & 3.7465 & TRN & \\
\hline CHEMBL39895 & 224214 & 5.3979 & 5.3183 & TRN & \\
\hline CHEMBL417873 & 224214 & 4.6021 & 4.1137 & TST & \\
\hline CHEMBL36771 & 224214 & 5.699 & 5.8592 & TRN & \\
\hline CHEMBL38067 & 224214 & 3.301 & 4.1145 & TRN & \\
\hline CHEMBL37197 & 224214 & 3.301 & 5.7911 & TST & \\
\hline CHEMBL 279582 & 224214 & 5.5229 & 5.40600 & 0000000001 & TST \\
\hline CHEMBL 38312 & 224214 & 5.699 & 5.4835 & TST & \\
\hline CHEMBL 37120 & 224214 & 5.5229 & 5.1603 & TST & \\
\hline CHEMBL35697 & 224214 & 5.5229 & 5.4306 & TST & \\
\hline CHEMBL 37382 & 224214 & 5.699 & 5.7978 & TST & \\
\hline CHEMBL40501 & 224214 & 4.8239 & 5.2634 & TST & \\
\hline CHEMBL37663 & 224214 & 6.0 & 5.4496 & TST & \\
\hline CHEMBL 33897 & 224214 & 5.3979 & 5.5957 & TST & \\
\hline CHEMBL416424 & 224214 & 5.5229 & 5.5179 & TST & \\
\hline CHEMBL435172 & 224214 & 5.699 & 5.3793 & TST & \\
\hline CHEMBL323958 & 217297 & 6.6021 & 6.9148 & TRN & \\
\hline CHEMBL326539 & 217297 & 8.699 & 8.5458 & TRN & \\
\hline
\end{tabular}


Supplemental Table S2.txt

\begin{tabular}{|c|c|c|c|c|c|}
\hline CHEMBL325753 & 217297 & 7.301 & 7.1101 & TRN & \\
\hline CHEMBL114678 & 217297 & 7.3979 & 6.8582 & TRN & \\
\hline CHEMBL324113 & 217297 & 7.8861 & 7.8298 & TRN & \\
\hline CHEMBL333166 & 217297 & 6.4949 & 7.6888 & TRN & \\
\hline CHEMBL324811 & 217297 & 3.9393 & 4.9567 & TRN & \\
\hline CHEMBL115597 & 217297 & 7.5086 & 6.3462 & TST & \\
\hline CHEMBL112321 & 217297 & 5.3768 & 5.7332 & TRN & \\
\hline CHEMBL432796 & 217297 & 9.0 & 8.584 & TRN & \\
\hline CHEMBL324283 & 217297 & 5.6778 & 5.8778 & TRN & \\
\hline CHEMBL323810 & 217297 & 5.2366 & 5.3015 & TRN & \\
\hline CHEMBL112704 & 217297 & 4.6778 & 4.8812 & TRN & \\
\hline CHEMBL115443 & 217297 & 6.6383 & 7.1453 & TRN & \\
\hline CHEMBL1790844 & 217297 & 8.301 & 8.7822 & TRN & \\
\hline CHEMBL432437 & 217297 & 8.0969 & 8.4235 & TRN & \\
\hline CHEMBL333631 & 217297 & 8.3979 & 8.5438 & TRN & \\
\hline CHEMBL114369 & 217297 & 7.4685 & 6.8464 & TRN & \\
\hline CHEMBL441822 & 217297 & 7.6383 & 7.421 & TRN & \\
\hline CHEMBL2370468 & 217297 & 7.3979 & 7.9878 & TRN & \\
\hline CHEMBL115715 & 217297 & 5.8861 & 5.75899 & 79999999995 & TRN \\
\hline CHEMBL439598 & 217297 & 6.7959 & 5.8873 & TRN & \\
\hline CHEMBL115881 & 217297 & 6.0506 & 7.1041 & TRN & \\
\hline CHEMBL420864 & 217297 & 6.9586 & 6.7087 & TRN & \\
\hline CHEMBL324281 & 217297 & 5.8239 & 6.5495 & TRN & \\
\hline CHEMBL114767 & 217297 & 7.699 & 7.3428 & TRN & \\
\hline CHEMBL432247 & 217297 & 4.4437 & 5.5278 & TRN & \\
\hline CHEMBL115882 & 217297 & 6.8539 & 5.8729 & TRN & \\
\hline CHEMBL419038 & 217297 & 6.8861 & 6.1079 & TST & \\
\hline CHEMBL116053 & 217297 & 6.6778 & 7.2262 & TRN & \\
\hline CHEMBL114889 & 217297 & 4.7447 & 5.2268 & TRN & \\
\hline CHEMBL114234 & 217297 & 7.2218 & 7.472 & TRN & \\
\hline CHEMBL326625 & 217297 & 7.3279 & 6.3177 & TRN & \\
\hline CHEMBL325911 & 217297 & 6.8729 & 6.0502 & TRN & \\
\hline CHEMBL325366 & 217297 & 5.9208 & \multicolumn{2}{|c|}{6.218999999999999} & TRN \\
\hline CHEMBL112675 & 217297 & 8.3979 & 8.5277 & TRN & \\
\hline CHEMBL 2370461 & 217297 & 8.301 & 7.7959 & TRN & \\
\hline CHEMBL326953 & 217297 & 5.8861 & 5.2721 & TRN & \\
\hline CHEMBL326394 & 217297 & 8.5229 & 8.2869 & TRN & \\
\hline CHEMBL114486 & 217297 & 5.5528 & \multicolumn{2}{|c|}{6.3260000000000005} & TRN \\
\hline CHEMBL115504 & 217297 & 8.1549 & 8.676 & TRN & \\
\hline CHEMBL 2372105 & 217297 & 8.5229 & 7.9585 & TRN & \\
\hline CHEMBL326500 & 217297 & 7.0 & 7.2591 & TST & \\
\hline CHEMBL324114 & 217297 & 6.5229 & 6.0938 & TRN & \\
\hline CHEMBL323250 & 217297 & 5.3372 & 5.7434 & TST & \\
\hline CHEMBL115564 & 217297 & 7.4202 & 6.3394 & TRN & \\
\hline CHEMBL325280 & 217297 & 8.301 & \multicolumn{2}{|c|}{7.872999999999999} & TRN \\
\hline CHEMBL112619 & 217297 & 5.9586 & 6.3972 & TRN & \\
\hline CHEMBL114882 & 217297 & 6.8539 & 6.7801 & TRN & \\
\hline CHEMBL114391 & 217297 & 5.7825 & 5.7568 & TRN & \\
\hline
\end{tabular}


Supplemental Table S2.txt

\begin{tabular}{|c|c|c|c|c|}
\hline 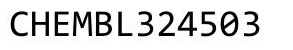 & 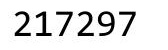 & 1 & 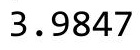 & \\
\hline CHEMBL: & 17297 & 8.3979 & 9816 & \\
\hline HEMBL 325904 & 17297 & 6.2757 & 2147 & \\
\hline HEMBL 326798 & 17297 & 7.1192 & 7.0957 & \\
\hline HEMBL112936 & 17297 & 5.2218 & 3881 & \\
\hline HEMBL115322 & 17297 & 6.6383 & 5484 & \\
\hline HEMBL431870 & 217297 & 5.0269 & 9493 & \\
\hline HEMBL424064 & 17297 & 7.0132 & 0194 & \\
\hline HEMBL110964 & 17297 & 7.0 & 5.0696 & \\
\hline HEMBL323192 & 17297 & 7.3979 & .4449 & \\
\hline HEMBL113731 & 217297 & 7.2676 & .3429 & \\
\hline JEMBL114583 & 217297 & 6.3872 & 6.1684 & \\
\hline HEMBL113720 & 17297 & 7.0458 & .9645 & \\
\hline HEMBL115605 & 17297 & 6.1487 & 7.8937 & \\
\hline HEMBL116274 & 17297 & 4.9208 & .3946 & \\
\hline HEMBL116286 & 217297 & 021 & .0748 & \\
\hline IEMBL114579 & 217297 & 4.6576 & 6.8679 & \\
\hline HEMBL 331602 & 17297 & 4.301 & 3.9839 & \\
\hline HEMBL114151 & 17297 & 6. & 5.4722 & \\
\hline HEMBL114708 & 217297 & 6. & .5861 & \\
\hline HEMBL 3929692 & 1528086 & 8. & .0217 & \\
\hline HEMBL3686375 & 1528086 & 6.1675 & 6.5303 & \\
\hline HEMBL3690959 & 1528086 & 8. & 7.4321 & \\
\hline HEMBL3986402 & 1528086 & 8. & 8.8868 & \\
\hline HEMBL3690974 & 1528086 & 7. & 7.2466 & \\
\hline L3695145 & 1528086 & 7. & 7.8107 & \\
\hline HEMBL3913025 & 1528086 & 7.7212 & 8.0167 & \\
\hline HEMBL 3941735 & 528086 & 8. & 8.4694 & \\
\hline HEMBL 3690848 & 1528086 & 7.1249 & 7.5274 & \\
\hline HEMBL3695139 & 1528086 & 8. & 7.9532 & \\
\hline L3934068 & 1528086 & 8. & 8.2424 & \\
\hline CHEMBL 3686380 & 1528086 & 6.0 & 7.2054 & \\
\hline HEMBL 3695074 & 528086 & 7.3279 & 7.0749 & \\
\hline HEMBL3686374 & 1528086 & 6.0 & 6.5495 & \\
\hline HEMBL3691025 & 1528086 & 7.8239 & 7.6993 & \\
\hline CHEMBL 3690898 & 1528086 & 7.8539 & 7.6197 & \\
\hline CHEMBL 3686462 & 1528086 & 6.0 & 6.9282 & \\
\hline HEMBL3937194 & 528086 & 6. & 7.6088 & \\
\hline HEMBL 3913982 & 1528086 & 7.6 & 8.2049 & \\
\hline HEMBL3905203 & 1528086 & 8. & 8.385 & \\
\hline CHEMBL3686368 & 1528086 & & 6.5153 & \\
\hline CHEMBL 3695150 & 1528086 & 7.7959 & 7.9117 & \\
\hline CHEMBL3896399 & 1528086 & 8.3279 & 8.1552 & \\
\hline CHEMBL3686386 & 1528086 & 7.9208 & 6.8551 & \\
\hline CHEMBL3690903 & 1528086 & 7.6021 & 7.6431 & \\
\hline CHEMBL3929591 & 1528086 & 7.4559 & 7.9794 & \\
\hline CHEMBL3690952 & 1528086 & 7.8097 & 7.1845 & \\
\hline CHEMBL3690918 & 1528086 & 6.0 & 6.4555 & \\
\hline
\end{tabular}


Supplemental Table S2.txt

\begin{tabular}{|c|c|c|c|c|}
\hline HEM & & 7.8861 & & \\
\hline HEMPI 2606197 & 528086 & 6.0 & .9644 & \\
\hline : & 28086 & 6 & & \\
\hline AEMBL & 28086 & 7.9208 & & \\
\hline HEMBL & 028686 & 8.9586 & 269 & \\
\hline HEMBL3962336 & 528086 & 8.3872 & .5631 & \\
\hline 37 & 528086 & .4815 & 026 & \\
\hline 60 & 528086 & & & \\
\hline AEMBL3691016 & 528086 & 7.8239 & 7.1502 & \\
\hline HEMBL3695176 & 528086 & 6.0 & 5.973 & \\
\hline HEMBL3900530 & 528086 & 8.0605 & . 3427 & \\
\hline IEMBL: & 28086 & 559 & 629 & \\
\hline AEMBL & & & & \\
\hline HEMBL3S & 528086 & 8.8539 & 8.5594 & \\
\hline AEMBL36 & 528086 & 8.6289 & 756 & \\
\hline AEMBL 394 & 528086 & 4.6968 & 7.045 & \\
\hline AEMBL36 & 8086 & 6 & 91 & 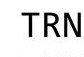 \\
\hline HEMBL3S & & 88 & & \\
\hline AEMBL 369 & 528086 & 7.4089 & 6.4792 & \\
\hline AEMBL3S & 86 & 8.3979 & & \\
\hline HEMBL= & 36 & 6 & 528 & 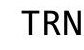 \\
\hline AEMBL: & 86 & 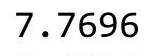 & 3502 & 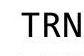 \\
\hline HEMBL; & 36 & 18 & 29 & \\
\hline 26 & 528086 & 6. & 5938 & \\
\hline AEMBL36 & 86 & 6.0 & & N \\
\hline HEMBL & 8086 & 8.40 & 8.7849 & $\cdots$ \\
\hline AEMBL & 36 & 6 & 11 & RN \\
\hline AFMRI & 86 & 8 . & 89 & RN \\
\hline AEMBL3 & & 5 & 6.1133 & 15 \\
\hline AEMBL3690951 & 36 & 7. & 33 & IRIV \\
\hline HEMBL3 & 3086 & 7.8861 & 87 & RN \\
\hline HEMBL & & 79 & 69 & RN \\
\hline 10 & 36 & 15 & 08 & RN \\
\hline AEMBL3691023 & & 7.5086 & 88 & IRN \\
\hline HEMBL3686387 & 528086 & & 6.6029 & TST \\
\hline HEMBL36 & 28086 & 27 & 7.8518 & $\Gamma \mathrm{RN}$ \\
\hline HᄃMD - & 36 & & 768 & RN \\
\hline HEMBL; & & 7.935 & 7.6675 & IST \\
\hline HEMBL3695110 & 528086 & 6 & 6.6781 & $\Gamma \mathrm{RN}$ \\
\hline IEMBL3 & 528086 & & 7.4686 & $\Gamma \mathrm{RN}$ \\
\hline HEMBL3S & 528086 & 8 & 3.6228 & \\
\hline HEMBL 36 & 528086 & 6.0 & 5.9889 & IST \\
\hline HEMBL39 & 528086 & $8.5 e$ & 8.46 & RN \\
\hline AEMBL369e & 528086 & 7.1249 & 6.9704 & TRN \\
\hline MRI 3 & $=200$ & 8 & 8.2069 & 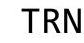 \\
\hline HEMBL36 & 528086 & & 5.9589 & \\
\hline HEMBL3686366 & 528086 & 6.0 & 6.4377 & \\
\hline LHEMBL3912063 & 1528086 & 8.5686 & 8.0789 & RN \\
\hline
\end{tabular}


Supplemental Table S2.txt

\begin{tabular}{|c|c|c|c|c|}
\hline CHEMBL3939834 & 1528086 & 7.9586 & 7.6428 & TRN \\
\hline CHEMBL3695192 & 1528086 & 7.6383 & 7.1362 & TRN \\
\hline CHEMBL3695102 & 1528086 & 8.2291 & 6.9545 & TRN \\
\hline CHEMBL3690981 & 1528086 & 7.4949 & 7.2322 & TRN \\
\hline CHEMBL3977717 & 1528086 & 8.0706 & 8.213 & TRN \\
\hline CHEMBL3930693 & 1528086 & 8.1308 & 8.0231 & TST \\
\hline CHEMBL 3690942 & 1528086 & 8.8239 & 6.5799 & TST \\
\hline CHEMBL 3945430 & 1528086 & 7.6576 & \multicolumn{2}{|c|}{ 7.718999999999999 } \\
\hline CHEMBL 3695133 & 1528086 & 8.1192 & 7.8891 & TRN \\
\hline CHEMBL3980385 & 1528086 & 7.6576 & 7.9766 & TRN \\
\hline CHEMBL 3691008 & 1528086 & 7.9393 & 8.1115 & TRN \\
\hline CHEMBL3695112 & 1528086 & 7.7696 & 7.3927 & TRN \\
\hline CHEMBL3942254 & 1528086 & 8.8539 & 8.7346 & TRN \\
\hline CHEMBL 3695160 & 1528086 & 8.2757 & 8.0692 & TRN \\
\hline CHEMBL3691035 & 1528086 & 7.9606 & 7.6461 & TRN \\
\hline CHEMBL3690961 & 1528086 & 7.3279 & 7.362 & TRN \\
\hline CHEMBL3695163 & 1528086 & 7.7447 & 7.7966 & TRN \\
\hline CHEMBL3695138 & 1528086 & 7.6576 & 7.9291 & TRN \\
\hline CHEMBL 3925251 & 1528086 & 8.6676 & 8.3951 & TRN \\
\hline CHEMBL3981185 & 1528086 & 7.9208 & \multicolumn{2}{|c|}{8.187999999999999} \\
\hline CHEMBL3695105 & 1528086 & 8.8539 & 8.9366 & TRN \\
\hline CHEMBL3690958 & 1528086 & 8.3279 & 7.0272 & TRN \\
\hline CHEMBL3695178 & 1528086 & 7.6198 & 7.3862 & TRN \\
\hline CHEMBL3691021 & 1528086 & 7.8239 & 8.2002 & TRN \\
\hline CHEMBL 3690976 & 1528086 & 8.475 & 8.0106 & TRN \\
\hline CHEMBL 3695073 & 1528086 & 8.3233 & 8.6708 & TRN \\
\hline CHEMBL 3690902 & 1528086 & 7.6576 & 7.3116 & TRN \\
\hline CHEMBL3639940 & 1528086 & 8.1024 & 8.1071 & TRN \\
\hline CHEMBL 3690940 & 1528086 & 6.0 & 7.0114 & TRN \\
\hline CHEMBL3904022 & 1528086 & 8.1871 & 8.5516 & TST \\
\hline CHEMBL 3686470 & 1528086 & 6.0 & 6.7232 & TST \\
\hline CHEMBL3690953 & 1528086 & 7.4089 & 7.1507 & TRN \\
\hline CHEMBL3690982 & 1528086 & 7.8539 & 7.4709 & TRN \\
\hline CHEMBL 3695124 & 1528086 & 8.0605 & 8.3117 & TRN \\
\hline CHEMBL 3686458 & 1528086 & 6.0 & 6.8488 & TRN \\
\hline CHEMBL3686461 & 1528086 & 7.3872 & 6.865 & TST \\
\hline CHEMBL3889564 & 1528086 & 8.4949 & 8.2275 & TRN \\
\hline CHEMBL3690983 & 1528086 & 6.0 & 7.1225 & TRN \\
\hline CHEMBL3690989 & 1528086 & 8.8239 & 6.8982 & TST \\
\hline CHEMBL3919159 & 1528086 & 7.2518 & 7.7715 & TST \\
\hline CHEMBL3948022 & 1528086 & 8.5528 & 8.3227 & TRN \\
\hline CHEMBL3945553 & 1528086 & 8.5086 & 8.4229 & TST \\
\hline CHEMBL3686451 & 1528086 & 6.0 & 6.928 & TRN \\
\hline CHEMBL3690934 & 1528086 & 8.2596 & 6.7043 & TRN \\
\hline CHEMBL3690834 & 1528086 & 7.8239 & 6.9786 & TRN \\
\hline CHEMBL3695071 & 1528086 & 8.3665 & 8.5917 & TRN \\
\hline CHEMBL3691018 & 1528086 & 8.426 & 8.1539 & TRN \\
\hline CHEMBL3972566 & 1528086 & 8.0362 & 8.4358 & TST \\
\hline
\end{tabular}




\begin{tabular}{|c|c|c|c|c|}
\hline \multicolumn{5}{|c|}{ Supplemental Table S2.txt } \\
\hline CHEMBL3686393 & 1528086 & 6.0 & 5.7404 & TRN \\
\hline CHEMBL 3695144 & 1528086 & 6.0 & 6.8609 & TRN \\
\hline CHEMBL3690970 & 1528086 & 7.7696 & 7.2466 & TRN \\
\hline CHEMBL 3968546 & 1528086 & 8.2716 & 8.0839 & TRN \\
\hline CHEMBL 3686444 & 1528086 & 6.0 & 6.3201 & TST \\
\hline CHEMBL3916746 & 1528086 & 8.8861 & 8.6508 & TST \\
\hline CHEMBL 3690922 & 1528086 & 6.7447 & 6.5377 & TRN \\
\hline CHEMBL3695196 & 1528086 & 7.8861 & 6.8186 & TRN \\
\hline CHEMBL3690999 & 1528086 & 7.8539 & 7.6425 & TRN \\
\hline CHEMBL 3893347 & 1528086 & 7.699 & 7.6337 & TRN \\
\hline CHEMBL3691014 & 1528086 & 7.9031 & 8.0214 & TRN \\
\hline CHEMBL 3955292 & 1528086 & 8.4815 & 8.7322 & TRN \\
\hline CHEMBL3695088 & 1528086 & 8.0 & 8.0193 & TRN \\
\hline CHEMBL 3980728 & 1528086 & 8.4202 & 8.2739 & TRN \\
\hline CHEMBL3686389 & 1528086 & 6.0 & 6.7714 & TRN \\
\hline CHEMBL3695143 & 1528086 & 6.0 & 6.3383 & TRN \\
\hline CHEMBL3695137 & 1528086 & 8.041 & 7.5882 & TRN \\
\hline CHEMBL3686373 & 1528086 & 7.5086 & 7.3728 & TRN \\
\hline CHEMBL3956350 & 1528086 & 6.7447 & 7.4106 & TST \\
\hline CHEMBL3695173 & 1528086 & 8.2441 & 6.7704 & TST \\
\hline CHEMBL3695106 & 1528086 & 8.4685 & 8.3232 & TRN \\
\hline CHEMBL 3930828 & 1528086 & 8.0605 & 7.8128 & TRN \\
\hline CHEMBL3961234 & 1528086 & 6.6778 & 8.0779 & TST \\
\hline CHEMBL3964127 & 1528086 & 8.3768 & 8.0836 & TRN \\
\hline CHEMBL3949968 & 1528086 & 8.2076 & 8.6117 & TST \\
\hline CHEMBL3695092 & 1528086 & 8.3665 & 8.7082 & TRN \\
\hline CHEMBL 3695172 & 1528086 & 7.3188 & 6.3952 & TST \\
\hline CHEMBL3691002 & 1528086 & 7.8861 & 7.9226 & TRN \\
\hline CHEMBL 3939386 & 1528086 & 7.3665 & 7.4032 & TRN \\
\hline CHEMBL3686360 & 1528086 & 6.0 & 6.6736 & TRN \\
\hline CHEMBL3695117 & 1528086 & 6.0 & 6.8449 & TRN \\
\hline CHEMBL 3695115 & 1528086 & 7.8239 & 7.513 & TRN \\
\hline CHEMBL3691003 & 1528086 & 6.0 & 6.7572 & TRN \\
\hline CHEMBL 3925173 & 1528086 & 8.1675 & 8.2082 & TST \\
\hline CHEMBL3916307 & 1528086 & 8.8539 & 8.7735 & TRN \\
\hline CHEMBL3686396 & 1528086 & 6.7212 & 7.0432 & TRN \\
\hline CHEMBL3686405 & 1528086 & 6.0 & 6.4033 & TST \\
\hline CHEMBL3974463 & 1528086 & 7.3872 & 8.0306 & TRN \\
\hline CHEMBL 3952564 & 1528086 & 7.5686 & 8.0994 & TRN \\
\hline CHEMBL3690947 & 1528086 & 7.7959 & 7.3509 & TST \\
\hline CHEMBL3690925 & 1528086 & 6.0 & 7.0194 & TRN \\
\hline CHEMBL3963120 & 1528086 & 7.7696 & 7.7541 & TST \\
\hline CHEMBL3962917 & 1528086 & 7.8539 & 7.8946 & TST \\
\hline CHEMBL 3946025 & 1528086 & 7.2596 & 9.0498 & TST \\
\hline CHEMBL3690835 & 1528086 & 7.4437 & 6.6927 & TRN \\
\hline CHEMBL3695158 & 1528086 & 7.7447 & 7.6193 & TRN \\
\hline CHEMBL3961134 & 1528086 & 6.3768 & 6.1471 & TST \\
\hline CHEMBL3889606 & 1528086 & 7.0706 & 7.7798 & TST \\
\hline
\end{tabular}


Supplemental Table S2.txt

\begin{tabular}{|c|c|c|c|c|c|}
\hline CHEMBL 3922117 & 1528086 & 8.5086 & 8.4156 & TRN & \\
\hline CHEMBL3977600 & 1528086 & 6.6576 & 7.8035 & TRN & \\
\hline CHEMBL3922777 & 1528086 & 8.4685 & 8.3539 & TRN & \\
\hline CHEMBL3690921 & 1528086 & 7.5686 & 6.9806 & TRN & \\
\hline CHEMBL 3695188 & 1528086 & 7.9208 & 7.9137 & TRN & \\
\hline CHEMBL 3686362 & 1528086 & 7.4815 & 6.5939 & TRN & \\
\hline CHEMBL3686429 & 1528086 & 6.0 & 7.0995 & TRN & \\
\hline CHEMBL 3695081 & 1528086 & 8.4622 & 7.9078 & TRN & \\
\hline CHEMBL3691017 & 1528086 & 8.0269 & 7.8199 & TRN & \\
\hline CHEMBL3695167 & 1528086 & 8.6383 & 8.6549 & TRN & \\
\hline CHEMBL3902979 & 1528086 & 8.4437 & 8.1507 & TRN & \\
\hline CHEMBL3940397 & 1528086 & 7.1805 & 7.6473 & TRN & \\
\hline CHEMBL3686364 & 1528086 & 5.7959 & 5.0122 & TRN & \\
\hline CHEMBL3940827 & 1528086 & 8.9208 & 8.851 & TRN & \\
\hline CHEMBL3695135 & 1528086 & 7.7212 & 8.0852 & TRN & \\
\hline CHEMBL3691030 & 1528086 & 8.1192 & 7.5419 & TRN & \\
\hline CHEMBL3892825 & 1528086 & 7.7212 & 8.3192 & TRN & \\
\hline CHEMBL3686355 & 1528086 & 6.0 & 6.1639 & TST & \\
\hline CHEMBL 3686385 & 1528086 & 6.0 & 6.7102 & TRN & \\
\hline CHEMBL3962089 & 1528086 & 7.6198 & 7.2678 & TRN & \\
\hline CHEMBL3690964 & 1528086 & 7.6576 & 6.996 & TRN & \\
\hline CHEMBL 3686378 & 1528086 & 6.8861 & 6.80399 & 9999999999 & TRN \\
\hline CHEMBL 3695120 & 1528086 & 7.6778 & 6.8828 & TRN & \\
\hline CHEMBL 3690927 & 1528086 & 6.0 & 6.7354 & TRN & \\
\hline CHEMBL3695089 & 1528086 & 8.1739 & 7.5451 & TRN & \\
\hline CHEMBL 3695084 & 1528086 & 7.4318 & 6.6899 & TRN & \\
\hline CHEMBL 3925870 & 1528086 & 7.5528 & 7.2227 & TST & \\
\hline CHEMBL3931349 & 1528086 & 7.1871 & 8.5178 & TST & \\
\hline CHEMBL3691005 & 1528086 & 7.6778 & 7.7125 & TRN & \\
\hline CHEMBL3691019 & 1528086 & 8.2441 & 8.2241 & TRN & \\
\hline CHEMBL 3695148 & 1528086 & 7.4202 & 7.8633 & TRN & \\
\hline CHEMBL3936057 & 1528086 & 8.7696 & 8.4291 & TRN & \\
\hline CHEMBL3951154 & 1528086 & 8.3979 & 7.5694 & TST & \\
\hline CHEMBL 3968503 & 1528086 & 8.0809 & 7.8489 & TRN & \\
\hline CHEMBL 3695193 & 1528086 & 8.1192 & 8.1553 & TRN & \\
\hline CHEMBL3940010 & 1528086 & 8.0315 & 7.9128 & TST & \\
\hline CHEMBL 3897357 & 1528086 & 9.1549 & 8.9339 & TST & \\
\hline CHEMBL 3963384 & 1528086 & 8.3188 & 7.9375 & TRN & \\
\hline CHEMBL3927185 & 1528086 & 9.0458 & 8.7627 & TRN & \\
\hline CHEMBL3935116 & 1528086 & 7.301 & 7.1188 & TST & \\
\hline CHEMBL3691004 & 1528086 & 8.0132 & 7.1809 & TRN & \\
\hline CHEMBL 3695070 & 1528086 & 7.8239 & 7.9809 & TRN & \\
\hline CHEMBL3695094 & 1528086 & 8.0915 & 8.1852 & TRN & \\
\hline CHEMBL 3695114 & 1528086 & 8.1549 & \multicolumn{2}{|c|}{6.167999999999999} & TRN \\
\hline CHEMBL3956340 & 1528086 & 8.4685 & 7.7407 & TST & \\
\hline CHEMBL3695086 & 1528086 & 6.0 & 6.7212 & TRN & \\
\hline CHEMBL3690950 & 1528086 & 7.71 & 7.1571 & TRN & \\
\hline CHEMBL 3690837 & 1528086 & 8.0809 & 7.4757 & TRN & \\
\hline
\end{tabular}


Supplemental Table S2.txt

\begin{tabular}{|c|c|c|c|c|c|}
\hline CHEMBL3690935 & 1528086 & 8.2924 & 6.9494 & TRN & \\
\hline CHEMBL 3690967 & 1528086 & 6.0 & 7.1452 & TRN & \\
\hline CHEMBL3938954 & 1528086 & 7.4949 & 7.9262 & TST & \\
\hline CHEMBL3925512 & 1528086 & 8.2882 & 8.0755 & TRN & \\
\hline CHEMBL 3690956 & 1528086 & 8.5229 & 6.3825 & TST & \\
\hline CHEMBL 3686383 & 1528086 & 6.0 & 6.1982 & TRN & \\
\hline CHEMBL3940159 & 1528086 & 8.1739 & 8.5786 & TST & \\
\hline CHEMBL 3984813 & 1528086 & 7.5528 & 8.7361 & TST & \\
\hline CHEMBL 3686367 & 1528086 & 5.3565 & 6.019 & TRN & \\
\hline CHEMBL 3695111 & 1528086 & 6.0 & 6.4198 & TRN & \\
\hline CHEMBL 3690973 & 1528086 & 7.2218 & 7.2133 & TRN & \\
\hline CHEMBL 3690988 & 1528086 & 7.4089 & 7.7468 & TRN & \\
\hline CHEMBL 3892744 & 1528086 & 8.6383 & 8.2817 & TST & \\
\hline CHEMBL3690932 & 1528086 & 6.0 & 7.0947 & TRN & \\
\hline CHEMBL 3964158 & 1528086 & 7.7696 & 8.0476 & TRN & \\
\hline CHEMBL3934475 & 1528086 & 8.4685 & 8.3205 & TRN & \\
\hline CHEMBL3929737 & 1528086 & 7.4318 & 7.3555 & TRN & \\
\hline CHEMBL3639853 & 1528086 & 6.0 & 6.937 & TRN & \\
\hline CHEMBL 3905092 & 1528086 & 8.3665 & 8.1303 & TRN & \\
\hline CHEMBL 3939981 & 1528086 & 7.4949 & 7.4714 & TST & \\
\hline CHEMBL3695091 & 1528086 & 8.3279 & 8.59799 & 9999999999 & TRN \\
\hline CHEMBL 3920555 & 1528086 & 7.3768 & 6.7734 & TST & \\
\hline CHEMBL3931769 & 1528086 & 8.1549 & 7.9365 & TRN & \\
\hline CHEMBL 3983357 & 1528086 & 7.9208 & 8.1345 & TRN & \\
\hline CHEMBL 3690832 & 1528086 & 7.6576 & 6.6535 & TRN & \\
\hline CHEMBL3951031 & 1528086 & 8.8861 & 8.0148 & TST & \\
\hline CHEMBL 3695182 & 1528086 & 7.8539 & 7.5532 & TRN & \\
\hline CHEMBL3690938 & 1528086 & 6.0 & 6.5963 & TST & \\
\hline CHEMBL 3695164 & 1528086 & 8.0362 & 7.5886 & TRN & \\
\hline CHEMBL 3919784 & 1528086 & 8.2596 & 8.1343 & TRN & \\
\hline CHEMBL3937268 & 1528086 & 7.1024 & 7.4277 & TST & \\
\hline CHEMBL 3929276 & 1528086 & 7.9586 & 8.5047 & TST & \\
\hline CHEMBL 3695125 & 1528086 & 7.9208 & 8.6333 & TRN & \\
\hline CHEMBL3949426 & 1528086 & 8.0022 & 7.7582 & TRN & \\
\hline CHEMBL3979235 & 1528086 & 8.6383 & 8.3534 & TRN & \\
\hline CHEMBL3695187 & 1528086 & 7.7696 & 7.6717 & TRN & \\
\hline CHEMBL 3690941 & 1528086 & 6.0 & 6.6329 & TRN & \\
\hline CHEMBL 3695200 & 1528086 & 7.2596 & 7.6773 & TRN & \\
\hline CHEMBL3691032 & 1528086 & 7.9208 & 6.9506 & TRN & \\
\hline CHEMBL3959967 & 1528086 & 7.5086 & 7.5253 & TRN & \\
\hline CHEMBL3695147 & 1528086 & 7.699 & 7.6142 & TRN & \\
\hline CHEMBL 3905060 & 1528086 & 4.8447 & 6.5185 & TST & \\
\hline CHEMBL3984989 & 1528086 & 8.3279 & 8.485 & TRN & \\
\hline CHEMBL 3690817 & 1528086 & 8.1135 & 6.4881 & TRN & \\
\hline CHEMBL 3903420 & 1528086 & 7.0315 & 7.4135 & TST & \\
\hline CHEMBL 3690985 & 1528086 & 7.5017 & 6.9097 & TRN & \\
\hline CHEMBL 3914674 & 1528086 & 8.7696 & 8.5226 & TRN & \\
\hline CHEMBL 3690995 & 1528086 & 6.0 & 6.3545 & TST & \\
\hline
\end{tabular}


Supplemental Table S2.txt

\begin{tabular}{|c|c|c|c|c|c|}
\hline CHEMBL3695186 & 1528086 & 7.8861 & 7.1519 & TRN & \\
\hline CHEMBL3695194 & 1528086 & 7.9208 & 7.9309 & TRN & \\
\hline CHEMBL3690960 & 1528086 & 8.6576 & 7.4791 & TRN & \\
\hline CHEMBL3691001 & 1528086 & 8.0555 & 8.0109 & TRN & \\
\hline CHEMBL3979552 & 1528086 & 7.3565 & 7.4392 & TST & \\
\hline CHEMBL3909291 & 1528086 & 6.0 & 7.8549 & TRN & \\
\hline CHEMBL3690818 & 1528086 & 7.7212 & 6.9889 & TRN & \\
\hline CHEMBL3950500 & 1528086 & 8.3188 & 8.1905 & TST & \\
\hline CHEMBL3686365 & 1528086 & 5.2596 & 5.2811 & TRN & \\
\hline CHEMBL3963408 & 1528086 & 8.0458 & 8.0616 & TRN & \\
\hline CHEMBL3695168 & 1528086 & 7.5229 & 6.5017 & TST & \\
\hline CHEMBL3902187 & 1528086 & 7.7447 & 7.4906 & TRN & \\
\hline CHEMBL3971193 & 1528086 & 7.8861 & 8.06299 & 7999999999 & TST \\
\hline CHEMBL3695126 & 1528086 & 7.2291 & 7.9471 & TRN & \\
\hline CHEMBL3691029 & 1528086 & 8.1051 & 7.4278 & TRN & \\
\hline CHEMBL3914329 & 1528086 & 8.0969 & 8.14 & TRN & \\
\hline CHEMBL3957486 & 1528086 & 7.6383 & 7.3841 & TST & \\
\hline CHEMBL3686403 & 1528086 & 6.0 & 7.035 & TRN & \\
\hline CHEMBL3979531 & 1528086 & 7.6383 & 8.2179 & TRN & \\
\hline CHEMBL3940767 & 1528086 & 8.4145 & 8.0782 & TRN & \\
\hline CHEMBL3691007 & 1528086 & 8.1707 & 7.675 & TRN & \\
\hline CHEMBL3690937 & 1528086 & 6.0 & 6.7517 & TST & \\
\hline CHEMBL3960421 & 1528086 & 8.7447 & 7.7153 & TST & \\
\hline CHEMBL3936930 & 1528086 & 8.2007 & 7.7803 & TRN & \\
\hline CHEMBL3916020 & 1528086 & 7.8539 & 7.65799 & 99999999995 & TRN \\
\hline CHEMBL3981190 & 1528086 & 7.699 & 7.3261 & TST & \\
\hline CHEMBL3686421 & 1528086 & 6.0 & 6.8551 & TRN & \\
\hline CHEMBL3690991 & 1528086 & 7.8861 & 7.9248 & TRN & \\
\hline CHEMBL3948866 & 1528086 & 6.0 & \multicolumn{2}{|c|}{7.5120000000000005} & TRN \\
\hline CHEMBL3690987 & 1528086 & 7.7696 & 7.1474 & TRN & \\
\hline CHEMBL 3695197 & 1528086 & 7.3372 & 7.4334 & TRN & \\
\hline CHEMBL 3690847 & 1528086 & 7.1805 & 7.2032 & TST & \\
\hline CHEMBL3690909 & 1528086 & 6.0 & 6.8318 & TRN & \\
\hline CHEMBL3967482 & 1528086 & 5.4559 & 6.3283 & TRN & \\
\hline CHEMBL3686442 & 1528086 & 6.0 & 5.5886 & TRN & \\
\hline CHEMBL3695104 & 1528086 & 8.6778 & 8.7511 & TRN & \\
\hline CHEMBL3686423 & 1528086 & 6.0 & 7.0871 & TRN & \\
\hline CHEMBL3948325 & 1528086 & 8.2366 & 8.3442 & TST & \\
\hline CHEMBL 3691020 & 1528086 & 8.2798 & 7.093 & TRN & \\
\hline CHEMBL3912457 & 1528086 & 8.3872 & 8.631 & TRN & \\
\hline CHEMBL3686414 & 1528086 & 6.0 & 6.8854 & TST & \\
\hline CHEMBL3895339 & 1528086 & 8.1871 & 8.4936 & TRN & \\
\hline CHEMBL3911163 & 1528086 & 8.4815 & 8.1634 & TRN & \\
\hline CHEMBL3984569 & 1528086 & 7.5376 & 7.6298 & TST & \\
\hline CHEMBL3695154 & 1528086 & 8.0809 & 8.2039 & TRN & \\
\hline CHEMBL3916006 & 1528086 & 8.5229 & 8.5296 & TST & \\
\hline CHEMBL3690901 & 1528086 & 7.9393 & 6.8331 & TRN & \\
\hline CHEMBL3691031 & 1528086 & 8.0969 & 7.6926 & TRN & \\
\hline
\end{tabular}


Supplemental Table S2.txt

\begin{tabular}{|c|c|c|c|c|}
\hline 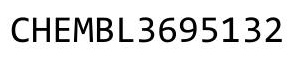 & & & & \\
\hline HEMBL3918224 & 528086 & 8.2291 & 8.1833 & \\
\hline & & & & \\
\hline 434 & 28086 & 6 & 081 & \\
\hline IEMBL3970495 & 528086 & 8.7696 & 9825 & \\
\hline AEMBL3904338 & 528086 & 8.1739 & 2631 & \\
\hline HEMBL3695157 & 528086 & .8861 & .7821 & \\
\hline 21 & 28086 & 696 & 9952 & \\
\hline IEMBL 3695134 & 528086 & 8.1871 & .7414 & \\
\hline AEMBL3964378 & 528086 & 6.8861 & .9528 & \\
\hline HEMBL3690997 & 528086 & 8.1972 & 3028 & \\
\hline HEMBL395 & 528086 & 135 & .3307 & \\
\hline 10 & & & & \\
\hline AEMBL & 528086 & 7.9586 & .7652 & \\
\hline AEMBL3690912 & 528086 & 6 . & 6183 & \\
\hline AEMBL3965453 & 528086 & 655 & 29 & \\
\hline HEMBL36 & 28086 & 862 & .3804 & \\
\hline HEMBL36 & & 188 & .9675 & \\
\hline HEMBL & 86 & 539 & .0626 & \\
\hline AEMBL3695155 & 8086 & 202 & 501 & \\
\hline AEMBL3903352 & 28086 & 021 & 9278 & KIV \\
\hline HEMBL3C & 86 & 37 & $\partial 11$ & RN \\
\hline HEMBL3S & 36 & & & \\
\hline 11 & 86 & 6 & & \\
\hline HEMBL 369 & 86 & 376 & 36 & RIV \\
\hline L3s & 28 & 24 & 33 & ГRN \\
\hline 5 & 28 & 685 & 16 & ST \\
\hline 0 & 36 & 61 & & \\
\hline AEMBL3 & 36 & & & SI - r r r \\
\hline AEMBL3S & 28 & 5. & 04 & RN \\
\hline IEMBL 3S & 28086 & 576 & 622 & ST \\
\hline 5 & 28 & 58 & 67 & ST \\
\hline 8 & 86 & 6 & & $\Gamma \mathrm{RN}$ \\
\hline HEMBL 3921 & & & & IST \\
\hline JEMBL3695087 & 528086 & 586 & 798 & RN \\
\hline AEMBL3 & 28086 & 208 & 089 & \\
\hline $15 \mathrm{MPI}=$ & $-2-2>$ & 18 & & ST \\
\hline & 6 & & 7.4776 & TRN \\
\hline HEMBL3695166 & 528086 & 8.4437 & 4188 & TRN \\
\hline IEMBL 394 & 528086 & 586 & 212 & TST \\
\hline HEMBL3690911 & 528086 & 6 & . 3151 & RN \\
\hline HEMBL3912468 & & & 2375 & ST \\
\hline HEMBL3690916 & 528086 & 6. & 8203 & ST \\
\hline HEMBL3938645 & 528086 & 8.2596 & 8.344 & ST \\
\hline IFMP 2600 & 5280 & & 5.7163 & 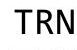 \\
\hline HEMBL3695 & 528086 & .0809 & 7.9893 & \\
\hline 和 & 528 & .1549 & 7.5651 & \\
\hline CHEMBL3695189 & 152808 & 7.7212 & 7.3632 & RN \\
\hline
\end{tabular}


Supplemental Table S2.txt

\begin{tabular}{|c|c|c|c|c|c|}
\hline CHEMBL3695153 & 1528086 & 7.9208 & 7.1545 & TRN & \\
\hline CHEMBL3920967 & 1528086 & 8.0362 & 8.8225 & TST & \\
\hline CHEMBL3690910 & 1528086 & 6.0 & 7.2513 & TRN & \\
\hline CHEMBL 3942641 & 1528086 & 7.5376 & 8.2803 & TST & \\
\hline CHEMBL3690965 & 1528086 & 7.699 & 7.3681 & TRN & \\
\hline CHEMBL3910766 & 1528086 & 8.28399 & 99999999 & 99 & 8.0875 \\
\hline CHEMBL 3970488 & 1528086 & 8.5376 & 7.9182 & TST & \\
\hline CHEMBL3695077 & 1528086 & 7.7959 & 8.2007 & TRN & \\
\hline CHEMBL3905890 & 1528086 & 7.9586 & 8.0937 & TRN & \\
\hline CHEMBL3690914 & 1528086 & 6.0 & 6.2159 & TST & \\
\hline CHEMBL3695122 & 1528086 & 7.4437 & 7.7177 & TRN & \\
\hline CHEMBL3954667 & 1528086 & 7.7959 & 7.9948 & TRN & \\
\hline CHEMBL3695075 & 1528086 & 7.699 & 8.0598 & TRN & \\
\hline CHEMBL3695090 & 1528086 & 8.2518 & 7.7611 & TRN & \\
\hline CHEMBL1383315 & 1528086 & 7.6576 & 7.0218 & TST & \\
\hline CHEMBL3691000 & 1528086 & 8.2757 & 7.9808 & TRN & \\
\hline CHEMBL3695162 & 1528086 & 7.5686 & 6.8454 & TRN & \\
\hline CHEMBL3978770 & 1528086 & 8.585 & 8.0583 & TRN & \\
\hline CHEMBL 3686448 & 1528086 & 6.0 & 7.1119 & TRN & \\
\hline CHEMBL3695118 & 1528086 & 8.1367 & 7.7482 & TRN & \\
\hline CHEMBL3695093 & 1528086 & 8.6383 & 8.7229 & TRN & \\
\hline CHEMBL3965503 & 1528086 & 7.2218 & 7.5104 & TRN & \\
\hline CHEMBL 3690972 & 1528086 & 7.7959 & 7.364 & TRN & \\
\hline CHEMBL3927526 & 1528086 & 8.3279 & 8.0426 & TST & \\
\hline CHEMBL 3686413 & 1528086 & 6.0 & 6.5887 & TST & \\
\hline CHEMBL 3686400 & 1528086 & 6.0 & 6.9063 & TRN & \\
\hline CHEMBL3691006 & 1528086 & 8.2798 & 7.7181 & TRN & \\
\hline CHEMBL 3690851 & 1528086 & 6.699 & 6.6318 & TST & \\
\hline CHEMBL3970064 & 1528086 & 7.8861 & 7.9575 & TRN & \\
\hline CHEMBL 3918583 & 1528086 & 7.7696 & 7.7992 & TRN & \\
\hline CHEMBL 3925031 & 1528086 & 8.8539 & 8.6521 & TST & \\
\hline CHEMBL 3902410 & 1528086 & 7.8539 & 8.1838 & TST & \\
\hline CHEMBL3691026 & 1528086 & 7.8861 & 7.8641 & TRN & \\
\hline CHEMBL3691028 & 1528086 & 7.9208 & 6.8116 & TRN & \\
\hline CHEMBL 3686427 & 1528086 & 6.0 & 6.7635 & TRN & \\
\hline CHEMBL 3690954 & 1528086 & 8.4949 & 6.9108 & TST & \\
\hline CHEMBL3695180 & 1528086 & 7.3468 & 7.3092 & TST & \\
\hline CHEMBL3695069 & 1528086 & 7.8861 & 7.7887 & TRN & \\
\hline CHEMBL3912300 & 1528086 & 8.6882 & 8.5958 & TRN & \\
\hline CHEMBL 3976886 & 1528086 & 7.2676 & 8.479 & TST & \\
\hline CHEMBL3904316 & 1528086 & 7.7212 & 7.6065 & TST & \\
\hline CHEMBL3975931 & 1528086 & 6.2441 & 6.6737 & TRN & \\
\hline CHEMBL3695076 & 1528086 & 7.8539 & 7.8575 & TRN & \\
\hline CHEMBL3686370 & 1528086 & 7.3979 & 6.8766 & TRN & \\
\hline CHEMBL3933121 & 1528086 & 8.6778 & 8.8087 & TST & \\
\hline CHEMBL3695068 & 1528086 & 7.9412 & 7.4701 & TRN & \\
\hline CHEMBL3695198 & 1528086 & 7.3979 & 7.8492 & TRN & \\
\hline CHEMBL3686369 & 1528086 & 7.9208 & 7.4087 & TRN & \\
\hline
\end{tabular}

Page 7781 
Supplemental Table S2.txt

\begin{tabular}{|c|c|c|c|c|}
\hline CHEMBL3686352 & 1528086 & 6.0 & 7.3152 & TRN \\
\hline CHEMBL3690971 & 1528086 & 7.2441 & 6.7936 & TRN \\
\hline CHEMBL3896207 & 1528086 & 8.8239 & 7.8707 & TRN \\
\hline CHEMBL3900389 & 1528086 & 6.3279 & 6.1355 & TST \\
\hline CHEMBL3690920 & 1528086 & 6.0 & 6.8819 & TRN \\
\hline CHEMBL 3691024 & 1528086 & 7.7212 & 6.6787 & TRN \\
\hline CHEMBL3690968 & 1528086 & 7.6021 & 7.374 & TRN \\
\hline CHEMBL3695123 & 1528086 & 8.1675 & 7.7432 & TRN \\
\hline CHEMBL3695121 & 1528086 & 7.6021 & 7.7366 & TRN \\
\hline CHEMBL3686382 & 1528086 & 6.0 & 6.5712 & TRN \\
\hline CHEMBL3690923 & 1528086 & 6.0 & 7.1537 & TRN \\
\hline CHEMBL3690930 & 1528086 & 6.0 & 7.0814 & TRN \\
\hline CHEMBL3695165 & 1528086 & 8.0706 & 7.7871 & TRN \\
\hline CHEMBL3690907 & 1528086 & 6.0 & 6.8465 & TST \\
\hline CHEMBL 3686372 & 1528086 & 7.1805 & 7.44 & TRN \\
\hline CHEMBL3695131 & 1528086 & 7.7447 & 7.2659 & TRN \\
\hline CHEMBL3686398 & 1528086 & 6.0 & 6.3142 & TRN \\
\hline CHEMBL 3892408 & 1528086 & 7.3279 & 7.7979 & TRN \\
\hline CHEMBL3932471 & 1528086 & 7.5528 & 7.9128 & TRN \\
\hline CHEMBL3953336 & 1528086 & 8.1135 & 8.4685 & TST \\
\hline CHEMBL3690936 & 1528086 & 7.6108 & 7.0796 & TRN \\
\hline CHEMBL3691034 & 1528086 & 8.3565 & 7.482 & TRN \\
\hline CHEMBL41571 & 28339 & 6.7212 & 6.96200 & 0000000001 \\
\hline CHEMBL40556 & 28339 & 7.2291 & 6.7776 & TRN \\
\hline CHEMBL41273 & 28339 & 7.0605 & 6.7776 & TRN \\
\hline CHEMBL 38789 & 28339 & 7.3098 & 6.8793 & TST \\
\hline CHEMBL40470 & 28339 & 6.4089 & 6.6203 & TRN \\
\hline CHEMBL41554 & 28339 & 6.1675 & 5.9719 & TRN \\
\hline CHEMBL44360 & 28339 & 5.5229 & 5.9473 & TRN \\
\hline CHEMBL40809 & 28339 & 7.2676 & 6.96200 & 0000000001 \\
\hline CHEMBL294929 & 28339 & 6.7447 & 7.0163 & TRN \\
\hline CHEMBL40985 & 28339 & 6.8861 & 5.8716 & TST \\
\hline CHEMBL41667 & 28339 & 5.8861 & 6.6428 & TRN \\
\hline CHEMBL295831 & 28339 & 7.284 & 7.4039 & TRN \\
\hline CHEMBL41085 & 28339 & 6.4559 & 5.9351 & TRN \\
\hline CHEMBL43984 & 28339 & 6.1249 & 6.5857 & TRN \\
\hline CHEMBL417517 & 28339 & 7.7696 & 6.7839 & TRN \\
\hline CHEMBL 287932 & 28339 & 6.7447 & 6.7776 & TRN \\
\hline CHEMBL40527 & 28339 & 7.6383 & 7.8273 & TRN \\
\hline CHEMBL40547 & 28339 & 7.3565 & 6.7776 & TRN \\
\hline CHEMBL 295156 & 28339 & 6.7122 & 6.6791 & TRN \\
\hline CHEMBL40689 & 28339 & 4.1249 & 5.0301 & TRN \\
\hline CHEMBL42371 & 28339 & 7.0132 & 6.7541 & TRN \\
\hline CHEMBL44020 & 28339 & 7.5229 & 6.8084 & TRN \\
\hline CHEMBL41330 & 28339 & 7.284 & 6.962006 & 3000000001 \\
\hline CHEMBL 295993 & 28339 & 7.2007 & 6.7776 & TRN \\
\hline CHEMBL 297834 & 28339 & 6.3872 & 6.6594 & TRN \\
\hline CHEMBL 289062 & 28339 & 6.6778 & 7.4322 & TRN \\
\hline
\end{tabular}




\begin{tabular}{|c|c|c|c|c|c|}
\hline \multicolumn{6}{|c|}{ Supplemental Table s2.txt } \\
\hline CHEMBL41891 & 28339 & 6.2218 & 6.1335 & TRN & \\
\hline CHEMBL41001 & 28339 & 7.4437 & 7.5289 & TRN & \\
\hline CHEMBL289033 & 28339 & 7.699 & 6.9699 & TRN & \\
\hline CHEMBL42575 & 28339 & 5.6383 & 6.6484 & TRN & \\
\hline CHEMBL42732 & 28339 & 6.6198 & 7.6148 & TRN & \\
\hline CHEMBL38836 & 28339 & 6.041 & 5.0775 & TRN & \\
\hline CHEMBL 297232 & 28339 & 7.1549 & 6.9218 & TST & \\
\hline CHEMBL44179 & 28339 & 5.0969 & 5.2482 & TRN & \\
\hline CHEMBL442351 & 28339 & 7.4949 & 6.9037 & TST & \\
\hline CHEMBL290606 & 28339 & 6.8861 & 7.5842 & TRN & \\
\hline CHEMBL42433 & 28339 & 7.2218 & 6.2366 & TRN & \\
\hline CHEMBL42048 & 28339 & 4.4949 & 6.1245 & TST & \\
\hline CHEMBL298330 & 28339 & 6.585 & 6.7097 & TRN & \\
\hline CHEMBL40688 & 28339 & 4.0 & 4.3795 & TRN & \\
\hline CHEMBL43810 & 28339 & 7.3565 & 6.7224 & TST & \\
\hline CHEMBL40781 & 28339 & 6.3665 & 5.83 & TRN & \\
\hline CHEMBL44099 & 28339 & 6.699 & 6.8963 & TRN & \\
\hline CHEMBL15611 & 28339 & 4.585 & 5.1272 & TRN & \\
\hline CHEMBL41184 & 28339 & 7.5086 & 7.5842 & TRN & \\
\hline CHEMBL42147 & 28339 & 6.2291 & 6.7278 & TST & \\
\hline CHEMBL 295227 & 28339 & 4.301 & 5.2478 & TRN & \\
\hline CHEMBL44016 & 28339 & 6.6778 & 6.7692 & TST & \\
\hline CHEMBL22373 & 28339 & 7.1367 & 6.7776 & TST & \\
\hline CHEMBL 297559 & 28339 & 4.9208 & 6.0441 & TST & \\
\hline CHEMBL42998 & 28339 & 7.8239 & 7.2201 & TRN & \\
\hline CHEMBL42143 & 28339 & 6.8239 & 6.8766 & TRN & \\
\hline CHEMBL41725 & 28339 & 5.7799 & 6.4471 & TST & \\
\hline CHEMBL42574 & 28339 & 7.4089 & 6.8821 & TST & \\
\hline CHEMBL291164 & 28339 & 6.284 & 6.0544 & TRN & \\
\hline CHEMBL44314 & 28339 & 5.9586 & 5.6668 & TRN & \\
\hline CHEMBL44024 & 28339 & 5.0362 & 5.3203 & TRN & \\
\hline CHEMBL40506 & 28339 & 4.0 & 6.4935 & TST & \\
\hline CHEMBL417159 & 28339 & 7.2366 & 6.8793 & TST & \\
\hline CHEMBL41714 & 28339 & 7.0315 & 6.9218 & TST & \\
\hline CHEMBL40767 & 28339 & 5.5229 & 6.4778 & TST & \\
\hline CHEMBL431513 & 28339 & 5.9208 & 5.2613 & TRN & \\
\hline CHEMBL44460 & 28339 & 7.1871 & 6.96200 & 0000000001 & TRN \\
\hline CHEMBL 288422 & 28339 & 6.8539 & 6.7765 & TST & \\
\hline CHEMBL40608 & 28339 & 8.1549 & 7.6077 & TRN & \\
\hline CHEMBL442157 & 28339 & 6.1549 & 6.8554 & TRN & \\
\hline CHEMBL40945 & 28339 & 5.9586 & 6.0087 & TRN & \\
\hline CHEMBL514499 & 955085 & 5.7326 & 5.7365 & TRN & \\
\hline CHEMBL 373751 & 955085 & 3.8682 & 3.8658 & TRN & \\
\hline CHEMBL3349342 & 955085 & 4.2047 & 4.2043 & TRN & \\
\hline CHEMBL1256459 & 955085 & 5.5296 & 5.5274 & TRN & \\
\hline CHEMBL1643959 & 955085 & 3.2412 & 3.2385 & TRN & \\
\hline CHEMBL412142 & 955085 & 3.3335 & 3.3317 & TRN & \\
\hline CHEMBL192566 & 955085 & 5.7075 & 7.27 & TST & \\
\hline
\end{tabular}




\begin{tabular}{|c|c|c|c|c|}
\hline \multirow[b]{2}{*}{ CHEMBL221137 } & \multicolumn{4}{|c|}{ Supplemental Table } \\
\hline & 955085 & 4.3035 & 4.3293 & TST \\
\hline CHEMBL1404918 & 955085 & 2.9195 & 2.9294 & TRN \\
\hline CHEMBL1788116 & 955085 & 4.3419 & 4.3406 & TRN \\
\hline CHEMBL3392440 & 955085 & 3.6958 & 3.6946 & TRN \\
\hline CHEMBL191334 & 955085 & 4.2788 & 4.2812 & TRN \\
\hline CHEMBL1230020 & 955085 & 4.3636 & 4.3668 & TRN \\
\hline CHEMBL220241 & 955085 & 3.6935 & 3.6923 & TRN \\
\hline CHEMBL240954 & 955085 & 4.1334 & 4.5355 & TST \\
\hline CHEMBL1673039 & 955085 & 3.7929 & 3.7918 & TRN \\
\hline CHEMBL92309 & 955085 & 2.9213 & 2.2238 & TST \\
\hline CHEMBL 300389 & 955085 & 6.9652 & 6.9645 & TRN \\
\hline CHEMBL1970879 & 955085 & 3.3816 & 3.3832 & TRN \\
\hline CHEMBL483849 & 955085 & 2.9133 & 2.9104 & TRN \\
\hline CHEMBL 202721 & 955085 & 5.2141 & 5.2153 & TRN \\
\hline CHEMBL472940 & 955085 & 2.9791 & 2.9758 & TRN \\
\hline CHEMBL585951 & 955085 & 5.7547 & 5.7516 & TRN \\
\hline CHEMBL 2005886 & 955085 & 4.2135 & 4.2136 & TRN \\
\hline CHEMBL1242367 & 955085 & 3.2934 & 3.2931 & TRN \\
\hline CHEMBL3186408 & 955085 & 4.4463 & 3.5947 & TST \\
\hline CHEMBL1590308 & 955085 & 2.4997 & 3.0938 & TST \\
\hline CHEMBL515416 & 955085 & 4.4559 & 4.4561 & TRN \\
\hline CHEMBL180127 & 955085 & 3.6818 & 3.6786 & TRN \\
\hline CHEMBL 222102 & 955085 & 3.8125 & 3.8066 & TRN \\
\hline CHEMBL1516890 & 955085 & 3.8001 & 3.8041 & TRN \\
\hline CHEMBL9470 & 955085 & 5.856 & 4.93 & TST \\
\hline CHEMBL 2363137 & 955085 & 4.1332 & 4.1372 & TRN \\
\hline CHEMBL1357247 & 955085 & 2.8138 & 2.8095 & TRN \\
\hline CHEMBL1909414 & 955085 & 5.1781 & 5.1754 & TRN \\
\hline CHEMBL512504 & 955085 & 6.267 & 6.2645 & TRN \\
\hline CHEMBL379300 & 955085 & 6.0276 & 6.029 & TRN \\
\hline CHEMBL573107 & 955085 & 4.7791 & 4.7803 & TRN \\
\hline CHEMBL1190711 & 955085 & 4.7706 & 4.7725 & TRN \\
\hline CHEMBL379975 & 955085 & 5.6285 & 5.6285 & TRN \\
\hline CHEMBL558642 & 955085 & 3.2971 & 3.299 & TRN \\
\hline CHEMBL189584 & 955085 & 5.4953 & 5.4962 & TRN \\
\hline CHEMBL135561 & 955085 & 4.3117 & 4.3122 & TRN \\
\hline CHEMBL 258844 & 955085 & 4.8697 & 4.8697 & TRN \\
\hline CHEMBL449158 & 955085 & 5.9072 & 6.6332 & TST \\
\hline CHEMBL65 & 955085 & 7.3647 & 7.3643 & TRN \\
\hline CHEMBL210618 & 955085 & 4.0942 & 4.1007 & TRN \\
\hline CHEMBL 259181 & 955085 & 3.5039 & 3.5055 & TRN \\
\hline CHEMBL 2144069 & 955085 & 4.3631 & 4.3602 & TRN \\
\hline CHEMBL3199475 & 955085 & 4.3256 & 4.3276 & TRN \\
\hline CHEMBL393929 & 955085 & 4.1088 & 4.1067 & TRN \\
\hline CHEMBL483847 & 955085 & 4.2936 & 4.2938 & TRN \\
\hline CHEMBL 209148 & 955085 & 4.5897 & 3.8577 & TST \\
\hline CHEMBL 213100 & 955085 & 3.6915 & 3.2482 & TST \\
\hline CHEMBL392695 & 955085 & 4.6872 & 4.3267 & TST \\
\hline
\end{tabular}




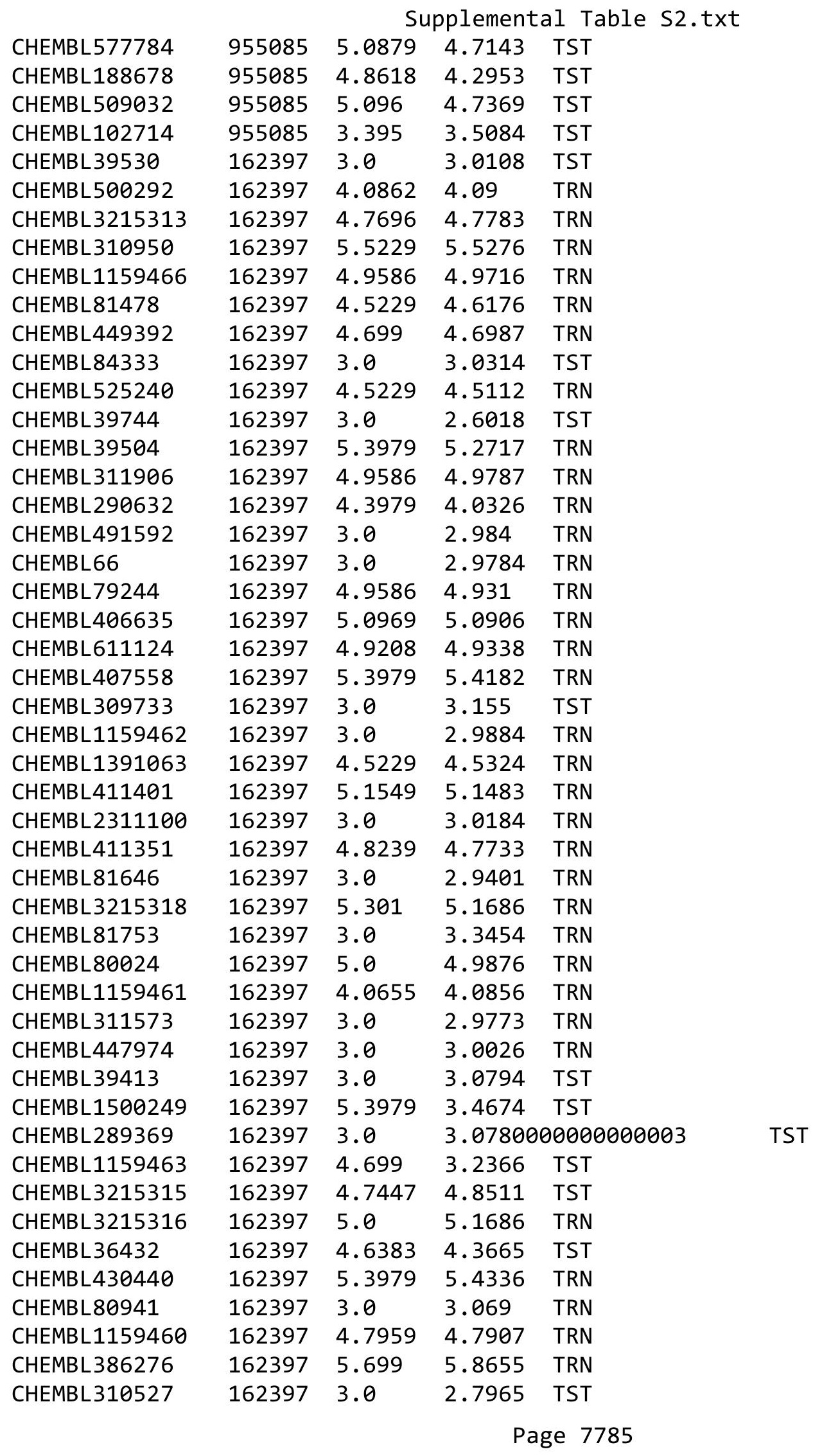




\begin{tabular}{|c|c|c|c|c|c|}
\hline \multicolumn{6}{|c|}{ Supplemental Table s2.txt } \\
\hline CHEMBL507308 & 162397 & 5.3979 & 5.3699 & TRN & \\
\hline CHEMBL78573 & 162397 & 4.3188 & 4.2652 & TRN & \\
\hline CHEMBL522251 & 162397 & 3.0 & 2.7616 & TST & \\
\hline CHEMBL82762 & 162397 & 4.8239 & 4.7955 & TRN & \\
\hline CHEMBL1159468 & 162397 & 4.699 & 4.7128 & TRN & \\
\hline CHEMBL1159467 & 162397 & 4.7959 & 4.7718 & TRN & \\
\hline CHEMBL3215502 & 162397 & 5.5229 & 5.5215 & TRN & \\
\hline CHEMBL36985 & 162397 & 4.1938 & 3.2021 & TST & \\
\hline CHEMBL407914 & 162397 & 5.3979 & 5.3815 & TRN & \\
\hline CHEMBL480283 & 162397 & 3.0 & 2.5036 & TST & \\
\hline CHEMBL458032 & 1636929 & 6.3002 & 6.45700 & 0000000001 & TRN \\
\hline CHEMBL3977695 & 1636929 & 5.6436 & 5.5987 & TRN & \\
\hline CHEMBL3909783 & 1636929 & 5.8775 & 5.9429 & TRN & \\
\hline CHEMBL474386 & 1636929 & 7.7959 & 7.2903 & TST & \\
\hline CHEMBL456789 & 1636929 & 7.3279 & 7.5679 & TRN & \\
\hline CHEMBL3894158 & 1636929 & 4.0 & 4.1401 & TRN & \\
\hline CHEMBL3901150 & 1636929 & 4.0 & 4.1037 & TRN & \\
\hline CHEMBL3928467 & 1636929 & 7.3768 & 7.0157 & TST & \\
\hline CHEMBL3964774 & 1636929 & 4.0 & 4.0227 & TRN & \\
\hline CHEMBL3902567 & 1636929 & 8.0458 & 8.1985 & TRN & \\
\hline CHEMBL3920429 & 1636929 & 6.3645 & 6.4152 & TRN & \\
\hline CHEMBL92968 & 1636929 & 4.0 & 3.9242 & TRN & \\
\hline CHEMBL1350192 & 1636929 & 7.4089 & 8.2438 & TST & \\
\hline CHEMBL456790 & 1636929 & 7.8861 & 7.8175 & TRN & \\
\hline CHEMBL1595169 & 1636929 & 7.3372 & 7.9158 & TST & \\
\hline CHEMBL3966552 & 1636929 & 4.0 & 5.2054 & TST & \\
\hline CHEMBL3953434 & 1636929 & 6.1325 & 6.9174 & TST & \\
\hline CHEMBL1584564 & 1636929 & 6.5376 & 7.4591 & TST & \\
\hline CHEMBL3930668 & 1636929 & 8.2218 & 8.3827 & TRN & \\
\hline CHEMBL3956835 & 1636929 & 7.699 & 7.63 & TRN & \\
\hline CHEMBL3982198 & 1636929 & 6.2495 & 6.0132 & TRN & \\
\hline CHEMBL3954826 & 1636929 & 4.0 & 4.5809 & TRN & \\
\hline CHEMBL492724 & 1636929 & 6.2652 & 6.5351 & TRN & \\
\hline CHEMBL1606905 & 1636929 & 6.8268 & 7.95100 & 00000000005 & TST \\
\hline CHEMBL3922080 & 1636929 & 7.6198 & 7.69799 & 99999999995 & TRN \\
\hline CHEMBL522491 & 1636929 & 9.0 & 8.3492 & TRN & \\
\hline CHEMBL3899799 & 1636929 & 5.393 & 5.8262 & TRN & \\
\hline CHEMBL1313846 & 1636929 & 6.8601 & 7.2686 & TST & \\
\hline CHEMBL3961510 & 1636929 & 7.3188 & 7.7459 & TRN & \\
\hline CHEMBL456374 & 1636929 & 4.0 & 3.58600 & 00000000003 & TRN \\
\hline CHEMBL444972 & 1636929 & 7.9586 & 7.7662 & TRN & \\
\hline CHEMBL3939246 & 1636929 & 4.0 & 4.0779 & TRN & \\
\hline CHEMBL3961515 & 1636929 & 4.0 & 4.1283 & TRN & \\
\hline CHEMBL1091488 & 1636929 & 6.2226 & 7.1713 & TST & \\
\hline CHEMBL3917157 & 1636929 & 6.8633 & 6.8788 & TRN & \\
\hline CHEMBL511514 & 1636929 & 6.5003 & 6.4518 & TRN & \\
\hline CHEMBL1544445 & 1636929 & 6.7352 & 6.8154 & TST & \\
\hline CHEMBL3905892 & 1636929 & 7.0506 & 7.0248 & TRN & \\
\hline
\end{tabular}


Supplemental Table S2.txt

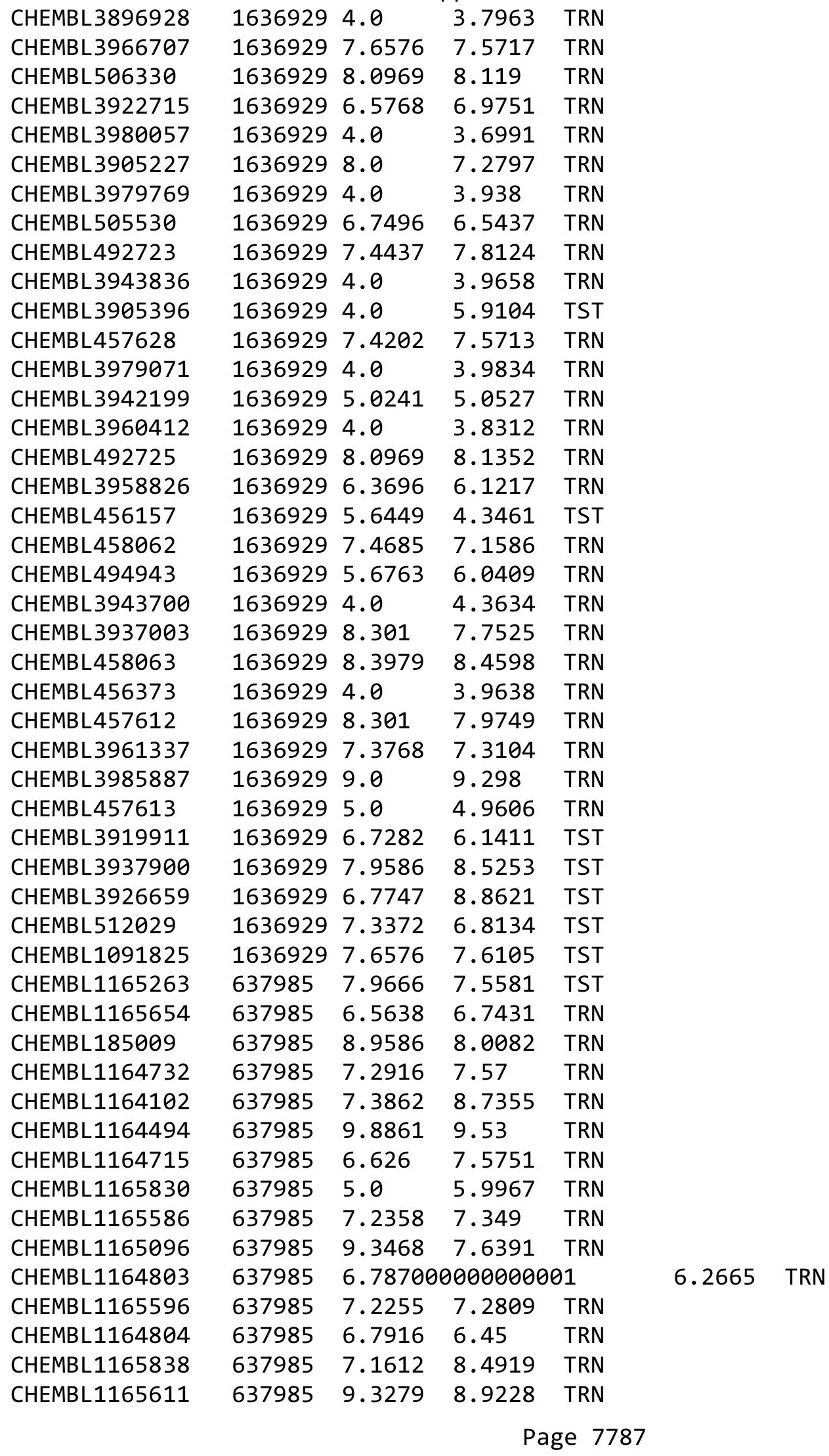




\begin{tabular}{|c|c|c|c|c|c|c|}
\hline \multicolumn{7}{|c|}{ Supplemental Table s2.txt } \\
\hline CHEMBL1165782 & 637985 & 8.1487 & 7.9644 & TST & & \\
\hline CHEMBL1165077 & 637985 & 8.6383 & 8.488 & TRN & & \\
\hline CHEMBL1164195 & 637985 & 8.0506 & 8.1759 & TRN & & \\
\hline CHEMBL1164604 & 637985 & 7.6968 & 8.1668 & TRN & & \\
\hline CHEMBL1164593 & 637985 & 8.1487 & 7.2553 & TRN & & \\
\hline CHEMBL1164798 & 637985 & 7.5045 & 7.3615 & TRN & & \\
\hline CHEMBL1165717 & 637985 & 5.0 & 6.4842 & TRN & & \\
\hline CHEMBL364616 & 637985 & 8.5686 & 8.3068 & TRN & & \\
\hline CHEMBL1164901 & 637985 & 7.4935 & 8.4094 & TRN & & \\
\hline CHEMBL1165068 & 637985 & 7.8125 & 7.9294 & TRN & & \\
\hline CHEMBL1165591 & 637985 & 5.0 & 7.9322 & TST & & \\
\hline CHEMBL1165251 & 637985 & 7.7122 & 6.8537 & TRN & & \\
\hline CHEMBL1164808 & 637985 & 7.58 & 8.1588 & TRN & & \\
\hline CHEMBL1164797 & 637985 & 8.7959 & 8.9662 & TRN & & \\
\hline CHEMBL1164963 & 637985 & 7.82100 & 000000000 & & .611000000000001 & TRN \\
\hline CHEMBL1164711 & 637985 & 7.7212 & 8.1747 & TRN & & \\
\hline CHEMBL1165037 & 637985 & 6.9389 & 7.3165 & TRN & & \\
\hline CHEMBL1165264 & 637985 & 7.5735 & 7.3143 & TST & & \\
\hline CHEMBL279144 & 637985 & 8.0969 & 7.3147 & TST & & \\
\hline CHEMBL1164669 & 637985 & 8.7447 & 8.0133 & TST & & \\
\hline CHEMBL1164668 & 637985 & 7.7878 & 9.1785 & TST & & \\
\hline CHEMBL1164676 & 637985 & 7.5421 & 7.9854 & TRN & & \\
\hline CHEMBL1165828 & 637985 & 7.8069 & 6.9666 & TRN & & \\
\hline CHEMBL1163362 & 637985 & 8.1938 & 8.064 & TRN & & \\
\hline CHEMBL1165110 & 637985 & 5.0 & 5.428 & TRN & & \\
\hline CHEMBL185148 & 637985 & 8.6021 & 7.4823 & TRN & & \\
\hline CHEMBL1165825 & 637985 & 7.8996 & 8.3597 & TRN & & \\
\hline CHEMBL1165725 & 637985 & 6.7825 & 7.1597 & TRN & & \\
\hline CHEMBL1165361 & 637985 & 7.6144 & 7.1783 & TRN & & \\
\hline CHEMBL1164103 & 637985 & 9.5528 & 8.0483 & TRN & & \\
\hline CHEMBL1164594 & 637985 & 7.3429 & 7.726 & TRN & & \\
\hline CHEMBL1164994 & 637985 & 7.1549 & 7.4071 & TST & & \\
\hline CHEMBL1164677 & 637985 & 8.0269 & 7.9792 & TST & & \\
\hline CHEMBL1164506 & 637985 & 6.9245 & 6.7331 & TRN & & \\
\hline CHEMBL1165690 & 637985 & 7.1163 & 6.9062 & TRN & & \\
\hline CHEMBL1165146 & 637985 & 8.0315 & 6.7654 & TRN & & \\
\hline CHEMBL1165592 & 637985 & 8.0555 & 8.6439 & TRN & & \\
\hline CHEMBL1165067 & 637985 & 7.9136 & 8.2848 & TRN & & \\
\hline CHEMBL1163863 & 637985 & 8.3098 & 8.2114 & TRN & & \\
\hline CHEMBL1165560 & 637985 & 10.0 & 8.1705 & TRN & & \\
\hline CHEMBL1165798 & 637985 & 7.5272 & 7.5487 & TRN & & \\
\hline CHEMBL1165084 & 637985 & 6.2423 & 6.2734 & TRN & & \\
\hline CHEMBL1165823 & 637985 & 7.8996 & 8.2544 & TRN & & \\
\hline CHEMBL1165777 & 637985 & 8.8539 & 8.3975 & TRN & & \\
\hline CHEMBL1165126 & 637985 & 7.3206 & 7.0301 & TRN & & \\
\hline CHEMBL1165105 & 637985 & 6.9747 & 7.247999 & 9999999999 & TRN & \\
\hline CHEMBL1164214 & 637985 & 5.0 & 6.0028 & TRN & & \\
\hline CHEMBL462584 & 637985 & 8.8539 & 7.9341 & TST & & \\
\hline
\end{tabular}


Supplemental Table S2.txt

\begin{tabular}{|c|c|c|c|c|}
\hline CHEMBL1164811 & 637985 & 9.2007 & 8.8283 & TRN \\
\hline CHEMBL1163795 & 637985 & 7.9872 & 8.0304 & TRN \\
\hline CHEMBL1164727 & 637985 & 6.794 & 6.871 & TRN \\
\hline CHEMBL1165147 & 637985 & 6.5884 & 6.3636 & TRN \\
\hline CHEMBL1165227 & 637985 & 8.8861 & 8.7606 & TST \\
\hline CHEMBL1165127 & 637985 & 7.0996 & 7.64 & TRN \\
\hline CHEMBL1165516 & 637985 & 7.5058 & \multicolumn{2}{|c|}{7.843999999999999} \\
\hline CHEMBL1164809 & 637985 & 7.8827 & 7.8513 & TRN \\
\hline CHEMBL1165820 & 637985 & 7.2147 & 7.0761 & TRN \\
\hline CHEMBL1165552 & 637985 & 7.8539 & 7.8694 & TRN \\
\hline CHEMBL1165066 & 637985 & 6.9431 & 7.1874 & TRN \\
\hline CHEMBL1164964 & 637985 & 7.9066 & 6.3302 & TST \\
\hline CHEMBL 363073 & 637985 & 7.8416 & 7.8356 & TST \\
\hline CHEMBL1164993 & 637985 & 7.7825 & 7.8862 & TST \\
\hline CHEMBL1164900 & 637985 & 7.2255 & 7.3395 & TST \\
\hline CHEMBL1164710 & 637985 & 7.7077 & 7.5962 & TST \\
\hline CHEMBL1165296 & 637985 & 7.7033 & 8.1273 & TST \\
\hline CHEMBL1164427 & 637985 & 8.0223 & 7.4181 & TST \\
\hline CHEMBL1165749 & 637985 & 7.7399 & 7.9541 & TST \\
\hline CHEMBL1165700 & 637985 & 7.3298 & 6.7053 & TST \\
\hline CHEMBL1164807 & 637985 & 7.0645 & 6.9439 & TST \\
\hline CHEMBL 282988 & 637985 & 6.3116 & 7.5842 & TST \\
\hline CHEMBL1367276 & 845103 & 3.0 & 2.8028 & TRN \\
\hline CHEMBL1416633 & 845103 & 3.0 & 3.0805 & TRN \\
\hline CHEMBL1338353 & 845103 & 3.0 & 3.2592 & TRN \\
\hline CHEMBL1462691 & 845103 & 4.2403 & 3.8453 & TRN \\
\hline CHEMBL 2133122 & 845103 & 4.71 & 3.7082 & TRN \\
\hline CHEMBL1905380 & 845103 & 4.4647 & 3.6616 & TRN \\
\hline CHEMBL1866688 & 845103 & 5.3354 & 3.6854 & TST \\
\hline CHEMBL1426003 & 845103 & 3.0 & 3.0407 & TRN \\
\hline CHEMBL1323988 & 845103 & 3.0 & 3.7064 & TRN \\
\hline CHEMBL1456230 & 845103 & 3.0 & 2.6892 & TST \\
\hline CHEMBL1548394 & 845103 & 3.0 & 3.3428 & TRN \\
\hline CHEMBL1536861 & 845103 & 3.0 & 2.9655 & TRN \\
\hline CHEMBL1457646 & 845103 & 3.0 & 2.7463 & TRN \\
\hline CHEMBL 2139061 & 845103 & 4.2284 & 4.1028 & TRN \\
\hline CHEMBL1510128 & 845103 & 4.5214 & 3.7567 & TRN \\
\hline CHEMBL1585462 & 845103 & 3.0 & 3.2953 & TRN \\
\hline CHEMBL1562798 & 845103 & 3.0 & 2.8252 & TST \\
\hline CHEMBL1381978 & 845103 & 3.0 & 2.9522 & TRN \\
\hline CHEMBL1528231 & 845103 & 4.3696 & 3.5236 & TRN \\
\hline CHEMBL1380586 & 845103 & 3.0 & 3.4826 & TRN \\
\hline CHEMBL1726785 & 845103 & 3.0 & 2.93300 & 00000000003 \\
\hline CHEMBL1308328 & 845103 & 3.0 & 2.8398 & TRN \\
\hline CHEMBL1405339 & 845103 & 3.0 & 3.2234 & TST \\
\hline CHEMBL1438369 & 845103 & 3.0 & 3.5408 & TRN \\
\hline CHEMBL1493429 & 845103 & 5.0367 & 3.9947 & TRN \\
\hline CHEMBL1532190 & 845103 & 4.8069 & 3.6689 & TRN \\
\hline
\end{tabular}




\begin{tabular}{|c|c|c|c|c|c|}
\hline \multicolumn{6}{|c|}{ Supplemental Table S2.txt } \\
\hline CHEMBL1539889 & 845103 & 3.0 & 3.3078 & TRN & \\
\hline CHEMBL1584091 & 845103 & 3.0 & 2.8003 & TRN & \\
\hline CHEMBL1565025 & 845103 & 3.0 & 3.3847 & TST & \\
\hline CHEMBL1453914 & 845103 & 3.0 & 3.4056 & TRN & \\
\hline CHEMBL1449966 & 845103 & 3.0 & 4.1609 & TRN & \\
\hline CHEMBL1527416 & 845103 & 3.0 & 3.1633 & TRN & \\
\hline CHEMBL1308696 & 845103 & 3.0 & 3.0682 & TRN & \\
\hline CHEMBL1425658 & 845103 & 3.0 & 3.6108 & TRN & \\
\hline CHEMBL1386687 & 845103 & 3.0 & 3.5771 & TRN & \\
\hline CHEMBL1609013 & 845103 & 3.0 & 2.5974 & TST & \\
\hline CHEMBL1566915 & 845103 & 4.7669 & 99999999 & 3.5396 & TRN \\
\hline CHEMBL1711563 & 845103 & 4.2262 & 4.1127 & TRN & \\
\hline CHEMBL1552035 & 845103 & 4.2815 & 3.6377 & TRN & \\
\hline CHEMBL1528482 & 845103 & 3.0 & 2.9189 & TRN & \\
\hline CHEMBL1467579 & 845103 & 5.3242 & 2.8377 & TST & \\
\hline CHEMBL1722498 & 845103 & 3.0 & 2.6003 & TRN & \\
\hline CHEMBL1345933 & 845103 & 3.0 & 2.83600 & 00000000003 & TRN \\
\hline CHEMBL1313891 & 845103 & 4.1163 & 4.1611 & TRN & \\
\hline CHEMBL1608635 & 845103 & 3.0 & 3.8473 & TRN & \\
\hline CHEMBL1303187 & 845103 & 3.0 & 3.6499 & TRN & \\
\hline CHEMBL1502936 & 845103 & 3.0 & 4.0748 & TRN & \\
\hline CHEMBL1362398 & 845103 & 4.52 & 4.1796 & TRN & \\
\hline CHEMBL1480147 & 845103 & 3.0 & 3.8087 & TRN & \\
\hline CHEMBL1432007 & 845103 & 3.0 & 3.8534 & TRN & \\
\hline CHEMBL1902238 & 845103 & 3.0 & 3.5972 & TRN & \\
\hline CHEMBL1558020 & 845103 & 3.0 & 3.4527 & TRN & \\
\hline CHEMBL1607435 & 845103 & 3.0 & 3.1205 & TRN & \\
\hline CHEMBL1542128 & 845103 & 3.0 & 2.9847 & TRN & \\
\hline CHEMBL1408099 & 845103 & 4.2688 & 4.2377 & TRN & \\
\hline CHEMBL1359286 & 845103 & 3.0 & 3.0333 & TRN & \\
\hline CHEMBL1482317 & 845103 & 3.0 & 2.8714 & TRN & \\
\hline CHEMBL1425795 & 845103 & 3.0 & 4.4047 & TRN & \\
\hline CHEMBL1482546 & 845103 & 3.0 & 3.6717 & TRN & \\
\hline CHEMBL1322232 & 845103 & 3.0 & 2.9399 & TRN & \\
\hline CHEMBL1874598 & 845103 & 3.0 & 3.3944 & TST & \\
\hline CHEMBL1552516 & 845103 & 3.0 & 3.5675 & TST & \\
\hline CHEMBL1899105 & 845103 & 4.1221 & 3.3863 & TRN & \\
\hline CHEMBL1430451 & 845103 & 4.8013 & 3.7173 & TST & \\
\hline CHEMBL1884458 & 845103 & 3.0 & 3.1752 & TRN & \\
\hline CHEMBL1422195 & 845103 & 3.0 & 3.7119 & TRN & \\
\hline CHEMBL1607487 & 845103 & 3.0 & 3.6477 & TRN & \\
\hline CHEMBL1426648 & 845103 & 3.0 & 3.6204 & TRN & \\
\hline CHEMBL1881925 & 845103 & 3.0 & 3.37 & TST & \\
\hline CHEMBL1312363 & 845103 & 3.0 & 3.1383 & TRN & \\
\hline CHEMBL1346274 & 845103 & 4.8153 & 3.875 & TRN & \\
\hline CHEMBL1345365 & 845103 & 3.0 & 3.0315 & TST & \\
\hline CHEMBL1987082 & 845103 & 3.0 & 3.656 & TRN & \\
\hline CHEMBL1401326 & 845103 & 3.0 & 3.0217 & TRN & \\
\hline
\end{tabular}




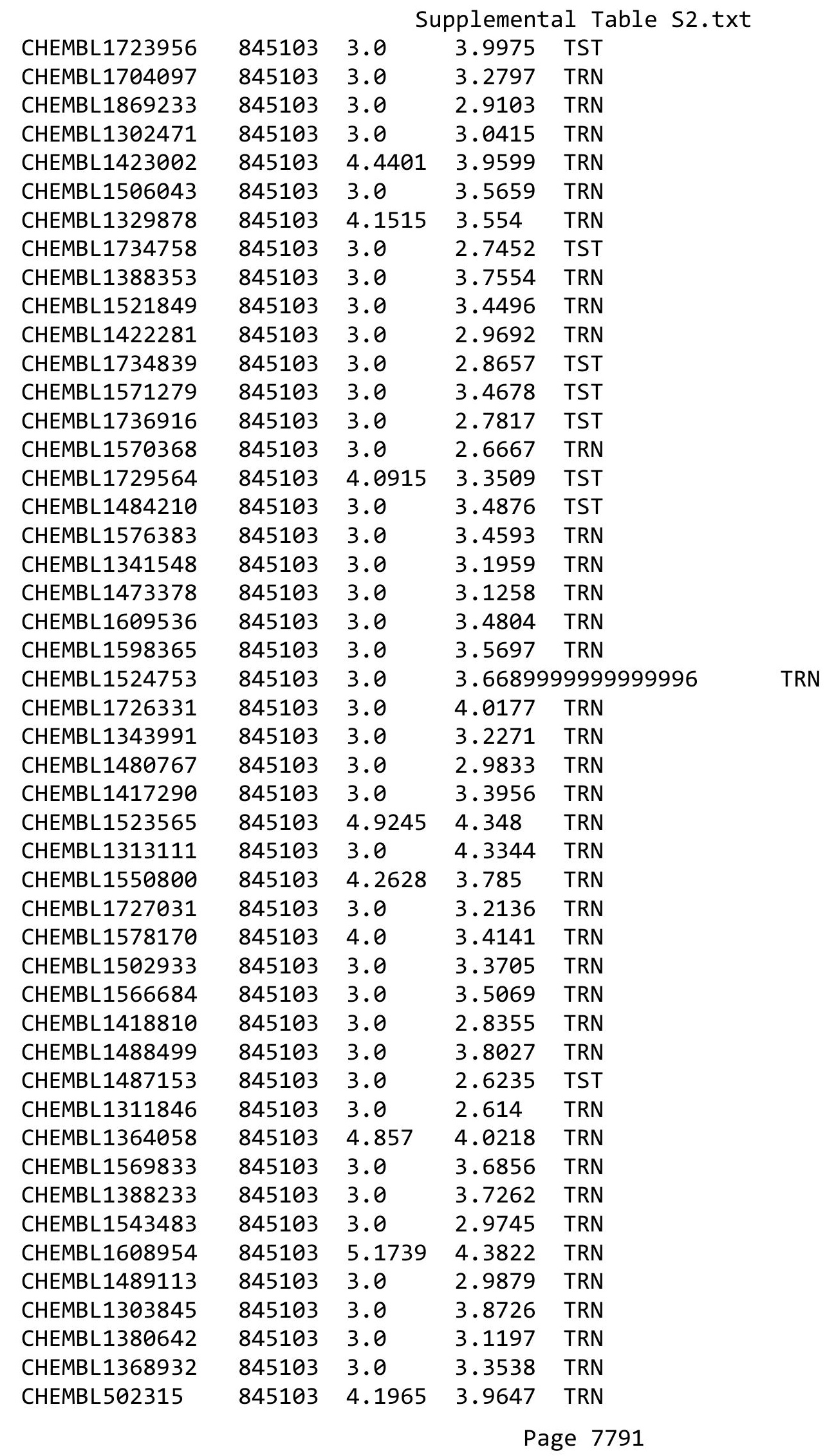




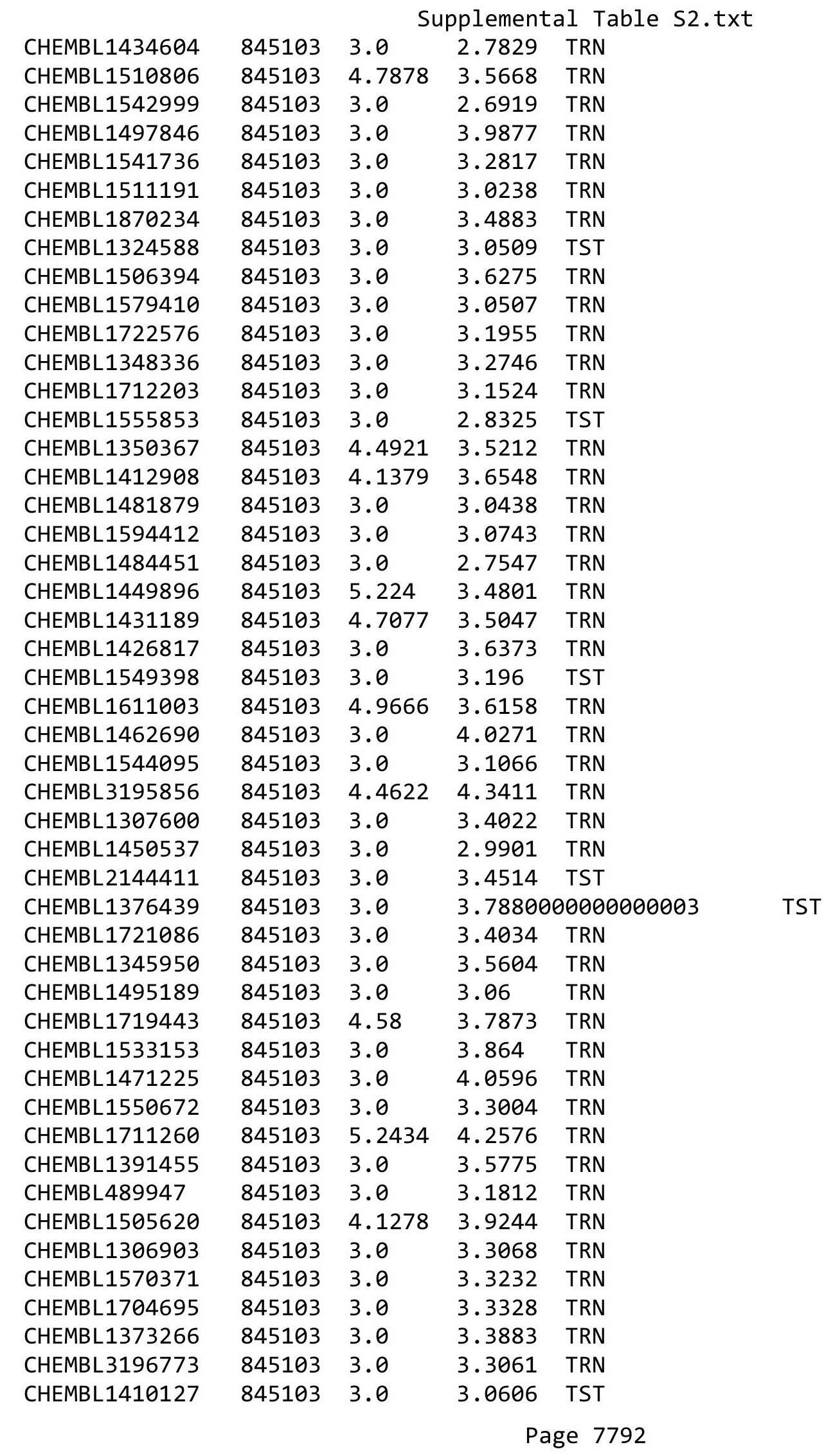




\begin{tabular}{|c|c|c|c|c|c|}
\hline \multirow[b]{2}{*}{ CHEMBL1700569 } & \multicolumn{5}{|c|}{ Supplemental Table S2.txt } \\
\hline & 845103 & 4.3696 & 2.6905 & TST & \\
\hline CHEMBL1299444 & 845103 & 3.0 & 4.2075 & TRN & \\
\hline CHEMBL1402568 & 845103 & 3.0 & 2.7956 & TRN & \\
\hline CHEMBL1727047 & 845103 & 3.0 & 3.1033 & TRN & \\
\hline CHEMBL1575926 & 845103 & 4.5513 & 4.0219 & TRN & \\
\hline CHEMBL1406961 & 845103 & 3.0 & 3.7861 & TRN & \\
\hline CHEMBL1369634 & 845103 & 3.0 & 3.0596 & TRN & \\
\hline CHEMBL1794158 & 845103 & 3.0 & 3.49300 & 20000000003 & TRN \\
\hline CHEMBL1710156 & 845103 & 3.0 & 2.9987 & TRN & \\
\hline CHEMBL127579 & 845103 & 4.6055 & 3.9679 & TRN & \\
\hline CHEMBL1540341 & 845103 & 3.0 & 3.1816 & TRN & \\
\hline CHEMBL1731096 & 845103 & 5.3215 & 3.5314 & TRN & \\
\hline CHEMBL1878679 & 845103 & 3.0 & 2.7192 & TST & \\
\hline CHEMBL1606256 & 845103 & 4.5751 & 4.386 & TRN & \\
\hline CHEMBL577758 & 845103 & 3.0 & 3.4109 & TRN & \\
\hline CHEMBL1341698 & 845103 & 4.0937 & 3.7165 & TST & \\
\hline CHEMBL1445429 & 845103 & 3.0 & 2.8437 & TRN & \\
\hline CHEMBL1736047 & 845103 & 3.0 & 3.9397 & TRN & \\
\hline CHEMBL1578078 & 845103 & 3.0 & 3.7704 & TRN & \\
\hline CHEMBL1542860 & 845103 & 3.0 & 3.0713 & TRN & \\
\hline CHEMBL1307639 & 845103 & 3.0 & 2.8507 & TST & \\
\hline CHEMBL1408307 & 845103 & 3.0 & 3.6486 & TRN & \\
\hline CHEMBL1319817 & 845103 & 3.0 & 4.0406 & TRN & \\
\hline CHEMBL1382099 & 845103 & 3.0 & 3.0627 & TST & \\
\hline CHEMBL1303887 & 845103 & 4.0246 & 3.7387 & TST & \\
\hline CHEMBL1423205 & 845103 & 3.0 & 2.6325 & TRN & \\
\hline CHEMBL1346891 & 845103 & 3.0 & 3.8769 & TRN & \\
\hline CHEMBL1375728 & 845103 & 3.0 & 3.0272 & TRN & \\
\hline CHEMBL1347974 & 845103 & 5.1831 & 4.3933 & TRN & \\
\hline CHEMBL1349809 & 845103 & 3.0 & 3.6121 & TST & \\
\hline CHEMBL1507634 & 845103 & 3.0 & 3.6046 & TRN & \\
\hline CHEMBL1502439 & 845103 & 3.0 & 2.7922 & TRN & \\
\hline CHEMBL1331878 & 845103 & 3.0 & 3.3553 & TRN & \\
\hline CHEMBL1366809 & 845103 & 3.0 & 3.4346 & TRN & \\
\hline CHEMBL1515847 & 845103 & 3.0 & 3.0045 & TRN & \\
\hline CHEMBL1872379 & 845103 & 3.0 & 2.7364 & TRN & \\
\hline CHEMBL1574799 & 845103 & 3.0 & 3.6015 & TRN & \\
\hline CHEMBL1462011 & 845103 & 4.2226 & 3.5406 & TRN & \\
\hline CHEMBL1712608 & 845103 & 3.0 & 2.6406 & TST & \\
\hline CHEMBL1501607 & 845103 & 3.0 & 3.2849 & TRN & \\
\hline CHEMBL233302 & 845103 & 4.5302 & 4.0315 & TRN & \\
\hline CHEMBL1517520 & 845103 & 3.0 & 3.1557 & TRN & \\
\hline CHEMBL1502576 & 845103 & 3.0 & 3.3071 & TRN & \\
\hline CHEMBL1531351 & 845103 & 4.5544 & 3.7454 & TRN & \\
\hline CHEMBL1536422 & 845103 & 3.0 & 3.4196 & TST & \\
\hline CHEMBL286593 & 845103 & 4.71899 & 99999999 & 3.6742 & TRN \\
\hline CHEMBL1390247 & 845103 & 3.0 & 3.2695 & TST & \\
\hline CHEMBL1442590 & 845103 & 4.0083 & 3.93300 & 20000000003 & TRN \\
\hline & & & & 7793 & \\
\hline
\end{tabular}




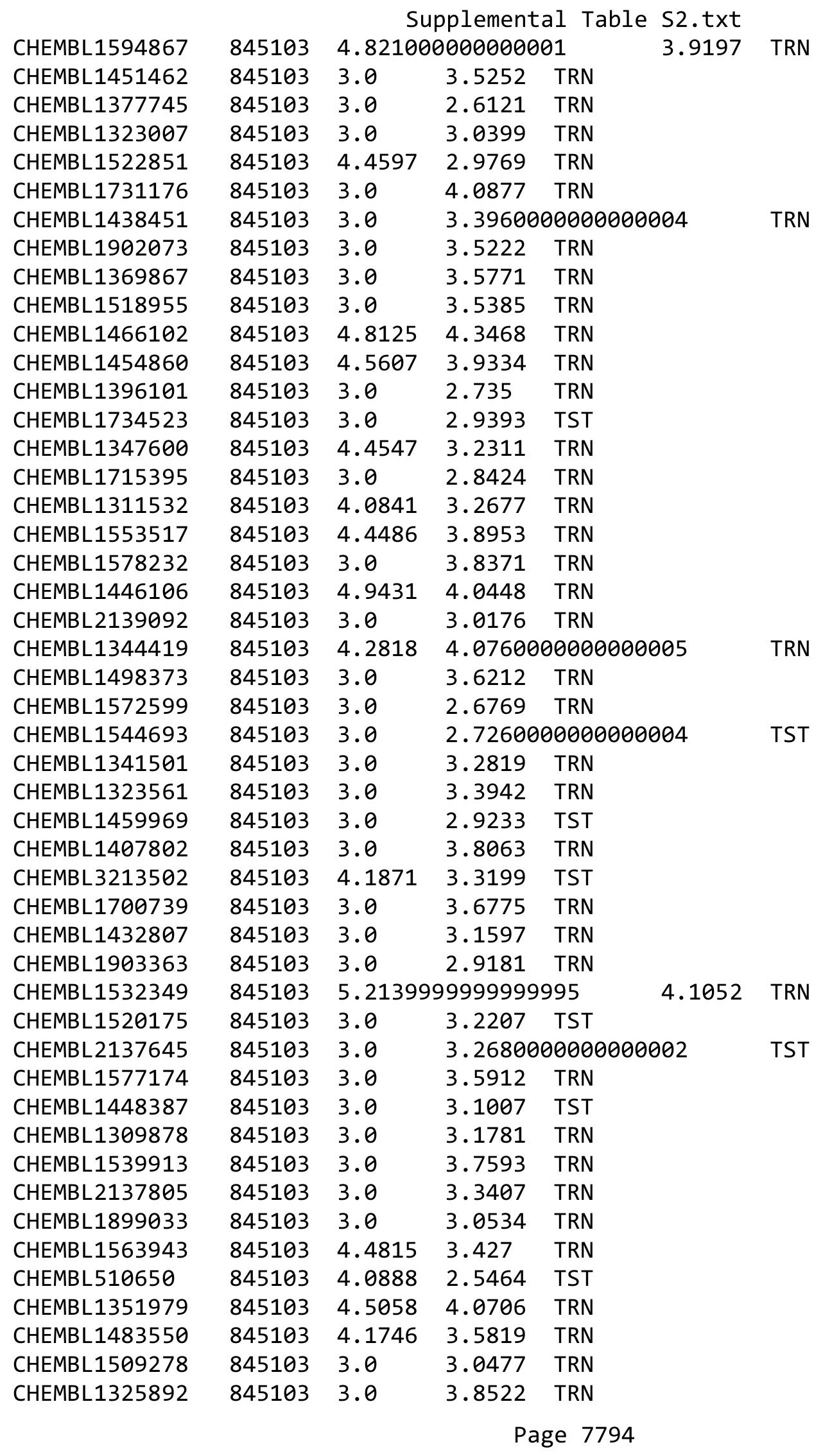




\begin{tabular}{|c|c|c|c|c|c|}
\hline \multicolumn{6}{|c|}{ Supplemental Table S2.txt } \\
\hline CHEMBL1487951 & 845103 & 3.0 & 3.1104 & TRN & \\
\hline CHEMBL1361426 & 845103 & 3.0 & 2.9932 & TRN & \\
\hline CHEMBL388823 & 845103 & 4.1029 & 3.8349 & TRN & \\
\hline CHEMBL1576578 & 845103 & 3.0 & 3.2766 & TRN & \\
\hline CHEMBL1890373 & 845103 & 4.0531 & 2.971 & TRN & \\
\hline CHEMBL1609945 & 845103 & 3.0 & 3.1618 & TRN & \\
\hline CHEMBL1487415 & 845103 & 3.0 & 3.35399 & 99999999996 & TRN \\
\hline CHEMBL1345791 & 845103 & 3.0 & 3.2494 & TRN & \\
\hline CHEMBL1886256 & 845103 & 3.0 & 2.6257 & TRN & \\
\hline CHEMBL1461991 & 845103 & 4.3788 & 3.9318 & TRN & \\
\hline CHEMBL1490702 & 845103 & 3.0 & 3.26800 & 00000000002 & TRN \\
\hline CHEMBL1581627 & 845103 & 4.0964 & 3.7928 & TRN & \\
\hline CHEMBL1879744 & 845103 & 3.0 & 2.9024 & TRN & \\
\hline CHEMBL1307154 & 845103 & 3.0 & 3.3054 & TRN & \\
\hline CHEMBL1362717 & 845103 & 3.0 & 2.9152 & TST & \\
\hline CHEMBL1404107 & 845103 & 3.0 & 3.7481 & TRN & \\
\hline CHEMBL1331586 & 845103 & 3.0 & 3.4991 & TRN & \\
\hline CHEMBL1612717 & 845103 & 3.0 & 3.1117 & TRN & \\
\hline CHEMBL3196491 & 845103 & 3.0 & 3.2484 & TRN & \\
\hline CHEMBL1603656 & 845103 & 3.0 & 3.5056 & TRN & \\
\hline CHEMBL 225257 & 845103 & 3.0 & 3.5712 & TST & \\
\hline CHEMBL1594218 & 845103 & 4.8069 & 4.261 & TRN & \\
\hline CHEMBL1535899 & 845103 & 4.8633 & 3.2679 & TST & \\
\hline CHEMBL1338476 & 845103 & 4.3161 & 3.7388 & TRN & \\
\hline CHEMBL1491984 & 845103 & 3.0 & 3.236 & TRN & \\
\hline CHEMBL1367428 & 845103 & 3.0 & 3.5697 & TST & \\
\hline CHEMBL1482207 & 845103 & 3.0 & 2.9505 & TRN & \\
\hline CHEMBL1561290 & 845103 & 4.6946 & 4.2049 & TRN & \\
\hline CHEMBL1392617 & 845103 & 3.0 & 3.1488 & TRN & \\
\hline CHEMBL1875380 & 845103 & 3.0 & 3.0977 & TRN & \\
\hline CHEMBL1440055 & 845103 & 4.8327 & 3.4697 & TRN & \\
\hline CHEMBL1583887 & 845103 & 3.0 & 3.0029 & TST & \\
\hline CHEMBL1484449 & 845103 & 3.0 & 3.0365 & TRN & \\
\hline CHEMBL1548473 & 845103 & 3.0 & 3.4144 & TRN & \\
\hline CHEMBL1518557 & 845103 & 3.0 & 3.7195 & TST & \\
\hline CHEMBL1899739 & 845103 & 5.4609 & 4.6473 & TRN & \\
\hline CHEMBL1510498 & 845103 & 3.0 & 3.8563 & TRN & \\
\hline CHEMBL1385607 & 845103 & 3.0 & 3.2571 & TRN & \\
\hline CHEMBL1884302 & 845103 & 3.0 & 2.7796 & TRN & \\
\hline CHEMBL1486052 & 845103 & 3.0 & 3.5114 & TRN & \\
\hline CHEMBL1604288 & 845103 & 3.0 & 2.8952 & TRN & \\
\hline CHEMBL1354208 & 845103 & 3.0 & 3.0767 & TST & \\
\hline CHEMBL1426651 & 845103 & 3.0 & 3.8638 & TRN & \\
\hline CHEMBL1718198 & 845103 & 3.0 & 3.6616 & TRN & \\
\hline CHEMBL1704972 & 845103 & 3.0 & 3.3425 & TRN & \\
\hline CHEMBL1585632 & 845103 & 4.6003 & 4.4721 & TRN & \\
\hline CHEMBL1608480 & 845103 & 5.1018 & 4.2026 & TRN & \\
\hline CHEMBL1389810 & 845103 & 4.3936 & 4.1979 & TRN & \\
\hline
\end{tabular}




\begin{tabular}{|c|c|c|c|c|c|}
\hline & & \multicolumn{4}{|c|}{ Supplemental Table S2.txt } \\
\hline CHEMBL1573125 & 845103 & 4.5376 & 3.7932 & TRN & \\
\hline CHEMBL1362324 & 845103 & 3.0 & 2.9112 & TRN & \\
\hline CHEMBL1442244 & 845103 & 3.0 & 2.6519 & TRN & \\
\hline CHEMBL1604558 & 845103 & 4.2366 & 3.8279 & TRN & \\
\hline CHEMBL1329650 & 845103 & 3.0 & 3.9986 & TRN & \\
\hline CHEMBL1423784 & 845103 & 3.0 & 3.0465 & TST & \\
\hline CHEMBL1597874 & 845103 & 3.0 & 3.2763 & TRN & \\
\hline CHEMBL1604614 & 845103 & 5.0575 & 4.3167 & TRN & \\
\hline CHEMBL1869264 & 845103 & 3.0 & 3.2727 & TRN & \\
\hline CHEMBL1890436 & 845103 & 4.1057 & 3.6773 & TRN & \\
\hline CHEMBL1557201 & 845103 & 4.2684 & 4.0439 & TRN & \\
\hline CHEMBL1566950 & 845103 & 3.0 & 3.4352 & TRN & \\
\hline CHEMBL1455325 & 845103 & 4.104 & 3.2299 & TRN & \\
\hline CHEMBL1401338 & 845103 & 3.0 & 3.0267 & TRN & \\
\hline CHEMBL560296 & 845103 & 3.0 & 3.6608 & TRN & \\
\hline CHEMBL1378016 & 845103 & 3.0 & 2.86800 & 00000000003 & TRN \\
\hline CHEMBL1352657 & 845103 & 3.0 & 3.3997 & TRN & \\
\hline CHEMBL1309525 & 845103 & 3.0 & 3.2635 & TRN & \\
\hline CHEMBL1582368 & 845103 & 4.5986 & 4.354 & TRN & \\
\hline CHEMBL1467661 & 845103 & 3.0 & 3.4012 & TST & \\
\hline CHEMBL1564386 & 845103 & 4.4855 & 4.1499 & TRN & \\
\hline CHEMBL534429 & 845103 & 3.0 & 3.2782 & TRN & \\
\hline CHEMBL1459012 & 845103 & 3.0 & 3.3877 & TRN & \\
\hline CHEMBL1390369 & 845103 & 4.4342 & 3.8548 & TRN & \\
\hline CHEMBL1352263 & 845103 & 3.0 & 4.1361 & TRN & \\
\hline CHEMBL1313107 & 845103 & 3.0 & 3.4853 & TRN & \\
\hline CHEMBL1511825 & 845103 & 3.0 & 3.4258 & TRN & \\
\hline CHEMBL1449705 & 845103 & 3.0 & 3.6733 & TST & \\
\hline CHEMBL1506681 & 845103 & 3.0 & 3.0044 & TRN & \\
\hline CHEMBL1350396 & 845103 & 3.0 & 3.1807 & TRN & \\
\hline CHEMBL1348691 & 845103 & 4.2321 & 3.2059 & TRN & \\
\hline CHEMBL1573557 & 845103 & 3.0 & 3.0774 & TRN & \\
\hline CHEMBL53738 & 845103 & 4.7905 & 4.2158 & TRN & \\
\hline CHEMBL1598347 & 845103 & 4.58 & 3.8696 & TRN & \\
\hline CHEMBL1877280 & 845103 & 3.0 & 3.5179 & TRN & \\
\hline CHEMBL1575487 & 845103 & 5.4776 & 4.6655 & TRN & \\
\hline CHEMBL1896676 & 845103 & 4.3449 & 4.0772 & TRN & \\
\hline CHEMBL1302134 & 845103 & 3.0 & 2.9796 & TRN & \\
\hline CHEMBL1427959 & 845103 & 3.0 & 3.4594 & TRN & \\
\hline CHEMBL1569790 & 845103 & 4.1349 & 3.3398 & TRN & \\
\hline CHEMBL1567184 & 845103 & 3.0 & 3.6688 & TRN & \\
\hline CHEMBL1523955 & 845103 & 4.1691 & 4.0742 & TRN & \\
\hline CHEMBL1337288 & 845103 & 3.0 & 3.2887 & TRN & \\
\hline CHEMBL1523828 & 845103 & 4.7055 & 4.3178 & TRN & \\
\hline CHEMBL1502660 & 845103 & 3.0 & 3.0679 & TRN & \\
\hline CHEMBL1404008 & 845103 & 3.0 & 3.3334 & TST & \\
\hline CHEMBL1307618 & 845103 & 4.6536 & 4.6865 & TRN & \\
\hline CHEMBL1452672 & 845103 & 3.0 & 4.0672 & TRN & \\
\hline
\end{tabular}




\begin{tabular}{|c|c|c|c|c|c|}
\hline \multicolumn{6}{|c|}{ Supplemental Table S2.txt } \\
\hline CHEMBL1878487 & 845103 & 3.0 & 3.0208 & TRN & \\
\hline CHEMBL1580249 & 845103 & 3.0 & 3.6137 & TRN & \\
\hline CHEMBL1493273 & 845103 & 4.3575 & 4.1821 & TRN & \\
\hline CHEMBL1598373 & 845103 & 3.0 & 2.7312 & TRN & \\
\hline CHEMBL1557386 & 845103 & 4.3799 & 3.6564 & TRN & \\
\hline CHEMBL1582199 & 845103 & 4.2426 & 2.9927 & TRN & \\
\hline CHEMBL1496585 & 845103 & 4.7011 & 3.3858 & TRN & \\
\hline CHEMBL1497907 & 845103 & 3.0 & 3.2509 & TRN & \\
\hline CHEMBL1332390 & 845103 & 4.1138 & 3.2218 & TRN & \\
\hline CHEMBL1467350 & 845103 & 4.1463 & 4.0209 & TRN & \\
\hline CHEMBL1450156 & 845103 & 3.0 & 3.3047 & TRN & \\
\hline CHEMBL1578212 & 845103 & 3.0 & 3.6207 & TRN & \\
\hline CHEMBL1701204 & 845103 & 3.0 & 3.7947 & TRN & \\
\hline CHEMBL1466997 & 845103 & 5.0137 & 4.2163 & TRN & \\
\hline CHEMBL1644341 & 845103 & 3.0 & 4.0185 & TRN & \\
\hline CHEMBL1371773 & 845103 & 4.382 & 3.5444 & TRN & \\
\hline CHEMBL1701759 & 845103 & 3.0 & 2.6687 & TST & \\
\hline CHEMBL1412461 & 845103 & 3.0 & 3.1768 & TRN & \\
\hline CHEMBL1381882 & 845103 & 3.0 & 3.6914 & TRN & \\
\hline CHEMBL1409772 & 845103 & 3.0 & 2.6019 & TRN & \\
\hline CHEMBL1562063 & 845103 & 3.0 & 2.61899 & 99999999998 & TRN \\
\hline CHEMBL1468310 & 845103 & 3.0 & 3.0512 & TRN & \\
\hline CHEMBL1388109 & 845103 & 3.0 & 2.5317 & TRN & \\
\hline CHEMBL1546928 & 845103 & 3.0 & 3.4841 & TRN & \\
\hline CHEMBL1868380 & 845103 & 4.6946 & 3.9829 & TRN & \\
\hline CHEMBL1303589 & 845103 & 4.5072 & 4.1637 & TRN & \\
\hline CHEMBL1370390 & 845103 & 3.0 & 3.6115 & TRN & \\
\hline CHEMBL1575708 & 845103 & 4.7696 & 4.2903 & TRN & \\
\hline CHEMBL1733096 & 845103 & 4.7399 & 3.8852 & TRN & \\
\hline CHEMBL1527299 & 845103 & 3.0 & 3.3147 & TRN & \\
\hline CHEMBL1409138 & 845103 & 3.0 & 3.4811 & TST & \\
\hline CHEMBL1519452 & 845103 & 5.2464 & 4.7672 & TRN & \\
\hline CHEMBL 2141565 & 845103 & 3.0 & 2.9264 & TRN & \\
\hline CHEMBL1504089 & 845103 & 4.8633 & 4.0494 & TRN & \\
\hline CHEMBL1307997 & 845103 & 3.0 & 2.6792 & TRN & \\
\hline CHEMBL1533836 & 845103 & 3.0 & 3.2162 & TRN & \\
\hline CHEMBL1563151 & 845103 & 3.0 & 2.8709 & TRN & \\
\hline CHEMBL1583879 & 845103 & 4.7282 & 3.2338 & TRN & \\
\hline CHEMBL429335 & 845103 & 4.1421 & 4.24100 & 00000000005 & TRN \\
\hline CHEMBL 3214522 & 845103 & 4.5258 & 3.4849 & TRN & \\
\hline CHEMBL1721798 & 845103 & 3.0 & 3.1152 & TRN & \\
\hline CHEMBL1300625 & 845103 & 3.0 & 3.1709 & TRN & \\
\hline CHEMBL1377160 & 845103 & 3.0 & 3.1457 & TRN & \\
\hline CHEMBL1891421 & 845103 & 4.5834 & 3.9208 & TST & \\
\hline CHEMBL1347898 & 845103 & 3.0 & 3.0836 & TRN & \\
\hline CHEMBL1711673 & 845103 & 4.1026 & 3.5376 & TRN & \\
\hline CHEMBL1595178 & 845103 & 4.7645 & 4.0072 & TRN & \\
\hline CHEMBL1885802 & 845103 & 3.0 & 3.0159 & TRN & \\
\hline
\end{tabular}




\begin{tabular}{|c|c|c|c|c|c|}
\hline \multicolumn{6}{|c|}{ Supplemental Table S2.txt } \\
\hline CHEMBL405317 & 845103 & 3.0 & 4.2399 & TRN & \\
\hline CHEMBL1464929 & 845103 & 3.0 & 3.47899 & 99999999996 & TRN \\
\hline CHEMBL93109 & 845103 & 3.0 & 3.7102 & TRN & \\
\hline CHEMBL1428659 & 845103 & 4.2877 & 3.9675 & TRN & \\
\hline CHEMBL1345354 & 845103 & 3.0 & 3.1484 & TRN & \\
\hline CHEMBL1352969 & 845103 & 3.0 & 2.6138 & TRN & \\
\hline CHEMBL1386843 & 845103 & 3.0 & 3.2169 & TRN & \\
\hline CHEMBL1517535 & 845103 & 4.618 & 3.8758 & TRN & \\
\hline CHEMBL1342264 & 845103 & 3.0 & 3.6846 & TRN & \\
\hline CHEMBL1893708 & 845103 & 3.0 & 3.9745 & TRN & \\
\hline CHEMBL1451649 & 845103 & 3.0 & 2.8385 & TST & \\
\hline CHEMBL1373913 & 845103 & 4.2708 & 3.5134 & TRN & \\
\hline CHEMBL265686 & 845103 & 3.0 & 4.1472 & TRN & \\
\hline CHEMBL1492008 & 845103 & 3.0 & 3.2668 & TRN & \\
\hline CHEMBL1539388 & 845103 & 4.1319 & 4.0611 & TRN & \\
\hline CHEMBL1504117 & 845103 & 3.0 & 3.03899 & 99999999997 & TRN \\
\hline CHEMBL1562639 & 845103 & 3.0 & 3.3682 & TRN & \\
\hline CHEMBL1339418 & 845103 & 4.0716 & 3.6554 & TRN & \\
\hline CHEMBL1497107 & 845103 & 3.0 & 3.3949 & TRN & \\
\hline CHEMBL1418667 & 845103 & 4.7447 & 4.1402 & TRN & \\
\hline CHEMBL 2138031 & 845103 & 3.0 & 3.4426 & TST & \\
\hline CHEMBL1703093 & 845103 & 3.0 & 2.938 & TRN & \\
\hline CHEMBL1728574 & 845103 & 3.0 & 3.3549 & TRN & \\
\hline CHEMBL1502772 & 845103 & 3.0 & 3.0191 & TST & \\
\hline CHEMBL1902266 & 845103 & 3.0 & 2.7677 & TST & \\
\hline CHEMBL1467262 & 845103 & 5.1986 & 4.1176 & TRN & \\
\hline CHEMBL1361114 & 845103 & 3.0 & 3.3226 & TRN & \\
\hline CHEMBL1408071 & 845103 & 3.0 & 3.7723 & TST & \\
\hline CHEMBL1348795 & 845103 & 3.0 & 2.8589 & TRN & \\
\hline CHEMBL1580407 & 845103 & 3.0 & 2.9654 & TST & \\
\hline CHEMBL1547654 & 845103 & 3.0 & 3.1337 & TRN & \\
\hline CHEMBL1412987 & 845103 & 3.0 & 3.6895 & TRN & \\
\hline CHEMBL1447344 & 845103 & 3.0 & 3.2273 & TST & \\
\hline CHEMBL1366289 & 845103 & 3.0 & 2.6861 & TST & \\
\hline CHEMBL1483857 & 845103 & 3.0 & 3.0618 & TRN & \\
\hline CHEMBL1488141 & 845103 & 4.8125 & 3.95 & TRN & \\
\hline CHEMBL1481725 & 845103 & 3.0 & 3.2673 & TRN & \\
\hline CHEMBL1535021 & 845103 & 3.0 & 3.9888 & TRN & \\
\hline CHEMBL1389668 & 845103 & 4.6364 & 3.7952 & TRN & \\
\hline CHEMBL1469808 & 845103 & 4.7545 & 3.87399 & 99999999997 & TRN \\
\hline CHEMBL1400357 & 845103 & 4.065 & 4.4576 & TRN & \\
\hline CHEMBL1521187 & 845103 & 3.0 & 4.4018 & TRN & \\
\hline CHEMBL1577715 & 845103 & 3.0 & 3.5554 & TST & \\
\hline CHEMBL1565095 & 845103 & 3.0 & 3.1786 & TRN & \\
\hline CHEMBL1376509 & 845103 & 3.0 & 2.97300 & 00000000003 & TRN \\
\hline CHEMBL1327031 & 845103 & 3.0 & 2.9486 & TRN & \\
\hline CHEMBL1399767 & 845103 & 3.0 & 3.7226 & TRN & \\
\hline CHEMBL1537655 & 845103 & 3.0 & 2.9994 & TRN & \\
\hline
\end{tabular}




\begin{tabular}{|c|c|c|c|c|}
\hline \multicolumn{5}{|c|}{ Supplemental Table S2.txt } \\
\hline CHEMBL1900495 & 845103 & 3.0 & 2.8909 & TRN \\
\hline CHEMBL1413306 & 845103 & 3.0 & 3.4652 & TRN \\
\hline CHEMBL1510155 & 845103 & 3.0 & 3.1795 & TRN \\
\hline CHEMBL1334110 & 845103 & 3.0 & 2.6449 & TRN \\
\hline CHEMBL1372633 & 845103 & 3.0 & 2.8624 & TRN \\
\hline CHEMBL1449916 & 845103 & 3.0 & 3.4702 & TRN \\
\hline CHEMBL1865792 & 845103 & 3.0 & 3.0344 & TRN \\
\hline CHEMBL1899791 & 845103 & 3.0 & 3.4819 & TRN \\
\hline CHEMBL1348618 & 845103 & 4.5654 & 3.6669 & TRN \\
\hline CHEMBL1449655 & 845103 & 3.0 & 3.3829 & TST \\
\hline CHEMBL1890067 & 845103 & 3.0 & 2.8082 & TST \\
\hline CHEMBL 2135230 & 845103 & 3.0 & 2.9026 & TRN \\
\hline CHEMBL1511363 & 845103 & 3.0 & 2.7818 & TST \\
\hline CHEMBL1326967 & 845103 & 4.2526 & 3.903 & TRN \\
\hline CHEMBL1312714 & 845103 & 3.0 & 3.4899 & TRN \\
\hline CHEMBL1607514 & 845103 & 5.3625 & 4.3223 & TRN \\
\hline CHEMBL1526993 & 845103 & 4.4935 & 4.1704 & TRN \\
\hline CHEMBL1413237 & 845103 & 3.0 & 2.855 & TRN \\
\hline CHEMBL1524842 & 845103 & 3.0 & 3.0752 & TRN \\
\hline CHEMBL1595337 & 845103 & 3.0 & 3.3205 & TST \\
\hline CHEMBL1885880 & 845103 & 4.7055 & 3.8589 & TRN \\
\hline CHEMBL1497296 & 845103 & 3.0 & 3.5908 & TRN \\
\hline CHEMBL1415169 & 845103 & 3.0 & 3.4627 & TRN \\
\hline CHEMBL1401095 & 845103 & 3.0 & 3.0971 & TRN \\
\hline CHEMBL1495910 & 845103 & 3.0 & 3.5779 & TRN \\
\hline CHEMBL1458622 & 845103 & 4.5391 & 3.91 & TRN \\
\hline CHEMBL1873331 & 845103 & 3.0 & 3.2571 & TRN \\
\hline CHEMBL1456197 & 845103 & 4.7959 & 4.2407 & TRN \\
\hline CHEMBL1453510 & 845103 & 4.9914 & 3.8135 & TRN \\
\hline CHEMBL1507540 & 845103 & 4.3696 & 4.0663 & TRN \\
\hline CHEMBL1528253 & 845103 & 3.0 & 2.6534 & TRN \\
\hline CHEMBL1717721 & 845103 & 4.426 & 3.2323 & TRN \\
\hline CHEMBL1718915 & 845103 & 4.6882 & 3.9098 & TST \\
\hline CHEMBL1585178 & 845103 & 4.6073 & 3.9236 & TRN \\
\hline CHEMBL1384027 & 845103 & 3.0 & 3.1072 & TRN \\
\hline CHEMBL1518980 & 845103 & 3.0 & 2.8557 & TST \\
\hline CHEMBL191015 & 845103 & 4.7258 & 4.3314 & TRN \\
\hline CHEMBL1312855 & 845103 & 3.0 & 2.7449 & TRN \\
\hline CHEMBL1524960 & 845103 & 3.0 & 3.3527 & TRN \\
\hline CHEMBL1564002 & 845103 & 3.0 & 3.1496 & TRN \\
\hline CHEMBL1377709 & 845103 & 4.1898 & 3.7328 & TRN \\
\hline CHEMBL1873092 & 845103 & 3.0 & 2.9568 & TRN \\
\hline CHEMBL1421547 & 845103 & 4.8633 & 3.5863 & TRN \\
\hline CHEMBL2137596 & 845103 & 3.0 & 3.4033 & TRN \\
\hline CHEMBL1380452 & 845103 & 4.7399 & 4.0238 & TRN \\
\hline CHEMBL1306578 & 845103 & 3.0 & 3.5176 & TRN \\
\hline CHEMBL1457036 & 845103 & 3.0 & 3.2407 & TRN \\
\hline CHEMBL151797 & 845103 & 3.0 & 3.4605 & TRN \\
\hline
\end{tabular}




\begin{tabular}{|c|c|c|c|c|c|}
\hline \multicolumn{6}{|c|}{ Supplemental Table S2.txt } \\
\hline CHEMBL1545587 & 845103 & 3.0 & 3.1898 & TRN & \\
\hline CHEMBL1366918 & 845103 & 4.4101 & 3.8493 & TRN & \\
\hline CHEMBL1871596 & 845103 & 4.6198 & 3.7343 & TRN & \\
\hline CHEMBL1605195 & 845103 & 3.0 & 2.6545 & TST & \\
\hline CHEMBL1339303 & 845103 & 4.5086 & 3.9616 & TRN & \\
\hline CHEMBL1376214 & 845103 & 4.71 & 4.3235 & TRN & \\
\hline CHEMBL3191183 & 845103 & 3.0 & 3.8827 & TRN & \\
\hline CHEMBL1364184 & 845103 & 3.0 & 3.5482 & TST & \\
\hline CHEMBL1543986 & 845103 & 3.0 & 3.4175 & TRN & \\
\hline CHEMBL1519056 & 845103 & 4.5003 & 4.51399 & 9999999999 & TRN \\
\hline CHEMBL1483745 & 845103 & 4.0362 & 3.995 & TRN & \\
\hline CHEMBL1707995 & 845103 & 3.0 & 3.2986 & TRN & \\
\hline CHEMBL3199825 & 845103 & 3.0 & 3.5438 & TST & \\
\hline CHEMBL1583174 & 845103 & 3.0 & 3.6241 & TRN & \\
\hline CHEMBL3192253 & 845103 & 4.6556 & 3.4944 & TST & \\
\hline CHEMBL1601699 & 845103 & 3.0 & 3.4399 & TST & \\
\hline CHEMBL1312057 & 845103 & 3.0 & 3.7908 & TRN & \\
\hline CHEMBL1596486 & 845103 & 4.2204 & 3.832 & TRN & \\
\hline CHEMBL1346854 & 845103 & 3.0 & 3.0121 & TRN & \\
\hline CHEMBL1559619 & 845103 & 3.0 & 3.3753 & TRN & \\
\hline CHEMBL1588034 & 845103 & 4.4828 & 4.0867 & TRN & \\
\hline CHEMBL1327828 & 845103 & 4.4547 & 4.3592 & TRN & \\
\hline CHEMBL1869471 & 845103 & 3.0 & 2.8995 & TRN & \\
\hline CHEMBL1582980 & 845103 & 3.0 & 2.7645 & TRN & \\
\hline CHEMBL1301407 & 845103 & 3.0 & 2.8207 & TRN & \\
\hline CHEMBL1301155 & 845103 & 3.0 & 3.3703 & TRN & \\
\hline CHEMBL1361268 & 845103 & 3.0 & 3.6819 & TRN & \\
\hline CHEMBL1453443 & 845103 & 3.0 & 3.4259 & TRN & \\
\hline CHEMBL1870090 & 845103 & 3.0 & 3.3247 & TRN & \\
\hline CHEMBL1464608 & 845103 & 3.0 & 3.1048 & TRN & \\
\hline CHEMBL1503172 & 845103 & 4.7399 & 4.3049 & TRN & \\
\hline CHEMBL1299383 & 845103 & 3.0 & 2.5721 & TRN & \\
\hline CHEMBL1416334 & 845103 & 3.0 & 3.1403 & TRN & \\
\hline CHEMBL1372078 & 845103 & 3.0 & 3.347 & TRN & \\
\hline CHEMBL1536591 & 845103 & 3.0 & 2.9652 & TST & \\
\hline CHEMBL1427044 & 845103 & 3.0 & 3.0135 & TRN & \\
\hline CHEMBL 1451774 & 845103 & 3.0 & 3.1217 & TST & \\
\hline CHEMBL1490892 & 845103 & 3.0 & 3.2774 & TRN & \\
\hline CHEMBL1431735 & 845103 & 3.0 & 2.9703 & TRN & \\
\hline CHEMBL1425420 & 845103 & 3.0 & 3.182 & TRN & \\
\hline CHEMBL1343985 & 845103 & 3.0 & 2.6506 & TST & \\
\hline CHEMBL1971601 & 845103 & 4.0 & 3.1331 & TRN & \\
\hline CHEMBL1600727 & 845103 & 3.0 & 4.0509 & TRN & \\
\hline CHEMBL1397915 & 845103 & 3.0 & 2.8839 & TRN & \\
\hline CHEMBL1416100 & 845103 & 5.3925 & 4.4909 & TRN & \\
\hline CHEMBL1509077 & 845103 & 3.0 & 3.0019 & TRN & \\
\hline CHEMBL 2143617 & 845103 & 3.0 & 2.7478 & TRN & \\
\hline CHEMBL1725693 & 845103 & 3.0 & 3.4758 & TRN & \\
\hline
\end{tabular}




\begin{tabular}{|c|c|c|c|c|c|}
\hline \multicolumn{6}{|c|}{ Supplemental Table S2.txt } \\
\hline CHEMBL1325006 & 845103 & 3.0 & 3.7259 & TRN & \\
\hline CHEMBL1409101 & 845103 & 4.3354 & 3.8955 & TRN & \\
\hline CHEMBL1571173 & 845103 & 3.0 & 2.9727 & TRN & \\
\hline CHEMBL1564062 & 845103 & 4.4498 & 3.9418 & TRN & \\
\hline CHEMBL1331494 & 845103 & 4.341 & 3.6245 & TRN & \\
\hline CHEMBL1878042 & 845103 & 3.0 & 3.5014 & TRN & \\
\hline CHEMBL1404806 & 845103 & 3.0 & 3.0448 & TRN & \\
\hline CHEMBL1307910 & 845103 & 4.6716 & 3.6053 & TRN & \\
\hline CHEMBL512366 & 845103 & 3.0 & 3.075 & TRN & \\
\hline CHEMBL1359029 & 845103 & 3.0 & 3.4661 & TRN & \\
\hline CHEMBL1494564 & 845103 & 4.6778 & 4.0346 & TRN & \\
\hline CHEMBL1384064 & 845103 & 3.0 & 3.0339 & TRN & \\
\hline CHEMBL1330310 & 845103 & 3.0 & 3.0277 & TRN & \\
\hline CHEMBL1586098 & 845103 & 3.0 & 2.5288 & TRN & \\
\hline CHEMBL1419839 & 845103 & 4.5346 & 3.7994 & TRN & \\
\hline CHEMBL1487784 & 845103 & 4.7878 & 4.6542 & TRN & \\
\hline CHEMBL1300494 & 845103 & 4.2161 & 2.9457 & TST & \\
\hline CHEMBL1307884 & 845103 & 3.0 & 3.1839 & TRN & \\
\hline CHEMBL1555526 & 845103 & 3.0 & 3.2216 & TRN & \\
\hline CHEMBL1726775 & 845103 & 4.2798 & 3.8764 & TRN & \\
\hline CHEMBL1544386 & 845103 & 3.0 & 3.2778 & TRN & \\
\hline CHEMBL1452027 & 845103 & 4.1586 & 3.833 & TRN & \\
\hline CHEMBL1698134 & 845103 & 4.6271 & 3.6734 & TRN & \\
\hline CHEMBL1898770 & 845103 & 3.0 & 3.2822 & TRN & \\
\hline CHEMBL1564713 & 845103 & 3.0 & 3.3329 & TRN & \\
\hline CHEMBL1307687 & 845103 & 3.0 & 2.736 & TRN & \\
\hline CHEMBL1718424 & 845103 & 3.0 & 3.3414 & TRN & \\
\hline CHEMBL1378195 & 845103 & 3.0 & 2.8705 & TRN & \\
\hline CHEMBL1503230 & 845103 & 3.0 & 2.74600 & 00000000004 & TRN \\
\hline CHEMBL1460429 & 845103 & 3.0 & 2.9119 & TRN & \\
\hline CHEMBL 2001904 & 845103 & 4.4647 & 3.2035 & TST & \\
\hline CHEMBL1472478 & 845103 & 4.163 & 4.0013 & TRN & \\
\hline CHEMBL1324205 & 845103 & 4.1273 & 3.3011 & TRN & \\
\hline CHEMBL1517869 & 845103 & 3.0 & 4.2189 & TRN & \\
\hline CHEMBL1373822 & 845103 & 4.8665 & 4.0765 & TRN & \\
\hline CHEMBL1720521 & 845103 & 3.0 & 2.9769 & TRN & \\
\hline CHEMBL1469170 & 845103 & 3.0 & 2.5544 & TST & \\
\hline CHEMBL1343760 & 845103 & 3.0 & 2.8634 & TRN & \\
\hline CHEMBL1335915 & 845103 & 5.1135 & 4.5591 & TRN & \\
\hline CHEMBL1508269 & 845103 & 3.0 & 3.5686 & TRN & \\
\hline CHEMBL417294 & 845103 & 4.7471 & 3.9003 & TRN & \\
\hline CHEMBL1613382 & 845103 & 3.0 & 3.2555 & TRN & \\
\hline CHEMBL1333960 & 845103 & 3.0 & 2.9157 & TRN & \\
\hline CHEMBL1502407 & 845103 & 4.4672 & 4.0898 & TST & \\
\hline CHEMBL1390831 & 845103 & 4.1938 & 3.7201 & TRN & \\
\hline CHEMBL1576060 & 845103 & 3.0 & 3.6286 & TRN & \\
\hline CHEMBL1306597 & 845103 & 4.4078 & 3.4627 & TRN & \\
\hline CHEMBL1588663 & 845103 & 3.0 & 3.7912 & TRN & \\
\hline
\end{tabular}




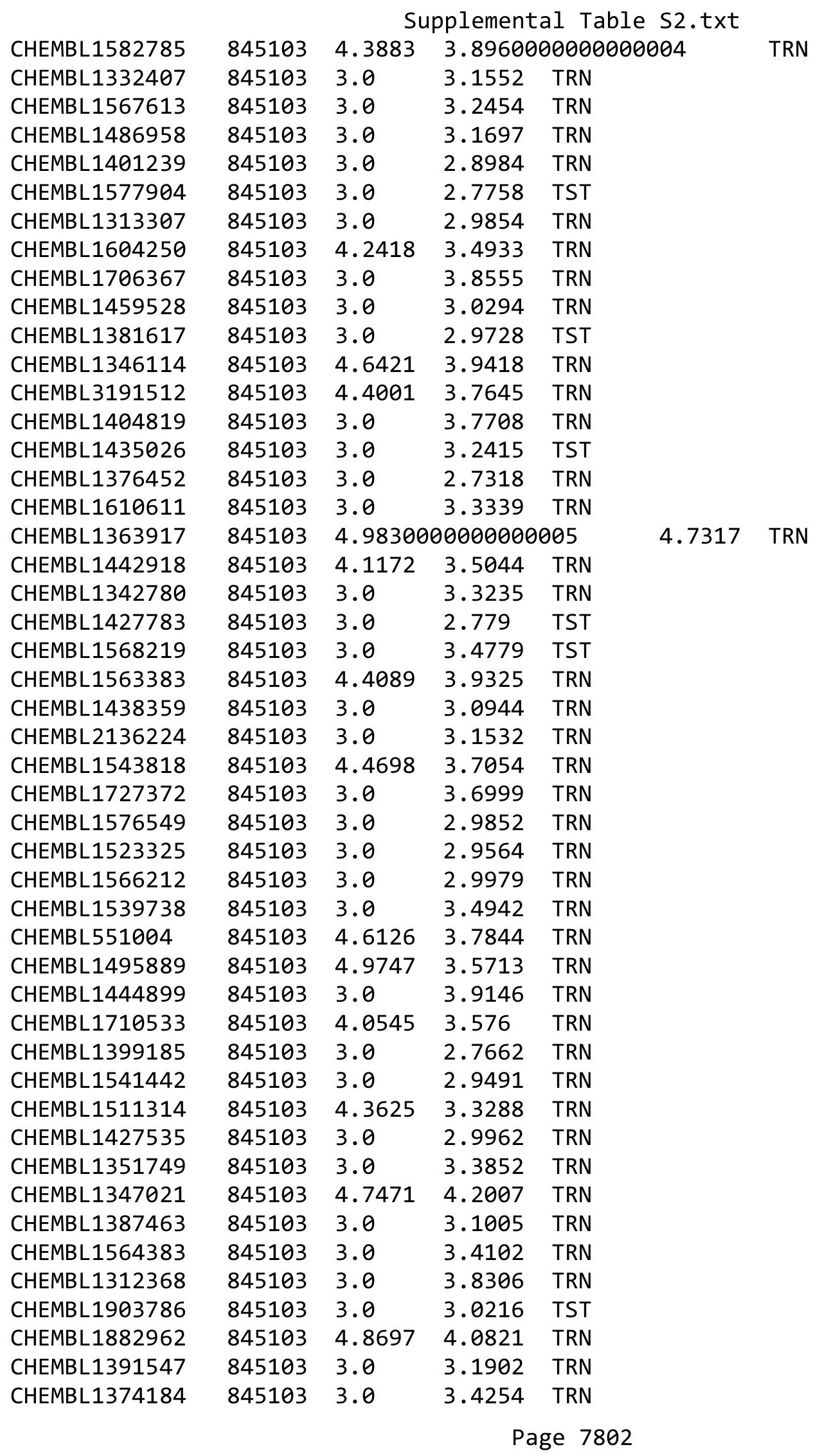




\begin{tabular}{|c|c|c|c|c|c|}
\hline \multicolumn{6}{|c|}{ Supplemental Table S2.txt } \\
\hline CHEMBL1439488 & 845103 & 3.0 & 3.387 & TST & \\
\hline CHEMBL1535093 & 845103 & 3.0 & 3.7577 & TST & \\
\hline CHEMBL1423889 & 845103 & 4.8729 & 3.9652 & TRN & \\
\hline CHEMBL1574079 & 845103 & 3.0 & 3.753 & TST & \\
\hline CHEMBL1863979 & 845103 & 3.0 & 2.9985 & TRN & \\
\hline CHEMBL1414754 & 845103 & 3.0 & 3.6092 & TRN & \\
\hline CHEMBL1474800 & 845103 & 3.0 & 3.2048 & TRN & \\
\hline CHEMBL1332371 & 845103 & 4.426 & 3.9932 & TRN & \\
\hline CHEMBL1512359 & 845103 & 4.1726 & 4.0792 & TRN & \\
\hline CHEMBL1558676 & 845103 & 3.0 & 3.4333 & TST & \\
\hline CHEMBL1408919 & 845103 & 4.4976 & 4.2498 & TRN & \\
\hline CHEMBL1881548 & 845103 & 3.0 & 2.9127 & TRN & \\
\hline CHEMBL1494661 & 845103 & 3.0 & 2.5542 & TRN & \\
\hline CHEMBL1325782 & 845103 & 6.5045 & 3.4559 & TST & \\
\hline CHEMBL1393461 & 845103 & 3.0 & 3.3289 & TRN & \\
\hline CHEMBL1983033 & 845103 & 4.1331 & 3.2251 & TST & \\
\hline CHEMBL 2142990 & 845103 & 3.0 & 3.3208 & TST & \\
\hline CHEMBL1494717 & 845103 & 3.0 & 3.2404 & TRN & \\
\hline CHEMBL1573757 & 845103 & 3.0 & 3.0434 & TRN & \\
\hline CHEMBL1502894 & 845103 & 3.0 & 2.7717 & TRN & \\
\hline CHEMBL1578896 & 845103 & 3.0 & 3.0682 & TRN & \\
\hline CHEMBL1546308 & 845103 & 3.0 & 2.8304 & TRN & \\
\hline CHEMBL1414085 & 845103 & 3.0 & 3.2183 & TRN & \\
\hline CHEMBL1457752 & 845103 & 3.0 & 2.7262 & TRN & \\
\hline CHEMBL1388075 & 845103 & 3.0 & 3.2759 & TRN & \\
\hline CHEMBL1392952 & 845103 & 3.0 & 3.41300 & 00000000003 & TRN \\
\hline CHEMBL1461506 & 845103 & 4.6819 & 3.6564 & TRN & \\
\hline CHEMBL1532351 & 845103 & 3.0 & 3.5668 & TRN & \\
\hline CHEMBL1344611 & 845103 & 3.0 & 3.5698 & TRN & \\
\hline CHEMBL1567905 & 845103 & 3.0 & 3.5692 & TRN & \\
\hline CHEMBL1439227 & 845103 & 4.2449 & 3.5778 & TRN & \\
\hline CHEMBL1592023 & 845103 & 4.2358 & 2.8192 & TRN & \\
\hline CHEMBL1717344 & 845103 & 4.2328 & 3.6211 & TST & \\
\hline CHEMBL1567560 & 845103 & 3.0 & 2.9218 & TRN & \\
\hline CHEMBL1604367 & 845103 & 3.0 & 3.7382 & TRN & \\
\hline CHEMBL1383899 & 845103 & 3.0 & 2.9279 & TST & \\
\hline CHEMBL1390388 & 845103 & 4.2877 & 3.9518 & TRN & \\
\hline CHEMBL1308898 & 845103 & 4.0902 & 3.5877 & TRN & \\
\hline CHEMBL1601657 & 845103 & 3.0 & 3.0853 & TRN & \\
\hline CHEMBL1538667 & 845103 & 3.0 & 2.7583 & TRN & \\
\hline CHEMBL1897903 & 845103 & 3.0 & 3.5275 & TRN & \\
\hline CHEMBL1539708 & 845103 & 3.0 & 2.8131 & TRN & \\
\hline CHEMBL1456864 & 845103 & 3.0 & 2.6739 & TRN & \\
\hline CHEMBL2137386 & 845103 & 3.0 & 2.6588 & TST & \\
\hline CHEMBL1418764 & 845103 & 4.0066 & 3.5743 & TRN & \\
\hline CHEMBL1412866 & 845103 & 3.0 & 3.43600 & 00000000004 & TRN \\
\hline CHEMBL1407390 & 845103 & 4.8508 & 4.287 & TRN & \\
\hline CHEMBL1715379 & 845103 & 3.0 & 2.824 & TRN & \\
\hline
\end{tabular}




\begin{tabular}{|c|c|c|c|c|}
\hline \multicolumn{5}{|c|}{ Supplemental Table } \\
\hline CHEMBL1700996 & 845103 & 4.0991 & 3.2049 & TST \\
\hline CHEMBL1339679 & 845103 & 3.0 & 3.633 & TRN \\
\hline CHEMBL1332600 & 845103 & 4.0835 & 3.5057 & TRN \\
\hline CHEMBL1496095 & 845103 & 3.0 & 2.9163 & TRN \\
\hline CHEMBL1734478 & 845103 & 3.0 & 3.5721 & TST \\
\hline CHEMBL1530081 & 845103 & 3.0 & 3.1884 & TST \\
\hline CHEMBL1729769 & 845103 & 3.0 & 3.5004 & TRN \\
\hline CHEMBL1486252 & 845103 & 3.0 & 3.6721 & TRN \\
\hline CHEMBL1381757 & 845103 & 3.0 & 3.4705 & TRN \\
\hline CHEMBL1605488 & 845103 & 3.0 & 3.7554 & TRN \\
\hline CHEMBL1306926 & 845103 & 3.0 & 2.9125 & TRN \\
\hline CHEMBL1406297 & 845103 & 3.0 & 3.5424 & TRN \\
\hline CHEMBL1488144 & 845103 & 3.0 & 3.2393 & TST \\
\hline CHEMBL26260 & 845103 & 3.0 & 3.9029 & TRN \\
\hline CHEMBL1530862 & 845103 & 5.4976 & 4.3193 & TRN \\
\hline CHEMBL1489252 & 845103 & 3.0 & 3.6008 & TST \\
\hline CHEMBL1499197 & 845103 & 3.0 & 3.2098 & TRN \\
\hline CHEMBL1865427 & 845103 & 3.0 & 2.8592 & TRN \\
\hline CHEMBL1313280 & 845103 & 4.1424 & 3.6985 & TRN \\
\hline CHEMBL1478006 & 845103 & 3.0 & 3.5559 & TRN \\
\hline CHEMBL1446687 & 845103 & 3.0 & 3.3377 & TRN \\
\hline CHEMBL1589020 & 845103 & 3.0 & 2.8474 & TRN \\
\hline CHEMBL1506905 & 845103 & 3.0 & 3.1874 & TRN \\
\hline CHEMBL1526643 & 845103 & 3.0 & 3.2008 & TRN \\
\hline CHEMBL1466151 & 845103 & 4.8477 & 3.972 & TRN \\
\hline CHEMBL1510913 & 845103 & 4.1605 & 3.7951 & TRN \\
\hline CHEMBL1735593 & 845103 & 4.1979 & 3.0403 & TRN \\
\hline CHEMBL17201 & 845103 & 4.9355 & 4.0211 & TRN \\
\hline CHEMBL1454365 & 845103 & 3.0 & 3.0401 & TRN \\
\hline CHEMBL1885228 & 845103 & 3.0 & 3.6361 & TST \\
\hline CHEMBL1444077 & 845103 & 3.0 & 3.6395 & TRN \\
\hline CHEMBL1726558 & 845103 & 3.0 & 3.0855 & TST \\
\hline CHEMBL1470702 & 845103 & 4.3279 & 3.4095 & TRN \\
\hline CHEMBL1491592 & 845103 & 3.0 & 3.6076 & TST \\
\hline CHEMBL585279 & 845103 & 3.0 & 3.6494 & TRN \\
\hline CHEMBL1570005 & 845103 & 3.0 & 2.8914 & TRN \\
\hline CHEMBL1543617 & 845103 & 3.0 & 3.2822 & TRN \\
\hline CHEMBL 2133694 & 845103 & 3.0 & 2.9958 & TRN \\
\hline CHEMBL1413622 & 845103 & 3.0 & 2.9502 & TRN \\
\hline CHEMBL1608049 & 845103 & 4.7807 & 4.2887 & TRN \\
\hline CHEMBL1411111 & 845103 & 3.0 & 3.7008 & TRN \\
\hline CHEMBL1340600 & 845103 & 3.0 & 3.0533 & TRN \\
\hline CHEMBL1712668 & 845103 & 5.1965 & 4.324 & TRN \\
\hline CHEMBL1379540 & 845103 & 3.0 & 3.1389 & TST \\
\hline CHEMBL1563270 & 845103 & 3.0 & 2.9696 & TRN \\
\hline CHEMBL1472058 & 845103 & 4.0565 & 3.8466 & TRN \\
\hline CHEMBL1352464 & 845103 & 3.0 & 3.0074 & TRN \\
\hline CHEMBL1366800 & 845103 & 3.0 & 3.4991 & TRN \\
\hline
\end{tabular}




\begin{tabular}{|c|c|c|c|c|c|}
\hline \multirow[b]{2}{*}{ CHEMBL1543847 } & \multicolumn{5}{|c|}{ Supplemental Table S2.txt } \\
\hline & 845103 & 4.7305 & 4.0662 & TRN & \\
\hline CHEMBL1542215 & 845103 & 3.0 & 3.313 & TRN & \\
\hline CHEMBL1387790 & 845103 & 3.0 & 3.2738 & TRN & \\
\hline CHEMBL1528777 & 845103 & 3.0 & 2.62899 & 99999999996 & TRN \\
\hline CHEMBL1378749 & 845103 & 3.0 & 3.2351 & TRN & \\
\hline CHEMBL1549529 & 845103 & 4.2434 & 3.491 & TRN & \\
\hline CHEMBL1409306 & 845103 & 3.0 & 3.2144 & TRN & \\
\hline CHEMBL112610 & 845103 & 4.2636 & 4.4215 & TRN & \\
\hline CHEMBL1341543 & 845103 & 3.0 & 2.8655 & TRN & \\
\hline CHEMBL1378710 & 845103 & 4.6198 & 4.4139 & TRN & \\
\hline CHEMBL1575201 & 845103 & 4.0635 & 3.7184 & TRN & \\
\hline CHEMBL1530789 & 845103 & 3.0 & 2.9527 & TRN & \\
\hline CHEMBL 2140080 & 845103 & 3.0 & 2.9096 & TRN & \\
\hline CHEMBL1389705 & 845103 & 3.0 & 2.9808 & TRN & \\
\hline CHEMBL1613483 & 845103 & 3.0 & 3.0243 & TRN & \\
\hline CHEMBL1523406 & 845103 & 3.0 & 3.1897 & TRN & \\
\hline CHEMBL1354756 & 845103 & 3.0 & 2.7275 & TRN & \\
\hline CHEMBL1491651 & 845103 & 4.6421 & 4.3075 & TRN & \\
\hline CHEMBL1590592 & 845103 & 3.0 & 3.0191 & TST & \\
\hline CHEMBL1529404 & 845103 & 3.0 & 3.5401 & TRN & \\
\hline CHEMBL1499023 & 845103 & 3.0 & 3.4497 & TRN & \\
\hline CHEMBL1462983 & 845103 & 5.3516 & 4.5242 & TRN & \\
\hline CHEMBL1482961 & 845103 & 4.7235 & 4.087 & TRN & \\
\hline CHEMBL1380884 & 845103 & 4.5768 & 3.7715 & TRN & \\
\hline CHEMBL1300254 & 845103 & 3.0 & 2.9201 & TRN & \\
\hline CHEMBL1489565 & 845103 & 4.8447 & 4.1136 & TRN & \\
\hline CHEMBL1378356 & 845103 & 3.0 & 2.7296 & TRN & \\
\hline CHEMBL1558870 & 845103 & 3.0 & 2.9757 & TRN & \\
\hline CHEMBL1535690 & 845103 & 3.0 & 3.0263 & TRN & \\
\hline CHEMBL1569778 & 845103 & 3.0 & 2.9834 & TRN & \\
\hline CHEMBL1427147 & 845103 & 3.0 & 2.9486 & TRN & \\
\hline CHEMBL1387393 & 845103 & 3.0 & 2.8301 & TRN & \\
\hline CHEMBL1410230 & 845103 & 3.0 & 3.5694 & TRN & \\
\hline CHEMBL1731328 & 845103 & 3.0 & 2.7023 & TRN & \\
\hline CHEMBL1368249 & 845103 & 3.0 & 3.0703 & TRN & \\
\hline CHEMBL1383700 & 845103 & 3.0 & 3.6355 & TRN & \\
\hline CHEMBL1541584 & 845103 & 3.0 & 3.1919 & TRN & \\
\hline CHEMBL1878879 & 845103 & 3.0 & 3.089 & TRN & \\
\hline CHEMBL1407512 & 845103 & 4.6253 & 3.9807 & TRN & \\
\hline CHEMBL1497856 & 845103 & 3.0 & 3.17100 & 00000000003 & TRN \\
\hline CHEMBL1728514 & 845103 & 4.1918 & 3.1837 & TST & \\
\hline CHEMBL1577593 & 845103 & 3.0 & 3.0649 & TRN & \\
\hline CHEMBL1529346 & 845103 & 3.0 & 2.8763 & TRN & \\
\hline CHEMBL1538973 & 845103 & 3.0 & 4.0624 & TRN & \\
\hline CHEMBL1887093 & 845103 & 4.3595 & 3.8829 & TRN & \\
\hline CHEMBL 3208367 & 845103 & 3.0 & 3.0907 & TRN & \\
\hline CHEMBL1724217 & 845103 & 4.8182 & 4.0501 & TRN & \\
\hline CHEMBL1599169 & 845103 & 3.0 & 3.1728 & TRN & \\
\hline
\end{tabular}




\begin{tabular}{|c|c|c|c|c|c|}
\hline \multicolumn{6}{|c|}{ Supplemental Table S2.txt } \\
\hline CHEMBL1609545 & 845103 & 3.0 & 3.5018 & TRN & \\
\hline CHEMBL1418232 & 845103 & 3.0 & 3.1886 & TRN & \\
\hline CHEMBL1350529 & 845103 & 4.0255 & 3.2301 & TRN & \\
\hline CHEMBL1375292 & 845103 & 3.0 & 3.9687 & TRN & \\
\hline CHEMBL1319917 & 845103 & 3.0 & 3.7355 & TRN & \\
\hline CHEMBL1320357 & 845103 & 3.0 & 3.155 & TRN & \\
\hline CHEMBL1971636 & 845103 & 3.0 & 3.3069 & TRN & \\
\hline CHEMBL1366278 & 845103 & 3.0 & 3.1164 & TRN & \\
\hline CHEMBL1870220 & 845103 & 3.0 & 2.9307 & TRN & \\
\hline CHEMBL1301042 & 845103 & 3.0 & 3.2866 & TRN & \\
\hline CHEMBL1442218 & 845103 & 3.0 & 3.2279 & TRN & \\
\hline CHEMBL1880117 & 845103 & 3.0 & 3.4664 & TRN & \\
\hline CHEMBL 2132821 & 845103 & 3.0 & 3.3074 & TRN & \\
\hline CHEMBL1709980 & 845103 & 3.0 & 3.1061 & TRN & \\
\hline CHEMBL1700625 & 845103 & 3.0 & 2.9927 & TRN & \\
\hline CHEMBL1448914 & 845103 & 3.0 & 3.3113 & TRN & \\
\hline CHEMBL1487525 & 845103 & 3.0 & 2.8408 & TRN & \\
\hline CHEMBL1598515 & 845103 & 4.0241 & 3.7238 & TRN & \\
\hline CHEMBL1493351 & 845103 & 3.0 & 3.5387 & TRN & \\
\hline CHEMBL1608180 & 845103 & 3.0 & 3.18 & TRN & \\
\hline CHEMBL1544408 & 845103 & 4.8996 & 4.0225 & TRN & \\
\hline CHEMBL1505604 & 845103 & 3.0 & 3.6271 & TRN & \\
\hline CHEMBL1709141 & 845103 & 3.0 & 3.4394 & TST & \\
\hline CHEMBL1704922 & 845103 & 4.3516 & 3.5216 & TRN & \\
\hline CHEMBL1452611 & 845103 & 3.0 & 3.2538 & TST & \\
\hline CHEMBL 2131435 & 845103 & 3.0 & 2.9359 & TRN & \\
\hline CHEMBL1565955 & 845103 & 4.5654 & 3.9436 & TRN & \\
\hline CHEMBL1301682 & 845103 & 3.0 & 2.8308 & TRN & \\
\hline CHEMBL1461578 & 845103 & 3.0 & 4.1693 & TRN & \\
\hline CHEMBL 2143056 & 845103 & 3.0 & 3.0899 & TRN & \\
\hline CHEMBL1560655 & 845103 & 4.2646 & 3.6807 & TRN & \\
\hline CHEMBL1308182 & 845103 & 3.0 & 2.4893 & TRN & \\
\hline CHEMBL1377992 & 845103 & 3.0 & 3.6609 & TRN & \\
\hline CHEMBL1383612 & 845103 & 3.0 & 3.1064 & TRN & \\
\hline CHEMBL1507480 & 845103 & 3.0 & 3.3386 & TRN & \\
\hline CHEMBL1463767 & 845103 & 5.1637 & 3.6715 & TRN & \\
\hline CHEMBL1367620 & 845103 & 3.0 & 3.3622 & TST & \\
\hline CHEMBL1349940 & 845103 & 3.0 & 2.8623 & TRN & \\
\hline CHEMBL1381505 & 845103 & 3.0 & 3.3839 & TRN & \\
\hline CHEMBL1440373 & 845103 & 3.0 & 3.1567 & TRN & \\
\hline CHEMBL1426917 & 845103 & 3.0 & 3.1206 & TRN & \\
\hline CHEMBL1565700 & 845103 & 3.0 & 3.637 & TRN & \\
\hline CHEMBL1612765 & 845103 & 3.0 & 3.202 & TRN & \\
\hline CHEMBL1318058 & 845103 & 3.0 & 3.3325 & TST & \\
\hline CHEMBL1508503 & 845103 & 3.0 & 3.57800 & 00000000003 & TRN \\
\hline CHEMBL1350113 & 845103 & 3.0 & 3.321 & TST & \\
\hline CHEMBL1596056 & 845103 & 3.0 & 3.0805 & TRN & \\
\hline CHEMBL1448281 & 845103 & 3.0 & 3.1789 & TRN & \\
\hline
\end{tabular}




\begin{tabular}{|c|c|c|c|c|c|}
\hline \multicolumn{6}{|c|}{ Supplemental Table S2.txt } \\
\hline CHEMBL1374279 & 845103 & 3.0 & 2.7536 & TST & \\
\hline CHEMBL1451476 & 845103 & 4.5638 & 4.4496 & TRN & \\
\hline CHEMBL1887321 & 845103 & 4.644 & 4.1573 & TRN & \\
\hline CHEMBL1570824 & 845103 & 3.0 & 3.7915 & TRN & \\
\hline CHEMBL 2137308 & 845103 & 3.0 & 3.4727 & TST & \\
\hline CHEMBL1722297 & 845103 & 3.0 & 2.9641 & TRN & \\
\hline CHEMBL1891294 & 845103 & 3.0 & 3.7628 & TRN & \\
\hline CHEMBL1537211 & 845103 & 3.0 & 4.1427 & TRN & \\
\hline CHEMBL1505809 & 845103 & 4.5768 & 3.93899 & 99999999996 & TRN \\
\hline CHEMBL1173036 & 845103 & 3.0 & 3.4477 & TRN & \\
\hline CHEMBL1721259 & 845103 & 3.0 & 3.1049 & TRN & \\
\hline CHEMBL1519411 & 845103 & 3.0 & 3.4232 & TRN & \\
\hline CHEMBL1726010 & 845103 & 4.1649 & 3.3198 & TRN & \\
\hline CHEMBL1358924 & 845103 & 6.5045 & 4.399 & TRN & \\
\hline CHEMBL1313566 & 845103 & 4.0762 & 3.9486 & TRN & \\
\hline CHEMBL1486966 & 845103 & 3.0 & 3.0102 & TRN & \\
\hline CHEMBL1359529 & 845103 & 5.1018 & 4.1672 & TRN & \\
\hline CHEMBL1424241 & 845103 & 3.0 & 3.6145 & TRN & \\
\hline CHEMBL1418887 & 845103 & 3.0 & 2.9568 & TRN & \\
\hline CHEMBL1584566 & 845103 & 3.0 & 3.2673 & TRN & \\
\hline CHEMBL1454747 & 845103 & 4.6216 & 4.0246 & TRN & \\
\hline CHEMBL 259853 & 845103 & 3.0 & 2.867 & TRN & \\
\hline CHEMBL1479807 & 845103 & 3.0 & 3.5597 & TRN & \\
\hline CHEMBL1409219 & 845103 & 4.9031 & 3.0455 & TRN & \\
\hline CHEMBL1502047 & 845103 & 4.6383 & 4.0393 & TRN & \\
\hline CHEMBL1482301 & 845103 & 3.0 & 2.9339 & TRN & \\
\hline CHEMBL1404619 & 845103 & 3.0 & 3.3892 & TST & \\
\hline CHEMBL1522596 & 845103 & 3.0 & 3.3596 & TRN & \\
\hline CHEMBL1301190 & 845103 & 3.0 & 3.3083 & TST & \\
\hline CHEMBL1529744 & 845103 & 3.0 & 2.918 & TRN & \\
\hline CHEMBL1705423 & 845103 & 4.2358 & 3.826 & TRN & \\
\hline CHEMBL1490017 & 845103 & 4.6459 & 4.0278 & TRN & \\
\hline CHEMBL1306864 & 845103 & 3.0 & 3.2947 & TRN & \\
\hline CHEMBL1585701 & 845103 & 3.0 & 3.8627 & TRN & \\
\hline CHEMBL1328220 & 845103 & 3.0 & 3.2197 & TRN & \\
\hline CHEMBL1414989 & 845103 & 4.4283 & 4.04 & TRN & \\
\hline CHEMBL1311572 & 845103 & 6.5045 & 4.7882 & TRN & \\
\hline CHEMBL1532182 & 845103 & 3.0 & 3.29399 & 99999999996 & TRN \\
\hline CHEMBL1342128 & 845103 & 3.0 & 3.2746 & TRN & \\
\hline CHEMBL1509217 & 845103 & 3.0 & 3.3799 & TRN & \\
\hline CHEMBL1571018 & 845103 & 4.0804 & 3.6457 & TRN & \\
\hline CHEMBL1533514 & 845103 & 3.0 & 2.7598 & TST & \\
\hline CHEMBL1556907 & 845103 & 3.0 & 3.2186 & TRN & \\
\hline CHEMBL1424200 & 845103 & 3.0 & 2.9996 & TRN & \\
\hline CHEMBL1575829 & 845103 & 3.0 & 2.7735 & TRN & \\
\hline CHEMBL1902300 & 845103 & 3.0 & 3.1454 & TRN & \\
\hline CHEMBL1606510 & 845103 & 4.1549 & 3.6255 & TRN & \\
\hline CHEMBL1351908 & 845103 & 4.1215 & 3.8996 & TRN & \\
\hline
\end{tabular}




\begin{tabular}{|c|c|c|c|c|c|}
\hline \multicolumn{6}{|c|}{ Supplemental Table s2.txt } \\
\hline CHEMBL1378372 & 845103 & 3.0 & 3.0361 & TRN & \\
\hline CHEMBL1598895 & 845103 & 3.0 & 3.0745 & TRN & \\
\hline CHEMBL1437691 & 845103 & 3.0 & 3.8279 & TST & \\
\hline CHEMBL1531504 & 845103 & 3.0 & 2.7832 & TRN & \\
\hline CHEMBL1345888 & 845103 & 4.6996 & 3.8328 & TRN & \\
\hline CHEMBL1497853 & 845103 & 3.0 & 3.4811 & TRN & \\
\hline CHEMBL1565801 & 845103 & 4.0822 & 4.0262 & TRN & \\
\hline CHEMBL1419246 & 845103 & 3.0 & 2.8396 & TRN & \\
\hline CHEMBL1322920 & 845103 & 3.0 & 3.2045 & TRN & \\
\hline CHEMBL1736267 & 845103 & 3.0 & 3.4992 & TRN & \\
\hline CHEMBL 3214040 & 845103 & 3.0 & 3.1085 & TST & \\
\hline CHEMBL1403349 & 845103 & 4.9788 & 4.7093 & TRN & \\
\hline CHEMBL1612968 & 845103 & 3.0 & 3.0751 & TRN & \\
\hline CHEMBL1480671 & 845103 & 3.0 & 3.2567 & TRN & \\
\hline CHEMBL1481520 & 845103 & 3.0 & 3.1496 & TRN & \\
\hline CHEMBL1341657 & 845103 & 3.0 & 2.9828 & TRN & \\
\hline CHEMBL1488090 & 845103 & 4.6126 & 3.4858 & TRN & \\
\hline CHEMBL1406610 & 845103 & 3.0 & 2.9066 & TRN & \\
\hline CHEMBL515248 & 845103 & 3.0 & 2.7399 & TRN & \\
\hline CHEMBL1450732 & 845103 & 4.6696 & 3.167 & TRN & \\
\hline CHEMBL1346320 & 845103 & 3.0 & 2.8424 & TRN & \\
\hline CHEMBL1467961 & 845103 & 3.0 & 2.759 & TST & \\
\hline CHEMBL1611005 & 845103 & 3.0 & 3.2924 & TRN & \\
\hline CHEMBL1600421 & 845103 & 4.8794 & 4.0988 & TRN & \\
\hline CHEMBL 2132937 & 845103 & 3.0 & 3.4813 & TRN & \\
\hline CHEMBL1883657 & 845103 & 3.0 & 3.0284 & TRN & \\
\hline CHEMBL 2131227 & 845103 & 6.5045 & 3.9675 & TRN & \\
\hline CHEMBL1325979 & 845103 & 4.7721 & 3.8418 & TRN & \\
\hline CHEMBL1723862 & 845103 & 5.0278 & 3.8805 & TRN & \\
\hline CHEMBL1497557 & 845103 & 3.0 & 3.7942 & TRN & \\
\hline CHEMBL1603696 & 845103 & 4.857 & 3.6332 & TST & \\
\hline CHEMBL1361794 & 845103 & 3.0 & 3.085 & TRN & \\
\hline CHEMBL1435407 & 845103 & 3.0 & 2.9918 & TRN & \\
\hline CHEMBL1420133 & 845103 & 4.6904 & 4.2361 & TRN & \\
\hline CHEMBL1339878 & 845103 & 3.0 & 2.3856 & TRN & \\
\hline CHEMBL1382206 & 845103 & 3.0 & 2.8688 & TRN & \\
\hline CHEMBL1904429 & 845103 & 3.0 & 2.6522 & TRN & \\
\hline CHEMBL1417740 & 845103 & 4.8996 & 3.9978 & TRN & \\
\hline CHEMBL1523365 & 845103 & 5.2154 & 4.3608 & TRN & \\
\hline CHEMBL1371785 & 845103 & 3.0 & 3.156 & TRN & \\
\hline CHEMBL1346548 & 845103 & 3.0 & 3.2623 & TRN & \\
\hline CHEMBL1895570 & 845103 & 3.0 & 3.46100 & 00000000003 & TRN \\
\hline CHEMBL1573949 & 845103 & 3.0 & 3.3569 & TRN & \\
\hline CHEMBL1340183 & 845103 & 3.0 & 2.9779 & TST & \\
\hline CHEMBL1442084 & 845103 & 4.0999 & 3.7651 & TRN & \\
\hline CHEMBL1580176 & 845103 & 3.0 & 2.6675 & TRN & \\
\hline CHEMBL1450724 & 845103 & 3.0 & 3.1491 & TRN & \\
\hline CHEMBL1417814 & 845103 & 3.0 & 4.391 & TRN & \\
\hline
\end{tabular}




\begin{tabular}{|c|c|c|c|c|c|}
\hline \multirow[b]{2}{*}{ CHEMBL1365469 } & \multicolumn{5}{|c|}{ Supplemental Table S2.txt } \\
\hline & 845103 & 4.3098 & 3.9497 & TRN & \\
\hline CHEMBL1525420 & 845103 & 3.0 & 2.642 & TRN & \\
\hline CHEMBL1542592 & 845103 & 3.0 & 3.8884 & TRN & \\
\hline CHEMBL1386766 & 845103 & 4.3726 & 3.5969 & TRN & \\
\hline CHEMBL1533888 & 845103 & 3.0 & 3.7377 & TRN & \\
\hline CHEMBL1502184 & 845103 & 3.0 & 3.9563 & TRN & \\
\hline CHEMBL1426407 & 845103 & 3.0 & 3.3989 & TRN & \\
\hline CHEMBL1716512 & 845103 & 3.0 & 3.4141 & TRN & \\
\hline CHEMBL1902084 & 845103 & 3.0 & 3.12 & TST & \\
\hline CHEMBL1543194 & 845103 & 4.9431 & 4.0063 & TRN & \\
\hline CHEMBL1408378 & 845103 & 3.0 & 3.5836 & TRN & \\
\hline CHEMBL1326897 & 845103 & 4.6021 & 3.5721 & TRN & \\
\hline CHEMBL1559618 & 845103 & 3.0 & 3.5344 & TRN & \\
\hline CHEMBL1303996 & 845103 & 3.0 & 3.6195 & TRN & \\
\hline CHEMBL1995078 & 845103 & 4.5482 & 3.3603 & TST & \\
\hline CHEMBL1376360 & 845103 & 3.0 & 3.7264 & TRN & \\
\hline CHEMBL1344582 & 845103 & 4.1343 & 4.1462 & TRN & \\
\hline CHEMBL1377500 & 845103 & 3.0 & 3.5123 & TRN & \\
\hline CHEMBL1886475 & 845103 & 3.0 & 2.8556 & TRN & \\
\hline CHEMBL1371088 & 845103 & 3.0 & 4.1415 & TRN & \\
\hline CHEMBL1424001 & 845103 & 3.0 & 2.8153 & TRN & \\
\hline CHEMBL1511924 & 845103 & 5.0264 & 3.8797 & TRN & \\
\hline CHEMBL1571364 & 845103 & 3.0 & 3.0064 & TRN & \\
\hline CHEMBL1462974 & 845103 & 3.0 & 2.8192 & TRN & \\
\hline CHEMBL1607713 & 845103 & 3.0 & 4.2201 & TRN & \\
\hline CHEMBL1373841 & 845103 & 3.0 & 3.5553 & TRN & \\
\hline CHEMBL1533772 & 845103 & 3.0 & 3.1584 & TST & \\
\hline CHEMBL1605575 & 845103 & 4.4449 & 3.97 & TRN & \\
\hline CHEMBL1328321 & 845103 & 3.0 & 2.758 & TRN & \\
\hline CHEMBL1477304 & 845103 & 4.9872 & 4.0914 & TRN & \\
\hline CHEMBL1413213 & 845103 & 3.0 & 2.9746 & TST & \\
\hline CHEMBL1381205 & 845103 & 3.0 & 4.1611 & TRN & \\
\hline CHEMBL1462886 & 845103 & 3.0 & 3.2894 & TRN & \\
\hline CHEMBL1483431 & 845103 & 4.4547 & 3.6905 & TRN & \\
\hline CHEMBL1421660 & 845103 & 3.0 & 2.6855 & TRN & \\
\hline CHEMBL1300962 & 845103 & 4.1158 & 3.2459 & TST & \\
\hline CHEMBL1451110 & 845103 & 3.0 & 3.7658 & TRN & \\
\hline CHEMBL1326812 & 845103 & 3.0 & 2.46199 & 99999999997 & TRN \\
\hline CHEMBL1370449 & 845103 & 3.0 & 3.4224 & TRN & \\
\hline CHEMBL1471417 & 845103 & 3.0 & 3.5873 & TRN & \\
\hline CHEMBL1613636 & 845103 & 3.0 & 3.0503 & TRN & \\
\hline CHEMBL 2004884 & 845103 & 3.0 & 2.9166 & TRN & \\
\hline CHEMBL1310714 & 845103 & 4.3706 & 3.8218 & TRN & \\
\hline CHEMBL66654 & 845103 & 3.0 & 3.5344 & TRN & \\
\hline CHEMBL1577814 & 845103 & 4.5272 & 3.9673 & TRN & \\
\hline CHEMBL1717884 & 845103 & 4.2941 & 4.0961 & TRN & \\
\hline CHEMBL1885376 & 845103 & 4.7447 & 3.7653 & TRN & \\
\hline CHEMBL1300882 & 845103 & 4.1858 & 4.372 & TRN & \\
\hline
\end{tabular}




\begin{tabular}{|c|c|c|c|c|}
\hline \multicolumn{5}{|c|}{ Supplemental Table S2.txt } \\
\hline CHEMBL1458038 & 845103 & 3.0 & 3.8199 & TRN \\
\hline CHEMBL1501376 & 845103 & 4.2059 & 3.3276 & TRN \\
\hline CHEMBL1346986 & 845103 & 3.0 & 3.9519 & TRN \\
\hline CHEMBL1488611 & 845103 & 3.0 & 3.1257 & TRN \\
\hline CHEMBL1362739 & 845103 & 3.0 & 3.3246 & TRN \\
\hline CHEMBL1867073 & 845103 & 3.0 & 3.1154 & TST \\
\hline CHEMBL1392046 & 845103 & 3.0 & 3.0218 & TRN \\
\hline CHEMBL1583069 & 845103 & 3.0 & 3.4782 & TST \\
\hline CHEMBL1469103 & 845103 & 3.0 & 3.3503 & TRN \\
\hline CHEMBL1500710 & 845103 & 4.4737 & 3.9705 & TRN \\
\hline CHEMBL1403993 & 845103 & 3.0 & 3.0353 & TST \\
\hline CHEMBL1377118 & 845103 & 3.0 & 3.029 & TRN \\
\hline CHEMBL1439255 & 845103 & 3.0 & 3.7584 & TRN \\
\hline CHEMBL1890961 & 845103 & 3.0 & 3.7138 & TST \\
\hline CHEMBL1321127 & 845103 & 3.0 & 3.3118 & TST \\
\hline CHEMBL1500042 & 845103 & 4.6635 & 4.1154 & TRN \\
\hline CHEMBL1607955 & 845103 & 3.0 & 3.4436 & TST \\
\hline CHEMBL1581245 & 845103 & 3.0 & 3.1056 & TRN \\
\hline CHEMBL1467284 & 845103 & 3.0 & 3.0194 & TRN \\
\hline CHEMBL1540421 & 845103 & 3.0 & 3.2972 & TRN \\
\hline CHEMBL1368016 & 845103 & 3.0 & 3.5154 & TRN \\
\hline CHEMBL1410072 & 845103 & 4.0521 & 3.5281 & TRN \\
\hline CHEMBL1571345 & 845103 & 3.0 & 3.2754 & TRN \\
\hline CHEMBL1586677 & 845103 & 3.0 & 3.0109 & TRN \\
\hline CHEMBL1516590 & 845103 & 3.0 & 3.6068 & TST \\
\hline CHEMBL1457561 & 845103 & 4.3497 & 3.6001 & TRN \\
\hline CHEMBL1361236 & 845103 & 4.4001 & 3.5037 & TRN \\
\hline CHEMBL1376423 & 845103 & 3.0 & 3.9167 & TRN \\
\hline CHEMBL1384647 & 845103 & 3.0 & 2.7197 & TST \\
\hline CHEMBL1308668 & 845103 & 3.0 & 3.0369 & TRN \\
\hline CHEMBL1325071 & 845103 & 4.6778 & 3.9676 & TRN \\
\hline CHEMBL1417859 & 845103 & 4.0329 & 3.8969 & TRN \\
\hline CHEMBL1387966 & 845103 & 3.0 & 2.7377 & TRN \\
\hline CHEMBL1520524 & 845103 & 3.0 & 3.8523 & TRN \\
\hline CHEMBL1610514 & 845103 & 3.0 & 2.7714 & TRN \\
\hline CHEMBL1610255 & 845103 & 4.1637 & 3.4425 & TRN \\
\hline CHEMBL1332240 & 845103 & 3.0 & 3.1093 & TRN \\
\hline CHEMBL547483 & 845103 & 3.0 & 3.5437 & TST \\
\hline CHEMBL1565749 & 845103 & 4.2351 & 3.1667 & TRN \\
\hline CHEMBL1509727 & 845103 & 4.9136 & 4.4238 & TRN \\
\hline CHEMBL1325452 & 845103 & 3.0 & 2.7971 & TRN \\
\hline CHEMBL1584639 & 845103 & 3.0 & 2.7693 & TRN \\
\hline CHEMBL1484152 & 845103 & 3.0 & 3.6266 & TRN \\
\hline CHEMBL1453890 & 845103 & 3.0 & 3.18899 & 99999999996 \\
\hline CHEMBL1355623 & 845103 & 3.0 & 3.8769 & TST \\
\hline CHEMBL1711725 & 845103 & 3.0 & 2.9915 & TRN \\
\hline CHEMBL1882185 & 845103 & 3.0 & 2.9725 & TRN \\
\hline CHEMBL1562928 & 845103 & 3.0 & 3.4066 & TRN \\
\hline
\end{tabular}

TRN 


\begin{tabular}{|c|c|c|c|c|c|}
\hline \multirow[b]{2}{*}{ CHEMBL1424434 } & \multicolumn{5}{|c|}{ Supplemental Table S2.txt } \\
\hline & 845103 & 4.2984 & 4.1353 & TRN & \\
\hline CHEMBL1427210 & 845103 & 3.0 & 3.264 & TRN & \\
\hline CHEMBL1360291 & 845103 & 4.475 & 3.884 & TRN & \\
\hline CHEMBL1906123 & 845103 & 3.0 & 2.8192 & TRN & \\
\hline CHEMBL1234578 & 845103 & 3.0 & 3.3263 & TST & \\
\hline CHEMBL1324305 & 845103 & 3.0 & 3.4667 & TST & \\
\hline CHEMBL1561348 & 845103 & 3.0 & 3.5866 & TRN & \\
\hline CHEMBL1388520 & 845103 & 3.0 & 3.0133 & TRN & \\
\hline CHEMBL1409735 & 845103 & 3.0 & 4.1452 & TRN & \\
\hline CHEMBL2132627 & 845103 & 3.0 & 3.1861 & TRN & \\
\hline CHEMBL2135745 & 845103 & 3.0 & 2.7711 & TRN & \\
\hline CHEMBL1574041 & 845103 & 3.0 & 3.0752 & TRN & \\
\hline CHEMBL1883934 & 845103 & 3.0 & 2.79399 & 99999999996 & TRN \\
\hline CHEMBL1443740 & 845103 & 4.2877 & 4.5865 & TRN & \\
\hline CHEMBL1365705 & 845103 & 3.0 & 3.3476 & TRN & \\
\hline CHEMBL1300383 & 845103 & 3.0 & 3.2787 & TRN & \\
\hline CHEMBL1868119 & 845103 & 3.0 & 3.6966 & TRN & \\
\hline CHEMBL1576328 & 845103 & 4.567 & 3.5958 & TRN & \\
\hline CHEMBL1490364 & 845103 & 3.0 & 3.202 & TRN & \\
\hline CHEMBL1480974 & 845103 & 3.0 & 3.2321 & TRN & \\
\hline CHEMBL1462302 & 845103 & 4.3134 & 3.426 & TRN & \\
\hline CHEMBL1497930 & 845103 & 3.0 & 3.8624 & TRN & \\
\hline CHEMBL1585962 & 845103 & 3.0 & 3.7035 & TST & \\
\hline CHEMBL1412393 & 845103 & 4.5421 & 3.6534 & TRN & \\
\hline CHEMBL1576589 & 845103 & 3.0 & 3.3513 & TRN & \\
\hline CHEMBL1325046 & 845103 & 3.0 & 3.4444 & TST & \\
\hline CHEMBL1364325 & 845103 & 3.0 & 3.1256 & TRN & \\
\hline CHEMBL 2132442 & 845103 & 3.0 & 2.7643 & TST & \\
\hline CHEMBL1329411 & 845103 & 3.0 & 3.8024 & TST & \\
\hline CHEMBL1507171 & 845103 & 3.0 & 4.0536 & TRN & \\
\hline CHEMBL1323785 & 845103 & 4.8962 & 4.1501 & TRN & \\
\hline CHEMBL1301373 & 845103 & 3.0 & 3.7766 & TRN & \\
\hline CHEMBL1542242 & 845103 & 3.0 & 3.029 & TRN & \\
\hline CHEMBL1162484 & 845103 & 3.0 & 3.3614 & TST & \\
\hline CHEMBL1533919 & 845103 & 3.0 & 3.2929 & TRN & \\
\hline CHEMBL1524020 & 845103 & 4.1302 & 4.2449 & TRN & \\
\hline CHEMBL1462274 & 845103 & 3.0 & 2.9879 & TRN & \\
\hline CHEMBL1880991 & 845103 & 5.426 & 4.6647 & TRN & \\
\hline CHEMBL1446942 & 845103 & 4.2636 & 4.0542 & TRN & \\
\hline CHEMBL1485736 & 845103 & 4.0164 & 3.6765 & TRN & \\
\hline CHEMBL1352778 & 845103 & 3.0 & 2.9362 & TRN & \\
\hline CHEMBL1546366 & 845103 & 3.0 & 3.7656 & TST & \\
\hline CHEMBL1429171 & 845103 & 3.0 & 3.6477 & TRN & \\
\hline CHEMBL1882098 & 845103 & 4.1527 & 3.7083 & TRN & \\
\hline CHEMBL1422934 & 845103 & 3.0 & 3.5192 & TRN & \\
\hline CHEMBL1488720 & 845103 & 3.0 & 2.9206 & TRN & \\
\hline CHEMBL1509866 & 845103 & 3.0 & 3.3584 & TRN & \\
\hline CHEMBL1885199 & 845103 & 3.0 & 3.1619 & TRN & \\
\hline
\end{tabular}




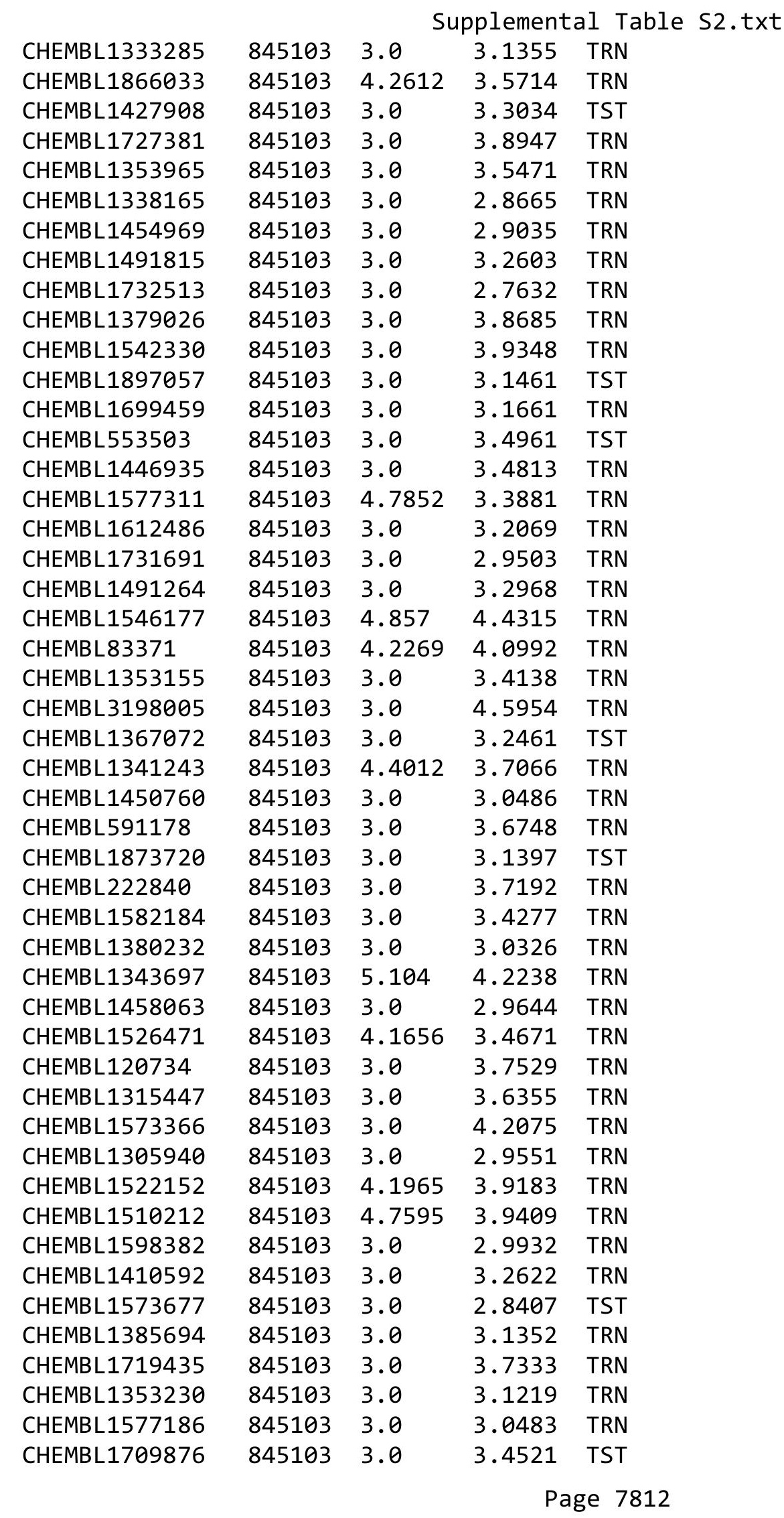




\begin{tabular}{|c|c|c|c|c|}
\hline \multicolumn{5}{|c|}{ Supplemental Table s2.txt } \\
\hline CHEMBL1414729 & 845103 & 3.0 & 3.3132 & TRN \\
\hline CHEMBL1444305 & 845103 & 4.0004 & 3.9151 & TRN \\
\hline CHEMBL1580871 & 845103 & 3.0 & 2.9648 & TRN \\
\hline CHEMBL1588930 & 845103 & 4.1206 & 3.9778 & TRN \\
\hline CHEMBL1523329 & 845103 & 3.0 & 2.9245 & TRN \\
\hline CHEMBL1550839 & 845103 & 3.0 & 3.1939 & TRN \\
\hline CHEMBL1439871 & 845103 & 3.0 & 3.1102 & TST \\
\hline CHEMBL1877995 & 845103 & 3.0 & 3.4784 & TRN \\
\hline CHEMBL1584315 & 845103 & 4.3778 & 3.7141 & TRN \\
\hline CHEMBL1564848 & 845103 & 4.6364 & 3.9742 & TRN \\
\hline CHEMBL1481353 & 845103 & 4.2369 & 4.1606 & TRN \\
\hline CHEMBL1452389 & 845103 & 3.0 & 3.2036 & TRN \\
\hline CHEMBL1464674 & 845103 & 3.0 & 3.009 & TRN \\
\hline CHEMBL 1454500 & 845103 & 3.0 & 2.9754 & TRN \\
\hline CHEMBL1462462 & 845103 & 3.0 & 3.8632 & TRN \\
\hline CHEMBL1327408 & 845103 & 3.0 & 3.8408 & TRN \\
\hline CHEMBL1471431 & 845103 & 3.0 & 3.8237 & TST \\
\hline CHEMBL1380497 & 845103 & 3.0 & 3.5805 & TRN \\
\hline CHEMBL1538954 & 845103 & 3.0 & 3.2914 & TRN \\
\hline CHEMBL1390473 & 845103 & 3.0 & 3.202 & TST \\
\hline CHEMBL1556848 & 845103 & 3.0 & 3.8341 & TRN \\
\hline CHEMBL1359037 & 845103 & 3.0 & 2.9161 & TRN \\
\hline CHEMBL 1444340 & 845103 & 3.0 & 2.7274 & TRN \\
\hline CHEMBL1491810 & 845103 & 3.0 & 3.4806 & TRN \\
\hline CHEMBL1478024 & 845103 & 3.0 & 3.2282 & TRN \\
\hline CHEMBL1517653 & 845103 & 3.0 & 3.0341 & TRN \\
\hline CHEMBL1502952 & 845103 & 4.4389 & 4.1373 & TRN \\
\hline CHEMBL1313683 & 845103 & 4.0 & 3.5283 & TRN \\
\hline CHEMBL1488784 & 845103 & 3.0 & 3.0678 & TST \\
\hline CHEMBL 2140910 & 845103 & 3.0 & 3.057 & TRN \\
\hline CHEMBL1546053 & 845103 & 3.0 & 3.6946 & TRN \\
\hline CHEMBL1417054 & 845103 & 3.0 & 3.2763 & TRN \\
\hline CHEMBL1569728 & 845103 & 3.0 & 3.8343 & TRN \\
\hline CHEMBL1498466 & 845103 & 4.5017 & 4.2405 & TRN \\
\hline CHEMBL1453783 & 845103 & 3.0 & 2.8666 & TST \\
\hline CHEMBL1600981 & 845103 & 3.0 & 3.1652 & TRN \\
\hline CHEMBL1359616 & 845103 & 3.0 & 3.2314 & TRN \\
\hline CHEMBL1387082 & 845103 & 3.0 & 3.2906 & TRN \\
\hline CHEMBL1533912 & 845103 & 3.0 & 3.5053 & TST \\
\hline CHEMBL1904461 & 845103 & 3.0 & 3.3317 & TRN \\
\hline CHEMBL1736307 & 845103 & 3.0 & 3.1128 & TRN \\
\hline CHEMBL1564100 & 845103 & 4.0635 & 3.5654 & TRN \\
\hline CHEMBL1301337 & 845103 & 3.0 & 3.4031 & TST \\
\hline CHEMBL1700293 & 845103 & 4.6003 & 3.6989 & TRN \\
\hline CHEMBL1511627 & 845103 & 3.0 & 3.1928 & TRN \\
\hline CHEMBL1346516 & 845103 & 3.0 & 3.6904 & TRN \\
\hline CHEMBL1603581 & 845103 & 3.0 & 3.7307 & TST \\
\hline CHEMBL1418168 & 845103 & 3.0 & 3.6457 & TST \\
\hline
\end{tabular}




\begin{tabular}{|c|c|c|c|c|}
\hline \multicolumn{5}{|c|}{ Supplemental Table S2.txt } \\
\hline CHEMBL1312656 & 845103 & 4.1637 & 3.2786 & TRN \\
\hline CHEMBL1902365 & 845103 & 3.0 & 3.4635 & TRN \\
\hline CHEMBL1448213 & 845103 & 3.0 & 4.0061 & TRN \\
\hline CHEMBL1537332 & 845103 & 3.0 & 2.989 & TRN \\
\hline CHEMBL1353847 & 845103 & 3.0 & 3.8134 & TRN \\
\hline CHEMBL1546910 & 845103 & 3.0 & 3.2503 & TRN \\
\hline CHEMBL1422456 & 845103 & 4.7471 & 4.1779 & TRN \\
\hline CHEMBL1427218 & 845103 & 3.0 & 4.2681 & TRN \\
\hline CHEMBL1333860 & 845103 & 3.0 & 3.2934 & TRN \\
\hline CHEMBL1330076 & 845103 & 3.0 & 3.9679 & TRN \\
\hline CHEMBL 1385844 & 845103 & 3.0 & 3.3623 & TRN \\
\hline CHEMBL1327119 & 845103 & 3.0 & 2.8111 & TRN \\
\hline CHEMBL1456766 & 845103 & 3.0 & 2.9255 & TRN \\
\hline CHEMBL1535826 & 845103 & 4.6716 & 4.0736 & TRN \\
\hline CHEMBL1444968 & 845103 & 3.0 & 3.1968 & TST \\
\hline CHEMBL 1373602 & 845103 & 3.0 & 2.9755 & TST \\
\hline CHEMBL1528475 & 845103 & 4.6108 & 4.4745 & TST \\
\hline CHEMBL1504620 & 845103 & 4.8996 & 3.6218 & TST \\
\hline CHEMBL1727324 & 845103 & 4.9626 & 3.6178 & TST \\
\hline CHEMBL1409600 & 845103 & 3.0 & 3.048 & TST \\
\hline CHEMBL1326533 & 845103 & 3.0 & 4.0986 & TST \\
\hline CHEMBL1600150 & 845103 & 3.0 & 2.8972 & TST \\
\hline CHEMBL1345085 & 845103 & 3.0 & 3.1669 & TST \\
\hline CHEMBL1735546 & 845103 & 3.0 & 2.8552 & TST \\
\hline CHEMBL1613656 & 845103 & 3.0 & 3.5368 & TST \\
\hline CHEMBL1603452 & 845103 & 3.0 & 3.2806 & TST \\
\hline CHEMBL1310561 & 845103 & 3.0 & 2.7853 & TST \\
\hline CHEMBL1574632 & 845103 & 3.0 & 2.978 & TST \\
\hline CHEMBL1353164 & 845103 & 3.0 & 3.1083 & TST \\
\hline CHEMBL1387197 & 845103 & 3.0 & 3.3414 & TST \\
\hline CHEMBL412603 & 845103 & 3.0 & 4.1384 & TST \\
\hline CHEMBL1391414 & 845103 & 3.0 & 3.3426 & TST \\
\hline CHEMBL1367191 & 845103 & 3.0 & 3.8538 & TST \\
\hline CHEMBL1547067 & 845103 & 3.0 & 3.3594 & TST \\
\hline CHEMBL1470592 & 845103 & 3.0 & 3.1485 & TST \\
\hline CHEMBL1467176 & 845103 & 3.0 & 3.3067 & TST \\
\hline CHEMBL1319461 & 845103 & 3.0 & 3.0978 & TST \\
\hline CHEMBL 1884784 & 845103 & 3.0 & 2.6805 & TST \\
\hline CHEMBL1705082 & 845103 & 3.0 & 3.2849 & TST \\
\hline CHEMBL1729674 & 845103 & 3.0 & 3.1763 & TST \\
\hline CHEMBL1359521 & 845103 & 4.7167 & 3.9171 & TST \\
\hline CHEMBL1872674 & 845103 & 3.0 & 3.6663 & TST \\
\hline CHEMBL1337391 & 845103 & 3.0 & 3.2592 & TST \\
\hline CHEMBL1410536 & 845103 & 4.4828 & 3.7793 & TST \\
\hline CHEMBL1427426 & 845103 & 4.1178 & 3.3607 & TST \\
\hline CHEMBL1561364 & 845103 & 3.0 & 3.0776 & TST \\
\hline CHEMBL1374009 & 845103 & 3.0 & 3.8084 & TST \\
\hline CHEMBL1905939 & 845103 & 3.0 & 3.0466 & TST \\
\hline
\end{tabular}




\begin{tabular}{|c|c|c|c|c|c|}
\hline \multicolumn{6}{|c|}{ Supplemental Table S2.txt } \\
\hline CHEMBL1992506 & 845103 & 3.0 & 3.6313 & TST & \\
\hline CHEMBL1511298 & 845103 & 3.0 & 2.7793 & TST & \\
\hline CHEMBL1610071 & 845103 & 4.0778 & 3.2334 & TST & \\
\hline CHEMBL1711567 & 845103 & 3.0 & 4.2376 & TST & \\
\hline CHEMBL1330717 & 845103 & 4.4895 & 3.8656 & TST & \\
\hline CHEMBL1479621 & 845103 & 3.0 & 2.8029 & TST & \\
\hline CHEMBL1366915 & 845103 & 3.0 & 3.1894 & TST & \\
\hline CHEMBL1400955 & 845103 & 4.2277 & 3.8227 & TST & \\
\hline CHEMBL1497019 & 845103 & 3.0 & 3.5401 & TST & \\
\hline CHEMBL1607862 & 845103 & 3.0 & 2.8459 & TST & \\
\hline CHEMBL1522021 & 845103 & 3.0 & 3.1363 & TST & \\
\hline CHEMBL1610263 & 845103 & 4.9957 & 3.6066 & TST & \\
\hline CHEMBL1509778 & 845103 & 4.8268 & 3.5591 & TST & \\
\hline CHEMBL1524205 & 845103 & 4.7595 & 3.8213 & TST & \\
\hline CHEMBL1478352 & 845103 & 3.0 & 3.077 & TST & \\
\hline CHEMBL1367183 & 845103 & 4.3468 & 3.7131 & TST & \\
\hline CHEMBL1887317 & 845103 & 4.1007 & 3.1614 & TST & \\
\hline CHEMBL3195155 & 845103 & 4.1838 & 3.4078 & TST & \\
\hline CHEMBL1538609 & 845103 & 3.0 & 3.0497 & TST & \\
\hline CHEMBL3214549 & 845103 & 3.0 & 2.7874 & TST & \\
\hline CHEMBL1522206 & 845103 & 4.0966 & 3.7635 & TST & \\
\hline CHEMBL1869945 & 845103 & 3.0 & 3.6145 & TST & \\
\hline CHEMBL1415045 & 845103 & 3.0 & 2.9662 & TST & \\
\hline CHEMBL1524515 & 845103 & 3.0 & 3.2525 & TST & \\
\hline CHEMBL1446343 & 845103 & 3.0 & 3.3702 & TST & \\
\hline CHEMBL1604474 & 845103 & 3.0 & 2.9504 & TST & \\
\hline CHEMBL528256 & 845103 & 3.0 & 3.4394 & TST & \\
\hline CHEMBL1467238 & 845103 & 4.0214 & 3.937 & TST & \\
\hline CHEMBL1558603 & 845103 & 4.0496 & 3.9685 & TST & \\
\hline CHEMBL1328661 & 845103 & 3.0 & 3.0807 & TST & \\
\hline CHEMBL1508567 & 845103 & 4.5686 & 3.8457 & TST & \\
\hline CHEMBL1530561 & 845103 & 3.0 & 3.213 & TST & \\
\hline CHEMBL1902581 & 845103 & 3.0 & 3.6488 & TST & \\
\hline CHEMBL1713652 & 845103 & 3.0 & 2.8185 & TST & \\
\hline CHEMBL1301395 & 845103 & 3.0 & 3.4751 & TST & \\
\hline CHEMBL1887094 & 845103 & 3.0 & 3.17199 & 99999999997 & TST \\
\hline CHEMBL1899567 & 845103 & 3.0 & 2.71 & TST & \\
\hline CHEMBL225354 & 845103 & 3.0 & 3.4981 & TST & \\
\hline CHEMBL1423082 & 845103 & 3.0 & 3.3727 & TST & \\
\hline CHEMBL1478628 & 845103 & 4.7258 & 4.1078 & TST & \\
\hline CHEMBL1411666 & 845103 & 3.0 & 3.1211 & TST & \\
\hline CHEMBL1336889 & 845103 & 4.3143 & 3.4928 & TST & \\
\hline CHEMBL1561754 & 845103 & 3.0 & 3.2189 & TST & \\
\hline CHEMBL367376 & 845103 & 4.6198 & 3.0745 & TST & \\
\hline CHEMBL1490430 & 845103 & 4.6819 & 3.7156 & TST & \\
\hline CHEMBL1510471 & 845103 & 3.0 & 2.8745 & TST & \\
\hline CHEMBL1522891 & 845103 & 4.5214 & 4.2594 & TST & \\
\hline CHEMBL1573066 & 845103 & 3.0 & 3.63199 & 99999999997 & TST \\
\hline & & & & e 7815 & \\
\hline
\end{tabular}




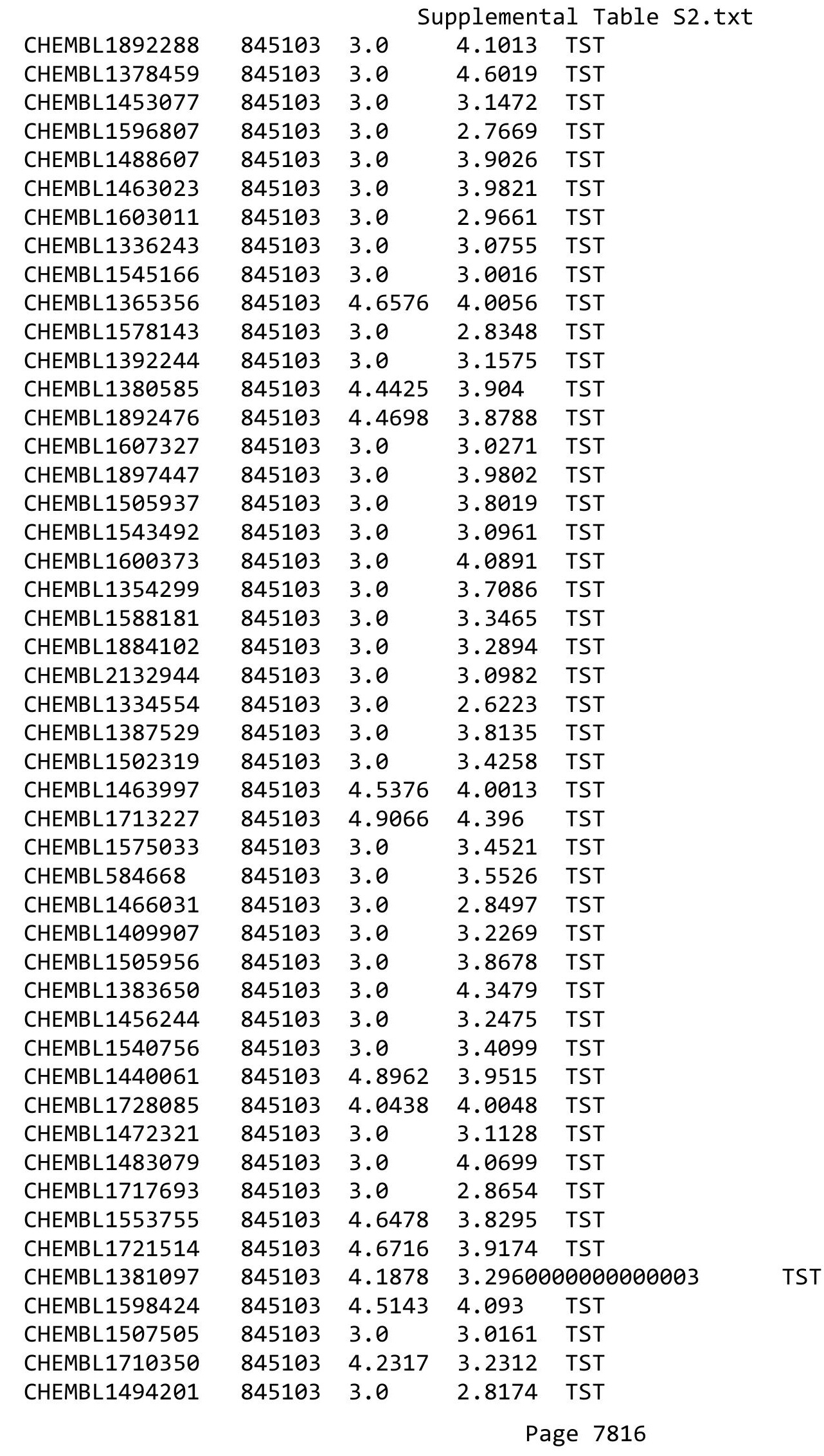




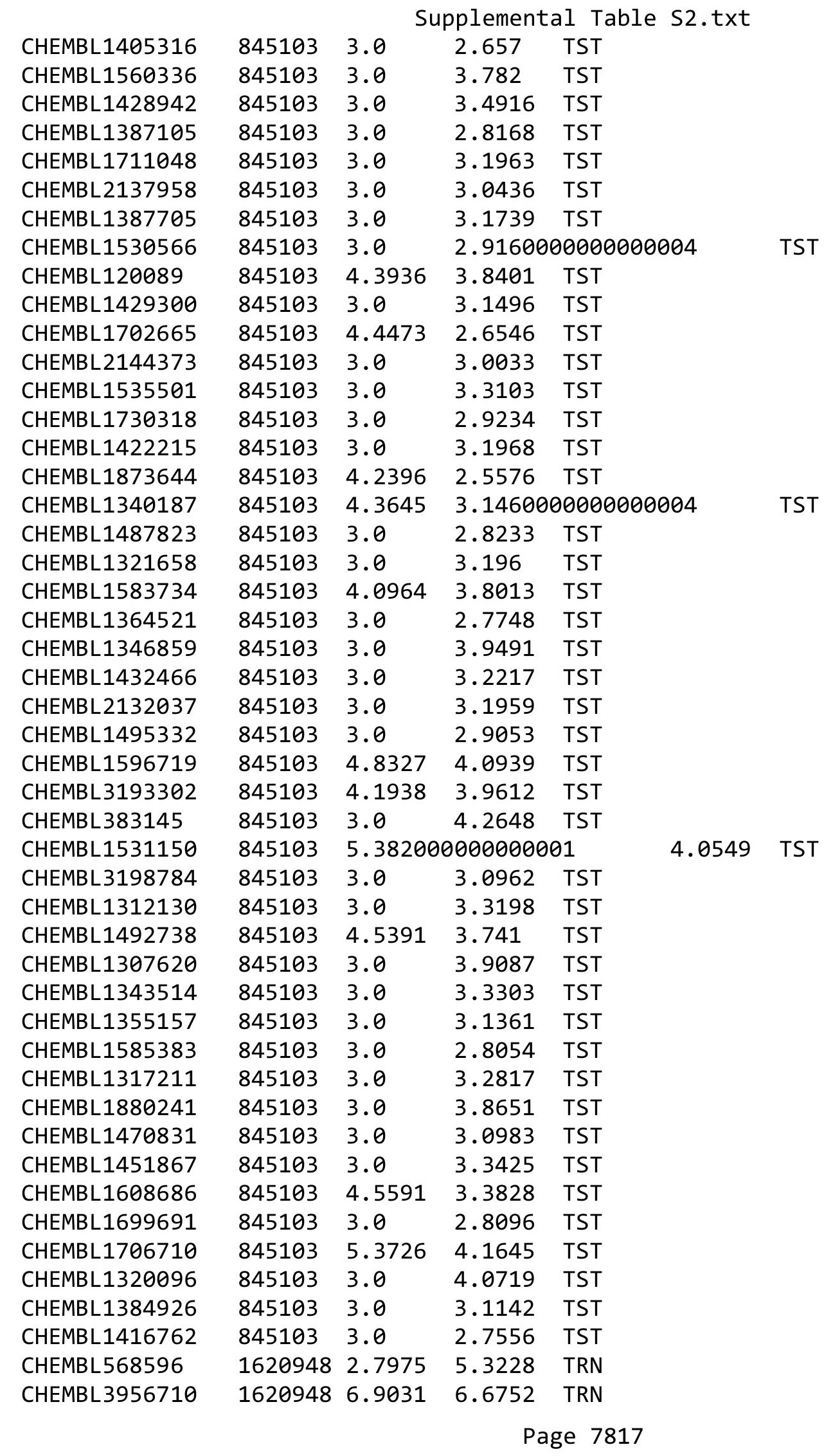


Supplemental Table S2.txt

\begin{tabular}{|c|c|c|c|c|c|c|}
\hline CHEMBL 3917957 & 1620948 & 6.4672 & 7.3878 & TRN & & \\
\hline CHEMBL230515 & 1620948 & 7.4815 & 7.518 & TRN & & \\
\hline CHEMBL 380899 & 1620948 & 6.6716 & 6.5291 & TRN & & \\
\hline CHEMBL 3930279 & 1620948 & 6.71899 & 9999999 & 99 & 7.1469 & TRN \\
\hline CHEMBL 3956103 & 1620948 & 5.4537 & 6.4441 & TRN & & \\
\hline CHEMBL 3893332 & 1620948 & 7.6576 & 8.0248 & TRN & & \\
\hline CHEMBL 3959175 & 1620948 & 7.3979 & 7.7805 & TRN & & \\
\hline CHEMBL 3948168 & 1620948 & 7.4089 & 7.4764 & TRN & & \\
\hline CHEMBL 3945250 & 1620948 & 6.8297 & 5.5701 & TST & & \\
\hline CHEMBL 3936343 & 1620948 & 6.38399 & 99999999 & 995 & 6.0411 & TST \\
\hline CHEMBL 3970270 & 1620948 & 7.5376 & 7.2901 & TRN & & \\
\hline CHEMBL1823802 & 1620948 & 6.3883 & 6.5141 & TRN & & \\
\hline CHEMBL 3909388 & 1620948 & 7.284 & 6.909 & TRN & & \\
\hline CHEMBL1823804 & 1620948 & 6.6498 & 6.5372 & TRN & & \\
\hline CHEMBL 3890124 & 1620948 & 7.4437 & 7.2158 & TRN & & \\
\hline CHEMBL1823803 & 1620948 & 6.2441 & 6.4058 & TRN & & \\
\hline CHEMBL 3924991 & 1620948 & 7.2218 & 7.1512 & TRN & & \\
\hline CHEMBL231616 & 1620948 & 6.4112 & 6.1463 & TST & & \\
\hline CHEMBL 3927255 & 1620948 & 6.7825 & 6.7347 & TRN & & \\
\hline CHEMBL 3929569 & 1620948 & 6.3261 & 5.3996 & TRN & & \\
\hline CHEMBL 3967845 & 1620948 & 6.8508 & 6.7336 & TRN & & \\
\hline CHEMBL 2348829 & 1620948 & 7.3372 & 6.5615 & TRN & & \\
\hline CHEMBL500110 & 1620948 & 6.1898 & 5.7212 & TRN & & \\
\hline CHEMBL1208633 & 1620948 & 6.8416 & 6.7445 & TRN & & \\
\hline CHEMBL 3965817 & 1620948 & 5.7696 & 6.0929 & TRN & & \\
\hline CHEMBL 2218926 & 1620948 & 7.1135 & 6.9158 & TRN & & \\
\hline CHEMBL140 & 1620948 & 6.9957 & 6.942 & TRN & & \\
\hline CHEMBL 338790 & 1620948 & 4.9476 & 5.3827 & TRN & & \\
\hline CHEMBL1061 & 1620948 & 6.2233 & 6.2252 & TRN & & \\
\hline CHEMBL602048 & 1620948 & 6.5017 & 6.4356 & TRN & & \\
\hline CHEMBL 224467 & 1620948 & 6.8665 & 6.685 & TRN & & \\
\hline CHEMBL 3967264 & 1620948 & 6.3851 & 5.6851 & TRN & & \\
\hline CHEMBL 3938874 & 1620948 & 6.5935 & 6.2523 & TRN & & \\
\hline CHEMBL496587 & 1620948 & 7.4318 & 6.517 & TRN & & \\
\hline CHEMBL183906 & 1620948 & 6.5272 & 6.4509 & TRN & & \\
\hline CHEMBL 3982310 & 1620948 & 6.8508 & 6.5467 & TST & & \\
\hline CHEMBL 255822 & 1620948 & 7.1308 & 7.3756 & TRN & & \\
\hline CHEMBL 224214 & 1620948 & 5.8248 & 5.835 & TRN & & \\
\hline CHEMBL 305695 & 1620948 & 7.1079 & 6.455 & TRN & & \\
\hline CHEMBL 3976274 & 1620948 & 6.857 & 6.5564 & TST & & \\
\hline CHEMBL 3979616 & 1620948 & 8.2218 & 6.507006 & 0000000001 & & 3 \\
\hline CHEMBL 2018126 & 1620948 & 7.0757 & 6.9705 & TST & & \\
\hline CHEMBL 3911800 & 1620948 & 6.0214 & 6.1569 & TST & & \\
\hline CHEMBL 3891346 & 1620948 & 6.8508 & 6.518 & TST & & \\
\hline CHEMBL150 & 1620948 & 6.8794 & 6.3435 & TST & & \\
\hline CHEMBL 3928502 & 1620948 & 6.0804 & 6.1829 & TST & & \\
\hline CHEMBL289159 & 1620948 & 6.8386 & 7.0522 & TST & & \\
\hline CHEMBL 3901608 & 1620948 & 6.2343 & 6.1161 & TST & & \\
\hline
\end{tabular}




\begin{tabular}{|c|c|c|c|c|c|}
\hline & & & & & \\
\hline CHEMBL592685 & 612848 & 7.2076 & 6.88399 & 99999999995 & TST \\
\hline CHEMBL591257 & 612848 & 4.5986 & 5.0947 & TRN & \\
\hline CHEMBL597605 & 612848 & 7.8239 & 7.0171 & TRN & \\
\hline CHEMBL599441 & 612848 & 6.2076 & 5.671 & TRN & \\
\hline CHEMBL598856 & 612848 & 3.0 & 5.3173 & TST & \\
\hline CHEMBL591263 & 612848 & 3.0 & 6.1121 & TST & \\
\hline CHEMBL599048 & 612848 & 6.9393 & 6.2181 & TRN & \\
\hline CHEMBL599235 & 612848 & 7.0458 & 7.3238 & TRN & \\
\hline CHEMBL598836 & 612848 & 3.0 & 4.7013 & TRN & \\
\hline CHEMBL597389 & 612848 & 6.5622 & 7.0786 & TST & \\
\hline CHEMBL599672 & 612848 & 6.71 & 7.1845 & TRN & \\
\hline CHEMBL603696 & 612848 & 6.1308 & 6.5563 & TST & \\
\hline CHEMBL599860 & 612848 & 6.0706 & 4.5715 & TRN & \\
\hline CHEMBL598428 & 612848 & 4.1024 & 6.2021 & TRN & \\
\hline CHEMBL598626 & 612848 & 6.4486 & 8.365 & TST & \\
\hline CHEMBL599861 & 612848 & 4.0 & 4.1775 & TRN & \\
\hline CHEMBL597592 & 612848 & 7.0506 & 8.1999 & TST & \\
\hline CHEMBL603674 & 612848 & 4.0 & 3.3509 & TRN & \\
\hline CHEMBL606404 & 612848 & 6.0362 & 5.6489 & TRN & \\
\hline CHEMBL601728 & 612848 & 7.4815 & 7.3252 & TRN & \\
\hline CHEMBL598019 & 612848 & 3.0 & 4.163 & TST & \\
\hline CHEMBL603253 & 612848 & 3.0 & 4.954 & TST & \\
\hline CHEMBL603161 & 612848 & 5.7799 & 5.4369 & TRN & \\
\hline CHEMBL597617 & 612848 & 3.0 & 4.282 & TST & \\
\hline CHEMBL599851 & 612848 & 6.3979 & 6.6738 & TST & \\
\hline CHEMBL599437 & 612848 & 6.6198 & 7.8881 & TRN & \\
\hline CHEMBL603328 & 612848 & 7.3188 & 7.5225 & TRN & \\
\hline CHEMBL591265 & 612848 & 5.9508 & 6.1609 & TRN & \\
\hline CHEMBL599660 & 612848 & 7.3979 & 7.816 & TRN & \\
\hline CHEMBL592438 & 612848 & 4.8539 & 4.3157 & TRN & \\
\hline CHEMBL603679 & 612848 & 4.0 & 4.7879 & TRN & \\
\hline CHEMBL605328 & 612848 & 8.301 & 7.7616 & TRN & \\
\hline CHEMBL590543 & 612848 & 8.0 & 7.50200 & 0000000001 & TRN \\
\hline CHEMBL606415 & 612848 & 6.9066 & 6.7929 & TRN & \\
\hline CHEMBL599041 & 612848 & 4.0 & 4.5814 & TRN & \\
\hline CHEMBL598835 & 612848 & 4.0269 & 3.2315 & TRN & \\
\hline CHEMBL602123 & 612848 & 8.1549 & 7.351 & TRN & \\
\hline CHEMBL596998 & 612848 & 7.6383 & 7.8881 & TRN & \\
\hline CHEMBL598624 & 612848 & 4.8125 & 4.9395 & TRN & \\
\hline CHEMBL599438 & 612848 & 6.7282 & 7.6837 & TRN & \\
\hline CHEMBL596984 & 612848 & 6.1367 & 4.0068 & TRN & \\
\hline CHEMBL598429 & 612848 & 7.3098 & 6.6104 & TRN & \\
\hline CHEMBL592616 & 612848 & 4.1675 & 4.6036 & TRN & \\
\hline CHEMBL589803 & 612848 & 7.1938 & 6.6963 & TRN & \\
\hline CHEMBL606189 & 612848 & 6.6198 & 5.3932 & TRN & \\
\hline CHEMBL598651 & 612848 & 6.0 & 5.5938 & TST & \\
\hline CHEMBL603185 & 612848 & 5.8069 & 5.9434 & TRN & \\
\hline CHEMBL603252 & 612848 & 4.9469 & 5.0856 & TRN & \\
\hline
\end{tabular}




\begin{tabular}{|c|c|c|c|c|c|}
\hline & & & & & \\
\hline CHEMBL591264 & 612848 & 5.5607 & 6.2479 & TRN & \\
\hline CHEMBL598004 & 612848 & 6.2291 & 7.9045 & TST & \\
\hline CHEMBL589802 & 612848 & 6.4685 & 4.6633 & TRN & \\
\hline CHEMBL599049 & 612848 & 7.3279 & 7.4144 & TRN & \\
\hline CHEMBL601302 & 612848 & 4.7986 & 5.8831 & TRN & \\
\hline CHEMBL599852 & 612848 & 4.6021 & 5.3353 & TRN & \\
\hline CHEMBL590711 & 612848 & 7.6383 & 6.427006 & 00000000005 & TRN \\
\hline CHEMBL596788 & 612848 & 4.0 & 4.3477 & TRN & \\
\hline CHEMBL597618 & 612848 & 4.6576 & 5.9098 & TST & \\
\hline CHEMBL596981 & 612848 & 5.1675 & 4.8937 & TRN & \\
\hline CHEMBL604705 & 612848 & 4.0 & 4.6198 & TRN & \\
\hline CHEMBL597593 & 612848 & 6.9101 & 8.075 & TST & \\
\hline CHEMBL599659 & 612848 & 7.7696 & 7.9159 & TRN & \\
\hline CHEMBL597619 & 612848 & 4.0315 & 4.138 & TRN & \\
\hline CHEMBL599440 & 612848 & 6.1612 & 5.5531 & TRN & \\
\hline CHEMBL596997 & 612848 & 7.1487 & 7.1008 & TRN & \\
\hline CHEMBL598005 & 612848 & 6.301 & 6.4281 & TST & \\
\hline CHEMBL599439 & 612848 & 3.0 & 4.1857 & TRN & \\
\hline CHEMBL591493 & 612848 & 7.4815 & 7.4663 & TRN & \\
\hline CHEMBL598652 & 612848 & 3.0 & 4.9838 & TST & \\
\hline CHEMBL599236 & 612848 & 5.3279 & 6.6284 & TRN & \\
\hline CHEMBL599661 & 612848 & 4.0 & 4.5253 & TRN & \\
\hline CHEMBL596793 & 612848 & 7.3665 & 6.649 & TRN & \\
\hline CHEMBL598834 & 612848 & 4.0605 & $3.45600 t$ & 00000000004 & TRN \\
\hline CHEMBL606192 & 612848 & 6.8928 & 8.0734 & TST & \\
\hline CHEMBL591492 & 612848 & 6.1135 & 5.5002 & TRN & \\
\hline CHEMBL598625 & 612848 & 3.0 & 4.1645 & TRN & \\
\hline CHEMBL597399 & 612848 & 3.0 & 3.7596 & TST & \\
\hline CHEMBL603693 & 612848 & 7.585 & 6.69 & TRN & \\
\hline CHEMBL591258 & 612848 & 3.0 & 4.3716 & TRN & \\
\hline CHEMBL603265 & 612848 & 7.2441 & 6.7125 & TRN & \\
\hline CHEMBL604919 & 612848 & 3.0 & 4.3343 & TRN & \\
\hline CHEMBL598008 & 612848 & 7.8539 & 7.5225 & TRN & \\
\hline CHEMBL596778 & 612848 & 7.8239 & 6.9861 & TRN & \\
\hline CHEMBL597388 & 612848 & 3.0 & 5.865 & TST & \\
\hline CHEMBL597589 & 612848 & 7.0605 & 6.0426 & TST & \\
\hline CHEMBL383263 & 355040 & 5.7423 & 5.6613 & TRN & \\
\hline CHEMBL381374 & 355040 & 5.8219 & 5.8643 & TRN & \\
\hline CHEMBL206876 & 355040 & 6.6345 & 5.4258 & TST & \\
\hline CHEMBL381262 & 355040 & 5.8153 & 5.6698 & TRN & \\
\hline CHEMBL207904 & 355040 & 4.0 & 4.3272 & TRN & \\
\hline CHEMBL206363 & 355040 & 4.0 & 3.4349 & TRN & \\
\hline CHEMBL379279 & 355040 & 6.3625 & 7.1056 & TRN & \\
\hline CHEMBL206255 & 355040 & 7.4318 & 6.8728 & TRN & \\
\hline CHEMBL207444 & 355040 & 6.5258 & 7.1975 & TRN & \\
\hline CHEMBL208370 & 355040 & 6.7399 & 6.2202 & TRN & \\
\hline CHEMBL378018 & 355040 & 5.3925 & 5.0365 & TST & \\
\hline CHEMBL207232 & 355040 & 6.1972 & 6.1669 & TRN & \\
\hline
\end{tabular}




\begin{tabular}{|c|c|c|c|c|c|}
\hline \multirow[b]{2}{*}{ CHEMBL205098 } & \multicolumn{5}{|c|}{ suppte } \\
\hline & 355040 & 6.6737 & 5.1595 & TST & \\
\hline CHEMBL204613 & 355040 & 4.0 & 4.8137 & TRN & \\
\hline CHEMBL207875 & 355040 & 5.5498 & 5.1594 & TRN & \\
\hline CHEMBL206731 & 355040 & 6.2976 & 5.9281 & TST & \\
\hline CHEMBL207161 & 355040 & 5.2907 & 5.4771 & TRN & \\
\hline CHEMBL209044 & 355040 & 6.9245 & 5.874 & TST & \\
\hline CHEMBL207126 & 355040 & 6.4802 & 6.4936 & TRN & \\
\hline CHEMBL207737 & 355040 & 6.6289 & 6.1892 & TRN & \\
\hline CHEMBL207787 & 355040 & 5.1355 & 5.4111 & TRN & \\
\hline CHEMBL206524 & 355040 & 7.0315 & 7.3194 & TRN & \\
\hline CHEMBL382452 & 355040 & 5.4908 & 5.7015 & TRN & \\
\hline CHEMBL378451 & 355040 & 4.0 & 4.5842 & TST & \\
\hline CHEMBL207015 & 355040 & 6.8996 & 6.7651 & TRN & \\
\hline CHEMBL207259 & 355040 & 6.4622 & 6.7675 & TRN & \\
\hline CHEMBL207614 & 355040 & 6.6556 & 6.0852 & TRN & \\
\hline CHEMBL206978 & 355040 & 5.3862 & 6.1611 & TRN & \\
\hline CHEMBL377708 & 355040 & 7.1367 & 7.3027 & TRN & \\
\hline CHEMBL207605 & 355040 & 7.4559 & 7.6086 & TRN & \\
\hline CHEMBL208939 & 355040 & 6.466 & 4.5329 & TST & \\
\hline CHEMBL208419 & 355040 & 6.9393 & 5.9584 & TST & \\
\hline CHEMBL380226 & 355040 & 6.556 & 6.86299 & 99999999995 & TRN \\
\hline CHEMBL207053 & 355040 & 5.82100 & 000000006 & 5.9729 & TRN \\
\hline CHEMBL207491 & 355040 & 8.3979 & 6.8804 & TST & \\
\hline CHEMBL439154 & 355040 & 6.9318 & 5.6636 & TRN & \\
\hline CHEMBL207961 & 355040 & 7.2676 & 6.2706 & TRN & \\
\hline CHEMBL378964 & 355040 & 5.5467 & 6.0735 & TRN & \\
\hline CHEMBL207499 & 355040 & 7.2007 & 5.8061 & TRN & \\
\hline CHEMBL382354 & 355040 & 7.2007 & 6.8754 & TRN & \\
\hline CHEMBL207551 & 355040 & 4.0 & 3.12100 & 00000000004 & TST \\
\hline CHEMBL379071 & 355040 & 4.0 & 5.0052 & TST & \\
\hline CHEMBL208468 & 355040 & 6.4921 & 6.3547 & TRN & \\
\hline CHEMBL206927 & 355040 & 6.2644 & 6.0127 & TRN & \\
\hline CHEMBL207721 & 355040 & 6.3757 & 6.0211 & TRN & \\
\hline CHEMBL207834 & 355040 & 6.1385 & 5.8852 & TRN & \\
\hline CHEMBL 208392 & 355040 & 4.0 & 5.1699 & TRN & \\
\hline CHEMBL208322 & 355040 & 5.4559 & 4.951006 & 00000000005 & TST \\
\hline CHEMBL207615 & 355040 & 5.567 & 5.6069 & TST & \\
\hline CHEMBL380515 & 355040 & 6.5817 & 6.2878 & TRN & \\
\hline CHEMBL205584 & 355040 & 5.1221 & 5.7005 & TRN & \\
\hline CHEMBL437693 & 355040 & 5.5513 & 4.9555 & TST & \\
\hline CHEMBL204686 & 355040 & 6.6271 & 6.462006 & $\partial 000000001$ & TRN \\
\hline CHEMBL207084 & 355040 & 7.5376 & 6.97 & TRN & \\
\hline CHEMBL380683 & 355040 & 6.5031 & 4.4087 & TST & \\
\hline CHEMBL208368 & 355040 & 6.295 & 6.1478 & TRN & \\
\hline CHEMBL208000 & 355040 & 6.0074 & 6.4183 & TRN & \\
\hline CHEMBL208384 & 355040 & 6.4012 & 5.7949 & TRN & \\
\hline CHEMBL209189 & 355040 & 4.0 & 5.5364 & TST & \\
\hline CHEMBL379837 & 355040 & 7.4202 & 6.8389 & TRN & \\
\hline & & & & 7821 & \\
\hline
\end{tabular}




\begin{tabular}{|c|c|c|c|c|c|}
\hline \\
\hline CHEMBL379748 & 355040 & 4.0 & 5.0871 & TST & \\
\hline CHEMBL379969 & 355040 & 5.8761 & 5.456 & TRN & \\
\hline CHEMBL378661 & 355040 & 6.4377 & 6.8873 & TRN & \\
\hline CHEMBL206890 & 355040 & 5.1871 & 5.0701 & TRN & \\
\hline CHEMBL383460 & 355040 & 4.0 & 4.855 & TST & \\
\hline CHEMBL379655 & 355040 & 6.0804 & 6.0856 & TRN & \\
\hline CHEMBL380312 & 355040 & 6.6162 & 7.2298 & TRN & \\
\hline CHEMBL208734 & 355040 & 6.1385 & 5.1517 & TST & \\
\hline CHEMBL262122 & 355040 & 4.0 & 4.7422 & TRN & \\
\hline CHEMBL380424 & 355040 & 6.0545 & 6.5178 & TRN & \\
\hline CHEMBL207131 & 355040 & 7.4202 & 6.9926 & TRN & \\
\hline CHEMBL206417 & 355040 & 4.0 & 4.5798 & TRN & \\
\hline CHEMBL382192 & 355040 & 6.4698 & 6.8773 & TRN & \\
\hline CHEMBL425418 & 355040 & 6.1979 & 6.03299 & 99999999995 & TRN \\
\hline CHEMBL206977 & 355040 & 5.2958 & 5.5719 & TRN & \\
\hline CHEMBL205095 & 355040 & 5.2366 & 5.4923 & TRN & \\
\hline CHEMBL379269 & 355040 & 4.0 & 3.9866 & TST & \\
\hline CHEMBL1968245 & 809174 & 5.6 & 5.7035 & TRN & \\
\hline CHEMBL1979577 & 809174 & 5.5 & 5.0229 & TRN & \\
\hline CHEMBL1233887 & 809174 & 4.2 & 4.2788 & TST & \\
\hline CHEMBL52387 & 809174 & 4.0 & 4.4887 & TST & \\
\hline CHEMBL1989006 & 809174 & 5.8 & 5.9478 & TRN & \\
\hline CHEMBL1979357 & 809174 & 5.1 & 5.6196 & TRN & \\
\hline CHEMBL1996817 & 809174 & 5.6 & 5.3769 & TRN & \\
\hline CHEMBL 2004355 & 809174 & 4.0 & 3.9422 & TRN & \\
\hline CHEMBL1996339 & 809174 & 6.1 & 5.8244 & TRN & \\
\hline CHEMBL 256835 & 809174 & 4.0 & 3.7232 & TRN & \\
\hline CHEMBL1974998 & 809174 & 4.2 & 4.0445 & TRN & \\
\hline CHEMBL1980142 & 809174 & 4.0 & 3.6553 & TRN & \\
\hline CHEMBL 2004438 & 809174 & 4.1 & 3.8716 & TRN & \\
\hline CHEMBL41783 & 809174 & 4.0 & 4.4965 & TRN & \\
\hline CHEMBL 271381 & 809174 & 5.2 & 4.6525 & TRN & \\
\hline CHEMBL1982466 & 809174 & 4.0 & 3.8363 & TRN & \\
\hline CHEMBL1990162 & 809174 & 5.4 & 5.2278 & TRN & \\
\hline CHEMBL1996390 & 809174 & 6.1 & 5.9066 & TRN & \\
\hline CHEMBL1992220 & 809174 & 6.0 & 6.1051 & TRN & \\
\hline CHEMBL 234085 & 809174 & 4.2 & 4.3282 & TRN & \\
\hline CHEMBL1998414 & 809174 & 4.0 & 3.5531 & TRN & \\
\hline CHEMBL1969042 & 809174 & 4.0 & 4.7716 & TRN & \\
\hline CHEMBL1999931 & 809174 & 6.4 & 5.605 & TRN & \\
\hline CHEMBL1976376 & 809174 & 4.2 & 4.2972 & TRN & \\
\hline CHEMBL1991640 & 809174 & 6.9 & 6.2767 & TST & \\
\hline CHEMBL1968868 & 809174 & 4.4 & 3.8983 & TRN & \\
\hline CHEMBL 2007064 & 809174 & 4.0 & 4.1467 & TRN & \\
\hline CHEMBL1997197 & 809174 & 4.2 & 4.2914 & TRN & \\
\hline CHEMBL1968151 & 809174 & 6.1 & 6.5115 & TRN & \\
\hline CHEMBL1381197 & 809174 & 6.8 & 6.3303 & TRN & \\
\hline CHEMBL1987009 & 809174 & 5.7 & 5.4205 & TRN & \\
\hline
\end{tabular}




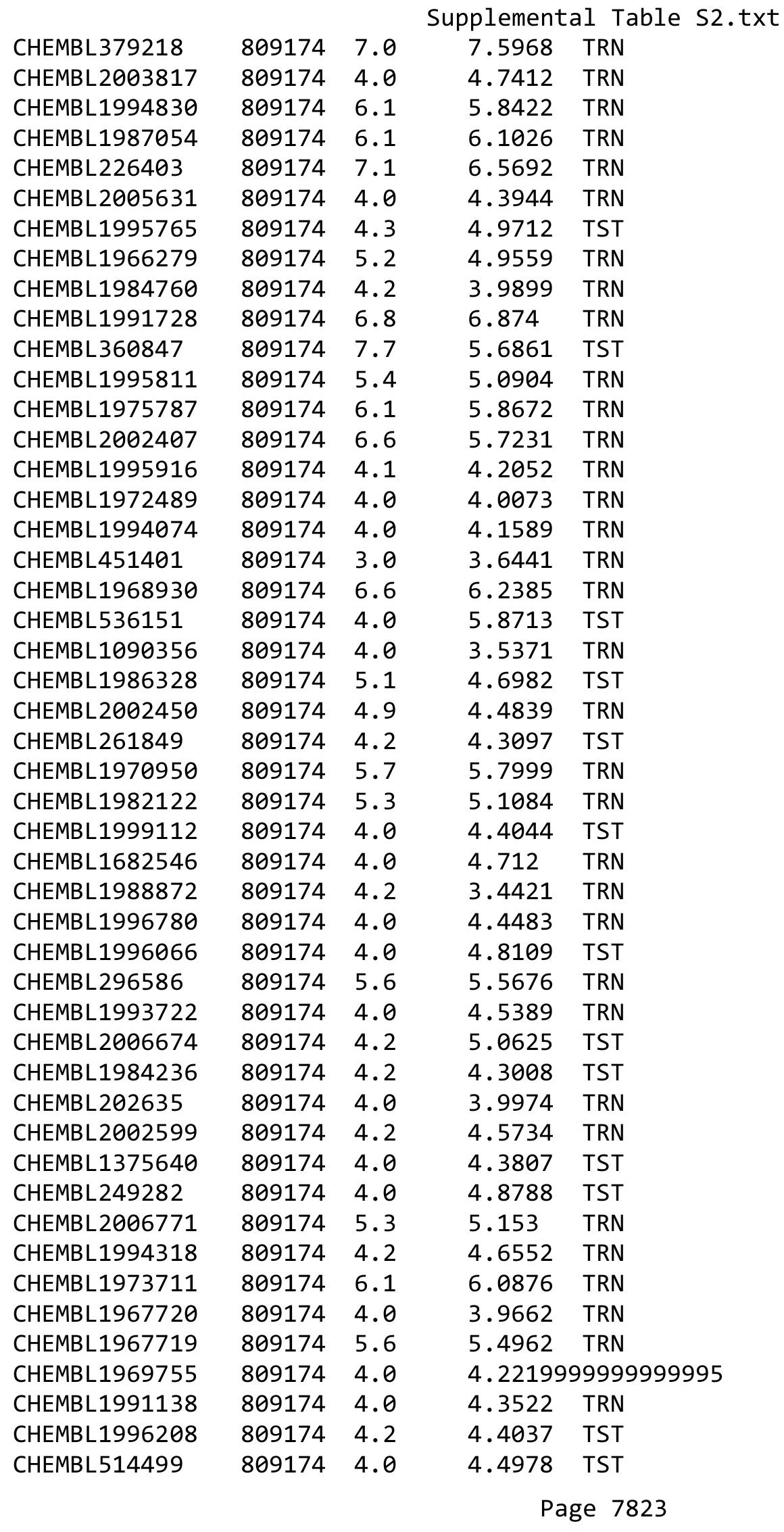

TRN 


\begin{tabular}{|c|c|c|c|c|c|}
\hline & & & & & \\
\hline CHEMBL1970352 & 809174 & 5.3 & 5.4859 & TST & \\
\hline CHEMBL1965631 & 809174 & 5.9 & 5.4833 & TRN & \\
\hline CHEMBL1980144 & 809174 & 5.1 & 5.3082 & TRN & \\
\hline CHEMBL1991188 & 809174 & 4.0 & 4.1447 & TRN & \\
\hline CHEMBL 377408 & 809174 & 4.2 & 3.9212 & TRN & \\
\hline CHEMBL 2003622 & 809174 & 5.3 & 5.0747 & TRN & \\
\hline CHEMBL 215152 & 809174 & 4.2 & 4.1762 & TRN & \\
\hline CHEMBL231209 & 809174 & 5.2 & 4.2551 & TRN & \\
\hline CHEMBL 2006765 & 809174 & 4.2 & 4.3809 & TRN & \\
\hline CHEMBL1976220 & 809174 & 4.0 & 4.2536 & TRN & \\
\hline CHEMBL1982383 & 809174 & 4.0 & 4.1943 & TRN & \\
\hline CHEMBL17370 & 809174 & 4.0 & 4.0835 & TRN & \\
\hline CHEMBL1980246 & 809174 & 4.2 & 4.1538 & TRN & \\
\hline CHEMBL1999484 & 809174 & 4.2 & 4.6812 & TRN & \\
\hline CHEMBL1997822 & 809174 & 4.0 & 4.0633 & TRN & \\
\hline CHEMBL1991285 & 809174 & 4.0 & 4.4861 & TRN & \\
\hline CHEMBL1984038 & 809174 & 4.2 & 3.319 & TRN & \\
\hline CHEMBL1974416 & 809174 & 4.0 & 4.823 & TRN & \\
\hline CHEMBL 2004615 & 809174 & 5.4 & 4.4585 & TST & \\
\hline CHEMBL1984039 & 809174 & 4.0 & 4.9494 & TST & \\
\hline CHEMBL1997872 & 809174 & 4.0 & 3.9657 & TRN & \\
\hline CHEMBL1964290 & 809174 & 5.4 & 5.1538 & TRN & \\
\hline CHEMBL2001398 & 809174 & 4.2 & 4.5256 & TRN & \\
\hline CHEMBL 2003768 & 809174 & 4.0 & 3.8834 & TRN & \\
\hline CHEMBL213505 & 809174 & 4.0 & 4.2558 & TRN & \\
\hline CHEMBL1982880 & 809174 & 6.3 & 6.2959 & TRN & \\
\hline CHEMBL1982881 & 809174 & 5.9 & 5.732 & TRN & \\
\hline CHEMBL1993941 & 809174 & 4.0 & 4.1054 & TRN & \\
\hline CHEMBL1980435 & 809174 & 4.4 & 4.4601 & TRN & \\
\hline CHEMBL1989293 & 809174 & 4.0 & 4.3739 & TRN & \\
\hline CHEMBL 377383 & 809174 & 4.0 & 4.0348 & TRN & \\
\hline CHEMBL578061 & 809174 & 4.8 & 4.6755 & TRN & \\
\hline CHEMBL1973142 & 809174 & 5.8 & 5.95799 & 9999999999 & TRN \\
\hline CHEMBL1973145 & 809174 & 4.0 & 4.6154 & TRN & \\
\hline CHEMBL1982924 & 809174 & 4.0 & 3.5885 & TRN & \\
\hline CHEMBL1964948 & 809174 & 4.2 & 4.2986 & TRN & \\
\hline CHEMBL1971141 & 809174 & 4.0 & 4.3235 & TRN & \\
\hline CHEMBL1995813 & 809174 & 6.3 & 6.4035 & TRN & \\
\hline CHEMBL1979718 & 809174 & 4.0 & 3.4924 & TRN & \\
\hline CHEMBL206236 & 809174 & 5.7 & 5.7511 & TRN & \\
\hline CHEMBL1989834 & 809174 & 3.3 & 3.7202 & TRN & \\
\hline CHEMBL1964288 & 809174 & 6.4 & 5.8871 & TRN & \\
\hline CHEMBL523823 & 809174 & 8.2 & 7.2583 & TST & \\
\hline CHEMBL 244378 & 809174 & 6.4 & 7.2203 & TRN & \\
\hline CHEMBL1990583 & 809174 & 7.2 & 6.0969 & TRN & \\
\hline CHEMBL1986943 & 809174 & 6.0 & 5.98600 & 0000000001 & TRN \\
\hline CHEMBL289959 & 809174 & 4.6 & 4.4679 & TRN & \\
\hline CHEMBL 2006263 & 809174 & 5.1 & 5.5483 & TST & \\
\hline
\end{tabular}




\begin{tabular}{|c|c|c|c|c|c|}
\hline & & & & & \\
\hline CHEMBL1993584 & 809174 & 5.1 & 5.0262 & TRN & \\
\hline CHEMBL 2000114 & 809174 & 4.0 & 3.7795 & TRN & \\
\hline CHEMBL210618 & 809174 & 4.0 & 3.9758 & TRN & \\
\hline CHEMBL1971172 & 809174 & 5.3 & 5.8527 & TRN & \\
\hline CHEMBL1975647 & 809174 & 4.0 & 5.0576 & TRN & \\
\hline CHEMBL1968380 & 809174 & 4.0 & 4.0134 & TRN & \\
\hline CHEMBL1997643 & 809174 & 6.3 & 5.3017 & TRN & \\
\hline CHEMBL1991734 & 809174 & 6.0 & 6.3829 & TST & \\
\hline CHEMBL1990912 & 809174 & 5.1 & 4.8767 & TRN & \\
\hline CHEMBL1988163 & 809174 & 5.5 & 5.0856 & TRN & \\
\hline CHEMBL1974480 & 809174 & 5.9 & 5.545 & TRN & \\
\hline CHEMBL1980671 & 809174 & 4.2 & 4.0705 & TRN & \\
\hline CHEMBL 2006493 & 809174 & 6.9 & 5.6584 & TST & \\
\hline CHEMBL1996923 & 809174 & 5.2 & 5.0828 & TST & \\
\hline CHEMBL1969735 & 809174 & 4.0 & 4.2267 & TRN & \\
\hline CHEMBL2003524 & 809174 & 6.0 & 4.4993 & TST & \\
\hline CHEMBL 2002649 & 809174 & 5.4 & 5.3314 & TRN & \\
\hline CHEMBL1989423 & 809174 & 4.1 & 4.1167 & TRN & \\
\hline CHEMBL1985367 & 809174 & 4.2 & 4.0716 & TST & \\
\hline CHEMBL1971227 & 809174 & 5.6 & 5.9417 & TST & \\
\hline CHEMBL1994321 & 809174 & 4.0 & 4.6911 & TRN & \\
\hline CHEMBL1978562 & 809174 & 5.9 & 4.5329 & TST & \\
\hline CHEMBL1964307 & 809174 & 4.0 & 4.3564 & TRN & \\
\hline CHEMBL1989471 & 809174 & 4.2 & 4.2065 & TST & \\
\hline CHEMBL 2000508 & 809174 & 4.0 & 4.5611 & TRN & \\
\hline CHEMBL1971694 & 809174 & 6.4 & $5.9110 e$ & 00000000005 & TST \\
\hline CHEMBL1978195 & 809174 & 5.5 & 5.8175 & TRN & \\
\hline CHEMBL1994361 & 809174 & 8.0 & 6.7423 & TRN & \\
\hline CHEMBL1986603 & 809174 & 4.0 & 3.9472 & TST & \\
\hline CHEMBL1977148 & 809174 & 4.0 & 4.538 & TRN & \\
\hline CHEMBL 2004443 & 809174 & 7.3 & 6.3926 & TRN & \\
\hline CHEMBL 2003286 & 809174 & 6.8 & 6.7456 & TRN & \\
\hline CHEMBL1992306 & 809174 & 4.0 & 3.6818 & TRN & \\
\hline CHEMBL 2002165 & 809174 & 4.0 & 4.1524 & TRN & \\
\hline CHEMBL1979318 & 809174 & 4.0 & 3.9724 & TRN & \\
\hline CHEMBL206382 & 809174 & 5.4 & 5.034 & TRN & \\
\hline CHEMBL127898 & 809174 & 4.0 & 5.4897 & TST & \\
\hline CHEMBL519697 & 809174 & 4.0 & 3.9217 & TRN & \\
\hline CHEMBL1981947 & 809174 & 5.1 & 4.4053 & TST & \\
\hline CHEMBL1968459 & 809174 & 6.8 & 7.0089 & TRN & \\
\hline CHEMBL1977619 & 809174 & 5.2 & 5.6155 & TST & \\
\hline CHEMBL1996345 & 809174 & 4.2 & 4.6321 & TST & \\
\hline CHEMBL1975128 & 809174 & 5.3 & 5.2243 & TRN & \\
\hline CHEMBL1970369 & 809174 & 4.0 & 4.0001 & TRN & \\
\hline CHEMBL1965033 & 809174 & 4.2 & 4.0575 & TRN & \\
\hline CHEMBL 2001485 & 809174 & 4.0 & 3.9012 & TRN & \\
\hline CHEMBL504950 & 809174 & 5.3 & 4.8652 & TRN & \\
\hline CHEMBL1966425 & 809174 & 5.6 & $6.1220 e$ & 2000000001 & TRN \\
\hline & & & & e 7825 & \\
\hline
\end{tabular}




\begin{tabular}{|c|c|c|c|c|}
\hline & & & pplement & al $\mathrm{Ta}$ \\
\hline CHEMBL1988608 & 809174 & 6.3 & 5.6874 & TRN \\
\hline CHEMBL184847 & 809174 & 5.0 & 4.6506 & TRN \\
\hline CHEMBL1971132 & 809174 & 4.2 & 4.0186 & TST \\
\hline CHEMBL178737 & 809174 & 6.1 & 5.4278 & TST \\
\hline CHEMBL1982563 & 809174 & 4.0 & 3.9928 & TRN \\
\hline CHEMBL1991377 & 809174 & 4.2 & 4.8226 & TRN \\
\hline CHEMBL539474 & 809174 & 4.0 & 5.3978 & TST \\
\hline CHEMBL575824 & 809174 & 7.4 & 7.1899 & TRN \\
\hline CHEMBL1988387 & 809174 & 4.0 & 4.3373 & TRN \\
\hline CHEMBL1973868 & 809174 & 4.2 & 4.9681 & TRN \\
\hline CHEMBL1972462 & 809174 & 4.2 & 4.1359 & TST \\
\hline CHEMBL1994968 & 809174 & 5.3 & 5.2243 & TRN \\
\hline CHEMBL1990288 & 809174 & 4.0 & 3.9127 & TRN \\
\hline CHEMBL1965702 & 809174 & 6.3 & 6.1332 & TRN \\
\hline CHEMBL1986970 & 809174 & 5.5 & 4.7189 & TRN \\
\hline CHEMBL 2002456 & 809174 & 5.8 & 5.5237 & TRN \\
\hline CHEMBL1958401 & 809174 & 5.3 & 4.7998 & TRN \\
\hline CHEMBL1984044 & 809174 & 5.4 & 4.9655 & TRN \\
\hline CHEMBL1972584 & 809174 & 4.0 & 4.1106 & TRN \\
\hline CHEMBL1982700 & 809174 & 4.2 & 5.0428 & TST \\
\hline CHEMBL326282 & 809174 & 7.6 & 6.4358 & TRN \\
\hline CHEMBL1997495 & 809174 & 5.3 & 4.8555 & TRN \\
\hline CHEMBL1992732 & 809174 & 6.8 & 4.3904 & TST \\
\hline CHEMBL1971186 & 809174 & 4.0 & 4.3517 & TRN \\
\hline CHEMBL 2003482 & 809174 & 4.0 & 3.7241 & TRN \\
\hline CHEMBL1976872 & 809174 & 3.0 & 3.3579 & TRN \\
\hline CHEMBL 2006456 & 809174 & 6.7 & 6.1484 & TRN \\
\hline CHEMBL1969156 & 809174 & 3.0 & 3.6037 & TST \\
\hline CHEMBL1973211 & 809174 & 5.3 & 4.6896 & TRN \\
\hline CHEMBL1964340 & 809174 & 6.1 & 5.9726 & TRN \\
\hline CHEMBL1976134 & 809174 & 5.7 & 5.317 & TRN \\
\hline CHEMBL1965131 & 809174 & 6.0 & 6.1181 & TRN \\
\hline CHEMBL1981215 & 809174 & 4.2 & 4.21 & TRN \\
\hline CHEMBL1974457 & 809174 & 6.1 & 5.9226 & TRN \\
\hline CHEMBL1967662 & 809174 & 6.4 & 6.3294 & TRN \\
\hline CHEMBL 2006580 & 809174 & 5.3 & 5.3929 & TRN \\
\hline CHEMBL 2006581 & 809174 & 4.0 & 4.0456 & TRN \\
\hline CHEMBL1979855 & 809174 & 4.0 & 3.5041 & TRN \\
\hline CHEMBL1970340 & 809174 & 4.9 & 5.1724 & TRN \\
\hline CHEMBL2005186 & 809174 & 4.0 & 4.0351 & TRN \\
\hline CHEMBL1995927 & 809174 & 4.0 & 3.9249 & TST \\
\hline CHEMBL1981671 & 809174 & 4.2 & 4.1031 & TRN \\
\hline CHEMBL 2006450 & 809174 & 4.2 & 4.3157 & TRN \\
\hline CHEMBL 2001987 & 809174 & 4.2 & 4.0318 & TRN \\
\hline CHEMBL 243518 & 809174 & 6.8 & 6.8719 & TRN \\
\hline CHEMBL1994555 & 809174 & 4.2 & 3.5607 & TST \\
\hline CHEMBL1997554 & 809174 & 5.6 & 5.5258 & TRN \\
\hline CHEMBL1997023 & 809174 & 6.3 & 5.1899 & TST \\
\hline
\end{tabular}




\begin{tabular}{|c|c|c|c|c|c|}
\hline \multicolumn{6}{|c|}{ Supplemental Table S2.txt } \\
\hline CHEMBL1971943 & 809174 & 4.5 & 4.1084 & TRN & \\
\hline CHEMBL1969049 & 809174 & 4.0 & 3.8089 & TRN & \\
\hline CHEMBL 2005828 & 809174 & 4.0 & 4.2094 & TRN & \\
\hline CHEMBL1991143 & 809174 & 4.0 & 4.4808 & TRN & \\
\hline CHEMBL1998611 & 809174 & 5.9 & 5.7608 & TRN & \\
\hline CHEMBL1975900 & 809174 & 5.1 & 4.9415 & TRN & \\
\hline CHEMBL255822 & 809174 & 7.4 & 7.4417 & TRN & \\
\hline CHEMBL 2006778 & 809174 & 5.3 & 4.8104 & TRN & \\
\hline CHEMBL378627 & 809174 & 4.0 & 4.2242 & TRN & \\
\hline CHEMBL1996979 & 809174 & 5.3 & 4.687 & TRN & \\
\hline CHEMBL1997025 & 809174 & 5.9 & 5.7849 & TRN & \\
\hline CHEMBL1968406 & 809174 & 4.0 & 4.4481 & TRN & \\
\hline CHEMBL1975921 & 809174 & 4.6 & 4.8992 & TRN & \\
\hline CHEMBL1982476 & 809174 & 4.0 & 4.56800 & 00000000005 & TRN \\
\hline CHEMBL1975923 & 809174 & 5.7 & 5.8723 & TST & \\
\hline CHEMBL 2005449 & 809174 & 4.2 & 3.7155 & TRN & \\
\hline CHEMBL 2006010 & 809174 & 4.0 & 4.4635 & TRN & \\
\hline CHEMBL1682558 & 809174 & 4.0 & 4.0149 & TRN & \\
\hline CHEMBL1990496 & 809174 & 4.2 & 4.2614 & TRN & \\
\hline CHEMBL1998068 & 809174 & 6.1 & 6.0936 & TRN & \\
\hline CHEMBL1977294 & 809174 & 5.3 & 4.7807 & TST & \\
\hline CHEMBL1993166 & 809174 & 6.6 & 6.5945 & TRN & \\
\hline CHEMBL1967094 & 809174 & 4.0 & 4.6383 & TRN & \\
\hline CHEMBL 2003341 & 809174 & 4.0 & 4.0709 & TRN & \\
\hline CHEMBL1992644 & 809174 & 4.7 & 4.4649 & TRN & \\
\hline CHEMBL1992645 & 809174 & 4.0 & 5.2028 & TST & \\
\hline CHEMBL1998110 & 809174 & 4.2 & 3.8477 & TRN & \\
\hline CHEMBL1999590 & 809174 & 4.0 & 4.4515 & TST & \\
\hline CHEMBL1981079 & 809174 & 4.2 & 5.0358 & TRN & \\
\hline CHEMBL1978166 & 809174 & 5.9 & 5.6543 & TRN & \\
\hline CHEMBL1980489 & 809174 & 4.0 & 4.15 & TRN & \\
\hline CHEMBL 2000832 & 809174 & 6.0 & 6.527 & TRN & \\
\hline CHEMBL1967116 & 809174 & 5.5 & 4.4422 & TRN & \\
\hline CHEMBL1990590 & 809174 & 4.2 & 4.2968 & TRN & \\
\hline CHEMBL1977814 & 809174 & 5.5 & 4.9743 & TRN & \\
\hline CHEMBL513846 & 809174 & 6.1 & 6.4822 & TRN & \\
\hline CHEMBL1974617 & 809174 & 4.8 & 4.1393 & TRN & \\
\hline CHEMBL1965660 & 809174 & 5.8 & 5.7268 & TRN & \\
\hline CHEMBL1998112 & 809174 & 4.0 & 3.7326 & TRN & \\
\hline CHEMBL1969126 & 809174 & 4.0 & 4.1672 & TRN & \\
\hline CHEMBL1980896 & 809174 & 4.0 & 3.9123 & TRN & \\
\hline CHEMBL1975208 & 809174 & 4.0 & 5.0598 & TST & \\
\hline CHEMBL1991429 & 809174 & 4.0 & 3.9171 & TRN & \\
\hline CHEMBL1967612 & 809174 & 4.1 & 5.0062 & TST & \\
\hline CHEMBL1971149 & 809174 & 4.0 & 3.8862 & TRN & \\
\hline CHEMBL1999714 & 809174 & 4.0 & 3.4738 & TRN & \\
\hline CHEMBL1994040 & 809174 & 4.0 & 3.9201 & TRN & \\
\hline CHEMBL 388978 & 809174 & 5.5 & 7.8678 & TST & \\
\hline
\end{tabular}




\begin{tabular}{|c|c|c|c|c|}
\hline & & & ent & al Table \\
\hline CHEMBL 2004716 & 809174 & 5.5 & 4.7927 & TRN \\
\hline CHEMBL1975233 & 809174 & 4.1 & 4.3167 & TRN \\
\hline CHEMBL1421720 & 809174 & 6.1 & 5.5423 & TRN \\
\hline CHEMBL 2002553 & 809174 & 4.0 & 4.7409 & TST \\
\hline CHEMBL1982135 & 809174 & 4.0 & 4.7449 & TRN \\
\hline CHEMBL1976090 & 809174 & 5.8 & 5.6374 & TRN \\
\hline CHEMBL 2004771 & 809174 & 5.7 & 5.4355 & TRN \\
\hline CHEMBL1992922 & 809174 & 4.0 & 4.2341 & TRN \\
\hline CHEMBL1997597 & 809174 & 4.0 & 3.9595 & TRN \\
\hline CHEMBL576113 & 809174 & 5.6 & 4.7014 & TST \\
\hline CHEMBL1976093 & 809174 & 4.0 & 4.0921 & TRN \\
\hline CHEMBL1996543 & 809174 & 6.3 & 6.8812 & TRN \\
\hline CHEMBL1975256 & 809174 & 4.0 & 4.7877 & TST \\
\hline CHEMBL1949855 & 809174 & 4.5 & 5.21 & TRN \\
\hline CHEMBL1999126 & 809174 & 6.0 & 6.3585 & TST \\
\hline CHEMBL1997503 & 809174 & 4.0 & 4.4307 & TST \\
\hline CHEMBL116070 & 809174 & 5.4 & 5.3761 & TRN \\
\hline CHEMBL1990821 & 809174 & 4.0 & 5.3006 & TST \\
\hline CHEMBL 2004871 & 809174 & 4.0 & 4.1832 & TRN \\
\hline CHEMBL 2004872 & 809174 & 4.0 & 3.7526 & TRN \\
\hline CHEMBL1727312 & 809174 & 3.3 & 3.1427 & TRN \\
\hline CHEMBL1990223 & 809174 & 4.2 & 4.3402 & TST \\
\hline CHEMBL1969879 & 809174 & 4.0 & 4.6145 & TRN \\
\hline CHEMBL1995932 & 809174 & 6.9 & 7.3926 & TRN \\
\hline CHEMBL1964382 & 809174 & 5.4 & 5.58700 & 0000000001 \\
\hline CHEMBL101311 & 809174 & 4.2 & 4.3324 & TRN \\
\hline CHEMBL1981720 & 809174 & 5.2 & 5.4061 & TRN \\
\hline CHEMBL1967704 & 809174 & 5.3 & 5.7871 & TRN \\
\hline CHEMBL419932 & 809174 & 5.8 & 5.7592 & TRN \\
\hline CHEMBL 2005699 & 809174 & 4.2 & 4.2034 & TRN \\
\hline CHEMBL1976328 & 809174 & 4.0 & 4.3112 & TRN \\
\hline CHEMBL1964399 & 809174 & 5.7 & 5.4863 & TRN \\
\hline CHEMBL1996831 & 809174 & 4.0 & 4.4037 & TST \\
\hline CHEMBL1980253 & 809174 & 6.2 & 5.8556 & TRN \\
\hline CHEMBL1965789 & 809174 & 5.7 & 5.6168 & TRN \\
\hline CHEMBL1978167 & 809174 & 4.2 & 4.5975 & TST \\
\hline CHEMBL1682357 & 809174 & 4.0 & 4.9335 & TRN \\
\hline CHEMBL225519 & 809174 & 4.2 & 5.5896 & TRN \\
\hline CHEMBL1978200 & 809174 & 4.0 & 4.1243 & TRN \\
\hline CHEMBL 2006631 & 809174 & 4.0 & 3.6891 & TRN \\
\hline CHEMBL1970522 & 809174 & 6.8 & 6.7286 & TRN \\
\hline CHEMBL1990415 & 809174 & 4.0 & 4.3445 & TRN \\
\hline CHEMBL1996931 & 809174 & 4.0 & 3.4675 & TRN \\
\hline CHEMBL1971223 & 809174 & 4.2 & 4.3205 & TRN \\
\hline CHEMBL1964413 & 809174 & 4.0 & 4.6259 & TRN \\
\hline CHEMBL1984432 & 809174 & 4.0 & 4.6895 & TRN \\
\hline CHEMBL1998470 & 809174 & 4.2 & 4.3213 & TRN \\
\hline CHEMBL1996980 & 809174 & 7.5 & 6.5622 & TRN \\
\hline
\end{tabular}




\begin{tabular}{|c|c|c|c|c|c|}
\hline \\
\hline CHEMBL1969920 & 809174 & 6.6 & 6.4334 & TRN & \\
\hline CHEMBL1975903 & 809174 & 4.2 & 3.4149 & TRN & \\
\hline CHEMBL 2004365 & 809174 & 5.6 & 5.7216 & TST & \\
\hline CHEMBL1522508 & 809174 & 3.8 & 4.2049 & TRN & \\
\hline CHEMBL1989474 & 809174 & 4.0 & 4.1403 & TRN & \\
\hline CHEMBL1090360 & 809174 & 4.0 & 3.5151 & TRN & \\
\hline CHEMBL210887 & 809174 & 4.0 & 4.229 & TRN & \\
\hline CHEMBL227271 & 809174 & 8.3 & 7.9412 & TRN & \\
\hline CHEMBL1969942 & 809174 & 5.3 & 4.7741 & TRN & \\
\hline CHEMBL1978567 & 809174 & 4.2 & 3.8477 & TRN & \\
\hline CHEMBL1994693 & 809174 & 5.2 & 5.064 & TRN & \\
\hline CHEMBL86755 & 809174 & 4.2 & 4.705 & TRN & \\
\hline CHEMBL1975138 & 809174 & 6.2 & 6.5228 & TRN & \\
\hline CHEMBL424872 & 809174 & 4.2 & 3.9273 & TRN & \\
\hline CHEMBL1971947 & 809174 & 4.0 & 4.44600 & 0000000001 & TRN \\
\hline CHEMBL 2004447 & 809174 & 4.0 & 4.2184 & TRN & \\
\hline CHEMBL1992231 & 809174 & 6.2 & 5.6767 & TRN & \\
\hline CHEMBL1983111 & 809174 & 4.2 & 4.5281 & TRN & \\
\hline CHEMBL1973860 & 809174 & 5.5 & 5.0266 & TRN & \\
\hline CHEMBL1977713 & 809174 & 4.0 & 3.7577 & TRN & \\
\hline CHEMBL1983157 & 809174 & 5.6 & 5.7603 & TRN & \\
\hline CHEMBL1982610 & 809174 & 6.1 & 6.3696 & TRN & \\
\hline CHEMBL1989569 & 809174 & 5.6 & 5.6888 & TRN & \\
\hline CHEMBL1998165 & 809174 & 5.7 & 5.1794 & TST & \\
\hline CHEMBL1999496 & 809174 & 4.0 & 4.1713 & TRN & \\
\hline CHEMBL1988300 & 809174 & 4.0 & 4.187 & TRN & \\
\hline CHEMBL 2001613 & 809174 & 4.8 & 4.6953 & TRN & \\
\hline CHEMBL1997275 & 809174 & 4.3 & 4.797 & TRN & \\
\hline CHEMBL1993904 & 809174 & 5.5 & 5.3504 & TRN & \\
\hline CHEMBL1989265 & 809174 & 6.6 & 6.4524 & TST & \\
\hline CHEMBL1965909 & 809174 & 5.6 & 5.4281 & TRN & \\
\hline CHEMBL1965910 & 809174 & 4.0 & 3.9766 & TRN & \\
\hline CHEMBL1996447 & 809174 & 5.8 & 5.4221 & TRN & \\
\hline CHEMBL1983963 & 809174 & 5.4 & 4.523 & TRN & \\
\hline CHEMBL1985092 & 809174 & 5.1 & 5.4394 & TRN & \\
\hline CHEMBL1981410 & 809174 & 4.0 & 3.872 & TRN & \\
\hline CHEMBL383264 & 809174 & 6.3 & 6.9752 & TRN & \\
\hline CHEMBL 2007421 & 809174 & 4.2 & 3.7299 & TST & \\
\hline CHEMBL1991434 & 809174 & 6.6 & 5.9437 & TRN & \\
\hline CHEMBL1973138 & 809174 & 4.2 & 4.2248 & TRN & \\
\hline CHEMBL340384 & 809174 & 5.3 & 5.0386 & TRN & \\
\hline CHEMBL1969151 & 809174 & 6.6 & 6.3377 & TRN & \\
\hline CHEMBL1996587 & 809174 & 4.0 & 3.9692 & TRN & \\
\hline CHEMBL1988692 & 809174 & 4.2 & 4.4201 & TRN & \\
\hline CHEMBL1975815 & 809174 & 5.4 & 5.3952 & TRN & \\
\hline CHEMBL592030 & 809174 & 4.5 & 6.9965 & TST & \\
\hline CHEMBL 2000071 & 809174 & 4.0 & 4.2181 & TRN & \\
\hline CHEMBL1979176 & 809174 & 4.0 & 3.5663 & TRN & \\
\hline
\end{tabular}




\begin{tabular}{|c|c|c|c|c|}
\hline & & & ole & \\
\hline CHEMBL 2002613 & 809174 & 4.2 & 4.6564 & TRN \\
\hline CHEMBL 2002736 & 809174 & 4.2 & 4.181 & TRN \\
\hline CHEMBL1983195 & 809174 & 5.4 & 4.0728 & TST \\
\hline CHEMBL1964444 & 809174 & 4.5 & 5.2565 & TRN \\
\hline CHEMBL1989957 & 809174 & 4.0 & 4.1902 & TRN \\
\hline CHEMBL1980540 & 809174 & 4.0 & 3.9593 & TRN \\
\hline CHEMBL278041 & 809174 & 4.2 & 4.2293 & TRN \\
\hline CHEMBL1984162 & 809174 & 6.7 & 6.2302 & TRN \\
\hline CHEMBL1998432 & 809174 & 6.9 & 6.7517 & TRN \\
\hline CHEMBL1870106 & 809174 & 7.7 & 7.2915 & TRN \\
\hline CHEMBL1996791 & 809174 & 4.0 & 4.1019 & TRN \\
\hline CHEMBL371206 & 809174 & 4.0 & 3.7943 & TRN \\
\hline CHEMBL1974664 & 809174 & 4.0 & 4.3306 & TST \\
\hline CHEMBL1998477 & 809174 & 5.4 & 5.3469 & TRN \\
\hline CHEMBL1970104 & 809174 & 4.0 & 4.3474 & TRN \\
\hline CHEMBL1984296 & 809174 & 5.9 & 5.1452 & TST \\
\hline CHEMBL196363 & 809174 & 4.0 & 4.5432 & TRN \\
\hline CHEMBL1996837 & 809174 & 3.0 & 3.2099 & TRN \\
\hline CHEMBL1190711 & 809174 & 4.0 & 4.5423 & TRN \\
\hline CHEMBL1964441 & 809174 & 4.2 & 4.738 & TRN \\
\hline CHEMBL546797 & 809174 & 5.4 & 4.7188 & TRN \\
\hline CHEMBL404367 & 809174 & 4.0 & 4.1506 & TRN \\
\hline CHEMBL1966343 & 809174 & 4.0 & 4.8473 & TRN \\
\hline CHEMBL1967887 & 809174 & 6.6 & 6.6626 & TRN \\
\hline CHEMBL1985469 & 809174 & 4.2 & 4.2821 & TST \\
\hline CHEMBL 2000568 & 809174 & 4.1 & 4.2526 & TRN \\
\hline CHEMBL 2000335 & 809174 & 4.0 & 4.6252 & TRN \\
\hline CHEMBL1980161 & 809174 & 3.0 & 3.4185 & TRN \\
\hline CHEMBL2007097 & 809174 & 4.8 & 4.8902 & TRN \\
\hline CHEMBL1993648 & 809174 & 5.1 & 5.3733 & TRN \\
\hline CHEMBL243298 & 809174 & 6.6 & 7.0249 & TRN \\
\hline CHEMBL1971951 & 809174 & 4.0 & 3.5463 & TRN \\
\hline CHEMBL143703 & 809174 & 4.1 & 3.6504 & TRN \\
\hline CHEMBL1973808 & 809174 & 4.0 & 4.0423 & TRN \\
\hline CHEMBL 2000429 & 809174 & 4.0 & 4.2383 & TRN \\
\hline CHEMBL1972576 & 809174 & 4.0 & 4.3288 & TRN \\
\hline CHEMBL1992555 & 809174 & 4.0 & 4.3925 & TRN \\
\hline CHEMBL1989069 & 809174 & 5.4 & 4.9501 & TRN \\
\hline CHEMBL 2003682 & 809174 & 5.2 & 5.2586 & TRN \\
\hline CHEMBL1988173 & 809174 & 6.6 & 6.5397 & TRN \\
\hline CHEMBL535331 & 809174 & 4.0 & 4.3529 & TRN \\
\hline CHEMBL1989805 & 809174 & 5.1 & 5.2338 & TST \\
\hline CHEMBL1982980 & 809174 & 4.0 & 5.2582 & TST \\
\hline CHEMBL1983025 & 809174 & 5.6 & 5.1358 & TRN \\
\hline CHEMBL1975927 & 809174 & 4.2 & 4.3161 & TRN \\
\hline CHEMBL 2002322 & 809174 & 5.6 & 5.6262 & TRN \\
\hline CHEMBL1985654 & 809174 & 5.9 & 5.7485 & TRN \\
\hline CHEMBL1997119 & 809174 & 4.4 & 4.1198 & TST \\
\hline
\end{tabular}




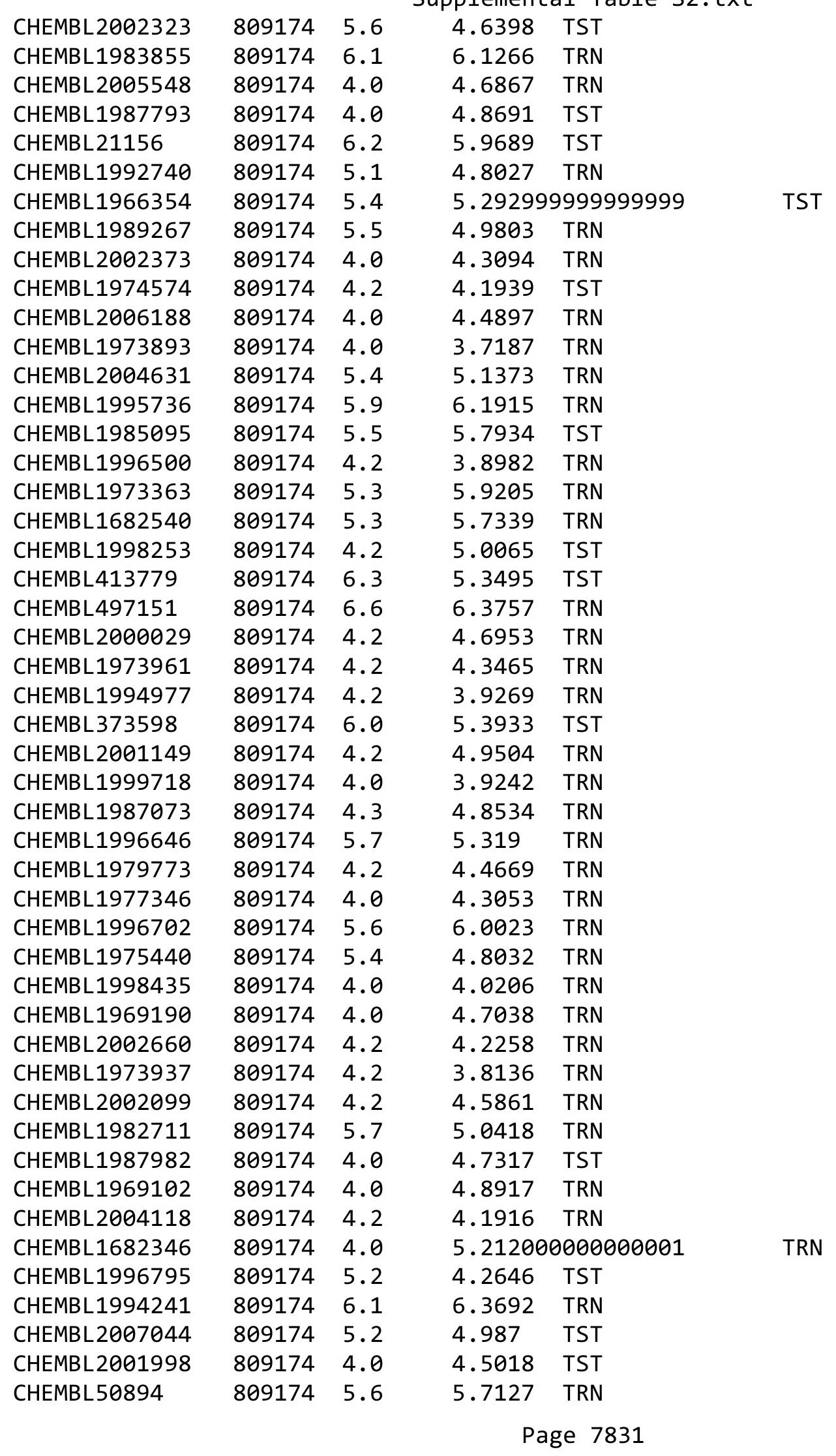




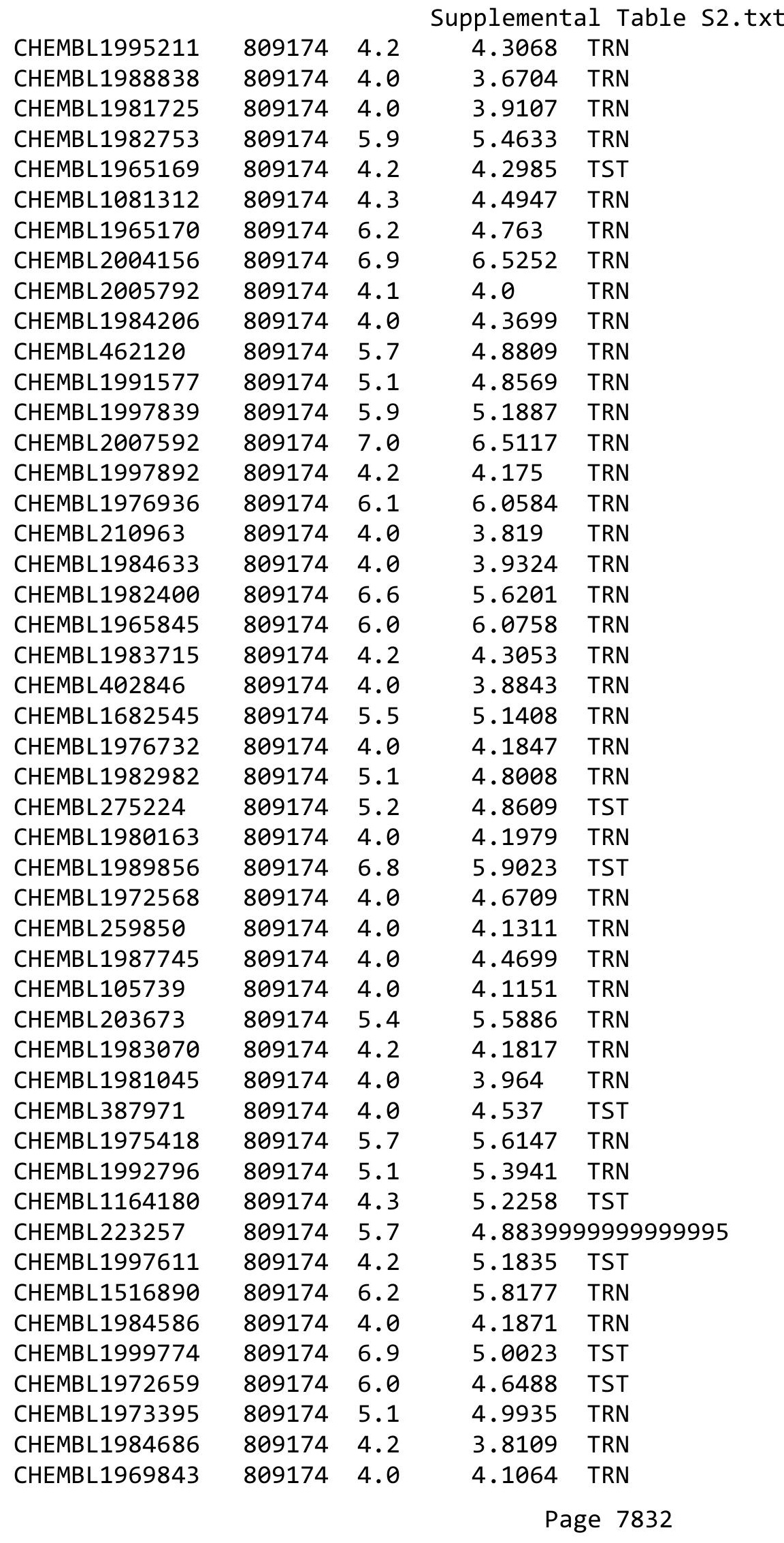




\begin{tabular}{|c|c|c|c|c|c|}
\hline \\
\hline CHEMBL 2007002 & 809174 & 4.0 & 4.6298 & TRN & \\
\hline CHEMBL1992073 & 809174 & 4.2 & 4.6833 & TRN & \\
\hline CHEMBL484390 & 809174 & 4.0 & 3.9321 & TRN & \\
\hline CHEMBL2007559 & 809174 & 4.2 & 4.3281 & TRN & \\
\hline CHEMBL 2004290 & 809174 & 4.2 & 4.3824 & TRN & \\
\hline CHEMBL 2000393 & 809174 & 5.5 & 5.9829 & TST & \\
\hline CHEMBL 2004072 & 809174 & 4.0 & 4.9589 & TRN & \\
\hline CHEMBL1089101 & 809174 & 5.3 & 5.3812 & TRN & \\
\hline CHEMBL1986166 & 809174 & 5.4 & 5.7063 & TRN & \\
\hline CHEMBL1242373 & 809174 & 5.4 & 5.0776 & TRN & \\
\hline CHEMBL 2000433 & 809174 & 5.4 & 4.6126 & TST & \\
\hline CHEMBL56543 & 809174 & 5.1 & 4.7722 & TST & \\
\hline CHEMBL1988075 & 809174 & 4.0 & 4.2172 & TRN & \\
\hline CHEMBL2001239 & 809174 & 5.7 & 5.4967 & TRN & \\
\hline CHEMBL 2001288 & 809174 & 4.0 & 4.1809 & TRN & \\
\hline CHEMBL1992363 & 809174 & 4.3 & 5.3498 & TRN & \\
\hline CHEMBL1999811 & 809174 & 5.5 & 5.6845 & TRN & \\
\hline CHEMBL235157 & 809174 & 4.2 & 4.739 & TST & \\
\hline CHEMBL2000481 & 809174 & 5.6 & 5.1975 & TRN & \\
\hline CHEMBL1992242 & 809174 & 4.0 & 4.0845 & TRN & \\
\hline CHEMBL1982271 & 809174 & 6.3 & 6.4718 & TRN & \\
\hline CHEMBL 2007138 & 809174 & 4.8 & 4.8019 & TRN & \\
\hline CHEMBL2004159 & 809174 & 4.2 & 3.9942 & TRN & \\
\hline CHEMBL1986530 & 809174 & 4.0 & 4.8513 & TST & \\
\hline CHEMBL440084 & 809174 & 4.2 & 4.3174 & TRN & \\
\hline CHEMBL1999321 & 809174 & 4.0 & 4.0873 & TRN & \\
\hline CHEMBL1968590 & 809174 & 4.0 & 4.3206 & TRN & \\
\hline CHEMBL2005375 & 809174 & 4.0 & 3.5428 & TRN & \\
\hline CHEMBL1972183 & 809174 & 4.0 & 4.3654 & TRN & \\
\hline CHEMBL1966501 & 809174 & 4.2 & 4.4627 & TST & \\
\hline CHEMBL1995391 & 809174 & 3.6 & 4.0497 & TRN & \\
\hline CHEMBL1980592 & 809174 & 6.1 & 6.2231 & TRN & \\
\hline CHEMBL1974702 & 809174 & 6.6 & 7.08206 & 0000000001 & TRN \\
\hline CHEMBL474432 & 809174 & 6.9 & 5.2428 & TST & \\
\hline CHEMBL1965387 & 809174 & 4.2 & 4.0614 & TRN & \\
\hline CHEMBL2001539 & 809174 & 4.3 & 4.9751 & TST & \\
\hline CHEMBL1997041 & 809174 & 4.3 & 4.275 & TRN & \\
\hline CHEMBL1487428 & 809174 & 4.7 & 4.2724 & TRN & \\
\hline CHEMBL550418 & 809174 & 5.5 & 5.4513 & TRN & \\
\hline CHEMBL2003637 & 809174 & 7.5 & 6.5955 & TST & \\
\hline CHEMBL1986666 & 809174 & 6.0 & 6.5652 & TRN & \\
\hline CHEMBL1971289 & 809174 & 6.4 & 6.2987 & TRN & \\
\hline CHEMBL1999556 & 809174 & 6.0 & 6.3189 & TRN & \\
\hline CHEMBL1988437 & 809174 & 4.2 & 4.7375 & TRN & \\
\hline CHEMBL1968646 & 809174 & 6.0 & 6.0176 & TST & \\
\hline CHEMBL1998121 & 809174 & 5.9 & 6.1328 & TRN & \\
\hline CHEMBL1991800 & 809174 & 4.0 & 3.9991 & TRN & \\
\hline CHEMBL2003689 & 809174 & 4.2 & 4.4381 & TRN & \\
\hline & & & & 783 & \\
\hline
\end{tabular}




\begin{tabular}{|c|c|c|c|c|}
\hline \multicolumn{5}{|c|}{ lemental T } \\
\hline CHEMBL1985566 & 809174 & 4.0 & 4.2828 & TRN \\
\hline CHEMBL379835 & 809174 & 4.0 & 4.5853 & TRN \\
\hline CHEMBL1980802 & 809174 & 4.0 & 4.7422 & TST \\
\hline CHEMBL1996649 & 809174 & 4.2 & 4.2187 & TRN \\
\hline CHEMBL1979554 & 809174 & 4.0 & 4.4614 & TRN \\
\hline CHEMBL1993962 & 809174 & 4.1 & 4.6092 & TRN \\
\hline CHEMBL1986756 & 809174 & 4.2 & 3.6828 & TRN \\
\hline CHEMBL3197315 & 809174 & 4.0 & 4.7334 & TST \\
\hline CHEMBL468280 & 809174 & 7.4 & 6.4852 & TST \\
\hline CHEMBL1990884 & 809174 & 4.0 & 3.9737 & TRN \\
\hline CHEMBL 3109278 & 809174 & 4.2 & 4.2242 & TRN \\
\hline CHEMBL1970006 & 809174 & 4.0 & 4.0779 & TST \\
\hline CHEMBL 2006276 & 809174 & 4.0 & 4.487 & TRN \\
\hline CHEMBL191003 & 809174 & 4.2 & 4.0703 & TRN \\
\hline CHEMBL 2002471 & 809174 & 5.6 & 5.6143 & TRN \\
\hline CHEMBL 2006785 & 809174 & 5.9 & 5.4725 & TRN \\
\hline CHEMBL1973359 & 809174 & 6.2 & 6.385 & TST \\
\hline CHEMBL1995740 & 809174 & 6.7 & 5.9929 & TRN \\
\hline CHEMBL1979690 & 809174 & 6.0 & 4.6796 & TRN \\
\hline CHEMBL1995832 & 809174 & 4.0 & 3.9057 & TRN \\
\hline CHEMBL 2000345 & 809174 & 6.2 & 6.5155 & TRN \\
\hline CHEMBL1983575 & 809174 & 5.9 & 5.9071 & TRN \\
\hline CHEMBL1375418 & 809174 & 6.7 & 6.6194 & TRN \\
\hline CHEMBL 302449 & 809174 & 7.0 & 6.8332 & TST \\
\hline CHEMBL1981047 & 809174 & 4.2 & 3.8362 & TRN \\
\hline CHEMBL 229968 & 809174 & 8.2 & 8.2079 & TRN \\
\hline CHEMBL1976196 & 809174 & 5.6 & 5.039 & TST \\
\hline CHEMBL1976240 & 809174 & 4.0 & 4.1125 & TRN \\
\hline CHEMBL1987948 & 809174 & 6.2 & 5.7478 & TRN \\
\hline CHEMBL1983630 & 809174 & 4.3 & 4.5159 & TRN \\
\hline CHEMBL1979093 & 809174 & 5.0 & 4.6472 & TRN \\
\hline CHEMBL336961 & 809174 & 5.2 & 4.9111 & TRN \\
\hline CHEMBL1970083 & 809174 & 5.7 & 5.1535 & TRN \\
\hline CHEMBL1994938 & 809174 & 4.0 & 3.9194 & TRN \\
\hline CHEMBL1977223 & 809174 & 6.2 & 5.4547 & TRN \\
\hline CHEMBL1976290 & 809174 & 4.6 & 4.5051 & TRN \\
\hline CHEMBL1236126 & 809174 & 4.0 & 4.1957 & TRN \\
\hline CHEMBL1997846 & 809174 & 4.4 & 4.6784 & TRN \\
\hline CHEMBL 2004419 & 809174 & 6.0 & 5.9036 & TRN \\
\hline CHEMBL 2007073 & 809174 & 4.2 & 3.9026 & TRN \\
\hline CHEMBL1992937 & 809174 & 4.2 & 4.2087 & TST \\
\hline CHEMBL1972119 & 809174 & 4.0 & 3.8037 & TRN \\
\hline CHEMBL95692 & 809174 & 4.0 & 4.4842 & TRN \\
\hline CHEMBL1976455 & 809174 & 5.7 & 5.7266 & TRN \\
\hline CHEMBL1983923 & 809174 & 4.1 & 4.8338 & TRN \\
\hline CHEMBL1983534 & 809174 & 4.0 & 4.5069 & TRN \\
\hline CHEMBL1982361 & 809174 & 5.6 & 5.0393 & TRN \\
\hline CHEMBL 2000801 & 809174 & 4.0 & 4.0082 & TRN \\
\hline
\end{tabular}




\begin{tabular}{|c|c|c|c|c|c|}
\hline \\
\hline CHEMBL1991395 & 809174 & 4.0 & 3.5827 & TRN & \\
\hline CHEMBL1971245 & 809174 & 4.0 & 4.5521 & TRN & \\
\hline CHEMBL1987648 & 809174 & 4.0 & 4.0513 & TRN & \\
\hline CHEMBL1972142 & 809174 & 4.0 & 4.2315 & TRN & \\
\hline CHEMBL1966514 & 809174 & 4.0 & 4.4034 & TRN & \\
\hline CHEMBL2003638 & 809174 & 4.6 & 4.9636 & TRN & \\
\hline CHEMBL1983393 & 809174 & 4.2 & 4.8628 & TRN & \\
\hline CHEMBL516429 & 809174 & 7.1 & 7.5511 & TRN & \\
\hline CHEMBL1972152 & 809174 & 4.0 & 4.7548 & TST & \\
\hline CHEMBL1970806 & 809174 & 6.8 & 6.2472 & TRN & \\
\hline CHEMBL1992371 & 809174 & 6.0 & 5.6168 & TRN & \\
\hline CHEMBL1979970 & 809174 & 4.0 & 4.1727 & TRN & \\
\hline CHEMBL1967252 & 809174 & 5.1 & 5.0281 & TRN & \\
\hline CHEMBL1970821 & 809174 & 6.3 & 6.0701 & TRN & \\
\hline CHEMBL 2004637 & 809174 & 5.4 & 5.0579 & TRN & \\
\hline CHEMBL1993374 & 809174 & 4.2 & 4.2766 & TST & \\
\hline CHEMBL1969264 & 809174 & 5.4 & 4.9865 & TRN & \\
\hline CHEMBL2006237 & 809174 & 6.6 & 6.2269 & TRN & \\
\hline CHEMBL1999506 & 809174 & 4.2 & 4.2131 & TRN & \\
\hline CHEMBL2005509 & 809174 & 6.4 & 6.1254 & TRN & \\
\hline CHEMBL1572266 & 809174 & 4.0 & 5.8919 & TST & \\
\hline CHEMBL1979516 & 809174 & 4.0 & 4.2748 & TRN & \\
\hline CHEMBL1972820 & 809174 & 4.0 & 5.9516 & TST & \\
\hline CHEMBL1605605 & 809174 & 4.2 & 4.5101 & TRN & \\
\hline CHEMBL1989029 & 809174 & 5.8 & 5.3207 & TRN & \\
\hline CHEMBL392642 & 809174 & 5.7 & 5.1511 & TRN & \\
\hline CHEMBL1682554 & 809174 & 6.3 & 6.525 & TRN & \\
\hline CHEMBL1980167 & 809174 & 6.5 & 4.4614 & TST & \\
\hline CHEMBL1972849 & 809174 & 4.0 & 3.9257 & TRN & \\
\hline CHEMBL1986855 & 809174 & 6.7 & 6.5382 & TRN & \\
\hline CHEMBL1975357 & 809174 & 5.8 & 4.7293 & TST & \\
\hline CHEMBL1989136 & 809174 & 4.0 & 4.1973 & TRN & \\
\hline CHEMBL 259922 & 809174 & 4.1 & 3.4639 & TST & \\
\hline CHEMBL1997617 & 809174 & 5.2 & 5.3246 & TRN & \\
\hline CHEMBL1969301 & 809174 & 4.0 & 3.6762 & TRN & \\
\hline CHEMBL1966068 & 809174 & 5.7 & $5.7020 e$ & 0000000001 & TRN \\
\hline CHEMBL1983932 & 809174 & 5.6 & 4.7658 & TRN & \\
\hline CHEMBL1987910 & 809174 & 4.0 & 4.21899 & 9999999999 & TRN \\
\hline CHEMBL1983980 & 809174 & 5.7 & 5.9972 & TRN & \\
\hline CHEMBL1973399 & 809174 & 3.0 & 4.2382 & TST & \\
\hline CHEMBL1966069 & 809174 & 4.0 & 4.5566 & TRN & \\
\hline CHEMBL1986899 & 809174 & 5.3 & 4.5209 & TRN & \\
\hline CHEMBL 243088 & 809174 & 6.4 & 7.3128 & TRN & \\
\hline CHEMBL1993661 & 809174 & 4.2 & 4.0425 & TRN & \\
\hline CHEMBL1230164 & 809174 & 5.3 & 5.2518 & TRN & \\
\hline CHEMBL202721 & 809174 & 4.2 & 4.1691 & TRN & \\
\hline CHEMBL1987034 & 809174 & 4.0 & 4.4607 & TRN & \\
\hline CHEMBL 2005886 & 809174 & 4.0 & 4.6322 & TST & \\
\hline
\end{tabular}




\begin{tabular}{|c|c|c|c|c|}
\hline & & & 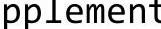 & al Ta \\
\hline CHEMBL1682345 & 809174 & 5.6 & 5.4493 & TRN \\
\hline CHEMBL481491 & 809174 & 5.2 & 4.0432 & TST \\
\hline CHEMBL388311 & 809174 & 6.2 & 6.9783 & TRN \\
\hline CHEMBL1807515 & 809174 & 6.6 & 6.9154 & TRN \\
\hline CHEMBL 2005936 & 809174 & 4.0 & 4.7901 & TRN \\
\hline CHEMBL1987430 & 809174 & 4.3 & 4.5029 & TRN \\
\hline CHEMBL1562756 & 809174 & 6.5 & 5.5803 & TST \\
\hline CHEMBL1993413 & 809174 & 4.4 & 4.0402 & TRN \\
\hline CHEMBL1969372 & 809174 & 4.0 & 3.3032 & TRN \\
\hline CHEMBL 2001957 & 809174 & 4.0 & 4.3014 & TRN \\
\hline CHEMBL1988662 & 809174 & 5.5 & 5.1209 & TRN \\
\hline CHEMBL1986263 & 809174 & 5.1 & 5.4615 & TRN \\
\hline CHEMBL1986265 & 809174 & 7.1 & 3.9254 & TST \\
\hline CHEMBL1964644 & 809174 & 4.0 & 4.1338 & TRN \\
\hline CHEMBL1981782 & 809174 & 4.0 & 4.2675 & TRN \\
\hline CHEMBL1970142 & 809174 & 4.0 & 3.6001 & TRN \\
\hline CHEMBL1977681 & 809174 & 6.2 & 5.51 & TRN \\
\hline CHEMBL1983348 & 809174 & 4.2 & 4.3284 & TRN \\
\hline CHEMBL1995592 & 809174 & 6.1 & 5.8139 & TRN \\
\hline CHEMBL 2000934 & 809174 & 4.2 & 4.4804 & TRN \\
\hline CHEMBL1986177 & 809174 & 5.3 & 5.1957 & TRN \\
\hline CHEMBL1982541 & 809174 & 4.0 & 4.3174 & TRN \\
\hline CHEMBL1992323 & 809174 & 6.5 & 5.6986 & TRN \\
\hline CHEMBL1983449 & 809174 & 4.0 & 4.2506 & TRN \\
\hline CHEMBL1983589 & 809174 & 7.2 & 6.4665 & TRN \\
\hline CHEMBL1996510 & 809174 & 7.0 & 5.6114 & TST \\
\hline CHEMBL1977874 & 809174 & 4.0 & 5.3097 & TST \\
\hline CHEMBL 2005718 & 809174 & 5.7 & 5.9087 & TRN \\
\hline CHEMBL437747 & 809174 & 5.9 & 5.6308 & TRN \\
\hline CHEMBL1995172 & 809174 & 4.2 & 4.256 & TST \\
\hline CHEMBL 2001584 & 809174 & 4.2 & 4.12 & TRN \\
\hline CHEMBL507936 & 809174 & 4.0 & 4.1372 & TRN \\
\hline CHEMBL1967998 & 809174 & 4.2 & 4.3761 & TRN \\
\hline CHEMBL104264 & 809174 & 4.0 & 4.4582 & TRN \\
\hline CHEMBL1997129 & 809174 & 6.6 & 6.7602 & TRN \\
\hline CHEMBL1984788 & 809174 & 5.7 & 5.7412 & TRN \\
\hline CHEMBL451964 & 809174 & 6.9 & 6.4283 & TRN \\
\hline CHEMBL1974875 & 809174 & 4.0 & 4.7559 & TST \\
\hline CHEMBL1996604 & 809174 & 5.8 & 5.5597 & TRN \\
\hline CHEMBL 2001547 & 809174 & 4.0 & 3.8675 & TRN \\
\hline CHEMBL 210928 & 809174 & 4.0 & 3.8384 & TRN \\
\hline CHEMBL1972840 & 809174 & 7.2 & 6.9273 & TRN \\
\hline CHEMBL2001668 & 809174 & 5.1 & 5.4846 & TRN \\
\hline CHEMBL1998585 & 809174 & 5.2 & 4.9619 & TRN \\
\hline CHEMBL 2004934 & 809174 & 4.0 & 3.8308 & TRN \\
\hline CHEMBL1987261 & 809174 & 6.7 & 6.454 & TRN \\
\hline CHEMBL 2004025 & 809174 & 6.8 & 4.9996 & TST \\
\hline CHEMBL1996048 & 809174 & 4.2 & 4.9032 & TST \\
\hline
\end{tabular}




\begin{tabular}{|c|c|c|c|c|c|}
\hline & & & & & \\
\hline CHEMBL1976158 & 809174 & 5.5 & 5.5949 & TST & \\
\hline CHEMBL461876 & 809174 & 5.4 & 4.9268 & TST & \\
\hline CHEMBL1997335 & 809174 & 4.2 & 4.592 & TRN & \\
\hline CHEMBL1978099 & 809174 & 4.0 & 3.9541 & TRN & \\
\hline CHEMBL1984363 & 809174 & 4.0 & 4.0585 & TRN & \\
\hline CHEMBL1977041 & 809174 & 5.4 & 5.4787 & TRN & \\
\hline CHEMBL1968070 & 809174 & 5.6 & 5.0182 & TRN & \\
\hline CHEMBL1985723 & 809174 & 6.4 & 6.3199 & TRN & \\
\hline CHEMBL1984367 & 809174 & 4.0 & 4.0033 & TRN & \\
\hline CHEMBL399530 & 809174 & 5.8 & 5.6423 & TRN & \\
\hline CHEMBL1977128 & 809174 & 4.2 & 4.5473 & TRN & \\
\hline CHEMBL1997759 & 809174 & 5.2 & 5.0443 & TRN & \\
\hline CHEMBL1970074 & 809174 & 4.0 & 4.6995 & TRN & \\
\hline CHEMBL1974803 & 809174 & 6.0 & 5.82700 & 0000000001 & TRN \\
\hline CHEMBL1984500 & 809174 & 4.3 & 3.4666 & TRN & \\
\hline CHEMBL2005112 & 809174 & 6.0 & 6.4806 & TST & \\
\hline CHEMBL2003456 & 809174 & 5.1 & 5.4053 & TRN & \\
\hline CHEMBL1966816 & 809174 & 6.3 & 5.5038 & TRN & \\
\hline CHEMBL2002992 & 809174 & 4.2 & 4.0771 & TRN & \\
\hline CHEMBL560813 & 809174 & 5.1 & 5.0947 & TRN & \\
\hline CHEMBL207253 & 809174 & 5.5 & 5.2322 & TRN & \\
\hline CHEMBL1890036 & 809174 & 4.0 & 5.1951 & TST & \\
\hline CHEMBL1968791 & 809174 & 4.0 & 4.5546 & TRN & \\
\hline CHEMBL2002682 & 809174 & 4.0 & 5.2388 & TST & \\
\hline CHEMBL1977634 & 809174 & 4.2 & 4.1349 & TRN & \\
\hline CHEMBL1984700 & 809174 & 4.0 & 4.1194 & TRN & \\
\hline CHEMBL1998953 & 809174 & 4.2 & 4.148 & TRN & \\
\hline CHEMBL2007151 & 809174 & 5.1 & 4.584 & TRN & \\
\hline CHEMBL1971606 & 809174 & 4.2 & 4.0564 & TRN & \\
\hline CHEMBL1461728 & 809174 & 4.0 & 3.9473 & TRN & \\
\hline CHEMBL1999279 & 809174 & 5.9 & 5.9047 & TRN & \\
\hline CHEMBL1995448 & 809174 & 4.0 & 4.3025 & TRN & \\
\hline CHEMBL1972158 & 809174 & 5.2 & 5.12799 & 9999999999 & TRN \\
\hline CHEMBL1999414 & 809174 & 4.3 & 4.4825 & TRN & \\
\hline CHEMBL1967336 & 809174 & 4.2 & 4.312 & TRN & \\
\hline CHEMBL2006481 & 809174 & 4.0 & 3.5716 & TRN & \\
\hline CHEMBL1967992 & 809174 & 4.2 & 4.1784 & TRN & \\
\hline CHEMBL1993424 & 809174 & 4.0 & 4.55399 & 9999999999 & TRN \\
\hline CHEMBL1975534 & 809174 & 4.0 & 4.0652 & TRN & \\
\hline CHEMBL1966703 & 809174 & 4.0 & 5.0738 & TST & \\
\hline CHEMBL1969561 & 809174 & 5.3 & 5.0635 & TRN & \\
\hline CHEMBL1983640 & 809174 & 5.3 & 4.9894 & TRN & \\
\hline CHEMBL1964687 & 809174 & 5.2 & 4.876 & TRN & \\
\hline CHEMBL1999918 & 809174 & 6.3 & 6.2618 & TRN & \\
\hline CHEMBL1974254 & 809174 & 4.0 & 4.3865 & TRN & \\
\hline CHEMBL1988537 & 809174 & 5.5 & 6.13299 & 9999999999 & TST \\
\hline CHEMBL2002240 & 809174 & 4.0 & 4.4544 & TRN & \\
\hline CHEMBL1980178 & 809174 & 6.9 & 5.8123 & TRN & \\
\hline & & & & 7837 & \\
\hline
\end{tabular}




\begin{tabular}{|c|c|c|c|c|}
\hline & & & ople & \\
\hline CHEMBL485556 & 809174 & 4.0 & 3.7498 & TRN \\
\hline CHEMBL1981511 & 809174 & 4.0 & 3.8723 & TRN \\
\hline CHEMBL1972221 & 809174 & 4.0 & 3.9978 & TRN \\
\hline CHEMBL1984274 & 809174 & 5.2 & 5.4074 & TST \\
\hline CHEMBL1998545 & 809174 & 4.0 & 3.6729 & TRN \\
\hline CHEMBL1986869 & 809174 & 4.0 & 4.2716 & TRN \\
\hline CHEMBL 2004033 & 809174 & 5.4 & 5.2858 & TST \\
\hline CHEMBL1987998 & 809174 & 4.2 & 3.6411 & TST \\
\hline CHEMBL1971534 & 809174 & 4.4 & 4.4838 & TRN \\
\hline CHEMBL242865 & 809174 & 6.0 & 6.1348 & TRN \\
\hline CHEMBL 2002799 & 809174 & 4.2 & 4.3045 & TST \\
\hline CHEMBL1997623 & 809174 & 4.0 & 4.1112 & TRN \\
\hline CHEMBL 2002479 & 809174 & 5.4 & 5.6065 & TRN \\
\hline CHEMBL1472492 & 809174 & 4.0 & 5.7477 & TST \\
\hline CHEMBL1966035 & 809174 & 4.0 & 4.5868 & TRN \\
\hline CHEMBL1990708 & 809174 & 5.5 & 5.9786 & TRN \\
\hline CHEMBL1974363 & 809174 & 4.0 & 4.8854 & TRN \\
\hline CHEMBL1982992 & 809174 & 5.5 & 5.2259 & TRN \\
\hline CHEMBL1972276 & 809174 & 6.7 & 5.8915 & TRN \\
\hline CHEMBL1970709 & 809174 & 4.0 & 4.1634 & TRN \\
\hline CHEMBL1985309 & 809174 & 5.7 & 5.5314 & TRN \\
\hline CHEMBL1992125 & 809174 & 5.6 & 5.2421 & TRN \\
\hline CHEMBL1972290 & 809174 & 6.1 & 6.4173 & TRN \\
\hline CHEMBL1964777 & 809174 & 5.6 & 5.5903 & TRN \\
\hline CHEMBL1987533 & 809174 & 4.0 & 4.0096 & TRN \\
\hline CHEMBL1984548 & 809174 & 6.2 & 5.8276 & TRN \\
\hline CHEMBL579246 & 809174 & 7.4 & 7.3577 & TRN \\
\hline CHEMBL398951 & 809174 & 4.2 & 4.8376 & TST \\
\hline CHEMBL1982506 & 809174 & 6.1 & 4.8837 & TST \\
\hline CHEMBL1968127 & 809174 & 4.0 & 4.0094 & TRN \\
\hline CHEMBL 2007603 & 809174 & 4.2 & 4.9555 & TRN \\
\hline CHEMBL1985406 & 809174 & 5.2 & 4.3247 & TRN \\
\hline CHEMBL 2000894 & 809174 & 4.0 & 4.2832 & TRN \\
\hline CHEMBL207400 & 809174 & 5.3 & 4.9594 & TRN \\
\hline CHEMBL1993243 & 809174 & 4.0 & 3.7624 & TRN \\
\hline CHEMBL399021 & 809174 & 4.0 & 3.9144 & TRN \\
\hline CHEMBL1969537 & 809174 & 7.6 & 7.1459 & TST \\
\hline CHEMBL210032 & 809174 & 4.0 & 4.1986 & TRN \\
\hline CHEMBL508928 & 809174 & 4.0 & 4.8426 & TRN \\
\hline CHEMBL1991356 & 809174 & 6.3 & 5.0479 & TST \\
\hline CHEMBL1983309 & 809174 & 5.2 & 4.9858 & TRN \\
\hline CHEMBL 2004892 & 809174 & 4.0 & 3.9118 & TRN \\
\hline CHEMBL1972339 & 809174 & 6.6 & 5.7428 & TRN \\
\hline CHEMBL1970314 & 809174 & 5.1 & 5.0301 & TRN \\
\hline CHEMBL 2006149 & 809174 & 4.2 & 4.207 & TRN \\
\hline CHEMBL1971463 & 809174 & 5.8 & 5.9543 & TRN \\
\hline CHEMBL262433 & 809174 & 4.0 & 3.8656 & TRN \\
\hline CHEMBL306380 & 809174 & 4.0 & 3.9136 & TRN \\
\hline
\end{tabular}




\begin{tabular}{|c|c|c|c|c|c|}
\hline \\
\hline CHEMBL1966722 & 809174 & 6.1 & 6.5128 & TRN & \\
\hline CHEMBL1983595 & 809174 & 4.2 & 4.7441 & TRN & \\
\hline CHEMBL1986588 & 809174 & 3.0 & 3.6847 & TRN & \\
\hline CHEMBL1988581 & 809174 & 7.1 & 7.5704 & TST & \\
\hline CHEMBL1975500 & 809174 & 5.6 & 5.9834 & TRN & \\
\hline CHEMBL394619 & 809174 & 5.3 & 4.7279 & TRN & \\
\hline CHEMBL 2006564 & 809174 & 4.2 & 4.1531 & TRN & \\
\hline CHEMBL411903 & 809174 & 4.0 & 4.6863 & TRN & \\
\hline CHEMBL1965988 & 809174 & 5.4 & 5.3426 & TRN & \\
\hline CHEMBL1990432 & 809174 & 5.3 & 5.2448 & TRN & \\
\hline CHEMBL418203 & 809174 & 6.1 & 6.5375 & TST & \\
\hline CHEMBL1989646 & 809174 & 4.0 & 4.8984 & TRN & \\
\hline CHEMBL209534 & 809174 & 4.0 & 4.0608 & TRN & \\
\hline CHEMBL1966087 & 809174 & 5.3 & 5.1772 & TRN & \\
\hline CHEMBL1964692 & 809174 & 4.0 & 3.7274 & TRN & \\
\hline CHEMBL1986767 & 809174 & 5.6 & 5.7861 & TRN & \\
\hline CHEMBL1973483 & 809174 & 4.0 & 4.203 & TRN & \\
\hline CHEMBL219722 & 809174 & 4.0 & 3.8294 & TRN & \\
\hline CHEMBL1970735 & 809174 & 4.0 & 3.7287 & TRN & \\
\hline CHEMBL1997340 & 809174 & 4.0 & 4.0289 & TRN & \\
\hline CHEMBL1994669 & 809174 & 6.5 & 5.9987 & TRN & \\
\hline CHEMBL458997 & 809174 & 4.4 & 4.6442 & TRN & \\
\hline CHEMBL1988805 & 809174 & 4.2 & 4.5458 & TST & \\
\hline CHEMBL1971021 & 809174 & 4.0 & 4.0376 & TRN & \\
\hline CHEMBL1974310 & 809174 & 5.7 & 6.193 & TRN & \\
\hline CHEMBL583144 & 809174 & 6.9 & 6.8929 & TRN & \\
\hline CHEMBL1982660 & 809174 & 4.2 & 4.9224 & TRN & \\
\hline CHEMBL1982957 & 809174 & 5.7 & 5.5277 & TRN & \\
\hline CHEMBL1725279 & 809174 & 6.3 & 7.7922 & TST & \\
\hline CHEMBL 2002346 & 809174 & 7.0 & 7.19799 & 99999999995 & TRN \\
\hline CHEMBL 2005767 & 809174 & 5.7 & 5.3658 & TRN & \\
\hline CHEMBL 2006836 & 809174 & 5.8 & 5.8323 & TST & \\
\hline CHEMBL412142 & 809174 & 4.0 & 4.165 & TST & \\
\hline CHEMBL1988000 & 809174 & 5.2 & 5.3626 & TST & \\
\hline CHEMBL1985153 & 809174 & 5.7 & 5.1726 & TRN & \\
\hline CHEMBL 2003271 & 809174 & 5.6 & 5.8423 & TRN & \\
\hline CHEMBL1980704 & 809174 & 6.2 & 6.2113 & TST & \\
\hline CHEMBL1966808 & 809174 & 7.5 & 6.9058 & TRN & \\
\hline CHEMBL1972365 & 809174 & 4.0 & 4.5937 & TST & \\
\hline CHEMBL 260135 & 809174 & 4.0 & 4.27 & TRN & \\
\hline CHEMBL220241 & 809174 & 6.5 & 6.99200 & 0000000001 & TRN \\
\hline CHEMBL 2004544 & 809174 & 4.0 & 4.9717 & TST & \\
\hline CHEMBL1988141 & 809174 & 7.1 & 7.0161 & TST & \\
\hline CHEMBL1966040 & 809174 & 5.9 & 6.9942 & TRN & \\
\hline CHEMBL1977134 & 809174 & 4.2 & 4.5678 & TRN & \\
\hline CHEMBL1970873 & 809174 & 3.3 & 2.9743 & TRN & \\
\hline CHEMBL 2006933 & 809174 & 6.4 & 6.1313 & TST & \\
\hline CHEMBL1985206 & 809174 & 5.4 & 4.5509 & TST & \\
\hline
\end{tabular}




\begin{tabular}{|c|c|c|c|c|}
\hline & & & CIIL & al Ta \\
\hline CHEMBL1991078 & 809174 & 4.3 & 4.3725 & TRN \\
\hline CHEMBL1987359 & 809174 & 4.0 & 4.4665 & TST \\
\hline CHEMBL1977749 & 809174 & 6.4 & 5.1544 & TST \\
\hline CHEMBL 2000685 & 809174 & 7.3 & 6.8546 & TRN \\
\hline CHEMBL1994438 & 809174 & 5.9 & 5.9592 & TRN \\
\hline CHEMBL1967513 & 809174 & 4.2 & 4.6315 & TRN \\
\hline CHEMBL1980376 & 809174 & 5.3 & 4.9924 & TRN \\
\hline CHEMBL1985311 & 809174 & 4.0 & 4.0506 & TRN \\
\hline CHEMBL 2000724 & 809174 & 4.2 & 4.158 & TRN \\
\hline CHEMBL1982413 & 809174 & 6.0 & 6.3311 & TRN \\
\hline CHEMBL1682553 & 809174 & 6.5 & 6.2719 & TRN \\
\hline CHEMBL1969502 & 809174 & 6.7 & 6.3436 & TRN \\
\hline CHEMBL 2004647 & 809174 & 6.1 & 5.2798 & TST \\
\hline CHEMBL1971430 & 809174 & 4.0 & 4.5961 & TRN \\
\hline CHEMBL 2000271 & 809174 & 8.0 & 7.438 & TRN \\
\hline CHEMBL1997764 & 809174 & 4.0 & 4.0315 & TRN \\
\hline CHEMBL562488 & 809174 & 5.1 & 4.9376 & TRN \\
\hline CHEMBL354676 & 809174 & 3.2 & 3.4468 & TRN \\
\hline CHEMBL1987535 & 809174 & 5.4 & 5.6356 & TRN \\
\hline CHEMBL1981792 & 809174 & 4.2 & 4.688 & TRN \\
\hline CHEMBL 2002586 & 809174 & 4.2 & 4.7364 & TRN \\
\hline CHEMBL 2004692 & 809174 & 4.0 & 5.2836 & TST \\
\hline CHEMBL1987815 & 809174 & 4.2 & 5.6267 & TST \\
\hline CHEMBL1996234 & 809174 & 4.0 & 4.2625 & TRN \\
\hline CHEMBL1967544 & 809174 & 6.9 & 6.468 & TRN \\
\hline CHEMBL1992673 & 809174 & 4.7 & 5.0454 & TRN \\
\hline CHEMBL 223367 & 809174 & 6.6 & 5.1699 & TST \\
\hline CHEMBL1993335 & 809174 & 5.4 & 4.9941 & TST \\
\hline CHEMBL 2007574 & 809174 & 6.0 & 5.9028 & TRN \\
\hline CHEMBL1964804 & 809174 & 5.3 & 4.7978 & TRN \\
\hline CHEMBL443962 & 809174 & 4.0 & 5.0428 & TST \\
\hline CHEMBL1965507 & 809174 & 6.0 & 5.3759 & TRN \\
\hline CHEMBL 2000354 & 809174 & 6.9 & 6.8113 & TRN \\
\hline CHEMBL 274064 & 809174 & 6.0 & 4.4744 & TRN \\
\hline CHEMBL1981107 & 809174 & 3.6 & 4.8035 & TST \\
\hline CHEMBL1967564 & 809174 & 4.0 & 3.9175 & TRN \\
\hline CHEMBL1970317 & 809174 & 4.2 & 3.907 & TRN \\
\hline CHEMBL 2000408 & 809174 & 4.0 & 3.7883 & TRN \\
\hline CHEMBL1978014 & 809174 & 4.0 & 4.1137 & TRN \\
\hline CHEMBL 248757 & 809174 & 5.0 & 5.2652 & TST \\
\hline CHEMBL1974250 & 809174 & 7.6 & 6.8732 & TRN \\
\hline CHEMBL1997007 & 809174 & 4.2 & 3.923 & TRN \\
\hline CHEMBL1994538 & 809174 & 4.1 & 4.1136 & TRN \\
\hline CHEMBL1975490 & 809174 & 5.8 & 5.973 & TRN \\
\hline CHEMBL 2002690 & 809174 & 4.2 & 4.6543 & TRN \\
\hline CHEMBL 383527 & 809174 & 5.5 & 5.3599 & TRN \\
\hline CHEMBL1986139 & 809174 & 5.1 & 4.9756 & TRN \\
\hline CHEMBL 2006567 & 809174 & 4.0 & 4.6505 & TRN \\
\hline
\end{tabular}




\begin{tabular}{|c|c|c|c|c|c|}
\hline \multirow[b]{2}{*}{ CHEMBL 2003229} & \multirow[b]{2}{*}{809174} & \\
\hline & & 5.3 & 5.6641 & TRN & \\
\hline CHEMBL1979883 & 809174 & 5.5 & 4.9966 & TRN & \\
\hline CHEMBL1988331 & 809174 & 6.3 & 5.8706 & TRN & \\
\hline CHEMBL491758 & 809174 & 4.0 & 4.1935 & TRN & \\
\hline CHEMBL1986590 & 809174 & 4.2 & 4.9154 & TRN & \\
\hline CHEMBL1998826 & 809174 & 5.3 & 6.0097 & TRN & \\
\hline CHEMBL1682360 & 809174 & 4.0 & 4.044 & TRN & \\
\hline CHEMBL549730 & 809174 & 5.3 & 5.0747 & TRN & \\
\hline CHEMBL1970189 & 809174 & 4.0 & 3.7639 & TRN & \\
\hline CHEMBL406845 & 809174 & 4.2 & 3.9479 & TRN & \\
\hline CHEMBL1974288 & 809174 & 4.0 & 4.0642 & TRN & \\
\hline CHEMBL213207 & 809174 & 4.0 & 5.3287 & TRN & \\
\hline CHEMBL1990346 & 809174 & 4.0 & 4.0242 & TRN & \\
\hline CHEMBL1968705 & 809174 & 4.3 & 4.5729 & TRN & \\
\hline CHEMBL1991410 & 809174 & 4.2 & 4.0561 & TRN & \\
\hline CHEMBL1978271 & 809174 & 4.2 & 4.0861 & TRN & \\
\hline CHEMBL 2007266 & 809174 & 4.2 & 4.095 & TRN & \\
\hline CHEMBL1994308 & 809174 & 4.2 & 4.6732 & TRN & \\
\hline CHEMBL1974328 & 809174 & 5.7 & 6.1718 & TRN & \\
\hline CHEMBL1988717 & 809174 & 4.0 & 4.6592 & TRN & \\
\hline CHEMBL509032 & 809174 & 4.1 & 3.9985 & TRN & \\
\hline CHEMBL1992342 & 809174 & 4.0 & 3.9831 & TRN & \\
\hline CHEMBL1973013 & 809174 & 4.2 & 4.5529 & TST & \\
\hline CHEMBL1966204 & 809174 & 6.2 & 5.5443 & TRN & \\
\hline CHEMBL1965423 & 809174 & 6.1 & 5.6682 & TRN & \\
\hline CHEMBL205415 & 809174 & 5.9 & 5.9454 & TRN & \\
\hline CHEMBL1977135 & 809174 & 4.0 & 4.1042 & TRN & \\
\hline CHEMBL1969473 & 809174 & 5.5 & 5.4488 & TRN & \\
\hline CHEMBL1999153 & 809174 & 6.3 & 5.7849 & TRN & \\
\hline CHEMBL 2001920 & 809174 & 7.2 & 6.1544 & TST & \\
\hline CHEMBL1977138 & 809174 & 5.7 & 5.8289 & TST & \\
\hline CHEMBL1241473 & 809174 & 6.5 & 6.53299 & 99999999995 & TRN \\
\hline CHEMBL1978448 & 809174 & 4.3 & 5.4471 & TST & \\
\hline CHEMBL 2004513 & 809174 & 4.0 & 3.8192 & TRN & \\
\hline CHEMBL1972258 & 809174 & 5.1 & 5.1859 & TRN & \\
\hline CHEMBL 2001257 & 809174 & 4.2 & 4.3247 & TRN & \\
\hline CHEMBL 2004515 & 809174 & 4.9 & 4.4598 & TRN & \\
\hline CHEMBL1980329 & 809174 & 6.6 & 6.1183 & TRN & \\
\hline CHEMBL1992042 & 809174 & 6.5 & 6.3633 & TST & \\
\hline CHEMBL1992536 & 809174 & 4.0 & 4.0822 & TRN & \\
\hline CHEMBL1994724 & 809174 & 4.2 & 4.6255 & TRN & \\
\hline CHEMBL1970290 & 809174 & 5.5 & 4.7598 & TRN & \\
\hline CHEMBL1967531 & 809174 & 4.0 & 4.1177 & TRN & \\
\hline CHEMBL1970913 & 809174 & 4.0 & 4.1323 & TRN & \\
\hline CHEMBL1997534 & 809174 & 5.5 & 4.5912 & TRN & \\
\hline CHEMBL1993877 & 809174 & 4.2 & 4.4741 & TRN & \\
\hline CHEMBL1977374 & 809174 & 4.0 & 4.4301 & TRN & \\
\hline CHEMBL1998551 & 809174 & 4.0 & 3.9701 & TRN & \\
\hline & & & & 7841 & \\
\hline
\end{tabular}




\begin{tabular}{|c|c|c|c|c|c|}
\hline CHEMBL1991180 & 809174 & 6.7 & 6.0823 & TST & \\
\hline CHEMBL1983315 & 809174 & 6.6 & 5.4109 & TRN & \\
\hline CHEMBL1978656 & 809174 & 6.2 & 5.6061 & TRN & \\
\hline CHEMBL1976420 & 809174 & 4.1 & 3.719 & TST & \\
\hline CHEMBL1981744 & 809174 & 4.3 & 4.0171 & TRN & \\
\hline CHEMBL1994864 & 809174 & 4.0 & 4.0251 & TRN & \\
\hline CHEMBL 2002446 & 809174 & 5.3 & 5.2301 & TST & \\
\hline CHEMBL 246970 & 809174 & 5.4 & 5.3577 & TRN & \\
\hline CHEMBL340921 & 809174 & 4.0 & 4.1202 & TRN & \\
\hline CHEMBL 2005478 & 809174 & 5.3 & 4.466 & TST & \\
\hline CHEMBL1276446 & 809174 & 5.8 & 5.8147 & TST & \\
\hline CHEMBL1995712 & 809174 & 6.0 & 6.0891 & TRN & \\
\hline CHEMBL1971649 & 809174 & 4.0 & 4.2315 & TRN & \\
\hline CHEMBL 2003657 & 809174 & 5.6 & 4.7693 & TRN & \\
\hline CHEMBL 2007124 & 809174 & 4.2 & 3.886 & TRN & \\
\hline CHEMBL2006439 & 809174 & 4.3 & 4.647 & TRN & \\
\hline CHEMBL 2006156 & 809174 & 4.0 & 4.0035 & TST & \\
\hline CHEMBL1985681 & 809174 & 4.2 & 4.9119 & TST & \\
\hline CHEMBL1949851 & 809174 & 5.1 & 5.023 & TRN & \\
\hline CHEMBL1991674 & 809174 & 6.0 & 5.7535 & TRN & \\
\hline CHEMBL262623 & 809174 & 4.7 & 4.2671 & TRN & \\
\hline CHEMBL1984842 & 809174 & 4.1 & 4.2601 & TRN & \\
\hline CHEMBL 223460 & 809174 & 4.0 & 4.3784 & TST & \\
\hline CHEMBL1998829 & 809174 & 4.0 & 3.8547 & TRN & \\
\hline CHEMBL 2006299 & 809174 & 4.2 & 4.0349 & TRN & \\
\hline CHEMBL 375284 & 809174 & 4.0 & 4.8676 & TRN & \\
\hline CHEMBL1972346 & 809174 & 5.6 & 6.2987 & TST & \\
\hline CHEMBL1980562 & 809174 & 4.2 & 5.6106 & TRN & \\
\hline CHEMBL1991818 & 809174 & 4.2 & 4.836 & TST & \\
\hline CHEMBL1982866 & 809174 & 4.0 & 3.844 & TRN & \\
\hline CHEMBL1968926 & 809174 & 4.0 & 4.2818 & TRN & \\
\hline CHEMBL365617 & 809174 & 5.6 & 5.4015 & TRN & \\
\hline CHEMBL1991867 & 809174 & 3.2 & 3.693 & TST & \\
\hline CHEMBL1979933 & 809174 & 6.8 & 6.4406 & TRN & \\
\hline CHEMBL1986503 & 809174 & 4.2 & 5.1163 & TST & \\
\hline CHEMBL1965570 & 809174 & 5.1 & 4.5866 & TRN & \\
\hline CHEMBL1972355 & 809174 & 6.4 & 6.5681 & TST & \\
\hline CHEMBL 2001641 & 809174 & 4.3 & 4.1879 & TRN & \\
\hline CHEMBL1997193 & 809174 & 6.0 & 5.4965 & TST & \\
\hline CHEMBL1964902 & 809174 & 4.2 & $4.4030 e$ & 00000000005 & TRN \\
\hline CHEMBL 2005387 & 809174 & 6.0 & 5.8546 & TRN & \\
\hline CHEMBL1082440 & 809174 & 4.0 & 5.3243 & TST & \\
\hline CHEMBL1614705 & 809174 & 4.0 & 3.9748 & TRN & \\
\hline CHEMBL1972362 & 809174 & 5.5 & 5.3009 & TRN & \\
\hline CHEMBL1972988 & 809174 & 5.8 & 5.5463 & TRN & \\
\hline CHEMBL 2007372 & 809174 & 4.0 & $3.8680 e$ & 00000000003 & TRN \\
\hline CHEMBL1982167 & 809174 & 5.3 & 5.4592 & TRN & \\
\hline CHEMBL1986597 & 809174 & 5.1 & 5.6149 & TRN & \\
\hline
\end{tabular}




\begin{tabular}{|c|c|c|c|c|}
\hline & & & Supplement & \\
\hline CHEMBL 2006715 & 809174 & 4.0 & 4.323 & TRN \\
\hline CHEMBL1971017 & 809174 & 6.3 & 6.5064 & TRN \\
\hline CHEMBL1990482 & 809174 & 5.7 & 5.4014 & TRN \\
\hline CHEMBL1990904 & 809174 & 4.0 & 3.4326 & TRN \\
\hline CHEMBL1987448 & 809174 & 5.7 & 6.0257 & TRN \\
\hline CHEMBL2005475 & 809174 & 5.2 & 5.1732 & TRN \\
\hline CHEMBL 2000104 & 809174 & 5.4 & 5.1326 & TRN \\
\hline CHEMBL183844 & 809174 & 4.0 & 4.3125 & TRN \\
\hline CHEMBL1997349 & 809174 & 6.1 & 6.9704 & TST \\
\hline CHEMBL220057 & 809174 & 4.0 & 4.31 & TRN \\
\hline CHEMBL383541 & 809174 & 6.4 & 6.2464 & TRN \\
\hline CHEMBL 2001224 & 809174 & 4.0 & 4.2229 & TRN \\
\hline CHEMBL10 & 809174 & 4.2 & 3.957 & TRN \\
\hline CHEMBL2005216 & 809174 & 6.4 & 5.8287 & TRN \\
\hline CHEMBL1964937 & 809174 & 5.3 & 5.2752 & TRN \\
\hline CHEMBL1980763 & 809174 & 4.2 & 4.1796 & TRN \\
\hline CHEMBL1969506 & 809174 & 4.0 & 4.6831 & TRN \\
\hline CHEMBL590109 & 809174 & 5.9 & 6.6169 & TST \\
\hline CHEMBL1977931 & 809174 & 4.1 & 4.2943 & TRN \\
\hline CHEMBL1972218 & 809174 & 5.3 & 5.9452 & TST \\
\hline CHEMBL1970879 & 809174 & 4.0 & 3.8117 & TRN \\
\hline CHEMBL2005899 & 809174 & 5.3 & 5.2824 & TRN \\
\hline CHEMBL1682552 & 809174 & 6.1 & 5.3725 & TST \\
\hline CHEMBL2007479 & 809174 & 4.2 & 4.3783 & TST \\
\hline CHEMBL1996155 & 809174 & 6.1 & 5.0458 & TST \\
\hline CHEMBL229799 & 809174 & 8.3 & 8.5198 & TST \\
\hline CHEMBL1682359 & 809174 & 5.1 & 4.6884 & TST \\
\hline CHEMBL 379300 & 809174 & 8.1 & 8.3705 & TST \\
\hline CHEMBL1972220 & 809174 & 5.7 & 4.4755 & TST \\
\hline CHEMBL1973720 & 809174 & 6.9 & 6.8371 & TST \\
\hline CHEMBL1969523 & 809174 & 6.1 & 6.5959 & TST \\
\hline CHEMBL207995 & 809174 & 4.0 & 4.3928 & TST \\
\hline CHEMBL1988995 & 809174 & 4.0 & 4.3633 & TST \\
\hline CHEMBL1986781 & 809174 & 4.0 & 3.6085 & TST \\
\hline CHEMBL2001923 & 809174 & 4.1 & 4.1499 & TST \\
\hline CHEMBL526133 & 809174 & 6.1 & 6.4808 & TST \\
\hline CHEMBL 2003514 & 809174 & 4.2 & 3.8254 & TST \\
\hline CHEMBL1989043 & 809174 & 4.2 & 4.0873 & TST \\
\hline CHEMBL1979057 & 809174 & 5.4 & 4.162 & TST \\
\hline CHEMBL1967538 & 809174 & 4.5 & 4.7504 & TST \\
\hline CHEMBL1999428 & 809174 & 4.0 & 4.4739 & TST \\
\hline CHEMBL1967560 & 809174 & 4.0 & 3.7817 & TST \\
\hline CHEMBL1682358 & 809174 & 4.0 & 4.8859 & TST \\
\hline CHEMBL211378 & 809174 & 4.0 & 4.0745 & TST \\
\hline CHEMBL1982465 & 809174 & 4.0 & 4.8037 & TST \\
\hline CHEMBL2003420 & 809174 & 4.0 & 3.8176 & TST \\
\hline CHEMBL 2002723 & 809174 & 5.4 & 4.3038 & TST \\
\hline CHEMBL 272453 & 809174 & 4.0 & 5.1337 & TST \\
\hline
\end{tabular}




\begin{tabular}{|c|c|c|c|c|}
\hline \multicolumn{5}{|c|}{ Supplemental Table S2.txt } \\
\hline CHEMBL1971801 & 809174 & 4.0 & 3.9214 & TST \\
\hline CHEMBL1970217 & 809174 & 4.0 & 4.2417 & TST \\
\hline CHEMBL1987143 & 809174 & 5.0 & 4.6805 & TST \\
\hline CHEMBL1968850 & 809174 & 4.0 & 4.3846 & TST \\
\hline CHEMBL 2005528 & 809174 & 6.0 & 5.3404 & TST \\
\hline CHEMBL185569 & 809174 & 5.6 & 5.0746 & TST \\
\hline CHEMBL1987007 & 809174 & 6.0 & 5.0407 & TST \\
\hline CHEMBL1973793 & 809174 & 5.8 & 4.6751 & TST \\
\hline CHEMBL1969588 & 809174 & 6.8 & 6.4852 & TST \\
\hline CHEMBL1984711 & 809174 & 4.0 & 3.8802 & TST \\
\hline CHEMBL1990212 & 809174 & 6.3 & 6.4977 & TST \\
\hline CHEMBL1986143 & 809174 & 4.2 & 4.1755 & TST \\
\hline CHEMBL1979252 & 809174 & 4.0 & 4.7723 & TST \\
\hline CHEMBL1972934 & 809174 & 4.7 & 4.515 & TST \\
\hline CHEMBL1682341 & 809174 & 5.0 & 4.7184 & TST \\
\hline CHEMBL1992581 & 809174 & 4.2 & 3.6314 & TST \\
\hline CHEMBL1972250 & 809174 & 4.0 & 4.5552 & TST \\
\hline CHEMBL1972937 & 809174 & 6.2 & 5.5866 & TST \\
\hline CHEMBL1986499 & 809174 & 4.0 & 4.8659 & TST \\
\hline CHEMBL 2001477 & 809174 & 4.0 & 4.4079 & TST \\
\hline CHEMBL 2004311 & 809174 & 4.0 & 4.0435 & TST \\
\hline CHEMBL1992634 & 809174 & 4.0 & 4.7399 & TST \\
\hline CHEMBL1984847 & 809174 & 4.2 & 4.1592 & TST \\
\hline CHEMBL316264 & 809174 & 4.0 & 4.1083 & TST \\
\hline CHEMBL 2001520 & 809174 & 5.3 & 5.2608 & TST \\
\hline CHEMBL1996576 & 809174 & 4.2 & 4.7169 & TST \\
\hline CHEMBL1991678 & 809174 & 4.2 & 3.9627 & TST \\
\hline CHEMBL1988594 & 809174 & 5.0 & 4.8343 & TST \\
\hline CHEMBL260092 & 809174 & 4.0 & 4.3865 & TST \\
\hline CHEMBL1965495 & 809174 & 5.4 & 4.968 & TST \\
\hline CHEMBL1985074 & 809174 & 7.0 & 5.6282 & TST \\
\hline CHEMBL1982874 & 809174 & 4.0 & 5.2631 & TST \\
\hline CHEMBL1991725 & 809174 & 5.5 & 5.7945 & TST \\
\hline CHEMBL 2007296 & 809174 & 4.0 & 3.6739 & TST \\
\hline CHEMBL396523 & 809174 & 7.2 & 6.9029 & TST \\
\hline CHEMBL208637 & 809174 & 4.0 & 3.5472 & TST \\
\hline CHEMBL1978371 & 809174 & 6.3 & 5.7693 & TST \\
\hline CHEMBL1970203 & 809174 & 4.0 & 4.9931 & TST \\
\hline CHEMBL 385478 & 809174 & 6.3 & 5.8292 & TST \\
\hline CHEMBL1999749 & 809174 & 4.0 & 4.6879 & TST \\
\hline CHEMBL1983006 & 809174 & 4.0 & 4.6903 & TST \\
\hline CHEMBL1984191 & 809174 & 4.0 & 4.5336 & TST \\
\hline CHEMBL1971029 & 809174 & 4.0 & 4.6399 & TST \\
\hline CHEMBL394790 & 809174 & 5.2 & 4.2379 & TST \\
\hline CHEMBL226471 & 809174 & 6.1 & 5.7831 & TST \\
\hline CHEMBL1996111 & 809174 & 4.0 & 4.9262 & TST \\
\hline CHEMBL1966175 & 809174 & 4.2 & 4.561 & TST \\
\hline CHEMBL1965589 & 809174 & 4.0 & 4.1033 & TST \\
\hline
\end{tabular}




\begin{tabular}{|c|c|c|c|c|c|c|}
\hline & & & & & & \\
\hline CHEMBL2007375 & 809174 & 4.2 & 4.4947 & TST & & \\
\hline CHEMBL1998193 & 809174 & 4.0 & 3.8775 & TST & & \\
\hline CHEMBL379975 & 809174 & 7.5 & 5.3127 & TST & & \\
\hline CHEMBL1973016 & 809174 & 4.2 & 3.5399 & TST & & \\
\hline CHEMBL1988153 & 809174 & 5.4 & 5.7852 & TST & & \\
\hline CHEMBL3950785 & 1640791 & 10.0088 & 10.1324 & TRN & & \\
\hline CHEMBL3908467 & 1640791 & 10.7471 & 10.5189 & TRN & & \\
\hline CHEMBL3945233 & 1640791 & 10.6038 & 10.6552 & TRN & & \\
\hline CHEMBL3931736 & 1640791 & 10.9393 & 10.3977 & TRN & & \\
\hline CHEMBL3924362 & 1640791 & 10.5702 & 10.5943 & TRN & & \\
\hline CHEMBL3925720 & 1640791 & 10.7055 & 11.4098 & TRN & & \\
\hline CHEMBL3902976 & 1640791 & 10.0625 & 9.9276 & TRN & & \\
\hline CHEMBL3962092 & 1640791 & 10.8729 & 11.22599 & 999999999 & 99 & TRN \\
\hline CHEMBL3969026 & 1640791 & 6.0 & 10.8582 & TST & & \\
\hline CHEMBL3920225 & 1640791 & 11.0088 & 10.6905 & TST & & \\
\hline CHEMBL3942541 & 1640791 & 9.5867 & 9.8812 & TRN & & \\
\hline CHEMBL3905204 & 1640791 & 10.9208 & 10.4638 & TRN & & \\
\hline CHEMBL3905140 & 1640791 & 10.6556 & 10.5595 & TRN & & \\
\hline CHEMBL3911615 & 1640791 & 10.5751 & 10.0325 & TRN & & \\
\hline CHEMBL3943478 & 1640791 & 10.7011 & 10.4638 & TRN & & \\
\hline CHEMBL3923277 & 1640791 & 10.1035 & 10.0588 & TRN & & \\
\hline CHEMBL3951645 & 1640791 & 10.4881 & 10.6565 & TRN & & \\
\hline CHEMBL3930895 & 1640791 & 6.0 & 9.5043 & TRN & & \\
\hline CHEMBL3957710 & 1640791 & 10.8268 & 10.2519 & TST & & \\
\hline CHEMBL3987027 & 1640791 & 10.2426 & 10.2976 & TRN & & \\
\hline CHEMBL3892470 & 1640791 & 9.4078 & 10.2121 & TRN & & \\
\hline CHEMBL3946202 & 1640791 & 9.8268 & 10.4116 & TST & & \\
\hline CHEMBL3945884 & 1640791 & 11.0706 & 11.22599 & 999999999 & 99 & TRN \\
\hline CHEMBL3902681 & 1640791 & 10.4123 & 10.3767 & TRN & & \\
\hline CHEMBL3943282 & 1640791 & 10.7747 & 9.7851 & TRN & & \\
\hline CHEMBL3923125 & 1640791 & 10.6383 & 10.4838 & TRN & & \\
\hline CHEMBL3976386 & 1640791 & 10.7799 & 10.6093 & TRN & & \\
\hline CHEMBL3912262 & 1640791 & 10.2034 & 10.3181 & TST & & \\
\hline CHEMBL3944841 & 1640791 & 9.8386 & 10.0205 & TRN & & \\
\hline CHEMBL3967591 & 1640791 & 10.762 & 10.3639 & TRN & & \\
\hline CHEMBL3985327 & 1640791 & 10.6345 & 10.5582 & TRN & & \\
\hline CHEMBL3892898 & 1640791 & 10.9829 & 999999999 & 999 & 10.5814 & TRN \\
\hline CHEMBL3967336 & 1640791 & 10.6216 & 10.3958 & TRN & & \\
\hline CHEMBL3980074 & 1640791 & 10.1675 & 9.8868 & TRN & & \\
\hline CHEMBL3938087 & 1640791 & 11.0223 & 10.5934 & TRN & & \\
\hline CHEMBL3955078 & 1640791 & 10.8601 & 10.6905 & TST & & \\
\hline CHEMBL3945220 & 1640791 & 11.0409 & 999999999 & 999 & 10.5943 & TRN \\
\hline CHEMBL3986433 & 1640791 & 10.71 & 10.5189 & TRN & & \\
\hline CHEMBL3982858 & 1640791 & 10.8633 & 10.3617 & TST & & \\
\hline CHEMBL3935030 & 1640791 & 10.4559 & 10.6093 & TRN & & \\
\hline CHEMBL3927473 & 1640791 & 10.4855 & 10.9503 & TST & & \\
\hline CHEMBL3911121 & 1640791 & 9.8996 & 9.7747 & TRN & & \\
\hline CHEMBL3940326 & 1640791 & 10.0555 & 10.1765 & TRN & & \\
\hline
\end{tabular}


Supplemental Table S2.txt

\begin{tabular}{|c|c|c|c|c|c|}
\hline CHEMBL 3921525 & 1640791 & 10.6253 & 11.4098 & TRN & \\
\hline CHEMBL 3965124 & 1640791 & 10.0706 & 9.828 & TRN & \\
\hline CHEMBL 3909048 & 1640791 & 10.284 & 10.0106 & TRN & \\
\hline CHEMBL 3946805 & 1640791 & 9.6819 & 9.9426 & TST & \\
\hline CHEMBL3961475 & 1640791 & 10.1192 & 10.0534 & TST & \\
\hline CHEMBL 3945303 & 1640791 & 10.5258 & 10.2519 & TST & \\
\hline CHEMBL 3963072 & 1640791 & 10.7447 & 10.2438 & TRN & \\
\hline CHEMBL 3927786 & 1640791 & 10.041 & 10.0232 & TST & \\
\hline CHEMBL 3980789 & 1640791 & 10.0605 & 10.0696 & TST & \\
\hline CHEMBL 3909497 & 1640791 & 10.98299 & 99999999 & 999 & 10.8645 TRN \\
\hline CHEMBL 3950698 & 1640791 & 9.9136 & 9.5264 & TRN & \\
\hline CHEMBL 3975976 & 1640791 & 10.5031 & 10.8765 & TRN & \\
\hline CHEMBL 3971468 & 1640791 & 10.8601 & 11.0061 & TRN & \\
\hline CHEMBL 3985718 & 1640791 & 9.9788 & 9.9276 & TRN & \\
\hline CHEMBL 3940225 & 1640791 & 9.7496 & 10.1126 & TST & \\
\hline CHEMBL 3948026 & 1640791 & 10.6038 & 10.9503 & TST & \\
\hline CHEMBL3915516 & 1640791 & 10.8601 & 10.6565 & TRN & \\
\hline CHEMBL 3939970 & 1640791 & 10.2581 & 10.2438 & TRN & \\
\hline CHEMBL 3956687 & 1640791 & 11.0555 & 10.3617 & TST & \\
\hline CHEMBL17893 & 75330 & 7.7212 & 7.7426 & TRN & \\
\hline CHEMBL18151 & 75330 & 7.7959 & 7.8051 & TRN & \\
\hline CHEMBL 276070 & 75330 & 7.4202 & 7.6 & TRN & \\
\hline CHEMBL17743 & 75330 & 4.0 & 3.9934 & TRN & \\
\hline CHEMBL 279875 & 75330 & 8.0044 & 8.0754 & TRN & \\
\hline CHEMBL18062 & 75330 & 6.4202 & 6.4815 & TRN & \\
\hline CHEMBL418731 & 75330 & 8.041 & 8.1436 & TRN & \\
\hline CHEMBL 278053 & 75330 & 7.9586 & 7.9642 & TRN & \\
\hline CHEMBL17763 & 75330 & 6.6198 & 6.6052 & TRN & \\
\hline CHEMBL17555 & 75330 & 7.7212 & 7.5687 & TRN & \\
\hline CHEMBL 278504 & 75330 & 7.8239 & 8.0607 & TRN & \\
\hline CHEMBL 273320 & 75330 & 7.699 & 7.6199 & TRN & \\
\hline CHEMBL16938 & 75330 & 6.1192 & 4.5547 & TST & \\
\hline CHEMBL17946 & 75330 & 6.8239 & 6.6885 & TRN & \\
\hline CHEMBL 279872 & 75330 & 7.8861 & 7.8824 & TRN & \\
\hline CHEMBL18255 & 75330 & 7.8239 & 7.8433 & TRN & \\
\hline CHEMBL17876 & 75330 & 7.7696 & 7.7817 & TRN & \\
\hline CHEMBL17931 & 75330 & 5.3768 & 6.6885 & TRN & \\
\hline CHEMBL 277749 & 75330 & 6.4949 & 6.9347 & TST & \\
\hline CHEMBL 279621 & 75330 & 5.8539 & 5.8485 & TRN & \\
\hline CHEMBL18233 & 75330 & 8.0 & 7.9906 & TRN & \\
\hline CHEMBL 276735 & 75330 & 8.1612 & 8.0205 & TRN & \\
\hline CHEMBL 280255 & 75330 & 7.5086 & 7.4977 & TRN & \\
\hline CHEMBL 276774 & 75330 & 7.1675 & 7.1789 & TRN & \\
\hline CHEMBL 273315 & 75330 & 8.0655 & 7.7356 & TRN & \\
\hline CHEMBL 278456 & 75330 & 7.301 & 7.1751 & TRN & \\
\hline CHEMBL18234 & 75330 & 7.7959 & 7.8177 & TRN & \\
\hline CHEMBL17808 & 75330 & 6.3665 & 6.3894 & TRN & \\
\hline CHEMBL 277311 & 75330 & 7.9208 & 7.8961 & TRN & \\
\hline
\end{tabular}




\begin{tabular}{|c|c|c|c|c|c|c|}
\hline & & \multicolumn{5}{|c|}{ Supplemental Table s2.txt } \\
\hline CHEMBL17474 & 75330 & 7.7959 & 7.7297 & TRN & & \\
\hline CHEMBL18060 & 75330 & 7.7447 & 7.8403 & TRN & & \\
\hline CHEMBL17635 & 75330 & 5.8539 & 6.3449 & TST & & \\
\hline CHEMBL 274747 & 75330 & 7.6021 & 7.56 & TRN & & \\
\hline CHEMBL17959 & 75330 & 6.5376 & 6.5505 & TRN & & \\
\hline CHEMBL17795 & 75330 & 8.0757 & 7.9458 & TRN & & \\
\hline CHEMBL 275383 & 75330 & 8.1308 & 8.3532 & TRN & & \\
\hline CHEMBL430338 & 75330 & 8.0 & 7.9698 & TRN & & \\
\hline CHEMBL16939 & 75330 & 6.301 & 6.184 & TST & & \\
\hline CHEMBL18122 & 75330 & 7.3768 & 7.3672 & TRN & & \\
\hline CHEMBL18123 & 75330 & 8.0 & 8.0195 & TRN & & \\
\hline CHEMBL17655 & 75330 & 6.2757 & 6.2289 & TRN & & \\
\hline CHEMBL18355 & 75330 & 4.5229 & 6.1408 & TST & & \\
\hline CHEMBL 278457 & 75330 & 7.585 & 6.6885 & TRN & & \\
\hline CHEMBL18561 & 75330 & 8.0 & 7.8224 & TRN & & \\
\hline CHEMBL17556 & 75330 & 6.0655 & 7.5332 & TST & & \\
\hline CHEMBL280081 & 75330 & 4.5229 & 6.2545 & TST & & \\
\hline CHEMBL416357 & 75330 & 8.0757 & 7.7047 & TST & & \\
\hline CHEMBL 274476 & 75330 & 4.5229 & 7.4235 & TST & & \\
\hline CHEMBL17246 & 75330 & 7.7696 & 6.8982 & TST & & \\
\hline CHEMBL 277956 & 75330 & 6.3872 & 6.8921 & TST & & \\
\hline CHEMBL18181 & 75330 & 7.5229 & 8.5056 & TST & & \\
\hline CHEMBL17349 & 75330 & 7.7447 & 7.4585 & TST & & \\
\hline CHEMBL17742 & 75330 & 7.5686 & 7.9293 & TST & & \\
\hline CHEMBL3683162 & 1528470 & 8.7447 & 8.6174 & TRN & & \\
\hline CHEMBL3898896 & 1528470 & 8.041 & 7.8949 & TRN & & \\
\hline CHEMBL3601397 & 1528470 & 8.7959 & 8.8813 & TRN & & \\
\hline CHEMBL3976939 & 1528470 & 6.2272 & 6.1169 & TRN & & \\
\hline CHEMBL 3974583 & 1528470 & 5.2592 & 5.3465 & TRN & & \\
\hline CHEMBL3925840 & 1528470 & 7.2907 & 7.3339 & TRN & & \\
\hline CHEMBL3601402 & 1528470 & 8.1549 & 8.3338 & TRN & & \\
\hline CHEMBL3601398 & 1528470 & 9.0969 & 8.9003 & TRN & & \\
\hline CHEMBL 3683171 & 1528470 & 8.699 & 8.7798 & TRN & & \\
\hline CHEMBL3966566 & 1528470 & 6.7203 & 6.7352 & TRN & & \\
\hline CHEMBL3903023 & 1528470 & 7.6576 & 7.7051 & TRN & & \\
\hline CHEMBL3919162 & 1528470 & 7.32700 & 30000000 & $\partial 1$ & 7.3864 & TRN \\
\hline CHEMBL3948320 & 1528470 & 8.4318 & 8.2523 & TRN & & \\
\hline CHEMBL3683159 & 1528470 & 8.5376 & 8.4987 & TRN & & \\
\hline CHEMBL3920413 & 1528470 & 7.9101 & 7.9209 & TRN & & \\
\hline CHEMBL3892426 & 1528470 & 7.9706 & 8.0251 & TRN & & \\
\hline CHEMBL3981474 & 1528470 & 8.4559 & 8.5105 & TRN & & \\
\hline CHEMBL3683178 & 1528470 & 8.9208 & 8.7453 & TRN & & \\
\hline CHEMBL3683158 & 1528470 & 8.3098 & 7.8877 & TST & & \\
\hline CHEMBL3683124 & 1528470 & 6.9205 & 8.2145 & TST & & \\
\hline CHEMBL3950372 & 1528470 & 4.7758 & 4.8202 & TRN & & \\
\hline CHEMBL 3953507 & 1528470 & 5.8592 & 5.7122 & TRN & & \\
\hline CHEMBL3900247 & 1528470 & 4.3475 & 4.26 & TRN & & \\
\hline CHEMBL3683172 & 1528470 & 8.7447 & 8.9013 & TRN & & \\
\hline
\end{tabular}


Supplemental Table S2.txt

\begin{tabular}{|c|c|c|c|c|c|}
\hline CHEMBL 3982236 & 1528470 & 6.6934 & 6.7645 & TRN & \\
\hline CHEMBL 3955002 & 1528470 & 4.2954 & 4.3234 & TRN & \\
\hline CHEMBL 3891884 & 1528470 & 6.9423 & 7.0531 & TRN & \\
\hline CHEMBL 3683109 & 1528470 & 5.7753 & 5.0138 & TST & \\
\hline CHEMBL3926552 & 1528470 & 5.8829 & 6.6322 & TST & \\
\hline CHEMBL 3683179 & 1528470 & 8.3665 & 8.3331 & TRN & \\
\hline CHEMBL 3963303 & 1528470 & 8.0757 & 8.1257 & TRN & \\
\hline CHEMBL3683183 & 1528470 & 8.4202 & 8.3783 & TRN & \\
\hline CHEMBL 3967756 & 1528470 & 5.2472 & 5.4698 & TRN & \\
\hline CHEMBL 3683168 & 1528470 & 6.1432 & 6.2222 & TRN & \\
\hline CHEMBL 3683114 & 1528470 & 4.59699 & 99999999 & 995 & 4.7868 \\
\hline CHEMBL 3924672 & 1528470 & 7.3706 & 7.4331 & TRN & \\
\hline CHEMBL 3683111 & 1528470 & 6.013 & 5.7137 & TST & \\
\hline CHEMBL 3683166 & 1528470 & 7.8477 & 7.5671 & TST & \\
\hline CHEMBL3938179 & 1528470 & 6.1407 & 6.0346 & TRN & \\
\hline CHEMBL 3683165 & 1528470 & 7.4572 & 7.5249 & TRN & \\
\hline CHEMBL3951277 & 1528470 & 6.2043 & 6.9392 & TST & \\
\hline CHEMBL 3949326 & 1528470 & 5.8598 & 5.862 & TRN & \\
\hline CHEMBL 3942639 & 1528470 & 7.1403 & 7.0176 & TRN & \\
\hline CHEMBL 3683123 & 1528470 & 6.813 & 8.3653 & TST & \\
\hline CHEMBL 3683121 & 1528470 & 6.4794 & 7.0391 & TST & \\
\hline CHEMBL 3683113 & 1528470 & 4.9876 & 4.8521 & TRN & \\
\hline CHEMBL 3683174 & 1528470 & 8.1135 & 8.1151 & TRN & \\
\hline CHEMBL 3913081 & 1528470 & 7.8182 & 7.7264 & TRN & \\
\hline CHEMBL 3890507 & 1528470 & 7.8182 & 7.4897 & TRN & \\
\hline CHEMBL 3683161 & 1528470 & 8.2007 & 8.2417 & TRN & \\
\hline CHEMBL 3683119 & 1528470 & 6.9382 & 6.907 & TRN & \\
\hline CHEMBL 3683169 & 1528470 & 7.6676 & 7.681 & TRN & \\
\hline CHEMBL 3683156 & 1528470 & 8.5686 & 8.5549 & TRN & \\
\hline CHEMBL 3683157 & 1528470 & 8.4437 & 8.2897 & TRN & \\
\hline CHEMBL 3925994 & 1528470 & 8.6383 & 8.7667 & TRN & \\
\hline CHEMBL 3950021 & 1528470 & 6.9359 & 6.8578 & TRN & \\
\hline CHEMBL 3601323 & 1528470 & 8.6021 & 8.7402 & TRN & \\
\hline CHEMBL 3601403 & 1528470 & 8.3665 & 8.3535 & TRN & \\
\hline CHEMBL 3950607 & 1528470 & 7.1593 & 6.8762 & TRN & \\
\hline CHEMBL3891976 & 1528470 & 6.2167 & 6.2746 & TRN & \\
\hline CHEMBL 3683184 & 1528470 & 7.4815 & 7.4735 & TRN & \\
\hline CHEMBL 3683177 & 1528470 & 8.3872 & 8.4168 & TRN & \\
\hline CHEMBL 3683180 & 1528470 & 8.1487 & 8.2676 & TRN & \\
\hline CHEMBL 3936602 & 1528470 & 6.5852 & 6.9627 & TRN & \\
\hline CHEMBL 3683173 & 1528470 & 8.8539 & 8.7223 & TRN & \\
\hline CHEMBL 3639820 & 1528470 & 6.983 & 7.4626 & TST & \\
\hline CHEMBL 3683163 & 1528470 & 8.8539 & 8.7977 & TRN & \\
\hline CHEMBL 3683164 & 1528470 & 7.4776 & 7.5194 & TRN & \\
\hline CHEMBL 3960970 & 1528470 & 6.7217 & 7.2237 & TRN & \\
\hline CHEMBL 3683160 & 1528470 & 8.4815 & 8.5859 & TRN & \\
\hline CHEMBL 3965908 & 1528470 & 6.871 & 6.6161 & TRN & \\
\hline CHEMBL 3683122 & 1528470 & 6.8 & 8.2966 & TST & \\
\hline
\end{tabular}


Supplemental Table S2.txt

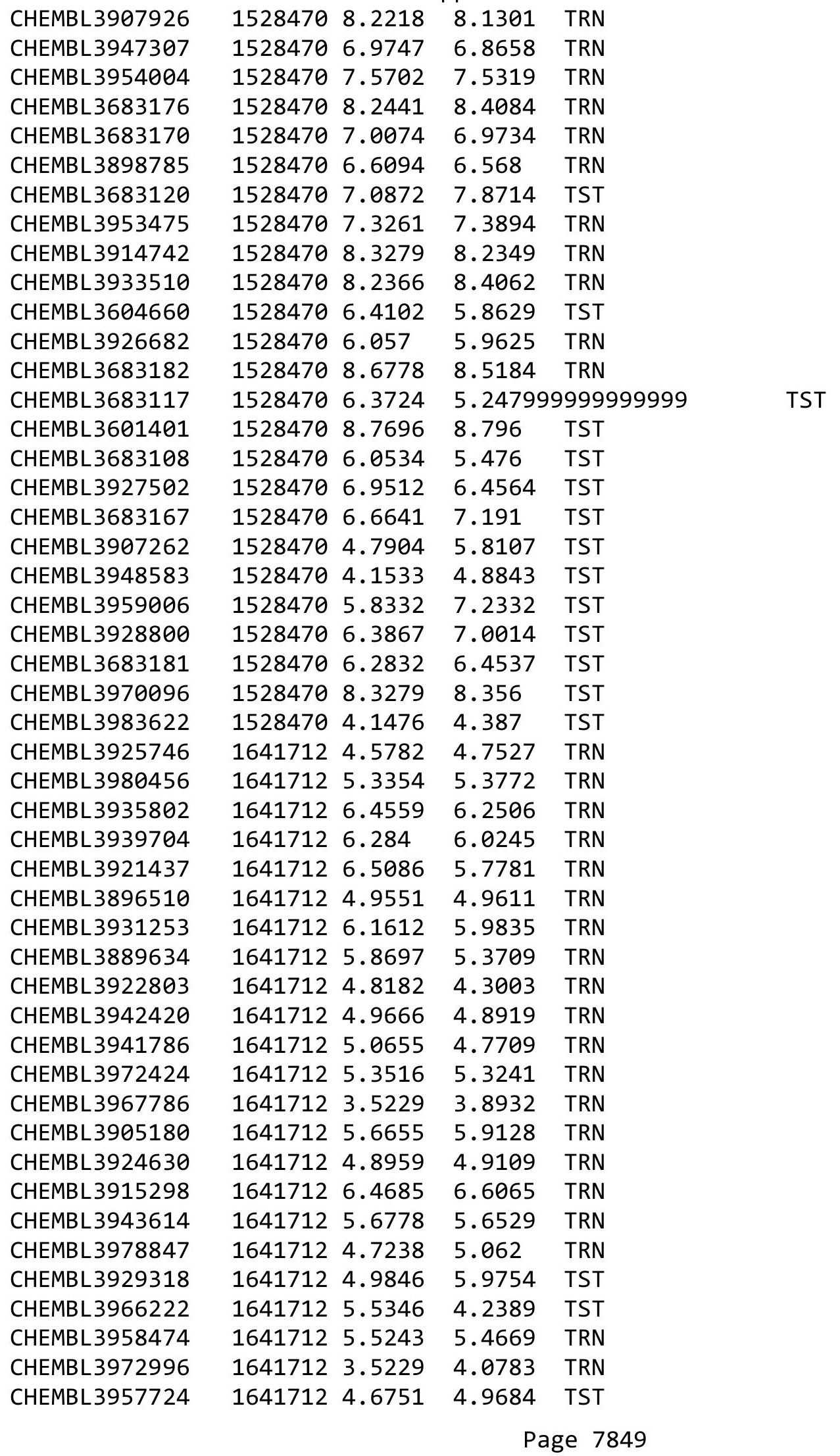




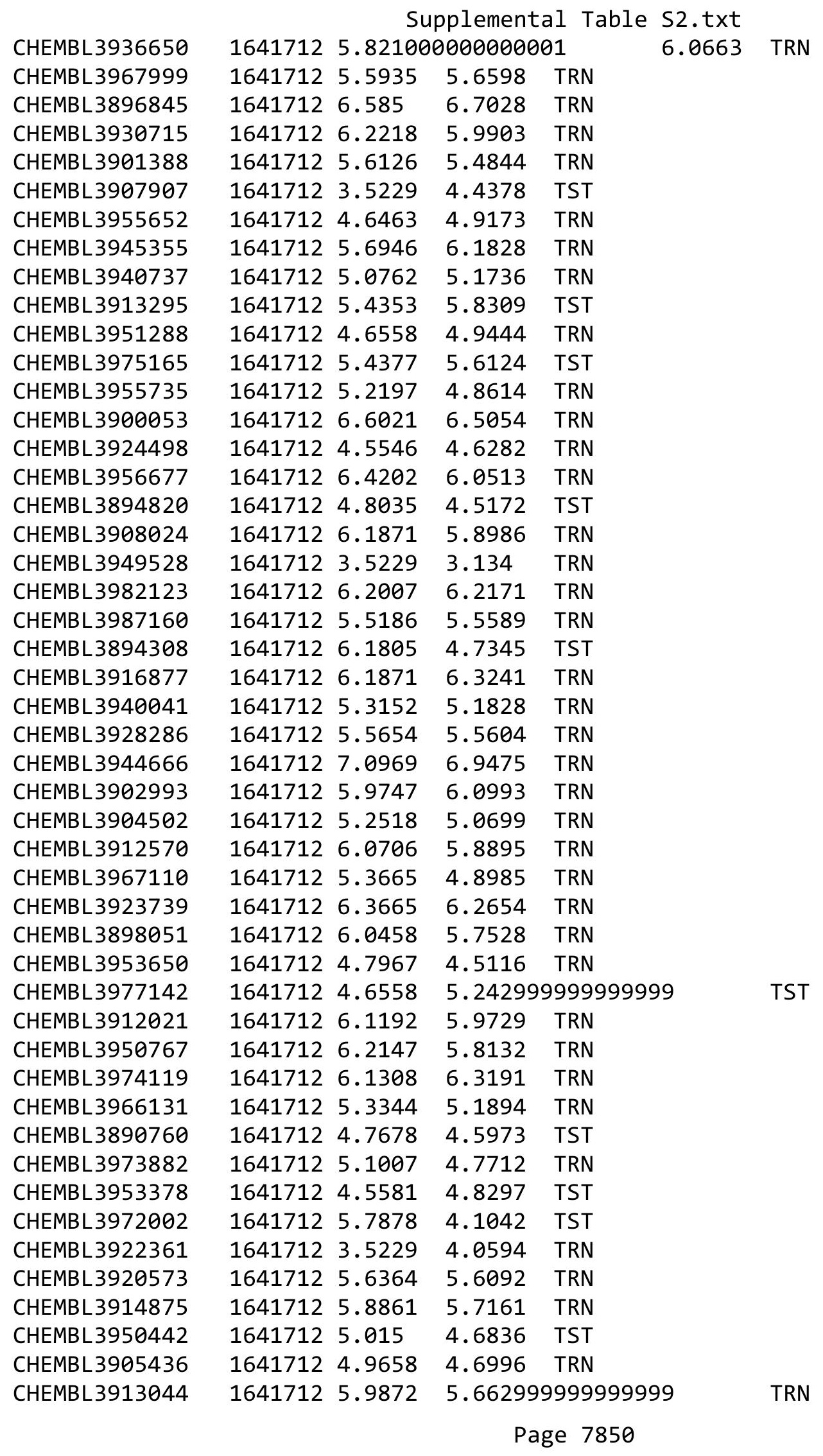


Supplemental Table S2.txt

\begin{tabular}{|c|c|c|c|c|}
\hline W & 1712 & & & \\
\hline & 641712 & 5.5361 & 7166 & \\
\hline & & & & \\
\hline AEMBL & 712 & & 8777 & $\mathrm{MI}$ \\
\hline AEMBL3922343 & 712 & & 393 & \\
\hline HEMBL3958039 & 712 & 5.0841 & 3256 & \\
\hline 519 & & & 958 & \\
\hline 120 & & & & \\
\hline AEMBL3900126 & 712 & 229 & 7735 & \\
\hline HEMBL3920381 & 712 & 101 & .8785 & \\
\hline HEMBL3980798 & 712 & 56 & 3819 & \\
\hline IEMBL39 & 112 & & 743 & \\
\hline AEMBL3S & & & & \\
\hline HEMBL39e & 712 & & 6.1359 & \\
\hline AEMBL3946257 & 712 & & & \\
\hline AEMBL39 & 2 & 97 & 5.4027 & \\
\hline AEMBL3 & 12 & & 1.2382 & \\
\hline HEMBL3S & & & 376 & \\
\hline AEMBL39 & & & 5.9574 & \\
\hline AEMBL3S & & & & \\
\hline HEMBL= & 2 & & 83 & 1SI \\
\hline AEMBL: & & & & RN \\
\hline HEMBL; & & & 75 & \\
\hline 764 & & & 802 & \\
\hline AEMBL3S & & & & I RIV \\
\hline HEMBL; & 12 & & 31 & RN \\
\hline AEMBL & & & 28 & RN \\
\hline$H F M B I=$ & 12 & & 279 & \\
\hline HEMBL3 & & & & TRN \\
\hline HEMBL 392 & 12 & & & IRN \\
\hline HEMBL3S & 12 & & 272 & SI \\
\hline HEMBL3 & 12 & & 787 & RN \\
\hline 6 & & & 32 & ST \\
\hline HEMBL 38 & & & & SI \\
\hline HEMBL3949074 & 112 & & 826 & 「RN \\
\hline HEMBL3S & 12 & & 044 & \\
\hline HFMRI & & & & RN \\
\hline HEMBL3 & & & 744 & IRN \\
\hline HEMBL3981131 & 712 & & 3156 & TRN \\
\hline IEMBL3 & & & 336 & RN \\
\hline HEMBL3898337 & 12 & & 143 & \\
\hline HEMBL 39 & & & & ST \\
\hline HEMBL3901934 & 712 & & 9021 & RN \\
\hline AEMBL3973812 & 712 & 08 & 933 & $\Gamma R$ \\
\hline $\mathrm{MRI}=$ & & & & \\
\hline HEMBL3 & & & .7518 & \\
\hline HEMBL 39 & & .0223 & 1178 & \\
\hline THEMBL3967447 & 1641712 & 5.1475 & 5.0875 & IST \\
\hline
\end{tabular}

Page 7851 
Supplemental Table S2.txt

\begin{tabular}{|c|c|c|c|c|}
\hline The & 1712 & & & \\
\hline & 641712 & 5.9208 & 6.1543 & \\
\hline & 712 & & & \\
\hline AEMBL & 712 & & 9575 & \\
\hline AEMBL3896216 & 641712 & 5.153 & 1562 & \\
\hline HEMBL3951716 & 641712 & 3.5229 & 2191 & \\
\hline & & & 1089 & \\
\hline IFMRI = & & & 1482 & 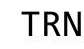 \\
\hline HEMBL393 & 712 & 3.5229 & 5716 & \\
\hline HEMBL3903042 & 712 & 5.2924 & 8436 & \\
\hline HEMBL3906732 & 712 & 6.6778 & 1391 & \\
\hline IEMBL39 & 112 & 29 & 314 & \\
\hline AEMBL3S & & & & \\
\hline HEMBL39e & 712 & 427 & 766 & \\
\hline HEMBL391 & 712 & 5 & 306 & \\
\hline AEMBL39 & 12 & 57 & 2767 & \\
\hline HEMBL3S & 12 & & 324 & \\
\hline HEMBL3S & & & 237 & \\
\hline HEMBL39 & & & 8896 & \\
\hline AEMBL3S & & & & \\
\hline AEMBL3 & 12 & & 501 & RIV \\
\hline AEMBL: & 12 & & 188 & 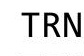 \\
\hline HEMBL & & & 75 & \\
\hline HFMRI & & & 511 & \\
\hline AEMBL39 & & & 367 & 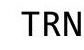 \\
\hline HEMBL3S & L2 & & 794 & 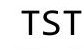 \\
\hline HEMBL3 & 12 & & 924 & RN \\
\hline$H F M B I=$ & 12 & & 627 & \\
\hline HEMBL3S & & & 1112 & in \\
\hline HEMBL390 & & & 827 & 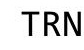 \\
\hline HEMBL3S & 12 & & 846 & SI \\
\hline HEMBL & 12 & & 389 & RN \\
\hline HEMBL; & & & 753 & N \\
\hline HEMBL389 & & & 198 & IRN \\
\hline HEMBL3904041 & 112 & & 568 & TRN \\
\hline HEMBL39 & 12 & & 986 & RN \\
\hline HFMRI & & & 74 & $\Gamma \mathrm{RN}$ \\
\hline HEMBL3 & & & 361 & IRN \\
\hline HEMBL3913356 & 112 & 3. & 109 & TST \\
\hline HEMBL393 & & & 665 & TRN \\
\hline HEMBL39 & 12 & 5 & 642 & \\
\hline CHEMBL 39 & & & 3887 & RN \\
\hline HEMBL3926 & 112 & 5.7959 & 5504 & TST \\
\hline AEMBL 397 & 712 & 6.0757 & 9665 & TRN \\
\hline MBL3 & & & 5078 & 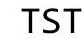 \\
\hline HEMBL3S & & 52 & 9439 & \\
\hline CHEMBL 390 & 712 & .6383 & 0667 & \\
\hline LHEMBL 3902920 & 1641712 & 5.1296 & 5.0376 & \\
\hline
\end{tabular}

Page 7852 
Supplemental Table S2.txt

\begin{tabular}{|c|c|c|c|c|c|}
\hline CHEMBL 3900793 & 1641712 & 5.5622 & 5.3221 & TRN & \\
\hline CHEMBL 3964237 & 1641712 & 5.0506 & 5.1594 & TRN & \\
\hline CHEMBL3967762 & 1641712 & 6.3468 & 6.1804 & TRN & \\
\hline CHEMBL3959142 & 1641712 & 5.0057 & 4.7957 & TRN & \\
\hline CHEMBL 3948832 & 1641712 & 3.5229 & 5.053 & TST & \\
\hline CHEMBL 3938273 & 1641712 & 6.6383 & 6.4023 & TRN & \\
\hline CHEMBL 3977264 & 1641712 & 5.3925 & 5.5935 & TRN & \\
\hline CHEMBL 3938142 & 1641712 & 6.5086 & 6.3395 & TST & \\
\hline CHEMBL3919676 & 1641712 & 5.1537 & 5.3772 & TRN & \\
\hline CHEMBL3931106 & 1641712 & 6.1024 & 6.2584 & TRN & \\
\hline CHEMBL3915724 & 1641712 & 6.5686 & 5.6623 & TST & \\
\hline CHEMBL3953456 & 1641712 & 3.5229 & 5.8807 & TST & \\
\hline CHEMBL3943683 & 1641712 & 6.5528 & 6.1858 & TRN & \\
\hline CHEMBL3909853 & 1641712 & 5.5421 & 5.1456 & TST & \\
\hline CHEMBL 3922295 & 1641712 & 5.5528 & 6.07299 & 99999999995 & TRN \\
\hline CHEMBL3982595 & 1641712 & 5.5086 & 5.5865 & TST & \\
\hline CHEMBL 3897815 & 1641712 & 3.5229 & 3.8661 & TRN & \\
\hline CHEMBL3944059 & 1641712 & 5.0721 & 5.2914 & TRN & \\
\hline CHEMBL 3940166 & 1641712 & 3.5229 & 5.8026 & TST & \\
\hline CHEMBL 3892400 & 1641712 & 5.9066 & 6.1538 & TRN & \\
\hline CHEMBL3974943 & 1641712 & 6.0088 & 5.6593 & TRN & \\
\hline CHEMBL3933839 & 1641712 & 5.3716 & 5.9565 & TST & \\
\hline CHEMBL 3937207 & 1641712 & 4.8834 & 5.5669 & TRN & \\
\hline CHEMBL 3945925 & 1641712 & 6.5376 & 6.4791 & TRN & \\
\hline CHEMBL 3915930 & 1641712 & 6.0862 & 6.0549 & TRN & \\
\hline CHEMBL3910725 & 1641712 & 5.1675 & 5.5398 & TRN & \\
\hline CHEMBL 3900542 & 1641712 & 5.0545 & 4.9944 & TRN & \\
\hline CHEMBL3926866 & 1641712 & 6.4949 & 6.5897 & TRN & \\
\hline CHEMBL 3980182 & 1641712 & 5.2549 & 5.2281 & TRN & \\
\hline CHEMBL 3957945 & 1641712 & 5.5376 & \multicolumn{2}{|c|}{5.957999999999999} & TRN \\
\hline CHEMBL3984052 & 1641712 & 5.8013 & 5.4589 & TRN & \\
\hline CHEMBL 3899738 & 1641712 & 4.7528 & 4.9075 & TRN & \\
\hline CHEMBL3923093 & 1641712 & 5.0477 & 5.4318 & TRN & \\
\hline CHEMBL3974849 & 1641712 & 5.0311 & 5.5314 & TRN & \\
\hline CHEMBL 3968763 & 1641712 & 4.6627 & 5.1122 & TRN & \\
\hline CHEMBL3925636 & 1641712 & 5.2848 & 6.1461 & TST & \\
\hline CHEMBL 3910528 & 1641712 & 4.8827 & 5.4536 & TST & \\
\hline CHEMBL3954780 & 1641712 & 5.2725 & 5.3309 & TRN & \\
\hline CHEMBL 3976793 & 1641712 & 5.6038 & 5.6682 & TRN & \\
\hline CHEMBL 3944511 & 1641712 & 6.2007 & 5.8731 & TRN & \\
\hline CHEMBL3981631 & 1641712 & 5.5935 & 5.2718 & TST & \\
\hline CHEMBL 3958641 & 1641712 & 5.5482 & 6.1 & TST & \\
\hline CHEMBL 3897607 & 1641712 & 4.67 & 4.9839 & TRN & \\
\hline CHEMBL 3976608 & 1641712 & 5.8894 & 5.7183 & TRN & \\
\hline CHEMBL3891038 & 1641712 & 4.9393 & 5.4755 & TRN & \\
\hline CHEMBL3913481 & 1641712 & 6.1871 & 6.0165 & TRN & \\
\hline CHEMBL 3903822 & 1641712 & 5.4989 & 5.7427 & TRN & \\
\hline CHEMBL3933599 & 1641712 & 5.6799 & 5.7208 & TRN & \\
\hline
\end{tabular}


Supplemental Table S2.txt

\begin{tabular}{|c|c|c|c|c|c|}
\hline CHEMBL3920902 & 1641712 & 5.8041 & 5.5925 & TRN & \\
\hline CHEMBL 3920215 & 1641712 & 6.4202 & 4.8899 & TST & \\
\hline CHEMBL3928072 & 1641712 & 5.3809 & 4.4096 & TST & \\
\hline CHEMBL3911098 & 1641712 & 5.5638 & 5.726 & TRN & \\
\hline CHEMBL 3977001 & 1641712 & 6.3665 & \multicolumn{2}{|c|}{6.468999999999999} & TRN \\
\hline CHEMBL 3921747 & 1641712 & 4.8894 & 4.4672 & TRN & \\
\hline CHEMBL3961010 & 1641712 & 5.9318 & 5.3946 & TST & \\
\hline CHEMBL3917469 & 1641712 & 5.699 & 6.0765 & TRN & \\
\hline CHEMBL 3983183 & 1641712 & 4.7729 & 4.9775 & TRN & \\
\hline CHEMBL 3942697 & 1641712 & 4.9017 & 4.1281 & TST & \\
\hline CHEMBL 3952935 & 1641712 & 5.6402 & 5.4221 & TRN & \\
\hline CHEMBL 3964446 & 1641712 & 5.0209 & 5.0064 & TST & \\
\hline CHEMBL 3947762 & 1641712 & 5.8539 & \multicolumn{2}{|c|}{5.861000000000001} & TRN \\
\hline CHEMBL3929414 & 1641712 & 4.7765 & 4.5975 & TRN & \\
\hline CHEMBL 3942810 & 1641712 & 5.3635 & 5.3086 & TRN & \\
\hline CHEMBL3977993 & 1641712 & 6.699 & 6.1626 & TRN & \\
\hline CHEMBL 3969248 & 1641712 & 6.2441 & 6.0436 & TRN & \\
\hline CHEMBL 3891371 & 1641712 & 5.3468 & 5.1492 & TST & \\
\hline CHEMBL3912301 & 1641712 & 4.7423 & 5.7753 & TST & \\
\hline CHEMBL 3922723 & 1641712 & 5.007 & 4.6336 & TST & \\
\hline CHEMBL3981444 & 1641712 & 5.8794 & 5.9211 & TRN & \\
\hline CHEMBL3924517 & 1641712 & 5.3206 & 5.1473 & TRN & \\
\hline CHEMBL 3928000 & 1641712 & 4.9488 & 5.2565 & TRN & \\
\hline CHEMBL 3898885 & 1641712 & 3.5229 & 4.4671 & TST & \\
\hline CHEMBL 3935974 & 1641712 & 6.1938 & 6.1179 & TRN & \\
\hline CHEMBL3918978 & 1641712 & 5.2644 & 5.1152 & TST & \\
\hline CHEMBL3927751 & 1641712 & 4.7496 & 5.0116 & TRN & \\
\hline CHEMBL 3967374 & 1641712 & 5.426 & 4.9812 & TST & \\
\hline CHEMBL3895182 & 1641712 & 5.153 & 5.1669 & TRN & \\
\hline CHEMBL 3915062 & 1641712 & 5.5884 & 5.5856 & TRN & \\
\hline CHEMBL3966880 & 1641712 & 5.0287 & 4.9663 & TST & \\
\hline CHEMBL 3951446 & 1641712 & 6.3768 & \multicolumn{2}{|c|}{6.053999999999999} & TRN \\
\hline CHEMBL 3918003 & 1641712 & 4.9706 & 4.9497 & TRN & \\
\hline CHEMBL3984750 & 1641712 & 5.032 & 5.2858 & TRN & \\
\hline CHEMBL3898299 & 1641712 & 5.8416 & 6.3037 & TRN & \\
\hline CHEMBL3889582 & 1641712 & 5.8508 & 6.4514 & TST & \\
\hline CHEMBL3965569 & 1641712 & 5.0804 & 4.8066 & TRN & \\
\hline CHEMBL 3952499 & 1641712 & 4.6788 & \multicolumn{2}{|c|}{5.702999999999999} & TST \\
\hline CHEMBL 3895368 & 1641712 & 5.5544 & 4.4969 & TST & \\
\hline CHEMBL3906077 & 1641712 & 5.5935 & 5.5082 & TRN & \\
\hline CHEMBL3895551 & 1641712 & 5.224 & 5.3148 & TRN & \\
\hline CHEMBL3933547 & 1641712 & 3.5229 & 5.3757 & TST & \\
\hline CHEMBL3890796 & 1641712 & 5.8416 & 6.5529 & TST & \\
\hline CHEMBL3947136 & 1641712 & 6.0458 & 5.4691 & TRN & \\
\hline CHEMBL3956895 & 1641712 & 4.9889 & 4.6469 & TRN & \\
\hline CHEMBL 3892577 & 1641712 & 5.6364 & 4.9061 & TST & \\
\hline CHEMBL3903539 & 1641712 & 6.0605 & 5.9616 & TRN & \\
\hline CHEMBL3906613 & 1641712 & 5.4179 & 5.2162 & TST & \\
\hline
\end{tabular}


Supplemental Table S2.txt

\begin{tabular}{|c|c|c|c|c|}
\hline 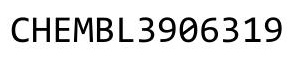 & 712 & & & \\
\hline HEMBL3985057 & 641712 & 5.7399 & 5.5975 & \\
\hline & & & & \\
\hline 222 & 712 & & & \\
\hline UEMBL3979502 & 712 & .3565 & 4362 & \\
\hline AEMBL3929136 & 641712 & 4089 & 809 & \\
\hline HEMBL3928147 & 712 & 983 & 1959 & \\
\hline 184 & 112 & & 864 & \\
\hline 46110 & & & 7838 & \\
\hline HEMBL3979788 & 712 & 6.0 & .5021 & \\
\hline AEMBL3976661 & 712 & 15 & 857 & \\
\hline AEMBL3957280 & 712 & 86 & .4961 & \\
\hline 1133 & & & & \\
\hline HEMBL & & & .1425 & \\
\hline AEMBL3943466 & 112 & 29 & 5302 & \\
\hline AEMBL3980072 & & 32 & $\partial 848$ & \\
\hline HEMBL3 & 12 & 57 & 48 & \\
\hline HEMBL3 & & & 537 & \\
\hline 0086 & & & 3136 & \\
\hline AEMBL3923342 & & 22 & 5113 & 1 1 \\
\hline 792 & 12 & 28 & 541 & IRN \\
\hline HEMBL3 & 12 & & 897 & \\
\hline 285 & & & 894 & \\
\hline 655 & & & & \\
\hline AEMBL3S & 12 & & 22 & RIV \\
\hline 256 & & 1 & 36 & ГRN \\
\hline 99889 & & & 59 & \\
\hline 33 & & & 14 & \\
\hline 58176 & & & & 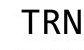 \\
\hline AEMBL3 & 12 & & 269 & RN \\
\hline 32637 & & & 819 & \\
\hline 377 & & & & \\
\hline 14 & & & & RN \\
\hline HEMBL3975688 & & & 348 & Is \\
\hline AEMBL3940177 & 12 & & 145 & IRN \\
\hline 07324 & & & 868 & \\
\hline 334 & & & & RN \\
\hline HEMBL3900256 & & & 519 & $\mathrm{RN}$ \\
\hline HEMBL3905168 & 112 & 5 . & 4.0602 & TST \\
\hline AEMBL3912064 & 12 & & 5.3861 & 「RN \\
\hline HEMBL3975360 & 12 & & 4.8915 & \\
\hline HEMBL3892889 & & & & I \\
\hline HEMBL3906563 & & & 4.7747 & TST \\
\hline AEMBL3903324 & 112 & 47 & .5986 & IST \\
\hline & & & .5525 & \\
\hline HEMBL3909585 & & & 1.8735 & \\
\hline HEMBL 3894482 & & .2652 & 5.364 & \\
\hline HEMBL 391920 & 1641712 & 5.3507 & 5.0383 & ГRN \\
\hline
\end{tabular}

Page 7855 
Supplemental Table S2.txt

\begin{tabular}{|c|c|c|c|c|}
\hline CHEMBL3974470 & 1641712 & 6.0506 & 6.3779 & TRN \\
\hline CHEMBL3960343 & 1641712 & 5.2381 & 5.0823 & TST \\
\hline CHEMBL3975224 & 1641712 & 3.5229 & 5.1056 & TST \\
\hline CHEMBL3946994 & 1641712 & 3.5229 & 4.3375 & TRN \\
\hline CHEMBL 3949240 & 1641712 & 6.5229 & 5.9367 & TRN \\
\hline CHEMBL3946621 & 1641712 & 5.5544 & 5.1961 & TRN \\
\hline CHEMBL3956396 & 1641712 & 5.7375 & 6.1433 & TRN \\
\hline CHEMBL3981063 & 1641712 & 4.8614 & 4.7436 & TRN \\
\hline CHEMBL3960025 & 1641712 & 4.628 & 4.8836 & TRN \\
\hline CHEMBL3962059 & 1641712 & 5.6383 & 6.0598 & TST \\
\hline CHEMBL 3897549 & 1641712 & 5.2815 & 5.4491 & TRN \\
\hline CHEMBL3962131 & 1641712 & 4.5855 & 4.713 & TRN \\
\hline CHEMBL3955722 & 1641712 & 5.1457 & 5.0363 & TST \\
\hline CHEMBL3938467 & 1641712 & 6.301 & 6.3018 & TRN \\
\hline CHEMBL1472080 & 737289 & 5.0472 & 4.7771 & TRN \\
\hline CHEMBL1306714 & 737289 & 4.9281 & 4.8009 & TST \\
\hline CHEMBL1533772 & 737289 & 5.4123 & 5.2126 & TRN \\
\hline CHEMBL1379673 & 737289 & 3.7959 & 4.467 & TRN \\
\hline CHEMBL1335787 & 737289 & 5.1713 & 4.7815 & TST \\
\hline CHEMBL1566684 & 737289 & 4.9626 & 5.144 & TRN \\
\hline CHEMBL1507424 & 737289 & 3.7959 & 4.8382 & TRN \\
\hline CHEMBL1389510 & 737289 & 4.8297 & 4.5302 & TST \\
\hline CHEMBL1424559 & 737289 & 3.7959 & 4.7279 & TRN \\
\hline CHEMBL1327648 & 737289 & 3.7959 & 5.0014 & TRN \\
\hline CHEMBL1497386 & 737289 & 3.7959 & 4.6322 & TST \\
\hline CHEMBL1332059 & 737289 & 4.9872 & 4.8657 & TST \\
\hline CHEMBL1430358 & 737289 & 5.1669 & $5.13700 e$ & 0000000005 \\
\hline CHEMBL1453231 & 737289 & 5.0315 & 4.9215 & TST \\
\hline CHEMBL1898721 & 737289 & 5.3516 & 4.9772 & TRN \\
\hline CHEMBL1983530 & 737289 & 5.3645 & 4.8607 & TRN \\
\hline CHEMBL1446608 & 737289 & 4.9393 & 4.8898 & TST \\
\hline CHEMBL1471761 & 737289 & 5.1415 & 4.7704 & TRN \\
\hline CHEMBL1550816 & 737289 & 5.0521 & 5.0791 & TST \\
\hline CHEMBL1541316 & 737289 & 5.2549 & 4.5996 & TRN \\
\hline CHEMBL1312189 & 737289 & 4.9469 & 5.1147 & TST \\
\hline CHEMBL1299502 & 737289 & 3.7959 & 4.4294 & TRN \\
\hline CHEMBL1331680 & 737289 & 5.2204 & 5.1477 & TRN \\
\hline CHEMBL1546414 & 737289 & 5.1267 & 4.8555 & TRN \\
\hline CHEMBL1991303 & 737289 & 5.0521 & 4.7501 & TRN \\
\hline CHEMBL1530303 & 737289 & 4.9318 & 5.4408 & TRN \\
\hline CHEMBL1564153 & 737289 & 4.8153 & 4.5688 & TRN \\
\hline CHEMBL1372672 & 737289 & 4.8477 & 5.1166 & TRN \\
\hline CHEMBL3189462 & 737289 & 5.0292 & 5.1195 & TRN \\
\hline CHEMBL1447647 & 737289 & 5.0164 & 5.3654 & TRN \\
\hline CHEMBL1344297 & 737289 & 5.1397 & 4.8303 & TRN \\
\hline CHEMBL1601599 & 737289 & 5.289 & 5.1507 & TRN \\
\hline CHEMBL1489356 & 737289 & 5.209 & 4.993 & TRN \\
\hline CHEMBL1604160 & 737289 & 5.0696 & 4.63 & TST \\
\hline
\end{tabular}




\begin{tabular}{|c|c|c|c|c|c|c|}
\hline & & \multicolumn{5}{|c|}{ Supplemental Table S2.txt } \\
\hline CHEMBL1517883 & 737289 & 3.7959 & 4.7429 & TRN & & \\
\hline CHEMBL1399533 & 737289 & 3.7959 & 4.9653 & TRN & & \\
\hline CHEMBL1365898 & 737289 & 5.0429 & 4.901 & TST & & \\
\hline CHEMBL1497574 & 737289 & 5.27 & 5.1378 & TRN & & \\
\hline CHEMBL1465435 & 737289 & 4.9208 & 4.9083 & TRN & & \\
\hline CHEMBL1600766 & 737289 & 5.2373 & 4.9476 & TRN & & \\
\hline CHEMBL1575470 & 737289 & 3.7959 & 4.3038 & TRN & & \\
\hline CHEMBL1574521 & 737289 & 5.52 & 5.1929 & TRN & & \\
\hline CHEMBL1561204 & 737289 & 5.0521 & 4.9234 & TRN & & \\
\hline CHEMBL1449468 & 737289 & 5.9066 & 4.9959 & TST & & \\
\hline CHEMBL1089894 & 737289 & 5.17200 & 00000000 & & 5.3852 & TRN \\
\hline CHEMBL1565500 & 737289 & 5.2741 & 5.0467 & TRN & & \\
\hline CHEMBL1565600 & 737289 & 5.098 & 5.0427 & TRN & & \\
\hline CHEMBL1341744 & 737289 & 4.9626 & 4.712 & TRN & & \\
\hline CHEMBL1352344 & 737289 & 5.0246 & 5.1436 & TRN & & \\
\hline CHEMBL1342798 & 737289 & 5.1427 & 5.4047 & TRN & & \\
\hline CHEMBL1419714 & 737289 & 3.7959 & 5.0223 & TRN & & \\
\hline CHEMBL1349197 & 737289 & 4.8297 & 4.809 & TST & & \\
\hline CHEMBL167542 & 737289 & 5.3747 & 4.9152 & TRN & & \\
\hline CHEMBL1467088 & 737289 & 5.9788 & 5.1005 & TRN & & \\
\hline CHEMBL1990748 & 737289 & 4.9431 & 5.0887 & TRN & & \\
\hline CHEMBL1577981 & 737289 & 5.5884 & 5.37 & TST & & \\
\hline CHEMBL1439036 & 737289 & 5.1925 & 4.9014 & TRN & & \\
\hline CHEMBL1582024 & 737289 & 3.7959 & 4.3811 & TRN & & \\
\hline CHEMBL1495790 & 737289 & 5.1891 & 5.2551 & TRN & & \\
\hline CHEMBL1352607 & 737289 & 5.2125 & 4.7382 & TRN & & \\
\hline CHEMBL1594911 & 737289 & 4.8761 & 5.016 & TRN & & \\
\hline CHEMBL1585011 & 737289 & 5.1694 & 5.1824 & TST & & \\
\hline CHEMBL1329915 & 737289 & 4.8633 & 4.9054 & TST & & \\
\hline CHEMBL1508769 & 737289 & 5.0926 & 4.9033 & TRN & & \\
\hline CHEMBL1347334 & 737289 & 5.5817 & 5.0563 & TRN & & \\
\hline CHEMBL1596619 & 737289 & 5.0851 & 4.8966 & TST & & \\
\hline CHEMBL1571034 & 737289 & 4.8697 & 4.7438 & TST & & \\
\hline CHEMBL1369513 & 737289 & 5.1637 & 4.7179 & TRN & & \\
\hline CHEMBL3195117 & 737289 & 4.9872 & 4.7922 & TST & & \\
\hline CHEMBL1610433 & 737289 & 3.7959 & 4.4804 & TRN & & \\
\hline CHEMBL1348043 & 737289 & 5.0835 & 5.138 & TST & & \\
\hline CHEMBL1539363 & 737289 & 5.1481 & 4.9927 & TRN & & \\
\hline CHEMBL1309478 & 737289 & 4.8041 & 4.7474 & TRN & & \\
\hline CHEMBL1466582 & 737289 & 5.1319 & 4.8936 & TST & & \\
\hline CHEMBL1607959 & 737289 & 5.1421 & 5.25200 & 0000000001 & & $1 \mathrm{~T}$ \\
\hline CHEMBL1340574 & 737289 & 3.7959 & 4.7898 & TST & & \\
\hline CHEMBL1543673 & 737289 & 5.4908 & 5.18 & TRN & & \\
\hline CHEMBL1547184 & 737289 & 5.5058 & 5.1616 & TRN & & \\
\hline CHEMBL1466743 & 737289 & 4.8665 & 4.7521 & TST & & \\
\hline CHEMBL1558301 & 737289 & 5.1135 & 4.8618 & TRN & & \\
\hline CHEMBL1306708 & 737289 & 5.0915 & 4.9708 & TRN & & \\
\hline CHEMBL1323013 & 737289 & 5.3251 & 4.8668 & TRN & & \\
\hline
\end{tabular}


Supplemental Table S2.txt

\begin{tabular}{|c|c|c|c|c|c|}
\hline CHEMBL1613508 & 737289 & 5.1798 & 4.9335 & TRN & \\
\hline CHEMBL1981539 & 737289 & 5.0273 & 4.4333 & TST & \\
\hline CHEMBL1308455 & 737289 & 4.9706 & 5.4078 & TRN & \\
\hline CHEMBL1428271 & 737289 & \multicolumn{3}{|c|}{5.0680000000000005} & 4.5048 \\
\hline CHEMBL1407632 & 737289 & 4.9355 & 4.7213 & TRN & \\
\hline CHEMBL1995565 & 737289 & 3.7959 & 4.539 & TRN & \\
\hline CHEMBL1997564 & 737289 & 5.0477 & 4.7857 & TRN & \\
\hline CHEMBL1352283 & 737289 & 5.2381 & 4.9529 & TST & \\
\hline CHEMBL1527994 & 737289 & 5.4353 & 5.1404 & TRN & \\
\hline CHEMBL1600311 & 737289 & 5.1739 & 4.6967 & TRN & \\
\hline CHEMBL1367178 & 737289 & 5.1057 & 5.0755 & TRN & \\
\hline CHEMBL1378294 & 737289 & 5.1296 & 4.5073 & TRN & \\
\hline CHEMBL1323828 & 737289 & 5.0092 & 4.766 & TRN & \\
\hline CHEMBL1455256 & 737289 & 3.7959 & 4.8185 & TST & \\
\hline CHEMBL1596391 & 737289 & 5.0306 & 4.9021 & TST & \\
\hline CHEMBL1346219 & 737289 & 3.7959 & 4.7438 & TRN & \\
\hline CHEMBL1471789 & 737289 & 5.1593 & 4.783 & TRN & \\
\hline CHEMBL1602489 & 737289 & 5.0391 & 4.8669 & TRN & \\
\hline CHEMBL61559 & 737289 & 5.0048 & 5.1846 & TRN & \\
\hline CHEMBL1419164 & 737289 & 3.7959 & 4.772 & TRN & \\
\hline CHEMBL1549568 & 737289 & 5.1746 & 5.1415 & TST & \\
\hline CHEMBL1327074 & 737289 & 4.857 & 4.6513 & TRN & \\
\hline CHEMBL3209591 & 737289 & 5.2692 & 5.0737 & TRN & \\
\hline CHEMBL515248 & 737289 & 5.2175 & 4.8021 & TRN & \\
\hline CHEMBL1891759 & 737289 & 3.7959 & 4.7116 & TRN & \\
\hline CHEMBL1351229 & 737289 & 4.8601 & 5.0462 & TRN & \\
\hline CHEMBL1599946 & 737289 & 3.7959 & 5.0286 & TRN & \\
\hline CHEMBL1483471 & 737289 & 5.5768 & 4.6703 & TRN & \\
\hline CHEMBL1437947 & 737289 & 4.9136 & 4.8268 & TRN & \\
\hline CHEMBL1322871 & 737289 & 4.8447 & 5.1116 & TRN & \\
\hline CHEMBL1411179 & 737289 & 5.0264 & 4.9635 & TRN & \\
\hline CHEMBL1491798 & 737289 & 5.1778 & 4.9158 & TRN & \\
\hline CHEMBL1343821 & 737289 & 5.2226 & 4.9561 & TRN & \\
\hline CHEMBL1463574 & 737289 & 4.9281 & 4.9053 & TRN & \\
\hline CHEMBL1547938 & 737289 & 4.8356 & 4.7701 & TRN & \\
\hline CHEMBL1313968 & 737289 & 5.1649 & 5.0297 & TRN & \\
\hline CHEMBL1416242 & 737289 & 5.0926 & 5.4217 & TRN & \\
\hline CHEMBL1386978 & 737289 & 5.7282 & 5.2021 & TRN & \\
\hline CHEMBL1587121 & 737289 & 5.1024 & 4.8009 & TST & \\
\hline CHEMBL1480005 & 737289 & 5.1759 & 4.7376 & TRN & \\
\hline CHEMBL 2006431 & 737289 & 4.9706 & 4.6894 & TST & \\
\hline CHEMBL1580066 & 737289 & 4.9872 & 4.9982 & TRN & \\
\hline CHEMBL1580969 & 737289 & 4.9101 & 5.0417 & TRN & \\
\hline CHEMBL1487918 & 737289 & 4.9245 & 4.6102 & TST & \\
\hline CHEMBL1537386 & 737289 & 4.8928 & 4.974 & TST & \\
\hline CHEMBL1387110 & 737289 & 5.064 & 4.949 & TRN & \\
\hline CHEMBL1523528 & 737289 & 5.04 & 5.2078 & TRN & \\
\hline CHEMBL1340454 & 737289 & 5.1361 & 4.9418 & TRN & \\
\hline
\end{tabular}




\begin{tabular}{|c|c|c|c|c|}
\hline \multicolumn{5}{|c|}{ Supplemental Table S2.txt } \\
\hline CHEMBL1329471 & 737289 & 5.6253 & 5.043 & TRN \\
\hline CHEMBL1448013 & 737289 & 5.061 & 4.9534 & TRN \\
\hline CHEMBL1483129 & 737289 & 5.1952 & 5.0466 & TRN \\
\hline CHEMBL3192206 & 737289 & 4.9547 & 4.6499 & TST \\
\hline CHEMBL1384436 & 737289 & 3.7959 & 4.6009 & TST \\
\hline CHEMBL1964290 & 809163 & 6.7 & 6.4851 & TRN \\
\hline CHEMBL 2003768 & 809163 & 4.0 & 3.4937 & TRN \\
\hline CHEMBL 213505 & 809163 & 4.0 & 4.5815 & TRN \\
\hline CHEMBL202721 & 809163 & 4.4 & 3.7791 & TRN \\
\hline CHEMBL1987034 & 809163 & 7.5 & 7.1517 & TRN \\
\hline CHEMBL1993941 & 809163 & 4.0 & 4.9854 & TRN \\
\hline CHEMBL1980435 & 809163 & 4.4 & 4.8532 & TRN \\
\hline CHEMBL377383 & 809163 & 5.1 & 5.4093 & TRN \\
\hline CHEMBL 2005886 & 809163 & 5.1 & 5.1715 & TRN \\
\hline CHEMBL481491 & 809163 & 4.0 & 3.9414 & TST \\
\hline CHEMBL1973142 & 809163 & 6.0 & 5.9421 & TRN \\
\hline CHEMBL 388311 & 809163 & 7.8 & 7.409 & TRN \\
\hline CHEMBL1973145 & 809163 & 5.0 & 4.1187 & TRN \\
\hline CHEMBL1982924 & 809163 & 5.6 & 5.4333 & TRN \\
\hline CHEMBL 2005936 & 809163 & 5.4 & 5.3479 & TRN \\
\hline CHEMBL1807515 & 809163 & 8.2 & 7.8944 & TRN \\
\hline CHEMBL1964948 & 809163 & 4.4 & 4.5045 & TRN \\
\hline CHEMBL1971141 & 809163 & 4.0 & 4.3678 & TRN \\
\hline CHEMBL1995813 & 809163 & 7.1 & 7.0228 & TRN \\
\hline CHEMBL206236 & 809163 & 4.0 & 5.1533 & TRN \\
\hline CHEMBL 1987430 & 809163 & 4.4 & 4.268 & TRN \\
\hline CHEMBL 244378 & 809163 & 7.8 & 7.5744 & TRN \\
\hline CHEMBL 2001957 & 809163 & 5.7 & 5.8697 & TRN \\
\hline CHEMBL1969372 & 809163 & 6.3 & 6.3263 & TRN \\
\hline CHEMBL1993413 & 809163 & 4.4 & 4.3647 & TRN \\
\hline CHEMBL1986943 & 809163 & 7.8 & 8.0811 & TRN \\
\hline CHEMBL 2006263 & 809163 & 5.5 & 5.7872 & TST \\
\hline CHEMBL1993584 & 809163 & 5.1 & 4.6415 & TRN \\
\hline CHEMBL1986263 & 809163 & 8.4 & 7.3986 & TRN \\
\hline CHEMBL 2000114 & 809163 & 5.7 & 5.1127 & TRN \\
\hline CHEMBL210618 & 809163 & 4.0 & 5.369 & TRN \\
\hline CHEMBL1986265 & 809163 & 4.4 & 4.2763 & TRN \\
\hline CHEMBL1971172 & 809163 & 6.4 & 6.4793 & TRN \\
\hline CHEMBL1975647 & 809163 & 5.4 & 5.2504 & TRN \\
\hline CHEMBL1968380 & 809163 & 6.9 & 5.9805 & TRN \\
\hline CHEMBL1964644 & 809163 & 4.0 & 3.8375 & TRN \\
\hline CHEMBL1991734 & 809163 & 6.4 & 5.506 & TST \\
\hline CHEMBL1981782 & 809163 & 6.0 & 5.3936 & TRN \\
\hline CHEMBL1977681 & 809163 & 6.7 & 6.3386 & TRN \\
\hline CHEMBL1990912 & 809163 & 6.6 & 5.2021 & TRN \\
\hline CHEMBL1991782 & 809163 & 3.1 & 3.3072 & TRN \\
\hline CHEMBL1983348 & 809163 & 4.4 & 5.407 & TRN \\
\hline CHEMBL1988163 & 809163 & 7.2 & 6.6944 & TRN \\
\hline
\end{tabular}




\begin{tabular}{|c|c|c|c|c|c|}
\hline \\
\hline CHEMBL1980671 & 809163 & 5.1 & 4.551 & TRN & \\
\hline CHEMBL 2006493 & 809163 & 4.0 & 3.8499 & TST & \\
\hline CHEMBL1986177 & 809163 & 4.4 & 4.7423 & TRN & \\
\hline CHEMBL1996923 & 809163 & 4.0 & 3.8472 & TST & \\
\hline CHEMBL1983449 & 809163 & 4.0 & 3.7553 & TRN & \\
\hline CHEMBL1992323 & 809163 & 4.0 & 4.0913 & TRN & \\
\hline CHEMBL1969735 & 809163 & 6.3 & 5.7398 & TRN & \\
\hline CHEMBL1983589 & 809163 & 8.0 & 6.6797 & TRN & \\
\hline CHEMBL1985367 & 809163 & 4.4 & 5.3254 & TST & \\
\hline CHEMBL1996510 & 809163 & 5.8 & 4.9392 & TST & \\
\hline CHEMBL 2005718 & 809163 & 7.1 & 6.9916 & TRN & \\
\hline CHEMBL1995172 & 809163 & 4.2 & 3.9799 & TST & \\
\hline CHEMBL2001584 & 809163 & 4.4 & 4.3135 & TRN & \\
\hline CHEMBL1967998 & 809163 & 7.3 & 6.8289 & TRN & \\
\hline CHEMBL1994321 & 809163 & 5.1 & 5.1408 & TRN & \\
\hline CHEMBL1978562 & 809163 & 4.4 & 4.9719 & TST & \\
\hline CHEMBL1997129 & 809163 & 8.4 & 7.564 & TRN & \\
\hline CHEMBL1984788 & 809163 & 4.0 & 4.5977 & TRN & \\
\hline CHEMBL1974875 & 809163 & 4.5 & 4.3969 & TST & \\
\hline CHEMBL1996604 & 809163 & 4.0 & 4.4354 & TRN & \\
\hline CHEMBL1989471 & 809163 & 4.4 & 5.3626 & TST & \\
\hline CHEMBL 2000508 & 809163 & 5.9 & 5.8372 & TRN & \\
\hline CHEMBL1971694 & 809163 & 4.0 & 4.1287 & TST & \\
\hline CHEMBL 2001547 & 809163 & 5.3 & 5.0498 & TRN & \\
\hline CHEMBL 210928 & 809163 & 4.0 & 4.6498 & TRN & \\
\hline CHEMBL1978195 & 809163 & 6.1 & 5.6514 & TRN & \\
\hline CHEMBL1986603 & 809163 & 4.0 & 4.7721 & TST & \\
\hline CHEMBL1977148 & 809163 & 4.0 & 3.6279 & TRN & \\
\hline CHEMBL1966842 & 809163 & 5.6 & 5.6269 & TRN & \\
\hline CHEMBL 2003286 & 809163 & 4.0 & 4.124 & TRN & \\
\hline CHEMBL1992306 & 809163 & 4.0 & 4.0706 & TRN & \\
\hline CHEMBL 2002165 & 809163 & 5.6 & 5.7055 & TRN & \\
\hline CHEMBL2001668 & 809163 & 4.0 & 4.2063 & TST & \\
\hline CHEMBL1979318 & 809163 & 4.0 & 3.66 & TST & \\
\hline CHEMBL206382 & 809163 & 5.7 & 5.1506 & TRN & \\
\hline CHEMBL1998585 & 809163 & 5.4 & 5.3999 & TRN & \\
\hline CHEMBL127898 & 809163 & 4.0 & $3.9010 e$ & 00000000002 & TST \\
\hline CHEMBL519697 & 809163 & 4.0 & 4.5573 & TRN & \\
\hline CHEMBL 2004934 & 809163 & 4.0 & 4.2568 & TRN & \\
\hline CHEMBL1987261 & 809163 & 6.5 & 7.1891 & TRN & \\
\hline CHEMBL1996345 & 809163 & 4.4 & 5.0736 & TST & \\
\hline CHEMBL1975128 & 809163 & 6.0 & 6.1611 & TRN & \\
\hline CHEMBL 2004025 & 809163 & 4.4 & 5.0932 & TRN & \\
\hline CHEMBL1996048 & 809163 & 5.8 & 5.4265 & TST & \\
\hline CHEMBL1970369 & 809163 & 4.0 & 4.0249 & TRN & \\
\hline CHEMBL461876 & 809163 & 6.4 & 6.3271 & TRN & \\
\hline CHEMBL1965033 & 809163 & 4.4 & 4.1321 & TRN & \\
\hline CHEMBL1971519 & 809163 & 4.1 & 4.4581 & TRN & \\
\hline
\end{tabular}




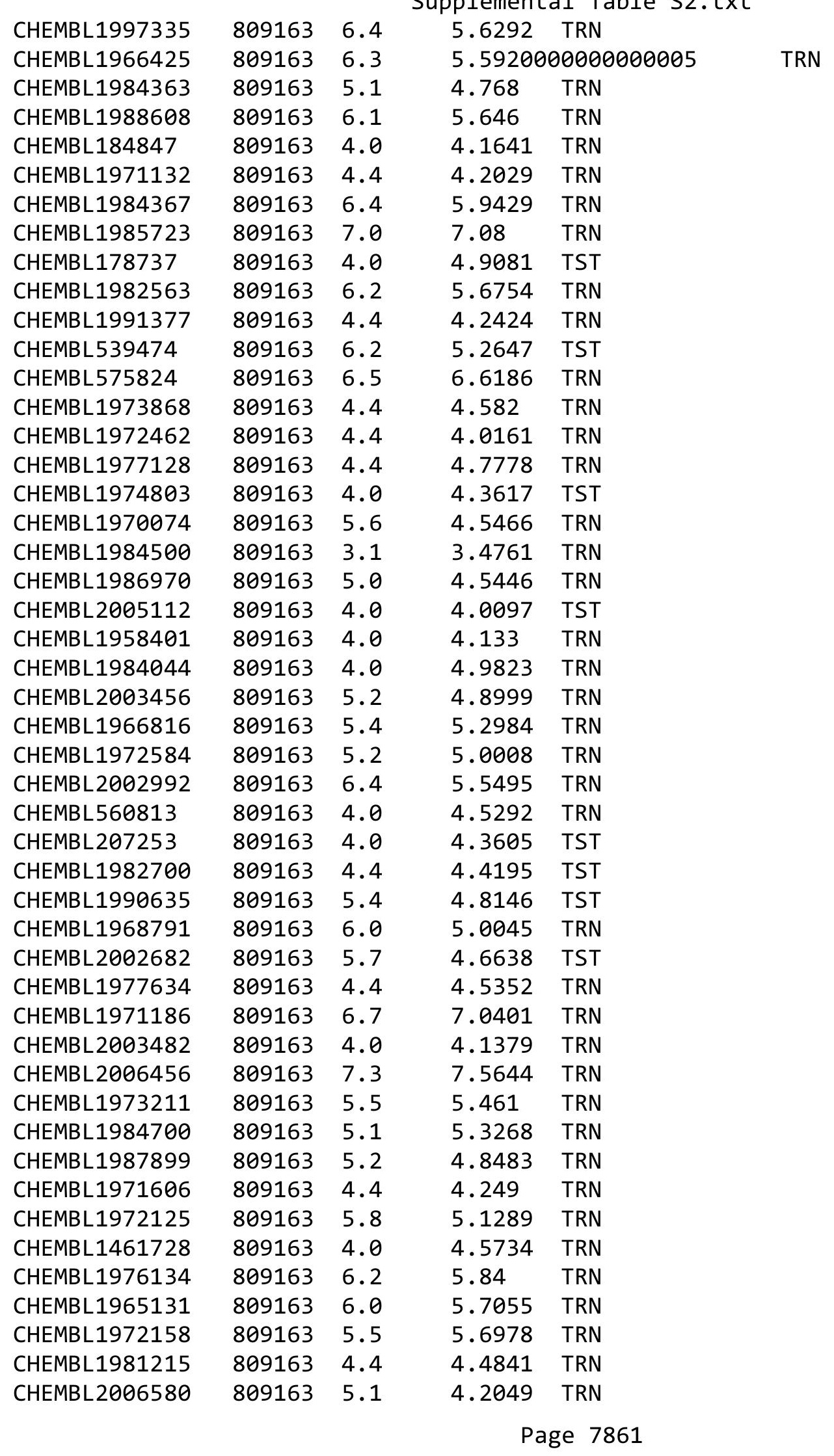




\begin{tabular}{|c|c|c|c|c|}
\hline \multicolumn{5}{|c|}{ Supplemental Tabl } \\
\hline CHEMBL1999414 & 809163 & 4.4 & 4.3763 & TRN \\
\hline CHEMBL1967336 & 809163 & 4.4 & 4.7581 & TRN \\
\hline CHEMBL 2001228 & 809163 & 4.4 & 5.0891 & TRN \\
\hline CHEMBL 2006481 & 809163 & 4.0 & 3.9048 & TRN \\
\hline CHEMBL1979855 & 809163 & 4.0 & 4.3492 & TRN \\
\hline CHEMBL1970340 & 809163 & 4.0 & 4.9147 & TRN \\
\hline CHEMBL1967992 & 809163 & 4.4 & 4.2333 & TRN \\
\hline CHEMBL1995927 & 809163 & 4.0 & 4.0993 & TRN \\
\hline CHEMBL1981671 & 809163 & 4.4 & 4.3878 & TRN \\
\hline CHEMBL 2006450 & 809163 & 4.4 & 4.4105 & TRN \\
\hline CHEMBL 1975534 & 809163 & 5.7 & 5.204 & TRN \\
\hline CHEMBL1993424 & 809163 & 5.9 & 6.5495 & TRN \\
\hline CHEMBL1966703 & 809163 & 4.0 & 4.2473 & TST \\
\hline CHEMBL 2001987 & 809163 & 4.4 & 4.2347 & TRN \\
\hline CHEMBL1969561 & 809163 & 4.0 & 5.169 & TRN \\
\hline CHEMBL1994555 & 809163 & 4.4 & 5.1126 & TRN \\
\hline CHEMBL1983640 & 809163 & 4.4 & 4.6059 & TRN \\
\hline CHEMBL1997023 & 809163 & 4.0 & 4.4079 & TST \\
\hline CHEMBL1964687 & 809163 & 5.6 & 4.8052 & TRN \\
\hline CHEMBL1971943 & 809163 & 4.5 & 5.1473 & TRN \\
\hline CHEMBL 1974254 & 809163 & 4.0 & 4.1229 & TRN \\
\hline CHEMBL1997924 & 809163 & 6.7 & 6.0525 & TRN \\
\hline CHEMBL1988537 & 809163 & 5.6 & 5.5381 & TST \\
\hline CHEMBL1969049 & 809163 & 4.0 & 4.2881 & TRN \\
\hline CHEMBL 2005828 & 809163 & 4.0 & 4.6201 & TRN \\
\hline CHEMBL 2002240 & 809163 & 4.0 & 4.5206 & TRN \\
\hline CHEMBL1978267 & 809163 & 4.4 & 4.9487 & TRN \\
\hline CHEMBL1991143 & 809163 & 4.0 & 3.9706 & TST \\
\hline CHEMBL1980178 & 809163 & 6.4 & 7.0635 & TRN \\
\hline CHEMBL1998611 & 809163 & 6.2 & 5.9134 & TRN \\
\hline CHEMBL1975900 & 809163 & 4.1 & 4.5272 & TRN \\
\hline CHEMBL255822 & 809163 & 5.2 & 4.7609 & TRN \\
\hline CHEMBL1972221 & 809163 & 4.0 & 4.4606 & TRN \\
\hline CHEMBL 2006778 & 809163 & 5.8 & 6.379 & TRN \\
\hline CHEMBL378627 & 809163 & 6.0 & 5.3874 & TRN \\
\hline CHEMBL1996979 & 809163 & 6.0 & 6.0148 & TRN \\
\hline CHEMBL1997025 & 809163 & 5.7 & 5.2623 & TRN \\
\hline CHEMBL1968406 & 809163 & 5.6 & 4.8869 & TRN \\
\hline CHEMBL1975921 & 809163 & 4.7 & 4.6701 & TRN \\
\hline CHEMBL1984274 & 809163 & 5.0 & 4.2128 & TST \\
\hline CHEMBL1998545 & 809163 & 4.0 & 3.8313 & TRN \\
\hline CHEMBL1975923 & 809163 & 4.7 & 5.0672 & TST \\
\hline CHEMBL 2005449 & 809163 & 4.4 & 4.9229 & TRN \\
\hline CHEMBL1987998 & 809163 & 4.4 & 4.2207 & TRN \\
\hline CHEMBL 2006010 & 809163 & 4.0 & 4.2853 & TRN \\
\hline CHEMBL1682558 & 809163 & 4.1 & 4.8513 & TRN \\
\hline CHEMBL1971534 & 809163 & 4.4 & 5.1461 & TRN \\
\hline CHEMBL1990496 & 809163 & 7.1 & 6.5244 & TRN \\
\hline
\end{tabular}




\begin{tabular}{|c|c|c|c|c|c|}
\hline \multicolumn{6}{|c|}{ Supplemental Table S2.txt } \\
\hline CHEMBL242865 & 809163 & 6.4 & 6.2519 & TRN & \\
\hline CHEMBL 2002479 & 809163 & 6.8 & 5.9637 & TRN & \\
\hline CHEMBL1983884 & 809163 & 3.1 & 4.6326 & TST & \\
\hline CHEMBL1967094 & 809163 & 6.8 & 6.669 & TRN & \\
\hline CHEMBL1966035 & 809163 & 4.0 & 3.6299 & TRN & \\
\hline CHEMBL 2003341 & 809163 & 4.0 & 4.3658 & TRN & \\
\hline CHEMBL1982992 & 809163 & 5.2 & 4.2824 & TRN & \\
\hline CHEMBL1998110 & 809163 & 4.4 & 3.8998 & TRN & \\
\hline CHEMBL1999590 & 809163 & 4.0 & 4.1081 & TST & \\
\hline CHEMBL1981079 & 809163 & 7.1 & 6.706 & TRN & \\
\hline CHEMBL1978166 & 809163 & 6.3 & 5.67700 & 00000000005 & TRN \\
\hline CHEMBL1972276 & 809163 & 5.1 & 4.4673 & TRN & \\
\hline CHEMBL1980489 & 809163 & 4.0 & 3.5872 & TRN & \\
\hline CHEMBL 2000832 & 809163 & 5.8 & 5.4249 & TRN & \\
\hline CHEMBL1967116 & 809163 & 5.2 & 5.2692 & TRN & \\
\hline CHEMBL1977814 & 809163 & 4.4 & 4.2233 & TST & \\
\hline CHEMBL513846 & 809163 & 5.0 & 5.0895 & TRN & \\
\hline CHEMBL1970709 & 809163 & 4.0 & 4.3035 & TRN & \\
\hline CHEMBL1974617 & 809163 & 4.9 & 4.6289 & TRN & \\
\hline CHEMBL1965660 & 809163 & 7.2 & 7.0471 & TRN & \\
\hline CHEMBL1992125 & 809163 & 5.9 & 5.527 & TRN & \\
\hline CHEMBL1998112 & 809163 & 4.0 & 4.6216 & TRN & \\
\hline CHEMBL1972290 & 809163 & 7.9 & 7.2955 & TRN & \\
\hline CHEMBL1969126 & 809163 & 6.2 & 5.9184 & TRN & \\
\hline CHEMBL1980896 & 809163 & 5.5 & 5.3255 & TRN & \\
\hline CHEMBL1975208 & 809163 & 4.0 & 3.7415 & TST & \\
\hline CHEMBL1970104 & 809163 & 4.0 & 4.9199 & TRN & \\
\hline CHEMBL1991429 & 809163 & 6.1 & 5.7132 & TRN & \\
\hline CHEMBL1964777 & 809163 & 5.2 & 4.8174 & TRN & \\
\hline CHEMBL1971149 & 809163 & 4.0 & 5.0386 & TRN & \\
\hline CHEMBL1999714 & 809163 & 4.0 & 3.2758 & TRN & \\
\hline CHEMBL1987533 & 809163 & 4.0 & 4.5718 & TRN & \\
\hline CHEMBL1994040 & 809163 & 5.1 & 5.4308 & TRN & \\
\hline CHEMBL 388978 & 809163 & 7.4 & 7.3182 & TST & \\
\hline CHEMBL1984548 & 809163 & 8.1 & 8.3878 & TRN & \\
\hline CHEMBL579246 & 809163 & 6.8 & 6.89 & TRN & \\
\hline CHEMBL398951 & 809163 & 4.3 & 4.0789 & TRN & \\
\hline CHEMBL1982506 & 809163 & 5.2 & 4.8992 & TST & \\
\hline CHEMBL1968127 & 809163 & 5.9 & 5.6122 & TRN & \\
\hline CHEMBL1975233 & 809163 & 5.7 & 4.5104 & TRN & \\
\hline CHEMBL1985406 & 809163 & 5.3 & 4.8677 & TRN & \\
\hline CHEMBL207400 & 809163 & 4.0 & 4.1798 & TST & \\
\hline CHEMBL 2000894 & 809163 & 6.0 & 5.5937 & TST & \\
\hline CHEMBL1421720 & 809163 & 5.5 & 4.8028 & TRN & \\
\hline CHEMBL1968130 & 809163 & 4.5 & 4.8191 & TST & \\
\hline CHEMBL 2002553 & 809163 & 4.0 & 3.779 & TST & \\
\hline CHEMBL1982135 & 809163 & 5.2 & 4.7137 & TRN & \\
\hline CHEMBL1976090 & 809163 & 6.1 & 6.1873 & TRN & \\
\hline
\end{tabular}




\begin{tabular}{|c|c|c|c|c|c|}
\hline \multicolumn{6}{|c|}{ Supplemental Table S2.txt } \\
\hline CHEMBL1993243 & 809163 & 6.0 & 5.7625 & TRN & \\
\hline CHEMBL 2004771 & 809163 & 4.0 & 4.4922 & TRN & \\
\hline CHEMBL1992922 & 809163 & 5.6 & 5.3281 & TRN & \\
\hline CHEMBL1997597 & 809163 & 4.0 & 5.2714 & TRN & \\
\hline CHEMBL1969537 & 809163 & 4.3 & 5.3405 & TST & \\
\hline CHEMBL576113 & 809163 & 4.4 & 4.3734 & TRN & \\
\hline CHEMBL1976093 & 809163 & 5.5 & 5.6795 & TRN & \\
\hline CHEMBL210032 & 809163 & 5.4 & 4.9177 & TRN & \\
\hline CHEMBL1975256 & 809163 & 4.0 & 3.5338 & TST & \\
\hline CHEMBL508928 & 809163 & 4.0 & 4.6931 & TRN & \\
\hline CHEMBL1991356 & 809163 & 4.0 & 4.6244 & TST & \\
\hline CHEMBL1983309 & 809163 & 4.0 & 4.2344 & TRN & \\
\hline CHEMBL 2004892 & 809163 & 5.3 & 5.2592 & TRN & \\
\hline CHEMBL1949855 & 809163 & 5.2 & 4.607 & TRN & \\
\hline CHEMBL1999126 & 809163 & 4.0 & 3.6241 & TST & \\
\hline CHEMBL1997503 & 809163 & 4.0 & 4.5192 & TST & \\
\hline CHEMBL1972339 & 809163 & 6.6 & 5.9533 & TRN & \\
\hline CHEMBL116070 & 809163 & 4.0 & 4.6753 & TRN & \\
\hline CHEMBL1968340 & 809163 & 5.3 & 5.1488 & TRN & \\
\hline CHEMBL1970314 & 809163 & 4.0 & 4.8165 & TRN & \\
\hline CHEMBL 2004871 & 809163 & 4.0 & 4.2494 & TRN & \\
\hline CHEMBL 2004872 & 809163 & 4.0 & 4.1177 & TRN & \\
\hline CHEMBL1727312 & 809163 & 4.0 & 3.3518 & TRN & \\
\hline CHEMBL1990223 & 809163 & 4.4 & 4.2009 & TRN & \\
\hline CHEMBL1969879 & 809163 & 4.0 & 4.0279 & TRN & \\
\hline CHEMBL1964382 & 809163 & 4.4 & 4.7897 & TST & \\
\hline CHEMBL101311 & 809163 & 5.9 & 5.71899 & 9999999999 & TRN \\
\hline CHEMBL1981720 & 809163 & 6.0 & 5.7544 & TRN & \\
\hline CHEMBL419932 & 809163 & 6.0 & 5.69600 & 0000000001 & TRN \\
\hline CHEMBL262433 & 809163 & 4.0 & 4.5786 & TRN & \\
\hline CHEMBL 306380 & 809163 & 5.5 & 5.6019 & TRN & \\
\hline CHEMBL1966722 & 809163 & 5.5 & 6.0754 & TRN & \\
\hline CHEMBL1983595 & 809163 & 4.4 & 4.5594 & TRN & \\
\hline CHEMBL1988581 & 809163 & 6.7 & 6.2574 & TST & \\
\hline CHEMBL 2005699 & 809163 & 4.4 & 4.3988 & TRN & \\
\hline CHEMBL1975500 & 809163 & 5.1 & 5.6481 & TRN & \\
\hline CHEMBL394619 & 809163 & 5.1 & 4.8897 & TRN & \\
\hline CHEMBL 2006564 & 809163 & 6.2 & 6.1184 & TRN & \\
\hline CHEMBL1996831 & 809163 & 5.3 & 5.1593 & TST & \\
\hline CHEMBL411903 & 809163 & 5.5 & 6.1389 & TRN & \\
\hline CHEMBL1980253 & 809163 & 7.1 & 6.9837 & TRN & \\
\hline CHEMBL1978167 & 809163 & 4.4 & 4.7438 & TST & \\
\hline CHEMBL1965988 & 809163 & 5.8 & 6.0266 & TRN & \\
\hline CHEMBL418203 & 809163 & 6.5 & 5.8573 & TST & \\
\hline CHEMBL1989646 & 809163 & 5.7 & 5.8744 & TRN & \\
\hline CHEMBL225519 & 809163 & 6.1 & 6.0127 & TRN & \\
\hline CHEMBL1978200 & 809163 & 5.8 & 6.0205 & TRN & \\
\hline CHEMBL2006631 & 809163 & 4.0 & 3.8078 & TRN & \\
\hline
\end{tabular}




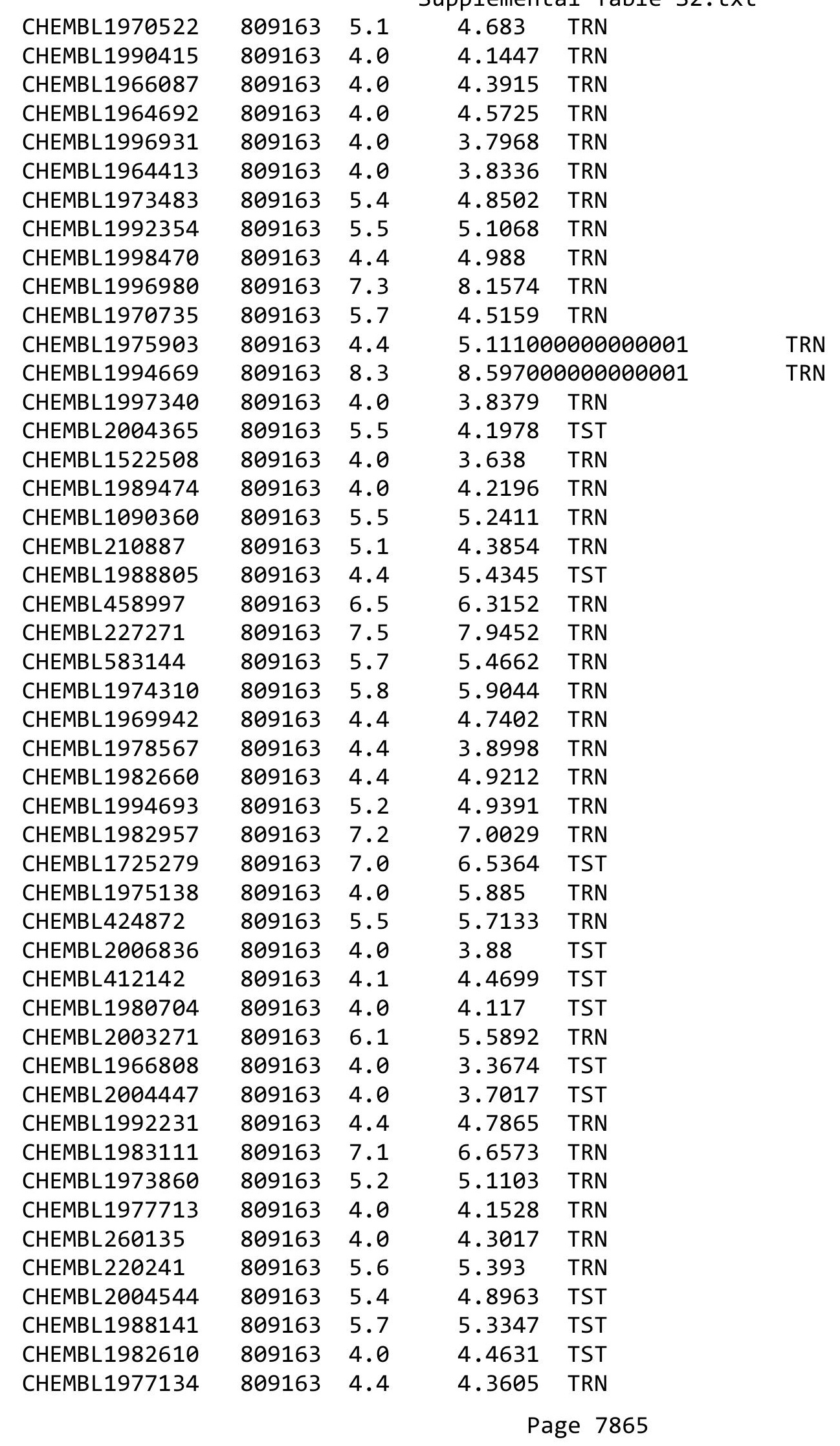




\begin{tabular}{|c|c|c|c|c|c|}
\hline & & & & & \\
\hline CHEMBL1999496 & 809163 & 4.0 & 3.7911 & TRN & \\
\hline CHEMBL1985206 & 809163 & 4.4 & 4.2047 & TRN & \\
\hline CHEMBL1988300 & 809163 & 4.3 & 4.9598 & TRN & \\
\hline CHEMBL1991078 & 809163 & 5.8 & 4.9966 & TRN & \\
\hline CHEMBL1987359 & 809163 & 4.0 & 3.839 & TST & \\
\hline CHEMBL1977749 & 809163 & 4.4 & 5.5147 & TST & \\
\hline CHEMBL1975212 & 809163 & 4.8 & 4.5738 & TRN & \\
\hline CHEMBL2001613 & 809163 & 5.5 & 4.3325 & TRN & \\
\hline CHEMBL1997275 & 809163 & 6.1 & 4.5171 & TRN & \\
\hline CHEMBL1993904 & 809163 & 6.5 & 6.0108 & TRN & \\
\hline CHEMBL1994438 & 809163 & 6.7 & 6.8109 & TRN & \\
\hline CHEMBL1967513 & 809163 & 4.4 & 4.5974 & TRN & \\
\hline CHEMBL1989265 & 809163 & 5.4 & 4.2701 & TST & \\
\hline CHEMBL1982413 & 809163 & 4.4 & 5.2284 & TRN & \\
\hline CHEMBL2004647 & 809163 & 4.0 & 3.8579 & TST & \\
\hline CHEMBL1969502 & 809163 & 6.2 & 6.3654 & TRN & \\
\hline CHEMBL1682553 & 809163 & 6.0 & 5.8363 & TRN & \\
\hline CHEMBL1983963 & 809163 & 5.2 & 4.6794 & TRN & \\
\hline CHEMBL1997764 & 809163 & 5.8 & 5.2089 & TRN & \\
\hline CHEMBL1981792 & 809163 & 4.4 & 4.6042 & TRN & \\
\hline CHEMBL1987535 & 809163 & 4.4 & 5.8013 & TRN & \\
\hline CHEMBL1985092 & 809163 & 5.4 & 5.859 & TRN & \\
\hline CHEMBL 2004692 & 809163 & 4.0 & 3.58600 & 20000000003 & TST \\
\hline CHEMBL1981410 & 809163 & 4.0 & 4.8851 & TRN & \\
\hline CHEMBL 2002586 & 809163 & 4.4 & 5.1501 & TRN & \\
\hline CHEMBL1996234 & 809163 & 4.0 & 3.6513 & TRN & \\
\hline CHEMBL383264 & 809163 & 6.7 & 6.70799 & 9999999999 & TRN \\
\hline CHEMBL 2007421 & 809163 & 4.4 & 5.24700 & 2000000001 & TRN \\
\hline CHEMBL1991434 & 809163 & 4.0 & 4.0454 & TRN & \\
\hline CHEMBL1967544 & 809163 & 5.4 & 6.1456 & TRN & \\
\hline CHEMBL1973138 & 809163 & 4.4 & 4.1852 & TRN & \\
\hline CHEMBL 223367 & 809163 & 5.0 & 4.6261 & TST & \\
\hline CHEMBL340384 & 809163 & 7.7 & 6.4536 & TST & \\
\hline CHEMBL1969151 & 809163 & 7.8 & 7.5036 & TRN & \\
\hline CHEMBL1996587 & 809163 & 6.2 & 5.6847 & TRN & \\
\hline CHEMBL1981492 & 809163 & 4.3 & 4.7308 & TRN & \\
\hline CHEMBL1993335 & 809163 & 4.4 & 5.0333 & TST & \\
\hline CHEMBL1988692 & 809163 & 4.4 & 4.5717 & TRN & \\
\hline CHEMBL 2007574 & 809163 & 6.6 & 6.6096 & TRN & \\
\hline CHEMBL1964804 & 809163 & 6.1 & 6.1237 & TRN & \\
\hline CHEMBL443962 & 809163 & 4.0 & 4.0721 & TST & \\
\hline CHEMBL 2000354 & 809163 & 5.3 & 4.9492 & TRN & \\
\hline CHEMBL1965507 & 809163 & 4.3 & 4.9116 & TRN & \\
\hline CHEMBL 274064 & 809163 & 6.6 & 6.266 & TRN & \\
\hline CHEMBL1998680 & 809163 & 4.4 & 4.6323 & TRN & \\
\hline CHEMBL1967564 & 809163 & 4.0 & 3.9752 & TRN & \\
\hline CHEMBL592030 & 809163 & 6.4 & 6.6237 & TST & \\
\hline CHEMBL 2000071 & 809163 & 5.9 & 5.101 & TRN & \\
\hline & & & & e 7866 & \\
\hline
\end{tabular}




\begin{tabular}{|c|c|c|c|c|}
\hline & & & Supplement & \\
\hline CHEMBL1979176 & 809163 & 4.0 & 4.768 & TRN \\
\hline CHEMBL1970317 & 809163 & 4.4 & 5.3398 & TRN \\
\hline CHEMBL 2002613 & 809163 & 4.4 & 4.6725 & TRN \\
\hline CHEMBL 2000408 & 809163 & 6.3 & 5.9903 & TRN \\
\hline CHEMBL 248757 & 809163 & 4.0 & 4.1768 & TST \\
\hline CHEMBL1978014 & 809163 & 4.0 & 4.1818 & TRN \\
\hline CHEMBL1997007 & 809163 & 4.4 & 5.1406 & TRN \\
\hline CHEMBL1994538 & 809163 & 5.5 & 4.8712 & TRN \\
\hline CHEMBL1983195 & 809163 & 5.2 & 4.2188 & TST \\
\hline CHEMBL1975490 & 809163 & 5.3 & 5.6426 & TRN \\
\hline CHEMBL1964444 & 809163 & 5.9 & 4.4885 & TRN \\
\hline CHEMBL1989957 & 809163 & 4.0 & 4.3055 & TRN \\
\hline CHEMBL 2002690 & 809163 & 4.4 & 4.0467 & TRN \\
\hline CHEMBL1986139 & 809163 & 4.0 & 3.8158 & TRN \\
\hline CHEMBL1980540 & 809163 & 4.0 & 4.2809 & TRN \\
\hline CHEMBL 278041 & 809163 & 5.6 & 5.5178 & TRN \\
\hline CHEMBL1979883 & 809163 & 5.5 & 5.4463 & TRN \\
\hline CHEMBL1984162 & 809163 & 4.0 & 4.4203 & TRN \\
\hline CHEMBL1997051 & 809163 & 6.0 & 5.7949 & TRN \\
\hline CHEMBL1998432 & 809163 & 7.5 & 7.6648 & TRN \\
\hline CHEMBL491758 & 809163 & 5.2 & 5.6733 & TRN \\
\hline CHEMBL1986590 & 809163 & 5.4 & 4.6018 & TRN \\
\hline CHEMBL549730 & 809163 & 4.0 & 3.7107 & TRN \\
\hline CHEMBL1970189 & 809163 & 4.0 & 3.7739 & TST \\
\hline CHEMBL1870106 & 809163 & 6.2 & 5.6784 & TRN \\
\hline CHEMBL1996791 & 809163 & 5.1 & 4.8417 & TRN \\
\hline CHEMBL371206 & 809163 & 4.0 & 4.5843 & TRN \\
\hline CHEMBL1974664 & 809163 & 4.0 & 4.4909 & TRN \\
\hline CHEMBL406845 & 809163 & 4.5 & 5.0612 & TRN \\
\hline CHEMBL482538 & 809163 & 4.6 & 4.7645 & TRN \\
\hline CHEMBL1974288 & 809163 & 4.0 & 4.6804 & TRN \\
\hline CHEMBL1984296 & 809163 & 5.8 & 4.7208 & TST \\
\hline CHEMBL196363 & 809163 & 5.1 & 4.6658 & TRN \\
\hline CHEMBL1996837 & 809163 & 4.3 & 4.8561 & TRN \\
\hline CHEMBL1190711 & 809163 & 7.5 & 6.2718 & TRN \\
\hline CHEMBL1981723 & 809163 & 5.7 & 5.0643 & TST \\
\hline CHEMBL1964718 & 809163 & 4.0 & 4.381 & TST \\
\hline CHEMBL1968705 & 809163 & 5.8 & 5.0482 & TRN \\
\hline CHEMBL1991410 & 809163 & 4.4 & 4.4441 & TRN \\
\hline CHEMBL1964441 & 809163 & 4.4 & 4.851 & TRN \\
\hline CHEMBL546797 & 809163 & 4.4 & 4.3941 & TRN \\
\hline CHEMBL404367 & 809163 & 5.2 & 5.0894 & TRN \\
\hline CHEMBL1966343 & 809163 & 6.0 & 5.5166 & TRN \\
\hline CHEMBL1978271 & 809163 & 4.4 & 5.0534 & TRN \\
\hline CHEMBL1967887 & 809163 & 6.9 & 7.2686 & TRN \\
\hline CHEMBL2007266 & 809163 & 4.4 & 4.348 & TRN \\
\hline CHEMBL 2000568 & 809163 & 5.5 & 5.11 & TRN \\
\hline CHEMBL1994308 & 809163 & 4.4 & 3.9762 & TRN \\
\hline
\end{tabular}




\begin{tabular}{|c|c|c|c|c|c|}
\hline & & \\
\hline CHEMBL 2000335 & 809163 & 5.6 & 4.857 & TRN & \\
\hline CHEMBL1977604 & 809163 & 4.0 & 3.9878 & TST & \\
\hline CHEMBL1988717 & 809163 & 4.0 & 4.4131 & TRN & \\
\hline CHEMBL1974328 & 809163 & 7.1 & 6.8975 & TRN & \\
\hline CHEMBL509032 & 809163 & 7.5 & 7.87200 & 0000000001 & TRN \\
\hline CHEMBL243298 & 809163 & 7.2 & 6.5304 & TRN & \\
\hline CHEMBL1973808 & 809163 & 5.4 & 4.8798 & TRN & \\
\hline CHEMBL 2000429 & 809163 & 5.5 & 5.7861 & TRN & \\
\hline CHEMBL1972576 & 809163 & 4.0 & 4.7163 & TRN & \\
\hline CHEMBL1992555 & 809163 & 4.0 & 3.7102 & TRN & \\
\hline CHEMBL1992342 & 809163 & 5.5 & 5.2771 & TRN & \\
\hline CHEMBL1988173 & 809163 & 5.6 & 6.1577 & TRN & \\
\hline CHEMBL1973013 & 809163 & 5.7 & 6.0819 & TRN & \\
\hline CHEMBL1164265 & 809163 & 6.9 & 5.0059 & TST & \\
\hline CHEMBL535331 & 809163 & 4.0 & 3.9302 & TRN & \\
\hline CHEMBL1989805 & 809163 & 5.7 & 4.8636 & TST & \\
\hline CHEMBL1966204 & 809163 & 5.8 & 5.433 & TRN & \\
\hline CHEMBL1982980 & 809163 & 4.0 & 4.1724 & TST & \\
\hline CHEMBL1965423 & 809163 & 8.0 & 7.4492 & TRN & \\
\hline CHEMBL1983025 & 809163 & 5.6 & 5.5402 & TRN & \\
\hline CHEMBL1975927 & 809163 & 4.4 & 5.2724 & TRN & \\
\hline CHEMBL 205415 & 809163 & 4.3 & 4.9908 & TRN & \\
\hline CHEMBL1977135 & 809163 & 4.0 & 4.07100 & 0000000001 & TRN \\
\hline CHEMBL 2001920 & 809163 & 4.0 & 5.6003 & TRN & \\
\hline CHEMBL1977138 & 809163 & 6.0 & 6.0463 & TST & \\
\hline CHEMBL1241473 & 809163 & 6.5 & 6.6937 & TRN & \\
\hline CHEMBL1978448 & 809163 & 4.7 & 4.9335 & TST & \\
\hline CHEMBL 2004513 & 809163 & 4.0 & 3.6642 & TRN & \\
\hline CHEMBL1972258 & 809163 & 5.5 & 4.7393 & TRN & \\
\hline CHEMBL1969483 & 809163 & 4.4 & 5.0146 & TRN & \\
\hline CHEMBL1980329 & 809163 & 4.4 & 5.1448 & TRN & \\
\hline CHEMBL 2004515 & 809163 & 4.9 & 5.0477 & TRN & \\
\hline CHEMBL 2001257 & 809163 & 4.3 & 4.6273 & TRN & \\
\hline CHEMBL1992042 & 809163 & 4.4 & 5.0664 & TRN & \\
\hline CHEMBL1992536 & 809163 & 4.0 & 4.0074 & TRN & \\
\hline CHEMBL21156 & 809163 & 7.1 & 4.5282 & TST & \\
\hline CHEMBL1992740 & 809163 & 4.0 & 4.1132 & TRN & \\
\hline CHEMBL1994724 & 809163 & 4.4 & 4.5463 & TRN & \\
\hline CHEMBL1989267 & 809163 & 6.4 & 5.777 & TRN & \\
\hline CHEMBL1997433 & 809163 & 5.9 & 4.7609 & TRN & \\
\hline CHEMBL 2002373 & 809163 & 5.2 & 4.7852 & TRN & \\
\hline CHEMBL439340 & 809163 & 4.0 & 4.4608 & TRN & \\
\hline CHEMBL1974574 & 809163 & 4.4 & 4.5934 & TST & \\
\hline CHEMBL 2006188 & 809163 & 4.0 & 4.2073 & TRN & \\
\hline CHEMBL1970290 & 809163 & 6.4 & 5.3733 & TRN & \\
\hline CHEMBL1967531 & 809163 & 4.0 & 4.8238 & TRN & \\
\hline CHEMBL1970913 & 809163 & 4.0 & 4.1143 & TRN & \\
\hline CHEMBL1973893 & 809163 & 4.0 & 4.2618 & TRN & \\
\hline
\end{tabular}




\begin{tabular}{|c|c|c|c|c|c|}
\hline CHEMBL1995736 & 809163 & 5.6 & 5.3735 & TRN & \\
\hline CHEMBL1997534 & 809163 & 6.1 & 6.0888 & TRN & \\
\hline CHEMBL1993877 & 809163 & 4.4 & 5.5656 & TRN & \\
\hline CHEMBL1996500 & 809163 & 4.4 & 5.6543 & TRN & \\
\hline CHEMBL1985095 & 809163 & 6.0 & 7.0407 & TST & \\
\hline CHEMBL1998551 & 809163 & 5.6 & 5.3625 & TRN & \\
\hline CHEMBL1973363 & 809163 & 5.5 & 5.3942 & TRN & \\
\hline CHEMBL1682540 & 809163 & 6.1 & 5.3921 & TRN & \\
\hline CHEMBL1976420 & 809163 & 4.2 & 4.5341 & TRN & \\
\hline CHEMBL1998253 & 809163 & 4.4 & 4.3339 & TST & \\
\hline CHEMBL1981744 & 809163 & 4.4 & 4.3074 & TRN & \\
\hline CHEMBL1994864 & 809163 & 4.0 & 3.4783 & TRN & \\
\hline CHEMBL2002446 & 809163 & 5.8 & 5.6147 & TRN & \\
\hline CHEMBL497151 & 809163 & 4.0 & 4.3129 & TRN & \\
\hline CHEMBL 2000029 & 809163 & 5.4 & 5.3617 & TRN & \\
\hline CHEMBL1973961 & 809163 & 4.4 & 4.6969 & TRN & \\
\hline CHEMBL340921 & 809163 & 6.1 & 5.494 & TST & \\
\hline CHEMBL1994977 & 809163 & 4.4 & 4.893 & TRN & \\
\hline CHEMBL 2001149 & 809163 & 5.8 & 4.8599 & TRN & \\
\hline CHEMBL1999718 & 809163 & 4.0 & 4.3643 & TRN & \\
\hline CHEMBL1987073 & 809163 & 4.4 & 4.6967 & TRN & \\
\hline CHEMBL 2000078 & 809163 & 4.4 & 4.9841 & TRN & \\
\hline CHEMBL 2005478 & 809163 & 4.4 & 5.0357 & TST & \\
\hline CHEMBL1996646 & 809163 & 6.0 & 5.4149 & TRN & \\
\hline CHEMBL1979773 & 809163 & 4.4 & 4.71899 & 9999999999 & TRN \\
\hline CHEMBL1977346 & 809163 & 4.0 & 4.4795 & TRN & \\
\hline CHEMBL1971649 & 809163 & 4.0 & 4.3232 & TRN & \\
\hline CHEMBL 2005482 & 809163 & 4.4 & 5.38899 & 9999999999 & TRN \\
\hline CHEMBL1996702 & 809163 & 5.6 & 5.2392 & TRN & \\
\hline CHEMBL1997909 & 809163 & 4.4 & 5.2543 & TRN & \\
\hline CHEMBL 2007124 & 809163 & 4.4 & 3.8881 & TRN & \\
\hline CHEMBL1998435 & 809163 & 4.0 & 4.2949 & TRN & \\
\hline CHEMBL 2006439 & 809163 & 4.7 & 6.08200 & 0000000001 & TRN \\
\hline CHEMBL 2006156 & 809163 & 5.0 & 4.6825 & TST & \\
\hline CHEMBL1985681 & 809163 & 5.5 & 5.3892 & TST & \\
\hline CHEMBL1969190 & 809163 & 5.2 & 4.6012 & TRN & \\
\hline CHEMBL1973937 & 809163 & 5.5 & 4.9278 & TRN & \\
\hline CHEMBL1991674 & 809163 & 6.8 & 6.2532 & TRN & \\
\hline CHEMBL1982711 & 809163 & 6.4 & 6.4048 & TRN & \\
\hline CHEMBL 262623 & 809163 & 4.9 & 5.1543 & TRN & \\
\hline CHEMBL1987982 & 809163 & 5.0 & 3.9922 & TST & \\
\hline CHEMBL1984842 & 809163 & 4.4 & 5.6281 & TRN & \\
\hline CHEMBL2004118 & 809163 & 4.4 & 4.7808 & TRN & \\
\hline CHEMBL 2007044 & 809163 & 4.0 & 4.4283 & TRN & \\
\hline CHEMBL1994241 & 809163 & 5.8 & 5.1626 & TRN & \\
\hline CHEMBL 223460 & 809163 & 4.0 & 4.5837 & TST & \\
\hline CHEMBL1998829 & 809163 & 5.3 & 5.2745 & TRN & \\
\hline \multirow[t]{2}{*}{ CHEMBL50894 } & 809163 & 4.6 & 4.17899 & 9999999999 & TST \\
\hline & & \multicolumn{4}{|c|}{ Page 7869} \\
\hline
\end{tabular}




\begin{tabular}{|c|c|c|c|c|c|}
\hline \multicolumn{6}{|c|}{ Supplemental Table S2.txt } \\
\hline CHEMBL1995211 & 809163 & 5.7 & 5.3074 & TRN & \\
\hline CHEMBL1981725 & 809163 & 7.4 & 6.2424 & TRN & \\
\hline CHEMBL 2006299 & 809163 & 4.4 & 4.1949 & TRN & \\
\hline CHEMBL1965169 & 809163 & 4.4 & 4.9227 & TST & \\
\hline CHEMBL1991818 & 809163 & 5.4 & 4.7523 & TST & \\
\hline CHEMBL1081312 & 809163 & 6.6 & 5.754 & TRN & \\
\hline CHEMBL1965170 & 809163 & 4.4 & 4.1652 & TRN & \\
\hline CHEMBL1982866 & 809163 & 4.0 & 4.0598 & TRN & \\
\hline CHEMBL 2005792 & 809163 & 5.6 & 5.7586 & TRN & \\
\hline CHEMBL1968926 & 809163 & 4.0 & 3.83100 & 00000000004 & TRN \\
\hline CHEMBL365617 & 809163 & 5.8 & 5.6713 & TRN & \\
\hline CHEMBL462120 & 809163 & 4.0 & 4.8772 & TST & \\
\hline CHEMBL1991867 & 809163 & 4.2 & 4.503 & TST & \\
\hline CHEMBL1979933 & 809163 & 6.1 & 5.1669 & TRN & \\
\hline CHEMBL1986503 & 809163 & 4.4 & 4.2902 & TST & \\
\hline CHEMBL1965570 & 809163 & 5.1 & 4.7152 & TRN & \\
\hline CHEMBL 2007592 & 809163 & 4.0 & 3.9233 & TST & \\
\hline CHEMBL1972355 & 809163 & 6.1 & 5.1211 & TRN & \\
\hline CHEMBL1997892 & 809163 & 4.4 & 4.2407 & TRN & \\
\hline CHEMBL 2001641 & 809163 & 4.3 & 4.6292 & TRN & \\
\hline CHEMBL1976936 & 809163 & 6.3 & 6.1763 & TRN & \\
\hline CHEMBL1997193 & 809163 & 4.4 & 4.2696 & TST & \\
\hline CHEMBL210963 & 809163 & 5.5 & 4.7762 & TRN & \\
\hline CHEMBL1964902 & 809163 & 4.4 & 4.5604 & TRN & \\
\hline CHEMBL1082440 & 809163 & 5.6 & 5.624 & TST & \\
\hline CHEMBL1614705 & 809163 & 4.0 & 4.5638 & TRN & \\
\hline CHEMBL1984633 & 809163 & 4.0 & 4.4086 & TRN & \\
\hline CHEMBL1972988 & 809163 & 4.4 & 5.3895 & TRN & \\
\hline CHEMBL1965845 & 809163 & 5.9 & 6.3605 & TRN & \\
\hline CHEMBL 2007372 & 809163 & 4.0 & 4.4604 & TRN & \\
\hline CHEMBL1983715 & 809163 & 7.0 & 7.0891 & TRN & \\
\hline CHEMBL 2006715 & 809163 & 5.7 & 5.8041 & TRN & \\
\hline CHEMBL1986597 & 809163 & 4.0 & 5.1212 & TRN & \\
\hline CHEMBL1990482 & 809163 & 5.6 & 5.9201 & TRN & \\
\hline CHEMBL1990904 & 809163 & 6.7 & 6.5318 & TRN & \\
\hline CHEMBL 2005475 & 809163 & 6.9 & 6.5711 & TRN & \\
\hline CHEMBL1987448 & 809163 & 7.2 & 6.7236 & TRN & \\
\hline CHEMBL402846 & 809163 & 5.1 & 5.0607 & TRN & \\
\hline CHEMBL1997349 & 809163 & 5.2 & 4.4278 & TST & \\
\hline CHEMBL183844 & 809163 & 4.0 & 4.1989 & TRN & \\
\hline CHEMBL220057 & 809163 & 5.1 & 4.9327 & TRN & \\
\hline CHEMBL1682545 & 809163 & 5.3 & 5.4112 & TRN & \\
\hline CHEMBL383541 & 809163 & 6.1 & 5.9968 & TRN & \\
\hline CHEMBL 2001224 & 809163 & 4.0 & 4.4171 & TRN & \\
\hline CHEMBL10 & 809163 & 4.4 & 5.3719 & TRN & \\
\hline CHEMBL1976732 & 809163 & 6.2 & 5.1942 & TRN & \\
\hline CHEMBL 2005216 & 809163 & 6.6 & 6.2506 & TRN & \\
\hline CHEMBL1969506 & 809163 & 4.1 & 4.6681 & TRN & \\
\hline
\end{tabular}




\begin{tabular}{|c|c|c|c|c|}
\hline \multicolumn{5}{|c|}{ Supplemental Tab } \\
\hline CHEMBL1980763 & 809163 & 4.4 & 4.6975 & TRN \\
\hline CHEMBL1980163 & 809163 & 4.0 & 3.8883 & TRN \\
\hline CHEMBL1977931 & 809163 & 4.4 & 4.476 & TRN \\
\hline CHEMBL 2005899 & 809163 & 4.0 & 3.9561 & TRN \\
\hline CHEMBL 2000919 & 809163 & 5.2 & 4.8415 & TRN \\
\hline CHEMBL1682552 & 809163 & 5.4 & 5.4884 & TRN \\
\hline CHEMBL1972568 & 809163 & 4.0 & 4.0 & TRN \\
\hline CHEMBL 2007479 & 809163 & 4.4 & 4.4622 & TRN \\
\hline CHEMBL1986851 & 809163 & 5.9 & 4.9485 & TRN \\
\hline CHEMBL 229799 & 809163 & 8.4 & 8.3133 & TRN \\
\hline CHEMBL1971223 & 809163 & 4.4 & 4.8159 & TRN \\
\hline CHEMBL105739 & 809163 & 5.3 & 5.3385 & TRN \\
\hline CHEMBL1972220 & 809163 & 4.4 & 4.6832 & TRN \\
\hline CHEMBL 379300 & 809163 & 8.3 & 7.899 & TRN \\
\hline CHEMBL 2003785 & 809163 & 4.2 & 4.5965 & TST \\
\hline CHEMBL 1973720 & 809163 & 8.3 & 8.1378 & TRN \\
\hline CHEMBL1969523 & 809163 & 6.8 & 6.0966 & TRN \\
\hline CHEMBL1988995 & 809163 & 6.0 & 5.386 & TRN \\
\hline CHEMBL 2001923 & 809163 & 4.4 & 3.8492 & TST \\
\hline CHEMBL1986781 & 809163 & 6.3 & 6.5574 & TRN \\
\hline CHEMBL526133 & 809163 & 5.8 & 5.4115 & TRN \\
\hline CHEMBL 2003514 & 809163 & 4.4 & 3.9156 & TRN \\
\hline CHEMBL1989043 & 809163 & 4.4 & 5.6089 & TRN \\
\hline CHEMBL1967538 & 809163 & 4.4 & 4.8706 & TRN \\
\hline CHEMBL1979057 & 809163 & 4.1 & 4.2131 & TRN \\
\hline CHEMBL387971 & 809163 & 4.0 & 4.7042 & TRN \\
\hline CHEMBL1164180 & 809163 & 5.9 & 4.8686 & TST \\
\hline CHEMBL1999428 & 809163 & 4.0 & 4.4843 & TRN \\
\hline CHEMBL1967560 & 809163 & 4.0 & 4.5937 & TRN \\
\hline CHEMBL1997611 & 809163 & 5.7 & 4.507 & TST \\
\hline CHEMBL1516890 & 809163 & 5.8 & 5.6447 & TRN \\
\hline CHEMBL 211378 & 809163 & 4.0 & 4.6157 & TRN \\
\hline CHEMBL1982465 & 809163 & 4.0 & 4.6697 & TRN \\
\hline CHEMBL 2001751 & 809163 & 8.2 & 8.0108 & TRN \\
\hline CHEMBL 2003420 & 809163 & 4.0 & 4.0238 & TRN \\
\hline CHEMBL1984586 & 809163 & 4.0 & 3.928 & TRN \\
\hline CHEMBL1972659 & 809163 & 4.0 & 4.4972 & TST \\
\hline CHEMBL272453 & 809163 & 4.0 & 4.0615 & TRN \\
\hline CHEMBL1970217 & 809163 & 4.0 & 4.6275 & TRN \\
\hline CHEMBL 2005528 & 809163 & 6.3 & 5.934 & TST \\
\hline CHEMBL1984686 & 809163 & 4.4 & 4.385 & TRN \\
\hline CHEMBL185569 & 809163 & 5.2 & 4.5097 & TRN \\
\hline CHEMBL1969843 & 809163 & 4.0 & 3.9591 & TRN \\
\hline CHEMBL 2007002 & 809163 & 4.0 & 4.9168 & TRN \\
\hline CHEMBL1987007 & 809163 & 6.2 & 6.3998 & TRN \\
\hline CHEMBL1973793 & 809163 & 4.4 & 4.5749 & TST \\
\hline CHEMBL1969588 & 809163 & 6.8 & 7.0054 & TRN \\
\hline CHEMBL1984711 & 809163 & 4.0 & 4.2264 & TRN \\
\hline
\end{tabular}




\begin{tabular}{|c|c|c|c|c|c|}
\hline \\
\hline CHEMBL1992073 & 809163 & 4.4 & 4.4791 & TRN & \\
\hline CHEMBL484390 & 809163 & 4.0 & 4.2715 & TRN & \\
\hline CHEMBL1979252 & 809163 & 4.0 & 4.0333 & TRN & \\
\hline CHEMBL1986143 & 809163 & 4.4 & 4.2707 & TRN & \\
\hline CHEMBL2007559 & 809163 & 4.4 & 4.9068 & TRN & \\
\hline CHEMBL1992581 & 809163 & 4.4 & 4.6865 & TRN & \\
\hline CHEMBL 2004290 & 809163 & 4.2 & 3.793 & TRN & \\
\hline CHEMBL1986499 & 809163 & 5.4 & 5.2779 & TRN & \\
\hline CHEMBL1972937 & 809163 & 4.0 & 3.5286 & TRN & \\
\hline CHEMBL 2000393 & 809163 & 5.8 & 5.3708 & TST & \\
\hline CHEMBL1992634 & 809163 & 6.3 & 5.9737 & TRN & \\
\hline CHEMBL1242373 & 809163 & 5.6 & 5.0868 & TRN & \\
\hline CHEMBL56543 & 809163 & 4.0 & 4.3345 & TRN & \\
\hline CHEMBL316264 & 809163 & 6.0 & 5.4813 & TRN & \\
\hline CHEMBL1988075 & 809163 & 4.0 & 5.0005 & TRN & \\
\hline CHEMBL1996576 & 809163 & 4.4 & 4.725 & TST & \\
\hline CHEMBL1988076 & 809163 & 4.4 & 5.3895 & TRN & \\
\hline CHEMBL1991678 & 809163 & 5.5 & 5.8823 & TRN & \\
\hline CHEMBL2001239 & 809163 & 7.0 & 6.5677 & TRN & \\
\hline CHEMBL1988594 & 809163 & 5.3 & 4.4528 & TRN & \\
\hline CHEMBL 2001288 & 809163 & 4.0 & 4.6105 & TRN & \\
\hline CHEMBL1992363 & 809163 & 4.4 & 5.0426 & TRN & \\
\hline CHEMBL1999811 & 809163 & 5.9 & 5.7585 & TRN & \\
\hline CHEMBL235157 & 809163 & 6.8 & 4.8698 & TST & \\
\hline CHEMBL1985074 & 809163 & 4.0 & 4.4789 & TST & \\
\hline CHEMBL2000481 & 809163 & 5.9 & 4.9669 & TRN & \\
\hline CHEMBL1982874 & 809163 & 7.7 & 7.25899 & 99999999995 & TRN \\
\hline CHEMBL1991725 & 809163 & 5.7 & 5.8092 & TRN & \\
\hline CHEMBL1992242 & 809163 & 4.0 & 4.1635 & TRN & \\
\hline CHEMBL 2007296 & 809163 & 4.0 & 4.1348 & TRN & \\
\hline CHEMBL208637 & 809163 & 5.4 & 5.2529 & TRN & \\
\hline CHEMBL396523 & 809163 & 7.8 & 7.6211 & TRN & \\
\hline CHEMBL 2004159 & 809163 & 4.4 & 4.0927 & TRN & \\
\hline CHEMBL1978371 & 809163 & 4.4 & 5.08899 & 99999999995 & TST \\
\hline CHEMBL1970203 & 809163 & 4.0 & 4.3115 & TRN & \\
\hline CHEMBL1986530 & 809163 & 4.0 & 4.6304 & TST & \\
\hline CHEMBL440084 & 809163 & 5.4 & 5.2259 & TRN & \\
\hline CHEMBL1999321 & 809163 & 4.0 & 3.6091 & TRN & \\
\hline CHEMBL1968590 & 809163 & 6.7 & 6.0185 & TRN & \\
\hline CHEMBL 2005375 & 809163 & 5.7 & 5.5221 & TRN & \\
\hline CHEMBL1984191 & 809163 & 5.2 & 4.3511 & TRN & \\
\hline CHEMBL1972183 & 809163 & 4.0 & 4.2373 & TST & \\
\hline CHEMBL1966501 & 809163 & 5.5 & 4.2459 & TRN & \\
\hline CHEMBL1971029 & 809163 & 8.1 & 7.6441 & TRN & \\
\hline CHEMBL 394790 & 809163 & 4.0 & 4.7591 & TRN & \\
\hline CHEMBL226471 & 809163 & 6.5 & 6.6633 & TRN & \\
\hline CHEMBL1974702 & 809163 & 4.0 & 4.3322 & TRN & \\
\hline CHEMBL1996111 & 809163 & 5.3 & 4.9024 & TRN & \\
\hline
\end{tabular}




\begin{tabular}{|c|c|c|c|c|}
\hline \multicolumn{5}{|c|}{ emental T } \\
\hline CHEMBL1966175 & 809163 & 4.4 & 4.1784 & TRN \\
\hline CHEMBL1965589 & 809163 & 5.8 & 5.9844 & TRN \\
\hline CHEMBL 2007375 & 809163 & 4.4 & 4.6374 & TRN \\
\hline CHEMBL1998193 & 809163 & 4.0 & 3.8847 & TRN \\
\hline CHEMBL379975 & 809163 & 4.4 & 5.4791 & TST \\
\hline CHEMBL474432 & 809163 & 4.2 & 4.1571 & TST \\
\hline CHEMBL1973016 & 809163 & 4.4 & 4.2901 & TRN \\
\hline CHEMBL1965387 & 809163 & 4.4 & 4.1595 & TRN \\
\hline CHEMBL 2001539 & 809163 & 4.9 & 4.9081 & TST \\
\hline CHEMBL1997041 & 809163 & 4.2 & 4.7673 & TRN \\
\hline CHEMBL1988153 & 809163 & 4.1 & 3.8399 & TRN \\
\hline CHEMBL550418 & 809163 & 5.5 & 4.5877 & TRN \\
\hline CHEMBL1986666 & 809163 & 6.4 & 6.0688 & TRN \\
\hline CHEMBL1971289 & 809163 & 5.6 & 4.962 & TRN \\
\hline CHEMBL1988437 & 809163 & 4.3 & 4.6443 & TST \\
\hline CHEMBL1979577 & 809163 & 5.5 & 6.0122 & TRN \\
\hline CHEMBL1998121 & 809163 & 6.9 & 6.8936 & TRN \\
\hline CHEMBL1233887 & 809163 & 4.4 & 4.431 & TST \\
\hline CHEMBL1992607 & 809163 & 4.0 & 4.5185 & TRN \\
\hline CHEMBL1991800 & 809163 & 5.3 & 5.3425 & TRN \\
\hline CHEMBL2003689 & 809163 & 4.4 & 4.3502 & TRN \\
\hline CHEMBL379835 & 809163 & 4.0 & 4.0058 & TST \\
\hline CHEMBL1979357 & 809163 & 4.0 & 4.417 & TRN \\
\hline CHEMBL1996649 & 809163 & 4.5 & 4.0621 & TRN \\
\hline CHEMBL1996817 & 809163 & 6.0 & 5.4417 & TRN \\
\hline CHEMBL1986756 & 809163 & 4.4 & 4.327 & TRN \\
\hline CHEMBL3197315 & 809163 & 4.0 & 3.6196 & TST \\
\hline CHEMBL468280 & 809163 & 4.0 & 4.1384 & TST \\
\hline CHEMBL1990884 & 809163 & 4.0 & 4.1133 & TRN \\
\hline CHEMBL 3109278 & 809163 & 4.8 & 5.1629 & TRN \\
\hline CHEMBL 256835 & 809163 & 5.8 & 5.2937 & TRN \\
\hline CHEMBL1970006 & 809163 & 4.0 & 4.7449 & TST \\
\hline CHEMBL1974998 & 809163 & 4.4 & 4.4843 & TRN \\
\hline CHEMBL1980142 & 809163 & 4.0 & 4.1064 & TRN \\
\hline CHEMBL41783 & 809163 & 4.0 & 4.0531 & TRN \\
\hline CHEMBL 2004438 & 809163 & 4.4 & 4.2692 & TRN \\
\hline CHEMBL 2006276 & 809163 & 4.0 & 4.4585 & TRN \\
\hline CHEMBL191003 & 809163 & 5.7 & 5.8788 & TRN \\
\hline CHEMBL 271381 & 809163 & 4.0 & 4.7692 & TRN \\
\hline CHEMBL 2006785 & 809163 & 4.0 & 3.5041 & TRN \\
\hline CHEMBL1973359 & 809163 & 6.4 & 5.8053 & TST \\
\hline CHEMBL249697 & 809163 & 5.4 & 5.5708 & TST \\
\hline CHEMBL1995740 & 809163 & 4.0 & 4.2245 & TRN \\
\hline CHEMBL1990162 & 809163 & 4.4 & 5.289 & TRN \\
\hline CHEMBL1992220 & 809163 & 8.0 & 7.7456 & TRN \\
\hline CHEMBL1979690 & 809163 & 7.0 & 6.9691 & TRN \\
\hline CHEMBL234085 & 809163 & 4.4 & 3.9574 & TRN \\
\hline CHEMBL209082 & 809163 & 5.1 & 5.1352 & TRN \\
\hline
\end{tabular}




\begin{tabular}{|c|c|c|c|c|c|}
\hline & & & & & \\
\hline CHEMBL1998414 & 809163 & 5.4 & 4.855 & TRN & \\
\hline CHEMBL1995832 & 809163 & 6.5 & 6.1475 & TRN & \\
\hline CHEMBL1969042 & 809163 & 5.8 & 5.9062 & TRN & \\
\hline CHEMBL 2000345 & 809163 & 5.5 & 5.1288 & TRN & \\
\hline CHEMBL1999931 & 809163 & 6.2 & 5.7801 & TRN & \\
\hline CHEMBL1976376 & 809163 & 4.4 & 4.4338 & TRN & \\
\hline CHEMBL1983575 & 809163 & 6.3 & 5.9686 & TRN & \\
\hline CHEMBL1968868 & 809163 & 4.4 & 4.8807 & TRN & \\
\hline CHEMBL1375418 & 809163 & 5.0 & 4.1899 & TRN & \\
\hline CHEMBL 2007064 & 809163 & 5.2 & 5.309 & TRN & \\
\hline CHEMBL1981047 & 809163 & 6.3 & 5.8275 & TRN & \\
\hline CHEMBL 229968 & 809163 & 8.4 & 8.4897 & TRN & \\
\hline CHEMBL1976196 & 809163 & 4.4 & 4.2105 & TST & \\
\hline CHEMBL1997197 & 809163 & 4.4 & 4.7385 & TRN & \\
\hline CHEMBL1983630 & 809163 & 4.2 & 4.4995 & TRN & \\
\hline CHEMBL1979093 & 809163 & 5.2 & 4.7284 & TRN & \\
\hline CHEMBL1968151 & 809163 & 4.0 & 3.4502 & TST & \\
\hline CHEMBL1987009 & 809163 & 6.7 & 6.9758 & TRN & \\
\hline CHEMBL379218 & 809163 & 6.8 & 7.4132 & TRN & \\
\hline CHEMBL 2003817 & 809163 & 5.1 & 5.459 & TRN & \\
\hline CHEMBL1994830 & 809163 & 4.0 & 4.3271 & TRN & \\
\hline CHEMBL226403 & 809163 & 6.6 & 7.2747 & TRN & \\
\hline CHEMBL 2005631 & 809163 & 5.2 & 4.6479 & TRN & \\
\hline CHEMBL1994938 & 809163 & 6.0 & 5.8132 & TRN & \\
\hline CHEMBL1977223 & 809163 & 5.6 & 4.8162 & TRN & \\
\hline CHEMBL1995765 & 809163 & 5.0 & 4.3723 & TST & \\
\hline CHEMBL1966279 & 809163 & 4.0 & 4.6692 & TRN & \\
\hline CHEMBL1236126 & 809163 & 4.0 & 4.0991 & TRN & \\
\hline CHEMBL1997846 & 809163 & 4.6 & 5.17899 & 9999999999 & TRN \\
\hline CHEMBL1984760 & 809163 & 4.4 & 5.0766 & TRN & \\
\hline CHEMBL 2004419 & 809163 & 7.3 & 6.9061 & TRN & \\
\hline CHEMBL 360847 & 809163 & 4.4 & 4.9468 & TST & \\
\hline CHEMBL 2007073 & 809163 & 4.4 & 4.7458 & TRN & \\
\hline CHEMBL1995811 & 809163 & 4.4 & 4.7745 & TRN & \\
\hline CHEMBL1972489 & 809163 & 4.0 & 4.3599 & TRN & \\
\hline CHEMBL1994074 & 809163 & 5.8 & 5.3741 & TRN & \\
\hline CHEMBL1992937 & 809163 & 4.5 & 4.6652 & TST & \\
\hline CHEMBL1968930 & 809163 & 6.8 & 7.3681 & TRN & \\
\hline CHEMBL1972119 & 809163 & 4.0 & 4.0682 & TRN & \\
\hline CHEMBL1986328 & 809163 & 5.1 & 4.1995 & TST & \\
\hline CHEMBL95692 & 809163 & 5.5 & 4.8813 & TRN & \\
\hline CHEMBL1090356 & 809163 & 6.6 & 5.4782 & TRN & \\
\hline CHEMBL1976455 & 809163 & 6.1 & 5.5432 & TRN & \\
\hline CHEMBL261849 & 809163 & 4.4 & 4.7758 & TST & \\
\hline CHEMBL1983923 & 809163 & 4.2 & 4.2346 & TRN & \\
\hline CHEMBL1983534 & 809163 & 4.0 & 4.5345 & TRN & \\
\hline CHEMBL1982361 & 809163 & 4.0 & 3.8327 & TST & \\
\hline CHEMBL1999112 & 809163 & 4.0 & 4.2066 & TST & \\
\hline
\end{tabular}




\begin{tabular}{|c|c|c|c|c|}
\hline \multicolumn{5}{|c|}{ Supplemental Tab } \\
\hline CHEMBL1982122 & 809163 & 5.0 & 4.408 & TST \\
\hline CHEMBL 2000801 & 809163 & 4.0 & 4.041 & TST \\
\hline CHEMBL1682546 & 809163 & 4.0 & 4.8615 & TST \\
\hline CHEMBL1988872 & 809163 & 5.5 & 5.0232 & TST \\
\hline CHEMBL1991395 & 809163 & 6.0 & 5.8517 & TST \\
\hline CHEMBL1971245 & 809163 & 5.5 & 4.9261 & TST \\
\hline CHEMBL1972142 & 809163 & 4.0 & 4.7548 & TST \\
\hline CHEMBL1966514 & 809163 & 5.4 & 5.4482 & TST \\
\hline CHEMBL 2003638 & 809163 & 6.1 & 5.3615 & TST \\
\hline CHEMBL1996066 & 809163 & 5.9 & 5.1849 & TST \\
\hline CHEMBL1983393 & 809163 & 5.9 & 5.0736 & TST \\
\hline CHEMBL1972152 & 809163 & 4.0 & 4.6973 & TST \\
\hline CHEMBL1993722 & 809163 & 4.0 & 4.6366 & TST \\
\hline CHEMBL1970806 & 809163 & 4.0 & 3.7886 & TST \\
\hline CHEMBL 2006674 & 809163 & 4.4 & 4.7781 & TST \\
\hline CHEMBL 1984236 & 809163 & 4.4 & 4.6901 & TST \\
\hline CHEMBL1992371 & 809163 & 6.1 & 5.4594 & TST \\
\hline CHEMBL1375640 & 809163 & 4.0 & 5.3494 & TST \\
\hline CHEMBL1979970 & 809163 & 4.0 & 4.2158 & TST \\
\hline CHEMBL 2002599 & 809163 & 4.4 & 5.1806 & TST \\
\hline CHEMBL 249282 & 809163 & 4.0 & 4.2588 & TST \\
\hline CHEMBL1967252 & 809163 & 5.6 & 5.4501 & TST \\
\hline CHEMBL 2004637 & 809163 & 6.4 & 5.1391 & TST \\
\hline CHEMBL1993374 & 809163 & 4.4 & 5.4437 & TST \\
\hline CHEMBL1994318 & 809163 & 5.7 & 4.8393 & TST \\
\hline CHEMBL 2006237 & 809163 & 5.4 & 5.5024 & TST \\
\hline CHEMBL1999506 & 809163 & 4.4 & 4.5124 & TST \\
\hline CHEMBL1967720 & 809163 & 5.2 & 5.7067 & TST \\
\hline CHEMBL 2005509 & 809163 & 8.3 & 7.7529 & TST \\
\hline CHEMBL1572266 & 809163 & 4.0 & 4.1464 & TST \\
\hline CHEMBL1991138 & 809163 & 5.6 & 4.5032 & TST \\
\hline CHEMBL1969755 & 809163 & 4.0 & 4.0448 & TST \\
\hline CHEMBL1979516 & 809163 & 4.0 & 4.0701 & TST \\
\hline CHEMBL1972820 & 809163 & 4.0 & 3.839 & TST \\
\hline CHEMBL1605605 & 809163 & 5.4 & 4.4234 & TST \\
\hline CHEMBL1996208 & 809163 & 4.2 & 3.9192 & TST \\
\hline CHEMBL1989029 & 809163 & 4.0 & 4.1121 & TST \\
\hline CHEMBL392642 & 809163 & 6.3 & 6.0442 & TST \\
\hline CHEMBL514499 & 809163 & 4.0 & 3.7135 & TST \\
\hline CHEMBL1970352 & 809163 & 4.4 & 4.9841 & TST \\
\hline CHEMBL1965631 & 809163 & 5.2 & 4.0904 & TST \\
\hline CHEMBL1980144 & 809163 & 5.0 & 4.3202 & TST \\
\hline CHEMBL1991188 & 809163 & 4.0 & 4.4996 & TST \\
\hline CHEMBL1980167 & 809163 & 4.4 & 4.9848 & TST \\
\hline CHEMBL1972849 & 809163 & 6.0 & 5.1214 & TST \\
\hline CHEMBL 377408 & 809163 & 6.1 & 6.0992 & TST \\
\hline CHEMBL1986855 & 809163 & 6.3 & 7.0779 & TST \\
\hline CHEMBL 215152 & 809163 & 4.5 & 4.0648 & TST \\
\hline
\end{tabular}




\begin{tabular}{|c|c|c|c|c|c|}
\hline \multicolumn{6}{|c|}{ Supplemental Table S2.txt } \\
\hline CHEMBL231209 & 809163 & 5.2 & 4.9273 & TST & \\
\hline CHEMBL1975357 & 809163 & 4.0 & 4.113 & TST & \\
\hline CHEMBL1976220 & 809163 & 5.3 & 4.8486 & TST & \\
\hline CHEMBL 2006765 & 809163 & 6.3 & 5.6722 & TST & \\
\hline CHEMBL259922 & 809163 & 4.0 & 3.9697 & TST & \\
\hline CHEMBL1997617 & 809163 & 6.7 & 6.0542 & TST & \\
\hline CHEMBL1969301 & 809163 & 4.0 & 4.5308 & TST & \\
\hline CHEMBL1982383 & 809163 & 6.1 & 5.3369 & TST & \\
\hline CHEMBL17370 & 809163 & 6.1 & 5.3593 & TST & \\
\hline CHEMBL1980246 & 809163 & 4.4 & 4.9335 & TST & \\
\hline CHEMBL1983932 & 809163 & 4.0 & 5.4163 & TST & \\
\hline CHEMBL1983980 & 809163 & 5.5 & 5.3148 & TST & \\
\hline CHEMBL1999484 & 809163 & 7.3 & 6.651 & TST & \\
\hline CHEMBL1986899 & 809163 & 4.4 & 4.3653 & TST & \\
\hline CHEMBL1991285 & 809163 & 4.0 & 4.7023 & TST & \\
\hline CHEMBL1997822 & 809163 & 5.7 & 5.7719 & TST & \\
\hline CHEMBL243088 & 809163 & 7.0 & 6.9545 & TST & \\
\hline CHEMBL1984038 & 809163 & 4.2 & 3.9062 & TST & \\
\hline CHEMBL1993661 & 809163 & 7.4 & 7.0579 & TST & \\
\hline CHEMBL1974416 & 809163 & 5.6 & 5.6942 & TST & \\
\hline CHEMBL 2004615 & 809163 & 4.0 & 4.4732 & TST & \\
\hline CHEMBL1997872 & 809163 & 4.0 & 4.9337 & TST & \\
\hline CHEMBL1082869 & 617125 & 8.5229 & 8.5453 & TRN & \\
\hline CHEMBL1087909 & 617125 & 8.2218 & 8.1374 & TRN & \\
\hline CHEMBL1081269 & 617125 & 6.0119 & 5.6861 & TRN & \\
\hline CHEMBL1087141 & 617125 & 5.7011 & 5.9816 & TRN & \\
\hline CHEMBL1081270 & 617125 & 6.1549 & 6.1698 & TRN & \\
\hline CHEMBL1081079 & 617125 & 5.7496 & 5.5956 & TRN & \\
\hline CHEMBL1081101 & 617125 & 3.699 & 5.4632 & TST & \\
\hline CHEMBL1080863 & 617125 & 5.1367 & 5.0589 & TRN & \\
\hline CHEMBL1080382 & 617125 & 8.2218 & 8.2303 & TRN & \\
\hline CHEMBL1087652 & 617125 & 3.699 & 3.725 & TRN & \\
\hline CHEMBL1090422 & 617125 & 7.0269 & 5.9648 & TST & \\
\hline CHEMBL1080685 & 617125 & 4.9172 & 4.8227 & TRN & \\
\hline CHEMBL1087139 & 617125 & 6.0177 & 6.1717 & TRN & \\
\hline CHEMBL1081271 & 617125 & 6.1838 & 6.2355 & TRN & \\
\hline CHEMBL1087911 & 617125 & 6.983 & 6.0903 & TST & \\
\hline CHEMBL1088176 & 617125 & 7.1871 & 7.0753 & TRN & \\
\hline CHEMBL1080383 & 617125 & 7.9208 & 7.78799 & 9999999999 & TRN \\
\hline CHEMBL1087282 & 617125 & 5.567 & 5.7966 & TRN & \\
\hline CHEMBL1081654 & 617125 & 5.9355 & 5.6861 & TRN & \\
\hline CHEMBL1081646 & 617125 & 6.426 & 6.8558 & TST & \\
\hline CHEMBL1090066 & 617125 & 7.4559 & 6.4585 & TST & \\
\hline CHEMBL1080865 & 617125 & 7.8861 & 8.0612 & TRN & \\
\hline CHEMBL1083828 & 617125 & 8.5229 & 8.6133 & TRN & \\
\hline CHEMBL1086158 & 617125 & 7.699 & 7.8599 & TRN & \\
\hline CHEMBL1088177 & 617125 & 8.7959 & 8.5717 & TRN & \\
\hline CHEMBL1086157 & 617125 & 7.4815 & 7.4096 & TRN & \\
\hline
\end{tabular}


Supplemental Table S2.txt

\begin{tabular}{|c|c|c|c|c|c|}
\hline CHEMBL1087771 & 617125 & 3.699 & 3.9553 & TRN & \\
\hline CHEMBL1076743 & 617125 & 7.4437 & 7.4079 & TRN & \\
\hline CHEMBL1080384 & 617125 & 7.9208 & 7.898 & TRN & \\
\hline CHEMBL1076708 & 617125 & 6.3925 & 6.3983 & TRN & \\
\hline CHEMBL1087785 & 617125 & 7.1367 & 6.4451 & TST & \\
\hline CHEMBL1076723 & 617125 & 6.4089 & 6.7953 & TRN & \\
\hline CHEMBL1076734 & 617125 & 3.699 & 3.6011 & TRN & \\
\hline CHEMBL1087651 & 617125 & 6.4179 & 6.4189 & TRN & \\
\hline CHEMBL1080748 & 617125 & 4.7773 & 4.5842 & TRN & \\
\hline CHEMBL1087770 & 617125 & 3.699 & 3.5934 & TRN & \\
\hline CHEMBL1081080 & 617125 & 3.699 & 3.8275 & TRN & \\
\hline CHEMBL1080880 & 617125 & 8.1549 & 7.876 & TRN & \\
\hline CHEMBL1080684 & 617125 & 6.3788 & 6.4975 & TRN & \\
\hline CHEMBL1081655 & 617125 & 6.3565 & 6.189 & TRN & \\
\hline CHEMBL1087910 & 617125 & 7.4089 & 6.2105 & TST & \\
\hline CHEMBL1081081 & 617125 & 3.699 & 4.4267 & TST & \\
\hline CHEMBL1081268 & 617125 & 5.6778 & 4.3761 & TST & \\
\hline CHEMBL1088178 & 617125 & 8.5376 & 8.5894 & TRN & \\
\hline CHEMBL1087664 & 617125 & 6.7144 & 7.249 & TST & \\
\hline CHEMBL1090065 & 617125 & 6.6234 & 6.732 & TRN & \\
\hline CHEMBL1090423 & 617125 & 7.7212 & 6.9486 & TST & \\
\hline CHEMBL1087140 & 617125 & 3.699 & 3.7436 & TRN & \\
\hline CHEMBL1082868 & 617125 & 6.6819 & \multicolumn{2}{|c|}{6.662000000000001} & TRN \\
\hline CHEMBL1080881 & 617125 & 6.6757 & 6.8086 & TRN & \\
\hline CHEMBL1080864 & 617125 & 8.0458 & 7.9424 & TST & \\
\hline CHEMBL1081645 & 617125 & 7.6021 & 7.6056 & TST & \\
\hline CHEMBL1087142 & 617125 & 6.3565 & 6.2992 & TST & \\
\hline CHEMBL110270 & 49996 & 6.5498 & 6.4549 & TRN & \\
\hline CHEMBL138285 & 49996 & 8.9586 & 8.9059 & TRN & \\
\hline CHEMBL138655 & 49996 & 7.5229 & 7.5915 & TRN & \\
\hline CHEMBL343826 & 49996 & 8.2518 & \multicolumn{2}{|c|}{8.142000000000001} & TRN \\
\hline CHEMBL139559 & 49996 & 8.9586 & 9.0269 & TRN & \\
\hline CHEMBL138879 & 49996 & 7.3665 & 7.2816 & TRN & \\
\hline CHEMBL106247 & 49996 & 7.2366 & 7.2569 & TRN & \\
\hline CHEMBL 323454 & 49996 & 6.7212 & 7.4219 & TST & \\
\hline CHEMBL106264 & 49996 & 6.4401 & 6.5261 & TRN & \\
\hline CHEMBL341928 & 49996 & 7.4815 & 7.5085 & TRN & \\
\hline CHEMBL107154 & 49996 & 8.0969 & 8.0282 & TRN & \\
\hline CHEMBL423000 & 49996 & 8.5229 & 8.5495 & TST & \\
\hline CHEMBL139459 & 49996 & 7.7447 & 7.6465 & TRN & \\
\hline CHEMBL342452 & 49996 & 7.1079 & 7.1907 & TRN & \\
\hline CHEMBL107092 & 49996 & 7.6021 & 7.6512 & TRN & \\
\hline CHEMBL106299 & 49996 & 7.1675 & \multicolumn{2}{|c|}{ 7.167999999999999 } & TRN \\
\hline CHEMBL109051 & 49996 & 6.0 & 6.9618 & TST & \\
\hline CHEMBL108569 & 49996 & 7.5376 & 7.6729 & TST & \\
\hline CHEMBL317476 & 49996 & 7.2596 & 7.3691 & TST & \\
\hline CHEMBL 317183 & 49996 & 5.301 & 5.3055 & TRN & \\
\hline CHEMBL139607 & 49996 & 7.7959 & 7.7599 & TRN & \\
\hline
\end{tabular}




\begin{tabular}{|c|c|c|c|c|c|}
\hline & & & pplement & al Table S & \\
\hline CHEMBL141802 & 49996 & 7.4815 & 7.4791 & TRN & \\
\hline CHEMBL138274 & 49996 & 8.3565 & 8.281 & TRN & \\
\hline CHEMBL139253 & 49996 & 6.5229 & 6.48 & TRN & \\
\hline CHEMBL106507 & 49996 & 7.2076 & 7.4252 & TRN & \\
\hline CHEMBL138263 & 49996 & 7.699 & 7.7681 & TRN & \\
\hline CHEMBL110809 & 49996 & 7.1739 & 7.1161 & TST & \\
\hline CHEMBL108845 & 49996 & 6.2248 & 6.1412 & TST & \\
\hline CHEMBL141345 & 49996 & 7.5229 & 7.4925 & TRN & \\
\hline CHEMBL140887 & 49996 & 6.5229 & 6.5616 & TRN & \\
\hline CHEMBL106406 & 49996 & 7.4815 & 7.3946 & TST & \\
\hline CHEMBL139029 & 49996 & 8.3468 & 8.3699 & TRN & \\
\hline CHEMBL140922 & 49996 & 6.5229 & 6.5051 & TRN & \\
\hline CHEMBL337364 & 49996 & 8.0458 & 8.0117 & TRN & \\
\hline CHEMBL110871 & 49996 & 7.2076 & 8.0881 & TST & \\
\hline CHEMBL138028 & 49996 & 7.585 & 7.5472 & TRN & \\
\hline CHEMBL138143 & 49996 & 7.6198 & 7.6982 & TRN & \\
\hline CHEMBL106369 & 49996 & 6.8097 & 7.0517 & TST & \\
\hline CHEMBL140283 & 49996 & 6.5229 & 6.5717 & TRN & \\
\hline CHEMBL 337340 & 49996 & 8.4685 & 8.412 & TRN & \\
\hline CHEMBL110463 & 49996 & 7.0655 & 7.1445 & TST & \\
\hline CHEMBL106982 & 49996 & 7.4815 & 7.5368 & TST & \\
\hline CHEMBL138975 & 49996 & 8.3979 & 8.4544 & TRN & \\
\hline CHEMBL106209 & 49996 & 7.2676 & 7.2845 & TRN & \\
\hline CHEMBL138198 & 49996 & 7.7212 & 7.6408 & TRN & \\
\hline CHEMBL141301 & 49996 & 8.2757 & 8.31200 & 0000000001 & TRN \\
\hline CHEMBL261950 & 49996 & 8.4202 & 8.4528 & TRN & \\
\hline CHEMBL341945 & 49996 & 8.1192 & 8.1031 & TRN & \\
\hline CHEMBL336246 & 49996 & 8.1549 & 8.2779 & TRN & \\
\hline CHEMBL107363 & 49996 & 7.9208 & 7.7698 & TRN & \\
\hline CHEMBL110786 & 49996 & 6.9469 & 7.0759 & TST & \\
\hline CHEMBL140003 & 49996 & 6.5229 & 6.4646 & TRN & \\
\hline CHEMBL 3908294 & 1639903 & 7.0 & 7.2712 & TRN & \\
\hline CHEMBL3894686 & 1639903 & 8.0 & 8.0918 & TRN & \\
\hline CHEMBL 3930141 & 1639903 & 8.0 & 8.0904 & TRN & \\
\hline CHEMBL3934156 & 1639903 & 8.0 & 7.9164 & TRN & \\
\hline CHEMBL3904450 & 1639903 & 8.0 & 7.9975 & TRN & \\
\hline CHEMBL3961740 & 1639903 & 8.0 & 7.516 & TRN & \\
\hline CHEMBL3950746 & 1639903 & 8.0 & 8.2344 & TRN & \\
\hline CHEMBL 3905860 & 1639903 & 8.0 & 8.1649 & TRN & \\
\hline CHEMBL3922091 & 1639903 & 8.0 & 7.8843 & TST & \\
\hline CHEMBL3982596 & 1639903 & 8.0 & 7.4977 & TST & \\
\hline CHEMBL3896094 & 1639903 & 8.0 & 8.1448 & TRN & \\
\hline CHEMBL3899043 & 1639903 & 8.0 & 7.5353 & TRN & \\
\hline CHEMBL 3921580 & 1639903 & 8.0 & 7.3081 & TRN & \\
\hline CHEMBL3893349 & 1639903 & 7.0 & 6.8364 & TRN & \\
\hline CHEMBL 3890844 & 1639903 & 8.0 & 7.9768 & TST & \\
\hline CHEMBL3969511 & 1639903 & 8.0 & 7.965 & TRN & \\
\hline CHEMBL3950255 & 1639903 & 8.0 & 7.5375 & TRN & \\
\hline
\end{tabular}




\begin{tabular}{|c|c|c|c|c|c|}
\hline \\
\hline CHEMBL3951002 & 1639903 & 8.0 & 8.1415 & TRN & \\
\hline CHEMBL3913651 & 1639903 & 8.0 & 7.8776 & TRN & \\
\hline CHEMBL3906473 & 1639903 & 7.0 & 7.5243 & TRN & \\
\hline CHEMBL3972228 & 1639903 & 8.0 & 8.0657 & TRN & \\
\hline CHEMBL3953464 & 1639903 & 8.0 & 8.1339 & TRN & \\
\hline CHEMBL3972006 & 1639903 & 8.0 & 8.1743 & TST & \\
\hline CHEMBL506862 & 1639903 & 8.0 & 7.4987 & TRN & \\
\hline CHEMBL3927744 & 1639903 & 8.0 & 7.9205 & TRN & \\
\hline CHEMBL3947568 & 1639903 & 5.301 & 7.8195 & TST & \\
\hline CHEMBL3968247 & 1639903 & 7.0 & 7.3516 & TRN & \\
\hline CHEMBL3959145 & 1639903 & 8.0 & 8.1829 & TRN & \\
\hline CHEMBL3971235 & 1639903 & 8.0 & 7.9778 & TRN & \\
\hline CHEMBL3942170 & 1639903 & 8.0 & 7.381 & TRN & \\
\hline CHEMBL3889680 & 1639903 & 5.301 & 6.6646 & TST & \\
\hline CHEMBL3918937 & 1639903 & 7.0 & 7.8032 & TST & \\
\hline CHEMBL3945814 & 1639903 & 8.0 & 8.112 & TRN & \\
\hline CHEMBL3979973 & 1639903 & 8.0 & 7.8865 & TRN & \\
\hline CHEMBL3917108 & 1639903 & 8.0 & 7.2101 & TRN & \\
\hline CHEMBL3915699 & 1639903 & 8.0 & 8.2187 & TRN & \\
\hline CHEMBL3961913 & 1639903 & 8.0 & 7.8861 & TRN & \\
\hline CHEMBL3894234 & 1639903 & 8.0 & 7.8645 & TRN & \\
\hline CHEMBL 3944142 & 1639903 & 8.0 & 7.5643 & TST & \\
\hline CHEMBL3984698 & 1639903 & 7.0 & 7.0895 & TST & \\
\hline CHEMBL3957736 & 1639903 & 7.0 & 7.3068 & TRN & \\
\hline CHEMBL3972920 & 1639903 & 8.0 & 8.0563 & TRN & \\
\hline CHEMBL3918940 & 1639903 & 8.0 & 7.9474 & TST & \\
\hline CHEMBL3946116 & 1639903 & 8.0 & 7.4403 & TRN & \\
\hline CHEMBL3976565 & 1639903 & 8.0 & 8.0713 & TRN & \\
\hline CHEMBL3911340 & 1639903 & 5.301 & 7.7917 & TST & \\
\hline CHEMBL3890964 & 1639903 & 8.0 & 8.13 & TRN & \\
\hline CHEMBL3934382 & 1639903 & 8.0 & 7.4539 & TST & \\
\hline CHEMBL3920487 & 1639903 & 7.0 & 7.3153 & TRN & \\
\hline CHEMBL3937247 & 1639903 & 8.0 & 8.0073 & TRN & \\
\hline CHEMBL3953680 & 1639903 & 8.0 & 8.1337 & TRN & \\
\hline CHEMBL3922419 & 1639903 & 7.0 & 7.61600 & 00000000005 & TRN \\
\hline CHEMBL466397 & 1639903 & 8.0 & 8.0907 & TRN & \\
\hline CHEMBL3957456 & 1639903 & 8.0 & 8.0502 & TRN & \\
\hline CHEMBL3929955 & 1639903 & 8.0 & 8.0324 & TRN & \\
\hline CHEMBL3944498 & 1639903 & 7.0 & 6.9711 & TRN & \\
\hline CHEMBL3930321 & 1639903 & 8.0 & 7.6794 & TST & \\
\hline CHEMBL3980301 & 1639903 & 8.0 & 7.8226 & TRN & \\
\hline CHEMBL447639 & 1639903 & 8.0 & 7.7415 & TRN & \\
\hline CHEMBL3933134 & 1639903 & 8.0 & 7.6887 & TST & \\
\hline CHEMBL3891415 & 1639903 & 8.0 & 8.1811 & TST & \\
\hline CHEMBL3930103 & 1639903 & 8.0 & 7.9533 & TST & \\
\hline CHEMBL3896404 & 1639903 & 5.301 & 6.9743 & TRN & \\
\hline CHEMBL3934864 & 1639903 & 7.0 & 7.24 & TRN & \\
\hline CHEMBL3919927 & 1639903 & 8.0 & 8.1527 & TRN & \\
\hline
\end{tabular}




\begin{tabular}{|c|c|c|c|c|}
\hline & & & & al lable s \\
\hline CHEMBL3898863 & 1639903 & 8.0 & 7.9657 & TRN \\
\hline CHEMBL3913225 & 1639903 & 8.0 & 7.1475 & TRN \\
\hline CHEMBL3896138 & 1639903 & 8.0 & 8.1424 & TRN \\
\hline CHEMBL 3894895 & 1639903 & 8.0 & 7.8831 & TRN \\
\hline CHEMBL3982306 & 1639903 & 7.0 & 7.5291 & TRN \\
\hline CHEMBL3973106 & 1639903 & 7.0 & 7.6652 & TST \\
\hline CHEMBL3941287 & 1639903 & 8.0 & 7.4424 & TST \\
\hline CHEMBL3902678 & 1639903 & 7.0 & 7.1492 & TRN \\
\hline CHEMBL3963196 & 1639903 & 8.0 & 7.8165 & TST \\
\hline CHEMBL3918624 & 1639903 & 7.0 & 7.8944 & TRN \\
\hline CHEMBL3914814 & 1639903 & 8.0 & 8.0964 & TST \\
\hline CHEMBL3940222 & 1639903 & 5.301 & 6.6871 & TRN \\
\hline CHEMBL3970170 & 1639903 & 8.0 & 8.1232 & TRN \\
\hline CHEMBL 3947574 & 1639903 & 8.0 & 7.9523 & TRN \\
\hline CHEMBL3930497 & 1639903 & 8.0 & 7.9346 & TRN \\
\hline CHEMBL3892197 & 1639903 & 8.0 & 7.487 & TRN \\
\hline CHEMBL3912500 & 1639903 & 8.0 & 7.9244 & TRN \\
\hline CHEMBL3937303 & 1639903 & 8.0 & 8.11399 & 9999999999 \\
\hline CHEMBL 3907857 & 1639903 & 8.0 & 7.5012 & TRN \\
\hline CHEMBL3909461 & 1639903 & 8.0 & 8.0166 & TST \\
\hline CHEMBL3986972 & 1639903 & 8.0 & 8.016 & TRN \\
\hline CHEMBL3946368 & 1639903 & 8.0 & 8.2089 & TRN \\
\hline CHEMBL3968197 & 1639903 & 8.0 & 7.5133 & TST \\
\hline CHEMBL3927706 & 1639903 & 7.0 & 6.8713 & TRN \\
\hline CHEMBL3956400 & 1639903 & 8.0 & 7.9611 & TST \\
\hline CHEMBL 3920934 & 1639903 & 8.0 & 7.9625 & TRN \\
\hline CHEMBL3951670 & 1639903 & 8.0 & 8.0347 & TRN \\
\hline CHEMBL3957642 & 1639903 & 8.0 & 7.1839 & TST \\
\hline CHEMBL 3903251 & 1639903 & 7.0 & 6.9378 & TRN \\
\hline CHEMBL3908084 & 1639903 & 8.0 & 8.1611 & TRN \\
\hline CHEMBL3971673 & 1639903 & 8.0 & 8.0125 & TRN \\
\hline CHEMBL3974124 & 1639903 & 8.0 & 7.53 & TRN \\
\hline CHEMBL3953006 & 1639903 & 8.0 & 7.2194 & TRN \\
\hline CHEMBL3898691 & 1639903 & 7.0 & 7.3516 & TRN \\
\hline CHEMBL3938801 & 1639903 & 8.0 & 7.9103 & TRN \\
\hline CHEMBL 3950784 & 1639903 & 8.0 & 8.0695 & TRN \\
\hline CHEMBL3937417 & 1639903 & 8.0 & 8.02 & TRN \\
\hline CHEMBL3947685 & 1639903 & 8.0 & 7.9009 & TRN \\
\hline CHEMBL453438 & 1639903 & 7.0 & 6.9206 & TST \\
\hline CHEMBL3967372 & 1639903 & 8.0 & 8.0106 & TRN \\
\hline CHEMBL502198 & 1639903 & 8.0 & 7.5139 & TRN \\
\hline CHEMBL3931447 & 1639903 & 8.0 & 7.4744 & TRN \\
\hline CHEMBL3896003 & 1639903 & 5.301 & 6.075 & TRN \\
\hline CHEMBL 3902796 & 1639903 & 8.0 & 7.9278 & TRN \\
\hline CHEMBL3979137 & 1639903 & 8.0 & 7.6661 & TRN \\
\hline CHEMBL 3954082 & 1639903 & 8.0 & 8.0237 & TRN \\
\hline CHEMBL448929 & 1639903 & 8.0 & 8.0668 & TRN \\
\hline CHEMBL 3944957 & 1639903 & 8.0 & 8.0783 & TRN \\
\hline
\end{tabular}




\begin{tabular}{|c|c|c|c|c|}
\hline \multicolumn{5}{|c|}{ oplemental Ta } \\
\hline CHEMBL3901948 & 1639903 & 8.0 & 7.9831 & TRN \\
\hline CHEMBL3951411 & 1639903 & 8.0 & 8.008 & TRN \\
\hline CHEMBL3901509 & 1639903 & 8.0 & 7.6109 & TST \\
\hline CHEMBL3963200 & 1639903 & 5.301 & 8.0301 & TRN \\
\hline CHEMBL3927429 & 1639903 & 8.0 & 8.0571 & TRN \\
\hline CHEMBL3919366 & 1639903 & 8.0 & 7.9912 & TST \\
\hline CHEMBL454796 & 1639903 & 7.0 & 7.6442 & TRN \\
\hline CHEMBL 3950577 & 1639903 & 8.0 & 7.5474 & TRN \\
\hline CHEMBL3920947 & 1639903 & 8.0 & 7.7824 & TRN \\
\hline CHEMBL3915154 & 1639903 & 8.0 & 7.91 & TRN \\
\hline CHEMBL3943489 & 1639903 & 8.0 & 7.9044 & TST \\
\hline CHEMBL3960623 & 1639903 & 8.0 & 7.308 & TST \\
\hline CHEMBL3981549 & 1639903 & 8.0 & 7.9173 & TRN \\
\hline CHEMBL3983417 & 1639903 & 7.0 & 6.8769 & TRN \\
\hline CHEMBL 3896493 & 1639903 & 8.0 & 8.1162 & TST \\
\hline CHEMBL3940401 & 1639903 & 8.0 & 7.3568 & TRN \\
\hline CHEMBL3893256 & 1639903 & 8.0 & 8.0219 & TRN \\
\hline CHEMBL449110 & 1639903 & 8.0 & 7.546 & TRN \\
\hline CHEMBL3937160 & 1639903 & 8.0 & 7.733 & TRN \\
\hline CHEMBL 3895132 & 1639903 & 8.0 & 8.0122 & TRN \\
\hline CHEMBL3902608 & 1639903 & 8.0 & 7.4987 & TRN \\
\hline CHEMBL3915202 & 1639903 & 8.0 & 7.9496 & TRN \\
\hline CHEMBL 3912542 & 1639903 & 8.0 & 7.8964 & TRN \\
\hline CHEMBL3910640 & 1639903 & 8.0 & 8.1064 & TRN \\
\hline CHEMBL 3899525 & 1639903 & 7.0 & 7.6849 & TRN \\
\hline CHEMBL3981747 & 1639903 & 7.0 & 7.0973 & TRN \\
\hline CHEMBL3934152 & 1639903 & 8.0 & 8.1417 & TRN \\
\hline CHEMBL3969290 & 1639903 & 8.0 & 7.968 & TRN \\
\hline CHEMBL 3897153 & 1639903 & 7.0 & 7.8058 & TST \\
\hline CHEMBL3949038 & 1639903 & 8.0 & 8.0064 & TRN \\
\hline CHEMBL 3973792 & 1639903 & 8.0 & 8.0061 & TRN \\
\hline CHEMBL3926128 & 1639903 & 8.0 & 7.4606 & TRN \\
\hline CHEMBL3953421 & 1639903 & 8.0 & 7.8852 & TST \\
\hline CHEMBL 3978486 & 1639903 & 7.0 & 7.4193 & TST \\
\hline CHEMBL3918852 & 1639903 & 7.0 & 7.2041 & TRN \\
\hline CHEMBL3984255 & 1639903 & 8.0 & 8.1049 & TRN \\
\hline CHEMBL3975048 & 1639903 & 5.301 & 6.5549 & TST \\
\hline CHEMBL3950325 & 1639903 & 8.0 & 7.9146 & TRN \\
\hline CHEMBL3937659 & 1639903 & 7.0 & 7.4255 & TRN \\
\hline CHEMBL3970155 & 1639903 & 7.0 & 7.0092 & TRN \\
\hline CHEMBL3894261 & 1639903 & 8.0 & 7.8704 & TRN \\
\hline CHEMBL3934556 & 1639903 & 8.0 & 7.9019 & TRN \\
\hline CHEMBL3917543 & 1639903 & 7.0 & 7.5264 & TRN \\
\hline CHEMBL 3930437 & 1639903 & 8.0 & 7.8408 & TST \\
\hline CHEMBL3905921 & 1639903 & 7.0 & 7.5258 & TRN \\
\hline CHEMBL3950296 & 1639903 & 8.0 & 7.8653 & TRN \\
\hline CHEMBL 3898274 & 1639903 & 8.0 & 8.0831 & TRN \\
\hline CHEMBL3957976 & 1639903 & 5.301 & 7.2282 & TST \\
\hline
\end{tabular}




\begin{tabular}{|c|c|c|c|c|}
\hline & & & & \\
\hline CHEMBL 3904361 & 1639903 & 8.0 & 7.8635 & TRN \\
\hline CHEMBL3915736 & 1639903 & 7.0 & 7.8068 & TST \\
\hline CHEMBL3923001 & 1639903 & 8.0 & 7.855 & TRN \\
\hline CHEMBL3907119 & 1639903 & 8.0 & 7.7557 & TRN \\
\hline CHEMBL3952960 & 1639903 & 8.0 & 7.7964 & TRN \\
\hline CHEMBL3910989 & 1639903 & 8.0 & 7.847 & TRN \\
\hline CHEMBL3971629 & 1639903 & 8.0 & 7.614 & TST \\
\hline CHEMBL3976855 & 1639903 & 8.0 & 7.5705 & TRN \\
\hline CHEMBL3955439 & 1639903 & 8.0 & 8.0529 & TRN \\
\hline CHEMBL3891515 & 1639903 & 7.0 & 6.7954 & TRN \\
\hline CHEMBL3956956 & 1639903 & 5.301 & 7.2467 & TST \\
\hline CHEMBL3915988 & 1639903 & 8.0 & 7.9581 & TRN \\
\hline CHEMBL3949909 & 1639903 & 8.0 & 7.8763 & TST \\
\hline CHEMBL3911054 & 1639903 & 7.0 & 7.4466 & TRN \\
\hline CHEMBL3983732 & 1639903 & 8.0 & 7.4258 & TRN \\
\hline CHEMBL3907756 & 1639903 & 7.0 & 7.4107 & TRN \\
\hline CHEMBL3932707 & 1639903 & 8.0 & 7.9492 & TST \\
\hline CHEMBL 3927527 & 1639903 & 8.0 & 7.91 & TRN \\
\hline CHEMBL3967147 & 1639903 & 8.0 & 8.0443 & TST \\
\hline CHEMBL3898780 & 1639903 & 8.0 & 7.6315 & TRN \\
\hline CHEMBL 3908198 & 1639903 & 8.0 & 7.938 & TRN \\
\hline CHEMBL3918216 & 1639903 & 8.0 & 7.0666 & TRN \\
\hline CHEMBL3915209 & 1639903 & 8.0 & 7.8256 & TRN \\
\hline CHEMBL3980159 & 1639903 & 8.0 & 7.7236 & TST \\
\hline CHEMBL3936820 & 1639903 & 8.0 & 7.8755 & TRN \\
\hline CHEMBL 3905410 & 1639903 & 8.0 & 8.1366 & TRN \\
\hline CHEMBL507714 & 1639903 & 8.0 & 7.941 & TRN \\
\hline CHEMBL3941932 & 1639903 & 8.0 & 8.051 & TRN \\
\hline CHEMBL3986506 & 1639903 & 7.0 & 7.5296 & TST \\
\hline CHEMBL 3907042 & 1639903 & 8.0 & 7.9805 & TRN \\
\hline CHEMBL 3940382 & 1639903 & 8.0 & 7.7302 & TST \\
\hline CHEMBL3918769 & 1639903 & 8.0 & 7.477 & TRN \\
\hline CHEMBL3896056 & 1639903 & 5.301 & 6.2243 & TRN \\
\hline CHEMBL 3973742 & 1639903 & 8.0 & 8.0064 & TRN \\
\hline CHEMBL3896361 & 1639903 & 8.0 & 8.1578 & TRN \\
\hline CHEMBL3925159 & 1639903 & 8.0 & 7.5135 & TST \\
\hline CHEMBL3982401 & 1639903 & 8.0 & 7.9742 & TST \\
\hline CHEMBL3976571 & 1639903 & 8.0 & 8.0414 & TRN \\
\hline CHEMBL 3959181 & 1639903 & 8.0 & 8.039 & TRN \\
\hline CHEMBL3948450 & 1639903 & 8.0 & 8.0166 & TRN \\
\hline CHEMBL3910511 & 1639903 & 8.0 & 8.1488 & TRN \\
\hline CHEMBL3913169 & 1639903 & 7.0 & 7.271 & TRN \\
\hline CHEMBL3936093 & 1639903 & 8.0 & 7.7725 & TRN \\
\hline CHEMBL 3952208 & 1639903 & 8.0 & 7.5327 & TRN \\
\hline CHEMBL3951885 & 1639903 & 8.0 & 7.9657 & TST \\
\hline CHEMBL3930609 & 1639903 & 5.301 & 7.43 & TST \\
\hline CHEMBL3968940 & 1639903 & 8.0 & 7.9772 & TRN \\
\hline CHEMBL3951967 & 1639903 & 7.0 & 7.2683 & TRN \\
\hline
\end{tabular}


Supplemental Table S2.txt

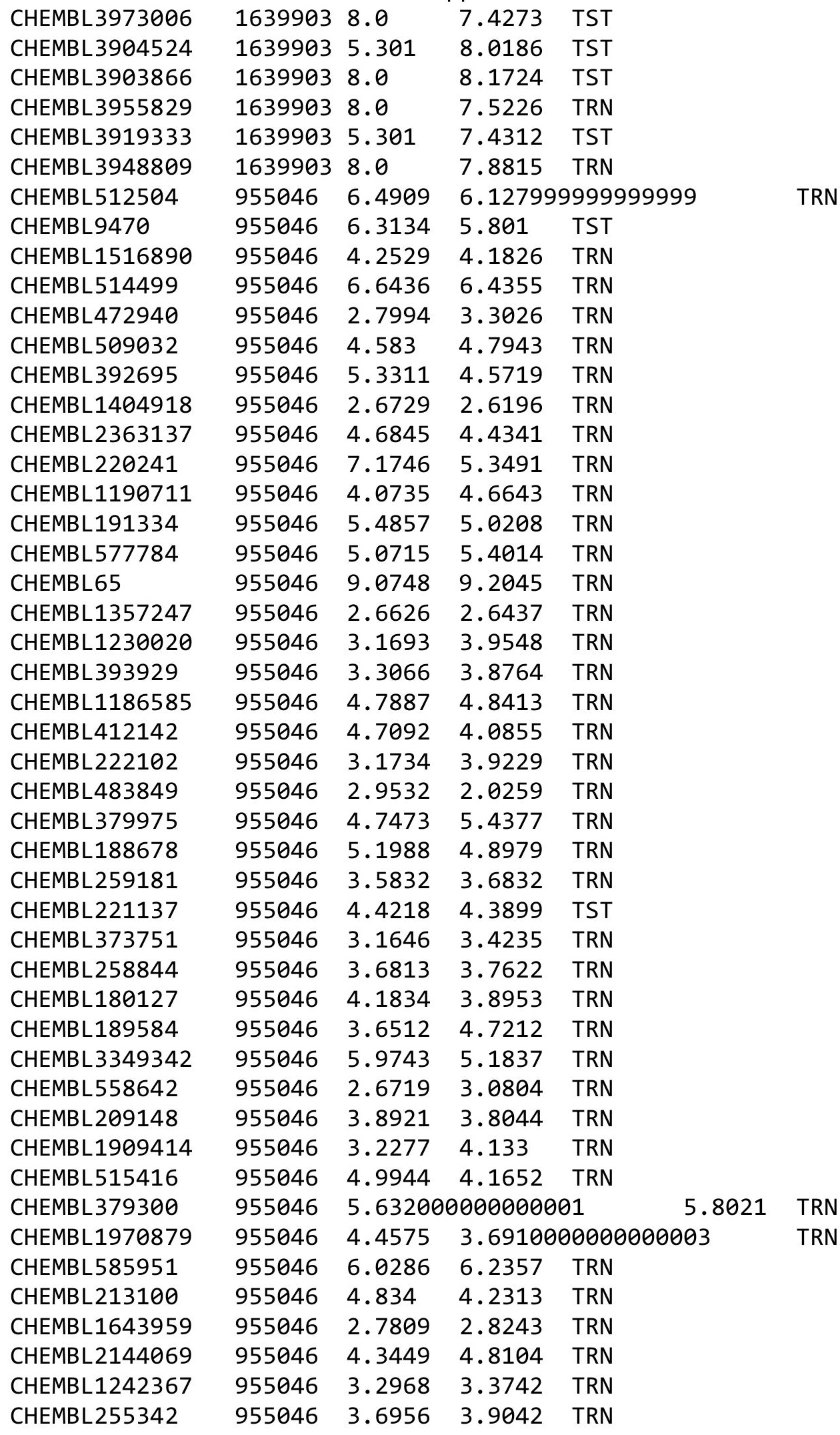


Supplemental Table S2.txt

\begin{tabular}{|c|c|c|c|c|c|}
\hline CHEMBL202721 & 955046 & 4.5578 & 5.2391 & TRN & \\
\hline CHEMBL92309 & 955046 & 1.5513 & 2.3367 & TST & \\
\hline CHEMBL3199475 & 955046 & 4.288 & 4.1903 & TRN & \\
\hline CHEMBL240954 & 955046 & 3.0637 & 3.8351 & TST & \\
\hline CHEMBL449158 & 955046 & 5.8814 & 7.2634 & TST & \\
\hline CHEMBL3186408 & 955046 & 4.4119 & 3.7208 & TST & \\
\hline CHEMBL300389 & 955046 & 6.6635 & 6.5956 & TRN & \\
\hline CHEMBL102714 & 955046 & 4.087 & 3.9932 & TRN & \\
\hline CHEMBL210618 & 955046 & 3.2019 & \multicolumn{2}{|c|}{3.4019999999999997} & TRN \\
\hline CHEMBL1256459 & 955046 & 5.0845 & 6.3113 & TST & \\
\hline CHEMBL192566 & 955046 & 7.3462 & 7.6755 & TST & \\
\hline CHEMBL1673039 & 955046 & 5.0709 & 4.317 & TST & \\
\hline CHEMBL 2005886 & 955046 & 3.4038 & 4.4256 & TST & \\
\hline CHEMBL135561 & 955046 & 3.7922 & 4.2 & TST & \\
\hline CHEMBL3392440 & 955046 & 3.6031 & 3.7978 & TST & \\
\hline CHEMBL573107 & 955046 & 4.5754 & 5.3359 & TST & \\
\hline CHEMBL1590308 & 955046 & 2.9227 & 3.2193 & TST & \\
\hline CHEMBL483847 & 955046 & 3.6846 & 3.9386 & TST & \\
\hline CHEMBL1788116 & 955046 & 3.8151 & 3.9248 & TST & \\
\hline CHEMBL396143 & 453677 & 4.8 & 5.0503 & TRN & \\
\hline CHEMBL397297 & 453677 & 4.0 & 4.3286 & TST & \\
\hline CHEMBL415084 & 453677 & 4.0 & 3.7564 & TRN & \\
\hline CHEMBL240450 & 453677 & 4.0 & 4.1779 & TRN & \\
\hline CHEMBL240449 & 453677 & 4.0 & 4.4145 & TRN & \\
\hline CHEMBL240448 & 453677 & 5.03 & 4.5886 & TRN & \\
\hline CHEMBL240259 & 453677 & 4.0 & 4.5109 & TRN & \\
\hline CHEMBL399815 & 453677 & 4.0 & 4.2324 & TRN & \\
\hline CHEMBL240258 & 453677 & 5.23 & 4.4734 & TRN & \\
\hline CHEMBL240834 & 453677 & 4.0 & 4.3232 & TST & \\
\hline CHEMBL398576 & 453677 & 4.0 & 3.5336 & TRN & \\
\hline CHEMBL240833 & 453677 & 4.0 & 4.0441 & TRN & \\
\hline CHEMBL240832 & 453677 & 4.0 & 4.6456 & TRN & \\
\hline CHEMBL240634 & 453677 & 4.53 & 4.5078 & TRN & \\
\hline CHEMBL240633 & 453677 & 4.48 & 4.3873 & TRN & \\
\hline CHEMBL240447 & 453677 & 4.43 & 4.5329 & TRN & \\
\hline CHEMBL392967 & 453677 & 4.0 & 4.2491 & TST & \\
\hline CHEMBL240446 & 453677 & 4.59 & 4.4573 & TRN & \\
\hline CHEMBL240445 & 453677 & 4.0 & 5.0667 & TST & \\
\hline CHEMBL392966 & 453677 & 4.0 & 4.2003 & TRN & \\
\hline CHEMBL240257 & 453677 & 5.21 & 5.0894 & TRN & \\
\hline CHEMBL240256 & 453677 & 5.12 & 5.0066 & TRN & \\
\hline CHEMBL392965 & 453677 & 4.98 & 5.0017 & TRN & \\
\hline CHEMBL240255 & 453677 & 5.15 & 5.2296 & TRN & \\
\hline CHEMBL240632 & 453677 & 5.03 & 5.2296 & TRN & \\
\hline CHEMBL240631 & 453677 & 5.24 & 4.9765 & TRN & \\
\hline CHEMBL240630 & 453677 & 5.04 & 5.17700 & 00000000005 & TRN \\
\hline CHEMBL239782 & 453677 & 4.0 & 4.8787 & TST & \\
\hline CHEMBL239576 & 453677 & 4.0 & 4.0934 & TRN & \\
\hline
\end{tabular}




\begin{tabular}{|c|c|c|c|c|c|}
\hline \multicolumn{6}{|c|}{ Supplemental Table S2.txt } \\
\hline CHEMBL239575 & 453677 & 4.53 & 4.6279 & TRN & \\
\hline CHEMBL 239574 & 453677 & 5.21 & 4.937 & TRN & \\
\hline CHEMBL391060 & 453677 & 4.88 & 4.9731 & TRN & \\
\hline CHEMBL391670 & 453677 & 5.22 & 4.9581 & TRN & \\
\hline CHEMBL 238947 & 453677 & 5.09 & 4.9581 & TRN & \\
\hline CHEMBL393518 & 453677 & 4.79 & 4.7719 & TRN & \\
\hline CHEMBL266797 & 453677 & 4.66 & 4.8816 & TRN & \\
\hline CHEMBL240239 & 453677 & 4.0 & 5.2489 & TST & \\
\hline CHEMBL240238 & 453677 & 4.0 & 4.4539 & TRN & \\
\hline CHEMBL 240237 & 453677 & 5.08 & 4.9563 & TRN & \\
\hline CHEMBL398986 & 453677 & 5.31 & 5.166 & TRN & \\
\hline CHEMBL 238967 & 453677 & 4.9 & 5.16700 & 0000000001 & TRN \\
\hline CHEMBL392348 & 453677 & 5.11 & 5.2274 & TRN & \\
\hline CHEMBL238966 & 453677 & 5.66 & 5.2379 & TRN & \\
\hline CHEMBL 238965 & 453677 & 5.18 & 5.2379 & TRN & \\
\hline CHEMBL394962 & 453677 & 5.19 & 5.0831 & TRN & \\
\hline CHEMBL394961 & 453677 & 5.21 & 5.255 & TRN & \\
\hline CHEMBL 241490 & 453677 & 4.0 & 4.9424 & TST & \\
\hline CHEMBL 241310 & 453677 & 4.71 & 4.623 & TRN & \\
\hline CHEMBL 240236 & 453677 & 5.19 & 5.0149 & TRN & \\
\hline CHEMBL392347 & 453677 & 4.97 & 5.0403 & TRN & \\
\hline CHEMBL 240234 & 453677 & 5.13 & 5.0403 & TRN & \\
\hline CHEMBL394960 & 453677 & 4.95 & 4.853 & TRN & \\
\hline CHEMBL451495 & 453677 & 5.01 & 4.9647 & TRN & \\
\hline CHEMBL 241488 & 453677 & 4.4 & 5.1028 & TST & \\
\hline CHEMBL241487 & 453677 & 4.0 & 4.2328 & TRN & \\
\hline CHEMBL241296 & 453677 & 5.24 & 5.0155 & TRN & \\
\hline CHEMBL241295 & 453677 & 5.3 & 5.1491 & TRN & \\
\hline CHEMBL241294 & 453677 & 4.97 & 5.1105 & TRN & \\
\hline CHEMBL394211 & 453677 & 5.62 & 5.303 & TRN & \\
\hline CHEMBL393273 & 453677 & 4.89 & 5.303 & TRN & \\
\hline CHEMBL430184 & 453677 & 4.83 & 5.0054 & TST & \\
\hline CHEMBL 241275 & 453677 & 5.43 & 5.2253 & TST & \\
\hline CHEMBL427686 & 453677 & 4.0 & 5.0305 & TST & \\
\hline CHEMBL 241273 & 453677 & 4.0 & 4.1525 & TST & \\
\hline CHEMBL428034 & 453677 & 4.76 & 4.6947 & TST & \\
\hline CHEMBL 241264 & 453677 & 5.1 & 5.0202 & TST & \\
\hline CHEMBL 241263 & 453677 & 5.19 & 5.0427 & TST & \\
\hline CHEMBL 240860 & 453677 & 5.68 & 5.1225 & TST & \\
\hline CHEMBL 391788 & 453677 & 5.13 & 5.1225 & TST & \\
\hline CHEMBL239367 & 453677 & 5.04 & 4.9354 & TST & \\
\hline CHEMBL 3647575 & 1528862 & 7.4306 & 7.6785 & TRN & \\
\hline CHEMBL 3647574 & 1528862 & 7.3925 & 7.3919 & TRN & \\
\hline CHEMBL 3647542 & 1528862 & 6.8327 & 6.7458 & TRN & \\
\hline CHEMBL 3647549 & 1528862 & 7.7852 & 7.9746 & TRN & \\
\hline CHEMBL 3647565 & 1528862 & 8.1261 & 8.336 & TRN & \\
\hline CHEMBL 3647544 & 1528862 & 7.129 & 6.7976 & TRN & \\
\hline CHEMBL 3647580 & 1528862 & 7.8416 & 8.0154 & TRN & \\
\hline
\end{tabular}


Supplemental Table S2.txt

\begin{tabular}{|c|c|c|c|c|c|c|}
\hline CHEMBL 3647564 & 1528862 & 7.4067 & 7.32 & TRN & & \\
\hline CHEMBL 3647556 & 1528862 & \multicolumn{3}{|c|}{5.757000000000001} & 6.1717 & TRN \\
\hline CHEMBL3647552 & 1528862 & 7.0391 & 7.7355 & TST & & \\
\hline CHEMBL 3647541 & 1528862 & 7.5072 & 6.9104 & TST & & \\
\hline CHEMBL 3647576 & 1528862 & 6.7696 & 6.6377 & TST & & \\
\hline CHEMBL3647555 & 1528862 & 7.5272 & 7.3987 & TRN & & \\
\hline CHEMBL 3647570 & 1528862 & 6.9914 & 6.5989 & TST & & \\
\hline CHEMBL3647571 & 1528862 & 7.7212 & 7.3573 & TST & & \\
\hline CHEMBL 3647558 & 1528862 & 7.0353 & 6.72 & TRN & & \\
\hline CHEMBL 3647567 & 1528862 & \multicolumn{3}{|c|}{7.4510000000000005} & 7.6789 & TRN \\
\hline CHEMBL3647563 & 1528862 & 7.2125 & 7.5088 & TRN & & \\
\hline CHEMBL 3647547 & 1528862 & 7.6216 & 7.5732 & TRN & & \\
\hline CHEMBL3647539 & 1528862 & 8.0128 & 8.0996 & TRN & & \\
\hline CHEMBL 3647582 & 1528862 & 7.5361 & 7.2485 & TRN & & \\
\hline CHEMBL 3647579 & 1528862 & 8.0675 & 8.3203 & TRN & & \\
\hline CHEMBL3647559 & 1528862 & 7.6635 & 7.6276 & TRN & & \\
\hline CHEMBL 3647578 & 1528862 & \multicolumn{3}{|c|}{7.718999999999999} & 8.0565 & TRN \\
\hline CHEMBL 3647540 & 1528862 & 6.5287 & 6.6732 & TST & & \\
\hline CHEMBL 3647568 & 1528862 & 7.7399 & 7.5556 & TRN & & \\
\hline CHEMBL 3647537 & 1528862 & 6.9666 & 7.2721 & TRN & & \\
\hline CHEMBL3647535 & 1528862 & 8.2941 & 8.1214 & TRN & & \\
\hline CHEMBL 3647534 & 1528862 & 7.9626 & 7.8246 & TRN & & \\
\hline CHEMBL 3647557 & 1528862 & 7.3915 & 6.8355 & TRN & & \\
\hline CHEMBL3647536 & 1528862 & 9.6073 & 8.0836 & TRN & & \\
\hline CHEMBL3647569 & 1528862 & 7.2518 & 6.7206 & TST & & \\
\hline CHEMBL3647566 & 1528862 & 7.9318 & 8.0241 & TRN & & \\
\hline CHEMBL3647533 & 1528862 & 7.5072 & 7.5892 & TRN & & \\
\hline CHEMBL3647561 & 1528862 & 8.1278 & 8.0041 & TRN & & \\
\hline CHEMBL 3647550 & 1528862 & 7.4622 & 7.4904 & TRN & & \\
\hline CHEMBL 3647573 & 1528862 & 7.1688 & 6.8531 & TST & & \\
\hline CHEMBL3647551 & 1528862 & 7.4112 & 7.2999 & TRN & & \\
\hline CHEMBL 3647546 & 1528862 & 6.9208 & 7.3444 & TRN & & \\
\hline CHEMBL 3647572 & 1528862 & 7.3635 & 7.1958 & TST & & \\
\hline CHEMBL 3647577 & 1528862 & 7.0585 & 7.5493 & TRN & & \\
\hline CHEMBL 3647545 & 1528862 & 6.9957 & 7.5571 & TST & & \\
\hline CHEMBL3647548 & 1528862 & 8.2351 & 8.132 & TRN & & \\
\hline CHEMBL 3647560 & 1528862 & \multicolumn{3}{|c|}{7.1579999999999995} & 7.4904 & TST \\
\hline CHEMBL 3647538 & 1528862 & 8.0218 & 7.9539 & TRN & & \\
\hline CHEMBL 3647553 & 1528862 & 6.9281 & 7.2533 & TST & & \\
\hline CHEMBL 3647581 & 1528862 & 7.8539 & 8.0066 & TRN & & \\
\hline CHEMBL3647543 & 1528862 & 7.4584 & 7.2967 & TST & & \\
\hline CHEMBL 3647554 & 1528862 & 6.1688 & 6.3571 & TRN & & \\
\hline CHEMBL 3647562 & 1528862 & \multicolumn{3}{|c|}{7.752000000000001} & 7.8538 & TRN \\
\hline CHEMBL1449414 & 752576 & 4.8225 & 4.4489 & TRN & & \\
\hline CHEMBL1560731 & 752576 & 5.2652 & 4.5329 & TRN & & \\
\hline CHEMBL1400666 & 752576 & 5.4202 & 4.9267 & TRN & & \\
\hline CHEMBL1518071 & 752576 & 4.1652 & 4.4909 & TRN & & \\
\hline CHEMBL1704776 & 752576 & 4.6536 & 5.0108 & TRN & & \\
\hline
\end{tabular}




\begin{tabular}{|c|c|c|c|c|c|}
\hline \\
\hline CHEMBL 3212840 & 752576 & 4.2267 & 4.5205 & TRN & \\
\hline CHEMBL 2001914 & 752576 & 4.8986 & 4.5225 & TRN & \\
\hline CHEMBL1430604 & 752576 & 5.284 & 5.2727 & TRN & \\
\hline CHEMBL1707746 & 752576 & 5.0731 & 5.0194 & TRN & \\
\hline CHEMBL1716272 & 752576 & 4.9169 & 4.8025 & TRN & \\
\hline CHEMBL1537562 & 752576 & 5.2197 & 5.2549 & TST & \\
\hline CHEMBL1523930 & 752576 & 5.6055 & 5.1289 & TRN & \\
\hline CHEMBL1351626 & 752576 & 5.6819 & 5.0069 & TRN & \\
\hline CHEMBL3209825 & 752576 & 4.6368 & 4.5891 & TRN & \\
\hline CHEMBL1897949 & 752576 & 4.9165 & 4.7621 & TRN & \\
\hline CHEMBL1462205 & 752576 & 4.6515 & 4.6289 & TRN & \\
\hline CHEMBL1905520 & 752576 & 4.5222 & 4.32600 & 00000000005 & TRN \\
\hline CHEMBL1505953 & 752576 & 5.2815 & 4.7943 & TRN & \\
\hline CHEMBL1398061 & 752576 & 4.4951 & 4.7723 & TRN & \\
\hline CHEMBL1419900 & 752576 & 5.0292 & 4.6946 & TRN & \\
\hline CHEMBL295786 & 752576 & 5.2676 & 5.239 & TST & \\
\hline CHEMBL3189821 & 752576 & 5.3507 & 5.5449 & TRN & \\
\hline CHEMBL1699651 & 752576 & 4.9303 & 4.4445 & TRN & \\
\hline CHEMBL1600573 & 752576 & 4.1013 & 5.1652 & TRN & \\
\hline CHEMBL1508257 & 752576 & 4.4641 & 4.8632 & TST & \\
\hline CHEMBL1437349 & 752576 & 5.7352 & 5.1584 & TRN & \\
\hline CHEMBL3212752 & 752576 & 4.9344 & 4.7736 & TRN & \\
\hline CHEMBL1340445 & 752576 & 4.5291 & 5.1617 & TRN & \\
\hline CHEMBL1488342 & 752576 & 4.9974 & 4.8971 & TRN & \\
\hline CHEMBL3193389 & 752576 & 4.7964 & 4.8859 & TRN & \\
\hline CHEMBL1573779 & 752576 & 4.9801 & 4.785 & TRN & \\
\hline CHEMBL1413681 & 752576 & 5.098 & 5.2475 & TRN & \\
\hline CHEMBL539027 & 752576 & 4.1495 & 4.5589 & TST & \\
\hline CHEMBL1546194 & 752576 & 4.762 & 4.5134 & TST & \\
\hline CHEMBL1438058 & 752576 & 6.0391 & 5.0007 & TST & \\
\hline CHEMBL1546422 & 752576 & 5.1308 & 4.7376 & TRN & \\
\hline CHEMBL1539096 & 752576 & 4.8935 & 4.8929 & TRN & \\
\hline CHEMBL1485923 & 752576 & 4.8159 & 5.0107 & TRN & \\
\hline CHEMBL1587031 & 752576 & 4.1005 & 4.658 & TST & \\
\hline CHEMBL1407834 & 752576 & 5.3737 & 5.268 & TRN & \\
\hline CHEMBL1381508 & 752576 & 5.4112 & 5.113 & TST & \\
\hline CHEMBL1540876 & 752576 & 4.8554 & 4.9524 & TRN & \\
\hline CHEMBL1402024 & 752576 & 5.0101 & 5.0301 & TST & \\
\hline CHEMBL1340840 & 752576 & 3.0 & 4.9676 & TST & \\
\hline CHEMBL1560044 & 752576 & 5.1226 & 4.5708 & TRN & \\
\hline CHEMBL1453858 & 752576 & 5.1113 & 4.8955 & TRN & \\
\hline CHEMBL1390613 & 752576 & 4.743 & 5.1336 & TST & \\
\hline CHEMBL1527578 & 752576 & 5.1524 & 4.9792 & TRN & \\
\hline CHEMBL1382265 & 752576 & 4.9274 & 4.7074 & TRN & \\
\hline CHEMBL1348562 & 752576 & 5.2211 & 4.8606 & TRN & \\
\hline CHEMBL1172022 & 752576 & 4.3104 & 4.7107 & TRN & \\
\hline CHEMBL1530823 & 752576 & 5.3635 & 5.2746 & TRN & \\
\hline CHEMBL1561078 & 752576 & 5.5607 & 4.749 & TRN & \\
\hline
\end{tabular}




\begin{tabular}{|c|c|c|c|c|c|}
\hline \multicolumn{6}{|c|}{ Supplemental Table S2.txt } \\
\hline CHEMBL1502451 & 752576 & 5.2284 & 5.0151 & TRN & \\
\hline CHEMBL1417888 & 752576 & 5.064 & 5.1923 & TRN & \\
\hline CHEMBL3191783 & 752576 & 4.9423 & 5.1391 & TRN & \\
\hline CHEMBL1407013 & 752576 & 3.0 & 4.9862 & TST & \\
\hline CHEMBL1310798 & 752576 & 4.6803 & 5.1961 & TRN & \\
\hline CHEMBL1607592 & 752576 & 5.9393 & 5.4144 & TRN & \\
\hline CHEMBL1454924 & 752576 & 5.2336 & 5.23799 & 99999999995 & TRN \\
\hline CHEMBL1425691 & 752576 & 5.317 & 5.5046 & TRN & \\
\hline CHEMBL1363179 & 752576 & 4.6202 & 4.6058 & TRN & \\
\hline CHEMBL3193715 & 752576 & 4.7192 & 4.7725 & TRN & \\
\hline CHEMBL1442299 & 752576 & 5.1772 & 4.6369 & TRN & \\
\hline CHEMBL1447981 & 752576 & 5.8928 & 4.9403 & TRN & \\
\hline CHEMBL1480899 & 752576 & 6.1198 & 5.2583 & TRN & \\
\hline CHEMBL1538873 & 752576 & 4.6031 & 4.9336 & TRN & \\
\hline CHEMBL1542284 & 752576 & 4.7001 & 5.6169 & TRN & \\
\hline CHEMBL1726052 & 752576 & 3.0 & 4.4219 & TRN & \\
\hline CHEMBL1382643 & 752576 & 4.7708 & 4.8553 & TRN & \\
\hline CHEMBL1499903 & 752576 & 5.1385 & 4.5689 & TRN & \\
\hline CHEMBL1603416 & 752576 & 4.6242 & 4.5984 & TRN & \\
\hline CHEMBL1305158 & 752576 & 5.0259 & 5.2273 & TRN & \\
\hline CHEMBL1406536 & 752576 & 4.8431 & 4.6146 & TST & \\
\hline CHEMBL1601826 & 752576 & 3.0 & 4.0083 & TRN & \\
\hline CHEMBL1978082 & 752576 & 5.5031 & 5.1518 & TRN & \\
\hline CHEMBL1415031 & 752576 & 4.5021 & 4.8612 & TRN & \\
\hline CHEMBL1437660 & 752576 & 4.7233 & 4.6149 & TRN & \\
\hline CHEMBL1544647 & 752576 & 4.8019 & 4.4462 & TRN & \\
\hline CHEMBL1440225 & 752576 & 4.9161 & 5.26200 & 00000000005 & TRN \\
\hline CHEMBL1729477 & 752576 & 5.6038 & 5.117 & TRN & \\
\hline CHEMBL1366764 & 752576 & 4.5277 & 4.7638 & TRN & \\
\hline CHEMBL1611833 & 752576 & 4.8529 & 5.0507 & TST & \\
\hline CHEMBL1455059 & 752576 & 5.2218 & 5.2682 & TRN & \\
\hline CHEMBL1556020 & 752576 & 6.1141 & 5.2031 & TRN & \\
\hline CHEMBL1368371 & 752576 & 4.1835 & 4.3882 & TRN & \\
\hline CHEMBL486706 & 752576 & 4.0271 & 4.7056 & TRN & \\
\hline CHEMBL1560459 & 752576 & 5.1858 & 4.7526 & TRN & \\
\hline CHEMBL1458952 & 752576 & 4.7523 & 4.5386 & TRN & \\
\hline CHEMBL1363800 & 752576 & 3.0 & 4.375 & TRN & \\
\hline CHEMBL1305718 & 752576 & 4.8778 & 5.0696 & TRN & \\
\hline CHEMBL406121 & 752576 & 5.2807 & 4.5232 & TRN & \\
\hline CHEMBL1441135 & 752576 & 5.4134 & 5.4791 & TRN & \\
\hline CHEMBL1594238 & 752576 & 4.9 & 5.0983 & TRN & \\
\hline CHEMBL1570221 & 752576 & 4.2006 & 4.9244 & TRN & \\
\hline CHEMBL1480163 & 752576 & 4.937 & 5.1561 & TRN & \\
\hline CHEMBL1402239 & 752576 & 4.6615 & 5.15 & TRN & \\
\hline CHEMBL1868919 & 752576 & 5.8697 & 4.8501 & TRN & \\
\hline CHEMBL1586238 & 752576 & 4.4747 & 4.8999 & TRN & \\
\hline CHEMBL1574523 & 752576 & 4.9855 & 4.5625 & TRN & \\
\hline CHEMBL1526266 & 752576 & 5.1107 & 4.6496 & TRN & \\
\hline
\end{tabular}




\begin{tabular}{|c|c|c|c|c|c|c|}
\hline \multicolumn{7}{|c|}{ Supplemental Table S2.txt } \\
\hline CHEMBL1403346 & 752576 & 4.9024 & 4.876 & TRN & & \\
\hline CHEMBL1518304 & 752576 & 5.767 & 5.3215 & TRN & & \\
\hline CHEMBL3210528 & 752576 & 5.5784 & 4.8346 & TRN & & \\
\hline CHEMBL1566885 & 752576 & 4.8579 & 5.3635 & TST & & \\
\hline CHEMBL1398181 & 752576 & 4.8557 & 4.5954 & TST & & \\
\hline CHEMBL3190356 & 752576 & 4.8665 & 5.1282 & TRN & & \\
\hline CHEMBL1582317 & 752576 & 4.9355 & 5.0801 & TRN & & \\
\hline CHEMBL1364803 & 752576 & 5.4776 & 5.388 & TRN & & \\
\hline CHEMBL1405851 & 752576 & 5.2366 & 4.908 & TRN & & \\
\hline CHEMBL1489610 & 752576 & $4.8210 \ell$ & 00000000 & & .7997 & TRN \\
\hline CHEMBL1346802 & 752576 & 4.9996 & 4.8995 & TRN & & \\
\hline CHEMBL1398902 & 752576 & 4.8128 & 5.2638 & TRN & & \\
\hline CHEMBL1437987 & 752576 & 5.4295 & 5.1423 & TRN & & \\
\hline CHEMBL1565099 & 752576 & 5.0241 & 5.1292 & TST & & \\
\hline CHEMBL1299499 & 752576 & 4.359 & 4.596 & TRN & & \\
\hline CHEMBL3190972 & 752576 & 5.2865 & 4.9373 & TRN & & \\
\hline CHEMBL1494764 & 752576 & 5.5901 & 5.6567 & TRN & & \\
\hline CHEMBL1335846 & 752576 & 4.6847 & 4.8662 & TRN & & \\
\hline CHEMBL3208660 & 752576 & 5.6635 & 5.0399 & TRN & & \\
\hline CHEMBL1520425 & 752576 & 4.4859 & 4.7962 & TRN & & \\
\hline CHEMBL512935 & 752576 & 4.6724 & 4.9794 & TRN & & \\
\hline CHEMBL1555914 & 752576 & 4.9423 & 4.8105 & TRN & & \\
\hline CHEMBL1409121 & 752576 & 4.9266 & 5.1584 & TRN & & \\
\hline CHEMBL1605463 & 752576 & 5.0691 & 5.3114 & TRN & & \\
\hline CHEMBL1520777 & 752576 & 4.7464 & 4.8582 & TRN & & \\
\hline CHEMBL3210236 & 752576 & 3.0 & 4.3678 & TRN & & \\
\hline CHEMBL1388639 & 752576 & 5.066 & 4.5501 & TRN & & \\
\hline CHEMBL1457908 & 752576 & 5.6383 & 5.3558 & TRN & & \\
\hline CHEMBL1385576 & 752576 & 5.0851 & 4.7815 & TRN & & \\
\hline CHEMBL 2003901 & 752576 & 4.9698 & 5.3034 & TRN & & \\
\hline CHEMBL1320465 & 752576 & 4.8891 & 4.6793 & TRN & & \\
\hline CHEMBL1303255 & 752576 & 5.0804 & 4.9792 & TST & & \\
\hline CHEMBL1356182 & 752576 & 4.4887 & 4.8708 & TRN & & \\
\hline CHEMBL1464388 & 752576 & 5.2358 & 4.6995 & TRN & & \\
\hline CHEMBL1573706 & 752576 & 3.0 & 5.15799 & 99999999995 & & TRN \\
\hline CHEMBL1501755 & 752576 & 4.9674 & 4.8783 & TRN & & \\
\hline CHEMBL1548086 & 752576 & 4.2339 & 4.4245 & TST & & \\
\hline CHEMBL1404438 & 752576 & 5.2336 & 5.3554 & TRN & & \\
\hline CHEMBL1458545 & 752576 & 5.0742 & 4.6185 & TRN & & \\
\hline CHEMBL1478000 & 752576 & 4.0594 & 4.8142 & TRN & & \\
\hline CHEMBL1392642 & 752576 & 4.6455 & 4.7721 & TST & & \\
\hline CHEMBL1607970 & 752576 & 4.8784 & 5.1301 & TRN & & \\
\hline CHEMBL1509494 & 752576 & 5.3655 & 5.4784 & TRN & & \\
\hline CHEMBL1302410 & 752576 & 6.7375 & 4.4934 & TST & & \\
\hline CHEMBL1349802 & 752576 & 5.0022 & 5.1218 & TRN & & \\
\hline CHEMBL1559673 & 752576 & 4.7693 & 4.7312 & TRN & & \\
\hline CHEMBL1343490 & 752576 & 3.0 & 4.6083 & TST & & \\
\hline CHEMBL3191715 & 752576 & 4.2634 & 4.221 & TRN & & \\
\hline
\end{tabular}


Supplemental Table S2.txt

\begin{tabular}{|c|c|c|c|c|}
\hline CHEMBL1376937 & 752576 & 4.2527 & 4.8792 & TRN \\
\hline CHEMBL1312600 & 752576 & 5.4962 & 4.8891 & TRN \\
\hline CHEMBL1541560 & 752576 & 4.5891 & 5.0678 & TRN \\
\hline CHEMBL1469535 & 752576 & 4.9087 & 5.1224 & TRN \\
\hline CHEMBL1528112 & 752576 & 5.1898 & 5.3827 & TRN \\
\hline CHEMBL1508764 & 752576 & 5.3242 & 4.6778 & TRN \\
\hline CHEMBL1595948 & 752576 & 5.1618 & 4.7672 & TRN \\
\hline CHEMBL1602800 & 752576 & 4.6838 & 4.7143 & TRN \\
\hline CHEMBL1330989 & 752576 & 5.6737 & 5.1109 & TRN \\
\hline CHEMBL1449107 & 752576 & 5.1662 & 4.8693 & TRN \\
\hline CHEMBL1489919 & 752576 & 6.7055 & 5.2493 & TRN \\
\hline CHEMBL1444205 & 752576 & 4.3879 & 5.1114 & TRN \\
\hline CHEMBL 1900250 & 752576 & 4.4464 & 4.6164 & TRN \\
\hline CHEMBL1381136 & 752576 & 4.9805 & 4.6749 & TRN \\
\hline CHEMBL1496095 & 752576 & 4.6212 & 4.8283 & TRN \\
\hline CHEMBL1326644 & 752576 & 4.7151 & 4.9559 & TRN \\
\hline CHEMBL1715414 & 752576 & 4.0059 & 4.5732 & TRN \\
\hline CHEMBL1483593 & 752576 & 5.9914 & 5.5559 & TRN \\
\hline CHEMBL1449029 & 752576 & 4.6334 & 4.8311 & TRN \\
\hline CHEMBL1200847 & 752576 & 3.0 & 4.6486 & TRN \\
\hline CHEMBL1573759 & 752576 & 4.3489 & 4.6334 & TRN \\
\hline CHEMBL1453099 & 752576 & 5.2865 & 4.6593 & TST \\
\hline CHEMBL1329111 & 752576 & 5.3696 & 4.6083 & TRN \\
\hline CHEMBL1547025 & 752576 & 5.0137 & 4.6921 & TRN \\
\hline CHEMBL1412708 & 752576 & 4.38 & 4.0847 & TST \\
\hline CHEMBL1701468 & 752576 & 4.7897 & 4.8384 & TRN \\
\hline CHEMBL 3194374 & 752576 & 4.3947 & 4.7664 & TRN \\
\hline CHEMBL1468861 & 752576 & 4.4461 & 4.886 & TRN \\
\hline CHEMBL1320912 & 752576 & 3.0 & 4.4317 & TRN \\
\hline CHEMBL1304061 & 752576 & 5.0092 & 4.7486 & TRN \\
\hline CHEMBL1424504 & 752576 & 4.8735 & 5.1499 & TRN \\
\hline CHEMBL1313808 & 752576 & 3.0 & 4.9279 & TST \\
\hline CHEMBL1576338 & 752576 & 4.8684 & 5.2793 & TRN \\
\hline CHEMBL1455253 & 752576 & 4.8286 & 5.3342 & TRN \\
\hline CHEMBL1402907 & 752576 & 5.5528 & 5.2009 & TST \\
\hline CHEMBL 3197063 & 752576 & 5.2857 & 4.5769 & TRN \\
\hline CHEMBL1601256 & 752576 & 4.2281 & 4.5593 & TST \\
\hline CHEMBL1330113 & 752576 & 4.8884 & 4.5472 & TST \\
\hline CHEMBL 2369184 & 752576 & 4.8986 & 4.8854 & TST \\
\hline CHEMBL1502833 & 752576 & 6.4622 & 5.1548 & TRN \\
\hline CHEMBL1895798 & 752576 & 4.7817 & 4.6933 & TST \\
\hline CHEMBL1441475 & 752576 & 4.8453 & 4.9134 & TST \\
\hline CHEMBL1359891 & 752576 & 5.0691 & 4.8233 & TST \\
\hline CHEMBL 225903 & 752576 & 5.1494 & 5.3625 & TST \\
\hline CHEMBL1422182 & 752576 & 5.0491 & 5.056 & TST \\
\hline CHEMBL1487609 & 752576 & 4.537 & 4.4948 & TST \\
\hline CHEMBL1530208 & 752576 & 5.6234 & 5.0026 & TST \\
\hline CHEMBL1483077 & 752576 & 3.0 & 4.706 & TST \\
\hline
\end{tabular}




\begin{tabular}{|c|c|c|c|c|c|}
\hline \multicolumn{6}{|c|}{ Supplemental Table S2.txt } \\
\hline CHEMBL1387237 & 752576 & 4.4531 & 4.8447 & TST & \\
\hline CHEMBL1402502 & 752576 & 4.6574 & 4.8483 & TST & \\
\hline CHEMBL1370674 & 752576 & 5.6478 & 4.9601 & TST & \\
\hline CHEMBL1419182 & 752576 & 5.5768 & 5.4167 & TST & \\
\hline CHEMBL1550764 & 752576 & 4.9314 & 5.2434 & TST & \\
\hline CHEMBL1491815 & 752576 & 4.6148 & 4.6524 & TST & \\
\hline CHEMBL1423947 & 752576 & 4.7899 & 4.7266 & TST & \\
\hline CHEMBL1439591 & 752576 & 5.8697 & 4.5164 & TST & \\
\hline CHEMBL3190607 & 752576 & 4.777 & 4.5057 & TST & \\
\hline CHEMBL1550601 & 752576 & 4.8492 & 5.1899 & TST & \\
\hline CHEMBL1464645 & 752576 & 3.0 & 4.7781 & TST & \\
\hline CHEMBL1894168 & 752576 & 4.8145 & 4.8929 & TST & \\
\hline CHEMBL1580028 & 752576 & 5.2832 & 4.7038 & TST & \\
\hline CHEMBL1365611 & 752576 & 4.9496 & 5.5875 & TST & \\
\hline CHEMBL 88584 & 752576 & 5.2644 & 5.0026 & TST & \\
\hline CHEMBL146525 & 752576 & 5.295 & 5.1316 & TST & \\
\hline CHEMBL1388853 & 752576 & 4.8914 & 5.1801 & TST & \\
\hline CHEMBL1516890 & 954806 & 3.7571 & 4.203 & TRN & \\
\hline CHEMBL240954 & 954806 & 3.9843 & 3.8516 & TST & \\
\hline CHEMBL509032 & 954806 & 6.5058 & 6.5881 & TRN & \\
\hline CHEMBL512504 & 954806 & 6.6106 & 5.1857 & TRN & \\
\hline CHEMBL1643959 & 954806 & 3.1165 & 4.0258 & TRN & \\
\hline CHEMBL 2144069 & 954806 & 5.7017 & 5.4949 & TRN & \\
\hline CHEMBL202721 & 954806 & 5.853 & 5.5987 & TRN & \\
\hline CHEMBL472940 & 954806 & 4.4521 & 3.6779 & TRN & \\
\hline CHEMBL1673039 & 954806 & 5.59 & 5.5033 & TRN & \\
\hline CHEMBL102714 & 954806 & 3.9707 & 3.4848 & TRN & \\
\hline CHEMBL1590308 & 954806 & 5.0289 & 3.4686 & TST & \\
\hline CHEMBL222102 & 954806 & 3.3282 & 3.8852 & TRN & \\
\hline CHEMBL191334 & 954806 & 5.6157 & 4.61100 & 0000000001 & TRN \\
\hline CHEMBL577784 & 954806 & 5.8362 & 5.843 & TRN & \\
\hline CHEMBL1788116 & 954806 & 4.6314 & 4.6453 & TRN & \\
\hline CHEMBL188678 & 954806 & 3.8391 & 4.6547 & TRN & \\
\hline CHEMBL 300389 & 954806 & 7.3888 & 7.7544 & TRN & \\
\hline CHEMBL 258844 & 954806 & 4.3617 & 4.6327 & TRN & \\
\hline CHEMBL1970879 & 954806 & 7.4082 & 5.5667 & TRN & \\
\hline CHEMBL1357247 & 954806 & 3.255 & 2.9646 & TRN & \\
\hline CHEMBL379975 & 954806 & 5.0074 & 5.3295 & TRN & \\
\hline CHEMBL 3186408 & 954806 & 3.4839 & 3.9434 & TST & \\
\hline CHEMBL514499 & 954806 & 7.2162 & 8.0255 & TRN & \\
\hline CHEMBL3199475 & 954806 & 4.3773 & 4.6705 & TRN & \\
\hline CHEMBL1190711 & 954806 & 5.6921 & 5.6816 & TRN & \\
\hline CHEMBL210618 & 954806 & 3.4668 & 3.4651 & TRN & \\
\hline CHEMBL189584 & 954806 & 4.4121 & 5.0539 & TRN & \\
\hline CHEMBL 2363137 & 954806 & 4.7636 & 4.9537 & TRN & \\
\hline CHEMBL392695 & 954806 & 6.0617 & 5.5124 & TRN & \\
\hline CHEMBL 3392440 & 954806 & 4.9615 & 4.0806 & TRN & \\
\hline CHEMBL65 & 954806 & 9.2203 & 9.2014 & TRN & \\
\hline
\end{tabular}




\begin{tabular}{|c|c|c|c|c|c|}
\hline \multicolumn{6}{|c|}{ semental } \\
\hline CHEMBL9470 & 954806 & 6.151 & 6.2791 & TST & \\
\hline CHEMBL379300 & 954806 & 6.6198 & 7.2665 & TRN & \\
\hline CHEMBL259181 & 954806 & 4.9652 & 4.8763 & TRN & \\
\hline CHEMBL 213100 & 954806 & 9.2241 & 6.1034 & TRN & \\
\hline CHEMBL180127 & 954806 & 4.9903 & 4.5288 & TRN & \\
\hline CHEMBL373751 & 954806 & 3.5136 & 3.9311 & TRN & \\
\hline CHEMBL1230020 & 954806 & 4.0559 & 4.1354 & TRN & \\
\hline CHEMBL515416 & 954806 & 5.5685 & 4.8934 & TRN & \\
\hline CHEMBL573107 & 954806 & 3.8795 & 5.5635 & TRN & \\
\hline CHEMBL220241 & 954806 & 5.3739 & 5.3572 & TRN & \\
\hline CHEMBL92309 & 954806 & 3.5505 & 2.7951 & TST & \\
\hline CHEMBL135561 & 954806 & 4.2373 & 4.7605 & TRN & \\
\hline CHEMBL393929 & 954806 & 3.5611 & 4.01699 & 99999999995 & TRN \\
\hline CHEMBL192566 & 954806 & 7.6525 & 9.1893 & TST & \\
\hline CHEMBL558642 & 954806 & 4.26 & 4.4604 & TRN & \\
\hline CHEMBL1909414 & 954806 & 4.0899 & 4.1552 & TRN & \\
\hline CHEMBL221137 & 954806 & 5.1207 & 4.8799 & TST & \\
\hline CHEMBL209148 & 954806 & 4.2583 & 5.0212 & TRN & \\
\hline CHEMBL483847 & 954806 & 3.5966 & 4.5832 & TRN & \\
\hline CHEMBL412142 & 954806 & 3.4601 & 4.1077 & TRN & \\
\hline CHEMBL1242367 & 954806 & 5.4607 & 4.5717 & TST & \\
\hline CHEMBL3349342 & 954806 & 3.4097 & 5.58299 & 9999999999 & TST \\
\hline CHEMBL1404918 & 954806 & 2.9205 & 2.8046 & TST & \\
\hline CHEMBL1256459 & 954806 & 8.6484 & 8.0574 & TST & \\
\hline CHEMBL585951 & 954806 & 6.146 & 6.76 & TST & \\
\hline CHEMBL483849 & 954806 & 2.8817 & 2.0657 & TST & \\
\hline CHEMBL 2005886 & 954806 & 4.6414 & 6.1146 & TST & \\
\hline CHEMBL449158 & 954806 & 7.6394 & 7.6798 & TST & \\
\hline CHEMBL 209954 & 404874 & 7.0506 & 6.82299 & 99999999995 & TRN \\
\hline CHEMBL 212146 & 404874 & 5.3098 & 4.9636 & TRN & \\
\hline CHEMBL 386123 & 404874 & 5.2291 & 5.0311 & TRN & \\
\hline CHEMBL 215741 & 404874 & 6.1079 & 6.0319 & TRN & \\
\hline CHEMBL 215712 & 404874 & 5.7212 & 5.9213 & TRN & \\
\hline CHEMBL 213776 & 404874 & 5.6576 & 5.675 & TRN & \\
\hline CHEMBL379625 & 404874 & 7.2441 & 6.3313 & TST & \\
\hline CHEMBL213381 & 404874 & 7.0269 & 6.61299 & 99999999995 & TRN \\
\hline CHEMBL213935 & 404874 & 5.6198 & 5.915 & TRN & \\
\hline CHEMBL212553 & 404874 & 5.7447 & 5.7262 & TRN & \\
\hline CHEMBL 214537 & 404874 & 5.6021 & 5.7277 & TRN & \\
\hline CHEMBL215935 & 404874 & 4.0 & 4.1855 & TRN & \\
\hline CHEMBL 213041 & 404874 & 6.4559 & 5.9195 & TRN & \\
\hline CHEMBL 212897 & 404874 & 7.2518 & 7.5549 & TRN & \\
\hline CHEMBL213953 & 404874 & 6.6778 & 6.4935 & TRN & \\
\hline CHEMBL 212653 & 404874 & 6.0 & 5.8045 & TRN & \\
\hline CHEMBL 211462 & 404874 & 5.5528 & 5.309 & TRN & \\
\hline CHEMBL 379792 & 404874 & 5.8539 & 5.2949 & TRN & \\
\hline CHEMBL 386868 & 404874 & 5.3979 & 5.7805 & TRN & \\
\hline CHEMBL215886 & 404874 & 7.0655 & 5.8691 & TST & \\
\hline
\end{tabular}




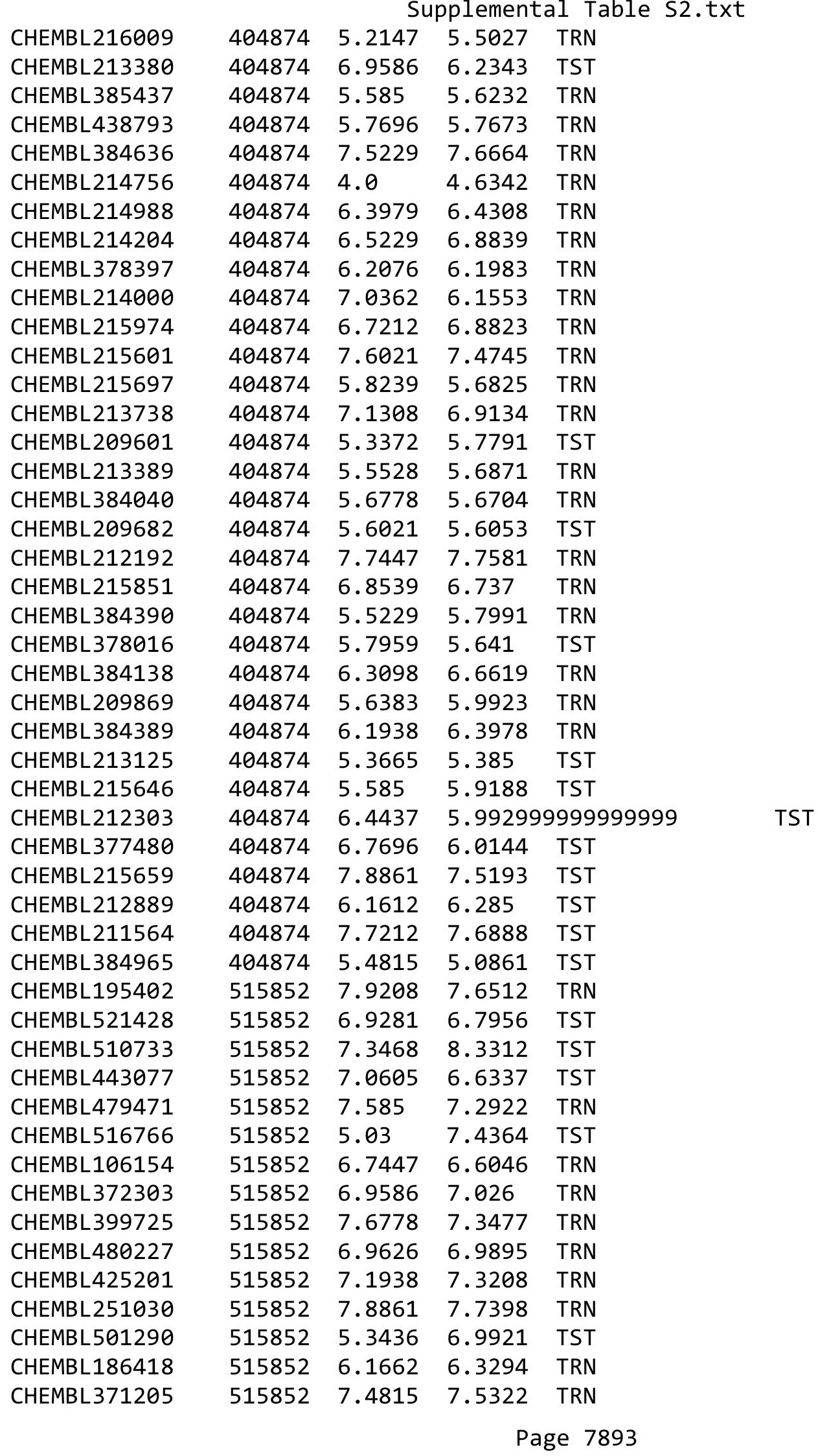


Supplemental Table S2.txt

\begin{tabular}{|c|c|c|c|c|c|}
\hline CHEMBL370217 & 515852 & 8.3872 & 8.2164 & TRN & \\
\hline CHEMBL452158 & 515852 & 6.6198 & 6.5257 & TST & \\
\hline CHEMBL481403 & 515852 & 7.0132 & 7.2998 & TRN & \\
\hline CHEMBL452100 & 515852 & 6.6498 & 6.6635 & TST & \\
\hline CHEMBL433356 & 515852 & 7.6021 & 7.5962 & TRN & \\
\hline CHEMBL196444 & 515852 & 8.301 & 8.3738 & TRN & \\
\hline CHEMBL481204 & 515852 & 6.9547 & 6.9145 & TRN & \\
\hline CHEMBL519778 & 515852 & 7.0555 & 7.2512 & TRN & \\
\hline CHEMBL 84044 & 515852 & 5.1249 & 6.2984 & TST & \\
\hline CHEMBL480615 & 515852 & 6.5622 & 6.5209 & TRN & \\
\hline CHEMBL479861 & 515852 & 7.5686 & 7.6836 & TRN & \\
\hline CHEMBL66761 & 515852 & 6.1135 & 6.6022 & TRN & \\
\hline CHEMBL194482 & 515852 & 6.9245 & 7.2824 & TRN & \\
\hline CHEMBL482012 & 515852 & 6.1232 & 6.7173 & TST & \\
\hline CHEMBL371244 & 515852 & 7.4437 & 7.3354 & TRN & \\
\hline CHEMBL196450 & 515852 & 8.1675 & 8.2897 & TRN & \\
\hline CHEMBL251028 & 515852 & 7.6383 & 7.7696 & TRN & \\
\hline CHEMBL425560 & 515852 & 7.0458 & 7.1954 & TRN & \\
\hline CHEMBL480234 & 515852 & 7.3372 & 7.3304 & TRN & \\
\hline CHEMBL 370838 & 515852 & 8.4202 & 8.4 & TRN & \\
\hline CHEMBL520924 & 515852 & 6.7932 & 6.7419 & TRN & \\
\hline CHEMBL81977 & 515852 & 5.0455 & 6.4693 & TST & \\
\hline CHEMBL480613 & 515852 & 7.2007 & 7.1586 & TRN & \\
\hline CHEMBL381208 & 515852 & 7.301 & 7.2231 & TRN & \\
\hline CHEMBL320031 & 515852 & 6.9355 & \multicolumn{2}{|c|}{6.9110000000000005} & TRN \\
\hline CHEMBL480108 & 515852 & 6.5243 & 6.651 & TRN & \\
\hline CHEMBL372450 & 515852 & 7.2518 & 7.1945 & TRN & \\
\hline CHEMBL480614 & 515852 & 6.6038 & 6.5458 & TRN & \\
\hline CHEMBL381652 & 515852 & 7.0458 & 7.1919 & TRN & \\
\hline CHEMBL196507 & 515852 & 7.2596 & 7.0909 & TRN & \\
\hline CHEMBL195913 & 515852 & 7.7212 & 7.4941 & TRN & \\
\hline CHEMBL480039 & 515852 & 7.6021 & 7.8146 & TRN & \\
\hline CHEMBL322268 & 515852 & 6.699 & 6.4462 & TRN & \\
\hline CHEMBL448447 & 515852 & 4.9066 & 7.0462 & TST & \\
\hline CHEMBL480452 & 515852 & 6.6198 & 6.5353 & TST & \\
\hline CHEMBL481511 & 515852 & 8.5229 & 8.5706 & TRN & \\
\hline CHEMBL481603 & 515852 & 6.9957 & \multicolumn{2}{|c|}{7.662000000000001} & TST \\
\hline CHEMBL371425 & 515852 & 7.699 & 7.4426 & TRN & \\
\hline CHEMBL401843 & 515852 & 7.7959 & 7.8132 & TRN & \\
\hline CHEMBL196559 & 515852 & 6.9208 & 6.9943 & TRN & \\
\hline CHEMBL294060 & 515852 & 6.8508 & 6.6606 & TRN & \\
\hline CHEMBL473036 & 515852 & 7.0 & 8.235 & TST & \\
\hline CHEMBL519443 & 515852 & 7.1487 & 6.8394 & TST & \\
\hline CHEMBL1186585 & 954934 & 3.4841 & 3.4881 & TRN & \\
\hline CHEMBL 213100 & 954934 & 4.8997 & 4.8935 & TRN & \\
\hline CHEMBL255342 & 954934 & 4.1982 & 4.1999 & TRN & \\
\hline CHEMBL577784 & 954934 & 5.1589 & 5.1605 & TRN & \\
\hline CHEMBL412142 & 954934 & 4.3696 & 4.3673 & TRN & \\
\hline
\end{tabular}




\begin{tabular}{|c|c|c|c|c|c|c|}
\hline \multirow[b]{2}{*}{ CHEMBL9470 } & \multicolumn{6}{|c|}{ Supplemental Table S2.txt } \\
\hline & 954934 & 4.8252 & 5.9778 & TST & & \\
\hline CHEMBL180127 & 954934 & 4.0623 & 4.066 & TRN & & \\
\hline CHEMBL512504 & 954934 & 4.354 & 4.3492 & TRN & & \\
\hline CHEMBL 222102 & 954934 & 3.8184 & 3.8316 & TRN & & \\
\hline CHEMBL188678 & 954934 & 5.3389 & 5.3229 & TRN & & \\
\hline CHEMBL514499 & 954934 & 7.5406 & 7.5392 & TRN & & \\
\hline CHEMBL3392440 & 954934 & 4.1739 & 4.1752 & TRN & & \\
\hline CHEMBL209148 & 954934 & 4.6625 & 4.6655 & TRN & & \\
\hline CHEMBL3199475 & 954934 & 5.1956 & 5.1967 & TRN & & \\
\hline CHEMBL258844 & 954934 & 4.8988 & 4.9029 & TRN & & \\
\hline CHEMBL1590308 & 954934 & 3.2893 & 3.2368 & TST & & \\
\hline CHEMBL259181 & 954934 & 4.395 & 4.4028 & TRN & & \\
\hline CHEMBL1190711 & 954934 & 5.3362 & 5.3274 & TRN & & \\
\hline CHEMBL449158 & 954934 & 6.3887 & 7.1993 & TST & & \\
\hline CHEMBL65 & 954934 & 8.4191 & 8.4268 & TRN & & \\
\hline CHEMBL1643959 & 954934 & 4.2196 & 4.2177 & TRN & & \\
\hline CHEMBL102714 & 954934 & 3.7844 & 3.7854 & TRN & & \\
\hline CHEMBL220241 & 954934 & 4.4827 & 4.489 & TRN & & \\
\hline CHEMBL509032 & 954934 & 4.9127 & 4.914 & TRN & & \\
\hline CHEMBL135561 & 954934 & 4.7128 & 4.6943 & TRN & & \\
\hline CHEMBL3349342 & 954934 & 5.7229 & 5.7186 & TRN & & \\
\hline CHEMBL2134202 & 954934 & 3.4538 & 3.4485 & TRN & & \\
\hline CHEMBL472940 & 954934 & 3.6319 & 3.6325 & TRN & & \\
\hline CHEMBL1788116 & 954934 & 5.0904 & 5.0935 & TRN & & \\
\hline CHEMBL2144069 & 954934 & 6.6901 & 6.6913 & TRN & & \\
\hline CHEMBL399530 & 954934 & 5.1605 & 5.1611 & TRN & & \\
\hline CHEMBL573107 & 954934 & 4.5732 & 4.5693 & TRN & & \\
\hline CHEMBL 300389 & 954934 & 6.9011 & 6.9073 & TRN & & \\
\hline CHEMBL483847 & 954934 & 4.802 & 4.8023 & TRN & & \\
\hline CHEMBL379300 & 954934 & 6.3501 & 6.3487 & TRN & & \\
\hline CHEMBL392695 & 954934 & 5.112 & 5.11 & TRN & & \\
\hline CHEMBL1242367 & 954934 & 4.4504 & 4.4517 & TRN & & \\
\hline CHEMBL192566 & 954934 & 9.1037 & 8.1672 & TST & & \\
\hline CHEMBL393929 & 954934 & 3.4259 & 3.4264 & TRN & & \\
\hline CHEMBL1970879 & 954934 & 6.0768 & 6.0863 & TRN & & \\
\hline CHEMBL483849 & 954934 & 2.1975 & 2.13199 & 9999999999 & 97 & TST \\
\hline CHEMBL210618 & 954934 & 3.2895 & 3.2917 & TRN & & \\
\hline CHEMBL1404918 & 954934 & 2.7781 & 2.7822 & TRN & & \\
\hline CHEMBL240954 & 954934 & 3.2083 & 3.9101 & TST & & \\
\hline CHEMBL2363137 & 954934 & 4.9505 & 4.9432 & TRN & & \\
\hline CHEMBL191334 & 954934 & 3.5036 & 3.5065 & TRN & & \\
\hline CHEMBL515416 & 954934 & 4.9697 & 4.9602 & TRN & & \\
\hline CHEMBL3186408 & 954934 & 3.3753 & 4.0142 & TST & & \\
\hline CHEMBL 2137530 & 954934 & 4.82100 & 30000000 & & 4.8233 & TRN \\
\hline CHEMBL92309 & 954934 & 3.2416 & 3.2063 & TST & & \\
\hline CHEMBL 373751 & 954934 & 3.2629 & 3.2624 & TRN & & \\
\hline CHEMBL585951 & 954934 & 6.0489 & 6.0456 & TRN & & \\
\hline CHEMBL189584 & 954934 & 3.88199 & 79999999 & 997 & 3.8802 & TRN \\
\hline
\end{tabular}




\begin{tabular}{|c|c|c|c|c|c|}
\hline \multirow[b]{2}{*}{ CHEMBL1230020 } & \multicolumn{5}{|c|}{ Supplemental Table S2.txt } \\
\hline & 954934 & 4.6445 & 4.6472 & TRN & \\
\hline CHEMBL1256459 & 954934 & 7.751 & 7.7525 & TRN & \\
\hline CHEMBL221137 & 954934 & 5.1025 & 5.1233 & TST & \\
\hline CHEMBL1357247 & 954934 & 3.5827 & 3.5844 & TRN & \\
\hline CHEMBL558642 & 954934 & 4.4219 & 4.491000 & 00000000005 & TST \\
\hline CHEMBL379975 & 954934 & 5.6508 & 4.9619 & TST & \\
\hline CHEMBL1909414 & 954934 & 5.1054 & 4.0201 & TST & \\
\hline CHEMBL217354 & 954934 & 6.6423 & 6.4364 & TST & \\
\hline CHEMBL202721 & 954934 & 4.5193 & 4.7924 & TST & \\
\hline CHEMBL 2005886 & 954934 & 5.3375 & 5.4365 & TST & \\
\hline CHEMBL1673039 & 954934 & 4.855 & 4.8391 & TST & \\
\hline CHEMBL1516890 & 954934 & 3.6101 & 4.0048 & TST & \\
\hline CHEMBL 3892520 & 1641661 & 10.1487 & 8.162 & TRN & \\
\hline CHEMBL3949894 & 1641661 & 6.0 & 9.437000 & 0000000001 & TRN \\
\hline CHEMBL3914816 & 1641661 & 9.7122 & 7.6221 & TRN & \\
\hline CHEMBL3985212 & 1641661 & 11.3979 & 8.5009 & TRN & \\
\hline CHEMBL3966935 & 1641661 & 10.2366 & 9.7835 & TRN & \\
\hline CHEMBL3918462 & 1641661 & 6.0 & 7.9065 & TRN & \\
\hline CHEMBL3957471 & 1641661 & 10.5086 & 10.1704 & TRN & \\
\hline CHEMBL 3932403 & 1641661 & 6.0 & 8.5938 & TRN & \\
\hline CHEMBL3927768 & 1641661 & 10.6778 & 9.6976 & TRN & \\
\hline CHEMBL3927888 & 1641661 & 9.5935 & 9.7211 & TRN & \\
\hline CHEMBL3919563 & 1641661 & 6.0 & 7.7882 & TRN & \\
\hline CHEMBL3928958 & 1641661 & 8.6819 & 8.6763 & TRN & \\
\hline CHEMBL3929517 & 1641661 & 6.0 & 7.7627 & TST & \\
\hline CHEMBL3956431 & 1641661 & 8.1427 & 8.5891 & TRN & \\
\hline CHEMBL3936383 & 1641661 & 6.0 & 10.0327 & TRN & \\
\hline CHEMBL3922816 & 1641661 & 10.4437 & 8.1957 & TRN & \\
\hline CHEMBL3906770 & 1641661 & 10.3872 & 9.898 & TRN & \\
\hline CHEMBL 3985167 & 1641661 & 10.8239 & 8.2289 & TRN & \\
\hline CHEMBL3953968 & 1641661 & 10.5528 & 9.7769 & TRN & \\
\hline CHEMBL3900901 & 1641661 & 10.4437 & 8.1867 & TRN & \\
\hline CHEMBL3899457 & 1641661 & 6.0 & 9.0097 & TRN & \\
\hline CHEMBL3957667 & 1641661 & 6.0 & 7.8132 & TRN & \\
\hline CHEMBL3948135 & 1641661 & 9.6778 & 9.5035 & TST & \\
\hline CHEMBL3901063 & 1641661 & 10.8447 & 8.3462 & TRN & \\
\hline CHEMBL3952611 & 1641661 & 9.8962 & 9.3681 & TRN & \\
\hline CHEMBL3920787 & 1641661 & 6.0 & 9.9159 & TRN & \\
\hline CHEMBL3912669 & 1641661 & 6.0 & 8.9085 & TRN & \\
\hline CHEMBL3913974 & 1641661 & 10.3009 & 999999999 & 9.6786 & $1 \mathrm{~T}$ \\
\hline CHEMBL 3938654 & 1641661 & 6.0 & 8.5601 & TRN & \\
\hline CHEMBL3981802 & 1641661 & 10.4559 & 9.8306 & TRN & \\
\hline CHEMBL3901912 & 1641661 & 10.7447 & 9.6116 & TRN & \\
\hline CHEMBL3936435 & 1641661 & 9.3893 & 7.5818 & TST & \\
\hline CHEMBL3956569 & 1641661 & 9.3556 & 7.7356 & TST & \\
\hline CHEMBL3895936 & 1641661 & 10.4318 & 9.0415 & TRN & \\
\hline CHEMBL 3889912 & 1641661 & 10.2366 & 8.5747 & TRN & \\
\hline CHEMBL3955653 & 1641661 & 9.0205 & 9.6704 & TRN & \\
\hline
\end{tabular}


Supplemental Table S2.txt

\begin{tabular}{|c|c|c|c|c|c|}
\hline CHEMBL3907594 & 1641661 & 10.8239 & 7.7614 & TST & \\
\hline CHEMBL3916107 & 1641661 & 9.8386 & 9.7549 & TRN & \\
\hline CHEMBL3909959 & 1641661 & 6.0 & 7.733 & TST & \\
\hline CHEMBL3951660 & 1641661 & 10.4089 & 9.6914 & TRN & \\
\hline CHEMBL3897552 & 1641661 & 10.2676 & 7.6671 & TRN & \\
\hline CHEMBL3912067 & 1641661 & 6.0 & 7.5438 & TRN & \\
\hline CHEMBL3918838 & 1641661 & 10.5686 & 9.7468 & TRN & \\
\hline CHEMBL3922077 & 1641661 & 10.4318 & 8.8707 & TRN & \\
\hline CHEMBL3911019 & 1641661 & 10.041 & 8.6162 & TRN & \\
\hline CHEMBL3318853 & 1641661 & 6.0 & 8.1007 & TST & \\
\hline CHEMBL3903299 & 1641661 & 9.1062 & 8.7663 & TRN & \\
\hline CHEMBL3935166 & 1641661 & 9.4179 & 7.9946 & TRN & \\
\hline CHEMBL3978364 & 1641661 & 9.5735 & 9.3085 & TST & \\
\hline CHEMBL3906678 & 1641661 & 10.4437 & 10.0604 & TRN & \\
\hline CHEMBL3913075 & 1641661 & 9.8447 & 9.1483 & TRN & \\
\hline CHEMBL3955893 & 1641661 & 6.0 & 7.8013 & TRN & \\
\hline CHEMBL3919989 & 1641661 & 11.0458 & 9.6466 & TRN & \\
\hline CHEMBL3951711 & 1641661 & 8.5058 & 9.7707 & TRN & \\
\hline CHEMBL3939838 & 1641661 & 9.6799 & 7.8532 & TST & \\
\hline CHEMBL3920572 & 1641661 & 9.4101 & 9.5461 & TRN & \\
\hline CHEMBL3892639 & 1641661 & 9.5969 & 9.38 & TRN & \\
\hline CHEMBL3909550 & 1641661 & 10.9208 & 9.9532 & TRN & \\
\hline CHEMBL3923413 & 1641661 & 10.4685 & 10.0685 & TRN & \\
\hline CHEMBL3946570 & 1641661 & 11.118 & 9.7512 & TRN & \\
\hline CHEMBL3958685 & 1641661 & 9.8894 & 9.3958 & TRN & \\
\hline CHEMBL3952815 & 1641661 & 6.2007 & 8.814 & TRN & \\
\hline CHEMBL3943714 & 1641661 & 9.6576 & 8.9535 & TRN & \\
\hline CHEMBL3962714 & 1641661 & 9.2441 & 9.1536 & TRN & \\
\hline CHEMBL3946292 & 1641661 & 6.0 & 9.9041 & TRN & \\
\hline CHEMBL3967593 & 1641661 & 8.7825 & 8.474 & TRN & \\
\hline CHEMBL3907216 & 1641661 & 6.0 & 9.6272 & TRN & \\
\hline CHEMBL3976924 & 1641661 & 6.0 & 10.02 & TRN & \\
\hline CHEMBL3926336 & 1641661 & 10.4437 & 10.2148 & TRN & \\
\hline CHEMBL3933850 & 1641661 & 6.0 & 7.9908 & TRN & \\
\hline CHEMBL3963144 & 1641661 & 6.0 & 7.8175 & TRN & \\
\hline CHEMBL3958579 & 1641661 & 10.0809 & 8.1517 & TRN & \\
\hline CHEMBL3941487 & 1641661 & 6.0 & 7.6365 & TRN & \\
\hline CHEMBL3923715 & 1641661 & 8.8297 & 9.7428 & TRN & \\
\hline CHEMBL3931750 & 1641661 & 9.9066 & 9.52799 & 9999999999 & TST \\
\hline CHEMBL3945957 & 1641661 & 10.0915 & 9.8496 & TRN & \\
\hline CHEMBL3943948 & 1641661 & 6.0 & 7.6857 & TRN & \\
\hline CHEMBL3924009 & 1641661 & 10.8539 & 9.4857 & TRN & \\
\hline CHEMBL3947776 & 1641661 & 11.1549 & 10.1556 & TRN & \\
\hline CHEMBL3934577 & 1641661 & 10.30099 & 99999999 & 8.27 & TRN \\
\hline CHEMBL3931814 & 1641661 & 10.284 & 8.1864 & TRN & \\
\hline CHEMBL3907409 & 1641661 & 6.0 & 9.5917 & TRN & \\
\hline CHEMBL3926401 & 1641661 & 10.3468 & 9.2073 & TRN & \\
\hline CHEMBL3920439 & 1641661 & 6.0 & 9.2213 & TRN & \\
\hline
\end{tabular}


Supplemental Table S2.txt

CHEMBL3929826

CHEMBL 3965176

CHEMBL3970304

CHEMBL 3942812

CHEMBL3960815

CHEMBL3967946

CHEMBL 3896605

CHEMBL 3909736

CHEMBL 3900444

CHEMBL3923922

CHEMBL 3933479

CHEMBL3924589

CHEMBL 3907856

CHEMBL3932486

CHEMBL3960878

CHEMBL3913211

CHEMBL 3956890

CHEMBL 3932414

CHEMBL3966433

CHEMBL 3890500

CHEMBL 3908298

CHEMBL 3949003

CHEMBL 3950008

CHEMBL 3934400

CHEMBL 3985869

CHEMBL 3905768

CHEMBL3929166

CHEMBL3955724

CHEMBL3960283

CHEMBL3967526

CHEMBL3962986

CHEMBL3920408

CHEMBL 3982938

CHEMBL 3937492

CHEMBL3955272

CHEMBL3946354

CHEMBL 3984745

CHEMBL3935143

CHEMBL3910710

CHEMBL3936458

CHEMBL3978459

CHEMBL3939746

CHEMBL3974972

CHEMBL 3922147

CHEMBL3930959

CHEMBL 3959203

CHEMBL3910046

CHEMBL 3967921

$\begin{array}{llll}1641661 & 10.4685 & 10.0921 & \text { TRN } \\ 1641661 & 10.585 & 8.6428 & \text { TRN } \\ 1641661 & 6.0 & 8.9365 & \text { TRN } \\ 1641661 & 6.0 & 7.6879 & \text { TST } \\ 1641661 & 10.6576 & 9.9312 & \text { TST } \\ 1641661 & 10.5229 & 10.0935 & \text { TRN } \\ 1641661 & 10.6383 & 9.906 & \text { TRN } \\ 1641661 & 9.9318 & 8.7074 & \text { TRN } \\ 1641661 & 10.2757 & 8.0014 & \text { TST } \\ 1641661 & 12.0 & 10.0522 & \text { TST } \\ 1641661 & 10.4559 & 9.9216 & \text { TRN } \\ 1641661 & 8.2284 & 8.6678 & \text { TRN } \\ 1641661 & 10.699000000000002 \\ 1641661 & 10.7447 & 9.4675 & \text { TRN } \\ 1641661 & 10.0362 & 8.0893 & \text { TRN } \\ 1641661 & 9.699 & 9.5983 & \text { TRN } \\ 1641661 & 9.9508 & 9.3897 & \text { TRN } \\ 1641661 & 10.2757 & 10.067 & \text { TRN } \\ 1641661 & 11.0458 & 9.5847 & \text { TST } \\ 1641661 & 10.0757 & 9.7899 & \text { TRN } \\ 1641661 & 10.0809 & 8.9932 & \text { TST } \\ 1641661 & 10.6383 & 9.5019 & \text { TST } \\ 1641661 & 10.5086 & 9.5164 & \text { TRN } \\ 1641661 & 11.5229 & 9.6109 & \text { TRN } \\ 1641661 & 10.3188 & 9.7075 & \text { TRN } \\ 1641661 & 9.9031 & 8.0705 & \text { TRN } \\ 1641661 & 6.0 & 9.9176 & \text { TRN } \\ 1641661 & 10.0809 & 8.0363 & \text { TRN } \\ 1641661 & 10.0315 & 9.7646 & \text { TRN } \\ 1641661 & 10.1675 & 8.6135 & \text { TRN } \\ 1641661 & 9.3143 & 7.6332 & \text { TST } \\ 1641661 & 9.6615 & 9.2629 & \text { TRN } \\ 1641661 & 6.0 & 7.6815 & \text { TRN } \\ 1641661 & 6.0 & 9.7799 & \text { TST } \\ 1641661 & 10.1079 & 10.0566 & \text { TST } \\ 1641661 & 10.4685 & 9.9957 & \text { TST } \\ 1641661 & 6.0 & 7.7907 & \text { TST } \\ 1641661 & 12.0 & 9.9473 & \text { TRN } \\ 1641661 & 10.0315 & 8.5165 & \text { TST } \\ 1641661 & 6.0 & 8.7119 & \text { TST } \\ 1641661 & 6.0 & 7.4774 & \text { TRN } \\ 1641661 & 6.0 & 10.2907 & \text { TST } \\ 1641661 & 10.8539 & 8.5292 & \text { TRN } \\ 1641661 & 6.0 & 9.6713 & \text { TRN } \\ 1641661 & 10.6576 & 8.8833 & \text { TST } \\ 1641661 & 10.8861 & 9.4541 & \text { TRN } \\ 1641661 & 6.0 & 9.5012 & \text { TRN } \\ 1641661 & 6.0 & 8.5912 & \text { TRN } \\ & & & \text { Page } \text { 7898 } \\ 16 & & & \end{array}$




\begin{tabular}{|c|c|c|c|c|c|c|}
\hline \multirow[b]{2}{*}{ CHEMBL 3931246} & \multicolumn{6}{|c|}{ Supplemental Table S2.txt } \\
\hline & 1641661 & 6.0 & 7.7424 & TST & & \\
\hline CHEMBL 3898671 & 1641661 & 9.9872 & 9.1592 & TRN & & \\
\hline CHEMBL3908398 & 1641661 & 9.3726 & 7.6936 & TRN & & \\
\hline CHEMBL3950110 & 1641661 & 6.0 & 7.5824 & TRN & & \\
\hline CHEMBL 3902421 & 1641661 & 9.0039 & 9.1009 & TRN & & \\
\hline CHEMBL3938462 & 1641661 & 6.0 & 7.8625 & TRN & & \\
\hline CHEMBL3956102 & 1641661 & 9.9281 & 8.5078 & TST & & \\
\hline CHEMBL3908838 & 1641661 & 6.0 & 7.709 & TRN & & \\
\hline CHEMBL3983032 & 1641661 & 9.3497 & 9.2876 & TRN & & \\
\hline CHEMBL 3943377 & 1641661 & 6.0 & 8.6879 & TRN & & \\
\hline CHEMBL3976609 & 1641661 & 10.5376 & 7.8023 & TST & & \\
\hline CHEMBL3900708 & 1641661 & 11.0 & 9.6638 & TRN & & \\
\hline CHEMBL3970039 & 1641661 & 8.0132 & 9.237 & TRN & & \\
\hline CHEMBL3942418 & 1641661 & 11.2218 & 9.9783 & TST & & \\
\hline CHEMBL3981369 & 1641661 & 10.6990 & 000000000 & 002 & 9.3386 & TRN \\
\hline CHEMBL3922547 & 1641661 & 6.0 & 8.9889 & TST & & \\
\hline CHEMBL3944114 & 1641661 & 9.2733 & 8.9556 & TRN & & \\
\hline CHEMBL3905325 & 1641661 & 9.9706 & 9.2052 & TRN & & \\
\hline CHEMBL3941875 & 1641661 & 8.4449 & 8.0227 & TRN & & \\
\hline CHEMBL3957314 & 1641661 & 6.0 & 8.1509 & TRN & & \\
\hline CHEMBL3982916 & 1641661 & 6.0 & 8.39 & TST & & \\
\hline CHEMBL 3947436 & 1641661 & 10.2924 & 8.7549 & TRN & & \\
\hline CHEMBL3941948 & 1641661 & 10.5086 & 9.0909 & TRN & & \\
\hline CHEMBL3961937 & 1641661 & 10.0706 & 8.658 & TST & & \\
\hline CHEMBL3929314 & 1641661 & 6.0 & 8.9493 & TRN & & \\
\hline CHEMBL3892929 & 1641661 & 11.6990 & 000000000 & 002 & 8.7812 & TST \\
\hline CHEMBL3936648 & 1641661 & 10.1938 & 9.4013 & TST & & \\
\hline CHEMBL3892365 & 1641661 & 9.8041 & 9.043 & TST & & \\
\hline CHEMBL3925116 & 1641661 & 9.5513 & 9.3076 & TRN & & \\
\hline CHEMBL3898682 & 1641661 & 10.4318 & 9.9936 & TST & & \\
\hline CHEMBL3972439 & 1641661 & 6.0 & 10.1791 & TST & & \\
\hline CHEMBL3951634 & 1641661 & 9.5482 & 9.3296 & TRN & & \\
\hline CHEMBL3978119 & 1641661 & 6.0 & 7.6311 & TRN & & \\
\hline CHEMBL3963332 & 1641661 & 8.9547 & 9.3765 & TRN & & \\
\hline CHEMBL3970174 & 1641661 & 10.5086 & 10.1571 & TRN & & \\
\hline CHEMBL3914897 & 1641661 & 10.7959 & 9.9152 & TST & & \\
\hline CHEMBL3911768 & 1641661 & 6.0 & 10.2804 & TST & & \\
\hline CHEMBL3956443 & 1641661 & 10.4559 & 9.3507 & TRN & & \\
\hline CHEMBL 3924420 & 1641661 & 10.2518 & 10.258 & TST & & \\
\hline CHEMBL3893466 & 1641661 & 11.1549 & 8.2942 & TRN & & \\
\hline CHEMBL3917137 & 1641661 & 9.3716 & 7.7896 & TRN & & \\
\hline CHEMBL3895788 & 1641661 & 6.0 & 8.1516 & TRN & & \\
\hline CHEMBL3929342 & 1641661 & 10.2147 & 9.7396 & TRN & & \\
\hline CHEMBL3953917 & 1641661 & 11.5229 & 9.7958 & TRN & & \\
\hline CHEMBL3954702 & 1641661 & 6.0 & 7.822 & TST & & \\
\hline CHEMBL3976480 & 1641661 & 11.1549 & 9.7842 & TRN & & \\
\hline CHEMBL3942906 & 1641661 & 10.4437 & 9.1435 & TRN & & \\
\hline CHEMBL3986150 & 1641661 & 6.0 & 9.9654 & TST & & \\
\hline
\end{tabular}


Supplemental Table S2.txt

\begin{tabular}{|c|c|c|c|c|c|}
\hline CHEMBL3905465 & 1641661 & 10.0809 & 9.7371 & TRN & \\
\hline CHEMBL 3901936 & 1641661 & 6.0 & 8.6349 & TRN & \\
\hline CHEMBL 3956513 & 1641661 & $11.6990 e$ & 000000000 & 10.1183 & TRN \\
\hline CHEMBL 3925922 & 1641661 & 6.0 & 7.6795 & TST & \\
\hline CHEMBL 3934037 & 1641661 & 10.9586 & 9.591000 & 0000000001 & TRN \\
\hline CHEMBL 3922266 & 1641661 & 9.1385 & 9.5127 & TRN & \\
\hline CHEMBL 3920424 & 1641661 & 11.0 & 8.977 & TRN & \\
\hline CHEMBL 3964214 & 1641661 & 8.7328 & 9.6106 & TRN & \\
\hline CHEMBL 3914930 & 1641661 & 10.4685 & 9.2659 & TRN & \\
\hline CHEMBL 3963752 & 1641661 & 9.767000 & 000000000 & 9.2497 & TRN \\
\hline CHEMBL 3910263 & 1641661 & 10.6198 & 9.6553 & TST & \\
\hline CHEMBL 3986706 & 1641661 & 9.289 & 7.7119 & TST & \\
\hline CHEMBL 3951554 & 1641661 & 6.0 & 7.4775 & TRN & \\
\hline CHEMBL 3906018 & 1641661 & 12.0 & 9.8717 & TRN & \\
\hline CHEMBL 3902532 & 1641661 & 10.8861 & 8.7573 & TST & \\
\hline CHEMBL 3977145 & 1641661 & 10.9586 & 9.533999 & 9999999999 & TRN \\
\hline CHEMBL 3923191 & 1641661 & 6.0 & 9.2308 & TRN & \\
\hline CHEMBL 3919573 & 1641661 & 11.0 & 8.8648 & TRN & \\
\hline CHEMBL 3922546 & 1641661 & 6.0 & 7.8219 & TRN & \\
\hline CHEMBL 3904340 & 1641661 & 9.7932 & 9.9735 & TST & \\
\hline CHEMBL 3973524 & 1641661 & 6.0 & 7.7258 & TST & \\
\hline CHEMBL 3983902 & 1641661 & 10.1249 & 9.8747 & TST & \\
\hline CHEMBL3899899 & 1641661 & 10.1675 & 9.506 & TRN & \\
\hline CHEMBL 3927066 & 1641661 & 10.3098 & 7.6021 & TRN & \\
\hline CHEMBL 3896751 & 1641661 & 9.7905 & 9.915 & TST & \\
\hline CHEMBL 3933891 & 1641661 & 6.0 & 9.4318 & TRN & \\
\hline CHEMBL 3919455 & 1641661 & 10.6778 & 8.8943 & TRN & \\
\hline CHEMBL3706586 & 202883 & 8.7447 & 8.9065 & TRN & \\
\hline CHEMBL 77144 & 202883 & 8.3468 & 7.4038 & TST & \\
\hline CHEMBL310711 & 202883 & 11.0 & 10.8171 & TRN & \\
\hline CHEMBL306289 & 202883 & 11.0 & 11.20099 & 99999999999 & TRN \\
\hline CHEMBL 75982 & 202883 & 8.4685 & 8.5495 & TRN & \\
\hline CHEMBL 311045 & 202883 & 9.3979 & 9.796 & TRN & \\
\hline CHEMBL311874 & 202883 & 8.3565 & 7.9305 & TST & \\
\hline CHEMBL77124 & 202883 & 9.301 & 9.2647 & TRN & \\
\hline CHEMBL77024 & 202883 & 11.0 & 11.2791 & TRN & \\
\hline CHEMBL 76803 & 202883 & 8.2218 & 8.0413 & TRN & \\
\hline CHEMBL432729 & 202883 & 8.7212 & 8.572000 & 0000000001 & TRN \\
\hline CHEMBL 75320 & 202883 & 8.0655 & 7.5744 & TRN & \\
\hline CHEMBL 76892 & 202883 & 8.6383 & 8.3661 & TRN & \\
\hline CHEMBL312531 & 202883 & 9.6383 & 9.5503 & TRN & \\
\hline CHEMBL430617 & 202883 & 11.0 & 11.0304 & TRN & \\
\hline CHEMBL3706585 & 202883 & 8.0915 & 8.31 & TRN & \\
\hline CHEMBL 76260 & 202883 & 8.7696 & 8.9772 & TRN & \\
\hline CHEMBL 2298601 & 202883 & 9.6383 & 8.5367 & TST & \\
\hline CHEMBL 78161 & 202883 & 8.4202 & 8.4099 & TRN & \\
\hline CHEMBL309585 & 202883 & 8.8861 & 9.2395 & TST & \\
\hline CHEMBL306507 & 202883 & 8.1739 & 7.8958 & TRN & \\
\hline
\end{tabular}




\begin{tabular}{|c|c|c|c|c|}
\hline \multicolumn{5}{|c|}{ Supplemental Table } \\
\hline CHEMBL309261 & 202883 & 8.2441 & 7.9615 & TST \\
\hline CHEMBL307181 & 202883 & 8.6778 & 8.2488 & TRN \\
\hline CHEMBL311818 & 202883 & 6.7696 & 6.5048 & TRN \\
\hline CHEMBL 78275 & 202883 & 8.8539 & 9.1496 & TRN \\
\hline CHEMBL311577 & 202883 & 9.5229 & 9.6068 & TRN \\
\hline CHEMBL307745 & 202883 & 11.0 & 10.7215 & TRN \\
\hline CHEMBL306722 & 202883 & 9.7959 & 9.9576 & TRN \\
\hline CHEMBL305855 & 202883 & 11.0 & 10.6451 & TRN \\
\hline CHEMBL412425 & 202883 & 9.9208 & 9.9033 & TRN \\
\hline CHEMBL 80520 & 202883 & 6.7447 & 7.2767 & TRN \\
\hline CHEMBL80669 & 202883 & 8.301 & 8.1514 & TST \\
\hline CHEMBL306554 & 202883 & 9.699 & 10.2909 & TRN \\
\hline CHEMBL3706581 & 202883 & 11.0 & 10.6399 & TRN \\
\hline CHEMBL24088 & 202883 & 11.0 & 10.5557 & TRN \\
\hline CHEMBL77328 & 202883 & 9.3979 & 9.6126 & TRN \\
\hline CHEMBL297524 & 202883 & 8.4949 & 8.9007 & TRN \\
\hline CHEMBL306781 & 202883 & 11.0 & 11.0357 & TRN \\
\hline CHEMBL310710 & 202883 & 7.4815 & 7.6438 & TRN \\
\hline CHEMBL 76671 & 202883 & 7.3979 & 8.1199 & TST \\
\hline CHEMBL 76192 & 202883 & 9.0555 & 8.9447 & TRN \\
\hline CHEMBL312143 & 202883 & 8.7696 & 8.8021 & TRN \\
\hline CHEMBL 76648 & 202883 & 8.8239 & 8.663 & TRN \\
\hline CHEMBL77129 & 202883 & 9.301 & 9.4448 & TRN \\
\hline CHEMBL307398 & 202883 & 9.3979 & 9.5959 & TRN \\
\hline CHEMBL24291 & 202883 & 8.1487 & 8.1393 & TRN \\
\hline CHEMBL 3085538 & 202883 & 11.0 & 11.0155 & TRN \\
\hline CHEMBL 77290 & 202883 & 11.0 & 10.7487 & TRN \\
\hline CHEMBL308107 & 202883 & 9.5229 & 9.7754 & TRN \\
\hline CHEMBL420020 & 202883 & 11.0 & 10.6725 & TRN \\
\hline CHEMBL 80160 & 202883 & 10.0 & 10.4009 & TST \\
\hline CHEMBL1159458 & 202883 & 11.0 & 10.4852 & TST \\
\hline CHEMBL73816 & 202883 & 8.8861 & 9.0302 & TRN \\
\hline CHEMBL308258 & 202883 & 11.0 & 10.8227 & TRN \\
\hline CHEMBL307626 & 202883 & 8.6198 & 8.206 & TRN \\
\hline CHEMBL 305932 & 202883 & 7.3768 & 7.6298 & TST \\
\hline CHEMBL421696 & 202883 & 7.9208 & 7.5745 & TST \\
\hline CHEMBL76693 & 202883 & 8.7447 & 8.1026 & TST \\
\hline CHEMBL3706584 & 202883 & 11.0 & 10.7738 & TRN \\
\hline CHEMBL 77378 & 202883 & 7.5376 & 7.3971 & TST \\
\hline CHEMBL 78064 & 202883 & 9.2218 & 9.5626 & TRN \\
\hline CHEMBL311783 & 202883 & 5.8239 & 7.6819 & TST \\
\hline CHEMBL308532 & 202883 & 8.4559 & 7.9024 & TST \\
\hline CHEMBL80163 & 202883 & 8.3768 & 7.5439 & TST \\
\hline CHEMBL 76637 & 202883 & 11.0 & 10.9495 & TRN \\
\hline CHEMBL442747 & 202883 & 5.5229 & 7.2035 & TST \\
\hline CHEMBL76536 & 202883 & 8.3098 & 8.2855 & TST \\
\hline CHEMBL3706583 & 202883 & 8.4559 & 8.7098 & TRN \\
\hline CHEMBL 77765 & 202883 & 8.4089 & 8.532 & TRN \\
\hline
\end{tabular}




\begin{tabular}{|c|c|c|c|c|c|c|}
\hline \multicolumn{7}{|c|}{ Supplemental Table S2.txt } \\
\hline CHEMBL179503 & 312381 & 10.5686 & 10.6345 & TRN & & \\
\hline CHEMBL178514 & 312381 & 9.8239 & 9.6906 & TRN & & \\
\hline CHEMBL359542 & 312381 & 8.1681 & 8.0744 & TRN & & \\
\hline CHEMBL360355 & 312381 & 8.4486 & 8.43 & TRN & & \\
\hline CHEMBL362074 & 312381 & 10.6021 & 10.6346 & TRN & & \\
\hline CHEMBL178280 & 312381 & 8.0937 & 8.0406 & TRN & & \\
\hline CHEMBL359598 & 312381 & 9.8861 & 9.6906 & TRN & & \\
\hline CHEMBL181948 & 312381 & 8.2411 & 8.2812 & TRN & & \\
\hline CHEMBL178116 & 312381 & \multicolumn{3}{|c|}{8.283999999999999} & 8.0603 & TST \\
\hline CHEMBL360956 & 312381 & 8.2733 & 8.2946 & TRN & & \\
\hline CHEMBL425699 & 312381 & 9.0 & 8.6336 & TST & & \\
\hline CHEMBL178339 & 312381 & 8.2907 & 8.2734 & TRN & & \\
\hline CHEMBL361825 & 312381 & 10.6778 & 11.0706 & TRN & & \\
\hline CHEMBL220238 & 312381 & 7.2832 & 7.3514 & TRN & & \\
\hline CHEMBL264344 & 312381 & 8.8153 & 8.7728 & TRN & & \\
\hline CHEMBL181623 & 312381 & 9.5229 & 9.807 & TRN & & \\
\hline CHEMBL181274 & 312381 & 8.9208 & 8.9143 & TRN & & \\
\hline CHEMBL360020 & 312381 & 8.0232 & 7.9731 & TRN & & \\
\hline CHEMBL447233 & 312381 & 8.1494 & 8.1328 & TRN & & \\
\hline CHEMBL359643 & 312381 & 7.0 & 7.1474 & TRN & & \\
\hline CHEMBL433771 & 312381 & \multicolumn{3}{|c|}{8.857000000000001} & 8.8881 & TRN \\
\hline CHEMBL362191 & 312381 & 8.0675 & 8.0445 & TRN & & \\
\hline CHEMBL181763 & 312381 & 8.8477 & 8.9653 & TRN & & \\
\hline CHEMBL367356 & 312381 & 8.8182 & 8.8532 & TRN & & \\
\hline CHEMBL181027 & 312381 & 8.5784 & 8.5901 & TRN & & \\
\hline CHEMBL182103 & 312381 & 7.301 & 7.3329 & TRN & & \\
\hline CHEMBL181768 & 312381 & 8.5114 & 8.492 & TRN & & \\
\hline CHEMBL180669 & 312381 & 11.5686 & 11.2007 & TRN & & \\
\hline CHEMBL178775 & 312381 & 8.0645 & 8.0137 & TRN & & \\
\hline CHEMBL179066 & 312381 & 8.0762 & 8.077 & TRN & & \\
\hline CHEMBL369290 & 312381 & 10.1079 & 10.0262 & TRN & & \\
\hline CHEMBL181396 & 312381 & 8.4089 & 8.4186 & TRN & & \\
\hline CHEMBL181775 & 312381 & 7.4214 & 8.3327 & TST & & \\
\hline CHEMBL180763 & 312381 & 8.1931 & 8.1234 & TRN & & \\
\hline CHEMBL361983 & 312381 & 8.1487 & 8.0814 & TRN & & \\
\hline CHEMBL180273 & 312381 & \multicolumn{3}{|c|}{8.466000000000001} & 8.479 & TRN \\
\hline CHEMBL361613 & 312381 & \multicolumn{3}{|c|}{8.341000000000001} & 8.3267 & TRN \\
\hline CHEMBL179551 & 312381 & 9.5229 & 9.4945 & TRN & & \\
\hline CHEMBL362213 & 312381 & 7.5229 & 8.3978 & TST & & \\
\hline CHEMBL360788 & 312381 & 8.9031 & 8.9157 & TRN & & \\
\hline CHEMBL441118 & 312381 & 8.7905 & 8.8247 & TRN & & \\
\hline CHEMBL178674 & 312381 & 8.8386 & 8.5435 & TST & & \\
\hline CHEMBL181295 & 312381 & 8.399 & 8.5517 & TST & & \\
\hline CHEMBL180623 & 312381 & 8.8601 & 9.621 & TST & & \\
\hline CHEMBL360915 & 312381 & 7.8153 & 8.17 & TST & & \\
\hline CHEMBL366927 & 312381 & 10.6778 & 10.5499 & TST & & \\
\hline CHEMBL443565 & 312381 & 7.5229 & 8.2135 & TST & & \\
\hline CHEMBL424789 & 312381 & 9.0757 & 7.7923 & TST & & \\
\hline
\end{tabular}


Supplemental Table S2.txt

\begin{tabular}{|c|c|c|c|c|}
\hline HEM & & & 8 & TST \\
\hline HFMRI 189616 & & 1.3188 & 10.2805 & \\
\hline HEMBL 2172218 & & 9547 & 3.063 & \\
\hline AEMBL2312902 & 6620 & 547 & $09<4$ & \\
\hline HEMBL 375623 & 36620 & .9586 & .7755 & \\
\hline HEMBL 231 & 6620 & 547 & 9367 & \\
\hline HEMBL 2 & & & 3768 & \\
\hline HEMBL 231 & 6620 & & .3596 & \\
\hline HEMBL 218884 & 36620 & 2366 & 5305 & \\
\hline HEMBL2312909 & 36620 & .9547 & 3.5567 & \\
\hline HEMBL2 & 6620 & 547 & 6979 & \\
\hline AEMBL2 & & & .3622 & \\
\hline HEMBL 2 & 620 & 239 & 4.4968 & \\
\hline AEMBL2 & 6620 & 547 & 4567 & \\
\hline AEMBL2. & 6620 & & 0398 & \\
\hline HEMBL 2 & 20 & 47 & 583 & \\
\hline HEMBL & & & 309 & \\
\hline HEMBL 2 & 620 & 68 & 6273 & \\
\hline AEMBL 2 & 20 & 47 & 0233 & \\
\hline AEMBL2 & 36620 & 47 & 3.0757 & \\
\hline HEMBL3 & 20 & & 381 & \\
\hline AEMBL & & & & \\
\hline HEMBL & 20 & & 1656 & \\
\hline AEMBL 2 & & & 328 & \\
\hline HEMBL 2 & 20 & 547 & 336 & \\
\hline AEMBL1 & & & 56 & \\
\hline AEME & & & & miv \\
\hline (1: & & & 99 & \\
\hline AEMBL2 & & & & \\
\hline HEMBL2 & 20 & 47 & 2.9136 & RI \\
\hline IEMBL2 2 & & 47 & & \\
\hline 2 & & & & NIV \\
\hline & & & & \\
\hline AEMBL 2 & & & & R \\
\hline AEMBL 2 & 20 & 17 & 4.25 & RI \\
\hline AFMRI? & & 17 & 21 & \\
\hline & & & & NIV \\
\hline HEMBL 2 & & & & RN \\
\hline AEMBL 2 & 20 & +1 & 228 & $\mathrm{R}$ \\
\hline EMB & & & 585 & $\mathrm{R}$ \\
\hline HEMBL2 & & 147 & 3.0726 & \\
\hline & & & & $\mathrm{R}^{-1}$ \\
\hline HEMBL3 & & 208 & 4.749 & $\mathrm{R}$ \\
\hline AEMBL 2 & 6620 & 2 . & 515 & $\mathrm{~F}$ \\
\hline MBL2 & & 547 & 3.0825 & \\
\hline HEMBL2 & & & 5.0578 & \\
\hline CHEMBL 2 & & 2.9547 & 2.5436 & \\
\hline CHEMBL2312882 & 936620 & 4.4318 & 4.1555 & 15 \\
\hline
\end{tabular}

Page 7903 


\begin{tabular}{|c|c|c|c|c|c|}
\hline & & \multicolumn{4}{|c|}{ Supplemental Table S2.txt } \\
\hline CHEMBL 2172300 & 936620 & 2.9547 & 2.96 & TST & \\
\hline CHEMBL 2172208 & 936620 & 4.4318 & 4.5689 & TST & \\
\hline CHEMBL242413 & 936620 & 4.4318 & 4.2905 & TST & \\
\hline CHEMBL 2312904 & 936620 & 4.9208 & 3.7906 & TST & \\
\hline CHEMBL456439 & 495622 & 5.3665 & 5.2639 & TST & \\
\hline CHEMBL457693 & 495622 & 5.3279 & 5.3977 & TRN & \\
\hline CHEMBL512371 & 495622 & 3.699 & 3.7317 & TRN & \\
\hline CHEMBL457524 & 495622 & 3.699 & 3.6408 & TRN & \\
\hline CHEMBL515058 & 495622 & 5.1249 & 5.1272 & TRN & \\
\hline CHEMBL447352 & 495622 & 5.5086 & 5.5561 & TRN & \\
\hline CHEMBL487349 & 495622 & 5.4685 & 5.6584 & TRN & \\
\hline CHEMBL514125 & 495622 & 5.3372 & 5.3472 & TRN & \\
\hline CHEMBL486740 & 495622 & 3.699 & 3.6995 & TRN & \\
\hline CHEMBL456668 & 495622 & 5.8861 & 5.8926 & TRN & \\
\hline CHEMBL487147 & 495622 & 5.1427 & 5.126 & TRN & \\
\hline CHEMBL486580 & 495622 & 5.3979 & 5.45700 & 0000000001 & TRN \\
\hline CHEMBL513974 & 495622 & 3.699 & 3.8175 & TRN & \\
\hline CHEMBL511369 & 495622 & 3.699 & 3.6832 & TRN & \\
\hline CHEMBL456453 & 495622 & 3.699 & 3.6321 & TRN & \\
\hline CHEMBL515996 & 495622 & 5.1739 & 5.1181 & TRN & \\
\hline CHEMBL508582 & 495622 & 5.3565 & 5.3976 & TRN & \\
\hline CHEMBL515855 & 495622 & 3.699 & 4.6023 & TST & \\
\hline CHEMBL515997 & 495622 & 5.5229 & 5.5353 & TRN & \\
\hline CHEMBL515504 & 495622 & 3.699 & 3.5687 & TRN & \\
\hline CHEMBL462991 & 495622 & 3.699 & 5.3846 & TST & \\
\hline CHEMBL464805 & 495622 & 3.699 & 3.6732 & TRN & \\
\hline CHEMBL486782 & 495622 & 5.0655 & 5.0296 & TRN & \\
\hline CHEMBL486535 & 495622 & 3.699 & 4.5596 & TST & \\
\hline CHEMBL457902 & 495622 & 5.6198 & 5.6647 & TRN & \\
\hline CHEMBL457733 & 495622 & 5.2676 & 5.1716 & TRN & \\
\hline CHEMBL520051 & 495622 & 3.699 & 3.699 & TRN & \\
\hline CHEMBL518376 & 495622 & 3.699 & 3.7072 & TRN & \\
\hline CHEMBL463188 & 495622 & 5.4202 & 5.4088 & TRN & \\
\hline CHEMBL456440 & 495622 & 5.0706 & 5.1786 & TRN & \\
\hline CHEMBL520062 & 495622 & 3.699 & 3.6724 & TRN & \\
\hline CHEMBL458835 & 495622 & 5.2007 & 5.1614 & TRN & \\
\hline CHEMBL458935 & 495622 & 3.699 & 3.424 & TRN & \\
\hline CHEMBL487362 & 495622 & 3.699 & 3.7113 & TRN & \\
\hline CHEMBL516833 & 495622 & 3.699 & 5.2327 & TST & \\
\hline CHEMBL457732 & 495622 & 4.8827 & 4.8217 & TRN & \\
\hline CHEMBL486522 & 495622 & 3.699 & 4.104 & TRN & \\
\hline CHEMBL515536 & 495622 & 5.301 & 5.081 & TRN & \\
\hline CHEMBL510765 & 495622 & 5.0223 & 5.1345 & TRN & \\
\hline CHEMBL511860 & 495622 & 3.699 & 2.7274 & TST & \\
\hline CHEMBL458963 & 495622 & 5.3872 & 5.0371 & TST & \\
\hline CHEMBL457692 & 495622 & 5.2924 & 5.3055 & TRN & \\
\hline CHEMBL458962 & 495622 & 3.699 & 3.7549 & TRN & \\
\hline CHEMBL520704 & 495622 & 3.699 & 4.445 & TST & \\
\hline
\end{tabular}




\begin{tabular}{|c|c|c|c|c|c|}
\hline \multicolumn{6}{|c|}{ Supplemental Table S2.txt } \\
\hline CHEMBL519058 & 495622 & 5.5686 & 4.9982 & TRN & \\
\hline CHEMBL487361 & 495622 & 3.699 & 4.4797 & TST & \\
\hline CHEMBL513638 & 495622 & 3.699 & 3.6294 & TRN & \\
\hline CHEMBL464806 & 495622 & 3.699 & 4.2351 & TRN & \\
\hline CHEMBL487566 & 495622 & 3.699 & 3.7138 & TRN & \\
\hline CHEMBL488392 & 495622 & 3.699 & 3.71100 & 00000000003 & TRN \\
\hline CHEMBL463187 & 495622 & 6.0132 & 5.8586 & TRN & \\
\hline CHEMBL458834 & 495622 & 3.699 & 3.7151 & TRN & \\
\hline CHEMBL458985 & 495622 & 5.2924 & 4.2362 & TST & \\
\hline CHEMBL456438 & 495622 & 3.699 & 5.6615 & TST & \\
\hline CHEMBL503623 & 495622 & 5.3372 & 4.4851 & TST & \\
\hline CHEMBL515678 & 495622 & 5.0862 & 5.8391 & TST & \\
\hline CHEMBL457903 & 495622 & 5.1427 & 5.8313 & TST & \\
\hline CHEMBL488393 & 495622 & 3.699 & 4.0634 & TST & \\
\hline CHEMBL1551808 & 1301735 & 4.7486 & 4.512 & TRN & \\
\hline CHEMBL1345220 & 1301735 & 3.0 & 4.5443 & TRN & \\
\hline CHEMBL1375289 & 1301735 & 3.0 & 4.2855 & TRN & \\
\hline CHEMBL1584985 & 1301735 & 4.1937 & 5.2763 & TST & \\
\hline CHEMBL 2356549 & 1301735 & 3.1549 & 3.85100 & 00000000004 & TRN \\
\hline CHEMBL1378851 & 1301735 & 4.5432 & 4.2365 & TST & \\
\hline CHEMBL1625031 & 1301735 & 3.0 & 4.31 & TRN & \\
\hline CHEMBL1396619 & 1301735 & 4.8735 & 4.4989 & TST & \\
\hline CHEMBL1559741 & 1301735 & 4.2384 & 4.167 & TRN & \\
\hline CHEMBL1420472 & 1301735 & 4.1575 & 4.2751 & TRN & \\
\hline CHEMBL1390112 & 1301735 & 5.209 & 4.9157 & TST & \\
\hline CHEMBL1866791 & 1301735 & 4.4969 & 4.2475 & TRN & \\
\hline CHEMBL1488060 & 1301735 & 5.3788 & 4.3153 & TST & \\
\hline CHEMBL3186267 & 1301735 & 3.4948 & 4.1112 & TRN & \\
\hline CHEMBL1622981 & 1301735 & 3.0 & 3.4506 & TRN & \\
\hline CHEMBL1711200 & 1301735 & 4.1397 & 3.9295 & TRN & \\
\hline CHEMBL 2359040 & 1301735 & 6.0 & 5.8772 & TRN & \\
\hline CHEMBL1321754 & 1301735 & 4.305 & 4.6117 & TRN & \\
\hline CHEMBL3183001 & 1301735 & 6.0 & 5.4741 & TRN & \\
\hline CHEMBL 2359110 & 1301735 & 4.4631 & 4.7128 & TRN & \\
\hline CHEMBL 2358729 & 1301735 & 5.0501 & 3.9786 & TRN & \\
\hline CHEMBL 2355890 & 1301735 & 3.1549 & 3.8 & TRN & \\
\hline CHEMBL1568022 & 1301735 & 4.7612 & 4.377 & TRN & \\
\hline CHEMBL1451348 & 1301735 & 5.2967 & 4.9736 & TRN & \\
\hline CHEMBL591363 & 1301735 & 5.8041 & 5.2917 & TRN & \\
\hline CHEMBL 2358770 & 1301735 & 3.1549 & 3.9505 & TRN & \\
\hline CHEMBL3186440 & 1301735 & 4.2832 & 3.4466 & TRN & \\
\hline CHEMBL 2362844 & 1301735 & 3.1549 & 5.0656 & TRN & \\
\hline CHEMBL 2357640 & 1301735 & 4.7135 & 3.861 & TRN & \\
\hline CHEMBL 3185444 & 1301735 & 5.0367 & 4.9221 & TRN & \\
\hline CHEMBL 2359406 & 1301735 & 3.4948 & 4.4899 & TRN & \\
\hline CHEMBL1418341 & 1301735 & 4.4478 & 4.3062 & TRN & \\
\hline CHEMBL 2358863 & 1301735 & 4.6236 & 4.3842 & TRN & \\
\hline CHEMBL1597245 & 1301735 & 5.684 & 4.8723 & TRN & \\
\hline
\end{tabular}




\begin{tabular}{|c|c|c|c|c|c|c|}
\hline \multicolumn{6}{|c|}{ Supplemental Table S2.txt } & \\
\hline CHEMBL1519285 & 1301735 & 4.51 & 4.1145 & TST & & \\
\hline CHEMBL 2355506 & 1301735 & 6.0 & 5.8793 & TRN & & \\
\hline CHEMBL1617452 & 1301735 & 4.2496 & 4.3184 & TRN & & \\
\hline CHEMBL2361006 & 1301735 & 4.6249 & 4.3569 & TRN & & \\
\hline CHEMBL2355724 & 1301735 & 4.6442 & 4.4074 & TRN & & \\
\hline CHEMBL2357235 & 1301735 & 3.1549 & 3.9585 & TRN & & \\
\hline CHEMBL1544797 & 1301735 & 4.8486 & 4.694 & TRN & & \\
\hline CHEMBL1500469 & 1301735 & 5.5086 & 4.9469 & TST & & \\
\hline CHEMBL1392527 & 1301735 & 4.8147 & 4.9215 & TST & & \\
\hline CHEMBL 2357026 & 1301735 & 6.0 & 5.7373 & TRN & & \\
\hline CHEMBL1582221 & 1301735 & 3.284 & 4.552 & TRN & & \\
\hline CHEMBL1579170 & 1301735 & 4.5351 & 4.1978 & TRN & & \\
\hline CHEMBL1487099 & 1301735 & 5.2255 & 5.0094 & TST & & \\
\hline CHEMBL 2356442 & 1301735 & 4.7342 & 3.7808 & TRN & & \\
\hline CHEMBL1321427 & 1301735 & 4.426 & 4.831 & TST & & \\
\hline CHEMBL1305372 & 1301735 & 3.0 & 3.9169 & TRN & & \\
\hline CHEMBL 2358940 & 1301735 & 4.6576 & 4.3046 & TRN & & \\
\hline CHEMBL257286 & 1301735 & 4.4891 & 4.5333 & TRN & & \\
\hline CHEMBL1489779 & 1301735 & 4.4695 & 4.4203 & TRN & & \\
\hline CHEMBL1904071 & 1301735 & 5.3546 & 4.7822 & TST & & \\
\hline CHEMBL1564801 & 1301735 & 5.4413 & 4.8984 & TRN & & \\
\hline CHEMBL1375884 & 1301735 & 4.8312 & 4.488 & TST & & \\
\hline CHEMBL3182522 & 1301735 & 6.0 & 5.7312 & TRN & & \\
\hline CHEMBL1483562 & 1301735 & 4.8918 & 5.0705 & TST & & \\
\hline CHEMBL1347023 & 1301735 & 4.3023 & 4.2676 & TST & & \\
\hline CHEMBL 2356271 & 1301735 & 4.3904 & 4.4197 & TRN & & \\
\hline CHEMBL2359612 & 1301735 & 4.8088 & 4.3211 & TRN & & \\
\hline CHEMBL1536108 & 1301735 & 3.0 & 3.2883 & TRN & & \\
\hline CHEMBL585827 & 1301735 & 5.6676 & 5.303 & TRN & & \\
\hline CHEMBL1873627 & 1301735 & 4.3195 & 2.9657 & TRN & & \\
\hline CHEMBL3184311 & 1301735 & 3.4948 & 4.0321 & TRN & & \\
\hline CHEMBL2355635 & 1301735 & 4.5597 & 4.7416 & TRN & & \\
\hline CHEMBL3188935 & 1301735 & 4.5438 & 4.591 & TRN & & \\
\hline CHEMBL2362298 & 1301735 & 4.465 & 4.2987 & TRN & & \\
\hline CHEMBL1350915 & 1301735 & 4.2042 & 3.5094 & TST & & \\
\hline CHEMBL1371507 & 1301735 & 5.4425 & 4.4752 & TST & & \\
\hline CHEMBL 3182041 & 1301735 & 4.3054 & 3.8913 & TST & & \\
\hline CHEMBL1378232 & 1301735 & 5.699 & 4.9334 & TST & & \\
\hline CHEMBL2356002 & 1301735 & 4.6824 & 4.6876 & TRN & & \\
\hline CHEMBL2361346 & 1301735 & 5.06800 & 000000000 & 005 & 4.9830000000000005 & TRN \\
\hline CHEMBL2357173 & 1301735 & 4.7268 & 4.3076 & TRN & & \\
\hline CHEMBL 2137170 & 1301735 & 3.1549 & 2.9951 & TRN & & \\
\hline CHEMBL2354712 & 1301735 & 6.0 & 5.8344 & TRN & & \\
\hline CHEMBL 2354497 & 1301735 & 6.0 & 5.5896 & TRN & & \\
\hline CHEMBL 3187821 & 1301735 & 4.7823 & 4.9821 & TRN & & \\
\hline CHEMBL 2357535 & 1301735 & 5.6421 & 4.6983 & TRN & & \\
\hline CHEMBL1405749 & 1301735 & 4.6498 & 5.0365 & TRN & & \\
\hline CHEMBL2359622 & 1301735 & 5.1397 & 4.6686 & TRN & & \\
\hline
\end{tabular}


Supplemental Table S2.txt

\begin{tabular}{|c|c|c|c|c|}
\hline HEMBL1560774 & 301735 & 506 & 3.9026 & TR \\
\hline HEMBL2355735 & 301735 & 5.0969 & 4.5929 & \\
\hline HFMBI 15 & סרי & 937 & & \\
\hline HEMBL2137524 & 301735 & 3766 & 4211 & $R N$ \\
\hline HEMBL1445297 & $301 / 35$ & 9501 & .2534 & \\
\hline HEMBL1321622 & 301735 & 5.0173 & 4.2765 & \\
\hline HEMBL2355378 & 3017 & 4.6078 & 4.4793 & \\
\hline HEMBL2356872 & 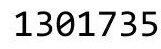 & 998 & 4.5402 & RN \\
\hline HEMBL1472681 & 30 & 5.9281 & 4.9324 & CT \\
\hline HEMBL2359502 & 301 & 4.5006 & 3.7808 & \\
\hline HEMBL1530866 & 30 & 4.1653 & 3.5164 & \\
\hline HEMBL3182148 & 30 & 3.0 & 4.2129 & \\
\hline HEMBL3187483 & 20 & 4 & 3.5666 & \\
\hline HEMBL1337726 & 30 & 4.2003 & 4.1224 & \\
\hline HEMBL1602637 & 30 & 4.4981 & 4.1835 & \\
\hline HEMBL1379675 & 30 & 5.1118 & 4.8704 & 5T \\
\hline HEMBL2354788 & 3 e & 948 & 4.4132 & RN \\
\hline HEMBL1452 & $3 e$ & 5.4921 & 5.0996 & \\
\hline HEMBL1704298 & 30 & 4.0515 & 4.0436 & \\
\hline HEMBL585947 & 95 & 5.0223 & $\partial 186$ & N \\
\hline HEMBL5 & 95 & 7 & 999 & Niv \\
\hline HEMBLS & 95 & 49 & 636 & RN \\
\hline HEMBL5 & 7 & 18 & 183 & \\
\hline HEMBL571207 & 57 & 7.0969 & 7.102 & \\
\hline HEMBL571435 & 7 & 5. & 5.5666 & N \\
\hline HEMBL 5 & 7 & 979 & 6.4463 & RN \\
\hline HEMBLS & 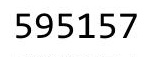 & 768 & 38 & RN \\
\hline HEMBL5 & 7 & 6.0 & 05 & RN \\
\hline HEMBL572057 & & 1549 & 5.1622 & TRN \\
\hline HEMBL585915 & 95 & 6.6778 & 5896 & TRN \\
\hline HEMBL5 & 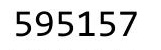 & 7.2218 & 7.2273 & $\mathrm{RN}$ \\
\hline HEMBL5 & 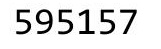 & 58 & 6.3297 & TRN \\
\hline HEMBL5 & 7 & 39 & 5.779 & $\mathrm{RN}$ \\
\hline HEMBL571183 & 95 & 6. & 6.6657 & TRN \\
\hline HEMBL570965 & 951 & 5.9586 & 5.9633 & TRN \\
\hline HEMBL5 & 7 & 881 & 5.5666 & $\Gamma \mathrm{RN}$ \\
\hline CHEMBL4 & 7 & 7. & 5.4258 & IST \\
\hline LHEMBL570991 & 7 & 5.6021 & 03 & TRN \\
\hline HEMBL571018 & 95 & 7.0458 & 7.0377 & TRN \\
\hline HEMBL570796 & 7 & 7 & 6.9652 & TRN \\
\hline CHEMBL 5 & 7 & 6 & 5.6738 & ונדו \\
\hline CHEMBL576128 & 57 & 6.30 & 6.2847 & TRN \\
\hline CHEMBL583908 & 95 & 6.0969 & 5.9034 & TST \\
\hline HEMBL 571872 & 95157 & 7.1549 & 7.1574 & TRN \\
\hline CHEMBL5 & 5 & 6.8861 & 6.8853 & $T$ \\
\hline CHEMBL570790 & 951 & 7.2596 & 7.2629 & \\
\hline CHEMBL571654 & 595157 & 7.0 & 6.9925 & \\
\hline CHEMBL577114 & 595157 & 5.5229 & 5.5044 & ГRN \\
\hline
\end{tabular}




\begin{tabular}{|c|c|c|c|c|c|}
\hline \\
\hline CHEMBL585945 & 595157 & 7.0 & 7.0049 & TRN & \\
\hline CHEMBL571847 & 595157 & 5.6021 & 5.6522 & TST & \\
\hline CHEMBL571840 & 595157 & 6.0706 & 6.07299 & э9999999995 & TRN \\
\hline CHEMBL585541 & 595157 & 7.0458 & 7.0528 & TRN & \\
\hline CHEMBL583038 & 595157 & 5.3979 & 5.6364 & TST & \\
\hline CHEMBL570326 & 595157 & 7.2596 & 7.2641 & TRN & \\
\hline CHEMBL576291 & 595157 & 6.3979 & 6.3661 & TRN & \\
\hline CHEMBL571182 & 595157 & 5.8239 & 6.0934 & TST & \\
\hline CHEMBL585727 & 595157 & 5.7328 & 6.0749 & TST & \\
\hline CHEMBL584097 & 595157 & 5.0 & 4.9997 & TRN & \\
\hline CHEMBL571844 & 595157 & 6.0969 & 5.8638 & TST & \\
\hline CHEMBL482734 & 595157 & 5.8239 & 5.6134 & TST & \\
\hline CHEMBL578622 & 595157 & 7.2596 & 6.7766 & TST & \\
\hline CHEMBL576114 & 595157 & 5.6478 & 5.7798 & TST & \\
\hline CHEMBL571426 & 595157 & 6.7447 & 6.7503 & TRN & \\
\hline CHEMBL482735 & 595157 & 6.0969 & 5.0504 & TST & \\
\hline CHEMBL570089 & 595157 & 6.5528 & 6.5438 & TRN & \\
\hline CHEMBL572062 & 595157 & 6.0458 & 6.0721 & TRN & \\
\hline CHEMBL583346 & 595157 & 6.699 & 6.6939 & TRN & \\
\hline CHEMBL585946 & 595157 & 6.8239 & 6.8136 & TRN & \\
\hline CHEMBL584749 & 595157 & 5.301 & 5.9324 & TST & \\
\hline CHEMBL602481 & 611932 & 3.0 & 3.1486 & TRN & \\
\hline CHEMBL600405 & 611932 & 5.5376 & 5.4778 & TRN & \\
\hline CHEMBL602076 & 611932 & 5.2147 & 3.6782 & TRN & \\
\hline CHEMBL510282 & 611932 & 3.0 & 3.3864 & TRN & \\
\hline CHEMBL599481 & 611932 & 5.1612 & 4.7349 & TRN & \\
\hline CHEMBL602265 & 611932 & 4.4815 & 3.6729 & TRN & \\
\hline CHEMBL601224 & 611932 & 3.0 & 4.6988 & TRN & \\
\hline CHEMBL602480 & 611932 & 3.0 & 4.9086 & TST & \\
\hline CHEMBL600593 & 611932 & 3.0 & 4.9092 & TRN & \\
\hline CHEMBL601414 & 611932 & 5.8861 & 4.9968 & TRN & \\
\hline CHEMBL601874 & 611932 & 3.0 & 4.8632 & TRN & \\
\hline CHEMBL605783 & 611932 & 3.0 & 4.8962 & TRN & \\
\hline CHEMBL605584 & 611932 & 3.0 & 3.9749 & TRN & \\
\hline CHEMBL603095 & 611932 & 6.1938 & 6.5848 & TRN & \\
\hline CHEMBL601229 & 611932 & 3.0 & 3.1309 & TRN & \\
\hline CHEMBL601207 & 611932 & 3.0 & 3.7021 & TRN & \\
\hline CHEMBL603094 & 611932 & 6.6021 & 6.8392 & TRN & \\
\hline CHEMBL600610 & 611932 & 4.3872 & 4.4927 & TRN & \\
\hline CHEMBL600992 & 611932 & 5.041 & 4.7511 & TRN & \\
\hline CHEMBL601856 & 611932 & 6.0 & 6.8889 & TST & \\
\hline CHEMBL600794 & 611932 & 5.5686 & 4.5769 & TRN & \\
\hline CHEMBL598551 & 611932 & 6.0969 & 5.9223 & TST & \\
\hline CHEMBL600404 & 611932 & 4.8861 & 4.7888 & TRN & \\
\hline CHEMBL599548 & 611932 & 4.4437 & 4.3046 & TST & \\
\hline CHEMBL 88502 & 611932 & 5.4949 & 6.5205 & TST & \\
\hline CHEMBL600819 & 611932 & 6.2007 & 5.2446 & TRN & \\
\hline CHEMBL600861 & 611932 & 3.0 & 3.9367 & TRN & \\
\hline
\end{tabular}


Supplemental Table S2.txt

\begin{tabular}{|c|c|c|c|c|}
\hline CHEMBL606031 & 611932 & 4.6021 & 3.8982 & TRN \\
\hline CHEMBL604728 & 611932 & 5.5528 & 5.0576 & TRN \\
\hline CHEMBL604536 & 611932 & 7.2218 & 7.08 & TRN \\
\hline CHEMBL601723 & 611932 & 6.2518 & 6.6445 & TST \\
\hline CHEMBL598726 & 611932 & 5.2218 & 4.4041 & TRN \\
\hline CHEMBL603493 & 611932 & 3.0 & 3.4056 & TRN \\
\hline CHEMBL598725 & 611932 & 5.6576 & 4.2285 & TRN \\
\hline CHEMBL603967 & 611932 & 4.8539 & 4.7861 & TRN \\
\hline CHEMBL 86771 & 611932 & 6.4949 & 6.7071 & TST \\
\hline CHEMBL602486 & 611932 & 3.0 & 6.5962 & TST \\
\hline CHEMBL602069 & 611932 & 4.7696 & 4.2399 & TRN \\
\hline CHEMBL591926 & 611932 & 3.0 & 2.4709 & TRN \\
\hline CHEMBL600388 & 611932 & 3.0 & 4.2945 & TRN \\
\hline CHEMBL603914 & 611932 & 6.0 & 4.9608 & TRN \\
\hline CHEMBL601413 & 611932 & 6.5229 & 6.0221 & TRN \\
\hline CHEMBL591458 & 611932 & 5.6576 & 4.938 & TRN \\
\hline CHEMBL601658 & 611932 & 3.0 & 2.4229 & TRN \\
\hline CHEMBL600009 & 611932 & 5.7212 & 6.3209 & TST \\
\hline CHEMBL600609 & 611932 & 4.7696 & 3.5821 & TST \\
\hline CHEMBL602467 & 611932 & 3.0 & 5.4864 & TST \\
\hline CHEMBL604535 & 611932 & 7.4949 & 7.0441 & TRN \\
\hline CHEMBL601208 & 611932 & 4.8239 & 4.6154 & TRN \\
\hline CHEMBL600416 & 611932 & 3.0 & 3.1457 & TRN \\
\hline CHEMBL600008 & 611932 & 6.2757 & 7.2133 & TST \\
\hline CHEMBL602266 & 611932 & 3.0 & 3.3302 & TRN \\
\hline CHEMBL600818 & 611932 & 3.0 & 3.3797 & TST \\
\hline CHEMBL605791 & 611932 & 3.0 & 3.7057 & TRN \\
\hline CHEMBL601021 & 611932 & 3.0 & 3.0036 & TRN \\
\hline CHEMBL601628 & 611932 & 3.9208 & 4.8392 & TST \\
\hline CHEMBL3914355 & 1642023 & 7.4949 & 6.8432 & TRN \\
\hline CHEMBL3956041 & 1642023 & 7.0969 & 7.1965 & TRN \\
\hline CHEMBL 3955541 & 1642023 & 6.5513 & 6.8775 & TRN \\
\hline CHEMBL 3898381 & 1642023 & 5.5079 & 5.7296 & TRN \\
\hline CHEMBL 3040405 & 1642023 & 6.8508 & 6.6461 & TRN \\
\hline CHEMBL 3934042 & 1642023 & 6.3958 & 6.9403 & TST \\
\hline CHEMBL 3944600 & 1642023 & 7.2676 & 6.8557 & TRN \\
\hline CHEMBL3933859 & 1642023 & 7.3468 & 6.2813 & TRN \\
\hline CHEMBL 3889914 & 1642023 & 6.8356 & 6.8626 & TRN \\
\hline CHEMBL 3930947 & 1642023 & 6.4622 & 6.8161 & TRN \\
\hline CHEMBL 3949246 & 1642023 & 7.3565 & 6.9121 & TRN \\
\hline CHEMBL 3950374 & 1642023 & 6.1637 & 6.07799 & 9999999999 \\
\hline CHEMBL 3906624 & 1642023 & 6.8794 & 7.1008 & TRN \\
\hline CHEMBL3953461 & 1642023 & 5.4734 & 6.0109 & TST \\
\hline CHEMBL3896116 & 1642023 & 6.7033 & 6.5031 & TRN \\
\hline CHEMBL 3965608 & 1642023 & 6.3098 & 6.3825 & TRN \\
\hline CHEMBL 3957743 & 1642023 & 7.301 & 7.2639 & TRN \\
\hline CHEMBL 3970703 & 1642023 & 7.0655 & 6.687 & TRN \\
\hline CHEMBL 3948020 & 1642023 & 5.9504 & 5.7316 & TRN \\
\hline
\end{tabular}




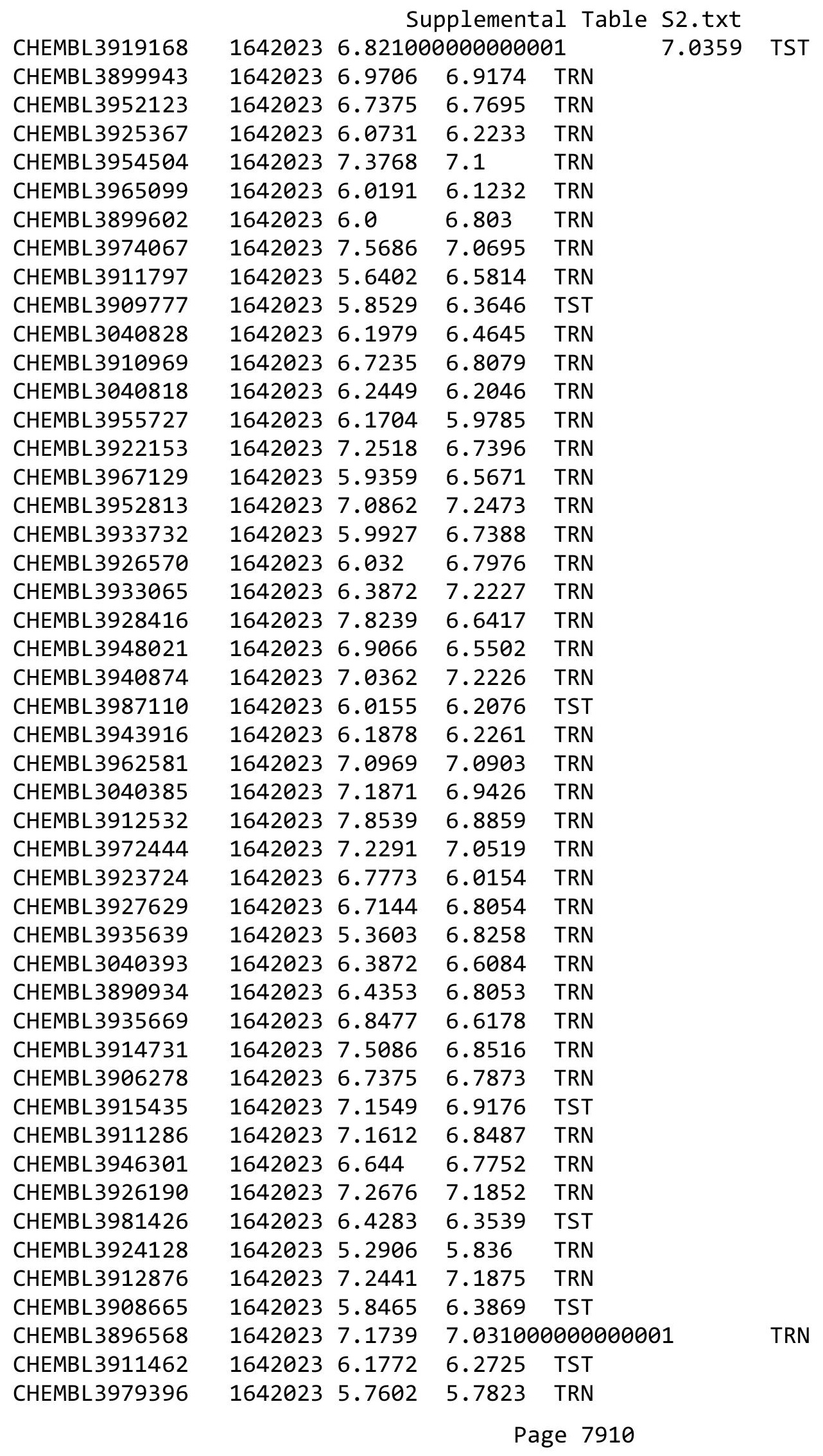


Supplemental Table S2.txt

\begin{tabular}{|c|c|c|c|c|c|c|}
\hline CHEMBL 3903864 & 1642023 & 7.0506 & 7.1107 & TRN & & \\
\hline CHEMBL 3944732 & 1642023 & 6.61799 & 99999999 & 99 & 6.7072 & TST \\
\hline CHEMBL3939245 & 1642023 & 7.6778 & 6.7433 & TRN & & \\
\hline CHEMBL3956026 & 1642023 & 5.7956 & 6.114 & TRN & & \\
\hline CHEMBL 3949640 & 1642023 & 5.2512 & 5.3397 & TRN & & \\
\hline CHEMBL3905369 & 1642023 & 6.6038 & 6.9423 & TST & & \\
\hline CHEMBL3932143 & 1642023 & 7.5376 & 6.7876 & TST & & \\
\hline CHEMBL3978353 & 1642023 & 5.1934 & 6.4963 & TST & & \\
\hline CHEMBL3948318 & 1642023 & 6.9355 & 6.7165 & TRN & & \\
\hline CHEMBL3986420 & 1642023 & 6.8182 & 6.8644 & TST & & \\
\hline CHEMBL3900944 & 1642023 & 6.0 & 6.7504 & TST & & \\
\hline CHEMBL 3921114 & 1642023 & 6.0555 & 6.8462 & TST & & \\
\hline CHEMBL3940451 & 1642023 & 6.6108 & 6.2901 & TST & & \\
\hline CHEMBL 3935349 & 1642023 & 6.7852 & 6.7779 & TRN & & \\
\hline CHEMBL 3891098 & 1642023 & 6.9281 & 6.96700 & 0000000000 & 05 & Trorv \\
\hline CHEMBL 3977386 & 1642023 & 5.0647 & 5.7842 & TST & & \\
\hline CHEMBL3948518 & 1642023 & 7.2596 & 6.6729 & TRN & & \\
\hline CHEMBL 3942830 & 1642023 & 7.0458 & 6.9407 & TRN & & \\
\hline CHEMBL 3977955 & 1642023 & 6.4179 & 6.6084 & TRN & & \\
\hline CHEMBL 3898307 & 1642023 & 6.5003 & 6.7452 & TRN & & \\
\hline CHEMBL3984921 & 1642023 & 6.4283 & 6.2587 & TST & & \\
\hline CHEMBL3943405 & 1642023 & 6.0 & 6.9629 & TST & & \\
\hline CHEMBL 3926445 & 1642023 & 5.2196 & 5.3588 & TRN & & \\
\hline CHEMBL3906466 & 1642023 & 7.3768 & 6.8268 & TST & & \\
\hline CHEMBL3902270 & 1642023 & 5.1314 & 6.7876 & TST & & \\
\hline CHEMBL3040868 & 1642023 & 6.9957 & 6.8386 & TST & & \\
\hline CHEMBL3905054 & 1642023 & 6.8729 & 7.1435 & TRN & & \\
\hline CHEMBL3917199 & 1642023 & 5.6639 & 6.5656 & TRN & & \\
\hline CHEMBL331516 & 139113 & 6.0217 & 5.8788 & TRN & & \\
\hline CHEMBL543890 & 139113 & 5.9352 & 5.9623 & TRN & & \\
\hline CHEMBL123099 & 139113 & 4.3735 & 4.393 & TRN & & \\
\hline CHEMBL121552 & 139113 & 6.0473 & 6.0193 & TRN & & \\
\hline CHEMBL120963 & 139113 & 5.113 & 5.2083 & TRN & & \\
\hline CHEMBL 334245 & 139113 & 6.2096 & 6.4502 & TRN & & \\
\hline CHEMBL120119 & 139113 & 6.8601 & 6.7964 & TRN & & \\
\hline CHEMBL324936 & 139113 & 6.9638 & 6.9537 & TRN & & \\
\hline CHEMBL 340780 & 139113 & 6.2421 & 6.4494 & TST & & \\
\hline CHEMBL332181 & 139113 & 6.1829 & 6.1726 & TRN & & \\
\hline CHEMBL 120080 & 139113 & \multicolumn{3}{|c|}{6.587000000000001} & 6.4502 & \\
\hline CHEMBL122354 & 139113 & 6.4353 & 6.4502 & TRN & & \\
\hline CHEMBL118553 & 139113 & 4.7082 & 4.95100 & 0000000000 & & $\mathrm{n}$ \\
\hline CHEMBL116601 & 139113 & 6.1543 & 6.0244 & TRN & & \\
\hline CHEMBL540316 & 139113 & 5.9461 & 5.8857 & TRN & & \\
\hline CHEMBL340561 & 139113 & 6.3641 & 6.231 & TRN & & \\
\hline CHEMBL 332405 & 139113 & 4.1983 & 4.8277 & TST & & \\
\hline CHEMBL120581 & 139113 & 6.1292 & 6.1837 & TRN & & \\
\hline CHEMBL332645 & 139113 & 4.5069 & 4.4525 & TRN & & \\
\hline CHEMBL121476 & 139113 & 5.6582 & 5.9065 & TRN & & \\
\hline
\end{tabular}




\begin{tabular}{|c|c|c|c|c|c|c|}
\hline & & \multicolumn{5}{|c|}{ Supplemental Table S2.txt } \\
\hline CHEMBL121385 & 139113 & 5.9329 & 5.5631 & TRN & & \\
\hline CHEMBL330892 & 139113 & 5.7593 & 5.9904 & TRN & & \\
\hline CHEMBL334093 & 139113 & 5.6219 & 5.3453 & TRN & & \\
\hline CHEMBL262198 & 139113 & 7.1568 & 6.8236 & TRN & & \\
\hline CHEMBL124173 & 139113 & 5.7555 & 5.9534 & TRN & & \\
\hline CHEMBL333940 & 139113 & 5.6729 & 5.9065 & TRN & & \\
\hline CHEMBL330885 & 139113 & 4.8847 & 4.4382 & TRN & & \\
\hline CHEMBL332320 & 139113 & \multicolumn{3}{|c|}{6.247000000000001} & 6.4502 & TRN \\
\hline CHEMBL330999 & 139113 & 6.7757 & 6.6753 & TRN & & \\
\hline CHEMBL338280 & 139113 & 5.0742 & 5.1499 & TRN & & \\
\hline CHEMBL123198 & 139113 & 5.3807 & 5.5937 & TST & & \\
\hline CHEMBL120329 & 139113 & 5.851 & 5.9654 & TRN & & \\
\hline CHEMBL121059 & 139113 & 6.5493 & 6.4502 & TRN & & \\
\hline CHEMBL120135 & 139113 & 6.0 & 6.4838 & TST & & \\
\hline CHEMBL431688 & 139113 & 5.0761 & 5.1036 & TST & & \\
\hline CHEMBL324712 & 139113 & 6.2807 & 6.0357 & TRN & & \\
\hline CHEMBL120472 & 139113 & 6.8706 & 6.5574 & TRN & & \\
\hline CHEMBL120539 & 139113 & 4.9837 & 5.2135 & TST & & \\
\hline CHEMBL122353 & 139113 & 5.4215 & 5.7588 & TST & & \\
\hline CHEMBL121298 & 139113 & 5.1295 & 5.1006 & TST & & \\
\hline CHEMBL333125 & 139113 & 5.5567 & 5.7745 & TRN & & \\
\hline CHEMBL120109 & 139113 & 4.8635 & 5.2123 & TRN & & \\
\hline CHEMBL121520 & 139113 & 6.8456 & 6.8369 & TRN & & \\
\hline CHEMBL541584 & 139113 & 6.8348 & 6.6209 & TST & & \\
\hline CHEMBL332335 & 139113 & 5.4913 & 5.62799 & 9999999999 & & TRN \\
\hline CHEMBL120972 & 139113 & 5.8019 & 5.9065 & TST & & \\
\hline CHEMBL120599 & 139113 & 6.0777 & 6.1371 & TST & & \\
\hline CHEMBL543177 & 139113 & 6.3253 & 6.4559 & TRN & & \\
\hline CHEMBL332980 & 139113 & 7.2076 & 7.3371 & TRN & & \\
\hline CHEMBL118241 & 139113 & 5.9031 & 5.9065 & TST & & \\
\hline CHEMBL121299 & 139113 & 5.6528 & 5.1793 & TST & & \\
\hline CHEMBL 3693234 & 1528877 & 3.0503 & 2.6443 & TRN & & \\
\hline CHEMBL 3683855 & 1528877 & 3.5876 & 4.0087 & TRN & & \\
\hline CHEMBL 3683898 & 1528877 & 2.7687 & 2.592 & TRN & & \\
\hline CHEMBL 3683849 & 1528877 & 6.0 & 4.8803 & TRN & & \\
\hline CHEMBL3938199 & 1528877 & 3.3349 & 3.7221 & TST & & \\
\hline CHEMBL3688801 & 1528877 & 3.9374 & 3.8417 & TRN & & \\
\hline CHEMBL 3688710 & 1528877 & 2.7364 & 3.7173 & TRN & & \\
\hline CHEMBL 3683844 & 1528877 & 3.5207 & 4.3881 & TRN & & \\
\hline CHEMBL 3693224 & 1528877 & 3.7699 & 3.1754 & TRN & & \\
\hline CHEMBL 3693259 & 1528877 & 3.6028 & 3.636 & TST & & \\
\hline CHEMBL 3688724 & 1528877 & 3.3496 & 3.8872 & TRN & & \\
\hline CHEMBL 3688635 & 1528877 & 3.5324 & 3.5574 & TRN & & \\
\hline CHEMBL 3688804 & 1528877 & 3.752 & 3.8857 & TST & & \\
\hline CHEMBL3688615 & 1528877 & 3.0545 & 3.8062 & TRN & & \\
\hline CHEMBL 3688821 & 1528877 & 2.3979 & 3.1126 & TRN & & \\
\hline CHEMBL 3639875 & 1528877 & 3.5995 & 3.2043 & TRN & & \\
\hline CHEMBL 3688622 & 1528877 & 2.9694 & 3.3576 & TRN & & \\
\hline
\end{tabular}




\begin{tabular}{|c|c|c|c|c|c|c|}
\hline & & \multicolumn{5}{|c|}{ Supplemental Table S2.txt } \\
\hline CHEMBL 3693232 & 1528877 & 3.6418 & 2.472 & TRN & & \\
\hline CHEMBL 3683874 & 1528877 & 2.969 & 3.3743 & TRN & & \\
\hline CHEMBL3688663 & 1528877 & 2.7431 & 3.7167 & TRN & & \\
\hline CHEMBL 3688657 & 1528877 & 3.0195 & 3.1747 & TRN & & \\
\hline CHEMBL3683922 & 1528877 & 3.0785 & 2.7456 & TRN & & \\
\hline CHEMBL 3688630 & 1528877 & 3.0184 & 3.2638 & TRN & & \\
\hline CHEMBL 3688727 & 1528877 & 3.4751 & 3.695 & TRN & & \\
\hline CHEMBL 3688690 & 1528877 & 3.6914 & 2.9643 & TST & & \\
\hline CHEMBL 3688614 & 1528877 & 3.2476 & 3.3324 & TRN & & \\
\hline CHEMBL3688679 & 1528877 & 3.7212 & 3.1258 & TRN & & \\
\hline CHEMBL 3688700 & 1528877 & 6.0 & 4.5297 & TRN & & \\
\hline CHEMBL 3895393 & 1528877 & 3.4589 & 4.1121 & TST & & \\
\hline CHEMBL3688671 & 1528877 & 2.9887 & 3.102 & TST & & \\
\hline CHEMBL 3688735 & 1528877 & 3.3548 & 3.4896 & TRN & & \\
\hline CHEMBL3693247 & 1528877 & 3.7503 & 3.6824 & TST & & \\
\hline CHEMBL 3688665 & 1528877 & 3.4856 & 3.5126 & TRN & & \\
\hline CHEMBL3693254 & 1528877 & 3.3099 & 2.9395 & TRN & & \\
\hline CHEMBL 3688723 & 1528877 & 3.3321 & 3.8138 & TRN & & \\
\hline CHEMBL 3683881 & 1528877 & 3.0054 & 3.3599 & TRN & & \\
\hline CHEMBL 3693248 & 1528877 & 3.2127 & 3.8455 & TST & & \\
\hline CHEMBL 3683879 & 1528877 & 2.9993 & 2.5853 & TRN & & \\
\hline CHEMBL 3688752 & 1528877 & 6.0 & 3.9591 & TST & & \\
\hline CHEMBL 3688718 & 1528877 & 3.1647 & 3.2805 & TRN & & \\
\hline CHEMBL 3955470 & 1528877 & 3.4242 & 3.3412 & TST & & \\
\hline CHEMBL 3683805 & 1528877 & 2.4623 & 2.8326 & TRN & & \\
\hline CHEMBL 3688795 & 1528877 & 3.9172 & 3.0666 & TST & & \\
\hline CHEMBL 3688678 & 1528877 & 4.1107 & 3.617 & TRN & & \\
\hline CHEMBL 3683884 & 1528877 & 3.253 & 4.4621 & TRN & & \\
\hline CHEMBL 3688670 & 1528877 & 2.7191 & 3.0912 & TRN & & \\
\hline CHEMBL3693255 & 1528877 & 3.0179 & 2.8208 & TRN & & \\
\hline CHEMBL 3960008 & 1528877 & 3.3103 & 4.0638 & TST & & \\
\hline CHEMBL3906496 & 1528877 & 3.3377 & 4.0007 & TST & & \\
\hline CHEMBL 3683900 & 1528877 & 3.5193 & 3.5232 & TRN & & \\
\hline CHEMBL3688716 & 1528877 & 3.1613 & 2.7944 & TRN & & \\
\hline CHEMBL3688704 & 1528877 & 6.0 & 4.4325 & TRN & & \\
\hline CHEMBL3688623 & 1528877 & 3.2286 & 3.6099 & TRN & & \\
\hline CHEMBL3693227 & 1528877 & 3.444 & 3.4835 & TRN & & \\
\hline CHEMBL 3693226 & 1528877 & 3.12600 & 00000000 & 003 & 3.4036 & TRN \\
\hline CHEMBL 3688652 & 1528877 & 3.2666 & 4.1718 & TRN & & \\
\hline CHEMBL3688739 & 1528877 & 6.0 & 5.7782 & TRN & & \\
\hline CHEMBL 3683882 & 1528877 & 3.4654 & 3.2511 & TRN & & \\
\hline CHEMBL 3688640 & 1528877 & 6.0 & 4.46 & TRN & & \\
\hline CHEMBL 3683871 & 1528877 & 2.524 & 2.9837 & TRN & & \\
\hline CHEMBL 3688743 & 1528877 & 3.2862 & 3.0765 & TRN & & \\
\hline CHEMBL 3688694 & 1528877 & 2.9934 & 3.0614 & TRN & & \\
\hline CHEMBL 3683891 & 1528877 & 3.1841 & 4.8018 & TRN & & \\
\hline CHEMBL3683905 & 1528877 & 6.0 & 5.586 & TRN & & \\
\hline CHEMBL3688719 & 1528877 & 3.3331 & 3.9174 & TRN & & \\
\hline
\end{tabular}


Supplemental Table S2.txt

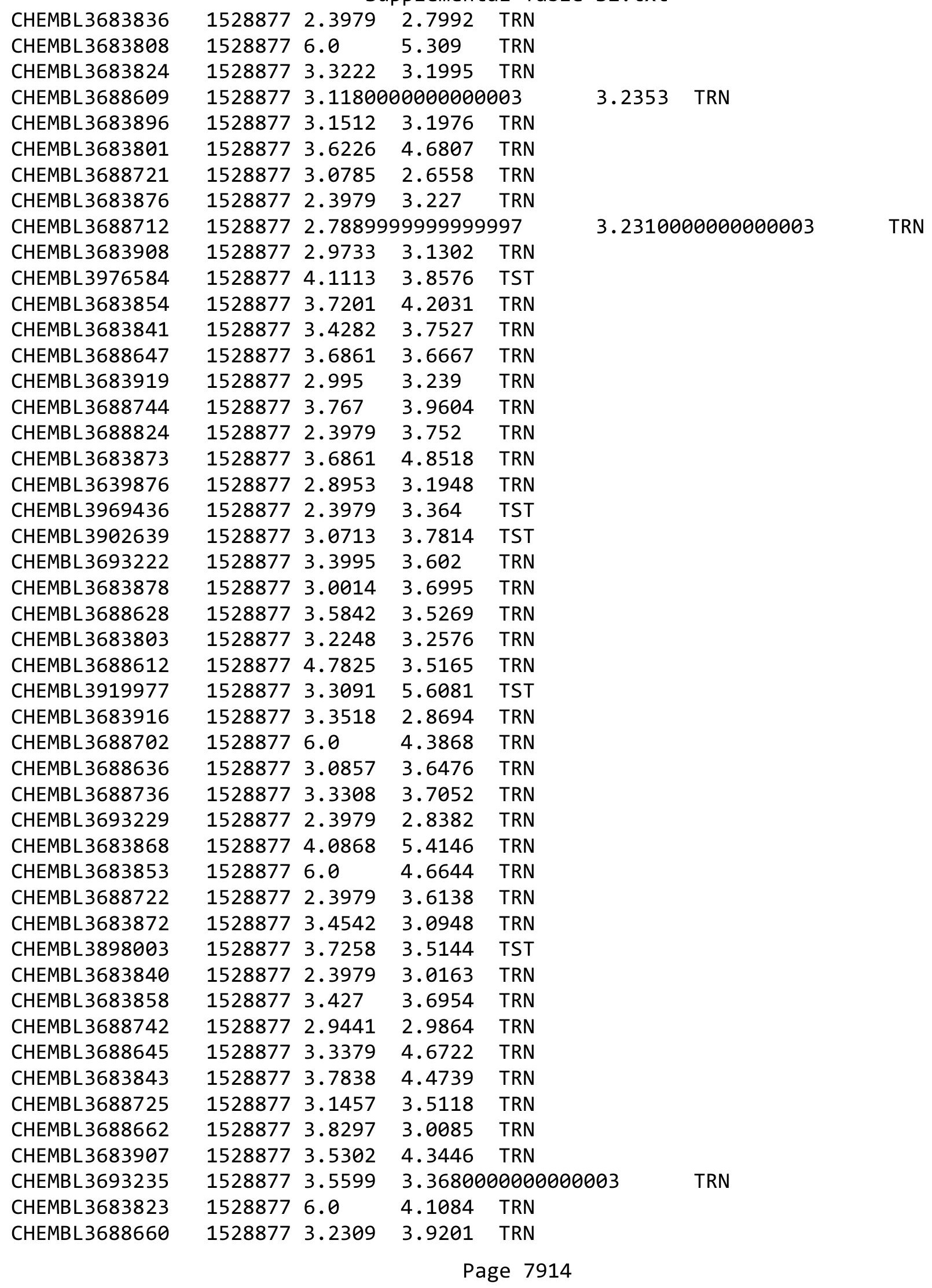


Supplemental Table S2.txt

\begin{tabular}{|c|c|c|c|c|c|}
\hline CHEMBL3688707 & 1528877 & 3.1873 & 3.6748 & TRN & \\
\hline CHEMBL3688800 & 1528877 & 3.6308 & 3.6219 & TRN & \\
\hline CHEMBL3683846 & 1528877 & 3.0395 & 3.6843 & TRN & \\
\hline CHEMBL 3688620 & 1528877 & 3.1135 & 3.22 & TRN & \\
\hline CHEMBL3688706 & 1528877 & 2.5426 & 2.9372 & TRN & \\
\hline CHEMBL3683917 & 1528877 & 3.0727 & 3.057 & TRN & \\
\hline CHEMBL3688688 & 1528877 & 3.9832 & 3.0926 & TRN & \\
\hline CHEMBL3683842 & 1528877 & 3.0498 & 3.6547 & TRN & \\
\hline CHEMBL 3688820 & 1528877 & 3.7044 & 3.3432 & TRN & \\
\hline CHEMBL3683889 & 1528877 & 6.0 & 5.4861 & TRN & \\
\hline CHEMBL3683920 & 1528877 & 3.0338 & 2.8647 & TRN & \\
\hline CHEMBL3683910 & 1528877 & 3.0223 & 3.6325 & TRN & \\
\hline CHEMBL3688668 & 1528877 & 4.3174 & 2.9026 & TRN & \\
\hline CHEMBL3688822 & 1528877 & 3.1609 & 4.08 & TRN & \\
\hline CHEMBL3688666 & 1528877 & 2.2279 & 3.3727 & TRN & \\
\hline CHEMBL3688610 & 1528877 & 3.2724 & 3.137 & TRN & \\
\hline CHEMBL3683883 & 1528877 & 3.1394 & 4.0793 & TRN & \\
\hline CHEMBL 3688680 & 1528877 & 3.5678 & 3.7691 & TST & \\
\hline CHEMBL3683851 & 1528877 & 3.8447 & 3.7977 & TRN & \\
\hline CHEMBL3688823 & 1528877 & 2.9626 & 3.571 & TRN & \\
\hline CHEMBL3683913 & 1528877 & 3.1151 & 2.7701 & TRN & \\
\hline CHEMBL3688803 & 1528877 & 4.2765 & 3.2491 & TST & \\
\hline CHEMBL 3688684 & 1528877 & 3.4802 & 3.2236 & TRN & \\
\hline CHEMBL3688731 & 1528877 & 2.3979 & 2.6034 & TRN & \\
\hline CHEMBL3683797 & 1528877 & 6.0 & 5.3947 & TRN & \\
\hline CHEMBL3683856 & 1528877 & 3.2278 & 3.7955 & TRN & \\
\hline CHEMBL3903848 & 1528877 & 3.5615 & 4.1818 & TST & \\
\hline CHEMBL3688747 & 1528877 & 3.6726 & 4.2667 & TST & \\
\hline CHEMBL3683877 & 1528877 & 2.9194 & 3.9214 & TRN & \\
\hline CHEMBL3688638 & 1528877 & 3.4316 & 3.7947 & TRN & \\
\hline CHEMBL3683795 & 1528877 & 6.0 & 5.629 & TRN & \\
\hline CHEMBL3688624 & 1528877 & 3.0578 & 3.043 & TRN & \\
\hline CHEMBL3683847 & 1528877 & 3.585 & 4.3361 & TRN & \\
\hline CHEMBL3688816 & 1528877 & 2.8686 & 2.8115 & TRN & \\
\hline CHEMBL3693253 & 1528877 & 3.1009 & 3.2524 & TRN & \\
\hline CHEMBL3693245 & 1528877 & 6.0 & 3.6955 & TST & \\
\hline CHEMBL3683845 & 1528877 & 3.2409 & 3.9643 & TRN & \\
\hline CHEMBL3688646 & 1528877 & 6.0 & 4.6251 & TRN & \\
\hline CHEMBL 3688711 & 1528877 & 3.1399 & 3.4921 & TRN & \\
\hline CHEMBL3688667 & 1528877 & 2.3979 & 2.9527 & TRN & \\
\hline CHEMBL 3683806 & 1528877 & 6.0 & 5.7979 & TRN & \\
\hline CHEMBL3688812 & 1528877 & 2.741 & 2.9685 & TRN & \\
\hline CHEMBL3688656 & 1528877 & 6.0 & 3.8666 & TRN & \\
\hline CHEMBL3688675 & 1528877 & 3.313 & 3.2337 & TRN & \\
\hline CHEMBL3683915 & 1528877 & 3.2352 & 2.8116 & TRN & \\
\hline CHEMBL3693231 & 1528877 & 3.1265 & 2.92 & TRN & \\
\hline CHEMBL3693250 & 1528877 & $3.5010 e$ & 000000000 & 203 & 3.8023 \\
\hline CHEMBL 3688818 & 1528877 & 2.972 & 3.1434 & TRN & \\
\hline
\end{tabular}


Supplemental Table S2.txt

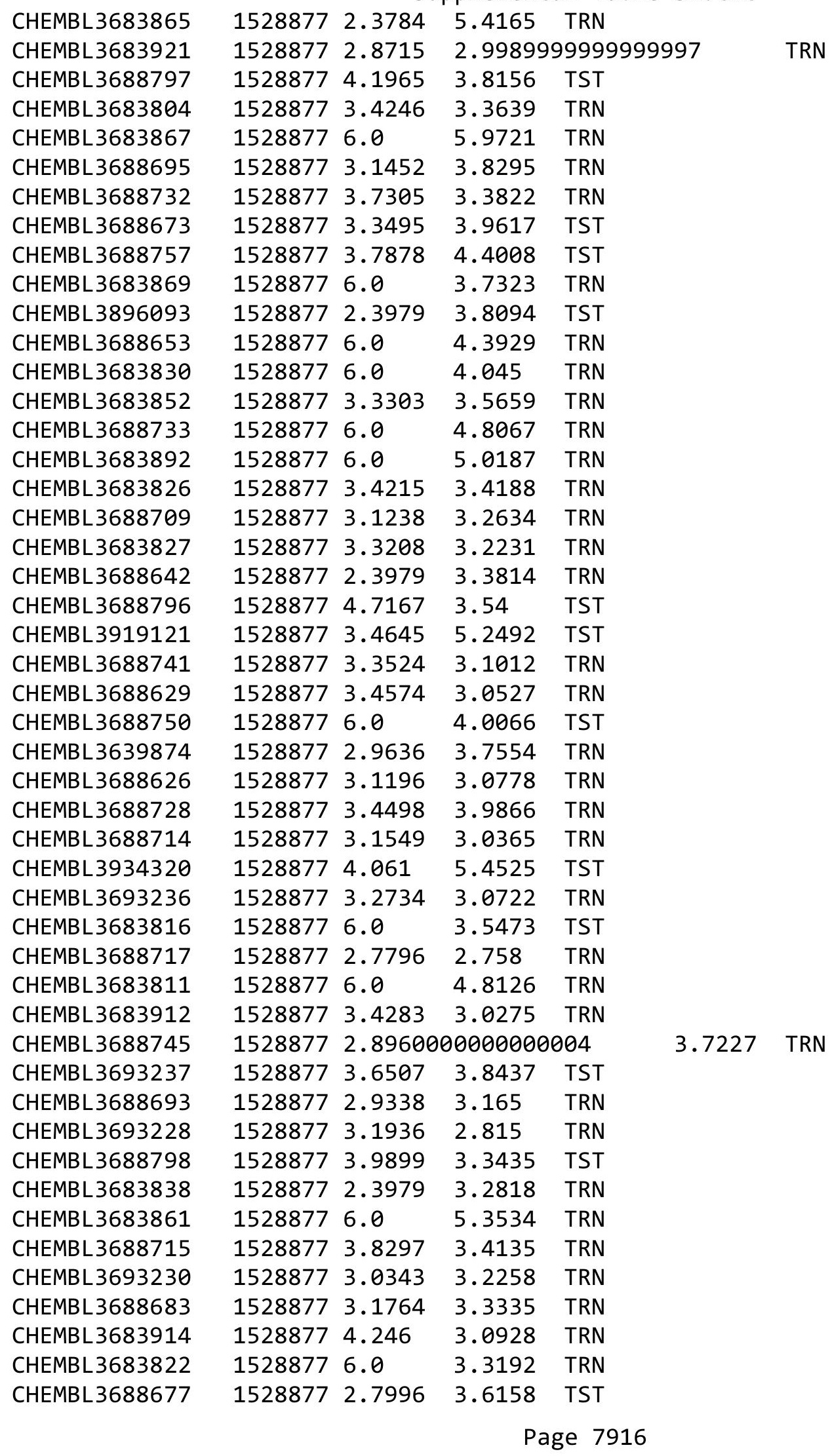


Supplemental Table S2.txt

\begin{tabular}{|c|c|c|c|c|}
\hline CHEMBL 3688698 & 1528877 & 6.0 & 3.5668 & TRN \\
\hline CHEMBL3971300 & 1528877 & 2.5398 & 4.2512 & TST \\
\hline CHEMBL 3688815 & 1528877 & 3.3553 & 4.2251 & TRN \\
\hline CHEMBL3688661 & 1528877 & 3.6135 & \multicolumn{2}{|c|}{ 3.7539999999999996 } \\
\hline CHEMBL3688619 & 1528877 & 3.7986 & 2.9326 & TRN \\
\hline CHEMBL3688729 & 1528877 & 3.5406 & 3.9105 & TRN \\
\hline CHEMBL 3683894 & 1528877 & 6.0 & 4.5837 & TRN \\
\hline CHEMBL 3688611 & 1528877 & 3.3239 & 3.346 & TRN \\
\hline CHEMBL 3688802 & 1528877 & 4.1032 & 3.4418 & TST \\
\hline CHEMBL3688651 & 1528877 & 6.0 & 4.9504 & TRN \\
\hline CHEMBL3688737 & 1528877 & 3.3762 & 3.3983 & TRN \\
\hline CHEMBL3936217 & 1528877 & 3.2386 & 3.7569 & TST \\
\hline CHEMBL3688616 & 1528877 & 3.1235 & 2.9741 & TRN \\
\hline CHEMBL3688669 & 1528877 & 2.3979 & 2.8239 & TRN \\
\hline CHEMBL3693233 & 1528877 & 2.8341 & 3.0939 & TRN \\
\hline CHEMBL3688617 & 1528877 & 3.1148 & 2.9295 & TRN \\
\hline CHEMBL3683918 & 1528877 & 3.4433 & 3.2604 & TRN \\
\hline CHEMBL 3688637 & 1528877 & 3.5075 & 3.6347 & TRN \\
\hline CHEMBL3688738 & 1528877 & 6.0 & 4.7962 & TST \\
\hline CHEMBL3688621 & 1528877 & 2.8341 & 3.1328 & TRN \\
\hline CHEMBL3683828 & 1528877 & 2.9538 & 3.003 & TRN \\
\hline CHEMBL3688618 & 1528877 & 3.1758 & 3.2506 & TRN \\
\hline CHEMBL 3683789 & 1528877 & 3.042 & 2.8422 & TRN \\
\hline CHEMBL3688814 & 1528877 & 3.1352 & 3.2564 & TRN \\
\hline CHEMBL 3688627 & 1528877 & 3.153 & 3.2211 & TRN \\
\hline CHEMBL3688632 & 1528877 & 3.2881 & 2.843 & TRN \\
\hline CHEMBL 3693238 & 1528877 & 4.1662 & 3.7038 & TST \\
\hline CHEMBL3688664 & 1528877 & 2.3717 & 3.3335 & TRN \\
\hline CHEMBL3683799 & 1528877 & 6.0 & 5.5648 & TRN \\
\hline CHEMBL 3683809 & 1528877 & 6.0 & 5.3888 & TRN \\
\hline CHEMBL 3688682 & 1528877 & 2.5912 & 2.9644 & TRN \\
\hline CHEMBL3683857 & 1528877 & 3.1177 & 2.6677 & TRN \\
\hline CHEMBL 3688654 & 1528877 & 3.4401 & 3.925 & TRN \\
\hline CHEMBL3688634 & 1528877 & 3.5185 & 3.4563 & TRN \\
\hline CHEMBL 3688686 & 1528877 & 3.9318 & 3.2881 & TRN \\
\hline CHEMBL3932092 & 1528877 & 4.0683 & 3.5614 & TST \\
\hline CHEMBL3683909 & 1528877 & 3.3331 & 3.8916 & TRN \\
\hline CHEMBL3683885 & 1528877 & 2.9549 & 3.5226 & TRN \\
\hline CHEMBL3683802 & 1528877 & 3.1334 & 2.85399 & 79999999996 \\
\hline CHEMBL 3688730 & 1528877 & 2.9843 & 2.7303 & TST \\
\hline CHEMBL3688813 & 1528877 & 3.4533 & 3.5158 & TST \\
\hline CHEMBL3683860 & 1528877 & 6.0 & 4.2037 & TST \\
\hline CHEMBL3688819 & 1528877 & 3.3215 & 3.1252 & TST \\
\hline CHEMBL3683864 & 1528877 & 6.0 & 5.99 & TST \\
\hline CHEMBL 3688676 & 1528877 & 2.9102 & 3.2707 & TST \\
\hline CHEMBL3683904 & 1528877 & 6.0 & 4.9175 & TST \\
\hline CHEMBL3688689 & 1528877 & 3.3526 & 3.3445 & TST \\
\hline CHEMBL3688708 & 1528877 & 2.8014 & 3.6957 & TST \\
\hline
\end{tabular}

Page 7917 
Supplemental Table S2.txt

\begin{tabular}{|c|c|c|c|c|}
\hline 3 & 528877 & 2.90 & 2.7189 & בו \\
\hline & 528877 & 6.0 & 5.7718 & \\
\hline HEMRI & 28877 & 3.2365 & & \\
\hline HEMBL & 3877 & 6227 & & \\
\hline AEMBL3688806 & 528877 & 3.7247 & 1198 & \\
\hline HEMBL368 & 528877 & 3.4968 & 5523 & \\
\hline HEMBL & 28877 & $\partial 911$ & & \\
\hline AEMBL & 8877 & 3.4899 & & \\
\hline HEMBL3688756 & 528877 & 6.0 & 9939 & \\
\hline HEMBL3693240 & 528877 & 3.0799 & 5905 & \\
\hline HEMBL 3693 & 528877 & 3.4139 & 5329 & \\
\hline IEME & 528877 & 277 & 844 & \\
\hline HEMBL; & 3877 & 3.1751 & 3067 & \\
\hline HEMBL3688625 & 528877 & 2.9117 & 8358 & \\
\hline HEMBL36838 & 528877 & 2.8944 & & \\
\hline HEMBL 368 & 877 & 3.2885 & 1028 & \\
\hline HEMBL & 877 & 3.3065 & 952 & \\
\hline HEMBL; & 877 & 3.4166 & 834 & \\
\hline HEMBL 3934 & 638060 & 8.7447 & 7906 & \\
\hline AEMBL 316 & 060 & 98 & & \\
\hline HEMBL & 060 & 7. & 383 & \\
\hline AEM & 60 & 57 & 22 & \\
\hline HEMBL & $\partial 60$ & 576 & 013 & \\
\hline HEMBL & $\partial 60$ & 3539 & & \\
\hline HEMBL119 & 060 & 6.6861 & 35 & \\
\hline HEMBL: & 3060 & 757 & 143 & \\
\hline HEME & 060 & 18 & 95 & 更 \\
\hline HEME & 60 & 928 & 412 & \\
\hline HEMBL 330 & & 229 & & RIN \\
\hline AEMBL90516 & 538060 & 6.8327 & 432 & RN \\
\hline HEMBL & 3060 & 147 & 93 & Niv \\
\hline HFM & 60 & 79 & & \\
\hline ح & & & & $\mathrm{RN}$ \\
\hline HEMBL914 & 8060 & 8 . & 65 & RN \\
\hline HEMBL 90268 & 3060 & 7.4815 & 279 & RN \\
\hline A & 060 & 18 & 72 & RN \\
\hline 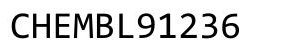 & 50 & & 331 & $\mathrm{RN}$ \\
\hline HEMBL199 & & 7.3 & 045 & TRN \\
\hline HEMBL 392 & 060 & 7.4559 & 232 & $\Gamma R$ \\
\hline Th & 360 & & 04 & RN \\
\hline HFMRI 3 & 060 & 96 & 421 & \\
\hline HEMBL3 & 060 & 6.7399 & 1989 & 「RN \\
\hline HEMBL398: & 638060 & 7.8861 & 9349 & $\Gamma R$ \\
\hline HEMBL316 & 638060 & 7.6021 & 046 & TR \\
\hline HEMBL & & & & \\
\hline HEMBL 90185 & 638060 & 7.9586 & 162 & \\
\hline CHEMBL91281 & 638060 & 8.301 & 5409 & \\
\hline LHEMBL 393046 & 1638060 & 7.7212 & 7.9832 & נI \\
\hline
\end{tabular}

Page 7918 
Supplemental Table S2.txt

\begin{tabular}{|c|c|c|c|c|c|}
\hline CHEMBL91442 & 1638060 & 6.8697 & 7.3465 & TRN & \\
\hline CHEMBL92355 & 1638060 & 7.2676 & 7.3147 & TRN & \\
\hline CHEMBL197579 & 1638060 & 7.6383 & 7.5934 & TRN & \\
\hline CHEMBL88795 & 1638060 & 8.1871 & 8.2722 & TRN & \\
\hline CHEMBL3897550 & 1638060 & 7.1938 & 6.7035 & TST & \\
\hline CHEMBL3977587 & 1638060 & 7.8861 & 8.0236 & TRN & \\
\hline CHEMBL3910303 & 1638060 & 7.9208 & 7.6877 & TRN & \\
\hline CHEMBL3907290 & 1638060 & 6.9355 & 7.206 & TRN & \\
\hline CHEMBL3976524 & 1638060 & 8.0223 & 7.9775 & TRN & \\
\hline CHEMBL3968852 & 1638060 & 6.9666 & 6.836 & TST & \\
\hline CHEMBL382967 & 1638060 & 8.1549 & 8.0003 & TRN & \\
\hline CHEMBL327207 & 1638060 & 8.1549 & 7.8136 & TRN & \\
\hline CHEMBL314096 & 1638060 & 8.1549 & 8.1062 & TRN & \\
\hline CHEMBL315868 & 1638060 & 8.3188 & 8.4532 & TRN & \\
\hline CHEMBL3917557 & 1638060 & 8.2147 & 8.2318 & TRN & \\
\hline CHEMBL371926 & 1638060 & 7.4202 & 7.5006 & TRN & \\
\hline CHEMBL197242 & 1638060 & 5.9957 & 6.8459 & TRN & \\
\hline CHEMBL1199647 & 1638060 & 8.2757 & 7.6482 & TRN & \\
\hline CHEMBL3922955 & 1638060 & 7.7959 & 7.8211 & TRN & \\
\hline CHEMBL90589 & 1638060 & 8.2218 & 8.3964 & TRN & \\
\hline CHEMBL3960740 & 1638060 & 8.2757 & 8.204 & TST & \\
\hline CHEMBL430839 & 1638060 & 8.0555 & 8.17799 & 9999999999 & TRN \\
\hline CHEMBL328066 & 1638060 & 7.3665 & 7.4844 & TRN & \\
\hline CHEMBL197674 & 1638060 & 7.7212 & 7.4028 & TRN & \\
\hline CHEMBL3961549 & 1638060 & 8.0044 & 7.8888 & TRN & \\
\hline CHEMBL3895160 & 1638060 & 5.8386 & 6.2537 & TRN & \\
\hline CHEMBL3909635 & 1638060 & 7.9586 & 8.2547 & TRN & \\
\hline CHEMBL90914 & 1638060 & 8.1308 & 8.1302 & TRN & \\
\hline CHEMBL314733 & 1638060 & 7.7959 & 7.5458 & TRN & \\
\hline CHEMBL327683 & 1638060 & 7.284 & 7.1089 & TST & \\
\hline CHEMBL3914770 & 1638060 & 8.2757 & 8.4642 & TST & \\
\hline CHEMBL194235 & 1638060 & 7.585 & 7.6127 & TRN & \\
\hline CHEMBL 88540 & 1638060 & 8.2441 & 8.231 & TRN & \\
\hline CHEMBL91305 & 1638060 & 8.1427 & 7.7693 & TRN & \\
\hline CHEMBL3944828 & 1638060 & 8.8539 & 8.0723 & TRN & \\
\hline CHEMBL440211 & 1638060 & 7.6021 & 7.4419 & TST & \\
\hline CHEMBL205821 & 1638060 & 7.8239 & 7.8145 & TST & \\
\hline CHEMBL330534 & 1638060 & 8.3468 & 7.9478 & TST & \\
\hline CHEMBL3954160 & 1638060 & 6.4449 & 6.8844 & TST & \\
\hline CHEMBL3928643 & 1638060 & 6.4685 & 6.98 & TST & \\
\hline CHEMBL3947447 & 1638060 & 6.1938 & 7.0319 & TST & \\
\hline CHEMBL3983710 & 1638060 & 6.5186 & 7.2298 & TST & \\
\hline CHEMBL3917051 & 1638060 & 6.6364 & 6.7396 & TST & \\
\hline CHEMBL3945053 & 1638060 & 7.5086 & 7.1923 & TST & \\
\hline CHEMBL1199895 & 1638060 & 4.6459 & 5.6918 & TST & \\
\hline CHEMBL3951248 & 1638060 & 8.4089 & 7.4608 & TST & \\
\hline CHEMBL262735 & 1638060 & 7.8539 & 7.8376 & TST & \\
\hline CHEMBL1371036 & 688723 & 3.0 & 2.7065 & TST & \\
\hline
\end{tabular}




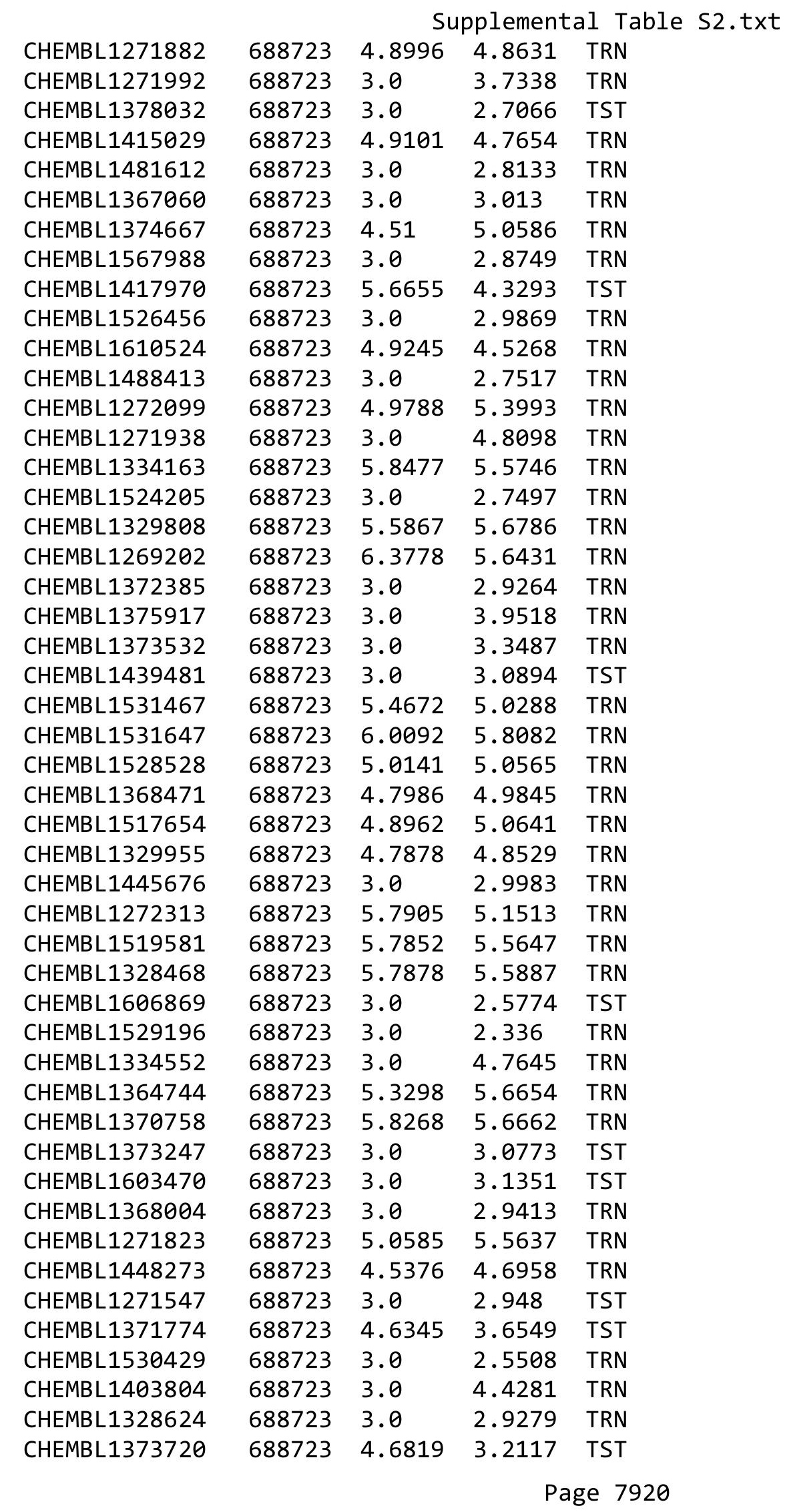




$$
\text { Supplemental Table S2.txt }
$$

\begin{tabular}{|c|c|c|c|c|c|}
\hline CHEMBL1271881 & 688723 & 5.6676 & 5.6205 & TRN & \\
\hline CHEMBL1271765 & 688723 & 5.6126 & 5.8644 & TRN & \\
\hline CHEMBL1598121 & 688723 & 5.9393 & 5.5141 & TRN & \\
\hline CHEMBL1604856 & 688723 & 3.0 & 3.2097 & TST & \\
\hline CHEMBL1325071 & 688723 & 3.0 & 2.8269 & TRN & \\
\hline CHEMBL1323507 & 688723 & \multicolumn{2}{|c|}{6.247999999999999} & 6.0991 & TRN \\
\hline CHEMBL1366249 & 688723 & 3.0 & 4.526 & TRN & \\
\hline CHEMBL1451200 & 688723 & 5.7212 & 5.0297 & TRN & \\
\hline CHEMBL1604250 & 688723 & 3.0 & 2.8107 & TRN & \\
\hline CHEMBL1453492 & 688723 & 3.0 & 2.9593 & TRN & \\
\hline CHEMBL1490796 & 688723 & 3.0 & 2.8776 & TRN & \\
\hline CHEMBL1487009 & 688723 & 3.0 & 4.1558 & TRN & \\
\hline CHEMBL1271764 & 688723 & 6.4413 & 5.6085 & TRN & \\
\hline CHEMBL1572273 & 688723 & 3.0 & 2.9872 & TRN & \\
\hline CHEMBL1271937 & 688723 & 3.0 & 3.3576 & TRN & \\
\hline CHEMBL1567695 & 688723 & 5.7696 & 5.0471 & TRN & \\
\hline CHEMBL1370355 & 688723 & 3.0 & 4.2424 & TRN & \\
\hline CHEMBL1397246 & 688723 & 3.0 & 2.7296 & TST & \\
\hline CHEMBL1484952 & 688723 & 6.0004 & 5.0099 & TST & \\
\hline CHEMBL1450886 & 688723 & 5.1688 & 4.7676 & TST & \\
\hline CHEMBL1360686 & 688723 & 4.9914 & 5.1211 & TRN & \\
\hline CHEMBL1440563 & 688723 & 3.0 & 3.0412 & TST & \\
\hline CHEMBL1438551 & 688723 & 3.0 & 2.6867 & TST & \\
\hline CHEMBL1325138 & 688723 & 3.0 & 3.1634 & TRN & \\
\hline CHEMBL1414442 & 688723 & 5.3925 & 5.2019 & TRN & \\
\hline CHEMBL1566387 & 688723 & 4.8239 & 4.7678 & TRN & \\
\hline CHEMBL1346587 & 688723 & 5.2684 & 4.963 & TST & \\
\hline CHEMBL1272210 & 688723 & 5.8996 & 4.8755 & TRN & \\
\hline CHEMBL1269036 & 688723 & 3.0 & 3.1914 & TST & \\
\hline CHEMBL1566104 & 688723 & 3.0 & 2.495 & TRN & \\
\hline CHEMBL1271883 & 688723 & 5.1681 & 5.3975 & TRN & \\
\hline CHEMBL1321450 & 688723 & 3.0 & 3.2621 & TRN & \\
\hline CHEMBL1566663 & 688723 & 3.0 & 3.0038 & TRN & \\
\hline CHEMBL1487799 & 688723 & 3.0 & 2.8604 & TRN & \\
\hline CHEMBL1272155 & 688723 & 5.3054 & 4.7386 & TRN & \\
\hline CHEMBL1271766 & 688723 & 5.5817 & 5.3235 & TRN & \\
\hline CHEMBL1327036 & 688723 & 3.0 & 4.281000 & 0000000001 & TST \\
\hline CHEMBL1331084 & 688723 & 5.7721 & 5.1255 & TST & \\
\hline CHEMBL1272049 & 688723 & 5.2495 & 5.2863 & TRN & \\
\hline CHEMBL1373117 & 688723 & 3.0 & 2.898 & TRN & \\
\hline CHEMBL1530820 & 688723 & 3.0 & 4.1214 & TRN & \\
\hline CHEMBL1272264 & 688723 & 3.0 & 3.2238 & TRN & \\
\hline CHEMBL1271494 & 688723 & 5.3904 & 5.421 & TRN & \\
\hline CHEMBL1595347 & 688723 & 3.0 & 2.8459 & TRN & \\
\hline CHEMBL1314651 & 688723 & 3.0 & 2.6661 & TST & \\
\hline CHEMBL1321179 & 688723 & 5.0721 & 4.8468 & TRN & \\
\hline CHEMBL1337701 & 688723 & 3.0 & 4.3627 & TRN & \\
\hline CHEMBL1606857 & 688723 & 4.4789 & 4.8335 & TRN & \\
\hline
\end{tabular}




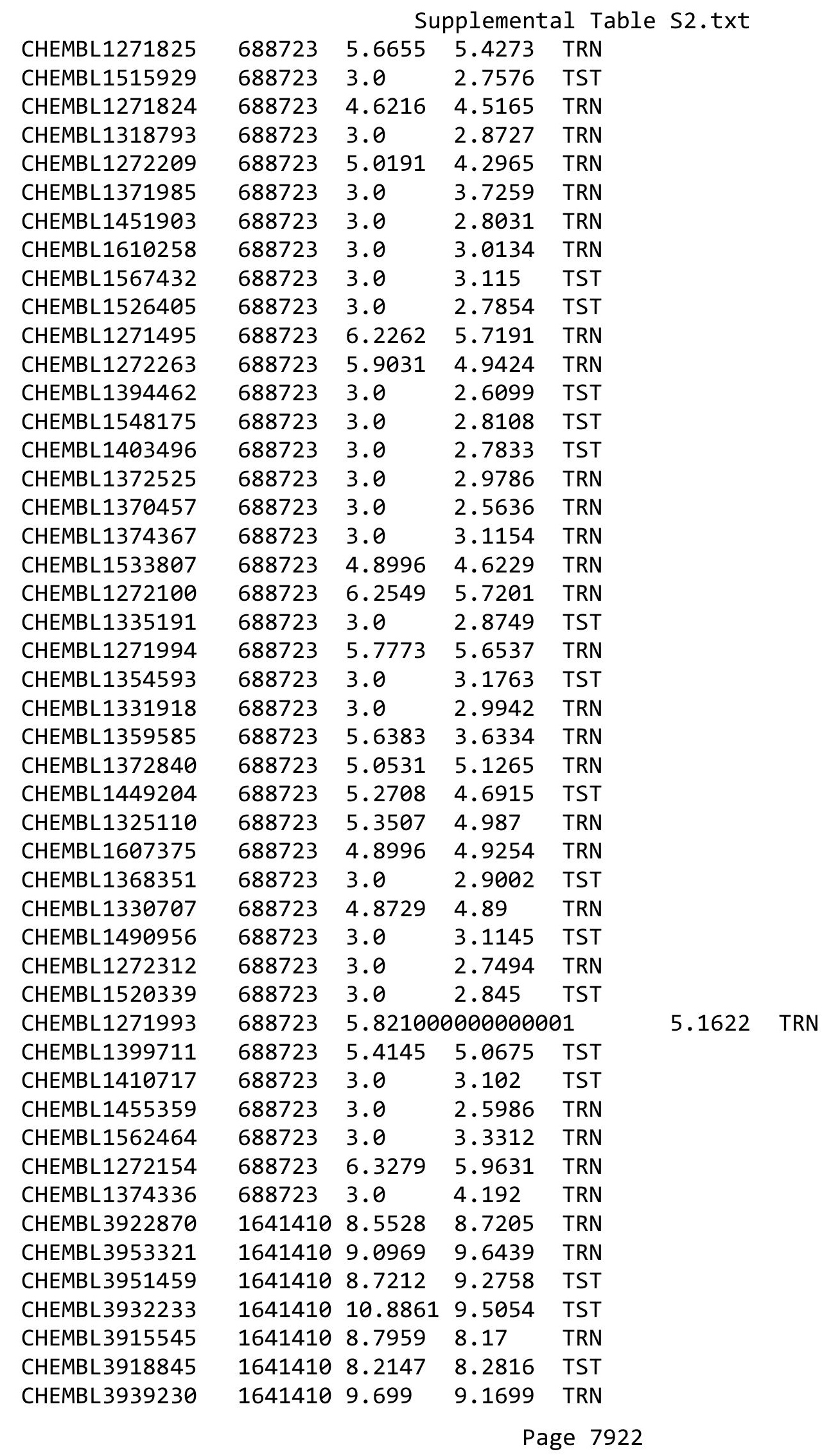


Supplemental Table S2.txt

\begin{tabular}{|c|c|c|c|c|}
\hline 2 & & & & \\
\hline HEMBL 39 & 641410 & 8.5686 & 8.4548 & \\
\hline & & & & \\
\hline 3518 & 10 & 58 & & \\
\hline IEMBL3908795 & 410 & 8.6021 & 5839 & \\
\hline HEMBL3937486 & 641410 & 9.1549 & 8179 & \\
\hline HEMBL3935608 & 10 & 8.9586 & 985 & \\
\hline 12 & 10 & 2218 & & \\
\hline EMBL3944135 & 10 & 9.5229 & 699 & \\
\hline AEMBL3953905 & 10 & 10.8861 & 5001 & \\
\hline HEMBL3906751 & 10 & 8.8861 & 9.0451 & \\
\hline HEMBL3945997 & 10 & 8.9586 & 9.4251 & \\
\hline IEMBL3S & & 8861 & & \\
\hline AEMBL3S & & 9.2218 & & \\
\hline AEMBL3933733 & 10 & 969 & & \\
\hline AEMBL39] & 10 & 9. & 15 & \\
\hline AEMBL39] & 10 & 979 & 39 & \\
\hline HEMBL 39 & & 696 & & \\
\hline HEMBL3 & & 696 & & \\
\hline HEMBL 389 & & 586 & & \\
\hline HEMBL39/59/1 & 10 & 8. & 71 & SI \\
\hline HEMBL3963874 & 0 & 979 & 57 & \\
\hline HEMBL 390 & & 18 & & \\
\hline AEMBL3916437 & & & & \\
\hline IEMBL 391 & & & & IRN \\
\hline HEMBL3908797 & 0 & & 39 & RN \\
\hline AEM & & 59 & 36 & RN \\
\hline 97 & & 28 & & RN \\
\hline AEMBL3S & & 586 & & R \\
\hline AEMBL3904036 & & & & RN \\
\hline HEMBL3985296 & & 969 & & \\
\hline 65 & 10 & 79 & & \\
\hline 42 & & 89 & & RN \\
\hline HEMBL3945494 & & & & RN \\
\hline HEMBL3939040 & 10 & 6. & 93 & RN \\
\hline AEMBL3936682 & & 9 & 39 & \\
\hline HEMRI 2 & & 16 & & RN \\
\hline HEMBL395 & & & 189 & RN \\
\hline HEMBL3901760 & 10 & 9.5229 & 3497 & RN \\
\hline AEMBL3912930 & 10 & 8. & 729 & $\mathrm{RN}$ \\
\hline HEMBL3922333 & 10 & 218 & 737 & RN \\
\hline HEMBL3953135 & & 8.6778 & & RN \\
\hline HEMBL3949052 & & 9. & 2931 & $\mathrm{RN}$ \\
\hline HEMBL3913833 & 10 & 9.1549 & 3704 & ST \\
\hline 39 & & 969 & & $K$ \\
\hline HEMBL3910619 & & 0.0 & 3.2712 & \\
\hline CHEMBL 39868 & & 9.22 & 9.3231 & \\
\hline CHEMBL3933980 & 1641410 & 8.7212 & 8.295 & $\mathrm{RN}$ \\
\hline
\end{tabular}

Page 7923 
Supplemental Table S2.txt

\begin{tabular}{|c|c|c|c|c|}
\hline HEMBL & & & & \\
\hline HEMRI 3927811 & & 9.0 & 8.8737 & \\
\hline HEMBL & & 9.1549 & 951 & \\
\hline AEMBL3891720 & 410 & 8.301 & 39 & \\
\hline HEMBL3891624 & 641410 & 8.6383 & 5857 & \\
\hline HEMBL; & 10 & 9.2218 & & \\
\hline AFMBI: & & & & \\
\hline HEMBL3908419 & & 8.0915 & & \\
\hline HEMBL3907285 & 10 & 9.301 & 369 & \\
\hline HEMBL3964879 & 10 & 8.6576 & & \\
\hline JEMBL391 & 10 & 6.0 & & \\
\hline AEMBL3 & & 9 & & \\
\hline HEMBL3S & 10 & 8. & & \\
\hline HEMBL 390 & 10 & 8.2291 & & \\
\hline HEMBL 393 & 10 & 9.1549 & & \\
\hline AEMBL: & 0 & 8. & & \\
\hline AEMBL & & & & \\
\hline HEMBL & & 9.2218 & & RN \\
\hline AEMBL3 & & 8.8539 & & \\
\hline AEMBL3 & 10 & 8. & 15 & KIV \\
\hline IEMBL & & 8. & & RN \\
\hline AEMBL & & & & RN \\
\hline HEMBL & & 8 . & & RN \\
\hline HEMBL & & 9.0 & & \\
\hline AEMBL3 3 & Lo & 8. & & RN \\
\hline AEMBL3 & & & & RN \\
\hline AEME & & & & $\mathrm{RN}$ \\
\hline 52 & & & & RN \\
\hline IEMBL: & & & & IRN \\
\hline HEMBL 398 & & 8 . & & $\mathrm{RN}$ \\
\hline FMBL & & & & RN \\
\hline 9 & & & & ST \\
\hline & & & & RN \\
\hline AEMBL3 & & & & TST \\
\hline HEMBL3986284 & & 8.2676 & & TRN \\
\hline IFMRI $=2>$ & & & & \\
\hline & & & & RN \\
\hline HEMBL3 & & & & RN \\
\hline HEMBL 389 & & & & $\Gamma R$ \\
\hline EMBL: & & & & RN \\
\hline HEMBL3 & & 8.7212 & & \\
\hline HEMBL3 & & 8.3279 & & $\mathrm{RN}$ \\
\hline HEMBL3909587 & & 8.9208 & 323 & RN \\
\hline HEMBL 393 & & 9.0969 & & TR \\
\hline met & & & & \\
\hline HEMBL 3917548 & & 10.8861 & & \\
\hline HEMBL3927461 & & 8.9208 & 9.4081 & \\
\hline CHEMBL3901118 & 1641410 & 8.0 & 8.237 & \\
\hline
\end{tabular}

Page 7924 
Supplemental Table S2.txt

\begin{tabular}{|c|c|c|c|c|c|}
\hline CHEMBL3919028 & 1641410 & 8.3468 & 8.6095 & TRN & \\
\hline CHEMBL 3898364 & 1641410 & 8.9586 & 9.2153 & TRN & \\
\hline CHEMBL3948119 & 1641410 & 8.4815 & 8.8681 & TRN & \\
\hline CHEMBL 3892443 & 1641410 & 7.9586 & 8.4685 & TST & \\
\hline CHEMBL 3899902 & 1641410 & 8.9586 & 8.7665 & TRN & \\
\hline CHEMBL 3905198 & 1641410 & 8.8861 & 7.9924 & TRN & \\
\hline CHEMBL3976713 & 1641410 & 9.1549 & 8.6035 & TRN & \\
\hline CHEMBL3968914 & 1641410 & 10.8861 & 9.2236 & TST & \\
\hline CHEMBL3891752 & 1641410 & 9.3979 & 8.6238 & TRN & \\
\hline CHEMBL3915104 & 1641410 & 8.699 & 8.9813 & TST & \\
\hline CHEMBL 3938427 & 1641410 & 9.2218 & 9.2379 & TRN & \\
\hline CHEMBL3920051 & 1641410 & 8.6383 & 8.016 & TRN & \\
\hline CHEMBL 3978082 & 1641410 & 8.8539 & 8.7101 & TST & \\
\hline CHEMBL3893997 & 1641410 & 9.0969 & 8.2809 & TRN & \\
\hline CHEMBL3957837 & 1641410 & 9.0 & 9.6929 & TRN & \\
\hline CHEMBL 3972134 & 1641410 & 8.5376 & 8.4916 & TRN & \\
\hline CHEMBL3954742 & 1641410 & 9.699 & 9.3645 & TRN & \\
\hline CHEMBL3917270 & 1641410 & 7.7959 & 8.5047 & TRN & \\
\hline CHEMBL 3892160 & 1641410 & 8.0706 & 8.3806 & TRN & \\
\hline CHEMBL3917852 & 1641410 & 9.301 & 9.3017 & TRN & \\
\hline CHEMBL 3944373 & 1641410 & 9.5229 & 9.5229 & TST & \\
\hline CHEMBL3952566 & 1641410 & 10.8861 & 9.3767 & TRN & \\
\hline CHEMBL 3933211 & 1641410 & 8.9208 & 8.3279 & TRN & \\
\hline CHEMBL3903657 & 1641410 & 10.8861 & 9.0813 & TRN & \\
\hline CHEMBL3980913 & 1641410 & 9.0458 & 8.5839 & TST & \\
\hline CHEMBL3949006 & 1641410 & 9.5229 & 9.6728 & TRN & \\
\hline CHEMBL3936091 & 1641410 & 9.2218 & 9.1497 & TRN & \\
\hline CHEMBL 3909820 & 1641410 & 6.0 & 8.0307 & TRN & \\
\hline CHEMBL3982190 & 1641410 & 8.9208 & 9.454 & TST & \\
\hline CHEMBL3911466 & 1641410 & 8.1024 & 8.27 & TRN & \\
\hline CHEMBL3979224 & 1641410 & 9.301 & 9.7342 & TST & \\
\hline CHEMBL3983928 & 1641410 & 8.8239 & 8.4586 & TRN & \\
\hline CHEMBL 3922791 & 1641410 & 9.5229 & 9.5616 & TRN & \\
\hline CHEMBL3960726 & 1641410 & 9.0 & 8.8384 & TST & \\
\hline CHEMBL3914499 & 1641410 & 9.2218 & 8.5783 & TRN & \\
\hline CHEMBL3960092 & 1641410 & 9.1549 & 9.3973 & TRN & \\
\hline CHEMBL3963846 & 1641410 & 8.5229 & 9.2831 & TRN & \\
\hline CHEMBL 3954688 & 1641410 & 9.0969 & 8.81200 & 0000000001 & TRN \\
\hline CHEMBL 3937525 & 1641410 & 9.699 & 9.4371 & TST & \\
\hline CHEMBL 3896686 & 1641410 & 8.7447 & 9.5172 & TST & \\
\hline CHEMBL3902058 & 1641410 & 6.0 & 8.2121 & TRN & \\
\hline CHEMBL3931127 & 1641410 & 9.301 & 9.1027 & TST & \\
\hline CHEMBL3896096 & 1641410 & 6.0 & 8.6291 & TRN & \\
\hline CHEMBL3954083 & 1641410 & 8.4559 & 8.4216 & TRN & \\
\hline CHEMBL 3897748 & 1641410 & 8.8539 & 9.3105 & TST & \\
\hline CHEMBL3900938 & 1641410 & 9.301 & 9.0775 & TRN & \\
\hline CHEMBL3986132 & 1641410 & 8.2596 & 8.0063 & TST & \\
\hline CHEMBL3915069 & 1641410 & 9.301 & 9.8237 & TST & \\
\hline
\end{tabular}


Supplemental Table S2.txt

\begin{tabular}{|c|c|c|}
\hline CHEMBL3982067 & 0 & \\
\hline CHEMBL3902822 & 1641410 & \\
\hline HEMBL3983665 & 1641410 & \\
\hline HEMBL 3934436 & 1641410 & \\
\hline HEMBL3919206 & 1641410 & \\
\hline AEMBL 3911268 & 1641410 & \\
\hline HEMBL3910054 & 1641410 & \\
\hline HEMBL3932037 & 1641410 & \\
\hline CHEMBL3942117 & 1641410 & \\
\hline HEMBL3928323 & 1641410 & \\
\hline HEMBL3895112 & 1641410 & \\
\hline HEMBL3927318 & 1641410 & \\
\hline HEMBL3939870 & 1641410 & \\
\hline CHEMBL3971948 & 1641410 & \\
\hline HEMBL3941486 & 1641410 & \\
\hline HEMBL3919275 & 1641410 & \\
\hline HEMBL3932002 & 1641410 & 9.3 \\
\hline HEMBL3894405 & 1641410 & \\
\hline CHEMBL3901163 & 1641410 & 6.0 \\
\hline HEMBL3897706 & 164 & \\
\hline HEMBL3914474 & 1641410 & \\
\hline HEMBL 3977220 & 1641410 & \\
\hline CHEMBL3906897 & 1641410 & \\
\hline CHEMBL3945801 & 164 & \\
\hline HEMBL3936455 & 164 & 8 . \\
\hline HEMBL3924434 & 1641410 & \\
\hline CHEMBL3890327 & 1641410 & \\
\hline CHEMBL3909590 & 1641410 & \\
\hline CHEMBL3937661 & 1641410 & \\
\hline CHEMBL3981169 & 1641410 & \\
\hline CHEMBL3907473 & 164 & 9.3 \\
\hline CHEMBL3901806 & 1641410 & \\
\hline CHEMBL3974180 & 1641410 & \\
\hline CHEMBL3921200 & 1641410 & \\
\hline CHEMBL3981125 & 164 & \\
\hline CHEMBL3979129 & 1641410 & 8. \\
\hline CHEMBL3965489 & 1641410 & 9.6 \\
\hline CHEMBL3940504 & 1528837 & 6.6 \\
\hline CHEMBL3969401 & 1528837 & 7.4 \\
\hline CHEMBL3668640 & 1528837 & \\
\hline CHEMBL3900266 & 1528837 & \\
\hline CHEMBL3668762 & 1528837 & 5.3 \\
\hline CHEMBL3919234 & 1528837 & 7. \\
\hline CHEMBL 3668713 & 1528837 & \\
\hline CHEMBL3965877 & 1528837 & \\
\hline CHEMBL3673766 & 1528837 & \\
\hline CHEMBL 3678871 & 1528837 & \\
\hline CHEMBL3919380 & 1528837 & 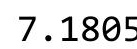 \\
\hline
\end{tabular}

$\begin{array}{ll}8.4863 & \text { TRN } \\ 8.0412 & \text { TRN } \\ 9.4174 & \text { TRN } \\ 9.4396 & \text { TST } \\ 8.074 & \text { TST } \\ 9.6006 & \text { TST } \\ 8.6304 & \text { TRN } \\ 8.6575 & \text { TRN } \\ 9.3431 & \text { TRN } \\ 9.0802 & \text { TST } \\ 8.5806 & \text { TRN } \\ 8.3641 & \text { TRN } \\ 8.3673 & \text { TRN } \\ 9.4059 & \text { TRN } \\ 9.2362 & \text { TRN } \\ 8.7732 & \text { TST } \\ 9.3456 & \text { TRN } \\ 9.8808 & \text { TRN } \\ 8.1972 & \text { TRN } \\ 9.3773 & \text { TRN } \\ 9.4331 & \text { TST } \\ 8.4973 & \text { TST } \\ 9.5272 & \text { TRN } \\ 9.1488 & \text { TRN } \\ 8.072000000000001 \\ 9.45 & \text { TST } \\ 8.7142 & \text { TRN } \\ 9.669 & \text { TST } \\ 9.2467 & \text { TRN } \\ 9.2878 & \text { TRN } \\ 9.5406 & \text { TRN } \\ 9.8722 & \text { TST } \\ 9.5792 & \text { TST } \\ 9.72 & \text { TST } \\ 8.2121 & \text { TRN } \\ 8.4481 & \text { TRN } \\ 9.259 & \text { TRN } \\ 7.4157 & \text { TRN } \\ 7.3769 & \text { TRN } \\ 8.4111 & \text { TRN } \\ 7.1179 & \text { TRN } \\ 5.1347 & \text { TRN } \\ 6.7776 & \text { TRN } \\ 7.1221 & \text { TRN } \\ 8.5139 & \text { TRN } \\ 6.4317 & \text { TRN } \\ 7.4798 & \text { TRN } \\ 6.9817 & \text { TRN } \\ & \\ 7\end{array}$

TST

Page 7926 
Supplemental Table S2.txt

\begin{tabular}{|c|c|c|c|c|c|}
\hline CHEMBL3932607 & 1528837 & 6.699 & 6.7605 & TRN & \\
\hline CHEMBL3664009 & 1528837 & 5.1107 & 5.1613 & TRN & \\
\hline CHEMBL3897493 & 1528837 & 8.2218 & 7.4017 & TST & \\
\hline CHEMBL3668641 & 1528837 & 6.0 & 6.6694 & TRN & \\
\hline CHEMBL3678876 & 1528837 & 7.4437 & 7.6049 & TRN & \\
\hline CHEMBL3983951 & 1528837 & 6.8508 & 6.9427 & TRN & \\
\hline CHEMBL3673891 & 1528837 & 5.7989 & 6.6265 & TRN & \\
\hline CHEMBL 3678762 & 1528837 & 5.9547 & 6.3074 & TRN & \\
\hline CHEMBL3929339 & 1528837 & 8.5229 & 8.3814 & TRN & \\
\hline CHEMBL3953699 & 1528837 & 7.0088 & 7.2632 & TRN & \\
\hline CHEMBL3923233 & 1528837 & 7.8239 & 7.5624 & TRN & \\
\hline CHEMBL3918018 & 1528837 & 8.0969 & 8.1891 & TRN & \\
\hline CHEMBL 3668744 & 1528837 & 6.1871 & 5.6629 & TST & \\
\hline CHEMBL3678873 & 1528837 & 7.7959 & 7.6153 & TRN & \\
\hline CHEMBL3953522 & 1528837 & 6.9172 & 7.3224 & TRN & \\
\hline CHEMBL3910183 & 1528837 & 8.0 & 7.2245 & TRN & \\
\hline CHEMBL3668572 & 1528837 & 6.4559 & 5.8669 & TRN & \\
\hline CHEMBL 3673862 & 1528837 & 7.4559 & 6.4984 & TRN & \\
\hline CHEMBL 3678787 & 1528837 & 7.8861 & 7.7362 & TRN & \\
\hline CHEMBL3918846 & 1528837 & 7.5528 & 7.7553 & TRN & \\
\hline CHEMBL3668590 & 1528837 & 4.8055 & 5.1845 & TRN & \\
\hline CHEMBL 3941541 & 1528837 & 7.2676 & 7.5745 & TRN & \\
\hline CHEMBL3925595 & 1528837 & 7.5086 & 7.5637 & TRN & \\
\hline CHEMBL3664005 & 1528837 & 5.9788 & 5.6337 & TRN & \\
\hline CHEMBL 3892491 & 1528837 & 6.9101 & 6.5893 & TRN & \\
\hline CHEMBL3668777 & 1528837 & 6.2013 & 5.862 & TRN & \\
\hline CHEMBL 3928987 & 1528837 & 4.7471 & 7.3661 & TST & \\
\hline CHEMBL3973081 & 1528837 & 4.7235 & 5.7625 & TRN & \\
\hline CHEMBL 3673727 & 1528837 & 6.8239 & 7.3318 & TRN & \\
\hline CHEMBL3668605 & 1528837 & 5.063 & 5.0723 & TRN & \\
\hline CHEMBL3683753 & 1528837 & 8.0458 & 7.97 & TST & \\
\hline CHEMBL3976409 & 1528837 & 4.9533 & 6.1162 & TRN & \\
\hline CHEMBL3673855 & 1528837 & 6.3605 & 6.1443 & TRN & \\
\hline CHEMBL3668665 & 1528837 & 7.0969 & 6.6322 & TST & \\
\hline CHEMBL3969909 & 1528837 & 5.5002 & 6.356 & TRN & \\
\hline CHEMBL3668668 & 1528837 & 6.0057 & 6.0697 & TRN & \\
\hline CHEMBL3986118 & 1528837 & 7.2596 & 7.4069 & TST & \\
\hline CHEMBL3951455 & 1528837 & 7.6021 & 7.406006 & 0000000001 & TRN \\
\hline CHEMBL3952459 & 1528837 & 6.6021 & 7.0779 & TRN & \\
\hline CHEMBL3673796 & 1528837 & 7.3468 & 6.4439 & TST & \\
\hline CHEMBL3974983 & 1528837 & 6.0 & 5.5117 & TRN & \\
\hline CHEMBL3974745 & 1528837 & 7.7212 & 7.7062 & TRN & \\
\hline CHEMBL3673912 & 1528837 & 7.8861 & 7.5655 & TRN & \\
\hline CHEMBL 3889845 & 1528837 & 6.0888 & 6.021 & TRN & \\
\hline CHEMBL3904085 & 1528837 & 6.5229 & 5.8708 & TRN & \\
\hline CHEMBL3982295 & 1528837 & 7.4437 & 7.3874 & TRN & \\
\hline CHEMBL3668763 & 1528837 & 5.4034 & 6.229 & TRN & \\
\hline CHEMBL3673921 & 1528837 & 6.7545 & 6.461 & TRN & \\
\hline
\end{tabular}


Supplemental Table S2.txt

\begin{tabular}{|c|c|c|c|c|}
\hline CHEMBL3673839 & 1528837 & 7.8239 & 7.2576 & TRN \\
\hline CHEMBL3668649 & 1528837 & 7.7212 & 7.4916 & TRN \\
\hline CHEMBL3673722 & 1528837 & 4.8018 & 5.1321 & TRN \\
\hline CHEMBL 3922628 & 1528837 & 6.0706 & 6.4654 & TRN \\
\hline CHEMBL3673801 & 1528837 & 7.0223 & 6.5204 & TRN \\
\hline CHEMBL3663997 & 1528837 & 4.9154 & 4.8029 & TRN \\
\hline CHEMBL3673786 & 1528837 & 6.983 & 6.6613 & TRN \\
\hline CHEMBL3668606 & 1528837 & 5.3979 & 5.4536 & TRN \\
\hline CHEMBL3905953 & 1528837 & 6.2027 & 6.4175 & TRN \\
\hline CHEMBL3907532 & 1528837 & 7.0223 & 7.4575 & TRN \\
\hline CHEMBL 3673734 & 1528837 & 7.1249 & 7.6019 & TRN \\
\hline CHEMBL3673863 & 1528837 & 6.6021 & 6.1428 & TST \\
\hline CHEMBL3673757 & 1528837 & 5.6478 & 4.8866 & TST \\
\hline CHEMBL3673820 & 1528837 & 7.5229 & 8.1097 & TST \\
\hline CHEMBL3967513 & 1528837 & 6.5935 & 6.6767 & TRN \\
\hline CHEMBL 3664000 & 1528837 & 7.0458 & 6.1647 & TRN \\
\hline CHEMBL3984045 & 1528837 & 5.2924 & 5.1876 & TRN \\
\hline CHEMBL3953191 & 1528837 & 7.3768 & 6.5198 & TRN \\
\hline CHEMBL 3928748 & 1528837 & 6.0 & 7.2252 & TRN \\
\hline CHEMBL3673856 & 1528837 & 6.1772 & 5.9536 & TRN \\
\hline CHEMBL3678869 & 1528837 & 6.4461 & 6.9762 & TST \\
\hline CHEMBL3894312 & 1528837 & 7.2366 & 7.5235 & TRN \\
\hline CHEMBL3916755 & 1528837 & 7.2924 & 7.3369 & TRN \\
\hline CHEMBL 3678825 & 1528837 & 5.8072 & 5.9122 & TRN \\
\hline CHEMBL3678791 & 1528837 & 6.063 & 7.632006 & 0000000001 \\
\hline CHEMBL 3673718 & 1528837 & 5.5768 & 6.1922 & TRN \\
\hline CHEMBL3678761 & 1528837 & 6.6108 & 6.4172 & TRN \\
\hline CHEMBL 3943741 & 1528837 & 7.4685 & 6.9772 & TST \\
\hline CHEMBL3952667 & 1528837 & 6.8794 & 6.8949 & TRN \\
\hline CHEMBL3934463 & 1528837 & 7.2518 & 7.1925 & TRN \\
\hline CHEMBL 3928788 & 1528837 & 5.8642 & 6.2345 & TRN \\
\hline CHEMBL3957905 & 1528837 & 7.7959 & 7.5679 & TRN \\
\hline CHEMBL3899805 & 1528837 & 6.3344 & 7.2235 & TRN \\
\hline CHEMBL3916816 & 1528837 & 7.7959 & 7.4905 & TRN \\
\hline CHEMBL3968855 & 1528837 & 7.7447 & 8.1475 & TRN \\
\hline CHEMBL 3678874 & 1528837 & 8.0 & 8.1285 & TRN \\
\hline CHEMBL3940688 & 1528837 & 6.857 & 7.0931 & TST \\
\hline CHEMBL3903643 & 1528837 & 8.0 & 7.9727 & TRN \\
\hline CHEMBL3891995 & 1528837 & 7.3872 & 7.6178 & TRN \\
\hline CHEMBL3678789 & 1528837 & 7.0044 & 7.3113 & TRN \\
\hline CHEMBL3668587 & 1528837 & 6.4881 & 5.7251 & TRN \\
\hline CHEMBL3899659 & 1528837 & 8.1549 & 7.809 & TRN \\
\hline CHEMBL3971770 & 1528837 & 7.585 & 7.7286 & TRN \\
\hline CHEMBL3969100 & 1528837 & 5.9718 & 6.1412 & TRN \\
\hline CHEMBL3949276 & 1528837 & 6.8416 & 6.8227 & TRN \\
\hline CHEMBL3936514 & 1528837 & 6.8041 & 7.3352 & TRN \\
\hline CHEMBL3969170 & 1528837 & 7.2147 & 7.2799 & TRN \\
\hline CHEMBL3939627 & 1528837 & 7.7447 & 7.2369 & TRN \\
\hline
\end{tabular}


Supplemental Table S2.txt

\begin{tabular}{|c|c|c|c|c|c|}
\hline CHEMBL3905514 & 1528837 & 5.9393 & 6.2202 & TST & \\
\hline CHEMBL 3944254 & 1528837 & 6.699 & 7.0251 & TRN & \\
\hline CHEMBL3901801 & 1528837 & 7.0706 & 7.1767 & TST & \\
\hline CHEMBL3907219 & 1528837 & 8.2218 & 7.6569 & TRN & \\
\hline CHEMBL3673864 & 1528837 & 6.8239 & 6.6699 & TRN & \\
\hline CHEMBL3969847 & 1528837 & 6.1599 & 6.3444 & TRN & \\
\hline CHEMBL 3899084 & 1528837 & 7.9208 & 7.0894 & TRN & \\
\hline CHEMBL3668612 & 1528837 & 4.6336 & 5.0782 & TRN & \\
\hline CHEMBL3668773 & 1528837 & 7.0809 & 6.7372 & TRN & \\
\hline CHEMBL3918105 & 1528837 & 5.6453 & 6.0194 & TRN & \\
\hline CHEMBL3937826 & 1528837 & 6.71899 & 79999999 & 6.1401 & TRN \\
\hline CHEMBL3939454 & 1528837 & 6.9431 & 6.8421 & TRN & \\
\hline CHEMBL3914117 & 1528837 & 7.2441 & 6.6322 & TST & \\
\hline CHEMBL 3668688 & 1528837 & 6.0 & 6.8917 & TRN & \\
\hline CHEMBL3668733 & 1528837 & 6.0969 & 5.9563 & TRN & \\
\hline CHEMBL 3673857 & 1528837 & 6.3206 & 6.9901 & TRN & \\
\hline CHEMBL3950155 & 1528837 & 6.7721 & 6.2576 & TST & \\
\hline CHEMBL3958687 & 1528837 & 7.5528 & 7.2778 & TRN & \\
\hline CHEMBL3663994 & 1528837 & 5.5977 & 5.5956 & TRN & \\
\hline CHEMBL3900735 & 1528837 & 8.0969 & 7.6398 & TRN & \\
\hline CHEMBL3954034 & 1528837 & 7.0809 & 7.3937 & TST & \\
\hline CHEMBL3891336 & 1528837 & 7.284 & 7.1516 & TST & \\
\hline CHEMBL 3673760 & 1528837 & 6.9914 & 6.3981 & TRN & \\
\hline CHEMBL3673888 & 1528837 & 7.1249 & 7.5567 & TRN & \\
\hline CHEMBL3673726 & 1528837 & 8.301 & 8.1902 & TRN & \\
\hline CHEMBL 3678730 & 1528837 & 6.3862 & 6.9678 & TST & \\
\hline CHEMBL3673843 & 1528837 & 6.5072 & 6.0219 & TRN & \\
\hline CHEMBL 3668595 & 1528837 & 5.3233 & 5.2199 & TRN & \\
\hline CHEMBL3918333 & 1528837 & 7.3279 & 7.3778 & TRN & \\
\hline CHEMBL 3673784 & 1528837 & 6.5986 & 6.6653 & TRN & \\
\hline CHEMBL3664012 & 1528837 & 4.6421 & 5.2693 & TRN & \\
\hline CHEMBL3951526 & 1528837 & 7.0223 & 7.4535 & TRN & \\
\hline CHEMBL3930658 & 1528837 & 5.5086 & 5.3376 & TRN & \\
\hline CHEMBL3913176 & 1528837 & 7.6021 & 7.1248 & TRN & \\
\hline CHEMBL3923260 & 1528837 & 5.4001 & 5.4705 & TRN & \\
\hline CHEMBL3668689 & 1528837 & 7.2007 & 6.7891 & TRN & \\
\hline CHEMBL 2181048 & 1528837 & 4.6064 & 5.24799 & 9999999999 & TRN \\
\hline CHEMBL3668715 & 1528837 & 7.5376 & 7.5431 & TRN & \\
\hline CHEMBL3908010 & 1528837 & 7.1487 & 7.0923 & TRN & \\
\hline CHEMBL 3889994 & 1528837 & 7.2076 & 6.9477 & TRN & \\
\hline CHEMBL3664002 & 1528837 & 5.4881 & 5.3481 & TRN & \\
\hline CHEMBL3975085 & 1528837 & 8.1549 & 7.7287 & TRN & \\
\hline CHEMBL3927484 & 1528837 & 8.3979 & 8.3041 & TRN & \\
\hline CHEMBL3668579 & 1528837 & 4.8827 & 5.55399 & 9999999999 & TRN \\
\hline CHEMBL 3889689 & 1528837 & 6.8239 & 6.5106 & TRN & \\
\hline CHEMBL3942895 & 1528837 & 7.0915 & 7.0026 & TRN & \\
\hline CHEMBL3668609 & 1528837 & 5.0942 & 5.7438 & TRN & \\
\hline CHEMBL3968675 & 1528837 & 4.945 & 5.7008 & TST & \\
\hline
\end{tabular}


Supplemental Table S2.txt

\begin{tabular}{|c|c|c|c|c|c|}
\hline CHEMBL3909802 & 1528837 & 7.7959 & 7.3819 & TRN & \\
\hline CHEMBL3956695 & 1528837 & 7.0706 & 6.8595 & TRN & \\
\hline CHEMBL3668632 & 1528837 & 5.5331 & 5.4888 & TST & \\
\hline CHEMBL3914498 & 1528837 & 7.1249 & 6.4491 & TST & \\
\hline CHEMBL3664015 & 1528837 & 6.0458 & 5.8505 & TRN & \\
\hline CHEMBL3905116 & 1528837 & 7.2441 & 7.2753 & TRN & \\
\hline CHEMBL3910141 & 1528837 & 7.8239 & 7.6799 & TRN & \\
\hline CHEMBL3668594 & 1528837 & 4.8254 & 5.5769 & TST & \\
\hline CHEMBL3939370 & 1528837 & 8.0 & 7.3592 & TST & \\
\hline CHEMBL3668658 & 1528837 & 5.0304 & 6.401 & TST & \\
\hline CHEMBL3673844 & 1528837 & 6.0 & 6.8719 & TRN & \\
\hline CHEMBL3673836 & 1528837 & 5.9788 & 6.2009 & TRN & \\
\hline CHEMBL3891141 & 1528837 & 8.1549 & 7.7758 & TRN & \\
\hline CHEMBL3976071 & 1528837 & 5.8684 & 5.6844 & TRN & \\
\hline CHEMBL3968070 & 1528837 & 7.0458 & 7.34399 & 9999999999 & TRN \\
\hline CHEMBL3673915 & 1528837 & 6.6696 & 6.9477 & TST & \\
\hline CHEMBL3668586 & 1528837 & 5.1549 & 5.7293 & TRN & \\
\hline CHEMBL3668757 & 1528837 & 6.4881 & 6.7878 & TRN & \\
\hline CHEMBL3668624 & 1528837 & 6.2596 & 5.1994 & TST & \\
\hline CHEMBL 3678800 & 1528837 & 6.8729 & 6.9336 & TRN & \\
\hline CHEMBL3937155 & 1528837 & 6.1314 & 6.3618 & TST & \\
\hline CHEMBL3966704 & 1528837 & 5.7924 & 7.4058 & TRN & \\
\hline CHEMBL3664001 & 1528837 & 5.5452 & 5.4391 & TRN & \\
\hline CHEMBL3933772 & 1528837 & 8.0 & 7.9299 & TRN & \\
\hline CHEMBL3968665 & 1528837 & 7.5686 & 7.21 & TRN & \\
\hline CHEMBL3981490 & 1528837 & 7.6198 & 7.4481 & TRN & \\
\hline CHEMBL3673812 & 1528837 & 8.3979 & 7.8073 & TRN & \\
\hline CHEMBL3984608 & 1528837 & 6.8508 & 7.5024 & TRN & \\
\hline CHEMBL3668610 & 1528837 & 6.0458 & 5.8064 & TRN & \\
\hline CHEMBL 3923291 & 1528837 & 6.5719 & 6.8352 & TST & \\
\hline CHEMBL3916025 & 1528837 & 7.699 & 6.9722 & TRN & \\
\hline CHEMBL3678729 & 1528837 & 7.1487 & 6.8283 & TRN & \\
\hline CHEMBL3928724 & 1528837 & 8.1549 & 7.6419 & TRN & \\
\hline CHEMBL 3673825 & 1528837 & 6.1759 & 5.4837 & TRN & \\
\hline CHEMBL3683755 & 1528837 & 7.5528 & 7.3758 & TRN & \\
\hline CHEMBL3928328 & 1528837 & 7.6576 & 7.1531 & TRN & \\
\hline CHEMBL3673903 & 1528837 & 6.5884 & 6.6102 & TRN & \\
\hline CHEMBL3909970 & 1528837 & 7.3979 & 7.3297 & TRN & \\
\hline CHEMBL3668653 & 1528837 & 8.0458 & 7.3303 & TRN & \\
\hline CHEMBL3668602 & 1528837 & 5.1135 & 5.1904 & TRN & \\
\hline CHEMBL 3664013 & 1528837 & 5.0482 & 5.3847 & TRN & \\
\hline CHEMBL 3668687 & 1528837 & 6.1871 & 6.3035 & TRN & \\
\hline CHEMBL3925266 & 1528837 & 7.2596 & 6.5754 & TST & \\
\hline CHEMBL3668608 & 1528837 & 5.8697 & 5.6614 & TRN & \\
\hline CHEMBL 3673824 & 1528837 & 7.6021 & 7.216 & TRN & \\
\hline CHEMBL3673849 & 1528837 & 5.9393 & 6.2959 & TRN & \\
\hline CHEMBL 3890943 & 1528837 & 7.5686 & 7.2613 & TRN & \\
\hline CHEMBL 3673894 & 1528837 & 6.0 & 6.432 & TRN & \\
\hline
\end{tabular}


Supplemental Table S2.txt

\begin{tabular}{|c|c|c|c|c|}
\hline (2) & & & 0064 & \\
\hline HEMBL3683750 & 528837 & 6.4559 & 6.9448 & \\
\hline 723 & & & 3931 & \\
\hline 37732 & 28837 & $\partial 8$ & 1874 & \\
\hline IEMBL 3668611 & 528837 & 328 & 3928 & \\
\hline HEMBL3678888 & 528837 & 7.6383 & 3484 & \\
\hline HEMBL3668677 & 528837 & 5229 & 8489 & \\
\hline IEMBL & 28837 & 351 & 283 & \\
\hline 98583 & 28837 & 506 & 3618 & \\
\hline HEMBL3926313 & 528837 & 6.2218 & 2381 & \\
\hline HEMBL3683752 & 528837 & 7.0555 & 7711 & \\
\hline AEMBL3668629 & 528837 & 263 & 8723 & \\
\hline AEMBL & & & 7573 & \\
\hline HEMBL & 528837 & & 7506 & \\
\hline AEMBL3673790 & 528837 & 021 & 8721 & \\
\hline AEMBL3938101 & 37 & 1612 & 3274 & \\
\hline AEMBL3 & 528837 & 694 & 453 & \\
\hline HEMBL & 37 & & 148 & \\
\hline HEMBL & 37 & & 938 & \\
\hline HEMBL36 & 528837 & & 116 & \\
\hline FEMB $3668 / 51$ & 208831 & 5.9805 & 3012 & I \\
\hline HEMBL3 & 28837 & 576 & 4854 & $\mathrm{RN}$ \\
\hline HEMBL & $28,-20$ & 208 & 354 & \\
\hline 3 & 37 & 88 & 844 & $C T$ \\
\hline AEMBL39 & 37 & & 865 & ST \\
\hline EMBL39 & 528 & 7. & 263 & SI \\
\hline HEMBL3S & 528837 & 706 & 22 & $\mathrm{RN}$ \\
\hline HEMBL3 & 7 & 79 & 2756 & ST \\
\hline HEM & & & .73 & ST \\
\hline L 36 & & & 31 & RN \\
\hline AEMBL3668694 & 528837 & 4. & 104 & ГRN \\
\hline HEMBL3939354 & 28837 & 441 & 101 & וס \\
\hline HEMBL3 & 7 & 59 & 707 & RN \\
\hline & & & 159 & RN \\
\hline AEMBL3668575 & 528837 & 5 . & 3302 & RN \\
\hline AEMBL36687 & 28837 & 59 & 7525 & \\
\hline HEMBL3673880 & 528837 & 872 & 003 & Niv \\
\hline & & & & RN \\
\hline HEMBL3668772 & & & 135 & $\mathrm{RN}$ \\
\hline HEMBL3958689 & 528837 & & 9673 & RN \\
\hline HEMBL3S & 528837 & 86 & & RN \\
\hline HEMBL3959929 & 528837 & & 859 & \\
\hline HEMBL3 & & & & ST \\
\hline HEMBL3900721 & 528837 & & 2684 & TST \\
\hline AEMBL 39834 & 528837 & & 371 & $\mathrm{R}$ \\
\hline IEMBL3S & & & 3393 & \\
\hline HEN & 31 & & & \\
\hline 2660711 & 152883 & & 7.7147 & \\
\hline
\end{tabular}

Page 7931 
Supplemental Table S2.txt

\begin{tabular}{|c|c|c|c|c|c|c|}
\hline CHEMBL3913598 & 1528837 & 8.3979 & 8.4207 & TRN & & \\
\hline CHEMBL 3668644 & 1528837 & 6.5229 & 5.8508 & TRN & & \\
\hline CHEMBL3678793 & 1528837 & 6.0742 & 6.6938 & TRN & & \\
\hline CHEMBL3957559 & 1528837 & 7.5229 & 7.6881 & TRN & & \\
\hline CHEMBL3958965 & 1528837 & 7.6383 & 7.3147 & TRN & & \\
\hline CHEMBL3673930 & 1528837 & 7.8539 & 7.6376 & TRN & & \\
\hline CHEMBL 3678850 & 1528837 & 7.8861 & 8.1323 & TST & & \\
\hline CHEMBL3895699 & 1528837 & 7.585 & 7.2941 & TRN & & \\
\hline CHEMBL 3673788 & 1528837 & 6.4101 & 7.325 & TRN & & \\
\hline CHEMBL3663993 & 1528837 & 5.0809 & 5.6742 & TRN & & \\
\hline CHEMBL3977045 & 1528837 & 5.9846 & 6.4391 & TRN & & \\
\hline CHEMBL3951201 & 1528837 & 6.9706 & 6.7143 & TST & & \\
\hline CHEMBL 3673744 & 1528837 & 6.9393 & 6.6098 & TRN & & \\
\hline CHEMBL 3673743 & 1528837 & 7.1549 & 7.5718 & TRN & & \\
\hline CHEMBL3673887 & 1528837 & 5.2041 & 7.313 & TST & & \\
\hline CHEMBL3668683 & 1528837 & 7.5229 & 7.8817 & TRN & & \\
\hline CHEMBL3668692 & 1528837 & 6.2596 & 6.5103 & TST & & \\
\hline CHEMBL3905795 & 1528837 & 5.7696 & 6.636 & TST & & \\
\hline CHEMBL 3673837 & 1528837 & 6.0 & 7.1211 & TRN & & \\
\hline CHEMBL3961179 & 1528837 & 7.2924 & 6.8944 & TST & & \\
\hline CHEMBL3668567 & 1528837 & 5.75700 & 000000000 & 31 & 5.5508 & TRN \\
\hline CHEMBL3961152 & 1528837 & 7.4949 & 7.5395 & TRN & & \\
\hline CHEMBL 3668614 & 1528837 & 4.8182 & 4.9352 & TRN & & \\
\hline CHEMBL3668659 & 1528837 & 5.3565 & 5.0324 & TST & & \\
\hline CHEMBL3668655 & 1528837 & 7.3468 & 7.3732 & TRN & & \\
\hline CHEMBL3678790 & 1528837 & 6.5467 & 7.3812 & TST & & \\
\hline CHEMBL3971707 & 1528837 & 7.3872 & 7.4042 & TST & & \\
\hline CHEMBL3949668 & 1528837 & 7.7959 & 7.895 & TRN & & \\
\hline CHEMBL3928076 & 1528837 & 7.699 & 6.63 & TST & & \\
\hline CHEMBL3921385 & 1528837 & 7.1024 & 7.2106 & TRN & & \\
\hline CHEMBL3933926 & 1528837 & 6.2604 & 6.5815 & TRN & & \\
\hline CHEMBL3923824 & 1528837 & 7.3768 & 7.2111 & TRN & & \\
\hline CHEMBL 3673764 & 1528837 & 6.3468 & 6.2226 & TRN & & \\
\hline CHEMBL3678839 & 1528837 & 7.7212 & 7.2443 & TST & & \\
\hline CHEMBL3668592 & 1528837 & 4.98300 & 200000000 & 305 & 5.09 & TRN \\
\hline CHEMBL3668676 & 1528837 & 6.5719 & 7.2844 & TRN & & \\
\hline CHEMBL 3678870 & 1528837 & 7.1079 & 7.6413 & TST & & \\
\hline CHEMBL3924885 & 1528837 & 6.4609 & 6.1827 & TST & & \\
\hline CHEMBL 3892173 & 1528837 & 8.0458 & 7.6619 & TRN & & \\
\hline CHEMBL3906187 & 1528837 & 8.0969 & 7.4885 & TRN & & \\
\hline CHEMBL3668576 & 1528837 & 7.0706 & 6.5054 & TRN & & \\
\hline CHEMBL3904751 & 1528837 & 7.5229 & 7.407 & TST & & \\
\hline CHEMBL3941580 & 1528837 & 8.3979 & 8.5107 & TST & & \\
\hline CHEMBL3668669 & 1528837 & 8.301 & 8.4881 & TRN & & \\
\hline CHEMBL3673926 & 1528837 & 6.32700 & 300000000 & $\partial 1$ & 6.7321 & TRN \\
\hline CHEMBL3668726 & 1528837 & 6.6326 & 6.8785 & TRN & & \\
\hline CHEMBL3678842 & 1528837 & 7.4202 & 7.915 & TST & & \\
\hline CHEMBL3975391 & 1528837 & 6.6144 & 6.6312 & TRN & & \\
\hline
\end{tabular}


Supplemental Table S2.txt

\begin{tabular}{|c|c|c|c|c|c|}
\hline CHEMBL3914796 & 1528837 & 7.8539 & 7.8284 & TRN & \\
\hline CHEMBL3683749 & 1528837 & 5.2499 & 5.2831 & TRN & \\
\hline CHEMBL3668707 & 1528837 & 7.6021 & 6.7454 & TRN & \\
\hline CHEMBL 3982402 & 1528837 & 6.8539 & 7.2429 & TRN & \\
\hline CHEMBL3972502 & 1528837 & 7.4685 & 7.2725 & TRN & \\
\hline CHEMBL3668580 & 1528837 & 7.1871 & 6.7636 & TRN & \\
\hline CHEMBL3683713 & 1528837 & 7.4437 & 7.3717 & TST & \\
\hline CHEMBL3900222 & 1528837 & 6.585 & 6.7871 & TRN & \\
\hline CHEMBL3960721 & 1528837 & 5.8277 & 6.0165 & TST & \\
\hline CHEMBL3919049 & 1528837 & 7.8539 & 7.4252 & TRN & \\
\hline CHEMBL3891333 & 1528837 & 6.2596 & 6.1645 & TST & \\
\hline CHEMBL3668768 & 1528837 & 6.699 & 6.6811 & TRN & \\
\hline CHEMBL3673753 & 1528837 & 7.0706 & 6.5196 & TST & \\
\hline CHEMBL 3982734 & 1528837 & 7.7447 & 7.5678 & TRN & \\
\hline CHEMBL3981103 & 1528837 & 7.5376 & 7.1211 & TRN & \\
\hline CHEMBL3909981 & 1528837 & 7.5686 & 7.4955 & TRN & \\
\hline CHEMBL3678843 & 1528837 & 7.7696 & 7.8034 & TST & \\
\hline CHEMBL3683730 & 1528837 & 8.301 & 8.2928 & TST & \\
\hline CHEMBL 3673827 & 1528837 & 5.5157 & 5.3674 & TRN & \\
\hline CHEMBL3663998 & 1528837 & 5.475 & 5.522 & TRN & \\
\hline CHEMBL3668600 & 1528837 & 5.3325 & 5.1642 & TRN & \\
\hline CHEMBL3983934 & 1528837 & 6.20200 & 000000000 & 6.4552 & TRN \\
\hline CHEMBL3668601 & 1528837 & 5.1675 & 5.4418 & TRN & \\
\hline CHEMBL3972137 & 1528837 & 7.6198 & 7.6933 & TRN & \\
\hline CHEMBL3966585 & 1528837 & 7.5086 & 7.452000 & 3000000001 & TRN \\
\hline CHEMBL3941893 & 1528837 & 6.8447 & 6.9454 & TRN & \\
\hline CHEMBL3673785 & 1528837 & 5.7788 & 6.3668 & TRN & \\
\hline CHEMBL3668581 & 1528837 & 4.6536 & 4.9184 & TRN & \\
\hline CHEMBL3929212 & 1528837 & 5.6778 & 6.397 & TRN & \\
\hline CHEMBL3948060 & 1528837 & 7.7696 & 6.9779 & TRN & \\
\hline CHEMBL3895652 & 1528837 & 6.6021 & 6.86 & TRN & \\
\hline CHEMBL 3668565 & 1528837 & 5.0706 & 5.3802 & TRN & \\
\hline CHEMBL3673907 & 1528837 & 6.7258 & 6.7435 & TRN & \\
\hline CHEMBL3905245 & 1528837 & 8.0 & 7.837999 & & TRN \\
\hline CHEMBL3668652 & 1528837 & 6.5229 & 6.2427 & TRN & \\
\hline CHEMBL3668582 & 1528837 & 4.82100 & 000000000 & 5.7176 & TRN \\
\hline CHEMBL 3678748 & 1528837 & 7.1427 & 6.4997 & TRN & \\
\hline CHEMBL3966474 & 1528837 & 6.5302 & 6.8911 & TRN & \\
\hline CHEMBL 3983000 & 1528837 & 7.301 & 7.2432 & TRN & \\
\hline CHEMBL 3683748 & 1528837 & 5.3188 & 5.3906 & TRN & \\
\hline CHEMBL3673733 & 1528837 & 7.0223 & 7.1673 & TRN & \\
\hline CHEMBL3668769 & 1528837 & 6.3979 & 6.8419 & TRN & \\
\hline CHEMBL3977605 & 1528837 & 6.7721 & 6.6733 & TRN & \\
\hline CHEMBL3668706 & 1528837 & 5.063 & 5.4951 & TST & \\
\hline CHEMBL3668597 & 1528837 & 5.2218 & 5.0922 & TRN & \\
\hline CHEMBL3673882 & 1528837 & 7.0706 & 7.5413 & TRN & \\
\hline CHEMBL3673798 & 1528837 & 5.0996 & 4.9837 & TRN & \\
\hline CHEMBL3908567 & 1528837 & 6.7496 & 7.5392 & TST & \\
\hline
\end{tabular}


Supplemental Table S2.txt

\begin{tabular}{|c|c|c|c|c|}
\hline - & & & & \\
\hline HEMBL 3673840 & 528837 & 7.585 & 2347 & \\
\hline & & & & \\
\hline 11 & 28837 & 478 & 98 & \\
\hline AEMBL3942410 & 528837 & .9031 & 4036 & \\
\hline AEMBL 3946134 & 528837 & 7212 & 4352 & \\
\hline HEMBL; & 528837 & .8239 & .0939 & \\
\hline 14 & 37 & & 27 & \\
\hline IEMBL39 & 528837 & 2218 & . 9148 & \\
\hline AEMBL3668604 & 528837 & 302 & 1814 & \\
\hline HEMBL 3950448 & 528837 & 458 & 5468 & \\
\hline AEMBL39 & 528837 & 33 & 46 & \\
\hline 71 & & & & \\
\hline HEMBL & 528837 & 49 & & \\
\hline AEMBL39 & 528837 & 01 & & \\
\hline AEMBL3668748 & 528837 & & 533 & \\
\hline HEMBL3S & 28837 & 928 & 78 & \\
\hline HEMBL3 & 28837 & 58 & & \\
\hline HEMBL & 528837 & 18 & 882 & \\
\hline AEMBL36 & 37 & 2 & 14 & RN \\
\hline$A E M B L S$ & 528837 & 6 & 68 & \\
\hline 562 & 28837 & 8 & 527 & \\
\hline HEM & 37 & & & \\
\hline 765 & 528837 & & 2801 & RN \\
\hline AEMBL39 & 37 & & 9 & RIV \\
\hline 74 & 28 & 3 & 06 & RN \\
\hline 55 & 28 & & & RN \\
\hline 96 & & & & RN \\
\hline AEMBL3S & 528837 & & & ו \\
\hline AEMBL39 & 528837 & 5 & 369 & RN \\
\hline AEMBL3S & 28837 & 8 & & \\
\hline 88 & 7 & & & \\
\hline & & & & RN \\
\hline HEMBL 398 & & & & ST \\
\hline AEMBL391 & 528837 & & 1971 & RN \\
\hline AEMBL3 & 28837 & & 042 & \\
\hline $45 M I^{-7}$ & 37 & & & RN \\
\hline & & & & RN \\
\hline HEMBL3910803 & 528837 & 7 & 194 & TRN \\
\hline IEMBL392 & 528837 & & 878 & RN \\
\hline HEMBL367 & 528837 & 596 & 967 & - \\
\hline HEMBL392 & & & & I \\
\hline HEMBL392 & 528837 & 7.2676 & 7.3424 & TRN \\
\hline AEMBL3970335 & 528837 & 469 & 6451 & TRN \\
\hline$\partial 14$ & $=200$ & & & \\
\hline HEMBL 3668731 & 528837 & & 6.6598 & KIV \\
\hline HEMBL397 & 1528837 & & 7.6828 & \\
\hline CHEMBL3891714 & 1528837 & 6.0969 & 5.9933 & TST \\
\hline
\end{tabular}

Page 7934 
Supplemental Table S2.txt

\begin{tabular}{|c|c|c|c|c|}
\hline IEN & 37 & 35 & 1 & \\
\hline HEMBL3980865 & 528837 & 8.5229 & 7.8999 & \\
\hline $\mathrm{AFMBL}$ & 28837 & & & \\
\hline HEMBL3910859 & 528837 & & & \\
\hline HEMBL3673833 & 528837 & 6.0 & 1569 & \\
\hline HEMBL3911482 & 528837 & 5.9714 & 4601 & \\
\hline HEMBL3895672 & 528837 & 7.9208 & 161 & \\
\hline AEMBL3668691 & 528837 & & 097 & \\
\hline AEMBL3668564 & 528837 & 4.6655 & .5659 & \\
\hline HEMBL3922181 & 528837 & 5.9393 & 5322 & \\
\hline HEMBL3663999 & 528837 & 4.6189 & .5218 & \\
\hline IEMBL367 & 528837 & 8.1549 & 7762 & \\
\hline AEMBL36 & 8837 & & 329 & \\
\hline HEMBL3673872 & 528837 & 7.7959 & 7.1978 & \\
\hline HEMBL366 & 528837 & 5.5376 & 5947 & \\
\hline HEMBL 39 & 528837 & 6. & 7.0162 & \\
\hline HEMBL39 & 528837 & 6. & 7.2966 & \\
\hline HEMBL21 & 528837 & 9.0 & 188 & \\
\hline HEMBL39 & 528837 & & 7.8629 & \\
\hline HEMBL 367 & 37 & 5 . & & \\
\hline HEMBL3S & I & 5 . & 948 & \\
\hline HEMBL36 & 37 & 6 . & 81 & \\
\hline AEMBL36 & 37 & $\partial 6$ & & \\
\hline HEMBL39 & 528837 & 7.8861 & 7.4155 & \\
\hline HEMBL 391 & 28837 & 6. & 78 & \\
\hline JEMBL 36 & 28837 & 5 . & 3743 & \\
\hline AEMBL36 & 37 & 447 & 07 & \\
\hline HEMBL36 & 528837 & 5.71 & 05 & \\
\hline HEMBL3986257 & & & 7.4849 & \\
\hline HEMBL 3974 & 528837 & 7. & 088 & \\
\hline HEMBL 367 & 528837 & 6. & 7.0277 & \\
\hline HEMBL3 & 37 & 7 & 7.8751 & \\
\hline HEMBL3 & & & 8.0163 & \\
\hline HEMBL3663996 & 528837 & 5.5 & 5.3228 & \\
\hline HEMBL3683720 & 528837 & 8.3979 & 7.5946 & \\
\hline HEMBL 397 & 528837 & 7. & 7.0056 & \\
\hline HEMBL3 & 37 & & 7.3729 & \\
\hline HEMBL3S & & 7. & 7.2084 & \\
\hline HEMBL3673720 & 528837 & 5.5 & 5.5616 & \\
\hline HEMBL367 & 528837 & 5.9031 & 5.6448 & \\
\hline CHEMBL367. & 1528837 & 8.3979 & 8.5569 & \\
\hline CHEMBL367. & 1528837 & & 6.5866 & \\
\hline CHEMBL3663982 & 528837 & 5.9586 & 6.0656 & \\
\hline HEMBL3968115 & 528837 & 6.4461 & 7.5369 & \\
\hline HEMBL 21 & 1528837 & 8.699 & 8.3243 & \\
\hline CHEMBL3911028 & 1528837 & 6.0 & 5.729 & \\
\hline ZHEMBL39 & 528837 & 7.15 & 7.2891 & \\
\hline CHEMBL3942499 & 1528837 & 6.1549 & 6.1018 & \\
\hline
\end{tabular}

Page 7935 
Supplemental Table S2.txt

\begin{tabular}{|c|c|c|c|c|c|}
\hline CHEMBL3946298 & 1528837 & 6.2557 & 6.7105 & TST & \\
\hline CHEMBL3925642 & 1528837 & 7.1675 & 7.0907 & TST & \\
\hline CHEMBL3668616 & 1528837 & 6.2596 & 5.9409 & TRN & \\
\hline CHEMBL3907392 & 1528837 & 7.3279 & 7.4134 & TRN & \\
\hline CHEMBL3898188 & 1528837 & 7.1675 & 7.5547 & TRN & \\
\hline CHEMBL3668747 & 1528837 & 6.6021 & 7.0941 & TRN & \\
\hline CHEMBL3949410 & 1528837 & 6.567 & 6.7376 & TRN & \\
\hline CHEMBL3930493 & 1528837 & 5.8827 & 5.7736 & TST & \\
\hline CHEMBL 3894263 & 1528837 & 8.2218 & 8.0682 & TRN & \\
\hline CHEMBL3678895 & 1528837 & 7.9208 & 8.1383 & TRN & \\
\hline CHEMBL3955568 & 1528837 & 6.9586 & 7.02 & TRN & \\
\hline CHEMBL3678792 & 1528837 & 6.6635 & 6.46200 & 0000000001 & TRN \\
\hline CHEMBL3927678 & 1528837 & 7.4949 & 7.1513 & TRN & \\
\hline CHEMBL 3678844 & 1528837 & 7.4437 & 7.9084 & TRN & \\
\hline CHEMBL3673892 & 1528837 & 7.3665 & 6.5785 & TRN & \\
\hline CHEMBL 3678824 & 1528837 & 5.7364 & 6.1411 & TRN & \\
\hline CHEMBL3921480 & 1528837 & 7.1805 & 7.2166 & TST & \\
\hline CHEMBL 3668568 & 1528837 & 5.7328 & 5.1392 & TRN & \\
\hline CHEMBL3668596 & 1528837 & 5.6478 & 5.6611 & TRN & \\
\hline CHEMBL3921380 & 1528837 & 7.8861 & 7.9066 & TRN & \\
\hline CHEMBL3984053 & 1528837 & 5.8239 & 5.7849 & TRN & \\
\hline CHEMBL 3891744 & 1528837 & 7.3188 & 6.3775 & TRN & \\
\hline CHEMBL3923519 & 1528837 & 7.1249 & 6.8966 & TRN & \\
\hline CHEMBL3955617 & 1528837 & 6.4225 & 6.3662 & TST & \\
\hline CHEMBL3954048 & 1528837 & 8.1549 & 7.3607 & TST & \\
\hline CHEMBL3934062 & 1528837 & 7.7696 & 7.1407 & TRN & \\
\hline CHEMBL3975398 & 1528837 & 6.7747 & 6.1972 & TRN & \\
\hline CHEMBL3939996 & 1528837 & 6.9626 & 6.9761 & TRN & \\
\hline CHEMBL3911018 & 1528837 & 7.6021 & \multicolumn{2}{|c|}{7.167000000000001} & TRN \\
\hline CHEMBL3895798 & 1528837 & 7.8539 & 6.8511 & TST & \\
\hline CHEMBL 3668648 & 1528837 & 6.1871 & 5.7485 & TRN & \\
\hline CHEMBL3976031 & 1528837 & 7.0223 & 6.7503 & TRN & \\
\hline CHEMBL3668760 & 1528837 & 6.8239 & 7.1739 & TRN & \\
\hline CHEMBL3905056 & 1528837 & 7.2076 & 7.8815 & TRN & \\
\hline CHEMBL3905521 & 1528837 & 7.7696 & 7.2065 & TRN & \\
\hline CHEMBL3922268 & 1528837 & 6.6253 & 7.0835 & TRN & \\
\hline CHEMBL3678785 & 1528837 & 6.5331 & 7.0791 & TST & \\
\hline CHEMBL3664007 & 1528837 & 5.4949 & 6.144 & TRN & \\
\hline CHEMBL3901974 & 1528837 & 7.3872 & 7.2059 & TST & \\
\hline CHEMBL3974924 & 1528837 & 7.1135 & 7.9205 & TRN & \\
\hline CHEMBL3678766 & 1528837 & 6.4401 & 6.9265 & TRN & \\
\hline CHEMBL3673729 & 1528837 & 6.4559 & 6.6712 & TRN & \\
\hline CHEMBL 3668627 & 1528837 & 5.8136 & 7.8752 & TST & \\
\hline CHEMBL3908111 & 1528837 & 6.3224 & 6.191 & TST & \\
\hline CHEMBL3673877 & 1528837 & 7.0458 & \multicolumn{2}{|c|}{6.3660000000000005} & TRN \\
\hline CHEMBL3916258 & 1528837 & 6.0458 & 6.5789 & TRN & \\
\hline CHEMBL3959824 & 1528837 & 8.0 & 7.2481 & TRN & \\
\hline CHEMBL 3668690 & 1528837 & 7.699 & 7.2333 & TRN & \\
\hline
\end{tabular}


Supplemental Table S2.txt

\begin{tabular}{|c|c|c|c|c|}
\hline CHEMBL3673739 & 1528837 & 4.8761 & 6.4835 & TST \\
\hline CHEMBL3668603 & 1528837 & 5.9393 & 5.395 & TRN \\
\hline CHEMBL3949115 & 1528837 & 7.2676 & 7.4598 & TRN \\
\hline CHEMBL 3895290 & 1528837 & 6.0405 & \multicolumn{2}{|c|}{6.007000000000001} \\
\hline CHEMBL3683754 & 1528837 & 8.0458 & 8.3064 & TST \\
\hline CHEMBL3933110 & 1528837 & 6.3161 & 6.2778 & TRN \\
\hline CHEMBL3986438 & 1528837 & 7.4437 & 8.1752 & TRN \\
\hline CHEMBL3929920 & 1528837 & 6.1415 & 6.8217 & TRN \\
\hline CHEMBL3678851 & 1528837 & 8.0458 & 8.1207 & TST \\
\hline CHEMBL3944517 & 1528837 & 7.4202 & 7.3427 & TRN \\
\hline CHEMBL3970108 & 1528837 & 6.1079 & 6.1634 & TRN \\
\hline CHEMBL3895664 & 1528837 & 7.1024 & 7.2431 & TST \\
\hline CHEMBL3925027 & 1528837 & 6.9245 & 6.7069 & TST \\
\hline CHEMBL 3668703 & 1528837 & 6.0 & 6.4368 & TRN \\
\hline CHEMBL3963953 & 1528837 & 7.9586 & 7.3794 & TRN \\
\hline CHEMBL3668775 & 1528837 & 5.7959 & 5.7772 & TRN \\
\hline CHEMBL3901278 & 1528837 & 7.8861 & 7.3583 & TRN \\
\hline CHEMBL3673742 & 1528837 & 6.3233 & 6.4323 & TST \\
\hline CHEMBL 3664003 & 1528837 & 4.6576 & 5.1986 & TRN \\
\hline CHEMBL3962977 & 1528837 & 7.1249 & 7.1474 & TRN \\
\hline CHEMBL3668569 & 1528837 & 6.9031 & 6.227 & TRN \\
\hline CHEMBL 2180766 & 1528837 & 8.5229 & 7.9935 & TRN \\
\hline CHEMBL 3970284 & 1528837 & 8.0 & 6.2859 & TST \\
\hline CHEMBL 3668571 & 1528837 & 5.8697 & 5.5847 & TRN \\
\hline CHEMBL3673745 & 1528837 & 5.8861 & 5.513 & TRN \\
\hline CHEMBL3983395 & 1528837 & 6.5952 & 6.9206 & TST \\
\hline CHEMBL3935821 & 1528837 & 6.4559 & 6.9353 & TRN \\
\hline CHEMBL3957624 & 1528837 & 7.5086 & 7.2895 & TRN \\
\hline CHEMBL 3668725 & 1528837 & 5.7328 & 5.7777 & TST \\
\hline CHEMBL3934978 & 1528837 & 6.9957 & 6.9623 & TST \\
\hline CHEMBL3919985 & 1528837 & 8.0969 & 7.4131 & TST \\
\hline CHEMBL3976528 & 1528837 & 5.1456 & 6.6829 & TST \\
\hline CHEMBL3909687 & 1528837 & 6.8729 & 6.9339 & TST \\
\hline CHEMBL 3678894 & 1528837 & 7.7212 & 7.5309 & TRN \\
\hline CHEMBL 3673800 & 1528837 & 6.0706 & 5.8259 & TRN \\
\hline CHEMBL3668699 & 1528837 & 4.7508 & 6.5085 & TST \\
\hline CHEMBL3913560 & 1528837 & 7.4318 & 7.5342 & TRN \\
\hline CHEMBL3934749 & 1528837 & 6.301 & 6.7432 & TST \\
\hline CHEMBL 3678893 & 1528837 & 7.7959 & 8.1501 & TRN \\
\hline CHEMBL3977498 & 1528837 & 6.4802 & 6.2645 & TRN \\
\hline CHEMBL3937679 & 1528837 & 5.4949 & 7.5885 & TST \\
\hline CHEMBL3977197 & 1528837 & 6.0448 & 6.9443 & TST \\
\hline CHEMBL3935550 & 1528837 & 7.8539 & 7.5093 & TRN \\
\hline CHEMBL3969186 & 1528837 & 7.2596 & 7.3138 & TRN \\
\hline CHEMBL3937955 & 1528837 & 8.3979 & 8.1155 & TRN \\
\hline CHEMBL3668740 & 1528837 & 6.8239 & 6.6684 & TRN \\
\hline CHEMBL3956567 & 1528837 & 7.284 & 7.1303 & TRN \\
\hline CHEMBL3668739 & 1528837 & 6.0706 & 5.0457 & TST \\
\hline
\end{tabular}


Supplemental Table S2.txt

\begin{tabular}{|c|c|c|c|c|c|}
\hline CHEMBL3668593 & 1528837 & 5.2218 & 6.1906 & TST & \\
\hline CHEMBL3941229 & 1528837 & 5.7328 & 5.8558 & TRN & \\
\hline CHEMBL 3933260 & 1528837 & 6.3979 & 6.4412 & TRN & \\
\hline CHEMBL 3975415 & 1528837 & 5.8035 & 7.2452 & TST & \\
\hline CHEMBL3961962 & 1528837 & 6.9393 & 7.0506 & TRN & \\
\hline CHEMBL 3668722 & 1528837 & 7.1871 & 7.6145 & TRN & \\
\hline CHEMBL 3673876 & 1528837 & 7.6021 & 7.2835 & TRN & \\
\hline CHEMBL 3898368 & 1528837 & 7.6778 & 8.0167 & TRN & \\
\hline CHEMBL3916221 & 1528837 & 7.5528 & 7.8199 & TRN & \\
\hline CHEMBL3673878 & 1528837 & 7.8239 & 7.7256 & TRN & \\
\hline CHEMBL 3950854 & 1528837 & 7.4318 & 7.272 & TRN & \\
\hline CHEMBL3931641 & 1528837 & 7.4202 & \multicolumn{2}{|c|}{7.082999999999999} & TRN \\
\hline CHEMBL 3673768 & 1528837 & 6.6021 & 6.0566 & TRN & \\
\hline CHEMBL 3939502 & 1528837 & 7.0 & 6.9964 & TRN & \\
\hline CHEMBL3922228 & 1528837 & 6.4134 & \multicolumn{2}{|c|}{6.122999999999999} & TRN \\
\hline CHEMBL 3900468 & 1528837 & 7.3188 & 7.3208 & TRN & \\
\hline CHEMBL3668635 & 1528837 & 5.699 & 5.5637 & TRN & \\
\hline CHEMBL3894618 & 1528837 & 6.9172 & 7.3568 & TST & \\
\hline CHEMBL 3683731 & 1528837 & 7.7696 & 8.6409 & TST & \\
\hline CHEMBL3668681 & 1528837 & 7.4559 & 7.1254 & TRN & \\
\hline CHEMBL 3678828 & 1528837 & 5.4643 & 6.1183 & TST & \\
\hline CHEMBL 3673714 & 1528837 & 5.4347 & 5.636 & TRN & \\
\hline CHEMBL 3668767 & 1528837 & 7.1249 & 6.62 & TRN & \\
\hline CHEMBL 3957434 & 1528837 & 7.7447 & 7.7197 & TRN & \\
\hline CHEMBL 3909623 & 1528837 & 5.699 & 7.1833 & TST & \\
\hline CHEMBL 3933803 & 1528837 & 6.6757 & 6.7196 & TST & \\
\hline CHEMBL 3668574 & 1528837 & 6.0969 & 5.8256 & TRN & \\
\hline CHEMBL 3893842 & 1528837 & 4.9014 & 5.7657 & TST & \\
\hline CHEMBL 3668607 & 1528837 & 4.9606 & 5.362 & TRN & \\
\hline CHEMBL3945700 & 1528837 & 6.0 & 7.4422 & TRN & \\
\hline CHEMBL 3977863 & 1528837 & 6.6021 & 7.3968 & TRN & \\
\hline CHEMBL 3668599 & 1528837 & 4.8447 & \multicolumn{2}{|c|}{5.507999999999999} & TRN \\
\hline CHEMBL3948044 & 1528837 & 6.9281 & 7.2827 & TRN & \\
\hline CHEMBL 3673871 & 1528837 & 6.2366 & 5.6683 & TRN & \\
\hline CHEMBL3959444 & 1528837 & 8.5229 & 8.3042 & TRN & \\
\hline CHEMBL3906096 & 1528837 & 7.3468 & 6.8344 & TRN & \\
\hline CHEMBL3664006 & 1528837 & 4.9527 & 4.9761 & TRN & \\
\hline CHEMBL 3969838 & 1528837 & 6.6517 & 6.5288 & TRN & \\
\hline CHEMBL 3668584 & 1528837 & 5.5892 & 5.563 & TRN & \\
\hline CHEMBL3932236 & 1528837 & 5.8368 & 5.6113 & TRN & \\
\hline CHEMBL 3678772 & 1528837 & 7.3565 & \multicolumn{2}{|c|}{7.082000000000001} & TRN \\
\hline CHEMBL3668712 & 1528837 & 7.8539 & 7.2234 & TRN & \\
\hline CHEMBL3922173 & 1528837 & 7.8239 & 7.1899 & TST & \\
\hline CHEMBL 3673772 & 1528837 & 7.0223 & 7.3896 & TST & \\
\hline CHEMBL3946067 & 1528837 & 5.5067 & 5.8745 & TST & \\
\hline CHEMBL3938094 & 1528837 & 6.9547 & 6.8686 & TRN & \\
\hline CHEMBL3892323 & 1528837 & 6.0947 & 6.4472 & TRN & \\
\hline CHEMBL3673927 & 1528837 & 6.3478 & 6.4015 & TRN & \\
\hline
\end{tabular}


Supplemental Table S2.txt

\begin{tabular}{|c|c|c|c|c|}
\hline CHEMBL 3678875 & 1528837 & 7.8861 & 7.8421 & TRN \\
\hline CHEMBL3984090 & 1528837 & 8.0969 & 8.1857 & TRN \\
\hline CHEMBL3673750 & 1528837 & 8.5229 & 8.0821 & TRN \\
\hline CHEMBL3966059 & 1528837 & 6.9066 & 6.9523 & TRN \\
\hline CHEMBL3673792 & 1528837 & 7.6021 & 6.8836 & TST \\
\hline CHEMBL3668730 & 1528837 & 6.1549 & 6.2286 & TRN \\
\hline CHEMBL3964027 & 1528837 & 4.9666 & 7.1411 & TST \\
\hline CHEMBL3668766 & 1528837 & 6.699 & 6.5387 & TRN \\
\hline CHEMBL3923761 & 1528837 & 7.4202 & 7.3276 & TRN \\
\hline CHEMBL3921175 & 1528837 & 7.6198 & 7.7193 & TRN \\
\hline CHEMBL3668639 & 1528837 & 7.7447 & 8.1379 & TRN \\
\hline CHEMBL3950455 & 1528837 & 6.8239 & 6.2093 & TST \\
\hline CHEMBL3935551 & 1528837 & 6.5229 & 7.2975 & TRN \\
\hline CHEMBL3969205 & 1528837 & 7.3279 & 6.9699 & TST \\
\hline CHEMBL3683751 & 1528837 & 7.4949 & 6.7431 & TST \\
\hline CHEMBL3895214 & 1528837 & 7.4437 & 7.007000 & 0000000001 \\
\hline CHEMBL3912124 & 1528837 & 6.8239 & 6.3158 & TRN \\
\hline CHEMBL3914289 & 1528837 & 5.3928 & 5.4892 & TRN \\
\hline CHEMBL 3917454 & 1528837 & 7.2757 & 7.4105 & TRN \\
\hline CHEMBL3678845 & 1528837 & 7.9586 & 8.1242 & TRN \\
\hline CHEMBL3683747 & 1528837 & 4.757 & 5.3922 & TST \\
\hline CHEMBL3984470 & 1528837 & 6.21899 & 999999999 & 6.3137 \\
\hline CHEMBL3913239 & 1528837 & 5.7696 & 6.9078 & TRN \\
\hline CHEMBL3980313 & 1528837 & 6.8069 & 7.0938 & TRN \\
\hline CHEMBL3965664 & 1528837 & 8.301 & 7.9018 & TRN \\
\hline CHEMBL3673850 & 1528837 & 5.0315 & 5.6441 & TRN \\
\hline CHEMBL3974596 & 1528837 & 7.7212 & 7.4627 & TST \\
\hline CHEMBL 3668578 & 1528837 & 4.6488 & 5.375 & TRN \\
\hline CHEMBL3966029 & 1528837 & 8.0 & 7.5825 & TRN \\
\hline CHEMBL3678872 & 1528837 & 7.6021 & 7.6985 & TRN \\
\hline CHEMBL3965208 & 1528837 & 5.5935 & 6.0347 & TRN \\
\hline CHEMBL3899925 & 1528837 & 7.5229 & 6.9693 & TRN \\
\hline CHEMBL3912861 & 1528837 & 7.041 & 7.1569 & TRN \\
\hline CHEMBL 3678784 & 1528837 & 6.3605 & 6.2474 & TRN \\
\hline CHEMBL 3673815 & 1528837 & 8.0969 & 8.6501 & TRN \\
\hline CHEMBL3967955 & 1528837 & 6.9393 & 7.2896 & TRN \\
\hline CHEMBL3664004 & 1528837 & 5.2007 & 5.1924 & TRN \\
\hline CHEMBL 3673731 & 1528837 & 5.7447 & 5.8734 & TRN \\
\hline CHEMBL3673797 & 1528837 & 5.4881 & 5.5309 & TRN \\
\hline CHEMBL3668667 & 1528837 & 5.8539 & 5.2323 & TST \\
\hline CHEMBL3678731 & 1528837 & 6.7144 & 6.9817 & TST \\
\hline CHEMBL3668671 & 1528837 & 6.3979 & 6.8353 & TRN \\
\hline CHEMBL3948943 & 1528837 & 7.7212 & 7.7526 & TRN \\
\hline CHEMBL3899286 & 1528837 & 6.4584 & 6.8016 & TRN \\
\hline CHEMBL3947496 & 1528837 & 7.5229 & 7.6432 & TRN \\
\hline CHEMBL3948109 & 1528837 & 8.1549 & 7.1568 & TST \\
\hline CHEMBL3940495 & 1528837 & 7.8539 & 7.4829 & TRN \\
\hline CHEMBL3678823 & 1528837 & 7.5528 & 6.6592 & TRN \\
\hline
\end{tabular}


Supplemental Table S2.txt

\begin{tabular}{|c|c|c|c|c|}
\hline HEMBL & & 4 & & \\
\hline HFMBI 3997947 & 528837 & 8.301 & 8.1141 & \\
\hline HEMBL & 28837 & & 9167 & \\
\hline AEMBL & 528837 & 7696 & 8989 & \\
\hline HEMBL3966883 & 528837 & 7.2596 & 5924 & \\
\hline HEMBL & 528837 & 6.3979 & 5379 & \\
\hline$A F M B$ & & & & \\
\hline HEMBL 3926 & 528837 & 599 & 1368 & \\
\hline HEMBL3954795 & 528837 & 7.3565 & 8925 & \\
\hline HEMBL3673762 & 528837 & 6.6021 & 3128 & \\
\hline HEMBL392 & 528837 & 7.6198 & 74 & \\
\hline HEMBL; & & & & \\
\hline HEMBL & 528837 & 557 & & \\
\hline AEMBL3 & 837 & 79 & & \\
\hline HEMBL 389 & 528837 & 6.6021 & 53 & \\
\hline AEMBL & 37 & 41 & & \\
\hline AEMBL & & & & IIV \\
\hline AEMBL & 37 & 5. & 716 & \\
\hline AEMBL3 & 37 & & & \\
\hline AEMBL3 & 37 & 8. & 36 & וJו \\
\hline IEMBL & 37 & 6 & 68 & ST \\
\hline IEME & & & & RIV \\
\hline HEMBL & 37 & 8 & 43 & \\
\hline HEMBL & 37 & & & \\
\hline HEMBL3 & 37 & 7. & 57 & $R N$ \\
\hline IEMBL3 & 7 & & & $\mathrm{RN}$ \\
\hline IEM & & & & $\mathrm{RN}$ \\
\hline נסMזM & & & & $\mathrm{RN}$ \\
\hline IEMBL: & & & & IRN \\
\hline HEMBL 394 & 528837 & 8. & $\partial 19$ & $\mathrm{RN}$ \\
\hline$A F M B L$ & 337 & & 01 & KIN \\
\hline 9 & & & & ST \\
\hline & & & & RN \\
\hline AEMBL3 & & & & ГST \\
\hline HEMBL 390 & 528837 & 69 & 948 & ГST \\
\hline IEMPI & 37 & 38 & 17 & ST \\
\hline & & & & RN \\
\hline HEMBL & & & 3691 & RN \\
\hline HEMBL 389 & 528837 & & 746 & TST \\
\hline EMBL & 337 & & 35 & RN \\
\hline HEMBL3 & 37 & 7. & 915 & Niv \\
\hline & & & & $\mathrm{RN}$ \\
\hline HEMBL3 & & & 1374 & RN \\
\hline AEMBL 366 & 528837 & 7. & 366 & TR \\
\hline 6 & & & & \\
\hline HEMBL 3983463 & & & & \\
\hline HEMBL 3678816 & .528837 & 7.8539 & 7.8516 & \\
\hline CHEMBL3942487 & 1528837 & 7.6021 & 7.5012 & \\
\hline
\end{tabular}

Page 7940 
Supplemental Table S2.txt

\begin{tabular}{|c|c|c|c|c|c|c|}
\hline CHEMBL 3945275 & 1528837 & 5.3372 & 5.7029 & TRN & & \\
\hline CHEMBL 3981428 & 1528837 & 7.2676 & 7.2987 & TST & & \\
\hline CHEMBL 3942116 & 1528837 & 5.70200 & 000000000 & & 5.6735 & TRN \\
\hline CHEMBL 3947648 & 1528837 & 6.9666 & 6.2505 & TRN & & \\
\hline CHEMBL 3668770 & 1528837 & 8.0 & 8.094 & TRN & & \\
\hline CHEMBL 3969089 & 1528837 & 7.6576 & 6.4774 & TST & & \\
\hline CHEMBL 3908849 & 1528837 & 6.0 & 5.6565 & TST & & \\
\hline CHEMBL 3917802 & 1528837 & 7.4089 & 7.2689 & TRN & & \\
\hline CHEMBL 3979635 & 1528837 & 7.3372 & 7.3325 & TRN & & \\
\hline CHEMBL 3668727 & 1528837 & 7.6383 & 7.3638 & TRN & & \\
\hline CHEMBL 3668573 & 1528837 & 5.1938 & 5.1091 & TRN & & \\
\hline CHEMBL 3976269 & 1528837 & 6.3556 & 6.7272 & TRN & & \\
\hline CHEMBL 3940647 & 1528837 & 7.8539 & 7.2511 & TST & & \\
\hline CHEMBL 3916936 & 1528837 & 7.4202 & 7.4073 & TST & & \\
\hline CHEMBL 3954681 & 1528837 & 7.2676 & 7.325 & TST & & \\
\hline CHEMBL 3956705 & 1528837 & 7.2596 & 6.9304 & TST & & \\
\hline CHEMBL 3673910 & 1528837 & 7.8239 & 7.7387 & TRN & & \\
\hline CHEMBL 3953134 & 1528837 & 7.6021 & 7.3882 & TST & & \\
\hline CHEMBL 3668734 & 1528837 & 7.0 & 6.7188 & TRN & & \\
\hline CHEMBL 3668588 & 1528837 & 5.4377 & 5.4053 & TRN & & \\
\hline CHEMBL 3668673 & 1528837 & 8.5229 & 7.7715 & TRN & & \\
\hline CHEMBL 3895319 & 1528837 & 7.0223 & 6.9341 & TST & & \\
\hline CHEMBL 3917000 & 1528837 & 6.38200 & 000000000 & 01 & 6.7476 & TST \\
\hline CHEMBL 3933690 & 1528837 & 7.1938 & 6.7996 & TRN & & \\
\hline CHEMBL 3919223 & 1528837 & 7.1612 & 7.7439 & TRN & & \\
\hline CHEMBL 3668577 & 1528837 & 4.9431 & 5.2218 & TRN & & \\
\hline CHEMBL 3981969 & 1528837 & 7.1487 & 6.9944 & TRN & & \\
\hline CHEMBL 3668642 & 1528837 & 7.2291 & 6.669 & TRN & & \\
\hline CHEMBL 3931259 & 1528837 & 7.9586 & 7.8226 & TRN & & \\
\hline CHEMBL 3673841 & 1528837 & 7.8539 & 6.9989 & TRN & & \\
\hline CHEMBL 3896852 & 1528837 & 6.6655 & 6.7702 & TST & & \\
\hline CHEMBL 3953666 & 1528837 & 6.9706 & 7.5339 & TST & & \\
\hline CHEMBL3668591 & 1528837 & 4.8371 & 5.3434 & TRN & & \\
\hline CHEMBL 3937595 & 1528837 & 6.8633 & 6.7751 & TST & & \\
\hline CHEMBL 3678852 & 1528837 & 8.301 & 8.5199 & TST & & \\
\hline CHEMBL 3926811 & 1528837 & 7.4318 & 8.1779 & TST & & \\
\hline CHEMBL 3678848 & 1528837 & 7.2757 & 6.8254 & TRN & & \\
\hline CHEMBL 3897859 & 1528837 & 6.0343 & 6.9968 & TST & & \\
\hline CHEMBL 3668716 & 1528837 & 6.0 & 6.2165 & TRN & & \\
\hline CHEMBL 3905091 & 1528837 & 7.0 & 7.0626 & TST & & \\
\hline CHEMBL 3678815 & 1528837 & 7.3372 & 7.1546 & TRN & & \\
\hline CHEMBL 3950425 & 1528837 & 8.0969 & 7.3499 & TST & & \\
\hline CHEMBL 3889876 & 1528837 & 7.2366 & 7.2431 & TRN & & \\
\hline CHEMBL 3908297 & 1528837 & 6.1249 & 5.7375 & TST & & \\
\hline CHEMBL 3961211 & 1528837 & 8.0458 & 7.8403 & TST & & \\
\hline CHEMBL 3951233 & 1528837 & 7.2596 & 6.6751 & TST & & \\
\hline CHEMBL 3668755 & 1528837 & 5.8462 & 5.6645 & TRN & & \\
\hline \multirow[t]{2}{*}{ CHEMBL3673763 } & 1528837 & 7.4559 & 6.63899 & 9999999999 & & \\
\hline & & \multicolumn{4}{|c|}{ Page 7941} & \\
\hline
\end{tabular}


Supplemental Table S2.txt

\begin{tabular}{|c|c|c|c|c|}
\hline CHEMBL3673885 & 1528837 & 6.6757 & 7.074 & TRN \\
\hline CHEMBL3668705 & 1528837 & 6.4473 & 7.0598 & TST \\
\hline CHEMBL3894432 & 1528837 & 5.8798 & 6.8675 & TST \\
\hline CHEMBL 3683714 & 1528837 & 7.0315 & 7.2828 & TST \\
\hline CHEMBL3917884 & 1528837 & 7.9208 & 7.5623 & TRN \\
\hline CHEMBL3926900 & 1528837 & 7.699 & 7.4972 & TST \\
\hline CHEMBL3980963 & 1528837 & 6.6676 & 6.8302 & TST \\
\hline CHEMBL3678911 & 1528837 & 7.5376 & 7.2403 & TST \\
\hline CHEMBL 3986535 & 1528837 & 6.3979 & 6.5866 & TST \\
\hline CHEMBL3668566 & 1528837 & 6.3979 & 6.2257 & TRN \\
\hline CHEMBL3673867 & 1528837 & 5.9788 & 6.12 & TST \\
\hline CHEMBL3904917 & 1528837 & 7.6021 & 6.9694 & TRN \\
\hline CHEMBL3673853 & 1528837 & 7.1675 & 6.954 & TRN \\
\hline CHEMBL3928307 & 1528837 & 7.699 & 6.6941 & TST \\
\hline CHEMBL3950009 & 1528837 & 6.9666 & 6.9865 & TRN \\
\hline CHEMBL3934817 & 1528837 & 8.5229 & 8.2833 & TST \\
\hline CHEMBL3946250 & 1528837 & 7.2218 & 7.2092 & TRN \\
\hline CHEMBL3981045 & 1528837 & 6.8729 & 6.6798 & TST \\
\hline CHEMBL 3947224 & 1528837 & 6.3799 & 6.0308 & TST \\
\hline CHEMBL3964500 & 1528837 & 7.4815 & 6.6249 & TRN \\
\hline CHEMBL 3668654 & 1528837 & 6.9208 & 6.8103 & TRN \\
\hline CHEMBL3906086 & 1528837 & 7.4089 & 7.684 & TRN \\
\hline CHEMBL3673897 & 1528837 & 7.0506 & 6.6251 & TRN \\
\hline CHEMBL 3912654 & 1528837 & 7.5229 & 7.28100 & 3000000001 \\
\hline CHEMBL3965532 & 1528837 & 6.8508 & 7.1293 & TRN \\
\hline CHEMBL549020 & 1479005 & 4.5 & 4.154 & TRN \\
\hline CHEMBL526199 & 1479005 & 3.3 & 3.9448 & TRN \\
\hline CHEMBL3430919 & 1479005 & 3.3 & 4.1624 & TRN \\
\hline CHEMBL528583 & 1479005 & 4.5 & 4.3268 & TRN \\
\hline CHEMBL530358 & 1479005 & 5.3 & 4.3257 & TRN \\
\hline CHEMBL534517 & 1479005 & 6.5 & 5.6572 & TRN \\
\hline CHEMBL3430921 & 1479005 & 4.6 & 5.0537 & TST \\
\hline CHEMBL3430922 & 1479005 & 3.3 & 4.7341 & TST \\
\hline CHEMBL 2098124 & 1479005 & 5.6 & 5.1552 & TRN \\
\hline CHEMBL 2098408 & 1479005 & 5.4 & 5.4163 & TRN \\
\hline CHEMBL1578482 & 1479005 & 5.5 & 5.4884 & TRN \\
\hline CHEMBL 2098276 & 1479005 & 4.6 & 3.9509 & TRN \\
\hline CHEMBL3430923 & 1479005 & 3.3 & 2.6307 & TST \\
\hline CHEMBL 3430924 & 1479005 & 6.0 & 5.2343 & TRN \\
\hline CHEMBL3430925 & 1479005 & 5.2 & 4.2853 & TST \\
\hline CHEMBL3430926 & 1479005 & 5.0 & 4.0611 & TST \\
\hline CHEMBL 2165401 & 1479005 & 3.3 & 3.7823 & TST \\
\hline CHEMBL3430928 & 1479005 & 5.9 & 5.0545 & TRN \\
\hline CHEMBL3430929 & 1479005 & 5.4 & 4.6012 & TRN \\
\hline CHEMBL3430930 & 1479005 & 3.3 & 3.4596 & TRN \\
\hline CHEMBL305686 & 1479005 & 5.3 & 4.1979 & TST \\
\hline CHEMBL3430931 & 1479005 & 3.3 & 3.5188 & TST \\
\hline CHEMBL3430932 & 1479005 & 3.3 & 3.1676 & TST \\
\hline
\end{tabular}




\begin{tabular}{|c|c|c|c|c|c|}
\hline \\
\hline CHEMBL1232777 & 1479005 & 3.3 & 5.2253 & & \\
\hline CHEMBL3430933 & 1479005 & 5.0 & 3.6902 & TRN & \\
\hline CHEMBL3430913 & 1479005 & 3.2 & 3.2061 & TRN & \\
\hline CHEMBL3430934 & 1479005 & 6.0 & 5.2307 & TRN & \\
\hline CHEMBL3430935 & 1479005 & 3.3 & 3.6259 & TST & \\
\hline CHEMBL3430936 & 1479005 & 3.3 & 2.8851 & TRN & \\
\hline CHEMBL3430937 & 1479005 & 5.7 & 4.2629 & TST & \\
\hline CHEMBL3430938 & 1479005 & 3.1 & 3.5028 & TRN & \\
\hline CHEMBL3430939 & 1479005 & 3.1 & 3.6535 & TRN & \\
\hline CHEMBL3430940 & 1479005 & 3.1 & 4.1502 & TRN & \\
\hline CHEMBL 3430941 & 1479005 & 3.1 & 3.323 & TRN & \\
\hline CHEMBL 3430942 & 1479005 & 3.3 & 3.6112 & TRN & \\
\hline CHEMBL3430943 & 1479005 & 3.2 & 3.5593 & TRN & \\
\hline CHEMBL 3430944 & 1479005 & 3.1 & 3.7182 & TRN & \\
\hline CHEMBL3430945 & 1479005 & 4.7 & 3.9097 & TRN & \\
\hline CHEMBL3430946 & 1479005 & 3.3 & 2.9185 & TRN & \\
\hline CHEMBL3430947 & 1479005 & 3.3 & 3.3246 & TRN & \\
\hline CHEMBL3430948 & 1479005 & 4.6 & 3.3607 & TRN & \\
\hline CHEMBL3430949 & 1479005 & 5.2 & 5.4868 & TRN & \\
\hline CHEMBL1388922 & 1479005 & 5.3 & 5.2935 & TRN & \\
\hline CHEMBL3430950 & 1479005 & 3.3 & 3.0303 & TRN & \\
\hline CHEMBL3430951 & 1479005 & 5.1 & 4.4915 & TST & \\
\hline CHEMBL1321334 & 1479005 & 3.3 & 3.2304 & TRN & \\
\hline CHEMBL3430953 & 1479005 & 3.3 & 3.6191 & TRN & \\
\hline CHEMBL3430954 & 1479005 & 3.3 & 3.6154 & TRN & \\
\hline CHEMBL3430955 & 1479005 & 3.3 & 4.0161 & TST & \\
\hline CHEMBL3430956 & 1479005 & 5.0 & 4.3666 & TRN & \\
\hline CHEMBL3430957 & 1479005 & 5.3 & 4.4817 & TRN & \\
\hline CHEMBL3430958 & 1479005 & 5.3 & 4.7316 & TRN & \\
\hline CHEMBL3430959 & 1479005 & 5.4 & 5.5151 & TRN & \\
\hline CHEMBL3430960 & 1479005 & 3.3 & 3.13100 & 00000000002 & TRN \\
\hline CHEMBL3430961 & 1479005 & 3.3 & 3.9924 & TRN & \\
\hline CHEMBL3430962 & 1479005 & 3.3 & 3.7252 & TRN & \\
\hline CHEMBL3430963 & 1479005 & 5.3 & 4.4806 & TRN & \\
\hline CHEMBL3430964 & 1479005 & 5.2 & 4.4828 & TRN & \\
\hline CHEMBL3430965 & 1479005 & 5.0 & 4.2022 & TRN & \\
\hline CHEMBL3430966 & 1479005 & 4.8 & 4.0834 & TRN & \\
\hline CHEMBL3430967 & 1479005 & 4.5 & 4.3162 & TRN & \\
\hline CHEMBL3430968 & 1479005 & 6.1 & 5.5923 & TRN & \\
\hline CHEMBL3430969 & 1479005 & 5.1 & 5.4975 & TRN & \\
\hline CHEMBL3430970 & 1479005 & 4.6 & 4.4735 & TRN & \\
\hline CHEMBL1482137 & 1479005 & 3.3 & 3.4835 & TRN & \\
\hline CHEMBL3430971 & 1479005 & 3.3 & 2.8889 & TRN & \\
\hline CHEMBL3430972 & 1479005 & 3.3 & 2.7829 & TRN & \\
\hline CHEMBL3430973 & 1479005 & 4.6 & 4.5862 & TRN & \\
\hline CHEMBL3430974 & 1479005 & 3.3 & 3.5822 & TRN & \\
\hline CHEMBL3430975 & 1479005 & 3.3 & 3.5498 & TRN & \\
\hline CHEMBL3430976 & 1479005 & 3.3 & 3.4828 & TRN & \\
\hline
\end{tabular}




\begin{tabular}{|c|c|c|c|c|}
\hline & & & pplement & al $\mathrm{Ta}$ \\
\hline CHEMBL3430977 & 1479005 & 3.3 & 3.7098 & TST \\
\hline CHEMBL164422 & 1479005 & 6.0 & 5.646 & TRN \\
\hline CHEMBL3430978 & 1479005 & 3.3 & 3.6515 & TRN \\
\hline CHEMBL3430979 & 1479005 & 3.3 & 3.0617 & TRN \\
\hline CHEMBL3430980 & 1479005 & 5.1 & 4.6995 & TRN \\
\hline CHEMBL1487481 & 1479005 & 3.3 & 4.0389 & TRN \\
\hline CHEMBL1487467 & 1479005 & 5.0 & 3.2402 & TRN \\
\hline CHEMBL3430981 & 1479005 & 3.3 & 3.6561 & TRN \\
\hline CHEMBL3430982 & 1479005 & 3.3 & 3.6996 & TRN \\
\hline CHEMBL3430983 & 1479005 & 3.3 & 3.5831 & TRN \\
\hline CHEMBL592827 & 1479005 & 3.3 & 3.2595 & TRN \\
\hline CHEMBL 3430984 & 1479005 & 3.3 & 3.7862 & TRN \\
\hline CHEMBL3430985 & 1479005 & 5.5 & 4.5561 & TRN \\
\hline CHEMBL1466712 & 1479005 & 5.7 & 5.2546 & TRN \\
\hline CHEMBL3430986 & 1479005 & 3.3 & 3.8748 & TRN \\
\hline CHEMBL3430987 & 1479005 & 3.3 & 4.4473 & TST \\
\hline CHEMBL3430988 & 1479005 & 3.3 & 3.6624 & TRN \\
\hline CHEMBL3430989 & 1479005 & 3.3 & 2.9263 & TRN \\
\hline CHEMBL3430990 & 1479005 & 3.3 & 3.1193 & TRN \\
\hline CHEMBL3430991 & 1479005 & 3.3 & 3.4852 & TRN \\
\hline CHEMBL3430992 & 1479005 & 3.3 & 3.5838 & TRN \\
\hline CHEMBL3430993 & 1479005 & 3.3 & 3.4192 & TRN \\
\hline CHEMBL3430994 & 1479005 & 3.3 & 3.7497 & TRN \\
\hline CHEMBL3430995 & 1479005 & 3.3 & 3.4377 & TST \\
\hline CHEMBL3430996 & 1479005 & 3.3 & 3.3995 & TRN \\
\hline CHEMBL3430997 & 1479005 & 3.3 & 2.7564 & TRN \\
\hline CHEMBL3430998 & 1479005 & 3.3 & 4.0779 & TRN \\
\hline CHEMBL3430999 & 1479005 & 4.5 & 4.1047 & TRN \\
\hline CHEMBL3431000 & 1479005 & 3.3 & 3.6103 & TRN \\
\hline CHEMBL3431001 & 1479005 & 3.3 & 3.4146 & TRN \\
\hline CHEMBL3431002 & 1479005 & 5.0 & 3.7157 & TST \\
\hline CHEMBL3431003 & 1479005 & 3.3 & 5.1194 & TRN \\
\hline CHEMBL3431004 & 1479005 & 5.3 & 5.3833 & TRN \\
\hline CHEMBL3431005 & 1479005 & 5.6 & 4.2456 & TRN \\
\hline CHEMBL3431006 & 1479005 & 5.6 & 4.8192 & TRN \\
\hline CHEMBL3431007 & 1479005 & 3.3 & 3.2987 & TRN \\
\hline CHEMBL3431008 & 1479005 & 3.3 & 5.074 & TST \\
\hline CHEMBL3431009 & 1479005 & 5.8 & 4.5772 & TRN \\
\hline CHEMBL2355685 & 1479005 & 6.7 & 5.1255 & TST \\
\hline CHEMBL3431010 & 1479005 & 4.5 & 4.056 & TRN \\
\hline CHEMBL3431011 & 1479005 & 5.6 & 4.364 & TRN \\
\hline CHEMBL3431012 & 1479005 & 3.3 & 3.4298 & TST \\
\hline CHEMBL1731664 & 1479005 & 3.3 & 4.4388 & TRN \\
\hline CHEMBL3431013 & 1479005 & 5.4 & 4.3946 & TRN \\
\hline CHEMBL3431014 & 1479005 & 6.2 & 5.0425 & TRN \\
\hline CHEMBL 3431015 & 1479005 & 3.3 & 4.2776 & TRN \\
\hline CHEMBL3431016 & 1479005 & 3.3 & 3.0027 & TRN \\
\hline CHEMBL3431017 & 1479005 & 3.3 & 3.2594 & TRN \\
\hline
\end{tabular}




\begin{tabular}{|c|c|c|c|c|}
\hline & & & 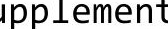 & \\
\hline CHEMBL3431018 & 1479005 & 4.6 & 5.7928 & TRN \\
\hline CHEMBL3431019 & 1479005 & 6.1 & 4.9168 & TRN \\
\hline CHEMBL3431020 & 1479005 & 3.3 & 2.9535 & TRN \\
\hline CHEMBL 3431021 & 1479005 & 3.3 & 3.7189 & TRN \\
\hline CHEMBL3431022 & 1479005 & 3.3 & 3.5641 & TRN \\
\hline CHEMBL3431023 & 1479005 & 5.6 & 4.4772 & TST \\
\hline CHEMBL3431024 & 1479005 & 3.3 & 2.9854 & TRN \\
\hline CHEMBL3431025 & 1479005 & 3.3 & 3.6466 & TRN \\
\hline CHEMBL3431026 & 1479005 & 5.9 & 4.6734 & TST \\
\hline CHEMBL3431027 & 1479005 & 4.6 & 3.5663 & TRN \\
\hline CHEMBL 3431028 & 1479005 & 3.3 & 3.0528 & TRN \\
\hline CHEMBL3431029 & 1479005 & 3.3 & 3.5038 & TRN \\
\hline CHEMBL3431030 & 1479005 & 4.9 & 5.1368 & TRN \\
\hline CHEMBL 3431031 & 1479005 & 4.3 & 3.9793 & TRN \\
\hline CHEMBL3431032 & 1479005 & 3.3 & 4.3243 & TRN \\
\hline CHEMBL1527364 & 1479005 & 4.9 & 3.8335 & TRN \\
\hline CHEMBL3430914 & 1479005 & 4.5 & 4.4875 & TRN \\
\hline CHEMBL3431033 & 1479005 & 4.6 & 3.7799 & TRN \\
\hline CHEMBL3431034 & 1479005 & 3.3 & 4.1919 & TRN \\
\hline CHEMBL3431035 & 1479005 & 3.3 & 3.8189 & TRN \\
\hline CHEMBL3431036 & 1479005 & 3.3 & 3.7877 & TRN \\
\hline CHEMBL3431037 & 1479005 & 3.3 & 3.2399 & TRN \\
\hline CHEMBL3431038 & 1479005 & 3.3 & 3.4718 & TRN \\
\hline CHEMBL3431039 & 1479005 & 3.3 & 2.9421 & TRN \\
\hline CHEMBL3431040 & 1479005 & 7.9 & 6.2463 & TRN \\
\hline CHEMBL1354075 & 1479005 & 5.3 & 5.0898 & TRN \\
\hline CHEMBL3431041 & 1479005 & 3.3 & 4.2003 & TRN \\
\hline CHEMBL3431042 & 1479005 & 3.3 & 2.8206 & TRN \\
\hline CHEMBL 3431043 & 1479005 & 3.3 & 3.8366 & TST \\
\hline CHEMBL 3431044 & 1479005 & 3.3 & 3.3342 & TST \\
\hline CHEMBL3431045 & 1479005 & 4.4 & 4.3834 & TRN \\
\hline CHEMBL3431046 & 1479005 & 6.2 & 5.2106 & TRN \\
\hline CHEMBL3431047 & 1479005 & 6.6 & 5.7931 & TRN \\
\hline CHEMBL 3431048 & 1479005 & 6.5 & 5.5963 & TRN \\
\hline CHEMBL3431049 & 1479005 & 6.3 & 5.6996 & TRN \\
\hline CHEMBL3431050 & 1479005 & 6.3 & 5.695 & TRN \\
\hline CHEMBL3431051 & 1479005 & 5.4 & 5.4571 & TRN \\
\hline CHEMBL3431052 & 1479005 & 4.9 & 5.0287 & TRN \\
\hline CHEMBL 3431053 & 1479005 & 5.7 & 5.3501 & TRN \\
\hline CHEMBL 2356808 & 1479005 & 3.3 & 3.1849 & TRN \\
\hline CHEMBL3431054 & 1479005 & 3.3 & 3.3242 & TRN \\
\hline CHEMBL3431055 & 1479005 & 3.3 & 3.8489 & TST \\
\hline CHEMBL3431056 & 1479005 & 3.3 & 2.7021 & TRN \\
\hline CHEMBL3431057 & 1479005 & 3.3 & 3.8332 & TST \\
\hline CHEMBL 2093320 & 1479005 & 4.8 & 3.5387 & TRN \\
\hline CHEMBL 3431058 & 1479005 & 3.3 & 3.3233 & TRN \\
\hline CHEMBL3431059 & 1479005 & 3.3 & 3.1734 & TRN \\
\hline CHEMBL3431060 & 1479005 & 3.3 & 3.3363 & TRN \\
\hline
\end{tabular}




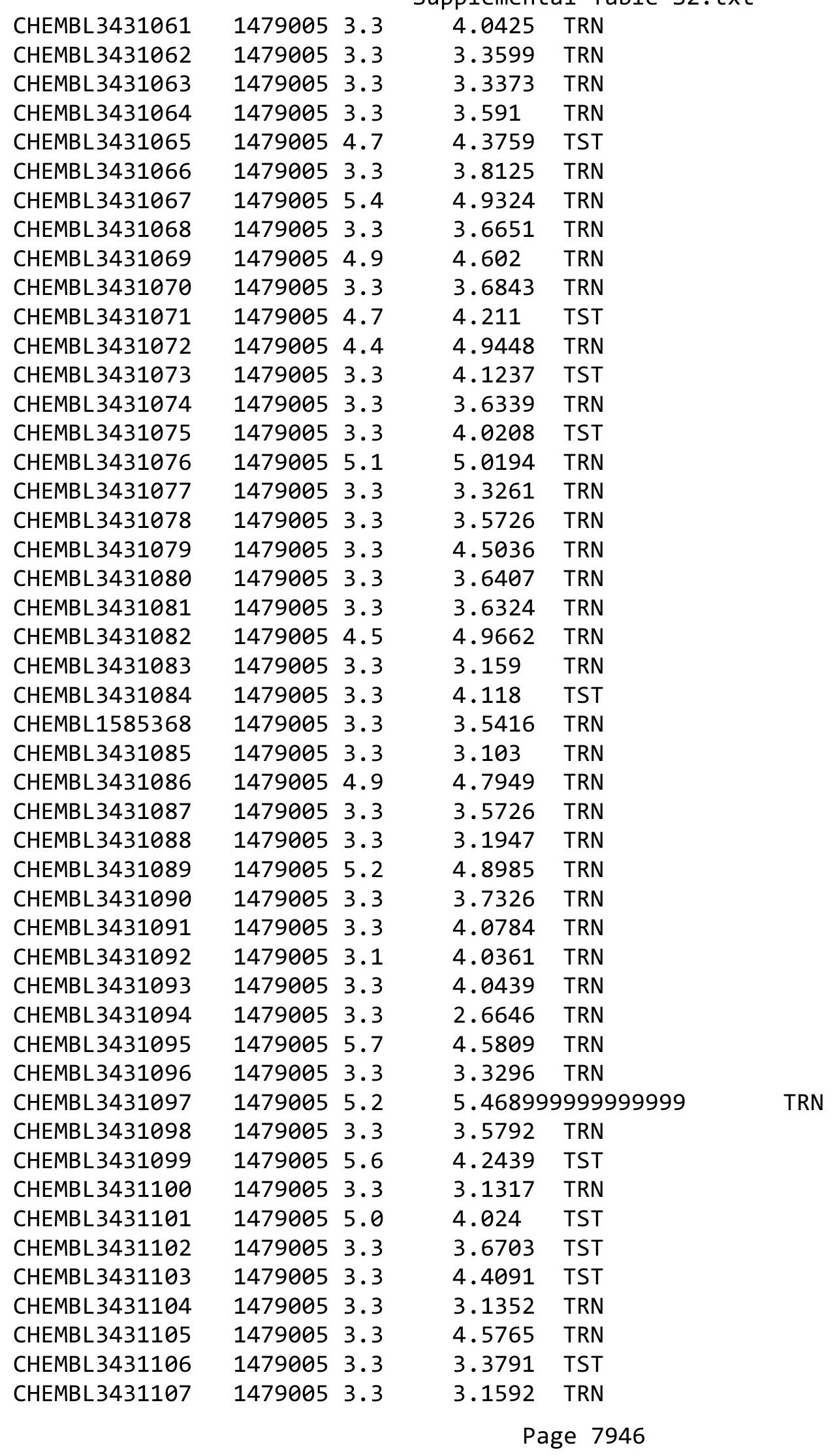




\begin{tabular}{|c|c|c|c|c|c|}
\hline & & & & & \\
\hline CHEMBL3431108 & 1479005 & 3.3 & 4.0533 & TRN & \\
\hline CHEMBL3431109 & 1479005 & 4.6 & 3.8334 & TRN & \\
\hline CHEMBL3431110 & 1479005 & 3.3 & 3.7028 & TRN & \\
\hline CHEMBL 3431111 & 1479005 & 3.3 & 3.904 & TRN & \\
\hline CHEMBL3431112 & 1479005 & 5.1 & 5.9521 & TRN & \\
\hline CHEMBL 3431113 & 1479005 & 5.7 & 6.1 & TRN & \\
\hline CHEMBL3431114 & 1479005 & 3.3 & 4.1144 & TRN & \\
\hline CHEMBL3431115 & 1479005 & 5.4 & 4.1788 & TST & \\
\hline CHEMBL 3431116 & 1479005 & 3.3 & 2.9449 & TRN & \\
\hline CHEMBL3431117 & 1479005 & 4.8 & 4.9568 & TRN & \\
\hline CHEMBL 3431118 & 1479005 & 3.3 & 3.5594 & TRN & \\
\hline CHEMBL3431119 & 1479005 & 3.3 & 3.9744 & TRN & \\
\hline CHEMBL 3431120 & 1479005 & 4.6 & 3.077 & TRN & \\
\hline CHEMBL3431121 & 1479005 & 3.3 & 3.9222 & TST & \\
\hline CHEMBL 3431122 & 1479005 & 3.3 & 4.5818 & TRN & \\
\hline CHEMBL 3431123 & 1479005 & 3.3 & 3.7505 & TRN & \\
\hline CHEMBL 3431124 & 1479005 & 3.3 & 3.9415 & TRN & \\
\hline CHEMBL3431125 & 1479005 & 3.3 & 3.1649 & TST & \\
\hline CHEMBL3431126 & 1479005 & 4.6 & 3.4135 & TRN & \\
\hline CHEMBL 3431128 & 1479005 & 5.0 & 5.0267 & TST & \\
\hline CHEMBL3431129 & 1479005 & 5.1 & 4.9363 & TST & \\
\hline CHEMBL 3431130 & 1479005 & 4.6 & 4.4703 & TST & \\
\hline CHEMBL3431131 & 1479005 & 5.5 & 5.2241 & TRN & \\
\hline CHEMBL3430915 & 1479005 & 3.3 & 3.2852 & TRN & \\
\hline CHEMBL 3431132 & 1479005 & 4.5 & 4.6772 & TRN & \\
\hline CHEMBL3431133 & 1479005 & 3.3 & 3.9552 & TRN & \\
\hline CHEMBL3431134 & 1479005 & 6.5 & 5.5582 & TRN & \\
\hline CHEMBL3431135 & 1479005 & 3.3 & 2.8192 & TRN & \\
\hline CHEMBL3431136 & 1479005 & 3.3 & 4.4722 & TRN & \\
\hline CHEMBL 3431137 & 1479005 & 3.3 & 4.5508 & TRN & \\
\hline CHEMBL 3431138 & 1479005 & 3.3 & 4.1352 & TST & \\
\hline CHEMBL3431139 & 1479005 & 4.5 & 4.8974 & TST & \\
\hline CHEMBL3431140 & 1479005 & 3.3 & 3.6639 & TST & \\
\hline CHEMBL3431141 & 1479005 & 3.3 & 3.6998 & TRN & \\
\hline CHEMBL 3431142 & 1479005 & 3.3 & 3.7586 & TST & \\
\hline CHEMBL 3431143 & 1479005 & 6.3 & 5.7074 & TRN & \\
\hline CHEMBL3431144 & 1479005 & 3.3 & 3.1379 & TRN & \\
\hline CHEMBL3431145 & 1479005 & 4.6 & 5.3948 & TRN & \\
\hline CHEMBL3431146 & 1479005 & 3.3 & 3.5728 & TRN & \\
\hline CHEMBL 3431147 & 1479005 & 5.1 & 4.4342 & TST & \\
\hline CHEMBL 3431148 & 1479005 & 3.3 & 3.16399 & 99999999997 & TRN \\
\hline CHEMBL3431149 & 1479005 & 5.9 & 5.2616 & TRN & \\
\hline CHEMBL3431150 & 1479005 & 3.3 & 3.4726 & TRN & \\
\hline CHEMBL3431151 & 1479005 & 6.2 & 4.8122 & TRN & \\
\hline CHEMBL 3431152 & 1479005 & 3.3 & 3.0082 & TRN & \\
\hline CHEMBL 3431153 & 1479005 & 3.3 & 3.0996 & TRN & \\
\hline CHEMBL 3431154 & 1479005 & 6.2 & 4.8438 & TST & \\
\hline CHEMBL 3431155 & 1479005 & 3.3 & 3.4515 & TRN & \\
\hline
\end{tabular}




\begin{tabular}{|c|c|c|c|c|c|}
\hline & & & & & \\
\hline CHEMBL3431156 & 1479005 & 3.3 & 2.8698 & TRN & \\
\hline CHEMBL3431157 & 1479005 & 3.3 & 3.8292 & TST & \\
\hline CHEMBL3431158 & 1479005 & 3.3 & 4.0826 & TST & \\
\hline CHEMBL3431159 & 1479005 & 3.3 & 3.2473 & TST & \\
\hline CHEMBL1593679 & 1479005 & 4.6 & 3.5568 & TRN & \\
\hline CHEMBL 3431160 & 1479005 & 5.2 & 4.6091 & TRN & \\
\hline CHEMBL3431161 & 1479005 & 3.3 & 3.85600 & 00000000003 & TST \\
\hline CHEMBL3431162 & 1479005 & 3.3 & 3.0329 & TST & \\
\hline CHEMBL 3431163 & 1479005 & 4.4 & 4.0174 & TRN & \\
\hline CHEMBL3431164 & 1479005 & 3.3 & 3.2041 & TRN & \\
\hline CHEMBL 3431165 & 1479005 & 3.3 & 3.6671 & TST & \\
\hline CHEMBL1458931 & 1479005 & 3.3 & 3.7829 & TRN & \\
\hline CHEMBL3431166 & 1479005 & 3.3 & 3.4213 & TRN & \\
\hline CHEMBL3431167 & 1479005 & 3.3 & 2.9909 & TRN & \\
\hline CHEMBL3431168 & 1479005 & 6.1 & 5.8909 & TRN & \\
\hline CHEMBL3431169 & 1479005 & 3.3 & 3.3359 & TRN & \\
\hline CHEMBL 3431170 & 1479005 & 8.4 & 6.9399 & TRN & \\
\hline CHEMBL3431171 & 1479005 & 3.3 & 3.5816 & TRN & \\
\hline CHEMBL3431172 & 1479005 & 6.3 & 6.2462 & TRN & \\
\hline CHEMBL 3431173 & 1479005 & 4.8 & 3.946 & TRN & \\
\hline CHEMBL 3431174 & 1479005 & 3.3 & 4.0044 & TRN & \\
\hline CHEMBL 3431175 & 1479005 & 3.3 & 3.6659 & TST & \\
\hline CHEMBL3431176 & 1479005 & 4.7 & 4.6645 & TRN & \\
\hline CHEMBL3431177 & 1479005 & 5.2 & 4.0487 & TRN & \\
\hline CHEMBL 3431178 & 1479005 & 3.2 & 4.0101 & TRN & \\
\hline CHEMBL3431179 & 1479005 & 3.3 & 3.61899 & 99999999998 & TRN \\
\hline CHEMBL3431180 & 1479005 & 4.3 & 4.8315 & TRN & \\
\hline CHEMBL3431181 & 1479005 & 5.8 & 5.5259 & TRN & \\
\hline CHEMBL3431182 & 1479005 & 3.3 & 4.5707 & TST & \\
\hline CHEMBL 3431183 & 1479005 & 3.3 & 3.1073 & TRN & \\
\hline CHEMBL 3431184 & 1479005 & 3.3 & 3.3298 & TRN & \\
\hline CHEMBL3431185 & 1479005 & 5.3 & 5.6123 & TRN & \\
\hline CHEMBL3431186 & 1479005 & 6.1 & 6.3153 & TRN & \\
\hline CHEMBL3431187 & 1479005 & 3.3 & 4.1339 & TRN & \\
\hline CHEMBL 3431188 & 1479005 & 6.4 & 6.7043 & TRN & \\
\hline CHEMBL3431189 & 1479005 & 4.5 & 4.57600 & 00000000005 & TST \\
\hline CHEMBL3431190 & 1479005 & 3.3 & 4.4768 & TRN & \\
\hline CHEMBL3431191 & 1479005 & 4.5 & 3.8639 & TRN & \\
\hline CHEMBL3431192 & 1479005 & 6.6 & 6.8788 & TRN & \\
\hline CHEMBL 3431193 & 1479005 & 6.9 & 6.9941 & TRN & \\
\hline CHEMBL 3431194 & 1479005 & 6.8 & 6.7172 & TRN & \\
\hline CHEMBL3431195 & 1479005 & 6.3 & 6.5702 & TRN & \\
\hline CHEMBL3431196 & 1479005 & 6.0 & 4.4881 & TRN & \\
\hline CHEMBL3431197 & 1479005 & 5.8 & 6.2788 & TRN & \\
\hline CHEMBL 3431198 & 1479005 & 6.1 & 6.4914 & TRN & \\
\hline CHEMBL3431199 & 1479005 & 4.8 & 4.2325 & TST & \\
\hline CHEMBL3431200 & 1479005 & 3.3 & 2.6498 & TRN & \\
\hline CHEMBL 3431201 & 1479005 & 5.2 & 3.3127 & TRN & \\
\hline
\end{tabular}




\begin{tabular}{|c|c|c|c|c|c|}
\hline & & & & & \\
\hline CHEMBL3431202 & 1479005 & 3.3 & 4.272 & TRN & \\
\hline CHEMBL3431203 & 1479005 & 6.2 & 6.6839 & TRN & \\
\hline CHEMBL3431204 & 1479005 & 4.7 & 4.0422 & TRN & \\
\hline CHEMBL3431205 & 1479005 & 4.8 & 3.9584 & TRN & \\
\hline CHEMBL3431206 & 1479005 & 8.2 & 7.5141 & TRN & \\
\hline CHEMBL3431207 & 1479005 & 6.3 & 6.5419 & TRN & \\
\hline CHEMBL3431208 & 1479005 & 3.3 & 4.5497 & TRN & \\
\hline CHEMBL3431209 & 1479005 & 7.0 & 7.0807 & TRN & \\
\hline CHEMBL3431210 & 1479005 & 3.3 & 3.2959 & TRN & \\
\hline CHEMBL3431211 & 1479005 & 6.2 & 5.8068 & TRN & \\
\hline CHEMBL3431212 & 1479005 & 5.1 & 4.9802 & TRN & \\
\hline CHEMBL3431213 & 1479005 & 3.3 & 3.9941 & TRN & \\
\hline CHEMBL3431214 & 1479005 & 3.3 & 2.9237 & TRN & \\
\hline CHEMBL 3431215 & 1479005 & 6.4 & 6.3799 & TRN & \\
\hline CHEMBL3431216 & 1479005 & 4.5 & 5.2182 & TRN & \\
\hline CHEMBL3431217 & 1479005 & 3.3 & 4.5489 & TRN & \\
\hline CHEMBL3431218 & 1479005 & 3.3 & 3.4847 & TRN & \\
\hline CHEMBL3431219 & 1479005 & 3.3 & 3.6078 & TRN & \\
\hline CHEMBL3431220 & 1479005 & 5.3 & 5.1483 & TRN & \\
\hline CHEMBL 3431221 & 1479005 & 5.9 & 6.0691 & TRN & \\
\hline CHEMBL3431222 & 1479005 & 3.3 & 3.9383 & TRN & \\
\hline CHEMBL3431223 & 1479005 & 3.3 & 3.0832 & TST & \\
\hline CHEMBL3431224 & 1479005 & 3.3 & 3.85699 & 99999999998 & TRN \\
\hline CHEMBL3431225 & 1479005 & 5.9 & 5.3013 & TRN & \\
\hline CHEMBL3431226 & 1479005 & 5.5 & 4.9281 & TRN & \\
\hline CHEMBL 3431227 & 1479005 & 3.3 & 3.9415 & TRN & \\
\hline CHEMBL3431228 & 1479005 & 3.3 & 4.4933 & TRN & \\
\hline CHEMBL3431229 & 1479005 & 6.6 & 6.8333 & TRN & \\
\hline CHEMBL3431230 & 1479005 & 6.8 & 6.7042 & TRN & \\
\hline CHEMBL 2441267 & 1479005 & 7.5 & 7.4173 & TRN & \\
\hline CHEMBL3430916 & 1479005 & 3.3 & 3.8755 & TRN & \\
\hline CHEMBL3431231 & 1479005 & 3.3 & 4.3095 & TRN & \\
\hline CHEMBL3431232 & 1479005 & 3.3 & 3.5591 & TRN & \\
\hline CHEMBL 3431233 & 1479005 & 5.5 & 5.5056 & TRN & \\
\hline CHEMBL 3431234 & 1479005 & 4.7 & 4.7481 & TRN & \\
\hline CHEMBL3431235 & 1479005 & 4.7 & 4.506 & TST & \\
\hline CHEMBL3431236 & 1479005 & 3.3 & 3.3641 & TST & \\
\hline CHEMBL3431237 & 1479005 & 3.3 & 3.5421 & TRN & \\
\hline CHEMBL 3431238 & 1479005 & 3.3 & 3.5043 & TRN & \\
\hline CHEMBL3431239 & 1479005 & 3.3 & 3.18300 & 00000000003 & TRN \\
\hline CHEMBL 3431240 & 1479005 & 3.3 & 3.8962 & TST & \\
\hline CHEMBL 3431241 & 1479005 & 3.3 & 4.3508 & TRN & \\
\hline CHEMBL3431242 & 1479005 & 3.3 & 2.8938 & TRN & \\
\hline CHEMBL3431243 & 1479005 & 3.3 & 2.7742 & TST & \\
\hline CHEMBL 3431244 & 1479005 & 3.3 & 3.4949 & TRN & \\
\hline CHEMBL 3431245 & 1479005 & 3.3 & 4.0947 & TRN & \\
\hline CHEMBL3431246 & 1479005 & 5.1 & 4.6145 & TRN & \\
\hline CHEMBL3431247 & 1479005 & 4.9 & 5.1394 & TRN & \\
\hline
\end{tabular}




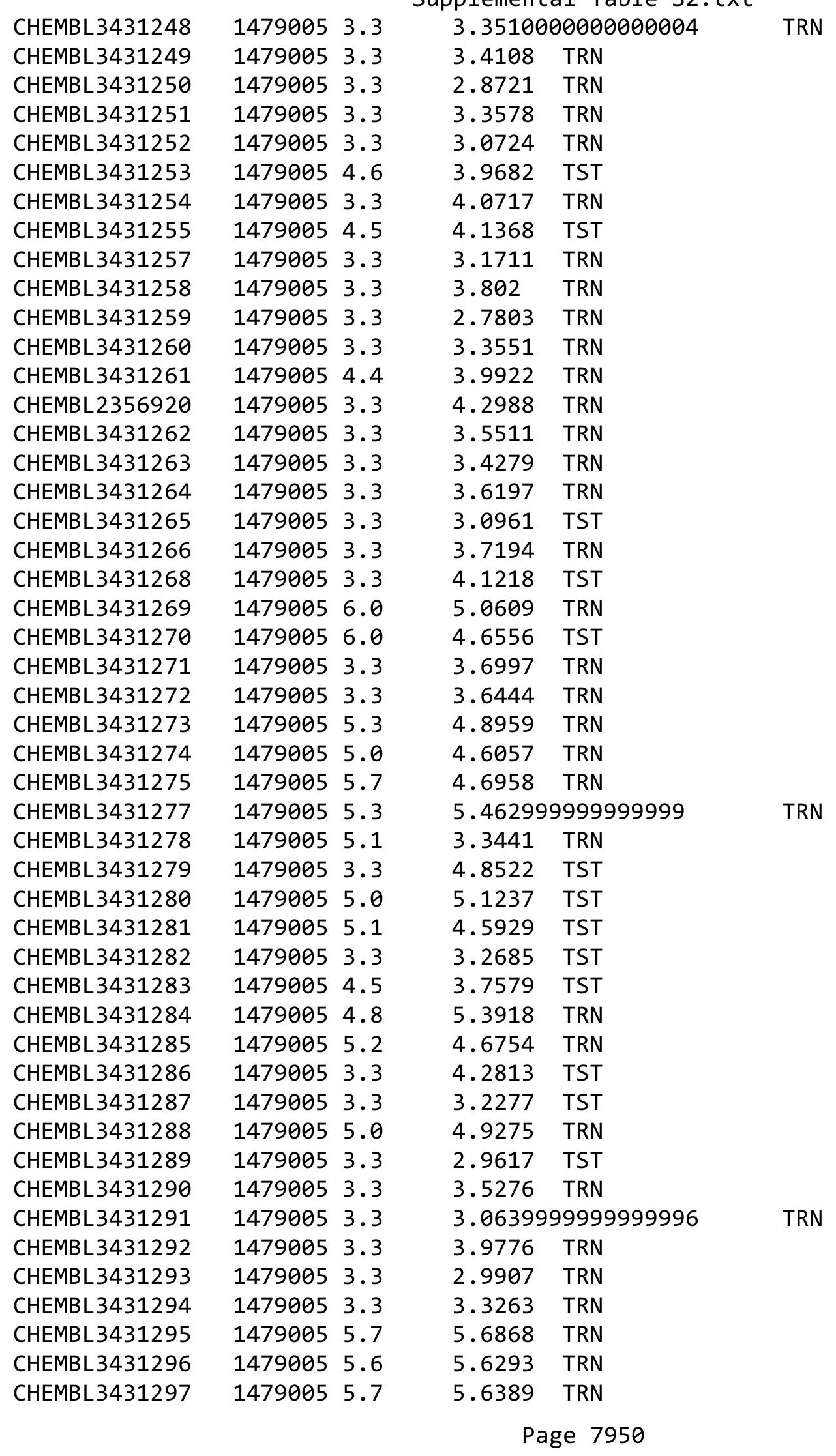




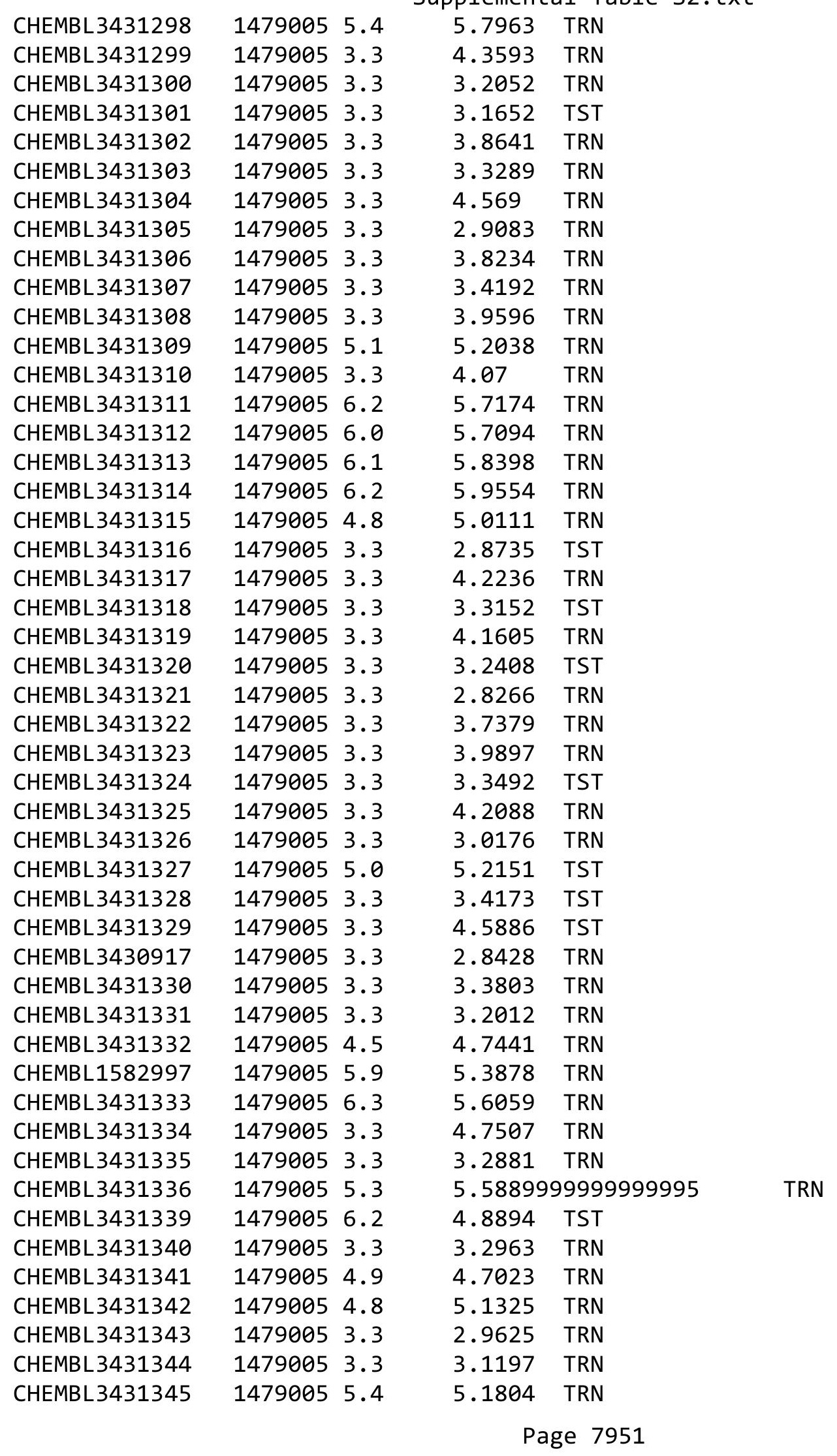




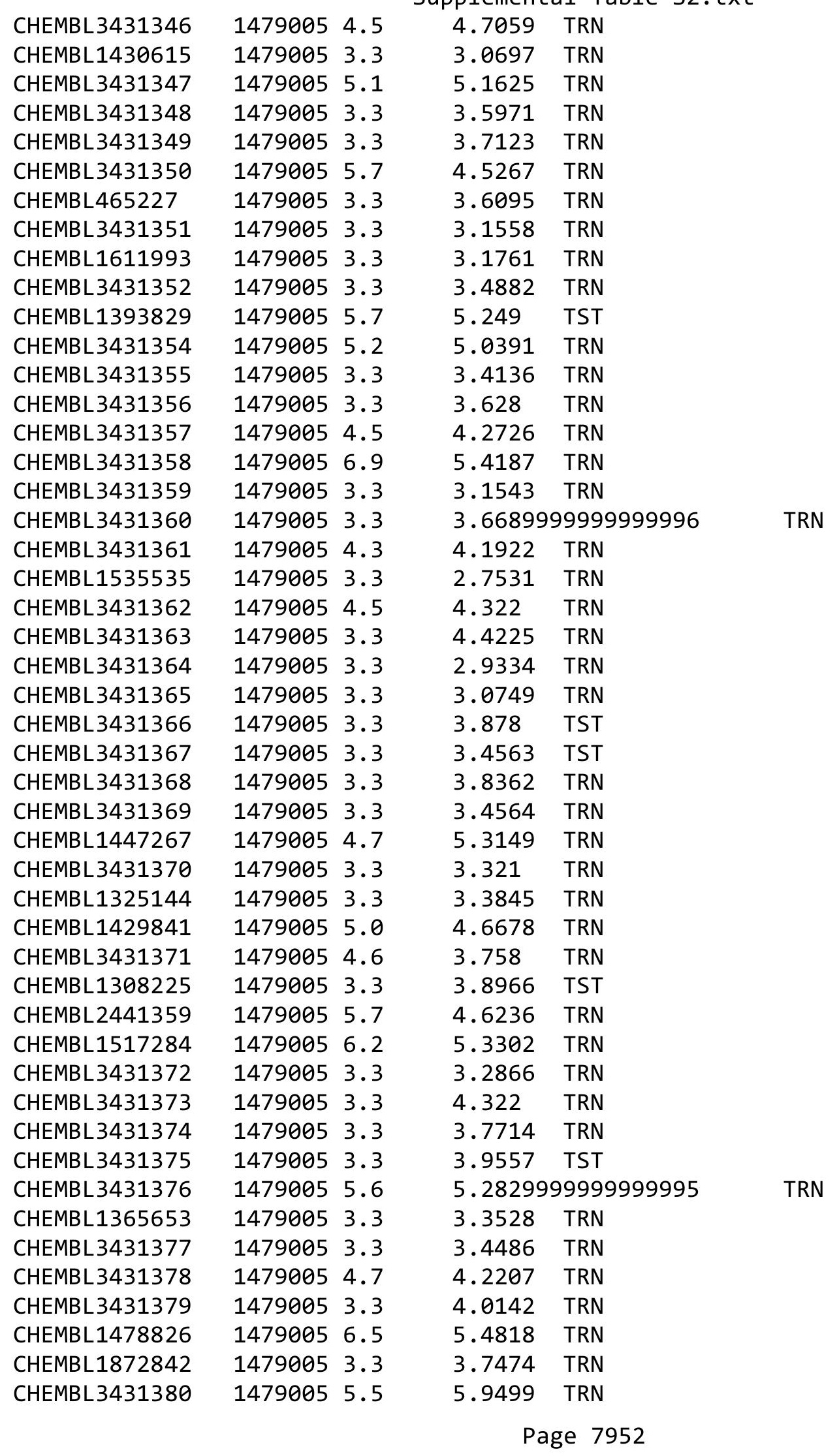




\begin{tabular}{|c|c|c|c|c|}
\hline \\
\hline CHEMBL3431381 & 1479005 & 3.3 & 4.9379 & TRN \\
\hline CHEMBL3431382 & 1479005 & 5.4 & 4.4705 & TRN \\
\hline CHEMBL3431383 & 1479005 & 4.4 & 4.0012 & TRN \\
\hline CHEMBL3431384 & 1479005 & 3.3 & 3.9482 & TRN \\
\hline CHEMBL3431385 & 1479005 & 3.3 & 3.3739 & TRN \\
\hline CHEMBL3431386 & 1479005 & 3.3 & 4.3014 & TRN \\
\hline CHEMBL1730515 & 1479005 & 5.3 & 4.6818 & TRN \\
\hline CHEMBL3431387 & 1479005 & 3.3 & 3.678 & TRN \\
\hline CHEMBL3431388 & 1479005 & 4.7 & 4.7288 & TRN \\
\hline CHEMBL1566898 & 1479005 & 4.6 & 4.3225 & TRN \\
\hline CHEMBL3431389 & 1479005 & 4.7 & 4.2349 & TRN \\
\hline CHEMBL3431390 & 1479005 & 6.2 & 4.5772 & TST \\
\hline CHEMBL3431391 & 1479005 & 3.3 & 3.7893 & TRN \\
\hline CHEMBL1489081 & 1479005 & 5.6 & 5.7254 & TRN \\
\hline CHEMBL3431392 & 1479005 & 3.3 & 4.1678 & TRN \\
\hline CHEMBL3431393 & 1479005 & 4.7 & 4.0165 & TRN \\
\hline CHEMBL3431394 & 1479005 & 5.5 & 4.4035 & TST \\
\hline CHEMBL3431395 & 1479005 & 3.3 & 3.0162 & TRN \\
\hline CHEMBL3431396 & 1479005 & 3.3 & 3.2378 & TRN \\
\hline CHEMBL3431397 & 1479005 & 4.6 & 4.2792 & TRN \\
\hline CHEMBL3431398 & 1479005 & 3.3 & 3.4129 & TRN \\
\hline CHEMBL3431399 & 1479005 & 3.3 & 3.3377 & TRN \\
\hline CHEMBL3431400 & 1479005 & 3.3 & 3.6745 & TRN \\
\hline CHEMBL1418463 & 1479005 & 3.3 & 3.8634 & TST \\
\hline CHEMBL3431401 & 1479005 & 3.3 & 3.3481 & TST \\
\hline CHEMBL3431402 & 1479005 & 6.9 & 4.6905 & TST \\
\hline CHEMBL3431403 & 1479005 & 3.3 & 3.7544 & TST \\
\hline CHEMBL3431404 & 1479005 & 3.3 & 4.1002 & TST \\
\hline CHEMBL3431405 & 1479005 & 3.3 & 3.4558 & TST \\
\hline CHEMBL3431406 & 1479005 & 6.7 & 4.5703 & TST \\
\hline CHEMBL3431407 & 1479005 & 4.5 & 3.6895 & TST \\
\hline CHEMBL3431408 & 1479005 & 3.3 & 3.478 & TST \\
\hline CHEMBL3431409 & 1479005 & 4.5 & 5.1137 & TST \\
\hline CHEMBL3431410 & 1479005 & 3.3 & 3.08600 & 00000000003 \\
\hline CHEMBL3431411 & 1479005 & 3.3 & 3.0914 & TST \\
\hline CHEMBL3431412 & 1479005 & 4.9 & 3.9595 & TST \\
\hline CHEMBL3431413 & 1479005 & 3.3 & 4.6542 & TST \\
\hline CHEMBL3431414 & 1479005 & 4.8 & 4.8591 & TST \\
\hline CHEMBL3431415 & 1479005 & 4.4 & 4.6473 & TST \\
\hline CHEMBL3431416 & 1479005 & 3.3 & 3.6654 & TST \\
\hline CHEMBL 291721 & 1479005 & 3.3 & 4.4463 & TST \\
\hline CHEMBL3431417 & 1479005 & 3.3 & 3.9104 & TST \\
\hline CHEMBL3431418 & 1479005 & 3.3 & 3.2054 & TST \\
\hline CHEMBL 487186 & 1479005 & 3.3 & 3.1438 & TST \\
\hline CHEMBL3431419 & 1479005 & 4.5 & 3.2718 & TST \\
\hline CHEMBL3431420 & 1479005 & 3.3 & 3.1862 & TST \\
\hline CHEMBL3431421 & 1479005 & 3.3 & 4.4632 & TST \\
\hline CHEMBL3431422 & 1479005 & 3.3 & 4.148 & TST \\
\hline
\end{tabular}




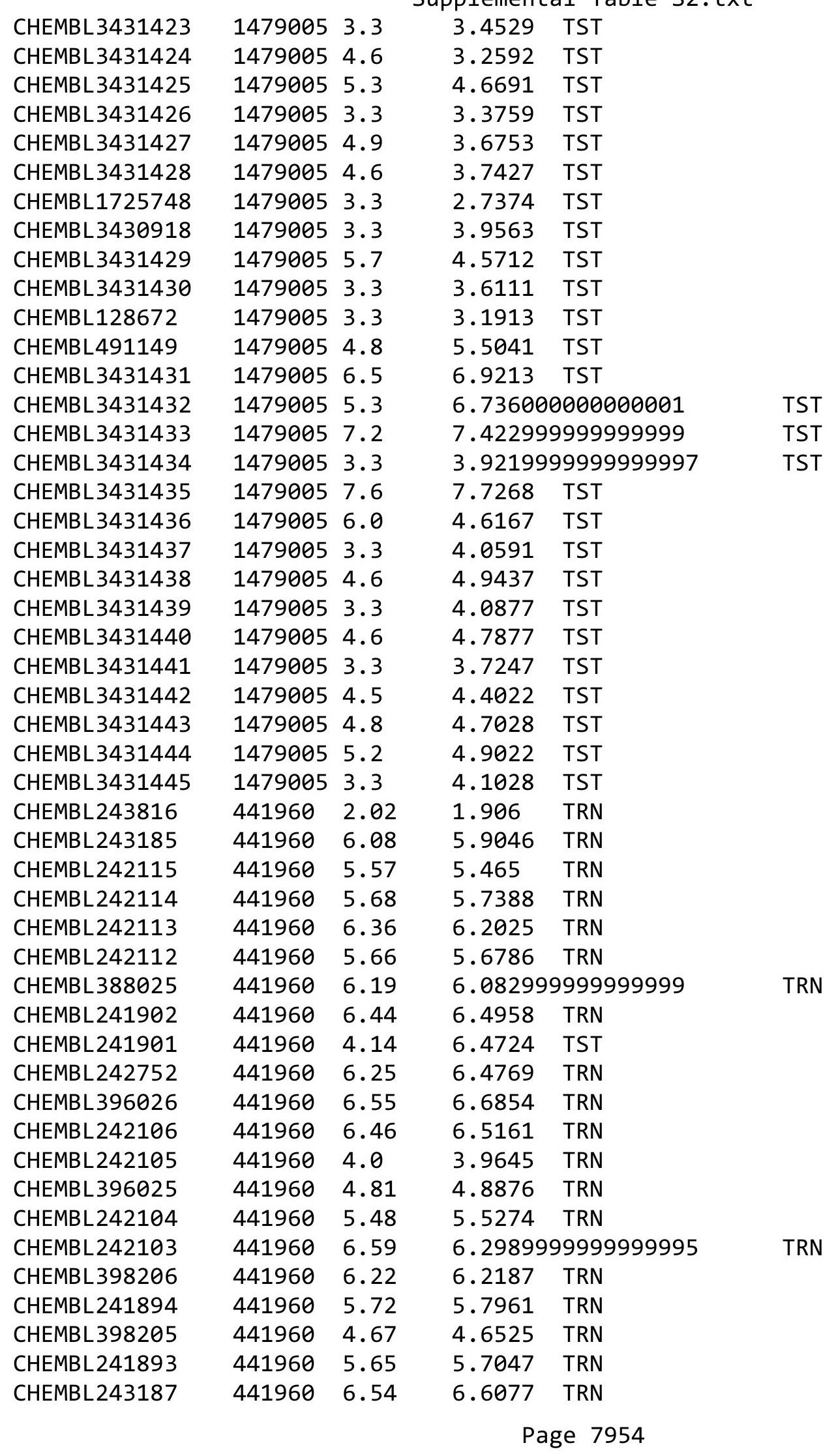




\begin{tabular}{|c|c|c|c|c|}
\hline \multicolumn{5}{|c|}{ Supplemental Table S2.txt } \\
\hline CHEMBL 243127 & 441960 & 5.98 & 5.8943 & TRN \\
\hline CHEMBL390625 & 441960 & 6.28 & 6.3471 & TRN \\
\hline CHEMBL108925 & 441960 & 2.38 & 1.9377 & TST \\
\hline CHEMBL 243587 & 441960 & 2.31 & 2.2088 & TST \\
\hline CHEMBL 222021 & 441960 & 2.05 & 2.1572 & TRN \\
\hline CHEMBL396295 & 441960 & 0.97 & 0.9292 & TRN \\
\hline CHEMBL 22585 & 441960 & 1.37 & 1.2706 & TRN \\
\hline CHEMBL13859 & 441960 & 2.24 & 2.2426 & TRN \\
\hline CHEMBL 275563 & 441960 & 1.6 & 1.8448 & TRN \\
\hline CHEMBL161577 & 441960 & 3.07 & 2.499 & TST \\
\hline CHEMBL 242748 & 441960 & 3.13 & 3.0653 & TRN \\
\hline CHEMBL 242962 & 441960 & 3.14 & 2.4709 & TST \\
\hline CHEMBL441343 & 441960 & 1.79 & 1.8901 & TRN \\
\hline CHEMBL 328910 & 441960 & 1.52 & 2.4381 & TST \\
\hline CHEMBL1461 & 441960 & 1.49 & 2.3831 & TST \\
\hline CHEMBL1462 & 441960 & 1.59 & 1.6943 & TRN \\
\hline CHEMBL242963 & 441960 & 2.42 & 2.2611 & TRN \\
\hline CHEMBL 22425 & 441960 & 1.88 & 1.8652 & TRN \\
\hline CHEMBL 21932 & 441960 & 2.26 & 2.2955 & TRN \\
\hline CHEMBL 88700 & 441960 & 1.32 & 1.4792 & TRN \\
\hline CHEMBL120568 & 441960 & 1.16 & 1.0551 & TRN \\
\hline CHEMBL116159 & 441960 & 2.76 & 2.8147 & TRN \\
\hline CHEMBL116157 & 441960 & 2.98 & 2.9664 & TRN \\
\hline CHEMBL93746 & 441960 & 2.68 & 2.5239 & TRN \\
\hline CHEMBL390624 & 441960 & 2.93 & 2.9227 & TRN \\
\hline CHEMBL14193 & 441960 & 2.51 & 2.1944 & TST \\
\hline CHEMBL 243186 & 441960 & 2.98 & 1.9222 & TST \\
\hline CHEMBL161598 & 441960 & 2.72 & 2.1809 & TST \\
\hline CHEMBL350966 & 441960 & 2.7 & 2.2032 & TST \\
\hline CHEMBL65369 & 441960 & 1.79 & 2.2137 & TST \\
\hline CHEMBL 37537 & 441960 & 1.53 & 1.6915 & TST \\
\hline CHEMBL116158 & 441960 & 2.72 & 2.4981 & TST \\
\hline CHEMBL2165271 & 860487 & 6.9586 & 6.9631 & TRN \\
\hline CHEMBL 2165028 & 860487 & 7.1739 & 7.351 & TRN \\
\hline CHEMBL2165027 & 860487 & 7.699 & 7.6946 & TRN \\
\hline CHEMBL2165268 & 860487 & 8.0458 & 8.2525 & TRN \\
\hline CHEMBL2165033 & 860487 & 8.2218 & 8.0128 & TRN \\
\hline CHEMBL2165007 & 860487 & 8.699 & 8.7753 & TRN \\
\hline CHEMBL1615182 & 860487 & 6.7212 & 7.3325 & TST \\
\hline CHEMBL2165049 & 860487 & 7.0915 & 7.0771 & TRN \\
\hline CHEMBL2165014 & 860487 & 7.3565 & 7.7019 & TRN \\
\hline CHEMBL2165011 & 860487 & 7.3872 & 7.3866 & TRN \\
\hline CHEMBL2165023 & 860487 & 7.1249 & 6.9896 & TRN \\
\hline CHEMBL 2165048 & 860487 & 6.2147 & 6.0942 & TRN \\
\hline CHEMBL2165037 & 860487 & 7.5528 & 7.5904 & TRN \\
\hline CHEMBL2165029 & 860487 & 8.0458 & 8.1852 & TRN \\
\hline CHEMBL2165044 & 860487 & 4.0 & 6.0729 & TST \\
\hline CHEMBL2165008 & 860487 & 7.1871 & 7.4735 & TRN \\
\hline
\end{tabular}




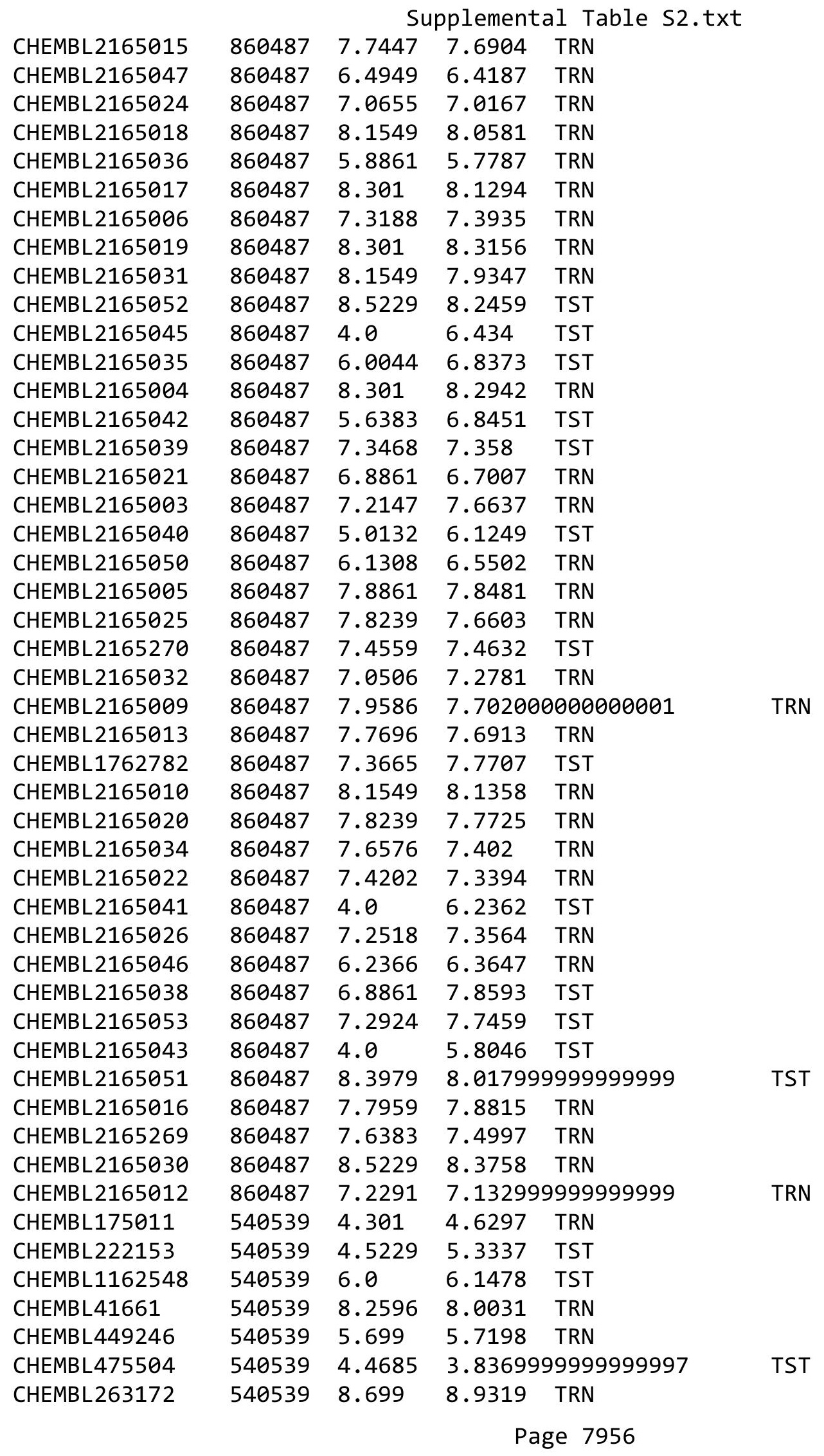




\begin{tabular}{|c|c|c|c|c|c|}
\hline & & & 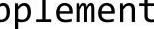 & & \\
\hline CHEMBL475710 & 540539 & 4.301 & 4.1701 & TST & \\
\hline CHEMBL16281 & 540539 & 4.301 & 4.5766 & TRN & \\
\hline CHEMBL506943 & 540539 & 6.0 & 6.2739 & TRN & \\
\hline CHEMBL475711 & 540539 & 4.301 & 4.4541 & TST & \\
\hline CHEMBL 264008 & 540539 & 5.8125 & 6.5336 & TRN & \\
\hline CHEMBL1162549 & 540539 & 6.0 & 5.7903 & TST & \\
\hline CHEMBL509825 & 540539 & 6.3768 & 6.5004 & TRN & \\
\hline CHEMBL280861 & 540539 & 5.2218 & 5.5225 & TRN & \\
\hline CHEMBL178016 & 540539 & 4.301 & 4.4188 & TRN & \\
\hline CHEMBL447631 & 540539 & 7.0 & 6.6513 & TRN & \\
\hline CHEMBL475702 & 540539 & 4.0 & 4.3952 & TST & \\
\hline CHEMBL474496 & 540539 & 7.3468 & 5.3776 & TST & \\
\hline CHEMBL175171 & 540539 & 6.4559 & 5.8899 & TRN & \\
\hline CHEMBL431312 & 540539 & 7.8539 & 8.1405 & TRN & \\
\hline CHEMBL174646 & 540539 & 4.3279 & 4.7159 & TRN & \\
\hline CHEMBL452691 & 540539 & 4.301 & 3.3883 & TST & \\
\hline CHEMBL367655 & 540539 & 5.6576 & 5.4868 & TRN & \\
\hline CHEMBL 24602 & 540539 & 5.4949 & 5.32600 & 00000000005 & TRN \\
\hline CHEMBL431911 & 540539 & 8.1938 & 8.0895 & TRN & \\
\hline CHEMBL40490 & 540539 & 8.585 & 8.5444 & TRN & \\
\hline CHEMBL449316 & 540539 & 4.2676 & 4.2841 & TRN & \\
\hline CHEMBL 290512 & 540539 & 8.5376 & 8.665 & TRN & \\
\hline CHEMBL 288413 & 540539 & 8.3279 & 8.3155 & TRN & \\
\hline CHEMBL509865 & 540539 & 6.0655 & 6.1327 & TRN & \\
\hline CHEMBL502951 & 540539 & 6.9208 & 6.6146 & TRN & \\
\hline CHEMBL 75558 & 540539 & 5.3979 & 4.33899 & 99999999995 & TRN \\
\hline CHEMBL 24548 & 540539 & 5.7447 & 5.4675 & TRN & \\
\hline CHEMBL 288155 & 540539 & 8.4437 & 8.6799 & TRN & \\
\hline CHEMBL46789 & 540539 & 4.301 & 4.1413 & TRN & \\
\hline CHEMBL40265 & 540539 & 8.5229 & 8.4831 & TRN & \\
\hline CHEMBL366828 & 540539 & 5.3979 & 5.4569 & TRN & \\
\hline CHEMBL39112 & 540539 & 8.8539 & 8.5994 & TRN & \\
\hline CHEMBL 289765 & 540539 & 8.4559 & 8.2859 & TRN & \\
\hline CHEMBL368481 & 540539 & 4.3565 & 4.302 & TRN & \\
\hline CHEMBL430718 & 540539 & 5.8539 & 5.5094 & TRN & \\
\hline CHEMBL430940 & 540539 & 8.6576 & 8.7526 & TRN & \\
\hline CHEMBL499668 & 540539 & 7.1427 & 6.4071 & TRN & \\
\hline CHEMBL442667 & 540539 & 6.9586 & 5.4221 & TST & \\
\hline CHEMBL451001 & 540539 & 6.3188 & 6.2245 & TRN & \\
\hline CHEMBL514323 & 540539 & 5.284 & 5.4398 & TST & \\
\hline CHEMBL432938 & 540539 & 4.0915 & 4.2413 & TRN & \\
\hline CHEMBL475718 & 540539 & 4.8239 & 6.0926 & TST & \\
\hline CHEMBL504504 & 540539 & 6.3565 & 6.309 & TRN & \\
\hline CHEMBL 373117 & 540539 & 4.0 & 3.9384 & TST & \\
\hline CHEMBL 263598 & 540539 & 6.6021 & 6.5614 & TRN & \\
\hline CHEMBL265015 & 540539 & 8.1549 & 7.3469 & TRN & \\
\hline CHEMBL85193 & 540539 & 3.7447 & 3.8089 & TRN & \\
\hline CHEMBL214100 & 540539 & 6.6778 & 7.249 & TRN & \\
\hline
\end{tabular}




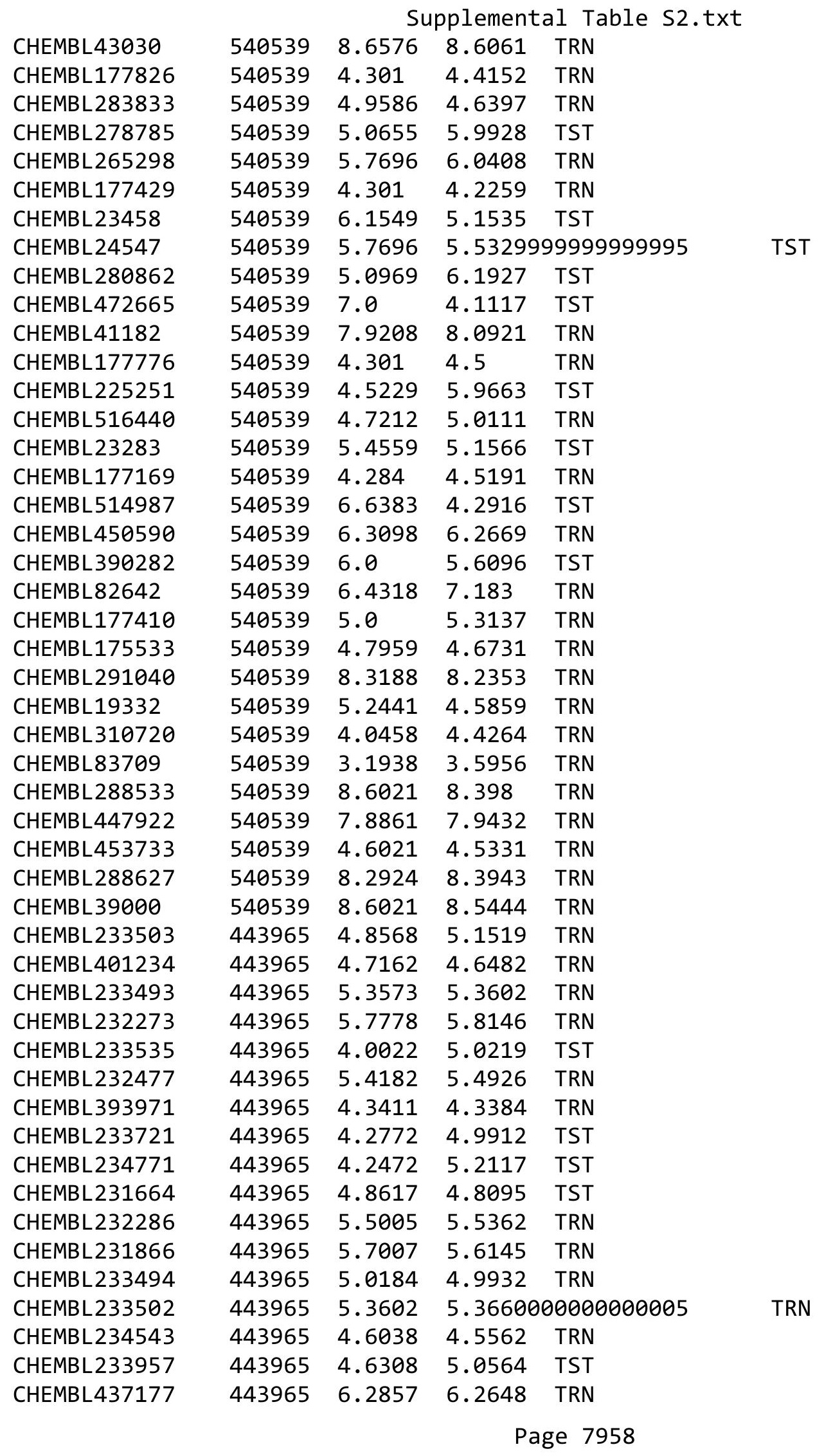




\begin{tabular}{|c|c|c|c|c|c|c|}
\hline & & \multicolumn{5}{|c|}{ Supplemental Table S2.txt } \\
\hline CHEMBL233326 & 443965 & 5.9165 & 5.932 & TRN & & \\
\hline CHEMBL400036 & 443965 & 5.0277 & 4.9599 & TRN & & \\
\hline CHEMBL233750 & 443965 & 5.5232 & 5.4122 & TRN & & \\
\hline CHEMBL232066 & 443965 & 5.4782 & 5.46299 & 99999995 & & TRN \\
\hline CHEMBL397761 & 443965 & 4.7258 & 5.0241 & TST & & \\
\hline CHEMBL398039 & 443965 & 3.8842 & 5.1055 & TST & & \\
\hline CHEMBL232074 & 443965 & 5.6117 & 5.6362 & TRN & & \\
\hline CHEMBL231874 & 443965 & 4.84 & 4.9007 & TRN & & \\
\hline CHEMBL393985 & 443965 & 4.9167 & 4.879 & TRN & & \\
\hline CHEMBL394695 & 443965 & 5.0912 & 5.2789 & TST & & \\
\hline CHEMBL441914 & 443965 & 6.2175 & 6.086 & TRN & & \\
\hline CHEMBL228690 & 443965 & 5.7783 & 5.6116 & TRN & & \\
\hline CHEMBL233956 & 443965 & 5.4943 & 5.47 & TRN & & \\
\hline CHEMBL437380 & 443965 & 5.1081 & 5.1315 & TRN & & \\
\hline CHEMBL231661 & 443965 & 4.8236 & 4.894 & TST & & \\
\hline CHEMBL232076 & 443965 & 5.7683 & 5.8498 & TRN & & \\
\hline CHEMBL395838 & 443965 & 5.251 & 5.3057 & TRN & & \\
\hline CHEMBL233536 & 443965 & 5.4827 & 5.5296 & TRN & & \\
\hline CHEMBL233955 & 443965 & 5.4316 & 5.3951 & TRN & & \\
\hline CHEMBL233501 & 443965 & 4.547 & 4.5428 & TRN & & \\
\hline CHEMBL400035 & 443965 & 5.0739 & 5.3205 & TRN & & \\
\hline CHEMBL 233749 & 443965 & 5.399 & 5.2585 & TRN & & \\
\hline CHEMBL393675 & 443965 & 4.477 & 4.4143 & TRN & & \\
\hline CHEMBL 392753 & 443965 & 5.1963 & 5.3205 & TRN & & \\
\hline CHEMBL232067 & 443965 & 4.817 & 4.8537 & TRN & & \\
\hline CHEMBL232285 & 443965 & 5.8 & 5.7655 & TRN & & \\
\hline CHEMBL 234773 & 443965 & 4.748 & 4.9757 & TST & & \\
\hline CHEMBL393356 & 443965 & 5.0513 & 5.3021 & TST & & \\
\hline CHEMBL233748 & 443965 & 5.0506 & 5.0267 & TRN & & \\
\hline CHEMBL398794 & 443965 & 5.4316 & 5.4466 & TRN & & \\
\hline CHEMBL232478 & 443965 & 6.1096 & 6.1249 & TRN & & \\
\hline CHEMBL232476 & 443965 & 5.251 & 5.3339 & TRN & & \\
\hline CHEMBL233327 & 443965 & 5.5426 & 5.3708 & TRN & & \\
\hline CHEMBL 233323 & 443965 & 5.0733 & 5.23 & TST & & \\
\hline CHEMBL394222 & 443965 & $5.5360 e$ & 30000000 & 005 & 5.5076 & $T$ \\
\hline CHEMBL232075 & 443965 & 5.9329 & 5.5631 & TST & & \\
\hline CHEMBL 1357247 & 954484 & 3.3894 & 3.5864 & TRN & & \\
\hline CHEMBL102714 & 954484 & 3.0043 & 3.1427 & TRN & & \\
\hline CHEMBL188678 & 954484 & 5.1359 & 4.4773 & TRN & & \\
\hline CHEMBL221137 & 954484 & 4.9104 & 4.8391 & TST & & \\
\hline CHEMBL240954 & 954484 & 3.2745 & 3.9564 & TST & & \\
\hline CHEMBL472940 & 954484 & 3.7611 & 4.0437 & TRN & & \\
\hline CHEMBL217354 & 954484 & 6.215 & 6.1923 & TRN & & \\
\hline CHEMBL 92309 & 954484 & 4.0278 & 3.5422 & TST & & \\
\hline CHEMBL1673039 & 954484 & 4.8142 & 4.9864 & TRN & & \\
\hline CHEMBL399530 & 954484 & 4.3575 & 4.5804 & TRN & & \\
\hline CHEMBL483849 & 954484 & 3.1246 & 3.0494 & TRN & & \\
\hline CHEMBL209148 & 954484 & 5.0166 & 5.1005 & TRN & & \\
\hline
\end{tabular}




\begin{tabular}{|c|c|c|c|c|c|}
\hline & & \multicolumn{4}{|c|}{ Supplemental Table S2.txt } \\
\hline CHEMBL1516890 & 954484 & 4.0589 & 4.0272 & TRN & \\
\hline CHEMBL1190711 & 954484 & 4.8048 & 5.1511 & TRN & \\
\hline CHEMBL 258844 & 954484 & 4.5162 & 4.8271 & TRN & \\
\hline CHEMBL449158 & 954484 & 6.4911 & 6.3765 & TST & \\
\hline CHEMBL1909414 & 954484 & 3.3783 & 3.4325 & TRN & \\
\hline CHEMBL3186408 & 954484 & 5.2084 & 4.0508 & TST & \\
\hline CHEMBL514499 & 954484 & 7.146 & 7.2574 & TRN & \\
\hline CHEMBL191334 & 954484 & 4.0635 & 3.5744 & TRN & \\
\hline CHEMBL9470 & 954484 & 6.1742 & 5.4941 & TST & \\
\hline CHEMBL3392440 & 954484 & 3.6249 & 3.9819 & TRN & \\
\hline CHEMBL1788116 & 954484 & 5.2443 & 4.9333 & TRN & \\
\hline CHEMBL202721 & 954484 & 5.0254 & 4.9589 & TRN & \\
\hline CHEMBL210618 & 954484 & 4.0162 & 3.8372 & TRN & \\
\hline CHEMBL 213100 & 954484 & 4.3917 & 4.5996 & TRN & \\
\hline CHEMBL1643959 & 954484 & 4.4263 & 4.5768 & TRN & \\
\hline CHEMBL220241 & 954484 & 5.0596 & 5.027 & TRN & \\
\hline CHEMBL558642 & 954484 & 4.4405 & 4.7828 & TRN & \\
\hline CHEMBL255342 & 954484 & 3.5271 & 3.5441 & TRN & \\
\hline CHEMBL180127 & 954484 & 4.8309 & 4.7826 & TRN & \\
\hline CHEMBL1186585 & 954484 & 4.2724 & 4.3303 & TRN & \\
\hline CHEMBL 2144069 & 954484 & 4.2706 & 4.2407 & TRN & \\
\hline CHEMBL259181 & 954484 & 5.0868 & 5.0367 & TRN & \\
\hline CHEMBL585951 & 954484 & 6.3304 & 5.977 & TRN & \\
\hline CHEMBL 1256459 & 954484 & 7.5095 & 7.4731 & TRN & \\
\hline CHEMBL 2005886 & 954484 & 5.3128 & 5.6451 & TRN & \\
\hline CHEMBL577784 & 954484 & 5.2126 & 5.2635 & TRN & \\
\hline CHEMBL393929 & 954484 & 4.6484 & 4.2557 & TRN & \\
\hline CHEMBL1242367 & 954484 & 5.2486 & 5.061 & TRN & \\
\hline CHEMBL379300 & 954484 & 6.6139 & 6.73799 & 99999999995 & TRN \\
\hline CHEMBL392695 & 954484 & 5.4201 & 5.5153 & TRN & \\
\hline CHEMBL1970879 & 954484 & 5.9846 & 5.8923 & TRN & \\
\hline CHEMBL412142 & 954484 & 3.8516 & 3.8952 & TRN & \\
\hline CHEMBL1404918 & 954484 & 2.9383 & 3.2488 & TRN & \\
\hline CHEMBL 2363137 & 954484 & 5.3367 & 4.8107 & TRN & \\
\hline CHEMBL 2137530 & 954484 & 4.8763 & 4.8539 & TRN & \\
\hline CHEMBL512504 & 954484 & 4.6726 & 4.4973 & TST & \\
\hline CHEMBL483847 & 954484 & 5.0665 & 4.6431 & TRN & \\
\hline CHEMBL 373751 & 954484 & 4.3817 & 4.4673 & TRN & \\
\hline CHEMBL135561 & 954484 & 4.4944 & 4.8148 & TRN & \\
\hline CHEMBL515416 & 954484 & 5.364 & 5.1173 & TRN & \\
\hline CHEMBL1590308 & 954484 & 4.1968 & 3.9268 & TST & \\
\hline CHEMBL573107 & 954484 & 5.1219 & 5.0373 & TRN & \\
\hline CHEMBL189584 & 954484 & 4.0456 & 4.3771 & TRN & \\
\hline CHEMBL192566 & 954484 & 8.5334 & 7.54 & TST & \\
\hline CHEMBL222102 & 954484 & 4.4836 & 4.0978 & TRN & \\
\hline CHEMBL3199475 & 954484 & 5.4515 & 4.7761 & TST & \\
\hline CHEMBL 2134202 & 954484 & 4.3793 & 4.3462 & TST & \\
\hline CHEMBL65 & 954484 & 6.7246 & 6.8233 & TST & \\
\hline
\end{tabular}




\begin{tabular}{|c|c|c|c|c|c|}
\hline \multicolumn{6}{|c|}{ Supplemental Table S2.txt } \\
\hline CHEMBL300389 & 954484 & 5.3138 & 6.6836 & TST & \\
\hline CHEMBL509032 & 954484 & 6.3918 & 5.8091 & TST & \\
\hline CHEMBL1230020 & 954484 & 4.0867 & 3.8897 & TST & \\
\hline CHEMBL3349342 & 954484 & 5.0339 & 4.7103 & TST & \\
\hline CHEMBL 204025 & 340344 & 7.3468 & 7.2634 & TST & \\
\hline CHEMBL204222 & 340344 & 7.4559 & 7.5835 & TRN & \\
\hline CHEMBL204819 & 340344 & 7.0862 & 7.3605 & TRN & \\
\hline CHEMBL203348 & 340344 & 7.6576 & 7.7299 & TRN & \\
\hline CHEMBL206439 & 340344 & 8.0969 & 7.7464 & TST & \\
\hline CHEMBL205934 & 340344 & 8.1739 & 8.1785 & TRN & \\
\hline CHEMBL206440 & 340344 & 6.5086 & 6.6686 & TRN & \\
\hline CHEMBL381622 & 340344 & 7.2757 & 7.1266 & TRN & \\
\hline CHEMBL 380362 & 340344 & 7.6198 & 7.37200 & 0000000001 & TST \\
\hline CHEMBL206500 & 340344 & 8.1079 & 7.8555 & TRN & \\
\hline CHEMBL426854 & 340344 & 5.6308 & 6.3046 & TRN & \\
\hline CHEMBL202781 & 340344 & 6.6676 & 6.9477 & TRN & \\
\hline CHEMBL206226 & 340344 & 7.3098 & 7.1935 & TRN & \\
\hline CHEMBL206120 & 340344 & 7.1739 & 7.2404 & TRN & \\
\hline CHEMBL 380838 & 340344 & 8.0 & 7.7862 & TRN & \\
\hline CHEMBL206441 & 340344 & 7.7959 & 7.5778 & TRN & \\
\hline CHEMBL204959 & 340344 & 7.0315 & 6.8473 & TRN & \\
\hline CHEMBL204922 & 340344 & 8.3872 & 7.71200 & 0000000001 & TRN \\
\hline CHEMBL206546 & 340344 & 7.2676 & 7.5663 & TRN & \\
\hline CHEMBL 204902 & 340344 & 7.8539 & 7.8223 & TRN & \\
\hline CHEMBL204118 & 340344 & 7.585 & 7.6176 & TRN & \\
\hline CHEMBL205614 & 340344 & 6.9318 & 7.2638 & TRN & \\
\hline CHEMBL 202673 & 340344 & 7.6576 & 7.4634 & TST & \\
\hline CHEMBL204024 & 340344 & 7.3098 & 7.6609 & TST & \\
\hline CHEMBL203123 & 340344 & 7.8861 & 7.6933 & TST & \\
\hline CHEMBL206727 & 340344 & 7.6778 & 7.4366 & TRN & \\
\hline CHEMBL206582 & 340344 & 7.1308 & 7.2643 & TST & \\
\hline CHEMBL202896 & 340344 & 7.1612 & 6.9535 & TRN & \\
\hline CHEMBL206227 & 340344 & 7.5686 & 7.5563 & TRN & \\
\hline CHEMBL 383753 & 340344 & 6.3635 & 6.2052 & TRN & \\
\hline CHEMBL203072 & 340344 & 8.6383 & 8.0105 & TST & \\
\hline CHEMBL205009 & 340344 & 6.5114 & 6.2046 & TRN & \\
\hline CHEMBL205119 & 340344 & 7.9208 & 7.3954 & TST & \\
\hline CHEMBL380358 & 340344 & 7.0969 & 7.6618 & TRN & \\
\hline CHEMBL 205350 & 340344 & 7.1739 & 7.6041 & TRN & \\
\hline CHEMBL204768 & 340344 & 7.7447 & 7.7375 & TRN & \\
\hline CHEMBL206218 & 340344 & 7.2441 & 7.3846 & TRN & \\
\hline CHEMBL 383518 & 340344 & 7.041 & 7.1717 & TRN & \\
\hline CHEMBL205989 & 340344 & 6.6819 & 7.0029 & TRN & \\
\hline CHEMBL 381337 & 340344 & 8.0969 & 7.5334 & TST & \\
\hline CHEMBL381697 & 340344 & 8.9393 & 8.5663 & TRN & \\
\hline CHEMBL204341 & 340344 & 6.0191 & 6.2757 & TRN & \\
\hline CHEMBL380717 & 340344 & 8.2441 & 8.1985 & TRN & \\
\hline CHEMBL380452 & 340344 & 6.9355 & 7.0923 & TRN & \\
\hline
\end{tabular}




\begin{tabular}{|c|c|c|c|c|c|}
\hline \multicolumn{6}{|c|}{ Supplemental Table S2 } \\
\hline CHEMBL204272 & 340344 & 6.7447 & 6.5117 & TRN & \\
\hline CHEMBL414859 & 340344 & 7.2676 & 7.4089 & TRN & \\
\hline CHEMBL206600 & 340344 & 7.3372 & 6.7679 & TRN & \\
\hline CHEMBL206406 & 340344 & 7.6198 & 7.57299 & 99999999995 & TRN \\
\hline CHEMBL204119 & 340344 & 7.699 & 7.7347 & TRN & \\
\hline CHEMBL203519 & 340344 & 5.8386 & 5.7315 & TRN & \\
\hline CHEMBL206584 & 340344 & 8.0458 & 7.7415 & TST & \\
\hline CHEMBL438977 & 340344 & 6.8928 & 6.4261 & TRN & \\
\hline CHEMBL206547 & 340344 & 8.4949 & 7.8796 & TST & \\
\hline CHEMBL380844 & 340344 & 6.5544 & 6.8566 & TRN & \\
\hline CHEMBL204056 & 340344 & 7.3565 & 7.5646 & TRN & \\
\hline CHEMBL438443 & 340344 & 7.1135 & 6.7376 & TRN & \\
\hline CHEMBL380720 & 340344 & 7.0458 & 7.0273 & TRN & \\
\hline CHEMBL378798 & 340344 & 7.0555 & 7.42299 & 9999999999 & TST \\
\hline CHEMBL 205988 & 340344 & 6.4868 & 6.756 & TST & \\
\hline CHEMBL203340 & 340344 & 7.7212 & 7.2934 & TST & \\
\hline CHEMBL485224 & 537478 & 5.6778 & 4.1784 & TRN & \\
\hline CHEMBL484194 & 537478 & 2.7212 & 2.9649 & TRN & \\
\hline CHEMBL485235 & 537478 & 4.0083 & 3.1296 & TRN & \\
\hline CHEMBL449450 & 537478 & 3.7352 & 3.9321 & TRN & \\
\hline CHEMBL443628 & 537478 & 3.9666 & 4.0682 & TRN & \\
\hline CHEMBL464601 & 537478 & 2.7375 & 2.5654 & TRN & \\
\hline CHEMBL520654 & 537478 & 4.7011 & 4.65300 & 00000000005 & TRN \\
\hline CHEMBL520186 & 537478 & 2.6635 & 3.5822 & TRN & \\
\hline CHEMBL519519 & 537478 & 2.7423 & 2.9597 & TRN & \\
\hline CHEMBL520143 & 537478 & 2.7011 & 3.0888 & TRN & \\
\hline CHEMBL485439 & 537478 & 3.8928 & 3.842 & TRN & \\
\hline CHEMBL520335 & 537478 & 2.7471 & 2.911 & TRN & \\
\hline CHEMBL485410 & 537478 & 2.7033 & 2.9152 & TRN & \\
\hline CHEMBL484351 & 537478 & 3.8827 & 4.1966 & TST & \\
\hline CHEMBL464397 & 537478 & 2.6556 & 3.8205 & TRN & \\
\hline CHEMBL521501 & 537478 & 5.1308 & 4.435 & TRN & \\
\hline CHEMBL485573 & 537478 & 2.7144 & 3.3902 & TRN & \\
\hline CHEMBL458546 & 537478 & 2.7144 & 3.3273 & TRN & \\
\hline CHEMBL483572 & 537478 & 4.4698 & 4.6665 & TRN & \\
\hline CHEMBL485423 & 537478 & 3.8239 & 3.2689 & TRN & \\
\hline CHEMBL485417 & 537478 & 2.7375 & 2.7315 & TRN & \\
\hline CHEMBL485414 & 537478 & 5.1739 & 5.8279 & TRN & \\
\hline CHEMBL451356 & 537478 & 5.3468 & 4.6126 & TRN & \\
\hline CHEMBL448231 & 537478 & 5.4815 & 4.7719 & TST & \\
\hline CHEMBL485438 & 537478 & 5.3565 & 4.4769 & TRN & \\
\hline CHEMBL483399 & 537478 & 4.6737 & 4.3665 & TST & \\
\hline CHEMBL484737 & 537478 & 5.2147 & 5.4622 & TRN & \\
\hline CHEMBL506885 & 537478 & 2.7011 & 2.7493 & TRN & \\
\hline CHEMBL520485 & 537478 & 4.8928 & 4.7163 & TRN & \\
\hline CHEMBL484563 & 537478 & 4.5114 & 4.1856 & TST & \\
\hline CHEMBL518085 & 537478 & 4.9547 & 4.2296 & TST & \\
\hline CHEMBL485424 & 537478 & 2.7447 & 2.3596 & TRN & \\
\hline
\end{tabular}


Supplemental Table S2.txt

\begin{tabular}{|c|c|c|c|c|c|c|}
\hline CHEMBL456434 & 537478 & 2.7282 & 2.207 & TRN & & \\
\hline CHEMBL442644 & 537478 & 3.7471 & 4.0083 & TRN & & \\
\hline CHEMBL511688 & 537478 & 3.7852 & 3.4354 & TRN & & \\
\hline CHEMBL484548 & 537478 & 2.6925 & 3.5872 & TST & & \\
\hline CHEMBL520518 & 537478 & 3.8041 & 4.2443 & TRN & & \\
\hline CHEMBL484195 & 537478 & 2.7328 & 2.6883 & TRN & & \\
\hline CHEMBL484181 & 537478 & 2.699 & 2.9346 & TRN & & \\
\hline CHEMBL500330 & 537478 & 6.0969 & 4.0952 & TST & & \\
\hline CHEMBL464396 & 537478 & \multicolumn{3}{|c|}{2.7569999999999997} & 2.7562 & TRN \\
\hline CHEMBL48217 & 537478 & 6.0655 & 4.7828 & TST & & \\
\hline CHEMBL354342 & 537478 & 5.7212 & 4.2668 & TST & & \\
\hline CHEMBL483571 & 537478 & 2.7011 & 3.0989 & TRN & & \\
\hline CHEMBL458959 & 537478 & 2.7235 & 3.1506 & TST & & \\
\hline CHEMBL520013 & 537478 & 4.5129 & 4.0769 & TST & & \\
\hline CHEMBL520807 & 537478 & 4.2269 & 5.3887 & TST & & \\
\hline CHEMBL447285 & 537478 & 4.4776 & 3.9826 & TRN & & \\
\hline CHEMBL353802 & 537478 & 4.4012 & 4.5544 & TST & & \\
\hline CHEMBL485225 & 537478 & 2.7471 & 2.8635 & TRN & & \\
\hline CHEMBL362996 & 303216 & 3.0 & 3.0 & TRN & & \\
\hline CHEMBL195713 & 303216 & 3.0 & 3.0 & TRN & & \\
\hline CHEMBL191739 & 303216 & 3.0 & 3.0 & TRN & & \\
\hline CHEMBL191800 & 303216 & 3.0 & 3.0 & TST & & \\
\hline CHEMBL192627 & 303216 & \multicolumn{3}{|c|}{6.787999999999999} & 3.0 & ST \\
\hline CHEMBL371371 & 303216 & 3.0 & 3.0 & TST & & \\
\hline CHEMBL191625 & 303216 & 3.0 & 3.0 & TRN & & \\
\hline CHEMBL191847 & 303216 & 3.0 & 3.0 & TRN & & \\
\hline CHEMBL193140 & 303216 & 3.0 & 3.0 & TRN & & \\
\hline CHEMBL192595 & 303216 & 3.0 & 3.0 & TRN & & \\
\hline CHEMBL192180 & 303216 & 3.0 & 3.0 & TRN & & \\
\hline CHEMBL190613 & 303216 & 3.0 & 3.0 & TST & & \\
\hline CHEMBL365517 & 303216 & 3.0 & 3.0 & TRN & & \\
\hline CHEMBL 372856 & 303216 & 3.0 & 3.0 & TRN & & \\
\hline CHEMBL189727 & 303216 & 3.0 & 3.0 & TST & & \\
\hline CHEMBL 365982 & 303216 & 3.0 & 3.0 & TRN & & \\
\hline CHEMBL365392 & 303216 & 3.0 & 3.0 & TRN & & \\
\hline CHEMBL191796 & 303216 & 3.0 & 3.0 & TRN & & \\
\hline CHEMBL191822 & 303216 & 3.0 & 3.0 & TRN & & \\
\hline CHEMBL193228 & 303216 & 3.0 & 3.0 & TRN & & \\
\hline CHEMBL192474 & 303216 & 3.0 & 3.0 & TRN & & \\
\hline CHEMBL425192 & 303216 & 3.0 & 3.0 & TRN & & \\
\hline CHEMBL365129 & 303216 & 3.0 & 3.0 & TRN & & \\
\hline CHEMBL193180 & 303216 & 3.0 & 3.0 & TRN & & \\
\hline CHEMBL364588 & 303216 & 3.0 & 3.0 & TRN & & \\
\hline CHEMBL192712 & 303216 & 3.0 & 3.0 & TST & & \\
\hline CHEMBL191676 & 303216 & 3.0 & 3.0 & TRN & & \\
\hline CHEMBL192252 & 303216 & 3.0 & 3.0 & TRN & & \\
\hline CHEMBL435109 & 303216 & 3.0 & 3.0 & TRN & & \\
\hline CHEMBL192410 & 303216 & 3.0 & 3.0 & TRN & & \\
\hline
\end{tabular}




\begin{tabular}{|c|c|c|c|c|c|}
\hline \multicolumn{6}{|c|}{ Supplemental Table S2.txt } \\
\hline CHEMBL189988 & 303216 & 3.0 & 3.0 & TRN & \\
\hline CHEMBL191513 & 303216 & 3.0 & 3.0 & TRN & \\
\hline CHEMBL192657 & 303216 & 3.0 & 3.0 & TRN & \\
\hline CHEMBL192589 & 303216 & 3.0 & 3.0 & TRN & \\
\hline CHEMBL371523 & 303216 & 3.0 & 3.0 & TRN & \\
\hline CHEMBL192809 & 303216 & 3.0 & 3.0 & TRN & \\
\hline CHEMBL 8320 & 303216 & 6.02 & 3.0 & TST & \\
\hline CHEMBL370059 & 303216 & 3.0 & 3.0 & TRN & \\
\hline CHEMBL363919 & 303216 & 3.0 & 3.0 & TST & \\
\hline CHEMBL192241 & 303216 & 3.0 & 3.0 & TRN & \\
\hline CHEMBL 371858 & 303216 & 3.0 & 3.0 & TRN & \\
\hline CHEMBL370299 & 303216 & 3.0 & 3.0 & TRN & \\
\hline CHEMBL192039 & 303216 & 3.0 & 3.0 & TRN & \\
\hline CHEMBL364729 & 303216 & 5.777 & 3.0 & TST & \\
\hline CHEMBL192625 & 303216 & 3.0 & 3.0 & TRN & \\
\hline CHEMBL193229 & 303216 & 3.0 & 3.0 & TRN & \\
\hline CHEMBL363186 & 303216 & 3.0 & 3.0 & TST & \\
\hline CHEMBL365161 & 303216 & 3.0 & 3.0 & TST & \\
\hline CHEMBL191688 & 303216 & 3.0 & 3.0 & TST & \\
\hline CHEMBL366205 & 303216 & 3.0 & 3.0 & TRN & \\
\hline CHEMBL90039 & 303216 & 3.0 & 3.0 & TRN & \\
\hline CHEMBL363855 & 303216 & 3.0 & 3.0 & TRN & \\
\hline CHEMBL365809 & 303216 & 3.0 & 3.0 & TRN & \\
\hline CHEMBL192139 & 303216 & 3.0 & 3.0 & TRN & \\
\hline CHEMBL189886 & 303216 & 3.0 & 3.0 & TRN & \\
\hline CHEMBL190496 & 303216 & 3.0 & 3.0 & TRN & \\
\hline CHEMBL 284028 & 303216 & 3.0 & 3.0 & TST & \\
\hline CHEMBL192648 & 303216 & 3.0 & 3.0 & TRN & \\
\hline CHEMBL364734 & 303216 & 3.0 & 3.0 & TST & \\
\hline CHEMBL192258 & 303216 & 3.0 & 3.0 & TST & \\
\hline CHEMBL201330 & 330270 & 5.81 & 6.5505 & TRN & \\
\hline CHEMBL439684 & 330270 & 5.66 & 5.87299 & & TRN \\
\hline CHEMBL201585 & 330270 & 6.67 & 7.0524 & TRN & \\
\hline CHEMBL201145 & 330270 & 8.66 & 8.5978 & TRN & \\
\hline CHEMBL 200011 & 330270 & 6.7 & 6.9902 & TRN & \\
\hline CHEMBL381473 & 330270 & 6.85 & 7.0282 & TRN & \\
\hline CHEMBL 201447 & 330270 & 7.04 & 7.7395 & TRN & \\
\hline CHEMBL203359 & 330270 & 7.08 & 6.7966 & TRN & \\
\hline CHEMBL 380901 & 330270 & 7.11 & 7.7056 & TRN & \\
\hline CHEMBL 201024 & 330270 & 7.2 & 7.5898 & TRN & \\
\hline CHEMBL201679 & 330270 & 7.22 & 7.1869 & TRN & \\
\hline CHEMBL199722 & 330270 & 7.22 & 6.8656 & TRN & \\
\hline CHEMBL199898 & 330270 & 7.25 & 7.3981 & TRN & \\
\hline CHEMBL199834 & 330270 & 7.28 & 7.2744 & TRN & \\
\hline CHEMBL199327 & 330270 & 7.43 & 7.3106 & TRN & \\
\hline CHEMBL198294 & 330270 & 7.46 & 7.5959 & TST & \\
\hline CHEMBL199399 & 330270 & 7.46 & 7.6266 & TRN & \\
\hline CHEMBL370629 & 330270 & 7.47 & 7.5055 & TRN & \\
\hline
\end{tabular}




\begin{tabular}{|c|c|c|c|c|}
\hline \multicolumn{5}{|c|}{ Supplemental Table S2.txt } \\
\hline CHEMBL27043 & 330270 & 7.48 & 7.3534 & TRN \\
\hline CHEMBL199326 & 330270 & 7.56 & 7.5283 & TRN \\
\hline CHEMBL425395 & 330270 & 7.56 & 7.6174 & TRN \\
\hline CHEMBL201791 & 330270 & 7.6 & 7.4284 & TRN \\
\hline CHEMBL203030 & 330270 & 7.61 & 7.8349 & TRN \\
\hline CHEMBL201321 & 330270 & 7.61 & 7.9088 & TRN \\
\hline CHEMBL203148 & 330270 & 7.64 & 7.635 & TRN \\
\hline CHEMBL198403 & 330270 & 7.7 & 7.9045 & TRN \\
\hline CHEMBL381522 & 330270 & 7.71 & 7.8657 & TRN \\
\hline CHEMBL383321 & 330270 & 7.72 & 7.4747 & TRN \\
\hline CHEMBL201054 & 330270 & 7.73 & 7.3959 & TRN \\
\hline CHEMBL201042 & 330270 & 7.76 & 7.4579 & TRN \\
\hline CHEMBL199583 & 330270 & 7.79 & 7.9684 & TRN \\
\hline CHEMBL199999 & 330270 & 7.85 & 8.0063 & TRN \\
\hline CHEMBL 200967 & 330270 & 7.86 & 7.9621 & TRN \\
\hline CHEMBL202359 & 330270 & 7.9 & 8.0761 & TRN \\
\hline CHEMBL377434 & 330270 & 7.91 & 7.7892 & TRN \\
\hline CHEMBL202358 & 330270 & 7.92 & 8.2931 & TRN \\
\hline CHEMBL381540 & 330270 & 7.95 & 7.7165 & TRN \\
\hline CHEMBL198338 & 330270 & 8.01 & 8.0563 & TRN \\
\hline CHEMBL202665 & 330270 & 8.03 & 7.96 & TRN \\
\hline CHEMBL377485 & 330270 & 8.05 & 7.8487 & TRN \\
\hline CHEMBL201128 & 330270 & 8.05 & 8.2569 & TST \\
\hline CHEMBL201157 & 330270 & 8.1 & 8.0409 & TST \\
\hline CHEMBL 201749 & 330270 & 8.1 & 8.0757 & TRN \\
\hline CHEMBL201008 & 330270 & 8.11 & 7.2539 & TST \\
\hline CHEMBL201493 & 330270 & 8.22 & 8.6502 & TRN \\
\hline CHEMBL202767 & 330270 & 8.29 & 8.4515 & TRN \\
\hline CHEMBL202766 & 330270 & 8.29 & 8.1259 & TRN \\
\hline CHEMBL381091 & 330270 & 8.32 & 8.2766 & TRN \\
\hline CHEMBL201281 & 330270 & 8.48 & 8.2142 & TRN \\
\hline CHEMBL380847 & 330270 & 8.49 & 8.34 & TRN \\
\hline CHEMBL382764 & 330270 & 8.5 & 8.3022 & TRN \\
\hline CHEMBL200105 & 330270 & 6.73 & 7.2998 & TRN \\
\hline CHEMBL199354 & 330270 & 6.83 & 6.7946 & TRN \\
\hline CHEMBL199353 & 330270 & 6.84 & 7.0272 & TRN \\
\hline CHEMBL 201745 & 330270 & 7.1 & 7.1652 & TRN \\
\hline CHEMBL426660 & 330270 & 7.16 & 7.1417 & TRN \\
\hline CHEMBL201243 & 330270 & 7.41 & 7.4635 & TRN \\
\hline CHEMBL199485 & 330270 & 7.6 & 7.4062 & TRN \\
\hline CHEMBL199884 & 330270 & 7.65 & 7.0324 & TST \\
\hline CHEMBL 201721 & 330270 & 7.96 & 7.9468 & TRN \\
\hline CHEMBL381214 & 330270 & 8.16 & 7.8756 & TRN \\
\hline CHEMBL199611 & 330270 & 8.32 & 8.1676 & TST \\
\hline CHEMBL199486 & 330270 & 8.41 & 8.4234 & TST \\
\hline CHEMBL382135 & 330270 & 8.42 & 8.1666 & TRN \\
\hline CHEMBL439868 & 330270 & 8.45 & 7.935 & TRN \\
\hline CHEMBL201750 & 330270 & 8.46 & 7.7992 & TRN \\
\hline
\end{tabular}




\begin{tabular}{|c|c|c|c|c|c|}
\hline \multicolumn{6}{|c|}{ Supplemental Table S2.txt } \\
\hline CHEMBL199446 & 330270 & 8.52 & 8.2532 & TRN & \\
\hline CHEMBL 370378 & 330270 & 8.58 & 8.6153 & TRN & \\
\hline CHEMBL 370588 & 330270 & 8.81 & 8.831 & TST & \\
\hline CHEMBL438071 & 330270 & 6.58 & 6.8384 & TRN & \\
\hline CHEMBL202980 & 330270 & 6.88 & 6.9073 & TRN & \\
\hline CHEMBL380481 & 330270 & 7.67 & 7.7884 & TRN & \\
\hline CHEMBL201554 & 330270 & 7.86 & 7.6244 & TRN & \\
\hline CHEMBL201496 & 330270 & 7.87 & 8.1968 & TRN & \\
\hline CHEMBL203088 & 330270 & 7.91 & 8.0098 & TRN & \\
\hline CHEMBL383638 & 330270 & 7.93 & 7.4205 & TRN & \\
\hline CHEMBL 381538 & 330270 & 8.02 & 8.0405 & TRN & \\
\hline CHEMBL203413 & 330270 & 8.11 & 8.0681 & TRN & \\
\hline CHEMBL200052 & 330270 & 8.23 & 7.9281 & TRN & \\
\hline CHEMBL201127 & 330270 & 8.25 & 8.2646 & TRN & \\
\hline CHEMBL372148 & 330270 & 8.28 & 7.9753 & TRN & \\
\hline CHEMBL199862 & 330270 & 8.33 & 8.1087 & TRN & \\
\hline CHEMBL382234 & 330270 & 6.73 & 6.6074 & TRN & \\
\hline CHEMBL201006 & 330270 & 6.76 & 6.9105 & TRN & \\
\hline CHEMBL 201580 & 330270 & 6.91 & 6.9162 & TRN & \\
\hline CHEMBL197605 & 330270 & 7.08 & 6.9091 & TRN & \\
\hline CHEMBL199826 & 330270 & 7.29 & 7.38700 & 00000000005 & TRN \\
\hline CHEMBL199688 & 330270 & 7.29 & 7.5572 & TRN & \\
\hline CHEMBL 202876 & 330270 & 7.37 & 7.1506 & TST & \\
\hline CHEMBL 202828 & 330270 & 7.56 & 7.48799 & 79999999995 & TST \\
\hline CHEMBL201109 & 330270 & 7.69 & 7.7664 & TRN & \\
\hline CHEMBL201323 & 330270 & 7.77 & 7.6188 & TRN & \\
\hline CHEMBL203305 & 330270 & 8.31 & 7.7391 & TRN & \\
\hline CHEMBL 201028 & 330270 & 8.39 & 7.8699 & TST & \\
\hline CHEMBL201773 & 330270 & 8.5 & 7.6081 & TRN & \\
\hline CHEMBL199330 & 330270 & 6.78 & 7.0637 & TRN & \\
\hline CHEMBL199280 & 330270 & 7.0 & 7.4269 & TST & \\
\hline CHEMBL201796 & 330270 & 7.15 & 7.267 & TRN & \\
\hline CHEMBL382663 & 330270 & 7.35 & 7.6952 & TRN & \\
\hline CHEMBL201895 & 330270 & 7.55 & 7.5361 & TRN & \\
\hline CHEMBL424671 & 330270 & 7.57 & 7.7668 & TRN & \\
\hline CHEMBL201026 & 330270 & 7.66 & 7.5002 & TST & \\
\hline CHEMBL201329 & 330270 & 7.68 & 7.5043 & TRN & \\
\hline CHEMBL203043 & 330270 & 7.7 & 7.4287 & TST & \\
\hline CHEMBL370205 & 330270 & 7.77 & 6.8557 & TST & \\
\hline CHEMBL 378815 & 330270 & 7.82 & 7.6602 & TST & \\
\hline CHEMBL201595 & 330270 & 7.9 & 7.8913 & TRN & \\
\hline CHEMBL201594 & 330270 & 7.96 & 8.0497 & TRN & \\
\hline CHEMBL379688 & 330270 & 7.97 & 8.2148 & TRN & \\
\hline CHEMBL201293 & 330270 & 8.11 & 8.0461 & TST & \\
\hline CHEMBL203037 & 330270 & 8.5 & 8.2719 & TRN & \\
\hline CHEMBL200012 & 330270 & 5.82 & 5.5331 & TRN & \\
\hline CHEMBL199664 & 330270 & 6.43 & 6.3589 & TRN & \\
\hline CHEMBL201548 & 330270 & 6.54 & 6.646 & TRN & \\
\hline
\end{tabular}




\begin{tabular}{|c|c|c|c|c|c|}
\hline \multicolumn{6}{|c|}{ Supplemental Table S2.txt } \\
\hline CHEMBL201547 & 330270 & 6.57 & 6.1871 & TRN & \\
\hline CHEMBL201133 & 330270 & 6.67 & 7.0305 & TRN & \\
\hline CHEMBL201523 & 330270 & 6.8 & 6.8256 & TRN & \\
\hline CHEMBL382413 & 330270 & 6.91 & 7.36799 & 9999999999 & TRN \\
\hline CHEMBL201108 & 330270 & 7.1 & 7.3578 & TRN & \\
\hline CHEMBL198191 & 330270 & 7.14 & 7.222 & TRN & \\
\hline CHEMBL201650 & 330270 & 7.18 & 6.6095 & TRN & \\
\hline CHEMBL198243 & 330270 & 7.34 & 7.2356 & TRN & \\
\hline CHEMBL199697 & 330270 & 7.36 & 7.6537 & TRN & \\
\hline CHEMBL198345 & 330270 & 7.36 & 7.4545 & TRN & \\
\hline CHEMBL200112 & 330270 & 7.8 & 7.4473 & TRN & \\
\hline CHEMBL201022 & 330270 & 5.23 & 7.5523 & TST & \\
\hline CHEMBL201407 & 330270 & 5.0 & 7.2223 & TST & \\
\hline CHEMBL202706 & 330270 & 5.0 & 6.6852 & TST & \\
\hline CHEMBL201789 & 330270 & 5.0 & 7.3917 & TST & \\
\hline CHEMBL378383 & 330270 & 5.0 & 7.1322 & TST & \\
\hline CHEMBL383319 & 330270 & 5.0 & 6.3495 & TST & \\
\hline CHEMBL199802 & 330270 & 5.0 & 6.7759 & TST & \\
\hline CHEMBL201692 & 330270 & 5.0 & 6.8375 & TST & \\
\hline CHEMBL201159 & 330270 & 5.0 & 7.3717 & TST & \\
\hline CHEMBL426656 & 330270 & 5.0 & 6.9703 & TST & \\
\hline CHEMBL27041 & 330270 & 7.4 & 7.6424 & TST & \\
\hline CHEMBL275605 & 330270 & 8.5 & 7.7855 & TST & \\
\hline CHEMBL273807 & 330270 & 8.7 & 8.0883 & TST & \\
\hline CHEMBL278039 & 330270 & 8.67 & 8.0284 & TST & \\
\hline CHEMBL432664 & 330270 & 8.72 & 8.2132 & TST & \\
\hline CHEMBL16677 & 330270 & 8.82 & 8.1939 & TST & \\
\hline CHEMBL16929 & 330270 & 8.65 & 8.3973 & TST & \\
\hline CHEMBL275427 & 330270 & 8.1 & 8.44700 & 0000000001 & TST \\
\hline CHEMBL17003 & 330270 & 8.62 & 8.7453 & TST & \\
\hline CHEMBL201239 & 330270 & 8.16 & 7.9295 & TRN & \\
\hline CHEMBL203196 & 330270 & 7.26 & 7.2709 & TST & \\
\hline CHEMBL1726155 & 737299 & 5.4342 & 5.4502 & TRN & \\
\hline CHEMBL1729120 & 737299 & 6.4401 & 5.8744 & TRN & \\
\hline CHEMBL1707988 & 737299 & 3.699 & 4.48300 & 00000000005 & TRN \\
\hline CHEMBL1728799 & 737299 & 5.8477 & 6.0324 & TRN & \\
\hline CHEMBL1699195 & 737299 & 3.699 & 5.0785 & TST & \\
\hline CHEMBL1719053 & 737299 & 4.7122 & 4.5263 & TRN & \\
\hline CHEMBL1706901 & 737299 & 4.7905 & 4.4891 & TRN & \\
\hline CHEMBL1698780 & 737299 & 5.3134 & 4.695 & TRN & \\
\hline CHEMBL1701756 & 737299 & 5.9318 & 5.809 & TRN & \\
\hline CHEMBL1724354 & 737299 & 3.699 & 4.9138 & TRN & \\
\hline CHEMBL1704988 & 737299 & 6.433 & 6.5247 & TRN & \\
\hline CHEMBL1715251 & 737299 & 3.699 & 4.1517 & TST & \\
\hline CHEMBL1702620 & 737299 & 6.8125 & 6.7112 & TRN & \\
\hline CHEMBL1719120 & 737299 & 6.059 & 5.5539 & TRN & \\
\hline CHEMBL1714757 & 737299 & 3.699 & 5.3961 & TST & \\
\hline CHEMBL1717312 & 737299 & 5.3054 & 6.1754 & TRN & \\
\hline
\end{tabular}




\begin{tabular}{|c|c|c|c|c|}
\hline \multicolumn{5}{|c|}{ Supplemental Table S2.txt } \\
\hline CHEMBL1702752 & 737299 & 5.5498 & 5.5702 & TRN \\
\hline CHEMBL1713635 & 737299 & 5.58 & 5.8582 & TRN \\
\hline CHEMBL1716094 & 737299 & 5.4191 & 5.2157 & TRN \\
\hline CHEMBL1711929 & 737299 & 5.5157 & 5.0711 & TRN \\
\hline CHEMBL1724868 & 737299 & 6.1791 & 5.5488 & TRN \\
\hline CHEMBL1721558 & 737299 & 5.6345 & 5.6179 & TRN \\
\hline CHEMBL1711389 & 737299 & 5.9318 & 5.2624 & TRN \\
\hline CHEMBL1719211 & 737299 & 6.1296 & 6.0798 & TRN \\
\hline CHEMBL1714925 & 737299 & 5.6402 & 5.8626 & TRN \\
\hline CHEMBL1706771 & 737299 & 3.699 & 4.6725 & TST \\
\hline CHEMBL1699177 & 737299 & 3.699 & 3.6621 & TRN \\
\hline CHEMBL1725847 & 737299 & 5.5768 & 5.9544 & TRN \\
\hline CHEMBL1736339 & 737299 & 5.2541 & 5.3795 & TRN \\
\hline CHEMBL1714715 & 737299 & 3.699 & 5.0056 & TST \\
\hline CHEMBL1721727 & 737299 & 4.8416 & 4.9265 & TRN \\
\hline CHEMBL1728022 & 737299 & 4.9172 & 5.1061 & TST \\
\hline CHEMBL1710945 & 737299 & 5.7375 & 5.4932 & TRN \\
\hline CHEMBL1720680 & 737299 & 3.699 & 4.4649 & TST \\
\hline CHEMBL1730909 & 737299 & 3.699 & 4.1923 & TRN \\
\hline CHEMBL1726781 & 737299 & 5.426 & 6.6569 & TST \\
\hline CHEMBL1714010 & 737299 & 3.699 & 3.905 & TST \\
\hline CHEMBL1732727 & 737299 & 3.699 & 3.5 & TRN \\
\hline CHEMBL1726077 & 737299 & 5.8794 & 5.5535 & TRN \\
\hline CHEMBL1725189 & 737299 & 3.699 & 3.7687 & TRN \\
\hline CHEMBL1715436 & 737299 & 5.3737 & 5.5735 & TRN \\
\hline CHEMBL1713943 & 737299 & 5.2534 & 5.7195 & TRN \\
\hline CHEMBL1730619 & 737299 & 3.699 & 3.7165 & TRN \\
\hline CHEMBL1718365 & 737299 & 4.8697 & 5.0464 & TRN \\
\hline CHEMBL1727825 & 737299 & 5.4634 & 4.9265 & TRN \\
\hline CHEMBL 1717840 & 737299 & 3.699 & 4.2472 & TRN \\
\hline CHEMBL1727011 & 737299 & 3.699 & 4.8817 & TST \\
\hline CHEMBL1725577 & 737299 & 5.3325 & 4.9994 & TRN \\
\hline CHEMBL1704494 & 737299 & 6.058 & 6.1292 & TST \\
\hline CHEMBL1736447 & 737299 & 3.699 & 4.1431 & TST \\
\hline CHEMBL1729980 & 737299 & 6.0862 & 5.231 & TRN \\
\hline CHEMBL1455766 & 737299 & 6.0685 & 6.3985 & TRN \\
\hline CHEMBL1707232 & 737299 & 3.699 & 3.9914 & TRN \\
\hline CHEMBL1699035 & 737299 & 4.7878 & 4.8697 & TRN \\
\hline CHEMBL1729417 & 737299 & 7.1113 & 6.2305 & TST \\
\hline CHEMBL1733754 & 737299 & 3.699 & 4.7382 & TST \\
\hline CHEMBL1725095 & 737299 & 3.699 & 4.7457 & TST \\
\hline CHEMBL3780772 & 1565338 & 6.7696 & 6.4541 & TRN \\
\hline CHEMBL3781573 & 1565338 & 4.0 & 3.7369 & TRN \\
\hline CHEMBL3781384 & 1565338 & 6.3665 & 6.6276 & TST \\
\hline CHEMBL3780785 & 1565338 & 7.1938 & 6.4653 & TST \\
\hline CHEMBL 3780043 & 1565338 & 7.0177 & 6.6038 & TRN \\
\hline CHEMBL3781149 & 1565338 & 7.2218 & 7.21 & TRN \\
\hline CHEMBL3780972 & 1565338 & 7.3979 & 7.1183 & TRN \\
\hline
\end{tabular}


Supplemental Table S2.txt

\begin{tabular}{|c|c|c|c|c|c|c|}
\hline CHEMBL 3781893 & 1565338 & 4.0 & 4.4386 & TRN & & \\
\hline CHEMBL 3781157 & 1565338 & 6.6021 & 7.1028 & TRN & & \\
\hline CHEMBL3781183 & 1565338 & 6.7696 & 6.5155 & TRN & & \\
\hline CHEMBL 3781548 & 1565338 & 7.3979 & 7.2046 & TRN & & \\
\hline CHEMBL3780717 & 1565338 & 7.1612 & 6.7712 & TRN & & \\
\hline CHEMBL 3780764 & 1565338 & 6.1675 & 6.3919 & TRN & & \\
\hline CHEMBL 3780765 & 1565338 & 6.4559 & 6.656000 & 000000000 & & TRN \\
\hline CHEMBL 3780527 & 1565338 & 6.9208 & 6.8421 & TRN & & \\
\hline CHEMBL 3781347 & 1565338 & 6.6021 & 7.2783 & TRN & & \\
\hline CHEMBL3780153 & 1565338 & 5.6576 & 5.5676 & TRN & & \\
\hline CHEMBL 3781290 & 1565338 & 5.9208 & 5.5152 & TRN & & \\
\hline CHEMBL 3781625 & 1565338 & 6.7696 & 6.394 & TRN & & \\
\hline CHEMBL 3780470 & 1565338 & 6.4949 & 7.0235 & TRN & & \\
\hline CHEMBL 3780054 & 1565338 & 6.2007 & 6.3227 & TST & & \\
\hline CHEMBL3781094 & 1565338 & 5.6882 & 5.8669 & TRN & & \\
\hline CHEMBL 3781447 & 1565338 & 6.2676 & 5.7703 & TRN & & \\
\hline CHEMBL 3781633 & 1565338 & 6.3188 & 6.3794 & TRN & & \\
\hline CHEMBL 3780845 & 1565338 & 5.7959 & 5.6313 & TRN & & \\
\hline CHEMBL 3781827 & 1565338 & 6.4949 & 6.4955 & TRN & & \\
\hline CHEMBL3780372 & 1565338 & 7.2218 & 7.5876 & TRN & & \\
\hline CHEMBL 3781308 & 1565338 & 6.9208 & 7.0683 & TRN & & \\
\hline CHEMBL 3780459 & 1565338 & 6.1675 & 6.4225 & TRN & & \\
\hline CHEMBL 3781194 & 1565338 & 6.699 & 7.0028 & TRN & & \\
\hline CHEMBL 3780595 & 1565338 & 6.4685 & 6.6092 & TRN & & \\
\hline CHEMBL 3781741 & 1565338 & 6.9208 & 6.8625 & TRN & & \\
\hline CHEMBL 3781835 & 1565338 & 7.1549 & 6.6771 & TRN & & \\
\hline CHEMBL 3780144 & 1565338 & 7.301 & 7.0519 & TRN & & \\
\hline CHEMBL 3781654 & 1565338 & 5.7959 & 6.0645 & TRN & & \\
\hline CHEMBL1551510 & 1565338 & 5.5229 & 5.899 & TRN & & \\
\hline CHEMBL 3781994 & 1565338 & 6.2676 & 6.2886 & TRN & & \\
\hline CHEMBL 3780729 & 1565338 & 6.0223 & 6.0865 & TRN & & \\
\hline CHEMBL 3780756 & 1565338 & 5.3979 & 5.5166 & TRN & & \\
\hline CHEMBL 3781668 & 1565338 & 4.0 & 4.315 & TRN & & \\
\hline CHEMBL 3780534 & 1565338 & \multicolumn{3}{|c|}{5.752000000000001} & 5.7047 & TRN \\
\hline CHEMBL 3781913 & 1565338 & 8.0969 & 7.4832 & TRN & & \\
\hline CHEMBL 3780235 & 1565338 & 6.9586 & 6.9529 & TRN & & \\
\hline CHEMBL 3781151 & 1565338 & 7.3372 & 7.1618 & TST & & \\
\hline CHEMBL 3780239 & 1565338 & 8.0 & 7.9022 & TST & & \\
\hline CHEMBL 3780460 & 1565338 & 7.0458 & 7.3603 & TST & & \\
\hline CHEMBL 3781797 & 1565338 & 5.8239 & 6.0124 & TST & & \\
\hline CHEMBL 3781161 & 1565338 & 5.0 & 5.4695 & TST & & \\
\hline CHEMBL 3781331 & 1565338 & 7.4318 & 7.4872 & TST & & \\
\hline CHEMBL 3780403 & 1565338 & 4.0 & 4.226 & TST & & \\
\hline CHEMBL 3781086 & 1565338 & 4.0 & 4.2731 & TST & & \\
\hline CHEMBL 3780349 & 1565338 & 6.0269 & 5.6043 & TST & & \\
\hline CHEMBL 3781757 & 1565338 & 5.699 & 5.6872 & TST & & \\
\hline CHEMBL 3781847 & 1565338 & \multicolumn{3}{|c|}{5.821000000000001} & 6.2093 & SI \\
\hline CHEMBL 3702705 & 1528855 & 5.2154 & 5.1869 & TRN & & \\
\hline
\end{tabular}


Supplemental Table S2.txt

\begin{tabular}{|c|c|c|c|c|c|}
\hline CHEMBL 3702823 & 1528855 & 3.6021 & 4.5834 & TRN & \\
\hline CHEMBL 3702779 & 1528855 & 5.6234 & 5.2759 & TRN & \\
\hline CHEMBL 3702822 & 1528855 & 5.0 & 4.7399 & TST & \\
\hline CHEMBL 3702758 & 1528855 & 4.7585 & 5.3103 & TRN & \\
\hline CHEMBL3699325 & 1528855 & 5.1175 & 4.3382 & TRN & \\
\hline CHEMBL 3702672 & 1528855 & 5.6596 & 4.6554 & TRN & \\
\hline CHEMBL 3640016 & 1528855 & 5.1308 & 5.1498 & TRN & \\
\hline CHEMBL 3702760 & 1528855 & 4.6519 & 5.3227 & TRN & \\
\hline CHEMBL 3702762 & 1528855 & 5.1675 & 5.1894 & TST & \\
\hline CHEMBL 3702825 & 1528855 & 5.6799 & 4.7805 & TST & \\
\hline CHEMBL3699335 & 1528855 & 3.6021 & 4.4839 & TST & \\
\hline CHEMBL 3702680 & 1528855 & 5.3363 & 4.5395 & TRN & \\
\hline CHEMBL 3702771 & 1528855 & 5.6655 & 5.1039 & TRN & \\
\hline CHEMBL 3702679 & 1528855 & 5.0696 & 4.5525 & TRN & \\
\hline CHEMBL 3702730 & 1528855 & 5.5003 & 5.2107 & TRN & \\
\hline CHEMBL 3699332 & 1528855 & 4.8633 & 4.3988 & TRN & \\
\hline CHEMBL 3702683 & 1528855 & 5.1864 & 4.6264 & TST & \\
\hline CHEMBL 3702801 & 1528855 & 4.7635 & 5.1663 & TRN & \\
\hline CHEMBL 3702799 & 1528855 & 5.3778 & 5.1502 & TRN & \\
\hline CHEMBL 3702724 & 1528855 & 5.6108 & 5.116000 & 00000000005 & TST \\
\hline CHEMBL 3699316 & 1528855 & 3.6021 & 4.4429 & TRN & \\
\hline CHEMBL 3699340 & 1528855 & 3.6021 & 4.1334 & TRN & \\
\hline CHEMBL 3702739 & 1528855 & 5.4389 & 5.2839 & TRN & \\
\hline CHEMBL 3702759 & 1528855 & 5.3206 & 5.3151 & TRN & \\
\hline CHEMBL 3702753 & 1528855 & 5.6055 & 5.2545 & TST & \\
\hline CHEMBL 3702773 & 1528855 & 5.118 & 5.1662 & TRN & \\
\hline CHEMBL 3702795 & 1528855 & 5.1586 & 5.1156 & TRN & \\
\hline CHEMBL 3702800 & 1528855 & 5.1586 & 5.1508 & TRN & \\
\hline CHEMBL 3702721 & 1528855 & 5.6517 & 5.0863 & TRN & \\
\hline CHEMBL 3640015 & 1528855 & 5.556 & 4.5635 & TST & \\
\hline CHEMBL 3699334 & 1528855 & 5.4672 & 4.5545 & TRN & \\
\hline CHEMBL 3699341 & 1528855 & 4.6635 & 4.6679 & TST & \\
\hline CHEMBL 3702687 & 1528855 & 5.5346 & 4.7087 & TRN & \\
\hline CHEMBL 3702695 & 1528855 & 4.9469 & 5.1059 & TRN & \\
\hline CHEMBL 3702712 & 1528855 & 4.9172 & 5.1182 & TRN & \\
\hline CHEMBL 3702689 & 1528855 & 5.4089 & 5.2066 & TRN & \\
\hline CHEMBL 3699322 & 1528855 & 5.6716 & 4.5988 & TRN & \\
\hline CHEMBL 3702694 & 1528855 & 5.04 & 5.0566 & TRN & \\
\hline CHEMBL 3702763 & 1528855 & 5.24799 & 999999999 & 5.2719 & TRN \\
\hline CHEMBL 3702761 & 1528855 & 5.6216 & 5.2902 & TRN & \\
\hline CHEMBL 3702790 & 1528855 & 5.15799 & 999999999 & 5.1943 & TRN \\
\hline CHEMBL 3702817 & 1528855 & 4.9492 & 5.1015 & TRN & \\
\hline CHEMBL 3702706 & 1528855 & 5.6055 & 5.2097 & TST & \\
\hline CHEMBL 3699344 & 1528855 & 3.6021 & 4.2121 & TRN & \\
\hline CHEMBL 3702714 & 1528855 & 4.9706 & 5.1355 & TRN & \\
\hline CHEMBL 3702710 & 1528855 & 5.4001 & 5.2148 & TRN & \\
\hline CHEMBL 3702702 & 1528855 & 3.6021 & 5.0314 & TRN & \\
\hline CHEMBL 3702735 & 1528855 & 4.7862 & 5.2318 & TRN & \\
\hline
\end{tabular}


Supplemental Table S2.txt

\begin{tabular}{|c|c|c|c|c|}
\hline CHEMBL3699321 & 1528855 & 3.6021 & 4.4305 & TRN \\
\hline CHEMBL3702704 & 1528855 & 5.2573 & 5.1677 & TRN \\
\hline CHEMBL3702748 & 1528855 & 4.9389 & 5.2356 & TRN \\
\hline CHEMBL3699323 & 1528855 & 4.7967 & 4.2778 & TRN \\
\hline CHEMBL3702774 & 1528855 & 4.9957 & 5.1671 & TRN \\
\hline CHEMBL3702691 & 1528855 & 5.0947 & 5.0979 & TRN \\
\hline CHEMBL3702741 & 1528855 & 5.5391 & 5.1854 & TST \\
\hline CHEMBL3699317 & 1528855 & 3.6021 & 4.5679 & TRN \\
\hline CHEMBL3702696 & 1528855 & 5.0315 & 5.1069 & TRN \\
\hline CHEMBL3702791 & 1528855 & 5.6556 & 5.1662 & TRN \\
\hline CHEMBL3702807 & 1528855 & 5.1993 & 5.1576 & TRN \\
\hline CHEMBL3702676 & 1528855 & 4.9788 & 4.5311 & TRN \\
\hline CHEMBL3702717 & 1528855 & 5.3036 & 5.1492 & TRN \\
\hline CHEMBL3702812 & 1528855 & 5.3872 & 5.1715 & TRN \\
\hline CHEMBL3702775 & 1528855 & 4.8851 & 5.1358 & TRN \\
\hline CHEMBL3702703 & 1528855 & 5.0878 & 5.0573 & TRN \\
\hline CHEMBL3702745 & 1528855 & 3.6021 & 5.258999 & 99999999995 \\
\hline CHEMBL3702781 & 1528855 & 5.3439 & 5.2934 & TRN \\
\hline CHEMBL3702776 & 1528855 & 5.1707 & 5.1963 & TRN \\
\hline CHEMBL3702718 & 1528855 & 5.1163 & 5.1091 & TST \\
\hline CHEMBL3702678 & 1528855 & 5.1079 & 4.5911 & TRN \\
\hline CHEMBL3702732 & 1528855 & 4.791 & 5.2999 & TRN \\
\hline CHEMBL3702778 & 1528855 & 5.5935 & 5.3013 & TRN \\
\hline CHEMBL3702804 & 1528855 & 3.6021 & 5.0798 & TRN \\
\hline CHEMBL3702711 & 1528855 & 5.6576 & 5.1643 & TRN \\
\hline CHEMBL3699343 & 1528855 & 3.6021 & 4.2996 & TST \\
\hline CHEMBL3699318 & 1528855 & 5.7545 & 4.433 & TST \\
\hline CHEMBL3702815 & 1528855 & 5.4078 & 5.1916 & TRN \\
\hline CHEMBL3702783 & 1528855 & 5.2716 & 5.2346 & TRN \\
\hline CHEMBL3702772 & 1528855 & 4.71899 & 79999999 & 5.131 \\
\hline CHEMBL3702805 & 1528855 & 5.4828 & 5.22 & TRN \\
\hline CHEMBL3702814 & 1528855 & 5.1169 & 5.1596 & TRN \\
\hline CHEMBL3702809 & 1528855 & 3.6021 & 4.9203 & TRN \\
\hline CHEMBL 3702808 & 1528855 & 4.6258 & 5.0188 & TRN \\
\hline CHEMBL3702770 & 1528855 & 5.5834 & 5.0118 & TRN \\
\hline CHEMBL3702819 & 1528855 & 5.58 & 5.1418 & TST \\
\hline CHEMBL3702674 & 1528855 & 3.6021 & 4.4879 & TST \\
\hline CHEMBL3702788 & 1528855 & 5.5901 & 5.3756 & TRN \\
\hline CHEMBL3699324 & 1528855 & 5.0931 & 4.3593 & TST \\
\hline CHEMBL3699329 & 1528855 & 4.71 & 4.2188 & TST \\
\hline CHEMBL3702754 & 1528855 & 5.6882 & 5.2542 & TRN \\
\hline CHEMBL3702813 & 1528855 & 5.5918 & 5.189 & TRN \\
\hline CHEMBL3702729 & 1528855 & 4.9281 & 5.1271 & TRN \\
\hline CHEMBL 3702747 & 1528855 & 5.5436 & 5.2898 & TRN \\
\hline CHEMBL3702737 & 1528855 & 5.6968 & 5.266 & TRN \\
\hline CHEMBL3699326 & 1528855 & 5.6162 & 4.3031 & TST \\
\hline CHEMBL3702750 & 1528855 & 5.9586 & 5.4078 & TRN \\
\hline CHEMBL3702673 & 1528855 & 3.6021 & 4.3784 & TST \\
\hline
\end{tabular}


Supplemental Table S2.txt

\begin{tabular}{|c|c|c|c|c|c|}
\hline CHEMBL 3702777 & 1528855 & 5.4622 & 5.2088 & TRN & \\
\hline CHEMBL 3699328 & 1528855 & 5.1851 & 4.2653 & TST & \\
\hline CHEMBL 3702803 & 1528855 & 5.1487 & 5.2454 & TST & \\
\hline CHEMBL 3702768 & 1528855 & 5.0155 & 4.9381 & TRN & \\
\hline CHEMBL 3702769 & 1528855 & 5.5272 & 5.2561 & TRN & \\
\hline CHEMBL3699330 & 1528855 & 3.6021 & 4.3582 & TST & \\
\hline CHEMBL 3702802 & 1528855 & 5.4012 & 5.2455 & TRN & \\
\hline CHEMBL 3702740 & 1528855 & 4.7474 & 5.2416 & TRN & \\
\hline CHEMBL 3702727 & 1528855 & 3.6021 & 5.1115 & TRN & \\
\hline CHEMBL3702756 & 1528855 & 5.6326 & 5.1924 & TRN & \\
\hline CHEMBL 3702757 & 1528855 & 5.2111 & 5.1666 & TRN & \\
\hline CHEMBL 3702743 & 1528855 & 5.4461 & 5.2124 & TRN & \\
\hline CHEMBL3702806 & 1528855 & 5.6253 & 5.2509 & TRN & \\
\hline CHEMBL 3702798 & 1528855 & 5.4353 & 5.2939 & TRN & \\
\hline CHEMBL3702690 & 1528855 & 4.9136 & 5.0785 & TRN & \\
\hline CHEMBL 3702731 & 1528855 & 5.6003 & 5.1997 & TRN & \\
\hline CHEMBL3702681 & 1528855 & 4.9914 & 4.7915 & TST & \\
\hline CHEMBL3702692 & 1528855 & 5.6498 & 5.2037 & TRN & \\
\hline CHEMBL3702734 & 1528855 & 5.4157 & 5.2712 & TRN & \\
\hline CHEMBL3702810 & 1528855 & 4.6672 & 4.9281 & TRN & \\
\hline CHEMBL3702744 & 1528855 & 5.4609 & 5.2272 & TRN & \\
\hline CHEMBL3699342 & 1528855 & 5.6459 & 4.3368 & TST & \\
\hline CHEMBL3702821 & 1528855 & 5.0301 & 4.6782 & TST & \\
\hline CHEMBL3702749 & 1528855 & 5.1079 & 5.1463 & TRN & \\
\hline CHEMBL 3702716 & 1528855 & 5.4134 & 5.115 & TRN & \\
\hline CHEMBL3699337 & 1528855 & 3.6021 & 4.3883 & TST & \\
\hline CHEMBL 3702700 & 1528855 & 5.5498 & 5.161000 & 00000000005 & TRN \\
\hline CHEMBL3702684 & 1528855 & 4.6906 & 4.6925 & TST & \\
\hline CHEMBL3702675 & 1528855 & 3.6021 & 4.5978 & TST & \\
\hline CHEMBL3702725 & 1528855 & 5.3478 & 5.1275 & TST & \\
\hline CHEMBL3702685 & 1528855 & 5.6596 & 4.7374 & TST & \\
\hline CHEMBL 3702713 & 1528855 & 5.2976 & 5.1101 & TRN & \\
\hline CHEMBL 3702766 & 1528855 & 5.16299 & 99999999 & 5.2189 & $1 \mathrm{KI}$ \\
\hline CHEMBL3702789 & 1528855 & 4.6765 & 5.2284 & TRN & \\
\hline CHEMBL3702708 & 1528855 & 5.1805 & 5.1639 & TRN & \\
\hline CHEMBL3702728 & 1528855 & 5.2226 & 5.2202 & TRN & \\
\hline CHEMBL3699327 & 1528855 & 4.7645 & 4.3418 & TST & \\
\hline CHEMBL3702736 & 1528855 & 5.5969 & 5.2021 & TRN & \\
\hline CHEMBL3702826 & 1528855 & 5.1931 & 4.7545 & TST & \\
\hline CHEMBL3702786 & 1528855 & 5.2366 & 5.3099 & TRN & \\
\hline CHEMBL3702709 & 1528855 & 4.8239 & 5.106 & TRN & \\
\hline CHEMBL3702723 & 1528855 & 5.6757 & 5.2167 & TRN & \\
\hline CHEMBL3702677 & 1528855 & 5.0232 & 4.3815 & TST & \\
\hline CHEMBL 3702720 & 1528855 & 5.2204 & 4.843 & TRN & \\
\hline CHEMBL3702785 & 1528855 & 5.6345 & 5.3828 & TRN & \\
\hline CHEMBL3702726 & 1528855 & 4.7375 & 5.1563 & TRN & \\
\hline CHEMBL3702787 & 1528855 & 5.1152 & 5.2581 & TRN & \\
\hline CHEMBL3702698 & 1528855 & 4.9626 & 5.105 & TRN & \\
\hline
\end{tabular}


Supplemental Table S2.txt

\begin{tabular}{|c|c|c|c|c|c|c|}
\hline CHEMBL3699339 & 1528855 & 3.6021 & 4.3031 & TST & & \\
\hline CHEMBL 3702688 & 1528855 & 5.466 & 5.0002 & TST & & \\
\hline CHEMBL 3702811 & 1528855 & 5.3125 & 5.2011 & TRN & & \\
\hline CHEMBL 3702820 & 1528855 & 5.4145 & 4.498 & TST & & \\
\hline CHEMBL 3699331 & 1528855 & 3.6021 & 4.4377 & TST & & \\
\hline CHEMBL 3702780 & 1528855 & 5.1707 & 5.2732 & TRN & & \\
\hline CHEMBL 3702693 & 1528855 & 5.1662 & 5.0847 & TRN & & \\
\hline CHEMBL 3699320 & 1528855 & 5.1524 & 4.2834 & TST & & \\
\hline CHEMBL 3702752 & 1528855 & 5.2976 & 5.1071 & TRN & & \\
\hline CHEMBL 3702824 & 1528855 & 3.6021 & 4.5486 & TST & & \\
\hline CHEMBL 3702746 & 1528855 & 5.0706 & 5.3788 & TRN & & \\
\hline CHEMBL 3702733 & 1528855 & 5.4342 & 5.2044 & TRN & & \\
\hline CHEMBL 3699338 & 1528855 & 3.6021 & 4.2188 & TST & & \\
\hline CHEMBL 3702722 & 1528855 & \multicolumn{3}{|c|}{5.0680000000000005} & 5.1349 & TRN \\
\hline CHEMBL 3702751 & 1528855 & 5.5952 & 5.2645 & TRN & & \\
\hline CHEMBL 3702764 & 1528855 & 5.0128 & 5.275 & TRN & & \\
\hline CHEMBL 3941944 & 1528855 & 4.963 & 5.2478 & TST & & \\
\hline CHEMBL 3702715 & 1528855 & 5.4815 & 5.1032 & TRN & & \\
\hline CHEMBL 3702782 & 1528855 & 5.3925 & 5.3876 & TRN & & \\
\hline CHEMBL 3702784 & 1528855 & 5.5969 & 5.3533 & TRN & & \\
\hline CHEMBL 3702701 & 1528855 & 3.6021 & 5.1113 & TRN & & \\
\hline CHEMBL3702765 & 1528855 & 5.2907 & 5.2273 & TRN & & \\
\hline CHEMBL 3702793 & 1528855 & 5.1192 & 5.0938 & TRN & & \\
\hline CHEMBL 3702794 & 1528855 & 5.2418 & 5.1124 & TRN & & \\
\hline CHEMBL 3702816 & 1528855 & 5.3372 & 5.2441 & TRN & & \\
\hline CHEMBL3702719 & 1528855 & 3.6021 & 4.7115 & TRN & & \\
\hline CHEMBL 3702797 & 1528855 & 5.2132 & 5.2149 & TRN & & \\
\hline CHEMBL 3702738 & 1528855 & 5.104 & 5.2589 & TRN & & \\
\hline CHEMBL3702699 & 1528855 & 4.9508 & 5.118 & TRN & & \\
\hline CHEMBL 3702767 & 1528855 & 5.2111 & 4.8089 & TRN & & \\
\hline CHEMBL 3702755 & 1528855 & 5.6615 & 5.2544 & TRN & & \\
\hline CHEMBL 3702682 & 1528855 & 5.1574 & 4.6749 & TST & & \\
\hline CHEMBL3699319 & 1528855 & 3.6021 & 4.2739 & TST & & \\
\hline CHEMBL 3702707 & 1528855 & 5.4401 & 5.1037 & TRN & & \\
\hline CHEMBL 3702792 & 1528855 & 5.5638 & 5.194 & TRN & & \\
\hline CHEMBL3699336 & 1528855 & 5.6003 & 4.4678 & TST & & \\
\hline CHEMBL 3699333 & 1528855 & 3.6021 & 4.5608 & TST & & \\
\hline CHEMBL 3702796 & 1528855 & \multicolumn{3}{|c|}{5.218999999999999} & 5.0914 & TRN \\
\hline CHEMBL 3702697 & 1528855 & 3.6021 & 5.0308 & TRN & & \\
\hline CHEMBL 581245 & 600885 & 5.0137 & 5.7349 & TRN & & \\
\hline CHEMBL584621 & 600885 & 6.8617 & 6.8139 & TRN & & \\
\hline CHEMBL601973 & 600885 & 4.9031 & 5.3738 & TRN & & \\
\hline CHEMBL577391 & 600885 & 7.2976 & 7.1166 & TRN & & \\
\hline CHEMBL600713 & 600885 & 3.9031 & 5.0771 & TST & & \\
\hline CHEMBL602582 & 600885 & 5.6026 & 5.4411 & TRN & & \\
\hline CHEMBL578744 & 600885 & 6.0 & 5.8126 & TRN & & \\
\hline CHEMBL612130 & 600885 & 6.433 & 6.5361 & TRN & & \\
\hline CHEMBL602198 & 600885 & 4.1891 & 5.0692 & TRN & & \\
\hline
\end{tabular}




\begin{tabular}{|c|c|c|c|c|}
\hline & & & & \\
\hline AEMBL598270 & 600885 & 6.3655 & 6.3275 & TST \\
\hline CHEMBL583532 & 600885 & 6.1308 & 6.2781 & \\
\hline HEMBL584251 & 600885 & 6.3706 & 9716 & \\
\hline CHEMBL582729 & 600885 & 5.9974 & 5.2881 & \\
\hline CHEMBL576402 & 600885 & 6.3536 & 6.271 & \\
\hline CHEMBL530562 & 600885 & 6.2118 & 5.9899 & \\
\hline CHEMBL577874 & 600885 & 7.5438 & 6.8218 & \\
\hline CHEMBL602639 & 600885 & 6.8077 & 6.4537 & \\
\hline CHEMBL599926 & 600885 & 6.6724 & 6.9607 & \\
\hline CHEMBL600753 & 600885 & 6.0205 & 6.1578 & \\
\hline CHEMBL607973 & 600885 & 5.8732 & 5.2333 & \\
\hline CHEMBL529062 & 600885 & 6.2604 & 5.7677 & \\
\hline CHEMBL585769 & 600885 & 4.9031 & 5.2486 & \\
\hline CHEMBL587592 & 600885 & 5.5591 & 5.7356 & \\
\hline CHEMBL602010 & 600885 & 7.1391 & 6.125 & \\
\hline CHEMBL580891 & 606 & 6.1163 & 5.9156 & \\
\hline CHEMBL611075 & 600885 & 4.8173 & 6.4435 & \\
\hline CHEMBL580151 & 600885 & 4.9031 & 6.1143 & \\
\hline CHEMBL585803 & 600885 & 5.9281 & 5.7133 & \\
\hline CHEMBL599302 & 600 & 5.0716 & 355 & \\
\hline CHEMBL488757 & 606 & 6.7675 & 494 & \\
\hline CHEMBL2368649 & 600885 & 6.605 & 6.2217 & \\
\hline CHEMBL535958 & 600885 & 6.7014 & 5.9766 & \\
\hline CHEMBL608146 & 600 & 6.4389 & 6.2228 & \\
\hline CHEMBL 58 & 606 & 4.8456 & 113 & \\
\hline CHEMBL580637 & 606 & 6.0 & 5.8916 & \\
\hline CHEMBL534063 & 600 & 5.7627 & 5.4902 & \\
\hline CHEMBL597463 & 606 & 3.9031 & 733 & \\
\hline CHEMBL600525 & 600885 & 6.6919 & 5.9877 & \\
\hline CHEMBL585068 & 600 & 6.0 & 09 & \\
\hline CHEMBL & 606 & 6.0 & 5.6857 & \\
\hline CHEMBL598075 & 600 & 6.1707 & 6.5643 & \\
\hline CHEMBL605752 & 600 & 6.1463 & 5.3352 & \\
\hline CHEMBL582701 & 600885 & 4.7737 & 5.9756 & \\
\hline CHEMBL 6 & 600 & 6.317 & 5.6711 & \\
\hline CHEMBL & 606 & 6.289 & 6.5381 & \\
\hline CHEMBL597468 & 600885 & 3.9303 & 6.3126 & \\
\hline CHEMBL579098 & 600885 & 4.9562 & 5.6316 & \\
\hline CHEMBL581469 & 600885 & 4.8362 & & \\
\hline CHEMBL579967 & 600885 & 5.317 & 5.7488 & \\
\hline CHEMBL584832 & 600885 & 6.0996 & 5.8576 & \\
\hline CHEMBL577835 & 600885 & 6.6297 & 6.2053 & \\
\hline CHEMBL576753 & 600885 & 5.9201 & 6.0677 & \\
\hline CHEMBL528933 & 600885 & 6.129 & 5.9644 & \\
\hline CHEMBL602016 & 600885 & 5.556 & 5.5573 & \\
\hline CHEMBL588294 & 600885 & 5.0434 & 5.4076 & \\
\hline CHEMBL6229 & 600885 & 6.2628 & 5.7045 & \\
\hline CHEMBL585269 & 600885 & 5.9897 & 5.7445 & \\
\hline
\end{tabular}




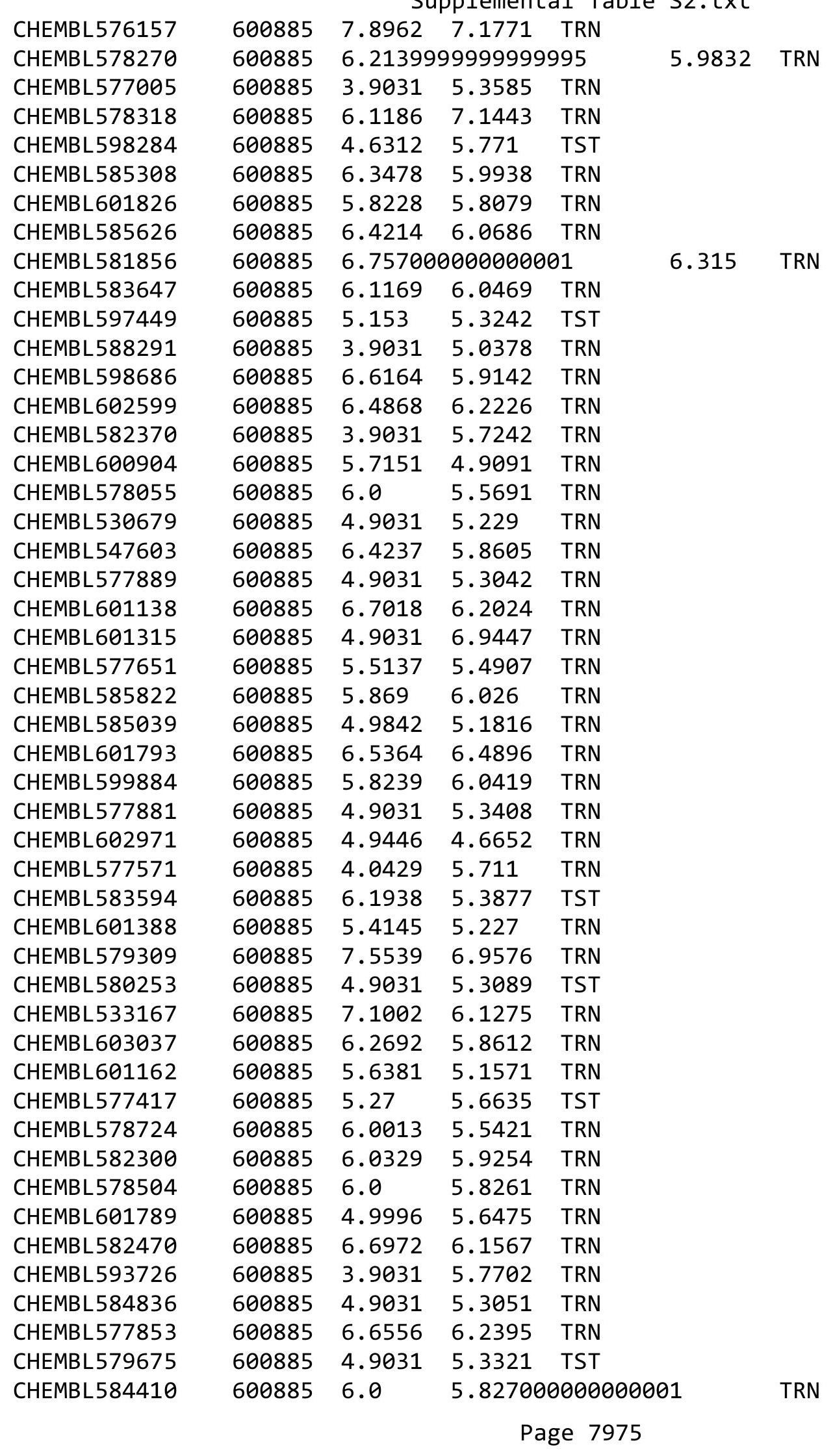




\begin{tabular}{|c|c|c|c|c|c|}
\hline & & & & & \\
\hline CHEMBL602377 & 600885 & 6.2798 & 7.4248 & TRN & \\
\hline CHEMBL582728 & 600885 & 5.8633 & 5.7624 & TRN & \\
\hline CHEMBL581689 & 600885 & 5.007 & 5.2448 & TRN & \\
\hline CHEMBL582573 & 600885 & 5.9348 & 5.1141 & TRN & \\
\hline CHEMBL578081 & 600885 & 4.9031 & 5.7998 & TRN & \\
\hline CHEMBL582694 & 600885 & 5.2218 & 5.6348 & TRN & \\
\hline CHEMBL578284 & 600885 & 7.6625 & 6.557 & TRN & \\
\hline CHEMBL610329 & 600885 & 3.9031 & 5.5172 & TRN & \\
\hline CHEMBL547588 & 600885 & 6.6645 & 6.7059 & TRN & \\
\hline CHEMBL602176 & 600885 & 7.8755 & 7.11600 & 00000000005 & TST \\
\hline CHEMBL580284 & 600885 & 6.8044 & 6.7622 & TRN & \\
\hline CHEMBL601569 & 600885 & 6.2388 & 6.2815 & TRN & \\
\hline CHEMBL600279 & 600885 & 3.9031 & 4.9696 & TRN & \\
\hline CHEMBL584482 & 600885 & 7.2204 & 6.2197 & TRN & \\
\hline CHEMBL602186 & 600885 & 6.5513 & 6.6285 & TRN & \\
\hline CHEMBL599498 & 600885 & 6.739 & 6.2564 & TRN & \\
\hline CHEMBL598052 & 600885 & 6.1433 & 5.1729 & TRN & \\
\hline CHEMBL583550 & 600885 & 6.0283 & 5.7633 & TRN & \\
\hline CHEMBL601821 & 600885 & 6.7918 & 5.9892 & TRN & \\
\hline CHEMBL582721 & 600885 & 5.7268 & 5.6164 & TRN & \\
\hline CHEMBL576400 & 600885 & 6.8233 & 6.0912 & TRN & \\
\hline CHEMBL582104 & 600885 & 5.6234 & 5.4325 & TRN & \\
\hline CHEMBL585236 & 600885 & 5.945 & 5.2286 & TRN & \\
\hline CHEMBL579145 & 600885 & 5.4634 & 5.5745 & TST & \\
\hline CHEMBL578089 & 600885 & 5.3565 & 5.6523 & TRN & \\
\hline CHEMBL582497 & 600885 & 6.5411 & 6.4747 & TRN & \\
\hline CHEMBL602193 & 600885 & 7.0035 & 6.2363 & TRN & \\
\hline CHEMBL584616 & 600885 & 6.0 & 5.8365 & TRN & \\
\hline CHEMBL527704 & 600885 & 5.7423 & 5.7623 & TRN & \\
\hline CHEMBL600563 & 600885 & 6.1013 & 5.2407 & TRN & \\
\hline CHEMBL579346 & 600885 & 3.9333 & 4.9054 & TRN & \\
\hline CHEMBL579348 & 600885 & 6.3036 & 5.91200 & 0000000001 & TST \\
\hline CHEMBL578875 & 600885 & 6.0675 & 5.943 & TRN & \\
\hline CHEMBL527465 & 600885 & 3.9031 & 5.67899 & 9999999999 & TRN \\
\hline CHEMBL600132 & 600885 & 4.8019 & 5.9394 & TST & \\
\hline CHEMBL585590 & 600885 & 5.6254 & 5.879 & TRN & \\
\hline CHEMBL579337 & 600885 & 5.5423 & 5.4124 & TRN & \\
\hline CHEMBL579362 & 600885 & 3.9031 & 5.5848 & TST & \\
\hline CHEMBL600301 & 600885 & 6.6538 & 5.75799 & 9999999999 & TRN \\
\hline CHEMBL599887 & 600885 & 5.2197 & 5.7238 & TRN & \\
\hline CHEMBL582076 & 600885 & 4.9031 & 5.6931 & TRN & \\
\hline CHEMBL588921 & 600885 & 6.9352 & 6.396 & TRN & \\
\hline CHEMBL600748 & 600885 & 6.0947 & 6.4911 & TRN & \\
\hline CHEMBL603944 & 600885 & 5.9454 & 6.006 & TRN & \\
\hline CHEMBL581437 & 600885 & 6.0 & 5.8223 & TRN & \\
\hline CHEMBL603045 & 600885 & 5.9401 & 6.88700 & 00000000005 & TRN \\
\hline CHEMBL527967 & 600885 & 7.266 & 7.1919 & TRN & \\
\hline CHEMBL576410 & 600885 & 6.6844 & 6.2408 & TST & \\
\hline
\end{tabular}




\begin{tabular}{|c|c|c|c|c|c|}
\hline & & & & & \\
\hline CHEMBL576606 & 600885 & 6.3872 & 5.8739 & TST & \\
\hline CHEMBL582699 & 600885 & 5.3979 & 5.3933 & TRN & \\
\hline CHEMBL605186 & 600885 & 5.9813 & 5.3414 & TRN & \\
\hline CHEMBL582468 & 600885 & 6.8752 & 5.9206 & TRN & \\
\hline CHEMBL601328 & 600885 & 4.9404 & 5.8193 & TST & \\
\hline CHEMBL547227 & 600885 & 6.9112 & 6.2403 & TRN & \\
\hline CHEMBL585768 & 600885 & 4.9031 & 5.9519 & TRN & \\
\hline CHEMBL597671 & 600885 & 5.8401 & 5.9502 & TRN & \\
\hline CHEMBL602157 & 600885 & 6.209 & 5.7665 & TRN & \\
\hline CHEMBL577654 & 600885 & 6.1255 & 5.83299 & 9999999999 & TRN \\
\hline CHEMBL581664 & 600885 & 5.7852 & 5.4115 & TRN & \\
\hline CHEMBL602212 & 600885 & 5.67899 & 99999999 & 5.822 & TST \\
\hline CHEMBL585224 & 600885 & 6.0026 & 6.1077 & TST & \\
\hline CHEMBL598056 & 600885 & 7.1568 & 6.1204 & TRN & \\
\hline CHEMBL588400 & 600885 & 4.9031 & 5.5104 & TRN & \\
\hline CHEMBL602826 & 600885 & 6.1337 & 5.8007 & TRN & \\
\hline CHEMBL579292 & 600885 & 8.1421 & 6.7628 & TST & \\
\hline CHEMBL606166 & 600885 & 6.6007 & 6.1553 & TRN & \\
\hline CHEMBL599921 & 600885 & 6.0 & 5.7077 & TRN & \\
\hline CHEMBL579423 & 600885 & 6.5112 & 6.1115 & TRN & \\
\hline CHEMBL578480 & 600885 & 7.3152 & 7.0978 & TRN & \\
\hline CHEMBL584841 & 600885 & 6.1427 & 6.3849 & TST & \\
\hline CHEMBL577863 & 600885 & 6.1904 & 5.9688 & TRN & \\
\hline CHEMBL597851 & 600885 & 6.1349 & 5.2833 & TRN & \\
\hline CHEMBL582667 & 600885 & 7.0405 & 6.7126 & TRN & \\
\hline CHEMBL583844 & 600885 & 5.6763 & 5.566 & TRN & \\
\hline CHEMBL584643 & 600885 & 4.9031 & 5.2958 & TRN & \\
\hline CHEMBL585270 & 600885 & 6.6927 & 6.3886 & TRN & \\
\hline CHEMBL601591 & 600885 & 4.9431 & 5.1659 & TRN & \\
\hline CHEMBL599721 & 600885 & 5.3028 & 5.8839 & TRN & \\
\hline CHEMBL588835 & 600885 & 4.9031 & 5.888 & TST & \\
\hline CHEMBL593483 & 600885 & 6.0 & 5.619 & TRN & \\
\hline CHEMBL602018 & 600885 & 4.9031 & 5.4083 & TRN & \\
\hline CHEMBL578082 & 600885 & 4.1858 & 5.5551 & TRN & \\
\hline CHEMBL586002 & 600885 & 6.8697 & 6.2733 & TRN & \\
\hline CHEMBL576619 & 600885 & 4.9031 & 5.4759 & TRN & \\
\hline CHEMBL585055 & 600885 & 5.6874 & 6.0338 & TST & \\
\hline CHEMBL600282 & 600885 & 4.9031 & 5.4878 & TRN & \\
\hline CHEMBL581880 & 600885 & 6.2741 & 6.3261 & TRN & \\
\hline CHEMBL582508 & 600885 & 5.9314 & 5.5695 & TRN & \\
\hline CHEMBL600303 & 600885 & 6.0 & 5.7526 & TST & \\
\hline CHEMBL602192 & 600885 & 6.3429 & 6.1875 & TRN & \\
\hline CHEMBL581857 & 600885 & 5.9055 & 6.021 & TST & \\
\hline CHEMBL576792 & 600885 & 6.0173 & 5.7509 & TRN & \\
\hline CHEMBL596637 & 600885 & 7.5439 & 6.5216 & TRN & \\
\hline CHEMBL599097 & 600885 & 5.8327 & 6.1228 & TRN & \\
\hline CHEMBL577620 & 600885 & 5.3925 & 5.5499 & TRN & \\
\hline CHEMBL585112 & 600885 & 6.2351 & 5.9548 & TRN & \\
\hline
\end{tabular}




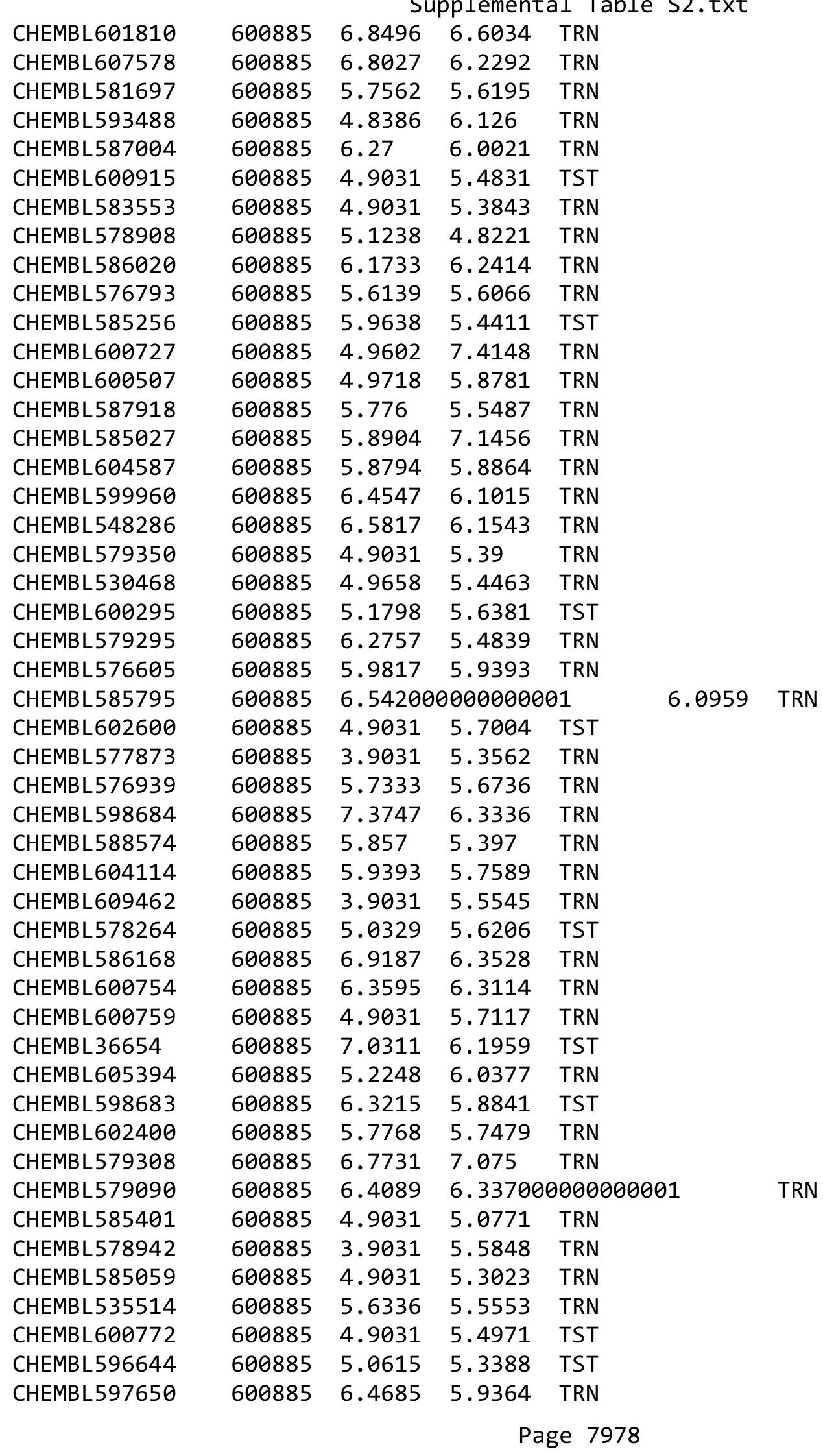




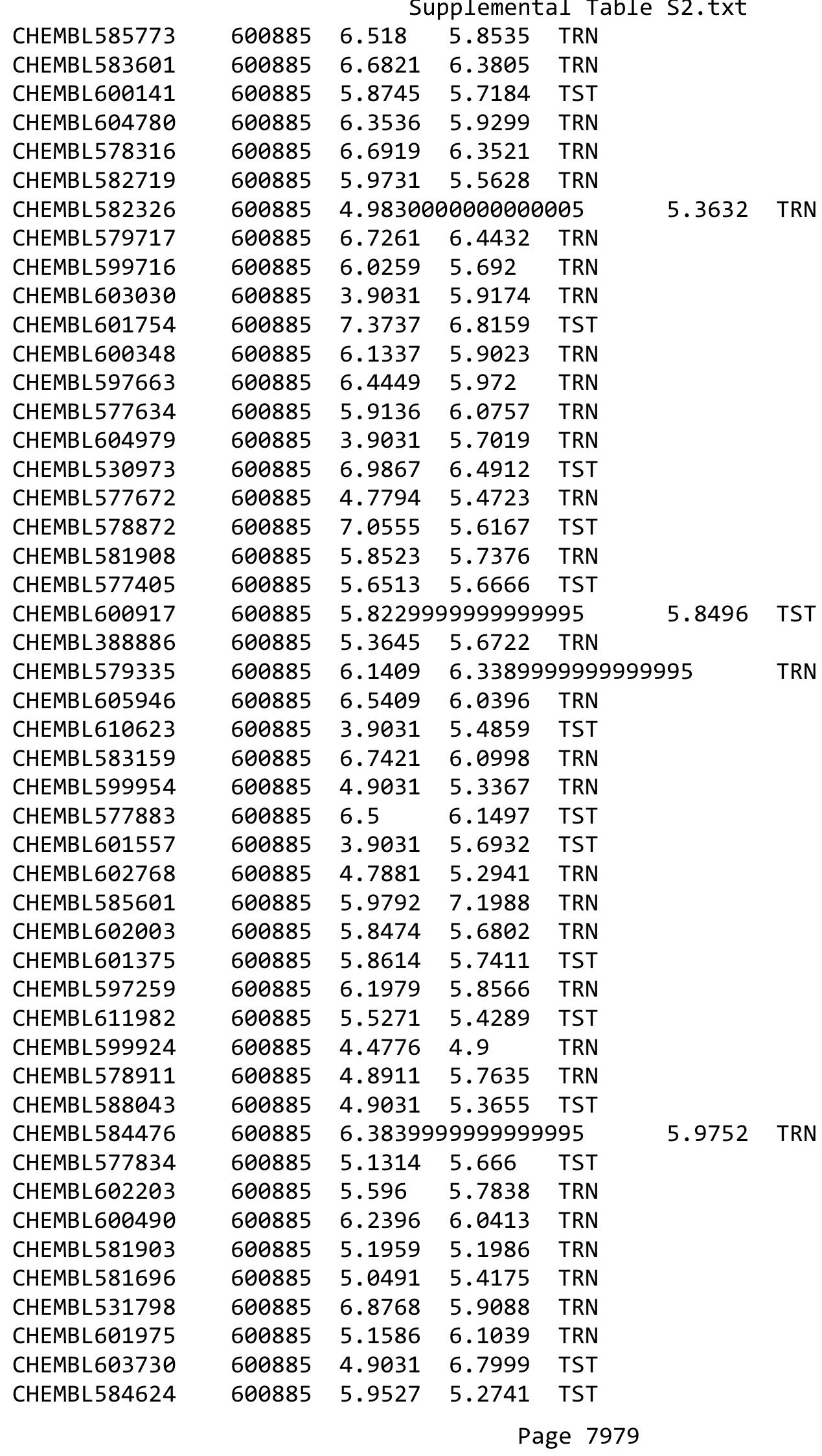




\begin{tabular}{|c|c|c|c|c|c|c|}
\hline \multicolumn{7}{|c|}{ supplemental I } \\
\hline CHEMBL577444 & 600885 & 6.466 & 6.3022 & TRN & & \\
\hline CHEMBL599094 & 600885 & 5.1707 & 5.8517 & TRN & & \\
\hline CHEMBL581030 & 600885 & 7.0391 & 6.0357 & TRN & & \\
\hline CHEMBL583168 & 600885 & 5.8969 & 6.0873 & TRN & & \\
\hline CHEMBL601327 & 600885 & 6.066 & 6.2437 & TST & & \\
\hline CHEMBL602013 & 600885 & 5.4989 & 5.7016 & TRN & & \\
\hline CHEMBL600948 & 600885 & 6.0731 & 5.6377 & TRN & & \\
\hline CHEMBL486232 & 600885 & 6.67700 & 00000000 & 205 & 6.3702 & TST \\
\hline CHEMBL528734 & 600885 & 5.1124 & 5.5704 & TRN & & \\
\hline CHEMBL548097 & 600885 & 6.4935 & 6.3485 & TRN & & \\
\hline CHEMBL530475 & 600885 & 5.6794 & 5.6085 & TRN & & \\
\hline CHEMBL597448 & 600885 & 6.1487 & 5.0313 & TRN & & \\
\hline CHEMBL602816 & 600885 & 4.9427 & 5.1371 & TRN & & \\
\hline CHEMBL601814 & 600885 & 6.5339 & 6.0853 & TRN & & \\
\hline CHEMBL582697 & 600885 & 5.856 & 5.6821 & TRN & & \\
\hline CHEMBL280196 & 600885 & 4.0123 & 5.7683 & TRN & & \\
\hline CHEMBL602201 & 600885 & 5.7286 & 5.2549 & TRN & & \\
\hline CHEMBL582272 & 600885 & 6.0297 & 5.6534 & TRN & & \\
\hline CHEMBL597873 & 600885 & 6.2168 & 5.6134 & TRN & & \\
\hline CHEMBL578743 & 600885 & 6.3125 & 5.7945 & TRN & & \\
\hline CHEMBL596836 & 600885 & 6.9303 & 6.2674 & TRN & & \\
\hline CHEMBL602571 & 600885 & 5.4535 & 4.8664 & TRN & & \\
\hline CHEMBL585426 & 600885 & 5.0022 & 5.4453 & TST & & \\
\hline CHEMBL600155 & 600885 & 4.9031 & 5.8237 & TRN & & \\
\hline CHEMBL580640 & 600885 & 6.0921 & 5.2287 & TRN & & \\
\hline CHEMBL580131 & 600885 & 7.699 & 6.2897 & TRN & & \\
\hline CHEMBL607687 & 600885 & 6.5049 & 5.7975 & TST & & \\
\hline CHEMBL583558 & 600885 & 6.0 & 5.8216 & TRN & & \\
\hline CHEMBL603006 & 600885 & 6.848 & 7.1533 & TRN & & \\
\hline CHEMBL598676 & 600885 & 5.9674 & 5.8065 & TRN & & \\
\hline CHEMBL587421 & 600885 & 6.2306 & 5.7389 & TRN & & \\
\hline CHEMBL568092 & 600885 & 6.4935 & 6.2827 & TST & & \\
\hline CHEMBL608433 & 600885 & 6.9158 & 6.0842 & TRN & & \\
\hline CHEMBL604739 & 600885 & 5.8794 & 5.4771 & TRN & & \\
\hline CHEMBL584454 & 600885 & 6.0074 & 6.1226 & TRN & & \\
\hline CHEMBL582288 & 600885 & 4.9485 & 5.5132 & TST & & \\
\hline CHEMBL585607 & 600885 & 5.0159 & 5.6236 & TRN & & \\
\hline CHEMBL602190 & 600885 & 6.0 & 5.9112 & TST & & \\
\hline CHEMBL579118 & 600885 & 6.9658 & 7.1919 & TRN & & \\
\hline CHEMBL598488 & 600885 & 3.9031 & 5.903 & TRN & & \\
\hline CHEMBL578752 & 600885 & 6.9416 & 6.348 & TRN & & \\
\hline CHEMBL602615 & 600885 & 6.8526 & 6.2044 & TRN & & \\
\hline CHEMBL585804 & 600885 & 5.7113 & 5.7421 & TRN & & \\
\hline CHEMBL581727 & 600885 & 5.8533 & 5.4479 & TRN & & \\
\hline CHEMBL535474 & 600885 & 5.7804 & 5.7033 & TRN & & \\
\hline CHEMBL579144 & 600885 & 5.5567 & 5.6103 & TST & & \\
\hline CHEMBL602776 & 600885 & 5.9014 & 5.7691 & TRN & & \\
\hline CHEMBL597059 & 600885 & 7.0721 & 6.1609 & TST & & \\
\hline
\end{tabular}




\begin{tabular}{|c|c|c|c|c|c|}
\hline & & \multicolumn{4}{|c|}{ Supplemental Table s2.txt } \\
\hline CHEMBL598895 & 600885 & 3.9031 & 5.8188 & TRN & \\
\hline CHEMBL603686 & 600885 & 6.0 & 5.6928 & TRN & \\
\hline CHEMBL598064 & 600885 & 6.6165 & 5.7841 & TST & \\
\hline CHEMBL582651 & 600885 & 4.9031 & 5.3079 & TST & \\
\hline CHEMBL600287 & 600885 & 6.7557 & 6.0035 & TRN & \\
\hline CHEMBL578311 & 600885 & 4.9031 & 5.5505 & TRN & \\
\hline CHEMBL583155 & 600885 & 4.9031 & 5.13899 & 9999999999 & TRN \\
\hline CHEMBL577868 & 600885 & 5.2358 & 5.4323 & TRN & \\
\hline CHEMBL586021 & 600885 & 6.4486 & 5.9618 & TST & \\
\hline CHEMBL577882 & 600885 & 6.0 & 5.8194 & TRN & \\
\hline CHEMBL584420 & 600885 & 4.9031 & 5.2562 & TRN & \\
\hline CHEMBL602625 & 600885 & 4.9031 & 5.3181 & TRN & \\
\hline CHEMBL525661 & 600885 & 4.9031 & 5.41 & TRN & \\
\hline CHEMBL599305 & 600885 & 6.091 & 5.6439 & TRN & \\
\hline CHEMBL527416 & 600885 & 5.9905 & 6.801 & TRN & \\
\hline CHEMBL602024 & 600885 & 6.9094 & 6.1889 & TST & \\
\hline CHEMBL609036 & 600885 & 6.2034 & 6.0082 & TRN & \\
\hline CHEMBL533302 & 600885 & 6.6552 & 5.8015 & TST & \\
\hline CHEMBL578473 & 600885 & 6.3344 & 6.0702 & TRN & \\
\hline CHEMBL584041 & 600885 & 3.9031 & 5.7286 & TRN & \\
\hline CHEMBL600294 & 600885 & 5.0191 & 5.4974 & TST & \\
\hline CHEMBL610216 & 600885 & 4.7755 & 6.2524 & TRN & \\
\hline CHEMBL584223 & 600885 & 6.4001 & 5.9218 & TRN & \\
\hline CHEMBL601391 & 600885 & 6.3429 & 5.8742 & TRN & \\
\hline CHEMBL529205 & 600885 & 6.0191 & 5.9583 & TRN & \\
\hline CHEMBL582655 & 600885 & 5.0325 & 5.2871 & TRN & \\
\hline CHEMBL578749 & 600885 & 5.7711 & 5.76 & TRN & \\
\hline CHEMBL600949 & 600885 & 5.9219 & 5.1151 & TRN & \\
\hline CHEMBL585600 & 600885 & 5.9855 & 7.2961 & TRN & \\
\hline CHEMBL581896 & 600885 & 6.4271 & 5.6698 & TRN & \\
\hline CHEMBL527494 & 600885 & 6.0915 & 5.7279 & TRN & \\
\hline CHEMBL585982 & 600885 & 6.5372 & 6.2449 & TRN & \\
\hline CHEMBL1744494 & 600885 & 4.9031 & 5.184 & TST & \\
\hline CHEMBL578506 & 600885 & 6.1331 & 5.9979 & TRN & \\
\hline CHEMBL585791 & 600885 & 5.4306 & 5.2294 & TRN & \\
\hline CHEMBL600340 & 600885 & 7.3536 & 6.5512 & TRN & \\
\hline CHEMBL599958 & 600885 & 4.9031 & 5.2499 & TRN & \\
\hline CHEMBL584657 & 600885 & 4.9255 & 5.6255 & TRN & \\
\hline CHEMBL578490 & 600885 & 5.8116 & 5.8724 & TRN & \\
\hline CHEMBL582319 & 600885 & 4.9431 & 5.2309 & TRN & \\
\hline CHEMBL580837 & 600885 & 5.1397 & 5.0652 & TRN & \\
\hline CHEMBL600923 & 600885 & 5.7945 & 5.7137 & TRN & \\
\hline CHEMBL578681 & 600885 & 6.5421 & 5.8551 & TRN & \\
\hline CHEMBL601373 & 600885 & 4.9031 & 5.7621 & TRN & \\
\hline CHEMBL531191 & 600885 & 5.3768 & 5.545 & TRN & \\
\hline CHEMBL601744 & 600885 & 6.3116 & 6.042006 & 0000000001 & TST \\
\hline CHEMBL580155 & 600885 & 5.0039 & 5.6054 & TRN & \\
\hline CHEMBL598065 & 600885 & 5.9363 & 5.9068 & TRN & \\
\hline
\end{tabular}




\begin{tabular}{|c|c|c|c|c|c|c|}
\hline & & & $=11$ & & & \\
\hline CHEMBL576810 & 600885 & 7.4584 & 6.477 & TST & & \\
\hline CHEMBL586571 & 600885 & 3.9031 & 5.36100 & 0000000001 & & TRN \\
\hline CHEMBL582466 & 600885 & 6.2226 & 6.17899 & 9999999999 & & TRN \\
\hline CHEMBL576991 & 600885 & 5.8162 & 5.6006 & TRN & & \\
\hline CHEMBL587159 & 600885 & 6.4056 & 5.2065 & TRN & & \\
\hline CHEMBL585749 & 600885 & 6.3788 & 6.4453 & TRN & & \\
\hline CHEMBL585807 & 600885 & 5.7899 & 5.6433 & TST & & \\
\hline CHEMBL596837 & 600885 & 5.1555 & 5.3219 & TRN & & \\
\hline CHEMBL587788 & 600885 & 5.0301 & 5.8368 & TRN & & \\
\hline CHEMBL583166 & 600885 & 6.54200 & 30000000 & 01 & 6.2649 & TRN \\
\hline CHEMBL577201 & 600885 & 6.5859 & 7.3881 & TRN & & \\
\hline CHEMBL528724 & 600885 & 5.5746 & 5.0239 & TRN & & \\
\hline CHEMBL 588602 & 600885 & 6.5544 & 7.0242 & TRN & & \\
\hline CHEMBL577637 & 600885 & 5.2161 & 5.3625 & TRN & & \\
\hline CHEMBL589018 & 600885 & 7.4473 & 6.2506 & TST & & \\
\hline CHEMBL528368 & 600885 & 5.9076 & 5.9138 & TRN & & \\
\hline CHEMBL578748 & 600885 & 6.5287 & 6.0151 & TRN & & \\
\hline CHEMBL578884 & 600885 & 8.0009 & 7.1078 & TRN & & \\
\hline CHEMBL577224 & 600885 & 5.9772 & 5.7236 & TST & & \\
\hline CHEMBL578927 & 600885 & 4.9031 & 5.3371 & TRN & & \\
\hline CHEMBL533670 & 600885 & 5.5638 & 5.6903 & TRN & & \\
\hline CHEMBL582090 & 600885 & 6.08200 & 00000000 & & 5.9355 & TRN \\
\hline CHEMBL602395 & 600885 & 6.0915 & 5.5522 & TRN & & \\
\hline CHEMBL587436 & 600885 & 3.9031 & 5.3669 & TST & & \\
\hline CHEMBL601533 & 600885 & 5.7913 & 5.1065 & TRN & & \\
\hline CHEMBL587819 & 600885 & 3.9031 & 5.2834 & TRN & & \\
\hline CHEMBL591861 & 600885 & 8.2069 & 7.0447 & TRN & & \\
\hline CHEMBL 3143972 & 600885 & 6.0106 & 6.0744 & TST & & \\
\hline CHEMBL582277 & 600885 & 6.5233 & 6.4445 & TRN & & \\
\hline CHEMBL 374744 & 600885 & 6.1068 & 5.77 & TRN & & \\
\hline CHEMBL599306 & 600885 & 6.1681 & 5.8343 & TRN & & \\
\hline CHEMBL586602 & 600885 & 6.8807 & 6.2766 & TRN & & \\
\hline CHEMBL585820 & 600885 & 5.636 & 6.0251 & TRN & & \\
\hline CHEMBL345083 & 600885 & 7.9215 & 6.8258 & TST & & \\
\hline CHEMBL603003 & 600885 & 5.3429 & 5.5086 & TST & & \\
\hline CHEMBL588461 & 600885 & 6.2581 & 5.8434 & TRN & & \\
\hline CHEMBL585811 & 600885 & 6.3316 & 6.2783 & TST & & \\
\hline CHEMBL607974 & 600885 & 5.6156 & 5.3106 & TRN & & \\
\hline CHEMBL579767 & 600885 & 5.0691 & 5.1498 & TST & & \\
\hline CHEMBL611212 & 600885 & 6.3575 & 5.92899 & 9999999999 & & TRN \\
\hline CHEMBL604156 & 600885 & 6.3188 & 5.3876 & TRN & & \\
\hline CHEMBL582056 & 600885 & 3.9031 & 5.035 & TRN & & \\
\hline CHEMBL585465 & 600885 & 3.9031 & 5.7745 & TST & & \\
\hline CHEMBL534578 & 600885 & 5.7058 & 5.4167 & TRN & & \\
\hline CHEMBL579287 & 600885 & 4.3063 & 5.4591 & TRN & & \\
\hline CHEMBL530796 & 600885 & 3.9031 & 4.7856 & TRN & & \\
\hline CHEMBL578074 & 600885 & 6.0 & 5.8195 & TRN & & \\
\hline CHEMBL1744493 & 600885 & 4.9481 & 5.2117 & TRN & & \\
\hline
\end{tabular}




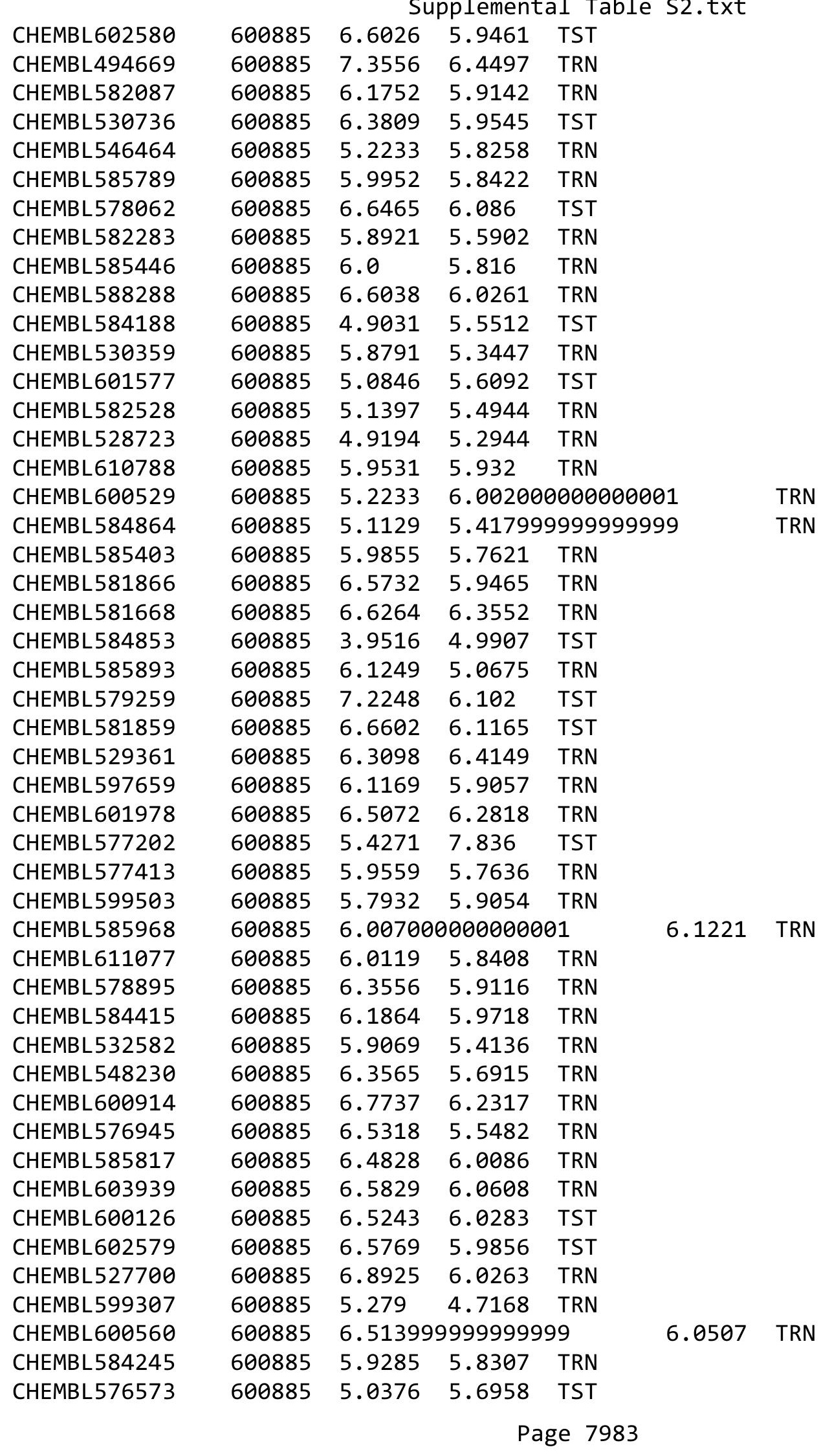




\begin{tabular}{|c|c|c|c|c|c|c|}
\hline \multicolumn{7}{|c|}{ Supplementa1 T } \\
\hline CHEMBL578636 & 600885 & 5.4868 & 5.7928 & TRN & & \\
\hline CHEMBL600511 & 600885 & 5.0867 & 5.871 & TRN & & \\
\hline CHEMBL587636 & 600885 & 7.0615 & 7.2915 & TRN & & \\
\hline CHEMBL587519 & 600885 & 3.9666 & 5.5019 & TRN & & \\
\hline CHEMBL588796 & 600885 & 7.104 & 6.8471 & TRN & & \\
\hline CHEMBL578746 & 600885 & 6.0278 & 5.8967 & TRN & & \\
\hline CHEMBL581207 & 600885 & 6.2916 & 5.8131 & TRN & & \\
\hline CHEMBL313938 & 600885 & 4.9374 & 5.6923 & TST & & \\
\hline CHEMBL589010 & 600885 & 4.9961 & 5.6025 & TRN & & \\
\hline CHEMBL600945 & 600885 & 6.4976 & 6.126 & TST & & \\
\hline CHEMBL600518 & 600885 & 5.4168 & 5.7206 & TRN & & \\
\hline CHEMBL599501 & 600885 & 5.1707 & 4.9961 & TRN & & \\
\hline CHEMBL586830 & 600885 & 6.0 & 5.8741 & TRN & & \\
\hline CHEMBL586363 & 600885 & 6.1931 & 6.1501 & TRN & & \\
\hline CHEMBL579946 & 600885 & 6.67299 & 99999999 & & 5.9568 & TRN \\
\hline CHEMBL585234 & 600885 & 6.24799 & 99999999 & & 5.9508 & TRN \\
\hline CHEMBL578471 & 600885 & 5.1278 & 5.5136 & TRN & & \\
\hline CHEMBL602636 & 600885 & 6.0804 & 6.7606 & TRN & & \\
\hline CHEMBL601958 & 600885 & 3.9144 & 5.9674 & TST & & \\
\hline CHEMBL598484 & 600885 & 5.539 & 5.6786 & TRN & & \\
\hline CHEMBL599890 & 600885 & 5.7627 & 5.7768 & TRN & & \\
\hline CHEMBL578242 & 600885 & 4.9031 & 5.3991 & TRN & & \\
\hline CHEMBL597058 & 600885 & 5.9846 & 5.8018 & TRN & & \\
\hline CHEMBL527981 & 600885 & 5.6507 & 5.7586 & TRN & & \\
\hline CHEMBL577667 & 600885 & 6.9378 & 7.2984 & TRN & & \\
\hline CHEMBL578513 & 600885 & 3.9755 & 5.0815 & TRN & & \\
\hline CHEMBL584419 & 600885 & 4.9031 & 5.3649 & TRN & & \\
\hline CHEMBL601785 & 600885 & 8.1838 & 6.806 & TST & & \\
\hline CHEMBL529143 & 600885 & 7.1096 & 6.2201 & TRN & & \\
\hline CHEMBL578754 & 600885 & 6.1379 & 7.4292 & TRN & & \\
\hline CHEMBL601325 & 600885 & 6.6761 & 6.1375 & TST & & \\
\hline CHEMBL602004 & 600885 & 5.5173 & 5.7955 & TRN & & \\
\hline CHEMBL579851 & 600885 & 6.1765 & 6.1221 & TST & & \\
\hline CHEMBL601588 & 600885 & 6.1918 & 5.9855 & TST & & \\
\hline CHEMBL578115 & 600885 & 4.9031 & 5.3486 & TRN & & \\
\hline CHEMBL600768 & 600885 & 6.6931 & 6.1211 & TRN & & \\
\hline CHEMBL586075 & 600885 & 4.9031 & 5.8216 & TST & & \\
\hline CHEMBL584225 & 600885 & 5.3655 & 6.2051 & TST & & \\
\hline CHEMBL599303 & 600885 & 5.8684 & 5.638 & TRN & & \\
\hline CHEMBL585076 & 600885 & 4.9031 & 5.1392 & TRN & & \\
\hline CHEMBL106525 & 600885 & 7.2464 & 6.4489 & TRN & & \\
\hline CHEMBL597036 & 600885 & 5.6182 & 5.8159 & TRN & & \\
\hline CHEMBL580156 & 600885 & 6.38399 & 99999999 & 995 & 5.9162 & TST \\
\hline CHEMBL601560 & 600885 & 6.1367 & 6.2458 & TRN & & \\
\hline CHEMBL585583 & 600885 & 6.0 & 5.5424 & TRN & & \\
\hline CHEMBL585248 & 600885 & 4.05699 & 99999999 & 995 & 5.0257 & TRN \\
\hline CHEMBL601370 & 600885 & 6.4535 & 5.933 & TRN & & \\
\hline CHEMBL582714 & 600885 & 4.0343 & 5.6101 & TST & & \\
\hline
\end{tabular}




\begin{tabular}{|c|c|c|c|c|c|c|}
\hline & & \multicolumn{5}{|c|}{ Supplemental Table s2.txt } \\
\hline CHEMBL602415 & 600885 & 5.9133 & 5.7421 & TRN & & \\
\hline CHEMBL530636 & 600885 & 5.3458 & 4.9825 & TRN & & \\
\hline CHEMBL596630 & 600885 & 6.1537 & 5.7679 & TRN & & \\
\hline CHEMBL598902 & 600885 & 6.5959 & 6.3386 & TRN & & \\
\hline CHEMBL600324 & 600885 & 5.8327 & 5.2993 & TRN & & \\
\hline CHEMBL581225 & 600885 & \multicolumn{3}{|c|}{6.4510000000000005} & 6.3014 & TST \\
\hline CHEMBL597444 & 600885 & 6.0195 & 5.9584 & TRN & & \\
\hline CHEMBL546828 & 600885 & 6.1785 & 5.6576 & TRN & & \\
\hline CHEMBL584851 & 600885 & 4.9031 & 5.315 & TST & & \\
\hline CHEMBL602593 & 600885 & 5.5342 & 5.3357 & TRN & & \\
\hline CHEMBL528024 & 600885 & 4.9618 & 5.1373 & TRN & & \\
\hline CHEMBL575039 & 600885 & 4.9031 & 5.5515 & TRN & & \\
\hline CHEMBL578934 & 600885 & 6.0926 & 6.2984 & TRN & & \\
\hline CHEMBL585430 & 600885 & 4.9031 & 5.1041 & TRN & & \\
\hline CHEMBL1978733 & 600885 & 7.4802 & 6.4837 & TRN & & \\
\hline CHEMBL533556 & 600885 & 7.3526 & 6.8192 & TRN & & \\
\hline CHEMBL604921 & 600885 & 6.1451 & 4.7532 & TRN & & \\
\hline CHEMBL579363 & 600885 & 4.9031 & 5.2068 & TRN & & \\
\hline CHEMBL601532 & 600885 & 6.1713 & 6.0619 & TRN & & \\
\hline CHEMBL602969 & 600885 & 7.3325 & 6.4022 & TRN & & \\
\hline CHEMBL600146 & 600885 & 5.7592 & 5.2808 & TST & & \\
\hline CHEMBL602179 & 600885 & 6.6633 & 5.7117 & TRN & & \\
\hline CHEMBL579644 & 600885 & 7.02 & 6.1967 & TRN & & \\
\hline CHEMBL602021 & 600885 & 4.9031 & 5.3331 & TRN & & \\
\hline CHEMBL582717 & 600885 & 6.5648 & 5.94600 & 0000000001 & & TRN \\
\hline CHEMBL585060 & 600885 & 6.0742 & 5.9451 & TRN & & \\
\hline CHEMBL599084 & 600885 & 6.9523 & 6.112 & TRN & & \\
\hline CHEMBL576797 & 600885 & 4.7951 & 5.7154 & TRN & & \\
\hline CHEMBL579940 & 600885 & 7.0123 & 6.4211 & TRN & & \\
\hline CHEMBL584844 & 600885 & 6.4112 & 5.9823 & TRN & & \\
\hline CHEMBL152117 & 600885 & 4.777 & 6.9973 & TRN & & \\
\hline CHEMBL609607 & 600885 & 3.9031 & 5.7554 & TST & & \\
\hline CHEMBL601358 & 600885 & 5.6582 & 5.6338 & TRN & & \\
\hline CHEMBL583366 & 600885 & 6.2291 & 5.9154 & TRN & & \\
\hline CHEMBL588954 & 600885 & 5.8074 & 5.8515 & TRN & & \\
\hline CHEMBL585462 & 600885 & 6.0237 & 5.8691 & TRN & & \\
\hline CHEMBL578909 & 600885 & 6.3925 & 6.2312 & TRN & & \\
\hline CHEMBL602586 & 600885 & 6.7575 & 5.9616 & TST & & \\
\hline CHEMBL587791 & 600885 & 6.1979 & 5.5852 & TRN & & \\
\hline CHEMBL585219 & 600885 & 6.6313 & 6.8302 & TRN & & \\
\hline CHEMBL602205 & 600885 & 3.9031 & 5.5365 & TRN & & \\
\hline CHEMBL579158 & 600885 & 6.2749 & 6.0315 & TRN & & \\
\hline CHEMBL581623 & 600885 & 6.2757 & 5.9178 & TRN & & \\
\hline CHEMBL529675 & 600885 & 6.0 & 5.8361 & TRN & & \\
\hline CHEMBL586946 & 600885 & 5.1035 & 7.0138 & TST & & \\
\hline CHEMBL600100 & 600885 & 6.0 & 5.7703 & TRN & & \\
\hline CHEMBL584466 & 600885 & 6.2441 & 6.5539 & TRN & & \\
\hline CHEMBL600125 & 600885 & 5.61600 & 30000000 & 05 & 5.6626 & TRN \\
\hline
\end{tabular}




\begin{tabular}{|c|c|c|c|c|c|}
\hline \\
\hline CHEMBL587581 & 600885 & 7.0835 & 7.4297 & TRN & \\
\hline CHEMBL600735 & 600885 & 6.6142 & 6.2914 & TRN & \\
\hline CHEMBL584651 & 600885 & 6.3233 & 6.093 & TRN & \\
\hline CHEMBL526199 & 600885 & 6.3915 & 5.8313 & TRN & \\
\hline CHEMBL599955 & 600885 & 6.624 & 6.5038 & TRN & \\
\hline CHEMBL585999 & 600885 & 6.6356 & 5.7579 & TRN & \\
\hline CHEMBL582684 & 600885 & 3.9031 & 5.6762 & TST & \\
\hline CHEMBL601119 & 600885 & 5.2549 & 5.45299 & 9999999999 & TRN \\
\hline CHEMBL343286 & 600885 & 6.3487 & 6.37799 & 9999999999 & TST \\
\hline CHEMBL586785 & 600885 & 7.0565 & 6.2681 & TRN & \\
\hline CHEMBL580752 & 600885 & 6.5203 & 6.4885 & TRN & \\
\hline CHEMBL604157 & 600885 & 4.9031 & 5.3489 & TRN & \\
\hline CHEMBL582524 & 600885 & 4.9382 & 5.3331 & TRN & \\
\hline CHEMBL580702 & 600885 & 5.7291 & 5.6617 & TST & \\
\hline CHEMBL581684 & 600885 & 3.9674 & 5.6459 & TRN & \\
\hline CHEMBL585454 & 600885 & 4.9031 & 6.4246 & TRN & \\
\hline CHEMBL600332 & 600885 & 5.4034 & 5.3589 & TRN & \\
\hline CHEMBL601965 & 600885 & 7.0074 & 6.2902 & TRN & \\
\hline CHEMBL534589 & 600885 & 3.9031 & 5.4832 & TRN & \\
\hline CHEMBL605951 & 600885 & 5.9404 & 6.0533 & TST & \\
\hline CHEMBL601147 & 600885 & 6.6321 & 6.7637 & TRN & \\
\hline CHEMBL584243 & 600885 & 5.8804 & 5.9138 & TRN & \\
\hline CHEMBL603009 & 600885 & 7.8636 & 7.1531 & TRN & \\
\hline CHEMBL585991 & 600885 & 4.9161 & 5.6182 & TST & \\
\hline CHEMBL529315 & 600885 & 7.0013 & 6.37 & TRN & \\
\hline CHEMBL601564 & 600885 & 6.7455 & 6.1746 & TRN & \\
\hline CHEMBL582732 & 600885 & 6.5256 & 5.9362 & TRN & \\
\hline CHEMBL605187 & 600885 & 4.7873 & 5.3671 & TRN & \\
\hline CHEMBL578535 & 600885 & 4.9031 & 5.6544 & TRN & \\
\hline CHEMBL601337 & 600885 & 6.1215 & 5.7483 & TRN & \\
\hline CHEMBL581242 & 600885 & 6.5743 & 6.1769 & TRN & \\
\hline CHEMBL599702 & 600885 & 6.0 & 5.7165 & TRN & \\
\hline CHEMBL578065 & 600885 & 6.301 & 6.643 & TRN & \\
\hline CHEMBL532079 & 600885 & 6.6012 & 6.6066 & TRN & \\
\hline CHEMBL602597 & 600885 & 3.9031 & 5.5185 & TRN & \\
\hline CHEMBL602763 & 600885 & 6.0137 & 6.0964 & TRN & \\
\hline CHEMBL578738 & 600885 & 8.0246 & 7.0693 & TRN & \\
\hline CHEMBL528006 & 600885 & 6.8114 & 6.2283 & TRN & \\
\hline CHEMBL602992 & 600885 & 4.2111 & 5.6304 & TRN & \\
\hline CHEMBL578257 & 600885 & 6.0 & 5.7828 & TRN & \\
\hline CHEMBL610790 & 600885 & 6.777 & 6.0143 & TST & \\
\hline CHEMBL578726 & 600885 & 6.3546 & 6.2104 & TRN & \\
\hline CHEMBL600751 & 600885 & 4.9031 & 6.0547 & TRN & \\
\hline CHEMBL601170 & 600885 & 6.3439 & 6.3416 & TRN & \\
\hline CHEMBL585638 & 600885 & 6.5521 & 6.2296 & TRN & \\
\hline CHEMBL596832 & 600885 & 5.4342 & 5.7197 & TRN & \\
\hline CHEMBL238800 & 600885 & 6.2403 & 5.3662 & TRN & \\
\hline CHEMBL603024 & 600885 & 6.7016 & 6.0944 & TRN & \\
\hline
\end{tabular}




\begin{tabular}{|c|c|c|c|c|c|}
\hline \multirow[b]{2}{*}{ CHEMBL582416 } & \multirow[b]{2}{*}{600885} & \\
\hline & & 5.0128 & 5.4034 & TST & \\
\hline CHEMBL580134 & 600885 & 5.9772 & 6.0469 & TRN & \\
\hline CHEMBL585845 & 600885 & 5.8248 & 6.2535 & TRN & \\
\hline CHEMBL581057 & 600885 & 4.9751 & 5.3121 & TST & \\
\hline CHEMBL578443 & 600885 & 6.3747 & 6.2259 & TRN & \\
\hline CHEMBL599708 & 600885 & 6.0 & 5.7045 & TRN & \\
\hline CHEMBL549210 & 600885 & 6.0 & 5.6844 & TRN & \\
\hline CHEMBL582456 & 600885 & 6.6494 & 6.4302 & TST & \\
\hline CHEMBL577431 & 600885 & 5.9465 & 5.402 & TRN & \\
\hline CHEMBL597050 & 600885 & 7.5921 & 6.4501 & TRN & \\
\hline CHEMBL600506 & 600885 & 3.9031 & 5.3911 & TRN & \\
\hline CHEMBL576725 & 600885 & 6.2741 & 5.6482 & TST & \\
\hline CHEMBL44789 & 600885 & \multicolumn{3}{|c|}{6.382000000000001} & TRN \\
\hline CHEMBL546162 & 600885 & 6.3161 & 6.4701 & TRN & \\
\hline CHEMBL527980 & 600885 & 6.2255 & 6.4162 & TRN & \\
\hline CHEMBL609319 & 600885 & 6.9485 & 6.2919 & TRN & \\
\hline CHEMBL579166 & 600885 & 5.9776 & 5.7687 & TST & \\
\hline CHEMBL531046 & 600885 & 6.4522 & \multicolumn{2}{|c|}{6.087000000000001} & TRN \\
\hline CHEMBL600946 & 600885 & 6.129 & 6.7899 & TRN & \\
\hline CHEMBL580838 & 600885 & 5.9073 & 5.3512 & TRN & \\
\hline CHEMBL585251 & 600885 & 3.9031 & 4.7761 & TST & \\
\hline CHEMBL604305 & 600885 & 5.8884 & 6.2459 & TRN & \\
\hline CHEMBL585070 & 600885 & 4.9031 & 6.0486 & TRN & \\
\hline CHEMBL610453 & 600885 & 5.5619 & 5.5795 & TRN & \\
\hline CHEMBL606024 & 600885 & 7.0904 & 6.6214 & TRN & \\
\hline CHEMBL600908 & 600885 & 5.7206 & 5.6274 & TRN & \\
\hline CHEMBL577199 & 600885 & 6.3575 & 5.9687 & TRN & \\
\hline CHEMBL600738 & 600885 & 5.5328 & 5.7494 & TRN & \\
\hline CHEMBL602630 & 600885 & 6.4202 & 6.1451 & TST & \\
\hline CHEMBL601788 & 600885 & 5.9055 & \multicolumn{2}{|c|}{6.0520000000000005} & TST \\
\hline CHEMBL579977 & 600885 & 3.9031 & 5.5425 & TRN & \\
\hline CHEMBL600706 & 600885 & 6.7181 & 6.2446 & TRN & \\
\hline CHEMBL583399 & 600885 & 3.9031 & 5.6817 & TST & \\
\hline CHEMBL581488 & 600885 & 3.9031 & 5.7473 & TRN & \\
\hline CHEMBL585078 & 600885 & 5.3197 & 5.2115 & TST & \\
\hline CHEMBL599935 & 600885 & 6.2048 & 5.6951 & TRN & \\
\hline CHEMBL582707 & 600885 & 6.6461 & 5.9587 & TRN & \\
\hline CHEMBL578954 & 600885 & 6.7765 & 6.6397 & TRN & \\
\hline CHEMBL585973 & 600885 & 4.9031 & 5.7079 & TRN & \\
\hline CHEMBL602814 & 600885 & 4.8114 & 5.5476 & TRN & \\
\hline CHEMBL598883 & 600885 & 7.2557 & 5.7883 & TRN & \\
\hline CHEMBL605754 & 600885 & 6.0 & 5.9267 & TRN & \\
\hline CHEMBL598474 & 600885 & 6.1244 & 5.8768 & TRN & \\
\hline CHEMBL579298 & 600885 & 6.0 & 5.7713 & TRN & \\
\hline CHEMBL581898 & 600885 & 4.9974 & 5.2197 & TRN & \\
\hline CHEMBL533063 & 600885 & 6.5795 & 6.2367 & TRN & \\
\hline CHEMBL578683 & 600885 & 5.9838 & 5.3758 & TST & \\
\hline \multirow[t]{2}{*}{ CHEMBL582312 } & 600885 & 6.4572 & 5.50299 & 9999999999 & TRN \\
\hline & & \multicolumn{3}{|c|}{ Page 7987} & \\
\hline
\end{tabular}




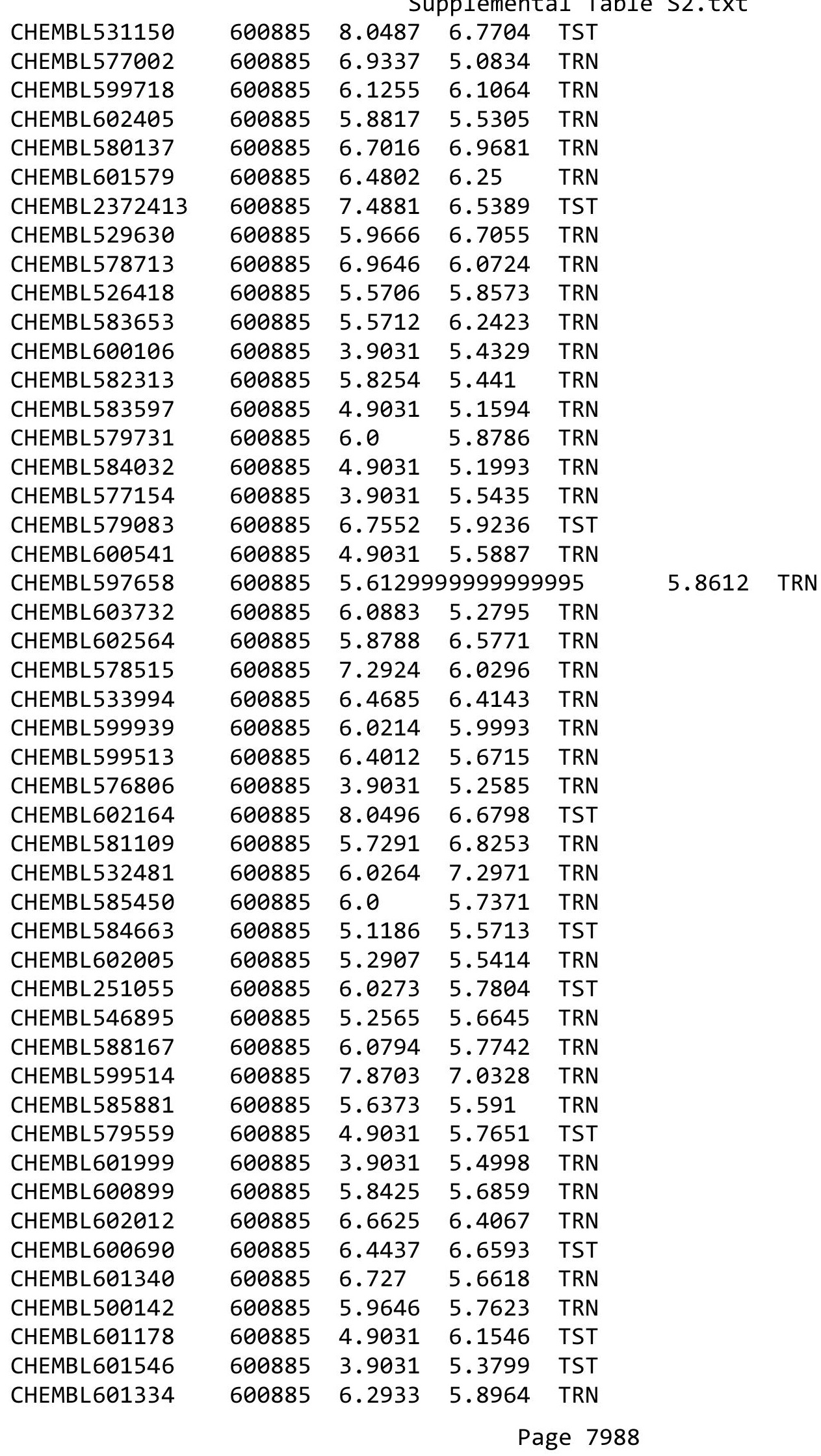




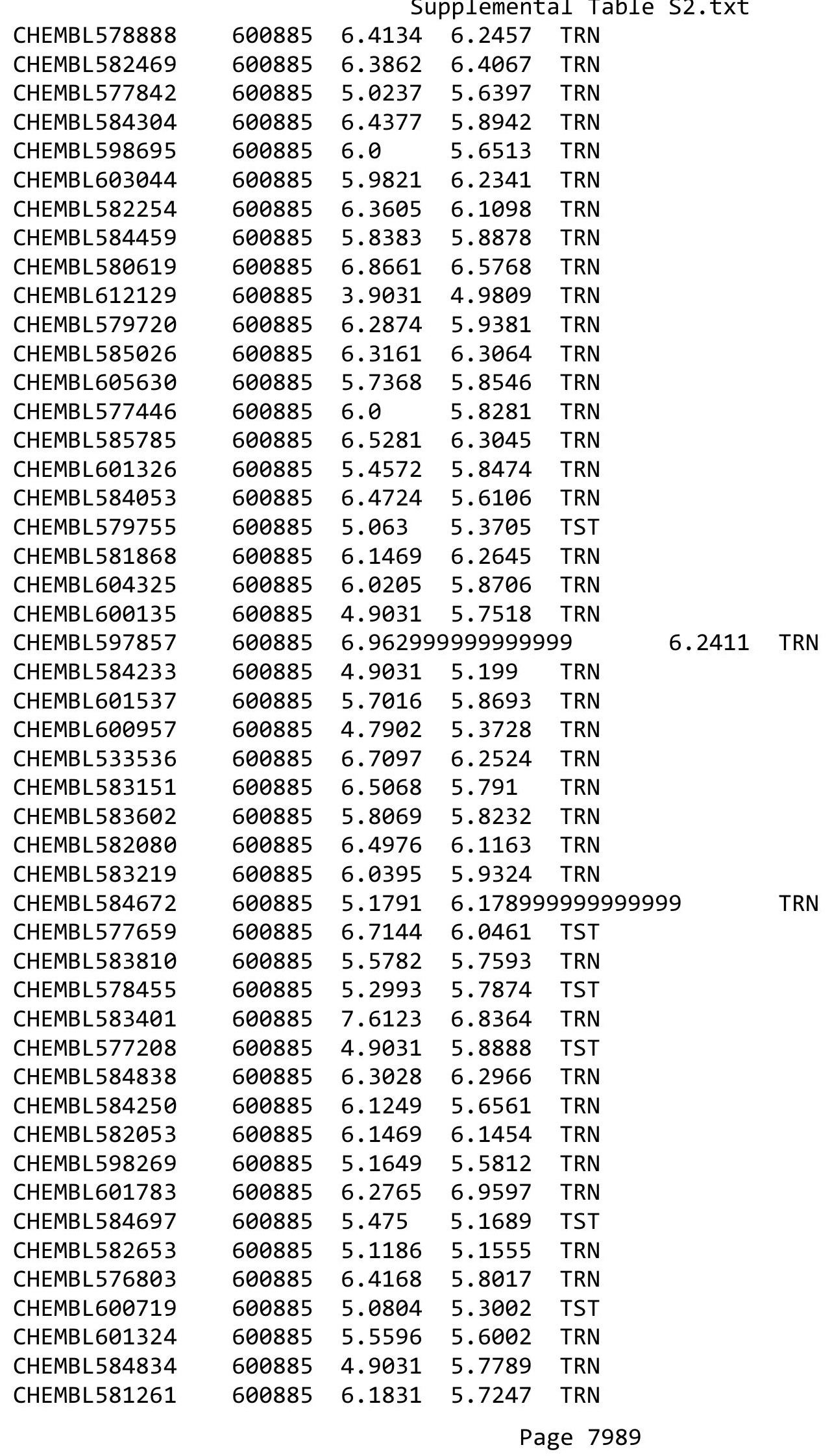




\begin{tabular}{|c|c|c|c|c|c|c|}
\hline & & \multicolumn{5}{|c|}{ Supplemental Table s2.txt } \\
\hline CHEMBL582712 & 600885 & 6.5869 & 6.0966 & TRN & & \\
\hline CHEMBL579101 & 600885 & 4.9031 & 5.7789 & TRN & & \\
\hline CHEMBL581873 & 600885 & 7.2076 & 6.1143 & TRN & & \\
\hline CHEMBL601781 & 600885 & 6.2967 & 6.1752 & TST & & \\
\hline CHEMBL602206 & 600885 & 5.90799 & 79999999 & 995 & 5.8629 & TRN \\
\hline CHEMBL601154 & 600885 & 6.0888 & 5.9427 & TRN & & \\
\hline CHEMBL599895 & 600885 & 6.0297 & 5.7325 & TRN & & \\
\hline CHEMBL600760 & 600885 & 4.7637 & 5.4872 & TRN & & \\
\hline CHEMBL585933 & 600885 & 4.9031 & 5.6333 & TRN & & \\
\hline CHEMBL597459 & 600885 & 5.05399 & 99999999 & 99 & 5.2986 & TRN \\
\hline CHEMBL602570 & 600885 & 6.0851 & 4.9401 & TRN & & \\
\hline CHEMBL597867 & 600885 & 6.4647 & 4.944 & TST & & \\
\hline CHEMBL585071 & 600885 & 6.0 & 5.7814 & TST & & \\
\hline CHEMBL585624 & 600885 & 6.1898 & 5.9331 & TST & & \\
\hline CHEMBL583364 & 600885 & 5.1152 & 5.1311 & TRN & & \\
\hline CHEMBL599288 & 600885 & 6.8077 & 6.3037 & TRN & & \\
\hline CHEMBL577631 & 600885 & 6.5458 & 5.9315 & TRN & & \\
\hline CHEMBL580160 & 600885 & 6.8477 & 6.1698 & TRN & & \\
\hline CHEMBL585847 & 600885 & 6.1385 & 6.7506 & TRN & & \\
\hline CHEMBL585805 & 600885 & 5.9097 & 5.9563 & TST & & \\
\hline CHEMBL602362 & 600885 & 4.9638 & 5.0688 & TRN & & \\
\hline CHEMBL593255 & 600885 & 4.7972 & 5.0093 & TRN & & \\
\hline CHEMBL585444 & 600885 & 5.8904 & 6.1894 & TST & & \\
\hline CHEMBL600149 & 600885 & 6.08200 & 300000006 & & 6.6036 & TRN \\
\hline CHEMBL578101 & 600885 & 3.9031 & 5.4354 & TRN & & \\
\hline CHEMBL530572 & 600885 & 6.1198 & 5.8037 & TST & & \\
\hline CHEMBL603891 & 600885 & 6.0173 & 6.0654 & TRN & & \\
\hline CHEMBL1615738 & 600885 & 5.5459 & 5.4719 & TRN & & \\
\hline CHEMBL578679 & 600885 & 6.1035 & 5.6085 & TRN & & \\
\hline CHEMBL579175 & 600885 & 6.3224 & 5.4093 & TRN & & \\
\hline CHEMBL601318 & 600885 & 6.7471 & 6.0812 & TRN & & \\
\hline CHEMBL582464 & 600885 & 6.3915 & 5.9914 & TRN & & \\
\hline CHEMBL529551 & 600885 & 5.8824 & 5.8492 & TST & & \\
\hline CHEMBL579151 & 600885 & 6.4698 & 5.9567 & TRN & & \\
\hline CHEMBL578933 & 600885 & 5.8935 & 5.5965 & TRN & & \\
\hline CHEMBL584414 & 600885 & 7.2277 & 6.4257 & TRN & & \\
\hline CHEMBL576544 & 600885 & 5.3686 & 5.3665 & TRN & & \\
\hline CHEMBL577219 & 600885 & 4.2941 & 5.3848 & TRN & & \\
\hline CHEMBL581247 & 600885 & 7.2041 & 6.7032 & TRN & & \\
\hline CHEMBL578951 & 600885 & 6.901 & 6.6541 & TRN & & \\
\hline CHEMBL584269 & 600885 & 6.71899 & 99999999 & 99 & 6.2893 & TRN \\
\hline CHEMBL579963 & 600885 & 5.5305 & 5.0052 & TRN & & \\
\hline CHEMBL601597 & 600885 & 6.0048 & 5.7596 & TST & & \\
\hline CHEMBL600121 & 600885 & 6.2984 & 6.0356 & TRN & & \\
\hline CHEMBL602435 & 600885 & 6.782 & 6.3569 & TRN & & \\
\hline CHEMBL611374 & 600885 & 6.2161 & 6.695 & TRN & & \\
\hline CHEMBL610251 & 600885 & 6.4389 & 5.8969 & TST & & \\
\hline CHEMBL2368644 & 600885 & 6.0 & 5.8826 & TRN & & \\
\hline
\end{tabular}


Supplemental Table S2.txt

\begin{tabular}{|c|c|c|c|c|}
\hline HEMBL606022 & 00885 & 031 & 5.8015 & TRN \\
\hline HEMBL576993 & 00885 & 4.9031 & 5.768 & \\
\hline HEMBL581050 & $\partial 0885$ & 0022 & 3197 & \\
\hline HEMBL 602169 & 00885 & 6.6778 & 3056 & \\
\hline HEMBL533327 & 00885 & 6.5613 & 9831 & \\
\hline HEMBL 578491 & 00885 & 6.0264 & 8232 & \\
\hline HEMBL 584449 & 00885 & .8758 & .1718 & \\
\hline HEMBL534190 & 00885 & 6.0 & .6647 & \\
\hline HEMBL599948 & 00885 & 7.5036 & .4142 & RN \\
\hline HEMBL582502 & 00885 & 5.7275 & 5.2517 & $\mathrm{~N}$ \\
\hline HEMBL585065 & 500885 & 4.0 & 619 & \\
\hline HEMBL602581 & 00885 & 6.3439 & 5.8449 & \\
\hline HEMBL 584025 & 00885 & .9516 & .864 & RN \\
\hline HEMBL 600163 & 00885 & 6.4123 & 5.9265 & RN \\
\hline HEMBL578718 & 00885 & .516 & . 9348 & RN \\
\hline HEMBL 580166 & 00885 & 6.9923 & 6.4695 & RN \\
\hline HEMBL584009 & 00885 & .817 & 5.3641 & \\
\hline HEMBL579155 & 00885 & .3958 & 7.2124 & RN \\
\hline HEMBL584666 & 00885 & 5.9842 & 5.6392 & RN \\
\hline HEMBL578263 & 00885 & 31 & 5.9444 & RN \\
\hline HEMBL582663 & 00885 & 19 & 5.6363 & R \\
\hline HEMBL 577015 & 00885 & 487 & 6.5916 & RN \\
\hline HEMBL578287 & $\partial 0885$ & $\partial 1$ & 6.2171 & RN \\
\hline HEMBL1500740 & 00885 & 26 & 5.7388 & RN \\
\hline HEMBL 547476 & $\partial 0885$ & & 6.3894 & RN \\
\hline HEMBL 578678 & 20885 & 8 & 1816 & ST \\
\hline HEMBL586016 & 00885 & 75 & 1306 & RN \\
\hline HEMBL601157 & 35 & 56 & 4716 & RN \\
\hline HEMBL600568 & 35 & & 6.4658 & RN \\
\hline HEMBL601357 & 85 & 55 & 5.9163 & $\mathrm{RN}$ \\
\hline HEMBL577148 & 00885 & 29 & 5.0369 & RN \\
\hline HEMBL600105 & 00885 & 31 & 5.3174 & ST \\
\hline CHEMBL530173 & 35 & 5 . & 5.815 & TRN \\
\hline LHEMBL578539 & 00885 & & 5.24 & SI \\
\hline HEMBL584822 & 00885 & 6.5745 & 6.2233 & TST \\
\hline HEMBL578936 & 00885 & 83 & 5.9246 & IST \\
\hline HEMBL585637 & 35 & & 273 & RN \\
\hline HEMBL586226 & 35 & 3.9031 & 5.3408 & TST \\
\hline CHEMBL139814 & 00885 & 6.8292 & 6.0936 & TRN \\
\hline HEMBL577589 & 500885 & 3.9031 & 5.5557 & 「RN \\
\hline CHEMBL599087 & 600885 & 6.0348 & 5.3345 & $\mathrm{RN}$ \\
\hline CHEMBL599896 & 600885 & 6.6891 & 6.7574 & RN \\
\hline CHEMBL578495 & 600885 & 6.433 & 5.5602 & TRN \\
\hline CHEMBL579146 & 600885 & 6.1945 & 6.2274 & TRN \\
\hline CHEMBL578715 & 600885 & 47 & 5.6739 & RIN \\
\hline CHEMBL578674 & 600885 & 5.0462 & 5.6665 & KIV \\
\hline CHEMBL600773 & 600885 & 6.575 & 6.1738 & RN \\
\hline CHEMBL577656 & 600885 & 6.9905 & 6.5072 & $\mathrm{R}$ \\
\hline
\end{tabular}

Page 7991 


\begin{tabular}{|c|c|c|c|c|c|c|}
\hline \\
\hline CHEMBL579345 & 600885 & 3.9031 & 5.4483 & TRN & & \\
\hline CHEMBL531135 & 600885 & 5.9662 & 4.7051 & TRN & & \\
\hline CHEMBL601343 & 600885 & 4.0026 & 5.4723 & TRN & & \\
\hline CHEMBL585790 & 600885 & 4.9031 & 5.465 & TST & & \\
\hline CHEMBL584878 & 600885 & 5.0894 & 5.2635 & TST & & \\
\hline CHEMBL610330 & 600885 & 5.3565 & 5.6166 & TRN & & \\
\hline CHEMBL599941 & 600885 & 5.399 & 5.5893 & TRN & & \\
\hline CHEMBL597056 & 600885 & 6.0794 & 6.0132 & TRN & & \\
\hline CHEMBL585656 & 600885 & 8.2269 & 6.8665 & TRN & & \\
\hline CHEMBL579924 & 600885 & 3.9031 & 5.4557 & TRN & & \\
\hline CHEMBL578097 & 600885 & 6.3851 & 6.1242 & TST & & \\
\hline CHEMBL582108 & 600885 & 4.9172 & 5.4066 & TST & & \\
\hline CHEMBL585635 & 600885 & 6.6629 & 6.2665 & TRN & & \\
\hline CHEMBL578308 & 600885 & 5.4318 & 5.4996 & TST & & \\
\hline CHEMBL525126 & 600885 & 6.9223 & 6.0546 & TRN & & \\
\hline CHEMBL599905 & 600885 & 6.6077 & 5.3924 & TST & & \\
\hline CHEMBL602411 & 600885 & 3.9031 & 5.6299 & TRN & & \\
\hline CHEMBL583225 & 600885 & 6.0487 & 5.6314 & TRN & & \\
\hline CHEMBL533105 & 600885 & 6.71399 & 99999999 & 995 & 6.4607 & TST \\
\hline CHEMBL581255 & 600885 & 5.4248 & 5.6596 & TRN & & \\
\hline CHEMBL601966 & 600885 & 4.9031 & 5.3376 & TRN & & \\
\hline CHEMBL581882 & 600885 & 6.04 & 5.8386 & TRN & & \\
\hline CHEMBL580157 & 600885 & 5.5193 & 5.5901 & TRN & & \\
\hline CHEMBL532857 & 600885 & 6.5071 & 6.3167 & TRN & & \\
\hline CHEMBL578057 & 600885 & 4.4498 & 5.2124 & TRN & & \\
\hline CHEMBL581196 & 600885 & 5.9722 & 5.8415 & TRN & & \\
\hline CHEMBL603307 & 600885 & 5.0232 & 6.0594 & TRN & & \\
\hline CHEMBL600144 & 600885 & 4.9031 & 5.8411 & TRN & & \\
\hline CHEMBL600724 & 600885 & 7.1637 & 6.3233 & TRN & & \\
\hline CHEMBL578730 & 600885 & 5.041 & 5.4087 & TRN & & \\
\hline CHEMBL586031 & 600885 & 7.5525 & 6.5999 & TRN & & \\
\hline CHEMBL585329 & 600885 & 6.0783 & 5.7446 & TRN & & \\
\hline CHEMBL601563 & 600885 & 6.0 & 5.7285 & TRN & & \\
\hline CHEMBL580609 & 600885 & 6.0035 & 6.0364 & TRN & & \\
\hline CHEMBL585978 & 600885 & 5.7857 & 5.6849 & TRN & & \\
\hline CHEMBL578306 & 600885 & 4.9031 & 5.5052 & TST & & \\
\hline CHEMBL588690 & 600885 & 4.9031 & 6.8349 & TRN & & \\
\hline CHEMBL581346 & 600885 & 6.4283 & 6.2625 & TRN & & \\
\hline CHEMBL531383 & 600885 & 6.2588 & 6.2281 & TRN & & \\
\hline CHEMBL577210 & 600885 & 7.129 & 6.8022 & TRN & & \\
\hline CHEMBL585087 & 600885 & 6.1113 & 5.3675 & TRN & & \\
\hline CHEMBL602187 & 600885 & 5.8465 & 5.3677 & TRN & & \\
\hline CHEMBL576323 & 600885 & 6.4134 & 6.1927 & TRN & & \\
\hline CHEMBL602635 & 600885 & 6.0 & 5.8025 & TRN & & \\
\hline CHEMBL581475 & 600885 & 6.0031 & 4.6712 & TRN & & \\
\hline CHEMBL611660 & 600885 & 3.9031 & 5.9292 & TRN & & \\
\hline CHEMBL586407 & 600885 & 4.9031 & 6.6486 & TRN & & \\
\hline CHEMBL585046 & 600885 & 5.6269 & 5.7415 & TRN & & \\
\hline
\end{tabular}




\begin{tabular}{|c|c|c|c|c|c|c|}
\hline & & \multicolumn{5}{|c|}{ Supplemental Table S2.txt } \\
\hline CHEMBL529241 & 600885 & 5.6934 & 5.2274 & TST & & \\
\hline CHEMBL605548 & 600885 & 6.2668 & 5.9415 & TRN & & \\
\hline CHEMBL599102 & 600885 & 6.2604 & 5.6927 & TRN & & \\
\hline CHEMBL600323 & 600885 & 3.9031 & 5.434 & TST & & \\
\hline CHEMBL587892 & 600885 & 6.2782 & 5.9377 & TRN & & \\
\hline CHEMBL602988 & 600885 & 6.0931 & 6.0419 & TRN & & \\
\hline CHEMBL600689 & 600885 & 6.5549 & 5.7982 & TRN & & \\
\hline CHEMBL587671 & 600885 & 6.1013 & 5.3912 & TRN & & \\
\hline CHEMBL585767 & 600885 & 5.3536 & 5.5776 & TRN & & \\
\hline CHEMBL533855 & 600885 & 5.8626 & 5.6725 & TRN & & \\
\hline CHEMBL582478 & 600885 & 5.9622 & 5.2152 & TRN & & \\
\hline CHEMBL579778 & 600885 & 4.9031 & 5.7486 & TRN & & \\
\hline CHEMBL599944 & 600885 & 4.9136 & 5.7644 & TRN & & \\
\hline CHEMBL529524 & 600885 & 5.1884 & 4.829 & TRN & & \\
\hline CHEMBL600330 & 600885 & 4.9031 & 5.449 & TRN & & \\
\hline CHEMBL582952 & 600885 & \multicolumn{3}{|c|}{6.922999999999999} & 6.1382 & TRN \\
\hline CHEMBL584436 & 600885 & 6.3872 & 5.9604 & TRN & & \\
\hline CHEMBL493863 & 600885 & 7.4976 & 6.2195 & TRN & & \\
\hline CHEMBL584493 & 600885 & 6.4168 & 6.025 & TRN & & \\
\hline CHEMBL477328 & 600885 & 6.513 & 5.6542 & TRN & & \\
\hline CHEMBL577622 & 600885 & 6.5284 & 5.8506 & TRN & & \\
\hline CHEMBL585217 & 600885 & 6.5959 & 6.1533 & TST & & \\
\hline CHEMBL598059 & 600885 & 3.9031 & 5.9009 & TST & & \\
\hline CHEMBL599099 & 600885 & 5.4559 & 5.7681 & TRN & & \\
\hline CHEMBL584020 & 600885 & 3.9918 & 4.7422 & TRN & & \\
\hline CHEMBL602979 & 600885 & \multicolumn{3}{|c|}{5.2620000000000005} & 6.2132 & TRN \\
\hline CHEMBL576777 & 600885 & 4.9031 & 5.6422 & TRN & & \\
\hline CHEMBL580701 & 600885 & 6.4776 & 6.581 & TRN & & \\
\hline CHEMBL598493 & 600885 & 5.7319 & 5.8125 & TRN & & \\
\hline CHEMBL582645 & 600885 & 6.7122 & 6.7724 & TRN & & \\
\hline CHEMBL602000 & 600885 & 5.7562 & 6.9476 & TRN & & \\
\hline CHEMBL602634 & 600885 & 3.9031 & 5.8643 & TRN & & \\
\hline CHEMBL585954 & 600885 & 5.0841 & 5.8875 & TRN & & \\
\hline CHEMBL604319 & 600885 & 6.1537 & 6.4117 & TST & & \\
\hline CHEMBL583753 & 600885 & 4.8533 & 5.4443 & TRN & & \\
\hline CHEMBL584618 & 600885 & 6.3546 & 5.7612 & TRN & & \\
\hline CHEMBL587536 & 600885 & 6.5324 & 6.1397 & TRN & & \\
\hline CHEMBL600333 & 600885 & 6.6187 & 6.277 & TRN & & \\
\hline CHEMBL585633 & 600885 & 5.9234 & 6.2368 & TRN & & \\
\hline CHEMBL528968 & 600885 & 6.8529 & 6.2288 & TRN & & \\
\hline CHEMBL527336 & 600885 & 6.8827 & 6.5903 & TRN & & \\
\hline CHEMBL577006 & 600885 & 5.1811 & 5.3899 & TRN & & \\
\hline CHEMBL585793 & 600885 & 6.6619 & 6.6062 & TRN & & \\
\hline CHEMBL1576338 & 600885 & 4.4789 & 4.8393 & TST & & \\
\hline CHEMBL600711 & 600885 & 3.9516 & 4.9768 & TST & & \\
\hline CHEMBL584622 & 600885 & 6.6633 & 5.8674 & TRN & & \\
\hline CHEMBL581595 & 600885 & 6.8677 & 6.2526 & TRN & & \\
\hline CHEMBL581853 & 600885 & 5.8044 & 5.3042 & TRN & & \\
\hline
\end{tabular}




\begin{tabular}{|c|c|c|c|c|c|c|}
\hline & & & & & & \\
\hline CHEMBL601341 & 600885 & 3.9031 & 5.5479 & TST & & \\
\hline CHEMBL601108 & 600885 & 6.0894 & 6.05 & TRN & & \\
\hline CHEMBL601336 & 600885 & 4.0123 & 5.3089 & TRN & & \\
\hline CHEMBL578315 & 600885 & 6.5474 & 6.3571 & TRN & & \\
\hline CHEMBL581675 & 600885 & 6.8422 & 5.6914 & TRN & & \\
\hline CHEMBL600361 & 600885 & 5.9867 & 6.1688 & TRN & & \\
\hline CHEMBL582713 & 600885 & 6.6657 & 6.0491 & TRN & & \\
\hline CHEMBL588802 & 600885 & 7.1791 & 6.9506 & TRN & & \\
\hline CHEMBL601808 & 600885 & 5.9751 & 6.4921 & TRN & & \\
\hline CHEMBL582182 & 600885 & 6.3585 & 6.8894 & TRN & & \\
\hline CHEMBL599502 & 600885 & 5.17200 & 000000006 & $\partial 1$ & 5.3794 & TRN \\
\hline CHEMBL585836 & 600885 & 7.1972 & 5.9149 & TRN & & \\
\hline CHEMBL578295 & 600885 & 5.7464 & 6.042006 & 0000000001 & & TST \\
\hline CHEMBL602219 & 600885 & 6.2076 & 5.8743 & TST & & \\
\hline CHEMBL582057 & 600885 & 6.0292 & 5.797006 & 0000000001 & & TRN \\
\hline CHEMBL579084 & 600885 & 6.3904 & 6.0552 & TRN & & \\
\hline CHEMBL546437 & 600885 & 6.5787 & 6.1816 & TRN & & \\
\hline CHEMBL601161 & 600885 & 6.0 & 5.899 & TRN & & \\
\hline CHEMBL600921 & 600885 & 5.2062 & 5.9533 & TRN & & \\
\hline CHEMBL585063 & 600885 & 6.1152 & 6.2228 & TRN & & \\
\hline CHEMBL582649 & 600885 & 6.1649 & 6.0714 & TRN & & \\
\hline CHEMBL601395 & 600885 & 4.8716 & 6.4671 & TRN & & \\
\hline CHEMBL585833 & 600885 & 6.104 & 6.0612 & TRN & & \\
\hline CHEMBL611659 & 600885 & 4.1624 & 4.7757 & TRN & & \\
\hline CHEMBL579323 & 600885 & 4.9439 & 5.5111 & TRN & & \\
\hline CHEMBL578533 & 600885 & 6.7192 & 6.5272 & TRN & & \\
\hline CHEMBL579302 & 600885 & 3.9031 & 5.5575 & TRN & & \\
\hline CHEMBL579161 & 600885 & 6.0783 & 6.0009 & TRN & & \\
\hline CHEMBL588099 & 600885 & 6.4609 & 6.5546 & TRN & & \\
\hline CHEMBL585959 & 600885 & 5.9658 & 5.2153 & TRN & & \\
\hline CHEMBL584017 & 600885 & 4.823 & 6.6324 & TRN & & \\
\hline CHEMBL579615 & 600885 & 6.6517 & 6.0574 & TRN & & \\
\hline CHEMBL597262 & 600885 & 7.7261 & 5.1951 & TRN & & \\
\hline CHEMBL585229 & 600885 & 6.0487 & 6.7741 & TRN & & \\
\hline CHEMBL401540 & 600885 & 6.5287 & 6.2036 & TST & & \\
\hline CHEMBL602417 & 600885 & 5.7975 & 5.0798 & TRN & & \\
\hline CHEMBL584249 & 600885 & 5.2967 & 6.0601 & TRN & & \\
\hline CHEMBL582473 & 600885 & 5.9337 & 5.7893 & TRN & & \\
\hline CHEMBL598697 & 600885 & 6.4134 & 5.9564 & TRN & & \\
\hline CHEMBL585425 & 600885 & 4.9031 & 5.7079 & TRN & & \\
\hline CHEMBL600961 & 600885 & 6.9465 & 5.99299 & 9999999999 & & TRN \\
\hline CHEMBL529773 & 600885 & 6.1543 & 6.0493 & TRN & & \\
\hline CHEMBL577645 & 600885 & 4.8365 & 5.3004 & TRN & & \\
\hline CHEMBL602821 & 600885 & 6.0867 & 5.6639 & TRN & & \\
\hline CHEMBL581459 & 600885 & 5.4353 & 5.4931 & TRN & & \\
\hline CHEMBL602972 & 600885 & 6.8687 & 6.8377 & TRN & & \\
\hline CHEMBL537724 & 600885 & 6.7373 & 6.1784 & TRN & & \\
\hline CHEMBL602156 & 600885 & 5.5096 & 4.8416 & TST & & \\
\hline
\end{tabular}




\begin{tabular}{|c|c|c|c|c|c|c|}
\hline \multicolumn{6}{|c|}{ Supplemental Table S2.txt } & \\
\hline CHEMBL534131 & 600885 & 5.9393 & 5.6926 & TRN & & \\
\hline CHEMBL579972 & 600885 & 6.04 & 5.5922 & TRN & & \\
\hline CHEMBL598262 & 600885 & 4.9031 & 6.4447 & TST & & \\
\hline CHEMBL534579 & 600885 & 5.8867 & 5.5446 & TST & & \\
\hline CHEMBL597858 & 600885 & 3.9031 & 5.5735 & TST & & \\
\hline CHEMBL584236 & 600885 & 6.4895 & 5.7513 & TRN & & \\
\hline CHEMBL604511 & 600885 & 6.1904 & 5.8023 & TST & & \\
\hline CHEMBL531808 & 600885 & 4.9618 & 7.6426 & TRN & & \\
\hline CHEMBL531730 & 600885 & 7.0177 & 5.9306 & TRN & & \\
\hline CHEMBL365324 & 600885 & 6.0 & 5.8913 & TRN & & \\
\hline CHEMBL579381 & 600885 & 6.4572 & 5.9721 & TST & & \\
\hline CHEMBL599906 & 600885 & 5.9658 & 5.8315 & TRN & & \\
\hline CHEMBL583584 & 600885 & 7.2396 & 6.0059 & TRN & & \\
\hline CHEMBL596845 & 600885 & 6.1785 & 6.3129 & TRN & & \\
\hline CHEMBL579970 & 600885 & 5.9751 & 5.7029 & TRN & & \\
\hline CHEMBL530217 & 600885 & 6.3706 & 6.0299 & TRN & & \\
\hline CHEMBL610911 & 600885 & 5.7637 & 5.6147 & TRN & & \\
\hline CHEMBL602626 & 600885 & 6.7203 & 5.0909 & TST & & \\
\hline CHEMBL602772 & 600885 & 5.0545 & 5.4 & TST & & \\
\hline CHEMBL576556 & 600885 & 6.2832 & 6.3417 & TRN & & \\
\hline CHEMBL304291 & 600885 & 6.0 & 5.69 & TST & & \\
\hline CHEMBL604564 & 600885 & 7.6385 & 6.8122 & TRN & & \\
\hline CHEMBL217366 & 600885 & 7.295 & 6.34 & TRN & & \\
\hline CHEMBL581700 & 600885 & 5.75799 & 99999999 & $5.8420 e$ & 00000000005 & TRN \\
\hline CHEMBL580142 & 600885 & 6.0022 & 5.9202 & TRN & & \\
\hline CHEMBL599287 & 600885 & 6.0899 & 6.4225 & TRN & & \\
\hline CHEMBL578464 & 600885 & 6.3605 & 6.23600 & 0000000001 & TST & \\
\hline CHEMBL576602 & 600885 & 4.9031 & 5.6505 & TRN & & \\
\hline CHEMBL596858 & 600885 & 6.1226 & 5.8186 & TRN & & \\
\hline CHEMBL582059 & 600885 & 5.8022 & 5.4559 & TRN & & \\
\hline CHEMBL584676 & 600885 & 6.38299 & 99999999 & 5.7348 & TRN & \\
\hline CHEMBL601610 & 600885 & 6.6817 & 6.0343 & TST & & \\
\hline CHEMBL602575 & 600885 & 7.0381 & 6.7282 & TST & & \\
\hline CHEMBL510650 & 600885 & 7.1325 & 5.8462 & TST & & \\
\hline CHEMBL582654 & 600885 & 3.9031 & 5.3394 & TRN & & \\
\hline CHEMBL600089 & 600885 & 6.2924 & 5.4572 & TST & & \\
\hline CHEMBL577864 & 600885 & 4.9031 & 5.2134 & TRN & & \\
\hline CHEMBL599916 & 600885 & 6.2076 & 6.2488 & TRN & & \\
\hline CHEMBL585244 & 600885 & 6.2233 & 6.03600 & 00000000005 & TST & \\
\hline CHEMBL584508 & 600885 & 6.1586 & 5.7344 & TRN & & \\
\hline CHEMBL582687 & 600885 & 5.8768 & 5.809 & TRN & & \\
\hline CHEMBL601586 & 600885 & 4.9292 & 5.3439 & TST & & \\
\hline CHEMBL582304 & 600885 & 6.0565 & 6.3945 & TRN & & \\
\hline CHEMBL532872 & 600885 & 6.4949 & 6.1238 & TRN & & \\
\hline CHEMBL585077 & 600885 & 4.301 & 4.8165 & TRN & & \\
\hline CHEMBL600277 & 600885 & 5.755 & 5.9818 & TRN & & \\
\hline CHEMBL586240 & 600885 & 6.4023 & 7.0436 & TST & & \\
\hline CHEMBL603007 & 600885 & 5.5666 & 6.1351 & TRN & & \\
\hline
\end{tabular}




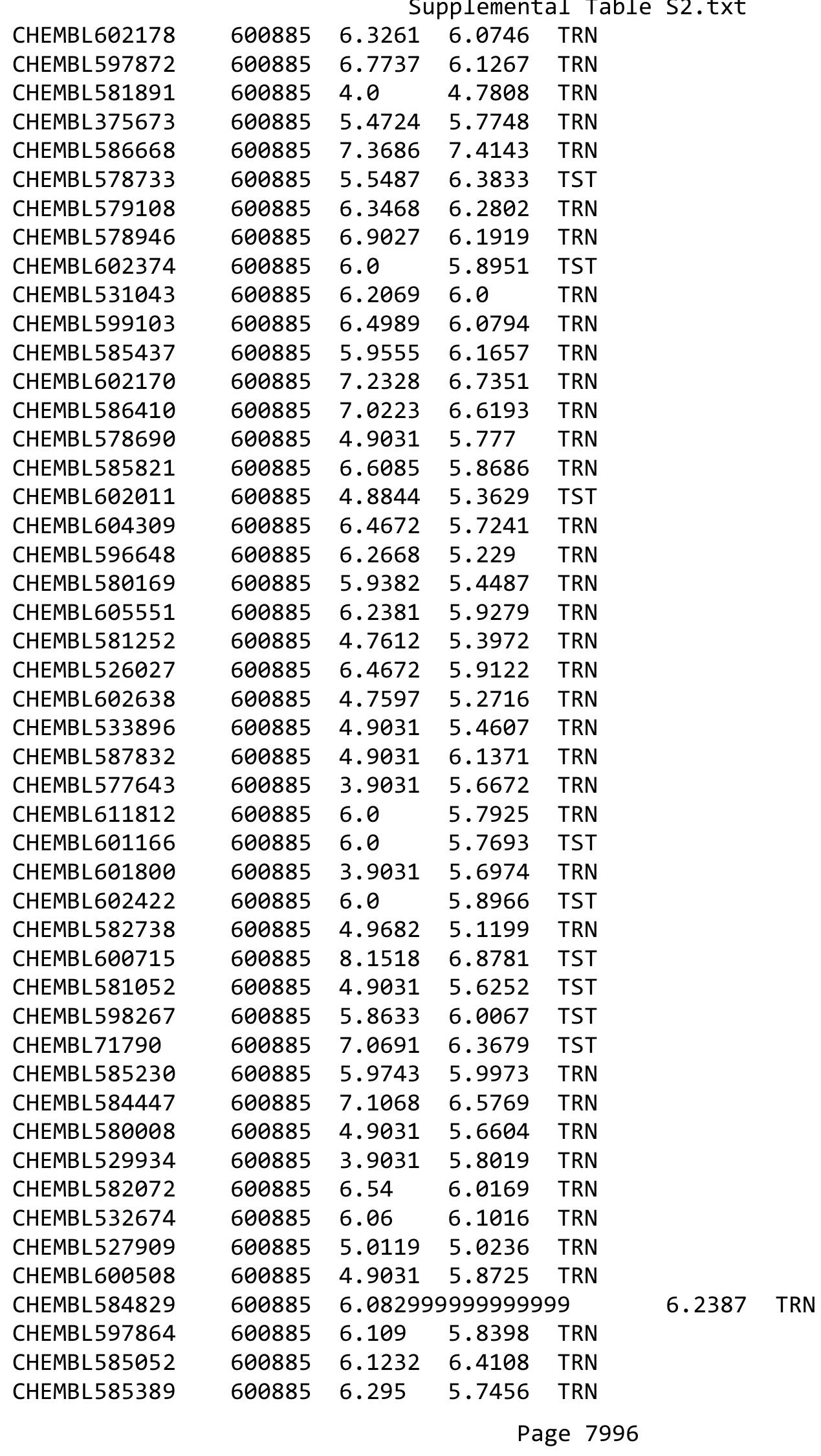




\begin{tabular}{|c|c|c|c|c|c|c|}
\hline & & \multicolumn{5}{|c|}{ Supplemental Table S2.txt } \\
\hline CHEMBL530293 & 600885 & 5.5519 & 5.0982 & TRN & & \\
\hline CHEMBL605947 & 600885 & 5.3536 & 6.029 & TRN & & \\
\hline CHEMBL582472 & 600885 & 4.9292 & 5.3645 & TST & & \\
\hline CHEMBL581055 & 600885 & 4.9031 & 5.7451 & TRN & & \\
\hline CHEMBL579174 & 600885 & 6.1024 & 5.4487 & TST & & \\
\hline CHEMBL582455 & 600885 & 6.3979 & 6.0799 & TRN & & \\
\hline CHEMBL600556 & 600885 & 6.2815 & 5.9803 & TRN & & \\
\hline CHEMBL602998 & 600885 & 6.059 & 5.8379 & TRN & & \\
\hline CHEMBL525864 & 600885 & 5.6047 & 5.6279 & TRN & & \\
\hline CHEMBL528165 & 600885 & 6.0696 & 5.9382 & TRN & & \\
\hline CHEMBL597465 & 600885 & 6.5737 & 6.3211 & TRN & & \\
\hline CHEMBL586181 & 600885 & 6.8959 & 7.5722 & TRN & & \\
\hline CHEMBL599889 & 600885 & 5.6838 & 5.7693 & TRN & & \\
\hline CHEMBL588844 & 600885 & 6.2933 & 6.1043 & TRN & & \\
\hline CHEMBL602421 & 600885 & 7.2248 & 6.5276 & TRN & & \\
\hline CHEMBL577211 & 600885 & 4.9031 & 6.5728 & TRN & & \\
\hline CHEMBL584036 & 600885 & 5.266 & 5.9621 & TRN & & \\
\hline CHEMBL580330 & 600885 & 6.27 & 6.6922 & TRN & & \\
\hline CHEMBL580639 & 600885 & 6.1186 & 5.816 & TRN & & \\
\hline CHEMBL598481 & 600885 & 3.9539 & 5.6939 & TRN & & \\
\hline CHEMBL600283 & 600885 & 4.9374 & 5.1976 & TST & & \\
\hline CHEMBL585841 & 600885 & 6.1624 & 6.9232 & TRN & & \\
\hline CHEMBL609461 & 600885 & 5.7562 & 6.0879 & TST & & \\
\hline CHEMBL602568 & 600885 & 5.16299 & 99999999 & 99 & 4.717 & TST \\
\hline CHEMBL581048 & 600885 & 4.0013 & 4.9906 & TRN & & \\
\hline CHEMBL600750 & 600885 & 5.8142 & 5.7204 & TRN & & \\
\hline CHEMBL586029 & 600885 & 6.6975 & 6.2781 & TRN & & \\
\hline CHEMBL582259 & 600885 & 5.6171 & 5.2398 & TRN & & \\
\hline CHEMBL582273 & 600885 & 4.9031 & 6.2652 & TRN & & \\
\hline CHEMBL577157 & 600885 & 5.5281 & 5.6776 & TRN & & \\
\hline CHEMBL1615700 & 600885 & 7.5119 & 6.3272 & TRN & & \\
\hline CHEMBL600764 & 600885 & 5.3936 & 4.8482 & TRN & & \\
\hline CHEMBL606162 & 600885 & 6.0706 & 5.2543 & TRN & & \\
\hline CHEMBL585840 & 600885 & 6.0362 & 5.8342 & TRN & & \\
\hline CHEMBL576603 & 600885 & 6.0 & 5.8368 & TRN & & \\
\hline CHEMBL584661 & 600885 & 6.5786 & 6.0122 & TRN & & \\
\hline CHEMBL580461 & 600885 & 6.5976 & 6.0728 & TRN & & \\
\hline CHEMBL600359 & 600885 & 6.0334 & 6.9077 & TRN & & \\
\hline CHEMBL580163 & 600885 & 4.0899 & 5.3582 & TRN & & \\
\hline CHEMBL582070 & 600885 & 6.1694 & 5.8109 & TRN & & \\
\hline CHEMBL600296 & 600885 & 6.1349 & 5.7453 & TST & & \\
\hline CHEMBL601544 & 600885 & 5.9477 & 5.5101 & TRN & & \\
\hline CHEMBL545872 & 600885 & 6.4413 & 5.9627 & TRN & & \\
\hline CHEMBL585967 & 600885 & 5.9948 & 6.4571 & TRN & & \\
\hline CHEMBL529610 & 600885 & 6.7744 & 6.1892 & TRN & & \\
\hline CHEMBL585747 & 600885 & 5.8861 & 5.9093 & TST & & \\
\hline CHEMBL581456 & 600885 & 6.0 & 5.7692 & TRN & & \\
\hline CHEMBL596831 & 600885 & 6.8841 & 6.5242 & TRN & & \\
\hline
\end{tabular}


Supplemental Table S2.txt

\begin{tabular}{|c|c|c|c|c|c|}
\hline CHEMBL585413 & 600885 & 6.1972 & 6.3492 & TRN & \\
\hline CHEMBL584457 & 600885 & 6.4908 & 5.6701 & TRN & \\
\hline CHEMBL585451 & 600885 & 4.9031 & 5.3535 & TRN & \\
\hline CHEMBL582286 & 600885 & 6.3036 & 5.42 & TRN & \\
\hline CHEMBL601118 & 600885 & 5.5393 & 5.6029 & TRN & \\
\hline CHEMBL580161 & 600885 & 6.0531 & 5.6231 & TRN & \\
\hline CHEMBL579123 & 600885 & 3.9031 & 5.6296 & TRN & \\
\hline CHEMBL584218 & 600885 & 6.1129 & 5.7266 & TRN & \\
\hline CHEMBL597473 & 600885 & 6.5264 & 6.0093 & TRN & \\
\hline CHEMBL528644 & 600885 & 5.6073 & 5.8437 & TRN & \\
\hline CHEMBL582114 & 600885 & 4.9666 & 5.278 & TRN & \\
\hline CHEMBL601534 & 600885 & 6.0013 & 5.8278 & TST & \\
\hline CHEMBL578957 & 600885 & 7.8533 & 6.3542 & TST & \\
\hline CHEMBL578085 & 600885 & 4.9031 & 5.2831 & TRN & \\
\hline CHEMBL601330 & 600885 & 6.3152 & 6.3954 & TRN & \\
\hline CHEMBL183 & 600885 & 6.1169 & 5.9741 & TST & \\
\hline CHEMBL578288 & 600885 & 6.0937 & 5.6686 & TST & \\
\hline CHEMBL 375781 & 600885 & 7.0128 & 6.46399 & 99999999995 & TST \\
\hline CHEMBL580095 & 600885 & 5.4672 & 5.5323 & TRN & \\
\hline CHEMBL 2368648 & 600885 & 6.5909 & 6.2385 & TST & \\
\hline CHEMBL583359 & 600885 & 6.3344 & 6.0121 & TRN & \\
\hline CHEMBL584496 & 600885 & 5.2503 & 5.8435 & TRN & \\
\hline CHEMBL579562 & 600885 & 5.7943 & 5.4087 & TRN & \\
\hline CHEMBL585813 & 600885 & 6.8582 & 6.4249 & TRN & \\
\hline CHEMBL582066 & 600885 & 5.7488 & 5.2289 & TRN & \\
\hline CHEMBL597859 & 600885 & 5.0405 & 4.8725 & TRN & \\
\hline CHEMBL576609 & 600885 & 6.1209 & 7.4598 & TRN & \\
\hline CHEMBL577793 & 600885 & 6.3556 & 5.8846 & TRN & \\
\hline CHEMBL603012 & 600885 & 3.9031 & 5.2854 & TRN & \\
\hline CHEMBL580171 & 600885 & 7.2464 & 6.1036 & TRN & \\
\hline CHEMBL585835 & 600885 & 6.2958 & 6.1821 & TRN & \\
\hline CHEMBL602409 & 600885 & 5.9519 & 5.2446 & TRN & \\
\hline CHEMBL583154 & 600885 & 5.9531 & 5.6557 & TST & \\
\hline CHEMBL602617 & 600885 & 6.0535 & 5.6899 & TRN & \\
\hline CHEMBL584884 & 600885 & 5.109 & 5.2271 & TRN & \\
\hline CHEMBL581875 & 600885 & 6.2343 & 5.7456 & TRN & \\
\hline CHEMBL584869 & 600885 & 4.9031 & 5.2413 & TRN & \\
\hline CHEMBL585034 & 600885 & 5.6021 & 5.9319 & TRN & \\
\hline CHEMBL588176 & 600885 & 6.1993 & 6.0239 & TRN & \\
\hline CHEMBL588987 & 600885 & 6.1367 & 6.2993 & TRN & \\
\hline CHEMBL530149 & 600885 & 6.3883 & 5.682 & TRN & \\
\hline CHEMBL600933 & 600885 & 5.0458 & 5.8093 & TRN & \\
\hline CHEMBL582670 & 600885 & 5.8867 & 5.8855 & TRN & \\
\hline CHEMBL597666 & 600885 & 5.2336 & 4.8696 & TRN & \\
\hline CHEMBL577233 & 600885 & 4.3354 & 5.3342 & TST & \\
\hline CHEMBL578729 & 600885 & 6.5336 & 6.1287 & TRN & \\
\hline CHEMBL577894 & 600885 & 3.9031 & 5.0912 & TRN & \\
\hline CHEMBL586220 & 600885 & 6.6647 & 6.6015 & TRN & \\
\hline
\end{tabular}




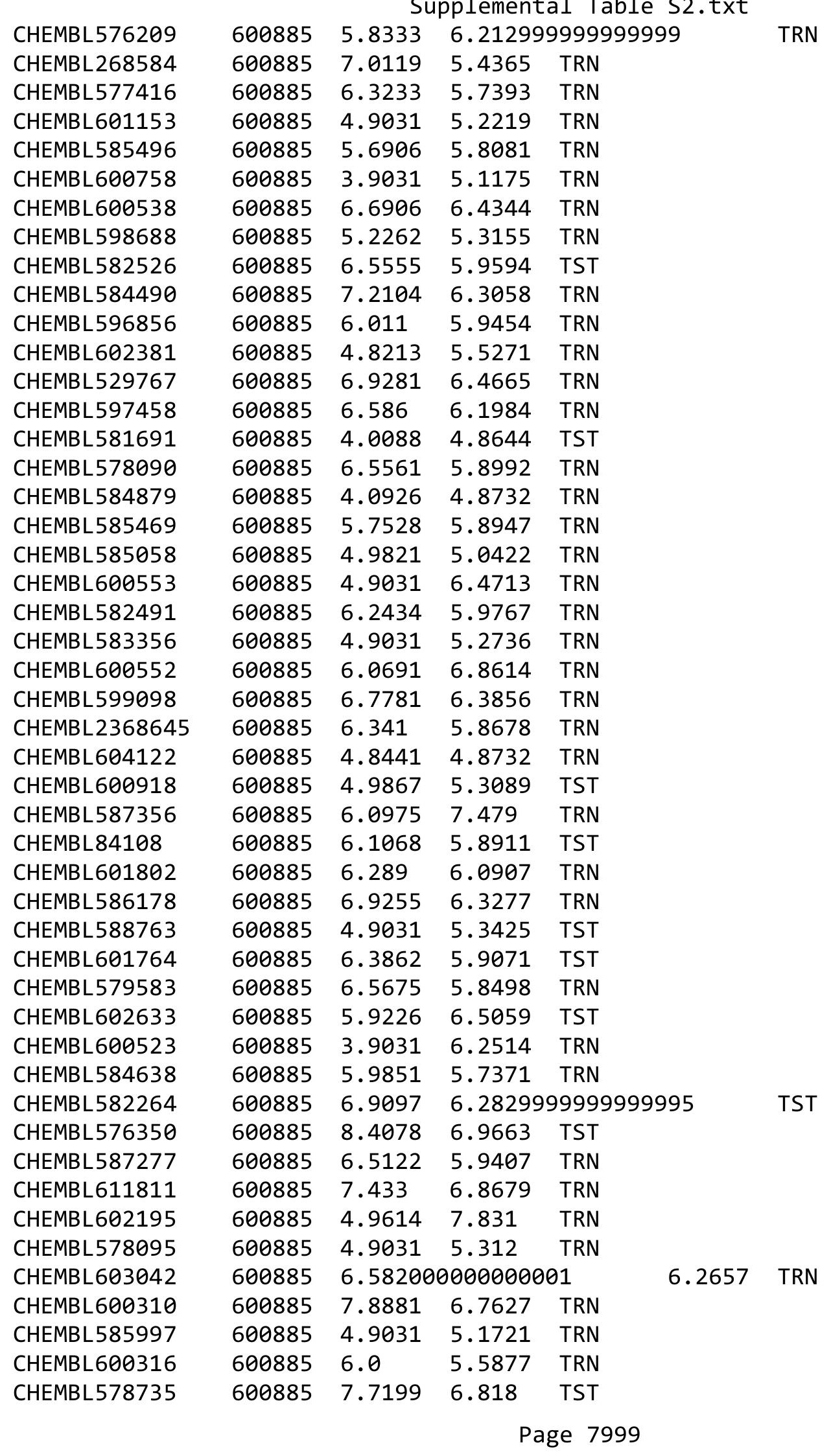




\begin{tabular}{|c|c|c|c|c|}
\hline & & & pplement & al $\mathrm{T}$ \\
\hline CHEMBL582671 & 600885 & 6.3045 & 5.9196 & TST \\
\hline CHEMBL596652 & 600885 & 6.4413 & 5.7594 & TRN \\
\hline CHEMBL579159 & 600885 & 6.251 & 6.1806 & TRN \\
\hline CHEMBL601377 & 600885 & 4.9031 & 5.7296 & TRN \\
\hline CHEMBL1197790 & 600885 & 6.7042 & 6.0984 & TST \\
\hline CHEMBL602410 & 600885 & 4.9031 & 5.6613 & TRN \\
\hline CHEMBL587779 & 600885 & 6.0 & 5.8559 & TRN \\
\hline CHEMBL533366 & 600885 & 7.1726 & 6.3664 & TRN \\
\hline CHEMBL579356 & 600885 & 5.5402 & 5.4753 & TRN \\
\hline CHEMBL584860 & 600885 & 6.5178 & 6.0173 & TRN \\
\hline CHEMBL602621 & 600885 & 6.284 & 6.183 & TRN \\
\hline CHEMBL1198336 & 600885 & 3.9031 & 5.4298 & TST \\
\hline CHEMBL582073 & 600885 & 6.1337 & 5.8887 & TRN \\
\hline CHEMBL585810 & 600885 & 6.4559 & 6.6123 & TRN \\
\hline CHEMBL586650 & 600885 & 4.7788 & 5.8943 & TRN \\
\hline CHEMBL582735 & 600885 & 5.8309 & 6.1056 & TRN \\
\hline CHEMBL579178 & 600885 & 6.4921 & 5.3266 & TST \\
\hline CHEMBL579950 & 600885 & 6.8844 & 6.1692 & TRN \\
\hline CHEMBL583161 & 600885 & 3.9996 & 5.7615 & TRN \\
\hline CHEMBL582327 & 600885 & 4.9842 & 5.3023 & TRN \\
\hline CHEMBL579750 & 600885 & 4.9512 & 5.4548 & TST \\
\hline CHEMBL261693 & 600885 & 5.6994 & 6.0399 & TRN \\
\hline CHEMBL582666 & 600885 & 6.1726 & 6.2983 & TRN \\
\hline CHEMBL6625 & 600885 & 4.9031 & 5.1376 & TST \\
\hline CHEMBL579551 & 600885 & 5.1403 & 5.4584 & TRN \\
\hline CHEMBL577837 & 600885 & 6.6651 & 6.0098 & TRN \\
\hline CHEMBL601374 & 600885 & 6.6254 & 5.3434 & TST \\
\hline CHEMBL585771 & 600885 & 4.9031 & 5.5541 & TRN \\
\hline CHEMBL583562 & 600885 & 4.9031 & 5.1621 & TRN \\
\hline CHEMBL604565 & 600885 & 7.0762 & 6.8269 & TRN \\
\hline CHEMBL577892 & 600885 & 6.2204 & 5.4431 & TRN \\
\hline CHEMBL597854 & 600885 & 5.8904 & 5.9128 & TST \\
\hline CHEMBL584855 & 600885 & 5.0814 & 5.3893 & TRN \\
\hline CHEMBL586000 & 600885 & 7.062 & 6.3554 & TST \\
\hline CHEMBL530405 & 600885 & 6.901 & 6.3251 & TRN \\
\hline CHEMBL584639 & 600885 & 3.9031 & 4.7369 & TST \\
\hline CHEMBL602987 & 600885 & 6.8548 & 5.808 & TRN \\
\hline CHEMBL602993 & 600885 & 4.9586 & 5.6455 & TRN \\
\hline CHEMBL603897 & 600885 & 6.9055 & 5.1397 & TRN \\
\hline CHEMBL581683 & 600885 & 5.266 & 5.4654 & TRN \\
\hline CHEMBL588102 & 600885 & 4.9031 & 5.7043 & TRN \\
\hline CHEMBL602017 & 600885 & 5.9727 & 5.5996 & TRN \\
\hline CHEMBL585459 & 600885 & 6.0904 & 5.9449 & TRN \\
\hline CHEMBL598480 & 600885 & 6.0362 & 5.2917 & TRN \\
\hline CHEMBL578502 & 600885 & 6.5957 & 6.1516 & TRN \\
\hline CHEMBL599927 & 600885 & 5.3665 & 5.3721 & TRN \\
\hline CHEMBL582317 & 600885 & 4.927 & 5.3011 & TRN \\
\hline CHEMBL579377 & 600885 & 6.0888 & 6.3665 & TRN \\
\hline
\end{tabular}




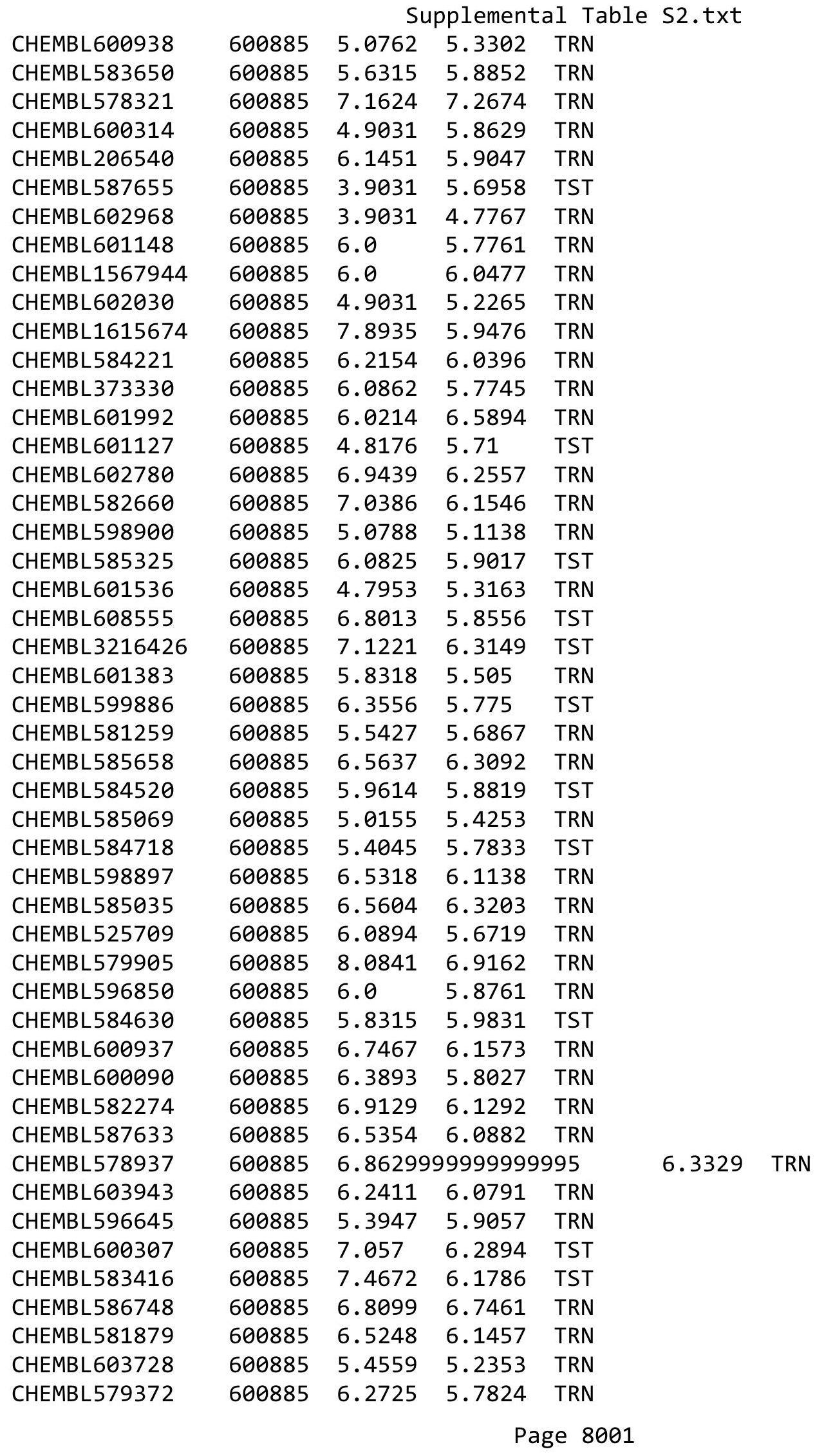




\begin{tabular}{|c|c|c|c|c|c|c|}
\hline \multirow[b]{2}{*}{ CHEMBL576796 } & \multicolumn{6}{|c|}{$=1160$} \\
\hline & 600885 & 4.9031 & 5.8517 & TRN & & \\
\hline CHEMBL600291 & 600885 & 6.224 & 5.8741 & TRN & & \\
\hline CHEMBL534547 & 600885 & 4.9031 & 5.6273 & TRN & & \\
\hline CHEMBL584673 & 600885 & 6.4698 & 6.1013 & TRN & & \\
\hline CHEMBL605333 & 600885 & 5.6413 & 5.682 & TRN & & \\
\hline CHEMBL602829 & 600885 & 5.2874 & 5.8286 & TRN & & \\
\hline CHEMBL601182 & 600885 & 5.3635 & 5.1346 & TST & & \\
\hline CHEMBL602163 & 600885 & 4.9226 & 5.2014 & TST & & \\
\hline CHEMBL576616 & 600885 & 4.9031 & 5.3964 & TRN & & \\
\hline CHEMBL578965 & 600885 & 7.1433 & 6.7917 & TRN & & \\
\hline CHEMBL598692 & 600885 & \multicolumn{3}{|c|}{6.3839999999999995} & 6.0042 & TRN \\
\hline CHEMBL585467 & 600885 & 6.2197 & 5.8827 & TRN & & \\
\hline CHEMBL578686 & 600885 & 5.9519 & 5.3584 & TRN & & \\
\hline CHEMBL585048 & 600885 & 5.644 & 6.1349 & TRN & & \\
\hline CHEMBL578890 & 600885 & 6.1421 & 5.6091 & TRN & & \\
\hline CHEMBL577875 & 600885 & 4.2403 & 6.0656 & TST & & \\
\hline CHEMBL583801 & 600885 & 6.0 & 5.7764 & TRN & & \\
\hline CHEMBL602436 & 600885 & 4.8582 & 5.4099 & TST & & \\
\hline CHEMBL586982 & 600885 & 6.0429 & 6.1716 & TRN & & \\
\hline CHEMBL602603 & 600885 & 5.4179 & 5.5149 & TRN & & \\
\hline CHEMBL528382 & 600885 & 6.5207 & 5.7651 & TRN & & \\
\hline CHEMBL601820 & 600885 & 6.6176 & 6.358 & TRN & & \\
\hline CHEMBL601386 & 600885 & 6.1403 & 6.0971 & TRN & & \\
\hline CHEMBL579498 & 600885 & 6.7378 & 6.1253 & TRN & & \\
\hline CHEMBL578898 & 600885 & 4.8719 & 5.9719 & TST & & \\
\hline CHEMBL602380 & 600885 & 4.9031 & 5.6691 & TST & & \\
\hline CHEMBL578523 & 600885 & 7.0101 & 6.3934 & TST & & \\
\hline CHEMBL602373 & 600885 & 7.2034 & 4.612 & TRN & & \\
\hline CHEMBL580769 & 600885 & 6.7217 & 6.2934 & TRN & & \\
\hline CHEMBL601823 & 600885 & 4.797 & 5.7644 & TRN & & \\
\hline CHEMBL585311 & 600885 & 5.7781 & 5.6696 & TRN & & \\
\hline CHEMBL600312 & 600885 & 4.7932 & 5.7831 & TRN & & \\
\hline CHEMBL600718 & 600885 & 5.6533 & 5.8037 & TST & & \\
\hline CHEMBL608857 & 600885 & 6.0 & 5.8691 & TRN & & \\
\hline CHEMBL581863 & 600885 & 5.2692 & 5.7823 & TRN & & \\
\hline CHEMBL601175 & 600885 & 6.4306 & 5.9522 & TRN & & \\
\hline CHEMBL602167 & 600885 & 5.766 & 5.9044 & TRN & & \\
\hline CHEMBL581448 & 600885 & 6.2899 & 5.6431 & TRN & & \\
\hline CHEMBL582801 & 600885 & 5.1255 & 5.2367 & TRN & & \\
\hline CHEMBL608259 & 600885 & 4.8928 & 6.8006 & TRN & & \\
\hline CHEMBL578283 & 600885 & 8.2967 & 7.1543 & TRN & & \\
\hline CHEMBL580130 & 600885 & 6.1864 & 6.3876 & TRN & & \\
\hline CHEMBL583818 & 600885 & 4.9031 & 5.1791 & TRN & & \\
\hline CHEMBL584008 & 600885 & 6.1397 & 5.8544 & TRN & & \\
\hline CHEMBL582662 & 600885 & 7.466 & 7.2179 & TRN & & \\
\hline CHEMBL600745 & 600885 & 4.8887 & 5.7062 & TRN & & \\
\hline CHEMBL578894 & 600885 & 5.8419 & 5.294 & TRN & & \\
\hline CHEMBL601984 & 600885 & $4.7860 e$ & 3000000 & 205 & 5.5744 & TRN \\
\hline & & & & e & & \\
\hline
\end{tabular}




\begin{tabular}{|c|c|c|c|c|c|}
\hline \multicolumn{6}{|c|}{ Supplemental Table S } \\
\hline CHEMBL581480 & 600885 & 5.7989 & 5.2793 & TST & \\
\hline CHEMBL602006 & 600885 & 6.1675 & 5.4924 & TRN & \\
\hline CHEMBL584214 & 600885 & 6.5373 & 5.9045 & TRN & \\
\hline CHEMBL601822 & 600885 & 4.9031 & 5.2342 & TRN & \\
\hline CHEMBL581855 & 600885 & 6.098 & 5.5952 & TRN & \\
\hline CHEMBL581273 & 600885 & 6.3242 & 5.2348 & TRN & \\
\hline CHEMBL602191 & 600885 & 5.4001 & 5.5177 & TRN & \\
\hline CHEMBL584664 & 600885 & 6.0057 & 5.7898 & TRN & \\
\hline CHEMBL582505 & 600885 & 5.9948 & 6.21899 & 7999999999 & TST \\
\hline CHEMBL600293 & 600885 & 5.9408 & 5.6316 & TRN & \\
\hline CHEMBL602835 & 600885 & 4.9031 & 6.3805 & TRN & \\
\hline CHEMBL578537 & 600885 & 4.9187 & 5.8981 & TRN & \\
\hline CHEMBL597462 & 600885 & 5.648 & 5.8618 & TRN & \\
\hline CHEMBL577441 & 600885 & 5.8877 & 5.8376 & TRN & \\
\hline CHEMBL597246 & 600885 & 6.3224 & 5.7572 & TRN & \\
\hline CHEMBL 274986 & 600885 & 6.4962 & 5.9658 & TRN & \\
\hline CHEMBL585267 & 600885 & 6.1537 & 5.9127 & TRN & \\
\hline CHEMBL602576 & 600885 & 7.0264 & 6.4738 & TST & \\
\hline CHEMBL578924 & 600885 & 7.4622 & 7.1882 & TRN & \\
\hline CHEMBL535760 & 600885 & 5.7194 & 5.0559 & TRN & \\
\hline CHEMBL602423 & 600885 & 5.4597 & 5.8645 & TRN & \\
\hline CHEMBL582379 & 600885 & 4.9031 & 6.1757 & TRN & \\
\hline CHEMBL578753 & 600885 & 6.6364 & 6.5473 & TRN & \\
\hline CHEMBL528984 & 600885 & 6.5112 & 5.9151 & TRN & \\
\hline CHEMBL583593 & 600885 & 5.8931 & 5.7565 & TRN & \\
\hline CHEMBL603023 & 600885 & 6.0159 & 5.7708 & TRN & \\
\hline CHEMBL585966 & 600885 & 6.5535 & 6.0518 & TRN & \\
\hline CHEMBL534144 & 600885 & 4.7711 & 5.7964 & TRN & \\
\hline CHEMBL582119 & 600885 & 5.6966 & 5.1561 & TRN & \\
\hline CHEMBL582957 & 600885 & 6.5519 & 6.3612 & TRN & \\
\hline CHEMBL597464 & 600885 & 6.6354 & 6.3799 & TRN & \\
\hline CHEMBL584310 & 600885 & 6.7916 & 6.5764 & TRN & \\
\hline CHEMBL579369 & 600885 & 6.1549 & 6.0368 & TRN & \\
\hline CHEMBL528585 & 600885 & 3.9031 & 5.5077 & TRN & \\
\hline CHEMBL585825 & 600885 & 4.9031 & 6.3248 & TST & \\
\hline CHEMBL600484 & 600885 & 4.9622 & 5.0578 & TRN & \\
\hline CHEMBL580480 & 600885 & 4.9031 & 6.4505 & TRN & \\
\hline CHEMBL581677 & 600885 & 5.5618 & 5.9714 & TRN & \\
\hline CHEMBL584715 & 600885 & 6.0039 & 6.061 & TRN & \\
\hline CHEMBL585412 & 600885 & 6.0372 & 6.266 & TRN & \\
\hline CHEMBL578669 & 600885 & 6.1752 & 5.79200 & 0000000001 & TRN \\
\hline CHEMBL578265 & 600885 & 6.2299 & 5.9257 & TST & \\
\hline CHEMBL581045 & 600885 & 4.9248 & 5.7824 & TST & \\
\hline CHEMBL588571 & 600885 & 6.3862 & 6.0397 & TRN & \\
\hline CHEMBL 270726 & 600885 & 6.0 & 6.0042 & TRN & \\
\hline CHEMBL579960 & 600885 & 4.9031 & 5.7801 & TRN & \\
\hline CHEMBL598062 & 600885 & 6.4023 & 5.6633 & TRN & \\
\hline CHEMBL584827 & 600885 & 6.5824 & 5.7675 & TRN & \\
\hline
\end{tabular}




\begin{tabular}{|c|c|c|c|c|c|}
\hline & & & & & \\
\hline CHEMBL583363 & 600885 & 4.9031 & 5.5562 & TRN & \\
\hline CHEMBL584445 & 600885 & 6.0438 & 5.8345 & TRN & \\
\hline CHEMBL578545 & 600885 & 6.8941 & 6.2802 & TRN & \\
\hline CHEMBL524973 & 600885 & 7.3307 & 6.5063 & TRN & \\
\hline CHEMBL599953 & 600885 & 5.7118 & 6.4705 & TRN & \\
\hline CHEMBL578676 & 600885 & 3.9031 & 5.3327 & TRN & \\
\hline CHEMBL578073 & 600885 & 5.3134 & 5.6543 & TRN & \\
\hline CHEMBL611380 & 600885 & 6.0899 & 6.0583 & TRN & \\
\hline CHEMBL609313 & 600885 & 6.0119 & 5.9537 & TST & \\
\hline CHEMBL585053 & 600885 & 4.9031 & 6.195 & TRN & \\
\hline CHEMBL580835 & 600885 & 5.9851 & 5.3773 & TST & \\
\hline CHEMBL577662 & 600885 & 6.5575 & 5.8148 & TRN & \\
\hline CHEMBL580836 & 600885 & 4.9855 & 5.5041 & TRN & \\
\hline CHEMBL585799 & 600885 & 6.0926 & 5.692 & TRN & \\
\hline CHEMBL578468 & 600885 & 4.9031 & 5.3813 & TST & \\
\hline CHEMBL600926 & 600885 & 5.0013 & 6.239 & TRN & \\
\hline CHEMBL601121 & 600885 & 7.0615 & 5.70299 & & TRN \\
\hline CHEMBL582256 & 600885 & 4.9031 & 5.7775 & TRN & \\
\hline CHEMBL530067 & 600885 & 6.3344 & 6.1355 & TST & \\
\hline CHEMBL588661 & 600885 & 3.9031 & 5.4226 & TRN & \\
\hline CHEMBL586035 & 600885 & 5.3536 & 5.814 & TRN & \\
\hline CHEMBL531672 & 600885 & 4.9031 & 5.9136 & TRN & \\
\hline CHEMBL600495 & 600885 & 7.0343 & 6.1794 & TRN & \\
\hline CHEMBL579088 & 600885 & 6.9855 & 5.9645 & TST & \\
\hline CHEMBL580172 & 600885 & 6.5086 & 6.0662 & TRN & \\
\hline CHEMBL598893 & 600885 & 6.1337 & 4.7684 & TRN & \\
\hline CHEMBL577657 & 600885 & 3.9031 & 5.58200 & 0000000001 & TRN \\
\hline CHEMBL599951 & 600885 & 6.2013 & 6.7102 & TRN & \\
\hline CHEMBL598890 & 600885 & 6.1884 & 5.0859 & TRN & \\
\hline CHEMBL609318 & 600885 & 5.5488 & 4.8642 & TRN & \\
\hline CHEMBL600755 & 600885 & 4.9427 & 5.20700 & 0000000001 & TRN \\
\hline CHEMBL536904 & 600885 & 5.7703 & 5.5816 & TRN & \\
\hline CHEMBL577880 & 600885 & 4.9031 & 5.8916 & TRN & \\
\hline CHEMBL600142 & 600885 & 6.7908 & 6.5977 & TRN & \\
\hline CHEMBL597874 & 600885 & 6.9055 & 6.1267 & TRN & \\
\hline CHEMBL585781 & 600885 & 5.9352 & 6.6449 & TRN & \\
\hline CHEMBL599720 & 600885 & 5.9281 & 6.0059 & TRN & \\
\hline CHEMBL532965 & 600885 & 6.0 & 5.7818 & TRN & \\
\hline CHEMBL583561 & 600885 & 4.9031 & 5.1749 & TRN & \\
\hline CHEMBL578290 & 600885 & 5.4597 & 5.6994 & TST & \\
\hline CHEMBL584821 & 600885 & 6.4815 & 6.1602 & TRN & \\
\hline CHEMBL582513 & 600885 & 6.0 & 5.6946 & TRN & \\
\hline CHEMBL533712 & 600885 & 5.3188 & 5.7016 & TRN & \\
\hline CHEMBL596849 & 600885 & 6.4547 & 6.0422 & TST & \\
\hline CHEMBL599919 & 600885 & 6.1124 & 7.4725 & TRN & \\
\hline CHEMBL600910 & 600885 & 4.9031 & 5.3908 & TRN & \\
\hline CHEMBL601356 & 600885 & 6.6834 & 6.2556 & TRN & \\
\hline CHEMBL584034 & 600885 & 5.8492 & 5.7441 & TRN & \\
\hline
\end{tabular}




\begin{tabular}{|c|c|c|c|c|c|c|}
\hline \multicolumn{7}{|c|}{ lemental Table S2. } \\
\hline CHEMBL596650 & 600885 & 4.9031 & 5.1798 & TRN & & \\
\hline CHEMBL578958 & 600885 & 4.9031 & 5.5094 & TST & & \\
\hline CHEMBL611387 & 600885 & 6.8102 & 6.1027 & TST & & \\
\hline CHEMBL597047 & 600885 & 6.0 & 5.843 & TRN & & \\
\hline CHEMBL577869 & 600885 & 6.6672 & 6.4104 & TRN & & \\
\hline CHEMBL579095 & 600885 & 5.2321 & 5.8478 & TST & & \\
\hline CHEMBL579672 & 600885 & 6.5453 & 5.8705 & TRN & & \\
\hline CHEMBL577650 & 600885 & 6.2204 & 6.3619 & TRN & & \\
\hline CHEMBL598681 & 600885 & 6.6221 & 6.2724 & TRN & & \\
\hline CHEMBL582452 & 600885 & 3.9031 & 5.3035 & TRN & & \\
\hline CHEMBL576324 & 600885 & 5.782999 & 79999999 & 995 & 9999999999 & TRN \\
\hline CHEMBL577235 & 600885 & 4.9031 & 5.0699 & TRN & & \\
\hline CHEMBL579968 & 600885 & 5.2132 & 5.7027 & TRN & & \\
\hline CHEMBL1493528 & 600885 & 6.6151 & 6.2264 & TRN & & \\
\hline CHEMBL578878 & 600885 & 5.4841 & 5.4954 & TRN & & \\
\hline CHEMBL586344 & 600885 & 6.2565 & 5.9977 & TST & & \\
\hline CHEMBL602778 & 600885 & 3.9031 & 5.3337 & TRN & & \\
\hline CHEMBL597258 & 600885 & 5.761 & 5.7209 & TST & & \\
\hline CHEMBL578524 & 600885 & 6.4225 & 6.4583 & TRN & & \\
\hline CHEMBL581912 & 600885 & 5.4056 & 5.2236 & TRN & & \\
\hline CHEMBL605817 & 600885 & 6.5447 & 5.7648 & TRN & & \\
\hline CHEMBL585834 & 600885 & 6.8265 & 6.2825 & TRN & & \\
\hline CHEMBL603000 & 600885 & 5.5627 & 5.5517 & TRN & & \\
\hline CHEMBL582094 & 600885 & 6.6026 & 6.3442 & TRN & & \\
\hline CHEMBL548572 & 600885 & 4.8851 & 6.3092 & TRN & & \\
\hline CHEMBL598678 & 600885 & 5.6375 & 6.0382 & TRN & & \\
\hline CHEMBL580827 & 600885 & 5.3768 & 5.5844 & TRN & & \\
\hline CHEMBL240752 & 600885 & 5.9266 & 5.0467 & TRN & & \\
\hline CHEMBL579338 & 600885 & 8.1733 & 7.25899 & 99999999995 & TRN & \\
\hline CHEMBL583900 & 600885 & 5.2765 & 5.5537 & TRN & & \\
\hline CHEMBL530401 & 600885 & 4.2749 & 5.7055 & TRN & & \\
\hline CHEMBL534139 & 600885 & 6.5638 & 5.9185 & TRN & & \\
\hline CHEMBL578525 & 600885 & 6.0975 & 6.1137 & TRN & & \\
\hline CHEMBL579288 & 600885 & 5.2924 & 5.6015 & TRN & & \\
\hline CHEMBL600143 & 600885 & 6.3778 & 6.2343 & TRN & & \\
\hline CHEMBL585665 & 600885 & 8.9097 & 7.3429 & TRN & & \\
\hline CHEMBL601106 & 600885 & 6.9776 & 4.9049 & TRN & & \\
\hline CHEMBL578084 & 600885 & 6.3546 & 6.0686 & TST & & \\
\hline CHEMBL585072 & 600885 & 10.2426 & 7.8042 & TST & & \\
\hline CHEMBL 578092 & 600885 & 3.9031 & 5.5582 & TRN & & \\
\hline CHEMBL604109 & 600885 & 5.6625 & 5.9009 & TRN & & \\
\hline CHEMBL576608 & 600885 & 6.4283 & 6.135 & TRN & & \\
\hline CHEMBL602836 & 600885 & 4.9031 & 6.2716 & TRN & & \\
\hline CHEMBL579311 & 600885 & 6.5586 & 6.0307 & TRN & & \\
\hline CHEMBL582635 & 600885 & 6.3655 & 6.3537 & TRN & & \\
\hline CHEMBL583352 & 600885 & 4.9788 & 5.7622 & TRN & & \\
\hline CHEMBL602431 & 600885 & 6.0773 & 6.364 & TRN & & \\
\hline CHEMBL584632 & 600885 & 6.5889 & 6.0902 & TRN & & \\
\hline
\end{tabular}


Supplemental Table S2.txt

\begin{tabular}{|c|c|c|c|c|}
\hline CHEMBL580340 & 600885 & 6.5758 & 6.0615 & RN \\
\hline HEMBL 527181 & 500885 & 5.3072 & 5.5817 & TPN \\
\hline HEMBL 600544 & 00885 & 8094 & & \\
\hline HEMBL601609 & 00885 & .0783 & .9832 & \\
\hline HEMBL599910 & 00885 & 6.657 & 5.716 & \\
\hline HEMBL 606382 & 00885 & .1349 & 5.6919 & \\
\hline HEMBL 579121 & 00885 & .5158 & 5.1287 & $\mathrm{RN}$ \\
\hline HEMBL610913 & 00885 & 5.6243 & 5.6403 & RN \\
\hline HEMBL579371 & 00885 & 4.9031 & 6.0124 & \\
\hline HEMBL585227 & 00885 & 6.0246 & 6.1073 & \\
\hline HEMBL579312 & 00885 & 3.9031 & 5.6538 & \\
\hline HEMBL 576181 & 00885 & 6.0975 & 5.8526 & $\mathrm{RN}$ \\
\hline HEMBL602818 & 00885 & 6.0022 & 5.6516 & $\mathrm{RN}$ \\
\hline HEMBL585612 & 00885 & .1319 & 5.563 & \\
\hline HEMBL576811 & 00885 & 7.8983 & 6.9346 & 「RN \\
\hline HEMBL 584241 & 00885 & 019 & 9918 & RIV \\
\hline HEMBL6 & 00885 & & 365 & RN \\
\hline HEMBL601585 & 500885 & 5 . & 5.2266 & 「RN \\
\hline HEMBL 581877 & 00885 & 24 & 5956 & TRN \\
\hline HEMBL599952 & 00885 & 57 & 6.1002 & 「RN \\
\hline HEMBL5 & 00885 & 53 & 3682 & TRN \\
\hline HEMBL & $\partial 0885$ & & 519 & ГST \\
\hline HEMBL585031 & 00885 & 94 & 7127 & TRN \\
\hline HEMBL602975 & 00885 & & 7702 & RIV \\
\hline HEMBL 601776 & 00885 & 544 & 507 & IRN \\
\hline HEMBL6 & 00885 & & 301 & ST \\
\hline HEMBLI & 85 & & 775 & 「RN \\
\hline HEMBL5 & 00885 & 33 & 5.8486 & 「RN \\
\hline HEMBL6 & 85 & & 319 & IRN \\
\hline HEMBL 601190 & 500885 & 72 & 7.1087 & TRN \\
\hline HEMBL 5 & 00885 & $\partial 1$ & 3902 & TRN \\
\hline HEMBL & 85 & & 128 & TRN \\
\hline HEMBL5 & & & 3442 & TRN \\
\hline HEMBL 581864 & 85 & 31 & 5423 & TRN \\
\hline HEMBL 587058 & 00885 & 486 & 8801 & TRN \\
\hline HEMBL6 & 00885 & 16 & 796 & TST \\
\hline CHEMBL & 85 & & & ST \\
\hline HEMBL581244 & 600885 & & 6.0317 & TST \\
\hline HEMBL579320 & 00885 & 5 . & 331 & TRN \\
\hline HEMBL5 & 00885 & 87 & 5.9081 & TRN \\
\hline CHEMBL528589 & 600885 & 36 & 5.8032 & TRN \\
\hline CHEMBL605950 & 600885 & 7.0301 & 6.4847 & TRN \\
\hline CHEMBL585064 & 600885 & 5.5303 & 5.5857 & TRN \\
\hline HEMBL599106 & 600885 & 6.1209 & 1445 & $\mathrm{TR}$ \\
\hline CHEMBL5 & 600885 & & 3894 & IRIV \\
\hline CHEMBL535252 & 500885 & 5.4672 & 5.6779 & \\
\hline CHEMBL585587 & 600885 & 6.6336 & 6.3353 & $2 \mathrm{~N}$ \\
\hline CHEMBL581685 & 600885 & 4.9031 & 6.1585 & 13 \\
\hline
\end{tabular}

Page 8006 


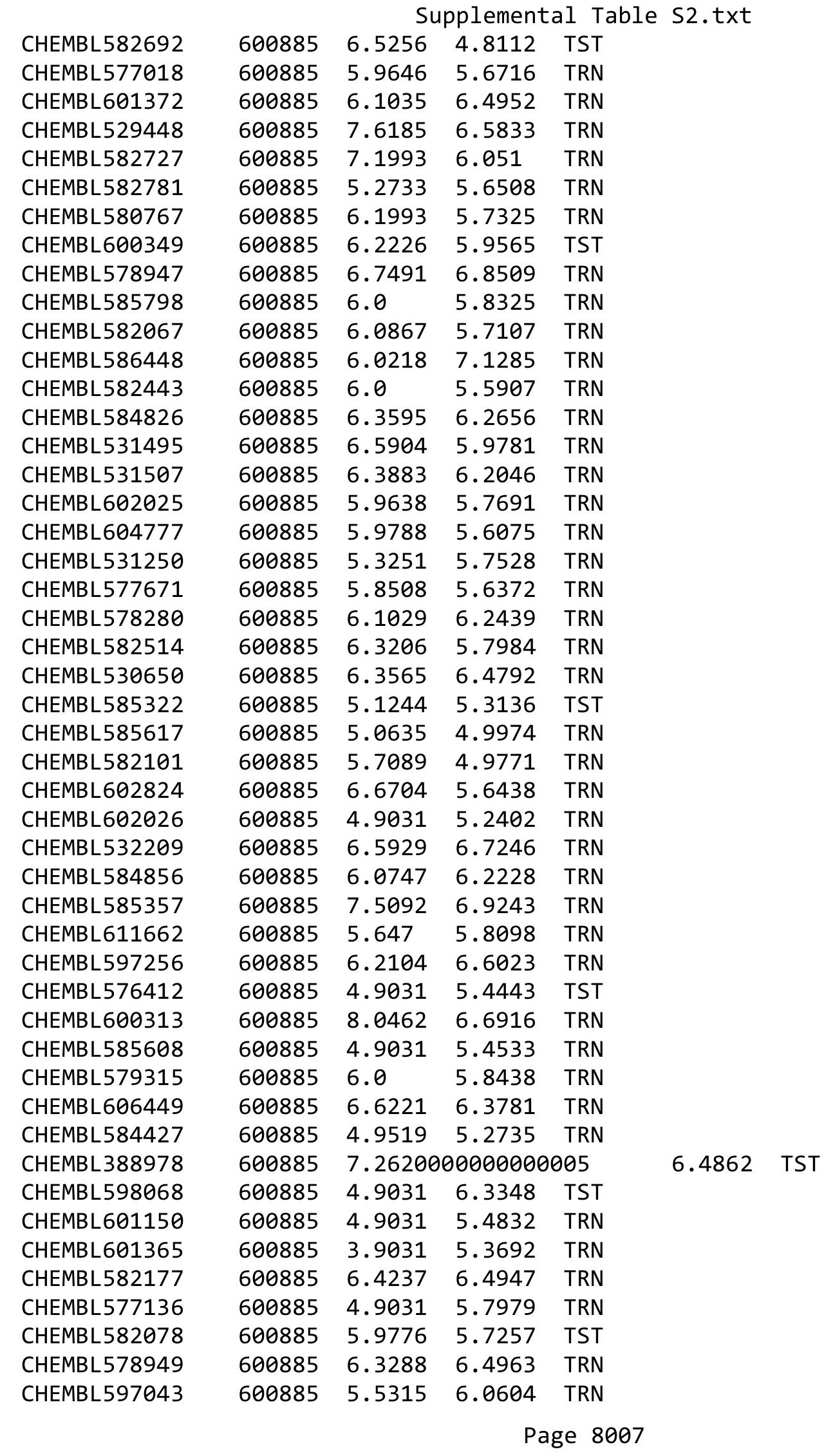




\begin{tabular}{|c|c|c|c|c|c|}
\hline & & & oplement & al lable s & \\
\hline CHEMBL600767 & 600885 & 6.6123 & 5.9976 & TRN & \\
\hline CHEMBL581674 & 600885 & 5.3546 & 5.83299 & 9999999999 & TRN \\
\hline CHEMBL581799 & 600885 & 6.3936 & 5.5608 & TST & \\
\hline CHEMBL578462 & 600885 & 5.2291 & 5.3396 & TRN & \\
\hline CHEMBL582099 & 600885 & 6.4248 & 6.1771 & TRN & \\
\hline CHEMBL584242 & 600885 & 6.5293 & 6.0135 & TRN & \\
\hline CHEMBL604530 & 600885 & 4.9031 & 6.2503 & TRN & \\
\hline CHEMBL600893 & 600885 & 5.9038 & 5.1316 & TRN & \\
\hline CHEMBL604531 & 600885 & 6.3872 & 5.7565 & TRN & \\
\hline CHEMBL587642 & 600885 & 7.4237 & 6.8519 & TRN & \\
\hline CHEMBL584074 & 600885 & 7.0395 & 6.11600 & 00000000005 & TRN \\
\hline CHEMBL578731 & 600885 & 5.9059 & 5.7435 & TST & \\
\hline CHEMBL601369 & 600885 & 3.9031 & 5.6836 & TST & \\
\hline CHEMBL598279 & 600885 & 6.6726 & 6.4841 & TRN & \\
\hline CHEMBL582731 & 600885 & 5.9983 & 5.3221 & TRN & \\
\hline CHEMBL579305 & 600885 & 5.8837 & 5.648 & TRN & \\
\hline CHEMBL602424 & 600885 & 4.9031 & 5.1379 & TRN & \\
\hline CHEMBL600930 & 600885 & 5.4908 & 5.7825 & TRN & \\
\hline CHEMBL579725 & 600885 & 6.3556 & 6.1651 & TRN & \\
\hline CHEMBL600354 & 600885 & 6.9259 & 6.9426 & TRN & \\
\hline CHEMBL585222 & 600885 & 6.6139 & 6.2593 & TRN & \\
\hline CHEMBL578106 & 600885 & 4.9031 & 5.3873 & TRN & \\
\hline CHEMBL585045 & 600885 & 6.466 & 5.8839 & TST & \\
\hline CHEMBL602414 & 600885 & 6.6676 & 5.9458 & TRN & \\
\hline CHEMBL599515 & 600885 & 4.9431 & 5.0759 & TRN & \\
\hline CHEMBL601570 & 600885 & 7.0867 & 6.5178 & TRN & \\
\hline CHEMBL599495 & 600885 & 5.1811 & 5.6834 & TRN & \\
\hline CHEMBL597039 & 600885 & 5.744 & 6.114 & TRN & \\
\hline CHEMBL319952 & 600885 & 6.055 & 6.3599 & TRN & \\
\hline CHEMBL601797 & 600885 & 4.9344 & 5.2894 & TRN & \\
\hline CHEMBL579891 & 600885 & 6.9446 & 6.1642 & TRN & \\
\hline CHEMBL602408 & 600885 & 4.0173 & 4.7625 & TRN & \\
\hline CHEMBL600941 & 600885 & 6.5696 & 6.33899 & 99999999995 & TRN \\
\hline CHEMBL533794 & 600885 & 6.6799 & 6.0881 & TRN & \\
\hline CHEMBL600329 & 600885 & 5.9481 & 6.0831 & TST & \\
\hline CHEMBL172 & 600885 & 7.2865 & 6.9309 & TST & \\
\hline CHEMBL584444 & 600885 & 6.6419 & 5.8931 & TST & \\
\hline CHEMBL605818 & 600885 & 4.9996 & 5.7656 & TST & \\
\hline CHEMBL579313 & 600885 & 7.6505 & 7.1573 & TRN & \\
\hline CHEMBL531956 & 600885 & 5.3197 & 5.4377 & TRN & \\
\hline CHEMBL601120 & 600885 & 5.1568 & 5.7202 & TRN & \\
\hline CHEMBL581176 & 600885 & 6.4572 & 6.9476 & TRN & \\
\hline CHEMBL598263 & 600885 & 6.0 & 5.7457 & TST & \\
\hline CHEMBL584861 & 600885 & 5.9133 & 6.3022 & TRN & \\
\hline CHEMBL602798 & 600885 & 3.9031 & 5.3062 & TRN & \\
\hline CHEMBL532640 & 600885 & 6.8465 & 6.335 & TRN & \\
\hline CHEMBL600339 & 600885 & 5.0123 & 5.2936 & TST & \\
\hline CHEMBL598079 & 600885 & 6.0 & 5.8054 & TRN & \\
\hline
\end{tabular}




\begin{tabular}{|c|c|c|c|c|c|c|}
\hline & & & & & & \\
\hline CHEMBL531229 & 600885 & 6.4989 & 6.0429 & TRN & & \\
\hline CHEMBL601382 & 600885 & 6.6776 & 6.0001 & TRN & & \\
\hline CHEMBL581662 & 600885 & 6.059 & 5.5653 & TRN & & \\
\hline CHEMBL577415 & 600885 & 3.9031 & 5.447 & TRN & & \\
\hline CHEMBL529493 & 600885 & 6.6472 & 5.9744 & TRN & & \\
\hline CHEMBL601559 & 600885 & 5.9465 & 5.9977 & TRN & & \\
\hline CHEMBL584837 & 600885 & 4.9352 & 5.3496 & TRN & & \\
\hline CHEMBL584866 & 600885 & 5.9237 & 5.4681 & TRN & & \\
\hline CHEMBL1583585 & 600885 & 7.5043 & 6.5319 & TRN & & \\
\hline CHEMBL581852 & 600885 & 6.1232 & 5.3304 & TST & & \\
\hline CHEMBL602425 & 600885 & 6.6776 & 6.4782 & TRN & & \\
\hline CHEMBL600102 & 600885 & 6.0 & 5.9525 & TRN & & \\
\hline CHEMBL579297 & 600885 & 6.3468 & 6.1018 & TRN & & \\
\hline CHEMBL579931 & 600885 & 6.0516 & 5.8378 & TST & & \\
\hline CHEMBL581041 & 600885 & 6.0867 & 5.9278 & TRN & & \\
\hline CHEMBL585987 & 600885 & 5.9851 & 5.3469 & TRN & & \\
\hline CHEMBL601189 & 600885 & 6.8356 & 6.2988 & TST & & \\
\hline CHEMBL317364 & 600885 & 8.1451 & 7.0497 & TRN & & \\
\hline CHEMBL578905 & 600885 & 6.4168 & 6.3202 & TRN & & \\
\hline CHEMBL602196 & 600885 & 4.9031 & 5.3932 & TRN & & \\
\hline CHEMBL601761 & 600885 & 6.1739 & 5.92899 & 9999999999 & & TRN \\
\hline CHEMBL534566 & 600885 & 5.0969 & 5.2483 & TRN & & \\
\hline CHEMBL584424 & 600885 & 6.4461 & 6.5137 & TRN & & \\
\hline CHEMBL602031 & 600885 & 5.9223 & 5.7752 & TRN & & \\
\hline CHEMBL600729 & 600885 & 6.3215 & 6.0411 & TRN & & \\
\hline CHEMBL599909 & 600885 & 4.8318 & 5.63399 & 9999999999 & 95 & TRN \\
\hline CHEMBL578091 & 600885 & 6.595 & 5.6806 & TRN & & \\
\hline CHEMBL582440 & 600885 & 6.4425 & 5.8526 & TRN & & \\
\hline CHEMBL579459 & 600885 & 6.3546 & 5.7091 & TST & & \\
\hline CHEMBL531165 & 600885 & 6.75700 & 30000000 & & 5.9727 & TRN \\
\hline CHEMBL546591 & 600885 & 7.0405 & 6.0929 & TRN & & \\
\hline CHEMBL600489 & 600885 & 4.06800 & 00000000 & 005 & 5.8032 & TRN \\
\hline CHEMBL582082 & 600885 & 6.3478 & 6.38200 & 0000000001 & & TRN \\
\hline CHEMBL530801 & 600885 & 3.9031 & 5.0632 & TRN & & \\
\hline CHEMBL582659 & 600885 & 6.0 & 5.7245 & TRN & & \\
\hline CHEMBL3189145 & 600885 & 6.6874 & 6.0425 & TRN & & \\
\hline CHEMBL601355 & 600885 & 4.9031 & 5.6674 & TRN & & \\
\hline CHEMBL579349 & 600885 & 5.1959 & 5.4109 & TRN & & \\
\hline CHEMBL602401 & 600885 & 6.1073 & 6.1933 & TRN & & \\
\hline CHEMBL602606 & 600885 & 6.5829 & 6.1873 & TRN & & \\
\hline CHEMBL582060 & 600885 & 5.2573 & 5.7984 & TRN & & \\
\hline CHEMBL578058 & 600885 & 5.8989 & 5.9202 & TRN & & \\
\hline CHEMBL584425 & 600885 & 6.3809 & 7.1876 & TRN & & \\
\hline CHEMBL602616 & 600885 & 4.8735 & 5.7626 & TRN & & \\
\hline CHEMBL602608 & 600885 & 6.2495 & 5.3139 & TRN & & \\
\hline CHEMBL577214 & 600885 & 4.9031 & 5.5033 & TRN & & \\
\hline CHEMBL581265 & 600885 & 4.9337 & 5.7592 & TRN & & \\
\hline CHEMBL578281 & 600885 & 5.2823 & 5.6192 & TRN & & \\
\hline
\end{tabular}




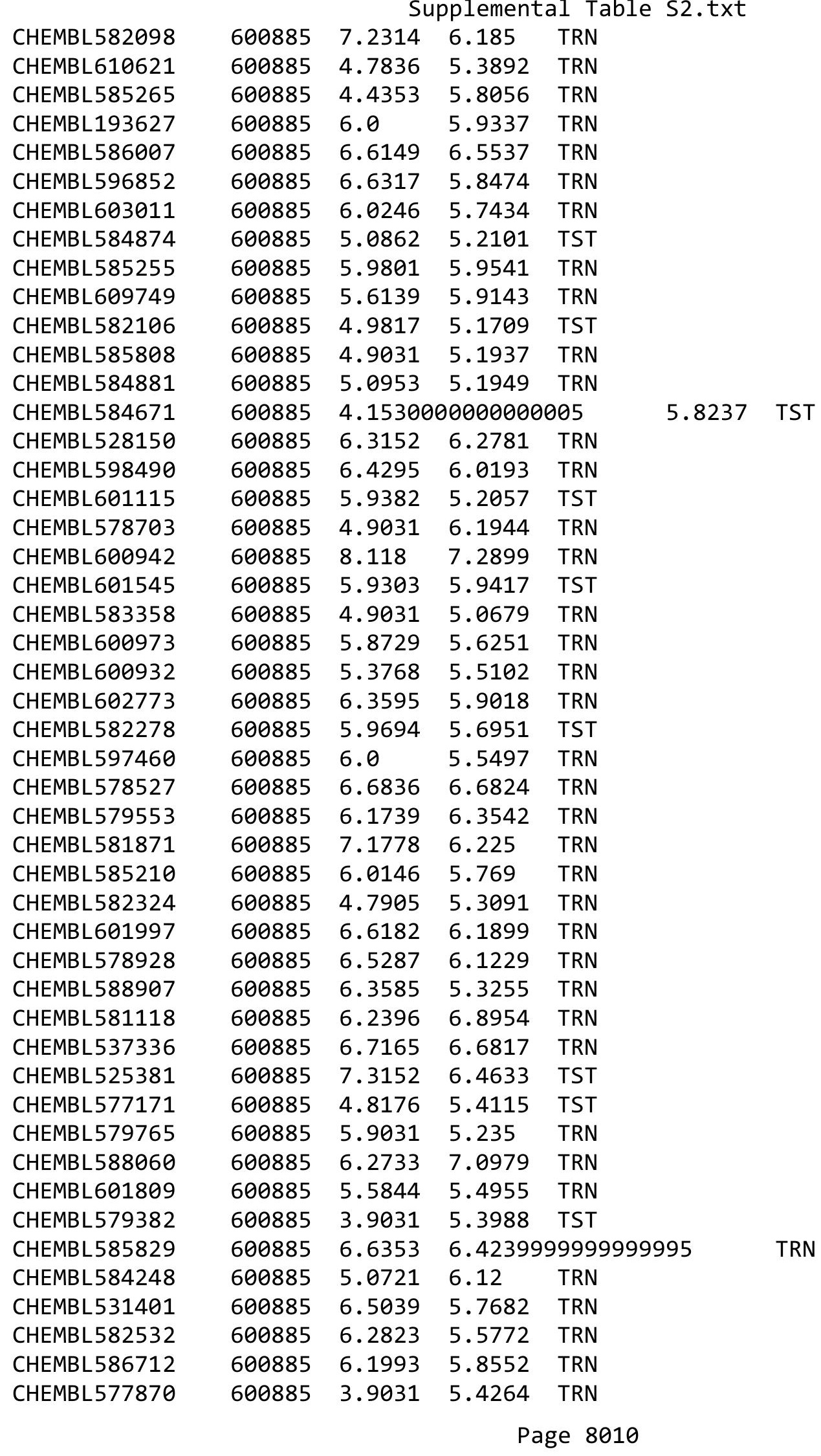




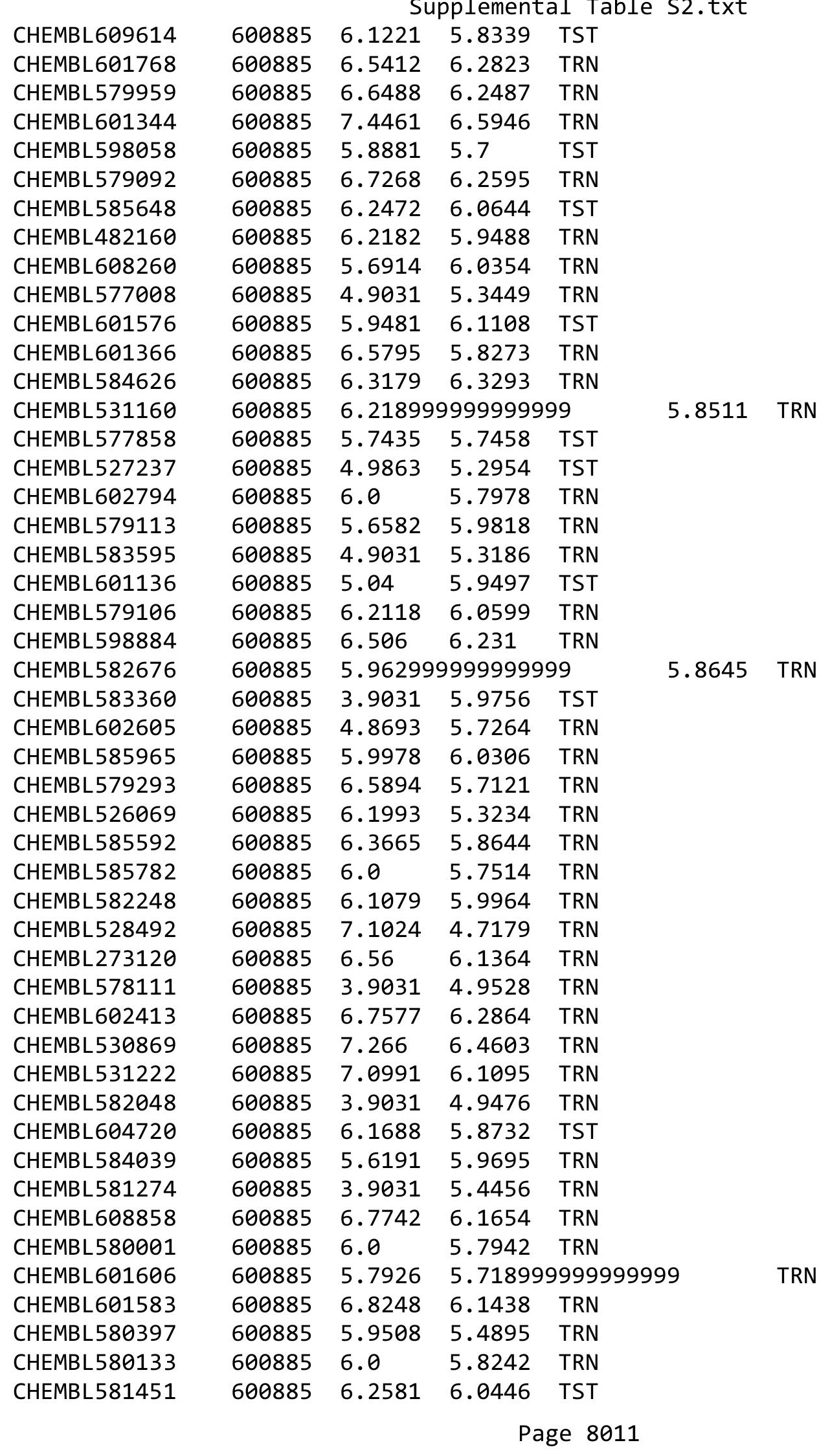




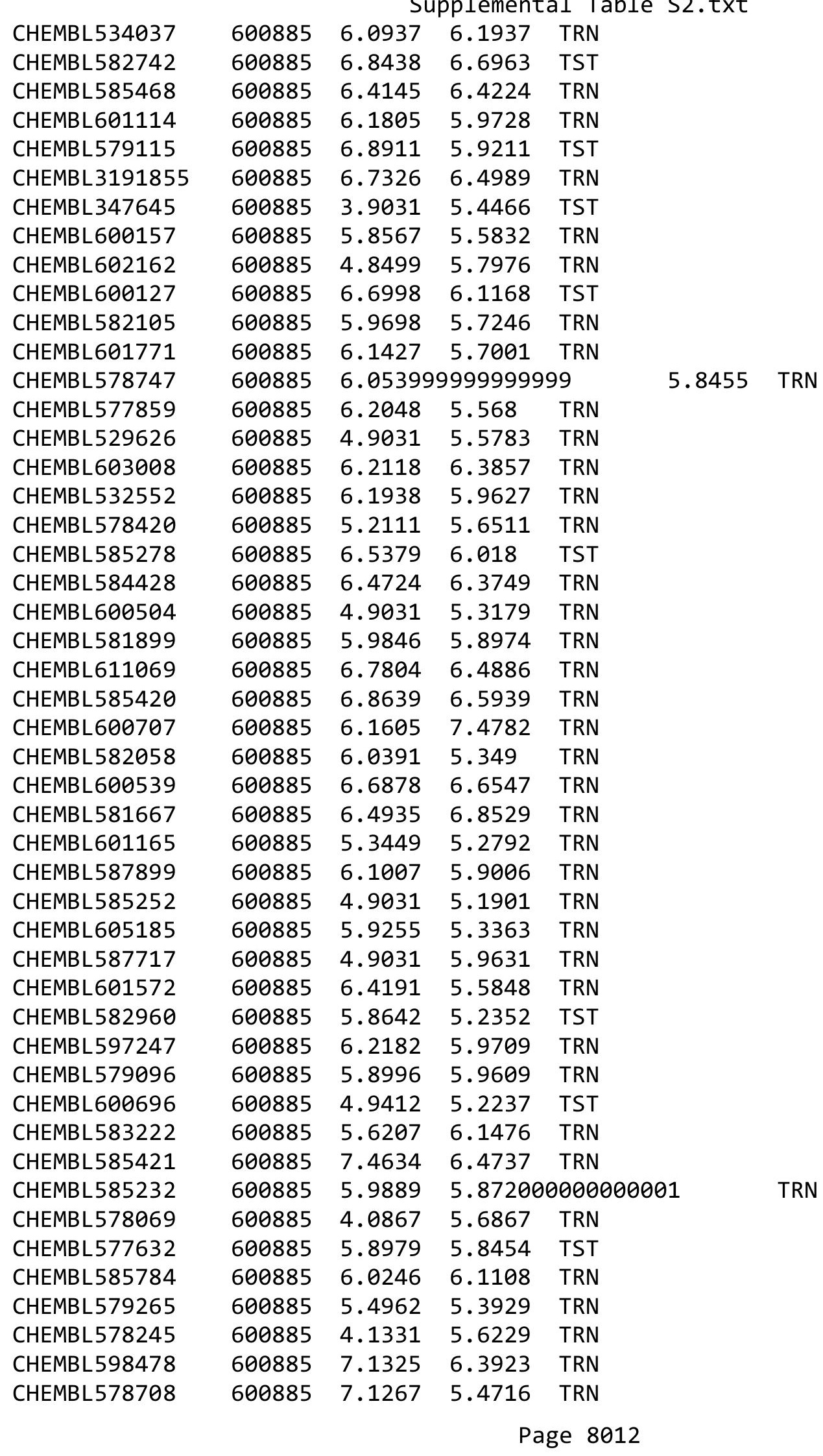




\begin{tabular}{|c|c|c|c|c|c|c|}
\hline \multirow[b]{2}{*}{ CHEMBL369895 } & \multicolumn{6}{|c|}{ Supplemental Table S2.txt } \\
\hline & 600885 & 6.1904 & 5.8028 & TRN & & \\
\hline CHEMBL582306 & 600885 & 6.0545 & 6.765 & TRN & & \\
\hline CHEMBL576600 & 600885 & 4.8063 & 5.7439 & TRN & & \\
\hline CHEMBL601990 & 600885 & 5.3546 & 5.6011 & TRN & & \\
\hline CHEMBL598680 & 600885 & 5.8847 & 5.4278 & TRN & & \\
\hline CHEMBL603020 & 600885 & 6.9423 & 6.2269 & TRN & & \\
\hline CHEMBL576401 & 600885 & 6.0453 & 6.1576 & TRN & & \\
\hline CHEMBL600502 & 600885 & 5.8831 & 6.0984 & TRN & & \\
\hline CHEMBL578461 & 600885 & 4.9535 & 5.4636 & TRN & & \\
\hline CHEMBL601173 & 600885 & 5.9965 & 5.7894 & TST & & \\
\hline CHEMBL603043 & 600885 & 6.4473 & 6.2548 & TRN & & \\
\hline CHEMBL587862 & 600885 & 6.5197 & 5.9343 & TRN & & \\
\hline CHEMBL582686 & 600885 & $5.6160 e$ & 30000000 & 205 & 5.591 & TRN \\
\hline CHEMBL586290 & 600885 & 3.9031 & 5.4442 & TRN & & \\
\hline CHEMBL602834 & 600885 & 6.4724 & 5.7726 & TRN & & \\
\hline CHEMBL601187 & 600885 & 6.92299 & 99999999 & 99 & 6.483 & TRN \\
\hline CHEMBL584240 & 600885 & 6.3936 & 6.4081 & TRN & & \\
\hline CHEMBL602210 & 600885 & 4.9212 & 5.4444 & TRN & & \\
\hline CHEMBL527297 & 600885 & 6.0937 & 5.9234 & TRN & & \\
\hline CHEMBL599710 & 600885 & 6.2041 & 5.7771 & TRN & & \\
\hline CHEMBL578071 & 600885 & 5.4012 & 5.6923 & TRN & & \\
\hline CHEMBL602803 & 600885 & 6.5998 & 6.6735 & TRN & & \\
\hline CHEMBL600101 & 600885 & 6.068 & 6.2419 & TRN & & \\
\hline CHEMBL581044 & 600885 & 6.0 & 5.6445 & TST & & \\
\hline CHEMBL579100 & 600885 & 5.4921 & 5.6556 & TRN & & \\
\hline CHEMBL579122 & 600885 & 5.7545 & 6.5302 & TRN & & \\
\hline CHEMBL596848 & 600885 & 7.3098 & 6.2993 & TST & & \\
\hline CHEMBL581258 & 600885 & 4.0862 & 5.7419 & TST & & \\
\hline CHEMBL600919 & 600885 & 6.71899 & 99999999 & & 5.7767 & TRN \\
\hline CHEMBL600134 & 600885 & 4.8665 & 5.657 & TRN & & \\
\hline CHEMBL581236 & 600885 & 5.5184 & 5.5761 & TST & & \\
\hline CHEMBL600896 & 600885 & 3.9031 & 5.8583 & TRN & & \\
\hline CHEMBL602999 & 600885 & 5.8814 & 5.83899 & 99999 & 995 & TRN \\
\hline CHEMBL588467 & 600885 & 6.1337 & 5.8027 & TRN & & \\
\hline CHEMBL89445 & 600885 & 6.8111 & 6.4812 & TRN & & \\
\hline CHEMBL600278 & 600885 & 4.9031 & 6.4465 & TRN & & \\
\hline CHEMBL598699 & 600885 & 6.0615 & 6.3027 & TRN & & \\
\hline CHEMBL582100 & 600885 & 3.9031 & 5.7259 & TST & & \\
\hline CHEMBL602761 & 600885 & 7.0044 & 6.4491 & TST & & \\
\hline CHEMBL601317 & 600885 & 5.6392 & 6.1966 & TST & & \\
\hline CHEMBL585460 & 600885 & 4.9031 & 6.5321 & TRN & & \\
\hline CHEMBL582709 & 600885 & 4.8693 & 5.7765 & TRN & & \\
\hline CHEMBL600722 & 600885 & 6.1403 & 5.8469 & TRN & & \\
\hline CHEMBL577626 & 600885 & 5.7326 & 5.5481 & TRN & & \\
\hline CHEMBL581911 & 600885 & 4.7905 & 5.7349 & TRN & & \\
\hline CHEMBL600514 & 600885 & 5.8058 & 5.4709 & TRN & & \\
\hline CHEMBL585814 & 600885 & 7.1046 & 6.6617 & TRN & & \\
\hline CHEMBL579325 & 600885 & 7.5947 & 7.129 & TRN & & \\
\hline
\end{tabular}




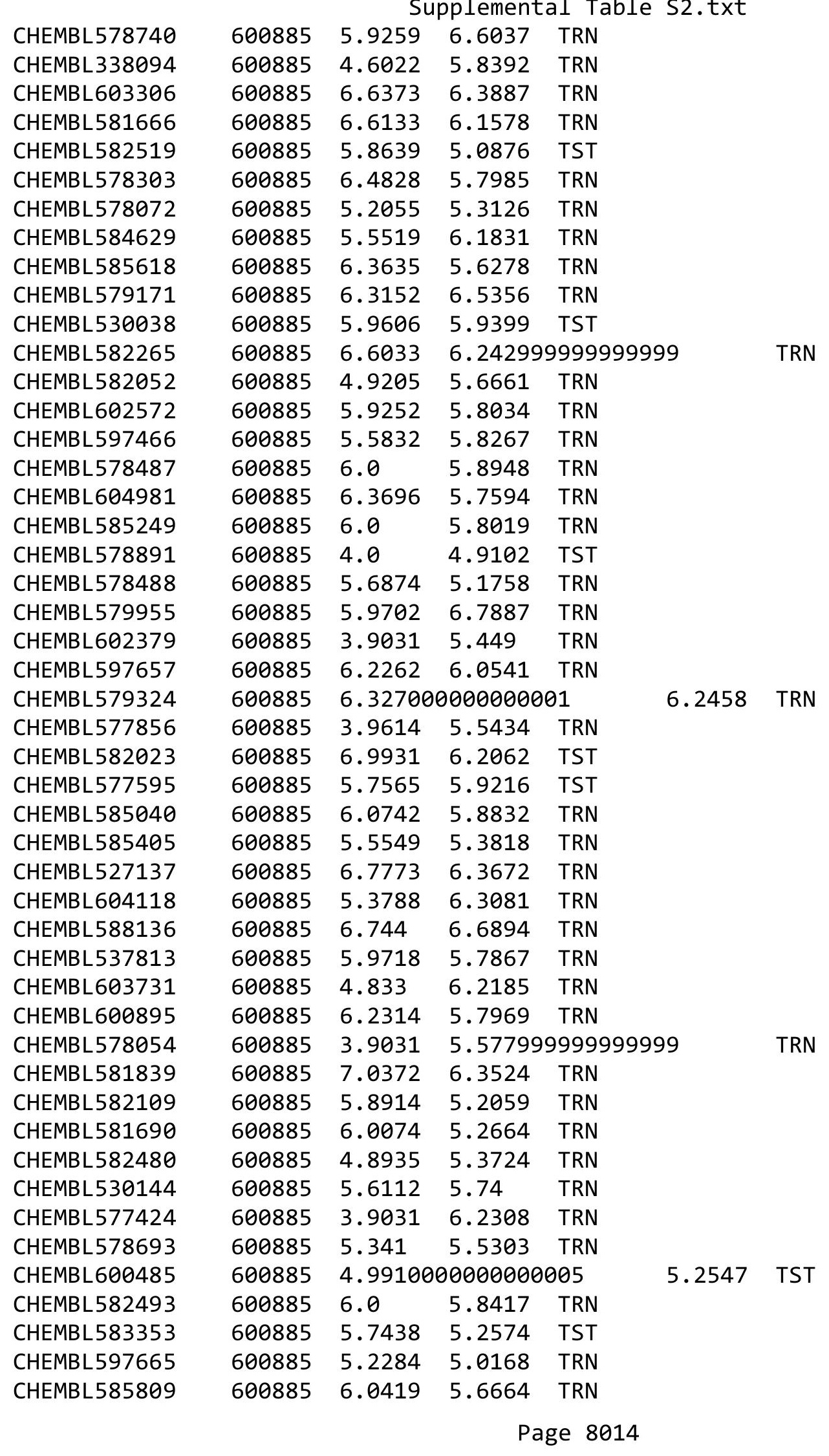




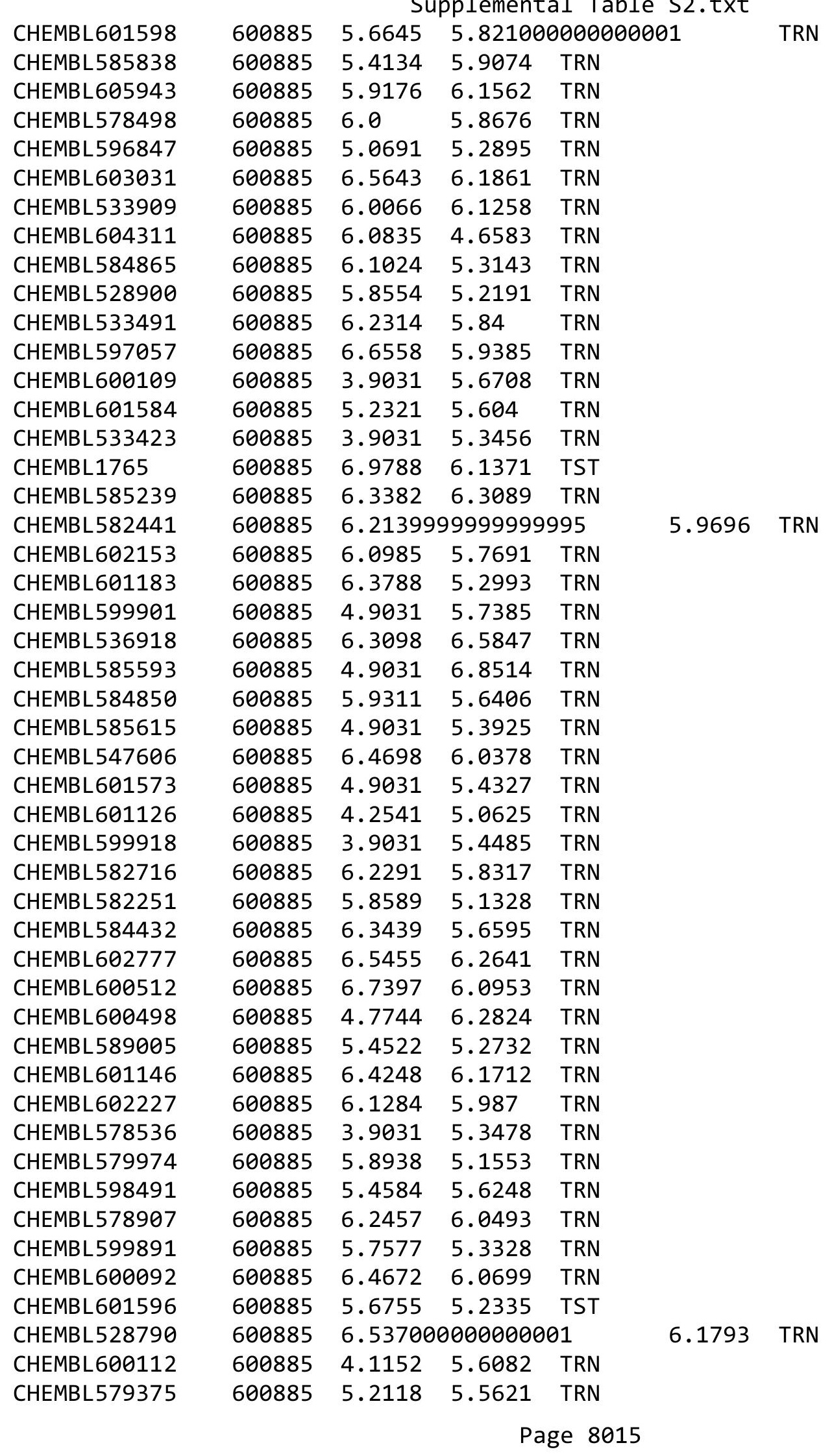


Supplemental Table S2.txt

\begin{tabular}{|c|c|c|c|c|c|}
\hline CHEMBL579941 & 600885 & 4.9031 & 7.2352 & TRN & \\
\hline CHEMBL577629 & 600885 & 6.6609 & 6.2298 & TRN & \\
\hline CHEMBL531637 & 600885 & 7.3179 & 6.2196 & TRN & \\
\hline CHEMBL603036 & 600885 & 4.9031 & 5.3553 & TRN & \\
\hline CHEMBL582318 & 600885 & 5.93 & 5.1485 & TRN & \\
\hline CHEMBL579285 & 600885 & 4.9031 & 5.4816 & TRN & \\
\hline CHEMBL582296 & 600885 & 5.9477 & 5.8479 & TRN & \\
\hline CHEMBL604528 & 600885 & 5.0747 & 5.3893 & TRN & \\
\hline CHEMBL600742 & 600885 & 5.9281 & 5.0758 & TRN & \\
\hline CHEMBL529033 & 600885 & 5.8471 & 5.8161 & TRN & \\
\hline CHEMBL588455 & 600885 & 6.0218 & 6.6329 & TRN & \\
\hline CHEMBL585644 & 600885 & 4.9031 & 6.3997 & TRN & \\
\hline CHEMBL 577430 & 600885 & 7.5872 & 6.8923 & TRN & \\
\hline CHEMBL582711 & 600885 & 4.9322 & 5.2671 & TRN & \\
\hline CHEMBL584467 & 600885 & 6.0985 & 5.7503 & TRN & \\
\hline CHEMBL581473 & 600885 & 4.1864 & 5.5288 & TRN & \\
\hline CHEMBL585133 & 600885 & 5.0857 & 5.5879 & TRN & \\
\hline CHEMBL532466 & 600885 & 6.0 & 5.9615 & TST & \\
\hline CHEMBL 588841 & 600885 & 6.2426 & 5.74799 & 999999999 & TRN \\
\hline CHEMBL588728 & 600885 & 4.9031 & 5.8542 & TRN & \\
\hline CHEMBL601110 & 600885 & 7.0061 & 6.1386 & TRN & \\
\hline CHEMBL582477 & 600885 & 6.1688 & 5.6538 & TRN & \\
\hline CHEMBL576407 & 600885 & 7.0462 & 6.2391 & TRN & \\
\hline CHEMBL529403 & 600885 & 4.9031 & 5.3649 & TRN & \\
\hline CHEMBL581892 & 600885 & 6.0 & 5.9968 & TRN & \\
\hline CHEMBL585277 & 600885 & 5.7542 & 5.8052 & TRN & \\
\hline CHEMBL579048 & 600885 & 7.1186 & 6.2455 & TRN & \\
\hline CHEMBL601124 & 600885 & 6.0177 & 6.0367 & TRN & \\
\hline CHEMBL528672 & 600885 & 4.7711 & 5.2324 & TRN & \\
\hline CHEMBL586034 & 600885 & 6.8969 & 6.1353 & TRN & \\
\hline CHEMBL582314 & 600885 & 4.9031 & 5.7315 & TST & \\
\hline CHEMBL581461 & 600885 & 5.3179 & 5.58200 & 000000001 & TRN \\
\hline CHEMBL578310 & 600885 & 6.5608 & 6.0155 & TRN & \\
\hline CHEMBL584464 & 600885 & 5.6931 & 5.9855 & TST & \\
\hline CHEMBL596651 & 600885 & 5.9555 & 5.7529 & TRN & \\
\hline CHEMBL576998 & 600885 & 4.9031 & 5.6416 & TRN & \\
\hline CHEMBL584627 & 600885 & 6.3696 & 6.629 & TRN & \\
\hline CHEMBL548209 & 600885 & 6.6149 & 6.2543 & TRN & \\
\hline CHEMBL585511 & 600885 & 6.0878 & 5.7251 & TRN & \\
\hline CHEMBL 577652 & 600885 & 6.1433 & 6.0418 & TRN & \\
\hline CHEMBL600154 & 600885 & 6.2668 & 6.3546 & TRN & \\
\hline CHEMBL531777 & 600885 & 3.9031 & 5.4901 & TRN & \\
\hline CHEMBL580566 & 600885 & 6.6838 & 6.561 & TRN & \\
\hline CHEMBL582690 & 600885 & 6.8976 & 6.3188 & TRN & \\
\hline CHEMBL576405 & 600885 & 6.6706 & 7.1276 & TRN & \\
\hline CHEMBL578528 & 600885 & 6.8441 & 6.7485 & TRN & \\
\hline CHEMBL587449 & 600885 & 6.1296 & 5.6656 & TRN & \\
\hline CHEMBL577418 & 600885 & 4.7602 & 5.8114 & TRN & \\
\hline
\end{tabular}




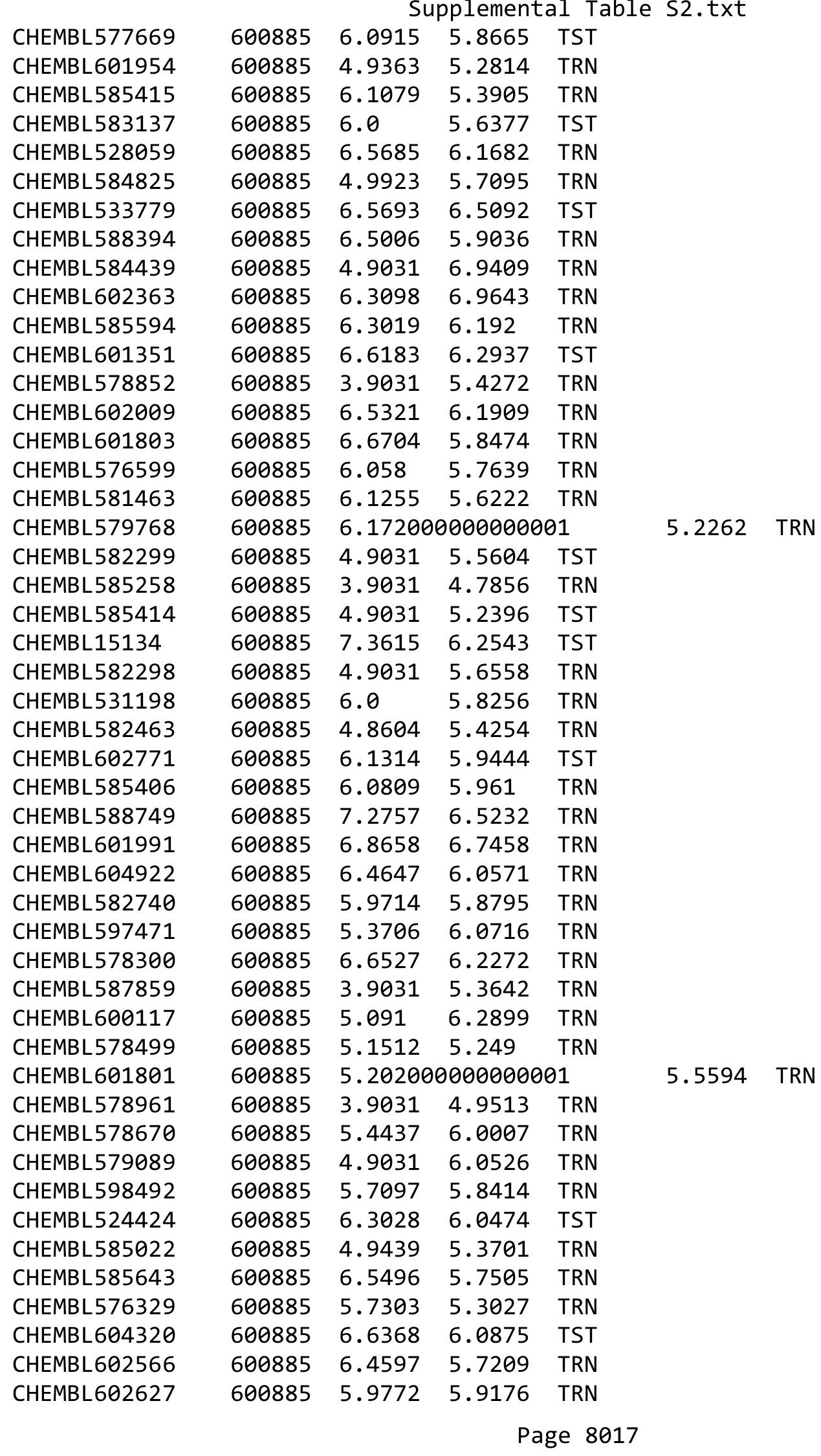




\begin{tabular}{|c|c|c|c|c|c|}
\hline \multirow[b]{2}{*}{ CHEMBL601986 } & \multicolumn{5}{|c|}{ Supplemental Table S2.txt } \\
\hline & 600885 & 5.7133 & 5.779 & TRN & \\
\hline CHEMBL584631 & 600885 & 5.1555 & 5.3161 & TST & \\
\hline CHEMBL603041 & 600885 & 4.9031 & 5.7633 & TRN & \\
\hline CHEMBL579103 & 600885 & 6.1046 & 5.67899 & 9999999999 & TRN \\
\hline CHEMBL597266 & 600885 & 6.4342 & 5.7723 & TST & \\
\hline CHEMBL1615695 & 600885 & 7.2154 & 5.2556 & TRN & \\
\hline CHEMBL602412 & 600885 & 5.0052 & 5.2746 & TRN & \\
\hline CHEMBL578103 & 600885 & 4.0809 & 5.5496 & TRN & \\
\hline CHEMBL585974 & 600885 & 6.8351 & 6.4132 & TRN & \\
\hline CHEMBL600145 & 600885 & 6.17200 & 30000000 & 7.2 & TRN \\
\hline CHEMBL602618 & 600885 & 5.3925 & 5.6174 & TRN & \\
\hline CHEMBL600318 & 600885 & 4.1249 & 5.5582 & TRN & \\
\hline CHEMBL601390 & 600885 & 6.0458 & 5.4776 & TRN & \\
\hline CHEMBL600528 & 600885 & 5.9073 & 5.5154 & TRN & \\
\hline CHEMBL599093 & 600885 & 5.9905 & 5.7869 & TST & \\
\hline CHEMBL488127 & 600885 & 7.5501 & 6.6511 & TRN & \\
\hline CHEMBL600728 & 600885 & 6.0 & 5.7156 & TRN & \\
\hline CHEMBL527454 & 600885 & 5.9263 & 5.1876 & TRN & \\
\hline CHEMBL585038 & 600885 & 4.9031 & 5.19600 & 2000000001 & TRN \\
\hline CHEMBL584232 & 600885 & 5.7972 & 5.7517 & TST & \\
\hline CHEMBL529407 & 600885 & 5.1409 & 5.4463 & TRN & \\
\hline CHEMBL582698 & 600885 & 5.0595 & 5.602 & TRN & \\
\hline CHEMBL602371 & 600885 & 6.5418 & 6.2011 & TRN & \\
\hline CHEMBL604116 & 600885 & 5.6264 & 5.5777 & TRN & \\
\hline CHEMBL581481 & 600885 & 5.9176 & 5.1136 & TRN & \\
\hline CHEMBL576169 & 600885 & 4.9031 & 5.9295 & TRN & \\
\hline CHEMBL544227 & 600885 & 9.0061 & 5.7816 & TRN & \\
\hline CHEMBL604324 & 600885 & 6.308 & 5.8549 & TRN & \\
\hline CHEMBL602769 & 600885 & 6.6657 & 6.1548 & TST & \\
\hline CHEMBL584452 & 600885 & 6.1959 & 5.8695 & TRN & \\
\hline CHEMBL602610 & 600885 & 4.9735 & 5.1695 & TST & \\
\hline CHEMBL584620 & 600885 & 6.0773 & 6.3841 & TRN & \\
\hline CHEMBL576207 & 600885 & 6.308 & 6.0556 & TRN & \\
\hline CHEMBL598886 & 600885 & 4.1255 & 5.7728 & TST & \\
\hline CHEMBL588450 & 600885 & 6.7387 & 6.1665 & TRN & \\
\hline CHEMBL596839 & 600885 & 5.1643 & 5.3327 & TRN & \\
\hline CHEMBL598071 & 600885 & 6.6519 & 5.9009 & TRN & \\
\hline CHEMBL546215 & 600885 & 6.3575 & 6.1732 & TRN & \\
\hline CHEMBL597649 & 600885 & 6.475 & 6.38 & TRN & \\
\hline CHEMBL585056 & 600885 & 4.87 & 5.4249 & TRN & \\
\hline CHEMBL602378 & 600885 & 6.3655 & 5.9468 & TRN & \\
\hline CHEMBL597457 & 600885 & 6.4672 & 5.8695 & TRN & \\
\hline CHEMBL582077 & 600885 & 3.9031 & 5.735 & TST & \\
\hline CHEMBL578505 & 600885 & 6.466 & 6.01200 & $\partial 0000000005$ & TST \\
\hline CHEMBL582529 & 600885 & 6.1993 & 5.8631 & TRN & \\
\hline CHEMBL602168 & 600885 & 4.8831 & 6.9913 & TST & \\
\hline CHEMBL586684 & 600885 & 7.0362 & 6.6801 & TRN & \\
\hline CHEMBL529837 & 600885 & 6.0 & 5.6953 & TRN & \\
\hline
\end{tabular}




\begin{tabular}{|c|c|c|c|c|c|}
\hline \multicolumn{6}{|c|}{ Supplemental Table S2.txt } \\
\hline CHEMBL600165 & 600885 & 6.5157 & 6.3063 & TRN & \\
\hline CHEMBL584877 & 600885 & 6.0878 & 5.1705 & TRN & \\
\hline CHEMBL600098 & 600885 & 6.0 & 5.7626 & TRN & \\
\hline CHEMBL576610 & 600885 & 6.4724 & 6.4615 & TRN & \\
\hline CHEMBL599304 & 600885 & 7.1439 & 6.1474 & TRN & \\
\hline CHEMBL588746 & 600885 & 6.9212 & 7.4669 & TRN & \\
\hline CHEMBL602614 & 600885 & 4.806 & 5.37 & TRN & \\
\hline CHEMBL596854 & 600885 & 5.1605 & 5.8155 & TRN & \\
\hline CHEMBL601798 & 600885 & 6.768 & 5.819 & TRN & \\
\hline CHEMBL578544 & 600885 & 6.7147 & 6.2631 & TRN & \\
\hline CHEMBL584037 & 600885 & 6.0074 & 5.985 & TRN & \\
\hline CHEMBL578113 & 600885 & 6.4672 & 6.164 & TRN & \\
\hline CHEMBL599711 & 600885 & 5.5223 & 5.9284 & TRN & \\
\hline CHEMBL597474 & 600885 & 5.9923 & 5.9444 & TRN & \\
\hline CHEMBL588470 & 600885 & 4.0615 & 5.6384 & TST & \\
\hline CHEMBL584222 & 600885 & 6.8422 & 6.13700 & 00000000005 & TRN \\
\hline CHEMBL578707 & 600885 & 6.0985 & 5.8033 & TRN & \\
\hline CHEMBL582703 & 600885 & 4.994 & 5.6966 & TRN & \\
\hline CHEMBL577426 & 600885 & 5.0132 & 5.6132 & TRN & \\
\hline CHEMBL586912 & 600885 & 6.1261 & 5.6739 & TRN & \\
\hline CHEMBL581537 & 600885 & 4.9031 & 6.8602 & TRN & \\
\hline CHEMBL585226 & 600885 & 7.0685 & 6.6994 & TRN & \\
\hline CHEMBL602171 & 600885 & 4.8703 & 5.5867 & TST & \\
\hline CHEMBL578948 & 600885 & 7.648 & 6.472 & TRN & \\
\hline CHEMBL578963 & 600885 & 6.2782 & 5.9002 & TRN & \\
\hline CHEMBL596844 & 600885 & 5.8254 & 5.8013 & TRN & \\
\hline CHEMBL532688 & 600885 & 5.7053 & 5.6763 & TRN & \\
\hline CHEMBL585097 & 600885 & 6.1694 & 5.8626 & TRN & \\
\hline CHEMBL578699 & 600885 & 6.7263 & 5.9911 & TRN & \\
\hline CHEMBL579326 & 600885 & 7.1158 & 7.1144 & TRN & \\
\hline CHEMBL601151 & 600885 & 6.2487 & 6.1445 & TRN & \\
\hline CHEMBL3216427 & 600885 & 8.2534 & 6.4438 & TRN & \\
\hline CHEMBL600304 & 600885 & 5.5372 & 5.9169 & TRN & \\
\hline CHEMBL611373 & 600885 & 5.2321 & 5.0953 & TRN & \\
\hline CHEMBL599286 & 600885 & 6.1192 & 6.6497 & TRN & \\
\hline CHEMBL576160 & 600885 & 5.1537 & 5.6437 & TRN & \\
\hline CHEMBL579028 & 600885 & 6.0511 & 5.2713 & TRN & \\
\hline CHEMBL581742 & 600885 & 4.7918 & 5.9049 & TRN & \\
\hline CHEMBL586200 & 600885 & 6.0057 & 6.306 & TRN & \\
\hline CHEMBL588004 & 600885 & 6.3382 & 6.2716 & TRN & \\
\hline CHEMBL581699 & 600885 & 4.9776 & 5.1488 & TRN & \\
\hline CHEMBL600345 & 600885 & 6.0482 & 5.3216 & TRN & \\
\hline CHEMBL581058 & 600885 & 4.9755 & 5.1511 & TRN & \\
\hline CHEMBL584463 & 600885 & 5.0625 & 5.6311 & TRN & \\
\hline CHEMBL609608 & 600885 & 6.2034 & 5.7555 & TRN & \\
\hline CHEMBL601952 & 600885 & 6.815 & 6.1213 & TRN & \\
\hline CHEMBL 2021448 & 600885 & 6.0 & 5.8942 & TST & \\
\hline CHEMBL602174 & 600885 & 6.8761 & 6.1135 & TRN & \\
\hline
\end{tabular}




\begin{tabular}{|c|c|c|c|c|c|c|}
\hline \multirow[b]{2}{*}{ CHEMBL611370 } & \multicolumn{6}{|c|}{ suppletiletras } \\
\hline & 600885 & 6.6994 & 5.9434 & TRN & & \\
\hline CHEMBL586249 & 600885 & 6.4389 & 6.3511 & TRN & & \\
\hline CHEMBL600113 & 600885 & 6.066 & 6.0156 & TRN & & \\
\hline CHEMBL601122 & 600885 & 6.945 & 6.3074 & TRN & & \\
\hline CHEMBL601149 & 600885 & 5.4921 & 4.7206 & TRN & & \\
\hline CHEMBL580135 & 600885 & 4.9031 & 5.5305 & TRN & & \\
\hline CHEMBL582678 & 600885 & 3.9516 & 4.8266 & TRN & & \\
\hline CHEMBL581267 & 600885 & 5.8496 & 5.6715 & TRN & & \\
\hline CHEMBL584645 & 600885 & 4.9031 & 6.995 & TRN & & \\
\hline CHEMBL578479 & 600885 & 7.7366 & 7.0337 & TRN & & \\
\hline CHEMBL601342 & 600885 & 5.7605 & 5.9051 & TRN & & \\
\hline CHEMBL579956 & 600885 & 5.6906 & 6.0302 & TST & & \\
\hline CHEMBL577192 & 600885 & 6.8983 & 6.8529 & TRN & & \\
\hline CHEMBL546917 & 600885 & 6.2055 & 6.401 & TRN & & \\
\hline CHEMBL532141 & 600885 & 5.4815 & 5.1986 & TRN & & \\
\hline CHEMBL585792 & 600885 & 6.4634 & 5.9147 & TRN & & \\
\hline CHEMBL600334 & 600885 & 4.8821 & 5.5851 & TRN & & \\
\hline CHEMBL600285 & 600885 & 4.9031 & 5.6996 & TST & & \\
\hline CHEMBL597264 & 600885 & 6.0685 & 6.7386 & TRN & & \\
\hline CHEMBL607577 & 600885 & 5.1013 & 5.7643 & TST & & \\
\hline CHEMBL598280 & 600885 & 5.82799 & 99999999 & 99 & 5.7768 & TRN \\
\hline CHEMBL576326 & 600885 & 5.4078 & 5.4096 & TRN & & \\
\hline CHEMBL530023 & 600885 & 3.9516 & 4.6887 & TRN & & \\
\hline CHEMBL603016 & 600885 & 6.4425 & 6.7163 & TRN & & \\
\hline CHEMBL602404 & 600885 & 4.9031 & 5.9856 & TRN & & \\
\hline CHEMBL606023 & 600885 & 4.9031 & 5.2856 & TRN & & \\
\hline CHEMBL602781 & 600885 & 6.5065 & 6.9301 & TRN & & \\
\hline CHEMBL579150 & 600885 & 5.5317 & 5.8332 & TRN & & \\
\hline CHEMBL581588 & 600885 & 7.1141 & 6.5695 & TRN & & \\
\hline CHEMBL585774 & 600885 & 6.4248 & 6.2656 & TRN & & \\
\hline CHEMBL585824 & 600885 & 7.475 & 6.4137 & TST & & \\
\hline CHEMBL585208 & 600885 & 6.3625 & 5.7007 & TRN & & \\
\hline CHEMBL579167 & 600885 & 5.0655 & 5.4382 & TRN & & \\
\hline CHEMBL582661 & 600885 & 7.3575 & 6.2996 & TRN & & \\
\hline CHEMBL584658 & 600885 & 5.7319 & 5.8451 & TRN & & \\
\hline CHEMBL577234 & 600885 & 4.7762 & 5.3693 & TRN & & \\
\hline CHEMBL582281 & 600885 & 6.1524 & 6.05399 & 9999999999 & & TRN \\
\hline CHEMBL579366 & 600885 & 6.0 & 5.669 & TRN & & \\
\hline CHEMBL532239 & 600885 & 6.3098 & 6.0439 & TRN & & \\
\hline CHEMBL584905 & 600885 & 6.2034 & 5.7855 & TRN & & \\
\hline CHEMBL578930 & 600885 & 4.9031 & 5.5676 & TST & & \\
\hline CHEMBL604111 & 600885 & 5.6745 & 5.9323 & TRN & & \\
\hline CHEMBL602182 & 600885 & 5.3307 & 5.2056 & TRN & & \\
\hline CHEMBL600903 & 600885 & 5.21399 & 79999999ऽ & 995 & 5.1801 & TRN \\
\hline CHEMBL576808 & 600885 & 7.0264 & 6.5066 & TRN & & \\
\hline CHEMBL577020 & 600885 & 6.2351 & 5.3424 & TRN & & \\
\hline CHEMBL588622 & 600885 & 4.9031 & 5.281006 & 0000000001 & & TRN \\
\hline CHEMBL605751 & 600885 & 5.5632 & 6.0044 & TRN & & \\
\hline
\end{tabular}




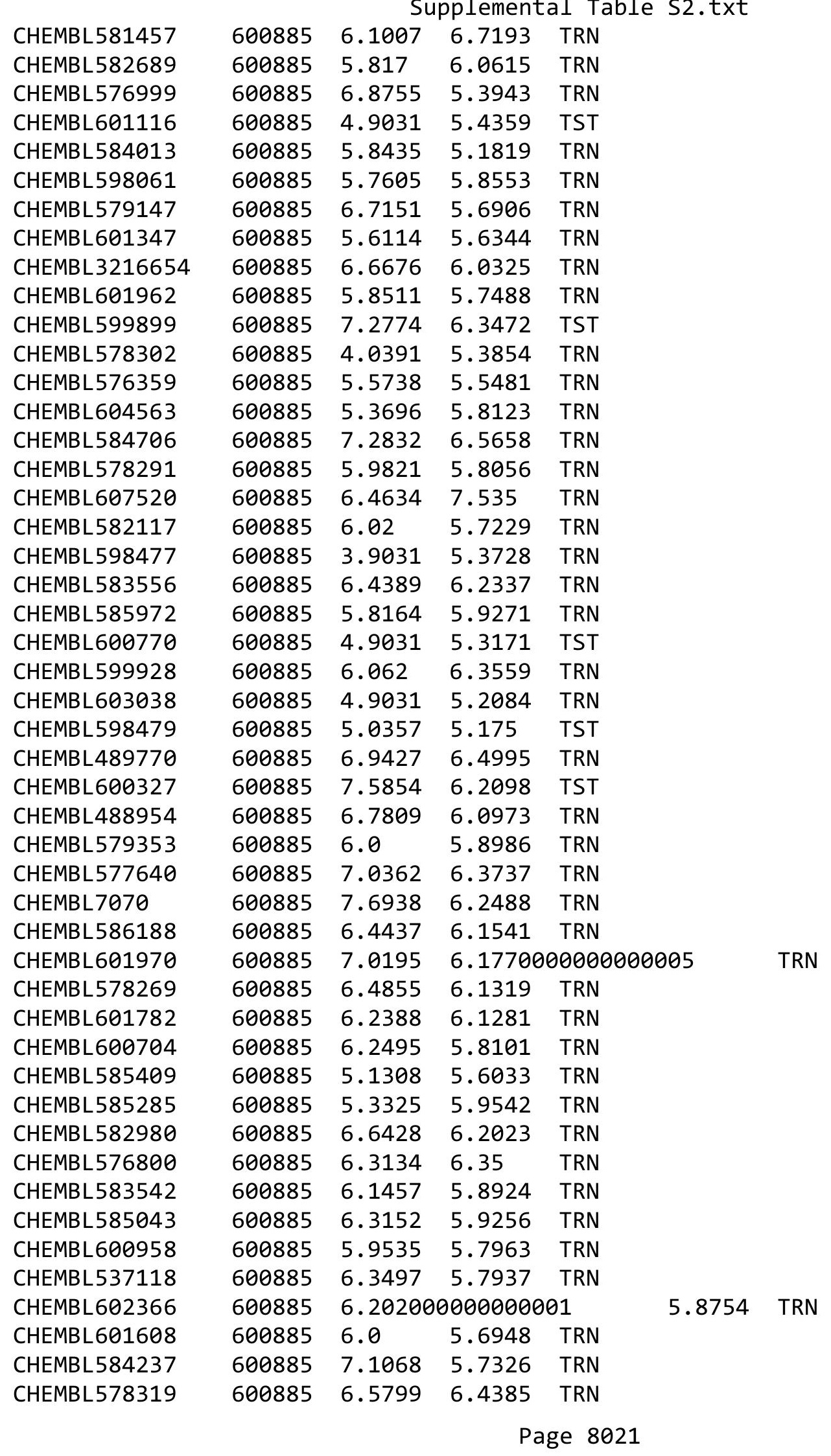




\begin{tabular}{|c|c|c|c|c|c|}
\hline \multicolumn{6}{|c|}{ Supplemental Table S2.txt } \\
\hline CHEMBL585963 & 600885 & 7.317 & 5.6572 & TRN & \\
\hline CHEMBL576601 & 600885 & 6.3645 & 5.8641 & TRN & \\
\hline CHEMBL577891 & 600885 & 6.1986 & 5.9368 & TRN & \\
\hline CHEMBL531932 & 600885 & 6.4067 & 5.9758 & TRN & \\
\hline CHEMBL583827 & 600885 & 5.284 & 5.6366 & TST & \\
\hline CHEMBL597248 & 600885 & 6.8016 & 6.5099 & TRN & \\
\hline CHEMBL602584 & 600885 & 6.0237 & 5.6943 & TRN & \\
\hline CHEMBL527682 & 600885 & 5.0195 & 4.9619 & TST & \\
\hline CHEMBL577628 & 600885 & 4.9031 & 5.3713 & TST & \\
\hline CHEMBL586032 & 600885 & 6.1073 & 5.7105 & TRN & \\
\hline CHEMBL580598 & 600885 & 5.6198 & 5.5141 & TRN & \\
\hline CHEMBL533082 & 600885 & 6.5081 & 6.3804 & TRN & \\
\hline CHEMBL602970 & 600885 & 4.9031 & 5.3746 & TRN & \\
\hline CHEMBL599493 & 600885 & 3.9031 & 5.65600 & 0000000001 & TRN \\
\hline CHEMBL578694 & 600885 & 5.1445 & 5.683 & TST & \\
\hline CHEMBL585419 & 600885 & 7.4461 & 6.2787 & TRN & \\
\hline CHEMBL604778 & 600885 & 5.7263 & 5.7954 & TST & \\
\hline CHEMBL601339 & 600885 & 5.7924 & 5.3936 & TRN & \\
\hline CHEMBL586026 & 600885 & 5.9416 & 5.7754 & TST & \\
\hline CHEMBL602375 & 600885 & 6.0 & 5.9547 & TST & \\
\hline CHEMBL577009 & 600885 & 5.8791 & 5.8221 & TRN & \\
\hline CHEMBL578541 & 600885 & 6.3565 & 5.9724 & TRN & \\
\hline CHEMBL603895 & 600885 & 5.5672 & 5.7583 & TST & \\
\hline CHEMBL577428 & 600885 & 7.1152 & 6.9748 & TRN & \\
\hline CHEMBL587728 & 600885 & 5.2041 & 5.3526 & TRN & \\
\hline CHEMBL582271 & 600885 & 7.04 & 5.7849 & TRN & \\
\hline CHEMBL600900 & 600885 & 5.3893 & 5.7031 & TST & \\
\hline CHEMBL600503 & 600885 & 6.0035 & 6.1872 & TRN & \\
\hline CHEMBL585263 & 600885 & 5.1409 & 5.1265 & TRN & \\
\hline CHEMBL529270 & 600885 & 5.0287 & 5.2442 & TRN & \\
\hline CHEMBL586061 & 600885 & 5.9048 & 5.6536 & TRN & \\
\hline CHEMBL583824 & 600885 & 6.0555 & 5.8644 & TRN & \\
\hline CHEMBL602563 & 600885 & 6.4202 & 6.1045 & TRN & \\
\hline CHEMBL599088 & 600885 & 5.5935 & 5.7404 & TRN & \\
\hline CHEMBL581474 & 600885 & 5.5061 & 5.4575 & TST & \\
\hline CHEMBL588732 & 600885 & 6.2765 & 5.8999 & TRN & \\
\hline CHEMBL597260 & 600885 & 5.2644 & 4.9743 & TRN & \\
\hline CHEMBL576611 & 600885 & 6.2993 & 5.9292 & TRN & \\
\hline CHEMBL584873 & 600885 & 5.2495 & 5.9352 & TRN & \\
\hline CHEMBL602577 & 600885 & 6.0 & 5.7892 & TST & \\
\hline CHEMBL600968 & 600885 & 6.0 & 5.7011 & TRN & \\
\hline CHEMBL608557 & 600885 & 4.0004 & 5.4594 & TRN & \\
\hline CHEMBL586017 & 600885 & 5.5415 & 6.1348 & TRN & \\
\hline CHEMBL599700 & 600885 & 6.0255 & 5.3004 & TRN & \\
\hline CHEMBL578043 & 600885 & 6.2262 & 5.7057 & TRN & \\
\hline CHEMBL587468 & 600885 & 4.9031 & 6.6191 & TRN & \\
\hline CHEMBL527923 & 600885 & 5.7277 & 5.9665 & TRN & \\
\hline CHEMBL602799 & 600885 & 6.3298 & 6.1172 & TRN & \\
\hline
\end{tabular}




\begin{tabular}{|c|c|c|c|c|c|}
\hline \multicolumn{6}{|c|}{ Supplemental Table s2.txt } \\
\hline CHEMBL603522 & 600885 & 6.0 & 5.8443 & TRN & \\
\hline CHEMBL586235 & 600885 & 6.0721 & 6.0895 & TRN & \\
\hline CHEMBL578722 & 600885 & 6.4815 & 6.3352 & TRN & \\
\hline CHEMBL605750 & 600885 & 6.2358 & 5.7174 & TRN & \\
\hline CHEMBL602805 & 600885 & 6.6445 & 6.0914 & TST & \\
\hline CHEMBL602393 & 600885 & 7.4962 & 6.8363 & TRN & \\
\hline CHEMBL576997 & 600885 & 6.0 & 5.8747 & TST & \\
\hline CHEMBL610249 & 600885 & 6.0 & 5.7857 & TST & \\
\hline CHEMBL604516 & 600885 & 5.2055 & 5.7197 & TRN & \\
\hline CHEMBL600920 & 600885 & 6.6972 & 6.1354 & TRN & \\
\hline CHEMBL601778 & 600885 & 6.129 & 5.8112 & TRN & \\
\hline CHEMBL577841 & 600885 & 4.9031 & 5.8087 & TRN & \\
\hline CHEMBL581249 & 600885 & 5.7411 & 5.7245 & TRN & \\
\hline CHEMBL600509 & 600885 & 7.0942 & 6.7231 & TRN & \\
\hline CHEMBL583997 & 600885 & 7.4802 & 6.7626 & TRN & \\
\hline CHEMBL597253 & 600885 & 6.0414 & 6.4971 & TRN & \\
\hline CHEMBL581890 & 600885 & 5.9179 & 5.8717 & TST & \\
\hline CHEMBL533947 & 600885 & 6.1273 & 6.6948 & TRN & \\
\hline CHEMBL578531 & 600885 & 7.0381 & 6.4961 & TRN & \\
\hline CHEMBL528609 & 600885 & 6.279 & 6.5602 & TRN & \\
\hline CHEMBL577419 & 600885 & 5.994 & 5.7663 & TRN & \\
\hline CHEMBL602020 & 600885 & 4.9031 & 5.2558 & TRN & \\
\hline CHEMBL600695 & 600885 & 3.9846 & 5.3077 & TRN & \\
\hline CHEMBL3144826 & 600885 & 6.0841 & 5.8981 & TRN & \\
\hline CHEMBL600731 & 600885 & 6.1451 & 5.9186 & TRN & \\
\hline CHEMBL579933 & 600885 & 6.6242 & 6.1184 & TRN & \\
\hline CHEMBL533563 & 600885 & 6.9698 & 6.6246 & TRN & \\
\hline CHEMBL580559 & 600885 & 6.0 & 5.8461 & TST & \\
\hline CHEMBL586694 & 600885 & 7.8499 & 6.7152 & TRN & \\
\hline CHEMBL577374 & 600885 & 6.9813 & 6.1645 & TRN & \\
\hline CHEMBL577212 & 600885 & 7.5651 & 6.8226 & TRN & \\
\hline CHEMBL603010 & 600885 & 6.2154 & 6.2073 & TRN & \\
\hline CHEMBL582316 & 600885 & 4.9263 & 5.278 & TRN & \\
\hline CHEMBL535101 & 600885 & 6.3036 & 6.09399 & 9999999999 & TST \\
\hline CHEMBL602985 & 600885 & 4.9031 & 5.835 & TST & \\
\hline CHEMBL584235 & 600885 & 6.697 & 6.8397 & TRN & \\
\hline CHEMBL582488 & 600885 & 6.9378 & 6.4737 & TRN & \\
\hline CHEMBL579317 & 600885 & 5.9115 & 5.675 & TRN & \\
\hline CHEMBL579280 & 600885 & 6.9851 & 6.9712 & TRN & \\
\hline CHEMBL596851 & 600885 & 5.6293 & 5.8906 & TRN & \\
\hline CHEMBL602828 & 600885 & 6.0 & 5.94600 & 0000000001 & TRN \\
\hline CHEMBL601955 & 600885 & 4.9755 & 5.2879 & TRN & \\
\hline CHEMBL585960 & 600885 & 7.0804 & 6.4275 & TRN & \\
\hline CHEMBL578671 & 600885 & 5.8983 & 6.1544 & TRN & \\
\hline CHEMBL597855 & 600885 & 6.2604 & 5.8902 & TRN & \\
\hline CHEMBL119315 & 600885 & 6.8083 & 5.1709 & TRN & \\
\hline CHEMBL608432 & 600885 & 7.4776 & 5.181 & TST & \\
\hline CHEMBL599915 & 600885 & 5.2027 & 5.5818 & TRN & \\
\hline
\end{tabular}




\begin{tabular}{|c|c|c|c|c|c|}
\hline & & & & & \\
\hline CHEMBL581243 & 600885 & 6.3778 & 6.0265 & TRN & \\
\hline CHEMBL527593 & 600885 & 5.9901 & 5.8342 & TRN & \\
\hline CHEMBL602573 & 600885 & 7.5875 & 6.6344 & TST & \\
\hline CHEMBL599095 & 600885 & 7.3307 & 6.684 & TRN & \\
\hline CHEMBL599894 & 600885 & 6.6209 & 6.356 & TRN & \\
\hline CHEMBL585686 & 600885 & 5.8752 & 5.835 & TST & \\
\hline CHEMBL604110 & 600885 & 5.6568 & 5.7366 & TRN & \\
\hline CHEMBL576527 & 600885 & 6.056 & 6.0475 & TRN & \\
\hline CHEMBL578880 & 600885 & 6.6231 & 5.9103 & TRN & \\
\hline CHEMBL584040 & 600885 & 4.8579 & 6.3016 & TRN & \\
\hline CHEMBL602815 & 600885 & 4.934 & 5.4784 & TRN & \\
\hline CHEMBL603014 & 600885 & 4.9031 & 5.3904 & TRN & \\
\hline CHEMBL600962 & 600885 & 4.8841 & 5.7214 & TRN & \\
\hline CHEMBL578056 & 600885 & 6.9104 & 5.6979 & TRN & \\
\hline CHEMBL602807 & 600885 & 5.4789 & 5.521 & TST & \\
\hline CHEMBL578950 & 600885 & 7.0857 & 6.9082 & TRN & \\
\hline CHEMBL604106 & 600885 & 6.0357 & 5.2309 & TRN & \\
\hline CHEMBL598287 & 600885 & 6.9183 & 6.2313 & TRN & \\
\hline CHEMBL531018 & 600885 & 6.2373 & 6.0759 & TRN & \\
\hline CHEMBL524612 & 600885 & 7.1192 & 6.5096 & TRN & \\
\hline CHEMBL600486 & 600885 & 5.7181 & 5.5925 & TRN & \\
\hline CHEMBL579343 & 600885 & 6.4976 & 6.2187 & TRN & \\
\hline CHEMBL581660 & 600885 & 5.5372 & 5.7796 & TRN & \\
\hline CHEMBL581458 & 600885 & 6.0 & 5.7987 & TST & \\
\hline CHEMBL585049 & 600885 & 6.3224 & 6.26399 & 9999999999 & TRN \\
\hline CHEMBL548646 & 600885 & 6.2204 & 5.6395 & TRN & \\
\hline CHEMBL586018 & 600885 & 6.3757 & 6.0779 & TRN & \\
\hline CHEMBL603729 & 600885 & 5.0757 & 5.4198 & TRN & \\
\hline CHEMBL600744 & 600885 & 3.9031 & 5.0636 & TST & \\
\hline CHEMBL578886 & 600885 & 6.0159 & 5.9149 & TRN & \\
\hline CHEMBL585815 & 600885 & 7.3279 & 6.5381 & TRN & \\
\hline CHEMBL528712 & 600885 & 6.6036 & 6.064 & TRN & \\
\hline CHEMBL586788 & 600885 & 6.2358 & 7.5688 & TRN & \\
\hline CHEMBL585772 & 600885 & 6.6008 & 6.0036 & TRN & \\
\hline CHEMBL601613 & 600885 & 6.4868 & 6.6112 & TRN & \\
\hline CHEMBL600300 & 600885 & 6.3893 & 6.5206 & TRN & \\
\hline CHEMBL582061 & 600885 & 4.1238 & 5.2748 & TRN & \\
\hline CHEMBL588625 & 600885 & 6.0 & 5.5781 & TRN & \\
\hline CHEMBL599507 & 600885 & 7.1739 & 6.6688 & TRN & \\
\hline CHEMBL601184 & 600885 & 6.3507 & 5.9817 & TRN & \\
\hline CHEMBL535079 & 600885 & 6.5728 & 6.7221 & TRN & \\
\hline CHEMBL601812 & 600885 & 6.3605 & 5.9017 & TRN & \\
\hline CHEMBL598682 & 600885 & 5.0367 & 5.1691 & TRN & \\
\hline CHEMBL531888 & 600885 & 3.9821 & 5.6183 & TST & \\
\hline CHEMBL606231 & 600885 & 4.4353 & 4.6941 & TRN & \\
\hline CHEMBL602370 & 600885 & 6.0794 & 5.7528 & TST & \\
\hline CHEMBL583165 & 600885 & 6.9094 & 6.011 & TRN & \\
\hline CHEMBL588133 & 600885 & 5.9957 & 7.42399 & 99999999995 & TRN \\
\hline
\end{tabular}




\begin{tabular}{|c|c|c|c|c|c|c|}
\hline & & \multicolumn{5}{|c|}{ Supplemental Table S2.txt } \\
\hline CHEMBL579135 & 600885 & 7.1624 & 6.1927 & TRN & & \\
\hline CHEMBL528197 & 600885 & 5.4597 & 5.8324 & TRN & & \\
\hline CHEMBL599295 & 600885 & 5.4868 & 6.1844 & TRN & & \\
\hline CHEMBL582445 & 600885 & 4.9031 & 5.6247 & TRN & & \\
\hline CHEMBL584024 & 600885 & 3.9516 & 4.7637 & TRN & & \\
\hline CHEMBL576980 & 600885 & 6.5156 & 5.9368 & TRN & & \\
\hline CHEMBL530733 & 600885 & 6.3458 & 6.5828 & TRN & & \\
\hline CHEMBL579172 & 600885 & 6.4123 & 6.62799 & 99999 & 99 & TRN \\
\hline CHEMBL579368 & 600885 & 6.6544 & 6.2005 & TRN & & \\
\hline CHEMBL576403 & 600885 & 6.7587 & 6.2869 & TRN & & \\
\hline CHEMBL602598 & 600885 & 5.3625 & 5.7849 & TST & & \\
\hline CHEMBL529057 & 600885 & 6.0953 & 6.4234 & TRN & & \\
\hline CHEMBL600936 & 600885 & 4.9031 & 5.8905 & TST & & \\
\hline CHEMBL601779 & 600885 & 6.1314 & 6.2121 & TRN & & \\
\hline CHEMBL584835 & 600885 & 6.57299 & 99999999 & 995 & 6.4017 & TRN \\
\hline CHEMBL582503 & 600885 & 6.919 & 6.2179 & TRN & & \\
\hline CHEMBL579310 & 600885 & 5.9914 & 5.9547 & TRN & & \\
\hline CHEMBL1989853 & 600885 & 6.6737 & 6.2087 & TRN & & \\
\hline CHEMBL583021 & 600885 & 5.1331 & 5.3994 & TRN & & \\
\hline CHEMBL49055 & 600885 & 6.1599 & 5.9917 & TRN & & \\
\hline CHEMBL581876 & 600885 & 5.6558 & 5.626 & TRN & & \\
\hline CHEMBL582454 & 600885 & 6.2967 & 6.1724 & TRN & & \\
\hline CHEMBL577451 & 600885 & 6.2636 & 5.9149 & TRN & & \\
\hline CHEMBL600091 & 600885 & 5.5781 & 4.8507 & TRN & & \\
\hline CHEMBL600894 & 600885 & 6.5358 & 5.9004 & TRN & & \\
\hline CHEMBL602213 & 600885 & 3.9031 & 5.5979 & TST & & \\
\hline CHEMBL584633 & 600885 & 6.3615 & 5.9571 & TST & & \\
\hline CHEMBL597660 & 600885 & 5.0367 & 5.1166 & TRN & & \\
\hline CHEMBL581645 & 600885 & 6.1785 & 5.6143 & TST & & \\
\hline CHEMBL582673 & 600885 & 6.6211 & 7.1257 & TST & & \\
\hline CHEMBL602228 & 600885 & 6.3809 & 6.0172 & TST & & \\
\hline CHEMBL603021 & 600885 & 5.1427 & 6.2021 & TRN & & \\
\hline CHEMBL585422 & 600885 & 6.9014 & 6.2771 & TRN & & \\
\hline CHEMBL602801 & 600885 & 5.5498 & 5.0381 & TST & & \\
\hline CHEMBL585786 & 600885 & 6.9322 & 6.0442 & TRN & & \\
\hline CHEMBL578521 & 600885 & 6.3872 & 6.0489 & TRN & & \\
\hline CHEMBL579969 & 600885 & 5.4498 & 5.1154 & TST & & \\
\hline CHEMBL579170 & 600885 & 6.4547 & 6.2458 & TRN & & \\
\hline CHEMBL602990 & 600885 & 5.70799 & 99999999 & 99 & 5.9657 & $\mathrm{TR}$ \\
\hline CHEMBL532858 & 600885 & 6.289 & 6.185 & TRN & & \\
\hline CHEMBL586013 & 600885 & 6.7708 & 6.1964 & TRN & & \\
\hline CHEMBL600701 & 600885 & 6.2708 & 5.8049 & TRN & & \\
\hline CHEMBL602372 & 600885 & 3.9031 & 5.5621 & TRN & & \\
\hline CHEMBL577810 & 600885 & 5.7303 & 5.7479 & TRN & & \\
\hline CHEMBL600289 & 600885 & 5.2857 & 4.7075 & TRN & & \\
\hline CHEMBL585443 & 600885 & 6.3904 & 5.8242 & TRN & & \\
\hline CHEMBL581678 & 600885 & 6.4306 & 5.88 & TRN & & \\
\hline CHEMBL582305 & 600885 & 3.9045 & 5.745 & TRN & & \\
\hline
\end{tabular}




\begin{tabular}{|c|c|c|c|c|c|}
\hline & & & & & \\
\hline CHEMBL579133 & 600885 & 7.2076 & 6.7599 & TRN & \\
\hline CHEMBL597060 & 600885 & 6.4962 & 6.4022 & TRN & \\
\hline CHEMBL602973 & 600885 & 4.9031 & 6.3319 & TRN & \\
\hline CHEMBL576204 & 600885 & 6.5599 & 6.1636 & TRN & \\
\hline CHEMBL576798 & 600885 & 4.9031 & 5.4187 & TST & \\
\hline CHEMBL578926 & 600885 & 4.8164 & 5.5757 & TRN & \\
\hline CHEMBL576804 & 600885 & 7.0814 & 6.00899 & 99999999995 & TRN \\
\hline CHEMBL577436 & 600885 & 6.0 & 5.5449 & TRN & \\
\hline CHEMBL581039 & 600885 & 5.8289 & 5.9 & TRN & \\
\hline CHEMBL584675 & 600885 & 7.3098 & 6.3082 & TRN & \\
\hline CHEMBL583431 & 600885 & 5.8798 & 6.1633 & TRN & \\
\hline CHEMBL527728 & 600885 & 5.1024 & 5.1608 & TRN & \\
\hline CHEMBL549275 & 600885 & 6.0472 & 5.6352 & TRN & \\
\hline CHEMBL601140 & 600885 & 6.0119 & 5.7297 & TRN & \\
\hline CHEMBL600897 & 600885 & 6.4881 & 6.07299 & 99999999995 & TST \\
\hline CHEMBL296622 & 600885 & 7.2328 & 5.0442 & TRN & \\
\hline CHEMBL580840 & 600885 & 5.2487 & 5.2195 & TRN & \\
\hline CHEMBL578739 & 600885 & 6.6737 & 6.8175 & TRN & \\
\hline CHEMBL585435 & 600885 & 6.153 & 6.6832 & TRN & \\
\hline CHEMBL586761 & 600885 & 6.6368 & 5.8732 & TST & \\
\hline CHEMBL577871 & 600885 & 6.8817 & 6.5786 & TRN & \\
\hline CHEMBL576330 & 600885 & 6.0 & 5.8591 & TRN & \\
\hline CHEMBL14435 & 600885 & 5.7742 & 5.7799 & TRN & \\
\hline CHEMBL600501 & 600885 & 3.9031 & 4.8267 & TRN & \\
\hline CHEMBL579944 & 600885 & 4.7747 & 5.6521 & TRN & \\
\hline CHEMBL577836 & 600885 & 6.4078 & 6.2577 & TRN & \\
\hline CHEMBL599931 & 600885 & 4.9133 & 5.1107 & TRN & \\
\hline CHEMBL203614 & 600885 & 6.6242 & 5.9901 & TRN & \\
\hline CHEMBL578093 & 600885 & 6.0186 & 5.8594 & TRN & \\
\hline CHEMBL576525 & 600885 & 4.9031 & 5.8165 & TST & \\
\hline CHEMBL601379 & 600885 & 5.8542 & 6.1943 & TRN & \\
\hline CHEMBL578727 & 600885 & 6.0 & 5.7521 & TRN & \\
\hline CHEMBL579939 & 600885 & 6.1858 & 6.1416 & TRN & \\
\hline CHEMBL530412 & 600885 & 6.9382 & 6.5954 & TRN & \\
\hline CHEMBL609030 & 600885 & 5.1512 & 4.797 & TST & \\
\hline CHEMBL596835 & 600885 & 5.8392 & 5.6829 & TRN & \\
\hline CHEMBL601529 & 600885 & 4.96899 & 99999999 & 5.1988 & TST \\
\hline CHEMBL600096 & 600885 & 6.1051 & 5.7821 & TRN & \\
\hline CHEMBL600317 & 600885 & 6.0039 & 6.1941 & TRN & \\
\hline CHEMBL599897 & 600885 & 3.9031 & 5.4714 & TRN & \\
\hline CHEMBL604321 & 600885 & 7.5382 & 6.9594 & TRN & \\
\hline CHEMBL582308 & 600885 & 6.056 & 5.2445 & TRN & \\
\hline CHEMBL611661 & 600885 & 6.0186 & 5.9158 & TRN & \\
\hline CHEMBL577427 & 600885 & 7.0788 & 6.7448 & TRN & \\
\hline CHEMBL529159 & 600885 & 6.4461 & 5.9128 & TRN & \\
\hline CHEMBL600902 & 600885 & 4.2083 & 4.9947 & TRN & \\
\hline CHEMBL578953 & 600885 & 6.9059 & 6.5434 & TRN & \\
\hline CHEMBL577456 & 600885 & 5.0804 & 5.2259 & TRN & \\
\hline
\end{tabular}




\begin{tabular}{|c|c|c|c|c|c|c|}
\hline & & \multicolumn{5}{|c|}{ Supplemental Table S2.txt } \\
\hline CHEMBL578251 & 600885 & 7.0531 & 5.8302 & TRN & & \\
\hline CHEMBL582085 & 600885 & 5.066 & 5.6885 & TST & & \\
\hline CHEMBL524376 & 600885 & 6.7783 & 6.0633 & TRN & & \\
\hline CHEMBL578917 & 600885 & 5.6588 & 5.476 & TRN & & \\
\hline CHEMBL601819 & 600885 & 6.098 & 5.966 & TRN & & \\
\hline CHEMBL580642 & 600885 & 7.0311 & 6.2098 & TRN & & \\
\hline CHEMBL578276 & 600885 & 5.8523 & 5.4301 & TRN & & \\
\hline CHEMBL600320 & 600885 & 7.0545 & 6.3396 & TRN & & \\
\hline CHEMBL586955 & 600885 & 6.4413 & 5.9482 & TRN & & \\
\hline CHEMBL577857 & 600885 & 6.1018 & 5.7198 & TRN & & \\
\hline CHEMBL601806 & 600885 & 5.426 & 5.3863 & TST & & \\
\hline CHEMBL602428 & 600885 & 4.9031 & 5.7804 & TRN & & \\
\hline CHEMBL527516 & 600885 & 5.8719 & 5.5886 & TRN & & \\
\hline CHEMBL588108 & 600885 & 6.098 & 6.1935 & TRN & & \\
\hline CHEMBL584022 & 600885 & 3.9516 & 4.6503 & TRN & & \\
\hline CHEMBL599945 & 600885 & 6.7286 & 6.4602 & TRN & & \\
\hline CHEMBL587731 & 600885 & 4.9031 & 5.4386 & TRN & & \\
\hline CHEMBL577012 & 600885 & 6.2277 & 6.3682 & TRN & & \\
\hline CHEMBL600559 & 600885 & 6.1624 & 5.3353 & TST & & \\
\hline CHEMBL585654 & 600885 & 6.3862 & 5.7747 & TST & & \\
\hline CHEMBL586424 & 600885 & 6.7095 & 5.4038 & TRN & & \\
\hline CHEMBL579256 & 600885 & 6.691 & 5.8574 & TRN & & \\
\hline CHEMBL600977 & 600885 & 6.0625 & 5.8164 & TRN & & \\
\hline CHEMBL579550 & 600885 & 6.0376 & 5.8691 & TRN & & \\
\hline CHEMBL258137 & 600885 & 5.2933 & 5.9457 & TRN & & \\
\hline CHEMBL579109 & 600885 & 6.1209 & 6.0393 & TRN & & \\
\hline CHEMBL584035 & 600885 & 5.9161 & 6.7274 & TRN & & \\
\hline CHEMBL585448 & 600885 & 4.9031 & 5.2775 & TRN & & \\
\hline CHEMBL598887 & 600885 & 7.3969 & 6.5231 & TRN & & \\
\hline CHEMBL577215 & 600885 & 7.2596 & 6.8761 & TRN & & \\
\hline CHEMBL582115 & 600885 & 4.9674 & 5.3944 & TRN & & \\
\hline CHEMBL605546 & 600885 & 6.2604 & 5.8562 & TST & & \\
\hline CHEMBL581680 & 600885 & 4.9031 & 5.8012 & TRN & & \\
\hline CHEMBL586271 & 600885 & 5.8871 & 5.2773 & TRN & & \\
\hline CHEMBL601349 & 600885 & 4.9031 & 5.278 & TRN & & \\
\hline CHEMBL587560 & 600885 & 4.9031 & 6.0415 & TST & & \\
\hline CHEMBL585082 & 600885 & 5.78299 & 79999999 & 995 & 6.1537 & TRN \\
\hline CHEMBL600118 & 600885 & 6.8159 & 6.7016 & TRN & & \\
\hline CHEMBL 602200 & 600885 & 6.7335 & 6.1045 & TRN & & \\
\hline CHEMBL585657 & 600885 & 5.1605 & 5.767 & TRN & & \\
\hline CHEMBL603017 & 600885 & 6.1986 & 5.5903 & TRN & & \\
\hline CHEMBL582507 & 600885 & 6.7602 & 5.8925 & TRN & & \\
\hline CHEMBL581884 & 600885 & 5.1549 & 5.7862 & TRN & & \\
\hline CHEMBL587853 & 600885 & 4.0044 & 5.2564 & TRN & & \\
\hline CHEMBL584038 & 600885 & 6.3161 & 6.1838 & TRN & & \\
\hline CHEMBL600913 & 600885 & 8.5084 & 6.9609 & TST & & \\
\hline CHEMBL578463 & 600885 & 6.0424 & 6.0582 & TRN & & \\
\hline CHEMBL585029 & 600885 & 4.7908 & 5.5451 & TRN & & \\
\hline
\end{tabular}




\begin{tabular}{|c|c|c|c|c|c|c|}
\hline \multicolumn{7}{|c|}{ supplemental } \\
\hline CHEMBL582706 & 600885 & 3.9031 & 5.7174 & TRN & & \\
\hline CHEMBL601185 & 600885 & 5.9923 & 6.4593 & TRN & & \\
\hline CHEMBL599902 & 600885 & 6.0106 & 5.6886 & TRN & & \\
\hline CHEMBL531569 & 600885 & 6.3439 & 5.8576 & TRN & & \\
\hline CHEMBL585211 & 600885 & 5.0565 & 5.94 & TRN & & \\
\hline CHEMBL602220 & 600885 & 4.9031 & 5.2497 & TRN & & \\
\hline CHEMBL600161 & 600885 & 6.0846 & 6.057 & TST & & \\
\hline CHEMBL598076 & 600885 & 6.65600 & 00000000 & $\partial 1$ & 5.8871 & TRN \\
\hline CHEMBL584456 & 600885 & 5.7967 & 5.6111 & TRN & & \\
\hline CHEMBL577003 & 600885 & 6.0223 & 6.1924 & TRN & & \\
\hline CHEMBL577180 & 600885 & 7.5109 & 5.5353 & TRN & & \\
\hline CHEMBL584654 & 600885 & 6.5293 & 7.5289 & TRN & & \\
\hline CHEMBL601816 & 600885 & 6.1308 & 6.5583 & TRN & & \\
\hline CHEMBL586810 & 600885 & 6.9296 & 6.3877 & TRN & & \\
\hline CHEMBL580381 & 600885 & 5.7951 & 5.4507 & TRN & & \\
\hline CHEMBL602997 & 600885 & 6.1851 & 5.8856 & TRN & & \\
\hline CHEMBL599496 & 600885 & 6.2628 & 5.8212 & TRN & & \\
\hline CHEMBL578494 & 600885 & 5.7025 & 5.5525 & TST & & \\
\hline CHEMBL603018 & 600885 & 6.475 & 5.9938 & TRN & & \\
\hline CHEMBL597856 & 600885 & 6.1433 & 5.8641 & TRN & & \\
\hline CHEMBL582263 & 600885 & 4.0773 & 5.5735 & TST & & \\
\hline CHEMBL580145 & 600885 & 6.8392 & 6.8237 & TRN & & \\
\hline CHEMBL600120 & 600885 & 6.1952 & 6.1332 & TRN & & \\
\hline CHEMBL577887 & 600885 & 6.5053 & 5.8662 & TRN & & \\
\hline CHEMBL578509 & 600885 & 3.9031 & 5.5587 & TRN & & \\
\hline CHEMBL586563 & 600885 & 6.9718 & 6.6889 & TST & & \\
\hline CHEMBL578701 & 600885 & 6.0 & 5.8224 & TRN & & \\
\hline CHEMBL586465 & 600885 & 6.0 & 5.8373 & TRN & & \\
\hline CHEMBL 244023 & 600885 & 6.0 & 5.7897 & TST & & \\
\hline CHEMBL579286 & 600885 & 5.4881 & 5.5282 & TST & & \\
\hline CHEMBL527634 & 600885 & 6.7533 & 6.1572 & TRN & & \\
\hline CHEMBL585995 & 600885 & 6.1445 & 6.03 & TRN & & \\
\hline CHEMBL598885 & 600885 & 4.9031 & 5.9992 & TST & & \\
\hline CHEMBL1316831 & 600885 & 6.5116 & 6.0438 & TST & & \\
\hline CHEMBL578010 & 600885 & 6.5487 & 6.0556 & TRN & & \\
\hline CHEMBL1744500 & 600885 & 6.0083 & 5.8165 & TRN & & \\
\hline CHEMBL579980 & 600885 & 6.063 & 5.8132 & TST & & \\
\hline CHEMBL530907 & 600885 & 3.9031 & 5.3389 & TST & & \\
\hline CHEMBL532308 & 600885 & 3.9031 & 5.5968 & TRN & & \\
\hline CHEMBL602165 & 600885 & 5.2941 & 5.6154 & TRN & & \\
\hline CHEMBL586024 & 600885 & 5.794 & 6.0302 & TRN & & \\
\hline CHEMBL581870 & 600885 & 7.2774 & 6.4405 & TRN & & \\
\hline CHEMBL597035 & 600885 & 5.8228 & 5.7894 & TRN & & \\
\hline CHEMBL601346 & 600885 & 3.9031 & 5.4293 & TRN & & \\
\hline CHEMBL584213 & 600885 & 5.1599 & 5.0806 & TRN & & \\
\hline CHEMBL579329 & 600885 & 5.118 & 5.4518 & TRN & & \\
\hline CHEMBL602823 & 600885 & 8.1361 & 5.7124 & TRN & & \\
\hline CHEMBL598881 & 600885 & 6.3665 & 5.9218 & TRN & & \\
\hline
\end{tabular}




\begin{tabular}{|c|c|c|c|c|c|}
\hline & & & & & \\
\hline CHEMBL582450 & 600885 & 5.1152 & 5.3794 & TRN & \\
\hline CHEMBL585260 & 600885 & 4.9031 & 5.2931 & TST & \\
\hline CHEMBL 2021322 & 600885 & 6.1688 & 5.965 & TRN & \\
\hline CHEMBL576206 & 600885 & 7.0531 & 6.4887 & TRN & \\
\hline CHEMBL578966 & 600885 & 7.266 & 6.4422 & TRN & \\
\hline CHEMBL599092 & 600885 & 5.9307 & 5.4857 & TRN & \\
\hline CHEMBL610789 & 600885 & 5.9918 & 5.881 & TRN & \\
\hline CHEMBL604980 & 600885 & 6.251 & 6.0007 & TRN & \\
\hline CHEMBL577365 & 600885 & 3.9031 & 5.3698 & TST & \\
\hline CHEMBL578320 & 600885 & 6.648 & 6.4062 & TRN & \\
\hline CHEMBL580834 & 600885 & 5.7542 & 5.2509 & TRN & \\
\hline CHEMBL600697 & 600885 & 5.9702 & 5.9033 & TRN & \\
\hline CHEMBL597667 & 600885 & 6.3401 & 6.1585 & TRN & \\
\hline CHEMBL534172 & 600885 & 5.8389 & 5.8157 & TST & \\
\hline CHEMBL585237 & 600885 & 6.2403 & 7.1722 & TRN & \\
\hline CHEMBL601164 & 600885 & 6.4597 & 6.2161 & TRN & \\
\hline CHEMBL600336 & 600885 & 5.8108 & 5.4591 & TRN & \\
\hline CHEMBL585639 & 600885 & 4.9031 & 6.3565 & TRN & \\
\hline CHEMBL586206 & 600885 & 4.9031 & 5.6746 & TRN & \\
\hline CHEMBL578929 & 600885 & 7.3595 & 5.2735 & TST & \\
\hline CHEMBL601144 & 600885 & 7.0685 & 6.4799 & TST & \\
\hline CHEMBL582675 & 600885 & 3.9038 & 5.53299 & 99999999995 & TRN \\
\hline CHEMBL 578902 & 600885 & 4.007 & 5.6547 & TRN & \\
\hline CHEMBL585062 & 600885 & 4.0 & 4.7682 & TRN & \\
\hline CHEMBL584228 & 600885 & 6.0 & 5.755 & TRN & \\
\hline CHEMBL578688 & 600885 & 6.4271 & 6.0967 & TRN & \\
\hline CHEMBL528471 & 600885 & 6.95700 & $00000000 t$ & 6.2434 & TRN \\
\hline CHEMBL583357 & 600885 & 5.9586 & 5.7426 & TRN & \\
\hline CHEMBL602180 & 600885 & 6.3107 & 5.9278 & TRN & \\
\hline CHEMBL600160 & 600885 & 4.9031 & 5.1772 & TRN & \\
\hline CHEMBL576408 & 600885 & 6.6847 & 6.45299 & 9999999999 & TRN \\
\hline CHEMBL580076 & 600885 & 7.0799 & 6.2648 & TRN & \\
\hline CHEMBL584868 & 600885 & 6.7185 & 6.041 & TRN & \\
\hline CHEMBL579091 & 600885 & 5.6033 & 5.5116 & TRN & \\
\hline CHEMBL601746 & 600885 & 4.9031 & 6.409 & TRN & \\
\hline CHEMBL601380 & 600885 & 6.4112 & 6.1276 & TRN & \\
\hline CHEMBL578309 & 600885 & 3.9776 & 5.7515 & TRN & \\
\hline CHEMBL602429 & 600885 & 6.1487 & 6.0234 & TST & \\
\hline CHEMBL548155 & 600885 & 7.7147 & 5.8567 & TRN & \\
\hline CHEMBL600520 & 600885 & 6.0 & 5.9111 & TRN & \\
\hline CHEMBL582734 & 600885 & 6.0521 & 5.2984 & TST & \\
\hline CHEMBL578323 & 600885 & 6.513 & 6.6244 & TRN & \\
\hline CHEMBL581909 & 600885 & 4.9578 & 5.4464 & TRN & \\
\hline CHEMBL579542 & 600885 & 6.5265 & 6.1388 & TRN & \\
\hline CHEMBL600710 & 600885 & 4.9031 & 5.403 & TST & \\
\hline CHEMBL599914 & 600885 & 5.3686 & 5.5763 & TRN & \\
\hline CHEMBL601993 & 600885 & 5.0655 & 5.8661 & TST & \\
\hline CHEMBL597475 & 600885 & 6.0665 & 6.0066 & TRN & \\
\hline
\end{tabular}




\begin{tabular}{|c|c|c|c|c|c|}
\hline & & & & & \\
\hline CHEMBL535331 & 600885 & 6.4815 & 6.0797 & TRN & \\
\hline CHEMBL579105 & 600885 & 7.1415 & 6.0464 & TRN & \\
\hline CHEMBL585983 & 600885 & 7.4711 & 6.7148 & TRN & \\
\hline CHEMBL584505 & 600885 & 6.1824 & 5.8164 & TRN & \\
\hline CHEMBL528139 & 600885 & 5.0209 & 5.2152 & TRN & \\
\hline CHEMBL533094 & 600885 & 6.5445 & 6.0657 & TRN & \\
\hline CHEMBL602831 & 600885 & 6.4711 & 6.3371 & TRN & \\
\hline CHEMBL529284 & 600885 & 3.9578 & 5.8718 & TRN & \\
\hline CHEMBL576773 & 600885 & 6.5504 & 6.351 & TRN & \\
\hline CHEMBL527626 & 600885 & 6.3072 & 6.1589 & TST & \\
\hline CHEMBL527403 & 600885 & 6.1308 & 5.5778 & TRN & \\
\hline CHEMBL582461 & 600885 & 6.3134 & 6.0778 & TRN & \\
\hline CHEMBL578941 & 600885 & 6.9274 & 6.3582 & TRN & \\
\hline CHEMBL581482 & 600885 & 4.9215 & 5.1348 & TRN & \\
\hline CHEMBL602430 & 600885 & 4.9031 & 5.4659 & TRN & \\
\hline CHEMBL604359 & 600885 & 4.8671 & 5.1761 & TRN & \\
\hline CHEMBL581698 & 600885 & 4.9759 & 5.1289 & TRN & \\
\hline CHEMBL584238 & 600885 & 6.0092 & 5.8514 & TRN & \\
\hline CHEMBL600906 & 600885 & 6.2007 & 6.0174 & TRN & \\
\hline CHEMBL602596 & 600885 & 5.0013 & 5.2256 & TST & \\
\hline CHEMBL579934 & 600885 & 6.5187 & 6.5671 & TRN & \\
\hline CHEMBL587760 & 600885 & 6.4584 & 6.4327 & TRN & \\
\hline CHEMBL576802 & 600885 & 6.1925 & 6.2698 & TRN & \\
\hline CHEMBL602426 & 600885 & 6.5163 & 6.1657 & TRN & \\
\hline CHEMBL576799 & 600885 & 6.4584 & 5.8357 & TRN & \\
\hline CHEMBL587049 & 600885 & 5.9702 & 6.0601 & TRN & \\
\hline CHEMBL535267 & 600885 & 8.1409 & 4.9649 & TRN & \\
\hline CHEMBL581854 & 600885 & 6.4353 & 5.4637 & TRN & \\
\hline CHEMBL547194 & 600885 & 5.6505 & 5.4842 & TRN & \\
\hline CHEMBL597244 & 600885 & 5.8959 & 5.6815 & TRN & \\
\hline CHEMBL586105 & 600885 & 4.9031 & 5.3603 & TRN & \\
\hline CHEMBL578737 & 600885 & 6.6265 & 6.7162 & TRN & \\
\hline CHEMBL585434 & 600885 & 4.9031 & 6.2057 & TRN & \\
\hline CHEMBL585402 & 600885 & 4.9031 & 5.5007 & TRN & \\
\hline CHEMBL582095 & 600885 & 5.4237 & 5.7459 & TRN & \\
\hline CHEMBL582261 & 600885 & 5.1427 & 5.403 & TRN & \\
\hline CHEMBL577218 & 600885 & 4.9031 & 5.4666 & TST & \\
\hline CHEMBL600131 & 600885 & 5.2676 & 5.3097 & TRN & \\
\hline CHEMBL583806 & 600885 & 7.0685 & 6.3125 & TRN & \\
\hline CHEMBL588175 & 600885 & 6.0 & 5.96299 & 9999999999 & TRN \\
\hline CHEMBL601338 & 600885 & 3.9031 & 5.1212 & TRN & \\
\hline CHEMBL579730 & 600885 & 5.3904 & 5.7511 & TRN & \\
\hline CHEMBL536013 & 600885 & 5.8179 & 5.6668 & TRN & \\
\hline CHEMBL602368 & 600885 & 5.8996 & 6.1576 & TRN & \\
\hline CHEMBL597042 & 600885 & 5.9281 & 5.9351 & TRN & \\
\hline CHEMBL581455 & 600885 & 6.9378 & 6.3087 & TRN & \\
\hline CHEMBL586014 & 600885 & 6.6192 & 6.0092 & TST & \\
\hline CHEMBL578458 & 600885 & 6.1688 & 5.6872 & TRN & \\
\hline
\end{tabular}




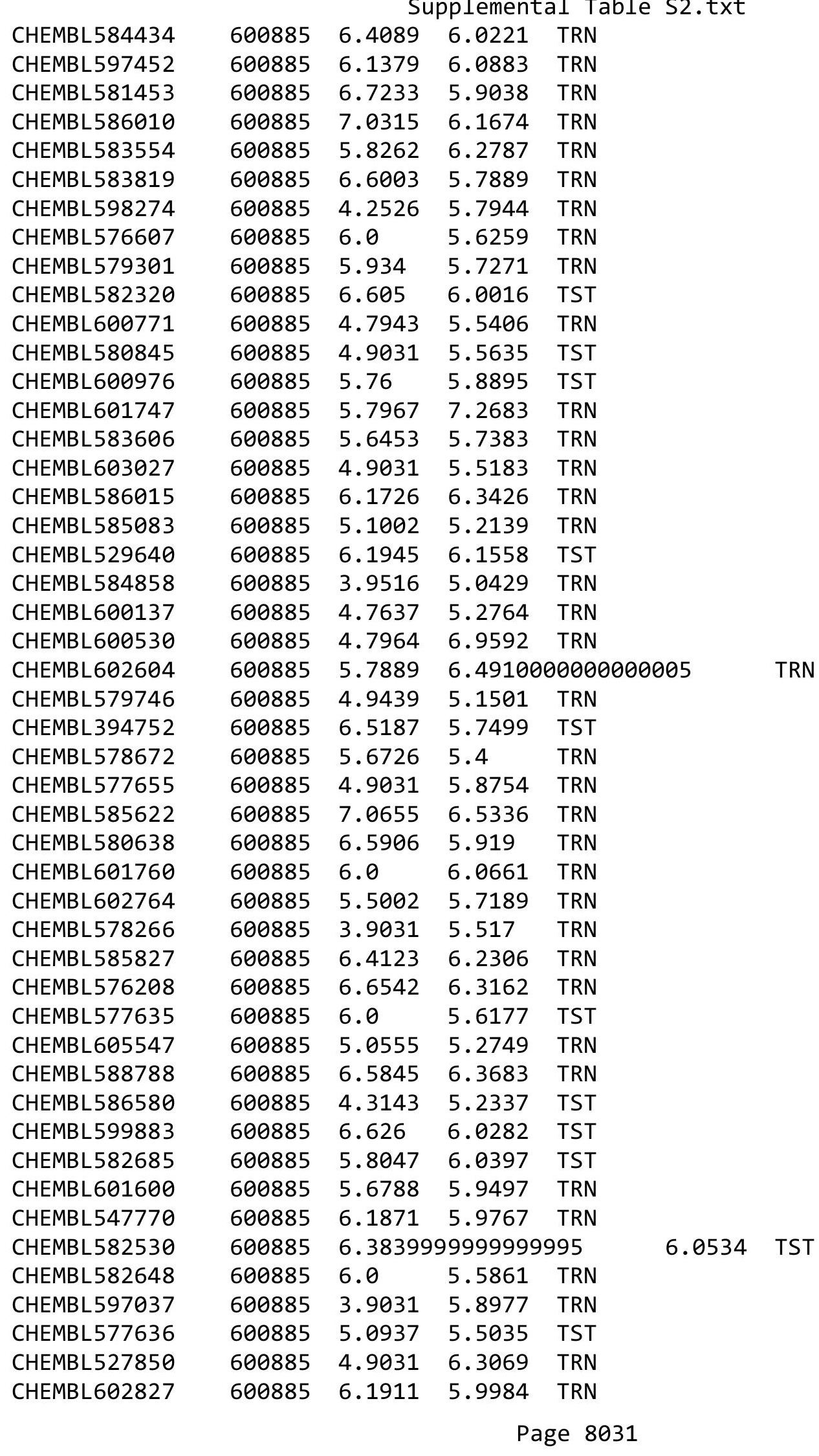




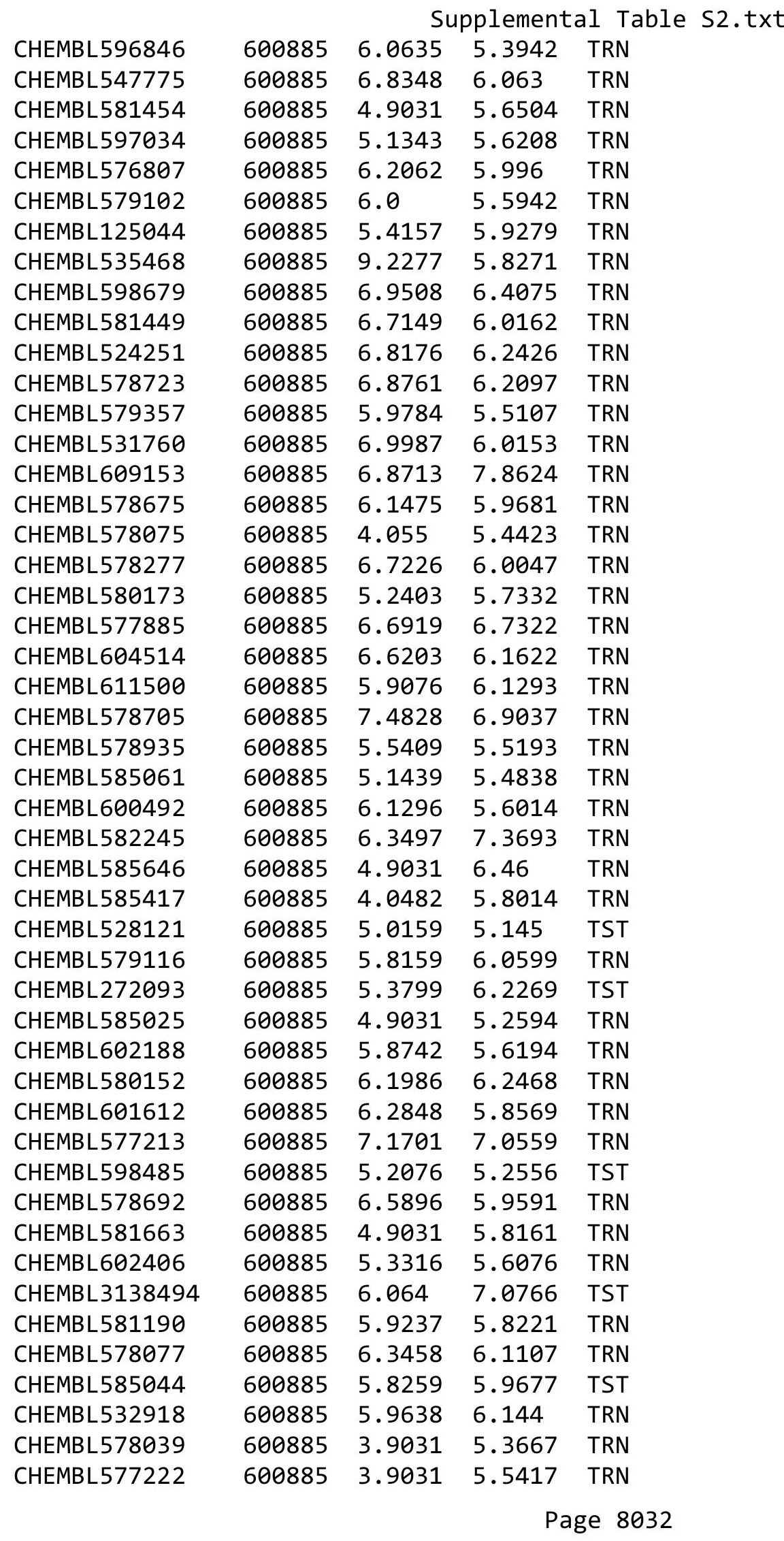




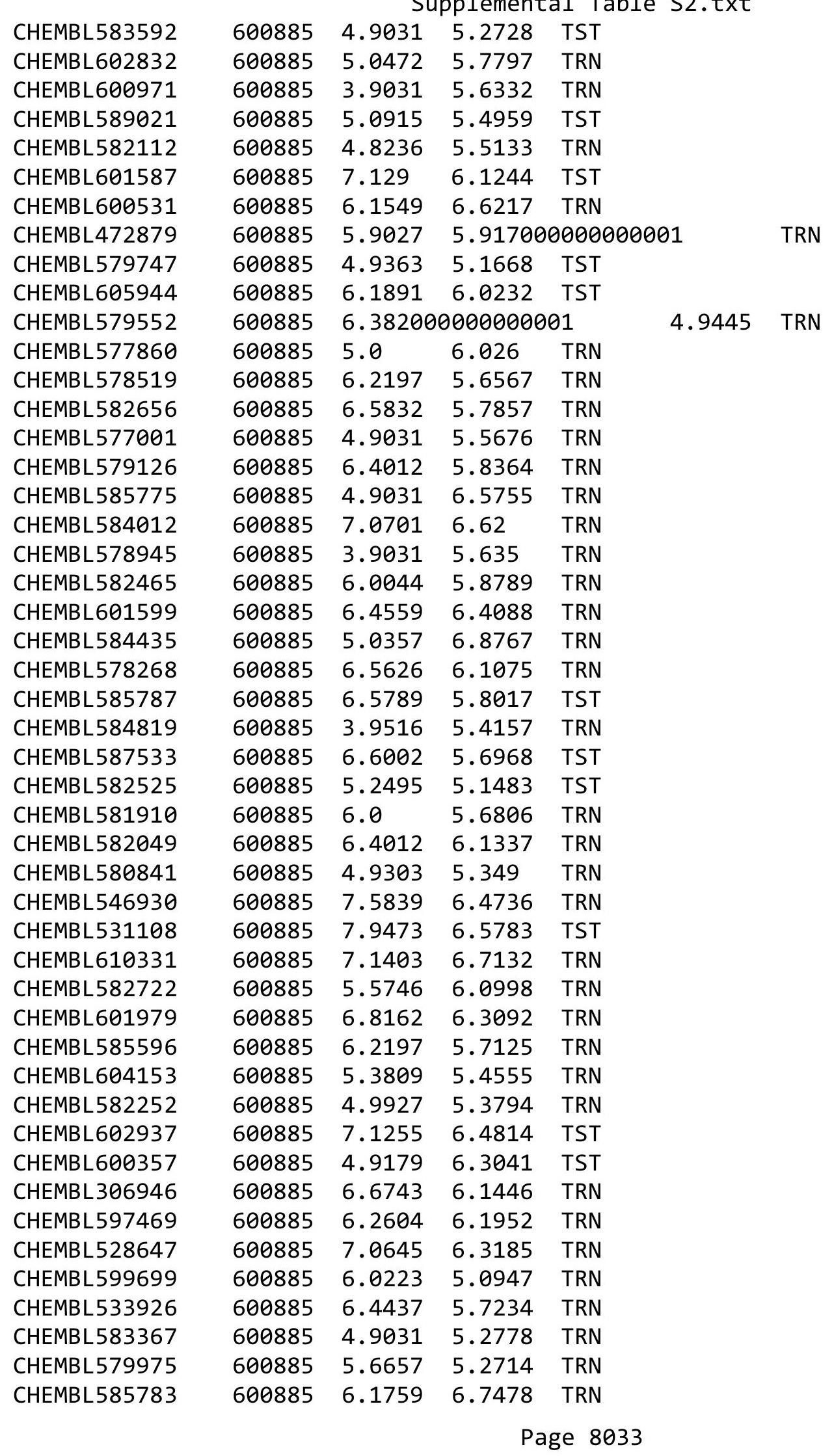




\begin{tabular}{|c|c|c|c|c|}
\hline & & & pplement & al $\mathrm{T}$ \\
\hline CHEMBL601825 & 600885 & 6.0506 & 5.9545 & TRN \\
\hline CHEMBL584244 & 600885 & 5.8173 & 6.5696 & TRN \\
\hline CHEMBL579143 & 600885 & 4.9031 & 5.9123 & TST \\
\hline CHEMBL578673 & 600885 & 3.9031 & 5.6346 & TST \\
\hline CHEMBL602809 & 600885 & 4.7804 & 5.7056 & TRN \\
\hline CHEMBL600111 & 600885 & 4.9031 & 5.9101 & TRN \\
\hline CHEMBL579373 & 600885 & 6.0701 & 5.6494 & TRN \\
\hline CHEMBL410467 & 600885 & 4.9031 & 5.223 & TRN \\
\hline CHEMBL578051 & 600885 & 5.2388 & 5.654 & TRN \\
\hline CHEMBL578322 & 600885 & 6.284 & 7.4576 & TRN \\
\hline CHEMBL534056 & 600885 & 4.1068 & 5.7622 & TRN \\
\hline CHEMBL579361 & 600885 & 6.9614 & 6.7218 & TRN \\
\hline CHEMBL602221 & 600885 & 3.9516 & 4.8009 & TST \\
\hline CHEMBL603688 & 600885 & 4.7932 & 5.9912 & TRN \\
\hline CHEMBL529351 & 600885 & 6.5011 & 5.6167 & TRN \\
\hline CHEMBL603233 & 600885 & 6.2299 & 6.5265 & TRN \\
\hline CHEMBL577627 & 600885 & 6.301 & 5.1798 & TRN \\
\hline CHEMBL587856 & 600885 & 6.1349 & 5.4832 & TRN \\
\hline CHEMBL598693 & 600885 & 5.9069 & 5.7817 & TST \\
\hline CHEMBL610912 & 600885 & 5.7016 & 5.888 & TRN \\
\hline CHEMBL582533 & 600885 & 6.3354 & 6.0803 & TRN \\
\hline CHEMBL579321 & 600885 & 4.9031 & 5.6709 & TRN \\
\hline CHEMBL578107 & 600885 & 4.9031 & 7.0695 & TRN \\
\hline CHEMBL582665 & 600885 & 5.0232 & 5.2111 & TRN \\
\hline CHEMBL527461 & 600885 & 6.0022 & 5.0238 & TST \\
\hline CHEMBL604512 & 600885 & 5.9952 & 6.5696 & TRN \\
\hline CHEMBL600698 & 600885 & 6.8164 & 6.0688 & TST \\
\hline CHEMBL581659 & 600885 & 6.1891 & 5.8153 & TRN \\
\hline CHEMBL607519 & 600885 & 5.2774 & 6.0338 & TRN \\
\hline CHEMBL600494 & 600885 & 4.9031 & 5.4293 & TST \\
\hline CHEMBL578913 & 600885 & 7.3565 & 5.8597 & TRN \\
\hline CHEMBL601580 & 600885 & 6.6229 & 6.3774 & TRN \\
\hline CHEMBL599090 & 600885 & 6.1965 & 6.5696 & TRN \\
\hline CHEMBL587836 & 600885 & 5.7747 & 5.3727 & TRN \\
\hline CHEMBL585837 & 600885 & 6.2328 & 5.8527 & TRN \\
\hline CHEMBL578893 & 600885 & 4.9031 & 5.5452 & TRN \\
\hline CHEMBL581851 & 600885 & 5.0799 & 5.3384 & TRN \\
\hline CHEMBL585645 & 600885 & 4.9031 & 6.4197 & TRN \\
\hline CHEMBL582517 & 600885 & 6.2557 & 6.1798 & TRN \\
\hline CHEMBL582958 & 600885 & 6.0 & 5.8067 & TST \\
\hline CHEMBL600136 & 600885 & 5.2487 & 5.695 & TRN \\
\hline CHEMBL368715 & 600885 & 5.7833 & 5.809 & TST \\
\hline CHEMBL585481 & 600885 & 5.5852 & 5.9332 & TRN \\
\hline CHEMBL578517 & 600885 & 6.4498 & 5.7787 & TRN \\
\hline CHEMBL193869 & 600885 & 6.0 & 5.8493 & TRN \\
\hline CHEMBL600733 & 600885 & 4.129 & 5.4402 & TRN \\
\hline CHEMBL601540 & 600885 & 6.06 & 5.6953 & TRN \\
\hline CHEMBL602562 & 600885 & 6.3251 & 5.8148 & TRN \\
\hline
\end{tabular}




\begin{tabular}{|c|c|c|c|c|c|c|}
\hline \multirow[b]{2}{*}{ CHEMBL583173 } & \multicolumn{6}{|c|}{ Supplemental Table S2.txt } \\
\hline & 600885 & 6.2684 & 5.4308 & TRN & & \\
\hline CHEMBL583539 & 600885 & 5.9626 & 6.0435 & TRN & & \\
\hline CHEMBL601135 & 600885 & 5.2396 & 5.8824 & TRN & & \\
\hline CHEMBL356687 & 600885 & 7.1163 & 6.0599 & TRN & & \\
\hline CHEMBL584254 & 600885 & 7.0862 & 6.7365 & TRN & & \\
\hline CHEMBL600534 & 600885 & 4.1244 & 5.6359 & TRN & & \\
\hline CHEMBL1744512 & 600885 & 6.0 & 5.6611 & TRN & & \\
\hline CHEMBL579787 & 600885 & 6.3565 & 6.297006 & 000000000 & & TRN \\
\hline CHEMBL581263 & 600885 & 5.9751 & 5.2052 & TRN & & \\
\hline CHEMBL585613 & 600885 & 6.4248 & 6.1137 & TRN & & \\
\hline CHEMBL599933 & 600885 & 6.5646 & 6.0999 & TRN & & \\
\hline CHEMBL600288 & 600885 & 5.691 & 5.3989 & TST & & \\
\hline CHEMBL585779 & 600885 & 6.4461 & 6.1099 & TRN & & \\
\hline CHEMBL597447 & 600885 & 6.1018 & 5.9039 & TRN & & \\
\hline CHEMBL602594 & 600885 & 6.1079 & 5.7532 & TRN & & \\
\hline CHEMBL602819 & 600885 & 4.2396 & 5.53 & TRN & & \\
\hline CHEMBL600743 & 600885 & 5.426 & 5.5505 & TRN & & \\
\hline CHEMBL604389 & 600885 & 4.677 & 5.2787 & TRN & & \\
\hline CHEMBL306147 & 600885 & 4.9031 & 6.6218 & TST & & \\
\hline CHEMBL586560 & 600885 & 7.3458 & 6.1749 & TRN & & \\
\hline CHEMBL1615737 & 600885 & 4.1415 & 5.2102 & TRN & & \\
\hline CHEMBL599509 & 600885 & 5.0726 & 5.4114 & TRN & & \\
\hline CHEMBL599722 & 600885 & 4.7734 & 5.7287 & TST & & \\
\hline CHEMBL578915 & 600885 & 5.8342 & 5.8931 & TRN & & \\
\hline CHEMBL578108 & 600885 & 7.0395 & 6.7936 & TRN & & \\
\hline CHEMBL586009 & 600885 & 6.2708 & 6.1251 & TST & & \\
\hline CHEMBL579162 & 600885 & 5.4841 & 5.1093 & TRN & & \\
\hline CHEMBL579128 & 600885 & 3.9454 & 5.3957 & TRN & & \\
\hline CHEMBL602631 & 600885 & 5.8871 & 6.0334 & TST & & \\
\hline CHEMBL582499 & 600885 & 4.8277 & 5.7582 & TRN & & \\
\hline CHEMBL599715 & 600885 & 5.9237 & 5.6298 & TRN & & \\
\hline CHEMBL577223 & 600885 & 3.9031 & 5.019 & TST & & \\
\hline CHEMBL576992 & 600885 & 6.6927 & 5.9624 & TRN & & \\
\hline CHEMBL599893 & 600885 & 5.8914 & 6.2272 & TST & & \\
\hline CHEMBL599086 & 600885 & 5.0329 & 5.1784 & TRN & & \\
\hline CHEMBL601758 & 600885 & 6.32700 & 00000000 & $\partial 1$ & 5.9351 & TRN \\
\hline CHEMBL602628 & 600885 & 6.1643 & 6.7574 & TRN & & \\
\hline CHEMBL582950 & 600885 & 6.5661 & 6.0775 & TRN & & \\
\hline CHEMBL604099 & 600885 & 5.1373 & 4.8316 & TST & & \\
\hline CHEMBL530610 & 600885 & 3.9031 & 5.3528 & TST & & \\
\hline CHEMBL601397 & 600885 & 6.3197 & 6.3721 & TRN & & \\
\hline CHEMBL601131 & 600885 & 5.8459 & 5.4764 & TRN & & \\
\hline CHEMBL587026 & 600885 & 7.0061 & 6.4506 & TRN & & \\
\hline CHEMBL524603 & 600885 & 5.1649 & 5.4265 & TRN & & \\
\hline CHEMBL578087 & 600885 & 5.75200 & 00000000 & $\partial 1$ & 5.6001 & TST \\
\hline CHEMBL601977 & 600885 & 6.794 & 6.1451 & TST & & \\
\hline CHEMBL600700 & 600885 & 5.9702 & 6.5504 & TRN & & \\
\hline CHEMBL579307 & 600885 & 5.0017 & 5.42 & TRN & & \\
\hline & & & & 8035 & & \\
\hline
\end{tabular}




\begin{tabular}{|c|c|c|c|c|c|}
\hline \multicolumn{6}{|c|}{ Supplemental Table S2.txt } \\
\hline CHEMBL547101 & 600885 & 7.8608 & 5.1985 & TRN & \\
\hline CHEMBL598272 & 600885 & 6.1549 & 6.0408 & TRN & \\
\hline CHEMBL579132 & 600885 & 6.1385 & 7.6472 & TST & \\
\hline CHEMBL528241 & 600885 & 6.068 & 5.4242 & TRN & \\
\hline CHEMBL599723 & 600885 & 6.1255 & 5.9142 & TRN & \\
\hline CHEMBL596857 & 600885 & 7.3063 & 6.4393 & TST & \\
\hline CHEMBL601393 & 600885 & 6.2132 & 6.1976 & TRN & \\
\hline CHEMBL582055 & 600885 & 6.2147 & 5.365 & TRN & \\
\hline CHEMBL578485 & 600885 & 7.8608 & 4.8497 & TRN & \\
\hline CHEMBL578467 & 600885 & 4.9031 & 5.4089 & TRN & \\
\hline CHEMBL578329 & 600885 & 4.8745 & 5.6057 & TST & \\
\hline CHEMBL583600 & 600885 & 6.0 & 5.7798 & TST & \\
\hline CHEMBL582246 & 600885 & 6.24799 & 999999999 & 6.0746 & TRN \\
\hline CHEMBL586504 & 600885 & 5.9374 & 7.457000 & 0000000001 & TRN \\
\hline CHEMBL583397 & 600885 & 5.6183 & 5.8572 & TRN & \\
\hline CHEMBL578717 & 600885 & 4.9031 & 5.7695 & TRN & \\
\hline CHEMBL582956 & 600885 & 6.3028 & 6.0751 & TRN & \\
\hline CHEMBL584301 & 600885 & 4.9031 & 5.7828 & TRN & \\
\hline CHEMBL585630 & 600885 & 4.9031 & 6.6947 & TRN & \\
\hline CHEMBL600491 & 600885 & 4.9031 & 5.9494 & TRN & \\
\hline CHEMBL588864 & 600885 & 6.7555 & 6.3226 & TRN & \\
\hline CHEMBL1521960 & 600885 & 5.7857 & 5.7911 & TRN & \\
\hline CHEMBL580794 & 600885 & 5.9017 & 6.0014 & TST & \\
\hline CHEMBL578879 & 600885 & 5.4067 & 5.5975 & TRN & \\
\hline CHEMBL585843 & 600885 & 6.8297 & 6.4182 & TRN & \\
\hline CHEMBL577442 & 600885 & 6.2782 & 5.8184 & TRN & \\
\hline CHEMBL585585 & 600885 & 7.058 & 6.4732 & TRN & \\
\hline CHEMBL577440 & 600885 & 5.9278 & 4.937 & TRN & \\
\hline CHEMBL529464 & 600885 & 5.1284 & 5.0071 & TST & \\
\hline CHEMBL599101 & 600885 & 6.0482 & 6.0603 & TST & \\
\hline CHEMBL601361 & 600885 & 5.7469 & 5.8269 & TRN & \\
\hline CHEMBL601142 & 600885 & 5.5519 & 5.1926 & TRN & \\
\hline CHEMBL576951 & 600885 & 5.0894 & 5.6388 & TRN & \\
\hline CHEMBL576054 & 600885 & 3.9031 & 5.5792 & TRN & \\
\hline CHEMBL600159 & 600885 & 6.7162 & 5.8922 & TRN & \\
\hline CHEMBL528390 & 600885 & 5.7238 & 5.8302 & TRN & \\
\hline CHEMBL527800 & 600885 & 6.3696 & 6.077000 & 0000000001 & TRN \\
\hline CHEMBL583449 & 600885 & 6.945 & 5.9683 & TRN & \\
\hline CHEMBL578721 & 600885 & 4.9031 & 6.1511 & TRN & \\
\hline CHEMBL581492 & 600885 & 5.671 & 5.4051 & TRN & \\
\hline CHEMBL580839 & 600885 & 5.9076 & 5.326000 & 00000000005 & rRN \\
\hline CHEMBL600756 & 600885 & 6.5478 & 5.7922 & TST & \\
\hline CHEMBL599707 & 600885 & 6.7552 & 5.1945 & TST & \\
\hline CHEMBL531478 & 600885 & 5.9872 & 6.0507 & TRN & \\
\hline CHEMBL583210 & 600885 & 5.1238 & 5.3858 & TRN & \\
\hline CHEMBL596834 & 600885 & 5.6334 & 5.6671 & TST & \\
\hline CHEMBL579489 & 600885 & 5.0009 & 5.437 & TRN & \\
\hline CHEMBL579086 & 600885 & 5.9348 & 5.3316 & TST & \\
\hline
\end{tabular}




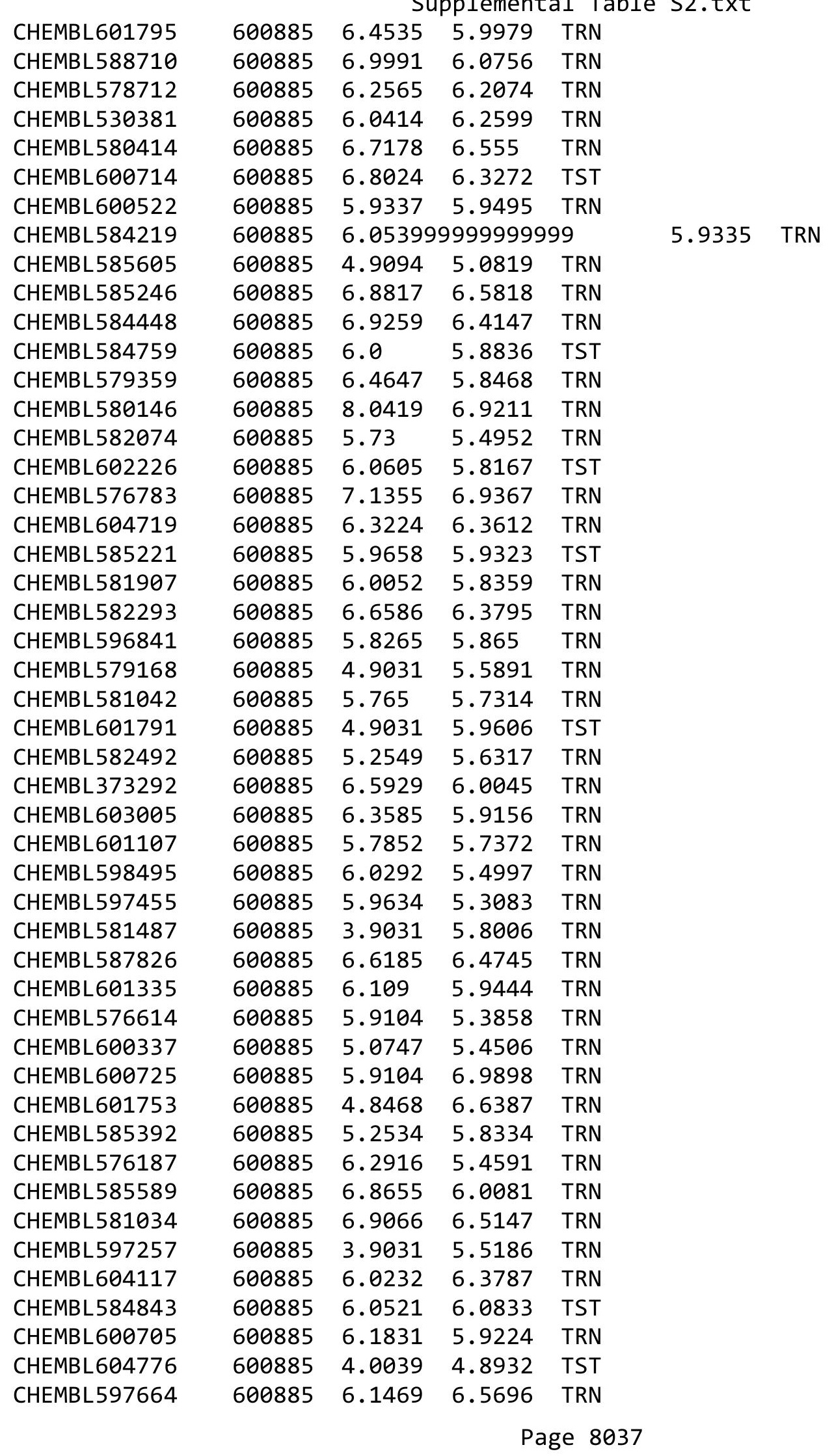




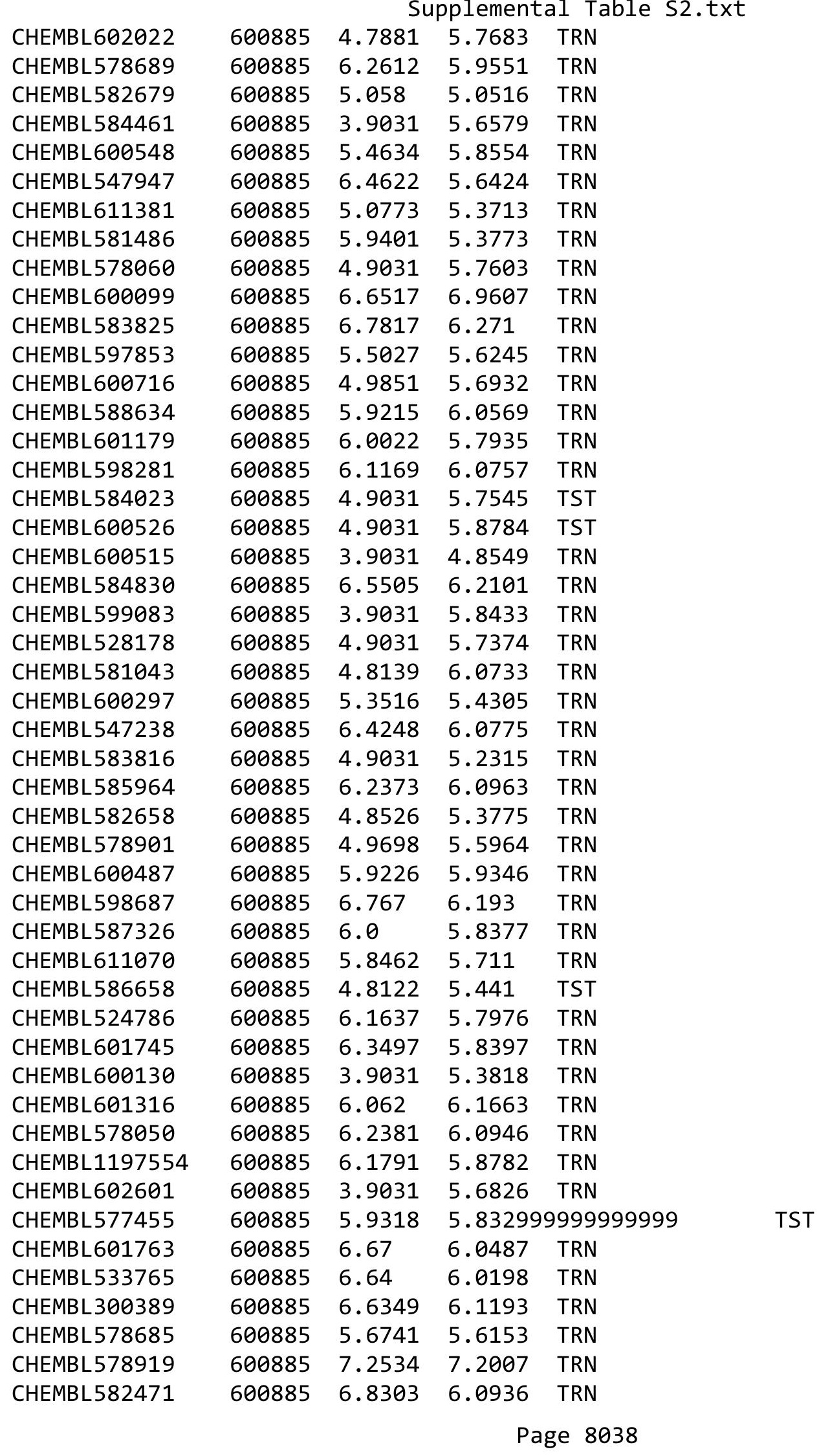




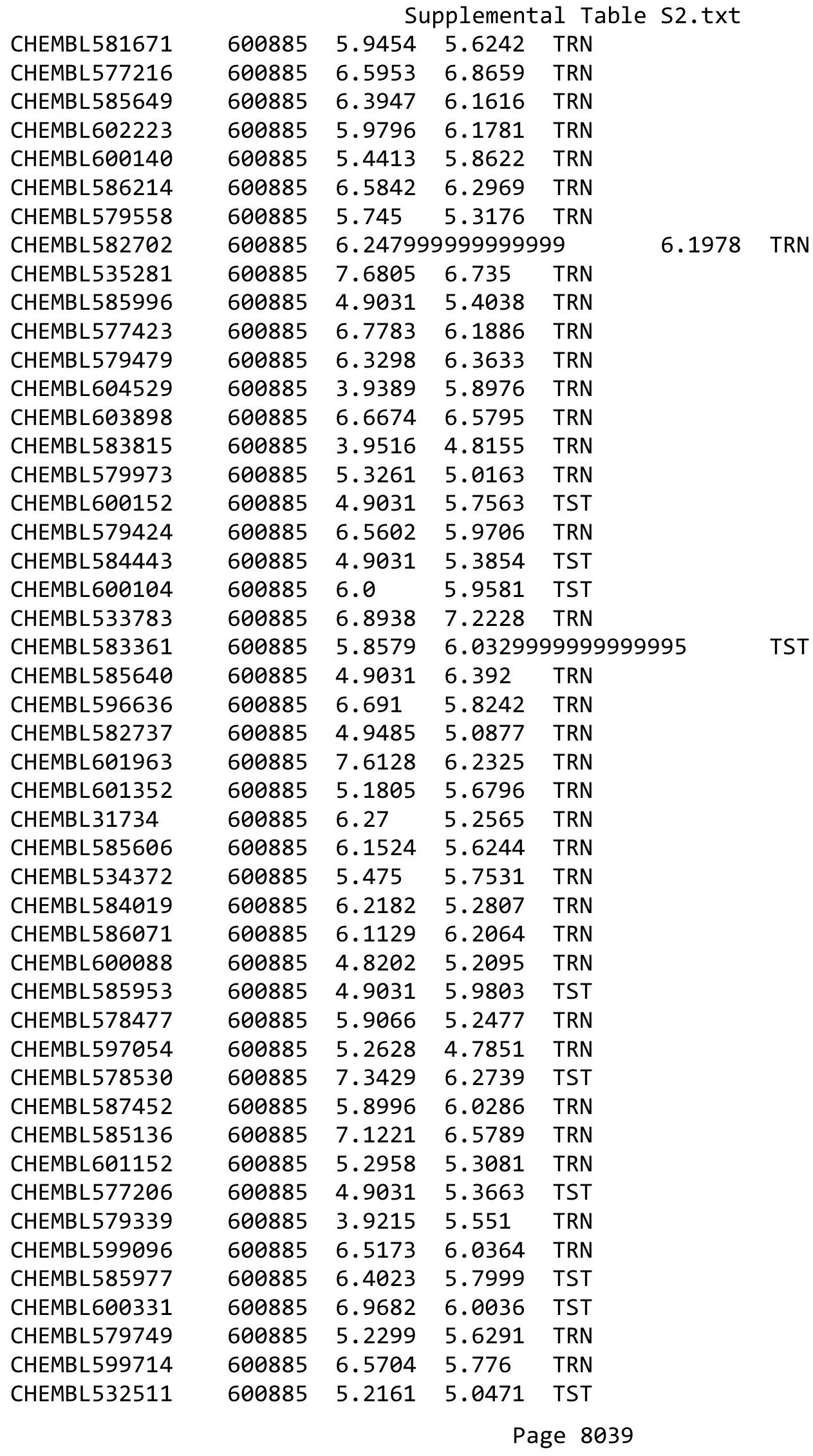


Supplemental Table S2.txt

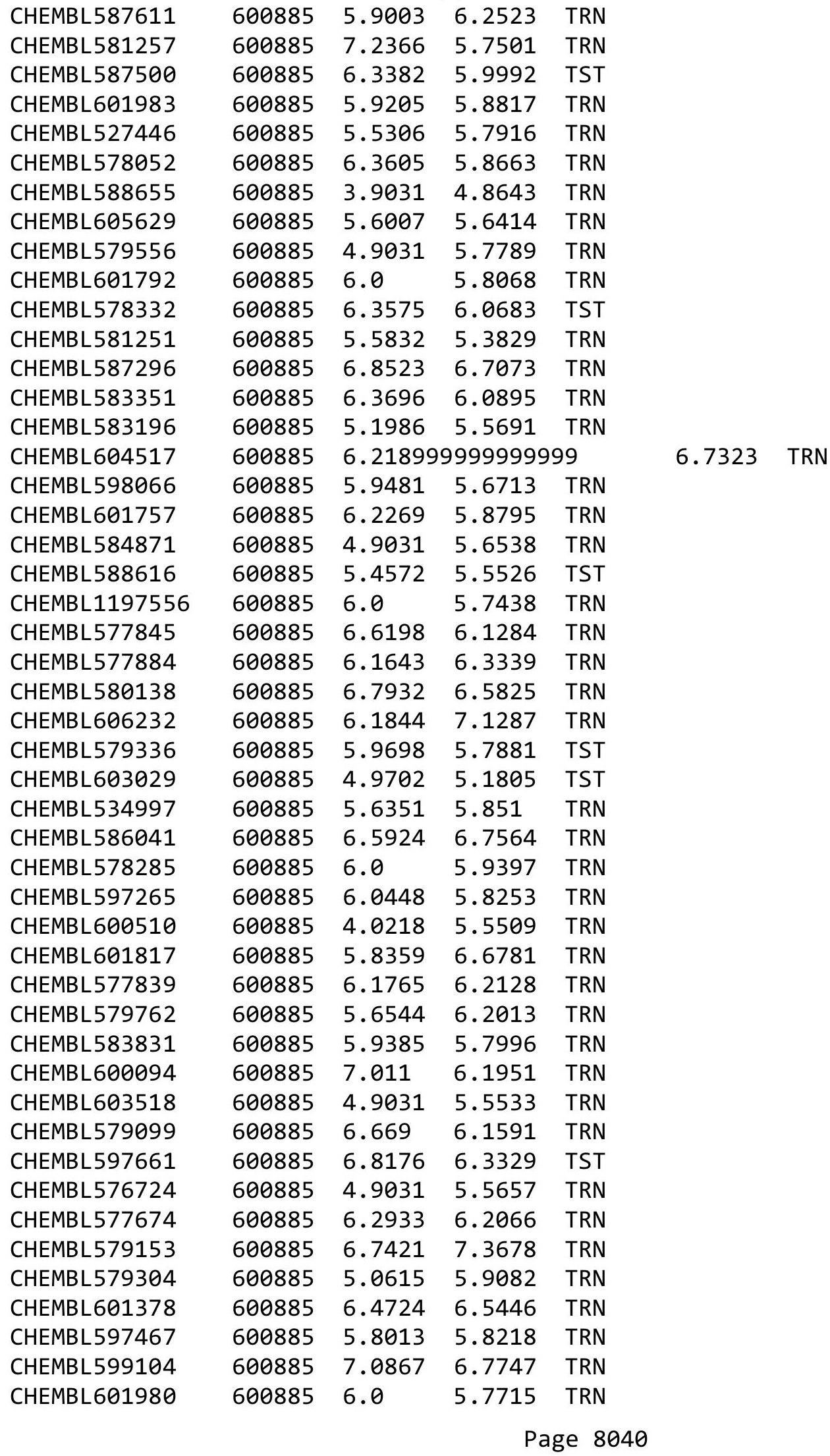




\begin{tabular}{|c|c|c|c|c|c|c|}
\hline & & \multicolumn{5}{|c|}{ Supplemental Table s2.txt } \\
\hline CHEMBL585976 & 600885 & 4.7918 & 5.3903 & TRN & & \\
\hline CHEMBL581833 & 600885 & 6.153 & 6.0752 & TRN & & \\
\hline CHEMBL577861 & 600885 & 6.4248 & 5.933 & TST & & \\
\hline CHEMBL579169 & 600885 & \multicolumn{3}{|c|}{5.587000000000001} & 6.0298 & TRN \\
\hline CHEMBL578542 & 600885 & 6.8111 & 5.9455 & TST & & \\
\hline CHEMBL598286 & 600885 & 6.9147 & 6.5492 & TRN & & \\
\hline CHEMBL599957 & 600885 & 7.3206 & 6.57799 & 9999999999 & & TST \\
\hline CHEMBL578301 & 600885 & 7.1805 & 6.0734 & TRN & & \\
\hline CHEMBL588631 & 600885 & 6.1379 & 6.00799 & 9999999999 & & TRN \\
\hline CHEMBL537911 & 600885 & 6.7828 & 6.0169 & TST & & \\
\hline CHEMBL583812 & 600885 & 4.7908 & 5.2825 & TST & & \\
\hline CHEMBL600328 & 600885 & 7.0991 & 6.4717 & TRN & & \\
\hline CHEMBL584031 & 600885 & 4.9031 & 5.2008 & TRN & & \\
\hline CHEMBL585266 & 600885 & 6.4949 & 6.2669 & TRN & & \\
\hline CHEMBL532671 & 600885 & 6.766 & 6.0553 & TRN & & \\
\hline CHEMBL577855 & 600885 & 4.9031 & 5.3033 & TRN & & \\
\hline CHEMBL580533 & 600885 & 6.2277 & 6.2598 & TRN & & \\
\hline CHEMBL600927 & 600885 & 6.2596 & 6.2315 & TRN & & \\
\hline CHEMBL579078 & 600885 & 6.2411 & 5.7424 & TRN & & \\
\hline CHEMBL602225 & 600885 & 4.9031 & 5.1973 & TST & & \\
\hline CHEMBL581489 & 600885 & 6.27 & 6.0721 & TRN & & \\
\hline CHEMBL578959 & 600885 & 6.1013 & 5.9795 & TRN & & \\
\hline CHEMBL584014 & 600885 & 5.9842 & 6.0789 & TRN & & \\
\hline CHEMBL585213 & 600885 & 6.2865 & 5.7537 & TST & & \\
\hline CHEMBL584021 & 600885 & 6.0048 & 5.7427 & TST & & \\
\hline CHEMBL602977 & 600885 & 6.5017 & 5.9866 & TRN & & \\
\hline CHEMBL585609 & 600885 & 5.98799 & 99999999 & 995 & 6.614 & TRN \\
\hline CHEMBL601592 & 600885 & 4.9031 & 6.1093 & TRN & & \\
\hline CHEMBL598265 & 600885 & 5.3947 & 5.8968 & TRN & & \\
\hline CHEMBL470514 & 600885 & 6.3904 & 6.1522 & TRN & & \\
\hline CHEMBL601614 & 600885 & 5.2204 & 5.8089 & TST & & \\
\hline CHEMBL582071 & 600885 & 5.5759 & 5.6246 & TST & & \\
\hline CHEMBL599937 & 600885 & 7.7926 & 6.7652 & TRN & & \\
\hline CHEMBL582531 & 600885 & 6.0 & 5.7141 & TRN & & \\
\hline CHEMBL602155 & 600885 & 6.2111 & 5.7637 & TRN & & \\
\hline CHEMBL578099 & 600885 & 4.9031 & 5.8654 & TST & & \\
\hline CHEMBL589027 & 600885 & 6.3686 & 5.7832 & TRN & & \\
\hline CHEMBL585571 & 600885 & 5.3179 & 4.8988 & TRN & & \\
\hline CHEMBL596653 & 600885 & 8.4572 & 6.78100 & 0000000001 & & TST \\
\hline CHEMBL602396 & 600885 & 3.9996 & 5.3891 & TRN & & \\
\hline CHEMBL585956 & 600885 & 3.9219 & 5.3878 & TRN & & \\
\hline CHEMBL277148 & 600885 & 5.9747 & 5.9978 & TRN & & \\
\hline CHEMBL601967 & 600885 & 3.9031 & 4.9466 & TST & & \\
\hline CHEMBL583446 & 600885 & 6.5077 & 5.1908 & TRN & & \\
\hline CHEMBL580314 & 600885 & 6.2798 & 6.7484 & TRN & & \\
\hline CHEMBL535197 & 600885 & 6.4908 & 6.2948 & TRN & & \\
\hline CHEMBL534573 & 600885 & 6.2993 & 6.1094 & TRN & & \\
\hline CHEMBL585842 & 600885 & 5.9194 & 7.0146 & TRN & & \\
\hline
\end{tabular}




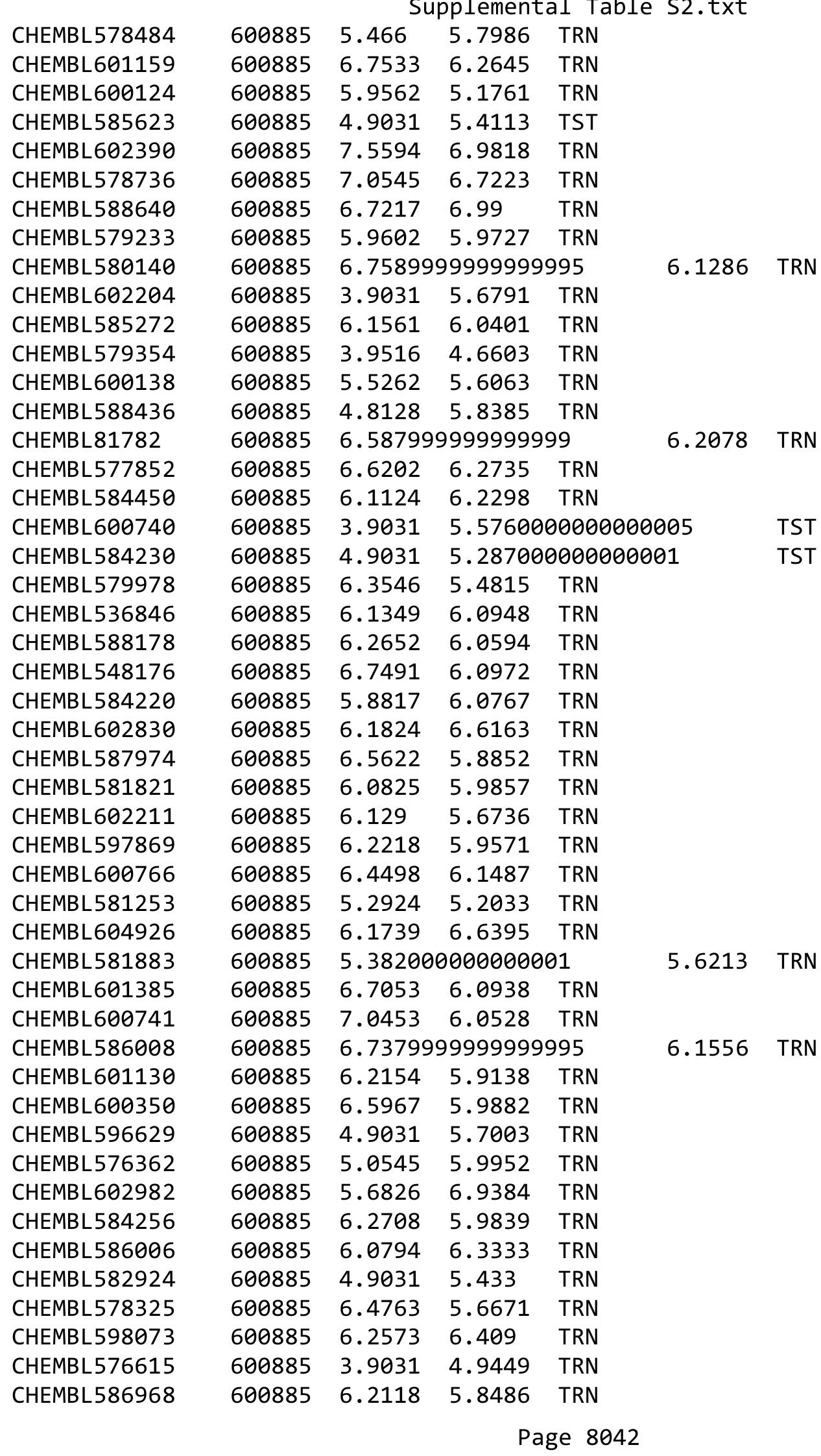




\begin{tabular}{|c|c|c|c|c|c|}
\hline \multirow[b]{2}{*}{ CHEMBL600280 } & \multicolumn{5}{|c|}{ Supplemental Table S2 } \\
\hline & 600885 & 4.9462 & 5.3427 & TRN & \multirow{3}{*}{ TST } \\
\hline CHEMBL582103 & 600885 & 6.1152 & \multicolumn{2}{|c|}{6.138999999999999} & \\
\hline CHEMBL601989 & 600885 & 3.9031 & 5.4283 & TST & \\
\hline CHEMBL599299 & 600885 & 6.0 & 5.7121 & TRN & \\
\hline CHEMBL602609 & 600885 & 5.8353 & 5.8347 & TRN & \\
\hline CHEMBL585970 & 600885 & 6.1158 & 5.8235 & TRN & \\
\hline CHEMBL602216 & 600885 & 5.9112 & 5.6882 & TRN & \\
\hline CHEMBL601394 & 600885 & 6.5074 & 6.0695 & TRN & \\
\hline CHEMBL236695 & 600885 & 6.5405 & 6.4668 & TRN & \\
\hline CHEMBL600527 & 600885 & 7.2565 & 6.4697 & TST & \\
\hline CHEMBL600505 & 600885 & 5.3458 & 5.4648 & TST & \\
\hline CHEMBL581614 & 600885 & 6.0311 & 5.8606 & TRN & \\
\hline CHEMBL585816 & 600885 & 6.6649 & 6.3242 & TRN & \\
\hline CHEMBL602775 & 600885 & 6.0958 & 5.8194 & TST & \\
\hline CHEMBL609460 & 600885 & 4.9031 & 5.7995 & TRN & \\
\hline CHEMBL576175 & 600885 & 4.3645 & 5.6098 & TST & \\
\hline CHEMBL602014 & 600885 & 4.9031 & 5.7192 & TRN & \\
\hline CHEMBL600550 & 600885 & 5.7889 & 5.6151 & TST & \\
\hline CHEMBL602797 & 600885 & 4.7662 & 6.0607 & TRN & \\
\hline CHEMBL532383 & 600885 & 6.1931 & 5.791 & TRN & \\
\hline CHEMBL530300 & 600885 & 4.8496 & 5.4548 & TRN & \\
\hline CHEMBL577648 & 600885 & 4.9031 & 5.4719 & TRN & \\
\hline CHEMBL601538 & 600885 & 6.1739 & 5.7121 & TST & \\
\hline CHEMBL576604 & 600885 & 4.95 & 5.4018 & TRN & \\
\hline CHEMBL587714 & 600885 & 7.0477 & 5.9764 & TST & \\
\hline CHEMBL600346 & 600885 & 7.3179 & 6.4825 & TST & \\
\hline CHEMBL578293 & 600885 & 6.3585 & 6.0235 & TRN & \\
\hline CHEMBL585033 & 600885 & 6.4622 & 5.8395 & TRN & \\
\hline CHEMBL531726 & 600885 & 6.0 & 5.9734 & TRN & \\
\hline CHEMBL585254 & 600885 & 3.9031 & 5.2928 & TRN & \\
\hline CHEMBL600924 & 600885 & 5.9337 & 5.7307 & TRN & \\
\hline CHEMBL578883 & 600885 & 4.9031 & 5.38899 & 9999999999 & TRN \\
\hline CHEMBL581887 & 600885 & 6.1146 & 5.7535 & TRN & \\
\hline CHEMBL597245 & 600885 & 6.1024 & 5.6867 & TST & \\
\hline CHEMBL534283 & 600885 & 5.6662 & 5.855 & TRN & \\
\hline CHEMBL528080 & 600885 & 4.9805 & 6.9832 & TRN & \\
\hline CHEMBL603040 & 600885 & 5.9559 & 5.8867 & TRN & \\
\hline CHEMBL583807 & 600885 & 6.1656 & 5.9547 & TRN & \\
\hline CHEMBL579374 & 600885 & 4.9031 & 6.00700 & $\partial 000000001$ & TRN \\
\hline CHEMBL602355 & 600885 & 6.5699 & 6.166 & TRN & \\
\hline CHEMBL578086 & 600885 & 4.9031 & 5.4322 & TRN & \\
\hline CHEMBL598074 & 600885 & 5.6874 & 5.8507 & TRN & \\
\hline CHEMBL531326 & 600885 & 7.2197 & 6.0579 & TRN & \\
\hline CHEMBL611078 & 600885 & 5.0357 & 5.2559 & TST & \\
\hline CHEMBL583817 & 600885 & 6.0 & 5.7952 & TRN & \\
\hline CHEMBL584882 & 600885 & 5.0996 & 4.9128 & TRN & \\
\hline CHEMBL584440 & 600885 & 5.8404 & 6.2705 & TRN & \\
\hline CHEMBL602166 & 600885 & 4.9031 & 5.28600 & 00000000005 & TST \\
\hline & & & & 8043 & \\
\hline
\end{tabular}




\begin{tabular}{|c|c|c|c|c|c|c|c|}
\hline \multicolumn{7}{|c|}{ 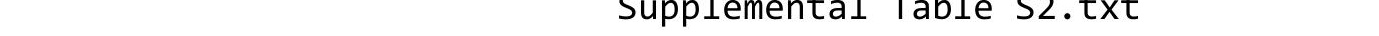 } & \\
\hline CHEMBL536002 & 600885 & 4.1403 & 5.7804 & TST & & & \\
\hline CHEMBL529555 & 600885 & 5.104 & 6.1005 & TRN & & & \\
\hline CHEMBL513104 & 600885 & 4.9031 & 6.0688 & TRN & & & \\
\hline CHEMBL577362 & 600885 & 5.739 & 5.4238 & TRN & & & \\
\hline CHEMBL527732 & 600885 & 5.3788 & 4.8265 & TST & & & \\
\hline CHEMBL578956 & 600885 & 6.0942 & 5.9237 & TST & & & \\
\hline CHEMBL532723 & 600885 & 6.4437 & 6.0638 & TST & & & \\
\hline CHEMBL601987 & 600885 & 7.0334 & 6.2756 & TRN & & & \\
\hline CHEMBL587147 & 600885 & 5.9442 & 5.8004 & TST & & & \\
\hline CHEMBL597653 & 600885 & 5.9606 & 5.9376 & TRN & & & \\
\hline CHEMBL533851 & 600885 & 6.0953 & 5.9474 & TST & & & \\
\hline CHEMBL580846 & 600885 & 5.1543 & 5.3677 & TST & & & \\
\hline CHEMBL2304386 & 600885 & 6.0 & 5.8329 & TRN & & & \\
\hline CHEMBL588932 & 600885 & 6.7003 & 6.1327 & TRN & & & \\
\hline CHEMBL585216 & 600885 & 6.7245 & 6.149 & TRN & & & \\
\hline CHEMBL582501 & 600885 & 7.1319 & 5.2404 & TRN & & & \\
\hline CHEMBL578273 & 600885 & 6.2366 & 6.8285 & TRN & & & \\
\hline CHEMBL582509 & 600885 & 6.7328 & 6.1641 & TRN & & & \\
\hline CHEMBL579379 & 600885 & 6.7109 & 6.3962 & TRN & & & \\
\hline CHEMBL596635 & 600885 & 6.3391 & 5.8846 & TRN & & & \\
\hline CHEMBL586793 & 600885 & 7.0804 & 6.3016 & TRN & & & \\
\hline CHEMBL602416 & 600885 & 6.0846 & 5.8384 & TRN & & & \\
\hline CHEMBL587064 & 600885 & 5.8102 & 5.6717 & TRN & & & \\
\hline CHEMBL585830 & 600885 & 4.9031 & 6.3978 & TST & & & \\
\hline CHEMBL585028 & 600885 & 5.9893 & 7.1726 & TRN & & & \\
\hline CHEMBL584662 & 600885 & 6.0799 & 5.4402 & TRN & & & \\
\hline CHEMBL577663 & 600885 & 4.7828 & 5.3917 & TRN & & & \\
\hline CHEMBL546399 & 600885 & 5.8236 & 5.4411 & TRN & & & \\
\hline CHEMBL582451 & 600885 & 6.16299 & 999999999 & 99 & 6.1804 & TRN & \\
\hline CHEMBL601160 & 600885 & 3.9031 & 5.7621 & TRN & & & \\
\hline CHEMBL602403 & 600885 & 7.1302 & 6.832999 & 9999999999 & & TRN & \\
\hline CHEMBL600567 & 600885 & 6.2807 & 6.0811 & TRN & & & \\
\hline CHEMBL583163 & 600885 & 6.8145 & 6.1486 & TRN & & & \\
\hline CHEMBL585429 & 600885 & 6.6137 & 6.349 & TRN & & & \\
\hline CHEMBL529171 & 600885 & 3.9031 & 4.8923 & TRN & & & \\
\hline CHEMBL578117 & 600885 & 4.9031 & 5.8953 & TRN & & & \\
\hline CHEMBL584431 & 600885 & 6.0 & 6.0594 & TRN & & & \\
\hline CHEMBL584030 & 600885 & 6.1409 & 5.905 & TRN & & & \\
\hline CHEMBL602008 & 600885 & 6.1308 & 6.4595 & TRN & & & \\
\hline CHEMBL585625 & 600885 & 6.5143 & 6.3947 & TRN & & & \\
\hline CHEMBL599705 & 600885 & 5.1733 & 5.1701 & TRN & & & \\
\hline CHEMBL580636 & 600885 & 6.0 & 5.8123 & TRN & & & \\
\hline CHEMBL582046 & 600885 & 6.007006 & 000000000 & & 6.15600 & 0000000001 & TRN \\
\hline CHEMBL578105 & 600885 & 6.9602 & 7.263 & TRN & & & \\
\hline CHEMBL576805 & 600885 & 6.0137 & 5.7411 & TRN & & & \\
\hline CHEMBL579322 & 600885 & 6.0 & 5.7908 & TRN & & & \\
\hline CHEMBL582068 & 600885 & 4.0218 & 5.6676 & TRN & & & \\
\hline CHEMBL577639 & 600885 & 5.6432 & 5.5871 & TRN & & & \\
\hline
\end{tabular}




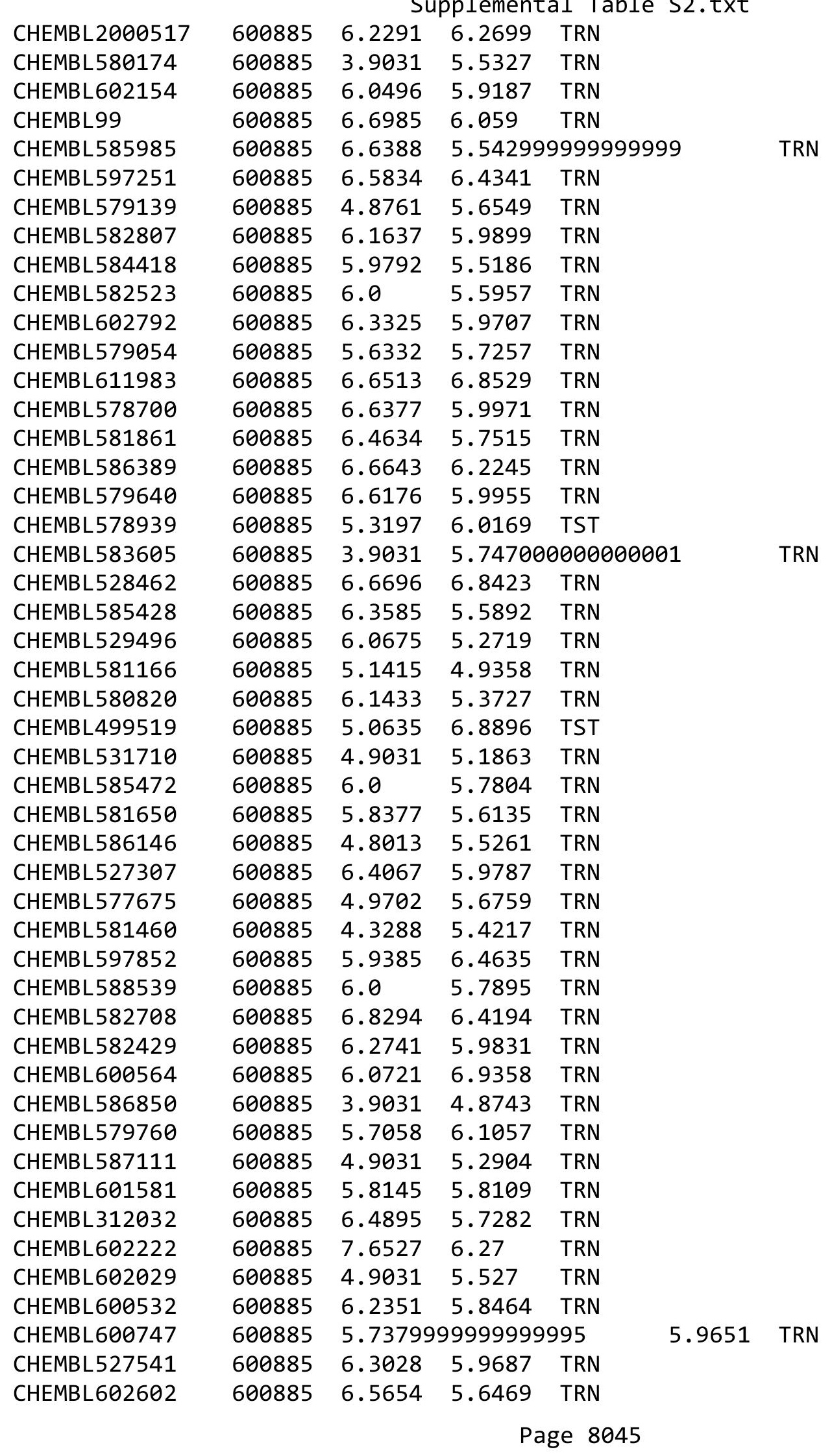




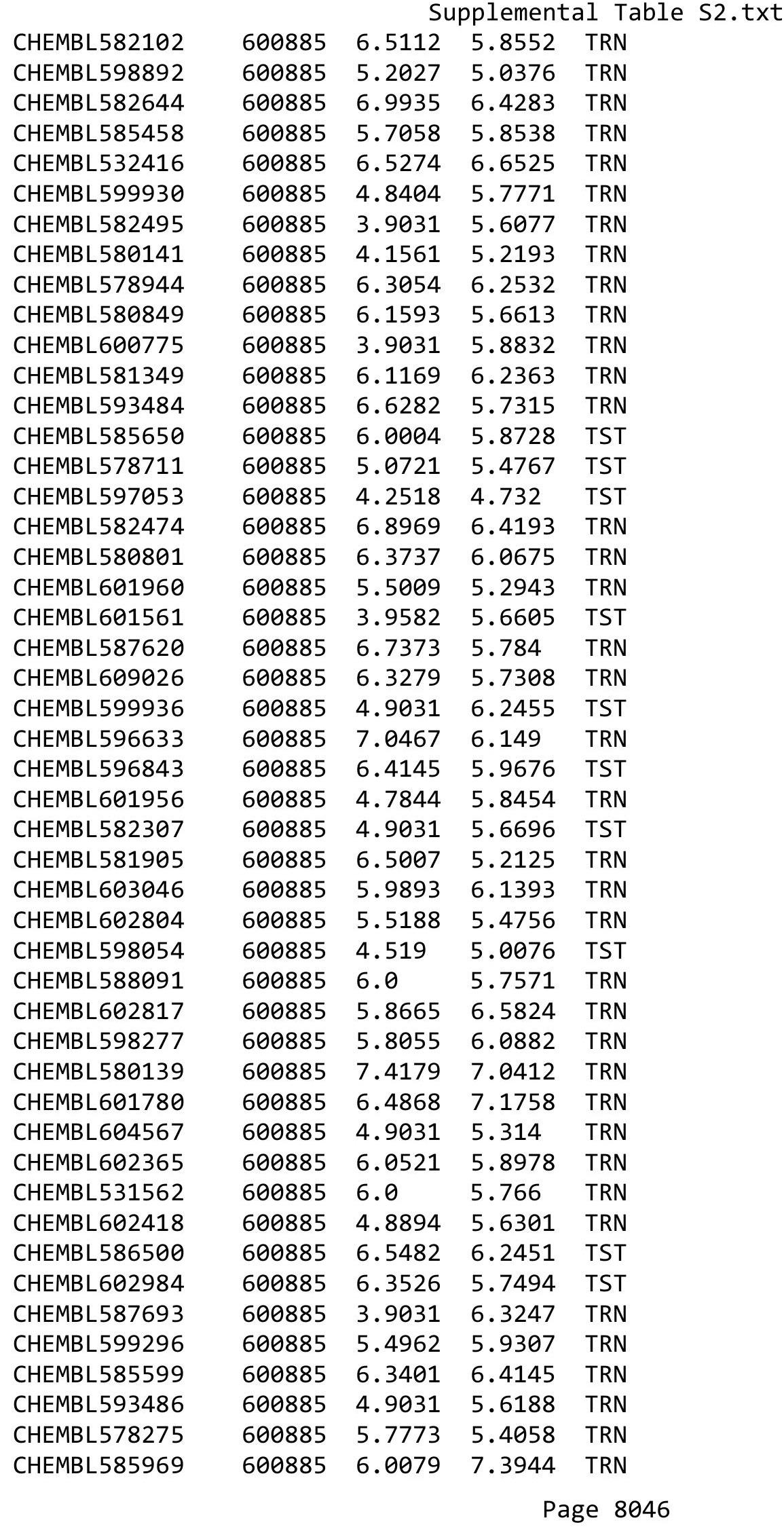




\begin{tabular}{|c|c|c|c|c|c|c|}
\hline \multirow[b]{2}{*}{ CHEMBL585407 } & \multicolumn{6}{|c|}{ Supplemental Table S2.txt } \\
\hline & 600885 & 6.2541 & 6.3679 & TRN & & \\
\hline CHEMBL605746 & 600885 & 5.945 & 5.9918 & TRN & & \\
\hline CHEMBL578630 & 600885 & 6.0443 & 5.5576 & TRN & & \\
\hline CHEMBL601396 & 600885 & 5.7366 & 6.1541 & TRN & & \\
\hline CHEMBL577658 & 600885 & 5.1343 & 5.5512 & TRN & & \\
\hline CHEMBL580164 & 600885 & 8.6135 & 7.0309 & TST & & \\
\hline CHEMBL603744 & 600885 & 6.626 & 6.2126 & TRN & & \\
\hline CHEMBL609025 & 600885 & 6.0 & 5.7032 & TRN & & \\
\hline CHEMBL602784 & 600885 & 5.3233 & 5.5341 & TRN & & \\
\hline CHEMBL578702 & 600885 & 6.0 & 5.8296 & TRN & & \\
\hline CHEMBL579080 & 600885 & 6.655 & 6.0936 & TRN & & \\
\hline CHEMBL585212 & 600885 & 4.9031 & 5.3977 & TST & & \\
\hline CHEMBL584212 & 600885 & 6.6073 & 5.4184 & TRN & & \\
\hline CHEMBL602420 & 600885 & 4.9031 & 5.7326 & TST & & \\
\hline CHEMBL581651 & 600885 & 6.7945 & 5.9197 & TRN & & \\
\hline CHEMBL578508 & 600885 & 6.8719 & 6.1357 & TRN & & \\
\hline CHEMBL600734 & 600885 & 6.1675 & 6.2667 & TRN & & \\
\hline CHEMBL578677 & 600885 & 6.0 & 5.8983 & TRN & & \\
\hline CHEMBL581264 & 600885 & 6.0645 & 5.8264 & TRN & & \\
\hline CHEMBL603519 & 600885 & 6.5051 & 6.0383 & TRN & & \\
\hline CHEMBL596853 & 600885 & 5.7142 & 5.9851 & TST & & \\
\hline CHEMBL601567 & 600885 & 5.7815 & 6.1523 & TRN & & \\
\hline CHEMBL587210 & 600885 & 7.0737 & 6.4193 & TRN & & \\
\hline CHEMBL579149 & 600885 & 4.8356 & 5.9126 & TRN & & \\
\hline CHEMBL601145 & 600885 & 5.7062 & 5.61299 & 9999999999 & 95 & TRN \\
\hline CHEMBL582118 & 600885 & 5.6874 & 5.2961 & TRN & & \\
\hline CHEMBL581465 & 600885 & 4.9031 & 5.7038 & TRN & & \\
\hline CHEMBL421088 & 600885 & 6.5727 & 6.1061 & TRN & & \\
\hline CHEMBL527904 & 600885 & 6.4389 & 6.2766 & TRN & & \\
\hline CHEMBL585423 & 600885 & 4.8162 & 5.8608 & TRN & & \\
\hline CHEMBL578897 & 600885 & 5.922999 & 99999999 & 99 & 5.5211 & TRN \\
\hline CHEMBL585024 & 600885 & 4.9031 & 5.1474 & TRN & & \\
\hline CHEMBL605816 & 600885 & 6.342006 & 300000006 & 205 & 6.4724 & TRN \\
\hline CHEMBL606474 & 600885 & 5.8444 & 5.6388 & TRN & & \\
\hline CHEMBL600128 & 600885 & 6.5351 & 5.9587 & TRN & & \\
\hline CHEMBL600969 & 600885 & 4.9031 & 5.452006 & 0000000001 & & TST \\
\hline CHEMBL584674 & 600885 & 4.9031 & 6.1758 & TRN & & \\
\hline CHEMBL579719 & 600885 & 4.9031 & 5.3396 & TRN & & \\
\hline CHEMBL601143 & 600885 & 6.0841 & 6.0616 & TST & & \\
\hline CHEMBL584257 & 600885 & 6.6317 & 5.6489 & TRN & & \\
\hline CHEMBL601985 & 600885 & 4.9031 & 5.4985 & TRN & & \\
\hline CHEMBL584847 & 600885 & 6.0969 & 5.5981 & TRN & & \\
\hline CHEMBL597446 & 600885 & 6.0 & 5.6261 & TRN & & \\
\hline CHEMBL602837 & 600885 & 6.1851 & 5.8728 & TRN & & \\
\hline CHEMBL579125 & 600885 & 5.9638 & 5.7959 & TRN & & \\
\hline CHEMBL528954 & 600885 & 5.71 & 5.5604 & TST & & \\
\hline CHEMBL583402 & 600885 & 4.4989 & 5.7774 & TRN & & \\
\hline CHEMBL579352 & 600885 & 7.1373 & 6.3261 & TRN & & \\
\hline
\end{tabular}




\begin{tabular}{|c|c|c|c|c|c|c|c|}
\hline & & & & & & & \\
\hline CHEMBL584479 & 600885 & 5.1746 & 5.7126 & TRN & & & \\
\hline CHEMBL597871 & 600885 & 5.7233 & 5.5707 & TRN & & & \\
\hline CHEMBL585050 & 600885 & 6.0878 & 7.0358 & TRN & & & \\
\hline CHEMBL577452 & 600885 & 6.2055 & 5.9907 & TRN & & & \\
\hline CHEMBL530051 & 600885 & 6.9983 & 6.2111 & TRN & & & \\
\hline CHEMBL529349 & 600885 & 6.0 & 5.8767 & TST & & & \\
\hline CHEMBL577437 & 600885 & 5.2197 & 5.3811 & TRN & & & \\
\hline CHEMBL578967 & 600885 & 7.5176 & 6.3603 & TRN & & & \\
\hline CHEMBL 2308884 & 600885 & 6.5782 & 6.0207 & TST & & & \\
\hline CHEMBL582081 & 600885 & 5.7937 & 5.7513 & TRN & & & \\
\hline CHEMBL605550 & 600885 & 5.7409 & 5.8124 & TRN & & & \\
\hline CHEMBL581869 & 600885 & 5.2211 & 5.67200 & 000000000 & & TRN & \\
\hline CHEMBL585562 & 600885 & 5.7126 & 5.8639 & TRN & & & \\
\hline CHEMBL581969 & 600885 & 4.9031 & 6.4951 & TST & & & \\
\hline CHEMBL54804 & 600885 & 4.9031 & 5.3259 & TST & & & \\
\hline CHEMBL600763 & 600885 & 6.2388 & 6.1994 & TRN & & & \\
\hline CHEMBL586764 & 600885 & 3.9031 & 5.7941 & TRN & & & \\
\hline CHEMBL531351 & 600885 & 6.0 & 6.237 & TRN & & & \\
\hline CHEMBL577848 & 600885 & 6.0 & 5.612 & TRN & & & \\
\hline CHEMBL577849 & 600885 & 5.8389 & 5.9177 & TRN & & & \\
\hline CHEMBL602808 & 600885 & 6.0555 & 6.0904 & TRN & & & \\
\hline CHEMBL576990 & 600885 & 5.9698 & 6.0171 & TRN & & & \\
\hline CHEMBL582743 & 600885 & 4.9031 & 5.3407 & TRN & & & \\
\hline CHEMBL586779 & 600885 & 4.9031 & 5.3941 & TRN & & & \\
\hline CHEMBL527397 & 600885 & 6.3487 & 5.9406 & TST & & & \\
\hline CHEMBL601759 & 600885 & 3.9031 & 5.5399 & TST & & & \\
\hline CHEMBL601603 & 600885 & 4.9031 & 5.4623 & TST & & & \\
\hline CHEMBL602432 & 600885 & 6.4881 & 6.0431 & TRN & & & \\
\hline CHEMBL603022 & 600885 & 6.066 & 5.8178 & TRN & & & \\
\hline CHEMBL584246 & 600885 & 7.2976 & 6.0396 & TST & & & \\
\hline CHEMBL585642 & 600885 & 6.4776 & 6.495 & TRN & & & \\
\hline CHEMBL598891 & 600885 & 6.2007 & 5.3911 & TRN & & & \\
\hline CHEMBL600943 & 600885 & 4.9031 & 5.3144 & TRN & & & \\
\hline CHEMBL576576 & 600885 & 4.852 & 5.4636 & TRN & & & \\
\hline CHEMBL601331 & 600885 & 5.34200 & 00000000 & 005 & 5.3820 & 0000000001 & TST \\
\hline CHEMBL600970 & 600885 & 6.7033 & 5.7882 & TRN & & & \\
\hline CHEMBL541417 & 600885 & 6.0 & 5.6342 & TRN & & & \\
\hline CHEMBL579138 & 600885 & 4.9927 & 5.568 & TRN & & & \\
\hline CHEMBL604323 & 600885 & 5.7498 & 5.8485 & TRN & & & \\
\hline CHEMBL530265 & 600885 & 6.5763 & 6.0182 & TRN & & & \\
\hline CHEMBL603033 & 600885 & 3.9516 & 4.7539 & TRN & & & \\
\hline CHEMBL529295 & 600885 & 6.1391 & 5.7116 & TRN & & & \\
\hline CHEMBL10835 & 600885 & 5.98799 & 99999999 & 995 & 5.782 & TRN & \\
\hline CHEMBL603001 & 600885 & 5.58200 & 00000000 & & 5.5343 & TRN & \\
\hline CHEMBL587942 & 600885 & 3.9031 & 5.9902 & TRN & & & \\
\hline CHEMBL604927 & 600885 & 5.1681 & 5.7708 & TST & & & \\
\hline CHEMBL597656 & 600885 & 6.1746 & 5.9811 & TRN & & & \\
\hline CHEMBL530620 & 600885 & 6.6908 & 6.7995 & TRN & & & \\
\hline
\end{tabular}




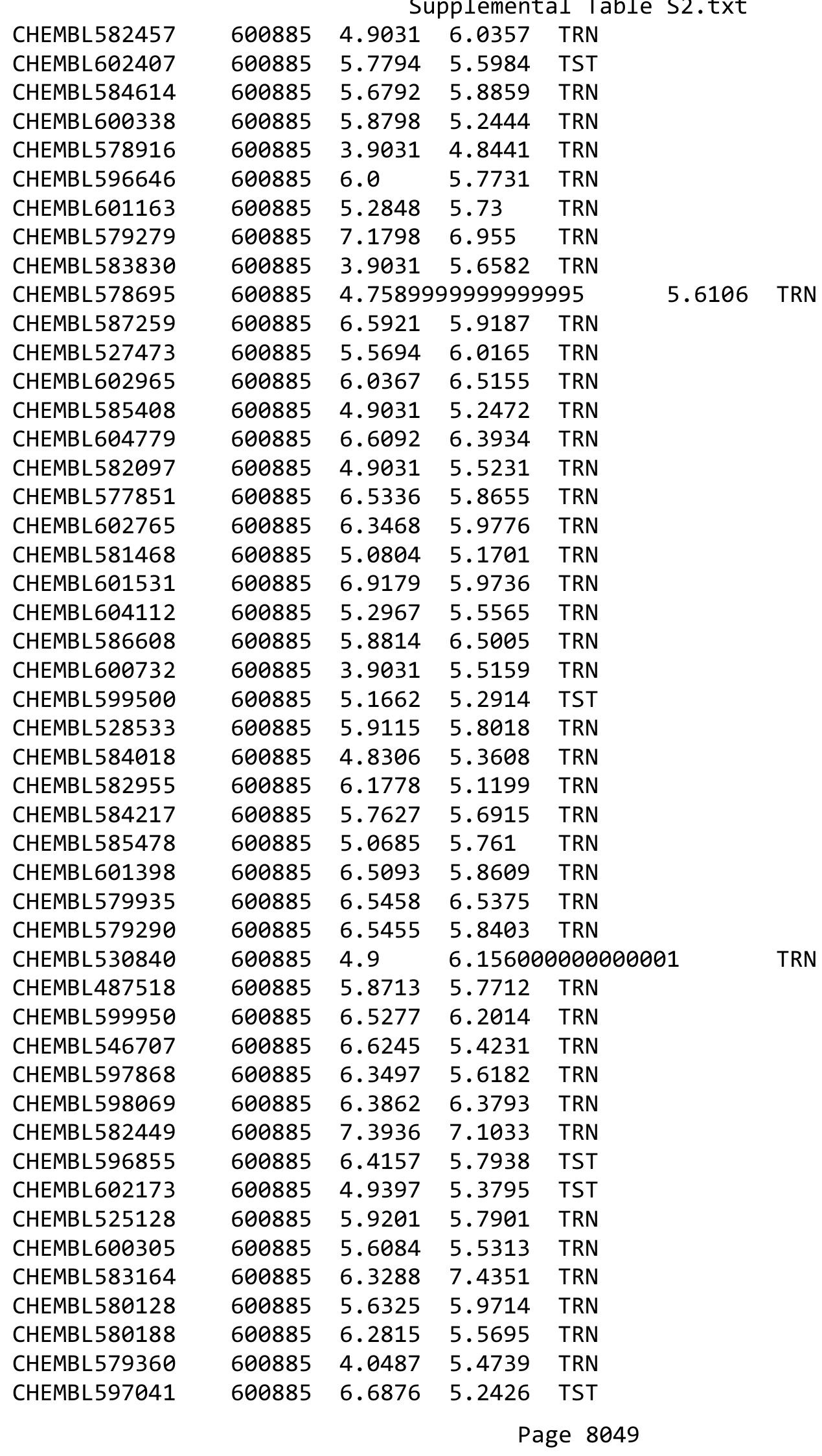




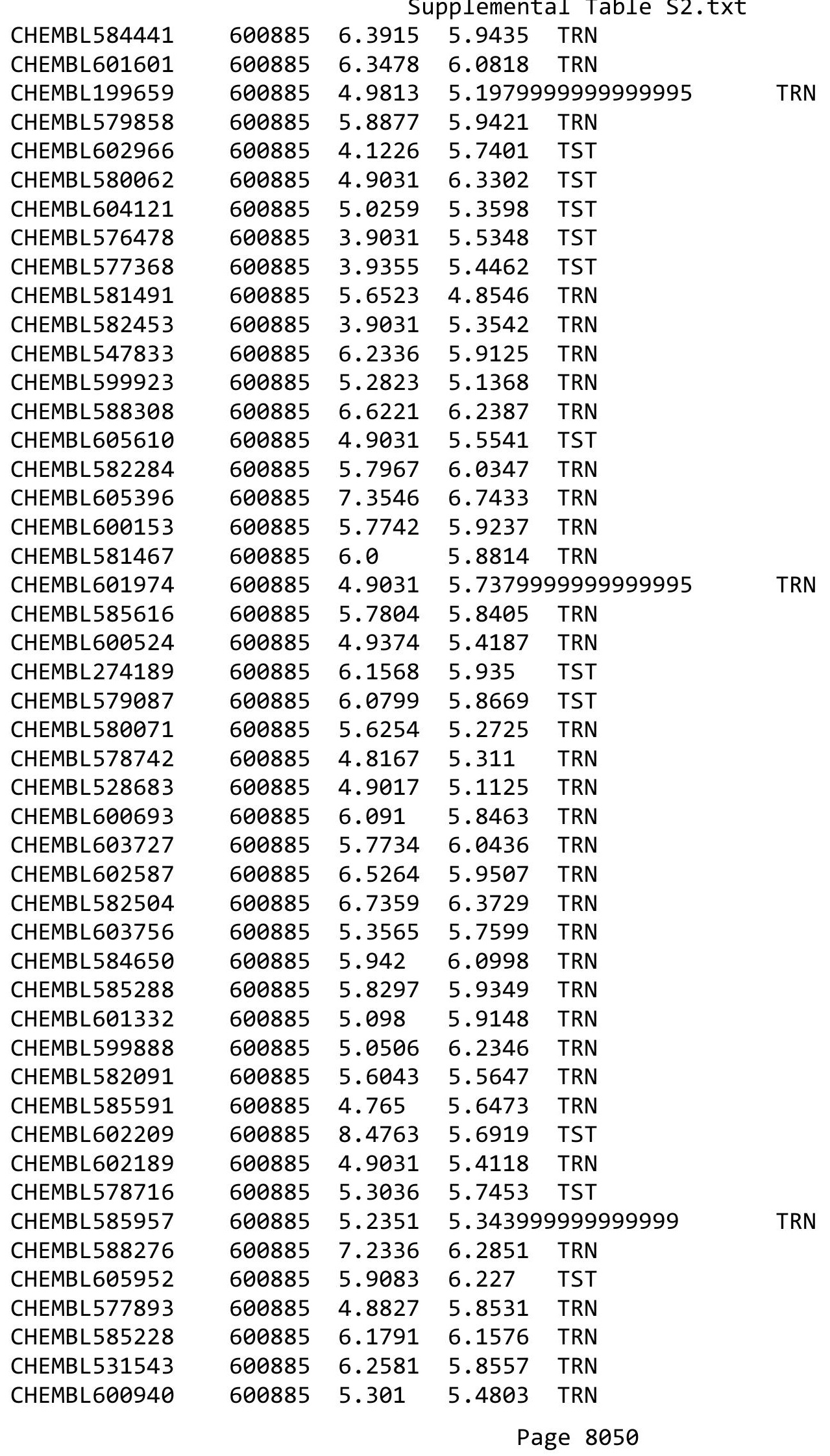




\begin{tabular}{|c|c|c|c|c|c|}
\hline & & & & & \\
\hline CHEMBL577439 & 600885 & 5.5002 & 5.1912 & TRN & \\
\hline CHEMBL582988 & 600885 & 5.7873 & 5.6722 & TRN & \\
\hline CHEMBL582268 & 600885 & 6.0 & 5.7141 & TST & \\
\hline CHEMBL583345 & 600885 & 6.3107 & 6.7956 & TRN & \\
\hline CHEMBL581889 & 600885 & 7.5643 & 6.687 & TRN & \\
\hline CHEMBL529589 & 600885 & 6.6131 & 5.085 & TRN & \\
\hline CHEMBL585418 & 600885 & 6.4145 & 6.0658 & TRN & \\
\hline CHEMBL582054 & 600885 & 4.9031 & 5.3225 & TRN & \\
\hline CHEMBL600286 & 600885 & 4.9031 & 5.3818 & TRN & \\
\hline CHEMBL583160 & 600885 & 6.857 & 6.2419 & TRN & \\
\hline CHEMBL601813 & 600885 & 5.1469 & 5.62200 & $\partial 000000001$ & TRN \\
\hline CHEMBL601548 & 600885 & 5.7506 & 5.8994 & TST & \\
\hline CHEMBL602588 & 600885 & 6.1445 & 6.1899 & TST & \\
\hline CHEMBL581266 & 600885 & 5.8639 & 5.1278 & TRN & \\
\hline CHEMBL578962 & 600885 & 6.0985 & 6.2055 & TRN & \\
\hline CHEMBL585094 & 600885 & 6.1373 & 6.5731 & TRN & \\
\hline CHEMBL585074 & 600885 & 4.9031 & 5.3487 & TST & \\
\hline CHEMBL601535 & 600885 & 5.6855 & 5.1606 & TRN & \\
\hline CHEMBL600928 & 600885 & 6.0 & 5.6502 & TRN & \\
\hline CHEMBL432537 & 600885 & 6.8283 & 6.2411 & TRN & \\
\hline CHEMBL600290 & 600885 & 3.9031 & 5.8508 & TRN & \\
\hline CHEMBL577621 & 600885 & 6.5357 & 5.5558 & TST & \\
\hline CHEMBL532611 & 600885 & 5.8697 & 6.3688 & TRN & \\
\hline CHEMBL1448140 & 600885 & 5.0114 & 5.2925 & TRN & \\
\hline CHEMBL611211 & 600885 & 4.9031 & 5.7743 & TST & \\
\hline CHEMBL585067 & 600885 & 4.8601 & 5.1746 & TRN & \\
\hline CHEMBL596842 & 600885 & 6.0851 & 6.6689 & TRN & \\
\hline CHEMBL580959 & 600885 & 7.0218 & 6.5148 & TRN & \\
\hline CHEMBL577226 & 600885 & 6.3036 & 6.0633 & TRN & \\
\hline CHEMBL602619 & 600885 & 5.9442 & 5.4532 & TRN & \\
\hline CHEMBL585471 & 600885 & 6.4881 & 5.862 & TRN & \\
\hline CHEMBL600929 & 600885 & 5.3546 & 5.216 & TRN & \\
\hline CHEMBL599719 & 600885 & 6.0 & 5.8129 & TRN & \\
\hline CHEMBL535261 & 600885 & 6.4225 & 6.0763 & TRN & \\
\hline CHEMBL582718 & 600885 & 6.3556 & 6.1774 & TRN & \\
\hline CHEMBL598278 & 600885 & 6.1284 & 6.775 & TRN & \\
\hline CHEMBL602361 & 600885 & 5.6951 & 6.0261 & TRN & \\
\hline CHEMBL581904 & 600885 & 6.1694 & 5.6461 & TRN & \\
\hline CHEMBL602629 & 600885 & 6.224 & 5.8239 & TRN & \\
\hline CHEMBL610217 & 600885 & 6.1844 & 5.8516 & TST & \\
\hline CHEMBL602783 & 600885 & 6.0726 & 5.78700 & 0000000001 & TRN \\
\hline CHEMBL536695 & 600885 & 5.4023 & 4.727 & TRN & \\
\hline CHEMBL578923 & 600885 & 4.3497 & 5.0093 & TRN & \\
\hline CHEMBL587680 & 600885 & 6.7587 & 7.0382 & TRN & \\
\hline CHEMBL582647 & 600885 & 5.9731 & 5.89 & TST & \\
\hline CHEMBL585453 & 600885 & 6.4271 & 6.0292 & TRN & \\
\hline CHEMBL601957 & 600885 & 6.11799 & 99999999 & 5.9674 & TRN \\
\hline CHEMBL579093 & 600885 & 4.8684 & 6.0364 & TRN & \\
\hline
\end{tabular}





\begin{tabular}{|c|c|c|c|c|c|}
\hline & & & & & \\
\hline CHEMBL582725 & 600885 & 5.6962 & 5.6269 & TRN & \\
\hline CHEMBL585823 & 600885 & 6.1898 & 6.6444 & TRN & \\
\hline CHEMBL577414 & 600885 & 4.7836 & 5.894 & TRN & \\
\hline CHEMBL576526 & 600885 & 3.9031 & 5.5143 & TST & \\
\hline CHEMBL604736 & 600885 & 5.295 & 4.9364 & TRN & \\
\hline CHEMBL585621 & 600885 & 5.5461 & 5.7835 & TRN & \\
\hline CHEMBL579766 & 600885 & 4.9031 & 5.5789 & TRN & \\
\hline CHEMBL578706 & 600885 & 8.2487 & 7.0544 & TRN & \\
\hline CHEMBL604154 & 600885 & 6.063 & 5.6343 & TRN & \\
\hline CHEMBL601129 & 600885 & 4.9031 & 5.2028 & TRN & \\
\hline CHEMBL584421 & 600885 & 6.7238 & 6.6037 & TRN & \\
\hline CHEMBL601796 & 600885 & 5.2007 & 6.0959 & TRN & \\
\hline CHEMBL582682 & 600885 & 6.5822 & 6.2197 & TRN & \\
\hline CHEMBL553098 & 600885 & 6.4868 & 5.3683 & TRN & \\
\hline CHEMBL585233 & 600885 & 5.1141 & 5.7115 & TRN & \\
\hline CHEMBL600352 & 600885 & 4.9031 & 5.223 & TRN & \\
\hline CHEMBL597049 & 600885 & 5.6066 & 5.6416 & TRN & \\
\hline CHEMBL581661 & 600885 & 6.6207 & 6.3004 & TRN & \\
\hline CHEMBL599289 & 600885 & 5.8404 & 5.87700 & 0000000001 & TST \\
\hline CHEMBL578304 & 600885 & 5.8047 & 4.9229 & TRN & \\
\hline CHEMBL600147 & 600885 & 5.4498 & 6.1317 & TRN & \\
\hline CHEMBL124006 & 600885 & 7.4855 & 6.1386 & TRN & \\
\hline CHEMBL584442 & 600885 & 6.8324 & 6.2805 & TRN & \\
\hline CHEMBL603013 & 600885 & 6.0004 & 5.9862 & TRN & \\
\hline CHEMBL582704 & 600885 & 6.0878 & 5.1285 & TRN & \\
\hline CHEMBL585424 & 600885 & 4.8196 & 5.7756 & TRN & \\
\hline CHEMBL524403 & 600885 & 6.4572 & 6.1693 & TRN & \\
\hline CHEMBL584642 & 600885 & 4.9031 & 5.2177 & TRN & \\
\hline CHEMBL601615 & 600885 & 5.959 & 7.518 & TRN & \\
\hline CHEMBL600302 & 600885 & 5.9948 & 5.8497 & TST & \\
\hline CHEMBL599291 & 600885 & 5.8383 & 5.74700 & 3000000001 & TRN \\
\hline CHEMBL585466 & 600885 & 6.4342 & 6.1775 & TRN & \\
\hline CHEMBL604100 & 600885 & 5.2487 & 5.8343 & TRN & \\
\hline CHEMBL583682 & 600885 & 6.4535 & 6.0514 & TRN & \\
\hline CHEMBL599959 & 600885 & 5.6474 & 5.6886 & TRN & \\
\hline CHEMBL601360 & 600885 & 5.9344 & 6.282 & TRN & \\
\hline CHEMBL578492 & 600885 & 5.7873 & 5.28 & TRN & \\
\hline CHEMBL582294 & 600885 & 6.2526 & 5.7222 & TRN & \\
\hline CHEMBL602812 & 600885 & 6.2899 & 5.0494 & TRN & \\
\hline CHEMBL600757 & 600885 & 4.8732 & 5.9541 & TRN & \\
\hline CHEMBL598894 & 600885 & 5.8336 & 5.9338 & TRN & \\
\hline CHEMBL601542 & 600885 & 6.1891 & 5.8888 & TST & \\
\hline CHEMBL586620 & 600885 & 4.9031 & 5.3939 & TST & \\
\hline CHEMBL582275 & 600885 & 4.9031 & 5.8919 & TRN & \\
\hline CHEMBL584215 & 600885 & 3.9031 & 4.8565 & TST & \\
\hline CHEMBL576379 & 600885 & 7.5728 & 6.6397 & TRN & \\
\hline CHEMBL581695 & 600885 & 5.8474 & 5.3553 & TRN & \\
\hline CHEMBL609156 & 600885 & 5.7791 & 5.5998 & TRN & \\
\hline
\end{tabular}




\begin{tabular}{|c|c|c|c|c|}
\hline & & & pıemen & \\
\hline CHEMBL422330 & 600885 & 6.1096 & 6.1365 & TRN \\
\hline CHEMBL582511 & 600885 & 5.4123 & 5.5139 & TRN \\
\hline CHEMBL598486 & 600885 & 6.2233 & 5.3598 & TRN \\
\hline CHEMBL600922 & 600885 & 5.9796 & 5.8083 & TST \\
\hline CHEMBL598475 & 600885 & 6.3665 & 5.7778 & TRN \\
\hline CHEMBL584648 & 600885 & 4.9031 & 5.39 & TRN \\
\hline CHEMBL582063 & 600885 & 6.4572 & 5.295 & TRN \\
\hline CHEMBL600688 & 600885 & 5.3883 & 4.9002 & TST \\
\hline CHEMBL585145 & 600885 & 7.5035 & 6.7112 & TRN \\
\hline CHEMBL1599370 & 600885 & 6.5521 & 6.112 & TRN \\
\hline CHEMBL582084 & 600885 & 5.0975 & 5.7153 & TRN \\
\hline CHEMBL576376 & 600885 & 7.1302 & 6.7556 & TRN \\
\hline CHEMBL599499 & 600885 & 6.0 & 5.6992 & TRN \\
\hline CHEMBL578887 & 600885 & 5.8465 & 5.8116 & TRN \\
\hline CHEMBL577649 & 600885 & 5.624 & 5.8068 & TRN \\
\hline CHEMBL578286 & 600885 & 6.7775 & 6.1253 & TST \\
\hline CHEMBL586279 & 600885 & 6.4776 & 5.9479 & TRN \\
\hline CHEMBL529858 & 600885 & 6.6156 & 6.0638 & TRN \\
\hline CHEMBL584266 & 600885 & 5.8091 & 5.8118 & TRN \\
\hline CHEMBL609152 & 600885 & 5.568 & 5.558 & TRN \\
\hline CHEMBL583560 & 600885 & 6.0205 & 5.8122 & TRN \\
\hline CHEMBL193528 & 600885 & 6.0 & 5.6918 & TRN \\
\hline CHEMBL582954 & 600885 & 6.2882 & 6.1696 & TRN \\
\hline CHEMBL581654 & 600885 & 5.6813 & 5.121 & TRN \\
\hline CHEMBL601320 & 600885 & 6.6857 & 6.0246 & TRN \\
\hline CHEMBL577807 & 600885 & 3.9031 & 5.522 & TRN \\
\hline CHEMBL586782 & 600885 & 6.1851 & 6.1348 & TRN \\
\hline CHEMBL578109 & 600885 & 6.2147 & 6.191 & TRN \\
\hline CHEMBL585023 & 600885 & 5.2083 & 5.1319 & TRN \\
\hline CHEMBL579837 & 600885 & 6.5569 & 5.8816 & TRN \\
\hline CHEMBL583873 & 600885 & 4.1568 & 5.8082 & TRN \\
\hline CHEMBL530609 & 600885 & 6.0645 & 5.8164 & TRN \\
\hline CHEMBL196573 & 600885 & 6.0 & 5.4984 & TRN \\
\hline CHEMBL578465 & 600885 & 3.9031 & 5.5493 & TRN \\
\hline CHEMBL371218 & 600885 & 6.2596 & 5.9324 & TRN \\
\hline CHEMBL601371 & 600885 & 4.9031 & 5.6849 & TST \\
\hline CHEMBL608145 & 600885 & 5.0424 & 5.2062 & TRN \\
\hline CHEMBL535265 & 600885 & 6.1624 & 5.6485 & TRN \\
\hline CHEMBL601367 & 600885 & 6.7326 & 6.3323 & TRN \\
\hline CHEMBL600898 & 600885 & 4.8468 & 6.4312 & TST \\
\hline CHEMBL528154 & 600885 & 3.9727 & 5.7731 & TST \\
\hline CHEMBL580168 & 600885 & 6.0348 & 5.2664 & TRN \\
\hline CHEMBL602607 & 600885 & 5.7873 & 5.6393 & TRN \\
\hline CHEMBL608558 & 600885 & 4.9031 & 5.2896 & TST \\
\hline CHEMBL588053 & 600885 & 6.6394 & 5.7799 & TRN \\
\hline CHEMBL578066 & 600885 & 6.2941 & 6.9586 & TRN \\
\hline CHEMBL533955 & 600885 & 6.6603 & 5.9429 & TRN \\
\hline CHEMBL583598 & 600885 & 6.6149 & 6.3772 & TRN \\
\hline
\end{tabular}




\begin{tabular}{|c|c|c|c|c|c|c|}
\hline \multirow[b]{2}{*}{ CHEMBL605549 } & \multicolumn{6}{|c|}{ Supplemental Table S2.txt } \\
\hline & 600885 & 5.7409 & 5.5514 & TRN & & \\
\hline CHEMBL588332 & 600885 & 4.9031 & 5.21200 & 000000000 & & TRN \\
\hline CHEMBL601362 & 600885 & 7.3595 & 6.9074 & TRN & & \\
\hline CHEMBL529833 & 600885 & 6.7133 & 5.9116 & TST & & \\
\hline CHEMBL582005 & 600885 & 6.1649 & 5.8033 & TRN & & \\
\hline CHEMBL599494 & 600885 & 6.4425 & 6.4957 & TRN & & \\
\hline CHEMBL579082 & 600885 & 6.5693 & 6.1201 & TST & & \\
\hline CHEMBL579160 & 600885 & 5.9412 & 6.2916 & TRN & & \\
\hline CHEMBL601769 & 600885 & 6.0788 & 6.0209 & TST & & \\
\hline CHEMBL577878 & 600885 & 5.091 & 5.4214 & TRN & & \\
\hline CHEMBL600123 & 600885 & 4.9031 & 5.2601 & TRN & & \\
\hline CHEMBL581649 & 600885 & 6.1746 & 5.9238 & TRN & & \\
\hline CHEMBL584668 & 600885 & 5.8193 & 6.0366 & TRN & & \\
\hline CHEMBL584840 & 600885 & 6.1993 & 5.9814 & TRN & & \\
\hline CHEMBL584623 & 600885 & 4.9031 & 5.3239 & TRN & & \\
\hline CHEMBL602033 & 600885 & 5.1772 & 5.7323 & TRN & & \\
\hline CHEMBL600093 & 600885 & 4.9031 & 5.7171 & TRN & & \\
\hline CHEMBL602015 & 600885 & 5.0348 & 5.5178 & TRN & & \\
\hline CHEMBL601141 & 600885 & 5.6453 & 5.752006 & 000000000 & & TST \\
\hline CHEMBL580612 & 600885 & 6.4157 & 5.6574 & TST & & \\
\hline CHEMBL582476 & 600885 & 4.8268 & 5.7124 & TRN & & \\
\hline CHEMBL 379386 & 600885 & 6.7089 & 6.1908 & TRN & & \\
\hline CHEMBL583530 & 600885 & 7.6722 & 6.239 & TST & & \\
\hline CHEMBL578297 & 600885 & 6.2076 & 6.2953 & TST & & \\
\hline CHEMBL580170 & 600885 & 6.9666 & 6.1504 & TRN & & \\
\hline CHEMBL111750 & 600885 & 6.0 & 5.9523 & TST & & \\
\hline CHEMBL 275177 & 600885 & 6.6621 & 5.9861 & TST & & \\
\hline CHEMBL 235891 & 600885 & 5.8265 & 5.5723 & TST & & \\
\hline CHEMBL601550 & 600885 & 6.0 & 5.857 & TRN & & \\
\hline CHEMBL578470 & 600885 & 4.1469 & 5.4123 & TRN & & \\
\hline CHEMBL599938 & 600885 & 6.2487 & 6.051 & TRN & & \\
\hline CHEMBL608736 & 600885 & 5.4622 & 6.4109 & TST & & \\
\hline CHEMBL578496 & 600885 & 5.0048 & 5.9867 & TRN & & \\
\hline CHEMBL585081 & 600885 & 6.3307 & 5.2261 & TRN & & \\
\hline CHEMBL585778 & 600885 & 5.8505 & 6.4643 & TRN & & \\
\hline CHEMBL598904 & 600885 & 5.9747 & 6.6272 & TRN & & \\
\hline CHEMBL597674 & 600885 & 3.9031 & 5.8063 & TRN & & \\
\hline CHEMBL586875 & 600885 & 6.8739 & 6.1032 & TRN & & \\
\hline CHEMBL601818 & 600885 & 5.0155 & 5.3323 & TRN & & \\
\hline CHEMBL601172 & 600885 & 5.8058 & 5.7133 & TRN & & \\
\hline CHEMBL600499 & 600885 & 5.3161 & 4.7349 & TRN & & \\
\hline CHEMBL599942 & 600885 & 4.9237 & 5.6664 & TST & & \\
\hline CHEMBL528661 & 600885 & 5.9618 & 6.0335 & TRN & & \\
\hline CHEMBL600947 & 600885 & 6.1574 & 5.9574 & TRN & & \\
\hline CHEMBL582784 & 600885 & 5.9825 & 6.1375 & TRN & & \\
\hline CHEMBL577000 & 600885 & 6.5411 & 5.9729 & TRN & & \\
\hline CHEMBL1615698 & 600885 & 5.70200 & 0000000 & $\partial 1$ & 5.6118 & TRN \\
\hline CHEMBL580848 & 600885 & 6.9194 & 6.178 & TRN & & \\
\hline
\end{tabular}




\begin{tabular}{|c|c|c|c|c|c|}
\hline & & \multicolumn{4}{|c|}{ ש } \\
\hline CHEMBL596634 & 600885 & 6.0851 & 6.8357 & TRN & \\
\hline CHEMBL581656 & 600885 & 4.9197 & 5.2316 & TST & \\
\hline CHEMBL593253 & 600885 & 4.6061 & 4.8418 & TRN & \\
\hline CHEMBL586012 & 600885 & 5.98799 & 99999999 & 6.8728 & TST \\
\hline CHEMBL585455 & 600885 & 6.6075 & 5.7743 & TRN & \\
\hline CHEMBL601389 & 600885 & 6.1791 & 5.6565 & TRN & \\
\hline CHEMBL607976 & 600885 & 4.7737 & 6.0888 & TRN & \\
\hline CHEMBL603047 & 600885 & 5.4498 & 5.8372 & TRN & \\
\hline CHEMBL600150 & 600885 & 7.2644 & 5.989 & TRN & \\
\hline CHEMBL584636 & 600885 & 7.8867 & 7.05 & TRN & \\
\hline CHEMBL601558 & 600885 & 5.8611 & 5.8697 & TST & \\
\hline CHEMBL576788 & 600885 & 6.694 & 5.9771 & TRN & \\
\hline CHEMBL602981 & 600885 & 6.6047 & 6.319 & TRN & \\
\hline CHEMBL581393 & 600885 & 5.9965 & 6.0422 & TRN & \\
\hline CHEMBL584226 & 600885 & 5.8024 & 6.7452 & TRN & \\
\hline CHEMBL586019 & 600885 & 6.1296 & 6.1456 & TRN & \\
\hline CHEMBL586685 & 600885 & 6.104 & 5.83299 & 9999999999 & TST \\
\hline CHEMBL581471 & 600885 & 5.04 & 5.3087 & TST & \\
\hline CHEMBL578938 & 600885 & 6.0297 & 6.2934 & TRN & \\
\hline CHEMBL579370 & 600885 & 6.4724 & 6.3068 & TRN & \\
\hline CHEMBL580343 & 600885 & 6.1433 & 6.9273 & TRN & \\
\hline CHEMBL577225 & 600885 & 5.683 & 5.3625 & TRN & \\
\hline CHEMBL582672 & 600885 & 6.8333 & 6.218 & TRN & \\
\hline CHEMBL598888 & 600885 & 6.0706 & 6.1351 & TRN & \\
\hline CHEMBL579344 & 600885 & 5.994 & 5.6995 & TRN & \\
\hline CHEMBL587334 & 600885 & 6.3279 & 6.0441 & TST & \\
\hline CHEMBL601981 & 600885 & 5.3179 & 5.2804 & TRN & \\
\hline CHEMBL601972 & 600885 & 4.7836 & 6.0136 & TST & \\
\hline CHEMBL581271 & 600885 & 4.9559 & 5.109 & TST & \\
\hline CHEMBL600513 & 600885 & 6.3363 & 4.6785 & TRN & \\
\hline CHEMBL579517 & 600885 & 6.1349 & 6.005 & TRN & \\
\hline CHEMBL579066 & 600885 & 6.1158 & 5.6951 & TRN & \\
\hline CHEMBL576404 & 600885 & 6.9172 & 6.2129 & TRN & \\
\hline CHEMBL584239 & 600885 & 5.8798 & 5.7652 & TRN & \\
\hline CHEMBL587221 & 600885 & 6.6531 & 6.1869 & TRN & \\
\hline CHEMBL585379 & 600885 & 4.9031 & 5.8341 & TRN & \\
\hline CHEMBL599712 & 600885 & 3.9031 & 5.4711 & TRN & \\
\hline CHEMBL395209 & 600885 & 6.5911 & 6.3672 & TRN & \\
\hline CHEMBL586027 & 600885 & 6.5953 & 6.6537 & TRN & \\
\hline CHEMBL602622 & 600885 & 6.2233 & 5.6594 & TRN & \\
\hline CHEMBL529569 & 600885 & 6.0701 & 5.2898 & TRN & \\
\hline CHEMBL585464 & 600885 & 6.2076 & 6.2452 & TRN & \\
\hline CHEMBL576205 & 600885 & 8.15 & 6.82799 & 9999999999 & TRN \\
\hline CHEMBL585271 & 600885 & 5.6629 & 5.9628 & TRN & \\
\hline CHEMBL582267 & 600885 & 3.9031 & 5.5169 & TRN & \\
\hline CHEMBL580358 & 600885 & 7.7031 & 6.3101 & TRN & \\
\hline CHEMBL602986 & 600885 & 6.3585 & 5.9302 & TST & \\
\hline CHEMBL582310 & 600885 & 4.9519 & 6.0832 & TRN & \\
\hline
\end{tabular}




\begin{tabular}{|c|c|c|c|c|c|}
\hline & & \multicolumn{4}{|c|}{ Supplemental Table S2.txt } \\
\hline CHEMBL1744502 & 600885 & 4.7768 & 6.2554 & TST & \\
\hline CHEMBL577221 & 600885 & 4.787 & 5.3039 & TST & \\
\hline CHEMBL585776 & 600885 & 4.9031 & 5.3262 & TRN & \\
\hline CHEMBL579834 & 600885 & 5.8979 & 6.1467 & TRN & \\
\hline CHEMBL580154 & 600885 & 4.994 & 5.4354 & TRN & \\
\hline CHEMBL535887 & 600885 & 3.9666 & 5.6961 & TRN & \\
\hline CHEMBL602158 & 600885 & 4.7528 & 5.6 & TRN & \\
\hline CHEMBL598482 & 600885 & 6.7778 & 6.3399 & TRN & \\
\hline CHEMBL601547 & 600885 & 6.6377 & 6.0926 & TRN & \\
\hline CHEMBL602983 & 600885 & 4.9031 & 5.5359 & TRN & \\
\hline CHEMBL584646 & 600885 & 5.9638 & 5.6391 & TRN & \\
\hline CHEMBL579690 & 600885 & 6.1096 & 7.0816 & TST & \\
\hline CHEMBL53034 & 600885 & 6.0915 & 5.9423 & TRN & \\
\hline CHEMBL525333 & 600885 & 7.0241 & 6.17200 & 3000000001 & TRN \\
\hline CHEMBL532641 & 600885 & 6.5759 & 6.0519 & TRN & \\
\hline CHEMBL588589 & 600885 & 4.9031 & 5.9677 & TST & \\
\hline CHEMBL602402 & 600885 & 6.475 & 6.0527 & TST & \\
\hline CHEMBL600959 & 600885 & 5.6256 & 5.6631 & TST & \\
\hline CHEMBL586516 & 600885 & 6.1278 & 6.2063 & TRN & \\
\hline CHEMBL525826 & 600885 & 6.9408 & 6.1493 & TRN & \\
\hline CHEMBL602620 & 600885 & 5.3757 & 5.5236 & TRN & \\
\hline CHEMBL578327 & 600885 & 6.0872 & 6.19 & TRN & \\
\hline CHEMBL602391 & 600885 & 3.9031 & 5.4148 & TRN & \\
\hline CHEMBL577232 & 600885 & 6.7007 & 6.4609 & TRN & \\
\hline CHEMBL585631 & 600885 & 6.5524 & 5.9924 & TRN & \\
\hline CHEMBL600972 & 600885 & 6.5581 & 5.8332 & TRN & \\
\hline CHEMBL585993 & 600885 & 6.3958 & 5.8658 & TRN & \\
\hline CHEMBL600974 & 600885 & 4.9031 & 5.7606 & TRN & \\
\hline CHEMBL 22148 & 600885 & 5.8088 & 5.3917 & TST & \\
\hline CHEMBL597242 & 600885 & 3.9031 & 5.7377 & TST & \\
\hline CHEMBL605188 & 600885 & 6.0841 & 6.526 & TRN & \\
\hline CHEMBL528716 & 600885 & 4.9031 & 5.5306 & TRN & \\
\hline CHEMBL578079 & 600885 & 4.317 & 5.5127 & TRN & \\
\hline CHEMBL602389 & 600885 & 8.6142 & 6.9819 & TRN & \\
\hline CHEMBL532496 & 600885 & 5.1068 & 5.4912 & TRN & \\
\hline CHEMBL600540 & 600885 & 5.9465 & 5.4428 & TRN & \\
\hline CHEMBL585253 & 600885 & 3.9516 & 4.7824 & TST & \\
\hline CHEMBL599908 & 600885 & 5.6167 & 5.8544 & TRN & \\
\hline CHEMBL601168 & 600885 & 3.9031 & 5.7275 & TRN & \\
\hline CHEMBL588216 & 600885 & 5.9367 & 5.6723 & TRN & \\
\hline CHEMBL602637 & 600885 & 5.9698 & 5.9518 & TRN & \\
\hline CHEMBL534535 & 600885 & 7.0809 & 6.4284 & TRN & \\
\hline CHEMBL530565 & 600885 & 7.0762 & 5.9986 & TST & \\
\hline CHEMBL599510 & 600885 & 5.0742 & 5.2671 & TST & \\
\hline CHEMBL600156 & 600885 & 5.4078 & 5.5767 & TRN & \\
\hline CHEMBL600148 & 600885 & 4.8236 & 5.3839 & TRN & \\
\hline CHEMBL576996 & 600885 & 6.1018 & 5.6736 & TST & \\
\hline CHEMBL609748 & 600885 & 8.0061 & 6.8516 & TRN & \\
\hline
\end{tabular}




\begin{tabular}{|c|c|c|c|c|c|c|}
\hline \multirow[b]{2}{*}{ CHEMBL582255 } & & \multicolumn{5}{|c|}{ Supplemental Table s2.txt } \\
\hline & 600885 & 4.9352 & 7.0286 & TRN & & \\
\hline CHEMBL602199 & 600885 & 6.66 & 6.3785 & TRN & & \\
\hline CHEMBL609320 & 600885 & 6.2652 & 6.4655 & TRN & & \\
\hline CHEMBL582339 & 600885 & 6.4855 & 5.9024 & TRN & & \\
\hline CHEMBL582262 & 600885 & \multicolumn{3}{|c|}{6.007000000000001} & 5.9727 & TRN \\
\hline CHEMBL602172 & 600885 & 5.8884 & 5.2999 & TRN & & \\
\hline CHEMBL536605 & 600885 & 6.0783 & 6.028 & TRN & & \\
\hline CHEMBL580843 & 600885 & 5.0164 & 5.353 & TST & & \\
\hline CHEMBL604361 & 600885 & 4.838 & 5.4823 & TST & & \\
\hline CHEMBL530195 & 600885 & 6.3915 & 4.6049 & TRN & & \\
\hline CHEMBL602007 & 600885 & 7.0264 & 5.9743 & TRN & & \\
\hline CHEMBL577666 & 600885 & 3.9031 & 5.3669 & TRN & & \\
\hline CHEMBL603028 & 600885 & 5.6142 & 5.5288 & TRN & & \\
\hline CHEMBL607688 & 600885 & 5.0757 & 5.4786 & TST & & \\
\hline CHEMBL532167 & 600885 & 5.1244 & 5.3387 & TRN & & \\
\hline CHEMBL601387 & 600885 & 7.7657 & 5.9489 & TRN & & \\
\hline CHEMBL598060 & 600885 & 3.9031 & 5.7864 & TRN & & \\
\hline CHEMBL600950 & 600885 & 4.9634 & 5.2621 & TRN & & \\
\hline CHEMBL577163 & 600885 & 7.0762 & 6.0277 & TRN & & \\
\hline CHEMBL585262 & 600885 & 3.9031 & 5.2579 & TST & & \\
\hline CHEMBL601602 & 600885 & 4.1543 & 5.8669 & TRN & & \\
\hline CHEMBL585802 & 600885 & 6.4921 & 6.7265 & TRN & & \\
\hline CHEMBL599962 & 600885 & 6.0106 & 5.7996 & TRN & & \\
\hline CHEMBL604105 & 600885 & 6.2161 & 6.0605 & TRN & & \\
\hline CHEMBL582302 & 600885 & 5.7217 & 5.4249 & TRN & & \\
\hline CHEMBL598271 & 600885 & 4.757 & 6.1236 & TRN & & \\
\hline CHEMBL581260 & 600885 & 4.9374 & 5.3068 & TRN & & \\
\hline CHEMBL578118 & 600885 & 6.2798 & 5.7617 & TRN & & \\
\hline CHEMBL602569 & 600885 & 6.0851 & 4.8675 & TRN & & \\
\hline CHEMBL585896 & 600885 & 8.1445 & 6.7509 & TRN & & \\
\hline CHEMBL577668 & 600885 & 6.1739 & 6.0498 & TRN & & \\
\hline CHEMBL579136 & 600885 & 6.3872 & 5.9961 & TRN & & \\
\hline CHEMBL585788 & 600885 & 5.0146 & 5.2617 & TST & & \\
\hline CHEMBL602782 & 600885 & \multicolumn{3}{|c|}{5.9910000000000005} & 5.691 & TRN \\
\hline CHEMBL533623 & 600885 & 5.8645 & 5.9923 & TRN & & \\
\hline CHEMBL605131 & 600885 & 5.4802 & 5.6702 & TRN & & \\
\hline CHEMBL601751 & 600885 & 6.2182 & 6.1116 & TRN & & \\
\hline CHEMBL601995 & 600885 & 5.6921 & 6.1245 & TRN & & \\
\hline CHEMBL603896 & 600885 & 6.3372 & 5.7941 & TRN & & \\
\hline CHEMBL529166 & 600885 & 4.9031 & 5.4296 & TRN & & \\
\hline CHEMBL601133 & 600885 & 4.9031 & 5.55399 & 9999999999 & & TRN \\
\hline CHEMBL602354 & 600885 & 5.9122 & 6.1632 & TRN & & \\
\hline CHEMBL600746 & 600885 & 6.2958 & 5.8416 & TRN & & \\
\hline CHEMBL609628 & 600885 & 6.5068 & 6.16200 & 0000000001 & & TRN \\
\hline CHEMBL580978 & 600885 & 6.7199 & 5.5004 & TRN & & \\
\hline CHEMBL585398 & 600885 & 6.2168 & 6.026 & TRN & & \\
\hline CHEMBL578330 & 600885 & 4.75899 & 99999999 & 995 & 5.2832 & TRN \\
\hline CHEMBL583396 & 600885 & 5.9307 & 5.6647 & TRN & & \\
\hline
\end{tabular}




\begin{tabular}{|c|c|c|c|c|c|c|}
\hline & & \multicolumn{5}{|c|}{ Supplemental Table S2.txt } \\
\hline CHEMBL1237217 & 600885 & 5.055 & 5.5328 & TRN & & \\
\hline CHEMBL584619 & 600885 & 6.3298 & 5.6614 & TRN & & \\
\hline CHEMBL597673 & 600885 & 6.3768 & 5.6602 & TRN & & \\
\hline CHEMBL529870 & 600885 & 6.6759 & 6.1685 & TRN & & \\
\hline CHEMBL585619 & 600885 & 5.5089 & 5.2724 & TRN & & \\
\hline CHEMBL579958 & 600885 & 6.4067 & 6.1701 & TRN & & \\
\hline CHEMBL577230 & 600885 & 6.2487 & 5.824 & TRN & & \\
\hline CHEMBL580144 & 600885 & 6.5725 & 6.9708 & TRN & & \\
\hline CHEMBL584613 & 600885 & 5.7799 & 5.4254 & TRN & & \\
\hline CHEMBL580785 & 600885 & 7.6269 & 6.7348 & TRN & & \\
\hline CHEMBL611068 & 600885 & 6.5569 & 6.2725 & TRN & & \\
\hline CHEMBL185912 & 600885 & 5.9944 & 5.7222 & TRN & & \\
\hline CHEMBL1615697 & 600885 & 5.8306 & 5.087 & TST & & \\
\hline CHEMBL599497 & 600885 & 6.5677 & 6.0215 & TRN & & \\
\hline CHEMBL601799 & 600885 & 6.7203 & 5.7425 & TST & & \\
\hline CHEMBL587249 & 600885 & \multicolumn{3}{|c|}{5.962999999999999} & .6495 & TRN \\
\hline CHEMBL600319 & 600885 & 6.6698 & 6.2855 & TRN & & \\
\hline CHEMBL530683 & 600885 & 3.9031 & 5.7752 & TRN & & \\
\hline CHEMBL582323 & 600885 & 6.4134 & 5.684 & TRN & & \\
\hline CHEMBL584888 & 600885 & 6.1599 & 5.6431 & TRN & & \\
\hline CHEMBL577838 & 600885 & 5.8066 & 5.9767 & TRN & & \\
\hline CHEMBL598882 & 600885 & 7.2248 & 6.3057 & TST & & \\
\hline CHEMBL577445 & 600885 & 8.1599 & 6.3077 & TRN & & \\
\hline CHEMBL586889 & 600885 & 6.766 & 6.7369 & TRN & & \\
\hline CHEMBL579929 & 600885 & 6.6158 & 6.8529 & TRN & & \\
\hline CHEMBL580054 & 600885 & 4.777 & 6.3345 & TRN & & \\
\hline CHEMBL610503 & 600885 & 5.5268 & 5.9537 & TRN & & \\
\hline CHEMBL578912 & 600885 & 3.9722 & 5.428 & TRN & & \\
\hline CHEMBL578294 & 600885 & 6.8216 & 6.2519 & TRN & & \\
\hline CHEMBL528586 & 600885 & 6.4935 & 6.0483 & TST & & \\
\hline CHEMBL529844 & 600885 & 5.0057 & 5.50299 & 9999999999 & & TRN \\
\hline CHEMBL585259 & 600885 & 6.6269 & 5.7544 & TRN & & \\
\hline CHEMBL581897 & 600885 & 5.9965 & 5.1577 & TRN & & \\
\hline CHEMBL602802 & 600885 & 7.565 & 6.3948 & TRN & & \\
\hline CHEMBL582064 & 600885 & \multicolumn{3}{|c|}{6.247999999999999} & 3052 & TRN \\
\hline CHEMBL604801 & 600885 & 6.1385 & 5.318 & TST & & \\
\hline CHEMBL584453 & 600885 & 6.2411 & 5.8069 & TRN & & \\
\hline CHEMBL600953 & 600885 & 6.0173 & 5.6739 & TRN & & \\
\hline CHEMBL600516 & 600885 & 3.9031 & 5.425 & TRN & & \\
\hline CHEMBL579294 & 600885 & 6.6029 & 6.0397 & TRN & & \\
\hline CHEMBL579291 & 600885 & 3.9318 & 5.8763 & TST & & \\
\hline CHEMBL583119 & 600885 & 6.5996 & 7.0716 & TRN & & \\
\hline CHEMBL586801 & 600885 & 6.4737 & 5.9838 & TRN & & \\
\hline CHEMBL585411 & 600885 & 7.0878 & 6.3022 & TST & & \\
\hline CHEMBL586825 & 600885 & 6.0 & 5.8393 & TST & & \\
\hline CHEMBL579620 & 600885 & 6.3028 & 5.967006 & 00000000005 & & TRN \\
\hline CHEMBL600702 & 600885 & 6.6621 & 5.9585 & TRN & & \\
\hline CHEMBL582088 & 600885 & 7.4365 & 6.4705 & TRN & & \\
\hline
\end{tabular}




\begin{tabular}{|c|c|c|c|c|c|}
\hline \multicolumn{6}{|c|}{ Supplemental Table S2.txt } \\
\hline CHEMBL600730 & 600885 & 7.0862 & 7.1465 & TRN & \\
\hline CHEMBL599290 & 600885 & 5.8847 & 6.5825 & TRN & \\
\hline CHEMBL584015 & 600885 & 5.9504 & 5.7751 & TRN & \\
\hline CHEMBL534346 & 600885 & 6.032 & 5.3062 & TRN & \\
\hline CHEMBL604174 & 600885 & 5.9066 & 6.7085 & TRN & \\
\hline CHEMBL602388 & 600885 & 4.0114 & 5.414 & TRN & \\
\hline CHEMBL583883 & 600885 & 6.0424 & 5.8714 & TRN & \\
\hline CHEMBL610250 & 600885 & 6.433 & 5.955 & TRN & \\
\hline CHEMBL579112 & 600885 & 4.9031 & 5.3967 & TRN & \\
\hline CHEMBL582269 & 600885 & 6.0 & 5.7645 & TRN & \\
\hline CHEMBL585231 & 600885 & 6.059 & 6.1413 & TRN & \\
\hline CHEMBL577888 & 600885 & 4.9031 & 5.3538 & TRN & \\
\hline CHEMBL598078 & 600885 & 5.6635 & 5.7033 & TRN & \\
\hline CHEMBL601128 & 600885 & 6.475 & 6.08799 & 9999999999 & TST \\
\hline CHEMBL587087 & 600885 & 6.0 & 5.9541 & TRN & \\
\hline CHEMBL579110 & 600885 & 6.4449 & 5.6992 & TRN & \\
\hline CHEMBL534288 & 600885 & 6.1284 & 6.3738 & TRN & \\
\hline CHEMBL579962 & 600885 & 4.9504 & 5.5084 & TRN & \\
\hline CHEMBL535432 & 600885 & 6.5525 & 6.5495 & TRN & \\
\hline CHEMBL585220 & 600885 & 6.1726 & 6.0484 & TRN & \\
\hline CHEMBL597040 & 600885 & 6.6085 & 5.1182 & TST & \\
\hline CHEMBL582315 & 600885 & 4.9727 & 5.7066 & TRN & \\
\hline CHEMBL582282 & 600885 & 3.9031 & 5.5399 & TRN & \\
\hline CHEMBL601565 & 600885 & 6.6162 & 6.8267 & TRN & \\
\hline CHEMBL597052 & 600885 & 4.0159 & 5.6256 & TRN & \\
\hline CHEMBL602360 & 600885 & 6.2573 & 6.1101 & TRN & \\
\hline CHEMBL578698 & 600885 & 5.9318 & 5.4073 & TRN & \\
\hline CHEMBL584281 & 600885 & 5.7807 & 5.7256 & TRN & \\
\hline CHEMBL599511 & 600885 & 6.5219 & 5.7556 & TRN & \\
\hline CHEMBL549170 & 600885 & 6.6275 & 5.9944 & TST & \\
\hline CHEMBL601109 & 600885 & 6.0391 & 6.1838 & TRN & \\
\hline CHEMBL606164 & 600885 & 6.7416 & 5.5784 & TRN & \\
\hline CHEMBL532987 & 600885 & 6.4413 & 6.4248 & TRN & \\
\hline CHEMBL602023 & 600885 & 4.9817 & 5.2765 & TST & \\
\hline CHEMBL579141 & 600885 & 5.6718 & 6.0101 & TRN & \\
\hline CHEMBL585441 & 600885 & 6.8207 & 6.3409 & TRN & \\
\hline CHEMBL1416605 & 600885 & 5.1314 & 5.3263 & TST & \\
\hline CHEMBL577203 & 600885 & 6.1215 & 5.9458 & TRN & \\
\hline CHEMBL577011 & 600885 & 6.3788 & 6.0853 & TRN & \\
\hline CHEMBL582297 & 600885 & 5.8128 & 5.6197 & TRN & \\
\hline CHEMBL481505 & 600885 & 5.4473 & 5.7833 & TRN & \\
\hline CHEMBL584845 & 600885 & 4.9031 & 5.2507 & TST & \\
\hline CHEMBL582321 & 600885 & 6.0 & 5.7689 & TRN & \\
\hline CHEMBL577448 & 600885 & 6.8847 & 6.6757 & TRN & \\
\hline CHEMBL598694 & 600885 & 6.1255 & 5.8588 & TRN & \\
\hline CHEMBL601176 & 600885 & 3.9031 & 5.7446 & TRN & \\
\hline CHEMBL585079 & 600885 & 4.9031 & 5.06 & TRN & \\
\hline CHEMBL601323 & 600885 & 6.5499 & 6.0616 & TRN & \\
\hline
\end{tabular}




\begin{tabular}{|c|c|c|c|c|c|c|}
\hline & & & & & & \\
\hline CHEMBL578328 & 600885 & 4.9031 & 5.2549 & TRN & & \\
\hline CHEMBL533195 & 600885 & 5.745 & 5.8338 & TST & & \\
\hline CHEMBL585264 & 600885 & 6.9469 & 6.0946 & TST & & \\
\hline CHEMBL602820 & 600885 & 6.0 & 5.9245 & TRN & & \\
\hline CHEMBL598261 & 600885 & 6.5393 & 5.3581 & TRN & & \\
\hline CHEMBL597263 & 600885 & 6.5324 & 6.2279 & TRN & & \\
\hline CHEMBL585235 & 600885 & 6.2899 & 5.9546 & TRN & & \\
\hline CHEMBL600103 & 600885 & 3.9031 & 5.4004 & TST & & \\
\hline CHEMBL601549 & 600885 & 5.8055 & 5.6594 & TRN & & \\
\hline CHEMBL579318 & 600885 & 5.82299 & 99999999 & 995 & 5.7469 & TRN \\
\hline CHEMBL579560 & 600885 & 5.7378 & 5.2449 & TST & & \\
\hline CHEMBL599917 & 600885 & 6.9241 & 6.1448 & TRN & & \\
\hline CHEMBL583158 & 600885 & 6.0565 & 5.9086 & TRN & & \\
\hline CHEMBL599506 & 600885 & 7.54899 & э9999999 & 995 & 6.5405 & TRN \\
\hline CHEMBL581900 & 600885 & 5.9066 & 5.7701 & TRN & & \\
\hline CHEMBL581452 & 600885 & 5.1002 & 5.6975 & TRN & & \\
\hline CHEMBL585457 & 600885 & 7.7442 & 6.4708 & TRN & & \\
\hline CHEMBL577633 & 600885 & 6.0 & 5.647 & TRN & & \\
\hline CHEMBL531643 & 600885 & 5.766 & 6.0232 & TRN & & \\
\hline CHEMBL600343 & 600885 & 4.9031 & 5.2946 & TRN & & \\
\hline CHEMBL582710 & 600885 & 5.1864 & 5.4201 & TRN & & \\
\hline CHEMBL588026 & 600885 & 4.9031 & 5.2182 & TRN & & \\
\hline CHEMBL600547 & 600885 & 6.8108 & 5.7896 & TRN & & \\
\hline CHEMBL585801 & 600885 & 3.9776 & 4.9029 & TRN & & \\
\hline CHEMBL577007 & 600885 & 6.0921 & 5.6903 & TRN & & \\
\hline CHEMBL578088 & 600885 & 4.0 & 5.0102 & TRN & & \\
\hline CHEMBL593254 & 600885 & 6.0 & 5.8854 & TRN & & \\
\hline CHEMBL548758 & 600885 & 6.2967 & 5.6115 & TRN & & \\
\hline CHEMBL577016 & 600885 & 7.0665 & 6.4538 & TRN & & \\
\hline CHEMBL599301 & 600885 & 6.17200 & 30000000 & $\partial 1$ & 5.8896 & TRN \\
\hline CHEMBL583828 & 600885 & 6.4935 & 6.2522 & TRN & & \\
\hline CHEMBL582132 & 600885 & 5.9602 & 6.1509 & TRN & & \\
\hline CHEMBL580159 & 600885 & 6.0357 & 5.9751 & TRN & & \\
\hline CHEMBL585800 & 600885 & 6.2175 & 5.8949 & TST & & \\
\hline CHEMBL581669 & 600885 & 6.27 & 5.8909 & TRN & & \\
\hline CHEMBL584848 & 600885 & 4.9031 & 5.2866 & TRN & & \\
\hline CHEMBL597850 & 600885 & 6.1379 & 5.9142 & TRN & & \\
\hline CHEMBL578529 & 600885 & 6.3429 & 7.3901 & TRN & & \\
\hline CHEMBL578510 & 600885 & 6.4306 & 6.3107 & TRN & & \\
\hline CHEMBL600493 & 600885 & 5.0367 & 5.3672 & TRN & & \\
\hline CHEMBL600723 & 600885 & 5.9731 & 5.3705 & TRN & & \\
\hline CHEMBL602383 & 600885 & 6.3279 & 5.6169 & TRN & & \\
\hline CHEMBL579340 & 600885 & 5.6131 & 5.4916 & TRN & & \\
\hline CHEMBL585588 & 600885 & 6.0 & 5.8309 & TRN & & \\
\hline CHEMBL582730 & 600885 & 5.9978 & 5.1284 & TRN & & \\
\hline CHEMBL601363 & 600885 & 4.9031 & 7.1085 & TRN & & \\
\hline CHEMBL599297 & 600885 & 6.0009 & 5.8477 & TRN & & \\
\hline CHEMBL600737 & 600885 & 5.9512 & 6.2691 & TRN & & \\
\hline
\end{tabular}




\begin{tabular}{|c|c|c|c|c|c|c|}
\hline \multicolumn{7}{|c|}{ Supplemental Table S2.txt } \\
\hline CHEMBL585499 & 600885 & 5.8225 & 5.8831 & TRN & & \\
\hline CHEMBL602980 & 600885 & 3.9031 & 5.2638 & TRN & & \\
\hline CHEMBL576995 & 600885 & 4.7794 & 6.1463 & TST & & \\
\hline CHEMBL581885 & 600885 & 5.0301 & 5.2383 & TST & & \\
\hline CHEMBL605335 & 600885 & 5.5538 & 4.6276 & TRN & & \\
\hline CHEMBL600139 & 600885 & 4.9031 & 5.76 & TRN & & \\
\hline CHEMBL582303 & 600885 & 7.1373 & 6.149 & TST & & \\
\hline CHEMBL584649 & 600885 & 5.9893 & 6.3949 & TRN & & \\
\hline CHEMBL584028 & 600885 & 6.1656 & 5.9509 & TST & & \\
\hline CHEMBL600944 & 600885 & 6.0269 & 5.7955 & TRN & & \\
\hline CHEMBL581686 & 600885 & 5.8072 & 5.13399 & 9999 & 995 & TRN \\
\hline CHEMBL579721 & 600885 & 4.9031 & 5.3529 & TRN & & \\
\hline CHEMBL601784 & 600885 & 6.062 & 6.0163 & TRN & & \\
\hline CHEMBL602762 & 600885 & 5.9435 & 5.9197 & TRN & & \\
\hline CHEMBL 2079780 & 600885 & 5.945 & 6.1151 & TST & & \\
\hline CHEMBL602019 & 600885 & 6.2321 & 5.6968 & TST & & \\
\hline CHEMBL113999 & 600885 & 4.9859 & 5.3676 & TRN & & \\
\hline CHEMBL582953 & 600885 & 6.0799 & 6.1257 & TST & & \\
\hline CHEMBL585200 & 600885 & 5.8801 & 6.1666 & TRN & & \\
\hline CHEMBL578489 & 600885 & 6.0 & 5.6108 & TRN & & \\
\hline CHEMBL581074 & 600885 & 6.6171 & 6.5914 & TRN & & \\
\hline CHEMBL527520 & 600885 & 6.8817 & 6.207006 & 0000 & & TST \\
\hline CHEMBL601762 & 600885 & 5.90799 & 99999999 & 995 & 5.7673 & TRN \\
\hline CHEMBL600956 & 600885 & 6.0467 & 5.8554 & TRN & & \\
\hline CHEMBL579262 & 600885 & 5.5243 & 5.9948 & TST & & \\
\hline CHEMBL585047 & 600885 & 6.1543 & 6.9229 & TRN & & \\
\hline CHEMBL600347 & 600885 & 4.9767 & 5.9044 & TST & & \\
\hline CHEMBL585225 & 600885 & 4.9031 & 6.0329 & TST & & \\
\hline CHEMBL585319 & 600885 & 5.5645 & 5.8238 & TRN & & \\
\hline CHEMBL579074 & 600885 & 6.3675 & 5.815 & TRN & & \\
\hline CHEMBL585839 & 600885 & 6.1904 & 5.6588 & TRN & & \\
\hline CHEMBL581530 & 600885 & 4.8055 & 5.3986 & TRN & & \\
\hline CHEMBL533917 & 600885 & 6.2733 & 6.0752 & TRN & & \\
\hline CHEMBL581479 & 600885 & 5.7823 & 5.0333 & TRN & & \\
\hline CHEMBL602991 & 600885 & 4.9031 & 5.5335 & TRN & & \\
\hline CHEMBL602197 & 600885 & 5.9751 & 5.5134 & TRN & & \\
\hline CHEMBL531387 & 600885 & 4.0685 & 5.082 & TRN & & \\
\hline CHEMBL585431 & 600885 & 5.2628 & 5.2493 & TRN & & \\
\hline CHEMBL 6742 & 600885 & 6.7587 & 5.7776 & TRN & & \\
\hline CHEMBL579555 & 600885 & 5.50200 & 300000000 & $\partial 1$ & 5.6279 & וב \\
\hline CHEMBL585694 & 600885 & 6.2765 & 6.3323 & TRN & & \\
\hline CHEMBL584216 & 600885 & 4.9031 & 5.5315 & TST & & \\
\hline CHEMBL537778 & 600885 & 6.0921 & 5.9072 & TRN & & \\
\hline CHEMBL599293 & 600885 & 5.4711 & 6.1746 & TRN & & \\
\hline CHEMBL582515 & 600885 & 6.2062 & 5.8035 & TRN & & \\
\hline CHEMBL584667 & 600885 & 6.0458 & 5.7557 & TRN & & \\
\hline CHEMBL579624 & 600885 & 6.7345 & 5.8199 & TRN & & \\
\hline CHEMBL531123 & 600885 & 6.0 & 5.7809 & TRN & & \\
\hline
\end{tabular}




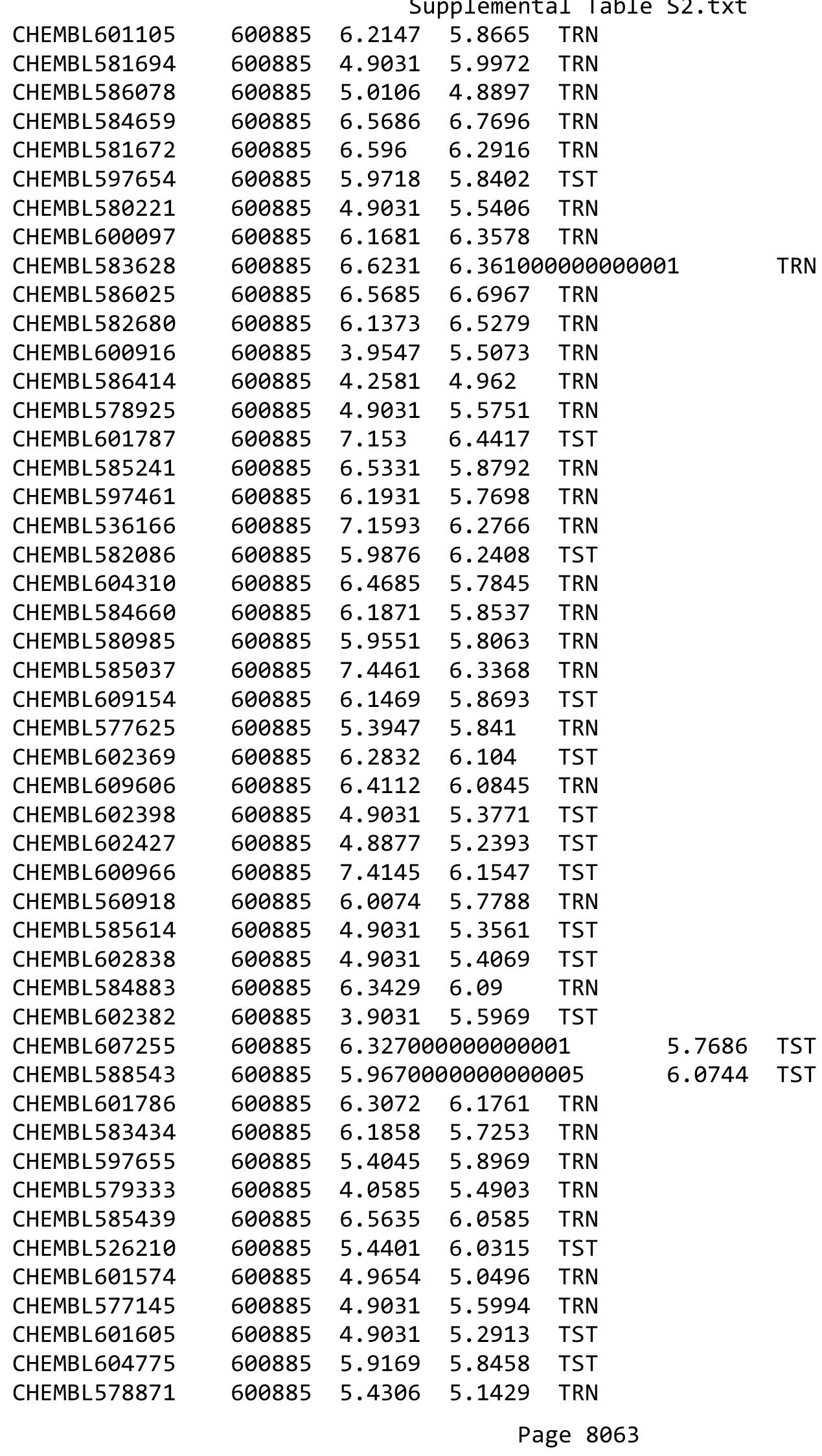




\begin{tabular}{|c|c|c|c|c|c|c|c|}
\hline \multicolumn{8}{|c|}{ splemental a } \\
\hline CHEMBL582260 & 600885 & 5.3143 & 5.1081 & TRN & & & \\
\hline CHEMBL580013 & 600885 & 5.9884 & 5.8251 & TST & & & \\
\hline CHEMBL610622 & 600885 & 5.9867 & 5.41299 & 9999999999 & & TST & \\
\hline CHEMBL528181 & 600885 & 7.0367 & 6.3831 & TRN & & & \\
\hline CHEMBL582527 & 600885 & 6.4413 & 5.1967 & TRN & & & \\
\hline CHEMBL602160 & 600885 & 6.4449 & 5.7885 & TRN & & & \\
\hline CHEMBL534338 & 600885 & 5.279 & 5.5428 & TRN & & & \\
\hline CHEMBL601589 & 600885 & 6.1226 & 5.9602 & TST & & & \\
\hline CHEMBL537500 & 600885 & 5.3696 & 5.1685 & TST & & & \\
\hline CHEMBL582705 & 600885 & 6.1296 & 5.7346 & TRN & & & \\
\hline CHEMBL601177 & 600885 & 5.8996 & 6.6272 & TRN & & & \\
\hline CHEMBL606381 & 600885 & 6.7326 & 6.4629 & TRN & & & \\
\hline CHEMBL599505 & 600885 & 6.2612 & 5.7715 & TST & & & \\
\hline CHEMBL584647 & 600885 & 4.7964 & 5.20700 & 0000000001 & & TRN & \\
\hline CHEMBL600537 & 600885 & 6.4248 & 6.3259 & TRN & & & \\
\hline CHEMBL602215 & 600885 & 5.1871 & 5.1595 & TRN & & & \\
\hline CHEMBL578068 & 600885 & 5.9674 & 6.0528 & TRN & & & \\
\hline CHEMBL581658 & 600885 & 3.9031 & 5.4232 & TRN & & & \\
\hline CHEMBL584712 & 600885 & 6.5129 & 6.2355 & TRN & & & \\
\hline CHEMBL585992 & 600885 & 4.9031 & 5.7546 & TST & & & \\
\hline CHEMBL584296 & 600885 & 6.0773 & 6.4263 & TRN & & & \\
\hline CHEMBL586162 & 600885 & 4.78600 & 20000000 & 005 & 5.2794 & TRN & \\
\hline CHEMBL582668 & 600885 & 6.3726 & 7.0494 & TRN & & & \\
\hline CHEMBL581653 & 600885 & 6.0 & 5.621 & TRN & & & \\
\hline CHEMBL608258 & 600885 & 4.8861 & 4.8229 & TST & & & \\
\hline CHEMBL602612 & 600885 & 6.9991 & 5.4891 & TRN & & & \\
\hline CHEMBL531121 & 600885 & 6.9024 & 6.2021 & TRN & & & \\
\hline CHEMBL585780 & 600885 & 4.9031 & 6.3695 & TRN & & & \\
\hline CHEMBL577429 & 600885 & 6.0334 & 5.9045 & TRN & & & \\
\hline CHEMBL600488 & 600885 & 5.8219 & 5.8127 & TRN & & & \\
\hline CHEMBL578896 & 600885 & 5.3799 & 5.1842 & TRN & & & \\
\hline CHEMBL577151 & 600885 & 6.1118 & 6.0052 & TRN & & & \\
\hline CHEMBL585598 & 600885 & 5.0443 & 5.5897 & TRN & & & \\
\hline CHEMBL582983 & 600885 & 7.1267 & 6.3679 & TST & & & \\
\hline CHEMBL601188 & 600885 & 5.96700 & j0000000 & 005 & 5.88299 & 9999999999 & TRN \\
\hline CHEMBL602785 & 600885 & 6.6784 & 5.91799 & 9999999999 & & TRN & \\
\hline CHEMBL599300 & 600885 & 7.2351 & 6.1893 & TRN & & & \\
\hline CHEMBL585066 & 600885 & 4.1367 & 4.9307 & TST & & & \\
\hline CHEMBL600955 & 600885 & 5.5296 & 5.7077 & TRN & & & \\
\hline CHEMBL582498 & 600885 & 4.9031 & 5.6704 & TRN & & & \\
\hline CHEMBL582490 & 600885 & 5.7328 & 5.7231 & TRN & & & \\
\hline CHEMBL599943 & 600885 & 6.5964 & 5.9772 & TRN & & & \\
\hline CHEMBL578697 & 600885 & 6.3536 & 6.3106 & TRN & & & \\
\hline CHEMBL608556 & 600885 & 5.9374 & 5.9351 & TST & & & \\
\hline CHEMBL546398 & 600885 & 6.2798 & 5.7457 & TRN & & & \\
\hline CHEMBL528926 & 600885 & 6.1152 & 6.0218 & TST & & & \\
\hline CHEMBL579554 & 600885 & 6.8105 & 6.2141 & TRN & & & \\
\hline CHEMBL597046 & 600885 & 6.8024 & 6.2836 & TRN & & & \\
\hline
\end{tabular}




\begin{tabular}{|c|c|c|c|c|c|}
\hline & & & & & \\
\hline CHEMBL578067 & 600885 & 6.1107 & 5.7 & TRN & \\
\hline CHEMBL3144827 & 600885 & 5.3288 & 5.199 & TRN & \\
\hline CHEMBL584823 & 600885 & 4.9031 & 5.1988 & TRN & \\
\hline CHEMBL602974 & 600885 & 4.967 & 5.3017 & TRN & \\
\hline CHEMBL582467 & 600885 & 5.8969 & 5.706 & TRN & \\
\hline CHEMBL534295 & 600885 & 3.9031 & 5.607 & TST & \\
\hline CHEMBL583604 & 600885 & 6.5901 & 6.3732 & TRN & \\
\hline CHEMBL579130 & 600885 & 7.4881 & 6.5394 & TRN & \\
\hline CHEMBL1301480 & 600885 & 6.8996 & 6.1385 & TRN & \\
\hline CHEMBL588918 & 600885 & 4.9944 & 6.0081 & TRN & \\
\hline CHEMBL597268 & 600885 & 6.2233 & 6.0144 & TRN & \\
\hline CHEMBL584523 & 600885 & 5.4989 & 6.0007 & TRN & \\
\hline CHEMBL581865 & 600885 & 5.7156 & 5.7831 & TST & \\
\hline CHEMBL598903 & 600885 & 6.4461 & 5.8729 & TST & \\
\hline CHEMBL585659 & 600885 & 6.0205 & 5.6905 & TRN & \\
\hline CHEMBL607975 & 600885 & 6.1506 & 5.8769 & TRN & \\
\hline CHEMBL599091 & 600885 & 6.8681 & 5.0212 & TRN & \\
\hline CHEMBL531990 & 600885 & 8.5541 & 7.6236 & TST & \\
\hline CHEMBL577664 & 600885 & 5.3726 & 5.4046 & TRN & \\
\hline CHEMBL577879 & 600885 & 3.9031 & 4.9759 & TRN & \\
\hline CHEMBL531809 & 600885 & 6.4101 & 7.1703 & TRN & \\
\hline CHEMBL597261 & 600885 & 6.5629 & 5.2838 & TRN & \\
\hline CHEMBL578881 & 600885 & 5.9978 & 5.7217 & TRN & \\
\hline CHEMBL586883 & 600885 & 6.64 & 6.6367 & TRN & \\
\hline CHEMBL577209 & 600885 & 4.9473 & 5.7143 & TRN & \\
\hline CHEMBL601381 & 600885 & 5.75799 & 99999999 & 5.2286 & TST \\
\hline CHEMBL597450 & 600885 & 6.1555 & 5.1697 & TRN & \\
\hline CHEMBL585812 & 600885 & 6.1433 & 6.4835 & TRN & \\
\hline CHEMBL578931 & 600885 & 6.2125 & 6.0922 & TRN & \\
\hline CHEMBL605422 & 600885 & 6.0 & 5.7523 & TRN & \\
\hline CHEMBL586001 & 600885 & 6.6759 & 6.1998 & TST & \\
\hline CHEMBL579355 & 600885 & 6.1261 & 5.9168 & TRN & \\
\hline CHEMBL535464 & 600885 & 5.7627 & 5.83899 & 99999999995 & TRN \\
\hline CHEMBL585302 & 600885 & 6.0137 & 5.7722 & TRN & \\
\hline CHEMBL585796 & 600885 & 6.0141 & 5.9139 & TRN & \\
\hline CHEMBL599294 & 600885 & 6.1707 & 5.7871 & TST & \\
\hline CHEMBL526981 & 600885 & 6.6737 & 5.7907 & TRN & \\
\hline CHEMBL527773 & 600885 & 6.6897 & 6.1663 & TRN & \\
\hline CHEMBL582116 & 600885 & 5.9654 & 6.5914 & TRN & \\
\hline CHEMBL584655 & 600885 & 5.9555 & 5.945 & TRN & \\
\hline CHEMBL583555 & 600885 & 6.3655 & 6.2308 & TRN & \\
\hline CHEMBL527796 & 600885 & 5.8841 & 5.8675 & TST & \\
\hline CHEMBL587142 & 600885 & 6.4377 & 5.88899 & 9999999999 & TRN \\
\hline CHEMBL605334 & 600885 & 6.251 & 6.0238 & TRN & \\
\hline CHEMBL602613 & 600885 & 6.0191 & 6.5574 & TRN & \\
\hline CHEMBL601593 & 600885 & 5.1096 & 5.2995 & TRN & \\
\hline CHEMBL600901 & 600885 & 5.914 & 5.7822 & TST & \\
\hline CHEMBL588153 & 600885 & 3.9031 & 4.742 & TRN & \\
\hline
\end{tabular}




\begin{tabular}{|c|c|c|c|c|c|c|}
\hline & & \multicolumn{5}{|c|}{ Supplemental Table s2.txt } \\
\hline CHEMBL603026 & 600885 & 4.0044 & 5.4788 & TRN & & \\
\hline CHEMBL582741 & 600885 & 5.8687 & 6.1025 & TRN & & \\
\hline CHEMBL587908 & 600885 & 3.9031 & 5.4402 & TST & & \\
\hline CHEMBL584859 & 600885 & 3.9516 & 4.942 & TRN & & \\
\hline CHEMBL576613 & 600885 & 6.5074 & 6.3061 & TRN & & \\
\hline CHEMBL609027 & 600885 & 5.95 & 5.9984 & TRN & & \\
\hline CHEMBL602583 & 600885 & 6.2034 & 5.9986 & TRN & & \\
\hline CHEMBL581476 & 600885 & 6.0 & 5.9469 & TRN & & \\
\hline CHEMBL529107 & 600885 & 6.4034 & 6.0869 & TRN & & \\
\hline CHEMBL578516 & 600885 & \multicolumn{3}{|c|}{5.957000000000001} & 5.8526 & TST \\
\hline CHEMBL599892 & 600885 & 6.4437 & 6.0113 & TRN & & \\
\hline CHEMBL530698 & 600885 & 6.6916 & 5.9196 & TRN & & \\
\hline CHEMBL605747 & 600885 & 6.4112 & 5.7039 & TRN & & \\
\hline CHEMBL579892 & 600885 & 6.0814 & 5.9987 & TRN & & \\
\hline CHEMBL600309 & 600885 & 6.8184 & 6.017 & TST & & \\
\hline CHEMBL585603 & 600885 & 3.9031 & 4.9628 & TRN & & \\
\hline CHEMBL587984 & 600885 & 5.7029 & 5.8459 & TRN & & \\
\hline CHEMBL600554 & 600885 & \multicolumn{3}{|c|}{5.2620000000000005} & 5.2748 & TRN \\
\hline CHEMBL605945 & 600885 & 6.2111 & 5.8799 & TRN & & \\
\hline CHEMBL580833 & 600885 & 5.7645 & 4.4919 & TRN & & \\
\hline CHEMBL600299 & 600885 & 6.8074 & 6.2917 & TRN & & \\
\hline CHEMBL579846 & 600885 & 6.098 & 5.9961 & TRN & & \\
\hline CHEMBL7892 & 600885 & 4.9031 & 5.4527 & TRN & & \\
\hline CHEMBL598696 & 600885 & \multicolumn{3}{|c|}{5.6339999999999995} & 5.8077 & TRN \\
\hline CHEMBL577890 & 600885 & 4.961 & 5.3231 & TRN & & \\
\hline CHEMBL577846 & 600885 & 6.6135 & 6.2428 & TST & & \\
\hline CHEMBL577014 & 600885 & 7.1331 & 6.7371 & TRN & & \\
\hline CHEMBL611382 & 600885 & 6.4191 & 5.865 & TRN & & \\
\hline CHEMBL598053 & 600885 & 4.5183 & 5.0276 & TRN & & \\
\hline CHEMBL585651 & 600885 & 6.2984 & 5.8971 & TRN & & \\
\hline CHEMBL586548 & 600885 & 5.9473 & 5.7551 & TRN & & \\
\hline CHEMBL579281 & 600885 & 5.6747 & 5.3421 & TRN & & \\
\hline CHEMBL601582 & 600885 & 4.9031 & 5.3622 & TST & & \\
\hline CHEMBL602224 & 600885 & 4.9031 & 5.4221 & TST & & \\
\hline CHEMBL577388 & 600885 & 4.8274 & 5.9492 & TST & & \\
\hline CHEMBL579299 & 600885 & 6.0424 & 5.9325 & TRN & & \\
\hline CHEMBL586704 & 600885 & 7.0675 & 6.3783 & TRN & & \\
\hline CHEMBL602810 & 600885 & 3.9574 & 5.5323 & TRN & & \\
\hline CHEMBL586545 & 600885 & 4.9031 & 5.4503 & TRN & & \\
\hline CHEMBL600500 & 600885 & 5.776 & 5.7669 & TRN & & \\
\hline CHEMBL578741 & 600885 & 6.9223 & 6.3113 & TRN & & \\
\hline CHEMBL495496 & 600885 & 6.1475 & 5.8229 & TRN & & \\
\hline CHEMBL602585 & 600885 & 6.6866 & 5.6833 & TRN & & \\
\hline CHEMBL530252 & 600885 & 4.9031 & 5.478 & TST & & \\
\hline CHEMBL584465 & 600885 & 6.4868 & 6.3941 & TRN & & \\
\hline CHEMBL602839 & 600885 & \multicolumn{3}{|c|}{5.9270000000000005} & 6.0778 & TRN \\
\hline CHEMBL582646 & 600885 & 6.0061 & 7.0499 & TRN & & \\
\hline CHEMBL582079 & 600885 & 6.5406 & 6.1513 & TRN & & \\
\hline
\end{tabular}




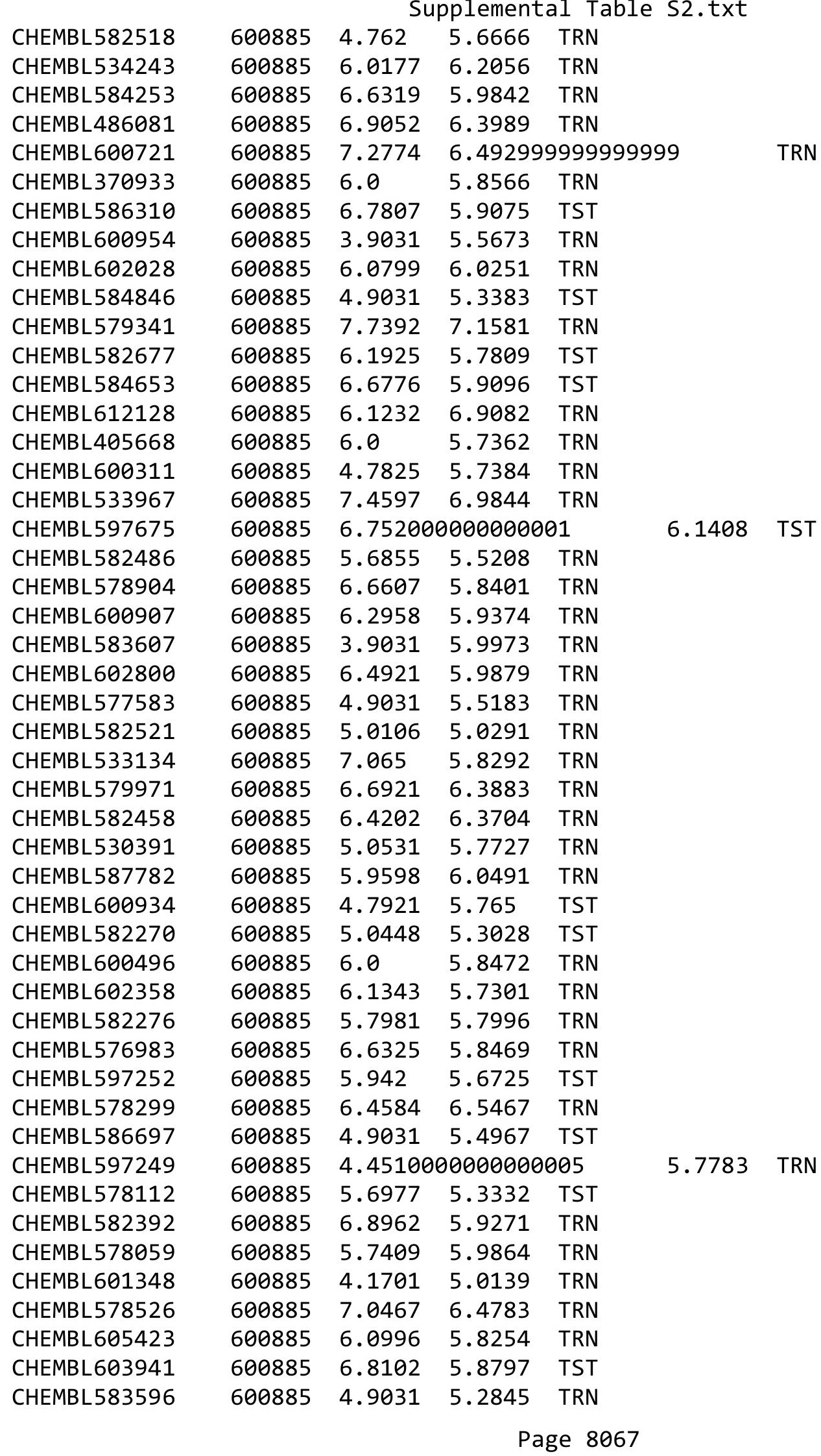




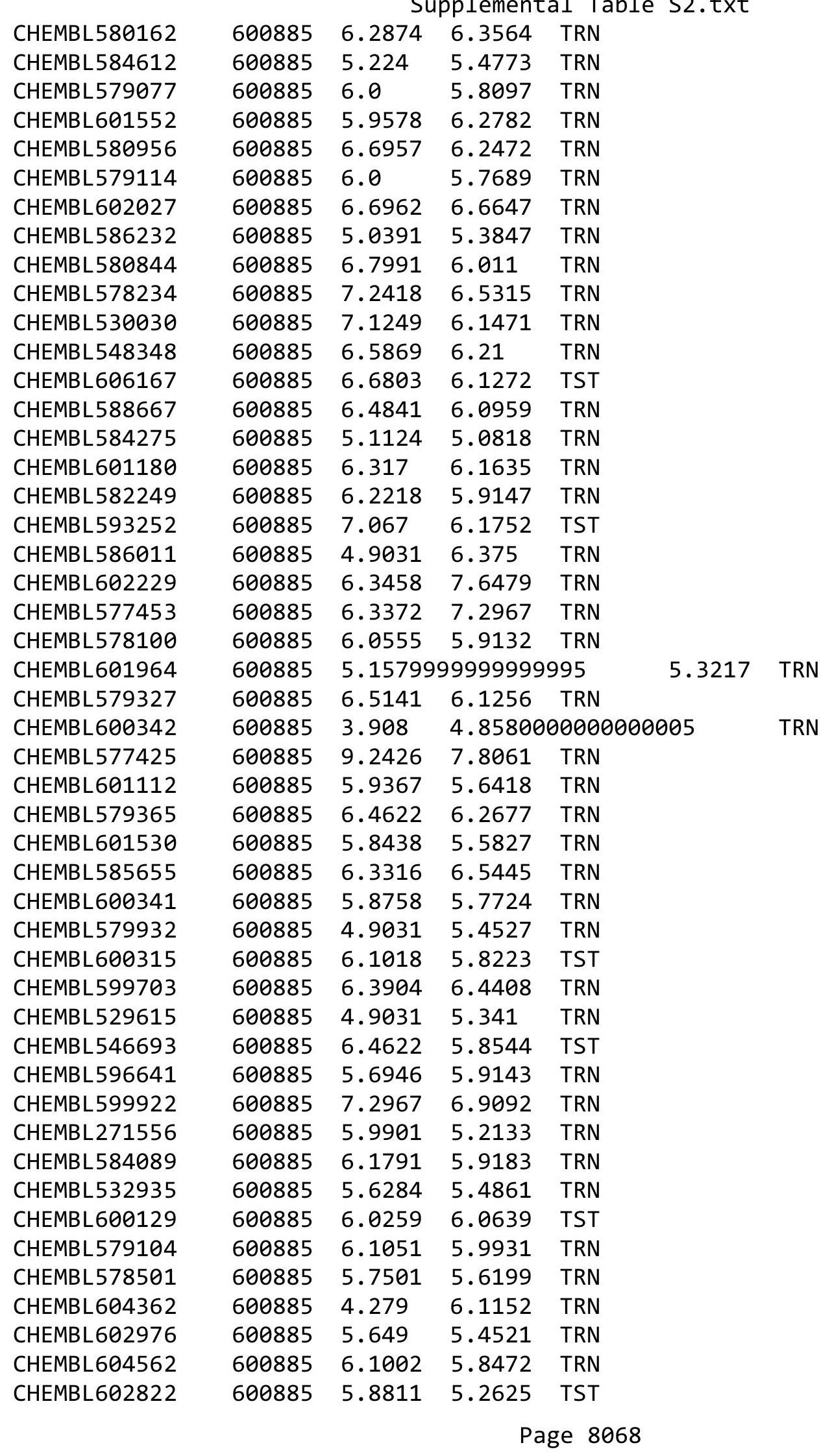




\begin{tabular}{|c|c|c|c|c|c|c|}
\hline \multicolumn{7}{|c|}{ Supplemental Ta } \\
\hline CHEMBL227959 & 600885 & 6.0 & 5.5739 & TRN & & \\
\hline CHEMBL525840 & 600885 & 3.9031 & 5.3197 & TRN & & \\
\hline CHEMBL601333 & 600885 & 3.9031 & 5.4729 & TST & & \\
\hline CHEMBL598268 & 600885 & 5.6527 & 5.5724 & TRN & & \\
\hline CHEMBL587884 & 600885 & 6.90799 & 99999999 & 995 & 6.5231 & TST \\
\hline CHEMBL583167 & 600885 & 6.7031 & 6.1792 & TRN & & \\
\hline CHEMBL584736 & 600885 & 6.1605 & 6.4084 & TRN & & \\
\hline CHEMBL528825 & 600885 & 7.0878 & 6.357 & TRN & & \\
\hline CHEMBL528950 & 600885 & 5.0044 & 5.3705 & TRN & & \\
\hline CHEMBL579316 & 600885 & 6.3197 & 5.9746 & TRN & & \\
\hline CHEMBL602978 & 600885 & 6.6436 & 6.1168 & TRN & & \\
\hline CHEMBL597662 & 600885 & 4.9252 & 5.8641 & TRN & & \\
\hline CHEMBL581655 & 600885 & 4.0237 & 5.59 & TRN & & \\
\hline CHEMBL602796 & 600885 & 5.0419 & 6.1126 & TRN & & \\
\hline CHEMBL597243 & 600885 & 6.96899 & 99999999 & 99 & 6.8052 & TRN \\
\hline CHEMBL600952 & 600885 & 4.9031 & 5.6674 & TRN & & \\
\hline CHEMBL579129 & 600885 & 5.1959 & 5.407 & TST & & \\
\hline CHEMBL578261 & 600885 & 3.9031 & 5.2703 & TRN & & \\
\hline CHEMBL601364 & 600885 & 6.0 & 5.8921 & TRN & & \\
\hline CHEMBL578696 & 600885 & 5.8052 & 5.8071 & TRN & & \\
\hline CHEMBL588925 & 600885 & 6.5574 & 5.9619 & TRN & & \\
\hline CHEMBL579979 & 600885 & 5.4763 & 5.6675 & TST & & \\
\hline CHEMBL579119 & 600885 & 6.9606 & 6.9936 & TRN & & \\
\hline CHEMBL609312 & 600885 & 6.5727 & 6.2117 & TRN & & \\
\hline CHEMBL579284 & 600885 & 3.9031 & 5.5374 & TRN & & \\
\hline CHEMBL585209 & 600885 & 4.9031 & 5.1416 & TRN & & \\
\hline CHEMBL576809 & 600885 & 7.2291 & 6.2044 & TRN & & \\
\hline CHEMBL582291 & 600885 & 6.3915 & 5.8314 & TRN & & \\
\hline CHEMBL531119 & 600885 & 3.9031 & 4.8639 & TRN & & \\
\hline CHEMBL585261 & 600885 & 6.0458 & 5.1022 & TRN & & \\
\hline CHEMBL588086 & 600885 & 3.9031 & 5.3904 & TST & & \\
\hline CHEMBL582258 & 600885 & 6.0 & 5.7231 & TRN & & \\
\hline CHEMBL581867 & 600885 & 5.2358 & 5.6513 & TST & & \\
\hline CHEMBL599516 & 600885 & 5.9179 & 5.2324 & TRN & & \\
\hline CHEMBL583809 & 600885 & 5.8398 & 5.6311 & TRN & & \\
\hline CHEMBL602632 & 600885 & 5.7371 & 5.8353 & TRN & & \\
\hline CHEMBL600158 & 600885 & 6.6985 & 6.3316 & TRN & & \\
\hline CHEMBL584027 & 600885 & 6.0491 & 5.8418 & TRN & & \\
\hline CHEMBL600939 & 600885 & 6.4572 & 6.2885 & TRN & & \\
\hline CHEMBL578503 & 600885 & 7.6953 & 5.0525 & TRN & & \\
\hline CHEMBL601319 & 600885 & 6.1878 & 5.8758 & TRN & & \\
\hline CHEMBL601756 & 600885 & 6.0 & 5.8435 & TRN & & \\
\hline CHEMBL601766 & 600885 & 7.6625 & 5.6385 & TRN & & \\
\hline CHEMBL597454 & 600885 & 5.0 & 6.2147 & TRN & & \\
\hline CHEMBL531982 & 600885 & 6.5455 & 6.3303 & TRN & & \\
\hline CHEMBL584451 & 600885 & 5.0857 & 5.8819 & TRN & & \\
\hline CHEMBL533376 & 600885 & 8.0496 & 6.8858 & TST & & \\
\hline CHEMBL578312 & 600885 & 6.768 & 7.3092 & TRN & & \\
\hline
\end{tabular}




\begin{tabular}{|c|c|c|c|c|c|}
\hline \\
\hline CHEMBL578540 & 600885 & 6.4145 & 6.2769 & TRN & \\
\hline CHEMBL584839 & 600885 & 4.9031 & 6.6268 & TRN & \\
\hline CHEMBL586554 & 600885 & 6.3478 & 5.9705 & TST & \\
\hline CHEMBL582657 & 600885 & 6.8477 & 6.2607 & TRN & \\
\hline CHEMBL600545 & 600885 & 5.2782 & 5.6445 & TRN & \\
\hline CHEMBL583619 & 600885 & 6.1481 & 5.7967 & TRN & \\
\hline CHEMBL585436 & 600885 & 5.584 & 6.0181 & TRN & \\
\hline CHEMBL599105 & 600885 & 6.1864 & 6.4638 & TRN & \\
\hline CHEMBL532518 & 600885 & 4.9935 & 5.1874 & TST & \\
\hline CHEMBL529852 & 600885 & 4.9031 & 5.2575 & TRN & \\
\hline CHEMBL577876 & 600885 & 6.0 & 5.8299 & TRN & \\
\hline CHEMBL578314 & 600885 & 6.862 & 6.4789 & TRN & \\
\hline CHEMBL530445 & 600885 & 5.7073 & 5.9618 & TRN & \\
\hline CHEMBL602356 & 600885 & 6.3546 & 5.8347 & TRN & \\
\hline CHEMBL601539 & 600885 & 4.9031 & 5.3043 & TRN & \\
\hline CHEMBL529984 & 600885 & 6.6413 & 6.0842 & TRN & \\
\hline CHEMBL577644 & 600885 & 6.731 & 6.3328 & TRN & \\
\hline CHEMBL596631 & 600885 & 6.0097 & 5.6647 & TRN & \\
\hline CHEMBL596838 & 600885 & 5.1637 & 5.316 & TST & \\
\hline CHEMBL578684 & 600885 & 6.4318 & 5.8702 & TRN & \\
\hline CHEMBL602578 & 600885 & 6.4461 & 5.7319 & TRN & \\
\hline CHEMBL548399 & 600885 & 5.7484 & 5.6011 & TRN & \\
\hline CHEMBL578061 & 600885 & 6.0947 & 5.8806 & TRN & \\
\hline CHEMBL582446 & 600885 & 6.4908 & 7.0531 & TRN & \\
\hline CHEMBL581858 & 600885 & 7.129 & 6.53 & TRN & \\
\hline CHEMBL601171 & 600885 & 6.0 & 5.6049 & TRN & \\
\hline CHEMBL530729 & 600885 & 4.9031 & 5.6291 & TRN & \\
\hline CHEMBL601541 & 600885 & 7.6698 & 6.4481 & TRN & \\
\hline CHEMBL599904 & 600885 & 5.9851 & 5.9361 & TRN & \\
\hline CHEMBL582506 & 600885 & 6.8019 & 6.3421 & TRN & \\
\hline CHEMBL598677 & 600885 & 3.9031 & 5.8301 & TST & \\
\hline CHEMBL581270 & 600885 & 5.9551 & 5.1451 & TRN & \\
\hline CHEMBL585054 & 600885 & 4.9031 & 5.2205 & TRN & \\
\hline CHEMBL588397 & 600885 & 5.0701 & 5.5584 & TRN & \\
\hline CHEMBL583141 & 600885 & 6.0794 & 6.0934 & TRN & \\
\hline CHEMBL587902 & 600885 & 6.4123 & 5.8382 & TRN & \\
\hline CHEMBL602032 & 600885 & 3.9031 & 5.474 & TRN & \\
\hline CHEMBL586483 & 600885 & 6.3116 & 6.159 & TRN & \\
\hline CHEMBL579157 & 600885 & 6.1811 & 5.8359 & TRN & \\
\hline CHEMBL582107 & 600885 & 7.0438 & 6.4678 & TRN & \\
\hline CHEMBL599940 & 600885 & 6.0 & 5.6834 & TST & \\
\hline CHEMBL600925 & 600885 & 7.3635 & 6.1522 & TST & \\
\hline CHEMBL582442 & 600885 & 5.3655 & 5.3794 & TST & \\
\hline CHEMBL581472 & 600885 & 5.3686 & 5.6302 & TRN & \\
\hline CHEMBL531190 & 600885 & 5.8074 & 5.54799 & 9999999999 & TRN \\
\hline CHEMBL593487 & 600885 & 5.0521 & 5.9071 & TST & \\
\hline CHEMBL578940 & 600885 & 4.1118 & 5.57700 & 3000000001 & TRN \\
\hline CHEMBL527131 & 600885 & 6.289 & 5.8391 & TRN & \\
\hline
\end{tabular}




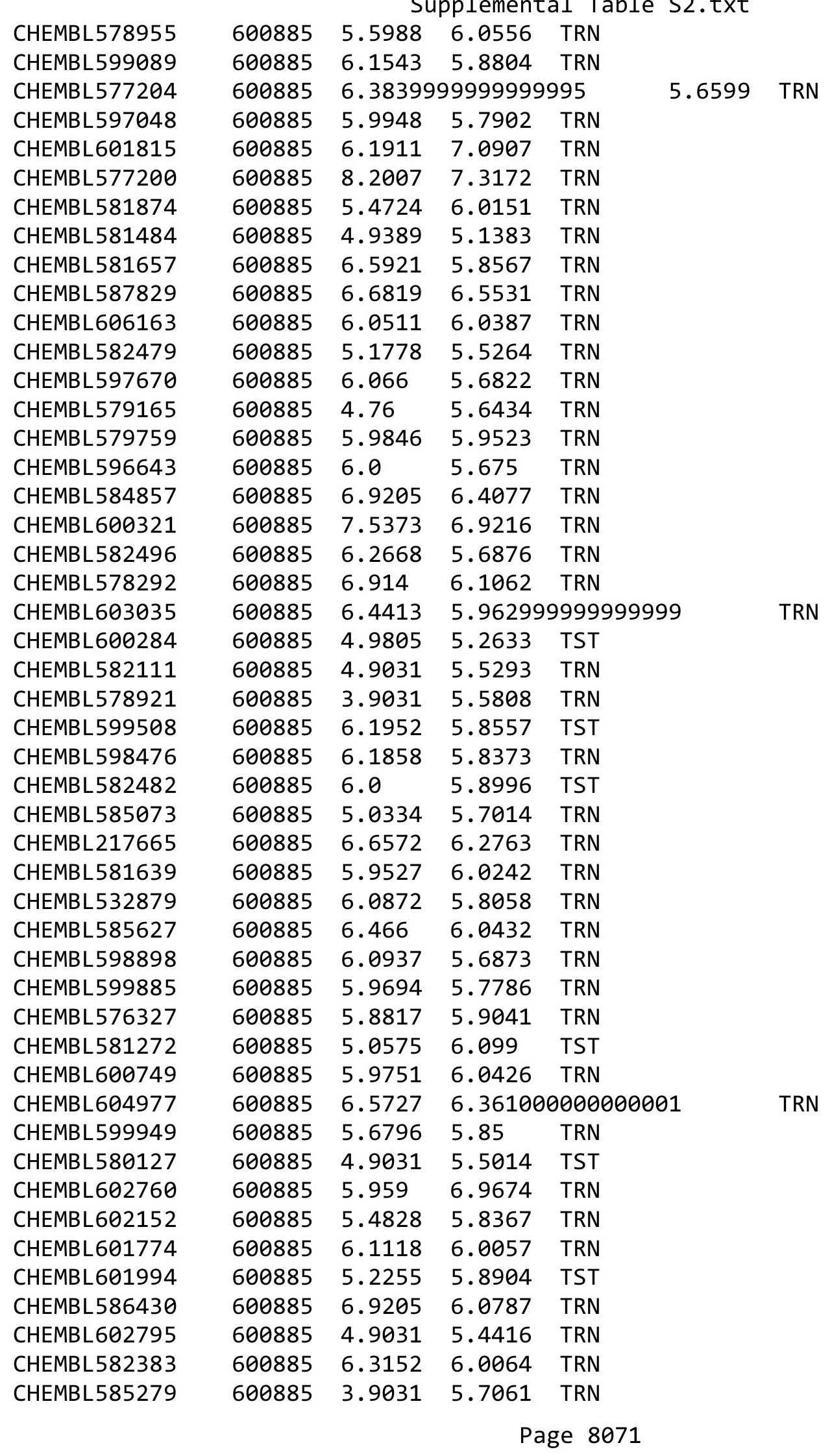


Supplemental Table S2.txt

CHEMBL585597
CHEMBL585777
CHEMBL1967497
CHEMBL586203
CHEMBL533293
CHEMBL579966
CHEMBL585245
CHEMBL578114
CHEMBL194986
CHEMBL585207
CHEMBL600546
CHEMBL582681
CHEMBL1312953
CHEMBL579332
CHEMBL584026
CHEMBL582485
CHEMBL585440
CHEMBL585984
CHEMBL530308
CHEMBL585075
CHEMBL608855
CHEMBL585986
CHEMBL576194
CHEMBL601575
CHEMBL599925
CHEMBL600087
CHEMBL596638
CHEMBL577865
CHEMBL602434
CHEMBL577872
CHEMBL603025
CHEMBL602791
CHEMBL582733
CHEMBL601125
CHEMBL531221
CHEMBL586396
CHEMBL527976
CHEMBL587924
CHEMBL579282
CHEMBL601376
CHEMBL578680
CHEMBL584669
CHEMBL579763
CHEMBL599100
CHEMBL585962

$\begin{array}{llll}600885 & 6.1574 & 5.8529 & \text { TRN } \\ 600885 & 6.5955 & 6.0903 & \text { TRN } \\ 600885 & 7.6008 & 6.6189 & \text { TRN } \\ 600885 & 6.5981 & 6.6497 & \text { TRN } \\ 600885 & 4.9031 & 5.7862 & \text { TRN } \\ 600885 & 5.3098 & 5.6464 & \text { TRN } \\ 600885 & 4.9031 & 5.686 & \text { TRN } \\ 600885 & 5.1713 & 5.7632 & \text { TST } \\ 600885 & 6.3028 & 5.7807 & \text { TRN } \\ 600885 & 6.3224 & 5.7796 & \text { TRN } \\ 600885 & 4.8871 & 5.5812 & \text { TRN } \\ 600885 & 5.9504 & 5.7889 & \text { TRN } \\ 600885 & 6.0 & 5.9351 & \text { TRN } \\ 600885 & 6.0329 & 5.8593 & \text { TST } \\ 600885 & 6.4949 & 5.65 & \text { TRN } \\ 600885 & 5.5297 & 5.6179 & \text { TRN } \\ 600885 & 6.2269 & 5.8397 & \text { TRN } \\ 600885 & 6.2204 & 5.6339 & \text { TRN } \\ 600885 & 6.4789 & 5.9758 & \text { TRN } \\ 600885 & 6.4949 & 5.6026 & \text { TRN } \\ 600885 & 5.58 & 5.4913 & \text { TRN } \\ 600885 & 6.0 & 5.9548 & \text { TST } \\ 600885 & 5.7635 & 5.6479 & \text { TST } \\ 600885 & 6.2857 & 5.8464 & \text { TRN } \\ 600885 & 6.8639 & 6.242000000000001 \\ 600885 & 6.1107 & 5.4314 & \text { TST } \\ 600885 & 6.0246 & 5.8731 & \text { TRN } \\ 600885 & 6.0 & 5.77 & \text { TRN } \\ 600885 & 6.6054 & 5.8517 & \text { TRN } \\ 600885 & 6.1073 & 6.4189 & \text { TRN } \\ 600885 & 5.6964 & 5.197 & \text { TST } \\ 600885 & 4.9031 & 5.3999 & \text { TRN } \\ 600885 & 5.7086 & 5.7652 & \text { TST } \\ 600885 & 6.4214 & 6.5696 & \text { TST } \\ 600885 & 7.3063 & 6.3168 & \text { TST } \\ 600885 & 5.0773 & 5.4074 & \text { TST } \\ 600885 & 3.9031 & 5.7289 & \text { TRN } \\ 600885 & 6.1007 & 6.0026 & \text { TRN } \\ 600885 & 5.4547 & 5.3558 & \text { TRN } \\ 600885 & 7.0783 & 6.5784 & \text { TRN } \\ 600885 & 3.9031 & 5.6762 & \text { TRN } \\ 600885 & 5.9165 & 6.6355 & \text { TRN } \\ 600885 & 3.9031 & 5.5793 & \text { TRN } \\ 600885 & 5.6254 & 5.8246 & \text { TRN } \\ 600885 & 6.4949 & 6.2385 & \text { TST } \\ 600885 & 5.2741 & 7.2615 & \text { TST } \\ 600885 & 5.9066 & 6.1403 & \text { TRN } \\ 600885 & 5.7683 & 5.5321 & \text { TRN }\end{array}$

TST

Page 8072 


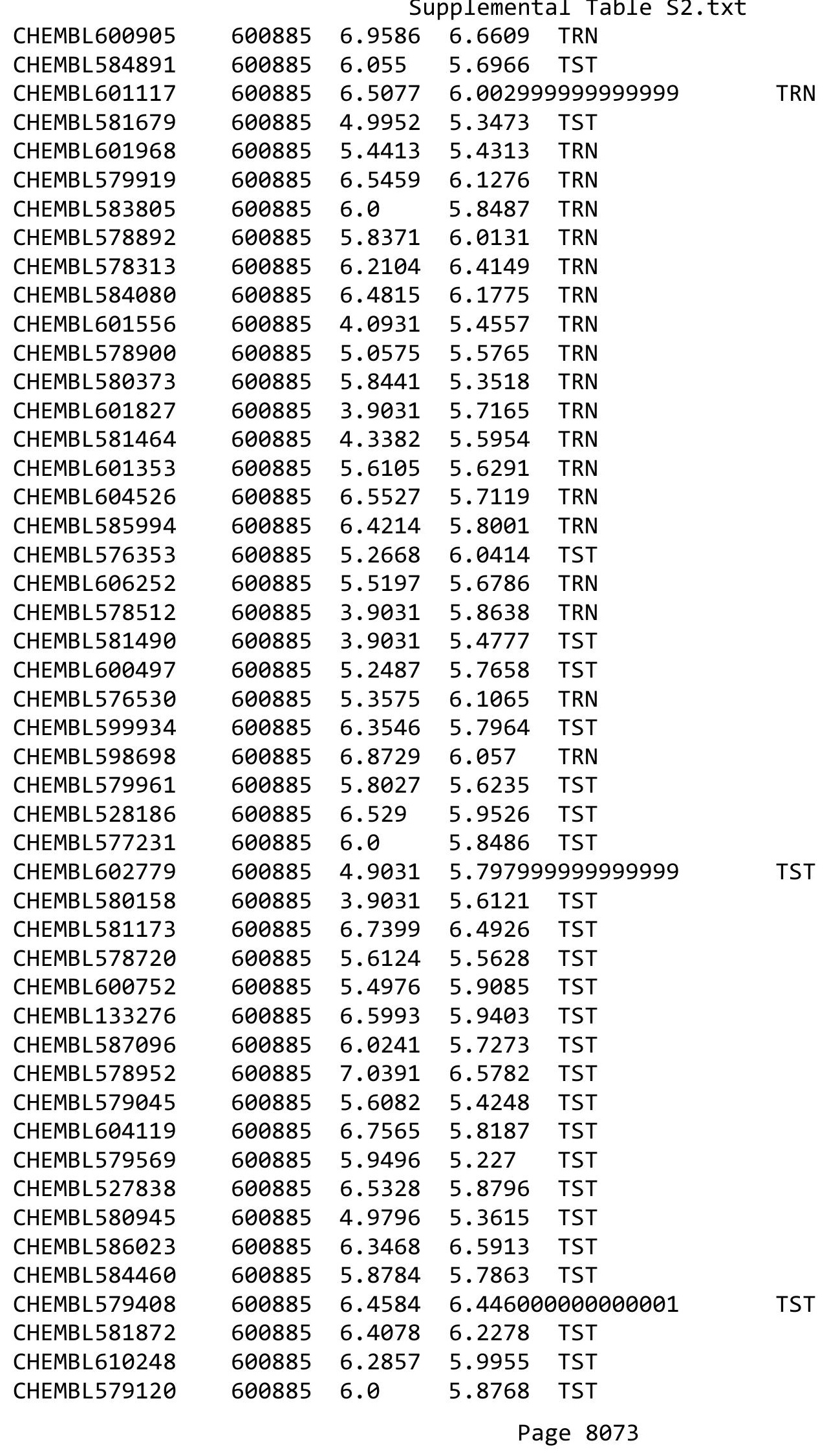




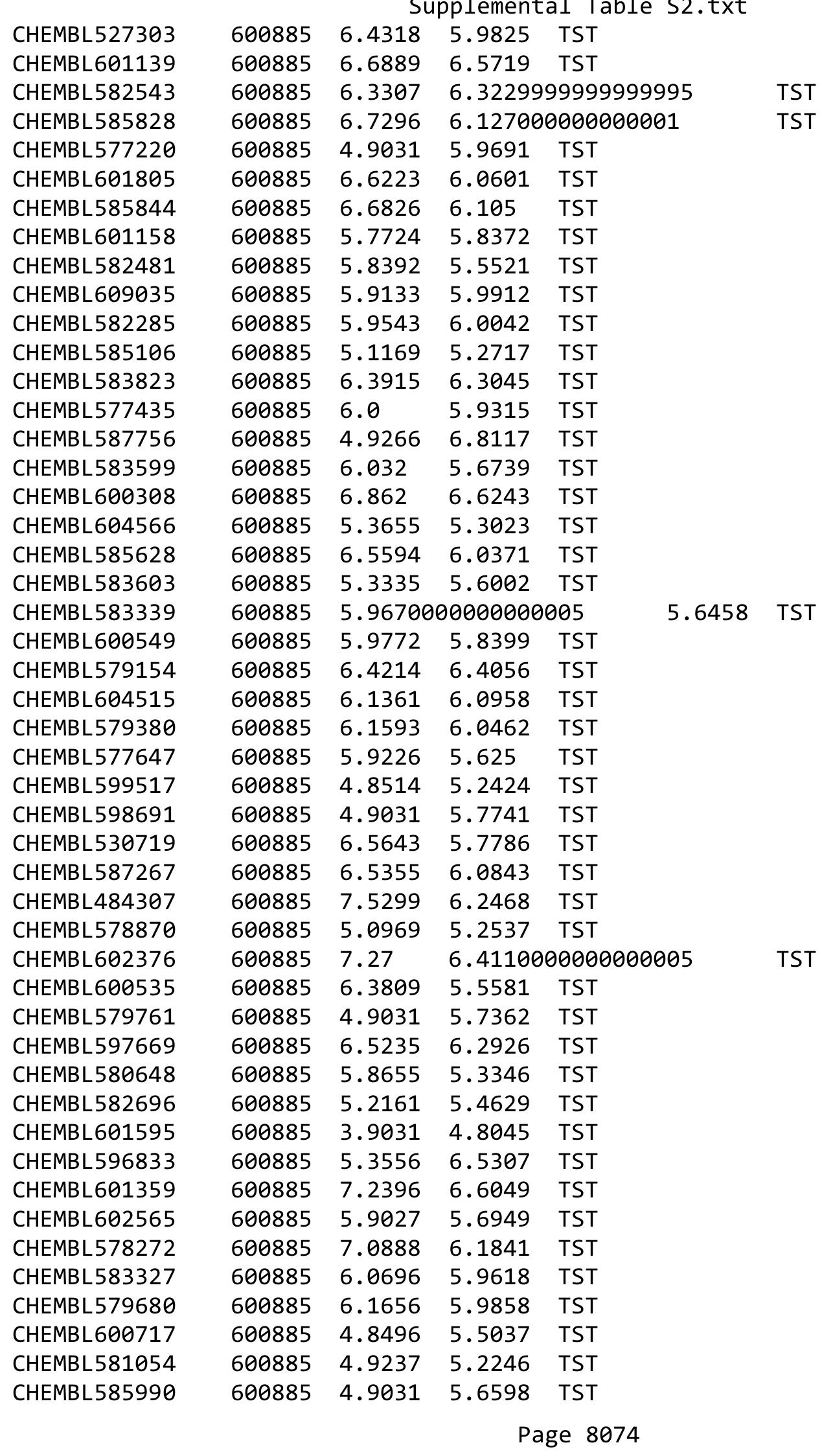




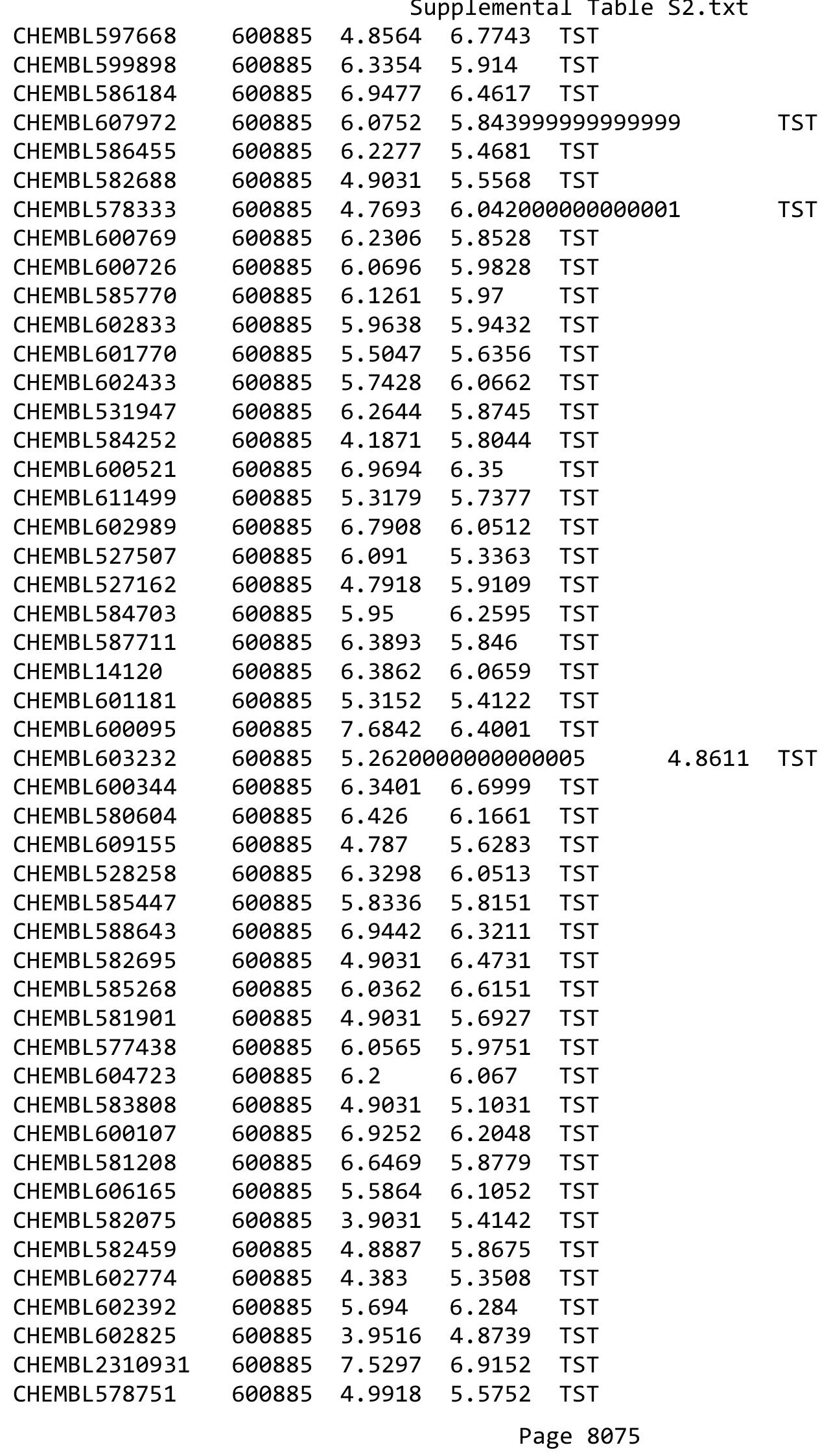




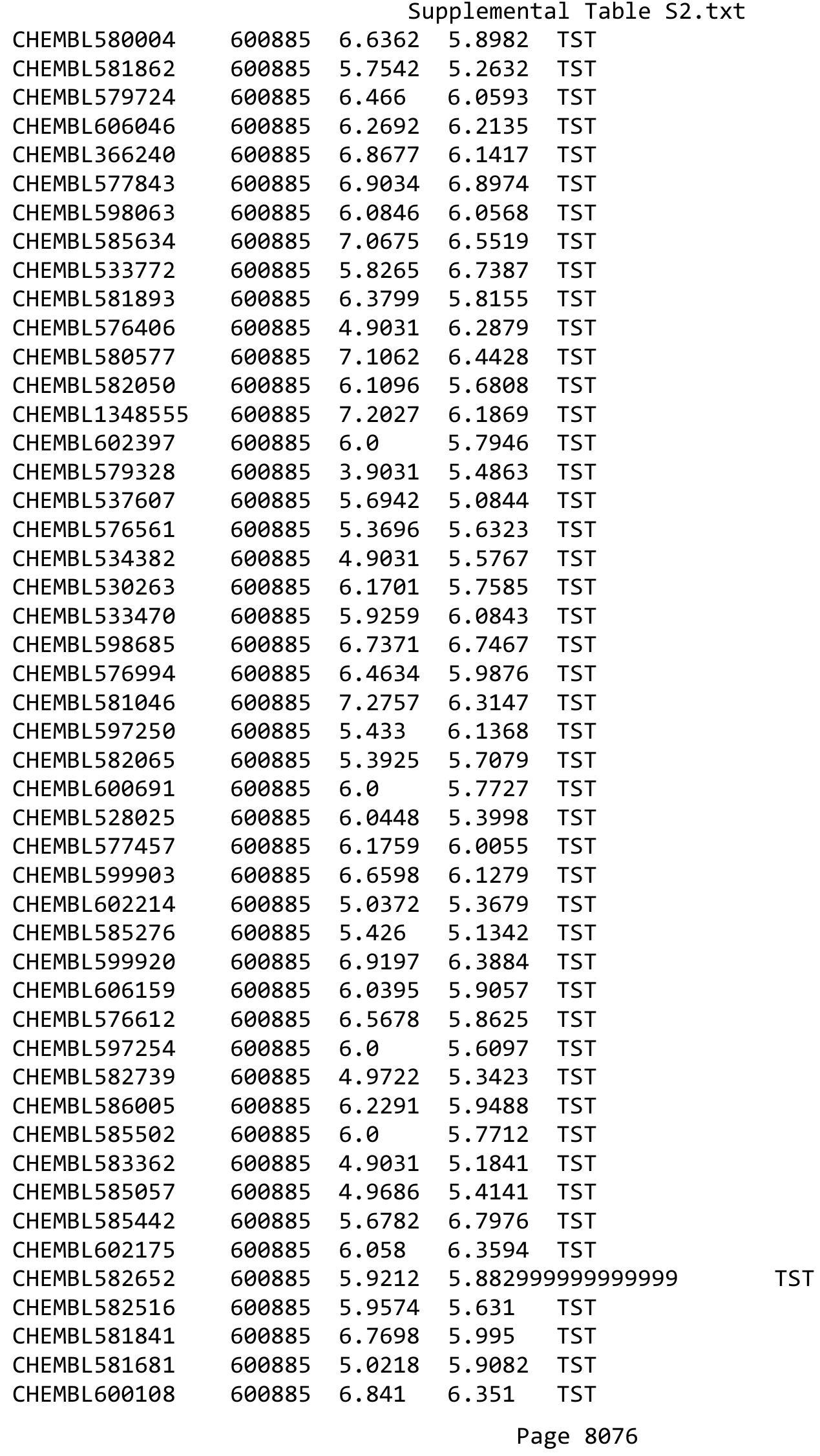




\begin{tabular}{|c|c|c|c|c|c|}
\hline & & & & & \\
\hline CHEMBL534600 & 600885 & 6.9393 & 6.155 & TST & \\
\hline CHEMBL581860 & 600885 & 6.8542 & 6.2609 & TST & \\
\hline CHEMBL529901 & 600885 & 6.1057 & 6.012006 & 00000000005 & TST \\
\hline CHEMBL577010 & 600885 & 4.98300 & 000000006 & 6.0343 & TST \\
\hline CHEMBL599298 & 600885 & 6.041 & 6.1857 & TST & \\
\hline CHEMBL583826 & 600885 & 3.9031 & 5.5654 & TST & \\
\hline CHEMBL599292 & 600885 & 6.1379 & 5.82600 & 00000000005 & TST \\
\hline CHEMBL581670 & 600885 & 5.857 & 5.8698 & TST & \\
\hline CHEMBL601790 & 600885 & 6.1938 & 5.8796 & TST & \\
\hline CHEMBL532847 & 600885 & 6.7368 & 6.0145 & TST & \\
\hline CHEMBL578903 & 600885 & 6.098 & 5.6989 & TST & \\
\hline CHEMBL587229 & 600885 & 6.0531 & 6.1389 & TST & \\
\hline CHEMBL602811 & 600885 & 4.9801 & 5.1742 & TST & \\
\hline CHEMBL601528 & 600885 & 6.5478 & 6.2876 & TST & \\
\hline CHEMBL584885 & 600885 & 6.1107 & 5.1969 & TST & \\
\hline CHEMBL593485 & 600885 & 4.9263 & 6.8646 & TST & \\
\hline CHEMBL579134 & 600885 & 6.8716 & 6.9713 & TST & \\
\hline CHEMBL577227 & 600885 & 5.9935 & 6.2628 & TST & \\
\hline CHEMBL579764 & 600885 & 4.9031 & 5.9203 & TST & \\
\hline CHEMBL598273 & 600885 & 6.1818 & 6.5461 & TST & \\
\hline CHEMBL600975 & 600885 & 6.7371 & 5.8598 & TST & \\
\hline CHEMBL600351 & 600885 & 4.9031 & 5.1983 & TST & \\
\hline CHEMBL577195 & 600885 & 4.7716 & 5.5474 & TST & \\
\hline CHEMBL599932 & 600885 & 3.9031 & 5.8575 & TST & \\
\hline CHEMBL585641 & 600885 & 4.9031 & 6.40799 & 99999999995 & TST \\
\hline CHEMBL527141 & 600885 & 6.1141 & 6.3066 & TST & \\
\hline CHEMBL600964 & 600885 & 6.0 & 5.6147 & TST & \\
\hline CHEMBL527233 & 600885 & 4.9547 & 5.2822 & TST & \\
\hline CHEMBL588495 & 600885 & 5.5187 & 5.716 & TST & \\
\hline CHEMBL582951 & 600885 & 6.4559 & 5.9921 & TST & \\
\hline CHEMBL577660 & 600885 & 6.7305 & 6.1834 & TST & \\
\hline CHEMBL582683 & 600885 & 6.3298 & 5.6333 & TST & \\
\hline CHEMBL578307 & 600885 & 5.994 & 5.9033 & TST & \\
\hline CHEMBL610052 & 600885 & 6.565 & 6.0607 & TST & \\
\hline CHEMBL578534 & 600885 & 6.4101 & 7.5559 & TST & \\
\hline CHEMBL578876 & 600885 & 6.1561 & 5.8639 & TST & \\
\hline CHEMBL588079 & 600885 & 6.0921 & 5.9812 & TST & \\
\hline CHEMBL588827 & 600885 & 6.5183 & 6.2045 & TST & \\
\hline CHEMBL585470 & 600885 & 6.301 & 6.004 & TST & \\
\hline CHEMBL582051 & 600885 & 6.6036 & 6.8015 & TST & \\
\hline CHEMBL1733652 & 600885 & 6.0 & 5.906006 & $\partial 000000001$ & TST \\
\hline CHEMBL600356 & 600885 & 6.4389 & 5.8458 & TST & \\
\hline CHEMBL600162 & 600885 & 6.0074 & 6.064 & TST & \\
\hline CHEMBL601551 & 600885 & 7.1284 & 6.2493 & TST & \\
\hline CHEMBL581026 & 600885 & 6.3768 & 6.1003 & TST & \\
\hline CHEMBL585086 & 600885 & 5.1113 & 4.8659 & TST & \\
\hline CHEMBL585647 & 600885 & 6.9378 & 6.137006 & 00000000005 & TST \\
\hline CHEMBL579503 & 600885 & 6.5764 & 5.7531 & TST & \\
\hline & & & & 8077 & \\
\hline
\end{tabular}




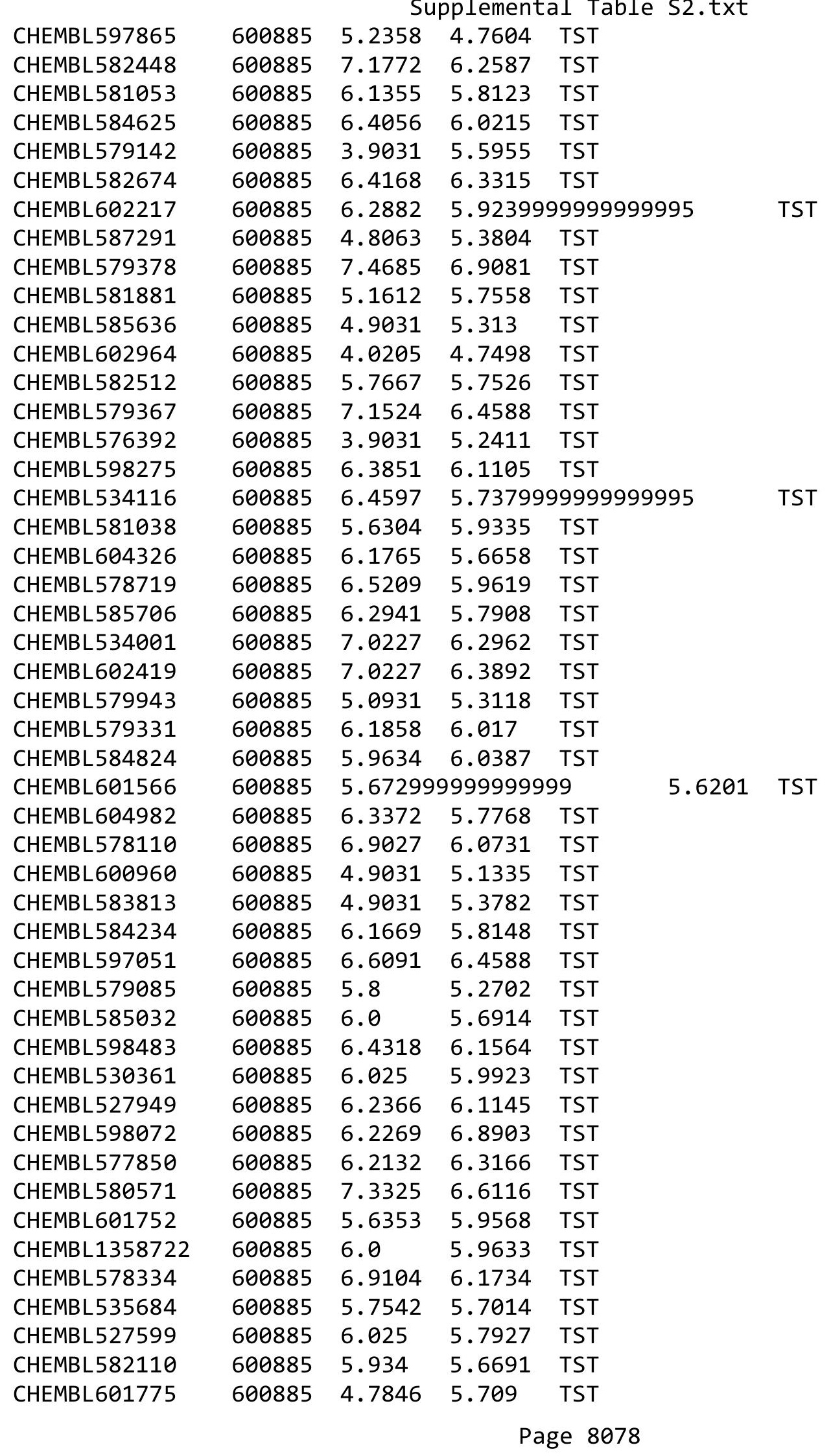




\begin{tabular}{|c|c|c|c|c|c|c|}
\hline \\
\hline CHEMBL581049 & 600885 & 5.0022 & 5.3013 & TST & & \\
\hline CHEMBL578472 & 600885 & 4.8339 & 5.8715 & TST & & \\
\hline CHEMBL601750 & 600885 & 6.4522 & 5.8481 & TST & & \\
\hline CHEMBL576767 & 600885 & 3.9031 & 5.4684 & TST & & \\
\hline CHEMBL601169 & 600885 & 6.3893 & 6.3246 & TST & & \\
\hline CHEMBL577382 & 600885 & 6.4572 & 6.3975 & TST & & \\
\hline CHEMBL582301 & 600885 & 6.4001 & 6.2811 & TST & & \\
\hline CHEMBL602793 & 600885 & 6.7844 & 6.169 & TST & & \\
\hline CHEMBL605745 & 600885 & 5.78700 & 00000000 & 01 & 5.7585 & TST \\
\hline CHEMBL598494 & 600885 & 7.0947 & 6.1385 & TST & & \\
\hline CHEMBL526034 & 600885 & 6.6603 & 6.244 & TST & & \\
\hline CHEMBL581652 & 600885 & 3.9031 & 5.6462 & TST & & \\
\hline CHEMBL600542 & 600885 & 4.9094 & 5.9764 & TST & & \\
\hline CHEMBL602208 & 600885 & 3.9031 & 5.1581 & TST & & \\
\hline CHEMBL578083 & 600885 & 5.9158 & 5.38 & TST & & \\
\hline CHEMBL583811 & 600885 & 6.1238 & 5.4291 & TST & & \\
\hline CHEMBL581665 & 600885 & 5.6662 & 5.5408 & TST & & \\
\hline CHEMBL588187 & 600885 & 6.5201 & 6.6534 & TST & & \\
\hline CHEMBL577665 & 600885 & 6.2218 & 5.7866 & TST & & \\
\hline CHEMBL202969 & 600885 & 5.9389 & 5.7119 & TST & & \\
\hline CHEMBL603034 & 600885 & 4.9031 & 5.4324 & TST & & \\
\hline CHEMBL528486 & 600885 & 5.9052 & 5.8629 & TST & & \\
\hline CHEMBL586004 & 600885 & 6.8139 & 6.1488 & TST & & \\
\hline CHEMBL587370 & 600885 & 5.9446 & 6.1869 & TST & & \\
\hline CHEMBL581673 & 600885 & 6.7873 & 5.9652 & TST & & \\
\hline CHEMBL579300 & 600885 & 6.3893 & 5.7679 & TST & & \\
\hline CHEMBL583162 & 600885 & 6.4828 & 6.1048 & TST & & \\
\hline CHEMBL603521 & 600885 & 6.0 & 5.6279 & TST & & \\
\hline CHEMBL581036 & 600885 & 6.2182 & 6.5437 & TST & & \\
\hline CHEMBL524594 & 600885 & 6.2041 & 5.8659 & TST & & \\
\hline CHEMBL584816 & 600885 & 4.9031 & 5.35 & TST & & \\
\hline CHEMBL601113 & 600885 & 6.062 & 5.8257 & TST & & \\
\hline CHEMBL604155 & 600885 & 6.3233 & 6.1632 & TST & & \\
\hline CHEMBL529111 & 600885 & 6.4763 & 6.1364 & TST & & \\
\hline CHEMBL494668 & 600885 & 5.4881 & 5.84 & TST & & \\
\hline CHEMBL585604 & 600885 & 6.0701 & 5.852 & TST & & \\
\hline CHEMBL578511 & 600885 & 4.9031 & 5.4608 & TST & & \\
\hline CHEMBL584462 & 600885 & 6.2782 & 6.1635 & TST & & \\
\hline CHEMBL578119 & 600885 & 3.9031 & 5.4806 & TST & & \\
\hline CHEMBL584875 & 600885 & 5.0872 & 5.2852 & TST & & \\
\hline CHEMBL227704 & 600885 & 6.9255 & 6.0668 & TST & & \\
\hline CHEMBL588250 & 600885 & 5.9821 & 5.7804 & TST & & \\
\hline CHEMBL576812 & 600885 & 6.5901 & 6.1193 & TST & & \\
\hline CHEMBL578030 & 600885 & 6.4634 & 6.0835 & TST & & \\
\hline CHEMBL584438 & 600885 & 6.2381 & 6.2659 & TST & & \\
\hline CHEMBL577661 & 600885 & 6.6813 & 6.1845 & TST & & \\
\hline CHEMBL527972 & 600885 & 5.8309 & 5.9786 & TST & & \\
\hline CHEMBL597861 & 600885 & 6.0516 & 5.1941 & TST & & \\
\hline
\end{tabular}




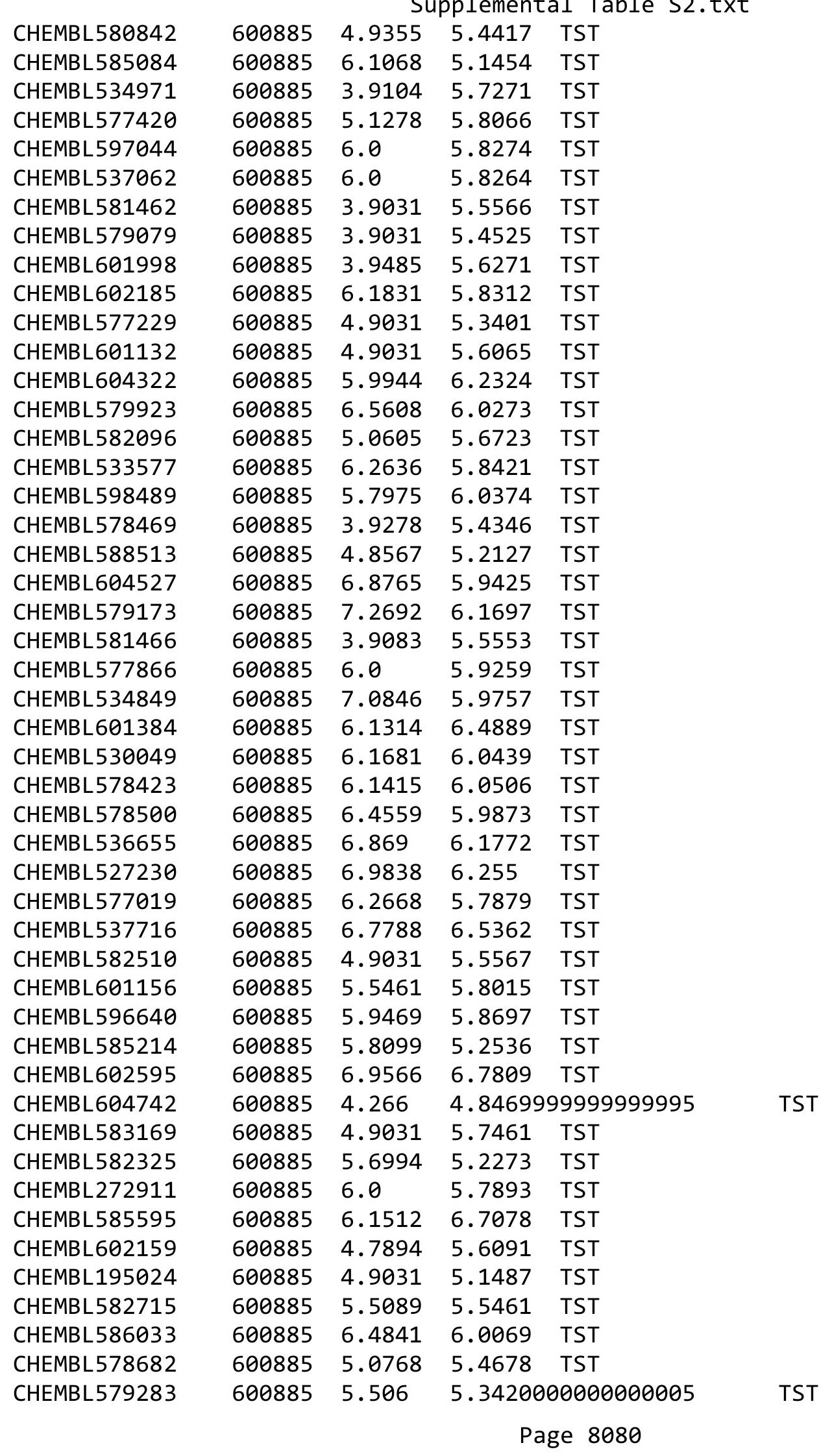




\begin{tabular}{|c|c|c|c|c|c|}
\hline & & & & & \\
\hline CHEMBL602624 & 600885 & 6.1884 & 5.761 & TST & \\
\hline CHEMBL7077 & 600885 & 6.1232 & 5.3319 & TST & \\
\hline CHEMBL598057 & 600885 & 5.9531 & 5.9138 & TST & \\
\hline CHEMBL96051 & 600885 & 6.2495 & 6.0572 & TST & \\
\hline CHEMBL599308 & 600885 & 5.2865 & 4.6967 & TST & \\
\hline CHEMBL585764 & 600885 & 6.2782 & 6.2116 & TST & \\
\hline CHEMBL579376 & 600885 & 4.8248 & 6.0525 & TST & \\
\hline CHEMBL598260 & 600885 & 5.5198 & 4.6538 & TST & \\
\hline CHEMBL600557 & 600885 & 5.6182 & 5.9758 & TST & \\
\hline CHEMBL579557 & 600885 & 5.7167 & 5.3577 & TST & \\
\hline CHEMBL531781 & 600885 & 5.4389 & 5.71399 & 99999999995 & TST \\
\hline CHEMBL588350 & 600885 & 4.9031 & 5.4398 & TST & \\
\hline CHEMBL596642 & 600885 & 5.9566 & 5.9459 & TST & \\
\hline CHEMBL546747 & 600885 & 6.2291 & 5.7518 & TST & \\
\hline CHEMBL602399 & 600885 & 6.3134 & 5.8067 & TST & \\
\hline CHEMBL578704 & 600885 & 6.8752 & 6.3602 & TST & \\
\hline CHEMBL584641 & 600885 & 7.6501 & 6.7722 & TST & \\
\hline CHEMBL600555 & 600885 & 5.8626 & 5.8204 & TST & \\
\hline CHEMBL601755 & 600885 & 5.8871 & 5.643 & TST & \\
\hline CHEMBL600911 & 600885 & 5.1367 & 5.5006 & TST & \\
\hline CHEMBL584894 & 600885 & 4.0453 & 5.7553 & TST & \\
\hline CHEMBL585238 & 600885 & 6.545 & 5.9152 & TST & \\
\hline CHEMBL582961 & 600885 & 4.9031 & 5.3093 & TST & \\
\hline CHEMBL1744505 & 600885 & 6.0 & 5.774 & TST & \\
\hline CHEMBL582726 & 600885 & 5.7836 & 5.7257 & TST & \\
\hline CHEMBL598264 & 600885 & 6.0241 & 6.7697 & TST & \\
\hline CHEMBL605611 & 600885 & 5.7129 & 5.6393 & TST & \\
\hline CHEMBL602364 & 600885 & 5.9435 & 5.9632 & TST & \\
\hline CHEMBL585247 & 600885 & 6.5887 & 6.7154 & TST & \\
\hline CHEMBL584637 & 600885 & 6.475 & 6.0788 & TST & \\
\hline CHEMBL579930 & 600885 & 5.32700 & 300000006 & 5.561 & TST \\
\hline CHEMBL600912 & 600885 & 3.9031 & 5.5269 & TST & \\
\hline CHEMBL601578 & 600885 & 5.9642 & 5.7337 & TST & \\
\hline CHEMBL601553 & 600885 & 6.8579 & 6.0031 & TST & \\
\hline CHEMBL577013 & 600885 & 6.5271 & 7.3879 & TST & \\
\hline CHEMBL604978 & 600885 & 5.7416 & 5.5989 & TST & \\
\hline CHEMBL581262 & 600885 & 4.9031 & 5.7293 & TST & \\
\hline CHEMBL588768 & 600885 & 6.0851 & 5.9335 & TST & \\
\hline CHEMBL598896 & 600885 & 6.0391 & 5.7451 & TST & \\
\hline CHEMBL579137 & 600885 & 4.8658 & 5.5545 & TST & \\
\hline CHEMBL536423 & 600885 & 6.2848 & 6.1646 & TST & \\
\hline CHEMBL577205 & 600885 & 6.6287 & 6.2736 & TST & \\
\hline CHEMBL582253 & 600885 & 5.6863 & 5.4813 & TST & \\
\hline CHEMBL585797 & 600885 & 3.9031 & 5.4355 & TST & \\
\hline CHEMBL588583 & 600885 & 3.9031 & 5.4203 & TST & \\
\hline CHEMBL602218 & 600885 & 6.058 & 5.8405 & TST & \\
\hline CHEMBL585243 & 600885 & 6.7172 & 6.0491 & TST & \\
\hline CHEMBL600276 & 600885 & 6.0297 & 5.1636 & TST & \\
\hline
\end{tabular}




\begin{tabular}{|c|c|c|c|c|c|}
\hline & & & & & \\
\hline CHEMBL582047 & 600885 & 5.4365 & 5.6543 & TST & \\
\hline CHEMBL584820 & 600885 & 6.1278 & 6.0908 & TST & \\
\hline CHEMBL578943 & 600885 & 5.7757 & 6.0822 & TST & \\
\hline CHEMBL610053 & 600885 & 6.1007 & 6.1669 & TST & \\
\hline CHEMBL584867 & 600885 & 6.433 & 6.0311 & TST & \\
\hline CHEMBL578279 & 600885 & 7.2358 & 5.8514 & TST & \\
\hline CHEMBL526240 & 600885 & 6.5899 & 6.7854 & TST & \\
\hline CHEMBL578665 & 600885 & 6.5971 & 6.1912 & TST & \\
\hline CHEMBL587041 & 600885 & 4.8703 & 5.6721 & TST & \\
\hline CHEMBL580353 & 600885 & 8.1662 & 6.4994 & TST & \\
\hline CHEMBL530432 & 600885 & 6.9431 & 6.4594 & TST & \\
\hline CHEMBL600151 & 600885 & 4.9031 & 5.4023 & TST & \\
\hline CHEMBL581886 & 600885 & 8.4425 & 6.8221 & TST & \\
\hline CHEMBL583610 & 600885 & 6.2147 & 5.6523 & TST & \\
\hline CHEMBL604101 & 600885 & 6.3036 & 5.8391 & TST & \\
\hline CHEMBL584290 & 600885 & 3.9031 & 5.7862 & TST & \\
\hline CHEMBL579314 & 600885 & 7.4763 & 7.0996 & TST & \\
\hline CHEMBL602359 & 600885 & 6.0191 & 5.83899 & 99999999995 & TST \\
\hline CHEMBL526955 & 600885 & 6.4342 & 6.6855 & TST & \\
\hline CHEMBL586635 & 600885 & 6.5348 & 6.5529 & TST & \\
\hline CHEMBL587658 & 600885 & 6.4935 & $6.13200 t$ & 0000000001 & TST \\
\hline CHEMBL601350 & 600885 & 4.9031 & 5.1708 & TST & \\
\hline CHEMBL584828 & 600885 & 4.8857 & 5.4683 & TST & \\
\hline CHEMBL601354 & 600885 & 4.9031 & 5.5121 & TST & \\
\hline CHEMBL603004 & 600885 & 6.5402 & 5.9568 & TST & \\
\hline CHEMBL581687 & 600885 & 5.8526 & 5.2333 & TST & \\
\hline CHEMBL601134 & 600885 & 4.0438 & 5.6213 & TST & \\
\hline CHEMBL582669 & 600885 & 6.1073 & 5.9331 & TST & \\
\hline CHEMBL581219 & 600885 & 5.8222 & 5.6352 & TST & \\
\hline CHEMBL582475 & 600885 & 5.8077 & 6.0468 & TST & \\
\hline CHEMBL611663 & 600885 & 6.7657 & 6.2606 & TST & \\
\hline CHEMBL585118 & 600885 & 3.9031 & 5.8456 & TST & \\
\hline CHEMBL578019 & 600885 & 5.129 & 5.4287 & TST & \\
\hline CHEMBL579111 & 600885 & 5.6221 & 5.4291 & TST & \\
\hline CHEMBL599706 & 600885 & 6.1818 & 5.2368 & TST & \\
\hline CHEMBL600110 & 600885 & 6.756 & 5.3769 & TST & \\
\hline CHEMBL573710 & 600885 & 6.1129 & 5.9867 & TST & \\
\hline CHEMBL585826 & 600885 & 6.0061 & 7.1049 & TST & \\
\hline CHEMBL580167 & 600885 & 6.0899 & 5.8688 & TST & \\
\hline CHEMBL604718 & 600885 & 6.1555 & 6.7676 & TST & \\
\hline CHEMBL582113 & 600885 & 4.942 & 5.1903 & TST & \\
\hline CHEMBL582664 & 600885 & 6.1599 & 6.0004 & TST & \\
\hline CHEMBL600536 & 600885 & 6.3516 & 5.8274 & TST & \\
\hline CHEMBL7961 & 600885 & 3.9031 & 5.6934 & TST & \\
\hline CHEMBL577604 & 600885 & 6.0 & 5.7257 & TST & \\
\hline CHEMBL601604 & 600885 & 6.5293 & 6.6161 & TST & \\
\hline CHEMBL582089 & 600885 & 5.96899 & 99999999 & 5.7819 & TST \\
\hline CHEMBL601137 & 600885 & 6.0 & 5.8196 & TST & \\
\hline
\end{tabular}




\begin{tabular}{|c|c|c|c|c|c|c|}
\hline & & \multicolumn{5}{|c|}{ Supplemental Table S2.txt } \\
\hline CHEMBL600736 & 600885 & 3.9031 & 5.715 & TST & & \\
\hline CHEMBL601111 & 600885 & 5.8474 & 5.7158 & TST & & \\
\hline CHEMBL585652 & 600885 & 7.1605 & 6.2273 & TST & & \\
\hline CHEMBL576547 & 600885 & 5.104 & 6.3082 & TST & & \\
\hline CHEMBL606160 & 600885 & 6.6194 & 5.8134 & TST & & \\
\hline CHEMBL606450 & 600885 & 5.3883 & 5.5086 & TST & & \\
\hline CHEMBL581037 & 600885 & 5.0292 & 5.5919 & TST & & \\
\hline CHEMBL582460 & 600885 & \multicolumn{3}{|c|}{4.763999999999999} & 5.8189 & TST \\
\hline CHEMBL588407 & 600885 & 4.9031 & 5.4001 & TST & & \\
\hline CHEMBL581682 & 600885 & 4.9614 & 5.1528 & TST & & \\
\hline CHEMBL578728 & 600885 & 5.4609 & 5.8485 & TST & & \\
\hline CHEMBL577847 & 600885 & 3.9031 & 5.349 & TST & & \\
\hline CHEMBL598283 & 600885 & 7.3605 & 6.1887 & TST & & \\
\hline CHEMBL578543 & 600885 & 6.7263 & 7.0663 & TST & & \\
\hline CHEMBL583559 & 600885 & 4.9031 & 5.2965 & TST & & \\
\hline CHEMBL577432 & 600885 & \multicolumn{3}{|c|}{5.968999999999999} & 5.9376 & TST \\
\hline CHEMBL581692 & 600885 & 3.9031 & 5.8978 & TST & & \\
\hline CHEMBL598266 & 600885 & 6.0 & 5.6943 & TST & & \\
\hline CHEMBL577004 & 600885 & 4.8162 & 5.2275 & TST & & \\
\hline CHEMBL601765 & 600885 & 5.9889 & 6.3335 & TST & & \\
\hline CHEMBL268356 & 600885 & 6.8306 & 5.2324 & TST & & \\
\hline CHEMBL576334 & 600885 & 4.9031 & 5.5184 & TST & & \\
\hline CHEMBL528422 & 600885 & 6.7862 & 6.6639 & TST & & \\
\hline CHEMBL582487 & 600885 & 3.9031 & 5.2337 & TST & & \\
\hline CHEMBL602207 & 600885 & 5.2541 & 5.5283 & TST & & \\
\hline CHEMBL578922 & 600885 & 3.9031 & 5.425 & TST & & \\
\hline CHEMBL588811 & 600885 & 5.2534 & 5.9397 & TST & & \\
\hline CHEMBL582093 & 600885 & 5.529 & 5.8755 & TST & & \\
\hline CHEMBL582520 & 600885 & 5.8847 & 5.3169 & TST & & \\
\hline CHEMBL585971 & 600885 & 5.4425 & 5.0735 & TST & & \\
\hline CHEMBL3215791 & 596429 & \multicolumn{3}{|c|}{6.757000000000001} & 6.4925 & TRN \\
\hline CHEMBL3216922 & 596429 & 7.4318 & 6.9745 & TRN & & \\
\hline CHEMBL3216918 & 596429 & 6.3497 & 6.0021 & TRN & & \\
\hline CHEMBL3216463 & 596429 & 4.9957 & 5.4118 & TRN & & \\
\hline CHEMBL3216044 & 596429 & 7.2757 & 7.3153 & TRN & & \\
\hline CHEMBL3216046 & 596429 & 7.6778 & 8.0407 & TRN & & \\
\hline CHEMBL3216042 & 596429 & 7.1135 & 6.1787 & TRN & & \\
\hline CHEMBL 3216445 & 596429 & 5.1778 & 6.3064 & TST & & \\
\hline CHEMBL 3216457 & 596429 & 7.7959 & 7.6294 & TRN & & \\
\hline CHEMBL3215589 & 596429 & 3.9914 & 4.7009 & TST & & \\
\hline CHEMBL3216450 & 596429 & 8.2218 & 7.8101 & TRN & & \\
\hline CHEMBL3215593 & 596429 & 6.153 & 6.4672 & TRN & & \\
\hline CHEMBL3215799 & 596429 & 4.9626 & 5.4871 & TRN & & \\
\hline CHEMBL3216043 & 596429 & 5.8601 & 5.5296 & TRN & & \\
\hline CHEMBL 3216242 & 596429 & 6.2684 & 6.1333 & TRN & & \\
\hline CHEMBL 3216687 & 596429 & 6.7595 & 7.04299 & 9999999999 & & TRN \\
\hline CHEMBL3216045 & 596429 & 8.0969 & 8.0513 & TRN & & \\
\hline CHEMBL3216243 & 596429 & 6.2175 & 6.0151 & TRN & & \\
\hline
\end{tabular}




\begin{tabular}{|c|c|c|c|c|c|c|}
\hline CHEMBL3216451 & 596429 & \multicolumn{4}{|c|}{ Supplemental Table S2.txt } & TRN \\
\hline CHEMBL 3216688 & 596429 & 4.8297 & 5.5119 & TRN & & \\
\hline CHEMBL3216683 & 596429 & 4.7077 & 5.3497 & TST & & \\
\hline CHEMBL3215792 & 596429 & 4.7282 & 4.9067 & TRN & & \\
\hline CHEMBL3216915 & 596429 & 6.4841 & 6.2388 & TRN & & \\
\hline CHEMBL569952 & 596429 & 6.9355 & 6.2474 & TRN & & \\
\hline CHEMBL3216691 & 596429 & 6.6968 & 7.1691 & TRN & & \\
\hline CHEMBL3215795 & 596429 & 6.3354 & 6.2016 & TRN & & \\
\hline CHEMBL3217130 & 596429 & 7.5086 & 8.6945 & TST & & \\
\hline CHEMBL3216916 & 596429 & 5.1062 & 5.8533 & TST & & \\
\hline CHEMBL 3217131 & 596429 & 5.7077 & 5.605 & TRN & & \\
\hline CHEMBL3216040 & 596429 & 7.0809 & 7.3473 & TRN & & \\
\hline CHEMBL1197423 & 596429 & 8.2218 & 7.2047 & TRN & & \\
\hline CHEMBL3215592 & 596429 & 8.301 & 7.9739 & TST & & \\
\hline CHEMBL3215801 & 596429 & 7.1135 & 7.3869 & TRN & & \\
\hline CHEMBL3215588 & 596429 & 8.0969 & 7.7875 & TRN & & \\
\hline CHEMBL1197424 & 596429 & 5.3958 & 6.2457 & TRN & & \\
\hline CHEMBL3216039 & 596429 & 4.3045 & 5.8047 & TST & & \\
\hline CHEMBL3216686 & 596429 & 8.3979 & 8.734 & TRN & & \\
\hline CHEMBL3216692 & 596429 & 6.9355 & 7.2575 & TRN & & \\
\hline CHEMBL3216690 & 596429 & 6.0009 & 5.9499 & TST & & \\
\hline CHEMBL3216693 & 596429 & 7.4202 & 7.7332 & TRN & & \\
\hline CHEMBL 3215800 & 596429 & 8.2218 & 7.6537 & TRN & & \\
\hline CHEMBL3216921 & 596429 & 7.3279 & 7.11100 & 0000000001 & & TRN \\
\hline CHEMBL 3215594 & 596429 & 6.6968 & 7.0537 & TRN & & \\
\hline CHEMBL3215803 & 596429 & 6.3002 & 6.9043 & TST & & \\
\hline CHEMBL 3217128 & 596429 & 7.9586 & 7.3501 & TRN & & \\
\hline CHEMBL3216449 & 596429 & 5.7825 & 8.2544 & TST & & \\
\hline CHEMBL1198787 & 596429 & 5.7282 & 5.9341 & TST & & \\
\hline CHEMBL3216458 & 596429 & 4.9547 & 5.2249 & TST & & \\
\hline CHEMBL3216459 & 596429 & 4.8508 & 5.6333 & TRN & & \\
\hline CHEMBL3216241 & 596429 & 4.857 & 4.3752 & TRN & & \\
\hline CHEMBL3216456 & 596429 & 5.9031 & 6.7061 & TRN & & \\
\hline CHEMBL3216919 & 596429 & 6.7905 & 6.5028 & TST & & \\
\hline CHEMBL1197563 & 596429 & 8.0969 & 9.1004 & TST & & \\
\hline CHEMBL3216249 & 596429 & 7.4202 & 7.305 & TRN & & \\
\hline CHEMBL3216920 & 596429 & 7.7959 & 8.5213 & TRN & & \\
\hline CHEMBL3215793 & 596429 & 7.3665 & 6.7982 & TRN & & \\
\hline CHEMBL3216248 & 596429 & 4.9318 & 5.5896 & TRN & & \\
\hline CHEMBL3216454 & 596429 & 6.3363 & 5.9827 & TRN & & \\
\hline CHEMBL3216685 & 596429 & 6.699 & 6.3297 & TRN & & \\
\hline CHEMBL3215590 & 596429 & 6.1707 & 6.5969 & TST & & \\
\hline CHEMBL1459029 & 737235 & 3.495 & 3.495 & TRN & & \\
\hline CHEMBL1389833 & 737235 & 3.495 & 3.495 & TST & & \\
\hline CHEMBL1718432 & 737235 & 3.495 & 3.495 & TRN & & \\
\hline CHEMBL1385076 & 737235 & 3.495 & 3.495 & TRN & & \\
\hline CHEMBL3192498 & 737235 & 3.495 & 3.495 & TST & & \\
\hline CHEMBL1453578 & 737235 & 3.495 & 3.495 & TRN & & \\
\hline
\end{tabular}




\begin{tabular}{|c|c|c|c|c|c|c|}
\hline & & \multicolumn{5}{|c|}{ Supplemental Table S2.txt } \\
\hline CHEMBL1707797 & 737235 & 3.495 & 3.495 & TRN & & \\
\hline CHEMBL1724622 & 737235 & 3.495 & 3.495 & TRN & & \\
\hline CHEMBL1532240 & 737235 & 3.495 & 3.495 & TST & & \\
\hline CHEMBL1592197 & 737235 & 3.495 & 3.495 & TRN & & \\
\hline CHEMBL1702427 & 737235 & 3.495 & 3.495 & TRN & & \\
\hline CHEMBL1569918 & 737235 & 3.495 & 3.495 & TST & & \\
\hline CHEMBL1416366 & 737235 & 3.495 & 3.495 & TST & & \\
\hline CHEMBL1715363 & 737235 & 3.495 & 3.495 & TRN & & \\
\hline CHEMBL1715811 & 737235 & 3.495 & 3.495 & TRN & & \\
\hline CHEMBL1724290 & 737235 & 3.495 & 3.495 & TRN & & \\
\hline CHEMBL1705711 & 737235 & 3.495 & 3.495 & TRN & & \\
\hline CHEMBL1735479 & 737235 & 3.495 & 3.495 & TRN & & \\
\hline CHEMBL1699880 & 737235 & 3.495 & 3.495 & TRN & & \\
\hline CHEMBL1332976 & 737235 & 3.495 & 3.495 & TST & & \\
\hline CHEMBL1545328 & 737235 & \multicolumn{3}{|c|}{7.042999999999999} & 3.495 & TST \\
\hline CHEMBL1714418 & 737235 & 3.495 & 3.495 & TRN & & \\
\hline CHEMBL1701630 & 737235 & 3.495 & 3.495 & TRN & & \\
\hline CHEMBL1724849 & 737235 & 3.495 & 3.495 & TRN & & \\
\hline CHEMBL3194269 & 737235 & 3.495 & 3.495 & TST & & \\
\hline CHEMBL1713121 & 737235 & 3.495 & 3.495 & TRN & & \\
\hline CHEMBL1712952 & 737235 & 3.495 & 3.495 & TRN & & \\
\hline CHEMBL1585996 & 737235 & 3.495 & 3.495 & TRN & & \\
\hline CHEMBL1709725 & 737235 & 3.495 & 3.495 & TRN & & \\
\hline CHEMBL1717635 & 737235 & 3.495 & 3.495 & TRN & & \\
\hline CHEMBL1714272 & 737235 & 3.495 & 3.495 & TRN & & \\
\hline CHEMBL1367646 & 737235 & 3.495 & 3.495 & TRN & & \\
\hline CHEMBL1722279 & 737235 & 3.495 & 3.495 & TRN & & \\
\hline CHEMBL1730617 & 737235 & 3.495 & 3.495 & TRN & & \\
\hline CHEMBL1734382 & 737235 & 3.495 & 3.495 & TRN & & \\
\hline CHEMBL1398414 & 737235 & 3.495 & 3.495 & TRN & & \\
\hline CHEMBL 3190906 & 737235 & 3.495 & 3.495 & TST & & \\
\hline CHEMBL1704166 & 737235 & 3.495 & 3.495 & TRN & & \\
\hline CHEMBL1697974 & 737235 & 3.495 & 3.495 & TRN & & \\
\hline CHEMBL1544821 & 737235 & 8.208 & 3.495 & TST & & \\
\hline CHEMBL1452827 & 737235 & 3.495 & 3.495 & TST & & \\
\hline CHEMBL1727119 & 737235 & 3.495 & 3.495 & TRN & & \\
\hline CHEMBL1718746 & 737235 & 3.495 & 3.495 & TRN & & \\
\hline CHEMBL1397703 & 737235 & 3.495 & 3.495 & TRN & & \\
\hline CHEMBL1705015 & 737235 & 3.495 & 3.495 & TRN & & \\
\hline CHEMBL1732131 & 737235 & 3.495 & 3.495 & TST & & \\
\hline CHEMBL1705027 & 737235 & 3.495 & 3.495 & TRN & & \\
\hline CHEMBL1709590 & 737235 & 3.495 & 3.495 & TRN & & \\
\hline CHEMBL1731489 & 737235 & 3.495 & 3.495 & TRN & & \\
\hline CHEMBL1494709 & 737235 & 3.495 & 3.495 & TRN & & \\
\hline CHEMBL1711005 & 737235 & 3.495 & 3.495 & TRN & & \\
\hline CHEMBL1733898 & 737235 & 3.495 & 3.495 & TRN & & \\
\hline CHEMBL1602521 & 737235 & 3.495 & 3.495 & TRN & & \\
\hline CHEMBL1733298 & 737235 & 3.495 & 3.495 & TRN & & \\
\hline
\end{tabular}


Supplemental Table S2.txt

\begin{tabular}{|c|c|c|c|c|}
\hline-3 & & & & \\
\hline HEMBL3197480 & 37235 & .495 & 3.495 & \\
\hline 2769 & & & & \\
\hline IEMBL1701470 & 7235 & & 195 & \\
\hline JEMBL1398595 & 37235 & & 495 & \\
\hline AEMBL1453321 & 37235 & 495 & 495 & \\
\hline HEMBL 2113184 & 26138 & 089 & 213 & \\
\hline AEMBL3706827 & & 512 & 237 & \\
\hline AEMBL3706825 & & 182 & .519 & \\
\hline AEMBL3706840 & 26138 & 2366 & .8147 & \\
\hline HEMBL 3706821 & 26138 & 8697 & .4662 & \\
\hline AEMBL2113188 & 38 & 3372 & .3408 & \\
\hline AEMBL3706 & & 212 & & $\cdots$ \\
\hline AEMBL3706841 & & 468 & 3379 & \\
\hline AEMBL3706824 & & 959 & 3823 & \\
\hline AEMBL 2113174 & 38 & 686 & 5004 & \\
\hline HEMBL2113178 & & 218 & .6321 & \\
\hline HEMBL37068 & & 924 & 3.3249 & \\
\hline HEMBL3706823 & & & 9828 & \\
\hline AEMBL199455 & & 658 & 169 & RN \\
\hline AEMBL2113167 & & 415 & 348 & ГRN \\
\hline HEMBL21131 & & 271 & 476 & RN \\
\hline HEMBL37068 & & 468 & 855 & \\
\hline AEMBL3706843 & & 665 & 7.5988 & \\
\hline AEMBL21131 & & 38 & 1003 & RN \\
\hline BL3706 & & 96 & 338 & ГRN \\
\hline L21131 & & 202 & 479 & RN \\
\hline 9 & & 87 & 6.5109 & RN \\
\hline HEMBL2113173 & & 33 & 3102 & 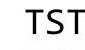 \\
\hline AEMBL37068 & & 74 & 6.9791 & SI \\
\hline AEMBL21131 & & 249 & 7.2593 & ST \\
\hline AEMBL 2113 & & & 9.4362 & RN \\
\hline 10 & & & 351 & RN \\
\hline HEMBL2113171 & & 79 & 9493 & RN \\
\hline AEMBL3706839 & & 9872 & 7.4615 & IST \\
\hline AEMBL21131 & & 768 & 085 & RN \\
\hline - רבMD & & 49 & 453 & RN \\
\hline HEMBL 2113170 & & 7.0716 & 7.4226 & ST \\
\hline HEMBL2113191 & 38 & 6383 & 8.3163 & TRN \\
\hline AEMBL 2007 & & & 9.2164 & RN \\
\hline HEMBL37068 & & 458 & 7.3207 & RN \\
\hline HEMBL37068 & & & 7.6915 & RN \\
\hline HEMBL2113186 & & 8.1192 & 7.4325 & TST \\
\hline AEMBL3706838 & 138 & & .0542 & TST \\
\hline FMPI 27060 & & & .5939 & \\
\hline HEMBL 21131 & & .2441 & 8.6953 & RIV \\
\hline 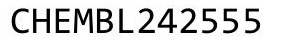 & 326138 & 7.3665 & 7.2151 & RIN \\
\hline HEMBL 370683 & 326138 & 7.7721 & 7.6581 & TRN \\
\hline
\end{tabular}

Page 8086 


\begin{tabular}{|c|c|c|c|c|}
\hline \multicolumn{5}{|c|}{ Supplemental Table S2.txt } \\
\hline CHEMBL3706828 & 326138 & 5.0 & 7.4166 & TST \\
\hline CHEMBL 2113166 & 326138 & 8.3565 & 7.7808 & TRN \\
\hline CHEMBL3706834 & 326138 & 7.7932 & 8.078 & TRN \\
\hline CHEMBL3706829 & 326138 & 7.8013 & 8.4595 & TRN \\
\hline CHEMBL3706816 & 326138 & 8.4437 & 8.3721 & TRN \\
\hline CHEMBL3706842 & 326138 & 8.8239 & 9.0159 & TRN \\
\hline CHEMBL3706833 & 326138 & 6.961 & 6.9459 & TRN \\
\hline CHEMBL3706822 & 326138 & 8.7696 & 8.3523 & TRN \\
\hline CHEMBL 2113176 & 326138 & 7.0521 & 6.5388 & TRN \\
\hline CHEMBL3706814 & 326138 & 7.1506 & 7.3088 & TRN \\
\hline CHEMBL3706817 & 326138 & 8.2924 & 8.0727 & TRN \\
\hline CHEMBL3706837 & 326138 & 8.4685 & 8.8044 & TRN \\
\hline CHEMBL202389 & 326138 & 8.585 & 8.829 & TRN \\
\hline CHEMBL200723 & 326138 & 6.6211 & 7.2616 & TST \\
\hline CHEMBL371551 & 326138 & 6.6262 & 6.6867 & TRN \\
\hline CHEMBL 2113175 & 326138 & 8.041 & 7.8984 & TRN \\
\hline CHEMBL 2113187 & 326138 & 9.0458 & 9.0821 & TRN \\
\hline CHEMBL 2113199 & 326138 & 8.0177 & 7.9618 & TRN \\
\hline CHEMBL396472 & 326138 & 7.5058 & 7.9279 & TRN \\
\hline CHEMBL 2113190 & 326138 & 7.2807 & 7.2142 & TRN \\
\hline CHEMBL 2113180 & 326138 & 6.4444 & 6.6156 & TST \\
\hline CHEMBL 2113164 & 326138 & 8.4949 & 8.4964 & TRN \\
\hline CHEMBL 2113168 & 326138 & 6.9948 & 6.8916 & TST \\
\hline CHEMBL 200818 & 326138 & 6.8761 & 6.776 & TST \\
\hline CHEMBL3945642 & 1641859 & 7.6383 & 7.7753 & TRN \\
\hline CHEMBL3982866 & 1641859 & 7.3665 & 7.0588 & TRN \\
\hline CHEMBL3922700 & 1641859 & 8.5229 & 7.9535 & TRN \\
\hline CHEMBL3948720 & 1641859 & 8.699 & 7.9045 & TST \\
\hline CHEMBL 3916634 & 1641859 & 7.6198 & 7.6749 & TRN \\
\hline CHEMBL3910604 & 1641859 & 7.0088 & 7.3575 & TRN \\
\hline CHEMBL3973237 & 1641859 & 8.301 & 7.7082 & TRN \\
\hline CHEMBL3908423 & 1641859 & 8.1549 & 8.1285 & TRN \\
\hline CHEMBL3932729 & 1641859 & 7.3468 & 7.7384 & TRN \\
\hline CHEMBL 3977222 & 1641859 & 8.0458 & 8.2228 & TST \\
\hline CHEMBL3920421 & 1641859 & 7.7696 & 7.8218 & TRN \\
\hline CHEMBL3921634 & 1641859 & 7.7696 & 7.6234 & TRN \\
\hline CHEMBL3934653 & 1641859 & 6.0 & 8.169 & TST \\
\hline CHEMBL3973952 & 1641859 & 8.3979 & 8.1726 & TST \\
\hline CHEMBL3974338 & 1641859 & 7.7696 & 7.7964 & TRN \\
\hline CHEMBL3940541 & 1641859 & 7.1427 & 7.7443 & TRN \\
\hline CHEMBL3956745 & 1641859 & 8.0969 & 8.53 & TRN \\
\hline CHEMBL3963059 & 1641859 & 7.9208 & 7.7861 & TRN \\
\hline CHEMBL3935544 & 1641859 & 7.0555 & 8.0629 & TST \\
\hline CHEMBL 3933277 & 1641859 & 6.4522 & 6.4529 & TRN \\
\hline CHEMBL3901115 & 1641859 & 6.9431 & 7.9715 & TST \\
\hline CHEMBL3939757 & 1641859 & 7.284 & 7.01 & TRN \\
\hline CHEMBL3892164 & 1641859 & 7.4815 & 7.7428 & TRN \\
\hline CHEMBL3965249 & 1641859 & 7.4202 & 7.4153 & TRN \\
\hline
\end{tabular}


Supplemental Table S2.txt

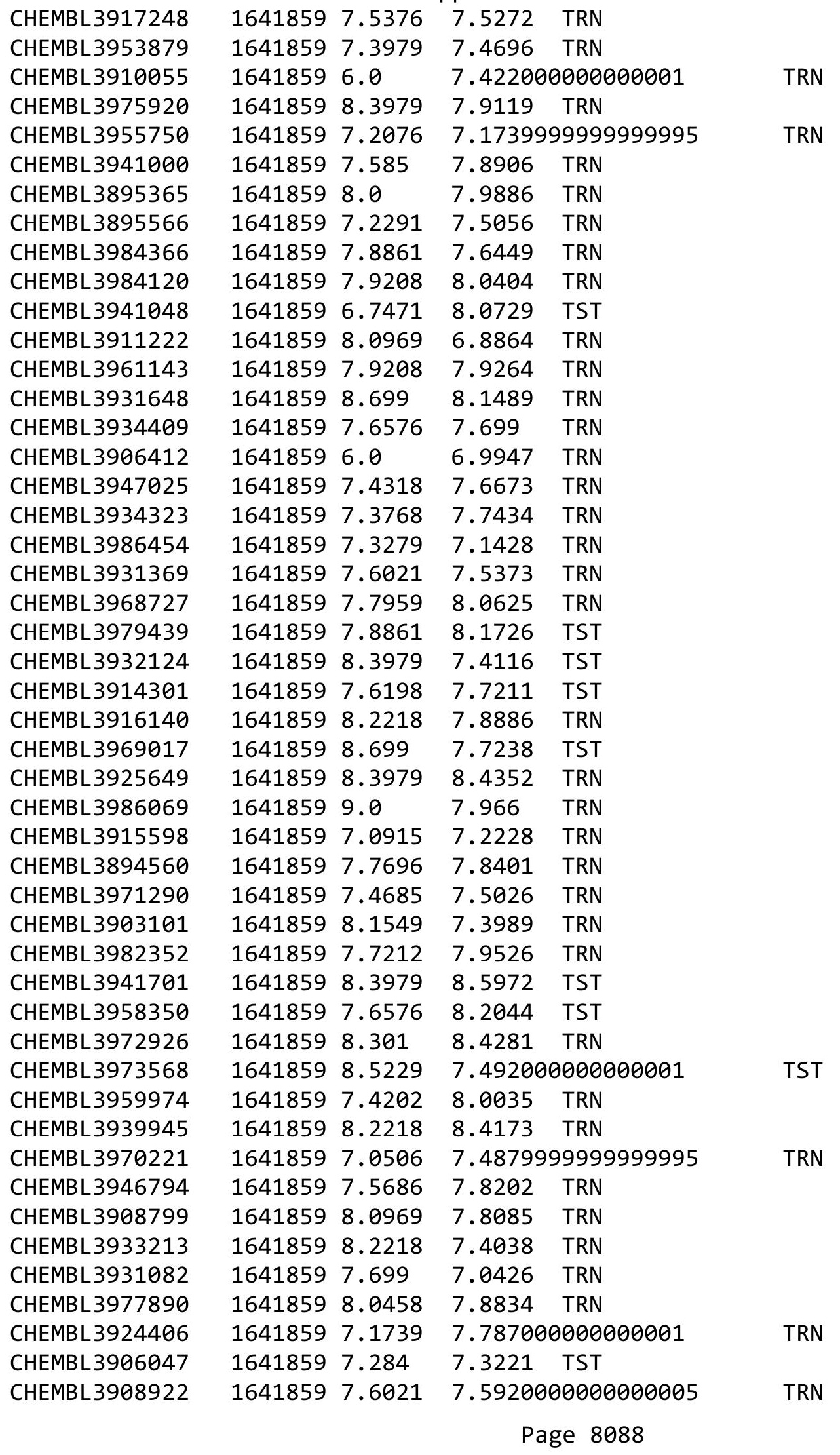




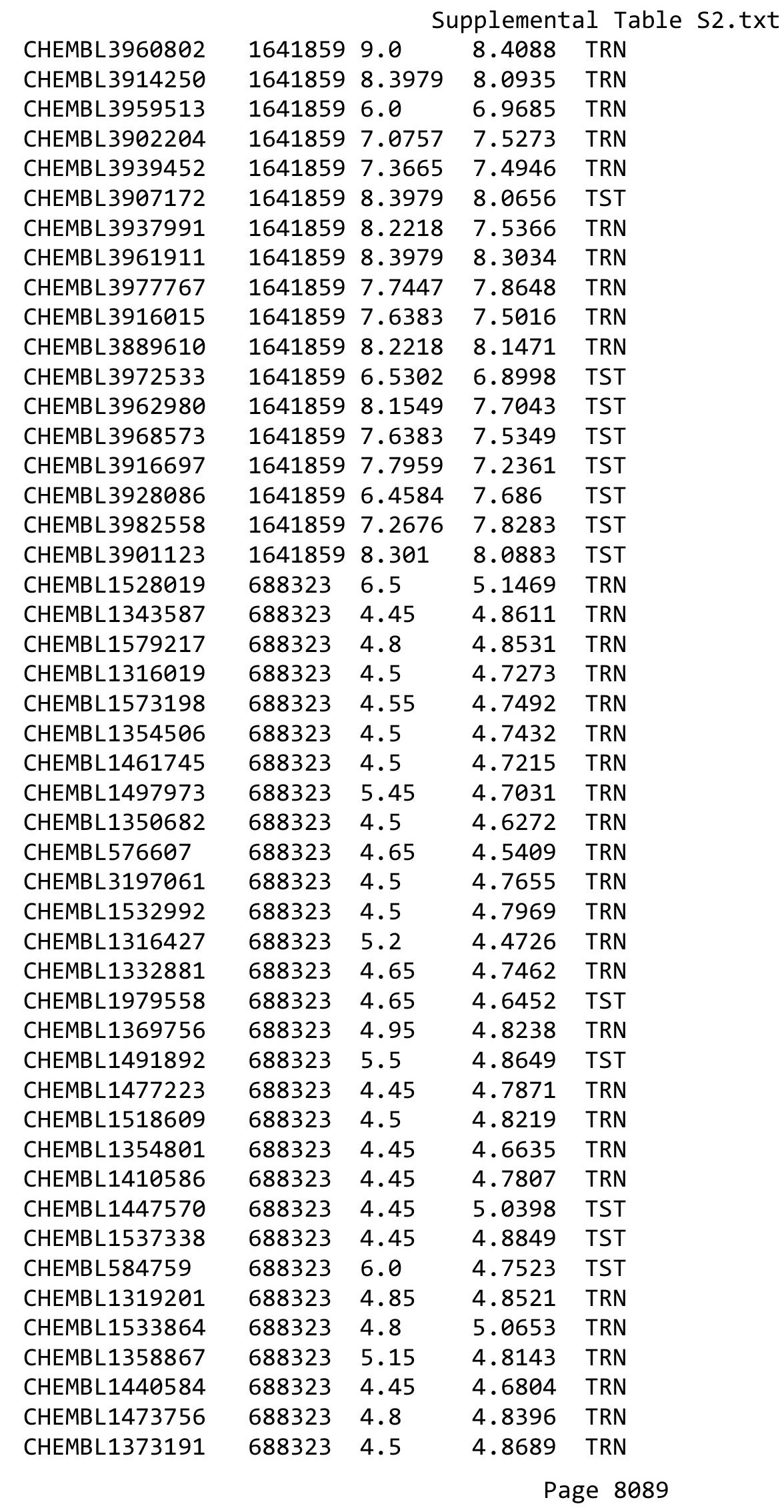




\begin{tabular}{|c|c|c|c|c|c|}
\hline \multicolumn{6}{|c|}{ Supplemental Table S2.txt } \\
\hline CHEMBL1543495 & 688323 & 4.75 & 4.6827 & TRN & \\
\hline CHEMBL597047 & 688323 & 4.85 & 4.7278 & TRN & \\
\hline CHEMBL1310204 & 688323 & 4.8 & 4.9084 & TRN & \\
\hline CHEMBL1608777 & 688323 & 4.8 & 4.7608 & TRN & \\
\hline CHEMBL1563848 & 688323 & 4.45 & 4.6618 & TRN & \\
\hline CHEMBL1322401 & 688323 & 4.65 & 4.9629 & TRN & \\
\hline CHEMBL1603776 & 688323 & 5.25 & 4.8279 & TST & \\
\hline CHEMBL1442155 & 688323 & 4.5 & 5.105 & TST & \\
\hline CHEMBL1591606 & 688323 & 4.8 & 4.8523 & TRN & \\
\hline CHEMBL1603938 & 688323 & 4.75 & 4.8368 & TRN & \\
\hline CHEMBL1606126 & 688323 & 4.7 & 4.8729 & TRN & \\
\hline CHEMBL1360980 & 688323 & 5.0 & 4.981 & TRN & \\
\hline CHEMBL546597 & 688323 & 4.5 & 4.8762 & TRN & \\
\hline CHEMBL1379048 & 688323 & 5.15 & 4.9043 & TST & \\
\hline CHEMBL1467060 & 688323 & 4.9 & 4.6969 & TRN & \\
\hline CHEMBL1432696 & 688323 & 4.6 & 4.6119 & TRN & \\
\hline CHEMBL1515629 & 688323 & 4.9 & 4.8766 & TRN & \\
\hline CHEMBL1404113 & 688323 & 4.8 & 4.7597 & TRN & \\
\hline CHEMBL1375452 & 688323 & 4.65 & 4.6731 & TST & \\
\hline CHEMBL1308799 & 688323 & 4.45 & 4.9041 & TRN & \\
\hline CHEMBL1470382 & 688323 & 4.45 & 4.5823 & TRN & \\
\hline CHEMBL3189462 & 688323 & 5.25 & 4.98 & TRN & \\
\hline CHEMBL1404301 & 688323 & 5.95 & 4.8703 & TRN & \\
\hline CHEMBL1422726 & 688323 & 4.55 & 4.8764 & TRN & \\
\hline CHEMBL1366771 & 688323 & 4.6 & 4.413 & TRN & \\
\hline CHEMBL1523000 & 688323 & 4.45 & 4.8321 & TRN & \\
\hline CHEMBL1518530 & 688323 & 4.45 & 4.7197 & TRN & \\
\hline CHEMBL1510623 & 688323 & 5.1 & 4.8022 & TRN & \\
\hline CHEMBL1521924 & 688323 & 5.0 & 4.6114 & TRN & \\
\hline CHEMBL1569027 & 688323 & 4.5 & 4.7822 & TRN & \\
\hline CHEMBL3207313 & 688323 & 5.0 & 4.7496 & TST & \\
\hline CHEMBL1492438 & 688323 & 4.6 & 4.6752 & TRN & \\
\hline CHEMBL1596856 & 688323 & 4.5 & 4.9129 & TRN & \\
\hline CHEMBL1326880 & 688323 & 4.9 & 4.6136 & TRN & \\
\hline CHEMBL1530330 & 688323 & 4.85 & 4.9833 & TRN & \\
\hline CHEMBL1513081 & 688323 & 4.45 & 4.7881 & TRN & \\
\hline CHEMBL1340080 & 688323 & 4.75 & 4.7687 & TRN & \\
\hline CHEMBL1973383 & 688323 & 4.6 & 4.70100 & 00000000005 & TST \\
\hline CHEMBL1579694 & 688323 & 7.0501 & 4.8931 & TST & \\
\hline CHEMBL530499 & 688323 & 4.6 & 5.019 & TRN & \\
\hline CHEMBL1336852 & 688323 & 4.45 & 4.5977 & TRN & \\
\hline CHEMBL1478867 & 688323 & 4.9 & 5.0335 & TRN & \\
\hline CHEMBL1569162 & 688323 & 4.95 & 4.8645 & TRN & \\
\hline CHEMBL1492164 & 688323 & 4.8 & 5.0146 & TRN & \\
\hline CHEMBL1391684 & 688323 & 4.45 & 4.8643 & TRN & \\
\hline CHEMBL1592904 & 688323 & 5.55 & 4.8027 & TRN & \\
\hline CHEMBL601119 & 688323 & 4.6 & 4.8248 & TRN & \\
\hline CHEMBL1453372 & 688323 & 7.0501 & 5.1088 & TST & \\
\hline
\end{tabular}




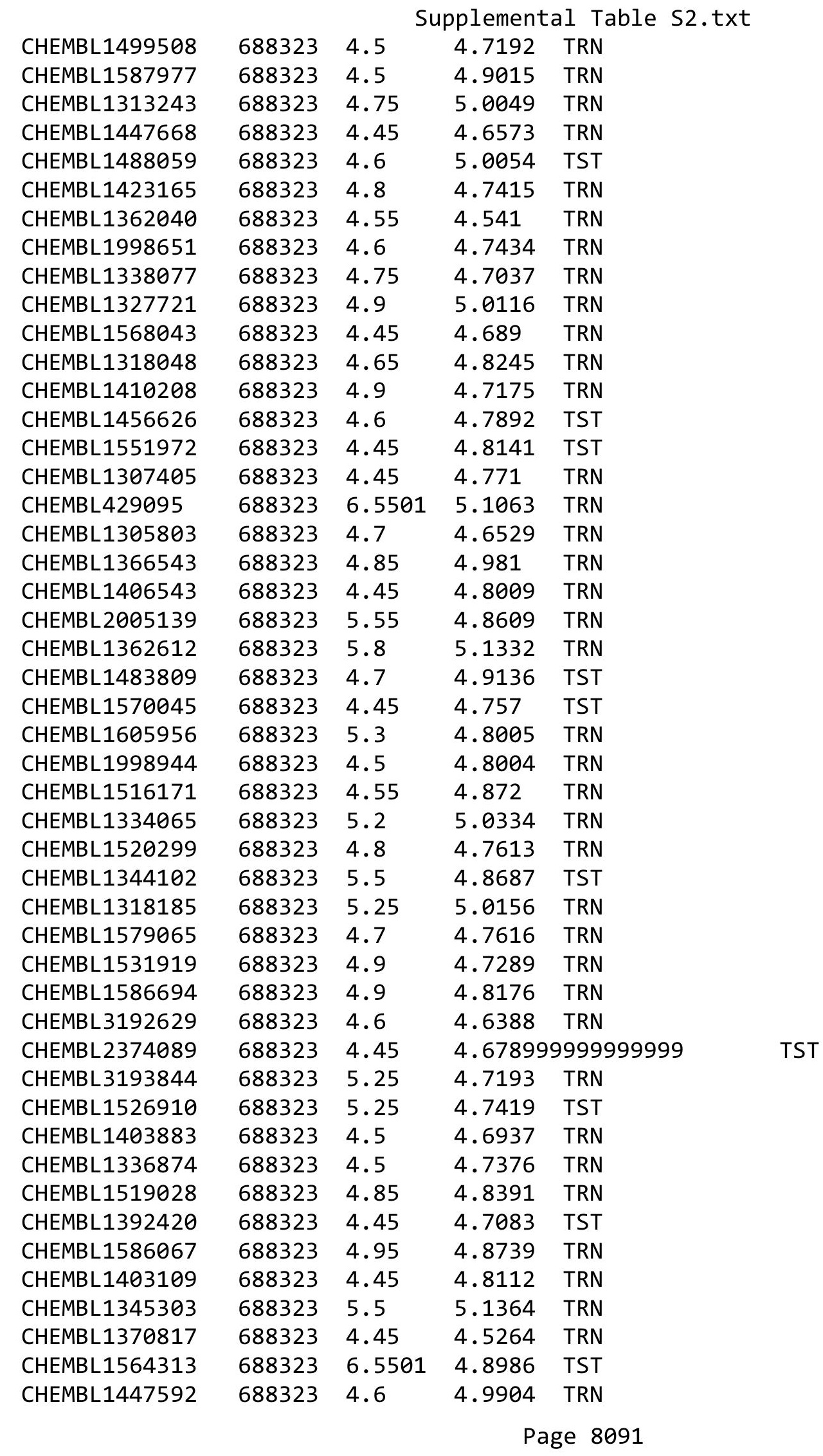




\begin{tabular}{|c|c|c|c|c|}
\hline \multicolumn{5}{|c|}{ Supplemental Table S2.txt } \\
\hline CHEMBL1599578 & 688323 & 4.7 & 4.6426 & TRN \\
\hline CHEMBL1474984 & 688323 & 4.9 & 4.823 & TRN \\
\hline CHEMBL2005434 & 688323 & 4.45 & 4.6857 & TST \\
\hline CHEMBL1352402 & 688323 & 4.6 & 5.0345 & TRN \\
\hline CHEMBL1559292 & 688323 & 4.5 & 4.666 & TRN \\
\hline CHEMBL1367309 & 688323 & 4.45 & 4.7019 & TRN \\
\hline CHEMBL 250711 & 688323 & 6.0 & 5.0471 & TRN \\
\hline CHEMBL1448406 & 688323 & 4.45 & 4.5491 & TRN \\
\hline CHEMBL1504590 & 688323 & 4.45 & 4.9919 & TRN \\
\hline CHEMBL1444573 & 688323 & 5.9 & 4.8993 & TRN \\
\hline CHEMBL1965254 & 688323 & 4.5 & 4.7776 & TRN \\
\hline CHEMBL1491566 & 688323 & 5.6 & 5.3346 & TRN \\
\hline CHEMBL1411208 & 688323 & 4.45 & 4.8328 & TRN \\
\hline CHEMBL1980226 & 688323 & 4.5 & 4.7395 & TRN \\
\hline CHEMBL1967081 & 688323 & 4.5 & 4.6515 & TRN \\
\hline CHEMBL1369885 & 688323 & 4.45 & 4.8149 & TRN \\
\hline CHEMBL1506364 & 688323 & 4.8 & 4.815 & TRN \\
\hline CHEMBL1546847 & 688323 & 4.75 & 4.792 & TRN \\
\hline CHEMBL1571368 & 688323 & 6.0 & 5.1395 & TRN \\
\hline CHEMBL1534756 & 688323 & 4.45 & 4.631 & TST \\
\hline CHEMBL1543673 & 688323 & 5.0 & 4.8737 & TRN \\
\hline CHEMBL1486218 & 688323 & 5.0 & 4.3674 & TRN \\
\hline CHEMBL1385531 & 688323 & 4.5 & 4.8598 & TRN \\
\hline CHEMBL1532054 & 688323 & 4.5 & 4.6394 & TRN \\
\hline CHEMBL1416300 & 688323 & 4.45 & 4.6351 & TRN \\
\hline CHEMBL1534297 & 688323 & 5.35 & 4.9524 & TRN \\
\hline CHEMBL1475048 & 688323 & 4.45 & 4.8659 & TST \\
\hline CHEMBL1374511 & 688323 & 4.65 & 4.694 & TRN \\
\hline CHEMBL1530638 & 688323 & 4.45 & 4.8392 & TST \\
\hline CHEMBL1329552 & 688323 & 4.5 & 4.8187 & TRN \\
\hline CHEMBL1423597 & 688323 & 5.25 & 4.9349 & TRN \\
\hline CHEMBL1350353 & 688323 & 4.55 & 4.9289 & TRN \\
\hline CHEMBL1332893 & 688323 & 4.6 & 4.6483 & TRN \\
\hline CHEMBL1532267 & 688323 & 5.2 & 5.1521 & TRN \\
\hline CHEMBL1543729 & 688323 & 4.45 & 4.7779 & TST \\
\hline CHEMBL167542 & 688323 & 4.8 & 4.8366 & TRN \\
\hline CHEMBL1378402 & 688323 & 4.45 & 4.5907 & TRN \\
\hline CHEMBL1519411 & 688323 & 4.75 & 4.9411 & TRN \\
\hline CHEMBL585071 & 688323 & 5.2 & 5.0039 & TRN \\
\hline CHEMBL1359702 & 688323 & 4.45 & 4.9979 & TST \\
\hline CHEMBL1470700 & 688323 & 6.8 & 5.1668 & TRN \\
\hline CHEMBL1474689 & 688323 & 5.2 & 4.9416 & TRN \\
\hline CHEMBL1562092 & 688323 & 4.55 & 4.7955 & TRN \\
\hline CHEMBL1496866 & 688323 & 4.65 & 4.7283 & TRN \\
\hline CHEMBL1310114 & 688323 & 4.8 & 4.9571 & TST \\
\hline CHEMBL1317114 & 688323 & 4.95 & 4.8398 & TRN \\
\hline CHEMBL1569124 & 688323 & 6.2 & 4.9275 & TRN \\
\hline CHEMBL1522995 & 688323 & 4.45 & 4.8385 & TST \\
\hline
\end{tabular}




\begin{tabular}{|c|c|c|c|c|}
\hline & & & pplement & al $\mathrm{Tc}$ \\
\hline CHEMBL1459294 & 688323 & 4.45 & 4.9389 & TST \\
\hline CHEMBL1610587 & 688323 & 4.55 & 4.9207 & TST \\
\hline CHEMBL1996555 & 688323 & 6.9 & 4.742 & TST \\
\hline CHEMBL1486081 & 688323 & 5.55 & 5.1494 & TST \\
\hline CHEMBL1314513 & 688323 & 5.15 & 4.7001 & TRN \\
\hline CHEMBL1586002 & 688323 & 7.0 & 4.8991 & TRN \\
\hline CHEMBL1436870 & 688323 & 4.55 & 4.6504 & TRN \\
\hline CHEMBL1484642 & 688323 & 4.5 & 4.6194 & TRN \\
\hline CHEMBL1458674 & 688323 & 4.8 & 4.9542 & TRN \\
\hline CHEMBL1589888 & 688323 & 4.9 & 4.8435 & TRN \\
\hline CHEMBL1330307 & 688323 & 5.45 & 5.0933 & TRN \\
\hline CHEMBL1519752 & 688323 & 4.5 & 4.5209 & TRN \\
\hline CHEMBL1334968 & 688323 & 4.5 & 4.7397 & TRN \\
\hline CHEMBL1435321 & 688323 & 5.4 & 4.9424 & TRN \\
\hline CHEMBL1527174 & 688323 & 6.05 & 4.8885 & TST \\
\hline CHEMBL1314081 & 688323 & 4.45 & 4.9694 & TRN \\
\hline CHEMBL1485995 & 688323 & 4.7 & 4.8191 & TRN \\
\hline CHEMBL1418235 & 688323 & 4.5 & 4.6187 & TRN \\
\hline CHEMBL1430601 & 688323 & 5.2 & 4.8913 & TST \\
\hline CHEMBL3192825 & 688323 & 4.5 & 4.9809 & TRN \\
\hline CHEMBL1609369 & 688323 & 5.4 & 5.0362 & TST \\
\hline CHEMBL1330139 & 688323 & 4.5 & 4.7134 & TST \\
\hline CHEMBL1594230 & 688323 & 4.95 & 4.6193 & TST \\
\hline CHEMBL1591711 & 688323 & 4.7 & 4.8978 & TRN \\
\hline CHEMBL1522505 & 688323 & 6.2 & 4.79 & TRN \\
\hline CHEMBL1496203 & 688323 & 4.85 & 4.6958 & TRN \\
\hline CHEMBL1301692 & 688323 & 4.45 & 4.877 & TRN \\
\hline CHEMBL1338262 & 688323 & 4.7 & 4.8082 & TST \\
\hline CHEMBL1511743 & 688323 & 4.5 & 4.7437 & TRN \\
\hline CHEMBL1591396 & 688323 & 4.6 & 4.8414 & TRN \\
\hline CHEMBL1367776 & 688323 & 5.0 & 4.8413 & TRN \\
\hline CHEMBL3196168 & 688323 & 4.45 & 4.7209 & TRN \\
\hline CHEMBL3210198 & 688323 & 4.5 & 4.9985 & TRN \\
\hline CHEMBL1419909 & 688323 & 5.45 & 4.8736 & TRN \\
\hline CHEMBL3145205 & 688323 & 4.5 & 4.8045 & TRN \\
\hline CHEMBL1405006 & 688323 & 4.9 & 4.8626 & TRN \\
\hline CHEMBL1369988 & 688323 & 4.9 & 4.8475 & TRN \\
\hline CHEMBL1572542 & 688323 & 4.6 & 4.8395 & TST \\
\hline CHEMBL1462570 & 688323 & 4.45 & 4.7736 & TST \\
\hline CHEMBL1399879 & 688323 & 4.5 & 4.7388 & TRN \\
\hline CHEMBL1412970 & 688323 & 4.9 & 4.9193 & TRN \\
\hline CHEMBL1359782 & 688323 & 4.6 & 4.5877 & TRN \\
\hline CHEMBL1470464 & 688323 & 4.5 & 4.785 & TRN \\
\hline CHEMBL3196901 & 688323 & 4.45 & 4.7893 & TRN \\
\hline CHEMBL1498190 & 688323 & 4.75 & 4.9087 & TST \\
\hline CHEMBL1436671 & 688323 & 4.55 & 4.7493 & TST \\
\hline CHEMBL1477007 & 688323 & 4.6 & 4.6865 & TRN \\
\hline CHEMBL1405432 & 688323 & 4.45 & 4.8593 & TRN \\
\hline
\end{tabular}




\begin{tabular}{|c|c|c|c|c|}
\hline & & & upplement & $T_{2}$ \\
\hline CHEMBL1386067 & 688323 & 5.4 & 4.9141 & TRN \\
\hline CHEMBL1386313 & 688323 & 4.6 & 4.9979 & TRN \\
\hline CHEMBL1470925 & 688323 & 4.6 & 4.8333 & TRN \\
\hline CHEMBL1498210 & 688323 & 5.85 & 5.0726 & TST \\
\hline CHEMBL1523175 & 688323 & 4.7 & 4.6902 & TRN \\
\hline CHEMBL1464837 & 688323 & 4.45 & 4.7633 & TRN \\
\hline CHEMBL1477038 & 688323 & 6.25 & 5.1355 & TRN \\
\hline CHEMBL1324111 & 688323 & 4.5 & 4.6745 & TST \\
\hline CHEMBL1340089 & 688323 & 5.15 & 4.7337 & TRN \\
\hline CHEMBL1503442 & 688323 & 4.65 & 4.7148 & TRN \\
\hline CHEMBL1465431 & 688323 & 4.95 & 5.0258 & TRN \\
\hline CHEMBL1534485 & 688323 & 4.45 & 4.8099 & TST \\
\hline CHEMBL1339385 & 688323 & 4.5 & 4.6007 & TRN \\
\hline CHEMBL1492455 & 688323 & 4.55 & 4.5854 & TRN \\
\hline CHEMBL1392595 & 688323 & 4.9 & 4.9333 & TRN \\
\hline CHEMBL1596100 & 688323 & 4.8 & 4.7513 & TRN \\
\hline CHEMBL1461533 & 688323 & 4.7 & 4.9838 & TRN \\
\hline CHEMBL1346981 & 688323 & 4.5 & 4.8838 & TST \\
\hline CHEMBL1378197 & 688323 & 4.6 & 4.9098 & TRN \\
\hline CHEMBL1405206 & 688323 & 4.6 & 4.7207 & TRN \\
\hline CHEMBL1511040 & 688323 & 4.8 & 4.7805 & TRN \\
\hline CHEMBL1377632 & 688323 & 4.6 & 4.5911 & TRN \\
\hline CHEMBL1396603 & 688323 & 4.95 & 4.7142 & TRN \\
\hline CHEMBL6291 & 688323 & 5.45 & 4.7866 & TST \\
\hline CHEMBL1303737 & 688323 & 4.95 & 4.8275 & TRN \\
\hline CHEMBL1467760 & 688323 & 5.5 & 4.8579 & TRN \\
\hline CHEMBL1323883 & 688323 & 5.05 & 4.993 & TST \\
\hline CHEMBL1370242 & 688323 & 4.45 & 4.7456 & TRN \\
\hline CHEMBL1400877 & 688323 & 4.45 & 4.9538 & TST \\
\hline CHEMBL1493396 & 688323 & 4.55 & 4.6826 & TRN \\
\hline CHEMBL1471328 & 688323 & 4.85 & 5.021 & TRN \\
\hline CHEMBL1483471 & 688323 & 5.6 & 4.9411 & TRN \\
\hline CHEMBL1448150 & 688323 & 4.5 & 4.8553 & TRN \\
\hline CHEMBL1359753 & 688323 & 4.45 & 4.9117 & TRN \\
\hline CHEMBL3198298 & 688323 & 4.95 & 4.7235 & TRN \\
\hline CHEMBL1990694 & 688323 & 5.35 & 4.8895 & TST \\
\hline CHEMBL 1607585 & 688323 & 4.7 & 4.9392 & TRN \\
\hline CHEMBL1464662 & 688323 & 4.5 & 4.757 & TRN \\
\hline CHEMBL3208258 & 688323 & 4.75 & 4.7842 & TRN \\
\hline CHEMBL1549083 & 688323 & 4.45 & 5.0641 & TRN \\
\hline CHEMBL1308802 & 688323 & 5.3 & 4.9507 & TST \\
\hline CHEMBL1459841 & 688323 & 5.0 & 4.8236 & TRN \\
\hline CHEMBL1376622 & 688323 & 4.7 & 4.8483 & TRN \\
\hline CHEMBL1366424 & 688323 & 4.75 & 4.9095 & TRN \\
\hline CHEMBL1521428 & 688323 & 4.95 & 4.3543 & TRN \\
\hline CHEMBL1606751 & 688323 & 4.7 & 4.8858 & TST \\
\hline CHEMBL1593142 & 688323 & 5.95 & 4.8717 & TRN \\
\hline CHEMBL3145330 & 688323 & 4.45 & 4.7134 & TRN \\
\hline
\end{tabular}




\begin{tabular}{|c|c|c|c|c|}
\hline \multicolumn{5}{|c|}{ Supplemental Table S2.txt } \\
\hline CHEMBL1354097 & 688323 & 4.8 & 4.6258 & TRN \\
\hline CHEMBL 1454848 & 688323 & 5.25 & 4.8858 & TRN \\
\hline CHEMBL1423369 & 688323 & 4.6 & 4.9228 & TRN \\
\hline CHEMBL1453970 & 688323 & 4.45 & 4.8914 & TRN \\
\hline CHEMBL1422579 & 688323 & 4.5 & 4.5414 & TRN \\
\hline CHEMBL1476806 & 688323 & 4.45 & 5.0448 & TRN \\
\hline CHEMBL1317643 & 688323 & 5.05 & 5.0236 & TRN \\
\hline CHEMBL1481579 & 688323 & 6.9 & 5.0928 & TRN \\
\hline CHEMBL1518447 & 688323 & 4.75 & 4.8281 & TST \\
\hline CHEMBL1472131 & 688323 & 5.5 & 5.0356 & TRN \\
\hline CHEMBL1526763 & 688323 & 4.45 & 4.833 & TRN \\
\hline CHEMBL1505696 & 688323 & 4.9 & 4.9103 & TRN \\
\hline CHEMBL1321734 & 688323 & 5.55 & 4.9511 & TST \\
\hline CHEMBL1401159 & 688323 & 6.0 & 4.8833 & TST \\
\hline CHEMBL1436531 & 688323 & 4.75 & 4.5467 & TRN \\
\hline CHEMBL1454636 & 688323 & 4.45 & 4.6504 & TRN \\
\hline CHEMBL1366964 & 688323 & 4.75 & 4.8318 & TST \\
\hline CHEMBL1555644 & 688323 & 4.8 & 4.8478 & TRN \\
\hline CHEMBL1314402 & 688323 & 5.05 & 4.8283 & TRN \\
\hline CHEMBL1551796 & 688323 & 7.1002 & 5.0948 & TRN \\
\hline CHEMBL1320074 & 688323 & 4.5 & 4.7267 & TRN \\
\hline CHEMBL1570631 & 688323 & 5.55 & 5.0452 & TRN \\
\hline CHEMBL1491222 & 688323 & 5.25 & 5.1605 & TRN \\
\hline CHEMBL1358861 & 688323 & 4.45 & 4.7381 & TRN \\
\hline CHEMBL43612 & 688323 & 4.6 & 4.8785 & TRN \\
\hline CHEMBL1377333 & 688323 & 4.55 & 4.8445 & TRN \\
\hline CHEMBL1361319 & 688323 & 5.35 & 5.2454 & TRN \\
\hline CHEMBL1501342 & 688323 & 5.2 & 5.0047 & TST \\
\hline CHEMBL1329597 & 688323 & 4.55 & 4.9042 & TRN \\
\hline CHEMBL1385145 & 688323 & 4.5 & 4.7846 & TRN \\
\hline CHEMBL2373615 & 688323 & 5.25 & 4.746 & TST \\
\hline CHEMBL576932 & 688323 & 5.0 & 4.6603 & TRN \\
\hline CHEMBL1313396 & 688323 & 5.2 & 4.9228 & TRN \\
\hline CHEMBL1315367 & 688323 & 4.75 & 4.5963 & TRN \\
\hline CHEMBL1543585 & 688323 & 4.95 & 4.6916 & TST \\
\hline CHEMBL1354930 & 688323 & 4.45 & 4.5755 & TRN \\
\hline CHEMBL1398673 & 688323 & 4.6 & 4.9609 & TRN \\
\hline CHEMBL1503639 & 688323 & 4.45 & 4.7872 & TRN \\
\hline CHEMBL1501506 & 688323 & 4.65 & 4.8622 & TST \\
\hline CHEMBL1599294 & 688323 & 4.45 & 4.7487 & TRN \\
\hline CHEMBL1318620 & 688323 & 4.9 & 4.9757 & TRN \\
\hline CHEMBL3192235 & 688323 & 4.75 & 4.8599 & TRN \\
\hline CHEMBL1588660 & 688323 & 4.65 & 4.4755 & TRN \\
\hline CHEMBL1084441 & 688323 & 4.5 & 4.824 & TRN \\
\hline CHEMBL1611417 & 688323 & 4.45 & 4.6396 & TST \\
\hline CHEMBL1478490 & 688323 & 4.5 & 4.5633 & TRN \\
\hline CHEMBL1596294 & 688323 & 4.45 & 4.5256 & TRN \\
\hline CHEMBL1544036 & 688323 & 4.45 & 4.6348 & TRN \\
\hline
\end{tabular}




\begin{tabular}{|c|c|c|c|c|}
\hline \multicolumn{5}{|c|}{ Supplemental Table S2.txt } \\
\hline CHEMBL1356994 & 688323 & 4.6 & 4.8763 & TRN \\
\hline CHEMBL1499679 & 688323 & 4.6 & 4.7289 & TRN \\
\hline CHEMBL1323410 & 688323 & 4.55 & 4.7645 & TRN \\
\hline CHEMBL1514486 & 688323 & 4.5 & 4.8781 & TST \\
\hline CHEMBL1596219 & 688323 & 5.2 & 4.7363 & TRN \\
\hline CHEMBL3197433 & 688323 & 5.6 & 4.6947 & TRN \\
\hline CHEMBL1559053 & 688323 & 7.0501 & 5.0423 & TRN \\
\hline CHEMBL1599946 & 688323 & 6.9 & 5.0638 & TRN \\
\hline CHEMBL1339651 & 688323 & 4.7 & 4.8915 & TST \\
\hline CHEMBL1551720 & 688323 & 4.9 & 4.8807 & TRN \\
\hline CHEMBL1562035 & 688323 & 4.45 & 4.4619 & TRN \\
\hline CHEMBL1972298 & 688323 & 4.5 & 4.6871 & TRN \\
\hline CHEMBL1464945 & 688323 & 4.45 & 4.84 & TRN \\
\hline CHEMBL1517629 & 688323 & 4.7 & 4.8064 & TRN \\
\hline CHEMBL1419815 & 688323 & 4.45 & 5.0327 & TRN \\
\hline CHEMBL1561819 & 688323 & 4.65 & 4.6081 & TRN \\
\hline CHEMBL 380979 & 688323 & 5.95 & 4.9956 & TRN \\
\hline CHEMBL1452421 & 688323 & 5.45 & 5.1763 & TRN \\
\hline CHEMBL3212315 & 688323 & 4.85 & 4.7799 & TRN \\
\hline CHEMBL3210668 & 688323 & 4.5 & 4.6823 & TST \\
\hline CHEMBL1417620 & 688323 & 5.25 & 4.9851 & TRN \\
\hline CHEMBL1520545 & 688323 & 4.6 & 4.7663 & TST \\
\hline CHEMBL1558070 & 688323 & 5.4 & 4.8546 & TRN \\
\hline CHEMBL1501305 & 688323 & 4.5 & 4.8365 & TRN \\
\hline CHEMBL1493604 & 688323 & 4.45 & 4.7346 & TRN \\
\hline CHEMBL1398884 & 688323 & 4.45 & 4.7959 & TRN \\
\hline CHEMBL1405721 & 688323 & 4.45 & 4.7808 & TRN \\
\hline CHEMBL1506622 & 688323 & 4.45 & 4.4991 & TRN \\
\hline CHEMBL1517141 & 688323 & 5.25 & 5.0998 & TRN \\
\hline CHEMBL1419714 & 688323 & 4.95 & 4.9994 & TRN \\
\hline CHEMBL1493200 & 688323 & 4.45 & 5.0124 & TRN \\
\hline CHEMBL1347200 & 688323 & 4.5 & 4.8774 & TRN \\
\hline CHEMBL1502550 & 688323 & 4.5 & 4.7221 & TRN \\
\hline CHEMBL1576055 & 688323 & 4.6 & 4.8144 & TRN \\
\hline CHEMBL1501982 & 688323 & 4.6 & 4.8509 & TRN \\
\hline CHEMBL1601122 & 688323 & 4.5 & 4.7835 & TRN \\
\hline CHEMBL1395155 & 688323 & 4.8 & 4.8998 & TRN \\
\hline CHEMBL1399458 & 688323 & 5.0 & 4.6585 & TRN \\
\hline CHEMBL1522548 & 688323 & 4.45 & 4.7902 & TRN \\
\hline CHEMBL1526433 & 688323 & 4.45 & 4.7071 & TRN \\
\hline CHEMBL1303807 & 688323 & 5.15 & 4.9251 & TRN \\
\hline CHEMBL3198576 & 688323 & 4.55 & 4.9545 & TRN \\
\hline CHEMBL1542569 & 688323 & 5.2 & 4.9141 & TRN \\
\hline CHEMBL1478571 & 688323 & 4.5 & 4.7675 & TRN \\
\hline CHEMBL1381873 & 688323 & 4.95 & 4.7115 & TRN \\
\hline CHEMBL1377316 & 688323 & 4.5 & 4.9538 & TRN \\
\hline CHEMBL1558458 & 688323 & 4.5 & 4.7485 & TRN \\
\hline CHEMBL1517271 & 688323 & 6.9 & 4.8829 & TRN \\
\hline
\end{tabular}




\begin{tabular}{|c|c|c|c|c|c|}
\hline \multicolumn{6}{|c|}{ Supplemental Table S2.txt } \\
\hline CHEMBL1464096 & 688323 & 4.45 & 4.7727 & TRN & \\
\hline CHEMBL1541141 & 688323 & 5.0 & 4.6773 & TRN & \\
\hline CHEMBL1602274 & 688323 & 5.0 & 4.6792 & TRN & \\
\hline CHEMBL1474324 & 688323 & 4.45 & 4.8506 & TRN & \\
\hline CHEMBL1525787 & 688323 & 4.9 & 4.8931 & TRN & \\
\hline CHEMBL1397562 & 688323 & 4.45 & 4.6572 & TRN & \\
\hline CHEMBL1474699 & 688323 & 4.45 & 4.8246 & TRN & \\
\hline CHEMBL1422188 & 688323 & 5.4 & 4.8614 & TRN & \\
\hline CHEMBL1593320 & 688323 & 5.7 & 5.215 & TRN & \\
\hline CHEMBL1987427 & 688323 & 4.45 & 4.57600 & 00000000005 & TRN \\
\hline CHEMBL1964868 & 688323 & 4.55 & 4.7909 & TST & \\
\hline CHEMBL1502800 & 688323 & 4.75 & 4.7549 & TRN & \\
\hline CHEMBL1453071 & 688323 & 4.55 & 4.6261 & TRN & \\
\hline CHEMBL1493578 & 688323 & 4.5 & 4.7074 & TRN & \\
\hline CHEMBL1344331 & 688323 & 4.45 & 4.9009 & TST & \\
\hline CHEMBL1586326 & 688323 & 4.5 & 4.6592 & TST & \\
\hline CHEMBL1487639 & 688323 & 5.05 & 5.0306 & TRN & \\
\hline CHEMBL1404959 & 688323 & 4.85 & 4.8676 & TRN & \\
\hline CHEMBL1518450 & 688323 & 5.25 & 4.7587 & TRN & \\
\hline CHEMBL1602160 & 688323 & 6.0 & 5.0557 & TRN & \\
\hline CHEMBL1600017 & 688323 & 4.45 & 4.6035 & TRN & \\
\hline CHEMBL1312723 & 688323 & 4.5 & 4.9344 & TRN & \\
\hline CHEMBL1611935 & 688323 & 4.45 & 4.8023 & TRN & \\
\hline CHEMBL1315967 & 688323 & 5.5 & 4.9674 & TST & \\
\hline CHEMBL456817 & 688323 & 4.5 & 5.0272 & TRN & \\
\hline CHEMBL1422285 & 688323 & 4.8 & 4.6762 & TRN & \\
\hline CHEMBL1572850 & 688323 & 4.45 & 4.8157 & TRN & \\
\hline CHEMBL1474917 & 688323 & 4.45 & 4.9107 & TRN & \\
\hline CHEMBL1300675 & 688323 & 4.65 & 4.8831 & TRN & \\
\hline CHEMBL1576361 & 688323 & 4.5 & 4.8365 & TRN & \\
\hline CHEMBL1479350 & 688323 & 4.75 & 4.8459 & TRN & \\
\hline CHEMBL1313925 & 688323 & 4.5 & 5.0073 & TRN & \\
\hline CHEMBL1308386 & 688323 & 4.65 & 4.7137 & TRN & \\
\hline CHEMBL1331702 & 688323 & 4.6 & 4.6632 & TRN & \\
\hline CHEMBL1594785 & 688323 & 4.85 & 4.6284 & TRN & \\
\hline CHEMBL1474426 & 688323 & 4.45 & 4.6648 & TRN & \\
\hline CHEMBL 1386577 & 688323 & 4.5 & 4.8773 & TRN & \\
\hline CHEMBL1324957 & 688323 & 4.6 & 4.5253 & TRN & \\
\hline CHEMBL1402010 & 688323 & 4.55 & 4.7507 & TST & \\
\hline CHEMBL1520131 & 688323 & 5.5 & 5.0287 & TRN & \\
\hline CHEMBL1555146 & 688323 & 4.45 & 4.6837 & TRN & \\
\hline CHEMBL1372659 & 688323 & 4.5 & 4.8895 & TRN & \\
\hline CHEMBL1486990 & 688323 & 4.45 & 4.8533 & TRN & \\
\hline CHEMBL1444351 & 688323 & 4.55 & 4.8313 & TRN & \\
\hline CHEMBL1514611 & 688323 & 4.45 & 4.6199 & TRN & \\
\hline CHEMBL1312331 & 688323 & 5.25 & 4.8027 & TRN & \\
\hline CHEMBL 1554330 & 688323 & 4.85 & 4.7204 & TRN & \\
\hline CHEMBL3208264 & 688323 & 4.6 & 4.8224 & TRN & \\
\hline
\end{tabular}




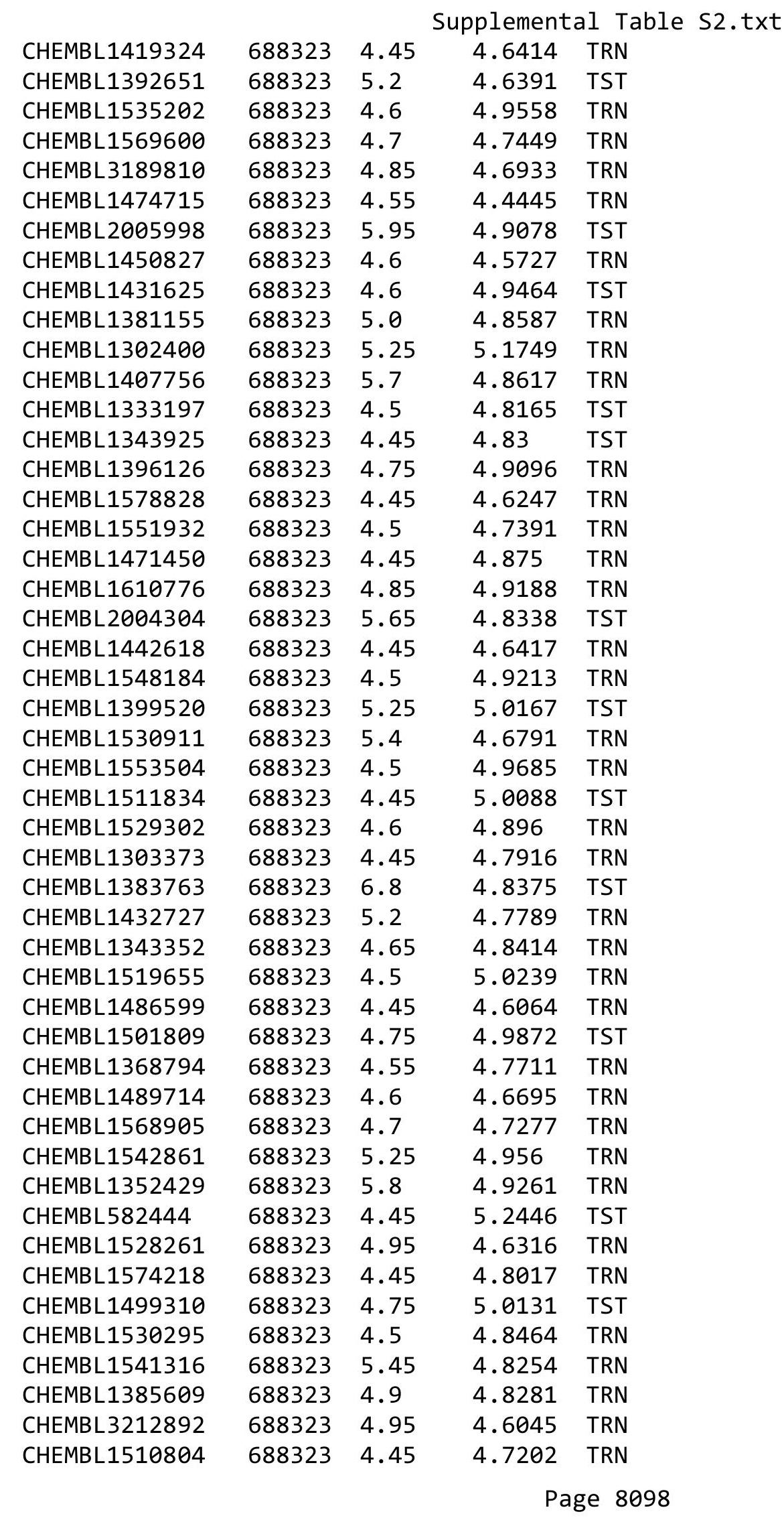




\begin{tabular}{|c|c|c|c|c|}
\hline \multicolumn{5}{|c|}{ Supplemental Table } \\
\hline CHEMBL1560522 & 688323 & 5.55 & 4.8115 & TRN \\
\hline CHEMBL1515779 & 688323 & 4.5 & 4.9303 & TRN \\
\hline CHEMBL1507425 & 688323 & 4.5 & 4.9114 & TRN \\
\hline CHEMBL1448323 & 688323 & 4.6 & 4.7638 & TRN \\
\hline CHEMBL1329917 & 688323 & 4.8 & 4.6654 & TRN \\
\hline CHEMBL1447402 & 688323 & 5.3 & 5.3218 & TRN \\
\hline CHEMBL1446020 & 688323 & 4.45 & 4.8408 & TRN \\
\hline CHEMBL1404752 & 688323 & 4.55 & 4.6468 & TRN \\
\hline CHEMBL1508058 & 688323 & 4.45 & 4.9496 & TRN \\
\hline CHEMBL1568038 & 688323 & 4.75 & 4.8139 & TRN \\
\hline CHEMBL1607314 & 688323 & 4.45 & 4.7942 & TRN \\
\hline CHEMBL1978330 & 688323 & 4.6 & 4.8194 & TRN \\
\hline CHEMBL1992382 & 688323 & 4.8 & 4.625 & TRN \\
\hline CHEMBL1508351 & 688323 & 4.5 & 4.8427 & TRN \\
\hline CHEMBL1488893 & 688323 & 5.2 & 4.6598 & TRN \\
\hline CHEMBL1361854 & 688323 & 4.45 & 4.7184 & TRN \\
\hline CHEMBL1547359 & 688323 & 4.45 & 4.8233 & TST \\
\hline CHEMBL1506182 & 688323 & 5.2 & 4.8616 & TRN \\
\hline CHEMBL 3211904 & 688323 & 4.6 & 4.6737 & TRN \\
\hline CHEMBL1357002 & 688323 & 4.45 & 4.9208 & TRN \\
\hline CHEMBL1510905 & 688323 & 4.5 & 4.9953 & TRN \\
\hline CHEMBL1360102 & 688323 & 4.7 & 4.7255 & TRN \\
\hline CHEMBL1407234 & 688323 & 4.5 & 4.7236 & TRN \\
\hline CHEMBL1455149 & 688323 & 4.65 & 4.956 & TRN \\
\hline CHEMBL3195767 & 688323 & 4.45 & 4.3571 & TRN \\
\hline CHEMBL1512481 & 688323 & 5.45 & 5.0218 & TRN \\
\hline CHEMBL1454084 & 688323 & 4.6 & 4.6688 & TRN \\
\hline CHEMBL1422117 & 688323 & 4.75 & 4.8291 & TRN \\
\hline CHEMBL1479867 & 688323 & 4.45 & 4.7732 & TRN \\
\hline CHEMBL1433520 & 688323 & 4.45 & 4.6722 & TRN \\
\hline CHEMBL1397875 & 688323 & 4.5 & 4.7464 & TRN \\
\hline CHEMBL1587389 & 688323 & 5.5 & 4.9432 & TST \\
\hline CHEMBL1313936 & 688323 & 4.5 & 4.9748 & TRN \\
\hline CHEMBL3192161 & 688323 & 4.8 & 4.7531 & TRN \\
\hline CHEMBL1549099 & 688323 & 5.4 & 4.8039 & TRN \\
\hline CHEMBL1453916 & 688323 & 4.7 & 4.6611 & TRN \\
\hline CHEMBL1599411 & 688323 & 4.45 & 4.8855 & TST \\
\hline CHEMBL1986425 & 688323 & 4.5 & 4.6457 & TRN \\
\hline CHEMBL1538540 & 688323 & 4.85 & 4.8561 & TRN \\
\hline CHEMBL1457472 & 688323 & 4.5 & 4.7325 & TRN \\
\hline CHEMBL1350978 & 688323 & 4.65 & 4.7478 & TST \\
\hline CHEMBL1331382 & 688323 & 5.0 & 4.7751 & TRN \\
\hline CHEMBL1560313 & 688323 & 4.8 & 4.7776 & TRN \\
\hline CHEMBL1601672 & 688323 & 4.7 & 4.7912 & TRN \\
\hline CHEMBL1591941 & 688323 & 4.85 & 4.7349 & TRN \\
\hline CHEMBL1557446 & 688323 & 4.8 & 4.6908 & TRN \\
\hline CHEMBL1348231 & 688323 & 4.5 & 4.9635 & TRN \\
\hline CHEMBL1412661 & 688323 & 5.05 & 4.8569 & TRN \\
\hline
\end{tabular}




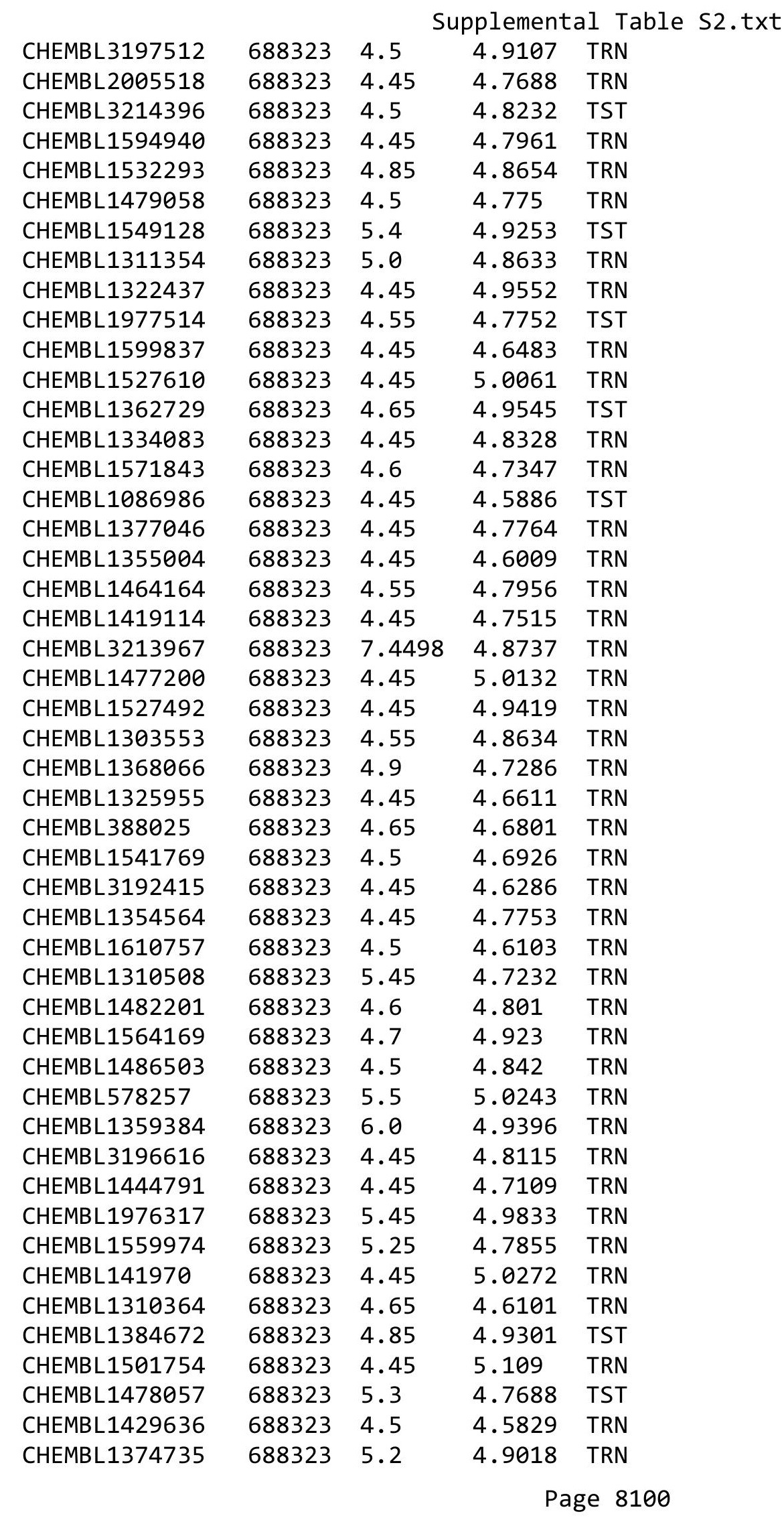




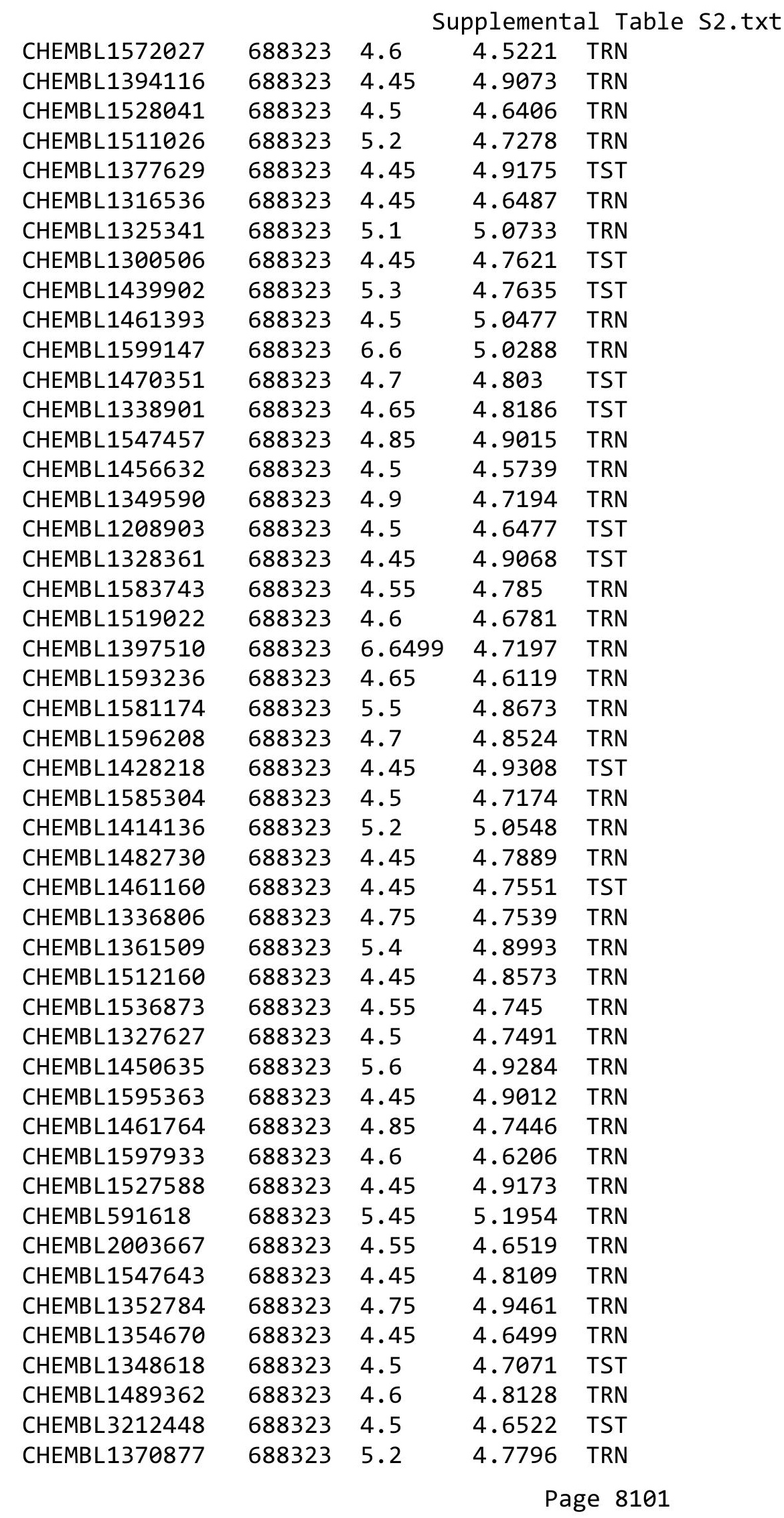




\begin{tabular}{|c|c|c|c|c|}
\hline \multicolumn{5}{|c|}{ Supplemental Table S2.txt } \\
\hline CHEMBL1373027 & 688323 & 7.0 & 4.8986 & TRN \\
\hline CHEMBL3195430 & 688323 & 4.45 & 4.766 & TRN \\
\hline CHEMBL1403519 & 688323 & 4.45 & 4.7418 & TRN \\
\hline CHEMBL1968326 & 688323 & 4.6 & 4.7928 & TRN \\
\hline CHEMBL2004361 & 688323 & 4.6 & 4.6623 & TRN \\
\hline CHEMBL1432276 & 688323 & 5.35 & 4.9286 & TRN \\
\hline CHEMBL1522485 & 688323 & 4.5 & 4.7595 & TRN \\
\hline CHEMBL1365396 & 688323 & 4.7 & 4.8842 & TRN \\
\hline CHEMBL1531103 & 688323 & 5.1 & 4.7978 & TRN \\
\hline CHEMBL1612672 & 688323 & 4.95 & 4.7451 & TRN \\
\hline CHEMBL466179 & 688323 & 4.5 & 4.7442 & TRN \\
\hline CHEMBL1499745 & 688323 & 5.5 & 5.0027 & TRN \\
\hline CHEMBL1405155 & 688323 & 4.45 & 4.5219 & TRN \\
\hline CHEMBL1543082 & 688323 & 4.45 & 4.5863 & TRN \\
\hline CHEMBL1388951 & 688323 & 4.5 & 4.8672 & TRN \\
\hline CHEMBL1356154 & 688323 & 4.5 & 4.8643 & TRN \\
\hline CHEMBL1316696 & 688323 & 4.5 & 4.6811 & TRN \\
\hline CHEMBL1510517 & 688323 & 5.2 & 4.9454 & TRN \\
\hline CHEMBL1388539 & 688323 & 5.15 & 4.9082 & TRN \\
\hline CHEMBL1392545 & 688323 & 4.55 & 4.955 & TRN \\
\hline CHEMBL1531677 & 688323 & 4.45 & 4.9888 & TRN \\
\hline CHEMBL3191517 & 688323 & 4.95 & 4.6921 & TRN \\
\hline CHEMBL1608719 & 688323 & 4.5 & 4.4879 & TRN \\
\hline CHEMBL1455701 & 688323 & 4.5 & 4.8634 & TRN \\
\hline CHEMBL1492116 & 688323 & 4.5 & 4.7763 & TRN \\
\hline CHEMBL1593658 & 688323 & 4.45 & 4.6996 & TRN \\
\hline CHEMBL1976308 & 688323 & 6.2 & 5.0081 & TRN \\
\hline CHEMBL1989294 & 688323 & 4.5 & 4.4008 & TRN \\
\hline CHEMBL1367373 & 688323 & 4.45 & 4.7424 & TRN \\
\hline CHEMBL1572325 & 688323 & 4.45 & 4.956 & TST \\
\hline CHEMBL1490506 & 688323 & 4.55 & 5.193 & TRN \\
\hline CHEMBL1997915 & 688323 & 4.5 & 4.8581 & TRN \\
\hline CHEMBL1498652 & 688323 & 5.1 & 4.8423 & TRN \\
\hline CHEMBL1398015 & 688323 & 4.45 & 4.6398 & TRN \\
\hline CHEMBL1362321 & 688323 & 7.0501 & 4.9157 & TRN \\
\hline CHEMBL1314100 & 688323 & 4.45 & 4.7684 & TRN \\
\hline CHEMBL453038 & 688323 & 4.5 & 4.8299 & TST \\
\hline CHEMBL1407277 & 688323 & 4.45 & 4.8265 & TRN \\
\hline CHEMBL1598836 & 688323 & 4.65 & 4.8263 & TRN \\
\hline CHEMBL1363728 & 688323 & 4.45 & 4.5994 & TRN \\
\hline CHEMBL1401397 & 688323 & 5.15 & 4.7726 & TRN \\
\hline CHEMBL1369513 & 688323 & 5.3 & 4.7987 & TRN \\
\hline CHEMBL1440178 & 688323 & 5.5 & 5.1553 & TRN \\
\hline CHEMBL1564250 & 688323 & 5.2 & 4.8579 & TRN \\
\hline CHEMBL1514512 & 688323 & 4.95 & 4.9028 & TST \\
\hline CHEMBL1537981 & 688323 & 4.75 & 4.8125 & TRN \\
\hline CHEMBL1515212 & 688323 & 4.9 & 4.8813 & TRN \\
\hline CHEMBL1427185 & 688323 & 5.45 & 5.0182 & TRN \\
\hline
\end{tabular}




\begin{tabular}{|c|c|c|c|c|}
\hline \multicolumn{5}{|c|}{ Supplemental Table S2.txt } \\
\hline CHEMBL 3198787 & 688323 & 4.85 & 4.9175 & TRN \\
\hline CHEMBL1541834 & 688323 & 5.4 & 5.0368 & TRN \\
\hline CHEMBL1969760 & 688323 & 4.5 & 4.7276 & TST \\
\hline CHEMBL1525152 & 688323 & 4.8 & 5.0136 & TRN \\
\hline CHEMBL1519184 & 688323 & 4.45 & 4.9578 & TRN \\
\hline CHEMBL1605719 & 688323 & 4.8 & 4.69 & TRN \\
\hline CHEMBL1567009 & 688323 & 4.45 & 4.9887 & TRN \\
\hline CHEMBL3391713 & 688323 & 4.75 & 4.7417 & TRN \\
\hline CHEMBL1445340 & 688323 & 4.6 & 4.8707 & TRN \\
\hline CHEMBL1575298 & 688323 & 5.2 & 4.8801 & TRN \\
\hline CHEMBL1342184 & 688323 & 4.85 & 4.8528 & TRN \\
\hline CHEMBL1548988 & 688323 & 4.5 & 4.8012 & TRN \\
\hline CHEMBL1397648 & 688323 & 4.45 & 4.6269 & TRN \\
\hline CHEMBL1432878 & 688323 & 4.85 & 5.0764 & TRN \\
\hline CHEMBL1521250 & 688323 & 4.5 & 4.7432 & TRN \\
\hline CHEMBL1374804 & 688323 & 4.6 & 4.6338 & TRN \\
\hline CHEMBL1592272 & 688323 & 4.45 & 4.5536 & TRN \\
\hline CHEMBL1603564 & 688323 & 4.8 & 4.7159 & TRN \\
\hline CHEMBL310578 & 688323 & 5.2 & 5.1958 & TST \\
\hline CHEMBL1569022 & 688323 & 4.55 & 4.9642 & TST \\
\hline CHEMBL1476793 & 688323 & 4.45 & 4.4135 & TRN \\
\hline CHEMBL1325458 & 688323 & 4.5 & 4.6288 & TST \\
\hline CHEMBL1434428 & 688323 & 4.45 & 4.6237 & TRN \\
\hline CHEMBL1580187 & 688323 & 4.45 & 4.9039 & TRN \\
\hline CHEMBL3213546 & 688323 & 4.75 & 4.7907 & TRN \\
\hline CHEMBL1439668 & 688323 & 4.9 & 4.5817 & TRN \\
\hline CHEMBL1452092 & 688323 & 4.45 & 4.7766 & TRN \\
\hline CHEMBL1520336 & 688323 & 4.5 & 4.9774 & TRN \\
\hline CHEMBL1393221 & 688323 & 4.45 & 4.794 & TRN \\
\hline CHEMBL3207685 & 688323 & 4.8 & 4.7379 & TRN \\
\hline CHEMBL1488079 & 688323 & 4.85 & 4.8903 & TRN \\
\hline CHEMBL1336663 & 688323 & 4.5 & 4.831 & TST \\
\hline CHEMBL1464986 & 688323 & 4.45 & 4.7154 & TRN \\
\hline CHEMBL1412184 & 688323 & 4.75 & 4.6865 & TRN \\
\hline CHEMBL1524147 & 688323 & 4.45 & 4.6407 & TRN \\
\hline CHEMBL1453386 & 688323 & 4.75 & 4.7271 & TRN \\
\hline CHEMBL1709970 & 688323 & 4.55 & 4.787 & TRN \\
\hline CHEMBL1580529 & 688323 & 4.5 & 4.7566 & TRN \\
\hline CHEMBL1591053 & 688323 & 4.45 & 4.7841 & TRN \\
\hline CHEMBL1481601 & 688323 & 5.3 & 4.89199 & 99999999995 \\
\hline CHEMBL1388377 & 688323 & 4.45 & 4.9618 & TRN \\
\hline CHEMBL1369276 & 688323 & 4.45 & 5.1183 & TRN \\
\hline CHEMBL1435611 & 688323 & 4.45 & 4.6509 & TRN \\
\hline CHEMBL1462919 & 688323 & 4.45 & 4.7946 & TST \\
\hline CHEMBL1319476 & 688323 & 4.6 & 4.8534 & TST \\
\hline CHEMBL1386467 & 688323 & 4.65 & 4.9765 & TRN \\
\hline CHEMBL1564721 & 688323 & 6.95 & 4.8353 & TRN \\
\hline CHEMBL1306011 & 688323 & 4.45 & 4.7429 & TRN \\
\hline
\end{tabular}

TRN 


\begin{tabular}{|c|c|c|c|c|}
\hline \multicolumn{5}{|c|}{ Supplemental Table S2.txt } \\
\hline CHEMBL1328950 & 688323 & 4.45 & 4.6324 & TRN \\
\hline CHEMBL1435951 & 688323 & 4.7 & 4.4136 & TRN \\
\hline CHEMBL1556102 & 688323 & 4.5 & 4.8255 & TRN \\
\hline CHEMBL1314783 & 688323 & 4.55 & 4.7083 & TRN \\
\hline CHEMBL1489068 & 688323 & 4.45 & 5.0126 & TRN \\
\hline CHEMBL1488681 & 688323 & 4.65 & 4.98 & TST \\
\hline CHEMBL1439111 & 688323 & 5.15 & 4.83 & TRN \\
\hline CHEMBL1530096 & 688323 & 4.5 & 4.8169 & TRN \\
\hline CHEMBL1550061 & 688323 & 5.45 & 4.8252 & TRN \\
\hline CHEMBL1425297 & 688323 & 4.5 & 4.9059 & TRN \\
\hline CHEMBL1446117 & 688323 & 5.75 & 5.0509 & TST \\
\hline CHEMBL1376678 & 688323 & 4.75 & 4.7856 & TRN \\
\hline CHEMBL1562894 & 688323 & 4.5 & 4.6822 & TRN \\
\hline CHEMBL1422144 & 688323 & 4.75 & 4.8455 & TRN \\
\hline CHEMBL1354748 & 688323 & 4.5 & 4.9367 & TRN \\
\hline CHEMBL1492639 & 688323 & 5.45 & 4.7202 & TRN \\
\hline CHEMBL2003886 & 688323 & 4.45 & 4.6114 & TRN \\
\hline CHEMBL1444103 & 688323 & 5.25 & 4.8614 & TST \\
\hline CHEMBL1452550 & 688323 & 4.45 & 4.5585 & TRN \\
\hline CHEMBL1416823 & 688323 & 4.9 & 4.7996 & TRN \\
\hline CHEMBL1472345 & 688323 & 4.6 & 4.8163 & TRN \\
\hline CHEMBL1361889 & 688323 & 4.5 & 4.7978 & TRN \\
\hline CHEMBL1493165 & 688323 & 4.45 & 5.1902 & TST \\
\hline CHEMBL1358727 & 688323 & 4.65 & 4.6048 & TRN \\
\hline CHEMBL1360784 & 688323 & 4.55 & 5.2548 & TRN \\
\hline CHEMBL1964776 & 688323 & 5.25 & 4.6761 & TRN \\
\hline CHEMBL1488885 & 688323 & 4.6 & 4.7895 & TRN \\
\hline CHEMBL1563482 & 688323 & 4.65 & 4.5904 & TRN \\
\hline CHEMBL1582394 & 688323 & 4.7 & 4.8208 & TST \\
\hline CHEMBL1303557 & 688323 & 4.8 & 5.0616 & TST \\
\hline CHEMBL1417406 & 688323 & 4.6 & 4.8006 & TRN \\
\hline CHEMBL1588194 & 688323 & 4.45 & 4.9319 & TRN \\
\hline CHEMBL1338805 & 688323 & 4.5 & 4.9413 & TRN \\
\hline CHEMBL128427 & 688323 & 4.5 & 4.8741 & TRN \\
\hline CHEMBL1583829 & 688323 & 4.7 & 4.8563 & TRN \\
\hline CHEMBL1356197 & 688323 & 4.5 & 4.8474 & TRN \\
\hline CHEMBL1531937 & 688323 & 4.5 & 4.6514 & TRN \\
\hline CHEMBL1502203 & 688323 & 4.45 & 4.7815 & TRN \\
\hline CHEMBL1496663 & 688323 & 4.45 & 4.874 & TRN \\
\hline CHEMBL1511294 & 688323 & 4.45 & 5.0884 & TRN \\
\hline CHEMBL2374044 & 688323 & 4.65 & 4.9568 & TST \\
\hline CHEMBL1461691 & 688323 & 5.0 & 4.9876 & TRN \\
\hline CHEMBL1428518 & 688323 & 4.45 & 5.1126 & TRN \\
\hline CHEMBL1535361 & 688323 & 4.45 & 4.9588 & TRN \\
\hline CHEMBL1299980 & 688323 & 4.5 & 4.7689 & TRN \\
\hline CHEMBL1604962 & 688323 & 5.0 & 4.9507 & TST \\
\hline CHEMBL1578299 & 688323 & 4.65 & 4.7437 & TRN \\
\hline CHEMBL1506234 & 688323 & 5.1 & 4.8559 & TRN \\
\hline
\end{tabular}




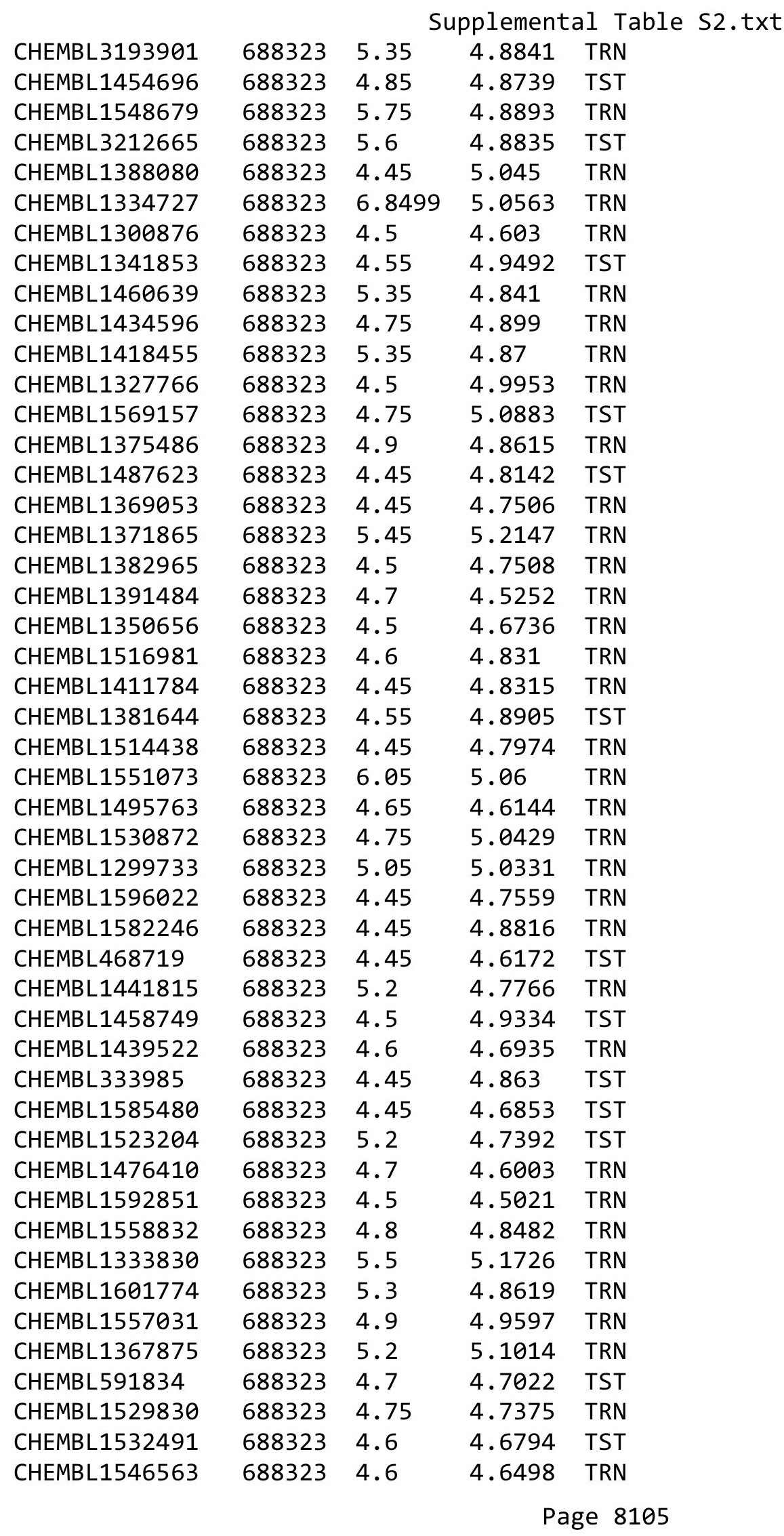




\begin{tabular}{|c|c|c|c|c|}
\hline \multicolumn{5}{|c|}{ Supplemental Table S2.txt } \\
\hline CHEMBL1340587 & 688323 & 4.45 & 4.651 & TRN \\
\hline CHEMBL3195537 & 688323 & 4.45 & 5.0878 & TRN \\
\hline CHEMBL1495072 & 688323 & 5.45 & 5.178 & TRN \\
\hline CHEMBL1397548 & 688323 & 5.2 & 4.7067 & TRN \\
\hline CHEMBL1441666 & 688323 & 4.7 & 4.577 & TRN \\
\hline CHEMBL1565125 & 688323 & 5.1 & 4.7573 & TST \\
\hline CHEMBL 3190277 & 688323 & 4.6 & 4.811 & TRN \\
\hline CHEMBL1305011 & 688323 & 4.6 & 4.9271 & TRN \\
\hline CHEMBL1502489 & 688323 & 5.25 & 4.9478 & TRN \\
\hline CHEMBL1553570 & 688323 & 4.45 & 4.773 & TRN \\
\hline CHEMBL1557835 & 688323 & 4.45 & 4.5604 & TRN \\
\hline CHEMBL1489471 & 688323 & 4.55 & 4.7326 & TST \\
\hline CHEMBL1561718 & 688323 & 4.5 & 4.9522 & TRN \\
\hline CHEMBL1415817 & 688323 & 4.45 & 4.8059 & TRN \\
\hline CHEMBL1524331 & 688323 & 4.45 & 4.7478 & TRN \\
\hline CHEMBL1996068 & 688323 & 4.5 & 4.6353 & TRN \\
\hline CHEMBL1424898 & 688323 & 4.45 & 4.8397 & TRN \\
\hline CHEMBL 2004505 & 688323 & 4.85 & 4.785 & TRN \\
\hline CHEMBL1482242 & 688323 & 4.65 & 4.7572 & TRN \\
\hline CHEMBL1496182 & 688323 & 4.5 & 4.9692 & TRN \\
\hline CHEMBL1545592 & 688323 & 4.5 & 4.9979 & TRN \\
\hline CHEMBL1552495 & 688323 & 4.6 & 4.7863 & TRN \\
\hline CHEMBL1347339 & 688323 & 4.45 & 4.882 & TRN \\
\hline CHEMBL285241 & 688323 & 4.45 & 4.7344 & TRN \\
\hline CHEMBL1516126 & 688323 & 4.95 & 4.5592 & TRN \\
\hline CHEMBL1541300 & 688323 & 4.45 & 4.9338 & TRN \\
\hline CHEMBL1532412 & 688323 & 4.9 & 5.0573 & TRN \\
\hline CHEMBL1370953 & 688323 & 4.45 & 4.9892 & TRN \\
\hline CHEMBL1612634 & 688323 & 4.9 & 5.0842 & TST \\
\hline CHEMBL1488787 & 688323 & 4.75 & 4.7155 & TRN \\
\hline CHEMBL1472956 & 688323 & 5.3 & 4.8941 & TRN \\
\hline CHEMBL1370515 & 688323 & 4.8 & 4.5111 & TRN \\
\hline CHEMBL1510343 & 688323 & 4.65 & 4.7672 & TRN \\
\hline CHEMBL1514781 & 688323 & 5.0 & 4.8696 & TRN \\
\hline CHEMBL1532794 & 688323 & 4.45 & 4.8215 & TST \\
\hline CHEMBL1333929 & 688323 & 4.45 & 4.7846 & TRN \\
\hline CHEMBL1489694 & 688323 & 4.45 & 4.6845 & TRN \\
\hline CHEMBL1517327 & 688323 & 4.45 & 4.7923 & TRN \\
\hline CHEMBL1438721 & 688323 & 4.6 & 4.834 & TST \\
\hline CHEMBL1530999 & 688323 & 4.5 & 4.6788 & TRN \\
\hline CHEMBL1387999 & 688323 & 5.25 & 4.8131 & TRN \\
\hline CHEMBL3212029 & 688323 & 4.65 & 4.8054 & TRN \\
\hline CHEMBL3193156 & 688323 & 4.45 & 4.9852 & TRN \\
\hline CHEMBL1535844 & 688323 & 4.45 & 5.2463 & TRN \\
\hline CHEMBL1539020 & 688323 & 4.6 & 4.8259 & TRN \\
\hline CHEMBL1584801 & 688323 & 4.45 & 4.6765 & TST \\
\hline CHEMBL1352543 & 688323 & 5.65 & 5.0599 & TRN \\
\hline CHEMBL3212699 & 688323 & 4.8 & 4.7071 & TRN \\
\hline
\end{tabular}




\begin{tabular}{|c|c|c|c|c|c|}
\hline \multicolumn{6}{|c|}{ Supplemental Table s2.txt } \\
\hline CHEMBL1587121 & 688323 & 5.5 & 4.8475 & TRN & \\
\hline CHEMBL1521691 & 688323 & 5.15 & 4.6352 & TRN & \\
\hline CHEMBL1413864 & 688323 & 5.15 & 4.7464 & TRN & \\
\hline CHEMBL1500296 & 688323 & 4.65 & 5.1121 & TRN & \\
\hline CHEMBL1511757 & 688323 & 4.7 & 4.8961 & TRN & \\
\hline CHEMBL1412943 & 688323 & 4.55 & 4.7592 & TRN & \\
\hline CHEMBL1530372 & 688323 & 4.45 & 4.71 & TRN & \\
\hline CHEMBL1433108 & 688323 & 4.6 & 4.6834 & TRN & \\
\hline CHEMBL1591213 & 688323 & 5.25 & 4.9014 & TRN & \\
\hline CHEMBL1515714 & 688323 & 5.2 & 5.06800 & 00000000005 & TRN \\
\hline CHEMBL1596730 & 688323 & 4.8 & 4.9687 & TST & \\
\hline CHEMBL1415277 & 688323 & 4.85 & 5.1111 & TST & \\
\hline CHEMBL1586677 & 688323 & 5.4 & 4.88899 & 9999999999 & TRN \\
\hline CHEMBL1452109 & 688323 & 6.9 & 4.8321 & TST & \\
\hline CHEMBL1446753 & 688323 & 4.8 & 4.8376 & TRN & \\
\hline CHEMBL1565771 & 688323 & 4.9 & 4.8875 & TRN & \\
\hline CHEMBL1420456 & 688323 & 4.6 & 4.6754 & TRN & \\
\hline CHEMBL1602261 & 688323 & 4.9 & 4.6939 & TRN & \\
\hline CHEMBL1393731 & 688323 & 4.45 & 4.5954 & TRN & \\
\hline CHEMBL1590476 & 688323 & 4.45 & 4.6285 & TRN & \\
\hline CHEMBL1399370 & 688323 & 4.7 & 4.8613 & TRN & \\
\hline CHEMBL1367239 & 688323 & 5.2 & 4.7596 & TRN & \\
\hline CHEMBL1082160 & 688323 & 5.55 & 4.7401 & TRN & \\
\hline CHEMBL 2002444 & 688323 & 4.45 & 4.8555 & TRN & \\
\hline CHEMBL1439239 & 688323 & 5.2 & 5.1064 & TRN & \\
\hline CHEMBL1399039 & 688323 & 4.6 & 4.6981 & TRN & \\
\hline CHEMBL1299567 & 688323 & 6.05 & 4.9707 & TRN & \\
\hline CHEMBL1457305 & 688323 & 4.6 & 4.7284 & TRN & \\
\hline CHEMBL1496222 & 688323 & 5.15 & 4.7205 & TRN & \\
\hline CHEMBL1349101 & 688323 & 4.5 & 4.8361 & TRN & \\
\hline CHEMBL1573031 & 688323 & 4.45 & 4.6565 & TRN & \\
\hline CHEMBL1354416 & 688323 & 5.55 & 4.9582 & TRN & \\
\hline CHEMBL1533351 & 688323 & 4.5 & 4.4516 & TRN & \\
\hline CHEMBL1474212 & 688323 & 4.5 & 4.9655 & TRN & \\
\hline CHEMBL455399 & 688323 & 4.45 & 4.9997 & TRN & \\
\hline CHEMBL1509266 & 688323 & 4.7 & 4.7595 & TRN & \\
\hline CHEMBL1464268 & 688323 & 4.45 & 5.0338 & TRN & \\
\hline CHEMBL1512059 & 688323 & 5.2 & 5.0223 & TRN & \\
\hline CHEMBL1514594 & 688323 & 4.9 & 4.8412 & TRN & \\
\hline CHEMBL1314707 & 688323 & 4.45 & 4.9938 & TRN & \\
\hline CHEMBL1364119 & 688323 & 4.85 & 5.0587 & TRN & \\
\hline CHEMBL1326813 & 688323 & 4.75 & 4.9079 & TRN & \\
\hline CHEMBL1534698 & 688323 & 4.5 & 4.7949 & TRN & \\
\hline CHEMBL1415510 & 688323 & 4.5 & 4.7955 & TRN & \\
\hline CHEMBL1607867 & 688323 & 4.95 & 4.9532 & TST & \\
\hline CHEMBL1462164 & 688323 & 4.45 & 4.7612 & TRN & \\
\hline CHEMBL1399534 & 688323 & 4.45 & 5.0439 & TRN & \\
\hline CHEMBL1549568 & 688323 & 5.2 & 4.8066 & TST & \\
\hline
\end{tabular}




\begin{tabular}{|c|c|c|c|c|c|}
\hline \multirow[b]{2}{*}{ CHEMBL1338705 } & \multicolumn{5}{|c|}{ Supplemental Table s2.txt } \\
\hline & 688323 & 4.45 & 4.987 & TRN & \\
\hline CHEMBL1440661 & 688323 & 4.6 & 4.7084 & TRN & \\
\hline CHEMBL1568373 & 688323 & 4.45 & 4.69600 & 0000000001 & TRN \\
\hline CHEMBL1394843 & 688323 & 4.45 & 4.7601 & TRN & \\
\hline CHEMBL1398615 & 688323 & 5.45 & 4.7987 & TRN & \\
\hline CHEMBL1387104 & 688323 & 4.5 & 4.7859 & TRN & \\
\hline CHEMBL3190432 & 688323 & 4.45 & 4.7376 & TRN & \\
\hline CHEMBL1597835 & 688323 & 4.8 & 4.9007 & TRN & \\
\hline CHEMBL1596431 & 688323 & 5.8 & 4.6826 & TRN & \\
\hline CHEMBL3194945 & 688323 & 5.0 & 4.7129 & TST & \\
\hline CHEMBL3189348 & 688323 & 4.6 & 4.8097 & TRN & \\
\hline CHEMBL 1457278 & 688323 & 4.7 & 4.6643 & TRN & \\
\hline CHEMBL1489365 & 688323 & 4.45 & 4.6003 & TST & \\
\hline CHEMBL1328564 & 688323 & 4.95 & 5.0439 & TST & \\
\hline CHEMBL1363219 & 688323 & 4.7 & 4.8169 & TRN & \\
\hline CHEMBL1540734 & 688323 & 5.95 & 5.0962 & TST & \\
\hline CHEMBL1335037 & 688323 & 4.5 & 4.5805 & TRN & \\
\hline CHEMBL1735171 & 688323 & 4.45 & 4.8797 & TRN & \\
\hline CHEMBL1255656 & 688323 & 4.5 & 4.9625 & TST & \\
\hline CHEMBL1529533 & 688323 & 4.65 & 4.7669 & TRN & \\
\hline CHEMBL1354466 & 688323 & 4.5 & 4.8959 & TRN & \\
\hline CHEMBL3214613 & 688323 & 4.8 & 4.7725 & TRN & \\
\hline CHEMBL1312315 & 688323 & 5.05 & 5.0363 & TRN & \\
\hline CHEMBL1597317 & 688323 & 4.85 & 4.5141 & TRN & \\
\hline CHEMBL1583552 & 688323 & 4.8 & 4.7362 & TRN & \\
\hline CHEMBL3194657 & 688323 & 4.9 & 4.5958 & TRN & \\
\hline CHEMBL1445981 & 688323 & 4.95 & 4.6236 & TRN & \\
\hline CHEMBL3211998 & 688323 & 5.15 & 4.9343 & TRN & \\
\hline CHEMBL1322923 & 688323 & 4.85 & 4.9771 & TRN & \\
\hline CHEMBL3189700 & 688323 & 4.45 & 4.6843 & TRN & \\
\hline CHEMBL1557655 & 688323 & 4.45 & 5.0067 & TST & \\
\hline CHEMBL1605750 & 688323 & 4.45 & 4.785 & TST & \\
\hline CHEMBL3193747 & 688323 & 4.45 & 4.8396 & TST & \\
\hline CHEMBL1510741 & 688323 & 4.55 & 4.8746 & TRN & \\
\hline CHEMBL1317889 & 688323 & 4.45 & 4.6354 & TRN & \\
\hline CHEMBL1394165 & 688323 & 4.75 & 4.3882 & TRN & \\
\hline CHEMBL1350179 & 688323 & 5.0 & 4.7995 & TRN & \\
\hline CHEMBL1539764 & 688323 & 5.2 & 4.7222 & TST & \\
\hline CHEMBL1357516 & 688323 & 7.8508 & 4.9616 & TRN & \\
\hline CHEMBL1440666 & 688323 & 4.9 & 4.7709 & TRN & \\
\hline CHEMBL1584343 & 688323 & 6.1 & 4.9444 & TRN & \\
\hline CHEMBL1584450 & 688323 & 4.5 & 4.756 & TRN & \\
\hline CHEMBL3209644 & 688323 & 4.5 & 4.61600 & 00000000005 & TRN \\
\hline CHEMBL1541149 & 688323 & 7.1002 & 4.9222 & TRN & \\
\hline CHEMBL1503057 & 688323 & 4.45 & 4.8093 & TRN & \\
\hline CHEMBL1521749 & 688323 & 5.2 & 4.7989 & TST & \\
\hline CHEMBL1451194 & 688323 & 4.6 & 4.8314 & TRN & \\
\hline CHEMBL1447011 & 688323 & 6.0 & 4.9021 & TRN & \\
\hline
\end{tabular}




\begin{tabular}{|c|c|c|c|c|c|}
\hline \multicolumn{6}{|c|}{ Supplemental Table S2.txt } \\
\hline CHEMBL1356792 & 688323 & 4.5 & 4.6185 & TRN & \\
\hline CHEMBL 1440025 & 688323 & 4.75 & 4.9796 & TRN & \\
\hline CHEMBL3212766 & 688323 & 5.1 & 4.8967 & TRN & \\
\hline CHEMBL1585764 & 688323 & 4.65 & 4.8205 & TRN & \\
\hline CHEMBL1592839 & 688323 & 4.45 & 4.5209 & TRN & \\
\hline CHEMBL1584752 & 688323 & 4.5 & 4.7989 & TRN & \\
\hline CHEMBL1416184 & 688323 & 5.35 & 4.9983 & TRN & \\
\hline CHEMBL1453545 & 688323 & 4.6 & 4.9127 & TRN & \\
\hline CHEMBL1548574 & 688323 & 4.7 & 5.0192 & TRN & \\
\hline CHEMBL1539132 & 688323 & 4.85 & 5.153 & TRN & \\
\hline CHEMBL1403798 & 688323 & 5.65 & 4.9491 & TRN & \\
\hline CHEMBL1997425 & 688323 & 4.5 & 4.7514 & TRN & \\
\hline CHEMBL1554783 & 688323 & 4.5 & 4.8931 & TRN & \\
\hline CHEMBL1513751 & 688323 & 4.85 & 4.8109 & TRN & \\
\hline CHEMBL1404476 & 688323 & 4.45 & 4.83899 & 99999999995 & TRN \\
\hline CHEMBL1376571 & 688323 & 4.55 & 4.8224 & TRN & \\
\hline CHEMBL1461649 & 688323 & 5.3 & 4.8837 & TRN & \\
\hline CHEMBL428496 & 688323 & 6.0 & 4.8064 & TST & \\
\hline CHEMBL584868 & 688323 & 4.45 & 4.8518 & TRN & \\
\hline CHEMBL1325470 & 688323 & 6.0 & 5.1151 & TST & \\
\hline CHEMBL1330070 & 688323 & 4.85 & 4.829 & TRN & \\
\hline CHEMBL1510332 & 688323 & 4.65 & 4.9056 & TRN & \\
\hline CHEMBL1517345 & 688323 & 4.5 & 5.1444 & TRN & \\
\hline CHEMBL1454358 & 688323 & 4.45 & 5.0373 & TRN & \\
\hline CHEMBL 2006615 & 688323 & 4.45 & 4.6154 & TRN & \\
\hline CHEMBL1312247 & 688323 & 5.4 & 4.7957 & TST & \\
\hline CHEMBL1533805 & 688323 & 5.5 & 4.9798 & TRN & \\
\hline CHEMBL1470412 & 688323 & 5.2 & 4.8086 & TRN & \\
\hline CHEMBL1473796 & 688323 & 5.35 & 4.9902 & TRN & \\
\hline CHEMBL1320236 & 688323 & 4.65 & 4.8053 & TRN & \\
\hline CHEMBL1477394 & 688323 & 6.9 & 5.183 & TRN & \\
\hline CHEMBL1353741 & 688323 & 4.65 & 4.8653 & TRN & \\
\hline CHEMBL1458253 & 688323 & 4.55 & 4.7195 & TRN & \\
\hline CHEMBL1528075 & 688323 & 4.45 & 4.7085 & TRN & \\
\hline CHEMBL1497732 & 688323 & 4.85 & 4.7639 & TRN & \\
\hline CHEMBL3192243 & 688323 & 4.45 & 4.747 & TRN & \\
\hline CHEMBL1607174 & 688323 & 4.7 & 4.6948 & TRN & \\
\hline CHEMBL1571238 & 688323 & 4.75 & 4.8716 & TRN & \\
\hline CHEMBL1529183 & 688323 & 4.5 & 4.8422 & TRN & \\
\hline CHEMBL1468368 & 688323 & 4.5 & 4.4988 & TRN & \\
\hline CHEMBL1362654 & 688323 & 4.5 & 4.6638 & TRN & \\
\hline CHEMBL1582024 & 688323 & 5.5 & 4.9077 & TRN & \\
\hline CHEMBL1445563 & 688323 & 4.65 & 4.8355 & TRN & \\
\hline CHEMBL1461976 & 688323 & 4.5 & 4.7893 & TRN & \\
\hline CHEMBL1302497 & 688323 & 5.4 & 5.0165 & TRN & \\
\hline CHEMBL1600380 & 688323 & 5.45 & 4.8783 & TRN & \\
\hline CHEMBL1515178 & 688323 & 4.8 & 4.6092 & TRN & \\
\hline CHEMBL1345877 & 688323 & 4.5 & 4.7144 & TST & \\
\hline
\end{tabular}




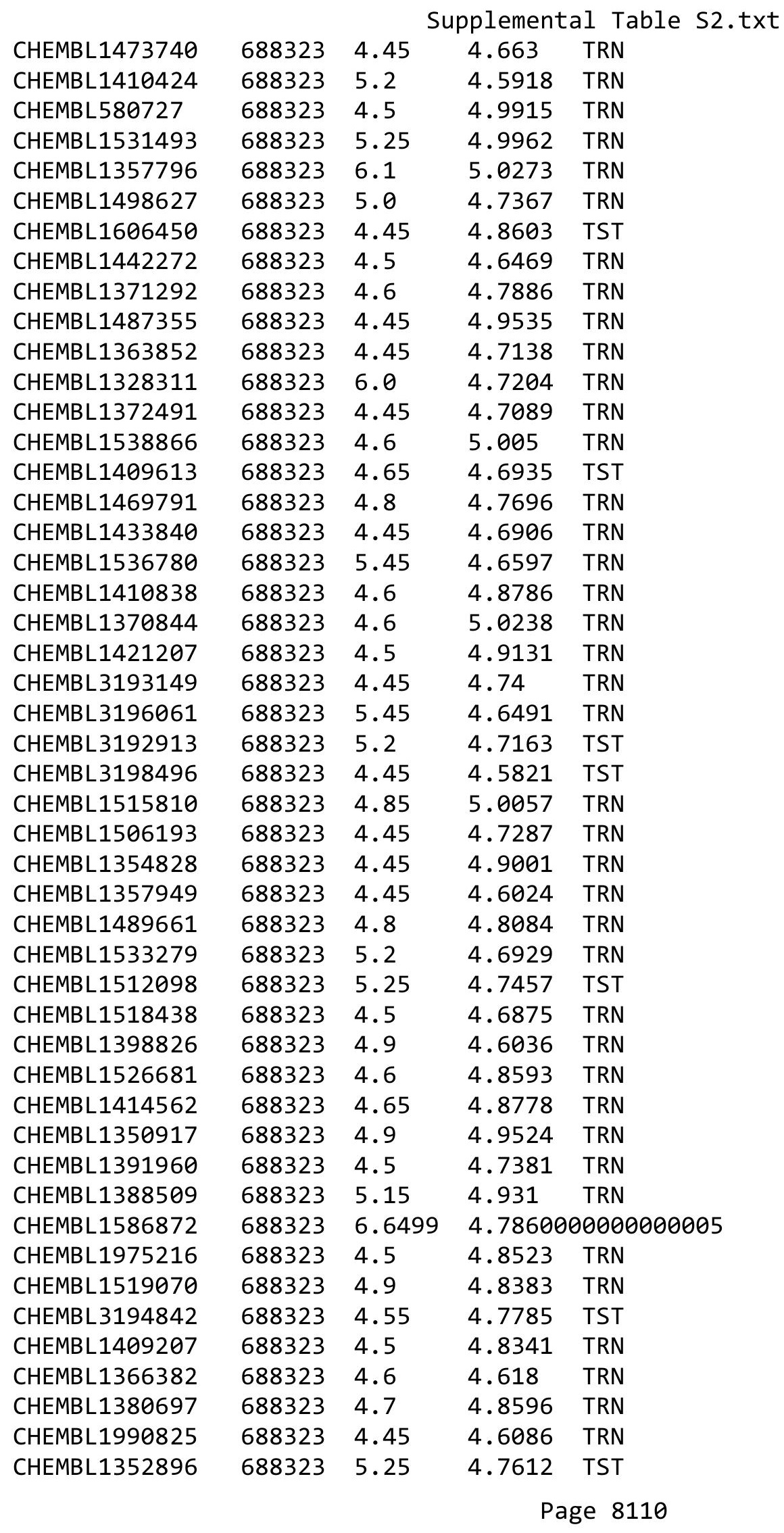




\begin{tabular}{|c|c|c|c|c|c|}
\hline \multicolumn{6}{|c|}{ Supplemental Table s2.txt } \\
\hline CHEMBL1499053 & 688323 & 4.5 & 4.7637 & TRN & \\
\hline CHEMBL1462928 & 688323 & 6.05 & 4.7644 & TST & \\
\hline CHEMBL1511298 & 688323 & 5.1 & 4.605 & TRN & \\
\hline CHEMBL1980827 & 688323 & 4.85 & 4.5568 & TRN & \\
\hline CHEMBL1589526 & 688323 & 5.25 & 4.8036 & TRN & \\
\hline CHEMBL1401983 & 688323 & 6.15 & 4.9155 & TRN & \\
\hline CHEMBL1335543 & 688323 & 5.55 & 5.1703 & TRN & \\
\hline CHEMBL1535905 & 688323 & 4.85 & 4.8227 & TRN & \\
\hline CHEMBL1588968 & 688323 & 5.2 & 4.937 & TRN & \\
\hline CHEMBL1519338 & 688323 & 4.65 & 5.16200 & 0000000001 & TRN \\
\hline CHEMBL1421153 & 688323 & 4.8 & 4.7884 & TST & \\
\hline CHEMBL584442 & 688323 & 5.1 & 4.9622 & TRN & \\
\hline CHEMBL3197214 & 688323 & 4.75 & 4.782 & TST & \\
\hline CHEMBL1508769 & 688323 & 4.65 & 4.7369 & TRN & \\
\hline CHEMBL1339485 & 688323 & 4.5 & 4.845 & TRN & \\
\hline CHEMBL1512122 & 688323 & 5.25 & 4.8685 & TST & \\
\hline CHEMBL1586531 & 688323 & 5.3 & 4.8379 & TRN & \\
\hline CHEMBL1495778 & 688323 & 4.65 & 4.7473 & TRN & \\
\hline CHEMBL1579393 & 688323 & 4.6 & 4.7364 & TST & \\
\hline CHEMBL1387313 & 688323 & 4.45 & 4.6551 & TRN & \\
\hline CHEMBL1427633 & 688323 & 4.45 & 4.4707 & TST & \\
\hline CHEMBL1603700 & 688323 & 4.55 & 4.9913 & TRN & \\
\hline CHEMBL1487507 & 688323 & 5.2 & 5.0483 & TST & \\
\hline CHEMBL1533601 & 688323 & 4.45 & 4.8677 & TRN & \\
\hline CHEMBL1329712 & 688323 & 4.5 & 4.9194 & TRN & \\
\hline CHEMBL1429368 & 688323 & 6.0 & 4.8098 & TRN & \\
\hline CHEMBL1512438 & 688323 & 4.5 & 4.5903 & TRN & \\
\hline CHEMBL1479550 & 688323 & 4.5 & 4.8893 & TRN & \\
\hline CHEMBL1454384 & 688323 & 5.55 & 4.9666 & TRN & \\
\hline CHEMBL1439824 & 688323 & 4.5 & 4.8698 & TRN & \\
\hline CHEMBL1605861 & 688323 & 4.45 & 4.803 & TRN & \\
\hline CHEMBL1544239 & 688323 & 4.45 & 4.7998 & TRN & \\
\hline CHEMBL1609326 & 688323 & 4.75 & 4.8587 & TRN & \\
\hline CHEMBL1408394 & 688323 & 4.45 & 4.9653 & TRN & \\
\hline CHEMBL3207791 & 688323 & 4.6 & 4.5202 & TRN & \\
\hline CHEMBL1438664 & 688323 & 5.35 & 4.7757 & TRN & \\
\hline CHEMBL1573365 & 688323 & 4.5 & 5.1539 & TST & \\
\hline CHEMBL1593193 & 688323 & 4.45 & 4.7637 & TRN & \\
\hline CHEMBL1541441 & 688323 & 5.25 & 4.7563 & TST & \\
\hline CHEMBL1573676 & 688323 & 4.8 & 4.6171 & TRN & \\
\hline CHEMBL1376204 & 688323 & 4.45 & 4.7925 & TRN & \\
\hline CHEMBL1354830 & 688323 & 5.2 & 4.92399 & 99999999995 & TRN \\
\hline CHEMBL1476332 & 688323 & 4.9 & 4.8414 & TRN & \\
\hline CHEMBL1406169 & 688323 & 4.6 & 4.8696 & TRN & \\
\hline CHEMBL1565518 & 688323 & 5.45 & 4.8452 & TRN & \\
\hline CHEMBL1598704 & 688323 & 4.45 & 4.8921 & TRN & \\
\hline CHEMBL1321240 & 688323 & 5.5 & 4.8625 & TRN & \\
\hline CHEMBL1341995 & 688323 & 5.2 & 5.0471 & TRN & \\
\hline
\end{tabular}




\begin{tabular}{|c|c|c|c|c|}
\hline \multicolumn{5}{|c|}{ Supplemental Table S2.txt } \\
\hline CHEMBL 3194048 & 688323 & 4.6 & 4.8103 & TRN \\
\hline CHEMBL1307467 & 688323 & 4.45 & 4.6662 & TRN \\
\hline CHEMBL3199322 & 688323 & 4.45 & 4.6408 & TRN \\
\hline CHEMBL1566725 & 688323 & 4.5 & 4.8787 & TRN \\
\hline CHEMBL 1479786 & 688323 & 5.4 & 5.0827 & TRN \\
\hline CHEMBL1458490 & 688323 & 4.5 & 4.7109 & TRN \\
\hline CHEMBL1433920 & 688323 & 4.8 & 4.6607 & TRN \\
\hline CHEMBL1299780 & 688323 & 4.8 & 4.7463 & TRN \\
\hline CHEMBL3194175 & 688323 & 4.6 & 4.7589 & TRN \\
\hline CHEMBL1513314 & 688323 & 4.45 & 4.6549 & TRN \\
\hline CHEMBL1418621 & 688323 & 4.5 & 4.5346 & TRN \\
\hline CHEMBL1593940 & 688323 & 4.7 & 4.7058 & TRN \\
\hline CHEMBL1472149 & 688323 & 7.0501 & 4.8887 & TST \\
\hline CHEMBL1380580 & 688323 & 4.45 & 4.6988 & TRN \\
\hline CHEMBL1529932 & 688323 & 4.6 & 4.9417 & TRN \\
\hline CHEMBL1456930 & 688323 & 4.6 & 4.6742 & TRN \\
\hline CHEMBL1309232 & 688323 & 5.25 & 4.9216 & TRN \\
\hline CHEMBL1395637 & 688323 & 4.5 & 4.8175 & TRN \\
\hline CHEMBL1414074 & 688323 & 4.8 & 4.8353 & TRN \\
\hline CHEMBL1487460 & 688323 & 4.45 & 4.8928 & TRN \\
\hline CHEMBL1373477 & 688323 & 6.15 & 4.779 & TRN \\
\hline CHEMBL1500469 & 688323 & 4.65 & 4.5686 & TRN \\
\hline CHEMBL1563652 & 688323 & 4.95 & 4.8691 & TRN \\
\hline CHEMBL1364308 & 688323 & 4.45 & 4.6911 & TRN \\
\hline CHEMBL1386291 & 688323 & 4.65 & 4.6602 & TRN \\
\hline CHEMBL1989210 & 688323 & 4.75 & 4.8208 & TRN \\
\hline CHEMBL1415476 & 688323 & 4.9 & 4.882 & TRN \\
\hline CHEMBL1568714 & 688323 & 5.4 & 5.0862 & TST \\
\hline CHEMBL1551629 & 688323 & 4.45 & 4.8386 & TRN \\
\hline CHEMBL1520214 & 688323 & 5.25 & 5.0184 & TRN \\
\hline CHEMBL1398441 & 688323 & 4.45 & 4.9182 & TRN \\
\hline CHEMBL1473745 & 688323 & 5.25 & 4.7028 & TRN \\
\hline CHEMBL1320193 & 688323 & 5.25 & 4.8305 & TRN \\
\hline CHEMBL1983116 & 688323 & 5.45 & 4.6668 & TRN \\
\hline CHEMBL1341945 & 688323 & 4.45 & 4.8941 & TRN \\
\hline CHEMBL1440577 & 688323 & 4.9 & 4.708 & TRN \\
\hline CHEMBL1326302 & 688323 & 5.3 & 4.6281 & TRN \\
\hline CHEMBL3190420 & 688323 & 4.45 & 4.9312 & TRN \\
\hline CHEMBL1591298 & 688323 & 5.2 & 4.7762 & TRN \\
\hline CHEMBL1310703 & 688323 & 4.95 & 4.8177 & TRN \\
\hline CHEMBL1472747 & 688323 & 4.45 & 4.7151 & TRN \\
\hline CHEMBL1583585 & 688323 & 4.95 & 4.9123 & TRN \\
\hline CHEMBL1579038 & 688323 & 6.6 & 4.9016 & TRN \\
\hline CHEMBL1454415 & 688323 & 4.5 & 4.7818 & TST \\
\hline CHEMBL444236 & 688323 & 4.5 & 5.0031 & TST \\
\hline CHEMBL1980453 & 688323 & 4.5 & 4.6802 & TRN \\
\hline CHEMBL1456872 & 688323 & 5.2 & 4.8975 & TST \\
\hline CHEMBL1398350 & 688323 & 4.65 & 4.6655 & TRN \\
\hline
\end{tabular}




\begin{tabular}{|c|c|c|c|c|c|}
\hline & & \multicolumn{4}{|c|}{ Supplemental Table s2.txt } \\
\hline CHEMBL1325839 & 688323 & 4.45 & 4.4677 & TRN & \\
\hline CHEMBL3208406 & 688323 & 4.9 & 4.6988 & TST & \\
\hline CHEMBL1329479 & 688323 & 4.95 & 4.9753 & TST & \\
\hline CHEMBL1375814 & 688323 & 4.5 & 4.9506 & TRN & \\
\hline CHEMBL1475571 & 688323 & 4.45 & 4.5463 & TRN & \\
\hline CHEMBL1307827 & 688323 & 5.35 & 5.0745 & TST & \\
\hline CHEMBL1585826 & 688323 & 4.5 & 4.8669 & TRN & \\
\hline CHEMBL3191962 & 688323 & 4.9 & 4.7421 & TRN & \\
\hline CHEMBL1341422 & 688323 & 4.75 & 4.7178 & TST & \\
\hline CHEMBL1565803 & 688323 & 4.45 & 5.0905 & TRN & \\
\hline CHEMBL1514759 & 688323 & 4.9 & 4.8504 & TRN & \\
\hline CHEMBL211481 & 688323 & 4.45 & 4.8541 & TST & \\
\hline CHEMBL1502774 & 688323 & 4.45 & 4.8918 & TRN & \\
\hline CHEMBL1428562 & 688323 & 5.4 & 4.9112 & TRN & \\
\hline CHEMBL1502014 & 688323 & 4.95 & 4.7696 & TST & \\
\hline CHEMBL1327172 & 688323 & 5.25 & 5.1327 & TRN & \\
\hline CHEMBL1325619 & 688323 & 5.4 & 5.0098 & TRN & \\
\hline CHEMBL1558840 & 688323 & 4.9 & 4.71899 & 9999999999 & TRN \\
\hline CHEMBL1546843 & 688323 & 5.25 & 4.7853 & TRN & \\
\hline CHEMBL1490048 & 688323 & 4.5 & 4.7973 & TST & \\
\hline CHEMBL1320357 & 688323 & 4.45 & 4.6052 & TRN & \\
\hline CHEMBL1610045 & 688323 & 4.45 & 4.9028 & TRN & \\
\hline CHEMBL1421023 & 688323 & 4.6 & 4.738 & TRN & \\
\hline CHEMBL1450203 & 688323 & 7.0 & 4.9273 & TRN & \\
\hline CHEMBL1445779 & 688323 & 4.7 & 5.1241 & TRN & \\
\hline CHEMBL 2000025 & 688323 & 4.6 & 4.8404 & TRN & \\
\hline CHEMBL48449 & 688323 & 5.5 & 4.9513 & TST & \\
\hline CHEMBL1414659 & 688323 & 6.95 & 5.0285 & TRN & \\
\hline CHEMBL1981539 & 688323 & 4.85 & 4.8396 & TST & \\
\hline CHEMBL1320345 & 688323 & 4.55 & 4.7307 & TRN & \\
\hline CHEMBL1533328 & 688323 & 4.5 & 4.8454 & TRN & \\
\hline CHEMBL1506369 & 688323 & 4.45 & 4.8784 & TST & \\
\hline CHEMBL1329129 & 688323 & 4.9 & 4.9241 & TRN & \\
\hline CHEMBL1338153 & 688323 & 4.6 & 4.6834 & TRN & \\
\hline CHEMBL1572550 & 688323 & 5.2 & 5.0286 & TRN & \\
\hline CHEMBL1310997 & 688323 & 4.8 & 4.6801 & TRN & \\
\hline CHEMBL1479249 & 688323 & 4.45 & 5.0968 & TRN & \\
\hline CHEMBL1362521 & 688323 & 4.5 & 4.8577 & TRN & \\
\hline CHEMBL1991573 & 688323 & 4.65 & 4.6794 & TRN & \\
\hline CHEMBL1474704 & 688323 & 5.05 & 4.6639 & TRN & \\
\hline CHEMBL1599205 & 688323 & 4.5 & 5.025 & TRN & \\
\hline CHEMBL1986381 & 688323 & 4.75 & 4.6349 & TRN & \\
\hline CHEMBL1484834 & 688323 & 4.6 & 4.8058 & TRN & \\
\hline CHEMBL1583398 & 688323 & 5.2 & 5.0023 & TRN & \\
\hline CHEMBL2006221 & 688323 & 4.45 & 4.6583 & TRN & \\
\hline CHEMBL1517489 & 688323 & 4.45 & 5.1138 & TST & \\
\hline CHEMBL1551606 & 688323 & 4.45 & 4.6462 & TRN & \\
\hline CHEMBL1495138 & 688323 & 4.85 & 4.7363 & TRN & \\
\hline
\end{tabular}




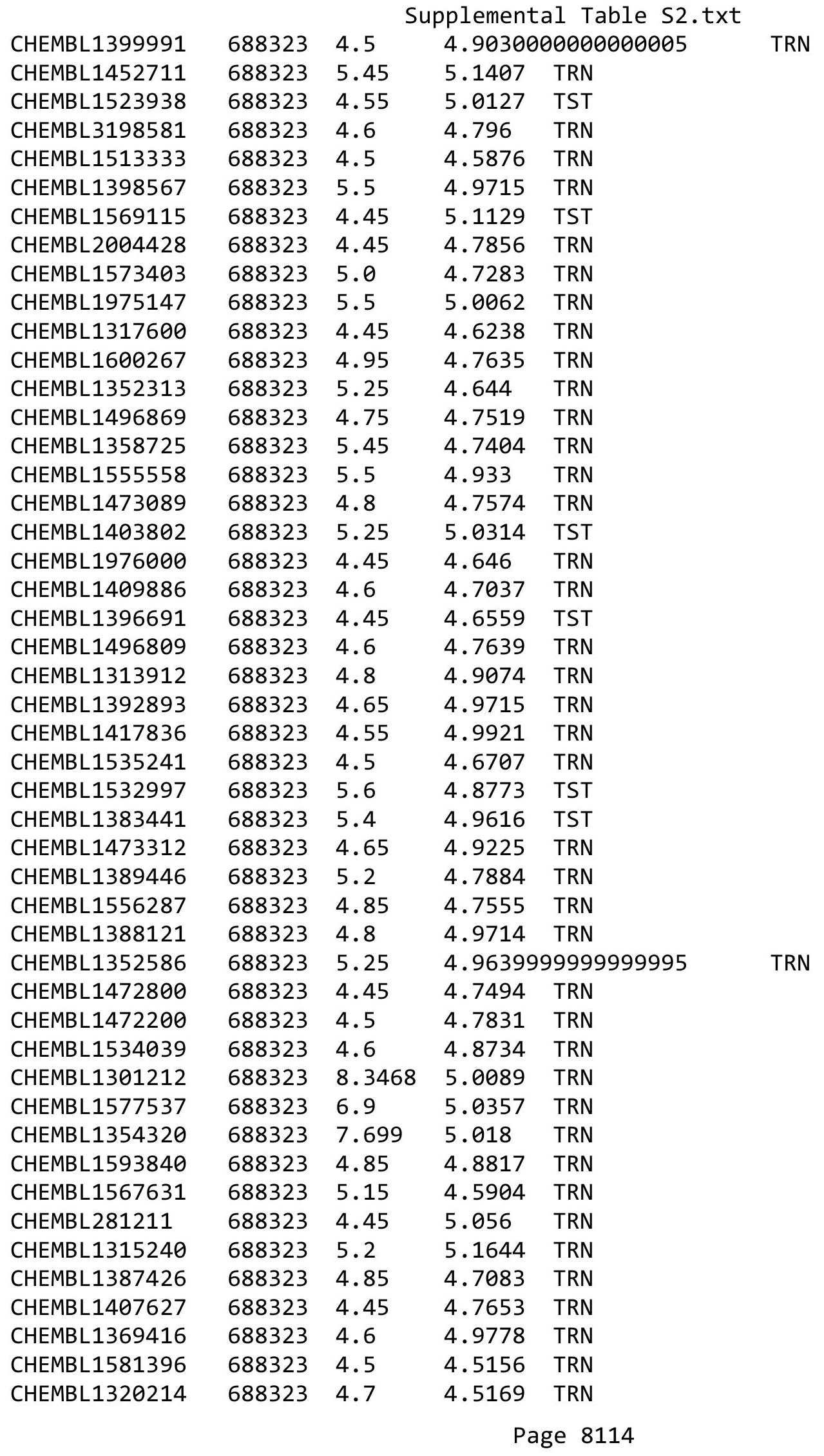




\begin{tabular}{|c|c|c|c|c|}
\hline \multicolumn{5}{|c|}{ Supplemental Table S2.txt } \\
\hline CHEMBL1493466 & 688323 & 6.0 & 5.164 & TRN \\
\hline CHEMBL1964891 & 688323 & 4.8 & 4.7684 & TRN \\
\hline CHEMBL1985765 & 688323 & 4.65 & 4.7603 & TRN \\
\hline CHEMBL1523046 & 688323 & 5.4 & 4.9122 & TRN \\
\hline CHEMBL1494115 & 688323 & 4.65 & 4.6087 & TRN \\
\hline CHEMBL1978373 & 688323 & 5.4 & 4.5329 & TRN \\
\hline CHEMBL1373845 & 688323 & 4.6 & 4.8289 & TRN \\
\hline CHEMBL1324532 & 688323 & 4.95 & 4.8779 & TRN \\
\hline CHEMBL1439041 & 688323 & 4.65 & 4.7154 & TRN \\
\hline CHEMBL1338243 & 688323 & 4.5 & 4.9719 & TRN \\
\hline CHEMBL1582695 & 688323 & 5.35 & 4.6129 & TRN \\
\hline CHEMBL1352760 & 688323 & 4.85 & 4.8012 & TRN \\
\hline CHEMBL1538799 & 688323 & 4.5 & 4.6355 & TRN \\
\hline CHEMBL1612081 & 688323 & 4.85 & 4.7194 & TRN \\
\hline CHEMBL1362676 & 688323 & 5.25 & 4.9229 & TRN \\
\hline CHEMBL1454465 & 688323 & 4.45 & 5.0001 & TRN \\
\hline CHEMBL1409611 & 688323 & 4.7 & 4.7586 & TRN \\
\hline CHEMBL1548291 & 688323 & 4.6 & 4.8607 & TST \\
\hline CHEMBL1442745 & 688323 & 4.85 & 4.8639 & TRN \\
\hline CHEMBL1378422 & 688323 & 4.5 & 4.745 & TRN \\
\hline CHEMBL1361503 & 688323 & 5.65 & 4.9481 & TRN \\
\hline CHEMBL1554051 & 688323 & 5.55 & 4.9107 & TRN \\
\hline CHEMBL3193378 & 688323 & 4.7 & 5.073 & TRN \\
\hline CHEMBL1599520 & 688323 & 5.35 & 5.0524 & TRN \\
\hline CHEMBL1467766 & 688323 & 4.45 & 4.9099 & TRN \\
\hline CHEMBL1438567 & 688323 & 4.5 & 4.7047 & TRN \\
\hline CHEMBL1567339 & 688323 & 4.85 & 5.0667 & TRN \\
\hline CHEMBL1368428 & 688323 & 4.95 & 4.9738 & TRN \\
\hline CHEMBL1361996 & 688323 & 4.8 & 4.8772 & TRN \\
\hline CHEMBL1559994 & 688323 & 5.05 & 4.7801 & TST \\
\hline CHEMBL1391041 & 688323 & 4.65 & 4.7581 & TRN \\
\hline CHEMBL1342148 & 688323 & 4.45 & 5.0735 & TRN \\
\hline CHEMBL1388415 & 688323 & 5.15 & 5.1649 & TRN \\
\hline CHEMBL1518886 & 688323 & 6.9 & 4.935 & TST \\
\hline CHEMBL1392412 & 688323 & 4.5 & 4.7947 & TRN \\
\hline CHEMBL1354767 & 688323 & 4.85 & 4.5951 & TRN \\
\hline CHEMBL1321278 & 688323 & 5.1 & 4.785 & TRN \\
\hline CHEMBL1551045 & 688323 & 4.75 & 5.064 & TRN \\
\hline CHEMBL1339632 & 688323 & 5.3 & 5.0638 & TRN \\
\hline CHEMBL1989372 & 688323 & 4.8 & 4.6233 & TRN \\
\hline CHEMBL3145112 & 688323 & 5.3 & 4.7214 & TRN \\
\hline CHEMBL1425166 & 688323 & 4.65 & 4.7262 & TST \\
\hline CHEMBL1561080 & 688323 & 4.65 & 4.6814 & TRN \\
\hline CHEMBL96051 & 688323 & 5.1 & 4.824 & TRN \\
\hline CHEMBL1454001 & 688323 & 4.5 & 4.9591 & TRN \\
\hline CHEMBL3195263 & 688323 & 5.5 & 4.7091 & TST \\
\hline CHEMBL 1330390 & 688323 & 4.45 & 4.5327 & TRN \\
\hline CHEMBL1564617 & 688323 & 4.9 & 5.1407 & TRN \\
\hline
\end{tabular}




\begin{tabular}{|c|c|c|c|c|c|}
\hline & & \multicolumn{4}{|c|}{ Supplemental Table S2.txt } \\
\hline CHEMBL1607685 & 688323 & 4.65 & 4.7858 & TRN & \\
\hline CHEMBL1425947 & 688323 & 5.5 & 4.9327 & TST & \\
\hline CHEMBL1479883 & 688323 & 4.95 & 4.8398 & TRN & \\
\hline CHEMBL1442173 & 688323 & 4.45 & 5.1026 & TST & \\
\hline CHEMBL1530382 & 688323 & 4.45 & 4.6386 & TRN & \\
\hline CHEMBL1352555 & 688323 & 5.45 & 4.8611 & TRN & \\
\hline CHEMBL1443651 & 688323 & 5.5 & 4.8113 & TRN & \\
\hline CHEMBL1316001 & 688323 & 4.8 & 4.8741 & TRN & \\
\hline CHEMBL1587807 & 688323 & 4.45 & 4.7442 & TRN & \\
\hline CHEMBL1512012 & 688323 & 4.5 & 4.6767 & TRN & \\
\hline CHEMBL1566417 & 688323 & 4.5 & 4.9027 & TRN & \\
\hline CHEMBL1434849 & 688323 & 6.8 & 4.9386 & TST & \\
\hline CHEMBL1528493 & 688323 & 5.45 & 5.0611 & TRN & \\
\hline CHEMBL1524630 & 688323 & 4.6 & 4.8989 & TRN & \\
\hline CHEMBL1335675 & 688323 & 4.45 & 4.7013 & TRN & \\
\hline CHEMBL1478787 & 688323 & 6.0 & 4.60800 & 00000000005 & TRN \\
\hline CHEMBL1512856 & 688323 & 5.45 & 4.7327 & TST & \\
\hline CHEMBL1379545 & 688323 & 4.45 & 4.7669 & TST & \\
\hline CHEMBL1404383 & 688323 & 5.2 & 4.8839 & TRN & \\
\hline CHEMBL1584440 & 688323 & 4.5 & 4.8846 & TRN & \\
\hline CHEMBL1503047 & 688323 & 4.6 & 4.8539 & TRN & \\
\hline CHEMBL1316834 & 688323 & 4.45 & 4.8425 & TRN & \\
\hline CHEMBL1579501 & 688323 & 5.3 & 4.7962 & TST & \\
\hline CHEMBL1444779 & 688323 & 4.8 & 4.9068 & TRN & \\
\hline CHEMBL1379737 & 688323 & 4.65 & 4.8114 & TRN & \\
\hline CHEMBL1318005 & 688323 & 4.45 & 5.001 & TST & \\
\hline CHEMBL1601374 & 688323 & 4.45 & 4.9688 & TST & \\
\hline CHEMBL1368433 & 688323 & 4.8 & 5.1461 & TRN & \\
\hline CHEMBL1397707 & 688323 & 4.6 & 4.8285 & TRN & \\
\hline CHEMBL1400236 & 688323 & 5.25 & 4.7392 & TRN & \\
\hline CHEMBL1544371 & 688323 & 5.3 & 5.1183 & TRN & \\
\hline CHEMBL1408109 & 688323 & 4.65 & 4.5384 & TRN & \\
\hline CHEMBL1534733 & 688323 & 4.5 & 4.5062 & TRN & \\
\hline CHEMBL1408705 & 688323 & 4.45 & 4.6108 & TRN & \\
\hline CHEMBL1999480 & 688323 & 4.65 & 4.7159 & TST & \\
\hline CHEMBL1376239 & 688323 & 5.25 & 4.8312 & TST & \\
\hline CHEMBL1448349 & 688323 & 4.45 & 4.8496 & TRN & \\
\hline CHEMBL1435013 & 688323 & 4.5 & 4.5491 & TRN & \\
\hline CHEMBL1347023 & 688323 & 4.7 & 5.0884 & TRN & \\
\hline CHEMBL1377465 & 688323 & 4.75 & 4.8666 & TRN & \\
\hline CHEMBL1601419 & 688323 & 4.6 & 4.89199 & 99999999995 & TRN \\
\hline CHEMBL1305470 & 688323 & 4.6 & 4.79 & TRN & \\
\hline CHEMBL1357636 & 688323 & 5.1 & 4.7008 & TRN & \\
\hline CHEMBL1446248 & 688323 & 5.2 & 4.8456 & TRN & \\
\hline CHEMBL3192894 & 688323 & 4.85 & 4.9816 & TRN & \\
\hline CHEMBL209793 & 688323 & 4.75 & 4.8737 & TST & \\
\hline CHEMBL1996203 & 688323 & 5.45 & 4.4099 & TRN & \\
\hline CHEMBL1433338 & 688323 & 5.2 & 5.0461 & TRN & \\
\hline
\end{tabular}




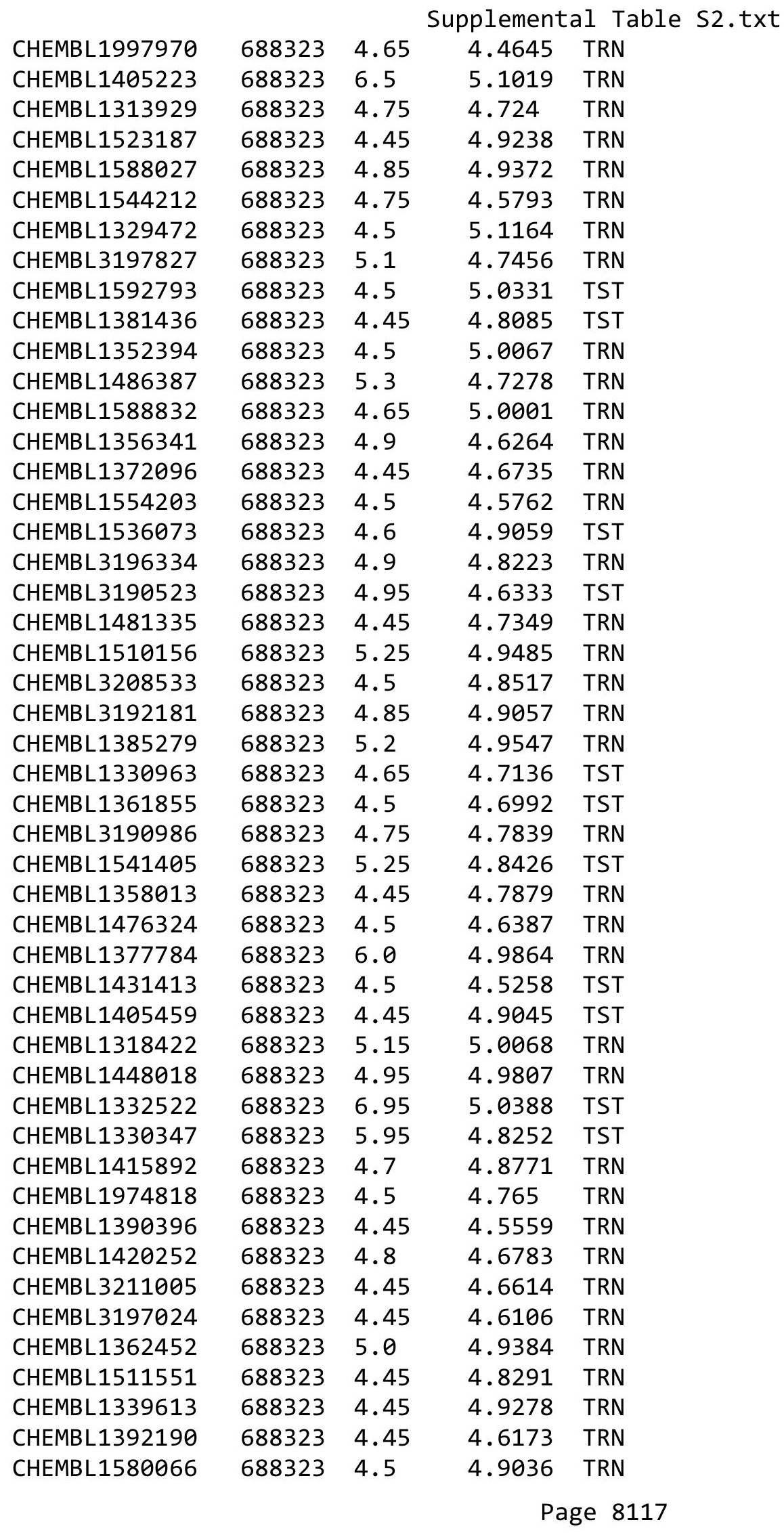




\begin{tabular}{|c|c|c|c|c|}
\hline \multicolumn{5}{|c|}{ Supplemental Table } \\
\hline CHEMBL1593864 & 688323 & 4.75 & 4.7845 & TRN \\
\hline CHEMBL1574936 & 688323 & 4.45 & 4.6589 & TRN \\
\hline CHEMBL3198723 & 688323 & 5.35 & 4.5942 & TRN \\
\hline CHEMBL1352990 & 688323 & 5.25 & 4.9075 & TRN \\
\hline CHEMBL1339881 & 688323 & 5.25 & 4.7466 & TRN \\
\hline CHEMBL3192616 & 688323 & 5.25 & 4.7049 & TRN \\
\hline CHEMBL1438186 & 688323 & 4.55 & 5.0057 & TRN \\
\hline CHEMBL1347992 & 688323 & 4.45 & 4.7072 & TRN \\
\hline CHEMBL1519800 & 688323 & 4.8 & 4.7212 & TRN \\
\hline CHEMBL1422230 & 688323 & 4.5 & 4.4999 & TRN \\
\hline CHEMBL3208408 & 688323 & 4.5 & 4.6846 & TRN \\
\hline CHEMBL1484731 & 688323 & 4.85 & 4.7588 & TRN \\
\hline CHEMBL192566 & 688323 & 6.0 & 4.5983 & TST \\
\hline CHEMBL1444885 & 688323 & 4.6 & 4.8109 & TRN \\
\hline CHEMBL1430815 & 688323 & 5.5 & 4.8897 & TRN \\
\hline CHEMBL1517042 & 688323 & 5.0 & 4.8621 & TRN \\
\hline CHEMBL1436076 & 688323 & 4.45 & 4.5981 & TRN \\
\hline CHEMBL1430628 & 688323 & 4.45 & 4.8326 & TST \\
\hline CHEMBL1449385 & 688323 & 4.6 & 4.6319 & TST \\
\hline CHEMBL1423708 & 688323 & 4.5 & 4.9801 & TST \\
\hline CHEMBL1562493 & 688323 & 4.45 & 4.9203 & TST \\
\hline CHEMBL1491530 & 688323 & 4.5 & 4.6862 & TRN \\
\hline CHEMBL 2006684 & 688323 & 5.55 & 4.8424 & TRN \\
\hline CHEMBL1373781 & 688323 & 4.55 & 4.7853 & TRN \\
\hline CHEMBL1549596 & 688323 & 4.65 & 4.9398 & TRN \\
\hline CHEMBL1506679 & 688323 & 4.55 & 4.845 & TST \\
\hline CHEMBL1480464 & 688323 & 5.05 & 4.7445 & TST \\
\hline CHEMBL1356614 & 688323 & 4.6 & 4.6547 & TRN \\
\hline CHEMBL138921 & 688323 & 6.0 & 5.0322 & TRN \\
\hline CHEMBL1454879 & 688323 & 5.1 & 5.0533 & TRN \\
\hline CHEMBL1317128 & 688323 & 5.15 & 4.9055 & TRN \\
\hline CHEMBL1586216 & 688323 & 4.45 & 4.7766 & TST \\
\hline CHEMBL1451812 & 688323 & 5.25 & 4.8775 & TRN \\
\hline CHEMBL1561655 & 688323 & 4.45 & 4.7708 & TST \\
\hline CHEMBL1312514 & 688323 & 5.75 & 4.7575 & TRN \\
\hline CHEMBL1304761 & 688323 & 5.25 & 5.1392 & TRN \\
\hline CHEMBL1579034 & 688323 & 5.2 & 4.6997 & TRN \\
\hline CHEMBL1567968 & 688323 & 5.25 & 5.1548 & TRN \\
\hline CHEMBL1586179 & 688323 & 5.7 & 4.8845 & TRN \\
\hline CHEMBL518575 & 688323 & 4.9 & 4.8848 & TRN \\
\hline CHEMBL1514960 & 688323 & 4.45 & 4.8605 & TRN \\
\hline CHEMBL1366812 & 688323 & 5.2 & 4.8029 & TST \\
\hline CHEMBL1509099 & 688323 & 5.95 & 4.9749 & TRN \\
\hline CHEMBL1541324 & 688323 & 5.25 & 4.8471 & TST \\
\hline CHEMBL1470321 & 688323 & 5.3 & 4.9205 & TST \\
\hline CHEMBL1428563 & 688323 & 4.95 & 4.5554 & TST \\
\hline CHEMBL1346450 & 688323 & 4.5 & 4.9269 & TRN \\
\hline CHEMBL1608666 & 688323 & 4.5 & 4.9357 & TRN \\
\hline
\end{tabular}




\begin{tabular}{|c|c|c|c|c|}
\hline \multicolumn{5}{|c|}{ Supplemental Table S2.txt } \\
\hline CHEMBL1545233 & 688323 & 4.45 & 4.744 & TST \\
\hline CHEMBL1556556 & 688323 & 5.2 & 4.6833 & TRN \\
\hline CHEMBL1567944 & 688323 & 4.75 & 4.9386 & TST \\
\hline CHEMBL1411179 & 688323 & 4.8 & 4.8239 & TRN \\
\hline CHEMBL1612390 & 688323 & 4.5 & 4.9915 & TST \\
\hline CHEMBL 3192475 & 688323 & 5.2 & 4.7893 & TRN \\
\hline CHEMBL3208118 & 688323 & 5.2 & 5.0254 & TRN \\
\hline CHEMBL1361136 & 688323 & 4.65 & 4.8623 & TRN \\
\hline CHEMBL1434147 & 688323 & 4.75 & 4.6883 & TRN \\
\hline CHEMBL1352867 & 688323 & 4.5 & 4.6701 & TRN \\
\hline CHEMBL1369691 & 688323 & 6.0 & 5.0562 & TRN \\
\hline CHEMBL1399533 & 688323 & 4.9 & 4.7736 & TRN \\
\hline CHEMBL1439190 & 688323 & 4.5 & 4.8592 & TRN \\
\hline CHEMBL1982869 & 688323 & 4.45 & 4.5543 & TRN \\
\hline CHEMBL1436010 & 688323 & 4.45 & 4.7687 & TRN \\
\hline CHEMBL1310629 & 688323 & 4.55 & 4.6901 & TRN \\
\hline CHEMBL1577981 & 688323 & 5.5 & 4.8662 & TRN \\
\hline CHEMBL1458404 & 688323 & 4.65 & 4.9529 & TRN \\
\hline CHEMBL1418745 & 688323 & 4.45 & 4.5333 & TRN \\
\hline CHEMBL1425169 & 688323 & 4.5 & 4.6952 & TRN \\
\hline CHEMBL1394929 & 688323 & 4.5 & 4.7894 & TRN \\
\hline CHEMBL1429291 & 688323 & 4.45 & 4.8636 & TRN \\
\hline CHEMBL1986343 & 688323 & 5.4 & 4.6807 & TRN \\
\hline CHEMBL1473156 & 688323 & 4.9 & 4.7585 & TRN \\
\hline CHEMBL1435999 & 688323 & 4.65 & 4.7059 & TRN \\
\hline CHEMBL1515897 & 688323 & 4.45 & 5.0853 & TRN \\
\hline CHEMBL1337614 & 688323 & 4.5 & 5.095 & TRN \\
\hline CHEMBL1543588 & 688323 & 4.45 & 4.6736 & TRN \\
\hline CHEMBL1311272 & 688323 & 4.6 & 4.9196 & TRN \\
\hline CHEMBL1492820 & 688323 & 4.9 & 4.776 & TRN \\
\hline CHEMBL3190566 & 688323 & 5.45 & 4.8743 & TRN \\
\hline CHEMBL1401103 & 688323 & 4.75 & 4.7725 & TRN \\
\hline CHEMBL1586413 & 688323 & 4.5 & 4.7712 & TRN \\
\hline CHEMBL3190774 & 688323 & 5.75 & 4.6348 & TRN \\
\hline CHEMBL1436928 & 688323 & 4.6 & 4.7816 & TRN \\
\hline CHEMBL1397115 & 688323 & 4.85 & 4.9048 & TRN \\
\hline CHEMBL1332291 & 688323 & 4.45 & 4.6978 & TRN \\
\hline CHEMBL1360208 & 688323 & 4.5 & 4.6768 & TRN \\
\hline CHEMBL1457644 & 688323 & 5.45 & 5.2513 & TRN \\
\hline CHEMBL1404614 & 688323 & 5.5 & 4.8003 & TST \\
\hline CHEMBL1569910 & 688323 & 6.0 & 4.9443 & TRN \\
\hline CHEMBL1371452 & 688323 & 5.25 & 4.9147 & TST \\
\hline CHEMBL1590943 & 688323 & 4.5 & 4.729 & TRN \\
\hline CHEMBL1503173 & 688323 & 6.7501 & 5.0957 & TRN \\
\hline CHEMBL1601897 & 688323 & 4.5 & 4.82 & TST \\
\hline CHEMBL1566684 & 688323 & 4.65 & 4.9638 & TRN \\
\hline CHEMBL1271764 & 688323 & 4.5 & 5.0196 & TRN \\
\hline CHEMBL1428651 & 688323 & 6.1 & 5.1749 & TST \\
\hline
\end{tabular}




\begin{tabular}{|c|c|c|c|c|}
\hline \multicolumn{5}{|c|}{ Supplemental Table S2.txt } \\
\hline CHEMBL1574908 & 688323 & 8.3468 & 4.7412 & TRN \\
\hline CHEMBL1588366 & 688323 & 4.6 & 4.9065 & TRN \\
\hline CHEMBL1374938 & 688323 & 4.45 & 4.7259 & TRN \\
\hline CHEMBL1319682 & 688323 & 4.45 & 4.7239 & TRN \\
\hline CHEMBL 2004884 & 688323 & 4.6 & 4.8781 & TRN \\
\hline CHEMBL1972650 & 688323 & 4.45 & 4.7393 & TRN \\
\hline CHEMBL1349690 & 688323 & 4.5 & 4.8623 & TRN \\
\hline CHEMBL1445354 & 688323 & 4.65 & 4.7076 & TRN \\
\hline CHEMBL3191058 & 688323 & 4.7 & 4.8348 & TST \\
\hline CHEMBL1364350 & 688323 & 4.45 & 4.8504 & TRN \\
\hline CHEMBL1366975 & 688323 & 4.5 & 4.6413 & TRN \\
\hline CHEMBL1374557 & 688323 & 4.55 & 4.8904 & TRN \\
\hline CHEMBL1503403 & 688323 & 4.55 & 4.7653 & TST \\
\hline CHEMBL1965669 & 688323 & 4.65 & 4.7707 & TRN \\
\hline CHEMBL1371905 & 688323 & 5.2 & 4.6921 & TRN \\
\hline CHEMBL3193537 & 688323 & 4.6 & 4.6893 & TRN \\
\hline CHEMBL3190563 & 688323 & 4.65 & 4.5968 & TST \\
\hline CHEMBL1543918 & 688323 & 4.85 & 5.0139 & TRN \\
\hline CHEMBL1558556 & 688323 & 6.25 & 5.2096 & TRN \\
\hline CHEMBL1404067 & 688323 & 5.45 & 4.637 & TRN \\
\hline CHEMBL1338027 & 688323 & 4.45 & 4.4055 & TRN \\
\hline CHEMBL1412583 & 688323 & 5.25 & 4.6799 & TRN \\
\hline CHEMBL1327091 & 688323 & 4.75 & 4.6942 & TRN \\
\hline CHEMBL3197507 & 688323 & 4.5 & 4.6206 & TRN \\
\hline CHEMBL1399883 & 688323 & 4.45 & 4.7777 & TRN \\
\hline CHEMBL 1441725 & 688323 & 4.45 & 4.6826 & TRN \\
\hline CHEMBL1408535 & 688323 & 4.7 & 4.8747 & TRN \\
\hline CHEMBL1323828 & 688323 & 5.45 & 4.9974 & TRN \\
\hline CHEMBL148296 & 688323 & 4.5 & 4.831 & TRN \\
\hline CHEMBL1334427 & 688323 & 4.55 & 4.7739 & TRN \\
\hline CHEMBL1580467 & 688323 & 4.45 & 4.7568 & TRN \\
\hline CHEMBL1566252 & 688323 & 5.5 & 4.8328 & TRN \\
\hline CHEMBL 2000008 & 688323 & 4.65 & 4.5151 & TRN \\
\hline CHEMBL1437631 & 688323 & 4.8 & 4.8279 & TRN \\
\hline CHEMBL1566523 & 688323 & 4.5 & 4.7837 & TRN \\
\hline CHEMBL1545832 & 688323 & 4.85 & 5.0072 & TRN \\
\hline CHEMBL1606531 & 688323 & 4.55 & 4.8727 & TRN \\
\hline CHEMBL1512751 & 688323 & 5.2 & 4.9718 & TRN \\
\hline CHEMBL1500519 & 688323 & 4.75 & 4.8125 & TRN \\
\hline CHEMBL1497139 & 688323 & 6.2 & 4.6075 & TRN \\
\hline CHEMBL1533587 & 688323 & 4.5 & 4.8766 & TRN \\
\hline CHEMBL505670 & 688323 & 5.0 & 5.0764 & TRN \\
\hline CHEMBL1324001 & 688323 & 5.25 & 4.9593 & TRN \\
\hline CHEMBL1349226 & 688323 & 4.45 & 4.8635 & TRN \\
\hline CHEMBL1418110 & 688323 & 5.45 & 4.8275 & TRN \\
\hline CHEMBL1378424 & 688323 & 4.5 & 4.7465 & TRN \\
\hline CHEMBL1568658 & 688323 & 5.4 & 4.9003 & TST \\
\hline CHEMBL1448020 & 688323 & 4.45 & 4.7409 & TRN \\
\hline
\end{tabular}




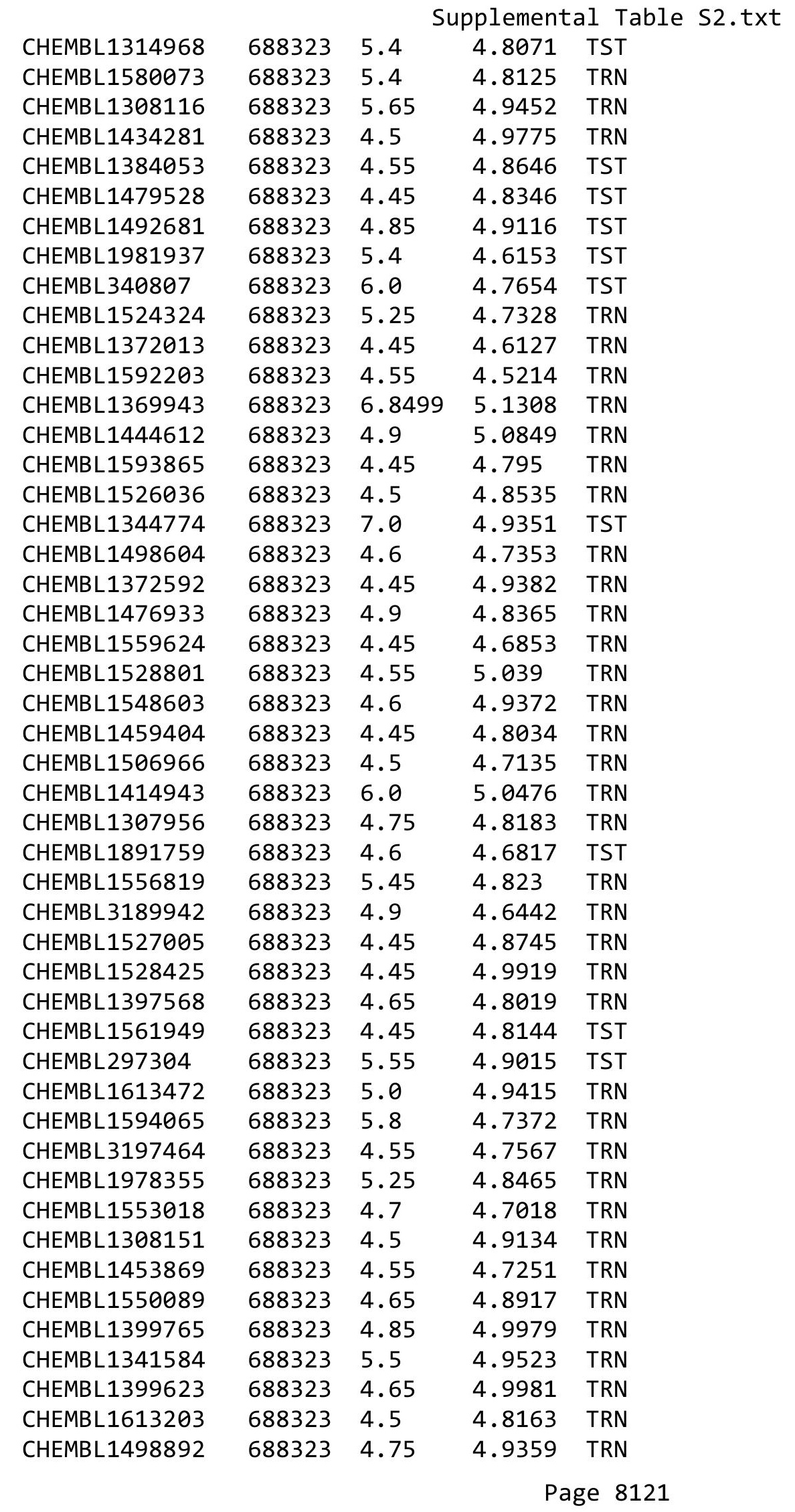




\begin{tabular}{|c|c|c|c|c|}
\hline \multicolumn{5}{|c|}{ Supplemental Table s2.txt } \\
\hline CHEMBL1447432 & 688323 & 6.2 & 4.9847 & TRN \\
\hline CHEMBL1584502 & 688323 & 5.45 & 5.0318 & TRN \\
\hline CHEMBL1513135 & 688323 & 4.85 & 4.7312 & TST \\
\hline CHEMBL1434996 & 688323 & 4.5 & 4.6952 & TRN \\
\hline CHEMBL1506351 & 688323 & 4.65 & 4.8432 & TRN \\
\hline CHEMBL1487567 & 688323 & 5.3 & 5.3647 & TRN \\
\hline CHEMBL1408741 & 688323 & 4.95 & 4.8507 & TRN \\
\hline CHEMBL139935 & 688323 & 4.5 & 5.0823 & TRN \\
\hline CHEMBL1316716 & 688323 & 4.8 & 4.7447 & TRN \\
\hline CHEMBL1994401 & 688323 & 4.6 & 4.6822 & TRN \\
\hline CHEMBL1338819 & 688323 & 4.5 & 4.562 & TRN \\
\hline CHEMBL1476836 & 688323 & 4.9 & 4.7228 & TRN \\
\hline CHEMBL1609214 & 688323 & 4.6 & 4.8589 & TRN \\
\hline CHEMBL1970925 & 688323 & 4.5 & 4.6696 & TRN \\
\hline CHEMBL1374992 & 688323 & 4.5 & 4.936 & TRN \\
\hline CHEMBL1369980 & 688323 & 4.5 & 4.988 & TST \\
\hline CHEMBL1596198 & 688323 & 4.45 & 4.6439 & TRN \\
\hline CHEMBL1337947 & 688323 & 6.0 & 4.9719 & TRN \\
\hline CHEMBL1539653 & 688323 & 6.05 & 4.8089 & TRN \\
\hline CHEMBL1546223 & 688323 & 4.5 & 4.8559 & TRN \\
\hline CHEMBL1991327 & 688323 & 4.55 & 4.8858 & TRN \\
\hline CHEMBL 227423 & 688323 & 4.5 & 4.5668 & TRN \\
\hline CHEMBL1511603 & 688323 & 4.6 & 4.8475 & TRN \\
\hline CHEMBL1602121 & 688323 & 4.6 & 4.5198 & TRN \\
\hline CHEMBL1398203 & 688323 & 4.45 & 4.8931 & TST \\
\hline CHEMBL1559707 & 688323 & 5.5 & 4.9238 & TRN \\
\hline CHEMBL1984796 & 688323 & 4.55 & 4.862 & TRN \\
\hline CHEMBL1319963 & 688323 & 5.15 & 4.8272 & TRN \\
\hline CHEMBL1328260 & 688323 & 4.6 & 4.9874 & TRN \\
\hline CHEMBL1565776 & 688323 & 4.5 & 4.8959 & TRN \\
\hline CHEMBL1537810 & 688323 & 4.9 & 4.8725 & TRN \\
\hline CHEMBL1455809 & 688323 & 4.65 & 4.9785 & TRN \\
\hline CHEMBL1358044 & 688323 & 4.6 & 4.9806 & TRN \\
\hline CHEMBL1328054 & 688323 & 4.65 & 4.8132 & TRN \\
\hline CHEMBL1586404 & 688323 & 4.45 & 4.8803 & TRN \\
\hline CHEMBL1417831 & 688323 & 5.2 & 4.6112 & TRN \\
\hline CHEMBL1431610 & 688323 & 5.15 & 4.8546 & TST \\
\hline CHEMBL1365469 & 688323 & 4.85 & 4.8958 & TST \\
\hline CHEMBL1315393 & 688323 & 4.45 & 4.7575 & TRN \\
\hline CHEMBL1508656 & 688323 & 5.45 & 4.9248 & TST \\
\hline CHEMBL1986765 & 688323 & 4.5 & 4.6045 & TST \\
\hline CHEMBL1511052 & 688323 & 4.95 & 4.8089 & TST \\
\hline CHEMBL1988416 & 688323 & 5.3 & 4.9198 & TST \\
\hline CHEMBL1609410 & 688323 & 4.65 & 4.9352 & TRN \\
\hline CHEMBL1349968 & 688323 & 4.45 & 4.7838 & TRN \\
\hline CHEMBL1606346 & 688323 & 6.15 & 4.7954 & TST \\
\hline CHEMBL1425170 & 688323 & 5.45 & 5.1179 & TST \\
\hline CHEMBL1427160 & 688323 & 4.9 & 5.0421 & TRN \\
\hline
\end{tabular}




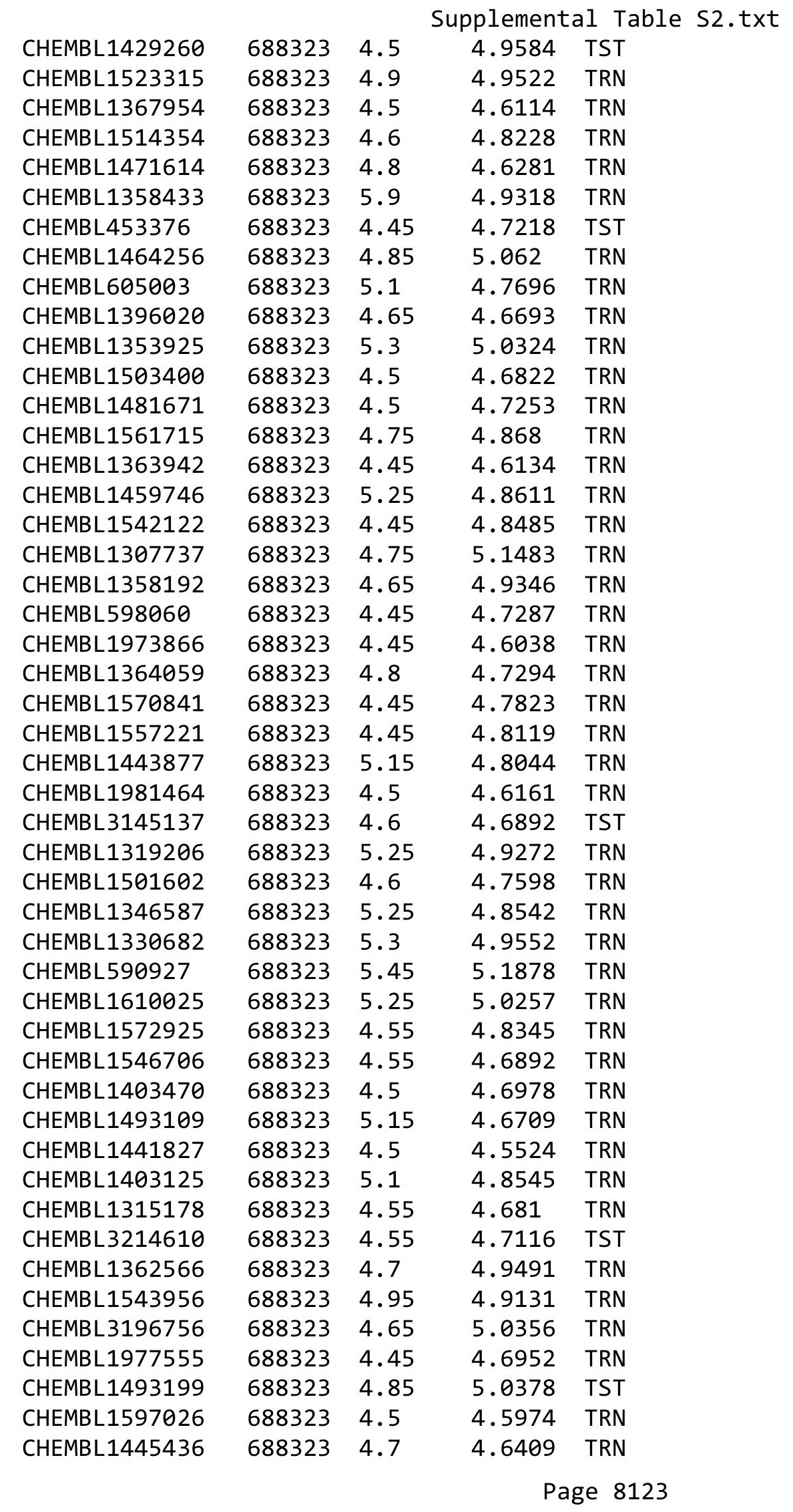




\begin{tabular}{|c|c|c|c|c|}
\hline \multicolumn{5}{|c|}{ Supplemental Table } \\
\hline CHEMBL1538966 & 688323 & 4.65 & 4.8519 & TST \\
\hline CHEMBL1343814 & 688323 & 5.5 & 5.0487 & TRN \\
\hline CHEMBL1477884 & 688323 & 4.5 & 4.8549 & TRN \\
\hline CHEMBL1484471 & 688323 & 7.0 & 5.0102 & TRN \\
\hline CHEMBL1558844 & 688323 & 4.7 & 4.9735 & TRN \\
\hline CHEMBL1474754 & 688323 & 4.7 & 4.7212 & TRN \\
\hline CHEMBL1498602 & 688323 & 4.45 & 4.7674 & TST \\
\hline CHEMBL1440866 & 688323 & 4.9 & 5.1074 & TRN \\
\hline CHEMBL1471271 & 688323 & 4.45 & 4.8281 & TRN \\
\hline CHEMBL1878966 & 688323 & 4.85 & 4.6925 & TST \\
\hline CHEMBL1376633 & 688323 & 4.65 & 4.7795 & TST \\
\hline CHEMBL1476347 & 688323 & 4.65 & 4.8872 & TRN \\
\hline CHEMBL1493903 & 688323 & 4.45 & 5.0153 & TST \\
\hline CHEMBL1355792 & 688323 & 4.8 & 4.7042 & TRN \\
\hline CHEMBL1999436 & 688323 & 4.6 & 4.9456 & TRN \\
\hline CHEMBL1481426 & 688323 & 4.45 & 5.1217 & TRN \\
\hline CHEMBL1596184 & 688323 & 4.7 & 4.9144 & TRN \\
\hline CHEMBL1339618 & 688323 & 4.45 & 4.8825 & TRN \\
\hline CHEMBL 3211855 & 688323 & 5.25 & 4.7758 & TRN \\
\hline CHEMBL1306093 & 688323 & 5.25 & 4.5047 & TST \\
\hline CHEMBL1571682 & 688323 & 4.6 & 5.006 & TRN \\
\hline CHEMBL1988120 & 688323 & 4.5 & 4.771 & TRN \\
\hline CHEMBL1525472 & 688323 & 4.65 & 4.8363 & TRN \\
\hline CHEMBL1371982 & 688323 & 4.6 & 4.8717 & TRN \\
\hline CHEMBL1312842 & 688323 & 4.5 & 4.8261 & TRN \\
\hline CHEMBL1388118 & 688323 & 5.25 & 4.8183 & TRN \\
\hline CHEMBL1427387 & 688323 & 4.45 & 4.7654 & TRN \\
\hline CHEMBL1421101 & 688323 & 5.15 & 4.9036 & TRN \\
\hline CHEMBL1362317 & 688323 & 4.45 & 4.6432 & TRN \\
\hline CHEMBL1397070 & 688323 & 5.05 & 4.8932 & TRN \\
\hline CHEMBL1511733 & 688323 & 5.2 & 4.9168 & TST \\
\hline CHEMBL1440262 & 688323 & 4.75 & 4.8928 & TRN \\
\hline CHEMBL1587355 & 688323 & 4.45 & 4.7347 & TRN \\
\hline CHEMBL1587563 & 688323 & 4.7 & 4.8083 & TRN \\
\hline CHEMBL1591498 & 688323 & 4.45 & 4.7585 & TRN \\
\hline CHEMBL1967121 & 688323 & 4.5 & 4.6891 & TRN \\
\hline CHEMBL3193510 & 688323 & 4.5 & 4.713 & TRN \\
\hline CHEMBL1598383 & 688323 & 5.2 & 4.9527 & TRN \\
\hline CHEMBL1477670 & 688323 & 4.5 & 4.7987 & TST \\
\hline CHEMBL1322633 & 688323 & 4.45 & 4.7847 & TRN \\
\hline CHEMBL1568859 & 688323 & 4.45 & 4.8093 & TRN \\
\hline CHEMBL1308000 & 688323 & 4.5 & 4.783 & TRN \\
\hline CHEMBL1317796 & 688323 & 4.5 & 4.6303 & TRN \\
\hline CHEMBL3190095 & 688323 & 5.35 & 4.8461 & TRN \\
\hline CHEMBL1318347 & 688323 & 4.45 & 4.8845 & TRN \\
\hline CHEMBL1510455 & 688323 & 5.25 & 4.801 & TRN \\
\hline CHEMBL1487546 & 688323 & 4.5 & 4.689 & TRN \\
\hline CHEMBL1366451 & 688323 & 4.45 & 4.7192 & TRN \\
\hline
\end{tabular}




\begin{tabular}{|c|c|c|c|c|}
\hline \multicolumn{5}{|c|}{ Supplemental Table S2.txt } \\
\hline CHEMBL1486335 & 688323 & 4.6 & 4.9814 & TRN \\
\hline CHEMBL1417537 & 688323 & 4.45 & 4.7958 & TRN \\
\hline CHEMBL1328428 & 688323 & 4.45 & 4.8984 & TST \\
\hline CHEMBL1487358 & 688323 & 4.8 & 4.9687 & TRN \\
\hline CHEMBL 1477136 & 688323 & 5.35 & 4.8997 & TRN \\
\hline CHEMBL1478681 & 688323 & 4.65 & 4.7841 & TRN \\
\hline CHEMBL1583574 & 688323 & 4.9 & 4.8571 & TST \\
\hline CHEMBL1522865 & 688323 & 5.2 & 4.8618 & TRN \\
\hline CHEMBL1561395 & 688323 & 5.25 & 4.8116 & TRN \\
\hline CHEMBL1480652 & 688323 & 4.95 & 4.8734 & TRN \\
\hline CHEMBL1336171 & 688323 & 5.35 & 4.8659 & TRN \\
\hline CHEMBL1518899 & 688323 & 4.6 & 4.6432 & TRN \\
\hline CHEMBL1453415 & 688323 & 5.25 & 4.8779 & TRN \\
\hline CHEMBL1418885 & 688323 & 4.45 & 4.5292 & TRN \\
\hline CHEMBL1500966 & 688323 & 5.2 & 5.0322 & TRN \\
\hline CHEMBL1390860 & 688323 & 4.85 & 4.7734 & TRN \\
\hline CHEMBL1385287 & 688323 & 4.55 & 4.7877 & TRN \\
\hline CHEMBL1557111 & 688323 & 4.55 & 4.7372 & TRN \\
\hline CHEMBL1598802 & 688323 & 4.9 & 4.5999 & TRN \\
\hline CHEMBL1361830 & 688323 & 4.45 & 5.0584 & TRN \\
\hline CHEMBL1503602 & 688323 & 4.5 & 4.698 & TRN \\
\hline CHEMBL1504221 & 688323 & 6.35 & 4.9166 & TRN \\
\hline CHEMBL1376203 & 688323 & 4.5 & 4.8514 & TRN \\
\hline CHEMBL1574854 & 688323 & 4.45 & 4.9368 & TRN \\
\hline CHEMBL1308993 & 688323 & 4.5 & 4.9459 & TST \\
\hline CHEMBL99 & 688323 & 6.0 & 4.8532 & TRN \\
\hline CHEMBL1978997 & 688323 & 4.5 & 4.8448 & TRN \\
\hline CHEMBL1489240 & 688323 & 5.25 & 5.1378 & TRN \\
\hline CHEMBL1480392 & 688323 & 5.25 & 4.7873 & TRN \\
\hline CHEMBL1424559 & 688323 & 4.85 & 4.9854 & TRN \\
\hline CHEMBL1436728 & 688323 & 4.45 & 4.8789 & TRN \\
\hline CHEMBL 2006168 & 688323 & 4.45 & 4.9436 & TRN \\
\hline CHEMBL1426984 & 688323 & 4.45 & 4.7532 & TRN \\
\hline CHEMBL3192097 & 688323 & 4.45 & 4.6886 & TRN \\
\hline CHEMBL1548261 & 688323 & 4.6 & 4.7642 & TRN \\
\hline CHEMBL1319013 & 688323 & 4.5 & 4.9423 & TRN \\
\hline CHEMBL1316920 & 688323 & 5.2 & 4.9546 & TRN \\
\hline CHEMBL1430486 & 688323 & 4.8 & 4.7557 & TRN \\
\hline CHEMBL1373537 & 688323 & 4.45 & 4.4754 & TRN \\
\hline CHEMBL1504009 & 688323 & 4.7 & 4.9084 & TST \\
\hline CHEMBL1491434 & 688323 & 4.6 & 4.8979 & TST \\
\hline CHEMBL1526126 & 688323 & 5.7 & 4.762 & TRN \\
\hline CHEMBL1384544 & 688323 & 4.5 & 4.7607 & TRN \\
\hline CHEMBL1411472 & 688323 & 4.65 & 4.8023 & TRN \\
\hline CHEMBL1329962 & 688323 & 4.5 & 4.7654 & TRN \\
\hline CHEMBL1605599 & 688323 & 4.45 & 4.77 & TRN \\
\hline CHEMBL590427 & 688323 & 6.15 & 4.8612 & TST \\
\hline CHEMBL1420871 & 688323 & 4.8 & 4.8301 & TRN \\
\hline
\end{tabular}




\begin{tabular}{|c|c|c|c|c|}
\hline \multicolumn{5}{|c|}{ Supplemental Table s2.txt } \\
\hline CHEMBL1501288 & 688323 & 5.1 & 4.9236 & TRN \\
\hline CHEMBL1331498 & 688323 & 4.5 & 4.8615 & TST \\
\hline CHEMBL1484163 & 688323 & 4.5 & 4.7873 & TRN \\
\hline CHEMBL1595001 & 688323 & 4.5 & 4.823 & TRN \\
\hline CHEMBL1524103 & 688323 & 4.75 & 4.8083 & TRN \\
\hline CHEMBL1593614 & 688323 & 4.45 & 4.6707 & TRN \\
\hline CHEMBL1322624 & 688323 & 4.65 & 5.2105 & TRN \\
\hline CHEMBL1466743 & 688323 & 4.6 & 4.6935 & TST \\
\hline CHEMBL1388542 & 688323 & 4.5 & 4.9099 & TRN \\
\hline CHEMBL1436855 & 688323 & 5.2 & 4.5237 & TRN \\
\hline CHEMBL1493410 & 688323 & 4.65 & 4.8105 & TRN \\
\hline CHEMBL1499361 & 688323 & 4.9 & 4.8843 & TRN \\
\hline CHEMBL1398517 & 688323 & 4.7 & 4.6752 & TRN \\
\hline CHEMBL1606236 & 688323 & 4.45 & 4.7854 & TRN \\
\hline CHEMBL1315108 & 688323 & 4.6 & 4.8528 & TRN \\
\hline CHEMBL1470633 & 688323 & 5.0 & 4.8773 & TRN \\
\hline CHEMBL1939687 & 688323 & 4.5 & 4.6759 & TRN \\
\hline CHEMBL1314976 & 688323 & 4.95 & 4.6357 & TRN \\
\hline CHEMBL1418179 & 688323 & 4.5 & 4.9249 & TRN \\
\hline CHEMBL1604522 & 688323 & 5.0 & 4.8429 & TRN \\
\hline CHEMBL1444398 & 688323 & 4.85 & 4.8959 & TST \\
\hline CHEMBL1301811 & 688323 & 5.25 & 4.8642 & TRN \\
\hline CHEMBL1576289 & 688323 & 4.55 & 4.7787 & TRN \\
\hline CHEMBL1563283 & 688323 & 4.5 & 4.7933 & TRN \\
\hline CHEMBL1580769 & 688323 & 4.95 & 5.013 & TRN \\
\hline CHEMBL1366086 & 688323 & 5.4 & 4.9053 & TRN \\
\hline CHEMBL1575735 & 688323 & 4.45 & 4.6018 & TRN \\
\hline CHEMBL1508807 & 688323 & 4.6 & 5.2368 & TRN \\
\hline CHEMBL1512662 & 688323 & 4.45 & 4.6142 & TRN \\
\hline CHEMBL1483654 & 688323 & 5.45 & 4.8322 & TRN \\
\hline CHEMBL1515385 & 688323 & 5.9 & 4.8637 & TST \\
\hline CHEMBL1337221 & 688323 & 4.45 & 4.8138 & TRN \\
\hline CHEMBL1319391 & 688323 & 4.45 & 4.7503 & TRN \\
\hline CHEMBL1371298 & 688323 & 4.45 & 4.8576 & TRN \\
\hline CHEMBL1590536 & 688323 & 4.45 & 4.7744 & TRN \\
\hline CHEMBL1516917 & 688323 & 4.75 & 4.6563 & TRN \\
\hline CHEMBL1478711 & 688323 & 4.8 & 4.6798 & TRN \\
\hline CHEMBL1579347 & 688323 & 4.75 & 4.7648 & TRN \\
\hline CHEMBL1533225 & 688323 & 4.55 & 4.6872 & TRN \\
\hline CHEMBL1558621 & 688323 & 4.8 & 4.6709 & TST \\
\hline CHEMBL1310549 & 688323 & 4.45 & 4.8415 & TRN \\
\hline CHEMBL1590004 & 688323 & 5.4 & 4.8563 & TST \\
\hline CHEMBL1403086 & 688323 & 4.5 & 4.7363 & TRN \\
\hline CHEMBL1989760 & 688323 & 4.5 & 4.4877 & TRN \\
\hline CHEMBL3925157 & 688323 & 4.45 & 4.7482 & TRN \\
\hline CHEMBL1423498 & 688323 & 4.55 & 4.7837 & TST \\
\hline CHEMBL1590145 & 688323 & 4.45 & 4.5263 & TRN \\
\hline CHEMBL1571859 & 688323 & 4.75 & 4.8436 & TST \\
\hline
\end{tabular}




\begin{tabular}{|c|c|c|c|c|c|}
\hline & & \multicolumn{4}{|c|}{ Supplemental Table S2.txt } \\
\hline CHEMBL1441921 & 688323 & 5.5 & 4.773 & TRN & \\
\hline CHEMBL1405039 & 688323 & 4.5 & 4.8022 & TRN & \\
\hline CHEMBL1434116 & 688323 & 5.25 & 5.044 & TRN & \\
\hline CHEMBL1357400 & 688323 & 5.4 & 4.5659 & TRN & \\
\hline CHEMBL3210072 & 688323 & 4.8 & 5.0836 & TRN & \\
\hline CHEMBL1355977 & 688323 & 4.6 & 4.7044 & TRN & \\
\hline CHEMBL1479026 & 688323 & 4.7 & 4.944 & TRN & \\
\hline CHEMBL3210043 & 688323 & 4.45 & 4.9087 & TRN & \\
\hline CHEMBL1442562 & 688323 & 6.05 & 4.9287 & TRN & \\
\hline CHEMBL1713905 & 688323 & 5.0 & 4.8937 & TST & \\
\hline CHEMBL1384397 & 688323 & 4.45 & 4.6767 & TRN & \\
\hline CHEMBL1395382 & 688323 & 4.55 & 4.7467 & TRN & \\
\hline CHEMBL1386348 & 688323 & 5.0 & 4.8429 & TRN & \\
\hline CHEMBL1581684 & 688323 & 5.1 & 4.5331 & TRN & \\
\hline CHEMBL 2005437 & 688323 & 5.05 & 4.7556 & TRN & \\
\hline CHEMBL1459766 & 688323 & 4.5 & 4.8953 & TRN & \\
\hline CHEMBL1426350 & 688323 & 5.4 & 4.9466 & TRN & \\
\hline CHEMBL1613112 & 688323 & 4.5 & 4.7011 & TRN & \\
\hline CHEMBL1592794 & 688323 & 4.7 & 4.6619 & TRN & \\
\hline CHEMBL1311453 & 688323 & 4.55 & 4.612 & TRN & \\
\hline CHEMBL3212972 & 688323 & 4.45 & 4.7059 & TST & \\
\hline CHEMBL1371318 & 688323 & 4.6 & 5.019 & TRN & \\
\hline CHEMBL1513346 & 688323 & 4.45 & 4.789 & TRN & \\
\hline CHEMBL1361827 & 688323 & 4.45 & 4.8101 & TRN & \\
\hline CHEMBL1303288 & 688323 & 4.95 & 4.9512 & TRN & \\
\hline CHEMBL1461922 & 688323 & 6.15 & 4.8338 & TRN & \\
\hline CHEMBL1451532 & 688323 & 5.0 & 5.0028 & TST & \\
\hline CHEMBL1534804 & 688323 & 4.7 & 4.6025 & TRN & \\
\hline CHEMBL 3209441 & 688323 & 4.6 & 4.8665 & TRN & \\
\hline CHEMBL1420406 & 688323 & 4.95 & 4.6849 & TRN & \\
\hline CHEMBL1351502 & 688323 & 4.5 & 5.1132 & TRN & \\
\hline CHEMBL1507506 & 688323 & 5.0 & 4.9181 & TRN & \\
\hline CHEMBL1364137 & 688323 & 4.45 & 4.636 & TRN & \\
\hline CHEMBL1411653 & 688323 & 4.7 & 4.7148 & TRN & \\
\hline CHEMBL1408389 & 688323 & 4.45 & 4.825 & TRN & \\
\hline CHEMBL1997585 & 688323 & 4.5 & 4.65300 & 00000000005 & TRN \\
\hline CHEMBL1480401 & 688323 & 4.45 & 4.7613 & TRN & \\
\hline CHEMBL1558301 & 688323 & 5.05 & 4.8123 & TRN & \\
\hline CHEMBL116438 & 688323 & 6.0 & 4.7549 & TRN & \\
\hline CHEMBL1964978 & 688323 & 4.45 & 4.5184 & TRN & \\
\hline CHEMBL1482634 & 688323 & 4.7 & 4.8085 & TST & \\
\hline CHEMBL1512013 & 688323 & 4.5 & 4.5768 & TRN & \\
\hline CHEMBL598263 & 688323 & 6.3 & 5.0069 & TST & \\
\hline CHEMBL1348406 & 688323 & 4.85 & 5.0084 & TRN & \\
\hline CHEMBL1508086 & 688323 & 4.55 & 4.6434 & TRN & \\
\hline CHEMBL1307735 & 688323 & 4.45 & 4.8032 & TRN & \\
\hline CHEMBL1602829 & 688323 & 4.85 & 5.115 & TST & \\
\hline CHEMBL1498599 & 688323 & 5.25 & 5.0135 & TRN & \\
\hline
\end{tabular}




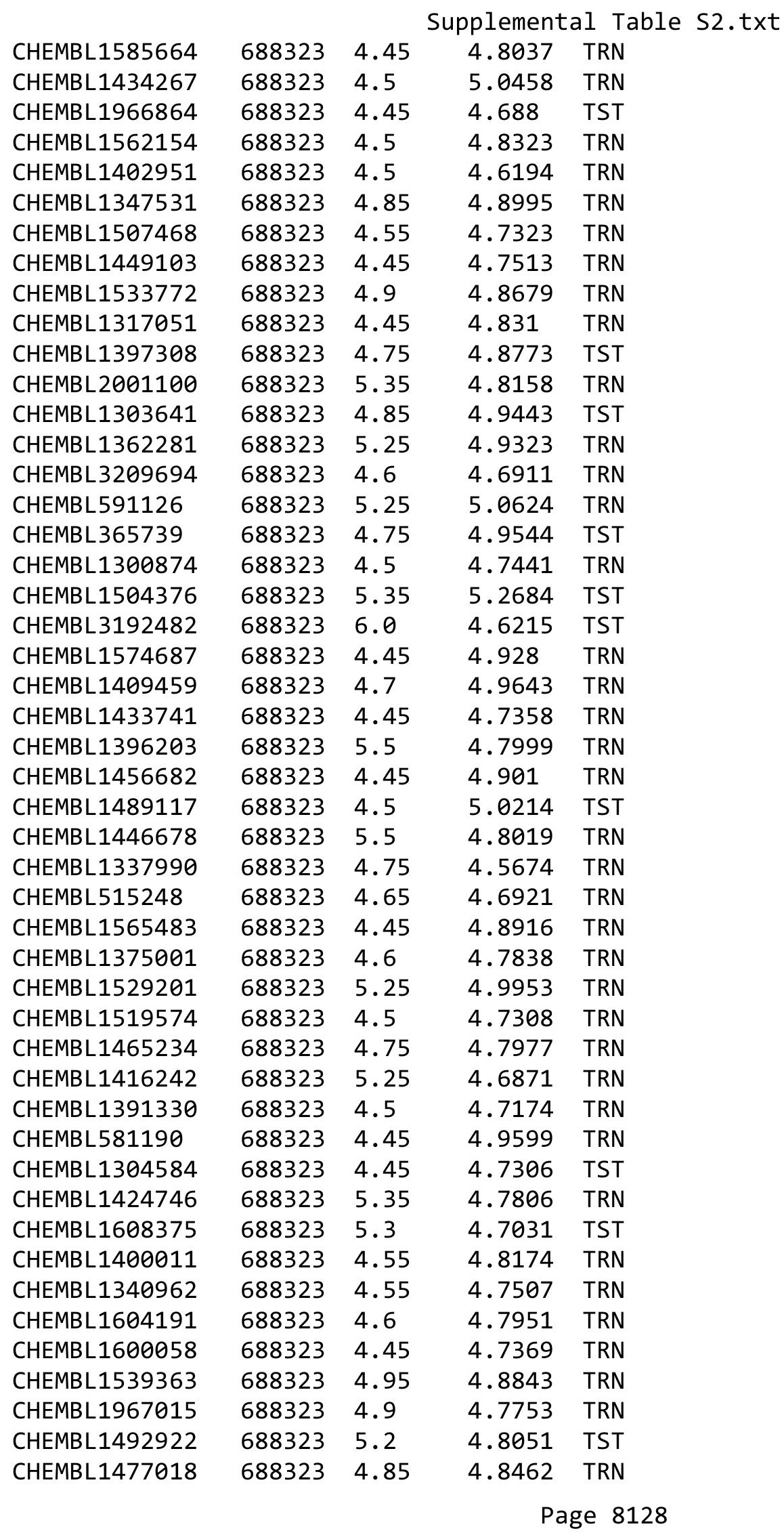




\begin{tabular}{|c|c|c|c|c|c|}
\hline & & \multicolumn{4}{|c|}{ Supplemental Table S2.txt } \\
\hline CHEMBL1589299 & 688323 & 4.45 & 4.583 & TRN & \\
\hline CHEMBL1508622 & 688323 & 4.5 & 4.9312 & TRN & \\
\hline CHEMBL1527794 & 688323 & 4.45 & 4.8082 & TRN & \\
\hline CHEMBL1482055 & 688323 & 4.45 & 4.7141 & TRN & \\
\hline CHEMBL1369069 & 688323 & 5.2 & 4.8353 & TRN & \\
\hline CHEMBL1556796 & 688323 & 4.5 & 4.81800 & 00000000005 & TRN \\
\hline CHEMBL1378237 & 688323 & 4.7 & 4.7811 & TRN & \\
\hline CHEMBL1990081 & 688323 & 4.5 & 4.6599 & TRN & \\
\hline CHEMBL1426233 & 688323 & 4.8 & 4.5852 & TRN & \\
\hline CHEMBL1396853 & 688323 & 4.45 & 4.7541 & TRN & \\
\hline CHEMBL1308657 & 688323 & 5.15 & 4.8644 & TRN & \\
\hline CHEMBL1496828 & 688323 & 4.45 & 4.9081 & TRN & \\
\hline CHEMBL1590726 & 688323 & 4.45 & 4.7315 & TRN & \\
\hline CHEMBL1483095 & 688323 & 4.65 & 4.6941 & TRN & \\
\hline CHEMBL455284 & 688323 & 5.25 & 5.0763 & TRN & \\
\hline CHEMBL1593983 & 688323 & 4.6 & 4.905 & TST & \\
\hline CHEMBL1571258 & 688323 & 4.45 & 4.7546 & TRN & \\
\hline CHEMBL1323097 & 688323 & 4.45 & 5.0497 & TRN & \\
\hline CHEMBL1429003 & 688323 & 4.5 & 4.8704 & TRN & \\
\hline CHEMBL1453276 & 688323 & 4.5 & 4.6618 & TST & \\
\hline CHEMBL1499860 & 688323 & 4.5 & 4.9475 & TRN & \\
\hline CHEMBL1457888 & 688323 & 5.4 & 4.9303 & TST & \\
\hline CHEMBL1509674 & 688323 & 4.55 & 4.7388 & TRN & \\
\hline CHEMBL1534269 & 688323 & 5.65 & 4.8015 & TST & \\
\hline CHEMBL1492284 & 688323 & 4.45 & 4.5148 & TRN & \\
\hline CHEMBL1359982 & 688323 & 4.45 & 4.7448 & TRN & \\
\hline CHEMBL1566515 & 688323 & 5.35 & 4.9313 & TRN & \\
\hline CHEMBL1356735 & 688323 & 4.95 & 4.6708 & TRN & \\
\hline CHEMBL1555911 & 688323 & 4.5 & 4.7776 & TST & \\
\hline CHEMBL1987895 & 688323 & 4.5 & 4.6495 & TRN & \\
\hline CHEMBL1968467 & 688323 & 5.15 & 4.5576 & TST & \\
\hline CHEMBL610198 & 688323 & 5.4 & 4.9536 & TST & \\
\hline CHEMBL1576852 & 688323 & 4.6 & 4.8119 & TRN & \\
\hline CHEMBL1548996 & 688323 & 4.45 & 4.6454 & TST & \\
\hline CHEMBL1367420 & 688323 & 4.55 & 4.8785 & TRN & \\
\hline CHEMBL1404423 & 688323 & 4.55 & 4.7903 & TRN & \\
\hline CHEMBL1355324 & 688323 & 4.65 & 4.79 & TRN & \\
\hline CHEMBL1603669 & 688323 & 4.55 & 4.6641 & TST & \\
\hline CHEMBL1540861 & 688323 & 4.45 & 4.8042 & TRN & \\
\hline CHEMBL1463795 & 688323 & 5.2 & 5.026 & TST & \\
\hline CHEMBL1389616 & 688323 & 4.45 & 4.6166 & TRN & \\
\hline CHEMBL1465583 & 688323 & 5.25 & 4.7491 & TRN & \\
\hline CHEMBL1323584 & 688323 & 5.45 & 5.1389 & TRN & \\
\hline CHEMBL1519427 & 688323 & 4.8 & 4.6953 & TRN & \\
\hline CHEMBL1461902 & 688323 & 4.65 & 5.1176 & TRN & \\
\hline CHEMBL1513298 & 688323 & 4.95 & 4.6791 & TRN & \\
\hline CHEMBL1411558 & 688323 & 5.2 & 4.9737 & TST & \\
\hline CHEMBL1464239 & 688323 & 4.45 & 4.6557 & TRN & \\
\hline
\end{tabular}




\begin{tabular}{|c|c|c|c|c|}
\hline \multicolumn{5}{|c|}{ Supplemental Table S2.txt } \\
\hline CHEMBL1313822 & 688323 & 6.2 & 4.7214 & TRN \\
\hline CHEMBL1311961 & 688323 & 5.1 & 4.7414 & TRN \\
\hline CHEMBL3212741 & 688323 & 4.45 & 4.5437 & TRN \\
\hline CHEMBL1605917 & 688323 & 4.55 & 4.8035 & TRN \\
\hline CHEMBL1306089 & 688323 & 4.6 & 5.0149 & TRN \\
\hline CHEMBL1355130 & 688323 & 5.15 & 4.9543 & TRN \\
\hline CHEMBL1565526 & 688323 & 5.45 & 4.7404 & TRN \\
\hline CHEMBL1604794 & 688323 & 4.45 & 4.725 & TRN \\
\hline CHEMBL1587229 & 688323 & 4.45 & 4.8119 & TRN \\
\hline CHEMBL1600898 & 688323 & 5.9 & 4.8521 & TRN \\
\hline CHEMBL1510433 & 688323 & 4.65 & 4.9211 & TRN \\
\hline CHEMBL1412448 & 688323 & 4.6 & 4.8592 & TRN \\
\hline CHEMBL1584754 & 688323 & 4.8 & 4.9345 & TST \\
\hline CHEMBL 3144896 & 688323 & 4.45 & 4.8344 & TRN \\
\hline CHEMBL1544912 & 688323 & 5.3 & 5.075 & TRN \\
\hline CHEMBL1600984 & 688323 & 5.85 & 4.7655 & TRN \\
\hline CHEMBL1529115 & 688323 & 5.25 & 4.7877 & TRN \\
\hline CHEMBL1418286 & 688323 & 4.5 & 4.6556 & TRN \\
\hline CHEMBL1507846 & 688323 & 4.5 & 4.6897 & TRN \\
\hline CHEMBL1967857 & 688323 & 4.5 & 4.7191 & TRN \\
\hline CHEMBL1586030 & 688323 & 5.0 & 4.9132 & TRN \\
\hline CHEMBL1404976 & 688323 & 4.6 & 4.8282 & TRN \\
\hline CHEMBL1444096 & 688323 & 4.6 & 4.9596 & TRN \\
\hline CHEMBL1393319 & 688323 & 4.65 & 4.9376 & TRN \\
\hline CHEMBL1969851 & 688323 & 4.5 & 4.8379 & TRN \\
\hline CHEMBL1314955 & 688323 & 4.55 & 4.7769 & TRN \\
\hline CHEMBL1413252 & 688323 & 4.5 & 4.7125 & TST \\
\hline CHEMBL1608041 & 688323 & 5.0 & 4.8747 & TRN \\
\hline CHEMBL1404688 & 688323 & 5.0 & 4.7978 & TRN \\
\hline CHEMBL1325966 & 688323 & 7.3002 & 4.8038 & TRN \\
\hline CHEMBL1404086 & 688323 & 4.55 & 4.6096 & TRN \\
\hline CHEMBL1436406 & 688323 & 4.45 & 4.8533 & TRN \\
\hline CHEMBL1557305 & 688323 & 5.2 & 4.9324 & TRN \\
\hline CHEMBL1434205 & 688323 & 4.45 & 4.6042 & TRN \\
\hline CHEMBL1470256 & 688323 & 5.95 & 4.9605 & TRN \\
\hline CHEMBL1483344 & 688323 & 6.0 & 5.0016 & TRN \\
\hline CHEMBL1420829 & 688323 & 4.5 & 4.8022 & TRN \\
\hline CHEMBL1503786 & 688323 & 4.45 & 4.7004 & TRN \\
\hline CHEMBL1417970 & 688323 & 5.25 & 4.7849 & TRN \\
\hline CHEMBL1446638 & 688323 & 4.45 & 4.95 & TRN \\
\hline CHEMBL1408355 & 688323 & 5.15 & 4.8644 & TRN \\
\hline CHEMBL1600562 & 688323 & 4.45 & 4.6868 & TRN \\
\hline CHEMBL1610395 & 688323 & 4.45 & 4.8454 & TRN \\
\hline CHEMBL1309478 & 688323 & 4.45 & 4.7033 & TRN \\
\hline CHEMBL1327966 & 688323 & 4.5 & 4.9776 & TRN \\
\hline CHEMBL1368193 & 688323 & 4.7 & 4.7779 & TRN \\
\hline CHEMBL1411167 & 688323 & 6.25 & 4.9666 & TRN \\
\hline CHEMBL1593139 & 688323 & 4.45 & 5.0882 & TRN \\
\hline
\end{tabular}




\begin{tabular}{|c|c|c|c|c|c|}
\hline & & \multicolumn{4}{|c|}{ Supplemental Table s2.txt } \\
\hline CHEMBL1987092 & 688323 & 4.45 & 4.638 & TRN & \\
\hline CHEMBL1547166 & 688323 & 4.85 & 4.9841 & TRN & \\
\hline CHEMBL1448302 & 688323 & 4.5 & 4.6338 & TRN & \\
\hline CHEMBL1578178 & 688323 & 4.45 & 4.7307 & TST & \\
\hline CHEMBL1322784 & 688323 & 4.45 & 4.72 & TRN & \\
\hline CHEMBL1353297 & 688323 & 4.45 & 5.0233 & TRN & \\
\hline CHEMBL3198793 & 688323 & 4.75 & 4.7043 & TRN & \\
\hline CHEMBL1986363 & 688323 & 4.45 & 4.6221 & TRN & \\
\hline CHEMBL1412429 & 688323 & 4.95 & 4.7464 & TRN & \\
\hline CHEMBL1609070 & 688323 & 4.45 & 4.8114 & TRN & \\
\hline CHEMBL1369134 & 688323 & 4.5 & 4.6382 & TRN & \\
\hline CHEMBL1590762 & 688323 & 4.55 & 4.7045 & TST & \\
\hline CHEMBL1410248 & 688323 & 5.85 & 5.2138 & TRN & \\
\hline CHEMBL1408320 & 688323 & 4.45 & 4.7863 & TRN & \\
\hline CHEMBL1602052 & 688323 & 5.25 & 4.8614 & TRN & \\
\hline CHEMBL1999810 & 688323 & 4.5 & 4.7029 & TRN & \\
\hline CHEMBL1562605 & 688323 & 4.5 & 4.707 & TRN & \\
\hline CHEMBL1452707 & 688323 & 5.45 & 4.9743 & TST & \\
\hline CHEMBL1494191 & 688323 & 4.75 & 4.8422 & TST & \\
\hline CHEMBL1354848 & 688323 & 4.45 & 4.979 & TRN & \\
\hline CHEMBL336467 & 688323 & 5.2 & 4.9147 & TST & \\
\hline CHEMBL1437744 & 688323 & 4.7 & 4.5401 & TRN & \\
\hline CHEMBL1541411 & 688323 & 5.15 & 4.7303 & TRN & \\
\hline CHEMBL1515058 & 688323 & 5.0 & 4.6098 & TRN & \\
\hline CHEMBL1473332 & 688323 & 4.7 & 4.8819 & TRN & \\
\hline CHEMBL1314834 & 688323 & 4.55 & 4.6738 & TRN & \\
\hline CHEMBL1999437 & 688323 & 4.65 & 4.8093 & TST & \\
\hline CHEMBL1504138 & 688323 & 4.45 & 4.6883 & TRN & \\
\hline CHEMBL1990748 & 688323 & 4.9 & 4.6584 & TRN & \\
\hline CHEMBL1577044 & 688323 & 5.3 & 4.7978 & TRN & \\
\hline CHEMBL1584363 & 688323 & 4.55 & 4.8419 & TRN & \\
\hline CHEMBL1412237 & 688323 & 4.55 & 4.5675 & TRN & \\
\hline CHEMBL1481822 & 688323 & 4.5 & 4.7265 & TRN & \\
\hline CHEMBL1387355 & 688323 & 4.45 & 4.7423 & TRN & \\
\hline CHEMBL1363883 & 688323 & 5.25 & 4.7631 & TST & \\
\hline CHEMBL1442746 & 688323 & 4.75 & 4.8611 & TRN & \\
\hline CHEMBL1459840 & 688323 & 5.2 & 4.8892 & TRN & \\
\hline CHEMBL1983266 & 688323 & 5.45 & 4.7481 & TRN & \\
\hline CHEMBL3192170 & 688323 & 4.65 & 4.7206 & TRN & \\
\hline CHEMBL1318421 & 688323 & 5.25 & 4.7323 & TST & \\
\hline CHEMBL1440500 & 688323 & 4.5 & 4.9019 & TRN & \\
\hline CHEMBL1300283 & 688323 & 4.45 & 4.5680 & 00000000005 & TRN \\
\hline CHEMBL1536935 & 688323 & 4.45 & 4.6499 & TST & \\
\hline CHEMBL1971674 & 688323 & 4.8 & 4.5923 & TRN & \\
\hline CHEMBL1316788 & 688323 & 4.85 & 4.8128 & TRN & \\
\hline CHEMBL3212159 & 688323 & 4.5 & 4.7451 & TRN & \\
\hline CHEMBL1592126 & 688323 & 5.4 & 5.0195 & TRN & \\
\hline CHEMBL1572627 & 688323 & 4.45 & 4.9795 & TRN & \\
\hline
\end{tabular}




\begin{tabular}{|c|c|c|c|c|c|}
\hline & & \multicolumn{4}{|c|}{ Supplemental Table S2.txt } \\
\hline CHEMBL3190280 & 688323 & 4.55 & 4.5925 & TST & \\
\hline CHEMBL1513969 & 688323 & 4.45 & 4.7805 & TRN & \\
\hline CHEMBL1458112 & 688323 & 4.45 & 4.822 & TRN & \\
\hline CHEMBL1467195 & 688323 & 4.5 & 4.7887 & TRN & \\
\hline CHEMBL1414599 & 688323 & 4.45 & 4.6284 & TRN & \\
\hline CHEMBL1299629 & 688323 & 4.6 & 4.9021 & TRN & \\
\hline CHEMBL1455720 & 688323 & 4.45 & 4.68199 & 99999999995 & TRN \\
\hline CHEMBL1613601 & 688323 & 4.55 & 4.6472 & TRN & \\
\hline CHEMBL1526982 & 688323 & 4.8 & 4.4295 & TRN & \\
\hline CHEMBL1557752 & 688323 & 5.35 & 5.0133 & TRN & \\
\hline CHEMBL1477578 & 688323 & 5.4 & 4.8896 & TRN & \\
\hline CHEMBL1442271 & 688323 & 4.55 & 5.0064 & TRN & \\
\hline CHEMBL1422647 & 688323 & 4.65 & 5.0563 & TRN & \\
\hline CHEMBL1459360 & 688323 & 4.8 & 4.7538 & TST & \\
\hline CHEMBL1419721 & 688323 & 4.6 & 4.462 & TST & \\
\hline CHEMBL1390607 & 688323 & 4.45 & 4.8725 & TRN & \\
\hline CHEMBL1433343 & 688323 & 5.45 & 4.8977 & TRN & \\
\hline CHEMBL1546596 & 688323 & 4.55 & 4.9391 & TST & \\
\hline CHEMBL1531495 & 688323 & 4.85 & 4.7065 & TRN & \\
\hline CHEMBL1394187 & 688323 & 4.8 & 5.1421 & TST & \\
\hline CHEMBL1443946 & 688323 & 4.5 & 5.0785 & TRN & \\
\hline CHEMBL1554500 & 688323 & 5.0 & 4.9585 & TRN & \\
\hline CHEMBL1441675 & 688323 & 5.75 & 4.9568 & TST & \\
\hline CHEMBL1984298 & 688323 & 4.65 & 4.5601 & TRN & \\
\hline CHEMBL565657 & 688323 & 4.55 & 4.8812 & TRN & \\
\hline CHEMBL1475554 & 688323 & 4.45 & 4.6172 & TRN & \\
\hline CHEMBL1625031 & 688323 & 5.4 & 5.1915 & TRN & \\
\hline CHEMBL605077 & 688323 & 5.6 & 4.9751 & TST & \\
\hline CHEMBL1606022 & 688323 & 4.8 & 4.6864 & TRN & \\
\hline CHEMBL1484167 & 688323 & 4.45 & 5.0048 & TRN & \\
\hline CHEMBL1506956 & 688323 & 5.4 & 4.9423 & TRN & \\
\hline CHEMBL3190594 & 688323 & 4.6 & 4.8239 & TRN & \\
\hline CHEMBL1401657 & 688323 & 4.9 & 4.9422 & TRN & \\
\hline CHEMBL1437782 & 688323 & 5.25 & 4.8597 & TST & \\
\hline CHEMBL1588786 & 688323 & 4.45 & 4.8352 & TRN & \\
\hline CHEMBL1463441 & 688323 & 4.55 & 4.9545 & TRN & \\
\hline CHEMBL3207795 & 688323 & 5.15 & 4.7732 & TST & \\
\hline CHEMBL1583531 & 688323 & 4.95 & 4.7558 & TRN & \\
\hline CHEMBL1574899 & 688323 & 5.4 & 4.8127 & TRN & \\
\hline CHEMBL 2004056 & 688323 & 4.75 & 4.9054 & TRN & \\
\hline CHEMBL448741 & 688323 & 4.45 & 5.0466 & TST & \\
\hline CHEMBL227881 & 688323 & 4.45 & 4.6454 & TRN & \\
\hline CHEMBL3145299 & 688323 & 4.9 & 4.6862 & TRN & \\
\hline CHEMBL1393332 & 688323 & 6.0 & 4.7198 & TRN & \\
\hline CHEMBL1350240 & 688323 & 4.65 & 4.7803 & TRN & \\
\hline CHEMBL1332191 & 688323 & 4.45 & 4.968 & TST & \\
\hline CHEMBL1524454 & 688323 & 4.55 & 4.7915 & TRN & \\
\hline CHEMBL1534704 & 688323 & 4.7 & 4.6984 & TRN & \\
\hline
\end{tabular}




\begin{tabular}{|c|c|c|c|c|}
\hline \multicolumn{5}{|c|}{ Supplemental Table } \\
\hline CHEMBL1457588 & 688323 & 5.25 & 4.7938 & TRN \\
\hline CHEMBL1509233 & 688323 & 4.6 & 4.8074 & TRN \\
\hline CHEMBL1443458 & 688323 & 5.25 & 4.9417 & TRN \\
\hline CHEMBL1377886 & 688323 & 4.45 & 4.9747 & TRN \\
\hline CHEMBL1538242 & 688323 & 4.45 & 5.0911 & TST \\
\hline CHEMBL1319047 & 688323 & 4.45 & 4.9179 & TRN \\
\hline CHEMBL1518985 & 688323 & 4.45 & 4.7129 & TRN \\
\hline CHEMBL1336262 & 688323 & 4.6 & 4.738 & TRN \\
\hline CHEMBL1309068 & 688323 & 4.45 & 4.707 & TRN \\
\hline CHEMBL1588352 & 688323 & 4.5 & 4.565 & TRN \\
\hline CHEMBL1574208 & 688323 & 4.45 & 4.7913 & TRN \\
\hline CHEMBL1451944 & 688323 & 4.5 & 4.5989 & TRN \\
\hline CHEMBL1508252 & 688323 & 5.4 & 4.8373 & TRN \\
\hline CHEMBL 20562 & 688323 & 4.6 & 5.0645 & TST \\
\hline CHEMBL1472601 & 688323 & 4.6 & 4.8657 & TRN \\
\hline CHEMBL1317129 & 688323 & 4.75 & 4.5908 & TRN \\
\hline CHEMBL1429437 & 688323 & 4.75 & 4.8833 & TRN \\
\hline CHEMBL1341130 & 688323 & 4.55 & 5.0029 & TRN \\
\hline CHEMBL1359346 & 688323 & 4.9 & 4.7382 & TRN \\
\hline CHEMBL1540401 & 688323 & 4.55 & 4.8071 & TRN \\
\hline CHEMBL151946 & 688323 & 4.5 & 4.8998 & TRN \\
\hline CHEMBL1473410 & 688323 & 4.5 & 4.7818 & TRN \\
\hline CHEMBL1503292 & 688323 & 5.25 & 4.9836 & TRN \\
\hline CHEMBL1580897 & 688323 & 4.8 & 5.153 & TRN \\
\hline CHEMBL1310717 & 688323 & 5.5 & 4.9752 & TRN \\
\hline CHEMBL1525485 & 688323 & 4.45 & 4.6375 & TRN \\
\hline CHEMBL 296586 & 688323 & 6.0 & 4.4714 & TST \\
\hline CHEMBL1476914 & 688323 & 4.45 & 4.8883 & TRN \\
\hline CHEMBL1513563 & 688323 & 4.45 & 4.6754 & TRN \\
\hline CHEMBL1479316 & 688323 & 6.2 & 5.0947 & TRN \\
\hline CHEMBL1491710 & 688323 & 4.45 & 4.5372 & TRN \\
\hline CHEMBL1426358 & 688323 & 4.8 & 5.042 & TRN \\
\hline CHEMBL1537100 & 688323 & 4.45 & 4.7484 & TRN \\
\hline CHEMBL3191552 & 688323 & 4.7 & 4.7538 & TRN \\
\hline CHEMBL1423500 & 688323 & 4.65 & 4.8186 & TST \\
\hline CHEMBL1583629 & 688323 & 4.5 & 4.5838 & TRN \\
\hline CHEMBL1997747 & 688323 & 5.0 & 4.9178 & TRN \\
\hline CHEMBL1977763 & 688323 & 4.55 & 4.7442 & TRN \\
\hline CHEMBL284742 & 688323 & 4.5 & 4.9628 & TRN \\
\hline CHEMBL1563561 & 688323 & 5.25 & 4.7572 & TRN \\
\hline CHEMBL 230056 & 688323 & 5.65 & 4.9669 & TST \\
\hline CHEMBL1500315 & 688323 & 4.45 & 4.7416 & TRN \\
\hline CHEMBL 2000670 & 688323 & 4.5 & 4.7223 & TRN \\
\hline CHEMBL1596914 & 688323 & 4.7 & 4.8844 & TRN \\
\hline CHEMBL1569877 & 688323 & 4.45 & 5.0246 & TRN \\
\hline CHEMBL1315303 & 688323 & 4.45 & 4.9138 & TRN \\
\hline CHEMBL1445640 & 688323 & 4.6 & 4.8144 & TRN \\
\hline CHEMBL1469245 & 688323 & 4.5 & 4.6848 & TRN \\
\hline
\end{tabular}




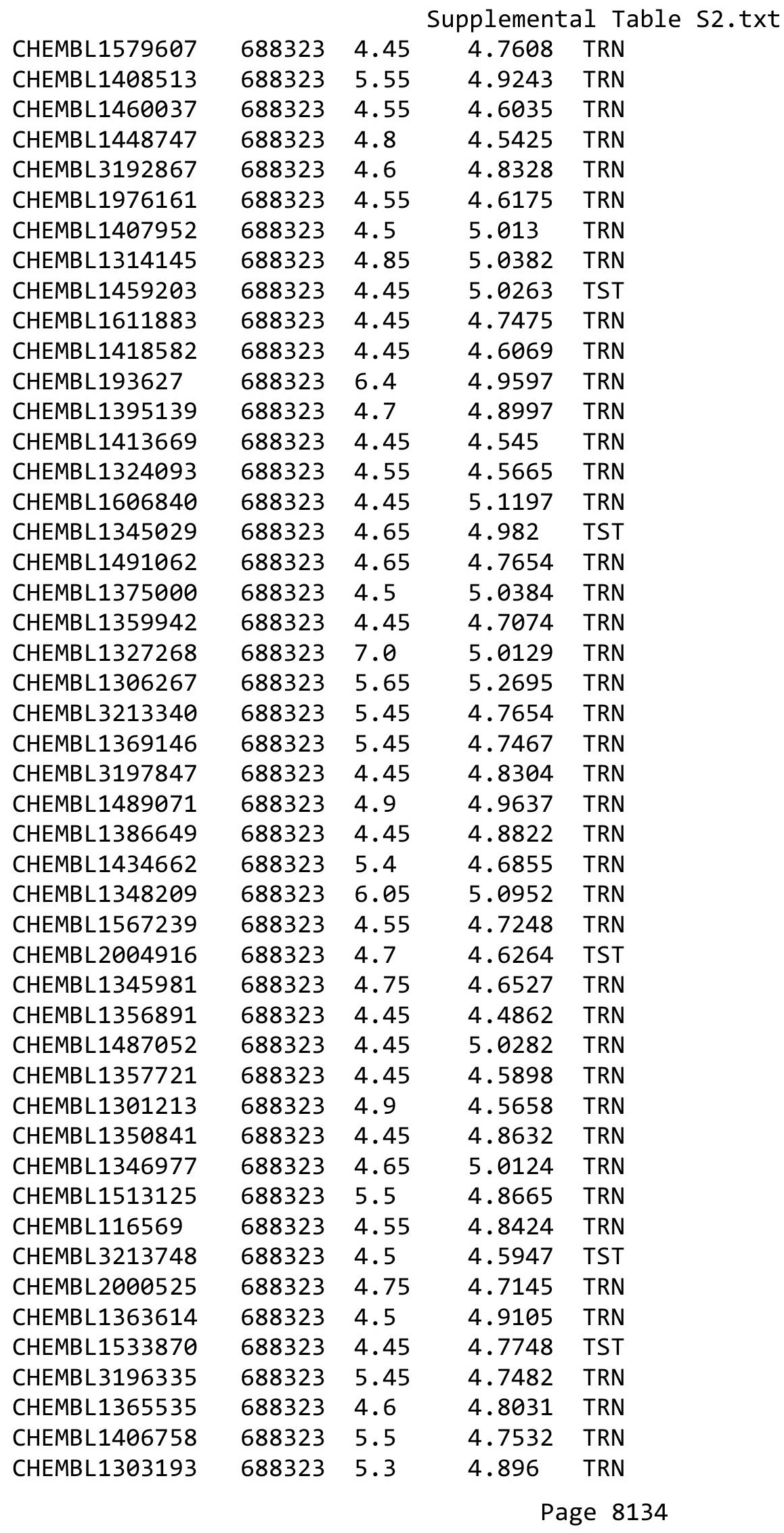




\begin{tabular}{|c|c|c|c|c|}
\hline \multicolumn{5}{|c|}{ Supplemental Table S2.txt } \\
\hline CHEMBL1513889 & 688323 & 4.5 & 4.8409 & TRN \\
\hline CHEMBL1172727 & 688323 & 4.5 & 4.7102 & TRN \\
\hline CHEMBL1323619 & 688323 & 4.75 & 4.7661 & TST \\
\hline CHEMBL1477495 & 688323 & 4.9 & 4.8128 & TRN \\
\hline CHEMBL3210006 & 688323 & 4.65 & 4.7074 & TRN \\
\hline CHEMBL1472661 & 688323 & 4.45 & 4.8173 & TRN \\
\hline CHEMBL1428367 & 688323 & 4.45 & 4.744 & TRN \\
\hline CHEMBL1568399 & 688323 & 4.6 & 4.851 & TRN \\
\hline CHEMBL1373821 & 688323 & 5.45 & 4.8558 & TRN \\
\hline CHEMBL1432794 & 688323 & 4.55 & 4.6295 & TRN \\
\hline CHEMBL1437037 & 688323 & 4.5 & 4.6581 & TST \\
\hline CHEMBL1358750 & 688323 & 4.7 & 4.7027 & TRN \\
\hline CHEMBL1473736 & 688323 & 4.6 & 4.6409 & TRN \\
\hline CHEMBL1995097 & 688323 & 4.5 & 4.5094 & TRN \\
\hline CHEMBL1349206 & 688323 & 5.25 & 4.6069 & TST \\
\hline CHEMBL1394323 & 688323 & 4.9 & 4.7288 & TRN \\
\hline CHEMBL1987106 & 688323 & 4.6 & 4.6279 & TRN \\
\hline CHEMBL1600766 & 688323 & 5.25 & 4.8144 & TRN \\
\hline CHEMBL1414210 & 688323 & 5.05 & 4.8404 & TRN \\
\hline CHEMBL1381814 & 688323 & 4.8 & 4.7889 & TST \\
\hline CHEMBL1380787 & 688323 & 5.55 & 5.1495 & TRN \\
\hline CHEMBL1475521 & 688323 & 5.15 & 4.6509 & TST \\
\hline CHEMBL1989414 & 688323 & 5.55 & 4.8281 & TRN \\
\hline CHEMBL1470712 & 688323 & 4.5 & 5.099 & TRN \\
\hline CHEMBL1314543 & 688323 & 4.45 & 5.0404 & TRN \\
\hline CHEMBL1604593 & 688323 & 5.25 & 4.723 & TST \\
\hline CHEMBL1307362 & 688323 & 4.6 & 4.7647 & TRN \\
\hline CHEMBL1385143 & 688323 & 4.5 & 4.8228 & TRN \\
\hline CHEMBL1479689 & 688323 & 4.8 & 5.0352 & TRN \\
\hline CHEMBL1524821 & 688323 & 4.45 & 4.9958 & TRN \\
\hline CHEMBL1606861 & 688323 & 4.45 & 4.9131 & TST \\
\hline CHEMBL1566613 & 688323 & 4.5 & 4.9195 & TRN \\
\hline CHEMBL1373780 & 688323 & 4.6 & 4.8053 & TRN \\
\hline CHEMBL1607596 & 688323 & 4.9 & 5.119 & TRN \\
\hline CHEMBL1354254 & 688323 & 4.75 & 4.8524 & TRN \\
\hline CHEMBL1350336 & 688323 & 4.45 & 4.9339 & TRN \\
\hline CHEMBL1407826 & 688323 & 5.05 & 5.0791 & TST \\
\hline CHEMBL1328822 & 688323 & 4.95 & 4.7908 & TRN \\
\hline CHEMBL1552979 & 688323 & 4.5 & 4.7107 & TRN \\
\hline CHEMBL1611783 & 688323 & 5.25 & 5.0219 & TRN \\
\hline CHEMBL1613209 & 688323 & 4.5 & 4.7784 & TRN \\
\hline CHEMBL1568243 & 688323 & 4.5 & 4.7276 & TRN \\
\hline CHEMBL1576489 & 688323 & 5.45 & 4.7494 & TRN \\
\hline CHEMBL1407417 & 688323 & 4.85 & 4.912 & TST \\
\hline CHEMBL1406159 & 688323 & 4.45 & 4.5255 & TRN \\
\hline CHEMBL1315329 & 688323 & 4.6 & 4.5644 & TRN \\
\hline CHEMBL1970824 & 688323 & 4.7 & 4.8105 & TRN \\
\hline CHEMBL1500101 & 688323 & 4.55 & 4.9738 & TRN \\
\hline
\end{tabular}




\begin{tabular}{|c|c|c|c|c|}
\hline \multicolumn{5}{|c|}{ Supplemental Table S2.txt } \\
\hline CHEMBL1452842 & 688323 & 6.4 & 5.007 & TRN \\
\hline CHEMBL1508982 & 688323 & 5.0 & 4.958 & TRN \\
\hline CHEMBL1337246 & 688323 & 4.7 & 4.9393 & TST \\
\hline CHEMBL1479923 & 688323 & 4.75 & 4.8496 & TRN \\
\hline CHEMBL1496432 & 688323 & 4.65 & 4.5688 & TRN \\
\hline CHEMBL1452571 & 688323 & 4.45 & 4.9244 & TRN \\
\hline CHEMBL1464396 & 688323 & 5.9 & 4.9542 & TRN \\
\hline CHEMBL1438388 & 688323 & 4.45 & 5.0676 & TRN \\
\hline CHEMBL1558607 & 688323 & 4.6 & 4.6545 & TRN \\
\hline CHEMBL1306076 & 688323 & 4.65 & 4.9612 & TRN \\
\hline CHEMBL1987510 & 688323 & 4.5 & 4.6186 & TRN \\
\hline CHEMBL1346468 & 688323 & 4.45 & 4.9324 & TRN \\
\hline CHEMBL1598910 & 688323 & 4.65 & 4.9015 & TRN \\
\hline CHEMBL1316831 & 688323 & 5.55 & 4.6566 & TST \\
\hline CHEMBL1451797 & 688323 & 4.8 & 4.9496 & TRN \\
\hline CHEMBL1576060 & 688323 & 4.6 & 4.8325 & TRN \\
\hline CHEMBL1465332 & 688323 & 4.45 & 4.7188 & TRN \\
\hline CHEMBL1325034 & 688323 & 4.6 & 5.1308 & TRN \\
\hline CHEMBL584074 & 688323 & 4.45 & 4.6659 & TRN \\
\hline CHEMBL1361821 & 688323 & 5.25 & 4.8427 & TRN \\
\hline CHEMBL1705518 & 688323 & 4.6 & 4.8371 & TRN \\
\hline CHEMBL1352285 & 688323 & 4.85 & 4.8741 & TRN \\
\hline CHEMBL3210913 & 688323 & 4.45 & 4.6943 & TST \\
\hline CHEMBL1334466 & 688323 & 4.65 & 4.7363 & TRN \\
\hline CHEMBL1316391 & 688323 & 4.45 & 4.6242 & TRN \\
\hline CHEMBL286721 & 688323 & 4.45 & 4.9086 & TST \\
\hline CHEMBL3210749 & 688323 & 4.85 & 4.6608 & TRN \\
\hline CHEMBL1549531 & 688323 & 5.05 & 4.7923 & TRN \\
\hline CHEMBL1572767 & 688323 & 4.95 & 4.8528 & TST \\
\hline CHEMBL1421655 & 688323 & 4.5 & 4.8858 & TST \\
\hline CHEMBL1569335 & 688323 & 5.25 & 4.9188 & TRN \\
\hline CHEMBL1494433 & 688323 & 4.45 & 4.897 & TRN \\
\hline CHEMBL1404932 & 688323 & 4.45 & 4.7451 & TST \\
\hline CHEMBL1301164 & 688323 & 4.65 & 4.4853 & TRN \\
\hline CHEMBL1556269 & 688323 & 4.75 & 4.8191 & TRN \\
\hline CHEMBL1504131 & 688323 & 4.55 & 4.8238 & TST \\
\hline CHEMBL1458690 & 688323 & 6.0 & 5.0053 & TRN \\
\hline CHEMBL1375846 & 688323 & 4.7 & 4.9658 & TRN \\
\hline CHEMBL1599451 & 688323 & 4.45 & 4.9281 & TRN \\
\hline CHEMBL1360348 & 688323 & 4.65 & 4.6168 & TRN \\
\hline CHEMBL1328807 & 688323 & 4.45 & 4.7242 & TRN \\
\hline CHEMBL1347724 & 688323 & 4.45 & 4.6558 & TRN \\
\hline CHEMBL1442280 & 688323 & 4.55 & 4.9358 & TRN \\
\hline CHEMBL1476522 & 688323 & 4.45 & 4.6803 & TRN \\
\hline CHEMBL1332802 & 688323 & 4.5 & 4.7346 & TRN \\
\hline CHEMBL1516858 & 688323 & 4.5 & 4.6912 & TRN \\
\hline CHEMBL1301016 & 688323 & 5.45 & 5.0059 & TRN \\
\hline CHEMBL1325745 & 688323 & 4.5 & 4.7586 & TRN \\
\hline
\end{tabular}




\begin{tabular}{|c|c|c|c|c|c|}
\hline & & \multicolumn{4}{|c|}{ Supplemental Table s2.txt } \\
\hline CHEMBL1591957 & 688323 & 4.85 & 4.6566 & TRN & \\
\hline CHEMBL1371615 & 688323 & 4.45 & 4.8379 & TRN & \\
\hline CHEMBL1477909 & 688323 & 4.6 & 4.9456 & TST & \\
\hline CHEMBL1408125 & 688323 & 4.65 & 4.5917 & TRN & \\
\hline CHEMBL1513634 & 688323 & 4.8 & 4.5325 & TRN & \\
\hline CHEMBL244683 & 688323 & 4.5 & 5.0582 & TRN & \\
\hline CHEMBL1397620 & 688323 & 4.45 & 4.9998 & TRN & \\
\hline CHEMBL528694 & 688323 & 6.3 & 5.019 & TRN & \\
\hline CHEMBL1308009 & 688323 & 5.5 & 4.6392 & TRN & \\
\hline CHEMBL1316433 & 688323 & 4.5 & 4.5812 & TRN & \\
\hline CHEMBL1591580 & 688323 & 5.0 & 4.7441 & TRN & \\
\hline CHEMBL 7976 & 688323 & 4.45 & 4.7092 & TRN & \\
\hline CHEMBL3192242 & 688323 & 4.8 & 4.7426 & TRN & \\
\hline CHEMBL1369159 & 688323 & 4.9 & 4.9388 & TST & \\
\hline CHEMBL3191354 & 688323 & 4.6 & 4.8588 & TRN & \\
\hline CHEMBL1376872 & 688323 & 6.05 & 4.666 & TRN & \\
\hline CHEMBL1425265 & 688323 & 4.45 & 4.7152 & TRN & \\
\hline CHEMBL 2369244 & 688323 & 4.65 & 4.77800 & 00000000005 & TST \\
\hline CHEMBL1433603 & 688323 & 4.45 & 4.7624 & TRN & \\
\hline CHEMBL1592769 & 688323 & 4.5 & 4.5974 & TRN & \\
\hline CHEMBL1361813 & 688323 & 4.6 & 4.5279 & TST & \\
\hline CHEMBL1429882 & 688323 & 4.65 & 4.9345 & TRN & \\
\hline CHEMBL1477915 & 688323 & 6.1 & 4.762 & TRN & \\
\hline CHEMBL1430266 & 688323 & 4.45 & 4.5883 & TRN & \\
\hline CHEMBL1586196 & 688323 & 4.8 & 5.0361 & TST & \\
\hline CHEMBL1991710 & 688323 & 4.6 & 4.7012 & TRN & \\
\hline CHEMBL1318384 & 688323 & 5.55 & 4.7883 & TRN & \\
\hline CHEMBL1408635 & 688323 & 4.8 & 4.7896 & TRN & \\
\hline CHEMBL1342830 & 688323 & 4.8 & 4.6007 & TST & \\
\hline CHEMBL1489368 & 688323 & 5.25 & 4.7548 & TRN & \\
\hline CHEMBL1522442 & 688323 & 4.9 & 4.8081 & TRN & \\
\hline CHEMBL1448982 & 688323 & 4.45 & 4.8259 & TRN & \\
\hline CHEMBL1450623 & 688323 & 4.45 & 5.0138 & TRN & \\
\hline CHEMBL1333641 & 688323 & 5.45 & 4.9434 & TRN & \\
\hline CHEMBL1520796 & 688323 & 4.7 & 4.7544 & TRN & \\
\hline CHEMBL1994034 & 688323 & 4.5 & 4.7825 & TRN & \\
\hline CHEMBL1420229 & 688323 & 4.8 & 4.7735 & TRN & \\
\hline CHEMBL1407161 & 688323 & 5.25 & 5.0886 & TRN & \\
\hline CHEMBL1521287 & 688323 & 5.4 & 4.6938 & TRN & \\
\hline CHEMBL1523008 & 688323 & 4.8 & 4.6127 & TRN & \\
\hline CHEMBL1605046 & 688323 & 4.7 & 5.0813 & TST & \\
\hline CHEMBL1502002 & 688323 & 4.75 & 5.0127 & TRN & \\
\hline CHEMBL1531537 & 688323 & 4.45 & 4.8073 & TRN & \\
\hline CHEMBL1356074 & 688323 & 4.45 & 4.958 & TRN & \\
\hline CHEMBL1594883 & 688323 & 4.45 & 4.7862 & TST & \\
\hline CHEMBL1405475 & 688323 & 4.5 & 4.8276 & TRN & \\
\hline CHEMBL1434907 & 688323 & 4.75 & 4.9377 & TRN & \\
\hline CHEMBL1435101 & 688323 & 4.9 & 4.8509 & TRN & \\
\hline
\end{tabular}




\begin{tabular}{|c|c|c|c|c|c|}
\hline \multicolumn{6}{|c|}{ Supplemental Table s2.txt } \\
\hline CHEMBL1335026 & 688323 & 4.75 & 4.7139 & TRN & \\
\hline CHEMBL1421328 & 688323 & 5.35 & 4.8045 & TST & \\
\hline CHEMBL1498273 & 688323 & 4.45 & 4.8133 & TRN & \\
\hline CHEMBL1504065 & 688323 & 4.8 & 4.8785 & TRN & \\
\hline CHEMBL1977877 & 688323 & 4.5 & 4.8845 & TRN & \\
\hline CHEMBL1318538 & 688323 & 4.5 & 4.5912 & TRN & \\
\hline CHEMBL1585527 & 688323 & 4.65 & 5.0814 & TRN & \\
\hline CHEMBL1521645 & 688323 & 4.6 & 4.8104 & TRN & \\
\hline CHEMBL1424495 & 688323 & 4.75 & 4.8035 & TRN & \\
\hline CHEMBL1467510 & 688323 & 4.45 & 4.9862 & TRN & \\
\hline CHEMBL1475493 & 688323 & 4.8 & 4.8932 & TRN & \\
\hline CHEMBL 3189329 & 688323 & 4.45 & 4.9159 & TRN & \\
\hline CHEMBL1375815 & 688323 & 4.5 & 4.6063 & TRN & \\
\hline CHEMBL1340055 & 688323 & 4.7 & 4.738 & TRN & \\
\hline CHEMBL1605894 & 688323 & 4.45 & 4.7529 & TRN & \\
\hline CHEMBL138927 & 688323 & 4.45 & 4.9783 & TRN & \\
\hline CHEMBL1355705 & 688323 & 4.95 & 4.6952 & TST & \\
\hline CHEMBL1494308 & 688323 & 4.45 & 4.7367 & TRN & \\
\hline CHEMBL1465727 & 688323 & 4.45 & 4.6388 & TRN & \\
\hline CHEMBL1319142 & 688323 & 4.45 & 4.7148 & TST & \\
\hline CHEMBL1322375 & 688323 & 4.6 & 4.7442 & TRN & \\
\hline CHEMBL1984648 & 688323 & 4.5 & 4.6467 & TST & \\
\hline CHEMBL528414 & 688323 & 4.65 & 4.7515 & TRN & \\
\hline CHEMBL 3212216 & 688323 & 4.5 & 4.8885 & TST & \\
\hline CHEMBL 3208294 & 688323 & 4.5 & 4.7869 & TRN & \\
\hline CHEMBL1558461 & 688323 & 5.5 & 4.9909 & TRN & \\
\hline CHEMBL1371464 & 688323 & 4.9 & 4.8167 & TST & \\
\hline CHEMBL1517917 & 688323 & 4.5 & 4.9132 & TRN & \\
\hline CHEMBL1327254 & 688323 & 5.2 & 4.8353 & TRN & \\
\hline CHEMBL1397921 & 688323 & 4.6 & 4.7645 & TRN & \\
\hline CHEMBL504977 & 688323 & 4.6 & 4.9322 & TRN & \\
\hline CHEMBL 3196560 & 688323 & 4.5 & 4.5369 & TRN & \\
\hline CHEMBL1463847 & 688323 & 4.5 & 4.8026 & TST & \\
\hline CHEMBL1564149 & 688323 & 4.45 & 4.8386 & TRN & \\
\hline CHEMBL1518392 & 688323 & 6.8499 & 4.8187 & TRN & \\
\hline CHEMBL1571047 & 688323 & 4.5 & 4.9861 & TRN & \\
\hline CHEMBL1300339 & 688323 & 5.05 & 4.9845 & TRN & \\
\hline CHEMBL 2006634 & 688323 & 4.8 & 4.7511 & TRN & \\
\hline CHEMBL1346771 & 688323 & 4.85 & 5.1087 & TRN & \\
\hline CHEMBL 2006258 & 688323 & 6.0 & 4.8714 & TRN & \\
\hline CHEMBL1375280 & 688323 & 5.4 & 4.81800 & 00000000005 & TRN \\
\hline CHEMBL1588674 & 688323 & 5.25 & 4.8256 & TRN & \\
\hline CHEMBL1446486 & 688323 & 4.7 & 4.9431 & TST & \\
\hline CHEMBL 395653 & 688323 & 4.7 & 4.8264 & TRN & \\
\hline CHEMBL3190220 & 688323 & 5.3 & 4.7707 & TRN & \\
\hline CHEMBL1595871 & 688323 & 4.45 & 4.6701 & TRN & \\
\hline CHEMBL1310681 & 688323 & 4.8 & 4.6773 & TST & \\
\hline CHEMBL1324746 & 688323 & 5.5 & 4.6044 & TRN & \\
\hline
\end{tabular}




\begin{tabular}{|c|c|c|c|c|c|}
\hline & & \multicolumn{4}{|c|}{ Supplemental Table S2.txt } \\
\hline CHEMBL3193507 & 688323 & 4.45 & 4.6204 & TRN & \\
\hline CHEMBL1404792 & 688323 & 6.35 & 5.1339 & TRN & \\
\hline CHEMBL1338965 & 688323 & 5.8 & 4.9906 & TRN & \\
\hline CHEMBL1430328 & 688323 & 5.3 & 5.0474 & TRN & \\
\hline CHEMBL1504421 & 688323 & 5.45 & 4.841 & TRN & \\
\hline CHEMBL1466406 & 688323 & 4.5 & 4.92399 & 99999999995 & TRN \\
\hline CHEMBL1594794 & 688323 & 4.75 & 4.8918 & TRN & \\
\hline CHEMBL3192393 & 688323 & 4.5 & 4.5014 & TRN & \\
\hline CHEMBL1466278 & 688323 & 4.5 & 4.8697 & TRN & \\
\hline CHEMBL1590033 & 688323 & 4.75 & 4.8575 & TRN & \\
\hline CHEMBL1509111 & 688323 & 4.5 & 4.9767 & TRN & \\
\hline CHEMBL1508616 & 688323 & 4.5 & 5.0465 & TRN & \\
\hline CHEMBL1431365 & 688323 & 4.5 & 4.8609 & TRN & \\
\hline CHEMBL1320386 & 688323 & 4.75 & 5.0108 & TRN & \\
\hline CHEMBL1603130 & 688323 & 4.5 & 4.6612 & TRN & \\
\hline CHEMBL1467153 & 688323 & 4.45 & 4.9286 & TRN & \\
\hline CHEMBL1487952 & 688323 & 5.25 & 4.925 & TRN & \\
\hline CHEMBL 1458840 & 688323 & 5.25 & 5.138 & TRN & \\
\hline CHEMBL1315148 & 688323 & 4.45 & 4.7621 & TRN & \\
\hline CHEMBL1386439 & 688323 & 5.15 & 4.8988 & TRN & \\
\hline CHEMBL1331661 & 688323 & 4.55 & 4.8555 & TRN & \\
\hline CHEMBL3192842 & 688323 & 5.25 & 4.5828 & TRN & \\
\hline CHEMBL1375592 & 688323 & 5.45 & 4.944 & TRN & \\
\hline CHEMBL1559782 & 688323 & 4.5 & 4.9955 & TRN & \\
\hline CHEMBL1541987 & 688323 & 4.45 & 4.7434 & TRN & \\
\hline CHEMBL1440105 & 688323 & 4.45 & 4.9055 & TRN & \\
\hline CHEMBL1330558 & 688323 & 5.25 & 5.0927 & TRN & \\
\hline CHEMBL1388790 & 688323 & 4.65 & 4.8136 & TRN & \\
\hline CHEMBL1540929 & 688323 & 4.7 & 4.8319 & TRN & \\
\hline CHEMBL1421316 & 688323 & 5.3 & 4.9116 & TRN & \\
\hline CHEMBL3191821 & 688323 & 4.45 & 4.8312 & TRN & \\
\hline CHEMBL1481415 & 688323 & 4.45 & 4.8396 & TRN & \\
\hline CHEMBL1389097 & 688323 & 4.7 & 4.8362 & TRN & \\
\hline CHEMBL1553263 & 688323 & 4.45 & 5.0609 & TST & \\
\hline CHEMBL1415999 & 688323 & 4.95 & 4.5598 & TRN & \\
\hline CHEMBL1564004 & 688323 & 4.5 & 4.7673 & TST & \\
\hline CHEMBL1555948 & 688323 & 4.6 & 4.8881 & TRN & \\
\hline CHEMBL1532268 & 688323 & 4.75 & 4.5316 & TRN & \\
\hline CHEMBL1554584 & 688323 & 4.45 & 4.7244 & TRN & \\
\hline CHEMBL1552568 & 688323 & 4.8 & 4.9988 & TRN & \\
\hline CHEMBL1367444 & 688323 & 5.2 & 4.8762 & TRN & \\
\hline CHEMBL1508072 & 688323 & 4.5 & 4.6815 & TRN & \\
\hline CHEMBL1435186 & 688323 & 4.5 & 4.806 & TRN & \\
\hline CHEMBL1383601 & 688323 & 4.45 & 4.7696 & TRN & \\
\hline CHEMBL1561478 & 688323 & 4.7 & 4.8269 & TRN & \\
\hline CHEMBL1707818 & 688323 & 4.8 & 4.5979 & TRN & \\
\hline CHEMBL1590308 & 688323 & 4.8 & 4.6491 & TST & \\
\hline CHEMBL1996199 & 688323 & 4.6 & 4.6461 & TRN & \\
\hline
\end{tabular}




\begin{tabular}{|c|c|c|c|c|c|}
\hline \multicolumn{6}{|c|}{ Supplemental Table S2.txt } \\
\hline CHEMBL1610858 & 688323 & 4.65 & 5.0459 & TRN & \\
\hline CHEMBL1561115 & 688323 & 4.5 & 4.5789 & TRN & \\
\hline CHEMBL1492222 & 688323 & 5.5 & 4.6876 & TRN & \\
\hline CHEMBL1375659 & 688323 & 4.6 & 4.7761 & TRN & \\
\hline CHEMBL1350258 & 688323 & 5.2 & 4.9818 & TST & \\
\hline CHEMBL1536007 & 688323 & 5.3 & 5.0421 & TRN & \\
\hline CHEMBL1455759 & 688323 & 7.699 & 5.064 & TRN & \\
\hline CHEMBL1395609 & 688323 & 4.45 & 4.6805 & TRN & \\
\hline CHEMBL1512755 & 688323 & 5.4 & 4.3986 & TRN & \\
\hline CHEMBL1421166 & 688323 & 4.45 & 4.8852 & TRN & \\
\hline CHEMBL1467505 & 688323 & 4.6 & 4.6164 & TRN & \\
\hline CHEMBL1314585 & 688323 & 4.95 & 4.7197 & TRN & \\
\hline CHEMBL1317896 & 688323 & 6.0 & 4.8016 & TRN & \\
\hline CHEMBL1359902 & 688323 & 5.35 & 4.7303 & TRN & \\
\hline CHEMBL1596226 & 688323 & 4.45 & 4.8895 & TST & \\
\hline CHEMBL1394231 & 688323 & 4.45 & 4.8636 & TRN & \\
\hline CHEMBL1339039 & 688323 & 4.45 & 4.9873 & TRN & \\
\hline CHEMBL1357655 & 688323 & 5.2 & 4.6373 & TRN & \\
\hline CHEMBL1598961 & 688323 & 4.5 & 4.5392 & TRN & \\
\hline CHEMBL1966852 & 688323 & 4.8 & 4.6545 & TRN & \\
\hline CHEMBL1436950 & 688323 & 4.55 & 4.6626 & TRN & \\
\hline CHEMBL1598083 & 688323 & 4.45 & 4.80699 & 99999999995 & TRN \\
\hline CHEMBL1317049 & 688323 & 4.45 & 4.7619 & TRN & \\
\hline CHEMBL1312165 & 688323 & 5.2 & 4.9331 & TST & \\
\hline CHEMBL 24983 & 688323 & 4.65 & 4.8923 & TRN & \\
\hline CHEMBL 210901 & 688323 & 5.2 & 5.0694 & TRN & \\
\hline CHEMBL1576754 & 688323 & 4.45 & 4.8715 & TRN & \\
\hline CHEMBL1368206 & 688323 & 4.65 & 4.8479 & TRN & \\
\hline CHEMBL1429422 & 688323 & 4.6 & 4.8849 & TRN & \\
\hline CHEMBL1544428 & 688323 & 4.5 & 4.5521 & TRN & \\
\hline CHEMBL1578010 & 688323 & 4.45 & 5.2906 & TRN & \\
\hline CHEMBL1327593 & 688323 & 4.75 & 4.9507 & TRN & \\
\hline CHEMBL1435318 & 688323 & 4.5 & 4.869 & TRN & \\
\hline CHEMBL1461585 & 688323 & 4.9 & 4.7025 & TRN & \\
\hline CHEMBL1501807 & 688323 & 8.3468 & 5.0606 & TRN & \\
\hline CHEMBL1476070 & 688323 & 4.55 & 4.6724 & TRN & \\
\hline CHEMBL1308547 & 688323 & 4.55 & 4.8329 & TRN & \\
\hline CHEMBL1593692 & 688323 & 4.5 & 5.0581 & TRN & \\
\hline CHEMBL1402602 & 688323 & 5.0 & 4.7628 & TRN & \\
\hline CHEMBL1513264 & 688323 & 5.2 & 4.8449 & TRN & \\
\hline CHEMBL1532878 & 688323 & 4.5 & 4.881 & TRN & \\
\hline CHEMBL1358485 & 688323 & 4.75 & 5.0432 & TST & \\
\hline CHEMBL1532186 & 688323 & 4.45 & 4.8166 & TRN & \\
\hline CHEMBL1504949 & 688323 & 4.6 & 4.6175 & TRN & \\
\hline CHEMBL1392382 & 688323 & 4.75 & 4.8543 & TST & \\
\hline CHEMBL1466593 & 688323 & 5.25 & 4.9366 & TST & \\
\hline CHEMBL73090 & 688323 & 4.8 & 4.7826 & TRN & \\
\hline CHEMBL3197479 & 688323 & 5.2 & 4.8277 & TRN & \\
\hline
\end{tabular}




\begin{tabular}{|c|c|c|c|c|c|}
\hline \multicolumn{6}{|c|}{ Supplemental Table S2.txt } \\
\hline CHEMBL1512373 & 688323 & 4.45 & 4.6496 & TRN & \\
\hline CHEMBL1515179 & 688323 & 4.6 & 4.56 & TRN & \\
\hline CHEMBL1986043 & 688323 & 5.0 & 4.6976 & TRN & \\
\hline CHEMBL1443749 & 688323 & 5.3 & 4.8783 & TRN & \\
\hline CHEMBL1545290 & 688323 & 4.6 & 5.0296 & TRN & \\
\hline CHEMBL1982845 & 688323 & 4.5 & 4.836 & TST & \\
\hline CHEMBL1563323 & 688323 & 5.3 & 5.0739 & TRN & \\
\hline CHEMBL1865025 & 688323 & 4.65 & 4.4629 & TRN & \\
\hline CHEMBL1510953 & 688323 & 4.65 & 4.8729 & TRN & \\
\hline CHEMBL 1421778 & 688323 & 4.6 & 4.7602 & TST & \\
\hline CHEMBL1514595 & 688323 & 4.45 & 4.4919 & TRN & \\
\hline CHEMBL1479144 & 688323 & 4.85 & 4.6019 & TRN & \\
\hline CHEMBL3191974 & 688323 & 4.5 & 4.7957 & TST & \\
\hline CHEMBL1358383 & 688323 & 4.7 & 4.6845 & TRN & \\
\hline CHEMBL1542119 & 688323 & 4.6 & 4.61600 & 00000000005 & TRN \\
\hline CHEMBL1478382 & 688323 & 4.6 & 4.8776 & TRN & \\
\hline CHEMBL1531665 & 688323 & 4.7 & 4.7591 & TRN & \\
\hline CHEMBL1967770 & 688323 & 4.6 & 4.4925 & TRN & \\
\hline CHEMBL1407632 & 688323 & 4.8 & 5.0417 & TRN & \\
\hline CHEMBL1363191 & 688323 & 5.6 & 5.0158 & TST & \\
\hline CHEMBL1310261 & 688323 & 5.1 & 4.7522 & TRN & \\
\hline CHEMBL1474543 & 688323 & 4.45 & 4.6815 & TRN & \\
\hline CHEMBL1976612 & 688323 & 4.5 & 4.6677 & TRN & \\
\hline CHEMBL1554260 & 688323 & 4.65 & 4.8414 & TRN & \\
\hline CHEMBL1426175 & 688323 & 4.55 & 4.817 & TRN & \\
\hline CHEMBL1417087 & 688323 & 4.45 & 4.9922 & TST & \\
\hline CHEMBL1611543 & 688323 & 4.45 & 4.6593 & TRN & \\
\hline CHEMBL1587433 & 688323 & 4.95 & 4.8125 & TRN & \\
\hline CHEMBL1393754 & 688323 & 4.7 & 4.6173 & TRN & \\
\hline CHEMBL1492376 & 688323 & 4.45 & 4.8269 & TRN & \\
\hline CHEMBL1435350 & 688323 & 4.7 & 4.8553 & TRN & \\
\hline CHEMBL1987785 & 688323 & 4.45 & 4.6203 & TRN & \\
\hline CHEMBL123 & 688323 & 6.0 & 4.9666 & TST & \\
\hline CHEMBL1525878 & 688323 & 5.35 & 5.1069 & TRN & \\
\hline CHEMBL1462078 & 688323 & 5.45 & 4.9429 & TRN & \\
\hline CHEMBL1441536 & 688323 & 4.85 & 4.9455 & TRN & \\
\hline CHEMBL1400021 & 688323 & 4.7 & 4.6986 & TRN & \\
\hline CHEMBL1509851 & 688323 & 4.5 & 4.7893 & TRN & \\
\hline CHEMBL1355272 & 688323 & 4.7 & 5.0204 & TST & \\
\hline CHEMBL1597772 & 688323 & 4.6 & 4.9539 & TRN & \\
\hline CHEMBL1492205 & 688323 & 4.45 & 4.6966 & TRN & \\
\hline CHEMBL1494100 & 688323 & 4.45 & 4.7735 & TRN & \\
\hline CHEMBL1564550 & 688323 & 4.9 & 4.7361 & TRN & \\
\hline CHEMBL1314376 & 688323 & 4.45 & 4.7007 & TST & \\
\hline CHEMBL3213088 & 688323 & 4.45 & 4.7215 & TRN & \\
\hline CHEMBL1586031 & 688323 & 5.2 & 5.0002 & TRN & \\
\hline CHEMBL1568007 & 688323 & 5.0 & 4.7609 & TST & \\
\hline CHEMBL1435285 & 688323 & 4.55 & 4.6997 & TRN & \\
\hline
\end{tabular}




\begin{tabular}{|c|c|c|c|c|c|}
\hline & & \multicolumn{4}{|c|}{ Supplemental Table S2.txt } \\
\hline CHEMBL1370702 & 688323 & 4.6 & 4.8318 & TRN & \\
\hline CHEMBL592611 & 688323 & 5.25 & 5.0911 & TRN & \\
\hline CHEMBL1570150 & 688323 & 4.65 & 4.6101 & TRN & \\
\hline CHEMBL1351599 & 688323 & 4.9 & 4.9643 & TRN & \\
\hline CHEMBL1426440 & 688323 & 4.5 & 4.7553 & TST & \\
\hline CHEMBL1422296 & 688323 & 5.7 & 4.8568 & TST & \\
\hline CHEMBL1485706 & 688323 & 4.5 & 4.7064 & TST & \\
\hline CHEMBL1445956 & 688323 & 5.45 & 5.03 & TRN & \\
\hline CHEMBL1328840 & 688323 & 4.8 & 5.0143 & TRN & \\
\hline CHEMBL1398298 & 688323 & 4.9 & 4.8249 & TRN & \\
\hline CHEMBL1390206 & 688323 & 4.9 & 5.091 & TRN & \\
\hline CHEMBL243250 & 688323 & 4.6 & 4.6099 & TRN & \\
\hline CHEMBL1515733 & 688323 & 4.45 & 4.65300 & 00000000005 & TRN \\
\hline CHEMBL1965184 & 688323 & 4.5 & 4.6816 & TST & \\
\hline CHEMBL1431191 & 688323 & 4.7 & 4.7371 & TRN & \\
\hline CHEMBL1478930 & 688323 & 4.9 & 4.9278 & TRN & \\
\hline CHEMBL1469995 & 688323 & 4.65 & 4.9885 & TST & \\
\hline CHEMBL1610831 & 688323 & 4.45 & 4.8355 & TRN & \\
\hline CHEMBL1386817 & 688323 & 4.45 & 4.9691 & TST & \\
\hline CHEMBL1523506 & 688323 & 5.15 & 4.5141 & TRN & \\
\hline CHEMBL1502019 & 688323 & 4.5 & 4.8402 & TRN & \\
\hline CHEMBL1395641 & 688323 & 4.8 & 4.8116 & TRN & \\
\hline CHEMBL1396734 & 688323 & 5.25 & 4.7819 & TRN & \\
\hline CHEMBL1315936 & 688323 & 4.45 & 4.8233 & TRN & \\
\hline CHEMBL1330244 & 688323 & 4.85 & 4.7974 & TRN & \\
\hline CHEMBL1441042 & 688323 & 4.5 & 5.092 & TRN & \\
\hline CHEMBL1332629 & 688323 & 4.45 & 4.713 & TRN & \\
\hline CHEMBL1555657 & 688323 & 4.45 & 4.743 & TRN & \\
\hline CHEMBL1347299 & 688323 & 4.6 & 4.8692 & TST & \\
\hline CHEMBL1353813 & 688323 & 4.45 & 4.6441 & TRN & \\
\hline CHEMBL1361224 & 688323 & 4.45 & 4.773 & TST & \\
\hline CHEMBL1575502 & 688323 & 6.5 & 5.1861 & TRN & \\
\hline CHEMBL1377712 & 688323 & 5.2 & 4.7666 & TRN & \\
\hline CHEMBL3194518 & 688323 & 4.45 & 4.817 & TRN & \\
\hline CHEMBL571700 & 688323 & 5.25 & 5.1313 & TST & \\
\hline CHEMBL1302851 & 688323 & 4.45 & 4.9457 & TRN & \\
\hline CHEMBL1370980 & 688323 & 4.8 & 4.8063 & TST & \\
\hline CHEMBL3192188 & 688323 & 4.9 & 4.6586 & TST & \\
\hline CHEMBL1532931 & 688323 & 4.65 & 4.997 & TRN & \\
\hline CHEMBL1983311 & 688323 & 4.5 & 4.5129 & TRN & \\
\hline CHEMBL1418601 & 688323 & 4.5 & 4.9715 & TRN & \\
\hline CHEMBL1354659 & 688323 & 4.45 & 4.8995 & TRN & \\
\hline CHEMBL1347354 & 688323 & 4.5 & 4.9499 & TST & \\
\hline CHEMBL1509603 & 688323 & 4.6 & 4.5533 & TRN & \\
\hline CHEMBL1511037 & 688323 & 4.65 & 4.5852 & TRN & \\
\hline CHEMBL1519423 & 688323 & 4.45 & 4.6129 & TRN & \\
\hline CHEMBL1315473 & 688323 & 4.75 & 4.8103 & TRN & \\
\hline CHEMBL1470967 & 688323 & 5.45 & 4.9156 & TRN & \\
\hline
\end{tabular}




\begin{tabular}{|c|c|c|c|c|c|}
\hline \multicolumn{6}{|c|}{ Supplemental Table S2.txt } \\
\hline CHEMBL512366 & 688323 & 4.5 & 4.7028 & TRN & \\
\hline CHEMBL1437836 & 688323 & 4.85 & 4.8089 & TRN & \\
\hline CHEMBL1593000 & 688323 & 6.25 & 5.1428 & TRN & \\
\hline CHEMBL1452710 & 688323 & 4.45 & 4.8445 & TRN & \\
\hline CHEMBL1402807 & 688323 & 4.45 & 4.8717 & TRN & \\
\hline CHEMBL1605422 & 688323 & 4.65 & 4.8061 & TRN & \\
\hline CHEMBL1454770 & 688323 & 4.45 & 4.9897 & TRN & \\
\hline CHEMBL1322754 & 688323 & 4.65 & 4.8278 & TST & \\
\hline CHEMBL1432452 & 688323 & 5.2 & 4.7024 & TRN & \\
\hline CHEMBL1449462 & 688323 & 4.45 & 4.5125 & TRN & \\
\hline CHEMBL1314331 & 688323 & 4.45 & 4.7226 & TRN & \\
\hline CHEMBL1323252 & 688323 & 4.65 & 4.71 & TRN & \\
\hline CHEMBL1587810 & 688323 & 4.5 & 4.8528 & TRN & \\
\hline CHEMBL1993532 & 688323 & 4.9 & 4.8337 & TRN & \\
\hline CHEMBL1562926 & 688323 & 5.6 & 5.1076 & TRN & \\
\hline CHEMBL1537357 & 688323 & 5.2 & 4.9121 & TST & \\
\hline CHEMBL1404648 & 688323 & 4.55 & 4.7537 & TST & \\
\hline CHEMBL1606825 & 688323 & 4.5 & 4.8366 & TRN & \\
\hline CHEMBL578504 & 688323 & 4.8 & 5.0453 & TRN & \\
\hline CHEMBL1587291 & 688323 & 4.5 & 4.5788 & TRN & \\
\hline CHEMBL1557706 & 688323 & 4.6 & 5.0831 & TST & \\
\hline CHEMBL1527266 & 688323 & 4.65 & 4.5588 & TRN & \\
\hline CHEMBL1584299 & 688323 & 4.8 & 4.8065 & TRN & \\
\hline CHEMBL1433340 & 688323 & 4.5 & 4.83899 & 99999999995 & TRN \\
\hline CHEMBL87482 & 688323 & 5.25 & 4.9778 & TST & \\
\hline CHEMBL1573836 & 688323 & 4.85 & 4.882 & TRN & \\
\hline CHEMBL1436351 & 688323 & 4.5 & 4.7493 & TRN & \\
\hline CHEMBL1466913 & 688323 & 4.8 & 4.8764 & TRN & \\
\hline CHEMBL1965122 & 688323 & 4.5 & 4.8775 & TRN & \\
\hline CHEMBL1725983 & 688323 & 5.2 & 4.6963 & TRN & \\
\hline CHEMBL1418093 & 688323 & 4.5 & 4.7362 & TRN & \\
\hline CHEMBL1383680 & 688323 & 4.9 & 4.7518 & TRN & \\
\hline CHEMBL1592258 & 688323 & 4.45 & 4.7882 & TRN & \\
\hline CHEMBL3210329 & 688323 & 5.45 & 4.9364 & TRN & \\
\hline CHEMBL1587764 & 688323 & 5.45 & 4.8886 & TRN & \\
\hline CHEMBL1361285 & 688323 & 5.25 & 4.9094 & TST & \\
\hline CHEMBL 3212686 & 688323 & 4.45 & 4.6938 & TRN & \\
\hline CHEMBL1404787 & 688323 & 4.65 & 4.7742 & TRN & \\
\hline CHEMBL1561538 & 688323 & 4.45 & 4.6726 & TRN & \\
\hline CHEMBL1321593 & 688323 & 4.55 & 4.9663 & TRN & \\
\hline CHEMBL3190176 & 688323 & 4.45 & 4.887 & TRN & \\
\hline CHEMBL1356848 & 688323 & 4.7 & 4.9233 & TRN & \\
\hline CHEMBL1320607 & 688323 & 4.85 & 5.0185 & TRN & \\
\hline CHEMBL1389243 & 688323 & 4.55 & 4.5333 & TRN & \\
\hline CHEMBL1552003 & 688323 & 4.45 & 4.9534 & TRN & \\
\hline CHEMBL1442635 & 688323 & 4.45 & 4.9142 & TRN & \\
\hline CHEMBL1358182 & 688323 & 5.25 & 4.98 & TRN & \\
\hline CHEMBL3212985 & 688323 & 4.9 & 4.6623 & TRN & \\
\hline
\end{tabular}




\begin{tabular}{|c|c|c|c|c|c|}
\hline \multicolumn{6}{|c|}{ Supplemental Table S2.txt } \\
\hline CHEMBL1410173 & 688323 & 4.5 & 4.8516 & TRN & \\
\hline CHEMBL1224755 & 688323 & 5.25 & 4.9646 & TRN & \\
\hline CHEMBL1387704 & 688323 & 5.2 & 4.8303 & TRN & \\
\hline CHEMBL428064 & 688323 & 5.3 & 5.0998 & TST & \\
\hline CHEMBL1573221 & 688323 & 6.0 & 4.9043 & TST & \\
\hline CHEMBL1371774 & 688323 & 5.55 & 4.9224 & TRN & \\
\hline CHEMBL1326951 & 688323 & 4.7 & 4.808 & TRN & \\
\hline CHEMBL1335911 & 688323 & 6.8 & 5.0165 & TRN & \\
\hline CHEMBL1418066 & 688323 & 4.55 & 4.9179 & TRN & \\
\hline CHEMBL1516082 & 688323 & 4.95 & 4.7784 & TRN & \\
\hline CHEMBL1390551 & 688323 & 5.45 & 4.893 & TRN & \\
\hline CHEMBL1553916 & 688323 & 4.85 & 4.8094 & TRN & \\
\hline CHEMBL1580372 & 688323 & 4.45 & 4.7174 & TRN & \\
\hline CHEMBL1487834 & 688323 & 4.45 & 4.6792 & TRN & \\
\hline CHEMBL1600187 & 688323 & 5.25 & 4.8725 & TST & \\
\hline CHEMBL1987419 & 688323 & 4.85 & 4.6759 & TRN & \\
\hline CHEMBL1489685 & 688323 & 6.0 & 4.9224 & TRN & \\
\hline CHEMBL1337540 & 688323 & 4.6 & 4.9388 & TRN & \\
\hline CHEMBL1362799 & 688323 & 4.6 & 4.5706 & TRN & \\
\hline CHEMBL1328809 & 688323 & 4.8 & 4.8282 & TRN & \\
\hline CHEMBL1447314 & 688323 & 5.2 & 4.94600 & 0000000001 & TRN \\
\hline CHEMBL1551610 & 688323 & 4.5 & 4.7195 & TST & \\
\hline CHEMBL123254 & 688323 & 4.45 & 4.9425 & TRN & \\
\hline CHEMBL1463349 & 688323 & 4.45 & 5.0302 & TRN & \\
\hline CHEMBL1487067 & 688323 & 4.7 & 5.1042 & TST & \\
\hline CHEMBL1408631 & 688323 & 5.3 & 4.755 & TRN & \\
\hline CHEMBL1358513 & 688323 & 4.45 & 4.6929 & TRN & \\
\hline CHEMBL3213879 & 688323 & 4.45 & 4.7119 & TRN & \\
\hline CHEMBL1355516 & 688323 & 5.05 & 4.8903 & TRN & \\
\hline CHEMBL1540360 & 688323 & 5.0 & 4.8621 & TST & \\
\hline CHEMBL1382917 & 688323 & 6.25 & 5.1385 & TRN & \\
\hline CHEMBL 244023 & 688323 & 4.45 & 4.8221 & TRN & \\
\hline CHEMBL1585681 & 688323 & 4.9 & 5.0098 & TRN & \\
\hline CHEMBL3198502 & 688323 & 4.5 & 4.6935 & TRN & \\
\hline CHEMBL1318334 & 688323 & 4.45 & 4.8477 & TRN & \\
\hline CHEMBL1461573 & 688323 & 4.6 & 4.7542 & TRN & \\
\hline CHEMBL 1490060 & 688323 & 4.9 & 4.8758 & TRN & \\
\hline CHEMBL1389025 & 688323 & 4.55 & 4.7182 & TST & \\
\hline CHEMBL1518995 & 688323 & 4.75 & 4.9486 & TRN & \\
\hline CHEMBL1519900 & 688323 & 5.3 & 4.9143 & TRN & \\
\hline CHEMBL1480191 & 688323 & 5.0 & 4.5468 & TRN & \\
\hline CHEMBL1384179 & 688323 & 4.45 & 4.6456 & TRN & \\
\hline CHEMBL1550816 & 688323 & 4.8 & 4.6511 & TRN & \\
\hline CHEMBL1403085 & 688323 & 4.6 & 4.8426 & TRN & \\
\hline CHEMBL1308255 & 688323 & 4.5 & 4.7326 & TRN & \\
\hline CHEMBL1541839 & 688323 & 4.55 & 4.6575 & TRN & \\
\hline CHEMBL1517543 & 688323 & 5.45 & 5.0072 & TRN & \\
\hline CHEMBL1347392 & 688323 & 4.6 & 4.6049 & TRN & \\
\hline
\end{tabular}




\begin{tabular}{|c|c|c|c|c|c|}
\hline \multicolumn{6}{|c|}{ Supplemental Table s2.txt } \\
\hline CHEMBL1427215 & 688323 & 4.5 & 4.7775 & TRN & \\
\hline CHEMBL1493936 & 688323 & 4.6 & 4.7413 & TRN & \\
\hline CHEMBL1311260 & 688323 & 4.9 & 4.6568 & TRN & \\
\hline CHEMBL1559622 & 688323 & 4.45 & 4.9427 & TRN & \\
\hline CHEMBL1341744 & 688323 & 4.5 & 4.725 & TRN & \\
\hline CHEMBL1317612 & 688323 & 4.6 & 4.6925 & TRN & \\
\hline CHEMBL1558877 & 688323 & 6.8 & 5.0374 & TRN & \\
\hline CHEMBL1995254 & 688323 & 5.25 & 4.6015 & TRN & \\
\hline CHEMBL1373322 & 688323 & 4.65 & 4.6994 & TRN & \\
\hline CHEMBL1466685 & 688323 & 4.45 & 4.631 & TST & \\
\hline CHEMBL1576798 & 688323 & 5.35 & 4.8935 & TST & \\
\hline CHEMBL1383774 & 688323 & 5.3 & 5.0619 & TRN & \\
\hline CHEMBL1451800 & 688323 & 4.85 & 4.6217 & TST & \\
\hline CHEMBL1308615 & 688323 & 4.45 & 4.7132 & TRN & \\
\hline CHEMBL1458833 & 688323 & 4.5 & 4.9152 & TRN & \\
\hline CHEMBL1362248 & 688323 & 4.9 & 4.7473 & TRN & \\
\hline CHEMBL1302595 & 688323 & 4.85 & 4.7931 & TRN & \\
\hline CHEMBL3195267 & 688323 & 4.5 & 4.7971 & TRN & \\
\hline CHEMBL3208936 & 688323 & 5.05 & 4.7786 & TRN & \\
\hline CHEMBL1462178 & 688323 & 4.45 & 4.9309 & TRN & \\
\hline CHEMBL1382902 & 688323 & 4.6 & 4.7795 & TST & \\
\hline CHEMBL65 & 688323 & 4.8 & 4.6562 & TST & \\
\hline CHEMBL1585589 & 688323 & 4.75 & 4.7094 & TST & \\
\hline CHEMBL1317752 & 688323 & 4.55 & 4.633 & TRN & \\
\hline CHEMBL1401951 & 688323 & 4.45 & 4.7038 & TRN & \\
\hline CHEMBL1984190 & 688323 & 6.05 & 4.7171 & TRN & \\
\hline CHEMBL1349390 & 688323 & 4.75 & 4.7278 & TRN & \\
\hline CHEMBL1521379 & 688323 & 4.8 & 4.775 & TRN & \\
\hline CHEMBL1540346 & 688323 & 5.25 & 4.8526 & TRN & \\
\hline CHEMBL591412 & 688323 & 5.15 & 5.1669 & TRN & \\
\hline CHEMBL1331573 & 688323 & 5.45 & 4.7931 & TRN & \\
\hline CHEMBL1342181 & 688323 & 4.5 & 4.9296 & TRN & \\
\hline CHEMBL 3210585 & 688323 & 5.3 & 4.9028 & TRN & \\
\hline CHEMBL1431885 & 688323 & 4.6 & 4.9415 & TST & \\
\hline CHEMBL1393596 & 688323 & 4.45 & 4.9797 & TRN & \\
\hline CHEMBL1477886 & 688323 & 4.55 & 4.7274 & TRN & \\
\hline CHEMBL1587124 & 688323 & 4.75 & 4.8001 & TRN & \\
\hline CHEMBL3191958 & 688323 & 4.55 & 4.7705 & TRN & \\
\hline CHEMBL1427726 & 688323 & 4.5 & 4.63899 & 9999999999 & TRN \\
\hline CHEMBL1350845 & 688323 & 4.85 & 5.0433 & TRN & \\
\hline CHEMBL343736 & 688323 & 4.7 & 4.9698 & TRN & \\
\hline CHEMBL1315440 & 688323 & 4.75 & 4.7323 & TRN & \\
\hline CHEMBL1375018 & 688323 & 5.25 & 4.7435 & TRN & \\
\hline CHEMBL1557179 & 688323 & 4.6 & 4.6217 & TRN & \\
\hline CHEMBL1334904 & 688323 & 4.75 & 4.5706 & TRN & \\
\hline CHEMBL1368532 & 688323 & 4.6 & 4.5137 & TRN & \\
\hline CHEMBL1499273 & 688323 & 4.45 & 4.7535 & TRN & \\
\hline CHEMBL1496787 & 688323 & 4.85 & 4.7021 & TST & \\
\hline
\end{tabular}




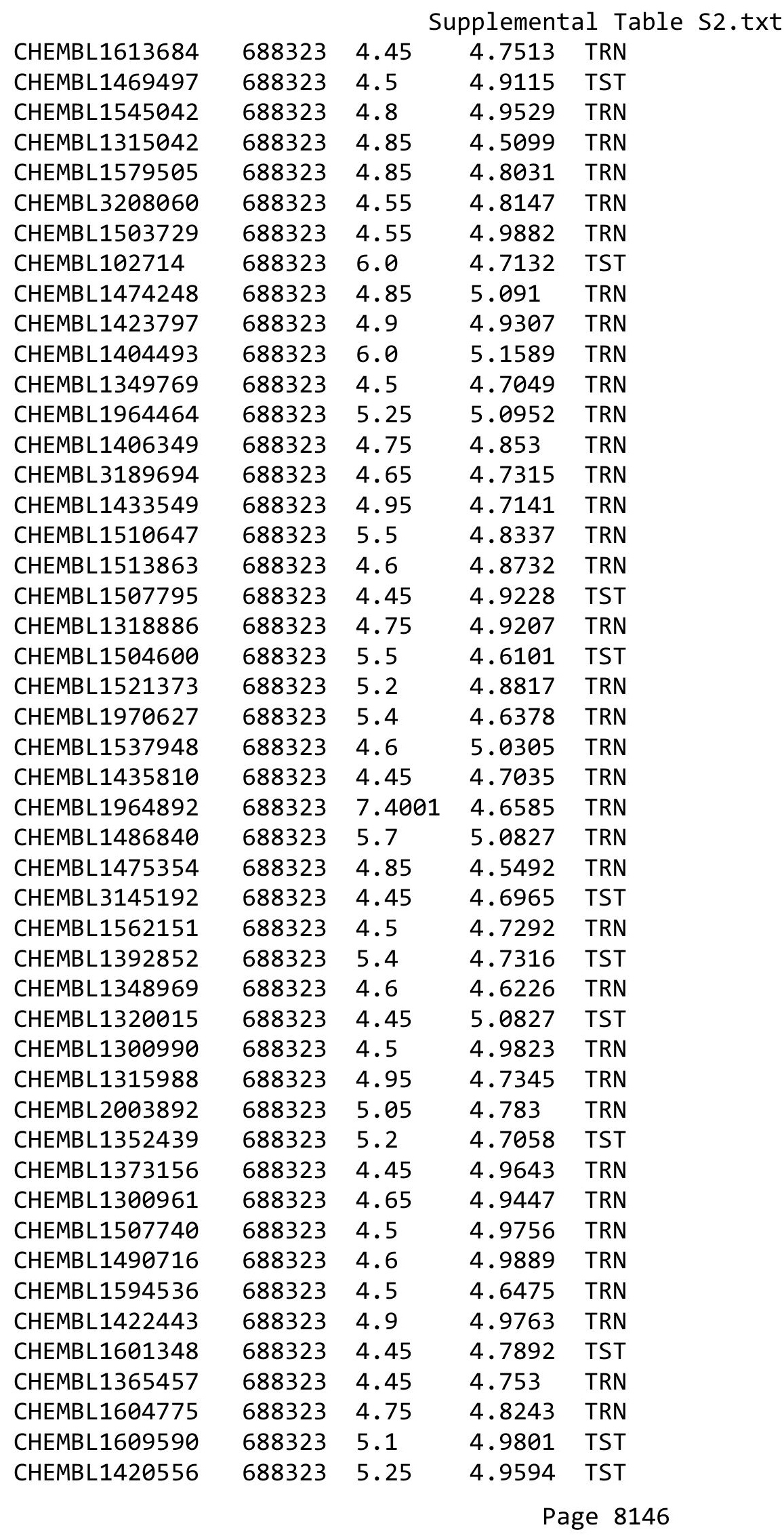




\begin{tabular}{|c|c|c|c|c|c|}
\hline & & \multicolumn{4}{|c|}{ Supplemental Table S2.txt } \\
\hline CHEMBL1474155 & 688323 & 4.45 & 4.5108 & TRN & \\
\hline CHEMBL1464060 & 688323 & 4.7 & 4.7963 & TRN & \\
\hline CHEMBL1369587 & 688323 & 4.55 & 4.7444 & TRN & \\
\hline CHEMBL1559609 & 688323 & 4.5 & 4.6765 & TRN & \\
\hline CHEMBL1300286 & 688323 & 4.45 & 4.806 & TRN & \\
\hline CHEMBL114544 & 688323 & 6.0 & 5.1195 & TRN & \\
\hline CHEMBL355280 & 688323 & 5.2 & 4.8048 & TRN & \\
\hline CHEMBL1439307 & 688323 & 4.45 & 4.7324 & TRN & \\
\hline CHEMBL 3213645 & 688323 & 4.45 & 4.5472 & TRN & \\
\hline CHEMBL1441823 & 688323 & 4.45 & 4.8994 & TRN & \\
\hline CHEMBL1566444 & 688323 & 4.85 & 4.669 & TRN & \\
\hline CHEMBL1576321 & 688323 & 4.65 & 4.7483 & TRN & \\
\hline CHEMBL1446060 & 688323 & 5.85 & 4.6765 & TST & \\
\hline CHEMBL1311342 & 688323 & 6.0 & 4.8975 & TRN & \\
\hline CHEMBL1359199 & 688323 & 4.75 & 4.7756 & TRN & \\
\hline CHEMBL1372792 & 688323 & 4.75 & 4.7216 & TRN & \\
\hline CHEMBL1523870 & 688323 & 4.45 & 4.8022 & TRN & \\
\hline CHEMBL1398043 & 688323 & 5.35 & 4.8931 & TRN & \\
\hline CHEMBL 3192563 & 688323 & 4.5 & 4.6388 & TRN & \\
\hline CHEMBL1965461 & 688323 & 4.65 & 4.8209 & TRN & \\
\hline CHEMBL1482109 & 688323 & 4.75 & 4.8413 & TRN & \\
\hline CHEMBL1573396 & 688323 & 4.45 & 4.6071 & TRN & \\
\hline CHEMBL1529148 & 688323 & 5.2 & 4.8844 & TRN & \\
\hline CHEMBL1350912 & 688323 & 5.2 & 4.8132 & TRN & \\
\hline CHEMBL1477837 & 688323 & 4.45 & 4.8583 & TRN & \\
\hline CHEMBL1374465 & 688323 & 4.95 & 4.629 & TST & \\
\hline CHEMBL1482691 & 688323 & 5.2 & 4.7625 & TRN & \\
\hline CHEMBL1554870 & 688323 & 4.8 & 4.5459 & TRN & \\
\hline CHEMBL1304735 & 688323 & 4.55 & 4.7236 & TRN & \\
\hline CHEMBL 1502558 & 688323 & 4.5 & 4.5726 & TRN & \\
\hline CHEMBL1364098 & 688323 & 5.25 & 4.8493 & TRN & \\
\hline CHEMBL1394607 & 688323 & 4.65 & 4.9727 & TRN & \\
\hline CHEMBL1447070 & 688323 & 4.5 & 4.6872 & TRN & \\
\hline CHEMBL1433182 & 688323 & 5.25 & 4.9313 & TRN & \\
\hline CHEMBL1597454 & 688323 & 5.4 & 4.938 & TRN & \\
\hline CHEMBL1354769 & 688323 & 4.6 & 4.5361 & TRN & \\
\hline CHEMBL1390516 & 688323 & 4.45 & 4.7869 & TRN & \\
\hline CHEMBL1399496 & 688323 & 4.5 & 4.694 & TRN & \\
\hline CHEMBL1494140 & 688323 & 4.95 & 4.7768 & TRN & \\
\hline CHEMBL1307040 & 688323 & 4.45 & 4.9252 & TRN & \\
\hline CHEMBL1553361 & 688323 & 4.95 & 4.8335 & TRN & \\
\hline CHEMBL1965069 & 688323 & 4.5 & 4.6292 & TRN & \\
\hline CHEMBL140 & 688323 & 6.0 & 4.8495 & TRN & \\
\hline CHEMBL1362844 & 688323 & 4.45 & 4.7198 & TRN & \\
\hline CHEMBL3196659 & 688323 & 4.45 & 4.7687 & TRN & \\
\hline CHEMBL1386223 & 688323 & 5.25 & 5.0583 & TST & \\
\hline CHEMBL1599187 & 688323 & 4.45 & 4.7562 & TRN & \\
\hline CHEMBL1477177 & 688323 & 4.55 & 4.89199 & 99999999995 & TRN \\
\hline & & & & 8147 & \\
\hline
\end{tabular}




\begin{tabular}{|c|c|c|c|c|}
\hline \multicolumn{5}{|c|}{ Supplemental Table S2.txt } \\
\hline CHEMBL3209511 & 688323 & 5.3 & 4.8066 & TRN \\
\hline CHEMBL1605816 & 688323 & 4.45 & 4.9226 & TRN \\
\hline CHEMBL1613489 & 688323 & 4.75 & 4.9235 & TST \\
\hline CHEMBL1422429 & 688323 & 5.5 & 4.9127 & TRN \\
\hline CHEMBL1965713 & 688323 & 4.95 & 5.078 & TRN \\
\hline CHEMBL1423154 & 688323 & 5.5 & 4.8614 & TRN \\
\hline CHEMBL1533823 & 688323 & 4.8 & 4.9062 & TRN \\
\hline CHEMBL1973156 & 688323 & 5.45 & 4.7589 & TRN \\
\hline CHEMBL1564251 & 688323 & 4.45 & 4.834 & TRN \\
\hline CHEMBL1305639 & 688323 & 4.45 & 4.8723 & TRN \\
\hline CHEMBL1441791 & 688323 & 4.6 & 5.0687 & TRN \\
\hline CHEMBL1320126 & 688323 & 4.45 & 4.7514 & TRN \\
\hline CHEMBL1405564 & 688323 & 4.8 & 4.6508 & TRN \\
\hline CHEMBL1516404 & 688323 & 4.5 & 4.912 & TST \\
\hline CHEMBL1319331 & 688323 & 4.5 & 4.5818 & TRN \\
\hline CHEMBL1402332 & 688323 & 5.25 & 5.1039 & TRN \\
\hline CHEMBL1349631 & 688323 & 5.25 & 4.8774 & TRN \\
\hline CHEMBL1304363 & 688323 & 4.65 & 5.073 & TRN \\
\hline CHEMBL1418325 & 688323 & 4.45 & 4.8538 & TRN \\
\hline CHEMBL1592244 & 688323 & 4.65 & 4.7262 & TRN \\
\hline CHEMBL1434886 & 688323 & 5.95 & 5.0348 & TST \\
\hline CHEMBL1336206 & 688323 & 4.75 & 4.7389 & TRN \\
\hline CHEMBL1369596 & 688323 & 5.45 & 4.8853 & TST \\
\hline CHEMBL600968 & 688323 & 4.55 & 4.8808 & TRN \\
\hline CHEMBL1965471 & 688323 & 4.7 & 4.6554 & TRN \\
\hline CHEMBL1327964 & 688323 & 4.5 & 4.8575 & TRN \\
\hline CHEMBL1434248 & 688323 & 4.45 & 4.7145 & TRN \\
\hline CHEMBL1999595 & 688323 & 4.45 & 4.853 & TRN \\
\hline CHEMBL172064 & 688323 & 4.9 & 4.9274 & TST \\
\hline CHEMBL1362588 & 688323 & 5.25 & 4.7024 & TST \\
\hline CHEMBL1515224 & 688323 & 4.85 & 4.5231 & TRN \\
\hline CHEMBL1580969 & 688323 & 4.6 & 4.9744 & TRN \\
\hline CHEMBL1517928 & 688323 & 4.5 & 5.0178 & TRN \\
\hline CHEMBL1494785 & 688323 & 4.45 & 4.6508 & TRN \\
\hline CHEMBL1518675 & 688323 & 4.75 & 4.923 & TRN \\
\hline CHEMBL1482710 & 688323 & 4.55 & 4.7683 & TRN \\
\hline CHEMBL1611608 & 688323 & 5.3 & 4.9799 & TRN \\
\hline CHEMBL1552916 & 688323 & 4.45 & 4.5881 & TRN \\
\hline CHEMBL1335945 & 688323 & 4.45 & 4.9062 & TST \\
\hline CHEMBL1520692 & 688323 & 5.2 & 4.8297 & TRN \\
\hline CHEMBL1546693 & 688323 & 4.5 & 4.6433 & TRN \\
\hline CHEMBL 1407280 & 688323 & 4.45 & 4.7796 & TRN \\
\hline CHEMBL1310900 & 688323 & 5.25 & 5.1313 & TRN \\
\hline CHEMBL1400298 & 688323 & 4.5 & 4.948 & TRN \\
\hline CHEMBL1602098 & 688323 & 4.75 & 4.9202 & TRN \\
\hline CHEMBL1502313 & 688323 & 4.5 & 4.8362 & TRN \\
\hline CHEMBL1326032 & 688323 & 4.7 & 4.5679 & TST \\
\hline CHEMBL1323872 & 688323 & 5.1 & 4.9378 & TRN \\
\hline
\end{tabular}




\begin{tabular}{|c|c|c|c|c|}
\hline & & & upplement & al $\mathrm{T}$ \\
\hline CHEMBL1325806 & 688323 & 5.35 & 4.7991 & TRN \\
\hline CHEMBL3191089 & 688323 & 6.4 & 4.7379 & TST \\
\hline CHEMBL1564153 & 688323 & 4.8 & 4.9257 & TRN \\
\hline CHEMBL1475311 & 688323 & 4.8 & 4.7504 & TRN \\
\hline CHEMBL1384649 & 688323 & 4.65 & 4.9982 & TST \\
\hline CHEMBL1467596 & 688323 & 4.45 & 4.9545 & TRN \\
\hline CHEMBL1564403 & 688323 & 5.25 & 5.0647 & TRN \\
\hline CHEMBL1578449 & 688323 & 4.7 & 5.0828 & TRN \\
\hline CHEMBL1457181 & 688323 & 5.15 & 4.7717 & TRN \\
\hline CHEMBL1603753 & 688323 & 4.6 & 5.0385 & TRN \\
\hline CHEMBL472031 & 688323 & 6.0 & 4.8221 & TST \\
\hline CHEMBL1388036 & 688323 & 4.95 & 4.9979 & TRN \\
\hline CHEMBL1595672 & 688323 & 4.45 & 4.9161 & TRN \\
\hline CHEMBL1982195 & 688323 & 4.45 & 4.7522 & TRN \\
\hline CHEMBL1330472 & 688323 & 5.4 & 4.8915 & TRN \\
\hline CHEMBL1995904 & 688323 & 5.2 & 4.7652 & TRN \\
\hline CHEMBL1489200 & 688323 & 4.45 & 4.833 & TRN \\
\hline CHEMBL3196817 & 688323 & 5.45 & 4.8455 & TST \\
\hline CHEMBL1443886 & 688323 & 4.45 & 4.7881 & TRN \\
\hline CHEMBL 2003304 & 688323 & 4.9 & 4.8801 & TST \\
\hline CHEMBL 2001455 & 688323 & 4.7 & 4.6653 & TRN \\
\hline CHEMBL1548690 & 688323 & 4.95 & 4.8524 & TRN \\
\hline CHEMBL1593455 & 688323 & 4.6 & 4.7225 & TRN \\
\hline CHEMBL1590278 & 688323 & 5.0 & 4.7412 & TRN \\
\hline CHEMBL1566913 & 688323 & 5.1 & 4.6936 & TRN \\
\hline CHEMBL1427273 & 688323 & 4.8 & 4.9538 & TRN \\
\hline CHEMBL 2001577 & 688323 & 4.65 & 4.7697 & TRN \\
\hline CHEMBL1516172 & 688323 & 4.45 & 4.6506 & TRN \\
\hline CHEMBL1548018 & 688323 & 4.75 & 5.2104 & TRN \\
\hline CHEMBL1367029 & 688323 & 4.85 & 4.8754 & TRN \\
\hline CHEMBL1476664 & 688323 & 4.7 & 4.6035 & TRN \\
\hline CHEMBL1495776 & 688323 & 4.55 & 4.9706 & TRN \\
\hline CHEMBL1488050 & 688323 & 5.35 & 4.7826 & TRN \\
\hline CHEMBL1344297 & 688323 & 4.45 & 4.7278 & TST \\
\hline CHEMBL1479047 & 688323 & 4.45 & 4.7811 & TRN \\
\hline CHEMBL1339451 & 688323 & 4.5 & 4.6717 & TRN \\
\hline CHEMBL1360916 & 688323 & 5.3 & 4.6006 & TST \\
\hline CHEMBL1550042 & 688323 & 4.7 & 4.8642 & TRN \\
\hline CHEMBL1377672 & 688323 & 4.5 & 4.7152 & TRN \\
\hline CHEMBL1427517 & 688323 & 4.9 & 4.8127 & TRN \\
\hline CHEMBL1472849 & 688323 & 4.5 & 4.6197 & TRN \\
\hline CHEMBL1520905 & 688323 & 4.8 & 4.4163 & TRN \\
\hline CHEMBL1305438 & 688323 & 4.55 & 4.6727 & TRN \\
\hline CHEMBL1314561 & 688323 & 4.6 & 4.743 & TRN \\
\hline CHEMBL1519291 & 688323 & 4.45 & 4.8005 & TRN \\
\hline CHEMBL60718 & 688323 & 6.0 & 4.9528 & TRN \\
\hline CHEMBL1984884 & 688323 & 4.45 & 4.774 & TRN \\
\hline CHEMBL1563921 & 688323 & 4.8 & 4.6106 & TRN \\
\hline
\end{tabular}




\begin{tabular}{|c|c|c|c|c|}
\hline & & & plement & al T \\
\hline CHEMBL168279 & 688323 & 5.2 & 5.0251 & TST \\
\hline CHEMBL1488032 & 688323 & 4.65 & 4.7461 & TST \\
\hline CHEMBL1460310 & 688323 & 4.65 & 4.695 & TRN \\
\hline CHEMBL1357311 & 688323 & 4.6 & 4.9626 & TRN \\
\hline CHEMBL1319601 & 688323 & 4.45 & 4.7902 & TRN \\
\hline CHEMBL1515669 & 688323 & 4.5 & 4.6354 & TRN \\
\hline CHEMBL1510643 & 688323 & 4.5 & 4.7686 & TST \\
\hline CHEMBL1980204 & 688323 & 4.5 & 4.7283 & TRN \\
\hline CHEMBL1473641 & 688323 & 5.25 & 4.8237 & TRN \\
\hline CHEMBL1452328 & 688323 & 4.7 & 4.7445 & TRN \\
\hline CHEMBL1318006 & 688323 & 4.65 & 4.6347 & TRN \\
\hline CHEMBL1603561 & 688323 & 4.75 & 4.7477 & TRN \\
\hline CHEMBL1420268 & 688323 & 4.5 & 4.7926 & TST \\
\hline CHEMBL1368942 & 688323 & 4.5 & 4.7318 & TRN \\
\hline CHEMBL1462108 & 688323 & 4.45 & 4.676 & TRN \\
\hline CHEMBL1487849 & 688323 & 5.1 & 5.1387 & TRN \\
\hline CHEMBL343002 & 688323 & 5.2 & 5.0791 & TST \\
\hline CHEMBL1453212 & 688323 & 5.5 & 4.8767 & TST \\
\hline CHEMBL1508965 & 688323 & 4.55 & 5.2554 & TRN \\
\hline CHEMBL1377738 & 688323 & 4.85 & 4.5736 & TRN \\
\hline CHEMBL338790 & 688323 & 4.75 & 4.7007 & TRN \\
\hline CHEMBL1427086 & 688323 & 4.55 & 5.073 & TRN \\
\hline CHEMBL1377522 & 688323 & 4.55 & 4.5642 & TRN \\
\hline CHEMBL1458901 & 688323 & 4.45 & 5.0828 & TRN \\
\hline CHEMBL1584463 & 688323 & 5.45 & 5.1581 & TRN \\
\hline CHEMBL1379673 & 688323 & 5.75 & 4.91 & TRN \\
\hline CHEMBL1256148 & 688323 & 5.2 & 5.0017 & TST \\
\hline CHEMBL3214598 & 688323 & 4.45 & 4.5025 & TRN \\
\hline CHEMBL1562320 & 688323 & 4.45 & 4.8264 & TRN \\
\hline CHEMBL1474404 & 688323 & 4.45 & 4.7444 & TST \\
\hline CHEMBL1474413 & 688323 & 4.7 & 4.7032 & TRN \\
\hline CHEMBL1390056 & 688323 & 4.5 & 4.9624 & TRN \\
\hline CHEMBL1496233 & 688323 & 6.5 & 5.0474 & TRN \\
\hline CHEMBL1372117 & 688323 & 4.8 & 4.8988 & TRN \\
\hline CHEMBL1451981 & 688323 & 4.45 & 4.7807 & TST \\
\hline CHEMBL1379270 & 688323 & 6.5501 & 5.0506 & TRN \\
\hline CHEMBL1429646 & 688323 & 4.5 & 4.9015 & TST \\
\hline CHEMBL1496644 & 688323 & 4.5 & 4.7523 & TRN \\
\hline CHEMBL1605161 & 688323 & 4.9 & 4.9307 & TRN \\
\hline CHEMBL1476835 & 688323 & 4.45 & 4.8608 & TRN \\
\hline CHEMBL1599498 & 688323 & 4.55 & 4.8568 & TRN \\
\hline CHEMBL1472934 & 688323 & 4.8 & 4.6819 & TST \\
\hline CHEMBL1553128 & 688323 & 4.9 & 4.984 & TRN \\
\hline CHEMBL1436384 & 688323 & 4.55 & 4.7375 & TRN \\
\hline CHEMBL1596996 & 688323 & 4.55 & 4.7749 & TRN \\
\hline CHEMBL1315206 & 688323 & 4.45 & 4.687 & TRN \\
\hline CHEMBL1456944 & 688323 & 4.8 & 5.0534 & TST \\
\hline CHEMBL1373515 & 688323 & 4.95 & 4.6619 & TRN \\
\hline
\end{tabular}




\begin{tabular}{|c|c|c|c|c|c|}
\hline \multirow[b]{2}{*}{ CHEMBL1535510 } & \multicolumn{5}{|c|}{ plemental labıe S2. } \\
\hline & 688323 & 4.7 & 5.0192 & TRN & \\
\hline CHEMBL1304925 & 688323 & 4.65 & 5.03100 & $\partial 000000001$ & TST \\
\hline CHEMBL1465945 & 688323 & 4.45 & 4.8305 & TRN & \\
\hline CHEMBL1601435 & 688323 & 5.2 & 5.0688 & TRN & \\
\hline CHEMBL1446405 & 688323 & 4.45 & 4.6805 & TRN & \\
\hline CHEMBL1302002 & 688323 & 4.5 & 5.0245 & TRN & \\
\hline CHEMBL1366316 & 688323 & 4.5 & 4.9755 & TST & \\
\hline CHEMBL1576354 & 688323 & 5.25 & 5.2127 & TRN & \\
\hline CHEMBL1600311 & 688323 & 5.25 & 5.0849 & TRN & \\
\hline CHEMBL1998893 & 688323 & 4.45 & 4.78600 & 00000000005 & TRN \\
\hline CHEMBL1417376 & 688323 & 4.45 & 4.6671 & TRN & \\
\hline CHEMBL1465242 & 688323 & 4.55 & 4.5391 & TRN & \\
\hline CHEMBL3196229 & 688323 & 4.55 & 4.7824 & TRN & \\
\hline CHEMBL1432344 & 688323 & 6.7501 & 5.048 & TRN & \\
\hline CHEMBL1342053 & 688323 & 5.65 & 4.9045 & TRN & \\
\hline CHEMBL1532050 & 688323 & 4.9 & 4.7293 & TRN & \\
\hline CHEMBL1976567 & 688323 & 4.55 & 5.0014 & TRN & \\
\hline CHEMBL1532253 & 688323 & 4.9 & 4.8739 & TRN & \\
\hline CHEMBL1601829 & 688323 & 5.2 & 4.8805 & TRN & \\
\hline CHEMBL1338196 & 688323 & 5.4 & 4.5942 & TRN & \\
\hline CHEMBL1330811 & 688323 & 5.4 & 4.6724 & TRN & \\
\hline CHEMBL1416996 & 688323 & 4.65 & 4.7298 & TRN & \\
\hline CHEMBL1356760 & 688323 & 4.45 & 4.8359 & TRN & \\
\hline CHEMBL1445785 & 688323 & 5.2 & 4.9314 & TRN & \\
\hline CHEMBL1373051 & 688323 & 4.45 & 4.952 & TRN & \\
\hline CHEMBL1609562 & 688323 & 4.45 & 4.8397 & TRN & \\
\hline CHEMBL1457787 & 688323 & 4.5 & 4.7144 & TRN & \\
\hline CHEMBL1385314 & 688323 & 4.65 & 4.6483 & TRN & \\
\hline CHEMBL1544136 & 688323 & 4.5 & 5.0841 & TRN & \\
\hline CHEMBL1458308 & 688323 & 4.85 & 4.6167 & TST & \\
\hline CHEMBL1328028 & 688323 & 6.5501 & 5.0763 & TRN & \\
\hline CHEMBL1593735 & 688323 & 4.45 & 4.8828 & TRN & \\
\hline CHEMBL1423331 & 688323 & 4.95 & 5.0131 & TST & \\
\hline CHEMBL1500316 & 688323 & 5.25 & 5.0078 & TST & \\
\hline CHEMBL1604283 & 688323 & 4.45 & 4.6527 & TST & \\
\hline CHEMBL1566391 & 688323 & 4.45 & 4.84699 & 99999999995 & TRN \\
\hline CHEMBL1336167 & 688323 & 6.0 & 5.003 & TRN & \\
\hline CHEMBL3193428 & 688323 & 4.45 & 4.6337 & TST & \\
\hline CHEMBL589715 & 688323 & 4.5 & 4.6697 & TRN & \\
\hline CHEMBL1593099 & 688323 & 4.45 & 4.6618 & TRN & \\
\hline CHEMBL1332392 & 688323 & 4.45 & 4.7064 & TRN & \\
\hline CHEMBL1439036 & 688323 & 4.65 & 4.749 & TRN & \\
\hline CHEMBL1493501 & 688323 & 4.65 & 4.7682 & TRN & \\
\hline CHEMBL1437605 & 688323 & 4.45 & 4.803 & TRN & \\
\hline CHEMBL1365743 & 688323 & 4.6 & 4.8163 & TRN & \\
\hline CHEMBL1313968 & 688323 & 4.6 & 4.8304 & TRN & \\
\hline CHEMBL1361550 & 688323 & 5.4 & 4.7505 & TRN & \\
\hline CHEMBL1483230 & 688323 & 4.45 & 4.8329 & TRN & \\
\hline
\end{tabular}




\begin{tabular}{|c|c|c|c|c|c|}
\hline \multicolumn{6}{|c|}{ Supplemental Table S2.txt } \\
\hline CHEMBL1474468 & 688323 & 5.5 & 4.9912 & TRN & \\
\hline CHEMBL1531547 & 688323 & 5.2 & 4.9246 & TST & \\
\hline CHEMBL3194486 & 688323 & 4.5 & 4.739 & TRN & \\
\hline CHEMBL1412481 & 688323 & 4.5 & 4.777 & TRN & \\
\hline CHEMBL1512472 & 688323 & 4.45 & 4.8144 & TRN & \\
\hline CHEMBL1473369 & 688323 & 4.45 & 4.7491 & TRN & \\
\hline CHEMBL1315055 & 688323 & 4.9 & 4.5415 & TST & \\
\hline CHEMBL1512551 & 688323 & 5.0 & 4.66 & TRN & \\
\hline CHEMBL3195153 & 688323 & 4.75 & 4.7237 & TRN & \\
\hline CHEMBL1515325 & 688323 & 4.8 & 4.9254 & TRN & \\
\hline CHEMBL3199483 & 688323 & 7.0 & 4.7786 & TRN & \\
\hline CHEMBL1326969 & 688323 & 4.45 & 4.8339 & TRN & \\
\hline CHEMBL1414803 & 688323 & 4.95 & 4.9444 & TRN & \\
\hline CHEMBL2003909 & 688323 & 4.6 & 4.65600 & 0000000001 & TRN \\
\hline CHEMBL1602561 & 688323 & 4.5 & 4.7392 & TRN & \\
\hline CHEMBL313737 & 688323 & 6.0 & 4.9023 & TST & \\
\hline CHEMBL1322289 & 688323 & 4.55 & 4.9691 & TRN & \\
\hline CHEMBL1386762 & 688323 & 4.5 & 4.827 & TRN & \\
\hline CHEMBL1965132 & 688323 & 4.6 & 4.7146 & TRN & \\
\hline CHEMBL1357247 & 688323 & 4.45 & 4.8014 & TST & \\
\hline CHEMBL3208333 & 688323 & 4.9 & 4.7988 & TRN & \\
\hline CHEMBL1364769 & 688323 & 4.45 & 4.7177 & TRN & \\
\hline CHEMBL1611773 & 688323 & 4.5 & 4.8739 & TST & \\
\hline CHEMBL1524995 & 688323 & 5.0 & 4.9288 & TRN & \\
\hline CHEMBL1529687 & 688323 & 4.95 & 4.9105 & TST & \\
\hline CHEMBL1428960 & 688323 & 4.45 & 4.8577 & TRN & \\
\hline CHEMBL1431470 & 688323 & 4.45 & 4.769 & TST & \\
\hline CHEMBL1438213 & 688323 & 4.45 & 4.9188 & TRN & \\
\hline CHEMBL1539894 & 688323 & 4.6 & 4.5687 & TRN & \\
\hline CHEMBL1998853 & 688323 & 4.7 & 4.8681 & TRN & \\
\hline CHEMBL 2006594 & 688323 & 4.85 & 4.8323 & TRN & \\
\hline CHEMBL1473106 & 688323 & 4.8 & 4.7922 & TRN & \\
\hline CHEMBL1324852 & 688323 & 6.9 & 5.0373 & TRN & \\
\hline CHEMBL1507842 & 688323 & 5.85 & 4.9047 & TRN & \\
\hline CHEMBL1442799 & 688323 & 4.8 & 4.8259 & TRN & \\
\hline CHEMBL1505230 & 688323 & 4.5 & 4.7905 & TRN & \\
\hline CHEMBL1347351 & 688323 & 4.45 & 4.963 & TRN & \\
\hline CHEMBL1513692 & 688323 & 4.45 & 4.8227 & TRN & \\
\hline CHEMBL1565888 & 688323 & 4.45 & 4.7157 & TRN & \\
\hline CHEMBL1355590 & 688323 & 4.45 & 4.5802 & TRN & \\
\hline CHEMBL1396718 & 688323 & 4.45 & 4.7397 & TRN & \\
\hline CHEMBL1498530 & 688323 & 4.95 & 5.0168 & TRN & \\
\hline CHEMBL1965889 & 688323 & 4.6 & 4.8458 & TRN & \\
\hline CHEMBL3189614 & 688323 & 6.25 & 4.7175 & TRN & \\
\hline CHEMBL1405755 & 688323 & 5.45 & 4.6747 & TRN & \\
\hline CHEMBL1468672 & 688323 & 4.45 & 5.0039 & TST & \\
\hline CHEMBL1356308 & 688323 & 5.25 & 5.1196 & TRN & \\
\hline CHEMBL1439210 & 688323 & 4.7 & 4.8512 & TRN & \\
\hline
\end{tabular}




\begin{tabular}{|c|c|c|c|c|}
\hline \multicolumn{5}{|c|}{ Supplemental Table S2.txt } \\
\hline CHEMBL1408989 & 688323 & 4.5 & 4.7734 & TRN \\
\hline CHEMBL1557690 & 688323 & 4.5 & 4.6861 & TRN \\
\hline CHEMBL1403438 & 688323 & 4.55 & 4.845 & TRN \\
\hline CHEMBL 234180 & 688323 & 4.85 & 5.018 & TRN \\
\hline CHEMBL1548122 & 688323 & 4.55 & 4.8099 & TST \\
\hline CHEMBL1489824 & 688323 & 4.45 & 4.8886 & TRN \\
\hline CHEMBL3189421 & 688323 & 4.55 & 4.7696 & TRN \\
\hline CHEMBL1436764 & 688323 & 4.45 & 4.7832 & TRN \\
\hline CHEMBL1387210 & 688323 & 6.35 & 4.81 & TST \\
\hline CHEMBL1366532 & 688323 & 4.6 & 4.9556 & TRN \\
\hline CHEMBL1515006 & 688323 & 4.85 & 4.8029 & TRN \\
\hline CHEMBL1353750 & 688323 & 4.7 & 4.7178 & TST \\
\hline CHEMBL1471334 & 688323 & 4.5 & 4.6848 & TRN \\
\hline CHEMBL1510024 & 688323 & 5.2 & 4.9807 & TRN \\
\hline CHEMBL1356298 & 688323 & 4.5 & 4.5859 & TRN \\
\hline CHEMBL3191730 & 688323 & 5.2 & 4.9888 & TRN \\
\hline CHEMBL1590695 & 688323 & 4.8 & 4.8471 & TRN \\
\hline CHEMBL1606436 & 688323 & 4.65 & 4.9914 & TRN \\
\hline CHEMBL1461633 & 688323 & 4.55 & 4.8248 & TRN \\
\hline CHEMBL3208842 & 688323 & 5.2 & 4.6461 & TST \\
\hline CHEMBL1475896 & 688323 & 4.5 & 4.792 & TRN \\
\hline CHEMBL146525 & 688323 & 4.75 & 4.7747 & TRN \\
\hline CHEMBL1403329 & 688323 & 5.25 & 5.2004 & TRN \\
\hline CHEMBL1310230 & 688323 & 5.0 & 4.9344 & TRN \\
\hline CHEMBL1515130 & 688323 & 4.65 & 4.9001 & TRN \\
\hline CHEMBL1565500 & 688323 & 5.2 & 4.9166 & TRN \\
\hline CHEMBL400912 & 688323 & 5.25 & 4.6642 & TRN \\
\hline CHEMBL1549271 & 688323 & 4.6 & 4.9506 & TRN \\
\hline CHEMBL1544947 & 688323 & 5.2 & 5.0685 & TRN \\
\hline CHEMBL1387110 & 688323 & 4.6 & 4.7487 & TRN \\
\hline CHEMBL1475876 & 688323 & 4.65 & 4.6231 & TRN \\
\hline CHEMBL1500790 & 688323 & 4.55 & 4.8097 & TRN \\
\hline CHEMBL1473691 & 688323 & 5.5 & 5.1546 & TRN \\
\hline CHEMBL1437222 & 688323 & 4.9 & 4.7572 & TRN \\
\hline CHEMBL1515670 & 688323 & 5.0 & 4.9276 & TRN \\
\hline CHEMBL1604303 & 688323 & 4.7 & 4.7653 & TRN \\
\hline CHEMBL1605722 & 688323 & 4.65 & 4.9698 & TST \\
\hline CHEMBL1516132 & 688323 & 5.15 & 4.9097 & TRN \\
\hline CHEMBL1502779 & 688323 & 5.5 & 4.8965 & TST \\
\hline CHEMBL68423 & 688323 & 4.45 & 4.9981 & TST \\
\hline CHEMBL1454512 & 688323 & 5.3 & 4.8354 & TST \\
\hline CHEMBL1386876 & 688323 & 4.65 & 4.7385 & TRN \\
\hline CHEMBL1487635 & 688323 & 5.25 & 4.9914 & TRN \\
\hline CHEMBL1573534 & 688323 & 6.0 & 5.1352 & TRN \\
\hline CHEMBL1432427 & 688323 & 4.9 & 5.0623 & TRN \\
\hline CHEMBL1326914 & 688323 & 6.15 & 4.9835 & TRN \\
\hline CHEMBL1306142 & 688323 & 4.9 & 4.8656 & TRN \\
\hline CHEMBL1449971 & 688323 & 4.6 & 4.7312 & TRN \\
\hline
\end{tabular}




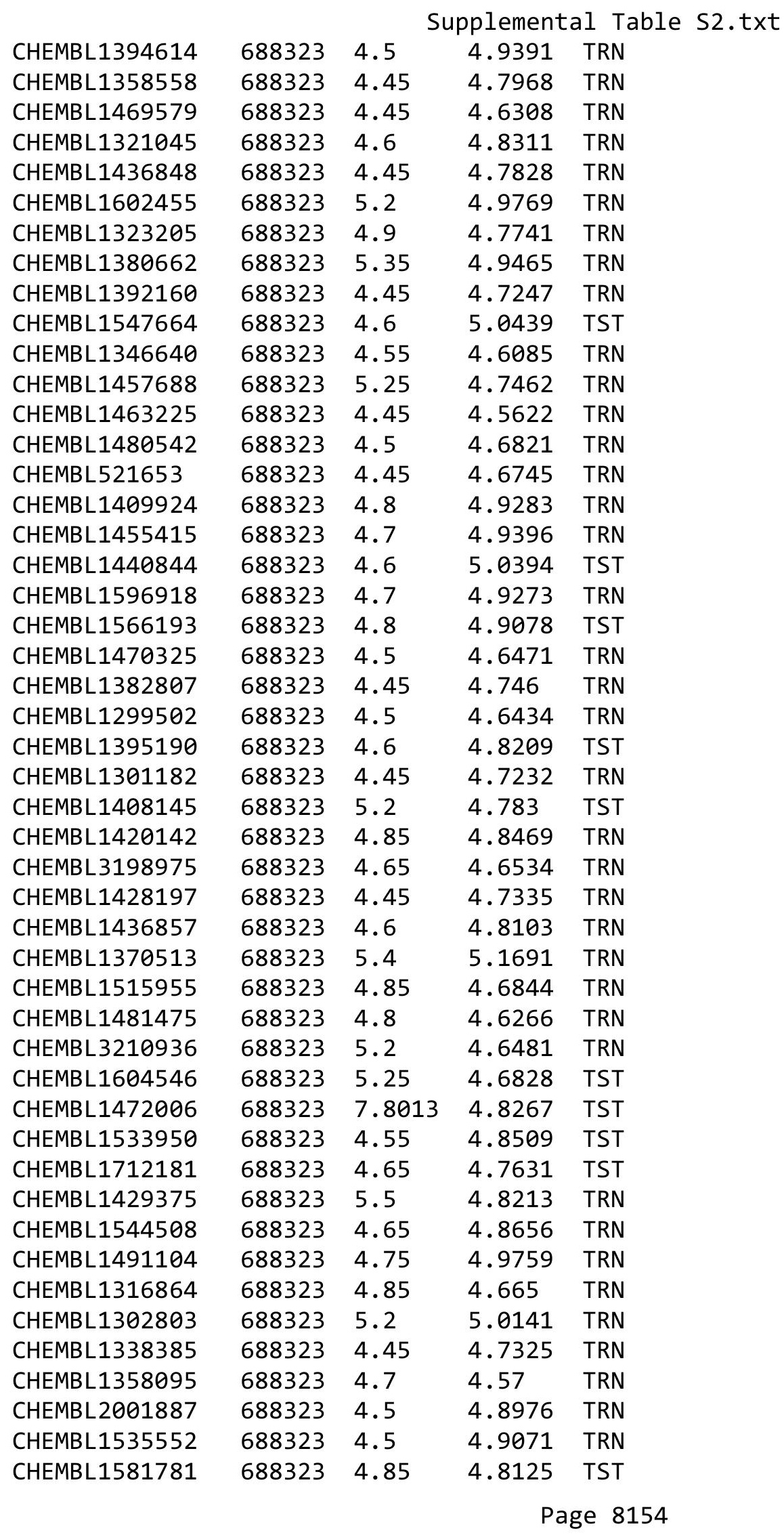




\begin{tabular}{|c|c|c|c|c|c|}
\hline \multicolumn{6}{|c|}{ Supplemental Table S2.txt } \\
\hline CHEMBL1463551 & 688323 & 4.65 & 4.8391 & TRN & \\
\hline CHEMBL1396322 & 688323 & 4.5 & 4.7098 & TRN & \\
\hline CHEMBL1400731 & 688323 & 5.3 & 5.1944 & TRN & \\
\hline CHEMBL1303653 & 688323 & 5.3 & 5.04 & TRN & \\
\hline CHEMBL1400162 & 688323 & 4.45 & 4.7814 & TRN & \\
\hline CHEMBL1431184 & 688323 & 4.45 & 4.6756 & TRN & \\
\hline CHEMBL1610417 & 688323 & 4.45 & 4.9265 & TRN & \\
\hline CHEMBL1460090 & 688323 & 6.5501 & 5.0376 & TRN & \\
\hline CHEMBL1328472 & 688323 & 4.95 & 4.9553 & TRN & \\
\hline CHEMBL3194606 & 688323 & 4.8 & 4.673 & TRN & \\
\hline CHEMBL1517097 & 688323 & 4.45 & 4.8516 & TRN & \\
\hline CHEMBL1408147 & 688323 & 5.15 & 4.75899 & 99999999995 & TRN \\
\hline CHEMBL1311109 & 688323 & 4.45 & 4.9102 & TST & \\
\hline CHEMBL1498523 & 688323 & 5.5 & 4.9471 & TST & \\
\hline CHEMBL 272221 & 688323 & 5.45 & 4.8555 & TST & \\
\hline CHEMBL1587254 & 688323 & 5.25 & 4.8124 & TRN & \\
\hline CHEMBL1489269 & 688323 & 4.7 & 4.6745 & TRN & \\
\hline CHEMBL1518296 & 688323 & 4.45 & 4.8466 & TRN & \\
\hline CHEMBL1502607 & 688323 & 4.55 & 4.8441 & TRN & \\
\hline CHEMBL1428530 & 688323 & 5.55 & 5.0547 & TST & \\
\hline CHEMBL1556676 & 688323 & 4.45 & 4.9775 & TRN & \\
\hline CHEMBL1391996 & 688323 & 5.9 & 4.585 & TST & \\
\hline CHEMBL1412832 & 688323 & 4.45 & 4.7403 & TRN & \\
\hline CHEMBL1515007 & 688323 & 4.65 & 4.8382 & TRN & \\
\hline CHEMBL1555890 & 688323 & 4.85 & 4.8919 & TRN & \\
\hline CHEMBL1446476 & 688323 & 5.4 & 4.7801 & TRN & \\
\hline CHEMBL1379069 & 688323 & 5.45 & 5.0572 & TRN & \\
\hline CHEMBL1415247 & 688323 & 5.55 & 4.9695 & TRN & \\
\hline CHEMBL1572826 & 688323 & 5.2 & 4.9208 & TRN & \\
\hline CHEMBL571087 & 688323 & 4.45 & 4.7242 & TRN & \\
\hline CHEMBL1985338 & 688323 & 5.45 & 4.7663 & TRN & \\
\hline CHEMBL1375998 & 688323 & 4.6 & 4.3943 & TRN & \\
\hline CHEMBL609606 & 688323 & 4.65 & 5.0623 & TRN & \\
\hline CHEMBL1444524 & 688323 & 4.65 & 4.7068 & TRN & \\
\hline CHEMBL1461491 & 688323 & 4.5 & 4.8332 & TST & \\
\hline CHEMBL1469505 & 688323 & 4.85 & 4.6695 & TRN & \\
\hline CHEMBL1305980 & 688323 & 4.5 & 5.079 & TRN & \\
\hline CHEMBL1550157 & 688323 & 4.75 & 4.6686 & TRN & \\
\hline CHEMBL3191763 & 688323 & 4.5 & 4.9259 & TRN & \\
\hline CHEMBL 2006338 & 688323 & 4.75 & 4.7541 & TRN & \\
\hline CHEMBL1474678 & 688323 & 4.45 & 4.6775 & TRN & \\
\hline CHEMBL 2007297 & 688323 & 4.5 & 4.5737 & TRN & \\
\hline CHEMBL3210441 & 688323 & 4.65 & 4.8737 & TRN & \\
\hline CHEMBL1354688 & 688323 & 4.5 & 4.5794 & TRN & \\
\hline CHEMBL1507251 & 688323 & 4.5 & 4.5316 & TRN & \\
\hline CHEMBL1356832 & 688323 & 4.5 & 4.9282 & TRN & \\
\hline CHEMBL1589062 & 688323 & 4.9 & 4.8002 & TRN & \\
\hline CHEMBL3191270 & 688323 & 4.65 & 4.891 & TRN & \\
\hline
\end{tabular}




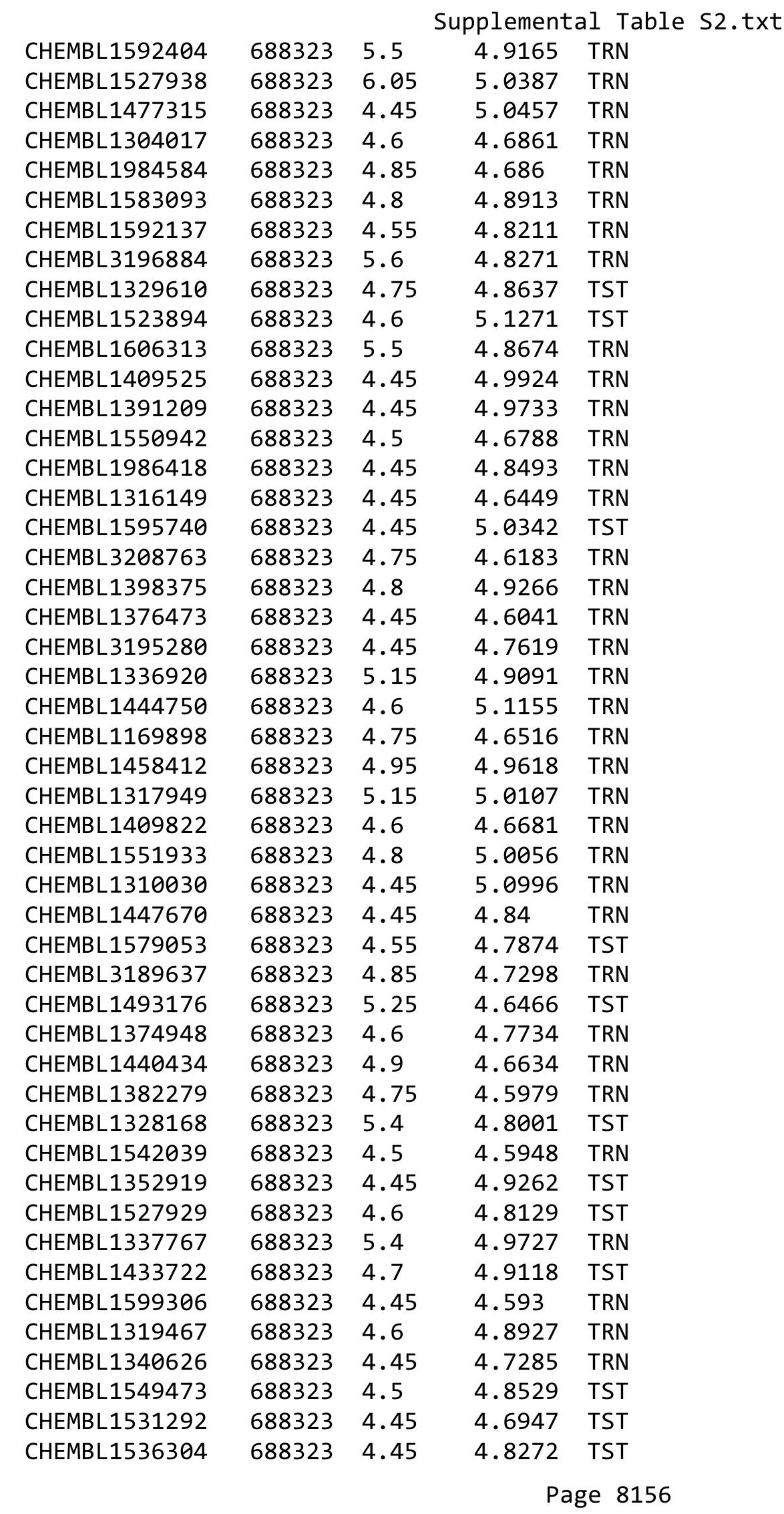




\begin{tabular}{|c|c|c|c|c|c|}
\hline \multicolumn{6}{|c|}{ Supplemental Table S2.txt } \\
\hline CHEMBL1485094 & 688323 & 4.8 & 4.8625 & TRN & \\
\hline CHEMBL1534959 & 688323 & 4.5 & 4.7549 & TRN & \\
\hline CHEMBL1326110 & 688323 & 5.25 & 4.8968 & TRN & \\
\hline CHEMBL1410466 & 688323 & 4.5 & 4.7761 & TRN & \\
\hline CHEMBL146710 & 688323 & 4.65 & 4.8016 & TRN & \\
\hline CHEMBL1502828 & 688323 & 5.25 & 4.81 & TST & \\
\hline CHEMBL1610433 & 688323 & 5.45 & 4.9651 & TRN & \\
\hline CHEMBL414890 & 688323 & 5.25 & 4.8196 & TRN & \\
\hline CHEMBL15594 & 688323 & 4.45 & 5.1286 & TRN & \\
\hline CHEMBL1539149 & 688323 & 4.45 & 4.845 & TST & \\
\hline CHEMBL1452821 & 688323 & 4.65 & 4.717 & TRN & \\
\hline CHEMBL3213482 & 688323 & 5.35 & 4.7067 & TRN & \\
\hline CHEMBL1361273 & 688323 & 4.45 & 4.9453 & TRN & \\
\hline CHEMBL1356096 & 688323 & 4.7 & 5.0127 & TRN & \\
\hline CHEMBL1532185 & 688323 & 6.2 & 4.809 & TST & \\
\hline CHEMBL1583426 & 688323 & 4.8 & 4.7599 & TRN & \\
\hline CHEMBL1432336 & 688323 & 4.5 & 4.8958 & TRN & \\
\hline CHEMBL1604398 & 688323 & 4.7 & 4.8887 & TRN & \\
\hline CHEMBL1344234 & 688323 & 4.55 & 5.0463 & TRN & \\
\hline CHEMBL1542748 & 688323 & 4.8 & 5.0413 & TRN & \\
\hline CHEMBL1520312 & 688323 & 5.45 & 5.1205 & TRN & \\
\hline CHEMBL1340895 & 688323 & 5.45 & 4.7513 & TRN & \\
\hline CHEMBL1974521 & 688323 & 4.75 & 4.6851 & TRN & \\
\hline CHEMBL1353112 & 688323 & 6.0 & 5.0157 & TRN & \\
\hline CHEMBL417096 & 688323 & 6.95 & 5.0717 & TST & \\
\hline CHEMBL 2002619 & 688323 & 4.5 & 4.5173 & TRN & \\
\hline CHEMBL1370351 & 688323 & 5.2 & 5.09399 & 9999999999 & TRN \\
\hline CHEMBL1573943 & 688323 & 5.15 & 4.9021 & TRN & \\
\hline CHEMBL1608332 & 688323 & 4.5 & 4.7171 & TRN & \\
\hline CHEMBL1522560 & 688323 & 4.45 & 4.6721 & TST & \\
\hline CHEMBL1443242 & 688323 & 5.35 & 4.8858 & TRN & \\
\hline CHEMBL1359641 & 688323 & 4.6 & 4.7541 & TRN & \\
\hline CHEMBL1529695 & 688323 & 4.45 & 4.987 & TRN & \\
\hline CHEMBL1358839 & 688323 & 4.95 & 4.6997 & TRN & \\
\hline CHEMBL1536626 & 688323 & 4.8 & 4.9199 & TRN & \\
\hline CHEMBL1407736 & 688323 & 4.45 & 4.7131 & TRN & \\
\hline CHEMBL1374384 & 688323 & 4.9 & 4.7634 & TRN & \\
\hline CHEMBL1567730 & 688323 & 5.2 & 4.7942 & TRN & \\
\hline CHEMBL1407691 & 688323 & 4.45 & 4.7521 & TRN & \\
\hline CHEMBL1438355 & 688323 & 4.45 & 4.8684 & TRN & \\
\hline CHEMBL1594652 & 688323 & 4.45 & 4.8007 & TRN & \\
\hline CHEMBL1320019 & 688323 & 6.0 & 4.8486 & TRN & \\
\hline CHEMBL1394559 & 688323 & 4.7 & 4.6616 & TRN & \\
\hline CHEMBL1318733 & 688323 & 4.8 & 4.7305 & TRN & \\
\hline CHEMBL1495905 & 688323 & 4.7 & 4.6768 & TRN & \\
\hline CHEMBL1495223 & 688323 & 5.0 & 4.788 & TRN & \\
\hline CHEMBL3190124 & 688323 & 4.45 & 5.0023 & TST & \\
\hline CHEMBL1534924 & 688323 & 4.75 & 4.7385 & TRN & \\
\hline
\end{tabular}




\begin{tabular}{|c|c|c|c|c|c|}
\hline & & \multicolumn{4}{|c|}{ Supplemental Table S2.txt } \\
\hline CHEMBL1379881 & 688323 & 4.5 & 4.8984 & TRN & \\
\hline CHEMBL97760 & 688323 & 4.5 & 4.8405 & TST & \\
\hline CHEMBL1521498 & 688323 & 5.0 & 4.8275 & TRN & \\
\hline CHEMBL1519630 & 688323 & 4.5 & 4.6319 & TRN & \\
\hline CHEMBL1979954 & 688323 & 5.4 & 4.7602 & TRN & \\
\hline CHEMBL1403956 & 688323 & 4.45 & 4.84699 & 99999999995 & TRN \\
\hline CHEMBL1522033 & 688323 & 4.75 & 5.0691 & TRN & \\
\hline CHEMBL1732967 & 688323 & 5.5 & 4.7713 & TRN & \\
\hline CHEMBL1463686 & 688323 & 4.45 & 4.7575 & TRN & \\
\hline CHEMBL1308455 & 688323 & 4.6 & 4.9061 & TRN & \\
\hline CHEMBL1514941 & 688323 & 4.45 & 4.8237 & TRN & \\
\hline CHEMBL1522198 & 688323 & 4.85 & 4.828 & TRN & \\
\hline CHEMBL1964389 & 688323 & 4.5 & 5.0125 & TRN & \\
\hline CHEMBL1542186 & 688323 & 4.5 & 4.5631 & TRN & \\
\hline CHEMBL1567663 & 688323 & 4.5 & 4.6925 & TRN & \\
\hline CHEMBL1452723 & 688323 & 4.7 & 4.7528 & TST & \\
\hline CHEMBL1543511 & 688323 & 4.5 & 4.688 & TRN & \\
\hline CHEMBL1505286 & 688323 & 4.7 & 4.9844 & TRN & \\
\hline CHEMBL1563792 & 688323 & 4.85 & 4.9097 & TRN & \\
\hline CHEMBL1477328 & 688323 & 5.3 & 4.9824 & TRN & \\
\hline CHEMBL1485473 & 688323 & 4.5 & 4.8122 & TRN & \\
\hline CHEMBL1556524 & 688323 & 4.45 & 4.6767 & TRN & \\
\hline CHEMBL1450118 & 688323 & 4.45 & 4.6347 & TRN & \\
\hline CHEMBL1334137 & 688323 & 4.7 & 4.773 & TRN & \\
\hline CHEMBL1323279 & 688323 & 4.45 & 4.8438 & TRN & \\
\hline CHEMBL1410565 & 688323 & 4.6 & 4.612 & TRN & \\
\hline CHEMBL1561650 & 688323 & 6.9 & 4.9153 & TRN & \\
\hline CHEMBL1301943 & 688323 & 4.45 & 4.7997 & TST & \\
\hline CHEMBL1472959 & 688323 & 4.45 & 4.8557 & TRN & \\
\hline CHEMBL3197927 & 688323 & 4.5 & 4.7983 & TRN & \\
\hline CHEMBL1575074 & 688323 & 4.5 & 4.7659 & TST & \\
\hline CHEMBL1364482 & 688323 & 5.1 & 4.7943 & TRN & \\
\hline CHEMBL1314249 & 688323 & 4.6 & 5.0028 & TRN & \\
\hline CHEMBL1416570 & 688323 & 4.5 & 4.7468 & TRN & \\
\hline CHEMBL1378907 & 688323 & 4.45 & 4.8872 & TST & \\
\hline CHEMBL3211278 & 688323 & 5.55 & 4.837 & TRN & \\
\hline CHEMBL1578831 & 688323 & 4.65 & 4.9564 & TRN & \\
\hline CHEMBL1610344 & 688323 & 6.9 & 5.1391 & TRN & \\
\hline CHEMBL1353871 & 688323 & 4.75 & 4.8468 & TRN & \\
\hline CHEMBL1526494 & 688323 & 4.5 & 4.8472 & TRN & \\
\hline CHEMBL1613725 & 688323 & 4.45 & 4.8482 & TRN & \\
\hline CHEMBL1467825 & 688323 & 5.9 & 4.763 & TST & \\
\hline CHEMBL1343462 & 688323 & 5.05 & 5.1237 & TRN & \\
\hline CHEMBL1533452 & 688323 & 4.5 & 4.6713 & TRN & \\
\hline CHEMBL1426572 & 688323 & 4.45 & 4.6347 & TRN & \\
\hline CHEMBL1358104 & 688323 & 4.5 & 4.6873 & TRN & \\
\hline CHEMBL1611933 & 688323 & 4.45 & 4.8898 & TRN & \\
\hline CHEMBL1975257 & 688323 & 5.0 & 4.6738 & TRN & \\
\hline
\end{tabular}




\begin{tabular}{|c|c|c|c|c|c|}
\hline & & \multicolumn{4}{|c|}{ Supplemental Table S2.txt } \\
\hline CHEMBL1436843 & 688323 & 4.65 & 4.6632 & TRN & \\
\hline CHEMBL1540404 & 688323 & 4.45 & 4.927 & TRN & \\
\hline CHEMBL1603107 & 688323 & 5.2 & 4.8588 & TRN & \\
\hline CHEMBL1442283 & 688323 & 4.75 & 4.7116 & TRN & \\
\hline CHEMBL1420365 & 688323 & 4.55 & 4.88899 & 9999999999 & TRN \\
\hline CHEMBL1479318 & 688323 & 4.6 & 4.8215 & TRN & \\
\hline CHEMBL1363249 & 688323 & 4.45 & 5.1541 & TRN & \\
\hline CHEMBL1491481 & 688323 & 5.35 & 5.0821 & TRN & \\
\hline CHEMBL1567852 & 688323 & 4.5 & 4.7076 & TRN & \\
\hline CHEMBL1425372 & 688323 & 4.8 & 4.7565 & TRN & \\
\hline CHEMBL1523965 & 688323 & 4.8 & 4.7941 & TRN & \\
\hline CHEMBL1600914 & 688323 & 5.4 & 4.7976 & TRN & \\
\hline CHEMBL1318123 & 688323 & 4.7 & 4.8342 & TRN & \\
\hline CHEMBL1370669 & 688323 & 4.75 & 4.7422 & TRN & \\
\hline CHEMBL1422472 & 688323 & 4.6 & 4.7917 & TRN & \\
\hline CHEMBL1355931 & 688323 & 4.45 & 4.6149 & TRN & \\
\hline CHEMBL1329709 & 688323 & 4.65 & 4.7302 & TST & \\
\hline CHEMBL1575219 & 688323 & 4.45 & 4.8311 & TRN & \\
\hline CHEMBL1995862 & 688323 & 4.45 & 4.7513 & TRN & \\
\hline CHEMBL1304187 & 688323 & 4.7 & 4.7101 & TRN & \\
\hline CHEMBL1480498 & 688323 & 5.45 & 4.9282 & TRN & \\
\hline CHEMBL1436091 & 688323 & 4.45 & 4.7221 & TRN & \\
\hline CHEMBL1313013 & 688323 & 4.65 & 4.9141 & TRN & \\
\hline CHEMBL1554084 & 688323 & 4.6 & 4.8022 & TRN & \\
\hline CHEMBL1335128 & 688323 & 5.35 & 4.802 & TST & \\
\hline CHEMBL1542319 & 688323 & 5.25 & 4.9387 & TRN & \\
\hline CHEMBL1469560 & 688323 & 4.75 & 4.8113 & TRN & \\
\hline CHEMBL1307845 & 688323 & 5.2 & 5.0546 & TRN & \\
\hline CHEMBL1367521 & 688323 & 4.8 & 4.7862 & TRN & \\
\hline CHEMBL1338442 & 688323 & 4.5 & 4.6521 & TRN & \\
\hline CHEMBL1317963 & 688323 & 5.15 & 4.4717 & TRN & \\
\hline CHEMBL1494096 & 688323 & 5.2 & 4.7925 & TRN & \\
\hline CHEMBL1357429 & 688323 & 4.5 & 4.952 & TST & \\
\hline CHEMBL1422457 & 688323 & 4.45 & 5.0288 & TRN & \\
\hline CHEMBL2003973 & 688323 & 5.1 & 4.8115 & TST & \\
\hline CHEMBL1455906 & 688323 & 4.45 & 4.8557 & TRN & \\
\hline CHEMBL1602220 & 688323 & 5.5 & 4.7987 & TRN & \\
\hline CHEMBL 2003872 & 688323 & 4.45 & 4.7601 & TRN & \\
\hline CHEMBL1482910 & 688323 & 4.45 & 4.7847 & TRN & \\
\hline CHEMBL1438570 & 688323 & 4.45 & 4.7932 & TRN & \\
\hline CHEMBL1487718 & 688323 & 4.45 & 4.8231 & TST & \\
\hline CHEMBL1365204 & 688323 & 4.65 & 5.1107 & TRN & \\
\hline CHEMBL1554851 & 688323 & 4.85 & 4.9114 & TRN & \\
\hline CHEMBL1364820 & 688323 & 4.5 & 4.9038 & TRN & \\
\hline CHEMBL1512414 & 688323 & 5.4 & 4.8021 & TRN & \\
\hline CHEMBL1365626 & 688323 & 5.2 & 4.9773 & TRN & \\
\hline CHEMBL1548101 & 688323 & 4.6 & 4.8027 & TRN & \\
\hline CHEMBL1998940 & 688323 & 4.7 & 4.8407 & TRN & \\
\hline
\end{tabular}




\begin{tabular}{|c|c|c|c|c|c|}
\hline \multicolumn{6}{|c|}{ Supplemental Table s2.txt } \\
\hline CHEMBL1375133 & 688323 & 4.5 & 4.7252 & TRN & \\
\hline CHEMBL1515418 & 688323 & 4.65 & 4.8298 & TRN & \\
\hline CHEMBL1440038 & 688323 & 4.8 & 4.6639 & TRN & \\
\hline CHEMBL1491798 & 688323 & 4.6 & 4.8997 & TRN & \\
\hline CHEMBL3192901 & 688323 & 4.45 & 4.6413 & TRN & \\
\hline CHEMBL1501307 & 688323 & 4.65 & 5.0062 & TRN & \\
\hline CHEMBL1482598 & 688323 & 4.8 & 4.6312 & TRN & \\
\hline CHEMBL1468883 & 688323 & 5.4 & 4.9583 & TRN & \\
\hline CHEMBL1329189 & 688323 & 4.45 & 4.9949 & TST & \\
\hline CHEMBL1576094 & 688323 & 4.6 & 4.9473 & TRN & \\
\hline CHEMBL1968824 & 688323 & 4.75 & 4.6732 & TRN & \\
\hline CHEMBL1363837 & 688323 & 5.0 & 4.6805 & TRN & \\
\hline CHEMBL1555591 & 688323 & 4.7 & 4.7345 & TRN & \\
\hline CHEMBL1420278 & 688323 & 4.5 & 5.1891 & TRN & \\
\hline CHEMBL1437016 & 688323 & 4.45 & 4.745 & TRN & \\
\hline CHEMBL1584153 & 688323 & 6.0 & 4.9284 & TRN & \\
\hline CHEMBL3208625 & 688323 & 4.55 & 4.9134 & TRN & \\
\hline CHEMBL1441404 & 688323 & 4.45 & 4.8611 & TRN & \\
\hline CHEMBL1601779 & 688323 & 4.75 & 4.8797 & TRN & \\
\hline CHEMBL1512962 & 688323 & 4.95 & 4.6836 & TRN & \\
\hline CHEMBL1561657 & 688323 & 4.8 & 4.9199 & TRN & \\
\hline CHEMBL1431687 & 688323 & 4.5 & 4.7001 & TST & \\
\hline CHEMBL1322541 & 688323 & 4.55 & 4.7707 & TRN & \\
\hline CHEMBL1509065 & 688323 & 4.45 & 5.0685 & TRN & \\
\hline CHEMBL1378885 & 688323 & 4.6 & 4.9664 & TRN & \\
\hline CHEMBL1557828 & 688323 & 4.75 & 4.8975 & TRN & \\
\hline CHEMBL1606716 & 688323 & 4.45 & 4.8627 & TRN & \\
\hline CHEMBL1489587 & 688323 & 4.45 & 5.119 & TRN & \\
\hline CHEMBL1340168 & 688323 & 5.25 & 4.8707 & TST & \\
\hline CHEMBL3193765 & 688323 & 4.45 & 4.4657 & TRN & \\
\hline CHEMBL1495985 & 688323 & 4.5 & 4.9974 & TRN & \\
\hline CHEMBL1543122 & 688323 & 5.0 & 4.6791 & TST & \\
\hline CHEMBL1402149 & 688323 & 5.15 & 4.7966 & TRN & \\
\hline CHEMBL1582748 & 688323 & 5.45 & 4.93199 & 99999999995 & TST \\
\hline CHEMBL1472080 & 688323 & 5.2 & 4.9745 & TRN & \\
\hline CHEMBL1434648 & 688323 & 4.5 & 4.4694 & TRN & \\
\hline CHEMBL3213245 & 688323 & 4.8 & 4.5755 & TST & \\
\hline CHEMBL1307056 & 688323 & 4.5 & 4.86100 & 0000000001 & TRN \\
\hline CHEMBL1485945 & 688323 & 5.25 & 4.9859 & TRN & \\
\hline CHEMBL1435584 & 688323 & 5.45 & 4.8044 & TRN & \\
\hline CHEMBL1386952 & 688323 & 4.8 & 4.7851 & TRN & \\
\hline CHEMBL1508692 & 688323 & 4.5 & 4.7768 & TRN & \\
\hline CHEMBL1571792 & 688323 & 4.8 & 4.8712 & TST & \\
\hline CHEMBL1361418 & 688323 & 4.7 & 4.7723 & TRN & \\
\hline CHEMBL1501508 & 688323 & 5.2 & 4.7617 & TRN & \\
\hline CHEMBL1547550 & 688323 & 4.45 & 4.9249 & TRN & \\
\hline CHEMBL1517176 & 688323 & 4.45 & 4.725 & TRN & \\
\hline CHEMBL1354646 & 688323 & 4.45 & 4.7245 & TRN & \\
\hline
\end{tabular}




\begin{tabular}{|c|c|c|c|c|}
\hline \multicolumn{5}{|c|}{ Supplemental Table s2.txt } \\
\hline CHEMBL1551628 & 688323 & 4.5 & 4.9693 & TRN \\
\hline CHEMBL1598769 & 688323 & 4.45 & 4.8694 & TRN \\
\hline CHEMBL1366282 & 688323 & 7.0501 & 4.953 & TRN \\
\hline CHEMBL1404668 & 688323 & 4.45 & 4.9912 & TRN \\
\hline CHEMBL1454440 & 688323 & 4.75 & 4.8971 & TRN \\
\hline CHEMBL1475822 & 688323 & 4.45 & 4.8112 & TRN \\
\hline CHEMBL1457146 & 688323 & 4.45 & 4.9626 & TRN \\
\hline CHEMBL1507376 & 688323 & 4.45 & 4.915 & TST \\
\hline CHEMBL1351707 & 688323 & 4.9 & 4.7808 & TRN \\
\hline CHEMBL1343938 & 688323 & 6.2 & 4.8226 & TRN \\
\hline CHEMBL1402055 & 688323 & 4.8 & 4.7087 & TST \\
\hline CHEMBL1468427 & 688323 & 4.6 & 4.9534 & TST \\
\hline CHEMBL1414009 & 688323 & 4.55 & 4.8527 & TRN \\
\hline CHEMBL1389081 & 688323 & 5.4 & 5.0571 & TRN \\
\hline CHEMBL1526690 & 688323 & 4.45 & 4.7235 & TRN \\
\hline CHEMBL48310 & 688323 & 6.0 & 4.9999 & TST \\
\hline CHEMBL1401373 & 688323 & 5.15 & 4.5124 & TRN \\
\hline CHEMBL1990078 & 688323 & 4.5 & 4.9805 & TRN \\
\hline CHEMBL 1347570 & 688323 & 4.45 & 4.8946 & TRN \\
\hline CHEMBL1512374 & 688323 & 5.35 & 4.9783 & TRN \\
\hline CHEMBL1613688 & 688323 & 6.0 & 4.8003 & TST \\
\hline CHEMBL1468403 & 688323 & 4.6 & 4.7842 & TRN \\
\hline CHEMBL1513368 & 688323 & 5.15 & 4.6783 & TRN \\
\hline CHEMBL1488727 & 688323 & 4.65 & 4.8546 & TRN \\
\hline CHEMBL1342798 & 688323 & 4.55 & 4.9094 & TRN \\
\hline CHEMBL 3194533 & 688323 & 4.45 & 4.6724 & TRN \\
\hline CHEMBL 3192892 & 688323 & 4.75 & 4.7213 & TRN \\
\hline CHEMBL1440596 & 688323 & 4.65 & 4.6335 & TRN \\
\hline CHEMBL1414571 & 688323 & 4.9 & 4.5792 & TST \\
\hline CHEMBL1440069 & 688323 & 6.7501 & 5.0022 & TRN \\
\hline CHEMBL1449651 & 688323 & 6.15 & 5.1676 & TST \\
\hline CHEMBL1445887 & 688323 & 4.7 & 4.8417 & TRN \\
\hline CHEMBL1576312 & 688323 & 4.45 & 4.9735 & TRN \\
\hline CHEMBL547675 & 688323 & 4.45 & 4.7682 & TRN \\
\hline CHEMBL1604163 & 688323 & 4.65 & 4.7736 & TRN \\
\hline CHEMBL3208451 & 688323 & 4.5 & 4.7457 & TRN \\
\hline CHEMBL1988851 & 688323 & 5.2 & 4.7152 & TRN \\
\hline CHEMBL1561449 & 688323 & 6.45 & 4.8144 & TRN \\
\hline CHEMBL 2001294 & 688323 & 5.5 & 4.8655 & TRN \\
\hline CHEMBL1441006 & 688323 & 4.8 & 4.7952 & TRN \\
\hline CHEMBL1479288 & 688323 & 4.45 & 5.0586 & TST \\
\hline CHEMBL1417269 & 688323 & 6.9 & 5.0421 & TST \\
\hline CHEMBL1473506 & 688323 & 4.45 & 4.73600 & 0000000001 \\
\hline CHEMBL1603284 & 688323 & 4.6 & 5.0492 & TRN \\
\hline CHEMBL1499127 & 688323 & 5.45 & 5.0559 & TRN \\
\hline CHEMBL 3210407 & 688323 & 4.5 & 4.4923 & TRN \\
\hline CHEMBL1515300 & 688323 & 4.45 & 4.765 & TRN \\
\hline CHEMBL1301572 & 688323 & 4.45 & 4.8553 & TST \\
\hline & & & & 8161 \\
\hline
\end{tabular}

TRN 


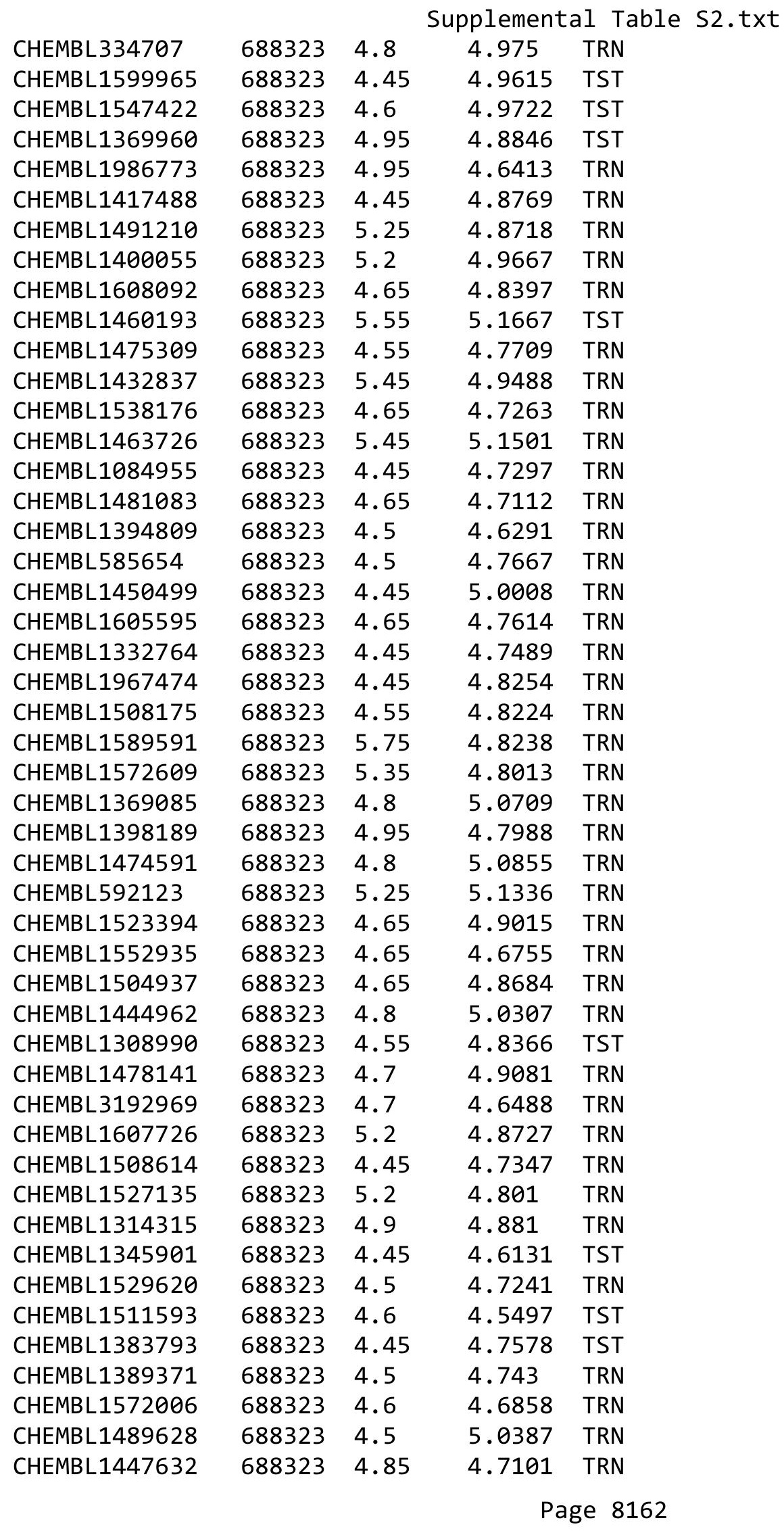




\begin{tabular}{|c|c|c|c|c|c|}
\hline \multirow[b]{2}{*}{ CHEMBL1497577 } & & \multicolumn{4}{|c|}{ Supplemental Table S2.txt } \\
\hline & 688323 & 4.45 & 4.8488 & TST & \\
\hline CHEMBL1306456 & 688323 & 4.5 & 4.88399 & 99999999995 & TST \\
\hline CHEMBL1980665 & 688323 & 4.45 & 4.5913 & TRN & \\
\hline CHEMBL1426496 & 688323 & 5.25 & 5.0416 & TRN & \\
\hline CHEMBL1412285 & 688323 & 4.5 & 4.9382 & TST & \\
\hline CHEMBL1556818 & 688323 & 4.6 & 4.8054 & TRN & \\
\hline CHEMBL1460225 & 688323 & 5.2 & 4.7364 & TRN & \\
\hline CHEMBL1379252 & 688323 & 4.65 & 4.6558 & TRN & \\
\hline CHEMBL1322881 & 688323 & 5.2 & 4.8855 & TRN & \\
\hline CHEMBL1598161 & 688323 & 4.5 & 4.7767 & TRN & \\
\hline CHEMBL1585609 & 688323 & 4.45 & 4.9021 & TST & \\
\hline CHEMBL1480683 & 688323 & 4.75 & 5.1308 & TRN & \\
\hline CHEMBL1527841 & 688323 & 5.25 & 4.8747 & TRN & \\
\hline CHEMBL1475817 & 688323 & 5.1 & 4.7494 & TRN & \\
\hline CHEMBL1358221 & 688323 & 4.65 & 4.6357 & TRN & \\
\hline CHEMBL1397049 & 688323 & 4.55 & 4.8607 & TRN & \\
\hline CHEMBL1431108 & 688323 & 4.7 & 4.8085 & TST & \\
\hline CHEMBL1466583 & 688323 & 6.25 & 4.9359 & TRN & \\
\hline CHEMBL1557478 & 688323 & 4.5 & 4.6257 & TRN & \\
\hline CHEMBL1413134 & 688323 & 4.5 & 4.8869 & TRN & \\
\hline CHEMBL1442412 & 688323 & 4.45 & 4.7169 & TRN & \\
\hline CHEMBL1354241 & 688323 & 4.8 & 4.7119 & TRN & \\
\hline CHEMBL1367212 & 688323 & 4.6 & 4.8983 & TRN & \\
\hline CHEMBL1325275 & 688323 & 4.5 & 4.6455 & TRN & \\
\hline CHEMBL1518735 & 688323 & 5.35 & 5.075 & TRN & \\
\hline CHEMBL1559958 & 688323 & 5.4 & 4.8145 & TRN & \\
\hline CHEMBL1412086 & 688323 & 6.0 & 4.8114 & TRN & \\
\hline CHEMBL1513292 & 688323 & 5.45 & 4.7958 & TRN & \\
\hline CHEMBL1390524 & 688323 & 4.45 & 4.8424 & TRN & \\
\hline CHEMBL3207650 & 688323 & 5.2 & 4.7982 & TRN & \\
\hline CHEMBL1571175 & 688323 & 4.75 & 4.6611 & TRN & \\
\hline CHEMBL1565944 & 688323 & 4.85 & 4.7386 & TRN & \\
\hline CHEMBL1319784 & 688323 & 4.45 & 4.6604 & TRN & \\
\hline CHEMBL1458566 & 688323 & 4.7 & 5.0153 & TRN & \\
\hline CHEMBL1346297 & 688323 & 4.9 & 4.9298 & TRN & \\
\hline CHEMBL1525545 & 688323 & 5.2 & 5.039 & TRN & \\
\hline CHEMBL1309785 & 688323 & 4.75 & 4.9215 & TRN & \\
\hline CHEMBL1518508 & 688323 & 4.5 & 4.7816 & TRN & \\
\hline CHEMBL3210131 & 688323 & 5.25 & 4.668 & TRN & \\
\hline CHEMBL1312215 & 688323 & 4.5 & 4.6412 & TRN & \\
\hline CHEMBL1377382 & 688323 & 4.45 & 4.8035 & TRN & \\
\hline CHEMBL1416676 & 688323 & 4.85 & 4.8388 & TRN & \\
\hline CHEMBL1525419 & 688323 & 5.45 & 4.8004 & TRN & \\
\hline CHEMBL1580335 & 688323 & 4.5 & 4.8568 & TRN & \\
\hline CHEMBL1315065 & 688323 & 4.9 & 4.6732 & TRN & \\
\hline CHEMBL1479362 & 688323 & 4.45 & 4.7074 & TRN & \\
\hline CHEMBL1964873 & 688323 & 4.45 & 4.8351 & TRN & \\
\hline CHEMBL3189963 & 688323 & 4.45 & 4.853 & TRN & \\
\hline
\end{tabular}




\begin{tabular}{|c|c|c|c|c|c|}
\hline & & \multicolumn{4}{|c|}{ Supplemental Table S2.txt } \\
\hline CHEMBL1612892 & 688323 & 4.55 & 4.5978 & TRN & \\
\hline CHEMBL1443129 & 688323 & 5.4 & 4.9288 & TRN & \\
\hline CHEMBL1324698 & 688323 & 4.45 & 4.7352 & TRN & \\
\hline CHEMBL1518073 & 688323 & 5.45 & 4.8002 & TRN & \\
\hline CHEMBL1969492 & 688323 & 4.45 & 4.5106 & TST & \\
\hline CHEMBL1434370 & 688323 & 4.6 & 4.7121 & TRN & \\
\hline CHEMBL1382927 & 688323 & 4.45 & 4.8383 & TST & \\
\hline CHEMBL1480625 & 688323 & 4.75 & 4.7633 & TRN & \\
\hline CHEMBL1610173 & 688323 & 5.05 & 4.7721 & TRN & \\
\hline CHEMBL1317008 & 688323 & 4.6 & 4.8211 & TRN & \\
\hline CHEMBL3192999 & 688323 & 4.75 & 4.7313 & TRN & \\
\hline CHEMBL1470183 & 688323 & 4.45 & 5.0786 & TRN & \\
\hline CHEMBL1355058 & 688323 & 4.95 & 4.7895 & TRN & \\
\hline CHEMBL1303552 & 688323 & 5.2 & 4.8392 & TRN & \\
\hline CHEMBL 2000172 & 688323 & 4.55 & 4.8689 & TRN & \\
\hline CHEMBL1344750 & 688323 & 4.7 & 4.9159 & TRN & \\
\hline CHEMBL1314239 & 688323 & 4.6 & 4.8075 & TRN & \\
\hline CHEMBL1486531 & 688323 & 5.3 & 4.8023 & TRN & \\
\hline CHEMBL1565403 & 688323 & 5.55 & 5.08899 & 99999999995 & TRN \\
\hline CHEMBL3193093 & 688323 & 4.5 & 4.666 & TRN & \\
\hline CHEMBL1609982 & 688323 & 5.25 & 4.7531 & TRN & \\
\hline CHEMBL1340713 & 688323 & 5.25 & 4.6501 & TRN & \\
\hline CHEMBL1334008 & 688323 & 4.45 & 4.8643 & TRN & \\
\hline CHEMBL1449334 & 688323 & 4.7 & 5.0689 & TRN & \\
\hline CHEMBL1444371 & 688323 & 5.25 & 4.8343 & TST & \\
\hline CHEMBL1500089 & 688323 & 4.65 & 4.9296 & TRN & \\
\hline CHEMBL1529766 & 688323 & 4.6 & 5.035 & TRN & \\
\hline CHEMBL1450195 & 688323 & 5.5 & 4.9734 & TRN & \\
\hline CHEMBL1531538 & 688323 & 5.3 & 4.9115 & TST & \\
\hline CHEMBL1516495 & 688323 & 4.55 & 4.7116 & TRN & \\
\hline CHEMBL1421666 & 688323 & 6.45 & 4.9452 & TST & \\
\hline CHEMBL1606807 & 688323 & 6.25 & 5.0586 & TST & \\
\hline CHEMBL1438245 & 688323 & 5.45 & 4.649 & TRN & \\
\hline CHEMBL1475862 & 688323 & 4.6 & 4.6787 & TRN & \\
\hline CHEMBL3186408 & 688323 & 6.0 & 4.7159 & TST & \\
\hline CHEMBL1414767 & 688323 & 4.5 & 4.8447 & TST & \\
\hline CHEMBL1407866 & 688323 & 6.8 & 5.0415 & TRN & \\
\hline CHEMBL1604905 & 688323 & 5.35 & 4.9105 & TRN & \\
\hline CHEMBL1411016 & 688323 & 4.85 & 4.7819 & TRN & \\
\hline CHEMBL1584937 & 688323 & 4.6 & 5.0024 & TST & \\
\hline CHEMBL1534196 & 688323 & 4.45 & 4.9145 & TRN & \\
\hline CHEMBL1543330 & 688323 & 5.4 & 4.8112 & TRN & \\
\hline CHEMBL1360664 & 688323 & 5.45 & 4.9666 & TST & \\
\hline CHEMBL1420687 & 688323 & 5.3 & 5.0047 & TST & \\
\hline CHEMBL1318405 & 688323 & 5.2 & 4.7685 & TRN & \\
\hline CHEMBL1606583 & 688323 & 5.35 & 5.1507 & TRN & \\
\hline CHEMBL1594176 & 688323 & 4.5 & 4.7127 & TRN & \\
\hline CHEMBL1463623 & 688323 & 4.45 & 4.8838 & TRN & \\
\hline
\end{tabular}




\begin{tabular}{|c|c|c|c|c|c|}
\hline & & \multicolumn{4}{|c|}{ Supplemental Table S2.txt } \\
\hline CHEMBL1368762 & 688323 & 4.45 & 4.8912 & TRN & \\
\hline CHEMBL1522724 & 688323 & 4.75 & 4.7898 & TRN & \\
\hline CHEMBL1421953 & 688323 & 4.5 & 4.8121 & TRN & \\
\hline CHEMBL1495790 & 688323 & 5.5 & 4.9594 & TRN & \\
\hline CHEMBL1341609 & 688323 & 4.6 & 4.8104 & TRN & \\
\hline CHEMBL1562949 & 688323 & 5.45 & 4.9913 & TRN & \\
\hline CHEMBL1500026 & 688323 & 4.5 & 4.7544 & TRN & \\
\hline CHEMBL1502020 & 688323 & 4.65 & 4.9014 & TRN & \\
\hline CHEMBL1330734 & 688323 & 4.45 & 4.9403 & TRN & \\
\hline CHEMBL1612974 & 688323 & 5.8 & 4.8116 & TRN & \\
\hline CHEMBL1605568 & 688323 & 4.55 & 5.0312 & TRN & \\
\hline CHEMBL1339559 & 688323 & 5.3 & 4.8528 & TST & \\
\hline CHEMBL1366006 & 688323 & 4.45 & 4.9409 & TRN & \\
\hline CHEMBL1562878 & 688323 & 4.8 & 4.7425 & TRN & \\
\hline CHEMBL1461287 & 688323 & 4.8 & 4.9074 & TRN & \\
\hline CHEMBL1460264 & 688323 & 4.95 & 4.7919 & TRN & \\
\hline CHEMBL1518917 & 688323 & 4.75 & 4.5951 & TRN & \\
\hline CHEMBL1486073 & 688323 & 6.95 & 4.8381 & TRN & \\
\hline CHEMBL1422971 & 688323 & 4.5 & 4.79 & TRN & \\
\hline CHEMBL1508893 & 688323 & 4.5 & 4.772 & TRN & \\
\hline CHEMBL1582374 & 688323 & 4.45 & 4.9417 & TRN & \\
\hline CHEMBL1424665 & 688323 & 4.6 & 5.2657 & TRN & \\
\hline CHEMBL1555793 & 688323 & 4.45 & 4.7821 & TRN & \\
\hline CHEMBL1565778 & 688323 & 4.75 & 4.5548 & TRN & \\
\hline CHEMBL1444359 & 688323 & 4.45 & 4.3971 & TRN & \\
\hline CHEMBL1437074 & 688323 & 4.45 & 4.7659 & TRN & \\
\hline CHEMBL1497267 & 688323 & 4.9 & 4.6963 & TRN & \\
\hline CHEMBL 3198210 & 688323 & 5.4 & 4.88899 & 9999999999 & TRN \\
\hline CHEMBL1441645 & 688323 & 4.45 & 4.8721 & TRN & \\
\hline CHEMBL1582052 & 688323 & 4.6 & 4.9068 & TRN & \\
\hline CHEMBL1519624 & 688323 & 4.45 & 4.6261 & TRN & \\
\hline CHEMBL1528169 & 688323 & 4.45 & 4.6762 & TRN & \\
\hline CHEMBL1366502 & 688323 & 4.45 & 4.8484 & TRN & \\
\hline CHEMBL1500265 & 688323 & 4.65 & 4.9829 & TRN & \\
\hline CHEMBL1344671 & 688323 & 4.8 & 4.9241 & TRN & \\
\hline CHEMBL195455 & 688323 & 5.3 & 4.7497 & TRN & \\
\hline CHEMBL1482026 & 688323 & 4.65 & 4.823 & TRN & \\
\hline CHEMBL1448713 & 688323 & 4.55 & 5.0733 & TRN & \\
\hline CHEMBL1385047 & 688323 & 4.75 & 4.876 & TRN & \\
\hline CHEMBL1350910 & 688323 & 4.75 & 4.8838 & TRN & \\
\hline CHEMBL1410063 & 688323 & 5.1 & 4.8736 & TRN & \\
\hline CHEMBL1367318 & 688323 & 4.45 & 4.7341 & TRN & \\
\hline CHEMBL1400574 & 688323 & 4.6 & 4.7013 & TRN & \\
\hline CHEMBL1331399 & 688323 & 4.9 & 4.691 & TRN & \\
\hline CHEMBL1324486 & 688323 & 4.65 & 4.8074 & TRN & \\
\hline CHEMBL1493117 & 688323 & 5.1 & 4.7408 & TST & \\
\hline CHEMBL1476151 & 688323 & 4.75 & 4.5978 & TRN & \\
\hline CHEMBL1469035 & 688323 & 5.45 & 4.863 & TRN & \\
\hline
\end{tabular}




\begin{tabular}{|c|c|c|c|c|c|}
\hline \multicolumn{6}{|c|}{ Supplemental Table s2.txt } \\
\hline CHEMBL1336439 & 688323 & 4.5 & 4.7075 & TST & \\
\hline CHEMBL1443184 & 688323 & 4.65 & 4.5872 & TRN & \\
\hline CHEMBL1450284 & 688323 & 4.45 & 4.7703 & TRN & \\
\hline CHEMBL601353 & 688323 & 4.55 & 4.5397 & TRN & \\
\hline CHEMBL1372891 & 688323 & 4.55 & 4.7388 & TRN & \\
\hline CHEMBL1887153 & 688323 & 5.9 & 4.646 & TRN & \\
\hline CHEMBL1382443 & 688323 & 4.65 & 5.035 & TRN & \\
\hline CHEMBL1482004 & 688323 & 4.9 & 4.8041 & TST & \\
\hline CHEMBL1481890 & 688323 & 4.45 & 4.7754 & TRN & \\
\hline CHEMBL1610002 & 688323 & 4.5 & 4.8251 & TST & \\
\hline CHEMBL1438038 & 688323 & 5.25 & 4.8417 & TRN & \\
\hline CHEMBL1594066 & 688323 & 4.5 & 4.8084 & TRN & \\
\hline CHEMBL1394771 & 688323 & 4.45 & 4.846 & TRN & \\
\hline CHEMBL1579993 & 688323 & 4.8 & 4.9537 & TST & \\
\hline CHEMBL1981951 & 688323 & 5.2 & 4.8038 & TRN & \\
\hline CHEMBL1550599 & 688323 & 5.9 & 4.9931 & TST & \\
\hline CHEMBL1354986 & 688323 & 5.5 & 5.0534 & TRN & \\
\hline CHEMBL1317423 & 688323 & 6.3 & 5.0184 & TRN & \\
\hline CHEMBL1492881 & 688323 & 4.5 & 4.662 & TRN & \\
\hline CHEMBL 2004475 & 688323 & 5.3 & 4.6411 & TST & \\
\hline CHEMBL1463964 & 688323 & 4.6 & 4.8275 & TRN & \\
\hline CHEMBL1460085 & 688323 & 4.5 & 4.7273 & TRN & \\
\hline CHEMBL1571635 & 688323 & 4.45 & 4.7474 & TRN & \\
\hline CHEMBL1537663 & 688323 & 5.2 & 4.9314 & TRN & \\
\hline CHEMBL1554379 & 688323 & 4.45 & 4.4885 & TRN & \\
\hline CHEMBL1376929 & 688323 & 4.5 & 4.6167 & TST & \\
\hline CHEMBL1496308 & 688323 & 4.5 & 4.7505 & TRN & \\
\hline CHEMBL1578962 & 688323 & 4.9 & 4.79899 & 99999999995 & TRN \\
\hline CHEMBL1317093 & 688323 & 4.45 & 4.6687 & TRN & \\
\hline CHEMBL1316127 & 688323 & 5.25 & 5.0116 & TRN & \\
\hline CHEMBL1606705 & 688323 & 4.45 & 4.6301 & TRN & \\
\hline CHEMBL1497933 & 688323 & 4.6 & 4.94300 & 00000000005 & TST \\
\hline CHEMBL1560307 & 688323 & 4.6 & 4.86100 & 0000000001 & TRN \\
\hline CHEMBL1513911 & 688323 & 4.9 & 4.9528 & TST & \\
\hline CHEMBL1418728 & 688323 & 4.5 & 4.8539 & TST & \\
\hline CHEMBL 2006431 & 688323 & 4.45 & 4.8067 & TST & \\
\hline CHEMBL1323336 & 688323 & 4.5 & 4.9854 & TRN & \\
\hline CHEMBL1416222 & 688323 & 5.35 & 4.9213 & TRN & \\
\hline CHEMBL1466641 & 688323 & 4.8 & 4.7749 & TRN & \\
\hline CHEMBL1515075 & 688323 & 4.9 & 4.7667 & TRN & \\
\hline CHEMBL1311585 & 688323 & 4.45 & 4.8276 & TRN & \\
\hline CHEMBL1606797 & 688323 & 5.2 & 4.9901 & TRN & \\
\hline CHEMBL1493546 & 688323 & 4.55 & 4.7635 & TST & \\
\hline CHEMBL1577708 & 688323 & 4.45 & 4.8876 & TRN & \\
\hline CHEMBL1394464 & 688323 & 4.45 & 4.7793 & TRN & \\
\hline CHEMBL1464174 & 688323 & 4.45 & 4.7617 & TRN & \\
\hline CHEMBL1604527 & 688323 & 4.45 & 4.7558 & TST & \\
\hline CHEMBL1337453 & 688323 & 4.6 & 4.4072 & TRN & \\
\hline
\end{tabular}




\begin{tabular}{|c|c|c|c|c|}
\hline \multicolumn{5}{|c|}{ Supplemental Table S2.txt } \\
\hline CHEMBL1502126 & 688323 & 5.2 & 4.9024 & TRN \\
\hline CHEMBL1443180 & 688323 & 4.45 & 4.7207 & TRN \\
\hline CHEMBL1979622 & 688323 & 5.5 & 4.6247 & TRN \\
\hline CHEMBL1597345 & 688323 & 4.75 & 4.8159 & TST \\
\hline CHEMBL1434312 & 688323 & 4.45 & 4.9724 & TST \\
\hline CHEMBL1599120 & 688323 & 4.45 & 4.7308 & TST \\
\hline CHEMBL1540377 & 688323 & 5.4 & 4.8636 & TRN \\
\hline CHEMBL1601306 & 688323 & 4.45 & 4.8053 & TRN \\
\hline CHEMBL1339752 & 688323 & 4.45 & 4.8613 & TRN \\
\hline CHEMBL1992346 & 688323 & 4.5 & 4.6726 & TRN \\
\hline CHEMBL1426378 & 688323 & 4.8 & 4.7401 & TST \\
\hline CHEMBL1371946 & 688323 & 4.45 & 4.7794 & TST \\
\hline CHEMBL1405870 & 688323 & 5.25 & 5.0637 & TRN \\
\hline CHEMBL1399460 & 688323 & 4.5 & 4.7934 & TRN \\
\hline CHEMBL1554222 & 688323 & 4.8 & 4.5064 & TRN \\
\hline CHEMBL1346646 & 688323 & 4.85 & 4.5923 & TRN \\
\hline CHEMBL1505604 & 688323 & 5.35 & 5.0789 & TRN \\
\hline CHEMBL1448309 & 688323 & 4.45 & 4.9623 & TST \\
\hline CHEMBL1386368 & 688323 & 4.8 & 4.8888 & TST \\
\hline CHEMBL1441656 & 688323 & 4.5 & 4.7619 & TRN \\
\hline CHEMBL1534476 & 688323 & 5.35 & 5.1133 & TST \\
\hline CHEMBL1512689 & 688323 & 4.45 & 4.912 & TRN \\
\hline CHEMBL1390804 & 688323 & 4.45 & 4.7492 & TST \\
\hline CHEMBL577938 & 688323 & 4.45 & 4.7136 & TRN \\
\hline CHEMBL 372629 & 688323 & 4.65 & 4.7483 & TRN \\
\hline CHEMBL1464832 & 688323 & 5.45 & 4.9523 & TRN \\
\hline CHEMBL1320080 & 688323 & 4.5 & 4.6779 & TRN \\
\hline CHEMBL1412425 & 688323 & 4.5 & 4.9154 & TRN \\
\hline CHEMBL1610925 & 688323 & 5.2 & 4.8373 & TST \\
\hline CHEMBL1538322 & 688323 & 4.45 & 4.7138 & TRN \\
\hline CHEMBL1372393 & 688323 & 4.45 & 4.7714 & TST \\
\hline CHEMBL1512190 & 688323 & 5.3 & 4.8071 & TRN \\
\hline CHEMBL1474432 & 688323 & 4.45 & 4.8164 & TRN \\
\hline CHEMBL1599820 & 688323 & 5.05 & 4.8972 & TRN \\
\hline CHEMBL1314165 & 688323 & 4.5 & 5.0204 & TRN \\
\hline CHEMBL1355235 & 688323 & 4.9 & 5.0332 & TRN \\
\hline CHEMBL1974056 & 688323 & 4.6 & 4.8348 & TRN \\
\hline CHEMBL1458314 & 688323 & 4.5 & 5.0523 & TRN \\
\hline CHEMBL1370727 & 688323 & 5.2 & 4.6802 & TRN \\
\hline CHEMBL1527878 & 688323 & 5.2 & 5.192 & TST \\
\hline CHEMBL1303157 & 688323 & 4.5 & 4.9171 & TRN \\
\hline CHEMBL1457225 & 688323 & 5.25 & 5.001 & TRN \\
\hline CHEMBL1355055 & 688323 & 4.5 & 4.7799 & TRN \\
\hline CHEMBL1340409 & 688323 & 5.2 & 4.8608 & TST \\
\hline CHEMBL1492901 & 688323 & 5.8 & 5.0595 & TRN \\
\hline CHEMBL1505246 & 688323 & 6.95 & 4.8969 & TRN \\
\hline CHEMBL1473864 & 688323 & 4.9 & 4.6819 & TRN \\
\hline CHEMBL1533656 & 688323 & 5.2 & 4.8787 & TRN \\
\hline
\end{tabular}




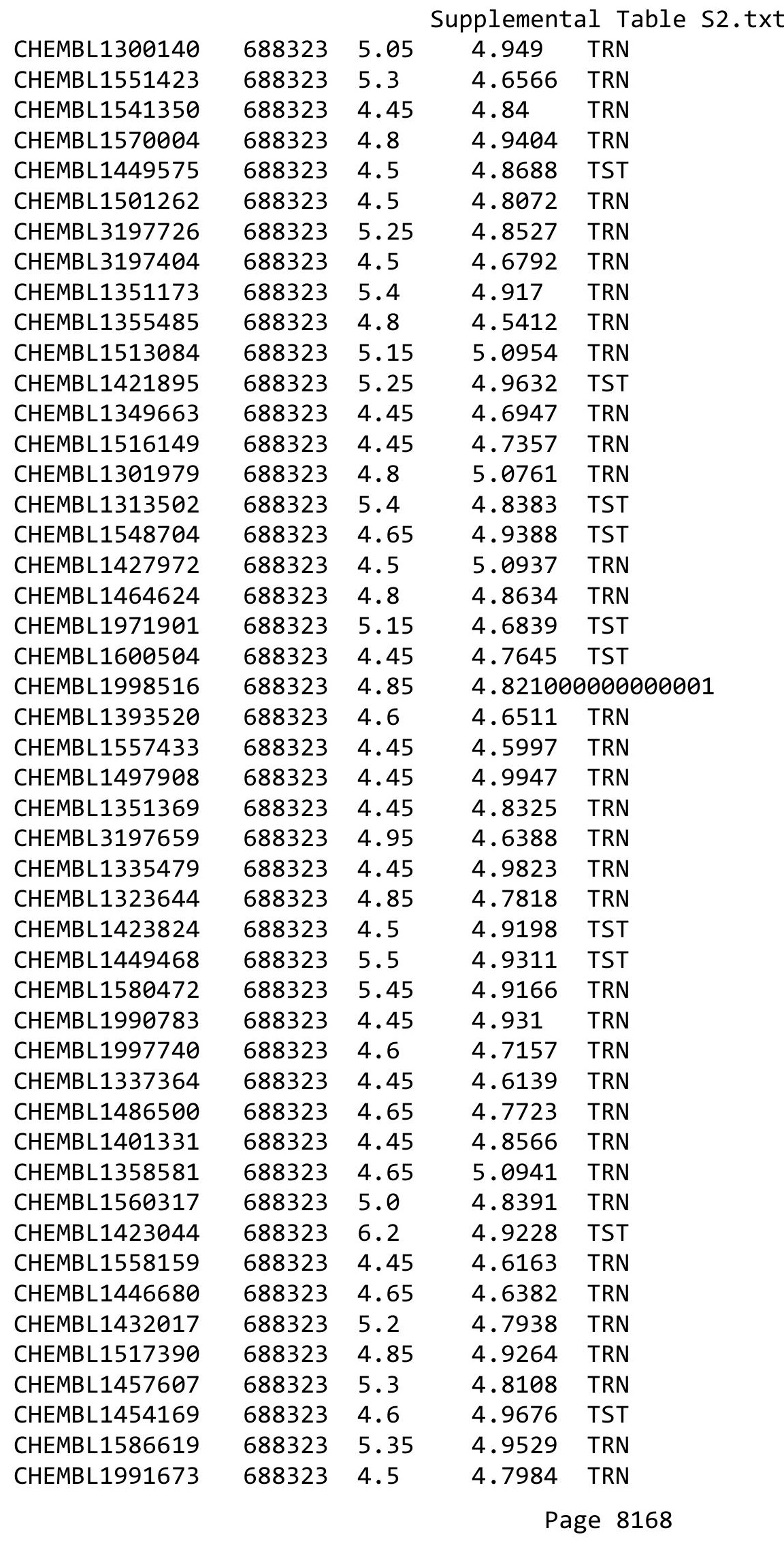




\begin{tabular}{|c|c|c|c|c|}
\hline \multicolumn{5}{|c|}{ Supplemental Table S2.txt } \\
\hline CHEMBL235891 & 688323 & 4.5 & 4.7178 & TST \\
\hline CHEMBL1336252 & 688323 & 4.5 & 4.8298 & TRN \\
\hline CHEMBL1355815 & 688323 & 5.5 & 4.8209 & TRN \\
\hline CHEMBL1422379 & 688323 & 5.55 & 4.8677 & TRN \\
\hline CHEMBL1479708 & 688323 & 4.6 & 4.7258 & TRN \\
\hline CHEMBL1435905 & 688323 & 4.45 & 4.5021 & TRN \\
\hline CHEMBL1552139 & 688323 & 4.55 & 4.8301 & TRN \\
\hline CHEMBL1356977 & 688323 & 4.45 & 4.8339 & TRN \\
\hline CHEMBL1510917 & 688323 & 5.2 & 4.8676 & TRN \\
\hline CHEMBL1337500 & 688323 & 5.25 & 4.9546 & TST \\
\hline CHEMBL1412253 & 688323 & 5.55 & 4.7625 & TST \\
\hline CHEMBL1472570 & 688323 & 6.15 & 4.8627 & TST \\
\hline CHEMBL1451936 & 688323 & 4.5 & 4.5681 & TRN \\
\hline CHEMBL1524024 & 688323 & 4.45 & 4.7704 & TRN \\
\hline CHEMBL1431789 & 688323 & 5.5 & 4.8611 & TRN \\
\hline CHEMBL1553997 & 688323 & 4.5 & 4.7301 & TRN \\
\hline CHEMBL1356765 & 688323 & 4.8 & 4.6573 & TRN \\
\hline CHEMBL1383190 & 688323 & 4.45 & 4.9159 & TRN \\
\hline CHEMBL1335315 & 688323 & 4.7 & 4.68 & TST \\
\hline CHEMBL1468698 & 688323 & 4.6 & 4.9642 & TRN \\
\hline CHEMBL18115 & 688323 & 4.45 & 5.0116 & TRN \\
\hline CHEMBL1300037 & 688323 & 4.5 & 4.6931 & TRN \\
\hline CHEMBL1355033 & 688323 & 4.45 & 4.6398 & TRN \\
\hline CHEMBL1606981 & 688323 & 4.45 & 4.8733 & TRN \\
\hline CHEMBL1585886 & 688323 & 5.05 & 4.6493 & TRN \\
\hline CHEMBL1482405 & 688323 & 4.45 & 4.7307 & TRN \\
\hline CHEMBL1382559 & 688323 & 5.7 & 4.832 & TRN \\
\hline CHEMBL1983220 & 688323 & 4.9 & 4.7072 & TST \\
\hline CHEMBL1310331 & 688323 & 4.45 & 4.8693 & TRN \\
\hline CHEMBL1610066 & 688323 & 4.6 & 4.6109 & TRN \\
\hline CHEMBL1583997 & 688323 & 4.45 & 4.7932 & TST \\
\hline CHEMBL1461796 & 688323 & 4.45 & 4.8294 & TRN \\
\hline CHEMBL1368847 & 688323 & 4.45 & 4.8748 & TRN \\
\hline CHEMBL1554982 & 688323 & 4.5 & 4.6683 & TRN \\
\hline CHEMBL3144962 & 688323 & 4.5 & 4.8135 & TRN \\
\hline CHEMBL1405838 & 688323 & 4.45 & 4.8047 & TRN \\
\hline CHEMBL1491385 & 688323 & 4.5 & 4.9148 & TRN \\
\hline CHEMBL1322145 & 688323 & 4.8 & 4.84 & TRN \\
\hline CHEMBL1308407 & 688323 & 4.45 & 4.593 & TRN \\
\hline CHEMBL1376371 & 688323 & 4.7 & 4.9033 & TST \\
\hline CHEMBL76904 & 688323 & 4.6 & 4.8146 & TRN \\
\hline CHEMBL1474805 & 688323 & 4.45 & 4.8701 & TRN \\
\hline CHEMBL1363476 & 688323 & 4.45 & 4.9045 & TRN \\
\hline CHEMBL1509630 & 688323 & 4.5 & 4.7752 & TST \\
\hline CHEMBL1366889 & 688323 & 4.45 & 4.6939 & TST \\
\hline CHEMBL1512633 & 688323 & 5.25 & 4.8877 & TRN \\
\hline CHEMBL1452716 & 688323 & 6.0 & 4.7116 & TST \\
\hline CHEMBL1380315 & 688323 & 4.55 & 4.9432 & TRN \\
\hline
\end{tabular}




\begin{tabular}{|c|c|c|c|c|}
\hline \multicolumn{5}{|c|}{ Supplemental Table S2.txt } \\
\hline CHEMBL1348277 & 688323 & 4.8 & 4.6785 & TRN \\
\hline CHEMBL1314305 & 688323 & 4.95 & 4.9646 & TRN \\
\hline CHEMBL1369731 & 688323 & 4.45 & 4.5767 & TST \\
\hline CHEMBL1566237 & 688323 & 5.2 & 5.03 & TRN \\
\hline CHEMBL1346343 & 688323 & 6.0 & 4.8847 & TRN \\
\hline CHEMBL1405215 & 688323 & 4.65 & 4.783 & TRN \\
\hline CHEMBL1594488 & 688323 & 4.45 & 4.8756 & TRN \\
\hline CHEMBL 328710 & 688323 & 6.0 & 4.795 & TRN \\
\hline CHEMBL1344059 & 688323 & 4.65 & 4.8409 & TRN \\
\hline CHEMBL1383635 & 688323 & 4.55 & 4.9457 & TRN \\
\hline CHEMBL1543131 & 688323 & 5.5 & 4.968 & TRN \\
\hline CHEMBL1480590 & 688323 & 4.8 & 5.0092 & TST \\
\hline CHEMBL1488348 & 688323 & 4.6 & 4.891 & TRN \\
\hline CHEMBL1472613 & 688323 & 5.25 & 4.7642 & TRN \\
\hline CHEMBL1965612 & 688323 & 4.5 & 4.7451 & TRN \\
\hline CHEMBL1394538 & 688323 & 4.65 & 4.7106 & TRN \\
\hline CHEMBL1514906 & 688323 & 4.45 & 5.0566 & TRN \\
\hline CHEMBL1483129 & 688323 & 5.0 & 4.8588 & TRN \\
\hline CHEMBL1312030 & 688323 & 4.6 & 4.8007 & TRN \\
\hline CHEMBL1508357 & 688323 & 4.7 & 4.8636 & TRN \\
\hline CHEMBL1543472 & 688323 & 8.301 & 4.8507 & TRN \\
\hline CHEMBL1587015 & 688323 & 5.25 & 4.9869 & TST \\
\hline CHEMBL1594911 & 688323 & 4.55 & 4.8674 & TRN \\
\hline CHEMBL 1255837 & 688323 & 4.65 & 4.8731 & TST \\
\hline CHEMBL1588753 & 688323 & 4.6 & 4.8226 & TST \\
\hline CHEMBL1580845 & 688323 & 5.2 & 4.8015 & TRN \\
\hline CHEMBL1578155 & 688323 & 4.5 & 5.1068 & TRN \\
\hline CHEMBL1302946 & 688323 & 4.5 & 4.6862 & TRN \\
\hline CHEMBL1540841 & 688323 & 4.5 & 4.7073 & TRN \\
\hline CHEMBL1574170 & 688323 & 6.8499 & 4.8965 & TRN \\
\hline CHEMBL1087119 & 688323 & 6.95 & 4.6843 & TST \\
\hline CHEMBL1397525 & 688323 & 4.45 & 4.5315 & TRN \\
\hline CHEMBL1319960 & 688323 & 4.95 & 4.8773 & TRN \\
\hline CHEMBL1399285 & 688323 & 4.6 & 4.641 & TRN \\
\hline CHEMBL1316455 & 688323 & 4.7 & 4.7749 & TRN \\
\hline CHEMBL1602650 & 688323 & 4.55 & 4.9085 & TRN \\
\hline CHEMBL1504973 & 688323 & 4.7 & 4.8216 & TRN \\
\hline CHEMBL 374308 & 688323 & 5.6 & 5.0621 & TST \\
\hline CHEMBL1415352 & 688323 & 4.45 & 4.3773 & TRN \\
\hline CHEMBL1989922 & 688323 & 4.65 & 4.7884 & TRN \\
\hline CHEMBL1391686 & 688323 & 4.45 & 4.7054 & TRN \\
\hline CHEMBL 3198540 & 688323 & 4.45 & 4.5831 & TRN \\
\hline CHEMBL1536170 & 688323 & 4.9 & 4.7718 & TRN \\
\hline CHEMBL1467374 & 688323 & 5.4 & 4.7824 & TRN \\
\hline CHEMBL1601471 & 688323 & 4.8 & 4.6768 & TRN \\
\hline CHEMBL1392676 & 688323 & 5.4 & 4.8663 & TRN \\
\hline CHEMBL1992719 & 688323 & 4.65 & 4.7576 & TRN \\
\hline CHEMBL1508166 & 688323 & 4.95 & 4.5455 & TST \\
\hline
\end{tabular}




\begin{tabular}{|c|c|c|c|c|}
\hline \multicolumn{5}{|c|}{ Supplemental Table } \\
\hline CHEMBL1545587 & 688323 & 5.25 & 4.9021 & TST \\
\hline CHEMBL1589652 & 688323 & 4.55 & 4.7557 & TRN \\
\hline CHEMBL1396816 & 688323 & 4.6 & 4.917 & TST \\
\hline CHEMBL1415147 & 688323 & 4.7 & 4.6359 & TRN \\
\hline CHEMBL1579471 & 688323 & 4.5 & 4.5811 & TRN \\
\hline CHEMBL1559211 & 688323 & 4.5 & 4.8691 & TRN \\
\hline CHEMBL1394581 & 688323 & 4.7 & 4.9021 & TRN \\
\hline CHEMBL1596166 & 688323 & 4.55 & 4.7374 & TRN \\
\hline CHEMBL1987579 & 688323 & 5.3 & 4.6139 & TRN \\
\hline CHEMBL1378670 & 688323 & 6.8 & 4.9146 & TRN \\
\hline CHEMBL1396946 & 688323 & 4.45 & 4.5456 & TRN \\
\hline CHEMBL1525329 & 688323 & 4.45 & 4.8807 & TRN \\
\hline CHEMBL1553195 & 688323 & 4.35 & 4.9112 & TRN \\
\hline CHEMBL1433819 & 688323 & 4.65 & 4.601 & TRN \\
\hline CHEMBL112362 & 688323 & 4.45 & 5.0543 & TST \\
\hline CHEMBL172066 & 688323 & 4.7 & 4.8246 & TST \\
\hline CHEMBL1375605 & 688323 & 4.5 & 4.9169 & TRN \\
\hline CHEMBL1308427 & 688323 & 4.8 & 5.0336 & TRN \\
\hline CHEMBL1339419 & 688323 & 4.45 & 4.8691 & TST \\
\hline CHEMBL1300370 & 688323 & 4.75 & 4.7149 & TRN \\
\hline CHEMBL1389146 & 688323 & 4.6 & 4.8788 & TRN \\
\hline CHEMBL1416045 & 688323 & 4.65 & 4.8981 & TRN \\
\hline CHEMBL1344730 & 688323 & 4.5 & 4.7605 & TRN \\
\hline CHEMBL1504020 & 688323 & 5.25 & 4.6293 & TRN \\
\hline CHEMBL1596115 & 688323 & 4.45 & 4.7096 & TRN \\
\hline CHEMBL1368127 & 688323 & 4.75 & 4.9914 & TRN \\
\hline CHEMBL1322138 & 688323 & 4.5 & 5.0099 & TST \\
\hline CHEMBL3190272 & 688323 & 4.45 & 4.8865 & TRN \\
\hline CHEMBL1513877 & 688323 & 6.4 & 5.0747 & TRN \\
\hline CHEMBL1508433 & 688323 & 4.8 & 4.9469 & TRN \\
\hline CHEMBL1376567 & 688323 & 4.85 & 4.9998 & TRN \\
\hline CHEMBL1461131 & 688323 & 4.85 & 4.9697 & TRN \\
\hline CHEMBL1444979 & 688323 & 4.75 & 4.6549 & TRN \\
\hline CHEMBL1418360 & 688323 & 5.3 & 4.9096 & TRN \\
\hline CHEMBL1358015 & 688323 & 4.65 & 4.7514 & TRN \\
\hline CHEMBL1445601 & 688323 & 4.55 & 4.8429 & TRN \\
\hline CHEMBL1422571 & 688323 & 4.45 & 4.7296 & TRN \\
\hline CHEMBL1554281 & 688323 & 4.8 & 4.6451 & TRN \\
\hline CHEMBL1533422 & 688323 & 4.45 & 5.05 & TRN \\
\hline CHEMBL1363093 & 688323 & 4.5 & 4.7369 & TRN \\
\hline CHEMBL1992359 & 688323 & 4.75 & 4.6344 & TRN \\
\hline CHEMBL1431928 & 688323 & 4.7 & 5.1088 & TRN \\
\hline CHEMBL 2000039 & 688323 & 4.45 & 4.6881 & TRN \\
\hline CHEMBL1325634 & 688323 & 4.6 & 4.9215 & TRN \\
\hline CHEMBL1316868 & 688323 & 4.45 & 4.7658 & TRN \\
\hline CHEMBL465843 & 688323 & 5.55 & 4.8476 & TRN \\
\hline CHEMBL1518098 & 688323 & 5.3 & 4.8278 & TST \\
\hline CHEMBL1433884 & 688323 & 4.55 & 4.8019 & TRN \\
\hline
\end{tabular}




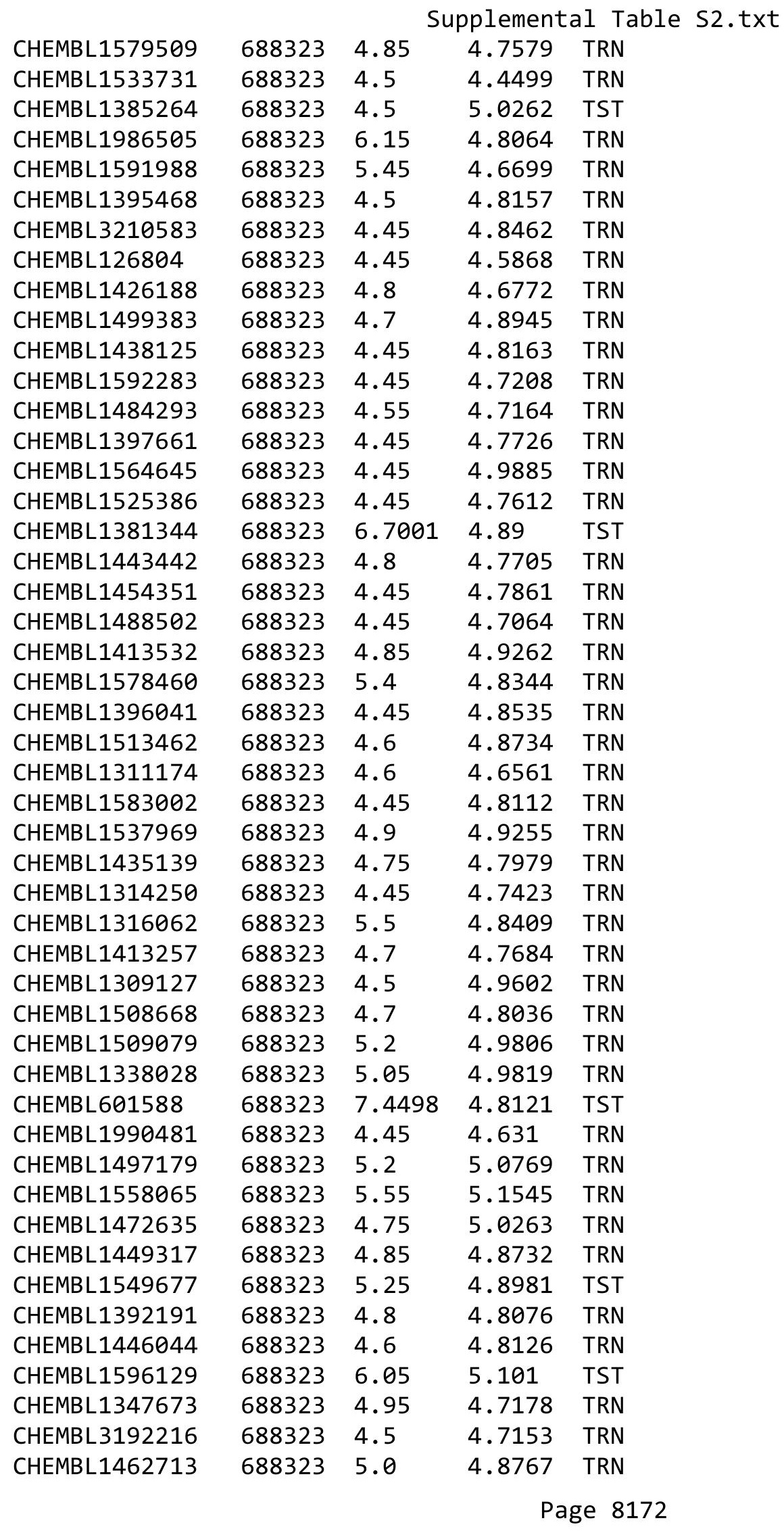




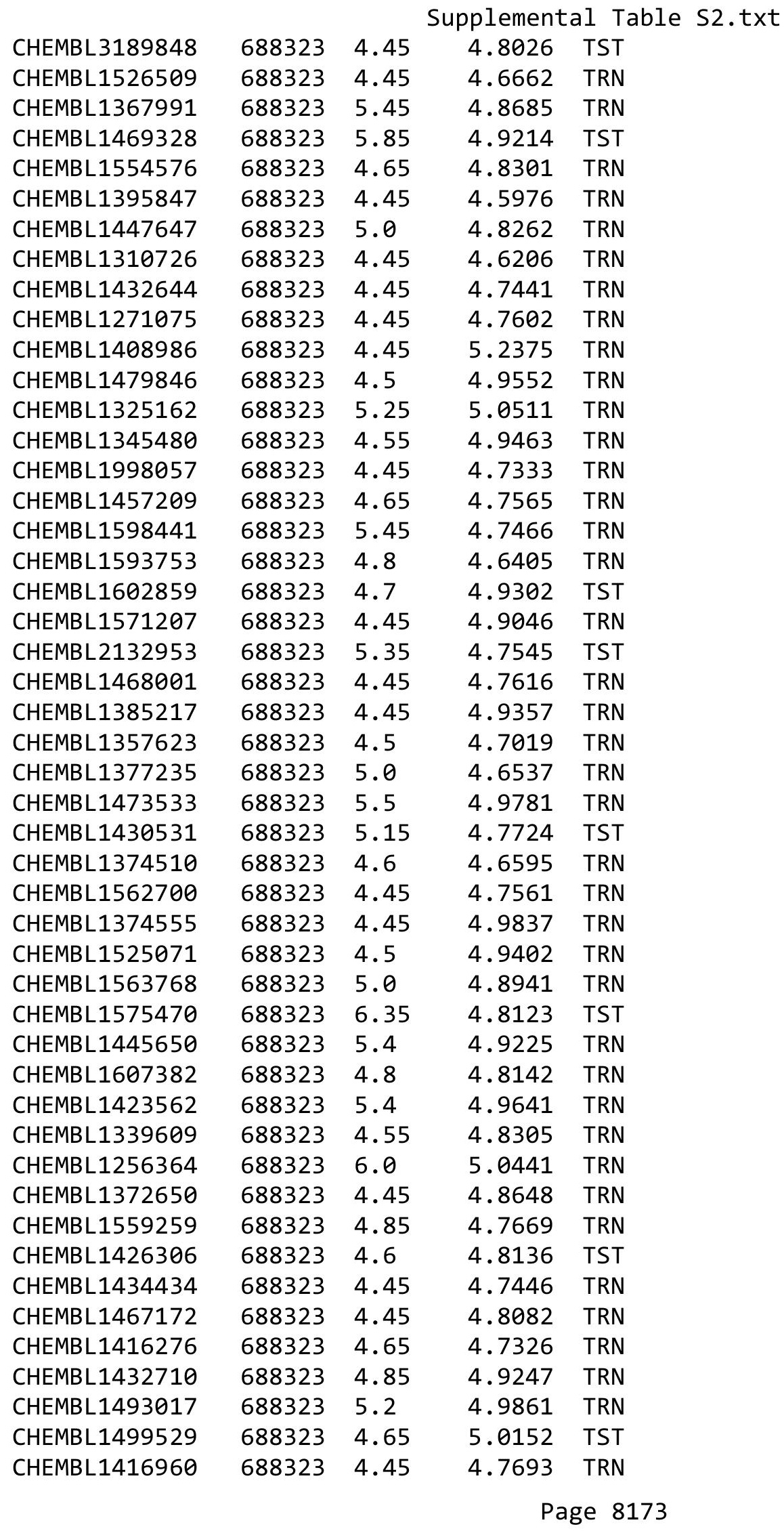




\begin{tabular}{|c|c|c|c|c|c|}
\hline \multicolumn{6}{|c|}{ Supplemental Table S2.txt } \\
\hline CHEMBL1601632 & 688323 & 4.9 & 4.9706 & TRN & \\
\hline CHEMBL1492000 & 688323 & 4.75 & 4.7714 & TST & \\
\hline CHEMBL1480005 & 688323 & 4.75 & 5.0689 & TRN & \\
\hline CHEMBL1467614 & 688323 & 4.6 & 5.0408 & TST & \\
\hline CHEMBL1598639 & 688323 & 4.45 & 4.7905 & TST & \\
\hline CHEMBL1365441 & 688323 & 4.45 & 4.9991 & TRN & \\
\hline CHEMBL1519289 & 688323 & 5.8 & 5.2036 & TRN & \\
\hline CHEMBL1581275 & 688323 & 4.85 & 4.7262 & TRN & \\
\hline CHEMBL1316032 & 688323 & 4.55 & 4.79899 & 99999999995 & TRN \\
\hline CHEMBL1554054 & 688323 & 5.0 & 4.7052 & TST & \\
\hline CHEMBL1442893 & 688323 & 5.2 & 4.8145 & TRN & \\
\hline CHEMBL1521402 & 688323 & 4.45 & 4.9548 & TRN & \\
\hline CHEMBL 2006988 & 688323 & 4.45 & 4.7433 & TRN & \\
\hline CHEMBL1526671 & 688323 & 4.45 & 4.9641 & TRN & \\
\hline CHEMBL1365962 & 688323 & 4.75 & 4.9069 & TST & \\
\hline CHEMBL1400825 & 688323 & 4.5 & 4.9002 & TRN & \\
\hline CHEMBL1319880 & 688323 & 5.2 & 4.8729 & TST & \\
\hline CHEMBL1589914 & 688323 & 5.85 & 4.7179 & TRN & \\
\hline CHEMBL1338381 & 688323 & 4.75 & 4.7857 & TRN & \\
\hline CHEMBL1343976 & 688323 & 4.55 & 4.8094 & TRN & \\
\hline CHEMBL1364673 & 688323 & 4.6 & 4.7503 & TRN & \\
\hline CHEMBL1406536 & 688323 & 4.5 & 4.8764 & TRN & \\
\hline CHEMBL1541861 & 688323 & 5.35 & 4.8111 & TRN & \\
\hline CHEMBL1418656 & 688323 & 4.65 & 4.8449 & TRN & \\
\hline CHEMBL1318772 & 688323 & 4.5 & 4.7321 & TRN & \\
\hline CHEMBL1305537 & 688323 & 4.45 & 4.7621 & TRN & \\
\hline CHEMBL1553775 & 688323 & 4.45 & 4.9237 & TRN & \\
\hline CHEMBL151937 & 688323 & 6.0 & 5.1713 & TRN & \\
\hline CHEMBL1392164 & 688323 & 4.6 & 4.673 & TRN & \\
\hline CHEMBL1299907 & 688323 & 5.45 & 4.796 & TRN & \\
\hline CHEMBL1481613 & 688323 & 4.45 & 5.0143 & TRN & \\
\hline CHEMBL1539325 & 688323 & 4.65 & 4.8617 & TRN & \\
\hline CHEMBL3198606 & 688323 & 5.4 & 4.763 & TRN & \\
\hline CHEMBL3195074 & 688323 & 4.5 & 4.9939 & TRN & \\
\hline CHEMBL1608747 & 688323 & 5.45 & 5.1405 & TST & \\
\hline CHEMBL1977502 & 688323 & 5.0 & 4.6903 & TRN & \\
\hline CHEMBL1461853 & 688323 & 4.6 & 4.8859 & TRN & \\
\hline CHEMBL1316747 & 688323 & 4.45 & 4.7433 & TRN & \\
\hline CHEMBL1394682 & 688323 & 6.0 & 4.5933 & TRN & \\
\hline CHEMBL1563504 & 688323 & 4.75 & 4.7863 & TRN & \\
\hline CHEMBL1403158 & 688323 & 5.45 & 5.0336 & TRN & \\
\hline CHEMBL 2004241 & 688323 & 6.2 & 4.9311 & TST & \\
\hline CHEMBL1528420 & 688323 & 4.5 & 4.7403 & TRN & \\
\hline CHEMBL1352607 & 688323 & 4.6 & 4.7838 & TRN & \\
\hline CHEMBL1462748 & 688323 & 4.5 & 4.5766 & TRN & \\
\hline CHEMBL1453311 & 688323 & 4.55 & 4.7288 & TRN & \\
\hline CHEMBL1312245 & 688323 & 4.8 & 5.0553 & TST & \\
\hline CHEMBL1469885 & 688323 & 4.5 & 4.995 & TRN & \\
\hline
\end{tabular}




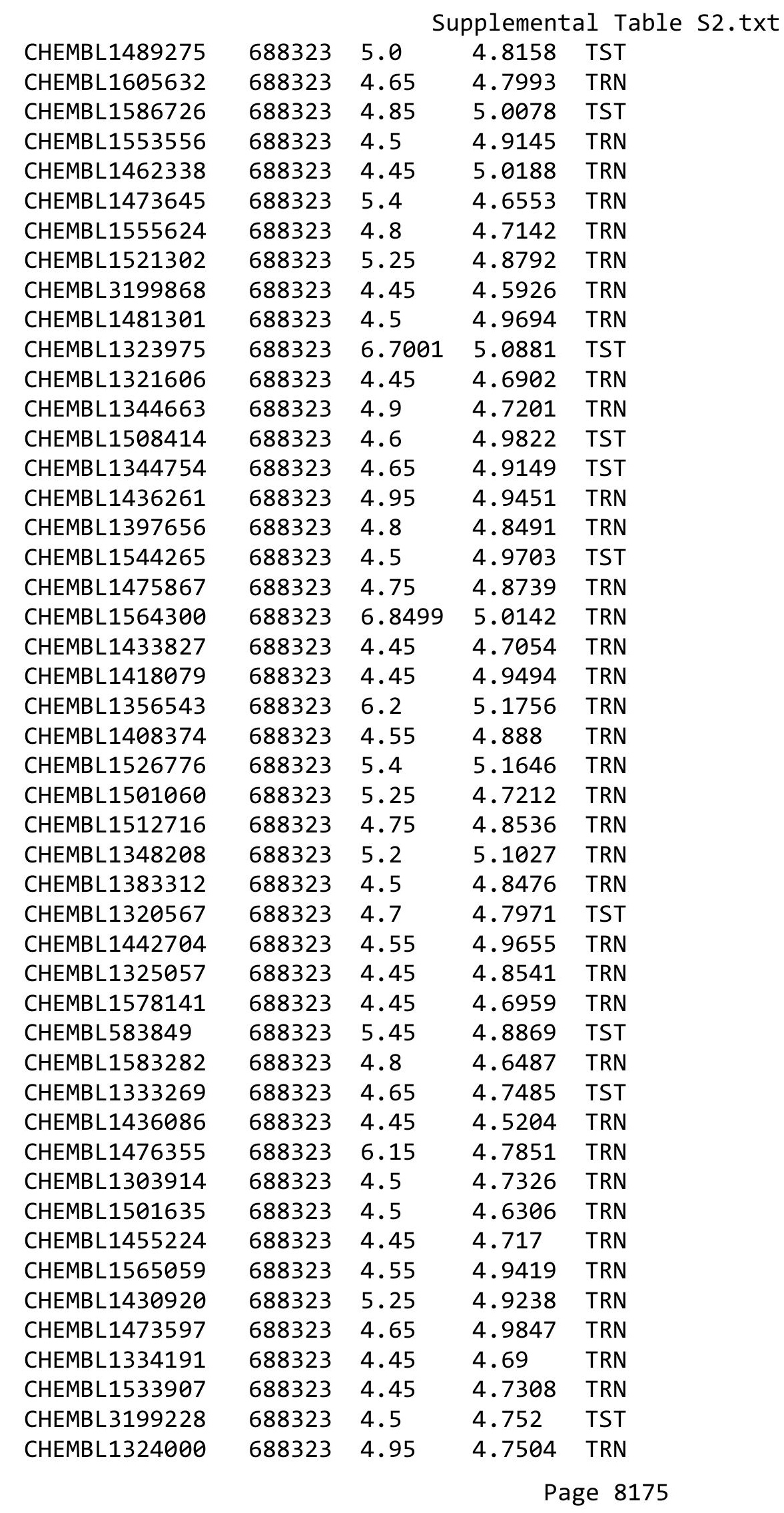




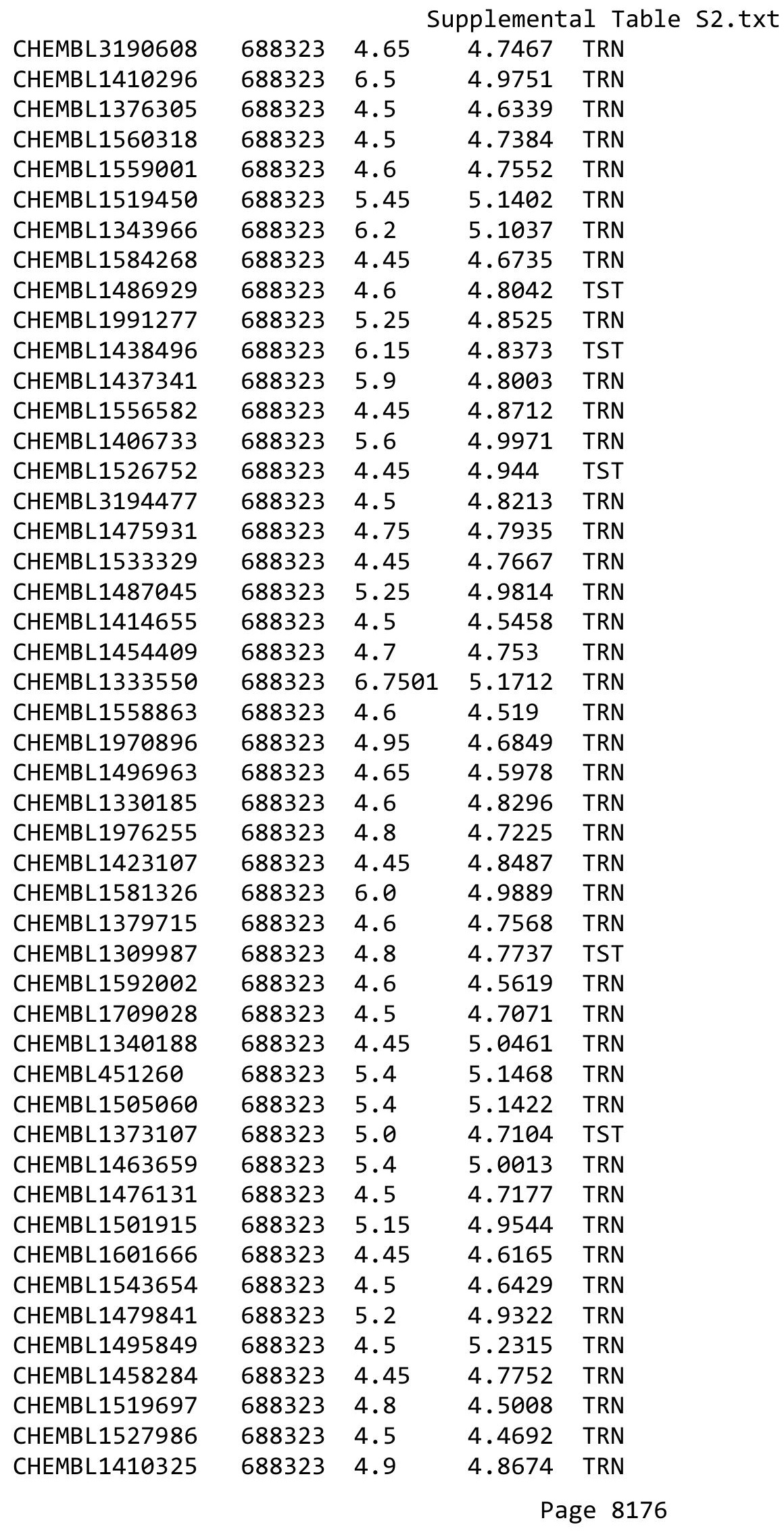




\begin{tabular}{|c|c|c|c|c|}
\hline \multicolumn{5}{|c|}{ Supplemental Table S2.txt } \\
\hline CHEMBL1403097 & 688323 & 4.55 & 4.7942 & TRN \\
\hline CHEMBL1350203 & 688323 & 5.35 & 4.9211 & TRN \\
\hline CHEMBL1476263 & 688323 & 4.5 & 4.7289 & TRN \\
\hline CHEMBL1412695 & 688323 & 4.45 & 4.8166 & TRN \\
\hline CHEMBL1405147 & 688323 & 4.9 & 4.6787 & TRN \\
\hline CHEMBL1333088 & 688323 & 4.45 & 5.1698 & TST \\
\hline CHEMBL1493051 & 688323 & 4.45 & 4.7277 & TRN \\
\hline CHEMBL1366122 & 688323 & 4.65 & 4.8521 & TRN \\
\hline CHEMBL1512590 & 688323 & 4.45 & 4.94 & TST \\
\hline CHEMBL1331329 & 688323 & 7.0 & 4.81 & TRN \\
\hline CHEMBL1598970 & 688323 & 4.45 & 4.7036 & TRN \\
\hline CHEMBL1412567 & 688323 & 6.8499 & 5.0431 & TST \\
\hline CHEMBL1966869 & 688323 & 6.1 & 4.619 & TRN \\
\hline CHEMBL1340646 & 688323 & 5.45 & 5.0057 & TRN \\
\hline CHEMBL1996867 & 688323 & 4.5 & 4.7596 & TRN \\
\hline CHEMBL1494141 & 688323 & 4.7 & 4.6505 & TRN \\
\hline CHEMBL1493811 & 688323 & 6.15 & 4.8662 & TRN \\
\hline CHEMBL1582053 & 688323 & 4.5 & 4.5978 & TRN \\
\hline CHEMBL1485895 & 688323 & 4.6 & 4.9304 & TRN \\
\hline CHEMBL1735892 & 688323 & 4.5 & 4.5885 & TRN \\
\hline CHEMBL1611357 & 688323 & 4.45 & 4.8643 & TRN \\
\hline CHEMBL1417204 & 688323 & 5.2 & 4.8735 & TRN \\
\hline CHEMBL1383626 & 688323 & 4.6 & 4.7826 & TST \\
\hline CHEMBL1364586 & 688323 & 7.0501 & 4.8352 & TST \\
\hline CHEMBL1429711 & 688323 & 4.5 & 4.9327 & TRN \\
\hline CHEMBL1338310 & 688323 & 4.45 & 4.8512 & TRN \\
\hline CHEMBL1498031 & 688323 & 4.45 & 5.1246 & TRN \\
\hline CHEMBL1431126 & 688323 & 4.8 & 4.8444 & TRN \\
\hline CHEMBL1378100 & 688323 & 4.45 & 4.7907 & TRN \\
\hline CHEMBL1492044 & 688323 & 4.75 & 4.7944 & TST \\
\hline CHEMBL1486803 & 688323 & 4.7 & 4.9964 & TST \\
\hline CHEMBL1363654 & 688323 & 4.5 & 4.9092 & TST \\
\hline CHEMBL1356317 & 688323 & 5.2 & 5.016 & TRN \\
\hline CHEMBL1350382 & 688323 & 4.45 & 5.0594 & TST \\
\hline CHEMBL1455047 & 688323 & 5.2 & 5.1819 & TRN \\
\hline CHEMBL1317034 & 688323 & 7.5003 & 4.9547 & TRN \\
\hline CHEMBL1321400 & 688323 & 4.45 & 4.6588 & TRN \\
\hline CHEMBL1976388 & 688323 & 5.05 & 4.7696 & TRN \\
\hline CHEMBL1993431 & 688323 & 4.5 & 4.6382 & TRN \\
\hline CHEMBL1612124 & 688323 & 4.5 & 4.8719 & TRN \\
\hline CHEMBL1601304 & 688323 & 5.2 & 4.7137 & TRN \\
\hline CHEMBL1498113 & 688323 & 5.0 & 4.8855 & TST \\
\hline CHEMBL1483221 & 688323 & 5.25 & 4.8225 & TRN \\
\hline CHEMBL1514158 & 688323 & 4.5 & 4.9903 & TRN \\
\hline CHEMBL1525438 & 688323 & 5.25 & 4.8993 & TST \\
\hline CHEMBL1303719 & 688323 & 5.1 & 4.6599 & TRN \\
\hline CHEMBL577635 & 688323 & 6.0 & 4.7998 & TST \\
\hline CHEMBL1572961 & 688323 & 4.45 & 4.6425 & TRN \\
\hline
\end{tabular}




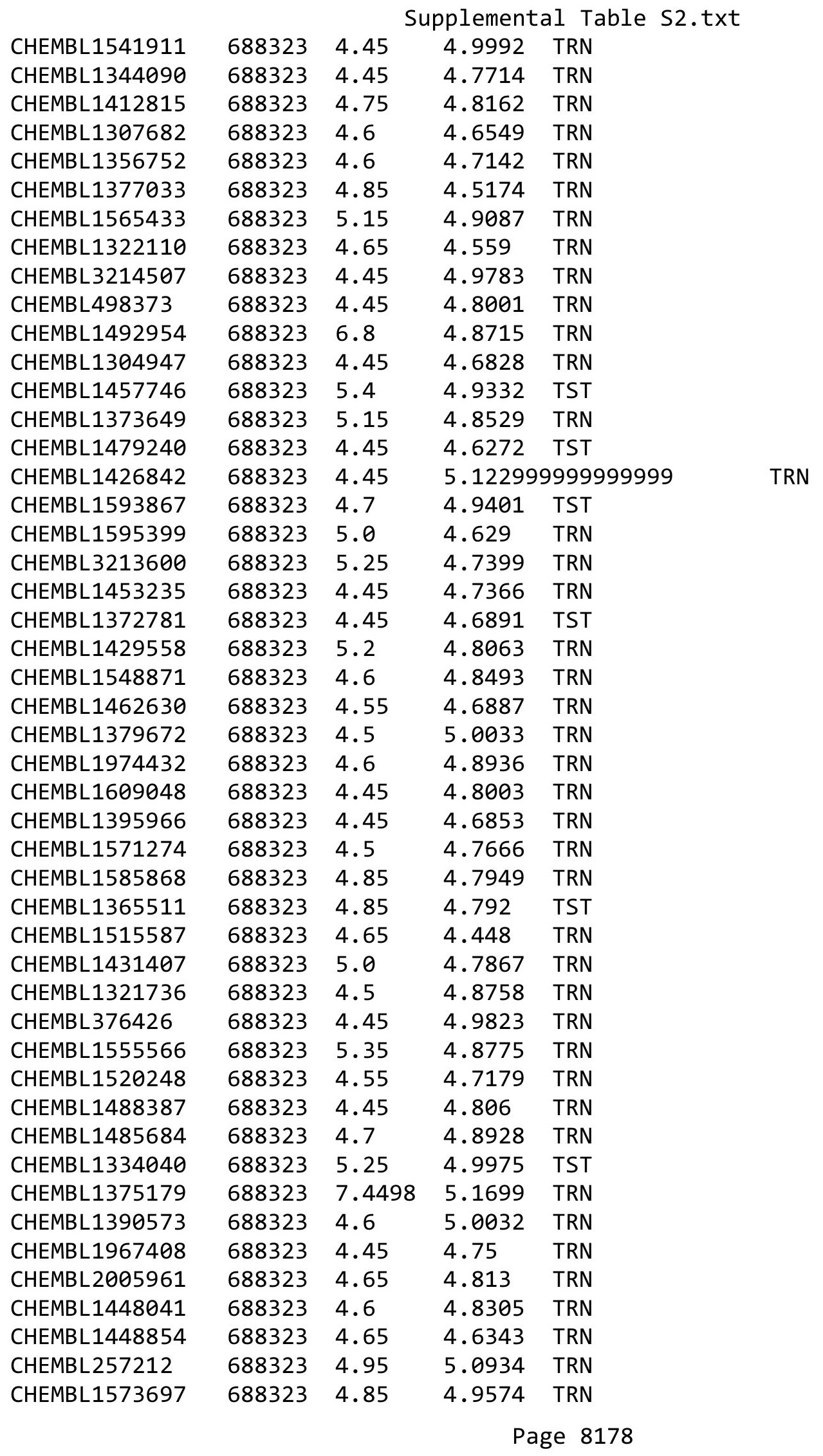




\begin{tabular}{|c|c|c|c|c|c|}
\hline \multicolumn{6}{|c|}{ Supplemental Table S2.txt } \\
\hline CHEMBL1557355 & 688323 & 4.6 & 4.8188 & TRN & \\
\hline CHEMBL1580363 & 688323 & 5.35 & 4.9215 & TRN & \\
\hline CHEMBL1545222 & 688323 & 4.5 & 4.7159 & TRN & \\
\hline CHEMBL1497119 & 688323 & 4.5 & 4.6741 & TST & \\
\hline CHEMBL1447181 & 688323 & 6.45 & 4.9475 & TST & \\
\hline CHEMBL1365755 & 688323 & 4.5 & 4.8261 & TST & \\
\hline CHEMBL555689 & 688323 & 4.45 & 4.9232 & TRN & \\
\hline CHEMBL1428853 & 688323 & 4.45 & 5.1214 & TST & \\
\hline CHEMBL1386117 & 688323 & 5.45 & 5.0586 & TRN & \\
\hline CHEMBL52347 & 688323 & 5.25 & 4.9265 & TRN & \\
\hline CHEMBL1592540 & 688323 & 4.85 & 4.5432 & TRN & \\
\hline CHEMBL1557727 & 688323 & 5.45 & 5.2848 & TRN & \\
\hline CHEMBL1358195 & 688323 & 5.8 & 4.8695 & TRN & \\
\hline CHEMBL1978358 & 688323 & 4.5 & 4.7558 & TRN & \\
\hline CHEMBL1607959 & 688323 & 4.6 & 4.8486 & TRN & \\
\hline CHEMBL1361994 & 688323 & 4.5 & 4.8567 & TRN & \\
\hline CHEMBL1321343 & 688323 & 5.4 & 4.6478 & TST & \\
\hline CHEMBL3191909 & 688323 & 5.2 & 4.6444 & TRN & \\
\hline CHEMBL1483658 & 688323 & 5.25 & 4.7156 & TST & \\
\hline CHEMBL1537624 & 688323 & 4.5 & 5.0246 & TRN & \\
\hline CHEMBL3214487 & 688323 & 4.6 & $4.7410 e$ & 00000000005 & TRN \\
\hline CHEMBL1606685 & 688323 & 4.45 & 4.9314 & TRN & \\
\hline CHEMBL1318246 & 688323 & 4.45 & 4.73 & TRN & \\
\hline CHEMBL1971604 & 688323 & 4.85 & 4.6295 & TRN & \\
\hline CHEMBL1486298 & 688323 & 4.6 & 4.7277 & TRN & \\
\hline CHEMBL1522087 & 688323 & 4.45 & 4.6687 & TRN & \\
\hline CHEMBL1354017 & 688323 & 4.75 & 4.7865 & TRN & \\
\hline CHEMBL1574096 & 688323 & 4.65 & 4.7416 & TRN & \\
\hline CHEMBL1558220 & 688323 & 4.45 & 4.9416 & TRN & \\
\hline CHEMBL 1428663 & 688323 & 4.6 & 4.8799 & TRN & \\
\hline CHEMBL1397433 & 688323 & 4.75 & 4.746 & TRN & \\
\hline CHEMBL1309190 & 688323 & 4.45 & 4.9325 & TST & \\
\hline CHEMBL1353861 & 688323 & 4.75 & 4.6537 & TRN & \\
\hline CHEMBL1309519 & 688323 & 5.0 & 4.6274 & TRN & \\
\hline CHEMBL1599154 & 688323 & 4.6 & 5.0539 & TRN & \\
\hline CHEMBL1457747 & 688323 & 4.8 & 4.7033 & TRN & \\
\hline CHEMBL1432594 & 688323 & 4.5 & 4.8124 & TRN & \\
\hline CHEMBL1481374 & 688323 & 5.15 & 5.0677 & TRN & \\
\hline CHEMBL1601954 & 688323 & 5.25 & 5.0707 & TST & \\
\hline CHEMBL1573175 & 688323 & 4.9 & 4.8536 & TRN & \\
\hline CHEMBL1587435 & 688323 & 5.4 & 4.6932 & TRN & \\
\hline CHEMBL3189412 & 688323 & 4.45 & 4.7907 & TRN & \\
\hline CHEMBL17594 & 688323 & 5.55 & 4.9044 & TRN & \\
\hline CHEMBL1563820 & 688323 & 5.55 & 4.9512 & TRN & \\
\hline CHEMBL1483865 & 688323 & 4.5 & 4.8717 & TRN & \\
\hline CHEMBL375270 & 688323 & 5.15 & 4.8088 & TRN & \\
\hline CHEMBL1382798 & 688323 & 4.45 & 4.6471 & TRN & \\
\hline CHEMBL1454982 & 688323 & 4.5 & 5.0107 & TRN & \\
\hline
\end{tabular}




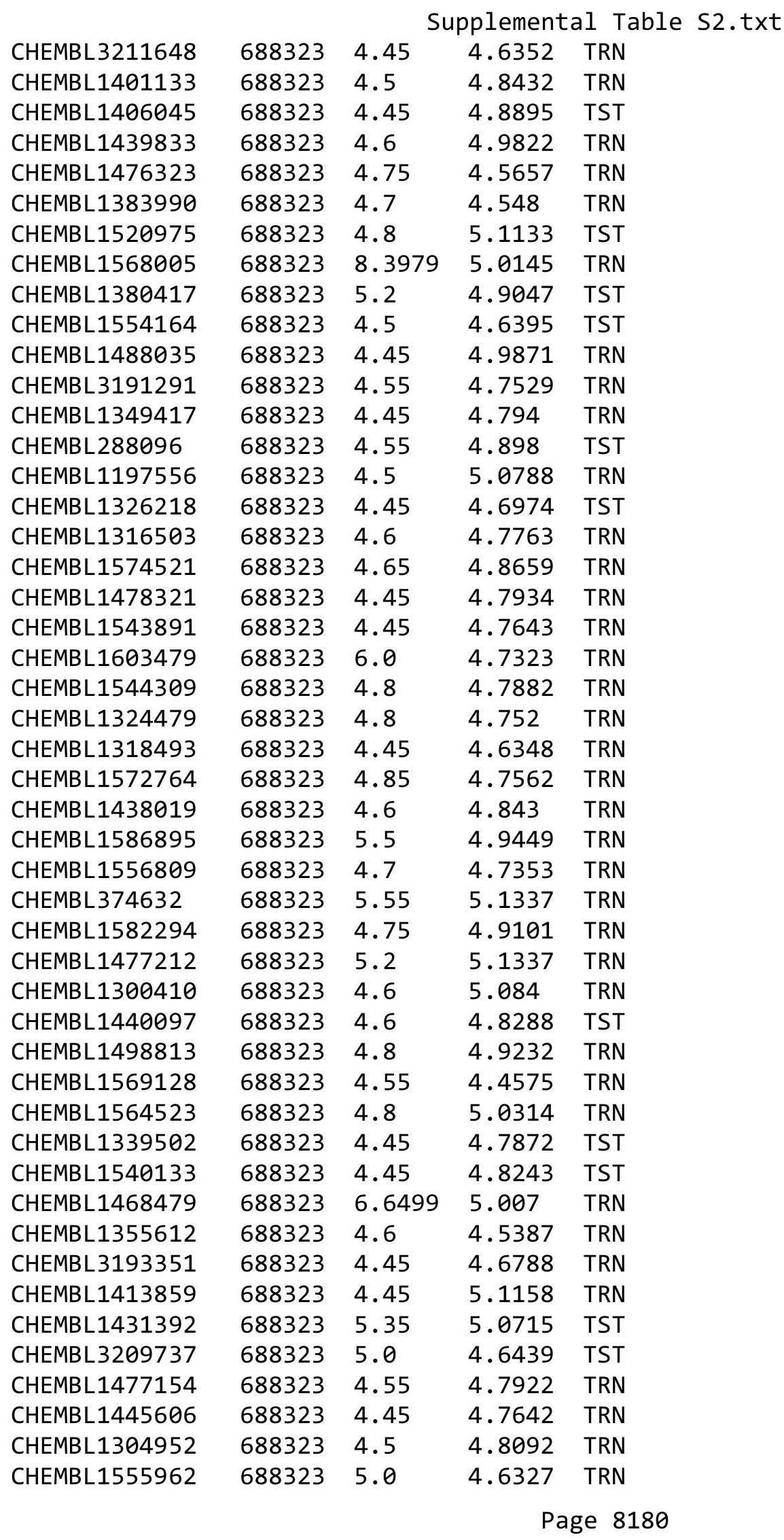




\begin{tabular}{|c|c|c|c|c|c|}
\hline & & \multicolumn{4}{|c|}{ Supplemental Table S2.txt } \\
\hline CHEMBL1501223 & 688323 & 4.6 & 4.93 & TST & \\
\hline CHEMBL1323186 & 688323 & 4.45 & 4.8079 & TRN & \\
\hline CHEMBL19954 & 688323 & 4.45 & 4.992 & TST & \\
\hline CHEMBL1413856 & 688323 & 6.1 & 4.8483 & TST & \\
\hline CHEMBL1320936 & 688323 & 4.65 & 4.7679 & TRN & \\
\hline CHEMBL1348866 & 688323 & 4.65 & 4.7071 & TRN & \\
\hline CHEMBL1340122 & 688323 & 4.7 & 4.787 & TRN & \\
\hline CHEMBL1335133 & 688323 & 4.95 & 4.6548 & TRN & \\
\hline CHEMBL1544330 & 688323 & 4.6 & 4.7128 & TRN & \\
\hline CHEMBL1592574 & 688323 & 5.2 & 4.7866 & TRN & \\
\hline CHEMBL1543760 & 688323 & 4.8 & 4.7353 & TRN & \\
\hline CHEMBL1448633 & 688323 & 5.35 & 4.9802 & TST & \\
\hline CHEMBL1414269 & 688323 & 4.45 & 4.7914 & TRN & \\
\hline CHEMBL456176 & 688323 & 4.65 & 5.0174 & TRN & \\
\hline CHEMBL1607922 & 688323 & 4.45 & 4.4725 & TRN & \\
\hline CHEMBL1505684 & 688323 & 5.4 & 4.8127 & TRN & \\
\hline CHEMBL1330519 & 688323 & 4.8 & 4.9087 & TST & \\
\hline CHEMBL1476313 & 688323 & 4.45 & 4.6976 & TST & \\
\hline CHEMBL1545633 & 688323 & 4.5 & 4.9559 & TST & \\
\hline CHEMBL1557321 & 688323 & 5.35 & 4.8074 & TRN & \\
\hline CHEMBL1391798 & 688323 & 4.45 & 4.9019 & TRN & \\
\hline CHEMBL1514567 & 688323 & 4.45 & 4.7943 & TRN & \\
\hline CHEMBL1350504 & 688323 & 4.75 & 4.8047 & TRN & \\
\hline CHEMBL1323013 & 688323 & 5.3 & 4.8529 & TRN & \\
\hline CHEMBL1461394 & 688323 & 4.75 & 4.8132 & TRN & \\
\hline CHEMBL1405729 & 688323 & 5.2 & 5.1643 & TRN & \\
\hline CHEMBL1347315 & 688323 & 4.55 & 5.0673 & TST & \\
\hline CHEMBL1495492 & 688323 & 5.3 & 4.9081 & TRN & \\
\hline CHEMBL1545480 & 688323 & 4.6 & 4.97199 & 99999999995 & TRN \\
\hline CHEMBL1486715 & 688323 & 4.45 & 4.7403 & TRN & \\
\hline CHEMBL1462728 & 688323 & 6.05 & 4.9069 & TRN & \\
\hline CHEMBL1452193 & 688323 & 4.45 & 4.7693 & TRN & \\
\hline CHEMBL1511956 & 688323 & 4.5 & 4.8177 & TRN & \\
\hline CHEMBL1572280 & 688323 & 4.65 & 4.8726 & TST & \\
\hline CHEMBL1474151 & 688323 & 5.55 & 4.8221 & TRN & \\
\hline CHEMBL1490996 & 688323 & 4.6 & 4.7773 & TRN & \\
\hline CHEMBL1488656 & 688323 & 4.45 & 4.537 & TRN & \\
\hline CHEMBL1898721 & 688323 & 4.5 & 4.7205 & TRN & \\
\hline CHEMBL1560838 & 688323 & 5.4 & 4.7372 & TRN & \\
\hline CHEMBL1579888 & 688323 & 5.1 & 4.9215 & TRN & \\
\hline CHEMBL1528709 & 688323 & 4.45 & 4.5554 & TRN & \\
\hline CHEMBL1320363 & 688323 & 4.6 & 4.5772 & TRN & \\
\hline CHEMBL1472575 & 688323 & 5.25 & 5.2132 & TST & \\
\hline CHEMBL1362937 & 688323 & 5.2 & 4.6737 & TRN & \\
\hline CHEMBL1480605 & 688323 & 4.6 & 4.8408 & TRN & \\
\hline CHEMBL1387607 & 688323 & 6.9 & 5.0288 & TRN & \\
\hline CHEMBL1455410 & 688323 & 5.1 & 4.7484 & TRN & \\
\hline CHEMBL1475295 & 688323 & 4.65 & 4.7753 & TRN & \\
\hline
\end{tabular}




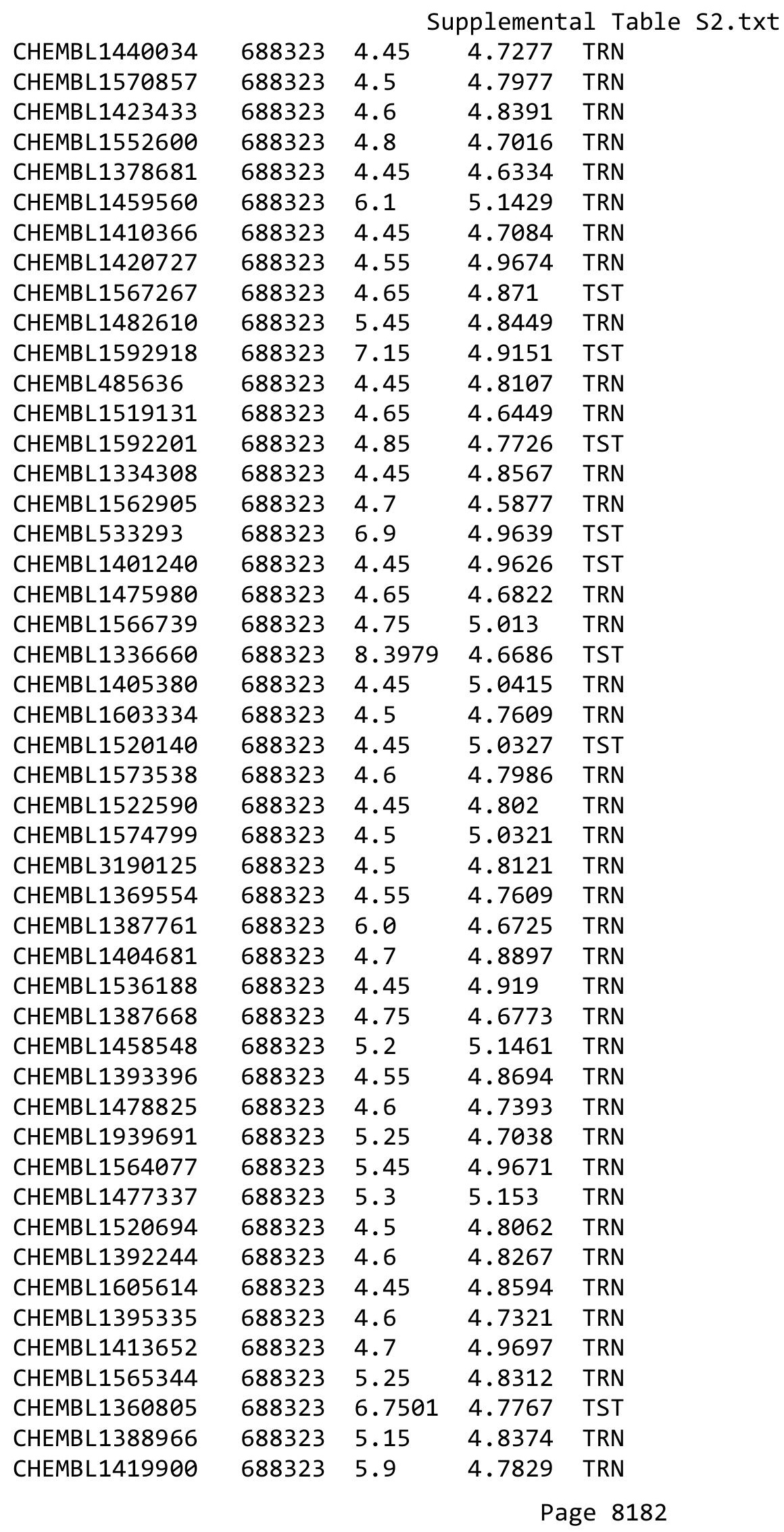




\begin{tabular}{|c|c|c|c|c|}
\hline \multicolumn{5}{|c|}{ Supplemental Table S2.txt } \\
\hline CHEMBL1301380 & 688323 & 5.1 & 4.851 & TRN \\
\hline CHEMBL1498154 & 688323 & 4.55 & 4.7915 & TRN \\
\hline CHEMBL1479491 & 688323 & 5.25 & 5.2587 & TRN \\
\hline CHEMBL1425743 & 688323 & 4.75 & 4.9689 & TST \\
\hline CHEMBL1438098 & 688323 & 4.65 & 4.649 & TRN \\
\hline CHEMBL1307587 & 688323 & 5.2 & 4.8934 & TST \\
\hline CHEMBL1973694 & 688323 & 4.8 & 4.8394 & TRN \\
\hline CHEMBL1599196 & 688323 & 4.45 & 5.0123 & TST \\
\hline CHEMBL1445768 & 688323 & 5.15 & 5.007 & TRN \\
\hline CHEMBL1606598 & 688323 & 4.6 & 4.7953 & TRN \\
\hline CHEMBL 225230 & 688323 & 4.5 & 4.9208 & TST \\
\hline CHEMBL1357564 & 688323 & 4.45 & 4.8558 & TRN \\
\hline CHEMBL1496706 & 688323 & 4.45 & 4.8473 & TRN \\
\hline CHEMBL1587434 & 688323 & 4.45 & 4.7259 & TRN \\
\hline CHEMBL1549255 & 688323 & 4.5 & 4.5819 & TRN \\
\hline CHEMBL 1344533 & 688323 & 4.45 & 4.9315 & TRN \\
\hline CHEMBL1430358 & 688323 & 4.95 & 4.9403 & TRN \\
\hline CHEMBL1583052 & 688323 & 4.5 & 4.8051 & TRN \\
\hline CHEMBL1523866 & 688323 & 4.85 & 4.9123 & TRN \\
\hline CHEMBL1434955 & 688323 & 6.7001 & 5.0798 & TRN \\
\hline CHEMBL1411184 & 688323 & 6.15 & 4.912 & TRN \\
\hline CHEMBL3195681 & 688323 & 6.7001 & 4.8095 & TRN \\
\hline CHEMBL1525473 & 688323 & 4.45 & 4.8782 & TST \\
\hline CHEMBL1430780 & 688323 & 4.5 & 4.739 & TRN \\
\hline CHEMBL1358343 & 688323 & 6.35 & 4.8459 & TRN \\
\hline CHEMBL 1438823 & 688323 & 4.6 & 4.7639 & TRN \\
\hline CHEMBL1324220 & 688323 & 5.2 & 5.0644 & TST \\
\hline CHEMBL1378426 & 688323 & 4.8 & 4.9081 & TRN \\
\hline CHEMBL1319447 & 688323 & 4.5 & 4.671 & TRN \\
\hline CHEMBL1552230 & 688323 & 4.8 & 4.3073 & TRN \\
\hline CHEMBL1320975 & 688323 & 4.65 & 4.6685 & TRN \\
\hline CHEMBL1368083 & 688323 & 4.6 & 4.7644 & TRN \\
\hline CHEMBL1412688 & 688323 & 4.75 & 4.8209 & TRN \\
\hline CHEMBL1481609 & 688323 & 5.0 & 4.8527 & TRN \\
\hline CHEMBL482477 & 688323 & 4.5 & 5.004 & TRN \\
\hline CHEMBL1342716 & 688323 & 5.25 & 4.7576 & TRN \\
\hline CHEMBL1478390 & 688323 & 4.6 & 4.8162 & TRN \\
\hline CHEMBL1418830 & 688323 & 4.5 & 4.7081 & TRN \\
\hline CHEMBL1567602 & 688323 & 6.9 & 5.0103 & TRN \\
\hline CHEMBL1356982 & 688323 & 5.4 & 4.9387 & TRN \\
\hline CHEMBL1603687 & 688323 & 4.45 & 4.5338 & TRN \\
\hline CHEMBL3211421 & 688323 & 4.85 & 4.8214 & TRN \\
\hline CHEMBL1319158 & 688323 & 4.45 & 4.8007 & TRN \\
\hline CHEMBL1363996 & 688323 & 4.6 & 4.572 & TRN \\
\hline CHEMBL1514171 & 688323 & 4.9 & 4.8413 & TRN \\
\hline CHEMBL 238798 & 688323 & 4.45 & 4.875 & TST \\
\hline CHEMBL1444126 & 688323 & 4.45 & 4.7073 & TRN \\
\hline CHEMBL 1358640 & 688323 & 4.45 & 4.9687 & TRN \\
\hline
\end{tabular}




\begin{tabular}{|c|c|c|c|c|}
\hline & & & pplement & al $\mathrm{Ta}$ \\
\hline CHEMBL1598001 & 688323 & 5.2 & 4.9445 & TST \\
\hline CHEMBL1569086 & 688323 & 4.5 & 4.8478 & TRN \\
\hline CHEMBL1373880 & 688323 & 4.6 & 4.8662 & TST \\
\hline CHEMBL1965698 & 688323 & 4.5 & 4.7503 & TRN \\
\hline CHEMBL1472528 & 688323 & 4.5 & 4.6419 & TRN \\
\hline CHEMBL1981990 & 688323 & 4.5 & 4.9045 & TRN \\
\hline CHEMBL1306185 & 688323 & 5.95 & 5.0148 & TST \\
\hline CHEMBL1510044 & 688323 & 4.5 & 4.7773 & TST \\
\hline CHEMBL1369647 & 688323 & 4.5 & 4.9079 & TRN \\
\hline CHEMBL1330711 & 688323 & 4.45 & 4.9548 & TRN \\
\hline CHEMBL1440291 & 688323 & 4.55 & 4.6427 & TRN \\
\hline CHEMBL1408737 & 688323 & 4.75 & 4.9987 & TRN \\
\hline CHEMBL1372939 & 688323 & 4.5 & 4.8203 & TST \\
\hline CHEMBL1510983 & 688323 & 4.55 & 4.7925 & TRN \\
\hline CHEMBL1416442 & 688323 & 4.45 & 4.8559 & TST \\
\hline CHEMBL1437284 & 688323 & 5.45 & 4.9101 & TRN \\
\hline CHEMBL1538098 & 688323 & 4.75 & 4.8205 & TRN \\
\hline CHEMBL1529000 & 688323 & 4.65 & 4.7627 & TRN \\
\hline CHEMBL1457161 & 688323 & 4.45 & 5.0272 & TRN \\
\hline CHEMBL1537509 & 688323 & 5.8 & 4.5956 & TST \\
\hline CHEMBL1571477 & 688323 & 4.5 & 4.7771 & TRN \\
\hline CHEMBL1306928 & 688323 & 4.55 & 4.7855 & TRN \\
\hline CHEMBL 2134693 & 688323 & 4.45 & 4.7459 & TRN \\
\hline CHEMBL 2003172 & 688323 & 4.95 & 4.6949 & TRN \\
\hline CHEMBL1464578 & 688323 & 5.2 & 4.7782 & TRN \\
\hline CHEMBL1507645 & 688323 & 4.75 & 5.181 & TRN \\
\hline CHEMBL1432884 & 688323 & 4.45 & 4.6157 & TRN \\
\hline CHEMBL1487782 & 688323 & 4.9 & 4.9068 & TRN \\
\hline CHEMBL1417638 & 688323 & 6.05 & 5.0402 & TRN \\
\hline CHEMBL1356964 & 688323 & 4.45 & 4.6624 & TRN \\
\hline CHEMBL1606759 & 688323 & 4.8 & 4.8159 & TRN \\
\hline CHEMBL1338689 & 688323 & 4.75 & 4.9957 & TRN \\
\hline CHEMBL3195775 & 688323 & 4.5 & 4.712 & TRN \\
\hline CHEMBL1327162 & 688323 & 4.6 & 5.0928 & TRN \\
\hline CHEMBL1447463 & 688323 & 4.6 & 4.8746 & TST \\
\hline CHEMBL1604357 & 688323 & 4.6 & 4.526 & TRN \\
\hline CHEMBL1527565 & 688323 & 5.45 & 4.8703 & TST \\
\hline CHEMBL1558210 & 688323 & 5.25 & 4.8575 & TRN \\
\hline CHEMBL1423575 & 688323 & 4.45 & 4.9796 & TRN \\
\hline CHEMBL1379279 & 688323 & 4.45 & 4.9956 & TST \\
\hline CHEMBL1613279 & 688323 & 4.45 & 4.8938 & TRN \\
\hline CHEMBL1554426 & 688323 & 4.45 & 5.0346 & TRN \\
\hline CHEMBL1388315 & 688323 & 4.45 & 4.629 & TRN \\
\hline CHEMBL1474094 & 688323 & 5.2 & 4.7882 & TRN \\
\hline CHEMBL1312201 & 688323 & 4.45 & 4.673 & TRN \\
\hline CHEMBL1548705 & 688323 & 4.45 & 4.6701 & TRN \\
\hline CHEMBL1563091 & 688323 & 4.45 & 4.8197 & TRN \\
\hline CHEMBL1321160 & 688323 & 6.1 & 4.9378 & TST \\
\hline
\end{tabular}




\begin{tabular}{|c|c|c|c|c|}
\hline \multicolumn{5}{|c|}{ Supplemental Table S2.txt } \\
\hline CHEMBL1515662 & 688323 & 5.2 & 4.7172 & TRN \\
\hline CHEMBL1365337 & 688323 & 4.6 & 4.9535 & TST \\
\hline CHEMBL1421549 & 688323 & 5.5 & 4.945 & TRN \\
\hline CHEMBL1422618 & 688323 & 4.85 & 4.8232 & TST \\
\hline CHEMBL3214151 & 688323 & 4.9 & 4.6657 & TRN \\
\hline CHEMBL1416095 & 688323 & 4.95 & 5.0102 & TRN \\
\hline CHEMBL1460126 & 688323 & 4.5 & 4.7752 & TRN \\
\hline CHEMBL1599828 & 688323 & 4.9 & 4.9544 & TST \\
\hline CHEMBL239275 & 688323 & 4.45 & 5.0883 & TRN \\
\hline CHEMBL1581964 & 688323 & 4.45 & 4.69 & TRN \\
\hline CHEMBL1315906 & 688323 & 4.9 & 4.6744 & TRN \\
\hline CHEMBL1499590 & 688323 & 5.0 & 5.0727 & TRN \\
\hline CHEMBL1572119 & 688323 & 4.45 & 4.7786 & TRN \\
\hline CHEMBL1319026 & 688323 & 4.55 & 4.6339 & TRN \\
\hline CHEMBL1326765 & 688323 & 4.6 & 4.8559 & TRN \\
\hline CHEMBL1998606 & 688323 & 4.75 & 4.6731 & TRN \\
\hline CHEMBL1545894 & 688323 & 4.65 & 4.9809 & TRN \\
\hline CHEMBL1607492 & 688323 & 4.8 & 4.7676 & TRN \\
\hline CHEMBL1481648 & 688323 & 4.6 & 4.6794 & TRN \\
\hline CHEMBL1403913 & 688323 & 5.0 & 4.7778 & TST \\
\hline CHEMBL1530169 & 688323 & 4.6 & 4.7868 & TRN \\
\hline CHEMBL1325748 & 688323 & 6.9 & 4.962 & TRN \\
\hline CHEMBL1483848 & 688323 & 4.85 & 4.7585 & TRN \\
\hline CHEMBL1482404 & 688323 & 4.65 & 5.0233 & TST \\
\hline CHEMBL3193170 & 688323 & 4.6 & 4.6469 & TRN \\
\hline CHEMBL1395356 & 688323 & 4.45 & 4.5861 & TRN \\
\hline CHEMBL2001139 & 688323 & 4.9 & 4.7634 & TRN \\
\hline CHEMBL1475520 & 688323 & 4.65 & 4.7012 & TRN \\
\hline CHEMBL1378977 & 688323 & 5.2 & 4.907 & TRN \\
\hline CHEMBL1315137 & 688323 & 4.65 & 4.7475 & TRN \\
\hline CHEMBL1362448 & 688323 & 4.65 & 4.8695 & TRN \\
\hline CHEMBL1531654 & 688323 & 4.7 & 4.6819 & TRN \\
\hline CHEMBL1975151 & 688323 & 4.5 & 4.5683 & TRN \\
\hline CHEMBL151176 & 688323 & 5.9 & 5.0052 & TRN \\
\hline CHEMBL1361112 & 688323 & 4.5 & 4.8345 & TRN \\
\hline CHEMBL1456780 & 688323 & 5.55 & 5.1731 & TRN \\
\hline CHEMBL1993190 & 688323 & 4.65 & 4.4855 & TRN \\
\hline CHEMBL3210024 & 688323 & 4.45 & 4.7646 & TRN \\
\hline CHEMBL1493515 & 688323 & 4.5 & 4.8066 & TST \\
\hline CHEMBL1523528 & 688323 & 4.5 & 4.876 & TRN \\
\hline CHEMBL1546205 & 688323 & 5.3 & 4.8581 & TST \\
\hline CHEMBL1444045 & 688323 & 4.45 & 5.0275 & TRN \\
\hline CHEMBL1534294 & 688323 & 4.7 & 4.8127 & TRN \\
\hline CHEMBL1457150 & 688323 & 4.45 & 4.9059 & TRN \\
\hline CHEMBL1610219 & 688323 & 5.05 & 4.8399 & TST \\
\hline CHEMBL1510324 & 688323 & 5.2 & 5.0043 & TRN \\
\hline CHEMBL1425509 & 688323 & 4.6 & 4.8389 & TRN \\
\hline CHEMBL1457796 & 688323 & 4.65 & 4.6323 & TRN \\
\hline
\end{tabular}




\begin{tabular}{|c|c|c|c|c|c|}
\hline \multicolumn{6}{|c|}{ Supplemental Table S2.txt } \\
\hline CHEMBL1507679 & 688323 & 5.25 & 5.0933 & TST & \\
\hline CHEMBL1586070 & 688323 & 4.65 & 4.692 & TRN & \\
\hline CHEMBL1417421 & 688323 & 4.9 & 4.6479 & TRN & \\
\hline CHEMBL1495193 & 688323 & 4.45 & 4.9619 & TRN & \\
\hline CHEMBL1337981 & 688323 & 4.6 & 4.8648 & TRN & \\
\hline CHEMBL1489113 & 688323 & 4.45 & 4.8005 & TRN & \\
\hline CHEMBL1550485 & 688323 & 5.4 & 4.7512 & TRN & \\
\hline CHEMBL 3145316 & 688323 & 4.65 & 4.5843 & TRN & \\
\hline CHEMBL1600370 & 688323 & 4.8 & 4.7091 & TRN & \\
\hline CHEMBL1322281 & 688323 & 4.6 & 4.8536 & TRN & \\
\hline CHEMBL1485047 & 688323 & 4.7 & 4.8244 & TRN & \\
\hline CHEMBL1994266 & 688323 & 4.45 & 4.703 & TRN & \\
\hline CHEMBL1461983 & 688323 & 4.6 & 4.5974 & TRN & \\
\hline CHEMBL1558612 & 688323 & 4.65 & 4.8855 & TRN & \\
\hline CHEMBL1344966 & 688323 & 4.5 & 4.9299 & TRN & \\
\hline CHEMBL1964702 & 688323 & 4.5 & 4.6974 & TRN & \\
\hline CHEMBL1563339 & 688323 & 4.7 & 4.692 & TRN & \\
\hline CHEMBL1550585 & 688323 & 4.5 & 4.793 & TST & \\
\hline CHEMBL1488192 & 688323 & 5.25 & 4.9418 & TRN & \\
\hline CHEMBL1456684 & 688323 & 4.45 & 4.7916 & TRN & \\
\hline CHEMBL3191688 & 688323 & 4.45 & 4.6058 & TRN & \\
\hline CHEMBL1536490 & 688323 & 4.45 & 4.7179 & TRN & \\
\hline CHEMBL1315554 & 688323 & 4.45 & 4.7352 & TRN & \\
\hline CHEMBL1444560 & 688323 & 4.65 & 4.7049 & TRN & \\
\hline CHEMBL1457484 & 688323 & 4.5 & 4.8071 & TRN & \\
\hline CHEMBL1317601 & 688323 & 4.55 & 4.9243 & TRN & \\
\hline CHEMBL1517429 & 688323 & 4.6 & 4.8088 & TRN & \\
\hline CHEMBL1542804 & 688323 & 5.25 & 4.9315 & TRN & \\
\hline CHEMBL1437918 & 688323 & 6.35 & 5.0972 & TRN & \\
\hline CHEMBL 2002248 & 688323 & 4.6 & 4.5026 & TRN & \\
\hline CHEMBL166486 & 688323 & 4.75 & 4.8178 & TRN & \\
\hline CHEMBL1864348 & 688323 & 4.45 & 4.7 & TRN & \\
\hline CHEMBL1438069 & 688323 & 4.6 & 4.9469 & TRN & \\
\hline CHEMBL1334819 & 688323 & 4.45 & 5.0295 & TRN & \\
\hline CHEMBL1344562 & 688323 & 5.25 & 4.7329 & TST & \\
\hline CHEMBL120734 & 688323 & 4.5 & 4.8931 & TRN & \\
\hline CHEMBL1531512 & 688323 & 5.75 & 5.0554 & TRN & \\
\hline CHEMBL1439785 & 688323 & 6.25 & 5.0937 & TRN & \\
\hline CHEMBL1480189 & 688323 & 4.55 & 4.9781 & TRN & \\
\hline CHEMBL1610378 & 688323 & 4.65 & 4.9973 & TRN & \\
\hline CHEMBL1372179 & 688323 & 4.45 & 4.9258 & TRN & \\
\hline CHEMBL1987380 & 688323 & 4.45 & 4.59399 & 9999999999 & TRN \\
\hline CHEMBL1310609 & 688323 & 4.45 & 4.9743 & TRN & \\
\hline CHEMBL1328520 & 688323 & 4.45 & 5.0195 & TST & \\
\hline CHEMBL1565808 & 688323 & 4.75 & 4.9456 & TRN & \\
\hline CHEMBL1431991 & 688323 & 4.8 & 4.5069 & TRN & \\
\hline CHEMBL1332612 & 688323 & 4.6 & 4.5043 & TRN & \\
\hline CHEMBL1511645 & 688323 & 5.15 & 4.8024 & TRN & \\
\hline
\end{tabular}




\begin{tabular}{|c|c|c|c|c|}
\hline \multicolumn{5}{|c|}{ Supplemental Table S2.txt } \\
\hline CHEMBL 3208083 & 688323 & 4.6 & 4.7843 & TRN \\
\hline CHEMBL1457717 & 688323 & 5.3 & 4.792 & TRN \\
\hline CHEMBL1456213 & 688323 & 4.6 & 4.8003 & TRN \\
\hline CHEMBL 2006357 & 688323 & 4.5 & 4.7364 & TRN \\
\hline CHEMBL1332450 & 688323 & 4.65 & 5.1218 & TRN \\
\hline CHEMBL1415866 & 688323 & 5.95 & 4.7432 & TRN \\
\hline CHEMBL1303203 & 688323 & 4.75 & 4.8607 & TRN \\
\hline CHEMBL117966 & 688323 & 5.55 & 4.9744 & TRN \\
\hline CHEMBL1349378 & 688323 & 4.6 & 5.0182 & TRN \\
\hline CHEMBL1347334 & 688323 & 5.65 & 4.7651 & TRN \\
\hline CHEMBL1335838 & 688323 & 4.6 & 4.8014 & TRN \\
\hline CHEMBL260148 & 688323 & 5.25 & 4.9789 & TST \\
\hline CHEMBL1319432 & 688323 & 5.65 & 4.9571 & TST \\
\hline CHEMBL1397653 & 688323 & 4.5 & 5.0031 & TRN \\
\hline CHEMBL1495323 & 688323 & 4.45 & 4.6494 & TRN \\
\hline CHEMBL1307453 & 688323 & 5.25 & 5.1425 & TRN \\
\hline CHEMBL1406013 & 688323 & 5.2 & 4.8139 & TRN \\
\hline CHEMBL1605463 & 688323 & 4.9 & 4.6939 & TRN \\
\hline CHEMBL1545178 & 688323 & 5.2 & 4.7782 & TRN \\
\hline CHEMBL1364842 & 688323 & 5.1 & 5.1155 & TST \\
\hline CHEMBL1417571 & 688323 & 4.55 & 4.8335 & TRN \\
\hline CHEMBL1429086 & 688323 & 5.55 & 4.8533 & TRN \\
\hline CHEMBL1321895 & 688323 & 4.5 & 5.0133 & TRN \\
\hline CHEMBL1982450 & 688323 & 5.25 & 4.5424 & TRN \\
\hline CHEMBL1572881 & 688323 & 5.5 & 4.9831 & TRN \\
\hline CHEMBL1538225 & 688323 & 4.55 & 4.8114 & TST \\
\hline CHEMBL1341023 & 688323 & 4.5 & 4.5045 & TRN \\
\hline CHEMBL1316934 & 688323 & 4.45 & 5.0318 & TRN \\
\hline CHEMBL1592189 & 688323 & 4.5 & 4.9715 & TRN \\
\hline CHEMBL1495165 & 688323 & 4.5 & 4.657 & TRN \\
\hline CHEMBL1336784 & 688323 & 6.0 & 4.7392 & TRN \\
\hline CHEMBL1412647 & 688323 & 4.65 & 4.4293 & TRN \\
\hline CHEMBL1979662 & 688323 & 5.25 & 5.08 & TRN \\
\hline CHEMBL1314184 & 688323 & 5.05 & 5.0197 & TRN \\
\hline CHEMBL1564136 & 688323 & 4.95 & 4.6821 & TST \\
\hline CHEMBL1428258 & 688323 & 4.7 & 4.9465 & TRN \\
\hline CHEMBL2373651 & 688323 & 5.25 & 4.8453 & TST \\
\hline CHEMBL1571839 & 688323 & 5.3 & 5.048 & TRN \\
\hline CHEMBL1317151 & 688323 & 4.5 & 4.6482 & TRN \\
\hline CHEMBL1395160 & 688323 & 4.95 & 4.7784 & TRN \\
\hline CHEMBL1592688 & 688323 & 5.0 & 4.8705 & TRN \\
\hline CHEMBL1516452 & 688323 & 4.45 & 4.5864 & TRN \\
\hline CHEMBL1597379 & 688323 & 4.65 & 4.7538 & TRN \\
\hline CHEMBL1308878 & 688323 & 4.75 & 4.6092 & TRN \\
\hline CHEMBL1443920 & 688323 & 4.8 & 4.8192 & TRN \\
\hline CHEMBL1611546 & 688323 & 4.45 & 4.6435 & TRN \\
\hline CHEMBL1493926 & 688323 & 4.45 & 5.01 & TRN \\
\hline CHEMBL1381837 & 688323 & 4.65 & 4.671 & TRN \\
\hline
\end{tabular}




\begin{tabular}{|c|c|c|c|c|c|}
\hline \multicolumn{6}{|c|}{ Supplemental Table s2.txt } \\
\hline CHEMBL1493304 & 688323 & 4.5 & 4.8657 & TRN & \\
\hline CHEMBL1422482 & 688323 & 4.5 & 4.7769 & TRN & \\
\hline CHEMBL1452118 & 688323 & 4.6 & 5.0641 & TRN & \\
\hline CHEMBL1538503 & 688323 & 4.55 & 4.7575 & TRN & \\
\hline CHEMBL1567499 & 688323 & 4.5 & 4.6762 & TRN & \\
\hline CHEMBL1355927 & 688323 & 4.95 & 4.7154 & TRN & \\
\hline CHEMBL1590575 & 688323 & 5.3 & 4.8212 & TRN & \\
\hline CHEMBL1985131 & 688323 & 4.5 & 4.6714 & TST & \\
\hline CHEMBL1340206 & 688323 & 5.45 & 4.9966 & TRN & \\
\hline CHEMBL3193269 & 688323 & 4.5 & 4.8226 & TRN & \\
\hline CHEMBL1587715 & 688323 & 4.6 & 4.4338 & TRN & \\
\hline CHEMBL1609402 & 688323 & 4.5 & 4.9815 & TRN & \\
\hline CHEMBL1319461 & 688323 & 6.0 & 4.8918 & TRN & \\
\hline CHEMBL 3194207 & 688323 & 5.1 & 4.5559 & TRN & \\
\hline CHEMBL1338747 & 688323 & 4.8 & 4.7653 & TST & \\
\hline CHEMBL1337427 & 688323 & 4.5 & 4.5713 & TRN & \\
\hline CHEMBL1563559 & 688323 & 4.5 & 4.6262 & TRN & \\
\hline CHEMBL1518054 & 688323 & 4.65 & 4.4561 & TRN & \\
\hline CHEMBL1424208 & 688323 & 5.2 & 4.551 & TRN & \\
\hline CHEMBL1586249 & 688323 & 4.45 & 4.8354 & TRN & \\
\hline CHEMBL1479067 & 688323 & 4.65 & 4.6885 & TRN & \\
\hline CHEMBL1571307 & 688323 & 4.6 & 4.7666 & TRN & \\
\hline CHEMBL1320696 & 688323 & 4.5 & 5.0225 & TRN & \\
\hline CHEMBL1461224 & 688323 & 4.85 & 4.8637 & TRN & \\
\hline CHEMBL1494307 & 688323 & 4.8 & 4.7664 & TRN & \\
\hline CHEMBL1458524 & 688323 & 5.6 & 4.997 & TRN & \\
\hline CHEMBL199925 & 688323 & 4.45 & 4.8972 & TRN & \\
\hline CHEMBL1532349 & 688323 & 5.45 & 4.9635 & TRN & \\
\hline CHEMBL1494619 & 688323 & 4.45 & 4.7479 & TRN & \\
\hline CHEMBL1447561 & 688323 & 5.35 & 4.8971 & TRN & \\
\hline CHEMBL1418440 & 688323 & 4.5 & 4.6401 & TRN & \\
\hline CHEMBL1393868 & 688323 & 6.8499 & 5.1969 & TRN & \\
\hline CHEMBL1341777 & 688323 & 4.6 & 4.638 & TRN & \\
\hline CHEMBL1345417 & 688323 & 4.75 & 4.8625 & TRN & \\
\hline CHEMBL1545927 & 688323 & 5.15 & 5.11600 & 00000000005 & TRN \\
\hline CHEMBL596674 & 688323 & 5.2 & 5.0397 & TRN & \\
\hline CHEMBL3195599 & 688323 & 4.45 & 4.856 & TRN & \\
\hline CHEMBL1525044 & 688323 & 4.55 & 4.8895 & TRN & \\
\hline CHEMBL1531095 & 688323 & 4.45 & 4.711 & TRN & \\
\hline CHEMBL1392367 & 688323 & 4.6 & 4.7713 & TRN & \\
\hline CHEMBL1521109 & 688323 & 4.45 & 4.887 & TRN & \\
\hline CHEMBL3145254 & 688323 & 4.5 & 4.5946 & TRN & \\
\hline CHEMBL1431701 & 688323 & 4.45 & 4.5839 & TRN & \\
\hline CHEMBL1400540 & 688323 & 4.45 & 4.6246 & TRN & \\
\hline CHEMBL1397762 & 688323 & 4.45 & 4.6244 & TRN & \\
\hline CHEMBL1371616 & 688323 & 4.45 & 4.8144 & TRN & \\
\hline CHEMBL1600323 & 688323 & 4.45 & 4.9092 & TRN & \\
\hline CHEMBL1569907 & 688323 & 5.55 & 4.8546 & TRN & \\
\hline
\end{tabular}




\begin{tabular}{|c|c|c|c|c|}
\hline \multicolumn{5}{|c|}{ Supplemental Table } \\
\hline CHEMBL1553892 & 688323 & 4.85 & 4.937 & TRN \\
\hline CHEMBL1374859 & 688323 & 4.45 & 4.6874 & TRN \\
\hline CHEMBL1611002 & 688323 & 5.5 & 5.1673 & TRN \\
\hline CHEMBL1597711 & 688323 & 4.95 & 4.6768 & TRN \\
\hline CHEMBL1609625 & 688323 & 4.45 & 4.8905 & TRN \\
\hline CHEMBL1982662 & 688323 & 4.45 & 4.6811 & TRN \\
\hline CHEMBL1513260 & 688323 & 4.45 & 4.5079 & TRN \\
\hline CHEMBL 3212672 & 688323 & 4.45 & 4.7592 & TRN \\
\hline CHEMBL1306514 & 688323 & 5.2 & 5.1259 & TRN \\
\hline CHEMBL1372576 & 688323 & 4.45 & 4.5761 & TRN \\
\hline CHEMBL1522662 & 688323 & 4.65 & 4.7064 & TRN \\
\hline CHEMBL1568839 & 688323 & 4.95 & 4.8727 & TRN \\
\hline CHEMBL1416491 & 688323 & 4.45 & 5.0638 & TRN \\
\hline CHEMBL164 & 688323 & 5.55 & 4.8087 & TRN \\
\hline CHEMBL1565600 & 688323 & 4.9 & 4.9144 & TRN \\
\hline CHEMBL1343705 & 688323 & 5.25 & 4.9201 & TRN \\
\hline CHEMBL1590359 & 688323 & 5.4 & 4.7502 & TRN \\
\hline CHEMBL1573661 & 688323 & 4.65 & 4.7778 & TRN \\
\hline CHEMBL1316281 & 688323 & 4.8 & 4.6483 & TRN \\
\hline CHEMBL1553692 & 688323 & 4.45 & 4.7518 & TRN \\
\hline CHEMBL1358465 & 688323 & 4.5 & 4.7946 & TRN \\
\hline CHEMBL1564418 & 688323 & 4.45 & 4.6915 & TRN \\
\hline CHEMBL1521739 & 688323 & 4.8 & 4.9058 & TST \\
\hline CHEMBL1484332 & 688323 & 5.5 & 4.8572 & TRN \\
\hline CHEMBL1491784 & 688323 & 4.65 & 4.8799 & TRN \\
\hline CHEMBL1327328 & 688323 & 4.95 & 4.8369 & TRN \\
\hline CHEMBL1578300 & 688323 & 4.5 & 4.862 & TRN \\
\hline CHEMBL3212192 & 688323 & 4.5 & 4.5708 & TRN \\
\hline CHEMBL1347993 & 688323 & 4.45 & 4.9295 & TRN \\
\hline CHEMBL1390427 & 688323 & 4.85 & 4.78 & TRN \\
\hline CHEMBL1432931 & 688323 & 4.45 & 4.6319 & TRN \\
\hline CHEMBL1361178 & 688323 & 4.95 & 4.9188 & TRN \\
\hline CHEMBL1459288 & 688323 & 4.45 & 4.7076 & TRN \\
\hline CHEMBL601941 & 688323 & 5.5 & 4.9487 & TRN \\
\hline CHEMBL1499828 & 688323 & 4.45 & 4.9511 & TRN \\
\hline CHEMBL1555180 & 688323 & 5.15 & 4.9048 & TRN \\
\hline CHEMBL1358243 & 688323 & 5.4 & 4.8532 & TST \\
\hline CHEMBL1367163 & 688323 & 4.5 & 4.8971 & TRN \\
\hline CHEMBL1438737 & 688323 & 4.95 & 4.8129 & TST \\
\hline CHEMBL1323268 & 688323 & 4.55 & 4.9289 & TRN \\
\hline CHEMBL1571835 & 688323 & 5.2 & 5.0936 & TRN \\
\hline CHEMBL1309512 & 688323 & 4.45 & 4.8707 & TRN \\
\hline CHEMBL1337669 & 688323 & 4.6 & 4.8525 & TRN \\
\hline CHEMBL1303353 & 688323 & 4.45 & 4.8386 & TRN \\
\hline CHEMBL1308154 & 688323 & 4.45 & 4.9038 & TRN \\
\hline CHEMBL1551826 & 688323 & 7.0 & 4.6402 & TRN \\
\hline CHEMBL1434469 & 688323 & 4.5 & 4.5295 & TST \\
\hline CHEMBL1424174 & 688323 & 5.35 & 5.0251 & TST \\
\hline
\end{tabular}




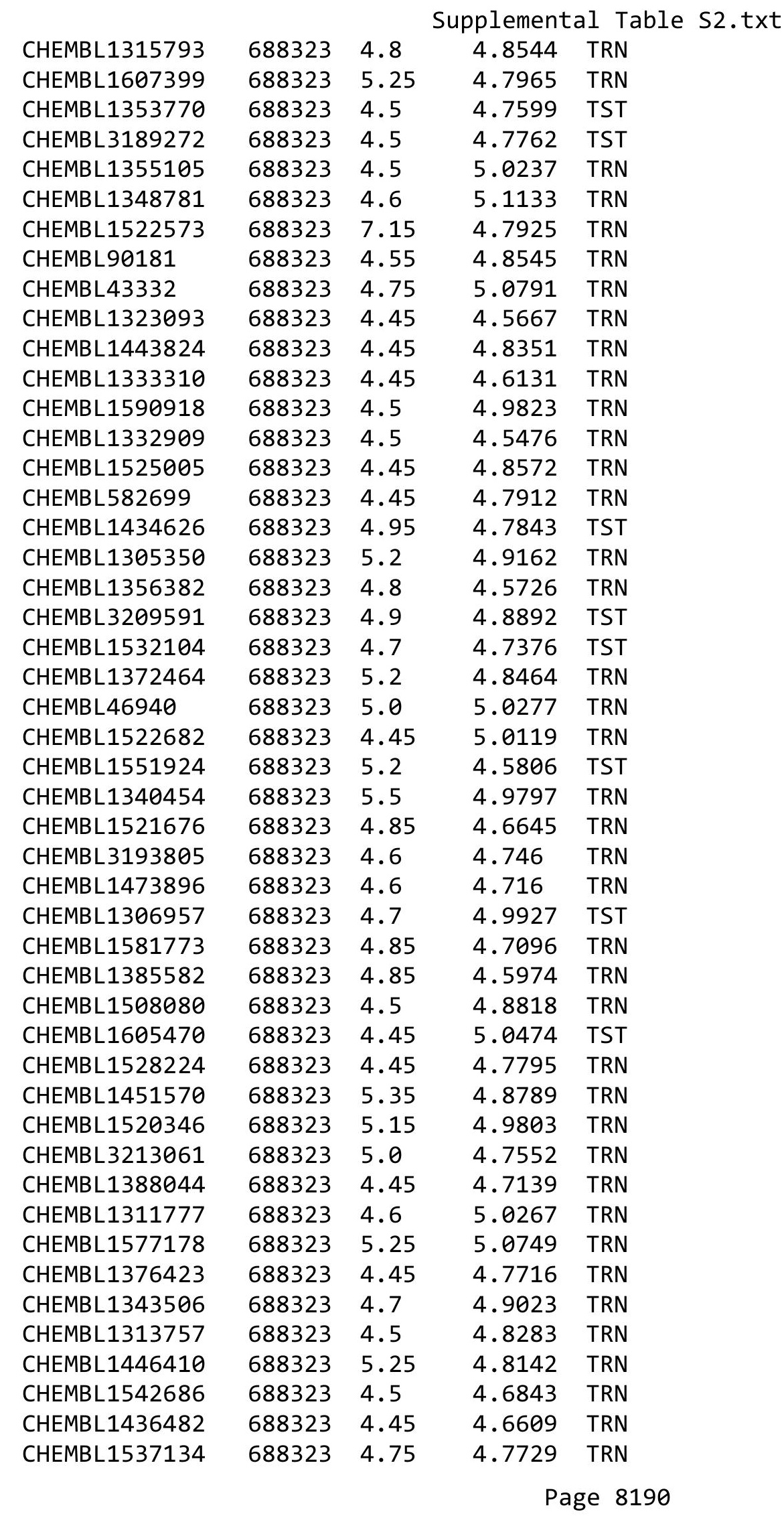




\begin{tabular}{|c|c|c|c|c|c|}
\hline \multicolumn{6}{|c|}{ Supplemental Table s2.txt } \\
\hline CHEMBL1374715 & 688323 & 4.7 & 4.8823 & TRN & \\
\hline CHEMBL1398822 & 688323 & 4.6 & 4.6494 & TRN & \\
\hline CHEMBL1550554 & 688323 & 4.55 & 4.7045 & TRN & \\
\hline CHEMBL1488016 & 688323 & 4.85 & 4.7399 & TRN & \\
\hline CHEMBL104255 & 688323 & 4.5 & 4.7322 & TRN & \\
\hline CHEMBL1602385 & 688323 & 5.4 & 4.9045 & TRN & \\
\hline CHEMBL3209829 & 688323 & 4.5 & 4.8983 & TRN & \\
\hline CHEMBL1463207 & 688323 & 4.45 & 4.7045 & TRN & \\
\hline CHEMBL1374389 & 688323 & 4.8 & 4.8185 & TRN & \\
\hline CHEMBL1476496 & 688323 & 4.6 & 4.6623 & TRN & \\
\hline CHEMBL1403706 & 688323 & 4.75 & 4.8266 & TRN & \\
\hline CHEMBL1443626 & 688323 & 6.7501 & 5.0747 & TRN & \\
\hline CHEMBL1364424 & 688323 & 5.2 & 4.8888 & TRN & \\
\hline CHEMBL1329974 & 688323 & 4.45 & 4.8911 & TST & \\
\hline CHEMBL1333548 & 688323 & 4.65 & 4.8167 & TST & \\
\hline CHEMBL1463930 & 688323 & 4.6 & 4.6624 & TST & \\
\hline CHEMBL1580272 & 688323 & 4.5 & 4.9066 & TST & \\
\hline CHEMBL1510661 & 688323 & 4.45 & 4.686 & TST & \\
\hline CHEMBL1409722 & 688323 & 4.45 & 4.7157 & TST & \\
\hline CHEMBL1484370 & 688323 & 4.5 & 4.6971 & TST & \\
\hline CHEMBL1551820 & 688323 & 4.75 & 4.801 & TST & \\
\hline CHEMBL1592628 & 688323 & 4.45 & 5.0408 & TST & \\
\hline CHEMBL1518928 & 688323 & 5.05 & 4.7351 & TST & \\
\hline CHEMBL1443971 & 688323 & 4.45 & 4.7267 & TST & \\
\hline CHEMBL1334062 & 688323 & 5.4 & 4.8161 & TST & \\
\hline CHEMBL1570405 & 688323 & 4.7 & 4.8687 & TST & \\
\hline CHEMBL1427004 & 688323 & 5.2 & 4.9611 & TST & \\
\hline CHEMBL1369328 & 688323 & 4.6 & 4.8807 & TST & \\
\hline CHEMBL1517667 & 688323 & 4.5 & 4.5729 & TST & \\
\hline CHEMBL3197171 & 688323 & 4.6 & 4.6927 & TST & \\
\hline CHEMBL1547092 & 688323 & 5.35 & 4.8831 & TST & \\
\hline CHEMBL1548387 & 688323 & 5.55 & 4.6769 & TST & \\
\hline CHEMBL1457985 & 688323 & 4.5 & 4.9163 & TST & \\
\hline CHEMBL1411411 & 688323 & 5.85 & 4.7497 & TST & \\
\hline CHEMBL1399683 & 688323 & 4.5 & 4.7512 & TST & \\
\hline CHEMBL1473510 & 688323 & 4.6 & 4.85800 & 00000000005 & TST \\
\hline CHEMBL1490835 & 688323 & 4.6 & 4.9306 & TST & \\
\hline CHEMBL1571973 & 688323 & 4.9 & 4.831 & TST & \\
\hline CHEMBL1357708 & 688323 & 4.55 & 4.814 & TST & \\
\hline CHEMBL1570309 & 688323 & 4.45 & 4.909 & TST & \\
\hline CHEMBL1608972 & 688323 & 6.9 & 4.9134 & TST & \\
\hline CHEMBL1365380 & 688323 & 4.65 & 5.0726 & TST & \\
\hline CHEMBL1411168 & 688323 & 4.75 & 4.8062 & TST & \\
\hline CHEMBL1985350 & 688323 & 4.5 & 4.5435 & TST & \\
\hline CHEMBL1523789 & 688323 & 5.2 & 4.8377 & TST & \\
\hline CHEMBL1534974 & 688323 & 4.45 & 4.7326 & TST & \\
\hline CHEMBL1973131 & 688323 & 5.35 & 4.6855 & TST & \\
\hline CHEMBL3211124 & 688323 & 5.45 & 5.0285 & TST & \\
\hline
\end{tabular}




\begin{tabular}{|c|c|c|c|c|c|}
\hline \multicolumn{6}{|c|}{ Supplemental Table S2.txt } \\
\hline CHEMBL1484892 & 688323 & 4.65 & 4.9833 & TST & \\
\hline CHEMBL1467900 & 688323 & 4.65 & 4.7606 & TST & \\
\hline CHEMBL602718 & 688323 & 5.45 & 5.1817 & TST & \\
\hline CHEMBL1397489 & 688323 & 4.45 & 4.8757 & TST & \\
\hline CHEMBL1343720 & 688323 & 5.45 & 4.8374 & TST & \\
\hline CHEMBL285480 & 688323 & 4.45 & 4.7637 & TST & \\
\hline CHEMBL1576113 & 688323 & 4.5 & 4.7591 & TST & \\
\hline CHEMBL1351848 & 688323 & 4.45 & 4.959 & TST & \\
\hline CHEMBL1597506 & 688323 & 5.2 & 4.731 & TST & \\
\hline CHEMBL1302193 & 688323 & 4.6 & 5.0393 & TST & \\
\hline CHEMBL586946 & 688323 & 4.55 & 4.8345 & TST & \\
\hline CHEMBL1552131 & 688323 & 4.55 & 4.6992 & TST & \\
\hline CHEMBL1378683 & 688323 & 4.65 & 4.9584 & TST & \\
\hline CHEMBL1443464 & 688323 & 5.45 & 4.7739 & TST & \\
\hline CHEMBL1491816 & 688323 & 4.45 & 4.9237 & TST & \\
\hline CHEMBL1466186 & 688323 & 4.85 & 4.83899 & 99999999995 & TST \\
\hline CHEMBL1524754 & 688323 & 4.85 & 5.0421 & TST & \\
\hline CHEMBL1600274 & 688323 & 5.25 & 4.7653 & TST & \\
\hline CHEMBL1504866 & 688323 & 5.2 & 4.8055 & TST & \\
\hline CHEMBL1372965 & 688323 & 4.5 & 4.8557 & TST & \\
\hline CHEMBL1341388 & 688323 & 4.75 & 4.7224 & TST & \\
\hline CHEMBL1581557 & 688323 & 5.2 & 5.21299 & 9999999999 & TST \\
\hline CHEMBL1411310 & 688323 & 4.45 & 4.8304 & TST & \\
\hline CHEMBL1546396 & 688323 & 4.5 & 4.7256 & TST & \\
\hline CHEMBL1558527 & 688323 & 5.25 & 4.8249 & TST & \\
\hline CHEMBL1383924 & 688323 & 5.25 & 4.8142 & TST & \\
\hline CHEMBL1314932 & 688323 & 4.5 & 4.7693 & TST & \\
\hline CHEMBL1453908 & 688323 & 4.45 & 4.6612 & TST & \\
\hline CHEMBL393136 & 688323 & 5.25 & 4.574 & TST & \\
\hline CHEMBL1574650 & 688323 & 4.5 & 4.9755 & TST & \\
\hline CHEMBL1326624 & 688323 & 4.45 & 4.8247 & TST & \\
\hline CHEMBL1487708 & 688323 & 4.85 & 5.0355 & TST & \\
\hline CHEMBL1466525 & 688323 & 4.7 & 4.8259 & TST & \\
\hline CHEMBL1397508 & 688323 & 4.45 & 4.6247 & TST & \\
\hline CHEMBL1986073 & 688323 & 4.8 & 4.7338 & TST & \\
\hline CHEMBL1316306 & 688323 & 4.65 & 4.5802 & TST & \\
\hline CHEMBL1604389 & 688323 & 4.65 & 4.6336 & TST & \\
\hline CHEMBL1411089 & 688323 & 4.55 & 4.7895 & TST & \\
\hline CHEMBL1416348 & 688323 & 4.45 & 4.6301 & TST & \\
\hline CHEMBL1551876 & 688323 & 4.45 & 4.63899 & 9999999999 & TST \\
\hline CHEMBL3189738 & 688323 & 4.45 & 4.7502 & TST & \\
\hline CHEMBL1321273 & 688323 & 5.2 & 4.979 & TST & \\
\hline CHEMBL1343242 & 688323 & 4.45 & 4.5577 & TST & \\
\hline CHEMBL3208973 & 688323 & 5.1 & 4.6107 & TST & \\
\hline CHEMBL1562857 & 688323 & 4.55 & 4.9339 & TST & \\
\hline CHEMBL1364253 & 688323 & 4.5 & 4.7026 & TST & \\
\hline CHEMBL1501616 & 688323 & 4.45 & 4.6929 & TST & \\
\hline CHEMBL1357254 & 688323 & 4.45 & 4.9081 & TST & \\
\hline
\end{tabular}




\begin{tabular}{|c|c|c|c|c|c|}
\hline & & \multicolumn{4}{|c|}{ Supplemental Table S2.txt } \\
\hline CHEMBL1533016 & 688323 & 4.45 & 4.6622 & TST & \\
\hline CHEMBL1613593 & 688323 & 6.05 & 5.0558 & TST & \\
\hline CHEMBL591148 & 688323 & 5.0 & 4.7073 & TST & \\
\hline CHEMBL1380666 & 688323 & 4.45 & 4.7794 & TST & \\
\hline CHEMBL1331727 & 688323 & 4.5 & 4.8122 & TST & \\
\hline CHEMBL1303003 & 688323 & 6.05 & 4.6861 & TST & \\
\hline CHEMBL1443220 & 688323 & 4.5 & 4.4905 & TST & \\
\hline CHEMBL1987798 & 688323 & 5.0 & 4.7116 & TST & \\
\hline CHEMBL3199352 & 688323 & 4.75 & 4.6689 & TST & \\
\hline CHEMBL1405775 & 688323 & 4.45 & 4.857 & TST & \\
\hline CHEMBL3198109 & 688323 & 4.45 & 4.543 & TST & \\
\hline CHEMBL1363764 & 688323 & 4.45 & 4.7697 & TST & \\
\hline CHEMBL1428950 & 688323 & 4.85 & 4.8619 & TST & \\
\hline CHEMBL1471553 & 688323 & 4.45 & 4.4762 & TST & \\
\hline CHEMBL1366526 & 688323 & 5.7 & 4.9354 & TST & \\
\hline CHEMBL1976375 & 688323 & 4.5 & 4.61100 & 0000000001 & TST \\
\hline CHEMBL1224757 & 688323 & 5.2 & 5.0214 & TST & \\
\hline CHEMBL1981840 & 688323 & 4.45 & 4.8715 & TST & \\
\hline CHEMBL1527302 & 688323 & 5.15 & 4.8896 & TST & \\
\hline CHEMBL1574027 & 688323 & 4.85 & 4.8397 & TST & \\
\hline CHEMBL1316544 & 688323 & 4.55 & 4.8645 & TST & \\
\hline CHEMBL1525700 & 688323 & 4.65 & 4.9457 & TST & \\
\hline CHEMBL1569055 & 688323 & 4.75 & 4.6985 & TST & \\
\hline CHEMBL1523995 & 688323 & 4.85 & 4.8378 & TST & \\
\hline CHEMBL1301825 & 688323 & 4.75 & 5.0796 & TST & \\
\hline CHEMBL1371665 & 688323 & 4.45 & 4.7933 & TST & \\
\hline CHEMBL1394468 & 688323 & 4.45 & 4.8996 & TST & \\
\hline CHEMBL1497919 & 688323 & 4.45 & 4.7766 & TST & \\
\hline CHEMBL1430338 & 688323 & 5.45 & 5.024 & TST & \\
\hline CHEMBL1501003 & 688323 & 4.5 & 4.9617 & TST & \\
\hline CHEMBL1299919 & 688323 & 4.45 & 4.8789 & TST & \\
\hline CHEMBL1432657 & 688323 & 4.8 & 5.0536 & TST & \\
\hline CHEMBL1542662 & 688323 & 4.6 & 4.8728 & TST & \\
\hline CHEMBL1589428 & 688323 & 4.75 & 5.0379 & TST & \\
\hline CHEMBL1587868 & 688323 & 4.45 & 4.864 & TST & \\
\hline CHEMBL1366992 & 688323 & 4.85 & 4.6079 & TST & \\
\hline CHEMBL1599138 & 688323 & 4.45 & 4.9867 & TST & \\
\hline CHEMBL1317710 & 688323 & 4.45 & 4.6713 & TST & \\
\hline CHEMBL1385239 & 688323 & 4.45 & 4.8251 & TST & \\
\hline CHEMBL1305141 & 688323 & 5.55 & 4.7941 & TST & \\
\hline CHEMBL1548149 & 688323 & 5.35 & 4.9472 & TST & \\
\hline CHEMBL1317956 & 688323 & 4.8 & 4.7444 & TST & \\
\hline CHEMBL1459316 & 688323 & 4.95 & 4.8921 & TST & \\
\hline CHEMBL1415864 & 688323 & 4.75 & 4.81 & TST & \\
\hline CHEMBL1334254 & 688323 & 4.45 & 5.0496 & TST & \\
\hline CHEMBL1545132 & 688323 & 6.1 & 5.0135 & TST & \\
\hline CHEMBL1417880 & 688323 & 4.8 & 4.922 & TST & \\
\hline CHEMBL1606291 & 688323 & 4.45 & 5.1037 & TST & \\
\hline
\end{tabular}




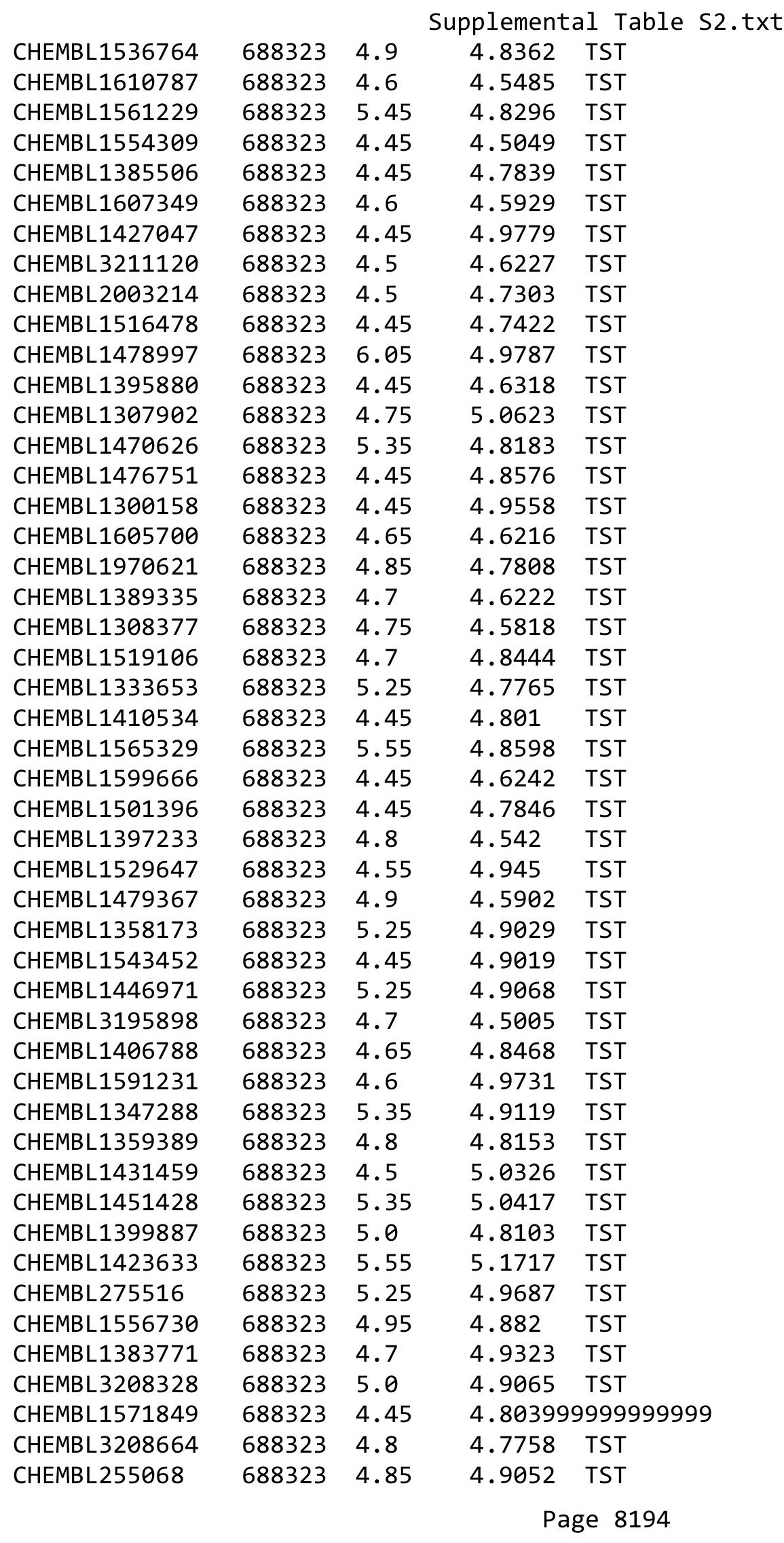




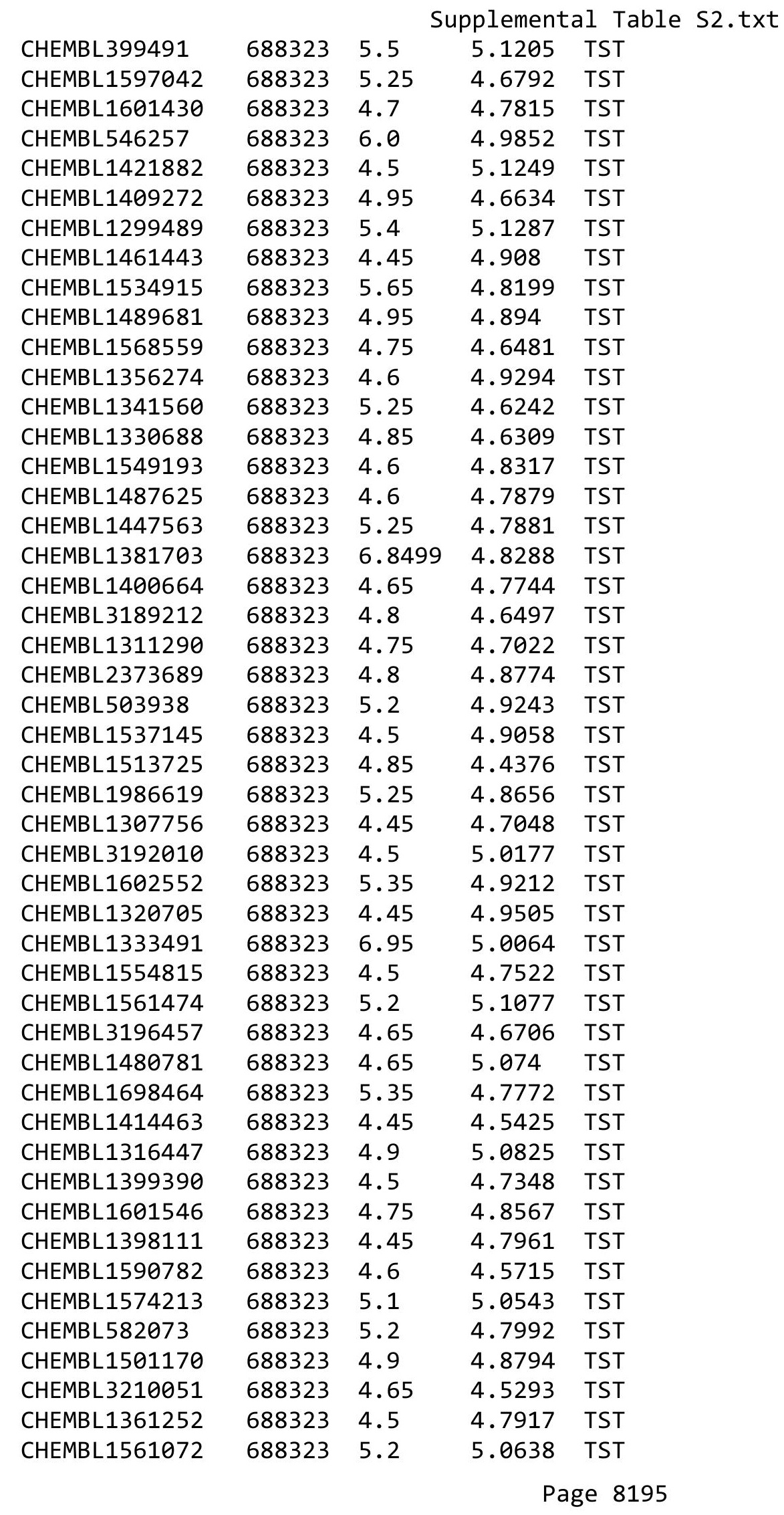




\begin{tabular}{|c|c|c|c|c|c|}
\hline \multicolumn{6}{|c|}{ Supplemental Table S2.txt } \\
\hline CHEMBL1348306 & 688323 & 4.95 & 4.5937 & TST & \\
\hline CHEMBL1489067 & 688323 & 6.6499 & 5.119 & TST & \\
\hline CHEMBL1397952 & 688323 & 5.25 & 5.0798 & TST & \\
\hline CHEMBL1578341 & 688323 & 5.3 & 4.8463 & TST & \\
\hline CHEMBL1398218 & 688323 & 4.5 & 4.6884 & TST & \\
\hline CHEMBL1478172 & 688323 & 4.65 & 4.6778 & TST & \\
\hline CHEMBL547924 & 688323 & 4.45 & 4.8537 & TST & \\
\hline CHEMBL1403702 & 688323 & 4.45 & 4.9495 & TST & \\
\hline CHEMBL1436332 & 688323 & 4.45 & 4.6942 & TST & \\
\hline CHEMBL1603273 & 688323 & 4.65 & 4.6377 & TST & \\
\hline CHEMBL1595917 & 688323 & 4.45 & 4.6313 & TST & \\
\hline CHEMBL1422024 & 688323 & 4.55 & 4.9572 & TST & \\
\hline CHEMBL1482926 & 688323 & 4.65 & 5.0161 & TST & \\
\hline CHEMBL1457929 & 688323 & 4.5 & 4.6907 & TST & \\
\hline CHEMBL1307669 & 688323 & 4.65 & 4.9121 & TST & \\
\hline CHEMBL1573007 & 688323 & 4.95 & 4.9206 & TST & \\
\hline CHEMBL1334903 & 688323 & 5.45 & 4.9164 & TST & \\
\hline CHEMBL1329839 & 688323 & 5.25 & 4.668 & TST & \\
\hline CHEMBL1543417 & 688323 & 4.5 & 4.7248 & TST & \\
\hline CHEMBL1320304 & 688323 & 4.5 & 4.6776 & TST & \\
\hline CHEMBL1495883 & 688323 & 4.6 & 4.8933 & TST & \\
\hline CHEMBL1405730 & 688323 & 4.45 & 4.7158 & TST & \\
\hline CHEMBL1358392 & 688323 & 4.45 & 4.5467 & TST & \\
\hline CHEMBL1464342 & 688323 & 4.45 & 4.8105 & TST & \\
\hline CHEMBL1396697 & 688323 & 4.45 & 4.55699 & 99999999995 & TST \\
\hline CHEMBL1467445 & 688323 & 4.85 & 4.8507 & TST & \\
\hline CHEMBL1359816 & 688323 & 4.5 & 4.6967 & TST & \\
\hline CHEMBL1545297 & 688323 & 4.45 & 4.7496 & TST & \\
\hline CHEMBL1545406 & 688323 & 4.55 & 4.8098 & TST & \\
\hline CHEMBL1386454 & 688323 & 5.45 & 4.7836 & TST & \\
\hline CHEMBL1611786 & 688323 & 4.45 & 4.6173 & TST & \\
\hline CHEMBL1426004 & 688323 & 4.45 & 4.9508 & TST & \\
\hline CHEMBL1409383 & 688323 & 4.55 & 4.6801 & TST & \\
\hline CHEMBL1493082 & 688323 & 5.2 & 5.0189 & TST & \\
\hline CHEMBL1495539 & 688323 & 4.45 & 4.9394 & TST & \\
\hline CHEMBL1472866 & 688323 & 4.55 & 4.8291 & TST & \\
\hline CHEMBL1396807 & 688323 & 4.45 & 4.6581 & TST & \\
\hline CHEMBL1301294 & 688323 & 4.75 & 4.7347 & TST & \\
\hline CHEMBL1484413 & 688323 & 5.15 & 4.8206 & TST & \\
\hline CHEMBL1516573 & 688323 & 5.65 & 4.9414 & TST & \\
\hline CHEMBL1400694 & 688323 & 4.45 & 4.6943 & TST & \\
\hline CHEMBL1597655 & 688323 & 5.45 & 5.1227 & TST & \\
\hline CHEMBL1361552 & 688323 & 4.45 & 4.9208 & TST & \\
\hline CHEMBL1333238 & 688323 & 5.35 & 4.7056 & TST & \\
\hline CHEMBL1995204 & 688323 & 4.55 & 4.7769 & TST & \\
\hline CHEMBL1517374 & 688323 & 4.45 & 4.7947 & TST & \\
\hline CHEMBL1566928 & 688323 & 4.95 & 4.9538 & TST & \\
\hline CHEMBL1396749 & 688323 & 5.0 & 4.7649 & TST & \\
\hline
\end{tabular}




\begin{tabular}{|c|c|c|c|c|c|}
\hline \multicolumn{6}{|c|}{ Supplemental Table S2.txt } \\
\hline CHEMBL1496760 & 688323 & 4.45 & 4.8161 & TST & \\
\hline CHEMBL3195461 & 688323 & 4.45 & 4.5589 & TST & \\
\hline CHEMBL1458873 & 688323 & 5.05 & 4.9431 & TST & \\
\hline CHEMBL1570136 & 688323 & 4.6 & 4.7821 & TST & \\
\hline CHEMBL1994390 & 688323 & 5.25 & 4.63 & TST & \\
\hline CHEMBL1436447 & 688323 & 4.5 & 4.8585 & TST & \\
\hline CHEMBL1311879 & 688323 & 5.0 & 4.9949 & TST & \\
\hline CHEMBL1392405 & 688323 & 4.45 & 4.7977 & TST & \\
\hline CHEMBL1321108 & 688323 & 4.5 & 4.6809 & TST & \\
\hline CHEMBL1435998 & 688323 & 6.4 & 5.05699 & 99999999995 & TST \\
\hline CHEMBL1313065 & 688323 & 4.9 & 4.6699 & TST & \\
\hline CHEMBL1356701 & 688323 & 4.5 & 4.7043 & TST & \\
\hline CHEMBL1381840 & 688323 & 5.45 & 4.9316 & TST & \\
\hline CHEMBL1590714 & 688323 & 5.0 & 4.9353 & TST & \\
\hline CHEMBL1382979 & 688323 & 4.6 & 4.7763 & TST & \\
\hline CHEMBL1348043 & 688323 & 5.3 & 4.9117 & TST & \\
\hline CHEMBL1390716 & 688323 & 4.5 & 4.8851 & TST & \\
\hline CHEMBL1312654 & 688323 & 5.45 & 5.0875 & TST & \\
\hline CHEMBL 3189220 & 688323 & 4.95 & 4.6205 & TST & \\
\hline CHEMBL1434612 & 688323 & 4.5 & 5.0134 & TST & \\
\hline CHEMBL1443210 & 688323 & 4.5 & 4.8147 & TST & \\
\hline CHEMBL1484806 & 688323 & 5.2 & 4.7436 & TST & \\
\hline CHEMBL1970784 & 688323 & 4.6 & 4.6394 & TST & \\
\hline CHEMBL3189281 & 688323 & 4.5 & 4.7607 & TST & \\
\hline CHEMBL1332213 & 688323 & 4.8 & 4.8671 & TST & \\
\hline CHEMBL 2004351 & 688323 & 4.9 & 4.7586 & TST & \\
\hline CHEMBL1533267 & 688323 & 4.75 & 4.6256 & TST & \\
\hline CHEMBL1390244 & 688323 & 5.4 & 5.0633 & TST & \\
\hline CHEMBL1331003 & 688323 & 4.85 & 4.7588 & TST & \\
\hline CHEMBL1325549 & 688323 & 4.6 & 4.8472 & TST & \\
\hline CHEMBL1354611 & 688323 & 5.45 & 5.0912 & TST & \\
\hline CHEMBL1336774 & 688323 & 5.45 & 4.7328 & TST & \\
\hline CHEMBL302449 & 688323 & 4.65 & 4.771 & TST & \\
\hline CHEMBL1438924 & 688323 & 4.8 & 4.8145 & TST & \\
\hline CHEMBL2000011 & 688323 & 4.45 & 5.0561 & TST & \\
\hline CHEMBL1434392 & 688323 & 5.25 & 5.0975 & TST & \\
\hline CHEMBL1345135 & 688323 & 4.7 & 4.6448 & TST & \\
\hline CHEMBL1591689 & 688323 & 4.55 & 4.7154 & TST & \\
\hline CHEMBL1966367 & 688323 & 4.45 & 4.8299 & TST & \\
\hline CHEMBL1458430 & 688323 & 4.5 & 4.7762 & TST & \\
\hline CHEMBL1998627 & 688323 & 4.65 & 5.0742 & TST & \\
\hline CHEMBL 291501 & 688323 & 4.45 & 4.7745 & TST & \\
\hline CHEMBL1467422 & 688323 & 4.45 & 4.4002 & TST & \\
\hline CHEMBL1344669 & 688323 & 8.3468 & 4.9658 & TST & \\
\hline CHEMBL1398097 & 688323 & 4.5 & 4.5704 & TST & \\
\hline CHEMBL1557186 & 688323 & 4.75 & 4.8208 & TST & \\
\hline CHEMBL1480726 & 688323 & 4.45 & 4.4534 & TST & \\
\hline CHEMBL1518859 & 688323 & 4.55 & 4.8541 & TST & \\
\hline
\end{tabular}




\begin{tabular}{|c|c|c|c|c|}
\hline \multicolumn{5}{|c|}{ Supplemental Table S2.txt } \\
\hline CHEMBL1587920 & 688323 & 4.45 & 4.8441 & TST \\
\hline CHEMBL1604160 & 688323 & 4.5 & 4.78600 & 00000000005 \\
\hline CHEMBL1550775 & 688323 & 5.0 & 4.6492 & TST \\
\hline CHEMBL1584144 & 688323 & 6.9 & 4.7648 & TST \\
\hline CHEMBL1512975 & 688323 & 4.45 & 4.7433 & TST \\
\hline CHEMBL1497405 & 688323 & 6.7001 & 4.9606 & TST \\
\hline CHEMBL1448203 & 688323 & 4.85 & 4.9097 & TST \\
\hline CHEMBL1538690 & 688323 & 4.45 & 5.1086 & TST \\
\hline CHEMBL1437468 & 688323 & 4.85 & 4.8567 & TST \\
\hline CHEMBL1490526 & 688323 & 5.95 & 4.7271 & TST \\
\hline CHEMBL1471761 & 688323 & 5.55 & 4.9154 & TST \\
\hline CHEMBL1964306 & 688323 & 4.65 & 4.6124 & TST \\
\hline CHEMBL1435835 & 688323 & 4.5 & 4.8726 & TST \\
\hline CHEMBL1353421 & 688323 & 6.2 & 5.1245 & TST \\
\hline CHEMBL3208903 & 688323 & 4.55 & 4.7522 & TST \\
\hline CHEMBL1451156 & 688323 & 4.45 & 4.6132 & TST \\
\hline CHEMBL1593058 & 688323 & 4.5 & 4.6411 & TST \\
\hline CHEMBL1370560 & 688323 & 4.45 & 4.8274 & TST \\
\hline CHEMBL1515823 & 688323 & 4.5 & 4.9529 & TST \\
\hline CHEMBL1432251 & 688323 & 5.2 & 5.0305 & TST \\
\hline CHEMBL1489943 & 688323 & 4.45 & 4.8045 & TST \\
\hline CHEMBL1531133 & 688323 & 5.5 & 4.9136 & TST \\
\hline CHEMBL1457585 & 688323 & 4.6 & 4.8794 & TST \\
\hline CHEMBL1302170 & 688323 & 4.6 & 4.8382 & TST \\
\hline CHEMBL1463767 & 688323 & 4.7 & 4.8603 & TST \\
\hline CHEMBL1317485 & 688323 & 4.95 & 4.9762 & TST \\
\hline CHEMBL1316577 & 688323 & 5.15 & 4.8452 & TST \\
\hline CHEMBL1485965 & 688323 & 5.25 & 5.1283 & TST \\
\hline CHEMBL1461142 & 688323 & 4.7 & 4.8333 & TST \\
\hline CHEMBL1408561 & 688323 & 5.35 & 4.9094 & TST \\
\hline CHEMBL1323452 & 688323 & 4.5 & 4.8492 & TST \\
\hline CHEMBL1376495 & 688323 & 4.5 & 4.9132 & TST \\
\hline CHEMBL69612 & 688323 & 5.25 & 4.8091 & TST \\
\hline CHEMBL1412748 & 688323 & 5.8 & 4.9356 & TST \\
\hline CHEMBL1597510 & 688323 & 4.45 & 4.6396 & TST \\
\hline CHEMBL1321179 & 688323 & 5.55 & 4.8912 & TST \\
\hline CHEMBL1553209 & 688323 & 4.65 & 4.7189 & TST \\
\hline CHEMBL1971613 & 688323 & 4.75 & 4.5521 & TST \\
\hline CHEMBL1541209 & 688323 & 4.5 & 4.7069 & TST \\
\hline CHEMBL1435396 & 688323 & 4.45 & 4.9613 & TST \\
\hline CHEMBL1356228 & 688323 & 4.8 & 4.894 & TST \\
\hline CHEMBL1422280 & 688323 & 5.0 & 4.9456 & TST \\
\hline CHEMBL1608455 & 688323 & 4.5 & 4.6145 & TST \\
\hline CHEMBL1330789 & 688323 & 5.8 & 4.9151 & TST \\
\hline CHEMBL1560228 & 688323 & 4.45 & 4.5715 & TST \\
\hline CHEMBL1590061 & 688323 & 5.05 & 4.6801 & TST \\
\hline CHEMBL1564508 & 688323 & 5.4 & 4.7036 & TST \\
\hline CHEMBL1561174 & 688323 & 4.5 & 4.9498 & TST \\
\hline
\end{tabular}




\begin{tabular}{|c|c|c|c|c|}
\hline \multicolumn{5}{|c|}{ Supplemental Table S2.txt } \\
\hline CHEMBL1358722 & 688323 & 6.0 & 4.982 & TST \\
\hline CHEMBL1416749 & 688323 & 4.5 & 4.7683 & TST \\
\hline CHEMBL1524021 & 688323 & 5.25 & 5.0757 & TST \\
\hline CHEMBL1602735 & 688323 & 4.85 & 4.6656 & TST \\
\hline CHEMBL1398282 & 688323 & 4.8 & 4.9123 & TST \\
\hline CHEMBL1478589 & 688323 & 4.45 & 4.7303 & TST \\
\hline CHEMBL1484321 & 688323 & 5.45 & 4.7155 & TST \\
\hline CHEMBL1606726 & 688323 & 4.5 & 4.9262 & TST \\
\hline CHEMBL1386658 & 688323 & 4.45 & 4.9376 & TST \\
\hline CHEMBL1416382 & 688323 & 4.45 & 4.4766 & TST \\
\hline CHEMBL1451163 & 688323 & 5.2 & 5.0662 & TST \\
\hline CHEMBL1505902 & 688323 & 5.25 & 4.9004 & TST \\
\hline CHEMBL1361276 & 688323 & 4.5 & 5.0638 & TST \\
\hline CHEMBL1481131 & 688323 & 4.85 & 4.8451 & TST \\
\hline CHEMBL 245264 & 688323 & 4.45 & 4.7006 & TST \\
\hline CHEMBL1578268 & 688323 & 4.45 & 4.7351 & TST \\
\hline CHEMBL1491686 & 688323 & 4.5 & 4.7804 & TST \\
\hline CHEMBL1500110 & 688323 & 4.45 & 4.8493 & TST \\
\hline CHEMBL1518760 & 688323 & 4.45 & 4.9937 & TST \\
\hline CHEMBL1299702 & 688323 & 4.8 & 4.9338 & TST \\
\hline CHEMBL1995823 & 688323 & 4.55 & 4.583 & TST \\
\hline CHEMBL1595864 & 688323 & 4.45 & 4.7986 & TST \\
\hline CHEMBL1597580 & 688323 & 4.55 & 4.815 & TST \\
\hline CHEMBL1416614 & 688323 & 4.75 & 4.8131 & TST \\
\hline CHEMBL1594527 & 688323 & 4.45 & 4.753 & TST \\
\hline CHEMBL1533597 & 688323 & 5.25 & 4.9055 & TST \\
\hline CHEMBL1582003 & 688323 & 4.45 & 4.8616 & TST \\
\hline CHEMBL1602557 & 688323 & 4.45 & 4.9061 & TST \\
\hline CHEMBL1437970 & 688323 & 4.45 & 4.668 & TST \\
\hline CHEMBL1355771 & 688323 & 4.65 & 4.8384 & TST \\
\hline CHEMBL1438931 & 688323 & 4.55 & 4.7508 & TST \\
\hline CHEMBL1309286 & 688323 & 4.45 & 4.9946 & TST \\
\hline CHEMBL1543229 & 688323 & 5.15 & 4.822 & TST \\
\hline CHEMBL1538967 & 688323 & 4.95 & 4.8152 & TST \\
\hline CHEMBL1441295 & 688323 & 4.5 & 4.9066 & TST \\
\hline CHEMBL1493415 & 688323 & 4.5 & 4.6852 & TST \\
\hline CHEMBL1354393 & 688323 & 4.7 & 4.6905 & TST \\
\hline CHEMBL1818881 & 688323 & 4.45 & 4.6125 & TST \\
\hline CHEMBL1336482 & 688323 & 4.55 & 4.6985 & TST \\
\hline CHEMBL1973525 & 688323 & 4.45 & 4.5599 & TST \\
\hline CHEMBL1553595 & 688323 & 8.3468 & 4.9185 & TST \\
\hline CHEMBL1535291 & 688323 & 4.5 & 4.6009 & TST \\
\hline CHEMBL3191322 & 688323 & 4.5 & 4.8693 & TST \\
\hline CHEMBL1565377 & 688323 & 4.9 & 4.9112 & TST \\
\hline CHEMBL1503122 & 688323 & 4.6 & 4.8796 & TST \\
\hline CHEMBL1569496 & 688323 & 4.5 & 4.8666 & TST \\
\hline CHEMBL3194909 & 688323 & 4.6 & 5.0748 & TST \\
\hline CHEMBL1985649 & 688323 & 4.65 & 4.548 & TST \\
\hline
\end{tabular}




\begin{tabular}{|c|c|c|c|c|c|}
\hline \multicolumn{6}{|c|}{ 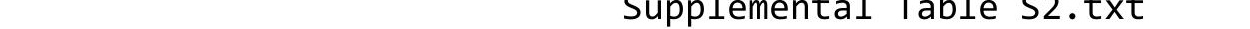 } \\
\hline CHEMBL1326482 & 688323 & 5.2 & 4.9006 & TST & \\
\hline CHEMBL1541855 & 688323 & 6.15 & 4.614 & TST & \\
\hline CHEMBL1547468 & 688323 & 4.6 & 4.6974 & TST & \\
\hline CHEMBL 3191412 & 688323 & 4.6 & 4.5528 & TST & \\
\hline CHEMBL1369852 & 688323 & 4.5 & 4.7967 & TST & \\
\hline CHEMBL1389248 & 688323 & 4.5 & 4.6362 & TST & \\
\hline CHEMBL1435221 & 688323 & 5.2 & 4.8359 & TST & \\
\hline CHEMBL1309905 & 688323 & 4.5 & 4.9431 & TST & \\
\hline CHEMBL1490152 & 688323 & 4.8 & 4.7224 & TST & \\
\hline CHEMBL1303431 & 688323 & 4.9 & 4.8843 & TST & \\
\hline CHEMBL1428554 & 688323 & 4.65 & 4.8265 & TST & \\
\hline CHEMBL1611097 & 688323 & 4.5 & 4.6494 & TST & \\
\hline CHEMBL1473728 & 688323 & 4.45 & 4.9326 & TST & \\
\hline CHEMBL1433312 & 688323 & 5.3 & 4.7684 & TST & \\
\hline CHEMBL1438907 & 688323 & 4.75 & 4.5976 & TST & \\
\hline CHEMBL1516548 & 688323 & 6.9 & 4.9249 & TST & \\
\hline CHEMBL3191125 & 688323 & 4.8 & 4.721 & TST & \\
\hline CHEMBL1393129 & 688323 & 4.65 & 5.164 & TST & \\
\hline CHEMBL1601133 & 688323 & 5.45 & 5.0813 & TST & \\
\hline CHEMBL1413827 & 688323 & 4.75 & 4.7898 & TST & \\
\hline CHEMBL1442939 & 688323 & 4.45 & 4.5903 & TST & \\
\hline CHEMBL1430795 & 688323 & 4.7 & 4.8952 & TST & \\
\hline CHEMBL1324122 & 688323 & 4.65 & 5.06 & TST & \\
\hline CHEMBL1523165 & 688323 & 5.25 & 4.8202 & TST & \\
\hline CHEMBL1592542 & 688323 & 5.3 & 4.8582 & TST & \\
\hline CHEMBL1359407 & 688323 & 4.95 & 4.8451 & TST & \\
\hline CHEMBL1972736 & 688323 & 4.5 & 4.73600 & 0000000001 & TST \\
\hline CHEMBL1360816 & 688323 & 4.55 & 4.9701 & TST & \\
\hline CHEMBL1574341 & 688323 & 4.5 & 4.8194 & TST & \\
\hline CHEMBL1491623 & 688323 & 4.45 & 4.7681 & TST & \\
\hline CHEMBL1525763 & 688323 & 4.45 & 4.6715 & TST & \\
\hline CHEMBL1394046 & 688323 & 5.0 & 4.888 & TST & \\
\hline CHEMBL1611566 & 688323 & 4.45 & 4.8067 & TST & \\
\hline CHEMBL1515965 & 688323 & 4.45 & 4.6279 & TST & \\
\hline CHEMBL1395630 & 688323 & 4.45 & 4.7782 & TST & \\
\hline CHEMBL1487483 & 688323 & 4.8 & 4.7739 & TST & \\
\hline CHEMBL1380874 & 688323 & 5.2 & 4.8024 & TST & \\
\hline CHEMBL1545846 & 688323 & 4.9 & 4.9761 & TST & \\
\hline CHEMBL1570993 & 688323 & 5.9 & 4.8729 & TST & \\
\hline CHEMBL1383025 & 688323 & 4.45 & 4.9014 & TST & \\
\hline CHEMBL1433014 & 688323 & 4.9 & 4.6669 & TST & \\
\hline CHEMBL1328741 & 688323 & 4.5 & 4.8137 & TST & \\
\hline CHEMBL1608805 & 688323 & 5.6 & 4.6826 & TST & \\
\hline CHEMBL1331963 & 688323 & 4.5 & 4.7029 & TST & \\
\hline CHEMBL1358883 & 688323 & 4.9 & 4.7215 & TST & \\
\hline CHEMBL1983549 & 688323 & 5.5 & 4.7646 & TST & \\
\hline CHEMBL3191942 & 688323 & 4.45 & 4.8217 & TST & \\
\hline CHEMBL1425516 & 688323 & 5.25 & 4.7042 & TST & \\
\hline
\end{tabular}




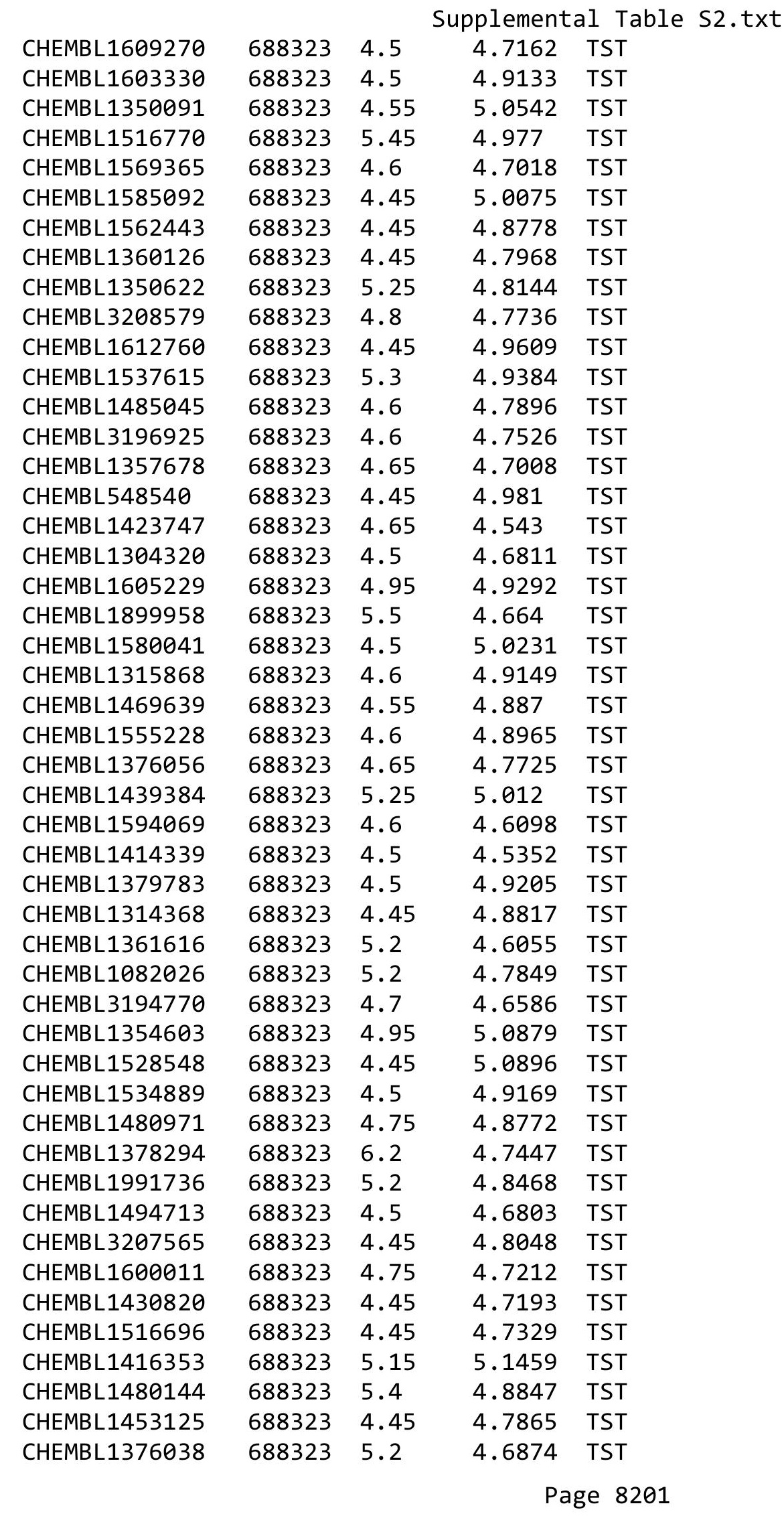




\begin{tabular}{|c|c|c|c|c|c|}
\hline \multirow{3}{*}{$\begin{array}{l}\text { CHEMBL1326984 } \\
\text { CHEMBL1534306 }\end{array}$} & \multirow{3}{*}{$\begin{array}{l}688323 \\
688323\end{array}$} & \multicolumn{4}{|c|}{ Supplemental Table S2.txt } \\
\hline & & 4.45 & \multicolumn{2}{|c|}{4.611000000000001} & \multirow{3}{*}{ TST } \\
\hline & & 4.7 & 4.6907 & TST & \\
\hline CHEMBL1485405 & 688323 & 5.35 & 4.9355 & TST & \\
\hline CHEMBL1596097 & 688323 & 4.5 & 4.73300 & 00000000005 & TST \\
\hline CHEMBL1419643 & 688323 & 4.45 & 4.4893 & TST & \\
\hline CHEMBL1535104 & 688323 & 4.5 & 4.7204 & TST & \\
\hline CHEMBL1309137 & 688323 & 4.6 & 4.8323 & TST & \\
\hline CHEMBL1386978 & 688323 & 4.75 & 4.7738 & TST & \\
\hline CHEMBL1466046 & 688323 & 4.95 & 4.7471 & TST & \\
\hline CHEMBL1407237 & 688323 & 4.45 & 4.5952 & TST & \\
\hline CHEMBL457419 & 688323 & 4.65 & 5.0934 & TST & \\
\hline CHEMBL1456187 & 688323 & 6.15 & 4.8282 & TST & \\
\hline CHEMBL1482883 & 688323 & 4.55 & 4.6581 & TST & \\
\hline CHEMBL1505198 & 688323 & 4.45 & 4.8558 & TST & \\
\hline CHEMBL1981833 & 688323 & 5.25 & 4.7634 & TST & \\
\hline CHEMBL1317046 & 688323 & 4.9 & 4.7016 & TST & \\
\hline CHEMBL548017 & 688323 & 4.45 & 4.7739 & TST & \\
\hline CHEMBL1396243 & 688323 & 4.45 & 4.8089 & TST & \\
\hline CHEMBL1369394 & 688323 & 5.0 & 4.7219 & TST & \\
\hline CHEMBL1601256 & 688323 & 5.5 & 4.9613 & TST & \\
\hline CHEMBL 2004141 & 688323 & 4.5 & 4.9579 & TST & \\
\hline CHEMBL1563950 & 688323 & 4.5 & 4.7202 & TST & \\
\hline CHEMBL1561812 & 688323 & 4.5 & 4.8319 & TST & \\
\hline CHEMBL1395213 & 688323 & 4.45 & 4.5248 & TST & \\
\hline CHEMBL1463829 & 688323 & 4.5 & 4.8001 & TST & \\
\hline CHEMBL1399653 & 688323 & 4.85 & 4.7184 & TST & \\
\hline CHEMBL1309334 & 688323 & 4.5 & 4.5996 & TST & \\
\hline CHEMBL1310477 & 688323 & 4.8 & 4.7602 & TST & \\
\hline CHEMBL3213103 & 688323 & 4.5 & 4.7868 & TST & \\
\hline CHEMBL1089894 & 688323 & 4.45 & 4.8179 & TST & \\
\hline CHEMBL1569989 & 688323 & 5.4 & 5.1604 & TST & \\
\hline CHEMBL1348276 & 688323 & 4.45 & 4.8199 & TST & \\
\hline CHEMBL1324556 & 688323 & 4.5 & 4.9492 & TST & \\
\hline CHEMBL1471789 & 688323 & 4.55 & 4.9296 & TST & \\
\hline CHEMBL1319998 & 688323 & 4.45 & 4.6554 & TST & \\
\hline CHEMBL1535324 & 688323 & 5.2 & 4.7642 & TST & \\
\hline CHEMBL1511371 & 688323 & 4.55 & 4.8938 & TST & \\
\hline CHEMBL1335880 & 688323 & 5.4 & 4.7074 & TST & \\
\hline CHEMBL1491402 & 688323 & 4.45 & 4.9282 & TST & \\
\hline CHEMBL1608798 & 688323 & 4.45 & 4.8179 & TST & \\
\hline CHEMBL1500987 & 688323 & 4.45 & 4.6788 & TST & \\
\hline CHEMBL1427795 & 688323 & 5.45 & 4.7455 & TST & \\
\hline CHEMBL1587184 & 688323 & 4.45 & 4.8016 & TST & \\
\hline CHEMBL1511138 & 688323 & 5.45 & 4.4321 & TST & \\
\hline CHEMBL1588840 & 688323 & 5.7 & 5.1755 & TST & \\
\hline CHEMBL1499214 & 688323 & 4.45 & 4.6779 & TST & \\
\hline CHEMBL 3823713 & 1587599 & 9.699 & 11.1 & TRN & \\
\hline CHEMBL 3823996 & 1587599 & 10.5229 & 10.9653 & TST & \\
\hline
\end{tabular}

Page 8202 


\begin{tabular}{|c|c|c|c|c|c|}
\hline \multicolumn{6}{|c|}{ Supplemental Table S2.txt } \\
\hline CHEMBL 3824302 & 1587599 & 11.0 & 11.1925 TRN & & \\
\hline CHEMBL 3824320 & 1587599 & 11.5229 & 11.1754 TRN & & \\
\hline CHEMBL3824254 & 1587599 & 11.3979 & 10.9419 TRN & & \\
\hline CHEMBL 3823085 & 1587599 & 11.3979 & 11.2524 TRN & & \\
\hline CHEMBL3822915 & 1587599 & 11.5229 & 11.1233 TST & & \\
\hline CHEMBL3823386 & 1587599 & 11.0 & 11.2306 TRN & & \\
\hline CHEMBL3823477 & 1587599 & 11.69906 & 00000000002 & 11.4913 & TRN \\
\hline CHEMBL 3822731 & 1587599 & 11.3979 & 11.0573 TRN & & \\
\hline CHEMBL 3824211 & 1587599 & 11.30099 & 99999999998 & 11.0084 & TRN \\
\hline CHEMBL 3822649 & 1587599 & 11.1549 & 11.0636 TRN & & \\
\hline CHEMBL 3822590 & 1587599 & 11.30099 & 99999999998 & 11.1976 & TRN \\
\hline CHEMBL 3823487 & 1587599 & 11.5229 & 11.1547 TRN & & \\
\hline CHEMBL3823011 & 1587599 & 11.69906 & 00000000002 & 11.1973 & TRN \\
\hline CHEMBL 3822783 & 1587599 & 10.2218 & 10.4471 TRN & & \\
\hline CHEMBL 3823143 & 1587599 & 11.0458 & 11.269 TRN & & \\
\hline CHEMBL 3824242 & 1587599 & 11.0 & 10.9562 TRN & & \\
\hline CHEMBL 3824348 & 1587599 & 10.3979 & 11.0427 TST & & \\
\hline CHEMBL3822820 & 1587599 & 11.3979 & 11.4259 TRN & & \\
\hline CHEMBL 3823064 & 1587599 & 11.5229 & 11.2196 TRN & & \\
\hline CHEMBL 3823673 & 1587599 & 12.0 & 11.6923 TRN & & \\
\hline CHEMBL3823959 & 1587599 & 10.7959 & 11.0716 TRN & & \\
\hline CHEMBL3822855 & 1587599 & 11.5229 & 11.4519 TRN & & \\
\hline CHEMBL 3823348 & 1587599 & 10.69906 & 00000000002 & 10.2904 & TRN \\
\hline CHEMBL 3823137 & 1587599 & 11.69906 & 00000000002 & 11.0844 & TRN \\
\hline CHEMBL 3824299 & 1587599 & 11.0 & 11.1389 TRN & & \\
\hline CHEMBL 3822738 & 1587599 & 11.0 & 11.1268 TRN & & \\
\hline CHEMBL 3824360 & 1587599 & 10.69906 & 00000000002 & 11.1967 & TRN \\
\hline CHEMBL3823433 & 1587599 & 11.2218 & 11.3297 TRN & & \\
\hline CHEMBL 3823508 & 1587599 & 11.69906 & 00000000002 & 11.6923 & TRN \\
\hline CHEMBL3823339 & 1587599 & 10.1549 & 10.8668 TRN & & \\
\hline CHEMBL 3822708 & 1587599 & 11.0 & 10.8604 TRN & & \\
\hline CHEMBL 3823304 & 1587599 & 11.0458 & 11.0726 TRN & & \\
\hline CHEMBL3822922 & 1587599 & 11.5229 & 11.205 TRN & & \\
\hline CHEMBL3823005 & 1587599 & 11.3979 & 10.9186 TST & & \\
\hline CHEMBL 3822854 & 1587599 & 10.69906 & 00000000002 & 11.102 & TRN \\
\hline CHEMBL3824128 & 1587599 & 11.2218 & 10.9671 TRN & & \\
\hline CHEMBL3823963 & 1587599 & 11.3979 & 10.9812 TRN & & \\
\hline CHEMBL3823413 & 1587599 & 11.2218 & 11.4565 TRN & & \\
\hline CHEMBL 3823374 & 1587599 & 11.1549 & 10.9804 TRN & & \\
\hline CHEMBL 3822868 & 1587599 & 11.0 & 11.1318 TRN & & \\
\hline CHEMBL3823763 & 1587599 & 10.0458 & 10.2457 TRN & & \\
\hline CHEMBL 3822665 & 1587599 & 10.69906 & 00000000002 & 11.2752 & TRN \\
\hline CHEMBL3822639 & 1587599 & 11.0 & 11.1817 TRN & & \\
\hline CHEMBL3823406 & 1587599 & 11.3979 & 11.3685 TST & & \\
\hline CHEMBL 3824167 & 1587599 & 11.5229 & 11.3297 TST & & \\
\hline CHEMBL 3823778 & 1587599 & 11.5229 & 11.2931 TST & & \\
\hline CHEMBL 3824025 & 1587599 & 11.5229 & 11.3661 TST & & \\
\hline CHEMBL3823298 & 1587599 & 8.5482 & 10.0482 TST & & \\
\hline
\end{tabular}




\begin{tabular}{|c|c|c|c|c|c|c|}
\hline \multicolumn{7}{|c|}{ Supplemental Table S2.txt } \\
\hline CHEMBL 3823065 & 1587599 & 11.0 & 11.0163 & TST & & \\
\hline CHEMBL 3823534 & 1587599 & 11.30099 & 99999999 & 998 & 11.2941 & TST \\
\hline CHEMBL 3824117 & 1587599 & 11.3979 & 11.0341 & TST & & \\
\hline CHEMBL 3823595 & 1587599 & 10.9586 & 11.2804 & TST & & \\
\hline CHEMBL 3823462 & 1587599 & 11.0458 & 10.9647 & TST & & \\
\hline CHEMBL 2440602 & 990485 & 6.6778 & 6.5039 & TRN & & \\
\hline CHEMBL 2440657 & 990485 & 3.5229 & 3.7412 & TST & & \\
\hline CHEMBL 2440665 & 990485 & 5.2573 & 5.2481 & TRN & & \\
\hline CHEMBL 2440667 & 990485 & 5.7471 & 6.6946 & TST & & \\
\hline CHEMBL 2440608 & 990485 & 5.9666 & 6.2202 & TRN & & \\
\hline CHEMBL 2440622 & 990485 & 6.9872 & 6.7698 & TRN & & \\
\hline CHEMBL 2440650 & 990485 & 5.4425 & 5.1254 & TST & & \\
\hline CHEMBL 2440664 & 990485 & 7.7212 & 7.7475 & TRN & & \\
\hline CHEMBL 2440670 & 990485 & 6.6635 & 6.6413 & TRN & & \\
\hline CHEMBL 2440606 & 990485 & 6.6676 & 6.8402 & TRN & & \\
\hline CHEMBL 2440648 & 990485 & 4.0 & 4.3646 & TST & & \\
\hline CHEMBL 2440636 & 990485 & 7.0177 & 7.0785 & TRN & & \\
\hline CHEMBL 2440651 & 990485 & 5.4225 & 5.1505 & TST & & \\
\hline CHEMBL 2440633 & 990485 & 6.8386 & 6.8651 & TRN & & \\
\hline CHEMBL 2440629 & 990485 & 6.51 & 6.5723 & TRN & & \\
\hline CHEMBL 2440596 & 990485 & 5.6576 & 5.6313 & TRN & & \\
\hline CHEMBL 2440646 & 990485 & 4.0 & 4.7173 & TST & & \\
\hline CHEMBL 2440638 & 990485 & 8.1249 & 8.0363 & TRN & & \\
\hline CHEMBL 2440656 & 990485 & 3.5229 & 4.224 & TST & & \\
\hline CHEMBL 2440609 & 990485 & 3.5229 & 3.4851 & TRN & & \\
\hline CHEMBL 2440628 & 990485 & 7.4437 & 7.5698 & TRN & & \\
\hline CHEMBL 2440621 & 990485 & 5.3625 & 5.4999 & TRN & & \\
\hline CHEMBL 2440644 & 990485 & 5.6596 & 4.356 & TST & & \\
\hline CHEMBL 2440637 & 990485 & 7.6021 & 7.7583 & TRN & & \\
\hline CHEMBL 2440603 & 990485 & 7.0223 & 7.1259 & TRN & & \\
\hline CHEMBL 2440618 & 990485 & 6.7721 & 6.9512 & TRN & & \\
\hline CHEMBL 2440619 & 990485 & 6.8539 & 6.6367 & TRN & & \\
\hline CHEMBL 2440641 & 990485 & 6.5467 & 6.152 & TST & & \\
\hline CHEMBL 2440598 & 990485 & 7.0862 & 7.162999 & 9999999999 & & TRI \\
\hline CHEMBL 2440626 & 990485 & 7.7447 & 7.8277 & TRN & & \\
\hline CHEMBL 2440661 & 990485 & 6.5482 & 6.5038 & TRN & & \\
\hline CHEMBL 2440614 & 990485 & 5.6345 & 5.6346 & TRN & & \\
\hline CHEMBL 2440662 & 990485 & 6.5157 & 6.5957 & TRN & & \\
\hline CHEMBL 2440615 & 990485 & 7.7696 & 7.699 & TRN & & \\
\hline CHEMBL 2440643 & 990485 & 5.7077 & 5.1562 & TST & & \\
\hline CHEMBL 2440655 & 990485 & 3.5229 & 3.5478 & TRN & & \\
\hline CHEMBL 2440625 & 990485 & 7.8539 & 8.0163 & TRN & & \\
\hline CHEMBL 2440635 & 990485 & 5.3497 & 5.2967 & TRN & & \\
\hline CHEMBL 2440632 & 990485 & 7.301 & 7.3333 & TRN & & \\
\hline CHEMBL 2440645 & 990485 & 6.0737 & 5.6817 & TST & & \\
\hline CHEMBL 2440653 & 990485 & 6.1124 & 6.0997 & TRN & & \\
\hline CHEMBL 2440634 & 990485 & 6.2993 & 6.3256 & TRN & & \\
\hline CHEMBL 2440597 & 990485 & 5.4908 & 5.6441 & TRN & & \\
\hline
\end{tabular}




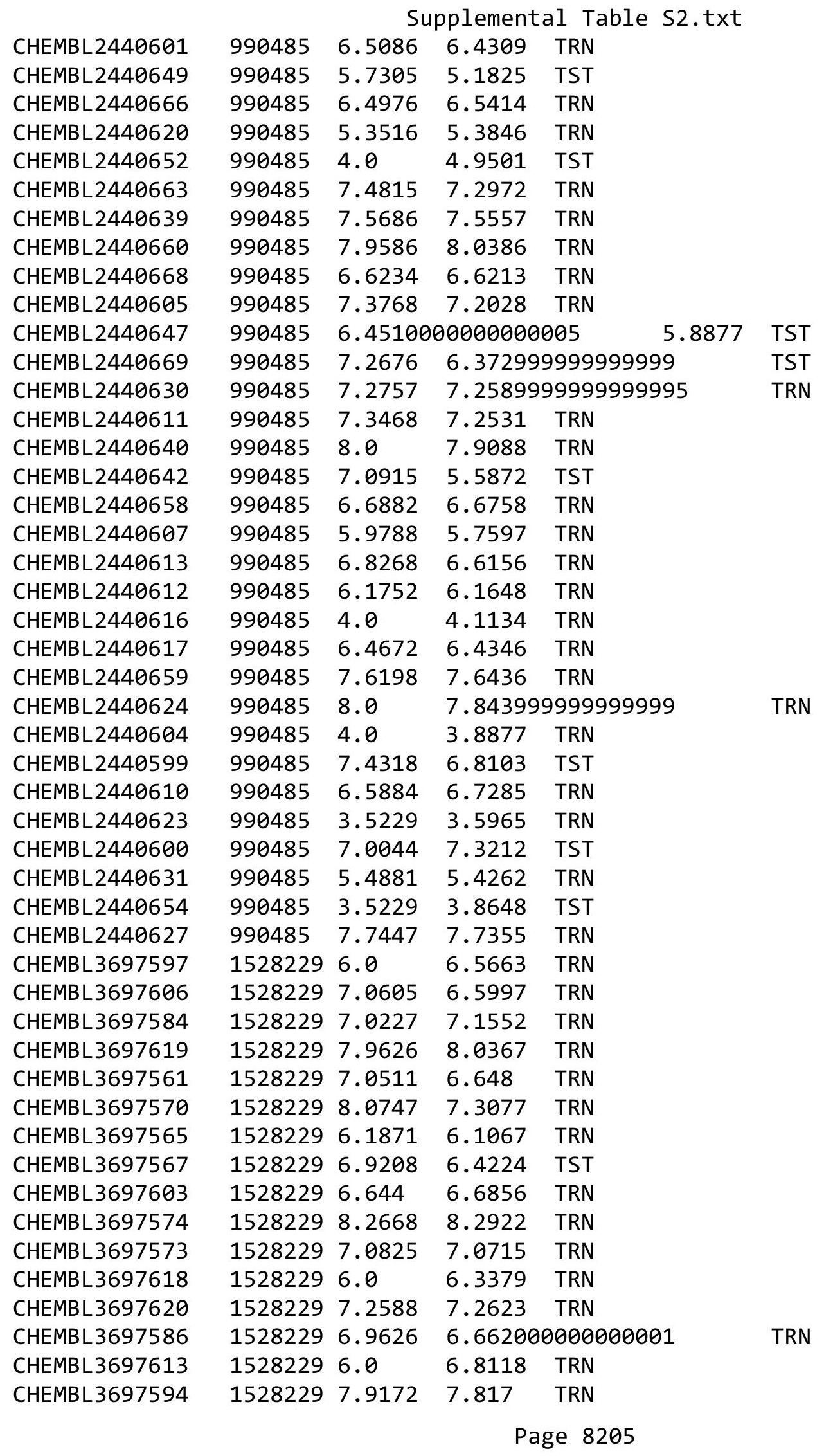


Supplemental Table S2.txt

\begin{tabular}{|c|c|c|c|c|c|c|}
\hline CHEMBL3697591 & 1528229 & 5.9136 & 6.3649 & TRN & & \\
\hline CHEMBL3697564 & 1528229 & 8.4425 & 8.0498 & TRN & & \\
\hline CHEMBL3697608 & 1528229 & 6.4724 & 6.2892 & TRN & & \\
\hline CHEMBL3697589 & 1528229 & 7.5157 & 6.9998 & TRN & & \\
\hline CHEMBL3697562 & 1528229 & 6.3107 & 6.2964 & TRN & & \\
\hline CHEMBL3697577 & 1528229 & 7.059 & 6.7525 & TRN & & \\
\hline CHEMBL3697572 & 1528229 & 7.8239 & 7.5894 & TRN & & \\
\hline CHEMBL3697581 & 1528229 & 9.2434 & 7.107 & TST & & \\
\hline CHEMBL 3697604 & 1528229 & 7.3625 & 7.853 & TRN & & \\
\hline CHEMBL3697582 & 1528229 & 6.5406 & 6.9999 & TST & & \\
\hline CHEMBL 3697578 & 1528229 & 6.0 & 6.6773 & TRN & & \\
\hline CHEMBL3697556 & 1528229 & 7.3382 & 7.7314 & TRN & & \\
\hline CHEMBL3697554 & 1528229 & 6.5028 & 6.8876 & TRN & & \\
\hline CHEMBL3697563 & 1528229 & 6.8069 & 6.849 & TRN & & \\
\hline CHEMBL3697555 & 1528229 & 7.0825 & 7.1481 & TRN & & \\
\hline CHEMBL3697595 & 1528229 & 7.8729 & 7.5746 & TST & & \\
\hline CHEMBL3697611 & 1528229 & 6.4572 & 6.6309 & TRN & & \\
\hline CHEMBL3697616 & 1528229 & 7.4802 & 7.2373 & TRN & & \\
\hline CHEMBL3697622 & 1528229 & 6.0 & 7.2491 & TST & & \\
\hline CHEMBL3697624 & 1528229 & 7.8894 & 6.5661 & TST & & \\
\hline CHEMBL3697607 & 1528229 & 6.45100 & 000000006 & 205 & 6.6955 & TRN \\
\hline CHEMBL3697558 & 1528229 & 7.4145 & 6.7417 & TRN & & \\
\hline CHEMBL3697605 & 1528229 & 6.4191 & 6.6169 & TRN & & \\
\hline CHEMBL 3697614 & 1528229 & 6.0 & 5.8677 & TRN & & \\
\hline CHEMBL3697610 & 1528229 & 6.9626 & 6.7242 & TRN & & \\
\hline CHEMBL3697600 & 1528229 & 7.4168 & 6.8476 & TRN & & \\
\hline CHEMBL3697579 & 1528229 & 8.1158 & 7.0317 & TST & & \\
\hline CHEMBL3697559 & 1528229 & 6.9318 & 6.8145 & TRN & & \\
\hline CHEMBL3697553 & 1528229 & 7.2782 & 7.2956 & TRN & & \\
\hline CHEMBL3697602 & 1528229 & 6.6655 & 6.7008 & TRN & & \\
\hline CHEMBL3697596 & 1528229 & 8.3799 & 7.4683 & TST & & \\
\hline CHEMBL3697615 & 1528229 & 7.2366 & 6.9806 & TRN & & \\
\hline CHEMBL3697583 & 1528229 & 7.9957 & 7.8598 & TRN & & \\
\hline CHEMBL3697568 & 1528229 & 6.6091 & 6.3342 & TRN & & \\
\hline CHEMBL3697609 & 1528229 & 7.4908 & 7.8814 & TRN & & \\
\hline CHEMBL3697580 & 1528229 & 7.0846 & 7.5041 & TRN & & \\
\hline CHEMBL3697601 & 1528229 & 6.8601 & 6.3712 & TST & & \\
\hline CHEMBL3697575 & 1528229 & 6.7282 & 6.8689 & TST & & \\
\hline CHEMBL 3697557 & 1528229 & 7.0357 & 6.9568 & TRN & & \\
\hline CHEMBL3697566 & 1528229 & 6.6498 & 6.7373 & TRN & & \\
\hline CHEMBL3697560 & 1528229 & 7.4413 & 7.3755 & TRN & & \\
\hline CHEMBL3697590 & 1528229 & 7.0645 & 6.8808 & TST & & \\
\hline CHEMBL3697585 & 1528229 & 7.2 & 6.9666 & TRN & & \\
\hline CHEMBL 3697569 & 1528229 & \multicolumn{3}{|c|}{6.082999999999999} & 6.1866 & TRN \\
\hline CHEMBL3697571 & 1528229 & 7.5072 & 7.3858 & TRN & & \\
\hline CHEMBL 3697588 & 1528229 & 6.3686 & 6.9159 & TST & & \\
\hline CHEMBL3697599 & 1528229 & 7.7721 & 6.4515 & TST & & \\
\hline CHEMBL 3697587 & 1528229 & 6.0 & 6.769 & TRN & & \\
\hline
\end{tabular}


Supplemental Table S2.txt

\begin{tabular}{|c|c|c|c|c|c|}
\hline CHEMBL3697612 & 1528229 & 7.2366 & 7.2089 & TRN & \\
\hline CHEMBL3697623 & 1528229 & 7.4473 & 6.7246 & TST & \\
\hline CHEMBL3697576 & 1528229 & 8.0155 & 7.0366 & TST & \\
\hline CHEMBL3697592 & 1528229 & 6.1152 & 6.9851 & TST & \\
\hline CHEMBL3697593 & 1528229 & 7.6234 & 7.6044 & TST & \\
\hline CHEMBL3697598 & 1528229 & 6.4622 & 7.5768 & TST & \\
\hline CHEMBL92309 & 954938 & 2.7586 & 3.1705 & TST & \\
\hline CHEMBL1242367 & 954938 & 4.6405 & 4.3112 & TRN & \\
\hline CHEMBL191334 & 954938 & 3.9853 & 3.788999 & & TRN \\
\hline CHEMBL1909414 & 954938 & 4.1594 & 4.0526 & TRN & \\
\hline CHEMBL3186408 & 954938 & 4.6226 & 3.7859 & TST & \\
\hline CHEMBL 2363137 & 954938 & 5.2714 & 4.7836 & TRN & \\
\hline CHEMBL240954 & 954938 & 4.7732 & 4.3445 & TST & \\
\hline CHEMBL472940 & 954938 & 3.553 & 4.1363 & TRN & \\
\hline CHEMBL209148 & 954938 & 3.6623 & 3.8138 & TRN & \\
\hline CHEMBL180127 & 954938 & 4.8329 & 4.7204 & TRN & \\
\hline CHEMBL1788116 & 954938 & 2.6364 & 3.308999 & 99999999997 & TRN \\
\hline CHEMBL 9470 & 954938 & 5.6806 & 5.3969 & TST & \\
\hline CHEMBL379300 & 954938 & 6.7338 & 6.897 & TRN & \\
\hline CHEMBL188678 & 954938 & 5.1783 & 5.1347 & TRN & \\
\hline CHEMBL1357247 & 954938 & 3.4934 & 3.0151 & TRN & \\
\hline CHEMBL189584 & 954938 & 5.1501 & 5.0246 & TRN & \\
\hline CHEMBL135561 & 954938 & 4.0575 & 4.1269 & TRN & \\
\hline CHEMBL258844 & 954938 & 2.9783 & 3.8125 & TRN & \\
\hline CHEMBL3349342 & 954938 & 3.7162 & 3.623999 & & TRN \\
\hline CHEMBL1643959 & 954938 & 2.8174 & 2.8881 & TRN & \\
\hline CHEMBL512504 & 954938 & 6.4222 & 6.6388 & TRN & \\
\hline CHEMBL1230020 & 954938 & 4.6063 & 4.3926 & TRN & \\
\hline CHEMBL213100 & 954938 & 3.3028 & 3.3191 & TRN & \\
\hline CHEMBL221137 & 954938 & 5.2157 & 4.6874 & TST & \\
\hline CHEMBL1673039 & 954938 & 4.8893 & 4.7613 & TRN & \\
\hline CHEMBL1516890 & 954938 & 3.8401 & 3.7802 & TRN & \\
\hline CHEMBL 2144069 & 954938 & 3.7081 & 3.4432 & TRN & \\
\hline CHEMBL393929 & 954938 & 3.5743 & 3.8598 & TRN & \\
\hline CHEMBL 2005886 & 954938 & 4.5233 & 4.5776 & TRN & \\
\hline CHEMBL573107 & 954938 & 5.23600 & 300000000 & 5.0139 & TRN \\
\hline CHEMBL392695 & 954938 & 6.0132 & 6.0541 & TRN & \\
\hline CHEMBL1256459 & 954938 & 7.0384 & 7.6332 & TRN & \\
\hline CHEMBL1404918 & 954938 & 2.5813 & 2.7736 & TRN & \\
\hline CHEMBL102714 & 954938 & 3.8481 & 3.9096 & TRN & \\
\hline CHEMBL379975 & 954938 & 5.8004 & 5.9977 & TRN & \\
\hline CHEMBL3392440 & 954938 & 3.5744 & 3.4397 & TRN & \\
\hline CHEMBL514499 & 954938 & 7.6741 & 8.0865 & TRN & \\
\hline CHEMBL3199475 & 954938 & 5.9225 & 5.3184 & TRN & \\
\hline CHEMBL 65 & 954938 & 8.5885 & 8.1129 & TRN & \\
\hline CHEMBL300389 & 954938 & 7.08 & 6.787999 & 9999999999 & TRN \\
\hline CHEMBL373751 & 954938 & 3.9473 & 3.7461 & TRN & \\
\hline CHEMBL412142 & 954938 & 3.5037 & 3.3028 & TRN & \\
\hline
\end{tabular}




\begin{tabular}{|c|c|c|c|c|c|}
\hline \multicolumn{6}{|c|}{ Supplemental Table S2.txt } \\
\hline CHEMBL515416 & 954938 & 3.3996 & 4.0074 & TRN & \\
\hline CHEMBL577784 & 954938 & 4.9043 & 4.7356 & TRN & \\
\hline CHEMBL1970879 & 954938 & 3.8913 & 3.6679 & TRN & \\
\hline CHEMBL449158 & 954938 & 5.822 & 6.3235 & TST & \\
\hline CHEMBL 222102 & 954938 & 4.9492 & 4.5558 & TRN & \\
\hline CHEMBL483847 & 954938 & 3.5362 & 3.7696 & TRN & \\
\hline CHEMBL483849 & 954938 & 2.4822 & 2.7175 & TRN & \\
\hline CHEMBL192566 & 954938 & 6.8517 & 7.6352 & TST & \\
\hline CHEMBL259181 & 954938 & 4.8629 & 4.7245 & TRN & \\
\hline CHEMBL202721 & 954938 & 5.1534 & 4.7546 & TST & \\
\hline CHEMBL585951 & 954938 & 6.1618 & 5.9757 & TST & \\
\hline CHEMBL558642 & 954938 & 4.2972 & 4.2425 & TST & \\
\hline CHEMBL220241 & 954938 & 3.4941 & 4.0524 & TST & \\
\hline CHEMBL210618 & 954938 & 3.2677 & 3.54600 & 00000000003 & TST \\
\hline CHEMBL509032 & 954938 & 4.6126 & 5.037 & TST & \\
\hline CHEMBL1590308 & 954938 & 2.7972 & 3.5549 & TST & \\
\hline CHEMBL1190711 & 954938 & 5.2048 & 4.8943 & TST & \\
\hline CHEMBL55747 & 195514 & 4.9208 & 4.4504 & TRN & \\
\hline CHEMBL55308 & 195514 & 5.8539 & 5.9075 & TST & \\
\hline CHEMBL415959 & 195514 & 4.8539 & 5.381 & TST & \\
\hline CHEMBL56465 & 195514 & 4.8239 & 5.1233 & TRN & \\
\hline CHEMBL54318 & 195514 & 6.301 & 6.2833 & TRN & \\
\hline CHEMBL 296376 & 195514 & 6.0177 & 5.66 & TRN & \\
\hline CHEMBL449041 & 195514 & 4.9208 & 4.9373 & TRN & \\
\hline CHEMBL54698 & 195514 & 5.4559 & 5.2472 & TRN & \\
\hline CHEMBL56178 & 195514 & 3.6778 & 3.5975 & TRN & \\
\hline CHEMBL55186 & 195514 & 7.3979 & 7.2021 & TRN & \\
\hline CHEMBL54600 & 195514 & 6.699 & 7.0082 & TRN & \\
\hline CHEMBL55951 & 195514 & 7.5229 & 7.416 & TRN & \\
\hline CHEMBL 292464 & 195514 & 5.5686 & 5.0829 & TST & \\
\hline CHEMBL55387 & 195514 & 6.0458 & 5.6879 & TRN & \\
\hline CHEMBL56841 & 195514 & 3.7212 & 3.7819 & TRN & \\
\hline CHEMBL 293963 & 195514 & 5.1487 & 4.9626 & TRN & \\
\hline CHEMBL56324 & 195514 & 5.7696 & 6.3767 & TRN & \\
\hline CHEMBL55997 & 195514 & 6.3979 & 6.63 & TRN & \\
\hline CHEMBL301086 & 195514 & 5.2291 & 5.1774 & TRN & \\
\hline CHEMBL54487 & 195514 & 3.699 & 3.87600 & 00000000003 & TRN \\
\hline CHEMBL52458 & 195514 & 3.6383 & 4.7077 & TRN & \\
\hline CHEMBL299271 & 195514 & 5.7447 & 5.7631 & TRN & \\
\hline CHEMBL55187 & 195514 & 8.0 & 8.1579 & TRN & \\
\hline CHEMBL55199 & 195514 & 6.2218 & 6.4799 & TRN & \\
\hline CHEMBL53896 & 195514 & 5.1367 & 4.9829 & TRN & \\
\hline CHEMBL51738 & 195514 & 5.8239 & 5.5468 & TRN & \\
\hline CHEMBL292644 & 195514 & 3.6576 & 4.6851 & TST & \\
\hline CHEMBL54970 & 195514 & 4.8861 & 5.6877 & TRN & \\
\hline CHEMBL298823 & 195514 & 5.2218 & 5.4125 & TRN & \\
\hline CHEMBL 293331 & 195514 & 4.9208 & 4.7226 & TST & \\
\hline CHEMBL52068 & 195514 & 5.0605 & 4.9076 & TRN & \\
\hline
\end{tabular}


Supplemental Table S2.txt

\begin{tabular}{|c|c|c|c|c|}
\hline CHEMBL & 195514 & 8.5229 & 8.2054 & TRN \\
\hline CHEMBL & 195514 & 4.7959 & 5.1976 & \\
\hline AEMBL293780 & 95514 & 4.9208 & 9871 & \\
\hline HEMBL56895 & 95514 & 3.699 & 8098 & \\
\hline HEMBL 5 & 95514 & 5.2441 & 391 & \\
\hline HEME & 95514 & 5.1612 & 5.3737 & \\
\hline HEMBL 297956 & 95514 & 6.0 & 6.0868 & \\
\hline HEMBL299001 & 95514 & 8.1549 & 8.3371 & \\
\hline HEMBL 300757 & 95514 & 5.1427 & 4.8871 & \\
\hline CHEMBL299781 & 95514 & 3.7212 & & \\
\hline HEMBL: & 95514 & 4.8861 & 4.5196 & \\
\hline HEMBL 2 & 195514 & 6.699 & 6.1387 & \\
\hline HEMBL56870 & 95514 & 3.7696 & .547 & \\
\hline HEMBL & 95514 & 6.9208 & 5.7192 & \\
\hline HEMBL5 & 195514 & 5.0 & 5.1425 & \\
\hline HEMI & 195514 & 8.301 & 8.3854 & \\
\hline AEMB & 195514 & 5.3468 & 5.6294 & \\
\hline HEMBL5 & 195514 & 3.6778 & 4.2925 & \\
\hline 53 & 14 & 3.8239 & & \\
\hline$H E M$ & 195514 & 3.6778 & 47 & \\
\hline AEMI & 195514 & 5.0044 & 692 & \\
\hline 27 & 195514 & 5.9586 & 331 & \\
\hline HEMBL & 195514 & 3.6778 & & \\
\hline 32 & 4 & & & \\
\hline $\mathrm{CHE}$ & 195514 & 5.2076 & & \\
\hline 1 & 195 & 6.8539 & 57 & \\
\hline $\mathrm{CHEl}$ & 195 & 4.7959 & 62 & \\
\hline 586 & 195514 & 5.041 & 72 & \\
\hline CHEMI & 95514 & 5.3188 & & \\
\hline $\mathrm{CHE}$ & 14 & 383 & & \\
\hline 5 & 14 & 29 & 48 & \\
\hline CHEME & 195514 & 3.8539 & & \\
\hline CHEMBL5 & 195514 & & & \\
\hline CHEME & 195514 & 5.9586 & & \\
\hline & 14 & & & \\
\hline $\mathrm{CHE}$ & 195 & 5 . & 62 & \\
\hline CHEMBL & 195514 & 3.7447 & 67 & \\
\hline CHEMBL: & 195514 & 4.7212 & 5.0831 & \\
\hline CHEMB & 195514 & 5.301 & 71 & $\mathrm{In}$ \\
\hline CHEME & 164 & & & \\
\hline CHEMBL & 1640425 & 5.3372 & 5 . & \\
\hline CHEMBL1 & 1640425 & 4.8261 & 5.9641 & TS \\
\hline CHEMBL & 1640425 & 5.0282 & 5.5153 & \\
\hline CHEMB & 1640425 & 5.2101 & & \\
\hline CHEMBL: & 1640425 & 5.2744 & 5.6181 & \\
\hline CHEMBL: & 1640425 & 5.6021 & 5.3959 & \\
\hline CHEMBL3944915 & 1640425 & 5.5607 & 5.6358 & \\
\hline CHEMBL3893065 & 1640425 & 5.4004 & 5.6671 & \\
\hline
\end{tabular}

Page 8209 
Supplemental Table S2.txt

\begin{tabular}{|c|c|c|c|c|c|}
\hline CHEMBL1366449 & 1640425 & 5.9974 & 5.4318 & TST & \\
\hline CHEMBL3908011 & 1640425 & 6.3019 & 5.2135 & TST & \\
\hline CHEMBL3961709 & 1640425 & 5.487 & 5.3228 & TRN & \\
\hline CHEMBL 3909212 & 1640425 & 5.0191 & 6.1711 & TRN & \\
\hline CHEMBL3962410 & 1640425 & 5.3887 & 5.8734 & TRN & \\
\hline CHEMBL1419634 & 1640425 & 6.0292 & 5.5505 & TRN & \\
\hline CHEMBL3902821 & 1640425 & 4.9157 & 5.6344 & TRN & \\
\hline CHEMBL 3964825 & 1640425 & 5.016999 & 99999999 & 5.3848 & TST \\
\hline CHEMBL1326627 & 1640425 & 5.053 & 6.0238 & TST & \\
\hline CHEMBL3929937 & 1640425 & 5.5918 & $5.55200 t$ & 00000000005 & TRN \\
\hline CHEMBL3931168 & 1640425 & 5.6091 & 5.7679 & TRN & \\
\hline CHEMBL1523162 & 1640425 & 5.1113 & 5.1902 & TRN & \\
\hline CHEMBL 3952395 & 1640425 & 5.3679 & 5.6058 & TRN & \\
\hline CHEMBL1499181 & 1640425 & 6.1421 & 5.2629 & TST & \\
\hline CHEMBL 3965603 & 1640425 & 6.1487 & 5.0768 & TST & \\
\hline CHEMBL3892212 & 1640425 & 5.5312 & 5.5483 & TRN & \\
\hline CHEMBL3905445 & 1640425 & 7.0362 & 6.4847 & TRN & \\
\hline CHEMBL 3970253 & 1640425 & 5.3347 & 5.1577 & TRN & \\
\hline CHEMBL 3902438 & 1640425 & 5.4472 & 5.3653 & TST & \\
\hline CHEMBL3920736 & 1640425 & 5.2694 & 5.5559 & TST & \\
\hline CHEMBL3977716 & 1640425 & 5.8548 & 5.4376 & TRN & \\
\hline CHEMBL 3921682 & 1640425 & 5.7908 & 5.9 & TRN & \\
\hline CHEMBL 3904387 & 1640425 & 6.9626 & 6.7294 & TRN & \\
\hline CHEMBL1434982 & 1640425 & 5.63 & 5.6727 & TRN & \\
\hline CHEMBL3970999 & 1640425 & 5.5337 & 5.4126 & TRN & \\
\hline CHEMBL 3899828 & 1640425 & 5.3481 & 5.347 & TRN & \\
\hline CHEMBL3952516 & 1640425 & 5.4353 & 5.7117 & TRN & \\
\hline CHEMBL3923737 & 1640425 & 4.9208 & 5.2598 & TRN & \\
\hline CHEMBL 3980678 & 1640425 & 5.3123 & 6.0223 & TST & \\
\hline CHEMBL3895501 & 1640425 & 5.7109 & 5.4064 & TRN & \\
\hline CHEMBL1356858 & 1640425 & 6.1726 & 6.0049 & TRN & \\
\hline CHEMBL3907807 & 1640425 & 6.3675 & 5.659 & TRN & \\
\hline CHEMBL3982834 & 1640425 & 5.8881 & 5.5388 & TRN & \\
\hline CHEMBL 3900023 & 1640425 & 5.5906 & 5.8451 & TRN & \\
\hline CHEMBL3909546 & 1640425 & 7.4437 & 6.8267 & TRN & \\
\hline CHEMBL 3945665 & 1640425 & 6.1512 & 5.1491 & TRN & \\
\hline CHEMBL3931998 & 1640425 & 5.7258 & 5.8511 & TRN & \\
\hline CHEMBL3911317 & 1640425 & 5.1403 & 5.0374 & TRN & \\
\hline CHEMBL 3980504 & 1640425 & 5.5367 & 5.4441 & TST & \\
\hline CHEMBL3976205 & 1640425 & 6.0747 & 6.3891 & TRN & \\
\hline CHEMBL 3092263 & 1640425 & 5.4597 & 5.7386 & TRN & \\
\hline CHEMBL3962122 & 1640425 & 6.5346 & 5.4861 & TST & \\
\hline CHEMBL3982311 & 1640425 & 5.6094 & 5.4731 & TRN & \\
\hline CHEMBL1503512 & 1640425 & 5.1129 & 5.3865 & TST & \\
\hline CHEMBL3938183 & 1640425 & 5.5229 & 5.3913 & TRN & \\
\hline CHEMBL 3956466 & 1640425 & 5.5408 & 5.3644 & TST & \\
\hline CHEMBL 3889984 & 1640425 & 5.6538 & 5.6136 & TRN & \\
\hline CHEMBL 3932940 & 1640425 & 5.0818 & 5.7655 & TRN & \\
\hline
\end{tabular}


Supplemental Table S2.txt

\begin{tabular}{|c|c|c|c|c|}
\hline CHEMBL3937130 & 1640425 & 5.3363 & 5.419 & TRN \\
\hline CHEMBL3901193 & 1640425 & 5.0 & 5.6086 & TRN \\
\hline CHEMBL3894540 & 1640425 & 6.2291 & 5.4857 & TRN \\
\hline CHEMBL3954619 & 1640425 & 5.2225 & 5.6265 & TRN \\
\hline CHEMBL 3893863 & 1640425 & 5.426 & 5.5012 & TRN \\
\hline CHEMBL3978325 & 1640425 & 5.6538 & 5.5227 & TRN \\
\hline CHEMBL3901989 & 1640425 & 6.7258 & 5.8286 & TRN \\
\hline CHEMBL3962098 & 1640425 & 5.7333 & 5.3193 & TRN \\
\hline CHEMBL3895068 & 1640425 & 7.8539 & 6.4948 & TRN \\
\hline CHEMBL3917592 & 1640425 & 6.4763 & 5.8 & TRN \\
\hline CHEMBL 3892708 & 1640425 & 5.7001 & 5.8086 & TRN \\
\hline CHEMBL1323541 & 1640425 & 5.2121 & 6.3032 & TST \\
\hline CHEMBL3972175 & 1640425 & 6.466 & 6.4795 & TRN \\
\hline CHEMBL 3892321 & 1640425 & 6.3915 & 5.9074 & TRN \\
\hline CHEMBL1401915 & 1640425 & 6.5784 & 5.1899 & TST \\
\hline CHEMBL3965320 & 1640425 & 5.0 & 5.4874 & TRN \\
\hline CHEMBL3982886 & 1640425 & 6.3019 & 6.6797 & TRN \\
\hline CHEMBL3978302 & 1640425 & 6.1688 & 5.6761 & TRN \\
\hline CHEMBL3930803 & 1640425 & 7.0809 & 7.0814 & TRN \\
\hline CHEMBL3976457 & 1640425 & 6.3382 & 5.9611 & TRN \\
\hline CHEMBL3970702 & 1640425 & 5.2052 & 5.1988 & TST \\
\hline CHEMBL3908873 & 1640425 & 5.6364 & 5.7796 & TRN \\
\hline CHEMBL3912878 & 1640425 & 5.2681 & 6.0771 & TRN \\
\hline CHEMBL3967689 & 1640425 & 5.5504 & 6.2078 & TRN \\
\hline CHEMBL3955017 & 1640425 & 5.2654 & 5.2888 & TST \\
\hline CHEMBL3907115 & 1640425 & 5.6641 & 5.5187 & TRN \\
\hline CHEMBL3946037 & 1640425 & 5.7825 & 6.0986 & TRN \\
\hline CHEMBL3907800 & 1640425 & 5.7823 & 6.3009 & TRN \\
\hline CHEMBL3916083 & 1640425 & 5.6171 & 5.5443 & TRN \\
\hline CHEMBL3953366 & 1640425 & 6.065 & 5.4238 & TST \\
\hline CHEMBL3925369 & 1640425 & 5.1522 & 5.5742 & TRN \\
\hline CHEMBL3986131 & 1640425 & 5.2958 & 5.3835 & TRN \\
\hline CHEMBL3911496 & 1640425 & 5.074 & 6.1604 & TRN \\
\hline CHEMBL3938203 & 1640425 & 5.0131 & 5.5425 & TST \\
\hline CHEMBL3946036 & 1640425 & 6.6198 & 6.3078 & TRN \\
\hline CHEMBL3892139 & 1640425 & 5.2029 & 5.3114 & TST \\
\hline CHEMBL3935097 & 1640425 & 5.763 & 5.1335 & TST \\
\hline CHEMBL3940903 & 1640425 & 5.9014 & 6.085 & TRN \\
\hline CHEMBL3954532 & 1640425 & 4.8239 & 5.1323 & TRN \\
\hline CHEMBL3983085 & 1640425 & 5.9547 & 6.0273 & TRN \\
\hline CHEMBL1082389 & 1640425 & 6.4045 & 5.6671 & TRN \\
\hline CHEMBL3902385 & 1640425 & 5.2995 & 5.983 & TST \\
\hline CHEMBL3954153 & 1640425 & 6.4622 & \multicolumn{2}{|c|}{5.757000000000001} \\
\hline CHEMBL3984415 & 1640425 & 5.0665 & 5.317 & TRN \\
\hline CHEMBL1711155 & 1640425 & 6.1175 & 5.3767 & TST \\
\hline CHEMBL3902826 & 1640425 & 5.3391 & 5.4292 & TRN \\
\hline CHEMBL3947157 & 1640425 & 5.4647 & 5.6003 & TRN \\
\hline CHEMBL3916784 & 1640425 & 5.8327 & 5.7944 & TRN \\
\hline
\end{tabular}




\begin{tabular}{|c|c|c|c|c|c|c|}
\hline \multirow[b]{2}{*}{ CHEMBL 3973557} & \multicolumn{6}{|c|}{ Supplemental Table S2.txt } \\
\hline & 1640425 & 5.2118 & 5.239 & TST & & \\
\hline CHEMBL3916808 & 1640425 & 6.0292 & 5.8241 & TRN & & \\
\hline CHEMBL 3891588 & 1640425 & 5.2834 & 5.3449 & TRN & & \\
\hline CHEMBL 3929345 & 1640425 & 5.382999 & 999999999 & 99 & 5.5517 & TRN \\
\hline CHEMBL3979438 & 1640425 & 5.624 & 5.2552 & TST & & \\
\hline CHEMBL3907785 & 1640425 & 7.2676 & 6.6457 & TRN & & \\
\hline CHEMBL1395308 & 1640425 & 4.8988 & 6.0769 & TST & & \\
\hline CHEMBL 3894410 & 1640425 & 5.6402 & 5.8324 & TRN & & \\
\hline CHEMBL3913926 & 1640425 & 4.9682 & 5.4761 & TRN & & \\
\hline CHEMBL3652919 & 1528368 & 10.8407 & 11.6109 & TRN & & \\
\hline CHEMBL3652895 & 1528368 & 11.0999 & 11.0558 & TRN & & \\
\hline CHEMBL3652975 & 1528368 & 10.7426 & 8.7821 & TST & & \\
\hline CHEMBL 3652907 & 1528368 & 11.0503 & 10.9731 & TRN & & \\
\hline CHEMBL 3656789 & 1528368 & 6.0 & 7.3061 & TRN & & \\
\hline CHEMBL 3656882 & 1528368 & 12.2007 & 11.944 & TRN & & \\
\hline CHEMBL3656863 & 1528368 & 11.3979 & 11.5087 & TRN & & \\
\hline CHEMBL3656817 & 1528368 & 12.0 & 10.2702 & TRN & & \\
\hline CHEMBL 3652995 & 1528368 & 6.0 & 9.6434 & TRN & & \\
\hline CHEMBL 3653057 & 1528368 & 6.0 & 6.6044 & TRN & & \\
\hline CHEMBL3652923 & 1528368 & 10.9535 & 11.4983 & TRN & & \\
\hline CHEMBL3653016 & 1528368 & 9.2872 & 10.0411 & TRN & & \\
\hline CHEMBL3652884 & 1528368 & 11.0999 & 9.5444 & TRN & & \\
\hline CHEMBL 3652882 & 1528368 & 6.0 & 8.234 & TRN & & \\
\hline CHEMBL 3656826 & 1528368 & 12.0 & 11.4079 & TRN & & \\
\hline CHEMBL 3656793 & 1528368 & 11.1002 & 11.7261 & TRN & & \\
\hline CHEMBL 3652892 & 1528368 & 11.0999 & 11.9443 & TRN & & \\
\hline CHEMBL3653036 & 1528368 & 10.3565 & 10.8482 & TST & & \\
\hline CHEMBL 3653054 & 1528368 & 11.1002 & 11.122 & TST & & \\
\hline CHEMBL 3656843 & 1528368 & 12.5229 & 12.1135 & TRN & & \\
\hline CHEMBL 3652974 & 1528368 & 9.8511 & 8.8538 & TRN & & \\
\hline CHEMBL 3653027 & 1528368 & 10.7212 & 10.5372 & TST & & \\
\hline CHEMBL 3656788 & 1528368 & 10.3735 & 11.6318 & TRN & & \\
\hline CHEMBL 3656816 & 1528368 & 12.0 & 12.8699 & TRN & & \\
\hline CHEMBL 3656784 & 1528368 & 10.3645 & 9.9207 & TST & & \\
\hline CHEMBL 3656866 & 1528368 & 12.7696 & 13.2474 & TRN & & \\
\hline CHEMBL3652958 & 1528368 & 6.0 & 5.5312 & TRN & & \\
\hline CHEMBL3652986 & 1528368 & 9.9076 & 10.3819 & TST & & \\
\hline CHEMBL3652933 & 1528368 & 11.0999 & 11.3381 & TRN & & \\
\hline CHEMBL 3656854 & 1528368 & 11.6990 & 000000000 & 002 & 11.7947 & TRN \\
\hline CHEMBL 3653061 & 1528368 & 10.4490 & 000000000 & 202 & 7.9077 & TST \\
\hline CHEMBL 3656774 & 1528368 & 10.2091 & 10.3439 & TRN & & \\
\hline CHEMBL3656838 & 1528368 & 11.0969 & 8.9377 & TST & & \\
\hline CHEMBL3652952 & 1528368 & 11.0435 & 10.85700 & 000000000 & 01 & TRN \\
\hline CHEMBL3652915 & 1528368 & 10.9492 & 10.9016 & TRN & & \\
\hline CHEMBL 3652900 & 1528368 & 11.0999 & 8.6458 & TST & & \\
\hline CHEMBL 3656825 & 1528368 & 11.6990 & 000000000 & 202 & 12.2801 & TRN \\
\hline CHEMBL3656869 & 1528368 & 12.7696 & 13.0337 & TRN & & \\
\hline CHEMBL 3656800 & 1528368 & 6.0 & 9.8427 & TRN & & \\
\hline
\end{tabular}


Supplemental Table S2.txt

\begin{tabular}{|c|c|c|c|c|c|c|}
\hline CHEMBL 3652890 & 1528368 & 11.0999 & 10.5433 & TRN & & \\
\hline CHEMBL3652927 & 1528368 & 10.4869 & 10.5389 & TRN & & \\
\hline CHEMBL3653002 & 1528368 & 11.0999 & 10.2074 & TRN & & \\
\hline CHEMBL3652885 & 1528368 & 11.0999 & 8.9185 & TRN & & \\
\hline CHEMBL3656778 & 1528368 & 10.2727 & 10.6987 & TRN & & \\
\hline CHEMBL3652905 & 1528368 & 10.3163 & 11.2068 & TRN & & \\
\hline CHEMBL3653008 & 1528368 & 9.6887 & 10.613 & TRN & & \\
\hline CHEMBL3653011 & 1528368 & 10.8011 & 10.5107 & TST & & \\
\hline CHEMBL3653051 & 1528368 & 9.9566 & 9.2584 & TRN & & \\
\hline CHEMBL3656779 & 1528368 & 10.9378 & 10.525 & TRN & & \\
\hline CHEMBL3652976 & 1528368 & 10.8147 & 9.8798 & TST & & \\
\hline CHEMBL3653021 & 1528368 & 9.4179 & 8.4995 & TRN & & \\
\hline CHEMBL3656849 & 1528368 & 11.3979 & 11.375 & TRN & & \\
\hline CHEMBL3656756 & 1528368 & 11.0999 & 11.3704 & TRN & & \\
\hline CHEMBL3652942 & 1528368 & 9.9416 & 11.4522 & TRN & & \\
\hline CHEMBL3652897 & 1528368 & 11.0926 & 10.3811 & TRN & & \\
\hline CHEMBL3656879 & 1528368 & 12.5229 & 12.2182 & TRN & & \\
\hline CHEMBL3652977 & 1528368 & 11.0999 & 10.4146 & TST & & \\
\hline CHEMBL3652984 & 1528368 & 11.0999 & 11.4017 & TRN & & \\
\hline CHEMBL3652950 & 1528368 & 10.4989 & 9.7222 & TST & & \\
\hline CHEMBL3656759 & 1528368 & 11.0999 & 10.8664 & TRN & & \\
\hline CHEMBL3656787 & 1528368 & 11.0794 & 11.1002 & TRN & & \\
\hline CHEMBL3652998 & 1528368 & 9.4088 & 9.5472 & TRN & & \\
\hline CHEMBL3652891 & 1528368 & 11.0999 & 10.3741 & TRN & & \\
\hline CHEMBL3653043 & 1528368 & 10.8861 & 9.9862 & TST & & \\
\hline CHEMBL3656827 & 1528368 & 12.0 & 11.5149 & TRN & & \\
\hline CHEMBL3656764 & 1528368 & 10.8283 & 11.0953 & TRN & & \\
\hline CHEMBL3652944 & 1528368 & 10.3811 & 9.5187 & TST & & \\
\hline CHEMBL3656847 & 1528368 & 11.0458 & 9.2095 & TST & & \\
\hline CHEMBL3656833 & 1528368 & 11.5229 & 11.3032 & TRN & & \\
\hline CHEMBL3652932 & 1528368 & 11.0999 & 10.9959 & TRN & & \\
\hline CHEMBL3653049 & 1528368 & 6.0 & 6.7854 & TRN & & \\
\hline CHEMBL3652953 & 1528368 & 10.9348 & 9.7684 & TST & & \\
\hline CHEMBL3652993 & 1528368 & 9.9344 & 10.4929 & TST & & \\
\hline CHEMBL3652904 & 1528368 & 10.5691 & 10.1535 & TRN & & \\
\hline CHEMBL3652981 & 1528368 & 10.5642 & 10.5255 & TRN & & \\
\hline CHEMBL3656767 & 1528368 & 6.0 & 6.9546 & TRN & & \\
\hline CHEMBL3656823 & 1528368 & 11.69906 & 00000006 & 302 & 9.4287 & TRN \\
\hline CHEMBL3656773 & 1528368 & 10.6786 & 10.1312 & TRN & & \\
\hline CHEMBL3652874 & 1528368 & 11.0999 & 10.0346 & TRN & & \\
\hline CHEMBL3656856 & 1528368 & 12.3098 & 11.8531 & TRN & & \\
\hline CHEMBL3652987 & 1528368 & 9.8573 & 10.3316 & TST & & \\
\hline CHEMBL3652978 & 1528368 & 10.8008 & 10.8354 & TRN & & \\
\hline CHEMBL3656830 & 1528368 & 6.0 & 6.6682 & TRN & & \\
\hline CHEMBL3652957 & 1528368 & 6.0 & 6.149 & TRN & & \\
\hline CHEMBL3652913 & 1528368 & 10.3181 & 10.9211 & TRN & & \\
\hline CHEMBL3656762 & 1528368 & 6.0 & 7.4848 & TRN & & \\
\hline CHEMBL3656848 & 1528368 & 12.585 & 12.4257 & TRN & & \\
\hline
\end{tabular}

Page 8213 
Supplemental Table S2.txt

CHEMBL 3652948

CHEMBL 3652886

CHEMBL3652929

CHEMBL 3653001

CHEMBL 3656876

CHEMBL 3653077

CHEMBL 3656842

CHEMBL 3652960

CHEMBL 3653022

CHEMBL 3653060

CHEMBL 3653010

CHEMBL 3653013

CHEMBL 3656783

CHEMBL3653086

CHEMBL 3653045

CHEMBL 3652910

CHEMBL3652887

CHEMBL 3652881

CHEMBL 3656880

CHEMBL 3656853

CHEMBL3656815

CHEMBL3652930

CHEMBL3652936

CHEMBL 3656806

CHEMBL 3653009

CHEMBL 3656786

CHEMBL 3656807

CHEMBL3656775

CHEMBL 3656864

CHEMBL 3656760

CHEMBL 3656858

CHEMBL3653037

CHEMBL 3652918

CHEMBL 3653003

CHEMBL3653028

CHEMBL 3656835

CHEMBL3656769

CHEMBL 3656877

CHEMBL3652939

CHEMBL3652893

CHEMBL3656885

CHEMBL 3652898

CHEMBL 3653040

CHEMBL 3656820

CHEMBL3656852

CHEMBL 3656809

CHEMBL3652968

CHEMBL 3653042

$\begin{array}{lll}1528368 & 10.6153 & 9.2383\end{array}$ TST

$\begin{array}{llll}1528368 & 9.2823 & 9.2612 & \text { TRN }\end{array}$

$\begin{array}{lll}1528368 & 11.0396 & 11.2902 \\ \text { TRN }\end{array}$

$\begin{array}{lll}1528368 & 10.8407 & 10.3496 \\ \text { TRN }\end{array}$

$\begin{array}{llll}1528368 & 12.7959 & 11.7393 & \text { TRN }\end{array}$

$\begin{array}{lll}1528368 & 10.2628 & 10.5048\end{array}$

$\begin{array}{lll}1528368 & 12.0 & 11.0768 \text { TST }\end{array}$

$15283686.0 \quad 5.9415$ TRN

$\begin{array}{lll}1528368 & 10.6383 & 8.9895\end{array}$

$\begin{array}{lll}1528368 & 10.3176 & 10.3348 \text { TRN }\end{array}$

$\begin{array}{lll}1528368 & 10.6432 & 10.0436\end{array}$

$\begin{array}{llll}1528368 & 11.0999 & 9.6645 & \text { TST }\end{array}$

$\begin{array}{lll}1528368 & 10.5468 & 9.0634\end{array}$ TST

$\begin{array}{lll}1528368 & 11.0999 & 10.7805 \\ \text { TRN }\end{array}$

$\begin{array}{llll}1528368 & 9.2644 & 9.2219 & \text { TST }\end{array}$

$\begin{array}{llll}1528368 & 11.0508 & 11.077 & \text { TRN }\end{array}$

$\begin{array}{lll}1528368 & 11.0999 & 10.9199 \\ \text { TRN }\end{array}$

$\begin{array}{llll}1528368 & 11.0999 & 9.8892 & \text { TRN }\end{array}$

$\begin{array}{llll}1528368 & 12.4437 & 12.3987 & \text { TST }\end{array}$

$\begin{array}{llll}1528368 & 6.0 & 8.1963 & \text { TRN }\end{array}$

$\begin{array}{lll}1528368 & 11.1002 & 12.5242 \text { TRN }\end{array}$

152836811.099911 .5754 TRN

$\begin{array}{lll}1528368 & 10.7662 & 10.8867 \\ \text { TRN }\end{array}$

$\begin{array}{llll}1528368 & 10.6396 & 8.1249 & \text { TST }\end{array}$

$\begin{array}{lll}1528368 & 10.5916 & 10.4358 \text { TRN }\end{array}$

$\begin{array}{lll}1528368 & 11.1002 & 10.9233 \text { TRN }\end{array}$

$\begin{array}{lll}1528368 & 10.4229 & 10.2677\end{array}$

$\begin{array}{lll}1528368 & 10.8122 \quad 10.0661 & \text { TRN }\end{array}$

$\begin{array}{lll}1528368 & 12.0 & 12.5085\end{array}$

$\begin{array}{lll}1528368 & 10.5865 & 9.6967\end{array}$

$\begin{array}{llll}1528368 & 6.0 & 6.7441 & \text { TRN }\end{array}$

$\begin{array}{lll}1528368 & 9.6615 & 11.2723\end{array}$

152836811.100211 .5116 TRN

$\begin{array}{llll}1528368 & 10.978 & 10.585999999999999 & \text { TRN }\end{array}$

$\begin{array}{lll}1528368 & 10.585 & 11.4295\end{array}$

$\begin{array}{llll}1528368 & 6.0 & 8.575 & \text { TRN }\end{array}$

$\begin{array}{lll}15283686.0 & 6.3362 & \text { TRN }\end{array}$

$\begin{array}{lll}1528368 & 12.6198 & 10.712\end{array}$

$\begin{array}{lll}1528368 & 9.8114 & 10.3785\end{array}$

$\begin{array}{lll}1528368 & 11.0999 & 11.4522 \\ 1 R N\end{array}$

$\begin{array}{lll}1528368 & 11.5086 & 10.2882\end{array}$

$\begin{array}{lll}1528368 & 10.7889 & 10.9404 \\ 10 R N\end{array}$

$\begin{array}{llll}1528368 & 10.5376 & 9.7101 & \text { TRN }\end{array}$

$\begin{array}{llll}1528368 & 11.5229 & 9.7216 & \text { TRN }\end{array}$

$\begin{array}{lll}1528368 & 11.5229 & 11.4352 \\ \text { TRN }\end{array}$

$\begin{array}{lll}1528368 & 11.0491 & 11.125\end{array}$

$\begin{array}{llll}1528368 & 9.3812 & 9.2482 & \text { TRN }\end{array}$

$\begin{array}{llll}1528368 & 10.6778 & 8.1548 & \text { TRN }\end{array}$

Page 8214 
Supplemental Table S2.txt

\begin{tabular}{|c|c|c|c|c|c|}
\hline CHEMBL 3656765 & 1528368 & 11.0999 & 10.7841 & TST & \\
\hline CHEMBL3652979 & 1528368 & 10.5989 & 10.8398 & TRN & \\
\hline CHEMBL3653026 & 1528368 & 8.8592 & 10.6117 & TST & \\
\hline CHEMBL3653006 & 1528368 & 10.5209 & 9.937999 & Э999999999 & TRN \\
\hline CHEMBL3652985 & 1528368 & 11.0999 & 10.8339 & TRN & \\
\hline CHEMBL3653014 & 1528368 & 10.7133 & 10.8724 & TST & \\
\hline CHEMBL 3652940 & 1528368 & 9.761000 & 00000000 & 11.1366 & TRN \\
\hline CHEMBL3652959 & 1528368 & 6.0 & 6.3236 & TRN & \\
\hline CHEMBL3652902 & 1528368 & 10.3483 & 10.3717 & TST & \\
\hline CHEMBL3656868 & 1528368 & 12.8239 & 12.5329 & TRN & \\
\hline CHEMBL3656799 & 1528368 & 11.1002 & 10.8265 & TRN & \\
\hline CHEMBL3656872 & 1528368 & 12.0 & 12.56599 & & TRN \\
\hline CHEMBL3656781 & 1528368 & 10.9755 & 10.1998 & TST & \\
\hline CHEMBL3652997 & 1528368 & 10.4768 & 7.9092 & TRN & \\
\hline CHEMBL3653047 & 1528368 & 11.1002 & 10.0189 & TRN & \\
\hline CHEMBL3652941 & 1528368 & 10.5624 & 11.47 & TRN & \\
\hline CHEMBL3656813 & 1528368 & 10.7932 & 10.7664 & TRN & \\
\hline CHEMBL 3653034 & 1528368 & 10.4318 & 11.0341 & TST & \\
\hline CHEMBL3652894 & 1528368 & 11.0999 & 11.12099 & 99999999999 & TRN \\
\hline CHEMBL3656850 & 1528368 & 12.0 & 11.0905 & TST & \\
\hline CHEMBL3656871 & 1528368 & 12.0 & 12.2357 & TRN & \\
\hline CHEMBL3656884 & 1528368 & 12.0 & 11.3086 & TRN & \\
\hline CHEMBL3652947 & 1528368 & 11.0999 & 9.6605 & TST & \\
\hline CHEMBL3652912 & 1528368 & 10.8901 & 11.0663 & TRN & \\
\hline CHEMBL3639557 & 1528368 & 12.0 & 11.1365 & TRN & \\
\hline CHEMBL3653019 & 1528368 & 10.5686 & 7.7772 & TRN & \\
\hline CHEMBL3656832 & 1528368 & 9.6596 & 7.5846 & TRN & \\
\hline CHEMBL3656792 & 1528368 & 11.1002 & 11.3111 & TRN & \\
\hline CHEMBL3656883 & 1528368 & 12.1549 & 10.2756 & TST & \\
\hline CHEMBL3656766 & 1528368 & 11.0999 & 11.1956 & TRN & \\
\hline CHEMBL 3656804 & 1528368 & 11.1002 & 10.9411 & TRN & \\
\hline CHEMBL3656819 & 1528368 & 12.0 & 11.8998 & TRN & \\
\hline CHEMBL3639517 & 1528368 & 11.0431 & 10.6828 & TRN & \\
\hline CHEMBL3652908 & 1528368 & 11.0999 & 10.7845 & TRN & \\
\hline CHEMBL3656812 & 1528368 & 10.8827 & 11.2106 & TRN & \\
\hline CHEMBL3652925 & 1528368 & 11.0999 & 11.2212 & TRN & \\
\hline CHEMBL3652972 & 1528368 & 9.9187 & 9.6227 & TST & \\
\hline CHEMBL3653063 & 1528368 & 11.1002 & 10.1142 & TRN & \\
\hline CHEMBL3653053 & 1528368 & 8.5624 & 10.2174 & TST & \\
\hline CHEMBL3656834 & 1528368 & 12.0 & 11.6086 & TRN & \\
\hline CHEMBL3656851 & 1528368 & 6.0 & 7.2123 & TRN & \\
\hline CHEMBL3656867 & 1528368 & 12.6383 & 12.2391 & TRN & \\
\hline CHEMBL3653081 & 1528368 & 6.0 & 7.6717 & TST & \\
\hline CHEMBL3656861 & 1528368 & 12.0 & 12.0233 & TRN & \\
\hline CHEMBL3652879 & 1528368 & 10.6057 & 8.7725 & TST & \\
\hline CHEMBL3652911 & 1528368 & 11.0999 & 10.8552 & TRN & \\
\hline CHEMBL3652969 & 1528368 & 9.1679 & 9.3079 & TRN & \\
\hline CHEMBL3656818 & 1528368 & 11.69900 & 00000000 & 10.9055 & TRN \\
\hline
\end{tabular}


Supplemental Table S2.txt

CHEMBL3652982

CHEMBL 3653041

CHEMBL 3656870

CHEMBL 3652903

CHEMBL3652916

CHEMBL 3656785

CHEMBL 3653029

CHEMBL3639519

CHEMBL 3652970

CHEMBL3653024

CHEMBL3656865

CHEMBL3653072

CHEMBL3653059

CHEMBL 3653075

CHEMBL 3652956

CHEMBL 3656776

CHEMBL3653005

CHEMBL 3652988

CHEMBL 3653004

CHEMBL 3653025

CHEMBL3639518

CHEMBL3652924

CHEMBL3653055

CHEMBL 3653031

CHEMBL 3652880

CHEMBL3653069

CHEMBL 3656791

CHEMBL 3656780

CHEMBL3653038

CHEMBL3653087

CHEMBL3653044

CHEMBL3653030

CHEMBL 3656837

CHEMBL 3653018

CHEMBL 3652920

CHEMBL3653039

CHEMBL 3656862

CHEMBL3656761

CHEMBL 3653066

CHEMBL 3656782

CHEMBL 3652983

CHEMBL 3652946

CHEMBL3656845

CHEMBL3652989

CHEMBL 3653020

CHEMBL 3653056

CHEMBL 3656810

CHEMBL 3652961 $\begin{array}{lll}1528368 & 10.2991 & 9.5759 \\ \text { TRN }\end{array}$

$\begin{array}{lll}1528368 & 10.6198 & 10.2494\end{array}$

$\begin{array}{lll}1528368 & 12.5086 & 12.7894 \\ \text { TRN }\end{array}$

$\begin{array}{lll}1528368 & 10.8239 & 10.7406\end{array}$

$\begin{array}{lll}1528368 & 11.0999 & 11.1063 \text { TRN }\end{array}$

$\begin{array}{lll}1528368 & 11.1002 & 10.963\end{array}$

$\begin{array}{lll}1528368 & 10.8539 & 9.6603\end{array}$ TRN

$\begin{array}{lll}1528368 & 9.7375 & 10.7934\end{array}$

$\begin{array}{lll}1528368 & 9.5105 & 10.4423 \\ \text { TRN }\end{array}$

$\begin{array}{lll}1528368 & 11.1024 & 10.8555 \\ \text { TRN }\end{array}$

$\begin{array}{lll}1528368 & 12.5686 & 12.5433\end{array}$

$\begin{array}{llll}1528368 & 6.0 & 7.4298 & \text { TST }\end{array}$

$\begin{array}{lll}1528368 & 11.1002 & 11.7962 \text { TRN }\end{array}$

$\begin{array}{llll}1528368 & 10.0657 & 10.2469 & \text { TST }\end{array}$

$\begin{array}{llll}1528368 & 6.0 & 7.2484 & \text { TRN }\end{array}$

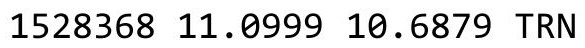

$\begin{array}{llll}1528368 & 9.6899 & 8.5884 & \text { TST }\end{array}$

$\begin{array}{llll}1528368 & 9.8111 & 9.7016 & \text { TRN }\end{array}$

$\begin{array}{llll}1528368 & 9.8474 & 8.4321 & \text { TRN }\end{array}$

$\begin{array}{lll}1528368 & 10.9586 & 10.7051\end{array}$

$\begin{array}{lll}1528368 & 10.2274 & 8.7775\end{array}$ TRN

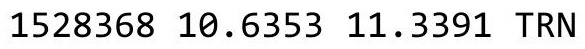

$\begin{array}{lll}1528368 & 11.1002 & 10.3663\end{array}$

$\begin{array}{llll}1528368 & 6.0 & 6.9496 & \text { TRN }\end{array}$

$\begin{array}{lll}1528368 & 10.0714 & 8.7116\end{array}$

$\begin{array}{llll}1528368 & 11.1002 & 10.298 & \text { TRN }\end{array}$

152836811.100211 .3326 TRN

$\begin{array}{lll}1528368 & 10.6951 & 10.2336 \\ \text { TRN }\end{array}$

$\begin{array}{llll}1528368 & 10.8239 & 7.8302 & \text { TST }\end{array}$

$\begin{array}{llll}1528368 & 11.0999 & 9.7867 & \text { TRN }\end{array}$

$\begin{array}{lll}1528368 & 9.9872 & 10.3231\end{array}$

$\begin{array}{lll}1528368 & 10.8861 & 10.6395 \\ \text { TRN }\end{array}$

$\begin{array}{lll}1528368 & 11.0458 & 10.3565\end{array}$

$\begin{array}{lll}1528368 & 11.0999 & 11.0689 \\ 1 R N\end{array}$

$\begin{array}{lll}1528368 & 11.0999 & 10.5795\end{array}$

$\begin{array}{lll}1528368 & 10.2076 & 10.141\end{array}$

$\begin{array}{lll}1528368 & 12.0 \quad 11.9582 \text { TRN }\end{array}$

$\begin{array}{llll}1528368 & 6.0 & 8.3067 & \text { TRN }\end{array}$

$\begin{array}{lll}1528368 & 11.1002 & 10.1188 \text { TRN }\end{array}$

$\begin{array}{lll}1528368 & 10.4976 & 10.4085\end{array}$

$\begin{array}{llll}1528368 & 6.0 & 9.2237 & \text { TRN }\end{array}$

$\begin{array}{lll}1528368 & 10.9555 & 10.2373 \text { TRN }\end{array}$

$\begin{array}{lll}1528368 & 12.0 & 12.1582\end{array}$

$\begin{array}{lll}1528368 & 10.341 & 10.4005\end{array}$

$\begin{array}{llll}1528368 & 8.8108 & 8.7037 & \text { TRN }\end{array}$

$\begin{array}{lll}1528368 & 10.0 \quad 10.0125 \text { TRN }\end{array}$

$\begin{array}{llll}15283686.0 & 8.767000000000001 & \text { TRN }\end{array}$

$\begin{array}{lll}1528368 & 6.0 & 6.9585\end{array}$
Page 8216 
Supplemental Table S2.txt

\begin{tabular}{|c|c|c|c|c|c|}
\hline CHEMBL3656841 & 1528368 & 6.0 & 10.6347 & TRN & \\
\hline CHEMBL3653062 & 1528368 & 9.0906 & 9.8208 & TST & \\
\hline CHEMBL3653067 & 1528368 & 6.0 & 7.6768 & TRN & \\
\hline CHEMBL 3656878 & 1528368 & 12.5528 & 11.4131 & TRN & \\
\hline CHEMBL 3656757 & 1528368 & 10.0368 & 10.084 & TRN & \\
\hline CHEMBL3653065 & 1528368 & 11.1002 & 10.978 & TRN & \\
\hline CHEMBL3652875 & 1528368 & 10.5923 & 9.8912 & TRN & \\
\hline CHEMBL 3652926 & 1528368 & 10.4059 & 999999999 & 10.6948 & TRN \\
\hline CHEMBL 3652876 & 1528368 & 9.6242 & 9.8434 & TRN & \\
\hline CHEMBL 3652877 & 1528368 & 10.4016 & 9.4467 & TRN & \\
\hline CHEMBL 3653064 & 1528368 & 11.1002 & 11.8024 & TRN & \\
\hline CHEMBL3652951 & 1528368 & 10.2658 & 9.4201 & TST & \\
\hline CHEMBL 3652991 & 1528368 & 11.0999 & 9.8522 & TRN & \\
\hline CHEMBL 3652955 & 1528368 & 10.1641 & 10.0306 & TRN & \\
\hline CHEMBL 3653015 & 1528368 & 6.0 & 6.7854 & TRN & \\
\hline CHEMBL 3653084 & 1528368 & 6.0 & 7.2149 & TRN & \\
\hline CHEMBL3652954 & 1528368 & 10.8502 & 9.355 & TST & \\
\hline CHEMBL 3656802 & 1528368 & 11.0999 & 11.76799 & 9999999 & TRN \\
\hline CHEMBL 3652980 & 1528368 & 10.5114 & 10.3107 & TRN & \\
\hline CHEMBL 3652949 & 1528368 & 11.0999 & 11.1967 & TRN & \\
\hline CHEMBL 3656777 & 1528368 & 10.1025 & 9.9865 & TRN & \\
\hline CHEMBL 3652934 & 1528368 & 10.2631 & 10.5079 & TRN & \\
\hline CHEMBL3653046 & 1528368 & 10.9161 & 9.6484 & TRN & \\
\hline CHEMBL 3653012 & 1528368 & 11.0999 & 10.1937 & TST & \\
\hline CHEMBL 3652878 & 1528368 & 9.8652 & 9.9001 & TST & \\
\hline CHEMBL 3656874 & 1528368 & 12.0 & 10.293 & TRN & \\
\hline CHEMBL3656875 & 1528368 & 12.0 & 11.7364 & TRN & \\
\hline CHEMBL3653007 & 1528368 & 10.9014 & 10.3092 & TRN & \\
\hline CHEMBL3652899 & 1528368 & 11.0999 & 8.2467 & TST & \\
\hline CHEMBL 3656763 & 1528368 & 11.0999 & 11.3977 & TRN & \\
\hline CHEMBL3652943 & 1528368 & 10.4532 & 10.5466 & TST & \\
\hline CHEMBL 3656846 & 1528368 & 10.7447 & 7.3917 & TST & \\
\hline CHEMBL3656881 & 1528368 & 12.3665 & 11.5501 & TRN & \\
\hline CHEMBL 3656821 & 1528368 & 6.0 & 9.0322 & TRN & \\
\hline CHEMBL 3653052 & 1528368 & 11.1002 & 10.1762 & TST & \\
\hline CHEMBL3652931 & 1528368 & 10.7423 & 10.3314 & TRN & \\
\hline CHEMBL 3656801 & 1528368 & 11.0892 & 8.1576 & TRN & \\
\hline CHEMBL 3653032 & 1528368 & 6.0 & 6.6997 & TRN & \\
\hline CHEMBL 3656840 & 1528368 & 10.4559 & 10.6628 & TRN & \\
\hline CHEMBL 3656844 & 1528368 & 12.0 & 10.9966 & TST & \\
\hline CHEMBL 3656839 & 1528368 & 12.0 & 10.7449 & TRN & \\
\hline CHEMBL 3652921 & 1528368 & 10.7602 & 11.35799 & 99999999999 & TRN \\
\hline CHEMBL 3652889 & 1528368 & 10.634 & 10.4635 & TRN & \\
\hline CHEMBL 3652888 & 1528368 & 10.6267 & 10.5577 & TRN & \\
\hline CHEMBL 3652909 & 1528368 & 11.0999 & 10.6994 & TRN & \\
\hline CHEMBL 3652994 & 1528368 & 6.0 & 6.3543 & TRN & \\
\hline CHEMBL 3653071 & 1528368 & 10.7577 & 8.8513 & TRN & \\
\hline CHEMBL 3652937 & 1528368 & 8.5935 & 10.8559 & TRN & \\
\hline
\end{tabular}


Supplemental Table S2.txt

\begin{tabular}{|c|c|c|c|c|c|c|}
\hline CHEMBL3652906 & 1528368 & 10.2537 & 10.6243 & TRN & & \\
\hline CHEMBL 3652896 & 1528368 & 10.9059 & 11.4989 & TRN & & \\
\hline CHEMBL 3653023 & 1528368 & 10.3468 & 10.3335 & TRN & & \\
\hline CHEMBL 3652928 & 1528368 & 10.5058 & 11.0547 & TRN & & \\
\hline CHEMBL 3656824 & 1528368 & 12.0 & 9.7387 & TRN & & \\
\hline CHEMBL 3652914 & 1528368 & 11.0999 & 11.2903 & TRN & & \\
\hline CHEMBL 3652922 & 1528368 & 10.7162 & 12.2241 & TRN & & \\
\hline CHEMBL 3656803 & 1528368 & 11.1002 & 8.8882 & TRN & & \\
\hline CHEMBL 3653074 & 1528368 & 11.1002 & 9.2477 & TRN & & \\
\hline CHEMBL 3653000 & 1528368 & 9.3281 & 8.0438 & TST & & \\
\hline CHEMBL 3652917 & 1528368 & 11.0999 & 11.2081 & TRN & & \\
\hline CHEMBL 3656814 & 1528368 & 10.213 & 11.6919 & TRN & & \\
\hline CHEMBL 3652971 & 1528368 & 6.0 & 6.7305 & TRN & & \\
\hline CHEMBL3656798 & 1528368 & 10.487 & 9.9217 & TST & & \\
\hline CHEMBL 3656758 & 1528368 & 11.0999 & 11.6397 & TRN & & \\
\hline CHEMBL 3652935 & 1528368 & 11.0999 & 11.1254 & TST & & \\
\hline CHEMBL 3653035 & 1528368 & 11.0458 & 10.0517 & TRN & & \\
\hline CHEMBL 3652945 & 1528368 & 10.8687 & 9.9072 & TRN & & \\
\hline CHEMBL 3656873 & 1528368 & 11.69900 & 00000000 & 002 & 10.9751 & TST \\
\hline CHEMBL 3656829 & 1528368 & 12.0 & 6.5473 & TST & & \\
\hline CHEMBL 3653070 & 1528368 & 6.0 & 7.5509 & TRN & & \\
\hline CHEMBL 3652938 & 1528368 & 9.5621 & 10.9094 & TRN & & \\
\hline CHEMBL 3653076 & 1528368 & 10.6776 & 9.7285 & TRN & & \\
\hline CHEMBL 3652901 & 1528368 & 11.0999 & 9.1801 & TST & & \\
\hline CHEMBL 3652999 & 1528368 & 9.7721 & 8.1278 & TST & & \\
\hline CHEMBL 3652990 & 1528368 & 6.0 & 6.6666 & TST & & \\
\hline CHEMBL3656805 & 1528368 & 11.1002 & 11.3738 & TST & & \\
\hline CHEMBL 3653078 & 1528368 & 10.8477 & 8.4358 & TRN & & \\
\hline CHEMBL 3652883 & 1528368 & 6.0 & 8.003 & TRN & & \\
\hline CHEMBL 3957349 & 1642026 & 5.9582 & 6.1062 & TRN & & \\
\hline CHEMBL 3906718 & 1642026 & 6.718999 & 99999999 & 99 & 6.9238 & TST \\
\hline CHEMBL 3922606 & 1642026 & 6.3526 & 6.0379 & TRN & & \\
\hline CHEMBL 3891708 & 1642026 & 6.8386 & 6.8792 & TRN & & \\
\hline CHEMBL3894591 & 1642026 & 7.2076 & 7.2287 & TRN & & \\
\hline CHEMBL 3908927 & 1642026 & 7.3565 & 7.4404 & TRN & & \\
\hline CHEMBL3920418 & 1642026 & 6.0 & 6.3507 & TST & & \\
\hline CHEMBL3925151 & 1642026 & 8.5229 & 8.4512 & TRN & & \\
\hline CHEMBL 3907309 & 1642026 & 7.6021 & 7.5439 & TRN & & \\
\hline CHEMBL 3934188 & 1642026 & 6.4535 & 6.6096 & TRN & & \\
\hline CHEMBL 3973945 & 1642026 & 7.0706 & 7.1077 & TRN & & \\
\hline CHEMBL 3972898 & 1642026 & 5.9706 & 5.8536 & TRN & & \\
\hline CHEMBL 3932494 & 1642026 & 6.0 & 6.17 & TRN & & \\
\hline CHEMBL 3977518 & 1642026 & 6.153 & 6.3819 & TRN & & \\
\hline CHEMBL 3957147 & 1642026 & 7.8861 & 7.9401 & TRN & & \\
\hline CHEMBL3951991 & 1642026 & 6.0 & 5.9339 & TRN & & \\
\hline CHEMBL 3972715 & 1642026 & 6.9208 & 6.974 & TRN & & \\
\hline CHEMBL 3895755 & 1642026 & 6.0 & 6.069 & TRN & & \\
\hline CHEMBL3959630 & 1642026 & 6.3862 & 6.3467 & TRN & & \\
\hline
\end{tabular}

Page 8218 


\begin{tabular}{|c|c|c|c|c|c|c|}
\hline \multicolumn{7}{|c|}{ Supplemental Table S2.txt } \\
\hline CHEMBL 3960643 & 1642026 & 6.0 & 5.9284 & TRN & & \\
\hline CHEMBL3942861 & 1642026 & 6.9318 & 6.8449 & TRN & & \\
\hline CHEMBL3980441 & 1642026 & 7.1308 & 7.4522 & TST & & \\
\hline CHEMBL3939218 & 1642026 & 6.0 & 6.7462 & TST & & \\
\hline CHEMBL3957690 & 1642026 & 6.6576 & 6.5482 & TRN & & \\
\hline CHEMBL3930581 & 1642026 & 7.0177 & 7.1255 & TRN & & \\
\hline CHEMBL3961679 & 1642026 & 7.0605 & 6.8744 & TRN & & \\
\hline CHEMBL 3928267 & 1642026 & 6.0 & 6.024 & TRN & & \\
\hline CHEMBL 3912265 & 1642026 & 8.2218 & 8.3523 & TRN & & \\
\hline CHEMBL3978312 & 1642026 & 7.4685 & 7.4995 & TRN & & \\
\hline CHEMBL3963722 & 1642026 & 6.0 & 5.7916 & TRN & & \\
\hline CHEMBL3931521 & 1642026 & 7.0862 & 7.2121 & TST & & \\
\hline CHEMBL3903415 & 1642026 & 7.1135 & 7.0419 & TRN & & \\
\hline CHEMBL 3910184 & 1642026 & 7.1192 & 7.1032 & TRN & & \\
\hline CHEMBL3959023 & 1642026 & 7.8539 & 7.846 & TRN & & \\
\hline CHEMBL3943349 & 1642026 & 6.0 & 5.795 & TRN & & \\
\hline CHEMBL3962386 & 1642026 & 9.699 & 7.1316 & TST & & \\
\hline CHEMBL3954457 & 1642026 & 7.2007 & 7.5202 & TST & & \\
\hline CHEMBL 3889987 & 1642026 & 7.699 & 7.6949 & TRN & & \\
\hline CHEMBL3986662 & 1642026 & 7.3768 & 7.4408 & TRN & & \\
\hline CHEMBL3972345 & 1642026 & 6.0 & 6.4778 & TST & & \\
\hline CHEMBL3897711 & 1642026 & 7.3279 & 7.2697 & TRN & & \\
\hline CHEMBL3923812 & 1642026 & 6.0 & 5.8934 & TRN & & \\
\hline CHEMBL 3909589 & 1642026 & 7.0177 & 6.9302 & TST & & \\
\hline CHEMBL3951691 & 1642026 & 5.96299 & 999999999 & 99 & 5.7542 & TRN \\
\hline CHEMBL3921073 & 1642026 & 7.3279 & 7.1525 & TRN & & \\
\hline CHEMBL3935618 & 1642026 & 7.9586 & 7.7466 & TST & & \\
\hline CHEMBL3974023 & 1642026 & 7.7212 & 7.6419 & TRN & & \\
\hline CHEMBL 3890003 & 1642026 & 6.5884 & 6.9305 & TST & & \\
\hline CHEMBL3911503 & 1642026 & 6.2733 & 7.0321 & TST & & \\
\hline CHEMBL3968173 & 1642026 & 7.8539 & 7.6869 & TRN & & \\
\hline CHEMBL 3900020 & 1642026 & 7.8539 & 7.6734 & TRN & & \\
\hline CHEMBL3941364 & 1642026 & 6.0 & 5.9887 & TRN & & \\
\hline CHEMBL 3928453 & 1642026 & 6.0783 & 6.4369 & TRN & & \\
\hline CHEMBL3914858 & 1642026 & 6.0 & 6.0475 & TRN & & \\
\hline CHEMBL3916034 & 1642026 & 7.4318 & 7.0237 & TST & & \\
\hline CHEMBL3947974 & 1642026 & 7.9208 & 7.8704 & TRN & & \\
\hline CHEMBL3892314 & 1642026 & 7.699 & 7.8186 & TRN & & \\
\hline CHEMBL3962537 & 1642026 & 7.4559 & 7.409 & TRN & & \\
\hline CHEMBL3918977 & 1642026 & 6.0 & 6.3167 & TST & & \\
\hline CHEMBL3934877 & 1642026 & 6.0 & 6.0846 & TRN & & \\
\hline CHEMBL3963075 & 1642026 & 6.9031 & 7.267 & TST & & \\
\hline CHEMBL3977697 & 1642026 & 7.284 & 7.3248 & TRN & & \\
\hline CHEMBL3903536 & 1642026 & 6.983 & 7.0028 & TRN & & \\
\hline CHEMBL3913755 & 1642026 & 6.0 & 6.1056 & TRN & & \\
\hline CHEMBL3917035 & 1642026 & 7.1135 & 7.1124 & TRN & & \\
\hline CHEMBL3941469 & 1642026 & 7.3872 & 7.3759 & TST & & \\
\hline CHEMBL3895925 & 1642026 & 6.0 & 6.1126 & TST & & \\
\hline
\end{tabular}


Supplemental Table S2.txt

\begin{tabular}{|c|c|c|c|c|}
\hline CHEMBL3940558 & 1642026 & 7.1805 & 7.1184 & TST \\
\hline CHEMBL3959433 & 1642026 & 6.0 & 6.1047 & TST \\
\hline CHEMBL3939728 & 1642026 & 6.7282 & 7.0262 & TRN \\
\hline CHEMBL3969549 & 1642026 & 6.0 & 6.3921 & TST \\
\hline CHEMBL3916210 & 1642026 & 7.2518 & 7.3287 & TRN \\
\hline CHEMBL3971320 & 1642026 & 7.2366 & 7.1877 & TRN \\
\hline CHEMBL3897013 & 1642026 & 7.7212 & 7.7582 & TRN \\
\hline CHEMBL 3940424 & 1642026 & 7.284 & 7.346 & TRN \\
\hline CHEMBL 3984667 & 1642026 & 6.6861 & 6.7518 & TST \\
\hline CHEMBL3983426 & 1642026 & 7.2147 & 7.309 & TRN \\
\hline CHEMBL3904885 & 1642026 & 6.0 & 5.9244 & TST \\
\hline CHEMBL3915805 & 1642026 & 8.301 & 8.071 & TRN \\
\hline CHEMBL 3897225 & 1642026 & 5.9543 & 5.8189 & TRN \\
\hline CHEMBL 3982494 & 1642026 & 7.7447 & 7.8725 & TRN \\
\hline CHEMBL3950332 & 1642026 & 6.9547 & 6.9771 & TRN \\
\hline CHEMBL3917864 & 1642026 & 7.3872 & 7.4057 & TRN \\
\hline CHEMBL3938373 & 1642026 & 6.0 & 6.1427 & TRN \\
\hline CHEMBL 3944948 & 1642026 & 7.585 & 7.6215 & TRN \\
\hline CHEMBL3939984 & 1642026 & 6.0 & 6.2817 & TST \\
\hline CHEMBL3967088 & 1642026 & 7.1024 & 7.2418 & TRN \\
\hline CHEMBL3906135 & 1642026 & 7.8239 & 7.4854 & TST \\
\hline CHEMBL3960403 & 1642026 & 6.0 & 5.8882 & TRN \\
\hline CHEMBL3986038 & 1642026 & 6.0 & 6.0569 & TRN \\
\hline CHEMBL3982966 & 1642026 & 7.6198 & 7.6315 & TRN \\
\hline CHEMBL3914926 & 1642026 & 4.8251 & 4.7606 & TRN \\
\hline CHEMBL3981030 & 1642026 & 6.0 & 5.682 & TRN \\
\hline CHEMBL3979242 & 1642026 & 7.1612 & 7.039 & TRN \\
\hline CHEMBL3893379 & 1642026 & 6.8697 & 6.82700 & 0000000001 \\
\hline CHEMBL 3958808 & 1642026 & 6.8297 & 7.0154 & TRN \\
\hline CHEMBL3971892 & 1642026 & 4.8251 & 5.2136 & TRN \\
\hline CHEMBL3902593 & 1642026 & 7.3665 & 7.3111 & TRN \\
\hline CHEMBL3928962 & 1642026 & 7.1249 & 7.0367 & TRN \\
\hline CHEMBL3974480 & 1642026 & 7.4318 & 7.2157 & TRN \\
\hline CHEMBL3966105 & 1642026 & 6.7799 & 6.6133 & TST \\
\hline CHEMBL3963053 & 1642026 & 7.0088 & 7.3001 & TST \\
\hline CHEMBL3899281 & 1642026 & 6.0 & 6.2546 & TST \\
\hline CHEMBL 3897260 & 1642026 & 6.4168 & 6.3113 & TRN \\
\hline CHEMBL3951673 & 1642026 & 7.2757 & 7.188 & TRN \\
\hline CHEMBL 3917134 & 1642026 & 8.0969 & 8.1523 & TRN \\
\hline CHEMBL3980920 & 1642026 & 4.8251 & 5.1146 & TRN \\
\hline CHEMBL3910056 & 1642026 & 7.4089 & 7.483 & TRN \\
\hline CHEMBL3968880 & 1642026 & 7.6576 & 7.6724 & TRN \\
\hline CHEMBL3908048 & 1642026 & 7.1192 & 7.2682 & TRN \\
\hline CHEMBL3916138 & 1642026 & 6.0 & 6.55 & TST \\
\hline CHEMBL3979357 & 1642026 & 7.0362 & 6.9958 & TRN \\
\hline CHEMBL3981489 & 1642026 & 7.4815 & 7.4468 & TST \\
\hline CHEMBL3927605 & 1642026 & 7.8239 & 7.6851 & TRN \\
\hline CHEMBL 3900971 & 1642026 & 6.3862 & 6.4599 & TRN \\
\hline
\end{tabular}


Supplemental Table S2.txt

\begin{tabular}{|c|c|c|c|c|c|}
\hline CHEMBL3941202 & 1642026 & 9.1549 & 7.5738 & TST & \\
\hline CHEMBL3970024 & 1642026 & 6.0 & 5.9747 & TRN & \\
\hline CHEMBL3289975 & 1366806 & 4.0 & 6.2184 & TST & \\
\hline CHEMBL3289953 & 1366806 & 7.3979 & 7.5643 & TRN & \\
\hline CHEMBL3289989 & 1366806 & 4.0 & 6.0432 & TST & \\
\hline CHEMBL3289946 & 1366806 & 7.1487 & 7.4216 & TRN & \\
\hline CHEMBL3289994 & 1366806 & 7.585 & 7.7731 & TRN & \\
\hline CHEMBL3290000 & 1366806 & 6.8861 & 7.0629 & TRN & \\
\hline CHEMBL3290002 & 1366806 & 7.0809 & 7.7797 & TRN & \\
\hline CHEMBL3289961 & 1366806 & 6.9208 & 7.2416 & TST & \\
\hline CHEMBL3289959 & 1366806 & 6.9586 & 7.2004 & TRN & \\
\hline CHEMBL3290004 & 1366806 & 6.8761 & 7.7774 & TRN & \\
\hline CHEMBL3289966 & 1366806 & 6.9208 & 7.2747 & TST & \\
\hline CHEMBL3289948 & 1366806 & 7.2518 & 6.9013 & TST & \\
\hline CHEMBL3289950 & 1366806 & 6.8539 & 7.0295 & TRN & \\
\hline CHEMBL3289997 & 1366806 & 7.4559 & 7.2899 & TRN & \\
\hline CHEMBL3290003 & 1366806 & 8.0555 & 7.8899 & TRN & \\
\hline CHEMBL3290021 & 1366806 & 7.1549 & 7.2941 & TRN & \\
\hline CHEMBL3289956 & 1366806 & 7.2147 & 7.3301 & TRN & \\
\hline CHEMBL3290019 & 1366806 & 7.0 & 6.9605 & TST & \\
\hline CHEMBL3289998 & 1366806 & 7.6383 & 7.3106 & TRN & \\
\hline CHEMBL3289958 & 1366806 & 7.4815 & 7.3152 & TRN & \\
\hline CHEMBL3289978 & 1366806 & 8.2076 & 7.1193 & TRN & \\
\hline CHEMBL3289971 & 1366806 & 6.4815 & 6.2434 & TRN & \\
\hline CHEMBL3290014 & 1366806 & 8.4815 & 8.1361 & TRN & \\
\hline CHEMBL3290016 & 1366806 & 8.4685 & 8.0885 & TST & \\
\hline CHEMBL3289957 & 1366806 & 7.2007 & 7.1211 & TRN & \\
\hline CHEMBL3290017 & 1366806 & 8.7447 & \multicolumn{2}{|c|}{8.232000000000001} & TST \\
\hline CHEMBL3289976 & 1366806 & 5.284 & 6.4914 & TST & \\
\hline CHEMBL3290015 & 1366806 & 7.6021 & 7.7342 & TST & \\
\hline CHEMBL3289967 & 1366806 & 5.8239 & 6.0553 & TRN & \\
\hline CHEMBL3289972 & 1366806 & 7.5686 & 7.1195 & TRN & \\
\hline CHEMBL3289982 & 1366806 & 5.9586 & \multicolumn{2}{|c|}{6.3660000000000005} & TRN \\
\hline CHEMBL3289952 & 1366806 & 6.1675 & 7.4354 & TRN & \\
\hline CHEMBL3289960 & 1366806 & 7.3468 & 7.3697 & TRN & \\
\hline CHEMBL3289973 & 1366806 & 5.6576 & 5.9632 & TRN & \\
\hline CHEMBL3289709 & 1366806 & 7.6576 & 7.4049 & TRN & \\
\hline CHEMBL3290018 & 1366806 & 7.0 & 7.2828 & TST & \\
\hline CHEMBL3290007 & 1366806 & 7.585 & 7.7711 & TRN & \\
\hline CHEMBL3289951 & 1366806 & 7.3768 & 7.3739 & TRN & \\
\hline CHEMBL3289988 & 1366806 & 4.0 & 5.5771 & TST & \\
\hline CHEMBL3289985 & 1366806 & 4.0 & 5.954 & TST & \\
\hline CHEMBL3289945 & 1366806 & 7.8239 & 7.3001 & TRN & \\
\hline CHEMBL3289983 & 1366806 & 6.2518 & 6.6502 & TRN & \\
\hline CHEMBL3289999 & 1366806 & 7.1805 & 7.3662 & TRN & \\
\hline CHEMBL3290006 & 1366806 & 8.6198 & 8.0116 & TRN & \\
\hline CHEMBL3289993 & 1366806 & 8.1487 & 7.8129 & TRN & \\
\hline CHEMBL3289962 & 1366806 & 7.2676 & 7.3884 & TST & \\
\hline
\end{tabular}


Supplemental Table S2.txt

\begin{tabular}{|c|c|c|c|c|}
\hline CHEMBL3290001 & 1366806 & 6.6021 & 7.6473 & TRN \\
\hline CHEMBL3289970 & 1366806 & 7.5376 & 6.9983 & TRN \\
\hline CHEMBL3289987 & 1366806 & 7.0223 & 6.7261 & TST \\
\hline CHEMBL3289969 & 1366806 & 5.9586 & 5.9933 & TRN \\
\hline CHEMBL3290009 & 1366806 & 7.8861 & 7.5411 & TRN \\
\hline CHEMBL3289965 & 1366806 & 7.5686 & 7.129 & TST \\
\hline CHEMBL3289995 & 1366806 & 8.7959 & 7.9645 & TRN \\
\hline CHEMBL3290010 & 1366806 & 7.8861 & 7.5556 & TRN \\
\hline CHEMBL3289944 & 1366806 & 7.0 & 7.6005 & TRN \\
\hline CHEMBL3286432 & 1366806 & 7.2757 & 7.4502 & TRN \\
\hline CHEMBL3289980 & 1366806 & 7.7447 & 6.836 & TRN \\
\hline CHEMBL3289991 & 1366806 & 7.8861 & 7.5982 & TRN \\
\hline CHEMBL3289981 & 1366806 & 7.4559 & 6.4238 & TRN \\
\hline CHEMBL3290012 & 1366806 & 8.1871 & 7.9754 & TRN \\
\hline CHEMBL3290008 & 1366806 & 8.6198 & 8.1116 & TRN \\
\hline CHEMBL3289708 & 1366806 & 6.3665 & 7.1295 & TRN \\
\hline CHEMBL3290005 & 1366806 & 7.4949 & 7.9219 & TRN \\
\hline CHEMBL 3290013 & 1366806 & 7.3565 & 7.7466 & TRN \\
\hline CHEMBL3289974 & 1366806 & 5.3188 & 6.1955 & TRN \\
\hline CHEMBL3289984 & 1366806 & 7.3372 & 6.9989 & TRN \\
\hline CHEMBL3290020 & 1366806 & 7.6383 & 6.954 & TRN \\
\hline CHEMBL3290011 & 1366806 & 7.3979 & 7.7428 & TRN \\
\hline CHEMBL3289977 & 1366806 & 5.7959 & 6.1301 & TRN \\
\hline CHEMBL3289992 & 1366806 & 6.8539 & 7.6579 & TRN \\
\hline CHEMBL3289955 & 1366806 & 7.0 & 7.3173 & TRN \\
\hline CHEMBL3289968 & 1366806 & 7.0605 & 6.7614 & TRN \\
\hline CHEMBL3289979 & 1366806 & 5.6383 & 5.5335 & TRN \\
\hline CHEMBL3289954 & 1366806 & 8.301 & 7.7483 & TRN \\
\hline CHEMBL3289996 & 1366806 & 7.3188 & 7.8176 & TRN \\
\hline CHEMBL3289963 & 1366806 & 7.0757 & 7.1194 & TST \\
\hline CHEMBL3289947 & 1366806 & 8.2924 & 7.3227 & TRN \\
\hline CHEMBL3289986 & 1366806 & 7.7696 & 6.853 & TST \\
\hline CHEMBL3289964 & 1366806 & 6.8539 & 7.2133 & TST \\
\hline CHEMBL3289990 & 1366806 & 6.6778 & 7.4845 & TST \\
\hline CHEMBL3289949 & 1366806 & 7.3279 & 7.0377 & TST \\
\hline CHEMBL1981446 & 737391 & 5.6819 & 5.5106 & TRN \\
\hline CHEMBL578512 & 737391 & 5.8665 & 5.5372 & TRN \\
\hline CHEMBL1453902 & 737391 & 5.0526 & 4.965 & TRN \\
\hline CHEMBL1393151 & 737391 & 5.7258 & 5.7763 & TRN \\
\hline CHEMBL1387693 & 737391 & 5.644 & 5.9993 & TRN \\
\hline CHEMBL1966168 & 737391 & 5.4179 & 5.3113 & TRN \\
\hline CHEMBL1441794 & 737391 & 5.6556 & 5.6068 & TRN \\
\hline CHEMBL1329141 & 737391 & 6.9101 & 7.2296 & TRN \\
\hline CHEMBL66953 & 737391 & 6.9101 & 5.6748 & TST \\
\hline CHEMBL1334970 & 737391 & 5.3605 & 5.3792 & TRN \\
\hline CHEMBL3199879 & 737391 & 5.8477 & 5.79299 & 9999999999 \\
\hline CHEMBL1384370 & 737391 & 5.6925 & 5.9319 & TRN \\
\hline CHEMBL1580684 & 737391 & 5.308 & 5.6188 & TRN \\
\hline
\end{tabular}


Supplemental Table S2.txt

\begin{tabular}{|c|c|c|c|c|c|}
\hline CHEMBL1981200 & 737391 & 5.2749 & 5.3804 & TRN & \\
\hline CHEMBL1701224 & 737391 & 5.8861 & 5.6082 & TRN & \\
\hline CHEMBL1313807 & 737391 & 4.9469 & 5.2867 & TRN & \\
\hline CHEMBL1460470 & 737391 & 6.9101 & 5.7831 & TST & \\
\hline CHEMBL1526088 & 737391 & 5.4056 & 5.3355 & TRN & \\
\hline CHEMBL 3145364 & 737391 & 5.767 & 5.6488 & TRN & \\
\hline CHEMBL1445488 & 737391 & 5.433 & $5.71200 e$ & 0000000001 & TRN \\
\hline CHEMBL1548812 & 737391 & 5.4437 & 5.5574 & TST & \\
\hline CHEMBL1373132 & 737391 & 6.9101 & 6.2326 & TRN & \\
\hline CHEMBL1467623 & 737391 & 5.5243 & 5.4302 & TRN & \\
\hline CHEMBL1584392 & 737391 & 5.1586 & 5.0282 & TRN & \\
\hline CHEMBL1578670 & 737391 & 5.7696 & 5.5193 & TST & \\
\hline CHEMBL1304193 & 737391 & 5.4522 & 5.246 & TRN & \\
\hline CHEMBL1322542 & 737391 & 5.4572 & 5.2236 & TST & \\
\hline CHEMBL256098 & 737391 & 5.7235 & 5.4894 & TRN & \\
\hline CHEMBL1566081 & 737391 & 5.0814 & 5.1465 & TRN & \\
\hline CHEMBL1325945 & 737391 & 5.2557 & 5.2529 & TRN & \\
\hline CHEMBL1439815 & 737391 & 5.7905 & 5.3089 & TRN & \\
\hline CHEMBL1372387 & 737391 & 5.1296 & 5.432 & TRN & \\
\hline CHEMBL 2001743 & 737391 & 5.6144 & 5.5587 & TRN & \\
\hline CHEMBL599924 & 737391 & 3.9747 & 4.7529 & TRN & \\
\hline CHEMBL3192879 & 737391 & 5.585 & 5.3842 & TRN & \\
\hline CHEMBL1390703 & 737391 & 5.2418 & 5.1462 & TRN & \\
\hline CHEMBL1455226 & 737391 & 6.9101 & 6.8662 & TRN & \\
\hline CHEMBL1605172 & 737391 & 5.2418 & 5.257006 & 0000000001 & \\
\hline CHEMBL1408579 & 737391 & 5.3655 & 5.4973 & TRN & \\
\hline CHEMBL1991573 & 737391 & 5.644 & 5.5626 & TRN & \\
\hline CHEMBL1971015 & 737391 & 5.2782 & 5.2209 & TRN & \\
\hline CHEMBL1321572 & 737391 & 5.3401 & 5.372999 & 7999999999 & TRN \\
\hline CHEMBL1463659 & 737391 & 4.9914 & 5.3733 & TRN & \\
\hline CHEMBL1324382 & 737391 & 5.2749 & 5.4944 & TRN & \\
\hline CHEMBL1385743 & 737391 & 5.6819 & 5.483 & TRN & \\
\hline CHEMBL1376711 & 737391 & 6.9101 & 7.2023 & TRN & \\
\hline CHEMBL1321933 & 737391 & 5.8069 & 5.6177 & TRN & \\
\hline CHEMBL1988133 & 737391 & 5.1778 & 4.9026 & TRN & \\
\hline CHEMBL1430983 & 737391 & \multicolumn{3}{|c|}{5.4510000000000005} & \\
\hline CHEMBL570345 & 737391 & 5.1261 & 5.7038 & TST & \\
\hline CHEMBL3212539 & 737391 & 5.8153 & 5.9271 & TRN & \\
\hline CHEMBL3193786 & 737391 & 5.1586 & 5.3426 & TRN & \\
\hline CHEMBL1536896 & 737391 & 6.9101 & 6.1383 & TRN & \\
\hline CHEMBL1471409 & 737391 & 5.2097 & 5.3252 & TRN & \\
\hline CHEMBL1672292 & 737391 & 5.0555 & 5.3262 & TRN & \\
\hline CHEMBL1612116 & 737391 & 5.6383 & 5.5956 & TRN & \\
\hline CHEMBL1305050 & 737391 & 5.3936 & 5.4605 & TRN & \\
\hline CHEMBL1982888 & 737391 & 5.5391 & 5.6339 & TRN & \\
\hline CHEMBL1385949 & 737391 & 5.3969 & 5.6581 & TST & \\
\hline CHEMBL1504939 & 737391 & 5.0696 & 5.4979 & TST & \\
\hline CHEMBL1407203 & 737391 & 5.0555 & 5.4799 & TST & \\
\hline
\end{tabular}


Supplemental Table S2.txt

\begin{tabular}{|c|c|c|c|c|c|}
\hline CHEMBL1608642 & 737391 & 5.4763 & 5.5946 & TST & \\
\hline CHEMBL1996572 & 737391 & 2.8013 & 5.3949 & TST & \\
\hline CHEMBL1421970 & 737391 & 5.4486 & 5.5113 & TST & \\
\hline CHEMBL1424694 & 737391 & 6.9101 & \multicolumn{2}{|c|}{6.082000000000001} & TST \\
\hline CHEMBL1478587 & 737391 & 5.4295 & 5.2777 & TST & \\
\hline CHEMBL1407368 & 737391 & 6.9101 & 5.428 & TST & \\
\hline CHEMBL3191015 & 737391 & 5.6216 & 5.5919 & TST & \\
\hline CHEMBL1325664 & 737391 & 5.6198 & 5.6282 & TST & \\
\hline CHEMBL1537922 & 737391 & 5.4711 & 5.5586 & TST & \\
\hline CHEMBL1836579 & 770788 & 5.0706 & 5.5018 & TRN & \\
\hline CHEMBL1836560 & 770788 & 5.7447 & 5.9399 & TRN & \\
\hline CHEMBL1836576 & 770788 & 5.3565 & 5.6367 & TRN & \\
\hline CHEMBL1836567 & 770788 & 6.3768 & 5.9964 & TRN & \\
\hline CHEMBL1836370 & 770788 & 5.8239 & 5.7701 & TRN & \\
\hline CHEMBL1836565 & 770788 & 5.8239 & 6.1731 & TRN & \\
\hline CHEMBL1836620 & 770788 & 4.699 & 5.4734 & TRN & \\
\hline CHEMBL1836610 & 770788 & 5.3098 & 4.9378 & TST & \\
\hline CHEMBL1836556 & 770788 & 3.0 & 3.7826 & TRN & \\
\hline CHEMBL1836604 & 770788 & 5.8861 & 5.3817 & TRN & \\
\hline CHEMBL1836383 & 770788 & 5.585 & 5.6925 & TRN & \\
\hline CHEMBL1836575 & 770788 & 5.1367 & 5.5592 & TRN & \\
\hline CHEMBL1836559 & 770788 & 6.0655 & 5.9044 & TRN & \\
\hline CHEMBL1836618 & 770788 & 5.1675 & 5.4348 & TRN & \\
\hline CHEMBL1836557 & 770788 & 4.9208 & 5.3942 & TST & \\
\hline CHEMBL1836365 & 770788 & 6.0315 & 6.0399 & TRN & \\
\hline CHEMBL1836374 & 770788 & 5.6576 & 5.8452 & TRN & \\
\hline CHEMBL1836605 & 770788 & 5.1024 & 5.6137 & TRN & \\
\hline CHEMBL1836372 & 770788 & 5.8861 & 5.9495 & TRN & \\
\hline CHEMBL1836384 & 770788 & 5.6778 & 5.7982 & TRN & \\
\hline CHEMBL1836602 & 770788 & 4.6198 & 5.9785 & TST & \\
\hline CHEMBL1836362 & 770788 & 4.0315 & 4.6211 & TST & \\
\hline CHEMBL1336863 & 770788 & 4.4318 & 5.6648 & TST & \\
\hline CHEMBL1836561 & 770788 & 5.8861 & 5.5243 & TRN & \\
\hline CHEMBL1836614 & 770788 & 5.8239 & 5.07600 & 00000000005 & TRN \\
\hline CHEMBL1836617 & 770788 & 5.3372 & 5.4717 & TRN & \\
\hline CHEMBL1836364 & 770788 & 3.0 & 4.4027 & TST & \\
\hline CHEMBL1836611 & 770788 & 6.1487 & 5.4212 & TST & \\
\hline CHEMBL1836621 & 770788 & 5.7959 & 5.4177 & TRN & \\
\hline CHEMBL1836554 & 770788 & 5.1675 & 4.6146 & TST & \\
\hline CHEMBL1836369 & 770788 & 5.4559 & 5.9721 & TRN & \\
\hline CHEMBL1300782 & 770788 & 4.6383 & 4.6138 & TST & \\
\hline CHEMBL1836612 & 770788 & 6.1367 & 5.5735 & TRN & \\
\hline CHEMBL1836572 & 770788 & 6.1024 & 5.5206 & TRN & \\
\hline CHEMBL1836603 & 770788 & 6.6383 & 5.7738 & TRN & \\
\hline CHEMBL1836619 & 770788 & 4.301 & 5.7795 & TST & \\
\hline CHEMBL1836373 & 770788 & 5.6576 & 5.9869 & TRN & \\
\hline CHEMBL1836609 & 770788 & 5.0809 & 5.4205 & TST & \\
\hline CHEMBL1836578 & 770788 & 5.0969 & 5.3771 & TRN & \\
\hline
\end{tabular}




\begin{tabular}{|c|c|c|c|c|c|}
\hline & & \multicolumn{4}{|c|}{ Supplemental Table S2.txt } \\
\hline CHEMBL1836368 & 770788 & 6.0269 & 5.971 & TRN & \\
\hline CHEMBL1836375 & 770788 & 5.9208 & 6.0038 & TRN & \\
\hline CHEMBL1836385 & 770788 & 5.6383 & 5.8355 & TRN & \\
\hline CHEMBL1836552 & 770788 & 4.4318 & 5.6788 & TST & \\
\hline CHEMBL1836607 & 770788 & 4.5528 & 4.9593 & TRN & \\
\hline CHEMBL1836568 & 770788 & 5.699 & 6.0807 & TRN & \\
\hline CHEMBL1836376 & 770788 & 5.7447 & 5.78100 & 0000000001 & TRN \\
\hline CHEMBL1836616 & 770788 & 5.9208 & 5.472 & TRN & \\
\hline CHEMBL1836608 & 770788 & 4.5686 & 5.4116 & TST & \\
\hline CHEMBL1836564 & 770788 & 5.7696 & 6.0257 & TRN & \\
\hline CHEMBL1836381 & 770788 & 5.699 & 5.7534 & TRN & \\
\hline CHEMBL1836555 & 770788 & 5.0269 & 4.8787 & TST & \\
\hline CHEMBL1836563 & 770788 & 5.8239 & 5.97 & TRN & \\
\hline CHEMBL1724038 & 770788 & 4.0506 & 4.5872 & TST & \\
\hline CHEMBL1836371 & 770788 & 6.0915 & 6.1269 & TRN & \\
\hline CHEMBL1727832 & 770788 & 4.1739 & 4.8495 & TST & \\
\hline CHEMBL1836363 & 770788 & 3.0 & 4.6462 & TST & \\
\hline CHEMBL1836367 & 770788 & 5.9586 & 5.5457 & TRN & \\
\hline CHEMBL1836562 & 770788 & 6.0915 & 5.933 & TRN & \\
\hline CHEMBL1836573 & 770788 & 5.8861 & 5.6204 & TRN & \\
\hline CHEMBL1836378 & 770788 & 6.0315 & 5.9408 & TRN & \\
\hline CHEMBL1836571 & 770788 & 6.1079 & 5.7914 & TRN & \\
\hline CHEMBL1836553 & 770788 & 4.4089 & 5.6479 & TST & \\
\hline CHEMBL1836574 & 770788 & 6.4559 & 5.7375 & TRN & \\
\hline CHEMBL1836377 & 770788 & 5.5528 & 6.0012 & TRN & \\
\hline CHEMBL1836382 & 770788 & 5.7696 & 5.9072 & TRN & \\
\hline CHEMBL1836606 & 770788 & 6.0458 & 5.4648 & TRN & \\
\hline CHEMBL1836615 & 770788 & 6.2291 & 5.5376 & TRN & \\
\hline CHEMBL1836570 & 770788 & 6.4318 & 6.1955 & TRN & \\
\hline CHEMBL1836569 & 770788 & 5.7959 & 5.6742 & TRN & \\
\hline CHEMBL1836379 & 770788 & 5.4559 & 5.981 & TRN & \\
\hline CHEMBL1836380 & 770788 & 6.0 & 6.0506 & TRN & \\
\hline CHEMBL1836601 & 770788 & 4.2757 & 5.9738 & TST & \\
\hline CHEMBL1566389 & 770788 & 4.8239 & 5.5419 & TST & \\
\hline CHEMBL1836566 & 770788 & 5.7959 & 5.9693 & TRN & \\
\hline CHEMBL1836613 & 770788 & 5.3098 & 5.5575 & TRN & \\
\hline CHEMBL1836558 & 770788 & 5.7696 & 5.7495 & TRN & \\
\hline CHEMBL1836577 & 770788 & 6.1024 & 5.5145 & TRN & \\
\hline CHEMBL1836366 & 770788 & 5.699 & 6.0607 & TRN & \\
\hline CHEMBL67512 & 216899 & 6.3979 & 6.1768 & TRN & \\
\hline CHEMBL69885 & 216899 & 7.0969 & 7.276 & TRN & \\
\hline CHEMBL69699 & 216899 & 6.0 & 6.0818 & TRN & \\
\hline CHEMBL431556 & 216899 & 6.5229 & 6.7364 & TRN & \\
\hline CHEMBL433103 & 216899 & 7.1549 & 7.1229 & TRN & \\
\hline CHEMBL67328 & 216899 & 3.0 & 6.2925 & TST & \\
\hline CHEMBL67918 & 216899 & 6.699 & 6.5209 & TRN & \\
\hline CHEMBL66503 & 216899 & 7.0458 & 7.1086 & TRN & \\
\hline CHEMBL 305003 & 216899 & 6.699 & 6.5382 & TRN & \\
\hline
\end{tabular}




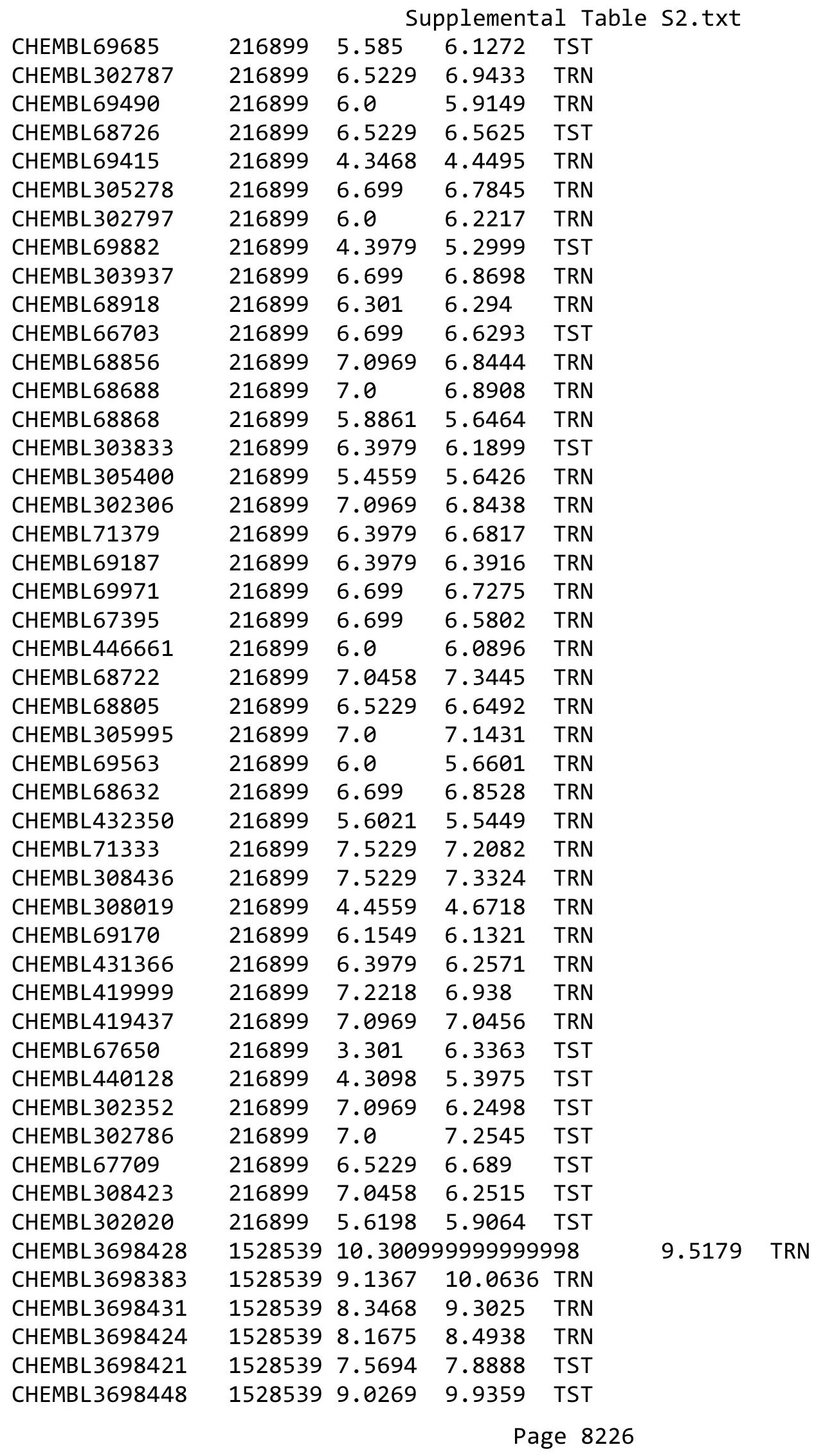


Supplemental Table S2.txt

\begin{tabular}{|c|c|c|c|c|c|c|c|}
\hline CHEMBL3698437 & 1528539 & 7.1237 & 7.5947 & TRN & & & \\
\hline CHEMBL3698433 & 1528539 & 9.1308 & 8.7674 & TRN & & & \\
\hline CHEMBL3698454 & 1528539 & 10.3009 & 99999999 & 998 & 10.2077 & TRN & \\
\hline CHEMBL3698452 & 1528539 & 10.3009 & 99999999 & 998 & 9.8786 & TRN & \\
\hline CHEMBL3698401 & 1528539 & 10.3009 & 99999999 & 998 & 9.9838 & TRN & \\
\hline CHEMBL3698425 & 1528539 & 8.4724 & 8.5664 & TRN & & & \\
\hline CHEMBL3698388 & 1528539 & 8.757 & 9.5617 & TRN & & & \\
\hline CHEMBL3698382 & 1528539 & 10.3009 & 99999999 & 998 & 10.5031 & TRN & \\
\hline CHEMBL3698384 & 1528539 & 8.9914 & 9.3694 & TRN & & & \\
\hline CHEMBL3698432 & 1528539 & 10.3009 & 99999999 & 998 & 9.9006 & TRN & \\
\hline CHEMBL3698396 & 1528539 & 8.4776 & 8.4177 & TST & & & \\
\hline CHEMBL3698451 & 1528539 & 10.3009 & 99999999 & 998 & 9.6474 & TRN & \\
\hline CHEMBL3698429 & 1528539 & 8.9281 & 9.3089 & TRN & & & \\
\hline CHEMBL3698426 & 1528539 & 9.1675 & 8.9951 & TST & & & \\
\hline CHEMBL3698393 & 1528539 & 7.8904 & 7.6495 & TRN & & & \\
\hline CHEMBL3698380 & 1528539 & 10.3009 & 99999999 & 998 & 10.7597 & TRN & \\
\hline CHEMBL3698378 & 1528539 & 10.3009 & 99999999 & 998 & 9.777999 & 9999999999 & TRN \\
\hline CHEMBL3698450 & 1528539 & 10.3009 & 99999999 & 998 & 10.1877 & TRN & \\
\hline CHEMBL3698442 & 1528539 & 8.9957 & 9.3321 & TRN & & & \\
\hline CHEMBL3698438 & 1528539 & 9.1079 & 9.2064 & TRN & & & \\
\hline CHEMBL3698404 & 1528539 & 8.2449 & 9.484 & TST & & & \\
\hline CHEMBL3698423 & 1528539 & 10.3009 & 99999999 & 998 & 8.5785 & TST & \\
\hline CHEMBL3698453 & 1528539 & 10.3009 & 99999999 & 998 & 9.847000 & 0000000001 & TRN \\
\hline CHEMBL3698397 & 1528539 & 8.0605 & 7.8761 & TRN & & & \\
\hline CHEMBL3698381 & 1528539 & 10.3009 & 99999999 & 998 & 10.4411 & TRN & \\
\hline CHEMBL3698387 & 1528539 & 9.1739 & 9.4379 & TRN & & & \\
\hline CHEMBL 3698430 & 1528539 & 9.1308 & 9.1659 & TRN & & & \\
\hline CHEMBL3698405 & 1528539 & 9.0809 & 9.6689 & TST & & & \\
\hline CHEMBL3698434 & 1528539 & 7.8193 & 8.3377 & TRN & & & \\
\hline CHEMBL3698435 & 1528539 & 10.3009 & 99999999 & 998 & 8.8787 & TRN & \\
\hline CHEMBL3698391 & 1528539 & 10.3009 & 99999999 & 998 & 9.7896 & TRN & \\
\hline CHEMBL 3698449 & 1528539 & 10.3009 & 99999999 & 998 & 10.134 & TRN & \\
\hline CHEMBL3698402 & 1528539 & 10.3009 & 99999999 & 998 & 9.3978 & TST & \\
\hline CHEMBL3698390 & 1528539 & 10.3009 & 99999999 & 998 & 9.7262 & TRN & \\
\hline CHEMBL3698389 & 1528539 & 10.3009 & 99999999 & 998 & 10.1692 & TRN & \\
\hline CHEMBL3698455 & 1528539 & 9.2518 & 10.0114 & TRN & & & \\
\hline CHEMBL 3698385 & 1528539 & 10.3009 & 99999999 & 998 & 10.35900 & 00000000002 & TRN \\
\hline CHEMBL3698422 & 1528539 & 10.3009 & 99999999 & 998 & 9.2068 & TST & \\
\hline CHEMBL3698447 & 1528539 & 10.3009 & 99999999 & 998 & 10.2882 & TRN & \\
\hline CHEMBL3698436 & 1528539 & 8.3936 & 8.5735 & TRN & & & \\
\hline CHEMBL3698400 & 1528539 & 8.7905 & 8.8484 & TRN & & & \\
\hline CHEMBL3698420 & 1528539 & 10.3009 & 99999999 & 998 & 9.2809 & TST & \\
\hline CHEMBL3698406 & 1528539 & 10.3009 & 99999999 & 998 & 9.6687 & TST & \\
\hline CHEMBL3698386 & 1528539 & 10.3009 & 99999999 & 998 & 9.7139 & TRN & \\
\hline CHEMBL3698407 & 1528539 & 6.0 & 7.9263 & TST & & & \\
\hline CHEMBL3698403 & 1528539 & 8.7011 & 9.4941 & TST & & & \\
\hline CHEMBL3698418 & 1528539 & 9.301 & 9.4653 & TRN & & & \\
\hline CHEMBL3698379 & 1528539 & 10.3009 & 99999999 & 998 & 10.6391 & TRN & \\
\hline
\end{tabular}


Supplemental Table S2.txt

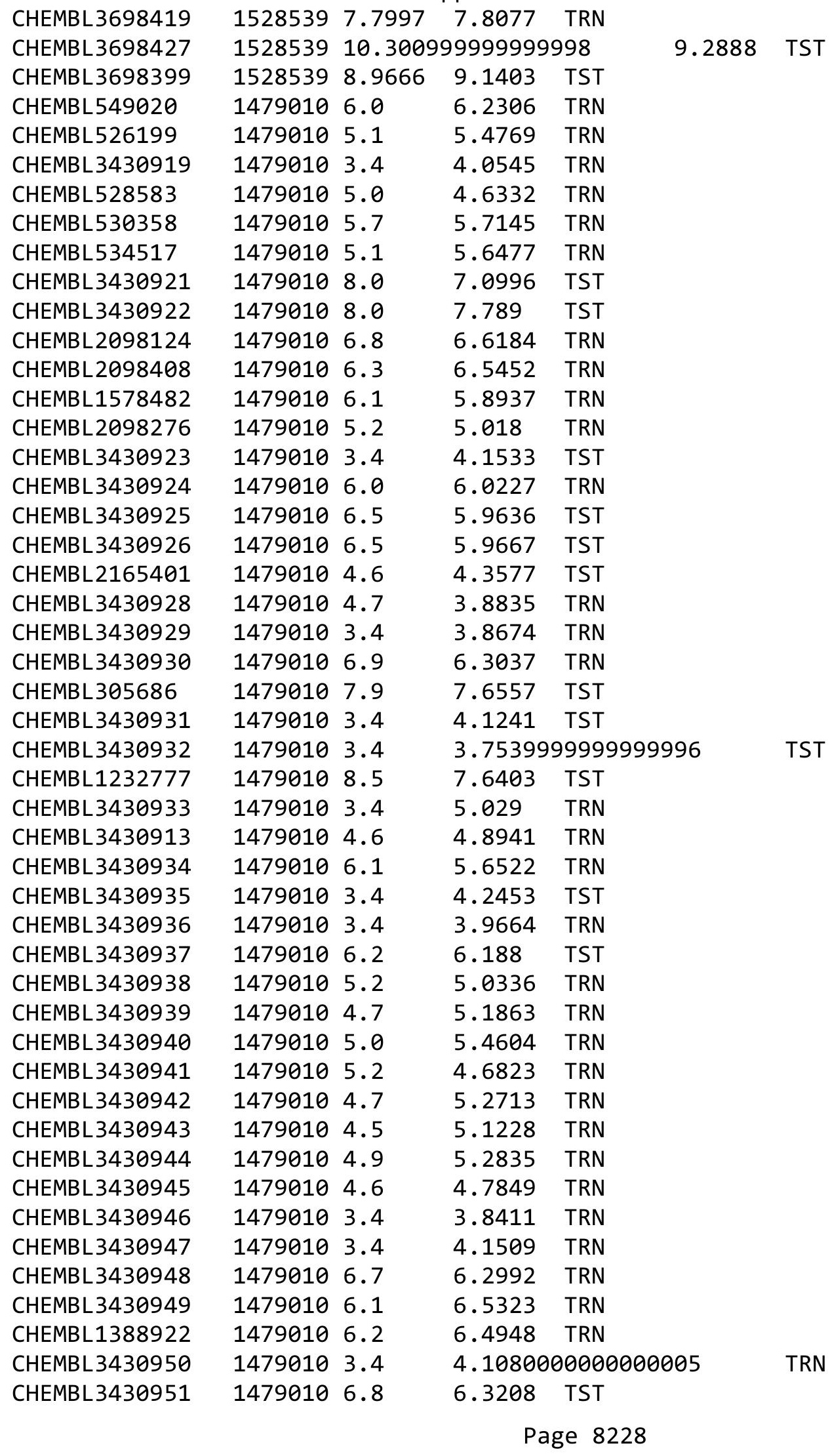




\begin{tabular}{|c|c|c|c|c|}
\hline & & & & aI \\
\hline CHEMBL1321334 & 1479010 & 4.5 & 4.07 & TRN \\
\hline CHEMBL3430953 & 1479010 & 6.5 & 6.6641 & TRN \\
\hline CHEMBL3430954 & 1479010 & 6.2 & 6.3577 & TRN \\
\hline CHEMBL3430955 & 1479010 & 4.5 & 4.3898 & TST \\
\hline CHEMBL3430956 & 1479010 & 5.9 & 5.9227 & TRN \\
\hline CHEMBL3430957 & 1479010 & 6.5 & 6.5082 & TRN \\
\hline CHEMBL3430958 & 1479010 & 7.0 & 6.2033 & TRN \\
\hline CHEMBL3430959 & 1479010 & 5.5 & 5.8719 & TRN \\
\hline CHEMBL3430960 & 1479010 & 3.4 & 3.7752 & TRN \\
\hline CHEMBL3430961 & 1479010 & 5.9 & 5.8677 & TRN \\
\hline CHEMBL3430962 & 1479010 & 6.2 & 5.9663 & TRN \\
\hline CHEMBL3430963 & 1479010 & 5.1 & 5.5568 & TRN \\
\hline CHEMBL3430964 & 1479010 & 5.3 & 5.5867 & TRN \\
\hline CHEMBL3430965 & 1479010 & 4.8 & 5.0758 & TRN \\
\hline CHEMBL3430966 & 1479010 & 4.8 & 4.6565 & TRN \\
\hline CHEMBL3430967 & 1479010 & 6.1 & 6.2446 & TRN \\
\hline CHEMBL3430968 & 1479010 & 6.3 & 6.27 & TRN \\
\hline CHEMBL3430969 & 1479010 & 6.3 & 6.5951 & TRN \\
\hline CHEMBL3430970 & 1479010 & 5.1 & 5.4 & TRN \\
\hline CHEMBL1482137 & 1479010 & 6.6 & 6.8609 & TRN \\
\hline CHEMBL3430971 & 1479010 & 4.7 & 4.0436 & TRN \\
\hline CHEMBL 3430972 & 1479010 & 3.4 & 4.0685 & TRN \\
\hline CHEMBL3430973 & 1479010 & 6.3 & 6.0438 & TRN \\
\hline CHEMBL3430974 & 1479010 & 3.4 & 4.2332 & TRN \\
\hline CHEMBL3430975 & 1479010 & 6.5 & 6.3768 & TRN \\
\hline CHEMBL3430976 & 1479010 & 6.2 & 6.3011 & TRN \\
\hline CHEMBL3430977 & 1479010 & 6.9 & 6.5923 & TST \\
\hline CHEMBL164422 & 1479010 & 6.0 & 6.2688 & TRN \\
\hline CHEMBL3430978 & 1479010 & 6.1 & 6.2985 & TRN \\
\hline CHEMBL3430979 & 1479010 & 5.2 & 4.1644 & TRN \\
\hline CHEMBL3430980 & 1479010 & 5.6 & 5.1457 & TRN \\
\hline CHEMBL1487481 & 1479010 & 5.9 & 5.9775 & TRN \\
\hline CHEMBL1487467 & 1479010 & 6.3 & 6.4317 & TRN \\
\hline CHEMBL3430981 & 1479010 & 4.8 & 5.0855 & TRN \\
\hline CHEMBL3430982 & 1479010 & 4.8 & 5.0363 & TRN \\
\hline CHEMBL3430983 & 1479010 & 5.3 & 5.1383 & TRN \\
\hline CHEMBL592827 & 1479010 & 4.6 & 3.7937 & TRN \\
\hline CHEMBL3430984 & 1479010 & 5.6 & 5.5785 & TRN \\
\hline CHEMBL3430985 & 1479010 & 5.6 & 5.7947 & TRN \\
\hline CHEMBL1466712 & 1479010 & 3.4 & 5.6303 & TRN \\
\hline CHEMBL3430986 & 1479010 & 6.6 & 6.4115 & TRN \\
\hline CHEMBL 3430987 & 1479010 & 4.7 & 5.0813 & TST \\
\hline CHEMBL3430988 & 1479010 & 3.4 & 4.0077 & TRN \\
\hline CHEMBL3430989 & 1479010 & 3.4 & 3.8987 & TRN \\
\hline CHEMBL 3430990 & 1479010 & 5.1 & 5.1671 & TRN \\
\hline CHEMBL3430991 & 1479010 & 4.7 & 4.0206 & TRN \\
\hline CHEMBL 3430992 & 1479010 & 4.8 & 4.9035 & TRN \\
\hline CHEMBL3430993 & 1479010 & 5.3 & 5.2756 & TRN \\
\hline
\end{tabular}




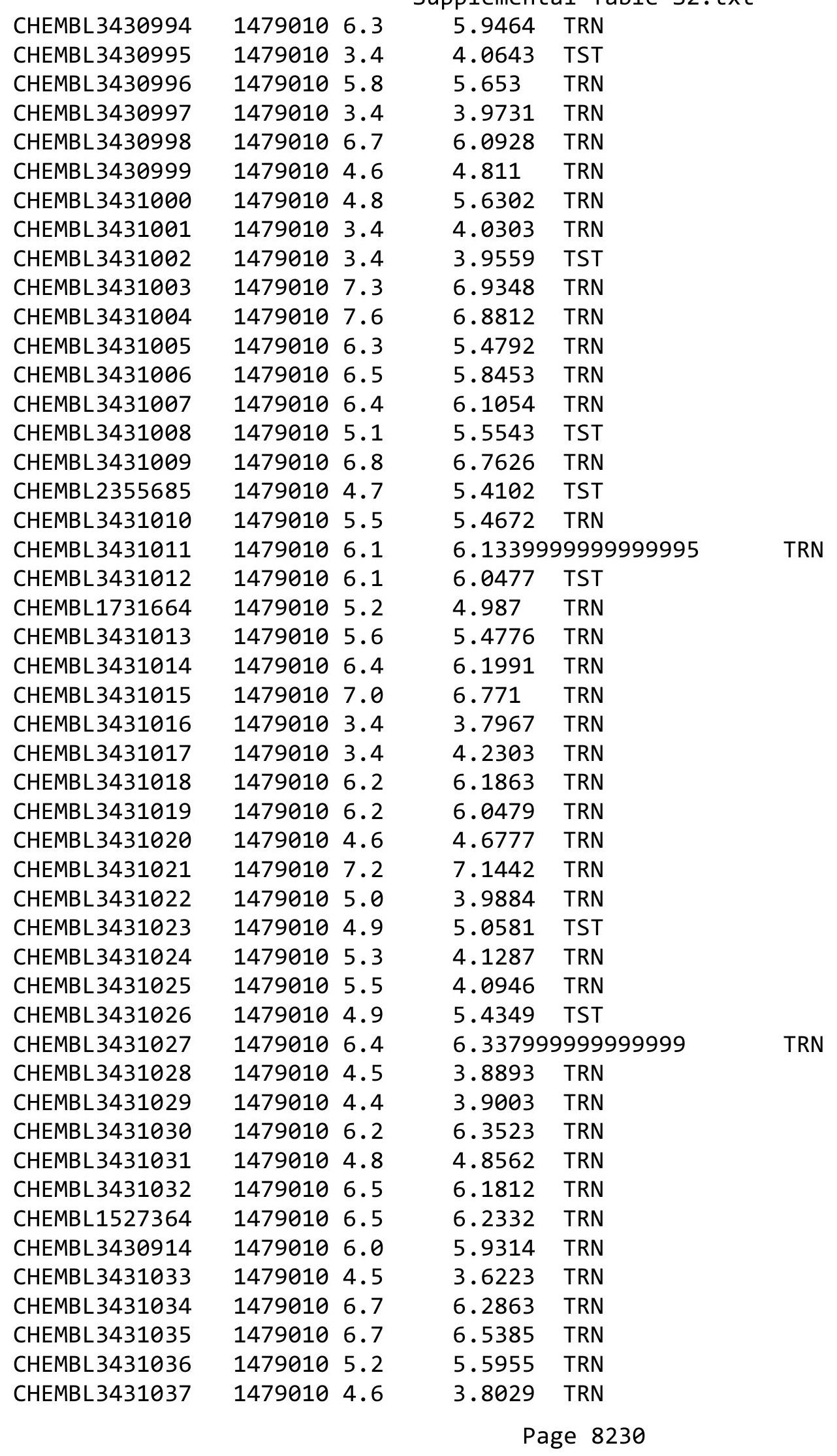




\begin{tabular}{|c|c|c|c|c|c|}
\hline & & & & & \\
\hline CHEMBL3431038 & 1479010 & 4.7 & 4.4164 & TRN & \\
\hline CHEMBL3431039 & 1479010 & 4.6 & 4.1317 & TRN & \\
\hline CHEMBL3431040 & 1479010 & 7.2 & 6.6275 & TRN & \\
\hline CHEMBL1354075 & 1479010 & 6.7 & 6.6079 & TRN & \\
\hline CHEMBL3431041 & 1479010 & 6.6 & 6.7326 & TRN & \\
\hline CHEMBL3431042 & 1479010 & 3.4 & 4.2755 & TRN & \\
\hline CHEMBL3431043 & 1479010 & 4.8 & 5.0232 & TST & \\
\hline CHEMBL 3431044 & 1479010 & 5.0 & 5.0943 & TST & \\
\hline CHEMBL3431045 & 1479010 & 6.9 & 6.5247 & TRN & \\
\hline CHEMBL3431046 & 1479010 & 4.8 & 5.1693 & TRN & \\
\hline CHEMBL3431047 & 1479010 & 4.6 & 5.2989 & TRN & \\
\hline CHEMBL3431048 & 1479010 & 4.9 & 5.2363 & TRN & \\
\hline CHEMBL3431049 & 1479010 & 5.3 & 5.5455 & TRN & \\
\hline CHEMBL 3431050 & 1479010 & 5.5 & 5.565 & TRN & \\
\hline CHEMBL3431051 & 1479010 & 5.4 & 5.3519 & TRN & \\
\hline CHEMBL3431052 & 1479010 & 5.7 & 5.3865 & TRN & \\
\hline CHEMBL3431053 & 1479010 & 6.0 & 5.6818 & TRN & \\
\hline CHEMBL2356808 & 1479010 & 6.4 & 6.6388 & TRN & \\
\hline CHEMBL3431054 & 1479010 & 6.2 & 6.4666 & TRN & \\
\hline CHEMBL3431055 & 1479010 & 4.9 & 5.2493 & TST & \\
\hline CHEMBL3431056 & 1479010 & 3.4 & 3.7617 & TRN & \\
\hline CHEMBL3431057 & 1479010 & 5.4 & 4.2016 & TST & \\
\hline CHEMBL 2093320 & 1479010 & 5.0 & 4.4517 & TRN & \\
\hline CHEMBL3431058 & 1479010 & 6.2 & 6.2223 & TRN & \\
\hline CHEMBL3431059 & 1479010 & 6.3 & 6.3688 & TRN & \\
\hline CHEMBL3431060 & 1479010 & 6.2 & 6.4005 & TRN & \\
\hline CHEMBL3431061 & 1479010 & 6.4 & 6.6045 & TRN & \\
\hline CHEMBL3431062 & 1479010 & 6.3 & 6.6307 & TRN & \\
\hline CHEMBL3431063 & 1479010 & 6.6 & 6.71700 & j0000000005 & TRN \\
\hline CHEMBL3431064 & 1479010 & 6.4 & 6.0187 & TRN & \\
\hline CHEMBL3431065 & 1479010 & 4.5 & 5.0527 & TST & \\
\hline CHEMBL3431066 & 1479010 & 6.2 & 6.5907 & TRN & \\
\hline CHEMBL3431067 & 1479010 & 6.6 & 6.3759 & TRN & \\
\hline CHEMBL3431068 & 1479010 & 4.5 & 3.7703 & TRN & \\
\hline CHEMBL3431069 & 1479010 & 5.0 & 5.2628 & TRN & \\
\hline CHEMBL3431070 & 1479010 & 4.5 & 3.6866 & TRN & \\
\hline CHEMBL3431071 & 1479010 & 6.0 & 5.5617 & TST & \\
\hline CHEMBL3431072 & 1479010 & 6.3 & 6.0736 & TRN & \\
\hline CHEMBL3431073 & 1479010 & 6.2 & 5.8255 & TST & \\
\hline CHEMBL 3431074 & 1479010 & 5.5 & 4.2894 & TRN & \\
\hline CHEMBL3431075 & 1479010 & 6.4 & 6.1238 & TST & \\
\hline CHEMBL3431076 & 1479010 & 6.1 & 5.91299 & 9999999999 & TRN \\
\hline CHEMBL3431077 & 1479010 & 3.4 & 4.7592 & TRN & \\
\hline CHEMBL3431078 & 1479010 & 4.6 & 4.8486 & TRN & \\
\hline CHEMBL3431079 & 1479010 & 4.5 & 4.3086 & TRN & \\
\hline CHEMBL 3431080 & 1479010 & 4.5 & 4.6995 & TRN & \\
\hline CHEMBL3431081 & 1479010 & 4.7 & 4.3707 & TRN & \\
\hline CHEMBL3431082 & 1479010 & 5.2 & 5.6021 & TRN & \\
\hline & & & & 8231 & \\
\hline
\end{tabular}




\begin{tabular}{|c|c|c|c|c|}
\hline & & & & as labıe \\
\hline CHEMBL3431083 & 1479010 & 6.3 & 6.2664 & TRN \\
\hline CHEMBL3431084 & 1479010 & 6.8 & 6.3513 & TST \\
\hline CHEMBL1585368 & 1479010 & 4.8 & 4.3558 & TRN \\
\hline CHEMBL3431085 & 1479010 & 4.5 & 3.8194 & TRN \\
\hline CHEMBL3431086 & 1479010 & 6.8 & 6.6405 & TRN \\
\hline CHEMBL3431087 & 1479010 & 4.6 & 4.7013 & TRN \\
\hline CHEMBL3431088 & 1479010 & 4.9 & 4.9037 & TRN \\
\hline CHEMBL3431089 & 1479010 & 6.6 & 6.5469 & TRN \\
\hline CHEMBL3431090 & 1479010 & 5.0 & 4.9634 & TRN \\
\hline CHEMBL3431091 & 1479010 & 4.9 & 5.0681 & TRN \\
\hline CHEMBL3431092 & 1479010 & 5.6 & 5.0916 & TRN \\
\hline CHEMBL3431093 & 1479010 & 5.1 & 5.4979 & TRN \\
\hline CHEMBL3431094 & 1479010 & 4.7 & 4.0432 & TRN \\
\hline CHEMBL3431095 & 1479010 & 6.5 & 6.322 & TRN \\
\hline CHEMBL3431096 & 1479010 & 6.6 & 6.6149 & TRN \\
\hline CHEMBL3431097 & 1479010 & 6.3 & 6.6437 & TRN \\
\hline CHEMBL3431098 & 1479010 & 3.4 & 3.7953 & TRN \\
\hline CHEMBL3431099 & 1479010 & 6.4 & 6.1887 & TST \\
\hline CHEMBL3431100 & 1479010 & 3.4 & 3.8764 & TRN \\
\hline CHEMBL3431101 & 1479010 & 5.1 & 5.3773 & TST \\
\hline CHEMBL3431102 & 1479010 & 6.3 & 5.8834 & TST \\
\hline CHEMBL3431103 & 1479010 & 4.6 & 4.9368 & TST \\
\hline CHEMBL3431104 & 1479010 & 3.4 & 3.8428 & TRN \\
\hline CHEMBL3431105 & 1479010 & 6.5 & 6.5568 & TRN \\
\hline CHEMBL3431106 & 1479010 & 3.4 & 3.9057 & TST \\
\hline CHEMBL3431107 & 1479010 & 4.4 & 3.9183 & TRN \\
\hline CHEMBL3431108 & 1479010 & 5.2 & 3.9262 & TRN \\
\hline CHEMBL3431109 & 1479010 & 5.1 & 5.2876 & TRN \\
\hline CHEMBL3431110 & 1479010 & 5.5 & 5.5816 & TRN \\
\hline CHEMBL3431111 & 1479010 & 5.7 & 5.4582 & TRN \\
\hline CHEMBL3431112 & 1479010 & 6.4 & 6.3328 & TRN \\
\hline CHEMBL3431113 & 1479010 & 7.3 & 6.7695 & TRN \\
\hline CHEMBL3431114 & 1479010 & 5.4 & 5.5968 & TRN \\
\hline CHEMBL3431115 & 1479010 & 6.2 & 6.2094 & TST \\
\hline CHEMBL3431116 & 1479010 & 4.6 & 3.9913 & TRN \\
\hline CHEMBL3431117 & 1479010 & 6.4 & $6.4170 e$ & 0000000001 \\
\hline CHEMBL3431118 & 1479010 & 4.7 & 5.4593 & TRN \\
\hline CHEMBL3431119 & 1479010 & 4.6 & 4.0503 & TRN \\
\hline CHEMBL3431120 & 1479010 & 4.5 & 4.2566 & TRN \\
\hline CHEMBL3431121 & 1479010 & 6.4 & 6.2347 & TST \\
\hline CHEMBL3431122 & 1479010 & 6.9 & 6.7193 & TRN \\
\hline CHEMBL3431123 & 1479010 & 5.0 & 4.2542 & TRN \\
\hline CHEMBL3431124 & 1479010 & 6.1 & 5.9106 & TRN \\
\hline CHEMBL3431125 & 1479010 & 4.6 & 4.2784 & TST \\
\hline CHEMBL 3431126 & 1479010 & 6.5 & 6.4735 & TRN \\
\hline CHEMBL 3431128 & 1479010 & 4.8 & 5.1829 & TST \\
\hline CHEMBL3431129 & 1479010 & 3.4 & 4.921 & TST \\
\hline CHEMBL3431130 & 1479010 & 4.9 & 5.3515 & TST \\
\hline
\end{tabular}




\begin{tabular}{|c|c|c|c|c|c|}
\hline \\
\hline CHEMBL 3431131 & 1479010 & 6.4 & 6.4556 & TRN & \\
\hline CHEMBL3430915 & 1479010 & 5.2 & 4.8981 & TRN & \\
\hline CHEMBL3431132 & 1479010 & 6.2 & 5.8637 & TRN & \\
\hline CHEMBL3431133 & 1479010 & 4.8 & 4.1446 & TRN & \\
\hline CHEMBL 3431134 & 1479010 & 8.3 & 7.4511 & TRN & \\
\hline CHEMBL 3431135 & 1479010 & 4.7 & 3.9706 & TRN & \\
\hline CHEMBL 3431136 & 1479010 & 6.4 & 5.4328 & TRN & \\
\hline CHEMBL3431137 & 1479010 & 5.6 & 5.9957 & TRN & \\
\hline CHEMBL3431138 & 1479010 & 6.5 & 6.5332 & TST & \\
\hline CHEMBL3431139 & 1479010 & 5.3 & 5.3634 & TST & \\
\hline CHEMBL 3431140 & 1479010 & 3.4 & 3.9768 & TST & \\
\hline CHEMBL 3431141 & 1479010 & 5.0 & 5.1537 & TRN & \\
\hline CHEMBL3431142 & 1479010 & 3.4 & 4.2731 & TST & \\
\hline CHEMBL3431143 & 1479010 & 6.7 & 6.6259 & TRN & \\
\hline CHEMBL3431144 & 1479010 & 5.3 & 5.3462 & TRN & \\
\hline CHEMBL 3431145 & 1479010 & 6.3 & 5.9508 & TRN & \\
\hline CHEMBL3431146 & 1479010 & 3.4 & 4.0856 & TRN & \\
\hline CHEMBL3431147 & 1479010 & 6.1 & 6.1546 & TST & \\
\hline CHEMBL 3431148 & 1479010 & 3.4 & 4.357 & TRN & \\
\hline CHEMBL3431149 & 1479010 & 6.4 & 6.5998 & TRN & \\
\hline CHEMBL3431150 & 1479010 & 3.4 & 4.5319 & TRN & \\
\hline CHEMBL3431151 & 1479010 & 7.1 & 7.0156 & TRN & \\
\hline CHEMBL3431152 & 1479010 & 3.4 & 3.7324 & TRN & \\
\hline CHEMBL3431153 & 1479010 & 3.4 & 3.8636 & TRN & \\
\hline CHEMBL3431154 & 1479010 & 6.2 & 6.3661 & TST & \\
\hline CHEMBL3431155 & 1479010 & 3.4 & 3.9953 & TRN & \\
\hline CHEMBL 3431156 & 1479010 & 4.5 & 3.8649 & TRN & \\
\hline CHEMBL 3431157 & 1479010 & 7.7 & 6.8798 & TST & \\
\hline CHEMBL3431158 & 1479010 & 5.2 & 4.5874 & TST & \\
\hline CHEMBL3431159 & 1479010 & 4.6 & 4.2394 & TST & \\
\hline CHEMBL1593679 & 1479010 & 4.8 & 4.583 & TRN & \\
\hline CHEMBL 3431160 & 1479010 & 6.5 & 6.5449 & TRN & \\
\hline CHEMBL 3431161 & 1479010 & 4.6 & 4.3048 & TST & \\
\hline CHEMBL3431162 & 1479010 & 4.6 & 5.0186 & TST & \\
\hline CHEMBL 3431163 & 1479010 & 4.7 & 4.6858 & TRN & \\
\hline CHEMBL3431164 & 1479010 & 3.4 & 4.004 & TRN & \\
\hline CHEMBL 3431165 & 1479010 & 6.1 & 6.1233 & TST & \\
\hline CHEMBL1458931 & 1479010 & 3.4 & 4.1169 & TRN & \\
\hline CHEMBL3431166 & 1479010 & 6.5 & 6.4479 & TRN & \\
\hline CHEMBL 3431167 & 1479010 & 4.8 & 4.1387 & TRN & \\
\hline CHEMBL3431168 & 1479010 & 6.7 & 6.5 & TRN & \\
\hline CHEMBL3431169 & 1479010 & 4.4 & 4.0837 & TRN & \\
\hline CHEMBL3431170 & 1479010 & 7.4 & 7.4917 & TRN & \\
\hline CHEMBL3431171 & 1479010 & 6.1 & 6.1754 & TRN & \\
\hline CHEMBL 3431172 & 1479010 & 7.1 & 7.1653 & TRN & \\
\hline CHEMBL3431173 & 1479010 & 4.7 & 5.01399 & 9999999999 & TRN \\
\hline CHEMBL3431174 & 1479010 & 5.2 & 4.8463 & TRN & \\
\hline CHEMBL3431175 & 1479010 & 4.5 & 4.17 & TST & \\
\hline & & & & e 8233 & \\
\hline
\end{tabular}

Supplemental Table S2.txt 


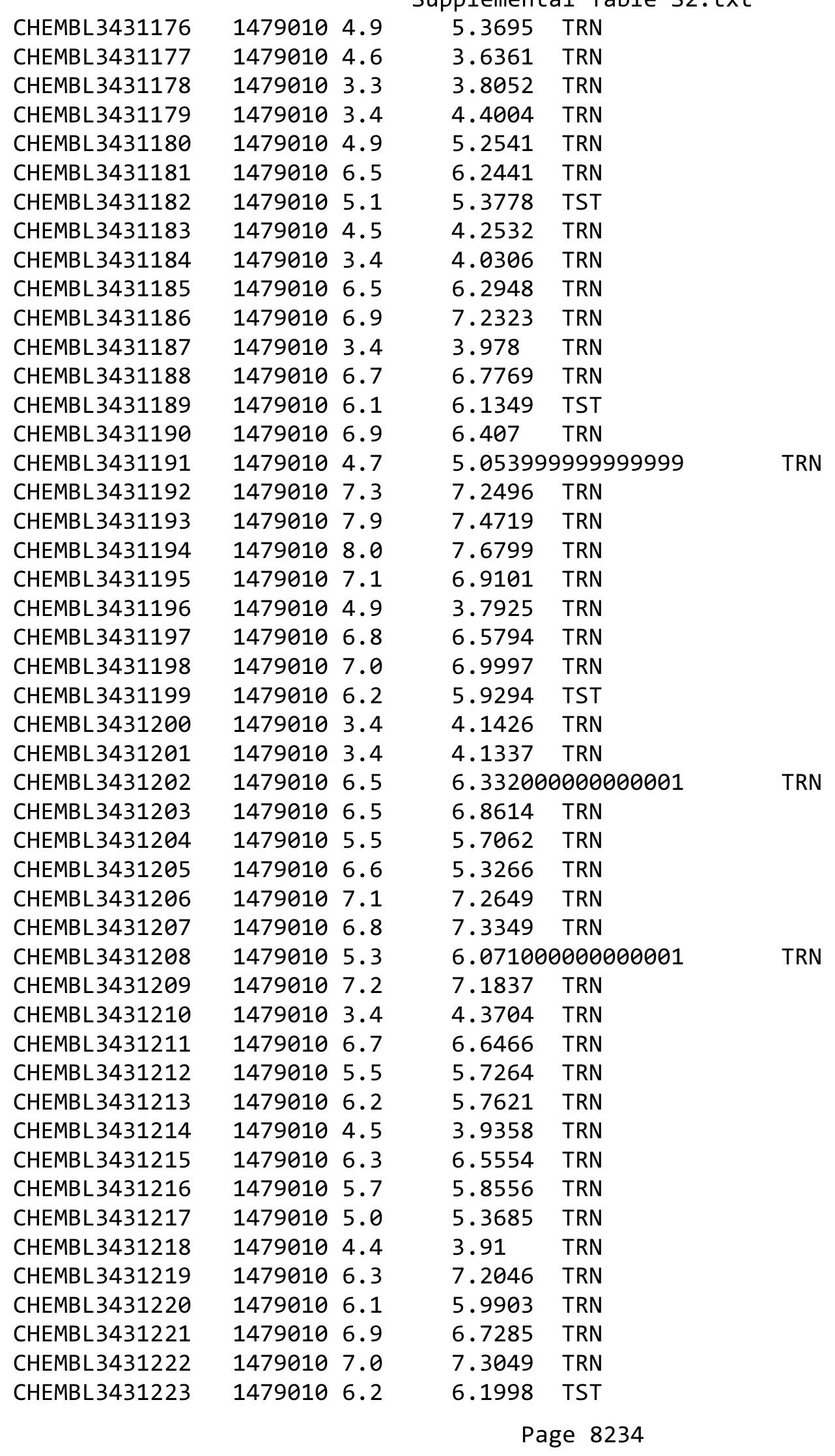




\begin{tabular}{|c|c|c|c|c|c|}
\hline \multirow{3}{*}{ CHEMBL 3431224} & \multirow{2}{*}{1479010} & \multirow{2}{*}{6.8} & \multirow{2}{*}{\multicolumn{3}{|c|}{6.999}} \\
\hline & & & & & \\
\hline & 1479010 & 6.4 & 6.2449 & TRN & \\
\hline CHEMBL3431226 & 1479010 & 7.3 & 6.4012 & TRN & \\
\hline CHEMBL3431227 & 1479010 & 4.8 & 4.5834 & TRN & \\
\hline CHEMBL3431228 & 1479010 & 6.9 & 6.4783 & TRN & \\
\hline CHEMBL3431229 & 1479010 & 7.2 & 7.1013 & TRN & \\
\hline CHEMBL3431230 & 1479010 & 7.2 & 7.1548 & TRN & \\
\hline CHEMBL 2441267 & 1479010 & 7.6 & 7.386 & TRN & \\
\hline CHEMBL3430916 & 1479010 & 5.8 & 5.9134 & TRN & \\
\hline CHEMBL3431231 & 1479010 & 3.4 & 4.2106 & TRN & \\
\hline CHEMBL3431232 & 1479010 & 4.7 & 4.2112 & TRN & \\
\hline CHEMBL3431233 & 1479010 & 5.1 & 5.3861 & TRN & \\
\hline CHEMBL 3431234 & 1479010 & 3.4 & 5.3123 & TRN & \\
\hline CHEMBL3431235 & 1479010 & 5.7 & 5.3375 & TST & \\
\hline CHEMBL3431236 & 1479010 & 4.8 & 4.7192 & TST & \\
\hline CHEMBL3431237 & 1479010 & 5.7 & 5.6296 & TRN & \\
\hline CHEMBL3431238 & 1479010 & 4.9 & 4.1399 & TRN & \\
\hline CHEMBL3431239 & 1479010 & 6.4 & 6.5932 & TRN & \\
\hline CHEMBL 3431240 & 1479010 & 5.7 & 5.69 & TST & \\
\hline CHEMBL3431241 & 1479010 & 4.8 & 4.3051 & TRN & \\
\hline CHEMBL3431242 & 1479010 & 3.4 & 3.8716 & TRN & \\
\hline CHEMBL3431243 & 1479010 & 3.4 & 3.9213 & TST & \\
\hline CHEMBL 3431244 & 1479010 & 5.1 & 4.9971 & TRN & \\
\hline CHEMBL3431245 & 1479010 & 5.3 & 5.4774 & TRN & \\
\hline CHEMBL3431246 & 1479010 & 5.3 & 5.1944 & TRN & \\
\hline CHEMBL3431247 & 1479010 & 6.2 & 6.0426 & TRN & \\
\hline CHEMBL3431248 & 1479010 & 3.4 & 3.8911 & TRN & \\
\hline CHEMBL3431249 & 1479010 & 4.5 & 3.7057 & TRN & \\
\hline CHEMBL3431250 & 1479010 & 3.4 & 4.0817 & TRN & \\
\hline CHEMBL3431251 & 1479010 & 6.2 & 5.9458 & TRN & \\
\hline CHEMBL3431252 & 1479010 & 6.1 & 5.9645 & TRN & \\
\hline CHEMBL3431253 & 1479010 & 4.9 & 4.8917 & TST & \\
\hline CHEMBL3431254 & 1479010 & 4.6 & 5.1359 & TRN & \\
\hline CHEMBL3431255 & 1479010 & 6.2 & 6.2445 & TST & \\
\hline CHEMBL 3431257 & 1479010 & 4.6 & 3.9955 & TRN & \\
\hline CHEMBL3431258 & 1479010 & 3.4 & 3.8728 & TRN & \\
\hline CHEMBL3431259 & 1479010 & 3.4 & 3.97600 & 00000000004 & TRN \\
\hline CHEMBL3431260 & 1479010 & 3.4 & 4.3204 & TRN & \\
\hline CHEMBL 3431261 & 1479010 & 4.7 & 4.7138 & TRN & \\
\hline CHEMBL 2356920 & 1479010 & 6.2 & 6.1109 & TRN & \\
\hline CHEMBL3431262 & 1479010 & 6.5 & 6.2096 & TRN & \\
\hline CHEMBL3431263 & 1479010 & 4.7 & 4.5549 & TRN & \\
\hline CHEMBL3431264 & 1479010 & 6.0 & 5.8386 & TRN & \\
\hline CHEMBL3431265 & 1479010 & 3.4 & 4.0646 & TST & \\
\hline CHEMBL3431266 & 1479010 & 4.6 & 4.5111 & TRN & \\
\hline CHEMBL3431268 & 1479010 & 5.4 & 5.3808 & TST & \\
\hline CHEMBL3431269 & 1479010 & 5.0 & 5.3963 & TRN & \\
\hline CHEMBL3431270 & 1479010 & 6.6 & 6.32 & TST & \\
\hline & & & & 8235 & \\
\hline
\end{tabular}




\begin{tabular}{|c|c|c|c|c|}
\hline & & & & \\
\hline CHEMBL 3431271 & 1479010 & 6.5 & 6.5383 & TRN \\
\hline CHEMBL3431272 & 1479010 & 6.9 & 6.6853 & TRN \\
\hline CHEMBL3431273 & 1479010 & 6.0 & 5.6295 & TRN \\
\hline CHEMBL 3431274 & 1479010 & 4.9 & 5.2238 & TRN \\
\hline CHEMBL3431275 & 1479010 & 6.4 & 6.4318 & TRN \\
\hline CHEMBL3431277 & 1479010 & 5.2 & 5.5795 & TRN \\
\hline CHEMBL3431278 & 1479010 & 6.4 & 6.3365 & TRN \\
\hline CHEMBL3431279 & 1479010 & 8.1 & 6.7982 & TST \\
\hline CHEMBL 3431280 & 1479010 & 6.4 & 6.6194 & TST \\
\hline CHEMBL3431281 & 1479010 & 5.1 & 5.3097 & TST \\
\hline CHEMBL3431282 & 1479010 & 6.2 & 5.8744 & TST \\
\hline CHEMBL3431283 & 1479010 & 6.2 & 5.9097 & TST \\
\hline CHEMBL 3431284 & 1479010 & 6.3 & 6.2192 & TRN \\
\hline CHEMBL3431285 & 1479010 & 5.5 & 5.4334 & TRN \\
\hline CHEMBL3431286 & 1479010 & 6.9 & 6.4664 & TST \\
\hline CHEMBL3431287 & 1479010 & 4.7 & 4.046 & TST \\
\hline CHEMBL3431288 & 1479010 & 6.3 & 6.2811 & TRN \\
\hline CHEMBL3431289 & 1479010 & 4.5 & 4.5114 & TST \\
\hline CHEMBL3431290 & 1479010 & 3.4 & 3.9783 & TRN \\
\hline CHEMBL3431291 & 1479010 & 3.4 & 3.9941 & TRN \\
\hline CHEMBL3431292 & 1479010 & 6.3 & 6.1984 & TRN \\
\hline CHEMBL3431293 & 1479010 & 3.4 & 3.7258 & TRN \\
\hline CHEMBL3431294 & 1479010 & 6.6 & 6.2237 & TRN \\
\hline CHEMBL3431295 & 1479010 & 6.8 & 7.0166 & TRN \\
\hline CHEMBL3431296 & 1479010 & 6.7 & 7.0765 & TRN \\
\hline CHEMBL3431297 & 1479010 & 6.9 & 7.0615 & TRN \\
\hline CHEMBL3431298 & 1479010 & 6.7 & 7.0566 & TRN \\
\hline CHEMBL3431299 & 1479010 & 5.4 & 4.172 & TRN \\
\hline CHEMBL3431300 & 1479010 & 3.4 & 4.0287 & TRN \\
\hline CHEMBL3431301 & 1479010 & 6.2 & 5.5668 & TST \\
\hline CHEMBL3431302 & 1479010 & 4.6 & 4.0861 & TRN \\
\hline CHEMBL3431303 & 1479010 & 3.4 & 3.8343 & TRN \\
\hline CHEMBL3431304 & 1479010 & 5.2 & 5.3351 & TRN \\
\hline CHEMBL3431305 & 1479010 & 3.4 & 3.9131 & TRN \\
\hline CHEMBL3431306 & 1479010 & 4.8 & 4.0427 & TRN \\
\hline CHEMBL3431307 & 1479010 & 3.4 & 3.8032 & TRN \\
\hline CHEMBL3431308 & 1479010 & 4.7 & 4.0471 & TRN \\
\hline CHEMBL3431309 & 1479010 & 5.2 & 5.5252 & TRN \\
\hline CHEMBL 3431310 & 1479010 & 4.9 & 5.2152 & TRN \\
\hline CHEMBL3431311 & 1479010 & 5.6 & 5.9055 & TRN \\
\hline CHEMBL3431312 & 1479010 & 5.9 & 5.9132 & TRN \\
\hline CHEMBL3431313 & 1479010 & 5.6 & 6.0671 & TRN \\
\hline CHEMBL3431314 & 1479010 & 5.7 & 6.0872 & TRN \\
\hline CHEMBL3431315 & 1479010 & 5.3 & 5.4171 & TRN \\
\hline CHEMBL3431316 & 1479010 & 3.4 & 4.1749 & TST \\
\hline CHEMBL3431317 & 1479010 & 3.9 & 5.0322 & TRN \\
\hline CHEMBL3431318 & 1479010 & 3.4 & 4.5687 & TST \\
\hline CHEMBL3431319 & 1479010 & 6.7 & 6.5513 & TRN \\
\hline
\end{tabular}




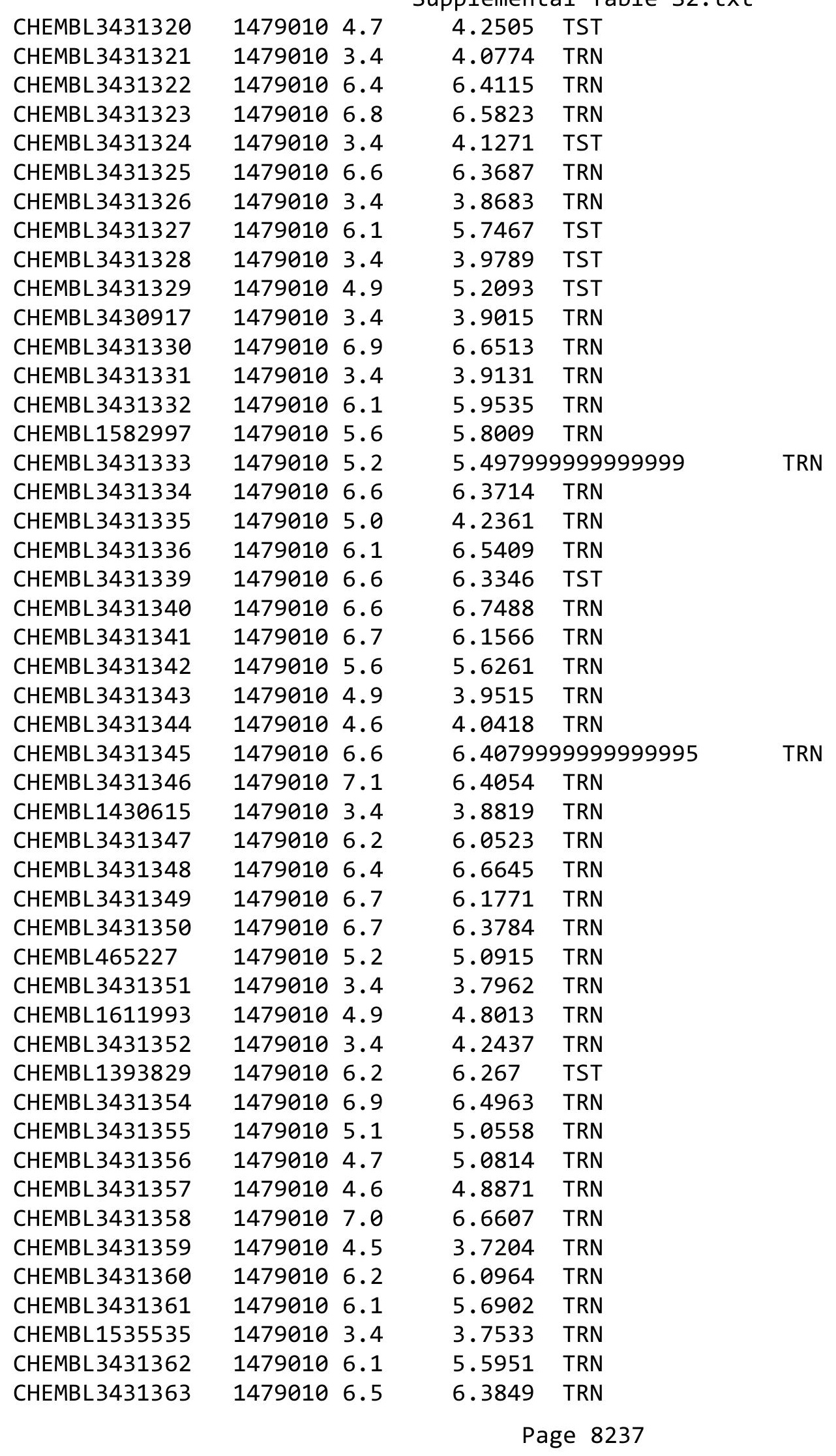




\begin{tabular}{|c|c|c|c|c|}
\hline \\
\hline CHEMBL3431364 & 1479010 & 3.4 & 4.0116 & TRN \\
\hline CHEMBL3431365 & 1479010 & 4.7 & 4.0936 & TRN \\
\hline CHEMBL3431366 & 1479010 & 6.6 & 6.3073 & TST \\
\hline CHEMBL3431367 & 1479010 & 5.0 & 5.1755 & TST \\
\hline CHEMBL3431368 & 1479010 & 5.5 & 5.7843 & TRN \\
\hline CHEMBL3431369 & 1479010 & 4.6 & 4.3327 & TRN \\
\hline CHEMBL1447267 & 1479010 & 6.3 & 6.4692 & TRN \\
\hline CHEMBL 3431370 & 1479010 & 5.0 & 4.0777 & TRN \\
\hline CHEMBL1325144 & 1479010 & 4.9 & 4.7481 & TRN \\
\hline CHEMBL1429841 & 1479010 & 4.8 & 5.1171 & TRN \\
\hline CHEMBL3431371 & 1479010 & 4.6 & 3.8485 & TRN \\
\hline CHEMBL1308225 & 1479010 & 6.4 & 6.3588 & TST \\
\hline CHEMBL2441359 & 1479010 & 4.7 & 5.0361 & TRN \\
\hline CHEMBL1517284 & 1479010 & 6.0 & 6.0516 & TRN \\
\hline CHEMBL3431372 & 1479010 & 3.4 & 4.0487 & TRN \\
\hline CHEMBL3431373 & 1479010 & 6.2 & 6.2165 & TRN \\
\hline CHEMBL3431374 & 1479010 & 4.9 & 5.1784 & TRN \\
\hline CHEMBL3431375 & 1479010 & 4.5 & 4.7262 & TST \\
\hline CHEMBL3431376 & 1479010 & 6.7 & 6.6152 & TRN \\
\hline CHEMBL1365653 & 1479010 & 5.2 & 4.3195 & TRN \\
\hline CHEMBL3431377 & 1479010 & 6.3 & 5.7647 & TRN \\
\hline CHEMBL 3431378 & 1479010 & 5.1 & 5.00899 & 99999999995 \\
\hline CHEMBL3431379 & 1479010 & 4.9 & 5.0546 & TRN \\
\hline CHEMBL1478826 & 1479010 & 5.2 & 5.4803 & TRN \\
\hline CHEMBL1872842 & 1479010 & 6.7 & 6.7345 & TRN \\
\hline CHEMBL3431380 & 1479010 & 6.7 & 6.5461 & TRN \\
\hline CHEMBL3431381 & 1479010 & 6.7 & 6.2673 & TRN \\
\hline CHEMBL 3431382 & 1479010 & 7.8 & 6.9021 & TRN \\
\hline CHEMBL 3431383 & 1479010 & 4.7 & 4.8592 & TRN \\
\hline CHEMBL 3431384 & 1479010 & 4.6 & 5.1947 & TRN \\
\hline CHEMBL3431385 & 1479010 & 6.5 & 6.2678 & TRN \\
\hline CHEMBL3431386 & 1479010 & 4.6 & 3.9813 & TRN \\
\hline CHEMBL1730515 & 1479010 & 6.6 & 6.2705 & TRN \\
\hline CHEMBL3431387 & 1479010 & 6.4 & 6.3557 & TRN \\
\hline CHEMBL3431388 & 1479010 & 6.6 & 6.7253 & TRN \\
\hline CHEMBL1566898 & 1479010 & 6.6 & 6.7651 & TRN \\
\hline CHEMBL3431389 & 1479010 & 6.5 & 6.6535 & TRN \\
\hline CHEMBL3431390 & 1479010 & 6.4 & 6.2552 & TST \\
\hline CHEMBL3431391 & 1479010 & 6.0 & 6.2258 & TRN \\
\hline CHEMBL1489081 & 1479010 & 6.4 & 6.556 & TRN \\
\hline CHEMBL3431392 & 1479010 & 6.0 & 6.2812 & TRN \\
\hline CHEMBL3431393 & 1479010 & 4.8 & 4.9255 & TRN \\
\hline CHEMBL3431394 & 1479010 & 6.2 & 6.1945 & TST \\
\hline CHEMBL3431395 & 1479010 & 5.1 & 4.9314 & TRN \\
\hline CHEMBL3431396 & 1479010 & 6.6 & 6.1069 & TRN \\
\hline CHEMBL3431397 & 1479010 & 5.0 & 4.776 & TRN \\
\hline CHEMBL3431398 & 1479010 & 5.1 & 4.0859 & TRN \\
\hline CHEMBL3431399 & 1479010 & 4.9 & 5.3628 & TRN \\
\hline
\end{tabular}




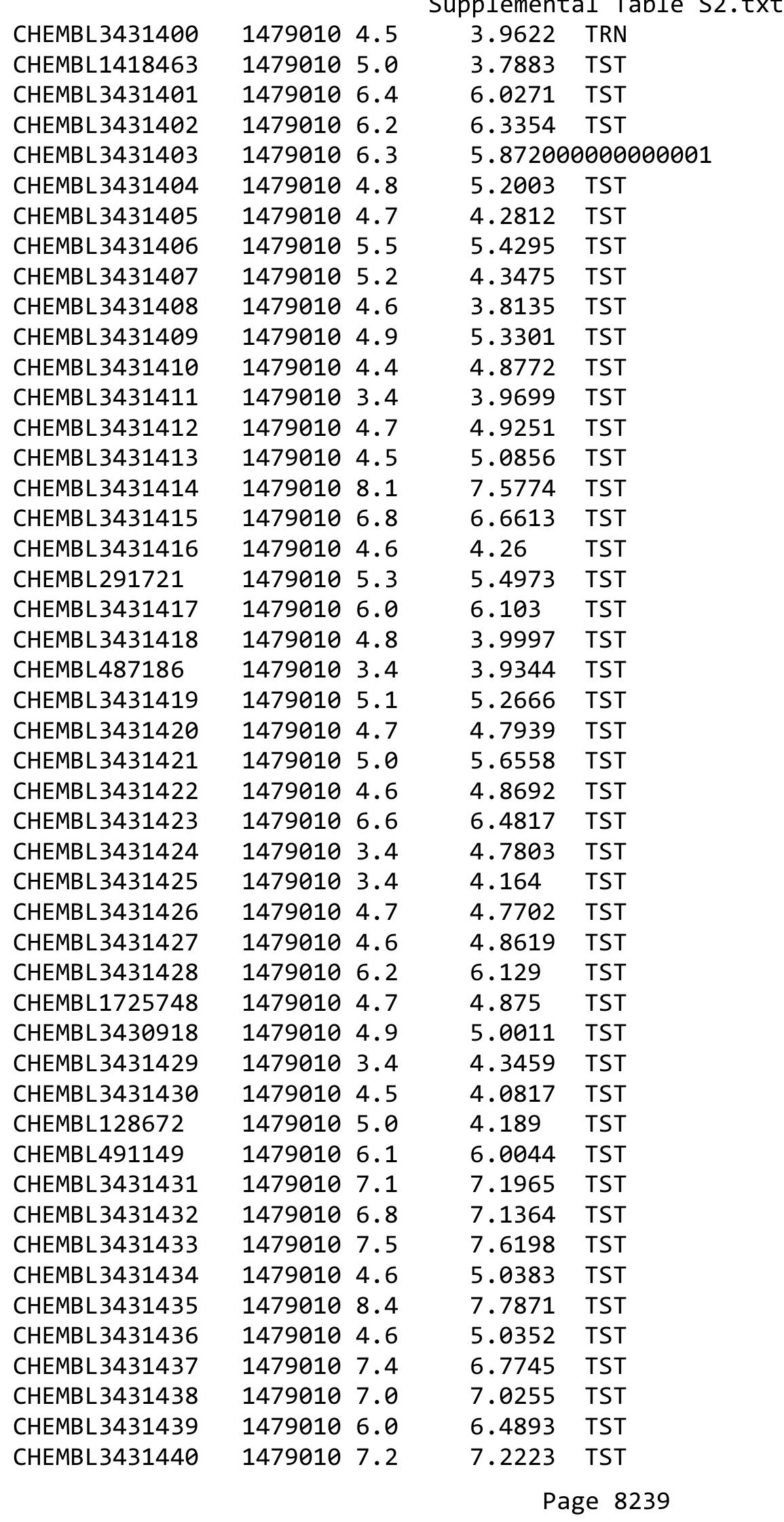




\begin{tabular}{|c|c|c|c|c|c|}
\hline \multicolumn{6}{|c|}{ Supplemental Table S2.txt } \\
\hline CHEMBL3431441 & 1479010 & 6.4 & 6.2092 & TST & \\
\hline CHEMBL3431442 & 1479010 & 6.5 & 6.8623 & TST & \\
\hline CHEMBL3431443 & 1479010 & 6.4 & 6.3382 & TST & \\
\hline CHEMBL3431444 & 1479010 & 6.4 & 6.5026 & TST & \\
\hline CHEMBL3431445 & 1479010 & 6.5 & 5.8848 & TST & \\
\hline CHEMBL1917837 & 787661 & 3.0 & 3.1994 & TST & \\
\hline CHEMBL1917827 & 787661 & 3.0 & 2.7817 & TRN & \\
\hline CHEMBL1917831 & 787661 & 3.0 & 2.95899 & 99999999996 & TST \\
\hline CHEMBL1917834 & 787661 & 3.0 & 2.8482 & TST & \\
\hline CHEMBL1917660 & 787661 & 4.8551 & 4.5846 & TRN & \\
\hline CHEMBL1917838 & 787661 & 3.0 & 3.0817 & TST & \\
\hline CHEMBL1917828 & 787661 & 4.6972 & 4.4959 & TRN & \\
\hline CHEMBL571146 & 787661 & 4.8216 & 4.8239 & TRN & \\
\hline CHEMBL1917662 & 787661 & 3.0 & 2.9723 & TRN & \\
\hline CHEMBL570465 & 787661 & 3.0 & 2.6664 & TRN & \\
\hline CHEMBL1917833 & 787661 & 4.4488 & 4.3718 & TST & \\
\hline CHEMBL1917671 & 787661 & 4.2551 & 3.8401 & TRN & \\
\hline CHEMBL1917667 & 787661 & 3.0 & 3.41399 & 99999999997 & TRN \\
\hline CHEMBL1917655 & 787661 & 5.1343 & 4.9088 & TRN & \\
\hline CHEMBL1917839 & 787661 & 3.0 & 2.8411 & TST & \\
\hline CHEMBL569115 & 787661 & 5.0088 & 6.0488 & TRN & \\
\hline CHEMBL1917664 & 787661 & 3.0 & 3.1286 & TRN & \\
\hline CHEMBL584953 & 787661 & 3.0 & 4.1524 & TRN & \\
\hline CHEMBL1917661 & 787661 & 4.3251 & 4.1581 & TRN & \\
\hline CHEMBL1917829 & 787661 & 3.0 & 3.1094 & TST & \\
\hline CHEMBL1917654 & 787661 & 5.7144 & 5.4717 & TRN & \\
\hline CHEMBL1917668 & 787661 & 3.0 & 2.7766 & TRN & \\
\hline CHEMBL578814 & 787661 & 5.9031 & 5.7882 & TRN & \\
\hline CHEMBL569338 & 787661 & 4.0196 & 4.0838 & TRN & \\
\hline CHEMBL1917830 & 787661 & 3.0 & 3.0177 & TST & \\
\hline CHEMBL570511 & 787661 & 3.0 & 3.3727 & TRN & \\
\hline CHEMBL1917835 & 787661 & 4.4102 & 4.2244 & TST & \\
\hline CHEMBL1917666 & 787661 & 4.3934 & 4.4863 & TRN & \\
\hline CHEMBL572026 & 787661 & 3.0 & 3.4635 & TRN & \\
\hline CHEMBL1917663 & 787661 & 4.9884 & 4.6736 & TRN & \\
\hline CHEMBL576070 & 787661 & 5.4123 & 4.665 & TRN & \\
\hline CHEMBL572024 & 787661 & 5.767 & 5.9462 & TRN & \\
\hline CHEMBL1917658 & 787661 & 3.0 & 3.1503 & TRN & \\
\hline CHEMBL1917669 & 787661 & 3.0 & 2.948 & TRN & \\
\hline CHEMBL1917659 & 787661 & 5.4145 & 5.169 & TRN & \\
\hline CHEMBL1917670 & 787661 & 3.0 & 3.5461 & TRN & \\
\hline CHEMBL1917832 & 787661 & 3.0 & 4.4624 & TST & \\
\hline CHEMBL572236 & 787661 & 3.0 & 2.9457 & TRN & \\
\hline CHEMBL1917836 & 787661 & 3.0 & 3.5518 & TST & \\
\hline CHEMBL1914493 & 787661 & 4.704 & 4.6425 & TST & \\
\hline CHEMBL583335 & 787661 & 4.7254 & 4.6788 & TRN & \\
\hline CHEMBL570510 & 787661 & 4.4145 & 4.1546 & TRN & \\
\hline CHEMBL570059 & 787661 & 5.3645 & 5.316 & TRN & \\
\hline
\end{tabular}




\begin{tabular}{|c|c|c|c|c|c|}
\hline & & \multicolumn{4}{|c|}{ Supplemental Table S2.txt } \\
\hline CHEMBL570466 & 787661 & 4.4438 & 4.5919 & TRN & \\
\hline CHEMBL569558 & 787661 & 3.0 & 3.7876 & TRN & \\
\hline CHEMBL1917657 & 787661 & 5.8996 & 5.5572 & TRN & \\
\hline CHEMBL571359 & 787661 & 5.0496 & 3.7876 & TRN & \\
\hline CHEMBL1917665 & 787661 & 3.0 & 3.2024 & TST & \\
\hline CHEMBL1917656 & 787661 & 4.8139 & 4.8443 & TRN & \\
\hline CHEMBL569557 & 787661 & 3.0 & 3.2414 & TRN & \\
\hline CHEMBL434024 & 68748 & 5.25 & 4.834 & TRN & \\
\hline CHEMBL56255 & 68748 & 4.39 & 4.2232 & TRN & \\
\hline CHEMBL55886 & 68748 & 4.68 & 3.7808 & TRN & \\
\hline CHEMBL299717 & 68748 & 4.46 & 4.0136 & TRN & \\
\hline CHEMBL 301247 & 68748 & 4.92 & 4.4456 & TRN & \\
\hline CHEMBL56011 & 68748 & 4.71 & 4.2788 & TRN & \\
\hline CHEMBL55959 & 68748 & 4.55 & 4.2617 & TRN & \\
\hline CHEMBL301065 & 68748 & 4.62 & 4.9035 & TRN & \\
\hline CHEMBL124324 & 68748 & 3.4 & 3.7078 & TST & \\
\hline CHEMBL56253 & 68748 & 4.33 & 4.3241 & TRN & \\
\hline CHEMBL55352 & 68748 & 4.08 & 3.335 & TRN & \\
\hline CHEMBL54926 & 68748 & 3.9 & 3.9445 & TRN & \\
\hline CHEMBL338622 & 68748 & 2.68 & 3.8435 & TST & \\
\hline CHEMBL127588 & 68748 & 2.05 & 2.9047 & TRN & \\
\hline CHEMBL412889 & 68748 & 3.96 & 4.3241 & TST & \\
\hline CHEMBL56556 & 68748 & 2.55 & 2.965 & TRN & \\
\hline CHEMBL291736 & 68748 & 4.81 & 5.2828 & TRN & \\
\hline CHEMBL54472 & 68748 & 4.89 & 3.7982 & TST & \\
\hline CHEMBL299988 & 68748 & 2.79 & 3.1155 & TRN & \\
\hline CHEMBL294191 & 68748 & 4.79 & 4.761 & TRN & \\
\hline CHEMBL54537 & 68748 & 3.92 & 3.9684 & TRN & \\
\hline CHEMBL293522 & 68748 & 3.04 & 3.8822 & TRN & \\
\hline CHEMBL124647 & 68748 & 4.2 & 3.8886 & TRN & \\
\hline CHEMBL331016 & 68748 & 4.17 & 3.7982 & TST & \\
\hline CHEMBL125029 & 68748 & 2.92 & 3.6659 & TST & \\
\hline CHEMBL55264 & 68748 & 2.68 & 3.1141 & TRN & \\
\hline CHEMBL125461 & 68748 & 4.63 & 3.5722 & TST & \\
\hline CHEMBL55140 & 68748 & 5.31 & 5.3572 & TRN & \\
\hline CHEMBL301244 & 68748 & 4.64 & 4.0116 & TRN & \\
\hline CHEMBL52137 & 68748 & 3.92 & 3.7982 & TST & \\
\hline CHEMBL 333503 & 68748 & 1.6 & 3.5396 & TRN & \\
\hline CHEMBL125887 & 68748 & 4.79 & 3.7577 & TRN & \\
\hline CHEMBL 316844 & 68748 & 3.85 & 4.2163 & TRN & \\
\hline CHEMBL54344 & 68748 & 2.54 & 3.1816 & TRN & \\
\hline CHEMBL55608 & 68748 & 4.89 & 4.3646 & TRN & \\
\hline CHEMBL125188 & 68748 & 3.96 & 2.989 & TRN & \\
\hline CHEMBL127801 & 68748 & 3.46 & 3.6865 & TST & \\
\hline CHEMBL127186 & 68748 & 2.78 & 3.6251 & TST & \\
\hline CHEMBL417932 & 68748 & 1.7 & 2.34099 & 99999999997 & TRN \\
\hline CHEMBL 340034 & 68748 & 5.14 & 3.7125 & TST & \\
\hline CHEMBL55358 & 68748 & 3.96 & 3.5798 & TRN & \\
\hline
\end{tabular}




\begin{tabular}{|c|c|c|c|c|c|}
\hline \multicolumn{6}{|c|}{ Supplemental Table s2.txt } \\
\hline CHEMBL 340090 & 68748 & 3.99 & 3.3349 & TRN & \\
\hline CHEMBL 299563 & 68748 & 3.22 & 3.1047 & TST & \\
\hline CHEMBL298771 & 68748 & 3.67 & 3.1952 & TRN & \\
\hline CHEMBL338917 & 68748 & 2.56 & 3.7333 & TST & \\
\hline CHEMBL55856 & 68748 & 4.33 & 4.1911 & TRN & \\
\hline CHEMBL417549 & 68748 & 3.77 & 4.032 & TRN & \\
\hline CHEMBL98110 & 68748 & 4.98 & 4.4265 & TRN & \\
\hline CHEMBL125706 & 68748 & 4.14 & 4.6229 & TRN & \\
\hline CHEMBL294192 & 68748 & 4.84 & 5.272 & TRN & \\
\hline CHEMBL124796 & 68748 & 4.17 & 5.0752 & TRN & \\
\hline CHEMBL55557 & 68748 & 4.84 & 4.9747 & TRN & \\
\hline CHEMBL58830 & 68748 & 4.26 & 4.2879 & TST & \\
\hline CHEMBL3896663 & 1527760 & 9.5229 & 9.3381 & TRN & \\
\hline CHEMBL 3953663 & 1527760 & 9.0 & 7.255 & TRN & \\
\hline CHEMBL3903203 & 1527760 & 7.7696 & 8.5631 & TRN & \\
\hline CHEMBL3954467 & 1527760 & 8.3979 & 8.6207 & TRN & \\
\hline CHEMBL3960074 & 1527760 & 9.301 & 9.0754 & TRN & \\
\hline CHEMBL3963036 & 1527760 & 7.1805 & 7.4004 & TRN & \\
\hline CHEMBL3974539 & 1527760 & 9.699 & 9.3826 & TRN & \\
\hline CHEMBL3956952 & 1527760 & 8.1549 & 8.2888 & TRN & \\
\hline CHEMBL3966623 & 1527760 & 7.1805 & 7.5771 & TRN & \\
\hline CHEMBL 3974451 & 1527760 & 9.0 & 8.1282 & TRN & \\
\hline CHEMBL3903454 & 1527760 & 6.1643 & 6.978 & TRN & \\
\hline CHEMBL 3986542 & 1527760 & 9.0 & 8.7587 & TST & \\
\hline CHEMBL3897857 & 1527760 & 8.3979 & 8.1282 & TRN & \\
\hline CHEMBL3980447 & 1527760 & 6.6498 & 7.6887 & TST & \\
\hline CHEMBL3955867 & 1527760 & 7.0809 & 7.0198 & TRN & \\
\hline CHEMBL3962680 & 1527760 & 6.71899 & 79999999ऽ & 7.7726 & TRN \\
\hline CHEMBL3949205 & 1527760 & 7.6778 & 8.2497 & TRN & \\
\hline CHEMBL3972541 & 1527760 & 7.699 & 9.0505 & TST & \\
\hline CHEMBL 3972286 & 1527760 & 7.7447 & 8.3159 & TST & \\
\hline CHEMBL3974006 & 1527760 & 7.6198 & 7.2594 & TRN & \\
\hline CHEMBL3932573 & 1527760 & 9.0 & 8.7448 & TRN & \\
\hline CHEMBL3969219 & 1527760 & 8.699 & 8.4083 & TRN & \\
\hline CHEMBL3945029 & 1527760 & 8.5229 & 7.83899 & 99999999995 & TRN \\
\hline CHEMBL 3900685 & 1527760 & 5.5253 & 5.58 & TRN & \\
\hline CHEMBL3900108 & 1527760 & 9.3979 & 8.7144 & TRN & \\
\hline CHEMBL3956633 & 1527760 & 6.8827 & 8.2669 & TRN & \\
\hline CHEMBL3918181 & 1527760 & 9.0 & 8.3971 & TRN & \\
\hline CHEMBL3674539 & 1527760 & 7.5528 & 8.502 & TRN & \\
\hline CHEMBL3947956 & 1527760 & 7.8539 & 7.3698 & TRN & \\
\hline CHEMBL 3674534 & 1527760 & 8.301 & 9.3093 & TST & \\
\hline CHEMBL3985612 & 1527760 & 7.1367 & 8.0354 & TRN & \\
\hline CHEMBL3986672 & 1527760 & 8.5229 & 8.7472 & TRN & \\
\hline CHEMBL3957672 & 1527760 & 8.0458 & 8.5526 & TRN & \\
\hline CHEMBL3929035 & 1527760 & 8.3979 & 8.1384 & TRN & \\
\hline CHEMBL3948292 & 1527760 & 6.9245 & 8.2289 & TST & \\
\hline CHEMBL3947111 & 1527760 & 7.1135 & 7.0341 & TST & \\
\hline
\end{tabular}


Supplemental Table S2.txt

\begin{tabular}{|c|c|c|c|c|}
\hline 19 & 527760 & 6.0306 & & \\
\hline & 527760 & 8.301 & & \\
\hline HFMRI & 27760 & 229 & & \\
\hline IEMBL & 27760 & 528 & 47 & \\
\hline AEMBL3982459 & 527760 & 6.6021 & 2174 & \\
\hline HEMBL3926022 & 527760 & 7.2147 & 5.4953 & \\
\hline 53 & 60 & 6.7986 & & \\
\hline AEMBL39 & 27760 & 9.0969 & & $\mathrm{M}$ \\
\hline HEMBL3981342 & 527760 & 8.5229 & 7.8369 & \\
\hline HEMBL3957109 & 527760 & 6.2291 & 5068 & \\
\hline HEMBL 397 & 60 & 8.5229 & 3733 & \\
\hline AEMBL3S & 60 & 7.9586 & 2431 & RN \\
\hline HEMBL3 & & 979 & 1336 & \\
\hline HEMBL3965678 & 527760 & 6.585 & 0305 & \\
\hline HEMBL3923620 & 60 & 458 & & זכה \\
\hline HEMBL3 & 0 & 8 . & 5647 & RIN \\
\hline HEMBL3 & $\theta$ & 979 & 303 & Niv \\
\hline HEMBL3 & 60 & 979 & 44 & \\
\hline HEMBL 390 & 60 & 9.0 & 6504 & \\
\hline HEMBL397 & & 7. & & IS \\
\hline HEMBL & $\theta$ & 7. & 084 & RI \\
\hline HEM & $\theta$ & & 832 & RN \\
\hline AEMBL & 60 & 29 & 945 & IST \\
\hline HEMBL3 & & & 352 & $|S|$ \\
\hline HEMBL398 & & 8. & 505 & ISI \\
\hline HEMBL3 & 50 & 7. & 69 & IST \\
\hline HEMBL & 50 & 9. & 55 & RN \\
\hline 47 & & 7. & 02 & TST \\
\hline HEMBL 396 & & & & IRIN \\
\hline HEMBL3947981 & & 9. & 942 & זRN \\
\hline HEMBL3 & & & 69 & TRN \\
\hline HFM & 0 & & & TST \\
\hline (IFMP & & & & TRN \\
\hline HEMBL 389 & & & & 「RN \\
\hline HEMBL39281€ & 50 & 6.7328 & 269 & ГRN \\
\hline JIMDI 2 & & 5 & 09 & ГST \\
\hline 1 & 0 & & & TRN \\
\hline HEMBL3 & & & 302 & TRN \\
\hline HEMBL 389 & 50 & 7. & 713 & TR \\
\hline LTIDL $>>+2$ & & & & IST \\
\hline HEMRI 3 & & 7. & 37 & 「RN \\
\hline HEMBL3 & 60 & 8.2218 & 768 & TRN \\
\hline HEMBL392 & 760 & 5.6103 & 3814 & TRN \\
\hline HEMBL 237 & 3 & 7. & 879 & TR \\
\hline CHEMPI 2511 & & & & RN \\
\hline HEMBL3 & & 7.29 & 4129 & \\
\hline HEMBL42: & 159043 & 6.1 & 3605 & RN \\
\hline CHEMBL192490 & 459043 & 5.72 & 5.5966 & $\mathrm{I}$ \\
\hline
\end{tabular}

Page 8243 


\begin{tabular}{|c|c|c|c|c|c|}
\hline \multirow{3}{*}{$\begin{array}{l}\text { CHEMBL } 235608 \\
\text { CHEMBL } 251090\end{array}$} & \multirow{3}{*}{$\begin{array}{l}459043 \\
459043\end{array}$} & \multicolumn{4}{|c|}{ Supplemental Table s2.txt } \\
\hline & & 7.45 & \multicolumn{2}{|c|}{7.8629999999999995} & TRN \\
\hline & & 8.02 & 8.1205 & TRN & \\
\hline CHEMBL236863 & 459043 & 7.12 & 7.2554 & TRN & \\
\hline CHEMBL236436 & 459043 & 9.11 & 9.1113 & TRN & \\
\hline CHEMBL442082 & 459043 & 7.68 & 7.965 & TRN & \\
\hline CHEMBL442280 & 459043 & 8.49 & 8.4998 & TRN & \\
\hline CHEMBL235788 & 459043 & 8.54 & 7.9859 & TRN & \\
\hline CHEMBL289965 & 459043 & 8.68 & 8.6022 & TRN & \\
\hline CHEMBL41314 & 459043 & 9.96 & 10.4454 & TST & \\
\hline CHEMBL418432 & 459043 & 9.82 & 10.0459 & TRN & \\
\hline CHEMBL40738 & 459043 & 7.68 & 7.8075 & TRN & \\
\hline CHEMBL289343 & 459043 & 10.6 & \multicolumn{2}{|c|}{10.745999999999999} & TRN \\
\hline CHEMBL203555 & 459043 & 7.82 & 7.2872 & TST & \\
\hline CHEMBL250880 & 459043 & 7.82 & 7.3222 & TRN & \\
\hline CHEMBL401392 & 459043 & 8.07 & 8.3603 & TST & \\
\hline CHEMBL203777 & 459043 & 10.22 & 10.2083 & TRN & \\
\hline CHEMBL425939 & 459043 & 9.55 & 9.6999 & TRN & \\
\hline CHEMBL202336 & 459043 & 7.35 & 7.1696 & TST & \\
\hline CHEMBL204609 & 459043 & 7.8 & 7.2747 & TST & \\
\hline CHEMBL205171 & 459043 & 7.33 & 7.0143 & TST & \\
\hline CHEMBL202940 & 459043 & 7.74 & 7.2832 & TST & \\
\hline CHEMBL202521 & 459043 & 6.85 & 6.8174 & TST & \\
\hline CHEMBL195556 & 459043 & 6.44 & 6.4262 & TST & \\
\hline CHEMBL193152 & 459043 & 5.24 & 5.5855 & TST & \\
\hline CHEMBL192508 & 459043 & 5.74 & 5.9977 & TST & \\
\hline CHEMBL195855 & 459043 & 5.74 & 6.1851 & TST & \\
\hline CHEMBL252717 & 459043 & 6.72 & 6.6336 & TST & \\
\hline CHEMBL253123 & 459043 & 6.11 & 6.3162 & TST & \\
\hline CHEMBL192426 & 459043 & 6.09 & 6.6846 & TST & \\
\hline CHEMBL192639 & 459043 & 5.82 & 6.0069 & TST & \\
\hline CHEMBL236864 & 459043 & 7.06 & 7.0674 & TRN & \\
\hline CHEMBL235385 & 459043 & 7.33 & 7.409 & TRN & \\
\hline CHEMBL237721 & 459043 & 6.86 & 6.8097 & TRN & \\
\hline CHEMBL235177 & 459043 & 9.33 & 8.9609 & TRN & \\
\hline CHEMBL235166 & 459043 & 7.08 & \multicolumn{2}{|c|}{7.3420000000000005} & TRN \\
\hline CHEMBL249445 & 459043 & 8.38 & 8.8717 & TRN & \\
\hline CHEMBL392925 & 459043 & 8.07 & 7.8244 & TRN & \\
\hline CHEMBL235607 & 459043 & 8.22 & 7.8547 & TRN & \\
\hline CHEMBL39174 & 459043 & 10.02 & 9.8929 & TRN & \\
\hline CHEMBL394644 & 459043 & 7.96 & 7.7734 & TRN & \\
\hline CHEMBL238178 & 459043 & 8.31 & 8.1032 & TRN & \\
\hline CHEMBL429078 & 459043 & 7.74 & 7.9528 & TRN & \\
\hline CHEMBL393489 & 459043 & 8.4 & 8.6009 & TRN & \\
\hline CHEMBL238179 & 459043 & 7.17 & 7.1448 & TRN & \\
\hline CHEMBL235384 & 459043 & 8.96 & \multicolumn{2}{|c|}{8.527000000000001} & TRN \\
\hline CHEMBL251456 & 459043 & 9.7 & 9.4349 & TRN & \\
\hline CHEMBL237958 & 459043 & 7.43 & 7.6499 & TRN & \\
\hline CHEMBL235383 & 459043 & 8.12 & 7.7813 & TRN & \\
\hline
\end{tabular}




\begin{tabular}{|c|c|c|c|c|}
\hline \multicolumn{5}{|c|}{ Supplemental Table S2.txt } \\
\hline CHEMBL442243 & 459043 & 9.07 & 9.0323 & TRN \\
\hline CHEMBL 235165 & 459043 & 8.22 & 8.1603 & TRN \\
\hline CHEMBL 254607 & 459043 & 8.46 & 8.7732 & TRN \\
\hline CHEMBL 236438 & 459043 & 8.47 & 8.5982 & TRN \\
\hline CHEMBL235609 & 459043 & 9.21 & 8.9589 & TRN \\
\hline CHEMBL 237722 & 459043 & 7.39 & 7.2071 & TRN \\
\hline CHEMBL41036 & 459043 & 8.96 & 8.8418 & TRN \\
\hline CHEMBL235816 & 459043 & 8.17 & 8.0009 & TRN \\
\hline CHEMBL 236648 & 459043 & 7.3 & 7.2218 & TRN \\
\hline CHEMBL235164 & 459043 & 7.55 & 7.1937 & TRN \\
\hline CHEMBL394199 & 459043 & 7.22 & 7.5611 & TRN \\
\hline CHEMBL428729 & 459043 & 6.91 & 7.0653 & TRN \\
\hline CHEMBL83215 & 158893 & 4.7212 & 5.0348 & TRN \\
\hline CHEMBL 76215 & 158893 & 7.1079 & 7.1959 & TRN \\
\hline CHEMBL83111 & 158893 & 7.284 & 7.4406 & TST \\
\hline CHEMBL315971 & 158893 & 5.301 & 5.4022 & TRN \\
\hline CHEMBL83127 & 158893 & 7.3665 & 7.4821 & TRN \\
\hline CHEMBL433145 & 158893 & 6.9586 & 7.0074 & TRN \\
\hline CHEMBL83212 & 158893 & 4.8239 & 5.2622 & TRN \\
\hline CHEMBL310772 & 158893 & 7.1739 & 7.5506 & TST \\
\hline CHEMBL86076 & 158893 & 7.3565 & 7.2437 & TRN \\
\hline CHEMBL316145 & 158893 & 7.0458 & 7.0638 & TST \\
\hline CHEMBL84324 & 158893 & 6.1249 & 6.1253 & TRN \\
\hline CHEMBL 311980 & 158893 & 6.699 & 6.6357 & TRN \\
\hline CHEMBL81890 & 158893 & 2.0969 & 5.6827 & TST \\
\hline CHEMBL 313708 & 158893 & 7.4949 & 7.2966 & TRN \\
\hline CHEMBL314165 & 158893 & 7.1079 & 7.1325 & TRN \\
\hline CHEMBL 278678 & 158893 & 4.1739 & 4.7704 & TRN \\
\hline CHEMBL83631 & 158893 & 7.5376 & 7.6581 & TRN \\
\hline CHEMBL84082 & 158893 & 6.9586 & 7.0971 & TRN \\
\hline CHEMBL313477 & 158893 & 6.7212 & 6.8477 & TRN \\
\hline CHEMBL84256 & 158893 & 5.4685 & 5.5504 & TRN \\
\hline CHEMBL441995 & 158893 & 6.8539 & 7.1987 & TST \\
\hline CHEMBL 315775 & 158893 & 7.1367 & 7.2114 & TRN \\
\hline CHEMBL 314390 & 158893 & 7.1739 & 7.0427 & TRN \\
\hline CHEMBL 309468 & 158893 & 4.1675 & 5.7664 & TST \\
\hline CHEMBL81955 & 158893 & 7.5229 & 7.4257 & TRN \\
\hline CHEMBL421721 & 158893 & 5.6021 & 5.5443 & TRN \\
\hline CHEMBL432365 & 158893 & 5.9208 & 5.6586 & TRN \\
\hline CHEMBL83439 & 158893 & 5.4437 & 5.4536 & TRN \\
\hline CHEMBL 3142487 & 158893 & 6.0 & 5.1371 & TRN \\
\hline CHEMBL313932 & 158893 & 7.3098 & 7.4596 & TRN \\
\hline CHEMBL313625 & 158893 & 6.0605 & 6.1184 & TRN \\
\hline CHEMBL316411 & 158893 & 6.6021 & 6.5637 & TRN \\
\hline CHEMBL82748 & 158893 & 4.6576 & 5.9684 & TST \\
\hline CHEMBL83149 & 158893 & 6.8861 & 7.1237 & TRN \\
\hline CHEMBL83839 & 158893 & 7.0458 & 6.9448 & TRN \\
\hline CHEMBL310992 & 158893 & 7.585 & 7.5415 & TST \\
\hline
\end{tabular}




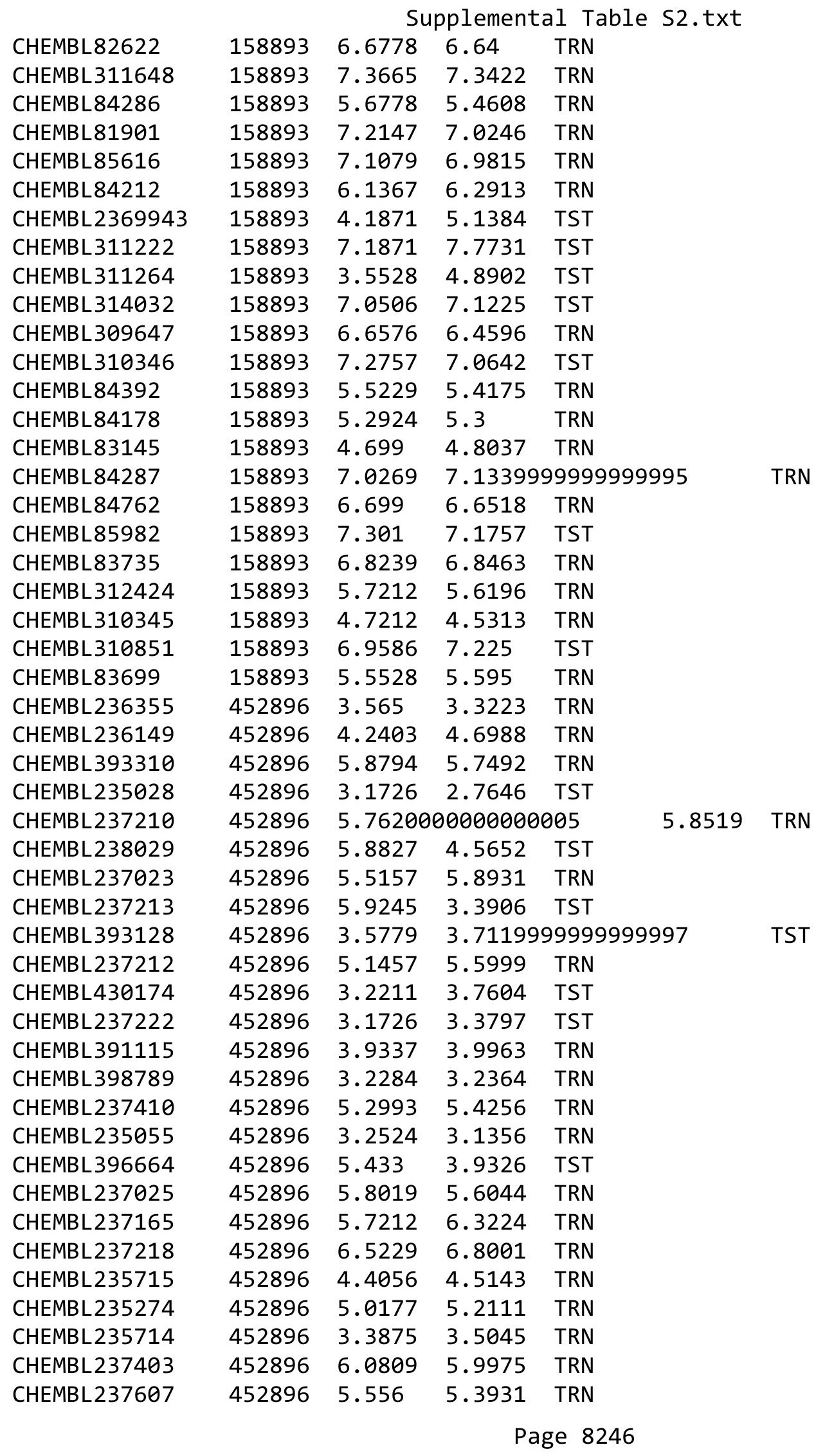




\begin{tabular}{|c|c|c|c|c|}
\hline & & & & \\
\hline CHEMBL400222 & 452896 & 5.0635 & 4.5084 & TST \\
\hline CHEMBL237029 & 452896 & 5.8386 & 5.4191 & \\
\hline CHEMBL391222 & 452896 & 5.8097 & 9559 & \\
\hline CHEMBL398807 & 452896 & 5.4145 & 7479 & \\
\hline CHEMBL398992 & 452896 & 5.0467 & 3403 & \\
\hline HEMBL 235936 & 52896 & 3.9477 & 3.7969 & \\
\hline CHEMBL237603 & 452896 & 3.2325 & 3.6782 & \\
\hline HEMBL235901 & 452896 & 3.2264 & 4425 & \\
\hline CHEMBL237027 & 452896 & 6.6198 & 6.4223 & \\
\hline CHEMBL235053 & 452896 & 3.2385 & 507 & \\
\hline HEMBL235705 & 452896 & 3.9658 & 169 & \\
\hline CHEMBL237215 & 452896 & 6.1308 & 573 & \\
\hline CHEMBL393311 & 452896 & 5.8697 & 3364 & \\
\hline CHEMBL237609 & 452896 & 3.1784 & 226 & \\
\hline CHEMBL237026 & 452896 & 5.4248 & 636 & \\
\hline CHEMBL2 & 45 & 6.3565 & & \\
\hline CHEMBL & 45 & 549 & 724 & \\
\hline CHEMBL237411 & 452896 & 5.1979 & 319 & \\
\hline CHEMBL391114 & 45 & 5.4437 & 28 & \\
\hline CHEMBL2 & 452 & 3.2528 & & \\
\hline CHEMBL 2 & 45 & 6.8861 & 398 & \\
\hline CHEMBL 2 & 45 & 548 & 61 & \\
\hline CHEMBL235099 & 452896 & 6.1871 & 773 & \\
\hline CHEMBL237030 & 45 & 5.8761 & 538 & \\
\hline CHEMBL237599 & 452896 & 4.4743 & 746 & \\
\hline CHEMBL3 & 45 & 716 & L33 & \\
\hline CHEMBL 4 & 45 & 648 & 59 & \\
\hline HEMBL237604 & 452896 & 5.5214 & & \\
\hline CHEMBL237032 & 452896 & 3.0976 & 3.5712 & 15 \\
\hline CHEMBL 238244 & 452896 & 5.3788 & 293 & ונ \\
\hline CHEMBL 2 & 45 & 768 & 57 & \\
\hline CHEMBL3 & 1278263 & 4.89 & 83 & . \\
\hline CHEMBL 3094020 & 1278263 & 4.41 & 045 & S \\
\hline CHEMBL3094019 & 1278263 & 6.3 & 6.3026 & $\mathrm{TF}$ \\
\hline CHEMBL 3094018 & 8263 & 7.47 & 964 & 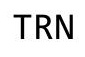 \\
\hline CHEMBL3 & 263 & 8.05 & 16 & \\
\hline CHEMBL 3094016 & 1278263 & 8.48 & 8.3923 & RA \\
\hline CHEMBL3094015 & 1278263 & 5.74 & 5.7407 & TRI \\
\hline CHEMBL3091489 & 1278263 & 7.57 & 329 & $T$ \\
\hline CHEMBL & 263 & & & $\mathrm{R}$ \\
\hline CHEMBL3094011 & 1278263 & 7.41 & 998 & ח \\
\hline CHEMBL 3094010 & 1278263 & 5.01 & 5.0193 & TRI \\
\hline CHEMBL3094009 & 1278263 & 5.11 & 161 & TR \\
\hline CHEMBL 3094008 & 1278263 & 7.55 & 303 & 7 \\
\hline CHEMBL 3094007 & 1278263 & 8.06 & 8.0478 & $\mathbf{n}$ \\
\hline CHEMBL3094006 & 1278263 & 5.39 & 5.3471 & r \\
\hline CHEMBL 3094005 & 1278263 & 7.34 & 7.3708 & $\mathrm{TR}$ \\
\hline CHEMBL3094004 & 1278263 & 6.5 & 6.5059 & $r R$ \\
\hline
\end{tabular}




\begin{tabular}{|c|c|c|c|c|}
\hline \multicolumn{5}{|c|}{ Supplemental Table S2.txt } \\
\hline CHEMBL 3094003 & 1278263 & 7.0 & 6.9916 & TRN \\
\hline CHEMBL3094002 & 1278263 & 4.61 & 4.5753 & TRN \\
\hline CHEMBL3094001 & 1278263 & 7.13 & 7.0793 & TRN \\
\hline CHEMBL 3094000 & 1278263 & 7.21 & 7.1833 & TRN \\
\hline CHEMBL3093999 & 1278263 & 6.39 & 6.4591 & TRN \\
\hline CHEMBL3093998 & 1278263 & 6.24 & 6.1853 & TRN \\
\hline CHEMBL3093997 & 1278263 & 6.9 & 6.9834 & TRN \\
\hline CHEMBL3093996 & 1278263 & 6.94 & 7.0524 & TRN \\
\hline CHEMBL3093995 & 1278263 & 6.58 & 6.4609 & TRN \\
\hline CHEMBL3093994 & 1278263 & 6.12 & 6.1297 & TRN \\
\hline CHEMBL3093993 & 1278263 & 8.24 & 8.1305 & TRN \\
\hline CHEMBL3093992 & 1278263 & 8.11 & 8.1308 & TRN \\
\hline CHEMBL3093991 & 1278263 & 7.44 & 7.4642 & TRN \\
\hline CHEMBL 3093990 & 1278263 & 7.0 & 7.075 & TRN \\
\hline CHEMBL3093989 & 1278263 & 5.64 & 5.6611 & TRN \\
\hline CHEMBL3094134 & 1278263 & 5.77 & 5.7553 & TRN \\
\hline CHEMBL574860 & 1278263 & 5.95 & 5.9791 & TRN \\
\hline CHEMBL 3094133 & 1278263 & 6.35 & 6.3738 & TRN \\
\hline CHEMBL 3094132 & 1278263 & 6.69 & 6.6698 & TRN \\
\hline CHEMBL3094131 & 1278263 & 7.96 & 7.8832 & TRN \\
\hline CHEMBL 239507 & 1278263 & 7.89 & 7.9668 & TRN \\
\hline CHEMBL572534 & 1278263 & 7.82 & 7.7877 & TRN \\
\hline CHEMBL577616 & 1278263 & 7.4 & 7.4018 & TRN \\
\hline CHEMBL575931 & 1278263 & 7.62 & 7.5985 & TRN \\
\hline CHEMBL575738 & 1278263 & 7.52 & 7.5101 & TRN \\
\hline CHEMBL575093 & 1278263 & 7.8 & 7.8115 & TRN \\
\hline CHEMBL3094039 & 1278263 & 7.11 & 4.7511 & TST \\
\hline CHEMBL 3094038 & 1278263 & 7.85 & 7.9013 & TRN \\
\hline CHEMBL3094037 & 1278263 & 8.28 & 8.241 & TRN \\
\hline CHEMBL3094036 & 1278263 & 6.66 & 6.6874 & TRN \\
\hline CHEMBL3094035 & 1278263 & 6.99 & 7.7044 & TST \\
\hline CHEMBL 3094034 & 1278263 & 6.63 & 6.608 & TRN \\
\hline CHEMBL 3094033 & 1278263 & 6.38 & 6.3743 & TRN \\
\hline CHEMBL 3094031 & 1278263 & 7.4 & 7.4635 & TRN \\
\hline CHEMBL239508 & 1278263 & 7.28 & 7.2558 & TRN \\
\hline CHEMBL3094030 & 1278263 & 7.32 & 7.1757 & TST \\
\hline CHEMBL3094029 & 1278263 & 6.31 & 7.5123 & TST \\
\hline CHEMBL 3094028 & 1278263 & 6.32 & 7.7211 & TST \\
\hline CHEMBL 3094027 & 1278263 & 5.68 & 6.932 & TST \\
\hline CHEMBL141326 & 1278263 & 5.04 & 6.579 & TST \\
\hline CHEMBL3094026 & 1278263 & 6.68 & 7.3633 & TST \\
\hline CHEMBL3094025 & 1278263 & 7.36 & 7.5405 & TST \\
\hline CHEMBL3094024 & 1278263 & 7.68 & 7.4952 & TST \\
\hline CHEMBL 3094023 & 1278263 & 6.06 & 5.6992 & TST \\
\hline CHEMBL 3094022 & 1278263 & 7.54 & 7.4234 & TST \\
\hline CHEMBL575934 & 1278263 & 8.13 & 7.086 & TST \\
\hline CHEMBL3094021 & 1278263 & 7.77 & 7.7901 & TST \\
\hline CHEMBL 262887 & 478840 & 8.1192 & 6.4141 & TST \\
\hline
\end{tabular}




\begin{tabular}{|c|c|c|c|c|c|}
\hline \multicolumn{6}{|c|}{ Supplemental Table s2.txt } \\
\hline CHEMBL260272 & 478840 & 5.8136 & 5.5609 & TST & \\
\hline CHEMBL411429 & 478840 & 7.6021 & 7.0637 & TRN & \\
\hline CHEMBL410423 & 478840 & 6.4486 & 6.3423 & TRN & \\
\hline CHEMBL263144 & 478840 & 6.2248 & 6.32299 & 99999999995 & TRN \\
\hline CHEMBL258477 & 478840 & 7.6778 & 7.0801 & TRN & \\
\hline CHEMBL263662 & 478840 & 7.2596 & 7.5217 & TRN & \\
\hline CHEMBL260241 & 478840 & 7.0506 & 7.046 & TRN & \\
\hline CHEMBL259940 & 478840 & 8.4202 & 6.375 & TST & \\
\hline CHEMBL259454 & 478840 & 7.699 & 7.6139 & TRN & \\
\hline CHEMBL261316 & 478840 & 6.5735 & 6.1583 & TRN & \\
\hline CHEMBL260215 & 478840 & 7.4202 & 6.9989 & TRN & \\
\hline CHEMBL264143 & 478840 & 5.7799 & 5.8932 & TRN & \\
\hline CHEMBL409332 & 478840 & 5.0505 & 4.6587 & TRN & \\
\hline CHEMBL261467 & 478840 & 4.9345 & 4.8586 & TRN & \\
\hline CHEMBL261689 & 478840 & 6.1475 & 6.1056 & TRN & \\
\hline CHEMBL260927 & 478840 & 6.6326 & 6.5808 & TRN & \\
\hline CHEMBL262100 & 478840 & 5.3839 & 5.1916 & TRN & \\
\hline CHEMBL428261 & 478840 & 5.8392 & 5.7418 & TRN & \\
\hline CHEMBL263408 & 478840 & 5.8735 & 6.4128 & TST & \\
\hline CHEMBL258751 & 478840 & 6.1537 & 6.2344 & TRN & \\
\hline CHEMBL409310 & 478840 & 6.1267 & 6.1987 & TRN & \\
\hline CHEMBL264403 & 478840 & 5.5621 & 5.6731 & TRN & \\
\hline CHEMBL411521 & 478840 & 5.6503 & 6.2756 & TST & \\
\hline CHEMBL260672 & 478840 & 6.0 & 6.7037 & TRN & \\
\hline CHEMBL409632 & 478840 & 5.8222 & 5.8499 & TRN & \\
\hline CHEMBL261847 & 478840 & 7.4318 & 7.3139 & TRN & \\
\hline CHEMBL411856 & 478840 & 6.0177 & 6.2706 & TRN & \\
\hline CHEMBL259286 & 478840 & 5.7547 & 6.2815 & TRN & \\
\hline CHEMBL261764 & 478840 & 6.8125 & 7.0612 & TRN & \\
\hline CHEMBL259453 & 478840 & 3.5229 & 3.8903 & TRN & \\
\hline CHEMBL409096 & 478840 & 7.2924 & 6.0584 & TST & \\
\hline CHEMBL409742 & 478840 & 5.3308 & 4.6175 & TRN & \\
\hline CHEMBL412152 & 478840 & 6.9393 & 6.7665 & TRN & \\
\hline CHEMBL261624 & 478840 & 6.6737 & 6.6245 & TST & \\
\hline CHEMBL261468 & 478840 & 6.1141 & 5.8433 & TRN & \\
\hline CHEMBL410333 & 478840 & 6.0 & 6.2848 & TRN & \\
\hline CHEMBL259519 & 478840 & 6.0 & 6.5083 & TRN & \\
\hline CHEMBL264142 & 478840 & 5.3794 & 5.7552 & TRN & \\
\hline CHEMBL261435 & 478840 & 5.1183 & 5.4528 & TRN & \\
\hline CHEMBL411953 & 478840 & 7.6198 & 7.5999 & TRN & \\
\hline CHEMBL258856 & 478840 & 7.0177 & 7.2137 & TRN & \\
\hline CHEMBL263145 & 478840 & 7.3665 & 7.262006 & 00000000005 & TRN \\
\hline CHEMBL261763 & 478840 & 5.4169 & 5.5453 & TST & \\
\hline CHEMBL260026 & 478840 & 6.3036 & 6.8153 & TST & \\
\hline CHEMBL411535 & 478840 & 6.3585 & 6.3075 & TRN & \\
\hline CHEMBL261675 & 478840 & 7.4437 & 6.8569 & TRN & \\
\hline CHEMBL411308 & 478840 & 7.9208 & 6.0986 & TST & \\
\hline CHEMBL411513 & 478840 & 8.2757 & 6.3455 & TST & \\
\hline
\end{tabular}




\begin{tabular}{|c|c|c|c|c|c|}
\hline \multicolumn{6}{|c|}{ Supplemental Table S2.txt } \\
\hline CHEMBL259521 & 478840 & 5.8861 & 5.9901 & TRN & \\
\hline CHEMBL259298 & 478840 & 6.0 & 6.3708 & TRN & \\
\hline CHEMBL411430 & 478840 & 6.8447 & 6.8628 & TRN & \\
\hline CHEMBL259285 & 478840 & 6.1203 & 6.3395 & TST & \\
\hline CHEMBL438208 & 478840 & 6.4976 & 6.6629 & TST & \\
\hline CHEMBL259506 & 478840 & 3.5229 & 5.6368 & TST & \\
\hline CHEMBL1817751 & 763493 & 4.0 & 4.6032 & TRN & \\
\hline CHEMBL1817701 & 763493 & 4.0 & 4.0757 & TRN & \\
\hline CHEMBL1817758 & 763493 & 6.0132 & 4.4222 & TST & \\
\hline CHEMBL1819543 & 763493 & 8.041 & 6.3791 & TRN & \\
\hline CHEMBL1817698 & 763493 & 4.0 & 3.9652 & TRN & \\
\hline CHEMBL1817767 & 763493 & 4.0 & 3.2976 & TST & \\
\hline CHEMBL1817697 & 763493 & 4.0 & 4.0365 & TRN & \\
\hline CHEMBL1819559 & 763493 & 4.0 & 3.6628 & TRN & \\
\hline CHEMBL1817671 & 763493 & 4.0 & 4.667 & TRN & \\
\hline CHEMBL1817771 & 763493 & 4.0 & 3.02 & TRN & \\
\hline CHEMBL1819551 & 763493 & 4.0 & 3.4988 & TRN & \\
\hline CHEMBL1817706 & 763493 & 7.4949 & 7.0628 & TRN & \\
\hline CHEMBL1817769 & 763493 & 4.0 & 3.2877 & TRN & \\
\hline CHEMBL1817690 & 763493 & 4.0 & 3.9556 & TRN & \\
\hline CHEMBL1817760 & 763493 & 4.0 & 2.7483 & TST & \\
\hline CHEMBL1817693 & 763493 & 4.0 & 3.5621 & TRN & \\
\hline CHEMBL1819540 & 763493 & 4.0 & 3.75699 & 99999999997 & TRN \\
\hline CHEMBL1817708 & 763493 & 7.3565 & 7.2513 & TRN & \\
\hline CHEMBL1817756 & 763493 & 6.585 & 6.1241 & TST & \\
\hline CHEMBL1817757 & 763493 & 4.0 & 3.0466 & TST & \\
\hline CHEMBL1817764 & 763493 & 4.0 & 3.6564 & TRN & \\
\hline CHEMBL1819557 & 763493 & 4.0 & 4.2234 & TRN & \\
\hline CHEMBL1817761 & 763493 & 6.9586 & 6.2098 & TST & \\
\hline CHEMBL1817704 & 763493 & 7.4815 & 7.315 & TRN & \\
\hline CHEMBL1819555 & 763493 & 4.0 & 5.3212 & TRN & \\
\hline CHEMBL1817703 & 763493 & 4.0 & 4.3735 & TRN & \\
\hline CHEMBL1817705 & 763493 & 7.7959 & 7.0832 & TRN & \\
\hline CHEMBL1817752 & 763493 & 6.9586 & 5.6302 & TRN & \\
\hline CHEMBL1819441 & 763493 & 4.0 & 4.1214 & TRN & \\
\hline CHEMBL1817750 & 763493 & 4.0 & 4.3329 & TRN & \\
\hline CHEMBL1819553 & 763493 & 4.0 & 4.2476 & TRN & \\
\hline CHEMBL1819549 & 763493 & 7.5229 & 6.1876 & TRN & \\
\hline CHEMBL1817759 & 763493 & 6.1079 & 3.5459 & TST & \\
\hline CHEMBL1817696 & 763493 & 4.0 & 3.8398 & TRN & \\
\hline CHEMBL1817772 & 763493 & 4.0 & 3.5516 & TRN & \\
\hline CHEMBL1817707 & 763493 & 7.4949 & 6.8936 & TRN & \\
\hline CHEMBL1817754 & 763493 & 4.0 & 4.9926 & TRN & \\
\hline CHEMBL1819545 & 763493 & 4.0 & 3.7241 & TRN & \\
\hline CHEMBL1819541 & 763493 & 8.4815 & 8.5573 & TRN & \\
\hline CHEMBL1819560 & 763493 & 4.0 & 3.8546 & TRN & \\
\hline CHEMBL1817702 & 763493 & 4.0 & 4.4211 & TRN & \\
\hline CHEMBL1817770 & 763493 & 4.0 & 4.9415 & TRN & \\
\hline
\end{tabular}




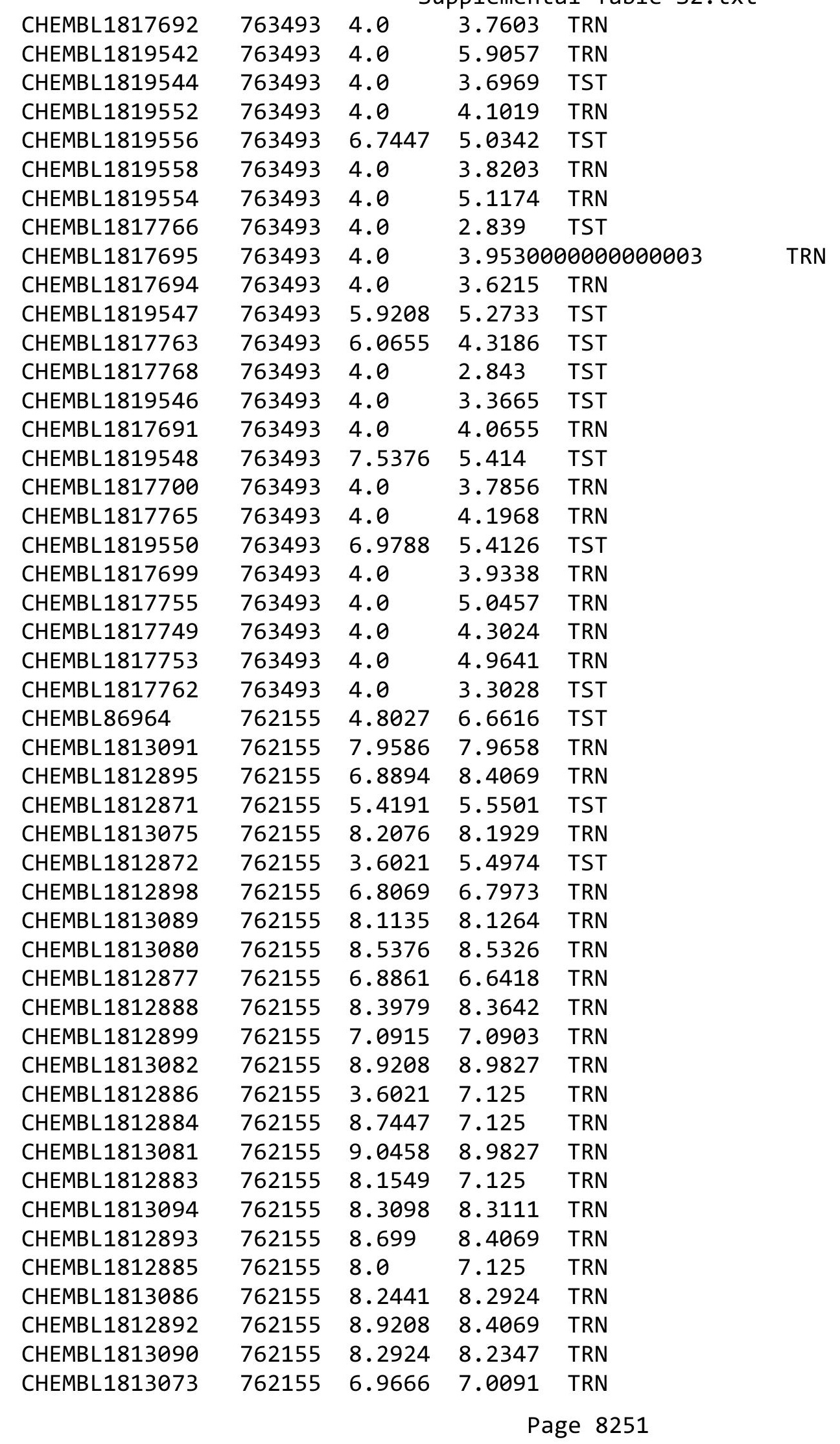




\begin{tabular}{|c|c|c|c|c|}
\hline \multicolumn{5}{|c|}{ Supplemental Table S2.txt } \\
\hline CHEMBL1812882 & 762155 & 7.7447 & 7.7309 & TRN \\
\hline CHEMBL1813087 & 762155 & 7.9586 & 7.928 & TRN \\
\hline CHEMBL1812897 & 762155 & 7.0655 & 7.0553 & TRN \\
\hline CHEMBL1813078 & 762155 & 8.6576 & 8.639 & TRN \\
\hline CHEMBL1813076 & 762155 & 8.585 & 8.6016 & TRN \\
\hline CHEMBL1812891 & 762155 & 8.9586 & 8.4069 & TRN \\
\hline CHEMBL1812896 & 762155 & 8.4559 & 8.455 & TRN \\
\hline CHEMBL1811930 & 762155 & 5.1096 & 5.5922 & TST \\
\hline CHEMBL 85537 & 762155 & 5.2111 & 6.6906 & TST \\
\hline CHEMBL1812870 & 762155 & 4.8652 & 5.8962 & TST \\
\hline CHEMBL1812894 & 762155 & 8.5376 & 8.4069 & TRN \\
\hline CHEMBL1813085 & 762155 & 8.3188 & 8.3189 & TRN \\
\hline CHEMBL1813084 & 762155 & 8.5376 & 8.5592 & TRN \\
\hline CHEMBL1812878 & 762155 & 6.3979 & 6.6418 & TRN \\
\hline CHEMBL1812875 & 762155 & 5.7986 & 5.8031 & TRN \\
\hline CHEMBL1812890 & 762155 & 8.8861 & 8.8926 & TRN \\
\hline CHEMBL1813093 & 762155 & 8.1739 & 8.1805 & TRN \\
\hline CHEMBL1812881 & 762155 & 6.6383 & 6.6336 & TRN \\
\hline CHEMBL1813092 & 762155 & 7.7375 & 7.7383 & TRN \\
\hline CHEMBL1813083 & 762155 & 8.5528 & 8.5592 & TRN \\
\hline CHEMBL1812873 & 762155 & 3.6021 & 5.5626 & TST \\
\hline CHEMBL1813077 & 762155 & 8.7447 & 8.639 & TST \\
\hline CHEMBL1813088 & 762155 & 8.2147 & 8.5903 & TST \\
\hline CHEMBL1812876 & 762155 & 6.3468 & 6.6418 & TST \\
\hline CHEMBL1812889 & 762155 & 8.5686 & 8.3642 & TST \\
\hline CHEMBL1813079 & 762155 & 7.9208 & 8.639 & TST \\
\hline CHEMBL1812887 & 762155 & 5.0899 & 6.5675 & TST \\
\hline CHEMBL3659205 & 1528624 & 7.1549 & 7.1735 & TRN \\
\hline CHEMBL 3659207 & 1528624 & 6.9208 & 7.0181 & TRN \\
\hline CHEMBL3659201 & 1528624 & 7.6778 & 7.6548 & TRN \\
\hline CHEMBL 3663403 & 1528624 & 7.1192 & 6.8649 & TRN \\
\hline CHEMBL3659240 & 1528624 & 6.7905 & 6.5094 & TST \\
\hline CHEMBL3663514 & 1528624 & 7.585 & 7.5692 & TRN \\
\hline CHEMBL3659209 & 1528624 & 5.301 & 5.6129 & TST \\
\hline CHEMBL 3659187 & 1528624 & 7.9208 & 7.9299 & TRN \\
\hline CHEMBL3663528 & 1528624 & 7.3372 & 7.2982 & TST \\
\hline CHEMBL3659212 & 1528624 & 6.6536 & 6.4797 & TST \\
\hline CHEMBL3663498 & 1528624 & 7.6021 & 7.7675 & TRN \\
\hline CHEMBL 3659178 & 1528624 & 6.0 & 6.0977 & TRN \\
\hline CHEMBL3659214 & 1528624 & 7.0862 & 6.7244 & TST \\
\hline CHEMBL3663454 & 1528624 & 5.0 & 5.0049 & TRN \\
\hline CHEMBL 3663544 & 1528624 & 8.0 & 8.1292 & TRN \\
\hline CHEMBL3663571 & 1528624 & 7.7212 & 7.5262 & TRN \\
\hline CHEMBL3659206 & 1528624 & 6.0 & 6.277 & TRN \\
\hline CHEMBL3663419 & 1528624 & 7.1079 & 7.2723 & TRN \\
\hline CHEMBL 3663438 & 1528624 & 5.8239 & 5.9541 & TRN \\
\hline CHEMBL 3659200 & 1528624 & 7.4815 & 7.2233 & TRN \\
\hline CHEMBL 3663452 & 1528624 & 6.6576 & 6.3968 & TST \\
\hline
\end{tabular}


Supplemental Table S2.txt

\begin{tabular}{|c|c|c|c|c|}
\hline CHEMBL 3663401 & 1528624 & 6.699 & 6.5768 & TRN \\
\hline CHEMBL 3663421 & 1528624 & 7.0862 & 7.0343 & TRN \\
\hline CHEMBL3663536 & 1528624 & 7.5686 & 7.5783 & TRN \\
\hline CHEMBL 3659177 & 1528624 & 6.0 & 7.0522 & TRN \\
\hline CHEMBL 3663432 & 1528624 & 5.2441 & 5.2614 & TRN \\
\hline CHEMBL 3663575 & 1528624 & 7.8239 & 7.6386 & TRN \\
\hline CHEMBL 3659186 & 1528624 & 7.3872 & 7.419 & TRN \\
\hline CHEMBL 3659190 & 1528624 & 6.5229 & 6.7947 & TRN \\
\hline CHEMBL 3663541 & 1528624 & 6.9914 & 6.9474 & TRN \\
\hline CHEMBL 3663492 & 1528624 & 5.8505 & 5.6367 & TST \\
\hline CHEMBL 3663510 & 1528624 & 7.1487 & 7.0787 & TST \\
\hline CHEMBL 3663450 & 1528624 & 6.7447 & 6.6848 & TRN \\
\hline CHEMBL 3659217 & 1528624 & 7.1612 & 7.0467 & TRN \\
\hline CHEMBL 3663526 & 1528624 & 7.3872 & 7.3875 & TRN \\
\hline CHEMBL 3659182 & 1528624 & 6.9281 & 6.9669 & TRN \\
\hline CHEMBL 3663443 & 1528624 & 5.3566 & 5.445 & TRN \\
\hline CHEMBL 3639580 & 1528624 & 6.3979 & 6.4359 & TRN \\
\hline CHEMBL 3659230 & 1528624 & 7.3372 & 7.2568 & TRN \\
\hline CHEMBL3663502 & 1528624 & 7.5229 & 7.5449 & TRN \\
\hline CHEMBL 3663537 & 1528624 & 6.8182 & 6.75 & TRN \\
\hline CHEMBL 3659188 & 1528624 & 6.0 & 6.1616 & TRN \\
\hline CHEMBL 3663525 & 1528624 & 6.7986 & 6.9255 & TRN \\
\hline CHEMBL 3663523 & 1528624 & 7.7212 & 7.7487 & TST \\
\hline CHEMBL3663553 & 1528624 & 6.9547 & 7.0466 & TRN \\
\hline CHEMBL 3659195 & 1528624 & 6.9318 & 7.0208 & TRN \\
\hline CHEMBL 3663549 & 1528624 & 7.6383 & 7.6867 & TRN \\
\hline CHEMBL 3659226 & 1528624 & 6.9318 & 6.7057 & TRN \\
\hline CHEMBL 3663567 & 1528624 & 7.5686 & 7.6702 & TRN \\
\hline CHEMBL3659197 & 1528624 & 7.8539 & 7.9103 & TRN \\
\hline CHEMBL 3663530 & 1528624 & 7.7696 & 7.4375 & TST \\
\hline CHEMBL 3659235 & 1528624 & 7.1612 & 7.1244 & TRN \\
\hline CHEMBL 3659191 & 1528624 & 7.3279 & 7.4007 & TRN \\
\hline CHEMBL 3663527 & 1528624 & 7.3468 & 7.2497 & TRN \\
\hline CHEMBL 3659232 & 1528624 & 7.6198 & 7.3926 & TRN \\
\hline CHEMBL 3663529 & 1528624 & 8.1549 & 8.1718 & TRN \\
\hline CHEMBL 3663574 & 1528624 & 7.4318 & 7.4393 & TRN \\
\hline CHEMBL 3663468 & 1528624 & 5.6383 & 5.5311 & TRN \\
\hline CHEMBL 3659208 & 1528624 & 7.5376 & 7.4009 & TRN \\
\hline CHEMBL 3663539 & 1528624 & 7.5376 & 7.4633 & TRN \\
\hline CHEMBL 3659184 & 1528624 & 7.2518 & 7.2368 & TRN \\
\hline CHEMBL 3663570 & 1528624 & 7.4949 & 7.4097 & TRN \\
\hline CHEMBL 3663576 & 1528624 & 8.0969 & 8.1385 & TRN \\
\hline CHEMBL 3663429 & 1528624 & 7.5376 & 7.3215 & TRN \\
\hline CHEMBL 3663451 & 1528624 & 5.2007 & 5.20200 & 000000001 \\
\hline CHEMBL 3659237 & 1528624 & 7.1938 & 7.0227 & TRN \\
\hline CHEMBL 3663522 & 1528624 & 7.7959 & 7.5903 & TRN \\
\hline CHEMBL 3663542 & 1528624 & 7.3188 & 7.3001 & TRN \\
\hline CHEMBL 3663453 & 1528624 & 6.7447 & 6.6897 & TRN \\
\hline
\end{tabular}


Supplemental Table S2.txt

\begin{tabular}{|c|c|c|c|c|}
\hline CHEMBL3663569 & 1528624 & 6.8928 & 6.9161 & TRN \\
\hline CHEMBL3663434 & 1528624 & 5.4318 & 5.2128 & TRN \\
\hline CHEMBL 3663577 & 1528624 & 8.2218 & 8.5051 & TRN \\
\hline CHEMBL3663400 & 1528624 & 7.1367 & 7.0644 & TRN \\
\hline CHEMBL3663437 & 1528624 & 5.8539 & 5.8483 & TST \\
\hline CHEMBL3663481 & 1528624 & 7.3188 & 7.3295 & TRN \\
\hline CHEMBL3659202 & 1528624 & 8.0458 & 7.797999 & 999999999 \\
\hline CHEMBL3663395 & 1528624 & 7.3098 & 7.4862 & TRN \\
\hline CHEMBL3659179 & 1528624 & 6.0 & 6.2772 & TRN \\
\hline CHEMBL3663440 & 1528624 & 5.1675 & 5.2301 & TRN \\
\hline CHEMBL3663456 & 1528624 & 5.9586 & 5.9439 & TST \\
\hline CHEMBL 3663480 & 1528624 & 6.7852 & 6.9522 & TRN \\
\hline CHEMBL3663431 & 1528624 & 6.7212 & 6.5017 & TST \\
\hline CHEMBL3659189 & 1528624 & 6.5686 & 6.7613 & TRN \\
\hline CHEMBL3659223 & 1528624 & 6.8239 & 6.7418 & TRN \\
\hline CHEMBL 3663444 & 1528624 & 5.5086 & 5.4074 & TRN \\
\hline CHEMBL3663551 & 1528624 & 7.2147 & 7.1391 & TRN \\
\hline CHEMBL3663418 & 1528624 & 7.3188 & 6.9373 & TRN \\
\hline CHEMBL3659203 & 1528624 & 7.2218 & 7.0994 & TRN \\
\hline CHEMBL3663489 & 1528624 & 7.4318 & 7.318 & TRN \\
\hline CHEMBL3663470 & 1528624 & 5.7133 & 5.8236 & TST \\
\hline CHEMBL3663540 & 1528624 & 7.2218 & 7.085 & TRN \\
\hline CHEMBL3663433 & 1528624 & 6.7212 & 6.5785 & TRN \\
\hline CHEMBL 3663441 & 1528624 & 6.0223 & 6.0556 & TST \\
\hline CHEMBL3663390 & 1528624 & 6.0 & 6.8885 & TRN \\
\hline CHEMBL3663546 & 1528624 & 6.75700 & 000000000 & 6.8524 \\
\hline CHEMBL 3663446 & 1528624 & 6.684 & 6.7776 & TRN \\
\hline CHEMBL3659196 & 1528624 & 6.1694 & 6.4803 & TST \\
\hline CHEMBL3663449 & 1528624 & 6.4685 & 6.3812 & TST \\
\hline CHEMBL 3663466 & 1528624 & 6.8153 & 6.8164 & TRN \\
\hline CHEMBL3663469 & 1528624 & 5.0458 & 5.3955 & TST \\
\hline CHEMBL 3663428 & 1528624 & 7.284 & 7.1325 & TRN \\
\hline CHEMBL3663445 & 1528624 & 6.5528 & 6.5813 & TST \\
\hline CHEMBL 3659238 & 1528624 & 7.2076 & 7.0048 & TRN \\
\hline CHEMBL3663436 & 1528624 & 5.0 & 4.9176 & TRN \\
\hline CHEMBL3659192 & 1528624 & 6.4921 & 6.5632 & TRN \\
\hline CHEMBL3663501 & 1528624 & 7.0223 & 7.0016 & TST \\
\hline CHEMBL3663442 & 1528624 & 6.2175 & 6.2719 & TRN \\
\hline CHEMBL 3659183 & 1528624 & 7.301 & 7.2164 & TRN \\
\hline CHEMBL3663471 & 1528624 & 6.1637 & 5.9393 & TST \\
\hline CHEMBL3659211 & 1528624 & 5.8938 & 6.0215 & TRN \\
\hline CHEMBL3663550 & 1528624 & 8.1549 & 8.4757 & TRN \\
\hline CHEMBL3663439 & 1528624 & 5.2676 & 5.3751 & TRN \\
\hline CHEMBL 3663426 & 1528624 & 6.8125 & 6.8084 & TRN \\
\hline CHEMBL3659181 & 1528624 & 6.0 & 6.1963 & TST \\
\hline CHEMBL3659231 & 1528624 & 7.6021 & 7.3595 & TRN \\
\hline CHEMBL3663435 & 1528624 & 5.0 & 4.977 & TRN \\
\hline CHEMBL3659198 & 1528624 & 7.9586 & 7.63 & TST \\
\hline
\end{tabular}


Supplemental Table S2.txt

\begin{tabular}{|c|c|c|c|c|}
\hline CHEMBL3663425 & 1528624 & 7.1675 & 6.9612 & TRN \\
\hline CHEMBL3663415 & 1528624 & 7.1739 & 7.2024 & TRN \\
\hline CHEMBL3663499 & 1528624 & 7.301 & 7.3841 & TRN \\
\hline CHEMBL3663555 & 1528624 & 7.3768 & 7.2506 & TRN \\
\hline CHEMBL3663491 & 1528624 & 5.0458 & 5.0105 & TST \\
\hline CHEMBL3663490 & 1528624 & 7.2147 & 7.2903 & TRN \\
\hline CHEMBL3663384 & 1528624 & 7.1805 & 6.9559 & TST \\
\hline CHEMBL3663557 & 1528624 & 7.9208 & 7.8896 & TRN \\
\hline CHEMBL3663532 & 1528624 & 6.9245 & 6.4435 & TST \\
\hline CHEMBL3663413 & 1528624 & 7.9208 & 7.9036 & TRN \\
\hline CHEMBL3663560 & 1528624 & 7.0132 & 6.9971 & TRN \\
\hline CHEMBL3663430 & 1528624 & 7.5686 & 7.5289 & TRN \\
\hline CHEMBL3659234 & 1528624 & 6.5331 & 6.4835 & TRN \\
\hline CHEMBL 3663404 & 1528624 & 7.4949 & 7.3267 & TRN \\
\hline CHEMBL 3659236 & 1528624 & 7.6576 & 7.5872 & TRN \\
\hline CHEMBL3659210 & 1528624 & 7.4559 & 7.4008 & TRN \\
\hline CHEMBL3663547 & 1528624 & 7.3872 & 7.3064 & TST \\
\hline CHEMBL3659185 & 1528624 & 7.699 & 7.6937 & TRN \\
\hline CHEMBL3663493 & 1528624 & 5.7867 & 5.474 & TST \\
\hline CHEMBL3659180 & 1528624 & 6.0 & 6.2899 & TRN \\
\hline CHEMBL3663511 & 1528624 & 7.3979 & 7.3765 & TST \\
\hline CHEMBL3663476 & 1528624 & 7.4815 & 7.5159 & TRN \\
\hline CHEMBL3663563 & 1528624 & 7.4318 & 7.2379 & TST \\
\hline CHEMBL3639623 & 1528624 & 5.7066 & 5.4933 & TST \\
\hline CHEMBL3663562 & 1528624 & 7.1135 & 7.1276 & TST \\
\hline CHEMBL3663564 & 1528624 & 7.7696 & 7.5906 & TST \\
\hline CHEMBL3663460 & 1528624 & 6.8729 & 6.7654 & TST \\
\hline CHEMBL3659193 & 1528624 & 6.9136 & 6.98 & TRN \\
\hline CHEMBL3659213 & 1528624 & 7.1024 & 7.0176 & TRN \\
\hline CHEMBL3663538 & 1528624 & 7.699 & 7.692 & TST \\
\hline CHEMBL3663533 & 1528624 & 7.2676 & 7.08 & TST \\
\hline CHEMBL3663424 & 1528624 & 7.8539 & 7.7195 & TRN \\
\hline CHEMBL3663414 & 1528624 & 7.699 & 7.6208 & TRN \\
\hline CHEMBL3659199 & 1528624 & 7.3279 & 7.2564 & TRN \\
\hline CHEMBL3663457 & 1528624 & 6.1612 & 6.2199 & TRN \\
\hline CHEMBL3663572 & 1528624 & 7.4559 & 7.6214 & TST \\
\hline CHEMBL3659194 & 1528624 & 7.1308 & 7.0685 & TRN \\
\hline CHEMBL3663505 & 1528624 & 7.2596 & 7.1884 & TST \\
\hline CHEMBL3663467 & 1528624 & 6.3883 & 6.4508 & TRN \\
\hline CHEMBL3663396 & 1528624 & 8.0 & 8.1608 & TRN \\
\hline CHEMBL3663478 & 1528624 & 6.4572 & 6.4866 & TST \\
\hline CHEMBL 3663448 & 1528624 & 5.4437 & 5.29200 & 0000000001 \\
\hline CHEMBL3663447 & 1528624 & 5.4089 & 5.3902 & TRN \\
\hline CHEMBL3659204 & 1528624 & 7.2366 & 7.0498 & TRN \\
\hline CHEMBL3663399 & 1528624 & 7.9586 & 7.8098 & TST \\
\hline CHEMBL3659243 & 1528624 & 8.1549 & 8.0727 & TRN \\
\hline CHEMBL3659176 & 1528624 & 7.3872 & 7.2464 & TRN \\
\hline CHEMBL 3663420 & 1528624 & 6.6021 & 6.8435 & TRN \\
\hline
\end{tabular}


Supplemental Table S2.txt

\begin{tabular}{|c|c|c|c|c|}
\hline CHEMBL 3663515 & 528624 & 6.699 & 6.8379 & TS \\
\hline HEMBL3663566 & 528624 & 8.0458 & 8.162 & \\
\hline HEMBL 36635 & 528624 & 7.585 & 5084 & \\
\hline HEMBL 36634 & 528624 & 5.0 & 4.8927 & בר \\
\hline HEMBL363344 & 05204 & 6.8539 & .8573 & \\
\hline HEMBL189792 & 05204 & 6.3188 & 6.3193 & \\
\hline HEMBL425186 & 05204 & 5.6383 & 4.37 & \\
\hline HEMBL195160 & 05204 & 5.6198 & 5.6179 & RN \\
\hline HEMBL192664 & 305204 & 5.4318 & 5.4316 & \\
\hline HEMBL193004 & 05204 & 6.8539 & 6.8534 & \\
\hline HEMBL 370954 & 305204 & 5.6383 & 5.6408 & \\
\hline HEMBL 365153 & 05204 & 5.5229 & .3462 & \\
\hline HEMBL192197 & 05204 & 4.4089 & 4.4081 & RN \\
\hline HEMBL 371801 & 05204 & 6.8861 & 6.8873 & \\
\hline HEMBL191456 & 05204 & 3.5229 & 3.5229 & \\
\hline HEMBL192109 & 305204 & 5.7696 & 5.7698 & \\
\hline HEMBL194157 & 05204 & 5.8861 & 5.8877 & 西 \\
\hline HEMBL189048 & 05204 & 5.9586 & 5.1268 & \\
\hline HEMBL436322 & 305204 & 3.5229 & 3.5214 & N \\
\hline HEMBL 366228 & 05204 & 6.1871 & 186 & \\
\hline HEMBL191671 & 305204 & 3.5229 & 3.5227 & 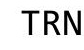 \\
\hline HEMBL366227 & 305204 & 5.8861 & 3856 & RN \\
\hline HEMBL192601 & 05204 & 5.7696 & 5.7701 & \\
\hline HEMBL192328 & 305204 & 3.5229 & 3.5219 & N \\
\hline HEMBL189789 & 04 & 83 & 88 & N \\
\hline HEMBL195277 & 305204 & 7.0315 & 7.0317 & RN \\
\hline HEMBL192825 & 305204 & 208 & 214 & RN \\
\hline HEMBL424813 & 05204 & 5.699 & 5.7007 & RN \\
\hline HEMBL195607 & 305204 & 308 & 4.7376 & TST \\
\hline HEMBL190607 & 05204 & 5.3565 & 3565 & IRN \\
\hline HEMBL192250 & 05204 & 686 & 5684 & $\mathrm{RN}$ \\
\hline HEMBL4 & 04 & 269 & 262 & RN \\
\hline HEMBL1 & 04 & 915 & 874 & 「RN \\
\hline HEMBL364731 & 05204 & 3.5229 & 3.5244 & TRN \\
\hline HEMBL373301 & 305204 & 3.5229 & 3.523 & TRN \\
\hline CHEMBL440029 & 05204 & 565 & 578 & TRN \\
\hline CHEMBL1 & 24 & 86 & 688 & IST \\
\hline CHEMBL364681 & 05204 & 5.1024 & 4.7068 & TST \\
\hline CHEMBL192634 & 305204 & 6.4685 & 6.4677 & TRN \\
\hline CHEMBL192635 & 05204 & 5.6198 & 5187 & TRN \\
\hline CHEMBL364735 & 305204 & 5.2218 & 5.4696 & TST \\
\hline CHEMBL364923 & 305204 & 4.8239 & 5.5573 & TST \\
\hline CHEMBL372051 & 305204 & 5.8539 & 5.8532 & TRN \\
\hline CHEMBL193311 & 305204 & 6.1367 & 6.1366 & TRN \\
\hline CHEMBL 364926 & 05204 & 5.4559 & 4.997 & ISI \\
\hline CHEMBL192151 & 305204 & 3.5229 & 3.5236 & \\
\hline CHEMBL192981 & 305204 & 4.699 & 4.8765 & \\
\hline CHEMBL192283 & 305204 & 3.5229 & 4.4293 & TST \\
\hline
\end{tabular}

Page 8256 


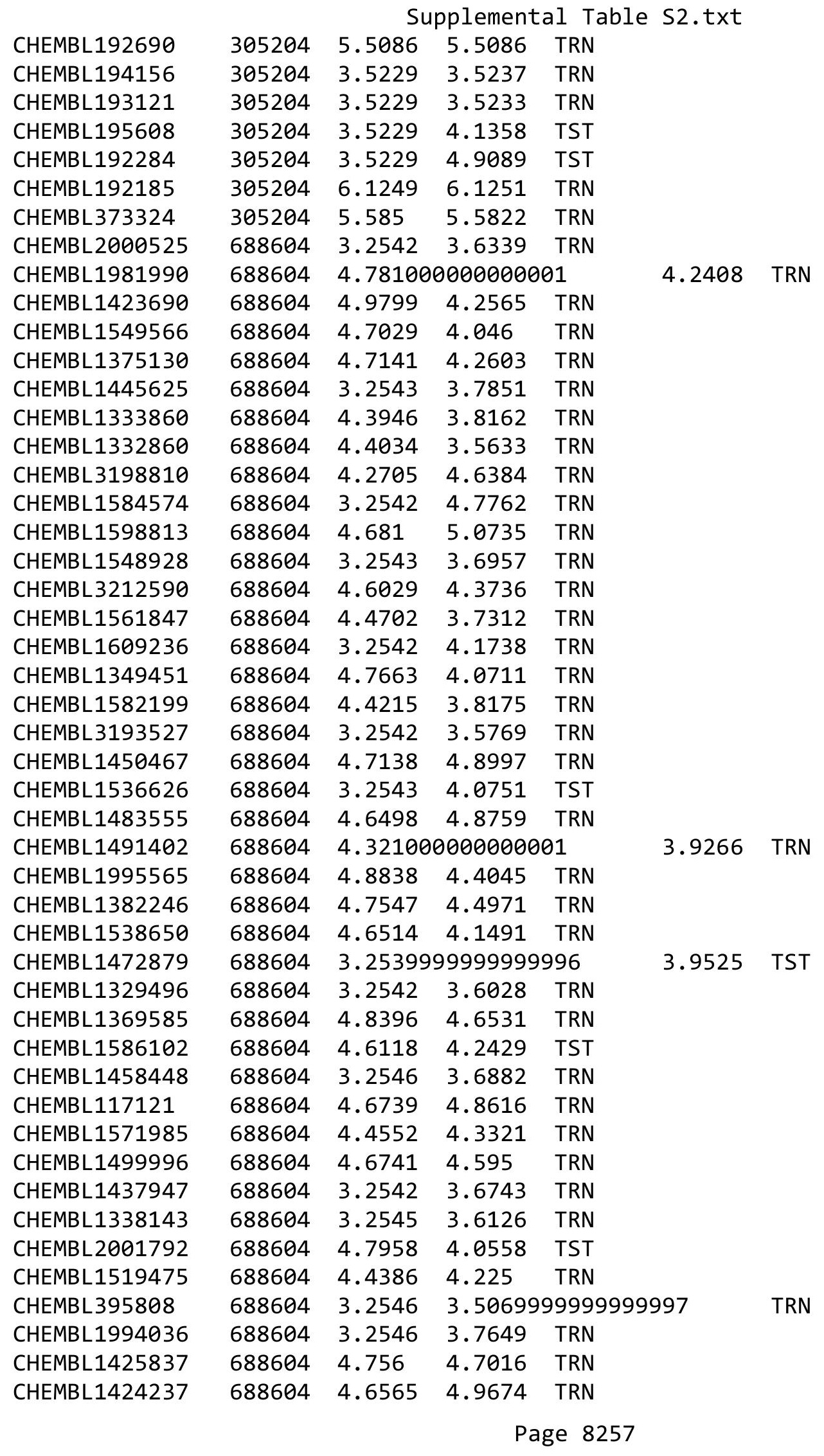




\begin{tabular}{|c|c|c|c|c|c|c|}
\hline & & \multicolumn{5}{|c|}{ Supplemental Table S2.txt } \\
\hline CHEMBL1366394 & 688604 & 4.6838 & 4.6295 & TRN & & \\
\hline CHEMBL1577321 & 688604 & 3.25399 & 99999999 & 996 & 4.5934 & TRN \\
\hline CHEMBL1309068 & 688604 & 4.7122 & 3.8072 & TRN & & \\
\hline CHEMBL1408874 & 688604 & 3.2542 & 3.7521 & TRN & & \\
\hline CHEMBL1414359 & 688604 & 4.7596 & 4.4703 & TRN & & \\
\hline CHEMBL1420311 & 688604 & 4.7822 & 3.9068 & TRN & & \\
\hline CHEMBL1363152 & 688604 & 3.2542 & 3.505 & TRN & & \\
\hline CHEMBL1344703 & 688604 & 4.6498 & 3.9768 & TRN & & \\
\hline CHEMBL1443120 & 688604 & 3.25399 & 99999999 & 996 & 3.3579 & TRN \\
\hline CHEMBL3196452 & 688604 & 4.3652 & 4.131 & TRN & & \\
\hline CHEMBL1377807 & 688604 & 4.735 & 4.5945 & TRN & & \\
\hline CHEMBL1596457 & 688604 & 4.7813 & 4.2058 & TRN & & \\
\hline CHEMBL1364530 & 688604 & 8.4089 & 4.9814 & TRN & & \\
\hline CHEMBL1428810 & 688604 & 3.2543 & 3.8938 & TST & & \\
\hline CHEMBL3212759 & 688604 & 3.2542 & 4.3702 & TRN & & \\
\hline CHEMBL1514082 & 688604 & 4.5665 & 4.8423 & TRN & & \\
\hline CHEMBL1469359 & 688604 & 4.6398 & 4.7985 & TRN & & \\
\hline CHEMBL1389865 & 688604 & 4.4425 & 4.7974 & TRN & & \\
\hline CHEMBL1571256 & 688604 & 3.2542 & 4.4564 & TRN & & \\
\hline CHEMBL 2003887 & 688604 & 3.2543 & 3.7541 & TRN & & \\
\hline CHEMBL1390206 & 688604 & 3.2543 & 3.991 & TST & & \\
\hline CHEMBL1342644 & 688604 & 4.6375 & 3.92199 & 999999999 & 97 & TRN \\
\hline CHEMBL1538176 & 688604 & 4.5956 & 4.2981 & TRN & & \\
\hline CHEMBL1526622 & 688604 & 4.6487 & 4.6604 & TRN & & \\
\hline CHEMBL 2005518 & 688604 & 3.2542 & 3.5331 & TRN & & \\
\hline CHEMBL3189228 & 688604 & 4.6988 & 4.1106 & TRN & & \\
\hline CHEMBL1366556 & 688604 & 4.8031 & 5.1278 & TRN & & \\
\hline CHEMBL1371792 & 688604 & 4.9597 & 4.1844 & TRN & & \\
\hline CHEMBL 393287 & 688604 & 4.8423 & 4.2256 & TST & & \\
\hline CHEMBL1548770 & 688604 & 3.2543 & 3.5197 & TRN & & \\
\hline CHEMBL1510798 & 688604 & 3.2544 & 4.0609 & TRN & & \\
\hline CHEMBL1388661 & 688604 & 4.6062 & 4.50899 & 9999999995 & כ9ן & TRN \\
\hline CHEMBL1489113 & 688604 & 4.7996 & 4.2151 & TST & & \\
\hline CHEMBL1440160 & 688604 & 4.4453 & 4.3044 & TRN & & \\
\hline CHEMBL1333989 & 688604 & 3.25399 & 99999999 & 996 & 4.1805 & TRN \\
\hline CHEMBL1514152 & 688604 & 4.408 & 4.3012 & TST & & \\
\hline CHEMBL1372672 & 688604 & 3.2545 & 3.6898 & TRN & & \\
\hline CHEMBL1533557 & 688604 & 3.2545 & 3.56100 & 0000000006 & 04 & TRN \\
\hline CHEMBL1607933 & 688604 & 4.2962 & 4.17399 & 999999999 & & TRN \\
\hline CHEMBL 2000039 & 688604 & 3.2544 & 4.1575 & TRN & & \\
\hline CHEMBL372629 & 688604 & 4.7421 & 3.7788 & TRN & & \\
\hline CHEMBL1375264 & 688604 & 3.2542 & 4.4081 & TRN & & \\
\hline CHEMBL1503134 & 688604 & 4.3386 & 3.9993 & TST & & \\
\hline CHEMBL1570108 & 688604 & 4.9365 & 4.2598 & TST & & \\
\hline CHEMBL597857 & 688604 & 4.8454 & 4.8811 & TRN & & \\
\hline CHEMBL1587291 & 688604 & 4.4205 & 3.8765 & TRN & & \\
\hline CHEMBL1388069 & 688604 & 4.4186 & 3.8849 & TRN & & \\
\hline CHEMBL1488626 & 688604 & 3.2542 & 4.1865 & TRN & & \\
\hline
\end{tabular}




\begin{tabular}{|c|c|c|c|c|c|c|}
\hline & & \multicolumn{5}{|c|}{ Supplemental Table S2.txt } \\
\hline CHEMBL1588953 & 688604 & 4.5281 & 4.6066 & TST & & \\
\hline CHEMBL 1410800 & 688604 & 4.6225 & 4.4628 & TST & & \\
\hline CHEMBL1333250 & 688604 & 4.4581 & 4.0594 & TRN & & \\
\hline CHEMBL1482383 & 688604 & 3.2543 & 3.721 & TRN & & \\
\hline CHEMBL1354431 & 688604 & 4.4356 & 4.106 & TRN & & \\
\hline CHEMBL1483950 & 688604 & 4.6467 & 4.3674 & TRN & & \\
\hline CHEMBL1569711 & 688604 & 4.8677 & 3.8 & TRN & & \\
\hline CHEMBL1544313 & 688604 & 3.2542 & 3.4967 & TRN & & \\
\hline CHEMBL3189447 & 688604 & \multicolumn{3}{|c|}{3.2539999999999996} & 3.7411 & TRN \\
\hline CHEMBL1494656 & 688604 & 3.2543 & 3.8321 & TRN & & \\
\hline CHEMBL1421228 & 688604 & 4.4979 & 3.8915 & TRN & & \\
\hline CHEMBL1970896 & 688604 & 4.5814 & 4.3608 & TRN & & \\
\hline CHEMBL1528985 & 688604 & 3.2543 & 4.0516 & TRN & & \\
\hline CHEMBL1399939 & 688604 & 3.2542 & 3.7867 & TRN & & \\
\hline CHEMBL1327785 & 688604 & 3.2543 & 3.9055 & TRN & & \\
\hline CHEMBL3196459 & 688604 & 3.2541 & 3.5867 & TRN & & \\
\hline CHEMBL1399533 & 688604 & 3.2542 & 3.3828 & TRN & & \\
\hline CHEMBL1522277 & 688604 & 4.5561 & 4.523 & TRN & & \\
\hline CHEMBL1596609 & 688604 & 4.9188 & 3.6505 & TRN & & \\
\hline CHEMBL1487402 & 688604 & 4.9532 & 4.1535 & TST & & \\
\hline CHEMBL1559626 & 688604 & 4.8105 & 4.1609 & TST & & \\
\hline CHEMBL1310158 & 688604 & 3.2544 & 4.4387 & TST & & \\
\hline CHEMBL1608223 & 688604 & 3.2539 & 3.9128 & TST & & \\
\hline CHEMBL1445779 & 688604 & 4.7397 & 4.9961 & TST & & \\
\hline CHEMBL1605463 & 688604 & 4.3848 & 4.1821 & TST & & \\
\hline CHEMBL1464398 & 688604 & 4.4468 & 4.7973 & TST & & \\
\hline CHEMBL1451796 & 688604 & 4.6232 & 4.4256 & TST & & \\
\hline CHEMBL1363026 & 688604 & 4.8416 & 4.3168 & TST & & \\
\hline CHEMBL1978101 & 688604 & 4.7882 & 4.0181 & TST & & \\
\hline CHEMBL1546527 & 688604 & 3.2543 & 3.6949 & TST & & \\
\hline CHEMBL1469797 & 688604 & 4.7212 & 3.8964 & TST & & \\
\hline CHEMBL1557186 & 688604 & 4.8526 & 3.7624 & TST & & \\
\hline CHEMBL1364419 & 688604 & 3.2542 & 4.5385 & TST & & \\
\hline CHEMBL1408792 & 688604 & 3.2543 & 3.8434 & TST & & \\
\hline CHEMBL1424188 & 688604 & 3.2543 & 4.05 & TST & & \\
\hline CHEMBL1458192 & 688604 & 4.7123 & 4.717 & TST & & \\
\hline CHEMBL1588106 & 688604 & 4.5215 & 3.9562 & TST & & \\
\hline CHEMBL1306708 & 688604 & 3.2544 & 3.7497 & TST & & \\
\hline CHEMBL 2011270 & 811041 & 8.301 & 8.2865 & TRN & & \\
\hline CHEMBL 2011096 & 811041 & 8.2218 & 8.1982 & TRN & & \\
\hline CHEMBL2011075 & 811041 & 7.7959 & 7.659 & TRN & & \\
\hline CHEMBL 2011087 & 811041 & 8.0969 & 8.1437 & TRN & & \\
\hline CHEMBL 2011078 & 811041 & 8.0458 & 8.0618 & TRN & & \\
\hline CHEMBL 2011265 & 811041 & 8.1549 & 8.191 & TRN & & \\
\hline CHEMBL 2011088 & 811041 & 8.0969 & 8.0692 & TRN & & \\
\hline CHEMBL 2011092 & 811041 & 8.0 & 8.0226 & TRN & & \\
\hline CHEMBL 2011065 & 811041 & 6.1249 & 6.1031 & TRN & & \\
\hline CHEMBL2011069 & 811041 & 5.1549 & 6.9434 & TST & & \\
\hline
\end{tabular}


Supplemental Table S2.txt

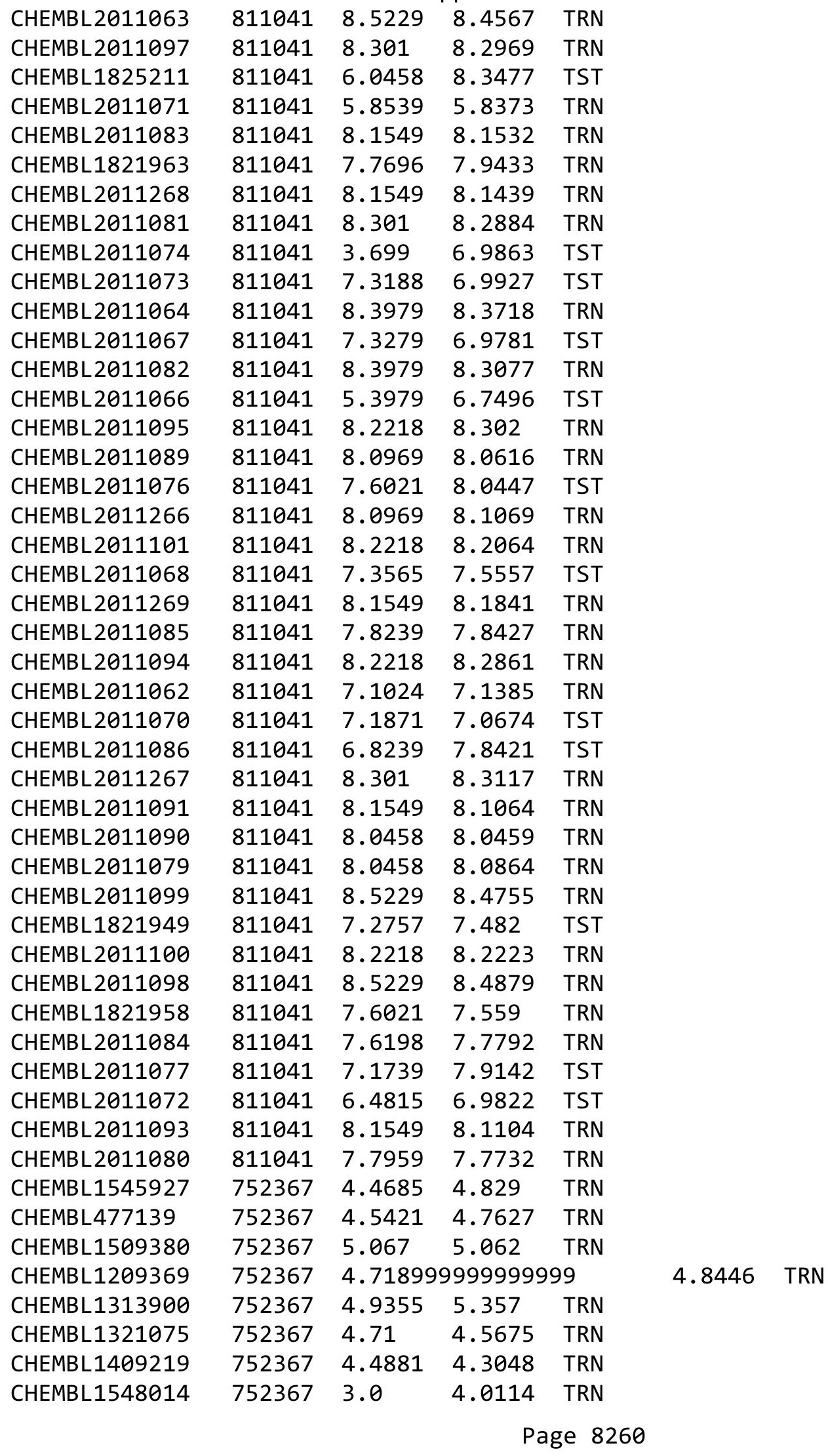


Supplemental Table S2.txt

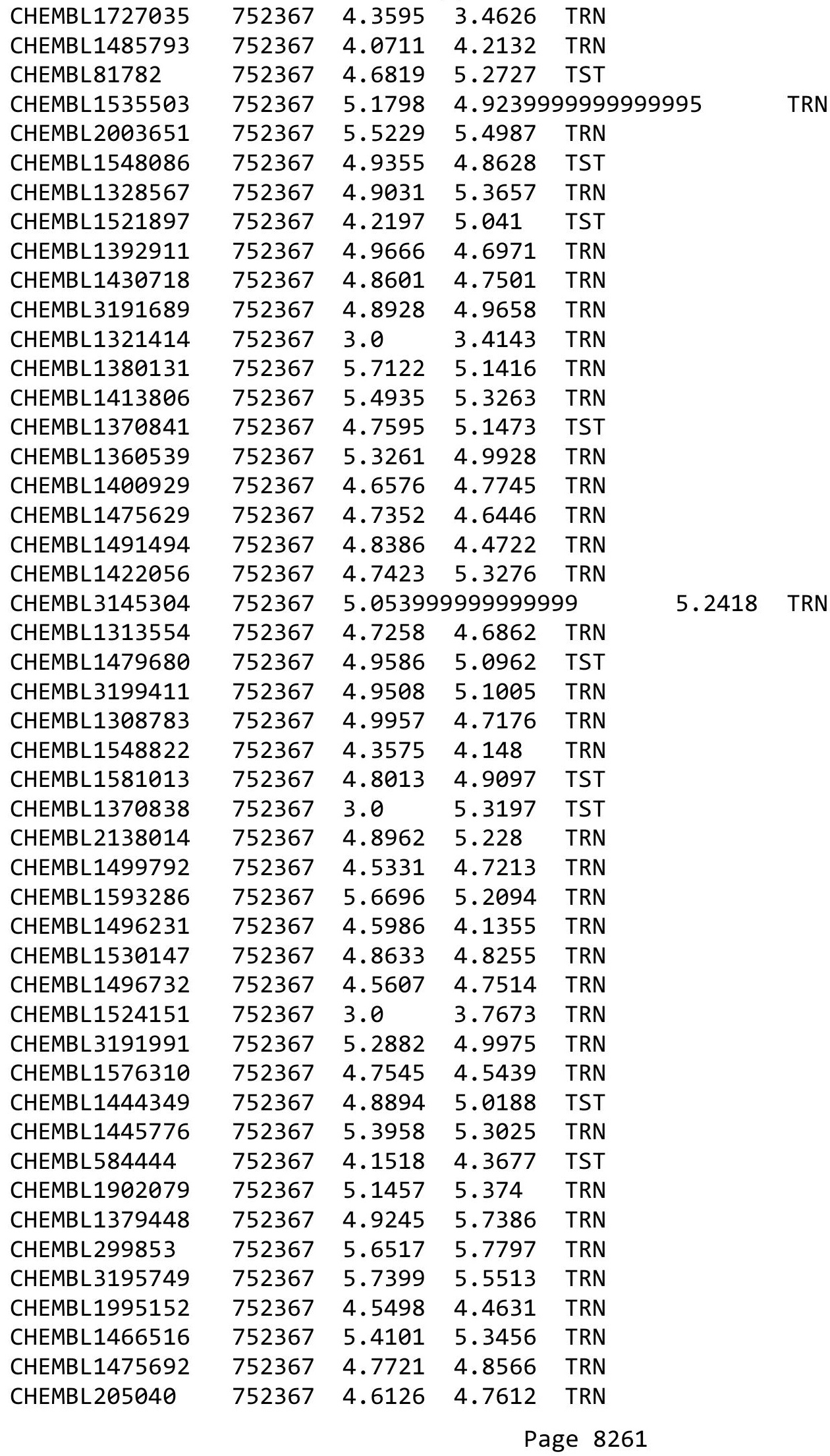


Supplemental Table S2.txt

\begin{tabular}{|c|c|c|c|c|c|}
\hline CHEMBL3190629 & 752367 & 5.3063 & 5.4797 & TST & \\
\hline CHEMBL1410383 & 752367 & 4.6576 & 5.1266 & TST & \\
\hline CHEMBL1331912 & 752367 & 5.3947 & 5.4019 & TRN & \\
\hline CHEMBL1518827 & 752367 & 4.6289 & 4.4077 & TRN & \\
\hline CHEMBL1347697 & 752367 & 4.4828 & 4.9812 & TRN & \\
\hline CHEMBL 2004487 & 752367 & 4.5654 & 4.0388 & TST & \\
\hline CHEMBL1469246 & 752367 & 4.5918 & 4.6604 & TRN & \\
\hline CHEMBL36654 & 752367 & 4.9914 & 4.9424 & TRN & \\
\hline CHEMBL1387843 & 752367 & 5.4935 & 5.0878 & TRN & \\
\hline CHEMBL1898479 & 752367 & 5.7352 & 5.3986 & TRN & \\
\hline CHEMBL1450648 & 752367 & 4.3958 & 4.4602 & TRN & \\
\hline CHEMBL600313 & 752367 & 4.6819 & 4.6771 & TRN & \\
\hline CHEMBL 2006503 & 752367 & 5.7328 & 5.8377 & TRN & \\
\hline CHEMBL1891759 & 752367 & 4.2277 & 4.6611 & TST & \\
\hline CHEMBL1559298 & 752367 & 4.1487 & 4.8538 & TST & \\
\hline CHEMBL1435528 & 752367 & 3.0 & 3.4553 & TRN & \\
\hline CHEMBL1609305 & 752367 & 3.0 & 3.8251 & TRN & \\
\hline CHEMBL1700040 & 752367 & 5.52 & 5.838999 & 99999999995 & TRN \\
\hline CHEMBL1487183 & 752367 & 5.1931 & 4.5628 & TST & \\
\hline CHEMBL1449923 & 752367 & 4.6162 & 4.7359 & TRN & \\
\hline CHEMBL1712864 & 752367 & 5.05399 & 999999999 & 5.5764 & TRN \\
\hline CHEMBL1375971 & 752367 & 4.9788 & 5.1364 & TST & \\
\hline CHEMBL1596475 & 752367 & 5.0565 & 4.9956 & TRN & \\
\hline CHEMBL1458860 & 752367 & 4.8416 & 5.0977 & TST & \\
\hline CHEMBL 3144906 & 752367 & 5.3799 & 5.1522 & TRN & \\
\hline CHEMBL3183391 & 752367 & 4.8761 & 5.0943 & TRN & \\
\hline CHEMBL1484549 & 752367 & 4.8297 & 4.7053 & TRN & \\
\hline CHEMBL601757 & 752367 & 7.426 & 6.4292 & TST & \\
\hline CHEMBL1599965 & 752367 & 4.8729 & 5.2168 & TRN & \\
\hline CHEMBL51931 & 752367 & 6.2604 & 5.8204 & TRN & \\
\hline CHEMBL1300612 & 752367 & 4.9914 & 4.8543 & TRN & \\
\hline CHEMBL1569333 & 752367 & \multicolumn{3}{|c|}{5.4510000000000005} & 7 \\
\hline CHEMBL1334307 & 752367 & 4.8041 & 4.1278 & TRN & \\
\hline CHEMBL1608143 & 752367 & 4.3335 & 4.3836 & TRN & \\
\hline CHEMBL 3196591 & 752367 & 5.9872 & 5.8262 & TRN & \\
\hline CHEMBL1362990 & 752367 & 3.0 & 3.6302 & TRN & \\
\hline CHEMBL1308668 & 752367 & 4.5607 & 4.8007 & TRN & \\
\hline CHEMBL1708466 & 752367 & 3.0 & 3.2209 & TRN & \\
\hline CHEMBL1485023 & 752367 & \multicolumn{2}{|c|}{ 4.718999999999999 } & 4.5903 & \\
\hline CHEMBL 3195410 & 752367 & 5.0177 & 5.4263 & TRN & \\
\hline CHEMBL584626 & 752367 & 5.1878 & 5.2567 & TRN & \\
\hline CHEMBL1522941 & 752367 & 5.4248 & 5.9083 & TRN & \\
\hline CHEMBL1508847 & 752367 & 4.4365 & 5.1178 & TST & \\
\hline CHEMBL1450086 & 752367 & 4.5901 & 4.1817 & TRN & \\
\hline CHEMBL1461822 & 752367 & 5.1512 & 4.5237 & TST & \\
\hline CHEMBL1389406 & 752367 & 4.6402 & 5.0986 & TST & \\
\hline CHEMBL1450505 & 752367 & 4.7122 & 4.9628 & TST & \\
\hline CHEMBL1438627 & 752367 & 4.6576 & 4.7439 & TRN & \\
\hline
\end{tabular}




\begin{tabular}{|c|c|c|c|c|c|c|}
\hline & & & & & & \\
\hline CHEMBL1974537 & 752367 & 4.4157 & 4.1211 & TST & & \\
\hline CHEMBL1421377 & 752367 & 4.7471 & 5.0564 & TST & & \\
\hline CHEMBL1531961 & 752367 & 3.0 & 4.1808 & TRN & & \\
\hline CHEMBL1597427 & 752367 & 3.0 & 3.9323 & TRN & & \\
\hline CHEMBL3210366 & 752367 & 4.7328 & 4.9344 & TRN & & \\
\hline CHEMBL2006418 & 752367 & 4.6696 & 5.29200 & 00000000 & & TRN \\
\hline CHEMBL1303970 & 752367 & 5.1451 & 5.1103 & TRN & & \\
\hline CHEMBL1585740 & 752367 & 5.0123 & 5.2366 & TRN & & \\
\hline CHEMBL1542809 & 752367 & 4.857 & 4.9037 & TRN & & \\
\hline CHEMBL1544947 & 752367 & 4.0506 & 4.6919 & TRN & & \\
\hline CHEMBL578944 & 752367 & 4.6946 & 4.3533 & TRN & & \\
\hline CHEMBL1371864 & 752367 & 4.9136 & 4.7544 & TRN & & \\
\hline CHEMBL1454614 & 752367 & 5.8962 & 5.8049 & TRN & & \\
\hline CHEMBL1324112 & 752367 & 3.0 & 3.3526 & TRN & & \\
\hline CHEMBL3145303 & 752367 & 5.4559 & 5.7136 & TRN & & \\
\hline CHEMBL1589425 & 752367 & 4.9747 & 4.8628 & TST & & \\
\hline CHEMBL1996724 & 752367 & 5.8297 & 5.9439 & TRN & & \\
\hline CHEMBL1534533 & 752367 & 5.2418 & 4.7755 & TRN & & \\
\hline CHEMBL1384702 & 752367 & 5.2765 & 4.9634 & TRN & & \\
\hline CHEMBL1465938 & 752367 & 4.4976 & 4.9736 & TRN & & \\
\hline CHEMBL1583566 & 752367 & 4.3391 & 3.6293 & TRN & & \\
\hline CHEMBL1338004 & 752367 & 4.9914 & 4.7519 & TRN & & \\
\hline CHEMBL1548761 & 752367 & 5.1046 & 4.8891 & TRN & & \\
\hline CHEMBL1735976 & 752367 & 3.0 & 3.647 & TRN & & \\
\hline CHEMBL1301183 & 752367 & 5.1024 & 5.0538 & TRN & & \\
\hline CHEMBL3197637 & 752367 & 5.1433 & 4.9986 & TRN & & \\
\hline CHEMBL1550490 & 752367 & 5.3251 & 5.0148 & TRN & & \\
\hline CHEMBL1307406 & 752367 & 4.2321 & 4.3443 & TRN & & \\
\hline CHEMBL1404277 & 752367 & 4.7959 & 4.6119 & TST & & \\
\hline CHEMBL1483235 & 752367 & 4.7986 & 4.877 & TRN & & \\
\hline CHEMBL1520694 & 752367 & 5.082 & 4.8459 & TRN & & \\
\hline CHEMBL1497070 & 752367 & 5.5498 & 5.2115 & TRN & & \\
\hline CHEMBL3198419 & 752367 & 4.8794 & 4.9373 & TRN & & \\
\hline CHEMBL1703515 & 752367 & 4.8125 & 5.0611 & TST & & \\
\hline CHEMBL1208858 & 752367 & 4.8962 & 4.8477 & TST & & \\
\hline CHEMBL1505544 & 752367 & 5.1555 & 4.9866 & TRN & & \\
\hline CHEMBL1477200 & 752367 & 5.4413 & 5.2359 & TRN & & \\
\hline CHEMBL1600763 & 752367 & 5.0467 & 4.4992 & TRN & & \\
\hline CHEMBL1864348 & 752367 & 6.1506 & 5.9375 & TRN & & \\
\hline CHEMBL1576254 & 752367 & 4.05399 & 99999999 & 99 & 4.5014 & 13 \\
\hline CHEMBL602990 & 752367 & 4.7932 & 5.0178 & TRN & & \\
\hline CHEMBL1335869 & 752367 & 4.6576 & 4.9554 & TRN & & \\
\hline CHEMBL1542862 & 752367 & 5.0921 & 5.0034 & TRN & & \\
\hline CHEMBL1335505 & 752367 & 4.6925 & 4.543 & TRN & & \\
\hline CHEMBL1441739 & 752367 & 4.9586 & 4.9846 & TRN & & \\
\hline CHEMBL1541973 & 752367 & 5.2676 & 5.1532 & TRN & & \\
\hline CHEMBL1987894 & 752367 & 5.7055 & 5.6775 & TRN & & \\
\hline CHEMBL1318757 & 752367 & 4.3747 & 4.816 & TRN & & \\
\hline
\end{tabular}




\begin{tabular}{|c|c|c|c|c|c|}
\hline & & \\
\hline CHEMBL1582178 & 752367 & 5.1433 & 4.9165 & TST & \\
\hline CHEMBL1437516 & 752367 & 4.4365 & 4.5333 & TRN & \\
\hline CHEMBL1596811 & 752367 & 4.6498 & 4.8027 & TST & \\
\hline CHEMBL1376540 & 752367 & 5.2899 & 5.0066 & TRN & \\
\hline CHEMBL1307329 & 752367 & 3.0 & 4.4133 & TRN & \\
\hline CHEMBL57013 & 752367 & 5.4698 & 4.833 & TST & \\
\hline CHEMBL1339245 & 752367 & 4.6364 & 4.4256 & TRN & \\
\hline CHEMBL1579122 & 752367 & 5.1733 & 4.9302 & TRN & \\
\hline CHEMBL1466766 & 752367 & 4.52 & 4.6495 & TRN & \\
\hline CHEMBL1582771 & 752367 & 4.8013 & 4.5027 & TRN & \\
\hline CHEMBL1422481 & 752367 & 4.301 & 4.2939 & TRN & \\
\hline CHEMBL1494979 & 752367 & 5.7799 & 5.0382 & TRN & \\
\hline CHEMBL1407756 & 752367 & 4.7144 & 5.2294 & TRN & \\
\hline CHEMBL 2369172 & 752367 & 3.0 & 4.3654 & TRN & \\
\hline CHEMBL1340633 & 752367 & 4.5735 & 4.5898 & TRN & \\
\hline CHEMBL1395907 & 752367 & 5.6737 & 5.9729 & TRN & \\
\hline CHEMBL1382884 & 752367 & 4.6676 & 3.3762 & TRN & \\
\hline CHEMBL86464 & 752367 & 5.0022 & 4.1461 & TRN & \\
\hline CHEMBL1559948 & 752367 & 5.1656 & 4.5558 & TST & \\
\hline CHEMBL 3144896 & 752367 & 4.618 & 4.9938 & TRN & \\
\hline CHEMBL1507051 & 752367 & 4.6882 & 5.0757 & TRN & \\
\hline CHEMBL599924 & 752367 & 7.2426 & 6.3474 & TST & \\
\hline CHEMBL1464468 & 752367 & 4.2041 & 4.4726 & TRN & \\
\hline CHEMBL1573910 & 752367 & 4.8665 & 5.4864 & TRN & \\
\hline CHEMBL1277150 & 752367 & 4.8729 & 4.6722 & TRN & \\
\hline CHEMBL1406738 & 752367 & 4.6345 & 4.0476 & TRN & \\
\hline CHEMBL1558216 & 752367 & 4.2857 & 5.2166 & TRN & \\
\hline CHEMBL1872457 & 752367 & 5.5918 & 5.7934 & TRN & \\
\hline CHEMBL 3193347 & 752367 & 5.295 & 5.1143 & TRN & \\
\hline CHEMBL1996133 & 752367 & 4.4353 & 4.16 & TST & \\
\hline CHEMBL405110 & 752367 & 4.8097 & 4.9057 & TRN & \\
\hline CHEMBL1541408 & 752367 & 4.5421 & 4.5732 & TRN & \\
\hline CHEMBL 3189714 & 752367 & 6.475 & 5.9905 & TRN & \\
\hline CHEMBL1537872 & 752367 & 4.9101 & 4.5485 & TRN & \\
\hline CHEMBL1346909 & 752367 & 4.8013 & 5.0159 & TST & \\
\hline CHEMBL1363238 & 752367 & 3.0 & 3.4563 & TRN & \\
\hline CHEMBL1235966 & 752367 & 4.7878 & 4.6768 & TRN & \\
\hline CHEMBL1580572 & 752367 & 4.6696 & 4.9555 & TRN & \\
\hline CHEMBL1324826 & 752367 & 5.0074 & 5.1944 & TRN & \\
\hline CHEMBL1543705 & 752367 & 4.5331 & 4.28600 & 30000000005 & TRN \\
\hline CHEMBL1408953 & 752367 & 4.684 & 4.51 & TRN & \\
\hline CHEMBL 2000342 & 752367 & 4.8447 & 4.5083 & TST & \\
\hline CHEMBL1535375 & 752367 & 4.8013 & 4.6655 & TRN & \\
\hline CHEMBL1472327 & 752367 & 4.8539 & 4.891 & TST & \\
\hline CHEMBL1730189 & 752367 & 4.3696 & 3.2381 & TRN & \\
\hline CHEMBL1458321 & 752367 & 5.5686 & 4.9859 & TRN & \\
\hline CHEMBL1707033 & 752367 & 5.6021 & 5.5178 & TRN & \\
\hline CHEMBL1583199 & 752367 & 6.7423 & 6.2766 & TST & \\
\hline & & & & 8264 & \\
\hline
\end{tabular}




\begin{tabular}{|c|c|c|c|c|c|c|}
\hline & & \multicolumn{5}{|c|}{ Supplemental Table S2.txt } \\
\hline CHEMBL1351074 & 752367 & 4.684 & 5.2516 & TST & & \\
\hline CHEMBL1598762 & 752367 & 5.1325 & 5.0863 & TRN & & \\
\hline CHEMBL1498652 & 752367 & 5.8827 & 5.4539 & TRN & & \\
\hline CHEMBL1310325 & 752367 & 5.3851 & 4.6417 & TRN & & \\
\hline CHEMBL1600855 & 752367 & 4.5607 & 4.109 & TST & & \\
\hline CHEMBL1315054 & 752367 & 4.1543 & 3.7724 & TRN & & \\
\hline CHEMBL1526855 & 752367 & 5.5058 & 5.1622 & TRN & & \\
\hline CHEMBL1888528 & 752367 & 5.9586 & 5.2834 & TRN & & \\
\hline CHEMBL1527341 & 752367 & 4.8447 & 4.9045 & TRN & & \\
\hline CHEMBL1531512 & 752367 & 4.9318 & 5.0039 & TRN & & \\
\hline CHEMBL581868 & 752367 & 4.5452 & 4.0769 & TRN & & \\
\hline CHEMBL1493281 & 752367 & 5.1343 & 5.188 & TRN & & \\
\hline CHEMBL1348993 & 752367 & 5.0362 & 5.0456 & TRN & & \\
\hline CHEMBL1575869 & 752367 & 4.8633 & 4.7433 & TRN & & \\
\hline CHEMBL1334390 & 752367 & 4.4989 & 5.1421 & TST & & \\
\hline CHEMBL1304024 & 752367 & 5.0362 & 4.6731 & TST & & \\
\hline CHEMBL1335953 & 752367 & $4.9830 e$ & 00000000 & 205 & 5.1897 & TRN \\
\hline CHEMBL1318103 & 752367 & 4.9172 & 4.5791 & TST & & \\
\hline CHEMBL1589837 & 752367 & 4.7773 & 4.8545 & TRN & & \\
\hline CHEMBL1497838 & 752367 & 4.9393 & 4.6133 & TRN & & \\
\hline CHEMBL1995720 & 752367 & 4.6021 & 4.2659 & TST & & \\
\hline CHEMBL1982305 & 752367 & 5.1355 & 5.2551 & TRN & & \\
\hline CHEMBL1474759 & 752367 & 4.2041 & 4.974 & TST & & \\
\hline CHEMBL339561 & 752367 & 4.5935 & 4.8846 & TRN & & \\
\hline CHEMBL3199424 & 752367 & 4.7799 & 5.0023 & TRN & & \\
\hline CHEMBL1305066 & 752367 & 4.3979 & 4.3779 & TRN & & \\
\hline CHEMBL1508674 & 752367 & 4.1146 & 4.1514 & TRN & & \\
\hline CHEMBL1341841 & 752367 & 5.1261 & 5.0222 & TRN & & \\
\hline CHEMBL1605867 & 752367 & 4.9208 & 4.7225 & TRN & & \\
\hline CHEMBL1345824 & 752367 & 4.5157 & 4.9471 & TRN & & \\
\hline CHEMBL1428504 & 752367 & 5.0 & 4.6681 & TRN & & \\
\hline CHEMBL1344702 & 752367 & 4.9431 & 4.974 & TRN & & \\
\hline CHEMBL1529201 & 752367 & 4.9318 & 5.1597 & TST & & \\
\hline CHEMBL3192939 & 752367 & 4.4776 & 5.19 & TRN & & \\
\hline CHEMBL1903283 & 752367 & 3.0 & 3.6893 & TRN & & \\
\hline CHEMBL1503359 & 752367 & 5.1681 & 5.3381 & TRN & & \\
\hline CHEMBL 1323518 & 752367 & 4.8601 & 5.31 & TST & & \\
\hline CHEMBL1098875 & 752367 & 5.4202 & 5.0414 & TRN & & \\
\hline CHEMBL1522827 & 752367 & 6.0985 & 5.6019 & TRN & & \\
\hline CHEMBL1551895 & 752367 & 3.0 & 3.5964 & TRN & & \\
\hline CHEMBL1308687 & 752367 & 4.8996 & 5.1151 & TRN & & \\
\hline CHEMBL1440235 & 752367 & 4.4318 & 4.4696 & TRN & & \\
\hline CHEMBL417727 & 752367 & 6.1146 & 6.1309 & TRN & & \\
\hline CHEMBL1968290 & 752367 & 4.5129 & 4.658 & TST & & \\
\hline CHEMBL3192701 & 752367 & 4.8153 & 4.8302 & TRN & & \\
\hline CHEMBL1520131 & 752367 & 4.7986 & 4.5612 & TRN & & \\
\hline CHEMBL1309059 & 752367 & 4.5751 & 4.6053 & TRN & & \\
\hline CHEMBL1598246 & 752367 & 3.0 & 3.997 & TRN & & \\
\hline
\end{tabular}




\begin{tabular}{|c|c|c|c|c|c|}
\hline & & & & & \\
\hline CHEMBL1464193 & 752367 & 4.1367 & 5.6906 & TST & \\
\hline CHEMBL3197208 & 752367 & 5.3507 & 4.8485 & TRN & \\
\hline CHEMBL1611833 & 752367 & 5.1319 & 5.3933 & TRN & \\
\hline CHEMBL3192555 & 752367 & 6.3862 & 6.0808 & TRN & \\
\hline CHEMBL429095 & 752367 & 4.8962 & 5.113 & TRN & \\
\hline CHEMBL3197091 & 752367 & 5.2211 & 5.4819 & TRN & \\
\hline CHEMBL1302199 & 752367 & 5.098 & 4.4284 & TRN & \\
\hline CHEMBL1343853 & 752367 & 4.684 & 4.6146 & TRN & \\
\hline CHEMBL1486690 & 752367 & 4.5114 & 5.0612 & TRN & \\
\hline CHEMBL1721853 & 752367 & 3.0 & 3.4179 & TRN & \\
\hline CHEMBL1605094 & 752367 & 4.3354 & 4.3857 & TRN & \\
\hline CHEMBL1526391 & 752367 & 4.9318 & 4.766 & TRN & \\
\hline CHEMBL1478825 & 752367 & 4.8996 & 4.5178 & TRN & \\
\hline CHEMBL527336 & 752367 & 5.3116 & 5.1047 & TRN & \\
\hline CHEMBL1407514 & 752367 & 6.098 & 5.1069 & TRN & \\
\hline CHEMBL1443251 & 752367 & 4.5834 & 4.5596 & TRN & \\
\hline CHEMBL1527778 & 752367 & 4.4056 & 4.995 & TST & \\
\hline CHEMBL1342248 & 752367 & 4.7905 & 4.732 & TRN & \\
\hline CHEMBL1438722 & 752367 & 4.2916 & 4.9164 & TRN & \\
\hline CHEMBL3193011 & 752367 & 5.6271 & 5.1771 & TRN & \\
\hline CHEMBL1437496 & 752367 & 4.4962 & 4.2415 & TRN & \\
\hline CHEMBL1520017 & 752367 & 4.8665 & 4.8467 & TRN & \\
\hline CHEMBL1459985 & 752367 & 5.3979 & 4.939 & TRN & \\
\hline CHEMBL3197805 & 752367 & 4.8761 & 4.775 & TRN & \\
\hline CHEMBL1558928 & 752367 & 5.1085 & 4.83899 & 99999999995 & TRN \\
\hline CHEMBL1321398 & 752367 & 4.6716 & 4.5905 & TRN & \\
\hline CHEMBL1371869 & 752367 & 4.7721 & 4.7446 & TRN & \\
\hline CHEMBL1560141 & 752367 & 4.7144 & 4.6059 & TST & \\
\hline CHEMBL1562466 & 752367 & 5.0867 & 5.15799 & 99999999995 & TRN \\
\hline CHEMBL1967479 & 752367 & 4.4437 & 4.6643 & TRN & \\
\hline CHEMBL1328510 & 752367 & 6.0 & 5.1643 & TRN & \\
\hline CHEMBL1367405 & 752367 & 4.8962 & 4.9043 & TST & \\
\hline CHEMBL1417929 & 752367 & 5.6778 & 4.8201 & TRN & \\
\hline CHEMBL1376516 & 752367 & 4.8356 & 4.5529 & TRN & \\
\hline CHEMBL1608044 & 752367 & 4.5901 & 4.4358 & TRN & \\
\hline CHEMBL1468886 & 752367 & 4.289 & 4.2389 & TRN & \\
\hline CHEMBL1581674 & 752367 & 4.3197 & 4.4283 & TRN & \\
\hline CHEMBL1523878 & 752367 & 3.0 & 3.9393 & TRN & \\
\hline CHEMBL1464975 & 752367 & 4.6144 & 4.6752 & TRN & \\
\hline CHEMBL1351750 & 752367 & 4.4012 & 4.616006 & 00000000005 & TRN \\
\hline CHEMBL3190539 & 752367 & 5.1568 & 5.2238 & TRN & \\
\hline CHEMBL590691 & 752367 & 4.5817 & 4.968 & TRN & \\
\hline CHEMBL1721516 & 752367 & 3.0 & 3.267 & TRN & \\
\hline CHEMBL1572216 & 752367 & 4.7595 & 4.5835 & TST & \\
\hline CHEMBL1477061 & 752367 & 5.2941 & 5.5481 & TRN & \\
\hline CHEMBL1339777 & 752367 & 4.4737 & 4.2016 & TRN & \\
\hline CHEMBL1415156 & 752367 & 5.1415 & 4.9147 & TRN & \\
\hline CHEMBL1576815 & 752367 & 4.0362 & 4.721 & TRN & \\
\hline
\end{tabular}




\begin{tabular}{|c|c|c|c|c|c|c|}
\hline \\
\hline CHEMBL1867220 & 752367 & 3.0 & 4.1718 & TRN & & \\
\hline CHEMBL1719459 & 752367 & \multicolumn{3}{|c|}{5.2139999999999995} & 5.4125 & TRN \\
\hline CHEMBL1469091 & 752367 & 4.8297 & 4.5175 & TST & & \\
\hline CHEMBL1463829 & 752367 & 4.8861 & 4.5704 & TRN & & \\
\hline CHEMBL1427763 & 752367 & 5.3883 & 4.5703 & TRN & & \\
\hline CHEMBL1361173 & 752367 & 4.7122 & 4.8745 & TRN & & \\
\hline CHEMBL1347107 & 752367 & 4.6216 & 4.9267 & TST & & \\
\hline CHEMBL1432707 & 752367 & 5.9957 & 5.6965 & TRN & & \\
\hline CHEMBL1498509 & 752367 & 6.5003 & 6.2934 & TRN & & \\
\hline CHEMBL1347600 & 752367 & 4.3605 & 4.4016 & TRN & & \\
\hline CHEMBL1996376 & 752367 & 5.5834 & 5.2641 & TRN & & \\
\hline CHEMBL3182716 & 752367 & 4.8239 & 5.3036 & TRN & & \\
\hline CHEMBL3191855 & 752367 & 6.3556 & 5.5989 & TRN & & \\
\hline CHEMBL1378634 & 752367 & 5.5272 & 5.271 & TRN & & \\
\hline CHEMBL1976638 & 752367 & 4.71 & 4.96399 & 999999999 & 95 & TST \\
\hline CHEMBL3194941 & 752367 & 5.0937 & 5.015 & TRN & & \\
\hline CHEMBL3145187 & 752367 & 4.8356 & 4.7088 & TRN & & \\
\hline CHEMBL1544377 & 752367 & 4.3391 & 4.7182 & TRN & & \\
\hline CHEMBL1443377 & 752367 & 4.0516 & 4.93 & TST & & \\
\hline CHEMBL1968355 & 752367 & 5.5376 & 4.5646 & TST & & \\
\hline CHEMBL1450615 & 752367 & 4.5302 & 4.9731 & TRN & & \\
\hline CHEMBL1734524 & 752367 & 3.0 & 3.1898 & TRN & & \\
\hline CHEMBL1346883 & 752367 & 4.7696 & 4.4338 & TRN & & \\
\hline CHEMBL3199870 & 752367 & 4.7595 & 4.5851 & TRN & & \\
\hline CHEMBL1500125 & 752367 & 5.1278 & 4.8274 & TST & & \\
\hline CHEMBL1999630 & 752367 & 5.7986 & 5.3554 & TRN & & \\
\hline CHEMBL1394969 & 752367 & 5.1785 & 4.8683 & TRN & & \\
\hline CHEMBL1330787 & 752367 & \multicolumn{3}{|c|}{4.718999999999999} & 4.3596 & TRN \\
\hline CHEMBL1370471 & 752367 & 5.0691 & 4.9818 & TRN & & \\
\hline CHEMBL1591383 & 752367 & 4.1255 & 4.05 & TRN & & \\
\hline CHEMBL1331573 & 752367 & 4.3215 & 4.6759 & TRN & & \\
\hline CHEMBL1439666 & 752367 & 4.4134 & 5.0186 & TRN & & \\
\hline CHEMBL600336 & 752367 & 5.0857 & 4.459 & TRN & & \\
\hline CHEMBL1430635 & 752367 & 5.7447 & 5.3117 & TRN & & \\
\hline CHEMBL1392394 & 752367 & 4.3028 & 4.4746 & TRN & & \\
\hline CHEMBL1501694 & 752367 & 4.757 & 5.3472 & TST & & \\
\hline CHEMBL582722 & 752367 & 4.5406 & 4.5692 & TRN & & \\
\hline CHEMBL1349676 & 752367 & 4.8125 & 4.9909 & TST & & \\
\hline CHEMBL1576896 & 752367 & 4.7282 & 4.904 & TRN & & \\
\hline CHEMBL1501132 & 752367 & 4.284 & 4.0298 & TRN & & \\
\hline CHEMBL1501505 & 752367 & 4.8894 & 4.8654 & TRN & & \\
\hline CHEMBL1415290 & 752367 & 4.4318 & 4.9705 & TST & & \\
\hline CHEMBL1408398 & 752367 & 4.8182 & 4.9759 & TRN & & \\
\hline CHEMBL1412077 & 752367 & 4.0585 & 4.3754 & TRN & & \\
\hline CHEMBL1409039 & 752367 & 5.6737 & 5.2852 & TRN & & \\
\hline CHEMBL1436778 & 752367 & 5.0691 & 5.0244 & TRN & & \\
\hline CHEMBL1604205 & 752367 & 4.5986 & 4.487 & TRN & & \\
\hline CHEMBL1391527 & 752367 & 4.5317 & 4.7776 & TRN & & \\
\hline
\end{tabular}


Supplemental Table S2.txt

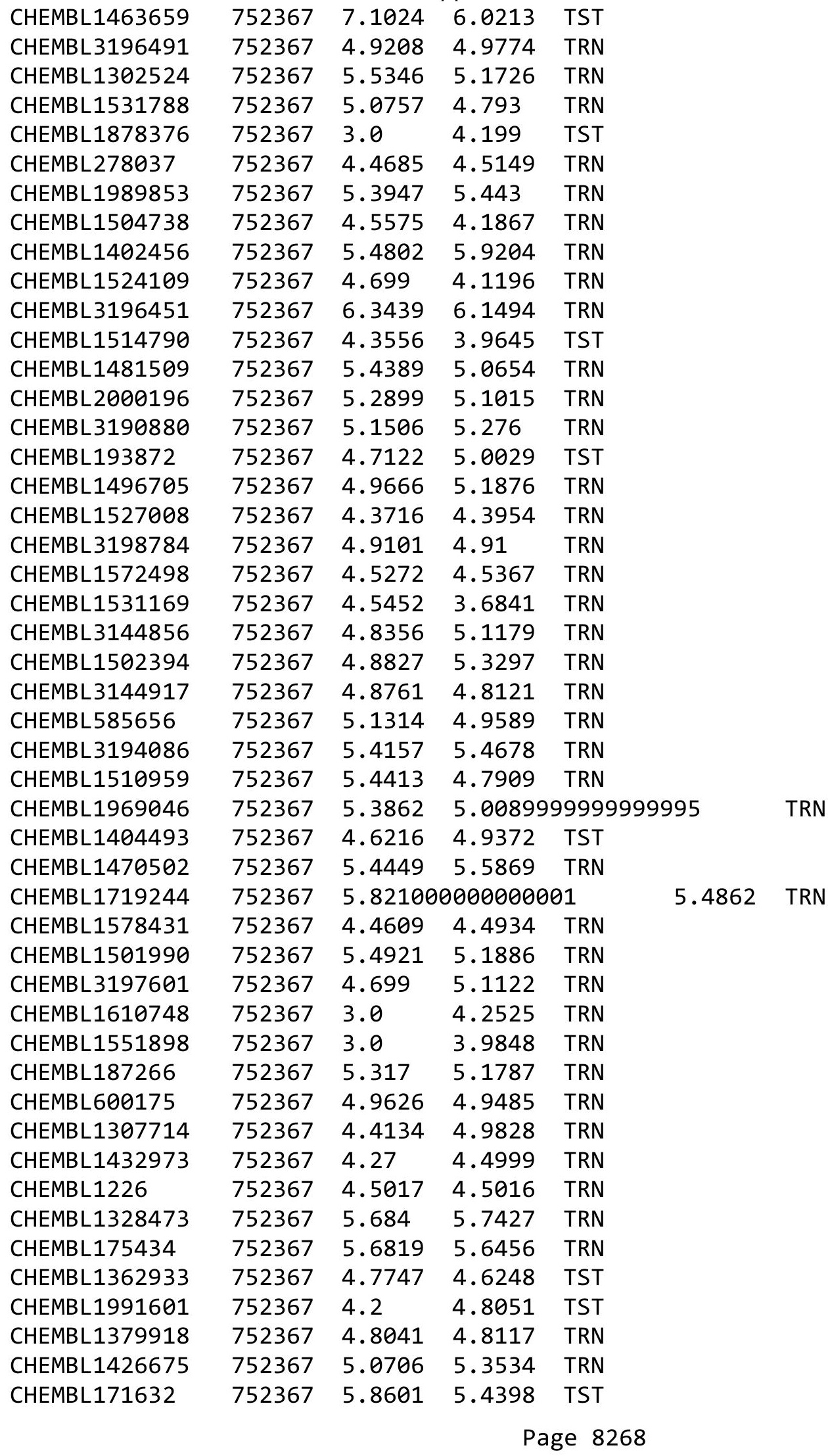




\begin{tabular}{|c|c|c|c|c|c|c|}
\hline & & \multicolumn{5}{|c|}{ Supplemental Table S2.txt } \\
\hline CHEMBL1563939 & 752367 & 4.8239 & 5.4179 & TST & & \\
\hline CHEMBL1451538 & 752367 & 4.4868 & 5.1228 & TST & & \\
\hline CHEMBL270362 & 752367 & 4.6925 & 4.9336 & TST & & \\
\hline CHEMBL3198812 & 752367 & 4.9318 & 4.7606 & TRN & & \\
\hline CHEMBL257359 & 752367 & 3.0 & 4.9224 & TST & & \\
\hline CHEMBL1347328 & 752367 & 4.4078 & 4.8432 & TRN & & \\
\hline CHEMBL1555406 & 752367 & 4.3152 & 3.3339 & TRN & & \\
\hline CHEMBL3196108 & 752367 & 5.58 & 5.4923 & TRN & & \\
\hline CHEMBL1472773 & 752367 & 4.6108 & 4.9361 & TST & & \\
\hline CHEMBL1405449 & 752367 & 4.9172 & 4.9303 & TRN & & \\
\hline CHEMBL1531003 & 752367 & 4.8416 & 4.6883 & TRN & & \\
\hline CHEMBL1583807 & 752367 & 4.6459 & 3.9958 & TRN & & \\
\hline CHEMBL1403270 & 752367 & 4.6126 & 5.1683 & TST & & \\
\hline CHEMBL1464453 & 752367 & 4.5143 & 4.9539 & TRN & & \\
\hline CHEMBL1427539 & 752367 & 4.7328 & 4.7081 & TRN & & \\
\hline CHEMBL1524916 & 752367 & 4.6021 & 5.0034 & TRN & & \\
\hline CHEMBL1432476 & 752367 & 4.3565 & 4.5122 & TST & & \\
\hline CHEMBL1313465 & 752367 & 4.5391 & 4.8319 & TRN & & \\
\hline CHEMBL3194001 & 752367 & 5.3363 & 4.7887 & TRN & & \\
\hline CHEMBL3145280 & 752367 & 5.109 & 4.6118 & TRN & & \\
\hline CHEMBL1299200 & 752367 & 4.7212 & 4.9613 & TST & & \\
\hline CHEMBL1569403 & 752367 & 4.4461 & 4.7034 & TRN & & \\
\hline CHEMBL1891899 & 752367 & 3.0 & 4.3341 & TST & & \\
\hline CHEMBL1428327 & 752367 & 4.295 & 4.9036 & TRN & & \\
\hline CHEMBL3187596 & 752367 & 5.5361 & 5.5171 & TRN & & \\
\hline CHEMBL1329140 & 752367 & 4.9508 & 5.1104 & TRN & & \\
\hline CHEMBL1434767 & 752367 & 5.9136 & 5.273 & TRN & & \\
\hline CHEMBL1393283 & 752367 & 4.5719 & 4.4869 & TRN & & \\
\hline CHEMBL1277060 & 752367 & 4.4597 & 4.6845 & TRN & & \\
\hline CHEMBL1520328 & 752367 & 5.015 & 4.7816 & TRN & & \\
\hline CHEMBL3194328 & 752367 & 4.5072 & 4.9041 & TST & & \\
\hline CHEMBL1995769 & 752367 & 4.5986 & 5.0471 & TST & & \\
\hline CHEMBL 274921 & 752367 & 3.0 & 4.8064 & TST & & \\
\hline CHEMBL1379048 & 752367 & 4.9586 & 5.2417 & TST & & \\
\hline CHEMBL1391342 & 752367 & 5.1818 & 4.613 & TST & & \\
\hline CHEMBL1403154 & 752367 & 5.21399 & 79999999ऽ & 995 & 5.1041 & TST \\
\hline CHEMBL1490793 & 752367 & 5.2882 & 5.0734 & TST & & \\
\hline CHEMBL1417815 & 752367 & 4.5867 & 4.7382 & TST & & \\
\hline CHEMBL1584037 & 752367 & 4.9355 & 5.2393 & TST & & \\
\hline CHEMBL578905 & 752367 & 5.3206 & 5.3288 & TST & & \\
\hline CHEMBL1320562 & 752367 & 4.2269 & 4.8701 & TST & & \\
\hline CHEMBL1572924 & 752367 & 4.8729 & 4.4171 & TST & & \\
\hline CHEMBL592115 & 752367 & 5.1079 & 5.148 & TST & & \\
\hline CHEMBL1605599 & 752367 & 4.8239 & 5.0516 & TST & & \\
\hline CHEMBL3211131 & 752367 & 4.71899 & 99999999 & 99 & 4.8877 & TST \\
\hline CHEMBL1369304 & 752367 & 4.7167 & 5.2512 & TST & & \\
\hline CHEMBL586031 & 752367 & 5.4789 & 5.1247 & TST & & \\
\hline CHEMBL1305658 & 752367 & 4.6216 & 4.6423 & TST & & \\
\hline
\end{tabular}




\begin{tabular}{|c|c|c|c|c|c|}
\hline & & & & & \\
\hline CHEMBL3192178 & 752367 & 4.4067 & 4.3986 & TST & \\
\hline CHEMBL1482438 & 752367 & 4.7144 & 4.68 & TST & \\
\hline CHEMBL1318350 & 752367 & 3.0 & 5.064 & TST & \\
\hline CHEMBL1895549 & 752367 & 3.0 & 3.6712 & TST & \\
\hline CHEMBL1998302 & 752367 & 5.5017 & 5.7059 & TST & \\
\hline CHEMBL1358008 & 752367 & 5.098 & 4.897 & TST & \\
\hline CHEMBL1969672 & 752367 & 4.8996 & 5.1539 & TST & \\
\hline CHEMBL1577193 & 752367 & 5.5935 & 5.2245 & TST & \\
\hline CHEMBL3144962 & 752367 & 4.6126 & 4.8975 & TST & \\
\hline CHEMBL1323371 & 752367 & 3.0 & 3.9426 & TST & \\
\hline CHEMBL1385481 & 752367 & 4.752 & 4.9026 & TST & \\
\hline CHEMBL3194415 & 752367 & 4.7595 & 4.5822 & TST & \\
\hline CHEMBL567967 & 752367 & 5.2366 & 5.3328 & TST & \\
\hline CHEMBL3197625 & 752367 & 4.2472 & 4.7816 & TST & \\
\hline CHEMBL1277149 & 752367 & 5.2464 & 4.7798 & TST & \\
\hline CHEMBL1427637 & 752367 & 4.9136 & 4.794 & TST & \\
\hline CHEMBL1453498 & 752367 & 4.4078 & 4.6834 & TST & \\
\hline CHEMBL3407901 & 1467939 & 6.1612 & 6.2821 & TRN & \\
\hline CHEMBL3407902 & 1467939 & 7.284 & 7.3853 & TRN & \\
\hline CHEMBL3407925 & 1467939 & 7.6198 & 7.6434 & TRN & \\
\hline CHEMBL3407879 & 1467939 & 5.3565 & 5.4472 & TRN & \\
\hline CHEMBL3407922 & 1467939 & 8.0969 & 8.0792 & TRN & \\
\hline CHEMBL3407915 & 1467939 & 4.0 & 4.2509 & TRN & \\
\hline CHEMBL3407899 & 1467939 & 6.6778 & 6.5869 & TRN & \\
\hline CHEMBL3407870 & 1467939 & 4.0 & 3.7653 & TST & \\
\hline CHEMBL 3407880 & 1467939 & 5.8239 & 5.8449 & TRN & \\
\hline CHEMBL 3407874 & 1467939 & 6.7696 & 6.88899 & & TRN \\
\hline CHEMBL3407919 & 1467939 & 7.9586 & 7.9272 & TRN & \\
\hline CHEMBL3407885 & 1467939 & 7.1391 & 7.1307 & TRN & \\
\hline CHEMBL3407903 & 1467939 & 7.8861 & 7.61299 & 99999999995 & TRN \\
\hline CHEMBL 3407878 & 1467939 & 5.4559 & 5.4236 & TRN & \\
\hline CHEMBL 3407883 & 1467939 & 6.6383 & 5.9771 & TST & \\
\hline CHEMBL 3407904 & 1467939 & 6.5086 & 6.5004 & TRN & \\
\hline CHEMBL3407906 & 1467939 & 5.1415 & 5.2373 & TRN & \\
\hline CHEMBL3407866 & 1467939 & 7.4815 & 7.6005 & TRN & \\
\hline CHEMBL3407911 & 1467939 & 5.1249 & 5.1567 & TRN & \\
\hline CHEMBL 3407876 & 1467939 & 6.5229 & 6.5017 & TRN & \\
\hline CHEMBL 3407868 & 1467939 & 4.0 & 3.9527 & TRN & \\
\hline CHEMBL3407916 & 1467939 & 4.0 & 3.7957 & TRN & \\
\hline CHEMBL3407869 & 1467939 & 4.0 & 5.2803 & TST & \\
\hline CHEMBL3407923 & 1467939 & 6.5686 & 6.5535 & TRN & \\
\hline CHEMBL3407873 & 1467939 & 4.0 & 3.832 & TRN & \\
\hline CHEMBL3407924 & 1467939 & 7.6778 & 7.7009 & TRN & \\
\hline CHEMBL3407884 & 1467939 & 7.2218 & 6.1955 & TST & \\
\hline CHEMBL3407921 & 1467939 & 7.6383 & 7.5992 & TRN & \\
\hline CHEMBL 3407882 & 1467939 & 5.3665 & 5.3938 & TRN & \\
\hline CHEMBL3407926 & 1467939 & 6.284 & 6.3156 & TRN & \\
\hline CHEMBL3407913 & 1467939 & 7.585 & 7.6392 & TRN & \\
\hline
\end{tabular}


Supplemental Table S2.txt

\begin{tabular}{|c|c|c|c|c|}
\hline CHEMBL3407865 & 1467939 & 6.5376 & 6.5647 & TRN \\
\hline CHEMBL3407914 & 1467939 & 6.4318 & 6.5075 & TRN \\
\hline CHEMBL3407871 & 1467939 & 4.0 & 3.9725 & TRN \\
\hline CHEMBL 3407920 & 1467939 & 7.7959 & 7.3795 & TRN \\
\hline CHEMBL3407877 & 1467939 & 5.0362 & 4.9957 & TRN \\
\hline CHEMBL3407917 & 1467939 & 5.3665 & 5.5358 & TRN \\
\hline CHEMBL 3407927 & 1467939 & 7.1938 & 7.3641 & TRN \\
\hline CHEMBL 3407872 & 1467939 & 4.0 & 5.1701 & TST \\
\hline CHEMBL 3407875 & 1467939 & 5.9586 & 5.9026 & TRN \\
\hline CHEMBL3407900 & 1467939 & 6.4949 & 6.5386 & TRN \\
\hline CHEMBL 3407907 & 1467939 & 5.7595 & 5.7213 & TRN \\
\hline CHEMBL 3407908 & 1467939 & 6.9208 & 6.8596 & TRN \\
\hline CHEMBL3407881 & 1467939 & 5.2596 & 5.5161 & TST \\
\hline CHEMBL3407886 & 1467939 & 6.2291 & 6.2576 & TST \\
\hline CHEMBL3407910 & 1467939 & 4.0 & $3.69100 t$ & 00000000003 \\
\hline CHEMBL3407912 & 1467939 & 4.0 & 5.5856 & TST \\
\hline CHEMBL3407918 & 1467939 & 6.4559 & 6.1906 & TST \\
\hline CHEMBL3407905 & 1467939 & 7.4202 & 6.9885 & TST \\
\hline CHEMBL3407909 & 1467939 & 4.0 & 5.4865 & TST \\
\hline CHEMBL3407867 & 1467939 & 4.0 & 5.0618 & TST \\
\hline CHEMBL1911573 & 775393 & 7.4089 & 7.3574 & TRN \\
\hline CHEMBL1911553 & 775393 & 7.7447 & 7.6204 & TRN \\
\hline CHEMBL1911556 & 775393 & 5.0 & 6.1353 & TST \\
\hline CHEMBL1911550 & 775393 & 6.6861 & 6.6957 & TRN \\
\hline CHEMBL1911430 & 775393 & 6.5229 & 6.505 & TRN \\
\hline CHEMBL1911560 & 775393 & 5.6234 & 5.6252 & TRN \\
\hline CHEMBL1911427 & 775393 & 5.9706 & 5.9594 & TRN \\
\hline CHEMBL1911564 & 775393 & 6.4989 & 6.5063 & TRN \\
\hline CHEMBL1911555 & 775393 & 6.5751 & 6.5713 & TRN \\
\hline CHEMBL1911576 & 775393 & 8.0 & 7.8042 & TRN \\
\hline CHEMBL1911561 & 775393 & 5.0 & 5.8527 & TST \\
\hline CHEMBL1911565 & 775393 & 7.4815 & 7.6246 & TRN \\
\hline CHEMBL1911441 & 775393 & 7.0655 & 7.0838 & TRN \\
\hline CHEMBL1911552 & 775393 & 6.6737 & 6.7221 & TRN \\
\hline CHEMBL1911440 & 775393 & 7.6021 & 7.5762 & TST \\
\hline CHEMBL1911574 & 775393 & 7.7696 & 7.7874 & TRN \\
\hline CHEMBL1911435 & 775393 & 7.5376 & 7.5462 & TRN \\
\hline CHEMBL1911433 & 775393 & 7.5376 & 7.4749 & TRN \\
\hline CHEMBL1911551 & 775393 & 7.0458 & 7.0297 & TRN \\
\hline CHEMBL1911572 & 775393 & 7.2218 & 7.2829 & TRN \\
\hline CHEMBL1911562 & 775393 & 5.0 & 6.0624 & TST \\
\hline CHEMBL1911429 & 775393 & 5.0 & 4.9893 & TRN \\
\hline CHEMBL1911434 & 775393 & 7.3098 & 7.4738 & TRN \\
\hline CHEMBL1911578 & 775393 & 7.7447 & 7.763 & TRN \\
\hline CHEMBL1911423 & 775393 & 6.983 & 6.9592 & TRN \\
\hline CHEMBL1911558 & 775393 & 6.7825 & 6.687 & TST \\
\hline CHEMBL1911559 & 775393 & 7.8861 & 7.2451 & TST \\
\hline CHEMBL1911575 & 775393 & 7.7447 & 7.7827 & TRN \\
\hline
\end{tabular}


Supplemental Table S2.txt

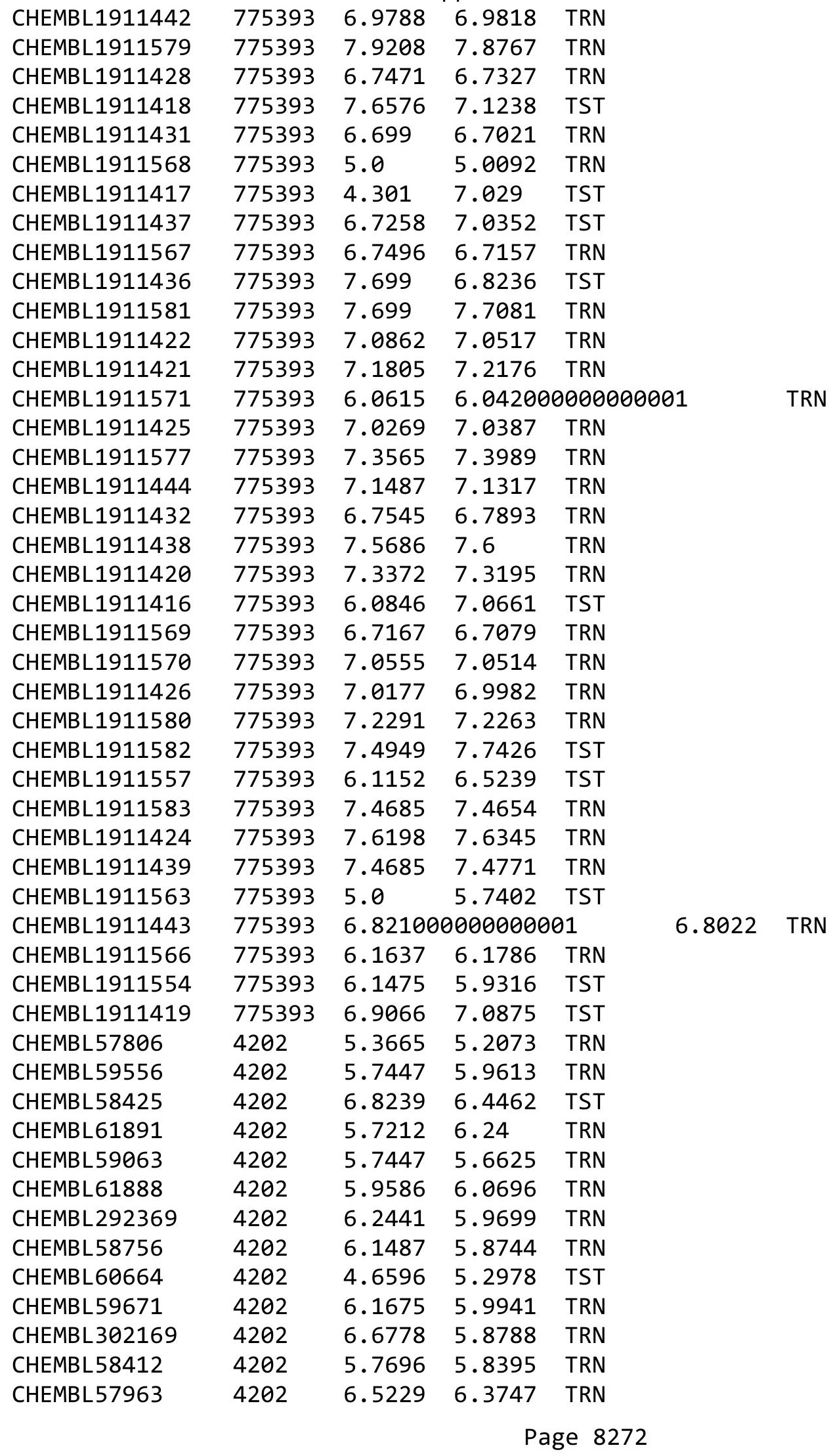




\begin{tabular}{|c|c|c|c|c|c|}
\hline & & \multicolumn{4}{|c|}{ Supplemental Table s2.txt } \\
\hline CHEMBL59450 & 4202 & 5.9208 & 6.0523 & TRN & \\
\hline CHEMBL61889 & 4202 & 4.4437 & 5.2962 & TRN & \\
\hline CHEMBL293141 & 4202 & 6.699 & 6.1237 & TRN & \\
\hline CHEMBL61892 & 4202 & 5.7447 & 6.3663 & TRN & \\
\hline CHEMBL301645 & 4202 & 4.9586 & 4.8445 & TST & \\
\hline CHEMBL292959 & 4202 & 5.3468 & 5.114 & TRN & \\
\hline CHEMBL61728 & 4202 & 6.0458 & 5.7271 & TRN & \\
\hline CHEMBL57936 & 4202 & 6.3468 & 6.2792 & TRN & \\
\hline CHEMBL294094 & 4202 & 6.0605 & 6.0153 & TRN & \\
\hline CHEMBL59838 & 4202 & 6.3188 & 6.3837 & TRN & \\
\hline CHEMBL293056 & 4202 & 4.8239 & 5.5647 & TST & \\
\hline CHEMBL58335 & 4202 & 7.0 & 6.6426 & TRN & \\
\hline CHEMBL300168 & 4202 & 5.5229 & 6.0578 & TRN & \\
\hline CHEMBL291733 & 4202 & 6.3768 & \multicolumn{2}{|c|}{6.5089999999999995} & TRN \\
\hline CHEMBL62163 & 4202 & 6.4815 & 6.5981 & TRN & \\
\hline CHEMBL291581 & 4202 & 6.1079 & 5.8859 & TRN & \\
\hline CHEMBL62162 & 4202 & 6.1805 & 6.1922 & TRN & \\
\hline CHEMBL292037 & 4202 & 4.8539 & 5.1627 & TRN & \\
\hline CHEMBL58246 & 4202 & 5.3468 & 5.2586 & TRN & \\
\hline CHEMBL413102 & 4202 & 6.8239 & \multicolumn{2}{|c|}{6.4110000000000005} & TRN \\
\hline CHEMBL58668 & 4202 & 4.5229 & 4.6993 & TRN & \\
\hline CHEMBL58463 & 4202 & 6.699 & 6.1998 & TRN & \\
\hline CHEMBL60910 & 4202 & 5.4949 & 5.8394 & TRN & \\
\hline CHEMBL61417 & 4202 & 6.2924 & 6.0534 & TRN & \\
\hline CHEMBL59449 & 4202 & 5.7959 & 6.0484 & TRN & \\
\hline CHEMBL60178 & 4202 & 5.301 & 5.9013 & TRN & \\
\hline CHEMBL59336 & 4202 & 5.7447 & 6.1478 & TRN & \\
\hline CHEMBL58346 & 4202 & 5.7212 & 5.6121 & TRN & \\
\hline CHEMBL59298 & 4202 & 5.2441 & 4.9196 & TST & \\
\hline CHEMBL418475 & 4202 & 6.699 & 5.5136 & TST & \\
\hline CHEMBL58180 & 4202 & 5.5686 & 5.7542 & TRN & \\
\hline CHEMBL59119 & 4202 & 6.7212 & 6.704 & TRN & \\
\hline CHEMBL60337 & 4202 & 6.4437 & 6.3458 & TRN & \\
\hline CHEMBL305336 & 4202 & 5.7696 & 6.1633 & TRN & \\
\hline CHEMBL62248 & 4202 & 6.2676 & 6.0145 & TRN & \\
\hline CHEMBL60174 & 4202 & 7.0 & 6.0237 & TST & \\
\hline CHEMBL291812 & 4202 & 5.2596 & 4.8644 & TST & \\
\hline CHEMBL58078 & 4202 & 5.9208 & 5.89 & TRN & \\
\hline CHEMBL433639 & 4202 & 6.4949 & 5.5967 & TST & \\
\hline CHEMBL59949 & 4202 & 5.5086 & 5.4895 & TRN & \\
\hline CHEMBL58309 & 4202 & 5.1487 & 5.95200 & 0000000001 & TRN \\
\hline CHEMBL58314 & 4202 & 6.9208 & 6.3047 & TRN & \\
\hline CHEMBL60903 & 4202 & 4.9355 & 4.7522 & TST & \\
\hline CHEMBL292371 & 4202 & 4.8239 & 5.1671 & TRN & \\
\hline CHEMBL61634 & 4202 & 5.8861 & 5.6278 & TRN & \\
\hline CHEMBL294818 & 4202 & 4.9208 & 5.3107 & TRN & \\
\hline CHEMBL300985 & 4202 & 7.0 & 6.1993 & TST & \\
\hline CHEMBL58785 & 4202 & 5.6778 & 5.2537 & TRN & \\
\hline
\end{tabular}




\begin{tabular}{|c|c|c|c|c|c|}
\hline & & \multicolumn{4}{|c|}{ Supplemental Table S2.txt } \\
\hline CHEMBL294092 & 4202 & 5.284 & 5.0066 & TRN & \\
\hline CHEMBL61752 & 4202 & 5.699 & 5.546 & TRN & \\
\hline CHEMBL58779 & 4202 & 6.7212 & 6.0391 & TRN & \\
\hline CHEMBL59895 & 4202 & 6.2676 & 6.4682 & TRN & \\
\hline CHEMBL302221 & 4202 & 4.9586 & 5.0603 & TRN & \\
\hline CHEMBL61706 & 4202 & 6.3979 & 6.0004 & TRN & \\
\hline CHEMBL59901 & 4202 & 5.8239 & 5.9653 & TRN & \\
\hline CHEMBL61782 & 4202 & 6.3979 & 6.7283 & TRN & \\
\hline CHEMBL301461 & 4202 & 5.8861 & 5.9654 & TRN & \\
\hline CHEMBL58950 & 4202 & 5.5376 & 5.3685 & TRN & \\
\hline CHEMBL301866 & 4202 & 5.3768 & 5.2884 & TRN & \\
\hline CHEMBL58909 & 4202 & 6.4559 & 5.6757 & TRN & \\
\hline CHEMBL58976 & 4202 & 4.0706 & 5.6458 & TST & \\
\hline CHEMBL58255 & 4202 & 6.1871 & 5.9078 & TRN & \\
\hline CHEMBL 292247 & 4202 & 6.1938 & 6.3136 & TRN & \\
\hline CHEMBL292571 & 4202 & 6.5229 & 6.37700 & 0000000001 & TRN \\
\hline CHEMBL302885 & 4202 & 4.7212 & 4.6632 & TRN & \\
\hline CHEMBL57935 & 4202 & 6.5229 & 5.7881 & TRN & \\
\hline CHEMBL62090 & 4202 & 5.4437 & 5.358 & TRN & \\
\hline CHEMBL58062 & 4202 & 5.2076 & 5.3138 & TRN & \\
\hline CHEMBL292576 & 4202 & 5.4318 & 5.6479 & TRN & \\
\hline CHEMBL61921 & 4202 & 5.5229 & 5.939 & TRN & \\
\hline CHEMBL294752 & 4202 & 6.4202 & 6.2256 & TRN & \\
\hline CHEMBL292833 & 4202 & 5.6778 & 5.769 & TRN & \\
\hline CHEMBL58336 & 4202 & 6.8239 & 6.456 & TRN & \\
\hline CHEMBL291993 & 4202 & 6.301 & 6.3411 & TST & \\
\hline CHEMBL59077 & 4202 & 6.2441 & 6.6437 & TRN & \\
\hline CHEMBL292973 & 4202 & 6.0 & 6.0648 & TRN & \\
\hline CHEMBL58225 & 4202 & 5.8239 & 5.6269 & TRN & \\
\hline CHEMBL303591 & 4202 & 5.5229 & 6.0232 & TRN & \\
\hline CHEMBL294190 & 4202 & 6.301 & 5.9448 & TRN & \\
\hline CHEMBL58778 & 4202 & 5.4559 & 5.6414 & TRN & \\
\hline CHEMBL61757 & 4202 & 4.8861 & 5.8641 & TRN & \\
\hline CHEMBL 292570 & 4202 & 5.5376 & 6.1514 & TST & \\
\hline CHEMBL292447 & 4202 & 5.1549 & 5.2696 & TRN & \\
\hline CHEMBL57958 & 4202 & 5.6198 & 5.75200 & 0000000001 & TRN \\
\hline CHEMBL59387 & 4202 & 4.7212 & 4.9445 & TST & \\
\hline CHEMBL59863 & 4202 & 5.3979 & 4.9989 & TST & \\
\hline CHEMBL 291840 & 4202 & 4.6198 & 5.1132 & TST & \\
\hline CHEMBL61874 & 4202 & 6.0915 & 5.7778 & TST & \\
\hline CHEMBL33281 & 4202 & 5.6198 & 5.74200 & 0000000001 & TST \\
\hline CHEMBL58721 & 4202 & 6.5229 & 5.7201 & TST & \\
\hline CHEMBL300779 & 4202 & 6.3768 & 6.2702 & TST & \\
\hline CHEMBL58448 & 4202 & 5.2924 & 5.2368 & TST & \\
\hline CHEMBL58906 & 4202 & 4.8539 & 6.0432 & TST & \\
\hline CHEMBL58021 & 4202 & 6.585 & 5.7466 & TST & \\
\hline CHEMBL303989 & 4202 & 5.5528 & 5.6746 & TST & \\
\hline CHEMBL61980 & 4202 & 5.1938 & 5.8825 & TST & \\
\hline
\end{tabular}




\begin{tabular}{|c|c|c|c|c|c|}
\hline \multicolumn{6}{|c|}{ supplemental } \\
\hline CHEMBL59301 & 4202 & 6.8861 & 6.0451 & TST & \\
\hline CHEMBL 303965 & 4202 & 5.4815 & 6.0734 & TST & \\
\hline CHEMBL64934 & 570758 & 3.8 & 4.5191 & TRN & \\
\hline CHEMBL560691 & 570758 & 3.6 & 4.1509 & TRN & \\
\hline CHEMBL540263 & 570758 & 5.7 & 5.6304 & TRN & \\
\hline CHEMBL564753 & 570758 & 7.2 & 6.5215 & TRN & \\
\hline CHEMBL538428 & 570758 & 6.2 & 6.3977 & TRN & \\
\hline CHEMBL553907 & 570758 & 5.1 & 5.5307 & TRN & \\
\hline CHEMBL560816 & 570758 & 3.9 & 4.2259 & TRN & \\
\hline CHEMBL560490 & 570758 & 4.1 & 3.1187 & TRN & \\
\hline CHEMBL563353 & 570758 & 3.2 & 3.773 & TST & \\
\hline CHEMBL 293370 & 570758 & 6.4 & 6.5128 & TRN & \\
\hline CHEMBL560950 & 570758 & 5.2 & 4.5718 & TST & \\
\hline CHEMBL538362 & 570758 & 6.2 & 6.2415 & TRN & \\
\hline CHEMBL554572 & 570758 & 6.6 & 6.8126 & TRN & \\
\hline CHEMBL542009 & 570758 & 6.4 & 6.2347 & TRN & \\
\hline CHEMBL556110 & 570758 & 5.0 & 5.61100 & 0000000001 & TRN \\
\hline CHEMBL550541 & 570758 & 4.1 & 2.4319 & TST & \\
\hline CHEMBL 550542 & 570758 & 5.7 & 5.1968 & TRN & \\
\hline CHEMBL556870 & 570758 & 4.9 & 5.6022 & TRN & \\
\hline CHEMBL117699 & 570758 & 7.5 & 7.0605 & TRN & \\
\hline CHEMBL557759 & 570758 & 5.1 & 5.494 & TRN & \\
\hline CHEMBL432339 & 570758 & 4.8 & 3.9852 & TRN & \\
\hline CHEMBL55553 & 570758 & 6.9 & 6.3115 & TRN & \\
\hline CHEMBL539916 & 570758 & 6.8 & 6.5923 & TRN & \\
\hline CHEMBL556112 & 570758 & 5.7 & 5.869 & TRN & \\
\hline CHEMBL539154 & 570758 & 6.5 & 6.4626 & TRN & \\
\hline CHEMBL561150 & 570758 & 4.8 & 5.1234 & TRN & \\
\hline CHEMBL551485 & 570758 & 4.7 & 5.4381 & TRN & \\
\hline CHEMBL138951 & 570758 & 4.2 & 3.7515 & TST & \\
\hline CHEMBL549752 & 570758 & 6.6 & 6.6075 & TRN & \\
\hline CHEMBL564403 & 570758 & 4.4 & 4.2847 & TRN & \\
\hline CHEMBL553867 & 570758 & 5.9 & 4.0511 & TST & \\
\hline CHEMBL539950 & 570758 & 5.3 & 5.5292 & TRN & \\
\hline CHEMBL555015 & 570758 & 6.4 & 6.5399 & TRN & \\
\hline CHEMBL539949 & 570758 & 3.5 & 2.9497 & TST & \\
\hline CHEMBL562238 & 570758 & 5.1 & 5.4199 & TRN & \\
\hline CHEMBL540187 & 570758 & 5.8 & 5.7141 & TRN & \\
\hline CHEMBL556729 & 570758 & 6.2 & 6.7342 & TRN & \\
\hline CHEMBL549753 & 570758 & 3.1 & 3.4618 & TST & \\
\hline CHEMBL541768 & 570758 & 5.4 & 6.4864 & TRN & \\
\hline CHEMBL559767 & 570758 & 3.9 & 3.6501 & TST & \\
\hline CHEMBL551844 & 570758 & 5.2 & 5.3604 & TRN & \\
\hline CHEMBL 186337 & 570758 & 4.8 & 4.9483 & TST & \\
\hline CHEMBL553391 & 570758 & 3.3 & 3.8437 & TST & \\
\hline CHEMBL563917 & 570758 & 2.5 & 2.7422 & TST & \\
\hline CHEMBL 185872 & 570758 & 4.9 & 5.1109 & TST & \\
\hline CHEMBL550132 & 570758 & 4.7 & 4.6674 & TRN & \\
\hline
\end{tabular}




\begin{tabular}{|c|c|c|c|c|c|}
\hline \multicolumn{6}{|c|}{ 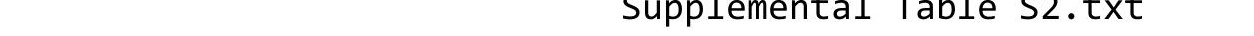 } \\
\hline CHEMBL541952 & 570758 & 6.0 & 6.4148 & TRN & \\
\hline CHEMBL139393 & 570758 & 4.3 & 3.4208 & TST & \\
\hline CHEMBL363687 & 570758 & 4.3 & 4.22 & TST & \\
\hline CHEMBL564603 & 570758 & 5.2 & 5.4921 & TRN & \\
\hline CHEMBL1230341 & 570758 & 7.7 & 6.9115 & TRN & \\
\hline CHEMBL549951 & 570758 & 2.5 & 3.1637 & TST & \\
\hline CHEMBL555016 & 570758 & 6.5 & 6.6606 & TRN & \\
\hline CHEMBL117869 & 570758 & 5.2 & 4.6456 & TST & \\
\hline CHEMBL559768 & 570758 & 4.3 & 4.548 & TRN & \\
\hline CHEMBL556738 & 570758 & 5.4 & 5.396 & TRN & \\
\hline CHEMBL 303333 & 570758 & 6.2 & 6.0598 & TRN & \\
\hline CHEMBL539951 & 570758 & 5.9 & 5.6229 & TRN & \\
\hline CHEMBL539642 & 570758 & 3.0 & 3.1251 & TST & \\
\hline CHEMBL555276 & 570758 & 5.0 & 4.6235 & TRN & \\
\hline CHEMBL551297 & 570758 & 4.7 & 4.6016 & TRN & \\
\hline CHEMBL561501 & 570758 & 5.4 & 5.4038 & TRN & \\
\hline CHEMBL55243 & 570758 & 7.2 & 6.506 & TRN & \\
\hline CHEMBL562239 & 570758 & 6.2 & 6.3222 & TRN & \\
\hline CHEMBL538192 & 570758 & 6.4 & 6.2844 & TRN & \\
\hline CHEMBL549754 & 570758 & 4.8 & 4.5753 & TST & \\
\hline CHEMBL 308192 & 570758 & 4.4 & 4.2908 & TRN & \\
\hline CHEMBL553247 & 570758 & 5.7 & 5.7122 & TST & \\
\hline CHEMBL559892 & 570758 & 5.4 & 5.4217 & TRN & \\
\hline CHEMBL551222 & 570758 & 5.0 & 4.9423 & TRN & \\
\hline CHEMBL539914 & 570758 & 5.7 & 6.0726 & TRN & \\
\hline CHEMBL557758 & 570758 & 5.4 & 5.37299 & 9999999999 & TRN \\
\hline CHEMBL417564 & 570758 & 4.4 & 4.3112 & TRN & \\
\hline CHEMBL556275 & 570758 & 6.4 & 6.4667 & TRN & \\
\hline CHEMBL 291557 & 570758 & 7.0 & 6.5072 & TRN & \\
\hline CHEMBL563483 & 570758 & 4.0 & 4.0764 & TRN & \\
\hline CHEMBL554920 & 570758 & 6.7 & 6.204 & TRN & \\
\hline CHEMBL559264 & 570758 & 5.4 & 5.0872 & TRN & \\
\hline CHEMBL67187 & 570758 & 4.9 & 4.3061 & TRN & \\
\hline CHEMBL501484 & 570758 & 5.4 & 5.5186 & TRN & \\
\hline CHEMBL501485 & 570758 & 5.9 & 6.3664 & TRN & \\
\hline CHEMBL563043 & 570758 & 5.1 & 5.0581 & TRN & \\
\hline CHEMBL292849 & 570758 & 6.0 & 6.5849 & TRN & \\
\hline CHEMBL54596 & 570758 & 6.7 & 6.5697 & TRN & \\
\hline CHEMBL553641 & 570758 & 6.6 & 6.8124 & TRN & \\
\hline CHEMBL554149 & 570758 & 3.0 & 2.9529 & TST & \\
\hline CHEMBL563006 & 570758 & 4.3 & 4.5826 & TST & \\
\hline CHEMBL558555 & 570758 & 7.7 & 6.9073 & TRN & \\
\hline CHEMBL556331 & 570758 & 5.4 & 5.9145 & TRN & \\
\hline CHEMBL333158 & 570758 & 3.9 & 3.0763 & TST & \\
\hline CHEMBL67188 & 570758 & 4.6 & 4.4312 & TRN & \\
\hline CHEMBL553946 & 570758 & 3.8 & 4.0571 & TRN & \\
\hline CHEMBL116605 & 570758 & 7.9 & 7.1783 & TRN & \\
\hline CHEMBL551084 & 570758 & 5.4 & 5.4286 & TRN & \\
\hline
\end{tabular}




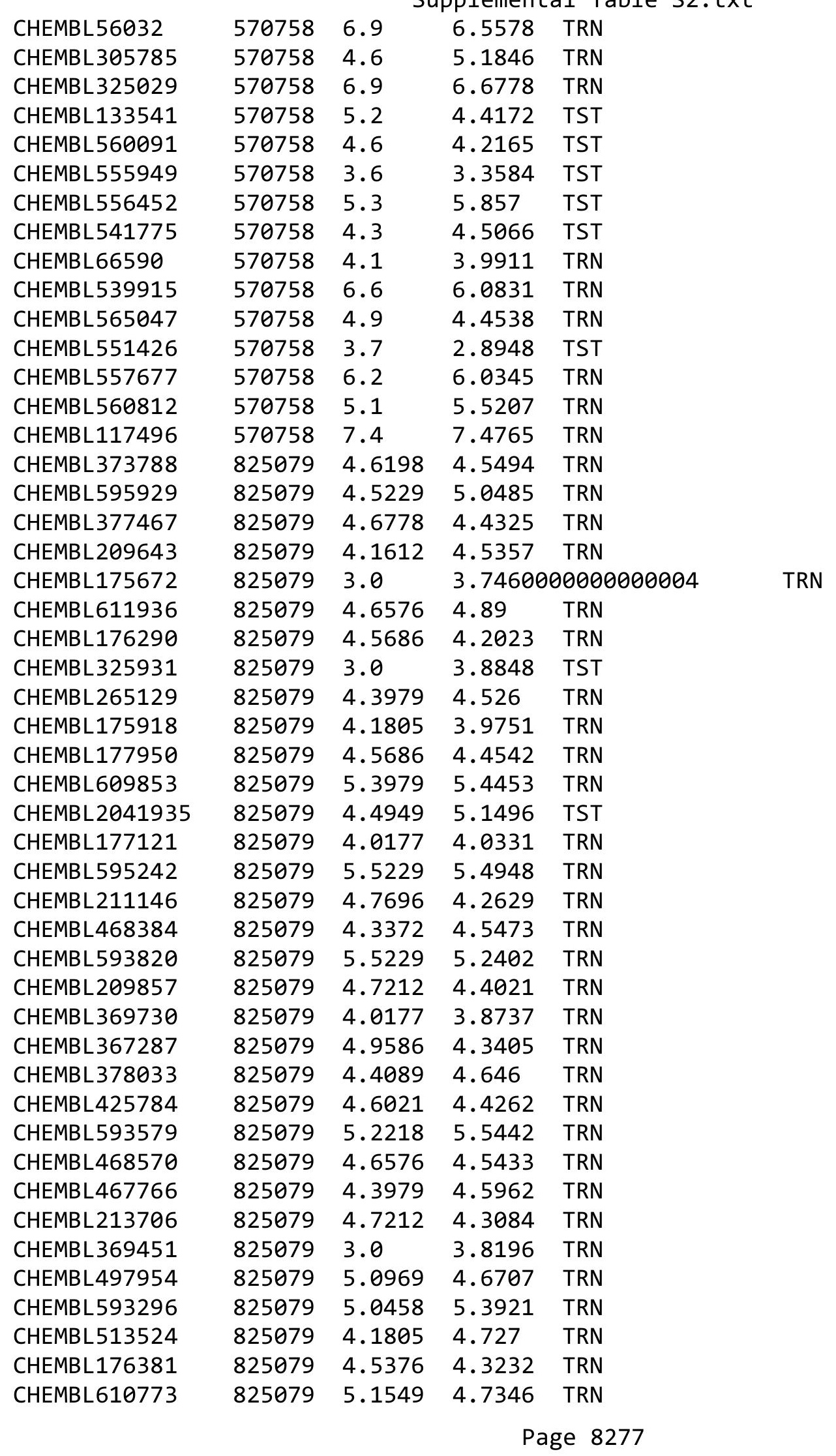




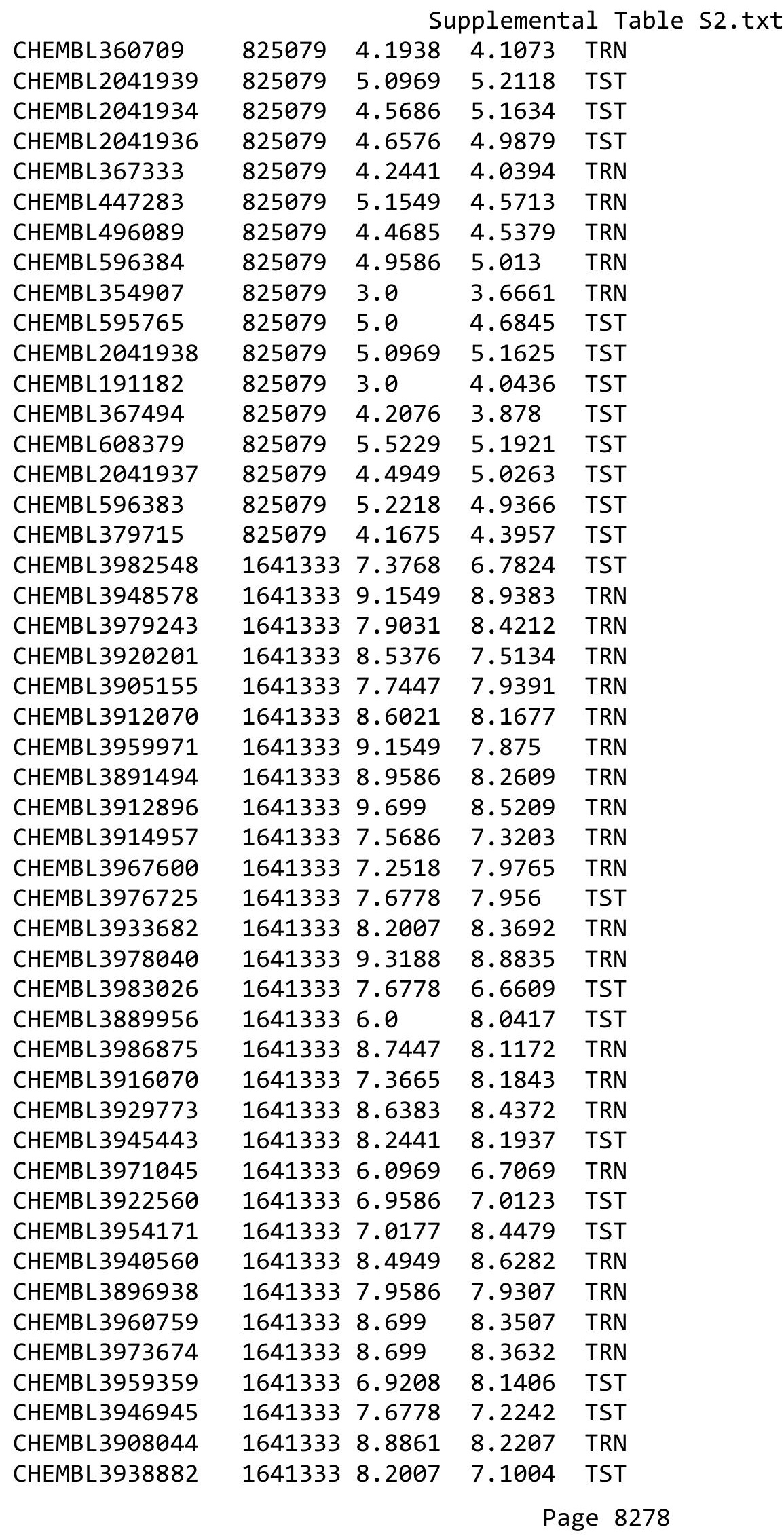


Supplemental Table S2.txt

\begin{tabular}{|c|c|c|c|c|c|c|}
\hline CHEMBL 3941466 & 1641333 & 6.7959 & 7.92 & TRN & & \\
\hline CHEMBL 3939798 & 1641333 & 6.8539 & 6.9116 & TST & & \\
\hline CHEMBL3920470 & 1641333 & 7.4559 & 7.9496 & TRN & & \\
\hline CHEMBL 3938786 & 1641333 & 6.0 & 8.4753 & TRN & & \\
\hline CHEMBL 3904238 & 1641333 & 8.9208 & 9.3159 & TRN & & \\
\hline CHEMBL 3951350 & 1641333 & 8.1675 & 8.0114 & TRN & & \\
\hline CHEMBL3951896 & 1641333 & 8.9208 & 8.2224 & TRN & & \\
\hline CHEMBL3908979 & 1641333 & 8.7212 & 8.3039 & TRN & & \\
\hline CHEMBL 3894459 & 1641333 & 8.2218 & 8.0602 & TRN & & \\
\hline CHEMBL3980691 & 1641333 & 7.2676 & 7.0979 & TST & & \\
\hline CHEMBL3912731 & 1641333 & 9.699 & 8.2454 & TST & & \\
\hline CHEMBL 3968334 & 1641333 & 9.3979 & 8.2146 & TRN & & \\
\hline CHEMBL 3941625 & 1641333 & 7.5229 & \multicolumn{3}{|c|}{7.162000000000001} & TST \\
\hline CHEMBL3926101 & 1641333 & 7.1643 & 6.9005 & TST & & \\
\hline CHEMBL 3966721 & 1641333 & 8.2366 & 8.2807 & TRN & & \\
\hline CHEMBL3985916 & 1641333 & 8.4685 & 8.0355 & TRN & & \\
\hline CHEMBL3975745 & 1641333 & 9.3979 & 9.0867 & TRN & & \\
\hline CHEMBL 3945126 & 1641333 & 6.7212 & 6.5067 & TST & & \\
\hline CHEMBL 3893612 & 1641333 & 7.4815 & 7.3166 & TST & & \\
\hline CHEMBL 3944778 & 1641333 & 8.7212 & 8.0493 & TRN & & \\
\hline CHEMBL 3955196 & 1641333 & 9.2218 & 8.5112 & TRN & & \\
\hline CHEMBL 3969343 & 1641333 & 7.6383 & 7.4856 & TRN & & \\
\hline CHEMBL 3897114 & 1641333 & 8.2596 & 7.8174 & TRN & & \\
\hline CHEMBL 3973588 & 1641333 & 9.1549 & 8.5696 & TRN & & \\
\hline CHEMBL 3926134 & 1641333 & 7.5528 & 7.6127 & TRN & & \\
\hline CHEMBL 3911617 & 1641333 & 6.1805 & 7.3212 & TRN & & \\
\hline CHEMBL 3903541 & 1641333 & 7.5086 & 7.4692 & TRN & & \\
\hline CHEMBL 3908926 & 1641333 & 7.6778 & 7.9467 & TRN & & \\
\hline CHEMBL 3924363 & 1641333 & 9.5229 & 9.1455 & TRN & & \\
\hline CHEMBL 3972276 & 1641333 & 8.5376 & 8.217 & TRN & & \\
\hline CHEMBL 3894855 & 1641333 & 7.4815 & 8.5226 & TRN & & \\
\hline CHEMBL 3952063 & 1641333 & 7.2366 & 8.9291 & TRN & & \\
\hline CHEMBL 3968952 & 1641333 & 8.0862 & 8.3851 & TRN & & \\
\hline CHEMBL 3986663 & 1641333 & 8.2291 & 8.5437 & TRN & & \\
\hline CHEMBL 3970084 & 1641333 & 7.5686 & 7.3433 & TRN & & \\
\hline CHEMBL3913338 & 1641333 & 7.8539 & 8.3639 & TRN & & \\
\hline CHEMBL3981599 & 1641333 & 6.6383 & 8.2556 & TST & & \\
\hline CHEMBL 3950552 & 1641333 & 8.0862 & 8.1821 & TRN & & \\
\hline CHEMBL3911846 & 1641333 & 8.6383 & \multicolumn{3}{|c|}{8.056000000000001} & TRI \\
\hline CHEMBL 3955341 & 1641333 & 8.585 & 8.6859 & TRN & & \\
\hline CHEMBL 3978835 & 1641333 & 6.0 & 8.2337 & TRN & & \\
\hline CHEMBL 3893959 & 1641333 & \multicolumn{3}{|c|}{6.757000000000001} & 8.1188 & $T$ \\
\hline CHEMBL3980336 & 1641333 & 7.699 & 8.1279 & TRN & & \\
\hline CHEMBL3899879 & 1641333 & \multicolumn{3}{|c|}{8.283999999999999} & 8.0274 & $\mathrm{TR}$ \\
\hline CHEMBL 3953504 & 1641333 & 11.0 & 9.7467 & TRN & & \\
\hline CHEMBL 3971213 & 1641333 & 7.8013 & \multicolumn{3}{|c|}{7.332000000000001} & $\mathrm{~K}$ \\
\hline CHEMBL 3957085 & 1641333 & 7.4318 & 8.1389 & TRN & & \\
\hline CHEMBL 3939822 & 1641333 & 8.0506 & 8.1618 & TRN & & \\
\hline
\end{tabular}


Supplemental Table S2.txt

\begin{tabular}{|c|c|c|c|c|c|c|}
\hline CHEMBL 3954670 & 1641333 & 7.9747 & 8.3225 & TRN & & \\
\hline CHEMBL 3978608 & 1641333 & 8.4089 & 9.0902 & TRN & & \\
\hline CHEMBL 3957240 & 1641333 & 7.699 & 7.1244 & TRN & & \\
\hline CHEMBL 3948579 & 1641333 & 10.0 & 8.5304 & TRN & & \\
\hline CHEMBL 3917034 & 1641333 & 9.0969 & 8.1206 & TRN & & \\
\hline CHEMBL3945836 & 1641333 & 8.9586 & 8.4635 & TRN & & \\
\hline CHEMBL 3896282 & 1641333 & 8.9586 & 8.7423 & TRN & & \\
\hline CHEMBL3969670 & 1641333 & 8.6021 & 8.7551 & TRN & & \\
\hline CHEMBL 3940525 & 1641333 & 7.6198 & 8.3702 & TRN & & \\
\hline CHEMBL3953863 & 1641333 & 7.3468 & 6.892 & TST & & \\
\hline CHEMBL3924179 & 1641333 & 7.7212 & 7.6963 & TRN & & \\
\hline CHEMBL3964830 & 1641333 & 8.0555 & 8.1495 & TRN & & \\
\hline CHEMBL 3942943 & 1641333 & 6.0915 & 6.8262 & TST & & \\
\hline CHEMBL 3924265 & 1641333 & 9.1549 & 8.7292 & TRN & & \\
\hline CHEMBL 3983290 & 1641333 & 8.4949 & 8.0773 & TRN & & \\
\hline CHEMBL3955498 & 1641333 & 7.75700 & 000000006 & $\partial 1$ & 8.1319 & TRN \\
\hline CHEMBL3936517 & 1641333 & 6.5229 & 6.9935 & TST & & \\
\hline CHEMBL3977760 & 1641333 & 7.3468 & 7.746 & TRN & & \\
\hline CHEMBL 3972471 & 1641333 & 8.4559 & 8.2109 & TST & & \\
\hline CHEMBL 3962621 & 1641333 & 7.7696 & 7.984 & TRN & & \\
\hline CHEMBL 3923150 & 1641333 & 8.7212 & 9.4348 & TRN & & \\
\hline CHEMBL 3931491 & 1641333 & 7.0088 & 6.7207 & TST & & \\
\hline CHEMBL3932491 & 1641333 & 8.0809 & 8.0268 & TRN & & \\
\hline CHEMBL 3904341 & 1641333 & 7.8697 & 8.6453 & TRN & & \\
\hline CHEMBL3889875 & 1641333 & 8.3098 & 8.082 & TRN & & \\
\hline CHEMBL 3951479 & 1641333 & 8.5229 & 9.1663 & TRN & & \\
\hline CHEMBL 3950276 & 1641333 & 7.301 & 6.8441 & TST & & \\
\hline CHEMBL3968338 & 1641333 & 9.699 & 9.0153 & TRN & & \\
\hline CHEMBL3925900 & 1641333 & 7.9208 & 8.0554 & TRN & & \\
\hline CHEMBL3979488 & 1641333 & 7.3979 & 8.0102 & TRN & & \\
\hline CHEMBL 3968553 & 1641333 & 9.2218 & 8.9272 & TRN & & \\
\hline CHEMBL3923618 & 1641333 & 7.8761 & 6.9981 & TST & & \\
\hline CHEMBL3947979 & 1641333 & 7.4881 & 6.6976 & TST & & \\
\hline CHEMBL3913839 & 1641333 & 8.9208 & 8.9499 & TRN & & \\
\hline CHEMBL3904499 & 1641333 & 8.6198 & 8.5829 & TRN & & \\
\hline CHEMBL3922033 & 1641333 & 9.3979 & 9.4486 & TRN & & \\
\hline CHEMBL3946444 & 1641333 & 9.5229 & 9.2135 & TRN & & \\
\hline CHEMBL3915180 & 1641333 & 9.5229 & 8.2846 & TRN & & \\
\hline CHEMBL 3953738 & 1641333 & 7.4881 & 7.1492 & TRN & & \\
\hline CHEMBL3945236 & 1641333 & 7.0223 & 7.5049 & TST & & \\
\hline CHEMBL3931083 & 1641333 & 8.7212 & 9.035 & TRN & & \\
\hline CHEMBL3940572 & 1641333 & 8.9208 & 8.1945 & TRN & & \\
\hline CHEMBL3973808 & 1641333 & 7.699 & 8.2751 & TRN & & \\
\hline CHEMBL3982349 & 1641333 & 8.0915 & 7.9676 & TRN & & \\
\hline CHEMBL3916036 & 1641333 & 6.0 & 7.6315 & TRN & & \\
\hline CHEMBL 3927056 & 1641333 & 9.0969 & 8.9616 & TRN & & \\
\hline CHEMBL 3982508 & 1641333 & 6.2076 & 7.4725 & TST & & \\
\hline CHEMBL3929437 & 1641333 & 7.2076 & 6.9337 & TRN & & \\
\hline
\end{tabular}


Supplemental Table S2.txt

\begin{tabular}{|c|c|c|c|c|c|}
\hline CHEMBL3940110 & 1641333 & 9.1549 & 8.9844 & TRN & \\
\hline CHEMBL 3985741 & 1641333 & 7.4089 & 8.0802 & TRN & \\
\hline CHEMBL3940039 & 1641333 & 9.0 & 8.3444 & TST & \\
\hline CHEMBL3964682 & 1641333 & 8.7696 & 7.9194 & TRN & \\
\hline CHEMBL3962493 & 1641333 & 8.2676 & 8.0366 & TST & \\
\hline CHEMBL3890235 & 1641333 & 8.1739 & 8.1758 & TST & \\
\hline CHEMBL3974651 & 1641333 & 8.8539 & 9.282 & TST & \\
\hline CHEMBL3976400 & 1641333 & 7.2924 & 8.0337 & TST & \\
\hline CHEMBL3966195 & 1641333 & 8.6021 & 9.1013 & TST & \\
\hline CHEMBL1084999 & 635026 & 8.3468 & 8.3901 & TRN & \\
\hline CHEMBL1084565 & 635026 & 6.2366 & 6.2608 & TRN & \\
\hline CHEMBL1083299 & 635026 & 7.4815 & 7.9367 & TST & \\
\hline CHEMBL1086015 & 635026 & 6.1192 & 6.6378 & TST & \\
\hline CHEMBL1083952 & 635026 & 8.2757 & 8.0088 & TRN & \\
\hline CHEMBL1084184 & 635026 & 6.8239 & 6.9778 & TRN & \\
\hline CHEMBL1086594 & 635026 & 7.8861 & 7.9893 & TRN & \\
\hline CHEMBL1085088 & 635026 & 6.2147 & 6.9155 & TST & \\
\hline CHEMBL1086380 & 635026 & 6.8861 & 6.9911 & TRN & \\
\hline CHEMBL1083920 & 635026 & 6.3279 & 7.6375 & TST & \\
\hline CHEMBL1084235 & 635026 & 7.8861 & 8.0221 & TRN & \\
\hline CHEMBL1083922 & 635026 & 7.8861 & 8.2481 & TST & \\
\hline CHEMBL1083036 & 635026 & 7.3098 & 7.2013 & TRN & \\
\hline CHEMBL1086016 & 635026 & 5.7696 & 6.9899 & TST & \\
\hline CHEMBL1082441 & 635026 & 5.9208 & 6.768 & TST & \\
\hline CHEMBL1083320 & 635026 & 7.7959 & 7.858 & TRN & \\
\hline CHEMBL1082963 & 635026 & 7.4685 & 7.4986 & TRN & \\
\hline CHEMBL1083035 & 635026 & 7.3665 & 6.9291 & TRN & \\
\hline CHEMBL1086061 & 635026 & 6.7212 & 6.2087 & TST & \\
\hline CHEMBL1082686 & 635026 & 7.1612 & 7.1376 & TRN & \\
\hline CHEMBL1083101 & 635026 & 6.7447 & 6.8371 & TRN & \\
\hline CHEMBL1086059 & 635026 & 5.7212 & 6.0374 & TRN & \\
\hline CHEMBL1082302 & 635026 & 8.0809 & 8.2413 & TRN & \\
\hline CHEMBL1083611 & 635026 & 7.5528 & 7.3993 & TRN & \\
\hline CHEMBL1083613 & 635026 & 6.585 & 6.6282 & TRN & \\
\hline CHEMBL1084564 & 635026 & 6.4559 & 6.3297 & TRN & \\
\hline CHEMBL1082444 & 635026 & 5.4949 & 7.3684 & TST & \\
\hline CHEMBL1085989 & 635026 & 6.3565 & 6.2574 & TRN & \\
\hline CHEMBL1083608 & 635026 & 6.7696 & 7.3057 & TRN & \\
\hline CHEMBL1084297 & 635026 & 6.4559 & 6.5032 & TRN & \\
\hline CHEMBL1084511 & 635026 & 7.7959 & 7.8888 & TRN & \\
\hline CHEMBL1084722 & 635026 & 5.1192 & 4.86 & TRN & \\
\hline CHEMBL1085265 & 635026 & 7.8861 & 7.853 & TRN & \\
\hline CHEMBL1086504 & 635026 & 8.2218 & 8.0271 & TRN & \\
\hline CHEMBL1083933 & 635026 & 8.28399 & 99999999 & 99 & 8.2525 \\
\hline CHEMBL1086060 & 635026 & 4.1549 & 6.6016 & TST & \\
\hline CHEMBL1085518 & 635026 & 7.1739 & 7.2276 & TRN & \\
\hline CHEMBL1086468 & 635026 & 8.041 & 8.0882 & TRN & \\
\hline CHEMBL1083319 & 635026 & 8.0458 & 8.0331 & TRN & \\
\hline
\end{tabular}




\begin{tabular}{|c|c|c|c|c|c|}
\hline & & & & & \\
\hline CHEMBL1082696 & 635026 & 8.2007 & 8.1251 & TRN & \\
\hline CHEMBL1086017 & 635026 & 6.0362 & 6.9876 & TST & \\
\hline CHEMBL1082443 & 635026 & 5.2366 & 7.1189 & TST & \\
\hline CHEMBL1086142 & 635026 & 7.1079 & 7.0903 & TRN & \\
\hline CHEMBL1082720 & 635026 & 6.9586 & 7.0318 & TRN & \\
\hline CHEMBL1082807 & 635026 & 5.3665 & 5.4128 & TRN & \\
\hline CHEMBL1086522 & 635026 & 6.4559 & 6.6513 & TRN & \\
\hline CHEMBL1082697 & 635026 & 7.2757 & 7.2586 & TRN & \\
\hline CHEMBL1083119 & 635026 & 5.7212 & 5.7863 & TRN & \\
\hline CHEMBL1082368 & 635026 & 6.5086 & 6.5333 & TRN & \\
\hline CHEMBL1083921 & 635026 & 8.3768 & 8.2274 & TRN & \\
\hline CHEMBL1083593 & 635026 & 6.7959 & 6.8117 & TRN & \\
\hline CHEMBL1083612 & 635026 & 6.8239 & 6.8388 & TRN & \\
\hline CHEMBL1083102 & 635026 & 7.6778 & 7.1215 & TRN & \\
\hline CHEMBL1082442 & 635026 & 5.7959 & 7.3639 & TST & \\
\hline CHEMBL1082685 & 635026 & 7.4949 & 7.489 & TRN & \\
\hline CHEMBL1082339 & 635026 & 6.7959 & 6.7139 & TRN & \\
\hline CHEMBL1082338 & 635026 & 7.9208 & 8.0052 & TRN & \\
\hline CHEMBL1083720 & 635026 & 5.3188 & 5.4023 & TRN & \\
\hline CHEMBL1086259 & 635026 & 7.2147 & 7.6618 & TST & \\
\hline CHEMBL1083935 & 635026 & 7.9208 & 7.4695 & TST & \\
\hline CHEMBL3142451 & 217323 & 5.4437 & 5.3649 & TRN & \\
\hline CHEMBL3142497 & 217323 & 3.699 & 3.5675 & TRN & \\
\hline CHEMBL3142485 & 217323 & 3.3979 & 3.5085 & TRN & \\
\hline CHEMBL3142495 & 217323 & 4.5376 & 4.4647 & TRN & \\
\hline CHEMBL3142439 & 217323 & 4.699 & 4.8602 & TRN & \\
\hline CHEMBL 3142440 & 217323 & 4.4815 & 4.6147 & TST & \\
\hline CHEMBL3142453 & 217323 & 4.5229 & 4.6841 & TRN & \\
\hline CHEMBL1626177 & 217323 & 4.3979 & 4.3137 & TRN & \\
\hline CHEMBL 3142498 & 217323 & 4.8861 & 4.8453 & TRN & \\
\hline CHEMBL3142481 & 217323 & 3.3979 & 4.7569 & TST & \\
\hline CHEMBL 3142447 & 217323 & 4.5376 & 4.6511 & TRN & \\
\hline CHEMBL3142471 & 217323 & 4.5686 & 4.5817 & TRN & \\
\hline CHEMBL3142437 & 217323 & 2.3979 & 3.6463 & TST & \\
\hline CHEMBL 3142452 & 217323 & 4.1739 & 4.7553 & TST & \\
\hline CHEMBL3142463 & 217323 & 4.9586 & 4.7594 & TRN & \\
\hline CHEMBL 3142489 & 217323 & 4.4815 & 4.4819 & TRN & \\
\hline CHEMBL3142433 & 217323 & 3.8239 & 3.7573 & TRN & \\
\hline CHEMBL3142472 & 217323 & 4.5229 & 4.5515 & TRN & \\
\hline CHEMBL 3142488 & 217323 & 4.301 & 4.2554 & TRN & \\
\hline CHEMBL3306988 & 217323 & 4.1612 & 4.3856 & TRN & \\
\hline CHEMBL 3142502 & 217323 & 5.3188 & 5.2866 & TRN & \\
\hline CHEMBL 3142483 & 217323 & 4.5376 & 4.6223 & TRN & \\
\hline CHEMBL3142496 & 217323 & 4.2757 & 4.1407 & TST & \\
\hline CHEMBL 3142470 & 217323 & 4.2757 & 4.6174 & TRN & \\
\hline CHEMBL 3142446 & 217323 & 4.301 & 3.7215 & TST & \\
\hline CHEMBL 3142448 & 217323 & 4.7696 & 4.6483 & TRN & \\
\hline CHEMBL3142469 & 217323 & 4.6021 & 4.45100 & 20000000005 & TRN \\
\hline & & & & 8282 & \\
\hline
\end{tabular}




\begin{tabular}{|c|c|c|c|c|c|}
\hline \multicolumn{6}{|c|}{ Supplemental Table S2.txt } \\
\hline CHEMBL 3142466 & 217323 & 4.0809 & 4.1488 & TRN & \\
\hline CHEMBL 3142492 & 217323 & 3.6198 & 3.6249 & TRN & \\
\hline CHEMBL3142490 & 217323 & 5.301 & 5.2592 & TRN & \\
\hline CHEMBL230552 & 217323 & 3.699 & 4.2109 & TRN & \\
\hline CHEMBL3142454 & 217323 & 5.699 & 5.7918 & TRN & \\
\hline CHEMBL 3142438 & 217323 & 4.0809 & 4.0331 & TST & \\
\hline CHEMBL 3142462 & 217323 & 3.8861 & 4.4454 & TST & \\
\hline CHEMBL3142435 & 217323 & 4.699 & 3.7507 & TST & \\
\hline CHEMBL3142461 & 217323 & 4.0969 & 4.06 & TST & \\
\hline CHEMBL3142456 & 217323 & 5.0 & 4.984 & TRN & \\
\hline CHEMBL 3142484 & 217323 & 5.6021 & 5.4802 & TRN & \\
\hline CHEMBL 3142493 & 217323 & 4.3188 & 4.0666 & TRN & \\
\hline CHEMBL 3142500 & 217323 & 4.0 & 3.8573 & TRN & \\
\hline CHEMBL3142436 & 217323 & 4.0969 & 4.0161 & TRN & \\
\hline CHEMBL3142503 & 217323 & 4.8861 & 4.9272 & TRN & \\
\hline CHEMBL 3142467 & 217323 & 4.4202 & 4.5436 & TRN & \\
\hline CHEMBL3142464 & 217323 & 4.7959 & 4.9658 & TRN & \\
\hline CHEMBL 3142434 & 217323 & 4.4437 & 4.5105 & TRN & \\
\hline CHEMBL3142442 & 217323 & 4.2518 & 4.295 & TRN & \\
\hline CHEMBL 3142430 & 217323 & 4.7447 & 5.0319 & TRN & \\
\hline CHEMBL 3142486 & 217323 & 4.699 & 4.5393 & TRN & \\
\hline CHEMBL3142477 & 217323 & 5.3372 & 4.9714 & TRN & \\
\hline CHEMBL3142501 & 217323 & 4.8239 & 4.6505 & TRN & \\
\hline CHEMBL3142491 & 217323 & 4.8861 & 5.0115 & TRN & \\
\hline CHEMBL 3142449 & 217323 & 4.2147 & 4.2925 & TRN & \\
\hline CHEMBL3142465 & 217323 & 4.2441 & 4.1165 & TRN & \\
\hline CHEMBL3142482 & 217323 & 4.6021 & 4.7088 & TRN & \\
\hline CHEMBL 3142444 & 217323 & 4.699 & 4.6577 & TRN & \\
\hline CHEMBL 3142445 & 217323 & 3.9208 & 3.8627 & TRN & \\
\hline CHEMBL 3142480 & 217323 & 5.4437 & 5.305 & TRN & \\
\hline CHEMBL 3142478 & 217323 & 5.4559 & 5.24100 & 00000000005 & TRN \\
\hline CHEMBL 3142441 & 217323 & 4.2757 & 4.7068 & TST & \\
\hline CHEMBL 3142479 & 217323 & 4.6021 & 4.565 & TST & \\
\hline CHEMBL3142499 & 217323 & 4.4815 & 4.1798 & TST & \\
\hline CHEMBL3142475 & 217323 & 4.3979 & 4.8246 & TST & \\
\hline CHEMBL3142460 & 217323 & 5.9208 & 5.28600 & 00000000005 & TST \\
\hline CHEMBL 3142443 & 217323 & 4.4318 & 4.5873 & TST & \\
\hline CHEMBL 3934757 & 1641261 & 9.0 & 9.3708 & TRN & \\
\hline CHEMBL3901072 & 1641261 & 6.0 & 6.955 & TST & \\
\hline CHEMBL3972197 & 1641261 & 7.5229 & 7.5007 & TST & \\
\hline CHEMBL3902115 & 1641261 & 7.699 & 7.4473 & TRN & \\
\hline CHEMBL3917963 & 1641261 & 6.6498 & 6.4081 & TRN & \\
\hline CHEMBL3977495 & 1641261 & 7.9208 & 7.7844 & TST & \\
\hline CHEMBL3957009 & 1641261 & 8.699 & 8.3362 & TRN & \\
\hline CHEMBL3924684 & 1641261 & 7.7447 & 7.6592 & TRN & \\
\hline CHEMBL 3919059 & 1641261 & 5.87 & 6.0687 & TRN & \\
\hline CHEMBL3918768 & 1641261 & 7.3372 & 7.3385 & TRN & \\
\hline CHEMBL3904700 & 1641261 & 8.301 & 7.9394 & TRN & \\
\hline
\end{tabular}


Supplemental Table S2.txt

\begin{tabular}{|c|c|c|c|c|}
\hline HEM & 541261 & 7.3565 & & \\
\hline UГM ו & 641261 & & 7.1452 & \\
\hline 35 & 261 & & & \\
\hline AEMBL3925219 & 261 & 1079 & 0118 & $2 \mathrm{~N}$ \\
\hline AEMBL3947108 & 261 & 108 & 8026 & \\
\hline HEMBL3955492 & 641261 & 6.9393 & .629 & \\
\hline 14 & & 291 & 534 & \\
\hline IFMRI 392 & & & & Du \\
\hline HEMBL 389 & 261 & 5.7899 & 6.1016 & \\
\hline HEMBL395 & 261 & 9.0 & .4607 & \\
\hline HEMBL 389 & 261 & 8.0969 & 7.5511 & \\
\hline IEMBL394 & 261 & & .162 & \\
\hline AEMBL38 & & & & \\
\hline HEMBL 391 & 261 & 768 & 7.5176 & \\
\hline AEMBL398 & 261 & 9.0 & 8.7463 & \\
\hline AEMBL389 & 6 & 9 & 7.4822 & \\
\hline AEMBL39 & 1 & 9 & 87 & . \\
\hline HEMBL39 & & & 52 & \\
\hline HEMBL39 & & 8.699 & 7.5952 & \\
\hline AEMBL39 & & & 7.7461 & N \\
\hline AEMBL3 & 6 & 8 & 963 & $\mathrm{IRIV}$ \\
\hline HEMBL3 & & 9 & 7.7344 & 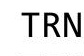 \\
\hline HEMBL3S & & & 88 & \\
\hline AFMRI 30 & & & 7.1806 & \\
\hline AEMBL39 & & & & N \\
\hline HEMBL3S & 6 & 16 & 7.2777 & RN \\
\hline HEMBL3 & & & 02 & RN \\
\hline HFMBI 36 & 61 & 79 & 45 & \\
\hline HEMBL3S & & & 7.2642 & I KIV \\
\hline HEMBL 395 & & & 3355 & I NIV \\
\hline HEMBL39 & 64 & & 24 & RN \\
\hline HEMBL; & & & 87 & RN \\
\hline HEMBL; & & 4 & & N \\
\hline HEMBL396 & 51 & & 2592 & IRN \\
\hline HEMBL3914636 & 61 & 3.2218 & 7.5746 & TST \\
\hline HEMBL3S & 6 & 79 & & TRN \\
\hline HFMRI $=2$ & \pm & 2 & & RN \\
\hline HEMBL3 & & & 8.0798 & RN \\
\hline HEMBL3933407 & 61 & 586 & 1366 & TRN \\
\hline EMBL & & 366 & 0043 & IRN \\
\hline HEMBL39 & 01 & & 9499 & \\
\hline CHEMBL39 & & & & IST \\
\hline HEMBL 396 & 261 & 549 & 7.9162 & $\Gamma \mathrm{RN}$ \\
\hline HEMBL3948257 & 261 & 599 & .2788 & TRN \\
\hline$M B L 3$ & & 0 & 7.7754 & \\
\hline HEMBL 39 & & & 8.872 & \\
\hline LHEMBL389 & & 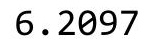 & 6.2222 & \\
\hline HEMBL3905412 & 1641261 & .0506 & 6.8243 & \\
\hline
\end{tabular}

Page 8284 
Supplemental Table S2.txt

\begin{tabular}{|c|c|c|c|c|}
\hline HEMB & 541261 & 7.2518 & & \\
\hline & 641261 & 7.8539 & 8.0435 & \\
\hline 17 & & & & \\
\hline AEMBL & 261 & 6021 & 9522 & $\mathrm{MI}$ \\
\hline AEMBL3971913 & 261 & 2218 & 5005 & \\
\hline HEMBL3951489 & 641261 & 8.0969 & .0675 & \\
\hline HEMBL393 & & & 5999 & \\
\hline IEMBL397 & & & 3412 & \\
\hline AEMBL39843. & 261 & .5086 & 7.3113 & \\
\hline HEMBL3973554 & 261 & 9.0 & 3.8706 & \\
\hline HEMBL3953358 & 261 & 7.6198 & .7672 & \\
\hline AEMBL38 & 261 & & .9155 & \\
\hline AEMBL3S & & & & \\
\hline HEMBL 398 & 261 & & 3.9823 & \\
\hline HEMBL392 & 261 & 8 & 1064 & \\
\hline HEMBL389 & 6 & 9 & .0404 & \\
\hline HEMBL39 & bI & & 9853 & m \\
\hline HEMBL 38 & & & 3632 & \\
\hline HEMBL 390 & & 4 & 6.8209 & \\
\hline HEMBL397 & 61 & & 137 & \\
\hline AEMBL3S & $\partial \perp$ & 6 & 929 & I RIV \\
\hline HEMBL3S & + & & 858 & TRN \\
\hline HEMBL3S & & & 577 & \\
\hline HFMBI 398 & & 1 & 7854 & \\
\hline AEMBL39 & & 39 & 279 & I RIV \\
\hline HEMBL39 & 1 & & 923 & I RN \\
\hline HEMBL3S & & & 354 & NIV \\
\hline HFMBI $3 c$ & 61 & 18 & 786 & \\
\hline HEMBL 392 & & & 357 & Ih \\
\hline HEMBL39568 & & & & IK \\
\hline HEMBL39258 & 61 & & & RN \\
\hline HEMBL & 1 & & 34 & RN \\
\hline HEMBL3 & 51 & & 248 & 200 \\
\hline HEMBL3921735 & & & 599 & IR \\
\hline HEMBL 3929831 & 61 & 9 & 8644 & TST \\
\hline HEMBL 396 & 61 & & 537 & TST \\
\hline HFMRI 3 & & & 88 & ГST \\
\hline HEMBL3 & & 08 & 7.8098 & TST \\
\hline HEMBL3942390 & 61 & 8.699 & 675 & TST \\
\hline HEMBL 394 & 51 & 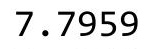 & 197 & TST \\
\hline HEMBL 394 & 01 & 12 & 3739 & $\Gamma \mathrm{ST}$ \\
\hline CHEMBL 3892914 & & & 7.8248 & ST \\
\hline HEMBL3918446 & 61 & 549 & 7.9514 & TST \\
\hline HEMBL39845 & 61 & 9706 & .1418 & TS \\
\hline MBL39 & & 9 & 0655 & TS \\
\hline HEMBL 39 & & & .0311 & \\
\hline CHEMBL3973236 & 164 & 5498 & 6.8849 & \\
\hline CHEMBL3920926 & 1641261 & 9.0 & 8.4633 & t \\
\hline
\end{tabular}

Page 8285 
Supplemental Table S2.txt

\begin{tabular}{|c|c|c|c|c|c|}
\hline CHEMBL3931305 & 1641261 & 7.9586 & 7.4194 & TST & \\
\hline CHEMBL3962449 & 1641261 & 8.699 & 8.5267 & TST & \\
\hline CHEMBL3895342 & 1641261 & 7.301 & 6.8322 & TST & \\
\hline CHEMBL3935376 & 1641261 & 7.2076 & 7.7501 & TST & \\
\hline CHEMBL1598921 & 737379 & 4.5646 & 4.2739 & TRN & \\
\hline CHEMBL1386752 & 737379 & 5.7673 & 5.5121 & TST & \\
\hline CHEMBL1993401 & 737379 & 5.5546 & 5.3287 & TRN & \\
\hline CHEMBL1900055 & 737379 & \multicolumn{3}{|c|}{5.247999999999999} & TRN \\
\hline CHEMBL1698474 & 737379 & 4.9842 & 5.16 & TRN & \\
\hline CHEMBL3214091 & 737379 & 5.8251 & 5.4753 & TST & \\
\hline CHEMBL1702298 & 737379 & 5.6262 & 5.4582 & TRN & \\
\hline CHEMBL 2007601 & 737379 & 6.1744 & 5.605 & TRN & \\
\hline CHEMBL1542491 & 737379 & \multicolumn{3}{|c|}{5.172000000000001} & TST \\
\hline CHEMBL3208231 & 737379 & 4.7062 & 4.8599 & TST & \\
\hline CHEMBL1336284 & 737379 & 2.71 & 4.3502 & TST & \\
\hline CHEMBL1381793 & 737379 & 5.1524 & 4.7706 & TRN & \\
\hline CHEMBL1981408 & 737379 & 5.4928 & 5.3062 & TRN & \\
\hline CHEMBL1366581 & 737379 & 5.3302 & 5.2872 & TRN & \\
\hline CHEMBL1562454 & 737379 & 5.5117 & 5.6244 & TRN & \\
\hline CHEMBL1304869 & 737379 & 5.1521 & 4.9054 & TRN & \\
\hline CHEMBL1307682 & 737379 & 6.1149 & 5.7136 & TRN & \\
\hline CHEMBL1502607 & 737379 & 5.1123 & 4.946000 & 0000000001 & TRN \\
\hline CHEMBL1538986 & 737379 & \multicolumn{2}{|c|}{$5.167000000000001 \quad 5.1031$} & 5.1031 & TRN \\
\hline CHEMBL1709184 & 737379 & 6.3371 & 6.6582 & TRN & \\
\hline CHEMBL1468731 & 737379 & 5.7091 & 5.6585 & TRN & \\
\hline CHEMBL1492617 & 737379 & 2.71 & 4.4156 & TRN & \\
\hline CHEMBL1324082 & 737379 & 5.6449 & 5.6352 & TRN & \\
\hline CHEMBL1726492 & 737379 & 5.4152 & 5.2453 & TRN & \\
\hline CHEMBL3198237 & 737379 & 5.0992 & 4.9117 & TRN & \\
\hline CHEMBL1523417 & 737379 & 4.4409 & 4.6539 & TRN & \\
\hline CHEMBL1452712 & 737379 & 2.71 & 4.535 & TRN & \\
\hline CHEMBL1608786 & 737379 & 5.5953 & 5.4484 & TRN & \\
\hline CHEMBL1315576 & 737379 & 5.2264 & 5.0752 & TRN & \\
\hline CHEMBL1325816 & 737379 & 5.5491 & 5.702000 & 0000000001 & TRN \\
\hline CHEMBL1400523 & 737379 & 5.1476 & 5.0043 & TST & \\
\hline CHEMBL3211198 & 737379 & 5.1716 & 4.903000 & 20000000005 & TRN \\
\hline CHEMBL1553738 & 737379 & 4.7075 & 4.6848 & TRN & \\
\hline CHEMBL1311176 & 737379 & 5.2217 & 5.1326 & TRN & \\
\hline CHEMBL1518057 & 737379 & 5.1642 & 4.9144 & TRN & \\
\hline CHEMBL1707296 & 737379 & 5.3029 & 5.0188 & TST & \\
\hline CHEMBL1504204 & 737379 & 5.2822 & 5.0736 & TRN & \\
\hline CHEMBL1496341 & 737379 & 5.0566 & 5.108000 & 00000000005 & TRN \\
\hline CHEMBL1517493 & 737379 & 5.0002 & 4.7105 & TRN & \\
\hline CHEMBL1579471 & 737379 & 5.1395 & 4.962 & TST & \\
\hline CHEMBL1607670 & 737379 & 4.1955 & 5.6161 & TRN & \\
\hline CHEMBL220845 & 737379 & 4.8761 & 5.1171 & TST & \\
\hline CHEMBL1441535 & 737379 & 5.2778 & 5.1252 & TRN & \\
\hline CHEMBL1602449 & 737379 & 5.8748 & 5.9023 & TRN & \\
\hline
\end{tabular}




\begin{tabular}{|c|c|c|c|c|c|c|}
\hline & & \multicolumn{5}{|c|}{ Supplemental Table S2.txt } \\
\hline CHEMBL1567891 & 737379 & 5.2907 & 5.1196 & TRN & & \\
\hline CHEMBL1520507 & 737379 & 4.8841 & 4.7879 & TRN & & \\
\hline CHEMBL1352441 & 737379 & 5.1438 & 5.2455 & TRN & & \\
\hline CHEMBL 2003688 & 737379 & 5.5467 & 5.3338 & TRN & & \\
\hline CHEMBL1499890 & 737379 & 5.6832 & 5.489 & TRN & & \\
\hline CHEMBL550294 & 737379 & 5.3701 & 4.8682 & TST & & \\
\hline CHEMBL3194892 & 737379 & \multicolumn{3}{|c|}{5.3260000000000005} & 5.8813 & TRN \\
\hline CHEMBL1701527 & 737379 & 5.806 & 5.5798 & TST & & \\
\hline CHEMBL1529352 & 737379 & 4.8652 & 4.9267 & TRN & & \\
\hline CHEMBL1573796 & 737379 & 5.0048 & 4.8579 & TRN & & \\
\hline CHEMBL1596084 & 737379 & 5.6716 & 5.4511 & TRN & & \\
\hline CHEMBL374350 & 737379 & 5.4492 & 5.2057 & TST & & \\
\hline CHEMBL1507404 & 737379 & 5.3943 & 5.5205 & TST & & \\
\hline CHEMBL1579186 & 737379 & 4.8102 & 4.6503 & TRN & & \\
\hline CHEMBL1491079 & 737379 & \multicolumn{3}{|c|}{5.763999999999999} & 5.3603 & TRN \\
\hline CHEMBL1310680 & 737379 & 4.8529 & 5.1227 & TRN & & \\
\hline CHEMBL1341845 & 737379 & 5.319 & 5.0797 & TRN & & \\
\hline CHEMBL1602334 & 737379 & 4.9646 & 5.0387 & TRN & & \\
\hline CHEMBL1308971 & 737379 & 4.6428 & 4.5325 & TRN & & \\
\hline CHEMBL3211859 & 737379 & 5.3442 & 5.2977 & TRN & & \\
\hline CHEMBL1352995 & 737379 & 5.1791 & 5.0003 & TRN & & \\
\hline CHEMBL46703 & 737379 & 5.3572 & 5.2941 & TST & & \\
\hline CHEMBL1447872 & 737379 & 5.4814 & 5.3768 & TRN & & \\
\hline CHEMBL1733922 & 737379 & 5.4288 & 5.4643 & TRN & & \\
\hline CHEMBL1710184 & 737379 & \multicolumn{3}{|c|}{5.6129999999999995} & 5.2728 & TRN \\
\hline CHEMBL1567553 & 737379 & 5.4134 & 5.0949 & TST & & \\
\hline CHEMBL1564305 & 737379 & 5.2527 & 5.2126 & TRN & & \\
\hline CHEMBL1400702 & 737379 & 5.0327 & 5.4912 & TRN & & \\
\hline CHEMBL1727618 & 737379 & 5.4757 & 5.4352 & TRN & & \\
\hline CHEMBL1608128 & 737379 & 4.7542 & 4.6414 & TRN & & \\
\hline CHEMBL1557089 & 737379 & 5.2866 & 5.0145 & TRN & & \\
\hline CHEMBL1569705 & 737379 & 5.2476 & 5.2222 & TRN & & \\
\hline CHEMBL3198420 & 737379 & 5.2903 & 5.3246 & TRN & & \\
\hline CHEMBL1585988 & 737379 & 5.2472 & 5.2245 & TRN & & \\
\hline CHEMBL1348510 & 737379 & 4.6936 & 5.0522 & TRN & & \\
\hline CHEMBL1386656 & 737379 & 6.1502 & 5.336 & TRN & & \\
\hline CHEMBL1491004 & 737379 & 5.4504 & 5.6174 & TRN & & \\
\hline CHEMBL1721358 & 737379 & 4.5769 & 4.2212 & TRN & & \\
\hline CHEMBL1423046 & 737379 & 5.5297 & 5.3954 & TST & & \\
\hline CHEMBL1736608 & 737379 & 2.71 & 3.3503 & TRN & & \\
\hline CHEMBL3197271 & 737379 & 4.2518 & 5.0435 & TRN & & \\
\hline CHEMBL1418191 & 737379 & 5.1031 & 5.0344 & TRN & & \\
\hline CHEMBL1475774 & 737379 & 5.3992 & 5.3743 & TST & & \\
\hline CHEMBL1597007 & 737379 & 4.8351 & 4.7226 & TRN & & \\
\hline CHEMBL1463693 & 737379 & 2.71 & 5.1584 & TST & & \\
\hline CHEMBL1299352 & 737379 & 5.2708 & 5.2651 & TST & & \\
\hline CHEMBL1544265 & 737379 & 6.2681 & 5.9759 & TST & & \\
\hline CHEMBL1353919 & 737379 & 5.3437 & 5.3294 & TRN & & \\
\hline
\end{tabular}


Supplemental Table S2.txt

\begin{tabular}{|c|c|c|c|c|}
\hline- & & & & \\
\hline HEMBL1443383 & 37379 & .0745 & 4.9992 & \\
\hline & 79 & & & \\
\hline EMBL78150 & 379 & & 25 & \\
\hline AEMBL1434041 & 37379 & & & \\
\hline AEMBL1585709 & 37379 & 5447 & 7519 & \\
\hline HEMBL1396895 & 7379 & 74 & 4904 & \\
\hline IEMBL17 & 79 & & & \\
\hline IEMBL158 & 379 & & 3354 & \\
\hline AEMBL3211221 & 37379 & 59 & 24 & \\
\hline HEMBL1509374 & 37379 & 42 & 2069 & \\
\hline AEMBL1337445 & 3379 & 51 & 3275 & \\
\hline AEMBL15 & & & & \\
\hline HEMBL13 & 79 & & & \\
\hline AEMBL1571290 & 37379 & & 5779 & \\
\hline IEMBL170 & 79 & 72 & 48 & \\
\hline HEMBL14 & 79 & 88 & 25 & \\
\hline HEMBL14 & & & & \\
\hline HEMBL 20 & 79 & & 3977 & \\
\hline AEMBL14 & & & 871 & \\
\hline AEMBL1606613 & 79 & 27 & 298 & KIV \\
\hline HEMBL 32 & 79 & 6 & 456 & \\
\hline HEMBL13 & & & 362 & \\
\hline$\partial 92$ & & & & \\
\hline AEMBL17 & & 2 & & I RIV \\
\hline HEMBL31 & 9 & & 035 & ST \\
\hline HEMBL14 & & & 221 & RN \\
\hline HFM & & & 14 & \\
\hline 231 & & & & ST \\
\hline HEMBL13. & & & & SI \\
\hline IEMBL13 & & & 54 & 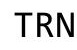 \\
\hline AFMBI 15 & & & 81 & KIV \\
\hline 57 & & & & RN \\
\hline HEMBL1345576 & & & & ST \\
\hline HEMBL1352912 & & & 924 & RN \\
\hline AEMBL31 & & & & \\
\hline 766 & & & & ST \\
\hline 17 & & & & $\mathrm{RN}$ \\
\hline HEMBL1299463 & 79 & & 822 & RN \\
\hline IEMBL19 & & & & RN \\
\hline HEMBL169 & 79 & & & \\
\hline HEMBL1729885 & & & & RN \\
\hline HEMBL15 & 37379 & & 9919 & $\mathrm{RN}$ \\
\hline AEMBL1587580 & 37379 & & 3134 & RN \\
\hline 14 & & & 992 & RIV \\
\hline HEMBL15 & & & 3076 & \\
\hline LHEMBL19؟ & 737379 & & .1302 & \\
\hline CHEMBL1362687 & 737379 & 5.2446 & 5.1668 & \\
\hline
\end{tabular}

Page 8288 


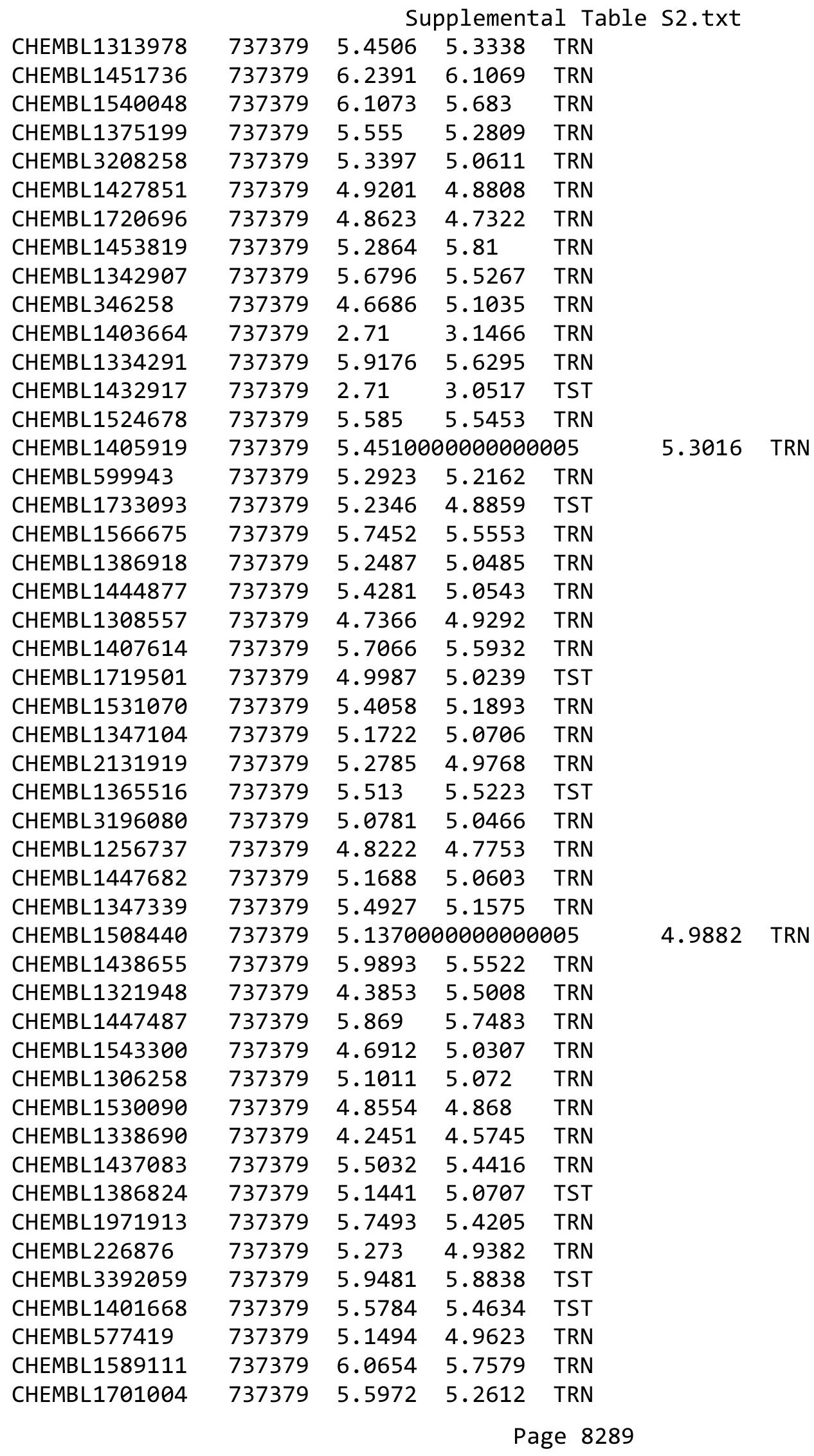


Supplemental Table S2.txt

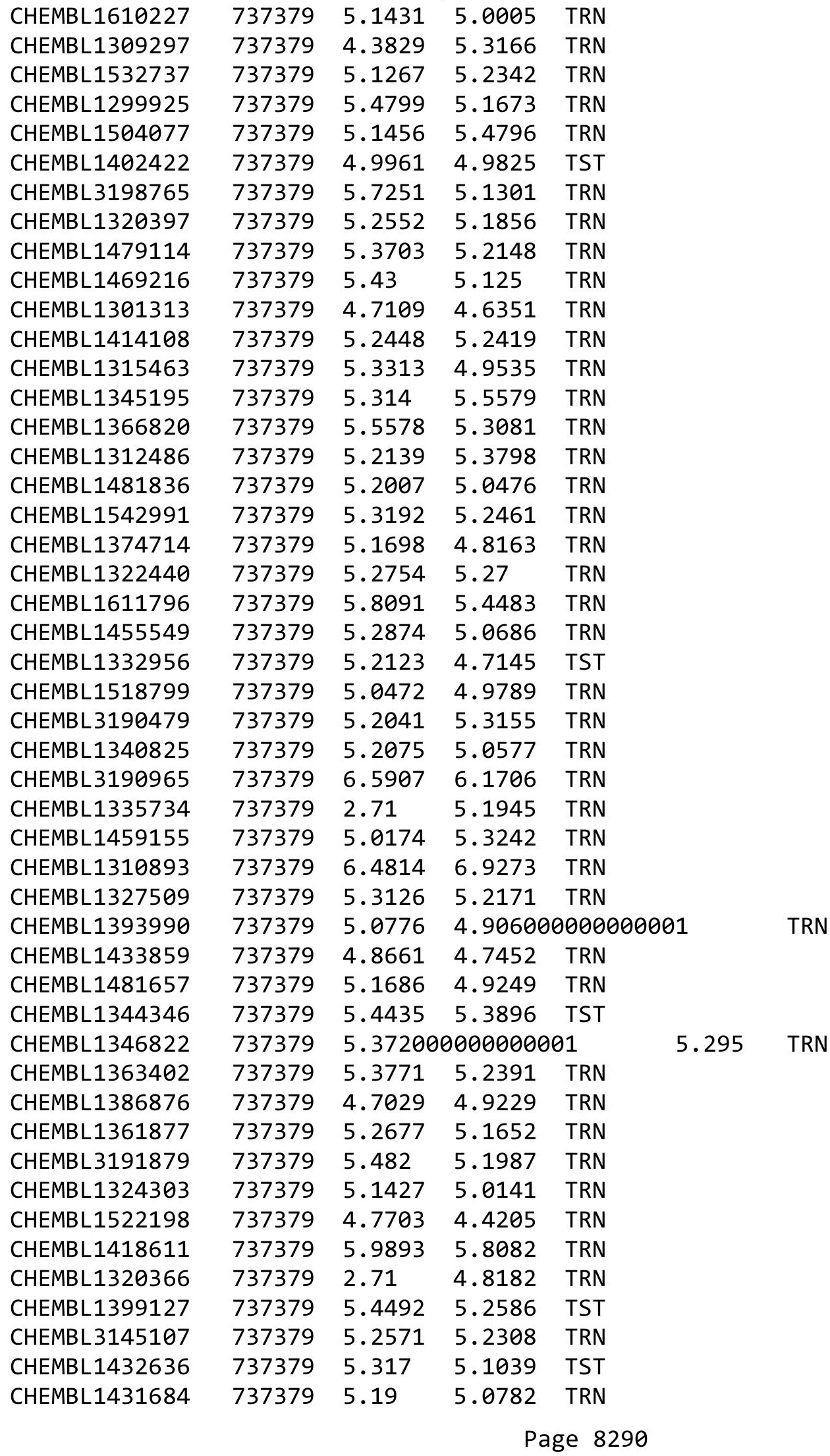




\begin{tabular}{|c|c|c|c|c|c|c|}
\hline \multirow[b]{2}{*}{ CHEMBL1372052 } & \multicolumn{6}{|c|}{ Supplemental Table S2.txt } \\
\hline & 737379 & 2.71 & 4.7833 & TST & & \\
\hline CHEMBL1566586 & 737379 & 4.9731 & 4.6071 & TRN & & \\
\hline CHEMBL1730785 & 737379 & 5.37299 & 99999999 & 99 & 5.0418 & TRN \\
\hline CHEMBL1558426 & 737379 & 4.2064 & 5.3218 & TRN & & \\
\hline CHEMBL570400 & 737379 & 5.1212 & 5.0983 & TRN & & \\
\hline CHEMBL1327791 & 737379 & 5.0899 & 4.8712 & TRN & & \\
\hline CHEMBL1569849 & 737379 & 2.71 & 4.5625 & TRN & & \\
\hline CHEMBL1505474 & 737379 & 5.4436 & 5.3348 & TST & & \\
\hline CHEMBL494083 & 737379 & 5.1924 & 4.8537 & TRN & & \\
\hline CHEMBL1450690 & 737379 & 5.7716 & 5.6697 & TRN & & \\
\hline CHEMBL3192206 & 737379 & 5.376 & 5.6142 & TRN & & \\
\hline CHEMBL1385250 & 737379 & 5.2649 & 5.2677 & TRN & & \\
\hline CHEMBL1457960 & 737379 & 5.0611 & 5.2304 & TST & & \\
\hline CHEMBL1412410 & 737379 & 2.71 & 3.9707 & TRN & & \\
\hline CHEMBL1526922 & 737379 & 3.8453 & 4.8378 & TRN & & \\
\hline CHEMBL1593654 & 737379 & 5.2014 & 5.1349 & TRN & & \\
\hline CHEMBL1394321 & 737379 & 5.1784 & 5.6744 & TST & & \\
\hline CHEMBL3210967 & 737379 & 5.7854 & 5.606 & TRN & & \\
\hline CHEMBL588028 & 737379 & 5.6623 & 5.5467 & TRN & & \\
\hline CHEMBL1411758 & 737379 & 4.9889 & 5.1738 & TRN & & \\
\hline CHEMBL1302894 & 737379 & 5.4839 & 5.3937 & TRN & & \\
\hline CHEMBL1350043 & 737379 & 2.71 & 5.2163 & TRN & & \\
\hline CHEMBL1341919 & 737379 & 4.8706 & 4.9668 & TST & & \\
\hline CHEMBL1482539 & 737379 & 5.1678 & 5.1905 & TRN & & \\
\hline CHEMBL1716500 & 737379 & 5.4352 & 5.405 & TRN & & \\
\hline CHEMBL1481444 & 737379 & 5.2668 & 5.0068 & TRN & & \\
\hline CHEMBL1486191 & 737379 & 5.4848 & 5.4372 & TRN & & \\
\hline CHEMBL1598561 & 737379 & 5.777 & 5.5077 & TRN & & \\
\hline CHEMBL1526090 & 737379 & 5.375 & 5.2628 & TRN & & \\
\hline CHEMBL3196721 & 737379 & 6.6192 & 5.8482 & TRN & & \\
\hline CHEMBL1470446 & 737379 & 5.4572 & 5.2417 & TRN & & \\
\hline CHEMBL1377902 & 737379 & 4.7632 & 4.5269 & TRN & & \\
\hline CHEMBL1432155 & 737379 & 6.1654 & 5.4854 & TRN & & \\
\hline CHEMBL1966497 & 737379 & 5.2311 & 5.1237 & TRN & & \\
\hline CHEMBL1583997 & 737379 & 5.1161 & 5.1883 & TRN & & \\
\hline CHEMBL1977487 & 737379 & 5.3164 & 4.8658 & TST & & \\
\hline CHEMBL1570710 & 737379 & 2.71 & 3.1886 & TRN & & \\
\hline CHEMBL1594949 & 737379 & 2.71 & 5.1011 & TRN & & \\
\hline CHEMBL1463219 & 737379 & 6.1633 & 5.8981 & TST & & \\
\hline CHEMBL1377200 & 737379 & 5.0588 & 5.0231 & TRN & & \\
\hline CHEMBL1415310 & 737379 & 5.49799 & 99999999 & 99 & 5.2922 & TRN \\
\hline CHEMBL1347011 & 737379 & 5.9359 & 5.6173 & TRN & & \\
\hline CHEMBL1602590 & 737379 & 5.3982 & 5.1666 & TRN & & \\
\hline CHEMBL1422809 & 737379 & 5.5693 & 5.4448 & TRN & & \\
\hline CHEMBL1385413 & 737379 & 6.0 & 5.74299 & 9999999999 & & TRN \\
\hline CHEMBL3194571 & 737379 & 5.4885 & 5.3777 & TRN & & \\
\hline CHEMBL1483540 & 737379 & 4.8395 & 4.5215 & TRN & & \\
\hline CHEMBL1600599 & 737379 & 2.71 & 3.0016 & TST & & \\
\hline
\end{tabular}




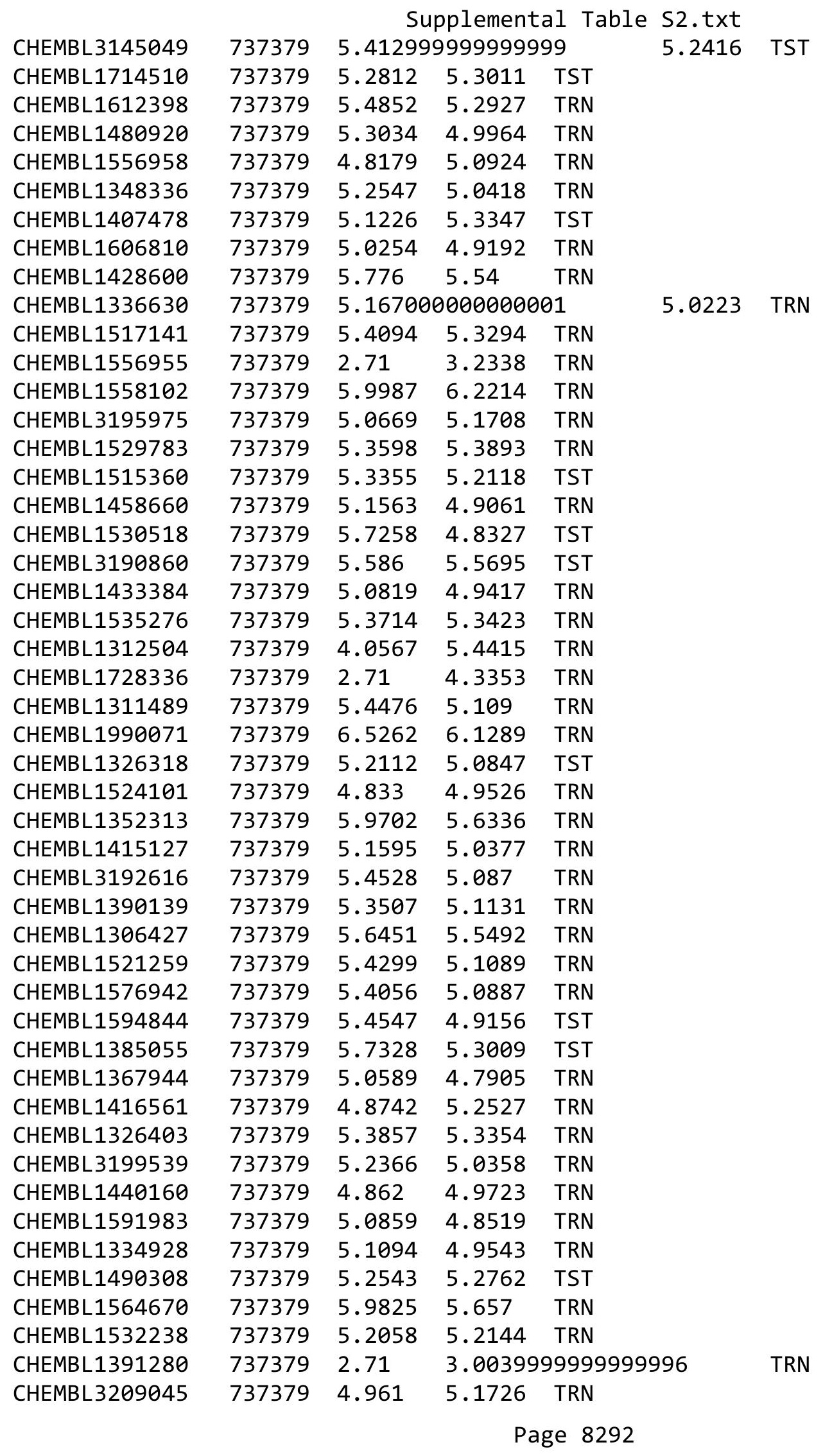




\begin{tabular}{|c|c|c|c|c|c|c|}
\hline & & \multicolumn{5}{|c|}{ Supplemental Table S2.txt } \\
\hline CHEMBL1525530 & 737379 & 5.4888 & 5.7522 & TRN & & \\
\hline CHEMBL 3192254 & 737379 & 4.7533 & 5.1345 & TRN & & \\
\hline CHEMBL1540688 & 737379 & 5.5844 & 5.2518 & TST & & \\
\hline CHEMBL1971604 & 737379 & 5.0635 & 5.2282 & TRN & & \\
\hline CHEMBL1462451 & 737379 & 5.0055 & 4.8628 & TST & & \\
\hline CHEMBL1508769 & 737379 & 6.0058 & 6.1255 & TRN & & \\
\hline CHEMBL1491556 & 737379 & 5.3972 & 5.1921 & TRN & & \\
\hline CHEMBL1327693 & 737379 & 5.2413 & 5.1432 & TRN & & \\
\hline CHEMBL1371897 & 737379 & 5.3786 & 5.3398 & TRN & & \\
\hline CHEMBL1601509 & 737379 & 4.6641 & 4.7443 & TRN & & \\
\hline CHEMBL1362055 & 737379 & 6.6366 & 6.093 & TRN & & \\
\hline CHEMBL1536814 & 737379 & 5.306 & 5.2569 & TRN & & \\
\hline CHEMBL1306816 & 737379 & 5.4338 & 5.12 & TRN & & \\
\hline CHEMBL1466948 & 737379 & 2.71 & 5.4191 & TRN & & \\
\hline CHEMBL1339398 & 737379 & 5.524 & 5.7464 & TST & & \\
\hline CHEMBL1309966 & 737379 & 5.4876 & 4.7928 & TRN & & \\
\hline CHEMBL1602792 & 737379 & 6.5627 & 5.6992 & TST & & \\
\hline CHEMBL1496769 & 737379 & 4.3916 & 5.4228 & TRN & & \\
\hline CHEMBL1577064 & 737379 & 5.2303 & 5.2032 & TST & & \\
\hline CHEMBL1699507 & 737379 & 5.0565 & 4.7414 & TRN & & \\
\hline CHEMBL1497119 & 737379 & 5.3111 & 5.4263 & TST & & \\
\hline CHEMBL1543340 & 737379 & 5.1815 & 5.4631 & TRN & & \\
\hline CHEMBL3190755 & 737379 & 4.7411 & 4.8426 & TRN & & \\
\hline CHEMBL3189930 & 737379 & 4.73 & 5.0256 & TRN & & \\
\hline CHEMBL1303524 & 737379 & 5.5308 & 5.3166 & TRN & & \\
\hline CHEMBL1590615 & 737379 & 5.1465 & 5.159 & TRN & & \\
\hline CHEMBL1723286 & 737379 & 5.3608 & 5.4655 & TRN & & \\
\hline CHEMBL1720389 & 737379 & 5.4706 & 5.235 & TRN & & \\
\hline CHEMBL1601686 & 737379 & 6.5198 & 7.0161 & TRN & & \\
\hline CHEMBL1433109 & 737379 & 5.12700 & 00000000 & $\partial 1$ & 4.9334 & TRN \\
\hline CHEMBL1439833 & 737379 & 5.5088 & 5.2526 & TRN & & \\
\hline CHEMBL1568267 & 737379 & 6.0443 & 5.9518 & TRN & & \\
\hline CHEMBL1567814 & 737379 & 5.7815 & 5.4553 & TRN & & \\
\hline CHEMBL1467036 & 737379 & 5.3751 & 5.2332 & TRN & & \\
\hline CHEMBL1383899 & 737379 & 4.9045 & 5.0088 & TST & & \\
\hline CHEMBL1713814 & 737379 & 4.813 & 4.8997 & TRN & & \\
\hline CHEMBL586061 & 737379 & 5.282 & 5.2179 & TRN & & \\
\hline CHEMBL1610796 & 737379 & 7.7959 & 6.999 & TRN & & \\
\hline CHEMBL1700254 & 737379 & 5.1309 & 4.9712 & TST & & \\
\hline CHEMBL1299745 & 737379 & 5.2902 & 5.1536 & TRN & & \\
\hline CHEMBL1541391 & 737379 & 5.4083 & 5.2199 & TRN & & \\
\hline CHEMBL1518077 & 737379 & 5.3016 & 5.3747 & TRN & & \\
\hline CHEMBL 259018 & 737379 & 5.2418 & 5.1594 & TST & & \\
\hline CHEMBL1377632 & 737379 & 5.0128 & 5.3057 & TRN & & \\
\hline CHEMBL1497889 & 737379 & 5.2941 & 5.3013 & TRN & & \\
\hline CHEMBL3192542 & 737379 & 5.604 & 5.3411 & TRN & & \\
\hline CHEMBL559612 & 737379 & 5.4562 & 5.2269 & TST & & \\
\hline CHEMBL1597004 & 737379 & 5.1704 & 4.8998 & TRN & & \\
\hline
\end{tabular}




\begin{tabular}{|c|c|c|c|c|c|c|}
\hline & & \multicolumn{5}{|c|}{ Supplemental Table S2.txt } \\
\hline CHEMBL1706157 & 737379 & 5.3611 & 5.2153 & TST & & \\
\hline CHEMBL1481139 & 737379 & 5.5078 & 5.5823 & TRN & & \\
\hline CHEMBL1999960 & 737379 & 5.1655 & 5.1004 & TRN & & \\
\hline CHEMBL1561063 & 737379 & 5.2817 & 5.2542 & TRN & & \\
\hline CHEMBL1351391 & 737379 & 2.71 & 3.2703 & TRN & & \\
\hline CHEMBL1584795 & 737379 & 5.53600 & 00000000 & 005 & 5.4967 & TST \\
\hline CHEMBL1481113 & 737379 & 5.1179 & 5.0881 & TRN & & \\
\hline CHEMBL1331933 & 737379 & 5.59399 & 79999999ऽ & 99 & 5.5689 & TST \\
\hline CHEMBL1523835 & 737379 & 5.2969 & 5.1194 & TST & & \\
\hline CHEMBL1722480 & 737379 & 5.471 & 5.2373 & TST & & \\
\hline CHEMBL1517532 & 737379 & 4.8771 & 4.9863 & TRN & & \\
\hline CHEMBL1341586 & 737379 & 5.5473 & 5.6294 & TRN & & \\
\hline CHEMBL1404620 & 737379 & 5.1462 & 4.9971 & TRN & & \\
\hline CHEMBL1705324 & 737379 & 2.71 & 2.9386 & TRN & & \\
\hline CHEMBL1373388 & 737379 & 5.5024 & 5.3898 & TRN & & \\
\hline CHEMBL1336508 & 737379 & 5.2727 & 5.2286 & TRN & & \\
\hline CHEMBL1343758 & 737379 & 5.1994 & 4.485 & TRN & & \\
\hline CHEMBL1546285 & 737379 & 4.545 & 5.0603 & TRN & & \\
\hline CHEMBL587849 & 737379 & 5.4911 & 5.4312 & TST & & \\
\hline CHEMBL1428368 & 737379 & 5.1617 & 4.8935 & TRN & & \\
\hline CHEMBL494252 & 737379 & 5.4567 & 5.1681 & TRN & & \\
\hline CHEMBL1476358 & 737379 & 5.6078 & 5.421 & TRN & & \\
\hline CHEMBL1431776 & 737379 & 5.1716 & 4.8961 & TRN & & \\
\hline CHEMBL3189663 & 737379 & 5.2819 & 4.9608 & TRN & & \\
\hline CHEMBL1562883 & 737379 & 4.5594 & 5.0134 & TRN & & \\
\hline CHEMBL 2006122 & 737379 & 5.1803 & 4.9839 & TRN & & \\
\hline CHEMBL1551370 & 737379 & 4.8938 & 4.948 & TRN & & \\
\hline CHEMBL1996343 & 737379 & 5.6868 & 5.5508 & TST & & \\
\hline CHEMBL3193504 & 737379 & 5.2721 & 5.2035 & TRN & & \\
\hline CHEMBL3189694 & 737379 & 4.4923 & 5.1389 & TRN & & \\
\hline CHEMBL1455530 & 737379 & 5.4521 & 5.1346 & TRN & & \\
\hline CHEMBL1443898 & 737379 & 3.7272 & 4.4876 & TST & & \\
\hline CHEMBL1340447 & 737379 & 5.1708 & 4.9226 & TRN & & \\
\hline CHEMBL1518479 & 737379 & 5.1398 & 5.1769 & TRN & & \\
\hline CHEMBL1584101 & 737379 & 5.23 & 4.9385 & TRN & & \\
\hline CHEMBL1485259 & 737379 & 5.4431 & 5.2517 & TRN & & \\
\hline CHEMBL1412039 & 737379 & 5.8765 & 5.6424 & TRN & & \\
\hline CHEMBL1523019 & 737379 & 5.1453 & 4.9823 & TRN & & \\
\hline CHEMBL3190556 & 737379 & 4.8801 & 5.3908 & TRN & & \\
\hline CHEMBL1329413 & 737379 & 4.8732 & 4.9091 & TRN & & \\
\hline CHEMBL1499306 & 737379 & 5.6381 & 5.5192 & TRN & & \\
\hline CHEMBL1443312 & 737379 & 5.4124 & 5.0819 & TRN & & \\
\hline CHEMBL1545093 & 737379 & 4.9747 & 4.9184 & TRN & & \\
\hline CHEMBL3195021 & 737379 & 5.7452 & 5.7062 & TRN & & \\
\hline CHEMBL1428417 & 737379 & 5.3919 & 5.197 & TRN & & \\
\hline CHEMBL1359270 & 737379 & 5.1489 & 5.0066 & TST & & \\
\hline CHEMBL564979 & 737379 & 4.8681 & 6.2507 & TRN & & \\
\hline CHEMBL1481229 & 737379 & 5.0011 & 4.6532 & TRN & & \\
\hline
\end{tabular}




\begin{tabular}{|c|c|c|c|c|}
\hline \multicolumn{5}{|c|}{ Supplemental Table s2.txt } \\
\hline CHEMBL3191071 & 737379 & 5.1944 & 5.2807 & TRN \\
\hline CHEMBL3189161 & 737379 & 5.5047 & 5.5745 & TRN \\
\hline CHEMBL1441459 & 737379 & 2.71 & 5.0354 & TRN \\
\hline CHEMBL1456324 & 737379 & 5.1115 & 5.1687 & TST \\
\hline CHEMBL1328373 & 737379 & 5.3278 & 5.2927 & TRN \\
\hline CHEMBL1584568 & 737379 & 5.2488 & 5.4552 & TRN \\
\hline CHEMBL1385433 & 737379 & 5.1043 & 4.9751 & TST \\
\hline CHEMBL1357867 & 737379 & 5.2696 & 5.1756 & TST \\
\hline CHEMBL 3193435 & 737379 & 5.3318 & 5.2405 & TRN \\
\hline CHEMBL1400514 & 737379 & 2.71 & 5.3425 & TRN \\
\hline CHEMBL1577629 & 737379 & 5.3094 & 5.8434 & TRN \\
\hline CHEMBL584444 & 737379 & 5.4332 & 5.0545 & TRN \\
\hline CHEMBL1413660 & 737379 & 4.7488 & 5.0734 & TST \\
\hline CHEMBL1506932 & 737379 & 5.3196 & 6.0044 & TST \\
\hline CHEMBL1497146 & 737379 & 5.3653 & 5.2038 & TRN \\
\hline CHEMBL1384298 & 737379 & 5.4068 & 5.1681 & TRN \\
\hline CHEMBL1310276 & 737379 & 5.7033 & 6.025 & TST \\
\hline CHEMBL1303689 & 737379 & 5.0872 & 5.0022 & TRN \\
\hline CHEMBL1441677 & 737379 & 5.1677 & 5.0323 & TRN \\
\hline CHEMBL1511091 & 737379 & 5.6946 & 5.816 & TRN \\
\hline CHEMBL1530766 & 737379 & 5.1079 & 5.1461 & TRN \\
\hline CHEMBL1427575 & 737379 & 5.4309 & 5.3554 & TRN \\
\hline CHEMBL1403913 & 737379 & 2.71 & 5.3335 & TRN \\
\hline CHEMBL 3210362 & 737379 & 5.5637 & 5.4778 & TRN \\
\hline CHEMBL17201 & 737379 & 5.5467 & 5.4507 & TRN \\
\hline CHEMBL1511276 & 737379 & 6.0 & 5.5424 & TRN \\
\hline CHEMBL1985606 & 737379 & 4.9996 & 4.8086 & TRN \\
\hline CHEMBL3209995 & 737379 & 2.71 & 2.8111 & TRN \\
\hline CHEMBL 3196765 & 737379 & 5.3758 & 5.3285 & TST \\
\hline CHEMBL3190645 & 737379 & 4.6047 & 4.7198 & TRN \\
\hline CHEMBL1573738 & 737379 & 5.4778 & 5.3273 & TRN \\
\hline CHEMBL1735851 & 737379 & 2.71 & 3.1699 & TRN \\
\hline CHEMBL1580116 & 737379 & 5.3917 & 5.2604 & TRN \\
\hline CHEMBL1500304 & 737379 & 5.6964 & 5.2927 & TRN \\
\hline CHEMBL1387773 & 737379 & 5.0533 & 4.9869 & TRN \\
\hline CHEMBL1603182 & 737379 & 5.8419 & 5.7707 & TRN \\
\hline CHEMBL1434037 & 737379 & 5.3592 & 5.3645 & TRN \\
\hline CHEMBL1728498 & 737379 & 4.4697 & 2.8556 & TRN \\
\hline CHEMBL1511289 & 737379 & 5.3913 & 5.3592 & TRN \\
\hline CHEMBL1376796 & 737379 & 2.71 & 5.1555 & TRN \\
\hline CHEMBL1328712 & 737379 & 5.5038 & 5.2606 & TRN \\
\hline CHEMBL1320794 & 737379 & 5.6617 & 5.3647 & TRN \\
\hline CHEMBL1469642 & 737379 & 4.2931 & 4.3177 & TRN \\
\hline CHEMBL1503239 & 737379 & 4.9978 & 4.7 & TRN \\
\hline CHEMBL1329311 & 737379 & 5.5302 & 5.5723 & TRN \\
\hline CHEMBL1609332 & 737379 & 5.1946 & 5.0942 & TRN \\
\hline CHEMBL1983745 & 737379 & 5.6747 & 5.3318 & TST \\
\hline CHEMBL 306783 & 737379 & 5.1715 & 4.95 & TRN \\
\hline
\end{tabular}




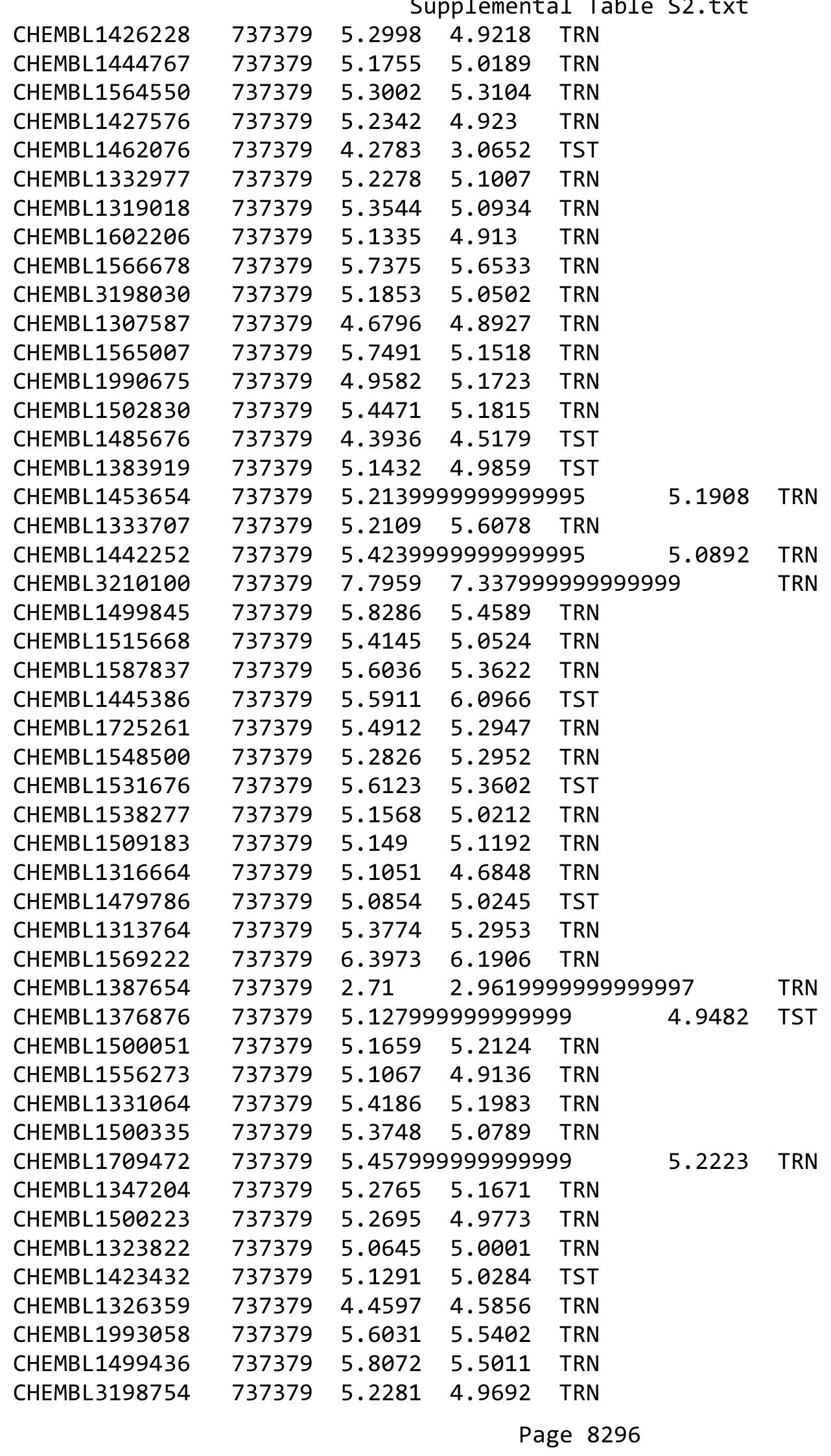




\begin{tabular}{|c|c|c|c|c|c|}
\hline \\
\hline CHEMBL1401945 & 737379 & 5.2434 & 4.9714 & TRN & \\
\hline CHEMBL1980322 & 737379 & 5.0575 & 5.2435 & TRN & \\
\hline CHEMBL1459514 & 737379 & 5.379 & 5.1621 & TRN & \\
\hline CHEMBL1493199 & 737379 & 5.1667 & 5.1417 & TRN & \\
\hline CHEMBL1425525 & 737379 & 5.4382 & 5.2705 & TRN & \\
\hline CHEMBL1334169 & 737379 & 5.4174 & 5.2735 & TRN & \\
\hline CHEMBL1308811 & 737379 & 2.71 & 4.4277 & TRN & \\
\hline CHEMBL1461458 & 737379 & 5.8377 & 5.808 & TRN & \\
\hline CHEMBL1522049 & 737379 & 5.5051 & 5.44799 & 99999999995 & TRN \\
\hline CHEMBL3145321 & 737379 & 5.3446 & 5.5218 & TST & \\
\hline CHEMBL1384349 & 737379 & 5.4487 & 5.3059 & TRN & \\
\hline CHEMBL1575267 & 737379 & 5.3988 & 5.3189 & TRN & \\
\hline CHEMBL3198116 & 737379 & 5.9161 & 5.5095 & TST & \\
\hline CHEMBL1998863 & 737379 & 5.4823 & 5.2768 & TRN & \\
\hline CHEMBL1355963 & 737379 & 5.7496 & 5.4883 & TST & \\
\hline CHEMBL1407237 & 737379 & 5.5056 & 5.4421 & TRN & \\
\hline CHEMBL1438084 & 737379 & 5.0923 & 5.3914 & TRN & \\
\hline CHEMBL1544136 & 737379 & 5.3024 & 6.1611 & TRN & \\
\hline CHEMBL1480273 & 737379 & 4.9073 & 5.1703 & TRN & \\
\hline CHEMBL1467843 & 737379 & 5.5525 & 5.4684 & TRN & \\
\hline CHEMBL1548377 & 737379 & 5.3963 & 5.1358 & TRN & \\
\hline CHEMBL1381760 & 737379 & 5.0518 & 5.0803 & TRN & \\
\hline CHEMBL1576810 & 737379 & 5.1953 & 4.4932 & TRN & \\
\hline CHEMBL1545240 & 737379 & 4.7476 & 4.3144 & TST & \\
\hline CHEMBL1344296 & 737379 & 5.8173 & 5.6455 & TRN & \\
\hline CHEMBL1343076 & 737379 & 4.6358 & 5.0065 & TRN & \\
\hline CHEMBL1371188 & 737379 & 4.87 & 4.8951 & TST & \\
\hline CHEMBL1480494 & 737379 & 4.8658 & 4.8373 & TRN & \\
\hline CHEMBL1509590 & 737379 & 5.5913 & 5.4966 & TRN & \\
\hline CHEMBL1600175 & 737379 & 4.7953 & 5.2936 & TRN & \\
\hline CHEMBL1609090 & 737379 & 4.8996 & 5.0047 & TRN & \\
\hline CHEMBL1542936 & 737379 & 5.3304 & 5.2094 & TRN & \\
\hline CHEMBL1413208 & 737379 & 5.1942 & 5.1707 & TRN & \\
\hline CHEMBL1726094 & 737379 & 5.4874 & 5.2392 & TST & \\
\hline CHEMBL 2001024 & 737379 & 5.2269 & 5.059 & TRN & \\
\hline CHEMBL1347710 & 737379 & 5.3373 & 5.0929 & TRN & \\
\hline CHEMBL1403285 & 737379 & 4.4621 & 4.6258 & TRN & \\
\hline CHEMBL1722190 & 737379 & 4.5996 & 4.9095 & TRN & \\
\hline CHEMBL1342385 & 737379 & 4.9662 & 5.1036 & TRN & \\
\hline CHEMBL1493071 & 737379 & 5.1757 & 4.9709 & TRN & \\
\hline CHEMBL1404327 & 737379 & 6.5168 & 6.0513 & TRN & \\
\hline CHEMBL1498161 & 737379 & 5.6371 & 5.7021 & TRN & \\
\hline CHEMBL1501102 & 737379 & 5.38 & 5.0063 & TRN & \\
\hline CHEMBL1476017 & 737379 & 5.9318 & 5.4521 & TRN & \\
\hline CHEMBL1392564 & 737379 & 5.2066 & 4.8284 & TRN & \\
\hline CHEMBL1484282 & 737379 & 5.0545 & 5.3975 & TRN & \\
\hline CHEMBL1461577 & 737379 & 5.8623 & 5.8362 & TRN & \\
\hline CHEMBL1500937 & 737379 & 5.4639 & 5.7338 & TRN & \\
\hline
\end{tabular}




\begin{tabular}{|c|c|c|c|c|c|c|}
\hline & & \multicolumn{5}{|c|}{ Supplemental Table S2.txt } \\
\hline CHEMBL1371554 & 737379 & 4.5795 & 5.6133 & TRN & & \\
\hline CHEMBL1400410 & 737379 & 6.24200 & 00000000 & & 6.0085 & TRN \\
\hline CHEMBL1445707 & 737379 & 6.7071 & 6.8619 & TST & & \\
\hline CHEMBL1325605 & 737379 & 5.226 & 5.1689 & TRN & & \\
\hline CHEMBL1310744 & 737379 & 5.3172 & 5.1493 & TRN & & \\
\hline CHEMBL1392673 & 737379 & 5.129 & 5.229 & TRN & & \\
\hline CHEMBL1577855 & 737379 & 5.2865 & 5.3577 & TRN & & \\
\hline CHEMBL1502455 & 737379 & 6.6891 & 6.8797 & TRN & & \\
\hline CHEMBL1360203 & 737379 & 5.24799 & 99999999 & 99 & 5.0343 & TRN \\
\hline CHEMBL1363916 & 737379 & 4.9289 & 5.2422 & TRN & & \\
\hline CHEMBL1575526 & 737379 & 5.1314 & 5.4414 & TRN & & \\
\hline CHEMBL596674 & 737379 & 5.0061 & 5.0328 & TRN & & \\
\hline CHEMBL1541593 & 737379 & 5.2886 & 5.4968 & TRN & & \\
\hline CHEMBL1381455 & 737379 & 5.4564 & 5.4892 & TRN & & \\
\hline CHEMBL1392793 & 737379 & 5.0856 & 5.0592 & TRN & & \\
\hline CHEMBL1351108 & 737379 & 5.2357 & 4.9138 & TRN & & \\
\hline CHEMBL1712620 & 737379 & 4.5253 & 5.0478 & TRN & & \\
\hline CHEMBL1600684 & 737379 & 4.8318 & 4.9869 & TRN & & \\
\hline CHEMBL1547962 & 737379 & 5.0988 & 5.1142 & TRN & & \\
\hline CHEMBL1372201 & 737379 & 5.2463 & 5.301 & TRN & & \\
\hline CHEMBL1469659 & 737379 & 5.2592 & 5.0403 & TRN & & \\
\hline CHEMBL1572829 & 737379 & 4.76 & 5.4739 & TRN & & \\
\hline CHEMBL1404113 & 737379 & 4.2488 & 5.1316 & TRN & & \\
\hline CHEMBL1344600 & 737379 & 5.6114 & 5.7449 & TRN & & \\
\hline CHEMBL1980661 & 737379 & 5.1677 & 4.8434 & TST & & \\
\hline CHEMBL1568198 & 737379 & 5.3155 & 5.2977 & TRN & & \\
\hline CHEMBL1703531 & 737379 & 5.1731 & 5.1755 & TST & & \\
\hline CHEMBL1520030 & 737379 & 5.4869 & 5.4942 & TRN & & \\
\hline CHEMBL1311835 & 737379 & 4.7501 & 5.1794 & TRN & & \\
\hline CHEMBL1588557 & 737379 & 5.2711 & 5.3371 & TRN & & \\
\hline CHEMBL1602217 & 737379 & 5.4195 & 5.2133 & TRN & & \\
\hline CHEMBL3195663 & 737379 & 5.2208 & 5.0992 & TST & & \\
\hline CHEMBL1562493 & 737379 & 5.1531 & 4.9687 & TRN & & \\
\hline CHEMBL539027 & 737379 & 5.1439 & 5.038 & TRN & & \\
\hline CHEMBL1493829 & 737379 & 5.3081 & 4.9785 & TRN & & \\
\hline CHEMBL1968992 & 737379 & 5.4571 & 5.2573 & TRN & & \\
\hline CHEMBL1382429 & 737379 & 5.7095 & 5.6638 & TRN & & \\
\hline CHEMBL236897 & 737379 & 4.8274 & 4.7475 & TRN & & \\
\hline CHEMBL1391377 & 737379 & 5.8492 & 5.6941 & TRN & & \\
\hline CHEMBL1341308 & 737379 & 5.4465 & 5.4018 & TRN & & \\
\hline CHEMBL1539411 & 737379 & 5.1202 & 5.1049 & TRN & & \\
\hline CHEMBL1522987 & 737379 & 4.9961 & 4.9305 & TRN & & \\
\hline CHEMBL1441983 & 737379 & 2.71 & 4.5986 & TRN & & \\
\hline CHEMBL1715324 & 737379 & 5.2817 & 5.1168 & TST & & \\
\hline CHEMBL1984804 & 737379 & 5.3749 & 5.1436 & TRN & & \\
\hline CHEMBL1387668 & 737379 & 5.4366 & 5.4478 & TRN & & \\
\hline CHEMBL1319866 & 737379 & 5.78299 & 99999999 & 995 & 5.5101 & TRN \\
\hline CHEMBL1579805 & 737379 & 4.9382 & 4.8035 & TRN & & \\
\hline
\end{tabular}




\begin{tabular}{|c|c|c|c|c|c|c|}
\hline & & \multicolumn{5}{|c|}{ Supplemental Table S2.txt } \\
\hline CHEMBL1463198 & 737379 & 5.2165 & 4.9281 & TRN & & \\
\hline CHEMBL1612814 & 737379 & 4.7878 & 5.0603 & TST & & \\
\hline CHEMBL1730631 & 737379 & 4.5615 & 4.6773 & TST & & \\
\hline CHEMBL1568184 & 737379 & 4.9066 & 5.0633 & TRN & & \\
\hline CHEMBL1504685 & 737379 & 5.1456 & 5.0007 & TST & & \\
\hline CHEMBL1513240 & 737379 & 5.2765 & 5.0314 & TRN & & \\
\hline CHEMBL1378686 & 737379 & 5.178 & 4.9036 & TRN & & \\
\hline CHEMBL3213728 & 737379 & 5.3722 & 5.3138 & TRN & & \\
\hline CHEMBL1313821 & 737379 & 2.71 & 4.0706 & TRN & & \\
\hline CHEMBL1717542 & 737379 & 2.71 & 2.9546 & TRN & & \\
\hline CHEMBL1577934 & 737379 & 2.71 & 3.0467 & TST & & \\
\hline CHEMBL1460871 & 737379 & 5.4877 & 4.9905 & TRN & & \\
\hline CHEMBL1489294 & 737379 & 5.8758 & 5.5584 & TRN & & \\
\hline CHEMBL1301717 & 737379 & 5.8033 & 4.6414 & TRN & & \\
\hline CHEMBL1406980 & 737379 & 5.7169 & 5.2623 & TRN & & \\
\hline CHEMBL1332670 & 737379 & $5.5470 e$ & 00000000 & & 5.4818 & TRN \\
\hline CHEMBL1418827 & 737379 & 4.6209 & 4.6104 & TST & & \\
\hline CHEMBL1423282 & 737379 & 5.5146 & 5.2371 & TST & & \\
\hline CHEMBL1363437 & 737379 & 5.0737 & 7.4217 & TRN & & \\
\hline CHEMBL1399663 & 737379 & 5.8636 & 5.7486 & TRN & & \\
\hline CHEMBL1542931 & 737379 & 5.7144 & 5.5969 & TRN & & \\
\hline CHEMBL1363275 & 737379 & 5.2712 & 5.0996 & TRN & & \\
\hline CHEMBL1580286 & 737379 & 5.1018 & 5.6668 & TRN & & \\
\hline CHEMBL 2021431 & 737379 & 5.4432 & 5.3486 & TST & & \\
\hline CHEMBL1506512 & 737379 & 5.1082 & 5.1953 & TRN & & \\
\hline CHEMBL1411526 & 737379 & 6.65799 & 99999999 & 995 & 6.9243 & TRN \\
\hline CHEMBL1698409 & 737379 & 5.4013 & 5.2385 & TST & & \\
\hline CHEMBL1712111 & 737379 & 5.0766 & 4.8697 & TRN & & \\
\hline CHEMBL1494743 & 737379 & 5.6353 & 5.6886 & TST & & \\
\hline CHEMBL567132 & 737379 & 5.3023 & 5.098 & TRN & & \\
\hline CHEMBL1608294 & 737379 & 6.1504 & 5.6697 & TRN & & \\
\hline CHEMBL 1577446 & 737379 & 5.4594 & 5.2271 & TRN & & \\
\hline CHEMBL1490441 & 737379 & 5.8824 & 5.4608 & TRN & & \\
\hline CHEMBL1542674 & 737379 & 5.1931 & 5.1273 & TRN & & \\
\hline CHEMBL1338406 & 737379 & 4.8502 & 4.7643 & TRN & & \\
\hline CHEMBL393244 & 737379 & 5.4062 & 5.3104 & TRN & & \\
\hline CHEMBL1599847 & 737379 & 5.2387 & 4.9337 & TRN & & \\
\hline CHEMBL1719643 & 737379 & 5.5511 & 5.4431 & TRN & & \\
\hline CHEMBL3199204 & 737379 & 4.085 & 4.5788 & TRN & & \\
\hline CHEMBL3196698 & 737379 & 5.8604 & 5.5734 & TRN & & \\
\hline CHEMBL1544622 & 737379 & 5.352 & 5.1927 & TRN & & \\
\hline CHEMBL1341120 & 737379 & 5.1686 & 5.1936 & TRN & & \\
\hline CHEMBL1474208 & 737379 & 5.2468 & 5.0836 & TST & & \\
\hline CHEMBL3197762 & 737379 & 5.3229 & 5.1122 & TRN & & \\
\hline CHEMBL1411991 & 737379 & 4.9987 & 5.1891 & TRN & & \\
\hline CHEMBL1483522 & 737379 & 5.4477 & 5.2994 & TRN & & \\
\hline CHEMBL1608333 & 737379 & 5.4597 & 5.4701 & TRN & & \\
\hline CHEMBL1365262 & 737379 & 4.9052 & 4.8199 & TRN & & \\
\hline
\end{tabular}




\begin{tabular}{|c|c|c|c|c|c|}
\hline & & \multicolumn{4}{|c|}{ Supplemental Table S2.txt } \\
\hline CHEMBL1326053 & 737379 & 5.265 & 5.0137 & TRN & \\
\hline CHEMBL1998606 & 737379 & 6.1772 & 5.8209 & TRN & \\
\hline CHEMBL1255733 & 737379 & 6.0 & 5.8517 & TST & \\
\hline CHEMBL1480812 & 737379 & 5.4604 & 5.2081 & TRN & \\
\hline CHEMBL1413963 & 737379 & 5.0768 & 5.0531 & TRN & \\
\hline CHEMBL1711149 & 737379 & 5.6474 & 5.5932 & TRN & \\
\hline CHEMBL1488371 & 737379 & 5.6158 & 5.5253 & TRN & \\
\hline CHEMBL1612163 & 737379 & 3.7357 & 5.8221 & TRN & \\
\hline CHEMBL1882689 & 737379 & 5.1522 & 5.1402 & TRN & \\
\hline CHEMBL1498256 & 737379 & 5.5566 & 5.2849 & TRN & \\
\hline CHEMBL1379737 & 737379 & 5.3732 & 5.081 & TRN & \\
\hline CHEMBL1479319 & 737379 & 5.2576 & 5.2733 & TRN & \\
\hline CHEMBL548458 & 737379 & 5.4237 & 5.3943 & TRN & \\
\hline CHEMBL1725605 & 737379 & 4.765 & 4.8027 & TRN & \\
\hline CHEMBL1610051 & 737379 & 5.4479 & 5.2901 & TRN & \\
\hline CHEMBL1727430 & 737379 & 5.4316 & 5.5118 & TRN & \\
\hline CHEMBL1569918 & 737379 & 5.2043 & 4.9928 & TRN & \\
\hline CHEMBL1545274 & 737379 & 4.46899 & 99999999 & 4.6134 & $\mathrm{TR}$ \\
\hline CHEMBL1967987 & 737379 & 5.0986 & 4.8689 & TRN & \\
\hline CHEMBL3193989 & 737379 & 5.0845 & 4.9071 & TRN & \\
\hline CHEMBL1480659 & 737379 & 5.4981 & 5.5091 & TRN & \\
\hline CHEMBL47940 & 737379 & 5.7696 & 5.2342 & TRN & \\
\hline CHEMBL1577182 & 737379 & 4.8735 & 4.6579 & TRN & \\
\hline CHEMBL1521702 & 737379 & 5.8887 & 5.7842 & TRN & \\
\hline CHEMBL1537261 & 737379 & 5.4963 & 5.7287 & TRN & \\
\hline CHEMBL1990959 & 737379 & 5.4777 & 5.2021 & TRN & \\
\hline CHEMBL1336428 & 737379 & 5.3394 & 5.1539 & TRN & \\
\hline CHEMBL1510676 & 737379 & 5.9172 & 5.6814 & TST & \\
\hline CHEMBL1575805 & 737379 & 4.9197 & 5.1412 & TRN & \\
\hline CHEMBL1598139 & 737379 & 5.4234 & 5.4021 & TRN & \\
\hline CHEMBL1568625 & 737379 & 4.5504 & 4.5378 & TRN & \\
\hline CHEMBL3193493 & 737379 & 5.1449 & 4.9003 & TRN & \\
\hline CHEMBL1469171 & 737379 & 5.1148 & 5.1023 & TRN & \\
\hline CHEMBL1993788 & 737379 & 5.169 & 5.3749 & TRN & \\
\hline CHEMBL1405850 & 737379 & 2.71 & 5.0446 & TRN & \\
\hline CHEMBL1324397 & 737379 & 5.1421 & 4.85800 & 00000000005 & $1 \mathrm{Kr}$ \\
\hline CHEMBL1579223 & 737379 & 5.8254 & 5.7179 & TRN & \\
\hline CHEMBL1392178 & 737379 & 5.614 & 5.2471 & TRN & \\
\hline CHEMBL3189613 & 737379 & 5.3545 & 5.0668 & TRN & \\
\hline CHEMBL1545718 & 737379 & 4.9462 & 5.4096 & TRN & \\
\hline CHEMBL1339861 & 737379 & 4.2084 & 5.1142 & TRN & \\
\hline CHEMBL1548173 & 737379 & 5.443 & 4.921 & TRN & \\
\hline CHEMBL1491729 & 737379 & 4.7537 & 5.0859 & TRN & \\
\hline CHEMBL1511042 & 737379 & 5.4356 & 5.1709 & TST & \\
\hline CHEMBL1411959 & 737379 & 5.223 & 5.0528 & TRN & \\
\hline CHEMBL1504341 & 737379 & 7.7959 & 7.0107 & TRN & \\
\hline CHEMBL3197008 & 737379 & 5.4326 & 5.3502 & TRN & \\
\hline CHEMBL1427962 & 737379 & 6.0062 & 4.9735 & TRN & \\
\hline
\end{tabular}




\begin{tabular}{|c|c|c|c|c|c|c|}
\hline & & \multicolumn{5}{|c|}{ Supplemental Table S2.txt } \\
\hline CHEMBL1320465 & 737379 & 5.118 & 4.8823 & TRN & & \\
\hline CHEMBL1423338 & 737379 & 4.7894 & 5.0317 & TST & & \\
\hline CHEMBL3144828 & 737379 & 4.9488 & 4.8327 & TRN & & \\
\hline CHEMBL1539706 & 737379 & 5.4658 & 5.8274 & TRN & & \\
\hline CHEMBL1337280 & 737379 & 5.3352 & 5.263 & TRN & & \\
\hline CHEMBL1502550 & 737379 & 5.4185 & 5.1152 & TRN & & \\
\hline CHEMBL1405781 & 737379 & \multicolumn{3}{|c|}{5.446000000000001} & \multirow{32}{*}{5.4171} & TRN \\
\hline CHEMBL1471980 & 737379 & 5.5078 & 5.5014 & TRN & & \\
\hline CHEMBL1406616 & 737379 & 5.0437 & 5.2817 & TRN & & \\
\hline CHEMBL3195351 & 737379 & 5.1148 & 4.9705 & TRN & & \\
\hline CHEMBL1725521 & 737379 & 5.1617 & 5.0421 & TRN & & \\
\hline CHEMBL1303489 & 737379 & 5.5855 & 5.4365 & TRN & & \\
\hline CHEMBL1547739 & 737379 & 5.5682 & 5.1762 & TRN & & \\
\hline CHEMBL1588500 & 737379 & 5.7479 & 5.0393 & TRN & & \\
\hline CHEMBL1603029 & 737379 & 5.5011 & 5.2102 & TST & & \\
\hline CHEMBL1473346 & 737379 & 5.1945 & 4.9712 & TRN & & \\
\hline CHEMBL3195477 & 737379 & 6.433 & 6.0413 & TRN & & \\
\hline CHEMBL3196747 & 737379 & 5.0756 & 5.2815 & TST & & \\
\hline CHEMBL 1702810 & 737379 & 5.3989 & 5.4477 & TRN & & \\
\hline CHEMBL1553138 & 737379 & 5.4323 & 5.3074 & TRN & & \\
\hline CHEMBL1341108 & 737379 & 5.4965 & 5.1758 & TRN & & \\
\hline CHEMBL1343265 & 737379 & 6.0716 & 5.9104 & TRN & & \\
\hline CHEMBL1549706 & 737379 & 5.5896 & 5.3019 & TST & & \\
\hline CHEMBL1519490 & 737379 & 5.3561 & 5.2156 & TST & & \\
\hline CHEMBL1380035 & 737379 & 5.3783 & 5.0574 & TRN & & \\
\hline CHEMBL1391387 & 737379 & 5.2812 & 7.6004 & TRN & & \\
\hline CHEMBL1444683 & 737379 & 5.3417 & 4.9606 & TRN & & \\
\hline CHEMBL1428003 & 737379 & 5.1702 & 5.0762 & TRN & & \\
\hline CHEMBL1548535 & 737379 & 5.1487 & 4.9325 & TRN & & \\
\hline CHEMBL1411680 & 737379 & 4.6996 & 5.0994 & TRN & & \\
\hline CHEMBL1413508 & 737379 & 4.9412 & 4.8151 & TRN & & \\
\hline CHEMBL3196852 & 737379 & 5.4658 & 5.4432 & TRN & & \\
\hline CHEMBL1374476 & 737379 & 5.0111 & 5.2285 & TRN & & \\
\hline CHEMBL1336255 & 737379 & 4.5989 & 5.2645 & TRN & & \\
\hline CHEMBL3195142 & 737379 & 5.3433 & 5.2378 & TRN & & \\
\hline CHEMBL1386393 & 737379 & 5.5201 & 5.3697 & TRN & & \\
\hline CHEMBL1369478 & 737379 & 5.3991 & 5.0882 & TRN & & \\
\hline CHEMBL3145106 & 737379 & 4.8011 & 5.1543 & TRN & & \\
\hline CHEMBL1402547 & 737379 & \multicolumn{3}{|c|}{5.587000000000001} & 5.5632 & $\mathrm{TR}$ \\
\hline CHEMBL1301155 & 737379 & 5.352 & 5.2724 & TRN & & \\
\hline CHEMBL1387172 & 737379 & 5.8456 & 5.6364 & TRN & & \\
\hline CHEMBL1335732 & 737379 & 5.2693 & 5.1707 & TRN & & \\
\hline CHEMBL 2003567 & 737379 & 5.3555 & 5.2248 & TRN & & \\
\hline CHEMBL1441505 & 737379 & 5.4187 & 5.1871 & TRN & & \\
\hline CHEMBL1708324 & 737379 & 7.7959 & 5.4979 & TRN & & \\
\hline CHEMBL1437106 & 737379 & 5.1768 & 5.3034 & TRN & & \\
\hline CHEMBL1481525 & 737379 & 5.1744 & 5.0211 & TRN & & \\
\hline CHEMBL1718912 & 737379 & 5.1991 & 5.2359 & TST & & \\
\hline
\end{tabular}




\begin{tabular}{|c|c|c|c|c|c|c|}
\hline & & \multicolumn{5}{|c|}{ Supplemental Table S2.txt } \\
\hline CHEMBL1440191 & 737379 & 4.5243 & 4.3499 & TRN & & \\
\hline CHEMBL1515023 & 737379 & 6.534 & 6.0838 & TRN & & \\
\hline CHEMBL1702433 & 737379 & 5.6396 & 5.1035 & TRN & & \\
\hline CHEMBL1452115 & 737379 & 5.1636 & 4.992 & TRN & & \\
\hline CHEMBL3198389 & 737379 & 5.5201 & 5.4063 & TRN & & \\
\hline CHEMBL1573661 & 737379 & 5.5442 & 5.3897 & TRN & & \\
\hline CHEMBL1382944 & 737379 & 5.1097 & 4.8977 & TRN & & \\
\hline CHEMBL3198904 & 737379 & 5.3708 & 5.1912 & TRN & & \\
\hline CHEMBL1555208 & 737379 & 5.1751 & 4.9663 & TRN & & \\
\hline CHEMBL1341114 & 737379 & 5.4835 & 5.6525 & TRN & & \\
\hline CHEMBL1611613 & 737379 & 4.7647 & 4.6422 & TRN & & \\
\hline CHEMBL3196949 & 737379 & 5.8153 & 5.1848 & TRN & & \\
\hline CHEMBL1491529 & 737379 & 5.2651 & 5.1986 & TRN & & \\
\hline CHEMBL1545403 & 737379 & 4.6368 & 5.4483 & TRN & & \\
\hline CHEMBL1433995 & 737379 & 5.4473 & 5.2721 & TST & & \\
\hline CHEMBL1514238 & 737379 & 5.6586 & 5.5299 & TRN & & \\
\hline CHEMBL1335220 & 737379 & 5.4306 & 5.2443 & TRN & & \\
\hline CHEMBL1381152 & 737379 & 4.3638 & 5.1067 & TRN & & \\
\hline CHEMBL1426274 & 737379 & 5.6238 & 5.4862 & TRN & & \\
\hline CHEMBL1442611 & 737379 & 5.7091 & 5.6851 & TRN & & \\
\hline CHEMBL1341442 & 737379 & 6.2152 & 6.0237 & TST & & \\
\hline CHEMBL1342029 & 737379 & 5.1961 & 5.2198 & TRN & & \\
\hline CHEMBL1433662 & 737379 & 5.3913 & 5.0687 & TRN & & \\
\hline CHEMBL3391726 & 737379 & 5.5981 & 5.5601 & TST & & \\
\hline CHEMBL1964667 & 737379 & 4.9772 & 5.1071 & TRN & & \\
\hline CHEMBL1470935 & 737379 & 5.1149 & 4.9005 & TST & & \\
\hline CHEMBL3188935 & 737379 & 5.4978 & 5.2438 & TRN & & \\
\hline CHEMBL1423708 & 737379 & 4.191 & 4.5024 & TST & & \\
\hline CHEMBL1727734 & 737379 & 5.9586 & 5.5931 & TRN & & \\
\hline CHEMBL1511464 & 737379 & 4.7206 & 4.9968 & TRN & & \\
\hline CHEMBL1388853 & 737379 & 3.8392 & 4.5405 & TST & & \\
\hline CHEMBL591370 & 737379 & 5.34 & 5.0387 & TRN & & \\
\hline CHEMBL1399370 & 737379 & 5.4053 & 5.1652 & TRN & & \\
\hline CHEMBL1380741 & 737379 & 5.61299 & 99999999 & 995 & 5.724 & TRN \\
\hline CHEMBL3198185 & 737379 & 4.9622 & 4.5425 & TRN & & \\
\hline CHEMBL3193507 & 737379 & 5.4012 & 5.2385 & TRN & & \\
\hline CHEMBL1445358 & 737379 & 5.4557 & 5.7919 & TRN & & \\
\hline CHEMBL1570920 & 737379 & 5.2086 & 5.011 & TST & & \\
\hline CHEMBL3197639 & 737379 & 4.8972 & 4.9881 & TRN & & \\
\hline CHEMBL1733950 & 737379 & 5.4133 & 5.1968 & TRN & & \\
\hline CHEMBL1313848 & 737379 & 5.1093 & 5.5996 & TRN & & \\
\hline CHEMBL1368599 & 737379 & 5.67200 & 00000000 & 01 & 5.4178 & TRN \\
\hline CHEMBL1555884 & 737379 & 5.4951 & 5.3957 & TST & & \\
\hline CHEMBL1448901 & 737379 & 2.71 & 4.3283 & TRN & & \\
\hline CHEMBL1485847 & 737379 & 4.727 & 5.8489 & TRN & & \\
\hline CHEMBL1420204 & 737379 & 5.0886 & 5.5536 & TRN & & \\
\hline CHEMBL1701759 & 737379 & 5.4475 & 5.1952 & TST & & \\
\hline CHEMBL1544036 & 737379 & 5.2018 & 5.0733 & TRN & & \\
\hline
\end{tabular}




\begin{tabular}{|c|c|c|c|c|c|c|}
\hline \multirow[b]{2}{*}{ CHEMBL1487312 } & \multicolumn{6}{|c|}{ Supplemental Table S2.txt } \\
\hline & 737379 & 2.71 & 3.0156 & TRN & & \\
\hline CHEMBL92824 & 737379 & \multicolumn{3}{|c|}{5.757999999999999} & 5.4848 & TRN \\
\hline CHEMBL1551880 & 737379 & 5.403 & 5.1748 & TST & & \\
\hline CHEMBL1599863 & 737379 & 6.1998 & 5.7767 & TRN & & \\
\hline CHEMBL1500199 & 737379 & 5.3798 & 5.3834 & TRN & & \\
\hline CHEMBL282489 & 737379 & 5.3823 & 5.3295 & TST & & \\
\hline CHEMBL1442309 & 737379 & 5.8471 & 5.3893 & TRN & & \\
\hline CHEMBL1375844 & 737379 & 4.5909 & 5.0037 & TRN & & \\
\hline CHEMBL1570845 & 737379 & 4.9255 & 5.2526 & TST & & \\
\hline CHEMBL1457982 & 737379 & 5.3181 & 5.2223 & TST & & \\
\hline CHEMBL1384920 & 737379 & 5.1791 & 4.9916 & TRN & & \\
\hline CHEMBL1585703 & 737379 & 2.71 & 2.9673 & TRN & & \\
\hline CHEMBL1698614 & 737379 & 2.71 & 4.4785 & TRN & & \\
\hline CHEMBL1346716 & 737379 & \multicolumn{3}{|c|}{5.162999999999999} & \multirow[t]{23}{*}{5.0294} & \multirow[t]{23}{*}{ TRN } \\
\hline CHEMBL1543478 & 737379 & 5.3914 & 4.9407 & TRN & & \\
\hline CHEMBL1417651 & 737379 & 4.8202 & 5.6035 & TRN & & \\
\hline CHEMBL1442438 & 737379 & 5.3157 & 5.3093 & TRN & & \\
\hline CHEMBL1485890 & 737379 & 5.5459 & 5.4778 & TRN & & \\
\hline CHEMBL1304209 & 737379 & 5.6722 & 5.4704 & TRN & & \\
\hline CHEMBL1595864 & 737379 & 5.2332 & 4.8748 & TRN & & \\
\hline CHEMBL1339865 & 737379 & 4.8153 & 4.7258 & TRN & & \\
\hline CHEMBL1462968 & 737379 & 5.4592 & 5.1821 & TRN & & \\
\hline CHEMBL1321278 & 737379 & 5.19 & 4.9247 & TRN & & \\
\hline CHEMBL1408097 & 737379 & 5.0472 & 4.9982 & TRN & & \\
\hline CHEMBL1609366 & 737379 & 5.5706 & 5.4781 & TRN & & \\
\hline CHEMBL1536544 & 737379 & 5.2438 & 5.1722 & TRN & & \\
\hline CHEMBL1429241 & 737379 & 4.7612 & 5.1149 & TRN & & \\
\hline CHEMBL1309718 & 737379 & 4.636 & 5.3357 & TRN & & \\
\hline CHEMBL1547342 & 737379 & 5.1199 & 4.9841 & TRN & & \\
\hline CHEMBL1536060 & 737379 & 5.1276 & 4.9723 & TRN & & \\
\hline CHEMBL1394747 & 737379 & 5.1797 & 5.0603 & TRN & & \\
\hline CHEMBL3193150 & 737379 & 4.683 & 4.4451 & TRN & & \\
\hline CHEMBL1368272 & 737379 & 4.8851 & 4.931 & TRN & & \\
\hline CHEMBL1301082 & 737379 & 5.1651 & 4.8791 & TRN & & \\
\hline CHEMBL1410260 & 737379 & 4.9337 & 5.0093 & TST & & \\
\hline CHEMBL1971674 & 737379 & 5.7791 & 5.5628 & TRN & & \\
\hline CHEMBL1402360 & 737379 & \multicolumn{3}{|c|}{5.492000000000001} & 5.2061 & TRN \\
\hline CHEMBL1422465 & 737379 & 5.2341 & 5.0001 & TRN & & \\
\hline CHEMBL1719132 & 737379 & 4.9889 & 5.2521 & TRN & & \\
\hline CHEMBL1489353 & 737379 & 5.5297 & 5.3097 & TRN & & \\
\hline CHEMBL1599453 & 737379 & 5.7724 & 5.2553 & TRN & & \\
\hline CHEMBL3199041 & 737379 & 4.9905 & 4.9278 & TRN & & \\
\hline CHEMBL1421466 & 737379 & 5.1724 & 5.2792 & TRN & & \\
\hline CHEMBL3145301 & 737379 & 5.2889 & 5.0814 & TST & & \\
\hline CHEMBL1453837 & 737379 & 4.3152 & 5.1512 & TRN & & \\
\hline CHEMBL1608361 & 737379 & 5.2608 & 4.7559 & TRN & & \\
\hline CHEMBL1085765 & 737379 & 5.3226 & 5.1167 & TRN & & \\
\hline CHEMBL1420800 & 737379 & \multicolumn{3}{|c|}{5.3229999999999995} & 5.1576 & TRN \\
\hline
\end{tabular}




\begin{tabular}{|c|c|c|c|c|c|c|}
\hline & & \multicolumn{5}{|c|}{ Supplemental Table S2.txt } \\
\hline CHEMBL2355735 & 737379 & 5.3244 & 5.0383 & TRN & & \\
\hline CHEMBL1419585 & 737379 & 5.0804 & 4.8479 & TRN & & \\
\hline CHEMBL1456092 & 737379 & 5.3666 & 5.0819 & TRN & & \\
\hline CHEMBL1508593 & 737379 & 5.178 & 5.1337 & TST & & \\
\hline CHEMBL1724733 & 737379 & 5.7066 & 5.5172 & TRN & & \\
\hline CHEMBL1349266 & 737379 & 6.0191 & 5.6522 & TRN & & \\
\hline CHEMBL1613694 & 737379 & 2.71 & 3.1678 & TST & & \\
\hline CHEMBL1464102 & 737379 & 5.7881 & 5.5407 & TRN & & \\
\hline CHEMBL3196457 & 737379 & \multicolumn{3}{|c|}{5.632999999999999} & 5.2672 & TRN \\
\hline CHEMBL1730026 & 737379 & 5.0731 & 4.9195 & TRN & & \\
\hline CHEMBL1542880 & 737379 & 5.6653 & 5.869 & TRN & & \\
\hline CHEMBL1460176 & 737379 & 4.8321 & 4.6236 & TRN & & \\
\hline CHEMBL1328132 & 737379 & 2.71 & 3.0473 & TRN & & \\
\hline CHEMBL1379160 & 737379 & 5.1182 & 4.9442 & TST & & \\
\hline CHEMBL1609818 & 737379 & 5.2344 & 5.3491 & TRN & & \\
\hline CHEMBL1482389 & 737379 & 5.5268 & 5.1854 & TRN & & \\
\hline CHEMBL1569094 & 737379 & 5.143 & 4.9198 & TRN & & \\
\hline CHEMBL1579341 & 737379 & 4.95 & 5.4446 & TRN & & \\
\hline CHEMBL 2006762 & 737379 & 4.6972 & 4.8384 & TRN & & \\
\hline CHEMBL498436 & 737379 & 5.4455 & 5.2329 & TST & & \\
\hline CHEMBL1463877 & 737379 & 5.3976 & 5.3493 & TRN & & \\
\hline CHEMBL1457501 & 737379 & 5.472 & 5.1833 & TRN & & \\
\hline CHEMBL1531156 & 737379 & 4.7547 & 4.8734 & TRN & & \\
\hline CHEMBL1554332 & 737379 & 5.1957 & 5.0881 & TRN & & \\
\hline CHEMBL472646 & 737379 & 5.4462 & 5.1766 & TST & & \\
\hline CHEMBL1558863 & 737379 & 2.71 & 4.2987 & TRN & & \\
\hline CHEMBL3197425 & 737379 & 5.1749 & 4.9639 & TRN & & \\
\hline CHEMBL1354069 & 737379 & 6.3301 & 5.5949 & TRN & & \\
\hline CHEMBL1718631 & 737379 & 5.8854 & 5.6023 & TST & & \\
\hline CHEMBL1498599 & 737379 & 5.3105 & 5.0772 & TRN & & \\
\hline CHEMBL1965045 & 737379 & 4.7158 & 4.81 & TRN & & \\
\hline CHEMBL1731400 & 737379 & 5.4667 & 5.3516 & TRN & & \\
\hline CHEMBL1704810 & 737379 & 5.4207 & 5.2566 & TRN & & \\
\hline CHEMBL3207920 & 737379 & 4.857 & 4.868 & TRN & & \\
\hline CHEMBL1382518 & 737379 & 5.4921 & 5.24200 & 0000000001 & & TRN \\
\hline CHEMBL1599111 & 737379 & 5.3337 & 5.101 & TST & & \\
\hline CHEMBL1728642 & 737379 & 6.0 & 5.6148 & TST & & \\
\hline CHEMBL1535538 & 737379 & 5.2323 & 5.0938 & TRN & & \\
\hline CHEMBL1606412 & 737379 & 4.492 & 5.105 & TRN & & \\
\hline CHEMBL1495621 & 737379 & 6.1797 & 5.7232 & TRN & & \\
\hline CHEMBL1501302 & 737379 & 5.1556 & 4.9277 & TRN & & \\
\hline CHEMBL1584002 & 737379 & 4.927 & 4.8972 & TRN & & \\
\hline CHEMBL1610389 & 737379 & 5.2025 & 5.3413 & TRN & & \\
\hline CHEMBL1531170 & 737379 & 5.8066 & 5.9641 & TRN & & \\
\hline CHEMBL3196840 & 737379 & 5.1001 & 5.0694 & TRN & & \\
\hline CHEMBL1582505 & 737379 & 5.6949 & 5.4051 & TRN & & \\
\hline CHEMBL1307744 & 737379 & 5.494 & 5.2962 & TRN & & \\
\hline CHEMBL1441609 & 737379 & 5.7823 & 5.9097 & TRN & & \\
\hline
\end{tabular}




\begin{tabular}{|c|c|c|c|c|c|}
\hline \multicolumn{6}{|c|}{ Supplemental Table S2.txt } \\
\hline CHEMBL1967859 & 737379 & 5.4425 & 5.2386 & TRN & \\
\hline CHEMBL1445171 & 737379 & 6.1216 & 5.6377 & TRN & \\
\hline CHEMBL3208752 & 737379 & 5.3629 & 5.1632 & TRN & \\
\hline CHEMBL1974432 & 737379 & 4.9582 & 4.7836 & TRN & \\
\hline CHEMBL1965821 & 737379 & 4.8993 & 5.3108 & TRN & \\
\hline CHEMBL1372616 & 737379 & 5.3468 & 5.1706 & TRN & \\
\hline CHEMBL1408368 & 737379 & 5.4641 & 5.1017 & TRN & \\
\hline CHEMBL1532863 & 737379 & 5.1422 & 4.9641 & TST & \\
\hline CHEMBL3190293 & 737379 & 5.4441 & 5.4223 & TRN & \\
\hline CHEMBL1408150 & 737379 & 5.8111 & 5.7071 & TST & \\
\hline CHEMBL577102 & 737379 & 5.3916 & 5.0001 & TRN & \\
\hline CHEMBL541845 & 737379 & 5.1153 & 5.02800 & 00000000005 & TRN \\
\hline CHEMBL1377544 & 737379 & 5.4234 & 5.3738 & TRN & \\
\hline CHEMBL1466614 & 737379 & 5.5113 & 5.2732 & TRN & \\
\hline CHEMBL1390112 & 737379 & 5.4076 & 5.1993 & TRN & \\
\hline CHEMBL 2006607 & 737379 & 5.7069 & 5.0237 & TRN & \\
\hline CHEMBL1733252 & 737379 & 4.8684 & 4.7469 & TRN & \\
\hline CHEMBL1328939 & 737379 & 5.7321 & 5.3443 & TRN & \\
\hline CHEMBL1387741 & 737379 & 4.9378 & 5.2093 & TRN & \\
\hline CHEMBL1486198 & 737379 & 5.3663 & 5.1035 & TRN & \\
\hline CHEMBL1513846 & 737379 & 2.71 & 5.1939 & TRN & \\
\hline CHEMBL1591082 & 737379 & 5.5412 & 5.2175 & TRN & \\
\hline CHEMBL1403670 & 737379 & 5.1974 & 5.2341 & TRN & \\
\hline CHEMBL1339232 & 737379 & 6.0928 & 5.8181 & TRN & \\
\hline CHEMBL1588525 & 737379 & 5.9952 & 5.669 & TRN & \\
\hline CHEMBL1603906 & 737379 & 5.169 & 5.0102 & TRN & \\
\hline CHEMBL1732120 & 737379 & 2.71 & 3.1944 & TRN & \\
\hline CHEMBL1518810 & 737379 & 5.769 & 5.2848 & TRN & \\
\hline CHEMBL1579771 & 737379 & 5.397 & 6.9843 & TRN & \\
\hline CHEMBL1607546 & 737379 & 4.232 & 5.0937 & TRN & \\
\hline CHEMBL1312872 & 737379 & 5.3119 & 5.0151 & TRN & \\
\hline CHEMBL1401378 & 737379 & 5.1404 & 5.0797 & TST & \\
\hline CHEMBL85139 & 737379 & 2.71 & 4.5484 & TRN & \\
\hline CHEMBL1559883 & 737379 & 5.3261 & 5.3515 & TST & \\
\hline CHEMBL3197921 & 737379 & 5.3932 & 5.0784 & TRN & \\
\hline CHEMBL1549957 & 737379 & 5.2047 & 5.25799 & 9999999999 & TRN \\
\hline CHEMBL1477805 & 737379 & 5.2126 & 4.9967 & TRN & \\
\hline CHEMBL1491315 & 737379 & 5.2661 & 4.8139 & TRN & \\
\hline CHEMBL1314100 & 737379 & 5.3498 & 5.331 & TRN & \\
\hline CHEMBL1549566 & 737379 & 5.4475 & 5.1585 & TRN & \\
\hline CHEMBL1339433 & 737379 & 5.4489 & 5.2021 & TRN & \\
\hline CHEMBL496633 & 737379 & 5.2016 & 5.0386 & TST & \\
\hline CHEMBL1482951 & 737379 & 5.6959 & 6.1069 & TRN & \\
\hline CHEMBL1710067 & 737379 & 5.5065 & 5.1617 & TST & \\
\hline CHEMBL1502878 & 737379 & 4.1067 & 2.9839 & TST & \\
\hline CHEMBL1543548 & 737379 & 4.8529 & 4.7888 & TRN & \\
\hline CHEMBL3190739 & 737379 & 5.4121 & 5.1426 & TST & \\
\hline CHEMBL1518291 & 737379 & 5.1711 & 4.7174 & TST & \\
\hline
\end{tabular}




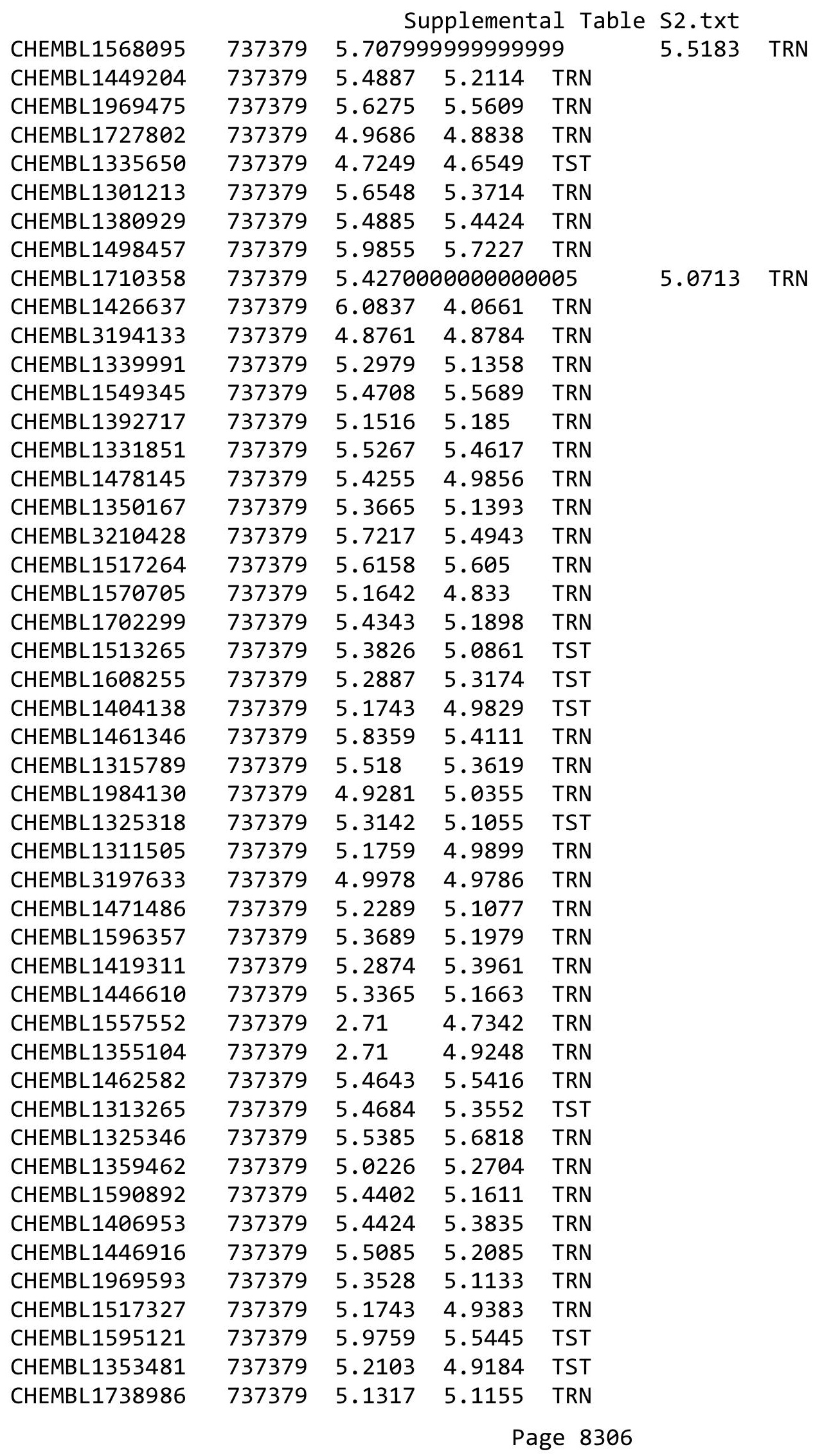




\begin{tabular}{|c|c|c|c|c|c|c|}
\hline & & \multicolumn{5}{|c|}{ Supplemental Table S2.txt } \\
\hline CHEMBL1584867 & 737379 & 5.4431 & 5.1986 & TRN & & \\
\hline CHEMBL1372805 & 737379 & 5.4461 & 5.2197 & TRN & & \\
\hline CHEMBL1093074 & 737379 & 5.3898 & 5.3344 & TRN & & \\
\hline CHEMBL1714892 & 737379 & 5.5082 & 5.3736 & TRN & & \\
\hline CHEMBL1712367 & 737379 & 5.3254 & 5.3808 & TRN & & \\
\hline CHEMBL1338462 & 737379 & 5.4034 & 5.3002 & TST & & \\
\hline CHEMBL1720216 & 737379 & 4.7657 & 5.0948 & TRN & & \\
\hline CHEMBL1708683 & 737379 & 2.71 & 2.9637 & TRN & & \\
\hline CHEMBL1302406 & 737379 & 5.4669 & 5.3856 & TRN & & \\
\hline CHEMBL1555870 & 737379 & 4.7945 & 4.7624 & TST & & \\
\hline CHEMBL1368203 & 737379 & 5.0372 & 4.7125 & TRN & & \\
\hline CHEMBL251005 & 737379 & 4.8891 & 5.8115 & TRN & & \\
\hline CHEMBL1471345 & 737379 & 5.9516 & 5.801 & TRN & & \\
\hline CHEMBL3214447 & 737379 & 5.4584 & 5.3409 & TRN & & \\
\hline CHEMBL1416769 & 737379 & 5.4056 & 5.4352 & TRN & & \\
\hline CHEMBL1353998 & 737379 & 5.477 & 5.4915 & TRN & & \\
\hline CHEMBL1382003 & 737379 & 4.9935 & 5.0043 & TRN & & \\
\hline CHEMBL1363461 & 737379 & 5.4492 & 5.1741 & TRN & & \\
\hline CHEMBL 3210478 & 737379 & 5.7721 & 5.1146 & TRN & & \\
\hline CHEMBL1302054 & 737379 & 5.3409 & 5.2219 & TRN & & \\
\hline CHEMBL1480024 & 737379 & 5.4415 & 5.1551 & TRN & & \\
\hline CHEMBL1549140 & 737379 & 5.1755 & 5.0057 & TRN & & \\
\hline CHEMBL1477416 & 737379 & 2.71 & 5.4836 & TST & & \\
\hline CHEMBL1325640 & 737379 & 5.4403 & 5.2483 & TST & & \\
\hline CHEMBL1591271 & 737379 & 5.3708 & 5.3042 & TST & & \\
\hline CHEMBL1596903 & 737379 & 5.0373 & 5.0989 & TRN & & \\
\hline CHEMBL1521599 & 737379 & 5.5834 & 5.4344 & TST & & \\
\hline CHEMBL1472987 & 737379 & 5.1642 & 5.0436 & TST & & \\
\hline CHEMBL1494288 & 737379 & $3.9610 e$ & 0000000 & $\partial 03$ & 4.3721 & TRN \\
\hline CHEMBL1372947 & 737379 & 6.3073 & 5.5211 & TST & & \\
\hline CHEMBL3197483 & 737379 & 5.471 & 5.2872 & TRN & & \\
\hline CHEMBL1468912 & 737379 & 2.71 & 3.0976 & TRN & & \\
\hline CHEMBL1440979 & 737379 & 4.5661 & 4.5705 & TRN & & \\
\hline CHEMBL1495748 & 737379 & 4.3606 & 5.3185 & TRN & & \\
\hline CHEMBL1430931 & 737379 & 5.6819 & 5.5706 & TRN & & \\
\hline CHEMBL1563171 & 737379 & 5.1251 & 4.9085 & TRN & & \\
\hline CHEMBL1429303 & 737379 & 2.71 & 4.3044 & TRN & & \\
\hline CHEMBL1511080 & 737379 & 5.6251 & 5.5423 & TRN & & \\
\hline CHEMBL1583716 & 737379 & 5.1221 & 4.9026 & TST & & \\
\hline CHEMBL155563 & 737379 & 5.6603 & 5.7611 & TRN & & \\
\hline CHEMBL1418082 & 737379 & 4.919 & 5.364 & TRN & & \\
\hline CHEMBL1439236 & 737379 & 5.2641 & 5.1704 & TRN & & \\
\hline CHEMBL1505956 & 737379 & 4.758 & 5.1286 & TRN & & \\
\hline CHEMBL3194032 & 737379 & 2.71 & 4.3524 & TRN & & \\
\hline CHEMBL1418230 & 737379 & 5.2972 & 4.9824 & TRN & & \\
\hline CHEMBL1429230 & 737379 & 2.71 & 5.4377 & TRN & & \\
\hline CHEMBL1399358 & 737379 & 4.8111 & 5.2592 & TRN & & \\
\hline CHEMBL1603602 & 737379 & 6.3208 & 5.8763 & TRN & & \\
\hline
\end{tabular}


Supplemental Table S2.txt

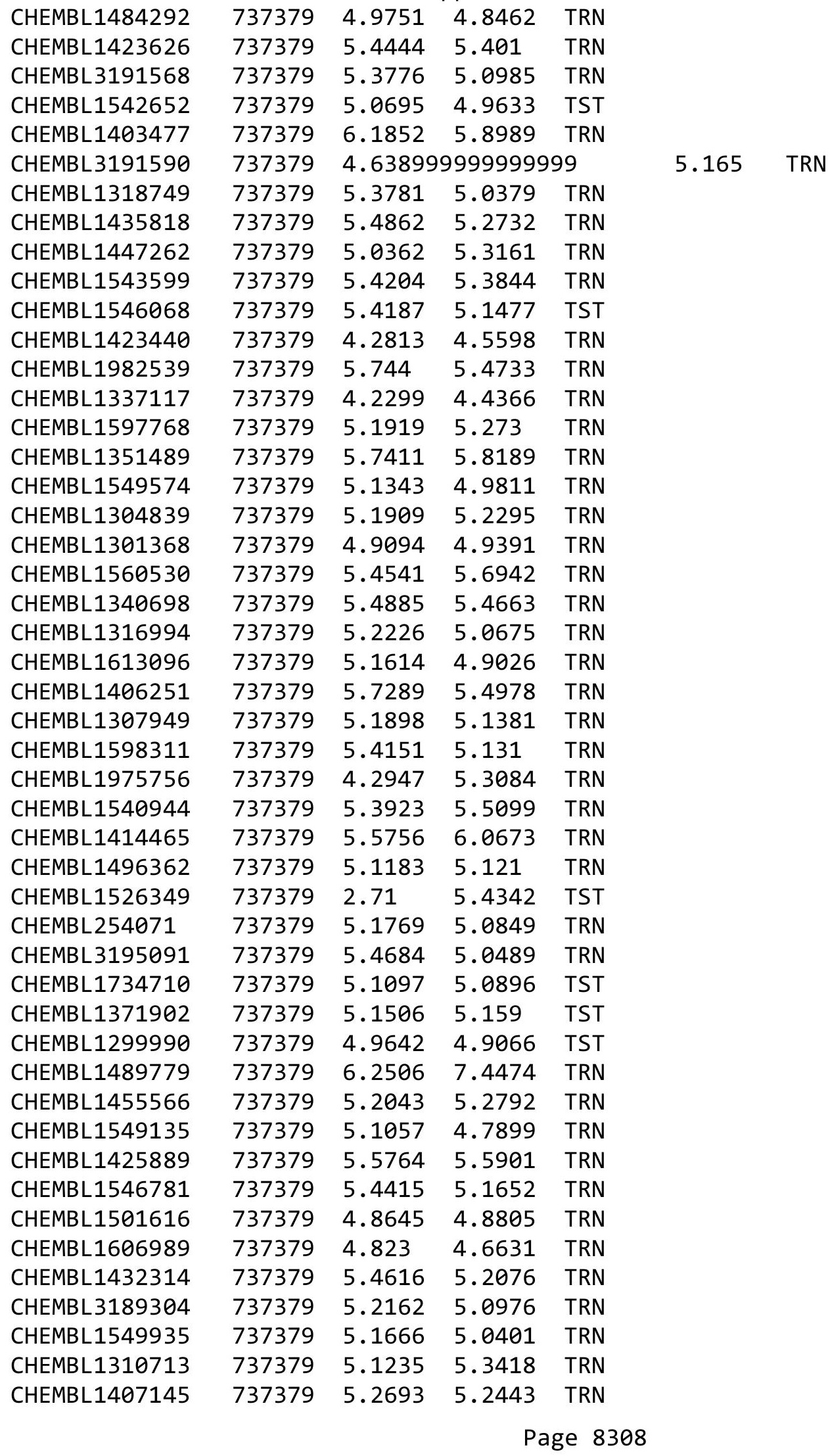


Supplemental Table S2.txt

\begin{tabular}{|c|c|c|c|c|c|c|}
\hline CHEMBL1439067 & 737379 & 5.1526 & 5.0096 & TRN & & \\
\hline CHEMBL1559129 & 737379 & 5.0171 & 4.8863 & TRN & & \\
\hline CHEMBL1549308 & 737379 & 5.2957 & 5.0852 & TRN & & \\
\hline CHEMBL1559928 & 737379 & 5.4717 & 5.8044 & TRN & & \\
\hline CHEMBL1313030 & 737379 & 4.8674 & 5.1164 & TST & & \\
\hline CHEMBL1732881 & 737379 & 5.3713 & 5.1745 & TST & & \\
\hline CHEMBL1472201 & 737379 & 5.4726 & 5.445 & TRN & & \\
\hline CHEMBL3189662 & 737379 & 5.5699 & 5.5034 & TRN & & \\
\hline CHEMBL1413988 & 737379 & 5.4679 & 5.2548 & TRN & & \\
\hline CHEMBL1348853 & 737379 & 5.4652 & 5.2825 & TRN & & \\
\hline CHEMBL1385727 & 737379 & 5.0017 & 5.0492 & TRN & & \\
\hline CHEMBL1982808 & 737379 & 5.4049 & 5.2174 & TRN & & \\
\hline CHEMBL1340197 & 737379 & 5.25 & 4.9472 & TRN & & \\
\hline CHEMBL1499929 & 737379 & 4.6578 & 4.6822 & TRN & & \\
\hline CHEMBL1364308 & 737379 & 4.9322 & 4.9699 & TRN & & \\
\hline CHEMBL1421071 & 737379 & 5.2923 & 5.1401 & TST & & \\
\hline CHEMBL1591413 & 737379 & 4.9248 & 7.0436 & TRN & & \\
\hline CHEMBL1414806 & 737379 & 5.5426 & 5.5215 & TRN & & \\
\hline CHEMBL1426592 & 737379 & 5.1567 & 5.1795 & TRN & & \\
\hline CHEMBL1555833 & 737379 & 5.3771 & 5.0508 & TRN & & \\
\hline CHEMBL1547736 & 737379 & 5.4293 & 5.0259 & TST & & \\
\hline CHEMBL1498873 & 737379 & 5.4162 & 5.4231 & TRN & & \\
\hline CHEMBL1459578 & 737379 & 4.871 & 5.2725 & TST & & \\
\hline CHEMBL3195449 & 737379 & 5.3001 & 4.7302 & TRN & & \\
\hline CHEMBL1490225 & 737379 & 5.4364 & 5.2417 & TRN & & \\
\hline CHEMBL1979756 & 737379 & 5.3378 & 5.0785 & TRN & & \\
\hline CHEMBL1595544 & 737379 & 5.3712 & 5.1054 & TRN & & \\
\hline CHEMBL1342173 & 737379 & 5.58799 & 999999995 & 99 & 5.4601 & TRN \\
\hline CHEMBL1475973 & 737379 & 5.1302 & 5.1829 & TRN & & \\
\hline CHEMBL1341399 & 737379 & 5.2334 & 5.0815 & TRN & & \\
\hline CHEMBL1448198 & 737379 & 6.0 & 5.5727 & TRN & & \\
\hline CHEMBL1358777 & 737379 & 2.71 & 4.455 & TST & & \\
\hline CHEMBL1709970 & 737379 & 5.3764 & 5.3262 & TRN & & \\
\hline CHEMBL1325908 & 737379 & 5.1611 & 4.8223 & TRN & & \\
\hline CHEMBL1328517 & 737379 & 4.6022 & 5.9141 & TRN & & \\
\hline CHEMBL1505606 & 737379 & 4.761 & 5.1351 & TRN & & \\
\hline CHEMBL1609900 & 737379 & 4.1101 & 5.336 & TRN & & \\
\hline CHEMBL3190609 & 737379 & 5.1367 & 5.2178 & TST & & \\
\hline CHEMBL1453663 & 737379 & 5.2837 & 5.23 & TRN & & \\
\hline CHEMBL3189946 & 737379 & 5.0893 & 4.891 & TRN & & \\
\hline CHEMBL1568695 & 737379 & 5.8356 & 5.4913 & TST & & \\
\hline CHEMBL1325313 & 737379 & 5.284 & 5.2834 & TRN & & \\
\hline CHEMBL1425314 & 737379 & 5.0665 & 5.3957 & TRN & & \\
\hline CHEMBL 2139687 & 737379 & 5.4573 & 5.1639 & TRN & & \\
\hline CHEMBL1454195 & 737379 & 5.6142 & 5.4895 & TRN & & \\
\hline CHEMBL1733515 & 737379 & \multicolumn{3}{|c|}{5.388999999999999} & 5.183 & TRN \\
\hline CHEMBL1586169 & 737379 & 5.4593 & 5.1142 & TST & & \\
\hline CHEMBL1345480 & 737379 & 5.2846 & 5.3227 & TRN & & \\
\hline
\end{tabular}


Supplemental Table S2.txt

\begin{tabular}{|c|c|c|c|c|}
\hline 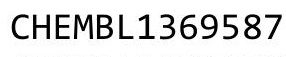 & & & & \\
\hline HEMBL1330058 & 37379 & 7867 & 5.29 & \\
\hline HEMBL1C & 7379 & 811 & 1917 & \\
\hline ILTILLIר & 79 & & & \\
\hline AEMBL16 & 79 & & & RN \\
\hline AEMBL3208968 & 37379 & 3751 & .4551 & \\
\hline HEMBL1445504 & 37379 & .4916 & .3005 & \\
\hline HEMBL51 & 79 & 7959 & 0577 & \\
\hline HEMBL15 & 379 & & .2854 & \\
\hline AEMBL13 & & & & \\
\hline HEMBL1571123 & 37379 & 1943 & .3451 & \\
\hline HEMBL1563874 & 37379 & 1514 & 0773 & \\
\hline HEMBL 58 & 79 & & 2645 & \\
\hline HEMBL13 & 79 & & 3155 & \\
\hline HEMBL1C & & & 3358 & \\
\hline HEMBL1566706 & 37379 & 572 & 4087 & \\
\hline AEMBL1728103 & & & 66 & \\
\hline HEMBL13 & 79 & 488 & 2646 & \\
\hline L15 & & & & \\
\hline HEM & & & 977 & \\
\hline AEMBL1344059 & 37379 & 2701 & & \\
\hline IEMBL146 & & & & \\
\hline HEMBL17 & 79 & 046 & 955 & IV \\
\hline HEMBL15 & & & . & \\
\hline 92 & 79 & & 913 & \\
\hline L14 & & & 5032 & 1 \\
\hline AEMBL1376799 & & & & IV \\
\hline HEMBL31 & & & 634 & \\
\hline HEN & & & 38 & \\
\hline 95 & 79 & $\partial 3$ & 2782 & RN \\
\hline AEMBL14 & & & & IRN \\
\hline AEMBL1606217 & & & 3.0104 & RN \\
\hline HEMBL15 & & & 91 & RN \\
\hline 8 & & & 57 & RN \\
\hline 8 & 79 & & 755 & $\mathrm{RN}$ \\
\hline AEMBL15 & & & 3296 & $\mathrm{RN}$ \\
\hline AEMBL1578975 & & & .701 & \\
\hline & & & & \\
\hline 4 & 79 & & 234 & I \\
\hline HEMBL14 & & & & ST \\
\hline AEMBL1347030 & 37379 & 15 & & $\mathrm{RN}$ \\
\hline AEMBL14 & 79 & & 677 & RN \\
\hline & & & .794 & \\
\hline HEMBL13 & & & 2183 & RIN \\
\hline HEMBL15 & 37379 & 94 & 5.5198 & $\mathrm{RN}$ \\
\hline IEMBL1736072 & 37379 & 519 & 5.1486 & RN \\
\hline 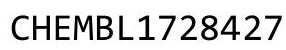 & & & 152 & \\
\hline ברנו 101 & & 5.1882 & 5.067 & \\
\hline
\end{tabular}

Page 8310 


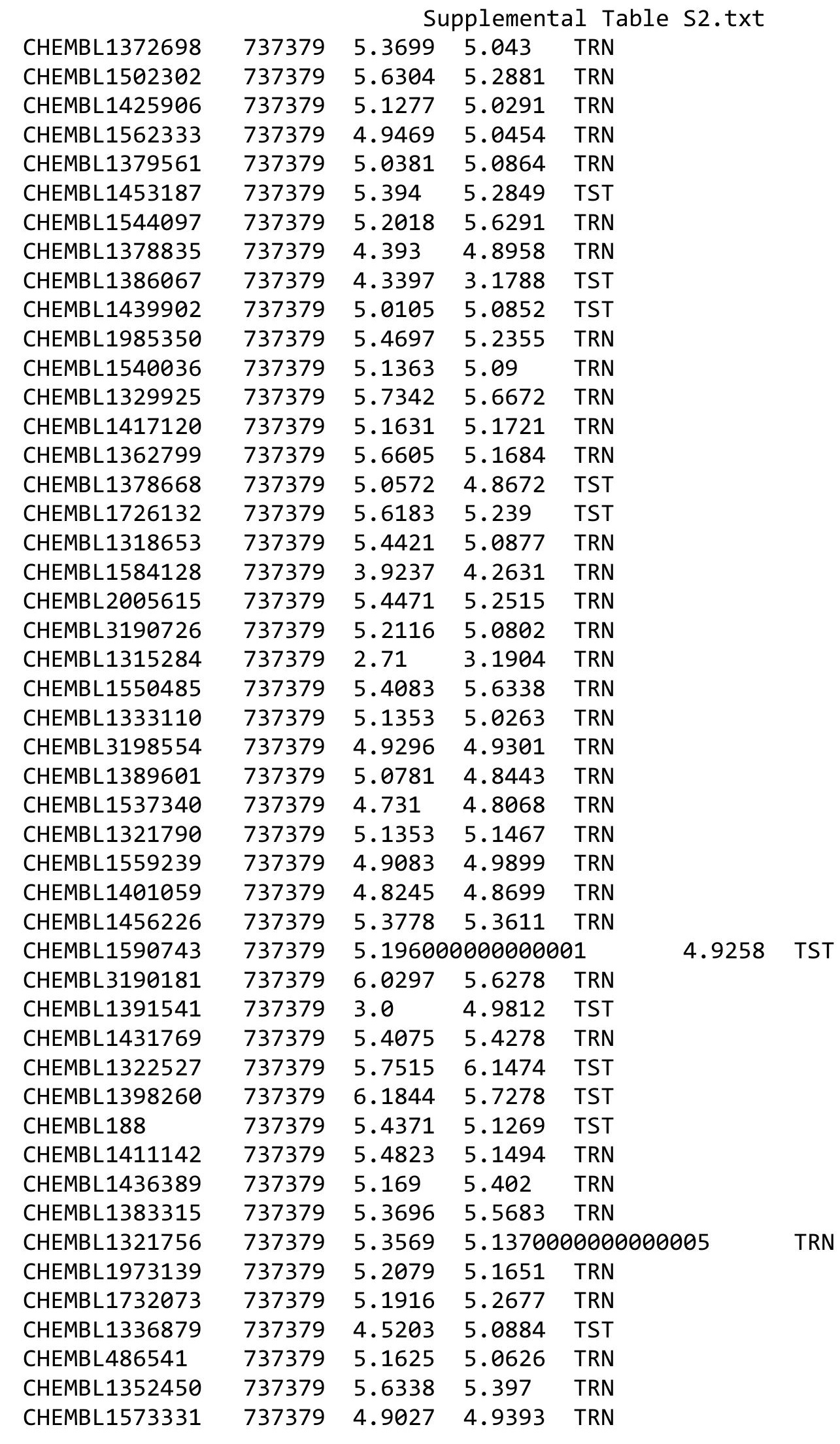

Page 8311 
Supplemental Table S2.txt

\begin{tabular}{|c|c|c|c|c|}
\hline CHEMBL3193922 & 737379 & 4.6377 & 5.4189 & TRN \\
\hline CHEMBL1731938 & 737379 & 5.0514 & 4.8514 & TRN \\
\hline CHEMBL1339537 & 737379 & 5.5622 & 5.7867 & TRN \\
\hline CHEMBL3189567 & 737379 & 4.0717 & 5.355 & TRN \\
\hline CHEMBL1479637 & 737379 & 5.4083 & 5.1588 & TRN \\
\hline CHEMBL1588976 & 737379 & 5.1807 & 5.0572 & TRN \\
\hline CHEMBL1487171 & 737379 & 5.7018 & 5.5845 & TRN \\
\hline CHEMBL1324044 & 737379 & 5.8617 & 5.5179 & TRN \\
\hline CHEMBL579082 & 737379 & 5.4323 & 5.2277 & TST \\
\hline CHEMBL3196955 & 737379 & 5.1831 & 5.0218 & TRN \\
\hline CHEMBL1405067 & 737379 & 6.0429 & 5.6121 & TRN \\
\hline CHEMBL1309341 & 737379 & 5.4841 & 5.3986 & TRN \\
\hline CHEMBL1542378 & 737379 & 4.9307 & 4.9282 & TRN \\
\hline CHEMBL1718750 & 737379 & 4.8392 & 5.0666 & TST \\
\hline CHEMBL1385815 & 737379 & 2.71 & 4.6254 & TRN \\
\hline CHEMBL1728809 & 737379 & 5.3311 & 5.1613 & TST \\
\hline CHEMBL3191688 & 737379 & 5.1699 & 5.1021 & TRN \\
\hline CHEMBL3189224 & 737379 & 5.17299 & 999999999 & 5.0807 \\
\hline CHEMBL1566415 & 737379 & 5.3321 & 5.0741 & TRN \\
\hline CHEMBL1529203 & 737379 & 5.2285 & 5.6493 & TRN \\
\hline CHEMBL1702334 & 737379 & 5.4425 & 5.1664 & TRN \\
\hline CHEMBL1307271 & 737379 & 5.3095 & 5.5796 & TRN \\
\hline CHEMBL3191789 & 737379 & 5.4142 & 5.2195 & TRN \\
\hline CHEMBL1735971 & 737379 & 5.8508 & 5.5692 & TRN \\
\hline CHEMBL1500686 & 737379 & 5.4318 & 5.2302 & TRN \\
\hline CHEMBL1373636 & 737379 & 5.0562 & 4.9297 & TRN \\
\hline CHEMBL1526705 & 737379 & 2.71 & 4.4466 & TRN \\
\hline CHEMBL1512775 & 737379 & 5.1432 & 5.3627 & TRN \\
\hline CHEMBL1450025 & 737379 & 4.5467 & 4.7131 & TRN \\
\hline CHEMBL1447343 & 737379 & 4.5707 & 4.3387 & TRN \\
\hline CHEMBL1424231 & 737379 & 5.0066 & 4.9022 & TRN \\
\hline CHEMBL275311 & 737379 & 5.4318 & 5.2405 & TRN \\
\hline CHEMBL1717333 & 737379 & 5.4763 & 5.226 & TRN \\
\hline CHEMBL1573697 & 737379 & 5.2068 & 5.088999 & \\
\hline CHEMBL1515852 & 737379 & 5.8254 & 5.8798 & TST \\
\hline CHEMBL1323248 & 737379 & 5.5181 & 5.2838 & TRN \\
\hline CHEMBL1344174 & 737379 & 6.0881 & 5.9348 & TRN \\
\hline CHEMBL1552042 & 737379 & 5.0238 & 4.9265 & TRN \\
\hline CHEMBL1593757 & 737379 & 5.1759 & 5.0909 & TRN \\
\hline CHEMBL 2001316 & 737379 & 5.2423 & 5.0515 & TRN \\
\hline CHEMBL1985744 & 737379 & 4.9772 & 4.7525 & TRN \\
\hline CHEMBL1572955 & 737379 & 5.1665 & 4.9824 & TRN \\
\hline CHEMBL1393630 & 737379 & 5.3179 & 5.0777 & TRN \\
\hline CHEMBL1524089 & 737379 & 5.3382 & 5.018 & TRN \\
\hline CHEMBL 1366770 & 737379 & 2.71 & 4.5655 & TRN \\
\hline CHEMBL 3214487 & 737379 & 5.1869 & 5.1843 & TRN \\
\hline CHEMBL21241 & 737379 & 5.2543 & 5.0268 & TST \\
\hline CHEMBL1610565 & 737379 & 5.9329 & 6.0892 & TRN \\
\hline
\end{tabular}




\begin{tabular}{|c|c|c|c|c|}
\hline \multicolumn{5}{|c|}{ Supplemental Table } \\
\hline CHEMBL1532147 & 737379 & 5.4123 & 5.1681 & TRN \\
\hline CHEMBL1323821 & 737379 & 5.4154 & 5.2085 & TRN \\
\hline CHEMBL1391715 & 737379 & 2.71 & 4.5254 & TRN \\
\hline CHEMBL1360873 & 737379 & 5.2254 & 5.3166 & TST \\
\hline CHEMBL1979574 & 737379 & 5.6692 & 5.1943 & TRN \\
\hline CHEMBL1567225 & 737379 & 5.1742 & 4.9124 & TRN \\
\hline CHEMBL1864436 & 737379 & 5.1875 & 5.0046 & TRN \\
\hline CHEMBL1493675 & 737379 & 4.637 & 5.6203 & TST \\
\hline CHEMBL1423370 & 737379 & 2.71 & 5.3535 & TRN \\
\hline CHEMBL1362520 & 737379 & 5.2179 & 4.578 & TRN \\
\hline CHEMBL1736978 & 737379 & 5.1618 & 5.0529 & TST \\
\hline CHEMBL1543714 & 737379 & 5.2567 & 5.1544 & TRN \\
\hline CHEMBL1428087 & 737379 & 6.4444 & 6.7812 & TRN \\
\hline CHEMBL1342448 & 737379 & 6.0877 & 5.5703 & TRN \\
\hline CHEMBL1553553 & 737379 & 5.4579 & 5.0459 & TRN \\
\hline CHEMBL1452409 & 737379 & 5.4566 & 5.3202 & TRN \\
\hline CHEMBL1537722 & 737379 & 5.1467 & 4.9592 & TRN \\
\hline CHEMBL3196847 & 737379 & 6.6755 & 6.961 & TRN \\
\hline CHEMBL1598340 & 737379 & 5.5178 & 5.2667 & TST \\
\hline CHEMBL 250711 & 737379 & 5.3368 & 5.2325 & TST \\
\hline CHEMBL1467739 & 737379 & 5.2099 & 4.987 & TRN \\
\hline CHEMBL1527120 & 737379 & 5.3778 & 5.2849 & TRN \\
\hline CHEMBL1524417 & 737379 & 4.6584 & 5.1896 & TRN \\
\hline CHEMBL3145111 & 737379 & 5.0844 & 5.039 & TRN \\
\hline CHEMBL1556485 & 737379 & 5.442 & 5.1559 & TRN \\
\hline CHEMBL1474058 & 737379 & 5.2847 & 5.4075 & TRN \\
\hline CHEMBL1563442 & 737379 & 5.1934 & 5.3805 & TRN \\
\hline CHEMBL1721990 & 737379 & 5.1774 & 5.0909 & TST \\
\hline CHEMBL1518036 & 737379 & 5.1681 & 5.043 & TRN \\
\hline CHEMBL591178 & 737379 & 5.3165 & 5.1614 & TRN \\
\hline CHEMBL1305815 & 737379 & 2.71 & 2.9757 & TRN \\
\hline CHEMBL1605393 & 737379 & 5.0496 & 4.9544 & TST \\
\hline CHEMBL1467073 & 737379 & 4.8781 & 4.6537 & TRN \\
\hline CHEMBL1543907 & 737379 & 5.1667 & 5.0956 & TRN \\
\hline CHEMBL1449008 & 737379 & 5.8492 & 5.4502 & TRN \\
\hline CHEMBL1352907 & 737379 & 4.8259 & 4.6463 & TRN \\
\hline CHEMBL1423474 & 737379 & 5.5211 & 5.2312 & TRN \\
\hline CHEMBL1539522 & 737379 & 5.1167 & 5.4117 & TRN \\
\hline CHEMBL1989294 & 737379 & 5.5605 & 5.4172 & TRN \\
\hline CHEMBL1403470 & 737379 & 4.9322 & 4.9309 & TRN \\
\hline CHEMBL1517861 & 737379 & 5.3025 & 4.8717 & TRN \\
\hline CHEMBL1474098 & 737379 & 5.1731 & 4.9244 & TST \\
\hline CHEMBL1504675 & 737379 & 5.1548 & 5.1276 & TRN \\
\hline CHEMBL1490267 & 737379 & 5.4129 & 5.0765 & TRN \\
\hline CHEMBL1735848 & 737379 & 5.5658 & 5.6121 & TRN \\
\hline CHEMBL1477528 & 737379 & 5.3863 & 5.4228 & TRN \\
\hline CHEMBL1076559 & 737379 & 5.1486 & 5.0104 & TRN \\
\hline CHEMBL1543257 & 737379 & 5.8719 & 5.7384 & TRN \\
\hline
\end{tabular}




\begin{tabular}{|c|c|c|c|c|c|}
\hline & & \multicolumn{4}{|c|}{ Supplemental Table S2.txt } \\
\hline CHEMBL1443328 & 737379 & 4.9658 & 5.3385 & TRN & \\
\hline CHEMBL1363346 & 737379 & 5.6317 & 5.24 & TRN & \\
\hline CHEMBL1319591 & 737379 & 4.475 & 4.6266 & TRN & \\
\hline CHEMBL1586807 & 737379 & 5.6807 & 5.5171 & TRN & \\
\hline CHEMBL1564038 & 737379 & 5.1765 & 4.9928 & TRN & \\
\hline CHEMBL1359188 & 737379 & 5.2276 & 5.5157 & TRN & \\
\hline CHEMBL1600941 & 737379 & 4.9872 & 4.8852 & TRN & \\
\hline CHEMBL1373490 & 737379 & 5.0025 & 5.0437 & TRN & \\
\hline CHEMBL1306481 & 737379 & 5.2961 & 5.2781 & TST & \\
\hline CHEMBL1996281 & 737379 & 5.4305 & 5.1627 & TRN & \\
\hline CHEMBL1332356 & 737379 & 5.6123 & 5.5181 & TRN & \\
\hline CHEMBL1572294 & 737379 & 5.545 & 5.4405 & TST & \\
\hline CHEMBL1427339 & 737379 & 5.6981 & 5.5204 & TRN & \\
\hline CHEMBL1309733 & 737379 & 5.3026 & 5.0678 & TRN & \\
\hline CHEMBL3197985 & 737379 & 5.3718 & 5.2258 & TST & \\
\hline CHEMBL3189686 & 737379 & 5.2836 & 4.9719 & TRN & \\
\hline CHEMBL3195824 & 737379 & 4.5204 & 4.5753 & TRN & \\
\hline CHEMBL 3212782 & 737379 & 4.8901 & 4.9404 & TST & \\
\hline CHEMBL1336887 & 737379 & 5.4297 & 5.7928 & TRN & \\
\hline CHEMBL1425736 & 737379 & 4.6073 & 4.2112 & TRN & \\
\hline CHEMBL1457787 & 737379 & 4.9834 & 4.9161 & TRN & \\
\hline CHEMBL1344000 & 737379 & 5.1998 & 5.0629 & TRN & \\
\hline CHEMBL1702908 & 737379 & 5.1734 & 4.822 & TRN & \\
\hline CHEMBL1331801 & 737379 & 5.0348 & 4.999 & TRN & \\
\hline CHEMBL1571821 & 737379 & 5.4406 & 5.7149 & TRN & \\
\hline CHEMBL1372667 & 737379 & 4.9108 & 4.7828 & TST & \\
\hline CHEMBL1507843 & 737379 & 5.3239 & 5.7386 & TRN & \\
\hline CHEMBL1533220 & 737379 & 5.8608 & 5.71399 & 99999999995 & TRN \\
\hline CHEMBL1385983 & 737379 & 5.5382 & 4.9933 & TRN & \\
\hline CHEMBL1411310 & 737379 & 4.6405 & 3.7622 & TRN & \\
\hline CHEMBL1521991 & 737379 & 5.3054 & 5.3242 & TRN & \\
\hline CHEMBL1600986 & 737379 & 5.3283 & 5.0893 & TRN & \\
\hline CHEMBL1578291 & 737379 & 5.1743 & 5.4566 & TRN & \\
\hline CHEMBL1592417 & 737379 & 5.1869 & 5.1272 & TRN & \\
\hline CHEMBL1549975 & 737379 & 5.1855 & 5.1523 & TRN & \\
\hline CHEMBL1575373 & 737379 & 4.9918 & 4.9952 & TRN & \\
\hline CHEMBL1423912 & 737379 & 4.555 & 4.6925 & TRN & \\
\hline CHEMBL1364796 & 737379 & 2.71 & 3.0268 & TST & \\
\hline CHEMBL1415703 & 737379 & 5.4225 & 5.1621 & TRN & \\
\hline CHEMBL1389765 & 737379 & 3.9226 & 5.3551 & TRN & \\
\hline CHEMBL1588813 & 737379 & 5.5988 & 5.9412 & TRN & \\
\hline CHEMBL1406019 & 737379 & 5.2725 & 5.2732 & TRN & \\
\hline CHEMBL1503209 & 737379 & 5.5683 & 5.2828 & TST & \\
\hline CHEMBL1980369 & 737379 & 5.1791 & 5.1481 & TRN & \\
\hline CHEMBL1533242 & 737379 & 5.2608 & 4.9231 & TRN & \\
\hline CHEMBL1486582 & 737379 & 4.4036 & 4.5843 & TRN & \\
\hline CHEMBL 3208834 & 737379 & 5.3016 & 5.2585 & TRN & \\
\hline CHEMBL1464444 & 737379 & 2.71 & 3.1462 & TST & \\
\hline
\end{tabular}




\begin{tabular}{|c|c|c|c|c|c|}
\hline \multicolumn{6}{|c|}{ Supplemental Table S2.txt } \\
\hline CHEMBL1357685 & 737379 & 5.0645 & 5.7159 & TRN & \\
\hline CHEMBL1574280 & 737379 & 6.3119 & 6.0285 & TRN & \\
\hline CHEMBL3191127 & 737379 & 4.4722 & 5.6149 & TRN & \\
\hline CHEMBL1508457 & 737379 & 5.12 & 5.05399 & 7999999999 & TRN \\
\hline CHEMBL1343590 & 737379 & 4.1241 & 5.2601 & TST & \\
\hline CHEMBL1731557 & 737379 & 5.3661 & 5.4655 & TRN & \\
\hline CHEMBL1735477 & 737379 & 5.7781 & 5.6078 & TRN & \\
\hline CHEMBL1608986 & 737379 & 4.7345 & 4.7997 & TRN & \\
\hline CHEMBL1443462 & 737379 & 5.8595 & 5.8156 & TRN & \\
\hline CHEMBL1455813 & 737379 & 5.3687 & 5.1085 & TRN & \\
\hline CHEMBL1612931 & 737379 & 4.9809 & 4.8888 & TRN & \\
\hline CHEMBL1579548 & 737379 & 5.5552 & 5.3284 & TRN & \\
\hline CHEMBL1601565 & 737379 & 5.4141 & 5.2311 & TRN & \\
\hline CHEMBL1386044 & 737379 & 5.3734 & 5.0407 & TRN & \\
\hline CHEMBL3190837 & 737379 & 5.1706 & 5.2068 & TRN & \\
\hline CHEMBL1501495 & 737379 & 5.2857 & 5.0342 & TRN & \\
\hline CHEMBL3210067 & 737379 & 5.2164 & 5.0644 & TRN & \\
\hline CHEMBL1341736 & 737379 & 5.3147 & 5.0148 & TRN & \\
\hline CHEMBL1401888 & 737379 & 5.1514 & 5.056 & TRN & \\
\hline CHEMBL1444540 & 737379 & 5.3057 & 5.4809 & TRN & \\
\hline CHEMBL1533110 & 737379 & 6.0292 & 5.87 & TRN & \\
\hline CHEMBL1436936 & 737379 & 5.1274 & 5.1245 & TRN & \\
\hline CHEMBL1453708 & 737379 & 5.4532 & 5.3057 & TST & \\
\hline CHEMBL1310553 & 737379 & 5.8342 & 5.5729 & TRN & \\
\hline CHEMBL1330524 & 737379 & 4.7219 & 4.6173 & TRN & \\
\hline CHEMBL1458403 & 737379 & 5.4786 & 4.9146 & TST & \\
\hline CHEMBL1343743 & 737379 & 5.4125 & 5.4541 & TRN & \\
\hline CHEMBL1517872 & 737379 & 5.8444 & 6.0734 & TRN & \\
\hline CHEMBL1733687 & 737379 & 5.2031 & 5.2495 & TRN & \\
\hline CHEMBL1441884 & 737379 & 5.4621 & 5.279 & TRN & \\
\hline CHEMBL1495094 & 737379 & 4.8693 & 5.0054 & TRN & \\
\hline CHEMBL1529482 & 737379 & 5.0384 & 4.9672 & TST & \\
\hline CHEMBL1398447 & 737379 & 5.1654 & 4.882 & TRN & \\
\hline CHEMBL1474042 & 737379 & 5.7525 & 5.7271 & TRN & \\
\hline CHEMBL1464497 & 737379 & 5.359 & 5.4526 & TRN & \\
\hline CHEMBL1379817 & 737379 & 5.8465 & 5.5043 & TRN & \\
\hline CHEMBL1328614 & 737379 & 4.9965 & 5.1768 & TRN & \\
\hline CHEMBL1478578 & 737379 & 5.1907 & 5.2183 & TRN & \\
\hline CHEMBL1398511 & 737379 & 5.4156 & 5.4161 & TRN & \\
\hline CHEMBL1504345 & 737379 & 5.3186 & 5.5153 & TRN & \\
\hline CHEMBL1478933 & 737379 & 7.7959 & 5.2068 & TRN & \\
\hline CHEMBL 2003356 & 737379 & 5.2448 & 5.0713 & TRN & \\
\hline CHEMBL1536646 & 737379 & 5.2278 & 5.0341 & TRN & \\
\hline CHEMBL1524733 & 737379 & 5.2069 & 4.7956 & TRN & \\
\hline CHEMBL1315006 & 737379 & 5.7183 & 5.5079 & TRN & \\
\hline CHEMBL 3190240 & 737379 & 2.71 & 3.0513 & TRN & \\
\hline CHEMBL1377699 & 737379 & 5.9359 & 6.0063 & TRN & \\
\hline CHEMBL1556321 & 737379 & 5.1009 & 5.1439 & TRN & \\
\hline
\end{tabular}




\begin{tabular}{|c|c|c|c|c|c|c|}
\hline & & \multicolumn{5}{|c|}{ Supplemental Table S2.txt } \\
\hline CHEMBL1304990 & 737379 & 5.2516 & 5.1663 & TRN & & \\
\hline CHEMBL1310995 & 737379 & 5.3094 & 5.1514 & TST & & \\
\hline CHEMBL1350336 & 737379 & 5.053 & 4.9908 & TRN & & \\
\hline CHEMBL1586230 & 737379 & 5.8303 & 5.7082 & TRN & & \\
\hline CHEMBL1547021 & 737379 & 4.8582 & 4.9821 & TRN & & \\
\hline CHEMBL1308415 & 737379 & 4.9385 & 4.9911 & TRN & & \\
\hline CHEMBL1344556 & 737379 & 5.1672 & 4.9374 & TRN & & \\
\hline CHEMBL1561338 & 737379 & 5.4177 & 5.3014 & TRN & & \\
\hline CHEMBL3191051 & 737379 & 5.4149 & 5.2039 & TRN & & \\
\hline CHEMBL1316573 & 737379 & 5.1443 & 4.9806 & TRN & & \\
\hline CHEMBL1596003 & 737379 & 5.4063 & 5.3533 & TRN & & \\
\hline CHEMBL1731981 & 737379 & 5.151 & 4.9945 & TRN & & \\
\hline CHEMBL1533968 & 737379 & 5.0952 & 4.9101 & TRN & & \\
\hline CHEMBL1713961 & 737379 & 4.9462 & 4.5885 & TRN & & \\
\hline CHEMBL1463521 & 737379 & 5.0203 & 5.0098 & TRN & & \\
\hline CHEMBL1411465 & 737379 & 5.1667 & 5.0092 & TRN & & \\
\hline CHEMBL1605622 & 737379 & 5.4194 & 5.1655 & TRN & & \\
\hline CHEMBL3194489 & 737379 & 5.3232 & 5.0892 & TRN & & \\
\hline CHEMBL1529093 & 737379 & 5.7506 & 5.4577 & TST & & \\
\hline CHEMBL1387474 & 737379 & 5.1782 & 5.2146 & TRN & & \\
\hline CHEMBL1722206 & 737379 & 5.4447 & 5.2247 & TRN & & \\
\hline CHEMBL1430105 & 737379 & 5.4531 & 5.2353 & TRN & & \\
\hline CHEMBL1401498 & 737379 & 3.9893 & 4.38 & TRN & & \\
\hline CHEMBL1557274 & 737379 & 5.6861 & 5.1899 & TST & & \\
\hline CHEMBL 3197454 & 737379 & 5.2674 & 4.7536 & TRN & & \\
\hline CHEMBL1348593 & 737379 & 5.25299 & 99999999 & 99 & 5.0844 & TST \\
\hline CHEMBL1470481 & 737379 & 4.7272 & 5.1548 & TRN & & \\
\hline CHEMBL1489573 & 737379 & 5.33299 & 99999999 & 99 & 4.9627 & TST \\
\hline CHEMBL1981538 & 737379 & 5.3554 & 5.5816 & TRN & & \\
\hline CHEMBL1337213 & 737379 & 5.0828 & 5.2441 & TRN & & \\
\hline CHEMBL 3197243 & 737379 & 5.246 & 5.037 & TRN & & \\
\hline CHEMBL1363773 & 737379 & 5.4459 & 5.3598 & TRN & & \\
\hline CHEMBL1550535 & 737379 & 5.1528 & 5.2197 & TRN & & \\
\hline CHEMBL582444 & 737379 & 5.4174 & 5.2802 & TST & & \\
\hline CHEMBL1469835 & 737379 & 4.9735 & 4.7303 & TRN & & \\
\hline CHEMBL1367691 & 737379 & 5.4686 & 5.2337 & TRN & & \\
\hline CHEMBL1487936 & 737379 & 5.3697 & 5.2731 & TRN & & \\
\hline CHEMBL1393529 & 737379 & 5.1409 & 5.224 & TRN & & \\
\hline CHEMBL1612379 & 737379 & 5.7014 & 5.5723 & TRN & & \\
\hline CHEMBL1361820 & 737379 & 5.4212 & 5.0254 & TRN & & \\
\hline CHEMBL1360535 & 737379 & 6.0 & 5.5718 & TST & & \\
\hline CHEMBL1391764 & 737379 & 5.2123 & 4.9889 & TRN & & \\
\hline CHEMBL1312320 & 737379 & 5.3145 & 5.0764 & TRN & & \\
\hline CHEMBL1576099 & 737379 & 2.71 & 3.02399 & 99999 & 996 & נוז \\
\hline CHEMBL398969 & 737379 & 5.4921 & 4.8459 & TRN & & \\
\hline CHEMBL1580604 & 737379 & 5.4462 & 5.1739 & TRN & & \\
\hline CHEMBL1382827 & 737379 & 5.4322 & 5.1505 & TRN & & \\
\hline CHEMBL1484231 & 737379 & 5.1904 & 5.0296 & TRN & & \\
\hline
\end{tabular}




\begin{tabular}{|c|c|c|c|c|}
\hline & & & pplement & al $\mathrm{T}$ \\
\hline CHEMBL1526505 & 737379 & 5.2435 & 5.2424 & TRN \\
\hline CHEMBL1503568 & 737379 & 5.1822 & 5.1655 & TRN \\
\hline CHEMBL1558884 & 737379 & 5.4695 & 5.3485 & TST \\
\hline CHEMBL3197314 & 737379 & 5.6488 & 5.4622 & TRN \\
\hline CHEMBL1483730 & 737379 & 4.9024 & 4.7887 & TST \\
\hline CHEMBL1581201 & 737379 & 4.5337 & 5.0074 & TRN \\
\hline CHEMBL1703850 & 737379 & 5.1752 & 5.0726 & TRN \\
\hline CHEMBL1708441 & 737379 & 5.3076 & 5.3803 & TRN \\
\hline CHEMBL1441485 & 737379 & 5.3435 & 5.1964 & TRN \\
\hline CHEMBL1975652 & 737379 & 5.2353 & 5.0414 & TRN \\
\hline CHEMBL1373688 & 737379 & 5.0951 & 5.4576 & TRN \\
\hline CHEMBL1308346 & 737379 & 5.006 & 4.8944 & TRN \\
\hline CHEMBL1520702 & 737379 & 6.5384 & 6.0006 & TRN \\
\hline CHEMBL1353015 & 737379 & 5.2413 & 5.2765 & TRN \\
\hline CHEMBL1348933 & 737379 & 5.3925 & 5.2658 & TRN \\
\hline CHEMBL1476181 & 737379 & 5.0892 & 4.8969 & TRN \\
\hline CHEMBL1468192 & 737379 & 5.4068 & 5.1275 & TRN \\
\hline CHEMBL416657 & 737379 & 5.6981 & 5.4315 & TST \\
\hline CHEMBL1405111 & 737379 & 5.2041 & 5.0509 & TRN \\
\hline CHEMBL1558527 & 737379 & 4.8069 & 5.3127 & TRN \\
\hline CHEMBL1537864 & 737379 & 5.1598 & 5.3666 & TRN \\
\hline CHEMBL1480264 & 737379 & 4.7905 & 4.9683 & TRN \\
\hline CHEMBL1510359 & 737379 & 5.1952 & 5.0889 & TST \\
\hline CHEMBL194400 & 737379 & 5.2014 & 4.9524 & TST \\
\hline CHEMBL1538205 & 737379 & 5.7133 & 5.5124 & TRN \\
\hline CHEMBL 3197720 & 737379 & 4.7833 & 5.0663 & TRN \\
\hline CHEMBL1373727 & 737379 & 5.246 & 5.3216 & TRN \\
\hline CHEMBL1573692 & 737379 & 5.0543 & 5.3282 & TRN \\
\hline CHEMBL1445941 & 737379 & 4.5354 & 4.6945 & TST \\
\hline CHEMBL1408593 & 737379 & 5.5211 & 5.7669 & TST \\
\hline CHEMBL1470925 & 737379 & 5.2278 & 5.0475 & TRN \\
\hline CHEMBL2144394 & 737379 & 5.4133 & 5.2824 & TRN \\
\hline CHEMBL1330145 & 737379 & 5.3367 & 5.5438 & TRN \\
\hline CHEMBL269277 & 737379 & 6.0 & 5.6512 & TST \\
\hline CHEMBL1451117 & 737379 & 4.8128 & 5.5787 & TRN \\
\hline CHEMBL1364395 & 737379 & 2.71 & 3.1582 & TST \\
\hline CHEMBL1367989 & 737379 & 5.1134 & 4.8273 & TRN \\
\hline CHEMBL590887 & 737379 & 5.4168 & 5.1956 & TRN \\
\hline CHEMBL1343101 & 737379 & 5.1675 & 5.0841 & TST \\
\hline CHEMBL1544703 & 737379 & 5.4852 & 5.2962 & TRN \\
\hline CHEMBL1974230 & 737379 & 5.2316 & 5.0742 & TRN \\
\hline CHEMBL1533963 & 737379 & 5.4391 & 4.9373 & TRN \\
\hline CHEMBL1312969 & 737379 & 5.501 & 5.6916 & TRN \\
\hline CHEMBL1496095 & 737379 & 5.1759 & 4.8995 & TRN \\
\hline CHEMBL1438308 & 737379 & 5.2655 & 5.0995 & TRN \\
\hline CHEMBL581868 & 737379 & 5.1294 & 5.7078 & TST \\
\hline CHEMBL1492763 & 737379 & 4.7841 & 5.2115 & TRN \\
\hline CHEMBL1445250 & 737379 & 5.4541 & 5.2722 & TRN \\
\hline
\end{tabular}




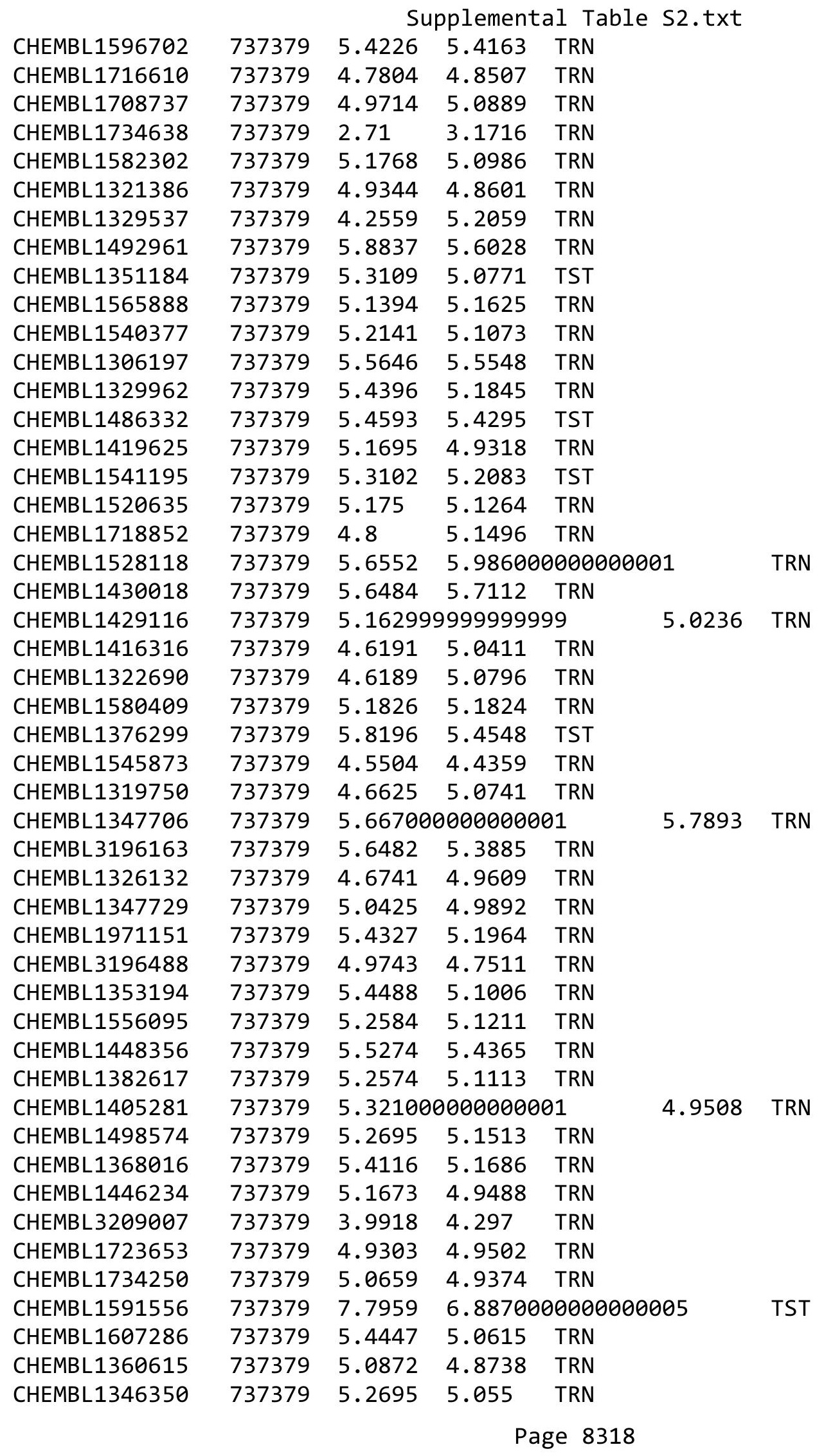




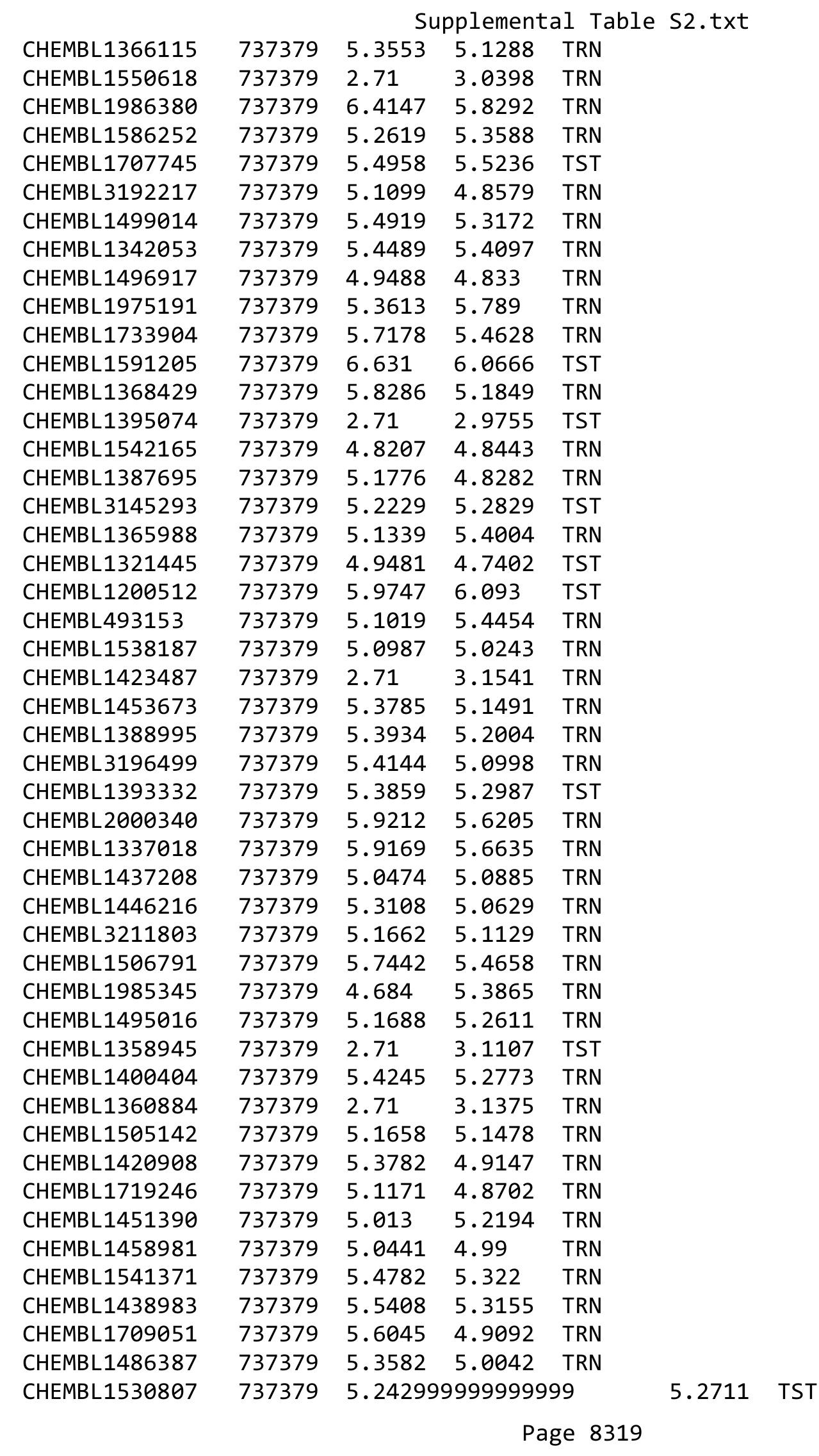




\begin{tabular}{|c|c|c|c|c|c|c|}
\hline & & \multicolumn{5}{|c|}{ Supplemental Table S2.txt } \\
\hline CHEMBL3199708 & 737379 & 5.2728 & 5.1177 & TRN & & \\
\hline CHEMBL 1409680 & 737379 & 4.9751 & 5.5616 & TRN & & \\
\hline CHEMBL1364807 & 737379 & 5.0975 & 5.1897 & TRN & & \\
\hline CHEMBL1561884 & 737379 & 5.1898 & 5.3154 & TRN & & \\
\hline CHEMBL1726040 & 737379 & 5.8016 & 5.2701 & TRN & & \\
\hline CHEMBL1596462 & 737379 & 2.71 & 4.6002 & TRN & & \\
\hline CHEMBL1449811 & 737379 & 5.5468 & 5.4429 & TRN & & \\
\hline CHEMBL1311726 & 737379 & 5.3503 & 5.4461 & TST & & \\
\hline CHEMBL1605111 & 737379 & 2.71 & 4.6185 & TRN & & \\
\hline CHEMBL1410068 & 737379 & 5.1252 & 4.939 & TRN & & \\
\hline CHEMBL1526149 & 737379 & 5.6611 & 5.41200 & 0000000001 & & TRN \\
\hline CHEMBL1570857 & 737379 & 5.5709 & 5.1321 & TRN & & \\
\hline CHEMBL1437139 & 737379 & 6.3503 & 6.0816 & TST & & \\
\hline CHEMBL1316838 & 737379 & \multicolumn{3}{|c|}{5.172999999999999} & 5.1604 & TRN \\
\hline CHEMBL1467329 & 737379 & 3.8128 & 5.0877 & TST & & \\
\hline CHEMBL1393195 & 737379 & 6.2523 & 5.8422 & TRN & & \\
\hline CHEMBL1518732 & 737379 & 5.1289 & 4.9854 & TRN & & \\
\hline CHEMBL 3189873 & 737379 & 5.596 & 5.58 & TRN & & \\
\hline CHEMBL 1430074 & 737379 & 5.4365 & 5.28700 & 0000000001 & & TST \\
\hline CHEMBL1441738 & 737379 & 5.3153 & 5.3086 & TRN & & \\
\hline CHEMBL598679 & 737379 & 5.3138 & 4.9403 & TRN & & \\
\hline CHEMBL1525259 & 737379 & 5.4554 & 5.3709 & TRN & & \\
\hline CHEMBL70704 & 737379 & 5.1707 & 5.4819 & TRN & & \\
\hline CHEMBL1496647 & 737379 & 5.3743 & 5.0781 & TST & & \\
\hline CHEMBL1703524 & 737379 & 5.2732 & 5.115 & TRN & & \\
\hline CHEMBL1705762 & 737379 & 4.2846 & 5.1789 & TRN & & \\
\hline CHEMBL1509245 & 737379 & 4.9401 & 4.9516 & TRN & & \\
\hline CHEMBL1999885 & 737379 & 4.7058 & 4.7099 & TRN & & \\
\hline CHEMBL1414364 & 737379 & 6.3694 & 6.1348 & TRN & & \\
\hline CHEMBL1441096 & 737379 & 5.1145 & 4.9587 & TRN & & \\
\hline CHEMBL1587928 & 737379 & 5.6799 & 5.1717 & TRN & & \\
\hline CHEMBL1429298 & 737379 & 5.5777 & 4.8863 & TRN & & \\
\hline CHEMBL576208 & 737379 & 5.0972 & 4.9324 & TRN & & \\
\hline CHEMBL1362904 & 737379 & 2.71 & 4.6706 & TRN & & \\
\hline CHEMBL3193991 & 737379 & 5.1385 & 5.3491 & TRN & & \\
\hline CHEMBL1714457 & 737379 & 5.49 & 5.2168 & TRN & & \\
\hline CHEMBL1404578 & 737379 & 5.1711 & 5.2467 & TRN & & \\
\hline CHEMBL1423674 & 737379 & 4.8444 & 4.7919 & TRN & & \\
\hline CHEMBL1381353 & 737379 & 4.9427 & 5.0863 & TRN & & \\
\hline CHEMBL1456632 & 737379 & 4.8545 & 4.8097 & TST & & \\
\hline CHEMBL1430058 & 737379 & 5.2258 & 5.36 & TRN & & \\
\hline CHEMBL1707764 & 737379 & 5.4403 & 5.3319 & TST & & \\
\hline CHEMBL1373985 & 737379 & 5.3355 & 5.1702 & TRN & & \\
\hline CHEMBL3195649 & 737379 & 5.2149 & 5.1375 & TST & & \\
\hline CHEMBL1386207 & 737379 & 2.71 & 3.3697 & TST & & \\
\hline CHEMBL1543298 & 737379 & 5.1407 & 5.0498 & TRN & & \\
\hline CHEMBL1422567 & 737379 & 5.2873 & 5.1373 & TRN & & \\
\hline CHEMBL1536342 & 737379 & 6.0143 & 6.2666 & TRN & & \\
\hline
\end{tabular}


Supplemental Table S2.txt

\begin{tabular}{|c|c|c|c|c|c|c|}
\hline CHEMBL1341395 & 737379 & 6.1212 & 5.4787 & TRN & & \\
\hline CHEMBL1531686 & 737379 & 5.1516 & 5.207999 & 999999999 & & TRN \\
\hline CHEMBL1390303 & 737379 & 5.1725 & 5.1413 & TRN & & \\
\hline CHEMBL1456411 & 737379 & 4.4579 & 4.778000 & 000000000 & 005 & \\
\hline CHEMBL1386684 & 737379 & 5.3962 & 5.5108 & TRN & & \\
\hline CHEMBL1539483 & 737379 & 5.1713 & 4.9342 & TRN & & \\
\hline CHEMBL1496539 & 737379 & 5.7791 & 5.0325 & TRN & & \\
\hline CHEMBL1335722 & 737379 & 5.3986 & 5.3133 & TST & & \\
\hline CHEMBL1705300 & 737379 & 5.2142 & 5.0915 & TST & & \\
\hline CHEMBL3211808 & 737379 & 5.1307 & 5.0023 & TRN & & \\
\hline CHEMBL1398061 & 737379 & 4.9961 & 4.8292 & TRN & & \\
\hline CHEMBL1612633 & 737379 & 5.3195 & 5.1259 & TRN & & \\
\hline CHEMBL1484874 & 737379 & 2.71 & 3.23 & TST & & \\
\hline CHEMBL1424746 & 737379 & 5.4292 & 5.5595 & TRN & & \\
\hline CHEMBL1589637 & 737379 & 5.1627 & 4.9406 & TRN & & \\
\hline CHEMBL1494564 & 737379 & 4.8864 & 4.8629 & TRN & & \\
\hline CHEMBL3195012 & 737379 & 5.4285 & 5.4046 & TRN & & \\
\hline CHEMBL1586805 & 737379 & 5.7347 & 5.4755 & TST & & \\
\hline CHEMBL1504972 & 737379 & 5.2229 & 4.9861 & TRN & & \\
\hline CHEMBL1348102 & 737379 & 5.1558 & 4.8477 & TST & & \\
\hline CHEMBL1593516 & 737379 & 5.1212 & 5.0143 & TRN & & \\
\hline CHEMBL1720579 & 737379 & 5.1847 & 4.8941 & TRN & & \\
\hline CHEMBL1484893 & 737379 & 5.129 & 5.2042 & TRN & & \\
\hline CHEMBL1537680 & 737379 & 5.4699 & 5.7145 & TRN & & \\
\hline CHEMBL1360793 & 737379 & 5.7003 & 5.3718 & TRN & & \\
\hline CHEMBL1605460 & 737379 & 5.357 & 5.189 & TST & & \\
\hline CHEMBL1713977 & 737379 & 5.4889 & 5.4481 & TRN & & \\
\hline CHEMBL1359790 & 737379 & 5.8851 & 5.7117 & TRN & & \\
\hline CHEMBL1594102 & 737379 & 5.0244 & 5.1088 & TRN & & \\
\hline CHEMBL1524527 & 737379 & 4.7645 & 5.0531 & TRN & & \\
\hline CHEMBL3195700 & 737379 & 4.7878 & 5.4055 & TRN & & \\
\hline CHEMBL1580134 & 737379 & 5.1709 & 4.9825 & TRN & & \\
\hline CHEMBL1573813 & 737379 & 4.8765 & 5.442 & TRN & & \\
\hline CHEMBL1383334 & 737379 & 5.9154 & 5.7954 & TRN & & \\
\hline CHEMBL1307636 & 737379 & 5.1697 & 4.8011 & TRN & & \\
\hline CHEMBL1395972 & 737379 & 5.83299 & 999999999 & 99 & 5.4013 & \\
\hline CHEMBL1454776 & 737379 & 5.2156 & 5.1822 & TRN & & \\
\hline CHEMBL1326634 & 737379 & 5.1518 & 5.1505 & TRN & & \\
\hline CHEMBL1459330 & 737379 & 5.3662 & 5.3116 & TRN & & \\
\hline CHEMBL1723226 & 737379 & 5.7496 & 5.5224 & TRN & & \\
\hline CHEMBL1733054 & 737379 & 5.16100 & 000000000 & 305 & 5.0537 & \\
\hline CHEMBL1402808 & 737379 & 4.2034 & 5.381 & TRN & & \\
\hline CHEMBL1581582 & 737379 & 5.7414 & 5.5436 & TRN & & \\
\hline CHEMBL1360808 & 737379 & 2.71 & 4.7101 & TRN & & \\
\hline CHEMBL1561237 & 737379 & 5.4996 & 5.114 & TRN & & \\
\hline CHEMBL1567547 & 737379 & 2.71 & 4.362 & TST & & \\
\hline CHEMBL1377059 & 737379 & 4.5884 & 5.0801 & TST & & \\
\hline CHEMBL1995378 & 737379 & 5.1332 & 4.9896 & TRN & & \\
\hline
\end{tabular}




\begin{tabular}{|c|c|c|c|c|c|c|}
\hline & & \multicolumn{5}{|c|}{ Supplemental Table S2.txt } \\
\hline CHEMBL1423285 & 737379 & 5.6146 & 5.9643 & TRN & & \\
\hline CHEMBL1703770 & 737379 & 5.9863 & 5.665 & TST & & \\
\hline CHEMBL1609651 & 737379 & 5.08 & 4.885 & TRN & & \\
\hline CHEMBL1427233 & 737379 & 5.1838 & 4.9509 & TST & & \\
\hline CHEMBL1467244 & 737379 & 2.71 & 2.9629 & TRN & & \\
\hline CHEMBL1363861 & 737379 & 5.175 & 5.2668 & TRN & & \\
\hline CHEMBL1319378 & 737379 & 5.1889 & 5.18 & TRN & & \\
\hline CHEMBL1603637 & 737379 & 5.1868 & 5.2567 & TRN & & \\
\hline CHEMBL1716833 & 737379 & 4.9678 & 5.065 & TRN & & \\
\hline CHEMBL1421592 & 737379 & 4.4062 & 5.2587 & TRN & & \\
\hline CHEMBL1387177 & 737379 & 5.8013 & 5.643 & TRN & & \\
\hline CHEMBL1504993 & 737379 & 5.4558 & 5.0621 & TRN & & \\
\hline CHEMBL1971234 & 737379 & 5.0444 & 4.7727 & TRN & & \\
\hline CHEMBL1358403 & 737379 & 5.2303 & 5.2862 & TRN & & \\
\hline CHEMBL1558327 & 737379 & 2.71 & 5.4231 & TRN & & \\
\hline CHEMBL1395408 & 737379 & 5.1057 & 4.9887 & TST & & \\
\hline CHEMBL1213137 & 737379 & 5.8102 & 5.5136 & TRN & & \\
\hline CHEMBL1449512 & 737379 & 5.2366 & 5.0813 & TRN & & \\
\hline CHEMBL1499233 & 737379 & 5.2372 & 5.2223 & TRN & & \\
\hline CHEMBL1556592 & 737379 & 5.5 & 5.6736 & TRN & & \\
\hline CHEMBL1492021 & 737379 & 5.1841 & 5.114 & TRN & & \\
\hline CHEMBL523375 & 737379 & 5.4521 & 5.4156 & TRN & & \\
\hline CHEMBL1581361 & 737379 & 5.2563 & 5.1616 & TRN & & \\
\hline CHEMBL1464265 & 737379 & 5.2462 & 5.1536 & TRN & & \\
\hline CHEMBL1543977 & 737379 & 5.8626 & 5.621 & TRN & & \\
\hline CHEMBL1545902 & 737379 & 5.3469 & 5.3732 & TRN & & \\
\hline CHEMBL3195045 & 737379 & 4.8582 & 4.8092 & TRN & & \\
\hline CHEMBL1526165 & 737379 & 5.4417 & 5.125 & TRN & & \\
\hline CHEMBL1505089 & 737379 & 5.1644 & 5.1549 & TRN & & \\
\hline CHEMBL1734062 & 737379 & 5.1697 & 5.1644 & TRN & & \\
\hline CHEMBL1467492 & 737379 & 5.5033 & 5.2881 & TRN & & \\
\hline CHEMBL1733223 & 737379 & 5.8529 & 5.7045 & TRN & & \\
\hline CHEMBL1701959 & 737379 & 2.71 & 3.1455 & TST & & \\
\hline CHEMBL547483 & 737379 & 5.5913 & 5.4386 & TST & & \\
\hline CHEMBL1594827 & 737379 & 5.3503 & 5.136 & TST & & \\
\hline CHEMBL1511037 & 737379 & 5.5351 & 5.35 & TRN & & \\
\hline CHEMBL1528043 & 737379 & 5.2833 & 4.9772 & TRN & & \\
\hline CHEMBL1342093 & 737379 & 5.4394 & 5.4025 & TRN & & \\
\hline CHEMBL1418937 & 737379 & 5.6853 & 5.415 & TRN & & \\
\hline CHEMBL3195531 & 737379 & 2.71 & 4.7159 & TRN & & \\
\hline CHEMBL3189193 & 737379 & 5.568 & 5.3883 & TRN & & \\
\hline CHEMBL1423533 & 737379 & 4.902 & 4.9545 & TRN & & \\
\hline CHEMBL1980103 & 737379 & 5.0289 & 5.0215 & TRN & & \\
\hline CHEMBL1305526 & 737379 & 5.45200 & 00000000 & $\partial 1$ & 5.1027 & TRN \\
\hline CHEMBL1380364 & 737379 & 4.8108 & 4.8407 & TRN & & \\
\hline CHEMBL1353750 & 737379 & 5.1701 & 5.2006 & TST & & \\
\hline CHEMBL1730110 & 737379 & 5.0102 & 5.0888 & TRN & & \\
\hline CHEMBL1309568 & 737379 & 5.3527 & 5.2744 & TRN & & \\
\hline
\end{tabular}


Supplemental Table S2.txt

\begin{tabular}{|c|c|c|c|c|c|}
\hline CHEMBL1414843 & 737379 & 5.1252 & 4.9711 & TRN & \\
\hline CHEMBL1479320 & 737379 & 5.4737 & 5.2963 & TRN & \\
\hline CHEMBL1612159 & 737379 & 5.4751 & 5.38299 & 9999999999 & TST \\
\hline CHEMBL1505520 & 737379 & 5.3797 & 5.1084 & TRN & \\
\hline CHEMBL1722313 & 737379 & 5.4127 & 5.2233 & TRN & \\
\hline CHEMBL1457360 & 737379 & 5.3029 & 5.6257 & TST & \\
\hline CHEMBL1320781 & 737379 & 5.4254 & 5.5341 & TRN & \\
\hline CHEMBL1333191 & 737379 & 5.1269 & 4.9255 & TRN & \\
\hline CHEMBL1705498 & 737379 & 5.6167 & 5.2975 & TRN & \\
\hline CHEMBL1369287 & 737379 & 5.5622 & 5.1233 & TRN & \\
\hline CHEMBL1967938 & 737379 & 5.2565 & 5.1535 & TRN & \\
\hline CHEMBL1481791 & 737379 & 5.3832 & 5.0627 & TST & \\
\hline CHEMBL1567159 & 737379 & 5.6041 & 5.46 & TRN & \\
\hline CHEMBL1312689 & 737379 & 7.7959 & 5.8708 & TST & \\
\hline CHEMBL1372179 & 737379 & 5.2822 & 5.1548 & TRN & \\
\hline CHEMBL583305 & 737379 & 5.2985 & 5.1306 & TRN & \\
\hline CHEMBL3193229 & 737379 & 2.71 & 4.6462 & TRN & \\
\hline CHEMBL1345981 & 737379 & 4.8904 & 4.7449 & TRN & \\
\hline CHEMBL3208712 & 737379 & 4.8438 & 4.905 & TRN & \\
\hline CHEMBL3195428 & 737379 & 5.1561 & 5.2568 & TRN & \\
\hline CHEMBL1493343 & 737379 & 5.5707 & 5.2567 & TRN & \\
\hline CHEMBL1974450 & 737379 & 3.0 & 4.5711 & TRN & \\
\hline CHEMBL1606938 & 737379 & 4.7138 & 4.7233 & TRN & \\
\hline CHEMBL1432288 & 737379 & 4.0212 & 4.5182 & TRN & \\
\hline CHEMBL1421010 & 737379 & 5.4504 & 5.2188 & TRN & \\
\hline CHEMBL1384414 & 737379 & 5.4417 & 5.3596 & TRN & \\
\hline CHEMBL1511045 & 737379 & 6.0073 & 6.2196 & TRN & \\
\hline CHEMBL1928483 & 737379 & 5.1815 & 4.8792 & TRN & \\
\hline CHEMBL1502522 & 737379 & 5.7319 & 5.7799 & TRN & \\
\hline CHEMBL1591393 & 737379 & 5.1525 & \multicolumn{2}{|c|}{5.1370000000000005} & TRN \\
\hline CHEMBL3208158 & 737379 & 5.5449 & 5.4086 & TRN & \\
\hline CHEMBL188423 & 737379 & 5.1523 & 5.0464 & TRN & \\
\hline CHEMBL1706626 & 737379 & 5.8219 & 5.7448 & TRN & \\
\hline CHEMBL1585375 & 737379 & 4.9884 & 5.4038 & TRN & \\
\hline CHEMBL1372844 & 737379 & 5.1363 & 5.0328 & TRN & \\
\hline CHEMBL1610842 & 737379 & 4.614 & 5.6304 & TST & \\
\hline CHEMBL1200792 & 737379 & 5.331 & 5.1582 & TRN & \\
\hline CHEMBL1503689 & 737379 & 4.9359 & 5.2202 & TRN & \\
\hline CHEMBL1478794 & 737379 & 5.2686 & 5.3338 & TRN & \\
\hline CHEMBL1423839 & 737379 & 5.3022 & 5.0161 & TRN & \\
\hline CHEMBL1348954 & 737379 & 4.942 & 4.894 & TST & \\
\hline CHEMBL1716939 & 737379 & 4.8891 & 4.9187 & TRN & \\
\hline CHEMBL1527664 & 737379 & 4.9743 & 4.9452 & TST & \\
\hline CHEMBL1497239 & 737379 & 5.3262 & 5.1615 & TRN & \\
\hline CHEMBL1711680 & 737379 & 5.4325 & 4.8385 & TRN & \\
\hline CHEMBL1331328 & 737379 & 5.4176 & \multicolumn{2}{|c|}{5.202999999999999} & TRN \\
\hline CHEMBL1375452 & 737379 & 5.4202 & 5.2553 & TST & \\
\hline CHEMBL1421741 & 737379 & 4.9274 & 5.0128 & TRN & \\
\hline
\end{tabular}




\begin{tabular}{|c|c|c|c|c|c|c|}
\hline & & \multicolumn{5}{|c|}{ Supplemental Table S2.txt } \\
\hline CHEMBL1495592 & 737379 & 5.4073 & 5.535 & TRN & & \\
\hline CHEMBL1584973 & 737379 & 4.9458 & \multicolumn{3}{|c|}{5.156000000000001} & TRN \\
\hline CHEMBL1367459 & 737379 & 2.71 & 3.0727 & TRN & & \\
\hline CHEMBL1497819 & 737379 & 4.7781 & 5.2031 & TRN & & \\
\hline CHEMBL1428166 & 737379 & 5.4295 & 5.314 & TST & & \\
\hline CHEMBL1396351 & 737379 & 5.481 & 5.2768 & TRN & & \\
\hline CHEMBL1516044 & 737379 & \multicolumn{3}{|c|}{5.452999999999999} & 4.8868 & TRN \\
\hline CHEMBL1713440 & 737379 & 5.5239 & 5.2972 & TRN & & \\
\hline CHEMBL1516308 & 737379 & 5.1492 & 4.9149 & TRN & & \\
\hline CHEMBL1435286 & 737379 & 5.4584 & 5.425 & TRN & & \\
\hline CHEMBL1561439 & 737379 & 5.644 & 5.6936 & TRN & & \\
\hline CHEMBL1454819 & 737379 & 5.4458 & 4.9818 & TRN & & \\
\hline CHEMBL1978651 & 737379 & 5.2504 & 5.1242 & TRN & & \\
\hline CHEMBL1362508 & 737379 & 2.71 & 4.1693 & TRN & & \\
\hline CHEMBL1344982 & 737379 & 5.4921 & 5.0982 & TRN & & \\
\hline CHEMBL1573869 & 737379 & 5.3305 & 5.2266 & TRN & & \\
\hline CHEMBL3191194 & 737379 & 5.0884 & 5.0847 & TRN & & \\
\hline CHEMBL1390555 & 737379 & 5.2003 & 5.2401 & TRN & & \\
\hline CHEMBL1585894 & 737379 & 5.0188 & 5.3464 & TRN & & \\
\hline CHEMBL1424510 & 737379 & 5.0394 & 4.952 & TRN & & \\
\hline CHEMBL1305478 & 737379 & 5.6979 & 5.4523 & TRN & & \\
\hline CHEMBL1998651 & 737379 & 5.4458 & 5.1254 & TRN & & \\
\hline CHEMBL1402899 & 737379 & 5.1622 & 5.1263 & TRN & & \\
\hline CHEMBL1354093 & 737379 & 6.2165 & 5.4131 & TRN & & \\
\hline CHEMBL1406219 & 737379 & 2.71 & 3.0995 & TRN & & \\
\hline CHEMBL1437950 & 737379 & 5.2941 & 5.4021 & TRN & & \\
\hline CHEMBL1308276 & 737379 & 5.8102 & 5.44600 & 0000000001 & & TRN \\
\hline CHEMBL1300905 & 737379 & 4.9686 & 4.7311 & TRN & & \\
\hline CHEMBL3198705 & 737379 & 5.335 & 5.3512 & TRN & & \\
\hline CHEMBL3190630 & 737379 & 4.6828 & 4.5249 & TRN & & \\
\hline CHEMBL3192891 & 737379 & 4.7007 & 4.0662 & TRN & & \\
\hline CHEMBL1496663 & 737379 & 5.3724 & 5.1018 & TRN & & \\
\hline CHEMBL3194039 & 737379 & 5.1578 & 4.9262 & TRN & & \\
\hline CHEMBL1732789 & 737379 & 5.1629 & 5.0959 & TRN & & \\
\hline CHEMBL578515 & 737379 & 5.4285 & 4.9952 & TRN & & \\
\hline CHEMBL1584391 & 737379 & 5.1937 & 5.0827 & TRN & & \\
\hline CHEMBL1580804 & 737379 & 5.2615 & 5.1843 & TRN & & \\
\hline CHEMBL1719938 & 737379 & 2.71 & 3.11 & TST & & \\
\hline CHEMBL1583099 & 737379 & 4.9255 & 4.9821 & TRN & & \\
\hline CHEMBL1594637 & 737379 & 5.1428 & 5.0232 & TST & & \\
\hline CHEMBL3192408 & 737379 & 6.2562 & 5.5569 & TST & & \\
\hline CHEMBL602990 & 737379 & 5.3264 & 5.1217 & TRN & & \\
\hline CHEMBL1420268 & 737379 & 4.7029 & 4.8868 & TRN & & \\
\hline CHEMBL1567321 & 737379 & 5.0399 & 4.96 & TRN & & \\
\hline CHEMBL1403645 & 737379 & 2.71 & 3.1854 & TRN & & \\
\hline CHEMBL1398209 & 737379 & 5.1565 & 5.0543 & TRN & & \\
\hline CHEMBL1326118 & 737379 & 5.601 & 5.4862 & TRN & & \\
\hline CHEMBL1328118 & 737379 & 5.15799 & (99999999 & 995 & 4.9532 & TRN \\
\hline
\end{tabular}




\begin{tabular}{|c|c|c|c|c|c|c|}
\hline & & \multicolumn{5}{|c|}{ Supplemental Table S2.txt } \\
\hline CHEMBL1367633 & 737379 & 5.1581 & 4.8498 & TRN & & \\
\hline CHEMBL1568646 & 737379 & 5.5193 & 5.375 & TRN & & \\
\hline CHEMBL 3196108 & 737379 & 5.2893 & 5.0853 & TRN & & \\
\hline CHEMBL1485593 & 737379 & 4.9104 & 4.9786 & TRN & & \\
\hline CHEMBL1589098 & 737379 & 2.71 & 5.6157 & TST & & \\
\hline CHEMBL 1468680 & 737379 & 5.3235 & 5.16200 & 0000000001 & & TRN \\
\hline CHEMBL1413724 & 737379 & 5.0408 & 4.9923 & TST & & \\
\hline CHEMBL1342999 & 737379 & 5.3723 & 5.4024 & TRN & & \\
\hline CHEMBL1563110 & 737379 & \multicolumn{3}{|c|}{5.2589999999999995} & 3442 & TRN \\
\hline CHEMBL3191107 & 737379 & 5.8798 & 6.1207 & TRN & & \\
\hline CHEMBL 2139269 & 737379 & 5.3521 & 5.0582 & TRN & & \\
\hline CHEMBL1500263 & 737379 & 2.71 & 5.0105 & TRN & & \\
\hline CHEMBL1348326 & 737379 & 5.437 & 5.4575 & TRN & & \\
\hline CHEMBL543876 & 737379 & 5.5057 & 5.185 & TRN & & \\
\hline CHEMBL1597772 & 737379 & 5.5632 & 5.2417 & TRN & & \\
\hline CHEMBL1455873 & 737379 & 5.1754 & 4.9065 & TRN & & \\
\hline CHEMBL1544664 & 737379 & 5.1886 & 5.1368 & TRN & & \\
\hline CHEMBL1488623 & 737379 & 4.8834 & 4.8473 & TRN & & \\
\hline CHEMBL1320095 & 737379 & 5.2865 & 5.2717 & TRN & & \\
\hline CHEMBL1388038 & 737379 & 4.8798 & 4.8268 & TRN & & \\
\hline CHEMBL1408272 & 737379 & 5.3701 & 5.1942 & TRN & & \\
\hline CHEMBL1334887 & 737379 & 5.4552 & 5.1405 & TRN & & \\
\hline CHEMBL1576593 & 737379 & 4.4224 & 4.8481 & TRN & & \\
\hline CHEMBL1345447 & 737379 & 5.3025 & 5.2502 & TRN & & \\
\hline CHEMBL1495763 & 737379 & 5.2929 & 5.3283 & TRN & & \\
\hline CHEMBL1382562 & 737379 & 5.2293 & 5.0458 & TRN & & \\
\hline CHEMBL1513694 & 737379 & \multicolumn{3}{|c|}{5.242000000000001} & .1462 & TRN \\
\hline CHEMBL1423656 & 737379 & 5.6931 & 5.4323 & TRN & & \\
\hline CHEMBL1388234 & 737379 & 5.4388 & 5.0462 & TRN & & \\
\hline CHEMBL1447350 & 737379 & 5.0869 & 5.1312 & TRN & & \\
\hline CHEMBL1502289 & 737379 & 5.2014 & 5.7023 & TRN & & \\
\hline CHEMBL3144830 & 737379 & 5.099 & 5.01699 & 9999999999 & & TRN \\
\hline CHEMBL1377321 & 737379 & 4.9439 & 5.2393 & TRN & & \\
\hline CHEMBL1535991 & 737379 & 6.1276 & 6.3706 & TRN & & \\
\hline CHEMBL1411724 & 737379 & 6.1907 & 5.7515 & TST & & \\
\hline CHEMBL1379526 & 737379 & 4.7496 & 4.9471 & TRN & & \\
\hline CHEMBL1463434 & 737379 & 5.7217 & 5.7258 & TRN & & \\
\hline CHEMBL1301926 & 737379 & 4.743 & 4.7758 & TRN & & \\
\hline CHEMBL1338723 & 737379 & 4.4402 & 6.1577 & TRN & & \\
\hline CHEMBL1705121 & 737379 & 5.2826 & 5.3403 & TRN & & \\
\hline CHEMBL3197771 & 737379 & 4.9634 & 4.8185 & TRN & & \\
\hline CHEMBL1491124 & 737379 & 4.9435 & 6.152 & TRN & & \\
\hline CHEMBL1256667 & 737379 & 5.5766 & 5.109 & TST & & \\
\hline CHEMBL1725546 & 737379 & 5.1483 & 5.0098 & TRN & & \\
\hline CHEMBL1427949 & 737379 & 5.1608 & 5.1357 & TRN & & \\
\hline CHEMBL1522312 & 737379 & 5.6182 & 5.4658 & TRN & & \\
\hline CHEMBL1532651 & 737379 & 5.7555 & 5.011 & TRN & & \\
\hline CHEMBL1532377 & 737379 & 5.5064 & 5.3462 & TRN & & \\
\hline
\end{tabular}


Supplemental Table S2.txt

\begin{tabular}{|c|c|c|c|c|c|}
\hline CHEMBL1466132 & 737379 & 5.6071 & 5.206 & TRN & \\
\hline CHEMBL1566829 & 737379 & 5.1537 & 4.9468 & TRN & \\
\hline CHEMBL1442370 & 737379 & 4.3208 & 4.7935 & TRN & \\
\hline CHEMBL1444854 & 737379 & 5.6757 & 5.681 & TRN & \\
\hline CHEMBL1594182 & 737379 & 5.2355 & 5.1266 & TRN & \\
\hline CHEMBL1462872 & 737379 & 5.2729 & 5.12200 & 0000000001 & TRN \\
\hline CHEMBL1711394 & 737379 & 6.2048 & 5.7855 & TRN & \\
\hline CHEMBL1522275 & 737379 & 5.0685 & 5.1215 & TST & \\
\hline CHEMBL1716774 & 737379 & 4.782 & 5.2677 & TRN & \\
\hline CHEMBL1339368 & 737379 & 4.8173 & 5.1033 & TRN & \\
\hline CHEMBL1473052 & 737379 & 5.3355 & 5.2214 & TRN & \\
\hline CHEMBL1420454 & 737379 & 4.6155 & 4.8313 & TRN & \\
\hline CHEMBL1982945 & 737379 & 5.4478 & 5.5047 & TRN & \\
\hline CHEMBL1381408 & 737379 & 5.0753 & 4.9057 & TRN & \\
\hline CHEMBL1427793 & 737379 & 5.2742 & 5.1609 & TRN & \\
\hline CHEMBL1590005 & 737379 & 4.9562 & 5.3293 & TRN & \\
\hline CHEMBL1516581 & 737379 & 4.9674 & 4.9986 & TRN & \\
\hline CHEMBL1539807 & 737379 & 5.5412 & 5.1614 & TRN & \\
\hline CHEMBL1719865 & 737379 & 2.71 & 4.3724 & TRN & \\
\hline CHEMBL1495140 & 737379 & 5.4658 & 5.4837 & TRN & \\
\hline CHEMBL1365132 & 737379 & 5.4426 & 5.3957 & TRN & \\
\hline CHEMBL1305960 & 737379 & 5.487 & 5.4226 & TRN & \\
\hline CHEMBL1588298 & 737379 & 5.1624 & 5.556 & TRN & \\
\hline CHEMBL1302460 & 737379 & 5.5005 & 5.4311 & TRN & \\
\hline CHEMBL1364506 & 737379 & 5.2646 & 5.0395 & TRN & \\
\hline CHEMBL3189459 & 737379 & 5.2265 & 5.1515 & TRN & \\
\hline CHEMBL1415447 & 737379 & 5.4478 & 5.1618 & TST & \\
\hline CHEMBL1397158 & 737379 & 5.1385 & 5.2252 & TRN & \\
\hline CHEMBL1388542 & 737379 & 5.2623 & 5.143 & TRN & \\
\hline CHEMBL 3212034 & 737379 & 4.8245 & 4.6047 & TRN & \\
\hline CHEMBL1309874 & 737379 & 5.5186 & 5.5503 & TRN & \\
\hline CHEMBL1338446 & 737379 & 5.3572 & 5.251 & TRN & \\
\hline CHEMBL1735413 & 737379 & 2.71 & 4.0265 & TRN & \\
\hline CHEMBL441282 & 737379 & 5.2149 & 5.2076 & TST & \\
\hline CHEMBL1323116 & 737379 & 5.5315 & 5.7687 & TRN & \\
\hline CHEMBL1380592 & 737379 & 6.0885 & 5.8894 & TRN & \\
\hline CHEMBL1998304 & 737379 & 5.1979 & 5.0218 & TRN & \\
\hline CHEMBL1547809 & 737379 & 4.9512 & 4.9706 & TST & \\
\hline CHEMBL1494802 & 737379 & 6.0611 & 6.0573 & TRN & \\
\hline CHEMBL1529236 & 737379 & 5.1637 & 5.2342 & TRN & \\
\hline CHEMBL1426361 & 737379 & 5.3429 & 5.1421 & TRN & \\
\hline CHEMBL1608073 & 737379 & 5.228 & 5.0863 & TRN & \\
\hline CHEMBL1599654 & 737379 & 5.4419 & 5.1916 & TST & \\
\hline CHEMBL1594604 & 737379 & \multicolumn{2}{|c|}{5.4510000000000005} & 5.0679 & - \\
\hline CHEMBL528506 & 737379 & 5.4385 & 5.1715 & TST & \\
\hline CHEMBL1536643 & 737379 & 5.7951 & 5.5934 & TST & \\
\hline CHEMBL1385598 & 737379 & 5.2302 & 5.0597 & TST & \\
\hline CHEMBL3189966 & 737379 & 5.2801 & 5.1528 & TST & \\
\hline
\end{tabular}




\begin{tabular}{|c|c|c|c|c|c|}
\hline \multicolumn{6}{|c|}{ Supplemental Table S2.txt } \\
\hline CHEMBL1569004 & 737379 & 2.71 & 4.3948 & TST & \\
\hline CHEMBL3198729 & 737379 & 5.4078 & 5.2076 & TST & \\
\hline CHEMBL3195171 & 737379 & 5.4323 & 5.0961 & TST & \\
\hline CHEMBL1453572 & 737379 & 4.4899 & 5.2856 & TST & \\
\hline CHEMBL1502104 & 737379 & 5.1307 & 5.1178 & TST & \\
\hline CHEMBL1339303 & 737379 & 5.3411 & 5.1848 & TST & \\
\hline CHEMBL1497731 & 737379 & 4.2923 & 4.453 & TST & \\
\hline CHEMBL3199926 & 737379 & 5.3114 & 5.0686 & TST & \\
\hline CHEMBL1415208 & 737379 & 5.2029 & 4.4588 & TST & \\
\hline CHEMBL1371925 & 737379 & 5.3595 & 5.0722 & TST & \\
\hline CHEMBL 3194327 & 737379 & 4.7036 & 4.7969 & TST & \\
\hline CHEMBL1439732 & 737379 & 5.1976 & 4.8951 & TST & \\
\hline CHEMBL1421583 & 737379 & 5.312 & 5.0667 & TST & \\
\hline CHEMBL1710307 & 737379 & 5.1392 & 5.1245 & TST & \\
\hline CHEMBL1311812 & 737379 & 5.4019 & 5.4751 & TST & \\
\hline CHEMBL1434681 & 737379 & 5.1962 & 5.2339 & TST & \\
\hline CHEMBL1421900 & 737379 & 4.7557 & 4.5781 & TST & \\
\hline CHEMBL1487501 & 737379 & 5.4634 & 5.3322 & TST & \\
\hline CHEMBL3190031 & 737379 & 5.4316 & 5.3312 & TST & \\
\hline CHEMBL1570687 & 737379 & 4.9469 & 5.1477 & TST & \\
\hline CHEMBL1540477 & 737379 & 5.1539 & 4.9548 & TST & \\
\hline CHEMBL1448503 & 737379 & 5.9508 & 5.7321 & TST & \\
\hline CHEMBL1328069 & 737379 & 6.4928 & 6.2935 & TST & \\
\hline CHEMBL1583461 & 737379 & 5.1497 & 5.0552 & TST & \\
\hline CHEMBL1404661 & 737379 & 4.7027 & 4.4443 & TST & \\
\hline CHEMBL3213830 & 737379 & 2.71 & 3.1619 & TST & \\
\hline CHEMBL1299780 & 737379 & 4.7506 & 4.8429 & TST & \\
\hline CHEMBL3193204 & 737379 & 5.1663 & 5.1415 & TST & \\
\hline CHEMBL1304238 & 737379 & 4.919 & 4.6925 & TST & \\
\hline CHEMBL1329561 & 737379 & 5.0127 & 5.3834 & TST & \\
\hline CHEMBL1256693 & 737379 & 5.8486 & 5.4272 & TST & \\
\hline CHEMBL1595269 & 737379 & 5.2086 & 5.0929 & TST & \\
\hline CHEMBL 3189770 & 737379 & 5.5005 & 5.16299 & 9999999999 & TST \\
\hline CHEMBL1568335 & 737379 & 5.186 & 5.1528 & TST & \\
\hline CHEMBL3207852 & 737379 & 6.6054 & 7.3377 & TST & \\
\hline CHEMBL1360269 & 737379 & 4.9755 & 5.6946 & TST & \\
\hline CHEMBL1367284 & 737379 & 5.7469 & 5.3858 & TST & \\
\hline CHEMBL3190986 & 737379 & 4.7891 & 5.0407 & TST & \\
\hline CHEMBL 2002945 & 737379 & 4.8996 & 5.6974 & TST & \\
\hline CHEMBL563585 & 737379 & 5.2567 & 4.9168 & TST & \\
\hline CHEMBL1546722 & 737379 & 5.6676 & 5.3729 & TST & \\
\hline CHEMBL3194407 & 737379 & 4.797 & 4.8574 & TST & \\
\hline CHEMBL3195343 & 737379 & 5.4086 & 5.3441 & TST & \\
\hline CHEMBL1588760 & 737379 & 5.4731 & 5.2414 & TST & \\
\hline CHEMBL3192490 & 737379 & 4.4716 & 3.2336 & TST & \\
\hline CHEMBL1506300 & 737379 & 5.1437 & 4.9158 & TST & \\
\hline CHEMBL1401784 & 737379 & 4.706 & 4.7246 & TST & \\
\hline CHEMBL1974180 & 737379 & 5.1414 & 4.9176 & TST & \\
\hline
\end{tabular}


Supplemental Table S2.txt

\begin{tabular}{|c|c|c|c|c|c|}
\hline CHEMBL1426530 & 737379 & 5.3879 & 5.0611 & TST & \\
\hline CHEMBL1378921 & 737379 & 5.0525 & 4.9179 & TST & \\
\hline CHEMBL1320663 & 737379 & 5.2845 & 5.5293 & TST & \\
\hline CHEMBL1337235 & 737379 & 5.1667 & 5.045 & TST & \\
\hline CHEMBL1392952 & 737379 & 2.71 & 4.1687 & TST & \\
\hline CHEMBL1592636 & 737379 & 5.5167 & 5.2309 & TST & \\
\hline CHEMBL1352748 & 737379 & 5.5345 & 5.4383 & TST & \\
\hline CHEMBL1570513 & 737379 & 5.4358 & 5.0979 & TST & \\
\hline CHEMBL 3190644 & 737379 & 5.2781 & 5.0168 & TST & \\
\hline CHEMBL1418095 & 737379 & 6.5884 & 6.7493 & TST & \\
\hline CHEMBL1426226 & 737379 & 5.5988 & 5.7493 & TST & \\
\hline CHEMBL1542282 & 737379 & 5.2899 & 5.1284 & TST & \\
\hline CHEMBL1494659 & 737379 & 6.416 & 6.1823 & TST & \\
\hline CHEMBL1589652 & 737379 & 5.1487 & 5.0057 & TST & \\
\hline CHEMBL3192903 & 737379 & 4.9212 & 4.7097 & TST & \\
\hline CHEMBL1509453 & 737379 & 5.4489 & 5.5003 & TST & \\
\hline CHEMBL1593581 & 737379 & 5.4753 & 6.0196 & TST & \\
\hline CHEMBL1564061 & 737379 & 6.1104 & 5.7454 & TST & \\
\hline CHEMBL1586404 & 737379 & 5.3148 & 5.003 & TST & \\
\hline CHEMBL1429887 & 737379 & 5.1397 & 4.8596 & TST & \\
\hline CHEMBL 1457472 & 737379 & 5.8122 & 5.6533 & TST & \\
\hline CHEMBL1542422 & 737379 & 4.5038 & 4.4998 & TST & \\
\hline CHEMBL1457877 & 737379 & 5.3003 & 5.2826 & TST & \\
\hline CHEMBL1328260 & 737379 & 2.71 & 5.4418 & TST & \\
\hline CHEMBL1999595 & 737379 & 5.4501 & 5.2986 & TST & \\
\hline CHEMBL1314665 & 737379 & 5.4536 & 5.2443 & TST & \\
\hline CHEMBL 2007313 & 737379 & 5.7645 & 5.2761 & TST & \\
\hline CHEMBL1712283 & 737379 & 6.5952 & 6.0935 & TST & \\
\hline CHEMBL1379991 & 737379 & 5.8251 & 5.5119 & TST & \\
\hline CHEMBL1497479 & 737379 & 5.1515 & 4.9686 & TST & \\
\hline CHEMBL1546891 & 737379 & 5.8187 & 5.4731 & TST & \\
\hline CHEMBL1337990 & 737379 & 5.7027 & 5.978 & TST & \\
\hline CHEMBL1387559 & 737379 & 2.71 & 3.3263 & TST & \\
\hline CHEMBL1597580 & 737379 & 5.9743 & 5.6806 & TST & \\
\hline CHEMBL1526806 & 737379 & 5.2146 & 4.9754 & TST & \\
\hline CHEMBL1547395 & 737379 & 5.1938 & 5.0946 & TST & \\
\hline CHEMBL1986381 & 737379 & 4.5317 & 4.5763 & TST & \\
\hline CHEMBL1452114 & 737379 & 5.1744 & 4.9814 & TST & \\
\hline CHEMBL1576310 & 737379 & 5.138 & 4.9084 & TST & \\
\hline CHEMBL1334707 & 737379 & 2.71 & 4.4509 & TST & \\
\hline CHEMBL1405705 & 737379 & 2.71 & 5.1147 & TST & \\
\hline CHEMBL590666 & 737379 & 5.2902 & 5.0366 & TST & \\
\hline CHEMBL1300242 & 737379 & $5.1370 e$ & 00000000 & 305 & 5.0084 \\
\hline CHEMBL607553 & 737379 & 5.3445 & 5.2428 & TST & \\
\hline CHEMBL1338667 & 737379 & 6.0281 & 5.4193 & TST & \\
\hline CHEMBL1322219 & 737379 & 5.4034 & 5.6806 & TST & \\
\hline CHEMBL1736729 & 737379 & 5.1013 & 5.1181 & TST & \\
\hline CHEMBL1732074 & 737379 & 7.7959 & 6.77 & TST & \\
\hline
\end{tabular}




\begin{tabular}{|c|c|c|c|c|c|}
\hline & & \multicolumn{4}{|c|}{ Supplemental Table S2.txt } \\
\hline CHEMBL1321447 & 737379 & 2.71 & 4.1759 & TST & \\
\hline CHEMBL1986591 & 737379 & 5.7307 & 5.5243 & TST & \\
\hline CHEMBL1335068 & 737379 & 5.2694 & 5.175 & TST & \\
\hline CHEMBL1384843 & 737379 & 5.1495 & 5.0115 & TST & \\
\hline CHEMBL1423709 & 737379 & 5.7688 & 5.6077 & TST & \\
\hline CHEMBL1430795 & 737379 & 5.4026 & 5.2617 & TST & \\
\hline CHEMBL1595033 & 737379 & 5.0804 & 4.9411 & TST & \\
\hline CHEMBL3196392 & 737379 & 5.1693 & 4.9814 & TST & \\
\hline CHEMBL1333664 & 737379 & 2.71 & 4.295 & TST & \\
\hline CHEMBL1537093 & 737379 & 5.4268 & 5.1446 & TST & \\
\hline CHEMBL1505688 & 737379 & 5.4561 & 5.1693 & TST & \\
\hline CHEMBL1406161 & 737379 & 4.6423 & 5.4827 & TST & \\
\hline CHEMBL1592251 & 737379 & 5.4053 & 5.1621 & TST & \\
\hline CHEMBL1573251 & 737379 & 5.3239 & 4.9204 & TST & \\
\hline CHEMBL1713496 & 737379 & 5.3462 & 5.144 & TST & \\
\hline CHEMBL1429000 & 737379 & 5.1719 & 4.9898 & TST & \\
\hline CHEMBL1417320 & 737379 & 5.1138 & 5.0548 & TST & \\
\hline CHEMBL1369071 & 737379 & 2.71 & 3.0814 & TST & \\
\hline CHEMBL1309208 & 737379 & 5.0843 & 5.4666 & TST & \\
\hline CHEMBL1561133 & 737379 & 5.3586 & 5.2083 & TST & \\
\hline CHEMBL1368434 & 737379 & 5.0204 & 5.5125 & TST & \\
\hline CHEMBL1508932 & 737379 & 5.7319 & 5.6488 & TST & \\
\hline CHEMBL 3198597 & 737379 & 5.6645 & 5.4379 & TST & \\
\hline CHEMBL1311878 & 737379 & 5.6077 & 5.5581 & TST & \\
\hline CHEMBL1391272 & 737379 & 5.439 & 5.2432 & TST & \\
\hline CHEMBL 283078 & 737379 & 6.3322 & 5.9603 & TST & \\
\hline CHEMBL1495254 & 737379 & 4.7251 & 4.7547 & TST & \\
\hline CHEMBL1444241 & 737379 & 5.1708 & 5.2669 & TST & \\
\hline CHEMBL1301107 & 737379 & 5.6596 & 5.4043 & TST & \\
\hline CHEMBL3193600 & 737379 & 4.4837 & 4.4182 & TST & \\
\hline CHEMBL1392852 & 737379 & 5.3075 & 5.0626 & TST & \\
\hline CHEMBL1521435 & 737379 & 2.71 & 6.2125 & TST & \\
\hline CHEMBL1557704 & 737379 & 5.034 & 5.81 & TST & \\
\hline CHEMBL1326819 & 737379 & 5.5496 & 5.2936 & TST & \\
\hline CHEMBL1431783 & 737379 & 5.0082 & 5.1078 & TST & \\
\hline CHEMBL1509716 & 737379 & 5.061 & 5.1433 & TST & \\
\hline CHEMBL1526479 & 737379 & 5.192 & 5.1069 & TST & \\
\hline CHEMBL1561791 & 737379 & 5.2437 & 5.2535 & TST & \\
\hline CHEMBL1426867 & 737379 & 5.1003 & 5.1508 & TST & \\
\hline CHEMBL1339659 & 737379 & 4.6313 & 5.095 & TST & \\
\hline CHEMBL3198079 & 737379 & 5.1492 & 4.9052 & TST & \\
\hline CHEMBL1385701 & 737379 & 5.3746 & 5.1182 & TST & \\
\hline CHEMBL3189832 & 737379 & 5.1639 & 5.0526 & TST & \\
\hline CHEMBL3193466 & 737379 & 5.1853 & 5.2328 & TST & \\
\hline CHEMBL1438538 & 737379 & 5.1328 & $5.06800 t$ & 00000000005 & TST \\
\hline CHEMBL1307980 & 737379 & 5.2326 & 5.0965 & TST & \\
\hline CHEMBL1359154 & 737379 & 5.3392 & 5.1796 & TST & \\
\hline CHEMBL1566671 & 737379 & 4.4522 & 4.6357 & TST & \\
\hline
\end{tabular}




\begin{tabular}{|c|c|c|c|c|c|}
\hline \multicolumn{6}{|c|}{ Supplemental Table S2.txt } \\
\hline CHEMBL1528413 & 737379 & 5.4551 & 5.2401 & TST & \\
\hline CHEMBL1393568 & 737379 & 5.5351 & 5.3493 & TST & \\
\hline CHEMBL578716 & 737379 & 5.791 & 5.6383 & TST & \\
\hline CHEMBL1363609 & 737379 & 4.5955 & 4.697 & TST & \\
\hline CHEMBL1311992 & 737379 & 5.3985 & 5.7701 & TST & \\
\hline CHEMBL1446827 & 737379 & 5.3321 & 5.3662 & TST & \\
\hline CHEMBL1598222 & 737379 & 5.0299 & 5.0138 & TST & \\
\hline CHEMBL1553387 & 737379 & 5.2793 & 5.6286 & TST & \\
\hline CHEMBL1449660 & 737379 & 5.0401 & 4.8655 & TST & \\
\hline CHEMBL1433155 & 737379 & 4.9622 & 5.11600 & 00000000005 & TST \\
\hline CHEMBL1341879 & 737379 & 5.1864 & 5.0562 & TST & \\
\hline CHEMBL1379449 & 737379 & 5.1087 & 5.0553 & TST & \\
\hline CHEMBL1558131 & 737379 & 5.8831 & 5.4944 & TST & \\
\hline CHEMBL1992154 & 737379 & 5.1923 & 5.1603 & TST & \\
\hline CHEMBL1445219 & 737379 & 4.9722 & 4.9295 & TST & \\
\hline CHEMBL1484169 & 737379 & 5.2429 & 5.1865 & TST & \\
\hline CHEMBL1311109 & 737379 & 5.0422 & 5.1825 & TST & \\
\hline CHEMBL 2141549 & 737379 & 5.1686 & 4.9475 & TST & \\
\hline CHEMBL3213915 & 737379 & 4.414 & 5.0268 & TST & \\
\hline CHEMBL1464042 & 737379 & 5.3688 & 5.0741 & TST & \\
\hline CHEMBL1392190 & 737379 & 4.5032 & 5.5593 & TST & \\
\hline CHEMBL1477773 & 737379 & 4.841 & 4.7132 & TST & \\
\hline CHEMBL3213965 & 737379 & 5.1617 & 5.0155 & TST & \\
\hline CHEMBL1429432 & 737379 & 5.5453 & 5.4113 & TST & \\
\hline CHEMBL1582319 & 737379 & 5.5567 & 6.039 & TST & \\
\hline CHEMBL1428014 & 737379 & 2.71 & 5.2981 & TST & \\
\hline CHEMBL1995377 & 737379 & 5.7881 & 5.7568 & TST & \\
\hline CHEMBL1494433 & 737379 & 5.4065 & 5.1417 & TST & \\
\hline CHEMBL1496050 & 737379 & 2.71 & 4.3354 & TST & \\
\hline CHEMBL3197948 & 737379 & 2.71 & 3.0097 & TST & \\
\hline CHEMBL1461508 & 737379 & 5.433 & 5.2718 & TST & \\
\hline CHEMBL503363 & 737379 & 5.4405 & 5.0901 & TST & \\
\hline CHEMBL1595152 & 737379 & 5.4467 & 5.1275 & TST & \\
\hline CHEMBL1493120 & 737379 & 4.8085 & 4.7658 & TST & \\
\hline CHEMBL1413669 & 737379 & 5.4027 & 5.5552 & TST & \\
\hline CHEMBL1538692 & 737379 & 5.1334 & 4.6082 & TST & \\
\hline CHEMBL1576580 & 737379 & 4.6655 & 4.8645 & TST & \\
\hline CHEMBL1977863 & 737379 & 5.3902 & 5.1754 & TST & \\
\hline CHEMBL1500197 & 737379 & 5.5435 & 5.318 & TST & \\
\hline CHEMBL1606870 & 737379 & 5.3375 & 5.0365 & TST & \\
\hline CHEMBL1425849 & 737379 & 5.8145 & 5.7027 & TST & \\
\hline CHEMBL1315654 & 737379 & 5.5709 & 5.3594 & TST & \\
\hline CHEMBL1720916 & 737379 & 5.1913 & 5.0939 & TST & \\
\hline CHEMBL1303161 & 737379 & 6.5402 & 6.1114 & TST & \\
\hline CHEMBL1345063 & 737379 & 5.4372 & 5.1747 & TST & \\
\hline CHEMBL1569238 & 737379 & 4.8601 & 4.744 & TST & \\
\hline CHEMBL1456848 & 737379 & 5.9303 & 5.7342 & TST & \\
\hline CHEMBL3191812 & 737379 & 4.8719 & 5.4256 & TST & \\
\hline
\end{tabular}


Supplemental Table S2.txt

\begin{tabular}{|c|c|c|c|c|c|}
\hline CHEMBL1324730 & 737379 & 4.3302 & 4.4956 & TST & \\
\hline CHEMBL 2000445 & 737379 & 5.1287 & 5.0212 & TST & \\
\hline CHEMBL63883 & 737379 & 5.0811 & 5.047 & TST & \\
\hline CHEMBL1409554 & 737379 & 5.1449 & 5.1349 & TST & \\
\hline CHEMBL1532181 & 737379 & 4.5035 & 4.574 & TST & \\
\hline CHEMBL 3199824 & 737379 & 5.345 & 5.3398 & TST & \\
\hline CHEMBL1348245 & 737379 & 5.188 & 5.0126 & TST & \\
\hline CHEMBL1555532 & 737379 & 5.4417 & 5.4986 & TST & \\
\hline CHEMBL1393611 & 737379 & 2.71 & 4.0102 & TST & \\
\hline CHEMBL1511739 & 737379 & 5.1935 & 5.0725 & TST & \\
\hline CHEMBL1534390 & 737379 & 5.6003 & 5.3227 & TST & \\
\hline CHEMBL1374800 & 737379 & 5.7279 & 5.8502 & TST & \\
\hline CHEMBL1465176 & 737379 & 5.6033 & 5.2647 & TST & \\
\hline CHEMBL1314190 & 737379 & 4.9234 & 4.9332 & TST & \\
\hline CHEMBL1972217 & 737379 & 5.2157 & 5.1801 & TST & \\
\hline CHEMBL1481361 & 737379 & 5.3405 & 5.241000 & 30000000005 & TST \\
\hline CHEMBL1373082 & 737379 & 5.4013 & 5.153 & TST & \\
\hline CHEMBL1546832 & 737379 & 5.6019 & 5.3934 & TST & \\
\hline CHEMBL1569824 & 737379 & 5.2703 & 5.385 & TST & \\
\hline CHEMBL1440277 & 737379 & 5.3457 & 5.2296 & TST & \\
\hline CHEMBL1494962 & 737379 & 5.4378 & 5.3297 & TST & \\
\hline CHEMBL1386049 & 737379 & 5.4201 & 5.2108 & TST & \\
\hline CHEMBL1495939 & 737379 & 5.3418 & 5.0134 & TST & \\
\hline CHEMBL1550862 & 737379 & 5.4747 & 5.4156 & TST & \\
\hline CHEMBL 3207339 & 737379 & 5.2068 & 5.2188 & TST & \\
\hline CHEMBL1375424 & 737379 & 5.08 & 5.0697 & TST & \\
\hline CHEMBL1563176 & 737379 & 5.2645 & 4.9676 & TST & \\
\hline CHEMBL1578411 & 737379 & 5.7883 & 5.4965 & TST & \\
\hline CHEMBL1434767 & 737379 & 5.13299 & 999999999 & 4.9397 & TS \\
\hline CHEMBL1486416 & 737379 & 5.9817 & 5.6605 & TST & \\
\hline CHEMBL1518309 & 737379 & 5.3718 & 5.3757 & TST & \\
\hline CHEMBL1491324 & 737379 & 5.347 & 5.6037 & TST & \\
\hline CHEMBL1527216 & 737379 & 6.24100 & 000000000 & 5.8311 & IJ \\
\hline CHEMBL 292687 & 737379 & 5.2506 & 5.0976 & TST & \\
\hline CHEMBL1336324 & 737379 & 5.6708 & 5.8374 & TST & \\
\hline CHEMBL1391399 & 737379 & 5.4396 & 5.2932 & TST & \\
\hline CHEMBL1443802 & 737379 & 5.3274 & 4.9535 & TST & \\
\hline CHEMBL1986081 & 737379 & 5.6137 & 5.8229 & TST & \\
\hline CHEMBL1712850 & 737379 & 5.6513 & 5.4039 & TST & \\
\hline CHEMBL 248847 & 737379 & 5.2727 & 5.5234 & TST & \\
\hline CHEMBL1395171 & 737379 & 5.7488 & 5.5651 & TST & \\
\hline CHEMBL1460151 & 737379 & 5.1077 & 4.997 & TST & \\
\hline CHEMBL379975 & 954480 & 5.53700 & 000000000 & 5.0298 & $1 \mathrm{KI}$ \\
\hline CHEMBL515416 & 954480 & 4.4068 & 4.6018 & TRN & \\
\hline CHEMBL392695 & 954480 & 5.1994 & 5.2715 & TRN & \\
\hline CHEMBL180127 & 954480 & 4.6516 & 4.3042 & TRN & \\
\hline CHEMBL1357247 & 954480 & 3.2296 & 3.1472 & TRN & \\
\hline CHEMBL221137 & 954480 & 5.0731 & 4.7616 & TST & \\
\hline
\end{tabular}




\begin{tabular}{|c|c|c|c|c|c|c|}
\hline \multirow[b]{2}{*}{ CHEMBL188678 } & \multirow[b]{2}{*}{954480} & \multicolumn{5}{|c|}{ Supplemental Table S2.txt } \\
\hline & & 3.8414 & 4.4404 & TRN & & \\
\hline CHEMBL202721 & 954480 & 5.16200 & 30000000 & & 5.0469 & TRN \\
\hline CHEMBL449158 & 954480 & 6.7649 & 6.9486 & TST & & \\
\hline CHEMBL1256459 & 954480 & 6.8817 & 7.3015 & TRN & & \\
\hline CHEMBL135561 & 954480 & 6.0765 & 4.5121 & TRN & & \\
\hline CHEMBL577784 & 954480 & 5.3897 & 5.28700 & 0000000001 & & TRN \\
\hline CHEMBL 213100 & 954480 & 4.8738 & 5.0824 & TRN & & \\
\hline CHEMBL2005886 & 954480 & 4.8014 & 5.5415 & TRN & & \\
\hline CHEMBL 217354 & 954480 & 6.4878 & 6.1555 & TRN & & \\
\hline CHEMBL1909414 & 954480 & 5.0972 & 4.0145 & TRN & & \\
\hline CHEMBL514499 & 954480 & 7.1087 & 7.1819 & TRN & & \\
\hline CHEMBL 2134202 & 954480 & 4.3491 & 4.362 & TRN & & \\
\hline CHEMBL1230020 & 954480 & 3.4384 & 4.0575 & TRN & & \\
\hline CHEMBL 255342 & 954480 & 3.9157 & 3.6359 & TRN & & \\
\hline CHEMBL92309 & 954480 & 3.6182 & 2.9683 & TST & & \\
\hline CHEMBL 210618 & 954480 & 3.7864 & 3.4534 & TRN & & \\
\hline CHEMBL1186585 & 954480 & 3.8956 & 4.4201 & TRN & & \\
\hline CHEMBL300389 & 954480 & 7.1187 & 6.9931 & TRN & & \\
\hline CHEMBL192566 & 954480 & 8.0008 & 8.3086 & TST & & \\
\hline CHEMBL1242367 & 954480 & 3.9043 & 4.2822 & TRN & & \\
\hline CHEMBL 220241 & 954480 & 4.8564 & 4.8742 & TRN & & \\
\hline CHEMBL259181 & 954480 & 5.0665 & 4.5645 & TRN & & \\
\hline CHEMBL240954 & 954480 & 3.0097 & 3.7252 & TST & & \\
\hline CHEMBL102714 & 954480 & 3.3058 & 3.5406 & TRN & & \\
\hline CHEMBL258844 & 954480 & 4.0033 & 4.4024 & TRN & & \\
\hline CHEMBL1590308 & 954480 & 2.8741 & 3.455 & TST & & \\
\hline CHEMBL3392440 & 954480 & 3.7442 & 3.9163 & TRN & & \\
\hline CHEMBL9470 & 954480 & 6.44600 & 30000000 & 01 & 5.8947 & TST \\
\hline CHEMBL222102 & 954480 & 3.1974 & 3.7873 & TRN & & \\
\hline CHEMBL189584 & 954480 & 4.0357 & 4.6431 & TRN & & \\
\hline CHEMBL483849 & 954480 & 1.2927 & 2.2164 & TST & & \\
\hline CHEMBL1788116 & 954480 & 3.5812 & 4.4377 & TRN & & \\
\hline CHEMBL1516890 & 954480 & 5.0233 & 4.07100 & 0000000001 & & TRN \\
\hline CHEMBL573107 & 954480 & 3.5767 & 5.1689 & TRN & & \\
\hline CHEMBL65 & 954480 & 8.6187 & 8.2162 & TRN & & \\
\hline CHEMBL3199475 & 954480 & 4.2257 & 4.4368 & TRN & & \\
\hline CHEMBL2137530 & 954480 & 4.7448 & 4.8356 & TRN & & \\
\hline CHEMBL393929 & 954480 & 4.1575 & 3.9479 & TRN & & \\
\hline CHEMBL3186408 & 954480 & 3.7107 & 3.8896 & TST & & \\
\hline CHEMBL512504 & 954480 & 4.0196 & 4.8528 & TRN & & \\
\hline CHEMBL483847 & 954480 & 3.9918 & 4.2923 & TRN & & \\
\hline CHEMBL 2144069 & 954480 & 6.7783 & 5.136 & TRN & & \\
\hline CHEMBL558642 & 954480 & 5.3832 & 4.1935 & TRN & & \\
\hline CHEMBL1643959 & 954480 & 3.95300 & 00000000 & 003 & 3.7737 & TRN \\
\hline CHEMBL399530 & 954480 & 5.1238 & 4.6156 & TRN & & \\
\hline CHEMBL585951 & 954480 & 6.4022 & 6.2621 & TRN & & \\
\hline CHEMBL472940 & 954480 & 2.5736 & 3.6616 & TRN & & \\
\hline CHEMBL412142 & 954480 & 3.739 & 4.0627 & TRN & & \\
\hline
\end{tabular}


Supplemental Table S2.txt

\begin{tabular}{|c|c|c|c|c|}
\hline HEMBL56 & 54480 & & & \\
\hline HEMBL1673039 & 54480 & 4.6718 & 4.9048 & \\
\hline & & & 3177 & \\
\hline IEMBL1 & 30 & 0013 & 265 & \\
\hline IEMBL209148 & 80 & 1711 & 528 & \\
\hline AEMBL 2363137 & 54480 & 1912 & 4.8737 & \\
\hline HEMBL334 & 80 & .3006 & 5.2029 & \\
\hline IEMBL37 & 30 & 3527 & & \\
\hline IEMBL1970879 & 0 & .2953 & 4.8257 & \\
\hline AEMBL373751 & 30 & 3.2506 & 3.7846 & S \\
\hline AEMBL1404918 & 80 & 2.9242 & 9059 & \\
\hline IEMBL25 & 30 & .73 & 25 & \\
\hline EMBL & & & & $\mathrm{RI}$ \\
\hline AEMBL1: & 0 & 3.062 & & \\
\hline AEMBL48 & 0 & 3.8963 & 3.8874 & RI \\
\hline AEMBL192566 & 30 & 6.0474 & 8.7528 & \\
\hline AEMBL1C & $\theta 0$ & 3.0399 & 87 & \\
\hline AEMBL1: & & 3.8326 & & $\mathrm{RI}$ \\
\hline HEMBL] & 0 & 4.7595 & 4.7528 & \\
\hline IEMBL392695 & 0 & 5.1783 & 749 & RI \\
\hline IEMBL41 & 0 & 3 . & 058 & RI \\
\hline AEMBL33 & $\theta$ & 3.6803 & 746 & RI \\
\hline IEMBL5e & & 4. & 235 & \\
\hline IEMBL334 & & 5.3446 & & \\
\hline IEMBL124 & 0 & 3 & 86 & $\mathrm{RN}$ \\
\hline EMBLI & 0 & 42 & 57 & $\mathrm{RI}$ \\
\hline IEMBL: & & .2568 & 76 & RN \\
\hline EM & & 39 & & ST \\
\hline IEMBL16 & & & & RN \\
\hline HEMBL164 & 0 & 3.67 & 89 & RN \\
\hline IEMBL47 & & 9 & 485 & RI \\
\hline EMBL 2 & & & 25 & \\
\hline & & & & TRN \\
\hline IEMBL159 & & & & SI \\
\hline IEMBL12 & 0 & 7.4141 & 7.4044 & RN \\
\hline IEMBL3S & & 561 & 89 & RI \\
\hline ריסני & & & & NIV \\
\hline & & & 3.6536 & $\mathrm{RN}$ \\
\hline HEMBL135561 & 0 & 4.5179 & 4.5107 & TRN \\
\hline IEMBL202 & 10 & .4298 & 225 & RN \\
\hline HEMBL 221 & & 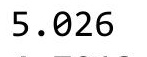 & 4.5783 & S \\
\hline CHEMBL577 & & & 4.7949 & RN \\
\hline HEMBL1909414 & & 3.9149 & 3.9169 & $\mathrm{RN}$ \\
\hline IEMBL188678 & $\partial 0$ & 4.8172 & 4.7929 & RI \\
\hline EMBL39392 & & 3.795 & 3.7921 & RI \\
\hline CHEMBL214406 & & 5.268 & 5.2787 & (1) \\
\hline CHEMBL92309 & 954700 & 2.965 & 2.6545 & ST \\
\hline CHEMBL65 & 954700 & 8.1319 & 8.1356 & 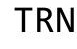 \\
\hline
\end{tabular}

Page 8333 


\begin{tabular}{|c|c|c|c|c|c|c|}
\hline \multirow[b]{2}{*}{ CHEMBL585951 } & \multirow[b]{2}{*}{954700} & \multicolumn{5}{|c|}{ Supplemental Table S2.txt } \\
\hline & & 6.4694 & 6.466 & TRN & & \\
\hline CHEMBL512504 & 954700 & 4.2361 & 4.2309 & TRN & & \\
\hline CHEMBL2363137 & 954700 & 5.17200 & 00000000 & & 5.1772 & TRN \\
\hline CHEMBL210618 & 954700 & 3.0627 & 3.0672 & TRN & & \\
\hline CHEMBL2137530 & 954700 & 4.5294 & 4.5384 & TRN & & \\
\hline CHEMBL9470 & 954700 & 5.9981 & 5.5996 & TST & & \\
\hline CHEMBL255342 & 954700 & 3.6446 & 3.6327 & TRN & & \\
\hline CHEMBL240954 & 954700 & 3.1277 & 3.2107 & TST & & \\
\hline CHEMBL300389 & 954700 & 7.0433 & 7.0468 & TRN & & \\
\hline CHEMBL217354 & 954700 & 6.0533 & 6.0597 & TRN & & \\
\hline CHEMBL379975 & 954700 & 3.9505 & 3.9479 & TRN & & \\
\hline CHEMBL 2005886 & 954700 & 4.8475 & 4.8489 & TRN & & \\
\hline CHEMBL220241 & 954700 & 4.0454 & 4.0414 & TRN & & \\
\hline CHEMBL258844 & 954700 & 5.3165 & 5.3241 & TRN & & \\
\hline CHEMBL3199475 & 954700 & 3.7249 & 3.717 & TRN & & \\
\hline CHEMBL180127 & 954700 & 3.8397 & 3.8437 & TRN & & \\
\hline CHEMBL2134202 & 954700 & 3.3824 & 3.3751 & TRN & & \\
\hline CHEMBL3186408 & 954700 & 4.5004 & 3.7199 & TST & & \\
\hline CHEMBL191334 & 954700 & 3.8111 & 3.8139 & TRN & & \\
\hline CHEMBL 209148 & 954700 & 3.9309 & 4.4515 & TST & & \\
\hline CHEMBL1230020 & 954700 & 3.0518 & 3.6941 & TST & & \\
\hline CHEMBL373751 & 954700 & 3.26 & 3.9877 & TST & & \\
\hline CHEMBL1970879 & 954700 & 4.5922 & 4.5163 & TST & & \\
\hline CHEMBL515416 & 954700 & 4.0449 & 4.2717 & TST & & \\
\hline CHEMBL1186585 & 954700 & 3.4833 & 3.7604 & TST & & \\
\hline CHEMBL558642 & 954700 & 4.3219 & 4.4514 & TST & & \\
\hline CHEMBL449158 & 954700 & 6.4086 & 7.0245 & TST & & \\
\hline CHEMBL1404918 & 954700 & 2.7691 & 2.5579 & TST & & \\
\hline CHEMBL320499 & 135581 & 6.2434 & 6.6906 & TRN & & \\
\hline CHEMBL309756 & 135581 & 7.3979 & 7.5293 & TRN & & \\
\hline CHEMBL13498 & 135581 & 5.8459 & 5.9265 & TRN & & \\
\hline CHEMBL273606 & 135581 & 6.9957 & 6.477 & TRN & & \\
\hline CHEMBL431862 & 135581 & 6.9508 & 7.5967 & TRN & & \\
\hline CHEMBL 77445 & 135581 & 6.9393 & 6.6848 & TRN & & \\
\hline CHEMBL105602 & 135581 & 6.7447 & 7.2439 & TST & & \\
\hline CHEMBL322483 & 135581 & 6.4089 & 6.1845 & TRN & & \\
\hline CHEMBL275241 & 135581 & 5.8677 & 5.2772 & TST & & \\
\hline CHEMBL268285 & 135581 & 6.61799 & 99999999 & 99 & 5.5906 & TRN \\
\hline CHEMBL105235 & 135581 & 6.9245 & 6.5542 & TRN & & \\
\hline CHEMBL 78752 & 135581 & 7.1487 & 6.7411 & TRN & & \\
\hline CHEMBL105415 & 135581 & 6.1831 & 5.8109 & TST & & \\
\hline CHEMBL319464 & 135581 & 7.2218 & 7.4004 & TST & & \\
\hline CHEMBL310995 & 135581 & 7.0555 & 7.3162 & TRN & & \\
\hline CHEMBL105504 & 135581 & 5.4356 & 5.8744 & TRN & & \\
\hline CHEMBL311328 & 135581 & 7.7212 & 8.1711 & TRN & & \\
\hline CHEMBL 275242 & 135581 & 6.3546 & 5.8514 & TRN & & \\
\hline CHEMBL13078 & 135581 & 8.2007 & 7.7776 & TRN & & \\
\hline CHEMBL13203 & 135581 & 4.0 & 3.9328 & TRN & & \\
\hline
\end{tabular}




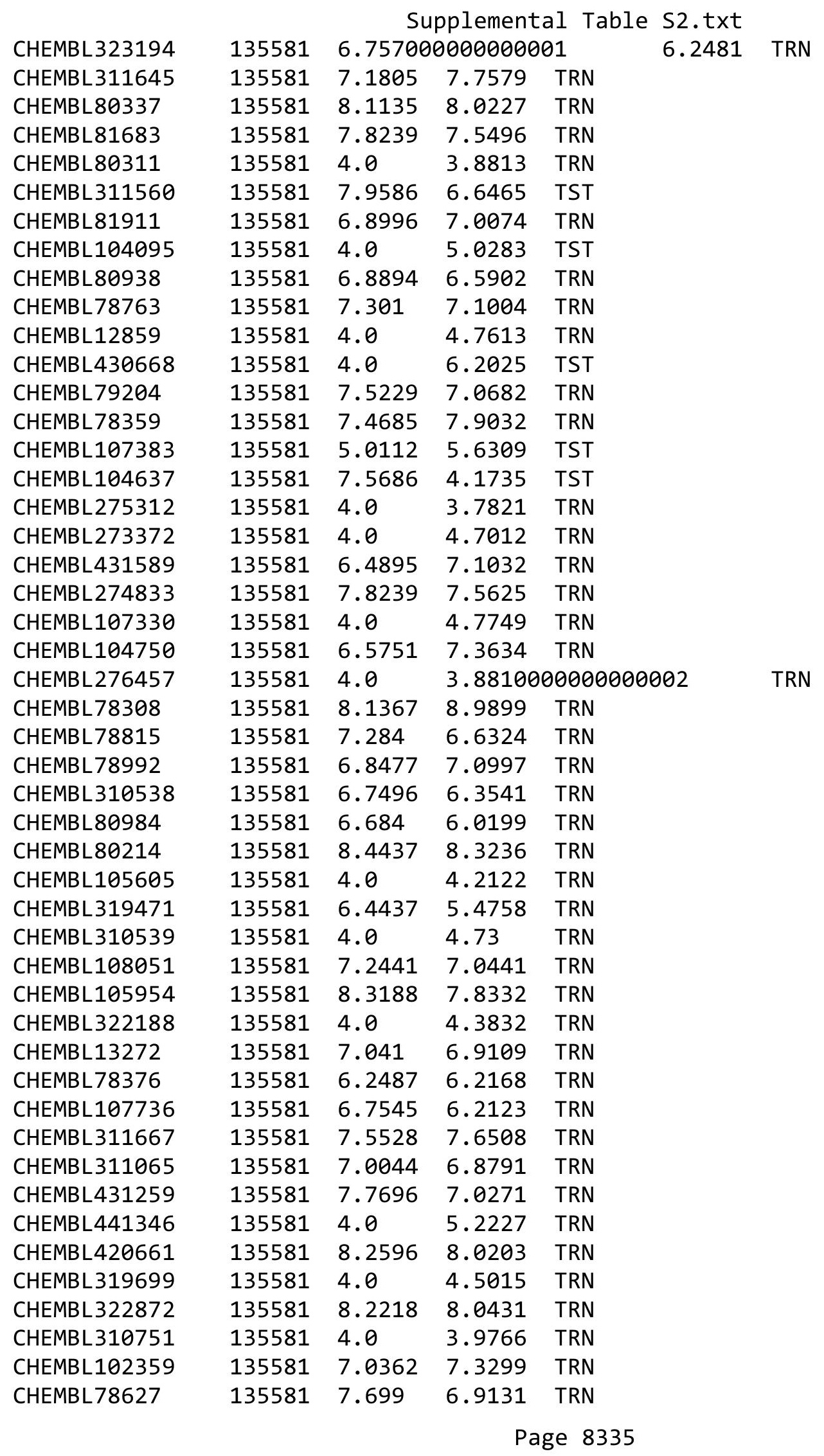




\begin{tabular}{|c|c|c|c|c|c|}
\hline \multicolumn{6}{|c|}{ Supplemental Table S2.txt } \\
\hline CHEMBL319640 & 135581 & 4.0 & 3.9457 & TRN & \\
\hline CHEMBL78710 & 135581 & 7.1024 & 6.7025 & TRN & \\
\hline CHEMBL321297 & 135581 & 5.3651 & 5.3068 & TST & \\
\hline CHEMBL78701 & 135581 & 7.1367 & 6.9944 & TRN & \\
\hline CHEMBL78713 & 135581 & 8.2147 & 8.4719 & TRN & \\
\hline CHEMBL427657 & 135581 & 5.7113 & 5.9543 & TRN & \\
\hline CHEMBL441016 & 135581 & 6.6861 & 6.9106 & TRN & \\
\hline CHEMBL307073 & 135581 & 7.5086 & 7.7841 & TRN & \\
\hline CHEMBL323501 & 135581 & 8.0088 & 7.7184 & TRN & \\
\hline CHEMBL104232 & 135581 & 4.0 & 4.3939 & TRN & \\
\hline CHEMBL322648 & 135581 & 5.0 & 5.0852 & TRN & \\
\hline CHEMBL78994 & 135581 & 7.8239 & 8.5469 & TRN & \\
\hline CHEMBL12955 & 135581 & 4.0 & 3.5501 & TRN & \\
\hline CHEMBL107121 & 135581 & 4.0 & 5.2176 & TST & \\
\hline CHEMBL420287 & 135581 & 4.0 & 5.1477 & TST & \\
\hline CHEMBL322682 & 135581 & 7.3768 & 7.6883 & TST & \\
\hline CHEMBL78375 & 135581 & 8.3372 & 7.8252 & TST & \\
\hline CHEMBL104023 & 135581 & 5.8033 & 5.5785 & TST & \\
\hline CHEMBL 309763 & 135581 & 8.0177 & 7.5155 & TST & \\
\hline CHEMBL318541 & 135581 & 4.0 & 5.5635 & TST & \\
\hline CHEMBL107107 & 135581 & 4.0 & 5.0261 & TST & \\
\hline CHEMBL312057 & 135581 & 7.6383 & 7.5511 & TST & \\
\hline CHEMBL310741 & 135581 & 4.0 & 5.6845 & TST & \\
\hline CHEMBL 309700 & 135581 & 6.9872 & 6.7253 & TST & \\
\hline CHEMBL107136 & 135581 & 7.7696 & 7.3953 & TST & \\
\hline CHEMBL13304 & 135581 & 6.1457 & 6.2274 & TST & \\
\hline CHEMBL 82361 & 135581 & 8.7696 & 9.2397 & TST & \\
\hline CHEMBL3675557 & 1535926 & 5.0 & 5.2197 & TRN & \\
\hline CHEMBL 3675590 & 1535926 & 7.0269 & 6.8041 & TST & \\
\hline CHEMBL3675570 & 1535926 & 6.644 & 6.4312 & TRN & \\
\hline CHEMBL 3675548 & 1535926 & 6.5686 & 6.2623 & TRN & \\
\hline CHEMBL3675589 & 1535926 & 7.1367 & 6.9211 & TRN & \\
\hline CHEMBL3670718 & 1535926 & 5.0 & 5.4997 & TST & \\
\hline CHEMBL3670706 & 1535926 & 6.5834 & 6.0467 & TRN & \\
\hline CHEMBL 3675578 & 1535926 & 5.0 & 5.2537 & TRN & \\
\hline CHEMBL3670704 & 1535926 & 5.0 & 6.3524 & TRN & \\
\hline CHEMBL3675553 & 1535926 & 6.032 & 6.0039 & TST & \\
\hline CHEMBL 3675587 & 1535926 & 7.2007 & 6.92399 & 99999999995 & TRN \\
\hline CHEMBL 3675597 & 1535926 & 5.0 & 5.3588 & TRN & \\
\hline CHEMBL 3675594 & 1535926 & 6.5129 & 6.3245 & TRN & \\
\hline CHEMBL3670699 & 1535926 & 6.1952 & 4.7449 & TRN & \\
\hline CHEMBL 3675584 & 1535926 & 7.3098 & 7.3175 & TRN & \\
\hline CHEMBL3675579 & 1535926 & 5.0 & 5.8203 & TRN & \\
\hline CHEMBL3670710 & 1535926 & 6.4789 & 5.7965 & TST & \\
\hline CHEMBL 3675574 & 1535926 & 5.0 & 5.8017 & TRN & \\
\hline CHEMBL3675599 & 1535926 & 6.4214 & 6.0263 & TRN & \\
\hline CHEMBL 3675588 & 1535926 & 7.3279 & 7.409 & TRN & \\
\hline CHEMBL3670695 & 1535926 & 6.2549 & 6.1013 & TRN & \\
\hline
\end{tabular}


Supplemental Table S2.txt

\begin{tabular}{|c|c|c|c|c|c|}
\hline CHEMBL 3675551 & 1535926 & 6.6904 & 6.4312 & TRN & \\
\hline CHEMBL 3675592 & 1535926 & 7.9872 & 7.3433 & TRN & \\
\hline CHEMBL 3639695 & 1535926 & 6.1878 & 5.8722 & TRN & \\
\hline CHEMBL 3670711 & 1535926 & 4.301 & 4.948 & TST & \\
\hline CHEMBL 3675607 & 1535926 & 6.6925 & 6.3617 & TRN & \\
\hline CHEMBL 3639744 & 1535926 & 6.6326 & \multicolumn{2}{|c|}{6.492000000000001} & TRN \\
\hline CHEMBL 3675580 & 1535926 & 5.0 & 4.6099 & TRN & \\
\hline CHEMBL 3670700 & 1535926 & 6.9431 & 6.4137 & TRN & \\
\hline CHEMBL 3675558 & 1535926 & 5.0 & 4.9048 & TRN & \\
\hline CHEMBL 3675604 & 1535926 & 6.1158 & \multicolumn{2}{|c|}{5.962000000000001} & TST \\
\hline CHEMBL 3670703 & 1535926 & 6.0799 & 6.724 & TRN & \\
\hline CHEMBL 3670715 & 1535926 & 6.0872 & 5.8442 & TRN & \\
\hline CHEMBL 3675601 & 1535926 & 6.1831 & 5.8012 & TRN & \\
\hline CHEMBL 3670705 & 1535926 & 5.0 & 6.0467 & TRN & \\
\hline CHEMBL 3675602 & 1535926 & 5.0 & 5.2499 & TRN & \\
\hline CHEMBL 3675571 & 1535926 & 6.2464 & 5.5885 & TRN & \\
\hline CHEMBL 3675581 & 1535926 & 7.3979 & 7.3983 & TRN & \\
\hline CHEMBL 3670712 & 1535926 & 5.0 & 5.1719 & TST & \\
\hline CHEMBL 3675582 & 1535926 & 7.3188 & 7.2058 & TRN & \\
\hline CHEMBL 3675545 & 1535926 & 6.5452 & 6.0709 & TRN & \\
\hline CHEMBL 3675603 & 1535926 & 6.1707 & 6.6164 & TST & \\
\hline CHEMBL 3670720 & 1535926 & 6.6364 & 6.4495 & TRN & \\
\hline CHEMBL 3670701 & 1535926 & 6.4168 & 6.8309 & TST & \\
\hline CHEMBL 3675564 & 1535926 & 6.3449 & 6.3963 & TRN & \\
\hline CHEMBL 3675575 & 1535926 & 6.063 & 6.5521 & TRN & \\
\hline CHEMBL 3670717 & 1535926 & 5.0 & 4.6545 & TRN & \\
\hline CHEMBL3675569 & 1535926 & 6.279 & 6.0783 & TRN & \\
\hline CHEMBL1232489 & 1535926 & 6.9508 & 6.2288 & TST & \\
\hline CHEMBL 3675549 & 1535926 & 6.5072 & 6.4186 & TRN & \\
\hline CHEMBL 3675543 & 1535926 & 6.8356 & 7.2101 & TRN & \\
\hline CHEMBL 3675600 & 1535926 & 4.301 & 5.1665 & TRN & \\
\hline CHEMBL 3675554 & 1535926 & 7.2007 & 6.8371 & TST & \\
\hline CHEMBL 3670719 & 1535926 & 5.0 & 5.1147 & TST & \\
\hline CHEMBL 3675596 & 1535926 & 4.0 & 5.3588 & TRN & \\
\hline CHEMBL 3675595 & 1535926 & 6.6326 & 6.5288 & TRN & \\
\hline CHEMBL 3675547 & 1535926 & \multicolumn{3}{|c|}{6.382999999999999} & I KIV \\
\hline CHEMBL 3675591 & 1535926 & 7.7447 & 7.6585 & TST & \\
\hline CHEMBL 3675556 & 1535926 & 5.0 & 4.9806 & TRN & \\
\hline CHEMBL 3675566 & 1535926 & 6.5421 & \multicolumn{2}{|c|}{6.492000000000001} & IN \\
\hline CHEMBL 3675560 & 1535926 & 4.301 & 5.4259 & TRN & \\
\hline CHEMBL 3670697 & 1535926 & 5.0 & 4.8676 & TST & \\
\hline CHEMBL 3675572 & 1535926 & 6.9788 & 6.0039 & TST & \\
\hline CHEMBL 3675562 & 1535926 & 6.0921 & 5.2911 & TRN & \\
\hline CHEMBL 3670721 & 1535926 & 6.4283 & 6.2591 & TRN & \\
\hline CHEMBL 3675567 & 1535926 & 6.1007 & 6.2623 & TRN & \\
\hline CHEMBL 3670698 & 1535926 & 6.3449 & 6.0882 & TST & \\
\hline CHEMBL 3675559 & 1535926 & 5.0 & 5.0992 & TRN & \\
\hline CHEMBL 3675593 & 1535926 & 6.4191 & 6.9677 & TRN & \\
\hline
\end{tabular}

Page 8337 
Supplemental Table S2.txt

\begin{tabular}{|c|c|c|c|c|}
\hline 65 & & & & \\
\hline HEMBL3675544 & 535926 & 6.6459 & 6.3083 & \\
\hline & & 84 & & \\
\hline 91 & 926 & 9245 & & \\
\hline IEMBL367 & 5926 & 5.0 & 303 & \\
\hline AEMBL 3670696 & 535926 & 6.0462 & 9488 & \\
\hline HEMBL367 & 535926 & 5.0 & 396 & \\
\hline & 35926 & 301 & & \\
\hline 550 & 535926 & 6.4698 & 783 & \\
\hline IEMBL3670707 & 535926 & 5.0 & 5.228 & \\
\hline AEMBL 3675586 & 535926 & 7.2076 & 4017 & \\
\hline IEMBL36 & 926 & 1389 & 885 & \\
\hline EMBL & & & & \\
\hline IEMBL & 26 & 6.2526 & & DN \\
\hline AEMBL36 & 535926 & & 3898 & \\
\hline EMBL3675546 & 535926 & 4 & 62 & \\
\hline IEMBL36 & 535926 & & 17 & \\
\hline IEMBL3 & & & & \\
\hline IEMBL & 26 & $5 a$ & 013 & \\
\hline IEMBL3 & 26 & 7 & & \\
\hline AEMBL 3670708 & & 0. & 229 & \\
\hline IEMBL36 & 6 & & 227 & \\
\hline IEMBL3 & & & & \\
\hline 716 & & & & \\
\hline IEMBL36 & 26 & & 55 & RN \\
\hline EMBL3 & 26 & 72 & 02 & $\mathrm{RI}$ \\
\hline IEMBL36 & 6 & & 15 & 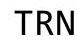 \\
\hline 16 & & & & \\
\hline IEMBL12 & & 36 & & \\
\hline IEMBL12: & 16 & & 56 & RN \\
\hline IEMBL12 & r & 93 & 4 & $\mathrm{RI}$ \\
\hline 380 & 7 & & 61 & NIV \\
\hline 30 & & & & RN \\
\hline IEMBL1222872 & & & & $\mathrm{RN}$ \\
\hline EMBL1222502 & 516 & 37 & 14 & RI \\
\hline IEMBL12 & 1627 & 374 & 077 & $\mathrm{RI}$ \\
\hline 306 & 7 & & & 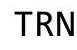 \\
\hline & & & 223 & $\mathrm{RN}$ \\
\hline AEMBL1222500 & 51627 & 8.0362 & 7.9127 & RN \\
\hline EMBL1223377 & 16 & 528 & 464 & RI \\
\hline HEMBL1223235 & $0<1$ & 959 & 8.2103 & RI \\
\hline HEMBL1222434 & & & & RN \\
\hline HEMBL1222873 & 1627 & 7.3279 & 199 & RN \\
\hline IEMBL1223378 & 1627 & .3768 & 15 & RI \\
\hline EMBL1 & 16 & & 98 & RI \\
\hline CHEMBL1222947 & & & 8.2808 & RN \\
\hline CHEMBL1222663 & 51627 & 7.0088 & 7.6268 & \\
\hline CHEMBL1223158 & 651627 & 9.3979 & 9.6441 & TR \\
\hline
\end{tabular}

Page 8338 


\begin{tabular}{|c|c|c|c|c|c|}
\hline & & \multicolumn{4}{|c|}{ Supplemental Table S2.txt } \\
\hline CHEMBL1222664 & 651627 & 7.4949 & 7.311 & TRN & \\
\hline CHEMBL1223237 & 651627 & 7.3872 & 7.4006 & TRN & \\
\hline CHEMBL1222946 & 651627 & 8.6576 & 8.7947 & TRN & \\
\hline CHEMBL1223309 & 651627 & 5.7233 & 5.4701 & TRN & \\
\hline CHEMBL1223080 & 651627 & 5.4423 & 5.0659 & TRN & \\
\hline CHEMBL1223310 & 651627 & 7.2366 & 7.4098 & TRN & \\
\hline CHEMBL1223156 & 651627 & 4.8473 & 5.2137 & TRN & \\
\hline CHEMBL1222433 & 651627 & 9.2218 & 8.6893 & TRN & \\
\hline CHEMBL1222595 & 651627 & 9.0458 & 9.065 & TRN & \\
\hline CHEMBL1223447 & 651627 & 7.2924 & 7.4418 & TRN & \\
\hline CHEMBL1223008 & 651627 & 6.61799 & 99999999 & 7. & TST \\
\hline CHEMBL1222501 & 651627 & 9.3979 & 9.5965 & TRN & \\
\hline CHEMBL1222499 & 651627 & 9.699 & 9.7287 & TRN & \\
\hline CHEMBL1223081 & 651627 & 5.6142 & 5.5638 & TRN & \\
\hline CHEMBL1222594 & 651627 & 8.2291 & 8.3082 & TRN & \\
\hline CHEMBL1222945 & 651627 & 6.4486 & 6.9974 & TRN & \\
\hline CHEMBL1223082 & 651627 & 5.6073 & 5.8872 & TRN & \\
\hline CHEMBL1222593 & 651627 & 9.1549 & 9.0533 & TRN & \\
\hline CHEMBL1223379 & 651627 & 7.8539 & 7.9103 & TRN & \\
\hline CHEMBL1222808 & 651627 & 7.6021 & 7.2654 & TRN & \\
\hline CHEMBL1223448 & 651627 & 7.4685 & 7.6213 & TRN & \\
\hline CHEMBL1221429 & 651627 & 8.5229 & 8.3928 & TRN & \\
\hline CHEMBL1223311 & 651627 & 7.7696 & 7.7109 & TRN & \\
\hline CHEMBL1222662 & 651627 & 6.9245 & 7.0495 & TRN & \\
\hline CHEMBL1223010 & 651627 & 6.7352 & 6.7182 & TRN & \\
\hline CHEMBL1223011 & 651627 & 5.3103 & 6.6933 & TST & \\
\hline CHEMBL1222435 & 651627 & 8.1871 & 8.1577 & TRN & \\
\hline CHEMBL1223236 & 651627 & 8.3372 & 8.2887 & TRN & \\
\hline CHEMBL1223079 & 651627 & 4.699 & 5.4887 & TST & \\
\hline CHEMBL1223157 & 651627 & 8.7959 & 9.0482 & TRN & \\
\hline CHEMBL1222728 & 651627 & 6.0458 & 6.1488 & TRN & \\
\hline CHEMBL1223514 & 651627 & 7.6778 & 8.225 & TST & \\
\hline CHEMBL1223450 & 651627 & 7.7212 & 7.8807 & TST & \\
\hline CHEMBL1221424 & 651627 & 7.2328 & 6.5096 & TST & \\
\hline CHEMBL1222948 & 651627 & 5.7542 & 5.9937 & TST & \\
\hline CHEMBL1222807 & 651627 & 5.5619 & 4.2523 & TST & \\
\hline CHEMBL1223308 & 651627 & 6.3233 & 6.4804 & TST & \\
\hline CHEMBL1223513 & 651627 & 9.5229 & 7.9715 & TST & \\
\hline CHEMBL1222729 & 651627 & 7.4815 & 7.5376 & TST & \\
\hline CHEMBL1222436 & 651627 & 8.9208 & 8.3231 & TST & \\
\hline CHEMBL1222805 & 651627 & 4.699 & 5.8937 & TST & \\
\hline CHEMBL1222870 & 651627 & 6.5452 & 7.25299 & 9999999999 & TST \\
\hline CHEMBL1222596 & 651627 & 7.9208 & 8.6252 & TST & \\
\hline CHEMBL581240 & 1479054 & 3.9208 & 3.8041 & TRN & \\
\hline CHEMBL547184 & 1479054 & 5.3275 & 4.9178 & TST & \\
\hline CHEMBL580819 & 1479054 & 3.9208 & 3.81699 & 99999999997 & TRN \\
\hline CHEMBL533226 & 1479054 & 5.6651 & 5.3913 & TST & \\
\hline CHEMBL587980 & 1479054 & 5.2112 & 5.2012 & TRN & \\
\hline
\end{tabular}


Supplemental Table S2.txt

\begin{tabular}{|c|c|c|c|c|c|}
\hline CHEMBL579584 & 1479054 & 5.267 & 5.3877 & TRN & \\
\hline CHEMBL532987 & 1479054 & 3.9208 & 3.9152 & TRN & \\
\hline CHEMBL532270 & 1479054 & 5.5206 & 5.7639 & TRN & \\
\hline CHEMBL602312 & 1479054 & 4.9325 & 5.0694 & TRN & \\
\hline CHEMBL577874 & 1479054 & 3.9208 & 3.6816 & TRN & \\
\hline CHEMBL586821 & 1479054 & 3.6383 & 3.8512 & TRN & \\
\hline CHEMBL526210 & 1479054 & 6.0227 & 5.9602 & TST & \\
\hline CHEMBL528705 & 1479054 & 5.8925 & 5.8744 & TST & \\
\hline CHEMBL49055 & 1479054 & 5.171 & 5.10800 & 00000000005 & TRN \\
\hline CHEMBL 2028050 & 1479054 & 5.171 & 5.3666 & TRN & \\
\hline CHEMBL580534 & 1479054 & 5.0058 & 5.0291 & TRN & \\
\hline CHEMBL535921 & 1479054 & 5.5213 & 5.4569 & TRN & \\
\hline CHEMBL604982 & 1479054 & 3.9208 & 3.8811 & TRN & \\
\hline CHEMBL535514 & 1479054 & 3.9208 & 3.8415 & TRN & \\
\hline CHEMBL586942 & 1479054 & 5.2354 & 5.1345 & TRN & \\
\hline CHEMBL338094 & 1479054 & 3.9208 & 3.8617 & TRN & \\
\hline CHEMBL527390 & 1479054 & 5.5137 & 5.5475 & TRN & \\
\hline CHEMBL546955 & 1479054 & 5.8788 & 5.8889 & TRN & \\
\hline CHEMBL170758 & 1479054 & 5.857 & 5.5847 & TRN & \\
\hline CHEMBL533941 & 1479054 & 5.3218 & 5.3735 & TRN & \\
\hline CHEMBL582393 & 1479054 & 5.4316 & 5.4652 & TRN & \\
\hline CHEMBL600174 & 1479054 & 3.9208 & 4.03100 & 0000000001 & TST \\
\hline CHEMBL587028 & 1479054 & 4.87 & 5.0646 & TRN & \\
\hline CHEMBL528063 & 1479054 & 5.2495 & 5.0268 & TRN & \\
\hline CHEMBL548111 & 1479054 & 5.1086 & 5.4782 & TRN & \\
\hline CHEMBL525149 & 1479054 & 6.4921 & 6.8372 & TRN & \\
\hline CHEMBL534605 & 1479054 & 5.7029 & 5.8002 & TST & \\
\hline CHEMBL591147 & 1479054 & 3.9208 & 3.9708 & TRN & \\
\hline CHEMBL533598 & 1479054 & 3.9208 & 3.9524 & TRN & \\
\hline CHEMBL528447 & 1479054 & 5.1086 & 4.9303 & TST & \\
\hline CHEMBL534803 & 1479054 & 5.2159 & 5.1898 & TRN & \\
\hline CHEMBL548176 & 1479054 & 5.3171 & 5.2659 & TRN & \\
\hline CHEMBL534797 & 1479054 & 5.2645 & 4.9086 & TRN & \\
\hline CHEMBL525486 & 1479054 & 3.9208 & 3.8986 & TRN & \\
\hline CHEMBL533284 & 1479054 & 5.2255 & 5.3697 & TRN & \\
\hline CHEMBL1437888 & 1479054 & 5.171 & 4.9533 & TST & \\
\hline CHEMBL600439 & 1479054 & 3.9208 & 4.0181 & TRN & \\
\hline CHEMBL580516 & 1479054 & 5.171 & 4.4018 & TST & \\
\hline CHEMBL1567944 & 1479054 & 3.6383 & 4.5144 & TRN & \\
\hline CHEMBL590919 & 1479054 & 3.9208 & 4.4407 & TRN & \\
\hline CHEMBL532510 & 1479054 & 3.9208 & 3.8444 & TST & \\
\hline CHEMBL 2028044 & 1479054 & 3.9208 & 3.8715 & TRN & \\
\hline CHEMBL2028046 & 1479054 & 3.9208 & 3.9142 & TRN & \\
\hline CHEMBL531003 & 1479054 & 5.4949 & 5.6385 & TRN & \\
\hline CHEMBL531222 & 1479054 & 3.9208 & 3.9873 & TRN & \\
\hline CHEMBL590182 & 1479054 & 3.9208 & 3.8475 & TRN & \\
\hline CHEMBL580809 & 1479054 & 5.3132 & 5.1441 & TST & \\
\hline CHEMBL533776 & 1479054 & 5.2799 & 5.4736 & TRN & \\
\hline
\end{tabular}


Supplemental Table S2.txt

\begin{tabular}{|c|c|c|c|c|c|}
\hline CHEMBL524580 & 1479054 & 5.8274 & 6.0391 & TRN & \\
\hline CHEMBL529055 & 1479054 & 5.1086 & 5.26200 & 00000000005 & TRN \\
\hline CHEMBL533917 & 1479054 & 5.171 & 5.1427 & TRN & \\
\hline CHEMBL580474 & 1479054 & 5.4697 & 5.3387 & TRN & \\
\hline CHEMBL603686 & 1479054 & 3.9208 & 3.9273 & TRN & \\
\hline CHEMBL532907 & 1479054 & 5.3599 & 5.5135 & TRN & \\
\hline CHEMBL602366 & 1479054 & 3.9208 & 4.1176 & TST & \\
\hline CHEMBL587612 & 1479054 & 6.1141 & 6.376 & TRN & \\
\hline CHEMBL531744 & 1479054 & 5.5795 & 5.6938 & TRN & \\
\hline CHEMBL578933 & 1479054 & 3.9208 & 3.8099 & TRN & \\
\hline CHEMBL586937 & 1479054 & 5.4049 & 5.3572 & TRN & \\
\hline CHEMBL524784 & 1479054 & 3.9208 & 4.0236 & TRN & \\
\hline CHEMBL528147 & 1479054 & 5.4486 & 5.3845 & TST & \\
\hline CHEMBL532525 & 1479054 & 3.9208 & 3.9455 & TRN & \\
\hline CHEMBL579893 & 1479054 & 5.6931 & 5.3433 & TRN & \\
\hline CHEMBL528564 & 1479054 & 5.3004 & 5.4454 & TRN & \\
\hline CHEMBL531938 & 1479054 & 5.482 & 5.2861 & TRN & \\
\hline CHEMBL580730 & 1479054 & 5.3485 & 5.2283 & TST & \\
\hline CHEMBL579535 & 1479054 & 5.3472 & 5.4412 & TRN & \\
\hline CHEMBL533999 & 1479054 & 3.9208 & 3.9922 & TRN & \\
\hline CHEMBL586033 & 1479054 & 4.9325 & 4.9438 & TRN & \\
\hline CHEMBL608855 & 1479054 & 3.9208 & 3.9279 & TST & \\
\hline CHEMBL535741 & 1479054 & 6.2083 & 5.8431 & TRN & \\
\hline CHEMBL602179 & 1479054 & 3.9208 & 3.9998 & TRN & \\
\hline CHEMBL609628 & 1479054 & 4.9325 & 4.7955 & TRN & \\
\hline CHEMBL581791 & 1479054 & 5.9582 & 5.7398 & TRN & \\
\hline CHEMBL533070 & 1479054 & 4.87 & 4.7691 & TRN & \\
\hline CHEMBL531184 & 1479054 & 5.0069 & 5.1065 & TRN & \\
\hline CHEMBL529385 & 1479054 & 3.9208 & 3.9775 & TRN & \\
\hline CHEMBL586178 & 1479054 & 3.9208 & 4.1382 & TRN & \\
\hline CHEMBL581065 & 1479054 & 5.6326 & 5.3737 & TST & \\
\hline CHEMBL 2028048 & 1479054 & 3.9208 & 3.8954 & TRN & \\
\hline CHEMBL535680 & 1479054 & 5.3685 & 5.3943 & TRN & \\
\hline CHEMBL581135 & 1479054 & 6.6819 & 6.76 & TRN & \\
\hline CHEMBL585243 & 1479054 & 3.9208 & 3.9013 & TRN & \\
\hline CHEMBL530438 & 1479054 & 3.9208 & 3.9768 & TRN & \\
\hline CHEMBL546309 & 1479054 & 5.8162 & 5.7841 & TRN & \\
\hline CHEMBL529968 & 1479054 & 3.9208 & 3.9768 & TRN & \\
\hline CHEMBL586471 & 1479054 & 5.1776 & 4.9521 & TST & \\
\hline CHEMBL586310 & 1479054 & 3.9208 & 3.8498 & TRN & \\
\hline CHEMBL548750 & 1479054 & 5.0513 & 4.9647 & TRN & \\
\hline CHEMBL546912 & 1479054 & 5.324 & 5.4446 & TRN & \\
\hline CHEMBL581077 & 1479054 & 5.2326 & 5.1745 & TRN & \\
\hline CHEMBL 2028043 & 1479054 & 3.9208 & 3.8521 & TRN & \\
\hline CHEMBL582547 & 1479054 & 5.171 & 5.147 & TRN & \\
\hline CHEMBL547775 & 1479054 & 5.5732 & 5.511 & TRN & \\
\hline CHEMBL601534 & 1479054 & 3.9208 & 4.1442 & TST & \\
\hline CHEMBL587825 & 1479054 & 3.9208 & 4.1703 & TRN & \\
\hline
\end{tabular}




\begin{tabular}{|c|c|c|c|c|c|c|}
\hline CHEMBL530649 & 1479054 & \multicolumn{3}{|c|}{$\begin{array}{l}\text { Supplemental Table } \\
5.611000000000001\end{array}$} & $\begin{array}{l}\text { S2.txt } \\
5.4468\end{array}$ & TRN \\
\hline CHEMBL529099 & 1479054 & 5.1933 & 5.3149 & TRN & & \\
\hline CHEMBL602413 & 1479054 & 5.2343 & 5.0721 & TRN & & \\
\hline CHEMBL529612 & 1479054 & 5.1838 & 4.6781 & TRN & & \\
\hline CHEMBL529312 & 1479054 & 5.1553 & 5.4081 & TRN & & \\
\hline CHEMBL529424 & 1479054 & 3.6383 & 3.6934 & TST & & \\
\hline CHEMBL531829 & 1479054 & 5.3179 & 5.0959 & TST & & \\
\hline CHEMBL528350 & 1479054 & 5.2173 & 5.0023 & TRN & & \\
\hline CHEMBL546355 & 1479054 & 5.2707 & 5.1455 & TST & & \\
\hline CHEMBL588636 & 1479054 & 5.5393 & 5.33899 & 9999999999 & 95 & TST \\
\hline CHEMBL601743 & 1479054 & 3.9208 & 3.8192 & TRN & & \\
\hline CHEMBL529792 & 1479054 & 5.9961 & 5.5166 & TST & & \\
\hline CHEMBL579331 & 1479054 & 3.9208 & 3.9295 & TRN & & \\
\hline CHEMBL528508 & 1479054 & 5.4645 & 5.4236 & TRN & & \\
\hline CHEMBL548002 & 1479054 & 5.4961 & 5.4899 & TRN & & \\
\hline CHEMBL600706 & 1479054 & 3.9208 & 3.9975 & TRN & & \\
\hline CHEMBL532762 & 1479054 & 5.4671 & 5.263 & TRN & & \\
\hline CHEMBL591183 & 1479054 & 5.171 & 5.1652 & TRN & & \\
\hline CHEMBL588020 & 1479054 & 5.8642 & 6.2646 & TRN & & \\
\hline CHEMBL548901 & 1479054 & 3.9208 & 4.0904 & TRN & & \\
\hline CHEMBL536393 & 1479054 & 3.9208 & 3.8499 & TRN & & \\
\hline CHEMBL527620 & 1479054 & 3.9208 & 3.8694 & TRN & & \\
\hline CHEMBL526243 & 1479054 & 6.27 & 6.3528 & TRN & & \\
\hline CHEMBL596856 & 1479054 & 3.9208 & 4.0816 & TRN & & \\
\hline CHEMBL535091 & 1479054 & 5.6347 & 5.535 & TRN & & \\
\hline CHEMBL580140 & 1479054 & 3.9208 & 4.1038 & TRN & & \\
\hline CHEMBL534210 & 1479054 & 5.3512 & 5.2687 & TRN & & \\
\hline CHEMBL352960 & 1479054 & 3.6383 & 4.1107 & TRN & & \\
\hline CHEMBL577014 & 1479054 & 3.9208 & 4.0362 & TRN & & \\
\hline CHEMBL586078 & 1479054 & 3.9208 & 3.9763 & TRN & & \\
\hline CHEMBL537576 & 1479054 & 5.3318 & 5.5637 & TRN & & \\
\hline CHEMBL529081 & 1479054 & 3.6383 & 3.8712 & TRN & & \\
\hline CHEMBL531880 & 1479054 & 5.0661 & 5.3801 & TRN & & \\
\hline CHEMBL548076 & 1479054 & 5.4984 & 5.5191 & TRN & & \\
\hline CHEMBL590683 & 1479054 & 5.171 & 5.0518 & TRN & & \\
\hline CHEMBL596643 & 1479054 & 3.9208 & 3.9072 & TRN & & \\
\hline CHEMBL549164 & 1479054 & 5.5857 & 5.1346 & TRN & & \\
\hline CHEMBL528186 & 1479054 & 5.26200 & $\partial 0000000$ & 205 & 5.4464 & TRN \\
\hline CHEMBL579790 & 1479054 & 5.4259 & 5.3934 & TRN & & \\
\hline CHEMBL606252 & 1479054 & 3.9208 & 4.0075 & TRN & & \\
\hline CHEMBL531290 & 1479054 & 3.9208 & 3.9264 & TST & & \\
\hline CHEMBL579467 & 1479054 & 6.0106 & 5.7471 & TRN & & \\
\hline CHEMBL589422 & 1479054 & 3.9208 & 3.9019 & TST & & \\
\hline CHEMBL590674 & 1479054 & 3.9208 & 3.9019 & TRN & & \\
\hline CHEMBL494669 & 1479054 & 3.9208 & 4.039 & TRN & & \\
\hline CHEMBL601580 & 1479054 & 5.171 & 4.9954 & TRN & & \\
\hline CHEMBL2028063 & 1479054 & 5.171 & 4.422 & TRN & & \\
\hline CHEMBL170760 & 1479054 & 6.1593 & 5.7109 & TRN & & \\
\hline
\end{tabular}




\begin{tabular}{|c|c|c|c|c|c|}
\hline \multicolumn{6}{|c|}{ Supplemental Table s2.txt } \\
\hline CHEMBL530989 & 1479054 & 4.87 & 5.142 & TRN & \\
\hline CHEMBL525462 & 1479054 & 4.87 & 4.9429 & TRN & \\
\hline CHEMBL528794 & 1479054 & 5.0489 & 5.0358 & TRN & \\
\hline CHEMBL532808 & 1479054 & 5.8582 & 5.8681 & TRN & \\
\hline CHEMBL589224 & 1479054 & 3.9208 & 3.8811 & TST & \\
\hline CHEMBL586888 & 1479054 & 3.9208 & 3.8443 & TRN & \\
\hline CHEMBL531849 & 1479054 & 5.2503 & 5.3435 & TST & \\
\hline CHEMBL524578 & 1479054 & 5.1825 & 5.3569 & TRN & \\
\hline CHEMBL598881 & 1479054 & 3.9208 & 4.0827 & TST & \\
\hline CHEMBL580609 & 1479054 & 5.6702 & 5.6525 & TRN & \\
\hline CHEMBL584829 & 1479054 & 3.9208 & 3.9591 & TRN & \\
\hline CHEMBL587344 & 1479054 & 5.6341 & 5.5559 & TRN & \\
\hline CHEMBL524930 & 1479054 & 3.9208 & 3.8527 & TRN & \\
\hline CHEMBL124006 & 1479054 & 5.6482 & 5.8992 & TRN & \\
\hline CHEMBL526110 & 1479054 & 6.8894 & 6.3428 & TRN & \\
\hline CHEMBL548338 & 1479054 & 3.9208 & 3.9971 & TST & \\
\hline CHEMBL586253 & 1479054 & 5.1735 & 5.2246 & TRN & \\
\hline CHEMBL586234 & 1479054 & 5.3904 & 5.8644 & TRN & \\
\hline CHEMBL533931 & 1479054 & 5.392 & 5.4395 & TRN & \\
\hline CHEMBL525308 & 1479054 & 5.4903 & 5.2431 & TRN & \\
\hline CHEMBL527911 & 1479054 & 5.8176 & 5.8446 & TRN & \\
\hline CHEMBL603945 & 1479054 & 3.9208 & 4.0327 & TRN & \\
\hline CHEMBL535077 & 1479054 & 7.0177 & 6.9275 & TRN & \\
\hline CHEMBL596852 & 1479054 & 5.171 & 4.8525 & TRN & \\
\hline CHEMBL530720 & 1479054 & 4.6314 & 4.8816 & TRN & \\
\hline CHEMBL590680 & 1479054 & 3.9208 & 3.9221 & TRN & \\
\hline CHEMBL591393 & 1479054 & 5.171 & 4.4269 & TRN & \\
\hline CHEMBL579459 & 1479054 & 3.9208 & 3.9674 & TST & \\
\hline CHEMBL125044 & 1479054 & 3.9208 & 3.8685 & TRN & \\
\hline CHEMBL531265 & 1479054 & 5.8517 & 5.8889 & TRN & \\
\hline CHEMBL602127 & 1479054 & 3.9208 & 3.7758 & TRN & \\
\hline CHEMBL591623 & 1479054 & 3.9208 & 3.9482 & TRN & \\
\hline CHEMBL582042 & 1479054 & 6.109 & 5.8227 & TRN & \\
\hline CHEMBL586093 & 1479054 & 5.5289 & 5.5543 & TRN & \\
\hline CHEMBL591887 & 1479054 & 3.9208 & 4.0101 & TRN & \\
\hline CHEMBL536161 & 1479054 & 5.1086 & 5.0595 & TRN & \\
\hline CHEMBL602234 & 1479054 & 3.9208 & 4.152 & TRN & \\
\hline CHEMBL600030 & 1479054 & 3.9208 & 3.9313 & TRN & \\
\hline CHEMBL536421 & 1479054 & 3.9208 & 3.8559 & TRN & \\
\hline CHEMBL532699 & 1479054 & 5.9382 & 5.94600 & 0000000001 & TRN \\
\hline CHEMBL586109 & 1479054 & 5.3545 & 5.2029 & TRN & \\
\hline CHEMBL470514 & 1479054 & 3.9208 & 4.0466 & TRN & \\
\hline CHEMBL534190 & 1479054 & 3.9208 & 3.9331 & TRN & \\
\hline CHEMBL546472 & 1479054 & 4.87 & 5.0922 & TRN & \\
\hline CHEMBL586442 & 1479054 & 3.9208 & 3.9151 & TRN & \\
\hline CHEMBL590933 & 1479054 & 5.171 & 4.8278 & TRN & \\
\hline CHEMBL2028058 & 1479054 & 3.9208 & 3.9164 & TST & \\
\hline CHEMBL586186 & 1479054 & 5.476 & 5.4368 & TRN & \\
\hline
\end{tabular}


Supplemental Table S2.txt

\begin{tabular}{|c|c|c|c|c|c|}
\hline CHEMBL606159 & 1479054 & 3.9208 & 3.8603 & TRN & \\
\hline CHEMBL588743 & 1479054 & 5.2395 & 5.2674 & TRN & \\
\hline CHEMBL527904 & 1479054 & 5.9165 & 6.2946 & TRN & \\
\hline CHEMBL548406 & 1479054 & 5.6515 & 5.7326 & TRN & \\
\hline CHEMBL106772 & 1479054 & 5.2603 & 5.1818 & TRN & \\
\hline CHEMBL536165 & 1479054 & 3.6383 & 3.7554 & TRN & \\
\hline CHEMBL547715 & 1479054 & 4.87 & 5.2038 & TRN & \\
\hline CHEMBL586962 & 1479054 & 3.9208 & 3.8649 & TRN & \\
\hline CHEMBL547180 & 1479054 & 5.4836 & 5.5225 & TRN & \\
\hline CHEMBL548372 & 1479054 & 5.3892 & 5.2809 & TRN & \\
\hline CHEMBL532560 & 1479054 & 3.9208 & 3.9287 & TRN & \\
\hline CHEMBL587485 & 1479054 & 3.9208 & 3.9007 & TRN & \\
\hline CHEMBL598263 & 1479054 & 6.6478 & 6.1565 & TST & \\
\hline CHEMBL579294 & 1479054 & 3.9208 & 3.8854 & TRN & \\
\hline CHEMBL589733 & 1479054 & 5.171 & 4.9712 & TRN & \\
\hline CHEMBL549210 & 1479054 & 3.9208 & 3.9136 & TRN & \\
\hline CHEMBL588599 & 1479054 & 5.3272 & 5.1437 & TRN & \\
\hline CHEMBL587923 & 1479054 & 3.9208 & 4.5009 & TRN & \\
\hline CHEMBL528849 & 1479054 & 6.1244 & 6.1253 & TRN & \\
\hline CHEMBL547552 & 1479054 & 5.9423 & 5.4859 & TRN & \\
\hline CHEMBL602552 & 1479054 & 3.9208 & 3.8451 & TST & \\
\hline CHEMBL528458 & 1479054 & 3.6383 & 3.6326 & TRN & \\
\hline CHEMBL584676 & 1479054 & 3.9208 & 3.8166 & TRN & \\
\hline CHEMBL 106525 & 1479054 & 5.171 & 5.0513 & TRN & \\
\hline CHEMBL602764 & 1479054 & 3.9208 & 4.1794 & TRN & \\
\hline CHEMBL601378 & 1479054 & 5.171 & 4.9975 & TRN & \\
\hline CHEMBL586553 & 1479054 & 5.2219 & 5.1001 & TRN & \\
\hline CHEMBL527691 & 1479054 & 5.0869 & 5.2777 & TRN & \\
\hline CHEMBL533855 & 1479054 & 3.9208 & 3.9114 & TRN & \\
\hline CHEMBL533268 & 1479054 & 5.4427 & 5.522 & TRN & \\
\hline CHEMBL606531 & 1479054 & 3.9208 & 3.85399 & 99999999996 & TRN \\
\hline CHEMBL604323 & 1479054 & 3.9208 & 4.0753 & TRN & \\
\hline CHEMBL527924 & 1479054 & 5.3709 & 5.3576 & TRN & \\
\hline CHEMBL1623028 & 1479054 & 3.9208 & 3.9401 & TRN & \\
\hline CHEMBL546451 & 1479054 & 5.1447 & 5.3832 & TRN & \\
\hline CHEMBL580580 & 1479054 & 5.6482 & 5.3222 & TRN & \\
\hline CHEMBL601957 & 1479054 & 3.9208 & 3.8631 & TRN & \\
\hline CHEMBL533564 & 1479054 & 5.4012 & 5.4182 & TST & \\
\hline CHEMBL532254 & 1479054 & 5.9889 & 5.9547 & TST & \\
\hline CHEMBL525106 & 1479054 & 3.9208 & 3.91300 & 20000000003 & TRN \\
\hline CHEMBL548482 & 1479054 & 3.6383 & 3.7613 & TRN & \\
\hline CHEMBL583844 & 1479054 & 3.9208 & 4.0673 & TST & \\
\hline CHEMBL579443 & 1479054 & 3.9208 & 3.9732 & TRN & \\
\hline CHEMBL532148 & 1479054 & 4.87 & 4.9792 & TRN & \\
\hline CHEMBL547136 & 1479054 & 5.4456 & 5.532 & TRN & \\
\hline CHEMBL533252 & 1479054 & 5.2185 & 5.0606 & TRN & \\
\hline CHEMBL582767 & 1479054 & 5.171 & 4.4748 & TST & \\
\hline CHEMBL548334 & 1479054 & 3.9208 & 4.0139 & TST & \\
\hline
\end{tabular}


Supplemental Table S2.txt

\begin{tabular}{|c|c|c|c|c|c|}
\hline CHEMBL577012 & 1479054 & 3.9208 & 4.0698 & TRN & \\
\hline CHEMBL548399 & 1479054 & 3.9208 & 3.8797 & TRN & \\
\hline CHEMBL1623897 & 1479054 & 3.9208 & 3.8543 & TRN & \\
\hline CHEMBL529225 & 1479054 & 5.0192 & 4.8579 & TRN & \\
\hline CHEMBL549093 & 1479054 & 5.3918 & 5.497999 & 9999999999 & TRN \\
\hline CHEMBL536424 & 1479054 & 5.4694 & 5.0138 & TRN & \\
\hline CHEMBL579457 & 1479054 & 4.87 & 5.0884 & TRN & \\
\hline CHEMBL527902 & 1479054 & 5.3886 & 5.2515 & TRN & \\
\hline CHEMBL580876 & 1479054 & 3.9208 & 4.0367 & TRN & \\
\hline CHEMBL527541 & 1479054 & 5.171 & 4.9702 & TRN & \\
\hline CHEMBL582420 & 1479054 & 3.9208 & 3.8444 & TRN & \\
\hline CHEMBL587824 & 1479054 & 5.70799 & 999999999 & 5.0282 & ז \\
\hline CHEMBL598369 & 1479054 & 3.9208 & 3.7955 & TRN & \\
\hline CHEMBL582070 & 1479054 & 3.9208 & 4.0281 & TRN & \\
\hline CHEMBL537087 & 1479054 & 3.9208 & 4.258 & TRN & \\
\hline CHEMBL589946 & 1479054 & 3.9208 & 3.8186 & TRN & \\
\hline CHEMBL261693 & 1479054 & 3.9208 & 3.844 & TRN & \\
\hline CHEMBL529990 & 1479054 & 5.7062 & 5.6366 & TRN & \\
\hline CHEMBL536627 & 1479054 & 3.6383 & 3.9064 & TRN & \\
\hline CHEMBL602580 & 1479054 & 5.171 & 5.1647 & TST & \\
\hline CHEMBL596652 & 1479054 & 3.9208 & 3.9061 & TRN & \\
\hline CHEMBL530149 & 1479054 & 3.9208 & 4.1061 & TRN & \\
\hline CHEMBL580496 & 1479054 & 4.8753 & 5.1039 & TRN & \\
\hline CHEMBL588127 & 1479054 & 5.2231 & 5.3184 & TRN & \\
\hline CHEMBL530291 & 1479054 & 6.4067 & 6.656000 & 2000000001 & TRN \\
\hline CHEMBL597248 & 1479054 & 3.9208 & 4.0714 & TRN & \\
\hline CHEMBL592123 & 1479054 & 5.3165 & 5.0545 & TRN & \\
\hline CHEMBL597262 & 1479054 & 3.9208 & 3.8121 & TRN & \\
\hline CHEMBL582478 & 1479054 & 5.171 & 5.0047 & TRN & \\
\hline CHEMBL577011 & 1479054 & 3.9208 & 3.9222 & TRN & \\
\hline CHEMBL586000 & 1479054 & 3.9208 & 4.7016 & TRN & \\
\hline CHEMBL532801 & 1479054 & 5.6295 & 5.575 & TRN & \\
\hline CHEMBL524746 & 1479054 & 5.4118 & 5.5199 & TRN & \\
\hline CHEMBL587420 & 1479054 & 4.87 & 3.8608 & TRN & \\
\hline CHEMBL583682 & 1479054 & 3.9208 & 3.8761 & TRN & \\
\hline CHEMBL549216 & 1479054 & 3.9208 & 3.9107 & TRN & \\
\hline CHEMBL581225 & 1479054 & 3.9208 & 3.997 & TST & \\
\hline CHEMBL549034 & 1479054 & 5.8508 & 5.8002 & TST & \\
\hline CHEMBL1740701 & 1479054 & 3.9208 & 3.9914 & TRN & \\
\hline CHEMBL582430 & 1479054 & 5.4447 & 5.3975 & TRN & \\
\hline CHEMBL611070 & 1479054 & 3.9208 & 4.0104 & TRN & \\
\hline CHEMBL535079 & 1479054 & 3.9208 & 4.3415 & TRN & \\
\hline CHEMBL 2028056 & 1479054 & 3.9208 & 3.8992 & TRN & \\
\hline CHEMBL591637 & 1479054 & 5.171 & 4.9004 & TRN & \\
\hline CHEMBL546974 & 1479054 & 4.87 & 5.2496 & TRN & \\
\hline CHEMBL609156 & 1479054 & 3.9208 & 3.973999 & 99999999998 & $\mathbf{n I}$ \\
\hline CHEMBL588516 & 1479054 & 3.9208 & 3.9874 & TRN & \\
\hline CHEMBL526818 & 1479054 & 5.1662 & 5.1146 & TRN & \\
\hline
\end{tabular}




\begin{tabular}{|c|c|c|c|c|c|}
\hline \multicolumn{6}{|c|}{ Supplemental Table S2.txt } \\
\hline CHEMBL532650 & 1479054 & 6.2111 & 6.2421 & TRN & \\
\hline CHEMBL581187 & 1479054 & 3.9208 & 3.8097 & TRN & \\
\hline CHEMBL546544 & 1479054 & 5.1227 & 5.0622 & TRN & \\
\hline CHEMBL601158 & 1479054 & 3.9208 & 4.0649 & TRN & \\
\hline CHEMBL92137 & 1479054 & 4.87 & 5.2483 & TRN & \\
\hline CHEMBL527221 & 1479054 & 3.6383 & 3.8409 & TRN & \\
\hline CHEMBL526587 & 1479054 & 3.9208 & 3.978 & TRN & \\
\hline CHEMBL580275 & 1479054 & 5.3694 & 5.5448 & TRN & \\
\hline CHEMBL547470 & 1479054 & 7.2007 & 6.9216 & TRN & \\
\hline CHEMBL590435 & 1479054 & 3.9208 & 3.8743 & TRN & \\
\hline CHEMBL589922 & 1479054 & 3.9208 & 3.8007 & TRN & \\
\hline CHEMBL317364 & 1479054 & 3.9208 & 3.6691 & TRN & \\
\hline CHEMBL546792 & 1479054 & 5.38700 & 20000000 & 5.4006 & TRN \\
\hline CHEMBL529823 & 1479054 & 5.3307 & 5.1974 & TRN & \\
\hline CHEMBL580539 & 1479054 & 5.9442 & 5.7159 & TRN & \\
\hline CHEMBL531534 & 1479054 & 5.6282 & 5.3914 & TRN & \\
\hline CHEMBL547140 & 1479054 & 5.7212 & 5.6171 & TRN & \\
\hline CHEMBL531695 & 1479054 & 5.6745 & 5.4859 & TST & \\
\hline CHEMBL532079 & 1479054 & 3.9208 & 4.0181 & TRN & \\
\hline CHEMBL1237253 & 1479054 & 4.87 & 4.2709 & TRN & \\
\hline CHEMBL 2028059 & 1479054 & 3.9208 & 3.7609 & TST & \\
\hline CHEMBL532103 & 1479054 & 5.3609 & 5.4595 & TRN & \\
\hline CHEMBL585431 & 1479054 & 3.9208 & 3.8868 & TST & \\
\hline CHEMBL536640 & 1479054 & 4.87 & 4.775 & TRN & \\
\hline CHEMBL600356 & 1479054 & 3.9208 & 3.9892 & TST & \\
\hline CHEMBL548432 & 1479054 & 5.3472 & 5.4115 & TRN & \\
\hline CHEMBL586031 & 1479054 & 3.9208 & 3.9663 & TST & \\
\hline CHEMBL590201 & 1479054 & 3.9208 & 3.8736 & TRN & \\
\hline CHEMBL529957 & 1479054 & 5.4472 & 4.9412 & TRN & \\
\hline CHEMBL546168 & 1479054 & 3.9208 & 3.8815 & TRN & \\
\hline CHEMBL1237214 & 1479054 & 5.7642 & 5.7123 & TRN & \\
\hline CHEMBL548918 & 1479054 & 5.3937 & 5.24100 & 00000000005 & TRN \\
\hline CHEMBL530308 & 1479054 & 3.9208 & 3.9297 & TST & \\
\hline CHEMBL580381 & 1479054 & 3.9208 & 3.8346 & TRN & \\
\hline CHEMBL1459149 & 1479054 & 3.9208 & 4.0546 & TST & \\
\hline CHEMBL589236 & 1479054 & 3.9208 & 3.951 & TRN & \\
\hline CHEMBL529603 & 1479054 & 3.9208 & 3.9603 & TRN & \\
\hline CHEMBL546162 & 1479054 & 5.171 & 4.7691 & TRN & \\
\hline CHEMBL579809 & 1479054 & 5.4305 & 5.268 & TRN & \\
\hline CHEMBL459199 & 1479054 & 3.9208 & 3.9437 & TRN & \\
\hline CHEMBL547193 & 1479054 & 3.9208 & 3.9943 & TRN & \\
\hline CHEMBL586375 & 1479054 & 5.8911 & 5.8433 & TRN & \\
\hline CHEMBL586632 & 1479054 & 5.4697 & 5.7794 & TRN & \\
\hline CHEMBL584240 & 1479054 & 3.9208 & 3.9399 & TRN & \\
\hline CHEMBL546211 & 1479054 & 4.87 & 5.0236 & TRN & \\
\hline CHEMBL579315 & 1479054 & 3.9208 & 3.9623 & TRN & \\
\hline CHEMBL578294 & 1479054 & 5.171 & 5.3199 & TRN & \\
\hline CHEMBL580654 & 1479054 & 3.9208 & 3.8337 & TRN & \\
\hline
\end{tabular}


Supplemental Table S2.txt

\begin{tabular}{|c|c|c|c|c|}
\hline CHEMBL532775 & 1479054 & 5.4342 & 5.0473 & TRN \\
\hline CHEMBL581860 & 1479054 & 3.9208 & 4.5883 & TRN \\
\hline CHEMBL537505 & 1479054 & 3.9208 & 3.9341 & TRN \\
\hline CHEMBL582079 & 1479054 & 3.9208 & 3.6952 & TRN \\
\hline CHEMBL535498 & 1479054 & 5.4374 & \multicolumn{2}{|c|}{5.417999999999999} \\
\hline CHEMBL585622 & 1479054 & 5.171 & 5.2272 & TRN \\
\hline CHEMBL529822 & 1479054 & 5.7796 & 5.9689 & TST \\
\hline CHEMBL533981 & 1479054 & 5.1898 & 5.2958 & TRN \\
\hline CHEMBL1237267 & 1479054 & 4.87 & 4.9576 & TRN \\
\hline CHEMBL547127 & 1479054 & 5.4051 & 5.2449 & TRN \\
\hline CHEMBL528734 & 1479054 & 3.9208 & 3.9944 & TRN \\
\hline CHEMBL587611 & 1479054 & 5.079 & 4.8653 & TRN \\
\hline CHEMBL580191 & 1479054 & 5.4214 & 5.5028 & TRN \\
\hline CHEMBL527419 & 1479054 & 3.6383 & 4.7418 & TST \\
\hline CHEMBL548126 & 1479054 & 4.87 & 5.1922 & TRN \\
\hline CHEMBL546383 & 1479054 & 5.3472 & 5.2154 & TRN \\
\hline CHEMBL592808 & 1479054 & 3.9208 & 3.8104 & TRN \\
\hline CHEMBL530372 & 1479054 & 5.4798 & 5.5326 & TRN \\
\hline CHEMBL526064 & 1479054 & 5.2172 & 5.3766 & TRN \\
\hline CHEMBL579411 & 1479054 & 5.6035 & 5.6218 & TRN \\
\hline CHEMBL261095 & 1479054 & 3.9208 & 3.9516 & TRN \\
\hline CHEMBL537039 & 1479054 & 5.4433 & 5.5902 & TRN \\
\hline CHEMBL546632 & 1479054 & 5.1086 & 5.5392 & TRN \\
\hline CHEMBL548861 & 1479054 & 5.4029 & 5.4613 & TRN \\
\hline CHEMBL529732 & 1479054 & 3.9208 & 3.9202 & TRN \\
\hline CHEMBL1744512 & 1479054 & 3.9208 & 3.9696 & TRN \\
\hline CHEMBL590944 & 1479054 & 3.9208 & 4.0105 & TRN \\
\hline CHEMBL537379 & 1479054 & 5.5 & 5.3657 & TRN \\
\hline CHEMBL529773 & 1479054 & 3.9208 & 3.8489 & TRN \\
\hline CHEMBL547488 & 1479054 & 3.9208 & 3.5974 & TRN \\
\hline CHEMBL587120 & 1479054 & 6.3809 & 6.068 & TRN \\
\hline CHEMBL547614 & 1479054 & 3.9208 & 4.0059 & TST \\
\hline CHEMBL532483 & 1479054 & 5.0627 & 5.2736 & TRN \\
\hline CHEMBL536676 & 1479054 & 5.3522 & 5.2349 & TRN \\
\hline CHEMBL533921 & 1479054 & 3.9208 & 4.1769 & TRN \\
\hline CHEMBL206540 & 1479054 & 3.9208 & 3.8364 & TRN \\
\hline CHEMBL591641 & 1479054 & 3.9208 & 3.9891 & TRN \\
\hline CHEMBL532597 & 1479054 & 3.9208 & 3.9921 & TST \\
\hline CHEMBL592344 & 1479054 & 3.9208 & 3.8328 & TRN \\
\hline CHEMBL 2028041 & 1479054 & 3.9208 & 3.9887 & TST \\
\hline CHEMBL546871 & 1479054 & 5.1962 & 5.1531 & TRN \\
\hline CHEMBL582180 & 1479054 & 3.9208 & 3.8801 & TRN \\
\hline CHEMBL588566 & 1479054 & 5.5033 & 5.1781 & TRN \\
\hline CHEMBL597857 & 1479054 & 3.9208 & 3.6626 & TRN \\
\hline CHEMBL607688 & 1479054 & 3.9208 & 3.8843 & TRN \\
\hline CHEMBL537153 & 1479054 & 5.3152 & 4.9957 & TRN \\
\hline CHEMBL475813 & 1479054 & 3.9208 & 4.0282 & TRN \\
\hline CHEMBL528437 & 1479054 & 3.9208 & 3.7926 & TRN \\
\hline
\end{tabular}


Supplemental Table S2.txt

\begin{tabular}{|c|c|c|c|c|c|}
\hline CHEMBL525519 & 1479054 & 3.9208 & 3.9204 & TRN & \\
\hline CHEMBL603943 & 1479054 & 3.9208 & 3.8785 & TRN & \\
\hline CHEMBL588473 & 1479054 & 5.4968 & 5.5268 & TRN & \\
\hline CHEMBL588641 & 1479054 & 5.7617 & 5.8882 & TRN & \\
\hline CHEMBL535730 & 1479054 & 3.9208 & 3.943 & TST & \\
\hline CHEMBL582400 & 1479054 & 5.7233 & 5.5078 & TRN & \\
\hline CHEMBL546565 & 1479054 & 5.1777 & 5.141 & TRN & \\
\hline CHEMBL547266 & 1479054 & 3.9208 & 4.5411 & TRN & \\
\hline CHEMBL532060 & 1479054 & 5.4232 & 5.2401 & TRN & \\
\hline CHEMBL586135 & 1479054 & 4.87 & 4.6046 & TRN & \\
\hline CHEMBL534875 & 1479054 & 5.3876 & 5.1982 & TRN & \\
\hline CHEMBL580199 & 1479054 & 5.2226 & 5.15 & TRN & \\
\hline CHEMBL588379 & 1479054 & 5.4241 & 5.1584 & TRN & \\
\hline CHEMBL586687 & 1479054 & 5.4787 & 5.4005 & TRN & \\
\hline CHEMBL579105 & 1479054 & 5.171 & 5.3332 & TRN & \\
\hline CHEMBL601325 & 1479054 & 3.9208 & 4.0316 & TST & \\
\hline CHEMBL548777 & 1479054 & 5.4624 & 5.3857 & TRN & \\
\hline CHEMBL600488 & 1479054 & 3.9208 & 3.9425 & TRN & \\
\hline CHEMBL583555 & 1479054 & 3.9208 & 3.9614 & TST & \\
\hline CHEMBL532015 & 1479054 & 3.9208 & 3.9714 & TST & \\
\hline CHEMBL584235 & 1479054 & 3.9208 & 3.9307 & TRN & \\
\hline CHEMBL530217 & 1479054 & 5.1415 & 5.3743 & TRN & \\
\hline CHEMBL524606 & 1479054 & 5.31 & 5.40799 & 99999999995 & TRN \\
\hline CHEMBL580249 & 1479054 & 3.9208 & 3.9456 & TRN & \\
\hline CHEMBL600374 & 1479054 & 3.9208 & 3.8354 & TRN & \\
\hline CHEMBL533000 & 1479054 & 5.4999 & 5.3589 & TRN & \\
\hline CHEMBL547442 & 1479054 & 5.3388 & 5.41100 & 00000000005 & TRN \\
\hline CHEMBL529984 & 1479054 & 3.9208 & 3.9827 & TRN & \\
\hline CHEMBL588786 & 1479054 & 5.5358 & 5.6102 & TRN & \\
\hline CHEMBL546661 & 1479054 & 3.6383 & 5.1509 & TRN & \\
\hline CHEMBL2028066 & 1479054 & 3.9208 & 4.1304 & TST & \\
\hline CHEMBL528533 & 1479054 & 5.171 & 4.4224 & TRN & \\
\hline CHEMBL468963 & 1479054 & 6.251 & 6.137006 & 00000000005 & TRN \\
\hline CHEMBL577445 & 1479054 & 3.9208 & 3.8963 & TRN & \\
\hline CHEMBL1198307 & 1479054 & 5.171 & 5.0685 & TRN & \\
\hline CHEMBL2028057 & 1479054 & 3.9208 & 3.6874 & TST & \\
\hline CHEMBL526627 & 1479054 & 5.6897 & 5.7207 & TRN & \\
\hline CHEMBL600904 & 1479054 & 3.9208 & 3.8048 & TRN & \\
\hline CHEMBL585686 & 1479054 & 3.9208 & 3.9742 & TST & \\
\hline CHEMBL588673 & 1479054 & 5.2284 & 5.013 & TST & \\
\hline CHEMBL526234 & 1479054 & 5.5223 & 5.3166 & TRN & \\
\hline CHEMBL588752 & 1479054 & 5.4021 & 5.3595 & TRN & \\
\hline CHEMBL534123 & 1479054 & 5.5751 & 5.3846 & TRN & \\
\hline CHEMBL535750 & 1479054 & 6.8041 & 6.6873 & TRN & \\
\hline CHEMBL548589 & 1479054 & 5.1798 & 5.3197 & TRN & \\
\hline CHEMBL536671 & 1479054 & 5.3587 & 5.1024 & TRN & \\
\hline CHEMBL601786 & 1479054 & 3.9208 & 3.9572 & TRN & \\
\hline CHEMBL580043 & 1479054 & 5.4204 & 5.4096 & TRN & \\
\hline
\end{tabular}




\begin{tabular}{|c|c|c|c|c|c|}
\hline \multicolumn{6}{|c|}{ Supplemental Table S2.txt } \\
\hline CHEMBL530139 & 1479054 & 5.5141 & 5.4843 & TRN & \\
\hline CHEMBL582666 & 1479054 & 5.171 & 4.8519 & TRN & \\
\hline CHEMBL549075 & 1479054 & 5.1084 & 5.1032 & TRN & \\
\hline CHEMBL527131 & 1479054 & 3.9208 & 3.9104 & TRN & \\
\hline CHEMBL577440 & 1479054 & 3.9208 & 3.861 & TRN & \\
\hline CHEMBL533079 & 1479054 & 5.66700 & 000000000 & 5.4918 & TRN \\
\hline CHEMBL530547 & 1479054 & 5.355 & 5.3169 & TST & \\
\hline CHEMBL591890 & 1479054 & 3.9208 & 3.9301 & TST & \\
\hline CHEMBL591128 & 1479054 & 3.9208 & 3.9524 & TRN & \\
\hline CHEMBL579920 & 1479054 & 5.3472 & 5.1306 & TRN & \\
\hline CHEMBL530399 & 1479054 & 4.87 & 4.976 & TRN & \\
\hline CHEMBL582486 & 1479054 & 3.9208 & 3.9192 & TST & \\
\hline CHEMBL532363 & 1479054 & 4.87 & 5.1364 & TRN & \\
\hline CHEMBL537071 & 1479054 & 3.9208 & 3.8752 & TRN & \\
\hline CHEMBL599100 & 1479054 & 3.9208 & 4.0156 & TRN & \\
\hline CHEMBL533069 & 1479054 & 4.87 & 5.0192 & TRN & \\
\hline CHEMBL586184 & 1479054 & 5.2776 & 5.2055 & TRN & \\
\hline CHEMBL589060 & 1479054 & 3.9208 & 3.9732 & TRN & \\
\hline CHEMBL586344 & 1479054 & 3.9208 & 3.868999 & 99999999998 & TST \\
\hline CHEMBL580757 & 1479054 & 3.9208 & 3.9225 & TRN & \\
\hline CHEMBL547476 & 1479054 & 3.9208 & 3.9648 & TRN & \\
\hline CHEMBL529452 & 1479054 & 5.9404 & 6.2186 & TRN & \\
\hline CHEMBL592332 & 1479054 & 3.9208 & 3.8694 & TRN & \\
\hline CHEMBL602409 & 1479054 & 3.9208 & 3.8611 & TRN & \\
\hline CHEMBL588184 & 1479054 & 5.29 & 5.294 & TRN & \\
\hline CHEMBL1485159 & 1479054 & 3.9208 & 4.0482 & TRN & \\
\hline CHEMBL 2028054 & 1479054 & 3.9208 & 4.0244 & TST & \\
\hline CHEMBL534279 & 1479054 & 5.0848 & 5.0081 & TRN & \\
\hline CHEMBL582286 & 1479054 & 3.9208 & 3.921999 & 99999999997 & TRN \\
\hline CHEMBL 2028045 & 1479054 & 3.9208 & 3.948 & TRN & \\
\hline CHEMBL601806 & 1479054 & 3.9208 & 3.9183 & TST & \\
\hline CHEMBL581191 & 1479054 & 5.5031 & 5.2714 & TRN & \\
\hline CHEMBL586933 & 1479054 & 3.9208 & 3.8128 & TRN & \\
\hline CHEMBL534151 & 1479054 & 5.6786 & 5.629 & TST & \\
\hline CHEMBL 2028047 & 1479054 & 3.9208 & 3.9126 & TRN & \\
\hline CHEMBL601566 & 1479054 & 3.9208 & 3.8925 & TRN & \\
\hline CHEMBL528761 & 1479054 & 5.4643 & 5.3709 & TRN & \\
\hline CHEMBL535475 & 1479054 & 6.1308 & 6.0613 & TRN & \\
\hline CHEMBL602940 & 1479054 & 3.9208 & 4.1959 & TST & \\
\hline CHEMBL529924 & 1479054 & 5.3429 & 5.3225 & TRN & \\
\hline CHEMBL 2028042 & 1479054 & 3.9208 & 3.8303 & TRN & \\
\hline CHEMBL600906 & 1479054 & 3.9208 & 3.9306 & TRN & \\
\hline CHEMBL534384 & 1479054 & 5.3881 & 5.2368 & TRN & \\
\hline CHEMBL536112 & 1479054 & 6.062 & 5.6928 & TST & \\
\hline CHEMBL587410 & 1479054 & 3.9208 & 4.0415 & TST & \\
\hline CHEMBL546937 & 1479054 & 5.4249 & 5.069 & TRN & \\
\hline CHEMBL588859 & 1479054 & 3.9208 & 4.0928 & TRN & \\
\hline CHEMBL514409 & 1479054 & 5.9531 & 5.5623 & TRN & \\
\hline
\end{tabular}




\begin{tabular}{|c|c|c|c|c|c|}
\hline \multicolumn{6}{|c|}{ Supplemental Table S2.txt } \\
\hline CHEMBL580307 & 1479054 & 6.341 & 6.3412 & TRN & \\
\hline CHEMBL588732 & 1479054 & 3.9208 & 3.7756 & TRN & \\
\hline CHEMBL601567 & 1479054 & 3.9208 & 3.8384 & TRN & \\
\hline CHEMBL600549 & 1479054 & 3.9208 & 3.8724 & TST & \\
\hline CHEMBL548288 & 1479054 & 3.6383 & 4.7268 & TRN & \\
\hline CHEMBL549208 & 1479054 & 3.9208 & 4.0298 & TST & \\
\hline CHEMBL528032 & 1479054 & 5.2912 & 5.3243 & TRN & \\
\hline CHEMBL592550 & 1479054 & 3.9208 & 3.8268 & TRN & \\
\hline CHEMBL 339050 & 1479054 & 5.5698 & 5.3907 & TRN & \\
\hline CHEMBL584015 & 1479054 & 5.171 & 5.2136 & TRN & \\
\hline CHEMBL 2028051 & 1479054 & 3.9208 & 3.9202 & TRN & \\
\hline CHEMBL549080 & 1479054 & 5.3582 & 5.1535 & TRN & \\
\hline CHEMBL587968 & 1479054 & 5.7981 & 5.67299 & э9999999999 & TRN \\
\hline CHEMBL587371 & 1479054 & 3.9208 & 3.9227 & TRN & \\
\hline CHEMBL537778 & 1479054 & 3.9208 & 3.9393 & TRN & \\
\hline CHEMBL588155 & 1479054 & 3.9208 & 4.0425 & TRN & \\
\hline CHEMBL525710 & 1479054 & 5.1086 & 5.3626 & TRN & \\
\hline CHEMBL586468 & 1479054 & 3.9208 & 4.1906 & TRN & \\
\hline CHEMBL546994 & 1479054 & 3.9208 & 3.9294 & TRN & \\
\hline CHEMBL1616787 & 1479054 & 3.9208 & 3.9523 & TRN & \\
\hline CHEMBL1237217 & 1479054 & 5.1516 & 5.3021 & TST & \\
\hline CHEMBL582119 & 1479054 & 3.9208 & 3.9189 & TST & \\
\hline CHEMBL173617 & 1479054 & 5.5772 & 5.6379 & TRN & \\
\hline CHEMBL529064 & 1479054 & 5.1701 & 4.9979 & TST & \\
\hline CHEMBL580388 & 1479054 & 3.9208 & 4.0086 & TST & \\
\hline CHEMBL580149 & 1479054 & 5.282 & 5.1825 & TST & \\
\hline CHEMBL592786 & 1479054 & 3.9208 & 4.0408 & TRN & \\
\hline CHEMBL580967 & 1479054 & 5.49200 & 00000000 & 5.4412 & TRN \\
\hline CHEMBL605751 & 1479054 & 3.9208 & 3.9395 & TRN & \\
\hline CHEMBL549003 & 1479054 & 5.5786 & 5.5844 & TRN & \\
\hline CHEMBL600444 & 1479054 & 3.9208 & 3.7825 & TRN & \\
\hline CHEMBL369258 & 1479054 & 5.856 & 5.6592 & TRN & \\
\hline CHEMBL546522 & 1479054 & 6.1864 & 6.3284 & TRN & \\
\hline CHEMBL 2028062 & 1479054 & 3.9208 & 3.9761 & TRN & \\
\hline CHEMBL 2028053 & 1479054 & 4.9325 & 4.8541 & TRN & \\
\hline CHEMBL549067 & 1479054 & 5.4226 & 5.5085 & TRN & \\
\hline CHEMBL547869 & 1479054 & 4.87 & 4.2738 & TST & \\
\hline CHEMBL609036 & 1479054 & 3.9208 & 3.9755 & TRN & \\
\hline CHEMBL1619026 & 1479054 & 3.9208 & 3.8551 & TRN & \\
\hline CHEMBL593290 & 1479054 & 6.2588 & 6.1328 & TRN & \\
\hline CHEMBL581162 & 1479054 & 5.3511 & 5.2352 & TRN & \\
\hline CHEMBL588280 & 1479054 & 5.0635 & 5.1462 & TRN & \\
\hline CHEMBL580188 & 1479054 & 3.9208 & 3.9004 & TRN & \\
\hline CHEMBL548209 & 1479054 & 3.9208 & 3.9123 & TRN & \\
\hline CHEMBL533389 & 1479054 & 3.6383 & 3.7854 & TST & \\
\hline CHEMBL531393 & 1479054 & 5.2033 & 5.3174 & TRN & \\
\hline CHEMBL581475 & 1479054 & 3.9208 & 3.9966 & TRN & \\
\hline CHEMBL547607 & 1479054 & 5.3893 & 5.20100 & 00000000005 & \\
\hline & & & & 8350 & \\
\hline
\end{tabular}


Supplemental Table S2.txt

\begin{tabular}{|c|c|c|c|c|c|}
\hline CHEMBL10835 & 1479054 & 3.9208 & 4.0614 & TRN & \\
\hline CHEMBL534319 & 1479054 & 3.9208 & 5.2918 & TRN & \\
\hline CHEMBL532141 & 1479054 & 3.9208 & 3.7955 & TRN & \\
\hline CHEMBL578952 & 1479054 & 3.9208 & 3.9311 & TRN & \\
\hline CHEMBL593052 & 1479054 & 6.4045 & \multicolumn{2}{|c|}{6.656000000000001} & TRN \\
\hline CHEMBL578030 & 1479054 & 3.9208 & 4.0542 & TRN & \\
\hline CHEMBL582552 & 1479054 & 3.9208 & 3.8399 & TRN & \\
\hline CHEMBL587022 & 1479054 & 3.9208 & 3.9558 & TST & \\
\hline CHEMBL587153 & 1479054 & 6.6055 & 6.3867 & TRN & \\
\hline CHEMBL535027 & 1479054 & 5.3227 & 5.1449 & TRN & \\
\hline CHEMBL530513 & 1479054 & 5.6171 & 5.6958 & TRN & \\
\hline CHEMBL547443 & 1479054 & 3.9208 & 3.8337 & TRN & \\
\hline CHEMBL529919 & 1479054 & 3.9208 & 3.9821 & TRN & \\
\hline CHEMBL588253 & 1479054 & 5.5909 & \multicolumn{2}{|c|}{5.468999999999999} & TRN \\
\hline CHEMBL547367 & 1479054 & 5.2945 & 5.2995 & TST & \\
\hline CHEMBL586656 & 1479054 & 5.6857 & 5.7277 & TRN & \\
\hline CHEMBL 2028060 & 1479054 & 3.9208 & 3.8742 & TRN & \\
\hline CHEMBL582610 & 1479054 & 5.3249 & 5.2797 & TRN & \\
\hline CHEMBL535659 & 1479054 & 5.4589 & 5.2793 & TRN & \\
\hline CHEMBL584655 & 1479054 & 3.9208 & 3.9666 & TRN & \\
\hline CHEMBL587208 & 1479054 & 5.5124 & \multicolumn{2}{|c|}{5.212000000000001} & TRN \\
\hline CHEMBL537082 & 1479054 & 5.0915 & 5.0408 & TST & \\
\hline CHEMBL533399 & 1479054 & 3.9208 & 4.0715 & TST & \\
\hline CHEMBL527374 & 1479054 & 5.7889 & 5.5943 & TRN & \\
\hline CHEMBL588939 & 1479054 & 5.3707 & 5.1899 & TRN & \\
\hline CHEMBL599885 & 1479054 & 3.9208 & 3.8675 & TRN & \\
\hline CHEMBL591395 & 1479054 & 3.9208 & 3.8832 & TRN & \\
\hline CHEMBL589723 & 1479054 & 3.9208 & 3.8887 & TRN & \\
\hline CHEMBL534441 & 1479054 & 4.87 & 4.9427 & TRN & \\
\hline CHEMBL533770 & 1479054 & 5.1823 & 5.15 & TRN & \\
\hline CHEMBL548061 & 1479054 & 5.3472 & 5.4931 & TRN & \\
\hline CHEMBL533110 & 1479054 & 3.6383 & 3.8662 & TRN & \\
\hline CHEMBL319952 & 1479054 & 3.9208 & 3.9538 & TRN & \\
\hline CHEMBL530073 & 1479054 & 5.2958 & 5.4265 & TRN & \\
\hline CHEMBL580252 & 1479054 & 5.3204 & 5.2121 & TST & \\
\hline CHEMBL528694 & 1479054 & 5.6868 & 5.4663 & TRN & \\
\hline CHEMBL581771 & 1479054 & 4.87 & 4.8592 & TRN & \\
\hline CHEMBL545880 & 1479054 & 3.9208 & 3.9329 & TRN & \\
\hline CHEMBL601771 & 1479054 & 3.9208 & 3.9321 & TST & \\
\hline CHEMBL580914 & 1479054 & 6.4225 & 6.1681 & TRN & \\
\hline CHEMBL601825 & 1479054 & 3.9208 & 3.9151 & TRN & \\
\hline CHEMBL548356 & 1479054 & 5.4557 & 5.468 & TRN & \\
\hline CHEMBL581359 & 1479054 & 5.2353 & 5.1014 & TRN & \\
\hline CHEMBL533788 & 1479054 & 5.2859 & 5.5035 & TRN & \\
\hline CHEMBL580698 & 1479054 & 5.5146 & 5.5234 & TRN & \\
\hline CHEMBL580353 & 1479054 & 3.9208 & 4.0465 & TRN & \\
\hline CHEMBL531060 & 1479054 & 3.9208 & 4.0535 & TRN & \\
\hline CHEMBL581358 & 1479054 & 5.4669 & 5.4943 & TRN & \\
\hline
\end{tabular}


Supplemental Table S2.txt

\begin{tabular}{|c|c|c|c|c|c|}
\hline CHEMBL1237255 & 1479054 & 3.9208 & 4.078 & TRN & \\
\hline CHEMBL525506 & 1479054 & 5.687 & 5.7392 & TRN & \\
\hline CHEMBL581175 & 1479054 & 3.9208 & 3.8077 & TRN & \\
\hline CHEMBL590159 & 1479054 & 3.9208 & 3.9646 & TRN & \\
\hline CHEMBL586255 & 1479054 & 5.0916 & 5.2351 & TRN & \\
\hline CHEMBL602586 & 1479054 & 3.9208 & 4.2703 & TST & \\
\hline CHEMBL580812 & 1479054 & 5.4261 & 5.312 & TRN & \\
\hline CHEMBL600132 & 1479054 & 3.9208 & 5.1022 & TST & \\
\hline CHEMBL584841 & 1479054 & 3.9208 & 4.0464 & TRN & \\
\hline CHEMBL547825 & 1479054 & 3.9208 & 4.0696 & TRN & \\
\hline CHEMBL546770 & 1479054 & 5.5232 & 5.2626 & TRN & \\
\hline CHEMBL601528 & 1479054 & 3.9208 & 3.963 & TRN & \\
\hline CHEMBL534288 & 1479054 & 3.9208 & 3.8759 & TRN & \\
\hline CHEMBL600235 & 1479054 & 5.171 & 4.9931 & TRN & \\
\hline CHEMBL587432 & 1479054 & 5.7711 & 5.6195 & TRN & \\
\hline CHEMBL530978 & 1479054 & 3.9208 & 3.8917 & TRN & \\
\hline CHEMBL588259 & 1479054 & 6.7545 & 6.42200 & 0000000001 & TRN \\
\hline CHEMBL548721 & 1479054 & 5.3649 & 5.4913 & TRN & \\
\hline CHEMBL582634 & 1479054 & 5.3571 & 5.3883 & TRN & \\
\hline CHEMBL529435 & 1479054 & 5.2501 & 5.1532 & TRN & \\
\hline CHEMBL547448 & 1479054 & 5.0539 & 5.1423 & TRN & \\
\hline CHEMBL1738986 & 1479054 & 3.9208 & 3.9311 & TRN & \\
\hline CHEMBL578508 & 1479054 & 3.9208 & 4.0042 & TRN & \\
\hline CHEMBL590686 & 1479054 & 3.9208 & 4.0089 & TRN & \\
\hline CHEMBL535557 & 1479054 & 5.1831 & 5.2082 & TRN & \\
\hline CHEMBL601492 & 1479054 & 3.9208 & 3.8644 & TST & \\
\hline CHEMBL525692 & 1479054 & 3.9208 & 3.8433 & TRN & \\
\hline CHEMBL586175 & 1479054 & 5.2272 & 5.3421 & TRN & \\
\hline CHEMBL590675 & 1479054 & 3.9208 & 3.8896 & TRN & \\
\hline CHEMBL532958 & 1479054 & 4.87 & 4.7425 & TRN & \\
\hline CHEMBL586026 & 1479054 & 3.9208 & 3.97399 & 99999999998 & TST \\
\hline CHEMBL531170 & 1479054 & 6.1675 & 6.2592 & TRN & \\
\hline CHEMBL587029 & 1479054 & 6.6216 & 6.2667 & TRN & \\
\hline CHEMBL547387 & 1479054 & 5.0807 & 5.2728 & TRN & \\
\hline CHEMBL601156 & 1479054 & 3.9208 & 4.1575 & TST & \\
\hline CHEMBL548005 & 1479054 & 5.8011 & 5.7343 & TRN & \\
\hline CHEMBL 2028068 & 1479054 & 3.9208 & 4.0368 & TST & \\
\hline CHEMBL 2028055 & 1479054 & 3.9208 & 3.7265 & TRN & \\
\hline CHEMBL547795 & 1479054 & 5.8002 & 5.5941 & TRN & \\
\hline CHEMBL548422 & 1479054 & 5.3661 & 5.4535 & TRN & \\
\hline CHEMBL529869 & 1479054 & 5.6968 & 5.6871 & TRN & \\
\hline CHEMBL533808 & 1479054 & 5.2298 & 5.1224 & TRN & \\
\hline CHEMBL537564 & 1479054 & 5.8447 & 5.6878 & TRN & \\
\hline CHEMBL547077 & 1479054 & 6.1397 & 6.2001 & TRN & \\
\hline CHEMBL535556 & 1479054 & 3.9208 & 4.0863 & TRN & \\
\hline CHEMBL534589 & 1479054 & 3.9208 & 3.9713 & TRN & \\
\hline CHEMBL602211 & 1479054 & 3.9208 & 3.8666 & TRN & \\
\hline CHEMBL601612 & 1479054 & 3.9208 & 4.0315 & TRN & \\
\hline
\end{tabular}


Supplemental Table S2.txt

\begin{tabular}{|c|c|c|c|c|c|}
\hline CHEMBL536685 & 1479054 & 5.1211 & 4.9751 & TRN & \\
\hline CHEMBL525826 & 1479054 & 3.9208 & 4.0558 & TRN & \\
\hline CHEMBL534612 & 1479054 & 3.9208 & 3.7726 & TRN & \\
\hline CHEMBL524764 & 1479054 & 5.3677 & 5.2975 & TRN & \\
\hline CHEMBL589920 & 1479054 & 3.9208 & 4.4078 & TST & \\
\hline CHEMBL592305 & 1479054 & 3.9208 & 3.9472 & TST & \\
\hline CHEMBL590914 & 1479054 & 3.9208 & 3.9572 & TRN & \\
\hline CHEMBL585966 & 1479054 & 3.9208 & 3.9048 & TRN & \\
\hline CHEMBL585983 & 1479054 & 3.9208 & 3.7695 & TRN & \\
\hline CHEMBL1545915 & 1479054 & 3.9208 & 3.8593 & TST & \\
\hline CHEMBL587104 & 1479054 & 3.9208 & 3.80800 & 00000000003 & TRN \\
\hline CHEMBL581194 & 1479054 & 3.9208 & 3.86800 & 00000000003 & TRN \\
\hline CHEMBL581619 & 1479054 & 4.87 & 5.1411 & TRN & \\
\hline CHEMBL597855 & 1479054 & 3.9208 & 3.9283 & TRN & \\
\hline CHEMBL530223 & 1479054 & 3.9208 & 3.9107 & TRN & \\
\hline CHEMBL533563 & 1479054 & 3.9208 & 4.0988 & TST & \\
\hline CHEMBL534283 & 1479054 & 3.9208 & 4.1212 & TRN & \\
\hline CHEMBL599886 & 1479054 & 3.9208 & 3.9305 & TST & \\
\hline CHEMBL580567 & 1479054 & 5.2148 & 5.1294 & TRN & \\
\hline CHEMBL588855 & 1479054 & 3.9208 & 4.3255 & TRN & \\
\hline CHEMBL601348 & 1479054 & 3.9208 & 4.0265 & TST & \\
\hline CHEMBL586298 & 1479054 & 5.9694 & 6.3443 & TRN & \\
\hline CHEMBL582010 & 1479054 & 5.6142 & 5.2671 & TRN & \\
\hline CHEMBL588727 & 1479054 & 5.5664 & 5.6226 & TRN & \\
\hline CHEMBL582356 & 1479054 & 5.3472 & 5.3682 & TRN & \\
\hline CHEMBL546826 & 1479054 & 5.2057 & 5.2625 & TRN & \\
\hline CHEMBL531121 & 1479054 & 5.4678 & 5.2923 & TRN & \\
\hline CHEMBL592338 & 1479054 & 3.9208 & 3.8983 & TRN & \\
\hline CHEMBL533377 & 1479054 & 5.6234 & 5.5129 & TRN & \\
\hline CHEMBL580699 & 1479054 & 5.239 & 5.0721 & TST & \\
\hline CHEMBL526944 & 1479054 & 5.5136 & 5.5341 & TRN & \\
\hline CHEMBL588501 & 1479054 & 5.171 & 5.0295 & TRN & \\
\hline CHEMBL527234 & 1479054 & 3.9208 & 3.8528 & TRN & \\
\hline CHEMBL533333 & 1479054 & 5.7997 & 5.6933 & TRN & \\
\hline CHEMBL548374 & 1479054 & 5.171 & 5.0419 & TRN & \\
\hline CHEMBL586095 & 1479054 & 5.3348 & 5.3535 & TRN & \\
\hline CHEMBL95606 & 1479054 & 3.9208 & 3.9862 & TST & \\
\hline CHEMBL587759 & 1479054 & 3.6383 & 3.7695 & TRN & \\
\hline CHEMBL589205 & 1479054 & 3.9208 & 3.8748 & TRN & \\
\hline CHEMBL536166 & 1479054 & 6.2248 & 6.2946 & TRN & \\
\hline CHEMBL534214 & 1479054 & 5.1129 & 5.166 & TRN & \\
\hline CHEMBL598279 & 1479054 & 5.3107 & 5.1072 & TRN & \\
\hline CHEMBL533195 & 1479054 & 5.3635 & 5.4854 & TST & \\
\hline CHEMBL580345 & 1479054 & 4.87 & 4.9382 & TRN & \\
\hline CHEMBL586700 & 1479054 & 4.87 & 5.1442 & TRN & \\
\hline CHEMBL548469 & 1479054 & 3.9208 & 4.7707 & TRN & \\
\hline CHEMBL535323 & 1479054 & 5.3021 & 5.3159 & TRN & \\
\hline CHEMBL579802 & 1479054 & 5.1955 & 5.0257 & TRN & \\
\hline
\end{tabular}


Supplemental Table S2.txt

\begin{tabular}{|c|c|c|c|c|c|}
\hline CHEMBL529640 & 1479054 & 3.9208 & 3.9393 & TRN & \\
\hline CHEMBL528336 & 1479054 & 4.87 & 4.706 & TRN & \\
\hline CHEMBL579760 & 1479054 & 3.9208 & 4.1453 & TRN & \\
\hline CHEMBL528043 & 1479054 & 5.7347 & 5.3922 & TRN & \\
\hline CHEMBL524973 & 1479054 & 3.9208 & 4.2237 & TRN & \\
\hline CHEMBL548545 & 1479054 & 5.6499 & 5.3474 & TRN & \\
\hline CHEMBL587989 & 1479054 & 3.9208 & 3.9484 & TST & \\
\hline CHEMBL582072 & 1479054 & 3.9208 & 3.8919 & TRN & \\
\hline CHEMBL579300 & 1479054 & 3.9208 & 3.8858 & TRN & \\
\hline CHEMBL529140 & 1479054 & 6.0737 & 6.3498 & TRN & \\
\hline CHEMBL 2028052 & 1479054 & 3.9208 & 4.1411 & TRN & \\
\hline CHEMBL528492 & 1479054 & 3.9208 & 3.8172 & TRN & \\
\hline CHEMBL531611 & 1479054 & 3.9208 & 4.0299 & TRN & \\
\hline CHEMBL528245 & 1479054 & 3.9208 & 3.8379 & TRN & \\
\hline CHEMBL529874 & 1479054 & 3.9208 & 3.9775 & TST & \\
\hline CHEMBL589951 & 1479054 & 3.9208 & 4.0371 & TST & \\
\hline CHEMBL527132 & 1479054 & 5.5038 & 5.2254 & TST & \\
\hline CHEMBL529348 & 1479054 & 3.9208 & 3.8578 & TST & \\
\hline CHEMBL592125 & 1479054 & 3.9208 & 4.0891 & TST & \\
\hline CHEMBL529372 & 1479054 & 5.5109 & 5.4761 & TST & \\
\hline CHEMBL532890 & 1479054 & 5.1459 & 4.9148 & TST & \\
\hline CHEMBL530531 & 1479054 & 3.9208 & 4.1654 & TST & \\
\hline CHEMBL525879 & 1479054 & 5.466 & 5.5674 & TST & \\
\hline CHEMBL532464 & 1479054 & 6.8356 & 6.9141 & TST & \\
\hline CHEMBL588481 & 1479054 & 3.9208 & 3.9721 & TST & \\
\hline CHEMBL588318 & 1479054 & 5.3883 & 5.2241 & TST & \\
\hline CHEMBL527906 & 1479054 & 5.6784 & 5.4768 & TST & \\
\hline CHEMBL531046 & 1479054 & 5.7319 & 5.5477 & TST & \\
\hline CHEMBL580918 & 1479054 & 6.327006 & 000000000 & 6.2946 & TST \\
\hline CHEMBL 2021322 & 1479054 & 3.9208 & \multicolumn{3}{|c|}{$3.8930000000000002 \quad$ TST } \\
\hline CHEMBL581349 & 1479054 & 3.9208 & 3.8649 & TST & \\
\hline CHEMBL1460047 & 1479054 & 3.9208 & 4.0485 & TST & \\
\hline CHEMBL533429 & 1479054 & 5.1086 & 5.315 & TST & \\
\hline CHEMBL590888 & 1479054 & 3.9208 & \multicolumn{2}{|c|}{4.1610000000000005} & TST \\
\hline CHEMBL587083 & 1479054 & 3.9208 & 3.9133 & TST & \\
\hline CHEMBL580264 & 1479054 & 5.3102 & 5.2187 & TST & \\
\hline CHEMBL531529 & 1479054 & 5.7263 & 5.4582 & TST & \\
\hline CHEMBL527213 & 1479054 & 5.3709 & 5.3128 & TST & \\
\hline CHEMBL526987 & 1479054 & 5.4465 & 5.2545 & TST & \\
\hline CHEMBL586723 & 1479054 & 5.4227 & 5.5546 & TST & \\
\hline CHEMBL581489 & 1479054 & 3.9208 & 3.9404 & TST & \\
\hline CHEMBL600305 & 1479054 & 3.9208 & 4.0314 & TST & \\
\hline CHEMBL530973 & 1479054 & 3.9208 & 3.8404 & TST & \\
\hline CHEMBL526981 & 1479054 & 3.9208 & 3.8961 & TST & \\
\hline CHEMBL533085 & 1479054 & 5.0041 & 4.8079 & TST & \\
\hline CHEMBL546799 & 1479054 & 3.9208 & 3.9276 & TST & \\
\hline CHEMBL586704 & 1479054 & 3.9208 & 3.9159 & TST & \\
\hline CHEMBL534671 & 1479054 & 5.5197 & 5.2116 & TST & \\
\hline
\end{tabular}


Supplemental Table S2.txt

\begin{tabular}{|c|c|c|c|c|}
\hline CHEMBL587892 & 1479054 & 3.9208 & 4.1285 & TST \\
\hline CHEMBL604389 & 1479054 & 3.9208 & 3.9035 & TST \\
\hline CHEMBL 2028064 & 1479054 & 3.9208 & 4.0681 & TST \\
\hline CHEMBL532879 & 1479054 & 3.9208 & 3.908 & TST \\
\hline CHEMBL532472 & 1479054 & 6.1221 & \multicolumn{2}{|c|}{6.327999999999999} \\
\hline CHEMBL582495 & 1479054 & 3.9208 & 4.0324 & TST \\
\hline CHEMBL 2028049 & 1479054 & 3.9208 & 4.0087 & TST \\
\hline CHEMBL534374 & 1479054 & 5.6753 & 5.6363 & TST \\
\hline CHEMBL581874 & 1479054 & 3.9208 & 3.9647 & TST \\
\hline CHEMBL1594640 & 1479054 & 3.9208 & 3.946 & TST \\
\hline CHEMBL591362 & 1479054 & 5.171 & 4.9745 & TST \\
\hline CHEMBL1615697 & 1479054 & 3.9208 & 4.0708 & TST \\
\hline CHEMBL586130 & 1479054 & 5.3351 & 5.2184 & TST \\
\hline CHEMBL605281 & 1479054 & 3.9208 & 3.8785 & TST \\
\hline CHEMBL528480 & 1479054 & 5.697 & 5.6054 & TST \\
\hline CHEMBL536892 & 1479054 & 5.4814 & 5.4298 & TST \\
\hline CHEMBL587090 & 1479054 & 6.1158 & 5.6227 & TST \\
\hline CHEMBL535029 & 1479054 & 5.3493 & 5.0939 & TST \\
\hline CHEMBL587802 & 1479054 & 5.3471 & 4.9579 & TST \\
\hline CHEMBL527730 & 1479054 & 3.9208 & 3.9076 & TST \\
\hline CHEMBL607975 & 1479054 & 3.9208 & 4.1979 & TST \\
\hline CHEMBL532570 & 1479054 & 5.5936 & 5.7346 & TST \\
\hline CHEMBL545822 & 1479054 & 5.2831 & 5.2342 & TST \\
\hline CHEMBL585839 & 1479054 & 3.9208 & 3.7723 & TST \\
\hline CHEMBL 2028061 & 1479054 & 3.9208 & 3.9287 & TST \\
\hline CHEMBL526800 & 1479054 & 3.9208 & 3.905 & TST \\
\hline CHEMBL601814 & 1479054 & 3.9208 & 3.8382 & TST \\
\hline CHEMBL547269 & 1479054 & 3.9208 & 3.8276 & TST \\
\hline CHEMBL527400 & 1479054 & 5.3472 & 5.4945 & TST \\
\hline CHEMBL353161 & 1479054 & 4.87 & 4.9452 & TST \\
\hline CHEMBL601122 & 1479054 & 5.171 & 4.8708 & TST \\
\hline CHEMBL532155 & 1479054 & 3.9208 & 3.9358 & TST \\
\hline CHEMBL533283 & 1479054 & 5.6602 & 5.70299 & 9999999999 \\
\hline CHEMBL589916 & 1479054 & 3.9208 & 3.9332 & TST \\
\hline CHEMBL597444 & 1479054 & 3.9208 & 3.8665 & TST \\
\hline CHEMBL532647 & 1479054 & 5.2406 & 5.1679 & TST \\
\hline CHEMBL602946 & 1479054 & 3.9208 & 4.8464 & TST \\
\hline CHEMBL592044 & 1479054 & 3.9208 & 4.2448 & TST \\
\hline CHEMBL530402 & 1479054 & 5.1041 & 5.0923 & TST \\
\hline CHEMBL584237 & 1479054 & 3.9208 & 3.9316 & TST \\
\hline CHEMBL549241 & 1479054 & 5.3472 & 5.3669 & TST \\
\hline CHEMBL588011 & 1479054 & 5.1086 & 4.8737 & TST \\
\hline CHEMBL533017 & 1479054 & 3.9208 & 4.062 & TST \\
\hline CHEMBL353621 & 1479054 & 6.0223 & 6.3766 & TST \\
\hline CHEMBL548388 & 1479054 & 4.87 & 5.3114 & TST \\
\hline CHEMBL580159 & 1479054 & 3.9208 & 3.9046 & TST \\
\hline CHEMBL587934 & 1479054 & 5.4073 & 5.5798 & TST \\
\hline CHEMBL607308 & 1479054 & 3.9208 & 3.9581 & TST \\
\hline
\end{tabular}


Supplemental Table S2.txt

\begin{tabular}{|c|c|c|c|c|}
\hline CHEMBL546531 & 1479054 & 3.9208 & 4.083 & TST \\
\hline CHEMBL527593 & 1479054 & 3.9208 & 4.0614 & TST \\
\hline CHEMBL533883 & 1479054 & 5.8901 & 5.761 & TST \\
\hline CHEMBL581933 & 1479054 & 5.5091 & 5.3788 & TST \\
\hline CHEMBL587288 & 1479054 & 3.9208 & 3.9382 & TST \\
\hline CHEMBL585264 & 1479054 & 3.9208 & 4.0871 & TST \\
\hline CHEMBL588062 & 1479054 & 5.3217 & 5.3776 & TST \\
\hline CHEMBL536115 & 1479054 & 6.1891 & 6.1129 & TST \\
\hline CHEMBL586695 & 1479054 & 5.3665 & 5.2306 & TST \\
\hline CHEMBL 2028067 & 1479054 & 3.9208 & 4.0259 & TST \\
\hline CHEMBL581702 & 1479054 & 6.7747 & 6.92899 & 9999999999 \\
\hline CHEMBL590212 & 1479054 & 3.9208 & 4.1431 & TST \\
\hline CHEMBL3769882 & 1556483 & 3.301 & 3.6089 & TRN \\
\hline CHEMBL3770280 & 1556483 & 4.3915 & 4.2348 & TRN \\
\hline CHEMBL3771214 & 1556483 & 3.301 & 3.7951 & TRN \\
\hline CHEMBL3769627 & 1556483 & 3.301 & 3.432 & TRN \\
\hline CHEMBL3771097 & 1556483 & 4.3391 & 4.0596 & TRN \\
\hline CHEMBL3770814 & 1556483 & 4.8697 & 4.7932 & TRN \\
\hline CHEMBL3769412 & 1556483 & 3.301 & 3.2492 & TRN \\
\hline CHEMBL3769549 & 1556483 & 3.301 & 3.1143 & TRN \\
\hline CHEMBL3769738 & 1556483 & 3.301 & 3.4626 & TRN \\
\hline CHEMBL3770296 & 1556483 & 3.301 & 3.4266 & TRN \\
\hline CHEMBL3770932 & 1556483 & 3.301 & 3.2558 & TRN \\
\hline CHEMBL3770552 & 1556483 & 4.7375 & 4.4245 & TRN \\
\hline CHEMBL3770781 & 1556483 & 3.301 & 3.2016 & TRN \\
\hline CHEMBL3769642 & 1556483 & 3.301 & 3.3262 & TRN \\
\hline CHEMBL3769608 & 1556483 & 3.301 & 3.2656 & TRN \\
\hline CHEMBL3770970 & 1556483 & 3.301 & 2.9344 & TST \\
\hline CHEMBL3771114 & 1556483 & 3.301 & 3.5925 & TRN \\
\hline CHEMBL3770089 & 1556483 & 3.301 & 3.3184 & TRN \\
\hline CHEMBL3769955 & 1556483 & 4.4789 & 4.6158 & TRN \\
\hline CHEMBL3769468 & 1556483 & 4.6615 & 4.6088 & TRN \\
\hline CHEMBL3771236 & 1556483 & 3.301 & 3.3928 & TRN \\
\hline CHEMBL3770052 & 1556483 & 3.301 & 3.1947 & TRN \\
\hline CHEMBL3770335 & 1556483 & 3.301 & 3.5719 & TRN \\
\hline CHEMBL3770742 & 1556483 & 3.301 & 3.3919 & TRN \\
\hline CHEMBL3769809 & 1556483 & 3.301 & 3.0901 & TRN \\
\hline CHEMBL3770376 & 1556483 & 4.3307 & 4.3012 & TRN \\
\hline CHEMBL3770085 & 1556483 & 4.301 & 3.8856 & TRN \\
\hline CHEMBL3769423 & 1556483 & 3.301 & 3.1733 & TST \\
\hline CHEMBL 3771301 & 1556483 & 3.301 & 3.2947 & TRN \\
\hline CHEMBL3771262 & 1556483 & 4.301 & 4.0705 & TRN \\
\hline CHEMBL3771257 & 1556483 & 5.6021 & 5.5788 & TRN \\
\hline CHEMBL3770373 & 1556483 & 5.5229 & 5.7236 & TRN \\
\hline CHEMBL3771126 & 1556483 & 3.301 & 3.2762 & TRN \\
\hline CHEMBL3770658 & 1556483 & 4.382 & 4.4977 & TRN \\
\hline CHEMBL3771318 & 1556483 & 3.301 & 3.4821 & TRN \\
\hline CHEMBL3770937 & 1556483 & 4.6421 & 4.6006 & TRN \\
\hline
\end{tabular}


Supplemental Table S2.txt

\begin{tabular}{|c|c|c|c|c|c|}
\hline CHEMBL3769726 & 1556483 & 3.301 & 3.2071 & TRN & \\
\hline CHEMBL3770881 & 1556483 & 3.301 & 3.3378 & TRN & \\
\hline CHEMBL3771040 & 1556483 & 6.0969 & 6.0634 & TRN & \\
\hline CHEMBL3769625 & 1556483 & 3.301 & 3.283 & TST & \\
\hline CHEMBL3770386 & 1556483 & 4.5575 & 3.9446 & TST & \\
\hline CHEMBL3769894 & 1556483 & 3.301 & 3.2182 & TRN & \\
\hline CHEMBL3769967 & 1556483 & 3.301 & 3.2184 & TRN & \\
\hline CHEMBL3769969 & 1556483 & 3.301 & 3.2523 & TST & \\
\hline CHEMBL3771121 & 1556483 & 5.4318 & 5.2458 & TST & \\
\hline CHEMBL3770069 & 1556483 & 5.1938 & 4.9882 & TST & \\
\hline CHEMBL3771107 & 1556483 & 4.3575 & 4.9082 & TST & \\
\hline CHEMBL3769467 & 1556483 & 5.2757 & 5.3389 & TST & \\
\hline CHEMBL3770172 & 1556483 & 4.7423 & 4.8446 & TST & \\
\hline CHEMBL3770007 & 1556483 & 4.5638 & 4.5699 & TST & \\
\hline CHEMBL3769886 & 1556483 & 3.0 & 1.926 & TST & \\
\hline CHEMBL 3770494 & 1556483 & 3.301 & 3.0653 & TST & \\
\hline CHEMBL3769884 & 1556483 & 3.301 & 2.9767 & TST & \\
\hline CHEMBL1506967 & 688152 & 5.0526 & 4.8704 & TRN & \\
\hline CHEMBL448741 & 688152 & 4.8539 & 4.6801 & TST & \\
\hline CHEMBL1084643 & 688152 & 3.699 & 3.7061 & TST & \\
\hline CHEMBL1604546 & 688152 & 5.2495 & 4.9892 & TST & \\
\hline CHEMBL1563323 & 688152 & 5.3686 & 5.0072 & TRN & \\
\hline CHEMBL1368226 & 688152 & 3.699 & 4.0226 & TRN & \\
\hline CHEMBL1342736 & 688152 & 5.0531 & 5.1306 & TRN & \\
\hline CHEMBL1455957 & 688152 & 5.3107 & 5.1966 & TRN & \\
\hline CHEMBL1200792 & 688152 & 4.8794 & 5.0579 & TRN & \\
\hline CHEMBL1586980 & 688152 & 4.93 & 4.8221 & TRN & \\
\hline CHEMBL1588762 & 688152 & 3.699 & 5.2562 & TRN & \\
\hline CHEMBL1577591 & 688152 & 5.0367 & 5.2601 & TRN & \\
\hline CHEMBL1346595 & 688152 & 5.1537 & 4.9802 & TRN & \\
\hline CHEMBL1603776 & 688152 & 4.8097 & 4.9479 & TRN & \\
\hline CHEMBL1556596 & 688152 & 3.699 & 3.9641 & TRN & \\
\hline CHEMBL1974112 & 688152 & 4.7878 & 4.8605 & TRN & \\
\hline CHEMBL52 & 688152 & 5.0232 & 4.9839 & TRN & \\
\hline CHEMBL1598493 & 688152 & 7.0458 & 6.4489 & TRN & \\
\hline CHEMBL1572060 & 688152 & 3.699 & 3.608 & TRN & \\
\hline CHEMBL1422158 & 688152 & 5.3686 & 5.2276 & TRN & \\
\hline CHEMBL1567944 & 688152 & 6.8239 & 7.1306 & TST & \\
\hline CHEMBL1491541 & 688152 & 5.1675 & 5.0737 & TRN & \\
\hline CHEMBL1491007 & 688152 & 5.2765 & 5.053999 & 9999999999 & TRN \\
\hline CHEMBL1376120 & 688152 & 5.0675 & 5.1467 & TRN & \\
\hline CHEMBL1488723 & 688152 & 4.9586 & 5.1065 & TRN & \\
\hline CHEMBL1455056 & 688152 & 5.04 & 5.1361 & TRN & \\
\hline CHEMBL1445142 & 688152 & 4.762 & 4.8228 & TRN & \\
\hline CHEMBL 2006590 & 688152 & 3.699 & 3.8829 & TRN & \\
\hline CHEMBL1346468 & 688152 & 4.9914 & 5.5011 & TRN & \\
\hline CHEMBL1522275 & 688152 & 5.0467 & 4.8678 & TRN & \\
\hline CHEMBL1445768 & 688152 & 5.4609 & 5.1749 & TRN & \\
\hline
\end{tabular}




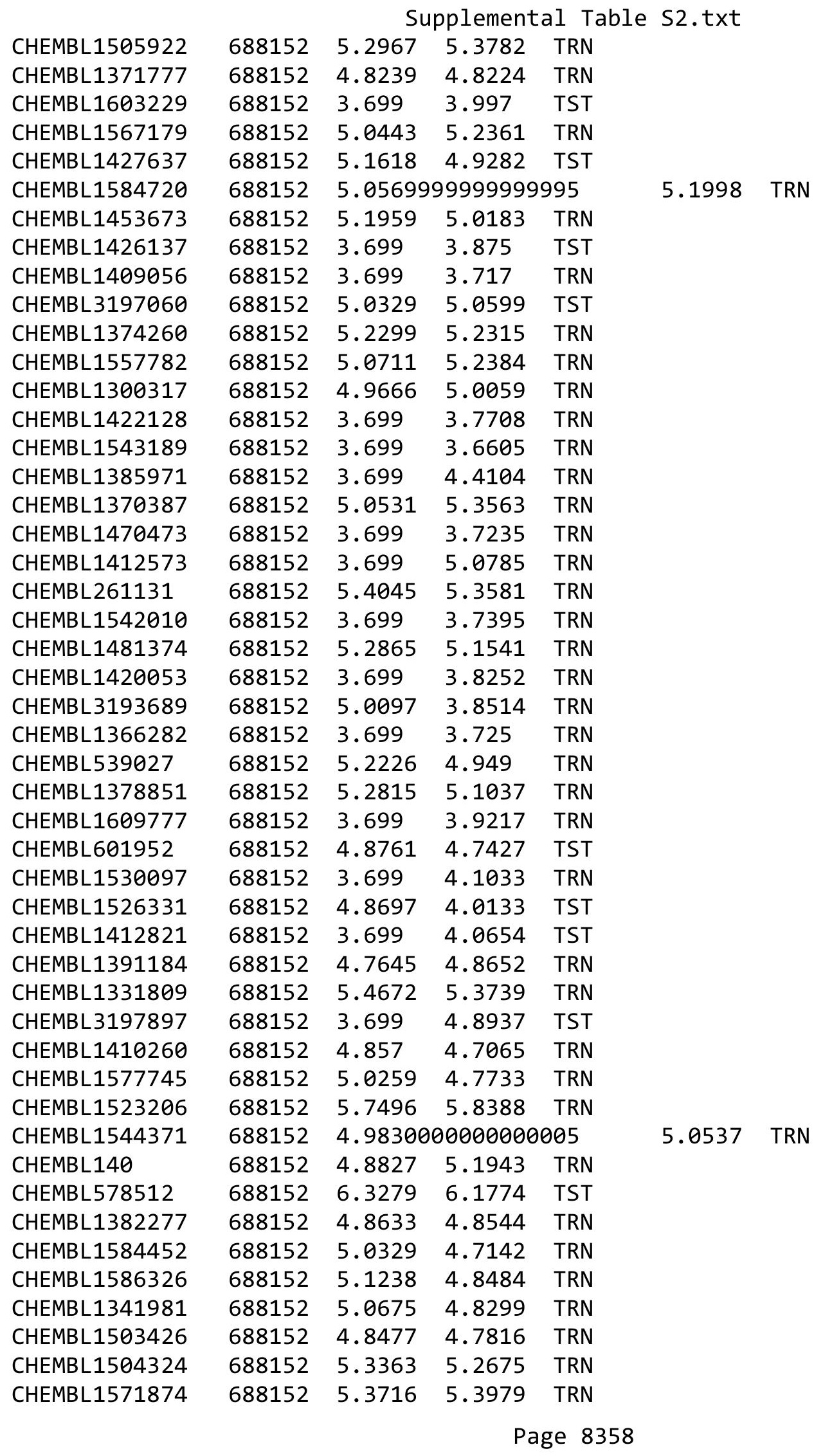




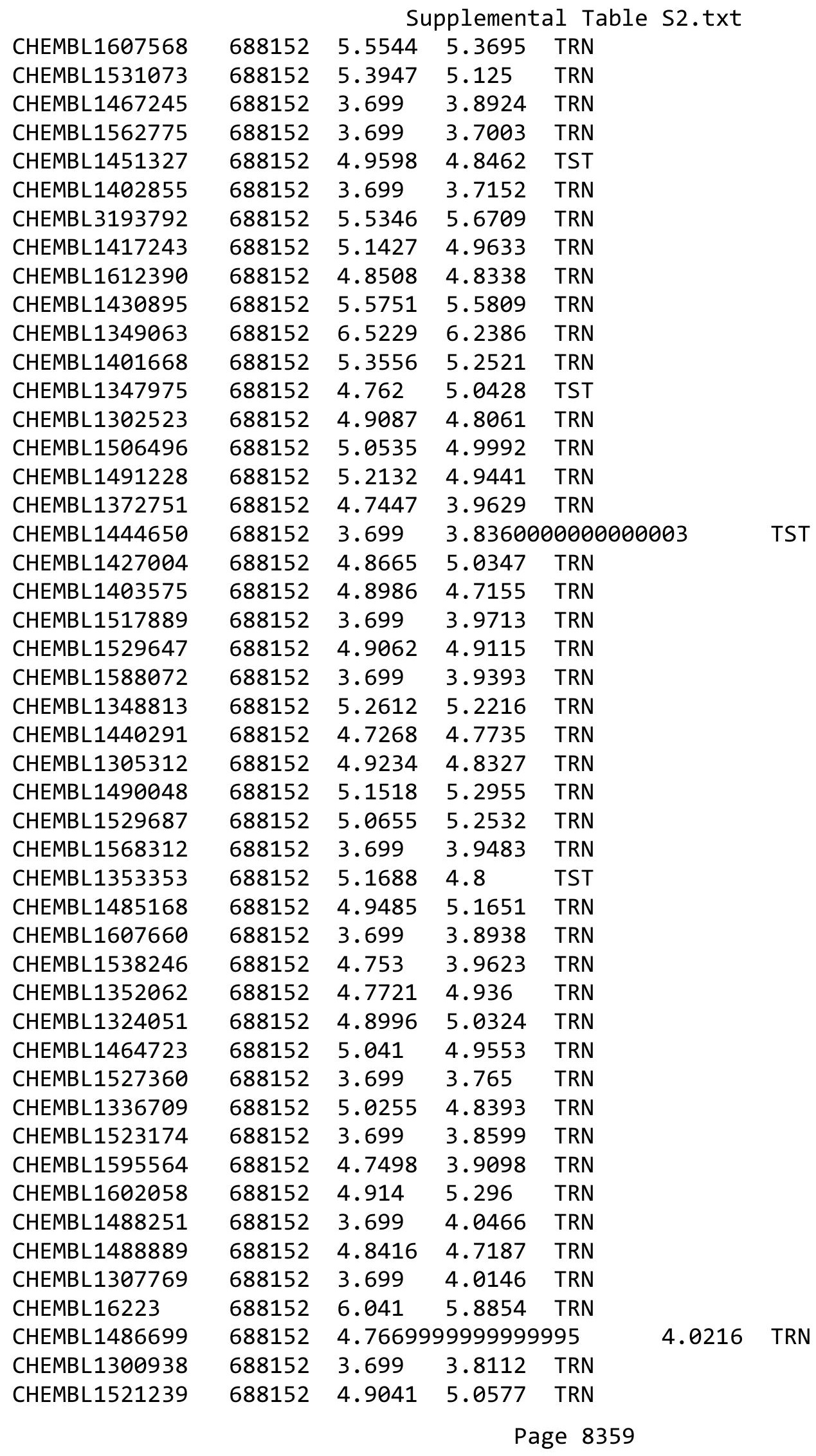




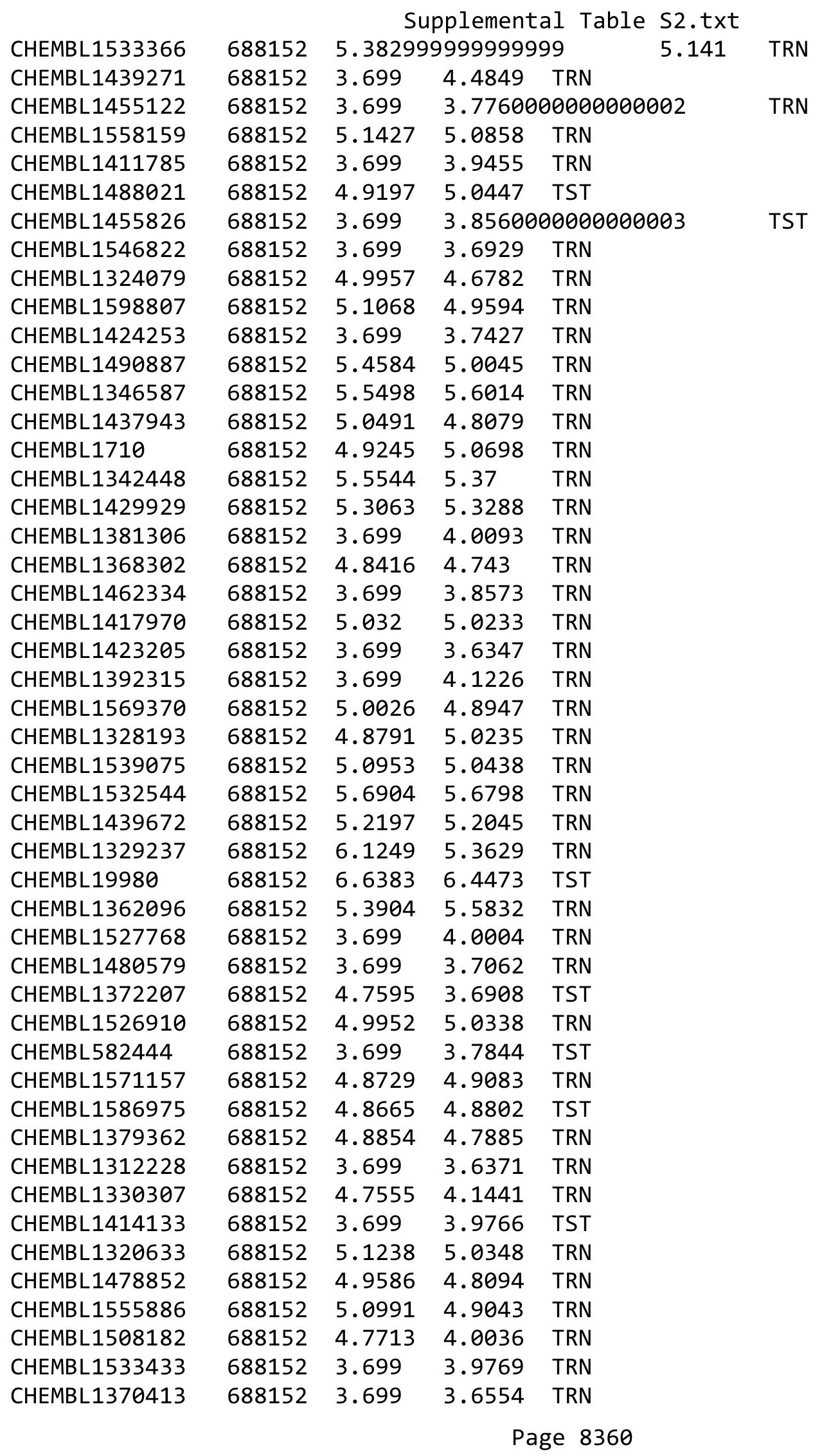




\begin{tabular}{|c|c|c|c|c|c|c|}
\hline & & \multicolumn{5}{|c|}{ Supplemental Table S2.txt } \\
\hline CHEMBL1465527 & 688152 & 5.7167 & 5.7253 & TRN & & \\
\hline CHEMBL1472193 & 688152 & 4.8935 & 5.2254 & TRN & & \\
\hline CHEMBL1432468 & 688152 & 3.699 & 3.9093 & TRN & & \\
\hline CHEMBL1588513 & 688152 & 5.0655 & 5.2923 & TRN & & \\
\hline CHEMBL1352844 & 688152 & 4.8125 & 4.5495 & TRN & & \\
\hline CHEMBL1567855 & 688152 & 4.7812 & 4.6932 & TRN & & \\
\hline CHEMBL1580990 & 688152 & 4.9031 & 5.1918 & TRN & & \\
\hline CHEMBL1560229 & 688152 & 5.153 & 4.8415 & TST & & \\
\hline CHEMBL1469736 & 688152 & 5.091 & 4.8269 & TRN & & \\
\hline CHEMBL1386456 & 688152 & 4.8821 & 4.9248 & TRN & & \\
\hline CHEMBL1584754 & 688152 & 5.3809 & 5.2057 & TRN & & \\
\hline CHEMBL1428417 & 688152 & 4.9245 & 5.2447 & TRN & & \\
\hline CHEMBL1345124 & 688152 & 3.699 & 3.8286 & TRN & & \\
\hline CHEMBL1381668 & 688152 & 4.8804 & 4.787 & TRN & & \\
\hline CHEMBL1438768 & 688152 & 3.699 & 3.8566 & TRN & & \\
\hline CHEMBL1310766 & 688152 & 3.699 & 3.7638 & TRN & & \\
\hline CHEMBL1975458 & 688152 & 4.9504 & 5.1326 & TRN & & \\
\hline CHEMBL3145067 & 688152 & 5.5638 & 5.721 & TRN & & \\
\hline CHEMBL1560366 & 688152 & 4.8945 & 5.0764 & TRN & & \\
\hline CHEMBL1605161 & 688152 & \multicolumn{3}{|c|}{5.172000000000001} & 5.3579 & TRN \\
\hline CHEMBL1509576 & 688152 & 3.699 & 3.8028 & TST & & \\
\hline CHEMBL1564871 & 688152 & 4.8041 & 4.8612 & TRN & & \\
\hline CHEMBL1360170 & 688152 & 4.7167 & 4.8454 & TRN & & \\
\hline CHEMBL1305911 & 688152 & 5.1373 & 5.0096 & TRN & & \\
\hline CHEMBL1525916 & 688152 & 5.0141 & 4.6012 & TRN & & \\
\hline CHEMBL1390573 & 688152 & 4.9983 & 5.069 & TRN & & \\
\hline CHEMBL1531839 & 688152 & 3.699 & 3.9204 & TST & & \\
\hline CHEMBL1458873 & 688152 & 4.8477 & 4.9956 & TRN & & \\
\hline CHEMBL1611371 & 688152 & 5.0888 & 5.0855 & TRN & & \\
\hline CHEMBL1410021 & 688152 & 3.699 & 4.2352 & TRN & & \\
\hline CHEMBL1545288 & 688152 & 4.9957 & 4.07100 & 0000000001 & & TRN \\
\hline CHEMBL1423096 & 688152 & 4.8242 & 4.8714 & TRN & & \\
\hline CHEMBL1347369 & 688152 & 5.1649 & 4.9509 & TRN & & \\
\hline CHEMBL1458697 & 688152 & 3.699 & 4.0421 & TRN & & \\
\hline CHEMBL123 & 688152 & 5.2097 & 5.4775 & TRN & & \\
\hline CHEMBL1589298 & 688152 & 4.7011 & 5.0493 & TRN & & \\
\hline CHEMBL1483522 & 688152 & 5.1169 & 5.2078 & TRN & & \\
\hline CHEMBL1528712 & 688152 & 3.699 & 4.015 & TRN & & \\
\hline CHEMBL1418843 & 688152 & 4.8911 & 4.7208 & TRN & & \\
\hline CHEMBL1504557 & 688152 & 3.699 & 3.7582 & TRN & & \\
\hline CHEMBL1538493 & 688152 & 4.9792 & 4.8765 & TST & & \\
\hline CHEMBL1565776 & 688152 & 5.2366 & 5.1958 & TRN & & \\
\hline CHEMBL1429775 & 688152 & 5.0424 & 5.2014 & TRN & & \\
\hline CHEMBL567130 & 688152 & 4.8401 & 4.6973 & TRN & & \\
\hline CHEMBL1344791 & 688152 & 5.1057 & 5.0423 & TRN & & \\
\hline CHEMBL3196476 & 688152 & 5.0467 & 5.0714 & TRN & & \\
\hline CHEMBL89445 & 688152 & \multicolumn{3}{|c|}{5.382999999999999} & 5.7794 & TRN \\
\hline CHEMBL393287 & 688152 & 5.1726 & 5.1043 & TRN & & \\
\hline
\end{tabular}


Supplemental Table S2.txt

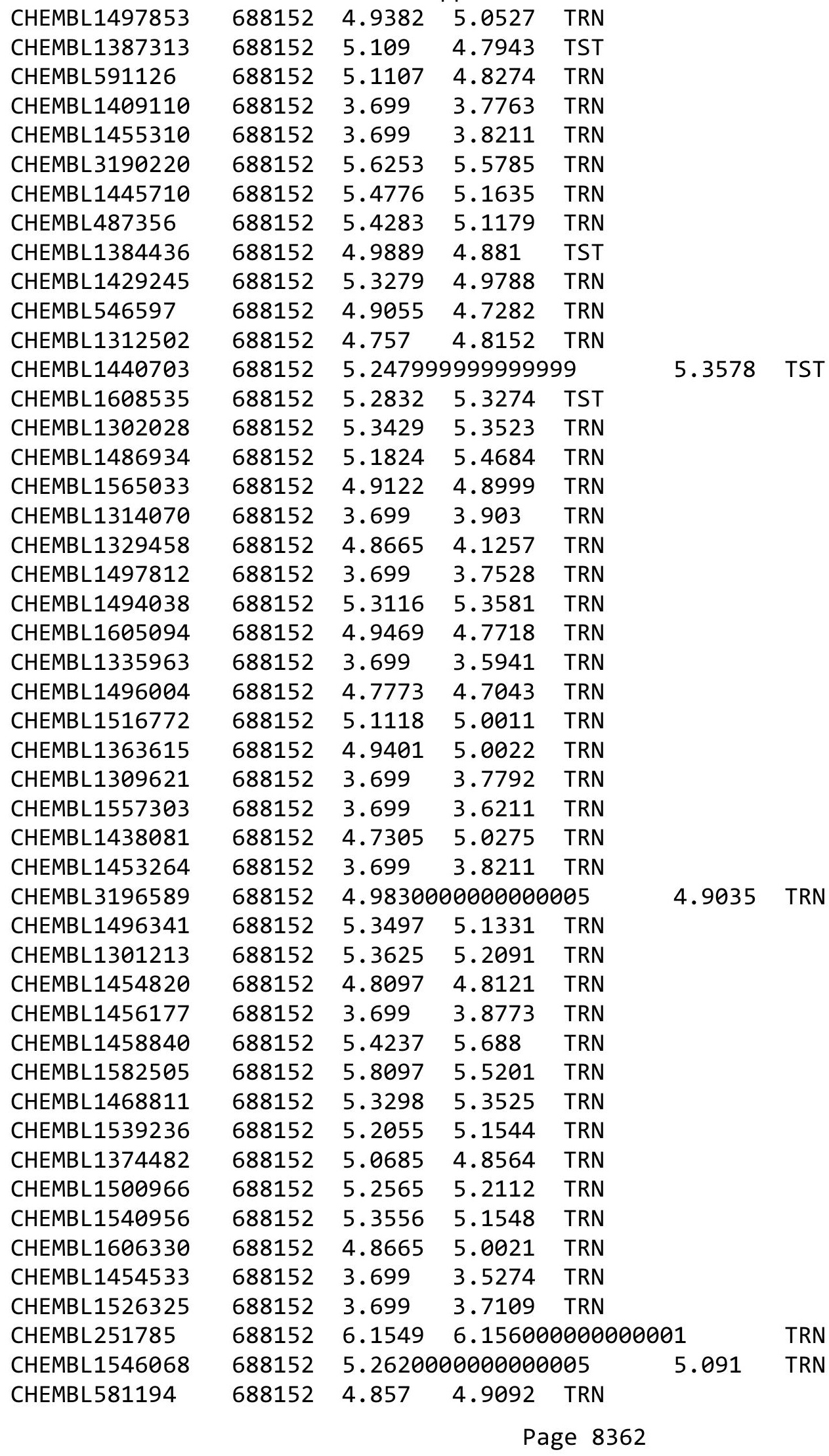




\begin{tabular}{|c|c|c|c|c|c|c|}
\hline & & \multicolumn{5}{|c|}{ Supplemental Table S2.txt } \\
\hline CHEMBL1299470 & 688152 & 4.8508 & 4.7186 & TRN & & \\
\hline CHEMBL1489578 & 688152 & 3.699 & 3.7659 & TRN & & \\
\hline CHEMBL1424968 & 688152 & 5.104 & 5.1 & TRN & & \\
\hline CHEMBL1386178 & 688152 & 5.0575 & 5.0199 & TRN & & \\
\hline CHEMBL1548229 & 688152 & 4.8887 & 4.9302 & TRN & & \\
\hline CHEMBL1555899 & 688152 & 5.1506 & 5.092 & TRN & & \\
\hline CHEMBL1557648 & 688152 & 5.5031 & 5.3741 & TRN & & \\
\hline CHEMBL1329396 & 688152 & 4.8072 & 4.8329 & TRN & & \\
\hline CHEMBL1480465 & 688152 & 4.8477 & 4.5309 & TST & & \\
\hline CHEMBL1485132 & 688152 & 3.699 & 3.9158 & TRN & & \\
\hline CHEMBL1455020 & 688152 & 4.9876 & 4.9891 & TRN & & \\
\hline CHEMBL1588679 & 688152 & \multicolumn{3}{|c|}{4.9830000000000005} & 4.8006 & TRN \\
\hline CHEMBL1414783 & 688152 & 3.699 & 3.8871 & TRN & & \\
\hline CHEMBL418068 & 688152 & 4.7033 & 5.6672 & TST & & \\
\hline CHEMBL1347618 & 688152 & 5.8416 & 5.7736 & TST & & \\
\hline CHEMBL1348071 & 688152 & 4.7033 & 4.8484 & TRN & & \\
\hline CHEMBL1492648 & 688152 & 5.3605 & 5.5191 & TRN & & \\
\hline CHEMBL1508674 & 688152 & 5.0035 & 4.7163 & TRN & & \\
\hline CHEMBL165 & 688152 & 5.1568 & 5.0142 & TRN & & \\
\hline CHEMBL1572266 & 688152 & 4.7317 & 4.5781 & TST & & \\
\hline CHEMBL1303518 & 688152 & 3.699 & 3.4809 & TRN & & \\
\hline CHEMBL1588463 & 688152 & 4.9431 & 5.0345 & TRN & & \\
\hline CHEMBL3189713 & 688152 & 4.9666 & 4.8341 & TST & & \\
\hline CHEMBL1733605 & 688152 & 3.699 & 3.9116 & TRN & & \\
\hline CHEMBL1383144 & 688152 & 4.7747 & 5.2579 & TRN & & \\
\hline CHEMBL1981770 & 688152 & 5.8327 & 5.6643 & TRN & & \\
\hline CHEMBL1596484 & 688152 & 3.699 & 3.8555 & TRN & & \\
\hline CHEMBL1555898 & 688152 & 4.8935 & 4.7193 & TRN & & \\
\hline CHEMBL1540038 & 688152 & 5.4895 & 5.5458 & TRN & & \\
\hline CHEMBL1310482 & 688152 & 3.699 & 3.7635 & TRN & & \\
\hline CHEMBL1337193 & 688152 & 3.699 & 3.9002 & TRN & & \\
\hline CHEMBL1561281 & 688152 & 4.7825 & 4.5393 & TRN & & \\
\hline CHEMBL1578082 & 688152 & 4.8193 & 3.8058 & TST & & \\
\hline CHEMBL1566928 & 688152 & 5.5086 & 5.4835 & TRN & & \\
\hline CHEMBL1578064 & 688152 & 5.0851 & 5.0939 & TRN & & \\
\hline CHEMBL1441325 & 688152 & 3.699 & 3.9615 & TRN & & \\
\hline CHEMBL1463540 & 688152 & 4.8752 & 4.7251 & TRN & & \\
\hline CHEMBL1407659 & 688152 & 4.8601 & 5.1688 & TST & & \\
\hline CHEMBL1362247 & 688152 & 3.699 & 3.6537 & TST & & \\
\hline CHEMBL3208118 & 688152 & 5.3251 & 5.2448 & TST & & \\
\hline CHEMBL587884 & 688152 & 5.5719 & 5.7438 & TST & & \\
\hline CHEMBL1535668 & 688152 & 3.699 & 3.8483 & TST & & \\
\hline CHEMBL1569782 & 688152 & 5.38399 & 99999999 & 995 & 5.2205 & TST \\
\hline CHEMBL1479249 & 688152 & 5.2403 & 4.258 & TST & & \\
\hline CHEMBL 259388 & 688152 & 4.7375 & 4.6616 & TST & & \\
\hline CHEMBL1541774 & 688152 & 3.699 & 3.7376 & TST & & \\
\hline CHEMBL1573627 & 688152 & 4.9318 & 4.9723 & TST & & \\
\hline CHEMBL1323835 & 688152 & 6.3098 & 4.0731 & TST & & \\
\hline
\end{tabular}




\begin{tabular}{|c|c|c|c|c|c|}
\hline & & \multicolumn{4}{|c|}{ Supplemental Table s2.txt } \\
\hline CHEMBL1505878 & 688152 & 4.8804 & 4.8793 & TST & \\
\hline CHEMBL1501475 & 688152 & 4.7552 & 3.8132 & TST & \\
\hline CHEMBL1495589 & 688152 & 4.959 & 4.9337 & TST & \\
\hline CHEMBL1303635 & 688152 & 5.0453 & 4.0177 & TST & \\
\hline CHEMBL1569203 & 688152 & 4.857 & 4.0097 & TST & \\
\hline CHEMBL1585481 & 688152 & 3.699 & 3.7822 & TST & \\
\hline CHEMBL1416112 & 688152 & 4.7799 & 4.63 & TST & \\
\hline CHEMBL1311755 & 688152 & 5.3116 & 5.4125 & TST & \\
\hline CHEMBL1373432 & 688152 & 5.1018 & 4.617 & TST & \\
\hline CHEMBL1522582 & 688152 & 4.8935 & 3.6454 & TST & \\
\hline CHEMBL1502512 & 688152 & 5.7496 & 5.3467 & TST & \\
\hline CHEMBL1586817 & 688152 & 5.1805 & 5.2028 & TST & \\
\hline CHEMBL1389722 & 688152 & 3.699 & 4.1787 & TST & \\
\hline CHEMBL1327738 & 688152 & 5.4597 & 5.272 & TST & \\
\hline CHEMBL1336847 & 688152 & 3.699 & 3.8569 & TST & \\
\hline CHEMBL1342173 & 688152 & 5.2118 & 4.9964 & TST & \\
\hline CHEMBL1418818 & 688152 & 5.4225 & 5.504 & TST & \\
\hline CHEMBL1598791 & 688152 & 5.1871 & 4.8445 & TST & \\
\hline CHEMBL1608078 & 688152 & 5.0491 & 4.891 & TST & \\
\hline CHEMBL1415885 & 688152 & $5.2620 e$ & 00000000 & 5.0159 & TST \\
\hline CHEMBL1327137 & 688152 & 5.1463 & 4.7549 & TST & \\
\hline CHEMBL1562591 & 688152 & 3.699 & 3.9066 & TST & \\
\hline CHEMBL1304814 & 688152 & 4.9547 & 4.88399 & 99999999995 & נו \\
\hline CHEMBL1596996 & 688152 & 5.2612 & 5.0782 & TST & \\
\hline CHEMBL1341815 & 688152 & 4.8193 & 4.8328 & TST & \\
\hline CHEMBL1493896 & 688152 & 3.699 & 4.0555 & TST & \\
\hline CHEMBL 2003973 & 688152 & 5.1349 & 5.1275 & TST & \\
\hline CHEMBL1564071 & 688152 & 3.699 & 3.7764 & TST & \\
\hline CHEMBL1331573 & 688152 & 5.5186 & 5.2931 & TST & \\
\hline CHEMBL1372884 & 688152 & 3.699 & 3.8367 & TST & \\
\hline CHEMBL1335944 & 688152 & 4.9547 & 5.3464 & TST & \\
\hline CHEMBL1350845 & 688152 & 3.699 & 4.1552 & TST & \\
\hline CHEMBL1526405 & 688152 & 4.8851 & 4.8909 & TST & \\
\hline CHEMBL1325494 & 688152 & 4.8827 & 5.2047 & TST & \\
\hline CHEMBL1540093 & 688152 & 3.699 & 3.673 & TST & \\
\hline CHEMBL1314042 & 688152 & 5.0022 & 5.1074 & TST & \\
\hline CHEMBL1371774 & 688152 & 5.3478 & 5.4178 & TST & \\
\hline CHEMBL1527929 & 688152 & 5.1278 & 5.1492 & TST & \\
\hline CHEMBL1444859 & 688152 & 5.1878 & 5.4689 & TST & \\
\hline CHEMBL1340321 & 688152 & 4.8179 & 4.9569 & TST & \\
\hline CHEMBL1329561 & 688152 & 3.699 & 3.8785 & TST & \\
\hline CHEMBL3930818 & 1624779 & 4.0 & 3.8877 & TRN & \\
\hline CHEMBL3394738 & 1624779 & 6.7959 & 7.0019 & TRN & \\
\hline CHEMBL3907541 & 1624779 & 6.4437 & 6.3232 & TRN & \\
\hline CHEMBL2393163 & 1624779 & 4.0 & 5.8504 & TST & \\
\hline CHEMBL3978996 & 1624779 & 4.0 & 4.1556 & TRN & \\
\hline CHEMBL3897803 & 1624779 & 6.0 & 6.1476 & TRN & \\
\hline CHEMBL3925878 & 1624779 & 4.0 & 4.1275 & TRN & \\
\hline
\end{tabular}




\begin{tabular}{|c|c|c|c|c|c|}
\hline & & & & & \\
\hline CHEMBL566757 & 1624779 & 5.4437 & 4.723 & TST & \\
\hline CHEMBL 2393183 & 1624779 & 4.0 & 3.7588 & TST & \\
\hline CHEMBL3394734 & 1624779 & 6.699 & 6.8173 & TRN & \\
\hline CHEMBL 3930755 & 1624779 & 4.0 & 4.0678 & TRN & \\
\hline CHEMBL3913503 & 1624779 & 4.0 & $3.99300 t$ & 00000000003 & TRN \\
\hline CHEMBL3963163 & 1624779 & 4.0 & 3.9633 & TRN & \\
\hline CHEMBL3948512 & 1624779 & 4.0 & 4.1558 & TRN & \\
\hline CHEMBL 3914526 & 1624779 & 4.0 & 4.0675 & TRN & \\
\hline CHEMBL3986197 & 1624779 & 4.0 & 3.9675 & TRN & \\
\hline CHEMBL 2420629 & 1624779 & 6.699 & 6.5588 & TST & \\
\hline CHEMBL3891956 & 1624779 & 5.4685 & 5.2122 & TRN & \\
\hline CHEMBL3958233 & 1624779 & 4.0 & 3.7931 & TRN & \\
\hline CHEMBL3939767 & 1624779 & 4.0 & 4.1611 & TRN & \\
\hline CHEMBL 2419515 & 1624779 & 7.0969 & 6.2819 & TST & \\
\hline CHEMBL 2393174 & 1624779 & 4.0 & 4.4643 & TST & \\
\hline CHEMBL3895553 & 1624779 & 4.0 & 4.0557 & TRN & \\
\hline CHEMBL3949594 & 1624779 & 4.0 & 4.0092 & TRN & \\
\hline CHEMBL3959982 & 1624779 & 6.4685 & 6.3072 & TRN & \\
\hline CHEMBL3940454 & 1624779 & 4.0 & 3.9537 & TRN & \\
\hline CHEMBL3968268 & 1624779 & 4.0 & 4.0416 & TRN & \\
\hline CHEMBL3958520 & 1624779 & 4.0 & 3.8423 & TRN & \\
\hline CHEMBL 3952257 & 1624779 & 4.0 & 4.3599 & TRN & \\
\hline CHEMBL 3889557 & 1624779 & 6.699 & 6.7251 & TRN & \\
\hline CHEMBL3932498 & 1624779 & 4.0 & 3.9992 & TRN & \\
\hline CHEMBL3986623 & 1624779 & 4.0 & 4.0537 & TRN & \\
\hline CHEMBL 3908644 & 1624779 & 6.3979 & 6.4569 & TRN & \\
\hline CHEMBL3974268 & 1624779 & 4.0 & 3.9821 & TRN & \\
\hline CHEMBL 3935485 & 1624779 & 6.3468 & 6.4123 & TRN & \\
\hline CHEMBL3923552 & 1624779 & 4.0 & 4.1945 & TRN & \\
\hline CHEMBL 3984355 & 1624779 & 4.0 & 3.9879 & TRN & \\
\hline CHEMBL3921880 & 1624779 & 4.0 & 4.3433 & TRN & \\
\hline CHEMBL3890621 & 1624779 & 5.4089 & 3.975 & TST & \\
\hline CHEMBL3960951 & 1624779 & 4.0 & 3.9452 & TRN & \\
\hline CHEMBL2391568 & 1624779 & 6.3768 & 5.6594 & TST & \\
\hline CHEMBL 3943545 & 1624779 & 4.0 & 3.9112 & TRN & \\
\hline CHEMBL2420620 & 1624779 & 7.2218 & 6.7087 & TRN & \\
\hline CHEMBL 2419506 & 1624779 & 4.0 & 3.6915 & TST & \\
\hline CHEMBL3981065 & 1624779 & 4.0 & 4.0722 & TRN & \\
\hline CHEMBL3972073 & 1624779 & 4.0 & 3.7838 & TRN & \\
\hline CHEMBL2391572 & 1624779 & 7.1549 & 5.0239 & TST & \\
\hline CHEMBL3904503 & 1624779 & 4.0 & 3.913006 & 20000000003 & TRN \\
\hline CHEMBL3962066 & 1624779 & 4.0 & 3.9537 & TRN & \\
\hline CHEMBL3127521 & 1624779 & 6.1427 & 4.9698 & TST & \\
\hline CHEMBL3902837 & 1624779 & 5.1427 & 5.1474 & TRN & \\
\hline CHEMBL 3934566 & 1624779 & 4.0 & 4.0942 & TRN & \\
\hline CHEMBL2419504 & 1624779 & 7.301 & 5.8875 & TST & \\
\hline CHEMBL3260358 & 1624779 & 7.1549 & 5.0601 & TST & \\
\hline CHEMBL17289 & 1624779 & 6.9208 & 5.3827 & TST & \\
\hline
\end{tabular}


Supplemental Table S2.txt

\begin{tabular}{|c|c|c|c|c|c|}
\hline CHEMBL3977721 & 1624779 & 4.0 & 3.6243 & TRN & \\
\hline CHEMBL2419505 & 1624779 & 7.301 & 5.476 & TST & \\
\hline CHEMBL3941475 & 1624779 & 4.0 & 4.0253 & TRN & \\
\hline CHEMBL 3889487 & 1624779 & 4.0 & 3.9457 & TRN & \\
\hline CHEMBL2417572 & 1624779 & 7.0969 & 6.2879 & TST & \\
\hline CHEMBL3921809 & 1624779 & 4.0 & 4.0007 & TRN & \\
\hline CHEMBL3913883 & 1624779 & 4.0 & 3.9918 & TRN & \\
\hline CHEMBL3797235 & 1572912 & 7.6198 & 7.8098 & TRN & \\
\hline CHEMBL3799487 & 1572912 & 8.699 & 8.3802 & TRN & \\
\hline CHEMBL3797572 & 1572912 & 7.9586 & 7.9083 & TRN & \\
\hline CHEMBL 3800161 & 1572912 & 7.5229 & 7.416 & TRN & \\
\hline CHEMBL3799853 & 1572912 & 8.1549 & 8.3655 & TRN & \\
\hline CHEMBL3798346 & 1572912 & 7.7959 & 7.9424 & TST & \\
\hline CHEMBL3797624 & 1572912 & 7.5229 & 7.5171 & TRN & \\
\hline CHEMBL3797858 & 1572912 & 7.6576 & 7.3993 & TRN & \\
\hline CHEMBL 3800627 & 1572912 & 7.7447 & 8.2008 & TRN & \\
\hline CHEMBL3798484 & 1572912 & 8.2218 & 8.1716 & TRN & \\
\hline CHEMBL3799199 & 1572912 & 7.6021 & 8.0356 & TRN & \\
\hline CHEMBL3799062 & 1572912 & 7.7212 & 6.9578 & TRN & \\
\hline CHEMBL3797882 & 1572912 & 8.0 & 7.8422 & TRN & \\
\hline CHEMBL 3800135 & 1572912 & 8.0969 & 7.6374 & TRN & \\
\hline CHEMBL3797343 & 1572912 & 5.5666 & 6.6006 & TST & \\
\hline CHEMBL3799957 & 1572912 & 6.7235 & 6.6971 & TRN & \\
\hline CHEMBL 3800270 & 1572912 & 8.0458 & 8.0456 & TRN & \\
\hline CHEMBL 3797425 & 1572912 & 7.6576 & 8.0824 & TRN & \\
\hline CHEMBL 3800062 & 1572912 & 8.5229 & 8.3559 & TRN & \\
\hline CHEMBL3797407 & 1572912 & 6.209 & 6.4977 & TRN & \\
\hline CHEMBL 3797668 & 1572912 & 6.6861 & 7.2487 & TST & \\
\hline CHEMBL3797948 & 1572912 & 7.1079 & 7.3532 & TRN & \\
\hline CHEMBL 3798723 & 1572912 & 7.5528 & 7.7854 & TRN & \\
\hline CHEMBL3798193 & 1572912 & 8.0969 & 8.0718 & TRN & \\
\hline CHEMBL3797290 & 1572912 & 7.7447 & 7.79 & TRN & \\
\hline CHEMBL3798612 & 1572912 & 8.2218 & 8.199 & TRN & \\
\hline CHEMBL3799348 & 1572912 & 7.6383 & 7.2198 & TRN & \\
\hline CHEMBL3799968 & 1572912 & 7.6021 & 7.5284 & TRN & \\
\hline CHEMBL3799220 & 1572912 & 7.8861 & 7.582006 & 2000000001 & TRN \\
\hline CHEMBL3799828 & 1572912 & 7.5229 & 7.7444 & TRN & \\
\hline CHEMBL3798670 & 1572912 & 7.2676 & 7.7375 & TRN & \\
\hline CHEMBL3799381 & 1572912 & 6.3197 & 6.5884 & TRN & \\
\hline CHEMBL3799229 & 1572912 & 8.5229 & 8.389 & TRN & \\
\hline CHEMBL3798104 & 1572912 & 7.2366 & 7.6681 & TST & \\
\hline CHEMBL3799583 & 1572912 & 6.9101 & 6.5052 & TST & \\
\hline CHEMBL3797825 & 1572912 & 7.9586 & 7.843 & TRN & \\
\hline CHEMBL3797989 & 1572912 & 7.8539 & 7.9805 & TRN & \\
\hline CHEMBL3799726 & 1572912 & 7.699 & 7.8837 & TST & \\
\hline CHEMBL3797603 & 1572912 & 7.8861 & 7.7952 & TST & \\
\hline CHEMBL 3800355 & 1572912 & 7.1367 & 7.4101 & TRN & \\
\hline CHEMBL3799770 & 1572912 & 7.7212 & 7.5608 & TRN & \\
\hline
\end{tabular}


Supplemental Table S2.txt

\begin{tabular}{|c|c|c|c|c|}
\hline 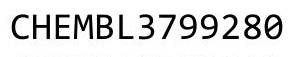 & 572912 & 5086 & 73 & \\
\hline HEMBL3799111 & 572912 & 8.301 & 9711 & \\
\hline HEMBL3800612 & 572912 & 6.9666 & 0839 & \\
\hline 0052 & 72912 & 959 & & \\
\hline AEMBL37 & 572912 & 7.7959 & 7728 & $T$ \\
\hline HEMBL3800183 & 572912 & 6.8928 & .1371 & \\
\hline HEMBL3798400 & 572912 & 7.6778 & 7.6826 & \\
\hline HEMBL3799829 & 572912 & 8.1549 & 3307 & \\
\hline AEMBL3797753 & 572912 & .9208 & . 7998 & \\
\hline AEMBL3800351 & 572912 & 7.0 & 7.4736 & \\
\hline HEMBL3798186 & 572912 & 8.301 & .2742 & \\
\hline HEMBL3798178 & 572912 & 8.2218 & 7.9234 & \\
\hline HEMBL3800291 & 912 & 7.8861 & 7.76 & \\
\hline HEMBL3800584 & 12 & .6576 & 7.9222 & \\
\hline HEMBL3797271 & 12 & .2218 & 8.2378 & \\
\hline HEMBL3800073 & 572912 & 7.7212 & 603 & \\
\hline HEMBL3799328 & 572912 & 7.2291 & 1455 & \\
\hline HEMBL3799395 & 12 & 06 & 1829 & KIV \\
\hline HEMBL3798681 & 12 & 468 & 13 & \\
\hline HEMBL3797880 & 912 & 101 & 7.0089 & \\
\hline HEMBL3798577 & 912 & 1079 & 8221 & \\
\hline HEMBL3798585 & 912 & 5.8788 & & \\
\hline HEMBL3798368 & 12 & 79 & 8.2158 & SI \\
\hline HEMBL 3800331 & 12 & 5576 & 7.3241 & $\mathrm{RN}$ \\
\hline HEMBL3798206 & 12 & 7.2924 & 7.4487 & ST \\
\hline HEMBL3800309 & 12 & 6.341 & 5917 & RN \\
\hline HEMBL490465 & 01 & 376 & 6248 & RN \\
\hline HEMBL4\& & 6 & 229 & 3884 & RN \\
\hline HEM & 6 & 55 & 07 & RN \\
\hline HEMBL4 & 6 & 7.4559 & 7.7654 & RN \\
\hline HEMBL490066 & 01 & 5. & & RN \\
\hline HEMBL484591 & 6 & 7.2441 & 7.1493 & ГRN \\
\hline HEMBL4 & 6 & 88 & 061 & RN \\
\hline HEM & 6 & 37 & 39 & $\mathrm{R}$ \\
\hline HEMBL484921 & 96 & & 068 & TST \\
\hline HEMBL489658 & 01 & 8.0915 & 847 & 「RN \\
\hline HEMBL471470 & 01 & 6.7932 & 6.6245 & TST \\
\hline HEMBL489263 & 6 & 696 & 7.8728 & TRN \\
\hline HEMBL 51 & 6 & 7. & 7.2331 & $\mathrm{RN}$ \\
\hline HEMBL499471 & 96 & 7.2291 & 7.2589 & RN \\
\hline HEMBL491463 & 96 & 7.3468 & 897 & ST \\
\hline HEMBL47 & 01 & 596 & 7.3373 & RN \\
\hline CHEMBL483740 & 501 & 6.7852 & 6.6025 & \\
\hline CHEMBL485150 & 96 & 7.041 & 6.9941 & RN \\
\hline CHEMBL501903 & 01796 & 7.2291 & 7.39 & RN \\
\hline HEMBL504618 & 01 & 7.8539 & 7.8662 & N \\
\hline CHEMBL4 & & 27 & 6.8973 & IIV \\
\hline HEMBL 50807 & 01796 & תבית & 7.3422 & \\
\hline
\end{tabular}

Page 8367 


\begin{tabular}{|c|c|c|c|c|}
\hline & & & pplement & al Table S \\
\hline CHEMBL446227 & 501796 & 7.5686 & 7.6055 & TRN \\
\hline CHEMBL482560 & 501796 & 7.3372 & 7.1715 & TRN \\
\hline CHEMBL482574 & 501796 & 6.9355 & 6.8785 & TRN \\
\hline CHEMBL484920 & 501796 & 6.7258 & 6.8024 & TRN \\
\hline CHEMBL490466 & 501796 & 7.3279 & 7.3933 & TRN \\
\hline CHEMBL451371 & 501796 & 7.5229 & 7.3926 & TRN \\
\hline CHEMBL507109 & 501796 & 6.9066 & 6.8612 & TRN \\
\hline CHEMBL484003 & 501796 & 7.4559 & 7.7438 & TRN \\
\hline CHEMBL484157 & 501796 & 6.7747 & 6.7799 & TRN \\
\hline CHEMBL522449 & 501796 & 7.2518 & 7.4355 & TRN \\
\hline CHEMBL521174 & 501796 & 6.6055 & 6.8062 & TRN \\
\hline CHEMBL484159 & 501796 & 7.301 & 7.2315 & TRN \\
\hline CHEMBL521913 & 501796 & 7.7696 & 7.6735 & TRN \\
\hline CHEMBL484788 & 501796 & 7.1871 & 7.3812 & TRN \\
\hline CHEMBL483553 & 501796 & 5.0 & 5.897 & TST \\
\hline CHEMBL483738 & 501796 & 7.4949 & 7.5024 & TRN \\
\hline CHEMBL483360 & 501796 & 7.6021 & 7.0183 & TRN \\
\hline CHEMBL483739 & 501796 & 8.0 & 7.7498 & TRN \\
\hline CHEMBL483340 & 501796 & 7.1805 & 7.0564 & TST \\
\hline CHEMBL484787 & 501796 & 7.0757 & 6.8491 & TRN \\
\hline CHEMBL513233 & 501796 & 6.6108 & 7.0652 & TST \\
\hline CHEMBL505395 & 501796 & 7.5086 & 7.5915 & TRN \\
\hline CHEMBL484002 & 501796 & 7.3279 & 7.2238 & TRN \\
\hline CHEMBL521448 & 501796 & 7.1079 & 6.9891 & TRN \\
\hline CHEMBL491073 & 501796 & 7.1612 & 7.2131 & TST \\
\hline CHEMBL484596 & 501796 & 7.3979 & 7.3209 & TST \\
\hline CHEMBL509277 & 501796 & 7.3768 & 7.3931 & TST \\
\hline CHEMBL484406 & 501796 & 7.3872 & 7.106 & TST \\
\hline CHEMBL451324 & 501796 & 7.585 & 7.6437 & TST \\
\hline CHEMBL449550 & 501796 & 7.1079 & 7.48600 & 2000000001 \\
\hline CHEMBL500031 & 501796 & 7.9586 & 7.6348 & TST \\
\hline CHEMBL1609579 & 688411 & 5.5 & 5.6117 & TRN \\
\hline CHEMBL568614 & 688411 & 6.4 & 6.3327 & TRN \\
\hline CHEMBL567331 & 688411 & 7.15 & 7.1527 & TRN \\
\hline CHEMBL1374544 & 688411 & 7.2 & 7.0456 & TST \\
\hline CHEMBL1372954 & 688411 & 5.15 & 5.2412 & TRN \\
\hline CHEMBL1489767 & 688411 & 5.35 & 5.3031 & TRN \\
\hline CHEMBL1444364 & 688411 & 4.9 & 5.0386 & TRN \\
\hline CHEMBL568636 & 688411 & 6.35 & 6.3605 & TRN \\
\hline CHEMBL568169 & 688411 & 6.2 & 6.1871 & TRN \\
\hline CHEMBL1494159 & 688411 & 6.15 & 6.0797 & TRN \\
\hline CHEMBL1315609 & 688411 & 5.65 & 5.7516 & TST \\
\hline CHEMBL1592581 & 688411 & 5.15 & 4.9962 & TRN \\
\hline CHEMBL1495595 & 688411 & 5.4 & 5.3294 & TRN \\
\hline CHEMBL1316791 & 688411 & 5.55 & 5.5086 & TRN \\
\hline CHEMBL1516409 & 688411 & 4.85 & 5.0093 & TRN \\
\hline CHEMBL1394132 & 688411 & 4.85 & 4.8594 & TST \\
\hline CHEMBL1434389 & 688411 & 5.45 & 5.7754 & TRN \\
\hline
\end{tabular}




\begin{tabular}{|c|c|c|c|c|c|}
\hline \multicolumn{6}{|c|}{ Supplemental Table S2.txt } \\
\hline CHEMBL566283 & 688411 & 6.25 & 6.3158 & TRN & \\
\hline CHEMBL1475370 & 688411 & 4.85 & 4.766 & TRN & \\
\hline CHEMBL1397881 & 688411 & 4.85 & 4.7588 & TRN & \\
\hline CHEMBL1610597 & 688411 & 6.25 & 6.1823 & TRN & \\
\hline CHEMBL1592698 & 688411 & 5.0 & 5.0328 & TRN & \\
\hline CHEMBL1446506 & 688411 & 5.9 & 5.8597 & TRN & \\
\hline CHEMBL566061 & 688411 & 6.8 & 6.7756 & TRN & \\
\hline CHEMBL1314875 & 688411 & 5.4 & 5.3182 & TRN & \\
\hline CHEMBL1526962 & 688411 & 5.1 & 5.0892 & TRN & \\
\hline CHEMBL1332033 & 688411 & 6.6 & 6.2118 & TST & \\
\hline CHEMBL1357559 & 688411 & 4.75 & 5.2104 & TST & \\
\hline CHEMBL1408427 & 688411 & 6.25 & 6.1521 & TRN & \\
\hline CHEMBL1480806 & 688411 & 4.9 & 4.9194 & TRN & \\
\hline CHEMBL1399528 & 688411 & 6.45 & 6.3586 & TST & \\
\hline CHEMBL568166 & 688411 & 5.55 & 5.5775 & TRN & \\
\hline CHEMBL1405981 & 688411 & 5.2 & 5.077 & TRN & \\
\hline CHEMBL566687 & 688411 & 6.8499 & 6.7575 & TRN & \\
\hline CHEMBL565654 & 688411 & 6.0 & 6.0912 & TRN & \\
\hline CHEMBL1332463 & 688411 & 5.55 & 5.63899 & 7999999999 & TRN \\
\hline CHEMBL1408995 & 688411 & 5.35 & 5.3164 & TRN & \\
\hline CHEMBL565856 & 688411 & 6.95 & 6.9525 & TRN & \\
\hline CHEMBL566501 & 688411 & 6.05 & 5.9805 & TRN & \\
\hline CHEMBL1433941 & 688411 & 5.1 & 5.1264 & TRN & \\
\hline CHEMBL1410859 & 688411 & 6.6499 & 6.2786 & TST & \\
\hline CHEMBL1370296 & 688411 & 6.6 & 6.4492 & TRN & \\
\hline CHEMBL566495 & 688411 & 5.9 & 6.0011 & TRN & \\
\hline CHEMBL1326793 & 688411 & 4.8 & 4.7649 & TRN & \\
\hline CHEMBL1408602 & 688411 & 5.2 & 5.2422 & TRN & \\
\hline CHEMBL1435151 & 688411 & 5.05 & 4.9971 & TRN & \\
\hline CHEMBL1418485 & 688411 & 5.15 & 5.1211 & TRN & \\
\hline CHEMBL1529880 & 688411 & 6.6499 & 6.5791 & TST & \\
\hline CHEMBL566722 & 688411 & 6.8499 & 6.9068 & TRN & \\
\hline CHEMBL1395933 & 688411 & 4.85 & 4.7288 & TST & \\
\hline CHEMBL1516785 & 688411 & 4.9 & 5.1048 & TRN & \\
\hline CHEMBL1355644 & 688411 & 5.1 & 5.0848 & TRN & \\
\hline CHEMBL1516009 & 688411 & 5.85 & 5.7184 & TST & \\
\hline CHEMBL566701 & 688411 & 6.9 & 6.9502 & TRN & \\
\hline CHEMBL1355974 & 688411 & 5.6 & 5.6213 & TST & \\
\hline CHEMBL1330317 & 688411 & 5.0 & 5.0305 & TST & \\
\hline CHEMBL566899 & 688411 & 5.6 & 5.5781 & TRN & \\
\hline CHEMBL1473959 & 688411 & 5.1 & 5.0355 & TRN & \\
\hline CHEMBL1557298 & 688411 & 5.75 & 5.8269 & TST & \\
\hline CHEMBL1473748 & 688411 & 4.85 & 5.1539 & TST & \\
\hline CHEMBL566062 & 688411 & 4.55 & 5.2137 & TST & \\
\hline CHEMBL1408593 & 688411 & 4.85 & 4.9834 & TST & \\
\hline CHEMBL3979462 & 1637645 & 6.2636 & 7.0731 & TST & \\
\hline CHEMBL3920898 & 1637645 & 7.8239 & 7.7013 & TRN & \\
\hline CHEMBL189937 & 1637645 & 8.301 & 8.0772 & TRN & \\
\hline
\end{tabular}


Supplemental Table S2.txt

\begin{tabular}{|c|c|c|c|c|c|}
\hline CHEMBL 3973181 & 1637645 & 7.9208 & 7.1434 & TRN & \\
\hline CHEMBL365339 & 1637645 & 6.0362 & 7.0682 & TRN & \\
\hline CHEMBL3954838 & 1637645 & 8.2218 & 8.6168 & TRN & \\
\hline CHEMBL3976143 & 1637645 & 7.7959 & 6.8637 & TRN & \\
\hline CHEMBL189745 & 1637645 & 6.0223 & 5.4955 & TRN & \\
\hline CHEMBL364317 & 1637645 & 8.2218 & 8.2556 & TRN & \\
\hline CHEMBL359761 & 1637645 & 5.1175 & 5.7805 & TST & \\
\hline CHEMBL191138 & 1637645 & 7.1308 & 6.9852 & TRN & \\
\hline CHEMBL192749 & 1637645 & 7.4318 & 7.5342 & TRN & \\
\hline CHEMBL 3893248 & 1637645 & 6.8697 & 7.296 & TRN & \\
\hline CHEMBL3977079 & 1637645 & 7.7447 & 7.4046 & TRN & \\
\hline CHEMBL371198 & 1637645 & 7.7447 & 7.3264 & TRN & \\
\hline CHEMBL3960859 & 1637645 & 8.2218 & 8.1864 & TRN & \\
\hline CHEMBL3901003 & 1637645 & 8.2218 & \multicolumn{2}{|c|}{8.892000000000001} & TRN \\
\hline CHEMBL 3960034 & 1637645 & 7.5229 & 7.4563 & TRN & \\
\hline CHEMBL3964646 & 1637645 & 8.301 & 8.2424 & TRN & \\
\hline CHEMBL3907408 & 1637645 & 8.301 & 7.2438 & TRN & \\
\hline CHEMBL190627 & 1637645 & 8.301 & 7.8206 & TRN & \\
\hline CHEMBL3919263 & 1637645 & 4.301 & 5.4898 & TRN & \\
\hline CHEMBL 3942419 & 1637645 & 4.301 & 6.7408 & TST & \\
\hline CHEMBL192060 & 1637645 & 7.8239 & \multicolumn{2}{|c|}{7.172000000000001} & TRN \\
\hline CHEMBL3962672 & 1637645 & 7.9586 & 7.82 & TRN & \\
\hline CHEMBL 3895532 & 1637645 & 7.7212 & 7.6443 & TST & \\
\hline CHEMBL140272 & 1637645 & 6.6778 & 6.9358 & TST & \\
\hline CHEMBL189308 & 1637645 & 7.6198 & 7.2488 & TST & \\
\hline CHEMBL3958430 & 1637645 & 8.301 & 8.5777 & TRN & \\
\hline CHEMBL 3984345 & 1637645 & 7.0555 & 6.6248 & TRN & \\
\hline CHEMBL3983877 & 1637645 & 7.8539 & \multicolumn{2}{|c|}{8.072000000000001} & TST \\
\hline CHEMBL3950533 & 1637645 & 8.3979 & 8.3878 & TRN & \\
\hline CHEMBL3973692 & 1637645 & 8.699 & 7.9678 & TRN & \\
\hline CHEMBL3905466 & 1637645 & 7.8239 & 8.1953 & TRN & \\
\hline CHEMBL 3945479 & 1637645 & 7.2924 & 7.0891 & TRN & \\
\hline CHEMBL3972301 & 1637645 & \multicolumn{3}{|c|}{6.757000000000001} & TST \\
\hline CHEMBL190804 & 1637645 & 6.7959 & 6.9977 & TRN & \\
\hline CHEMBL3970752 & 1637645 & 7.7447 & 8.0665 & TRN & \\
\hline CHEMBL3935761 & 1637645 & 8.699 & 8.3289 & TRN & \\
\hline CHEMBL189543 & 1637645 & 7.5086 & 7.4512 & TRN & \\
\hline CHEMBL372712 & 1637645 & 7.6778 & 7.7541 & TRN & \\
\hline CHEMBL370295 & 1637645 & 8.3979 & 7.8913 & TRN & \\
\hline CHEMBL189317 & 1637645 & 6.2366 & 7.2058 & TRN & \\
\hline CHEMBL3953207 & 1637645 & 6.2255 & 7.3608 & TRN & \\
\hline CHEMBL3952178 & 1637645 & 7.8861 & 7.4014 & TRN & \\
\hline CHEMBL3908855 & 1637645 & 7.7212 & 7.3236 & TRN & \\
\hline CHEMBL189579 & 1637645 & 6.8386 & 5.8324 & TST & \\
\hline CHEMBL425546 & 1637645 & 4.301 & 6.9759 & TST & \\
\hline CHEMBL 3928814 & 1637645 & 7.5686 & 7.2362 & TRN & \\
\hline CHEMBL189978 & 1637645 & 7.2007 & 6.6802 & TRN & \\
\hline CHEMBL 3897354 & 1637645 & 8.1549 & 8.2997 & TRN & \\
\hline
\end{tabular}


Supplemental Table S2.txt

\begin{tabular}{|c|c|c|c|c|}
\hline CHEMBL1908963 & 1637645 & 6.8386 & 7.2402 & TRN \\
\hline CHEMBL3903712 & 1637645 & 6.9101 & 7.4782 & TRN \\
\hline CHEMBL193184 & 1637645 & 7.8539 & 7.6157 & TRN \\
\hline CHEMBL189732 & 1637645 & 5.9586 & 6.4906 & TST \\
\hline CHEMBL3941758 & 1637645 & 7.699 & 7.9155 & TRN \\
\hline CHEMBL373300 & 1637645 & 7.8861 & 7.1686 & TRN \\
\hline CHEMBL189490 & 1637645 & 5.71 & 7.0806 & TRN \\
\hline CHEMBL190302 & 1637645 & 6.3565 & 6.5971 & TST \\
\hline CHEMBL3927156 & 1637645 & 9.0 & 8.4364 & TRN \\
\hline CHEMBL3968467 & 1637645 & 5.7696 & 6.9558 & TRN \\
\hline CHEMBL3895697 & 1637645 & 8.2218 & 8.5847 & TRN \\
\hline CHEMBL3918866 & 1637645 & 7.8861 & 6.9405 & TST \\
\hline CHEMBL3907135 & 1637645 & 8.301 & 7.5175 & TST \\
\hline CHEMBL3895953 & 1637645 & 8.301 & 8.3671 & TRN \\
\hline CHEMBL189848 & 1637645 & 6.8697 & 7.0015 & TRN \\
\hline CHEMBL3931560 & 1637645 & 8.0458 & 8.0111 & TRN \\
\hline CHEMBL193177 & 1637645 & 7.9208 & 7.8455 & TRN \\
\hline CHEMBL364029 & 1637645 & 6.9066 & 7.2164 & TST \\
\hline CHEMBL360675 & 1637645 & 8.1549 & 8.224 & TST \\
\hline CHEMBL3971207 & 1637645 & 8.3979 & 8.2089 & TST \\
\hline CHEMBL190332 & 1637645 & 7.4437 & 7.0609 & TST \\
\hline CHEMBL3221183 & 1330011 & 4.0 & 4.0455 & TRN \\
\hline CHEMBL 3221194 & 1330011 & 4.0 & 4.1994 & TRN \\
\hline CHEMBL3220945 & 1330011 & 4.0 & 3.9954 & TST \\
\hline CHEMBL 3221191 & 1330011 & 5.2104 & 4.8722 & TRN \\
\hline CHEMBL3221182 & 1330011 & 4.0 & 3.8891 & TRN \\
\hline CHEMBL3220955 & 1330011 & 4.0 & 3.6885 & TRN \\
\hline CHEMBL 3221211 & 1330011 & 4.0 & 4.0209 & TRN \\
\hline CHEMBL 3221203 & 1330011 & 4.0 & 4.5742 & TRN \\
\hline CHEMBL3221196 & 1330011 & 4.8508 & 4.9822 & TRN \\
\hline CHEMBL3221186 & 1330011 & 5.0 & 5.0443 & TRN \\
\hline CHEMBL3220946 & 1330011 & 4.0 & 4.3132 & TST \\
\hline CHEMBL 3221206 & 1330011 & 4.0 & 4.0569 & TRN \\
\hline CHEMBL3221193 & 1330011 & 4.0 & 4.0829 & TRN \\
\hline CHEMBL3221189 & 1330011 & 5.7825 & 5.274 & TRN \\
\hline CHEMBL3220950 & 1330011 & 4.0 & 3.9571 & TST \\
\hline CHEMBL3220954 & 1330011 & 4.0 & 3.8884 & TRN \\
\hline CHEMBL3221190 & 1330011 & 5.5935 & 5.3384 & TRN \\
\hline CHEMBL3220944 & 1330011 & 4.0 & 4.0595 & TST \\
\hline CHEMBL 3221188 & 1330011 & 6.5544 & 4.9182 & TRN \\
\hline CHEMBL3221204 & 1330011 & 4.0 & 4.0986 & TST \\
\hline CHEMBL3221205 & 1330011 & 4.0 & 4.1695 & TRN \\
\hline CHEMBL3221201 & 1330011 & 5.3363 & 5.2652 & TRN \\
\hline CHEMBL3221209 & 1330011 & 4.0 & 4.0438 & TRN \\
\hline CHEMBL 3221181 & 1330011 & 4.0 & 3.9812 & TRN \\
\hline CHEMBL3221187 & 1330011 & 5.1415 & 4.9473 & TRN \\
\hline CHEMBL 3221180 & 1330011 & 4.0 & 3.9688 & TRN \\
\hline CHEMBL3221185 & 1330011 & 4.0 & 3.8268 & TRN \\
\hline
\end{tabular}




\begin{tabular}{|c|c|c|c|c|c|c|}
\hline \multicolumn{7}{|c|}{ Supplemental Table S2.txt } \\
\hline CHEMBL3220949 & 1330011 & 4.0 & 4.0181 & TST & & \\
\hline CHEMBL3221199 & 1330011 & 4.0 & 4.8082 & TRN & & \\
\hline CHEMBL3220943 & 1330011 & 5.1904 & 5.1652 & TRN & & \\
\hline CHEMBL3221198 & 1330011 & 4.0 & 4.8475 & TRN & & \\
\hline CHEMBL3220959 & 1330011 & 4.0 & 4.0348 & TRN & & \\
\hline CHEMBL3221192 & 1330011 & 5.1972 & 5.2451 & TRN & & \\
\hline CHEMBL3221195 & 1330011 & 4.0 & 4.1887 & TRN & & \\
\hline CHEMBL3221208 & 1330011 & 4.0 & 4.0322 & TRN & & \\
\hline CHEMBL3220956 & 1330011 & 4.0 & 3.8146 & TRN & & \\
\hline CHEMBL3220957 & 1330011 & 4.0 & 3.7296 & TRN & & \\
\hline CHEMBL3220951 & 1330011 & 4.0 & 3.9652 & TST & & \\
\hline CHEMBL3220947 & 1330011 & 4.0 & 3.9309 & TST & & \\
\hline CHEMBL3217791 & 1330011 & 4.8447 & 5.2834 & TRN & & \\
\hline CHEMBL3221210 & 1330011 & 4.0 & 4.1127 & TRN & & \\
\hline CHEMBL3221202 & 1330011 & 4.0 & 4.4307 & TRN & & \\
\hline CHEMBL3221184 & 1330011 & 4.0 & 3.8924 & TRN & & \\
\hline CHEMBL3221200 & 1330011 & 5.1884 & 5.268 & TRN & & \\
\hline CHEMBL 3220948 & 1330011 & 4.0 & 4.243 & TST & & \\
\hline CHEMBL3221197 & 1330011 & 5.0 & 4.8761 & TRN & & \\
\hline CHEMBL3220958 & 1330011 & 4.0 & 4.083 & TRN & & \\
\hline CHEMBL3220952 & 1330011 & 4.0 & 3.908 & TST & & \\
\hline CHEMBL3220953 & 1330011 & 4.0 & 3.8554 & TST & & \\
\hline CHEMBL 3221207 & 1330011 & 4.0 & 4.3741 & TST & & \\
\hline CHEMBL161343 & 1330011 & 4.0 & 3.9258 & TST & & \\
\hline CHEMBL270221 & 470061 & 10.8861 & 9.6948 & TST & & \\
\hline CHEMBL272115 & 470061 & 7.585 & 7.6703 & TRN & & \\
\hline CHEMBL402892 & 470061 & 6.1367 & 6.2673 & TRN & & \\
\hline CHEMBL404119 & 470061 & 9.4559 & 9.4323 & TRN & & \\
\hline CHEMBL272349 & 470061 & 8.6198 & 8.7119 & TRN & & \\
\hline CHEMBL 256458 & 470061 & 6.699 & 6.7239 & TRN & & \\
\hline CHEMBL408044 & 470061 & 9.0555 & 9.0934 & TRN & & \\
\hline CHEMBL272136 & 470061 & 9.1487 & 9.1799 & TRN & & \\
\hline CHEMBL403291 & 470061 & 7.5528 & 8.231 & TST & & \\
\hline CHEMBL429741 & 470061 & 7.7959 & 8.8185 & TST & & \\
\hline CHEMBL402828 & 470061 & 9.3665 & 9.3309 & TRN & & \\
\hline CHEMBL256628 & 470061 & 9.0757 & 8.9936 & TRN & & \\
\hline CHEMBL402321 & 470061 & 7.2147 & 7.2568 & TRN & & \\
\hline CHEMBL442804 & 470061 & 6.7959 & 6.7798 & TRN & & \\
\hline CHEMBL272736 & 470061 & 7.6383 & 7.3706 & TRN & & \\
\hline CHEMBL403106 & 470061 & 8.6576 & 8.6285 & TRN & & \\
\hline CHEMBL 257451 & 470061 & 7.1367 & 7.1687 & TRN & & \\
\hline CHEMBL 256820 & 470061 & 10.0 & 9.3233 & TST & & \\
\hline CHEMBL269955 & 470061 & 10.30099 & 99999999 & 998 & 9.003 & TST \\
\hline CHEMBL409678 & 470061 & 6.585 & 6.5648 & TRN & & \\
\hline CHEMBL255799 & 470061 & 7.7212 & 7.6724 & TRN & & \\
\hline CHEMBL270862 & 470061 & $10.6990 e$ & 00000000 & 002 & 9.2448 & TST \\
\hline CHEMBL271904 & 470061 & 9.9586 & 8.9528 & TST & & \\
\hline CHEMBL257240 & 470061 & 7.0 & 7.0182 & TRN & & \\
\hline
\end{tabular}




\begin{tabular}{|c|c|c|c|c|}
\hline & & Sul & oplement & al Ta \\
\hline CHEMBL 271851 & 470061 & 5.585 & 5.5991 & TRN \\
\hline CHEMBL402064 & 470061 & 8.2757 & 8.2974 & TRN \\
\hline CHEMBL272977 & 470061 & 6.2518 & 6.27 & TRN \\
\hline CHEMBL 257037 & 470061 & 8.0 & 8.7832 & TST \\
\hline CHEMBL271427 & 470061 & 9.0 & 8.9834 & TRN \\
\hline CHEMBL442457 & 470061 & 9.8861 & 9.4333 & TST \\
\hline CHEMBL 257453 & 470061 & 7.5528 & 7.5113 & TRN \\
\hline CHEMBL257241 & 470061 & 6.3768 & 6.2908 & TRN \\
\hline CHEMBL 272737 & 470061 & 7.1079 & 7.1025 & TRN \\
\hline CHEMBL270034 & 470061 & 10.4318 & 9.5854 & TST \\
\hline CHEMBL 271080 & 470061 & 5.4949 & 5.4543 & TRN \\
\hline CHEMBL 270565 & 470061 & 8.7696 & 9.9514 & TST \\
\hline CHEMBL402237 & 470061 & 7.7447 & 7.8804 & TRN \\
\hline CHEMBL 272116 & 470061 & 6.5686 & 6.4576 & TRN \\
\hline CHEMBL270829 & 470061 & 8.9586 & 8.9759 & TRN \\
\hline CHEMBL272976 & 470061 & 6.3468 & 6.3335 & TRN \\
\hline CHEMBL 257854 & 470061 & 8.5686 & 8.6351 & TRN \\
\hline CHEMBL 258274 & 470061 & 10.3665 & 9.5292 & TST \\
\hline CHEMBL402730 & 470061 & 6.1871 & 6.1981 & TRN \\
\hline CHEMBL401788 & 470061 & 9.6778 & 9.9229 & TST \\
\hline CHEMBL 272772 & 470061 & 7.2757 & 7.3409 & TRN \\
\hline CHEMBL 272959 & 470061 & 7.3516 & 7.4248 & TRN \\
\hline CHEMBL 256890 & 470061 & 8.6383 & 8.5171 & TRN \\
\hline CHEMBL 257319 & 470061 & 6.4318 & 6.5288 & TRN \\
\hline CHEMBL 270255 & 470061 & 8.6576 & 8.6849 & TRN \\
\hline CHEMBL429758 & 470061 & 7.7212 & 7.6312 & TRN \\
\hline CHEMBL 257242 & 470061 & 6.4202 & 6.4278 & TRN \\
\hline CHEMBL1456906 & 688562 & 4.3 & 4.5588 & TRN \\
\hline CHEMBL140 & 688562 & 4.4 & 4.3808 & TRN \\
\hline CHEMBL1562104 & 688562 & 4.8 & 4.878 & TRN \\
\hline CHEMBL1585396 & 688562 & 4.4 & 4.5545 & TRN \\
\hline CHEMBL1495381 & 688562 & 5.7 & 5.5633 & TRN \\
\hline CHEMBL1492884 & 688562 & 4.4 & 4.4023 & TRN \\
\hline CHEMBL509531 & 688562 & 5.1 & 4.8141 & TST \\
\hline CHEMBL1407826 & 688562 & 4.4 & 4.5766 & TST \\
\hline CHEMBL1303139 & 688562 & 4.6 & 4.5113 & TRN \\
\hline CHEMBL1559341 & 688562 & 4.4 & 4.3484 & TRN \\
\hline CHEMBL 70582 & 688562 & 4.4 & 4.5342 & TRN \\
\hline CHEMBL1569493 & 688562 & 5.2 & 5.2994 & TRN \\
\hline CHEMBL1304981 & 688562 & 4.4 & 4.3466 & TRN \\
\hline CHEMBL1142 & 688562 & 4.3 & 4.2823 & TRN \\
\hline CHEMBL1414154 & 688562 & 4.4 & 4.2293 & TRN \\
\hline CHEMBL1319452 & 688562 & 4.4 & 4.5969 & TRN \\
\hline CHEMBL1579130 & 688562 & 6.0 & 5.32 & TST \\
\hline CHEMBL1558796 & 688562 & 4.5 & 4.3826 & TRN \\
\hline CHEMBL1496957 & 688562 & 4.6 & 4.5444 & TRN \\
\hline CHEMBL1200471 & 688562 & 6.1 & 6.234 & TRN \\
\hline CHEMBL1609459 & 688562 & 4.8 & 4.7665 & TRN \\
\hline
\end{tabular}




\begin{tabular}{|c|c|c|c|c|}
\hline \multicolumn{5}{|c|}{ olemental } \\
\hline CHEMBL1569226 & 688562 & 4.6 & 4.6813 & TRN \\
\hline CHEMBL1526319 & 688562 & 4.4 & 4.3379 & TRN \\
\hline CHEMBL 70971 & 688562 & 4.5 & 4.7194 & TRN \\
\hline CHEMBL1612246 & 688562 & 4.8 & 4.7012 & TRN \\
\hline CHEMBL1409985 & 688562 & 4.8 & 4.6816 & TRN \\
\hline CHEMBL1578983 & 688562 & 4.1 & 4.3825 & TRN \\
\hline CHEMBL3391990 & 688562 & 4.3 & 4.4236 & TST \\
\hline CHEMBL329673 & 688562 & 4.4 & 4.4088 & TRN \\
\hline CHEMBL1611235 & 688562 & 4.9 & 4.6555 & TRN \\
\hline CHEMBL1452158 & 688562 & 4.3 & 4.3416 & TRN \\
\hline CHEMBL194399 & 688562 & 4.4 & 4.3577 & TST \\
\hline CHEMBL1545634 & 688562 & 6.0 & 5.9468 & TRN \\
\hline CHEMBL196537 & 688562 & 4.3 & 4.3598 & TST \\
\hline CHEMBL1408847 & 688562 & 4.4 & 4.4193 & TRN \\
\hline CHEMBL1517425 & 688562 & 4.3 & 4.1237 & TRN \\
\hline CHEMBL1450123 & 688562 & 4.4 & 4.6288 & TRN \\
\hline CHEMBL327919 & 688562 & 4.8 & 4.6634 & TRN \\
\hline CHEMBL220845 & 688562 & 4.3 & 4.3449 & TRN \\
\hline CHEMBL1530684 & 688562 & 4.4 & 4.2795 & TRN \\
\hline CHEMBL1471289 & 688562 & 4.4 & 4.4659 & TRN \\
\hline CHEMBL1450607 & 688562 & 4.3 & 4.4068 & TST \\
\hline CHEMBL334255 & 688562 & 5.1 & 5.0032 & TRN \\
\hline CHEMBL388676 & 688562 & 4.8 & 4.9254 & TST \\
\hline CHEMBL1078384 & 688562 & 4.3 & 4.513 & TRN \\
\hline CHEMBL251389 & 688562 & 4.8 & 5.0801 & TRN \\
\hline CHEMBL1566504 & 688562 & 4.4 & 4.3851 & TST \\
\hline CHEMBL1489064 & 688562 & 4.4 & 4.2578 & TRN \\
\hline CHEMBL1447588 & 688562 & 5.7 & 5.2687 & TRN \\
\hline CHEMBL1449018 & 688562 & 4.3 & 4.2596 & TRN \\
\hline CHEMBL1535689 & 688562 & 4.4 & 4.3385 & TRN \\
\hline CHEMBL1510786 & 688562 & 4.3 & 4.4665 & TRN \\
\hline CHEMBL36296 & 688562 & 4.3 & 4.4974 & TRN \\
\hline CHEMBL1524617 & 688562 & 4.5 & 4.7638 & TST \\
\hline CHEMBL1600998 & 688562 & 4.9 & 4.8099 & TRN \\
\hline CHEMBL172064 & 688562 & 4.3 & 4.4775 & TRN \\
\hline CHEMBL1391326 & 688562 & 4.4 & 4.5987 & TRN \\
\hline CHEMBL1366408 & 688562 & 4.4 & 4.545 & TRN \\
\hline CHEMBL280998 & 688562 & 4.8 & 4.5881 & TRN \\
\hline CHEMBL1565705 & 688562 & 4.1 & 4.3644 & TRN \\
\hline CHEMBL1522486 & 688562 & 4.9 & 4.7469 & TRN \\
\hline CHEMBL440287 & 688562 & 4.4 & 4.4486 & TRN \\
\hline CHEMBL1519327 & 688562 & 5.6 & 5.7368 & TRN \\
\hline CHEMBL1499545 & 688562 & 5.4 & 5.1623 & TRN \\
\hline CHEMBL1448387 & 688562 & 4.3 & 4.5036 & TRN \\
\hline CHEMBL224282 & 688562 & 4.5 & 4.8186 & TRN \\
\hline CHEMBL1308088 & 688562 & 4.9 & 4.7705 & TRN \\
\hline CHEMBL454173 & 688562 & 6.0 & 5.8641 & TRN \\
\hline CHEMBL165 & 688562 & 4.4 & 4.4826 & TRN \\
\hline
\end{tabular}




\begin{tabular}{|c|c|c|c|c|}
\hline \multicolumn{5}{|c|}{ Supplemental Table S2.txt } \\
\hline CHEMBL1338613 & 688562 & 5.4 & 4.4022 & TRN \\
\hline CHEMBL196590 & 688562 & 4.3 & 4.3122 & TST \\
\hline CHEMBL28 & 688562 & 4.4 & 4.6286 & TST \\
\hline CHEMBL1230309 & 688562 & 4.1 & 4.4879 & TST \\
\hline CHEMBL44072 & 688562 & 4.9 & 4.6038 & TST \\
\hline CHEMBL402063 & 688562 & 6.0 & 5.2234 & TST \\
\hline CHEMBL1527567 & 688562 & 4.3 & 4.1599 & TST \\
\hline CHEMBL1602699 & 688562 & 5.3 & 4.9213 & TST \\
\hline CHEMBL184450 & 688562 & 4.1 & 4.4182 & TST \\
\hline CHEMBL935 & 688562 & 4.3 & 4.3743 & TST \\
\hline CHEMBL192627 & 688562 & 4.4 & 4.2768 & TST \\
\hline CHEMBL1256654 & 688551 & 6.0 & 5.7679 & TRN \\
\hline CHEMBL517986 & 688551 & 5.1 & 6.1558 & TRN \\
\hline CHEMBL1256995 & 688551 & 6.05 & 5.2571 & TRN \\
\hline CHEMBL1256749 & 688551 & 5.65 & 5.7616 & TRN \\
\hline CHEMBL122270 & 688551 & 5.25 & 5.5091 & TRN \\
\hline CHEMBL 28626 & 688551 & 7.699 & 6.4964 & TRN \\
\hline CHEMBL338790 & 688551 & 4.8 & 6.1447 & TRN \\
\hline CHEMBL1512111 & 688551 & 4.7 & \multicolumn{2}{|c|}{5.678999999999999} \\
\hline CHEMBL1480136 & 688551 & 7.3497 & 6.4535 & TRN \\
\hline CHEMBL146855 & 688551 & 7.6498 & 6.5087 & TRN \\
\hline CHEMBL1434950 & 688551 & 7.9508 & 5.4775 & TRN \\
\hline CHEMBL363554 & 688551 & 7.2503 & 5.9661 & TST \\
\hline CHEMBL268868 & 688551 & 7.0501 & 6.0614 & TRN \\
\hline CHEMBL11348 & 688551 & 6.35 & 6.085 & TRN \\
\hline CHEMBL21260 & 688551 & 4.55 & 5.5721 & TRN \\
\hline CHEMBL416657 & 688551 & 6.6499 & 5.9229 & TRN \\
\hline CHEMBL 24510 & 688551 & 6.8499 & 6.0663 & TRN \\
\hline CHEMBL1255733 & 688551 & 6.1 & 5.6085 & TST \\
\hline CHEMBL 23194 & 688551 & 6.05 & 6.4184 & TRN \\
\hline CHEMBL1256623 & 688551 & 7.2503 & 6.4623 & TRN \\
\hline CHEMBL553503 & 688551 & 4.8 & 5.7069 & TRN \\
\hline CHEMBL33884 & 688551 & 4.6 & 4.83 & TRN \\
\hline CHEMBL1329927 & 688551 & 5.75 & 5.5822 & TRN \\
\hline CHEMBL293349 & 688551 & 4.85 & 5.2052 & TRN \\
\hline CHEMBL355496 & 688551 & 7.0 & 6.4924 & TRN \\
\hline CHEMBL1256735 & 688551 & 4.55 & 5.2381 & TRN \\
\hline CHEMBL556001 & 688551 & 5.0 & 5.2277 & TRN \\
\hline CHEMBL 280563 & 688551 & 7.4001 & \multicolumn{2}{|c|}{6.617999999999999} \\
\hline CHEMBL1517187 & 688551 & 5.15 & 5.4509 & TRN \\
\hline CHEMBL1253351 & 688551 & 7.699 & 6.0438 & TST \\
\hline CHEMBL1570350 & 688551 & 5.35 & 4.6941 & TRN \\
\hline CHEMBL1338229 & 688551 & 4.9 & 5.6086 & TRN \\
\hline CHEMBL1556654 & 688551 & 4.8 & 6.1828 & TST \\
\hline CHEMBL25236 & 688551 & 4.85 & 4.4975 & TRN \\
\hline CHEMBL58033 & 688551 & 6.0 & 4.8718 & TRN \\
\hline CHEMBL1256290 & 688551 & 5.2 & 6.1359 & TRN \\
\hline CHEMBL1626274 & 688551 & 6.0 & 5.7374 & TRN \\
\hline
\end{tabular}




\begin{tabular}{|c|c|c|c|c|c|}
\hline \multicolumn{6}{|c|}{ Supplemental Table S2.txt } \\
\hline CHEMBL1256916 & 688551 & 4.9 & 5.1308 & TRN & \\
\hline CHEMBL183 & 688551 & 4.65 & 5.579 & TRN & \\
\hline CHEMBL1256698 & 688551 & 4.7 & 5.5643 & TRN & \\
\hline CHEMBL1553428 & 688551 & 4.65 & 5.0782 & TRN & \\
\hline CHEMBL1255831 & 688551 & 6.45 & 6.4561 & TRN & \\
\hline CHEMBL1200462 & 688551 & 6.8499 & 6.2212 & TRN & \\
\hline CHEMBL376103 & 688551 & 4.95 & 6.2835 & TRN & \\
\hline CHEMBL1315457 & 688551 & 4.7 & 6.3524 & TST & \\
\hline CHEMBL34730 & 688551 & 8.5528 & 5.5918 & TRN & \\
\hline CHEMBL1593815 & 688551 & 5.55 & 6.4973 & TRN & \\
\hline CHEMBL 2448607 & 688551 & 4.7 & 6.5081 & TST & \\
\hline CHEMBL1256390 & 688551 & 7.6003 & 6.3965 & TRN & \\
\hline CHEMBL1553768 & 688551 & 4.75 & 5.3696 & TRN & \\
\hline CHEMBL1257003 & 688551 & 5.0 & 5.7284 & TRN & \\
\hline CHEMBL 287045 & 688551 & 4.75 & 5.7347 & TRN & \\
\hline CHEMBL18840 & 688551 & 4.7 & 6.1329 & TRN & \\
\hline CHEMBL1200450 & 688551 & 5.9 & 5.5371 & TRN & \\
\hline CHEMBL 2374062 & 688551 & 6.6499 & 6.205 & TST & \\
\hline CHEMBL 290943 & 688551 & 5.35 & 6.2031 & TST & \\
\hline CHEMBL47940 & 688551 & 5.15 & 5.8527 & TRN & \\
\hline CHEMBL1366616 & 688551 & 5.65 & 5.2952 & TRN & \\
\hline CHEMBL1256191 & 688551 & 4.55 & 6.0183 & TRN & \\
\hline CHEMBL 305195 & 688551 & 5.25 & 5.4058 & TRN & \\
\hline CHEMBL1322702 & 688551 & 4.7 & 4.9345 & TRN & \\
\hline CHEMBL1522778 & 688551 & 5.6 & 5.6909 & TRN & \\
\hline CHEMBL 280822 & 688551 & 4.65 & 5.5284 & TRN & \\
\hline CHEMBL270299 & 688551 & 4.55 & 6.3749 & TST & \\
\hline CHEMBL1256709 & 688551 & 4.8 & 5.0275 & TRN & \\
\hline CHEMBL1255747 & 688551 & 6.3 & 6.4342 & TRN & \\
\hline CHEMBL1526852 & 688551 & 4.55 & 6.1514 & TRN & \\
\hline CHEMBL1354145 & 688551 & 6.45 & 6.2739 & TRN & \\
\hline CHEMBL1257075 & 688551 & 7.7496 & 5.1598 & TRN & \\
\hline CHEMBL1590552 & 688551 & 7.4498 & 6.50899 & 99999999995 & TRN \\
\hline CHEMBL608555 & 688551 & 4.55 & 6.6632 & TRN & \\
\hline CHEMBL1567944 & 688551 & 4.9 & 5.0636 & TRN & \\
\hline CHEMBL51697 & 688551 & 7.15 & 5.6424 & TRN & \\
\hline CHEMBL49247 & 688551 & 5.65 & 5.4635 & TRN & \\
\hline CHEMBL261634 & 688551 & 6.9 & 6.1351 & TST & \\
\hline CHEMBL13790 & 688551 & 6.0 & 5.7947 & TRN & \\
\hline CHEMBL402468 & 688551 & 7.6498 & 6.4443 & TRN & \\
\hline CHEMBL36148 & 688551 & 4.9 & 5.4946 & TRN & \\
\hline CHEMBL26320 & 688551 & 6.05 & 5.1926 & TRN & \\
\hline CHEMBL39 & 688551 & 7.0 & 6.2025 & TRN & \\
\hline CHEMBL410873 & 688551 & 7.4498 & 6.28100 & 2000000001 & TRN \\
\hline CHEMBL1256737 & 688551 & 5.65 & 5.4961 & TRN & \\
\hline CHEMBL1319741 & 688551 & 7.2503 & 5.4564 & TST & \\
\hline CHEMBL1324405 & 688551 & 5.0 & 5.9534 & TRN & \\
\hline CHEMBL310798 & 688551 & 7.8996 & 6.6533 & TRN & \\
\hline
\end{tabular}




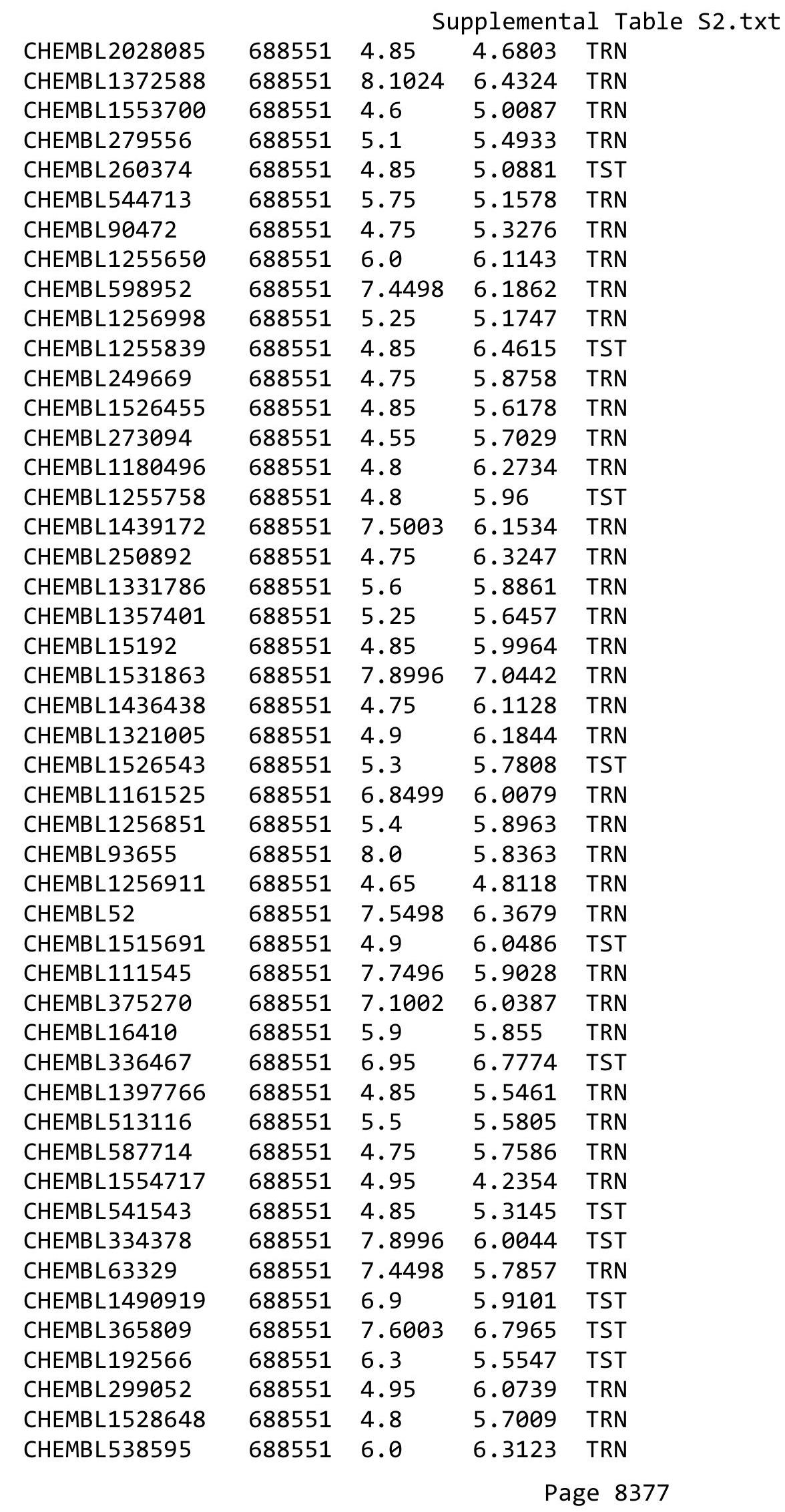




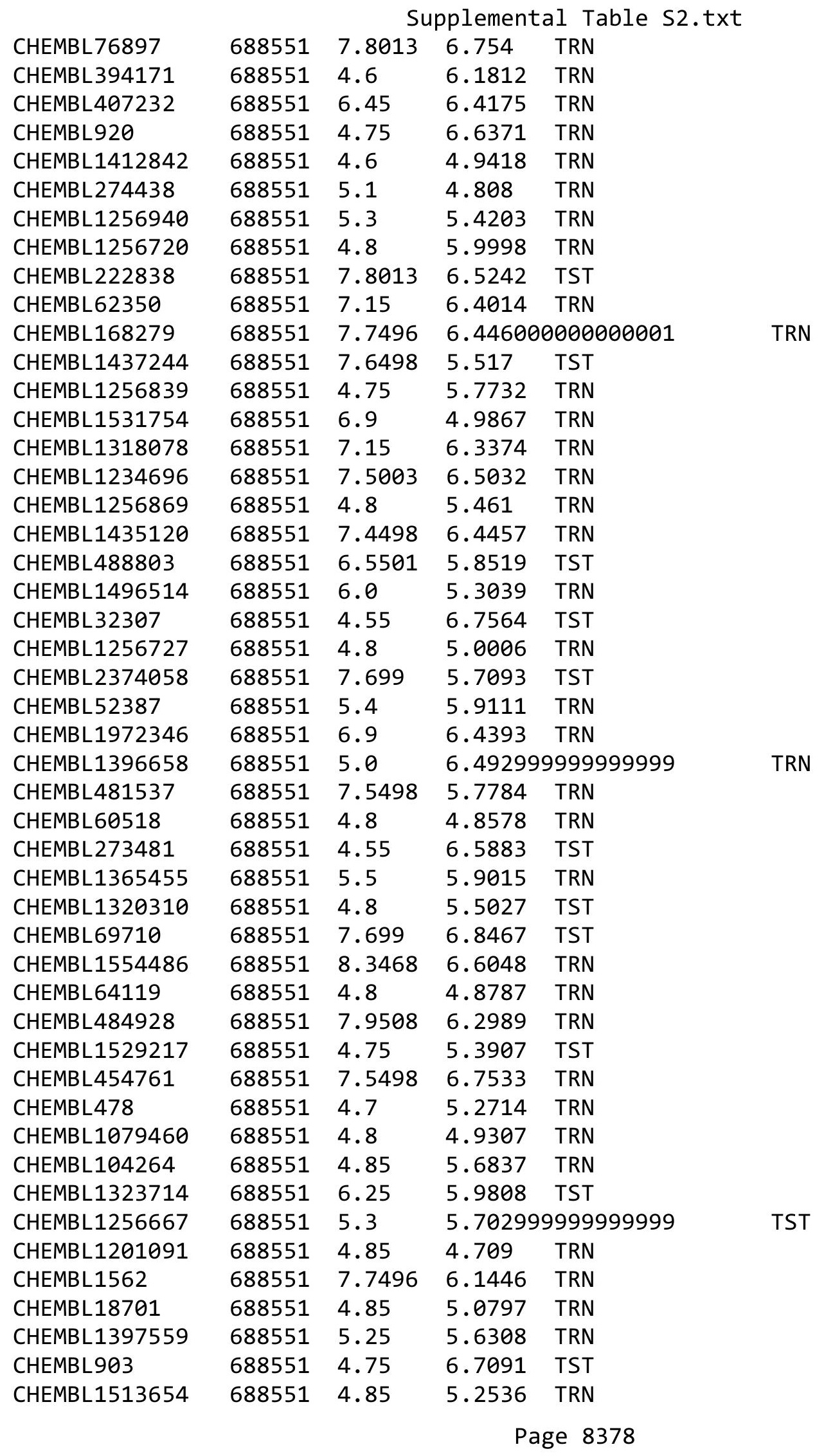




\begin{tabular}{|c|c|c|c|c|c|}
\hline \multicolumn{6}{|c|}{ Supplemental Table S2.txt } \\
\hline CHEMBL520992 & 688551 & 4.7 & 5.4085 & TRN & \\
\hline CHEMBL604119 & 688551 & 4.85 & 5.1415 & TST & \\
\hline CHEMBL428768 & 688551 & 5.2 & 5.2625 & TRN & \\
\hline CHEMBL1256173 & 688551 & 5.65 & 6.1287 & TRN & \\
\hline CHEMBL30432 & 688551 & 4.5 & 5.3275 & TRN & \\
\hline CHEMBL1456417 & 688551 & 4.55 & 5.8262 & TRN & \\
\hline CHEMBL269362 & 688551 & 6.0 & 6.5097 & TRN & \\
\hline CHEMBL1096400 & 688551 & 7.4001 & 6.1434 & TRN & \\
\hline CHEMBL1593930 & 688551 & 4.5 & 5.2376 & TRN & \\
\hline CHEMBL1255866 & 688551 & 6.05 & 6.1166 & TRN & \\
\hline CHEMBL1598680 & 688551 & 5.5 & 5.1585 & TRN & \\
\hline CHEMBL418509 & 688551 & 6.9 & 6.4438 & TRN & \\
\hline CHEMBL1336727 & 688551 & 4.85 & 5.1403 & TRN & \\
\hline CHEMBL 1255940 & 688551 & 5.5 & 6.65799 & 99999999995 & TRN \\
\hline CHEMBL1256678 & 688551 & 4.95 & 4.8507 & TRN & \\
\hline CHEMBL539027 & 688551 & 4.9 & 5.2083 & TRN & \\
\hline CHEMBL153057 & 688551 & 6.9 & 5.8636 & TST & \\
\hline CHEMBL106265 & 688551 & 4.55 & 5.8516 & TRN & \\
\hline CHEMBL72631 & 688551 & 4.75 & 4.8945 & TRN & \\
\hline CHEMBL 26138 & 688551 & 6.7001 & 5.9391 & TRN & \\
\hline CHEMBL1256770 & 688551 & 4.65 & 4.8644 & TRN & \\
\hline CHEMBL1360725 & 688551 & 4.75 & 5.2002 & TRN & \\
\hline CHEMBL 2374259 & 688551 & 5.45 & 5.1202 & TRN & \\
\hline CHEMBL545050 & 688551 & 4.6 & 5.4988 & TRN & \\
\hline CHEMBL1256666 & 688551 & 5.55 & 5.8534 & TRN & \\
\hline CHEMBL1256751 & 688551 & 6.95 & 5.9143 & TRN & \\
\hline CHEMBL570383 & 688551 & 5.25 & 6.6627 & TRN & \\
\hline CHEMBL1161461 & 688551 & 5.0 & 5.6287 & TST & \\
\hline CHEMBL 3084891 & 688551 & 7.8508 & 7.0163 & TRN & \\
\hline CHEMBL1255749 & 688551 & 8.0506 & 6.2331 & TRN & \\
\hline CHEMBL1406513 & 688551 & 5.3 & 6.1022 & TRN & \\
\hline CHEMBL62 & 688551 & 5.4 & 5.4021 & TRN & \\
\hline CHEMBL1367076 & 688551 & 4.85 & 5.4626 & TRN & \\
\hline CHEMBL 282489 & 688551 & 4.9 & 6.011 & TRN & \\
\hline CHEMBL1366846 & 688551 & 4.7 & 5.3431 & TST & \\
\hline CHEMBL1448979 & 688551 & 4.75 & 5.9067 & TRN & \\
\hline CHEMBL567175 & 688551 & 5.2 & 5.3861 & TRN & \\
\hline CHEMBL277525 & 688551 & 7.5003 & 5.8094 & TST & \\
\hline CHEMBL 1257002 & 688551 & 4.7 & 5.6403 & TRN & \\
\hline CHEMBL1398537 & 688551 & 6.8 & 6.2593 & TRN & \\
\hline CHEMBL285819 & 688551 & 7.5003 & 6.5482 & TRN & \\
\hline CHEMBL335231 & 688551 & 7.15 & 6.0292 & TST & \\
\hline CHEMBL1394801 & 688551 & 7.8508 & 6.9976 & TRN & \\
\hline CHEMBL1607062 & 688551 & 4.8 & 5.8072 & TRN & \\
\hline CHEMBL225230 & 688551 & 7.5003 & 5.6524 & TRN & \\
\hline CHEMBL1208858 & 688551 & 5.8 & 5.6705 & TST & \\
\hline CHEMBL1605916 & 688551 & 7.5498 & 5.7911 & TST & \\
\hline CHEMBL112816 & 688551 & 7.0 & 5.8289 & TRN & \\
\hline
\end{tabular}




\begin{tabular}{|c|c|c|c|c|}
\hline & & & oplement & al Ta \\
\hline CHEMBL260629 & 688551 & 7.3002 & 6.2758 & TRN \\
\hline CHEMBL64239 & 688551 & 7.699 & 6.2309 & TRN \\
\hline CHEMBL1255865 & 688551 & 5.05 & 6.2587 & TRN \\
\hline CHEMBL36060 & 688551 & 5.45 & 5.7746 & TRN \\
\hline CHEMBL1414236 & 688551 & 6.8499 & 5.2661 & TST \\
\hline CHEMBL95606 & 688551 & 6.1 & 6.4034 & TRN \\
\hline CHEMBL56 & 688551 & 5.4 & 5.9988 & TRN \\
\hline CHEMBL441948 & 688551 & 8.1487 & 6.0334 & TRN \\
\hline CHEMBL1256624 & 688551 & 7.6003 & 5.7968 & TRN \\
\hline CHEMBL66654 & 688551 & 4.7 & 6.5302 & TRN \\
\hline CHEMBL1552095 & 688551 & 4.55 & 4.6203 & TRN \\
\hline CHEMBL1591158 & 688551 & 4.8 & 6.1529 & TRN \\
\hline CHEMBL388054 & 688551 & 5.5 & 5.9884 & TRN \\
\hline CHEMBL 277120 & 688551 & 5.05 & 5.4157 & TRN \\
\hline CHEMBL1256923 & 688551 & 5.1 & 5.937 & TST \\
\hline CHEMBL1256020 & 688551 & 5.25 & 6.1014 & TRN \\
\hline CHEMBL310578 & 688551 & 7.6498 & 5.6275 & TST \\
\hline CHEMBL1255935 & 688551 & 5.0 & 5.1027 & TRN \\
\hline CHEMBL 295212 & 688551 & 4.8 & 5.6195 & TRN \\
\hline CHEMBL1191361 & 688551 & 7.5498 & 6.9409 & TST \\
\hline CHEMBL47814 & 688551 & 4.85 & 5.7652 & TRN \\
\hline CHEMBL544115 & 688551 & 4.55 & 5.1539 & TRN \\
\hline CHEMBL2449003 & 688551 & 6.0 & 6.2813 & TRN \\
\hline CHEMBL1520394 & 688551 & 7.0501 & 6.1521 & TRN \\
\hline CHEMBL399491 & 688551 & 5.35 & 5.9073 & TST \\
\hline CHEMBL288591 & 688551 & 4.7 & 5.4089 & TRN \\
\hline CHEMBL1435477 & 688551 & 6.8499 & 6.5157 & TRN \\
\hline CHEMBL1256325 & 688551 & 7.2 & 6.4212 & TRN \\
\hline CHEMBL1506225 & 688551 & 6.0 & 6.6308 & TRN \\
\hline CHEMBL1437831 & 688551 & 5.2 & 6.2704 & TST \\
\hline CHEMBL17468 & 688551 & 5.5 & 5.5175 & TRN \\
\hline CHEMBL1435381 & 688551 & 4.95 & 5.4509 & TRN \\
\hline CHEMBL 279998 & 688551 & 7.5498 & 6.12 & TST \\
\hline CHEMBL1514375 & 688551 & 4.95 & 4.9057 & TRN \\
\hline CHEMBL187734 & 688551 & 6.9 & 6.388 & TRN \\
\hline CHEMBL1062 & 688551 & 4.85 & 5.8166 & TST \\
\hline CHEMBL1406871 & 688551 & 7.4498 & 5.4468 & TST \\
\hline CHEMBL1329033 & 688551 & 4.75 & 5.7522 & TRN \\
\hline CHEMBL76232 & 688551 & 5.35 & 6.6818 & TRN \\
\hline CHEMBL344127 & 688551 & 4.75 & 5.2745 & TRN \\
\hline CHEMBL494887 & 688551 & 6.6 & 6.3045 & TST \\
\hline CHEMBL 305881 & 688551 & 5.7 & 5.1506 & TRN \\
\hline CHEMBL1355762 & 688551 & 6.9 & 6.6407 & TRN \\
\hline CHEMBL1336469 & 688551 & 4.85 & 6.0562 & TRN \\
\hline CHEMBL 328710 & 688551 & 4.9 & 6.0166 & TRN \\
\hline CHEMBL1257041 & 688551 & 7.4001 & 5.7813 & TRN \\
\hline CHEMBL102740 & 688551 & 4.75 & 6.4108 & TRN \\
\hline CHEMBL1256797 & 688551 & 4.75 & 5.3231 & TRN \\
\hline
\end{tabular}




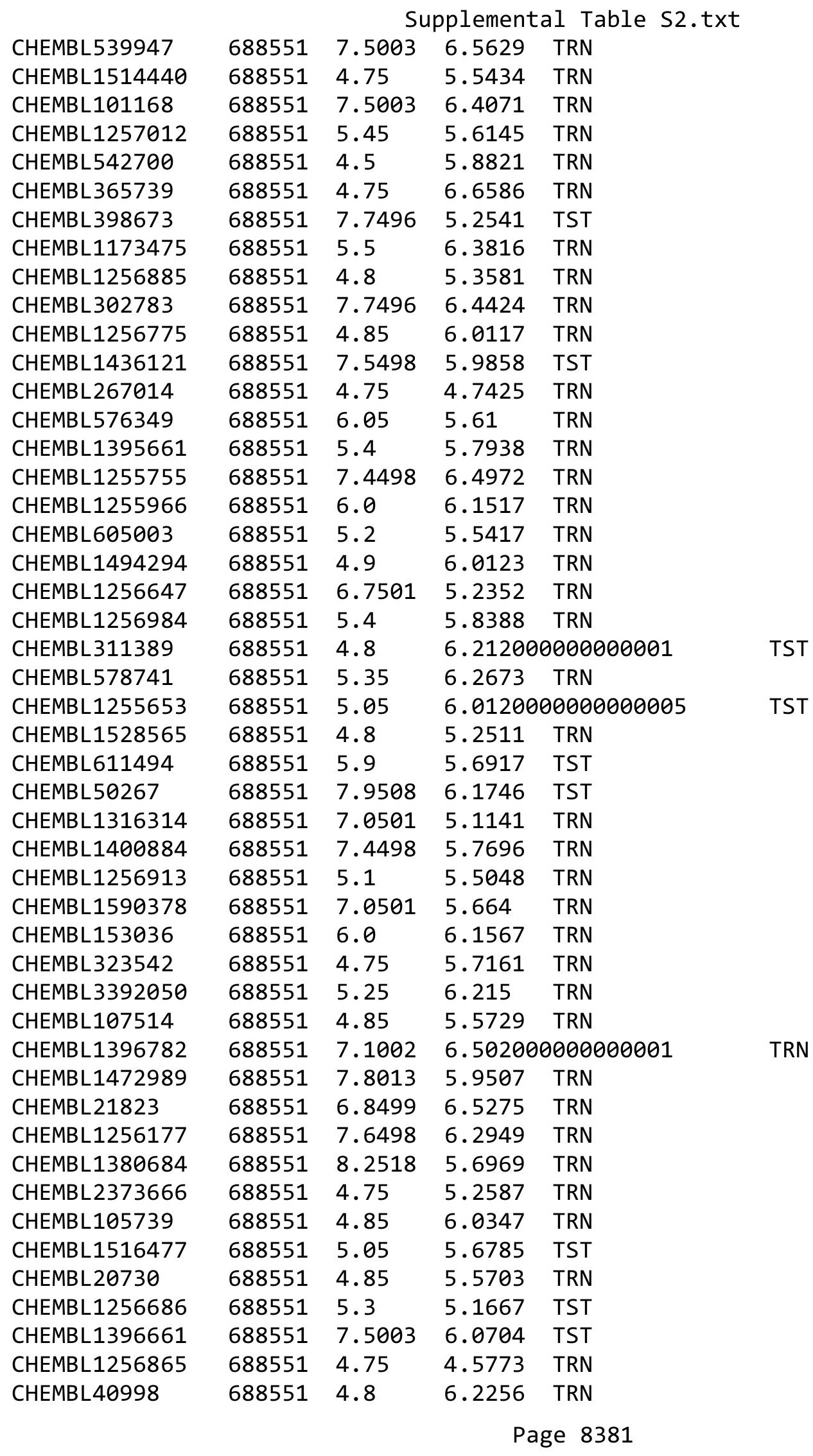




\begin{tabular}{|c|c|c|c|c|}
\hline \multicolumn{5}{|c|}{ Supplemental Table S2.txt } \\
\hline CHEMBL126077 & 688551 & 6.95 & 6.5128 & TRN \\
\hline CHEMBL541585 & 688551 & 4.75 & 5.1429 & TRN \\
\hline CHEMBL1358762 & 688551 & 6.4 & 6.2037 & TRN \\
\hline CHEMBL3216928 & 688551 & 6.4 & 6.0614 & TRN \\
\hline CHEMBL 1256360 & 688551 & 4.45 & 6.256 & TRN \\
\hline CHEMBL78150 & 688551 & 7.699 & 6.6881 & TRN \\
\hline CHEMBL1256776 & 688551 & 4.75 & 5.6001 & TRN \\
\hline CHEMBL13647 & 688551 & 4.9 & 4.585 & TRN \\
\hline CHEMBL1257083 & 688551 & 5.2 & 5.3382 & TRN \\
\hline CHEMBL1256577 & 688551 & 4.75 & 5.5974 & TRN \\
\hline CHEMBL1256576 & 688551 & 4.6 & 6.6343 & TRN \\
\hline CHEMBL1256660 & 688551 & 5.75 & 5.3679 & TRN \\
\hline CHEMBL1457550 & 688551 & 5.7 & 6.0757 & TRN \\
\hline CHEMBL1256148 & 688551 & 6.0 & 6.268 & TRN \\
\hline CHEMBL420060 & 688551 & 4.75 & 4.4651 & TRN \\
\hline CHEMBL1357558 & 688551 & 7.0501 & 5.4177 & TRN \\
\hline CHEMBL1448326 & 688551 & 7.5003 & 6.1483 & TRN \\
\hline CHEMBL275311 & 688551 & 7.0501 & 5.75 & TST \\
\hline CHEMBL1355634 & 688551 & 4.6 & 4.755 & TRN \\
\hline CHEMBL168461 & 688551 & 5.5 & 6.4298 & TRN \\
\hline CHEMBL1523589 & 688551 & 7.2 & 6.4277 & TRN \\
\hline CHEMBL1527442 & 688551 & 4.9 & 5.8349 & TST \\
\hline CHEMBL1373981 & 688551 & 7.8996 & 5.9023 & TST \\
\hline CHEMBL1256661 & 688551 & 6.4 & 5.9382 & TRN \\
\hline CHEMBL1256659 & 688551 & 4.75 & 5.3872 & TRN \\
\hline CHEMBL11608 & 688551 & 7.3002 & 6.6056 & TRN \\
\hline CHEMBL66 & 688551 & 7.6498 & 6.2353 & TRN \\
\hline CHEMBL595227 & 688551 & 7.4498 & 5.7692 & TRN \\
\hline CHEMBL 262083 & 688551 & 6.5 & 6.2835 & TRN \\
\hline CHEMBL 303579 & 688551 & 5.35 & 6.2418 & TRN \\
\hline CHEMBL1378659 & 688551 & 4.95 & 6.6475 & TRN \\
\hline CHEMBL1493579 & 688551 & 4.7 & 5.9774 & TRN \\
\hline CHEMBL247378 & 688551 & 7.0 & 6.1564 & TST \\
\hline CHEMBL1255660 & 688551 & 4.55 & 6.5315 & TRN \\
\hline CHEMBL1256835 & 688551 & 4.8 & 4.7827 & TRN \\
\hline CHEMBL1255832 & 688551 & 4.75 & 6.0645 & TRN \\
\hline CHEMBL1331383 & 688551 & 6.8499 & 6.7285 & TRN \\
\hline CHEMBL36028 & 688551 & 6.8499 & 5.8161 & TRN \\
\hline CHEMBL 278755 & 688551 & 8.0506 & 6.153 & TRN \\
\hline CHEMBL1317148 & 688551 & 4.8 & 6.0494 & TST \\
\hline CHEMBL405358 & 688551 & 5.35 & 6.546 & TRN \\
\hline CHEMBL1529009 & 688551 & 5.05 & 4.3883 & TRN \\
\hline CHEMBL12014 & 688551 & 4.6 & 6.2674 & TRN \\
\hline CHEMBL1256180 & 688551 & 7.4001 & 6.2202 & TRN \\
\hline CHEMBL8618 & 688551 & 5.25 & 4.8198 & TRN \\
\hline CHEMBL286136 & 688551 & 4.6 & 4.8165 & TRN \\
\hline CHEMBL1554131 & 688551 & 6.45 & 6.5897 & TRN \\
\hline CHEMBL252909 & 688551 & 7.5003 & 6.4341 & TRN \\
\hline
\end{tabular}




\begin{tabular}{|c|c|c|c|c|c|}
\hline \multicolumn{6}{|c|}{ Supplemental Table s2.txt } \\
\hline CHEMBL107251 & 688551 & 5.6 & 6.0219 & TRN & \\
\hline CHEMBL1554789 & 688551 & 6.0 & 6.2981 & TRN & \\
\hline CHEMBL188 & 688551 & 5.2 & 5.4187 & TRN & \\
\hline CHEMBL1402894 & 688551 & 5.65 & 5.2379 & TRN & \\
\hline CHEMBL1476762 & 688551 & 6.0 & 6.3138 & TRN & \\
\hline CHEMBL1256754 & 688551 & 6.3 & 5.7664 & TRN & \\
\hline CHEMBL 288174 & 688551 & 8.1487 & 5.3819 & TST & \\
\hline CHEMBL2374027 & 688551 & 5.25 & 5.7606 & TRN & \\
\hline CHEMBL1319469 & 688551 & 6.0 & 6.3922 & TRN & \\
\hline CHEMBL1255841 & 688551 & 6.0 & 5.1817 & TRN & \\
\hline CHEMBL1553145 & 688551 & 6.4 & 6.28700 & 0000000001 & TRN \\
\hline CHEMBL419815 & 688551 & 4.75 & 5.2385 & TRN & \\
\hline CHEMBL288096 & 688551 & 8.2007 & 5.7169 & TRN & \\
\hline CHEMBL 2373602 & 688551 & 4.8 & 5.3141 & TRN & \\
\hline CHEMBL1255664 & 688551 & 6.9 & 6.1742 & TRN & \\
\hline CHEMBL1257125 & 688551 & 8.0506 & 7.124 & TRN & \\
\hline CHEMBL1256514 & 688551 & 4.5 & 6.7385 & TST & \\
\hline CHEMBL1256996 & 688551 & 6.0 & 6.2941 & TRN & \\
\hline CHEMBL113830 & 688551 & 4.9 & 5.3576 & TRN & \\
\hline CHEMBL1418227 & 688551 & 4.75 & 5.3765 & TRN & \\
\hline CHEMBL107201 & 688551 & 5.35 & 6.3141 & TRN & \\
\hline CHEMBL 9843 & 688551 & 7.1002 & 6.0123 & TRN & \\
\hline CHEMBL1523894 & 688551 & 6.9 & 6.7784 & TST & \\
\hline CHEMBL 93403 & 688551 & 4.95 & 4.32 & TRN & \\
\hline CHEMBL1316222 & 688551 & 4.8 & 5.9972 & TRN & \\
\hline CHEMBL1256844 & 688551 & 4.85 & 4.979 & TRN & \\
\hline CHEMBL1256693 & 688551 & 4.95 & 4.8523 & TRN & \\
\hline CHEMBL 72365 & 688551 & 5.4 & 5.99799 & 9999999999 & TRN \\
\hline CHEMBL34155 & 688551 & 7.0 & 5.7972 & TST & \\
\hline CHEMBL1600780 & 688551 & 6.9 & 6.07299 & 99999999995 & TRN \\
\hline CHEMBL1314260 & 688551 & 8.0506 & 6.2056 & TST & \\
\hline CHEMBL197027 & 688551 & 5.15 & 5.9815 & TST & \\
\hline CHEMBL534084 & 688551 & 5.0 & 5.0551 & TRN & \\
\hline CHEMBL 327708 & 688551 & 5.3 & 5.0769 & TRN & \\
\hline CHEMBL1415777 & 688551 & 6.05 & 6.0128 & TST & \\
\hline CHEMBL63154 & 688551 & 7.0501 & 5.8159 & TRN & \\
\hline CHEMBL1256910 & 688551 & 4.8 & 5.0012 & TRN & \\
\hline CHEMBL1318739 & 688551 & 6.25 & 6.5115 & TRN & \\
\hline CHEMBL1256687 & 688551 & 5.3 & 5.9021 & TRN & \\
\hline CHEMBL299155 & 688551 & 7.7496 & 6.4048 & TRN & \\
\hline CHEMBL1256646 & 688551 & 5.2 & 5.7431 & TRN & \\
\hline CHEMBL 313833 & 688551 & 4.75 & 6.345 & TRN & \\
\hline CHEMBL1594935 & 688551 & 7.4498 & 6.7969 & TRN & \\
\hline CHEMBL251904 & 688551 & 7.15 & 6.5924 & TRN & \\
\hline CHEMBL1256866 & 688551 & 4.85 & 4.9251 & TRN & \\
\hline CHEMBL6567 & 688551 & 6.8 & 6.5883 & TRN & \\
\hline CHEMBL1595524 & 688551 & 6.8 & 6.4011 & TRN & \\
\hline CHEMBL1338358 & 688551 & 7.9508 & 5.8875 & TRN & \\
\hline
\end{tabular}




\begin{tabular}{|c|c|c|c|c|c|}
\hline \multicolumn{6}{|c|}{ Supplemental Table S2.txt } \\
\hline CHEMBL1400543 & 688551 & 6.0 & 6.5198 & TRN & \\
\hline CHEMBL250447 & 688551 & 5.3 & 5.9037 & TRN & \\
\hline CHEMBL32590 & 688551 & 7.2 & 5.6606 & TRN & \\
\hline CHEMBL 7917 & 688551 & 4.85 & 5.3992 & TRN & \\
\hline CHEMBL362863 & 688551 & 5.25 & 5.2753 & TST & \\
\hline CHEMBL451226 & 688551 & 7.2 & 6.7887 & TRN & \\
\hline CHEMBL402063 & 688551 & 4.55 & 5.785 & TST & \\
\hline CHEMBL1369414 & 688551 & 7.5003 & 5.5608 & TRN & \\
\hline CHEMBL1514670 & 688551 & 6.6499 & 6.0907 & TRN & \\
\hline CHEMBL47529 & 688551 & 4.7 & 6.0313 & TST & \\
\hline CHEMBL1593765 & 688551 & 5.25 & 4.8497 & TRN & \\
\hline CHEMBL500996 & 688551 & 6.05 & 5.6954 & TRN & \\
\hline CHEMBL1256695 & 688551 & 4.85 & 5.8389 & TRN & \\
\hline CHEMBL67378 & 688551 & 4.85 & 4.8835 & TRN & \\
\hline CHEMBL1097940 & 688551 & 6.7501 & 5.885 & TRN & \\
\hline CHEMBL1499 & 688551 & 4.7 & 5.8255 & TST & \\
\hline CHEMBL157351 & 688551 & 6.0 & 5.86299 & 99999999995 & TRN \\
\hline CHEMBL420937 & 688551 & 5.45 & 5.521 & TST & \\
\hline CHEMBL576997 & 688551 & 6.0 & 4.7524 & TST & \\
\hline CHEMBL1491340 & 688551 & 4.85 & 5.9743 & TST & \\
\hline CHEMBL429023 & 688551 & 5.3 & 5.6431 & TRN & \\
\hline CHEMBL501701 & 688551 & 4.75 & 5.3995 & TRN & \\
\hline CHEMBL 2062333 & 688551 & 4.65 & 4.8734 & TRN & \\
\hline CHEMBL1256656 & 688551 & 4.85 & 4.6399 & TRN & \\
\hline CHEMBL1256186 & 688551 & 4.9 & 4.6875 & TST & \\
\hline CHEMBL10284 & 688551 & 5.3 & 6.1298 & TRN & \\
\hline CHEMBL102714 & 688551 & 4.85 & 5.5454 & TRN & \\
\hline CHEMBL545184 & 688551 & 7.8013 & 6.4387 & TST & \\
\hline CHEMBL275006 & 688551 & 7.6498 & 6.1005 & TST & \\
\hline CHEMBL445102 & 688551 & 4.95 & 5.1293 & TST & \\
\hline CHEMBL479014 & 688551 & 4.9 & 6.3316 & TST & \\
\hline CHEMBL1320485 & 688551 & 4.8 & 6.1334 & TST & \\
\hline CHEMBL448741 & 688551 & 5.05 & 6.5754 & TST & \\
\hline CHEMBL1426948 & 688551 & 4.7 & 5.1991 & TST & \\
\hline CHEMBL35482 & 688551 & 5.5 & 5.7478 & TST & \\
\hline CHEMBL536950 & 688551 & 5.3 & 6.256 & TST & \\
\hline CHEMBL1256178 & 688551 & 4.65 & 6.3695 & TST & \\
\hline CHEMBL 28140 & 688551 & 4.9 & 6.1341 & TST & \\
\hline CHEMBL441618 & 688551 & 4.75 & 5.4486 & TST & \\
\hline CHEMBL1590980 & 688551 & 5.25 & 4.8269 & TST & \\
\hline CHEMBL16857 & 688551 & 4.75 & 6.1942 & TST & \\
\hline CHEMBL85139 & 688551 & 4.75 & 5.7627 & TST & \\
\hline CHEMBL291278 & 688551 & 7.8508 & 6.6259 & TST & \\
\hline CHEMBL536803 & 688551 & 4.75 & 5.3913 & TST & \\
\hline CHEMBL1354398 & 688551 & 6.3 & 6.2755 & TST & \\
\hline CHEMBL559934 & 688551 & 6.7501 & 6.2835 & TST & \\
\hline CHEMBL1437711 & 688551 & 7.2503 & 5.7135 & TST & \\
\hline CHEMBL310310 & 688551 & 7.699 & 6.819 & TST & \\
\hline
\end{tabular}




\begin{tabular}{|c|c|c|c|c|c|}
\hline \multicolumn{6}{|c|}{ Supplemental Table S2.txt } \\
\hline CHEMBL1363347 & 688551 & 6.8 & 6.4337 & TST & \\
\hline CHEMBL1256878 & 688551 & 4.8 & 5.9296 & TST & \\
\hline CHEMBL1230270 & 688551 & 8.2518 & 6.4504 & TST & \\
\hline CHEMBL1256663 & 688551 & 5.15 & 4.9533 & TST & \\
\hline CHEMBL26915 & 688551 & 5.25 & 5.5668 & TST & \\
\hline CHEMBL326967 & 688551 & 4.95 & 5.205 & TST & \\
\hline CHEMBL1355224 & 688551 & 5.1 & 5.1629 & TST & \\
\hline CHEMBL1256359 & 688551 & 5.95 & 6.3345 & TST & \\
\hline CHEMBL261642 & 688551 & 6.95 & 6.3675 & TST & \\
\hline CHEMBL252310 & 688551 & 4.9 & 5.8533 & TST & \\
\hline CHEMBL1515001 & 688551 & 5.5 & 5.1968 & TST & \\
\hline CHEMBL1455369 & 688551 & 4.55 & 6.1655 & TST & \\
\hline CHEMBL1256914 & 688551 & 5.35 & 6.2133 & TST & \\
\hline CHEMBL1472936 & 688551 & 7.8996 & 6.1645 & TST & \\
\hline CHEMBL263972 & 688551 & 6.4 & 6.2924 & TST & \\
\hline CHEMBL1487371 & 688551 & 4.8 & 6.1199 & TST & \\
\hline CHEMBL1356870 & 688551 & 7.6003 & 5.8395 & TST & \\
\hline CHEMBL1551643 & 688551 & 7.5003 & 6.3363 & TST & \\
\hline CHEMBL1256625 & 688551 & 7.2 & 6.0851 & TST & \\
\hline CHEMBL519202 & 502048 & 3.0 & 3.0029 & TST & \\
\hline CHEMBL482735 & 502048 & 6.0969 & 6.0235 & TRN & \\
\hline CHEMBL520307 & 502048 & 3.0 & 4.0323 & TST & \\
\hline CHEMBL484923 & 502048 & 3.0 & 2.998 & TRN & \\
\hline CHEMBL482992 & 502048 & 4.3979 & 4.3898 & TRN & \\
\hline CHEMBL482734 & 502048 & 5.8239 & 5.8999 & TRN & \\
\hline CHEMBL483354 & 502048 & 5.9586 & 6.0436 & TRN & \\
\hline CHEMBL484782 & 502048 & 4.0 & 4.0017 & TRN & \\
\hline CHEMBL482951 & 502048 & 3.0 & 3.5993 & TST & \\
\hline CHEMBL515436 & 502048 & 4.301 & 4.2973 & TRN & \\
\hline CHEMBL515243 & 502048 & 4.301 & 4.285 & TRN & \\
\hline CHEMBL520490 & 502048 & 5.3468 & 5.3442 & TRN & \\
\hline CHEMBL483163 & 502048 & 4.0 & 3.8227 & TST & \\
\hline CHEMBL484592 & 502048 & 4.0 & 3.9934 & TRN & \\
\hline CHEMBL483556 & 502048 & 5.2596 & 5.25899 & 99999999995 & TRN \\
\hline CHEMBL520175 & 502048 & 3.0 & 3.0111 & TRN & \\
\hline CHEMBL521504 & 502048 & 2.0 & 1.9918 & TRN & \\
\hline CHEMBL475305 & 502048 & 5.4815 & 5.4714 & TRN & \\
\hline CHEMBL475304 & 502048 & 4.1549 & 4.1514 & TRN & \\
\hline CHEMBL520176 & 502048 & 3.0 & 2.9944 & TRN & \\
\hline CHEMBL482561 & 502048 & 5.301 & 5.3029 & TRN & \\
\hline CHEMBL484332 & 502048 & 6.0458 & 6.0566 & TRN & \\
\hline CHEMBL483849 & 502048 & 4.9208 & 5.1662 & TST & \\
\hline CHEMBL520489 & 502048 & 3.6021 & 3.6085 & TRN & \\
\hline CHEMBL514803 & 502048 & 5.8239 & 5.8243 & TRN & \\
\hline CHEMBL519503 & 502048 & 5.301 & 5.3143 & TRN & \\
\hline CHEMBL483999 & 502048 & 4.6383 & 4.6401 & TRN & \\
\hline CHEMBL507312 & 502048 & 6.1549 & 6.0694 & TRN & \\
\hline CHEMBL485009 & 502048 & 2.0 & 2.0033 & TRN & \\
\hline
\end{tabular}




\begin{tabular}{|c|c|c|c|c|}
\hline \multirow[b]{2}{*}{ CHEMBL519996 } & \multicolumn{4}{|c|}{ Supplemental Table S2.txt } \\
\hline & 502048 & 4.0 & 3.8773 & TST \\
\hline CHEMBL519477 & 502048 & 5.699 & 5.7022 & TRN \\
\hline CHEMBL520998 & 502048 & 4.0 & 4.0088 & TRN \\
\hline CHEMBL514660 & 502048 & 5.8539 & 5.8564 & TRN \\
\hline CHEMBL448582 & 502048 & 2.0 & 2.0008 & TRN \\
\hline CHEMBL485130 & 502048 & 3.0 & 2.6486 & TST \\
\hline CHEMBL484922 & 502048 & 3.8239 & 3.8178 & TRN \\
\hline CHEMBL519361 & 502048 & 3.0 & 2.6934 & TST \\
\hline CHEMBL483356 & 502048 & 3.0 & 3.99600 & 00000000004 \\
\hline CHEMBL482991 & 502048 & 2.0 & 2.0062 & TRN \\
\hline CHEMBL484136 & 502048 & 4.041 & 4.0373 & TRN \\
\hline CHEMBL484331 & 502048 & 4.5528 & 4.5628 & TRN \\
\hline CHEMBL510249 & 502048 & 5.7447 & 5.7421 & TRN \\
\hline CHEMBL519692 & 502048 & 4.8861 & 4.8856 & TRN \\
\hline CHEMBL485361 & 502048 & 4.3188 & 4.333 & TRN \\
\hline CHEMBL485144 & 502048 & 3.0 & 4.2918 & TST \\
\hline CHEMBL483555 & 502048 & 4.0 & 3.9898 & TRN \\
\hline CHEMBL484135 & 502048 & 4.0 & 4.0056 & TRN \\
\hline CHEMBL520009 & 502048 & 4.0 & 4.0025 & TRN \\
\hline CHEMBL519641 & 502048 & 4.0 & 3.9907 & TRN \\
\hline CHEMBL483355 & 502048 & 3.8539 & 4.2296 & TST \\
\hline CHEMBL519323 & 502048 & 4.0 & 3.7131 & TST \\
\hline CHEMBL484774 & 502048 & 2.301 & 2.3041 & TRN \\
\hline CHEMBL484160 & 502048 & 3.8386 & 3.8344 & TRN \\
\hline CHEMBL447259 & 502048 & 5.7959 & 5.7901 & TRN \\
\hline CHEMBL519845 & 502048 & 4.4559 & 3.9686 & TST \\
\hline CHEMBL521165 & 502048 & 4.0 & 3.6711 & TST \\
\hline CHEMBL485129 & 502048 & 3.0 & 2.8406 & TST \\
\hline CHEMBL1784183 & 752183 & 3.4815 & 4.3637 & TST \\
\hline CHEMBL1784234 & 752183 & 6.2366 & 5.9126 & TST \\
\hline CHEMBL1784227 & 752183 & 5.5229 & 5.5253 & TRN \\
\hline CHEMBL1782536 & 752183 & 5.7696 & 5.7555 & TRN \\
\hline CHEMBL1784229 & 752183 & 5.699 & 5.7026 & TRN \\
\hline CHEMBL1784209 & 752183 & 5.5229 & 5.5294 & TRN \\
\hline CHEMBL1784204 & 752183 & 6.5528 & 6.5591 & TRN \\
\hline CHEMBL1784216 & 752183 & 6.4815 & 6.4785 & TRN \\
\hline CHEMBL1784212 & 752183 & 7.0 & 6.9961 & TRN \\
\hline CHEMBL1784223 & 752183 & 6.5686 & 6.572 & TRN \\
\hline CHEMBL1784225 & 752183 & 6.3098 & 6.4532 & TST \\
\hline CHEMBL1784201 & 752183 & 5.585 & 5.5884 & TRN \\
\hline CHEMBL1784203 & 752183 & 5.7959 & 5.7991 & TRN \\
\hline CHEMBL1784196 & 752183 & 5.9586 & 5.984 & TRN \\
\hline CHEMBL1784218 & 752183 & 6.6198 & 6.6037 & TRN \\
\hline CHEMBL1784194 & 752183 & 5.9747 & 5.9549 & TRN \\
\hline CHEMBL1784211 & 752183 & 5.9586 & 5.9641 & TRN \\
\hline CHEMBL1784230 & 752183 & 6.3372 & 6.3349 & TRN \\
\hline CHEMBL1784205 & 752183 & 6.3768 & 6.3642 & TRN \\
\hline CHEMBL1784191 & 752183 & 6.0223 & 6.025 & TRN \\
\hline
\end{tabular}




\begin{tabular}{|c|c|c|c|c|}
\hline \multicolumn{5}{|c|}{ Supplemental Table } \\
\hline CHEMBL1784219 & 752183 & 6.3468 & 6.3816 & TRN \\
\hline CHEMBL1782540 & 752183 & 3.4815 & 3.4822 & TRN \\
\hline CHEMBL1784192 & 752183 & 6.4949 & 6.4823 & TRN \\
\hline CHEMBL1782534 & 752183 & 6.1675 & 6.1837 & TRN \\
\hline CHEMBL1784195 & 752183 & 5.2596 & 5.263 & TRN \\
\hline CHEMBL1784213 & 752183 & 6.4202 & 6.4175 & TRN \\
\hline CHEMBL1784193 & 752183 & 6.5229 & 6.5021 & TRN \\
\hline CHEMBL1784198 & 752183 & 7.0809 & 7.0808 & TRN \\
\hline CHEMBL1784214 & 752183 & 5.7447 & 5.7332 & TRN \\
\hline CHEMBL1784210 & 752183 & 5.3372 & 5.3172 & TRN \\
\hline CHEMBL1784231 & 752183 & 5.301 & 5.3038 & TRN \\
\hline CHEMBL1784222 & 752183 & 6.1938 & 6.1892 & TRN \\
\hline CHEMBL1784233 & 752183 & 5.8539 & 5.8577 & TRN \\
\hline CHEMBL1782537 & 752183 & 5.6576 & 5.6558 & TRN \\
\hline CHEMBL1782542 & 752183 & 5.0706 & 5.0712 & TRN \\
\hline CHEMBL1784207 & 752183 & 6.0706 & 6.0854 & TRN \\
\hline CHEMBL1784202 & 752183 & 5.699 & 5.7065 & TRN \\
\hline CHEMBL1784238 & 752183 & 5.6383 & 5.638 & TRN \\
\hline CHEMBL1784185 & 752183 & 5.8861 & 5.9055 & TRN \\
\hline CHEMBL1784187 & 752183 & 6.0 & 5.9923 & TRN \\
\hline CHEMBL1784215 & 752183 & 6.5686 & 6.5621 & TRN \\
\hline CHEMBL1784228 & 752183 & 5.9586 & 5.9439 & TRN \\
\hline CHEMBL1784240 & 752183 & 5.6778 & 5.6756 & TRN \\
\hline CHEMBL1784178 & 752183 & 5.1938 & 5.1812 & TRN \\
\hline CHEMBL1784217 & 752183 & 6.4559 & 6.6653 & TST \\
\hline CHEMBL1784186 & 752183 & 5.9208 & 6.0621 & TST \\
\hline CHEMBL1784188 & 752183 & 5.8239 & 6.2993 & TST \\
\hline CHEMBL1784184 & 752183 & 5.0132 & 5.0135 & TRN \\
\hline CHEMBL1784232 & 752183 & 6.3468 & 6.3406 & TRN \\
\hline CHEMBL1782535 & 752183 & 5.585 & 5.5831 & TRN \\
\hline CHEMBL1784241 & 752183 & 4.5376 & 5.2324 & TST \\
\hline CHEMBL1784208 & 752183 & 5.9586 & 5.9811 & TRN \\
\hline CHEMBL1784221 & 752183 & 6.7447 & 6.7086 & TST \\
\hline CHEMBL1784206 & 752183 & 6.0177 & 6.03 & TRN \\
\hline CHEMBL1782541 & 752183 & 5.0655 & 5.0629 & TRN \\
\hline CHEMBL1784190 & 752183 & 6.7447 & 6.5944 & TST \\
\hline CHEMBL1782078 & 752183 & 5.7696 & 5.7873 & TRN \\
\hline CHEMBL1782538 & 752183 & 5.4202 & 5.3391 & TST \\
\hline CHEMBL1784189 & 752183 & 6.6778 & 6.8285 & TST \\
\hline CHEMBL1784226 & 752183 & 6.1549 & 6.1511 & TRN \\
\hline CHEMBL1784235 & 752183 & 6.1192 & 6.1753 & TST \\
\hline CHEMBL1784200 & 752183 & 5.4318 & 5.4167 & TRN \\
\hline CHEMBL1784199 & 752183 & 6.0177 & 6.4801 & TST \\
\hline CHEMBL1784197 & 752183 & 6.6383 & 6.2669 & TST \\
\hline CHEMBL1782539 & 752183 & 3.4815 & 3.7027 & TST \\
\hline CHEMBL1784224 & 752183 & 6.7212 & 6.1407 & TST \\
\hline CHEMBL1784220 & 752183 & 6.9586 & 6.5133 & TST \\
\hline CHEMBL81301 & 48316 & 4.301 & 4.9294 & TRN \\
\hline
\end{tabular}




\begin{tabular}{|c|c|c|c|c|c|}
\hline \multicolumn{6}{|c|}{ Supplemental Table S2.txt } \\
\hline CHEMBL81893 & 48316 & 4.301 & 4.4724 & TRN & \\
\hline CHEMBL83743 & 48316 & 4.301 & 4.305 & TRN & \\
\hline CHEMBL 82040 & 48316 & 4.301 & 4.3301 & TRN & \\
\hline CHEMBL 83324 & 48316 & 4.301 & 4.2064 & TRN & \\
\hline CHEMBL79344 & 48316 & 4.301 & 4.2442 & TRN & \\
\hline CHEMBL83925 & 48316 & 4.301 & 4.4441 & TRN & \\
\hline CHEMBL81579 & 48316 & 4.301 & 4.2585 & TRN & \\
\hline CHEMBL81932 & 48316 & 4.301 & 4.4873 & TRN & \\
\hline CHEMBL 84502 & 48316 & 5.2757 & 5.4022 & TRN & \\
\hline CHEMBL 83003 & 48316 & 4.301 & 4.4568 & TRN & \\
\hline CHEMBL309879 & 48316 & 6.1675 & 6.3586 & TST & \\
\hline CHEMBL 70730 & 48316 & 4.301 & 4.3789 & TRN & \\
\hline CHEMBL49636 & 48316 & 4.6576 & 4.9236 & TRN & \\
\hline CHEMBL310373 & 48316 & 5.8539 & 6.2756 & TST & \\
\hline CHEMBL84379 & 48316 & 4.301 & 4.4421 & TRN & \\
\hline CHEMBL83106 & 48316 & 5.5229 & 5.6439 & TRN & \\
\hline CHEMBL83798 & 48316 & 4.301 & 4.4056 & TRN & \\
\hline CHEMBL432939 & 48316 & 5.4685 & 5.9471 & TST & \\
\hline CHEMBL 82873 & 48316 & 4.301 & 5.4941 & TST & \\
\hline CHEMBL 83392 & 48316 & 4.301 & 5.1669 & TRN & \\
\hline CHEMBL309617 & 48316 & 4.301 & 4.9265 & TST & \\
\hline CHEMBL441450 & 48316 & 5.3098 & 5.0562 & TRN & \\
\hline CHEMBL419651 & 48316 & 5.9586 & 5.1669 & TRN & \\
\hline CHEMBL82339 & 48316 & 4.301 & 6.3465 & TST & \\
\hline CHEMBL 79258 & 48316 & 4.301 & 4.6728 & TRN & \\
\hline CHEMBL 81852 & 48316 & 4.301 & 4.4504 & TRN & \\
\hline CHEMBL309717 & 48316 & 4.301 & 4.0831 & TRN & \\
\hline CHEMBL83431 & 48316 & 4.301 & 4.1515 & TRN & \\
\hline CHEMBL79986 & 48316 & 5.6383 & 5.277 & TRN & \\
\hline CHEMBL311788 & 48316 & 4.301 & 4.6487 & TRN & \\
\hline CHEMBL79996 & 48316 & 4.301 & 4.3484 & TRN & \\
\hline CHEMBL 80119 & 48316 & 4.301 & 4.3582 & TRN & \\
\hline CHEMBL82006 & 48316 & 5.2924 & 6.0792 & TST & \\
\hline CHEMBL315014 & 48316 & 4.301 & 6.1886 & TST & \\
\hline CHEMBL84482 & 48316 & 4.301 & 4.0555 & TRN & \\
\hline CHEMBL 79828 & 48316 & 6.1871 & 5.92899 & 9999999999 & TST \\
\hline CHEMBL314591 & 48316 & 6.1367 & 6.0937 & TRN & \\
\hline CHEMBL82127 & 48316 & 4.301 & 4.2826 & TRN & \\
\hline CHEMBL 82739 & 48316 & 4.301 & 4.1831 & TRN & \\
\hline CHEMBL 84437 & 48316 & 6.9208 & 6.8882 & TST & \\
\hline CHEMBL82925 & 48316 & 6.7212 & 6.9562 & TRN & \\
\hline CHEMBL310575 & 48316 & 5.7447 & 5.4362 & TRN & \\
\hline CHEMBL83675 & 48316 & 5.585 & 5.6186 & TRN & \\
\hline CHEMBL 309541 & 48316 & 6.7447 & 6.2358 & TST & \\
\hline CHEMBL312592 & 48316 & 4.301 & 4.7978 & TST & \\
\hline CHEMBL310857 & 48316 & 4.301 & 4.0706 & TRN & \\
\hline CHEMBL48604 & 48316 & 4.5686 & 5.0816 & TST & \\
\hline CHEMBL420963 & 48316 & 6.1308 & 5.7836 & TRN & \\
\hline
\end{tabular}




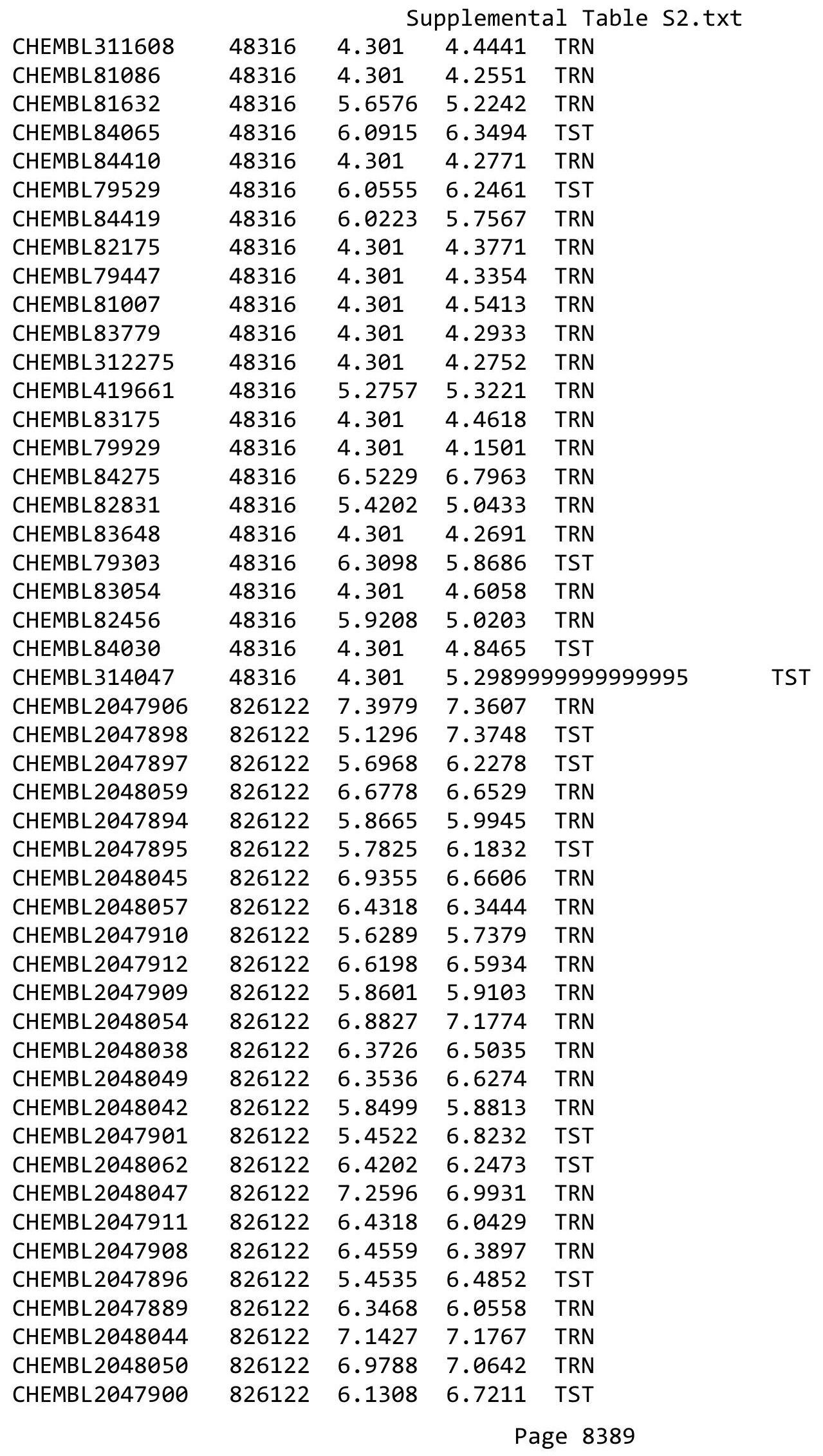


Supplemental Table S2.txt

\begin{tabular}{|c|c|c|c|c|c|}
\hline CHEMBL 2047888 & 826122 & 6.2007 & 6.0535 & TRN & \\
\hline CHEMBL 2048063 & 826122 & 6.3279 & 6.3473 & TRN & \\
\hline CHEMBL 2047905 & 826122 & 6.2518 & 6.4937 & TRN & \\
\hline CHEMBL 2048037 & 826122 & 6.5086 & 6.7145 & TRN & \\
\hline CHEMBL 2048043 & 826122 & 6.6478 & 6.5767 & TRN & \\
\hline CHEMBL 2048040 & 826122 & 6.6676 & 6.8344 & TRN & \\
\hline CHEMBL 2048053 & 826122 & 7.301 & 7.2104 & TRN & \\
\hline CHEMBL 2047891 & 826122 & 5.3028 & 5.4462 & TRN & \\
\hline CHEMBL 2047899 & 826122 & 5.6861 & 6.5962 & TST & \\
\hline CHEMBL 2047890 & 826122 & 6.6021 & 6.5362 & TRN & \\
\hline CHEMBL 2048041 & 826122 & 6.9281 & 6.6478 & TRN & \\
\hline CHEMBL 2048061 & 826122 & 6.0223 & 5.8577 & TRN & \\
\hline CHEMBL 2047907 & 826122 & 6.2366 & 6.2408 & TRN & \\
\hline CHEMBL 2048046 & 826122 & 5.9872 & 6.3297 & TRN & \\
\hline CHEMBL 2048048 & 826122 & 6.4179 & 6.2728 & TRN & \\
\hline CHEMBL 2048060 & 826122 & 6.8861 & 6.4421 & TST & \\
\hline CHEMBL 2048058 & 826122 & 6.7696 & 6.7359 & TRN & \\
\hline CHEMBL 2047904 & 826122 & 5.75200 & j00000006 & 91 & 5.8992 \\
\hline CHEMBL 2047915 & 826122 & 6.9393 & 6.9421 & TRN & \\
\hline CHEMBL 2047913 & 826122 & 6.3872 & 6.4886 & TRN & \\
\hline CHEMBL 2047902 & 826122 & 7.0969 & 6.6652 & TST & \\
\hline CHEMBL 2047914 & 826122 & 5.3516 & 5.4242 & TRN & \\
\hline CHEMBL 2048039 & 826122 & 6.8239 & 6.7006 & TRN & \\
\hline CHEMBL 2047903 & 826122 & 6.5229 & 6.9622 & TST & \\
\hline CHEMBL 2047893 & 826122 & 6.2596 & 6.1574 & TST & \\
\hline CHEMBL 2047892 & 826122 & 5.9508 & 6.6456 & TST & \\
\hline CHEMBL3237899 & 1338730 & 5.5086 & 5.8476 & TST & \\
\hline CHEMBL3238229 & 1338730 & 4.0 & 3.9472 & TRN & \\
\hline CHEMBL 3238214 & 1338730 & 4.0 & 4.0589 & TRN & \\
\hline CHEMBL3237924 & 1338730 & 4.0 & 4.0335 & TRN & \\
\hline CHEMBL3237917 & 1338730 & 4.0 & 3.9791 & TST & \\
\hline CHEMBL 3238240 & 1338730 & 4.0 & 3.9882 & TRN & \\
\hline CHEMBL 3238224 & 1338730 & 4.0 & 4.0308 & TRN & \\
\hline CHEMBL 3238235 & 1338730 & 6.8539 & 4.5047 & TST & \\
\hline CHEMBL3238225 & 1338730 & 4.0 & 3.9936 & TRN & \\
\hline CHEMBL3238223 & 1338730 & 4.0 & 4.1422 & TRN & \\
\hline CHEMBL3238234 & 1338730 & 5.699 & 5.7458 & TRN & \\
\hline CHEMBL 3238227 & 1338730 & 4.0 & 4.006 & TST & \\
\hline CHEMBL 3238232 & 1338730 & 4.0 & 4.018 & TRN & \\
\hline CHEMBL3238226 & 1338730 & 4.0 & 4.0069 & TRN & \\
\hline CHEMBL3238216 & 1338730 & 4.0 & 4.029 & TRN & \\
\hline CHEMBL3238243 & 1338730 & 4.0 & 4.0145 & TRN & \\
\hline CHEMBL3237928 & 1338730 & 4.0 & 4.0205 & TRN & \\
\hline CHEMBL3237903 & 1338730 & 4.0 & 3.9907 & TRN & \\
\hline CHEMBL 3238217 & 1338730 & 4.0 & 4.0481 & TRN & \\
\hline CHEMBL3238246 & 1338730 & 4.0 & 4.0033 & TRN & \\
\hline CHEMBL3238228 & 1338730 & 4.0 & 3.9567 & TST & \\
\hline CHEMBL3238220 & 1338730 & 4.0 & 3.9153 & TRN & \\
\hline
\end{tabular}


Supplemental Table S2.txt

\begin{tabular}{|c|c|c|c|c|c|}
\hline CHEMBL3238242 & 1338730 & 4.0 & 3.9613 & TRN & \\
\hline CHEMBL3237906 & 1338730 & 5.4089 & 5.4189 & TRN & \\
\hline CHEMBL3237921 & 1338730 & 4.0 & 4.0168 & TRN & \\
\hline CHEMBL3237907 & 1338730 & 4.0 & 4.0089 & TRN & \\
\hline CHEMBL3237909 & 1338730 & 4.0 & 4.1124 & TRN & \\
\hline CHEMBL3237927 & 1338730 & 4.0 & 4.0379 & TRN & \\
\hline CHEMBL3237898 & 1338730 & 5.1367 & 5.9921 & TST & \\
\hline CHEMBL3237925 & 1338730 & 4.0 & 3.97 & TRN & \\
\hline CHEMBL3237902 & 1338730 & 4.0 & 3.9724 & TRN & \\
\hline CHEMBL3238218 & 1338730 & 4.0 & \multicolumn{2}{|c|}{3.9760000000000004} & TRN \\
\hline CHEMBL3237901 & 1338730 & 5.2007 & 5.086 & TRN & \\
\hline CHEMBL3237916 & 1338730 & 4.0 & 3.9764 & TRN & \\
\hline CHEMBL3237912 & 1338730 & 4.0 & 3.9929 & TRN & \\
\hline CHEMBL3238231 & 1338730 & 4.0 & 3.9802 & TRN & \\
\hline CHEMBL3237915 & 1338730 & 4.0 & 3.9995 & TRN & \\
\hline CHEMBL3237914 & 1338730 & 4.0 & 4.0651 & TRN & \\
\hline CHEMBL3237900 & 1338730 & 5.2518 & 5.2017 & TRN & \\
\hline CHEMBL 3237922 & 1338730 & 4.0 & 3.9709 & TRN & \\
\hline CHEMBL3238233 & 1338730 & 4.0 & 3.9985 & TRN & \\
\hline CHEMBL3238219 & 1338730 & 4.0 & 3.8475 & TRN & \\
\hline CHEMBL3238215 & 1338730 & 4.0 & 3.9954 & TRN & \\
\hline CHEMBL3238221 & 1338730 & 4.0 & 3.9945 & TRN & \\
\hline CHEMBL3237904 & 1338730 & 5.1079 & 3.6857 & TST & \\
\hline CHEMBL3237918 & 1338730 & 6.0969 & 4.2159 & TST & \\
\hline CHEMBL3237923 & 1338730 & 4.0 & \multicolumn{2}{|c|}{4.0089999999999995} & TRN \\
\hline CHEMBL3238222 & 1338730 & 4.0 & 3.9906 & TRN & \\
\hline CHEMBL3237910 & 1338730 & 4.0 & 4.4531 & TST & \\
\hline CHEMBL3237905 & 1338730 & 5.3665 & 4.2588 & TST & \\
\hline CHEMBL3237913 & 1338730 & 5.6576 & 4.6314 & TST & \\
\hline CHEMBL3237911 & 1338730 & 4.0 & 3.5777 & TST & \\
\hline CHEMBL 3237897 & 1338730 & 4.0 & 5.0586 & TST & \\
\hline CHEMBL3238241 & 1338730 & 4.0 & 4.018 & TRN & \\
\hline CHEMBL3237908 & 1338730 & 5.3565 & 4.3112 & TST & \\
\hline CHEMBL3238230 & 1338730 & 4.0 & \multicolumn{2}{|c|}{3.9730000000000003} & TRN \\
\hline CHEMBL1884442 & 752548 & 4.8125 & 5.6347 & TRN & \\
\hline CHEMBL1865901 & 752548 & 3.0044 & 2.855 & TRN & \\
\hline CHEMBL1316867 & 752548 & 6.2366 & 6.1606 & TRN & \\
\hline CHEMBL1870914 & 752548 & 6.1858 & 5.9238 & TRN & \\
\hline CHEMBL1896451 & 752548 & 5.317 & 4.1463 & TST & \\
\hline CHEMBL1878061 & 752548 & 4.9747 & 5.2235 & TRN & \\
\hline CHEMBL1904728 & 752548 & 3.0044 & 3.6864 & TST & \\
\hline CHEMBL1865625 & 752548 & 5.3261 & 5.1586 & TRN & \\
\hline CHEMBL1577231 & 752548 & 5.8996 & 6.0845 & TRN & \\
\hline CHEMBL 1864230 & 752548 & 3.0044 & 3.215 & TRN & \\
\hline CHEMBL1887272 & 752548 & 5.1765 & 5.1358 & TRN & \\
\hline CHEMBL1883614 & 752548 & 3.0044 & 3.4317 & TST & \\
\hline CHEMBL1901621 & 752548 & 3.0044 & 2.9209 & TRN & \\
\hline CHEMBL1879719 & 752548 & 3.0044 & 3.14 & TRN & \\
\hline
\end{tabular}


Supplemental Table S2.txt

\begin{tabular}{|c|c|c|c|c|}
\hline CHEMBL1872841 & 752548 & 4.8697 & 5.1009 & TRN \\
\hline CHEMBL1404762 & 752548 & 3.0044 & 3.2262 & TRN \\
\hline CHEMBL1904010 & 752548 & 3.0044 & 2.888 & TRN \\
\hline CHEMBL1876444 & 752548 & 3.0044 & 2.9152 & TRN \\
\hline CHEMBL1868902 & 752548 & 5.7352 & 5.3879 & TRN \\
\hline CHEMBL1877394 & 752548 & 3.0044 & 2.8625 & TST \\
\hline CHEMBL1866613 & 752548 & 5.8268 & 5.6485 & TRN \\
\hline CHEMBL1864520 & 752548 & 3.0044 & 3.0852 & TRN \\
\hline CHEMBL1897885 & 752548 & 4.7773 & 4.7127 & TRN \\
\hline CHEMBL1904381 & 752548 & 3.0044 & 3.0075 & TRN \\
\hline CHEMBL1871228 & 752548 & 6.0278 & 5.9331 & TRN \\
\hline CHEMBL1881032 & 752548 & 3.0044 & 4.0006 & TST \\
\hline CHEMBL1889468 & 752548 & 3.0044 & 2.9902 & TRN \\
\hline CHEMBL1564500 & 752548 & 4.6091 & 4.5737 & TRN \\
\hline CHEMBL1885482 & 752548 & 4.5129 & 3.9922 & TRN \\
\hline CHEMBL1873865 & 752548 & 3.0044 & 3.637 & TST \\
\hline CHEMBL1882689 & 752548 & 3.0044 & 3.1348 & TRN \\
\hline CHEMBL1904649 & 752548 & 3.0044 & 3.1175 & TST \\
\hline CHEMBL145850 & 752548 & 3.0044 & 3.0747 & TRN \\
\hline CHEMBL1902007 & 752548 & 5.1726 & 5.0278 & TRN \\
\hline CHEMBL1899871 & 752548 & 3.0044 & 2.9392 & TRN \\
\hline CHEMBL1890960 & 752548 & 4.0788 & 3.911 & TRN \\
\hline CHEMBL1878043 & 752548 & 5.1349 & 5.3654 & TRN \\
\hline CHEMBL1870753 & 752548 & 3.0044 & 3.2532 & TRN \\
\hline CHEMBL1365469 & 752548 & 5.0846 & 5.0799 & TRN \\
\hline CHEMBL1333222 & 752548 & 3.0044 & 3.4229 & TRN \\
\hline CHEMBL1903348 & 752548 & 5.6946 & 5.355 & TRN \\
\hline CHEMBL1883713 & 752548 & 3.0044 & 3.2165 & TRN \\
\hline CHEMBL1869506 & 752548 & 5.6819 & 5.587999 & 999999999 \\
\hline CHEMBL1409038 & 752548 & 3.0044 & 2.8899 & TRN \\
\hline CHEMBL1872300 & 752548 & 3.0044 & 3.0164 & TRN \\
\hline CHEMBL1302779 & 752548 & 5.9355 & 5.7722 & TRN \\
\hline CHEMBL1437840 & 752548 & 3.0044 & 2.8616 & TRN \\
\hline CHEMBL 1886662 & 752548 & 5.5391 & 5.5199 & TRN \\
\hline CHEMBL1894778 & 752548 & 3.0044 & 3.0707 & TRN \\
\hline CHEMBL1870529 & 752548 & 3.0044 & 3.589 & TST \\
\hline CHEMBL1904648 & 752548 & 5.7375 & 5.8147 & TRN \\
\hline CHEMBL1876947 & 752548 & 3.0044 & 3.4969 & TST \\
\hline CHEMBL1877480 & 752548 & 3.0044 & 3.1174 & TRN \\
\hline CHEMBL 3188020 & 752548 & 4.3635 & 4.3538 & TST \\
\hline CHEMBL1864747 & 752548 & 5.6737 & 5.4681 & TRN \\
\hline CHEMBL1905960 & 752548 & 3.0044 & 3.2902 & TST \\
\hline CHEMBL1896001 & 752548 & 3.0044 & 2.969 & TRN \\
\hline CHEMBL1869393 & 752548 & 5.9393 & 5.8373 & TRN \\
\hline CHEMBL1882443 & 752548 & 5.129 & 5.3719 & TRN \\
\hline CHEMBL1898423 & 752548 & 4.9318 & 5.1409 & TRN \\
\hline CHEMBL1874506 & 752548 & 4.6308 & 5.0053 & TRN \\
\hline CHEMBL1897348 & 752548 & 3.0044 & 2.7785 & TRN \\
\hline
\end{tabular}




\begin{tabular}{|c|c|c|c|c|c|}
\hline & & & & & \\
\hline CHEMBL1875484 & 752548 & 3.0044 & 2.9151 & TST & \\
\hline CHEMBL1883149 & 752548 & 3.0044 & 3.2169 & TST & \\
\hline CHEMBL1319405 & 752548 & 5.8697 & 5.7874 & TRN & \\
\hline CHEMBL1868274 & 752548 & 5.684 & 5.5947 & TRN & \\
\hline CHEMBL1900875 & 752548 & 3.0044 & 3.1409 & TRN & \\
\hline CHEMBL1885365 & 752548 & 3.0044 & 3.0206 & TRN & \\
\hline CHEMBL1899595 & 752548 & 5.52 & 5.42399 & 99999999995 & TRN \\
\hline CHEMBL1894520 & 752548 & 3.0044 & 3.9468 & TST & \\
\hline CHEMBL1878555 & 752548 & 3.0044 & 2.8115 & TRN & \\
\hline CHEMBL1483649 & 752548 & 5.8386 & 5.6307 & TRN & \\
\hline CHEMBL1888240 & 752548 & 3.0044 & 3.25399 & 99999999996 & TST \\
\hline CHEMBL1893861 & 752548 & 3.0044 & 2.9801 & TST & \\
\hline CHEMBL1901952 & 752548 & 5.8239 & 5.711 & TRN & \\
\hline CHEMBL1878966 & 752548 & 3.0044 & 2.9733 & TST & \\
\hline CHEMBL1885333 & 752548 & 3.0044 & 2.931 & TRN & \\
\hline CHEMBL566295 & 752548 & 3.0044 & 2.7044 & TRN & \\
\hline CHEMBL1899813 & 752548 & 4.0246 & 4.1846 & TRN & \\
\hline CHEMBL1890481 & 752548 & 3.0044 & 3.0633 & TST & \\
\hline CHEMBL1903024 & 752548 & 4.1124 & 4.1313 & TST & \\
\hline CHEMBL1891206 & 752548 & 5.9245 & 5.8685 & TRN & \\
\hline CHEMBL1553773 & 752548 & 5.8153 & 5.7727 & TRN & \\
\hline CHEMBL1898996 & 752548 & 3.0044 & 3.0917 & TRN & \\
\hline CHEMBL1699684 & 752548 & 3.0044 & 3.1606 & TRN & \\
\hline CHEMBL1413278 & 752548 & 4.2048 & 4.6284 & TRN & \\
\hline CHEMBL1905421 & 752548 & 3.0044 & 3.0204 & TST & \\
\hline CHEMBL1886655 & 752548 & 3.0044 & 2.9114 & TRN & \\
\hline CHEMBL1904269 & 752548 & 3.0044 & 3.6241 & TST & \\
\hline CHEMBL1874988 & 752548 & 4.6596 & 4.3962 & TRN & \\
\hline CHEMBL1865073 & 752548 & 3.0044 & 2.9295 & TST & \\
\hline CHEMBL1896263 & 752548 & 5.5391 & 5.612 & TRN & \\
\hline CHEMBL1883257 & 752548 & 5.0665 & 4.7581 & TRN & \\
\hline CHEMBL1899989 & 752548 & 5.6904 & 5.8514 & TRN & \\
\hline CHEMBL1903767 & 752548 & 3.0044 & 3.7142 & TST & \\
\hline CHEMBL1877777 & 752548 & 5.8861 & 6.0149 & TRN & \\
\hline CHEMBL1873341 & 752548 & 3.0044 & 3.0044 & TRN & \\
\hline CHEMBL1895639 & 752548 & 3.0044 & 3.1917 & TST & \\
\hline CHEMBL464086 & 535394 & 3.0 & 3.0532 & TRN & \\
\hline CHEMBL489373 & 535394 & 3.7212 & 3.6407 & TRN & \\
\hline CHEMBL489981 & 535394 & 4.0 & 3.634 & TRN & \\
\hline CHEMBL492037 & 535394 & 3.0 & 3.7994 & TST & \\
\hline CHEMBL452676 & 535394 & 4.7447 & 4.8614 & TRN & \\
\hline CHEMBL477607 & 535394 & 3.2147 & 3.5239 & TRN & \\
\hline CHEMBL518286 & 535394 & 4.0 & 3.9831 & TRN & \\
\hline CHEMBL451317 & 535394 & 3.8861 & 3.8942 & TRN & \\
\hline CHEMBL475475 & 535394 & 3.2007 & 3.2312 & TRN & \\
\hline CHEMBL448446 & 535394 & 3.5229 & 3.5231 & TRN & \\
\hline CHEMBL450704 & 535394 & 4.0 & 4.0699 & TRN & \\
\hline CHEMBL450720 & 535394 & 4.0 & 3.9104 & TRN & \\
\hline
\end{tabular}




\begin{tabular}{|c|c|c|c|c|c|}
\hline \multicolumn{6}{|c|}{ Supplemental Table S2.txt } \\
\hline CHEMBL490396 & 535394 & 4.0969 & 4.1273 & TRN & \\
\hline CHEMBL445306 & 535394 & 3.699 & 3.7003 & TRN & \\
\hline CHEMBL448665 & 535394 & 3.0 & 2.8282 & TRN & \\
\hline CHEMBL476984 & 535394 & 3.5528 & 3.6261 & TRN & \\
\hline CHEMBL523441 & 535394 & 4.0 & 3.9812 & TRN & \\
\hline CHEMBL491207 & 535394 & 3.699 & 3.6637 & TRN & \\
\hline CHEMBL478859 & 535394 & 3.1739 & 3.1785 & TRN & \\
\hline CHEMBL510108 & 535394 & 3.2291 & 3.286 & TRN & \\
\hline CHEMBL491006 & 535394 & 4.1249 & 4.163 & TRN & \\
\hline CHEMBL489982 & 535394 & 4.7447 & 4.4262 & TRN & \\
\hline CHEMBL476973 & 535394 & 4.9208 & 4.8088 & TRN & \\
\hline CHEMBL442570 & 535394 & 3.0 & 4.4411 & TST & \\
\hline CHEMBL477177 & 535394 & 4.2218 & 4.2202 & TRN & \\
\hline CHEMBL446474 & 535394 & 4.7959 & 4.8108 & TRN & \\
\hline CHEMBL489779 & 535394 & 4.0969 & 4.0697 & TRN & \\
\hline CHEMBL489169 & 535394 & 3.5229 & 3.3142 & TRN & \\
\hline CHEMBL489168 & 535394 & 5.301 & 4.0834 & TST & \\
\hline CHEMBL522098 & 535394 & 3.4559 & 3.7174 & TRN & \\
\hline CHEMBL564201 & 535394 & 3.0 & 5.0328 & TST & \\
\hline CHEMBL515944 & 535394 & 3.8539 & 3.333 & TST & \\
\hline CHEMBL476783 & 535394 & 3.7447 & 2.9614 & TST & \\
\hline CHEMBL489777 & 535394 & 3.0 & 2.9629 & TRN & \\
\hline CHEMBL418899 & 535394 & 5.7696 & 6.3255 & TST & \\
\hline CHEMBL1162372 & 535394 & 3.699 & 3.97899 & 99999999996 & TST \\
\hline CHEMBL490999 & 535394 & 4.301 & 4.3371 & TRN & \\
\hline CHEMBL522585 & 535394 & 5.2218 & 5.2497 & TRN & \\
\hline CHEMBL446919 & 535394 & 3.8861 & 3.7131 & TST & \\
\hline CHEMBL522753 & 535394 & 3.1675 & 3.4224 & TRN & \\
\hline CHEMBL478882 & 535394 & 3.4437 & 3.3803 & TRN & \\
\hline CHEMBL477823 & 535394 & 4.3372 & 4.4121 & TST & \\
\hline CHEMBL442892 & 535394 & 4.7447 & 4.6827 & TST & \\
\hline CHEMBL476983 & 535394 & 5.301 & 5.2826 & TRN & \\
\hline CHEMBL492036 & 535394 & 3.1427 & 4.0038 & TST & \\
\hline CHEMBL498976 & 535394 & 3.8539 & 3.7028 & TRN & \\
\hline CHEMBL518440 & 535394 & 5.4559 & 5.3411 & TRN & \\
\hline CHEMBL476358 & 535394 & 4.6778 & 4.5985 & TST & \\
\hline CHEMBL490997 & 535394 & 3.0 & 3.0822 & TRN & \\
\hline CHEMBL478860 & 535394 & 3.6778 & 3.7166 & TRN & \\
\hline CHEMBL508059 & 535394 & 4.3979 & 4.3891 & TRN & \\
\hline CHEMBL517807 & 535394 & 3.1308 & 3.00600 & 00000000002 & TST \\
\hline CHEMBL452739 & 535394 & 3.0 & 2.9939 & TRN & \\
\hline CHEMBL489564 & 535394 & 3.8861 & 3.8981 & TRN & \\
\hline CHEMBL477596 & 535394 & 3.3188 & 3.2012 & TRN & \\
\hline CHEMBL502905 & 535394 & 4.9586 & 4.9055 & TRN & \\
\hline CHEMBL505701 & 535394 & 4.0655 & 4.2138 & TRN & \\
\hline CHEMBL477606 & 535394 & 4.5528 & 4.2522 & TRN & \\
\hline CHEMBL490061 & 535394 & 3.2218 & 3.2858 & TRN & \\
\hline CHEMBL470987 & 535394 & 5.1549 & 5.1929 & TRN & \\
\hline
\end{tabular}




\begin{tabular}{|c|c|c|c|c|c|}
\hline & & \multicolumn{4}{|c|}{ Supplemental Table S2.txt } \\
\hline CHEMBL476974 & 535394 & 3.2366 & 3.2937 & TRN & \\
\hline CHEMBL476784 & 535394 & 3.6576 & 3.1576 & TST & \\
\hline CHEMBL491007 & 535394 & 4.0458 & 4.1037 & TRN & \\
\hline CHEMBL490784 & 535394 & 4.1549 & 4.1925 & TRN & \\
\hline CHEMBL1203972 & 535394 & 3.0 & 2.9713 & TRN & \\
\hline CHEMBL448250 & 535394 & 6.0969 & 6.1359 & TRN & \\
\hline CHEMBL490761 & 535394 & 3.0 & 3.1666 & TRN & \\
\hline CHEMBL476918 & 535394 & 4.0458 & 4.0648 & TRN & \\
\hline CHEMBL501654 & 535394 & 3.5528 & 3.5673 & TRN & \\
\hline CHEMBL477550 & 535394 & 3.0 & 3.043 & TRN & \\
\hline CHEMBL477176 & 535394 & 4.7212 & 4.9278 & TRN & \\
\hline CHEMBL470505 & 535394 & 4.6778 & 4.7067 & TST & \\
\hline CHEMBL448063 & 535394 & 4.2147 & 4.1599 & TRN & \\
\hline CHEMBL476992 & 535394 & 3.0 & 3.3167 & TST & \\
\hline CHEMBL478881 & 535394 & 4.699 & 4.7226 & TST & \\
\hline CHEMBL476147 & 535394 & 5.0458 & 5.6209 & TST & \\
\hline CHEMBL476148 & 535394 & 4.9586 & 4.9433 & TST & \\
\hline CHEMBL504564 & 535394 & 3.5229 & 3.3962 & TRN & \\
\hline CHEMBL499938 & 535394 & 3.1938 & 3.1077 & TRN & \\
\hline CHEMBL490998 & 535394 & 4.0 & 4.0835 & TRN & \\
\hline CHEMBL502222 & 535394 & 3.2518 & 3.2683 & TRN & \\
\hline CHEMBL477187 & 535394 & 5.0 & 4.6899 & TST & \\
\hline CHEMBL478880 & 535394 & 5.2596 & 5.5492 & TST & \\
\hline CHEMBL489776 & 535394 & 3.5086 & 3.6419 & TRN & \\
\hline CHEMBL491005 & 535394 & 4.1549 & 4.1239 & TRN & \\
\hline CHEMBL392695 & 954864 & 5.6418 & 5.4611 & TRN & \\
\hline CHEMBL1190711 & 954864 & 4.8057 & 4.6115 & TRN & \\
\hline CHEMBL 202721 & 954864 & 4.9156 & 5.3314 & TRN & \\
\hline CHEMBL1256459 & 954864 & 6.7442 & 6.9644 & TRN & \\
\hline CHEMBL192566 & 954864 & 7.7395 & 7.4273 & TST & \\
\hline CHEMBL1242367 & 954864 & 3.9979 & 4.2944 & TRN & \\
\hline CHEMBL585951 & 954864 & 5.8413 & 5.8464 & TRN & \\
\hline CHEMBL 102714 & 954864 & 2.9659 & 3.4281 & TRN & \\
\hline CHEMBL65 & 954864 & 7.4699 & 7.3602 & TRN & \\
\hline CHEMBL 2137530 & 954864 & 5.3885 & 4.9328 & TRN & \\
\hline CHEMBL379975 & 954864 & 5.8157 & 5.17399 & 99999999995 & TRN \\
\hline CHEMBL 209148 & 954864 & 5.3661 & 5.2175 & TRN & \\
\hline CHEMBL1673039 & 954864 & 6.0511 & 5.8585 & TRN & \\
\hline CHEMBL 217354 & 954864 & 6.3945 & 6.4238 & TRN & \\
\hline CHEMBL1186585 & 954864 & 4.2803 & 4.5723 & TRN & \\
\hline CHEMBL1516890 & 954864 & 3.9694 & 4.0784 & TRN & \\
\hline CHEMBL393929 & 954864 & 4.9881 & 4.521 & TRN & \\
\hline CHEMBL1357247 & 954864 & 3.5602 & 3.2342 & TRN & \\
\hline CHEMBL 2144069 & 954864 & 5.8887 & 5.4822 & TRN & \\
\hline CHEMBL577784 & 954864 & 5.7293 & 5.6967 & TRN & \\
\hline CHEMBL135561 & 954864 & 4.8231 & 4.7215 & TRN & \\
\hline CHEMBL189584 & 954864 & 5.3422 & 5.131 & TRN & \\
\hline CHEMBL1970879 & 954864 & 5.6398 & 5.456 & TRN & \\
\hline
\end{tabular}


Supplemental Table S2.txt

\begin{tabular}{|c|c|c|c|c|c|}
\hline CHEMBL210618 & 954864 & 2.9655 & 3.5896 & TRN & \\
\hline CHEMBL 222102 & 954864 & 3.4032 & 3.7647 & TRN & \\
\hline CHEMBL3392440 & 954864 & 3.9773 & 4.2448 & TRN & \\
\hline CHEMBL 255342 & 954864 & 4.1091 & 3.9249 & TRN & \\
\hline CHEMBL221137 & 954864 & 4.0486 & 4.4542 & TST & \\
\hline CHEMBL1909414 & 954864 & 3.7039 & 3.5244 & TRN & \\
\hline CHEMBL 213100 & 954864 & 5.4879 & 5.4833 & TRN & \\
\hline CHEMBL220241 & 954864 & 7.3053 & 7.4348 & TRN & \\
\hline CHEMBL1788116 & 954864 & 4.5827 & 4.9087 & TRN & \\
\hline CHEMBL188678 & 954864 & 5.0132 & 4.7164 & TRN & \\
\hline CHEMBL515416 & 954864 & 5.5989 & 5.4228 & TRN & \\
\hline CHEMBL514499 & 954864 & 7.0542 & 7.3103 & TRN & \\
\hline CHEMBL9470 & 954864 & 6.2583 & 5.841 & TST & \\
\hline CHEMBL1230020 & 954864 & 3.3295 & 3.2937 & TRN & \\
\hline CHEMBL92309 & 954864 & 2.6744 & 2.8613 & TST & \\
\hline CHEMBL509032 & 954864 & 5.9024 & 6.3557 & TRN & \\
\hline CHEMBL472940 & 954864 & 2.5344 & 2.6741 & TRN & \\
\hline CHEMBL3199475 & 954864 & 3.6506 & 3.4785 & TRN & \\
\hline CHEMBL483849 & 954864 & 1.5281 & 1.9901 & TST & \\
\hline CHEMBL 258844 & 954864 & 4.3122 & 4.1208 & TRN & \\
\hline CHEMBL 259181 & 954864 & 2.9306 & 3.0899 & TRN & \\
\hline CHEMBL191334 & 954864 & 5.2059 & 5.1431 & TRN & \\
\hline CHEMBL1404918 & 954864 & 2.8906 & 2.7149 & TRN & \\
\hline CHEMBL 373751 & 954864 & 4.2416 & 4.5281 & TRN & \\
\hline CHEMBL180127 & 954864 & 4.7668 & 4.8536 & TRN & \\
\hline CHEMBL 2005886 & 954864 & 5.6862 & 5.9163 & TRN & \\
\hline CHEMBL558642 & 954864 & 3.418999 & 999999999 & 96 & 3.364 \\
\hline CHEMBL 2134202 & 954864 & 4.5012 & 4.6031 & TRN & \\
\hline CHEMBL3186408 & 954864 & 4.6347 & 4.7617 & TST & \\
\hline CHEMBL449158 & 954864 & 7.1967 & 7.34 & TST & \\
\hline CHEMBL3349342 & 954864 & 5.8003 & 5.6012 & TRN & \\
\hline CHEMBL483847 & 954864 & 4.2052 & 4.3375 & TRN & \\
\hline CHEMBL 240954 & 954864 & 2.9494 & 3.6106 & TST & \\
\hline CHEMBL 399530 & 954864 & 5.1099 & 4.5876 & TST & \\
\hline CHEMBL 379300 & 954864 & 6.5553 & 6.6101 & TST & \\
\hline CHEMBL573107 & 954864 & 5.1372 & 5.4613 & TST & \\
\hline CHEMBL512504 & 954864 & 4.1943 & 4.6002 & TST & \\
\hline CHEMBL412142 & 954864 & 3.7407 & 4.4359 & TST & \\
\hline CHEMBL 2363137 & 954864 & 4.941 & 4.635 & TST & \\
\hline CHEMBL1590308 & 954864 & 3.7259 & 4.3163 & TST & \\
\hline CHEMBL1643959 & 954864 & 3.7458 & 4.3817 & TST & \\
\hline CHEMBL 300389 & 954864 & 6.9771 & 7.2256 & TST & \\
\hline CHEMBL343698 & 92493 & 3.301 & 2.615 & TRN & \\
\hline CHEMBL415732 & 92493 & 4.6676 & 4.864 & TRN & \\
\hline CHEMBL144419 & 92493 & 3.301 & 4.4171 & TST & \\
\hline CHEMBL 344352 & 92493 & 4.6021 & 4.3623 & TRN & \\
\hline CHEMBL144150 & 92493 & 5.1549 & 5.3078 & TRN & \\
\hline CHEMBL148135 & 92493 & 7.6289 & 7.5262 & TRN & \\
\hline
\end{tabular}




\begin{tabular}{|c|c|c|c|c|c|}
\hline \multicolumn{6}{|c|}{ Supplemental Table S2 } \\
\hline CHEMBL146072 & 92493 & 4.7212 & 4.52 & TRN & \\
\hline CHEMBL357691 & 92493 & 5.2007 & 5.5169 & TRN & \\
\hline CHEMBL144135 & 92493 & 3.301 & 2.9582 & TRN & \\
\hline CHEMBL144242 & 92493 & 5.2218 & 4.8148 & TRN & \\
\hline CHEMBL141931 & 92493 & 5.0458 & 4.3314 & TRN & \\
\hline CHEMBL147969 & 92493 & 3.301 & 3.5445 & TRN & \\
\hline CHEMBL357619 & 92493 & 5.699 & 5.7811 & TRN & \\
\hline CHEMBL148176 & 92493 & 5.6021 & 6.2619 & TST & \\
\hline CHEMBL144023 & 92493 & 5.0969 & 4.7759 & TRN & \\
\hline CHEMBL144879 & 92493 & 4.7212 & 4.5393 & TRN & \\
\hline CHEMBL344725 & 92493 & 3.301 & 3.4482 & TRN & \\
\hline CHEMBL144125 & 92493 & 5.301 & 5.3773 & TRN & \\
\hline CHEMBL147970 & 92493 & 3.301 & 3.0729 & TRN & \\
\hline CHEMBL147579 & 92493 & 8.2218 & 7.3009 & TRN & \\
\hline CHEMBL142894 & 92493 & 6.2757 & 6.5263 & TRN & \\
\hline CHEMBL144587 & 92493 & 3.301 & 4.0037 & TRN & \\
\hline CHEMBL423023 & 92493 & 3.301 & 3.8613 & TRN & \\
\hline CHEMBL144179 & 92493 & 3.301 & 3.4982 & TRN & \\
\hline CHEMBL144923 & 92493 & 4.7696 & 5.7895 & TRN & \\
\hline CHEMBL143109 & 92493 & 3.301 & 3.0349 & TRN & \\
\hline CHEMBL144487 & 92493 & 3.301 & 4.6428 & TST & \\
\hline CHEMBL148427 & 92493 & 5.9355 & 5.4639 & TRN & \\
\hline CHEMBL424109 & 92493 & 5.301 & 4.6859 & TRN & \\
\hline CHEMBL144519 & 92493 & 5.699 & 5.6916 & TRN & \\
\hline CHEMBL144647 & 92493 & 8.3979 & 8.1027 & TRN & \\
\hline CHEMBL142893 & 92493 & 5.0315 & 4.4594 & TST & \\
\hline CHEMBL423738 & 92493 & 3.301 & 3.541006 & 00000000004 & TRN \\
\hline CHEMBL144339 & 92493 & 6.9031 & 7.0684 & TRN & \\
\hline CHEMBL144759 & 92493 & 4.5157 & 5.1324 & TRN & \\
\hline CHEMBL358968 & 92493 & 7.0969 & 6.8028 & TRN & \\
\hline CHEMBL144565 & 92493 & 4.3979 & 4.4827 & TRN & \\
\hline CHEMBL344979 & 92493 & 7.2596 & 7.4491 & TRN & \\
\hline CHEMBL142739 & 92493 & 3.301 & 3.3486 & TRN & \\
\hline CHEMBL145070 & 92493 & 3.301 & 3.5449 & TRN & \\
\hline CHEMBL147270 & 92493 & 5.6576 & 5.8713 & TRN & \\
\hline CHEMBL147798 & 92493 & 4.5229 & 6.4832 & TST & \\
\hline CHEMBL144062 & 92493 & 5.0458 & 5.0586 & TRN & \\
\hline CHEMBL148113 & 92493 & 4.6576 & 5.1939 & TRN & \\
\hline CHEMBL148079 & 92493 & 6.3979 & 6.1424 & TST & \\
\hline CHEMBL144353 & 92493 & 5.3979 & 6.3551 & TST & \\
\hline CHEMBL144253 & 92493 & 4.8928 & 5.2673 & TST & \\
\hline CHEMBL433551 & 92493 & 4.8386 & 4.3417 & TST & \\
\hline CHEMBL146071 & 92493 & 5.5229 & 5.7956 & TST & \\
\hline CHEMBL342346 & 92493 & 4.9586 & 2.0834 & TST & \\
\hline CHEMBL421953 & 92493 & 5.3188 & 6.7446 & TST & \\
\hline CHEMBL357406 & 92493 & 5.7447 & 6.3738 & TST & \\
\hline CHEMBL1230020 & 954541 & 6.3828 & 6.1938 & TRN & \\
\hline CHEMBL2137530 & 954541 & 5.0566 & 4.8981 & TRN & \\
\hline
\end{tabular}




\begin{tabular}{|c|c|c|c|c|c|c|}
\hline & & \multicolumn{5}{|c|}{ Supplemental Table S2.txt } \\
\hline CHEMBL258844 & 954541 & 4.0431 & 4.4195 & TRN & & \\
\hline CHEMBL3186408 & 954541 & 4.8163 & 4.2131 & TST & & \\
\hline CHEMBL209148 & 954541 & 5.6031 & 5.1392 & TRN & & \\
\hline CHEMBL1190711 & 954541 & 4.3237 & 4.4905 & TRN & & \\
\hline CHEMBL3349342 & 954541 & 7.0675 & 7.6385 & TRN & & \\
\hline CHEMBL3199475 & 954541 & 3.6878 & 4.3804 & TRN & & \\
\hline CHEMBL1673039 & 954541 & 5.7011 & 5.1285 & TRN & & \\
\hline CHEMBL102714 & 954541 & 3.2909 & 3.8937 & TRN & & \\
\hline CHEMBL217354 & 954541 & 6.6443 & 6.6973 & TRN & & \\
\hline CHEMBL373751 & 954541 & 4.7107 & 4.1831 & TRN & & \\
\hline CHEMBL514499 & 954541 & 6.9108 & 7.2944 & TRN & & \\
\hline CHEMBL135561 & 954541 & 4.3745 & 4.8958 & TRN & & \\
\hline CHEMBL1357247 & 954541 & 3.8169 & 3.1821 & TRN & & \\
\hline CHEMBL1643959 & 954541 & 3.9545 & 3.8857 & TRN & & \\
\hline CHEMBL191334 & 954541 & 4.7549 & 5.1737 & TRN & & \\
\hline CHEMBL393929 & 954541 & 3.7819 & 3.6728 & TRN & & \\
\hline CHEMBL213100 & 954541 & 5.6736 & 5.7319 & TRN & & \\
\hline CHEMBL379300 & 954541 & 6.7329 & 6.69 & TRN & & \\
\hline CHEMBL189584 & 954541 & 3.8562 & 4.2764 & TRN & & \\
\hline CHEMBL1909414 & 954541 & 6.0905 & 5.7483 & TRN & & \\
\hline CHEMBL 2134202 & 954541 & 4.2665 & 4.2158 & TRN & & \\
\hline CHEMBL92309 & 954541 & 2.6153 & 3.1208 & TST & & \\
\hline CHEMBL3392440 & 954541 & 3.804 & 4.2266 & TRN & & \\
\hline CHEMBL180127 & 954541 & 4.0604 & 4.3763 & TRN & & \\
\hline CHEMBL573107 & 954541 & 4.7698 & 5.1013 & TRN & & \\
\hline CHEMBL1970879 & 954541 & 6.0396 & 5.5748 & TRN & & \\
\hline CHEMBL483847 & 954541 & 4.7886 & 4.6274 & TRN & & \\
\hline CHEMBL1590308 & 954541 & 3.36899 & 99999999 & 998 & 3.8408 & TST \\
\hline CHEMBL512504 & 954541 & 4.8256 & 4.4116 & TRN & & \\
\hline CHEMBL1788116 & 954541 & 4.7968 & 4.4273 & TRN & & \\
\hline CHEMBL412142 & 954541 & 3.548 & 4.2663 & TRN & & \\
\hline CHEMBL515416 & 954541 & 5.1423 & 5.0636 & TRN & & \\
\hline CHEMBL65 & 954541 & 7.2233 & 7.2871 & TRN & & \\
\hline CHEMBL210618 & 954541 & 3.3087 & 3.5433 & TRN & & \\
\hline CHEMBL202721 & 954541 & 4.1629 & 4.6601 & TRN & & \\
\hline CHEMBL399530 & 954541 & 4.309 & 4.5949 & TRN & & \\
\hline CHEMBL1242367 & 954541 & 5.4799 & 4.8194 & TRN & & \\
\hline CHEMBL392695 & 954541 & 5.6365 & 5.3568 & TRN & & \\
\hline CHEMBL379975 & 954541 & 5.7835 & 5.0365 & TRN & & \\
\hline CHEMBL449158 & 954541 & 6.7002 & 7.4324 & TST & & \\
\hline CHEMBL483849 & 954541 & 2.5361 & 2.4455 & TST & & \\
\hline CHEMBL 222102 & 954541 & 3.2993 & 3.7591 & TRN & & \\
\hline CHEMBL509032 & 954541 & 5.4831 & 5.3323 & TRN & & \\
\hline CHEMBL1256459 & 954541 & 7.4459 & 7.5262 & TRN & & \\
\hline CHEMBL221137 & 954541 & 4.6038 & 4.91 & TST & & \\
\hline CHEMBL472940 & 954541 & 2.8394 & 2.8522 & TRN & & \\
\hline CHEMBL 2005886 & 954541 & 6.0547 & 5.6965 & TRN & & \\
\hline CHEMBL 2363137 & 954541 & 5.8586 & 5.635 & TRN & & \\
\hline
\end{tabular}




\begin{tabular}{|c|c|c|c|c|c|}
\hline \multirow[b]{2}{*}{ CHEMBL255342 } & \multicolumn{5}{|c|}{ Supplemental Table S2.txt } \\
\hline & 954541 & 3.2454 & 3.5178 & TRN & \\
\hline CHEMBL220241 & 954541 & 5.2399 & 4.76399 & 9999999999 & TRN \\
\hline CHEMBL1516890 & 954541 & 4.2409 & 4.1603 & TRN & \\
\hline CHEMBL558642 & 954541 & 4.3854 & 4.0501 & TRN & \\
\hline CHEMBL 1186585 & 954541 & 3.9622 & 4.0385 & TST & \\
\hline CHEMBL1404918 & 954541 & 3.8421 & 3.1041 & TST & \\
\hline CHEMBL192566 & 954541 & 7.7503 & 8.004 & TST & \\
\hline CHEMBL259181 & 954541 & 4.752 & 4.7686 & TST & \\
\hline CHEMBL 2144069 & 954541 & 8.5216 & 7.5562 & TST & \\
\hline CHEMBL577784 & 954541 & 4.7347 & 4.7805 & TST & \\
\hline CHEMBL240954 & 954541 & 3.043 & 3.8293 & TST & \\
\hline CHEMBL188678 & 954541 & 4.2727 & 4.4251 & TST & \\
\hline CHEMBL9470 & 954541 & 6.4302 & 5.8414 & TST & \\
\hline CHEMBL585951 & 954541 & 6.3869 & 6.1643 & TST & \\
\hline CHEMBL 300389 & 954541 & 6.4712 & 6.9521 & TST & \\
\hline CHEMBL3950135 & 1641179 & 7.9586 & 7.532 & TRN & \\
\hline CHEMBL3964959 & 1641179 & 7.6778 & 7.3113 & TST & \\
\hline CHEMBL3910074 & 1641179 & 8.5229 & 8.2508 & TRN & \\
\hline CHEMBL3970334 & 1641179 & 8.2291 & 7.9168 & TRN & \\
\hline CHEMBL3975185 & 1641179 & 8.2076 & 7.9468 & TRN & \\
\hline CHEMBL3952122 & 1641179 & 7.9586 & 7.8391 & TRN & \\
\hline CHEMBL 3913404 & 1641179 & 7.301 & 7.6953 & TRN & \\
\hline CHEMBL3895089 & 1641179 & 7.7959 & 7.9961 & TRN & \\
\hline CHEMBL3980172 & 1641179 & 7.8861 & 7.6719 & TRN & \\
\hline CHEMBL3946364 & 1641179 & 7.8239 & 8.2329 & TRN & \\
\hline CHEMBL3959749 & 1641179 & 7.6383 & 8.1728 & TRN & \\
\hline CHEMBL3900818 & 1641179 & 8.2147 & 7.8753 & TRN & \\
\hline CHEMBL3911156 & 1641179 & 7.3188 & 7.5246 & TST & \\
\hline CHEMBL 3981087 & 1641179 & 7.7959 & 7.3659 & TST & \\
\hline CHEMBL3933534 & 1641179 & 8.5528 & 8.1699 & TST & \\
\hline CHEMBL3972336 & 1641179 & 8.1427 & 8.1937 & TRN & \\
\hline CHEMBL3909559 & 1641179 & 8.6021 & 8.2139 & TRN & \\
\hline CHEMBL3891984 & 1641179 & 7.8239 & 7.9744 & TRN & \\
\hline CHEMBL 3924542 & 1641179 & 8.6576 & 7.3917 & TST & \\
\hline CHEMBL3964067 & 1641179 & 8.0458 & 7.6264 & TRN & \\
\hline CHEMBL3900521 & 1641179 & 7.6383 & 7.2517 & TRN & \\
\hline CHEMBL3912146 & 1641179 & 8.3979 & 7.7294 & TRN & \\
\hline CHEMBL3914485 & 1641179 & 7.0862 & 7.4707 & TST & \\
\hline CHEMBL 3934767 & 1641179 & 6.9281 & 7.9438 & TRN & \\
\hline CHEMBL3922319 & 1641179 & 7.5686 & 7.6847 & TRN & \\
\hline CHEMBL3927663 & 1641179 & 7.4437 & 7.7827 & TRN & \\
\hline CHEMBL3946815 & 1641179 & 8.4437 & 7.9584 & TRN & \\
\hline CHEMBL3973250 & 1641179 & 8.4318 & 8.2344 & TRN & \\
\hline CHEMBL3907581 & 1641179 & 8.7696 & 8.3615 & TST & \\
\hline CHEMBL3915438 & 1641179 & 7.8861 & 7.6895 & TRN & \\
\hline CHEMBL3952317 & 1641179 & 8.4559 & 8.1199 & TST & \\
\hline CHEMBL3890740 & 1641179 & 7.5528 & 7.7607 & TST & \\
\hline CHEMBL3950958 & 1641179 & 7.8239 & 8.0671 & TRN & \\
\hline
\end{tabular}


Supplemental Table S2.txt

\begin{tabular}{|c|c|c|c|c|}
\hline CHEMBL3925738 & 1641179 & 7.6576 & 7.682 & TRN \\
\hline CHEMBL3897645 & 1641179 & 8.0809 & 7.6313 & TST \\
\hline CHEMBL3928095 & 1641179 & 8.6198 & 8.1058 & TST \\
\hline CHEMBL3889924 & 1641179 & 8.301 & 7.6539 & TRN \\
\hline CHEMBL3964926 & 1641179 & 7.4685 & 7.7117 & TRN \\
\hline CHEMBL3918894 & 1641179 & 8.2291 & 7.8873 & TRN \\
\hline CHEMBL3897366 & 1641179 & 7.8539 & 7.3553 & TST \\
\hline CHEMBL3901028 & 1641179 & 7.7696 & 8.2287 & TRN \\
\hline CHEMBL 3940153 & 1641179 & 8.3665 & 7.7844 & TRN \\
\hline CHEMBL3932020 & 1641179 & 8.041 & 8.0825 & TRN \\
\hline CHEMBL3896463 & 1641179 & 6.6345 & 7.45 & TRN \\
\hline CHEMBL3934628 & 1641179 & 7.284 & 7.7428 & TST \\
\hline CHEMBL3933399 & 1641179 & 8.0915 & 7.8085 & TRN \\
\hline CHEMBL 3942583 & 1641179 & 8.4559 & 7.3796 & TST \\
\hline CHEMBL3923067 & 1641179 & 8.5686 & 8.4762 & TRN \\
\hline CHEMBL3937500 & 1641179 & 8.2007 & 8.0183 & TRN \\
\hline CHEMBL3938012 & 1641179 & 8.3565 & 8.0648 & TRN \\
\hline CHEMBL3901732 & 1641179 & 6.4895 & 7.1891 & TRN \\
\hline CHEMBL3929682 & 1641179 & 7.585 & 7.6955 & TRN \\
\hline CHEMBL3976257 & 1641179 & 7.0706 & 7.2341 & TST \\
\hline CHEMBL3943731 & 1641179 & 7.2441 & 7.7554 & TRN \\
\hline CHEMBL3925552 & 1641179 & 8.0706 & 8.2037 & TRN \\
\hline CHEMBL3964193 & 1641179 & 7.4815 & 7.7333 & TRN \\
\hline CHEMBL 3898057 & 1641179 & 7.4559 & 8.1556 & TRN \\
\hline CHEMBL3895435 & 1641179 & 8.5229 & 8.2618 & TRN \\
\hline CHEMBL 3940354 & 1641179 & 8.5528 & 8.4778 & TRN \\
\hline CHEMBL3957468 & 1640191 & 7.8508 & 7.7439 & TRN \\
\hline CHEMBL3907419 & 1640191 & 8.4056 & 8.5336 & TRN \\
\hline CHEMBL194186 & 1640191 & 9.1355 & 9.2586 & TRN \\
\hline CHEMBL3979386 & 1640191 & 8.9872 & 8.9643 & TRN \\
\hline CHEMBL48813 & 1640191 & 8.7595 & 8.6881 & TST \\
\hline CHEMBL3955803 & 1640191 & 8.7747 & 8.7532 & TRN \\
\hline CHEMBL3968842 & 1640191 & 8.5058 & 8.7221 & TRN \\
\hline CHEMBL3966335 & 1640191 & 5.9872 & 6.0426 & TST \\
\hline CHEMBL3910588 & 1640191 & 9.1409 & 9.0486 & TRN \\
\hline CHEMBL3942651 & 1640191 & 5.4498 & 5.5291 & TST \\
\hline CHEMBL3305961 & 1640191 & 7.6904 & 7.7973 & TRN \\
\hline CHEMBL196551 & 1640191 & 8.1215 & 8.0982 & TRN \\
\hline CHEMBL3986101 & 1640191 & 9.0 & 9.0556 & TRN \\
\hline CHEMBL3961484 & 1640191 & 9.1085 & 8.9363 & TRN \\
\hline CHEMBL557915 & 1640191 & 8.7212 & 8.779 & TRN \\
\hline CHEMBL1235423 & 1640191 & 7.5935 & \multicolumn{2}{|c|}{7.247000000000001} \\
\hline CHEMBL364284 & 1640191 & 9.6326 & 9.756 & TRN \\
\hline CHEMBL436293 & 1640191 & 7.1113 & 6.9607 & TRN \\
\hline CHEMBL3904655 & 1640191 & 8.6198 & 8.5889 & TRN \\
\hline CHEMBL3304291 & 1640191 & 8.2848 & 8.4177 & TRN \\
\hline CHEMBL3928201 & 1640191 & 7.6421 & 7.3727 & TST \\
\hline CHEMBL196669 & 1640191 & 5.2351 & 5.2556 & TRN \\
\hline
\end{tabular}


Supplemental Table S2.txt

\begin{tabular}{|c|c|c|c|c|c|c|}
\hline CHEMBL 3974641 & 1640191 & 7.5935 & 7.3583 & \multicolumn{2}{|l|}{ TST } & \\
\hline CHEMBL194810 & 1640191 & 7.7645 & \multicolumn{3}{|c|}{8.017000000000001} & TRN \\
\hline CHEMBL 372568 & 1640191 & 6.3595 & 6.41 & TRN & & \\
\hline CHEMBL197547 & 1640191 & \multicolumn{3}{|c|}{7.382999999999999} & 7.246 & TRN \\
\hline CHEMBL196162 & 1640191 & 8.4976 & 7.7918 & TRN & & \\
\hline CHEMBL 3960154 & 1640191 & 9.1475 & 8.9549 & TST & & \\
\hline CHEMBL198654 & 1640191 & 8.2111 & 8.4064 & TRN & & \\
\hline CHEMBL 371106 & 1640191 & 7.4724 & 7.7461 & TRN & & \\
\hline CHEMBL194889 & 1640191 & \multicolumn{3}{|c|}{6.327000000000001} & 6.3487 & \\
\hline CHEMBL372956 & 1640191 & 8.6968 & 8.5012 & TRN & & \\
\hline CHEMBL550453 & 1640191 & 8.163 & \multicolumn{3}{|c|}{8.261000000000001} & \\
\hline CHEMBL190142 & 1640191 & 8.8097 & 8.4549 & TRN & & \\
\hline CHEMBL196589 & 1640191 & \multicolumn{3}{|c|}{7.162999999999999} & 7.3406 & \\
\hline CHEMBL 3956658 & 1640191 & 8.0814 & 8.2094 & TRN & & \\
\hline CHEMBL198421 & 1640191 & 6.585 & 6.7917 & TRN & & \\
\hline CHEMBL196539 & 1640191 & 9.0762 & 9.1558 & TRN & & \\
\hline CHEMBL 3972969 & 1640191 & 8.0841 & 8.2931 & TRN & & \\
\hline CHEMBL 93087 & 1640191 & 7.1278 & 7.1475 & TST & & \\
\hline CHEMBL196492 & 1640191 & 8.3372 & 8.1253 & TRN & & \\
\hline CHEMBL 370614 & 1640191 & 8.9914 & 8.8708 & TRN & & \\
\hline CHEMBL 3912108 & 1640191 & \multicolumn{3}{|c|}{8.857000000000001} & 8.4864 & TRN \\
\hline CHEMBL564248 & 1640191 & 8.8697 & 8.9055 & TRN & & \\
\hline CHEMBL383361 & 1640191 & 9.0675 & 9.172 & TRN & & \\
\hline CHEMBL 3972799 & 1640191 & 9.1469 & 9.0468 & TRN & & \\
\hline CHEMBL197377 & 1640191 & 9.1605 & 9.1353 & TRN & & \\
\hline CHEMBL120413 & 1640191 & 7.3028 & 7.0221 & TST & & \\
\hline CHEMBL316053 & 1640191 & 7.4949 & 7.2121 & TST & & \\
\hline CHEMBL381866 & 1640191 & 8.3757 & 8.4205 & TRN & & \\
\hline CHEMBL 370176 & 1640191 & 6.8539 & 6.9438 & TST & & \\
\hline CHEMBL197624 & 1640191 & 7.5214 & \multicolumn{3}{|c|}{7.582999999999999} & \\
\hline CHEMBL 3958789 & 1640191 & 8.5421 & 8.4834 & TST & & \\
\hline CHEMBL 3959350 & 1640191 & 7.4828 & 7.1249 & TST & & \\
\hline CHEMBL467460 & 500574 & 5.3492 & 5.2845 & TRN & & \\
\hline CHEMBL494167 & 500574 & 7.699 & 7.7355 & TRN & & \\
\hline CHEMBL468708 & 500574 & 5.7044 & 5.7538 & TRN & & \\
\hline CHEMBL468095 & 500574 & 6.8477 & \multicolumn{3}{|c|}{6.888999999999999} & \\
\hline CHEMBL 253680 & 500574 & 7.9586 & 7.8956 & TRN & & \\
\hline CHEMBL494823 & 500574 & 6.2366 & 6.3644 & TRN & & \\
\hline CHEMBL466024 & 500574 & 7.8416 & 7.5164 & TRN & & \\
\hline CHEMBL512275 & 500574 & 7.0904 & 7.0379 & TRN & & \\
\hline CHEMBL466460 & 500574 & 6.7258 & 6.6813 & TRN & & \\
\hline CHEMBL492384 & 500574 & 7.0996 & 7.0086 & TRN & & \\
\hline CHEMBL 2093894 & 500574 & 8.3565 & 7.0892 & TST & & \\
\hline CHEMBL468739 & 500574 & 6.5229 & 6.5664 & TRN & & \\
\hline CHEMBL513645 & 500574 & 6.9706 & 6.9847 & TRN & & \\
\hline CHEMBL512468 & 500574 & 4.0 & 5.1202 & TST & & \\
\hline CHEMBL466656 & 500574 & 7.2007 & 7.3495 & TRN & & \\
\hline CHEMBL469138 & 500574 & 7.2218 & 7.2289 & TRN & & \\
\hline
\end{tabular}

Page 8401 


\begin{tabular}{|c|c|c|c|c|c|}
\hline \\
\hline CHEMBL493179 & 500574 & 6.6021 & 6.6862 & TRN & \\
\hline CHEMBL512081 & 500574 & 8.0458 & 7.9905 & TRN & \\
\hline CHEMBL466045 & 500574 & 7.3279 & 6.8976 & TST & \\
\hline CHEMBL493177 & 500574 & 6.6737 & 6.7049 & TRN & \\
\hline CHEMBL513822 & 500574 & 5.7328 & 5.6671 & TRN & \\
\hline CHEMBL513655 & 500574 & 7.1871 & 7.1586 & TRN & \\
\hline CHEMBL511895 & 500574 & 7.3188 & 7.28799 & & TRN \\
\hline CHEMBL466052 & 500574 & 7.71 & 7.6547 & TRN & \\
\hline CHEMBL513148 & 500574 & 5.7447 & 5.6948 & TRN & \\
\hline CHEMBL466060 & 500574 & 7.2441 & 7.2681 & TRN & \\
\hline CHEMBL494824 & 500574 & 6.7423 & 6.6931 & TRN & \\
\hline CHEMBL467687 & 500574 & 7.6021 & 7.6051 & TRN & \\
\hline CHEMBL467682 & 500574 & 4.0 & 5.8138 & TST & \\
\hline CHEMBL467257 & 500574 & 7.1427 & 7.1355 & TRN & \\
\hline CHEMBL466208 & 500574 & 6.4089 & 6.4545 & TRN & \\
\hline CHEMBL468102 & 500574 & 4.0 & 5.5966 & TST & \\
\hline CHEMBL511433 & 500574 & 6.7645 & 6.7721 & TRN & \\
\hline CHEMBL468737 & 500574 & 7.0 & 6.9171 & TRN & \\
\hline CHEMBL466664 & 500574 & 4.0 & 4.0829 & TRN & \\
\hline CHEMBL468731 & 500574 & 7.2175 & 7.345 & TRN & \\
\hline CHEMBL467459 & 500574 & 5.9355 & 6.0315 & TRN & \\
\hline CHEMBL468738 & 500574 & 4.9473 & 4.7631 & TRN & \\
\hline CHEMBL512613 & 500574 & 7.6021 & 7.5657 & TRN & \\
\hline CHEMBL468101 & 500574 & 8.0088 & 8.1837 & TRN & \\
\hline CHEMBL468103 & 500574 & 4.0 & 5.5033 & TST & \\
\hline CHEMBL466249 & 500574 & 7.8697 & 7.9538 & TRN & \\
\hline CHEMBL492383 & 500574 & 6.7878 & 6.8563 & TRN & \\
\hline CHEMBL469125 & 500574 & 4.0 & 5.2571 & TST & \\
\hline CHEMBL493178 & 500574 & 6.6108 & 6.593 & TRN & \\
\hline CHEMBL466657 & 500574 & 6.9101 & 6.8709 & TRN & \\
\hline CHEMBL466237 & 500574 & 8.1549 & 8.1659 & TRN & \\
\hline CHEMBL512237 & 500574 & 6.9586 & 7.0385 & TRN & \\
\hline CHEMBL511729 & 500574 & 5.1427 & 5.1868 & TRN & \\
\hline CHEMBL493989 & 500574 & 7.1871 & 7.0832 & TRN & \\
\hline CHEMBL468096 & 500574 & 7.0458 & 6.9759 & TRN & \\
\hline CHEMBL467262 & 500574 & 6.9788 & 6.9818 & TRN & \\
\hline CHEMBL466461 & 500574 & 6.4881 & 6.5027 & TRN & \\
\hline CHEMBL466663 & 500574 & 4.8386 & 4.9053 & TRN & \\
\hline CHEMBL512243 & 500574 & 6.5528 & 6.9777 & TST & \\
\hline CHEMBL440498 & 500574 & 8.699 & 7.5686 & TST & \\
\hline CHEMBL466445 & 500574 & 6.8447 & 7.0089 & TST & \\
\hline CHEMBL513823 & 500574 & 6.6162 & 6.9803 & TST & \\
\hline CHEMBL466059 & 500574 & 7.4225 & 7.1909 & TST & \\
\hline CHEMBL512061 & 500574 & 7.9208 & 7.3163 & TST & \\
\hline CHEMBL499159 & 500574 & 7.1675 & 6.8941 & TST & \\
\hline CHEMBL466625 & 500574 & 5.6021 & 5.9549 & TST & \\
\hline CHEMBL467482 & 500574 & 6.6383 & 6.9801 & TST & \\
\hline CHEMBL3907586 & 1641314 & 5.0 & 5.1504 & TRN & \\
\hline
\end{tabular}


Supplemental Table S2.txt

\begin{tabular}{|c|c|c|c|c|c|}
\hline CHEMBL 3959013 & 1641314 & 6.2596 & 5.9677 & TST & \\
\hline CHEMBL3923008 & 1641314 & 6.2596 & 6.6649 & TRN & \\
\hline CHEMBL3922602 & 1641314 & 6.2596 & 5.7586 & TRN & \\
\hline CHEMBL 3962518 & 1641314 & 5.0 & 5.5459 & TRN & \\
\hline CHEMBL3931513 & 1641314 & 5.0 & 5.6904 & TRN & \\
\hline CHEMBL3902091 & 1641314 & 5.0 & 5.1339 & TST & \\
\hline CHEMBL3935980 & 1641314 & 6.2596 & 5.6722 & TRN & \\
\hline CHEMBL3940834 & 1641314 & 6.2596 & 6.2842 & TRN & \\
\hline CHEMBL 3900390 & 1641314 & 5.0 & 5.5231 & TRN & \\
\hline CHEMBL3955690 & 1641314 & 6.2596 & 5.7279 & TST & \\
\hline CHEMBL 3922388 & 1641314 & 5.0 & 4.9455 & TRN & \\
\hline CHEMBL3907068 & 1641314 & 5.0 & 5.1469 & TRN & \\
\hline CHEMBL 3924491 & 1641314 & 6.2596 & 6.6097 & TRN & \\
\hline CHEMBL3970101 & 1641314 & 6.2596 & 6.1984 & TRN & \\
\hline CHEMBL3937838 & 1641314 & 5.0 & 4.9544 & TRN & \\
\hline CHEMBL 3805337 & 1641314 & 8.0 & 7.2331 & TRN & \\
\hline CHEMBL3960130 & 1641314 & 5.0 & 5.4977 & TRN & \\
\hline CHEMBL 3962520 & 1641314 & 8.0 & 7.0316 & TRN & \\
\hline CHEMBL3950928 & 1641314 & 5.0 & 5.2485 & TRN & \\
\hline CHEMBL 3984727 & 1641314 & 5.0 & 5.8484 & TST & \\
\hline CHEMBL 3967978 & 1641314 & 5.0 & 6.224 & TRN & \\
\hline CHEMBL 3894743 & 1641314 & 8.0 & 7.1522 & TRN & \\
\hline CHEMBL3949799 & 1641314 & 5.0 & 4.9164 & TRN & \\
\hline CHEMBL 3805061 & 1641314 & 8.0 & 7.3685 & TRN & \\
\hline CHEMBL3899091 & 1641314 & 5.0 & 4.8634 & TRN & \\
\hline CHEMBL 3906822 & 1641314 & 6.2596 & 6.0111 & TRN & \\
\hline CHEMBL3961581 & 1641314 & 5.0 & 4.7785 & TRN & \\
\hline CHEMBL3936315 & 1641314 & 5.0 & 4.8186 & TST & \\
\hline CHEMBL3915079 & 1641314 & 6.2596 & 6.1766 & TRN & \\
\hline CHEMBL3919058 & 1641314 & 5.0 & 5.2468 & TRN & \\
\hline CHEMBL 3891821 & 1641314 & 5.0 & 6.1348 & TRN & \\
\hline CHEMBL 3935531 & 1641314 & 8.0 & 7.5492 & TST & \\
\hline CHEMBL3963832 & 1641314 & 6.2596 & 5.8726 & TST & \\
\hline CHEMBL3951359 & 1641314 & 6.2596 & \multicolumn{2}{|c|}{5.757999999999999} & TRN \\
\hline CHEMBL3960871 & 1641314 & 5.0 & 4.5954 & TRN & \\
\hline CHEMBL3937519 & 1641314 & 8.0 & 8.0634 & TST & \\
\hline CHEMBL3938430 & 1641314 & 6.2596 & 5.4226 & TST & \\
\hline CHEMBL3928621 & 1641314 & 5.0 & 5.1727 & TRN & \\
\hline CHEMBL 3900762 & 1641314 & 5.0 & 5.1557 & TRN & \\
\hline CHEMBL3977922 & 1641314 & 6.2596 & 6.3822 & TRN & \\
\hline CHEMBL3926413 & 1641314 & 5.0 & 6.0048 & TRN & \\
\hline CHEMBL3969032 & 1641314 & 5.0 & 5.1569 & TRN & \\
\hline CHEMBL3946133 & 1641314 & 5.0 & 4.9741 & TRN & \\
\hline CHEMBL3985786 & 1641314 & 6.2596 & 5.7599 & TRN & \\
\hline CHEMBL3901914 & 1641314 & 5.0 & 6.8795 & TRN & \\
\hline CHEMBL 3894395 & 1641314 & 5.0 & 4.8989 & TRN & \\
\hline CHEMBL 3901264 & 1641314 & 5.0 & 5.6517 & TST & \\
\hline CHEMBL3929687 & 1641314 & 6.2596 & 6.3287 & TRN & \\
\hline
\end{tabular}

Page 8403 
Supplemental Table S2.txt

\begin{tabular}{|c|c|c|c|c|}
\hline 3482 & 1641314 & 6.2596 & 6.8278 & \\
\hline HEMBL3950633 & 1641314 & 5.0 & 5.2732 & \\
\hline HEMBL3946520 & 641314 & 5.0 & 4322 & \\
\hline HEMBL3956195 & 641314 & 6.2596 & 6348 & \\
\hline HEMBL3964884 & 641314 & 8.0 & .5318 & \\
\hline HEMBL 3976500 & 641314 & 5.0 & .2864 & \\
\hline HEMBL3908091 & 641314 & 5.0 & .2833 & \\
\hline HEMBL3914621 & 314 & 6.2596 & 5029 & \\
\hline HEMBL3954547 & 314 & 6.2596 & .6125 & \\
\hline HEMBL3958476 & 314 & 6.2596 & 6.5007 & \\
\hline HEMBL 3945447 & 641314 & 6.2596 & 3343 & \\
\hline HEMBL 3924120 & 641314 & 5.0 & 5.099 & \\
\hline HEMBL3973117 & 314 & 5.0 & 8996 & \\
\hline HEMBL3986194 & 314 & 6.2596 & 9763 & \\
\hline HEMBL3896991 & 314 & 6.2596 & 1105 & \\
\hline HEMBL 3922036 & 314 & 6.2596 & 6.2189 & \\
\hline HEMBL3985129 & 314 & 5.0 & 4.7663 & \\
\hline HEMBL 3914201 & 14 & 5.0 & 5.4901 & \\
\hline HEMBL3915903 & 16 & 5.0 & 4.8306 & \\
\hline HEMBL3902512 & 14 & 5.0 & .75 & \\
\hline HEMBL3892650 & 164 & 5.0 & 4.7482 & \\
\hline HEMBL3952571 & 14 & 5.0 & 98 & \\
\hline HEMBL 3919714 & 14 & 5.0 & 155 & \\
\hline HEMBL3930845 & 14 & 8.0 & 7.6028 & \\
\hline HEMBL 3972643 & 14 & 5.0 & & \\
\hline HEMBL3911495 & 164 & 6.2596 & 814 & \\
\hline HEMBL3959531 & 14 & 6.2596 & 59 & \\
\hline HEMBL39 & 14 & 5.0 & 14 & \\
\hline HEMBL3945844 & 162 & 6.2596 & 81 & \\
\hline HEMBL3943275 & 164 & 8.0 & 23 & \\
\hline HEMBL3908064 & 16 & 5 . & 9454 & \\
\hline HEMBL3893512 & 14 & 5.0 & 927 & \\
\hline HEMBL3919255 & 14 & 8.0 & 163 & \\
\hline HEMBL3917559 & 164 & 6.2596 & 164 & \\
\hline HEMBL 3903827 & 164 & 5.0 & 5.7877 & \\
\hline HEMBL3935121 & 16 & 6.2596 & 5.7146 & \\
\hline CHEMBL 39 & 16 & 5.0 & 33 & \\
\hline CHEMBL3959485 & 164 & 5.0 & 5.3284 & \\
\hline CHEMBL3971322 & 164 & 6.2596 & 6.4692 & \\
\hline HEMBL3892931 & 164 & 5.0 & 5.6272 & \\
\hline CHEMBL3948382 & 164 & 5.0 & 5.5586 & \\
\hline CHEMBL 3955573 & & 5.0 & 4.8964 & \\
\hline CHEMBL3972988 & 164 & 5.0 & 4.7563 & \\
\hline CHEMBL3932612 & 1641314 & 6.2596 & 5.2737 & \\
\hline CHEMBL3961281 & 164 & 5.0 & 4.9227 & \\
\hline CHEMBL3923690 & 1641314 & 8.0 & 8.0381 & \\
\hline CHEMBL3925201 & 164 & 5.0 & 5.1679 & \\
\hline CHEMBL3902489 & 1641314 & 8.0 & 7.2054 & \\
\hline
\end{tabular}


Supplemental Table S2.txt

\begin{tabular}{|c|c|c|c|c|c|}
\hline CHEMBL 3923649 & 1641314 & 5.0 & 5.5986 & TST & \\
\hline CHEMBL3946867 & 1641314 & 5.0 & 4.7861 & TRN & \\
\hline CHEMBL3934086 & 1641314 & 6.2596 & 5.7232 & TRN & \\
\hline CHEMBL 3804882 & 1641314 & 6.2596 & 6.6499 & TRN & \\
\hline CHEMBL3957723 & 1641314 & 5.0 & 4.729 & TRN & \\
\hline CHEMBL3901439 & 1641314 & 5.0 & 5.6943 & TST & \\
\hline CHEMBL3942778 & 1641314 & 5.0 & 5.6649 & TST & \\
\hline CHEMBL3890805 & 1641314 & 5.0 & \multicolumn{2}{|c|}{5.031000000000001} & TRN \\
\hline CHEMBL3953484 & 1641314 & 8.0 & 7.1389 & TRN & \\
\hline CHEMBL3916948 & 1641314 & 5.0 & 4.9859 & TST & \\
\hline CHEMBL3970591 & 1641314 & 5.0 & 4.9279 & TRN & \\
\hline CHEMBL3919742 & 1641314 & 5.0 & 5.2746 & TRN & \\
\hline CHEMBL3969543 & 1641314 & 5.0 & 5.1675 & TRN & \\
\hline CHEMBL3913035 & 1641314 & 5.0 & 4.1503 & TRN & \\
\hline CHEMBL3891379 & 1641314 & 5.0 & 5.2732 & TRN & \\
\hline CHEMBL3806195 & 1641314 & 8.0 & 8.2284 & TRN & \\
\hline CHEMBL3914780 & 1641314 & 5.0 & \multicolumn{2}{|c|}{5.5489999999999995} & TST \\
\hline CHEMBL3944491 & 1641314 & 6.2596 & 5.9156 & TRN & \\
\hline CHEMBL3965130 & 1641314 & 5.0 & 6.0626 & TST & \\
\hline CHEMBL3917126 & 1641314 & 5.0 & 5.1935 & TST & \\
\hline CHEMBL3915257 & 1641314 & 5.0 & 4.9403 & TRN & \\
\hline CHEMBL3961942 & 1641314 & 8.0 & 7.5168 & TRN & \\
\hline CHEMBL 3984444 & 1641314 & 5.0 & 5.8668 & TST & \\
\hline CHEMBL3983189 & 1641314 & 5.0 & 4.5645 & TRN & \\
\hline CHEMBL3805019 & 1641314 & 6.2596 & 5.8779 & TRN & \\
\hline CHEMBL3916345 & 1641314 & 5.0 & 5.6997 & TRN & \\
\hline CHEMBL3984593 & 1641314 & 5.0 & 5.0863 & TRN & \\
\hline CHEMBL3951402 & 1641314 & 8.0 & 6.8869 & TST & \\
\hline CHEMBL3963325 & 1641314 & 6.2596 & 6.7396 & TRN & \\
\hline CHEMBL3943827 & 1641314 & 8.0 & 8.1851 & TRN & \\
\hline CHEMBL3954063 & 1641314 & 5.0 & 4.5456 & TRN & \\
\hline CHEMBL3906328 & 1641314 & 6.2596 & 6.9396 & TRN & \\
\hline CHEMBL3979594 & 1641314 & 5.0 & 5.0246 & TRN & \\
\hline CHEMBL3909896 & 1641314 & 5.0 & 5.0493 & TRN & \\
\hline CHEMBL3964862 & 1641314 & 5.0 & 5.3441 & TRN & \\
\hline CHEMBL3908658 & 1641314 & 5.0 & 5.0462 & TRN & \\
\hline CHEMBL3976222 & 1641314 & 6.2596 & 6.4495 & TRN & \\
\hline CHEMBL3910328 & 1641314 & 6.2596 & 5.8 & TRN & \\
\hline CHEMBL 3898042 & 1641314 & 5.0 & 5.2394 & TRN & \\
\hline CHEMBL3946382 & 1641314 & 5.0 & 5.0803 & TRN & \\
\hline CHEMBL3895810 & 1641314 & 5.0 & 5.2052 & TRN & \\
\hline CHEMBL3922409 & 1641314 & 5.0 & 4.9249 & TRN & \\
\hline CHEMBL3906875 & 1641314 & 8.0 & 7.1277 & TRN & \\
\hline CHEMBL3967711 & 1641314 & 5.0 & 5.3295 & TRN & \\
\hline CHEMBL3931327 & 1641314 & 8.0 & 7.405 & TRN & \\
\hline CHEMBL3908150 & 1641314 & 6.2596 & 6.1531 & TST & \\
\hline CHEMBL3936046 & 1641314 & 5.0 & 5.7706 & TST & \\
\hline CHEMBL3944692 & 1641314 & 5.0 & 5.3669 & TRN & \\
\hline
\end{tabular}




\begin{tabular}{|c|c|c|c|c|}
\hline \multicolumn{5}{|c|}{ Supplemental Table S2.txt } \\
\hline CHEMBL3908612 & 1641314 & 5.0 & 5.9768 & TST \\
\hline CHEMBL3943986 & 1641314 & 6.2596 & 6.2421 & TRN \\
\hline CHEMBL3896111 & 1641314 & 6.2596 & 5.6391 & TST \\
\hline CHEMBL 3920650 & 1641314 & 5.0 & 5.2823 & TRN \\
\hline CHEMBL3915305 & 1641314 & 6.2596 & 6.4359 & TRN \\
\hline CHEMBL 3806228 & 1641314 & 5.0 & 5.8238 & TST \\
\hline CHEMBL3907367 & 1641314 & 6.2596 & 6.9983 & TST \\
\hline CHEMBL3909257 & 1641314 & 5.0 & 5.2858 & TST \\
\hline CHEMBL 3905764 & 1641314 & 5.0 & 6.0531 & TST \\
\hline CHEMBL 3945040 & 1641314 & 5.0 & 5.6403 & TST \\
\hline CHEMBL3947550 & 1641314 & 5.0 & 5.1183 & TST \\
\hline CHEMBL3981331 & 1641314 & 6.2596 & 6.6225 & TST \\
\hline CHEMBL3960691 & 1641314 & 5.0 & 5.1293 & TST \\
\hline CHEMBL 3952804 & 1641314 & 5.0 & 5.9874 & TST \\
\hline CHEMBL3961122 & 1641314 & 6.2596 & 5.8749 & TST \\
\hline CHEMBL1964290 & 809276 & 4.7 & 5.0427 & TRN \\
\hline CHEMBL213505 & 809276 & 4.7 & 5.0989 & TRN \\
\hline CHEMBL1987034 & 809276 & 7.4 & 6.8077 & TRN \\
\hline CHEMBL1993941 & 809276 & 6.5 & 6.7446 & TRN \\
\hline CHEMBL 377383 & 809276 & 4.7 & 4.6932 & TRN \\
\hline CHEMBL578061 & 809276 & 5.8 & 5.4716 & TRN \\
\hline CHEMBL 2005886 & 809276 & 7.2 & 6.6091 & TRN \\
\hline CHEMBL481491 & 809276 & 4.7 & 5.1226 & TST \\
\hline CHEMBL1682345 & 809276 & 4.7 & 5.1009 & TRN \\
\hline CHEMBL1973142 & 809276 & 4.7 & 5.1764 & TRN \\
\hline CHEMBL1973145 & 809276 & 4.7 & 5.3387 & TRN \\
\hline CHEMBL1982924 & 809276 & 4.7 & 4.9316 & TRN \\
\hline CHEMBL 2005936 & 809276 & 4.7 & 4.418 & TRN \\
\hline CHEMBL1807515 & 809276 & 4.7 & 5.0261 & TRN \\
\hline CHEMBL1971141 & 809276 & 4.7 & 4.4481 & TRN \\
\hline CHEMBL1995813 & 809276 & 4.7 & 4.9093 & TRN \\
\hline CHEMBL1979718 & 809276 & 4.7 & 4.8436 & TRN \\
\hline CHEMBL 206236 & 809276 & 4.7 & 4.6567 & TRN \\
\hline CHEMBL1989834 & 809276 & 3.7 & 3.9888 & TRN \\
\hline CHEMBL523823 & 809276 & 4.7 & 4.8149 & TST \\
\hline CHEMBL244378 & 809276 & 6.6 & 6.2955 & TRN \\
\hline CHEMBL 2001957 & 809276 & 4.7 & 4.9625 & TRN \\
\hline CHEMBL1969372 & 809276 & 4.7 & 4.9223 & TRN \\
\hline CHEMBL1990583 & 809276 & 4.7 & 4.4458 & TRN \\
\hline CHEMBL1986943 & 809276 & 4.7 & 5.1751 & TRN \\
\hline CHEMBL289959 & 809276 & 3.7 & 4.0136 & TRN \\
\hline CHEMBL 2006263 & 809276 & 4.7 & 4.8339 & TST \\
\hline CHEMBL1993584 & 809276 & 4.7 & 4.6046 & TRN \\
\hline CHEMBL1986263 & 809276 & 6.1 & 5.8212 & TRN \\
\hline CHEMBL 2000114 & 809276 & 4.7 & 5.2198 & TRN \\
\hline CHEMBL 210618 & 809276 & 4.7 & 4.6074 & TRN \\
\hline CHEMBL1975647 & 809276 & 4.7 & 4.9935 & TRN \\
\hline CHEMBL1968380 & 809276 & 4.7 & 4.9672 & TRN \\
\hline
\end{tabular}




\begin{tabular}{|c|c|c|c|c|}
\hline CHEMBL1964644 & 809276 & 4.7 & 4.6579 & TRN \\
\hline CHEMBL1981782 & 809276 & 4.7 & 4.6889 & TRN \\
\hline CHEMBL1977681 & 809276 & 4.7 & 4.9822 & TRN \\
\hline CHEMBL1970142 & 809276 & 7.2 & 6.6525 & TRN \\
\hline CHEMBL1990912 & 809276 & 4.7 & 4.6204 & TRN \\
\hline CHEMBL1995592 & 809276 & 5.9 & 5.3376 & TST \\
\hline CHEMBL 2006493 & 809276 & 4.7 & 4.6866 & TST \\
\hline CHEMBL1983449 & 809276 & 4.7 & 4.5587 & TRN \\
\hline CHEMBL1992323 & 809276 & 4.7 & 4.6316 & TRN \\
\hline CHEMBL1969735 & 809276 & 4.7 & 4.6025 & TRN \\
\hline CHEMBL 2003524 & 809276 & 4.7 & 4.9273 & TST \\
\hline CHEMBL 2002649 & 809276 & 6.5 & 5.2891 & TRN \\
\hline CHEMBL1989423 & 809276 & 3.7 & 3.8605 & TRN \\
\hline CHEMBL437747 & 809276 & 4.7 & 4.6361 & TRN \\
\hline CHEMBL1995172 & 809276 & 4.5 & 4.0784 & TST \\
\hline CHEMBL507936 & 809276 & 4.7 & 4.0616 & TRN \\
\hline CHEMBL104264 & 809276 & 4.7 & 4.7396 & TST \\
\hline CHEMBL1994321 & 809276 & 7.0 & 6.4404 & TRN \\
\hline CHEMBL1997129 & 809276 & 4.7 & 5.2646 & TRN \\
\hline CHEMBL451964 & 809276 & 4.7 & 4.5532 & TRN \\
\hline CHEMBL1964307 & 809276 & 4.7 & 4.954 & TRN \\
\hline CHEMBL 2000508 & 809276 & 4.7 & 5.0074 & TRN \\
\hline CHEMBL1971694 & 809276 & 4.7 & 4.631 & TST \\
\hline CHEMBL 2001547 & 809276 & 4.7 & 4.689 & TRN \\
\hline CHEMBL210928 & 809276 & 4.7 & 4.6638 & TRN \\
\hline CHEMBL1994361 & 809276 & 4.7 & 4.7681 & TRN \\
\hline CHEMBL1986603 & 809276 & 4.7 & 4.7178 & TST \\
\hline CHEMBL1972840 & 809276 & 4.7 & 4.7723 & TRN \\
\hline CHEMBL1977148 & 809276 & 4.7 & 5.8139 & TRN \\
\hline CHEMBL1966842 & 809276 & 4.5 & 4.9082 & TRN \\
\hline CHEMBL 2003286 & 809276 & 4.7 & 4.6029 & TRN \\
\hline CHEMBL 2002165 & 809276 & 6.7 & 6.8613 & TRN \\
\hline CHEMBL206382 & 809276 & 4.7 & 4.6643 & TRN \\
\hline CHEMBL1998585 & 809276 & 7.2 & 6.6184 & TRN \\
\hline CHEMBL127898 & 809276 & 4.7 & 4.1884 & TST \\
\hline CHEMBL519697 & 809276 & 4.7 & 4.3485 & TST \\
\hline CHEMBL 2004934 & 809276 & 4.7 & 4.7137 & TRN \\
\hline CHEMBL1977619 & 809276 & 3.7 & 4.0832 & TST \\
\hline CHEMBL1975128 & 809276 & 5.8 & 5.3798 & TRN \\
\hline CHEMBL1996048 & 809276 & 4.7 & 5.0096 & TST \\
\hline CHEMBL461876 & 809276 & 4.7 & 4.6472 & TRN \\
\hline CHEMBL 2001485 & 809276 & 6.7 & 6.2041 & TRN \\
\hline CHEMBL504950 & 809276 & 4.7 & 5.0397 & TRN \\
\hline CHEMBL1984363 & 809276 & 4.7 & 4.8365 & TRN \\
\hline CHEMBL1978099 & 809276 & 6.6 & 6.1707 & TRN \\
\hline CHEMBL1977041 & 809276 & 6.6 & 6.2805 & TRN \\
\hline CHEMBL1968070 & 809276 & 4.7 & 5.2087 & TRN \\
\hline \multirow[t]{2}{*}{ CHEMBL1988608 } & 809276 & 4.7 & 4.93199 & 99999999995 \\
\hline & & \multicolumn{3}{|c|}{ Page 8407} \\
\hline
\end{tabular}




\begin{tabular}{|c|c|c|c|c|c|}
\hline \multicolumn{6}{|c|}{ Supplemental Table s2.txt } \\
\hline CHEMBL184847 & 809276 & 4.7 & 4.2119 & TRN & \\
\hline CHEMBL1984367 & 809276 & 4.7 & 4.8557 & TRN & \\
\hline CHEMBL226898 & 809276 & 4.7 & 4.7726 & TRN & \\
\hline CHEMBL1982563 & 809276 & 4.7 & 4.5832 & TRN & \\
\hline CHEMBL539474 & 809276 & 4.7 & 5.2126 & TST & \\
\hline CHEMBL575824 & 809276 & 4.7 & 4.8465 & TRN & \\
\hline CHEMBL 1988387 & 809276 & 7.3 & 6.8655 & TRN & \\
\hline CHEMBL1990288 & 809276 & 4.7 & 4.6529 & TRN & \\
\hline CHEMBL1970074 & 809276 & 4.7 & 4.5047 & TRN & \\
\hline CHEMBL1986970 & 809276 & 4.7 & 4.6227 & TRN & \\
\hline CHEMBL1958401 & 809276 & 4.7 & 4.6019 & TRN & \\
\hline CHEMBL 2003456 & 809276 & 4.7 & 4.5239 & TRN & \\
\hline CHEMBL1966816 & 809276 & 4.7 & 4.7373 & TRN & \\
\hline CHEMBL1972584 & 809276 & 4.7 & 5.2718 & TRN & \\
\hline CHEMBL 2002992 & 809276 & 4.7 & 4.8234 & TRN & \\
\hline CHEMBL560813 & 809276 & 4.7 & 4.4966 & TRN & \\
\hline CHEMBL1968791 & 809276 & 4.7 & 4.91100 & 00000000005 & TRN \\
\hline CHEMBL326282 & 809276 & 4.7 & 4.5309 & TST & \\
\hline CHEMBL1992732 & 809276 & 4.7 & 4.525 & TST & \\
\hline CHEMBL1971186 & 809276 & 4.7 & 4.4692 & TRN & \\
\hline CHEMBL 2003482 & 809276 & 4.7 & 4.72199 & 99999999995 & TRN \\
\hline CHEMBL 1976872 & 809276 & 3.7 & 3.9748 & TST & \\
\hline CHEMBL1969156 & 809276 & 3.7 & 4.3683 & TST & \\
\hline CHEMBL1973211 & 809276 & 6.6 & 6.2462 & TRN & \\
\hline CHEMBL1984700 & 809276 & 4.7 & 5.0098 & TRN & \\
\hline CHEMBL 2007151 & 809276 & 4.7 & 5.0996 & TRN & \\
\hline CHEMBL1972125 & 809276 & 4.7 & 4.783 & TRN & \\
\hline CHEMBL1976134 & 809276 & 4.7 & 5.6111 & TRN & \\
\hline CHEMBL1965131 & 809276 & 5.7 & 4.9277 & TRN & \\
\hline CHEMBL1972158 & 809276 & 4.7 & 4.5977 & TRN & \\
\hline CHEMBL1974457 & 809276 & 4.7 & 4.8787 & TRN & \\
\hline CHEMBL 2001228 & 809276 & 4.5 & 5.1278 & TRN & \\
\hline CHEMBL 2006581 & 809276 & 4.7 & 4.619 & TRN & \\
\hline CHEMBL1979855 & 809276 & 4.7 & 4.6429 & TRN & \\
\hline CHEMBL1970340 & 809276 & 4.7 & 4.6999 & TRN & \\
\hline CHEMBL 2005186 & 809276 & 4.7 & 4.7883 & TRN & \\
\hline CHEMBL1975534 & 809276 & 4.7 & 4.7471 & TRN & \\
\hline CHEMBL1966703 & 809276 & 4.7 & 4.7291 & TST & \\
\hline CHEMBL1969561 & 809276 & 4.7 & 4.5783 & TRN & \\
\hline CHEMBL1997023 & 809276 & 4.7 & 4.7299 & TST & \\
\hline CHEMBL1964687 & 809276 & 4.7 & 4.7786 & TRN & \\
\hline CHEMBL1971943 & 809276 & 5.8 & 4.7821 & TST & \\
\hline CHEMBL1999918 & 809276 & 6.1 & 5.7987 & TRN & \\
\hline CHEMBL1974254 & 809276 & 4.7 & 6.5926 & TRN & \\
\hline CHEMBL1997924 & 809276 & 8.5 & 6.8607 & TST & \\
\hline CHEMBL1988537 & 809276 & 4.7 & 4.9056 & TST & \\
\hline CHEMBL1969049 & 809276 & 4.7 & 4.676 & TRN & \\
\hline CHEMBL 2005828 & 809276 & 4.7 & 4.3184 & TRN & \\
\hline
\end{tabular}




\begin{tabular}{|c|c|c|c|c|}
\hline & & & ient & al Ta \\
\hline CHEMBL1978267 & 809276 & 4.5 & 4.6667 & TRN \\
\hline CHEMBL1998611 & 809276 & 5.8 & 5.0447 & TRN \\
\hline CHEMBL485556 & 809276 & 6.3 & 4.5804 & TST \\
\hline CHEMBL1975900 & 809276 & 4.7 & 4.3972 & TRN \\
\hline CHEMBL 255822 & 809276 & 4.7 & 4.5941 & TRN \\
\hline CHEMBL1972221 & 809276 & 4.7 & 4.9937 & TRN \\
\hline CHEMBL 2006778 & 809276 & 8.6 & 7.8687 & TRN \\
\hline CHEMBL378627 & 809276 & 4.7 & 4.5884 & TRN \\
\hline CHEMBL1996979 & 809276 & 4.7 & 4.8054 & TRN \\
\hline CHEMBL1968406 & 809276 & 4.7 & 4.7434 & TRN \\
\hline CHEMBL1982476 & 809276 & 8.0 & 7.6237 & TRN \\
\hline CHEMBL1998545 & 809276 & 4.7 & 4.6387 & TRN \\
\hline CHEMBL1986869 & 809276 & 4.7 & 4.7476 & TRN \\
\hline CHEMBL1682558 & 809276 & 4.7 & 4.83 & TRN \\
\hline CHEMBL1990496 & 809276 & 4.7 & 4.7801 & TRN \\
\hline CHEMBL1997623 & 809276 & 4.7 & 4.5358 & TRN \\
\hline CHEMBL 2002479 & 809276 & 4.7 & 4.503 & TRN \\
\hline CHEMBL1967094 & 809276 & 4.7 & 5.165 & TRN \\
\hline CHEMBL 2003341 & 809276 & 4.7 & 4.6877 & TRN \\
\hline CHEMBL1992644 & 809276 & 4.3 & 4.7285 & TRN \\
\hline CHEMBL1992645 & 809276 & 4.7 & 4.6887 & TST \\
\hline CHEMBL1982992 & 809276 & 4.7 & 4.4906 & TRN \\
\hline CHEMBL1999590 & 809276 & 4.7 & 4.5368 & TST \\
\hline CHEMBL1981079 & 809276 & 4.7 & 4.7515 & TRN \\
\hline CHEMBL1980489 & 809276 & 4.7 & 4.4393 & TRN \\
\hline CHEMBL1967116 & 809276 & 7.8 & 7.4503 & TRN \\
\hline CHEMBL 2000832 & 809276 & 4.7 & 4.4908 & TRN \\
\hline CHEMBL1970709 & 809276 & 4.7 & 4.6477 & TRN \\
\hline CHEMBL1965660 & 809276 & 4.7 & 4.7061 & TRN \\
\hline CHEMBL1998112 & 809276 & 4.7 & 4.4179 & TRN \\
\hline CHEMBL1969126 & 809276 & 4.7 & 4.8956 & TRN \\
\hline CHEMBL1980896 & 809276 & 4.7 & 5.0923 & TRN \\
\hline CHEMBL1970104 & 809276 & 6.8 & 5.7658 & TRN \\
\hline CHEMBL1971149 & 809276 & 4.7 & 4.711 & TRN \\
\hline CHEMBL1999714 & 809276 & 4.7 & 4.4498 & TRN \\
\hline CHEMBL1994040 & 809276 & 4.7 & 4.7559 & TRN \\
\hline CHEMBL 388978 & 809276 & 7.4 & 6.5022 & TST \\
\hline CHEMBL579246 & 809276 & 4.7 & 4.7562 & TRN \\
\hline CHEMBL398951 & 809276 & 4.7 & 4.3998 & TST \\
\hline CHEMBL1982506 & 809276 & 4.7 & 4.8938 & TST \\
\hline CHEMBL2004716 & 809276 & 7.6 & 7.2344 & TRN \\
\hline CHEMBL1968127 & 809276 & 4.7 & 4.6922 & TRN \\
\hline CHEMBL1975233 & 809276 & 4.7 & 4.7119 & TRN \\
\hline CHEMBL1985406 & 809276 & 4.7 & 4.6299 & TRN \\
\hline CHEMBL 207400 & 809276 & 4.7 & 4.6837 & TST \\
\hline CHEMBL 2000894 & 809276 & 4.7 & 4.6439 & TST \\
\hline CHEMBL1982135 & 809276 & 4.7 & 4.529 & TRN \\
\hline CHEMBL1976090 & 809276 & 4.7 & 5.077 & TRN \\
\hline
\end{tabular}




\begin{tabular}{|c|c|c|c|c|c|}
\hline \multicolumn{6}{|c|}{ Supplemental Table S2.txt } \\
\hline CHEMBL1993243 & 809276 & 7.4 & 7.0959 & TRN & \\
\hline CHEMBL1992922 & 809276 & 5.9 & 5.2453 & TRN & \\
\hline CHEMBL 2004771 & 809276 & 4.7 & 4.2705 & TRN & \\
\hline CHEMBL 399021 & 809276 & 4.7 & 4.9019 & TRN & \\
\hline CHEMBL1997597 & 809276 & 4.7 & 4.8804 & TRN & \\
\hline CHEMBL1969537 & 809276 & 4.7 & 5.2975 & TST & \\
\hline CHEMBL1976093 & 809276 & 4.7 & 4.7638 & TRN & \\
\hline CHEMBL1975256 & 809276 & 4.7 & 4.6373 & TST & \\
\hline CHEMBL508928 & 809276 & 4.7 & 5.4737 & TRN & \\
\hline CHEMBL1991356 & 809276 & 4.7 & 4.8616 & TST & \\
\hline CHEMBL 2004892 & 809276 & 4.7 & 4.8635 & TRN & \\
\hline CHEMBL116070 & 809276 & 4.7 & 4.9888 & TRN & \\
\hline CHEMBL1970314 & 809276 & 4.7 & 4.3253 & TRN & \\
\hline CHEMBL 2004871 & 809276 & 4.7 & 4.4088 & TRN & \\
\hline CHEMBL 2004872 & 809276 & 4.7 & 4.6824 & TRN & \\
\hline CHEMBL1727312 & 809276 & 4.0 & 3.9995 & TRN & \\
\hline CHEMBL1969879 & 809276 & 4.7 & 4.8586 & TRN & \\
\hline CHEMBL1981720 & 809276 & 4.7 & 4.7384 & TRN & \\
\hline CHEMBL419932 & 809276 & 4.7 & 4.7982 & TRN & \\
\hline CHEMBL 262433 & 809276 & 5.9 & 5.3438 & TRN & \\
\hline CHEMBL 306380 & 809276 & 5.9 & 6.1517 & TRN & \\
\hline CHEMBL1966722 & 809276 & 4.7 & 4.5569 & TST & \\
\hline CHEMBL1976328 & 809276 & 4.7 & 4.9688 & TRN & \\
\hline CHEMBL1975500 & 809276 & 4.7 & 4.2909 & TRN & \\
\hline CHEMBL394619 & 809276 & 6.0 & 5.3899 & TRN & \\
\hline CHEMBL1964399 & 809276 & 6.0 & 5.8821 & TRN & \\
\hline CHEMBL1996831 & 809276 & 4.7 & 4.4286 & TST & \\
\hline CHEMBL411903 & 809276 & 4.7 & 5.2265 & TRN & \\
\hline CHEMBL1965988 & 809276 & 6.6 & 6.3161 & TRN & \\
\hline CHEMBL418203 & 809276 & 4.7 & 4.5539 & TST & \\
\hline CHEMBL1989646 & 809276 & 4.7 & 4.9654 & TRN & \\
\hline CHEMBL1682357 & 809276 & 4.7 & 4.9398 & TRN & \\
\hline CHEMBL225519 & 809276 & 4.7 & 4.8468 & TRN & \\
\hline CHEMBL209534 & 809276 & 4.7 & 4.65300 & 20000000005 & TRN \\
\hline CHEMBL1978200 & 809276 & 4.7 & 4.8204 & TRN & \\
\hline CHEMBL1970522 & 809276 & 4.7 & 4.3908 & TRN & \\
\hline CHEMBL402846 & 809276 & 4.7 & 4.3324 & TRN & \\
\hline CHEMBL1964692 & 809276 & 4.7 & 5.2284 & TRN & \\
\hline CHEMBL1996931 & 809276 & 4.7 & 4.5503 & TRN & \\
\hline CHEMBL1964413 & 809276 & 4.7 & 4.6444 & TRN & \\
\hline CHEMBL1973483 & 809276 & 4.7 & 4.6878 & TRN & \\
\hline CHEMBL1984432 & 809276 & 4.7 & 4.5481 & TRN & \\
\hline CHEMBL219722 & 809276 & 4.7 & 5.1057 & TRN & \\
\hline CHEMBL1997340 & 809276 & 4.7 & 4.6819 & TRN & \\
\hline CHEMBL1522508 & 809276 & 4.7 & 4.3952 & TRN & \\
\hline CHEMBL1989474 & 809276 & 4.7 & 4.6611 & TRN & \\
\hline CHEMBL458997 & 809276 & 6.3 & 5.9788 & TRN & \\
\hline CHEMBL1971021 & 809276 & 4.7 & 4.572 & TRN & \\
\hline
\end{tabular}




\begin{tabular}{|c|c|c|c|c|c|}
\hline CHEMBL227271 & 809276 & 4.7 & 4.5506 & TRN & \\
\hline CHEMBL583144 & 809276 & 4.7 & 4.57100 & 0000000001 & TRN \\
\hline CHEMBL1974310 & 809276 & 5.8 & 5.2144 & TRN & \\
\hline CHEMBL1982660 & 809276 & 6.1 & 5.1854 & TRN & \\
\hline CHEMBL1994693 & 809276 & 4.7 & 4.4975 & TRN & \\
\hline CHEMBL1982957 & 809276 & 6.7 & 6.045 & TRN & \\
\hline CHEMBL1725279 & 809276 & 6.8 & 5.4427 & TST & \\
\hline CHEMBL 2002346 & 809276 & 4.7 & 5.734 & TRN & \\
\hline CHEMBL1975138 & 809276 & 4.7 & 4.3964 & TST & \\
\hline CHEMBL424872 & 809276 & 4.7 & 4.7804 & TRN & \\
\hline CHEMBL1971947 & 809276 & 4.7 & 6.2548 & TRN & \\
\hline CHEMBL412142 & 809276 & 4.7 & 4.954 & TST & \\
\hline CHEMBL1980704 & 809276 & 4.7 & 4.4852 & TST & \\
\hline CHEMBL 2003271 & 809276 & 4.7 & 5.1058 & TRN & \\
\hline CHEMBL1972365 & 809276 & 3.7 & 4.7416 & TST & \\
\hline CHEMBL1966808 & 809276 & 4.7 & 4.7351 & TST & \\
\hline CHEMBL2004447 & 809276 & 4.7 & 4.7444 & TRN & \\
\hline CHEMBL1983111 & 809276 & 8.3 & 7.0414 & TST & \\
\hline CHEMBL1973860 & 809276 & 4.7 & 4.6461 & TRN & \\
\hline CHEMBL260135 & 809276 & 4.7 & 4.9203 & TRN & \\
\hline CHEMBL 220241 & 809276 & 4.7 & 4.6501 & TRN & \\
\hline CHEMBL1982610 & 809276 & 4.7 & 5.166 & TST & \\
\hline CHEMBL1999496 & 809276 & 4.7 & 4.7506 & TRN & \\
\hline CHEMBL2006933 & 809276 & 4.7 & 5.3023 & TST & \\
\hline CHEMBL1988300 & 809276 & 6.5 & 5.94 & TRN & \\
\hline CHEMBL1991078 & 809276 & 6.8 & 6.0806 & TRN & \\
\hline CHEMBL1987359 & 809276 & 4.7 & 4.8105 & TST & \\
\hline CHEMBL 2000685 & 809276 & 6.0 & 5.1749 & TRN & \\
\hline CHEMBL1985311 & 809276 & 4.7 & 5.0125 & TRN & \\
\hline CHEMBL1969502 & 809276 & 6.6 & 6.4954 & TST & \\
\hline CHEMBL1965910 & 809276 & 4.7 & 5.1 & TRN & \\
\hline CHEMBL1682553 & 809276 & 4.7 & 4.6897 & TRN & \\
\hline CHEMBL1971430 & 809276 & 4.7 & 4.5875 & TRN & \\
\hline CHEMBL1997764 & 809276 & 4.7 & 4.5852 & TRN & \\
\hline CHEMBL1983963 & 809276 & 4.7 & 5.665 & TRN & \\
\hline CHEMBL2000271 & 809276 & 4.7 & 5.1125 & TRN & \\
\hline CHEMBL562488 & 809276 & 3.7 & 4.1114 & TRN & \\
\hline CHEMBL1985092 & 809276 & 4.7 & 4.6305 & TST & \\
\hline CHEMBL1981410 & 809276 & 4.7 & 4.9397 & TRN & \\
\hline CHEMBL1996234 & 809276 & 4.7 & 4.8429 & TRN & \\
\hline CHEMBL1991434 & 809276 & 4.7 & 4.754 & TST & \\
\hline CHEMBL1967544 & 809276 & 4.7 & 4.6351 & TRN & \\
\hline CHEMBL223367 & 809276 & 4.7 & 5.0402 & TST & \\
\hline CHEMBL340384 & 809276 & 4.7 & 5.3648 & TST & \\
\hline CHEMBL1996587 & 809276 & 4.7 & 4.7752 & TRN & \\
\hline CHEMBL1964804 & 809276 & 4.7 & 4.5812 & TRN & \\
\hline CHEMBL443962 & 809276 & 4.7 & 4.9582 & TST & \\
\hline CHEMBL2000354 & 809276 & 4.7 & 4.3462 & TRN & \\
\hline
\end{tabular}




\begin{tabular}{|c|c|c|c|c|c|}
\hline \multicolumn{6}{|c|}{ Supplemental Table S2.txt } \\
\hline CHEMBL1965507 & 809276 & 4.7 & 5.2051 & TRN & \\
\hline CHEMBL274064 & 809276 & 4.7 & 4.4407 & TRN & \\
\hline CHEMBL1967564 & 809276 & 4.7 & 4.7213 & TRN & \\
\hline CHEMBL592030 & 809276 & 4.7 & 5.1042 & TST & \\
\hline CHEMBL 2000071 & 809276 & 5.8 & 5.3085 & TRN & \\
\hline CHEMBL1979176 & 809276 & 4.7 & 4.6377 & TRN & \\
\hline CHEMBL1970317 & 809276 & 7.1 & 6.7283 & TRN & \\
\hline CHEMBL 2000408 & 809276 & 4.7 & 4.6749 & TRN & \\
\hline CHEMBL 248757 & 809276 & 4.7 & 5.3713 & TST & \\
\hline CHEMBL1978014 & 809276 & 4.7 & 4.7656 & TRN & \\
\hline CHEMBL1994538 & 809276 & 4.7 & 4.9788 & TRN & \\
\hline CHEMBL1975490 & 809276 & 4.7 & 4.7482 & TRN & \\
\hline CHEMBL1964444 & 809276 & 4.7 & 4.454 & TRN & \\
\hline CHEMBL 2006567 & 809276 & 4.7 & 4.5045 & TRN & \\
\hline CHEMBL1986139 & 809276 & 4.7 & 4.4196 & TRN & \\
\hline CHEMBL383527 & 809276 & 5.9 & 4.7466 & TRN & \\
\hline CHEMBL1980540 & 809276 & 4.7 & 4.69600 & 0000000001 & TRN \\
\hline CHEMBL1979883 & 809276 & 6.5 & 6.2348 & TRN & \\
\hline CHEMBL1984162 & 809276 & 6.8 & 7.4988 & TRN & \\
\hline CHEMBL1997051 & 809276 & 4.5 & 4.7369 & TRN & \\
\hline CHEMBL491758 & 809276 & 6.2 & 5.8939 & TRN & \\
\hline CHEMBL549730 & 809276 & 4.7 & 4.7714 & TRN & \\
\hline CHEMBL1970189 & 809276 & 4.7 & 4.7668 & TRN & \\
\hline CHEMBL1996791 & 809276 & 4.7 & 5.2883 & TRN & \\
\hline CHEMBL371206 & 809276 & 6.7 & 6.0494 & TRN & \\
\hline CHEMBL1974664 & 809276 & 4.7 & 5.4399 & TST & \\
\hline CHEMBL1974288 & 809276 & 4.7 & 4.6624 & TRN & \\
\hline CHEMBL196363 & 809276 & 6.7 & 6.3847 & TRN & \\
\hline CHEMBL1996837 & 809276 & 3.7 & 4.1311 & TRN & \\
\hline CHEMBL1190711 & 809276 & 4.7 & 4.4407 & TRN & \\
\hline CHEMBL1990346 & 809276 & 4.7 & 5.0523 & TRN & \\
\hline CHEMBL1968705 & 809276 & 4.7 & 4.6662 & TRN & \\
\hline CHEMBL404367 & 809276 & 4.7 & 4.8391 & TRN & \\
\hline CHEMBL1966343 & 809276 & 4.7 & 5.0233 & TRN & \\
\hline CHEMBL1967887 & 809276 & 4.7 & 4.6831 & TRN & \\
\hline CHEMBL 2000568 & 809276 & 4.7 & 4.5638 & TRN & \\
\hline CHEMBL 2000335 & 809276 & 6.6 & 6.4241 & TRN & \\
\hline CHEMBL1988717 & 809276 & 6.2 & 5.496 & TRN & \\
\hline CHEMBL1974328 & 809276 & 4.7 & 5.7027 & TRN & \\
\hline CHEMBL509032 & 809276 & 7.4 & 6.8203 & TRN & \\
\hline CHEMBL1973808 & 809276 & 4.7 & 4.6103 & TRN & \\
\hline CHEMBL 2000429 & 809276 & 4.7 & 5.0894 & TRN & \\
\hline CHEMBL1972576 & 809276 & 4.7 & 4.8912 & TRN & \\
\hline CHEMBL1990254 & 809276 & 4.7 & 4.637 & TRN & \\
\hline CHEMBL1992342 & 809276 & 4.7 & 4.9123 & TRN & \\
\hline CHEMBL1988173 & 809276 & 4.7 & 4.8197 & TST & \\
\hline CHEMBL1164265 & 809276 & 5.8 & 5.4385 & TST & \\
\hline CHEMBL1989805 & 809276 & 4.7 & 4.8219 & TST & \\
\hline
\end{tabular}




\begin{tabular}{|c|c|c|c|c|c|}
\hline \multicolumn{6}{|c|}{ Supplemental Table S2.txt } \\
\hline CHEMBL1965423 & 809276 & 4.7 & 4.8497 & TRN & \\
\hline CHEMBL1983025 & 809276 & 6.5 & 6.1605 & TRN & \\
\hline CHEMBL205415 & 809276 & 4.7 & 4.8486 & TRN & \\
\hline CHEMBL1977135 & 809276 & 4.7 & 4.56 & TRN & \\
\hline CHEMBL 2001920 & 809276 & 4.7 & 4.75 & TRN & \\
\hline CHEMBL 2002322 & 809276 & 4.7 & 4.8493 & TRN & \\
\hline CHEMBL1241473 & 809276 & 7.3 & 7.0812 & TRN & \\
\hline CHEMBL 2002323 & 809276 & 4.7 & 4.5648 & TST & \\
\hline CHEMBL1978448 & 809276 & 4.7 & 4.6835 & TST & \\
\hline CHEMBL1969483 & 809276 & 6.1 & 5.2883 & TRN & \\
\hline CHEMBL 2001257 & 809276 & 6.0 & 5.9719 & TRN & \\
\hline CHEMBL 2005548 & 809276 & 4.7 & 4.6958 & TRN & \\
\hline CHEMBL1992536 & 809276 & 4.7 & 4.6548 & TRN & \\
\hline CHEMBL1992740 & 809276 & 4.7 & 4.7231 & TRN & \\
\hline CHEMBL439340 & 809276 & 4.7 & 4.7762 & TRN & \\
\hline CHEMBL 2002373 & 809276 & 4.7 & 4.4849 & TRN & \\
\hline CHEMBL 2006188 & 809276 & 4.7 & 4.6658 & TRN & \\
\hline CHEMBL1967531 & 809276 & 4.7 & 5.7251 & TRN & \\
\hline CHEMBL1970913 & 809276 & 4.7 & 4.7512 & TRN & \\
\hline CHEMBL1973893 & 809276 & 4.7 & 4.9482 & TRN & \\
\hline CHEMBL1997534 & 809276 & 4.7 & 4.466 & TRN & \\
\hline CHEMBL1996500 & 809276 & 4.7 & 4.4972 & TRN & \\
\hline CHEMBL1985095 & 809276 & 4.7 & 4.9396 & TST & \\
\hline CHEMBL1991180 & 809276 & 4.7 & 4.9606 & TST & \\
\hline CHEMBL1682540 & 809276 & 4.7 & 4.6979 & TRN & \\
\hline CHEMBL1976420 & 809276 & 6.1 & 5.956 & TST & \\
\hline CHEMBL1994864 & 809276 & 4.7 & 4.5139 & TRN & \\
\hline CHEMBL413779 & 809276 & 4.7 & 5.2015 & TST & \\
\hline CHEMBL 2002446 & 809276 & 6.0 & 4.6704 & TST & \\
\hline CHEMBL497151 & 809276 & 4.7 & 5.2183 & TRN & \\
\hline CHEMBL1973961 & 809276 & 4.7 & 4.9119 & TRN & \\
\hline CHEMBL 246970 & 809276 & 4.7 & 4.7593 & TRN & \\
\hline CHEMBL340921 & 809276 & 4.7 & 4.9646 & TST & \\
\hline CHEMBL 373598 & 809276 & 4.7 & 5.0372 & TST & \\
\hline CHEMBL1999718 & 809276 & 4.7 & 4.7817 & TRN & \\
\hline CHEMBL 2000078 & 809276 & 4.5 & 5.2518 & TRN & \\
\hline CHEMBL1276446 & 809276 & 7.9 & 6.31 & TST & \\
\hline CHEMBL1977346 & 809276 & 6.4 & 5.4085 & TRN & \\
\hline CHEMBL1971649 & 809276 & 4.7 & 3.6379 & TRN & \\
\hline CHEMBL 2003657 & 809276 & 4.7 & 5.1661 & TRN & \\
\hline CHEMBL 2005482 & 809276 & 6.0 & 5.9099 & TRN & \\
\hline CHEMBL1997909 & 809276 & 4.5 & 5.1526 & TRN & \\
\hline CHEMBL2006439 & 809276 & 4.7 & 4.9677 & TRN & \\
\hline CHEMBL1969190 & 809276 & 4.7 & 4.5656 & TRN & \\
\hline CHEMBL1973937 & 809276 & 4.7 & 5.0129 & TRN & \\
\hline CHEMBL1991674 & 809276 & 4.7 & 5.0802 & TRN & \\
\hline CHEMBL1982711 & 809276 & 4.7 & 5.0816 & TRN & \\
\hline CHEMBL1984842 & 809276 & 4.7 & 4.63899 & 9999999999 & TRN \\
\hline & & & & e 8413 & \\
\hline
\end{tabular}




\begin{tabular}{|c|c|c|c|c|}
\hline \multicolumn{5}{|c|}{ plemental } \\
\hline CHEMBL1969102 & 809276 & 7.6 & 7.2076 & TRN \\
\hline CHEMBL1682346 & 809276 & 4.7 & 5.2458 & TRN \\
\hline CHEMBL 2007044 & 809276 & 4.7 & 4.3538 & TST \\
\hline CHEMBL 2001998 & 809276 & 4.7 & 4.551 & TST \\
\hline CHEMBL1994241 & 809276 & 4.7 & 4.5683 & TRN \\
\hline CHEMBL223460 & 809276 & 4.7 & 5.1154 & TST \\
\hline CHEMBL1998829 & 809276 & 4.7 & 4.5044 & TRN \\
\hline CHEMBL50894 & 809276 & 4.7 & 5.4498 & TRN \\
\hline CHEMBL1988838 & 809276 & 6.8 & 6.6457 & TRN \\
\hline CHEMBL1981725 & 809276 & 6.7 & 5.8322 & TRN \\
\hline CHEMBL 375284 & 809276 & 4.7 & 4.461 & TRN \\
\hline CHEMBL1982866 & 809276 & 4.7 & 4.7503 & TRN \\
\hline CHEMBL 2005792 & 809276 & 4.7 & 4.5983 & TRN \\
\hline CHEMBL1984206 & 809276 & 4.7 & 4.6628 & TRN \\
\hline CHEMBL1991577 & 809276 & 4.7 & 4.5472 & TRN \\
\hline CHEMBL1965570 & 809276 & 4.7 & 6.1243 & TRN \\
\hline CHEMBL 2007592 & 809276 & 4.7 & 4.6004 & TST \\
\hline CHEMBL210963 & 809276 & 4.7 & 4.6247 & TRN \\
\hline CHEMBL1082440 & 809276 & 4.7 & 5.4799 & TST \\
\hline CHEMBL1614705 & 809276 & 4.7 & 4.6703 & TRN \\
\hline CHEMBL1972362 & 809276 & 5.8 & 4.9643 & TRN \\
\hline CHEMBL1984633 & 809276 & 4.7 & 4.6563 & TRN \\
\hline CHEMBL1965845 & 809276 & 4.7 & 4.9977 & TRN \\
\hline CHEMBL1986597 & 809276 & 4.7 & 4.4566 & TRN \\
\hline CHEMBL1971017 & 809276 & 6.1 & 5.6714 & TRN \\
\hline CHEMBL1990482 & 809276 & 4.7 & 4.6178 & TRN \\
\hline CHEMBL1990904 & 809276 & 4.7 & 5.2128 & TRN \\
\hline CHEMBL 2005475 & 809276 & 4.7 & 4.992 & TRN \\
\hline CHEMBL 2000104 & 809276 & 4.7 & 5.0387 & TRN \\
\hline CHEMBL183844 & 809276 & 4.7 & 4.6086 & TRN \\
\hline CHEMBL220057 & 809276 & 4.7 & 5.2223 & TRN \\
\hline CHEMBL1682545 & 809276 & 4.7 & 4.9191 & TRN \\
\hline CHEMBL383541 & 809276 & 4.7 & 4.6974 & TRN \\
\hline CHEMBL 2001224 & 809276 & 4.7 & 4.6846 & TRN \\
\hline CHEMBL10 & 809276 & 4.7 & 4.6734 & TRN \\
\hline CHEMBL1976732 & 809276 & 4.7 & 4.6597 & TRN \\
\hline CHEMBL1964937 & 809276 & 4.7 & 4.8932 & TRN \\
\hline CHEMBL1969506 & 809276 & 4.7 & 4.7569 & TRN \\
\hline CHEMBL1980163 & 809276 & 4.7 & 4.2232 & TRN \\
\hline CHEMBL590109 & 809276 & 4.7 & 4.9288 & TST \\
\hline CHEMBL1970879 & 809276 & 4.7 & 5.5815 & TRN \\
\hline CHEMBL1989856 & 809276 & 4.7 & 4.7305 & TST \\
\hline CHEMBL 2005899 & 809276 & 4.7 & 4.757 & TRN \\
\hline CHEMBL1682552 & 809276 & 4.7 & 4.6808 & TRN \\
\hline CHEMBL259850 & 809276 & 4.7 & 4.4903 & TRN \\
\hline CHEMBL229799 & 809276 & 4.7 & 4.8552 & TRN \\
\hline CHEMBL1682359 & 809276 & 4.7 & 4.5848 & TRN \\
\hline CHEMBL105739 & 809276 & 6.1 & 5.3173 & TRN \\
\hline
\end{tabular}




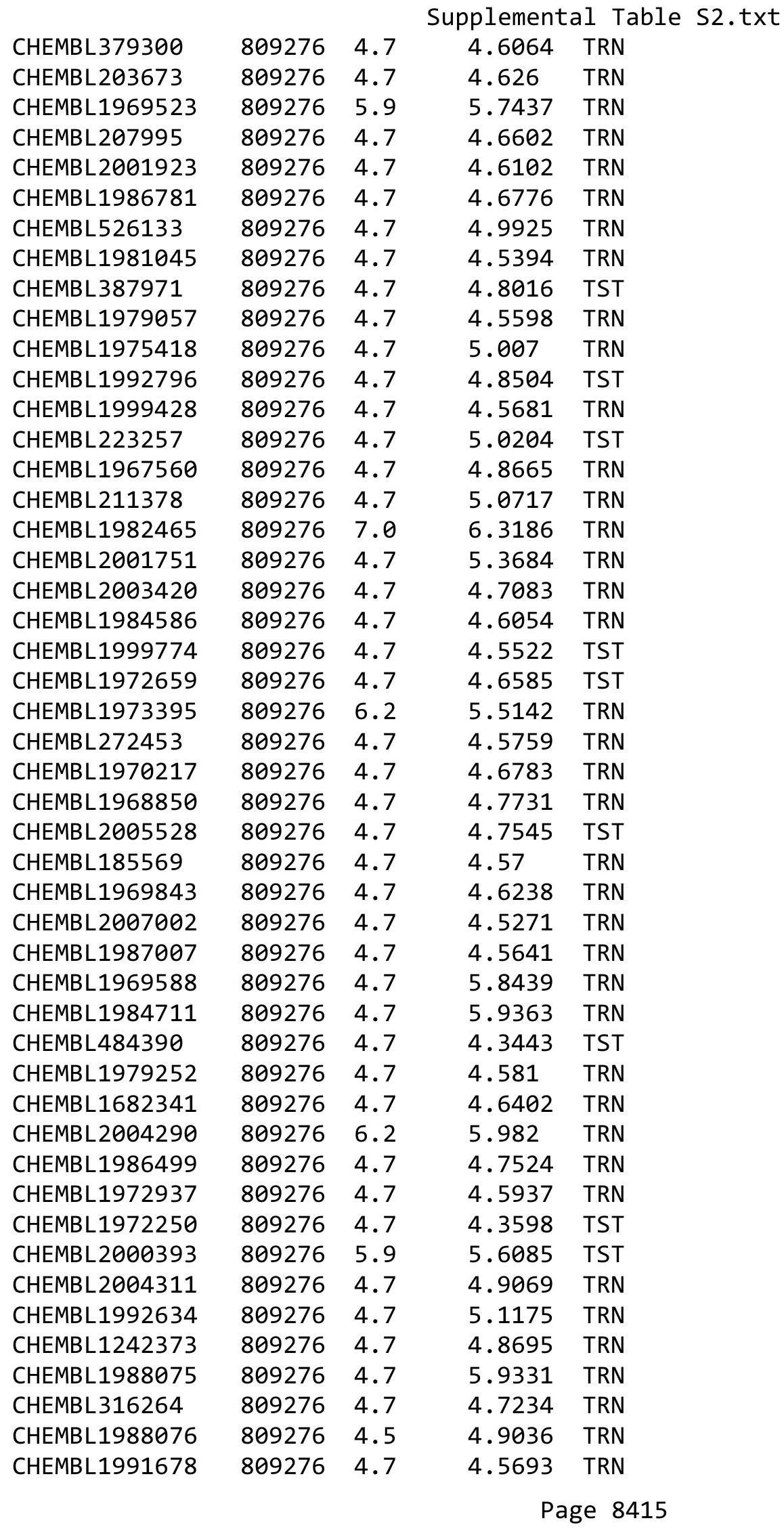




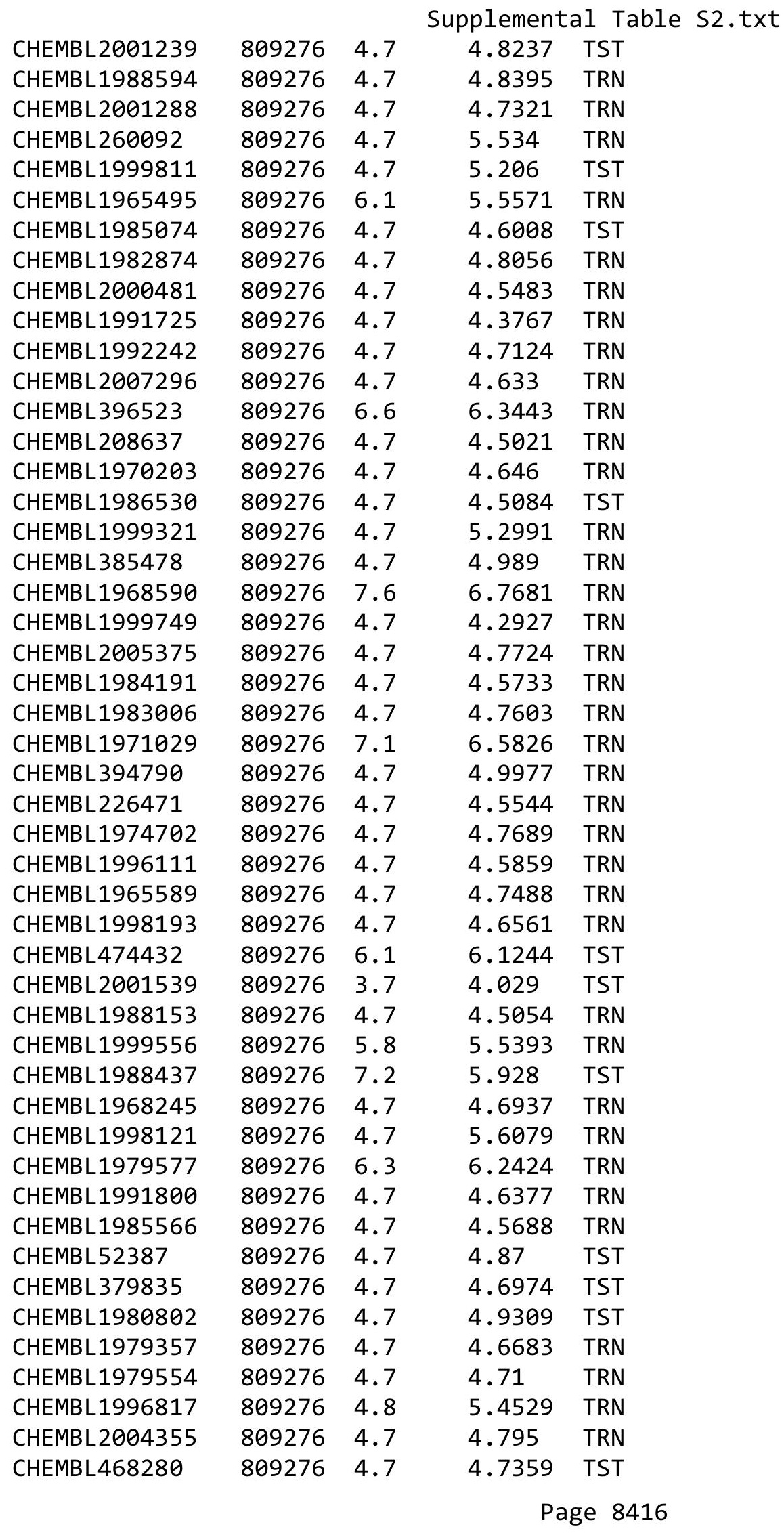




\begin{tabular}{|c|c|c|c|c|c|}
\hline \\
\hline CHEMBL1990884 & 809276 & 4.7 & 5.8044 & TRN & \\
\hline CHEMBL3109278 & 809276 & 6.4 & 5.3363 & TRN & \\
\hline CHEMBL256835 & 809276 & 4.7 & 4.3854 & TRN & \\
\hline CHEMBL1980142 & 809276 & 4.7 & 4.7835 & TRN & \\
\hline CHEMBL41783 & 809276 & 4.7 & 4.6916 & TRN & \\
\hline CHEMBL2004438 & 809276 & 4.7 & 4.2387 & TRN & \\
\hline CHEMBL 2006276 & 809276 & 4.7 & 4.6113 & TRN & \\
\hline CHEMBL271381 & 809276 & 4.7 & 5.118 & TRN & \\
\hline CHEMBL 2006785 & 809276 & 4.7 & 4.5816 & TRN & \\
\hline CHEMBL1982466 & 809276 & 6.3 & 6.6949 & TRN & \\
\hline CHEMBL1995740 & 809276 & 4.7 & 4.3547 & TRN & \\
\hline CHEMBL1996390 & 809276 & 4.7 & 4.8501 & TRN & \\
\hline CHEMBL234085 & 809276 & 4.7 & 5.0931 & TRN & \\
\hline CHEMBL1995832 & 809276 & 4.7 & 4.9776 & TRN & \\
\hline CHEMBL1969042 & 809276 & 4.7 & 5.0086 & TST & \\
\hline CHEMBL 2000345 & 809276 & 4.7 & 4.504 & TRN & \\
\hline CHEMBL1999931 & 809276 & 6.4 & 5.8029 & TRN & \\
\hline CHEMBL1991640 & 809276 & 4.7 & 4.9537 & TST & \\
\hline CHEMBL 302449 & 809276 & 4.7 & 5.6835 & TST & \\
\hline CHEMBL 2007064 & 809276 & 6.4 & 5.8504 & TRN & \\
\hline CHEMBL1981047 & 809276 & 7.5 & 7.2897 & TRN & \\
\hline CHEMBL229968 & 809276 & 4.7 & 4.5169 & TRN & \\
\hline CHEMBL1976240 & 809276 & 4.7 & 4.6007 & TRN & \\
\hline CHEMBL1979093 & 809276 & 4.7 & 4.5975 & TRN & \\
\hline CHEMBL1968151 & 809276 & 4.7 & 4.703 & TST & \\
\hline CHEMBL1381197 & 809276 & 4.7 & 4.1144 & TRN & \\
\hline CHEMBL1987009 & 809276 & 4.7 & 5.2565 & TRN & \\
\hline CHEMBL 379218 & 809276 & 4.7 & 4.57600 & 00000000005 & TRN \\
\hline CHEMBL2003817 & 809276 & 4.7 & 5.1471 & TRN & \\
\hline CHEMBL336961 & 809276 & 4.7 & 4.8729 & TRN & \\
\hline CHEMBL1994830 & 809276 & 4.7 & 4.905 & TRN & \\
\hline CHEMBL1987054 & 809276 & 7.1 & 7.3465 & TRN & \\
\hline CHEMBL1970083 & 809276 & 7.3 & 6.9954 & TRN & \\
\hline CHEMBL 226403 & 809276 & 4.7 & 4.6491 & TRN & \\
\hline CHEMBL2005631 & 809276 & 8.4 & 7.2998 & TRN & \\
\hline CHEMBL1994938 & 809276 & 7.0 & 6.8659 & TRN & \\
\hline CHEMBL1977223 & 809276 & 4.7 & 4.7039 & TRN & \\
\hline CHEMBL1236126 & 809276 & 4.7 & 4.6346 & TST & \\
\hline CHEMBL1966279 & 809276 & 4.7 & 4.3523 & TRN & \\
\hline CHEMBL1997846 & 809276 & 4.7 & 4.8611 & TRN & \\
\hline CHEMBL 2004419 & 809276 & 4.7 & 4.5582 & TRN & \\
\hline CHEMBL1991728 & 809276 & 4.7 & 4.7973 & TRN & \\
\hline CHEMBL1975787 & 809276 & 6.0 & 5.687 & TRN & \\
\hline CHEMBL 2002407 & 809276 & 4.7 & 4.4902 & TRN & \\
\hline CHEMBL1972489 & 809276 & 4.7 & 4.6674 & TRN & \\
\hline CHEMBL1994074 & 809276 & 4.7 & 4.4019 & TRN & \\
\hline CHEMBL1992937 & 809276 & 4.7 & 4.9579 & TST & \\
\hline CHEMBL451401 & 809276 & 3.7 & 4.5454 & TRN & \\
\hline
\end{tabular}




\begin{tabular}{|c|c|c|c|c|c|}
\hline \\
\hline CHEMBL1986328 & 809276 & 4.7 & 4.685 & TST & \\
\hline CHEMBL1090356 & 809276 & 4.7 & 5.1065 & TRN & \\
\hline CHEMBL95692 & 809276 & 4.7 & 4.475 & TRN & \\
\hline CHEMBL1976455 & 809276 & 4.9 & 4.7772 & TRN & \\
\hline CHEMBL1983923 & 809276 & 7.0 & 6.0536 & TST & \\
\hline CHEMBL1983534 & 809276 & 4.7 & 4.3519 & TRN & \\
\hline CHEMBL1982361 & 809276 & 4.7 & 4.6543 & TRN & \\
\hline CHEMBL1999112 & 809276 & 4.7 & 5.29299 & 9999999999 & TST \\
\hline CHEMBL1982122 & 809276 & 4.7 & 4.5097 & TRN & \\
\hline CHEMBL 2000801 & 809276 & 4.7 & 4.7274 & TRN & \\
\hline CHEMBL1682546 & 809276 & 4.7 & 4.6396 & TST & \\
\hline CHEMBL1991395 & 809276 & 4.7 & 4.6483 & TST & \\
\hline CHEMBL1971245 & 809276 & 6.3 & 5.0217 & TST & \\
\hline CHEMBL1987648 & 809276 & 4.7 & 4.60800 & 00000000005 & TST \\
\hline CHEMBL1996780 & 809276 & 4.7 & 4.6895 & TST & \\
\hline CHEMBL1972142 & 809276 & 4.7 & 4.3476 & TST & \\
\hline CHEMBL1966514 & 809276 & 5.9 & 6.2346 & TST & \\
\hline CHEMBL2003638 & 809276 & 6.0 & 5.6613 & TST & \\
\hline CHEMBL 296586 & 809276 & 4.7 & 5.1928 & TST & \\
\hline CHEMBL1996066 & 809276 & 7.2 & 5.4063 & TST & \\
\hline CHEMBL516429 & 809276 & 4.7 & 5.1855 & TST & \\
\hline CHEMBL1993722 & 809276 & 4.7 & 4.8106 & TST & \\
\hline CHEMBL1970806 & 809276 & 4.7 & 4.68 & TST & \\
\hline CHEMBL1375640 & 809276 & 4.7 & 4.7392 & TST & \\
\hline CHEMBL1979970 & 809276 & 4.7 & 4.8329 & TST & \\
\hline CHEMBL 249282 & 809276 & 4.7 & 4.3171 & TST & \\
\hline CHEMBL1969264 & 809276 & 4.7 & 4.689 & TST & \\
\hline CHEMBL1973711 & 809276 & 4.7 & 4.7314 & TST & \\
\hline CHEMBL 2006237 & 809276 & 4.7 & 4.5459 & TST & \\
\hline CHEMBL1967720 & 809276 & 7.2 & 6.7507 & TST & \\
\hline CHEMBL1572266 & 809276 & 4.7 & 5.1066 & TST & \\
\hline CHEMBL1991138 & 809276 & 4.7 & 4.7998 & TST & \\
\hline CHEMBL1969755 & 809276 & 4.7 & 4.6676 & TST & \\
\hline CHEMBL1979516 & 809276 & 7.5 & 6.4909 & TST & \\
\hline CHEMBL1605605 & 809276 & 4.7 & 4.5893 & TST & \\
\hline CHEMBL1989029 & 809276 & 4.7 & 4.55399 & 9999999999 & TS \\
\hline CHEMBL514499 & 809276 & 4.7 & 5.809 & TST & \\
\hline CHEMBL1965631 & 809276 & 4.7 & 4.595 & TST & \\
\hline CHEMBL1980144 & 809276 & 4.7 & 4.6777 & TST & \\
\hline CHEMBL1991188 & 809276 & 4.7 & 4.7261 & TST & \\
\hline CHEMBL1972849 & 809276 & 4.7 & 4.7418 & TST & \\
\hline CHEMBL 377408 & 809276 & 4.7 & 4.6019 & TST & \\
\hline CHEMBL215152 & 809276 & 4.7 & 4.1175 & TST & \\
\hline CHEMBL231209 & 809276 & 4.7 & 4.5787 & TST & \\
\hline CHEMBL1976220 & 809276 & 4.7 & 5.1984 & TST & \\
\hline CHEMBL259922 & 809276 & 4.7 & 4.613 & TST & \\
\hline CHEMBL1997617 & 809276 & 7.6 & 6.1423 & TST & \\
\hline CHEMBL1982383 & 809276 & 4.7 & 4.1896 & TST & \\
\hline
\end{tabular}




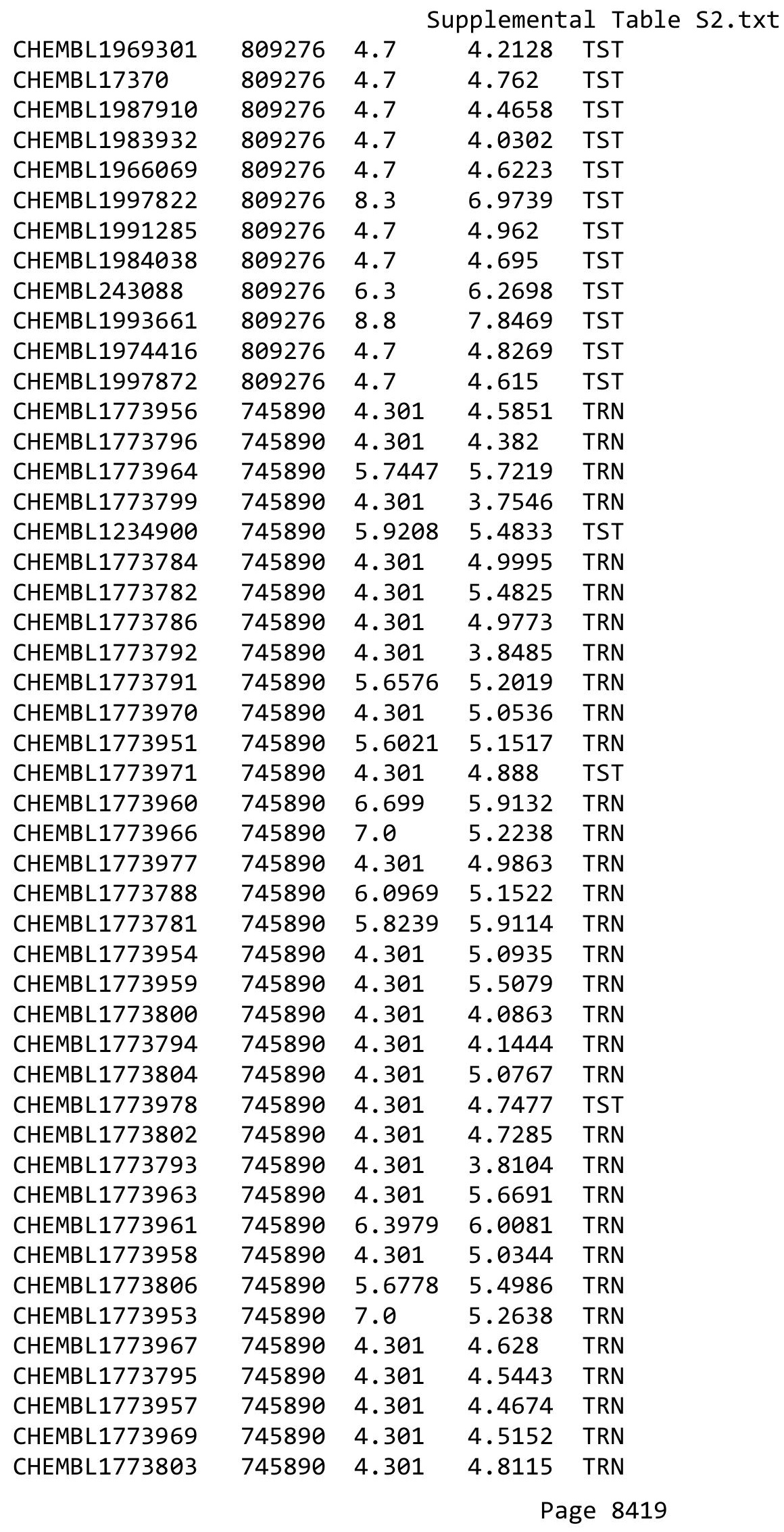




\begin{tabular}{|c|c|c|c|c|c|}
\hline & & \multicolumn{4}{|c|}{ Supplemental Table s2.txt } \\
\hline CHEMBL1773797 & 745890 & 4.301 & 4.5735 & TRN & \\
\hline CHEMBL1773968 & 745890 & 4.301 & 4.2596 & TST & \\
\hline CHEMBL1773955 & 745890 & 4.301 & 4.5401 & TRN & \\
\hline CHEMBL1773801 & 745890 & 4.301 & 4.7468 & TRN & \\
\hline CHEMBL1773785 & 745890 & 5.6778 & 4.8586 & TRN & \\
\hline CHEMBL1773965 & 745890 & 5.8861 & 5.2086 & TRN & \\
\hline CHEMBL1235660 & 745890 & 7.0 & 5.447 & TRN & \\
\hline CHEMBL1773807 & 745890 & 5.9586 & 5.4411 & TRN & \\
\hline CHEMBL1773798 & 745890 & 4.301 & 4.1282 & TST & \\
\hline CHEMBL1773952 & 745890 & 4.301 & 5.0604 & TST & \\
\hline CHEMBL1773972 & 745890 & 4.301 & 4.9986 & TST & \\
\hline CHEMBL1773805 & 745890 & 4.301 & 5.308 & TST & \\
\hline CHEMBL1773783 & 745890 & 4.301 & 5.042 & TST & \\
\hline CHEMBL1773081 & 745890 & 4.301 & 4.9491 & TST & \\
\hline CHEMBL1773790 & 745890 & 4.301 & 4.7438 & TST & \\
\hline CHEMBL1773789 & 745890 & 4.301 & 5.0525 & TST & \\
\hline CHEMBL1773787 & 745890 & 4.301 & 4.7902 & TST & \\
\hline CHEMBL1773962 & 745890 & 6.5229 & 6.0422 & TST & \\
\hline CHEMBL256894 & 466159 & 8.3098 & 8.0654 & TRN & \\
\hline CHEMBL 272923 & 466159 & 7.5528 & 7.5348 & TRN & \\
\hline CHEMBL 257079 & 466159 & 6.4647 & 6.5881 & TRN & \\
\hline CHEMBL429592 & 466159 & 5.0 & 4.6151 & TST & \\
\hline CHEMBL 270588 & 466159 & 7.8539 & 7.915 & TRN & \\
\hline CHEMBL402284 & 466159 & 5.0 & 5.0849 & TRN & \\
\hline CHEMBL271054 & 466159 & 6.7352 & 6.5567 & TRN & \\
\hline CHEMBL410037 & 466159 & 8.0969 & 7.9398 & TRN & \\
\hline CHEMBL 270838 & 466159 & 8.1487 & 8.0933 & TRN & \\
\hline CHEMBL 255370 & 466159 & 7.4815 & 7.5094 & TRN & \\
\hline CHEMBL 270568 & 466159 & 8.0605 & 8.1447 & TRN & \\
\hline CHEMBL402893 & 466159 & 8.1135 & 8.05 & TRN & \\
\hline CHEMBL442803 & 466159 & 8.28399 & 99999999 & 8.5738 & TRN \\
\hline CHEMBL270667 & 466159 & 8.5376 & 8.6632 & TRN & \\
\hline CHEMBL403334 & 466159 & 7.0706 & 6.9649 & TRN & \\
\hline CHEMBL 247234 & 466159 & 6.699 & 7.5985 & TST & \\
\hline CHEMBL257461 & 466159 & 7.7447 & 7.8522 & TRN & \\
\hline CHEMBL404160 & 466159 & 7.7959 & 7.8017 & TRN & \\
\hline CHEMBL403921 & 466159 & 7.7696 & 7.7978 & TRN & \\
\hline CHEMBL270879 & 466159 & 8.0458 & 7.9624 & TRN & \\
\hline CHEMBL409835 & 466159 & 8.2366 & 8.3237 & TRN & \\
\hline CHEMBL271263 & 466159 & 6.6108 & 5.2384 & TST & \\
\hline CHEMBL 257462 & 466159 & 8.2366 & 8.3687 & TRN & \\
\hline CHEMBL271428 & 466159 & 7.5528 & 7.67700 & 00000000005 & TRN \\
\hline CHEMBL271853 & 466159 & 5.0 & 5.0061 & TRN & \\
\hline CHEMBL 270143 & 466159 & 8.5086 & 8.4072 & TRN & \\
\hline CHEMBL270668 & 466159 & 8.9208 & 9.11399 & 9999999999 & TRN \\
\hline CHEMBL 270839 & 466159 & 7.3279 & 7.4271 & TRN & \\
\hline CHEMBL271221 & 466159 & 8.7212 & 8.5916 & TRN & \\
\hline CHEMBL271019 & 466159 & 7.4437 & 7.4509 & TRN & \\
\hline
\end{tabular}




\begin{tabular}{|c|c|c|c|c|}
\hline \multicolumn{5}{|c|}{ Supplemental Table s2.txt } \\
\hline CHEMBL 255369 & 466159 & 8.2441 & 8.1042 & TRN \\
\hline CHEMBL 255570 & 466159 & 5.0 & 4.9474 & TST \\
\hline CHEMBL415099 & 466159 & 6.7496 & 6.9646 & TST \\
\hline CHEMBL403178 & 466159 & 7.1675 & 6.0917 & TST \\
\hline CHEMBL403666 & 466159 & 5.0 & 4.9537 & TRN \\
\hline CHEMBL 257204 & 466159 & 7.7696 & 7.725 & TRN \\
\hline CHEMBL 270575 & 466159 & 9.2218 & 8.92 & TRN \\
\hline CHEMBL403179 & 466159 & 7.9586 & 8.1521 & TRN \\
\hline CHEMBL411457 & 466159 & 7.1079 & 7.1343 & TST \\
\hline CHEMBL403966 & 466159 & 7.1135 & 6.9909 & TRN \\
\hline CHEMBL438386 & 466159 & 7.2218 & 7.4503 & TRN \\
\hline CHEMBL 255843 & 466159 & 7.5376 & 7.5193 & TRN \\
\hline CHEMBL403172 & 466159 & 7.699 & 7.6266 & TRN \\
\hline CHEMBL 255950 & 466159 & 8.1612 & 8.1233 & TRN \\
\hline CHEMBL 271502 & 466159 & 5.0 & 6.4594 & TST \\
\hline CHEMBL 272788 & 466159 & 7.585 & 7.5204 & TRN \\
\hline CHEMBL411852 & 466159 & 8.2924 & 8.3405 & TRN \\
\hline CHEMBL 257203 & 466159 & 8.0 & 7.8177 & TRN \\
\hline CHEMBL402351 & 466159 & 7.9586 & 7.8444 & TRN \\
\hline CHEMBL429913 & 466159 & 8.4685 & 8.3257 & TRN \\
\hline CHEMBL 272789 & 466159 & 7.2757 & 7.7173 & TST \\
\hline CHEMBL404192 & 466159 & 6.3585 & 4.7695 & TST \\
\hline CHEMBL403761 & 466159 & 7.8539 & 7.9963 & TRN \\
\hline CHEMBL 273143 & 466159 & 6.6968 & 6.8631 & TRN \\
\hline CHEMBL 255521 & 466159 & 6.5331 & 6.74700 & 0000000001 \\
\hline CHEMBL401864 & 466159 & 7.9586 & 8.0171 & TRN \\
\hline CHEMBL 273141 & 466159 & 7.0177 & 7.4448 & TST \\
\hline CHEMBL403173 & 466159 & 6.4089 & 4.9555 & TST \\
\hline CHEMBL 256161 & 466159 & 8.3279 & 8.0616 & TST \\
\hline CHEMBL404183 & 466159 & 8.7959 & 8.5652 & TST \\
\hline CHEMBL95469 & 159279 & 3.1805 & 3.63 & TRN \\
\hline CHEMBL327751 & 159279 & 3.1805 & 2.9799 & TRN \\
\hline CHEMBL95572 & 159279 & 3.1805 & 3.362 & TRN \\
\hline CHEMBL319766 & 159279 & 4.2757 & 4.2405 & TRN \\
\hline CHEMBL95921 & 159279 & 3.699 & 3.3685 & TRN \\
\hline CHEMBL 265078 & 159279 & 3.1805 & 2.9558 & TRN \\
\hline CHEMBL319764 & 159279 & 4.3468 & 4.7078 & TRN \\
\hline CHEMBL 320140 & 159279 & 3.1805 & 1.079 & TST \\
\hline CHEMBL316484 & 159279 & 3.1805 & 2.3104 & TST \\
\hline CHEMBL95988 & 159279 & 3.1805 & 2.9044 & TRN \\
\hline CHEMBL100092 & 159279 & 3.1805 & 3.552 & TRN \\
\hline CHEMBL 97042 & 159279 & 3.1805 & 3.1099 & TRN \\
\hline CHEMBL95479 & 159279 & 3.1805 & 3.3752 & TRN \\
\hline CHEMBL421570 & 159279 & 3.1805 & 3.1079 & TRN \\
\hline CHEMBL95625 & 159279 & 3.1805 & 2.9691 & TRN \\
\hline CHEMBL97562 & 159279 & 4.1805 & 3.8219 & TRN \\
\hline CHEMBL319825 & 159279 & 3.1805 & 3.7182 & TRN \\
\hline CHEMBL97040 & 159279 & 3.1805 & 3.0648 & TRN \\
\hline
\end{tabular}




\begin{tabular}{|c|c|c|c|c|}
\hline \multicolumn{5}{|c|}{ Supplemental Table S2.txt } \\
\hline CHEMBL95402 & 159279 & 4.7696 & 3.6136 & TRN \\
\hline CHEMBL96954 & 159279 & 5.6021 & 4.1408 & TRN \\
\hline CHEMBL95380 & 159279 & 3.1805 & 2.6163 & TST \\
\hline CHEMBL100091 & 159279 & 3.1805 & 3.9001 & TRN \\
\hline CHEMBL329292 & 159279 & 3.1805 & 3.4437 & TRN \\
\hline CHEMBL317321 & 159279 & 3.1805 & 4.0482 & TST \\
\hline CHEMBL73572 & 159279 & 4.4815 & 3.5195 & TRN \\
\hline CHEMBL97411 & 159279 & 3.1805 & 3.552 & TRN \\
\hline CHEMBL99199 & 159279 & 3.1805 & 3.5681 & TRN \\
\hline CHEMBL95659 & 159279 & 3.1805 & 4.3254 & TRN \\
\hline CHEMBL329052 & 159279 & 4.4318 & 3.5505 & TRN \\
\hline CHEMBL 330200 & 159279 & 3.1805 & 3.2845 & TRN \\
\hline CHEMBL433160 & 159279 & 3.1805 & 3.4109 & TRN \\
\hline CHEMBL95643 & 159279 & 3.1805 & 3.5555 & TRN \\
\hline CHEMBL319999 & 159279 & 3.1805 & 2.0535 & TST \\
\hline CHEMBL100331 & 159279 & 4.1805 & 3.6136 & TRN \\
\hline CHEMBL97219 & 159279 & 4.7696 & 3.3075 & TST \\
\hline CHEMBL96057 & 159279 & 5.5229 & 4.0093 & TRN \\
\hline CHEMBL 318410 & 159279 & 3.1805 & 2.7093 & TRN \\
\hline CHEMBL421385 & 159279 & 7.2218 & 6.28 & TRN \\
\hline CHEMBL330194 & 159279 & 3.1805 & 3.552 & TRN \\
\hline CHEMBL 317332 & 159279 & 5.0969 & 5.1919 & TRN \\
\hline CHEMBL319359 & 159279 & 5.3979 & 5.6549 & TRN \\
\hline CHEMBL 24415 & 159279 & 3.1805 & 3.2716 & TRN \\
\hline CHEMBL99933 & 159279 & 3.1805 & 3.4156 & TRN \\
\hline CHEMBL 327510 & 159279 & 3.1805 & 3.6653 & TRN \\
\hline CHEMBL97834 & 159279 & 3.1805 & 3.7381 & TRN \\
\hline CHEMBL95508 & 159279 & 3.1805 & 3.1691 & TRN \\
\hline CHEMBL329480 & 159279 & 3.1805 & 3.8889 & TRN \\
\hline CHEMBL318053 & 159279 & 3.1805 & 3.405 & TRN \\
\hline CHEMBL328161 & 159279 & 3.1805 & 2.8254 & TRN \\
\hline CHEMBL 95052 & 159279 & 3.1805 & 2.4772 & TST \\
\hline CHEMBL316866 & 159279 & 3.1805 & 3.4346 & TRN \\
\hline CHEMBL 97088 & 159279 & 3.1805 & 3.5689 & TRN \\
\hline CHEMBL97130 & 159279 & 3.1805 & 2.4922 & TST \\
\hline CHEMBL72631 & 159279 & 3.1805 & 2.6438 & TST \\
\hline CHEMBL318495 & 159279 & 3.1805 & 3.3758 & TRN \\
\hline CHEMBL95558 & 159279 & 3.1805 & 3.1078 & TRN \\
\hline CHEMBL 96011 & 159279 & 3.1805 & 3.3715 & TRN \\
\hline CHEMBL97467 & 159279 & 3.1805 & 2.9608 & TRN \\
\hline CHEMBL330381 & 159279 & 3.1805 & 3.3076 & TRN \\
\hline CHEMBL 97846 & 159279 & 3.1805 & 2.8404 & TRN \\
\hline CHEMBL98514 & 159279 & 3.1805 & 3.6998 & TRN \\
\hline CHEMBL95989 & 159279 & 3.1805 & 3.6356 & TRN \\
\hline CHEMBL319148 & 159279 & 4.3468 & 5.0054 & TST \\
\hline CHEMBL318881 & 159279 & 5.5229 & 3.7262 & TST \\
\hline CHEMBL 95640 & 159279 & 3.1805 & 3.0296 & TST \\
\hline CHEMBL94944 & 159279 & 3.1805 & 4.5469 & TST \\
\hline
\end{tabular}




\begin{tabular}{|c|c|c|c|c|c|}
\hline \\
\hline CHEMBL97808 & 159279 & 3.1805 & 4.2661 & TST & \\
\hline CHEMBL330162 & 159279 & 3.1805 & 3.8113 & TST & \\
\hline CHEMBL328864 & 159279 & 3.1805 & 3.0976 & TST & \\
\hline CHEMBL95311 & 159279 & 3.1805 & 3.1238 & TST & \\
\hline CHEMBL97179 & 159279 & 3.1805 & 3.4483 & TST & \\
\hline CHEMBL 2012178 & 812132 & 6.8239 & 5.5621 & TST & \\
\hline CHEMBL 2012268 & 812132 & 7.0969 & 7.226 & TRN & \\
\hline CHEMBL 2012288 & 812132 & 5.0132 & 5.1006 & TRN & \\
\hline CHEMBL 2012298 & 812132 & 7.3979 & 7.2093 & TRN & \\
\hline CHEMBL 2012291 & 812132 & 6.5229 & 6.4461 & TRN & \\
\hline CHEMBL2012300 & 812132 & 7.5229 & 7.4712 & TRN & \\
\hline CHEMBL 2012270 & 812132 & 5.4572 & 5.2474 & TRN & \\
\hline CHEMBL2012296 & 812132 & 6.2924 & 6.5057 & TRN & \\
\hline CHEMBL 2012274 & 812132 & 6.7959 & 6.9109 & TRN & \\
\hline CHEMBL 2012295 & 812132 & 6.7447 & 6.3908 & TRN & \\
\hline CHEMBL2012265 & 812132 & 7.3979 & 7.5992 & TRN & \\
\hline CHEMBL 2012262 & 812132 & 7.301 & 7.4817 & TRN & \\
\hline CHEMBL 2012282 & 812132 & 4.8539 & 5.2259 & TRN & \\
\hline CHEMBL 2012289 & 812132 & 5.0177 & 4.9995 & TRN & \\
\hline CHEMBL 2012285 & 812132 & 6.5686 & 6.5212 & TRN & \\
\hline CHEMBL 2012284 & 812132 & 5.3372 & 5.3101 & TRN & \\
\hline CHEMBL 2012279 & 812132 & 5.3279 & 5.544 & TRN & \\
\hline CHEMBL 2012290 & 812132 & 6.4815 & 6.3951 & TRN & \\
\hline CHEMBL 2012273 & 812132 & 7.5229 & 7.4751 & TRN & \\
\hline CHEMBL 2012248 & 812132 & 5.1427 & 5.2589 & TRN & \\
\hline CHEMBL 2012301 & 812132 & 7.2218 & 6.9245 & TRN & \\
\hline CHEMBL2012259 & 812132 & 7.699 & 7.7622 & TRN & \\
\hline CHEMBL 2012260 & 812132 & 6.9208 & 6.9913 & TRN & \\
\hline CHEMBL 2012280 & 812132 & 5.5686 & 5.4225 & TRN & \\
\hline CHEMBL 2012246 & 812132 & 5.6402 & 5.8291 & TRN & \\
\hline CHEMBL 2012247 & 812132 & 6.0809 & 5.1249 & TST & \\
\hline CHEMBL2012244 & 812132 & 6.585 & 5.6526 & TRN & \\
\hline CHEMBL 2012256 & 812132 & 3.5229 & 3.5096 & TRN & \\
\hline CHEMBL 2012181 & 812132 & 7.3979 & 5.3795 & TST & \\
\hline CHEMBL 2012281 & 812132 & 5.8539 & 5.67899 & 9999999999 & TRN \\
\hline CHEMBL 2012283 & 812132 & 5.7696 & 5.8514 & TRN & \\
\hline CHEMBL 2012251 & 812132 & 5.1805 & 5.1324 & TRN & \\
\hline CHEMBL 2012180 & 812132 & 7.2218 & 5.5207 & TST & \\
\hline CHEMBL 2012272 & 812132 & 7.699 & 7.9306 & TRN & \\
\hline CHEMBL 2012267 & 812132 & 5.5376 & 5.3983 & TRN & \\
\hline CHEMBL 2012250 & 812132 & 7.0 & 5.4534 & TST & \\
\hline CHEMBL2012179 & 812132 & 7.301 & 5.8327 & TST & \\
\hline CHEMBL 2012252 & 812132 & 3.5229 & 3.8269 & TRN & \\
\hline CHEMBL 2012249 & 812132 & 6.8539 & 5.6595 & TST & \\
\hline CHEMBL 2012286 & 812132 & 5.1871 & 5.3951 & TRN & \\
\hline CHEMBL 2012293 & 812132 & 6.7212 & 6.5847 & TRN & \\
\hline CHEMBL 2012264 & 812132 & 5.4191 & 5.4675 & TRN & \\
\hline CHEMBL 2012277 & 812132 & 5.9586 & 5.7253 & TRN & \\
\hline
\end{tabular}




\begin{tabular}{|c|c|c|c|c|}
\hline & & \multicolumn{3}{|c|}{ Supplemental Table S2.txt } \\
\hline CHEMBL 2012294 & 812132 & 5.9469 & 6.1598 & TRN \\
\hline CHEMBL 2012292 & 812132 & 6.0223 & 6.0144 & TRN \\
\hline CHEMBL2012271 & 812132 & 7.699 & 7.7706 & TRN \\
\hline CHEMBL 2012258 & 812132 & 5.4868 & 5.0373 & TST \\
\hline CHEMBL 2012261 & 812132 & 5.118 & 5.1873 & TRN \\
\hline CHEMBL 2012257 & 812132 & 4.5986 & 4.7186 & TRN \\
\hline CHEMBL 2012269 & 812132 & 6.8861 & 6.8219 & TRN \\
\hline CHEMBL2012287 & 812132 & 6.9586 & 5.1976 & TST \\
\hline CHEMBL 2012254 & 812132 & 5.4547 & 5.6154 & TST \\
\hline CHEMBL 2012245 & 812132 & 6.5086 & 5.7762 & TST \\
\hline CHEMBL 2012266 & 812132 & 7.1549 & 6.75299 & 9999999999 \\
\hline CHEMBL 2012297 & 812132 & 5.2882 & 5.0915 & TST \\
\hline CHEMBL 2012263 & 812132 & 7.1549 & 6.9428 & TST \\
\hline CHEMBL 2012299 & 812132 & 7.3979 & 7.2757 & TST \\
\hline CHEMBL94525 & 63185 & 4.0 & 5.2045 & TRN \\
\hline CHEMBL265734 & 63185 & 5.301 & 4.8406 & TRN \\
\hline CHEMBL384728 & 63185 & 6.301 & 7.2652 & TRN \\
\hline CHEMBL330144 & 63185 & 6.8539 & 6.9015 & TRN \\
\hline CHEMBL319660 & 63185 & 7.7696 & 6.9015 & TRN \\
\hline CHEMBL269428 & 63185 & 4.9586 & 4.8438 & TRN \\
\hline CHEMBL 2370245 & 63185 & 5.0 & 5.7847 & TST \\
\hline CHEMBL329609 & 63185 & 6.4949 & 6.1612 & TRN \\
\hline CHEMBL 327590 & 63185 & 4.0 & 4.025 & TRN \\
\hline CHEMBL 2370254 & 63185 & 5.6576 & 5.1546 & TRN \\
\hline CHEMBL265116 & 63185 & 6.699 & 6.209 & TRN \\
\hline CHEMBL405599 & 63185 & 8.3979 & 8.2168 & TRN \\
\hline CHEMBL262229 & 63185 & 5.0 & 5.4032 & TRN \\
\hline CHEMBL439435 & 63185 & 4.0 & 4.7734 & TRN \\
\hline CHEMBL405709 & 63185 & 5.3979 & 6.209 & TRN \\
\hline CHEMBL386181 & 63185 & 6.6021 & 5.8633 & TRN \\
\hline CHEMBL327523 & 63185 & 5.4949 & 5.3585 & TST \\
\hline CHEMBL216082 & 63185 & 6.2366 & 7.0141 & TRN \\
\hline CHEMBL 2370252 & 63185 & 4.0 & 3.3702 & TRN \\
\hline CHEMBL94730 & 63185 & 4.0 & 3.5717 & TST \\
\hline CHEMBL385492 & 63185 & 7.1675 & 7.221 & TRN \\
\hline CHEMBL384052 & 63185 & 5.2007 & 5.8729 & TRN \\
\hline CHEMBL 2370247 & 63185 & 5.1487 & 4.1326 & TST \\
\hline CHEMBL319719 & 63185 & 7.4559 & 7.69600 & 0000000001 \\
\hline CHEMBL415238 & 63185 & 5.585 & 5.7872 & TRN \\
\hline CHEMBL433406 & 63185 & 6.0706 & 5.9765 & TRN \\
\hline CHEMBL94983 & 63185 & 7.8861 & 6.7083 & TRN \\
\hline CHEMBL328942 & 63185 & 7.3979 & 6.4828 & TRN \\
\hline CHEMBL262993 & 63185 & 8.4559 & 6.1611 & TST \\
\hline CHEMBL407933 & 63185 & 5.699 & 5.1925 & TRN \\
\hline CHEMBL97431 & 63185 & 6.6383 & 6.4828 & TRN \\
\hline CHEMBL 2370253 & 63185 & 5.301 & 4.7305 & TRN \\
\hline CHEMBL319537 & 63185 & 5.6778 & 5.505 & TRN \\
\hline CHEMBL414082 & 63185 & 5.2076 & 5.3167 & TRN \\
\hline
\end{tabular}




\begin{tabular}{|c|c|c|c|c|c|}
\hline \multicolumn{6}{|c|}{ Supplemental Table S2.txt } \\
\hline CHEMBL264579 & 63185 & 5.4437 & 5.3336 & TRN & \\
\hline CHEMBL317099 & 63185 & 6.041 & 7.0266 & TRN & \\
\hline CHEMBL94689 & 63185 & 5.9586 & 5.8033 & TRN & \\
\hline CHEMBL96822 & 63185 & 6.2676 & 6.2109 & TRN & \\
\hline CHEMBL433349 & 63185 & 7.6778 & 6.7101 & TRN & \\
\hline CHEMBL431433 & 63185 & 4.0 & 5.2045 & TRN & \\
\hline CHEMBL405178 & 63185 & 5.585 & 5.3342 & TRN & \\
\hline CHEMBL97470 & 63185 & 7.6021 & 7.1241 & TRN & \\
\hline CHEMBL 2370255 & 63185 & 6.3188 & 6.2731 & TRN & \\
\hline CHEMBL329170 & 63185 & 4.0 & 5.5021 & TRN & \\
\hline CHEMBL94907 & 63185 & 7.0 & 6.916 & TST & \\
\hline CHEMBL411797 & 63185 & 6.4202 & 6.8637 & TST & \\
\hline CHEMBL413179 & 63185 & 5.4559 & 5.1687 & TST & \\
\hline CHEMBL323331 & 63185 & 6.0 & 5.5735 & TST & \\
\hline CHEMBL318020 & 63185 & 6.0 & 5.5021 & TST & \\
\hline CHEMBL 2370246 & 63185 & 4.0 & 3.1853 & TST & \\
\hline CHEMBL263295 & 63185 & 6.1871 & 5.9109 & TST & \\
\hline CHEMBL421190 & 63185 & 7.4437 & 6.5682 & TST & \\
\hline CHEMBL 2165329 & 859880 & 6.3401 & 6.3044 & TRN & \\
\hline CHEMBL 2165333 & 859880 & 6.2958 & 6.1931 & TRN & \\
\hline CHEMBL 2165330 & 859880 & 6.1475 & 6.3408 & TRN & \\
\hline CHEMBL 2163713 & 859880 & 6.3372 & 6.2086 & TRN & \\
\hline CHEMBL 2163718 & 859880 & 6.1838 & 6.2043 & TRN & \\
\hline CHEMBL 2163708 & 859880 & 7.7144 & 7.5874 & TRN & \\
\hline CHEMBL 2163711 & 859880 & 6.4237 & 6.3586 & TRN & \\
\hline CHEMBL 2165328 & 859880 & 6.2798 & 6.3266 & TRN & \\
\hline CHEMBL 2163700 & 859880 & 5.8236 & 5.7984 & TRN & \\
\hline CHEMBL 2163690 & 859880 & 6.1057 & 6.1559 & TRN & \\
\hline CHEMBL 2163702 & 859880 & 6.6655 & 6.6423 & TRN & \\
\hline CHEMBL 2163705 & 859880 & 6.8386 & 6.829 & TRN & \\
\hline CHEMBL 2163701 & 859880 & 6.3363 & 6.3382 & TRN & \\
\hline CHEMBL 2163691 & 859880 & 6.3298 & 6.40600 & 0000000001 & TRN \\
\hline CHEMBL 2163719 & 859880 & 6.4921 & 6.7063 & TRN & \\
\hline CHEMBL 2165327 & 859880 & 9.6819 & 5.9859 & TST & \\
\hline CHEMBL 2165338 & 859880 & 6.0809 & 6.1764 & TRN & \\
\hline CHEMBL 2163710 & 859880 & 5.4585 & 5.6056 & TRN & \\
\hline CHEMBL 2165337 & 859880 & 6.0904 & 6.086 & TRN & \\
\hline CHEMBL 2163707 & 859880 & 4.0 & 3.9876 & TRN & \\
\hline CHEMBL 2163717 & 859880 & 6.7122 & 6.4173 & TRN & \\
\hline CHEMBL 2163716 & 859880 & 6.8327 & 6.631 & TRN & \\
\hline CHEMBL 2163706 & 859880 & 6.3726 & 6.3628 & TRN & \\
\hline CHEMBL 2165336 & 859880 & 5.6066 & 6.6667 & TST & \\
\hline CHEMBL 2163693 & 859880 & 5.5146 & 5.7892 & TST & \\
\hline CHEMBL 2163698 & 859880 & 6.3325 & 6.48 & TRN & \\
\hline CHEMBL 2163724 & 859880 & 6.251 & 6.4127 & TRN & \\
\hline CHEMBL1269102 & 859880 & 5.0 & 6.3815 & TST & \\
\hline CHEMBL 2163721 & 859880 & 6.3401 & 6.2619 & TRN & \\
\hline CHEMBL 2165332 & 859880 & 6.3556 & 6.3813 & TST & \\
\hline
\end{tabular}


Supplemental Table S2.txt

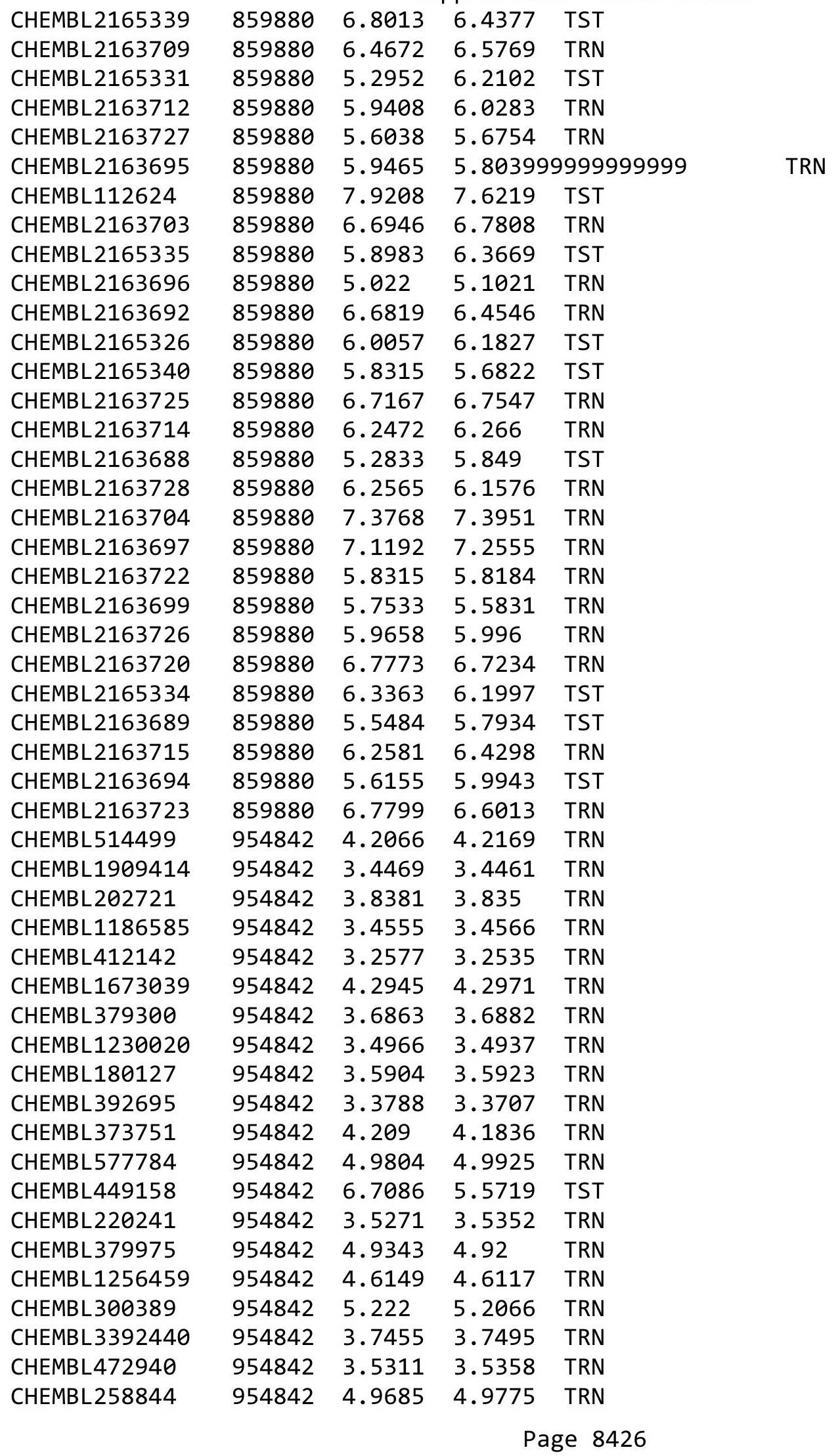


Supplemental Table S2.txt

\begin{tabular}{|c|c|c|c|c|c|c|}
\hline CHEMBL 2144069 & 954842 & 5.2023 & 5.2074 & TRN & & \\
\hline CHEMBL189584 & 954842 & 3.8977 & 3.8929 & TRN & & \\
\hline CHEMBL 2005886 & 954842 & 3.2582 & 3.2598 & TRN & & \\
\hline CHEMBL573107 & 954842 & \multicolumn{3}{|c|}{5.4670000000000005} & 5.4531 & TRN \\
\hline CHEMBL 3349342 & 954842 & 4.029 & 4.0326 & TRN & & \\
\hline CHEMBL 259181 & 954842 & \multicolumn{3}{|c|}{3.4160000000000004} & 3.411 & TRN \\
\hline CHEMBL515416 & 954842 & 3.327 & 3.3153 & TRN & & \\
\hline CHEMBL 255342 & 954842 & 3.235 & 3.235 & TRN & & \\
\hline CHEMBL1788116 & 954842 & 3.2715 & 3.2731 & TRN & & \\
\hline CHEMBL 2137530 & 954842 & 4.6548 & 4.6677 & TRN & & \\
\hline CHEMBL 213100 & 954842 & 3.1697 & 3.1665 & TRN & & \\
\hline CHEMBL509032 & 954842 & 5.0153 & 5.0128 & TRN & & \\
\hline CHEMBL1404918 & 954842 & 3.6276 & 3.6294 & TRN & & \\
\hline CHEMBL188678 & 954842 & 4.2098 & 4.1971 & TRN & & \\
\hline CHEMBL92309 & 954842 & 2.9782 & 2.5029 & TST & & \\
\hline CHEMBL512504 & 954842 & 3.9936 & 3.9915 & TRN & & \\
\hline CHEMBL1970879 & 954842 & 3.7986 & 3.8093 & TRN & & \\
\hline CHEMBL399530 & 954842 & 5.0376 & 5.0335 & TRN & & \\
\hline CHEMBL1590308 & 954842 & 3.0286 & 3.0571 & TST & & \\
\hline CHEMBL 210618 & 954842 & 3.2925 & 3.2876 & TRN & & \\
\hline CHEMBL 240954 & 954842 & \multicolumn{3}{|c|}{3.5610000000000004} & 3.7934 & TST \\
\hline CHEMBL135561 & 954842 & 4.2157 & 4.2274 & TRN & & \\
\hline CHEMBL1357247 & 954842 & 3.4923 & 3.4951 & TRN & & \\
\hline CHEMBL1242367 & 954842 & 3.7311 & 3.7189 & TRN & & \\
\hline CHEMBL 222102 & 954842 & \multicolumn{3}{|c|}{2.9960000000000004} & 3.0307 & $\mathrm{~N}$ \\
\hline CHEMBL393929 & 954842 & 3.2729 & 3.2685 & TRN & & \\
\hline CHEMBL65 & 954842 & 8.5753 & 8.5822 & TRN & & \\
\hline CHEMBL1643959 & 954842 & 2.7938 & 2.7901 & TRN & & \\
\hline CHEMBL1516890 & 954842 & 4.2233 & 4.2392 & TRN & & \\
\hline CHEMBL483849 & 954842 & 2.9642 & 1.9907 & TST & & \\
\hline CHEMBL191334 & 954842 & 3.1526 & 3.1538 & TRN & & \\
\hline CHEMBL558642 & 954842 & 2.5275 & 2.529 & TRN & & \\
\hline CHEMBL102714 & 954842 & 3.3536 & \multicolumn{3}{|c|}{3.3480000000000003} & $\mathrm{NI}^{\prime}$ \\
\hline CHEMBL 3199475 & 954842 & 4.5259 & 4.2451 & TST & & \\
\hline CHEMBL9470 & 954842 & 6.3495 & 4.949 & TST & & \\
\hline CHEMBL 3186408 & 954842 & 3.4122 & 3.5766 & TST & & \\
\hline CHEMBL1190711 & 954842 & 5.0221 & 3.8412 & TST & & \\
\hline CHEMBL221137 & 954842 & 4.2332 & 4.3783 & TST & & \\
\hline CHEMBL192566 & 954842 & 7.2614 & 5.8769 & TST & & \\
\hline CHEMBL 217354 & 954842 & 6.3623 & 6.2638 & TST & & \\
\hline CHEMBL585951 & 954842 & 5.9177 & 5.0954 & TST & & \\
\hline CHEMBL 2363137 & 954842 & 4.442 & 4.0351 & TST & & \\
\hline CHEMBL483847 & 954842 & 3.9073 & 3.5115 & TST & & \\
\hline CHEMBL 209148 & 954842 & 4.9621 & 3.2939 & TST & & \\
\hline CHEMBL 2134202 & 954842 & 3.5491 & 3.7097 & TST & & \\
\hline CHEMBL 3657166 & 1528692 & 8.3979 & 7.9606 & TRN & & \\
\hline CHEMBL 3657153 & 1528692 & 7.3279 & 7.4233 & TRN & & \\
\hline CHEMBL 3657183 & 1528692 & 7.0 & 6.9899 & TRN & & \\
\hline
\end{tabular}


Supplemental Table S2.txt

\begin{tabular}{|c|c|c|c|c|}
\hline CHEMBL 3657147 & 1528692 & 7.0 & 6.919 & TST \\
\hline CHEMBL 3657174 & 1528692 & 7.0969 & 7.1582 & TRN \\
\hline CHEMBL 3657162 & 1528692 & 8.2596 & 8.1115 & TRN \\
\hline CHEMBL 3657170 & 1528692 & 6.8239 & 6.9826 & TRN \\
\hline CHEMBL 3657169 & 1528692 & 7.8861 & 7.8083 & TRN \\
\hline CHEMBL 3657138 & 1528692 & 6.5229 & 6.5014 & TRN \\
\hline CHEMBL 3657161 & 1528692 & 8.0458 & 7.9157 & TRN \\
\hline CHEMBL 3657143 & 1528692 & 6.699 & 6.8007 & TRN \\
\hline CHEMBL 3657146 & 1528692 & 6.699 & 6.8201 & TST \\
\hline CHEMBL3657167 & 1528692 & 7.6198 & 7.8306 & TRN \\
\hline CHEMBL 3657144 & 1528692 & 7.5229 & 7.1559 & TRN \\
\hline CHEMBL 3657184 & 1528692 & 7.1549 & 7.0871 & TRN \\
\hline CHEMBL 3657151 & 1528692 & 7.4318 & 7.3614 & TRN \\
\hline CHEMBL 3657149 & 1528692 & 7.699 & 7.1013 & TST \\
\hline CHEMBL 3657163 & 1528692 & 7.8861 & 8.1115 & TRN \\
\hline CHEMBL 3657142 & 1528692 & 7.0458 & 7.0778 & TRN \\
\hline CHEMBL3657154 & 1528692 & 7.0 & 7.1162 & TRN \\
\hline CHEMBL 3657140 & 1528692 & 6.284 & 6.1735 & TRN \\
\hline CHEMBL 3657159 & 1528692 & 6.9586 & 7.0328 & TRN \\
\hline CHEMBL 3657152 & 1528692 & 6.8239 & 6.85 & TRN \\
\hline CHEMBL3657135 & 1528692 & 6.9208 & 6.8419 & TRN \\
\hline CHEMBL 3657155 & 1528692 & 7.3979 & 7.1162 & TRN \\
\hline CHEMBL 3657176 & 1528692 & 6.3468 & 6.6888 & TRN \\
\hline CHEMBL 3657175 & 1528692 & 7.2441 & 7.1582 & TRN \\
\hline CHEMBL 3657172 & 1528692 & 7.6383 & 7.71200 & 0000000001 \\
\hline CHEMBL3657157 & 1528692 & 6.7696 & 6.8791 & TRN \\
\hline CHEMBL 3657158 & 1528692 & 6.9586 & 6.9884 & TRN \\
\hline CHEMBL 3657136 & 1528692 & 7.5229 & 7.3357 & TRN \\
\hline CHEMBL3657150 & 1528692 & 6.7696 & 6.9977 & TRN \\
\hline CHEMBL 3657141 & 1528692 & 7.2076 & 7.0778 & TRN \\
\hline CHEMBL 3657168 & 1528692 & 7.5376 & 7.8306 & TRN \\
\hline CHEMBL 3657160 & 1528692 & 7.7212 & 7.9157 & TRN \\
\hline CHEMBL 3657180 & 1528692 & 7.1549 & 7.1306 & TST \\
\hline CHEMBL 3657137 & 1528692 & 6.4559 & 6.4433 & TRN \\
\hline CHEMBL 3657148 & 1528692 & 7.5528 & 6.8367 & TST \\
\hline CHEMBL 3657181 & 1528692 & 9.0 & 7.1746 & TST \\
\hline CHEMBL 3657145 & 1528692 & 7.0969 & 7.0447 & TST \\
\hline CHEMBL 3657178 & 1528692 & 7.3979 & 7.0701 & TST \\
\hline CHEMBL 3657165 & 1528692 & 7.301 & 7.2301 & TRN \\
\hline CHEMBL 3657173 & 1528692 & 7.0044 & 7.0844 & TRN \\
\hline CHEMBL3705039 & 1528692 & 7.0 & 7.1837 & TST \\
\hline CHEMBL 3657139 & 1528692 & 6.2218 & 6.1735 & TRN \\
\hline CHEMBL 3657185 & 1528692 & 7.0969 & 6.9801 & TST \\
\hline CHEMBL3657156 & 1528692 & 7.0969 & 6.9899 & TRN \\
\hline CHEMBL3657164 & 1528692 & 6.9208 & 6.9115 & TRN \\
\hline CHEMBL 3657177 & 1528692 & 7.2218 & 7.0188 & TST \\
\hline CHEMBL 3657182 & 1528692 & 6.8239 & 7.3707 & TST \\
\hline CHEMBL 3657171 & 1528692 & 7.9586 & 7.71200 & 0000000001 \\
\hline
\end{tabular}




\begin{tabular}{|c|c|c|c|c|}
\hline \multicolumn{5}{|c|}{ Supplemental Table S2.txt } \\
\hline CHEMBL22527 & 142139 & 3.0 & 3.1744 & TRN \\
\hline CHEMBL21978 & 142139 & 3.0 & 2.9325 & TRN \\
\hline CHEMBL22894 & 142139 & 5.4949 & 6.1602 & TRN \\
\hline CHEMBL22608 & 142139 & 4.2495 & 4.2409 & TRN \\
\hline CHEMBL21349 & 142139 & 4.3098 & 5.0269 & TST \\
\hline CHEMBL22720 & 142139 & 5.6383 & 4.6735 & TST \\
\hline CHEMBL22083 & 142139 & 5.1675 & 5.185 & TST \\
\hline CHEMBL22700 & 142139 & 4.0 & 4.2713 & TRN \\
\hline CHEMBL22530 & 142139 & 5.6198 & 5.5423 & TRN \\
\hline CHEMBL21641 & 142139 & 5.0757 & 5.0103 & TST \\
\hline CHEMBL21856 & 142139 & 6.5686 & 6.2835 & TRN \\
\hline CHEMBL22338 & 142139 & 7.1805 & 6.5191 & TRN \\
\hline CHEMBL283805 & 142139 & 3.0 & 2.3866 & TRN \\
\hline CHEMBL 21587 & 142139 & 5.7447 & 5.0954 & TRN \\
\hline CHEMBL22082 & 142139 & 3.0 & 3.7983 & TST \\
\hline CHEMBL50267 & 142139 & 6.699 & 6.4492 & TRN \\
\hline CHEMBL22462 & 142139 & 6.2007 & 5.2596 & TRN \\
\hline CHEMBL21826 & 142139 & 3.0 & 3.8674 & TRN \\
\hline CHEMBL311389 & 142139 & 6.2518 & 5.3374 & TRN \\
\hline CHEMBL278325 & 142139 & 3.0 & 5.4392 & TST \\
\hline CHEMBL282672 & 142139 & 4.4134 & 3.7367 & TST \\
\hline CHEMBL429233 & 142139 & 6.1871 & 6.3069 & TRN \\
\hline CHEMBL22339 & 142139 & 3.0 & 3.0229 & TRN \\
\hline CHEMBL282003 & 142139 & 5.4685 & 5.8649 & TST \\
\hline CHEMBL22493 & 142139 & 5.284 & 5.1146 & TRN \\
\hline CHEMBL22586 & 142139 & 5.2518 & 5.1763 & TRN \\
\hline CHEMBL280701 & 142139 & 3.0 & 3.2657 & TRN \\
\hline CHEMBL23044 & 142139 & 5.0809 & 2.3871 & TST \\
\hline CHEMBL22895 & 142139 & 7.4949 & 6.813 & TRN \\
\hline CHEMBL299155 & 142139 & 4.3872 & 3.3659 & TST \\
\hline CHEMBL22588 & 142139 & 3.0 & 3.2139 & TRN \\
\hline CHEMBL22640 & 142139 & 3.0 & 2.99 & TRN \\
\hline CHEMBL284028 & 142139 & 5.5086 & 5.2746 & TST \\
\hline CHEMBL442102 & 142139 & 3.0 & 3.3818 & TRN \\
\hline CHEMBL418747 & 142139 & 5.3098 & 5.4117 & TRN \\
\hline CHEMBL278854 & 142139 & 7.0655 & 7.295 & TRN \\
\hline CHEMBL416555 & 142139 & 5.1805 & 3.7092 & TST \\
\hline CHEMBL 22807 & 142139 & 5.6778 & 4.9102 & TRN \\
\hline CHEMBL 22274 & 142139 & 3.0 & 4.7663 & TRN \\
\hline CHEMBL25054 & 142139 & 6.585 & 6.0146 & TRN \\
\hline CHEMBL440462 & 142139 & 5.9586 & 7.0541 & TRN \\
\hline CHEMBL283345 & 142139 & 3.0 & 3.5856 & TST \\
\hline CHEMBL277675 & 142139 & 3.0 & 3.0807 & TRN \\
\hline CHEMBL21529 & 142139 & 5.9208 & 6.1266 & TRN \\
\hline CHEMBL22239 & 142139 & 6.0862 & 7.237 & TRN \\
\hline CHEMBL279740 & 142139 & 3.0 & 3.6724 & TRN \\
\hline CHEMBL416006 & 142139 & 6.2676 & 5.9713 & TRN \\
\hline CHEMBL22933 & 142139 & 5.3188 & 4.5957 & TRN \\
\hline
\end{tabular}




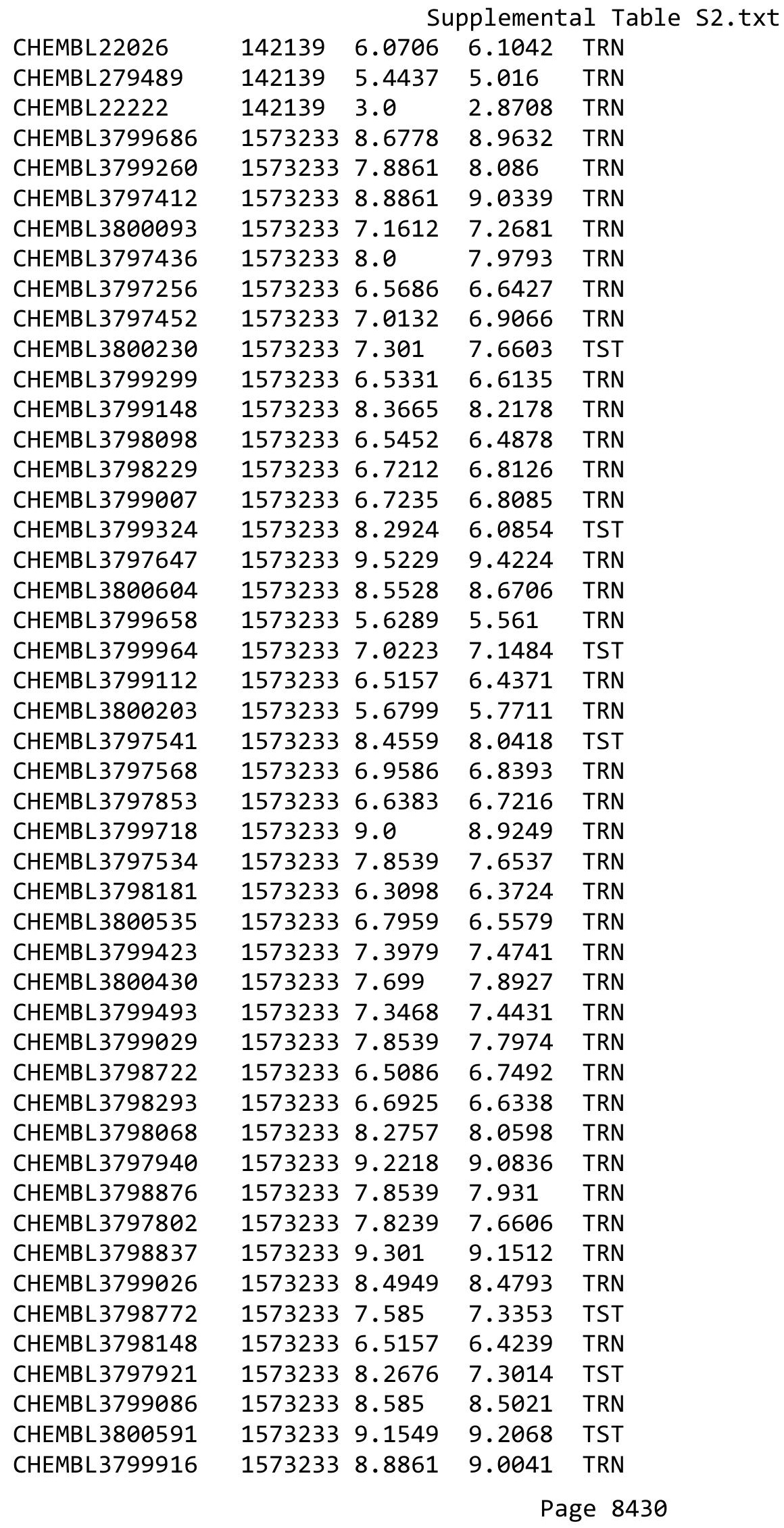


Supplemental Table S2.txt

\begin{tabular}{|c|c|c|c|c|c|}
\hline CHEMBL 3799441 & 1573233 & 9.301 & 9.2739 & TST & \\
\hline CHEMBL 3126592 & 1573233 & 9.2218 & 7.7705 & TST & \\
\hline CHEMBL 3799888 & 1573233 & 8.9586 & 8.8099 & TRN & \\
\hline CHEMBL 3798420 & 1573233 & 8.1487 & 7.9713 & TRN & \\
\hline CHEMBL3799923 & 1573233 & 6.8097 & 8.071 & TST & \\
\hline CHEMBL3799355 & 1573233 & 8.9586 & 9.0244 & TRN & \\
\hline CHEMBL 3800102 & 1573233 & 8.1938 & 7.8481 & TST & \\
\hline CHEMBL 3797410 & 1573233 & 6.4145 & 6.4065 & TRN & \\
\hline CHEMBL 3126595 & 1573233 & 8.1024 & 7.6717 & TST & \\
\hline CHEMBL 3799109 & 1573233 & 8.1675 & 7.6386 & TST & \\
\hline CHEMBL 3798240 & 1573233 & 8.3872 & 8.4481 & TRN & \\
\hline CHEMBL 3797596 & 1573233 & 9.0 & 8.9049 & TRN & \\
\hline CHEMBL 3798697 & 1573233 & 8.0706 & 8.1987 & TRN & \\
\hline CHEMBL 3799748 & 1573233 & 8.4437 & 8.3149 & TRN & \\
\hline CHEMBL 3799690 & 1573233 & 6.6383 & 6.6386 & TRN & \\
\hline CHEMBL 3124957 & 1573233 & 9.699 & 7.6135 & TST & \\
\hline CHEMBL 3798218 & 1573233 & 8.0969 & 8.3579 & TRN & \\
\hline CHEMBL 3800086 & 1573233 & 9.0458 & 9.0786 & TST & \\
\hline CHEMBL 3798807 & 1573233 & 7.2596 & 7.7114 & TST & \\
\hline CHEMBL 3797357 & 1573233 & 8.5528 & 8.7185 & TST & \\
\hline CHEMBL463182 & 514433 & 6.8539 & 6.8735 & TRN & \\
\hline CHEMBL458927 & 514433 & 6.0969 & 6.3366 & TRN & \\
\hline CHEMBL59765 & 514433 & 4.4949 & 5.9532 & TST & \\
\hline CHEMBL497453 & 514433 & 5.0 & 5.2215 & TRN & \\
\hline CHEMBL516002 & 514433 & 6.699 & 6.2977 & TRN & \\
\hline CHEMBL 271576 & 514433 & 6.5528 & 4.7554 & TST & \\
\hline CHEMBL497847 & 514433 & 5.0 & 5.9362 & TRN & \\
\hline CHEMBL498302 & 514433 & 5.0 & 5.2975 & TRN & \\
\hline CHEMBL456971 & 514433 & 5.0 & 5.2136 & TRN & \\
\hline CHEMBL526472 & 514433 & 5.0 & 4.7718 & TRN & \\
\hline CHEMBL509729 & 514433 & 7.1612 & 7.3557 & TRN & \\
\hline CHEMBL457629 & 514433 & 6.1871 & 6.3218 & TRN & \\
\hline CHEMBL498304 & 514433 & 6.3098 & 6.2252 & TRN & \\
\hline CHEMBL497115 & 514433 & 5.0 & 5.1591 & TRN & \\
\hline CHEMBL457839 & 514433 & 6.1107 & 5.9789 & TRN & \\
\hline CHEMBL503209 & 514433 & 5.0 & 5.1724 & TRN & \\
\hline CHEMBL456795 & 514433 & 5.0 & 4.8957 & TRN & \\
\hline CHEMBL450842 & 514433 & 6.2076 & 6.0319 & TRN & \\
\hline CHEMBL498703 & 514433 & 7.1549 & 7.0336 & TRN & \\
\hline CHEMBL462780 & 514433 & 6.0 & 5.9352 & TRN & \\
\hline CHEMBL458271 & 514433 & 5.0 & 5.5353 & TST & \\
\hline CHEMBL457840 & 514433 & 5.0 & 5.1989 & TRN & \\
\hline CHEMBL458923 & 514433 & \multicolumn{3}{|c|}{6.7620000000000005} & 6.9211 \\
\hline CHEMBL514102 & 514433 & 6.0376 & 6.0135 & TRN & \\
\hline CHEMBL525358 & 514433 & 6.0 & 5.8446 & TRN & \\
\hline CHEMBL457847 & 514433 & 5.0 & 5.0258 & TRN & \\
\hline CHEMBL456972 & 514433 & 5.0 & 5.0433 & TRN & \\
\hline CHEMBL456578 & 514433 & 6.4815 & 6.4879 & TRN & \\
\hline
\end{tabular}




\begin{tabular}{|c|c|c|c|c|c|c|}
\hline & & \multicolumn{5}{|c|}{ Supplemental Table S2.txt } \\
\hline CHEMBL456352 & 514433 & 6.0506 & 5.6408 & TRN & & \\
\hline CHEMBL457199 & 514433 & 6.5086 & 6.5541 & TRN & & \\
\hline CHEMBL498303 & 514433 & 6.0 & 5.8533 & TRN & & \\
\hline CHEMBL498305 & 514433 & 5.8239 & 5.3867 & TRN & & \\
\hline CHEMBL514094 & 514433 & 6.3188 & 6.081 & TRN & & \\
\hline CHEMBL456772 & 514433 & 5.0 & 5.1407 & TRN & & \\
\hline CHEMBL498704 & 514433 & 6.0 & 6.0588 & TRN & & \\
\hline CHEMBL498531 & 514433 & 6.7959 & 6.5219 & TRN & & \\
\hline CHEMBL456353 & 514433 & 6.4437 & 6.6629 & TRN & & \\
\hline CHEMBL514265 & 514433 & 6.0835 & 5.8328 & TRN & & \\
\hline CHEMBL498519 & 514433 & 6.0 & 5.9114 & TRN & & \\
\hline CHEMBL497280 & 514433 & 6.1739 & 5.2185 & TST & & \\
\hline CHEMBL496467 & 514433 & 6.0 & 5.8495 & TRN & & \\
\hline CHEMBL459133 & 514433 & 6.0088 & 6.5417 & TST & & \\
\hline CHEMBL497113 & 514433 & 5.0 & 6.1135 & TST & & \\
\hline CHEMBL463181 & 514433 & 6.5686 & 6.9605 & TST & & \\
\hline CHEMBL527037 & 514433 & 6.0 & 6.5039 & TST & & \\
\hline CHEMBL409828 & 514433 & 6.0 & 5.6309 & TST & & \\
\hline CHEMBL497281 & 514433 & 6.0 & 5.3501 & TST & & \\
\hline CHEMBL515349 & 514433 & 6.4685 & 6.8777 & TST & & \\
\hline CHEMBL498145 & 514433 & 5.0 & 4.4015 & TST & & \\
\hline CHEMBL452129 & 514433 & 6.0 & 5.2709 & TST & & \\
\hline CHEMBL 232409 & 922573 & 6.456 & 6.3186 & TRN & & \\
\hline CHEMBL 234843 & 922573 & 6.398 & 6.341 & TRN & & \\
\hline CHEMBL394256 & 922573 & 6.409 & 6.3368 & TRN & & \\
\hline CHEMBL 234674 & 922573 & 5.50899 & 99999999 & 995 & .2271 & TRN \\
\hline CHEMBL 234672 & 922573 & 6.553 & 6.2077 & TRN & & \\
\hline CHEMBL394115 & 922573 & 6.347 & 6.2111 & TRN & & \\
\hline CHEMBL392868 & 922573 & 6.824 & 6.3452 & TRN & & \\
\hline CHEMBL392659 & 922573 & 7.31 & 6.2708 & TRN & & \\
\hline CHEMBL 233638 & 922573 & 6.456 & 6.3194 & TRN & & \\
\hline CHEMBL234206 & 922573 & 6.824 & 6.0903 & TRN & & \\
\hline CHEMBL233635 & 922573 & 4.996 & 6.0832 & TST & & \\
\hline CHEMBL 234461 & 922573 & 6.222 & 6.2916 & TST & & \\
\hline CHEMBL 240636 & 922573 & 6.319 & 5.8848 & TRN & & \\
\hline CHEMBL2281962 & 922573 & 6.222 & 6.2135 & TST & & \\
\hline CHEMBL240037 & 922573 & 4.85 & 6.2324 & TST & & \\
\hline CHEMBL394684 & 922573 & 5.37700 & 30000000 & & 6.1613 & TST \\
\hline CHEMBL2281961 & 922573 & 6.398 & 6.1673 & TST & & \\
\hline CHEMBL 2281960 & 922573 & 7.032 & 6.0045 & TST & & \\
\hline CHEMBL240639 & 922573 & 6.22 & 6.0032 & TRN & & \\
\hline CHEMBL238545 & 922573 & 6.155 & 5.8916 & TRN & & \\
\hline CHEMBL239154 & 922573 & 6.301 & 5.8644 & TRN & & \\
\hline CHEMBL239153 & 922573 & 4.408 & 5.3754 & TRN & & \\
\hline CHEMBL2281959 & 922573 & 6.347 & 7.0959 & TRN & & \\
\hline CHEMBL2281958 & 922573 & 5.824 & 6.9016 & TRN & & \\
\hline CHEMBL2281957 & 922573 & 6.0760 & 30000000 & 005 & .9114 & RN \\
\hline CHEMBL 2281956 & 922573 & 6.678 & 6.3556 & TRN & & \\
\hline
\end{tabular}


Supplemental Table S2.txt

\begin{tabular}{|c|c|c|c|c|c|c|}
\hline CHEMBL237896 & 922573 & 5.959 & 6.3698 & TRN & & \\
\hline CHEMBL234896 & 922573 & 6.237 & 6.2569 & TRN & & \\
\hline CHEMBL393004 & 922573 & 6.237 & 6.2275 & TRN & & \\
\hline CHEMBL 240638 & 922573 & 5.77 & 5.6274 & TRN & & \\
\hline CHEMBL395607 & 922573 & 6.046 & 5.7189 & TRN & & \\
\hline CHEMBL232412 & 922573 & 5.886 & 6.2213 & TRN & & \\
\hline CHEMBL 234844 & 922573 & 5.886 & 6.1588 & TRN & & \\
\hline CHEMBL240637 & 922573 & 5.699 & 5.7694 & TRN & & \\
\hline CHEMBL391378 & 922573 & 5.886 & 6.1537 & TRN & & \\
\hline CHEMBL234634 & 922573 & 5.854 & 6.1912 & TST & & \\
\hline CHEMBL 233385 & 922573 & 5.959 & 6.2848 & TST & & \\
\hline CHEMBL 233845 & 922573 & 5.77 & 6.1235 & TST & & \\
\hline CHEMBL429641 & 922573 & 6.222 & 6.0212 & TRN & & \\
\hline CHEMBL2281892 & 922573 & 6.0 & 6.0273 & TST & & \\
\hline CHEMBL2281971 & 922573 & 5.854 & 6.1355 & TST & & \\
\hline CHEMBL439223 & 922573 & 5.699 & 6.1634 & TST & & \\
\hline CHEMBL394685 & 922573 & 6.125 & 6.136 & TST & & \\
\hline CHEMBL397296 & 922573 & 6.097 & 5.8426 & TRN & & \\
\hline CHEMBL393274 & 922573 & 6.854 & 6.1432 & TST & & \\
\hline CHEMBL241097 & 922573 & 6.699 & 6.1368 & TST & & \\
\hline CHEMBL397295 & 922573 & 5.721 & 5.5629 & TRN & & \\
\hline CHEMBL241057 & 922573 & 6.222 & 6.077999 & 9999999999 & & TRN \\
\hline CHEMBL 240640 & 922573 & 5.468 & 5.9851 & TRN & & \\
\hline CHEMBL395843 & 922573 & 5.921 & 5.9011 & TRN & & \\
\hline CHEMBL238549 & 922573 & 5.06 & 5.6832 & TRN & & \\
\hline CHEMBL 2281970 & 922573 & 5.432 & 5.8164 & TRN & & \\
\hline CHEMBL391379 & 922573 & 6.0 & 6.2156 & TRN & & \\
\hline CHEMBL393068 & 922573 & 5.77 & 5.6942 & TRN & & \\
\hline CHEMBL 238546 & 922573 & \multicolumn{3}{|c|}{5.537999999999999} & 5.6493 & TRN \\
\hline CHEMBL239783 & 922573 & 5.77 & 5.777 & TRN & & \\
\hline CHEMBL238949 & 922573 & 5.796 & 5.6887 & TRN & & \\
\hline CHEMBL241251 & 922573 & 5.886 & 5.8504 & TRN & & \\
\hline CHEMBL2281969 & 922573 & 7.456 & 7.2267 & TRN & & \\
\hline CHEMBL2281968 & 922573 & 7.959 & 7.1898 & TRN & & \\
\hline CHEMBL2281967 & 922573 & \multicolumn{3}{|c|}{7.327999999999999} & 7.2114 & TRN \\
\hline CHEMBL2281966 & 922573 & 7.0 & 7.135 & TRN & & \\
\hline CHEMBL2281965 & 922573 & 6.77 & 7.1261 & TRN & & \\
\hline CHEMBL2281964 & 922573 & 7.244 & 7.2044 & TRN & & \\
\hline CHEMBL2281963 & 922573 & 6.495 & 7.0938 & TST & & \\
\hline CHEMBL240655 & 922573 & 5.244 & 5.6096 & TRN & & \\
\hline CHEMBL1812386 & 762744 & 5.2848 & 5.2863 & TRN & & \\
\hline CHEMBL1812241 & 762744 & 3.699 & 3.6989 & TRN & & \\
\hline CHEMBL1812234 & 762744 & 5.1694 & 5.1775 & TRN & & \\
\hline CHEMBL1812256 & 762744 & 5.2684 & 5.3053 & TRN & & \\
\hline CHEMBL1812269 & 762744 & 5.3778 & 5.3758 & TRN & & \\
\hline CHEMBL1812261 & 762744 & 3.699 & 3.6881 & TRN & & \\
\hline CHEMBL1812236 & 762744 & 5.7447 & 5.7353 & TRN & & \\
\hline CHEMBL1812232 & 762744 & 5.3893 & 5.3947 & TRN & & \\
\hline
\end{tabular}


Supplemental Table S2.txt

\begin{tabular}{|c|c|c|c|c|}
\hline (1) & 762744 & & & \\
\hline CHEMBL18 & & 1045 & & \\
\hline AEMBL1812265 & 52744 & 904 & 9922 & \\
\hline HEMBL1812238 & 52744 & 4.7852 & 7938 & \\
\hline 1812253 & 62744 & 4.8834 & 532 & \\
\hline AEMBL1812246 & 52744 & 4.8945 & 124 & \\
\hline AEMBL1812272 & 62744 & 245 & 1991 & \\
\hline AEMBL1812243 & 62744 & .9439 & 9569 & \\
\hline AEMBL1812231 & 62744 & 326 & 5316 & \\
\hline AEMBL1812259 & 62744 & & 5962 & \\
\hline AEMBL1812258 & 62744 & & 5956 & \\
\hline AEMBL1812394 & 62744 & 136 & 1743 & \\
\hline AEMBL1812255 & 62744 & & 578 & RI \\
\hline L1812235 & 44 & 2 & 53 & \\
\hline L1812248 & 52744 & & & \\
\hline L1812245 & 52744 & & & \\
\hline L1812392 & 52744 & 5. & & -2 \\
\hline 1812240 & 44 & & & RI \\
\hline 1812270 & 4 & & 56 & \\
\hline 812268 & 744 & 45 & & \\
\hline 812383 & & & & RN \\
\hline L1812252 & 14 & & & 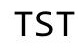 \\
\hline 1812267 & 4 & & & RN \\
\hline 812266 & 4 & 1 & & ST \\
\hline 312262 & 44 & & & $x_{-1}+2+2$ \\
\hline 12395 & 14 & & & ST \\
\hline 1812254 & & 773 & & $0_{0}+2>$ \\
\hline 1812230 & & & & \\
\hline AEMBL1812390 & 44 & & & RN \\
\hline 1812391 & 44 & 62 & 95 & 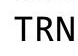 \\
\hline 12263 & 14 & & & $\mathrm{RN}$ \\
\hline 1812382 & & & & RN \\
\hline AEMBL1812260 & & & & RI \\
\hline HEMBL1812387 & 62 & 382 & & RN \\
\hline L1812251 & 14 & & 27 & RN \\
\hline L1812249 & 14 & & & ST \\
\hline AEMBL1812244 & & & & TST \\
\hline AEMBL1812229 & 627 & & 897 & $S$ \\
\hline IEMBL1812233 & 62 & 374 & 175 & si \\
\hline L1812242 & 4 & & 186 & T- \\
\hline & 14 & & & ST \\
\hline AEMBL1812271 & 762744 & & 5952 & RN \\
\hline HEMBL1812264 & 52 & 604 & 621 & $\mathrm{R}$ \\
\hline HEMBL1812237 & 762 & 355 & 551 & S \\
\hline HEMBL1812250 & 762744 & & 7275 & ST \\
\hline CHEMBL12914 & 46820 & 2.68 & 5794 & RN \\
\hline AEMBL104412 & 46820 & 3.02 & 0707 & $T R$ \\
\hline HEMBL441060 & 46820 & 2.95 & 2.9489 & $T R$ \\
\hline
\end{tabular}




\begin{tabular}{|c|c|c|c|c|c|}
\hline \multicolumn{6}{|c|}{ Supplemental Table S2.txt } \\
\hline CHEMBL309756 & 46820 & 2.38 & 2.397 & TRN & \\
\hline CHEMBL69593 & 46820 & 0.88 & 2.5673 & TST & \\
\hline CHEMBL275242 & 46820 & 3.15 & 3.1818 & TRN & \\
\hline CHEMBL81473 & 46820 & 0.04 & 0.1305 & TRN & \\
\hline CHEMBL312057 & 46820 & 1.64 & 1.5574 & TRN & \\
\hline CHEMBL78710 & 46820 & 2.82 & 2.8586 & TRN & \\
\hline CHEMBL341569 & 46820 & 1.48 & 1.3999 & TST & \\
\hline CHEMBL78994 & 46820 & 0.94 & 0.8649 & TRN & \\
\hline CHEMBL311065 & 46820 & 2.42 & 2.3996 & TRN & \\
\hline CHEMBL13078 & 46820 & 0.78 & 0.8005 & TRN & \\
\hline CHEMBL431589 & 46820 & 2.52 & 2.5093 & TRN & \\
\hline CHEMBL312259 & 46820 & 2.47 & 2.4485 & TRN & \\
\hline CHEMBL309763 & 46820 & 0.67 & 0.706 & TRN & \\
\hline CHEMBL80337 & 46820 & 1.28 & 1.1139 & TRN & \\
\hline CHEMBL13272 & 46820 & 2.8 & 2.6913 & TRN & \\
\hline CHEMBL 78701 & 46820 & 2.65 & 2.8664 & TST & \\
\hline CHEMBL310539 & 46820 & 3.17 & 3.8792 & TST & \\
\hline CHEMBL310751 & 46820 & 3.06 & 3.8106 & TST & \\
\hline CHEMBL80214 & 46820 & 0.35 & 0.2649 & TRN & \\
\hline CHEMBL302948 & 46820 & 1.61 & 1.5885 & TST & \\
\hline CHEMBL78992 & 46820 & 2.59 & 2.5551 & TRN & \\
\hline CHEMBL421497 & 46820 & 2.74 & 3.0344 & TST & \\
\hline CHEMBL311645 & 46820 & 1.47 & 1.466 & TRN & \\
\hline CHEMBL 307073 & 46820 & 1.67 & 1.7471 & TRN & \\
\hline CHEMBL311667 & 46820 & 2.04 & 2.09099 & 99999999997 & TRN \\
\hline CHEMBL67652 & 46820 & 2.59 & 3.1148 & TST & \\
\hline CHEMBL70952 & 46820 & 0.72 & 1.4293 & TST & \\
\hline CHEMBL 78763 & 46820 & 2.01 & 1.9461 & TRN & \\
\hline CHEMBL273606 & 46820 & 2.49 & 2.4714 & TRN & \\
\hline CHEMBL78627 & 46820 & 1.74 & 1.7424 & TRN & \\
\hline CHEMBL 78359 & 46820 & 0.74 & 0.8097 & TRN & \\
\hline CHEMBL 78815 & 46820 & 1.94 & 1.9155 & TRN & \\
\hline CHEMBL310538 & 46820 & 3.08 & 3.1612 & TST & \\
\hline CHEMBL 78550 & 46820 & 2.69 & 3.2566 & TST & \\
\hline CHEMBL 78752 & 46820 & 2.38 & 2.4029 & TRN & \\
\hline CHEMBL80938 & 46820 & 2.34 & 2.4126 & TRN & \\
\hline CHEMBL107136 & 46820 & 1.75 & 1.7489 & TRN & \\
\hline CHEMBL77445 & 46820 & 2.35 & 2.3868 & TRN & \\
\hline CHEMBL80984 & 46820 & 2.48 & 2.49300 & 20000000003 & TRN \\
\hline CHEMBL 78713 & 46820 & 0.9 & 0.8764 & TRN & \\
\hline CHEMBL80311 & 46820 & 3.37 & 3.3941 & TRN & \\
\hline CHEMBL 78995 & 46820 & 2.04 & 2.0388 & TRN & \\
\hline CHEMBL78375 & 46820 & 1.15 & 1.1415 & TRN & \\
\hline CHEMBL82361 & 46820 & 0.44 & 0.5029 & TRN & \\
\hline CHEMBL311328 & 46820 & 2.17 & 2.1798 & TRN & \\
\hline CHEMBL79204 & 46820 & 1.67 & 1.7429 & TRN & \\
\hline CHEMBL 78415 & 46820 & 0.9 & 0.8963 & TRN & \\
\hline CHEMBL 78940 & 46820 & 0.9 & 0.975 & TRN & \\
\hline
\end{tabular}




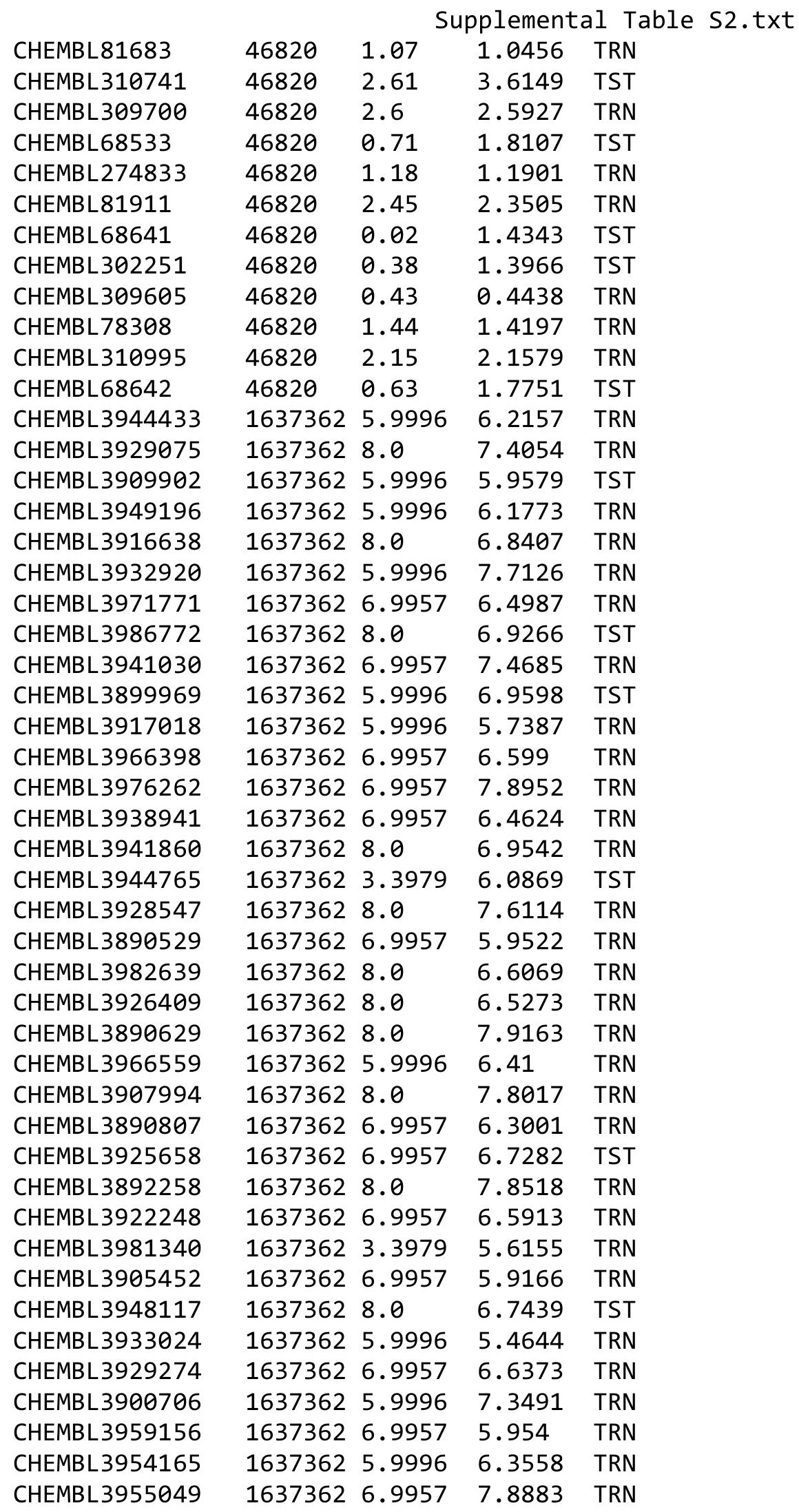

Page 8436 
Supplemental Table S2.txt

\begin{tabular}{|c|c|c|c|c|c|}
\hline CHEMBL3904336 & 1637362 & 6.9957 & 7.2105 & TRN & \\
\hline CHEMBL3902050 & 1637362 & 5.9996 & 7.3333 & TRN & \\
\hline CHEMBL3980202 & 1637362 & 6.9957 & 6.4973 & TRN & \\
\hline CHEMBL 3897425 & 1637362 & 5.9996 & 6.8419 & TRN & \\
\hline CHEMBL3941426 & 1637362 & 6.9957 & 7.2582 & TRN & \\
\hline CHEMBL3908544 & 1637362 & 5.9996 & 6.2823 & TRN & \\
\hline CHEMBL3900181 & 1637362 & 5.9996 & \multicolumn{2}{|c|}{5.9270000000000005} & TRN \\
\hline CHEMBL3980870 & 1637362 & 6.9957 & 6.5467 & TRN & \\
\hline CHEMBL3956214 & 1637362 & 5.9996 & 6.0214 & TRN & \\
\hline CHEMBL3896220 & 1637362 & 8.0 & 6.4301 & TST & \\
\hline CHEMBL3926226 & 1637362 & 5.9996 & 5.9261 & TST & \\
\hline CHEMBL3985432 & 1637362 & 6.9957 & 7.0725 & TST & \\
\hline CHEMBL3914826 & 1637362 & 5.9996 & 6.6261 & TRN & \\
\hline CHEMBL3909355 & 1637362 & 6.9957 & 6.4158 & TRN & \\
\hline CHEMBL 3891414 & 1637362 & 6.9957 & 6.7105 & TRN & \\
\hline CHEMBL3962230 & 1637362 & 6.9957 & 7.0083 & TRN & \\
\hline CHEMBL3928473 & 1637362 & 6.9957 & 6.5961 & TRN & \\
\hline CHEMBL 3922882 & 1637362 & 6.9957 & 6.3726 & TRN & \\
\hline CHEMBL3923543 & 1637362 & 8.0 & 7.0433 & TRN & \\
\hline CHEMBL3896659 & 1637362 & 8.0 & 7.5047 & TRN & \\
\hline CHEMBL3963134 & 1637362 & 6.9957 & 7.0089 & TRN & \\
\hline CHEMBL3914876 & 1637362 & 5.9996 & 6.2705 & TRN & \\
\hline CHEMBL3951524 & 1637362 & 4.0 & 6.2427 & TST & \\
\hline CHEMBL3957350 & 1637362 & 6.9957 & 6.7633 & TST & \\
\hline CHEMBL3912237 & 1637362 & 6.9957 & 6.7477 & TRN & \\
\hline CHEMBL3914380 & 1637362 & 5.9996 & 6.8608 & TST & \\
\hline CHEMBL1620574 & 1637362 & 5.0 & 6.2296 & TRN & \\
\hline CHEMBL3934870 & 1637362 & 5.0 & 6.1435 & TST & \\
\hline CHEMBL3918269 & 1637362 & 6.9957 & 6.7865 & TST & \\
\hline CHEMBL3917718 & 1637362 & 6.9957 & 6.562 & TRN & \\
\hline CHEMBL3955389 & 1637362 & 5.9996 & 6.8868 & TRN & \\
\hline CHEMBL3960918 & 1637362 & 6.9957 & 6.7259 & TRN & \\
\hline CHEMBL3922346 & 1637362 & 5.9996 & 6.6719 & TRN & \\
\hline CHEMBL3955305 & 1637362 & 5.9996 & 6.3025 & TST & \\
\hline CHEMBL3929701 & 1637362 & 6.9957 & 7.0473 & TRN & \\
\hline CHEMBL3970708 & 1637362 & 6.9957 & 7.28 & TRN & \\
\hline CHEMBL3898318 & 1637362 & 8.0 & 7.6591 & TRN & \\
\hline CHEMBL3961190 & 1637362 & 6.0 & 6.137006 & 00000000005 & TRN \\
\hline CHEMBL3902279 & 1637362 & 6.9957 & 5.899 & TRN & \\
\hline CHEMBL3948740 & 1637362 & 6.9957 & 7.7939 & TRN & \\
\hline CHEMBL3984791 & 1637362 & 6.9957 & 6.6627 & TST & \\
\hline CHEMBL 3898653 & 1637362 & 8.0 & 7.8368 & TRN & \\
\hline CHEMBL3970543 & 1637362 & 8.0 & 7.17399 & & TRN \\
\hline CHEMBL3957735 & 1637362 & 5.9996 & 5.715 & TST & \\
\hline CHEMBL3935257 & 1637362 & 5.9996 & 6.7956 & TST & \\
\hline CHEMBL3912130 & 1637362 & 5.0 & 6.4063 & TRN & \\
\hline CHEMBL3986666 & 1637362 & 8.0 & 7.2501 & TRN & \\
\hline CHEMBL3927355 & 1637362 & 8.0 & 8.0033 & TRN & \\
\hline
\end{tabular}


Supplemental Table S2.txt

\begin{tabular}{|c|c|c|c|c|c|}
\hline CHEMBL3971820 & 1637362 & 3.3979 & 6.4264 & TST & \\
\hline CHEMBL3948348 & 1637362 & 5.0 & 6.9693 & TST & \\
\hline CHEMBL3907356 & 1637362 & 8.0 & \multicolumn{2}{|c|}{7.321000000000001} & TRN \\
\hline CHEMBL 3936288 & 1637362 & 8.0 & 7.1328 & TRN & \\
\hline CHEMBL3961207 & 1637362 & 5.9996 & 6.1978 & TRN & \\
\hline CHEMBL3909606 & 1637362 & 6.9957 & 6.4957 & TRN & \\
\hline CHEMBL 3957726 & 1637362 & 6.9957 & 7.5967 & TST & \\
\hline CHEMBL3921911 & 1637362 & 5.9996 & 7.1129 & TST & \\
\hline CHEMBL 3950751 & 1637362 & 5.9996 & 5.9832 & TRN & \\
\hline CHEMBL3969694 & 1637362 & 5.9996 & 6.4107 & TST & \\
\hline CHEMBL 3895648 & 1637362 & 8.0 & 7.3499 & TRN & \\
\hline CHEMBL3946358 & 1637362 & 3.3979 & 5.8564 & TST & \\
\hline CHEMBL 3890510 & 1637362 & 6.0 & 6.6915 & TRN & \\
\hline CHEMBL 3927772 & 1637362 & 5.9996 & 7.0493 & TST & \\
\hline CHEMBL3894627 & 1637362 & 5.9996 & 7.0436 & TRN & \\
\hline CHEMBL3893221 & 1637362 & 6.9957 & 7.1617 & TRN & \\
\hline CHEMBL3913886 & 1637362 & 5.9996 & 6.1098 & TRN & \\
\hline CHEMBL3924519 & 1637362 & 6.9957 & 6.9729 & TRN & \\
\hline CHEMBL3925913 & 1637362 & 5.9996 & 6.0734 & TST & \\
\hline CHEMBL3899907 & 1637362 & 8.0 & 7.3399 & TRN & \\
\hline CHEMBL3917463 & 1637362 & 8.0 & 7.9443 & TRN & \\
\hline CHEMBL 3983260 & 1637362 & 5.9996 & 7.0259 & TRN & \\
\hline CHEMBL 3924231 & 1637362 & 8.0 & 7.3523 & TRN & \\
\hline CHEMBL3917923 & 1637362 & 6.9957 & 7.3003 & TRN & \\
\hline CHEMBL3890412 & 1637362 & 5.9996 & 6.7383 & TRN & \\
\hline CHEMBL3908186 & 1637362 & 6.9957 & 6.5823 & TST & \\
\hline CHEMBL3920188 & 1637362 & 8.0 & 8.1062 & TRN & \\
\hline CHEMBL 3896778 & 1637362 & 6.9957 & 6.9397 & TRN & \\
\hline CHEMBL3901267 & 1637362 & 6.9957 & 6.6049 & TRN & \\
\hline CHEMBL3907157 & 1637362 & 6.9957 & 6.9761 & TRN & \\
\hline CHEMBL3933554 & 1637362 & 8.0 & 7.5809 & TRN & \\
\hline CHEMBL3972261 & 1637362 & 5.0 & 6.9492 & TRN & \\
\hline CHEMBL 3975063 & 1637362 & 8.0 & 6.7057 & TST & \\
\hline CHEMBL3926915 & 1637362 & 5.9996 & 6.8186 & TST & \\
\hline CHEMBL3892142 & 1637362 & 5.9996 & 7.1548 & TRN & \\
\hline CHEMBL3933483 & 1637362 & 6.9957 & 6.1242 & TRN & \\
\hline CHEMBL3952410 & 1637362 & 6.0 & 6.9889 & TRN & \\
\hline CHEMBL3986002 & 1637362 & 8.0 & 7.3269 & TRN & \\
\hline CHEMBL 3945227 & 1637362 & 6.9957 & 6.8713 & TRN & \\
\hline CHEMBL3894360 & 1637362 & 5.9996 & 6.1116 & TRN & \\
\hline CHEMBL3973363 & 1637362 & 6.9957 & 6.8671 & TRN & \\
\hline CHEMBL3981847 & 1637362 & 6.9957 & 6.8255 & TST & \\
\hline CHEMBL3985688 & 1637362 & 8.0 & 7.6499 & TRN & \\
\hline CHEMBL 3962444 & 1637362 & 8.0 & 7.7629 & TRN & \\
\hline CHEMBL3933805 & 1637362 & 5.9996 & 6.169 & TST & \\
\hline CHEMBL3984281 & 1637362 & 8.0 & 6.8935 & TRN & \\
\hline CHEMBL3941649 & 1637362 & 6.9957 & 6.4469 & TRN & \\
\hline CHEMBL3967274 & 1637362 & 6.9957 & 6.6126 & TST & \\
\hline
\end{tabular}


Supplemental Table S2.txt

\begin{tabular}{|c|c|c|c|c|}
\hline HEMBL & 637362 & 6.9957 & 6.9305 & \\
\hline HEMBL3946966 & 637362 & 6.9957 & 6.1914 & \\
\hline HEMBL3920442 & 37362 & 9957 & 165 & \\
\hline HEMBL 3891724 & 537362 & 8.0 & 4885 & \\
\hline HEMBL3916686 & 637362 & 5.9996 & 4535 & \\
\hline HEMBL 3898324 & 637362 & 5.9996 & .9738 & \\
\hline HEMBL3924960 & 637362 & 8.0 & .9836 & \\
\hline HEMBL 3966491 & 362 & & 8421 & \\
\hline HEMBL 3960747 & 362 & 5.9996 & 5.4553 & \\
\hline HEMBL3924745 & 637362 & 5.9996 & .4125 & \\
\hline HEMBL3910579 & 637362 & 6.9957 & .8283 & \\
\hline HEMBL3952930 & 637362 & 8.0 & 7.2348 & \\
\hline HEMBL393 & & 996 & 7.0137 & \\
\hline HEMBL 392 & 62 & 957 & 7.0961 & \\
\hline HEMBL3960415 & 362 & 957 & 7.2101 & \\
\hline HEMBL 3956748 & 362 & 8.0 & 6.4708 & \\
\hline HEMBL3891246 & 02 & 5.9996 & 509 & \\
\hline HEMBL3890752 & & & & \\
\hline HEMBL3922931 & 362 & 8. & 5454 & \\
\hline HEMBL3960602 & 62 & 8. & 289 & \\
\hline HEMBL3944192 & 22 & 979 & 6.0252 & \\
\hline HEMBL396 & 2 & 957 & 7.2653 & \\
\hline HEMBL 393 & & 996 & 481 & \\
\hline HEMBL3890922 & & 957 & 7.5391 & \\
\hline HEMBL 3940292 & 63 & 8 & 7.5622 & \\
\hline HEMBL3973446 & 62 & 4 & 5.7422 & \\
\hline HEMBL3911311 & 63 & 5. & 499 & \\
\hline HEMBL 398 & 52 & 6 . & 39 & \\
\hline HEMBL394 & 52 & 8.0 & 6.7021 & \\
\hline HEMBL3905635 & 63 & 957 & 6.9452 & \\
\hline HEMBL1619901 & 63 & 996 & 9716 & \\
\hline HEMBL 394 & 2 & 96 & 146 & \\
\hline HEMBL392 & 52 & 5. & 2798 & \\
\hline HEMBL3986339 & 63 & 6.9957 & 6.9828 & \\
\hline HEMBL3915701 & 637 & 6.9957 & 6.7289 & \\
\hline HEMBL3965210 & 163 & 8 & 7.8677 & \\
\hline HEMBL39 & 16 & 57 & 5466 & \\
\hline HEMBL393 & 163 & 996 & 6.5452 & \\
\hline HEMBL3891993 & 1637362 & 5.9996 & 6.3155 & \\
\hline HEMBL3950937 & 1637 & 5.9996 & 6.1901 & \\
\hline CHEMBL3891681 & 1637 & 8. & 6.8289 & \\
\hline CHEMBL3916551 & & 6.5 & 7.1035 & \\
\hline HEMBL3963906 & 1637362 & 6.9957 & 6.1108 & \\
\hline CHEMBL3930175 & 1637362 & 5.9996 & 7.015 & \\
\hline HEMBL391 & 1637 & 5.9996 & 6.8502 & \\
\hline CHEMBL3982974 & 1637 & 5.9996 & 6.3048 & \\
\hline CHEMBL3964063 & 16373 & 5.9996 & 6.3404 & \\
\hline CHEMBL3978769 & 1637362 & 8.0 & 7.1474 & \\
\hline
\end{tabular}

Page 8439 


\begin{tabular}{|c|c|c|c|c|c|}
\hline \multicolumn{6}{|c|}{ Supplemental Table S2.txt } \\
\hline CHEMBL 3954820 & 1637362 & 8.0 & 6.8428 & TST & \\
\hline CHEMBL 3935523 & 1637362 & 3.3979 & 6.1568 & TST & \\
\hline CHEMBL 3946950 & 1637362 & 6.9957 & 6.0879 & TRN & \\
\hline CHEMBL 3944543 & 1637362 & 6.9957 & 6.5403 & TST & \\
\hline CHEMBL3919395 & 1637362 & 8.0 & 7.9942 & TRN & \\
\hline CHEMBL 3983821 & 1637362 & 6.9957 & 6.9205 & TRN & \\
\hline CHEMBL 3941254 & 1637362 & 5.9996 & 6.2706 & TRN & \\
\hline CHEMBL 3951357 & 1637362 & 5.9996 & 7.4004 & TRN & \\
\hline CHEMBL 3920305 & 1637362 & 8.0 & 7.4858 & TST & \\
\hline CHEMBL3940342 & 1637362 & 6.9957 & 6.6011 & TRN & \\
\hline CHEMBL 3963298 & 1637362 & 8.0 & 7.8445 & TRN & \\
\hline CHEMBL 3899100 & 1637362 & 8.0 & 7.0557 & TRN & \\
\hline CHEMBL3979843 & 1637362 & 6.9957 & 6.8952 & TRN & \\
\hline CHEMBL 3962174 & 1637362 & 8.0 & 6.8648 & TRN & \\
\hline CHEMBL3983062 & 1637362 & 6.9957 & 6.0982 & TRN & \\
\hline CHEMBL 3928672 & 1637362 & 8.0 & 7.2451 & TRN & \\
\hline CHEMBL3966230 & 1637362 & 5.9996 & 6.3563 & TRN & \\
\hline CHEMBL3969042 & 1637362 & 5.0 & 6.3208 & TST & \\
\hline CHEMBL 3900173 & 1637362 & 6.9957 & 6.9147 & TRN & \\
\hline CHEMBL3965164 & 1637362 & 8.0 & 7.3079 & TRN & \\
\hline CHEMBL3926039 & 1637362 & 6.9957 & 5.6107 & TRN & \\
\hline CHEMBL 3979584 & 1637362 & 5.9996 & 6.4849 & TRN & \\
\hline CHEMBL3977569 & 1637362 & 8.0 & 7.306 & TRN & \\
\hline CHEMBL 3944553 & 1637362 & 4.0 & 6.9067 & TRN & \\
\hline CHEMBL 3956160 & 1637362 & 6.9957 & 7.0854 & TRN & \\
\hline CHEMBL 3895025 & 1637362 & 6.9957 & 5.5573 & TRN & \\
\hline CHEMBL3919568 & 1637362 & 5.9996 & 6.7995 & TRN & \\
\hline CHEMBL3946437 & 1637362 & 6.9957 & 6.0607 & TST & \\
\hline CHEMBL 3969083 & 1637362 & 6.9957 & 6.5266 & TRN & \\
\hline CHEMBL 3957514 & 1637362 & 6.9957 & 6.8049 & TRN & \\
\hline CHEMBL 3905390 & 1637362 & 8.0 & 7.4912 & TST & \\
\hline CHEMBL 3891869 & 1637362 & 3.3979 & 6.1986 & TST & \\
\hline CHEMBL3908885 & 1637362 & 5.9996 & 6.8462 & TRN & \\
\hline CHEMBL 3959743 & 1637362 & 6.9957 & 6.2309 & TRN & \\
\hline CHEMBL3968729 & 1637362 & 6.9957 & 6.3238 & TRN & \\
\hline CHEMBL 3950225 & 1637362 & 8.0 & 7.0452 & TST & \\
\hline CHEMBL3970011 & 1637362 & 8.0 & 8.11399 & 9999999999 & TRN \\
\hline CHEMBL3932894 & 1637362 & 5.0 & 7.1837 & TRN & \\
\hline CHEMBL 3905430 & 1637362 & 6.9957 & 6.5562 & TRN & \\
\hline CHEMBL3949952 & 1637362 & 6.9957 & 6.9929 & TRN & \\
\hline CHEMBL 3892082 & 1637362 & 6.9957 & 6.7355 & TST & \\
\hline CHEMBL3982230 & 1637362 & 6.9957 & 6.5805 & TRN & \\
\hline CHEMBL3954212 & 1637362 & 5.9996 & 6.2651 & TRN & \\
\hline CHEMBL3902680 & 1637362 & 8.0 & 7.5354 & TRN & \\
\hline CHEMBL3950711 & 1637362 & 3.3979 & 5.4283 & TRN & \\
\hline CHEMBL 3962471 & 1637362 & 6.9957 & 6.2181 & TRN & \\
\hline CHEMBL3929897 & 1637362 & 5.9996 & 5.9901 & TST & \\
\hline CHEMBL3940321 & 1637362 & 6.9957 & 6.4173 & TRN & \\
\hline
\end{tabular}


Supplemental Table S2.txt

\begin{tabular}{|c|c|c|c|c|}
\hline 78 & 362 & 957 & 19 & \\
\hline HEMBL3918772 & 637362 & 6.9957 & 7.2282 & \\
\hline HEMBL3961135 & 37362 & 996 & 452 & \\
\hline HEMBL3945187 & 637362 & 5.9996 & 9002 & \\
\hline HEMBL3963844 & 637362 & 6.9957 & .6944 & \\
\hline HEMBL3889494 & 637362 & 6.9957 & 7.5025 & \\
\hline HEMBL3916066 & 637362 & 6.9957 & .0729 & \\
\hline HEMBL3896169 & 637362 & 6.9957 & .1808 & \\
\hline HEMBL3927867 & 1637362 & 5.0 & 6.4991 & \\
\hline HEMBL3926597 & 637362 & 6.9957 & 7.7396 & \\
\hline HEMBL3940313 & 362 & 5.9996 & 5.4217 & \\
\hline HEMBL3915327 & 362 & 6.9957 & .9317 & \\
\hline HEMBL 390 & 362 & & 7.7382 & \\
\hline HEMBL3954888 & 1637362 & 6.99 & 6.4632 & \\
\hline HEMBL3890421 & 637362 & 6.0 & .3586 & \\
\hline HEMBL395 & 63 & 6 . & 6.3616 & \\
\hline IEMBL392 & 62 & 6 . & 324 & \\
\hline HEMBL 395 & 62 & 996 & 689 & \\
\hline HEMBL 393 & 362 & 8.0 & 7.9114 & \\
\hline HEMBL396 & 52 & 996 & 6.7375 & \\
\hline HEMBL39 & $6=$ & 6 . & 6.4679 & \\
\hline HEMBL39 & 62 & & 915 & \\
\hline HEMBL398 & 62 & & 946 & \\
\hline HEMBL390 & 362 & 5.9996 & 6.8654 & \\
\hline HEMBL 390 & & 5.9996 & 6.5832 & \\
\hline HEMBL 392 & 163 & 8 & 7.6703 & \\
\hline HEMBL 38 & 2 & 5. & 59 & \\
\hline HEMBL391 & 62 & 5 . & 342 & \\
\hline HEMBL3909796 & 637362 & 8.0 & 7.8454 & \\
\hline HEMBL3950383 & 63 & 3.3979 & 6.0934 & \\
\hline HEMBL 396 & 63 & 5 & 6.2435 & \\
\hline HEMBL16 & 2 & 5 . & & \\
\hline HEMBL 397 & & 5 . & 769 & \\
\hline HEMBL3958159 & 1637362 & 8.0 & 7.0213 & \\
\hline HEMBL3907657 & 637362 & 5.9996 & 5.8153 & \\
\hline HEMBL390 & 63 & 5.9996 & 5.8008 & \\
\hline CHEMBL 38 & 2 & 6 . & 26 & \\
\hline HEMBL 397 & 1637 & 6. & 6.7964 & \\
\hline HEMBL3928770 & 1637362 & 6.9957 & 6.8551 & \\
\hline HEMBL 394 & 637362 & 5.9996 & 6.6655 & \\
\hline HEMBL390 & 1637362 & 8 . & 7.1942 & \\
\hline CHEMBL3928965 & 1637362 & 8.0 & 7.777 & \\
\hline CHEMBL3916630 & 1637362 & 5.9996 & 6.5166 & \\
\hline CHEMBL3902727 & 1637362 & 6.9957 & 6.8592 & \\
\hline CHEMBL 389 & 1637 & 8. & 7.6822 & \\
\hline CHEMBL3922397 & 1637362 & - & 6.9968 & \\
\hline CHEMBL3941290 & 1637362 & 6.9957 & 6.9321 & \\
\hline CHEMBL3906553 & 1637362 & 8.0 & 7.6827 & \\
\hline
\end{tabular}

Page 8441 


\begin{tabular}{|c|c|c|c|c|c|}
\hline \multicolumn{6}{|c|}{ Supplemental Table s2.txt } \\
\hline CHEMBL3955392 & 1637362 & 8.0 & 7.5069 & TRN & \\
\hline CHEMBL 3980355 & 1637362 & 5.9996 & 5.9209 & TST & \\
\hline CHEMBL 3891026 & 1637362 & 6.9957 & 6.3615 & TRN & \\
\hline CHEMBL 3904388 & 1637362 & 8.0 & 6.9651 & TRN & \\
\hline CHEMBL 3973800 & 1637362 & 6.9957 & 7.8899 & TRN & \\
\hline CHEMBL3942155 & 1637362 & 5.0 & 6.6563 & TST & \\
\hline CHEMBL 3938821 & 1637362 & 6.9957 & 6.3064 & TST & \\
\hline CHEMBL 3974877 & 1637362 & 6.9957 & 6.4667 & TRN & \\
\hline CHEMBL 3919385 & 1637362 & 5.9996 & 6.5671 & TRN & \\
\hline CHEMBL3893239 & 1637362 & 6.9957 & 5.3618 & TRN & \\
\hline CHEMBL 3947825 & 1637362 & 5.9996 & 5.8403 & TST & \\
\hline CHEMBL 3951648 & 1637362 & 5.9996 & 6.4183 & TST & \\
\hline CHEMBL3904606 & 1637362 & 5.9996 & 7.3877 & TST & \\
\hline CHEMBL3947909 & 1637362 & 6.9957 & 6.9264 & TRN & \\
\hline CHEMBL 3987017 & 1637362 & 8.0 & 7.3611 & TRN & \\
\hline CHEMBL3895763 & 1637362 & 8.0 & 7.8923 & TRN & \\
\hline CHEMBL3973033 & 1637362 & 4.0 & 7.2167 & TRN & \\
\hline CHEMBL3917767 & 1637362 & 5.0 & 6.2877 & TST & \\
\hline CHEMBL 3956921 & 1637362 & 3.3979 & 6.1187 & TST & \\
\hline CHEMBL3920992 & 1637362 & 6.9957 & 6.4599 & TST & \\
\hline CHEMBL3966337 & 1637362 & 5.9996 & 6.1993 & TRN & \\
\hline CHEMBL 3960428 & 1637362 & 5.9996 & 6.3032 & TRN & \\
\hline CHEMBL3982868 & 1637362 & 3.3979 & 5.9384 & TRN & \\
\hline CHEMBL 3912492 & 1637362 & 6.9957 & 6.4804 & TRN & \\
\hline CHEMBL3952615 & 1637362 & 6.9957 & 6.6427 & TRN & \\
\hline CHEMBL3937746 & 1637362 & 5.9996 & 6.5449 & TRN & \\
\hline CHEMBL 3916222 & 1637362 & 8.0 & 7.1932 & TST & \\
\hline CHEMBL3964927 & 1637362 & 3.301 & 6.8349 & TRN & \\
\hline CHEMBL 3940728 & 1637362 & 6.9957 & 7.0752 & TST & \\
\hline CHEMBL3910325 & 1637362 & 6.9957 & 7.4577 & TRN & \\
\hline CHEMBL3904147 & 1637362 & 8.0 & 7.1697 & TRN & \\
\hline CHEMBL3903577 & 1637362 & 5.9996 & 6.0484 & TST & \\
\hline CHEMBL3898153 & 1637362 & 8.0 & 6.4563 & TRN & \\
\hline CHEMBL3906136 & 1637362 & 5.9996 & 5.9833 & TRN & \\
\hline CHEMBL3953561 & 1637362 & 8.0 & 7.5796 & TRN & \\
\hline CHEMBL3918386 & 1637362 & 6.9957 & 7.2221 & TRN & \\
\hline CHEMBL3954646 & 1637362 & 5.9996 & 6.1695 & TST & \\
\hline CHEMBL3898456 & 1637362 & 8.0 & 6.9066 & TRN & \\
\hline CHEMBL3986033 & 1637362 & 8.0 & 7.3042 & TRN & \\
\hline CHEMBL3977556 & 1637362 & 5.0 & 6.1646 & TRN & \\
\hline CHEMBL3906316 & 1637362 & 6.9957 & 6.2267 & TRN & \\
\hline CHEMBL 3977275 & 1637362 & 6.9957 & 6.04299 & 9999999999 & TRN \\
\hline CHEMBL3917581 & 1637362 & 8.0 & 7.3493 & TRN & \\
\hline CHEMBL 3937654 & 1637362 & 8.0 & 8.0339 & TRN & \\
\hline CHEMBL3979777 & 1637362 & 8.0 & 7.5253 & TRN & \\
\hline CHEMBL3951746 & 1637362 & 5.0 & 6.6248 & TST & \\
\hline CHEMBL 3937999 & 1637362 & 6.9957 & 7.2564 & TST & \\
\hline CHEMBL3968945 & 1637362 & 3.3979 & 6.1048 & TRN & \\
\hline
\end{tabular}


Supplemental Table S2.txt

\begin{tabular}{|c|c|c|c|c|c|}
\hline CHEMBL3899421 & 1637362 & 5.9996 & 5.7848 & TST & \\
\hline CHEMBL3889999 & 1637362 & 6.9957 & 5.9285 & TRN & \\
\hline CHEMBL3983333 & 1637362 & 5.0 & 6.0537 & TST & \\
\hline CHEMBL3972835 & 1637362 & 5.9996 & 6.5744 & TRN & \\
\hline CHEMBL3981786 & 1637362 & 6.9957 & \multicolumn{2}{|c|}{6.127999999999999} & TRN \\
\hline CHEMBL3965311 & 1637362 & 6.9957 & 7.5656 & TRN & \\
\hline CHEMBL3938549 & 1637362 & 6.9957 & 6.1656 & TRN & \\
\hline CHEMBL3981337 & 1637362 & 5.9996 & 6.6544 & TRN & \\
\hline CHEMBL 3974293 & 1637362 & 5.9996 & 6.3617 & TST & \\
\hline CHEMBL3979855 & 1637362 & 6.9957 & 6.1035 & TRN & \\
\hline CHEMBL3966974 & 1637362 & 8.0 & 8.0341 & TRN & \\
\hline CHEMBL3927193 & 1637362 & 5.9996 & 6.5581 & TRN & \\
\hline CHEMBL3926304 & 1637362 & 6.9957 & 6.3916 & TRN & \\
\hline CHEMBL3921974 & 1637362 & 5.9996 & 5.8951 & TST & \\
\hline CHEMBL3910851 & 1637362 & 8.0 & 7.7938 & TRN & \\
\hline CHEMBL3975798 & 1637362 & 6.9957 & 6.9206 & TRN & \\
\hline CHEMBL3890459 & 1637362 & 8.0 & 7.5104 & TRN & \\
\hline CHEMBL3905876 & 1637362 & 6.9957 & 6.2857 & TST & \\
\hline CHEMBL3945461 & 1637362 & 5.9996 & 5.9349 & TST & \\
\hline CHEMBL3898507 & 1637362 & 6.9957 & 6.5486 & TRN & \\
\hline CHEMBL3979171 & 1637362 & 8.0 & 7.4312 & TST & \\
\hline CHEMBL3897321 & 1637362 & 5.9996 & 7.1406 & TRN & \\
\hline CHEMBL3919749 & 1637362 & 5.0 & 6.6252 & TRN & \\
\hline CHEMBL 3894153 & 1637362 & 5.9996 & 5.9495 & TST & \\
\hline CHEMBL3910795 & 1637362 & 8.0 & 6.9345 & TST & \\
\hline CHEMBL3899089 & 1637362 & 5.9996 & 5.70799 & 9999999999 & TRN \\
\hline CHEMBL3890473 & 1637362 & 5.9996 & 5.928 & TRN & \\
\hline CHEMBL3958390 & 1637362 & 6.9957 & 6.8434 & TRN & \\
\hline CHEMBL3955889 & 1637362 & 5.9996 & 6.0186 & TRN & \\
\hline CHEMBL3913480 & 1637362 & 6.9957 & 6.1349 & TRN & \\
\hline CHEMBL3964758 & 1637362 & 5.9996 & 5.943 & TST & \\
\hline CHEMBL3898925 & 1637362 & 5.9996 & 6.6102 & TRN & \\
\hline CHEMBL 3975684 & 1637362 & 3.3979 & 6.0118 & TRN & \\
\hline CHEMBL3955377 & 1637362 & 5.9996 & 5.7952 & TST & \\
\hline CHEMBL3955096 & 1637362 & 6.9957 & 8.1924 & TRN & \\
\hline CHEMBL3975207 & 1637362 & 5.9996 & 6.8765 & TST & \\
\hline CHEMBL3889794 & 1637362 & 5.9996 & 6.3475 & TRN & \\
\hline CHEMBL3957932 & 1637362 & 6.9957 & 6.5752 & TST & \\
\hline CHEMBL3891222 & 1637362 & 8.0 & 7.5231 & TRN & \\
\hline CHEMBL3919157 & 1637362 & 6.9957 & 6.6123 & TRN & \\
\hline CHEMBL3923632 & 1637362 & 8.0 & 7.3413 & TRN & \\
\hline CHEMBL3908535 & 1637362 & 5.9996 & 6.099 & TRN & \\
\hline CHEMBL3890195 & 1637362 & 5.9996 & 7.3435 & TST & \\
\hline CHEMBL3893985 & 1637362 & 8.0 & 7.1976 & TRN & \\
\hline CHEMBL3916202 & 1637362 & 8.0 & 6.6259 & TRN & \\
\hline CHEMBL3910540 & 1637362 & 6.9957 & 7.4128 & TRN & \\
\hline CHEMBL3910913 & 1637362 & 6.9957 & 6.8089 & TRN & \\
\hline CHEMBL3937566 & 1637362 & 6.9957 & 7.1288 & TRN & \\
\hline
\end{tabular}


Supplemental Table S2.txt

\begin{tabular}{|c|c|c|c|c|}
\hline 495 & 537362 & 996 & 2899 & בו \\
\hline & 637362 & 4.0 & 6.7004 & \\
\hline HFMRI & 362 & 5.9996 & 094 & \\
\hline HEMBL3904961 & 37362 & 57 & & \\
\hline HEMBL3973095 & 637362 & 6.9957 & 5932 & \\
\hline HEMBL392 & 637362 & 6.9957 & 938 & \\
\hline 96539 & 362 & 8.0 & 8712 & \\
\hline AEMBL3919817 & 362 & 3 & 5067 & \\
\hline HEMBL3948289 & 637362 & 8.0 & 9756 & \\
\hline HEMBL3947169 & 637362 & 6.9957 & .6927 & \\
\hline HEMBL3935690 & 362 & 8.0 & 2361 & \\
\hline AEMBL & 62 & 996 & 4178 & \\
\hline HEMBL & & 8. & 1146 & \\
\hline HEMBL3975590 & 637362 & 6.95 & 6132 & \\
\hline HEMBL3962652 & 362 & 6.6 & 5435 & \\
\hline HEMBL3 & 63 & 6. & 7447 & \\
\hline HEMBL3 & 62 & & 572 & r \\
\hline HEMBL3 & 62 & 5. & 091 & \\
\hline HEMBL3 & 62 & & 6719 & \\
\hline HEMBL390 & & 957 & 5821 & RIN \\
\hline HEMBL & 63 & & 738 & ГRN \\
\hline AEM & & & 169 & ונס \\
\hline HEMBL & 52 & 979 & 5196 & \\
\hline HEMBL3 & & 957 & 5673 & IST \\
\hline HEMBL389 & & 996 & 5481 & IRN \\
\hline HEMBL3 & & 957 & 925 & RN \\
\hline HEM & & 957 & 25 & RN \\
\hline HEM & 62 & 8 . & 2879 & RN \\
\hline HEMBL3 & & & 213 & IRN \\
\hline HEMBL3968691 & 63 & 6. & 3662 & TST \\
\hline AEMBL3 & & & 943 & IST \\
\hline HFM & & & 944 & 「RN \\
\hline - & & 3 . & 1707 & 「RN \\
\hline HEMBL 3943 & & & 392 & ГST \\
\hline HEMBL3984769 & 62 & 8 & 5361 & ГRN \\
\hline 3 & & & 745 & TRN \\
\hline 9 & & 5. & 426 & ГRN \\
\hline HEMBL 394 & & 8.0 & 7.5071 & TRN \\
\hline HEMBL 396 & & 5.999 & 7666 & $\Gamma R$ \\
\hline EMBL & & 8 & 2404 & RN \\
\hline HEMBL3 & & 37 & 745 & ГST \\
\hline HEMBL3 & & 6.9957 & 6742 & TRN \\
\hline HEMBL398 & & 6.9957 & 3308 & TRN \\
\hline HEMBL3 & 52 & 996 & 754 & TS \\
\hline CHEMBL39738 & & & & \\
\hline HEMBL3901941 & & 5.9996 & 7.0368 & \\
\hline CHEMBL3911947 & 1637 & 8.0 & 7.6445 & IST \\
\hline CHEMBL3913682 & 1637362 & 6.0 & 6.3972 & 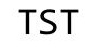 \\
\hline
\end{tabular}

Page 8444 
Supplemental Table S2.txt

\begin{tabular}{|c|c|c|c|c|}
\hline CHEMBL 3893397 & 1637362 & 6.9957 & 7.0299 & TRN \\
\hline CHEMBL 3921352 & 1637362 & 6.9957 & 7.4355 & TRN \\
\hline CHEMBL3987146 & 1637362 & 8.0 & 7.2954 & TRN \\
\hline CHEMBL 3902252 & 1637362 & 6.9957 & 6.7031 & TRN \\
\hline CHEMBL3976295 & 1637362 & 8.0 & 7.9695 & TRN \\
\hline CHEMBL3895263 & 1637362 & 6.0 & 6.529 & TST \\
\hline CHEMBL 3893934 & 1637362 & 8.0 & 7.5441 & TRN \\
\hline CHEMBL 3973890 & 1637362 & 5.9996 & 6.2597 & TRN \\
\hline CHEMBL3959839 & 1637362 & 6.9957 & 6.686 & TRN \\
\hline CHEMBL3950985 & 1637362 & 5.0 & 6.49 & TST \\
\hline CHEMBL3941509 & 1637362 & 6.9957 & 7.1059 & TRN \\
\hline CHEMBL 3922031 & 1637362 & 3.3979 & 5.5333 & TRN \\
\hline CHEMBL 3973489 & 1637362 & 8.0 & 7.2364 & TRN \\
\hline CHEMBL 3903812 & 1637362 & 4.0 & 6.9231 & TRN \\
\hline CHEMBL 3891293 & 1637362 & 5.9996 & 6.7326 & TST \\
\hline CHEMBL3913468 & 1637362 & 6.9957 & 6.4591 & TST \\
\hline CHEMBL3970714 & 1637362 & 5.9996 & 7.1506 & TST \\
\hline CHEMBL3919197 & 1637362 & 5.9996 & 6.7158 & TST \\
\hline CHEMBL3957114 & 1637362 & 5.9996 & 7.0458 & TRN \\
\hline CHEMBL 3982286 & 1637362 & 6.9957 & 6.5968 & TRN \\
\hline CHEMBL3897062 & 1637362 & 5.9996 & 5.8148 & TRN \\
\hline CHEMBL3914054 & 1637362 & 6.9957 & 6.4453 & TRN \\
\hline CHEMBL 3964615 & 1637362 & 6.9957 & 6.4829 & TRN \\
\hline CHEMBL3958259 & 1637362 & 6.9957 & 6.6458 & TRN \\
\hline CHEMBL 3964454 & 1637362 & 6.9957 & 6.5069 & TRN \\
\hline CHEMBL3968900 & 1637362 & 8.0 & 7.5381 & TRN \\
\hline CHEMBL3943231 & 1637362 & 6.9957 & 6.1699 & TRN \\
\hline CHEMBL 3953672 & 1637362 & 5.9996 & 6.1874 & TRN \\
\hline CHEMBL3935211 & 1637362 & 5.9996 & 5.9843 & TST \\
\hline CHEMBL 3964517 & 1637362 & 5.9996 & 6.6777 & TRN \\
\hline CHEMBL3962631 & 1637362 & 8.0 & 7.7977 & TRN \\
\hline CHEMBL 3898039 & 1637362 & 6.9957 & 6.6978 & TRN \\
\hline CHEMBL 3983508 & 1637362 & 8.0 & 7.9716 & TRN \\
\hline CHEMBL3922558 & 1637362 & 6.9957 & 6.4164 & TST \\
\hline CHEMBL 3893815 & 1637362 & 8.0 & 7.3945 & TRN \\
\hline CHEMBL1626013 & 1637362 & 5.9957 & 6.3955 & TST \\
\hline CHEMBL3938994 & 1637362 & 5.9996 & 6.3437 & TST \\
\hline CHEMBL 3979364 & 1637362 & 6.9957 & 5.949 & TRN \\
\hline CHEMBL3971809 & 1637362 & 6.9957 & 6.574 & TRN \\
\hline CHEMBL 3925073 & 1637362 & 6.9957 & 7.0455 & TRN \\
\hline CHEMBL 3952453 & 1637362 & 5.9996 & 6.2742 & TRN \\
\hline CHEMBL 3911384 & 1637362 & 5.0 & 6.7588 & TST \\
\hline CHEMBL3966708 & 1637362 & 3.301 & 6.504 & TRN \\
\hline CHEMBL3906293 & 1637362 & 3.3979 & 6.0299 & TST \\
\hline CHEMBL3966235 & 1637362 & 6.9957 & 5.9767 & TRN \\
\hline CHEMBL3906566 & 1637362 & 6.9957 & 5.66 & TRN \\
\hline CHEMBL 3891133 & 1637362 & 8.0 & 7.8095 & TRN \\
\hline CHEMBL3963520 & 1637362 & 8.0 & 8.53 & TRN \\
\hline
\end{tabular}




\begin{tabular}{|c|c|c|c|c|c|c|}
\hline \multicolumn{7}{|c|}{ Supplemental Table S2.txt } \\
\hline CHEMBL 3957051 & 1637362 & 8.0 & 7.2693 & TRN & & \\
\hline CHEMBL 3902774 & 1637362 & 3.3979 & 6.079 & TRN & & \\
\hline CHEMBL3979136 & 1637362 & 4.0 & 6.7672 & TST & & \\
\hline CHEMBL3938054 & 1637362 & 5.9996 & 6.4775 & TST & & \\
\hline CHEMBL3925527 & 1637362 & 8.0 & 7.9729 & TRN & & \\
\hline CHEMBL 3985317 & 1637362 & 6.9957 & 6.4844 & TRN & & \\
\hline CHEMBL3912990 & 1637362 & 6.9957 & 6.7428 & TRN & & \\
\hline CHEMBL3929265 & 1637362 & 6.9957 & 6.7453 & TRN & & \\
\hline CHEMBL3942441 & 1637362 & 6.9957 & 6.0365 & TRN & & \\
\hline CHEMBL3897685 & 1637362 & 6.9957 & 6.1077 & TRN & & \\
\hline CHEMBL3935766 & 1637362 & 6.9957 & 6.2442 & TRN & & \\
\hline CHEMBL3942912 & 1637362 & 5.9996 & 5.9693 & TRN & & \\
\hline CHEMBL3937295 & 1637362 & 5.9996 & 6.2377 & TRN & & \\
\hline CHEMBL3904247 & 1637362 & 5.9996 & 6.4612 & TRN & & \\
\hline CHEMBL3906658 & 1637362 & 8.0 & 7.3751 & TST & & \\
\hline CHEMBL 3943707 & 1637362 & 6.9957 & 7.4775 & TRN & & \\
\hline CHEMBL3899273 & 1637362 & 6.9957 & 6.9552 & TRN & & \\
\hline CHEMBL3907887 & 1637362 & 6.9957 & 6.6887 & TRN & & \\
\hline CHEMBL 3985527 & 1637362 & 6.9957 & 6.5223 & TST & & \\
\hline CHEMBL3921023 & 1637362 & 6.9957 & 6.5011 & TRN & & \\
\hline CHEMBL 3956242 & 1637362 & 8.0 & 8.0722 & TRN & & \\
\hline CHEMBL3925818 & 1637362 & 8.0 & 7.1356 & TRN & & \\
\hline CHEMBL3932053 & 1637362 & 5.9996 & 6.1441 & TRN & & \\
\hline CHEMBL3691937 & 1528613 & 11.0 & 10.9174 & TRN & & \\
\hline CHEMBL3687431 & 1528613 & 9.7696 & 10.2614 & TRN & & \\
\hline CHEMBL 3687418 & 1528613 & 10.5229 & 11.0895 & TRN & & \\
\hline CHEMBL3687465 & 1528613 & 9.8861 & 9.2711 & TRN & & \\
\hline CHEMBL 3687457 & 1528613 & 6.0 & 5.5666 & TRN & & \\
\hline CHEMBL3687427 & 1528613 & 10.3979 & 10.5983 & TRN & & \\
\hline CHEMBL3687492 & 1528613 & 6.0 & 6.1184 & TRN & & \\
\hline CHEMBL 3691927 & 1528613 & 10.30099 & 999999999 & 998 & 10.3366 & TRN \\
\hline CHEMBL 3687461 & 1528613 & 8.752 & 7.786000 & 0000000006 & 05 & TRN \\
\hline CHEMBL 3687525 & 1528613 & 10.1549 & 10.2368 & TRN & & \\
\hline CHEMBL 3687471 & 1528613 & 10.5229 & 10.3662 & TRN & & \\
\hline CHEMBL3691931 & 1528613 & 10.5229 & 10.6086 & TRN & & \\
\hline CHEMBL3691942 & 1528613 & 10.3979 & 10.6359 & TRN & & \\
\hline CHEMBL3691986 & 1528613 & 10.3009 & 999999999 & 998 & 10.3092 & TRN \\
\hline CHEMBL 3687490 & 1528613 & 10.5229 & 10.8597 & TRN & & \\
\hline CHEMBL 3687463 & 1528613 & 6.0 & 5.8582 & TRN & & \\
\hline CHEMBL3691930 & 1528613 & 10.69906 & 000000000 & 002 & 11.2873 & TRN \\
\hline CHEMBL 3687417 & 1528613 & 10.2218 & 9.9259 & TRN & & \\
\hline CHEMBL3691971 & 1528613 & 10.3979 & 10.1337 & TST & & \\
\hline CHEMBL3691933 & 1528613 & 10.0969 & 9.5234 & TRN & & \\
\hline CHEMBL3691975 & 1528613 & 9.7212 & 9.9376 & TRN & & \\
\hline CHEMBL3687519 & 1528613 & 9.3979 & 10.4593 & TST & & \\
\hline CHEMBL3691980 & 1528613 & 9.5086 & 10.1848 & TST & & \\
\hline CHEMBL 3687445 & 1528613 & 6.0 & 6.1475 & TRN & & \\
\hline CHEMBL3687531 & 1528613 & 10.3009 & 999999999 & 998 & 9.8654 & TRN \\
\hline
\end{tabular}


Supplemental Table S2.txt

CHEMBL 3687482

CHEMBL 3687438

CHEMBL 3691928

CHEMBL 3687493

CHEMBL 3687517

CHEMBL3687515

CHEMBL3687474

CHEMBL 3687514

CHEMBL 3639863

CHEMBL3691921

CHEMBL3687424

CHEMBL 3687436

CHEMBL 3687518

CHEMBL3687433

CHEMBL3687415

CHEMBL 3687423

CHEMBL3691939

CHEMBL 3687450

CHEMBL3687454

CHEMBL 3691962

CHEMBL3691926

CHEMBL 3687420

CHEMBL 3687527

CHEMBL 3687426

CHEMBL 3687475

CHEMBL3691944

CHEMBL3691923

CHEMBL3691955

CHEMBL 3691978

CHEMBL3687529

CHEMBL3687510

CHEMBL 3691953

CHEMBL 3687530

CHEMBL3691945

CHEMBL3691963

CHEMBL3687468

CHEMBL 3687535

CHEMBL3691940

CHEMBL3691959

CHEMBL 3687522

CHEMBL3691915

CHEMBL3687516

CHEMBL3691984

CHEMBL 3687504

CHEMBL3687466

CHEMBL3691970

CHEMBL 3687419

CHEMBL 3687432
152861310.522910 .6426 TRN

$\begin{array}{llll}1528613 & 6.0 & 6.678999999999999 & \text { TRN }\end{array}$

$\begin{array}{lll}1528613 & 10.699000000000002 & 10.9069 \text { TRN }\end{array}$

$15286136.0 \quad 6.5373$ TRN

$\begin{array}{lll}1528613 & 10.300999999999998 & 10.3174 \text { TRN }\end{array}$

152861310.221810 .0289 TRN

$\begin{array}{llll}1528613 & 6.0 & 6.343999999999999 & \text { TRN }\end{array}$

$\begin{array}{llll}1528613 & 8.2716 & 7.76 & \text { TRN }\end{array}$

$\begin{array}{llll}1528613 & 10.5229 & 9.845 \quad \text { TRN }\end{array}$

152861310.699000000000002

$\begin{array}{llll}1528613 & 9.4202 & 8.4311 & \text { TST }\end{array}$

$15286136.0 \quad 6.5321$ TRN

152861310.096910 .8154 TRN

152861310.300999999999998

$\begin{array}{llll}1528613 & 9.4437 & 8.6878 & \text { TRN }\end{array}$

$\begin{array}{llll}1528613 & 6.0 & 6.9939 & \text { TRN }\end{array}$

$\begin{array}{lll}1528613 & 10.2218 & 10.1942 \text { TST }\end{array}$

$\begin{array}{llll}1528613 & 9.7696 & 7.9571 & \text { TRN }\end{array}$

$\begin{array}{lll}15286136.0 & 6.4466 & \text { TRN }\end{array}$

$\begin{array}{llll}1528613 & 9.7959 & 9.3491 & \text { TRN }\end{array}$

$\begin{array}{llll}1528613 & 6.0 & 7.0555 & \text { TRN }\end{array}$

152861310.397910 .7368 TRN

152861310.699000000000002

$\begin{array}{llll}1528613 & 6.0 & 6.8012 & \text { TST }\end{array}$

$\begin{array}{llll}1528613 & 7.3919 & 6.5333 & \text { TRN }\end{array}$

152861310.300999999999998

152861310.699000000000002

152861310.699000000000002

152861310.300999999999998

$\begin{array}{llll}1528613 & 8.8539 & 7.76 & \text { TST }\end{array}$

$\begin{array}{llll}1528613 & 6.0 & 6.6725 & \text { TRN }\end{array}$

$\begin{array}{llll}1528613 & 9.1024 & 8.9701 & \text { TST }\end{array}$

152861310.300999999999998

152861310.699000000000002

$\begin{array}{lll}1528613 & 10.5229 & 10.0997\end{array}$

152861310.699000000000002

$\begin{array}{lll}1528613 & 9.1549 & 10.0992\end{array}$

$\begin{array}{lll}1528613 & 10.3979 & 10.2755 \text { TRN }\end{array}$

$\begin{array}{lll}1528613 & 10.045810 .5575 \text { TRN }\end{array}$

$\begin{array}{lll}1528613 & 10.096910 .5583 \text { TRN }\end{array}$

152861310.300999999999998

$\begin{array}{llll}1528613 & 9.5086 & 9.2984 & \text { TRN }\end{array}$

$\begin{array}{llll}1528613 & 9.7696 & 8.9152 & \text { TRN }\end{array}$

$\begin{array}{lll}1528613 & 10.5229 & 10.5892 \text { TRN }\end{array}$

152861310.699000000000002

152861310.300999999999998

$\begin{array}{llll}1528613 & 9.6198 & 9.0645 & \text { TST }\end{array}$

$\begin{array}{lll}1528613 & 9.8539 & 9.7029\end{array}$

10.1555 TRN

10.8624 TRN

10.3367 TRN

9.9257 TRN

10.9092 TRN

10.0737 TST

9.8325 TRN

10.3367 TRN

10.1768 TST

10.4922 TRN

9.8717 TST 
Supplemental Table S2.txt

CHEMBL3639862 CHEMBL 3687505 CHEMBL 3687509 CHEMBL 3691932 CHEMBL 3687430 CHEMBL 3691964 CHEMBL3691943 CHEMBL3691916 CHEMBL3691922 CHEMBL3687532 CHEMBL 3691976 CHEMBL3687501 CHEMBL3687502 CHEMBL3691967 CHEMBL3691917 CHEMBL3691981 CHEMBL3687452 CHEMBL 3687507 CHEMBL3691935 CHEMBL 3691925 CHEMBL3687537 CHEMBL 3687512 CHEMBL3687459 CHEMBL 3691979 CHEMBL3691958 CHEMBL3691968 CHEMBL3691961 CHEMBL 3639908 CHEMBL 3687476 CHEMBL3691974 CHEMBL3691966 CHEMBL 3691956 CHEMBL 3687534 CHEMBL3691938 CHEMBL 3687491 CHEMBL3691977 CHEMBL3691924 CHEMBL3687422 CHEMBL 3687467 CHEMBL3691965 CHEMBL3691983 CHEMBL 3691954 CHEMBL3691913 CHEMBL 3687470 CHEMBL3691918 CHEMBL3691957 CHEMBL3687536 CHEMBL3687481 $\begin{array}{lll}1528613 & 10.1549 & 10.2891 \text { TRN }\end{array}$ $\begin{array}{lll}1528613 & 10.699000000000002 & 10.1005 \text { TRN }\end{array}$ $152861311.0 \quad 11.0371$ TRN $\begin{array}{lll}1528613 & 10.699000000000002 & 10.8218 \text { TRN }\end{array}$ $\begin{array}{lll}1528613 & 10.300999999999998 & 10.8575 \text { TRN }\end{array}$ $\begin{array}{llll}1528613 & 9.8861 & 9.2845 & \text { TRN }\end{array}$ $\begin{array}{lll}1528613 & 10.699000000000002 & 10.4592 \text { TRN }\end{array}$ $15286136.0 \quad 6.6821$ TST $15286136.0 \quad 7.1851$ TRN $\begin{array}{llll}1528613 & 6.0 & 5.6979999999999995 & \text { TRN }\end{array}$ $\begin{array}{lll}1528613 & 10.3979 & 10.3875 \text { TST }\end{array}$ $\begin{array}{llll}15286136.0 & 6.0139 & \text { TRN }\end{array}$ $15286136.0 \quad 6.0501$ TRN $\begin{array}{lll}1528613 & 11.0 \quad 11.3114 \text { TRN }\end{array}$ $\begin{array}{llll}1528613 & 9.2441 & 8.3925 & \text { TST }\end{array}$ $\begin{array}{lll}1528613 & 10.1549 & 9.7566\end{array}$ $\begin{array}{lll}15286136.0 & 6.1186 & \text { TST }\end{array}$ $\begin{array}{lll}1528613 & 10.397910 .7477 \text { TRN }\end{array}$ $\begin{array}{lll}1528613 & 10.3979 & 9.9636 \\ \text { TRN }\end{array}$ $\begin{array}{lll}1528613 & 10.699000000000002 & 10.4525 \text { TRN }\end{array}$ $\begin{array}{llll}1528613 & 9.6198 & 10.809000000000001 & \text { TST }\end{array}$ $\begin{array}{lll}1528613 & 6.0 & 6.2917 \\ 1528613 & 6.0 & 6.4388\end{array}$ $15286136.0 \quad 6.4388$ TST $\begin{array}{lll}1528613 & 10.0 \quad 9.4403 & \text { TST }\end{array}$ $\begin{array}{lll}1528613 & 10.699000000000002 & 10.5333 \text { TRN }\end{array}$ $\begin{array}{lll}1528613 & 10.699000000000002 & 11.068 \text { TRN }\end{array}$ $\begin{array}{lll}1528613 & 10.3979 & 9.7734 \\ 10 R N\end{array}$

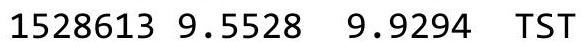
$\begin{array}{lll}1528613 & 10.5229 & 10.8691 \text { TRN }\end{array}$ $\begin{array}{llll}1528613 & 6.0 & 6.0425 & \text { TRN }\end{array}$

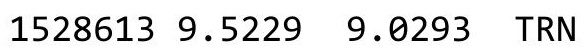
$\begin{array}{lll}1528613 & 10.3979 & 10.8492 \text { TST }\end{array}$ $\begin{array}{llll}1528613 & 10.3979 & 10.072000000000001 & \text { TRN }\end{array}$ $\begin{array}{lll}1528613 & 10.300999999999998 & 10.6329\end{array}$ $\begin{array}{llll}1528613 & 10.3979 & 11.135 \text { TRN }\end{array}$ $\begin{array}{lll}1528613 & 10.5229 & 10.7443 \text { TRN }\end{array}$ 152861310.699000000000002 $\begin{array}{llll}1528613 & 9.3979 & 8.484 & \text { TRN }\end{array}$ $\begin{array}{llll}1528613 & 9.7696 & 9.6517 & \text { TRN }\end{array}$ $\begin{array}{lll}1528613 & 10.5229 & 10.5539\end{array}$ $\begin{array}{llll}1528613 & 8.7696 & 9.8763 & \text { TST }\end{array}$ $\begin{array}{llll}1528613 & 9.9208 \quad 9.9016 & \text { TRN }\end{array}$ $\begin{array}{lll}1528613 & 10.300999999999998 & 10.0277 \text { TRN }\end{array}$ $\begin{array}{llll}1528613 & 6.0 & 5.5879 & \text { TRN }\end{array}$ $15286136.0 \quad 5.7902$ TST 152861310.300999999999998 $\begin{array}{llll}1528613 & 6.0 & 7.0184 & \text { TRN }\end{array}$ $\begin{array}{lll}1528613 & 10.3979 & 10.2872 \text { TRN }\end{array}$
10.7051 TRN $10.0277 \mathrm{TRN}$ 10.4672 TRN 
Supplemental Table S2.txt

\begin{tabular}{|c|c|c|c|c|c|c|c|}
\hline CHEMBL3687497 & 1528613 & 10.5229 & 11.0141 & TST & & & \\
\hline CHEMBL3687498 & 1528613 & 6.0 & 6.2273 & TRN & & & \\
\hline CHEMBL3687526 & 1528613 & 9.9208 & 9.9958 & TRN & & & \\
\hline CHEMBL3691941 & 1528613 & 10.3979 & 10.5972 & TST & & & \\
\hline CHEMBL3687487 & 1528613 & 6.0 & 6.2723 & TRN & & & \\
\hline CHEMBL3691936 & 1528613 & 6.0 & 7.562 & TST & & & \\
\hline CHEMBL3687446 & 1528613 & 6.0 & 6.1736 & TST & & & \\
\hline CHEMBL 3687414 & 1528613 & 10.2218 & 10.6187 & TST & & & \\
\hline CHEMBL3691950 & 1528613 & 10.69900 & 000000006 & 302 & 11.1617 & TRN & \\
\hline CHEMBL3687483 & 1528613 & 6.0 & 6.2515 & TRN & & & \\
\hline CHEMBL3687495 & 1528613 & 6.0 & 6.0063 & TRN & & & \\
\hline CHEMBL3687416 & 1528613 & 9.8539 & 8.2244 & TRN & & & \\
\hline CHEMBL3687421 & 1528613 & 9.4559 & 8.8832 & TRN & & & \\
\hline CHEMBL 3687520 & 1528613 & 10.0458 & 9.5514 & TRN & & & \\
\hline CHEMBL3687464 & 1528613 & 10.0458 & 9.3985 & TST & & & \\
\hline CHEMBL3687528 & 1528613 & 10.1549 & 9.8979 & TRN & & & \\
\hline CHEMBL3691960 & 1528613 & $10.6990 e$ & 000000000 & 302 & 10.9377 & TST & \\
\hline CHEMBL3691951 & 1528613 & 9.7447 & 9.8252 & TRN & & & \\
\hline CHEMBL3691929 & 1528613 & 10.3979 & 10.5305 & TRN & & & \\
\hline CHEMBL3687521 & 1528613 & 10.0969 & 11.3294 & TST & & & \\
\hline CHEMBL3691985 & 1528613 & 9.4202 & 9.1689 & TRN & & & \\
\hline CHEMBL 3687440 & 1528613 & 6.0 & 6.256 & TST & & & \\
\hline CHEMBL3691949 & 1528613 & $10.6990 e$ & 000000000 & 202 & 11.1256 & TRN & \\
\hline CHEMBL3691982 & 1528613 & 10.30099 & 999999999 & 998 & 9.7444 & TST & \\
\hline CHEMBL3687480 & 1528613 & 6.0 & 6.4041 & TRN & & & \\
\hline CHEMBL3687447 & 1528613 & 6.0 & 6.9332 & TRN & & & \\
\hline CHEMBL3687448 & 1528613 & 6.0 & 6.0701 & TRN & & & \\
\hline CHEMBL3691914 & 1528613 & 10.5229 & 10.4751 & TRN & & & \\
\hline CHEMBL3691919 & 1528613 & $10.6990 e$ & 000000000 & 302 & 10.85900 & 30000000002 & TRN \\
\hline CHEMBL 2170890 & 865015 & 7.5229 & 7.7662 & TRN & & & \\
\hline CHEMBL 2170862 & 865015 & 6.4685 & 6.2433 & TST & & & \\
\hline CHEMBL 2171060 & 865015 & 10.0 & 6.952000 & 0000000001 & & TRN & \\
\hline CHEMBL 2170860 & 865015 & 6.6576 & 6.8384 & TRN & & & \\
\hline CHEMBL 2170892 & 865015 & 7.5229 & 7.9102 & TRN & & & \\
\hline CHEMBL 2171080 & 865015 & 10.0 & 9.8672 & TRN & & & \\
\hline CHEMBL 2170883 & 865015 & 7.2218 & 7.4229 & TRN & & & \\
\hline CHEMBL 2170873 & 865015 & 7.301 & 7.4153 & TRN & & & \\
\hline CHEMBL 2170872 & 865015 & 6.6576 & 6.7397 & TRN & & & \\
\hline CHEMBL2170859 & 865015 & 6.7212 & 6.2472 & TST & & & \\
\hline CHEMBL 2171053 & 865015 & 3.8239 & 4.0344 & TRN & & & \\
\hline CHEMBL 2171064 & 865015 & 3.8239 & 4.3431 & TRN & & & \\
\hline CHEMBL 2171066 & 865015 & 3.8239 & 4.2464 & TRN & & & \\
\hline CHEMBL 2170905 & 865015 & 3.8239 & 3.976000 & 000000000 & & TRN & \\
\hline CHEMBL582392 & 865015 & 7.2218 & 6.0886 & TST & & & \\
\hline CHEMBL 2171081 & 865015 & 10.0 & 7.7445 & TRN & & & \\
\hline CHEMBL 2171077 & 865015 & 10.0 & 8.751 & TRN & & & \\
\hline CHEMBL1093370 & 865015 & 8.0 & 8.4424 & TRN & & & \\
\hline CHEMBL 2170867 & 865015 & 6.7212 & 6.4461 & TRN & & & \\
\hline
\end{tabular}




\begin{tabular}{|c|c|c|c|c|c|}
\hline & & \multicolumn{4}{|c|}{ Supplemental Table S2.txt } \\
\hline CHEMBL 2171076 & 865015 & 3.8239 & 4.5695 & TRN & \\
\hline CHEMBL 2170885 & 865015 & 7.0458 & 6.775 & TRN & \\
\hline CHEMBL 2170893 & 865015 & 3.8239 & 3.7191 & TRN & \\
\hline CHEMBL 2170888 & 865015 & 7.0 & 7.1939 & TRN & \\
\hline CHEMBL 2170869 & 865015 & 3.8239 & 3.8264 & TST & \\
\hline CHEMBL 2171078 & 865015 & 10.0 & 8.8963 & TRN & \\
\hline CHEMBL 2171052 & 865015 & 3.8239 & 3.6717 & TRN & \\
\hline CHEMBL 2171082 & 865015 & 10.0 & 9.6763 & TRN & \\
\hline CHEMBL 2170895 & 865015 & 7.2218 & 7.6398 & TRN & \\
\hline CHEMBL1093371 & 865015 & 8.0 & 8.1019 & TRN & \\
\hline CHEMBL 2171084 & 865015 & 10.0 & 8.9088 & TRN & \\
\hline CHEMBL 2171083 & 865015 & 8.699 & 9.5874 & TRN & \\
\hline CHEMBL 2171057 & 865015 & 6.7696 & 7.2136 & TRN & \\
\hline CHEMBL 2171079 & 865015 & 10.0 & 9.6372 & TRN & \\
\hline CHEMBL 2171070 & 865015 & 10.0 & 9.0041 & TRN & \\
\hline CHEMBL1090974 & 865015 & 6.2218 & 5.4868 & TRN & \\
\hline CHEMBL 2170865 & 865015 & 6.8239 & 6.8075 & TRN & \\
\hline CHEMBL 2170889 & 865015 & 7.5229 & 7.9682 & TST & \\
\hline CHEMBL 2170882 & 865015 & 8.0 & 9.2148 & TRN & \\
\hline CHEMBL 2170863 & 865015 & 3.8239 & 4.8611 & TST & \\
\hline CHEMBL 2170877 & 865015 & 8.0 & 8.224 & TRN & \\
\hline CHEMBL 2170901 & 865015 & 8.0 & 8.4618 & TST & \\
\hline CHEMBL 2170881 & 865015 & 6.9208 & 6.5233 & TST & \\
\hline CHEMBL 2170900 & 865015 & 7.2218 & 7.8052 & TST & \\
\hline CHEMBL 2170876 & 865015 & 7.301 & 7.0999 & TRN & \\
\hline CHEMBL 2170879 & 865015 & 6.9586 & 7.0912 & TRN & \\
\hline CHEMBL 2171054 & 865015 & 3.8239 & 3.94100 & 00000000003 & TRN \\
\hline CHEMBL 2171074 & 865015 & 5.3098 & 4.4358 & TRN & \\
\hline CHEMBL 2171059 & 865015 & 10.0 & 6.5958 & TRN & \\
\hline CHEMBL 2170902 & 865015 & 6.4815 & 6.4557 & TST & \\
\hline CHEMBL 2170864 & 865015 & 5.9586 & 4.75 & TST & \\
\hline CHEMBL 2171075 & 865015 & 3.8239 & 2.9662 & TST & \\
\hline CHEMBL 2171073 & 865015 & 3.8239 & 6.5958 & TRN & \\
\hline CHEMBL 2171063 & 865015 & 6.5686 & 6.6554 & TRN & \\
\hline CHEMBL 2170887 & 865015 & 7.301 & 7.347 & TRN & \\
\hline CHEMBL 2170904 & 865015 & 6.4559 & 6.5922 & TRN & \\
\hline CHEMBL 2170891 & 865015 & 8.0 & 9.0329 & TRN & \\
\hline CHEMBL 2170880 & 865015 & 7.699 & 7.9978 & TST & \\
\hline CHEMBL 2170878 & 865015 & 6.8861 & 7.1484 & TRN & \\
\hline CHEMBL 2171062 & 865015 & 3.8239 & 4.5804 & TRN & \\
\hline CHEMBL 2170899 & 865015 & 7.699 & 7.7522 & TST & \\
\hline CHEMBL 2170858 & 865015 & 3.8239 & 4.148 & TST & \\
\hline CHEMBL 2171065 & 865015 & 3.8239 & 4.2106 & TRN & \\
\hline CHEMBL1093728 & 865015 & 6.5686 & 6.8478 & TRN & \\
\hline CHEMBL 2170861 & 865015 & 6.7959 & 6.8439 & TRN & \\
\hline CHEMBL 2170884 & 865015 & 8.0 & 8.2358 & TRN & \\
\hline CHEMBL 2170898 & 865015 & 5.8861 & 6.789 & TRN & \\
\hline CHEMBL 2171056 & 865015 & 6.8539 & 6.4781 & TST & \\
\hline
\end{tabular}


Supplemental Table S2.txt

\begin{tabular}{|c|c|c|c|c|}
\hline CHEMBL 2171071 & 865015 & 6.1871 & 7.7445 & TRN \\
\hline CHEMBL 2170903 & 865015 & 3.8239 & 3.4914 & TST \\
\hline CHEMBL 2170897 & 865015 & 6.699 & 8.6565 & TRN \\
\hline CHEMBL1093726 & 865015 & 10.0 & 8.7787 & TRN \\
\hline CHEMBL 2170870 & 865015 & 3.8239 & 3.2602 & TST \\
\hline CHEMBL 2171055 & 865015 & 3.8239 & 3.71199 & 99999999997 \\
\hline CHEMBL 2171061 & 865015 & 6.0 & 4.6942 & TRN \\
\hline CHEMBL 2170894 & 865015 & 3.8239 & 3.5784 & TST \\
\hline CHEMBL 2171085 & 865015 & 10.0 & 9.0723 & TRN \\
\hline CHEMBL 2171072 & 865015 & 3.8239 & 3.0793 & TST \\
\hline CHEMBL 2170886 & 865015 & 6.0605 & 6.3101 & TRN \\
\hline CHEMBL 2170875 & 865015 & 7.699 & 8.1241 & TRN \\
\hline CHEMBL 2171051 & 865015 & 5.8539 & 5.75 & TRN \\
\hline CHEMBL 2170871 & 865015 & 7.5229 & 7.3151 & TRN \\
\hline CHEMBL2171058 & 865015 & 6.1805 & 6.4973 & TRN \\
\hline CHEMBL 2171067 & 865015 & 7.699 & 8.781 & TRN \\
\hline CHEMBL 2170896 & 865015 & 7.2218 & 7.3199 & TRN \\
\hline CHEMBL 2170866 & 865015 & 7.1549 & 7.1119 & TRN \\
\hline CHEMBL 2170868 & 865015 & 3.8239 & 5.0908 & TST \\
\hline CHEMBL1092774 & 865015 & 7.3979 & 8.9212 & TRN \\
\hline CHEMBL 2171069 & 865015 & 3.8239 & 4.7273 & TST \\
\hline CHEMBL1093727 & 865015 & 6.5686 & 6.4019 & TRN \\
\hline CHEMBL 2171068 & 865015 & 10.0 & 9.0936 & TRN \\
\hline CHEMBL 2170874 & 865015 & 7.5229 & 6.6647 & TST \\
\hline CHEMBL512504 & 954674 & 4.0419 & 4.0418 & TRN \\
\hline CHEMBL509032 & 954674 & 5.3494 & 5.3493 & TRN \\
\hline CHEMBL135561 & 954674 & 4.1382 & 4.1382 & TRN \\
\hline CHEMBL 220241 & 954674 & 4.8553 & 4.8553 & TRN \\
\hline CHEMBL2363137 & 954674 & 4.7816 & 4.7816 & TRN \\
\hline CHEMBL 221137 & 954674 & 4.8026 & 4.3707 & TST \\
\hline CHEMBL189584 & 954674 & 3.8478 & 3.8477 & TRN \\
\hline CHEMBL 300389 & 954674 & 7.3193 & 7.3193 & TRN \\
\hline CHEMBL577784 & 954674 & 5.5213 & 5.5214 & TRN \\
\hline CHEMBL 2005886 & 954674 & 5.3194 & 5.3194 & TRN \\
\hline CHEMBL412142 & 954674 & 4.6951 & 4.6951 & TRN \\
\hline CHEMBL1970879 & 954674 & 5.3757 & 5.3757 & TRN \\
\hline CHEMBL92309 & 954674 & 3.5615 & 2.5091 & TST \\
\hline CHEMBL1590308 & 954674 & 3.759 & 4.126 & TST \\
\hline CHEMBL573107 & 954674 & 5.575 & 5.575 & TRN \\
\hline CHEMBL191334 & 954674 & 3.654 & 3.654 & TRN \\
\hline CHEMBL393929 & 954674 & 3.6529 & 3.6529 & TRN \\
\hline CHEMBL392695 & 954674 & 6.2101 & 6.2102 & TRN \\
\hline CHEMBL1909414 & 954674 & 3.7262 & 3.7263 & TRN \\
\hline CHEMBL1230020 & 954674 & 2.9755 & 2.9755 & TRN \\
\hline CHEMBL1516890 & 954674 & 3.8081 & \multicolumn{2}{|c|}{3.8080000000000003} \\
\hline CHEMBL3349342 & 954674 & 5.1551 & 5.1552 & TRN \\
\hline CHEMBL102714 & 954674 & 3.0333 & 3.0333 & TRN \\
\hline CHEMBL240954 & 954674 & 4.0697 & 3.1563 & TST \\
\hline
\end{tabular}


Supplemental Table S2.txt

\begin{tabular}{|c|c|c|c|c|c|}
\hline CHEMBL472940 & 954674 & 2.5629 & 2.5629 & TRN & \\
\hline CHEMBL 209148 & 954674 & 4.0089 & 4.0089 & TRN & \\
\hline CHEMBL449158 & 954674 & 6.4759 & 7.1426 & TST & \\
\hline CHEMBL 213100 & 954674 & 7.1951 & 7.1951 & TRN & \\
\hline CHEMBL1788116 & 954674 & 5.3621 & 5.3621 & TRN & \\
\hline CHEMBL379975 & 954674 & 4.9136 & 4.9136 & TRN & \\
\hline CHEMBL65 & 954674 & 7.6319 & 7.6319 & TRN & \\
\hline CHEMBL 373751 & 954674 & 3.2338 & 3.234 & TRN & \\
\hline CHEMBL 3186408 & 954674 & 3.9107 & 3.9933 & TST & \\
\hline CHEMBL 2134202 & 954674 & 4.1243 & 4.1245 & TRN & \\
\hline CHEMBL515416 & 954674 & 4.4895 & 4.4895 & TRN & \\
\hline CHEMBL399530 & 954674 & 5.3302 & 5.3301 & TRN & \\
\hline CHEMBL 3199475 & 954674 & 3.6845 & 3.6845 & TRN & \\
\hline CHEMBL1357247 & 954674 & 3.3521 & 3.352 & TRN & \\
\hline CHEMBL 3392440 & 954674 & 5.2801 & 5.2801 & TRN & \\
\hline CHEMBL514499 & 954674 & 7.2238 & 7.2238 & TRN & \\
\hline CHEMBL1643959 & 954674 & 3.576 & 3.576 & TRN & \\
\hline CHEMBL 210618 & 954674 & 2.9382 & 2.9382 & TRN & \\
\hline CHEMBL1256459 & 954674 & 7.1925 & 7.1924 & TRN & \\
\hline CHEMBL 258844 & 954674 & 4.9507 & 4.9506 & TRN & \\
\hline CHEMBL 2144069 & 954674 & 4.6663 & 4.6662 & TRN & \\
\hline CHEMBL1186585 & 954674 & 4.0547 & 4.0545 & TRN & \\
\hline CHEMBL192566 & 954674 & 6.87 & 7.9493 & TST & \\
\hline CHEMBL483847 & 954674 & 4.0728 & 4.0728 & TRN & \\
\hline CHEMBL483849 & 954674 & 1.4713 & 1.8163 & TST & \\
\hline CHEMBL1242367 & 954674 & 3.5759 & 3.5759 & TRN & \\
\hline CHEMBL585951 & 954674 & 5.9735 & 5.9735 & TRN & \\
\hline CHEMBL180127 & 954674 & 5.237 & 5.2369 & TRN & \\
\hline CHEMBL1190711 & 954674 & 4.1183 & 4.1183 & TRN & \\
\hline CHEMBL 202721 & 954674 & 4.7355 & 4.7354 & TRN & \\
\hline CHEMBL259181 & 954674 & 3.2855 & 3.2855 & TRN & \\
\hline CHEMBL 222102 & 954674 & 3.8532 & 3.8533 & TRN & \\
\hline CHEMBL 2137530 & 954674 & 5.1038 & 4.7442 & TST & \\
\hline CHEMBL9470 & 954674 & 5.8007 & 5.51200 & 00000000005 & TST \\
\hline CHEMBL 379300 & 954674 & 6.5183 & 6.4471 & TST & \\
\hline CHEMBL 255342 & 954674 & 4.0399 & 3.4356 & TST & \\
\hline CHEMBL1673039 & 954674 & $5.1270 e$ & 00000000 & 4.8215 & TST \\
\hline CHEMBL558642 & 954674 & 3.6653 & 3.6224 & TST & \\
\hline CHEMBL1404918 & 954674 & 2.7349 & 2.6339 & TST & \\
\hline CHEMBL188678 & 954674 & 4.8841 & 4.1293 & TST & \\
\hline CHEMBL217354 & 954674 & $6.6160 e$ & 00000000 & 6.6248 & TST \\
\hline CHEMBL477177 & 535396 & 4.0 & 3.4438 & TRN & \\
\hline CHEMBL518286 & 535396 & 3.3872 & 3.3583 & TRN & \\
\hline CHEMBL489777 & 535396 & 3.2218 & 3.2738 & TRN & \\
\hline CHEMBL564201 & 535396 & 4.585 & 4.4864 & TST & \\
\hline CHEMBL476358 & 535396 & 3.301 & 3.4449 & TRN & \\
\hline CHEMBL489373 & 535396 & 3.3372 & 3.3134 & TRN & \\
\hline CHEMBL464086 & 535396 & 3.0 & 2.7345 & TRN & \\
\hline
\end{tabular}




\begin{tabular}{|c|c|c|c|c|}
\hline \multicolumn{5}{|c|}{ Supplemental Table S2.txt } \\
\hline CHEMBL517807 & 535396 & 3.5086 & 4.4685 & TST \\
\hline CHEMBL478881 & 535396 & 3.0 & 3.1372 & TRN \\
\hline CHEMBL452676 & 535396 & 4.4437 & 4.023 & TRN \\
\hline CHEMBL489776 & 535396 & 3.7212 & 3.5105 & TRN \\
\hline CHEMBL478859 & 535396 & 3.2147 & 3.3385 & TRN \\
\hline CHEMBL477550 & 535396 & 3.0969 & 3.0275 & TRN \\
\hline CHEMBL478882 & 535396 & 3.3188 & 3.6295 & TST \\
\hline CHEMBL489168 & 535396 & 3.3188 & 3.6511 & TST \\
\hline CHEMBL510108 & 535396 & 3.2076 & 3.7196 & TRN \\
\hline CHEMBL489169 & 535396 & 3.4685 & 3.264 & TRN \\
\hline CHEMBL491005 & 535396 & 5.0 & 5.0633 & TRN \\
\hline CHEMBL476983 & 535396 & 3.0 & 3.1293 & TRN \\
\hline CHEMBL489982 & 535396 & 4.0 & 3.5877 & TRN \\
\hline CHEMBL476148 & 535396 & 3.0 & 3.8463 & TST \\
\hline CHEMBL502222 & 535396 & 4.0 & 3.7597 & TRN \\
\hline CHEMBL522585 & 535396 & 3.699 & 3.4652 & TRN \\
\hline CHEMBL475475 & 535396 & 3.0862 & 3.7895 & TRN \\
\hline CHEMBL490997 & 535396 & 3.1249 & 3.2284 & TRN \\
\hline CHEMBL476918 & 535396 & 3.0 & 3.0991 & TRN \\
\hline CHEMBL477176 & 535396 & 3.1487 & 3.1301 & TRN \\
\hline CHEMBL448063 & 535396 & 4.0969 & 3.7384 & TRN \\
\hline CHEMBL522753 & 535396 & 3.0223 & 2.9982 & TRN \\
\hline CHEMBL478880 & 535396 & 3.0 & 3.2148 & TST \\
\hline CHEMBL476973 & 535396 & 3.0706 & 3.1355 & TRN \\
\hline CHEMBL490999 & 535396 & 4.3768 & 4.3604 & TRN \\
\hline CHEMBL418899 & 535396 & 6.0 & 3.9083 & TST \\
\hline CHEMBL452739 & 535396 & 3.0 & 3.1439 & TRN \\
\hline CHEMBL489779 & 535396 & 3.3979 & 3.426 & TRN \\
\hline CHEMBL491006 & 535396 & 5.1249 & 4.9353 & TRN \\
\hline CHEMBL442570 & 535396 & 3.0 & 2.7872 & TST \\
\hline CHEMBL490761 & 535396 & 3.0315 & 3.1109 & TRN \\
\hline CHEMBL442892 & 535396 & 3.1135 & 2.6249 & TST \\
\hline CHEMBL450704 & 535396 & 3.0 & 2.8973 & TRN \\
\hline CHEMBL477823 & 535396 & 3.0 & 3.7813 & TST \\
\hline CHEMBL502905 & 535396 & 3.0 & 2.9972 & TRN \\
\hline CHEMBL490061 & 535396 & 3.1612 & 3.3884 & TRN \\
\hline CHEMBL478860 & 535396 & 3.2924 & 3.2828 & TRN \\
\hline CHEMBL491007 & 535396 & 5.0458 & 5.0373 & TRN \\
\hline CHEMBL476784 & 535396 & 3.6021 & 4.2402 & TST \\
\hline CHEMBL470505 & 535396 & 3.2596 & 3.5782 & TST \\
\hline CHEMBL476984 & 535396 & 4.6576 & 4.6367 & TRN \\
\hline CHEMBL490998 & 535396 & 3.0 & 3.1707 & TRN \\
\hline CHEMBL476974 & 535396 & 3.0 & 3.1735 & TRN \\
\hline CHEMBL490396 & 535396 & 3.3098 & 3.2545 & TRN \\
\hline CHEMBL489981 & 535396 & 3.0605 & 3.1114 & TRN \\
\hline CHEMBL504564 & 535396 & 4.3372 & 4.2373 & TRN \\
\hline CHEMBL518440 & 535396 & 3.2924 & 3.335 & TRN \\
\hline CHEMBL515944 & 535396 & 3.6576 & 4.7662 & TST \\
\hline
\end{tabular}




\begin{tabular}{|c|c|c|c|c|c|}
\hline \multicolumn{6}{|c|}{ Supplemental } \\
\hline CHEMBL448250 & 535396 & 3.0223 & 2.8045 & TRN & \\
\hline CHEMBL1203972 & 535396 & 3.0 & 2.9641 & TRN & \\
\hline CHEMBL501654 & 535396 & 3.0 & 2.9252 & TRN & \\
\hline CHEMBL492037 & 535396 & 3.0 & 2.4899 & TST & \\
\hline CHEMBL491207 & 535396 & 4.9208 & 4.9227 & TRN & \\
\hline CHEMBL446474 & 535396 & 3.6383 & 3.553 & TST & \\
\hline CHEMBL505701 & 535396 & 3.0 & 3.2331 & TRN & \\
\hline CHEMBL448446 & 535396 & 3.2676 & 3.4423 & TRN & \\
\hline CHEMBL451317 & 535396 & 3.1612 & 3.0819 & TRN & \\
\hline CHEMBL522098 & 535396 & 3.3872 & 3.3935 & TRN & \\
\hline CHEMBL523441 & 535396 & 3.2076 & 3.2359 & TRN & \\
\hline CHEMBL477606 & 535396 & 3.3565 & 3.1684 & TRN & \\
\hline CHEMBL477187 & 535396 & 3.0 & 3.03899 & 99999999997 & TST \\
\hline CHEMBL477607 & 535396 & 3.0 & 3.3209 & TRN & \\
\hline CHEMBL492036 & 535396 & 3.6778 & 2.9782 & TST & \\
\hline CHEMBL498976 & 535396 & 3.0 & 2.9481 & TRN & \\
\hline CHEMBL445306 & 535396 & 3.3372 & 3.4339 & TRN & \\
\hline CHEMBL446919 & 535396 & 3.0 & 2.5771 & TST & \\
\hline CHEMBL476992 & 535396 & 3.0 & 3.5535 & TST & \\
\hline CHEMBL448665 & 535396 & 3.0 & 2.6717 & TRN & \\
\hline CHEMBL476783 & 535396 & 3.699 & 4.9218 & TST & \\
\hline CHEMBL450720 & 535396 & 3.3098 & 3.4228 & TRN & \\
\hline CHEMBL508059 & 535396 & 3.0 & 3.4458 & TRN & \\
\hline CHEMBL470987 & 535396 & 3.4202 & 3.2456 & TRN & \\
\hline CHEMBL499938 & 535396 & 3.0862 & 3.1827 & TRN & \\
\hline CHEMBL1162372 & 535396 & 3.3279 & 2.5093 & TST & \\
\hline CHEMBL490784 & 535396 & 4.6383 & 4.1046 & TRN & \\
\hline CHEMBL489564 & 535396 & 4.699 & 4.9093 & TRN & \\
\hline CHEMBL477596 & 535396 & 3.0458 & 3.5269 & TRN & \\
\hline CHEMBL476147 & 535396 & 5.1549 & 3.4736 & TST & \\
\hline CHEMBL1988011 & 809016 & 3.0969 & 3.0669 & TRN & \\
\hline CHEMBL1878632 & 809016 & 3.0969 & 3.8596 & TRN & \\
\hline CHEMBL1479786 & 809016 & 4.2749 & 4.2978 & TRN & \\
\hline CHEMBL1698833 & 809016 & 3.0969 & 3.3971 & TRN & \\
\hline CHEMBL1999049 & 809016 & 4.6055 & 3.31699 & 99999999997 & TST \\
\hline CHEMBL1545417 & 809016 & 4.3872 & 4.7009 & TRN & \\
\hline CHEMBL1325765 & 809016 & 4.8729 & 4.3431 & TRN & \\
\hline CHEMBL1503867 & 809016 & 3.0969 & 3.3993 & TRN & \\
\hline CHEMBL1542861 & 809016 & 3.0969 & 3.0283 & TRN & \\
\hline CHEMBL1734299 & 809016 & 3.0969 & 3.1423 & TRN & \\
\hline CHEMBL1546279 & 809016 & 3.0969 & 3.2092 & TRN & \\
\hline CHEMBL1491420 & 809016 & 3.0969 & 3.4964 & TRN & \\
\hline CHEMBL1895423 & 809016 & 3.0969 & 3.2619 & TRN & \\
\hline CHEMBL1896885 & 809016 & 3.0969 & 2.9284 & TRN & \\
\hline CHEMBL1468786 & 809016 & 7.8069 & 3.6442 & TST & \\
\hline CHEMBL1967371 & 809016 & 3.0969 & 2.8552 & TRN & \\
\hline CHEMBL1724102 & 809016 & 3.0969 & 2.5898 & TRN & \\
\hline CHEMBL1487952 & 809016 & 3.0969 & 3.3319 & TRN & \\
\hline
\end{tabular}




\begin{tabular}{|c|c|c|c|c|c|}
\hline \multicolumn{6}{|c|}{ Supplemental Table S2.txt } \\
\hline CHEMBL585071 & 809016 & 4.8894 & 5.1225 & TRN & \\
\hline CHEMBL1736090 & 809016 & 5.0595 & 3.8372 & TRN & \\
\hline CHEMBL1725046 & 809016 & 3.0969 & 3.8785 & TST & \\
\hline CHEMBL1982017 & 809016 & 3.0969 & 2.7025 & TRN & \\
\hline CHEMBL1578828 & 809016 & 4.8069 & 4.3702 & TRN & \\
\hline CHEMBL1585390 & 809016 & 4.8894 & 4.8273 & TRN & \\
\hline CHEMBL1345436 & 809016 & 3.0969 & 2.6808 & TRN & \\
\hline CHEMBL1994142 & 809016 & 3.0969 & 2.9239 & TRN & \\
\hline CHEMBL1873317 & 809016 & 4.5834 & 4.2651 & TRN & \\
\hline CHEMBL1422620 & 809016 & 3.0969 & 3.0255 & TRN & \\
\hline CHEMBL1600430 & 809016 & 3.0969 & 2.6784 & TRN & \\
\hline CHEMBL1224755 & 809016 & 4.9957 & 5.3985 & TRN & \\
\hline CHEMBL1488722 & 809016 & 3.0969 & 2.8249 & TRN & \\
\hline CHEMBL1983689 & 809016 & 3.0969 & 3.0325 & TRN & \\
\hline CHEMBL1576229 & 809016 & 5.2269 & 4.7446 & TRN & \\
\hline CHEMBL 2007391 & 809016 & 3.0969 & 3.4311 & TRN & \\
\hline CHEMBL1561595 & 809016 & 3.0969 & 2.9772 & TRN & \\
\hline CHEMBL1303518 & 809016 & 3.0969 & 2.694 & TRN & \\
\hline CHEMBL1414808 & 809016 & 4.327 & 3.8003 & TRN & \\
\hline CHEMBL1351239 & 809016 & 3.0969 & 3.0704 & TRN & \\
\hline CHEMBL1368410 & 809016 & 3.0969 & 3.0792 & TRN & \\
\hline CHEMBL1575353 & 809016 & 5.1325 & 5.4691 & TRN & \\
\hline CHEMBL1903046 & 809016 & 3.0969 & 3.6419 & TRN & \\
\hline CHEMBL1890592 & 809016 & 4.6904 & 4.61100 & 0000000001 & TRN \\
\hline CHEMBL1715378 & 809016 & 4.6882 & 4.5453 & TRN & \\
\hline CHEMBL1499255 & 809016 & 3.0969 & 3.0869 & TRN & \\
\hline CHEMBL1432016 & 809016 & 4.3696 & 4.2537 & TRN & \\
\hline CHEMBL1999078 & 809016 & 3.0969 & 3.3336 & TRN & \\
\hline CHEMBL1346379 & 809016 & 4.4145 & 3.5984 & TST & \\
\hline CHEMBL1741436 & 809016 & 4.9666 & 4.5356 & TRN & \\
\hline CHEMBL1580276 & 809016 & 3.0969 & 3.1593 & TRN & \\
\hline CHEMBL1865562 & 809016 & 5.9136 & 5.4752 & TRN & \\
\hline CHEMBL510515 & 809016 & 5.4962 & 4.5363 & TRN & \\
\hline CHEMBL1392042 & 809016 & 3.0969 & 3.7038 & TRN & \\
\hline CHEMBL1419914 & 809016 & 3.0969 & 2.8915 & TRN & \\
\hline CHEMBL1307198 & 809016 & 3.0969 & 2.8075 & TRN & \\
\hline CHEMBL1571129 & 809016 & 3.0969 & 3.205 & TST & \\
\hline CHEMBL1348585 & 809016 & 3.0969 & 3.1915 & TRN & \\
\hline CHEMBL1595251 & 809016 & 3.0969 & 3.6958 & TRN & \\
\hline CHEMBL1983210 & 809016 & 3.0969 & 3.3381 & TRN & \\
\hline CHEMBL1873790 & 809016 & 4.2549 & 4.1911 & TRN & \\
\hline CHEMBL1702179 & 809016 & 6.3487 & 3.7378 & TST & \\
\hline CHEMBL1370113 & 809016 & 3.0969 & 3.1999 & TRN & \\
\hline CHEMBL1589202 & 809016 & 3.0969 & 3.5303 & TRN & \\
\hline CHEMBL1333102 & 809016 & 3.0969 & 2.9815 & TRN & \\
\hline CHEMBL1567623 & 809016 & 5.0246 & 4.5505 & TRN & \\
\hline CHEMBL1173672 & 809016 & 3.0969 & 2.6777 & TRN & \\
\hline CHEMBL1461159 & 809016 & 3.0969 & 3.2421 & TRN & \\
\hline
\end{tabular}


Supplemental Table S2.txt

\begin{tabular}{|c|c|c|c|c|}
\hline CHEMBL1385701 & 809016 & 5.9788 & 6.0379 & TRN \\
\hline CHEMBL1990598 & 809016 & 5.1993 & 4.2823 & TRN \\
\hline CHEMBL1573841 & 809016 & 3.0969 & 3.6084 & TRN \\
\hline CHEMBL1964358 & 809016 & 4.4012 & 4.4848 & TRN \\
\hline CHEMBL1308313 & 809016 & 6.0 & 5.5001 & TRN \\
\hline CHEMBL3392476 & 809016 & 3.0969 & 3.2971 & TRN \\
\hline CHEMBL1328416 & 809016 & 3.0969 & 3.7427 & TRN \\
\hline CHEMBL1338993 & 809016 & 3.0969 & 3.3273 & TRN \\
\hline CHEMBL1566415 & 809016 & 5.5513 & 5.6344 & TRN \\
\hline CHEMBL1906136 & 809016 & 4.9508 & 5.0259 & TRN \\
\hline CHEMBL1370276 & 809016 & 5.4855 & 4.8488 & TRN \\
\hline CHEMBL1531245 & 809016 & 5.2503 & 4.1933 & TRN \\
\hline CHEMBL1490757 & 809016 & 3.0969 & 3.3193 & TRN \\
\hline CHEMBL1379246 & 809016 & 3.0969 & 3.642 & TST \\
\hline CHEMBL1304940 & 809016 & 4.5986 & 4.8181 & TRN \\
\hline CHEMBL1891021 & 809016 & 3.0969 & 3.3409 & TRN \\
\hline CHEMBL1984674 & 809016 & 3.0969 & 3.0728 & TRN \\
\hline CHEMBL1978938 & 809016 & 3.0969 & 3.1645 & TRN \\
\hline CHEMBL1597789 & 809016 & 4.8633 & 5.2201 & TRN \\
\hline CHEMBL1303669 & 809016 & 4.2161 & 4.335 & TRN \\
\hline CHEMBL1971601 & 809016 & 4.8827 & 5.2549 & TRN \\
\hline CHEMBL1906688 & 809016 & 4.5901 & 4.4405 & TRN \\
\hline CHEMBL75773 & 809016 & 5.5391 & 4.9294 & TRN \\
\hline CHEMBL1709727 & 809016 & 4.5143 & 3.4834 & TRN \\
\hline CHEMBL1475489 & 809016 & 3.0969 & 3.27 & TRN \\
\hline CHEMBL1571713 & 809016 & 3.0969 & 3.6807 & TST \\
\hline CHEMBL1995929 & 809016 & 4.4225 & 4.5092 & TRN \\
\hline CHEMBL1406428 & 809016 & 3.0969 & 3.4373 & TST \\
\hline CHEMBL1572591 & 809016 & 3.0969 & 3.5944 & TRN \\
\hline CHEMBL 3392492 & 809016 & 3.0969 & 3.4643 & TRN \\
\hline CHEMBL1998338 & 809016 & 5.1752 & 4.9002 & TRN \\
\hline CHEMBL1439974 & 809016 & 3.0969 & 3.4484 & TST \\
\hline CHEMBL1306949 & 809016 & 3.0969 & 3.3154 & TRN \\
\hline CHEMBL1440265 & 809016 & 3.0969 & 3.1078 & TRN \\
\hline CHEMBL1501511 & 809016 & 3.0969 & 3.6925 & TST \\
\hline CHEMBL1481813 & 809016 & 3.0969 & 3.0277 & TRN \\
\hline CHEMBL1563765 & 809016 & 4.5918 & 4.4952 & TRN \\
\hline CHEMBL1357867 & 809016 & 5.9547 & 2.9928 & TST \\
\hline CHEMBL1990443 & 809016 & 3.0969 & 3.1325 & TRN \\
\hline CHEMBL1464024 & 809016 & 3.0969 & 3.4509 & TRN \\
\hline CHEMBL1331446 & 809016 & 3.0969 & 3.2961 & TRN \\
\hline CHEMBL1364044 & 809016 & 3.0969 & 4.01699 & 99999999995 \\
\hline CHEMBL540848 & 809016 & 3.0969 & 4.3904 & TRN \\
\hline CHEMBL1394580 & 809016 & 3.0969 & 3.38 & TRN \\
\hline CHEMBL1608248 & 809016 & 3.0969 & 3.489 & TRN \\
\hline CHEMBL1337041 & 809016 & 3.0969 & 2.8519 & TRN \\
\hline CHEMBL1576035 & 809016 & 3.0969 & 3.0116 & TRN \\
\hline CHEMBL1407756 & 809016 & 3.0969 & 3.6987 & TRN \\
\hline
\end{tabular}




\begin{tabular}{|c|c|c|c|c|}
\hline \multicolumn{5}{|c|}{ Supplemental Tab. } \\
\hline CHEMBL1537016 & 809016 & 4.8069 & 5.3361 & TRN \\
\hline CHEMBL1420916 & 809016 & 3.0969 & 3.5081 & TRN \\
\hline CHEMBL1498705 & 809016 & 3.0969 & 3.5316 & TRN \\
\hline CHEMBL1303426 & 809016 & 3.0969 & 4.4908 & TST \\
\hline CHEMBL1878954 & 809016 & 3.0969 & 2.559 & TST \\
\hline CHEMBL1893121 & 809016 & 3.0969 & 4.0034 & TST \\
\hline CHEMBL1713923 & 809016 & 3.0969 & 3.9728 & TST \\
\hline CHEMBL1309463 & 809016 & 3.0969 & 3.97 & TST \\
\hline CHEMBL1709177 & 809016 & 3.0969 & 4.4652 & TST \\
\hline CHEMBL1350225 & 809016 & 3.0969 & 3.4147 & TST \\
\hline CHEMBL1410374 & 809016 & 3.0969 & 4.1521 & TST \\
\hline CHEMBL1508832 & 809016 & 3.0969 & 4.4132 & TST \\
\hline CHEMBL1598442 & 809016 & 4.3893 & 3.8546 & TST \\
\hline CHEMBL1536244 & 809016 & 3.0969 & 2.4201 & TST \\
\hline CHEMBL1705317 & 809016 & 3.0969 & 2.833 & TST \\
\hline CHEMBL1319618 & 809016 & 5.0773 & 4.8979 & TST \\
\hline CHEMBL1416089 & 809016 & 3.0969 & 3.46 & TST \\
\hline CHEMBL1534379 & 809016 & 4.7986 & 4.8127 & TST \\
\hline CHEMBL1534791 & 809016 & 5.0061 & 4.5647 & TST \\
\hline CHEMBL1391187 & 809016 & 3.0969 & 3.4885 & TST \\
\hline CHEMBL1361072 & 809016 & 4.5072 & 2.5845 & TST \\
\hline CHEMBL1478881 & 809016 & 3.0969 & 4.1348 & TST \\
\hline CHEMBL1889412 & 809016 & 3.0969 & 3.3595 & TST \\
\hline CHEMBL1595937 & 809016 & 4.279 & 5.3281 & TST \\
\hline CHEMBL1470453 & 809016 & 3.0969 & 4.2382 & TST \\
\hline CHEMBL1393325 & 688403 & 4.1 & 4.3018 & TRN \\
\hline CHEMBL1518369 & 688403 & 4.1 & 4.3461 & TRN \\
\hline CHEMBL1514512 & 688403 & 4.3 & 4.2509 & TRN \\
\hline CHEMBL36296 & 688403 & 4.1 & 4.1876 & TRN \\
\hline CHEMBL1303139 & 688403 & 5.2 & 5.0524 & TRN \\
\hline CHEMBL1527567 & 688403 & 4.3 & 4.2189 & TRN \\
\hline CHEMBL1609459 & 688403 & 5.1 & 5.0602 & TRN \\
\hline CHEMBL224282 & 688403 & 4.1 & 4.1963 & TRN \\
\hline CHEMBL1576086 & 688403 & 4.3 & 4.357 & TRN \\
\hline CHEMBL57394 & 688403 & 4.4 & 4.4063 & TRN \\
\hline CHEMBL1579130 & 688403 & 6.0 & 5.5664 & TST \\
\hline CHEMBL8320 & 688403 & 4.3 & 4.3267 & TRN \\
\hline CHEMBL1451833 & 688403 & 4.4 & 4.3979 & TRN \\
\hline CHEMBL1612246 & 688403 & 4.4 & 4.4416 & TRN \\
\hline CHEMBL1418603 & 688403 & 4.1 & 4.1765 & TRN \\
\hline CHEMBL1200471 & 688403 & 6.6 & 6.653 & TRN \\
\hline CHEMBL1492884 & 688403 & 4.4 & 4.3177 & TRN \\
\hline CHEMBL1562104 & 688403 & 5.2 & 5.3514 & TRN \\
\hline CHEMBL1559341 & 688403 & 4.4 & 4.3905 & TRN \\
\hline CHEMBL1489064 & 688403 & 4.3 & 4.1872 & TRN \\
\hline CHEMBL1414154 & 688403 & 4.1 & 4.1215 & TRN \\
\hline CHEMBL1602699 & 688403 & 5.3 & 5.2327 & TRN \\
\hline CHEMBL486193 & 688403 & 4.1 & 4.7041 & TST \\
\hline
\end{tabular}




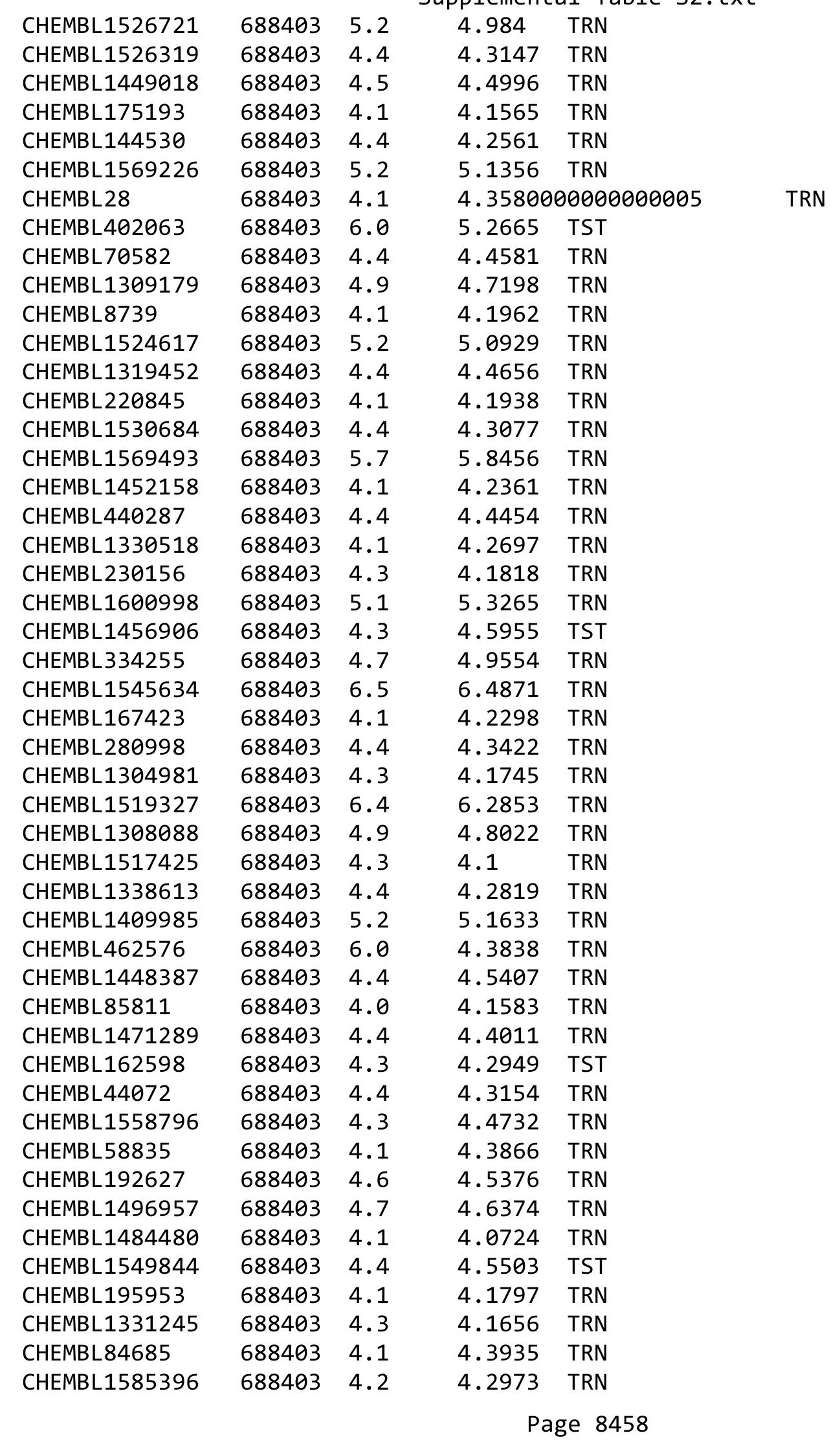




\begin{tabular}{|c|c|c|c|c|c|}
\hline \multicolumn{6}{|c|}{ Supplemental Table S2.txt } \\
\hline CHEMBL1565705 & 688403 & 4.1 & 4.2663 & TRN & \\
\hline CHEMBL1566504 & 688403 & 4.3 & 4.2976 & TRN & \\
\hline CHEMBL1430204 & 688403 & 4.3 & 4.3535 & TRN & \\
\hline CHEMBL1492104 & 688403 & 4.4 & 4.7433 & TST & \\
\hline CHEMBL935 & 688403 & 4.3 & 4.3136 & TRN & \\
\hline CHEMBL194400 & 688403 & 4.1 & 4.2049 & TRN & \\
\hline CHEMBL388676 & 688403 & 5.2 & 4.7235 & TST & \\
\hline CHEMBL443949 & 688403 & 4.4 & 4.3821 & TRN & \\
\hline CHEMBL1535689 & 688403 & 4.4 & 4.2816 & TST & \\
\hline CHEMBL1522486 & 688403 & 4.6 & 4.5669 & TST & \\
\hline CHEMBL509531 & 688403 & 4.7 & 4.831 & TST & \\
\hline CHEMBL1499545 & 688403 & 5.2 & 5.2492 & TST & \\
\hline CHEMBL1450607 & 688403 & 4.6 & 4.5487 & TST & \\
\hline CHEMBL1407826 & 688403 & 4.4 & 4.67399 & 99999999995 & TST \\
\hline CHEMBL1462419 & 688403 & 4.1 & 4.4057 & TST & \\
\hline CHEMBL140 & 688403 & 4.5 & 4.349 & TST & \\
\hline CHEMBL418068 & 688403 & 4.4 & 4.4342 & TST & \\
\hline CHEMBL1485360 & 688403 & 4.7 & 4.5413 & TST & \\
\hline CHEMBL1142 & 688403 & 4.4 & 4.2821 & TST & \\
\hline CHEMBL1366408 & 688403 & 4.3 & 4.5834 & TST & \\
\hline CHEMBL1344952 & 688403 & 4.3 & 4.2785 & TST & \\
\hline CHEMBL1408847 & 688403 & 5.2 & 5.1942 & TST & \\
\hline CHEMBL1447588 & 688403 & 4.7 & 4.9727 & TST & \\
\hline CHEMBL105712 & 688403 & 4.9 & 4.9113 & TST & \\
\hline CHEMBL3951553 & 1641839 & 7.9586 & 7.8885 & TRN & \\
\hline CHEMBL3960266 & 1641839 & 6.9626 & 6.9933 & TRN & \\
\hline CHEMBL3924433 & 1641839 & 7.7959 & 7.5671 & TST & \\
\hline CHEMBL3907705 & 1641839 & 8.5229 & 8.6558 & TRN & \\
\hline CHEMBL3959462 & 1641839 & 8.0 & 8.0392 & TRN & \\
\hline CHEMBL3962379 & 1641839 & 7.284 & 7.2205 & TRN & \\
\hline CHEMBL3952524 & 1641839 & 7.9208 & 7.9498 & TRN & \\
\hline CHEMBL3947462 & 1641839 & 8.0458 & 8.0583 & TRN & \\
\hline CHEMBL 3898918 & 1641839 & 7.4437 & 7.3998 & TRN & \\
\hline CHEMBL3952998 & 1641839 & 7.2147 & 7.2698 & TRN & \\
\hline CHEMBL3954150 & 1641839 & 6.3665 & 8.1744 & TST & \\
\hline CHEMBL3928995 & 1641839 & 7.301 & 7.3126 & TRN & \\
\hline CHEMBL3946753 & 1641839 & 7.9208 & 7.901 & TRN & \\
\hline CHEMBL3933239 & 1641839 & 8.0458 & 8.06200 & 3000000001 & TRN \\
\hline CHEMBL3939909 & 1641839 & 6.567 & 8.127 & TST & \\
\hline CHEMBL3950475 & 1641839 & 7.9208 & 7.874 & TRN & \\
\hline CHEMBL3895246 & 1641839 & 7.8539 & 8.4221 & TST & \\
\hline CHEMBL3937783 & 1641839 & 7.4815 & 7.2253 & TST & \\
\hline CHEMBL3932157 & 1641839 & 8.5229 & 8.5033 & TRN & \\
\hline CHEMBL3924456 & 1641839 & 7.8239 & 7.88700 & 00000000005 & TRN \\
\hline CHEMBL3893066 & 1641839 & 7.8239 & 7.9328 & TRN & \\
\hline CHEMBL3925314 & 1641839 & 7.0862 & 7.0507 & TST & \\
\hline CHEMBL3923209 & 1641839 & 7.0362 & 7.5474 & TST & \\
\hline CHEMBL3949582 & 1641839 & 8.0 & 7.9243 & TRN & \\
\hline
\end{tabular}


Supplemental Table S2.txt

\begin{tabular}{|c|c|c|c|c|c|}
\hline CHEMBL3966328 & 1641839 & 8.1549 & 8.0499 & TRN & \\
\hline CHEMBL3976354 & 1641839 & 7.8861 & 7.8401 & TRN & \\
\hline CHEMBL3917772 & 1641839 & 7.9208 & 8.2876 & TST & \\
\hline CHEMBL3938675 & 1641839 & 8.301 & 8.2395 & TST & \\
\hline CHEMBL3971568 & 1641839 & 7.6383 & 7.6732 & TRN & \\
\hline CHEMBL3944969 & 1641839 & 7.8539 & 7.9787 & TST & \\
\hline CHEMBL3898489 & 1641839 & 7.4559 & 7.4559 & TRN & \\
\hline CHEMBL3946027 & 1641839 & 7.8239 & 7.9679 & TRN & \\
\hline CHEMBL3961703 & 1641839 & 6.7055 & \multicolumn{2}{|c|}{7.4510000000000005} & TST \\
\hline CHEMBL3916319 & 1641839 & 8.0458 & 7.9723 & TRN & \\
\hline CHEMBL3895147 & 1641839 & 8.2218 & 8.1718 & TRN & \\
\hline CHEMBL3970660 & 1641839 & 8.301 & 8.2335 & TRN & \\
\hline CHEMBL3923841 & 1641839 & 7.5376 & 7.6296 & TRN & \\
\hline CHEMBL3941988 & 1641839 & 7.7212 & 7.7492 & TRN & \\
\hline CHEMBL3971102 & 1641839 & 8.301 & 7.9108 & TRN & \\
\hline CHEMBL3954716 & 1641839 & 7.7447 & 7.7372 & TRN & \\
\hline CHEMBL3965362 & 1641839 & 6.0969 & 7.4997 & TST & \\
\hline CHEMBL3933008 & 1641839 & 8.0969 & 8.1703 & TRN & \\
\hline CHEMBL3895826 & 1641839 & 7.7447 & 8.1911 & TST & \\
\hline CHEMBL3927563 & 1641839 & 8.301 & 8.0311 & TST & \\
\hline CHEMBL3925726 & 1641839 & 8.0458 & 8.0651 & TRN & \\
\hline CHEMBL3978643 & 1641839 & 8.0 & 7.89 & TRN & \\
\hline CHEMBL3927335 & 1641839 & 7.699 & 7.7719 & TRN & \\
\hline CHEMBL 3895903 & 1641839 & 7.585 & 7.4478 & TRN & \\
\hline CHEMBL3942160 & 1641839 & 8.1549 & 8.279 & TRN & \\
\hline CHEMBL 3938288 & 1641839 & 7.9208 & 7.9977 & TRN & \\
\hline CHEMBL3913846 & 1641839 & 8.5229 & 8.6156 & TRN & \\
\hline CHEMBL3952517 & 1641839 & 6.4789 & \multicolumn{2}{|c|}{6.6739999999999995} & TRN \\
\hline CHEMBL3971757 & 1641839 & 7.8239 & 7.9725 & TRN & \\
\hline CHEMBL3974503 & 1641839 & 7.6576 & 7.7261 & TRN & \\
\hline CHEMBL3979835 & 1641839 & 8.301 & 8.124 & TRN & \\
\hline CHEMBL3918135 & 1641839 & 7.6576 & 7.4912 & TRN & \\
\hline CHEMBL 3727441 & 1537610 & 5.9957 & 5.8905 & TRN & \\
\hline CHEMBL 3728118 & 1537610 & 5.9957 & 6.4442 & TRN & \\
\hline CHEMBL3727633 & 1537610 & 6.9957 & 6.3189 & TRN & \\
\hline CHEMBL3730039 & 1537610 & 8.0 & \multicolumn{2}{|c|}{7.747999999999999} & TRN \\
\hline CHEMBL 3732372 & 1537610 & 5.9957 & 6.606 & TRN & \\
\hline CHEMBL3730249 & 1537610 & 6.9957 & 7.3528 & TRN & \\
\hline CHEMBL3731643 & 1537610 & 6.9957 & 7.2314 & TRN & \\
\hline CHEMBL3727825 & 1537610 & 6.9957 & 6.3225 & TST & \\
\hline CHEMBL3727867 & 1537610 & 8.0 & 7.4539 & TRN & \\
\hline CHEMBL3729444 & 1537610 & 5.9957 & 6.0603 & TRN & \\
\hline CHEMBL3730361 & 1537610 & 5.9957 & 4.6631 & TST & \\
\hline CHEMBL3728608 & 1537610 & 6.9957 & 7.4349 & TRN & \\
\hline CHEMBL3728835 & 1537610 & 6.9957 & 6.974 & TRN & \\
\hline CHEMBL 3728057 & 1537610 & 6.9957 & 6.3326 & TRN & \\
\hline CHEMBL3731497 & 1537610 & 6.9957 & 6.8207 & TRN & \\
\hline CHEMBL3729994 & 1537610 & 6.9957 & 7.53 & TRN & \\
\hline
\end{tabular}




\begin{tabular}{|c|c|c|c|c|c|}
\hline \multicolumn{6}{|c|}{ Supplemental Table S2.txt } \\
\hline CHEMBL 3731747 & 1537610 & 8.0 & 7.4298 & TRN & \\
\hline CHEMBL3731974 & 1537610 & 8.0 & 7.6898 & TRN & \\
\hline CHEMBL3729685 & 1537610 & 8.0 & 7.8936 & TRN & \\
\hline CHEMBL3732749 & 1537610 & 6.9957 & 7.3024 & TRN & \\
\hline CHEMBL3728569 & 1537610 & 6.9957 & 6.9636 & TRN & \\
\hline CHEMBL3731336 & 1537610 & 5.9957 & 5.056 & TRN & \\
\hline CHEMBL3727658 & 1537610 & 8.0 & 7.4095 & TRN & \\
\hline CHEMBL 3732945 & 1537610 & 6.9957 & 7.0479 & TRN & \\
\hline CHEMBL 3728780 & 1537610 & 6.9957 & 7.2999 & TRN & \\
\hline CHEMBL3729200 & 1537610 & 6.9957 & 6.6937 & TRN & \\
\hline CHEMBL 3733027 & 1537610 & 6.9957 & 7.5932 & TRN & \\
\hline CHEMBL3733328 & 1537610 & 5.9957 & 6.0549 & TRN & \\
\hline CHEMBL3732233 & 1537610 & 3.9996 & 4.5663 & TRN & \\
\hline CHEMBL 3728504 & 1537610 & 6.9957 & 6.9502 & TRN & \\
\hline CHEMBL3729357 & 1537610 & 3.9996 & 4.8427 & TRN & \\
\hline CHEMBL3727585 & 1537610 & 5.9957 & 6.1474 & TRN & \\
\hline CHEMBL3728233 & 1537610 & 8.0 & 7.3365 & TRN & \\
\hline CHEMBL 3730300 & 1537610 & 3.9996 & 4.03600 & 00000000005 & TRN \\
\hline CHEMBL3732710 & 1537610 & 8.0 & 7.4961 & TRN & \\
\hline CHEMBL3732015 & 1537610 & 6.9957 & 7.4891 & TRN & \\
\hline CHEMBL3729895 & 1537610 & 3.9996 & 3.657 & TRN & \\
\hline CHEMBL 3730284 & 1537610 & 6.9957 & 7.3627 & TRN & \\
\hline CHEMBL 3732520 & 1537610 & 5.9957 & 6.518 & TRN & \\
\hline CHEMBL3728514 & 1537610 & 6.9957 & 7.7235 & TRN & \\
\hline CHEMBL3732867 & 1537610 & 8.0 & 7.4822 & TRN & \\
\hline CHEMBL3731923 & 1537610 & 8.0 & 7.407 & TRN & \\
\hline CHEMBL3729439 & 1537610 & 6.9957 & 6.749 & TST & \\
\hline CHEMBL 3732458 & 1537610 & 5.9957 & 5.87200 & 2000000001 & TRN \\
\hline CHEMBL 3727751 & 1537610 & 8.0 & 7.4186 & TRN & \\
\hline CHEMBL3732451 & 1537610 & 6.9957 & 6.4484 & TRN & \\
\hline CHEMBL3730602 & 1537610 & 6.9957 & 5.1636 & TST & \\
\hline CHEMBL3730000 & 1537610 & 6.9957 & 6.4203 & TRN & \\
\hline CHEMBL3729064 & 1537610 & 8.0 & 7.9371 & TRN & \\
\hline CHEMBL3728469 & 1537610 & 6.9957 & 7.2182 & TRN & \\
\hline CHEMBL3729041 & 1537610 & 8.0 & 7.2837 & TRN & \\
\hline CHEMBL3731897 & 1537610 & 8.0 & 7.6573 & TRN & \\
\hline CHEMBL3728331 & 1537610 & 6.9957 & 7.13 & TST & \\
\hline CHEMBL3732495 & 1537610 & 8.0 & 7.1466 & TRN & \\
\hline CHEMBL3731627 & 1537610 & 5.9957 & 5.7679 & TRN & \\
\hline CHEMBL3727458 & 1537610 & 8.0 & 7.1531 & TRN & \\
\hline CHEMBL3730439 & 1537610 & 3.9996 & 4.5093 & TRN & \\
\hline CHEMBL3733045 & 1537610 & 8.0 & 7.2961 & TRN & \\
\hline CHEMBL3731444 & 1537610 & 6.9957 & 6.6758 & TRN & \\
\hline CHEMBL3731155 & 1537610 & 6.9957 & 6.5522 & TRN & \\
\hline CHEMBL3730617 & 1537610 & 5.9957 & 5.4627 & TRN & \\
\hline CHEMBL 3731856 & 1537610 & 6.9957 & 7.5062 & TRN & \\
\hline CHEMBL3732664 & 1537610 & 3.9996 & 4.4816 & TST & \\
\hline CHEMBL3732299 & 1537610 & 8.0 & 7.50200 & 2000000001 & TRN \\
\hline & & & & 846 & \\
\hline
\end{tabular}


Supplemental Table S2.txt

\begin{tabular}{|c|c|c|c|c|c|}
\hline CHEMBL3729290 & 1537610 & 6.9957 & 6.4801 & TRN & \\
\hline CHEMBL3732435 & 1537610 & 8.0 & 7.1441 & TRN & \\
\hline CHEMBL3731824 & 1537610 & 5.9957 & 6.0921 & TRN & \\
\hline CHEMBL3730872 & 1537610 & 5.9957 & 6.2623 & TRN & \\
\hline CHEMBL3730388 & 1537610 & 8.0 & 7.5879 & TRN & \\
\hline CHEMBL3730678 & 1537610 & 6.9957 & 6.4507 & TRN & \\
\hline CHEMBL3731650 & 1537610 & 3.9996 & 5.2167 & TRN & \\
\hline CHEMBL3732526 & 1537610 & 6.9957 & 7.1849 & TRN & \\
\hline CHEMBL3731819 & 1537610 & 6.9957 & 6.7712 & TRN & \\
\hline CHEMBL3732251 & 1537610 & 6.9957 & 7.6131 & TRN & \\
\hline CHEMBL3733051 & 1537610 & 6.9957 & 7.4715 & TRN & \\
\hline CHEMBL3730288 & 1537610 & 8.0 & 7.3195 & TST & \\
\hline CHEMBL3727953 & 1537610 & 3.9996 & 4.3987 & TRN & \\
\hline CHEMBL3729451 & 1537610 & 5.9957 & 5.9792 & TRN & \\
\hline CHEMBL3731350 & 1537610 & 3.9996 & 4.2513 & TRN & \\
\hline CHEMBL3732065 & 1537610 & 8.0 & 7.3761 & TRN & \\
\hline CHEMBL3727977 & 1537610 & 6.9957 & 7.2334 & TRN & \\
\hline CHEMBL3730613 & 1537610 & 6.9957 & \multicolumn{2}{|c|}{7.377000000000001} & TRN \\
\hline CHEMBL3727671 & 1537610 & 6.9957 & 6.6318 & TRN & \\
\hline CHEMBL 3732200 & 1537610 & 3.9996 & 3.8605 & TRN & \\
\hline CHEMBL3727939 & 1537610 & 3.9996 & 5.1791 & TRN & \\
\hline CHEMBL 3731224 & 1537610 & 6.9957 & 7.5104 & TRN & \\
\hline CHEMBL3729745 & 1537610 & 6.9957 & 7.4043 & TRN & \\
\hline CHEMBL3729924 & 1537610 & 3.9996 & 2.9463 & TRN & \\
\hline CHEMBL3731556 & 1537610 & 6.9957 & 6.7293 & TRN & \\
\hline CHEMBL3730681 & 1537610 & 6.9957 & 5.6301 & TRN & \\
\hline CHEMBL 3728941 & 1537610 & 5.9957 & 6.4964 & TRN & \\
\hline CHEMBL3729037 & 1537610 & 6.9957 & 7.6021 & TRN & \\
\hline CHEMBL3731496 & 1537610 & 8.0 & 6.1658 & TST & \\
\hline CHEMBL3728225 & 1537610 & 8.0 & 7.2614 & TST & \\
\hline CHEMBL3731935 & 1537610 & 6.9957 & 7.3513 & TST & \\
\hline CHEMBL3728151 & 1537610 & 8.0 & 7.9102 & TRN & \\
\hline CHEMBL3732399 & 1537610 & 6.9957 & \multicolumn{2}{|c|}{7.122000000000001} & TRN \\
\hline CHEMBL3731329 & 1537610 & 3.9996 & 4.6995 & TST & \\
\hline CHEMBL3731645 & 1537610 & 6.9957 & 7.4308 & TRN & \\
\hline CHEMBL3732331 & 1537610 & 5.9957 & 5.0448 & TST & \\
\hline CHEMBL3729310 & 1537610 & 5.9957 & 6.3585 & TST & \\
\hline CHEMBL3731941 & 1537610 & 6.9957 & 6.1728 & TRN & \\
\hline CHEMBL3729790 & 1537610 & 5.9957 & 6.2042 & TRN & \\
\hline CHEMBL3733146 & 1537610 & 5.9957 & 5.9081 & TRN & \\
\hline CHEMBL3732176 & 1537610 & 8.0 & 7.3648 & TRN & \\
\hline CHEMBL3732598 & 1537610 & 6.9957 & 7.4094 & TRN & \\
\hline CHEMBL3728269 & 1537610 & 6.9957 & 7.1459 & TRN & \\
\hline CHEMBL3731218 & 1537610 & 6.9957 & 6.9681 & TRN & \\
\hline CHEMBL3728730 & 1537610 & 8.0 & 7.6749 & TST & \\
\hline CHEMBL3728399 & 1537610 & 6.9957 & 7.0007 & TST & \\
\hline CHEMBL3730831 & 1537610 & 3.9996 & 2.0023 & TST & \\
\hline CHEMBL 3732143 & 1537610 & 8.0 & 7.5303 & TRN & \\
\hline
\end{tabular}


Supplemental Table S2.txt

\begin{tabular}{|c|c|c|c|c|c|}
\hline CHEMBL3730101 & 1537610 & 8.0 & 7.4116 & TRN & \\
\hline CHEMBL3729860 & 1537610 & 6.9957 & 7.3187 & TRN & \\
\hline CHEMBL3732321 & 1537610 & 3.9996 & 5.3449 & TRN & \\
\hline CHEMBL3731188 & 1537610 & 8.0 & 7.2976 & TRN & \\
\hline CHEMBL3732582 & 1537610 & 3.9996 & 4.2944 & TRN & \\
\hline CHEMBL3729679 & 1537610 & 5.9957 & 6.2566 & TRN & \\
\hline CHEMBL3730232 & 1537610 & 6.9957 & 7.7272 & TRN & \\
\hline CHEMBL3731301 & 1537610 & 5.9957 & 6.1567 & TRN & \\
\hline CHEMBL3731412 & 1537610 & 3.9996 & 2.3539 & TRN & \\
\hline CHEMBL3733231 & 1537610 & 6.9957 & 6.5906 & TRN & \\
\hline CHEMBL3728131 & 1537610 & 6.9957 & 7.4398 & TRN & \\
\hline CHEMBL3733291 & 1537610 & 8.0 & 7.7719 & TRN & \\
\hline CHEMBL3728929 & 1537610 & 5.9957 & 6.4189 & TRN & \\
\hline CHEMBL3730256 & 1537610 & 3.9996 & 4.853 & TST & \\
\hline CHEMBL3732950 & 1537610 & 3.9996 & 2.4287 & TST & \\
\hline CHEMBL3730068 & 1537610 & 6.9957 & 6.6993 & TRN & \\
\hline CHEMBL3730648 & 1537610 & 5.9957 & 5.4706 & TRN & \\
\hline CHEMBL 3731601 & 1537610 & 6.9957 & 6.3517 & TRN & \\
\hline CHEMBL3728532 & 1537610 & 6.9957 & 7.23799 & 99999999995 & TRN \\
\hline CHEMBL3729188 & 1537610 & 6.9957 & 6.7422 & TRN & \\
\hline CHEMBL3727855 & 1537610 & 8.0 & 7.71200 & 0000000001 & TRN \\
\hline CHEMBL3731243 & 1537610 & 6.9957 & 7.2827 & TRN & \\
\hline CHEMBL3730769 & 1537610 & 6.9957 & 6.9379 & TRN & \\
\hline CHEMBL3731502 & 1537610 & 8.0 & 7.2519 & TRN & \\
\hline CHEMBL3728183 & 1537610 & 5.9957 & 6.7029 & TRN & \\
\hline CHEMBL3730707 & 1537610 & 6.9957 & 6.6321 & TST & \\
\hline CHEMBL3731459 & 1537610 & 3.9996 & 4.3995 & TRN & \\
\hline CHEMBL3729836 & 1537610 & 8.0 & 7.4642 & TRN & \\
\hline CHEMBL3728465 & 1537610 & 6.9957 & 7.5695 & TRN & \\
\hline CHEMBL3728572 & 1537610 & 3.9996 & 5.9039 & TRN & \\
\hline CHEMBL3731863 & 1537610 & 8.0 & 7.3599 & TRN & \\
\hline CHEMBL3729336 & 1537610 & 6.9957 & 7.0566 & TRN & \\
\hline CHEMBL3728102 & 1537610 & 5.9957 & 6.2107 & TST & \\
\hline CHEMBL3729452 & 1537610 & 5.9957 & 6.4132 & TRN & \\
\hline CHEMBL3733159 & 1537610 & 3.9996 & 4.6314 & TST & \\
\hline CHEMBL3729025 & 1537610 & 6.9957 & 7.2294 & TRN & \\
\hline CHEMBL3731482 & 1537610 & 6.9957 & 7.4668 & TRN & \\
\hline CHEMBL 3729744 & 1537610 & 8.0 & 7.5347 & TRN & \\
\hline CHEMBL3732174 & 1537610 & 5.9957 & 6.8184 & TRN & \\
\hline CHEMBL3731425 & 1537610 & 5.9957 & 5.7422 & TRN & \\
\hline CHEMBL 3727787 & 1537610 & 5.9957 & 6.3126 & TRN & \\
\hline CHEMBL3729689 & 1537610 & 8.0 & 7.5819 & TRN & \\
\hline CHEMBL 3728648 & 1537610 & 6.9957 & 7.1523 & TRN & \\
\hline CHEMBL3729893 & 1537610 & 6.9957 & \multicolumn{2}{|c|}{7.5329999999999995} & TRN \\
\hline CHEMBL3729954 & 1537610 & 6.9957 & 6.6344 & TRN & \\
\hline CHEMBL3728909 & 1537610 & 6.9957 & 7.0144 & TRN & \\
\hline CHEMBL3731909 & 1537610 & 8.0 & \multicolumn{2}{|c|}{7.452999999999999} & TRN \\
\hline CHEMBL 3729727 & 1537610 & 8.0 & 7.4216 & TRN & \\
\hline
\end{tabular}


Supplemental Table S2.txt

\begin{tabular}{|c|c|c|c|c|}
\hline HEMBL & & & 2 & TS \\
\hline HFMRI 3727837 & 537610 & 8.0 & 72504 & \\
\hline HEMBL & & 996 & 1576 & \\
\hline AEMBL3728124 & 37610 & 8.0 & 3818 & \\
\hline HEMBL3731479 & 537610 & 5.9957 & 6025 & \\
\hline HEMBL & 37610 & 6.9957 & 1796 & \\
\hline AEMBL & 610 & 9957 & 2695 & \\
\hline HEMBL3729906 & 537610 & 8.0 & 5398 & \\
\hline HEMBL3729620 & 537610 & 6.9957 & .5255 & \\
\hline HEMBL3729074 & 537610 & 5.9957 & .9268 & \\
\hline HEMBL37 & 37610 & 8.0 & .7447 & \\
\hline HEMBL & & 57 & .4978 & \\
\hline HEMBL3 & 610 & 3.9996 & 4661 & \\
\hline HEMBL37 & 610 & 8.0 & 398 & \\
\hline HEMBL37 & 610 & 5.9957 & 4387 & \\
\hline HEMBL3 & 10 & 8. & 102 & \\
\hline AEMBL. & 510 & 6 & 211 & \\
\hline HEMBL3 & 610 & 957 & 211 & \\
\hline HEMBL37 & 510 & 957 & 5891 & \\
\hline AEMBL37 & 510 & 8.0 & 7228 & \\
\hline AEMBL & 10 & 957 & 3362 & RN \\
\hline AEMBL. & & 57 & 61 & \\
\hline HEMBL3 & 510 & 957 & 2033 & \\
\hline AEMBL3 & & 957 & 122 & \\
\hline AEMBL3 & 10 & 957 & 7568 & IRN \\
\hline IEMBL3 & & 957 & 989 & $R \Lambda$ \\
\hline AEM & & 996 & & \\
\hline 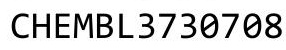 & & 8. & 941 & \\
\hline AEMBL3 & & 5. & & $\mid$ \\
\hline AEMBL37 & 10 & 6.9957 & 736 & RN \\
\hline AFMBL: & 10 & 57 & 96 & RN \\
\hline 3 & & 57 & & \\
\hline & & & 206 & RN \\
\hline AEMBL37 & & 6.995 & 36 & 「RN \\
\hline HEMBL37 & 510 & & 3687 & 「RN \\
\hline AEMBI 3 & 10 & 8 & 132 & RN \\
\hline & & & & RN \\
\hline HEMBL3 & & & & RN \\
\hline AEMBL37 & 10 & 3.9996 & 175 & TST \\
\hline IEMBL3 & 10 & 6.9957 & 338 & 「RN \\
\hline HEMBL3 & & 5.9957 & 548 & \\
\hline & & 6.9957 & 7.0248 & RN \\
\hline HEMBL3 & & 6.9957 & 5858 & RN \\
\hline AEMBL3 & 510 & 6.9957 & 25 & TS \\
\hline MBL3 & & 8 . & 247 & RN \\
\hline HEMBL 37 & & .9996 & 4.5638 & \\
\hline CHEMBL37 & 537610 & .9957 & 7.1628 & \\
\hline CHEMBL3729712 & 1537610 & 5.9957 & 5.8893 & \\
\hline
\end{tabular}


Supplemental Table S2.txt

\begin{tabular}{|c|c|c|c|c|}
\hline HEM & 537610 & & & \\
\hline & 537610 & 5.9957 & & \\
\hline 11 & 510 & 957 & 75 & \\
\hline AEMBL & 37610 & 8.0 & & \\
\hline HEMBL3730448 & 537610 & 9996 & נ05 & \\
\hline HEMBL3 & 537610 & 957 & 7093 & \\
\hline HEMBL & 37610 & 957 & 7419 & \\
\hline AEMBL3 & 610 & 957 & & ל \\
\hline HEMBL3731920 & 537610 & 3.9996 & 6682 & \\
\hline HEMBL3732101 & 537610 & 6.9957 & 6057 & \\
\hline AEMBL & 610 & 996 & & \\
\hline AEMBL & 10 & 957 & 3617 & RN \\
\hline HEMBL. & & 957 & & \\
\hline HEMBL3 & 537610 & 5.9957 & 5395 & \\
\hline AEMBL3 & 610 & 996 & & ГST \\
\hline HEMBL; & 10 & 8 & 4239 & RN \\
\hline HEMBL & & 957 & 916 & KIV \\
\hline HEMBL. & 10 & 996 & 564 & RN \\
\hline HEMBL3 & 510 & 8 . & 466 & \\
\hline HEMBL3 & & 57 & & \\
\hline HEMBL & 10 & & 3881 & SI \\
\hline HEM & & & 055 & RN \\
\hline HEMBL & 10 & 957 & 1312 & RN \\
\hline HEMBL3 & 10 & 8. & 341 & I RIV \\
\hline HEMBL3 & & 5 & 35 & IRN \\
\hline HEMBL; & & & 09 & 「RN \\
\hline HEME & 10 & & & RN \\
\hline 6 & 10 & & & TST \\
\hline HEMBL3 & & & & IRIN \\
\hline AEMBL3 & 10 & 6. & 048 & TRN \\
\hline AEMBL & 10 & 57 & 93 & 「RN \\
\hline HFM & & & & 「RN \\
\hline נ & & & & TST \\
\hline HEMBL3 & & 6.99 & & 「RN \\
\hline HEMBL3 & 510 & & 936 & ГRN \\
\hline JEMP & 10 & 9 & 382 & TRN \\
\hline 5 & 10 & & 35 & ГRN \\
\hline HEMBL3 & & 6.995 & & TRN \\
\hline HEMBL3 & 510 & & 203 & $\Gamma R$ \\
\hline TIL & & & 89 & 「RN \\
\hline HEMBL3 & & קו & 395 & TRN \\
\hline & 10 & 957 & 598 & ST \\
\hline HEMBL3 & 610 & 3.9996 & 4739 & ГRN \\
\hline HEMBL3 & 510 & 8. & 979 & TR \\
\hline $3+$ & & 8 & 62 & $\mathrm{~N}$ \\
\hline HEMBL & & 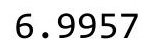 & & \\
\hline CHEMBL3 & 537610 & 6.9957 & 7.6868 & \\
\hline CHEMBL3730320 & 1537610 & 6.9957 & 6.4339 & 13 \\
\hline
\end{tabular}

Page 8465 
Supplemental Table S2.txt

\begin{tabular}{|c|c|c|c|c|}
\hline$\theta$ & 37610 & & & \\
\hline & 537610 & 6.9957 & & \\
\hline 189 & 610 & 957 & & \\
\hline IEMBL & 37610 & & & \\
\hline AEMBL3733007 & 537610 & 957 & 4115 & \\
\hline HEMBL3 & 537610 & 6.9957 & .4334 & \\
\hline 52 & 610 & & 948 & \\
\hline AEMBL & 610 & & & \\
\hline HEMBL3732412 & 537610 & 8.0 & . 7227 & \\
\hline HEMBL3728122 & 537610 & 6.9957 & 2173 & \\
\hline HEMBL3 & 537610 & & 5296 & \\
\hline IEME & 10 & & 9216 & \\
\hline HEMBL; & 10 & & 816 & \\
\hline HEMBL3 & 537610 & 6 . & 4651 & \\
\hline AEMBL3 & 610 & 957 & & \\
\hline AEMBL. & 10 & 6 & 176 & \\
\hline AEMBL & & & 882 & \\
\hline AEMBL. & 10 & 957 & 7864 & \\
\hline HFMBI 3 & 510 & 957 & 3577 & \\
\hline AEMBL3 & 10 & 957 & 7774 & I nIV \\
\hline HEMBL & 10 & 957 & 727 & ГRN \\
\hline HEM & & & 39 & 促 \\
\hline HEMBL & 10 & & 073 & \\
\hline 723 & & & 4558 & I RIV \\
\hline AEMBL & 10 & & 5036 & I RI \\
\hline HEMBL & & & 9441 & ST \\
\hline HEME & & 0 & .77 & ST \\
\hline 99 & & 3 & 4.3439 & \\
\hline AEMBL & & & & |S| \\
\hline AEMBL3 & 10 & 5.9957 & 4204 & TST \\
\hline AEMBL & 10 & & 571 & IST \\
\hline JEN $>>$ & & & 96 & \\
\hline & & & & 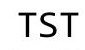 \\
\hline HEMBL3 & & & 1624 & TST \\
\hline AEMBL3 & 10 & 6. & 382 & ГST \\
\hline IFM & & 7 & 588 & ГST \\
\hline 1 & & & & \\
\hline HEMBL3 & & & 6.2635 & TST \\
\hline HEMBL3 & 10 & 957 & 25 & TS \\
\hline 0 & & $\gamma$ & 751 & IST \\
\hline HEMBL; & & 57 & 666 & TST \\
\hline HEMBL; & & 6.9957 & 176 & TST \\
\hline HEMBL3 & 537610 & 8.0 & 1945 & TS \\
\hline HEMBL3 & 10 & 6.9957 & & $\pi s^{2}$ \\
\hline CHEMPI 2 & & 0 & & IS \\
\hline HEMBL3 & & ולבלה. & .0872 & \\
\hline CHEMBL3 & .537610 & .9957 & 5.8788 & IST \\
\hline CHEMBL3729108 & 1537610 & 6.9957 & 7.0808 & - \\
\hline
\end{tabular}

Page 8466 


\begin{tabular}{|c|c|c|c|c|}
\hline \multicolumn{5}{|c|}{ Supplemental Table S2.txt } \\
\hline CHEMBL 3733360 & 1537610 & 8.0 & 7.6735 & TST \\
\hline CHEMBL 3727870 & 1537610 & 8.0 & 7.5894 & TST \\
\hline CHEMBL3732905 & 1537610 & 6.9957 & 6.6168 & TST \\
\hline CHEMBL 3729684 & 1537610 & 6.9957 & 7.2989 & TST \\
\hline CHEMBL3733161 & 1537610 & 8.0 & 7.5541 & TST \\
\hline CHEMBL 3732830 & 1537610 & 6.9957 & 7.0104 & TST \\
\hline CHEMBL3728962 & 1537610 & 5.9957 & 6.666 & TST \\
\hline CHEMBL 3731238 & 1537610 & 6.9957 & 6.5664 & TST \\
\hline CHEMBL 3733226 & 1537610 & 6.9957 & 7.2324 & TST \\
\hline CHEMBL3731762 & 1537610 & 5.9957 & 5.7956 & TST \\
\hline CHEMBL3731565 & 1537610 & 8.0 & 7.7521 & TST \\
\hline CHEMBL3732816 & 1537610 & 3.9996 & 2.8299 & TST \\
\hline CHEMBL3729081 & 1537610 & 6.9957 & 6.9181 & TST \\
\hline CHEMBL 3727727 & 1537610 & 3.9996 & 4.626 & TST \\
\hline CHEMBL3729011 & 1537610 & 6.9957 & 7.7162 & TST \\
\hline CHEMBL3731365 & 1537610 & 3.9996 & 4.772 & TST \\
\hline CHEMBL3731821 & 1537610 & 6.9957 & 7.1968 & TST \\
\hline CHEMBL364976 & 305065 & 3.0 & 3.5121 & TRN \\
\hline CHEMBL193427 & 305065 & 7.1549 & 7.5126 & TRN \\
\hline CHEMBL195243 & 305065 & 4.699 & 4.9207 & TRN \\
\hline CHEMBL195087 & 305065 & 4.3565 & 4.6584 & TRN \\
\hline CHEMBL 373120 & 305065 & 5.8539 & 5.5105 & TST \\
\hline CHEMBL193480 & 305065 & 4.5528 & 4.6394 & TRN \\
\hline CHEMBL 370081 & 305065 & 5.0269 & 4.7093 & TRN \\
\hline CHEMBL195310 & 305065 & 3.0 & 5.7946 & TST \\
\hline CHEMBL193403 & 305065 & 5.5086 & 6.0443 & TRN \\
\hline CHEMBL192108 & 305065 & 3.0 & 3.1087 & TRN \\
\hline CHEMBL195576 & 305065 & 3.0 & 3.4378 & TRN \\
\hline CHEMBL193549 & 305065 & 5.4089 & 5.3104 & TRN \\
\hline CHEMBL194131 & 305065 & 4.5686 & 4.3825 & TRN \\
\hline CHEMBL195256 & 305065 & 5.2596 & 6.0056 & TRN \\
\hline CHEMBL193981 & 305065 & 5.1612 & 6.1651 & TRN \\
\hline CHEMBL363165 & 305065 & 3.0 & 4.6196 & TRN \\
\hline CHEMBL193525 & 305065 & 4.6576 & 4.4641 & TRN \\
\hline CHEMBL193630 & 305065 & 5.585 & 5.9567 & TST \\
\hline CHEMBL192054 & 305065 & 5.1612 & 4.409 & TRN \\
\hline CHEMBL 371410 & 305065 & 5.8861 & 5.3954 & TRN \\
\hline CHEMBL 373305 & 305065 & 6.2366 & 5.3155 & TRN \\
\hline CHEMBL 366197 & 305065 & 7.5229 & 6.6488 & TRN \\
\hline CHEMBL425017 & 305065 & 4.8861 & 4.5504 & TRN \\
\hline CHEMBL370326 & 305065 & 5.0605 & 4.7259 & TRN \\
\hline CHEMBL 371388 & 305065 & 4.9208 & 5.1237 & TRN \\
\hline CHEMBL194116 & 305065 & 5.3979 & 5.2825 & TRN \\
\hline CHEMBL 364668 & 305065 & 4.699 & 4.2594 & TST \\
\hline CHEMBL 364460 & 305065 & 4.6021 & 3.8484 & TRN \\
\hline CHEMBL195476 & 305065 & 6.699 & 6.4134 & TRN \\
\hline CHEMBL195492 & 305065 & 4.3279 & 4.7155 & TRN \\
\hline CHEMBL363178 & 305065 & 4.1805 & 4.518 & TRN \\
\hline
\end{tabular}




\begin{tabular}{|c|c|c|c|c|c|c|}
\hline & & & & & & \\
\hline CHEMBL195798 & 305065 & 5.8861 & 5.9592 & TST & & \\
\hline CHEMBL194178 & 305065 & 5.8239 & 4.3537 & TST & & \\
\hline CHEMBL371573 & 305065 & 6.5086 & 6.5501 & TRN & & \\
\hline CHEMBL195565 & 305065 & 3.0 & 3.4162 & TRN & & \\
\hline CHEMBL370679 & 305065 & 7.3979 & 5.3011 & TRN & & \\
\hline CHEMBL364072 & 305065 & 5.2218 & 5.5392 & TRN & & \\
\hline CHEMBL193508 & 305065 & 4.3188 & 4.303 & TRN & & \\
\hline CHEMBL363563 & 305065 & 6.1805 & 6.2833 & TST & & \\
\hline CHEMBL364301 & 305065 & 5.2518 & 5.2085 & TRN & & \\
\hline CHEMBL195772 & 305065 & 4.7696 & 5.0429 & TRN & & \\
\hline CHEMBL191813 & 305065 & 4.8239 & 5.0398 & TST & & \\
\hline CHEMBL364017 & 305065 & 5.5229 & 5.1347 & TRN & & \\
\hline CHEMBL425915 & 305065 & 4.9586 & 6.09 & TST & & \\
\hline CHEMBL188442 & 305065 & 7.0 & 5.3546 & TST & & \\
\hline CHEMBL194380 & 305065 & 5.7447 & 5.1864 & TST & & \\
\hline CHEMBL372498 & 305065 & 4.1367 & 4.5386 & TST & & \\
\hline CHEMBL193520 & 305065 & 3.0 & 3.4137 & TRN & & \\
\hline CHEMBL372060 & 305065 & 5.8861 & 6.3779 & TRN & & \\
\hline CHEMBL193049 & 305065 & 5.1739 & 4.2531 & TRN & & \\
\hline CHEMBL194438 & 305065 & 6.699 & 6.755 & TST & & \\
\hline CHEMBL365127 & 305065 & 5.284 & 6.1803 & TST & & \\
\hline CHEMBL194064 & 305065 & 5.3372 & 5.6471 & TRN & & \\
\hline CHEMBL3903273 & 1640886 & 5.0 & 6.3427 & TST & & \\
\hline CHEMBL3966732 & 1640886 & 6.0 & 6.3142 & TRN & & \\
\hline CHEMBL3918076 & 1640886 & 9.301 & 9.5104 & TRN & & \\
\hline CHEMBL3927505 & 1640886 & 7.9626 & 8.6376 & TRN & & \\
\hline CHEMBL3923683 & 1640886 & 6.0 & 6.1609 & TRN & & \\
\hline CHEMBL3919646 & 1640886 & 6.0 & 6.2039 & TRN & & \\
\hline CHEMBL 3932460 & 1640886 & 9.301 & 9.2287 & TRN & & \\
\hline CHEMBL3940201 & 1640886 & 6.0 & 6.487 & TST & & \\
\hline CHEMBL 3957474 & 1640886 & 8.041 & 8.334 & TRN & & \\
\hline CHEMBL3941443 & 1640886 & 6.9586 & 7.4403 & TRN & & \\
\hline CHEMBL3952938 & 1640886 & 7.9747 & 8.1095 & TST & & \\
\hline CHEMBL3949500 & 1640886 & 7.4634 & 7.4563 & TST & & \\
\hline CHEMBL3922101 & 1640886 & 6.7328 & 7.6313 & TST & & \\
\hline CHEMBL3981694 & 1640886 & 5.0 & 6.5488 & TST & & \\
\hline CHEMBL3931386 & 1640886 & 8.5229 & 8.5138 & TRN & & \\
\hline CHEMBL3965074 & 1640886 & 6.0 & 5.8152 & TRN & & \\
\hline CHEMBL3900646 & 1640886 & 6.0 & 6.3249 & TRN & & \\
\hline CHEMBL3921064 & 1640886 & 8.1871 & 7.4275 & TRN & & \\
\hline CHEMBL 3890530 & 1640886 & 9.3979 & 9.2654 & TRN & & \\
\hline CHEMBL3944210 & 1640886 & 5.0 & 5.7818 & TST & & \\
\hline CHEMBL3928490 & 1640886 & 5.0 & 5.6202 & TRN & & \\
\hline CHEMBL3912242 & 1640886 & 7.5086 & 7.8362 & TRN & & \\
\hline CHEMBL 3914834 & 1640886 & 7.45100 & 00000000 & 005 & 7.6586 & TST \\
\hline CHEMBL 3936842 & 1640886 & 6.8996 & 7.1739 & TRN & & \\
\hline CHEMBL3924011 & 1640886 & 7.8097 & 7.9697 & TST & & \\
\hline CHEMBL3919837 & 1640886 & 7.5157 & 7.9191 & TST & & \\
\hline
\end{tabular}


Supplemental Table S2.txt

\begin{tabular}{|c|c|c|c|c|c|}
\hline CHEMBL3914768 & 1640886 & 5.0 & 5.0182 & TRN & \\
\hline CHEMBL3920197 & 1640886 & 7.5229 & 7.3064 & TRN & \\
\hline CHEMBL3928216 & 1640886 & 9.3979 & 8.6429 & TRN & \\
\hline CHEMBL 3974415 & 1640886 & 8.0177 & 7.9604 & TRN & \\
\hline CHEMBL 3893193 & 1640886 & 8.4949 & 8.5874 & TRN & \\
\hline CHEMBL 3959100 & 1640886 & 6.7959 & 6.9192 & TRN & \\
\hline CHEMBL3916248 & 1640886 & 8.2757 & 8.5678 & TRN & \\
\hline CHEMBL3905239 & 1640886 & 7.9208 & 8.1567 & TRN & \\
\hline CHEMBL 3937423 & 1640886 & 8.1938 & 8.0888 & TRN & \\
\hline CHEMBL3947580 & 1640886 & 8.4089 & 8.3215 & TST & \\
\hline CHEMBL 3930148 & 1640886 & 6.0 & 8.0046 & TRN & \\
\hline CHEMBL 3900795 & 1640886 & 6.0 & 5.7756 & TRN & \\
\hline CHEMBL3986154 & 1640886 & 9.301 & 9.0149 & TRN & \\
\hline CHEMBL 3902228 & 1640886 & 6.0 & 6.1785 & TRN & \\
\hline CHEMBL3970651 & 1640886 & 7.9586 & 7.7743 & TRN & \\
\hline CHEMBL 3924352 & 1640886 & 8.5229 & 7.6615 & TRN & \\
\hline CHEMBL3915354 & 1640886 & 7.1135 & 7.3855 & TRN & \\
\hline CHEMBL3892307 & 1640886 & 6.0 & 5.3663 & TRN & \\
\hline CHEMBL3950192 & 1640886 & 7.0044 & 7.24200 & 0000000001 & TRN \\
\hline CHEMBL3936992 & 1640886 & 9.2218 & 8.7431 & TRN & \\
\hline CHEMBL 3920733 & 1640886 & 8.585 & 8.7348 & TRN & \\
\hline CHEMBL 3914287 & 1640886 & 8.9586 & 9.0265 & TRN & \\
\hline CHEMBL3936320 & 1640886 & 10.0 & 9.8441 & TRN & \\
\hline CHEMBL3935874 & 1640886 & 6.8665 & 6.6829 & TRN & \\
\hline CHEMBL 3952051 & 1640886 & 6.1938 & 5.4955 & TRN & \\
\hline CHEMBL 3942827 & 1640886 & 8.8861 & 8.6647 & TRN & \\
\hline CHEMBL 3972742 & 1640886 & 7.1811 & 7.0668 & TRN & \\
\hline CHEMBL3982322 & 1640886 & 7.5686 & 7.8527 & TST & \\
\hline CHEMBL 3910008 & 1640886 & 8.5229 & 8.1355 & TRN & \\
\hline CHEMBL3969621 & 1640886 & 7.1325 & 6.9435 & TST & \\
\hline CHEMBL 3898611 & 1640886 & 6.0 & 5.7038 & TRN & \\
\hline CHEMBL3960752 & 1640886 & 6.8125 & 6.3799 & TRN & \\
\hline CHEMBL3902922 & 1640886 & 6.5513 & 6.9317 & TST & \\
\hline CHEMBL 3922469 & 1640886 & 8.699 & 8.302 & TRN & \\
\hline CHEMBL3937943 & 1640886 & 7.0044 & 7.4043 & TST & \\
\hline CHEMBL3973689 & 1640886 & 6.9172 & 7.6892 & TST & \\
\hline CHEMBL3904472 & 1640886 & 5.0 & 4.8841 & TRN & \\
\hline CHEMBL3963604 & 1640886 & 5.0 & 6.0837 & TST & \\
\hline CHEMBL3900463 & 1640886 & 8.8861 & 8.4657 & TRN & \\
\hline CHEMBL3951503 & 1640886 & 5.0 & 5.8258 & TRN & \\
\hline CHEMBL 29813 & 114300 & 3.7696 & 3.5926 & TRN & \\
\hline CHEMBL 27968 & 114300 & 1.8508 & 2.5376 & TST & \\
\hline CHEMBL28515 & 114300 & 3.2218 & 3.5041 & TRN & \\
\hline CHEMBL 282355 & 114300 & 3.2366 & 2.7098 & TST & \\
\hline CHEMBL 282153 & 114300 & 2.041 & 3.1763 & TRN & \\
\hline CHEMBL 286276 & 114300 & 2.8697 & 2.4875 & TRN & \\
\hline CHEMBL 282779 & 114300 & 1.8297 & 2.4319 & TRN & \\
\hline CHEMBL 28878 & 114300 & 3.4089 & 2.5967 & TRN & \\
\hline
\end{tabular}




\begin{tabular}{|c|c|c|c|c|c|}
\hline & & & 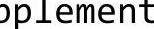 & 政 & \\
\hline CHEMBL28887 & 114300 & 3.2757 & 3.3519 & TRN & \\
\hline CHEMBL286990 & 114300 & 3.5086 & 3.5573 & TRN & \\
\hline CHEMBL286954 & 114300 & 2.7959 & 2.9901 & TRN & \\
\hline CHEMBL28793 & 114300 & 3.5086 & 2.7929 & TST & \\
\hline CHEMBL 28024 & 114300 & 2.7447 & 2.6407 & TRN & \\
\hline CHEMBL28126 & 114300 & 3.6021 & 3.043 & TST & \\
\hline CHEMBL285120 & 114300 & 1.9245 & 2.3805 & TRN & \\
\hline CHEMBL29300 & 114300 & 3.6576 & 2.9126 & TRN & \\
\hline CHEMBL283665 & 114300 & 3.5376 & 3.7033 & TRN & \\
\hline CHEMBL281100 & 114300 & 3.1675 & 2.9763 & TRN & \\
\hline CHEMBL28238 & 114300 & 1.9172 & 2.7194 & TRN & \\
\hline CHEMBL283084 & 114300 & 3.1487 & 2.8966 & TRN & \\
\hline CHEMBL 28554 & 114300 & 3.4685 & 3.571 & TRN & \\
\hline CHEMBL280629 & 114300 & 3.6778 & 2.9182 & TRN & \\
\hline CHEMBL283030 & 114300 & 4.5229 & 3.2617 & TRN & \\
\hline CHEMBL28927 & 114300 & 3.6021 & 3.6389 & TRN & \\
\hline CHEMBL33051 & 114300 & 2.7773 & 2.8016 & TST & \\
\hline CHEMBL28705 & 114300 & 3.2147 & 3.4083 & TRN & \\
\hline CHEMBL280829 & 114300 & 3.6383 & 3.0707 & TRN & \\
\hline CHEMBL 280637 & 114300 & 3.5528 & 2.9941 & TRN & \\
\hline CHEMBL28083 & 114300 & 1.8928 & 2.5719 & TRN & \\
\hline CHEMBL29812 & 114300 & 3.5528 & 3.5696 & TRN & \\
\hline CHEMBL282354 & 114300 & 1.8729 & 2.1315 & TST & \\
\hline CHEMBL 27972 & 114300 & 3.301 & 3.7396 & TRN & \\
\hline CHEMBL 283674 & 114300 & 3.1805 & 2.9733 & TRN & \\
\hline CHEMBL29463 & 114300 & 4.2218 & 3.3892 & TRN & \\
\hline CHEMBL280618 & 114300 & 1.8861 & 3.2186 & TRN & \\
\hline CHEMBL281701 & 114300 & 2.7773 & 2.72899 & 99999999996 & TRN \\
\hline CHEMBL282620 & 114300 & 2.9318 & 2.8699 & TRN & \\
\hline CHEMBL 27906 & 114300 & 3.6576 & 3.5387 & TRN & \\
\hline CHEMBL28962 & 114300 & 2.7696 & 3.0324 & TRN & \\
\hline CHEMBL29809 & 114300 & 3.1612 & 2.6926 & TRN & \\
\hline CHEMBL28193 & 114300 & 3.4685 & 2.89399 & 99999999997 & TRN \\
\hline CHEMBL287648 & 114300 & 3.4437 & 3.2682 & TRN & \\
\hline CHEMBL 28823 & 114300 & 3.3565 & 3.5336 & TRN & \\
\hline CHEMBL27675 & 114300 & 2.5686 & 2.5171 & TRN & \\
\hline CHEMBL28571 & 114300 & 1.8297 & 2.8133 & TRN & \\
\hline CHEMBL282974 & 114300 & 3.4815 & 2.4936 & TRN & \\
\hline CHEMBL283453 & 114300 & 2.4318 & 2.7828 & TRN & \\
\hline CHEMBL 28183 & 114300 & 1.8894 & 2.7557 & TST & \\
\hline CHEMBL28510 & 114300 & 3.2676 & 2.7594 & TST & \\
\hline CHEMBL28720 & 114300 & 3.5376 & 2.8003 & TRN & \\
\hline CHEMBL28827 & 114300 & 2.9957 & 2.7939 & TRN & \\
\hline CHEMBL283881 & 114300 & 1.9957 & 2.7445 & TRN & \\
\hline CHEMBL 28481 & 114300 & 3.1871 & 2.9909 & TRN & \\
\hline CHEMBL28710 & 114300 & 2.8327 & 2.6049 & TRN & \\
\hline CHEMBL32086 & 114300 & 3.5686 & 3.3712 & TRN & \\
\hline CHEMBL27916 & 114300 & 1.8928 & 2.8204 & TRN & \\
\hline
\end{tabular}




\begin{tabular}{|c|c|c|c|c|c|c|}
\hline \multirow[b]{2}{*}{ CHEMBL29095 } & \multicolumn{6}{|c|}{ Supplemental Table S2.txt } \\
\hline & 114300 & 3.1249 & 3.3654 & TRN & & \\
\hline CHEMBL 284221 & 114300 & 1.9586 & 2.6898 & TRN & & \\
\hline CHEMBL29314 & 114300 & 1.8928 & 2.4781 & TRN & & \\
\hline CHEMBL286742 & 114300 & 3.2218 & 3.3614 & TRN & & \\
\hline CHEMBL282400 & 114300 & 3.1805 & 2.6846 & TRN & & \\
\hline CHEMBL283709 & 114300 & 3.699 & 3.3915 & TRN & & \\
\hline CHEMBL29638 & 114300 & 1.7595 & $2.94100 t$ & 000000000 & 03 & TST \\
\hline CHEMBL280877 & 114300 & 3.8861 & 3.0821 & TRN & & \\
\hline CHEMBL283003 & 114300 & 2.9101 & 2.6931 & TRN & & \\
\hline CHEMBL281461 & 114300 & 1.8477 & 2.6226 & TRN & & \\
\hline CHEMBL28522 & 114300 & 3.0223 & 2.8249 & TRN & & \\
\hline CHEMBL28944 & 114300 & 3.4559 & 3.6565 & TRN & & \\
\hline CHEMBL29882 & 114300 & 2.9872 & 3.1472 & TRN & & \\
\hline CHEMBL29816 & 114300 & 3.4948 & 3.5688 & TRN & & \\
\hline CHEMBL 28085 & 114300 & 2.9586 & 2.6752 & TST & & \\
\hline CHEMBL29135 & 114300 & 2.9508 & 3.0414 & TST & & \\
\hline CHEMBL282211 & 114300 & 2.9547 & 3.1067 & TST & & \\
\hline CHEMBL28832 & 114300 & 1.8697 & 2.4594 & TST & & \\
\hline CHEMBL27973 & 114300 & 3.5528 & 2.9648 & TST & & \\
\hline CHEMBL417842 & 114300 & 3.2366 & 2.7099 & TST & & \\
\hline CHEMBL285616 & 114300 & 2.8508 & 2.6577 & TST & & \\
\hline CHEMBL28894 & 114300 & 3.4815 & 3.6329 & TST & & \\
\hline CHEMBL281904 & 114300 & 1.8761 & 2.7406 & TST & & \\
\hline CHEMBL 28537 & 114300 & 3.6021 & 3.5303 & TST & & \\
\hline CHEMBL27747 & 114300 & 1.9101 & 2.9806 & TST & & \\
\hline CHEMBL 29900 & 114300 & 3.3665 & 3.4717 & TST & & \\
\hline CHEMBL445636 & 158652 & 7.6576 & 7.3959 & TRN & & \\
\hline CHEMBL123928 & 158652 & 6.9208 & 8.1613 & TST & & \\
\hline CHEMBL340284 & 158652 & 6.8239 & 8.1543 & TST & & \\
\hline CHEMBL340137 & 158652 & 6.6861 & 7.0723 & TST & & \\
\hline CHEMBL338330 & 158652 & 6.75700 & 000000006 & $\partial 1$ & 6.9347 & TRN \\
\hline CHEMBL338619 & 158652 & 5.7799 & 5.8329 & TRN & & \\
\hline CHEMBL124073 & 158652 & 6.3979 & 6.1094 & TRN & & \\
\hline CHEMBL125277 & 158652 & 7.4949 & 7.8476 & TST & & \\
\hline CHEMBL125146 & 158652 & 5.2277 & 5.4822 & TRN & & \\
\hline CHEMBL125431 & 158652 & 6.8239 & 6.7664 & TRN & & \\
\hline CHEMBL340234 & 158652 & 6.9101 & 6.6112 & TRN & & \\
\hline CHEMBL125761 & 158652 & 6.8539 & 6.5789 & TRN & & \\
\hline CHEMBL334169 & 158652 & 4.8548 & 5.0498 & TRN & & \\
\hline CHEMBL125141 & 158652 & 5.8447 & 6.087006 & 000000000 & & TRN \\
\hline CHEMBL124439 & 158652 & 4.7109 & 4.9358 & TRN & & \\
\hline CHEMBL333648 & 158652 & 6.2211 & 6.0456 & TRN & & \\
\hline CHEMBL125717 & 158652 & 6.7375 & 7.5295 & TST & & \\
\hline CHEMBL124369 & 158652 & 6.5768 & 6.638 & TRN & & \\
\hline CHEMBL340431 & 158652 & 6.6536 & 6.4543 & TRN & & \\
\hline CHEMBL340439 & 158652 & 6.284 & 6.2768 & TRN & & \\
\hline CHEMBL125721 & 158652 & 6.1979 & 7.1851 & TST & & \\
\hline CHEMBL125028 & 158652 & 5.3288 & 5.4949 & TRN & & \\
\hline
\end{tabular}


Supplemental Table S2.txt

\begin{tabular}{|c|c|c|c|c|}
\hline CHEMBL127581 & 158652 & 5.6556 & 5.9087 & TRN \\
\hline CHEMBL124949 & 158652 & 6.7773 & 7.057 & TST \\
\hline CHEMBL107599 & 158652 & 7.4559 & 7.5933 & TRN \\
\hline CHEMBL59735 & 158652 & 6.9172 & 6.8148 & TRN \\
\hline CHEMBL127753 & 158652 & 6.475 & 6.7914 & TRN \\
\hline CHEMBL338597 & 158652 & 7.2218 & 7.2089 & TRN \\
\hline CHEMBL332083 & 158652 & 5.1707 & 5.1052 & TST \\
\hline CHEMBL339685 & 158652 & 6.2798 & 7.2854 & TST \\
\hline CHEMBL 330863 & 158652 & 7.2924 & 7.6856 & TRN \\
\hline CHEMBL124827 & 158652 & 6.6778 & 7.0185 & TRN \\
\hline CHEMBL338827 & 158652 & 5.4486 & 5.471 & TRN \\
\hline CHEMBL339403 & 158652 & 6.6198 & 6.6924 & TRN \\
\hline CHEMBL126699 & 158652 & 7.5376 & 7.3022 & TRN \\
\hline CHEMBL340157 & 158652 & 6.3768 & 6.947 & TST \\
\hline CHEMBL125171 & 158652 & 6.5346 & 6.5 & TRN \\
\hline CHEMBL125304 & 158652 & 5.2865 & 5.3158 & TRN \\
\hline CHEMBL125811 & 158652 & 6.301 & 7.8825 & TST \\
\hline CHEMBL124983 & 158652 & 5.9101 & 6.1144 & TRN \\
\hline CHEMBL125252 & 158652 & 6.2351 & 5.8832 & TRN \\
\hline CHEMBL125898 & 158652 & 7.2218 & 7.2396 & TRN \\
\hline CHEMBL 340144 & 158652 & 6.2757 & 6.3365 & TRN \\
\hline CHEMBL127786 & 158652 & 6.4559 & 6.4556 & TRN \\
\hline CHEMBL124895 & 158652 & $6.7520 e$ & t00000006 & 6.6399 \\
\hline CHEMBL 341489 & 158652 & 6.5157 & 6.2851 & TRN \\
\hline CHEMBL337920 & 158652 & 5.4908 & 4.9217 & TRN \\
\hline CHEMBL127635 & 158652 & 5.8996 & 6.0572 & TRN \\
\hline CHEMBL127748 & 158652 & 6.0969 & 5.9235 & TRN \\
\hline CHEMBL125451 & 158652 & 6.5229 & 6.7221 & TRN \\
\hline CHEMBL124089 & 158652 & 7.0458 & 6.8434 & TRN \\
\hline CHEMBL338623 & 158652 & 5.1085 & 5.2926 & TRN \\
\hline CHEMBL127731 & 158652 & 6.7825 & 6.6077 & TRN \\
\hline CHEMBL126173 & 158652 & 6.1427 & 5.9141 & TRN \\
\hline CHEMBL124487 & 158652 & 7.0458 & 7.0252 & TRN \\
\hline CHEMBL124313 & 158652 & 6.1675 & 6.0983 & TRN \\
\hline CHEMBL121829 & 158652 & 6.7447 & 7.0593 & TST \\
\hline CHEMBL339974 & 158652 & 5.5272 & 5.5947 & TRN \\
\hline CHEMBL341258 & 158652 & 7.0969 & 7.6571 & TST \\
\hline CHEMBL444064 & 158652 & 6.7696 & 6.6098 & TRN \\
\hline CHEMBL 340200 & 158652 & 5.5735 & 5.8071 & TRN \\
\hline CHEMBL340235 & 158652 & 7.0132 & 6.7831 & TRN \\
\hline CHEMBL125805 & 158652 & 6.7212 & 7.5319 & TST \\
\hline CHEMBL122572 & 158652 & 6.6861 & 6.91200 & 0000000001 \\
\hline CHEMBL419785 & 158652 & 5.041 & 5.2584 & TRN \\
\hline CHEMBL124872 & 158652 & 5.6038 & 5.8237 & TRN \\
\hline CHEMBL442402 & 158652 & 4.8119 & 4.7358 & TRN \\
\hline CHEMBL127429 & 158652 & 6.4202 & 6.2224 & TRN \\
\hline CHEMBL125367 & 158652 & 6.9586 & 7.0252 & TRN \\
\hline CHEMBL124035 & 158652 & 6.6655 & 6.4102 & TRN \\
\hline
\end{tabular}




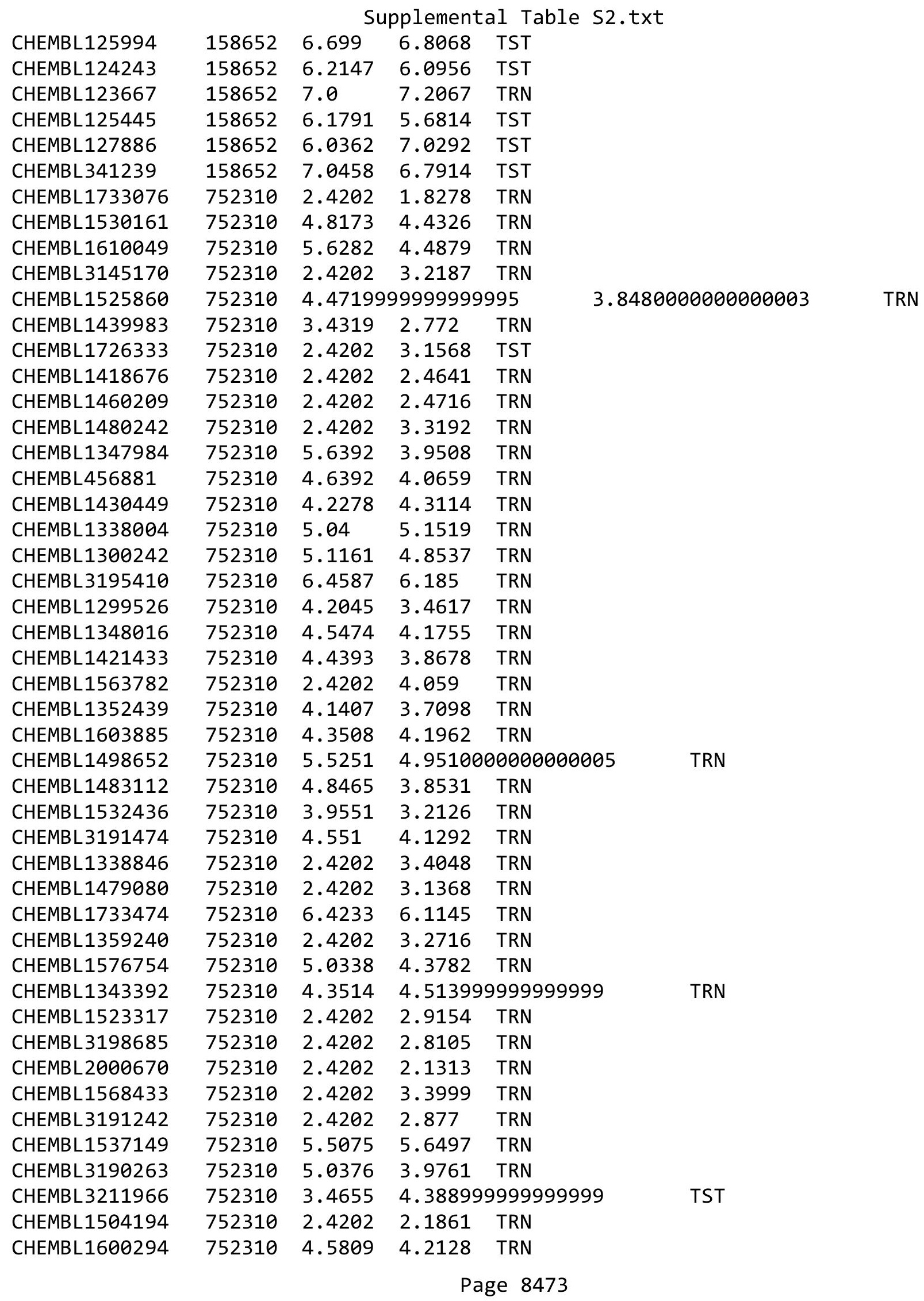


Supplemental Table S2.txt

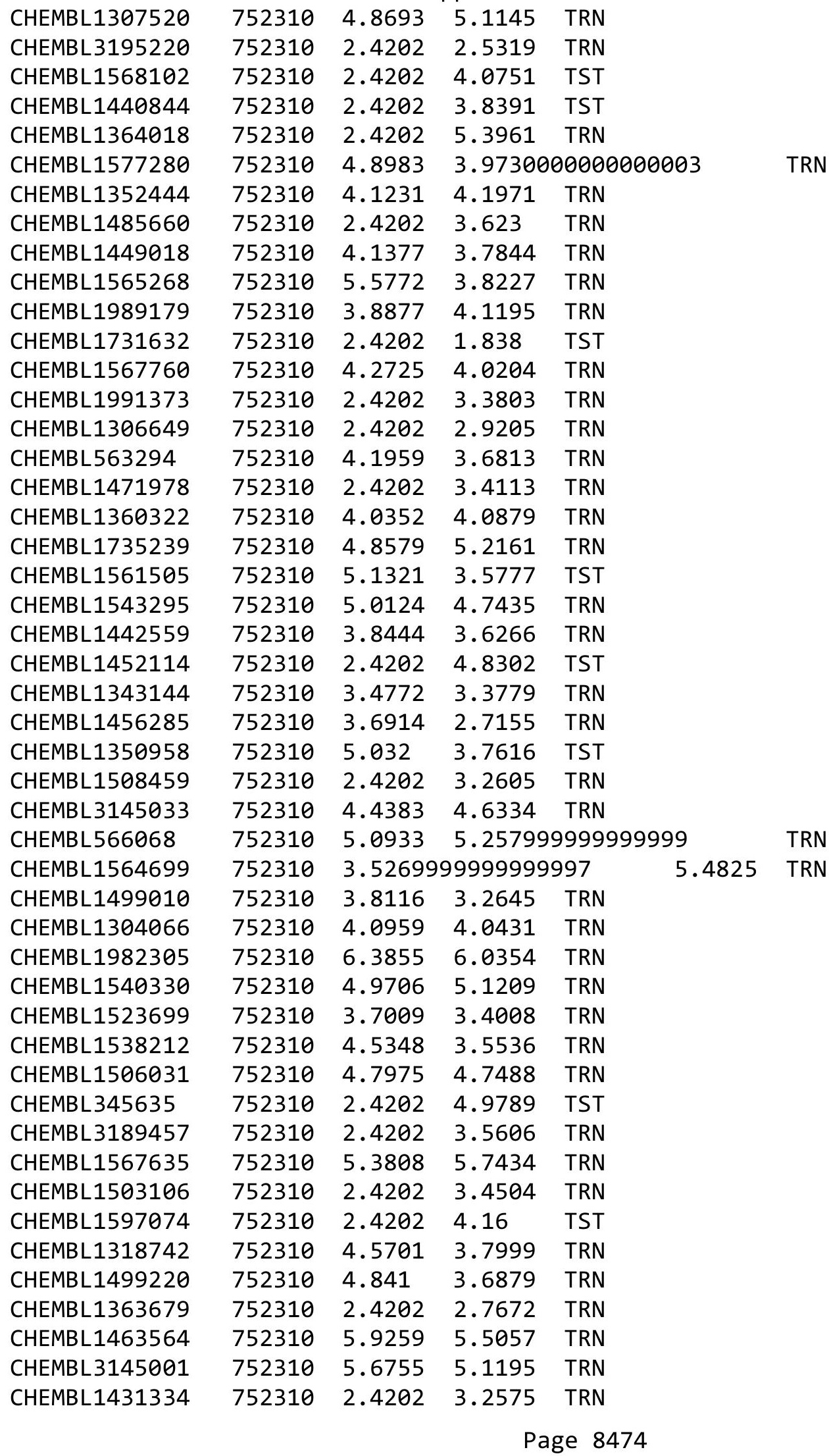




\begin{tabular}{|c|c|c|c|c|c|}
\hline \multicolumn{6}{|c|}{ Supplemental } \\
\hline CHEMBL505618 & 752310 & 2.4202 & 3.1306 & TST & \\
\hline CHEMBL3144999 & 752310 & 5.4111 & 4.7161 & TRN & \\
\hline CHEMBL1338987 & 752310 & 5.574 & 3.8805 & TST & \\
\hline CHEMBL1535578 & 752310 & 4.8867 & 2.3431 & TST & \\
\hline CHEMBL1302460 & 752310 & 3.9097 & 4.2789 & TRN & \\
\hline CHEMBL 2000517 & 752310 & 6.7467 & 6.7074 & TRN & \\
\hline CHEMBL1405837 & 752310 & 2.4202 & 4.3382 & TST & \\
\hline CHEMBL1464832 & 752310 & 3.7698 & 4.0183 & TRN & \\
\hline CHEMBL1546947 & 752310 & 5.2092 & 4.63 & TRN & \\
\hline CHEMBL1460524 & 752310 & 4.7452 & 4.3484 & TRN & \\
\hline CHEMBL1359734 & 752310 & 4.3241 & 2.9042 & TRN & \\
\hline CHEMBL1431075 & 752310 & 2.4202 & 3.2711 & TRN & \\
\hline CHEMBL1496552 & 752310 & 4.3126 & 3.9459 & TRN & \\
\hline CHEMBL1442141 & 752310 & 3.6071 & 3.6265 & TRN & \\
\hline CHEMBL1441508 & 752310 & 3.7791 & 4.2052 & TST & \\
\hline CHEMBL1366838 & 752310 & 5.9129 & 5.7878 & TRN & \\
\hline CHEMBL1534185 & 752310 & 2.4202 & 3.5054 & TST & \\
\hline CHEMBL584626 & 752310 & 5.1233 & 5.6403 & TRN & \\
\hline CHEMBL1342248 & 752310 & 4.8671 & 4.269 & TRN & \\
\hline CHEMBL1341919 & 752310 & 3.9226 & 2.9637 & TST & \\
\hline CHEMBL1427272 & 752310 & 3.8431 & 3.3742 & TRN & \\
\hline CHEMBL1472154 & 752310 & 4.7688 & 4.6716 & TRN & \\
\hline CHEMBL1322995 & 752310 & 2.4202 & 3.2758 & TRN & \\
\hline CHEMBL1707641 & 752310 & 2.4202 & 4.5826 & TRN & \\
\hline CHEMBL1557105 & 752310 & 3.572 & 3.713 & TRN & \\
\hline CHEMBL1338246 & 752310 & 2.4202 & 3.1924 & TST & \\
\hline CHEMBL1733991 & 752310 & 4.8752 & 4.522 & TRN & \\
\hline CHEMBL1590201 & 752310 & 5.909 & 3.9184 & TST & \\
\hline CHEMBL1570005 & 752310 & 4.2093 & 3.7098 & TRN & \\
\hline CHEMBL1347107 & 752310 & 5.7967 & 5.2112 & TRN & \\
\hline CHEMBL1388137 & 752310 & 5.4482 & 5.7128 & TRN & \\
\hline CHEMBL1344648 & 752310 & 4.7421 & 4.4286 & TRN & \\
\hline CHEMBL1487834 & 752310 & 5.1517 & 5.068006 & 00000000005 & TRN \\
\hline CHEMBL1463659 & 752310 & 6.7535 & 6.7138 & TRN & \\
\hline CHEMBL1582076 & 752310 & 4.5245 & 4.2783 & TRN & \\
\hline CHEMBL1430882 & 752310 & 4.6625 & 4.8317 & TRN & \\
\hline CHEMBL1385690 & 752310 & 2.4202 & 4.0452 & TRN & \\
\hline CHEMBL1520989 & 752310 & 2.4202 & 3.3739 & TRN & \\
\hline CHEMBL1562392 & 752310 & 4.235 & 3.7192 & TRN & \\
\hline CHEMBL1981002 & 752310 & 2.4202 & 3.7172 & TRN & \\
\hline CHEMBL1484906 & 752310 & 5.3964 & 4.3436 & TRN & \\
\hline CHEMBL1420857 & 752310 & 2.4202 & 3.46199 & 999999999997 & TRN \\
\hline CHEMBL1452938 & 752310 & 2.4202 & 3.0068 & TRN & \\
\hline CHEMBL1425874 & 752310 & 5.2355 & 4.1633 & TRN & \\
\hline CHEMBL3192994 & 752310 & 4.668 & 4.2883 & TRN & \\
\hline CHEMBL1413380 & 752310 & 2.4202 & 2.7197 & TRN & \\
\hline CHEMBL1483809 & 752310 & 4.6726 & 4.1741 & TST & \\
\hline CHEMBL1406350 & 752310 & 4.6805 & 3.932 & TRN & \\
\hline
\end{tabular}


Supplemental Table S2.txt

\begin{tabular}{|c|c|c|c|c|c|}
\hline CHEMBL1494202 & 752310 & 5.0526 & 4.0495 & TRN & \\
\hline CHEMBL1532953 & 752310 & 2.4202 & 3.7136 & TRN & \\
\hline CHEMBL1970242 & 752310 & 4.3729 & 3.7282 & TRN & \\
\hline CHEMBL1462919 & 752310 & 2.4202 & 2.4944 & TST & \\
\hline CHEMBL1443448 & 752310 & 5.3081 & 5.0245 & TRN & \\
\hline CHEMBL1533867 & 752310 & 2.4202 & 3.8023 & TRN & \\
\hline CHEMBL1451942 & 752310 & 4.4239 & 3.8176 & TST & \\
\hline CHEMBL1417929 & 752310 & 5.9307 & 5.0845 & TRN & \\
\hline CHEMBL1396209 & 752310 & 5.1793 & 5.0683 & TST & \\
\hline CHEMBL1511238 & 752310 & 2.4202 & 2.4874 & TRN & \\
\hline CHEMBL1995641 & 752310 & 2.4202 & 2.699 & TRN & \\
\hline CHEMBL1486463 & 752310 & 2.4202 & 1.7192 & TRN & \\
\hline CHEMBL1432590 & 752310 & 3.6836 & 4.0012 & TRN & \\
\hline CHEMBL1569091 & 752310 & 3.549 & 3.3536 & TRN & \\
\hline CHEMBL1471088 & 752310 & 2.4202 & 3.3639 & TRN & \\
\hline CHEMBL1568113 & 752310 & 5.2914 & 4.5901 & TRN & \\
\hline CHEMBL1329597 & 752310 & 5.7716 & 5.2168 & TST & \\
\hline CHEMBL1489005 & 752310 & 5.5167 & 3.89300 & 30000000002 & TRN \\
\hline CHEMBL1471498 & 752310 & 4.7371 & 4.16 & TRN & \\
\hline CHEMBL1540053 & 752310 & 2.4202 & 3.5261 & TST & \\
\hline CHEMBL175434 & 752310 & 5.1264 & 5.6553 & TRN & \\
\hline CHEMBL3145304 & 752310 & 5.0486 & 4.0243 & TRN & \\
\hline CHEMBL1557253 & 752310 & 5.6568 & 4.3147 & TRN & \\
\hline CHEMBL1322313 & 752310 & 3.5333 & 3.5756 & TRN & \\
\hline CHEMBL1422133 & 752310 & 2.9208 & 2.6109 & TRN & \\
\hline CHEMBL1596996 & 752310 & 4.0363 & 4.3524 & TRN & \\
\hline CHEMBL1326624 & 752310 & 4.1585 & 4.1172 & TRN & \\
\hline CHEMBL1165723 & 752310 & 4.7361 & 4.6215 & TRN & \\
\hline CHEMBL1706216 & 752310 & 4.7625 & 4.8001 & TRN & \\
\hline CHEMBL1548704 & 752310 & 5.2465 & 5.1246 & TRN & \\
\hline CHEMBL1325970 & 752310 & 2.4202 & 3.1794 & TST & \\
\hline CHEMBL1418601 & 752310 & 3.5067 & 3.4528 & TRN & \\
\hline CHEMBL1606827 & 752310 & 4.4637 & 3.7901 & TRN & \\
\hline CHEMBL1594394 & 752310 & 2.4202 & 3.0469 & TRN & \\
\hline CHEMBL1560679 & 752310 & 4.9241 & 4.9434 & TRN & \\
\hline CHEMBL1535577 & 752310 & 2.4202 & 2.8605 & TRN & \\
\hline CHEMBL1375966 & 752310 & 4.1204 & 3.5714 & TRN & \\
\hline CHEMBL1517886 & 752310 & 2.4202 & 3.7474 & TST & \\
\hline CHEMBL1437741 & 752310 & 2.4202 & 3.0196 & TRN & \\
\hline CHEMBL1501597 & 752310 & 4.8729 & 5.955 & TRN & \\
\hline CHEMBL 3212479 & 752310 & 2.4202 & 4.5477 & TST & \\
\hline CHEMBL1362714 & 752310 & 2.4202 & 4.4008 & TST & \\
\hline CHEMBL1305275 & 752310 & 4.8755 & 4.5069 & TRN & \\
\hline CHEMBL1602314 & 752310 & 4.6902 & 4.881 & TRN & \\
\hline CHEMBL1996376 & 752310 & 2.4202 & 4.4212 & TRN & \\
\hline CHEMBL1794290 & 752310 & 2.4202 & 2.8301 & TST & \\
\hline CHEMBL3193480 & 752310 & 2.4202 & 2.9353 & TRN & \\
\hline CHEMBL1444859 & 752310 & 2.4202 & 1.8435 & TRN & \\
\hline
\end{tabular}

Page 8476 


\begin{tabular}{|c|c|c|c|c|}
\hline & & & oplement & al $\mathrm{T}$ \\
\hline CHEMBL1519374 & 752310 & 5.4257 & 5.3258 & TRN \\
\hline CHEMBL1402496 & 752310 & 4.5541 & 3.6077 & TST \\
\hline CHEMBL1378877 & 752310 & 2.4202 & 3.3261 & TRN \\
\hline CHEMBL1501444 & 752310 & 5.3673 & 4.6583 & TRN \\
\hline CHEMBL 3208288 & 752310 & 2.4202 & 2.2906 & TRN \\
\hline CHEMBL1432432 & 752310 & 3.9626 & 4.0085 & TST \\
\hline CHEMBL3199015 & 752310 & 5.0134 & 3.7804 & TRN \\
\hline CHEMBL1323586 & 752310 & 5.4984 & 3.7753 & TRN \\
\hline CHEMBL1409900 & 752310 & 2.4202 & 2.6621 & TRN \\
\hline CHEMBL 3144984 & 752310 & 4.9859 & 4.2257 & TRN \\
\hline CHEMBL1364176 & 752310 & 5.0762 & 5.0683 & TRN \\
\hline CHEMBL1405374 & 752310 & 2.4202 & 4.0144 & TRN \\
\hline CHEMBL1607176 & 752310 & 2.4202 & 2.7896 & TRN \\
\hline CHEMBL1349850 & 752310 & 2.4202 & 2.9438 & TRN \\
\hline CHEMBL183656 & 752310 & 2.4202 & 3.3502 & TRN \\
\hline CHEMBL1430372 & 752310 & 4.0929 & 3.8372 & TRN \\
\hline CHEMBL1486335 & 752310 & 2.4202 & 3.8546 & TRN \\
\hline CHEMBL1366927 & 752310 & 2.4202 & 2.7465 & TST \\
\hline CHEMBL1386968 & 752310 & 3.5686 & 3.6025 & TRN \\
\hline CHEMBL1381436 & 752310 & 3.9126 & 4.3779 & TST \\
\hline CHEMBL1308404 & 752310 & 4.0661 & 4.2803 & TRN \\
\hline CHEMBL1589425 & 752310 & 5.2931 & 5.1606 & TST \\
\hline CHEMBL3195577 & 752310 & 4.0475 & 3.425 & TRN \\
\hline CHEMBL1586263 & 752310 & 5.0433 & 4.7591 & TRN \\
\hline CHEMBL3191525 & 752310 & 4.1333 & 3.9311 & TRN \\
\hline CHEMBL1544483 & 752310 & 4.3536 & 3.1221 & TST \\
\hline CHEMBL1466363 & 752310 & 3.7342 & 3.6492 & TST \\
\hline CHEMBL1469117 & 752310 & 5.09 & 4.9596 & TRN \\
\hline CHEMBL1408271 & 752310 & 3.5802 & 3.4854 & TRN \\
\hline CHEMBL527336 & 752310 & 5.0904 & 5.2061 & TRN \\
\hline CHEMBL1313693 & 752310 & 2.4202 & 4.1361 & TST \\
\hline CHEMBL601757 & 752310 & 7.068 & 6.8858 & TRN \\
\hline CHEMBL1548411 & 752310 & 4.2418 & 3.9004 & TST \\
\hline CHEMBL465226 & 752310 & 4.3513 & 3.6988 & TST \\
\hline CHEMBL1438154 & 752310 & 5.0151 & 4.3323 & TRN \\
\hline CHEMBL1794123 & 752310 & 2.4202 & 4.2465 & TRN \\
\hline CHEMBL1418852 & 752310 & 5.1888 & 4.8237 & TRN \\
\hline CHEMBL1573118 & 752310 & 3.4569 & 3.7167 & TRN \\
\hline CHEMBL1519379 & 752310 & 5.595 & 5.0739 & TST \\
\hline CHEMBL1541973 & 752310 & 4.8745 & 5.129 & TRN \\
\hline CHEMBL1486606 & 752310 & 4.6757 & 4.6281 & TRN \\
\hline CHEMBL1313352 & 752310 & 3.5599 & 3.5207 & TRN \\
\hline CHEMBL1309290 & 752310 & 4.6411 & 5.2197 & TRN \\
\hline CHEMBL1304384 & 752310 & 3.5186 & 3.0022 & TRN \\
\hline CHEMBL1330597 & 752310 & 4.5453 & 4.6667 & TRN \\
\hline CHEMBL1599023 & 752310 & 2.4202 & 3.1678 & TST \\
\hline CHEMBL312032 & 752310 & 4.5081 & 2.963 & TRN \\
\hline CHEMBL1478235 & 752310 & 4.9263 & 3.6055 & TRN \\
\hline
\end{tabular}


Supplemental Table S2.txt

\begin{tabular}{|c|c|c|c|c|}
\hline CHEMBL1429937 & 752310 & 2.4202 & 2.9955 & TRN \\
\hline CHEMBL1454614 & 752310 & 5.3461 & 5.1747 & TRN \\
\hline CHEMBL1359282 & 752310 & 2.4202 & 4.2998 & TRN \\
\hline CHEMBL1446060 & 752310 & 3.8844 & 3.0501 & TRN \\
\hline CHEMBL1584397 & 752310 & 3.5459 & 3.4671 & TRN \\
\hline CHEMBL1510532 & 752310 & 4.3873 & 2.3657 & TRN \\
\hline CHEMBL1434250 & 752310 & 2.4202 & 3.4269 & TRN \\
\hline CHEMBL1309232 & 752310 & 4.4533 & 4.1358 & TRN \\
\hline CHEMBL3196976 & 752310 & 2.4202 & 3.1274 & TRN \\
\hline CHEMBL1327934 & 752310 & 4.8182 & 3.9246 & TRN \\
\hline CHEMBL1522100 & 752310 & 2.4202 & 1.8029 & TST \\
\hline CHEMBL1330054 & 752310 & 2.4202 & 3.1618 & TRN \\
\hline CHEMBL1611843 & 752310 & 5.1188 & 4.982 & TRN \\
\hline CHEMBL1994973 & 752310 & 2.4202 & 2.5212 & TRN \\
\hline CHEMBL405110 & 752310 & 4.6607 & 4.1012 & TST \\
\hline CHEMBL1464383 & 752310 & 2.4202 & 4.285 & TRN \\
\hline CHEMBL1453114 & 752310 & 4.787 & 3.2668 & TST \\
\hline CHEMBL1467745 & 752310 & 5.4185 & 4.6463 & TRN \\
\hline CHEMBL1531735 & 752310 & 4.075 & 4.0362 & TRN \\
\hline CHEMBL1380131 & 752310 & 4.4413 & 4.487 & TRN \\
\hline CHEMBL1990545 & 752310 & 2.4202 & 3.3143 & TRN \\
\hline CHEMBL1491019 & 752310 & 2.4202 & 4.1948 & TRN \\
\hline CHEMBL1497005 & 752310 & 2.4202 & 2.2611 & TST \\
\hline CHEMBL1611833 & 752310 & 2.4202 & 4.5623 & TRN \\
\hline CHEMBL1608276 & 752310 & 2.4202 & 2.9538 & TRN \\
\hline CHEMBL1580600 & 752310 & 2.4202 & 2.8893 & TRN \\
\hline CHEMBL1564294 & 752310 & 4.9702 & 5.0487 & TRN \\
\hline CHEMBL1427517 & 752310 & 3.7247 & 3.54100 & 0000000004 \\
\hline CHEMBL1347736 & 752310 & 4.7192 & 3.6412 & TRN \\
\hline CHEMBL3187596 & 752310 & 5.6851 & 4.4022 & TRN \\
\hline CHEMBL1368829 & 752310 & 2.4202 & 3.24899 & 9999999997 \\
\hline CHEMBL1500315 & 752310 & 3.9991 & 3.3222 & TRN \\
\hline CHEMBL1341762 & 752310 & 2.4202 & 2.9491 & TRN \\
\hline CHEMBL1568820 & 752310 & 2.4202 & 2.9508 & TRN \\
\hline CHEMBL1590402 & 752310 & 5.1654 & 5.3426 & TRN \\
\hline CHEMBL1537553 & 752310 & 5.3474 & 4.3708 & TRN \\
\hline CHEMBL1794098 & 752310 & 2.4202 & 2.9219 & TST \\
\hline CHEMBL1331211 & 752310 & 5.657 & 6.2547 & TRN \\
\hline CHEMBL586135 & 752310 & 5.2967 & 5.4458 & TRN \\
\hline CHEMBL1364861 & 752310 & 2.4202 & 3.448 & TRN \\
\hline CHEMBL1369737 & 752310 & 4.7994 & 4.1676 & TRN \\
\hline CHEMBL1544131 & 752310 & 3.8965 & 4.2551 & TRN \\
\hline CHEMBL1393098 & 752310 & 2.4202 & 2.7281 & TRN \\
\hline CHEMBL1978855 & 752310 & 2.4202 & 2.91300 & 0000000003 \\
\hline CHEMBL1428623 & 752310 & 2.4202 & 2.7937 & TST \\
\hline CHEMBL1494363 & 752310 & 4.5405 & 4.3477 & TRN \\
\hline CHEMBL1610146 & 752310 & 2.4202 & 2.9973 & TRN \\
\hline CHEMBL1384604 & 752310 & 4.7802 & 3.5227 & TST \\
\hline
\end{tabular}




\begin{tabular}{|c|c|c|c|c|c|}
\hline \multirow{3}{*}{ CHEMBL1305658 } & & \multicolumn{4}{|c|}{ Supplemental Table S2.txt } \\
\hline & 752310 & 4.7331 & 4.13399 & 99999999995 & TRN \\
\hline & 752310 & 2.4202 & 3.4299 & TRN & \\
\hline CHEMBL1430379 & 752310 & 2.4202 & 3.3736 & TRN & \\
\hline CHEMBL1433113 & 752310 & 2.4202 & 2.4221 & TST & \\
\hline CHEMBL1495230 & 752310 & 2.4202 & 3.9276 & TRN & \\
\hline CHEMBL1432707 & 752310 & 5.9355 & 4.3261 & TRN & \\
\hline CHEMBL1481657 & 752310 & 4.9784 & 4.9361 & TST & \\
\hline CHEMBL1555858 & 752310 & 4.6362 & 3.1964 & TRN & \\
\hline CHEMBL1424829 & 752310 & 2.4202 & 3.4218 & TRN & \\
\hline CHEMBL1576520 & 752310 & 2.4202 & 2.3814 & TRN & \\
\hline CHEMBL1300870 & 752310 & 2.4202 & 2.4817 & TST & \\
\hline CHEMBL1303810 & 752310 & 4.2169 & 4.8219 & TRN & \\
\hline CHEMBL1573265 & 752310 & 2.4202 & 4.0064 & TST & \\
\hline CHEMBL1585072 & 752310 & 5.6317 & 4.0361 & TRN & \\
\hline CHEMBL1359236 & 752310 & 2.4202 & 2.9871 & TRN & \\
\hline CHEMBL1794141 & 752310 & 4.7014 & 4.3208 & TRN & \\
\hline CHEMBL1369200 & 752310 & 5.0881 & 4.0572 & TRN & \\
\hline CHEMBL1987894 & 752310 & 6.2516 & 6.6744 & TRN & \\
\hline CHEMBL1306161 & 752310 & 4.9412 & 2.3791 & TRN & \\
\hline CHEMBL1349646 & 752310 & 5.4827 & 5.0739 & TRN & \\
\hline CHEMBL1487851 & 752310 & 4.8529 & 4.928 & TRN & \\
\hline CHEMBL1451917 & 752310 & 2.4202 & 4.0616 & TRN & \\
\hline CHEMBL1568043 & 752310 & 2.4202 & 3.4822 & TRN & \\
\hline CHEMBL1362565 & 752310 & 5.256 & 5.6976 & TRN & \\
\hline CHEMBL445304 & 752310 & 4.5659 & 3.154 & TRN & \\
\hline CHEMBL1557927 & 752310 & 4.3765 & 3.3934 & TRN & \\
\hline CHEMBL1428407 & 752310 & 4.7908 & 5.2123 & TRN & \\
\hline CHEMBL1567159 & 752310 & 5.1233 & 4.6145 & TRN & \\
\hline CHEMBL1558070 & 752310 & 2.4202 & 3.3676 & TST & \\
\hline CHEMBL1525064 & 752310 & 4.6202 & 3.9535 & TST & \\
\hline CHEMBL1445135 & 752310 & 4.0416 & 3.167 & TRN & \\
\hline CHEMBL1352007 & 752310 & 3.8729 & 4.5009 & TRN & \\
\hline CHEMBL1407193 & 752310 & 2.4202 & 2.6236 & TRN & \\
\hline CHEMBL594707 & 752310 & 3.9281 & 4.2168 & TRN & \\
\hline CHEMBL1369671 & 752310 & 5.1094 & 5.6346 & TRN & \\
\hline CHEMBL1428217 & 752310 & 2.4202 & 3.5217 & TRN & \\
\hline CHEMBL1447341 & 752310 & 5.3986 & 4.7237 & TRN & \\
\hline CHEMBL1466241 & 752310 & 2.4202 & 2.6566 & TRN & \\
\hline CHEMBL1562304 & 752310 & 5.1075 & 5.0813 & TST & \\
\hline CHEMBL1322720 & 752310 & 2.4202 & 3.9193 & TRN & \\
\hline CHEMBL1363844 & 752310 & 2.4202 & 3.1645 & TST & \\
\hline CHEMBL1410562 & 752310 & 4.1894 & 4.394 & TRN & \\
\hline CHEMBL1503209 & 752310 & 4.6096 & 4.0518 & TST & \\
\hline CHEMBL1531210 & 752310 & 4.4176 & 3.9998 & TRN & \\
\hline CHEMBL1306457 & 752310 & 3.6209 & 2.6178 & TRN & \\
\hline CHEMBL1567402 & 752310 & 4.493 & 3.555 & TRN & \\
\hline CHEMBL1307050 & 752310 & 2.4202 & 3.2878 & TRN & \\
\hline CHEMBL1583127 & 752310 & 3.6659 & 2.9111 & TRN & \\
\hline
\end{tabular}


Supplemental Table S2.txt

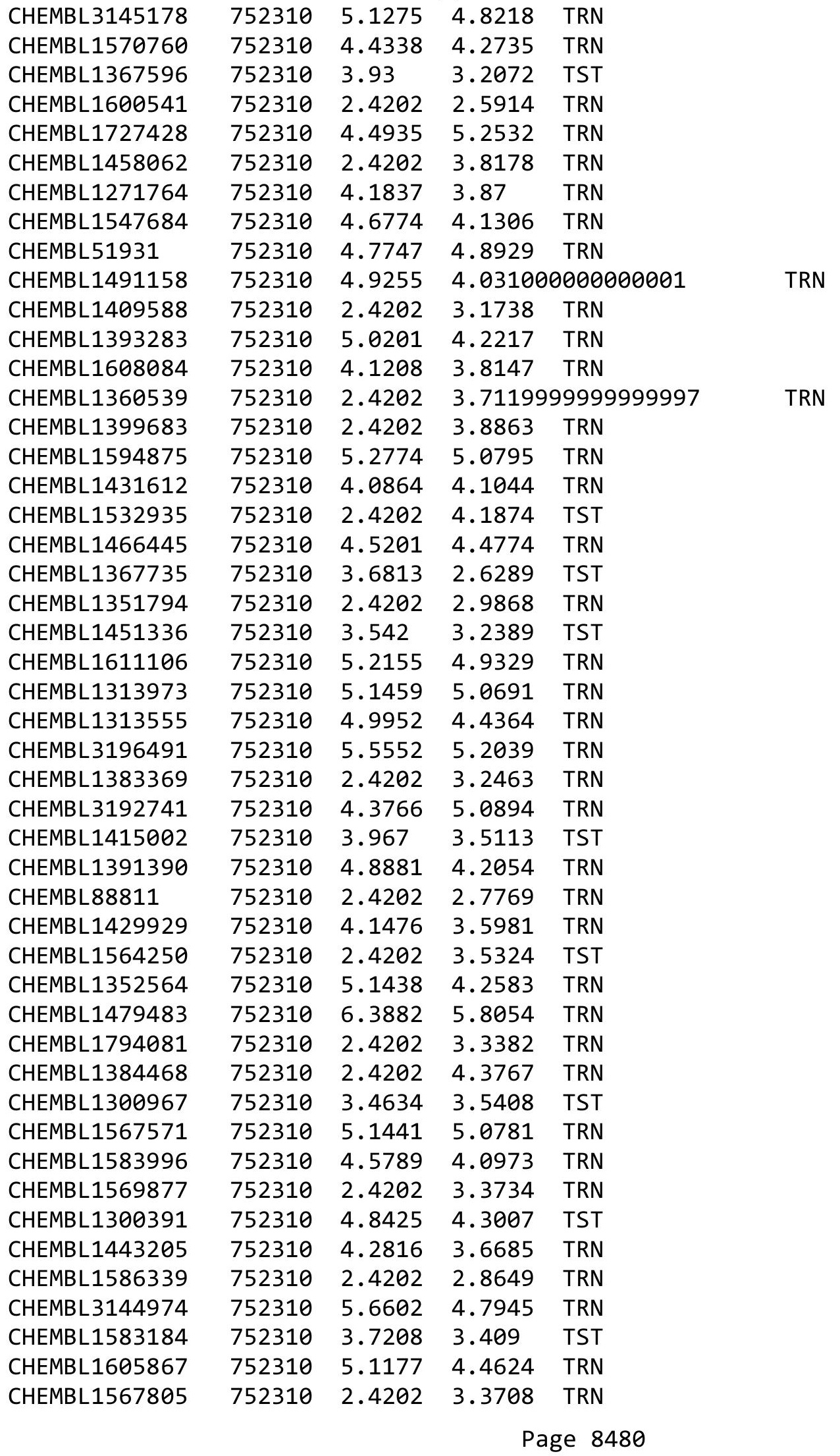


Supplemental Table S2.txt

\begin{tabular}{|c|c|c|c|c|c|}
\hline CHEMBL1596226 & 752310 & 4.4171 & 3.1706 & TST & \\
\hline CHEMBL1496473 & 752310 & 4.8687 & 3.5964 & TST & \\
\hline CHEMBL1588411 & 752310 & 3.7929 & 3.8858 & TRN & \\
\hline CHEMBL1461824 & 752310 & 4.4927 & 3.1806 & TRN & \\
\hline CHEMBL1338327 & 752310 & 2.4202 & \multicolumn{2}{|c|}{3.3080000000000003} & TRN \\
\hline CHEMBL1449387 & 752310 & 2.4202 & 3.4773 & TRN & \\
\hline CHEMBL3191438 & 752310 & 6.0 & 5.0098 & TRN & \\
\hline CHEMBL1347560 & 752310 & 2.4202 & 2.7373 & TRN & \\
\hline CHEMBL1464798 & 752310 & 2.4202 & 3.3653 & TRN & \\
\hline CHEMBL1488429 & 752310 & 4.5814 & 3.9909 & TRN & \\
\hline CHEMBL1543357 & 752310 & 2.4202 & 1.8674 & TST & \\
\hline CHEMBL1596753 & 752310 & 4.8894 & 3.5267 & TRN & \\
\hline CHEMBL1570551 & 752310 & 2.4202 & 2.1498 & TRN & \\
\hline CHEMBL1465424 & 752310 & 2.4202 & 3.4061 & TRN & \\
\hline CHEMBL1366252 & 752310 & 5.0514 & 4.5043 & TRN & \\
\hline CHEMBL1452937 & 752310 & 3.7597 & 3.7622 & TRN & \\
\hline CHEMBL1308879 & 752310 & 4.9662 & 5.1922 & TRN & \\
\hline CHEMBL1493256 & 752310 & 2.4202 & 3.3827 & TST & \\
\hline CHEMBL1511042 & 752310 & 5.2586 & 3.5279 & TST & \\
\hline CHEMBL1442702 & 752310 & 2.4202 & 3.2593 & TRN & \\
\hline CHEMBL1526067 & 752310 & 5.1373 & 4.5301 & TRN & \\
\hline CHEMBL590691 & 752310 & 5.0392 & 4.4267 & TRN & \\
\hline CHEMBL1411044 & 752310 & 5.193 & 5.1598 & TRN & \\
\hline CHEMBL1351542 & 752310 & 2.4202 & 4.8868 & TST & \\
\hline CHEMBL1600094 & 752310 & 4.3587 & \multicolumn{2}{|c|}{ 4.1339999999999995 } & TRN \\
\hline CHEMBL1558210 & 752310 & 3.8533 & 4.242 & TRN & \\
\hline CHEMBL1572585 & 752310 & 3.7612 & 2.9787 & TRN & \\
\hline CHEMBL1304700 & 752310 & 2.4202 & 4.0485 & TRN & \\
\hline CHEMBL1383058 & 752310 & 5.4418 & 5.0381 & TRN & \\
\hline CHEMBL1523399 & 752310 & 2.4202 & 2.2203 & TST & \\
\hline CHEMBL1508040 & 752310 & 3.7217 & 3.8184 & TRN & \\
\hline CHEMBL1548898 & 752310 & 4.2175 & 5.6976 & TRN & \\
\hline CHEMBL1400638 & 752310 & 5.1868 & 4.7862 & TST & \\
\hline CHEMBL1333510 & 752310 & 2.4202 & 3.5168 & TRN & \\
\hline CHEMBL1557932 & 752310 & 4.0739 & 3.6638 & TST & \\
\hline CHEMBL1401259 & 752310 & 4.6803 & 4.1406 & TRN & \\
\hline CHEMBL1556185 & 752310 & 5.3992 & 4.2997 & TRN & \\
\hline CHEMBL1501990 & 752310 & 5.0239 & 4.1202 & TRN & \\
\hline CHEMBL1503634 & 752310 & 5.083 & 4.7288 & TRN & \\
\hline CHEMBL1421463 & 752310 & 4.4226 & 4.3937 & TRN & \\
\hline CHEMBL1495048 & 752310 & 3.5357 & 4.3987 & TRN & \\
\hline CHEMBL551842 & 752310 & 5.0596 & 3.8713 & TST & \\
\hline CHEMBL1582771 & 752310 & 4.8925 & 3.5637 & TRN & \\
\hline CHEMBL1509317 & 752310 & 2.4202 & 3.1448 & TRN & \\
\hline CHEMBL1308667 & 752310 & 4.2485 & 3.1423 & TRN & \\
\hline CHEMBL1529238 & 752310 & 2.4202 & \multicolumn{2}{|c|}{3.0660000000000003} & TRN \\
\hline CHEMBL1309645 & 752310 & 4.1898 & 2.7425 & TRN & \\
\hline CHEMBL586029 & 752310 & 4.6774 & 4.6155 & TRN & \\
\hline
\end{tabular}




\begin{tabular}{|c|c|c|c|c|c|c|}
\hline \multirow[b]{2}{*}{ CHEMBL1504305 } & & \multicolumn{5}{|c|}{ Supplemental Table S2.txt } \\
\hline & 752310 & 2.4202 & \multicolumn{3}{|c|}{3.6010000000000004} & TRN \\
\hline CHEMBL1303970 & 752310 & 5.0926 & 4.9746 & TRN & & \\
\hline CHEMBL1529389 & 752310 & 3.6169 & 3.4517 & TRN & & \\
\hline CHEMBL1391217 & 752310 & 2.4202 & 3.4642 & TST & & \\
\hline CHEMBL1526855 & 752310 & 5.5542 & 4.7214 & TRN & & \\
\hline CHEMBL3145223 & 752310 & 5.558 & 5.1842 & TRN & & \\
\hline CHEMBL1343101 & 752310 & 5.3355 & 3.9875 & TST & & \\
\hline CHEMBL3198784 & 752310 & 4.6556 & 3.8429 & TRN & & \\
\hline CHEMBL1385433 & 752310 & \multicolumn{3}{|c|}{4.611000000000001} & 3.2475 & TST \\
\hline CHEMBL1507407 & 752310 & 5.2377 & 5.3188 & TRN & & \\
\hline CHEMBL1328462 & 752310 & 2.4202 & 2.9853 & TRN & & \\
\hline CHEMBL1540682 & 752310 & 4.9706 & 3.7763 & TST & & \\
\hline CHEMBL1520852 & 752310 & 5.8598 & 4.9933 & TRN & & \\
\hline CHEMBL 2006893 & 752310 & 4.1258 & 3.5121 & TRN & & \\
\hline CHEMBL1579122 & 752310 & \multicolumn{3}{|c|}{5.242999999999999} & 4.7761 & TRN \\
\hline CHEMBL1584687 & 752310 & 4.6055 & 4.5652 & TST & & \\
\hline CHEMBL592115 & 752310 & 5.4152 & 4.9048 & TRN & & \\
\hline CHEMBL1584304 & 752310 & 2.4202 & 3.5597 & TRN & & \\
\hline CHEMBL1342385 & 752310 & 4.7254 & 2.3175 & TST & & \\
\hline CHEMBL1364183 & 752310 & 2.4202 & 2.4182 & TRN & & \\
\hline CHEMBL1320429 & 752310 & 4.4851 & 4.3183 & TRN & & \\
\hline CHEMBL1469676 & 752310 & 5.8911 & 5.8302 & TRN & & \\
\hline CHEMBL1359835 & 752310 & 2.4202 & 4.0191 & TST & & \\
\hline CHEMBL1387436 & 752310 & 3.9566 & 3.594 & TRN & & \\
\hline CHEMBL1351750 & 752310 & 4.4633 & 4.6158 & TRN & & \\
\hline CHEMBL581677 & 752310 & 4.7881 & 4.6767 & TRN & & \\
\hline CHEMBL1410788 & 752310 & 2.4202 & 3.6214 & TRN & & \\
\hline CHEMBL1558809 & 752310 & 5.2292 & 4.5019 & TRN & & \\
\hline CHEMBL1391118 & 752310 & 4.4915 & 3.9883 & TRN & & \\
\hline CHEMBL1413839 & 752310 & 4.7921 & 4.1069 & TRN & & \\
\hline CHEMBL1993627 & 752310 & 5.3977 & 4.2693 & TRN & & \\
\hline CHEMBL1303737 & 752310 & 4.3935 & 3.9143 & TRN & & \\
\hline CHEMBL1561842 & 752310 & 2.4202 & 3.0682 & TST & & \\
\hline CHEMBL1417290 & 752310 & 4.4295 & 2.8485 & TST & & \\
\hline CHEMBL1340016 & 752310 & 2.4202 & 2.3741 & TRN & & \\
\hline CHEMBL1339512 & 752310 & 2.4202 & 5.2577 & TRN & & \\
\hline CHEMBL 1321538 & 752310 & 5.8911 & 5.8589 & TRN & & \\
\hline CHEMBL602990 & 752310 & 4.3494 & 4.4198 & TRN & & \\
\hline CHEMBL1399100 & 752310 & 4.4161 & 3.498 & TRN & & \\
\hline CHEMBL1383283 & 752310 & 4.157 & 3.9878 & TRN & & \\
\hline CHEMBL1333290 & 752310 & 4.5719 & 3.2997 & TST & & \\
\hline CHEMBL1407128 & 752310 & 5.0797 & 5.0847 & TRN & & \\
\hline CHEMBL1330781 & 752310 & 3.6055 & 4.1926 & TST & & \\
\hline CHEMBL1335964 & 752310 & 2.4202 & 3.4141 & TRN & & \\
\hline CHEMBL1326083 & 752310 & 5.2737 & 5.4691 & TST & & \\
\hline CHEMBL1376311 & 752310 & 5.0842 & 4.4243 & TRN & & \\
\hline CHEMBL1333637 & 752310 & 4.6114 & 2.9268 & TRN & & \\
\hline CHEMBL1569472 & 752310 & 3.8441 & 3.887 & TRN & & \\
\hline
\end{tabular}


Supplemental Table S2.txt

\begin{tabular}{|c|c|c|c|c|c|}
\hline CHEMBL1526076 & 752310 & 4.1856 & 3.513 & TRN & \\
\hline CHEMBL1547301 & 752310 & 5.9285 & 5.282 & TRN & \\
\hline CHEMBL1603293 & 752310 & 4.6668 & 4.1609 & TRN & \\
\hline CHEMBL1516834 & 752310 & 5.8114 & 5.185 & TRN & \\
\hline CHEMBL1325021 & 752310 & 5.6273 & 5.2964 & TRN & \\
\hline CHEMBL1407253 & 752310 & 3.4541 & 4.4838 & TRN & \\
\hline CHEMBL1965172 & 752310 & 2.4202 & 3.8955 & TRN & \\
\hline CHEMBL1577151 & 752310 & 5.4371 & 4.4916 & TRN & \\
\hline CHEMBL1598985 & 752310 & 4.5064 & 2.8618 & TRN & \\
\hline CHEMBL1508896 & 752310 & 2.4202 & 3.3965 & TRN & \\
\hline CHEMBL3144975 & 752310 & 2.4202 & 4.1051 & TRN & \\
\hline CHEMBL1719244 & 752310 & 5.2167 & 4.6023 & TRN & \\
\hline CHEMBL1423919 & 752310 & 4.5109 & 3.7229 & TRN & \\
\hline CHEMBL1483312 & 752310 & 5.837999 & 999999999 & 5.3732 & \\
\hline CHEMBL1415513 & 752310 & 5.4033 & 5.4615 & TRN & \\
\hline CHEMBL1447306 & 752310 & 5.071006 & 000000000 & 4.8876 & TRN \\
\hline CHEMBL1488929 & 752310 & 3.8202 & 3.0707 & TRN & \\
\hline CHEMBL1576254 & 752310 & 2.4202 & 3.118000 & 30000000003 & ונ \\
\hline CHEMBL1700040 & 752310 & 5.2177 & 4.2401 & TRN & \\
\hline CHEMBL599924 & 752310 & 7.1765 & 6.5618 & TRN & \\
\hline CHEMBL1499853 & 752310 & 5.0775 & 3.9974 & TRN & \\
\hline CHEMBL1521758 & 752310 & 6.2232 & 5.8213 & TRN & \\
\hline CHEMBL1581601 & 752310 & 2.4202 & 2.5914 & TRN & \\
\hline CHEMBL1320517 & 752310 & 5.6544 & 3.5917 & TRN & \\
\hline CHEMBL1462615 & 752310 & 4.6778 & 4.0767 & TRN & \\
\hline CHEMBL1543839 & 752310 & 4.292 & 4.5823 & TRN & \\
\hline CHEMBL1546217 & 752310 & 2.4202 & 3.0373 & TRN & \\
\hline CHEMBL1320799 & 752310 & 4.6098 & 3.7849 & TST & \\
\hline CHEMBL52347 & 752310 & 4.8256 & 4.4003 & TRN & \\
\hline CHEMBL578905 & 752310 & 4.9014 & 4.9577 & TRN & \\
\hline CHEMBL1389505 & 752310 & 4.3811 & 4.0908 & TRN & \\
\hline CHEMBL1491717 & 752310 & 5.3239 & 5.3898 & TRN & \\
\hline CHEMBL1542492 & 752310 & 2.4202 & 2.6403 & TRN & \\
\hline CHEMBL127757 & 752310 & 4.1674 & 4.4579 & TRN & \\
\hline CHEMBL1332048 & 752310 & 5.0003 & 4.8788 & TRN & \\
\hline CHEMBL1309419 & 752310 & 2.4202 & 3.13100 & 00000000002 & 1. \\
\hline CHEMBL1349651 & 752310 & 4.1722 & 4.0491 & TRN & \\
\hline CHEMBL1506351 & 752310 & 3.8732 & 3.8464 & TRN & \\
\hline CHEMBL1999630 & 752310 & 4.8318 & 5.0778 & TRN & \\
\hline CHEMBL1970867 & 752310 & 4.6467 & 3.2417 & TRN & \\
\hline CHEMBL1480059 & 752310 & 4.8745 & 4.5117 & TST & \\
\hline CHEMBL1524399 & 752310 & 4.6115 & 4.5529 & TST & \\
\hline CHEMBL1402682 & 752310 & 2.4202 & 3.037 & TRN & \\
\hline CHEMBL1527008 & 752310 & 4.6054 & 4.0077 & TRN & \\
\hline CHEMBL1317919 & 752310 & 2.4202 & 3.1327 & TRN & \\
\hline CHEMBL1409991 & 752310 & 4.7086 & 3.6022 & TRN & \\
\hline CHEMBL1421313 & 752310 & 2.4202 & 4.8745 & TST & \\
\hline CHEMBL1445606 & 752310 & 2.4202 & 3.4194 & TST & \\
\hline
\end{tabular}


Supplemental Table S2.txt

\begin{tabular}{|c|c|c|c|c|}
\hline CHEMBL1449922 & 752310 & 2.4202 & 2.8153 & TRN \\
\hline CHEMBL1479754 & 752310 & 2.4202 & 3.9833 & TST \\
\hline CHEMBL3191961 & 752310 & 4.2762 & 3.8213 & TRN \\
\hline CHEMBL1197872 & 752310 & 4.628 & 4.6331 & TRN \\
\hline CHEMBL1581233 & 752310 & 4.467 & 4.4217 & TRN \\
\hline CHEMBL1395907 & 752310 & 4.9842 & 5.0881 & TRN \\
\hline CHEMBL1548086 & 752310 & 5.3211 & 5.1606 & TST \\
\hline CHEMBL1546134 & 752310 & 5.0158 & 4.8454 & TRN \\
\hline CHEMBL1471341 & 752310 & 2.4202 & 3.068 & TRN \\
\hline CHEMBL1620590 & 752310 & 4.9219 & 5.0179 & TRN \\
\hline CHEMBL 390559 & 752310 & 4.8294 & 3.8032 & TRN \\
\hline CHEMBL3191681 & 752310 & 4.5157 & 4.1511 & TRN \\
\hline CHEMBL1368727 & 752310 & 4.7347 & 4.3313 & TRN \\
\hline CHEMBL1370838 & 752310 & 5.5887 & 3.1495 & TST \\
\hline CHEMBL3210642 & 752310 & 5.2784 & 3.7515 & TRN \\
\hline CHEMBL1346853 & 752310 & 4.6834 & 4.9292 & TST \\
\hline CHEMBL1407208 & 752310 & 2.4202 & 3.3516 & TRN \\
\hline CHEMBL1588697 & 752310 & 2.4202 & 4.9097 & TRN \\
\hline CHEMBL1422689 & 752310 & 5.0 & 4.9253 & TRN \\
\hline CHEMBL1461198 & 752310 & 2.4202 & 1.6817 & TRN \\
\hline CHEMBL1374511 & 752310 & 4.1922 & 3.7118 & TRN \\
\hline CHEMBL3144830 & 752310 & 5.2638 & 4.8863 & TRN \\
\hline CHEMBL1581648 & 752310 & 4.2578 & 4.0749 & TRN \\
\hline CHEMBL1559655 & 752310 & 5.2153 & 5.3698 & TRN \\
\hline CHEMBL1535938 & 752310 & 5.1579 & 4.18 & TRN \\
\hline CHEMBL1726348 & 752310 & 4.083 & 4.7609 & TST \\
\hline CHEMBL 2001831 & 752310 & 4.8748 & 4.2945 & TST \\
\hline CHEMBL1506353 & 752310 & 4.7435 & 4.9006 & TRN \\
\hline CHEMBL1714915 & 752310 & 4.1192 & 4.4549 & TRN \\
\hline CHEMBL1585742 & 752310 & 2.4202 & 3.5997 & TRN \\
\hline CHEMBL1595992 & 752310 & 2.4202 & 2.8776 & TRN \\
\hline CHEMBL1499567 & 752310 & 4.7731 & 3.85100 & 30000000004 \\
\hline CHEMBL1472126 & 752310 & 6.0187 & 5.75 & TRN \\
\hline CHEMBL1301720 & 752310 & 2.4202 & 3.2588 & TRN \\
\hline CHEMBL1373992 & 752310 & 4.7147 & 4.5405 & TRN \\
\hline CHEMBL1698464 & 752310 & 4.0578 & 3.6438 & TRN \\
\hline CHEMBL1449346 & 752310 & 4.1441 & 3.7983 & TRN \\
\hline CHEMBL1335254 & 752310 & 2.4202 & 2.3623 & TRN \\
\hline CHEMBL1597440 & 752310 & 4.3093 & 4.3389 & TRN \\
\hline CHEMBL1383249 & 752310 & 4.2772 & 4.5927 & TRN \\
\hline CHEMBL1374291 & 752310 & 3.5017 & 4.4068 & TRN \\
\hline CHEMBL1529352 & 752310 & 4.5193 & 4.2232 & TRN \\
\hline CHEMBL1568257 & 752310 & 4.3077 & 3.6783 & TRN \\
\hline CHEMBL1589428 & 752310 & 3.4737 & 3.5868 & TRN \\
\hline CHEMBL1541259 & 752310 & 5.0977 & 3.9967 & TRN \\
\hline CHEMBL1465979 & 752310 & 2.4202 & 3.7088 & TST \\
\hline CHEMBL1604205 & 752310 & 4.8972 & 3.719 & TRN \\
\hline CHEMBL1430291 & 752310 & 4.6022 & 4.2738 & TRN \\
\hline
\end{tabular}




\begin{tabular}{|c|c|c|c|c|c|}
\hline & & \multicolumn{4}{|c|}{ Supplemental Table S2.txt } \\
\hline CHEMBL1533236 & 752310 & 4.4521 & 3.3346 & TRN & \\
\hline CHEMBL1432126 & 752310 & 5.1232 & 3.7537 & TRN & \\
\hline CHEMBL1420116 & 752310 & 4.8821 & 3.3319 & TRN & \\
\hline CHEMBL1587473 & 752310 & 5.803 & 5.2999 & TRN & \\
\hline CHEMBL1522349 & 752310 & 2.4202 & 3.1938 & TRN & \\
\hline CHEMBL1335953 & 752310 & 4.9735 & 4.6409 & TRN & \\
\hline CHEMBL1497070 & 752310 & 6.0 & 4.7263 & TST & \\
\hline CHEMBL373839 & 752310 & 5.4311 & 4.7165 & TRN & \\
\hline CHEMBL1569820 & 752310 & 2.4202 & 3.725 & TRN & \\
\hline CHEMBL1605956 & 752310 & 4.2804 & 4.4327 & TRN & \\
\hline CHEMBL1365696 & 752310 & 2.4202 & 3.3007 & TRN & \\
\hline CHEMBL1333268 & 752310 & 2.4202 & 2.8443 & TRN & \\
\hline CHEMBL1533676 & 752310 & 3.5261 & 4.4224 & TRN & \\
\hline CHEMBL1579891 & 752310 & 2.4202 & 1.9528 & TRN & \\
\hline CHEMBL1444473 & 752310 & 4.9566 & 4.0445 & TRN & \\
\hline CHEMBL1426692 & 752310 & 2.4202 & 3.6859 & TRN & \\
\hline CHEMBL1453825 & 752310 & 2.4202 & 2.556 & TRN & \\
\hline CHEMBL1368609 & 752310 & 5.138 & 3.887 & TST & \\
\hline CHEMBL1308497 & 752310 & 4.3846 & 3.9269 & TRN & \\
\hline CHEMBL1389827 & 752310 & 3.8536 & 3.7252 & TST & \\
\hline CHEMBL1510599 & 752310 & 2.4202 & 4.6106 & TST & \\
\hline CHEMBL1312285 & 752310 & 4.3324 & 3.8046 & TRN & \\
\hline CHEMBL 2006750 & 752310 & 2.4202 & 3.3201 & TRN & \\
\hline CHEMBL3195461 & 752310 & 2.4202 & 2.9325 & TRN & \\
\hline CHEMBL1597748 & 752310 & 2.4202 & 3.7026 & TST & \\
\hline CHEMBL1438646 & 752310 & 2.4202 & 2.9963 & TRN & \\
\hline CHEMBL1428096 & 752310 & 4.5996 & 3.9904 & TRN & \\
\hline CHEMBL1379918 & 752310 & 4.6936 & 4.5373 & TRN & \\
\hline CHEMBL1345722 & 752310 & 4.066 & 3.7975 & TRN & \\
\hline CHEMBL1556187 & 752310 & 4.0727 & 3.1173 & TRN & \\
\hline CHEMBL1430105 & 752310 & 5.7778 & 4.6356 & TRN & \\
\hline CHEMBL1343352 & 752310 & 4.7943 & 4.06800 & 00000000005 & TRN \\
\hline CHEMBL1341756 & 752310 & 5.7755 & 5.6006 & TRN & \\
\hline CHEMBL1098875 & 752310 & 2.4202 & 2.9436 & TRN & \\
\hline CHEMBL1414479 & 752310 & 3.5894 & 4.2125 & TRN & \\
\hline CHEMBL1330489 & 752310 & 4.6805 & 4.11600 & 00000000005 & TST \\
\hline CHEMBL1315948 & 752310 & 5.083 & 4.1267 & TRN & \\
\hline CHEMBL1492648 & 752310 & 2.4202 & 3.55800 & 00000000003 & TRN \\
\hline CHEMBL1548695 & 752310 & 2.4202 & 3.9174 & TRN & \\
\hline CHEMBL1313206 & 752310 & 5.4774 & 5.0401 & TRN & \\
\hline CHEMBL1611642 & 752310 & 3.8102 & 3.8925 & TRN & \\
\hline CHEMBL1534947 & 752310 & 5.3743 & 4.4229 & TRN & \\
\hline CHEMBL1524916 & 752310 & 4.8545 & 3.1837 & TRN & \\
\hline CHEMBL1499893 & 752310 & 4.8891 & 4.66 & TRN & \\
\hline CHEMBL1477488 & 752310 & 4.295 & 4.47 & TRN & \\
\hline CHEMBL1477756 & 752310 & 4.3833 & 4.3333 & TRN & \\
\hline CHEMBL1372179 & 752310 & 2.4202 & 3.6154 & TST & \\
\hline CHEMBL1341870 & 752310 & 4.823 & 2.7616 & TRN & \\
\hline
\end{tabular}


Supplemental Table S2.txt

\begin{tabular}{|c|c|c|c|c|c|}
\hline CHEMBL1439124 & 752310 & 2.4202 & 3.5815 & TRN & \\
\hline CHEMBL1374701 & 752310 & 3.48199 & 79999999 & 998 & 3.8347 \\
\hline CHEMBL1506210 & 752310 & 4.8884 & 5.61 & TRN & \\
\hline CHEMBL1326349 & 752310 & 2.4202 & 4.0312 & TRN & \\
\hline CHEMBL3213571 & 752310 & 2.4202 & 2.0308 & TRN & \\
\hline CHEMBL1341835 & 752310 & 4.819 & 4.1679 & TRN & \\
\hline CHEMBL1525505 & 752310 & 4.963 & 4.675 & TRN & \\
\hline CHEMBL1309059 & 752310 & 4.908 & 4.908 & TRN & \\
\hline CHEMBL1565816 & 752310 & 6.3637 & 3.7851 & TRN & \\
\hline CHEMBL1556498 & 752310 & 4.1735 & 3.8673 & TRN & \\
\hline CHEMBL1454680 & 752310 & 5.0241 & 5.1598 & TRN & \\
\hline CHEMBL1549657 & 752310 & 5.2647 & 4.7084 & TRN & \\
\hline CHEMBL1465938 & 752310 & 5.6694 & 5.3913 & TRN & \\
\hline CHEMBL1550425 & 752310 & 4.0554 & 3.6088 & TRN & \\
\hline CHEMBL1579455 & 752310 & 2.4202 & 3.1434 & TRN & \\
\hline CHEMBL1425245 & 752310 & 4.7484 & 4.3182 & TRN & \\
\hline CHEMBL1449718 & 752310 & 2.4202 & 2.8578 & TRN & \\
\hline CHEMBL1447513 & 752310 & 3.813 & 3.8308 & TRN & \\
\hline CHEMBL1538410 & 752310 & 4.9122 & 3.8167 & TRN & \\
\hline CHEMBL1549691 & 752310 & 4.5085 & 3.6928 & TRN & \\
\hline CHEMBL1347117 & 752310 & 5.1742 & 4.9454 & TST & \\
\hline CHEMBL1430473 & 752310 & 4.963 & 3.4753 & TST & \\
\hline CHEMBL1324640 & 752310 & 2.4202 & 3.2627 & TST & \\
\hline CHEMBL1416421 & 752310 & 4.3729 & 3.284 & TRN & \\
\hline CHEMBL1377005 & 752310 & 4.0373 & 4.5996 & TRN & \\
\hline CHEMBL1405964 & 752310 & 2.4202 & 3.7136 & TRN & \\
\hline CHEMBL1576555 & 752310 & 4.3944 & 3.6711 & TRN & \\
\hline CHEMBL1483729 & 752310 & 2.4202 & 3.8027 & TRN & \\
\hline CHEMBL1410768 & 752310 & 5.649 & 3.4121 & TRN & \\
\hline CHEMBL3144926 & 752310 & 5.4808 & 4.4907 & TRN & \\
\hline CHEMBL1383240 & 752310 & 5.4934 & 4.5216 & TRN & \\
\hline CHEMBL1347986 & 752310 & 2.4202 & 3.0725 & TRN & \\
\hline CHEMBL1392532 & 752310 & 2.4202 & 3.5162 & TRN & \\
\hline CHEMBL1724435 & 752310 & 4.4108 & 4.1626 & TRN & \\
\hline CHEMBL1469208 & 752310 & 4.3563 & 4.4163 & TST & \\
\hline CHEMBL1503995 & 752310 & 2.4202 & 2.9934 & TRN & \\
\hline CHEMBL1501421 & 752310 & 2.4202 & 2.8624 & TST & \\
\hline CHEMBL1533621 & 752310 & 4.6164 & 4.5326 & TRN & \\
\hline CHEMBL1970909 & 752310 & 2.4202 & 3.0399 & TRN & \\
\hline CHEMBL1607696 & 752310 & 2.9208 & 4.2902 & TRN & \\
\hline CHEMBL1470357 & 752310 & 4.2367 & 4.2418 & TRN & \\
\hline CHEMBL1507776 & 752310 & 5.5539 & 4.3388 & TRN & \\
\hline CHEMBL1325219 & 752310 & 5.4715 & 4.8102 & TRN & \\
\hline CHEMBL1585390 & 752310 & 3.451 & 3.6809 & TRN & \\
\hline CHEMBL1353194 & 752310 & 4.0827 & 3.3766 & TRN & \\
\hline CHEMBL1423138 & 752310 & 5.5824 & 4.1058 & TRN & \\
\hline CHEMBL1310302 & 752310 & 4.5203 & 4.1776 & TRN & \\
\hline CHEMBL3210913 & 752310 & 2.4202 & 2.9251 & TRN & \\
\hline
\end{tabular}


Supplemental Table S2.txt

\begin{tabular}{|c|c|c|c|c|}
\hline CHEMBL1531579 & 752310 & 4.4905 & 2.9821 & TST \\
\hline CHEMBL1508085 & 752310 & 4.5774 & 4.2156 & TRN \\
\hline CHEMBL1400469 & 752310 & 4.4121 & 4.5335 & TRN \\
\hline CHEMBL1369862 & 752310 & 5.2402 & 4.2479 & TRN \\
\hline CHEMBL1344806 & 752310 & 4.1454 & 4.345 & TRN \\
\hline CHEMBL1581068 & 752310 & 4.6708 & 3.8676 & TRN \\
\hline CHEMBL1432044 & 752310 & 4.9935 & 4.0065 & TRN \\
\hline CHEMBL1477528 & 752310 & 2.4202 & 2.6615 & TRN \\
\hline CHEMBL1410091 & 752310 & 3.6368 & 3.5618 & TRN \\
\hline CHEMBL1401841 & 752310 & 4.7924 & 2.9333 & TRN \\
\hline CHEMBL1497597 & 752310 & 4.2318 & 4.1707 & TRN \\
\hline CHEMBL1388084 & 752310 & 2.4202 & 3.1304 & TRN \\
\hline CHEMBL1577840 & 752310 & 4.0862 & 3.733 & TRN \\
\hline CHEMBL1363249 & 752310 & 4.7962 & 4.2181 & TST \\
\hline CHEMBL1543907 & 752310 & 2.4202 & 3.5812 & TRN \\
\hline CHEMBL1590615 & 752310 & 6.0 & 4.2371 & TRN \\
\hline CHEMBL1643542 & 752310 & 4.8768 & 4.3281 & TRN \\
\hline CHEMBL171637 & 752310 & 5.2156 & 4.3743 & TST \\
\hline CHEMBL1586437 & 752310 & 2.4202 & 1.8282 & TST \\
\hline CHEMBL1510339 & 752310 & 4.7675 & 3.4463 & TRN \\
\hline CHEMBL1528844 & 752310 & 2.4202 & 3.4157 & TRN \\
\hline CHEMBL1735634 & 752310 & 2.4202 & 3.9503 & TRN \\
\hline CHEMBL1359931 & 752310 & 4.8844 & 3.5732 & TRN \\
\hline CHEMBL1606823 & 752310 & 4.3966 & 4.1655 & TRN \\
\hline CHEMBL604321 & 752310 & 5.4297 & 5.3281 & TRN \\
\hline CHEMBL1467381 & 752310 & 2.4202 & 2.4714 & TRN \\
\hline CHEMBL1432348 & 752310 & 4.1674 & 3.7394 & TRN \\
\hline CHEMBL1531428 & 752310 & 5.2944 & 3.1376 & TRN \\
\hline CHEMBL1370681 & 752310 & 2.4202 & 3.2238 & TRN \\
\hline CHEMBL1350396 & 752310 & 3.7878 & 4.3253 & TRN \\
\hline CHEMBL1471461 & 752310 & 2.4202 & 2.4471 & TST \\
\hline CHEMBL1352082 & 752310 & 2.4202 & 3.0219 & TRN \\
\hline CHEMBL1717678 & 752310 & 4.4374 & 4.2343 & TRN \\
\hline CHEMBL1390139 & 752310 & 4.7964 & 4.2652 & TRN \\
\hline CHEMBL1507534 & 752310 & 2.4202 & 3.4959 & TRN \\
\hline CHEMBL1576666 & 752310 & 4.8309 & 4.4653 & TRN \\
\hline CHEMBL1520701 & 752310 & 3.7156 & 3.2321 & TRN \\
\hline CHEMBL1365287 & 752310 & 4.3925 & 4.0795 & TRN \\
\hline CHEMBL494083 & 752310 & 4.7846 & 4.1738 & TST \\
\hline CHEMBL1496959 & 752310 & 5.3489 & 3.3772 & TST \\
\hline CHEMBL1485945 & 752310 & 4.5236 & 3.575 & TRN \\
\hline CHEMBL1496705 & 752310 & 5.0517 & 5.29200 & 0000000001 \\
\hline CHEMBL1719147 & 752310 & 2.4202 & 2.5801 & TRN \\
\hline CHEMBL1483870 & 752310 & 3.6627 & 3.7332 & TRN \\
\hline CHEMBL585656 & 752310 & 5.1202 & 5.5055 & TRN \\
\hline CHEMBL1583199 & 752310 & 6.1115 & 4.6604 & TRN \\
\hline CHEMBL3144940 & 752310 & 4.3353 & 4.1833 & TRN \\
\hline CHEMBL1491275 & 752310 & 2.4202 & 3.1558 & TRN \\
\hline
\end{tabular}


Supplemental Table S2.txt

\begin{tabular}{|c|c|c|c|c|}
\hline & & & & \\
\hline IEMBL1495412 & 2310 & 2.4202 & 9878 & \\
\hline AEMBL1445962 & 2310 & 5572 & 604 & \\
\hline AEMBL1467422 & 52310 & 456 & 2991 & \\
\hline 9420 & 2310 & 202 & 2356 & \\
\hline AEMBL3189879 & 2310 & 341 & 253 & \\
\hline AEMBL1432870 & 52310 & 4.1148 & 9805 & \\
\hline AEMBL179161 & 52310 & 2.4202 & .5178 & \\
\hline AEMBL1310865 & 52310 & 5.5514 & 4.7875 & \\
\hline AEMBL15 & 52310 & 205 & 1731 & \\
\hline AEMBL1557914 & 52310 & 887 & 766 & \\
\hline AEMBL1404492 & 52310 & 202 & 6994 & \\
\hline AEMBL3214581 & 52310 & 202 & 8601 & \\
\hline IEMBL157 & 10 & 2. & 7203 & \\
\hline IEMBL13 & 2310 & 174 & 99 & \\
\hline AEMBL 14 & 2310 & 02 & 819 & \\
\hline AEMBL1463793 & 52310 & 507 & 3.6739 & \\
\hline IEMBL1496635 & 10 & 202 & 69 & \\
\hline IEMBLIS & 0 & 4. & 98 & \\
\hline IEMBL15] & 10 & & 105 & \\
\hline AEMBL319 & 10 & 02 & 373 & \\
\hline AEMBL1502394 & 52310 & 084 & 14 & \\
\hline IEMBL1969046 & & $\partial 2$ & & \\
\hline IEMBL17 & 0 & 2. & 716 & \\
\hline IEMBL14 & 10 & 311 & & \\
\hline IFMDI 15 & 10 & 202 & 096 & וכ \\
\hline AEMBL1984648 & 0 & & 7762 & RN \\
\hline IEMBL1496053 & & & 78 & \\
\hline IEMBL1406895 & 0 & 17 & 2882 & ST \\
\hline 831 & 0 & 82 & 32 & RN \\
\hline 255 & 0 & 65 & 35 & \\
\hline AEMBL1596076 & & & & RN \\
\hline AEMBL1382562 & $\theta$ & & 93 & ST \\
\hline AEMBL137 & 0 & & 43 & RI \\
\hline רד 1 1 ו & 0 & 02 & 84 & \\
\hline 2 & & & & ST \\
\hline AEMBL1608963 & 52 & & 248 & S \\
\hline AEMBL1496534 & $\theta$ & & 146 & ST \\
\hline IEMBL14 & 0 & 02 & 376 & RI \\
\hline 1 & 0 & 15 & 683 & \\
\hline HEMBL13 & & 2. & 252 & RN \\
\hline AEMBL1417901 & 10 & 3.8204 & 3.6898 & $\mathrm{RN}$ \\
\hline AEMBL321 & 0 & 02 & 445 & \\
\hline EIDLIXC & & & & \\
\hline HEMBL 314 & & & & \\
\hline HEMBL145 & & 2. & 384 & RN \\
\hline AEMBL1596475 & 52310 & 4.2825 & 4.9611 & \\
\hline HFMBI 1528757 & 52310 & 5.0153 & 3.7754 & \\
\hline
\end{tabular}




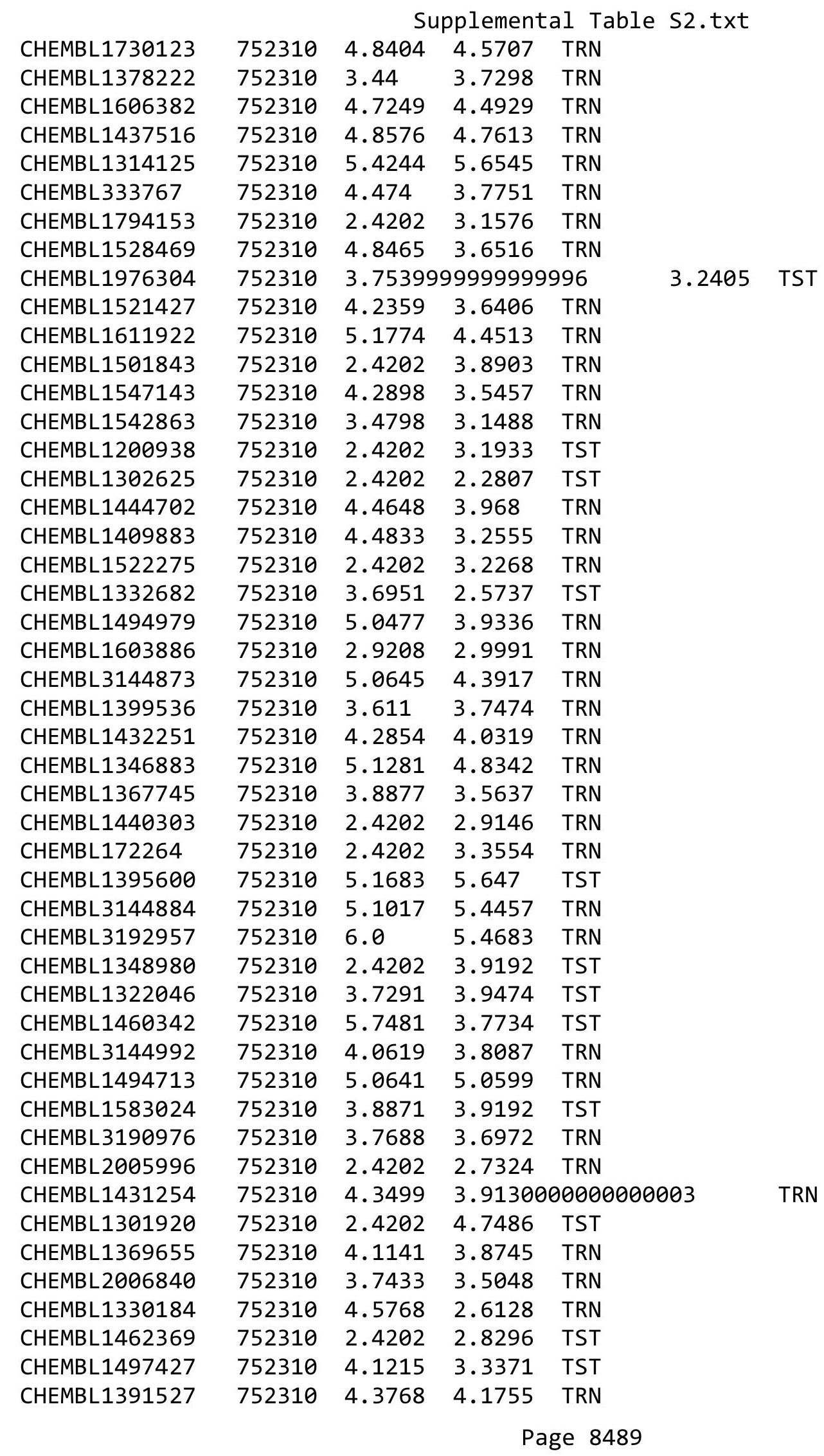


Supplemental Table S2.txt

\begin{tabular}{|c|c|c|c|c|c|}
\hline CHEMBL3193366 & 752310 & 2.4202 & 2.9879 & TRN & \\
\hline CHEMBL1409494 & 752310 & 2.4202 & 3.5884 & TRN & \\
\hline CHEMBL 3196053 & 752310 & 2.4202 & 3.2373 & TRN & \\
\hline CHEMBL1367316 & 752310 & 2.4202 & 3.5696 & TRN & \\
\hline CHEMBL1545701 & 752310 & 2.4202 & 3.7426 & TRN & \\
\hline CHEMBL1299407 & 752310 & 3.4877 & 4.0117 & TRN & \\
\hline CHEMBL1408577 & 752310 & 2.4202 & 2.881999 & 99999999997 & TRN \\
\hline CHEMBL1610747 & 752310 & 2.4202 & 3.6362 & TRN & \\
\hline CHEMBL3208859 & 752310 & 3.5116 & 3.7382 & TRN & \\
\hline CHEMBL1597358 & 752310 & 5.3612 & 5.0686 & TRN & \\
\hline CHEMBL3197999 & 752310 & 3.8271 & 4.234 & TRN & \\
\hline CHEMBL1543601 & 752310 & 5.4007 & 4.6921 & TRN & \\
\hline CHEMBL1412588 & 752310 & 5.0782 & 5.6249 & TRN & \\
\hline CHEMBL1341867 & 752310 & 4.8668 & 4.5449 & TRN & \\
\hline CHEMBL1536137 & 752310 & 4.0944 & 3.1079 & TRN & \\
\hline CHEMBL1707500 & 752310 & 4.0281 & 3.6986 & TRN & \\
\hline CHEMBL1571875 & 752310 & 5.3335 & 5.1385 & TRN & \\
\hline CHEMBL1308037 & 752310 & 2.4202 & 2.1667 & TRN & \\
\hline CHEMBL1568915 & 752310 & 4.9694 & 3.8946 & TST & \\
\hline CHEMBL1611041 & 752310 & 5.0778 & 4.906000 & 000000001 & TRN \\
\hline CHEMBL1300420 & 752310 & 2.4202 & 3.1732 & TRN & \\
\hline CHEMBL1979558 & 752310 & 5.569 & 4.1803 & TRN & \\
\hline CHEMBL 3194086 & 752310 & 5.1827 & 4.6952 & TRN & \\
\hline CHEMBL1456225 & 752310 & 4.6358 & 4.2966 & TRN & \\
\hline CHEMBL1597039 & 752310 & 5.8948 & 5.1415 & TRN & \\
\hline CHEMBL1519108 & 752310 & 4.553 & 4.0744 & TRN & \\
\hline CHEMBL1307792 & 752310 & 2.4202 & 1.891 & TRN & \\
\hline CHEMBL1308904 & 752310 & 4.2778 & 3.5355 & TRN & \\
\hline CHEMBL1331912 & 752310 & 4.0084 & 4.1909 & TRN & \\
\hline CHEMBL1404559 & 752310 & 4.1827 & 3.7447 & TRN & \\
\hline CHEMBL1498127 & 752310 & 4.2057 & 2.7022 & TST & \\
\hline CHEMBL1520740 & 752310 & 2.4202 & 3.4749 & TRN & \\
\hline CHEMBL1412448 & 752310 & 4.4035 & 3.876000 & 30000000003 & TRN \\
\hline CHEMBL1519280 & 752310 & 3.5126 & 2.7451 & TRN & \\
\hline CHEMBL1555488 & 752310 & 4.8677 & 4.3034 & TRN & \\
\hline CHEMBL1458150 & 752310 & 2.4202 & 3.7455 & TRN & \\
\hline CHEMBL1471907 & 752310 & 5.2342 & 4.2666 & TRN & \\
\hline CHEMBL1350983 & 752310 & 2.4202 & 3.5211 & TRN & \\
\hline CHEMBL1604350 & 752310 & 3.4921 & 3.6332 & TRN & \\
\hline CHEMBL1309241 & 752310 & 2.4202 & 3.4597 & TRN & \\
\hline CHEMBL1423623 & 752310 & 3.767 & 5.1648 & TRN & \\
\hline CHEMBL1323351 & 752310 & 4.2679 & 4.4171 & TRN & \\
\hline CHEMBL1411089 & 752310 & 4.23 & 2.9688 & TST & \\
\hline CHEMBL1380913 & 752310 & 3.5478 & 3.9077 & TRN & \\
\hline CHEMBL1472108 & 752310 & 2.4202 & 3.8001 & TRN & \\
\hline CHEMBL1321952 & 752310 & 4.0222 & 3.681 & TRN & \\
\hline CHEMBL1545902 & 752310 & 4.8831 & 4.6779 & TST & \\
\hline CHEMBL 3145111 & 752310 & 4.8824 & 4.6006 & TRN & \\
\hline
\end{tabular}




\begin{tabular}{|c|c|c|c|c|c|c|}
\hline & & \multicolumn{5}{|c|}{ Supplemental Table S2.txt } \\
\hline CHEMBL3192031 & 752310 & 5.3303 & 4.2053 & TRN & & \\
\hline CHEMBL 3207440 & 752310 & 5.329 & 4.129 & TRN & & \\
\hline CHEMBL1455957 & 752310 & 3.7471 & 4.3432 & TST & & \\
\hline CHEMBL88326 & 752310 & 3.8167 & 4.2325 & TRN & & \\
\hline CHEMBL3194415 & 752310 & 4.574 & 4.4647 & TRN & & \\
\hline CHEMBL1559156 & 752310 & 2.4202 & 4.1855 & TST & & \\
\hline CHEMBL1505358 & 752310 & 4.8345 & 4.8884 & TRN & & \\
\hline CHEMBL1404013 & 752310 & 2.4202 & 2.7259 & TRN & & \\
\hline CHEMBL1520615 & 752310 & \multicolumn{3}{|c|}{ 3.7969999999999997 } & 3.2166 & TST \\
\hline CHEMBL3216654 & 752310 & 4.743 & 5.3753 & TRN & & \\
\hline CHEMBL 3193450 & 752310 & 4.2911 & 4.6325 & TRN & & \\
\hline CHEMBL1428450 & 752310 & 4.1763 & \multicolumn{3}{|c|}{3.7319999999999998} & TRN \\
\hline CHEMBL1372597 & 752310 & 3.7775 & \multicolumn{3}{|c|}{3.4989999999999997} & TRN \\
\hline CHEMBL1480031 & 752310 & 3.4911 & 3.2511 & TRN & & \\
\hline CHEMBL1443601 & 752310 & 3.4445 & 3.4475 & TRN & & \\
\hline CHEMBL533226 & 752310 & 5.0979 & 4.6664 & TRN & & \\
\hline CHEMBL1964615 & 752310 & 4.6392 & 3.7989 & TST & & \\
\hline CHEMBL 2003651 & 752310 & 6.6396 & 6.1892 & TRN & & \\
\hline CHEMBL1480243 & 752310 & 2.4202 & 2.5051 & TRN & & \\
\hline CHEMBL1444960 & 752310 & 2.4202 & 3.9549 & TRN & & \\
\hline CHEMBL1460225 & 752310 & 2.4202 & 2.8784 & TRN & & \\
\hline CHEMBL1500823 & 752310 & 3.8401 & 3.4018 & TRN & & \\
\hline CHEMBL1390061 & 752310 & 3.8794 & 3.79 & TRN & & \\
\hline CHEMBL3214024 & 752310 & 2.4202 & 2.7939 & TRN & & \\
\hline CHEMBL580340 & 752310 & 5.0965 & 4.9803 & TRN & & \\
\hline CHEMBL1720482 & 752310 & 4.9805 & 3.9256 & TRN & & \\
\hline CHEMBL1539236 & 752310 & 3.9598 & 3.7109 & TST & & \\
\hline CHEMBL1300711 & 752310 & 2.4202 & 1.6869 & TRN & & \\
\hline CHEMBL1384489 & 752310 & \multicolumn{3}{|c|}{4.0280000000000005} & 3.44 & TRN \\
\hline CHEMBL1584739 & 752310 & 4.4408 & 4.3875 & TRN & & \\
\hline CHEMBL3210821 & 752310 & 4.1393 & 3.7153 & TRN & & \\
\hline CHEMBL1612699 & 752310 & 4.1 & 3.1389 & TRN & & \\
\hline CHEMBL1576785 & 752310 & 5.0613 & 3.3473 & TST & & \\
\hline CHEMBL1307207 & 752310 & 5.7062 & 4.7669 & TRN & & \\
\hline CHEMBL1700372 & 752310 & 4.6676 & 4.0947 & TRN & & \\
\hline CHEMBL1600712 & 752310 & 3.7387 & 3.2265 & TST & & \\
\hline CHEMBL3198684 & 752310 & 2.4202 & 3.4678 & TRN & & \\
\hline CHEMBL1445675 & 752310 & 2.4202 & 3.5233 & TRN & & \\
\hline CHEMBL1577384 & 752310 & 3.9136 & 3.053 & TRN & & \\
\hline CHEMBL1414704 & 752310 & 4.9248 & 4.7218 & TRN & & \\
\hline CHEMBL3191754 & 752310 & 4.4265 & 3.485 & TRN & & \\
\hline CHEMBL1588306 & 752310 & 2.4202 & 2.9063 & TST & & \\
\hline CHEMBL1499544 & 752310 & 6.1726 & 5.7945 & TRN & & \\
\hline CHEMBL1541405 & 752310 & 2.4202 & 3.785 & TRN & & \\
\hline CHEMBL1546297 & 752310 & 4.595 & 4.5188 & TRN & & \\
\hline CHEMBL1706657 & 752310 & 2.9208 & 2.8548 & TRN & & \\
\hline CHEMBL1471779 & 752310 & 2.4202 & 3.6891 & TRN & & \\
\hline CHEMBL1477770 & 752310 & 4.0184 & 4.7611 & TST & & \\
\hline
\end{tabular}


Supplemental Table S2.txt

\begin{tabular}{|c|c|c|c|c|}
\hline . & & 75 & & \\
\hline CHEMBL3198718 & 52310 & 2.4202 & 8 & \\
\hline HEMBL1581228 & 52310 & .4202 & & \\
\hline 08 & 310 & 202 & & \\
\hline EMBL1; & 2310 & 1736 & & \\
\hline AEMBL1606613 & 52310 & 659 & 5955 & \\
\hline HEMBL3144858 & 52310 & 4407 & 51 & \\
\hline AEMBL & 52310 & & & \\
\hline 27 & 52310 & & & \\
\hline AEMBL: & 52310 & 759 & & \\
\hline AEMBL1334307 & 52310 & 3869 & 504 & \\
\hline AEMBL: & 52310 & 4202 & & \\
\hline AEMBL: & 52310 & 202 & & \\
\hline IEMBL & 52310 & & & \\
\hline HEMBL: & 52310 & 5.3329 & & \\
\hline AEMBL] & 52310 & 59 & & \\
\hline AEMBL: & 52310 & .4202 & 47 & \\
\hline AEMBL & 52310 & & & \\
\hline IEMBL & 52310 & & & \\
\hline AEMBL & 52310 & 669 & & \\
\hline IEMBL & & & & \\
\hline 32 & 52310 & 4.9722 & 36 & \\
\hline EMBL & 10 & & & \\
\hline 80 & 10 & & & \\
\hline IEMBL & 52310 & & & \\
\hline EMBL & & & & $2 \mathrm{~N}$ \\
\hline IEMBL & 52310 & 16 & 04 & \\
\hline 43 & 10 & 2 & & 4 \\
\hline 30 & 10 & & & \\
\hline |EMB| & & & & $\mathrm{RN}$ \\
\hline AEMBL & & & & RI \\
\hline IEMBL & 10 & 4.7991 & & RI \\
\hline 27 & 10 & 2 & & . \\
\hline 1 & & & & KIV \\
\hline IEMBL: & & & & RN \\
\hline IEMBL: & 52310 & & & \\
\hline HEMB & 10 & $\partial 2$ & & $\mathrm{R}$ \\
\hline 30 & & & & \\
\hline & & & & ST \\
\hline IEMBL: & 310 & 405 & & RI \\
\hline EMBL & 10 & 835 & & $\mathrm{RI}$ \\
\hline HEMBL & 52310 & & 72 & \\
\hline & & & & \\
\hline HEMBL: & 52310 & 882 & 3.8983 & RI \\
\hline IEMBL: & 52310 & 4.2336 & 4.1277 & $\mathrm{R}$ \\
\hline EMBL & & & & \\
\hline CHEMBL: & 52310 & & 4.1001 & \\
\hline CHEMBL & 52310 & & 3.989 & \\
\hline
\end{tabular}

Page 8492 
Supplemental Table S2.txt

\begin{tabular}{|c|c|c|c|c|}
\hline CHEMBL1716843 & 752310 & 2.4202 & 3.142 & TRN \\
\hline CHEMBL1323536 & 752310 & 4.6073 & 3.9241 & TRN \\
\hline CHEMBL1599965 & 752310 & 5.8523 & 4.2231 & TRN \\
\hline CHEMBL1572216 & 752310 & 2.4202 & 4.1902 & TRN \\
\hline CHEMBL1547025 & 752310 & 5.1187 & 4.6379 & TRN \\
\hline CHEMBL1533269 & 752310 & 4.8505 & 4.1776 & TRN \\
\hline CHEMBL1500316 & 752310 & 2.4202 & 2.8189 & TST \\
\hline CHEMBL1329532 & 752310 & 4.5064 & 4.6359 & TRN \\
\hline CHEMBL1555899 & 752310 & 2.4202 & 3.6519 & TST \\
\hline CHEMBL1402954 & 752310 & 4.9539 & 4.7069 & TRN \\
\hline CHEMBL1586948 & 752310 & 3.8401 & 4.0518 & TRN \\
\hline CHEMBL1510510 & 752310 & 2.4202 & 3.2132 & TRN \\
\hline CHEMBL1427221 & 752310 & 4.7838 & 4.8056 & TRN \\
\hline CHEMBL1577545 & 752310 & 3.7552 & 3.9441 & TRN \\
\hline CHEMBL1505544 & 752310 & 2.4202 & 3.2132 & TRN \\
\hline CHEMBL1405577 & 752310 & 4.01399 & 99999999 & 4.0393 \\
\hline CHEMBL1539522 & 752310 & 2.4202 & 2.7651 & TRN \\
\hline CHEMBL 3145109 & 752310 & 5.0692 & 4.923999 & 99999999995 \\
\hline CHEMBL600526 & 752310 & 2.4202 & 3.4684 & TRN \\
\hline CHEMBL 3197978 & 752310 & 2.4202 & 4.0039 & TRN \\
\hline CHEMBL1389212 & 752310 & 4.6036 & 3.9901 & TST \\
\hline CHEMBL1487321 & 752310 & 2.4202 & 3.4571 & TRN \\
\hline CHEMBL1484934 & 752310 & 6.2125 & 6.2121 & TRN \\
\hline CHEMBL1509349 & 752310 & 4.3685 & 4.3521 & TRN \\
\hline CHEMBL1585332 & 752310 & 5.2365 & 4.2796 & TST \\
\hline CHEMBL1365234 & 752310 & 4.8821 & 4.6532 & TRN \\
\hline CHEMBL1515286 & 752310 & 4.9952 & 3.8813 & TRN \\
\hline CHEMBL1719459 & 752310 & 4.8088 & 5.1506 & TRN \\
\hline CHEMBL1603720 & 752310 & 2.4202 & 2.0704 & TST \\
\hline CHEMBL1526410 & 752310 & 2.4202 & 3.2319 & TST \\
\hline CHEMBL1466804 & 752310 & 5.079 & 4.0647 & TRN \\
\hline CHEMBL1602221 & 752310 & 2.4202 & 2.8477 & TST \\
\hline CHEMBL1987742 & 752310 & 5.3339 & 3.7596 & TST \\
\hline CHEMBL1735523 & 752310 & 2.4202 & 2.1611 & TRN \\
\hline CHEMBL1327965 & 752310 & 2.4202 & 3.5367 & TRN \\
\hline CHEMBL1483657 & 752310 & 2.4202 & 3.4393 & TRN \\
\hline CHEMBL1399938 & 752310 & 5.6853 & 5.6402 & TRN \\
\hline CHEMBL1470321 & 752310 & 2.4202 & 3.3886 & TRN \\
\hline CHEMBL1429018 & 752310 & 3.9678 & 3.9845 & TRN \\
\hline CHEMBL1578949 & 752310 & 2.4202 & 2.0825 & TRN \\
\hline CHEMBL1464786 & 752310 & 3.991 & 4.1089 & TRN \\
\hline CHEMBL1606736 & 752310 & 5.4632 & 4.9333 & TRN \\
\hline CHEMBL1794195 & 752310 & 4.194 & 4.6087 & TRN \\
\hline CHEMBL1327390 & 752310 & 4.7378 & 3.5898 & TRN \\
\hline CHEMBL571501 & 752310 & 2.4202 & 3.5771 & TRN \\
\hline CHEMBL1468055 & 752310 & 4.8703 & 3.7278 & TRN \\
\hline CHEMBL1600684 & 752310 & 6.2719 & 6.5926 & TRN \\
\hline CHEMBL1430827 & 752310 & 5.1504 & 5.2599 & TRN \\
\hline
\end{tabular}

Page 8493 


\begin{tabular}{|c|c|c|c|c|c|}
\hline \multicolumn{6}{|c|}{ splemental lable sa } \\
\hline CHEMBL1570497 & 752310 & 5.1635 & 4.3716 & TRN & \\
\hline CHEMBL1978279 & 752310 & 2.4202 & 3.3477 & TRN & \\
\hline CHEMBL1443497 & 752310 & 2.4202 & 3.106006 & 00000000003 & TST \\
\hline CHEMBL1332119 & 752310 & 2.4202 & 3.87399 & 99999999997 & TRN \\
\hline CHEMBL1390923 & 752310 & 4.7203 & 3.8465 & TRN & \\
\hline CHEMBL1492668 & 752310 & 2.4202 & 2.7485 & TRN & \\
\hline CHEMBL1567632 & 752310 & 4.0001 & 3.9603 & TRN & \\
\hline CHEMBL1794145 & 752310 & 2.4202 & 1.8262 & TST & \\
\hline CHEMBL1326534 & 752310 & 5.0744 & 4.2905 & TRN & \\
\hline CHEMBL1348813 & 752310 & 4.9574 & 4.2239 & TRN & \\
\hline CHEMBL1392791 & 752310 & 5.0135 & 4.5849 & TRN & \\
\hline CHEMBL1597736 & 752310 & 2.4202 & 2.0311 & TST & \\
\hline CHEMBL1430450 & 752310 & 5.129 & 4.1441 & TRN & \\
\hline CHEMBL1300684 & 752310 & 2.4202 & 3.1274 & TRN & \\
\hline CHEMBL1376540 & 752310 & 5.2155 & 4.1858 & TRN & \\
\hline CHEMBL1467136 & 752310 & 5.4319 & 3.6595 & TST & \\
\hline CHEMBL1400375 & 752310 & 5.8128 & 4.7043 & TRN & \\
\hline CHEMBL1536119 & 752310 & 2.4202 & 2.839 & TRN & \\
\hline CHEMBL1401000 & 752310 & 2.4202 & 2.9519 & TRN & \\
\hline CHEMBL1991885 & 752310 & 4.6684 & 4.6785 & TRN & \\
\hline CHEMBL1331111 & 752310 & 5.3366 & 4.6658 & TRN & \\
\hline CHEMBL2369166 & 752310 & 4.0258 & 3.6218 & TRN & \\
\hline CHEMBL1332910 & 752310 & 4.4837 & 2.9106 & TRN & \\
\hline CHEMBL1339245 & 752310 & 4.8435 & 4.7002 & TRN & \\
\hline CHEMBL1348289 & 752310 & 2.4202 & 1.9873 & TRN & \\
\hline CHEMBL1347633 & 752310 & 4.1665 & 3.79399 & 99999999996 & TST \\
\hline CHEMBL1305537 & 752310 & 4.5727 & 4.1357 & TRN & \\
\hline CHEMBL1567670 & 752310 & 4.8668 & 4.1579 & TRN & \\
\hline CHEMBL1563903 & 752310 & 4.7222 & 5.5561 & TRN & \\
\hline CHEMBL1512368 & 752310 & 2.4202 & 2.9953 & TRN & \\
\hline CHEMBL1566610 & 752310 & 3.9914 & 3.0039 & TST & \\
\hline CHEMBL1389508 & 752310 & 4.1401 & 3.8007 & TST & \\
\hline CHEMBL1500227 & 752310 & 5.8601 & 5.7753 & TRN & \\
\hline CHEMBL1330963 & 752310 & 5.3203 & 3.6565 & TRN & \\
\hline CHEMBL 3212445 & 752310 & 4.5114 & 3.9637 & TST & \\
\hline CHEMBL3144906 & 752310 & 4.9555 & 4.7236 & TRN & \\
\hline CHEMBL1427646 & 752310 & 2.4202 & 2.5791 & TST & \\
\hline CHEMBL1576896 & 752310 & 2.4202 & 3.1894 & TRN & \\
\hline CHEMBL3209454 & 752310 & 2.4202 & 3.4541 & TRN & \\
\hline CHEMBL99408 & 752310 & 4.8105 & 4.4627 & TRN & \\
\hline CHEMBL1543655 & 752310 & 2.4202 & 2.1498 & TRN & \\
\hline CHEMBL1337144 & 752310 & 2.4202 & 3.1852 & TRN & \\
\hline CHEMBL1450196 & 752310 & 4.4851 & 4.0669 & TRN & \\
\hline CHEMBL1371353 & 752310 & 5.1993 & 5.2814 & TRN & \\
\hline CHEMBL1578324 & 752310 & 2.4202 & 3.2995 & TRN & \\
\hline CHEMBL1496059 & 752310 & 2.4202 & 2.9652 & TRN & \\
\hline CHEMBL1341981 & 752310 & 2.4202 & 2.56399 & 99999999996 & TRN \\
\hline CHEMBL1320274 & 752310 & 6.0302 & 5.6636 & TRN & \\
\hline
\end{tabular}


Supplemental Table S2.txt

\begin{tabular}{|c|c|c|c|c|}
\hline CHEMBL1334554 & 752310 & 2.4202 & 2.9073 & TST \\
\hline CHEMBL1541219 & 752310 & 4.2676 & 3.6514 & TRN \\
\hline CHEMBL1328712 & 752310 & 4.1983 & 3.3789 & TRN \\
\hline CHEMBL1349637 & 752310 & 4.8851 & 4.4365 & TRN \\
\hline CHEMBL1483562 & 752310 & 5.5089 & 3.9846 & TRN \\
\hline CHEMBL1504810 & 752310 & 5.0426 & 4.488 & TST \\
\hline CHEMBL1312673 & 752310 & 3.4595 & 2.1873 & TRN \\
\hline CHEMBL1479114 & 752310 & 5.0192 & 3.9909 & TRN \\
\hline CHEMBL1378851 & 752310 & 4.2489 & 3.3843 & TRN \\
\hline CHEMBL1312974 & 752310 & 2.4202 & 3.4692 & TST \\
\hline CHEMBL1794157 & 752310 & 2.4202 & 3.4165 & TRN \\
\hline CHEMBL1573221 & 752310 & 2.4202 & 2.5665 & TRN \\
\hline CHEMBL1570673 & 752310 & 4.5223 & 3.4875 & TRN \\
\hline CHEMBL1344573 & 752310 & 4.0335 & 3.9784 & TRN \\
\hline CHEMBL1422754 & 752310 & 4.6494 & 4.3374 & TRN \\
\hline CHEMBL1568150 & 752310 & 2.4202 & 2.9521 & TRN \\
\hline CHEMBL1305372 & 752310 & 4.3298 & 3.5656 & TRN \\
\hline CHEMBL1324556 & 752310 & 3.5064 & 3.5846 & TRN \\
\hline CHEMBL1537961 & 752310 & 4.4988 & 4.0272 & TRN \\
\hline CHEMBL1300695 & 752310 & 2.4202 & 4.3529 & TRN \\
\hline CHEMBL1407708 & 752310 & 3.9796 & 3.7193 & TRN \\
\hline CHEMBL1389509 & 752310 & 5.4159 & 4.388 & TST \\
\hline CHEMBL1313043 & 752310 & 3.8041 & 3.1147 & TRN \\
\hline CHEMBL1547262 & 752310 & 2.4202 & 3.8013 & TRN \\
\hline CHEMBL1416543 & 752310 & 5.1854 & 2.97 & TST \\
\hline CHEMBL1497049 & 752310 & 4.3261 & 3.1914 & TRN \\
\hline CHEMBL582722 & 752310 & 4.7786 & 4.3148 & TRN \\
\hline CHEMBL1486332 & 752310 & 5.2535 & 5.1083 & TRN \\
\hline CHEMBL1606109 & 752310 & 2.4202 & 2.9409 & TRN \\
\hline CHEMBL1499903 & 752310 & 5.0076 & 4.1204 & TST \\
\hline CHEMBL 3145078 & 752310 & 2.4202 & 3.2002 & TRN \\
\hline CHEMBL1376281 & 752310 & 2.4202 & 3.70899 & 99999999996 \\
\hline CHEMBL1974506 & 752310 & 4.7033 & 4.2896 & TST \\
\hline CHEMBL1603760 & 752310 & 5.2406 & 5.5354 & TRN \\
\hline CHEMBL1307882 & 752310 & 3.8074 & 4.0782 & TRN \\
\hline CHEMBL1416184 & 752310 & 4.4908 & 4.9177 & TRN \\
\hline CHEMBL1508402 & 752310 & 4.7491 & 4.6445 & TRN \\
\hline CHEMBL1507448 & 752310 & 4.8962 & 5.3045 & TRN \\
\hline CHEMBL1566134 & 752310 & 2.4202 & 3.5647 & TRN \\
\hline CHEMBL1343343 & 752310 & 4.7635 & 5.3444 & TRN \\
\hline CHEMBL3199919 & 752310 & 4.5588 & 4.6078 & TST \\
\hline CHEMBL1560396 & 752310 & 2.4202 & 3.4341 & TRN \\
\hline CHEMBL1520239 & 752310 & 2.4202 & \multicolumn{2}{|c|}{2.7030000000000003} \\
\hline CHEMBL1459914 & 752310 & 4.2712 & 4.1761 & TRN \\
\hline CHEMBL1553074 & 752310 & 2.4202 & 2.9577 & TRN \\
\hline CHEMBL 3145051 & 752310 & 2.4202 & 3.3212 & TRN \\
\hline CHEMBL600175 & 752310 & 3.4899 & 4.7155 & TRN \\
\hline CHEMBL1510362 & 752310 & 2.4202 & 3.6637 & TRN \\
\hline
\end{tabular}

Page 8495 
Supplemental Table S2.txt

\begin{tabular}{|c|c|c|c|c|}
\hline CHEMBL1437683 & 752310 & 2.4202 & 2.735 & TRN \\
\hline CHEMBL1374709 & 752310 & 2.4202 & 2.4297 & TST \\
\hline CHEMBL1535367 & 752310 & 2.4202 & 1.6598 & TRN \\
\hline CHEMBL1981464 & 752310 & 2.4202 & 2.4971 & TRN \\
\hline CHEMBL1997668 & 752310 & 4.6611 & 4.0505 & TRN \\
\hline CHEMBL1364384 & 752310 & 2.4202 & 2.5831 & TRN \\
\hline CHEMBL1422056 & 752310 & 4.7368 & 4.5508 & TRN \\
\hline CHEMBL1427637 & 752310 & 4.8245 & 4.7573 & TRN \\
\hline CHEMBL1519313 & 752310 & 4.4885 & 3.8022 & TST \\
\hline CHEMBL1706100 & 752310 & 2.9208 & 3.2674 & TRN \\
\hline CHEMBL3198239 & 752310 & 2.4202 & 2.9988 & TRN \\
\hline CHEMBL1406341 & 752310 & 2.4202 & 4.0502 & TRN \\
\hline CHEMBL1337382 & 752310 & 2.4202 & 2.88100 & 00000000002 \\
\hline CHEMBL1540603 & 752310 & 2.4202 & 3.3093 & TRN \\
\hline CHEMBL 3145026 & 752310 & 5.7158 & 4.9724 & TRN \\
\hline CHEMBL523200 & 752310 & 3.5328 & 4.3579 & TRN \\
\hline CHEMBL1337442 & 752310 & 2.4202 & 1.9513 & TST \\
\hline CHEMBL1429164 & 752310 & 2.4202 & 3.1596 & TRN \\
\hline CHEMBL1569134 & 752310 & 2.4202 & 2.9183 & TRN \\
\hline CHEMBL1501755 & 752310 & 5.2196 & 4.1676 & TRN \\
\hline CHEMBL1574908 & 752310 & 4.9197 & 4.6951 & TRN \\
\hline CHEMBL1478145 & 752310 & 4.8219 & 4.1083 & TST \\
\hline CHEMBL1563864 & 752310 & 4.4001 & 4.3341 & TRN \\
\hline CHEMBL1415772 & 752310 & 4.399 & 4.1128 & TRN \\
\hline CHEMBL1537132 & 752310 & 5.7708 & 3.9372 & TRN \\
\hline CHEMBL 3145187 & 752310 & 5.2604 & 4.3468 & TRN \\
\hline CHEMBL1499951 & 752310 & 2.4202 & 4.0553 & TRN \\
\hline CHEMBL1734820 & 752310 & 4.5558 & 4.518 & TRN \\
\hline CHEMBL1576509 & 752310 & 2.4202 & 4.6537 & TRN \\
\hline CHEMBL1377533 & 752310 & 4.5305 & 4.0197 & TRN \\
\hline CHEMBL1380020 & 752310 & 2.4202 & 2.6505 & TRN \\
\hline CHEMBL 3199424 & 752310 & 5.5299 & 4.9538 & TRN \\
\hline CHEMBL1442944 & 752310 & 2.4202 & 4.2081 & TRN \\
\hline CHEMBL1566496 & 752310 & 4.2232 & 4.0601 & TRN \\
\hline CHEMBL1508129 & 752310 & 5.0017 & 4.3548 & TRN \\
\hline CHEMBL1447796 & 752310 & 3.6396 & 3.7596 & TST \\
\hline CHEMBL1463563 & 752310 & 4.5259 & 3.9096 & TRN \\
\hline CHEMBL1418568 & 752310 & 5.5079 & 3.4711 & TRN \\
\hline CHEMBL1487749 & 752310 & 2.4202 & 3.2256 & TST \\
\hline CHEMBL1532323 & 752310 & 4.8324 & 3.8514 & TRN \\
\hline CHEMBL1441170 & 752310 & 3.6189 & 3.764 & TST \\
\hline CHEMBL 3194773 & 752310 & 2.4202 & 3.1851 & TRN \\
\hline CHEMBL 3195684 & 752310 & 2.4202 & 2.9817 & TRN \\
\hline CHEMBL1348057 & 752310 & 4.49 & 3.6621 & TRN \\
\hline CHEMBL1313412 & 752310 & 5.1304 & 5.7913 & TRN \\
\hline CHEMBL 3186541 & 752310 & 5.2185 & 5.145 & TRN \\
\hline CHEMBL1453579 & 752310 & 2.4202 & 3.7626 & TRN \\
\hline CHEMBL 3144874 & 752310 & 6.0351 & 4.4194 & TRN \\
\hline
\end{tabular}




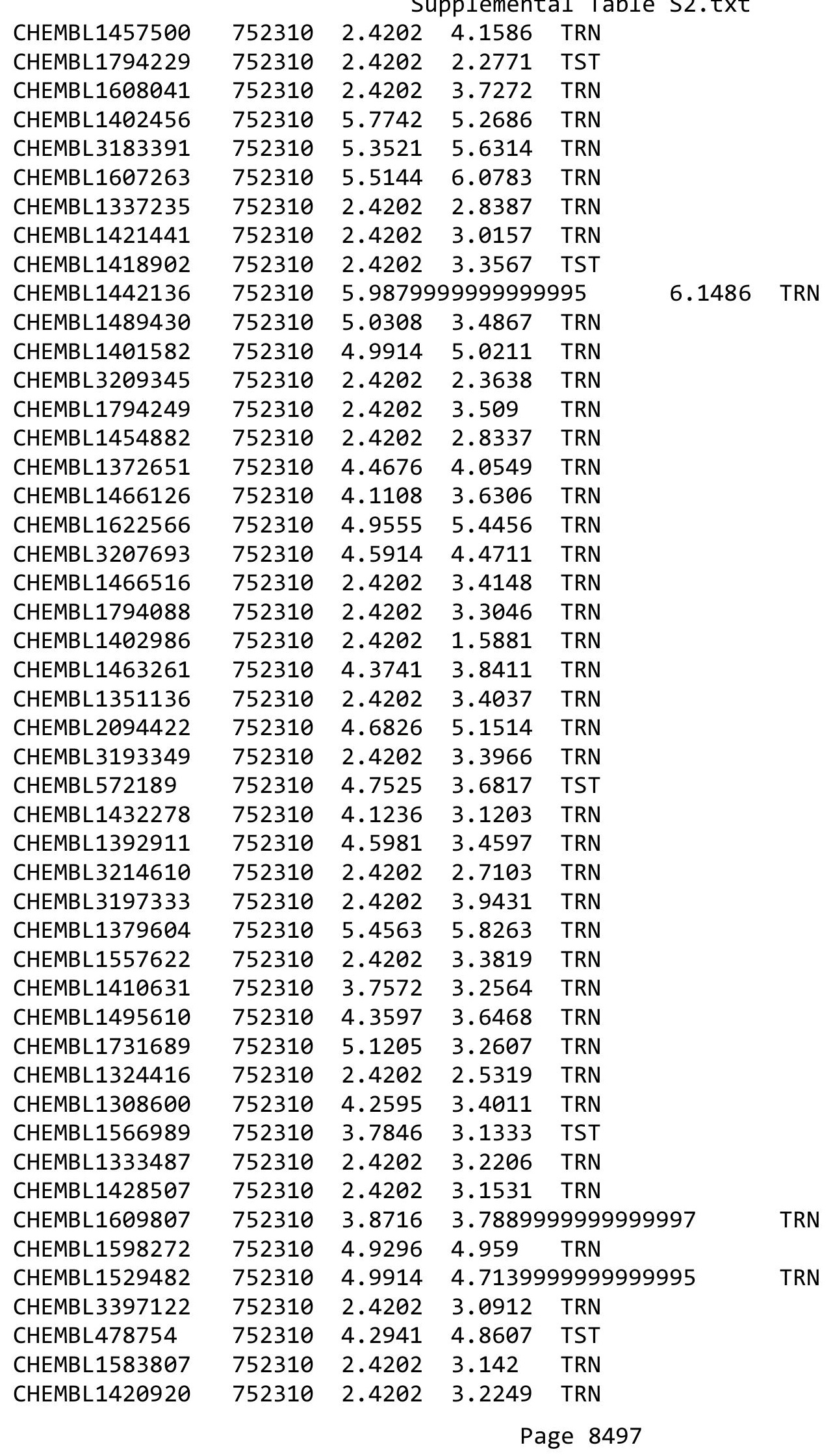


Supplemental Table S2.txt

\begin{tabular}{|c|c|c|c|c|}
\hline CHEMBL1989853 & 752310 & 5.5333 & 5.0822 & TRN \\
\hline CHEMBL1364896 & 752310 & 4.6451 & 4.0109 & TST \\
\hline CHEMBL1320781 & 752310 & 2.4202 & 4.2065 & TRN \\
\hline CHEMBL1532588 & 752310 & 5.5187 & 4.2345 & TST \\
\hline CHEMBL1391913 & 752310 & 2.4202 & 4.1451 & TRN \\
\hline CHEMBL1386493 & 752310 & 4.5016 & 4.1674 & TRN \\
\hline CHEMBL1541821 & 752310 & 2.4202 & 3.8498 & TRN \\
\hline CHEMBL1313900 & 752310 & 5.5226 & 3.8935 & TST \\
\hline CHEMBL1436932 & 752310 & 2.4202 & 3.6416 & TRN \\
\hline CHEMBL3145116 & 752310 & 5.2092 & 4.4485 & TRN \\
\hline CHEMBL3191689 & 752310 & 4.7627 & 4.3478 & TRN \\
\hline CHEMBL1390555 & 752310 & 5.3939 & 4.4673 & TRN \\
\hline CHEMBL1305832 & 752310 & 2.4202 & 3.9687 & TST \\
\hline CHEMBL1307096 & 752310 & 2.4202 & 4.2986 & TST \\
\hline CHEMBL1301722 & 752310 & 2.4202 & 3.3446 & TRN \\
\hline CHEMBL1330558 & 752310 & 5.0743 & 4.733000 & 0000000005 \\
\hline CHEMBL1600855 & 752310 & 4.9187 & 4.7172 & TST \\
\hline CHEMBL1928483 & 752310 & 2.4202 & 3.0969 & TRN \\
\hline CHEMBL1584201 & 752310 & 5.2916 & 3.1847 & TRN \\
\hline CHEMBL1460748 & 752310 & 4.7721 & 4.1943 & TRN \\
\hline CHEMBL1710140 & 752310 & 2.4202 & 4.5175 & TST \\
\hline CHEMBL3213220 & 752310 & 2.4202 & 3.3771 & TRN \\
\hline CHEMBL1794259 & 752310 & 2.4202 & 2.3143 & TRN \\
\hline CHEMBL1400512 & 752310 & 5.0739 & 4.1453 & TST \\
\hline CHEMBL1589625 & 752310 & 4.0174 & 3.7878 & TRN \\
\hline CHEMBL1330013 & 752310 & 2.4202 & 3.154 & TRN \\
\hline CHEMBL1568333 & 752310 & 2.4202 & 3.6435 & TRN \\
\hline CHEMBL1542804 & 752310 & 4.21899 & 999999999 & 5.0204 \\
\hline CHEMBL1310221 & 752310 & 2.4202 & 4.5342 & TRN \\
\hline CHEMBL1336010 & 752310 & 2.4202 & 3.6851 & TRN \\
\hline CHEMBL1491264 & 752310 & 2.4202 & 2.8695 & TRN \\
\hline CHEMBL1309228 & 752310 & 3.5137 & 3.2981 & TRN \\
\hline CHEMBL1395972 & 752310 & 5.4721 & 3.6253 & TST \\
\hline CHEMBL1518895 & 752310 & 5.5429 & 4.5437 & TRN \\
\hline CHEMBL1472344 & 752310 & 4.4907 & 3.4904 & TRN \\
\hline CHEMBL1582891 & 752310 & 2.4202 & 3.8586 & TRN \\
\hline CHEMBL1562359 & 752310 & 2.4202 & 3.0494 & TRN \\
\hline CHEMBL1377610 & 752310 & 2.4202 & 3.7551 & TRN \\
\hline CHEMBL1393716 & 752310 & 2.4202 & 3.2697 & TRN \\
\hline CHEMBL3190845 & 752310 & 4.5124 & 4.7389 & TRN \\
\hline CHEMBL1605235 & 752310 & 5.6893 & 4.4498 & TRN \\
\hline CHEMBL1522503 & 752310 & 3.4778 & 4.0704 & TRN \\
\hline CHEMBL1351412 & 752310 & 4.2288 & 3.6579 & TRN \\
\hline CHEMBL1310115 & 752310 & 3.838 & 3.1301 & TST \\
\hline CHEMBL1794130 & 752310 & 3.5284 & 4.3465 & TRN \\
\hline CHEMBL1384771 & 752310 & 3.9957 & 3.8915 & TRN \\
\hline CHEMBL1424118 & 752310 & 4.8033 & 5.4671 & TRN \\
\hline CHEMBL1380942 & 752310 & 2.4202 & 3.665 & TRN \\
\hline
\end{tabular}


Supplemental Table S2.txt

\begin{tabular}{|c|c|c|c|c|}
\hline 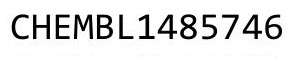 & & 174 & & \\
\hline HEMBL3214593 & 52310 & 4202 & 2.8786 & \\
\hline HEMBL3145191 & 310 & 202 & & \\
\hline 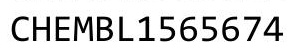 & 10 & 727 & & \\
\hline AEMBL1. & & & & \\
\hline HEMBL1390013 & 52310 & 202 & 1791 & \\
\hline HEMBL1525315 & 52310 & 4.8477 & .6207 & \\
\hline HEMBL14 & 10 & 202 & & \\
\hline AEMBL14 & 10 & 859 & 4774 & \\
\hline IEMBL31 & & & & \\
\hline HEMBL1373969 & 52310 & 224 & 16 & \\
\hline HEMBL1456115 & 52310 & 4.8013 & 29 & \\
\hline HEMBL14e & 10 & 28 & 89 & \\
\hline HEMBL16 & 10 & 02 & & \\
\hline HEMBL15 & & 31 & & \\
\hline HEMBL 140 & 52310 & 658 & 4601 & \\
\hline HEMBL136 & & & & \\
\hline HEMBL15 & 10 & & 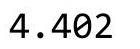 & \\
\hline L13 & & & 22 & \\
\hline HEMBL13 & & 02 & & RN \\
\hline HEMBL152 & 10 & 494 & 8082 & RN \\
\hline HEMBL141 & & & & \\
\hline HEMBL19 & 10 & & 06 & \\
\hline L14 & & & 66 & \\
\hline 10 & & $\partial 2$ & 64 & RN \\
\hline L14. & & & & RN \\
\hline AEMBL31S & & & & RN \\
\hline AEMBL15 & 10 & & 22 & 10 \\
\hline HEN & $\theta$ & & & RN \\
\hline AEMBL12 & Lo & $\partial 2$ & & RN \\
\hline AEMBL321 & & & & ST \\
\hline HEMBL144 & 10 & & & TST \\
\hline AEMBL3: & & & & RN \\
\hline 49 & $\theta$ & & & RN \\
\hline HEMBL 14 & & & & RN \\
\hline HEMBL318 & 10 & & & RN \\
\hline AEMBL1550423 & 10 & & & RN \\
\hline مמ & 0 & & & RN \\
\hline 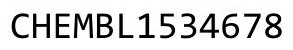 & $\theta$ & & 85 & $\mathrm{R} N \mathrm{~N}$ \\
\hline IEMBL15 & & & & RN \\
\hline HEMBL142 & 10 & 02 & 808 & RN \\
\hline AEMBL13 & 10 & & & RN \\
\hline 79 & & & & \\
\hline HEMBL158 & 10 & & & RN \\
\hline HEMBL1452061 & & & 9325 & ST \\
\hline IEMBL132 & 10 & 2 . & 311 & RN \\
\hline & & & & \\
\hline & 752310 & 2.4202 & & \\
\hline
\end{tabular}

Page 8499 
Supplemental Table S2.txt

\begin{tabular}{|c|c|c|c|c|}
\hline CHEMBL1419822 & 752310 & 2.4202 & 2.7723 & TRN \\
\hline CHEMBL1308867 & 752310 & 2.4202 & 1.8189 & TRN \\
\hline CHEMBL1528476 & 752310 & 5.3604 & 4.6652 & TRN \\
\hline CHEMBL3193444 & 752310 & 3.8005 & 3.6715 & TRN \\
\hline CHEMBL1556273 & 752310 & 4.1014 & 4.0361 & TRN \\
\hline CHEMBL1447473 & 752310 & 5.4785 & 4.8478 & TRN \\
\hline CHEMBL1384089 & 752310 & 4.5666 & 4.7672 & TRN \\
\hline CHEMBL1314042 & 752310 & 4.8674 & 3.5507 & TRN \\
\hline CHEMBL1535849 & 752310 & 4.6354 & 4.4057 & TST \\
\hline CHEMBL1301509 & 752310 & 4.4725 & 3.3455 & TST \\
\hline CHEMBL1505548 & 752310 & 4.7118 & 4.2865 & TRN \\
\hline CHEMBL1579903 & 752310 & 2.4202 & 3.4736 & TRN \\
\hline CHEMBL1581553 & 752310 & 2.4202 & 2.7115 & TRN \\
\hline CHEMBL1571795 & 752310 & 2.4202 & 3.1078 & TRN \\
\hline CHEMBL1339956 & 752310 & 5.0787 & 3.2873 & TRN \\
\hline CHEMBL1391614 & 752310 & 3.7932 & 3.8361 & TRN \\
\hline CHEMBL3145071 & 752310 & 4.2229 & 4.3234 & TRN \\
\hline CHEMBL1309763 & 752310 & 4.7828 & 3.3205 & TRN \\
\hline CHEMBL1409606 & 752310 & 5.1585 & 4.6624 & TRN \\
\hline CHEMBL1537588 & 752310 & 4.5418 & 5.0115 & TRN \\
\hline CHEMBL1574219 & 752310 & 2.4202 & 2.2398 & TRN \\
\hline CHEMBL1713433 & 752310 & 3.4965 & 3.4171 & TRN \\
\hline CHEMBL600734 & 752310 & 5.6607 & 5.3709 & TRN \\
\hline CHEMBL1595409 & 752310 & 4.4874 & 4.1391 & TRN \\
\hline CHEMBL1507657 & 752310 & 4.8959 & 4.1482 & TRN \\
\hline CHEMBL1534860 & 752310 & 4.2797 & 4.2525 & TRN \\
\hline CHEMBL1409740 & 752310 & 2.4202 & 4.0132 & TRN \\
\hline CHEMBL1391921 & 752310 & 2.4202 & 2.9702 & TRN \\
\hline CHEMBL1337958 & 752310 & 2.4202 & 1.7155 & TRN \\
\hline CHEMBL1423410 & 752310 & 2.4202 & 3.8474 & TRN \\
\hline CHEMBL1435915 & 752310 & 2.4202 & 3.3744 & TRN \\
\hline CHEMBL1371925 & 752310 & 2.4202 & 2.4056 & TRN \\
\hline CHEMBL1421972 & 752310 & 4.4216 & 4.0274 & TST \\
\hline CHEMBL1581740 & 752310 & 4.6225 & 4.0859 & TRN \\
\hline CHEMBL1422763 & 752310 & 6.0 & 5.1684 & TRN \\
\hline CHEMBL1370471 & 752310 & 5.1593 & 5.4138 & TRN \\
\hline CHEMBL1337591 & 752310 & 4.6653 & 3.7674 & TRN \\
\hline CHEMBL1331573 & 752310 & 5.0585 & 4.4519 & TRN \\
\hline CHEMBL1516591 & 752310 & 2.4202 & 2.1803 & TST \\
\hline CHEMBL1364083 & 752310 & 3.7788 & 2.9389 & TRN \\
\hline CHEMBL1384715 & 752310 & 2.4202 & 4.0532 & TRN \\
\hline CHEMBL1386232 & 752310 & 2.4202 & 4.3357 & TRN \\
\hline CHEMBL1410350 & 752310 & 4.8677 & 5.2872 & TRN \\
\hline CHEMBL1378952 & 752310 & 4.605 & 4.8164 & TST \\
\hline CHEMBL1359342 & 752310 & 3.8962 & 3.4034 & TRN \\
\hline CHEMBL1429966 & 752310 & 2.9208 & 2.79699 & 99999999997 \\
\hline CHEMBL1548297 & 752310 & 4.5147 & 3.3713 & TRN \\
\hline CHEMBL1518077 & 752310 & 2.4202 & 2.8672 & TRN \\
\hline
\end{tabular}


Supplemental Table S2.txt

\begin{tabular}{|c|c|c|c|c|c|}
\hline CHEMBL1419252 & 752310 & 2.4202 & 4.4924 & TRN & \\
\hline CHEMBL1465185 & 752310 & 2.4202 & 3.9501 & TRN & \\
\hline CHEMBL1362545 & 752310 & 2.4202 & 3.5274 & TRN & \\
\hline CHEMBL1444045 & 752310 & 3.9485 & 3.4689 & TRN & \\
\hline CHEMBL1547454 & 752310 & 5.1998 & 4.7239 & TRN & \\
\hline CHEMBL1561949 & 752310 & 2.4202 & 3.4792 & TST & \\
\hline CHEMBL576208 & 752310 & 4.1536 & 4.5336 & TRN & \\
\hline CHEMBL3145082 & 752310 & 5.0668 & 5.2436 & TRN & \\
\hline CHEMBL1443679 & 752310 & 4.9348 & 4.6117 & TRN & \\
\hline CHEMBL1518678 & 752310 & 2.4202 & 3.1083 & TST & \\
\hline CHEMBL1998946 & 752310 & 5.355 & 4.6069 & TRN & \\
\hline CHEMBL1560706 & 752310 & 3.9905 & 3.4156 & TRN & \\
\hline CHEMBL1330951 & 752310 & 2.4202 & 4.2637 & TST & \\
\hline CHEMBL1571290 & 752310 & 4.5702 & 4.1604 & TRN & \\
\hline CHEMBL1390452 & 752310 & 4.5743 & 4.293 & TST & \\
\hline CHEMBL1459167 & 752310 & 4.7385 & 4.4658 & TRN & \\
\hline CHEMBL1428823 & 752310 & 4.5824 & 3.9586 & TRN & \\
\hline CHEMBL1328510 & 752310 & 6.0 & 5.2607 & TRN & \\
\hline CHEMBL1565623 & 752310 & 5.0086 & 5.5012 & TRN & \\
\hline CHEMBL1332955 & 752310 & 2.4202 & 2.7078 & TRN & \\
\hline CHEMBL1439672 & 752310 & 2.4202 & 4.3771 & TRN & \\
\hline CHEMBL 2095095 & 752310 & 6.6453 & 6.8119 & TRN & \\
\hline CHEMBL1455110 & 752310 & 4.4344 & 4.5301 & TST & \\
\hline CHEMBL1333634 & 752310 & 3.5112 & 2.842 & TRN & \\
\hline CHEMBL1310030 & 752310 & 2.4202 & 4.2284 & TRN & \\
\hline CHEMBL1999049 & 752310 & 5.6121 & 4.3597 & TRN & \\
\hline CHEMBL1522941 & 752310 & 5.5892 & 5.5552 & TRN & \\
\hline CHEMBL1374665 & 752310 & 2.4202 & 3.1782 & TRN & \\
\hline CHEMBL1502410 & 752310 & 5.0112 & 4.723 & TRN & \\
\hline CHEMBL1585923 & 752310 & 4.6772 & 3.7866 & TRN & \\
\hline CHEMBL1330787 & 752310 & 2.9208 & 2.5634 & TRN & \\
\hline CHEMBL1582351 & 752310 & 2.4202 & 3.0564 & TRN & \\
\hline CHEMBL1521393 & 752310 & 5.0102 & 4.4393 & TRN & \\
\hline CHEMBL1973501 & 752310 & 3.4235 & 3.0946 & TRN & \\
\hline CHEMBL1467857 & 752310 & 4.6678 & 3.9844 & TRN & \\
\hline CHEMBL3190218 & 752310 & 2.4202 & 3.8332 & TRN & \\
\hline CHEMBL3209456 & 752310 & 2.4202 & 3.0234 & TRN & \\
\hline CHEMBL1580896 & 752310 & 5.38299 & 99999999 & 99 & 5.0493 \\
\hline CHEMBL1353816 & 752310 & 4.3694 & 4.2274 & TRN & \\
\hline CHEMBL1479725 & 752310 & 2.4202 & 3.4207 & TRN & \\
\hline CHEMBL1377692 & 752310 & 2.4202 & 2.7998 & TRN & \\
\hline CHEMBL1380801 & 752310 & 5.7557 & 4.4592 & TRN & \\
\hline CHEMBL1483627 & 752310 & 6.1553 & 5.1038 & TRN & \\
\hline CHEMBL1488495 & 752310 & 2.4202 & 2.3133 & TST & \\
\hline CHEMBL1441739 & 752310 & 5.1543 & 4.8065 & TRN & \\
\hline CHEMBL1462950 & 752310 & 4.3129 & 3.6099 & TRN & \\
\hline CHEMBL1456352 & 752310 & 2.4202 & 3.1118 & TRN & \\
\hline CHEMBL1417970 & 752310 & 3.6946 & 3.699 & TRN & \\
\hline
\end{tabular}


Supplemental Table S2.txt

\begin{tabular}{|c|c|c|c|c|c|}
\hline CHEMBL1532174 & 752310 & 4.4382 & 2.6847 & TST & \\
\hline CHEMBL1403089 & 752310 & 2.4202 & 2.5412 & TRN & \\
\hline CHEMBL1330160 & 752310 & 2.4202 & 2.4146 & TRN & \\
\hline CHEMBL1603753 & 752310 & 2.4202 & 3.0407 & TRN & \\
\hline CHEMBL1469314 & 752310 & 4.2952 & 2.4492 & TRN & \\
\hline CHEMBL1463885 & 752310 & 4.5638 & 4.2013 & TRN & \\
\hline CHEMBL1482281 & 752310 & 2.4202 & 3.4781 & TRN & \\
\hline CHEMBL1713763 & 752310 & 3.9108 & 3.4385 & TST & \\
\hline CHEMBL1481417 & 752310 & 4.426 & 3.8694 & TRN & \\
\hline CHEMBL460366 & 752310 & 2.4202 & 3.8009 & TRN & \\
\hline CHEMBL1547116 & 752310 & 2.4202 & 4.2946 & TST & \\
\hline CHEMBL1451931 & 752310 & 5.2283 & 4.5713 & TRN & \\
\hline CHEMBL1308783 & 752310 & 4.8677 & 4.4274 & TRN & \\
\hline CHEMBL1557816 & 752310 & 2.4202 & 3.8905 & TRN & \\
\hline CHEMBL1465186 & 752310 & 5.1872 & 4.3677 & TRN & \\
\hline CHEMBL3212615 & 752310 & 4.5411 & 3.8365 & TRN & \\
\hline CHEMBL1529127 & 752310 & 2.4202 & 3.9057 & TRN & \\
\hline CHEMBL1359736 & 752310 & 4.5003 & 3.9248 & TRN & \\
\hline CHEMBL 3145018 & 752310 & 5.0234 & 3.9448 & TRN & \\
\hline CHEMBL1076559 & 752310 & 2.4202 & 4.3893 & TRN & \\
\hline CHEMBL1428166 & 752310 & 4.8386 & 5.432 & TRN & \\
\hline CHEMBL1485010 & 752310 & 4.1818 & 4.7589 & TRN & \\
\hline CHEMBL1599188 & 752310 & 2.4202 & 3.2291 & TST & \\
\hline CHEMBL1551808 & 752310 & 4.3076 & 4.0888 & TRN & \\
\hline CHEMBL1610008 & 752310 & 3.5719 & 3.6566 & TRN & \\
\hline CHEMBL3210668 & 752310 & 2.4202 & 3.0199 & TRN & \\
\hline CHEMBL1544548 & 752310 & 2.4202 & 3.3736 & TRN & \\
\hline CHEMBL1516744 & 752310 & 2.9208 & 2.6626 & TRN & \\
\hline CHEMBL1455724 & 752310 & 2.4202 & 3.11800 & 00000000003 & TRN \\
\hline CHEMBL1492922 & 752310 & 2.4202 & 2.4461 & TST & \\
\hline CHEMBL1301672 & 752310 & 4.1959 & 4.02 & TST & \\
\hline CHEMBL1463943 & 752310 & 5.6613 & 3.4151 & TRN & \\
\hline CHEMBL1334552 & 752310 & 2.4202 & 3.0666 & TRN & \\
\hline CHEMBL1414814 & 752310 & 3.4326 & 2.9438 & TRN & \\
\hline CHEMBL1387293 & 752310 & 2.4202 & 3.3852 & TRN & \\
\hline CHEMBL1341778 & 752310 & 4.3633 & 3.137 & TST & \\
\hline CHEMBL1385784 & 752310 & 5.6828 & 6.0098 & TRN & \\
\hline CHEMBL1335426 & 752310 & 2.4202 & 2.3135 & TRN & \\
\hline CHEMBL1438890 & 752310 & 4.815 & 4.3081 & TRN & \\
\hline CHEMBL1304902 & 752310 & 5.8897 & 5.8505 & TRN & \\
\hline CHEMBL1405221 & 752310 & 4.1049 & 3.5159 & TST & \\
\hline CHEMBL1577004 & 752310 & 5.1846 & 4.6886 & TRN & \\
\hline CHEMBL1445617 & 752310 & 5.7757 & 5.2496 & TRN & \\
\hline CHEMBL1492541 & 752310 & 2.4202 & 4.202 & TST & \\
\hline CHEMBL417727 & 752310 & 4.7545 & 5.0988 & TRN & \\
\hline CHEMBL1563469 & 752310 & 2.4202 & 2.6191 & TST & \\
\hline CHEMBL1535665 & 752310 & 4.9374 & 3.3858 & TRN & \\
\hline CHEMBL1486196 & 752310 & 2.4202 & 3.1878 & TRN & \\
\hline
\end{tabular}


Supplemental Table S2.txt

\begin{tabular}{|c|c|c|c|c|c|}
\hline CHEMBL1319867 & 752310 & 4.3104 & 4.2767 & TRN & \\
\hline CHEMBL1340601 & 752310 & 2.4202 & 2.3052 & TRN & \\
\hline CHEMBL1709281 & 752310 & 5.0306 & 3.8497 & TRN & \\
\hline CHEMBL1336261 & 752310 & 4.3644 & 4.1707 & TRN & \\
\hline CHEMBL1503292 & 752310 & 2.4202 & 2.9513 & TRN & \\
\hline CHEMBL1486359 & 752310 & 4.3697 & 3.8422 & TRN & \\
\hline CHEMBL1393351 & 752310 & 4.7471 & 3.9697 & TST & \\
\hline CHEMBL1610025 & 752310 & 4.2556 & 4.4979 & TRN & \\
\hline CHEMBL1492010 & 752310 & 4.8474 & 5.5843 & TRN & \\
\hline CHEMBL1530209 & 752310 & 2.4202 & 3.0266 & TRN & \\
\hline CHEMBL1342141 & 752310 & 2.4202 & 3.4877 & TRN & \\
\hline CHEMBL1346860 & 752310 & 5.8097 & 4.6982 & TRN & \\
\hline CHEMBL1613716 & 752310 & 3.7018 & 4.4665 & TRN & \\
\hline CHEMBL1568691 & 752310 & 4.8693 & 5.584 & TRN & \\
\hline CHEMBL1558874 & 752310 & 4.2835 & 3.7765 & TST & \\
\hline CHEMBL1398450 & 752310 & 2.4202 & 2.5949 & TRN & \\
\hline CHEMBL1428758 & 752310 & 4.4522 & 4.4238 & TRN & \\
\hline CHEMBL1375045 & 752310 & 4.9618 & 4.7639 & TST & \\
\hline CHEMBL1311688 & 752310 & 2.4202 & 3.4293 & TST & \\
\hline CHEMBL1493944 & 752310 & 5.4985 & 4.7314 & TRN & \\
\hline CHEMBL1462872 & 752310 & 4.9978 & 4.8199 & TST & \\
\hline CHEMBL1349747 & 752310 & 2.4202 & 4.2416 & TRN & \\
\hline CHEMBL1364004 & 752310 & 3.6247 & 3.5953 & TRN & \\
\hline CHEMBL1698050 & 752310 & 2.4202 & 3.42199 & 99999999997 & TRN \\
\hline CHEMBL1485159 & 752310 & 4.9978 & 4.6667 & TRN & \\
\hline CHEMBL1482637 & 752310 & 3.9201 & 3.11 & TST & \\
\hline CHEMBL1458321 & 752310 & 4.9045 & 3.9513 & TRN & \\
\hline CHEMBL1465144 & 752310 & 2.4202 & 4.1578 & TRN & \\
\hline CHEMBL1969760 & 752310 & 2.4202 & 2.6964 & TRN & \\
\hline CHEMBL1526391 & 752310 & 2.4202 & 2.5706 & TRN & \\
\hline CHEMBL1439030 & 752310 & 2.4202 & 3.1099 & TST & \\
\hline CHEMBL306946 & 752310 & 2.4202 & 4.3889 & TRN & \\
\hline CHEMBL1415423 & 752310 & 2.4202 & 2.5594 & TRN & \\
\hline CHEMBL1699978 & 752310 & 4.4058 & 4.2941 & TRN & \\
\hline CHEMBL 3145133 & 752310 & 4.0871 & 3.6119 & TRN & \\
\hline CHEMBL1318998 & 752310 & 5.3842 & 4.61 & TRN & \\
\hline CHEMBL1387615 & 752310 & 2.4202 & 3.0995 & TRN & \\
\hline CHEMBL1575284 & 752310 & 3.6672 & 2.3064 & TRN & \\
\hline CHEMBL1602856 & 752310 & 4.5471 & 3.6483 & TRN & \\
\hline CHEMBL1451836 & 752310 & 5.2566 & 5.5086 & TRN & \\
\hline CHEMBL1501982 & 752310 & 2.4202 & 2.506 & TST & \\
\hline CHEMBL1580684 & 752310 & 4.0709 & 4.5752 & TRN & \\
\hline CHEMBL3193655 & 752310 & 4.569 & 4.8574 & TRN & \\
\hline CHEMBL1399145 & 752310 & 4.2958 & 3.681 & TRN & \\
\hline CHEMBL1499282 & 752310 & 5.7129 & 5.3752 & TRN & \\
\hline CHEMBL1383937 & 752310 & 5.2615 & 4.0054 & TST & \\
\hline CHEMBL1318943 & 752310 & 4.7773 & 4.7745 & TRN & \\
\hline CHEMBL1598762 & 752310 & 5.2048 & 3.7602 & TRN & \\
\hline
\end{tabular}




\begin{tabular}{|c|c|c|c|c|c|c|}
\hline & & \multicolumn{4}{|c|}{ Supplemental Table S2.txt } & \\
\hline CHEMBL1502234 & 752310 & 5.02800 & 0000000 & 005 & 4.4729 & TRN \\
\hline CHEMBL1313748 & 752310 & 2.4202 & 4.3819 & TST & & \\
\hline CHEMBL1302463 & 752310 & 4.2256 & 3.8219 & TRN & & \\
\hline CHEMBL1347334 & 752310 & 2.4202 & 3.1867 & TRN & & \\
\hline CHEMBL1364145 & 752310 & 2.4202 & 3.5625 & TRN & & \\
\hline CHEMBL1382518 & 752310 & 5.1679 & 4.184 & TRN & & \\
\hline CHEMBL1453368 & 752310 & 3.8911 & 3.9185 & TRN & & \\
\hline CHEMBL1402422 & 752310 & 5.0261 & 4.516 & TST & & \\
\hline CHEMBL1299841 & 752310 & 2.4202 & 3.0964 & TST & & \\
\hline CHEMBL1502781 & 752310 & 4.8005 & 5.2647 & TRN & & \\
\hline CHEMBL 3188273 & 752310 & 4.7662 & 4.2363 & TRN & & \\
\hline CHEMBL1309737 & 752310 & 3.6868 & 3.648 & TST & & \\
\hline CHEMBL1432524 & 752310 & 4.4994 & 3.7691 & TRN & & \\
\hline CHEMBL1389273 & 752310 & 3.863 & 3.9465 & TRN & & \\
\hline CHEMBL1477097 & 752310 & 4.8545 & 4.131 & TRN & & \\
\hline CHEMBL1555752 & 752310 & 4.9041 & 3.6145 & TST & & \\
\hline CHEMBL578502 & 752310 & 4.803 & 3.7548 & TRN & & \\
\hline CHEMBL1337500 & 752310 & 4.16 & 3.6679 & TST & & \\
\hline CHEMBL1342337 & 752310 & 5.58799 & 99999999 & 99 & 5.3146 & TRN \\
\hline CHEMBL1361173 & 752310 & 4.9473 & 4.5209 & TRN & & \\
\hline CHEMBL1142 & 752310 & 4.3915 & 2.7057 & TST & & \\
\hline CHEMBL1403980 & 752310 & 5.6148 & 5.4617 & TST & & \\
\hline CHEMBL1560220 & 752310 & 3.4974 & 3.1596 & TRN & & \\
\hline CHEMBL3195005 & 752310 & 3.7518 & 3.8038 & TRN & & \\
\hline CHEMBL1400164 & 752310 & 2.4202 & 3.4945 & TRN & & \\
\hline CHEMBL1571825 & 752310 & 4.5569 & 4.0272 & TRN & & \\
\hline CHEMBL1494100 & 752310 & 2.4202 & 4.0502 & TRN & & \\
\hline CHEMBL1325982 & 752310 & 4.4182 & 4.1516 & TRN & & \\
\hline CHEMBL1454239 & 752310 & 4.9416 & 4.1207 & TRN & & \\
\hline CHEMBL1712155 & 752310 & 2.4202 & 2.4291 & TST & & \\
\hline CHEMBL1398826 & 752310 & 3.5112 & 4.4764 & TRN & & \\
\hline CHEMBL1452136 & 752310 & 2.4202 & 3.4736 & TST & & \\
\hline CHEMBL1533248 & 752310 & 4.1214 & 3.7356 & TRN & & \\
\hline CHEMBL1384670 & 752310 & 4.96899 & 99999999 & 99 & 4.6161 & TRN \\
\hline CHEMBL1413355 & 752310 & 4.4255 & 3.4488 & TST & & \\
\hline CHEMBL1385073 & 752310 & 5.114 & 3.8449 & TRN & & \\
\hline CHEMBL1305307 & 752310 & 3.4631 & 3.6887 & TRN & & \\
\hline CHEMBL1493700 & 752310 & 4.2841 & 4.1371 & TRN & & \\
\hline CHEMBL1325451 & 752310 & 4.8636 & 4.2975 & TRN & & \\
\hline CHEMBL1580129 & 752310 & 4.6706 & 3.7029 & TST & & \\
\hline CHEMBL1487875 & 752310 & 4.5286 & 3.7729 & TRN & & \\
\hline CHEMBL1980681 & 752310 & 3.5552 & 3.4444 & TRN & & \\
\hline CHEMBL1734499 & 752310 & 3.522 & 3.6875 & TRN & & \\
\hline CHEMBL1560640 & 752310 & 3.8824 & 3.799 & TRN & & \\
\hline CHEMBL1371896 & 752310 & 2.4202 & 4.0303 & TRN & & \\
\hline CHEMBL1350085 & 752310 & 5.4551 & 4.6706 & TRN & & \\
\hline CHEMBL505670 & 752310 & 5.0327 & 4.0611 & TRN & & \\
\hline CHEMBL1546213 & 752310 & 2.4202 & 3.5667 & TRN & & \\
\hline
\end{tabular}


Supplemental Table S2.txt

\begin{tabular}{|c|c|c|c|c|}
\hline 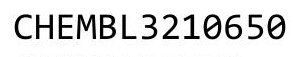 & & & & \\
\hline JEMBL17551 & 52310 & 7951 & 7722 & \\
\hline AEMBL1419788 & 2310 & 918 & & \\
\hline 091 & 2310 & & & \\
\hline EMBL1545034 & 2310 & 57 & & \\
\hline AEMBL1595795 & 52310 & 202 & 5091 & \\
\hline AEMBL1602084 & 52310 & 4.7452 & 4008 & \\
\hline AEMBL3193639 & & & & \\
\hline EMBL13 & 52310 & & 567 & \\
\hline EMBL15 & 52310 & & & \\
\hline AEMBL1429260 & 52310 & 202 & 9518 & \\
\hline AEMBL3192701 & 52310 & & & \\
\hline AEMBL1456821 & 10 & & 886 & \\
\hline AEMBL579318 & 10 & & & \\
\hline AEMBL1537615 & 10 & & & \\
\hline AEMBL1352586 & 52310 & & 47 & \\
\hline AEMBL3214331 & & & 72 & \\
\hline IEMBL16 & 0 & & & \\
\hline HEMBL156 & & & & \\
\hline AEMBL1405287 & 10 & & & \\
\hline AEMBL3192535 & 10 & & & \\
\hline AEMBL1402869 & & & & \\
\hline AEMBL1448321 & 0 & & & \\
\hline AEMBL1609318 & & & & \\
\hline 227 & & & & \\
\hline 6824 & & & & \\
\hline IEMBL1471012 & & & & \\
\hline AEMBL14200 & $\theta$ & & & \\
\hline ALMP & & & & \\
\hline JFMPI 15 & & & & \\
\hline AEMBL1306254 & & & & \\
\hline IEMBL1388639 & 0 & & & \\
\hline & & & & \\
\hline$\theta$ & 0 & & & \\
\hline & & & & \\
\hline AEMBL1587432 & 0 & & & S \\
\hline AEMBL1495539 & 0 & & 899 & F \\
\hline 327574 & 0 & & 91 & \\
\hline 94 & & & & \\
\hline & & & & $\mathrm{RN}$ \\
\hline AEMBL3192509 & 10 & 2 . & 075 & TS \\
\hline MBL1608787 & 0 & & & $\Gamma S$ \\
\hline & & & & \\
\hline & & & & 1 \\
\hline AEMBL1376516 & & & & $\mathrm{R}$ \\
\hline AEMBL1572077 & 52 & 4. & 45 & 11 \\
\hline & & & & \\
\hline & & & & \\
\hline
\end{tabular}

Page 8505 
Supplemental Table S2.txt

\begin{tabular}{|c|c|c|c|c|c|}
\hline CHEMBL1424773 & 752310 & 2.4202 & 3.0052 & TRN & \\
\hline CHEMBL1449008 & 752310 & 4.4079 & 4.0374 & TRN & \\
\hline CHEMBL259018 & 752310 & 2.4202 & 3.6192 & TRN & \\
\hline CHEMBL1496231 & 752310 & 2.4202 & 3.0351 & TRN & \\
\hline CHEMBL 3189264 & 752310 & 4.2279 & 4.029 & TST & \\
\hline CHEMBL1405071 & 752310 & 2.4202 & 3.2685 & TRN & \\
\hline CHEMBL1463817 & 752310 & 2.4202 & 2.7167 & TRN & \\
\hline CHEMBL1419538 & 752310 & 2.4202 & 4.0439 & TST & \\
\hline CHEMBL1488412 & 752310 & 4.5837 & 4.379 & TRN & \\
\hline CHEMBL1597827 & 752310 & 4.7948 & 4.3514 & TST & \\
\hline CHEMBL1529781 & 752310 & 4.471 & 4.55 & TRN & \\
\hline CHEMBL1431126 & 752310 & 4.648 & 3.2107 & TST & \\
\hline CHEMBL1503656 & 752310 & 5.1424 & 4.8519 & TRN & \\
\hline CHEMBL1383632 & 752310 & 5.0477 & 5.0732 & TRN & \\
\hline CHEMBL 36654 & 752310 & 2.4202 & 5.2465 & TST & \\
\hline CHEMBL578512 & 752310 & 7.0773 & 6.7307 & TRN & \\
\hline CHEMBL1339869 & 752310 & 2.4202 & 2.7532 & TRN & \\
\hline CHEMBL1421056 & 752310 & 5.2617 & 4.566 & TRN & \\
\hline CHEMBL1344491 & 752310 & 2.4202 & 1.9306 & TRN & \\
\hline CHEMBL1480387 & 752310 & 4.9935 & 3.7457 & TRN & \\
\hline CHEMBL1380853 & 752310 & 4.0906 & 3.4239 & TRN & \\
\hline CHEMBL1450393 & 752310 & 2.4202 & 3.7766 & TST & \\
\hline CHEMBL584269 & 752310 & 5.1315 & 5.1304 & TRN & \\
\hline CHEMBL1527341 & 752310 & 5.1274 & 5.2147 & TRN & \\
\hline CHEMBL3195920 & 752310 & 3.9355 & 4.282 & TRN & \\
\hline CHEMBL1988416 & 752310 & 4.0224 & 4.614 & TRN & \\
\hline CHEMBL1536089 & 752310 & 2.4202 & 3.4291 & TRN & \\
\hline CHEMBL1430314 & 752310 & 5.4408 & 4.7148 & TRN & \\
\hline CHEMBL1077990 & 752310 & 4.445 & 3.7489 & TRN & \\
\hline CHEMBL1337592 & 752310 & 6.2389 & 6.1968 & TRN & \\
\hline CHEMBL1405490 & 752310 & 4.4658 & 3.8146 & TRN & \\
\hline CHEMBL1978549 & 752310 & 3.5296 & 3.0539 & TRN & \\
\hline CHEMBL1345762 & 752310 & 4.777 & 4.6393 & TRN & \\
\hline CHEMBL3197985 & 752310 & 4.2073 & 3.6461 & TRN & \\
\hline CHEMBL3195106 & 752310 & 4.301 & 3.9173 & TRN & \\
\hline CHEMBL1432973 & 752310 & 4.3679 & 4.6629 & TRN & \\
\hline CHEMBL1389296 & 752310 & 4.95 & 5.3627 & TRN & \\
\hline CHEMBL1393004 & 752310 & 5.0203 & 4.8757 & TRN & \\
\hline CHEMBL1575453 & 752310 & 4.8213 & 3.9968 & TST & \\
\hline CHEMBL1339644 & 752310 & $3.87100 t$ & & & \\
\hline CHEMBL1331399 & 752310 & 4.1991 & \multicolumn{3}{|c|}{$\begin{array}{ll}3.7239999999999998 & \text { TRN }\end{array}$} \\
\hline CHEMBL1601281 & 752310 & 5.4143 & 4.5654 & TRN & \\
\hline CHEMBL3189876 & 752310 & 2.4202 & 3.6118 & TRN & \\
\hline CHEMBL1308058 & 752310 & 3.6119 & 2.9991 & TRN & \\
\hline CHEMBL1609672 & 752310 & 4.0043 & 4.2556 & TRN & \\
\hline CHEMBL1464853 & 752310 & 2.4202 & 3.5213 & TRN & \\
\hline CHEMBL1510765 & 752310 & 4.8545 & 4.3217 & TST & \\
\hline CHEMBL1346986 & 752310 & 4.1015 & 2.5924 & TRN & \\
\hline
\end{tabular}


Supplemental Table S2.txt

\begin{tabular}{|c|c|c|c|c|}
\hline & & & & \\
\hline AEMBL 14 & 2310 & 2.4202 & & \\
\hline IEMBL1415639 & 2310 & 4432 & 242 & \\
\hline AEMBL1476225 & 52310 & 4.9073 & 376 & \\
\hline IEMBL994 & 2310 & & & \\
\hline AEMBL1490942 & 2310 & & 268 & \\
\hline AEMBL1433014 & 52310 & 1202 & 2473 & \\
\hline AEMBL1429537 & 52310 & 2.4202 & 5784 & \\
\hline HEMBL31 & 52310 & & 006 & \\
\hline IEMBL13 & 52310 & & 031 & \\
\hline HEMBL 15 & 52310 & & 392 & \\
\hline HEMBL60718 & 52310 & & 5453 & \\
\hline AEMBL1321365 & 52310 & & & RI \\
\hline IEMBL13 & 10 & & 267 & \\
\hline IEMBL15 & 52310 & & 84 & \\
\hline AEMBL 31 & 52310 & & & \\
\hline AEMBL1428683 & 52310 & & 1747 & RN \\
\hline JEMBL14 & 52310 & & 14 & \\
\hline IEMBLIS & 52 & & 25 & \\
\hline HEMBL 14 & 2310 & & 67 & \\
\hline HEMBL15 & 52310 & & 01 & RN \\
\hline AEMBL1326529 & 52310 & & 732 & RN \\
\hline JEMBL13 & & & 196 & \\
\hline EMMBL1: & 0 & & 35 & ST \\
\hline HEMBL1 & 10 & & 47 & 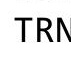 \\
\hline AFMRI 1 & 10 & & 964 & RN \\
\hline AEMBL1302639 & 10 & & 523 & RN \\
\hline JEMBL15 & & & & \\
\hline IEMBL13 & 0 & & 244 & RN \\
\hline 86 & 0 & & 304 & 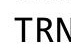 \\
\hline 297 & 0 & & 94 & $\mathrm{RN}$ \\
\hline AEMBL15 & & & & RN \\
\hline AEMBL17: & 0 & & & RI \\
\hline JEMBL14 & 0 & & 586 & RN \\
\hline AEMBL13 & 0 & & & ועל \\
\hline 95 & & & 45 & ST \\
\hline AEMBL3144896 & 52 & & 566 & $\mathrm{R}$ \\
\hline AEMBL3191991 & 0 & & 412 & $\mathrm{R}$ \\
\hline IEMBL13 & 0 & & 588 & ST \\
\hline 984 & 0 & & 134 & $w$ \\
\hline HEMBL 14 & & & 933 & RN \\
\hline AEMBL1440300 & 52310 & & 2535 & RI \\
\hline AEMBL1536196 & 0 & & 386 & TS \\
\hline HEMBL13 & & & & \\
\hline CHEMBL13. & & & & \\
\hline CHEMBL137 & & & 3.6062 & ST \\
\hline HEMBL1598857 & 52310 & 4.3365 & 4.0288 & $T R$ \\
\hline HEMBL1364506 & 52310 & 5.9846 & 3.8496 & \\
\hline
\end{tabular}

Page 8507 
Supplemental Table S2.txt

\begin{tabular}{|c|c|c|c|c|}
\hline- & & & -0 & \\
\hline HEMBL1501898 & 52310 & .8324 & 2.8629 & \\
\hline & & & & \\
\hline MPI 1 & 310 & 202 & 36 & \\
\hline IEMBL1565022 & 52310 & 202 & 9586 & \\
\hline AEMBL1488395 & 52310 & 4202 & 9744 & \\
\hline HEMBL14 & 52310 & 3608 & .9604 & \\
\hline AFMB 13 & 2310 & 614 & 107 & \\
\hline IEMBL1384 & 52310 & 681 & .5117 & \\
\hline AEMBL1445372 & 52310 & 202 & .5438 & \\
\hline HEMBL1974348 & 52310 & 5519 & . 1972 & \\
\hline IEMBL1386 & 52310 & 989 & 514 & \\
\hline IEMBL16 & & & & \\
\hline IEMBL31 & 52310 & 301 & .5558 & \\
\hline JEMBL1409997 & 52310 & & 64 & \\
\hline AEMBL1321472 & 52310 & 038 & 7864 & \\
\hline HEMBL13 & 310 & 43 & 59 & \\
\hline HEMBL14 & 310 & & & \\
\hline HEMBL1C & 52310 & 202 & 39 & \\
\hline AEMBL14 & 310 & 207 & & RN \\
\hline AEIMBL 198 & 10 & 28 & 28 & IS \\
\hline AEMBL13 & 310 & 345 & 8 & \\
\hline HEM & 310 & & & \\
\hline 17 & 310 & 202 & 86 & 30 \\
\hline AEMBL157 & 10 & 34 & & RIN \\
\hline IEMBL1C & 10 & 51 & 38 & RN \\
\hline HEME & 310 & 29 & . & - \\
\hline HFM & 10 & $\partial 2$ & & RN \\
\hline HEM & & & & RIN \\
\hline IEMBL14 & 0 & 89 & & RIN \\
\hline IEMBL1463 & 10 & 391 & 74 & RN \\
\hline 13 & 10 & & & RIV \\
\hline - & & & & RN \\
\hline AEMBL1388 & & & & RN \\
\hline AEMBL15584 & 10 & 02 & 3.5953 & RN \\
\hline AEMBL14 & 10 & 202 & 04 & \\
\hline 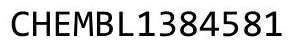 & 10 & & & RN \\
\hline HEMBL1334€ & & & 7.1555 & RN \\
\hline HEMBL1335893 & 52310 & 202 & 2.9538 & TRN \\
\hline IEMBL3192 & 10 & 642 & .2768 & IST \\
\hline HEMBL1302 & 10 & 202 & 4.2101 & IST \\
\hline 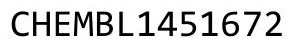 & & & & RN \\
\hline HEMBL321e & 52310 & 202 & .0629 & TRN \\
\hline IEMBL3145143 & 52310 & 677 & 4.3524 & TRN \\
\hline 1172 & & & .4808 & \\
\hline HEMBL13 & & & 3.9275 & \\
\hline (6) & 52310 & 4.6863 & 4.8977 & \\
\hline HEMBL 314493 & 752310 & 5.7645 & 5.0406 & ГRN \\
\hline
\end{tabular}

Page 8508 


\begin{tabular}{|c|c|c|c|c|c|c|}
\hline \multicolumn{7}{|c|}{ ple sL.tX } \\
\hline CHEMBL1455639 & 752310 & 2.4202 & 3.7383 & TST & & \\
\hline CHEMBL3145176 & 752310 & 5.5399 & 5.1671 & TRN & & \\
\hline CHEMBL1454307 & 752310 & 2.4202 & 2.0665 & TST & & \\
\hline CHEMBL1388358 & 752310 & 5.9991 & 5.5686 & TRN & & \\
\hline CHEMBL1403143 & 752310 & 4.11100 & 000000006 & & 3.821 & TST \\
\hline CHEMBL1453636 & 752310 & 3.5161 & 3.2177 & TRN & & \\
\hline CHEMBL1566889 & 752310 & 5.4577 & 4.3213 & TRN & & \\
\hline CHEMBL1586439 & 752310 & 2.4202 & 3.5094 & TRN & & \\
\hline CHEMBL1326847 & 752310 & 2.4202 & 3.3992 & TRN & & \\
\hline CHEMBL1505902 & 752310 & 2.4202 & 3.3937 & TST & & \\
\hline CHEMBL1707033 & 752310 & 5.7158 & 4.8328 & TRN & & \\
\hline CHEMBL3192555 & 752310 & 6.5173 & 6.1068 & TRN & & \\
\hline CHEMBL1352919 & 752310 & 2.4202 & 4.4459 & TST & & \\
\hline CHEMBL1702692 & 752310 & 5.2778 & 4.7408 & TRN & & \\
\hline CHEMBL1539293 & 752310 & 3.6297 & 4.2907 & TRN & & \\
\hline CHEMBL1387692 & 752310 & 2.4202 & 4.488 & TST & & \\
\hline CHEMBL1510262 & 752310 & 3.9393 & 3.5578 & TRN & & \\
\hline CHEMBL1381243 & 752310 & 2.4202 & 3.6114 & TRN & & \\
\hline CHEMBL1426377 & 752310 & 2.4202 & 1.7374 & TST & & \\
\hline CHEMBL3145089 & 752310 & 5.8604 & 4.9357 & TRN & & \\
\hline CHEMBL1557116 & 752310 & 4.71899 & 79999999ऽ & 99 & 3.7772 & TST \\
\hline CHEMBL1527129 & 752310 & 2.4202 & 3.6858 & TRN & & \\
\hline CHEMBL1559031 & 752310 & 2.4202 & 2.449 & TRN & & \\
\hline CHEMBL1506757 & 752310 & 4.268 & 3.7733 & TRN & & \\
\hline CHEMBL1322618 & 752310 & 5.5284 & 5.6745 & TRN & & \\
\hline CHEMBL1479534 & 752310 & 4.4378 & 3.4982 & TRN & & \\
\hline CHEMBL1407961 & 752310 & 3.6772 & 3.8871 & TRN & & \\
\hline CHEMBL1428977 & 752310 & 2.9208 & 3.0325 & TRN & & \\
\hline CHEMBL3210366 & 752310 & 4.5711 & 4.3704 & TRN & & \\
\hline CHEMBL1589309 & 752310 & 2.4202 & 3.4157 & TRN & & \\
\hline CHEMBL1567226 & 752310 & 4.9176 & 5.4376 & TRN & & \\
\hline CHEMBL1562713 & 752310 & 4.6251 & 4.28100 & 0000000001 & & TST \\
\hline CHEMBL1361500 & 752310 & 4.11 & 2.8674 & TRN & & \\
\hline CHEMBL1541950 & 752310 & 2.4202 & 3.9012 & TRN & & \\
\hline CHEMBL1520259 & 752310 & 4.387 & 3.6771 & TST & & \\
\hline CHEMBL1441329 & 752310 & 4.8173 & 4.4339 & TST & & \\
\hline CHEMBL1344426 & 752310 & 4.4098 & 4.7538 & TRN & & \\
\hline CHEMBL3392069 & 752310 & 4.2177 & 4.2565 & TRN & & \\
\hline CHEMBL1609009 & 752310 & 4.9412 & 4.3168 & TRN & & \\
\hline CHEMBL1548439 & 752310 & 2.4202 & 2.4692 & TRN & & \\
\hline CHEMBL1538796 & 752310 & 2.4202 & 3.2374 & TRN & & \\
\hline CHEMBL1719512 & 752310 & 2.4202 & 2.5432 & TST & & \\
\hline CHEMBL1556750 & 752310 & 5.1957 & 5.1004 & TRN & & \\
\hline CHEMBL1213137 & 752310 & 5.019 & 3.6272 & TST & & \\
\hline CHEMBL1494762 & 752310 & 2.4202 & 2.8066 & TRN & & \\
\hline CHEMBL1462675 & 752310 & 5.3477 & 5.3912 & TRN & & \\
\hline CHEMBL1449794 & 752310 & 2.4202 & 2.9236 & TRN & & \\
\hline CHEMBL602776 & 752310 & 5.181 & 5.1162 & TRN & & \\
\hline
\end{tabular}


Supplemental Table S2.txt

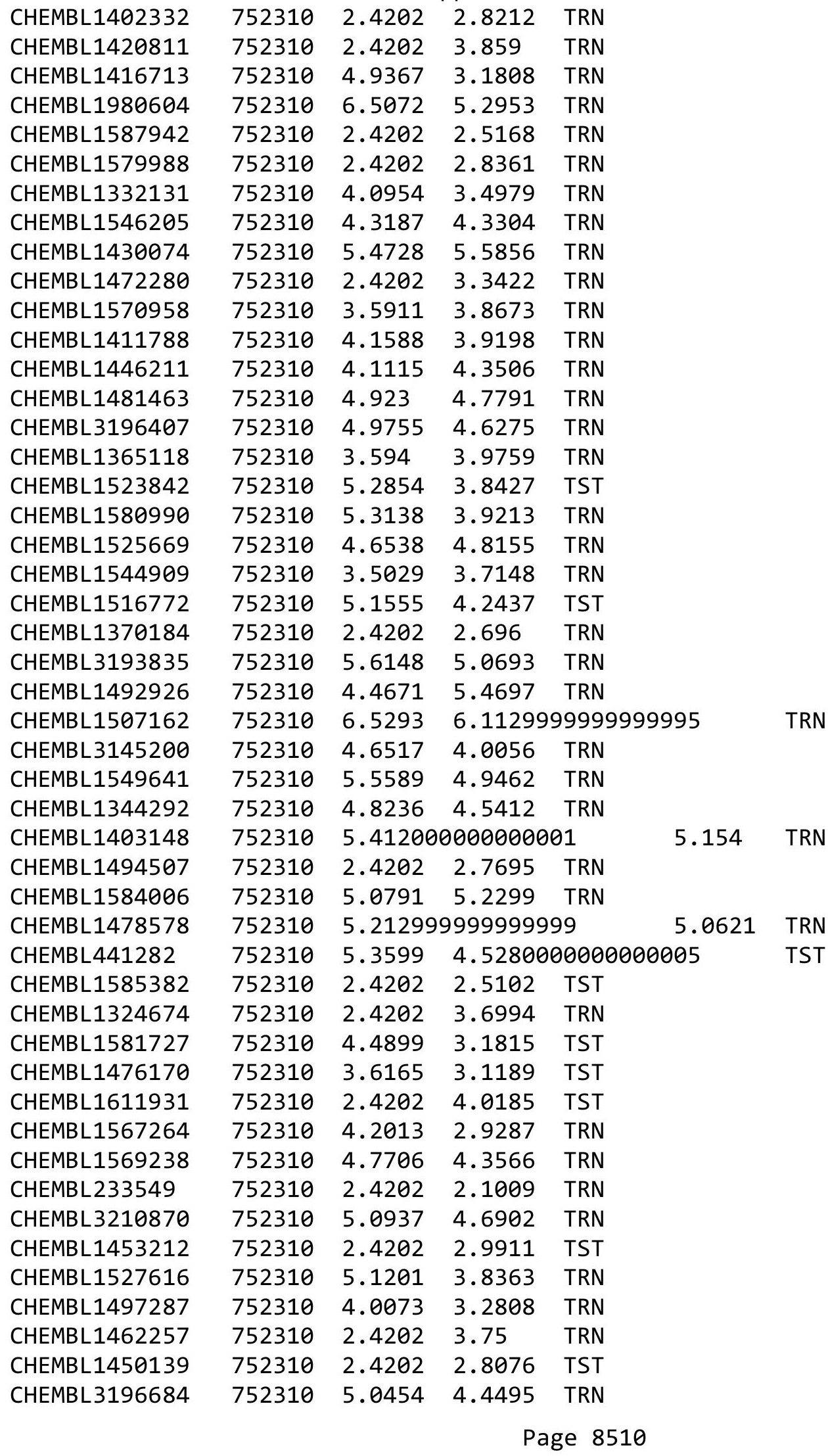


Supplemental Table S2.txt

\begin{tabular}{|c|c|c|c|c|}
\hline 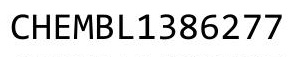 & & & & \\
\hline HEMBL1586425 & 2310 & 2.4202 & 9101 & \\
\hline HEMBL1609405 & 2310 & 202 & & \\
\hline 056 & 310 & 202 & & \\
\hline EMBL15 & 310 & 345 & 7757 & \\
\hline HEMBL1594685 & 52310 & 486 & 504 & \\
\hline HEMBL3199406 & 52310 & 2.4202 & 4135 & \\
\hline HEMBL1517493 & 52310 & 303 & 548 & \\
\hline AEMBL: & 310 & 392 & 81 & \\
\hline IEMBL] & 310 & & 995 & \\
\hline HEMBL1540795 & 52310 & 996 & 5235 & \\
\hline HEMBL1375884 & 52310 & .4202 & 9015 & \\
\hline HEMBL1601712 & 52310 & & 133 & \\
\hline 0942 & 310 & & 864 & \\
\hline AEMBL & 310 & 282 & 531 & \\
\hline HEMBL1373799 & 52310 & 02 & 5029 & \\
\hline HEMBL1979747 & 52310 & 07 & 1439 & \\
\hline HEMBL13 & 10 & & 646 & \\
\hline HEMBL13 & & & 1992 & \\
\hline HEMBL1C & 10 & & 874 & PN \\
\hline HEMBL1426 & & & & \\
\hline HEMBL3198793 & 10 & & 271 & RN \\
\hline HEMBL15 & 10 & & 979 & \\
\hline HEME & & & & \\
\hline 34 & 10 & & 75 & RN \\
\hline HEMBL158 & & & & RN \\
\hline HEMBL321: & 10 & 31 & 1054 & $\mathrm{RN}$ \\
\hline HEMBL149 & 10 & 36 & 205 & RN \\
\hline HEM & 10 & & 42 & RN \\
\hline HEME & & & 3442 & RN \\
\hline HEMBL160 & & & & $\mathrm{R}$ \\
\hline HEMBL 577764 & 52310 & & 1761 & ST \\
\hline HEMBL1C & 10 & & 459 & RN \\
\hline 0 & 10 & & & RN \\
\hline HEMBL31 & & & 349 & RN \\
\hline HEMBL1545792 & 10 & & 728 & $2 \mathrm{~N}-2-2-3-2$ \\
\hline HEMBL1393568 & 10 & & 7329 & RN \\
\hline HEMBL1460909 & 10 & & 106 & RN \\
\hline 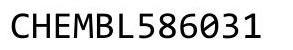 & & & & RN \\
\hline HEMBL15 & & & 7705 & RN \\
\hline HEMBL1418643 & 10 & & 744 & RN \\
\hline AEMBL1: & 10 & & 349 & RI \\
\hline HEMBL1794101 & & & & \\
\hline HEMBL1381901 & & & 3649 & RN \\
\hline HEMBL152911 & & & 9064 & RN \\
\hline HEMBL1578 & 10 & & 1214 & \\
\hline 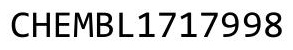 & & & & \\
\hline & & 5.3846 & & \\
\hline
\end{tabular}

Page 8511 
Supplemental Table S2.txt

\begin{tabular}{|c|c|c|c|c|}
\hline S & & .4202 & & \\
\hline & 52310 & 5.0799 & 4.1223 & \\
\hline & & & & \\
\hline HEMBL1 & & & & \\
\hline AEMBL 314 & 2310 & & 7821 & \\
\hline HEMBL1368065 & 52310 & 1623 & 9501 & \\
\hline 351 & 310 & 02 & 758 & \\
\hline 004 & & & & \\
\hline AEMBL1321007 & 52310 & & 3904 & \\
\hline AEMBL1311742 & 52310 & 642 & 5546 & \\
\hline HEMBL1373049 & 52310 & 202 & 1349 & \\
\hline IEMBL 3192605 & 310 & 61 & 022 & \\
\hline IEMBL] & & & & \\
\hline HEMBL1558461 & 52310 & 752 & 3886 & \\
\hline IEMBL1469091 & 10 & & 1539 & \\
\hline AEMBL1583537 & 10 & 11 & 29 & \\
\hline AEMBL14 & 10 & & 144 & \\
\hline AEMBL13 & & & 824 & \\
\hline AEMBL3198015 & 52310 & 57 & 7736 & \\
\hline AEMBL156 & & & & \\
\hline HEMBLIC & 10 & & 16 & Niv \\
\hline AEMBL15 & 10 & & 88 & \\
\hline JEMBL13 & 10 & & & \\
\hline 552 & & & & \\
\hline IEMBL13 & & & & \\
\hline AEMBL1; & 10 & & 41 & | \\
\hline AEMBL & & & 21 & NIV \\
\hline AFMRI 1 & 10 & 02 & 302 & \\
\hline HEMBL1343329 & & & & $1 \mathrm{KIV}$ \\
\hline HEMBL3190880 & & & & 15 \\
\hline HEMBL1: & & & 182 & ST \\
\hline HEMBL & & & 146 & ST \\
\hline 79 & 10 & & 114 & $C_{T}$ \\
\hline HEMBL3191597 & & & -5 & is \\
\hline HEMBL1456937 & 10 & & 896 & TST \\
\hline HEMBL155 & 10 & & 67 & TST \\
\hline HEMPI 1 & & & & ST \\
\hline HEMBL15 & & & & TS \\
\hline HEMBL1465170 & 52310 & & 427 & TST \\
\hline IEMBL1388180 & 10 & & 02 & TST \\
\hline HEMBL1399371 & 10 & & 608 & ГST \\
\hline HEMBL1310967 & & & 191 & ST \\
\hline HEMBL15 & & & 2723 & TST \\
\hline AEMBL1462012 & 52310 & 202 & 365 & TS \\
\hline MRI 1 & & & 322 & 15 \\
\hline HEMBL15 & & & .5289 & \\
\hline CHEMBL1506656 & 52310 & & 2.8328 & \\
\hline HEMBL 57013 & 752310 & 6.1176 & 3.7905 & t \\
\hline
\end{tabular}

Page 8512 
Supplemental Table S2.txt

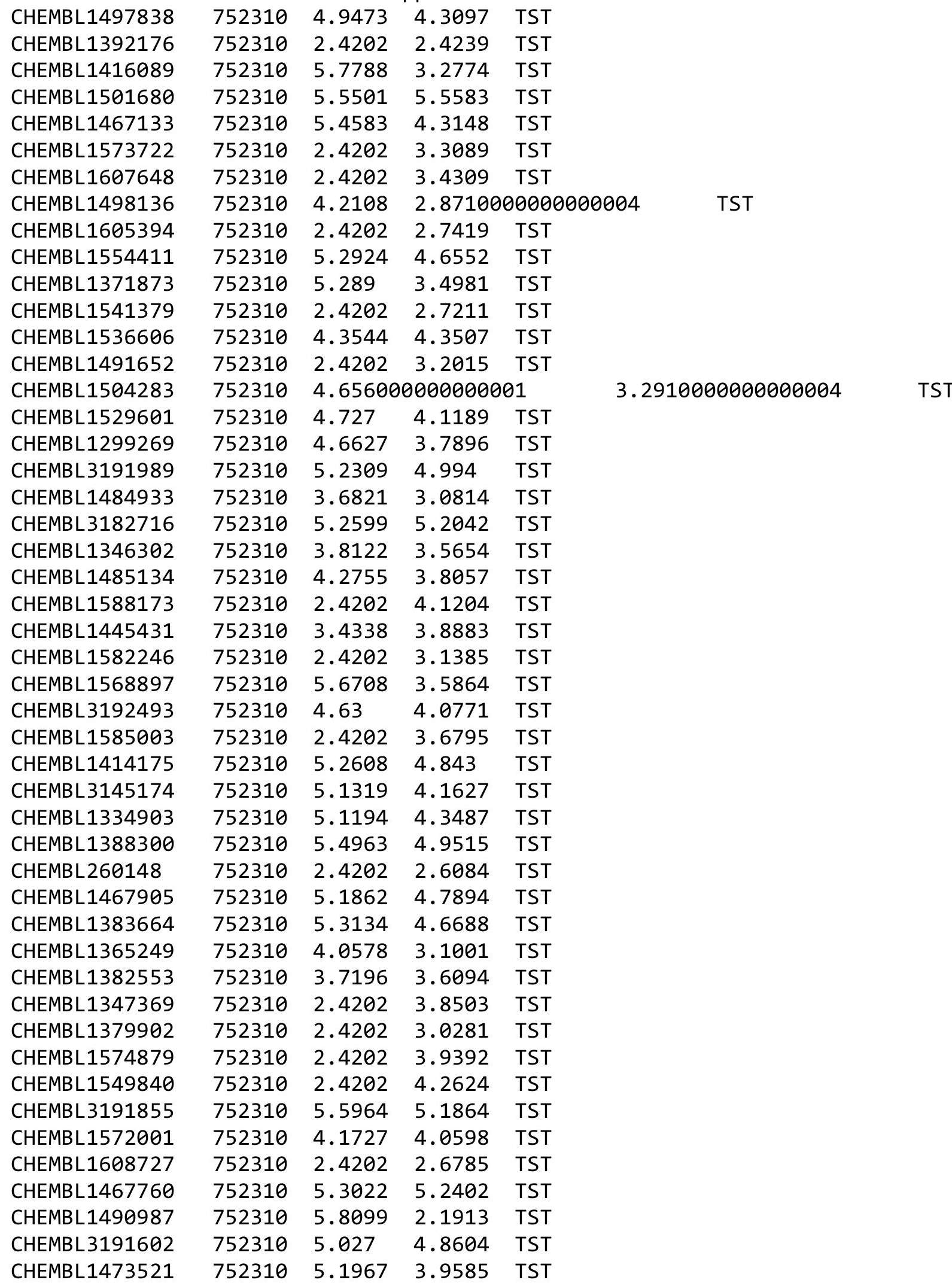

Page 8513 
Supplemental Table S2.txt

\begin{tabular}{|c|c|c|c|c|}
\hline CHEMBL1794196 & 752310 & 4.336 & 3.3339 & TST \\
\hline CHEMBL1531656 & 752310 & 3.8671 & 4.372 & TST \\
\hline CHEMBL1417099 & 752310 & 4.5337 & 4.3899 & TST \\
\hline CHEMBL1560379 & 752310 & 4.6017 & 4.0482 & TST \\
\hline CHEMBL 3144828 & 752310 & 5.4688 & 4.355 & TST \\
\hline CHEMBL1403329 & 752310 & 2.4202 & 3.9882 & TST \\
\hline CHEMBL3196913 & 752310 & 4.8011 & 4.9201 & TST \\
\hline CHEMBL1310969 & 752310 & 2.4202 & 3.6646 & TST \\
\hline CHEMBL1496555 & 752310 & 4.15 & 2.8847 & TST \\
\hline CHEMBL1469590 & 752310 & 2.4202 & 3.123 & TST \\
\hline CHEMBL3194896 & 752310 & 2.4202 & 2.5278 & TST \\
\hline CHEMBL1332543 & 752310 & 4.7326 & 4.4687 & TST \\
\hline CHEMBL1424664 & 752310 & 2.4202 & 2.9915 & TST \\
\hline CHEMBL1523567 & 752310 & 5.1494 & 5.1459 & TST \\
\hline CHEMBL1345835 & 752310 & 6.0959 & 4.6334 & TST \\
\hline CHEMBL1458294 & 752310 & 2.4202 & 2.9889 & TST \\
\hline CHEMBL1385214 & 752310 & 3.6135 & 2.0655 & TST \\
\hline CHEMBL1485425 & 752310 & 2.4202 & 3.785 & TST \\
\hline CHEMBL1488050 & 752310 & 4.0235 & 3.6714 & TST \\
\hline CHEMBL1489956 & 752310 & 4.4162 & 4.3454 & TST \\
\hline CHEMBL1299266 & 752310 & 4.4297 & \multicolumn{2}{|c|}{3.5010000000000003} \\
\hline CHEMBL1403320 & 752310 & 2.4202 & 2.9371 & TST \\
\hline CHEMBL3190539 & 752310 & 5.4269 & 3.8869 & TST \\
\hline CHEMBL1600360 & 752310 & 2.4202 & 3.1533 & TST \\
\hline CHEMBL1571318 & 752310 & 2.4202 & 3.2233 & TST \\
\hline CHEMBL1605939 & 752310 & 4.0776 & 3.3153 & TST \\
\hline CHEMBL1449705 & 752310 & 4.2455 & 3.7902 & TST \\
\hline CHEMBL1506201 & 752310 & 2.4202 & 2.0383 & TST \\
\hline CHEMBL1574609 & 752310 & 4.6258 & 2.2594 & TST \\
\hline CHEMBL1302170 & 752310 & 5.2855 & 4.7014 & TST \\
\hline CHEMBL1568301 & 752310 & 5.38 & \multicolumn{2}{|c|}{3.2489999999999997} \\
\hline CHEMBL3210545 & 752310 & 3.9658 & 3.7216 & TST \\
\hline CHEMBL1497295 & 752310 & 6.1274 & 6.6378 & TST \\
\hline CHEMBL1587031 & 752310 & 5.0716 & 5.1524 & TST \\
\hline CHEMBL1556583 & 752310 & 2.4202 & 2.6574 & TST \\
\hline CHEMBL1329726 & 752310 & 5.0433 & 5.4064 & TST \\
\hline CHEMBL1556868 & 752310 & 4.251 & 3.4572 & TST \\
\hline CHEMBL1382853 & 752310 & 4.8837 & 3.9755 & TST \\
\hline CHEMBL1565520 & 752310 & 4.6584 & 4.6512 & TST \\
\hline CHEMBL1568510 & 752310 & 5.0773 & 5.0142 & TST \\
\hline CHEMBL171632 & 752310 & 5.4651 & 3.326 & TST \\
\hline CHEMBL1571123 & 752310 & 2.4202 & 2.8205 & TST \\
\hline CHEMBL1485700 & 752310 & 4.507 & 3.8549 & TST \\
\hline CHEMBL1365552 & 752310 & 4.7891 & \multicolumn{2}{|c|}{4.6160000000000005} \\
\hline CHEMBL1301371 & 752310 & 4.2148 & 2.7554 & TST \\
\hline CHEMBL1489347 & 752310 & 4.2092 & 3.8492 & TST \\
\hline CHEMBL517444 & 752310 & 4.7948 & 4.1083 & TST \\
\hline CHEMBL1539943 & 752310 & 4.6645 & 3.4713 & TST \\
\hline
\end{tabular}


Supplemental Table S2.txt

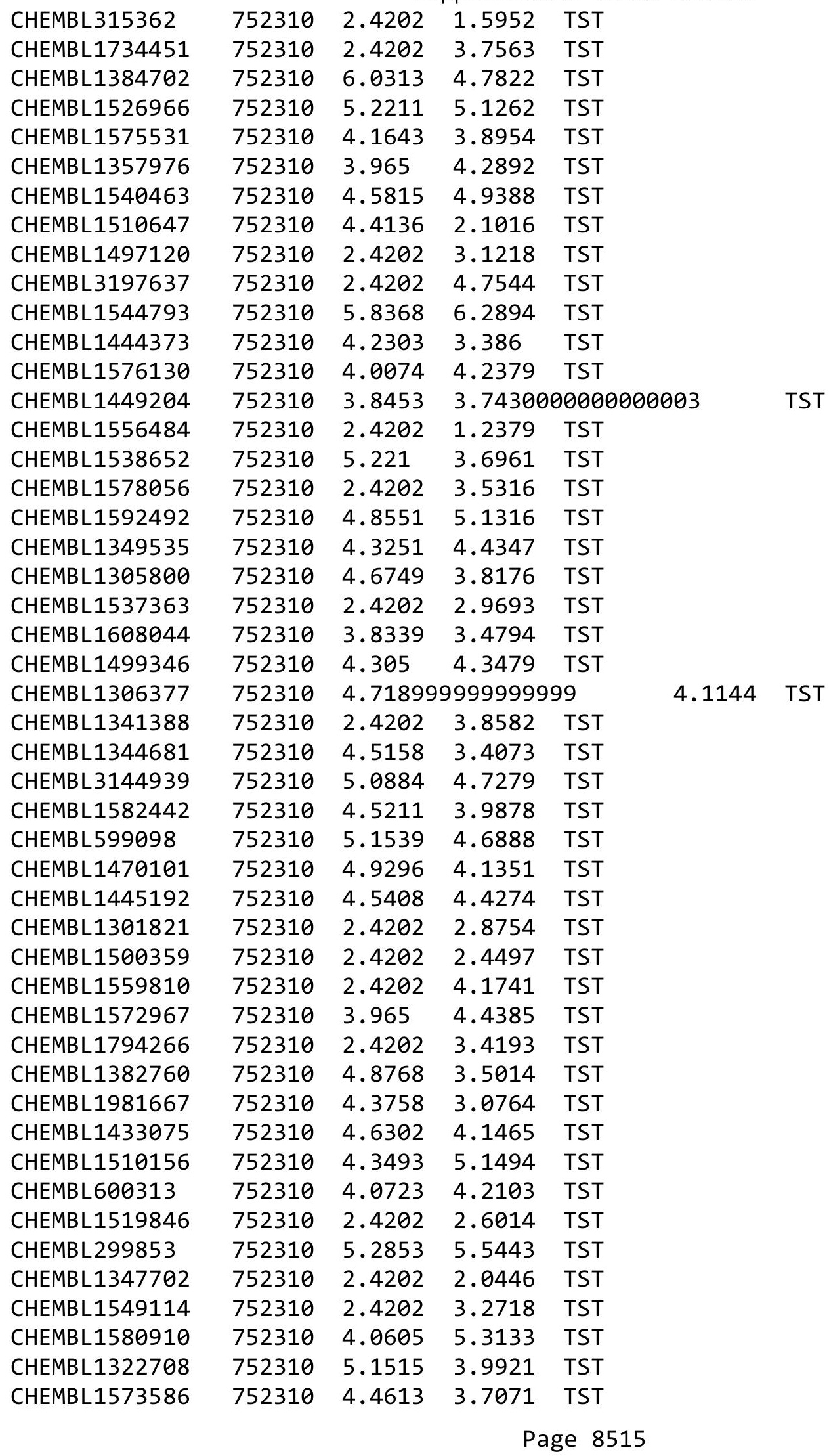


Supplemental Table S2.txt

\begin{tabular}{|c|c|c|c|c|}
\hline CHEMBL1606280 & 752310 & 2.4202 & 3.5202 & TST \\
\hline CHEMBL1335223 & 752310 & 4.4191 & 4.7056 & TST \\
\hline CHEMBL1981564 & 752310 & 2.4202 & 1.5245 & TST \\
\hline CHEMBL3145155 & 752310 & 5.6282 & 4.8328 & TST \\
\hline CHEMBL1387900 & 752310 & 2.4202 & 3.2296 & TST \\
\hline CHEMBL1535546 & 752310 & 4.276 & 3.7709 & TST \\
\hline CHEMBL1302401 & 752310 & 2.4202 & 3.5668 & TST \\
\hline CHEMBL1471206 & 752310 & 2.4202 & 2.1218 & TST \\
\hline CHEMBL 2001337 & 752310 & 4.8049 & 3.0657 & TST \\
\hline CHEMBL1412143 & 752310 & 4.1979 & 4.46399 & 99999999995 \\
\hline CHEMBL1464042 & 752310 & 5.2431 & 4.808 & TST \\
\hline CHEMBL1557820 & 752310 & 3.6666 & 4.4293 & TST \\
\hline CHEMBL1540021 & 752310 & 2.4202 & 4.3933 & TST \\
\hline CHEMBL1521024 & 752310 & 4.6949 & 5.2362 & TST \\
\hline CHEMBL1489633 & 752310 & 5.63 & 5.0265 & TST \\
\hline CHEMBL1425350 & 752310 & 4.1422 & 3.7285 & TST \\
\hline CHEMBL1375820 & 752310 & 2.4202 & 3.2983 & TST \\
\hline CHEMBL1329297 & 752310 & 2.4202 & 3.4285 & TST \\
\hline CHEMBL1712864 & 752310 & 2.4202 & 3.7134 & TST \\
\hline CHEMBL1481347 & 752310 & 2.4202 & 5.54 & TST \\
\hline CHEMBL1326933 & 752310 & 2.4202 & 2.858 & TST \\
\hline CHEMBL3194842 & 752310 & 2.4202 & 3.8606 & TST \\
\hline CHEMBL1351159 & 752310 & 4.5343 & 4.7775 & TST \\
\hline CHEMBL1458840 & 752310 & 4.752 & 4.289 & TST \\
\hline CHEMBL1570637 & 752310 & 4.4484 & 5.0797 & TST \\
\hline CHEMBL1307306 & 752310 & 3.7279 & 3.889 & TST \\
\hline CHEMBL1369492 & 752310 & 5.2232 & 4.2085 & TST \\
\hline CHEMBL1361855 & 752310 & 4.4667 & 3.8153 & TST \\
\hline CHEMBL1535312 & 752310 & 2.4202 & 2.6068 & TST \\
\hline CHEMBL1472327 & 752310 & 4.9594 & 4.5923 & TST \\
\hline CHEMBL1389480 & 752310 & 5.7226 & 5.9321 & TST \\
\hline CHEMBL1424562 & 752310 & 2.4202 & 3.533 & TST \\
\hline CHEMBL3666973 & 1528912 & 8.1427 & 8.0633 & TST \\
\hline CHEMBL3897521 & 1528912 & 8.9208 & 9.2792 & TRN \\
\hline CHEMBL3666903 & 1528912 & 7.2218 & 7.28799 & 9999999999 \\
\hline CHEMBL3666961 & 1528912 & 5.8239 & 5.6582 & TST \\
\hline CHEMBL 3662276 & 1528912 & 7.0 & 6.9071 & TRN \\
\hline CHEMBL3943186 & 1528912 & 6.0 & 6.0974 & TRN \\
\hline CHEMBL3666970 & 1528912 & 8.1308 & 8.2642 & TRN \\
\hline CHEMBL 3890074 & 1528912 & 6.0 & 5.9883 & TRN \\
\hline CHEMBL 3662247 & 1528912 & 7.2518 & 7.3008 & TST \\
\hline CHEMBL3916534 & 1528912 & 7.4949 & 7.4357 & TRN \\
\hline CHEMBL3666967 & 1528912 & 9.3279 & 9.546 & TRN \\
\hline CHEMBL3945180 & 1528912 & 6.0 & 5.9175 & TRN \\
\hline CHEMBL3954835 & 1528912 & 8.3565 & 8.22 & TRN \\
\hline CHEMBL 3667008 & 1528912 & 7.8239 & 7.8277 & TRN \\
\hline CHEMBL 3666965 & 1528912 & 9.1805 & 9.3122 & TRN \\
\hline CHEMBL3917825 & 1528912 & 6.0 & 6.2783 & TRN \\
\hline
\end{tabular}


Supplemental Table S2.txt

\begin{tabular}{|c|c|c|c|c|}
\hline W & 28912 & 3861 & & \\
\hline & 528912 & & 7.4192 & \\
\hline & 912 & & & \\
\hline AEMBL & 8912 & 198 & & \\
\hline AEMBL3667013 & 528912 & 778 & 4921 & \\
\hline HEMBL3662241 & 528912 & 8.0 & .791 & \\
\hline 8018 & 528912 & 57 & 7273 & \\
\hline 5896 & 528912 & & 203 & \\
\hline AEMBL3666960 & 528912 & 376 & 5492 & \\
\hline HEMBL3666946 & 528912 & 861 & 8475 & \\
\hline AEMBL3666927 & 528912 & 549 & 2932 & \\
\hline 390 & 28912 & 383 & 376 & \\
\hline AEMBL & 8912 & & & \\
\hline HEMBL3\& & 528912 & 586 & .0554 & \\
\hline AEMBL3662256 & 528912 & 86 & & \\
\hline AEMBL3662269 & 528912 & 49 & 64 & \\
\hline AEMBL3S & 3912 & 47 & 99 & \\
\hline AEMBL36 & 912 & & & \\
\hline AEMBL39 & 528912 & 778 & 17 & \\
\hline AEMBL3S & 912 & 6. & & \\
\hline HEMBL= & 2 & 8 & 96 & t. \\
\hline AEMBL: & 912 & & & 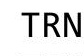 \\
\hline AEMBL & 912 & & 81 & \\
\hline 866 & 528912 & & & \\
\hline HEMBL366 & & & 97 & I RIV \\
\hline AEMBL & 3912 & 6 & 32 & $R N$ \\
\hline AEMBL; & 912 & & & Niv \\
\hline AFMRI : & 912 & $\partial 8$ & 82 & RN \\
\hline AEMBL3 & & 239 & & וכו \\
\hline AEMBL3927623 & 528912 & 7. & 35 & ISI \\
\hline HEMBL3S & 3912 & 6 & 29 & RN \\
\hline 95 & 12 & & & ונכ \\
\hline 70 & 12 & 59 & 33 & M \\
\hline HEMBL3957641 & 528912 & & & IR \\
\hline HEMBL3667011 & 528912 & 6. & 97 & ГRN \\
\hline HEMBL36 & 12 & 6 & 99 & \\
\hline 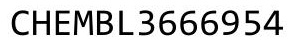 & 12 & 6 & 39 & RN \\
\hline HEMBL & & & 157 & IRN \\
\hline HEMBL3667012 & 528912 & 7.5376 & & $\Gamma \mathrm{RN}$ \\
\hline EMBL & 12 & 208 & & RN \\
\hline HEMBL36 & 12 & 208 & 19 & \\
\hline HEMBL 36 & & 8.2218 & & ST \\
\hline HEMBL39 & 528912 & 8.0132 & 9263 & RN \\
\hline AEMBL366 & 528912 & 6 & 12 & TRN \\
\hline $1=$ & 528912 & 6 & & $n$ \\
\hline HEMBL36 & 12 & 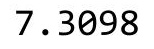 & .4721 & \\
\hline HEMBL3901015 & 528912 & 8.1805 & 8.1506 & \\
\hline HEMBL3933160 & 1528912 & 8.3979 & 7.8434 & ГRN \\
\hline
\end{tabular}

Page 8517 
Supplemental Table S2.txt

\begin{tabular}{|c|c|c|c|c|}
\hline CHEMBL3639611 & 1528912 & 7.3468 & 7.2944 & TRN \\
\hline CHEMBL3662251 & 1528912 & 6.1249 & 6.1637 & TRN \\
\hline CHEMBL3975988 & 1528912 & 8.5376 & 8.5379 & TST \\
\hline CHEMBL3666996 & 1528912 & 7.0 & 7.1192 & TST \\
\hline CHEMBL 3667010 & 1528912 & 7.5229 & 7.5053 & TRN \\
\hline CHEMBL3666950 & 1528912 & 6.0809 & 6.0151 & TST \\
\hline CHEMBL3666908 & 1528912 & 6.0 & 5.8171 & TRN \\
\hline CHEMBL3964743 & 1528912 & 8.8539 & 8.6822 & TST \\
\hline CHEMBL 3666937 & 1528912 & 6.3665 & 6.3767 & TRN \\
\hline CHEMBL3666964 & 1528912 & 9.1938 & 8.9278 & TRN \\
\hline CHEMBL3666975 & 1528912 & 7.4437 & \multicolumn{2}{|c|}{7.577000000000001} \\
\hline CHEMBL3667006 & 1528912 & \multicolumn{3}{|c|}{ 8.283999999999999 } \\
\hline CHEMBL3666935 & 1528912 & 7.3979 & 7.4391 & TRN \\
\hline CHEMBL3666942 & 1528912 & 6.0 & 6.1694 & TST \\
\hline CHEMBL3666966 & 1528912 & 8.6021 & 8.0625 & TRN \\
\hline CHEMBL3897729 & 1528912 & 8.2676 & 8.1551 & TRN \\
\hline CHEMBL3662242 & 1528912 & 7.7447 & 7.5312 & TST \\
\hline CHEMBL3666940 & 1528912 & 6.0362 & 5.9177 & TRN \\
\hline CHEMBL3666929 & 1528912 & 7.2366 & \multicolumn{2}{|c|}{7.178999999999999} \\
\hline CHEMBL3949092 & 1528912 & 8.4437 & 8.3684 & TRN \\
\hline CHEMBL3662281 & 1528912 & 7.3372 & 7.2807 & TRN \\
\hline CHEMBL3666911 & 1528912 & 8.4815 & 8.0482 & TST \\
\hline CHEMBL3662254 & 1528912 & 7.6198 & 7.5267 & TRN \\
\hline CHEMBL3906740 & 1528912 & 7.5229 & 7.5891 & TRN \\
\hline CHEMBL3666956 & 1528912 & 8.0706 & 8.2641 & TRN \\
\hline CHEMBL3662261 & 1528912 & 7.0969 & 7.2974 & TRN \\
\hline CHEMBL3662257 & 1528912 & 7.2147 & 6.6605 & TST \\
\hline CHEMBL3666957 & 1528912 & 7.8539 & 7.8205 & TRN \\
\hline CHEMBL3947987 & 1528912 & 7.7212 & 7.4682 & TRN \\
\hline CHEMBL3666923 & 1528912 & 6.6021 & 6.7472 & TRN \\
\hline CHEMBL3961020 & 1528912 & 8.3768 & 8.5486 & TST \\
\hline CHEMBL3666910 & 1528912 & 7.0706 & 7.0392 & TRN \\
\hline CHEMBL3662252 & 1528912 & 8.0969 & 8.0083 & TRN \\
\hline CHEMBL3666900 & 1528912 & 7.7696 & 7.6608 & TRN \\
\hline CHEMBL 3667000 & 1528912 & 6.0 & 7.0609 & TRN \\
\hline CHEMBL3666955 & 1528912 & 6.7959 & 7.1137 & TRN \\
\hline CHEMBL3930056 & 1528912 & 8.1024 & 8.2841 & TST \\
\hline CHEMBL3963509 & 1528912 & 8.9586 & 8.8156 & TRN \\
\hline CHEMBL3906240 & 1528912 & 6.0 & 6.3339 & TRN \\
\hline CHEMBL3666901 & 1528912 & 6.0 & 5.7076 & TRN \\
\hline CHEMBL3662239 & 1528912 & 6.0 & 5.7246 & TRN \\
\hline CHEMBL3666907 & 1528912 & 7.6778 & 7.2877 & TST \\
\hline CHEMBL3921259 & 1528912 & 8.6198 & 8.6602 & TRN \\
\hline CHEMBL3666959 & 1528912 & 7.6198 & 7.6443 & TRN \\
\hline CHEMBL3931434 & 1528912 & 8.4318 & 8.2019 & TRN \\
\hline CHEMBL3662275 & 1528912 & 5.7258 & 5.6869 & TRN \\
\hline CHEMBL3666972 & 1528912 & 7.1938 & 7.563 & TST \\
\hline CHEMBL 3662284 & 1528912 & 7.2924 & 7.3046 & TRN \\
\hline
\end{tabular}

Page 8518 
Supplemental Table S2.txt

\begin{tabular}{|c|c|c|c|c|c|}
\hline CHEMBL3666909 & 1528912 & 7.6198 & 7.5555 & TST & \\
\hline CHEMBL3667009 & 1528912 & 7.6021 & 7.6127 & TRN & \\
\hline CHEMBL3667005 & 1528912 & 6.0 & 6.5937 & TRN & \\
\hline CHEMBL3662266 & 1528912 & 6.0 & 6.3274 & TRN & \\
\hline CHEMBL3666949 & 1528912 & 6.8239 & 6.4804 & TST & \\
\hline CHEMBL3666969 & 1528912 & 8.2924 & 8.3026 & TST & \\
\hline CHEMBL3666994 & 1528912 & 8.1079 & 8.1426 & TRN & \\
\hline CHEMBL3666904 & 1528912 & 7.284 & 7.3027 & TST & \\
\hline CHEMBL3662246 & 1528912 & 6.0 & 5.9131 & TRN & \\
\hline CHEMBL3662282 & 1528912 & 7.2366 & 7.2204 & TRN & \\
\hline CHEMBL 3662253 & 1528912 & 6.0 & 6.16299 & 9999999999 & TRN \\
\hline CHEMBL3667007 & 1528912 & 7.8861 & 7.8365 & TST & \\
\hline CHEMBL3666915 & 1528912 & 8.2291 & 8.03 & TRN & \\
\hline CHEMBL3666974 & 1528912 & 7.9586 & 7.3254 & TST & \\
\hline CHEMBL3983068 & 1528912 & 7.5229 & 7.55399 & 9999999999 & TRN \\
\hline CHEMBL3666981 & 1528912 & 6.2076 & 6.1107 & TRN & \\
\hline CHEMBL3667001 & 1528912 & 9.3768 & 9.395 & TRN & \\
\hline CHEMBL 3662272 & 1528912 & 6.9586 & 6.9341 & TST & \\
\hline CHEMBL3929140 & 1528912 & 7.8861 & 8.2097 & TST & \\
\hline CHEMBL549020 & 1479009 & 3.3 & 4.2394 & TRN & \\
\hline CHEMBL526199 & 1479009 & 4.3 & 3.8348 & TRN & \\
\hline CHEMBL3430919 & 1479009 & 3.3 & 3.6826 & TRN & \\
\hline CHEMBL528583 & 1479009 & 4.9 & 4.0287 & TRN & \\
\hline CHEMBL530358 & 1479009 & 5.2 & 4.2286 & TRN & \\
\hline CHEMBL530275 & 1479009 & 4.7 & 4.915 & TRN & \\
\hline CHEMBL534517 & 1479009 & 4.6 & 5.149 & TRN & \\
\hline CHEMBL3430920 & 1479009 & 5.3 & 4.7883 & TRN & \\
\hline CHEMBL3430921 & 1479009 & 4.7 & 4.5827 & TST & \\
\hline CHEMBL3430922 & 1479009 & 4.5 & 4.4344 & TST & \\
\hline CHEMBL2098124 & 1479009 & 5.4 & 4.8262 & TRN & \\
\hline CHEMBL 2098408 & 1479009 & 4.7 & 4.8942 & TRN & \\
\hline CHEMBL1578482 & 1479009 & 5.4 & 4.6767 & TRN & \\
\hline CHEMBL 2098276 & 1479009 & 3.3 & 4.305 & TRN & \\
\hline CHEMBL3430923 & 1479009 & 3.3 & 3.2394 & TST & \\
\hline CHEMBL3430924 & 1479009 & 4.8 & 5.0773 & TRN & \\
\hline CHEMBL3430925 & 1479009 & 4.9 & 4.4306 & TST & \\
\hline CHEMBL3430926 & 1479009 & 3.3 & 4.2496 & TST & \\
\hline CHEMBL2165401 & 1479009 & 3.3 & 3.6365 & TST & \\
\hline CHEMBL3430927 & 1479009 & 3.3 & 4.689 & TRN & \\
\hline CHEMBL3430928 & 1479009 & 4.7 & 4.7769 & TRN & \\
\hline CHEMBL3430929 & 1479009 & 3.3 & 4.5342 & TRN & \\
\hline CHEMBL3430930 & 1479009 & 3.3 & 3.6907 & TRN & \\
\hline CHEMBL305686 & 1479009 & 3.3 & 4.7773 & TST & \\
\hline CHEMBL3430931 & 1479009 & 3.3 & 3.6956 & TST & \\
\hline CHEMBL3430932 & 1479009 & 3.3 & 3.2192 & TST & \\
\hline CHEMBL1232777 & 1479009 & 3.3 & 4.5464 & TST & \\
\hline CHEMBL3430933 & 1479009 & 4.7 & 4.0633 & TRN & \\
\hline CHEMBL3430913 & 1479009 & 3.2 & 3.4287 & TRN & \\
\hline
\end{tabular}




\begin{tabular}{|c|c|c|c|c|}
\hline & & & & $a+1$ \\
\hline CHEMBL 3430934 & 1479009 & 4.7 & 4.8944 & TRN \\
\hline CHEMBL3430935 & 1479009 & 3.3 & 3.4501 & TST \\
\hline CHEMBL3430936 & 1479009 & 3.3 & 3.108 & TRN \\
\hline CHEMBL 3430937 & 1479009 & 4.4 & 4.71 & TRN \\
\hline CHEMBL3430938 & 1479009 & 3.1 & 3.7059 & TRN \\
\hline CHEMBL3430939 & 1479009 & 3.1 & 3.7152 & TRN \\
\hline CHEMBL 3430940 & 1479009 & 4.7 & 3.6779 & TRN \\
\hline CHEMBL 3430941 & 1479009 & 3.1 & 3.6706 & TRN \\
\hline CHEMBL 3430942 & 1479009 & 3.3 & 3.7773 & TRN \\
\hline CHEMBL3430943 & 1479009 & 3.2 & 3.6487 & TRN \\
\hline CHEMBL 3430944 & 1479009 & 3.1 & 3.7515 & TRN \\
\hline CHEMBL3430945 & 1479009 & 4.8 & 4.0261 & TRN \\
\hline CHEMBL3430946 & 1479009 & 3.3 & 3.6006 & TRN \\
\hline CHEMBL 3430947 & 1479009 & 3.3 & 3.5825 & TRN \\
\hline CHEMBL3430948 & 1479009 & 3.3 & 4.5185 & TRN \\
\hline CHEMBL3430949 & 1479009 & 5.0 & 5.0645 & TRN \\
\hline CHEMBL1388922 & 1479009 & 5.3 & 4.8891 & TRN \\
\hline CHEMBL3430950 & 1479009 & 3.3 & 3.1712 & TRN \\
\hline CHEMBL3430951 & 1479009 & 4.9 & 4.5623 & TST \\
\hline CHEMBL1321334 & 1479009 & 3.3 & 3.5484 & TRN \\
\hline CHEMBL3430952 & 1479009 & 3.3 & 4.5366 & TRN \\
\hline CHEMBL3430953 & 1479009 & 3.3 & 3.8341 & TRN \\
\hline CHEMBL3430954 & 1479009 & 3.3 & 4.0592 & TRN \\
\hline CHEMBL3430955 & 1479009 & 4.4 & 3.7834 & TST \\
\hline CHEMBL3430956 & 1479009 & 3.3 & 4.6369 & TRN \\
\hline CHEMBL3430957 & 1479009 & 4.6 & 4.5096 & TRN \\
\hline CHEMBL3430958 & 1479009 & 5.2 & 4.4826 & TRN \\
\hline CHEMBL3430959 & 1479009 & 5.1 & 4.842 & TRN \\
\hline CHEMBL3430960 & 1479009 & 3.3 & 3.2413 & TRN \\
\hline CHEMBL3430961 & 1479009 & 3.3 & 4.0178 & TRN \\
\hline CHEMBL3430962 & 1479009 & 3.3 & 3.8152 & TRN \\
\hline CHEMBL3430963 & 1479009 & 4.5 & 4.4549 & TRN \\
\hline CHEMBL 3430964 & 1479009 & 4.5 & 4.4685 & TRN \\
\hline CHEMBL3430965 & 1479009 & 3.3 & 4.1963 & TRN \\
\hline CHEMBL3430966 & 1479009 & 4.5 & 4.0309 & TRN \\
\hline CHEMBL3430967 & 1479009 & 4.8 & 4.2473 & TRN \\
\hline CHEMBL3430968 & 1479009 & 5.1 & 5.2049 & TRN \\
\hline CHEMBL3430969 & 1479009 & 5.1 & 4.8839 & TRN \\
\hline CHEMBL 3430970 & 1479009 & 3.3 & 4.4441 & TRN \\
\hline CHEMBL1482137 & 1479009 & 3.3 & 3.8864 & TRN \\
\hline CHEMBL3430971 & 1479009 & 3.3 & 3.3008 & TRN \\
\hline CHEMBL 3430972 & 1479009 & 3.3 & 3.2413 & TRN \\
\hline CHEMBL3430973 & 1479009 & 4.7 & 4.3534 & TRN \\
\hline CHEMBL 3430974 & 1479009 & 3.3 & 3.5638 & TRN \\
\hline CHEMBL3430975 & 1479009 & 3.3 & 3.7754 & TRN \\
\hline CHEMBL3430976 & 1479009 & 3.3 & 3.7366 & TRN \\
\hline CHEMBL3430977 & 1479009 & 3.3 & 3.7342 & TST \\
\hline CHEMBL164422 & 1479009 & 5.2 & 5.2379 & TRN \\
\hline
\end{tabular}




\begin{tabular}{|c|c|c|c|c|c|}
\hline \\
\hline CHEMBL3430978 & 1479009 & 4.5 & 3.8315 & TRN & \\
\hline CHEMBL3430979 & 1479009 & 3.3 & 3.5151 & TRN & \\
\hline CHEMBL3430980 & 1479009 & 4.6 & 4.3155 & TRN & \\
\hline CHEMBL1487481 & 1479009 & 4.7 & 3.8644 & TRN & \\
\hline CHEMBL1487467 & 1479009 & 3.3 & 4.1083 & TRN & \\
\hline CHEMBL3430981 & 1479009 & 3.3 & 3.8737 & TRN & \\
\hline CHEMBL3430982 & 1479009 & 3.3 & 3.8462 & TRN & \\
\hline CHEMBL3430983 & 1479009 & 3.3 & 3.8407 & TRN & \\
\hline CHEMBL592827 & 1479009 & 3.3 & 3.7945 & TRN & \\
\hline CHEMBL3430984 & 1479009 & 3.3 & 3.6436 & TRN & \\
\hline CHEMBL3430985 & 1479009 & 4.4 & 4.4518 & TRN & \\
\hline CHEMBL1466712 & 1479009 & 4.5 & 4.5886 & TRN & \\
\hline CHEMBL3430986 & 1479009 & 3.3 & 3.8836 & TRN & \\
\hline CHEMBL 3430987 & 1479009 & 4.4 & 3.8485 & TST & \\
\hline CHEMBL3430988 & 1479009 & 3.3 & 3.6406 & TRN & \\
\hline CHEMBL3430989 & 1479009 & 3.3 & 3.2376 & TRN & \\
\hline CHEMBL3430990 & 1479009 & 3.3 & 3.6087 & TRN & \\
\hline CHEMBL3430991 & 1479009 & 4.4 & 3.6491 & TRN & \\
\hline CHEMBL3430992 & 1479009 & 4.8 & 3.6078 & TRN & \\
\hline CHEMBL3430993 & 1479009 & 3.3 & 3.5166 & TRN & \\
\hline CHEMBL3430994 & 1479009 & 4.8 & 3.6669 & TRN & \\
\hline CHEMBL3430995 & 1479009 & 3.3 & 3.4055 & TST & \\
\hline CHEMBL3430996 & 1479009 & 3.3 & 3.552 & TRN & \\
\hline CHEMBL3430997 & 1479009 & 3.3 & 3.2378 & TRN & \\
\hline CHEMBL3430998 & 1479009 & 3.3 & 3.9566 & TRN & \\
\hline CHEMBL3430999 & 1479009 & 4.8 & 3.9079 & TRN & \\
\hline CHEMBL3431000 & 1479009 & 4.7 & 3.733 & TRN & \\
\hline CHEMBL3431001 & 1479009 & 4.8 & 3.5304 & TRN & \\
\hline CHEMBL3431002 & 1479009 & 4.5 & 3.9843 & TST & \\
\hline CHEMBL3431003 & 1479009 & 4.9 & 4.5514 & TRN & \\
\hline CHEMBL3431004 & 1479009 & 4.9 & 5.1326 & TRN & \\
\hline CHEMBL3431005 & 1479009 & 3.3 & 4.6913 & TRN & \\
\hline CHEMBL3431006 & 1479009 & 4.8 & 4.9079 & TRN & \\
\hline CHEMBL3431007 & 1479009 & 3.3 & 3.8611 & TRN & \\
\hline CHEMBL 3431008 & 1479009 & 4.6 & $4.1080 e$ & 00000000005 & TST \\
\hline CHEMBL3431009 & 1479009 & 3.3 & 5.0584 & TRN & \\
\hline CHEMBL2355685 & 1479009 & 5.2 & 4.9096 & TST & \\
\hline CHEMBL3431010 & 1479009 & 3.3 & 4.4548 & TRN & \\
\hline CHEMBL3431011 & 1479009 & 5.2 & 4.2581 & TRN & \\
\hline CHEMBL3431012 & 1479009 & 3.3 & 3.61899 & 99999999998 & TST \\
\hline CHEMBL1731664 & 1479009 & 4.9 & 3.9442 & TRN & \\
\hline CHEMBL3431013 & 1479009 & 4.6 & 4.3729 & TRN & \\
\hline CHEMBL3431014 & 1479009 & 5.2 & 5.1909 & TRN & \\
\hline CHEMBL3431015 & 1479009 & 4.5 & 4.0445 & TRN & \\
\hline CHEMBL3431016 & 1479009 & 3.3 & 3.4509 & TRN & \\
\hline CHEMBL3431017 & 1479009 & 3.3 & 3.366 & TRN & \\
\hline CHEMBL3431018 & 1479009 & 5.2 & 4.5948 & TRN & \\
\hline CHEMBL3431019 & 1479009 & 5.1 & 5.1443 & TRN & \\
\hline
\end{tabular}




\begin{tabular}{|c|c|c|c|c|}
\hline & & & & $a \perp 1 a$ \\
\hline CHEMBL 3431020 & 1479009 & 3.3 & 3.3667 & TRN \\
\hline CHEMBL3431021 & 1479009 & 3.3 & 4.0296 & TRN \\
\hline CHEMBL3431022 & 1479009 & 3.3 & 3.6554 & TRN \\
\hline CHEMBL 3431023 & 1479009 & 5.0 & 4.2345 & TST \\
\hline CHEMBL3431024 & 1479009 & 3.3 & 3.4707 & TRN \\
\hline CHEMBL3431025 & 1479009 & 4.9 & 3.5577 & TRN \\
\hline CHEMBL3431026 & 1479009 & 3.3 & 4.7986 & TST \\
\hline CHEMBL3431027 & 1479009 & 3.3 & 4.4135 & TRN \\
\hline CHEMBL 3431028 & 1479009 & 3.3 & 3.1761 & TRN \\
\hline CHEMBL3431029 & 1479009 & 4.4 & 3.575 & TRN \\
\hline CHEMBL3431030 & 1479009 & 5.0 & 4.8203 & TRN \\
\hline CHEMBL3431031 & 1479009 & 4.5 & 4.0598 & TRN \\
\hline CHEMBL3431032 & 1479009 & 3.3 & 4.0976 & TRN \\
\hline CHEMBL1527364 & 1479009 & 3.3 & 4.3537 & TRN \\
\hline CHEMBL3431033 & 1479009 & 3.3 & 4.2048 & TRN \\
\hline CHEMBL3431034 & 1479009 & 3.3 & 4.1112 & TRN \\
\hline CHEMBL3431035 & 1479009 & 3.3 & 4.1563 & TRN \\
\hline CHEMBL3431036 & 1479009 & 5.0 & 3.7843 & TRN \\
\hline CHEMBL3431037 & 1479009 & 3.3 & 3.6976 & TRN \\
\hline CHEMBL3431038 & 1479009 & 3.3 & 3.9294 & TRN \\
\hline CHEMBL3431039 & 1479009 & 3.3 & 3.2742 & TRN \\
\hline CHEMBL 3431040 & 1479009 & 6.1 & 6.1982 & TRN \\
\hline CHEMBL1354075 & 1479009 & 5.0 & 4.9266 & TRN \\
\hline CHEMBL3431041 & 1479009 & 4.6 & 3.8994 & TRN \\
\hline CHEMBL3431042 & 1479009 & 3.3 & 3.5592 & TRN \\
\hline CHEMBL3431043 & 1479009 & 3.3 & 3.6404 & TST \\
\hline CHEMBL3431044 & 1479009 & 3.3 & 3.5694 & TST \\
\hline CHEMBL3431045 & 1479009 & 4.9 & 4.2863 & TRN \\
\hline CHEMBL3431046 & 1479009 & 3.3 & 4.9905 & TRN \\
\hline CHEMBL3431047 & 1479009 & 4.7 & 5.1766 & TRN \\
\hline CHEMBL3431048 & 1479009 & 4.6 & 5.1827 & TRN \\
\hline CHEMBL3431049 & 1479009 & 4.7 & 5.1015 & TRN \\
\hline CHEMBL3431050 & 1479009 & 4.6 & 5.2353 & TRN \\
\hline CHEMBL3431051 & 1479009 & 4.6 & 5.0278 & TRN \\
\hline CHEMBL3431052 & 1479009 & 4.7 & 4.6186 & TRN \\
\hline CHEMBL3431053 & 1479009 & 5.0 & 4.8674 & TRN \\
\hline CHEMBL 2356808 & 1479009 & 3.3 & 3.6712 & TRN \\
\hline CHEMBL3431054 & 1479009 & 3.3 & 3.5807 & TRN \\
\hline CHEMBL 3431055 & 1479009 & 4.8 & 3.8342 & TST \\
\hline CHEMBL3431056 & 1479009 & 3.3 & 3.1796 & TRN \\
\hline CHEMBL3431057 & 1479009 & 3.3 & 3.7596 & TST \\
\hline CHEMBL2093320 & 1479009 & 4.8 & 3.9259 & TRN \\
\hline CHEMBL3431058 & 1479009 & 3.3 & 3.7001 & TRN \\
\hline CHEMBL3431059 & 1479009 & 3.3 & 3.6266 & TRN \\
\hline CHEMBL3431060 & 1479009 & 3.3 & 3.6569 & TRN \\
\hline CHEMBL3431061 & 1479009 & 5.1 & 3.8248 & TRN \\
\hline CHEMBL3431062 & 1479009 & 3.3 & 3.6576 & TRN \\
\hline CHEMBL3431063 & 1479009 & 3.3 & 3.6589 & TRN \\
\hline
\end{tabular}




\begin{tabular}{|c|c|c|c|c|c|}
\hline & & & & & \\
\hline CHEMBL3431064 & 1479009 & 5.2 & 3.6238 & TRN & \\
\hline CHEMBL3431065 & 1479009 & 4.6 & 4.2193 & TST & \\
\hline CHEMBL3431066 & 1479009 & 4.8 & 3.7375 & TRN & \\
\hline CHEMBL3431067 & 1479009 & 5.0 & 5.043 & TRN & \\
\hline CHEMBL3431068 & 1479009 & 3.3 & 3.7063 & TRN & \\
\hline CHEMBL3431069 & 1479009 & 3.3 & 4.4602 & TRN & \\
\hline CHEMBL3431070 & 1479009 & 3.3 & 3.8515 & TRN & \\
\hline CHEMBL3431071 & 1479009 & 4.6 & 4.4027 & TST & \\
\hline CHEMBL3431072 & 1479009 & 5.0 & 4.3513 & TRN & \\
\hline CHEMBL3431073 & 1479009 & 4.9 & 3.8653 & TST & \\
\hline CHEMBL3431074 & 1479009 & 4.8 & 3.555 & TRN & \\
\hline CHEMBL3431075 & 1479009 & 3.3 & 3.8646 & TST & \\
\hline CHEMBL3431076 & 1479009 & 5.1 & 4.5635 & TRN & \\
\hline CHEMBL3431077 & 1479009 & 3.3 & 3.6971 & TRN & \\
\hline CHEMBL3431078 & 1479009 & 3.3 & 3.76899 & 99999999997 & TRN \\
\hline CHEMBL3431079 & 1479009 & 4.6 & 4.0362 & TRN & \\
\hline CHEMBL3431080 & 1479009 & 5.0 & 3.3836 & TRN & \\
\hline CHEMBL3431081 & 1479009 & 3.3 & 3.8371 & TRN & \\
\hline CHEMBL3431082 & 1479009 & 3.3 & 4.54899 & 99999999995 & TRN \\
\hline CHEMBL3431083 & 1479009 & 3.3 & 3.6441 & TRN & \\
\hline CHEMBL 3431084 & 1479009 & 4.9 & 3.70600 & 00000000004 & TST \\
\hline CHEMBL1585368 & 1479009 & 3.3 & 3.6874 & TRN & \\
\hline CHEMBL3431085 & 1479009 & 3.3 & 3.3598 & TRN & \\
\hline CHEMBL3431086 & 1479009 & 4.9 & 5.1108 & TRN & \\
\hline CHEMBL3431087 & 1479009 & 3.3 & 3.6711 & TRN & \\
\hline CHEMBL3431088 & 1479009 & 3.3 & 3.6544 & TRN & \\
\hline CHEMBL3431089 & 1479009 & 4.6 & 4.7292 & TRN & \\
\hline CHEMBL3431090 & 1479009 & 4.7 & 3.8219 & TRN & \\
\hline CHEMBL3431091 & 1479009 & 4.3 & 3.9748 & TRN & \\
\hline CHEMBL3431092 & 1479009 & 3.3 & 3.983 & TRN & \\
\hline CHEMBL3431093 & 1479009 & 3.3 & 3.8805 & TRN & \\
\hline CHEMBL3431094 & 1479009 & 3.3 & 3.3534 & TRN & \\
\hline CHEMBL3431095 & 1479009 & 5.5 & 4.6907 & TRN & \\
\hline CHEMBL3431096 & 1479009 & 4.7 & 3.7647 & TRN & \\
\hline CHEMBL3431097 & 1479009 & 5.2 & 4.8878 & TRN & \\
\hline CHEMBL3431098 & 1479009 & 4.9 & 3.42100 & 00000000003 & TRN \\
\hline CHEMBL3431099 & 1479009 & 5.2 & 4.6078 & TST & \\
\hline CHEMBL3431100 & 1479009 & 3.3 & 3.4247 & TRN & \\
\hline CHEMBL3431101 & 1479009 & 3.3 & 4.3483 & TST & \\
\hline CHEMBL3431102 & 1479009 & 3.3 & 3.87100 & 00000000004 & TST \\
\hline CHEMBL3431103 & 1479009 & 4.8 & 3.7544 & TST & \\
\hline CHEMBL3431104 & 1479009 & 3.3 & 3.2431 & TRN & \\
\hline CHEMBL3431105 & 1479009 & 5.5 & 3.9145 & TRN & \\
\hline CHEMBL3431106 & 1479009 & 3.3 & 3.5614 & TST & \\
\hline CHEMBL3431107 & 1479009 & 3.3 & 3.614 & TRN & \\
\hline CHEMBL3431108 & 1479009 & 5.2 & 3.8992 & TRN & \\
\hline CHEMBL3431109 & 1479009 & 3.3 & 4.0363 & TRN & \\
\hline CHEMBL3431110 & 1479009 & 3.3 & 3.7403 & TRN & \\
\hline
\end{tabular}




\begin{tabular}{|c|c|c|c|c|c|}
\hline & & & & & \\
\hline CHEMBL3431111 & 1479009 & 3.3 & 3.7492 & TRN & \\
\hline CHEMBL3431112 & 1479009 & 5.1 & 5.0857 & TRN & \\
\hline CHEMBL3431113 & 1479009 & 5.2 & 5.3644 & TRN & \\
\hline CHEMBL3431114 & 1479009 & 5.4 & 4.1516 & TRN & \\
\hline CHEMBL3431115 & 1479009 & 4.7 & 4.5318 & TRN & \\
\hline CHEMBL3431116 & 1479009 & 3.3 & 3.3719 & TRN & \\
\hline CHEMBL3431117 & 1479009 & 4.4 & 4.645 & TRN & \\
\hline CHEMBL3431118 & 1479009 & 4.8 & 3.6649 & TRN & \\
\hline CHEMBL3431119 & 1479009 & 4.4 & 3.845 & TRN & \\
\hline CHEMBL3431120 & 1479009 & 3.3 & 3.7907 & TRN & \\
\hline CHEMBL3431121 & 1479009 & 3.3 & 3.8738 & TST & \\
\hline CHEMBL3431122 & 1479009 & 3.3 & 4.3385 & TRN & \\
\hline CHEMBL3431123 & 1479009 & 4.9 & 3.7598 & TRN & \\
\hline CHEMBL3431124 & 1479009 & 4.5 & 3.7625 & TRN & \\
\hline CHEMBL3431125 & 1479009 & 3.3 & 3.4225 & TST & \\
\hline CHEMBL3431126 & 1479009 & 3.3 & 4.0216 & TRN & \\
\hline CHEMBL3431127 & 1479009 & 4.8 & 4.369 & TST & \\
\hline CHEMBL3431128 & 1479009 & 4.6 & 4.42399 & 99999999995 & TST \\
\hline CHEMBL3431129 & 1479009 & 4.5 & 4.4001 & TST & \\
\hline CHEMBL3431130 & 1479009 & 3.3 & 4.2343 & TST & \\
\hline CHEMBL3431131 & 1479009 & 5.8 & 4.6851 & TRN & \\
\hline CHEMBL3430915 & 1479009 & 3.3 & 3.4086 & TRN & \\
\hline CHEMBL3431132 & 1479009 & 4.5 & 4.2499 & TRN & \\
\hline CHEMBL3431133 & 1479009 & 4.8 & 3.6581 & TRN & \\
\hline CHEMBL3431134 & 1479009 & 6.1 & 5.6096 & TRN & \\
\hline CHEMBL3431135 & 1479009 & 3.3 & 3.3549 & TRN & \\
\hline CHEMBL3431136 & 1479009 & 3.3 & 4.2944 & TRN & \\
\hline CHEMBL3431137 & 1479009 & 4.5 & 4.0563 & TRN & \\
\hline CHEMBL3431138 & 1479009 & 3.3 & 3.7055 & TST & \\
\hline CHEMBL3431139 & 1479009 & 3.3 & 4.3113 & TST & \\
\hline CHEMBL3431140 & 1479009 & 4.4 & 3.5271 & TST & \\
\hline CHEMBL3431141 & 1479009 & 4.9 & 3.7383 & TRN & \\
\hline CHEMBL3431142 & 1479009 & 4.8 & 3.549 & TST & \\
\hline CHEMBL3431143 & 1479009 & 5.6 & 5.2582 & TRN & \\
\hline CHEMBL 3431144 & 1479009 & 3.3 & 3.6247 & TRN & \\
\hline CHEMBL3431145 & 1479009 & 5.0 & 4.8218 & TRN & \\
\hline CHEMBL3431146 & 1479009 & 3.3 & 3.5677 & TRN & \\
\hline CHEMBL3431147 & 1479009 & 5.0 & 4.373 & TST & \\
\hline CHEMBL 3431148 & 1479009 & 3.3 & 3.43399 & 99999999997 & TRN \\
\hline CHEMBL3431149 & 1479009 & 5.8 & 4.8583 & TRN & \\
\hline CHEMBL3431150 & 1479009 & 4.5 & 3.3544 & TRN & \\
\hline CHEMBL3431151 & 1479009 & 3.3 & 5.062 & TRN & \\
\hline CHEMBL3431152 & 1479009 & 3.3 & 3.3313 & TRN & \\
\hline CHEMBL3431153 & 1479009 & 4.5 & 3.196 & TRN & \\
\hline CHEMBL3431154 & 1479009 & 5.5 & 4.8977 & TST & \\
\hline CHEMBL3431155 & 1479009 & 3.3 & 3.7741 & TRN & \\
\hline CHEMBL3431156 & 1479009 & 3.3 & 3.3291 & TRN & \\
\hline CHEMBL3431157 & 1479009 & 3.3 & 4.0722 & TST & \\
\hline
\end{tabular}




\begin{tabular}{|c|c|c|c|c|c|}
\hline & & & & & \\
\hline CHEMBL3431158 & 1479009 & 3.3 & 4.0855 & TST & \\
\hline CHEMBL3431159 & 1479009 & 3.3 & 3.5947 & TST & \\
\hline CHEMBL1593679 & 1479009 & 3.3 & 3.7998 & TRN & \\
\hline CHEMBL3431160 & 1479009 & 4.9 & 4.7488 & TRN & \\
\hline CHEMBL3431161 & 1479009 & 5.3 & 3.7317 & TST & \\
\hline CHEMBL3431162 & 1479009 & 3.3 & 3.6195 & TST & \\
\hline CHEMBL3431163 & 1479009 & 4.6 & 3.9859 & TRN & \\
\hline CHEMBL3431164 & 1479009 & 4.5 & 3.2111 & TRN & \\
\hline CHEMBL3431165 & 1479009 & 3.3 & 3.7749 & TST & \\
\hline CHEMBL1458931 & 1479009 & 4.8 & 3.5474 & TRN & \\
\hline CHEMBL3431166 & 1479009 & 3.3 & 3.7647 & TRN & \\
\hline CHEMBL3431167 & 1479009 & 3.3 & 3.4308 & TRN & \\
\hline CHEMBL3431168 & 1479009 & 6.0 & 5.1353 & TRN & \\
\hline CHEMBL3431169 & 1479009 & 3.3 & 3.6722 & TRN & \\
\hline CHEMBL 3431170 & 1479009 & 7.5 & 6.3521 & TRN & \\
\hline CHEMBL3431171 & 1479009 & 4.5 & 3.8158 & TRN & \\
\hline CHEMBL3431172 & 1479009 & 6.1 & 5.7218 & TRN & \\
\hline CHEMBL3431173 & 1479009 & 3.3 & 4.2087 & TRN & \\
\hline CHEMBL3431174 & 1479009 & 3.3 & 3.9871 & TRN & \\
\hline CHEMBL3431175 & 1479009 & 3.3 & 3.5924 & TST & \\
\hline CHEMBL3431176 & 1479009 & 3.3 & 4.447 & TRN & \\
\hline CHEMBL3431177 & 1479009 & 3.2 & 4.6274 & TRN & \\
\hline CHEMBL3431178 & 1479009 & 3.2 & 4.07600 & 00000000005 & TRN \\
\hline CHEMBL3431179 & 1479009 & 3.3 & 3.614 & TRN & \\
\hline CHEMBL3431180 & 1479009 & 4.6 & 4.332 & TRN & \\
\hline CHEMBL 3431181 & 1479009 & 6.0 & 5.0797 & TRN & \\
\hline CHEMBL3431182 & 1479009 & 4.6 & 3.772 & TRN & \\
\hline CHEMBL3431183 & 1479009 & 3.3 & 3.7133 & TRN & \\
\hline CHEMBL3431184 & 1479009 & 3.3 & 3.4856 & TRN & \\
\hline CHEMBL3431185 & 1479009 & 5.5 & 4.9427 & TRN & \\
\hline CHEMBL3431186 & 1479009 & 6.0 & 5.6747 & TRN & \\
\hline CHEMBL3431187 & 1479009 & 3.3 & 3.5729 & TRN & \\
\hline CHEMBL3431188 & 1479009 & 7.0 & 5.45100 & 00000000005 & TRN \\
\hline CHEMBL3431189 & 1479009 & 4.5 & 4.2701 & TST & \\
\hline CHEMBL3431190 & 1479009 & 4.8 & 4.1499 & TRN & \\
\hline CHEMBL3431191 & 1479009 & 3.3 & 4.144 & TRN & \\
\hline CHEMBL3431192 & 1479009 & 6.9 & 5.7416 & TRN & \\
\hline CHEMBL 3431193 & 1479009 & 6.9 & 6.0465 & TRN & \\
\hline CHEMBL3431194 & 1479009 & 6.0 & 6.0685 & TRN & \\
\hline CHEMBL3431195 & 1479009 & 6.4 & 5.7981 & TRN & \\
\hline CHEMBL3431196 & 1479009 & 4.9 & 4.8444 & TRN & \\
\hline CHEMBL3431197 & 1479009 & 6.2 & 5.5381 & TRN & \\
\hline CHEMBL3431198 & 1479009 & 6.4 & 5.8046 & TRN & \\
\hline CHEMBL3431199 & 1479009 & 4.7 & 4.3206 & TST & \\
\hline CHEMBL 3431200 & 1479009 & 3.3 & 3.2575 & TRN & \\
\hline CHEMBL 3431201 & 1479009 & 3.3 & 4.3449 & TRN & \\
\hline CHEMBL3431202 & 1479009 & 3.3 & 4.1695 & TRN & \\
\hline CHEMBL3431203 & 1479009 & 6.4 & 5.8692 & TRN & \\
\hline
\end{tabular}




\begin{tabular}{|c|c|c|c|c|c|}
\hline & & & & & \\
\hline CHEMBL3431204 & 1479009 & 4.5 & 4.2624 & TRN & \\
\hline CHEMBL3431205 & 1479009 & 5.0 & 4.4443 & TRN & \\
\hline CHEMBL3431206 & 1479009 & 7.7 & 6.3268 & TRN & \\
\hline CHEMBL3431207 & 1479009 & 6.3 & 6.0026 & TRN & \\
\hline CHEMBL3431208 & 1479009 & 3.3 & 3.8354 & TRN & \\
\hline CHEMBL3431209 & 1479009 & 7.0 & 6.0881 & TRN & \\
\hline CHEMBL3431210 & 1479009 & 3.3 & 3.5354 & TRN & \\
\hline CHEMBL3431211 & 1479009 & 6.0 & 5.3685 & TRN & \\
\hline CHEMBL3431212 & 1479009 & 5.0 & 4.4301 & TRN & \\
\hline CHEMBL3431213 & 1479009 & 3.3 & 3.9467 & TRN & \\
\hline CHEMBL3431214 & 1479009 & 3.3 & 3.3765 & TRN & \\
\hline CHEMBL3431215 & 1479009 & 6.4 & 5.6026 & TRN & \\
\hline CHEMBL3431216 & 1479009 & 4.7 & 4.6609 & TRN & \\
\hline CHEMBL3431217 & 1479009 & 5.2 & 4.0447 & TRN & \\
\hline CHEMBL3431218 & 1479009 & 4.9 & 3.7279 & TRN & \\
\hline CHEMBL3431219 & 1479009 & 3.3 & 3.765 & TRN & \\
\hline CHEMBL3431220 & 1479009 & 4.7 & 4.9106 & TRN & \\
\hline CHEMBL 3431221 & 1479009 & 5.7 & 5.3953 & TRN & \\
\hline CHEMBL3431222 & 1479009 & 3.3 & 4.0536 & TRN & \\
\hline CHEMBL3431223 & 1479009 & 3.3 & 3.67 & TST & \\
\hline CHEMBL 3431224 & 1479009 & 3.3 & 3.7369 & TRN & \\
\hline CHEMBL3431225 & 1479009 & 5.4 & 5.125 & TRN & \\
\hline CHEMBL3431226 & 1479009 & 3.3 & 5.0182 & TRN & \\
\hline CHEMBL3431227 & 1479009 & 4.8 & 3.8482 & TRN & \\
\hline CHEMBL3431228 & 1479009 & 5.0 & 4.2683 & TRN & \\
\hline CHEMBL3431229 & 1479009 & 6.7 & 6.1177 & TRN & \\
\hline CHEMBL3431230 & 1479009 & 6.5 & 6.0879 & TRN & \\
\hline CHEMBL 2441267 & 1479009 & 7.6 & 6.1968 & TRN & \\
\hline CHEMBL3430916 & 1479009 & 3.3 & 3.7132 & TRN & \\
\hline CHEMBL3431231 & 1479009 & 3.3 & 3.87600 & 00000000003 & TRN \\
\hline CHEMBL3431232 & 1479009 & 3.3 & 3.8711 & TRN & \\
\hline CHEMBL3431233 & 1479009 & 5.3 & 4.7653 & TRN & \\
\hline CHEMBL3431234 & 1479009 & 3.3 & 4.2513 & TRN & \\
\hline CHEMBL3431235 & 1479009 & 4.7 & 4.1757 & TST & \\
\hline CHEMBL3431236 & 1479009 & 3.3 & 3.6198 & TST & \\
\hline CHEMBL3431237 & 1479009 & 3.3 & 4.296 & TRN & \\
\hline CHEMBL3431238 & 1479009 & 3.3 & 3.8108 & TRN & \\
\hline CHEMBL3431239 & 1479009 & 3.3 & 3.7719 & TRN & \\
\hline CHEMBL 3431240 & 1479009 & 3.3 & 3.5965 & TST & \\
\hline CHEMBL 3431241 & 1479009 & 3.3 & 4.4707 & TRN & \\
\hline CHEMBL3431242 & 1479009 & 3.3 & 3.2083 & TRN & \\
\hline CHEMBL3431243 & 1479009 & 3.3 & 3.2821 & TST & \\
\hline CHEMBL3431244 & 1479009 & 3.3 & 3.5995 & TRN & \\
\hline CHEMBL 3431245 & 1479009 & 4.5 & 4.0018 & TRN & \\
\hline CHEMBL3431246 & 1479009 & 4.7 & 4.2405 & TRN & \\
\hline CHEMBL 3431247 & 1479009 & 5.1 & 4.6307 & TRN & \\
\hline CHEMBL 3431248 & 1479009 & 4.4 & 3.3965 & TRN & \\
\hline CHEMBL3431249 & 1479009 & 3.3 & 3.603 & TRN & \\
\hline
\end{tabular}




\begin{tabular}{|c|c|c|c|c|c|}
\hline \\
\hline CHEMBL 3431250 & 1479009 & 3.3 & 3.1808 & TRN & \\
\hline CHEMBL 3431251 & 1479009 & 3.3 & 3.6412 & TRN & \\
\hline CHEMBL3431252 & 1479009 & 3.3 & 3.8399 & TRN & \\
\hline CHEMBL 3431253 & 1479009 & 4.4 & 4.0218 & TST & \\
\hline CHEMBL 3431254 & 1479009 & 3.3 & 3.678 & TRN & \\
\hline CHEMBL 3431255 & 1479009 & 4.5 & 4.0102 & TST & \\
\hline CHEMBL 3431256 & 1479009 & 5.2 & 4.3459 & TST & \\
\hline CHEMBL 3431257 & 1479009 & 3.3 & 3.5073 & TRN & \\
\hline CHEMBL 3431258 & 1479009 & 3.3 & 3.5532 & TRN & \\
\hline CHEMBL3431259 & 1479009 & 3.3 & 3.1838 & TRN & \\
\hline CHEMBL 3431260 & 1479009 & 5.3 & 3.7171 & TRN & \\
\hline CHEMBL 3431261 & 1479009 & 4.6 & 3.9733 & TRN & \\
\hline CHEMBL 2356920 & 1479009 & 3.3 & 4.0805 & TRN & \\
\hline CHEMBL 3431262 & 1479009 & 3.3 & 3.6066 & TRN & \\
\hline CHEMBL3431263 & 1479009 & 3.3 & 3.5897 & TRN & \\
\hline CHEMBL 3431264 & 1479009 & 3.3 & 3.8154 & TRN & \\
\hline CHEMBL3431265 & 1479009 & 3.3 & 3.2717 & TST & \\
\hline CHEMBL 3431266 & 1479009 & 4.7 & 3.8649 & TRN & \\
\hline CHEMBL 3431267 & 1479009 & 4.9 & 4.0329 & TRN & \\
\hline CHEMBL 3431268 & 1479009 & 3.3 & 3.9352 & TST & \\
\hline CHEMBL3431269 & 1479009 & 4.8 & 4.8943 & TRN & \\
\hline CHEMBL 3431270 & 1479009 & 4.6 & 5.1002 & TST & \\
\hline CHEMBL 3431271 & 1479009 & 3.3 & 3.5945 & TRN & \\
\hline CHEMBL 3431272 & 1479009 & 3.3 & 3.6946 & TRN & \\
\hline CHEMBL 3431273 & 1479009 & 5.1 & 4.637 & TRN & \\
\hline CHEMBL 3431274 & 1479009 & 4.9 & 4.4129 & TRN & \\
\hline CHEMBL 3431275 & 1479009 & 4.5 & 4.5915 & TRN & \\
\hline CHEMBL 3431276 & 1479009 & 3.3 & 3.9786 & TST & \\
\hline CHEMBL 3431277 & 1479009 & 4.7 & 4.8805 & TRN & \\
\hline CHEMBL 3431278 & 1479009 & 3.3 & 4.3401 & TRN & \\
\hline CHEMBL3431279 & 1479009 & 4.7 & 4.0979 & TST & \\
\hline CHEMBL 3431280 & 1479009 & 4.6 & 4.4748 & TST & \\
\hline CHEMBL 3431281 & 1479009 & 5.0 & 4.4223 & TST & \\
\hline CHEMBL 3431282 & 1479009 & 3.3 & 3.7552 & TST & \\
\hline CHEMBL 3431283 & 1479009 & 4.3 & 4.0271 & TST & \\
\hline CHEMBL3431284 & 1479009 & 4.8 & 4.6287 & TRN & \\
\hline CHEMBL 3431285 & 1479009 & 5.1 & 4.5327 & TRN & \\
\hline CHEMBL 3431286 & 1479009 & 3.3 & 4.0415 & TST & \\
\hline CHEMBL 3431287 & 1479009 & 3.3 & 3.6908 & TST & \\
\hline CHEMBL 3431288 & 1479009 & 4.4 & 4.8539 & TRN & \\
\hline CHEMBL 3431289 & 1479009 & 3.3 & 3.6366 & TST & \\
\hline CHEMBL 3431290 & 1479009 & 3.3 & 3.7033 & TRN & \\
\hline CHEMBL3431291 & 1479009 & 3.3 & 3.221 & TRN & \\
\hline CHEMBL 3431292 & 1479009 & 4.7 & 3.97899 & 99999999996 & TRN \\
\hline CHEMBL 3431293 & 1479009 & 3.3 & 3.1688 & TRN & \\
\hline CHEMBL 3431294 & 1479009 & 3.3 & 3.7632 & TRN & \\
\hline CHEMBL 3431295 & 1479009 & 5.1 & 4.9876 & TRN & \\
\hline CHEMBL3431296 & 1479009 & 5.3 & 4.9334 & TRN & \\
\hline
\end{tabular}

Supplemental Table S2.txt 


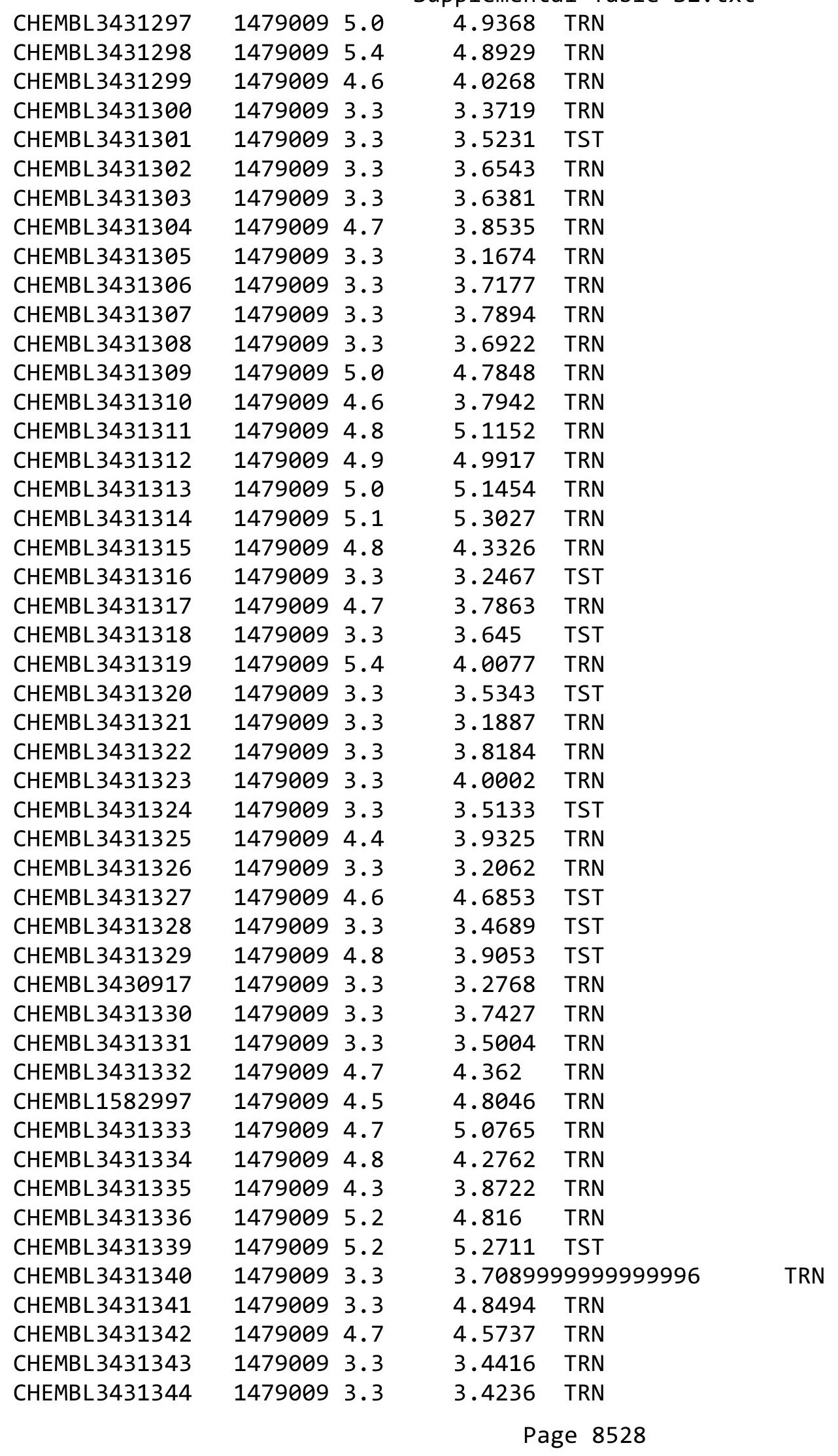




\begin{tabular}{|c|c|c|c|c|}
\hline & & & ient & a 1 \\
\hline CHEMBL 3431345 & 1479009 & 5.1 & 4.9215 & TRN \\
\hline CHEMBL3431346 & 1479009 & 3.3 & 4.8163 & TRN \\
\hline CHEMBL1430615 & 1479009 & 3.3 & 3.4871 & TRN \\
\hline CHEMBL 3431347 & 1479009 & 5.0 & 4.7056 & TRN \\
\hline CHEMBL3431348 & 1479009 & 5.1 & 3.7169 & TRN \\
\hline CHEMBL3431349 & 1479009 & 3.3 & 3.7751 & TRN \\
\hline CHEMBL3431350 & 1479009 & 3.3 & 4.7797 & TRN \\
\hline CHEMBL465227 & 1479009 & 4.3 & 3.6248 & TRN \\
\hline CHEMBL3431351 & 1479009 & 3.3 & 3.3246 & TRN \\
\hline CHEMBL1611993 & 1479009 & 3.3 & 3.4084 & TRN \\
\hline CHEMBL3431352 & 1479009 & 3.3 & 3.6526 & TRN \\
\hline CHEMBL3431353 & 1479009 & 4.8 & 3.7429 & TRN \\
\hline CHEMBL1393829 & 1479009 & 5.8 & 4.7109 & TST \\
\hline CHEMBL3431354 & 1479009 & 4.5 & 4.9563 & TRN \\
\hline CHEMBL3431355 & 1479009 & 4.8 & 3.9246 & TRN \\
\hline CHEMBL3431356 & 1479009 & 3.3 & 3.8617 & TRN \\
\hline CHEMBL3431357 & 1479009 & 5.2 & 4.2294 & TRN \\
\hline CHEMBL3431358 & 1479009 & 4.6 & 5.4307 & TRN \\
\hline CHEMBL3431359 & 1479009 & 3.3 & 3.3557 & TRN \\
\hline CHEMBL3431360 & 1479009 & 3.3 & 3.9048 & TRN \\
\hline CHEMBL3431361 & 1479009 & 4.6 & 4.0232 & TRN \\
\hline CHEMBL1535535 & 1479009 & 3.3 & 3.2841 & TRN \\
\hline CHEMBL3431362 & 1479009 & 4.8 & 4.1471 & TRN \\
\hline CHEMBL3431363 & 1479009 & 4.4 & 4.0508 & TRN \\
\hline CHEMBL3431364 & 1479009 & 3.3 & 3.2528 & TRN \\
\hline CHEMBL3431365 & 1479009 & 3.3 & 3.5735 & TRN \\
\hline CHEMBL3431366 & 1479009 & 3.3 & 3.8989 & TST \\
\hline CHEMBL3431367 & 1479009 & 4.7 & 3.5349 & TST \\
\hline CHEMBL3431368 & 1479009 & 4.7 & 3.7794 & TRN \\
\hline CHEMBL3431369 & 1479009 & 3.3 & 3.5075 & TRN \\
\hline CHEMBL1447267 & 1479009 & 5.1 & 4.711 & TRN \\
\hline CHEMBL3431370 & 1479009 & 3.3 & 3.6175 & TRN \\
\hline CHEMBL1325144 & 1479009 & 3.3 & 3.4162 & TRN \\
\hline CHEMBL1429841 & 1479009 & 4.6 & 4.4171 & TRN \\
\hline CHEMBL3431371 & 1479009 & 4.7 & 4.2308 & TRN \\
\hline CHEMBL1308225 & 1479009 & 3.3 & 3.7229 & TST \\
\hline CHEMBL 2441359 & 1479009 & 3.3 & 4.7444 & TRN \\
\hline CHEMBL1517284 & 1479009 & 3.3 & 5.0827 & TRN \\
\hline CHEMBL 3431372 & 1479009 & 3.3 & 3.3939 & TRN \\
\hline CHEMBL3431373 & 1479009 & 4.9 & 3.9819 & TRN \\
\hline CHEMBL 3431374 & 1479009 & 4.4 & 3.5523 & TRN \\
\hline CHEMBL3431375 & 1479009 & 4.7 & 3.6742 & TST \\
\hline CHEMBL3431376 & 1479009 & 5.0 & 5.1353 & TRN \\
\hline CHEMBL1365653 & 1479009 & 3.3 & 3.5439 & TRN \\
\hline CHEMBL3431377 & 1479009 & 3.3 & 3.7622 & TRN \\
\hline CHEMBL3431378 & 1479009 & 3.3 & 4.2177 & TRN \\
\hline CHEMBL3431379 & 1479009 & 3.3 & 3.8777 & TRN \\
\hline CHEMBL1478826 & 1479009 & 4.8 & 5.0399 & TRN \\
\hline
\end{tabular}




\begin{tabular}{|c|c|c|c|c|}
\hline CHEMBL1872842 & 1479009 & 4.8 & 3.6521 & TRN \\
\hline CHEMBL3431380 & 1479009 & 5.3 & 5.1888 & TRN \\
\hline CHEMBL3431381 & 1479009 & 4.9 & 4.4774 & TRN \\
\hline CHEMBL3431382 & 1479009 & 4.7 & 4.6404 & TRN \\
\hline CHEMBL3431383 & 1479009 & 4.4 & 3.8995 & TRN \\
\hline CHEMBL3431384 & 1479009 & 4.3 & 3.6132 & TRN \\
\hline CHEMBL3431385 & 1479009 & 3.3 & 3.7692 & TRN \\
\hline CHEMBL3431386 & 1479009 & 4.3 & 3.5815 & TRN \\
\hline CHEMBL1730515 & 1479009 & 4.4 & 4.9398 & TRN \\
\hline CHEMBL3431387 & 1479009 & 3.3 & 4.0053 & TRN \\
\hline CHEMBL 3431388 & 1479009 & 4.4 & 4.5375 & TRN \\
\hline CHEMBL1566898 & 1479009 & 4.5 & \multicolumn{2}{|c|}{4.5089999999999995} \\
\hline CHEMBL3431389 & 1479009 & 4.5 & 4.5746 & TRN \\
\hline CHEMBL3431390 & 1479009 & 4.8 & 5.2837 & TST \\
\hline CHEMBL3431391 & 1479009 & 3.3 & 4.1574 & TRN \\
\hline CHEMBL1489081 & 1479009 & 4.9 & 5.1054 & TRN \\
\hline CHEMBL3431392 & 1479009 & 4.9 & 4.07 & TRN \\
\hline CHEMBL3431393 & 1479009 & 3.3 & 4.2505 & TRN \\
\hline CHEMBL3431394 & 1479009 & 4.4 & 4.7406 & TRN \\
\hline CHEMBL3431395 & 1479009 & 3.3 & 3.5314 & TRN \\
\hline CHEMBL3431396 & 1479009 & 3.3 & 3.7769 & TRN \\
\hline CHEMBL3431397 & 1479009 & 4.5 & 4.0439 & TRN \\
\hline CHEMBL3431398 & 1479009 & 3.3 & 3.6518 & TRN \\
\hline CHEMBL3431399 & 1479009 & 3.3 & 3.8158 & TRN \\
\hline CHEMBL 3431400 & 1479009 & 4.4 & 3.7284 & TST \\
\hline CHEMBL1418463 & 1479009 & 3.3 & 3.8819 & TST \\
\hline CHEMBL3431401 & 1479009 & 3.3 & 3.7745 & TST \\
\hline CHEMBL3431402 & 1479009 & 4.4 & 5.3735 & TST \\
\hline CHEMBL3431403 & 1479009 & 3.3 & 3.9218 & TST \\
\hline CHEMBL3431404 & 1479009 & 4.5 & 3.9156 & TST \\
\hline CHEMBL3431405 & 1479009 & 3.3 & 3.8864 & TST \\
\hline CHEMBL3431406 & 1479009 & 4.7 & 4.7239 & TST \\
\hline CHEMBL 3431407 & 1479009 & 4.4 & 4.0446 & TST \\
\hline CHEMBL3431408 & 1479009 & 3.3 & 3.616 & TST \\
\hline CHEMBL3431409 & 1479009 & 5.2 & 4.3466 & TST \\
\hline CHEMBL3431410 & 1479009 & 3.3 & 3.4168 & TST \\
\hline CHEMBL3431411 & 1479009 & 3.3 & 3.1811 & TST \\
\hline CHEMBL3431412 & 1479009 & 3.3 & 4.1668 & TST \\
\hline CHEMBL3431413 & 1479009 & 4.3 & 3.944 & TST \\
\hline CHEMBL3431414 & 1479009 & 3.3 & 4.5916 & TST \\
\hline CHEMBL3431415 & 1479009 & 4.6 & 4.2832 & TST \\
\hline CHEMBL 3431416 & 1479009 & 3.3 & 3.6987 & TST \\
\hline CHEMBL291721 & 1479009 & 4.4 & 3.8025 & TST \\
\hline CHEMBL3431417 & 1479009 & 3.3 & 3.9673 & TST \\
\hline CHEMBL3431418 & 1479009 & 3.3 & 3.4303 & TST \\
\hline CHEMBL487186 & 1479009 & 3.3 & 3.2119 & TST \\
\hline CHEMBL3431419 & 1479009 & 3.3 & 3.8984 & TST \\
\hline CHEMBL3431420 & 1479009 & 3.3 & 3.5151 & TST \\
\hline
\end{tabular}




\begin{tabular}{|c|c|c|c|c|c|}
\hline \multicolumn{6}{|c|}{ Supplemental Table S2.txt } \\
\hline CHEMBL3431421 & 1479009 & 4.9 & 3.5512 & TST & \\
\hline CHEMBL3431422 & 1479009 & 5.0 & 3.6893 & TST & \\
\hline CHEMBL3431423 & 1479009 & 3.3 & 3.8543 & TST & \\
\hline CHEMBL3431424 & 1479009 & 3.3 & 4.026 & TST & \\
\hline CHEMBL3431425 & 1479009 & 3.3 & 4.4971 & TST & \\
\hline CHEMBL3431426 & 1479009 & 3.3 & 3.5653 & TST & \\
\hline CHEMBL3431427 & 1479009 & 4.6 & 3.9919 & TST & \\
\hline CHEMBL3431428 & 1479009 & 3.3 & 4.1896 & TST & \\
\hline CHEMBL1725748 & 1479009 & 3.3 & 3.4745 & TST & \\
\hline CHEMBL3430918 & 1479009 & 4.4 & 3.7551 & TST & \\
\hline CHEMBL522630 & 1479009 & 4.7 & 4.4114 & TST & \\
\hline CHEMBL3431429 & 1479009 & 3.3 & 4.4353 & TST & \\
\hline CHEMBL523468 & 1479009 & 4.7 & 4.4483 & TST & \\
\hline CHEMBL523303 & 1479009 & 4.7 & 4.4159 & TST & \\
\hline CHEMBL3431430 & 1479009 & 4.4 & 3.6562 & TST & \\
\hline CHEMBL128672 & 1479009 & 3.3 & 3.7913 & TST & \\
\hline CHEMBL491149 & 1479009 & 4.7 & 4.5127 & TST & \\
\hline CHEMBL3431431 & 1479009 & 6.6 & 5.79799 & 9999999999 & TST \\
\hline CHEMBL3431432 & 1479009 & 6.2 & 5.4029 & TST & \\
\hline CHEMBL3431433 & 1479009 & 8.0 & 6.0867 & TST & \\
\hline CHEMBL3431434 & 1479009 & 3.3 & 3.7366 & TST & \\
\hline CHEMBL3431435 & 1479009 & 8.1 & 6.3451 & TST & \\
\hline CHEMBL3431436 & 1479009 & 3.3 & 4.7634 & TST & \\
\hline CHEMBL 3431437 & 1479009 & 3.3 & 4.0032 & TST & \\
\hline CHEMBL3431438 & 1479009 & 4.8 & 4.5546 & TST & \\
\hline CHEMBL3431439 & 1479009 & 3.3 & 3.9564 & TST & \\
\hline CHEMBL3431440 & 1479009 & 4.7 & 4.5408 & TST & \\
\hline CHEMBL3431441 & 1479009 & 3.3 & 3.72 & TST & \\
\hline CHEMBL3431442 & 1479009 & 4.7 & 4.3322 & TST & \\
\hline CHEMBL3431443 & 1479009 & 4.6 & 4.598 & TST & \\
\hline CHEMBL3431444 & 1479009 & 4.7 & 4.60800 & 00000000005 & TST \\
\hline CHEMBL 3431445 & 1479009 & 4.6 & 3.9954 & TST & \\
\hline CHEMBL3318547 & 1456629 & 5.8996 & 5.8953 & TRN & \\
\hline CHEMBL3318561 & 1456629 & 4.0 & 3.9679 & TRN & \\
\hline CHEMBL3318585 & 1456629 & 7.5686 & 7.5521 & TRN & \\
\hline CHEMBL3318557 & 1456629 & 6.585 & 6.636 & TRN & \\
\hline CHEMBL3318559 & 1456629 & 5.15 & 5.129 & TRN & \\
\hline CHEMBL3318548 & 1456629 & 7.4437 & 7.4792 & TRN & \\
\hline CHEMBL3318543 & 1456629 & 6.5686 & 6.5678 & TRN & \\
\hline CHEMBL 3318574 & 1456629 & 7.6198 & 7.5877 & TRN & \\
\hline CHEMBL3318575 & 1456629 & 6.3215 & 6.1777 & TST & \\
\hline CHEMBL3318565 & 1456629 & 5.5686 & 5.5627 & TRN & \\
\hline CHEMBL3318542 & 1456629 & 5.301 & 5.3139 & TRN & \\
\hline CHEMBL3318572 & 1456629 & 6.1549 & 6.1727 & TRN & \\
\hline CHEMBL3318546 & 1456629 & 5.2211 & 5.2081 & TRN & \\
\hline CHEMBL3318558 & 1456629 & 5.1543 & 6.1535 & TST & \\
\hline CHEMBL3318552 & 1456629 & 7.4685 & 7.4412 & TRN & \\
\hline CHEMBL3318582 & 1456629 & 6.2321 & 7.1354 & TST & \\
\hline
\end{tabular}


Supplemental Table S2.txt

\begin{tabular}{|c|c|c|c|c|c|}
\hline CHEMBL1594803 & 1456629 & 6.5528 & 6.5183 & TRN & \\
\hline CHEMBL 3318544 & 1456629 & 5.6615 & 5.6686 & TRN & \\
\hline CHEMBL3318583 & 1456629 & 5.8729 & 6.9985 & TST & \\
\hline CHEMBL3318573 & 1456629 & 7.2757 & 7.2655 & TRN & \\
\hline CHEMBL3318539 & 1456629 & 4.0 & 4.007 & TRN & \\
\hline CHEMBL3318568 & 1456629 & 5.9914 & 5.9736 & TRN & \\
\hline CHEMBL3318578 & 1456629 & 6.4067 & 6.4398 & TRN & \\
\hline CHEMBL3318570 & 1456629 & 4.0 & 3.9966 & TRN & \\
\hline CHEMBL3318563 & 1456629 & 7.4685 & 7.4696 & TRN & \\
\hline CHEMBL3318541 & 1456629 & 5.8861 & 5.871 & TRN & \\
\hline CHEMBL3318553 & 1456629 & 7.1135 & 7.1052 & TRN & \\
\hline CHEMBL3318556 & 1456629 & 6.6383 & 6.595 & TRN & \\
\hline CHEMBL3318577 & 1456629 & 6.8928 & 6.8969 & TRN & \\
\hline CHEMBL3318586 & 1456629 & 7.7447 & 7.7227 & TRN & \\
\hline CHEMBL3318560 & 1456629 & 5.6517 & 5.6291 & TRN & \\
\hline CHEMBL3318581 & 1456629 & 7.0506 & 7.0435 & TRN & \\
\hline CHEMBL1508710 & 1456629 & 5.8297 & 5.8801 & TRN & \\
\hline CHEMBL3318571 & 1456629 & 4.0 & 4.0379 & TRN & \\
\hline CHEMBL3318564 & 1456629 & 7.2147 & 7.2586 & TRN & \\
\hline CHEMBL3318551 & 1456629 & 6.7212 & 6.7457 & TRN & \\
\hline CHEMBL3318576 & 1456629 & 7.1192 & 7.1037 & TRN & \\
\hline CHEMBL3318555 & 1456629 & 6.7212 & 6.735 & TRN & \\
\hline CHEMBL3318587 & 1456629 & 6.1851 & 6.207006 & 2000000001 & TRN \\
\hline CHEMBL3318540 & 1456629 & 6.8356 & 6.0231 & TST & \\
\hline CHEMBL3318566 & 1456629 & 5.71 & 5.7469 & TRN & \\
\hline CHEMBL1531102 & 1456629 & 5.4634 & 5.4067 & TRN & \\
\hline CHEMBL3318567 & 1456629 & 6.5686 & 6.5671 & TRN & \\
\hline CHEMBL3317462 & 1456629 & 7.284 & 7.2965 & TRN & \\
\hline CHEMBL3318562 & 1456629 & 6.8239 & 7.1469 & TST & \\
\hline CHEMBL1543754 & 1456629 & 6.7959 & 5.8882 & TST & \\
\hline CHEMBL3318584 & 1456629 & 7.4437 & 7.8016 & TST & \\
\hline CHEMBL3318545 & 1456629 & 5.7258 & 5.965 & TST & \\
\hline CHEMBL3318554 & 1456629 & 7.1192 & 6.8784 & TST & \\
\hline CHEMBL3318549 & 1456629 & 7.1487 & 6.7291 & TST & \\
\hline CHEMBL3318550 & 1456629 & 7.1367 & 6.6435 & TST & \\
\hline CHEMBL3318569 & 1456629 & 6.0605 & 4.3789 & TST & \\
\hline CHEMBL3746750 & 1546248 & 4.8239 & 4.89 & TRN & \\
\hline CHEMBL3746810 & 1546248 & 4.1249 & 5.2168 & TST & \\
\hline CHEMBL3747416 & 1546248 & 4.0 & 4.0165 & TRN & \\
\hline CHEMBL3746264 & 1546248 & 6.1249 & 6.1805 & TRN & \\
\hline CHEMBL3746527 & 1546248 & 5.301 & 5.3416 & TST & \\
\hline CHEMBL3746863 & 1546248 & 4.8239 & 4.7157 & TRN & \\
\hline CHEMBL3747706 & 1546248 & 4.8239 & 4.8471 & TRN & \\
\hline CHEMBL3747252 & 1546248 & 5.301 & 5.3324 & TRN & \\
\hline CHEMBL3747456 & 1546248 & 5.0 & 5.0419 & TRN & \\
\hline CHEMBL3746910 & 1546248 & 5.301 & 5.7709 & TRN & \\
\hline CHEMBL3745961 & 1546248 & 6.0 & 5.7152 & TRN & \\
\hline CHEMBL3747679 & 1546248 & 4.1249 & 4.0816 & TRN & \\
\hline
\end{tabular}


Supplemental Table S2.txt

\begin{tabular}{|c|c|c|c|c|c|}
\hline CHEMBL3746631 & 1546248 & 5.5229 & 5.6056 & TRN & \\
\hline CHEMBL3746399 & 1546248 & 6.1249 & 6.2699 & TRN & \\
\hline CHEMBL3747652 & 1546248 & 5.8239 & 5.7074 & TRN & \\
\hline CHEMBL 3745967 & 1546248 & 5.301 & 5.2051 & TRN & \\
\hline CHEMBL3747088 & 1546248 & 6.1249 & 6.1546 & TRN & \\
\hline CHEMBL 3745733 & 1546248 & 5.301 & 5.2042 & TST & \\
\hline CHEMBL3746929 & 1546248 & 5.301 & 5.369 & TRN & \\
\hline CHEMBL 3747229 & 1546248 & 5.0 & 4.9529 & TRN & \\
\hline CHEMBL3745839 & 1546248 & 4.8239 & \multicolumn{2}{|c|}{4.781000000000001} & TRN \\
\hline CHEMBL3747187 & 1546248 & 6.1249 & 6.0903 & TRN & \\
\hline CHEMBL 3747007 & 1546248 & 4.8239 & 4.7781 & TST & \\
\hline CHEMBL 3745879 & 1546248 & 6.3979 & 6.3257 & TRN & \\
\hline CHEMBL3745735 & 1546248 & 5.0 & 4.7652 & TST & \\
\hline CHEMBL3745753 & 1546248 & 6.1249 & 6.188 & TRN & \\
\hline CHEMBL3745814 & 1546248 & 5.0 & 5.1886 & TST & \\
\hline CHEMBL3746707 & 1546248 & 5.301 & 5.4082 & TRN & \\
\hline CHEMBL3746176 & 1546248 & 5.301 & 5.4675 & TST & \\
\hline CHEMBL3747192 & 1546248 & 4.5229 & 4.6424 & TRN & \\
\hline CHEMBL3746450 & 1546248 & 5.301 & 5.3819 & TRN & \\
\hline CHEMBL3746978 & 1546248 & 4.5229 & 4.4917 & TRN & \\
\hline CHEMBL 3746832 & 1546248 & 5.0 & 4.9751 & TRN & \\
\hline CHEMBL3745885 & 1546248 & 7.1249 & 6.9369 & TRN & \\
\hline CHEMBL3746466 & 1546248 & 6.1249 & 5.8391 & TRN & \\
\hline CHEMBL 3747103 & 1546248 & 5.0 & 5.0188 & TRN & \\
\hline CHEMBL3746038 & 1546248 & 5.301 & 5.329 & TRN & \\
\hline CHEMBL 3746772 & 1546248 & 5.0 & 4.9934 & TRN & \\
\hline CHEMBL 3746481 & 1546248 & 6.0 & 6.1064 & TRN & \\
\hline CHEMBL3746494 & 1546248 & 5.301 & 5.2052 & TRN & \\
\hline CHEMBL 3746416 & 1546248 & 4.6021 & 4.9065 & TRN & \\
\hline CHEMBL3746296 & 1546248 & 6.301 & 6.2791 & TRN & \\
\hline CHEMBL 3747115 & 1546248 & 5.0969 & 5.0075 & TRN & \\
\hline CHEMBL3745981 & 1546248 & 5.301 & 5.3304 & TRN & \\
\hline CHEMBL 3747173 & 1546248 & 5.301 & \multicolumn{2}{|c|}{5.218999999999999} & TRN \\
\hline CHEMBL3746423 & 1546248 & 5.0 & 5.0658 & TRN & \\
\hline CHEMBL3747002 & 1546248 & 6.5229 & 6.6396 & TRN & \\
\hline CHEMBL 3746805 & 1546248 & 4.301 & 5.0652 & TST & \\
\hline CHEMBL3747750 & 1546248 & 6.301 & 6.2019 & TRN & \\
\hline CHEMBL 3747298 & 1546248 & 5.301 & 5.1894 & TRN & \\
\hline CHEMBL 3745789 & 1546248 & 6.0 & 6.0643 & TRN & \\
\hline CHEMBL3747358 & 1546248 & 6.0 & 5.9789 & TRN & \\
\hline CHEMBL3745731 & 1546248 & 4.301 & 4.3401 & TST & \\
\hline CHEMBL3747145 & 1546248 & 6.0 & 6.028 & TRN & \\
\hline CHEMBL3747595 & 1546248 & 6.301 & 6.2617 & TRN & \\
\hline CHEMBL 3746075 & 1546248 & 6.6021 & 6.5924 & TRN & \\
\hline CHEMBL3747074 & 1546248 & 4.5229 & 4.4214 & TRN & \\
\hline CHEMBL3746281 & 1546248 & 6.1249 & 6.1344 & TRN & \\
\hline CHEMBL3746270 & 1546248 & 6.301 & 6.3179 & TRN & \\
\hline CHEMBL3746442 & 1546248 & 6.1249 & 6.0782 & TRN & \\
\hline
\end{tabular}


Supplemental Table S2.txt

\begin{tabular}{|c|c|c|c|c|c|}
\hline CHEMBL 3747714 & 1546248 & 6.8239 & \multicolumn{2}{|c|}{6.167999999999999} & TST \\
\hline CHEMBL 3745740 & 1546248 & 5.301 & 5.2133 & TRN & \\
\hline CHEMBL3746401 & 1546248 & 4.8239 & 5.0419 & TST & \\
\hline CHEMBL3746014 & 1546248 & 5.0 & 5.2494 & TST & \\
\hline CHEMBL3746651 & 1546248 & 6.6021 & 6.4684 & TST & \\
\hline CHEMBL3746303 & 1546248 & 4.0 & 4.4324 & TST & \\
\hline CHEMBL3747009 & 1546248 & 5.0 & 5.1072 & TST & \\
\hline CHEMBL3747228 & 1546248 & 4.0 & 4.6914 & TST & \\
\hline CHEMBL3746323 & 1546248 & 5.0 & 5.1029 & TST & \\
\hline CHEMBL3747507 & 1546248 & 5.301 & 4.9841 & TST & \\
\hline CHEMBL91568 & 148191 & 7.7696 & 7.8446 & TRN & \\
\hline CHEMBL88325 & 148191 & 6.699 & 6.2769 & TRN & \\
\hline CHEMBL91274 & 148191 & 6.585 & 6.5846 & TRN & \\
\hline CHEMBL90261 & 148191 & 4.0 & 5.4425 & TRN & \\
\hline CHEMBL91196 & 148191 & 5.6198 & 5.6195 & TRN & \\
\hline CHEMBL 88486 & 148191 & 8.2924 & 8.2885 & TRN & \\
\hline CHEMBL91165 & 148191 & 6.4089 & 6.3579 & TST & \\
\hline CHEMBL315863 & 148191 & 7.0809 & 7.6517 & TST & \\
\hline CHEMBL328318 & 148191 & 7.3768 & 7.3794 & TRN & \\
\hline CHEMBL314731 & 148191 & 7.5376 & 7.5387 & TRN & \\
\hline CHEMBL328354 & 148191 & 6.2924 & 7.0184 & TRN & \\
\hline CHEMBL90252 & 148191 & 4.0 & 5.2181 & TST & \\
\hline CHEMBL327390 & 148191 & 6.6198 & 6.622006 & 0000000001 & TRN \\
\hline CHEMBL88546 & 148191 & 7.2757 & 7.2715 & TRN & \\
\hline CHEMBL314219 & 148191 & 7.9208 & 7.8446 & TRN & \\
\hline CHEMBL314238 & 148191 & 7.0969 & 6.45299 & 9999999999 & TST \\
\hline CHEMBL91652 & 148191 & 7.3565 & 7.3525 & TRN & \\
\hline CHEMBL92440 & 148191 & 7.5376 & 7.5363 & TRN & \\
\hline CHEMBL328148 & 148191 & 7.2757 & 7.2747 & TRN & \\
\hline CHEMBL328126 & 148191 & 5.8539 & 6.2769 & TRN & \\
\hline CHEMBL91648 & 148191 & 7.2218 & 7.2255 & TRN & \\
\hline CHEMBL90373 & 148191 & 6.5528 & 6.5399 & TRN & \\
\hline CHEMBL91730 & 148191 & 7.4559 & 5.8837 & TST & \\
\hline CHEMBL315192 & 148191 & 6.1612 & 6.1661 & TRN & \\
\hline CHEMBL91376 & 148191 & 6.041 & 6.0413 & TRN & \\
\hline CHEMBL91331 & 148191 & 5.301 & 5.3116 & TRN & \\
\hline CHEMBL330010 & 148191 & 6.301 & 5.8837 & TST & \\
\hline CHEMBL329889 & 148191 & 5.7696 & 5.7598 & TRN & \\
\hline CHEMBL92498 & 148191 & 7.2218 & 7.2349 & TRN & \\
\hline CHEMBL91721 & 148191 & 5.6383 & 5.6402 & TRN & \\
\hline CHEMBL316275 & 148191 & 8.0088 & 8.0089 & TRN & \\
\hline CHEMBL314162 & 148191 & 7.5229 & 7.5215 & TRN & \\
\hline CHEMBL88925 & 148191 & 6.2757 & 6.2289 & TST & \\
\hline CHEMBL88844 & 148191 & 6.9431 & 6.945 & TRN & \\
\hline CHEMBL431216 & 148191 & 6.8861 & 5.4425 & TRN & \\
\hline CHEMBL314761 & 148191 & 6.9208 & 6.9197 & TRN & \\
\hline CHEMBL312942 & 148191 & 8.2147 & 8.2192 & TRN & \\
\hline CHEMBL90169 & 148191 & 7.0132 & 6.9934 & TST & \\
\hline
\end{tabular}




\begin{tabular}{|c|c|c|c|c|c|}
\hline \multirow[b]{2}{*}{ CHEMBL91459 } & \multicolumn{5}{|c|}{ Supplemental Table S2.txt } \\
\hline & 148191 & 6.2007 & 6.2289 & TST & \\
\hline CHEMBL330292 & 148191 & 6.3468 & 6.3473 & TRN & \\
\hline CHEMBL328150 & 148191 & 7.7447 & 7.0184 & TRN & \\
\hline CHEMBL88538 & 148191 & 5.9136 & 6.8395 & TRN & \\
\hline CHEMBL88904 & 148191 & 7.8539 & 7.8562 & TRN & \\
\hline CHEMBL327911 & 148191 & 7.4685 & 7.4675 & TRN & \\
\hline CHEMBL433350 & 148191 & 5.0 & 4.9992 & TRN & \\
\hline CHEMBL91540 & 148191 & 6.1487 & 6.1466 & TRN & \\
\hline CHEMBL419128 & 148191 & 7.7696 & 6.8395 & TRN & \\
\hline CHEMBL330563 & 148191 & 7.0 & 7.0004 & TRN & \\
\hline CHEMBL91630 & 148191 & 8.3565 & 6.7534 & TST & \\
\hline CHEMBL91934 & 148191 & 8.2218 & 7.2362 & TST & \\
\hline CHEMBL541213 & 148191 & 6.1805 & 6.7966 & TST & \\
\hline CHEMBL89428 & 148191 & 7.5528 & 6.4554 & TST & \\
\hline CHEMBL90341 & 148191 & 6.301 & 7.8146 & TST & \\
\hline CHEMBL114306 & 142500 & 4.9788 & 4.6144 & TRN & \\
\hline CHEMBL114366 & 142500 & 3.0 & 4.5019 & TRN & \\
\hline CHEMBL111910 & 142500 & 5.1475 & 5.2345 & TRN & \\
\hline CHEMBL114008 & 142500 & 3.0 & 4.2309 & TRN & \\
\hline CHEMBL114137 & 142500 & 6.5686 & 6.8586 & TRN & \\
\hline CHEMBL117661 & 142500 & 5.0315 & 3.9821 & TRN & \\
\hline CHEMBL104297 & 142500 & 5.1938 & 4.6149 & TST & \\
\hline CHEMBL114367 & 142500 & 5.5003 & 3.90199 & 99999999997 & TST \\
\hline CHEMBL322030 & 142500 & 4.5607 & 5.2433 & TRN & \\
\hline CHEMBL432601 & 142500 & 4.8125 & 4.1898 & TST & \\
\hline CHEMBL114095 & 142500 & 2.0 & 3.0882 & TRN & \\
\hline CHEMBL324930 & 142500 & 5.7932 & 4.6226 & TRN & \\
\hline CHEMBL326277 & 142500 & 4.327 & 4.4035 & TRN & \\
\hline CHEMBL115058 & 142500 & 4.585 & 4.3807 & TRN & \\
\hline CHEMBL112809 & 142500 & 3.0 & 3.7469 & TST & \\
\hline CHEMBL115108 & 142500 & 3.0 & 4.0467 & TRN & \\
\hline CHEMBL115501 & 142500 & 5.9706 & 5.5845 & TRN & \\
\hline CHEMBL114089 & 142500 & 4.7773 & 4.2184 & TST & \\
\hline CHEMBL115225 & 142500 & 6.3768 & 4.2391 & TRN & \\
\hline CHEMBL327148 & 142500 & 3.0 & 3.072 & TRN & \\
\hline CHEMBL320554 & 142500 & 3.0 & 3.7262 & TRN & \\
\hline CHEMBL114529 & 142500 & 5.2125 & 5.2555 & TRN & \\
\hline CHEMBL114279 & 142500 & 5.51 & 4.3145 & TRN & \\
\hline CHEMBL116288 & 142500 & 6.3665 & 6.2423 & TRN & \\
\hline CHEMBL115337 & 142500 & 5.7399 & 5.7267 & TRN & \\
\hline CHEMBL324697 & 142500 & 5.5229 & 5.75 & TRN & \\
\hline CHEMBL115893 & 142500 & 3.0 & 3.8403 & TRN & \\
\hline CHEMBL324517 & 142500 & 3.0 & 4.1189 & TST & \\
\hline CHEMBL114254 & 142500 & 5.1993 & 4.2377 & TRN & \\
\hline CHEMBL114382 & 142500 & 5.1643 & 5.0304 & TRN & \\
\hline CHEMBL326853 & 142500 & 3.0 & 2.6017 & TRN & \\
\hline CHEMBL113660 & 142500 & 6.7696 & 6.7201 & TRN & \\
\hline CHEMBL116214 & 142500 & 3.0 & 3.9899 & TRN & \\
\hline & & & & 8535 & \\
\hline
\end{tabular}




\begin{tabular}{|c|c|c|c|c|}
\hline & & & pplement & al $\mathrm{T}$ \\
\hline CHEMBL113678 & 142500 & 5.4089 & 4.4959 & TST \\
\hline CHEMBL117942 & 142500 & 4.9101 & 4.9961 & TRN \\
\hline CHEMBL113980 & 142500 & 5.0458 & 5.4016 & TRN \\
\hline CHEMBL113921 & 142500 & 3.0 & 3.8992 & TRN \\
\hline CHEMBL325827 & 142500 & 5.7055 & 5.4482 & TRN \\
\hline CHEMBL112353 & 142500 & 4.5952 & 4.8223 & TRN \\
\hline CHEMBL114365 & 142500 & 5.1925 & 5.0132 & TRN \\
\hline CHEMBL114621 & 142500 & 3.0 & 4.0679 & TRN \\
\hline CHEMBL439964 & 142500 & 5.5331 & 4.8288 & TRN \\
\hline CHEMBL114778 & 142500 & 5.2351 & 3.8658 & TRN \\
\hline CHEMBL114714 & 142500 & 3.0 & 4.2144 & TST \\
\hline CHEMBL115077 & 142500 & 6.0315 & 4.375 & TRN \\
\hline CHEMBL117660 & 142500 & 3.0 & 3.9099 & TST \\
\hline CHEMBL112690 & 142500 & 5.5817 & 6.0234 & TRN \\
\hline CHEMBL114194 & 142500 & 5.5784 & 5.9535 & TRN \\
\hline CHEMBL112872 & 142500 & 4.0 & 4.2858 & TST \\
\hline CHEMBL114965 & 142500 & 4.8665 & 4.2925 & TST \\
\hline CHEMBL115447 & 142500 & 5.6216 & 4.8017 & TST \\
\hline CHEMBL115232 & 142500 & 3.0 & 3.9416 & TST \\
\hline CHEMBL3918937 & 1639642 & 7.0 & 6.9148 & TST \\
\hline CHEMBL3911340 & 1639642 & 7.0 & 7.1354 & TST \\
\hline CHEMBL 3928784 & 1639642 & 7.0 & 6.9589 & TST \\
\hline CHEMBL3926128 & 1639642 & 7.0 & 7.0254 & TRN \\
\hline CHEMBL3940401 & 1639642 & 6.0 & 6.7256 & TRN \\
\hline CHEMBL3930609 & 1639642 & 8.0 & 7.6599 & TST \\
\hline CHEMBL3919333 & 1639642 & 8.0 & 7.9667 & TST \\
\hline CHEMBL 3897153 & 1639642 & 6.0 & 7.9292 & TST \\
\hline CHEMBL3982471 & 1639642 & 8.0 & 6.4469 & TST \\
\hline CHEMBL3985011 & 1639642 & 6.0 & 6.7128 & TST \\
\hline CHEMBL3978486 & 1639642 & 8.0 & 8.0227 & TST \\
\hline CHEMBL3980871 & 1639642 & 8.0 & 7.3609 & TST \\
\hline CHEMBL 3932468 & 1639642 & 8.0 & 6.3523 & TST \\
\hline CHEMBL 3942220 & 1639642 & 8.0 & 8.0515 & TST \\
\hline CHEMBL3957976 & 1639642 & 8.0 & 7.3307 & TST \\
\hline CHEMBL3960623 & 1639642 & 8.0 & 6.4673 & TST \\
\hline CHEMBL3956956 & 1639642 & 8.0 & 7.9714 & TST \\
\hline CHEMBL3970155 & 1639642 & 8.0 & 8.0252 & TRN \\
\hline CHEMBL 3974421 & 1639642 & 8.0 & 7.6596 & TST \\
\hline CHEMBL448668 & 1639642 & 8.0 & 7.8412 & TST \\
\hline CHEMBL 3923275 & 1639642 & 6.0 & 7.9756 & TST \\
\hline CHEMBL506862 & 1639642 & 8.0 & 7.6741 & TRN \\
\hline CHEMBL3976855 & 1639642 & 7.0 & 6.8469 & TRN \\
\hline CHEMBL3916077 & 1639642 & 8.0 & 8.0635 & TST \\
\hline CHEMBL3901819 & 1639642 & 7.0 & 7.0966 & TST \\
\hline CHEMBL 3904524 & 1639642 & 7.0 & 7.2616 & TST \\
\hline CHEMBL 3947568 & 1639642 & 8.0 & 7.9779 & TST \\
\hline CHEMBL3909929 & 1639642 & 7.0 & 7.1859 & TST \\
\hline CHEMBL3957183 & 1639642 & 8.0 & 7.9211 & TST \\
\hline
\end{tabular}




\begin{tabular}{|c|c|c|c|c|}
\hline & & & & 1 labıe \\
\hline CHEMBL3954571 & 1639642 & 6.0 & 7.3692 & TRN \\
\hline CHEMBL3961627 & 1639642 & 7.0 & 6.6296 & TRN \\
\hline CHEMBL3896404 & 1639642 & 8.0 & 8.0305 & TRN \\
\hline CHEMBL 3902678 & 1639642 & 8.0 & 7.92299 & 9999999999 \\
\hline CHEMBL3951967 & 1639642 & 8.0 & 7.7963 & TRN \\
\hline CHEMBL3981747 & 1639642 & 8.0 & 7.7901 & TRN \\
\hline CHEMBL3973006 & 1639642 & 8.0 & 7.6814 & TST \\
\hline CHEMBL3941287 & 1639642 & 8.0 & 8.0043 & TST \\
\hline CHEMBL502652 & 1639642 & 8.0 & 8.2266 & TRN \\
\hline CHEMBL3983417 & 1639642 & 8.0 & 7.7291 & TRN \\
\hline CHEMBL3891515 & 1639642 & 8.0 & 7.8509 & TRN \\
\hline CHEMBL3893349 & 1639642 & 8.0 & 7.8725 & TRN \\
\hline CHEMBL3896056 & 1639642 & 8.0 & 8.0225 & TRN \\
\hline CHEMBL3903251 & 1639642 & 8.0 & 7.972 & TRN \\
\hline CHEMBL3905921 & 1639642 & 6.0 & 5.7862 & TRN \\
\hline CHEMBL3907756 & 1639642 & 6.0 & 6.0941 & TRN \\
\hline CHEMBL3917543 & 1639642 & 8.0 & 7.8752 & TRN \\
\hline CHEMBL454796 & 1639642 & 8.0 & 8.1465 & TRN \\
\hline CHEMBL3920487 & 1639642 & 8.0 & 8.1889 & TRN \\
\hline CHEMBL3957642 & 1639642 & 8.0 & 7.9619 & TRN \\
\hline CHEMBL3902608 & 1639642 & 8.0 & 7.6741 & TRN \\
\hline CHEMBL3937659 & 1639642 & 8.0 & 8.0421 & TRN \\
\hline CHEMBL3934864 & 1639642 & 8.0 & 7.9709 & TRN \\
\hline CHEMBL3927706 & 1639642 & 8.0 & 7.767 & TRN \\
\hline CHEMBL 3975048 & 1639642 & 8.0 & 7.7754 & TST \\
\hline CHEMBL 3889680 & 1639642 & 7.0 & 6.8468 & TST \\
\hline CHEMBL3984698 & 1639642 & 7.0 & 6.8471 & TST \\
\hline CHEMBL3936093 & 1639642 & 8.0 & 7.7935 & TRN \\
\hline CHEMBL507714 & 1639642 & 8.0 & 7.5587 & TRN \\
\hline CHEMBL3898863 & 1639642 & 8.0 & 7.9918 & TRN \\
\hline CHEMBL3917108 & 1639642 & 8.0 & 8.013 & TRN \\
\hline CHEMBL3950296 & 1639642 & 6.0 & 6.8284 & TRN \\
\hline CHEMBL3953006 & 1639642 & 8.0 & 7.8829 & TRN \\
\hline CHEMBL3912542 & 1639642 & 7.0 & 6.919 & TRN \\
\hline CHEMBL3915209 & 1639642 & 8.0 & 7.9086 & TRN \\
\hline CHEMBL3971235 & 1639642 & 7.0 & 7.0869 & TRN \\
\hline CHEMBL 3973792 & 1639642 & 7.0 & 7.1697 & TRN \\
\hline CHEMBL3911054 & 1639642 & 8.0 & 8.2138 & TRN \\
\hline CHEMBL3908294 & 1639642 & 8.0 & 7.8746 & TRN \\
\hline CHEMBL 3920934 & 1639642 & 7.0 & 6.7294 & TRN \\
\hline CHEMBL447639 & 1639642 & 8.0 & 7.9583 & TRN \\
\hline CHEMBL 3967622 & 1639642 & 8.0 & 8.0619 & TRN \\
\hline CHEMBL3955829 & 1639642 & 6.0 & 5.9438 & TRN \\
\hline CHEMBL3906473 & 1639642 & 6.0 & 7.6744 & TRN \\
\hline CHEMBL 3903740 & 1639642 & 8.0 & 7.9671 & TRN \\
\hline CHEMBL 3946744 & 1639642 & 8.0 & 8.0176 & TRN \\
\hline CHEMBL502198 & 1639642 & 8.0 & 7.8234 & TRN \\
\hline CHEMBL449110 & 1639642 & 8.0 & 8.1684 & TRN \\
\hline
\end{tabular}




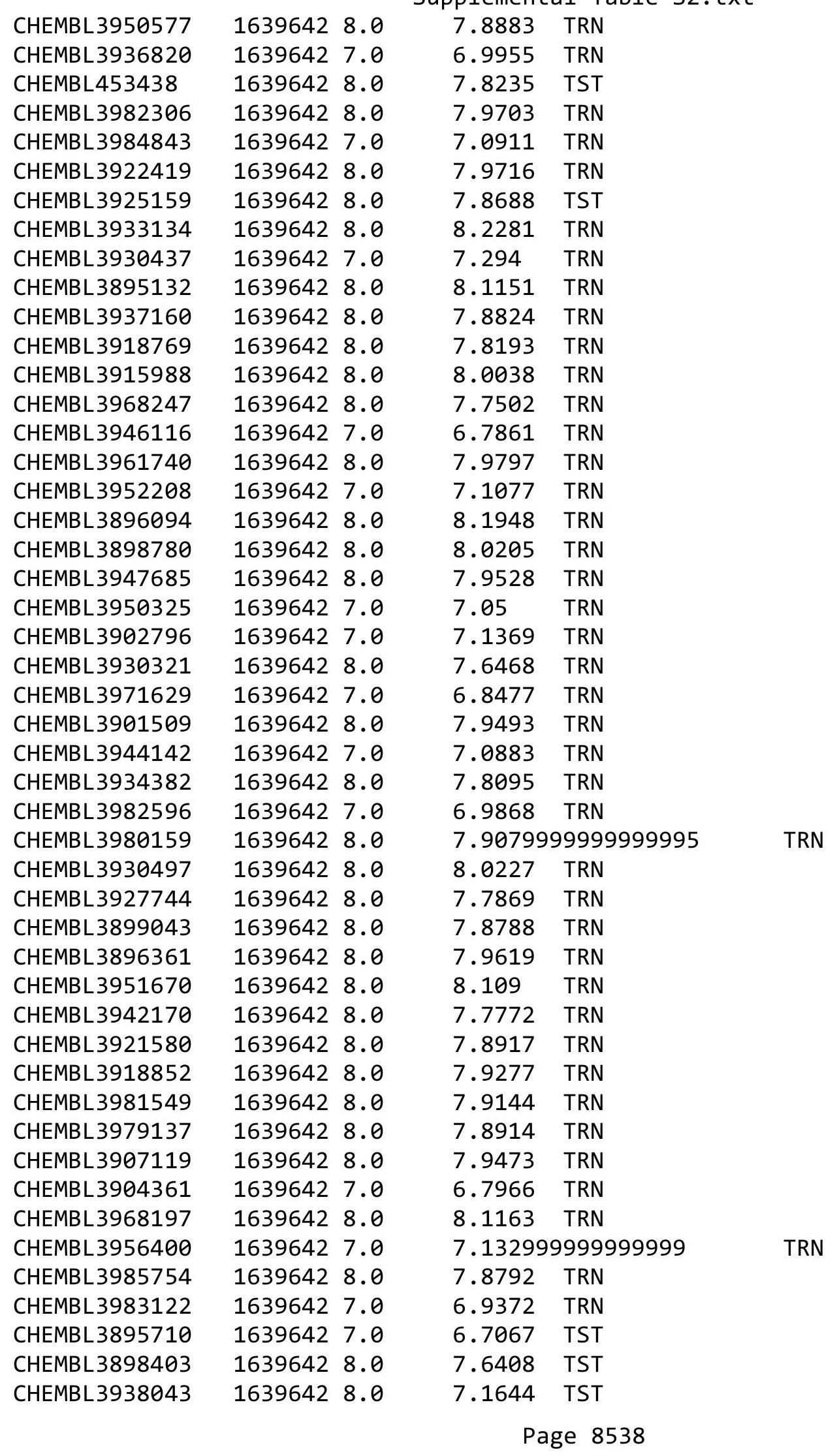




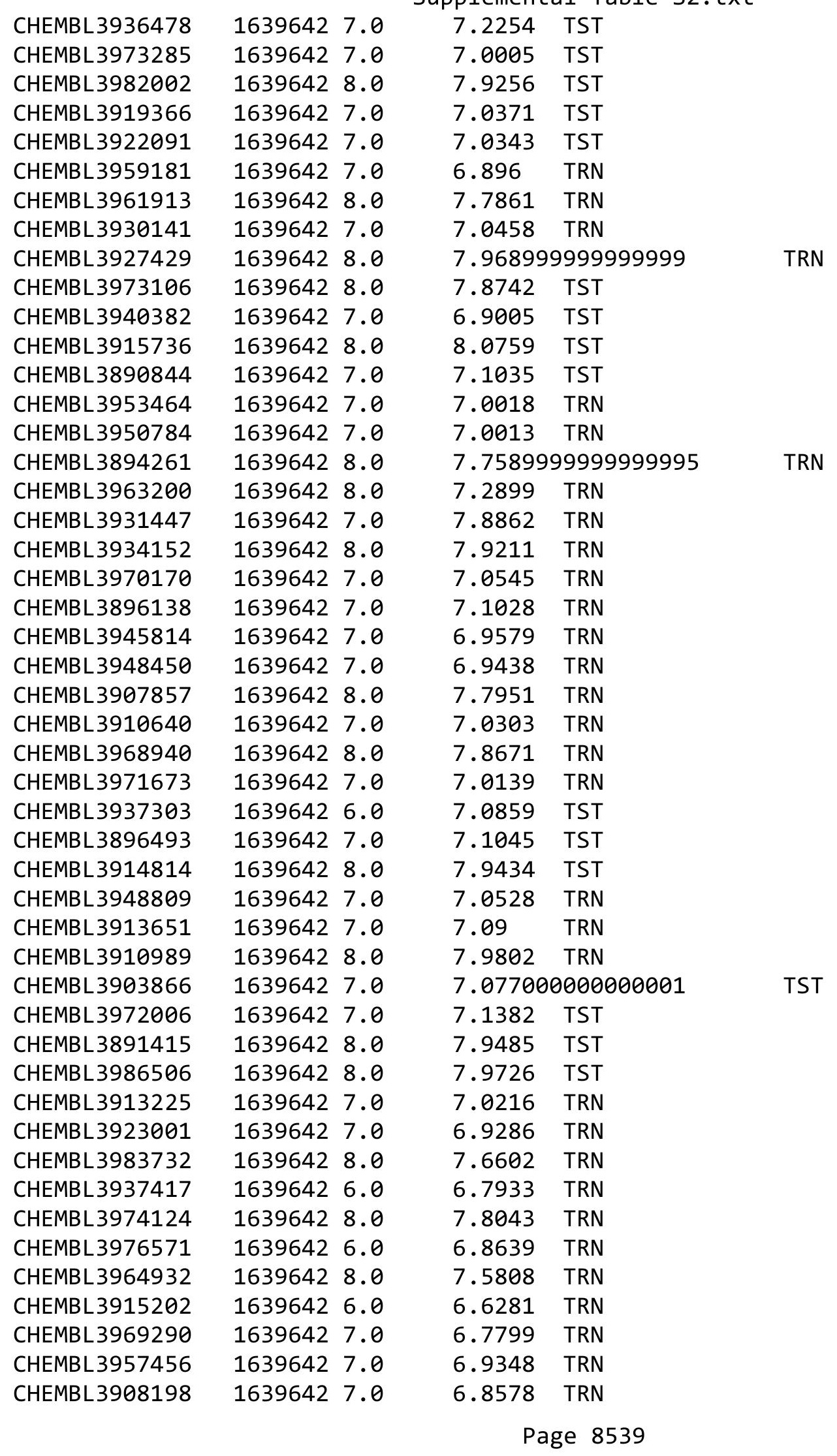




\begin{tabular}{|c|c|c|c|c|c|}
\hline CHEMBL 3905410 & 1639642 & 8.0 & 7.971 & TRN & \\
\hline CHEMBL 3953680 & 1639642 & 7.0 & 7.0733 & TRN & \\
\hline CHEMBL3951002 & 1639642 & 7.0 & 7.1576 & TRN & \\
\hline CHEMBL 3893256 & 1639642 & 8.0 & 7.858 & TRN & \\
\hline CHEMBL3919927 & 1639642 & 7.0 & 7.1223 & TRN & \\
\hline CHEMBL3976565 & 1639642 & 7.0 & 7.0822 & TRN & \\
\hline CHEMBL 3967372 & 1639642 & 7.0 & \multicolumn{2}{|c|}{7.087999999999999} & TRN \\
\hline CHEMBL3910511 & 1639642 & 7.0 & 7.0351 & TRN & \\
\hline CHEMBL3913169 & 1639642 & 8.0 & 8.0337 & TRN & \\
\hline CHEMBL 3940222 & 1639642 & 8.0 & 8.0387 & TRN & \\
\hline CHEMBL3944498 & 1639642 & 8.0 & 7.9945 & TRN & \\
\hline CHEMBL 3896003 & 1639642 & 8.0 & 7.9762 & TRN & \\
\hline CHEMBL3898691 & 1639642 & 8.0 & 7.9002 & TRN & \\
\hline CHEMBL3899525 & 1639642 & 8.0 & 8.1918 & TRN & \\
\hline CHEMBL3957736 & 1639642 & 8.0 & 7.9075 & TRN & \\
\hline CHEMBL3918216 & 1639642 & 8.0 & 7.7445 & TRN & \\
\hline CHEMBL3920947 & 1639642 & 8.0 & 7.6354 & TRN & \\
\hline CHEMBL3952960 & 1639642 & 7.0 & 6.8365 & TRN & \\
\hline CHEMBL3950255 & 1639642 & 7.0 & \multicolumn{2}{|c|}{6.7860000000000005} & TRN \\
\hline CHEMBL 3915154 & 1639642 & 7.0 & 6.7377 & TRN & \\
\hline CHEMBL3912500 & 1639642 & 7.0 & 7.0041 & TRN & \\
\hline CHEMBL 3938801 & 1639642 & 7.0 & 6.8695 & TRN & \\
\hline CHEMBL 3918624 & 1639642 & 8.0 & 7.7901 & TRN & \\
\hline CHEMBL3941932 & 1639642 & 7.0 & 7.0949 & TRN & \\
\hline CHEMBL 3890964 & 1639642 & 7.0 & 6.886 & TRN & \\
\hline CHEMBL3986972 & 1639642 & 7.0 & 6.8517 & TRN & \\
\hline CHEMBL 3984255 & 1639642 & 7.0 & 6.9421 & TRN & \\
\hline CHEMBL 3909461 & 1639642 & 7.0 & 7.0185 & TRN & \\
\hline CHEMBL3930103 & 1639642 & 7.0 & 6.9903 & TRN & \\
\hline CHEMBL 3967147 & 1639642 & 7.0 & 7.0656 & TRN & \\
\hline CHEMBL3972920 & 1639642 & 7.0 & 7.0366 & TRN & \\
\hline CHEMBL 3905860 & 1639642 & 7.0 & 7.0568 & TRN & \\
\hline CHEMBL3915699 & 1639642 & 7.0 & 7.0016 & TRN & \\
\hline CHEMBL3950746 & 1639642 & 7.0 & 6.9399 & TRN & \\
\hline CHEMBL3953421 & 1639642 & 7.0 & 7.1076 & TST & \\
\hline CHEMBL3963196 & 1639642 & 7.0 & 7.0313 & TST & \\
\hline CHEMBL 3894234 & 1639642 & 7.0 & 6.8551 & TRN & \\
\hline CHEMBL3949909 & 1639642 & 7.0 & 7.0259 & TST & \\
\hline CHEMBL3934156 & 1639642 & 7.0 & 7.0117 & TST & \\
\hline CHEMBL3982401 & 1639642 & 7.0 & 7.0808 & TST & \\
\hline CHEMBL3979973 & 1639642 & 7.0 & 6.9853 & TST & \\
\hline CHEMBL 3943489 & 1639642 & 6.0 & 7.7595 & TST & \\
\hline CHEMBL3927527 & 1639642 & 7.0 & 6.7927 & TRN & \\
\hline CHEMBL3973742 & 1639642 & 7.0 & 6.8332 & TRN & \\
\hline CHEMBL 3934556 & 1639642 & 6.0 & 7.51 & TRN & \\
\hline CHEMBL 3908084 & 1639642 & 7.0 & 6.733 & TRN & \\
\hline CHEMBL 3898274 & 1639642 & 7.0 & 7.4574 & TRN & \\
\hline CHEMBL3894895 & 1639642 & 7.0 & 6.8647 & TRN & \\
\hline
\end{tabular}




\begin{tabular}{|c|c|c|c|c|}
\hline \multirow[b]{2}{*}{ CHEMBL3907042 } & \multicolumn{4}{|c|}{ Supplemental Ta } \\
\hline & 1639642 & 7.0 & 6.8985 & TRN \\
\hline CHEMBL3951885 & 1639642 & 7.0 & 7.1122 & TST \\
\hline CHEMBL3918940 & 1639642 & 7.0 & 7.0521 & TST \\
\hline CHEMBL3969511 & 1639642 & 6.0 & 7.8673 & TST \\
\hline CHEMBL3972228 & 1639642 & 7.0 & 6.6786 & TRN \\
\hline CHEMBL3955439 & 1639642 & 7.0 & 6.4932 & TRN \\
\hline CHEMBL 3904450 & 1639642 & 6.0 & 7.3121 & TRN \\
\hline CHEMBL 3946368 & 1639642 & 7.0 & 7.0779 & TRN \\
\hline CHEMBL3949038 & 1639642 & 7.0 & 6.8828 & TRN \\
\hline CHEMBL466397 & 1639642 & 7.0 & 6.8947 & TRN \\
\hline CHEMBL3937247 & 1639642 & 7.0 & 6.8826 & TRN \\
\hline CHEMBL3901948 & 1639642 & 7.0 & 6.785 & TRN \\
\hline CHEMBL 3892197 & 1639642 & 7.0 & 7.7351 & TRN \\
\hline CHEMBL3954082 & 1639642 & 7.0 & 6.9772 & TRN \\
\hline CHEMBL3951411 & 1639642 & 7.0 & 6.9098 & TRN \\
\hline CHEMBL3980301 & 1639642 & 8.0 & 7.8233 & TRN \\
\hline CHEMBL448929 & 1639642 & 8.0 & 7.7373 & TRN \\
\hline CHEMBL3947574 & 1639642 & 8.0 & 7.6993 & TRN \\
\hline CHEMBL 3944957 & 1639642 & 8.0 & 7.8521 & TRN \\
\hline CHEMBL3959145 & 1639642 & 7.0 & 7.1079 & TRN \\
\hline CHEMBL3894686 & 1639642 & 7.0 & 7.0653 & TRN \\
\hline CHEMBL3929955 & 1639642 & 7.0 & 7.0781 & TRN \\
\hline CHEMBL 3932707 & 1639642 & 7.0 & 7.0129 & TST \\
\hline CHEMBL 235715 & 452897 & 4.4056 & 4.4903 & TRN \\
\hline CHEMBL398807 & 452897 & 3.9535 & 3.9643 & TRN \\
\hline CHEMBL 235901 & 452897 & 3.2264 & 3.4236 & TRN \\
\hline CHEMBL 237023 & 452897 & 3.2355 & 3.5092 & TRN \\
\hline CHEMBL 237215 & 452897 & 3.4013 & 4.8353 & TST \\
\hline CHEMBL 237403 & 452897 & 3.2406 & 3.8614 & TRN \\
\hline CHEMBL235705 & 452897 & 3.9658 & 4.0568 & TRN \\
\hline CHEMBL238029 & 452897 & 3.2494 & 4.4929 & TST \\
\hline CHEMBL237218 & 452897 & 6.0223 & 6.6324 & TRN \\
\hline CHEMBL396664 & 452897 & 3.2253 & 3.2577 & TST \\
\hline CHEMBL 237609 & 452897 & 3.1784 & 1.4497 & TST \\
\hline CHEMBL237219 & 452897 & 6.6576 & 6.2877 & TRN \\
\hline CHEMBL 237603 & 452897 & 3.2325 & 3.2867 & TST \\
\hline CHEMBL236149 & 452897 & 5.7122 & 5.1091 & TRN \\
\hline CHEMBL430174 & 452897 & 3.2211 & 1.9129 & TST \\
\hline CHEMBL 237025 & 452897 & 3.2553 & 3.2453 & TRN \\
\hline CHEMBL237029 & 452897 & 3.2063 & 2.8937 & TRN \\
\hline CHEMBL 237411 & 452897 & 5.0691 & 4.1546 & TRN \\
\hline CHEMBL398992 & 452897 & 5.6021 & 5.6782 & TRN \\
\hline CHEMBL393311 & 452897 & 3.4674 & 4.1524 & TST \\
\hline CHEMBL428719 & 452897 & 3.2648 & 3.786 & TRN \\
\hline CHEMBL391115 & 452897 & 3.9337 & 3.9811 & TRN \\
\hline CHEMBL 237212 & 452897 & 5.0022 & 4.8348 & TRN \\
\hline CHEMBL 237410 & 452897 & 5.8356 & 5.5914 & TRN \\
\hline CHEMBL237026 & 452897 & 5.0878 & 5.2431 & TRN \\
\hline
\end{tabular}




\begin{tabular}{|c|c|c|c|c|c|}
\hline & & & & & \\
\hline CHEMBL237030 & 452897 & 3.2009 & 3.1245 & TRN & \\
\hline CHEMBL237604 & 452897 & 5.7645 & 5.6166 & TRN & \\
\hline CHEMBL236355 & 452897 & 3.565 & 3.6978 & TRN & \\
\hline CHEMBL235707 & 452897 & 3.2611 & 3.2152 & TRN & \\
\hline CHEMBL237213 & 452897 & 3.2063 & 3.3174 & TST & \\
\hline CHEMBL400028 & 452897 & 3.2504 & 3.7915 & TRN & \\
\hline CHEMBL235706 & 452897 & 3.2648 & 2.9953 & TRN & \\
\hline CHEMBL391222 & 452897 & 6.1675 & 5.4682 & TRN & \\
\hline CHEMBL 235028 & 452897 & 3.1726 & 1.7289 & TST & \\
\hline CHEMBL393310 & 452897 & 3.2063 & 3.9631 & TST & \\
\hline CHEMBL393128 & 452897 & 3.5779 & 2.1728 & TST & \\
\hline CHEMBL237222 & 452897 & 3.1726 & 1.3896 & TST & \\
\hline CHEMBL235055 & 452897 & 3.2524 & 2.9328 & TRN & \\
\hline CHEMBL237027 & 452897 & 6.5528 & 6.3368 & TRN & \\
\hline CHEMBL391221 & 452897 & 3.2222 & 3.2667 & TRN & \\
\hline CHEMBL391114 & 452897 & 5.8996 & 5.7711 & TRN & \\
\hline CHEMBL398789 & 452897 & 3.2284 & 3.6194 & TRN & \\
\hline CHEMBL400222 & 452897 & 3.2543 & 3.2559 & TST & \\
\hline CHEMBL235714 & 452897 & 3.3875 & 3.625 & TRN & \\
\hline CHEMBL235937 & 452897 & 7.1549 & 7.2795 & TRN & \\
\hline CHEMBL235053 & 452897 & 3.2385 & 2.8873 & TRN & \\
\hline CHEMBL235098 & 452897 & 3.2528 & 3.4075 & TRN & \\
\hline CHEMBL237599 & 452897 & 4.6048 & 3.9403 & TRN & \\
\hline CHEMBL235274 & 452897 & 5.0177 & 5.4236 & TRN & \\
\hline CHEMBL237165 & 452897 & 5.7212 & 5.1703 & TRN & \\
\hline CHEMBL235936 & 452897 & 3.9477 & 4.4843 & TRN & \\
\hline CHEMBL235099 & 452897 & 6.4949 & 6.6882 & TRN & \\
\hline CHEMBL 238244 & 452897 & 3.2366 & 3.6493 & TST & \\
\hline CHEMBL 236148 & 452897 & 6.2007 & 6.4889 & TRN & \\
\hline CHEMBL237032 & 452897 & 3.0976 & 1.7415 & TST & \\
\hline CHEMBL235067 & 452897 & 3.49300 & 00000000 & 3.6652 & TRN \\
\hline CHEMBL237607 & 452897 & 3.2211 & 3.4015 & TRN & \\
\hline CHEMBL 2002105 & 809152 & 4.2 & 4.8496 & TRN & \\
\hline CHEMBL1983348 & 809152 & 5.8 & 5.7407 & TRN & \\
\hline CHEMBL1988163 & 809152 & 6.5 & 5.9224 & TRN & \\
\hline CHEMBL1974480 & 809152 & 5.4 & 5.2187 & TRN & \\
\hline CHEMBL 2000934 & 809152 & 4.2 & 4.0316 & TRN & \\
\hline CHEMBL1980671 & 809152 & 5.0 & 4.4745 & TRN & \\
\hline CHEMBL1986177 & 809152 & 4.2 & 4.3395 & TRN & \\
\hline CHEMBL1992323 & 809152 & 4.9 & 5.0061 & TRN & \\
\hline CHEMBL 2002649 & 809152 & 4.9 & 5.50899 & 99999999995 & TRN \\
\hline CHEMBL1989423 & 809152 & 3.4 & 4.5278 & TRN & \\
\hline CHEMBL1985367 & 809152 & 4.2 & 5.0362 & TRN & \\
\hline CHEMBL1996510 & 809152 & 5.4 & 5.4295 & TRN & \\
\hline CHEMBL1995172 & 809152 & 4.1 & 4.6772 & TST & \\
\hline CHEMBL 2001584 & 809152 & 4.2 & 4.3236 & TRN & \\
\hline CHEMBL1967998 & 809152 & 7.0 & 7.5574 & TRN & \\
\hline CHEMBL1978562 & 809152 & 5.5 & 4.9194 & TRN & \\
\hline
\end{tabular}




\begin{tabular}{|c|c|c|c|c|}
\hline & & & pl & \\
\hline CHEMBL1997129 & 809152 & 4.9 & 5.0452 & TRN \\
\hline CHEMBL229799 & 809152 & 4.9 & 5.1039 & TRN \\
\hline CHEMBL1984788 & 809152 & 6.0 & 5.2393 & TRN \\
\hline CHEMBL1989471 & 809152 & 5.5 & 5.6216 & TST \\
\hline CHEMBL 2000508 & 809152 & 4.9 & 4.8714 & TRN \\
\hline CHEMBL 2001547 & 809152 & 4.9 & 4.7486 & TRN \\
\hline CHEMBL210928 & 809152 & 4.9 & 4.7439 & TST \\
\hline CHEMBL1978195 & 809152 & 4.2 & 4.4789 & TRN \\
\hline CHEMBL1986603 & 809152 & 4.9 & 5.2119 & TST \\
\hline CHEMBL1966842 & 809152 & 4.5 & 5.2577 & TRN \\
\hline CHEMBL1974061 & 809152 & 7.4 & 7.1251 & TRN \\
\hline CHEMBL 2003286 & 809152 & 4.9 & 4.8934 & TRN \\
\hline CHEMBL1992306 & 809152 & 4.9 & 5.3656 & TRN \\
\hline CHEMBL1998585 & 809152 & 7.9 & 6.8665 & TRN \\
\hline CHEMBL127898 & 809152 & 4.2 & 4.9947 & TST \\
\hline CHEMBL519697 & 809152 & 4.9 & 5.093 & TRN \\
\hline CHEMBL 2004934 & 809152 & 4.9 & 4.4398 & TRN \\
\hline CHEMBL1977619 & 809152 & 3.9 & 4.7992 & TST \\
\hline CHEMBL1996345 & 809152 & 4.4 & 4.4551 & TST \\
\hline CHEMBL 2004025 & 809152 & 5.8 & 5.2955 & TRN \\
\hline CHEMBL1996048 & 809152 & 6.4 & 5.5953 & TST \\
\hline CHEMBL1976158 & 809152 & 4.5 & 5.0083 & TST \\
\hline CHEMBL461876 & 809152 & 8.9 & 7.3973 & TRN \\
\hline CHEMBL1965033 & 809152 & 4.2 & 5.2699 & TRN \\
\hline CHEMBL 2001485 & 809152 & 6.8 & 6.6936 & TRN \\
\hline CHEMBL1999485 & 809152 & 6.3 & 7.1157 & TRN \\
\hline CHEMBL1971519 & 809152 & 4.2 & 4.2076 & TRN \\
\hline CHEMBL1997335 & 809152 & 5.8 & 5.8606 & TRN \\
\hline CHEMBL1978099 & 809152 & 6.6 & 6.3101 & TRN \\
\hline CHEMBL1988608 & 809152 & 4.9 & 4.7139 & TRN \\
\hline CHEMBL184847 & 809152 & 4.9 & 5.2841 & TRN \\
\hline CHEMBL1971132 & 809152 & 4.2 & 4.3327 & TRN \\
\hline CHEMBL1984367 & 809152 & 4.9 & 4.8108 & TRN \\
\hline CHEMBL226898 & 809152 & 4.9 & 4.9172 & TRN \\
\hline CHEMBL1991377 & 809152 & 4.2 & 4.5743 & TRN \\
\hline CHEMBL539474 & 809152 & 4.7 & 5.5704 & TST \\
\hline CHEMBL575824 & 809152 & 4.9 & 4.89 & TRN \\
\hline CHEMBL1988387 & 809152 & 6.6 & 7.4277 & TRN \\
\hline CHEMBL1973868 & 809152 & 4.2 & 4.3331 & TRN \\
\hline CHEMBL1972462 & 809152 & 4.2 & 4.4978 & TRN \\
\hline CHEMBL1990288 & 809152 & 4.9 & 4.8837 & TRN \\
\hline CHEMBL1967620 & 809152 & 4.5 & 5.0479 & TST \\
\hline CHEMBL1986970 & 809152 & 4.9 & 4.7954 & TRN \\
\hline CHEMBL1958401 & 809152 & 4.9 & 4.7091 & TRN \\
\hline CHEMBL1966816 & 809152 & 4.9 & 4.5964 & TRN \\
\hline CHEMBL1972584 & 809152 & 7.1 & 5.8884 & TRN \\
\hline CHEMBL 2002992 & 809152 & 5.7 & 5.1099 & TRN \\
\hline CHEMBL560813 & 809152 & 4.9 & 4.9299 & TRN \\
\hline
\end{tabular}




\begin{tabular}{|c|c|c|c|c|}
\hline \multicolumn{5}{|c|}{ Supplemental Table S2.txt } \\
\hline CHEMBL1982700 & 809152 & 4.2 & 4.7389 & TST \\
\hline CHEMBL1968791 & 809152 & 7.2 & 5.0409 & TRN \\
\hline CHEMBL1977634 & 809152 & 4.2 & 4.2101 & TRN \\
\hline CHEMBL1971186 & 809152 & 6.3 & 4.9016 & TRN \\
\hline CHEMBL 2003482 & 809152 & 4.9 & 4.7465 & TRN \\
\hline CHEMBL1976872 & 809152 & 3.9 & 4.7283 & TRN \\
\hline CHEMBL1969156 & 809152 & 3.9 & 4.9575 & TRN \\
\hline CHEMBL1973211 & 809152 & 6.3 & 6.2747 & TRN \\
\hline CHEMBL1998953 & 809152 & 4.2 & 4.8011 & TRN \\
\hline CHEMBL1971606 & 809152 & 4.2 & 4.2862 & TRN \\
\hline CHEMBL1972125 & 809152 & 4.9 & 4.9279 & TRN \\
\hline CHEMBL1976134 & 809152 & 4.9 & 5.7416 & TRN \\
\hline CHEMBL1965131 & 809152 & 4.9 & 4.7777 & TRN \\
\hline CHEMBL1972158 & 809152 & 4.9 & 4.898 & TRN \\
\hline CHEMBL1981215 & 809152 & 4.2 & 4.2353 & TRN \\
\hline CHEMBL1974457 & 809152 & 4.3 & 4.9205 & TRN \\
\hline CHEMBL1999414 & 809152 & 6.3 & 5.8566 & TRN \\
\hline CHEMBL1967336 & 809152 & 4.2 & 4.2777 & TRN \\
\hline CHEMBL 2001228 & 809152 & 4.5 & 4.6058 & TRN \\
\hline CHEMBL1970340 & 809152 & 5.2 & 4.1355 & TRN \\
\hline CHEMBL1967992 & 809152 & 4.2 & 4.3479 & TRN \\
\hline CHEMBL2005186 & 809152 & 4.9 & 4.8238 & TRN \\
\hline CHEMBL1981671 & 809152 & 4.2 & 4.6515 & TRN \\
\hline CHEMBL 2006450 & 809152 & 4.2 & 4.2237 & TRN \\
\hline CHEMBL1975534 & 809152 & 4.9 & 4.8399 & TRN \\
\hline CHEMBL1993424 & 809152 & 7.1 & 6.0892 & TRN \\
\hline CHEMBL 2001987 & 809152 & 4.2 & 4.2763 & TRN \\
\hline CHEMBL1994555 & 809152 & 5.3 & 5.1201 & TRN \\
\hline CHEMBL1975121 & 809152 & 4.2 & 4.2232 & TRN \\
\hline CHEMBL1983640 & 809152 & 6.1 & 6.2928 & TRN \\
\hline CHEMBL1997023 & 809152 & 4.9 & 4.9135 & TST \\
\hline CHEMBL1964687 & 809152 & 6.8 & 6.2004 & TRN \\
\hline CHEMBL1971943 & 809152 & 4.4 & 4.4543 & TRN \\
\hline CHEMBL1997924 & 809152 & 7.2 & 7.1283 & TRN \\
\hline CHEMBL1969049 & 809152 & 4.9 & 4.522 & TRN \\
\hline CHEMBL 2005828 & 809152 & 4.9 & 4.9395 & TRN \\
\hline CHEMBL1978267 & 809152 & 4.5 & 4.6304 & TRN \\
\hline CHEMBL485556 & 809152 & 5.8 & 5.0084 & TRN \\
\hline CHEMBL1992334 & 809152 & 4.2 & 4.5122 & TRN \\
\hline CHEMBL 255822 & 809152 & 4.9 & 4.8158 & TRN \\
\hline CHEMBL1972221 & 809152 & 4.9 & 5.0071 & TRN \\
\hline CHEMBL378627 & 809152 & 4.9 & 4.8798 & TST \\
\hline CHEMBL1996979 & 809152 & 6.0 & 5.2962 & TRN \\
\hline CHEMBL1997025 & 809152 & 5.6 & 5.1979 & TRN \\
\hline CHEMBL1975921 & 809152 & 4.2 & 4.5259 & TRN \\
\hline CHEMBL1998545 & 809152 & 4.9 & 4.7493 & TRN \\
\hline CHEMBL1986869 & 809152 & 4.9 & 4.7846 & TRN \\
\hline CHEMBL 2004033 & 809152 & 5.3 & 4.3326 & TST \\
\hline
\end{tabular}




\begin{tabular}{|c|c|c|c|c|c|}
\hline \multicolumn{6}{|c|}{ Supplemental Table S2.txt } \\
\hline CHEMBL1975923 & 809152 & 5.8 & 4.6094 & TST & \\
\hline CHEMBL 2005449 & 809152 & 6.1 & 6.3085 & TRN & \\
\hline CHEMBL1987998 & 809152 & 4.2 & 4.231 & TRN & \\
\hline CHEMBL1992527 & 809152 & 7.1 & 7.0903 & TRN & \\
\hline CHEMBL1971534 & 809152 & 4.2 & 4.3957 & TRN & \\
\hline CHEMBL1990496 & 809152 & 4.4 & 4.4592 & TRN & \\
\hline CHEMBL 2002799 & 809152 & 4.2 & 4.963 & TST & \\
\hline CHEMBL242865 & 809152 & 5.8 & 5.8328 & TRN & \\
\hline CHEMBL550275 & 809152 & 5.8 & 5.1454 & TST & \\
\hline CHEMBL1982992 & 809152 & 4.9 & 4.9392 & TRN & \\
\hline CHEMBL1998110 & 809152 & 4.2 & 4.0952 & TRN & \\
\hline CHEMBL1981079 & 809152 & 4.9 & 4.5037 & TRN & \\
\hline CHEMBL1978166 & 809152 & 6.2 & 6.0022 & TRN & \\
\hline CHEMBL1980489 & 809152 & 4.9 & 4.8336 & TRN & \\
\hline CHEMBL 2000832 & 809152 & 4.9 & 5.1795 & TRN & \\
\hline CHEMBL1990590 & 809152 & 4.2 & 4.0347 & TRN & \\
\hline CHEMBL1977814 & 809152 & 5.3 & 4.9228 & TST & \\
\hline CHEMBL1974617 & 809152 & 4.1 & 4.329 & TRN & \\
\hline CHEMBL1965660 & 809152 & 4.9 & 4.2838 & TRN & \\
\hline CHEMBL1992125 & 809152 & 5.8 & 5.574 & TRN & \\
\hline CHEMBL1998112 & 809152 & 4.9 & 5.0856 & TRN & \\
\hline CHEMBL1969126 & 809152 & 4.9 & 4.9965 & TRN & \\
\hline CHEMBL1980896 & 809152 & 4.9 & 5.3121 & TRN & \\
\hline CHEMBL1970104 & 809152 & 6.4 & 5.6594 & TRN & \\
\hline CHEMBL1991429 & 809152 & 6.1 & 5.01699 & 99999999995 & TRN \\
\hline CHEMBL1971149 & 809152 & 4.9 & 4.6361 & TRN & \\
\hline CHEMBL1999714 & 809152 & 4.9 & 4.8893 & TRN & \\
\hline CHEMBL1994040 & 809152 & 4.9 & 4.7768 & TRN & \\
\hline CHEMBL388978 & 809152 & 8.3 & 6.8861 & TST & \\
\hline CHEMBL1998773 & 809152 & 5.4 & 5.2393 & TRN & \\
\hline CHEMBL579246 & 809152 & 4.9 & 4.8712 & TRN & \\
\hline CHEMBL1983106 & 809152 & 6.0 & 6.49700 & 0000000001 & TRN \\
\hline CHEMBL398951 & 809152 & 4.4 & 4.4212 & TST & \\
\hline CHEMBL1982506 & 809152 & 4.9 & 4.47199 & 99999999995 & TST \\
\hline CHEMBL 2004716 & 809152 & 6.2 & 6.6614 & TRN & \\
\hline CHEMBL1968127 & 809152 & 4.9 & 4.8123 & TRN & \\
\hline CHEMBL1975233 & 809152 & 4.9 & 5.12700 & 2000000001 & TRN \\
\hline CHEMBL1985406 & 809152 & 4.9 & 4.7943 & TRN & \\
\hline CHEMBL 2007603 & 809152 & 4.2 & 4.0857 & TRN & \\
\hline CHEMBL 207400 & 809152 & 4.9 & 4.868 & TST & \\
\hline CHEMBL1421720 & 809152 & 5.6 & 5.3233 & TRN & \\
\hline CHEMBL1968130 & 809152 & 4.5 & 4.4304 & TRN & \\
\hline CHEMBL1976090 & 809152 & 4.9 & 4.8319 & TRN & \\
\hline CHEMBL1993243 & 809152 & 4.9 & 5.1462 & TRN & \\
\hline CHEMBL1997597 & 809152 & 4.9 & 4.8641 & TRN & \\
\hline CHEMBL1969537 & 809152 & 4.9 & 5.3887 & TST & \\
\hline CHEMBL576113 & 809152 & 4.2 & 5.0135 & TRN & \\
\hline CHEMBL1976093 & 809152 & 4.9 & 4.7925 & TRN & \\
\hline
\end{tabular}




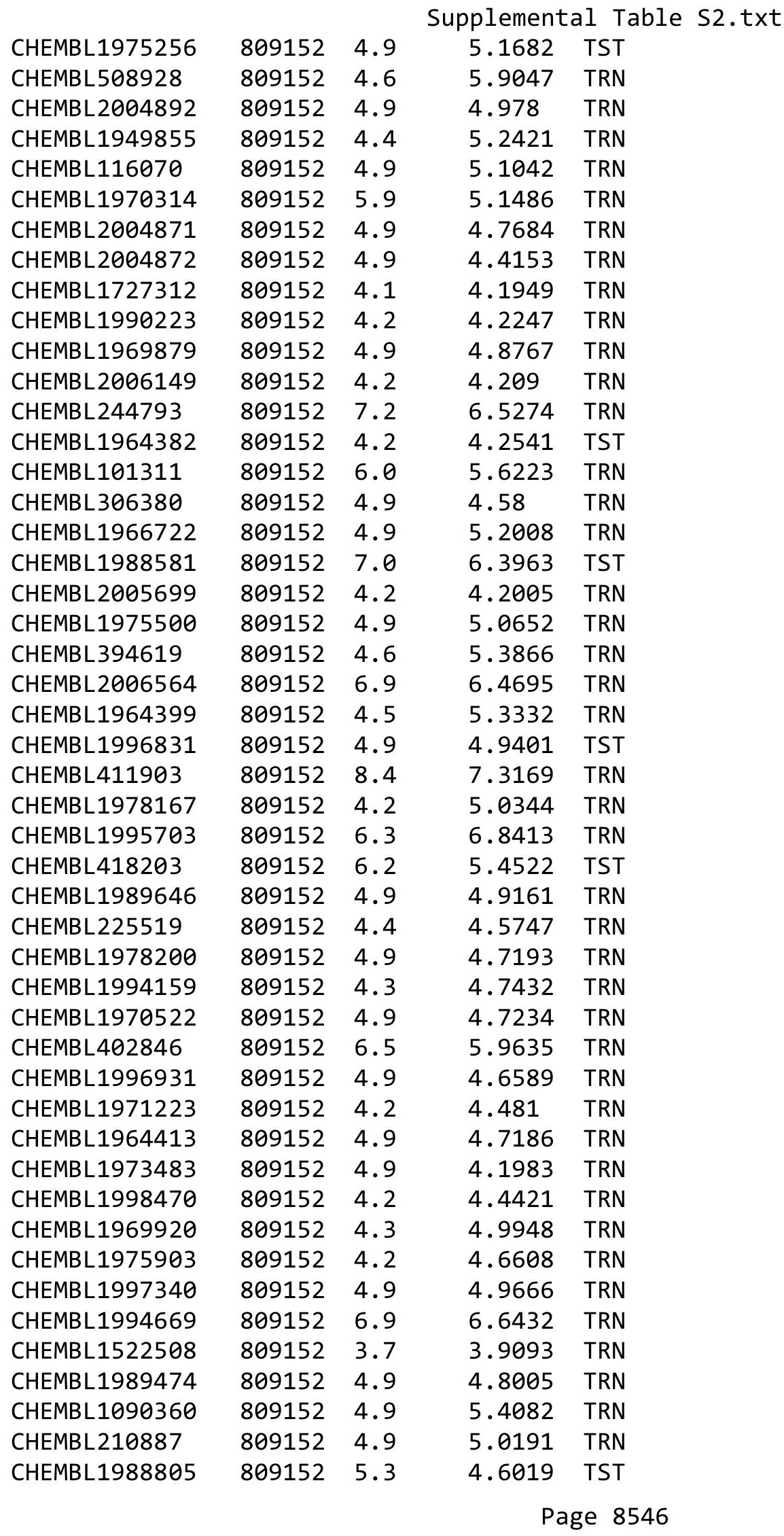




\begin{tabular}{|c|c|c|c|c|c|}
\hline \multirow{3}{*}{$\begin{array}{l}\text { CHEMBL } 458997 \\
\text { CHEMBL1971021 }\end{array}$} & \multirow{3}{*}{$\begin{array}{l}809152 \\
809152\end{array}$} & \multicolumn{4}{|c|}{ Supplemental Table S2.txt } \\
\hline & & 7.6 & 7.4920 & 2000000001 & TRN \\
\hline & & 6.9 & 5.8195 & TRN & \\
\hline CHEMBL227271 & 809152 & 4.9 & 4.9513 & TRN & \\
\hline CHEMBL583144 & 809152 & 5.9 & 5.4021 & TRN & \\
\hline CHEMBL1974310 & 809152 & 4.9 & 4.6337 & TRN & \\
\hline CHEMBL1969942 & 809152 & 4.2 & 4.2399 & TRN & \\
\hline CHEMBL1978567 & 809152 & 4.2 & 4.0952 & TRN & \\
\hline CHEMBL1982660 & 809152 & 4.9 & 4.3384 & TRN & \\
\hline CHEMBL 2002346 & 809152 & 4.5 & 5.1846 & TRN & \\
\hline CHEMBL1975138 & 809152 & 4.9 & 4.9735 & TRN & \\
\hline CHEMBL424872 & 809152 & 4.2 & 4.4917 & TST & \\
\hline CHEMBL3145328 & 809152 & 6.7 & 4.8022 & TST & \\
\hline CHEMBL412142 & 809152 & 4.9 & 5.087 & TST & \\
\hline CHEMBL1980704 & 809152 & 4.9 & 4.868 & TST & \\
\hline CHEMBL 2003271 & 809152 & 4.9 & 4.8054 & TRN & \\
\hline CHEMBL1972365 & 809152 & 5.1 & 4.8862 & TRN & \\
\hline CHEMBL1966808 & 809152 & 4.9 & 4.8851 & TRN & \\
\hline CHEMBL 2004447 & 809152 & 4.9 & 4.9973 & TST & \\
\hline CHEMBL1983111 & 809152 & 7.0 & 7.1222 & TRN & \\
\hline CHEMBL1973860 & 809152 & 4.5 & 4.7901 & TST & \\
\hline CHEMBL260135 & 809152 & 4.9 & 4.7164 & TRN & \\
\hline CHEMBL220241 & 809152 & 4.9 & 4.7988 & TRN & \\
\hline CHEMBL1988141 & 809152 & 6.2 & 5.7592 & TST & \\
\hline CHEMBL1982610 & 809152 & 4.9 & 5.0444 & TST & \\
\hline CHEMBL1977134 & 809152 & 4.2 & 4.9959 & TRN & \\
\hline CHEMBL1970873 & 809152 & 3.3 & 4.9924 & TRN & \\
\hline CHEMBL1985206 & 809152 & 4.2 & 4.3113 & TST & \\
\hline CHEMBL1991078 & 809152 & 4.2 & 4.1643 & TRN & \\
\hline CHEMBL1977749 & 809152 & 6.6 & 5.4931 & TST & \\
\hline CHEMBL1975212 & 809152 & 4.4 & 4.4431 & TRN & \\
\hline CHEMBL 2001613 & 809152 & 4.1 & 4.647 & TRN & \\
\hline CHEMBL1997275 & 809152 & 5.2 & 5.0597 & TRN & \\
\hline CHEMBL1993904 & 809152 & 5.6 & 5.4513 & TRN & \\
\hline CHEMBL1980376 & 809152 & 4.0 & 4.5343 & TRN & \\
\hline CHEMBL1967513 & 809152 & 4.2 & 4.0565 & TRN & \\
\hline CHEMBL 2000724 & 809152 & 4.2 & 4.0582 & TRN & \\
\hline CHEMBL1982413 & 809152 & 5.5 & 5.1021 & TRN & \\
\hline CHEMBL1969502 & 809152 & 4.9 & 5.5253 & TST & \\
\hline CHEMBL1682553 & 809152 & 4.9 & 4.6929 & TRN & \\
\hline CHEMBL1983963 & 809152 & 5.8 & 5.7344 & TRN & \\
\hline CHEMBL1997764 & 809152 & 4.9 & 5.0507 & TRN & \\
\hline CHEMBL1981792 & 809152 & 4.2 & 4.4232 & TRN & \\
\hline CHEMBL1987535 & 809152 & 4.2 & 4.4125 & TRN & \\
\hline CHEMBL1985092 & 809152 & 4.9 & 5.0617 & TRN & \\
\hline CHEMBL1981410 & 809152 & 5.9 & 5.3572 & TRN & \\
\hline CHEMBL 2002586 & 809152 & 5.6 & 5.7169 & TRN & \\
\hline CHEMBL1987815 & 809152 & 4.1 & 4.5756 & TST & \\
\hline CHEMBL1996234 & 809152 & 4.9 & 4.7341 & TRN & \\
\hline
\end{tabular}




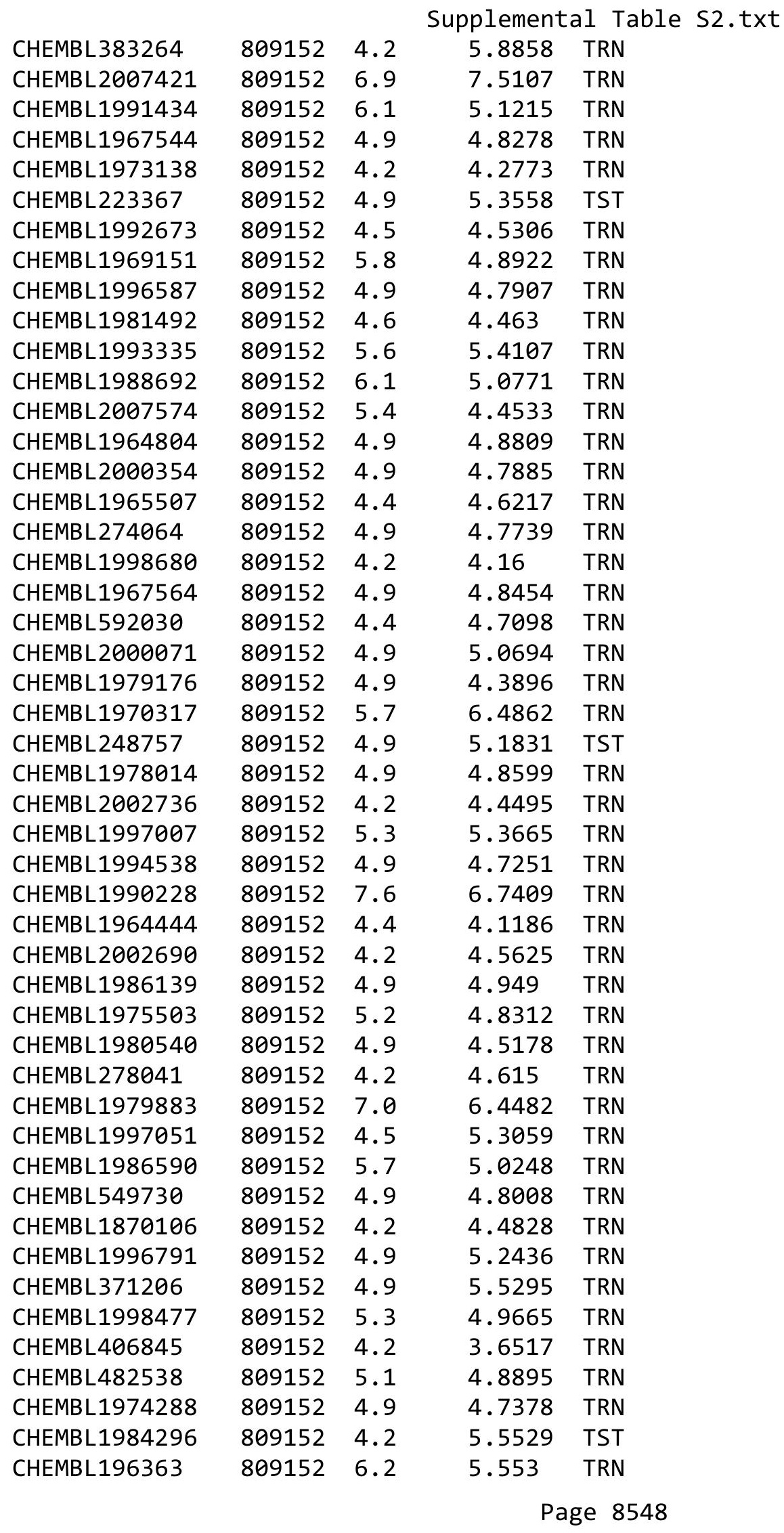




\begin{tabular}{|c|c|c|c|c|}
\hline \multicolumn{5}{|c|}{ Supplemental Table S2.txt } \\
\hline CHEMBL1996837 & 809152 & 3.9 & 4.467 & TST \\
\hline CHEMBL1190711 & 809152 & 4.9 & 5.4359 & TRN \\
\hline CHEMBL1971914 & 809152 & 7.8 & 7.0489 & TRN \\
\hline CHEMBL1968705 & 809152 & 4.2 & 4.2747 & TRN \\
\hline CHEMBL1964441 & 809152 & 5.6 & 5.9801 & TRN \\
\hline CHEMBL1991410 & 809152 & 4.2 & 4.3634 & TRN \\
\hline CHEMBL546797 & 809152 & 5.8 & 4.6099 & TST \\
\hline CHEMBL404367 & 809152 & 5.9 & 5.6468 & TRN \\
\hline CHEMBL1966343 & 809152 & 4.9 & 4.9524 & TRN \\
\hline CHEMBL1978271 & 809152 & 4.2 & 4.2681 & TRN \\
\hline CHEMBL1967887 & 809152 & 4.9 & 4.8134 & TRN \\
\hline CHEMBL 2007266 & 809152 & 5.3 & 4.8522 & TRN \\
\hline CHEMBL 2000568 & 809152 & 4.6 & 4.768 & TRN \\
\hline CHEMBL1985469 & 809152 & 4.2 & 4.8596 & TST \\
\hline CHEMBL1994308 & 809152 & 4.2 & 4.4025 & TST \\
\hline CHEMBL1983430 & 809152 & 6.0 & 6.1355 & TRN \\
\hline CHEMBL2007097 & 809152 & 4.1 & 4.6706 & TRN \\
\hline CHEMBL1988717 & 809152 & 6.0 & 5.9659 & TRN \\
\hline CHEMBL1974328 & 809152 & 7.2 & 6.7394 & TRN \\
\hline CHEMBL1973808 & 809152 & 4.9 & 4.7058 & TRN \\
\hline CHEMBL1986367 & 809152 & 6.4 & 6.3989 & TRN \\
\hline CHEMBL1976878 & 809152 & 5.9 & 6.4011 & TRN \\
\hline CHEMBL1972576 & 809152 & 4.9 & 4.5516 & TRN \\
\hline CHEMBL1992342 & 809152 & 4.9 & 4.8917 & TRN \\
\hline CHEMBL1973013 & 809152 & 5.7 & 5.4937 & TRN \\
\hline CHEMBL1164265 & 809152 & 7.0 & 7.396 & TST \\
\hline CHEMBL1965423 & 809152 & 4.9 & 4.9436 & TRN \\
\hline CHEMBL1975927 & 809152 & 5.6 & 6.0616 & TRN \\
\hline CHEMBL205415 & 809152 & 4.4 & 4.5011 & TRN \\
\hline CHEMBL 2001920 & 809152 & 4.9 & 4.9791 & TRN \\
\hline CHEMBL1977138 & 809152 & 7.2 & 6.6132 & TST \\
\hline CHEMBL1241473 & 809152 & 7.0 & 7.357 & TRN \\
\hline CHEMBL2000879 & 809152 & 4.3 & 4.7621 & TST \\
\hline CHEMBL1978448 & 809152 & 4.5 & 4.7669 & TST \\
\hline CHEMBL1969483 & 809152 & 4.5 & 4.3864 & TRN \\
\hline CHEMBL 2001257 & 809152 & 4.6 & 5.7683 & TRN \\
\hline CHEMBL 2004515 & 809152 & 5.3 & 5.1978 & TRN \\
\hline CHEMBL1980329 & 809152 & 7.9 & 6.2923 & TRN \\
\hline CHEMBL1992042 & 809152 & 5.5 & 4.5927 & TST \\
\hline CHEMBL1992536 & 809152 & 4.9 & 4.746 & TRN \\
\hline CHEMBL21156 & 809152 & 6.8 & 5.5754 & TST \\
\hline CHEMBL1992740 & 809152 & 4.9 & 4.9072 & TRN \\
\hline CHEMBL1994724 & 809152 & 4.2 & 4.2627 & TRN \\
\hline CHEMBL1989267 & 809152 & 5.3 & 4.8863 & TRN \\
\hline CHEMBL439340 & 809152 & 4.9 & 5.0085 & TRN \\
\hline CHEMBL2006188 & 809152 & 4.9 & 4.7385 & TRN \\
\hline CHEMBL1970290 & 809152 & 6.3 & 5.5711 & TRN \\
\hline CHEMBL1974574 & 809152 & 4.2 & 4.6177 & TST \\
\hline
\end{tabular}




\begin{tabular}{|c|c|c|c|c|}
\hline & & & ient & \\
\hline CHEMBL1967531 & 809152 & 4.9 & 5.2996 & TRN \\
\hline CHEMBL1970913 & 809152 & 4.9 & 4.8971 & TRN \\
\hline CHEMBL1973893 & 809152 & 4.9 & 5.0472 & TRN \\
\hline CHEMBL1997534 & 809152 & 4.9 & 4.6636 & TRN \\
\hline CHEMBL1993877 & 809152 & 6.5 & 5.795 & TRN \\
\hline CHEMBL1996500 & 809152 & 4.3 & 4.3932 & TRN \\
\hline CHEMBL1985095 & 809152 & 4.9 & 4.7279 & TRN \\
\hline CHEMBL1973363 & 809152 & 5.5 & 5.1251 & TRN \\
\hline CHEMBL1989708 & 809152 & 7.2 & 6.8124 & TRN \\
\hline CHEMBL1976420 & 809152 & 5.9 & 4.8622 & TRN \\
\hline CHEMBL1998253 & 809152 & 4.2 & 4.5413 & TST \\
\hline CHEMBL1981744 & 809152 & 4.2 & 4.3471 & TRN \\
\hline CHEMBL1994864 & 809152 & 4.9 & 4.88 & TRN \\
\hline CHEMBL497151 & 809152 & 4.9 & 5.1969 & TRN \\
\hline CHEMBL 2000029 & 809152 & 4.2 & 5.0031 & TRN \\
\hline CHEMBL1973961 & 809152 & 7.4 & 6.3868 & TRN \\
\hline CHEMBL246970 & 809152 & 4.9 & 5.1829 & TRN \\
\hline CHEMBL340921 & 809152 & 4.9 & 5.186 & TST \\
\hline CHEMBL1994977 & 809152 & 4.2 & 4.1725 & TRN \\
\hline CHEMBL 2001149 & 809152 & 4.2 & 4.9327 & TRN \\
\hline CHEMBL1999718 & 809152 & 4.9 & 4.6925 & TRN \\
\hline CHEMBL 2000078 & 809152 & 4.5 & 5.0218 & TRN \\
\hline CHEMBL 2005478 & 809152 & 5.5 & 5.1108 & TRN \\
\hline CHEMBL1276446 & 809152 & 6.2 & 5.5188 & TST \\
\hline CHEMBL1996646 & 809152 & 5.7 & 4.9295 & TRN \\
\hline CHEMBL1979773 & 809152 & 4.2 & 4.3444 & TRN \\
\hline CHEMBL1977346 & 809152 & 4.9 & 4.9635 & TRN \\
\hline CHEMBL 2005482 & 809152 & 4.5 & 5.4075 & TRN \\
\hline CHEMBL1996702 & 809152 & 6.6 & 5.1785 & TRN \\
\hline CHEMBL1997909 & 809152 & 4.5 & 4.938 & TRN \\
\hline CHEMBL 2007124 & 809152 & 4.2 & 4.8963 & TRN \\
\hline CHEMBL 2006439 & 809152 & 4.4 & 4.8642 & TRN \\
\hline CHEMBL1985681 & 809152 & 5.6 & 5.2718 & TST \\
\hline CHEMBL 2002660 & 809152 & 4.2 & 4.3368 & TRN \\
\hline CHEMBL1973937 & 809152 & 7.3 & 6.1895 & TRN \\
\hline CHEMBL1991674 & 809152 & 4.6 & 4.8656 & TRN \\
\hline CHEMBL1982711 & 809152 & 4.7 & 4.8276 & TRN \\
\hline CHEMBL262623 & 809152 & 5.0 & 5.034 & TRN \\
\hline CHEMBL1967875 & 809152 & 5.4 & 4.9861 & TST \\
\hline CHEMBL1984842 & 809152 & 4.2 & 4.412 & TRN \\
\hline CHEMBL2004118 & 809152 & 5.4 & 5.401 & TRN \\
\hline CHEMBL1996795 & 809152 & 4.2 & 4.9942 & TST \\
\hline CHEMBL 2007044 & 809152 & 4.9 & 4.8876 & TST \\
\hline CHEMBL1994241 & 809152 & 4.9 & 4.8529 & TST \\
\hline CHEMBL223460 & 809152 & 4.9 & 5.3992 & TST \\
\hline CHEMBL50894 & 809152 & 4.4 & 4.5927 & TST \\
\hline CHEMBL1995211 & 809152 & 5.7 & 5.6464 & TRN \\
\hline CHEMBL1988838 & 809152 & 6.7 & 6.9582 & TRN \\
\hline
\end{tabular}




\begin{tabular}{|c|c|c|c|c|c|}
\hline \multicolumn{6}{|c|}{ Supplemental Table S2.txt } \\
\hline CHEMBL1981725 & 809152 & 4.6 & 5.8612 & TRN & \\
\hline CHEMBL1982753 & 809152 & 5.9 & 5.8827 & TRN & \\
\hline CHEMBL 2006299 & 809152 & 4.2 & 4.2093 & TRN & \\
\hline CHEMBL1972346 & 809152 & 6.6 & 5.6564 & TST & \\
\hline CHEMBL1965169 & 809152 & 4.2 & 4.3184 & TRN & \\
\hline CHEMBL1991818 & 809152 & 4.2 & 5.2735 & TST & \\
\hline CHEMBL1081312 & 809152 & 6.2 & 5.6606 & TRN & \\
\hline CHEMBL1965170 & 809152 & 5.6 & 6.1485 & TRN & \\
\hline CHEMBL1982866 & 809152 & 4.9 & 4.7095 & TRN & \\
\hline CHEMBL 2005792 & 809152 & 4.2 & 4.3858 & TRN & \\
\hline CHEMBL1986503 & 809152 & 4.2 & 4.5737 & TST & \\
\hline CHEMBL 2007592 & 809152 & 4.9 & 4.8994 & TRN & \\
\hline CHEMBL1972355 & 809152 & 5.9 & 6.07299 & 99999999995 & TST \\
\hline CHEMBL1997892 & 809152 & 4.2 & 4.7595 & TRN & \\
\hline CHEMBL 2001641 & 809152 & 4.1 & 4.4293 & TRN & \\
\hline CHEMBL1997193 & 809152 & 5.7 & 4.5875 & TST & \\
\hline CHEMBL210963 & 809152 & 4.9 & 4.7476 & TST & \\
\hline CHEMBL1964902 & 809152 & 4.2 & 4.1483 & TRN & \\
\hline CHEMBL1082440 & 809152 & 4.9 & 4.6611 & TST & \\
\hline CHEMBL1614705 & 809152 & 4.9 & 4.8391 & TRN & \\
\hline CHEMBL1984633 & 809152 & 4.9 & 4.687 & TRN & \\
\hline CHEMBL1965845 & 809152 & 4.9 & 4.7379 & TRN & \\
\hline CHEMBL1983715 & 809152 & 6.0 & 6.4645 & TRN & \\
\hline CHEMBL 2006715 & 809152 & 4.9 & 4.9885 & TRN & \\
\hline CHEMBL1990482 & 809152 & 4.9 & 4.6737 & TRN & \\
\hline CHEMBL1990904 & 809152 & 4.9 & 4.9618 & TRN & \\
\hline CHEMBL 2005475 & 809152 & 4.9 & 5.0327 & TRN & \\
\hline CHEMBL1991999 & 809152 & 5.8 & 6.6203 & TRN & \\
\hline CHEMBL220057 & 809152 & 5.8 & 6.0635 & TRN & \\
\hline CHEMBL1682545 & 809152 & 4.9 & 4.8849 & TRN & \\
\hline CHEMBL383541 & 809152 & 4.9 & 4.8305 & TRN & \\
\hline CHEMBL 2001224 & 809152 & 4.9 & 5.086 & TRN & \\
\hline CHEMBL10 & 809152 & 4.2 & 4.1288 & TRN & \\
\hline CHEMBL1976732 & 809152 & 4.9 & 4.7842 & TRN & \\
\hline CHEMBL1964937 & 809152 & 4.9 & 5.0318 & TRN & \\
\hline CHEMBL1980763 & 809152 & 5.6 & 5.7939 & TRN & \\
\hline CHEMBL 2005899 & 809152 & 4.9 & 4.6482 & TRN & \\
\hline CHEMBL1682552 & 809152 & 4.9 & 4.8196 & TRN & \\
\hline CHEMBL 2007479 & 809152 & 4.2 & 4.2698 & TRN & \\
\hline CHEMBL1986851 & 809152 & 6.0 & 6.5882 & TRN & \\
\hline CHEMBL105739 & 809152 & 6.7 & 5.7978 & TRN & \\
\hline CHEMBL1972220 & 809152 & 6.5 & 7.2789 & TRN & \\
\hline CHEMBL379300 & 809152 & 4.9 & 5.0235 & TRN & \\
\hline CHEMBL1973720 & 809152 & 6.2 & 5.1623 & TRN & \\
\hline CHEMBL 2003785 & 809152 & 4.2 & 4.6092 & TRN & \\
\hline CHEMBL1969523 & 809152 & 4.9 & 5.1691 & TRN & \\
\hline CHEMBL 2001923 & 809152 & 4.2 & 4.6298 & TST & \\
\hline CHEMBL1986781 & 809152 & 4.9 & 5.0092 & TRN & \\
\hline
\end{tabular}




\begin{tabular}{|c|c|c|c|c|c|}
\hline \multicolumn{6}{|c|}{ Supplemental Table S2.txt } \\
\hline CHEMBL1983070 & 809152 & 4.2 & 4.3072 & TRN & \\
\hline CHEMBL 2000645 & 809152 & 5.6 & 6.4166 & TRN & \\
\hline CHEMBL526133 & 809152 & 4.9 & 4.8491 & TRN & \\
\hline CHEMBL 2003514 & 809152 & 4.2 & 4.1768 & TRN & \\
\hline CHEMBL1989043 & 809152 & 6.5 & 5.2549 & TRN & \\
\hline CHEMBL387971 & 809152 & 4.9 & 5.4169 & TST & \\
\hline CHEMBL1164180 & 809152 & 7.3 & 7.4856 & TST & \\
\hline CHEMBL1967560 & 809152 & 4.5 & 5.38899 & 9999999999 & TRN \\
\hline CHEMBL1997611 & 809152 & 4.2 & 5.1055 & TST & \\
\hline CHEMBL1516890 & 809152 & 6.1 & 5.0797 & TRN & \\
\hline CHEMBL211378 & 809152 & 4.9 & 5.0966 & TRN & \\
\hline CHEMBL 2001751 & 809152 & 4.9 & 5.5044 & TRN & \\
\hline CHEMBL1984586 & 809152 & 4.9 & 4.8295 & TRN & \\
\hline CHEMBL1972659 & 809152 & 4.9 & 4.9519 & TST & \\
\hline CHEMBL 2002723 & 809152 & 5.7 & 5.5814 & TST & \\
\hline CHEMBL1987143 & 809152 & 4.9 & 4.5767 & TRN & \\
\hline CHEMBL1970217 & 809152 & 4.9 & 4.5386 & TRN & \\
\hline CHEMBL 2005528 & 809152 & 4.9 & 4.6898 & TRN & \\
\hline CHEMBL1984686 & 809152 & 4.2 & 4.5597 & TST & \\
\hline CHEMBL185569 & 809152 & 6.3 & 5.7242 & TRN & \\
\hline CHEMBL1969843 & 809152 & 4.9 & 4.7921 & TRN & \\
\hline CHEMBL 2007002 & 809152 & 4.9 & 5.0196 & TRN & \\
\hline CHEMBL1987007 & 809152 & 4.9 & 4.8578 & TRN & \\
\hline CHEMBL1973793 & 809152 & 5.6 & 4.6683 & TST & \\
\hline CHEMBL1969588 & 809152 & 6.5 & 5.5915 & TRN & \\
\hline CHEMBL1992073 & 809152 & 6.0 & 5.2326 & TRN & \\
\hline CHEMBL484390 & 809152 & 4.9 & 5.1071 & TRN & \\
\hline CHEMBL1979252 & 809152 & 4.9 & 4.8785 & TRN & \\
\hline CHEMBL1986143 & 809152 & 4.2 & 4.3041 & TRN & \\
\hline CHEMBL1972934 & 809152 & 4.4 & 4.6638 & TRN & \\
\hline CHEMBL 2007559 & 809152 & 4.2 & 4.712 & TRN & \\
\hline CHEMBL1992581 & 809152 & 5.5 & 4.8109 & TRN & \\
\hline CHEMBL 2004290 & 809152 & 5.9 & 6.3184 & TRN & \\
\hline CHEMBL1986499 & 809152 & 4.9 & 4.9931 & TRN & \\
\hline CHEMBL1972937 & 809152 & 4.9 & 4.8181 & TRN & \\
\hline CHEMBL 2000393 & 809152 & 7.3 & 5.8627 & TST & \\
\hline CHEMBL1983573 & 809152 & 4.2 & 4.8579 & TRN & \\
\hline CHEMBL 2004311 & 809152 & 6.8 & 6.1842 & TRN & \\
\hline CHEMBL1992634 & 809152 & 4.9 & 5.4519 & TRN & \\
\hline CHEMBL1984847 & 809152 & 4.2 & 4.5901 & TRN & \\
\hline CHEMBL316264 & 809152 & 4.9 & 4.5444 & TRN & \\
\hline CHEMBL1988075 & 809152 & 5.9 & 6.2479 & TRN & \\
\hline CHEMBL1996576 & 809152 & 4.2 & 4.3803 & TST & \\
\hline CHEMBL1988076 & 809152 & 4.5 & 4.8986 & TRN & \\
\hline CHEMBL1991678 & 809152 & 4.2 & 4.3492 & TRN & \\
\hline CHEMBL 2001239 & 809152 & 4.9 & 4.6808 & TRN & \\
\hline CHEMBL1988594 & 809152 & 4.9 & 4.7097 & TRN & \\
\hline CHEMBL2001288 & 809152 & 4.9 & 5.0591 & TRN & \\
\hline
\end{tabular}




\begin{tabular}{|c|c|c|c|c|c|}
\hline & & & Supplement & Table S2 & \\
\hline CHEMBL1999811 & 809152 & 4.9 & 5.1043 & TRN & \\
\hline CHEMBL 235157 & 809152 & 4.2 & 4.5328 & TST & \\
\hline CHEMBL1985074 & 809152 & 4.9 & 4.7833 & TST & \\
\hline CHEMBL1982874 & 809152 & 4.9 & 4.8524 & TRN & \\
\hline CHEMBL 2000481 & 809152 & 4.9 & 5.159 & TRN & \\
\hline CHEMBL1991725 & 809152 & 4.9 & 4.7788 & TRN & \\
\hline CHEMBL 2007296 & 809152 & 4.9 & 4.4362 & TRN & \\
\hline CHEMBL396523 & 809152 & 4.6 & 5.8849 & TRN & \\
\hline CHEMBL2004159 & 809152 & 4.2 & 4.1653 & TRN & \\
\hline CHEMBL1978371 & 809152 & 5.3 & 5.4074 & TST & \\
\hline CHEMBL1970203 & 809152 & 4.9 & 4.6399 & TRN & \\
\hline CHEMBL1986530 & 809152 & 4.9 & 5.1883 & TST & \\
\hline CHEMBL440084 & 809152 & 4.2 & 4.3406 & TRN & \\
\hline CHEMBL385478 & 809152 & 6.0 & 5.0192 & TRN & \\
\hline CHEMBL 2005375 & 809152 & 4.8 & 5.6332 & TRN & \\
\hline CHEMBL1969400 & 809152 & 6.5 & 6.7822 & TRN & \\
\hline CHEMBL1984191 & 809152 & 4.9 & 4.8181 & TRN & \\
\hline CHEMBL1966501 & 809152 & 4.2 & 4.1293 & TRN & \\
\hline CHEMBL1971029 & 809152 & 8.8 & 7.9989 & TRN & \\
\hline CHEMBL1974702 & 809152 & 4.9 & 4.9677 & TRN & \\
\hline CHEMBL1996111 & 809152 & 4.9 & 4.8837 & TRN & \\
\hline CHEMBL1966175 & 809152 & 4.2 & 4.8976 & TRN & \\
\hline CHEMBL1965589 & 809152 & 4.9 & 4.8106 & TRN & \\
\hline CHEMBL2007375 & 809152 & 4.2 & 4.1406 & TRN & \\
\hline CHEMBL1998193 & 809152 & 4.2 & 4.85800 & 00000000005 & TRN \\
\hline CHEMBL379975 & 809152 & 5.5 & 4.4594 & TST & \\
\hline CHEMBL474432 & 809152 & 6.2 & 5.1882 & TST & \\
\hline CHEMBL1973016 & 809152 & 4.2 & 4.7096 & TRN & \\
\hline CHEMBL1965387 & 809152 & 4.2 & 4.0225 & TRN & \\
\hline CHEMBL2001539 & 809152 & 3.8 & 4.5205 & TST & \\
\hline CHEMBL1997041 & 809152 & 5.3 & 4.5226 & TRN & \\
\hline CHEMBL550418 & 809152 & 5.8 & 5.2928 & TRN & \\
\hline CHEMBL1971289 & 809152 & 4.2 & 4.4312 & TRN & \\
\hline CHEMBL1988437 & 809152 & 5.7 & 4.4398 & TST & \\
\hline CHEMBL1998121 & 809152 & 4.9 & 4.6601 & TRN & \\
\hline CHEMBL1233887 & 809152 & 4.2 & 4.4305 & TRN & \\
\hline CHEMBL1992607 & 809152 & 4.2 & 4.5765 & TRN & \\
\hline CHEMBL1991800 & 809152 & 4.9 & 4.8115 & TRN & \\
\hline CHEMBL2003689 & 809152 & 4.2 & 4.2707 & TRN & \\
\hline CHEMBL1979357 & 809152 & 4.9 & 4.7067 & TRN & \\
\hline CHEMBL1996649 & 809152 & 5.6 & 5.0194 & TRN & \\
\hline CHEMBL1996817 & 809152 & 4.7 & 5.3433 & TRN & \\
\hline CHEMBL1986756 & 809152 & 4.2 & 4.0932 & TRN & \\
\hline CHEMBL3197315 & 809152 & 5.9 & 5.067 & TST & \\
\hline CHEMBL1083785 & 809152 & 5.6 & 6.5012 & TRN & \\
\hline CHEMBL468280 & 809152 & 4.9 & 4.9086 & TST & \\
\hline CHEMBL1990884 & 809152 & 4.9 & 5.7226 & TRN & \\
\hline CHEMBL 3109278 & 809152 & 4.8 & 5.1263 & TRN & \\
\hline
\end{tabular}




\begin{tabular}{|c|c|c|c|c|c|}
\hline \multicolumn{6}{|c|}{ Supplemental Table S2.txt } \\
\hline CHEMBL256835 & 809152 & 4.9 & 4.9265 & TRN & \\
\hline CHEMBL2005953 & 809152 & 5.5 & 6.3223 & TRN & \\
\hline CHEMBL1974998 & 809152 & 4.2 & 4.2938 & TRN & \\
\hline CHEMBL1980142 & 809152 & 4.9 & 4.5299 & TRN & \\
\hline CHEMBL41783 & 809152 & 4.9 & 4.8344 & TRN & \\
\hline CHEMBL 2004438 & 809152 & 4.2 & 4.5784 & TRN & \\
\hline CHEMBL 2006276 & 809152 & 4.9 & 4.9763 & TRN & \\
\hline CHEMBL191003 & 809152 & 5.9 & 5.5749 & TRN & \\
\hline CHEMBL271381 & 809152 & 7.8 & 7.1133 & TRN & \\
\hline CHEMBL 2006785 & 809152 & 4.9 & 5.1181 & TRN & \\
\hline CHEMBL1974090 & 809152 & 5.5 & 5.2749 & TRN & \\
\hline CHEMBL1982466 & 809152 & 6.3 & 6.6627 & TRN & \\
\hline CHEMBL1973359 & 809152 & 6.2 & 6.2141 & TST & \\
\hline CHEMBL1986943 & 809152 & 4.9 & 5.6945 & TRN & \\
\hline CHEMBL1979690 & 809152 & 7.6 & 7.4948 & TRN & \\
\hline CHEMBL 234085 & 809152 & 4.2 & 4.67899 & 9999999999 & TRN \\
\hline CHEMBL1969042 & 809152 & 4.9 & 5.1129 & TRN & \\
\hline CHEMBL 2005714 & 809152 & 6.9 & 5.9037 & TRN & \\
\hline CHEMBL1991186 & 809152 & 6.8 & 6.5613 & TRN & \\
\hline CHEMBL 2000345 & 809152 & 4.9 & 4.834 & TST & \\
\hline CHEMBL1999931 & 809152 & 4.9 & 4.2764 & TRN & \\
\hline CHEMBL1976376 & 809152 & 4.2 & 4.1487 & TRN & \\
\hline CHEMBL1983575 & 809152 & 6.3 & 5.8842 & TRN & \\
\hline CHEMBL2006873 & 809152 & 4.5 & 4.8579 & TRN & \\
\hline CHEMBL1968868 & 809152 & 4.2 & 4.322 & TRN & \\
\hline CHEMBL 2007064 & 809152 & 6.7 & 5.8081 & TRN & \\
\hline CHEMBL1981047 & 809152 & 7.6 & 7.4466 & TRN & \\
\hline CHEMBL229968 & 809152 & 6.1 & 5.2463 & TRN & \\
\hline CHEMBL1976196 & 809152 & 4.2 & 4.7837 & TST & \\
\hline CHEMBL1976240 & 809152 & 4.9 & 4.665 & TRN & \\
\hline CHEMBL1997197 & 809152 & 4.2 & 4.4295 & TRN & \\
\hline CHEMBL1983630 & 809152 & 4.2 & 4.5892 & TRN & \\
\hline CHEMBL1968151 & 809152 & 4.9 & 4.7666 & TRN & \\
\hline CHEMBL379218 & 809152 & 4.9 & 4.8994 & TRN & \\
\hline CHEMBL 2003817 & 809152 & 4.9 & 4.3952 & TRN & \\
\hline CHEMBL1970083 & 809152 & 7.6 & 6.5411 & TRN & \\
\hline CHEMBL 226403 & 809152 & 4.9 & 4.7221 & TRN & \\
\hline CHEMBL1994938 & 809152 & 4.9 & 5.3275 & TRN & \\
\hline CHEMBL1977223 & 809152 & 4.9 & 4.4907 & TRN & \\
\hline CHEMBL1995765 & 809152 & 4.5 & 4.6805 & TST & \\
\hline CHEMBL1236126 & 809152 & 4.9 & 5.0539 & TRN & \\
\hline CHEMBL1966279 & 809152 & 4.9 & 5.074 & TRN & \\
\hline CHEMBL1984760 & 809152 & 5.4 & 5.7221 & TRN & \\
\hline CHEMBL1997846 & 809152 & 4.4 & 4.6196 & TRN & \\
\hline CHEMBL 2004419 & 809152 & 4.9 & 4.8921 & TRN & \\
\hline CHEMBL360847 & 809152 & 5.5 & 4.3477 & TST & \\
\hline CHEMBL 2007073 & 809152 & 4.2 & 4.1304 & TRN & \\
\hline CHEMBL1995811 & 809152 & 4.2 & 4.0242 & TRN & \\
\hline
\end{tabular}




\begin{tabular}{|c|c|c|c|c|c|}
\hline CHEMBL1994074 & 809152 & 4.9 & \multicolumn{2}{|c|}{4.8180000000000005} & TRN \\
\hline CHEMBL1992937 & 809152 & 4.2 & 4.5506 & TST & \\
\hline CHEMBL451401 & 809152 & 3.5 & 4.552 & TRN & \\
\hline CHEMBL1972119 & 809152 & 4.9 & 4.8155 & TRN & \\
\hline CHEMBL95692 & 809152 & 4.9 & 4.8978 & TRN & \\
\hline CHEMBL1242995 & 809152 & 6.7 & 6.4246 & TRN & \\
\hline CHEMBL1090356 & 809152 & 4.9 & \multicolumn{2}{|c|}{5.2139999999999995} & TRN \\
\hline CHEMBL1976455 & 809152 & 4.9 & 4.582 & TRN & \\
\hline CHEMBL261849 & 809152 & 4.2 & 4.9586 & TST & \\
\hline CHEMBL1983923 & 809152 & 4.6 & 5.3114 & TRN & \\
\hline CHEMBL1983534 & 809152 & 4.9 & 4.6605 & TRN & \\
\hline CHEMBL1982361 & 809152 & 4.9 & 4.879 & TRN & \\
\hline CHEMBL1999112 & 809152 & 4.9 & 4.9754 & TST & \\
\hline CHEMBL1982122 & 809152 & 4.9 & 4.5643 & TRN & \\
\hline CHEMBL 2000801 & 809152 & 4.9 & 4.9891 & TRN & \\
\hline CHEMBL1682546 & 809152 & 4.9 & 4.7502 & TRN & \\
\hline CHEMBL1991395 & 809152 & 4.9 & 4.7668 & TRN & \\
\hline CHEMBL1988872 & 809152 & 4.2 & 4.869 & TRN & \\
\hline CHEMBL1971245 & 809152 & 4.9 & 5.2913 & TRN & \\
\hline CHEMBL1993634 & 809152 & 4.2 & 4.8424 & TRN & \\
\hline CHEMBL1972142 & 809152 & 4.6 & 5.2205 & TRN & \\
\hline CHEMBL 2002182 & 809152 & 4.0 & 4.6163 & TRN & \\
\hline CHEMBL 2003638 & 809152 & 4.9 & 4.2628 & TRN & \\
\hline CHEMBL1996066 & 809152 & 6.4 & 4.9179 & TST & \\
\hline CHEMBL1983393 & 809152 & 4.2 & 4.7341 & TRN & \\
\hline CHEMBL 2006674 & 809152 & 4.2 & 4.5964 & TST & \\
\hline CHEMBL1984236 & 809152 & 4.2 & 4.1489 & TST & \\
\hline CHEMBL1992371 & 809152 & 5.5 & 4.8894 & TRN & \\
\hline CHEMBL1375640 & 809152 & 4.9 & 4.6948 & TST & \\
\hline CHEMBL1979970 & 809152 & 4.9 & 4.8741 & TRN & \\
\hline CHEMBL2002599 & 809152 & 4.2 & 4.3518 & TRN & \\
\hline CHEMBL 249282 & 809152 & 4.9 & 4.8249 & TST & \\
\hline CHEMBL1967252 & 809152 & 4.9 & 4.6707 & TRN & \\
\hline CHEMBL2004637 & 809152 & 5.5 & 5.5178 & TRN & \\
\hline CHEMBL1993374 & 809152 & 5.2 & 5.4766 & TRN & \\
\hline CHEMBL1994318 & 809152 & 4.2 & 4.8441 & TRN & \\
\hline CHEMBL 2006237 & 809152 & 4.9 & 4.8094 & TRN & \\
\hline CHEMBL1999506 & 809152 & 4.2 & 4.1449 & TRN & \\
\hline CHEMBL1967720 & 809152 & 6.0 & 6.6673 & TRN & \\
\hline CHEMBL1991138 & 809152 & 4.9 & 5.0156 & TST & \\
\hline CHEMBL1979516 & 809152 & 7.8 & 5.3864 & TST & \\
\hline CHEMBL1605605 & 809152 & 4.2 & 4.828 & TST & \\
\hline CHEMBL1996208 & 809152 & 4.2 & 4.9247 & TST & \\
\hline CHEMBL1989029 & 809152 & 6.0 & 5.3135 & TST & \\
\hline CHEMBL392642 & 809152 & 4.9 & 5.1937 & TST & \\
\hline CHEMBL1970352 & 809152 & 5.6 & 4.8958 & TST & \\
\hline CHEMBL1965631 & 809152 & 4.9 & 4.4877 & TST & \\
\hline CHEMBL1980144 & 809152 & 4.9 & 4.5849 & TST & \\
\hline
\end{tabular}




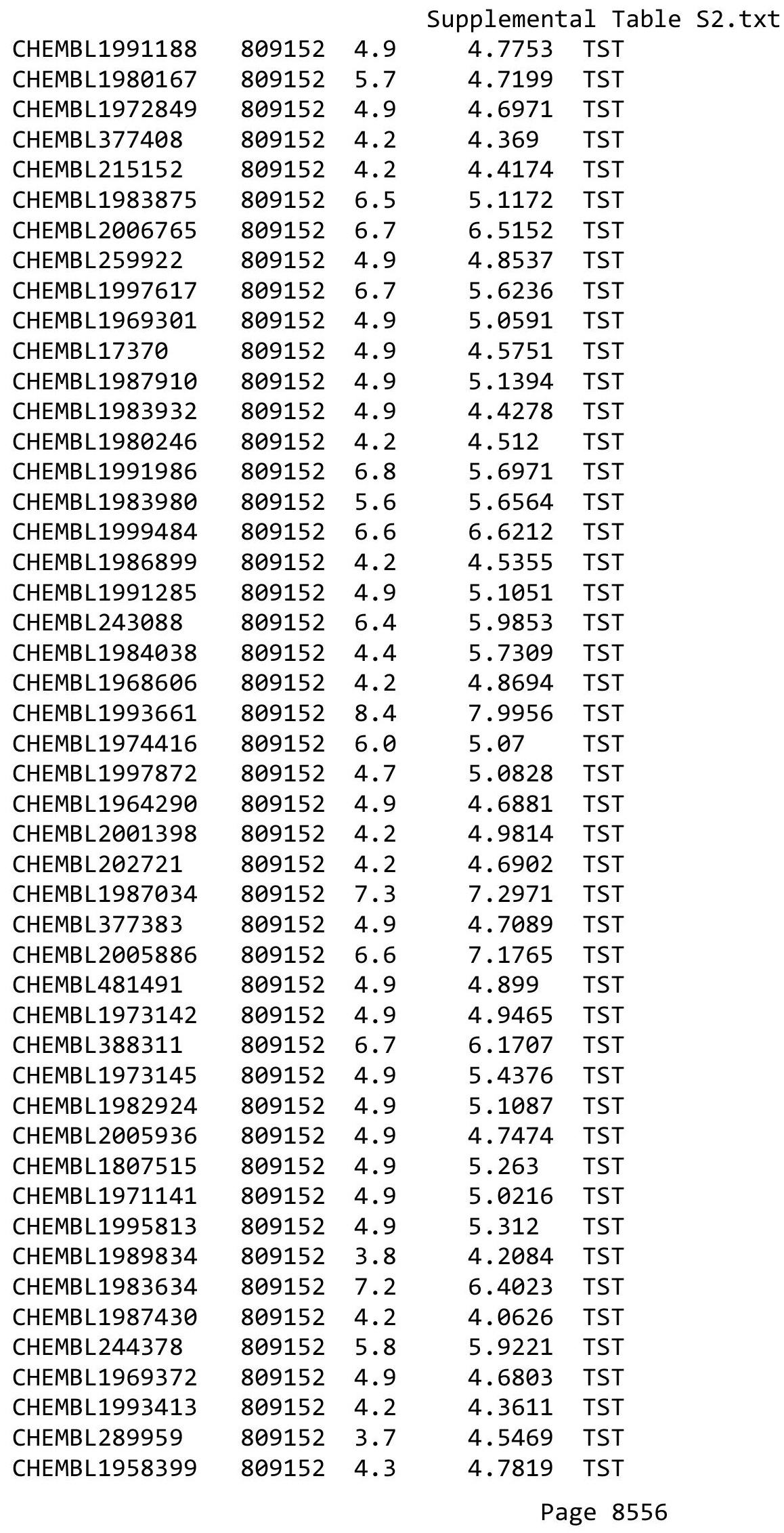




\begin{tabular}{|c|c|c|c|c|c|}
\hline \multicolumn{6}{|c|}{ Supplemental Table S2.txt } \\
\hline CHEMBL1972752 & 809152 & 4.5 & 4.7943 & TST & \\
\hline CHEMBL1993584 & 809152 & 4.9 & 4.8205 & TST & \\
\hline CHEMBL1986263 & 809152 & 4.9 & 5.343 & TST & \\
\hline CHEMBL 2000114 & 809152 & 4.9 & 5.0741 & TST & \\
\hline CHEMBL1986265 & 809152 & 4.2 & 4.1958 & TST & \\
\hline CHEMBL1975647 & 809152 & 4.9 & 4.6976 & TST & \\
\hline CHEMBL1968380 & 809152 & 6.6 & 5.7122 & TST & \\
\hline CHEMBL1967211 & 809152 & 4.0 & 4.6445 & TST & \\
\hline CHEMBL1964644 & 809152 & 4.9 & 4.7418 & TST & \\
\hline CHEMBL1991734 & 809152 & 6.0 & 6.0244 & TST & \\
\hline CHEMBL1981782 & 809152 & 4.9 & 4.7281 & TST & \\
\hline CHEMBL1977681 & 809152 & 4.9 & 4.6512 & TST & \\
\hline CHEMBL1970142 & 809152 & 6.7 & 6.6378 & TST & \\
\hline CHEMBL 272868 & 472994 & 9.0 & 8.8363 & TRN & \\
\hline CHEMBL411937 & 472994 & 8.5376 & 7.4634 & TRN & \\
\hline CHEMBL271805 & 472994 & 6.6234 & 6.7686 & TRN & \\
\hline CHEMBL409537 & 472994 & 5.0 & 5.8056 & TRN & \\
\hline CHEMBL271527 & 472994 & 8.5229 & 8.2114 & TRN & \\
\hline CHEMBL270082 & 472994 & 8.4949 & 8.8912 & TRN & \\
\hline CHEMBL 272189 & 472994 & 7.2366 & 8.1888 & TRN & \\
\hline CHEMBL406399 & 472994 & 7.585 & 7.3059 & TRN & \\
\hline CHEMBL271553 & 472994 & 5.0 & 6.2992 & TRN & \\
\hline CHEMBL271158 & 472994 & 9.6778 & 9.6942 & TRN & \\
\hline CHEMBL409647 & 472994 & 7.5229 & 7.4313 & TRN & \\
\hline CHEMBL 272176 & 472994 & 7.6778 & 8.4361 & TRN & \\
\hline CHEMBL271838 & 472994 & 9.1871 & 9.2244 & TRN & \\
\hline CHEMBL272658 & 472994 & 7.1427 & 6.4328 & TRN & \\
\hline CHEMBL272876 & 472994 & 8.8861 & 8.452 & TRN & \\
\hline CHEMBL270955 & 472994 & 8.7212 & 8.1749 & TRN & \\
\hline CHEMBL271810 & 472994 & 8.8539 & 8.4742 & TRN & \\
\hline CHEMBL408430 & 472994 & 7.9393 & 7.9 & TST & \\
\hline CHEMBL 259253 & 472994 & 8.4089 & 8.6623 & TRN & \\
\hline CHEMBL406918 & 472994 & 5.0 & 6.4315 & TRN & \\
\hline CHEMBL411244 & 472994 & 9.3872 & 9.419 & TRN & \\
\hline CHEMBL410676 & 472994 & 8.5229 & 8.1244 & TRN & \\
\hline CHEMBL410677 & 472994 & 8.7959 & 8.1613 & TRN & \\
\hline CHEMBL 270125 & 472994 & 9.1549 & 8.6704 & TRN & \\
\hline CHEMBL259462 & 472994 & 8.0315 & 7.6448 & TRN & \\
\hline CHEMBL259463 & 472994 & 8.1805 & 7.9837 & TRN & \\
\hline CHEMBL408964 & 472994 & 8.4815 & 8.7469 & TRN & \\
\hline CHEMBL409669 & 472994 & 8.301 & 8.4936 & TST & \\
\hline CHEMBL271565 & 472994 & 8.5086 & 9.0135 & TRN & \\
\hline CHEMBL1203961 & 472994 & 7.5686 & 7.3282 & TST & \\
\hline CHEMBL409265 & 472994 & 5.7986 & 6.973 & TRN & \\
\hline CHEMBL262865 & 472994 & 8.3565 & 7.8516 & TRN & \\
\hline CHEMBL272882 & 472994 & 8.3372 & 8.045 & TRN & \\
\hline CHEMBL409231 & 472994 & 6.6253 & 5.9186 & TRN & \\
\hline CHEMBL409491 & 472994 & 8.0706 & 8.43700 & 0000000001 & TRN \\
\hline & & & $P$ & e 8557 & \\
\hline
\end{tabular}




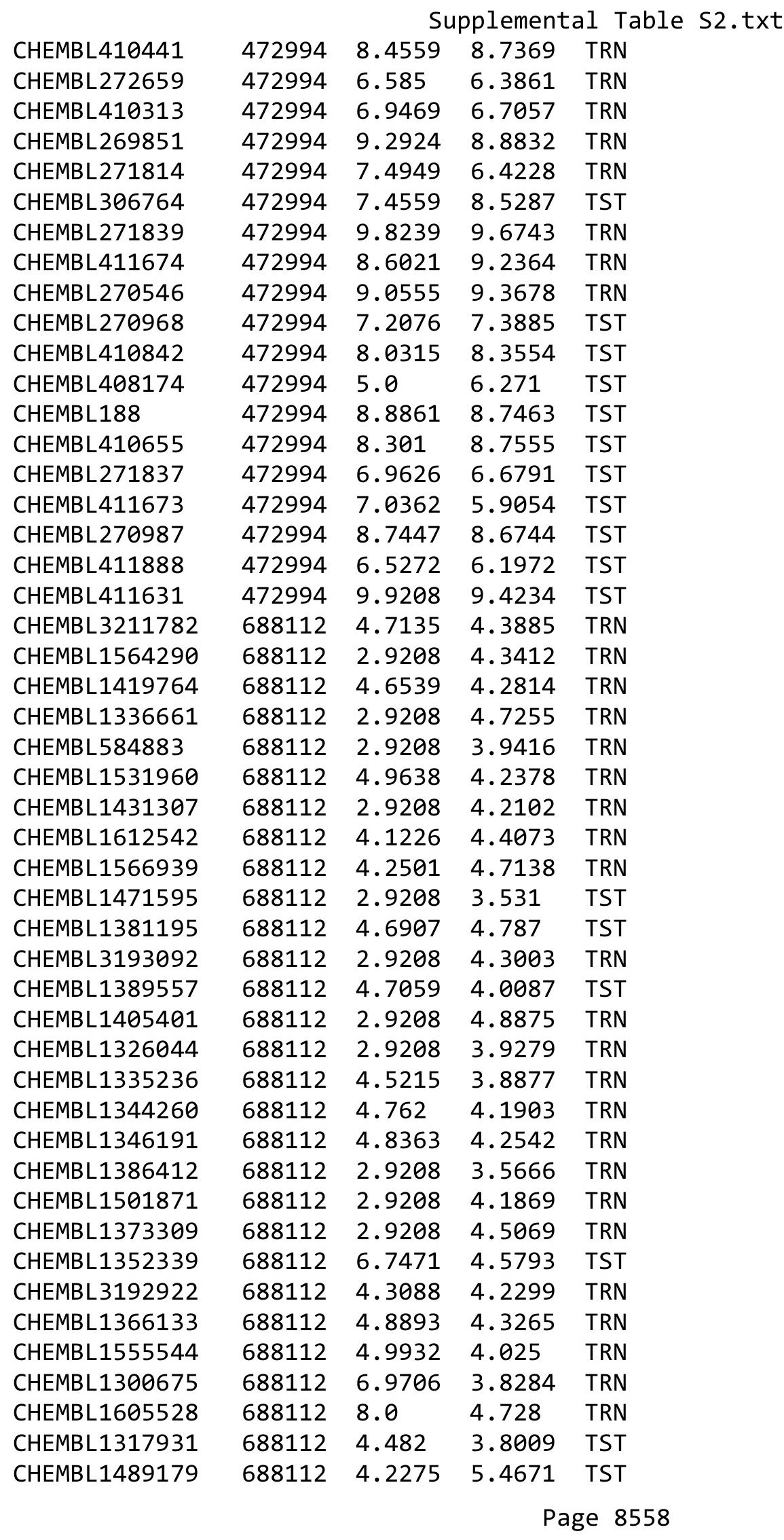


Supplemental Table S2.txt

\begin{tabular}{|c|c|c|c|c|}
\hline CHEMBL1548782 & 688112 & 4.2966 & 4.2847 & TST \\
\hline CHEMBL1348831 & 688112 & 5.1262 & 4.5244 & TRN \\
\hline CHEMBL1339768 & 688112 & 2.9208 & 4.4705 & TRN \\
\hline CHEMBL1393784 & 688112 & 2.9208 & 4.8504 & TST \\
\hline CHEMBL1588860 & 688112 & 3.9938 & 4.8894 & TRN \\
\hline CHEMBL1505428 & 688112 & 2.9208 & 4.381 & TST \\
\hline CHEMBL1405942 & 688112 & 4.8517 & 4.3882 & TRN \\
\hline CHEMBL1536507 & 688112 & 2.9208 & 4.8344 & TRN \\
\hline CHEMBL1452106 & 688112 & 5.224 & 4.4171 & TRN \\
\hline CHEMBL1571896 & 688112 & 4.2948 & 4.4773 & TRN \\
\hline CHEMBL1362093 & 688112 & 2.9208 & 3.6614 & TRN \\
\hline CHEMBL1340051 & 688112 & 2.9208 & 3.6005 & TRN \\
\hline CHEMBL1417043 & 688112 & 4.8714 & 4.3208 & TRN \\
\hline CHEMBL1501925 & 688112 & 2.9208 & 4.3257 & TRN \\
\hline CHEMBL1536561 & 688112 & 2.9208 & 3.8604 & TRN \\
\hline CHEMBL1493059 & 688112 & 4.6741 & 4.1874 & TRN \\
\hline CHEMBL1472038 & 688112 & 4.763 & 4.395 & TRN \\
\hline CHEMBL1454225 & 688112 & 4.32 & 4.3822 & TRN \\
\hline CHEMBL1575467 & 688112 & 5.0214 & 4.0166 & TST \\
\hline CHEMBL1385987 & 688112 & 4.9562 & 4.1059 & TRN \\
\hline CHEMBL1566633 & 688112 & 6.6271 & 4.505 & TRN \\
\hline CHEMBL1418134 & 688112 & 4.81800 & 00000006 & 4.3709 \\
\hline CHEMBL1609703 & 688112 & 4.9582 & 3.6015 & TST \\
\hline CHEMBL1454540 & 688112 & 4.7892 & 4.2526 & TRN \\
\hline CHEMBL1308593 & 688112 & 4.7372 & 4.3747 & TRN \\
\hline CHEMBL3192253 & 688112 & 4.2487 & 4.6171 & TRN \\
\hline CHEMBL1560769 & 688112 & 6.224 & 4.3777 & TRN \\
\hline CHEMBL1386650 & 688112 & 4.1618 & 4.2557 & TST \\
\hline CHEMBL1422155 & 688112 & 5.3283 & 4.2226 & TRN \\
\hline CHEMBL1431210 & 688112 & 5.2536 & 4.9155 & TRN \\
\hline CHEMBL1432801 & 688112 & 6.7055 & 4.298 & TRN \\
\hline CHEMBL1499905 & 688112 & 4.8196 & 4.9579 & TRN \\
\hline CHEMBL3190953 & 688112 & 4.2769 & 5.1367 & TRN \\
\hline CHEMBL1473601 & 688112 & 2.9208 & 4.0049 & TRN \\
\hline CHEMBL3198916 & 688112 & 4.0062 & 4.3486 & TRN \\
\hline CHEMBL1520621 & 688112 & 4.3963 & 3.9443 & TRN \\
\hline CHEMBL1392472 & 688112 & 3.2218 & 4.233006 & 00000000005 \\
\hline CHEMBL1497725 & 688112 & 5.1017 & 4.1243 & TRN \\
\hline CHEMBL3207847 & 688112 & 4.9309 & 4.3358 & TRN \\
\hline CHEMBL1407379 & 688112 & 4.6634 & 4.4047 & TST \\
\hline CHEMBL1303140 & 688112 & 4.9645 & 4.2973 & TRN \\
\hline CHEMBL1350621 & 688112 & 5.6192 & 4.9995 & TRN \\
\hline CHEMBL1326529 & 688112 & 4.8699 & 4.1676 & TRN \\
\hline CHEMBL1521031 & 688112 & 4.3815 & 4.4877 & TRN \\
\hline CHEMBL1570507 & 688112 & 2.9208 & 4.3609 & TRN \\
\hline CHEMBL1443303 & 688112 & 2.9208 & 3.6098 & TRN \\
\hline CHEMBL1602816 & 688112 & 2.9208 & 4.2996 & TRN \\
\hline CHEMBL1375907 & 688112 & 4.8582 & 4.2887 & TRN \\
\hline
\end{tabular}


Supplemental Table S2.txt

\begin{tabular}{|c|c|c|c|c|c|}
\hline CHEMBL1302976 & 688112 & 4.2936 & 4.2829 & TRN & \\
\hline CHEMBL1534724 & 688112 & 4.4239 & 4.3682 & TRN & \\
\hline CHEMBL3208571 & 688112 & 4.5705 & 4.3232 & TRN & \\
\hline CHEMBL 3194314 & 688112 & 4.8093 & 4.336 & TRN & \\
\hline CHEMBL 3208442 & 688112 & 4.4903 & 4.2048 & TST & \\
\hline CHEMBL1390359 & 688112 & 4.7078 & 4.3678 & TRN & \\
\hline CHEMBL1453005 & 688112 & 6.5214 & 4.4779 & TRN & \\
\hline CHEMBL1321472 & 688112 & 5.1578 & 4.6683 & TRN & \\
\hline CHEMBL1302780 & 688112 & 4.2226 & 4.2257 & TRN & \\
\hline CHEMBL1322183 & 688112 & 4.8227 & 4.2705 & TRN & \\
\hline CHEMBL1365808 & 688112 & 4.7267 & 4.6604 & TRN & \\
\hline CHEMBL1411542 & 688112 & 2.9208 & 4.8346 & TRN & \\
\hline CHEMBL1409419 & 688112 & 5.255 & 3.7101 & TST & \\
\hline CHEMBL1425445 & 688112 & 2.9208 & 4.3632 & TRN & \\
\hline CHEMBL1528180 & 688112 & 2.9208 & 4.4057 & TRN & \\
\hline CHEMBL1579176 & 688112 & 4.4393 & 4.3352 & TRN & \\
\hline CHEMBL1440263 & 688112 & 4.678 & 4.2893 & TRN & \\
\hline CHEMBL1606705 & 688112 & 2.9208 & 4.1775 & TRN & \\
\hline CHEMBL1543194 & 688112 & 4.6114 & 4.2969 & TRN & \\
\hline CHEMBL1416166 & 688112 & 6.9586 & 4.523 & TRN & \\
\hline CHEMBL1429728 & 688112 & 4.2819 & 4.5191 & TRN & \\
\hline CHEMBL1367627 & 688112 & 2.9208 & 3.62899 & 99999999996 & TRN \\
\hline CHEMBL1545467 & 688112 & 4.4969 & 4.8147 & TRN & \\
\hline CHEMBL1464193 & 688112 & 2.9208 & 4.3112 & TST & \\
\hline CHEMBL 3190857 & 688112 & 2.9208 & 3.9495 & TRN & \\
\hline CHEMBL3211096 & 688112 & 4.2096 & 4.3429 & TRN & \\
\hline CHEMBL1578912 & 688112 & 2.9208 & 3.4844 & TRN & \\
\hline CHEMBL1337580 & 688112 & 4.7024 & 4.1271 & TRN & \\
\hline CHEMBL1538461 & 688112 & 2.9208 & 3.9605 & TRN & \\
\hline CHEMBL1495905 & 688112 & 2.9208 & 4.7587 & TRN & \\
\hline CHEMBL1526676 & 688112 & 5.0996 & 4.1423 & TST & \\
\hline CHEMBL1429292 & 688112 & 4.7322 & 4.3042 & TRN & \\
\hline CHEMBL1601639 & 688112 & 4.7227 & 4.0832 & TRN & \\
\hline CHEMBL1384739 & 688112 & 7.0 & 4.7132 & TRN & \\
\hline CHEMBL1377181 & 688112 & 2.9208 & 4.2379 & TST & \\
\hline CHEMBL1312335 & 688112 & 4.8697 & 3.9914 & TRN & \\
\hline CHEMBL1331362 & 688112 & 2.9208 & 4.3776 & TRN & \\
\hline CHEMBL1569976 & 688112 & 4.5587 & 4.2517 & TRN & \\
\hline CHEMBL1343994 & 688112 & 4.0454 & 4.3903 & TRN & \\
\hline CHEMBL1508580 & 688112 & 4.3539 & 3.5714 & TST & \\
\hline CHEMBL1451064 & 688112 & 4.4819 & 4.4294 & TRN & \\
\hline CHEMBL1307534 & 688112 & 2.9208 & 3.6074 & TRN & \\
\hline CHEMBL1469600 & 688112 & 4.8955 & 4.3582 & TST & \\
\hline CHEMBL1426292 & 688112 & 5.1261 & 4.13 & TRN & \\
\hline CHEMBL1334545 & 688112 & 4.6941 & 4.2749 & TST & \\
\hline CHEMBL1991055 & 688112 & 8.0 & 5.1068 & TRN & \\
\hline CHEMBL1358862 & 688112 & 2.9208 & 4.4104 & TRN & \\
\hline CHEMBL1396533 & 688112 & 4.4604 & 4.3167 & TRN & \\
\hline
\end{tabular}


Supplemental Table S2.txt

\begin{tabular}{|c|c|c|c|c|}
\hline - & & & & \\
\hline HEMBL1342952 & 88112 & 4.7747 & 4.2831 & \\
\hline & & & & \\
\hline 347 & 12 & $\partial 8$ & 78 & \\
\hline IEMBL1507676 & 88112 & & 239 & \\
\hline AEMBL3211892 & 88112 & 9208 & 8875 & \\
\hline HEMBL13 & 88112 & 8561 & 1424 & \\
\hline IEMBL15 & 8112 & & 5844 & \\
\hline EMBL13 & 88112 & & .2572 & \\
\hline AEMBL1582073 & 88112 & 418 & 1705 & \\
\hline AEMBL1467253 & 88112 & 9208 & 5907 & \\
\hline IEMBL13 & 88112 & 329 & 3478 & \\
\hline IEMBL16 & 112 & & & \\
\hline AEMBL20 & 88112 & 208 & 3754 & \\
\hline IEMBL144 & 88112 & 208 & 525 & \\
\hline IEMBL169 & 88112 & 476 & & \\
\hline AEMBL13 & 88112 & 208 & 178 & \\
\hline HEMBL13 & 38112 & 717 & & \\
\hline 5 & 88112 & 208 & 375 & \\
\hline AEMBL15 & 38112 & 208 & & \\
\hline FIMLIS & 112 & 832 & 18 & |SI \\
\hline AEMBL14 & 38112 & 208 & 833 & RN \\
\hline HEM & 38112 & 12 & & \\
\hline 52 & 12 & & & \\
\hline IEMBL14 & 12 & 8 & 54 & RIV \\
\hline 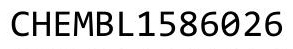 & 2 & 98 & 852 & RN \\
\hline 6 & 38112 & 49 & 006 & \\
\hline $\mathrm{FN}>$ & 8112 & 08 & & \\
\hline AEMBL13 & & & & $\omega_{3}+2$ \\
\hline AEMBL16 & 88112 & $34 /$ & 59 & SI \\
\hline IEMBL13 & 38112 & & 93 & RN \\
\hline AFMRI $1=$ & 12 & & & RN \\
\hline & & & & RN \\
\hline HEMBL134 & & & & RN \\
\hline AEMBL137 & 88112 & & & RN \\
\hline AEMBL16 & 88112 & 96 & 728 & RN \\
\hline 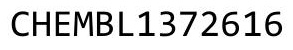 & & 38 & & RN \\
\hline HEMBL1462179 & & & & RN \\
\hline HEMBL3196035 & 88112 & 208 & 304 & IST \\
\hline IEMBL160 & 88112 & & 497 & IST \\
\hline HEMBL142 & 88112 & 379 & 833 & \\
\hline 1 & & & & RN \\
\hline HEMBL13 & 8112 & & 162 & $\mathrm{RN}$ \\
\hline AEMBL1511429 & 88112 & 547 & 6999 & ST \\
\hline 3L137 & & & 303 & \\
\hline HEMBL132 & 588112 & & 1748 & \\
\hline 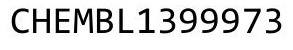 & 688112 & 4.0075 & 4.6964 & \\
\hline SHEMBL1301421 & 688112 & 2.9208 & 4.5791 & RN \\
\hline
\end{tabular}

Page 8561 
Supplemental Table S2.txt

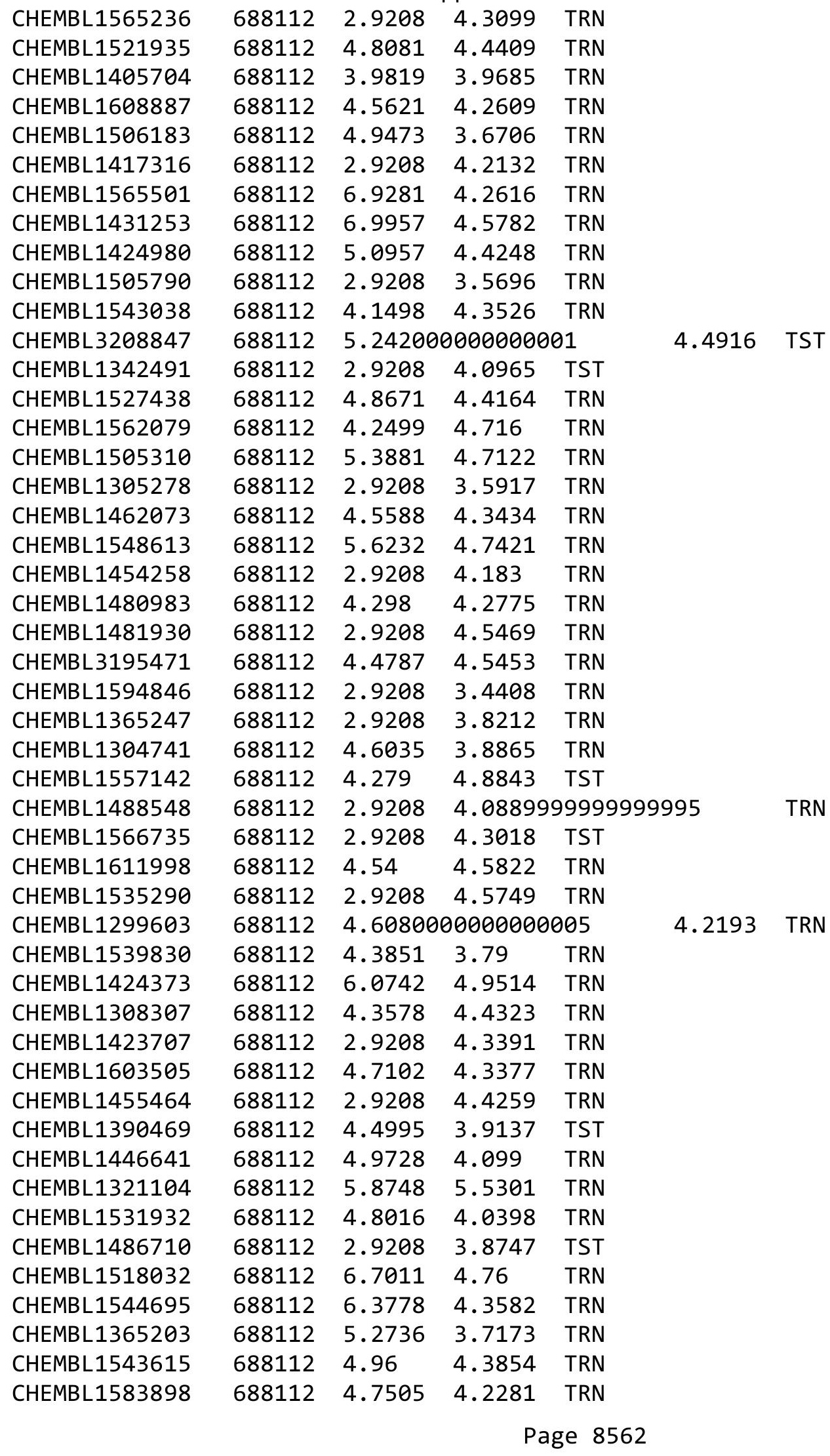




\begin{tabular}{|c|c|c|c|c|}
\hline \multicolumn{5}{|c|}{ Supplemental Table S2.txt } \\
\hline CHEMBL1553750 & 688112 & 6.0521 & 4.319 & TRN \\
\hline CHEMBL1340076 & 688112 & 4.1019 & 3.972 & TRN \\
\hline CHEMBL1561328 & 688112 & 2.9208 & 3.6517 & TRN \\
\hline CHEMBL1530182 & 688112 & 5.3743 & 4.6628 & TRN \\
\hline CHEMBL 2369161 & 688112 & 2.9208 & 4.7002 & TST \\
\hline CHEMBL1442140 & 688112 & 2.9208 & 4.4639 & TRN \\
\hline CHEMBL579380 & 688112 & 2.9208 & 3.8203 & TRN \\
\hline CHEMBL1318394 & 688112 & 2.9208 & 4.5931 & TRN \\
\hline CHEMBL1368046 & 688112 & 2.9208 & 3.5937 & TRN \\
\hline CHEMBL1428684 & 688112 & 4.3573 & 4.7095 & TRN \\
\hline CHEMBL 1477844 & 688112 & 5.0478 & 4.034 & TRN \\
\hline CHEMBL1447912 & 688112 & 2.9208 & 4.2986 & TRN \\
\hline CHEMBL 223496 & 688112 & 4.8057 & 3.8271 & TRN \\
\hline CHEMBL1446574 & 688112 & 4.5274 & 5.1916 & TRN \\
\hline CHEMBL3192954 & 688112 & 2.9208 & 4.9841 & TRN \\
\hline CHEMBL 1597510 & 688112 & 2.9208 & 3.9682 & TST \\
\hline CHEMBL1418678 & 688112 & 4.6109 & 4.0163 & TRN \\
\hline CHEMBL1583182 & 688112 & 4.1371 & 4.2626 & TRN \\
\hline CHEMBL1518185 & 688112 & 2.9208 & 3.5183 & TST \\
\hline CHEMBL1446545 & 688112 & 4.0171 & 4.5277 & TRN \\
\hline CHEMBL1339266 & 688112 & 2.9208 & 3.8233 & TRN \\
\hline CHEMBL1305698 & 688112 & 4.8967 & 4.0508 & TRN \\
\hline CHEMBL1323007 & 688112 & 4.6521 & 4.1301 & TRN \\
\hline CHEMBL1567107 & 688112 & 5.1449 & 4.5437 & TRN \\
\hline CHEMBL3195205 & 688112 & 5.0874 & 4.4775 & TST \\
\hline CHEMBL 1605089 & 688112 & 5.2052 & 4.2787 & TRN \\
\hline CHEMBL1332894 & 688112 & 4.0083 & 4.3476 & TRN \\
\hline CHEMBL1530542 & 688112 & 4.2163 & 4.3588 & TRN \\
\hline CHEMBL1376513 & 688112 & 5.2734 & 4.2119 & TRN \\
\hline CHEMBL1450952 & 688112 & 4.73 & 4.4008 & TRN \\
\hline CHEMBL3197079 & 688112 & 3.9231 & 4.5287 & TRN \\
\hline CHEMBL1494524 & 688112 & 2.9208 & 4.5311 & TRN \\
\hline CHEMBL1339785 & 688112 & 2.9208 & 4.6835 & TST \\
\hline CHEMBL1419590 & 688112 & 4.9946 & 4.3183 & TRN \\
\hline CHEMBL3192388 & 688112 & 4.0569 & 4.2674 & TRN \\
\hline CHEMBL1544322 & 688112 & 2.9208 & 4.1245 & TRN \\
\hline CHEMBL1499004 & 688112 & 2.9208 & 4.1754 & TRN \\
\hline CHEMBL1573309 & 688112 & 2.9208 & 4.2466 & TRN \\
\hline CHEMBL1433155 & 688112 & 2.9208 & 5.074 & TRN \\
\hline CHEMBL1605162 & 688112 & 5.1911 & 3.866 & TRN \\
\hline CHEMBL1408969 & 688112 & 4.9352 & 4.8738 & TRN \\
\hline CHEMBL1994673 & 688112 & 2.9208 & 4.9296 & TRN \\
\hline CHEMBL1594893 & 688112 & 2.9208 & 3.9339 & TRN \\
\hline CHEMBL1543843 & 688112 & 2.9208 & 4.187 & TRN \\
\hline CHEMBL1415109 & 688112 & 2.9208 & 4.3268 & TRN \\
\hline CHEMBL1323437 & 688112 & 2.9208 & 3.6915 & TRN \\
\hline CHEMBL1421605 & 688112 & 2.9208 & 4.2868 & TST \\
\hline CHEMBL1399096 & 688112 & 4.8086 & 3.8991 & TRN \\
\hline
\end{tabular}


Supplemental Table S2.txt

\begin{tabular}{|c|c|c|c|c|c|}
\hline CHEMBL1544693 & 688112 & 2.9208 & 3.6177 & TST & \\
\hline CHEMBL1305388 & 688112 & 4.7598 & 4.2307 & TRN & \\
\hline CHEMBL1990390 & 688112 & 4.0743 & 4.2689 & TRN & \\
\hline CHEMBL1536236 & 688112 & 2.9208 & 4.1216 & TRN & \\
\hline CHEMBL1402372 & 688112 & 4.9253 & 4.2395 & TRN & \\
\hline CHEMBL1489593 & 688112 & 4.692 & 4.5636 & TRN & \\
\hline CHEMBL1609109 & 688112 & 4.5469 & 3.9222 & TRN & \\
\hline CHEMBL1468717 & 688112 & 5.0377 & 4.224 & TRN & \\
\hline CHEMBL1384659 & 688112 & 2.9208 & 3.6188 & TST & \\
\hline CHEMBL1308386 & 688112 & 5.4309 & 4.0645 & TRN & \\
\hline CHEMBL1461600 & 688112 & 6.7932 & 4.9102 & TST & \\
\hline CHEMBL601070 & 688112 & 2.9208 & 4.0163 & TRN & \\
\hline CHEMBL1500007 & 688112 & 4.6032 & 4.2954 & TRN & \\
\hline CHEMBL1541456 & 688112 & 2.9208 & 4.3285 & TRN & \\
\hline CHEMBL 2007227 & 688112 & 2.9208 & 4.9854 & TRN & \\
\hline CHEMBL1460534 & 688112 & 5.1903 & 5.2082 & TRN & \\
\hline CHEMBL1377188 & 688112 & 4.3935 & 4.5982 & TRN & \\
\hline CHEMBL1323478 & 688112 & 3.2218 & 4.3845 & TRN & \\
\hline CHEMBL567829 & 688112 & 2.9208 & 3.5872 & TST & \\
\hline CHEMBL1477280 & 688112 & 4.7903 & 4.6748 & TRN & \\
\hline CHEMBL1453649 & 688112 & 2.9208 & 4.3241 & TRN & \\
\hline CHEMBL1484081 & 688112 & 4.2201 & 4.46399 & 99999999995 & TRN \\
\hline CHEMBL1374534 & 688112 & 4.8819 & 4.038 & TRN & \\
\hline CHEMBL1301526 & 688112 & 5.0335 & 4.38399 & & TRN \\
\hline CHEMBL1384906 & 688112 & 4.4393 & 4.3138 & TRN & \\
\hline CHEMBL1392461 & 688112 & 4.6935 & 4.25 & TRN & \\
\hline CHEMBL1423670 & 688112 & 5.5471 & 4.2631 & TRN & \\
\hline CHEMBL 3199580 & 688112 & 5.1468 & 4.8182 & TRN & \\
\hline CHEMBL1477080 & 688112 & 3.9671 & 4.5294 & TRN & \\
\hline CHEMBL1378580 & 688112 & 4.7818 & 4.391 & TRN & \\
\hline CHEMBL1360086 & 688112 & 2.9208 & 4.9862 & TRN & \\
\hline CHEMBL1602119 & 688112 & 4.8846 & 4.2155 & TRN & \\
\hline CHEMBL 3211742 & 688112 & 4.694 & 4.2779 & TRN & \\
\hline CHEMBL1387916 & 688112 & 4.7921 & 3.8719 & TRN & \\
\hline CHEMBL1401099 & 688112 & 2.9208 & 4.6984 & TRN & \\
\hline CHEMBL1550083 & 688112 & 5.1909 & 4.9456 & TRN & \\
\hline CHEMBL1365216 & 688112 & 4.8918 & 4.5016 & TRN & \\
\hline CHEMBL1363615 & 688112 & 8.0 & 4.909 & TRN & \\
\hline CHEMBL1374465 & 688112 & 2.9208 & 4.2033 & TST & \\
\hline CHEMBL 3209043 & 688112 & 3.9326 & 4.359 & TRN & \\
\hline CHEMBL1568689 & 688112 & 2.9208 & 4.246 & TRN & \\
\hline CHEMBL1376944 & 688112 & 4.3684 & 4.3029 & TRN & \\
\hline CHEMBL1492589 & 688112 & 2.9208 & 4.1829 & TST & \\
\hline CHEMBL1366559 & 688112 & 5.6992 & 4.3733 & TRN & \\
\hline CHEMBL 3197479 & 688112 & 6.8153 & 4.4658 & TRN & \\
\hline CHEMBL1382917 & 688112 & 2.9208 & 4.1925 & TST & \\
\hline CHEMBL1564468 & 688112 & 4.247 & 4.0049 & TRN & \\
\hline CHEMBL1597878 & 688112 & 2.9208 & 4.4202 & TRN & \\
\hline
\end{tabular}


Supplemental Table S2.txt

\begin{tabular}{|c|c|c|c|c|c|c|}
\hline CHEMBL 3209422 & 688112 & 2.9208 & 3.7608 & TST & & \\
\hline CHEMBL1374459 & 688112 & 2.9208 & 3.6158 & TRN & & \\
\hline CHEMBL1383996 & 688112 & 4.9496 & 4.6103 & TRN & & \\
\hline CHEMBL1499250 & 688112 & 2.9208 & 4.6482 & TRN & & \\
\hline CHEMBL1490718 & 688112 & 5.0818 & 4.8389 & TRN & & \\
\hline CHEMBL1417174 & 688112 & 6.6576 & 5.0765 & TRN & & \\
\hline CHEMBL1372085 & 688112 & 4.9038 & 4.3342 & TRN & & \\
\hline CHEMBL 3211496 & 688112 & 4.0109 & 4.2435 & TRN & & \\
\hline CHEMBL1341023 & 688112 & 2.9208 & 3.5781 & TRN & & \\
\hline CHEMBL1603512 & 688112 & 4.8113 & 4.3057 & TRN & & \\
\hline CHEMBL1333794 & 688112 & 4.1945 & 4.5859 & TRN & & \\
\hline CHEMBL1420308 & 688112 & 4.3276 & 4.4912 & TRN & & \\
\hline CHEMBL1525001 & 688112 & 2.9208 & 4.256 & TRN & & \\
\hline CHEMBL1381436 & 688112 & 2.9208 & 3.5955 & TRN & & \\
\hline CHEMBL 3192101 & 688112 & 4.8879 & 4.4685 & TRN & & \\
\hline CHEMBL1342723 & 688112 & 5.9473 & 4.3445 & TRN & & \\
\hline CHEMBL1347487 & 688112 & 4.7215 & 4.0546 & TRN & & \\
\hline CHEMBL1561085 & 688112 & 2.9208 & 3.9607 & TST & & \\
\hline CHEMBL1425355 & 688112 & 4.2667 & 4.2361 & TRN & & \\
\hline CHEMBL1374559 & 688112 & 2.9208 & 3.7141 & TRN & & \\
\hline CHEMBL1531900 & 688112 & 4.3461 & 4.3304 & TRN & & \\
\hline CHEMBL 3199635 & 688112 & 4.3137 & 4.3634 & TRN & & \\
\hline CHEMBL 3194251 & 688112 & 4.3748 & 3.5733 & TRN & & \\
\hline CHEMBL1571801 & 688112 & \multicolumn{3}{|c|}{6.382999999999999} & 4.4417 & TST \\
\hline CHEMBL1373344 & 688112 & 4.0179 & 4.3487 & TRN & & \\
\hline CHEMBL1582836 & 688112 & 2.9208 & 3.6646 & TRN & & \\
\hline CHEMBL1336959 & 688112 & 4.0545 & 3.8805 & TRN & & \\
\hline CHEMBL1509816 & 688112 & 4.9243 & 4.2633 & TRN & & \\
\hline CHEMBL 3195155 & 688112 & 4.8462 & 4.3855 & TST & & \\
\hline CHEMBL 3189738 & 688112 & 4.6991 & 4.3647 & TRN & & \\
\hline CHEMBL1463302 & 688112 & 2.9208 & 4.3215 & TRN & & \\
\hline CHEMBL1303994 & 688112 & \multicolumn{3}{|c|}{4.6080000000000005} & 4.3983 & TRN \\
\hline CHEMBL1416015 & 688112 & 2.9208 & 4.3479 & TRN & & \\
\hline CHEMBL 3213621 & 688112 & 2.9208 & 4.3072 & TRN & & \\
\hline CHEMBL1338990 & 688112 & 2.9208 & 3.5508 & TST & & \\
\hline CHEMBL1601249 & 688112 & 5.1244 & 4.5678 & TST & & \\
\hline CHEMBL 1515973 & 688112 & \multicolumn{3}{|c|}{4.5680000000000005} & 3.9109 & TRN \\
\hline CHEMBL1468965 & 688112 & 4.7073 & 3.8707 & TRN & & \\
\hline CHEMBL1440560 & 688112 & 2.9208 & 4.7582 & TST & & \\
\hline CHEMBL 1462769 & 688112 & 4.5473 & 4.2012 & TRN & & \\
\hline CHEMBL1517544 & 688112 & 4.6295 & 3.9523 & TRN & & \\
\hline CHEMBL1471484 & 688112 & 4.2414 & 4.1829 & TRN & & \\
\hline CHEMBL1413839 & 688112 & 2.9208 & 4.0775 & TRN & & \\
\hline CHEMBL1483048 & 688112 & 2.9208 & 4.7769 & TRN & & \\
\hline CHEMBL1575543 & 688112 & 6.399 & 4.5149 & TRN & & \\
\hline CHEMBL1480985 & 688112 & 2.9208 & 3.6513 & TRN & & \\
\hline CHEMBL 3196261 & 688112 & 6.284 & 4.1185 & TRN & & \\
\hline CHEMBL 3197566 & 688112 & 4.5496 & 3.7086 & TST & & \\
\hline
\end{tabular}


Supplemental Table S2.txt

\begin{tabular}{|c|c|c|c|c|}
\hline CHEMBL1364203 & 688112 & 4.8301 & 3.9709 & TST \\
\hline CHEMBL1977995 & 688112 & 2.9208 & 3.5345 & TST \\
\hline CHEMBL1597227 & 688112 & 4.3468 & 4.4002 & TRN \\
\hline CHEMBL1539723 & 688112 & 2.9208 & 4.4958 & TRN \\
\hline CHEMBL1543489 & 688112 & 2.9208 & 4.8616 & TRN \\
\hline CHEMBL1581385 & 688112 & 4.5011 & 4.4762 & TRN \\
\hline CHEMBL1870966 & 688112 & 2.9208 & 4.0508 & TRN \\
\hline CHEMBL240333 & 688112 & 6.9031 & 4.8408 & TRN \\
\hline CHEMBL 2001794 & 688112 & 2.9208 & 3.6499 & TRN \\
\hline CHEMBL3191360 & 688112 & 4.6365 & 4.4163 & TRN \\
\hline CHEMBL1569671 & 688112 & 2.9208 & 4.3489 & TST \\
\hline CHEMBL1461809 & 688112 & 2.9208 & 4.8058 & TRN \\
\hline CHEMBL1546461 & 688112 & 2.9208 & 4.3958 & TRN \\
\hline CHEMBL1388766 & 688112 & 2.9208 & 3.609 & TRN \\
\hline CHEMBL1603032 & 688112 & 4.0891 & 4.3667 & TST \\
\hline CHEMBL1487591 & 688112 & 4.7334 & 4.4562 & TRN \\
\hline CHEMBL1373061 & 688112 & 5.1357 & 4.3273 & TRN \\
\hline CHEMBL1577430 & 688112 & 4.2766 & 4.4121 & TRN \\
\hline CHEMBL1405940 & 688112 & 2.9208 & 4.7797 & TRN \\
\hline CHEMBL1388701 & 688112 & 4.5796 & 4.1689 & TRN \\
\hline CHEMBL1597187 & 688112 & 4.8252 & 4.3213 & TRN \\
\hline CHEMBL1300552 & 688112 & 4.9589 & 4.2876 & TST \\
\hline CHEMBL1541273 & 688112 & 2.9208 & 4.0103 & TRN \\
\hline CHEMBL117813 & 688112 & 4.4789 & 3.93899 & 99999999996 \\
\hline CHEMBL1524817 & 688112 & 2.9208 & 4.4829 & TRN \\
\hline CHEMBL1427062 & 688112 & 2.9208 & 4.9049 & TRN \\
\hline CHEMBL1439149 & 688112 & 4.3144 & 3.9262 & TRN \\
\hline CHEMBL1303649 & 688112 & 2.9208 & 4.2342 & TRN \\
\hline CHEMBL1370754 & 688112 & 4.8631 & 4.2258 & TRN \\
\hline CHEMBL1377753 & 688112 & 6.7747 & 4.54 & TST \\
\hline CHEMBL1489440 & 688112 & 5.4678 & 4.6273 & TRN \\
\hline CHEMBL1327154 & 688112 & 4.9916 & 4.3172 & TRN \\
\hline CHEMBL1486606 & 688112 & 2.9208 & 3.7856 & TRN \\
\hline CHEMBL1324123 & 688112 & 8.0 & 4.4799 & TRN \\
\hline CHEMBL1326031 & 688112 & 5.0842 & 4.4992 & TRN \\
\hline CHEMBL1533386 & 688112 & 2.9208 & 4.2822 & TST \\
\hline CHEMBL1481836 & 688112 & 4.9997 & 4.2775 & TRN \\
\hline CHEMBL1306086 & 688112 & 2.9208 & 3.5921 & TRN \\
\hline CHEMBL3195910 & 688112 & 4.5244 & 4.0186 & TRN \\
\hline CHEMBL3207793 & 688112 & 4.9551 & 4.3077 & TST \\
\hline CHEMBL3199337 & 688112 & 2.9208 & 4.2377 & TRN \\
\hline CHEMBL1466147 & 688112 & 5.7849 & 4.9238 & TRN \\
\hline CHEMBL1413214 & 688112 & 4.6516 & 4.0109 & TRN \\
\hline CHEMBL1971604 & 688112 & 4.3653 & 4.4917 & TRN \\
\hline CHEMBL1991209 & 688112 & 6.2403 & 4.149 & TRN \\
\hline CHEMBL1480651 & 688112 & 2.9208 & 4.4181 & TRN \\
\hline CHEMBL1575735 & 688112 & 2.9208 & 4.2076 & TRN \\
\hline CHEMBL1382847 & 688112 & 4.1839 & 4.2569 & TRN \\
\hline
\end{tabular}

Page 8566 


\begin{tabular}{|c|c|c|c|c|}
\hline & & & pplement & al $\mathrm{T}$ \\
\hline CHEMBL3198019 & 688112 & 4.2731 & 4.2597 & TRN \\
\hline CHEMBL1577017 & 688112 & 4.9457 & 4.2528 & TST \\
\hline CHEMBL1608766 & 688112 & 4.1026 & 4.5441 & TRN \\
\hline CHEMBL 3189751 & 688112 & 5.9031 & 4.3478 & TRN \\
\hline CHEMBL1563027 & 688112 & 2.9208 & 3.5536 & TST \\
\hline CHEMBL453974 & 688112 & 2.9208 & 4.0834 & TST \\
\hline CHEMBL1601967 & 688112 & 4.7851 & 4.3061 & TST \\
\hline CHEMBL1520096 & 688112 & 5.2174 & 4.1532 & TRN \\
\hline CHEMBL1578551 & 688112 & 2.9208 & 3.9472 & TST \\
\hline CHEMBL1425241 & 688112 & 2.9208 & 3.6562 & TRN \\
\hline CHEMBL1353083 & 688112 & 5.1519 & 4.1764 & TRN \\
\hline CHEMBL1427857 & 688112 & 4.1631 & 4.3 & TRN \\
\hline CHEMBL1562955 & 688112 & 4.5458 & 4.2987 & TRN \\
\hline CHEMBL1557161 & 688112 & 4.7721 & 4.3393 & TRN \\
\hline CHEMBL1613483 & 688112 & 5.5042 & 4.5707 & TRN \\
\hline CHEMBL1541948 & 688112 & 6.0357 & 4.8703 & TRN \\
\hline CHEMBL1520703 & 688112 & 5.1944 & 4.9371 & TRN \\
\hline CHEMBL3191975 & 688112 & 8.0 & 4.5719 & TST \\
\hline CHEMBL1487531 & 688112 & 2.9208 & 3.7516 & TST \\
\hline CHEMBL1364610 & 688112 & 5.7645 & 4.1025 & TRN \\
\hline CHEMBL1332476 & 688112 & 4.4033 & 4.3161 & TRN \\
\hline CHEMBL1430573 & 688112 & 5.02 & 4.1813 & TRN \\
\hline CHEMBL1424478 & 688112 & 4.5042 & 4.6874 & TRN \\
\hline CHEMBL1307447 & 688112 & 4.8043 & 4.3499 & TRN \\
\hline CHEMBL1496663 & 688112 & 2.9208 & 3.9702 & TRN \\
\hline CHEMBL1568646 & 688112 & 6.6091 & 4.7964 & TRN \\
\hline CHEMBL1415813 & 688112 & 4.2386 & 4.3405 & TRN \\
\hline CHEMBL1549548 & 688112 & 2.9208 & 3.8302 & TRN \\
\hline CHEMBL1419848 & 688112 & 8.0 & 4.6064 & TRN \\
\hline CHEMBL1574394 & 688112 & 4.7814 & 4.2938 & TRN \\
\hline CHEMBL1578141 & 688112 & 4.4812 & 4.1869 & TRN \\
\hline CHEMBL1436348 & 688112 & 2.9208 & 4.1501 & TRN \\
\hline CHEMBL1453235 & 688112 & 4.7171 & 4.1694 & TRN \\
\hline CHEMBL449336 & 688112 & 5.0026 & 4.2256 & TST \\
\hline CHEMBL1466824 & 688112 & 4.7317 & 4.1494 & TRN \\
\hline CHEMBL1506203 & 688112 & 4.1229 & 4.9131 & TRN \\
\hline CHEMBL1362125 & 688112 & 4.7502 & 3.5934 & TRN \\
\hline CHEMBL1359250 & 688112 & 2.9208 & 4.0011 & TRN \\
\hline CHEMBL1451192 & 688112 & 4.7969 & 4.1146 & TRN \\
\hline CHEMBL1600446 & 688112 & 4.8138 & 4.297 & TRN \\
\hline CHEMBL1520991 & 688112 & 2.9208 & 3.9331 & TRN \\
\hline CHEMBL1610220 & 688112 & 4.12 & 4.1992 & TRN \\
\hline CHEMBL1588880 & 688112 & 5.8019 & 4.9746 & TRN \\
\hline CHEMBL1357756 & 688112 & 2.9208 & 4.5686 & TRN \\
\hline CHEMBL1575523 & 688112 & 2.9208 & 3.9704 & TRN \\
\hline CHEMBL 3212742 & 688112 & 2.9208 & 4.2303 & TST \\
\hline CHEMBL546475 & 688112 & 2.9208 & 3.8454 & TRN \\
\hline CHEMBL1342766 & 688112 & 2.9208 & 4.3941 & TST \\
\hline
\end{tabular}


Supplemental Table S2.txt

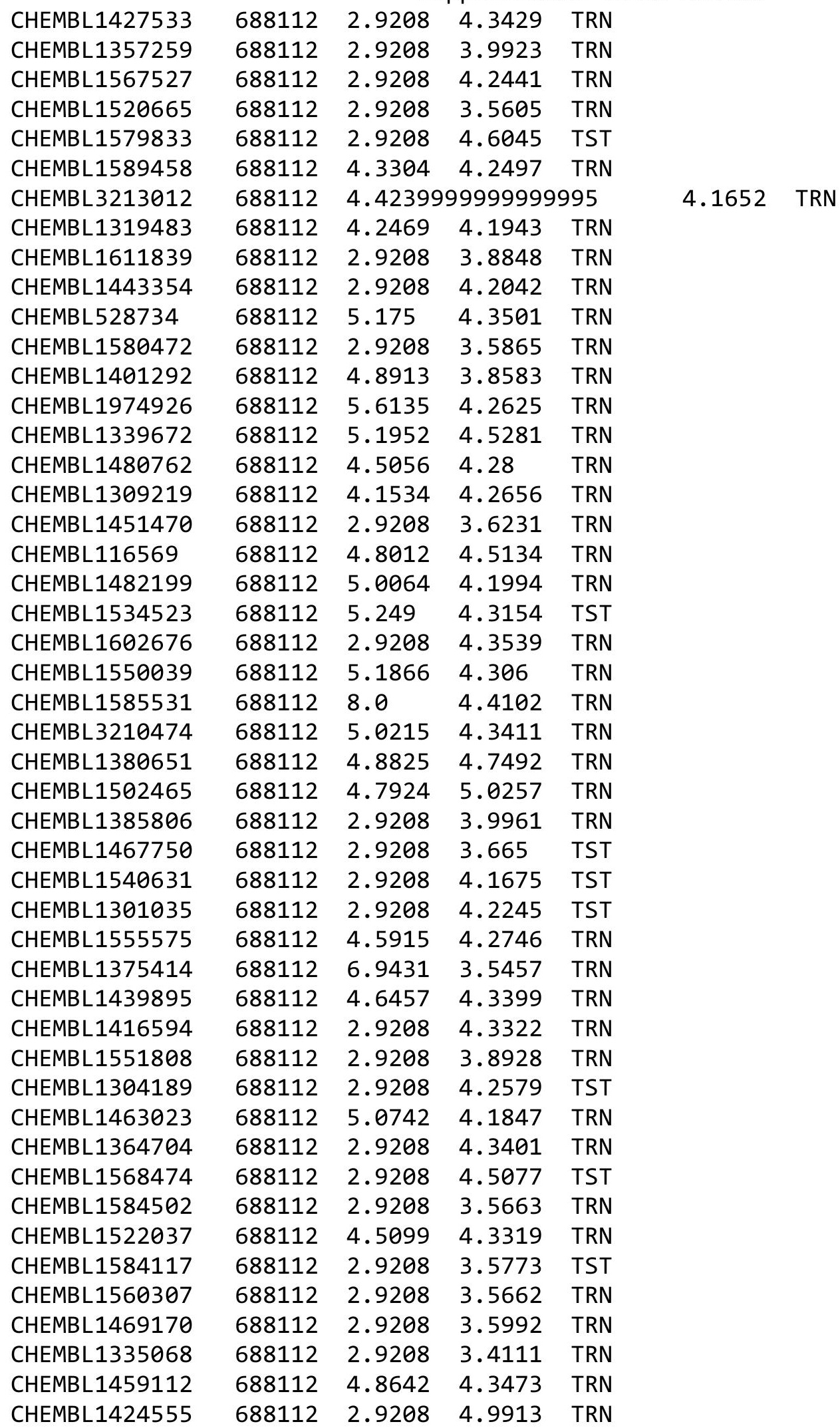

Page 8568 


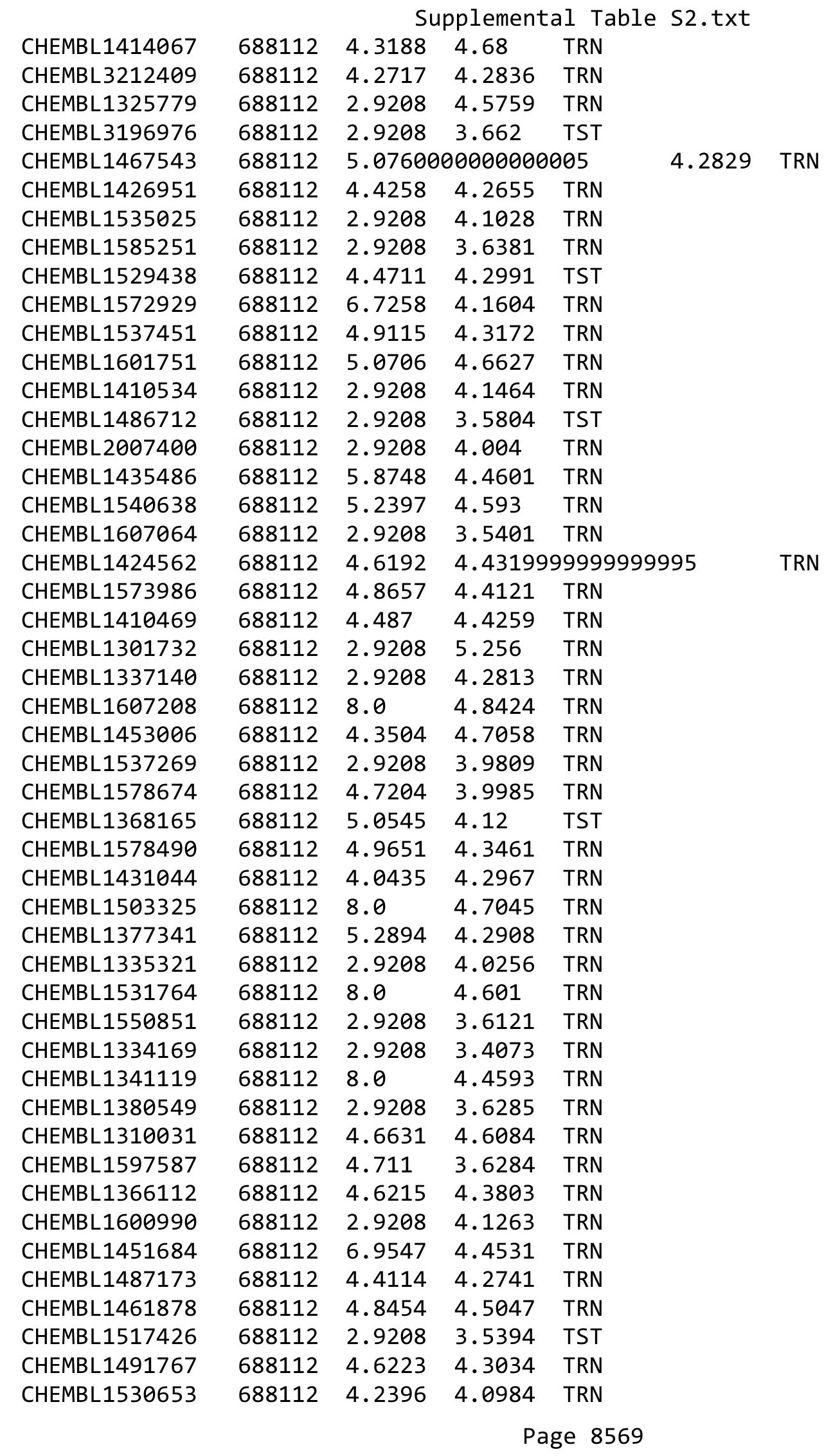




\begin{tabular}{|c|c|c|c|c|c|c|}
\hline & & \multicolumn{5}{|c|}{ Supplemental Table S2.txt } \\
\hline CHEMBL1488590 & 688112 & 4.4222 & 3.5618 & TRN & & \\
\hline CHEMBL1480414 & 688112 & 2.9208 & 3.569 & TRN & & \\
\hline CHEMBL3190074 & 688112 & 4.9508 & 4.0092 & TRN & & \\
\hline CHEMBL1578372 & 688112 & 8.0 & 4.5073 & TRN & & \\
\hline CHEMBL1506291 & 688112 & 5.0085 & 4.456 & TRN & & \\
\hline CHEMBL3193751 & 688112 & 4.7744 & 4.2799 & TRN & & \\
\hline CHEMBL1308658 & 688112 & 6.8297 & 5.1094 & TRN & & \\
\hline CHEMBL1352417 & 688112 & 4.4361 & 4.3312 & TRN & & \\
\hline CHEMBL1349074 & 688112 & 2.9208 & 4.293 & TRN & & \\
\hline CHEMBL1080213 & 688112 & 2.9208 & 5.0683 & TRN & & \\
\hline CHEMBL1321322 & 688112 & 4.6603 & 4.2067 & TRN & & \\
\hline CHEMBL1383194 & 688112 & 5.3266 & 4.0002 & TRN & & \\
\hline CHEMBL1557898 & 688112 & 6.857 & 5.0061 & TRN & & \\
\hline CHEMBL1334136 & 688112 & 2.9208 & 5.0178 & TRN & & \\
\hline CHEMBL1524916 & 688112 & 4.4671 & 3.9427 & TST & & \\
\hline CHEMBL3196616 & 688112 & 5.2895 & 4.4862 & TRN & & \\
\hline CHEMBL1542533 & 688112 & 5.4402 & 5.1363 & TRN & & \\
\hline CHEMBL1509078 & 688112 & 2.9208 & 3.5914 & TRN & & \\
\hline CHEMBL1340446 & 688112 & 4.7608 & 4.3237 & TST & & \\
\hline CHEMBL1383700 & 688112 & 4.322 & 4.5129 & TRN & & \\
\hline CHEMBL1438797 & 688112 & 2.9208 & 3.5735 & TRN & & \\
\hline CHEMBL600090 & 688112 & 2.9208 & 4.4588 & TRN & & \\
\hline CHEMBL3190926 & 688112 & 2.9208 & 3.9266 & TRN & & \\
\hline CHEMBL1301373 & 688112 & 4.4674 & 4.6307 & TRN & & \\
\hline CHEMBL1584711 & 688112 & 4.8345 & 4.1965 & TRN & & \\
\hline CHEMBL1342363 & 688112 & 2.9208 & 3.6655 & TRN & & \\
\hline CHEMBL1309580 & 688112 & 6.983 & 4.4456 & TRN & & \\
\hline CHEMBL1458725 & 688112 & 4.7335 & 4.1338 & TRN & & \\
\hline CHEMBL1383152 & 688112 & 4.4204 & 4.3397 & TRN & & \\
\hline CHEMBL1612424 & 688112 & 4.6195 & 4.2603 & TRN & & \\
\hline CHEMBL3192157 & 688112 & 4.7236 & 4.3168 & TRN & & \\
\hline CHEMBL1478726 & 688112 & 4.9637 & 4.4232 & TRN & & \\
\hline CHEMBL1384582 & 688112 & 2.9208 & 4.9802 & TRN & & \\
\hline CHEMBL1392796 & 688112 & 2.9208 & 3.6349 & TRN & & \\
\hline CHEMBL1509216 & 688112 & 5.1054 & 4.9449 & TST & & \\
\hline CHEMBL1405368 & 688112 & 4.8106 & 4.5553 & TRN & & \\
\hline CHEMBL1574741 & 688112 & 4.8887 & 4.3899 & TRN & & \\
\hline CHEMBL1607650 & 688112 & 4.7574 & 3.9565 & TRN & & \\
\hline CHEMBL1577289 & 688112 & 4.7267 & 4.3212 & TRN & & \\
\hline CHEMBL1596117 & 688112 & 5.21899 & 99999999 & 99 & 4.6166 & TRN \\
\hline CHEMBL1364646 & 688112 & 6.7799 & 5.0228 & TRN & & \\
\hline CHEMBL1385904 & 688112 & 4.6974 & 4.765 & TRN & & \\
\hline CHEMBL1599132 & 688112 & 2.9208 & 4.0623 & TRN & & \\
\hline CHEMBL1351967 & 688112 & 2.9208 & 3.9981 & TST & & \\
\hline CHEMBL1346228 & 688112 & 4.8252 & 3.9256 & TST & & \\
\hline CHEMBL1508071 & 688112 & 4.8586 & 4.3687 & TRN & & \\
\hline CHEMBL3193288 & 688112 & 2.9208 & 4.4009 & TRN & & \\
\hline CHEMBL567967 & 688112 & 4.6984 & 4.2566 & TRN & & \\
\hline
\end{tabular}




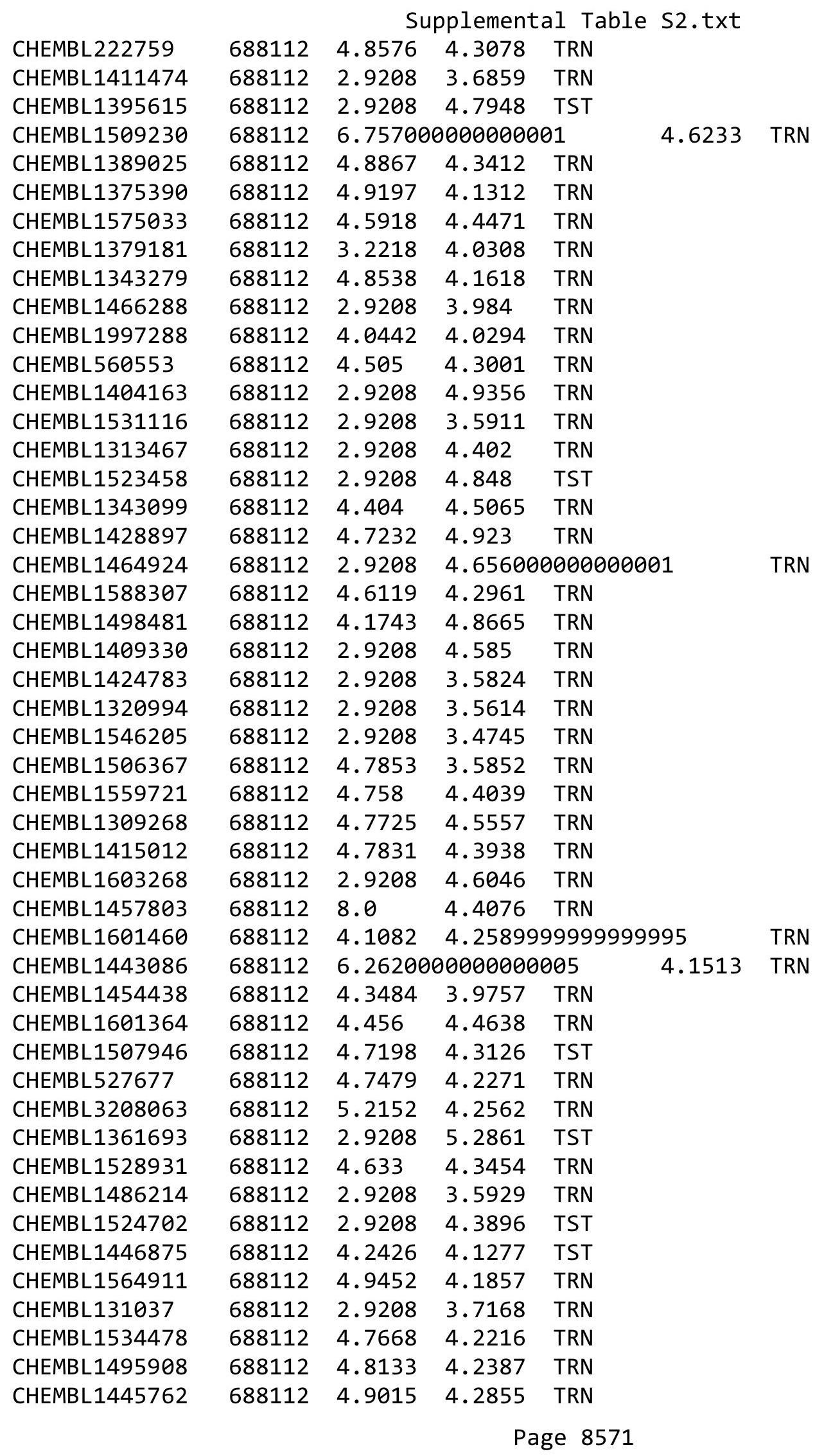


Supplemental Table S2.txt

\begin{tabular}{|c|c|c|c|c|c|c|}
\hline CHEMBL1976271 & 688112 & 4.3573 & 4.335 & TRN & & \\
\hline CHEMBL1462785 & 688112 & 2.9208 & 3.6274 & TRN & & \\
\hline CHEMBL1401589 & 688112 & 4.6691 & 4.3968 & TRN & & \\
\hline CHEMBL1495198 & 688112 & 2.9208 & 4.4704 & TRN & & \\
\hline CHEMBL1556113 & 688112 & 2.9208 & 4.3292 & TRN & & \\
\hline CHEMBL1361072 & 688112 & 2.9208 & 3.6157 & TRN & & \\
\hline CHEMBL1403575 & 688112 & 2.9208 & 3.8494 & TRN & & \\
\hline CHEMBL1402159 & 688112 & 5.0489 & 4.2857 & TRN & & \\
\hline CHEMBL1396449 & 688112 & 4.2309 & 4.4217 & TRN & & \\
\hline CHEMBL1605565 & 688112 & 2.9208 & 4.5879 & TRN & & \\
\hline CHEMBL1477375 & 688112 & 4.9707 & 5.1409 & TRN & & \\
\hline CHEMBL1603658 & 688112 & 2.9208 & 4.1925 & TRN & & \\
\hline CHEMBL1345184 & 688112 & 2.9208 & 3.8064 & TRN & & \\
\hline CHEMBL1380103 & 688112 & 4.4327 & 4.9897 & TRN & & \\
\hline CHEMBL1428180 & 688112 & 5.0079 & 4.3525 & TRN & & \\
\hline CHEMBL3191418 & 688112 & 4.5926 & 4.873 & TRN & & \\
\hline CHEMBL1565407 & 688112 & 2.9208 & 4.5466 & TRN & & \\
\hline CHEMBL1542591 & 688112 & 4.9791 & 4.3315 & TRN & & \\
\hline CHEMBL1374228 & 688112 & 4.5519 & 4.0257 & TRN & & \\
\hline CHEMBL1460850 & 688112 & 5.2371 & 4.4877 & TRN & & \\
\hline CHEMBL1530088 & 688112 & 4.7223 & 5.0263 & TRN & & \\
\hline CHEMBL1602928 & 688112 & 2.9208 & 4.8595 & TRN & & \\
\hline CHEMBL1418980 & 688112 & 2.9208 & 3.846 & TRN & & \\
\hline CHEMBL1574508 & 688112 & 4.1992 & 4.0936 & TRN & & \\
\hline CHEMBL1599602 & 688112 & 4.6491 & 4.2714 & TRN & & \\
\hline CHEMBL1363543 & 688112 & 4.7041 & 3.8592 & TRN & & \\
\hline CHEMBL1352816 & 688112 & 2.9208 & 4.0967 & TRN & & \\
\hline CHEMBL1367639 & 688112 & 2.9208 & 3.5947 & TRN & & \\
\hline CHEMBL1565794 & 688112 & 4.7853 & 4.4311 & TRN & & \\
\hline CHEMBL1307237 & 688112 & 4.7292 & 4.4882 & TRN & & \\
\hline CHEMBL1387465 & 688112 & 4.4273 & 4.2748 & TRN & & \\
\hline CHEMBL1511487 & 688112 & 4.9286 & 4.2279 & TRN & & \\
\hline CHEMBL1440086 & 688112 & \multicolumn{3}{|c|}{6.3420000000000005} & 4.1879 & TRN \\
\hline CHEMBL1602646 & 688112 & 2.9208 & 3.4507 & TRN & & \\
\hline CHEMBL1325969 & 688112 & 3.9553 & 3.7875 & TRN & & \\
\hline CHEMBL1576462 & 688112 & 5.149 & 3.9899 & TRN & & \\
\hline CHEMBL1561135 & 688112 & 4.6934 & 5.2812 & TRN & & \\
\hline CHEMBL1449896 & 688112 & 4.6426 & 4.3039 & TRN & & \\
\hline CHEMBL3211206 & 688112 & 4.8027 & 4.2468 & TRN & & \\
\hline CHEMBL1585599 & 688112 & 4.5797 & 4.3564 & TRN & & \\
\hline CHEMBL1598916 & 688112 & 4.4759 & 4.4222 & TRN & & \\
\hline CHEMBL3198486 & 688112 & 2.9208 & 3.9476 & TRN & & \\
\hline CHEMBL1422053 & 688112 & 4.8857 & 5.0324 & TRN & & \\
\hline CHEMBL1601835 & 688112 & 2.9208 & 3.8944 & TRN & & \\
\hline CHEMBL1414244 & 688112 & 2.9208 & 3.862 & TRN & & \\
\hline CHEMBL1517515 & 688112 & 4.6968 & 4.1902 & TRN & & \\
\hline CHEMBL1371851 & 688112 & 4.8853 & 3.9993 & TRN & & \\
\hline CHEMBL1412792 & 688112 & 4.3027 & 3.9481 & TRN & & \\
\hline
\end{tabular}


Supplemental Table S2.txt

\begin{tabular}{|c|c|c|c|c|}
\hline CHEMBL1428468 & 688112 & 5.6878 & 4.0143 & TRN \\
\hline CHEMBL1502977 & 688112 & 4.1769 & 4.258 & TRN \\
\hline CHEMBL1424179 & 688112 & 5.0401 & 3.9211 & TRN \\
\hline CHEMBL1337770 & 688112 & 4.9346 & 4.4442 & TST \\
\hline CHEMBL1472137 & 688112 & 2.9208 & 4.3515 & TRN \\
\hline CHEMBL1334049 & 688112 & 4.8234 & 4.4047 & TST \\
\hline CHEMBL1453532 & 688112 & 2.9208 & 4.3285 & TRN \\
\hline CHEMBL1583892 & 688112 & 4.4853 & 4.1509 & TRN \\
\hline CHEMBL1368806 & 688112 & 2.9208 & 3.655 & TRN \\
\hline CHEMBL1967184 & 688112 & 4.6631 & 4.1607 & TST \\
\hline CHEMBL1561777 & 688112 & 4.9474 & 4.543 & TST \\
\hline CHEMBL1410519 & 688112 & 2.9208 & 3.8898 & TRN \\
\hline CHEMBL3199125 & 688112 & 4.727 & 4.5834 & TRN \\
\hline CHEMBL1323133 & 688112 & 2.9208 & 4.8356 & TRN \\
\hline CHEMBL1197872 & 688112 & 2.9208 & 3.99899 & 99999999997 \\
\hline CHEMBL1381275 & 688112 & 4.6848 & 4.1177 & TRN \\
\hline CHEMBL1361637 & 688112 & 4.8194 & 4.0575 & TRN \\
\hline CHEMBL1411596 & 688112 & 4.5037 & 4.9697 & TRN \\
\hline CHEMBL1543054 & 688112 & 2.9208 & 4.8101 & TRN \\
\hline CHEMBL1999595 & 688112 & 2.9208 & 4.3984 & TRN \\
\hline CHEMBL1513113 & 688112 & 2.9208 & 4.4202 & TRN \\
\hline CHEMBL1341924 & 688112 & 4.7783 & 4.2953 & TRN \\
\hline CHEMBL1538034 & 688112 & 4.6324 & 4.1964 & TRN \\
\hline CHEMBL1344475 & 688112 & 2.9208 & 4.4816 & TRN \\
\hline CHEMBL1340584 & 688112 & 4.2268 & 4.2393 & TRN \\
\hline CHEMBL1386822 & 688112 & 5.7688 & 4.8589 & TRN \\
\hline CHEMBL1997978 & 688112 & 5.2329 & 4.0395 & TRN \\
\hline CHEMBL1534249 & 688112 & 2.9208 & 4.1429 & TST \\
\hline CHEMBL1587263 & 688112 & 6.341 & 4.6178 & TRN \\
\hline CHEMBL1977683 & 688112 & 4.96 & 4.5465 & TRN \\
\hline CHEMBL1589285 & 688112 & 4.8953 & 4.1734 & TRN \\
\hline CHEMBL1511747 & 688112 & 5.5449 & 4.393 & TRN \\
\hline CHEMBL1600243 & 688112 & 4.0011 & 4.4529 & TRN \\
\hline CHEMBL1585789 & 688112 & 4.8126 & 3.6055 & TRN \\
\hline CHEMBL1481805 & 688112 & 4.5481 & 4.008 & TRN \\
\hline CHEMBL1470875 & 688112 & 4.4432 & 4.498 & TRN \\
\hline CHEMBL1387020 & 688112 & 5.7471 & 4.2032 & TRN \\
\hline CHEMBL1579339 & 688112 & 6.9957 & 5.2935 & TRN \\
\hline CHEMBL1359952 & 688112 & 4.6755 & 4.6662 & TRN \\
\hline CHEMBL1328527 & 688112 & 4.8262 & 4.9151 & TRN \\
\hline CHEMBL1586122 & 688112 & 2.9208 & 3.5853 & TRN \\
\hline CHEMBL1380182 & 688112 & 4.8316 & 4.3457 & TST \\
\hline CHEMBL1582517 & 688112 & 2.9208 & 4.2731 & TRN \\
\hline CHEMBL 3213515 & 688112 & 4.1982 & 4.5418 & TRN \\
\hline CHEMBL1439783 & 688112 & 2.9208 & 3.7242 & TRN \\
\hline CHEMBL1400463 & 688112 & 4.2001 & 4.1916 & TRN \\
\hline CHEMBL1423521 & 688112 & 4.7189 & 4.2138 & TRN \\
\hline CHEMBL1374706 & 688112 & 2.9208 & 4.9076 & TST \\
\hline
\end{tabular}


Supplemental Table S2.txt

\begin{tabular}{|c|c|c|c|c|c|}
\hline CHEMBL1305886 & 688112 & 2.9208 & 4.5057 & TRN & \\
\hline CHEMBL1522903 & 688112 & 2.9208 & 4.8482 & TRN & \\
\hline CHEMBL3211314 & 688112 & 4.625 & 4.2696 & TST & \\
\hline CHEMBL1562098 & 688112 & 4.6503 & 3.9491 & TRN & \\
\hline CHEMBL1467146 & 688112 & 4.6784 & 4.2589 & TST & \\
\hline CHEMBL580324 & 688112 & 6.2161 & 4.3042 & TRN & \\
\hline CHEMBL1521778 & 688112 & 2.9208 & 3.6792 & TRN & \\
\hline CHEMBL1556666 & 688112 & 2.9208 & 3.9415 & TRN & \\
\hline CHEMBL1358035 & 688112 & 5.721 & 4.4817 & TRN & \\
\hline CHEMBL 2003964 & 688112 & 4.1534 & 4.2757 & TST & \\
\hline CHEMBL1575925 & 688112 & 4.7955 & 3.928 & TST & \\
\hline CHEMBL1373880 & 688112 & 2.9208 & 3.5596 & TST & \\
\hline CHEMBL1576454 & 688112 & 5.1526 & 4.3945 & TST & \\
\hline CHEMBL1465386 & 688112 & 4.7213 & 4.2536 & TRN & \\
\hline CHEMBL1362757 & 688112 & 2.9208 & 3.62899 & 799999999996 & TRN \\
\hline CHEMBL1311739 & 688112 & 4.5007 & 4.2609 & TRN & \\
\hline CHEMBL1339111 & 688112 & 2.9208 & 4.3962 & TRN & \\
\hline CHEMBL1557196 & 688112 & 2.9208 & 3.633 & TRN & \\
\hline CHEMBL3211069 & 688112 & 4.3543 & 4.2434 & TRN & \\
\hline CHEMBL1501969 & 688112 & 4.8807 & 4.2852 & TRN & \\
\hline CHEMBL1383088 & 688112 & 5.0968 & 4.3498 & TRN & \\
\hline CHEMBL1535665 & 688112 & 2.9208 & 3.5365 & TRN & \\
\hline CHEMBL1367860 & 688112 & 4.7537 & 4.3484 & TST & \\
\hline CHEMBL1567309 & 688112 & 2.9208 & 3.5891 & TRN & \\
\hline CHEMBL1342141 & 688112 & 4.0555 & 4.298 & TRN & \\
\hline CHEMBL1393395 & 688112 & 4.492 & 3.9609 & TRN & \\
\hline CHEMBL3196175 & 688112 & 2.9208 & 4.4208 & TRN & \\
\hline CHEMBL1547182 & 688112 & 2.9208 & 4.0697 & TST & \\
\hline CHEMBL1373916 & 688112 & 2.9208 & 3.6022 & TST & \\
\hline CHEMBL1551926 & 688112 & 4.3784 & 4.3959 & TST & \\
\hline CHEMBL1471700 & 688112 & 2.9208 & 4.8297 & TST & \\
\hline CHEMBL1977867 & 688112 & 2.9208 & 3.8725 & TRN & \\
\hline CHEMBL1610045 & 688112 & 4.2033 & 4.2101 & TRN & \\
\hline CHEMBL1554017 & 688112 & 2.9208 & \multicolumn{2}{|c|}{3.4939999999999998} & TRN \\
\hline CHEMBL1517603 & 688112 & 4.3861 & 4.8951 & TRN & \\
\hline CHEMBL1540046 & 688112 & 2.9208 & 3.5306 & TRN & \\
\hline CHEMBL1545149 & 688112 & 4.8403 & 4.3805 & TRN & \\
\hline CHEMBL1448363 & 688112 & 4.9962 & \multicolumn{2}{|c|}{ 4. 2669999999999995} & TRN \\
\hline CHEMBL1331497 & 688112 & 2.9208 & 4.4188 & TRN & \\
\hline CHEMBL1470577 & 688112 & 4.3741 & 4.1744 & TRN & \\
\hline CHEMBL1327494 & 688112 & 5.1912 & 4.2438 & TRN & \\
\hline CHEMBL1519624 & 688112 & 4.6851 & 4.4249 & TRN & \\
\hline CHEMBL1324465 & 688112 & 4.9613 & 4.4109 & TRN & \\
\hline CHEMBL1535460 & 688112 & 4.4373 & 4.3786 & TRN & \\
\hline CHEMBL1539373 & 688112 & 2.9208 & 4.2784 & TRN & \\
\hline CHEMBL1448972 & 688112 & 2.9208 & 4.6761 & TRN & \\
\hline CHEMBL1359482 & 688112 & 5.3012 & 4.6997 & TRN & \\
\hline CHEMBL1466699 & 688112 & 2.9208 & 3.965 & TRN & \\
\hline
\end{tabular}


Supplemental Table S2.txt

\begin{tabular}{|c|c|c|c|c|}
\hline AEMBL1545240 & 8112 & & & \\
\hline HEMBL1525073 & 38112 & 4.6652 & 3.9473 & \\
\hline & & & & \\
\hline EMBL3199616 & 3112 & & & \\
\hline AEMBL3 & 8112 & & 2948 & \\
\hline AEMBL1526067 & 38112 & 946 & 5516 & \\
\hline AEMBL & 112 & & 2725 & \\
\hline 99 & & & & \\
\hline AEMBL] & 38112 & & 5162 & \\
\hline AEMBL1363291 & 38112 & & 4.7306 & \\
\hline AEMBL: & 38112 & & 6159 & \\
\hline IEMBL: & 112 & & 818 & \\
\hline IEMBL & & & & \\
\hline AEMBL & 38112 & & 9324 & RI \\
\hline IEMBL: & 112 & & 1474 & \\
\hline EMBL: & 12 & & 54 & \\
\hline IEMBL & 112 & & 11 & \\
\hline IEMBL & 112 & & & \\
\hline IEMBL & 112 & & & \\
\hline IEMBL & 12 & & & \\
\hline IEMBL & 12 & & 732 & \\
\hline EMB & 12 & & 23 & \\
\hline EMB & 112 & & 15 & \\
\hline 00 & & & & \\
\hline IEMBL: & & & & KN \\
\hline IEMBL & 12 & & $\partial 91$ & \\
\hline EMB & 112 & & 11 & 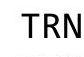 \\
\hline 92 & 12 & & & RN \\
\hline IEMBL & & & & RN \\
\hline AEMBL: & & & & IST \\
\hline IEMBL & 12 & & 588 & II \\
\hline 29 & 12 & & 57 & RIV \\
\hline & 12 & & 27 & RN \\
\hline EMBL & & & 109 & ST \\
\hline AEMBL] & 8112 & & 682 & RI \\
\hline IEMBL & 112 & & 417 & 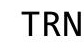 \\
\hline 7 & & & 21 & RN \\
\hline & & & 7637 & RN \\
\hline AEMBL: & 8112 & & 9715 & RI \\
\hline EMBL & 3112 & & 778 & $\mathrm{RI}$ \\
\hline AEMBL & 112 & & 51 & TST \\
\hline & & & & RN \\
\hline AEMBL & & & 1816 & RN \\
\hline EMBL: & 8112 & & 464 & RI \\
\hline EML & & & 861 & \\
\hline HEMBL & & & 4.2735 & \\
\hline CHEMBLI & & & 4.2944 & \\
\hline CHEMBL1531035 & 688112 & 4.8109 & 4.3551 & $\Gamma \mathrm{R}$ \\
\hline
\end{tabular}

Page 8575 


\begin{tabular}{|c|c|c|c|c|}
\hline \multicolumn{5}{|c|}{ Supplemental Table S2.txt } \\
\hline CHEMBL1352372 & 688112 & 4.9711 & 4.1947 & TST \\
\hline CHEMBL1532364 & 688112 & 4.8398 & 4.2522 & TRN \\
\hline CHEMBL1392667 & 688112 & 6.9136 & 4.4199 & TRN \\
\hline CHEMBL1328281 & 688112 & 4.746 & 3.8285 & TRN \\
\hline CHEMBL1582469 & 688112 & 4.2561 & 4.3127 & TST \\
\hline CHEMBL1984604 & 688112 & 4.4732 & 4.4236 & TRN \\
\hline CHEMBL3192016 & 688112 & 4.6339 & 4.3763 & TRN \\
\hline CHEMBL1511867 & 688112 & 2.9208 & 3.9064 & TRN \\
\hline CHEMBL1531533 & 688112 & 2.9208 & 4.3878 & TRN \\
\hline CHEMBL1592550 & 688112 & 4.6376 & 4.3594 & TRN \\
\hline CHEMBL 1343740 & 688112 & 2.9208 & 4.3239 & TRN \\
\hline CHEMBL3190273 & 688112 & 2.9208 & 5.1735 & TRN \\
\hline CHEMBL1528404 & 688112 & 2.9208 & 4.3974 & TRN \\
\hline CHEMBL1986090 & 688112 & 4.0139 & 5.4072 & TRN \\
\hline CHEMBL1563059 & 688112 & 2.9208 & 4.4453 & TRN \\
\hline CHEMBL1536037 & 688112 & 2.9208 & 3.6108 & TRN \\
\hline CHEMBL1446744 & 688112 & 2.9208 & 3.5647 & TRN \\
\hline CHEMBL1358960 & 688112 & 4.3456 & 4.3099 & TRN \\
\hline CHEMBL1543100 & 688112 & 2.9208 & 3.5303 & TRN \\
\hline CHEMBL1453471 & 688112 & 4.6459 & 4.0409 & TRN \\
\hline CHEMBL1360192 & 688112 & 2.9208 & 4.3391 & TRN \\
\hline CHEMBL1521872 & 688112 & 4.3954 & 4.5099 & TST \\
\hline CHEMBL1513271 & 688112 & 2.9208 & 3.9143 & TRN \\
\hline CHEMBL1467999 & 688112 & 3.9288 & 4.3959 & TRN \\
\hline CHEMBL1562181 & 688112 & 2.9208 & 4.3374 & TST \\
\hline CHEMBL 1464300 & 688112 & 4.7886 & 4.4094 & TRN \\
\hline CHEMBL1352590 & 688112 & 6.9393 & 4.2333 & TRN \\
\hline CHEMBL1423344 & 688112 & 4.4763 & 4.1735 & TRN \\
\hline CHEMBL1519639 & 688112 & 4.5404 & 5.2747 & TRN \\
\hline CHEMBL1473575 & 688112 & 4.8574 & 4.2268 & TRN \\
\hline CHEMBL1570977 & 688112 & 4.7231 & 4.2618 & TRN \\
\hline CHEMBL1381492 & 688112 & 2.9208 & 4.2858 & TST \\
\hline CHEMBL1390335 & 688112 & 5.1585 & 4.2503 & TRN \\
\hline CHEMBL1528629 & 688112 & 2.9208 & 3.5546 & TRN \\
\hline CHEMBL1565500 & 688112 & 4.7824 & 4.936 & TST \\
\hline CHEMBL1586319 & 688112 & 4.8275 & 3.8355 & TRN \\
\hline CHEMBL1969332 & 688112 & 6.7055 & 4.4678 & TRN \\
\hline CHEMBL1588679 & 688112 & 2.9208 & 3.6715 & TST \\
\hline CHEMBL3208511 & 688112 & 4.8256 & 4.0205 & TRN \\
\hline CHEMBL1450953 & 688112 & 4.9604 & 4.1384 & TRN \\
\hline CHEMBL1373732 & 688112 & 4.5942 & 4.3702 & TST \\
\hline CHEMBL483137 & 688112 & 2.9208 & 4.1141 & TRN \\
\hline CHEMBL1496209 & 688112 & 5.1556 & 3.9475 & TRN \\
\hline CHEMBL1539056 & 688112 & 2.9208 & 3.9371 & TRN \\
\hline CHEMBL1409789 & 688112 & 4.3163 & 4.2522 & TRN \\
\hline CHEMBL 1421394 & 688112 & 3.2218 & 4.0322 & TRN \\
\hline CHEMBL1492000 & 688112 & 4.5547 & 4.3475 & TST \\
\hline CHEMBL1517230 & 688112 & 2.9208 & 4.2064 & TRN \\
\hline
\end{tabular}


Supplemental Table S2.txt

\begin{tabular}{|c|c|c|c|c|c|c|}
\hline CHEMBL1399142 & 688112 & 2.9208 & 3.5281 & TRN & & \\
\hline CHEMBL1502542 & 688112 & 4.8112 & 4.3473 & TRN & & \\
\hline CHEMBL1408191 & 688112 & 4.658 & 4.6775 & TRN & & \\
\hline CHEMBL3190599 & 688112 & 2.9208 & 3.64899 & 999999999 & 996 & TRN \\
\hline CHEMBL1582707 & 688112 & 2.9208 & 4.5048 & TRN & & \\
\hline CHEMBL1572722 & 688112 & 4.5206 & 4.56 & TRN & & \\
\hline CHEMBL1520661 & 688112 & 4.6931 & 4.38899 & 999999995 & & TST \\
\hline CHEMBL1349436 & 688112 & 2.9208 & 4.6606 & TRN & & \\
\hline CHEMBL1505083 & 688112 & 4.2611 & 4.3361 & TRN & & \\
\hline CHEMBL1542043 & 688112 & 4.8594 & 4.1697 & TRN & & \\
\hline CHEMBL1330191 & 688112 & 2.9208 & 4.2676 & TRN & & \\
\hline CHEMBL1511276 & 688112 & 2.9208 & 3.8957 & TRN & & \\
\hline CHEMBL1455877 & 688112 & 2.9208 & 3.6069 & TRN & & \\
\hline CHEMBL1581302 & 688112 & 4.3978 & 3.9767 & TST & & \\
\hline CHEMBL1439775 & 688112 & 5.3443 & 4.3513 & TRN & & \\
\hline CHEMBL1596590 & 688112 & 5.5787 & 4.3191 & TRN & & \\
\hline CHEMBL1534490 & 688112 & 2.9208 & 3.5865 & TST & & \\
\hline CHEMBL1310403 & 688112 & 4.0517 & 4.3052 & TRN & & \\
\hline CHEMBL1525529 & 688112 & \multicolumn{3}{|c|}{4.6530000000000005} & 4.6048 & TRN \\
\hline CHEMBL1498440 & 688112 & 5.3765 & 4.4697 & TRN & & \\
\hline CHEMBL1382658 & 688112 & 4.9832 & 4.8945 & TRN & & \\
\hline CHEMBL1605328 & 688112 & 2.9208 & 3.9885 & TST & & \\
\hline CHEMBL1393134 & 688112 & 4.2264 & 3.5682 & TRN & & \\
\hline CHEMBL1612605 & 688112 & 4.9731 & 3.8394 & TRN & & \\
\hline CHEMBL1533823 & 688112 & 2.9208 & 4.0336 & TRN & & \\
\hline CHEMBL1401361 & 688112 & \multicolumn{3}{|c|}{6.2620000000000005} & 5.3108 & \\
\hline CHEMBL1445389 & 688112 & 4.8706 & 4.3912 & TRN & & \\
\hline CHEMBL1378835 & 688112 & 2.9208 & 4.2843 & TRN & & \\
\hline CHEMBL1311629 & 688112 & 4.4956 & 4.1906 & TRN & & \\
\hline CHEMBL1549611 & 688112 & 2.9208 & 4.1459 & TRN & & \\
\hline CHEMBL3194711 & 688112 & 3.9662 & 4.331 & TST & & \\
\hline CHEMBL492116 & 688112 & 2.9208 & 4.1088 & TRN & & \\
\hline CHEMBL1494085 & 688112 & 2.9208 & 4.2029 & TRN & & \\
\hline CHEMBL1564117 & 688112 & 2.9208 & 3.6497 & TRN & & \\
\hline CHEMBL1478644 & 688112 & 2.9208 & 4.9349 & TRN & & \\
\hline CHEMBL1445482 & 688112 & 2.9208 & 3.5256 & TRN & & \\
\hline CHEMBL1311838 & 688112 & 4.6756 & 4.4903 & TRN & & \\
\hline CHEMBL1502624 & 688112 & 2.9208 & 4.6277 & TRN & & \\
\hline CHEMBL1510647 & 688112 & 4.8399 & 4.1529 & TRN & & \\
\hline CHEMBL1416282 & 688112 & 2.9208 & 4.8346 & TRN & & \\
\hline CHEMBL1533752 & 688112 & 2.9208 & 4.3738 & TST & & \\
\hline CHEMBL3213109 & 688112 & 4.5405 & 4.2801 & TST & & \\
\hline CHEMBL1542766 & 688112 & 5.1712 & 3.7606 & TST & & \\
\hline CHEMBL1361242 & 688112 & 5.6964 & 4.538 & TRN & & \\
\hline CHEMBL1465534 & 688112 & 4.8245 & 3.9457 & TRN & & \\
\hline CHEMBL1378851 & 688112 & 2.9208 & 4.6438 & TST & & \\
\hline CHEMBL473162 & 688112 & 4.8635 & 4.9663 & TRN & & \\
\hline CHEMBL1589770 & 688112 & 5.0994 & 3.8051 & TRN & & \\
\hline
\end{tabular}


Supplemental Table S2.txt

\begin{tabular}{|c|c|c|c|c|}
\hline CHEMBL1573657 & 688112 & 5.0197 & 4.4349 & TRN \\
\hline CHEMBL1374157 & 688112 & 4.1484 & 4.282 & TRN \\
\hline CHEMBL1428107 & 688112 & 4.8714 & 4.2342 & TRN \\
\hline CHEMBL1331466 & 688112 & 4.7224 & 3.9992 & TRN \\
\hline CHEMBL1505173 & 688112 & 5.5514 & 4.2937 & TRN \\
\hline CHEMBL1346887 & 688112 & 4.6561 & 4.1807 & TRN \\
\hline CHEMBL1405274 & 688112 & 5.3728 & 3.62399 & 99999999997 \\
\hline CHEMBL1542660 & 688112 & 3.9652 & 4.7396 & TRN \\
\hline CHEMBL1530579 & 688112 & 5.6151 & 4.2326 & TRN \\
\hline CHEMBL1451747 & 688112 & 2.9208 & 3.6279 & TRN \\
\hline CHEMBL1581554 & 688112 & 2.9208 & 4.3311 & TRN \\
\hline CHEMBL1566026 & 688112 & 5.49700 & 00000000 & 4.9356 \\
\hline CHEMBL1575576 & 688112 & 4.3967 & 4.0607 & TRN \\
\hline CHEMBL1509760 & 688112 & 2.9208 & 4.2513 & TRN \\
\hline CHEMBL1498632 & 688112 & 4.7708 & 3.9131 & TRN \\
\hline CHEMBL1423951 & 688112 & 4.9321 & 4.7819 & TRN \\
\hline CHEMBL3195592 & 688112 & 2.9208 & 4.3491 & TRN \\
\hline CHEMBL1599365 & 688112 & 2.9208 & 3.5984 & TST \\
\hline CHEMBL1379768 & 688112 & 4.7634 & 4.3098 & TRN \\
\hline CHEMBL1400744 & 688112 & 4.7479 & 4.4005 & TRN \\
\hline CHEMBL1352675 & 688112 & 2.9208 & 3.8415 & TRN \\
\hline CHEMBL1462522 & 688112 & 5.0314 & 4.2861 & TRN \\
\hline CHEMBL1490976 & 688112 & 6.3883 & 4.9579 & TRN \\
\hline CHEMBL1503105 & 688112 & 5.3315 & 4.0599 & TRN \\
\hline CHEMBL1387487 & 688112 & 2.9208 & 4.6871 & TRN \\
\hline CHEMBL1504873 & 688112 & 4.7926 & 4.6451 & TRN \\
\hline CHEMBL1525320 & 688112 & 4.2096 & 4.2726 & TRN \\
\hline CHEMBL1573190 & 688112 & 4.4762 & 4.4236 & TRN \\
\hline CHEMBL1520731 & 688112 & 5.1568 & 4.8683 & TST \\
\hline CHEMBL1421266 & 688112 & 2.9208 & 4.431 & TRN \\
\hline CHEMBL1525437 & 688112 & 5.1842 & 4.1461 & TRN \\
\hline CHEMBL1335318 & 688112 & 4.4492 & 5.4518 & TRN \\
\hline CHEMBL1599076 & 688112 & 4.551 & 4.5114 & TRN \\
\hline CHEMBL1981770 & 688112 & 2.9208 & 3.6143 & TST \\
\hline CHEMBL1326037 & 688112 & 2.9208 & 4.1034 & TRN \\
\hline CHEMBL1325503 & 688112 & 5.3181 & 4.6745 & TRN \\
\hline CHEMBL 3207881 & 688112 & 4.3705 & 3.6312 & TRN \\
\hline CHEMBL1387969 & 688112 & 5.1749 & 4.0345 & TST \\
\hline CHEMBL1605898 & 688112 & 4.9479 & 3.9996 & TST \\
\hline CHEMBL1567874 & 688112 & 5.1487 & 4.2381 & TRN \\
\hline CHEMBL 2369261 & 688112 & 4.9734 & 4.3028 & TRN \\
\hline CHEMBL1532369 & 688112 & 4.7493 & 3.6159 & TRN \\
\hline CHEMBL1376011 & 688112 & 4.1261 & 5.0137 & TRN \\
\hline CHEMBL1501848 & 688112 & 4.9978 & 4.4711 & TRN \\
\hline CHEMBL3192335 & 688112 & 2.9208 & 4.6419 & TRN \\
\hline CHEMBL1414223 & 688112 & 2.9208 & 4.6581 & TST \\
\hline CHEMBL1387546 & 688112 & 5.4093 & 4.3776 & TRN \\
\hline CHEMBL1404286 & 688112 & 4.8081 & 4.3381 & TRN \\
\hline
\end{tabular}


Supplemental Table S2.txt

\begin{tabular}{|c|c|c|c|c|}
\hline CHEMBL1571239 & 688112 & 6.3116 & 4.9917 & TRN \\
\hline CHEMBL1971282 & 688112 & 5.5648 & 4.5032 & TRN \\
\hline CHEMBL1301226 & 688112 & 2.9208 & 4.0738 & TRN \\
\hline CHEMBL1336834 & 688112 & 4.3436 & 4.3881 & TRN \\
\hline CHEMBL1359565 & 688112 & 6.6635 & 4.8069 & TRN \\
\hline CHEMBL3190267 & 688112 & 4.6351 & 4.4644 & TRN \\
\hline CHEMBL1453224 & 688112 & 4.6571 & 4.3217 & TRN \\
\hline CHEMBL1545433 & 688112 & 6.9318 & 4.3708 & TRN \\
\hline CHEMBL1439444 & 688112 & 2.9208 & 3.9844 & TRN \\
\hline CHEMBL1353660 & 688112 & 4.8214 & 4.3015 & TRN \\
\hline CHEMBL1548929 & 688112 & 5.7135 & 4.5742 & TRN \\
\hline CHEMBL1401683 & 688112 & 4.9582 & 4.1425 & TRN \\
\hline CHEMBL1444483 & 688112 & 5.3518 & 4.7425 & TRN \\
\hline CHEMBL1509227 & 688112 & 2.9208 & 4.3646 & TRN \\
\hline CHEMBL1464980 & 688112 & 4.3134 & 4.4077 & TRN \\
\hline CHEMBL1574581 & 688112 & 4.3307 & 3.5966 & TRN \\
\hline CHEMBL1499697 & 688112 & 2.9208 & 3.9653 & TRN \\
\hline CHEMBL1319024 & 688112 & 4.5948 & 4.1948 & TRN \\
\hline CHEMBL1311224 & 688112 & 4.1424 & 4.3262 & TST \\
\hline CHEMBL1556655 & 688112 & 2.9208 & 4.3195 & TRN \\
\hline CHEMBL1561296 & 688112 & 2.9208 & 4.26399 & 9999999999 \\
\hline CHEMBL1535064 & 688112 & 4.5758 & 4.2126 & TST \\
\hline CHEMBL1499121 & 688112 & 4.3369 & 4.5196 & TRN \\
\hline CHEMBL1544075 & 688112 & 4.3981 & 4.4381 & TST \\
\hline CHEMBL1605642 & 688112 & 4.721 & 4.23600 & 0000000001 \\
\hline CHEMBL1523093 & 688112 & 4.8994 & 4.4325 & TRN \\
\hline CHEMBL1596703 & 688112 & 4.8933 & 4.1323 & TRN \\
\hline CHEMBL1604258 & 688112 & 4.9848 & 4.3391 & TRN \\
\hline CHEMBL1433770 & 688112 & 4.0499 & 4.3567 & TRN \\
\hline CHEMBL1393076 & 688112 & 4.7734 & 3.9722 & TRN \\
\hline CHEMBL1607544 & 688112 & 4.8939 & 4.3916 & TRN \\
\hline CHEMBL1574671 & 688112 & 8.0 & 4.9143 & TST \\
\hline CHEMBL1392365 & 688112 & 2.9208 & 3.8958 & TRN \\
\hline CHEMBL1410151 & 688112 & 4.6349 & 4.4107 & TRN \\
\hline CHEMBL1400312 & 688112 & 4.501 & 4.2851 & TRN \\
\hline CHEMBL1539171 & 688112 & 4.7474 & 4.2751 & TRN \\
\hline CHEMBL1326481 & 688112 & 3.9645 & 4.6834 & TRN \\
\hline CHEMBL1445899 & 688112 & 2.9208 & 3.5609 & TRN \\
\hline CHEMBL1428141 & 688112 & 4.0105 & 4.268 & TRN \\
\hline CHEMBL1558072 & 688112 & 4.4955 & 4.3716 & TRN \\
\hline CHEMBL1526806 & 688112 & 4.2715 & 4.4182 & TRN \\
\hline CHEMBL1329596 & 688112 & 4.5605 & 5.0114 & TRN \\
\hline CHEMBL407817 & 688112 & 2.9208 & 4.3739 & TRN \\
\hline CHEMBL1434993 & 688112 & 2.9208 & 4.2846 & TST \\
\hline CHEMBL1537753 & 688112 & 4.9972 & 3.9652 & TRN \\
\hline CHEMBL1534933 & 688112 & 4.3999 & 3.8649 & TRN \\
\hline CHEMBL1540417 & 688112 & 8.0 & 4.9729 & TRN \\
\hline CHEMBL1501121 & 688112 & 6.4365 & 4.2545 & TRN \\
\hline
\end{tabular}

Page 8579 


\begin{tabular}{|c|c|c|c|c|c|}
\hline \multirow{3}{*}{$\begin{array}{l}\text { CHEMBL1595926 } \\
\text { CHEMBL1485369 }\end{array}$} & \multicolumn{5}{|c|}{ Supplemental Table S2.txt } \\
\hline & 688112 & 4.8926 & 4.29899 & 99999999995 & TST \\
\hline & 688112 & 4.3045 & 3.6928 & TRN & \\
\hline CHEMBL1490486 & 688112 & 2.9208 & 3.5224 & TST & \\
\hline CHEMBL1463674 & 688112 & 4.9624 & 4.311 & TRN & \\
\hline CHEMBL1308206 & 688112 & 5.1939 & 4.2524 & TRN & \\
\hline CHEMBL3195612 & 688112 & 4.1671 & 5.0403 & TRN & \\
\hline CHEMBL1577624 & 688112 & 5.0576 & 4.5501 & TRN & \\
\hline CHEMBL1355755 & 688112 & 4.8208 & 5.1854 & TRN & \\
\hline CHEMBL1371624 & 688112 & 2.9208 & 4.4961 & TRN & \\
\hline CHEMBL1364689 & 688112 & 2.9208 & 4.379 & TST & \\
\hline CHEMBL1325354 & 688112 & 2.9208 & 5.1548 & TST & \\
\hline CHEMBL1092508 & 688112 & 4.5281 & 4.1865 & TRN & \\
\hline CHEMBL1402437 & 688112 & 4.4924 & 4.8924 & TRN & \\
\hline CHEMBL1401958 & 688112 & 3.2218 & 3.94 & TRN & \\
\hline CHEMBL1469054 & 688112 & 4.3513 & 4.7027 & TRN & \\
\hline CHEMBL1530057 & 688112 & 4.3336 & 4.284 & TRN & \\
\hline CHEMBL1470281 & 688112 & 5.0358 & 4.0796 & TST & \\
\hline CHEMBL1577623 & 688112 & 4.5405 & 4.2999 & TRN & \\
\hline CHEMBL252901 & 688112 & 5.11 & 4.7494 & TRN & \\
\hline CHEMBL1597773 & 688112 & 2.9208 & 3.6254 & TRN & \\
\hline CHEMBL1562944 & 688112 & 5.0547 & 4.2482 & TRN & \\
\hline CHEMBL1449473 & 688112 & 4.425 & 4.367 & TRN & \\
\hline CHEMBL1445361 & 688112 & 4.165 & 4.1435 & TST & \\
\hline CHEMBL469058 & 688112 & 4.1307 & 4.2317 & TRN & \\
\hline CHEMBL1409532 & 688112 & 2.9208 & 4.3548 & TRN & \\
\hline CHEMBL1595573 & 688112 & 5.025 & 4.3792 & TRN & \\
\hline CHEMBL1549398 & 688112 & 5.1589 & 4.5875 & TRN & \\
\hline CHEMBL3195196 & 688112 & 2.9208 & 4.8036 & TRN & \\
\hline CHEMBL1564261 & 688112 & 8.0 & 4.2872 & TRN & \\
\hline CHEMBL1586474 & 688112 & 4.742 & 4.3274 & TRN & \\
\hline CHEMBL1435015 & 688112 & 2.9208 & 4.0556 & TRN & \\
\hline CHEMBL1427221 & 688112 & 3.2218 & 5.0331 & TRN & \\
\hline CHEMBL1523967 & 688112 & 4.9555 & 4.3628 & TRN & \\
\hline CHEMBL1350769 & 688112 & 4.3247 & 4.341 & TST & \\
\hline CHEMBL1529331 & 688112 & 4.7395 & 4.2527 & TST & \\
\hline CHEMBL1608645 & 688112 & 2.9208 & 4.3149 & TRN & \\
\hline CHEMBL1560251 & 688112 & 4.285 & 4.3014 & TRN & \\
\hline CHEMBL1565105 & 688112 & 4.5125 & 4.2485 & TRN & \\
\hline CHEMBL1527152 & 688112 & 2.9208 & 3.9181 & TRN & \\
\hline CHEMBL1330543 & 688112 & 5.1373 & 4.313 & TRN & \\
\hline CHEMBL1520975 & 688112 & 4.7487 & 3.9653 & TRN & \\
\hline CHEMBL1550249 & 688112 & 4.7995 & 4.33899 & 99999999995 & TRN \\
\hline CHEMBL1478880 & 688112 & 5.0864 & 4.11100 & 0000000001 & TRN \\
\hline CHEMBL1548132 & 688112 & 2.9208 & 4.4805 & TRN & \\
\hline CHEMBL3194100 & 688112 & 2.9208 & 4.0361 & TRN & \\
\hline CHEMBL1438752 & 688112 & 5.0071 & 4.3531 & TRN & \\
\hline CHEMBL3198976 & 688112 & 4.3341 & 4.4705 & TRN & \\
\hline CHEMBL1345845 & 688112 & 5.5768 & 4.4826 & TRN & \\
\hline
\end{tabular}


Supplemental Table S2.txt

\begin{tabular}{|c|c|c|c|c|c|c|}
\hline CHEMBL1337171 & 688112 & 4.6106 & 4.2631 & TRN & & \\
\hline CHEMBL3192618 & 688112 & 4.6991 & 4.4577 & TRN & & \\
\hline CHEMBL1489931 & 688112 & 4.9595 & 4.4087 & TRN & & \\
\hline CHEMBL1965956 & 688112 & 2.9208 & 3.9675 & TRN & & \\
\hline CHEMBL1310825 & 688112 & 4.4976 & 4.3916 & TRN & & \\
\hline CHEMBL1410857 & 688112 & 2.9208 & 3.5381 & TRN & & \\
\hline CHEMBL1346199 & 688112 & 4.3154 & 4.2308 & TRN & & \\
\hline CHEMBL1389746 & 688112 & 2.9208 & 4.2796 & TRN & & \\
\hline CHEMBL1367297 & 688112 & 4.2717 & 4.2093 & TST & & \\
\hline CHEMBL3195278 & 688112 & 4.315 & 4.2637 & TRN & & \\
\hline CHEMBL1309765 & 688112 & 2.9208 & 4.3431 & TRN & & \\
\hline CHEMBL3208632 & 688112 & 6.1007 & 4.0916 & TRN & & \\
\hline CHEMBL1441799 & 688112 & 2.9208 & 4.2464 & TRN & & \\
\hline CHEMBL1391219 & 688112 & 4.873 & 4.4559 & TRN & & \\
\hline CHEMBL1470349 & 688112 & 4.59 & 4.2257 & TRN & & \\
\hline CHEMBL1427687 & 688112 & 4.9794 & 4.039 & TRN & & \\
\hline CHEMBL1458423 & 688112 & 4.3548 & 4.3019 & TRN & & \\
\hline CHEMBL1383057 & 688112 & 5.2816 & 4.6424 & TRN & & \\
\hline CHEMBL1317605 & 688112 & 4.7381 & 4.359 & TRN & & \\
\hline CHEMBL1476282 & 688112 & 4.8369 & 4.3187 & TRN & & \\
\hline CHEMBL1596598 & 688112 & 4.8828 & 4.3505 & TRN & & \\
\hline CHEMBL1578622 & 688112 & 4.9417 & 4.2575 & TRN & & \\
\hline CHEMBL1306578 & 688112 & 2.9208 & 4.3361 & TST & & \\
\hline CHEMBL1536326 & 688112 & 2.9208 & 4.4911 & TRN & & \\
\hline CHEMBL 3190842 & 688112 & \multicolumn{3}{|c|}{5.343999999999999} & 4.2127 & TRN \\
\hline CHEMBL1556289 & 688112 & 2.9208 & 4.4224 & TRN & & \\
\hline CHEMBL1569442 & 688112 & 6.2581 & 5.325 & TRN & & \\
\hline CHEMBL1385055 & 688112 & 2.9208 & 4.0434 & TRN & & \\
\hline CHEMBL1407407 & 688112 & 4.644 & 4.3875 & TST & & \\
\hline CHEMBL1349916 & 688112 & 4.989 & 4.0109 & TRN & & \\
\hline CHEMBL1576324 & 688112 & \multicolumn{3}{|c|}{5.0280000000000005} & 4.3531 & TST \\
\hline CHEMBL1328740 & 688112 & 2.9208 & 4.2955 & TRN & & \\
\hline CHEMBL1464737 & 688112 & 5.0123 & 4.4673 & TRN & & \\
\hline CHEMBL3193613 & 688112 & 5.5935 & 4.8115 & TRN & & \\
\hline CHEMBL1438259 & 688112 & 2.9208 & 4.6846 & TRN & & \\
\hline CHEMBL1579395 & 688112 & 4.6372 & 4.325 & TRN & & \\
\hline CHEMBL1527045 & 688112 & 4.6307 & 4.3546 & TRN & & \\
\hline CHEMBL1387150 & 688112 & 6.0057 & 4.2515 & TRN & & \\
\hline CHEMBL1565691 & 688112 & 2.9208 & 4.8729 & TRN & & \\
\hline CHEMBL3213703 & 688112 & 2.9208 & 4.1759 & TST & & \\
\hline CHEMBL3195432 & 688112 & 5.965 & 4.9342 & TRN & & \\
\hline CHEMBL1414633 & 688112 & 2.9208 & 4.6709 & TRN & & \\
\hline CHEMBL585622 & 688112 & 2.9208 & 4.0122 & TRN & & \\
\hline CHEMBL3198603 & 688112 & 4.7846 & 4.3652 & TST & & \\
\hline CHEMBL1542110 & 688112 & 4.1761 & 4.5094 & TRN & & \\
\hline CHEMBL1606193 & 688112 & 2.9208 & 4.535 & TRN & & \\
\hline CHEMBL1446080 & 688112 & 4.5725 & 4.1304 & TRN & & \\
\hline CHEMBL1351353 & 688112 & 2.9208 & 4.4776 & TST & & \\
\hline
\end{tabular}


Supplemental Table S2.txt

\begin{tabular}{|c|c|c|c|c|}
\hline CHEMBL1381159 & 688112 & 2.9208 & 3.6431 & TRN \\
\hline CHEMBL1382098 & 688112 & 3.2218 & 4.2515 & TRN \\
\hline CHEMBL1583455 & 688112 & 4.386 & 3.9151 & TST \\
\hline CHEMBL1418909 & 688112 & 5.1034 & 4.58899 & 99999999995 \\
\hline CHEMBL1491745 & 688112 & 2.9208 & 4.5765 & TRN \\
\hline CHEMBL1353405 & 688112 & 4.1201 & 4.2904 & TRN \\
\hline CHEMBL1383500 & 688112 & 4.2093 & 4.3797 & TRN \\
\hline CHEMBL1544748 & 688112 & 4.5755 & 3.9353 & TRN \\
\hline CHEMBL1528986 & 688112 & 4.1462 & 4.3547 & TRN \\
\hline CHEMBL1404510 & 688112 & 2.9208 & 4.3578 & TRN \\
\hline CHEMBL1604264 & 688112 & 4.5609 & 4.2965 & TRN \\
\hline CHEMBL1583314 & 688112 & 4.9442 & 3.6388 & TRN \\
\hline CHEMBL1449627 & 688112 & 2.9208 & 5.356 & TRN \\
\hline CHEMBL 3184145 & 688112 & 2.9208 & 4.0131 & TRN \\
\hline CHEMBL1522206 & 688112 & 4.0277 & 4.6272 & TRN \\
\hline CHEMBL1350043 & 688112 & 5.1104 & 4.873 & TRN \\
\hline CHEMBL1389445 & 688112 & 4.8329 & 4.2282 & TRN \\
\hline CHEMBL1421850 & 688112 & 2.9208 & 3.7077 & TRN \\
\hline CHEMBL1470903 & 688112 & 2.9208 & 5.317 & TRN \\
\hline CHEMBL1325363 & 688112 & 2.9208 & 3.6389 & TRN \\
\hline CHEMBL1457749 & 688112 & 2.9208 & 4.1443 & TRN \\
\hline CHEMBL1449261 & 688112 & 2.9208 & 3.9289 & TRN \\
\hline CHEMBL1327254 & 688112 & 6.9914 & 4.4386 & TST \\
\hline CHEMBL1588778 & 688112 & 2.9208 & 4.2562 & TRN \\
\hline CHEMBL 3191871 & 688112 & 8.0 & 4.3697 & TRN \\
\hline CHEMBL1559258 & 688112 & 2.9208 & 3.8902 & TRN \\
\hline CHEMBL1977963 & 688112 & 2.9208 & 3.6502 & TRN \\
\hline CHEMBL1498536 & 688112 & 4.7473 & 4.2459 & TRN \\
\hline CHEMBL3211285 & 688112 & 4.6698 & 4.1222 & TRN \\
\hline CHEMBL1170485 & 688112 & 4.0073 & 3.6645 & TST \\
\hline CHEMBL1492232 & 688112 & 2.9208 & 4.1786 & TRN \\
\hline CHEMBL1362521 & 688112 & 4.4488 & 3.8464 & TRN \\
\hline CHEMBL1399208 & 688112 & 4.9243 & 4.5063 & TRN \\
\hline CHEMBL1377682 & 688112 & 2.9208 & 3.614 & TRN \\
\hline CHEMBL 3189244 & 688112 & 3.9258 & 3.6436 & TRN \\
\hline CHEMBL1489535 & 688112 & 2.9208 & 3.8903 & TST \\
\hline CHEMBL1343552 & 688112 & 5.0829 & 4.3263 & TRN \\
\hline CHEMBL1459418 & 688112 & 4.7943 & 4.4564 & TRN \\
\hline CHEMBL1508330 & 688112 & 4.2954 & 4.0744 & TRN \\
\hline CHEMBL1431361 & 688112 & 6.1051 & 4.8825 & TRN \\
\hline CHEMBL1450961 & 688112 & 4.5192 & 4.2888 & TRN \\
\hline CHEMBL1425046 & 688112 & 4.8232 & 4.9095 & TRN \\
\hline CHEMBL1584686 & 688112 & 2.9208 & 3.967 & TST \\
\hline CHEMBL1510913 & 688112 & 2.9208 & 4.7819 & TRN \\
\hline CHEMBL1463032 & 688112 & 4.8482 & 4.3326 & TRN \\
\hline CHEMBL1510805 & 688112 & 4.5027 & 4.3167 & TRN \\
\hline CHEMBL1583989 & 688112 & 5.1283 & 4.4363 & TRN \\
\hline CHEMBL1482145 & 688112 & 2.9208 & 4.3604 & TRN \\
\hline
\end{tabular}


Supplemental Table S2.txt

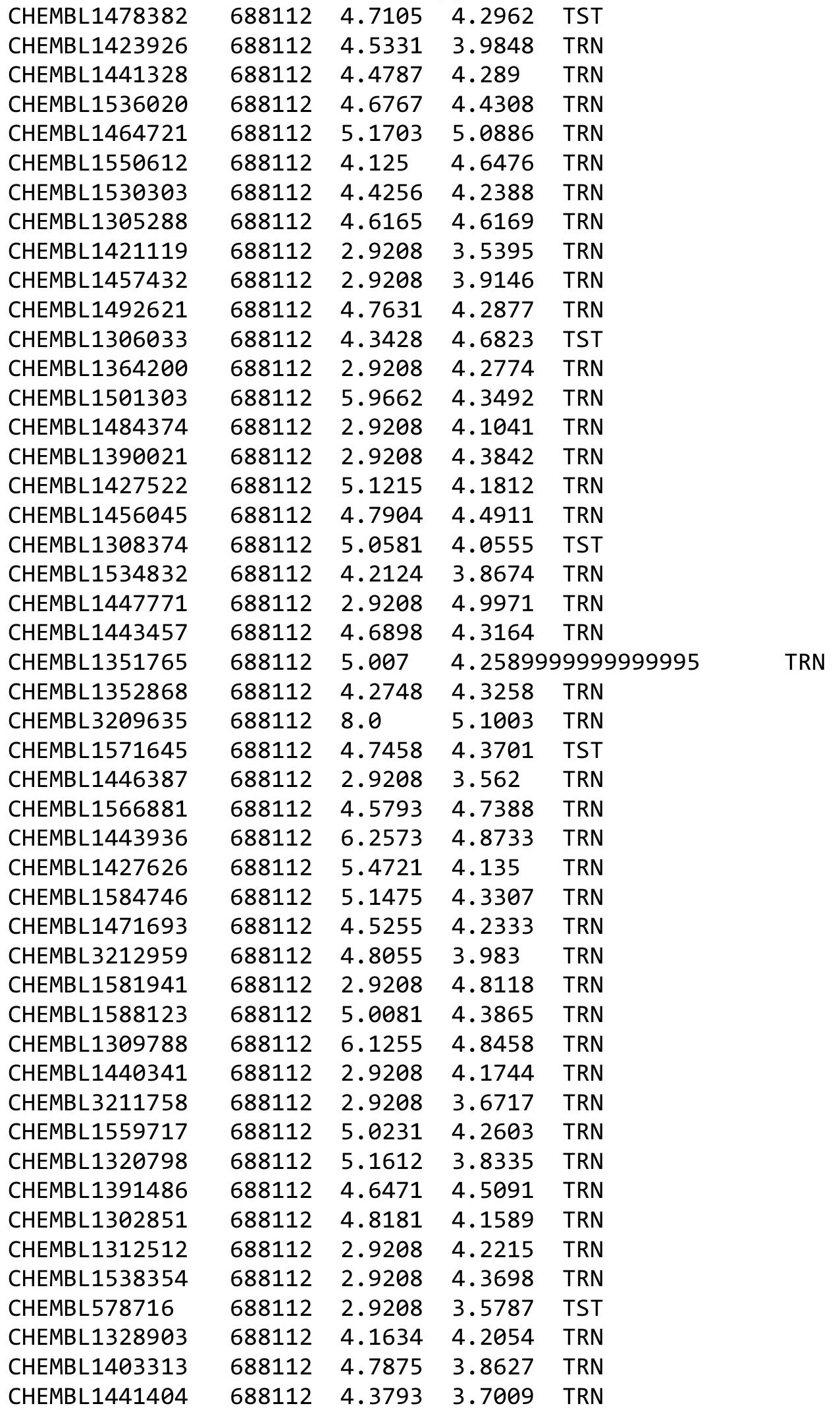

Page 8583 


\begin{tabular}{|c|c|c|c|c|}
\hline & & & pplement & al $\mathrm{Tc}$ \\
\hline CHEMBL1535680 & 688112 & 5.0043 & 4.4803 & TRN \\
\hline CHEMBL547833 & 688112 & 2.9208 & 3.9823 & TRN \\
\hline CHEMBL1542918 & 688112 & 4.8862 & 4.1896 & TRN \\
\hline CHEMBL 3197003 & 688112 & 2.9208 & 3.4622 & TRN \\
\hline CHEMBL1306817 & 688112 & 3.2218 & 4.3654 & TRN \\
\hline CHEMBL1318940 & 688112 & 4.5308 & 3.9041 & TRN \\
\hline CHEMBL1609490 & 688112 & 2.9208 & 3.9131 & TRN \\
\hline CHEMBL1392445 & 688112 & 2.9208 & 4.5159 & TRN \\
\hline CHEMBL1467284 & 688112 & 2.9208 & 3.5144 & TRN \\
\hline CHEMBL1733957 & 688112 & 2.9208 & 3.7979 & TRN \\
\hline CHEMBL3197088 & 688112 & 2.9208 & 3.6312 & TRN \\
\hline CHEMBL1549571 & 688112 & 4.0469 & 4.3733 & TRN \\
\hline CHEMBL1582426 & 688112 & 2.9208 & 3.8769 & TRN \\
\hline CHEMBL1447669 & 688112 & 4.7181 & 4.5161 & TRN \\
\hline CHEMBL1418545 & 688112 & 4.705 & 4.0304 & TRN \\
\hline CHEMBL1442956 & 688112 & 2.9208 & 4.2702 & TRN \\
\hline CHEMBL1566477 & 688112 & 2.9208 & 4.3231 & TRN \\
\hline CHEMBL1337145 & 688112 & 4.7984 & 4.3734 & TRN \\
\hline CHEMBL1322536 & 688112 & 4.7094 & 3.9315 & TRN \\
\hline CHEMBL1488333 & 688112 & 2.9208 & 4.5883 & TRN \\
\hline CHEMBL1571228 & 688112 & 4.2645 & 4.3067 & TRN \\
\hline CHEMBL1525026 & 688112 & 5.1565 & 4.0917 & TRN \\
\hline CHEMBL1322727 & 688112 & 5.1846 & 4.9598 & TRN \\
\hline CHEMBL3197286 & 688112 & 4.5536 & 4.022 & TST \\
\hline CHEMBL1585607 & 688112 & 5.0029 & 4.3179 & TRN \\
\hline CHEMBL1570658 & 688112 & 6.2807 & 4.1712 & TRN \\
\hline CHEMBL1540320 & 688112 & 3.9531 & 3.9895 & TRN \\
\hline CHEMBL1525865 & 688112 & 4.3467 & 4.2959 & TRN \\
\hline CHEMBL1410076 & 688112 & 2.9208 & 3.9064 & TRN \\
\hline CHEMBL1525390 & 688112 & 2.9208 & 4.4229 & TRN \\
\hline CHEMBL1366816 & 688112 & 4.9084 & 4.792 & TRN \\
\hline CHEMBL1328052 & 688112 & 2.9208 & 4.0149 & TRN \\
\hline CHEMBL1331678 & 688112 & 4.1847 & 4.626 & TRN \\
\hline CHEMBL1308320 & 688112 & 3.2218 & 4.4107 & TST \\
\hline CHEMBL1449685 & 688112 & 5.1235 & 4.8061 & TRN \\
\hline CHEMBL1522298 & 688112 & 2.9208 & 4.2914 & TRN \\
\hline CHEMBL1510632 & 688112 & 2.9208 & 3.9993 & TRN \\
\hline CHEMBL1542537 & 688112 & 2.9208 & 4.226 & TRN \\
\hline CHEMBL1427379 & 688112 & 4.1457 & 3.7257 & TRN \\
\hline CHEMBL1561067 & 688112 & 2.9208 & 3.571 & TRN \\
\hline CHEMBL1313911 & 688112 & 2.9208 & 3.9121 & TRN \\
\hline CHEMBL1450011 & 688112 & 4.7821 & 4.2941 & TRN \\
\hline CHEMBL1534465 & 688112 & 2.9208 & 4.37 & TRN \\
\hline CHEMBL1340291 & 688112 & 4.8171 & 4.0002 & TRN \\
\hline CHEMBL1556013 & 688112 & 4.5011 & 3.9106 & TRN \\
\hline CHEMBL1484314 & 688112 & 4.8418 & 4.1952 & TRN \\
\hline CHEMBL1531774 & 688112 & 4.8525 & 4.3208 & TRN \\
\hline CHEMBL1549222 & 688112 & 2.9208 & 4.0238 & TRN \\
\hline
\end{tabular}


Supplemental Table S2.txt

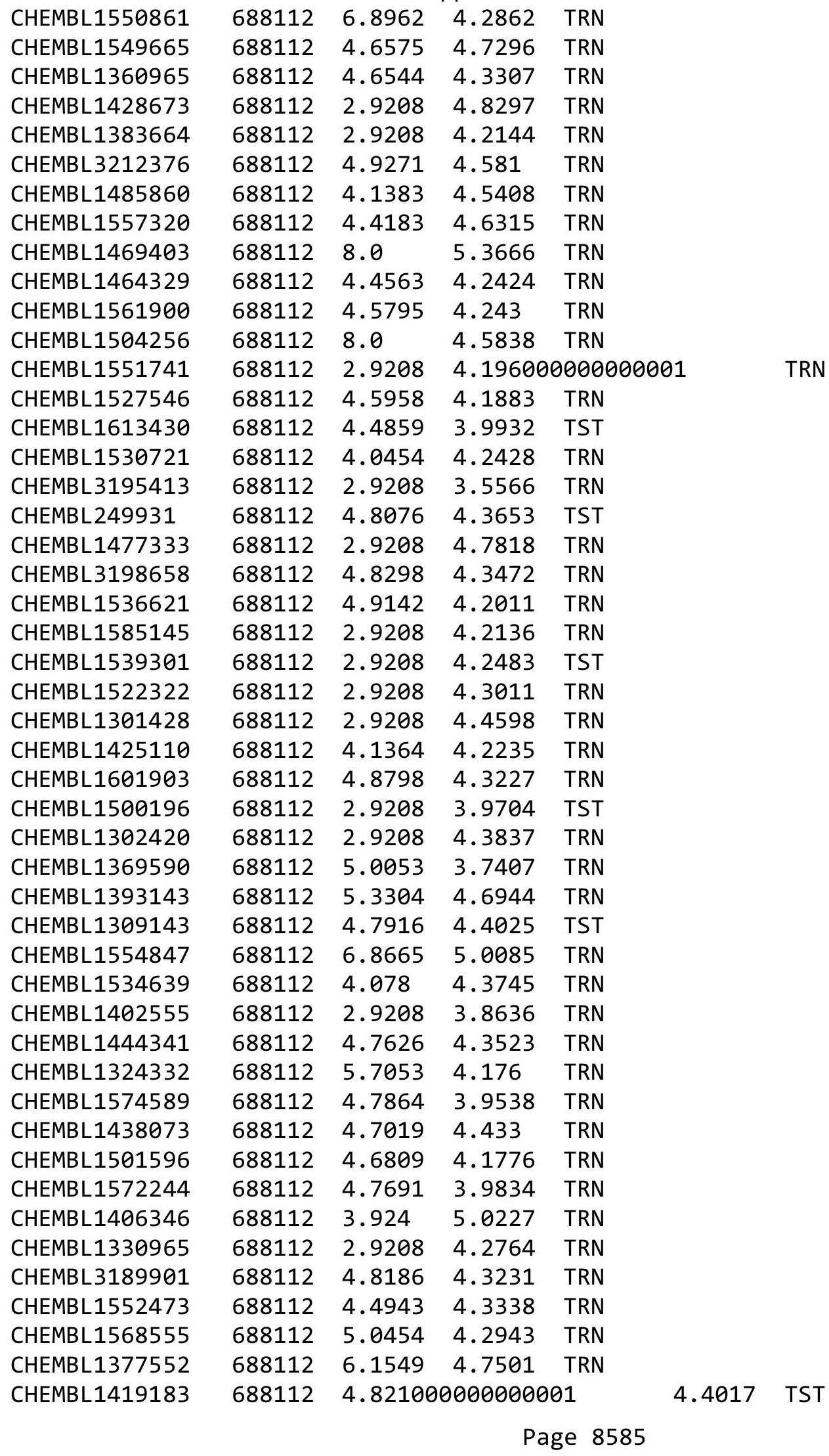


Supplemental Table S2.txt

\begin{tabular}{|c|c|c|c|c|c|}
\hline CHEMBL1534798 & 688112 & 4.2703 & 4.2111 & TRN & \\
\hline CHEMBL1568905 & 688112 & 5.3354 & 4.3759 & TRN & \\
\hline CHEMBL1446575 & 688112 & 4.8882 & 4.2283 & TRN & \\
\hline CHEMBL1605139 & 688112 & 2.9208 & 4.3667 & TST & \\
\hline CHEMBL1417740 & 688112 & 5.7615 & 4.2131 & TST & \\
\hline CHEMBL1253586 & 688112 & 4.5628 & 4.3451 & TST & \\
\hline CHEMBL1384726 & 688112 & 2.9208 & 3.6227 & TRN & \\
\hline CHEMBL1556906 & 688112 & 4.7432 & 4.2188 & TRN & \\
\hline CHEMBL1366110 & 688112 & 2.9208 & 3.5676 & TRN & \\
\hline CHEMBL1347104 & 688112 & 4.7663 & 3.9177 & TRN & \\
\hline CHEMBL1378221 & 688112 & 4.4203 & 4.4031 & TRN & \\
\hline CHEMBL1508470 & 688112 & 4.9589 & 4.4158 & TRN & \\
\hline CHEMBL1444579 & 688112 & 4.7141 & 4.2554 & TRN & \\
\hline CHEMBL1494477 & 688112 & 5.0472 & 4.1328 & TRN & \\
\hline CHEMBL1603695 & 688112 & 2.9208 & 4.1113 & TRN & \\
\hline CHEMBL1421506 & 688112 & 2.9208 & 3.5219 & TRN & \\
\hline CHEMBL1342306 & 688112 & 2.9208 & 4.19600 & 0000000001 & TRN \\
\hline CHEMBL1586235 & 688112 & 5.1506 & 4.3914 & TRN & \\
\hline CHEMBL1422056 & 688112 & 4.6296 & 3.9367 & TRN & \\
\hline CHEMBL 3197741 & 688112 & 6.2798 & 5.42 & TRN & \\
\hline CHEMBL1488108 & 688112 & 5.2434 & 4.463 & TRN & \\
\hline CHEMBL3213940 & 688112 & 4.8894 & 4.1284 & TRN & \\
\hline CHEMBL1575008 & 688112 & 4.913 & 4.2756 & TRN & \\
\hline CHEMBL1611417 & 688112 & 2.9208 & 4.0435 & TRN & \\
\hline CHEMBL1465725 & 688112 & 4.0809 & 4.3172 & TRN & \\
\hline CHEMBL1392187 & 688112 & 4.6248 & 4.2636 & TRN & \\
\hline CHEMBL1327719 & 688112 & 5.0379 & 4.3322 & TRN & \\
\hline CHEMBL 3210221 & 688112 & 5.0287 & 3.8393 & TST & \\
\hline CHEMBL1483686 & 688112 & 2.9208 & 4.3505 & TRN & \\
\hline CHEMBL1547757 & 688112 & 4.8822 & 4.4012 & TRN & \\
\hline CHEMBL1610644 & 688112 & 2.9208 & 4.2941 & TRN & \\
\hline CHEMBL1468819 & 688112 & 4.6825 & 4.2202 & TRN & \\
\hline CHEMBL1568672 & 688112 & 4.6566 & 3.8917 & TRN & \\
\hline CHEMBL1497338 & 688112 & 2.9208 & 3.7111 & TRN & \\
\hline CHEMBL1350429 & 688112 & 4.3982 & \multicolumn{2}{|c|}{4.2010000000000005} & TRN \\
\hline CHEMBL1344387 & 688112 & 4.8219 & 4.2936 & TRN & \\
\hline CHEMBL1603448 & 688112 & 4.467 & 4.2776 & TRN & \\
\hline CHEMBL1463521 & 688112 & 4.8602 & 3.475 & TRN & \\
\hline CHEMBL1493226 & 688112 & 5.1674 & 4.7492 & TRN & \\
\hline CHEMBL1487137 & 688112 & 4.7726 & 4.1554 & TRN & \\
\hline CHEMBL473106 & 688112 & 8.0 & 4.4393 & TRN & \\
\hline CHEMBL1421415 & 688112 & 4.8139 & 4.3847 & TRN & \\
\hline CHEMBL1443597 & 688112 & 4.2952 & 4.3262 & TRN & \\
\hline CHEMBL1414419 & 688112 & 4.0422 & 4.2921 & TST & \\
\hline CHEMBL3192482 & 688112 & 2.9208 & 4.0166 & TRN & \\
\hline CHEMBL1304209 & 688112 & 4.7486 & 4.2354 & TRN & \\
\hline CHEMBL1345705 & 688112 & 4.9996 & 3.8863 & TRN & \\
\hline CHEMBL1313750 & 688112 & 4.9335 & 4.331 & TST & \\
\hline
\end{tabular}


Supplemental Table S2.txt

\begin{tabular}{|c|c|c|c|c|c|}
\hline CHEMBL1371198 & 688112 & 2.9208 & 4.0541 & TRN & \\
\hline CHEMBL1560260 & 688112 & 2.9208 & 4.2068 & TRN & \\
\hline CHEMBL1577922 & 688112 & 5.138 & 4.9062 & TRN & \\
\hline CHEMBL1477760 & 688112 & 4.687 & 4.3325 & TST & \\
\hline CHEMBL3196868 & 688112 & 4.3162 & 5.0515 & TST & \\
\hline CHEMBL1544498 & 688112 & 4.3989 & 4.3944 & TRN & \\
\hline CHEMBL1471358 & 688112 & 5.0652 & 4.0671 & TRN & \\
\hline CHEMBL1401381 & 688112 & 2.9208 & 4.3173 & TRN & \\
\hline CHEMBL 3192004 & 688112 & 2.9208 & 4.3754 & TRN & \\
\hline CHEMBL1499860 & 688112 & 4.9102 & 4.3054 & TRN & \\
\hline CHEMBL1411342 & 688112 & 4.2784 & 4.6 & TRN & \\
\hline CHEMBL1360493 & 688112 & 4.5402 & 4.0077 & TST & \\
\hline CHEMBL1491779 & 688112 & 4.5374 & 3.9194 & TRN & \\
\hline CHEMBL1335434 & 688112 & 5.1136 & 4.0419 & TRN & \\
\hline CHEMBL1549607 & 688112 & 5.1131 & 4.2776 & TRN & \\
\hline CHEMBL1459714 & 688112 & 2.9208 & 4.7908 & TRN & \\
\hline CHEMBL1302741 & 688112 & 5.7452 & 5.0227 & TRN & \\
\hline CHEMBL1536255 & 688112 & 5.694 & 4.4066 & TRN & \\
\hline CHEMBL3208320 & 688112 & 4.7937 & 3.9181 & TRN & \\
\hline CHEMBL1491252 & 688112 & 2.9208 & 3.5637 & TST & \\
\hline CHEMBL1416732 & 688112 & 4.7171 & 4.16100 & 00000000005 & TRN \\
\hline CHEMBL1508105 & 688112 & 4.3371 & 4.3188 & TRN & \\
\hline CHEMBL1566003 & 688112 & 2.9208 & 4.7618 & TRN & \\
\hline CHEMBL1998648 & 688112 & 2.9208 & 3.7001 & TRN & \\
\hline CHEMBL1522801 & 688112 & 5.2652 & 4.4025 & TRN & \\
\hline CHEMBL1351722 & 688112 & 4.8211 & 4.4061 & TRN & \\
\hline CHEMBL1526136 & 688112 & 4.4359 & 4.3192 & TRN & \\
\hline CHEMBL1344790 & 688112 & 2.9208 & 4.0434 & TRN & \\
\hline CHEMBL1518080 & 688112 & 5.7049 & 4.7656 & TST & \\
\hline CHEMBL1499681 & 688112 & 4.4815 & 4.9369 & TRN & \\
\hline CHEMBL1549871 & 688112 & 4.0033 & 4.3687 & TRN & \\
\hline CHEMBL3195749 & 688112 & 5.7245 & 3.7132 & TRN & \\
\hline CHEMBL1484631 & 688112 & 4.5429 & 3.6407 & TRN & \\
\hline CHEMBL1561202 & 688112 & 4.1451 & 3.9741 & TRN & \\
\hline CHEMBL1312289 & 688112 & 2.9208 & 4.9015 & TRN & \\
\hline CHEMBL1594327 & 688112 & 4.794 & 3.7923 & TRN & \\
\hline CHEMBL1610870 & 688112 & 2.9208 & 4.2809 & TST & \\
\hline CHEMBL1441858 & 688112 & 8.0 & 4.3113 & TRN & \\
\hline CHEMBL1402375 & 688112 & 2.9208 & 4.334 & TRN & \\
\hline CHEMBL 3212000 & 688112 & 4.5601 & 4.7217 & TRN & \\
\hline CHEMBL1586171 & 688112 & 4.8905 & 4.2874 & TRN & \\
\hline CHEMBL1303339 & 688112 & 4.8524 & 3.9738 & TRN & \\
\hline CHEMBL1581155 & 688112 & 2.9208 & 4.0316 & TST & \\
\hline CHEMBL1520533 & 688112 & 4.5539 & 3.904 & TRN & \\
\hline CHEMBL1377687 & 688112 & 2.9208 & 4.5131 & TRN & \\
\hline CHEMBL1543948 & 688112 & 2.9208 & 4.8144 & TRN & \\
\hline CHEMBL1541465 & 688112 & 2.9208 & 3.855 & TST & \\
\hline CHEMBL1402878 & 688112 & 4.8636 & 3.9075 & TRN & \\
\hline
\end{tabular}

Page 8587 
Supplemental Table S2.txt

\begin{tabular}{|c|c|c|c|c|}
\hline IE & & & & \\
\hline & 88112 & .9208 & 4.5579 & \\
\hline & & & & \\
\hline AEMBL] & 112 & & 2954 & \\
\hline AEMBL1420870 & 38112 & & 3387 & \\
\hline HEMBL3194597 & 88112 & 5655 & 1584 & \\
\hline HEMBL] & 112 & & 596 & \\
\hline IFMBI & & & & \\
\hline AEMBL13 & 88112 & & 4103 & \\
\hline HEMBL1518652 & 88112 & & 2994 & \\
\hline HEMBL1517682 & 88112 & & & \\
\hline IEMBL1 & 112 & & 541 & \\
\hline AEMBL1 & & & & \\
\hline HEMBL3 & 88112 & & 3651 & \\
\hline HEMBL157 & 112 & & & \\
\hline AEMBL1 & 12 & 98 & 26 & \\
\hline HEMBL1 & 112 & & 32 & \\
\hline HEMBL1 & & & & \\
\hline HEMBL1 & 112 & & 3329 & \\
\hline AEMBL1 & 12 & & & 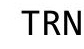 \\
\hline HEMBL: & & & 71 & \\
\hline AEMBL & & & & \\
\hline HEMBL: & 12 & & & \\
\hline 36 & & & & \\
\hline AEMBL13 & 12 & & & RIN \\
\hline HEMBL & 12 & & 669 & ГRN \\
\hline HEMBL & & & & Niv \\
\hline HFMBI & 12 & & & \\
\hline HEMBL1 & & & & 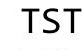 \\
\hline HEMBL1467 & 12 & & & ISI \\
\hline HEMBL1 & & & & ST \\
\hline HEMBL & & & & RN \\
\hline HEMBL1 & & & 24 & $\mathrm{RN}$ \\
\hline HEMBL132 & & & 125 & $\Gamma \mathrm{RN}$ \\
\hline HEMBL1387889 & & & & TRN \\
\hline HEMBL2 & 12 & & 366 & ST \\
\hline - & & & & RN \\
\hline HEMBL1 & & & 2628 & $\mathrm{RN}$ \\
\hline HEMBL1610160 & 88112 & & 2998 & TRN \\
\hline EMBL & & & 2776 & RN \\
\hline HEMBL1 & 12 & & 1669 & \\
\hline HEMBL3 & & & & RN \\
\hline HEMBL1 & & & 8953 & RN \\
\hline AEMBL3212690 & 38112 & & 2576 & ГRN \\
\hline$M I_{1}$ & & & 3549 & \\
\hline HEMBL1 & & & 5478 & \\
\hline HEMBL 15 & & 2.9208 & & \\
\hline HEMBL144909 & 688112 & 4.6619 & 4.2169 & RN \\
\hline
\end{tabular}

Page 8588 
Supplemental Table S2.txt

\begin{tabular}{|c|c|c|c|c|}
\hline CHEMBL1428992 & 688112 & 5.183 & 4.4193 & TRN \\
\hline CHEMBL1329726 & 688112 & 3.2218 & 4.3222 & TST \\
\hline CHEMBL473613 & 688112 & 4.3629 & 3.8675 & TRN \\
\hline CHEMBL1490334 & 688112 & 5.4252 & 5.2148 & TRN \\
\hline CHEMBL1527192 & 688112 & 4.7039 & 4.1574 & TRN \\
\hline CHEMBL1422468 & 688112 & 4.9287 & \multicolumn{2}{|c|}{ 4.4319999999999995 } \\
\hline CHEMBL1415834 & 688112 & 4.7788 & 4.272 & TRN \\
\hline CHEMBL1466758 & 688112 & 4.2243 & 4.2993 & TRN \\
\hline CHEMBL1991311 & 688112 & 5.077 & 4.4325 & TRN \\
\hline CHEMBL1485878 & 688112 & 4.5516 & 4.258 & TRN \\
\hline CHEMBL1402410 & 688112 & 2.9208 & 3.9985 & TRN \\
\hline CHEMBL1549029 & 688112 & 5.1935 & 4.7022 & TRN \\
\hline CHEMBL1330446 & 688112 & 5.0249 & 4.9605 & TRN \\
\hline CHEMBL1409618 & 688112 & 4.1122 & 4.8652 & TRN \\
\hline CHEMBL1479454 & 688112 & 4.774 & 4.362 & TRN \\
\hline CHEMBL1357281 & 688112 & 4.505 & 4.4353 & TRN \\
\hline CHEMBL1549700 & 688112 & 4.2379 & 4.2631 & TRN \\
\hline CHEMBL1343460 & 688112 & 4.9886 & 4.9825 & TRN \\
\hline CHEMBL1978063 & 688112 & 5.1428 & 4.8678 & TRN \\
\hline CHEMBL1412908 & 688112 & 4.8931 & 4.6161 & TRN \\
\hline CHEMBL1490778 & 688112 & 2.9208 & 4.3958 & TRN \\
\hline CHEMBL1589689 & 688112 & 4.7876 & 4.3189 & TRN \\
\hline CHEMBL1392554 & 688112 & 2.9208 & 4.3344 & TRN \\
\hline CHEMBL3198668 & 688112 & 4.3551 & 4.7192 & TRN \\
\hline CHEMBL1586234 & 688112 & 4.3541 & 4.5068 & TRN \\
\hline CHEMBL1352852 & 688112 & 2.9208 & 3.4969 & TRN \\
\hline CHEMBL1524528 & 688112 & 2.9208 & 5.0257 & TRN \\
\hline CHEMBL1339310 & 688112 & 5.1008 & 4.4603 & TRN \\
\hline CHEMBL3196435 & 688112 & 4.5097 & 4.2823 & TRN \\
\hline CHEMBL1581881 & 688112 & 4.8411 & 3.9602 & TRN \\
\hline CHEMBL1450360 & 688112 & 5.2391 & 4.2479 & TST \\
\hline CHEMBL3212230 & 688112 & 4.4587 & 4.4164 & TRN \\
\hline CHEMBL1313565 & 688112 & 5.1989 & 4.1197 & TRN \\
\hline CHEMBL1994148 & 688112 & 4.4575 & 4.4416 & TRN \\
\hline CHEMBL1561715 & 688112 & 4.9115 & 4.2979 & TRN \\
\hline CHEMBL1589378 & 688112 & 2.9208 & 4.4716 & TRN \\
\hline CHEMBL1461433 & 688112 & 4.6787 & 4.4015 & TRN \\
\hline CHEMBL1432814 & 688112 & 4.8457 & 4.1735 & TRN \\
\hline CHEMBL3189326 & 688112 & 4.8605 & 3.9621 & TST \\
\hline CHEMBL139250 & 688112 & 2.9208 & 3.9763 & TRN \\
\hline CHEMBL1359655 & 688112 & 2.9208 & 3.5229 & TRN \\
\hline CHEMBL1364848 & 688112 & 2.9208 & 3.5567 & TST \\
\hline CHEMBL1306816 & 688112 & 2.9208 & 4.2437 & TRN \\
\hline CHEMBL1468329 & 688112 & 2.9208 & 4.5934 & TRN \\
\hline CHEMBL1483951 & 688112 & 6.71 & 4.8247 & TRN \\
\hline CHEMBL1312308 & 688112 & 2.9208 & 3.6432 & TST \\
\hline CHEMBL1443669 & 688112 & 4.8827 & 4.305 & TRN \\
\hline CHEMBL1580491 & 688112 & 4.8241 & 4.1108 & TRN \\
\hline
\end{tabular}


Supplemental Table S2.txt

\begin{tabular}{|c|c|c|c|c|}
\hline & & 4.8522 & & \\
\hline CHEMBL1481541 & 38112 & 1791 & 523 & \\
\hline AEMBL1396872 & 88112 & 5.0066 & & \\
\hline & & 08 & & \\
\hline 183 & 112 & 08 & & \\
\hline AEMBL1584476 & 88112 & 298 & 72 & \\
\hline AEMBL 3190711 & 88112 & 5.0783 & & \\
\hline AEMBL1310486 & & & & \\
\hline IEMBL 3194650 & 38112 & 147 & & \\
\hline EMBL135 & 38112 & 208 & & \\
\hline AEMBL1604106 & 88112 & 272 & 612 & \\
\hline IEMBL1479114 & 88112 & 208 & & \\
\hline 7 7LIMLL 319 & 2 & 4.8833 & & \\
\hline HEMI & 38112 & 208 & & \\
\hline 66 & 88112 & 752 & & \\
\hline AEMBL1340348 & 88112 & 158 & & \\
\hline 413789 & 12 & 67 & & \\
\hline 49 & 2 & 51 & & \\
\hline 51 & 12 & 37 & & \\
\hline 57 & 12 & 391 & & \\
\hline$\partial 18$ & 2 & 208 & & \\
\hline 329 & & & & \\
\hline 58 & 2 & 86 & & \\
\hline & & 39 & & \\
\hline 64 & & 163 & & \\
\hline 102 & 2 & & & \\
\hline 563844 & 2 & & & \\
\hline 99 & & & & \\
\hline 0 & 2 & 98 & & \\
\hline 13 & & 82 & & \\
\hline & & & & \\
\hline MBL 3196688 & & 11 & & \\
\hline & & & & \\
\hline 7 & & & & \\
\hline 309378 & & & & \\
\hline AEMBL1376590 & & 383 & & \\
\hline 35700 & & 351 & & \\
\hline & & 91 & & \\
\hline 93 & 2 & 29 & & \\
\hline CHEMBL3211514 & & & & \\
\hline AEMBL1491264 & 12 & 208 & & \\
\hline 3 & & 95 & & \\
\hline 82 & & 208 & & \\
\hline CHEMBL1494066 & 688 & 4.0735 & & \\
\hline MBL1499023 & & 482 & 4.2713 & $\mathbf{n}$ \\
\hline AEMBL1393333 & 688 & 208 & 337 & \\
\hline & & & & \\
\hline & 688112 & 4.7273 & 4.1443 & \\
\hline
\end{tabular}

Page 8590 
Supplemental Table S2.txt

\begin{tabular}{|c|c|c|c|c|}
\hline HEN & & & 8862 & \\
\hline HEMBL 372840 & & .9208 & 3.9285 & \\
\hline 220 & & & & \\
\hline AEMBL] & & 94 & & \\
\hline AEMBL13 & 8112 & 023 & 325 & \\
\hline HEMBL1520326 & 88112 & 103 & 0109 & \\
\hline & & 208 & 967 & \\
\hline |FMRI & & & & RN \\
\hline AEMBL15 & 38112 & 531 & 1868 & \\
\hline HEMBL154 & 88112 & & 3282 & \\
\hline AEMBL133 & 88112 & 97 & 36 & \\
\hline IEMBL1 & 112 & 208 & 288 & \\
\hline AEMBL1 & & & & \\
\hline HEMBL14 & 88112 & 53 & 7906 & \\
\hline AEMBL15 & 112 & & 25 & \\
\hline AEMBL1 & 12 & 56 & 33 & \\
\hline AEMBL1 & 112 & 59 & 56 & \\
\hline HEMBL1: & 112 & & & \\
\hline HEMBL16 & 112 & & 7116 & \\
\hline IEMBL15 & 12 & & & \\
\hline 化MBLI & & 08 & & \\
\hline HEMBL3 & & & 719 & ודת \\
\hline AEMBL1 & 12 & & 83 & \\
\hline 30 & & & 793 & \\
\hline AEMBL16e & & & & ( \\
\hline HEMBL1 & & & 366 & RN \\
\hline HEMBL1 & & & & RN \\
\hline HFMBI 1 & 12 & & 563 & RN \\
\hline HEMBL1: & & & & 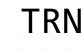 \\
\hline HEMBL146 & & & & s \\
\hline HEMBL1 & & & 613 & RN \\
\hline HEMBL & & & 68 & RN \\
\hline $15 \mathrm{MPI}$ & & & 557 & RN \\
\hline HEMBL1C & & & 3475 & IR \\
\hline HEMBL1481964 & & 208 & 5985 & TST \\
\hline HEMBL: & & & 825 & RN \\
\hline HᄃMP I 1 & & & 935 & RN \\
\hline HEMBL14 & & & & RN \\
\hline HEMBL1387115 & 88112 & 98 & 3313 & TRN \\
\hline AEMBL13 & & & 291 & ГRN \\
\hline HEMBL1 & & 55 & 279 & \\
\hline HEMBL 1 & & 472 & 4.0881 & Niv \\
\hline HEMBL1350667 & & 732 & 1554 & RN \\
\hline AEMBL1503386 & 8112 & & & ST \\
\hline MBL3 & & & 9773 & \\
\hline HEMBL150 & & & 3349 & \\
\hline HEMBL1303471 & & & 4.4936 & \\
\hline HEMBL1572878 & 688112 & 4.2243 & 3.9373 & RN \\
\hline
\end{tabular}

Page 8591 
Supplemental Table S2.txt

\begin{tabular}{|c|c|c|c|c|c|}
\hline CHEMBL1457445 & 688112 & 2.9208 & 4.4074 & TRN & \\
\hline CHEMBL1598791 & 688112 & 5.2257 & 4.4124 & TST & \\
\hline CHEMBL1599460 & 688112 & 4.5041 & 4.4652 & TRN & \\
\hline CHEMBL1448605 & 688112 & 2.9208 & 5.0547 & TRN & \\
\hline CHEMBL1534185 & 688112 & 2.9208 & 4.0366 & TST & \\
\hline CHEMBL1424754 & 688112 & 2.9208 & 5.1786 & TRN & \\
\hline CHEMBL1331513 & 688112 & 4.6179 & 4.4221 & TRN & \\
\hline CHEMBL1550657 & 688112 & 5.0268 & 4.5849 & TRN & \\
\hline CHEMBL1516666 & 688112 & 6.0964 & 4.7787 & TRN & \\
\hline CHEMBL3198073 & 688112 & 2.9208 & 4.46899 & 9999999999 & TRN \\
\hline CHEMBL1560147 & 688112 & 4.7021 & 4.8235 & TRN & \\
\hline CHEMBL1545721 & 688112 & 5.909 & 4.1734 & TRN & \\
\hline CHEMBL1483680 & 688112 & 5.0139 & 4.6726 & TRN & \\
\hline CHEMBL 3213314 & 688112 & 5.0296 & 4.9611 & TRN & \\
\hline CHEMBL1392817 & 688112 & 4.3502 & 4.5394 & TRN & \\
\hline CHEMBL1406155 & 688112 & 4.6371 & 4.721 & TRN & \\
\hline CHEMBL1389262 & 688112 & 4.4531 & 4.7585 & TRN & \\
\hline CHEMBL1364299 & 688112 & 2.9208 & 4.2578 & TST & \\
\hline CHEMBL1306554 & 688112 & 4.7202 & 4.1451 & TRN & \\
\hline CHEMBL1320349 & 688112 & 2.9208 & 4.0595 & TRN & \\
\hline CHEMBL1595927 & 688112 & 4.2482 & 4.4964 & TRN & \\
\hline CHEMBL1610086 & 688112 & 2.9208 & 4.3868 & TRN & \\
\hline CHEMBL1391325 & 688112 & 4.9914 & 4.8023 & TRN & \\
\hline CHEMBL1447118 & 688112 & 4.8237 & 4.3007 & TRN & \\
\hline CHEMBL3193828 & 688112 & 8.0 & 4.5924 & TST & \\
\hline CHEMBL1486199 & 688112 & 4.3663 & 4.3586 & TRN & \\
\hline CHEMBL1410615 & 688112 & 2.9208 & 4.3197 & TRN & \\
\hline CHEMBL 2000202 & 688112 & 4.4676 & 3.9519 & TRN & \\
\hline CHEMBL1306147 & 688112 & 2.9208 & 4.0392 & TRN & \\
\hline CHEMBL1342888 & 688112 & 2.9208 & 4.5487 & TRN & \\
\hline CHEMBL1488300 & 688112 & 5.0918 & 4.34399 & 9999999999 & TRN \\
\hline CHEMBL1476311 & 688112 & 5.0791 & 4.8917 & TRN & \\
\hline CHEMBL1537737 & 688112 & 4.3809 & 4.1317 & TRN & \\
\hline CHEMBL1610276 & 688112 & 4.9063 & 4.343 & TRN & \\
\hline CHEMBL1602826 & 688112 & 5.0016 & 4.4045 & TRN & \\
\hline CHEMBL1372066 & 688112 & 4.9013 & 4.338 & TRN & \\
\hline CHEMBL3199114 & 688112 & 4.9648 & 4.4268 & TRN & \\
\hline CHEMBL1299663 & 688112 & 4.6028 & 4.245 & TST & \\
\hline CHEMBL1416301 & 688112 & 4.3651 & 4.2547 & TRN & \\
\hline CHEMBL1439902 & 688112 & 6.0521 & 4.8889 & TST & \\
\hline CHEMBL1530113 & 688112 & 5.3856 & 4.4646 & TRN & \\
\hline CHEMBL1334134 & 688112 & 2.9208 & 4.0567 & TRN & \\
\hline CHEMBL1479595 & 688112 & 8.0 & 4.25899 & 99999999995 & TRN \\
\hline CHEMBL1486332 & 688112 & 2.9208 & 3.9021 & TRN & \\
\hline CHEMBL1472505 & 688112 & 2.9208 & 3.94199 & 79999999997 & TRN \\
\hline CHEMBL3212098 & 688112 & 4.3913 & 4.2653 & TRN & \\
\hline CHEMBL1395312 & 688112 & 2.9208 & 4.5086 & TRN & \\
\hline CHEMBL1388278 & 688112 & 2.9208 & 4.6821 & TRN & \\
\hline
\end{tabular}


Supplemental Table S2.txt

\begin{tabular}{|c|c|c|c|c|c|}
\hline CHEMBL1335206 & 688112 & 2.9208 & 3.6099 & TST & \\
\hline CHEMBL1521723 & 688112 & 3.9459 & 4.3451 & TRN & \\
\hline CHEMBL1305128 & 688112 & 2.9208 & 3.9828 & TRN & \\
\hline CHEMBL1326724 & 688112 & 5.2611 & 4.6035 & TRN & \\
\hline CHEMBL1583427 & 688112 & 2.9208 & 4.4103 & TRN & \\
\hline CHEMBL1387251 & 688112 & 2.9208 & 5.0189 & TRN & \\
\hline CHEMBL1478305 & 688112 & 2.9208 & 4.021 & TRN & \\
\hline CHEMBL3198034 & 688112 & 6.9914 & 4.6661 & TRN & \\
\hline CHEMBL1481951 & 688112 & 2.9208 & 4.3058 & TST & \\
\hline CHEMBL1565061 & 688112 & 4.8239 & 4.3474 & TRN & \\
\hline CHEMBL1350122 & 688112 & 2.9208 & 4.2694 & TRN & \\
\hline CHEMBL1974351 & 688112 & 2.9208 & 4.1605 & TRN & \\
\hline CHEMBL1362558 & 688112 & 2.9208 & 4.3633 & TRN & \\
\hline CHEMBL1518811 & 688112 & 4.6751 & 4.0089 & TRN & \\
\hline CHEMBL1376118 & 688112 & 4.8394 & 4.8797 & TRN & \\
\hline CHEMBL1395051 & 688112 & 4.3037 & 4.2366 & TRN & \\
\hline CHEMBL1369984 & 688112 & 4.8592 & 4.4362 & TRN & \\
\hline CHEMBL1520035 & 688112 & 4.5236 & 5.2496 & TRN & \\
\hline CHEMBL1479133 & 688112 & 4.2682 & 4.5764 & TRN & \\
\hline CHEMBL1612547 & 688112 & 2.9208 & 3.5805 & TRN & \\
\hline CHEMBL1308677 & 688112 & 5.0287 & 4.2914 & TRN & \\
\hline CHEMBL1597364 & 688112 & 2.9208 & 4.0286 & TRN & \\
\hline CHEMBL1327977 & 688112 & 4.6642 & 5.007 & TRN & \\
\hline CHEMBL1323910 & 688112 & 2.9208 & 4.3212 & TST & \\
\hline CHEMBL1462536 & 688112 & 4.5097 & 4.329 & TRN & \\
\hline CHEMBL 3211273 & 688112 & 2.9208 & 4.508 & TRN & \\
\hline CHEMBL1364392 & 688112 & 6.9508 & 4.6161 & TRN & \\
\hline CHEMBL1570236 & 688112 & 4.8567 & 4.2109 & TRN & \\
\hline CHEMBL1350591 & 688112 & 2.9208 & 3.9109 & TRN & \\
\hline CHEMBL1376768 & 688112 & 4.8188 & 4.437 & TRN & \\
\hline CHEMBL1321895 & 688112 & 2.9208 & 4.1102 & TRN & \\
\hline CHEMBL1491711 & 688112 & 2.9208 & 3.9333 & TRN & \\
\hline CHEMBL1494242 & 688112 & 2.9208 & 4.3 & TRN & \\
\hline CHEMBL3211169 & 688112 & 2.9208 & 3.573 & TRN & \\
\hline CHEMBL1336874 & 688112 & 4.2653 & 4.0354 & TRN & \\
\hline CHEMBL1414311 & 688112 & 2.9208 & 3.6264 & TRN & \\
\hline CHEMBL1460749 & 688112 & 2.9208 & 3.6041 & TRN & \\
\hline CHEMBL1336412 & 688112 & 4.3566 & 4.0123 & TRN & \\
\hline CHEMBL1455567 & 688112 & 2.9208 & 3.6296 & TST & \\
\hline CHEMBL3207928 & 688112 & 5.0511 & 4.4129 & TRN & \\
\hline CHEMBL1445723 & 688112 & 6.7825 & 4.292 & TRN & \\
\hline CHEMBL1351643 & 688112 & 6.1681 & 4.2353 & TRN & \\
\hline CHEMBL1350563 & 688112 & 2.9208 & 3.8725 & TRN & \\
\hline CHEMBL1343030 & 688112 & 4.513 & 3.9226 & TRN & \\
\hline CHEMBL1488450 & 688112 & 4.46899 & 999999999 & 99 & 4.3936 \\
\hline CHEMBL1422230 & 688112 & 8.0 & 5.1209 & TST & \\
\hline CHEMBL1373917 & 688112 & 6.3072 & 4.224 & TST & \\
\hline CHEMBL1389832 & 688112 & 5.4048 & 3.628 & TST & \\
\hline
\end{tabular}




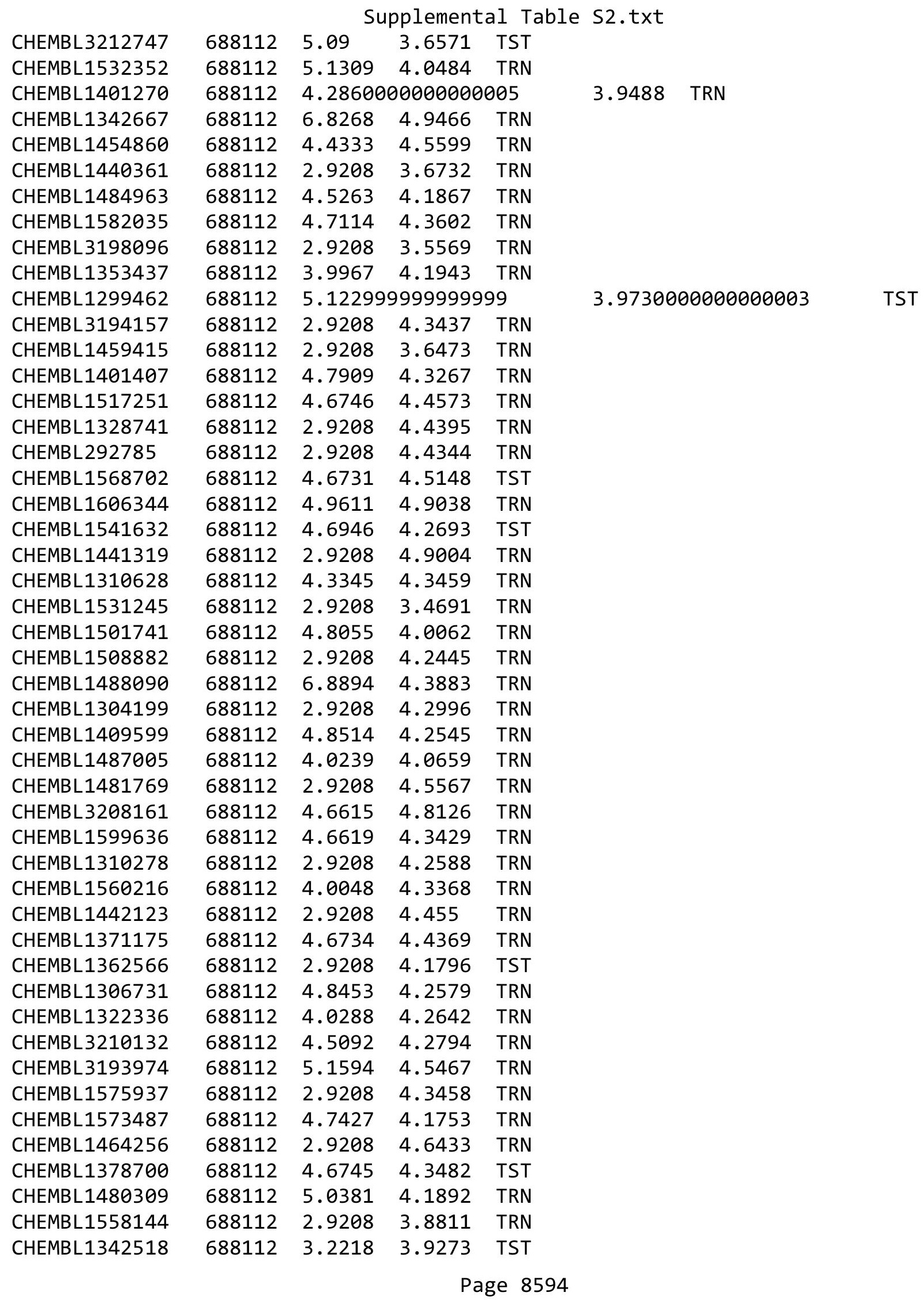


Supplemental Table S2.txt

\begin{tabular}{|c|c|c|c|c|c|}
\hline CHEMBL1559251 & 688112 & 4.9043 & 5.5175 & TRN & \\
\hline CHEMBL1437043 & 688112 & 2.9208 & 4.3716 & TRN & \\
\hline CHEMBL1384623 & 688112 & 4.599 & 4.0255 & TRN & \\
\hline CHEMBL1353881 & 688112 & 2.9208 & 4.0776 & TRN & \\
\hline CHEMBL1423459 & 688112 & 4.4536 & 3.9967 & TRN & \\
\hline CHEMBL1300939 & 688112 & 4.5988 & 4.8654 & TST & \\
\hline CHEMBL1560476 & 688112 & 4.6996 & 4.3467 & TRN & \\
\hline CHEMBL1378837 & 688112 & 2.9208 & 4.2078 & TRN & \\
\hline CHEMBL1427219 & 688112 & 5.0877 & 4.05 & TRN & \\
\hline CHEMBL1491320 & 688112 & 4.5402 & 4.3509 & TRN & \\
\hline CHEMBL1527590 & 688112 & 4.1337 & 4.2608 & TST & \\
\hline CHEMBL1409944 & 688112 & 4.2098 & 4.3038 & TRN & \\
\hline CHEMBL1575402 & 688112 & 6.5498 & 4.9035 & TRN & \\
\hline CHEMBL1344382 & 688112 & 4.7078 & 3.9071 & TST & \\
\hline CHEMBL1513595 & 688112 & 5.3443 & 4.5508 & TST & \\
\hline CHEMBL1305131 & 688112 & 4.1703 & 4.09 & TST & \\
\hline CHEMBL3212478 & 688112 & 5.4713 & 4.5663 & TRN & \\
\hline CHEMBL3199347 & 688112 & 2.9208 & 4.5416 & TRN & \\
\hline CHEMBL1496902 & 688112 & 4.7325 & 4.1927 & TRN & \\
\hline CHEMBL1541650 & 688112 & 2.9208 & \multicolumn{2}{|c|}{4.0360000000000005} & TRN \\
\hline CHEMBL1384746 & 688112 & 4.0921 & 4.6454 & TRN & \\
\hline CHEMBL1418014 & 688112 & 2.9208 & 4.0291 & TRN & \\
\hline CHEMBL1472807 & 688112 & 4.9106 & 4.3213 & TRN & \\
\hline CHEMBL1422573 & 688112 & 4.827 & \multicolumn{2}{|c|}{5.1770000000000005} & TRN \\
\hline CHEMBL3210095 & 688112 & 4.5205 & 4.9368 & TST & \\
\hline CHEMBL1462502 & 688112 & 2.9208 & 3.5378 & TRN & \\
\hline CHEMBL1308045 & 688112 & 2.9208 & 4.2219 & TRN & \\
\hline CHEMBL1603132 & 688112 & 2.9208 & 4.2257 & TRN & \\
\hline CHEMBL1378325 & 688112 & 2.9208 & 3.6684 & TRN & \\
\hline CHEMBL1526362 & 688112 & 4.6685 & 4.3864 & TRN & \\
\hline CHEMBL1354346 & 688112 & 2.9208 & 3.4566 & TRN & \\
\hline CHEMBL1303143 & 688112 & 5.1191 & 4.3803 & TST & \\
\hline CHEMBL1563664 & 688112 & 2.9208 & 4.466 & TRN & \\
\hline CHEMBL1366431 & 688112 & 5.2032 & 4.3959 & TRN & \\
\hline CHEMBL1347694 & 688112 & 4.7286 & 3.9458 & TRN & \\
\hline CHEMBL1574562 & 688112 & 6.4895 & 4.2343 & TRN & \\
\hline CHEMBL1503609 & 688112 & 2.9208 & 4.0084 & TRN & \\
\hline CHEMBL1331702 & 688112 & 2.9208 & 4.5233 & TRN & \\
\hline CHEMBL1534071 & 688112 & 5.7675 & 4.2228 & TRN & \\
\hline CHEMBL1609144 & 688112 & 4.8469 & 3.9114 & TRN & \\
\hline CHEMBL1325762 & 688112 & 2.9208 & 3.9045 & TRN & \\
\hline CHEMBL1346165 & 688112 & 5.3757 & 4.2194 & TRN & \\
\hline CHEMBL1485166 & 688112 & 5.1465 & 4.2639 & TRN & \\
\hline CHEMBL1483099 & 688112 & 5.0687 & 4.2378 & TRN & \\
\hline CHEMBL1570344 & 688112 & 6.9626 & 4.73 & TRN & \\
\hline CHEMBL1462286 & 688112 & 5.3744 & 4.5939 & TRN & \\
\hline CHEMBL1574660 & 688112 & 4.5933 & 4.2563 & TRN & \\
\hline CHEMBL1393056 & 688112 & 4.3432 & 4.2033 & TST & \\
\hline
\end{tabular}

Page 8595 
Supplemental Table S2.txt

\begin{tabular}{|c|c|c|c|c|}
\hline 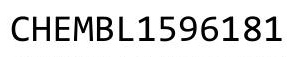 & 112 & & & \\
\hline HEMBL1530938 & 88112 & 4.3507 & 4.2073 & \\
\hline & & & & \\
\hline EMPI 1 & 8112 & 63 & & \\
\hline IEMBL1530766 & 88112 & 208 & 4227 & \\
\hline HEMBL1326068 & 88112 & 5717 & 4753 & \\
\hline AEMBL1506611 & 88112 & .7825 & 3174 & \\
\hline 10 & 8112 & 208 & & \\
\hline EMBL1306342 & 88112 & & 474 & \\
\hline AEMBL1531080 & 88112 & 278 & 4.368 & \\
\hline HEMBL1569541 & 88112 & 051 & 5257 & \\
\hline AEMBL1523917 & 88112 & 5842 & 1976 & \\
\hline IEMBL13 & 12 & & & \\
\hline AEMBL3199639 & 88112 & & & \\
\hline AEMBL1452245 & 88112 & 08 & 5541 & \\
\hline AEMBL1499853 & 88112 & & 06 & \\
\hline AEMBL1349012 & 88112 & 08 & 3501 & \\
\hline AEMBL32 & 38112 & & & \\
\hline AEMBL13 & 88112 & & 065 & \\
\hline AEMBL1462378 & 88112 & 946 & 399 & RN \\
\hline AEMBL1530257 & 88112 & 49 & 2875 & S \\
\hline HEMBL1558669 & 88112 & & 54 & RN \\
\hline HEMBL15 & 38112 & 38 & & \\
\hline 699 & 12 & & & DMN \\
\hline IEMBL1415140 & 12 & & & RN \\
\hline IEMBL1405593 & 88112 & 66 & & KIV \\
\hline HEMBL1555525 & 88112 & 685 & 1736 & 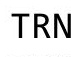 \\
\hline HEMBL19 & 38112 & 81 & 73 & \\
\hline 366 & & & & RN \\
\hline IEMBL1381292 & 12 & & & RN \\
\hline IEMBL1485806 & 88112 & & 11 & RN \\
\hline HEMBL1329152 & 88112 & 02 & 83 & 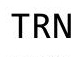 \\
\hline HEMBL1601509 & 38112 & & & RN \\
\hline & & & & RN \\
\hline AEMBL1305543 & 38112 & 38 & 74 & RN \\
\hline AEMBL1200717 & 8112 & 08 & 568 & - \\
\hline HEMBL1329938 & 88112 & 41 & 829 & Niv \\
\hline & & & & $\mathrm{RN}$ \\
\hline HEMBL1519102 & & & 3514 & ST \\
\hline AEMBL1370978 & 88112 & 35 & 2441 & ST \\
\hline HEMBL1381002 & 88112 & 208 & 389 & ST \\
\hline HEMBL1432011 & 12 & & 3656 & ונד \\
\hline HEMBL1600400 & & & & ST \\
\hline HEMBL1369424 & 38112 & 849 & 5766 & TST \\
\hline IEMBL1490834 & 88112 & $\partial 8$ & 346 & ST \\
\hline MBL14. & & & & \\
\hline HEN & 88112 & 08 & & \\
\hline 8687 & & & & \\
\hline
\end{tabular}

Page 8596 


\begin{tabular}{|c|c|c|c|c|c|}
\hline \multicolumn{6}{|c|}{ Supplemental Table S2.txt } \\
\hline CHEMBL1987798 & 688112 & 8.0 & 5.5211 & TST & \\
\hline CHEMBL1441326 & 688112 & 4.6768 & 4.2757 & TST & \\
\hline CHEMBL1496960 & 688112 & 4.3736 & 4.5112 & TST & \\
\hline CHEMBL1441613 & 688112 & 6.4763 & 4.2349 & TST & \\
\hline CHEMBL1508749 & 688112 & 4.7727 & 4.3023 & TST & \\
\hline CHEMBL1588575 & 688112 & 5.0971 & 4.4817 & TST & \\
\hline CHEMBL476190 & 688112 & 2.9208 & 4.444 & TST & \\
\hline CHEMBL1478232 & 688112 & 2.9208 & 5.1308 & TST & \\
\hline CHEMBL1588752 & 688112 & 4.4242 & 4.3829 & TST & \\
\hline CHEMBL1427637 & 688112 & 4.0995 & 3.63 & TST & \\
\hline CHEMBL1547533 & 688112 & 2.9208 & 4.1673 & TST & \\
\hline CHEMBL1347452 & 688112 & 4.808 & 3.9918 & TST & \\
\hline CHEMBL1325593 & 688112 & 4.9833 & 4.3448 & TST & \\
\hline CHEMBL3197511 & 688112 & 2.9208 & 3.6353 & TST & \\
\hline CHEMBL 1477847 & 688112 & 4.0691 & 4.2889 & TST & \\
\hline CHEMBL1448583 & 688112 & 4.684 & 4.3508 & TST & \\
\hline CHEMBL3191391 & 688112 & 5.1706 & 3.9024 & TST & \\
\hline CHEMBL1493921 & 688112 & 8.0 & 4.34399 & 9999999999 & TST \\
\hline CHEMBL1566972 & 688112 & 4.8079 & 4.6102 & TST & \\
\hline CHEMBL 201039 & 688112 & 2.9208 & 3.5603 & TST & \\
\hline CHEMBL1401553 & 688112 & 4.9701 & 4.3923 & TST & \\
\hline CHEMBL1556354 & 688112 & 4.8805 & 4.2368 & TST & \\
\hline CHEMBL1588037 & 688112 & 4.7633 & 4.3067 & TST & \\
\hline CHEMBL 3213546 & 688112 & 2.9208 & 4.5896 & TST & \\
\hline CHEMBL1304331 & 688112 & 4.5804 & 4.3666 & TST & \\
\hline CHEMBL1488035 & 688112 & 2.9208 & 3.728 & TST & \\
\hline CHEMBL1391573 & 688112 & 2.9208 & 4.2842 & TST & \\
\hline CHEMBL1493546 & 688112 & 4.6724 & 4.0923 & TST & \\
\hline CHEMBL1410134 & 688112 & 4.0919 & 4.4632 & TST & \\
\hline CHEMBL1390899 & 688112 & 4.1858 & 4.2699 & TST & \\
\hline CHEMBL1566120 & 688112 & 4.3931 & 4.3383 & TST & \\
\hline CHEMBL1428009 & 688112 & 2.9208 & 3.6497 & TST & \\
\hline CHEMBL1539579 & 688112 & 3.9965 & 3.9342 & TST & \\
\hline CHEMBL3208065 & 688112 & 4.7333 & 4.2932 & TST & \\
\hline CHEMBL1382656 & 688112 & 4.8433 & 4.4724 & TST & \\
\hline CHEMBL1600748 & 688112 & 4.0243 & 4.022 & TST & \\
\hline CHEMBL1496585 & 688112 & 2.9208 & 4.3845 & TST & \\
\hline CHEMBL1307720 & 688112 & 2.9208 & 4.1078 & TST & \\
\hline CHEMBL1533107 & 688112 & 2.9208 & 4.8541 & TST & \\
\hline CHEMBL3197411 & 688112 & 4.0148 & 4.6516 & TST & \\
\hline CHEMBL1548850 & 688112 & 4.5463 & 4.2578 & TST & \\
\hline CHEMBL1327688 & 688112 & 4.0267 & 4.2923 & TST & \\
\hline CHEMBL1502638 & 688112 & 4.5654 & 3.895 & TST & \\
\hline CHEMBL1312428 & 688112 & 4.6988 & 4.3884 & TST & \\
\hline CHEMBL1553636 & 688112 & 3.9209 & 3.9769 & TST & \\
\hline CHEMBL1385946 & 688112 & 5.8468 & 4.8866 & TST & \\
\hline CHEMBL1539263 & 688112 & 4.877 & 4.1499 & TST & \\
\hline CHEMBL3212956 & 688112 & 4.0875 & 4.1985 & TST & \\
\hline
\end{tabular}


Supplemental Table S2.txt

\begin{tabular}{|c|c|c|c|c|}
\hline 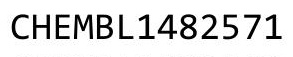 & & & & \\
\hline HEMBL1523560 & 88112 & 2.9208 & 9466 & \\
\hline HEMBL 31 & 8112 & & 41 & \\
\hline 58 & & 08 & & \\
\hline IEMBL13 & & & & \\
\hline AEMBL1603708 & 88112 & 687 & 2799 & \\
\hline HEMBL1531352 & 88112 & 4.034 & 4.3315 & \\
\hline HEMBL137 & 88112 & 04 & & \\
\hline AEMBL13 & 12 & 57 & & \\
\hline AEMBL13 & & & & \\
\hline HEMBL1504204 & 88112 & 2.9208 & 4.0053 & \\
\hline HEMBL1555260 & 88112 & 4.4442 & 3.8483 & \\
\hline HEMBL3198682 & 2 & 16 & 4.0073 & \\
\hline L31 & & 57 & & \\
\hline JEMBL144 & & & & \\
\hline HEMBL1334962 & 88112 & 2.9208 & 188 & \\
\hline HEMBL160 & 12 & 08 & & \\
\hline HEMBL 14 & 12 & 18 & 28 & \\
\hline L13 & & & & \\
\hline 89 & & & & \\
\hline HEMBL 143 & 12 & 754 & $\partial 865$ & \\
\hline IEMBL132 & & & & \\
\hline HEMBL13 & 12 & 091 & 323 & \\
\hline L15 & & $\partial 8$ & & \\
\hline 02 & & & & \\
\hline L15 & & & & \\
\hline HEMBL140 & & & & \\
\hline HEMBL132 & & 208 & 29 & \\
\hline HEN & & 8 . & 33 & \\
\hline 63 & & 98 & 28 & \\
\hline AEMBL145 & & & & \\
\hline HEMBL1602966 & & & 977 & \\
\hline AEMBL13 & & & & \\
\hline 7 & & & 88 & \\
\hline 3 & & & & \\
\hline AEMBL1335336 & & & & \\
\hline HEMBL1598240 & & 208 & & \\
\hline 76 & & 52 & & \\
\hline 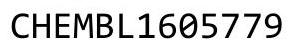 & & & & \\
\hline IEMBL15 & & & & ST \\
\hline AEMBL1367908 & 12 & 156 & 154 & \\
\hline AEMBL14 & & & & \\
\hline HEMBL147 & & & & \\
\hline HEMBL 149 & & & & \\
\hline HEMBL3194617 & & & 9285 & ST \\
\hline IEMBL15S & 12 & 5 . & & \\
\hline 2 & & & & \\
\hline & 688112 & 2.9208 & 4381 & \\
\hline
\end{tabular}

Page 8598 
Supplemental Table S2.txt

\begin{tabular}{|c|c|c|c|c|}
\hline CHEMBL1450173 & 688112 & 4.9511 & 4.3985 & TST \\
\hline CHEMBL1422337 & 688112 & 4.9443 & 4.3792 & TST \\
\hline CHEMBL1407825 & 688112 & 2.9208 & 4.2139 & TST \\
\hline CHEMBL1517447 & 688112 & 4.8458 & 4.4456 & TST \\
\hline CHEMBL1325798 & 688112 & 4.4366 & 4.43199 & 99999999995 \\
\hline CHEMBL1613478 & 688112 & 5.0631 & 4.3486 & TST \\
\hline CHEMBL1502201 & 688112 & 5.0931 & 4.2496 & TST \\
\hline CHEMBL1420871 & 688112 & 4.9486 & 4.7152 & TST \\
\hline CHEMBL1450777 & 688112 & 5.1014 & 4.2566 & TST \\
\hline CHEMBL1349795 & 688112 & 4.2944 & 4.2696 & TST \\
\hline CHEMBL1302081 & 688112 & 4.9943 & 4.3866 & TST \\
\hline CHEMBL1998940 & 688112 & 2.9208 & 4.0332 & TST \\
\hline CHEMBL1987082 & 688112 & 5.0824 & 5.4674 & TST \\
\hline CHEMBL1367788 & 688112 & 2.9208 & 4.5268 & TST \\
\hline CHEMBL1509837 & 688112 & 2.9208 & 3.9721 & TST \\
\hline CHEMBL1529647 & 688112 & 2.9208 & 4.5637 & TST \\
\hline CHEMBL1488336 & 688112 & 2.9208 & 3.6429 & TST \\
\hline CHEMBL1405384 & 688112 & 2.9208 & 3.9444 & TST \\
\hline CHEMBL1315386 & 688112 & 4.2543 & 4.2536 & TST \\
\hline CHEMBL1369567 & 688112 & 4.1562 & 4.2783 & TST \\
\hline CHEMBL1499934 & 688112 & 8.0 & 4.2441 & TST \\
\hline CHEMBL1303281 & 688112 & 2.9208 & 3.6342 & TST \\
\hline CHEMBL1499277 & 688112 & 2.9208 & 4.4566 & TST \\
\hline CHEMBL3196904 & 688112 & 4.7471 & 4.3026 & TST \\
\hline CHEMBL1455144 & 688112 & 4.4223 & 4.1907 & TST \\
\hline CHEMBL1402346 & 688112 & 5.1547 & 4.2605 & TST \\
\hline CHEMBL1570117 & 688112 & 4.1241 & 4.3792 & TST \\
\hline CHEMBL1323962 & 688112 & 4.4835 & 4.2435 & TST \\
\hline CHEMBL3211154 & 688112 & 8.0 & 5.3258 & TST \\
\hline CHEMBL1304553 & 688112 & 4.9649 & 4.2522 & TST \\
\hline CHEMBL1528010 & 688112 & 4.4112 & 4.2759 & TST \\
\hline CHEMBL1368839 & 688112 & 4.3235 & 4.4133 & TST \\
\hline CHEMBL1493135 & 688112 & 5.1759 & 4.4175 & TST \\
\hline CHEMBL 3211626 & 688112 & 4.9243 & 4.0876 & TST \\
\hline CHEMBL1461372 & 688112 & 4.1234 & 4.3818 & TST \\
\hline CHEMBL1478376 & 688112 & 4.8148 & 4.3845 & TST \\
\hline CHEMBL1523424 & 688112 & 5.18 & 4.2705 & TST \\
\hline CHEMBL1518828 & 688112 & 2.9208 & 4.6075 & TST \\
\hline CHEMBL1424944 & 688112 & 4.3415 & 4.2572 & TST \\
\hline CHEMBL1613402 & 688112 & 2.9208 & 4.1703 & TST \\
\hline CHEMBL1460831 & 688112 & 2.9208 & 3.5425 & TST \\
\hline CHEMBL1586605 & 688112 & 2.9208 & 3.9827 & TST \\
\hline CHEMBL1375371 & 688112 & 4.8314 & 4.3486 & TST \\
\hline CHEMBL1452993 & 688112 & 4.9854 & 4.3162 & TST \\
\hline CHEMBL1426718 & 688112 & 2.9208 & 4.42 & TST \\
\hline CHEMBL1579931 & 688112 & 5.0195 & \multicolumn{2}{|c|}{4.3389999999999995} \\
\hline CHEMBL1397547 & 688112 & 4.4575 & 4.1227 & TST \\
\hline CHEMBL1372941 & 688112 & 2.9208 & 3.6957 & TST \\
\hline
\end{tabular}




\begin{tabular}{|c|c|c|c|c|c|c|}
\hline & & \multicolumn{5}{|c|}{ Supplemental Table S2.txt } \\
\hline CHEMBL1350313 & 688112 & 4.8138 & 3.8376 & TST & & \\
\hline CHEMBL1539762 & 688112 & 2.9208 & 4.3226 & TST & & \\
\hline CHEMBL1352992 & 688112 & 5.1049 & 4.3803 & TST & & \\
\hline CHEMBL3191856 & 688112 & 4.2043 & 4.6651 & TST & & \\
\hline CHEMBL1343527 & 688112 & \multicolumn{3}{|c|}{4.4110000000000005} & 5.2496 & TST \\
\hline CHEMBL1583812 & 688112 & 2.9208 & 3.5667 & TST & & \\
\hline CHEMBL1424732 & 688112 & 4.5192 & 3.6802 & TST & & \\
\hline CHEMBL1533679 & 688112 & 4.8359 & 4.2368 & TST & & \\
\hline CHEMBL1485099 & 688112 & 4.7247 & 4.2313 & TST & & \\
\hline CHEMBL1401280 & 688112 & 2.9208 & 4.1302 & TST & & \\
\hline CHEMBL1558912 & 688112 & 2.9208 & 4.2112 & TST & & \\
\hline CHEMBL1389228 & 688112 & 4.4306 & 4.2406 & TST & & \\
\hline CHEMBL1534302 & 688112 & 4.3356 & 4.6521 & TST & & \\
\hline CHEMBL1613264 & 688112 & 2.9208 & 4.5238 & TST & & \\
\hline CHEMBL1582340 & 688112 & 5.8925 & 4.4567 & TST & & \\
\hline CHEMBL1440476 & 688112 & 4.9054 & 4.3147 & TST & & \\
\hline CHEMBL1485736 & 688112 & 5.2595 & 4.2585 & TST & & \\
\hline CHEMBL1494473 & 688112 & 7.71 & 4.5784 & TST & & \\
\hline CHEMBL1336531 & 688112 & 4.2149 & 4.9183 & TST & & \\
\hline CHEMBL3192269 & 688112 & 5.7118 & 4.2979 & TST & & \\
\hline CHEMBL1518669 & 688112 & 4.49 & 3.5086 & TST & & \\
\hline CHEMBL1587454 & 688112 & 4.8799 & 4.28 & TST & & \\
\hline CHEMBL1371482 & 688112 & 4.0191 & 4.3365 & TST & & \\
\hline CHEMBL1535599 & 688112 & 4.2051 & 4.2636 & TST & & \\
\hline CHEMBL1610786 & 688112 & 5.9259 & 4.7559 & TST & & \\
\hline CHEMBL1432072 & 688112 & 3.9685 & 4.2666 & TST & & \\
\hline CHEMBL1483754 & 688112 & 2.9208 & 4.2268 & TST & & \\
\hline CHEMBL1528899 & 688112 & 6.1469 & 3.8201 & TST & & \\
\hline CHEMBL1331973 & 688112 & 2.9208 & 3.5977 & TST & & \\
\hline CHEMBL1389856 & 688112 & 4.3569 & 4.3586 & TST & & \\
\hline CHEMBL1607974 & 688112 & 4.8269 & 4.0358 & TST & & \\
\hline CHEMBL3209992 & 688112 & 5.6498 & 4.6388 & TST & & \\
\hline CHEMBL1998566 & 688112 & 4.3338 & 4.208 & TST & & \\
\hline CHEMBL3189879 & 688112 & \multicolumn{3}{|c|}{4.6080000000000005} & 4.2848 & TST \\
\hline CHEMBL1345630 & 688112 & 3.9702 & 4.1491 & TST & & \\
\hline CHEMBL1341673 & 688112 & 4.3297 & 4.4922 & TST & & \\
\hline CHEMBL1389637 & 688112 & 2.9208 & 4.4203 & TST & & \\
\hline CHEMBL3194581 & 688112 & 4.6524 & 4.2252 & TST & & \\
\hline CHEMBL1574154 & 688112 & 4.4696 & 4.447 & TST & & \\
\hline CHEMBL1327643 & 688112 & 5.09 & 4.3026 & TST & & \\
\hline CHEMBL1524235 & 688112 & 4.4484 & 4.2258 & TST & & \\
\hline CHEMBL1370907 & 688112 & 5.2059 & 4.3501 & TST & & \\
\hline CHEMBL1508085 & 688112 & 2.9208 & 3.4877 & TST & & \\
\hline CHEMBL1578816 & 688112 & 2.9208 & 4.279 & TST & & \\
\hline CHEMBL1398613 & 688112 & 4.7191 & 4.2284 & TST & & \\
\hline CHEMBL1359492 & 688112 & 4.7569 & 4.3484 & TST & & \\
\hline CHEMBL1590783 & 688112 & 2.9208 & 4.2187 & TST & & \\
\hline CHEMBL 3212041 & 688112 & 4.475 & 4.2774 & TST & & \\
\hline
\end{tabular}


Supplemental Table S2.txt

\begin{tabular}{|c|c|c|c|c|}
\hline $\mathrm{HEI}$ & & 9208 & & \\
\hline & 88112 & .4496 & 4.2829 & \\
\hline & & & & \\
\hline IEMBL1 & & & & \\
\hline AEMBL1498971 & 8112 & & 18 & \\
\hline HEMBL1389755 & 88112 & 539 & .7749 & \\
\hline HEMBL15 & 8112 & & 2819 & \\
\hline IFMBI 14 & & & & \\
\hline AEMBL15 & 88112 & & 5187 & \\
\hline HEMBL1457697 & 38112 & & 0864 & \\
\hline HEMBL147 & 88112 & & 1938 & \\
\hline IEMBL14 & 112 & & 733 & \\
\hline IEMBL15 & & & & \\
\hline IEMBL158 & 3112 & & 2538 & \\
\hline AEMBL157 & 12 & & 6409 & \\
\hline AEMBL31 & 12 & & 24 & \\
\hline AEMBL14 & 112 & & 35 & \\
\hline HEMBL 14 & & & & \\
\hline AEMBL13 & 112 & & 5002 & \\
\hline IEMBL14 & 12 & & & \\
\hline AEMBLII & & & 38 & \\
\hline HEMBL14 & & & 513 & \\
\hline HEMBL31 & 12 & & .75 & \\
\hline AEMBL13 & & & & \\
\hline HEMBL13 & 12 & & & \\
\hline HEMBL31 & 12 & & 15 & \\
\hline AEMBL1C & & & & \\
\hline HFMBI 14 & 12 & & 08 & \\
\hline AEMBL14 & & & & \\
\hline HEMBL 256 & 2 & & & ГST \\
\hline HEMBL31 & & & 74 & ST \\
\hline HEMBL1 14 & & & 61 & \\
\hline 4 & & & & \\
\hline HEMBL132 & & & & \\
\hline HEMBL1420382 & & & 345 & TST \\
\hline JEMBL15 & & & & \\
\hline HЕMPI 1 & & & 66 & \\
\hline HEMBL13 & & & 836 & ST \\
\hline HEMBL1479324 & 88112 & & 2683 & ГST \\
\hline EMBL1 & & & 399 & TST \\
\hline HEMBL14 & 2 & & 067 & \\
\hline CHEMBL15e & & & & 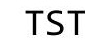 \\
\hline HEMBL 31 & & & 3569 & IST \\
\hline HEMBL142 & 8112 & 08 & 5025 & is \\
\hline MBL1 & & & 1919 & \\
\hline CHEMBL159 & & & & \\
\hline CHEMBL153 & & & 113 & \\
\hline SHEMBL1327517 & 688112 & 2.9208 & 3.568 & ГST \\
\hline
\end{tabular}

Page 8601 


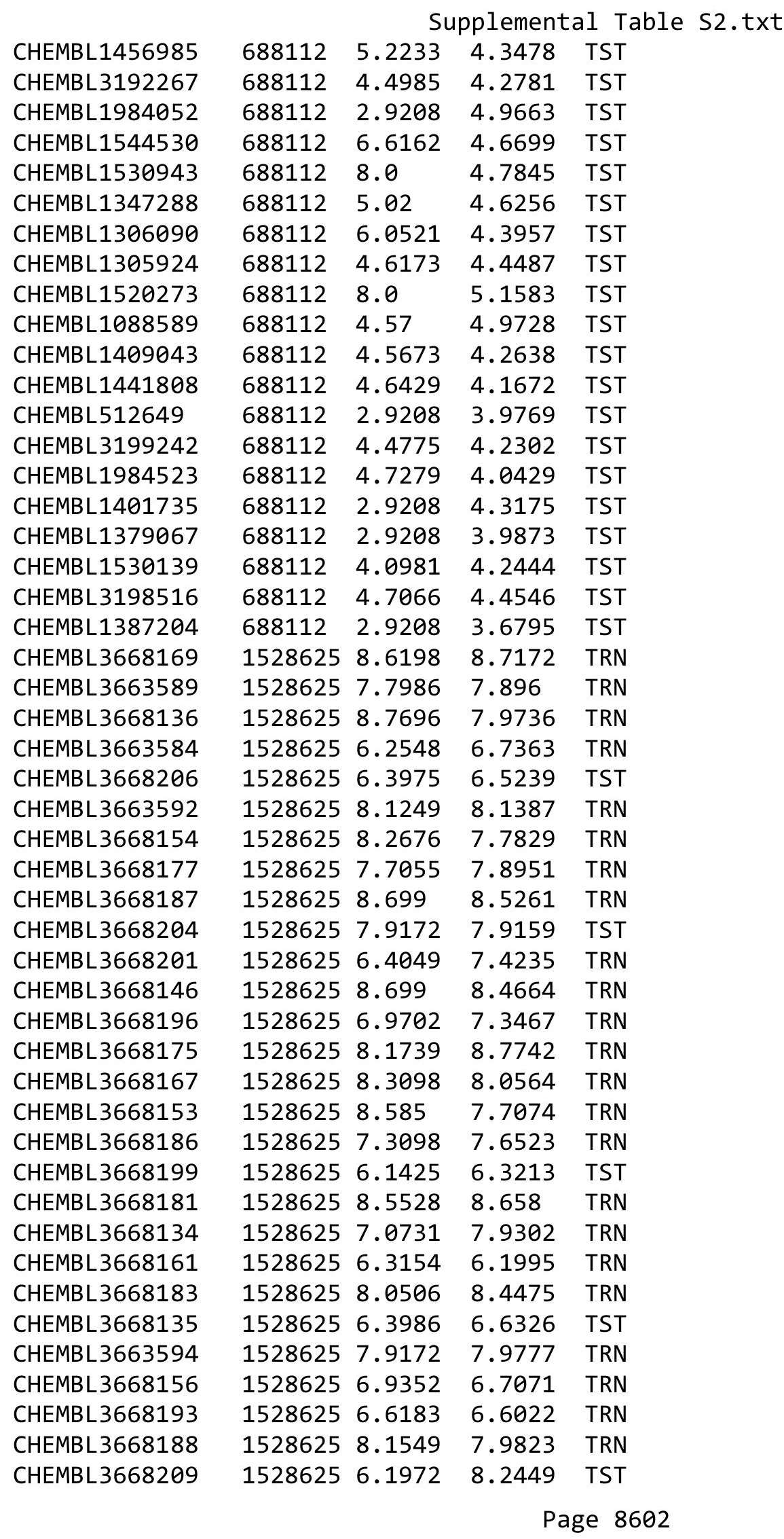


Supplemental Table S2.txt

\begin{tabular}{|c|c|c|c|c|c|}
\hline CHEMBL3668141 & 1528625 & 7.8928 & 7.9653 & TRN & \\
\hline CHEMBL3668149 & 1528625 & 6.8193 & 7.5094 & TRN & \\
\hline CHEMBL3668140 & 1528625 & 7.6402 & 7.3974 & TRN & \\
\hline CHEMBL3668205 & 1528625 & 6.7392 & 8.7797 & TST & \\
\hline CHEMBL 3668194 & 1528625 & 5.7934 & 6.2712 & TRN & \\
\hline CHEMBL3668203 & 1528625 & 6.5967 & 8.4657 & TST & \\
\hline CHEMBL3668158 & 1528625 & 8.5376 & 9.1001 & TRN & \\
\hline CHEMBL3668190 & 1528625 & 6.6578 & 6.5059 & TST & \\
\hline CHEMBL3668198 & 1528625 & 9.1549 & 9.2695 & TRN & \\
\hline CHEMBL3663582 & 1528625 & 8.1805 & 7.8654 & TRN & \\
\hline CHEMBL3668151 & 1528625 & 7.7167 & 7.2562 & TRN & \\
\hline CHEMBL3663580 & 1528625 & 5.1761 & 6.3452 & TST & \\
\hline CHEMBL3668168 & 1528625 & 7.4622 & 7.1259 & TRN & \\
\hline CHEMBL 2431841 & 1528625 & 8.041 & 8.4752 & TRN & \\
\hline CHEMBL 3663579 & 1528625 & 5.1761 & 6.2112 & TST & \\
\hline CHEMBL3668133 & 1528625 & 5.6858 & 7.3989 & TRN & \\
\hline CHEMBL3668182 & 1528625 & 7.5702 & 8.1451 & TRN & \\
\hline CHEMBL3936296 & 1528625 & 7.5436 & 8.3693 & TST & \\
\hline CHEMBL3668207 & 1528625 & 6.7655 & 8.3582 & TST & \\
\hline CHEMBL 3668163 & 1528625 & 7.1349 & 6.8605 & TRN & \\
\hline CHEMBL3663595 & 1528625 & 7.6234 & 6.7623 & TRN & \\
\hline CHEMBL585293 & 1528625 & 6.8508 & 6.7492 & TRN & \\
\hline CHEMBL3663581 & 1528625 & 8.0315 & 8.4715 & TRN & \\
\hline CHEMBL3668159 & 1528625 & 6.7726 & 6.7141 & TRN & \\
\hline CHEMBL 3668189 & 1528625 & 5.4834 & 5.9881 & TRN & \\
\hline CHEMBL 3668142 & 1528625 & 8.6576 & \multicolumn{2}{|c|}{8.431000000000001} & TRN \\
\hline CHEMBL565843 & 1528625 & 8.5686 & 8.5791 & TRN & \\
\hline CHEMBL566685 & 1528625 & 8.4949 & 8.0082 & TRN & \\
\hline CHEMBL3668210 & 1528625 & 7.7545 & 7.2616 & TRN & \\
\hline CHEMBL 3668178 & 1528625 & 7.2 & 7.8134 & TRN & \\
\hline CHEMBL3668160 & 1528625 & 8.0362 & 6.6768 & TST & \\
\hline CHEMBL 3668144 & 1528625 & 6.5822 & 6.6396 & TRN & \\
\hline CHEMBL3668132 & 1528625 & 9.0458 & 6.9962 & TRN & \\
\hline CHEMBL 3668185 & 1528625 & 9.5229 & 9.1692 & TRN & \\
\hline CHEMBL3668173 & 1528625 & 8.3279 & 7.8944 & TRN & \\
\hline CHEMBL494793 & 1528625 & 8.1549 & 7.8654 & TRN & \\
\hline CHEMBL3663588 & 1528625 & 7.1355 & 7.1698 & TRN & \\
\hline CHEMBL496101 & 1528625 & 5.9097 & 5.4012 & TRN & \\
\hline CHEMBL3668179 & 1528625 & 8.0223 & 7.4289 & TRN & \\
\hline CHEMBL3663583 & 1528625 & 5.7195 & \multicolumn{2}{|c|}{6.5920000000000005} & TRN \\
\hline CHEMBL 3668138 & 1528625 & 6.2547 & 7.0001 & TRN & \\
\hline CHEMBL3668162 & 1528625 & 7.2993 & 7.5034 & TRN & \\
\hline CHEMBL3668184 & 1528625 & 8.4949 & 8.2015 & TRN & \\
\hline CHEMBL3668137 & 1528625 & 6.1201 & 6.2315 & TRN & \\
\hline CHEMBL 3668180 & 1528625 & 7.279 & 7.4664 & TRN & \\
\hline CHEMBL 3668165 & 1528625 & 8.9208 & 8.7827 & TRN & \\
\hline CHEMBL3668150 & 1528625 & 8.1024 & \multicolumn{2}{|c|}{7.202000000000001} & TRN \\
\hline CHEMBL 3663586 & 1528625 & 6.8765 & 6.1234 & TST & \\
\hline
\end{tabular}




\begin{tabular}{|c|c|c|c|c|c|c|}
\hline \multicolumn{6}{|c|}{ Supplemental Table S2.txt } & \\
\hline CHEMBL 3668157 & 1528625 & 8.28399 & 99999999 & & 8.7485 TRN & \\
\hline CHEMBL 3668130 & 1528625 & 8.301 & 8.787 & TRN & & \\
\hline CHEMBL3668131 & 1528625 & 8.1739 & 7.959 & TRN & & \\
\hline CHEMBL 3903888 & 1528625 & 7.0788 & 7.1732 & TRN & & \\
\hline CHEMBL3663591 & 1528625 & 7.2967 & 7.2567 & TRN & & \\
\hline CHEMBL3668166 & 1528625 & 8.2076 & 8.0563 & TRN & & \\
\hline CHEMBL 3663593 & 1528625 & 5.3712 & 5.4987 & TRN & & \\
\hline CHEMBL3668152 & 1528625 & 5.8023 & 8.138 & TST & & \\
\hline CHEMBL 3668172 & 1528625 & 8.0506 & 7.9527 & TRN & & \\
\hline CHEMBL3668171 & 1528625 & 7.6253 & 7.2743 & TRN & & \\
\hline CHEMBL 3668147 & 1528625 & 8.6198 & 8.8192 & TRN & & \\
\hline CHEMBL 3663578 & 1528625 & 4.699 & 5.8111 & TRN & & \\
\hline CHEMBL3668155 & 1528625 & 7.5654 & 7.2544 & TRN & & \\
\hline CHEMBL 3668148 & 1528625 & 4.699 & 5.6954 & TST & & \\
\hline CHEMBL 3668200 & 1528625 & 10.0 & 8.4105 & TRN & & \\
\hline CHEMBL 3668174 & 1528625 & 7.3958 & 7.9535 & TRN & & \\
\hline CHEMBL3668170 & 1528625 & 8.1249 & 8.3456 & TRN & & \\
\hline CHEMBL3414733 & 1528625 & 7.4389 & 7.7206 & TST & & \\
\hline CHEMBL3668139 & 1528625 & 6.4261 & 6.1848 & TRN & & \\
\hline CHEMBL567908 & 1528625 & 8.7959 & 7.9182 & TRN & & \\
\hline CHEMBL 3668202 & 1528625 & 6.4584 & 6.7789 & TRN & & \\
\hline CHEMBL 3668197 & 1528625 & 6.3809 & 8.0321 & TST & & \\
\hline CHEMBL3668176 & 1528625 & 8.585 & 8.2135 & TST & & \\
\hline CHEMBL 3668145 & 1528625 & 7.5834 & 7.8329 & TST & & \\
\hline CHEMBL3668192 & 1528625 & 6.0689 & 6.5512 & TST & & \\
\hline CHEMBL 3663587 & 1528625 & 7.7595 & 7.8286 & TST & & \\
\hline CHEMBL 3663590 & 1528625 & 7.4318 & 7.7052 & TST & & \\
\hline CHEMBL3668195 & 1528625 & 4.699 & 5.5126 & TST & & \\
\hline CHEMBL 3663585 & 1528625 & 6.09399 & 99999999 & 99 & 6.1610000000000005 & TST \\
\hline CHEMBL 3668164 & 1528625 & 7.2941 & 7.4193 & TST & & \\
\hline CHEMBL 3668191 & 1528625 & 6.0724 & 6.6999 & TST & & \\
\hline CHEMBL 2086543 & 841032 & 5.2924 & 5.29799 & 9999999999 & TRN & \\
\hline CHEMBL 2086539 & 841032 & 5.1938 & 5.2656 & TRN & & \\
\hline CHEMBL2086527 & 841032 & 5.2676 & 5.2311 & TRN & & \\
\hline CHEMBL 2086509 & 841032 & 5.2147 & 5.4477 & TRN & & \\
\hline CHEMBL 2086525 & 841032 & 5.3872 & 5.3399 & TRN & & \\
\hline CHEMBL 2086519 & 841032 & 5.6021 & 5.4328 & TRN & & \\
\hline CHEMBL 2086507 & 841032 & 5.3872 & 5.2408 & TRN & & \\
\hline CHEMBL2089393 & 841032 & 5.0223 & 5.1921 & TRN & & \\
\hline CHEMBL 2086466 & 841032 & 3.0969 & 3.2404 & TRN & & \\
\hline CHEMBL 2086501 & 841032 & 4.8539 & 4.9349 & TRN & & \\
\hline CHEMBL 2086540 & 841032 & 5.4685 & 5.2541 & TRN & & \\
\hline CHEMBL2086506 & 841032 & 5.1739 & 5.274 & TRN & & \\
\hline CHEMBL 2086887 & 841032 & 3.0969 & 4.266 & TST & & \\
\hline CHEMBL 2086520 & 841032 & 5.0 & 4.9849 & TRN & & \\
\hline CHEMBL 2086891 & 841032 & 6.0223 & 5.9652 & TRN & & \\
\hline CHEMBL 2086888 & 841032 & 4.9586 & 4.1993 & TST & & \\
\hline CHEMBL 2086489 & 841032 & 5.0555 & 5.0578 & TRN & & \\
\hline
\end{tabular}




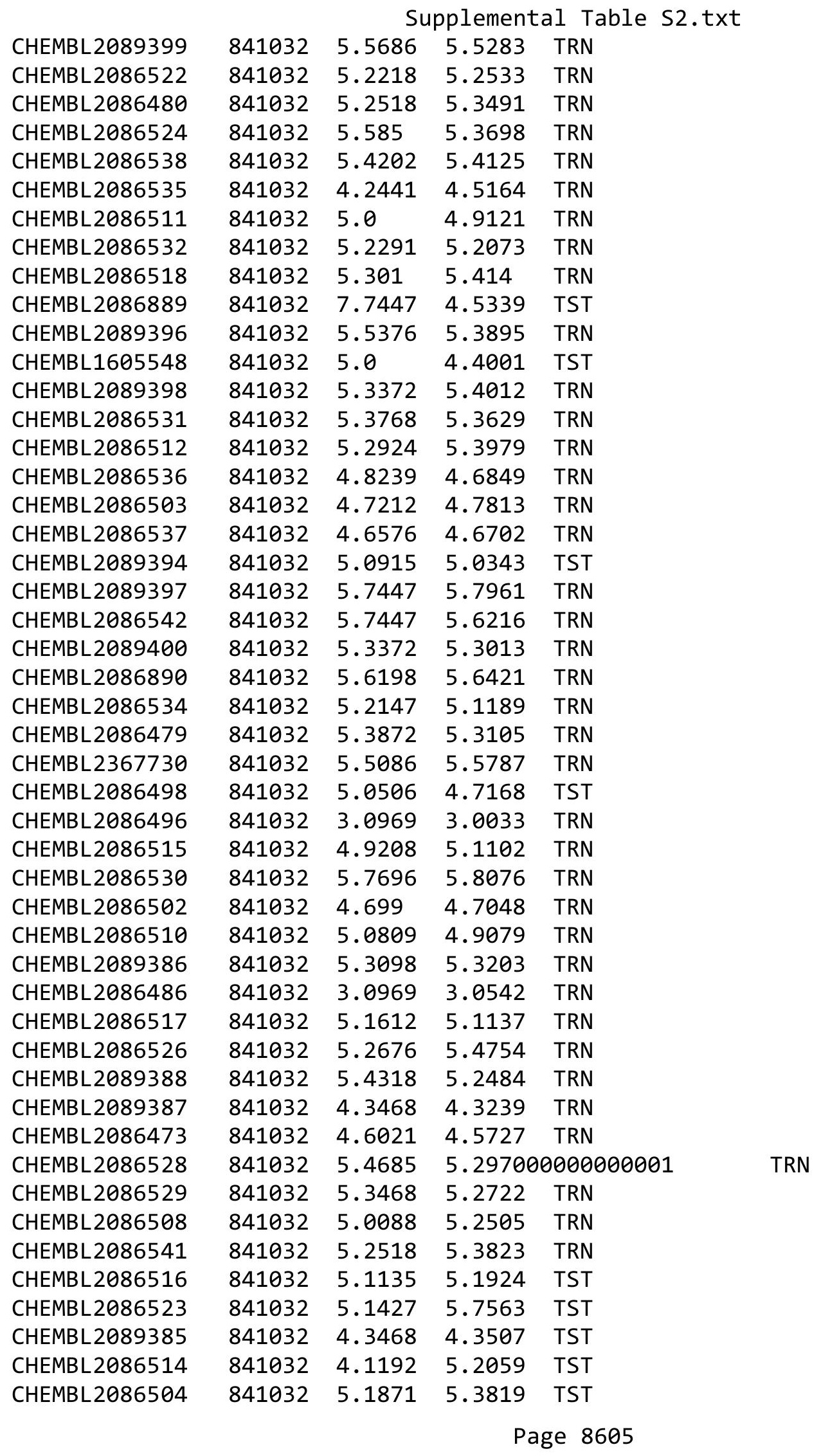


Supplemental Table S2.txt

\begin{tabular}{|c|c|c|c|c|}
\hline HEMBL 20 & 41032 & 229 & 5.6681 & TS \\
\hline HEMBL2086499 & 341032 & 5.1938 & 4.0119 & \\
\hline HEMBL2086483 & 1032 & & 9761 & \\
\hline HEMBL 2086482 & 41032 & 969 & 3052 & \\
\hline HEMBL2086505 & 41032 & .8539 & .6925 & \\
\hline HEMBL 2086513 & 341032 & 1675 & .3758 & \\
\hline HEMBL 2086533 & 41032 & .7447 & .9961 & \\
\hline HEMBL2089395 & 41032 & .8539 & .1641 & \\
\hline HEMBL 557062 & 85133 & 6.6799 & .365 & \\
\hline HEMBL557553 & 85133 & .2441 & .0547 & \\
\hline HEMBL555342 & 85133 & .7447 & .7595 & \\
\hline HEMBL561007 & 85133 & .1675 & .1247 & \\
\hline HEMBL549307 & 5133 & 932 & .0024 & \\
\hline HEMBL562405 & 85133 & 6778 & .5951 & \\
\hline HEMBL556446 & 85133 & 6925 & .6975 & \\
\hline HEMBL 549727 & 85133 & 6.7235 & .7538 & \\
\hline HEMBL557535 & 85133 & 437 & 7.4599 & \\
\hline HEMBL 560748 & 85133 & 949 & 7.5336 & \\
\hline HEMBL559126 & 85133 & 1938 & 7.1945 & \\
\hline HEMBL553654 & 5133 & 192 & 1149 & $\mathrm{IV}$ \\
\hline HEMBL561484 & 5133 & 362 & 6.9874 & \\
\hline HEMBL550206 & 5133 & 089 & 7.4154 & \\
\hline HEMBL539983 & 35133 & 815 & 7.4838 & \\
\hline HEMBL559259 & 85133 & 431 & 6.9414 & $2 \mathrm{~N}$ \\
\hline HEMBL550415 & 133 & 356 & 6.864 & RN \\
\hline HEMBL564552 & 133 & 665 & 7.7685 & $\mathrm{~N}$ \\
\hline HEMBL539661 & 5133 & 315 & 7.0393 & RN \\
\hline HEMBL540737 & 133 & 685 & 7.4825 & RN \\
\hline HEMBL551484 & 5133 & 239 & 6.3058 & ST \\
\hline HEMBL562406 & 5133 & 223 & 7.0452 & TRN \\
\hline HEMBL556142 & 133 & 239 & 8.4695 & ST \\
\hline HEMBL539734 & 133 & 549 & 079 & RN \\
\hline CHEMBL563041 & 133 & 686 & 7.5762 & RN \\
\hline LHEMBL562546 & 5133 & 4.2441 & 4.1062 & TST \\
\hline HEMBL561406 & 85133 & 7.6383 & 7.6326 & TRN \\
\hline HEMBL552921 & 5133 & 486 & 5.2157 & ST \\
\hline CHEMBL5397 & 33 & 98 & 7.6397 & RN \\
\hline CHEMBL560882 & 85133 & 7.0177 & 7.0155 & TRN \\
\hline CHEMBL549724 & 85133 & 7.5376 & 7.5127 & TRN \\
\hline HEMBL538171 & 85133 & 7.0915 & 6.8758 & TST \\
\hline CHEMBL556330 & 585133 & 7.7447 & 7.8026 & IRN \\
\hline CHEMBL538415 & 585133 & 7.3279 & 7.104 & ST \\
\hline CHEMBL540736 & 85133 & 7.3979 & 7.4046 & TRN \\
\hline CHEMBL549594 & 85133 & 6.3152 & 5.8191 & TST \\
\hline CHEMBL552973 & 85133 & 7.7447 & 7.7651 & RN \\
\hline CHEMBL538644 & 585133 & 6.8041 & 6.794 & \\
\hline CHEMBL563183 & 585133 & 7.3768 & 7.3718 & RN \\
\hline CHEMBL551620 & 585133 & 7.4559 & 7.4559 & $2 \mathrm{~N}$ \\
\hline
\end{tabular}

Page 8606 


\begin{tabular}{|c|c|c|c|c|c|c|}
\hline & & \multicolumn{5}{|c|}{ Supplemental Table S2.txt } \\
\hline CHEMBL551020 & 585133 & 7.5686 & 7.5916 & TRN & & \\
\hline CHEMBL549308 & 585133 & 5.6126 & 5.6192 & TRN & & \\
\hline CHEMBL556239 & 585133 & 6.34200 & 30000000 & 205 & 6.3431 & TRN \\
\hline CHEMBL559340 & 585133 & 7.3098 & 7.3091 & TRN & & \\
\hline CHEMBL561692 & 585133 & 6.4283 & 5.1983 & TST & & \\
\hline CHEMBL551750 & 585133 & 5.4389 & 4.8347 & TST & & \\
\hline CHEMBL552022 & 585133 & 7.0044 & 6.989 & TRN & & \\
\hline CHEMBL561810 & 585133 & 6.5686 & 6.5904 & TRN & & \\
\hline CHEMBL564981 & 585133 & 8.1549 & 7.7685 & TRN & & \\
\hline CHEMBL560809 & 585133 & 4.2676 & 4.0952 & TST & & \\
\hline CHEMBL551217 & 585133 & 6.4841 & 6.4739 & TRN & & \\
\hline CHEMBL556522 & 585133 & 7.9586 & 7.9065 & TRN & & \\
\hline CHEMBL562344 & 585133 & 7.1675 & 7.1611 & TRN & & \\
\hline CHEMBL554782 & 585133 & 7.5528 & 7.5465 & TRN & & \\
\hline CHEMBL538645 & 585133 & 7.3188 & 7.3491 & TST & & \\
\hline CHEMBL564150 & 585133 & 7.8539 & 7.7685 & TRN & & \\
\hline CHEMBL562485 & 585133 & 6.8041 & 6.8701 & TRN & & \\
\hline CHEMBL560084 & 585133 & 4.2441 & 4.5531 & TST & & \\
\hline CHEMBL552971 & 585133 & 8.0 & 7.9988 & TRN & & \\
\hline CHEMBL551619 & 585133 & 6.6696 & 6.66200 & 0000000001 & & TRN \\
\hline CHEMBL552972 & 585133 & 8.4202 & 8.397 & TRN & & \\
\hline CHEMBL556723 & 585133 & 6.8386 & 6.7841 & TRN & & \\
\hline CHEMBL559689 & 585133 & 5.9245 & 5.1306 & TST & & \\
\hline CHEMBL549797 & 585133 & 6.1349 & 5.7826 & TST & & \\
\hline CHEMBL553572 & 585133 & 7.585 & 7.5968 & TRN & & \\
\hline CHEMBL553856 & 585133 & 7.1612 & 7.1536 & TRN & & \\
\hline CHEMBL560009 & 585133 & 7.9586 & 8.0377 & TRN & & \\
\hline CHEMBL563429 & 585133 & 7.0044 & 6.9941 & TRN & & \\
\hline CHEMBL541742 & 585133 & 6.7212 & 6.71 & TRN & & \\
\hline CHEMBL540672 & 585133 & 7.9208 & 7.9798 & TRN & & \\
\hline CHEMBL550278 & 585133 & 7.8539 & 7.8373 & TRN & & \\
\hline CHEMBL541745 & 585133 & 7.4437 & 8.2086 & TST & & \\
\hline CHEMBL556493 & 585133 & 7.0969 & 7.4416 & TST & & \\
\hline CHEMBL1190711 & 955009 & 4.9487 & 4.914 & TRN & & \\
\hline CHEMBL180127 & 955009 & 3.7809 & 3.7362 & TRN & & \\
\hline CHEMBL449158 & 955009 & 6.4173 & 6.5688 & TST & & \\
\hline CHEMBL65 & 955009 & 5.1352 & 5.1219 & TRN & & \\
\hline CHEMBL379975 & 955009 & 3.7589 & 3.8005 & TRN & & \\
\hline CHEMBL 1242367 & 955009 & 5.1815 & 5.112 & TRN & & \\
\hline CHEMBL 2005886 & 955009 & 5.2143 & 5.2275 & TRN & & \\
\hline CHEMBL188678 & 955009 & 4.22 & 4.1101 & TRN & & \\
\hline CHEMBL 2137530 & 955009 & 4.5232 & 4.4312 & TRN & & \\
\hline CHEMBL393929 & 955009 & 3.4977 & 3.5424 & TRN & & \\
\hline CHEMBL412142 & 955009 & 3.4839 & 3.4898 & TRN & & \\
\hline CHEMBL102714 & 955009 & 3.9415 & 3.9706 & TRN & & \\
\hline CHEMBL1590308 & 955009 & 2.9472 & 2.6401 & TST & & \\
\hline CHEMBL1186585 & 955009 & 3.7383 & 3.81 & TRN & & \\
\hline CHEMBL1404918 & 955009 & 2.7351 & 2.7599 & TRN & & \\
\hline
\end{tabular}




\begin{tabular}{|c|c|c|c|c|c|}
\hline & & & & & \\
\hline CHEMBL577784 & 955009 & 5.0627 & 5.0926 & TRN & \\
\hline CHEMBL585951 & 955009 & 5.9024 & 5.7711 & TRN & \\
\hline CHEMBL209148 & 955009 & 4.3091 & 4.2535 & TRN & \\
\hline CHEMBL1256459 & 955009 & 7.2261 & 7.2987 & TRN & \\
\hline CHEMBL258844 & 955009 & 4.2525 & 4.2842 & TRN & \\
\hline CHEMBL220241 & 955009 & 4.4064 & 4.328 & TRN & \\
\hline CHEMBL399530 & 955009 & 3.6526 & 3.6911 & TRN & \\
\hline CHEMBL213100 & 955009 & 5.3609 & 5.3753 & TRN & \\
\hline CHEMBL92309 & 955009 & 2.2695 & 3.1994 & TST & \\
\hline CHEMBL373751 & 955009 & 3.2349 & 3.2338 & TRN & \\
\hline CHEMBL509032 & 955009 & 5.8193 & 5.7593 & TRN & \\
\hline CHEMBL191334 & 955009 & 3.5327 & 3.5756 & TRN & \\
\hline CHEMBL1909414 & 955009 & 3.7807 & 3.7632 & TRN & \\
\hline CHEMBL483849 & 955009 & 3.1609 & 2.2483 & TST & \\
\hline CHEMBL 222102 & 955009 & 3.0546 & 3.1785 & TRN & \\
\hline CHEMBL1673039 & 955009 & 4.5371 & 4.5569 & TRN & \\
\hline CHEMBL558642 & 955009 & 4.6781 & 4.6183 & TRN & \\
\hline CHEMBL217354 & 955009 & 5.6586 & 5.7539 & TRN & \\
\hline CHEMBL1230020 & 955009 & 3.4477 & 3.5126 & TRN & \\
\hline CHEMBL3199475 & 955009 & 4.8428 & 4.8937 & TRN & \\
\hline CHEMBL192566 & 955009 & 8.2055 & 8.1552 & TST & \\
\hline CHEMBL512504 & 955009 & 4.2233 & 4.2532 & TRN & \\
\hline CHEMBL202721 & 955009 & 4.2063 & 4.177 & TRN & \\
\hline CHEMBL 9470 & 955009 & 6.2695 & 5.751 & TST & \\
\hline CHEMBL210618 & 955009 & 2.9584 & 2.8082 & TRN & \\
\hline CHEMBL1970879 & 955009 & 5.0494 & 5.1088 & TRN & \\
\hline CHEMBL3392440 & 955009 & 4.0909 & 4.0015 & TRN & \\
\hline CHEMBL3186408 & 955009 & 3.5546 & 3.4746 & TST & \\
\hline CHEMBL515416 & 955009 & 5.2195 & 5.2184 & TRN & \\
\hline CHEMBL573107 & 955009 & 4.6985 & 4.5905 & TRN & \\
\hline CHEMBL2363137 & 955009 & 5.0353 & 5.0739 & TRN & \\
\hline CHEMBL300389 & 955009 & 7.0316 & 7.0431 & TRN & \\
\hline CHEMBL514499 & 955009 & 6.7141 & 6.7149 & TRN & \\
\hline CHEMBL135561 & 955009 & 4.2863 & 4.3232 & TRN & \\
\hline CHEMBL 255342 & 955009 & 3.7299 & 3.6284 & TRN & \\
\hline CHEMBL189584 & 955009 & 4.0789 & 4.198 & TRN & \\
\hline CHEMBL240954 & 955009 & 3.705 & 3.3961 & TST & \\
\hline CHEMBL259181 & 955009 & 5.0227 & 5.1625 & TRN & \\
\hline CHEMBL221137 & 955009 & 5.026 & 4.6676 & TST & \\
\hline CHEMBL392695 & 955009 & 4.0202 & 4.1091 & TRN & \\
\hline CHEMBL 379300 & 955009 & 6.4722 & 6.36299 & 99999999995 & TRN \\
\hline CHEMBL3349342 & 955009 & 5.601 & 5.6167 & TRN & \\
\hline CHEMBL483847 & 955009 & 4.5186 & 4.59399 & 9999999999 & TST \\
\hline CHEMBL472940 & 955009 & 5.0554 & 3.7909 & TST & \\
\hline CHEMBL1516890 & 955009 & 3.7507 & 4.0966 & TST & \\
\hline CHEMBL 2134202 & 955009 & 4.2398 & 4.1373 & TST & \\
\hline CHEMBL1643959 & 955009 & 4.0879 & 4.2191 & TST & \\
\hline CHEMBL 2144069 & 955009 & 4.9753 & 4.8464 & TST & \\
\hline
\end{tabular}




\begin{tabular}{|c|c|c|c|c|c|}
\hline & & \multicolumn{4}{|c|}{ Supplemental Table S2.txt } \\
\hline CHEMBL1357247 & 955009 & 3.4944 & 3.0694 & TST & \\
\hline CHEMBL1788116 & 955009 & 4.8566 & 4.1267 & TST & \\
\hline CHEMBL1170333 & 641177 & 6.0 & 5.6692 & TRN & \\
\hline CHEMBL1172689 & 641177 & 6.0 & 5.9837 & TRN & \\
\hline CHEMBL1169739 & 641177 & 6.4559 & 6.3294 & TRN & \\
\hline CHEMBL1170546 & 641177 & 6.0 & 5.2182 & TST & \\
\hline CHEMBL138286 & 641177 & 6.0 & 5.6973 & TST & \\
\hline CHEMBL1170773 & 641177 & 6.0 & 6.3895 & TRN & \\
\hline CHEMBL1171737 & 641177 & 7.0088 & 6.9448 & TRN & \\
\hline CHEMBL1171724 & 641177 & 6.0 & 6.059 & TRN & \\
\hline CHEMBL1171872 & 641177 & 6.0 & 6.1831 & TRN & \\
\hline CHEMBL1170963 & 641177 & 6.0 & 5.9624 & TRN & \\
\hline CHEMBL1171736 & 641177 & 6.8416 & 6.9684 & TRN & \\
\hline CHEMBL1170547 & 641177 & 6.0 & 5.9813 & TRN & \\
\hline CHEMBL1171726 & 641177 & 6.0 & 3.9184 & TST & \\
\hline CHEMBL1170544 & 641177 & 6.0 & 6.0726 & TRN & \\
\hline CHEMBL1169950 & 641177 & 9.4949 & 8.912 & TRN & \\
\hline CHEMBL1171781 & 641177 & 6.0 & 5.9675 & TRN & \\
\hline CHEMBL1171555 & 641177 & 6.0 & 5.2597 & TST & \\
\hline CHEMBL1172688 & 641177 & 6.0 & 6.13200 & 0000000001 & TRN \\
\hline CHEMBL1169962 & 641177 & 6.0 & 5.8034 & TRN & \\
\hline CHEMBL1171727 & 641177 & 6.0 & 5.9416 & TRN & \\
\hline CHEMBL1172292 & 641177 & 8.0 & 8.0427 & TRN & \\
\hline CHEMBL1171725 & 641177 & 6.0 & 5.9548 & TRN & \\
\hline CHEMBL1171419 & 641177 & 6.0 & 6.0936 & TRN & \\
\hline CHEMBL1170545 & 641177 & 6.0 & 5.5806 & TST & \\
\hline CHEMBL513470 & 641177 & 6.0 & 5.53299 & 99999999995 & TST \\
\hline CHEMBL1172291 & 641177 & 6.0 & 6.08799 & 9999999999 & TRN \\
\hline CHEMBL1171738 & 641177 & 6.7077 & 6.66700 & 0000000001 & TRN \\
\hline CHEMBL1171418 & 641177 & 6.0 & 5.9792 & TRN & \\
\hline CHEMBL1170769 & 641177 & 6.0 & 6.0747 & TRN & \\
\hline CHEMBL1169778 & 641177 & 6.0 & 6.0642 & TRN & \\
\hline CHEMBL1172059 & 641177 & 6.0 & 5.8147 & TRN & \\
\hline CHEMBL1171366 & 641177 & 6.0 & 6.0876 & TRN & \\
\hline CHEMBL1172686 & 641177 & 6.0 & 6.2723 & TRN & \\
\hline CHEMBL1172094 & 641177 & 6.0 & 5.99200 & 0000000001 & TRN \\
\hline CHEMBL1170982 & 641177 & 6.0 & 5.8894 & TRN & \\
\hline CHEMBL1170334 & 641177 & 6.0 & 6.0352 & TRN & \\
\hline CHEMBL1171905 & 641177 & 6.0 & 6.0595 & TRN & \\
\hline CHEMBL1172492 & 641177 & 7.2007 & 7.0952 & TRN & \\
\hline CHEMBL1170754 & 641177 & 6.0 & 6.0736 & TRN & \\
\hline CHEMBL1170969 & 641177 & 7.5376 & 7.6714 & TRN & \\
\hline CHEMBL1169953 & 641177 & 9.5229 & 9.5531 & TRN & \\
\hline CHEMBL1169779 & 641177 & 6.0 & 5.9277 & TRN & \\
\hline CHEMBL1169951 & 641177 & 8.2291 & 8.5162 & TRN & \\
\hline CHEMBL1171554 & 641177 & 6.0 & 5.9192 & TRN & \\
\hline CHEMBL1169777 & 641177 & 6.0 & 6.1578 & TRN & \\
\hline CHEMBL1172687 & 641177 & 6.0 & 5.6702 & TRN & \\
\hline
\end{tabular}




\begin{tabular}{|c|c|c|c|c|c|}
\hline \\
\hline CHEMBL1171232 & 641177 & 6.0 & 5.3206 & TST & \\
\hline CHEMBL1170965 & 641177 & 6.0 & 5.6638 & TST & \\
\hline CHEMBL1170968 & 641177 & 9.0 & 7.8652 & TST & \\
\hline CHEMBL1170149 & 641177 & 6.0 & 5.3944 & TST & \\
\hline CHEMBL1170964 & 641177 & 6.0 & 7.6203 & TST & \\
\hline CHEMBL1171916 & 641177 & 6.0 & 5.1628 & TST & \\
\hline CHEMBL1169952 & 641177 & 8.1135 & 9.5246 & TST & \\
\hline CHEMBL1171689 & 641177 & 6.0 & 5.5363 & TST & \\
\hline CHEMBL483847 & 954758 & 4.5043 & 4.5042 & TRN & \\
\hline CHEMBL514499 & 954758 & 7.0205 & 7.0204 & TRN & \\
\hline CHEMBL1970879 & 954758 & 3.4864 & 3.4863 & TRN & \\
\hline CHEMBL65 & 954758 & 7.8595 & 7.8594 & TRN & \\
\hline CHEMBL379975 & 954758 & 5.4201 & 5.4201 & TRN & \\
\hline CHEMBL1673039 & 954758 & 4.5673 & 4.5672 & TRN & \\
\hline CHEMBL1404918 & 954758 & 2.865 & 2.8652 & TRN & \\
\hline CHEMBL192566 & 954758 & 6.4626 & 7.8164 & TST & \\
\hline CHEMBL1516890 & 954758 & 4.5112 & 4.5116 & TRN & \\
\hline CHEMBL2005886 & 954758 & 3.2893 & 3.2891 & TRN & \\
\hline CHEMBL449158 & 954758 & 6.5503 & 6.41 & TST & \\
\hline CHEMBL585951 & 954758 & 6.2649 & 6.265 & TRN & \\
\hline CHEMBL3186408 & 954758 & 3.194 & 3.4577 & TST & \\
\hline CHEMBL1788116 & 954758 & 4.8651 & 4.8649 & TRN & \\
\hline CHEMBL222102 & 954758 & 4.849 & 4.8492 & TRN & \\
\hline CHEMBL3199475 & 954758 & 4.6522 & 4.6527 & TRN & \\
\hline CHEMBL3392440 & 954758 & 3.4294 & 3.4292 & TRN & \\
\hline CHEMBL191334 & 954758 & 3.9186 & 3.9186 & TRN & \\
\hline CHEMBL 202721 & 954758 & 4.9613 & 4.9615 & TRN & \\
\hline CHEMBL188678 & 954758 & 4.9308 & 4.931 & TRN & \\
\hline CHEMBL 300389 & 954758 & 7.0228 & 7.0228 & TRN & \\
\hline CHEMBL392695 & 954758 & 5.6814 & 5.6815 & TRN & \\
\hline CHEMBL 2144069 & 954758 & 4.0509 & 4.0509 & TRN & \\
\hline CHEMBL1190711 & 954758 & 5.2334 & 5.2332 & TRN & \\
\hline CHEMBL 220241 & 954758 & 3.4811 & 3.4813 & TRN & \\
\hline CHEMBL577784 & 954758 & 5.0501 & 5.0499 & TRN & \\
\hline CHEMBL92309 & 954758 & 3.2519 & 2.7966 & TST & \\
\hline CHEMBL209148 & 954758 & 4.0359 & 4.0362 & TRN & \\
\hline CHEMBL393929 & 954758 & 3.7813 & 3.7814 & TRN & \\
\hline CHEMBL512504 & 954758 & 6.5193 & 6.5192 & TRN & \\
\hline CHEMBL 210618 & 954758 & 3.4004 & 3.4 & TRN & \\
\hline CHEMBL1357247 & 954758 & 3.1187 & 3.1186 & TRN & \\
\hline CHEMBL1230020 & 954758 & 3.6519 & 3.65199 & 99999999997 & TRN \\
\hline CHEMBL 9470 & 954758 & 6.3974 & 5.5248 & TST & \\
\hline CHEMBL1590308 & 954758 & 3.2398 & 3.3314 & TST & \\
\hline CHEMBL 240954 & 954758 & 4.5825 & 4.5944 & TST & \\
\hline CHEMBL483849 & 954758 & 3.0486 & 3.0486 & TRN & \\
\hline CHEMBL1909414 & 954758 & 4.3633 & 4.3631 & TRN & \\
\hline CHEMBL135561 & 954758 & 4.3949 & 4.3949 & TRN & \\
\hline CHEMBL259181 & 954758 & 4.7247 & 4.7246 & TRN & \\
\hline
\end{tabular}


Supplemental Table S2.txt

\begin{tabular}{|c|c|c|c|c|c|}
\hline CHEMBL3349342 & 954758 & 3.657 & 3.6571 & TRN & \\
\hline CHEMBL102714 & 954758 & 4.3415 & 4.3411 & TRN & \\
\hline CHEMBL558642 & 954758 & 4.5878 & 4.5878 & TRN & \\
\hline CHEMBL1256459 & 954758 & 7.3409 & 7.341 & TRN & \\
\hline CHEMBL2363137 & 954758 & 4.9173 & 4.9174 & TRN & \\
\hline CHEMBL509032 & 954758 & 4.9321 & 4.9322 & TRN & \\
\hline CHEMBL472940 & 954758 & 4.6924 & 4.6926 & TRN & \\
\hline CHEMBL1242367 & 954758 & 4.0274 & 4.0276 & TRN & \\
\hline CHEMBL180127 & 954758 & \multicolumn{2}{|c|}{4.5169999999999995} & 4.5169 & TRN \\
\hline CHEMBL 258844 & 954758 & 4.8082 & 4.808 & TRN & \\
\hline CHEMBL412142 & 954758 & 3.3479 & \multicolumn{2}{|c|}{3.3480000000000003} & TRN \\
\hline CHEMBL1643959 & 954758 & 3.1296 & 3.5569 & TST & \\
\hline CHEMBL 379300 & 954758 & 7.0998 & 6.5432 & TST & \\
\hline CHEMBL573107 & 954758 & 4.7213 & 5.2027 & TST & \\
\hline CHEMBL515416 & 954758 & 3.5658 & 4.0794 & TST & \\
\hline CHEMBL373751 & 954758 & 3.2864 & 3.4417 & TST & \\
\hline CHEMBL189584 & 954758 & 4.8686 & 5.0284 & TST & \\
\hline CHEMBL221137 & 954758 & 4.6858 & 4.8648 & TST & \\
\hline CHEMBL 213100 & 954758 & 4.1284 & 3.7912 & TST & \\
\hline CHEMBL 370367 & 333106 & 7.4685 & 7.0461 & TRN & \\
\hline CHEMBL201850 & 333106 & 7.0 & 6.6387 & TRN & \\
\hline CHEMBL414675 & 333106 & 6.9101 & 6.9036 & TST & \\
\hline CHEMBL381637 & 333106 & 7.041 & 6.4008 & TST & \\
\hline CHEMBL381422 & 333106 & 7.0706 & 7.2287 & TRN & \\
\hline CHEMBL383204 & 333106 & 7.0362 & 7.0262 & TRN & \\
\hline CHEMBL201963 & 333106 & 6.4437 & 6.9119 & TST & \\
\hline CHEMBL201849 & 333106 & 7.1427 & 6.8745 & TRN & \\
\hline CHEMBL372289 & 333106 & 6.6819 & \multicolumn{2}{|c|}{6.2379999999999995} & TRN \\
\hline CHEMBL201265 & 333106 & 6.5751 & 6.5424 & TRN & \\
\hline CHEMBL381509 & 333106 & 6.9431 & 6.9903 & TRN & \\
\hline CHEMBL 379020 & 333106 & 5.5686 & 5.811 & TRN & \\
\hline CHEMBL 202180 & 333106 & 6.8447 & 7.2419 & TRN & \\
\hline CHEMBL380882 & 333106 & 6.1938 & 7.0554 & TST & \\
\hline CHEMBL202171 & 333106 & 6.2284 & \multicolumn{2}{|c|}{6.803999999999999} & TST \\
\hline CHEMBL 377505 & 333106 & 6.6635 & 7.0059 & TRN & \\
\hline CHEMBL201785 & 333106 & 6.6271 & 6.603 & TST & \\
\hline CHEMBL 202048 & 333106 & 7.4685 & 6.8879 & TRN & \\
\hline CHEMBL202066 & 333106 & 6.2343 & 6.4032 & TRN & \\
\hline CHEMBL202517 & 333106 & 6.6234 & 6.223 & TRN & \\
\hline CHEMBL372165 & 333106 & 4.4989 & 7.0155 & TST & \\
\hline CHEMBL372288 & 333106 & 6.9586 & 6.9367 & TRN & \\
\hline CHEMBL 373206 & 333106 & 6.983 & 7.1031 & TRN & \\
\hline CHEMBL383738 & 333106 & 6.2321 & 6.5212 & TRN & \\
\hline CHEMBL 370344 & 333106 & 6.1124 & 5.7706 & TRN & \\
\hline CHEMBL 202108 & 333106 & 6.6126 & 6.7828 & TRN & \\
\hline CHEMBL202102 & 333106 & 7.3372 & 6.8815 & TRN & \\
\hline CHEMBL371424 & 333106 & 7.2676 & 7.1512 & TRN & \\
\hline CHEMBL202592 & 333106 & 6.2291 & 6.6686 & TST & \\
\hline
\end{tabular}




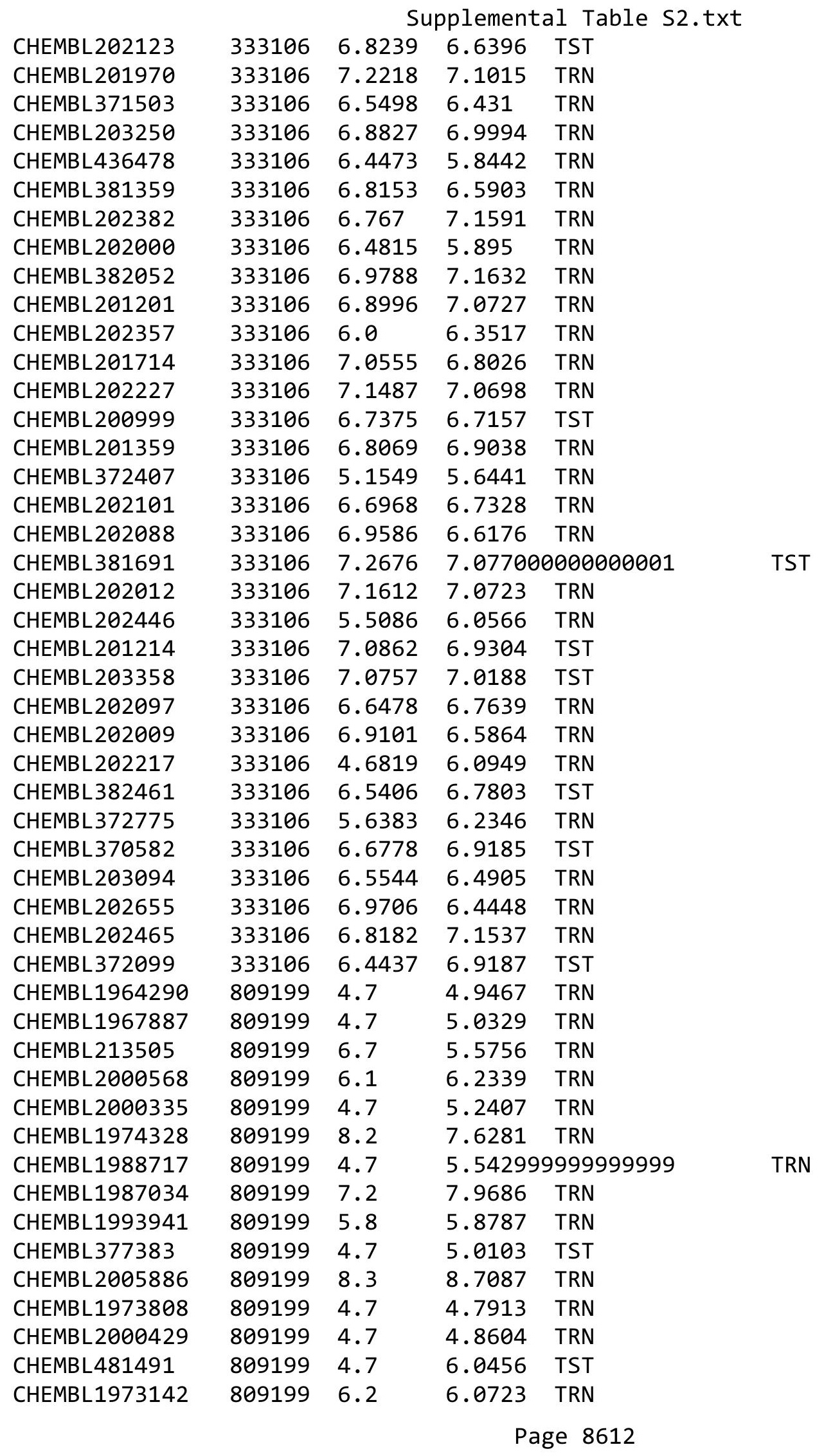




\begin{tabular}{|c|c|c|c|c|c|}
\hline & & & & & \\
\hline CHEMBL1972576 & 809199 & 4.7 & 4.9483 & TRN & \\
\hline CHEMBL1990254 & 809199 & 4.7 & 4.8206 & TRN & \\
\hline CHEMBL1973145 & 809199 & 4.7 & 4.1954 & TRN & \\
\hline CHEMBL1982924 & 809199 & 4.7 & 4.6147 & TRN & \\
\hline CHEMBL1992342 & 809199 & 6.2 & 5.4347 & TRN & \\
\hline CHEMBL 2005936 & 809199 & 4.7 & 4.2971 & TRN & \\
\hline CHEMBL1807515 & 809199 & 4.7 & 5.3756 & TRN & \\
\hline CHEMBL1988173 & 809199 & 4.7 & 5.2208 & TST & \\
\hline CHEMBL1164265 & 809199 & 6.5 & 6.58899 & 99999999995 & TST \\
\hline CHEMBL1971141 & 809199 & 4.7 & 5.1412 & TRN & \\
\hline CHEMBL1995813 & 809199 & 4.7 & 5.6422 & TRN & \\
\hline CHEMBL1989805 & 809199 & 4.7 & 4.6607 & TST & \\
\hline CHEMBL206236 & 809199 & 4.7 & 4.5661 & TRN & \\
\hline CHEMBL244378 & 809199 & 7.1 & 7.38700 & 00000000005 & TRN \\
\hline CHEMBL1965423 & 809199 & 4.7 & 5.1008 & TRN & \\
\hline CHEMBL 2001957 & 809199 & 4.7 & 4.9178 & TRN & \\
\hline CHEMBL1969372 & 809199 & 4.7 & 4.9427 & TRN & \\
\hline CHEMBL205415 & 809199 & 4.7 & 4.6596 & TRN & \\
\hline CHEMBL1977135 & 809199 & 4.7 & 4.8052 & TRN & \\
\hline CHEMBL1986943 & 809199 & 6.8 & 5.9154 & TRN & \\
\hline CHEMBL 2001920 & 809199 & 4.7 & 5.25299 & 9999999999 & TRN \\
\hline CHEMBL 2006263 & 809199 & 4.7 & 5.5049 & TST & \\
\hline CHEMBL1978448 & 809199 & 7.3 & 5.3799 & TST & \\
\hline CHEMBL1993584 & 809199 & 5.7 & 5.038 & TRN & \\
\hline CHEMBL1969483 & 809199 & 4.5 & 4.2444 & TRN & \\
\hline CHEMBL1986263 & 809199 & 6.8 & 5.7322 & TRN & \\
\hline CHEMBL 2000114 & 809199 & 6.0 & 6.4125 & TRN & \\
\hline CHEMBL 2001257 & 809199 & 4.7 & 4.5796 & TRN & \\
\hline CHEMBL1975647 & 809199 & 4.7 & 4.4658 & TRN & \\
\hline CHEMBL1992536 & 809199 & 4.7 & 4.7037 & TRN & \\
\hline CHEMBL1968380 & 809199 & 4.7 & 4.8189 & TRN & \\
\hline CHEMBL1964644 & 809199 & 4.7 & 4.2037 & TRN & \\
\hline CHEMBL1981782 & 809199 & 4.7 & 4.4934 & TRN & \\
\hline CHEMBL1977681 & 809199 & 4.7 & 4.8441 & TRN & \\
\hline CHEMBL1970142 & 809199 & 8.7 & 7.2518 & TRN & \\
\hline CHEMBL1990912 & 809199 & 4.7 & 4.9366 & TRN & \\
\hline CHEMBL 2002373 & 809199 & 4.7 & 4.5834 & TRN & \\
\hline CHEMBL 2006188 & 809199 & 4.7 & 4.1767 & TRN & \\
\hline CHEMBL1967531 & 809199 & 4.7 & 4.7444 & TRN & \\
\hline CHEMBL1970913 & 809199 & 4.7 & 4.6912 & TRN & \\
\hline CHEMBL1973893 & 809199 & 4.7 & 5.1744 & TRN & \\
\hline CHEMBL1997534 & 809199 & 4.7 & 4.8257 & TRN & \\
\hline CHEMBL1988163 & 809199 & 7.6 & 8.0 & TRN & \\
\hline CHEMBL1985095 & 809199 & 4.7 & 5.2101 & TST & \\
\hline CHEMBL1996500 & 809199 & 4.7 & 4.6268 & TRN & \\
\hline CHEMBL 2006493 & 809199 & 4.7 & 5.1668 & TST & \\
\hline CHEMBL1682540 & 809199 & 4.7 & 4.9409 & TRN & \\
\hline CHEMBL1983449 & 809199 & 4.7 & 4.7495 & TRN & \\
\hline & & & & 8613 & \\
\hline
\end{tabular}




\begin{tabular}{|c|c|c|c|c|}
\hline \multicolumn{5}{|c|}{ Supplemental Table S2.txt } \\
\hline CHEMBL1992323 & 809199 & 4.7 & 5.3041 & TRN \\
\hline CHEMBL1969735 & 809199 & 4.7 & 5.1065 & TRN \\
\hline CHEMBL 2002649 & 809199 & 6.4 & 5.8339 & TRN \\
\hline CHEMBL1994864 & 809199 & 4.7 & 4.6132 & TRN \\
\hline CHEMBL497151 & 809199 & 4.7 & 4.6491 & TST \\
\hline CHEMBL1995172 & 809199 & 6.0 & 5.6422 & TST \\
\hline CHEMBL1973961 & 809199 & 6.9 & 6.4322 & TRN \\
\hline CHEMBL246970 & 809199 & 4.7 & 5.5055 & TST \\
\hline CHEMBL340921 & 809199 & 4.7 & 4.3772 & TST \\
\hline CHEMBL 2000078 & 809199 & 4.5 & 4.3036 & TRN \\
\hline CHEMBL1276446 & 809199 & 4.7 & 6.6123 & TST \\
\hline CHEMBL1977346 & 809199 & 6.3 & 5.7391 & TRN \\
\hline CHEMBL1971649 & 809199 & 4.7 & 4.3403 & TRN \\
\hline CHEMBL 2000508 & 809199 & 4.7 & 4.5619 & TRN \\
\hline CHEMBL1971694 & 809199 & 4.7 & 5.4199 & TST \\
\hline CHEMBL 2001547 & 809199 & 4.7 & 4.5928 & TRN \\
\hline CHEMBL 2005482 & 809199 & 4.5 & 4.9898 & TRN \\
\hline CHEMBL 210928 & 809199 & 4.7 & 4.6107 & TST \\
\hline CHEMBL1997909 & 809199 & 4.5 & 4.2363 & TRN \\
\hline CHEMBL 2006439 & 809199 & 4.7 & 5.0016 & TRN \\
\hline CHEMBL1969190 & 809199 & 5.7 & 5.7015 & TRN \\
\hline CHEMBL1977148 & 809199 & 4.7 & 5.0352 & TRN \\
\hline CHEMBL1966842 & 809199 & 5.8 & 4.7793 & TRN \\
\hline CHEMBL1973937 & 809199 & 4.7 & 5.0152 & TRN \\
\hline CHEMBL1991674 & 809199 & 6.1 & 6.1671 & TRN \\
\hline CHEMBL 2003286 & 809199 & 4.7 & 4.4296 & TRN \\
\hline CHEMBL1992306 & 809199 & 6.0 & 5.7839 & TRN \\
\hline CHEMBL 2002165 & 809199 & 6.2 & 6.2361 & TRN \\
\hline CHEMBL1982711 & 809199 & 7.1 & 6.4906 & TRN \\
\hline CHEMBL1979318 & 809199 & 6.2 & 5.4261 & TST \\
\hline CHEMBL206382 & 809199 & 4.7 & 4.6122 & TRN \\
\hline CHEMBL1998585 & 809199 & 6.4 & 6.0821 & TRN \\
\hline CHEMBL519697 & 809199 & 4.7 & 4.4809 & TST \\
\hline CHEMBL 2004934 & 809199 & 4.7 & 4.3587 & TRN \\
\hline CHEMBL1975128 & 809199 & 4.7 & 5.2264 & TRN \\
\hline CHEMBL1996048 & 809199 & 4.7 & 6.1487 & TST \\
\hline CHEMBL1998829 & 809199 & 4.7 & 5.0445 & TRN \\
\hline CHEMBL461876 & 809199 & 8.6 & 7.4213 & TRN \\
\hline CHEMBL1988838 & 809199 & 7.5 & 7.8274 & TRN \\
\hline CHEMBL 2001485 & 809199 & 7.6 & 6.7983 & TRN \\
\hline CHEMBL1982753 & 809199 & 6.5 & 7.0516 & TRN \\
\hline CHEMBL1981725 & 809199 & 6.9 & 6.4792 & TRN \\
\hline CHEMBL1972346 & 809199 & 6.1 & 5.5796 & TST \\
\hline CHEMBL1984363 & 809199 & 4.7 & 4.5958 & TRN \\
\hline CHEMBL1978099 & 809199 & 6.8 & 6.9317 & TRN \\
\hline CHEMBL1988608 & 809199 & 5.7 & 4.9909 & TRN \\
\hline CHEMBL184847 & 809199 & 4.7 & 4.9304 & TRN \\
\hline CHEMBL1982866 & 809199 & 4.7 & 4.3124 & TRN \\
\hline
\end{tabular}




\begin{tabular}{|c|c|c|c|c|c|}
\hline & & \multicolumn{4}{|c|}{ Supplemental Table S2.txt } \\
\hline CHEMBL1984367 & 809199 & 4.7 & 4.6234 & TRN & \\
\hline CHEMBL 2007592 & 809199 & 4.7 & 4.6196 & TST & \\
\hline CHEMBL1965570 & 809199 & 4.7 & 5.4514 & TRN & \\
\hline CHEMBL226898 & 809199 & 6.4 & 5.9635 & TRN & \\
\hline CHEMBL1982563 & 809199 & 4.7 & 4.9855 & TRN & \\
\hline CHEMBL539474 & 809199 & 6.5 & 5.1255 & TST & \\
\hline CHEMBL575824 & 809199 & 4.7 & 4.9098 & TRN & \\
\hline CHEMBL 210963 & 809199 & 4.7 & 4.0116 & TST & \\
\hline CHEMBL1988387 & 809199 & 8.5 & 7.0655 & TRN & \\
\hline CHEMBL1614705 & 809199 & 4.7 & 4.3725 & TRN & \\
\hline CHEMBL1990288 & 809199 & 4.7 & 5.0129 & TRN & \\
\hline CHEMBL1984633 & 809199 & 4.7 & 4.2698 & TRN & \\
\hline CHEMBL1965845 & 809199 & 4.7 & 4.7957 & TRN & \\
\hline CHEMBL1986970 & 809199 & 4.7 & 4.4412 & TRN & \\
\hline CHEMBL 2006715 & 809199 & 4.7 & 4.606 & TRN & \\
\hline CHEMBL1958401 & 809199 & 4.7 & 4.3779 & TRN & \\
\hline CHEMBL1990482 & 809199 & 4.7 & 5.1193 & TRN & \\
\hline CHEMBL1990904 & 809199 & 4.7 & 4.9256 & TRN & \\
\hline CHEMBL2005475 & 809199 & 4.7 & 4.7375 & TRN & \\
\hline CHEMBL 2003456 & 809199 & 4.7 & 5.18 & TRN & \\
\hline CHEMBL1966816 & 809199 & 4.7 & 5.3056 & TRN & \\
\hline CHEMBL402846 & 809199 & 4.7 & 4.2159 & TRN & \\
\hline CHEMBL 2002992 & 809199 & 4.7 & 6.1328 & TST & \\
\hline CHEMBL183844 & 809199 & 4.7 & 5.0125 & TRN & \\
\hline CHEMBL560813 & 809199 & 4.7 & 4.1343 & TRN & \\
\hline CHEMBL1682545 & 809199 & 5.8 & 5.2203 & TRN & \\
\hline CHEMBL220057 & 809199 & 5.7 & 5.0291 & TRN & \\
\hline CHEMBL 383541 & 809199 & 4.7 & 4.9647 & TRN & \\
\hline CHEMBL2001224 & 809199 & 4.7 & 4.2461 & TRN & \\
\hline CHEMBL1968791 & 809199 & 4.7 & 5.251 & TRN & \\
\hline CHEMBL10 & 809199 & 4.6 & 4.7598 & TRN & \\
\hline CHEMBL1976732 & 809199 & 4.7 & 4.8269 & TRN & \\
\hline CHEMBL1969506 & 809199 & 4.7 & 4.93199 & 99999999995 & TRN \\
\hline CHEMBL1964937 & 809199 & 4.7 & 5.1596 & TRN & \\
\hline CHEMBL1980163 & 809199 & 6.1 & 5.1678 & TRN & \\
\hline CHEMBL1971186 & 809199 & 4.7 & 4.8313 & TRN & \\
\hline CHEMBL 2003482 & 809199 & 4.7 & 4.746 & TRN & \\
\hline CHEMBL1973211 & 809199 & 4.7 & 4.9821 & TRN & \\
\hline CHEMBL1984700 & 809199 & 4.7 & 4.8784 & TRN & \\
\hline CHEMBL 2005899 & 809199 & 4.7 & 4.7857 & TRN & \\
\hline CHEMBL1682552 & 809199 & 4.7 & 4.522 & TRN & \\
\hline CHEMBL1998953 & 809199 & 6.0 & 6.2295 & TRN & \\
\hline CHEMBL1972125 & 809199 & 4.7 & 4.9631 & TRN & \\
\hline CHEMBL229799 & 809199 & 6.2 & 5.8141 & TRN & \\
\hline CHEMBL105739 & 809199 & 4.7 & 5.5876 & TRN & \\
\hline CHEMBL1976134 & 809199 & 6.8 & 6.8569 & TRN & \\
\hline CHEMBL1965131 & 809199 & 6.2 & 5.9408 & TRN & \\
\hline CHEMBL379300 & 809199 & 6.1 & 5.574 & TRN & \\
\hline
\end{tabular}




\begin{tabular}{|c|c|c|c|c|}
\hline \multicolumn{5}{|c|}{ Supplemental Table S2.txt } \\
\hline CHEMBL1972158 & 809199 & 4.7 & 4.8405 & TRN \\
\hline CHEMBL 2001228 & 809199 & 4.5 & 4.7307 & TRN \\
\hline CHEMBL1986781 & 809199 & 4.7 & 4.6246 & TRN \\
\hline CHEMBL526133 & 809199 & 4.7 & 4.7923 & TRN \\
\hline CHEMBL1970340 & 809199 & 4.7 & 4.6938 & TRN \\
\hline CHEMBL2005186 & 809199 & 4.7 & 5.0254 & TRN \\
\hline CHEMBL1975534 & 809199 & 4.7 & 5.615 & TRN \\
\hline CHEMBL1993424 & 809199 & 8.1 & 7.5652 & TRN \\
\hline CHEMBL1979057 & 809199 & 4.7 & 5.2632 & TRN \\
\hline CHEMBL1966703 & 809199 & 4.7 & 5.4819 & TST \\
\hline CHEMBL387971 & 809199 & 4.7 & 4.1673 & TST \\
\hline CHEMBL1969561 & 809199 & 4.7 & 4.859 & TRN \\
\hline CHEMBL1975121 & 809199 & 4.7 & 4.3877 & TRN \\
\hline CHEMBL1999428 & 809199 & 4.7 & 4.8569 & TRN \\
\hline CHEMBL1967560 & 809199 & 4.7 & 4.7214 & TRN \\
\hline CHEMBL1516890 & 809199 & 4.7 & 5.034 & TRN \\
\hline CHEMBL211378 & 809199 & 4.7 & 4.7081 & TRN \\
\hline CHEMBL1997023 & 809199 & 4.7 & 4.4683 & TST \\
\hline CHEMBL2001751 & 809199 & 6.0 & 5.744 & TRN \\
\hline CHEMBL1964687 & 809199 & 4.7 & 5.0258 & TRN \\
\hline CHEMBL1971943 & 809199 & 6.4 & 5.6788 & TST \\
\hline CHEMBL1984586 & 809199 & 4.7 & 4.4449 & TRN \\
\hline CHEMBL1974254 & 809199 & 4.7 & 5.5328 & TRN \\
\hline CHEMBL1972659 & 809199 & 4.7 & 4.6405 & TRN \\
\hline CHEMBL1997924 & 809199 & 9.0 & 7.9844 & TRN \\
\hline CHEMBL 272453 & 809199 & 4.7 & 4.8991 & TRN \\
\hline CHEMBL1970217 & 809199 & 4.7 & 4.1301 & TRN \\
\hline CHEMBL1988537 & 809199 & 6.2 & 5.2347 & TST \\
\hline CHEMBL1969049 & 809199 & 4.7 & 4.2939 & TRN \\
\hline CHEMBL 2005828 & 809199 & 4.7 & 4.7215 & TRN \\
\hline CHEMBL 2002240 & 809199 & 5.8 & 4.3864 & TST \\
\hline CHEMBL 2005528 & 809199 & 4.7 & 4.9331 & TST \\
\hline CHEMBL1969843 & 809199 & 4.7 & 4.4816 & TRN \\
\hline CHEMBL185569 & 809199 & 4.7 & 5.2742 & TRN \\
\hline CHEMBL1978267 & 809199 & 4.5 & 4.3865 & TRN \\
\hline CHEMBL 2007002 & 809199 & 4.7 & 4.6521 & TRN \\
\hline CHEMBL1987007 & 809199 & 4.7 & 4.5685 & TRN \\
\hline CHEMBL1998611 & 809199 & 5.7 & 5.8243 & TRN \\
\hline CHEMBL1975900 & 809199 & 4.7 & 4.5737 & TRN \\
\hline CHEMBL 255822 & 809199 & 4.7 & 4.4564 & TRN \\
\hline CHEMBL1972221 & 809199 & 4.7 & 4.9956 & TRN \\
\hline CHEMBL484390 & 809199 & 4.7 & 4.3924 & TST \\
\hline CHEMBL1979252 & 809199 & 4.7 & 4.8034 & TRN \\
\hline CHEMBL 378627 & 809199 & 4.7 & 4.6382 & TST \\
\hline CHEMBL1996979 & 809199 & 5.8 & 5.421 & TRN \\
\hline CHEMBL1968406 & 809199 & 4.7 & 4.9448 & TRN \\
\hline CHEMBL1972937 & 809199 & 4.7 & 4.1626 & TRN \\
\hline CHEMBL 2004290 & 809199 & 4.7 & 5.5052 & TRN \\
\hline
\end{tabular}




\begin{tabular}{|c|c|c|c|c|c|}
\hline \multicolumn{6}{|c|}{ Supplemental Table S2.txt } \\
\hline CHEMBL1986499 & 809199 & 4.7 & 5.0116 & TRN & \\
\hline CHEMBL 2000393 & 809199 & 7.7 & 6.2855 & TST & \\
\hline CHEMBL 2004311 & 809199 & 7.2 & 6.4264 & TRN & \\
\hline CHEMBL1992634 & 809199 & 6.2 & 6.447 & TRN & \\
\hline CHEMBL1242373 & 809199 & 5.7 & 5.0593 & TRN & \\
\hline CHEMBL1998545 & 809199 & 4.7 & 4.9725 & TRN & \\
\hline CHEMBL1986869 & 809199 & 4.7 & 4.3486 & TRN & \\
\hline CHEMBL316264 & 809199 & 4.7 & 4.80399 & 9999999999 & TRN \\
\hline CHEMBL1988075 & 809199 & 4.7 & 5.1552 & TRN & \\
\hline CHEMBL1988076 & 809199 & 4.5 & 4.5062 & TRN & \\
\hline CHEMBL1991678 & 809199 & 4.7 & 4.7771 & TRN & \\
\hline CHEMBL1682558 & 809199 & 4.7 & 4.503 & TRN & \\
\hline CHEMBL 2001239 & 809199 & 4.7 & 5.3049 & TST & \\
\hline CHEMBL1990496 & 809199 & 4.6 & 5.0213 & TRN & \\
\hline CHEMBL1988594 & 809199 & 4.7 & 5.0362 & TRN & \\
\hline CHEMBL 2001288 & 809199 & 6.1 & 5.3265 & TRN & \\
\hline CHEMBL1999811 & 809199 & 6.2 & 4.9297 & TST & \\
\hline CHEMBL1985074 & 809199 & 4.7 & 5.3009 & TST & \\
\hline CHEMBL2000481 & 809199 & 5.9 & 4.9171 & TRN & \\
\hline CHEMBL1982874 & 809199 & 4.7 & 4.7474 & TRN & \\
\hline CHEMBL1991725 & 809199 & 4.7 & 4.7619 & TRN & \\
\hline CHEMBL 2007296 & 809199 & 4.7 & 4.7476 & TRN & \\
\hline CHEMBL 208637 & 809199 & 4.7 & 4.1286 & TST & \\
\hline CHEMBL396523 & 809199 & 7.1 & 7.08700 & 0000000001 & TRN \\
\hline CHEMBL1970300 & 809199 & 5.8 & 5.0332 & TRN & \\
\hline CHEMBL1967094 & 809199 & 4.7 & 5.0782 & TRN & \\
\hline CHEMBL 2003341 & 809199 & 4.7 & 4.9613 & TRN & \\
\hline CHEMBL1970203 & 809199 & 4.7 & 5.2129 & TRN & \\
\hline CHEMBL1986530 & 809199 & 4.7 & 5.442 & TST & \\
\hline CHEMBL1968590 & 809199 & 4.7 & 4.9204 & TRN & \\
\hline CHEMBL 2005375 & 809199 & 4.7 & 4.6565 & TRN & \\
\hline CHEMBL1984191 & 809199 & 4.7 & 5.0508 & TRN & \\
\hline CHEMBL1982992 & 809199 & 4.7 & 5.135 & TRN & \\
\hline CHEMBL1999590 & 809199 & 4.7 & 5.1577 & TST & \\
\hline CHEMBL1981079 & 809199 & 4.7 & 4.6618 & TRN & \\
\hline CHEMBL1978166 & 809199 & 4.5 & 4.8985 & TRN & \\
\hline CHEMBL1980489 & 809199 & 4.7 & 4.6099 & TRN & \\
\hline CHEMBL 2000832 & 809199 & 6.5 & 5.8459 & TRN & \\
\hline CHEMBL394790 & 809199 & 4.7 & 4.8821 & TRN & \\
\hline CHEMBL1970709 & 809199 & 4.7 & 4.5859 & TRN & \\
\hline CHEMBL1965660 & 809199 & 4.7 & 4.8799 & TRN & \\
\hline CHEMBL1974702 & 809199 & 4.7 & 4.9307 & TRN & \\
\hline CHEMBL1998112 & 809199 & 7.2 & 6.7062 & TRN & \\
\hline CHEMBL1996111 & 809199 & 4.7 & 4.6897 & TRN & \\
\hline CHEMBL1969126 & 809199 & 4.7 & 4.7783 & TRN & \\
\hline CHEMBL1965589 & 809199 & 4.7 & 4.569 & TRN & \\
\hline CHEMBL1980896 & 809199 & 4.7 & 4.588 & TRN & \\
\hline CHEMBL1970104 & 809199 & 5.9 & 6.3019 & TRN & \\
\hline
\end{tabular}




\begin{tabular}{|c|c|c|c|c|c|}
\hline \multicolumn{6}{|c|}{ Supplemental Table S2.txt } \\
\hline CHEMBL1991429 & 809199 & 4.7 & 4.6022 & TRN & \\
\hline CHEMBL1999714 & 809199 & 4.7 & 5.0742 & TRN & \\
\hline CHEMBL1971149 & 809199 & 4.7 & 4.5146 & TRN & \\
\hline CHEMBL1994040 & 809199 & 4.7 & 4.5815 & TRN & \\
\hline CHEMBL388978 & 809199 & 9.3 & 6.8144 & TST & \\
\hline CHEMBL1988153 & 809199 & 4.7 & 4.518 & TST & \\
\hline CHEMBL579246 & 809199 & 4.7 & 5.0721 & TRN & \\
\hline CHEMBL1972584 & 809199 & 6.8 & 6.3918 & TRN & \\
\hline CHEMBL1982506 & 809199 & 4.7 & 5.5066 & TST & \\
\hline CHEMBL1968127 & 809199 & 4.7 & 4.7206 & TRN & \\
\hline CHEMBL1975233 & 809199 & 4.7 & 4.5085 & TRN & \\
\hline CHEMBL1985406 & 809199 & 4.7 & 4.8795 & TRN & \\
\hline CHEMBL 207400 & 809199 & 4.7 & 4.8377 & TST & \\
\hline CHEMBL 2000894 & 809199 & 4.7 & 4.1547 & TST & \\
\hline CHEMBL1998121 & 809199 & 6.2 & 5.4739 & TRN & \\
\hline CHEMBL1982135 & 809199 & 4.7 & 4.3057 & TRN & \\
\hline CHEMBL1976090 & 809199 & 5.8 & 5.7683 & TRN & \\
\hline CHEMBL52387 & 809199 & 4.7 & 5.9056 & TST & \\
\hline CHEMBL1993243 & 809199 & 4.7 & 5.0719 & TRN & \\
\hline CHEMBL379835 & 809199 & 4.7 & 5.0093 & TST & \\
\hline CHEMBL1997597 & 809199 & 4.7 & 5.4093 & TRN & \\
\hline CHEMBL1969537 & 809199 & 6.6 & 5.5678 & TST & \\
\hline CHEMBL1976093 & 809199 & 4.7 & 4.7087 & TRN & \\
\hline CHEMBL1979357 & 809199 & 4.7 & 4.422 & TRN & \\
\hline CHEMBL1996817 & 809199 & 7.1 & 6.5848 & TRN & \\
\hline CHEMBL1975256 & 809199 & 4.7 & 4.4283 & TST & \\
\hline CHEMBL508928 & 809199 & 4.7 & 5.3896 & TRN & \\
\hline CHEMBL1991356 & 809199 & 4.7 & 4.703 & TRN & \\
\hline CHEMBL 2004892 & 809199 & 6.4 & 5.5467 & TRN & \\
\hline CHEMBL468280 & 809199 & 4.7 & 4.7039 & TST & \\
\hline CHEMBL116070 & 809199 & 4.7 & 4.8992 & TST & \\
\hline CHEMBL1990884 & 809199 & 4.7 & 5.41100 & 00000000005 & TRN \\
\hline CHEMBL1990821 & 809199 & 4.7 & 5.2637 & TST & \\
\hline CHEMBL 3109278 & 809199 & 4.6 & 5.0185 & TRN & \\
\hline CHEMBL 256835 & 809199 & 4.7 & 5.1067 & TRN & \\
\hline CHEMBL1970314 & 809199 & 7.0 & 5.809 & TRN & \\
\hline CHEMBL 2004871 & 809199 & 4.7 & 4.7527 & TRN & \\
\hline CHEMBL 2004872 & 809199 & 4.7 & 4.3982 & TRN & \\
\hline CHEMBL1969879 & 809199 & 4.7 & 5.6799 & TST & \\
\hline CHEMBL1980142 & 809199 & 4.7 & 4.988 & TRN & \\
\hline CHEMBL41783 & 809199 & 4.7 & 4.7509 & TRN & \\
\hline CHEMBL1981720 & 809199 & 4.7 & 4.45100 & 00000000005 & TRN \\
\hline CHEMBL 2006276 & 809199 & 4.7 & 5.1449 & TRN & \\
\hline CHEMBL191003 & 809199 & 6.3 & 7.0194 & TRN & \\
\hline CHEMBL419932 & 809199 & 4.7 & 4.854 & TRN & \\
\hline CHEMBL271381 & 809199 & 6.2 & 5.7623 & TRN & \\
\hline CHEMBL 262433 & 809199 & 4.7 & 4.83899 & 99999999995 & TRN \\
\hline CHEMBL 2006785 & 809199 & 4.7 & 4.6094 & TRN & \\
\hline
\end{tabular}




\begin{tabular}{|c|c|c|c|c|c|}
\hline \multirow{2}{*}{ CHEMBL1982466 } & \multirow{2}{*}{809199} & \\
\hline & & 8.4 & 6.6914 & TRN & \\
\hline CHEMBL306380 & 809199 & 5.7 & 5.9607 & TRN & \\
\hline CHEMBL1966722 & 809199 & 5.7 & 5.1886 & TST & \\
\hline CHEMBL1995740 & 809199 & 4.7 & 4.8966 & TRN & \\
\hline CHEMBL1975500 & 809199 & 6.3 & 5.8414 & TRN & \\
\hline CHEMBL394619 & 809199 & 4.7 & 4.6998 & TRN & \\
\hline CHEMBL1996831 & 809199 & 4.7 & 5.0512 & TST & \\
\hline CHEMBL411903 & 809199 & 6.6 & 6.6343 & TRN & \\
\hline CHEMBL234085 & 809199 & 4.5 & \multicolumn{2}{|c|}{5.656000000000001} & TST \\
\hline CHEMBL1998414 & 809199 & 6.1 & 5.0658 & TRN & \\
\hline CHEMBL1995832 & 809199 & 4.7 & 4.6406 & TRN & \\
\hline CHEMBL418203 & 809199 & 6.6 & 4.8087 & TST & \\
\hline CHEMBL1969042 & 809199 & 4.7 & \multicolumn{2}{|c|}{5.3020000000000005} & TRN \\
\hline CHEMBL 225519 & 809199 & 4.8 & 4.5486 & TRN & \\
\hline CHEMBL1999931 & 809199 & 4.7 & 5.3261 & TRN & \\
\hline CHEMBL1978200 & 809199 & 4.7 & 4.7415 & TRN & \\
\hline CHEMBL1970522 & 809199 & 4.7 & 4.3896 & TRN & \\
\hline CHEMBL1375418 & 809199 & 4.7 & 5.3297 & TRN & \\
\hline CHEMBL 2007064 & 809199 & 6.0 & 5.9648 & TRN & \\
\hline CHEMBL1964692 & 809199 & 4.7 & 5.0715 & TRN & \\
\hline CHEMBL1996931 & 809199 & 4.7 & 5.0637 & TRN & \\
\hline CHEMBL1981047 & 809199 & 8.1 & 8.3004 & TRN & \\
\hline CHEMBL229968 & 809199 & 6.2 & 5.9084 & TRN & \\
\hline CHEMBL1973483 & 809199 & 4.7 & 5.1768 & TRN & \\
\hline CHEMBL1976240 & 809199 & 4.7 & 4.5373 & TRN & \\
\hline CHEMBL1997340 & 809199 & 4.7 & 4.686 & TRN & \\
\hline CHEMBL1522508 & 809199 & 4.7 & 5.1362 & TRN & \\
\hline CHEMBL1968151 & 809199 & 4.7 & 4.7975 & TST & \\
\hline CHEMBL1979093 & 809199 & 4.7 & 5.2811 & TRN & \\
\hline CHEMBL1989474 & 809199 & 4.7 & 4.6317 & TRN & \\
\hline CHEMBL1090360 & 809199 & 4.7 & 4.9064 & TRN & \\
\hline CHEMBL1987009 & 809199 & 4.7 & 4.8711 & TRN & \\
\hline CHEMBL 2003817 & 809199 & 4.7 & 4.5982 & TRN & \\
\hline CHEMBL 379218 & 809199 & 4.7 & 5.6402 & TRN & \\
\hline CHEMBL1994830 & 809199 & 4.7 & 4.2708 & TST & \\
\hline CHEMBL210887 & 809199 & 4.7 & 4.8669 & TST & \\
\hline CHEMBL458997 & 809199 & 8.3 & 8.565 & TRN & \\
\hline CHEMBL226403 & 809199 & 4.7 & 4.5111 & TRN & \\
\hline CHEMBL227271 & 809199 & 6.0 & 5.5586 & TRN & \\
\hline CHEMBL1971021 & 809199 & 6.4 & 6.5976 & TRN & \\
\hline CHEMBL583144 & 809199 & 5.9 & 5.8487 & TRN & \\
\hline CHEMBL1974310 & 809199 & 5.8 & 5.1034 & TST & \\
\hline CHEMBL1982660 & 809199 & 7.2 & 5.4952 & TRN & \\
\hline CHEMBL1994693 & 809199 & 4.7 & 4.3955 & TRN & \\
\hline CHEMBL1994938 & 809199 & 6.0 & 5.6445 & TRN & \\
\hline CHEMBL1825138 & 809199 & 8.8 & 6.2601 & TST & \\
\hline CHEMBL1982957 & 809199 & 6.1 & 6.5594 & TRN & \\
\hline CHEMBL1966279 & 809199 & 4.7 & 4.7686 & TRN & \\
\hline
\end{tabular}




\begin{tabular}{|c|c|c|c|c|c|}
\hline \multicolumn{6}{|c|}{ Supplemental Table S2.txt } \\
\hline CHEMBL1975138 & 809199 & 4.7 & 5.3307 & TST & \\
\hline CHEMBL424872 & 809199 & 4.5 & 4.4412 & TST & \\
\hline CHEMBL1997846 & 809199 & 6.7 & 5.4654 & TRN & \\
\hline CHEMBL 2004419 & 809199 & 4.7 & 4.8919 & TRN & \\
\hline CHEMBL1980704 & 809199 & 4.7 & 5.1634 & TST & \\
\hline CHEMBL 2003271 & 809199 & 4.7 & 5.775 & TRN & \\
\hline CHEMBL1966808 & 809199 & 4.7 & 4.4483 & TST & \\
\hline CHEMBL 2004447 & 809199 & 4.7 & 4.9843 & TST & \\
\hline CHEMBL1983111 & 809199 & 7.5 & 8.0141 & TST & \\
\hline CHEMBL1973860 & 809199 & 4.7 & 4.8388 & TRN & \\
\hline CHEMBL1972489 & 809199 & 4.7 & 4.8883 & TRN & \\
\hline CHEMBL260135 & 809199 & 4.7 & 5.1763 & TRN & \\
\hline CHEMBL1994074 & 809199 & 4.7 & 5.1971 & TRN & \\
\hline CHEMBL 220241 & 809199 & 4.7 & 3.705 & TST & \\
\hline CHEMBL 2004544 & 809199 & 5.7 & 5.0866 & TST & \\
\hline CHEMBL1982610 & 809199 & 4.7 & 5.57799 & 9999999999 & TST \\
\hline CHEMBL1999496 & 809199 & 4.7 & 4.5564 & TRN & \\
\hline CHEMBL1970873 & 809199 & 5.8 & 5.2074 & TRN & \\
\hline CHEMBL1988300 & 809199 & 4.7 & 4.7675 & TRN & \\
\hline CHEMBL1972119 & 809199 & 4.7 & 4.5933 & TRN & \\
\hline CHEMBL1986328 & 809199 & 5.8 & 4.6837 & TST & \\
\hline CHEMBL95692 & 809199 & 4.7 & 4.7091 & TRN & \\
\hline CHEMBL1090356 & 809199 & 4.7 & 4.7752 & TRN & \\
\hline CHEMBL1976455 & 809199 & 4.7 & 4.8065 & TRN & \\
\hline CHEMBL1983923 & 809199 & 6.7 & 6.6929 & TST & \\
\hline CHEMBL1983534 & 809199 & 4.7 & 4.5932 & TRN & \\
\hline CHEMBL1982361 & 809199 & 4.7 & 4.822 & TRN & \\
\hline CHEMBL1999112 & 809199 & 4.7 & 4.5684 & TST & \\
\hline CHEMBL2000801 & 809199 & 4.7 & 4.2176 & TRN & \\
\hline CHEMBL1982122 & 809199 & 4.7 & 4.5623 & TRN & \\
\hline CHEMBL1682546 & 809199 & 4.7 & 5.0065 & TRN & \\
\hline CHEMBL1991395 & 809199 & 4.7 & 4.7535 & TRN & \\
\hline CHEMBL1971245 & 809199 & 6.6 & 6.2388 & TRN & \\
\hline CHEMBL1972142 & 809199 & 6.1 & 6.3305 & TRN & \\
\hline CHEMBL1969502 & 809199 & 7.1 & 5.9764 & TST & \\
\hline CHEMBL1682553 & 809199 & 4.7 & 4.9029 & TRN & \\
\hline CHEMBL1971430 & 809199 & 4.7 & 4.8444 & TRN & \\
\hline CHEMBL1997764 & 809199 & 4.7 & 4.7043 & TRN & \\
\hline CHEMBL1983963 & 809199 & 4.7 & 4.9597 & TRN & \\
\hline CHEMBL1996066 & 809199 & 4.7 & 4.9187 & TST & \\
\hline CHEMBL1985092 & 809199 & 4.7 & 5.1913 & TRN & \\
\hline CHEMBL1981410 & 809199 & 4.7 & 5.4443 & TRN & \\
\hline CHEMBL1970806 & 809199 & 4.7 & 4.0873 & TST & \\
\hline CHEMBL1996234 & 809199 & 4.7 & 5.439 & TRN & \\
\hline CHEMBL1991434 & 809199 & 4.7 & 5.1478 & TRN & \\
\hline CHEMBL1967544 & 809199 & 4.7 & 4.6424 & TRN & \\
\hline CHEMBL1375640 & 809199 & 6.1 & 5.0133 & TST & \\
\hline CHEMBL340384 & 809199 & 6.3 & 4.8097 & TST & \\
\hline
\end{tabular}




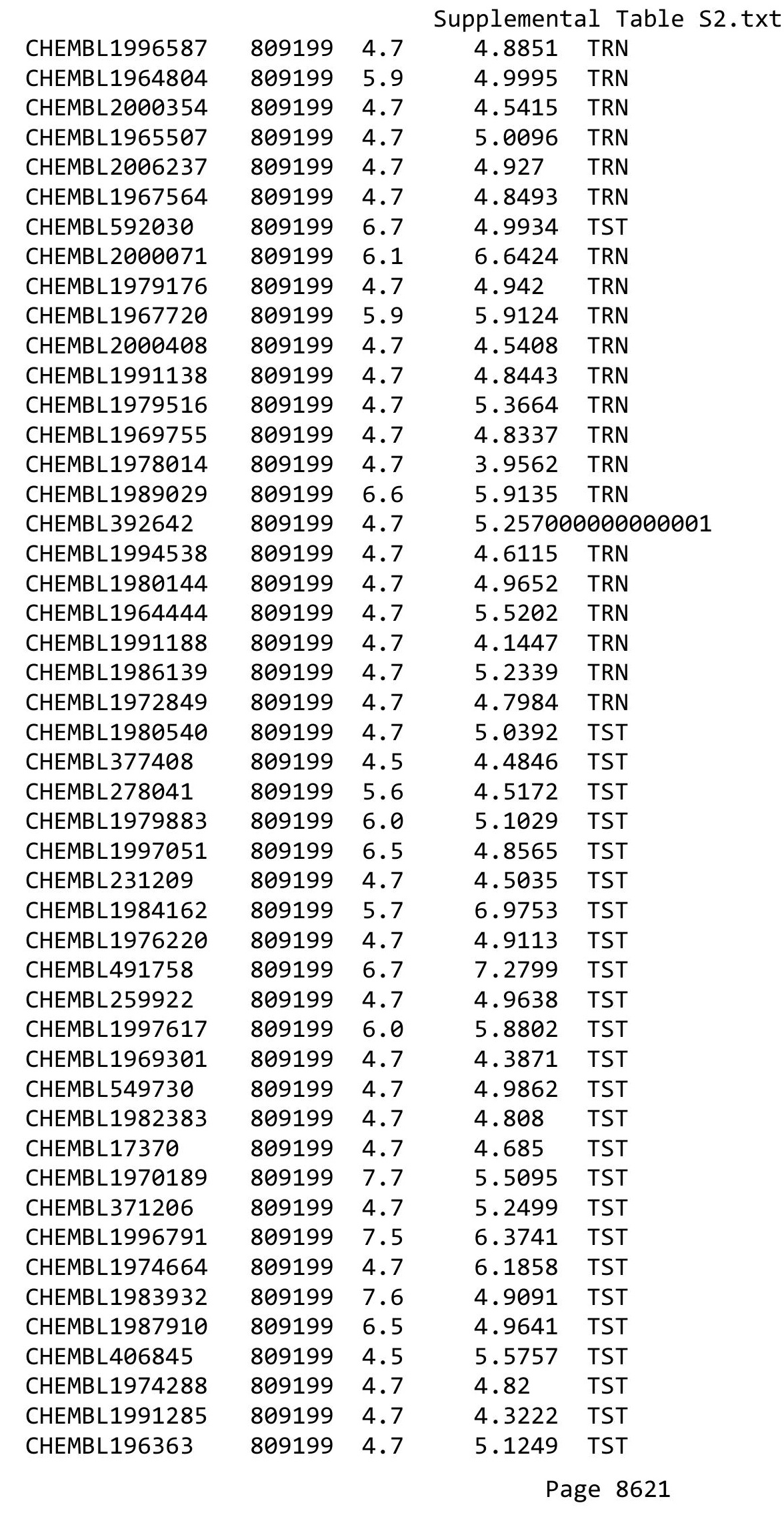




\begin{tabular}{|c|c|c|c|c|}
\hline \multicolumn{5}{|c|}{ Supplemental Table S2.txt } \\
\hline CHEMBL 243088 & 809199 & 7.2 & 6.7506 & TST \\
\hline CHEMBL1984038 & 809199 & 4.6 & 5.3119 & TST \\
\hline CHEMBL1974416 & 809199 & 4.7 & 5.1837 & TST \\
\hline CHEMBL1993661 & 809199 & 9.4 & 9.4396 & TST \\
\hline CHEMBL 2004615 & 809199 & 6.2 & 5.625 & TST \\
\hline CHEMBL1997872 & 809199 & 5.8 & 5.8458 & TST \\
\hline CHEMBL1966343 & 809199 & 6.8 & 5.5029 & TST \\
\hline CHEMBL404367 & 809199 & 4.7 & 4.2964 & TST \\
\hline CHEMBL 301574 & 596645 & 3.0 & 2.9546 & TRN \\
\hline CHEMBL566607 & 596645 & 3.0 & 2.8569 & TRN \\
\hline CHEMBL33316 & 596645 & 5.1669 & 3.9671 & TST \\
\hline CHEMBL 375190 & 596645 & 3.0 & 2.8789 & TRN \\
\hline CHEMBL578157 & 596645 & 3.0 & 3.3263 & TRN \\
\hline CHEMBL566793 & 596645 & 4.7399 & 3.8961 & TRN \\
\hline CHEMBL566183 & 596645 & 5.4855 & 4.3024 & TRN \\
\hline CHEMBL566277 & 596645 & 3.5229 & 3.781 & TRN \\
\hline CHEMBL449329 & 596645 & 4.9586 & 4.3358 & TRN \\
\hline CHEMBL569275 & 596645 & 3.0 & 3.2108 & TRN \\
\hline CHEMBL576076 & 596645 & 5.6383 & 4.1301 & TRN \\
\hline CHEMBL394752 & 596645 & 5.8601 & 3.5596 & TST \\
\hline CHEMBL566182 & 596645 & 5.4045 & 4.2706 & TRN \\
\hline CHEMBL63783 & 596645 & 3.0 & 4.2238 & TRN \\
\hline CHEMBL566794 & 596645 & 4.6073 & 4.3642 & TRN \\
\hline CHEMBL445696 & 596645 & 4.3089 & 3.9412 & TRN \\
\hline CHEMBL576447 & 596645 & 3.0 & 2.7343 & TRN \\
\hline CHEMBL569502 & 596645 & 3.0 & 3.6722 & TRN \\
\hline CHEMBL567012 & 596645 & 3.0 & 2.7815 & TRN \\
\hline CHEMBL356894 & 596645 & 3.0 & 4.2338 & TST \\
\hline CHEMBL 393474 & 596645 & 6.301 & 3.5925 & TST \\
\hline CHEMBL576115 & 596645 & 2.6021 & 4.3043 & TRN \\
\hline CHEMBL150192 & 596645 & 4.5686 & 4.212 & TRN \\
\hline CHEMBL454802 & 596645 & 4.6216 & 3.5566 & TST \\
\hline CHEMBL566791 & 596645 & 3.5229 & 3.7888 & TRN \\
\hline CHEMBL566569 & 596645 & 3.5229 & 3.6738 & TRN \\
\hline CHEMBL566398 & 596645 & 3.0 & 2.7712 & TRN \\
\hline CHEMBL285819 & 596645 & 3.0 & 3.0716 & TRN \\
\hline CHEMBL577928 & 596645 & 5.5258 & 4.6207 & TRN \\
\hline CHEMBL579029 & 596645 & 3.0 & 3.1785 & TRN \\
\hline CHEMBL 266094 & 596645 & 3.0 & 3.8648 & TRN \\
\hline CHEMBL576077 & 596645 & 4.1244 & 4.3122 & TRN \\
\hline CHEMBL65276 & 596645 & 3.0 & 3.7105 & TRN \\
\hline CHEMBL565451 & 596645 & 5.1864 & 3.4353 & TST \\
\hline CHEMBL566808 & 596645 & 3.5229 & 3.8633 & TRN \\
\hline CHEMBL566158 & 596645 & 5.1759 & 3.0161 & TST \\
\hline CHEMBL571682 & 596645 & 5.3458 & 4.317 & TRN \\
\hline CHEMBL319387 & 596645 & 3.0 & 2.9025 & TRN \\
\hline CHEMBL569241 & 596645 & 3.5229 & 3.9609 & TRN \\
\hline CHEMBL579385 & 596645 & 4.9747 & 3.5629 & TST \\
\hline
\end{tabular}




\begin{tabular}{|c|c|c|c|c|c|c|}
\hline \multicolumn{7}{|c|}{ Supplemental Table S2.txt } \\
\hline CHEMBL566365 & 596645 & 3.0 & 3.3776 & TST & & \\
\hline CHEMBL565936 & 596645 & 3.0 & 3.5019 & TST & & \\
\hline CHEMBL567755 & 596645 & 4.7852 & 3.3291 & TST & & \\
\hline CHEMBL1230671 & 596645 & 3.0 & 3.3325 & TST & & \\
\hline CHEMBL569925 & 596645 & 4.6882 & 4.293 & TRN & & \\
\hline CHEMBL566399 & 596645 & 3.0 & 3.0351 & TRN & & \\
\hline CHEMBL569242 & 596645 & 3.0 & 3.9839 & TRN & & \\
\hline CHEMBL569692 & 596645 & 3.0 & 3.4411 & TST & & \\
\hline CHEMBL578786 & 596645 & 3.0 & 2.7608 & TRN & & \\
\hline CHEMBL569454 & 596645 & 5.5452 & 3.5505 & TST & & \\
\hline CHEMBL569687 & 596645 & 4.3716 & 4.2924 & TRN & & \\
\hline CHEMBL569023 & 596645 & 3.0 & 3.6654 & TRN & & \\
\hline CHEMBL569487 & 596645 & 4.9706 & 4.3176 & TRN & & \\
\hline CHEMBL1163018 & 596645 & 3.0 & 4.3267 & TST & & \\
\hline CHEMBL566606 & 596645 & 3.0 & 2.6106 & TRN & & \\
\hline CHEMBL45891 & 596645 & 3.0 & 3.1388 & TRN & & \\
\hline CHEMBL577929 & 596645 & 3.0 & 2.8808 & TRN & & \\
\hline CHEMBL578818 & 596645 & 2.6021 & 4.4604 & TRN & & \\
\hline CHEMBL569501 & 596645 & 3.0 & 2.905 & TRN & & \\
\hline CHEMBL3929911 & 1641453 & 7.1249 & 7.595 & TRN & & \\
\hline CHEMBL3925243 & 1641453 & 4.5751 & 5.831 & TST & & \\
\hline CHEMBL3943708 & 1641453 & 5.2503 & 5.7048 & TST & & \\
\hline CHEMBL 3972147 & 1641453 & 7.1805 & 7.1789 & TRN & & \\
\hline CHEMBL3905256 & 1641453 & 4.5719 & 5.6876 & TST & & \\
\hline CHEMBL3963645 & 1641453 & 7.8239 & 7.268 & TRN & & \\
\hline CHEMBL3925742 & 1641453 & 8.0223 & 7.6977 & TRN & & \\
\hline CHEMBL3919193 & 1641453 & 7.699 & 7.5814 & TRN & & \\
\hline CHEMBL3897411 & 1641453 & 7.3665 & 7.2183 & TRN & & \\
\hline CHEMBL3935512 & 1641453 & 8.3279 & 8.4498 & TRN & & \\
\hline CHEMBL3943888 & 1641453 & 6.266 & 5.8145 & TST & & \\
\hline CHEMBL3903960 & 1641453 & 7.9957 & 7.6264 & TRN & & \\
\hline CHEMBL3953251 & 1641453 & 7.4828 & 6.9368 & TRN & & \\
\hline CHEMBL3971064 & 1641453 & 4.4295 & 4.9996 & TST & & \\
\hline CHEMBL3944783 & 1641453 & 7.2924 & 7.7879 & TRN & & \\
\hline CHEMBL3914410 & 1641453 & 7.4202 & 7.5052 & TRN & & \\
\hline CHEMBL3973710 & 1641453 & 6.75200 & 30000000 & 01 & 6.8426 & TST \\
\hline CHEMBL3939817 & 1641453 & 7.4949 & 6.9403 & TST & & \\
\hline CHEMBL 3917242 & 1641453 & 6.9066 & 7.3605 & TRN & & \\
\hline CHEMBL3930009 & 1641453 & 7.9586 & 7.4276 & TST & & \\
\hline CHEMBL3926112 & 1641453 & 7.5622 & 7.5401 & TRN & & \\
\hline CHEMBL3956483 & 1641453 & 7.2366 & 7.2764 & TRN & & \\
\hline CHEMBL3908807 & 1641453 & 4.4815 & 5.6886 & TRN & & \\
\hline CHEMBL3916241 & 1641453 & 4.6882 & 6.0474 & TST & & \\
\hline CHEMBL3952931 & 1641453 & 6.2933 & 6.5959 & TST & & \\
\hline CHEMBL 3902460 & 1641453 & 7.4318 & 7.0307 & TRN & & \\
\hline CHEMBL3934218 & 1641453 & 3.3979 & 4.8235 & TST & & \\
\hline CHEMBL 3954148 & 1641453 & 7.5452 & 7.3509 & TRN & & \\
\hline CHEMBL 3960890 & 1641453 & 8.2218 & 8.3535 & TRN & & \\
\hline
\end{tabular}


Supplemental Table S2.txt

\begin{tabular}{|c|c|c|c|c|}
\hline HEMBL & (1) & 7.7471 & & \\
\hline סבר & & 8.0969 & 7.8708 & \\
\hline ITS & & & & \\
\hline HEMBL 397 & & 9.699 & & $2 \mathrm{~N}$ \\
\hline HEMBL3899306 & כ & 7.2076 & & \\
\hline HEMBL3961673 & 641453 & 6.9872 & 0021 & \\
\hline HEMBL & & 7.3979 & 268 & \\
\hline AEMBL38 & & & & \\
\hline HEMBL 398 & & 6.0031 & 5592 & \\
\hline HEMBL395 & 64 & 5.71 & 4426 & \\
\hline HEMBL395 & 64 & 8.2218 & .8065 & \\
\hline AEMBL3S & 6 & 7.699 & 155 & \\
\hline AEMBL3 & & 979 & & \\
\hline HEMBL 39 & & 7.6198 & 7.8058 & \\
\hline AEMBL397 & 62 & 7.2147 & & \\
\hline AEMBL39 & 6 & 7.5686 & קו & \\
\hline HEMBL3S & 6 & 31 & 71 & \\
\hline HEMBL3S & & 57 & & \\
\hline HEMBL39 & & 5.0214 & .6326 & \\
\hline HEMBL 39 & 6 & 6. & & \\
\hline AEMBL3 & 6 & 7. & 47 & KIV \\
\hline HEMBL3S & & 51 & 56 & \\
\hline HEMBL3S & & 383 & 13 & \\
\hline HFMRI 36 & & 6 . & 3797 & \\
\hline HEMBL $39 e$ & & 52 & & 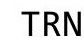 \\
\hline HEMBL3S & 6 & 7.0555 & 56 & $\cdots$ \\
\hline HEMBL3 & 6 & 6. & & RN \\
\hline HFMBI 36 & 3 & 6. & 303 & \\
\hline HEMBL39 & & & & iv \\
\hline HEMBL 396 & & 6. & & r \\
\hline HEMBL39 & & 3 & 586 & SI \\
\hline HEMBL & & 33 & 542 & RN \\
\hline HEMBL3S & & 8 & 21 & $\mathrm{RN}$ \\
\hline HEMBL 398 & & 5.7852 & 04 & IR \\
\hline HEMBL $395^{\circ}$ & & 7.2487 & 1221 & TRN \\
\hline HEMBL38 & & 5 . & 97 & ST \\
\hline HFMRI 3 & & 7. & & RN \\
\hline HEMBL3 & & 6. & 84 & IRN \\
\hline HEMBL392 & 62 & 7.699 & 5469 & TRN \\
\hline AEMBL39 & & 7. & 307 & TRN \\
\hline HEMBL39 & 6 & 35 & 356 & \\
\hline CHEMBL39 & & & 7.2766 & RN \\
\hline HEMBL398 & & 7.6234 & 7.0969 & RN \\
\hline HEMBL3946502 & 6 & 7.4815 & .0975 & TRN \\
\hline MBL3 & & 4.7212 & 5.8241 & \\
\hline HEMBL 39 & & .53 & 7.6233 & \\
\hline CHEMBL395 & & 7.1024 & 7.3347 & \\
\hline LHEMBL3970713 & 1641453 & 7.0088 & 7.0514 & \\
\hline
\end{tabular}


Supplemental Table S2.txt

\begin{tabular}{|c|c|c|c|c|}
\hline 965 & & & & \\
\hline HEMRI 3921065 & 641453 & 7.4584 & 7.4247 & \\
\hline HEMBL; & & 7.556 & & \\
\hline AEMBL3906250 & 641453 & 6.0 & $4 / 81$ & \\
\hline HEMBL3905535 & 641453 & 6.4763 & .8679 & \\
\hline HEMBL3948514 & 3 & 3.3979 & 4.8889 & \\
\hline AEMBL: & 3 & 7.5376 & 7.2376 & \\
\hline HEMBL2347208 & 3 & 7.5171 & 1986 & \\
\hline HEMBL3964029 & 453 & 7.7959 & 7.3742 & \\
\hline HEMBL3934911 & 64 & 5.466 & 5.522 & \\
\hline HEMBL396 & 3 & 6.6861 & 8859 & \\
\hline HEMBL; & & 2924 & 588 & \\
\hline HEMBL3S & 3 & 7.4089 & 7.7613 & \\
\hline HEMBL390 & 3 & 7.5229 & 304 & \\
\hline HEMBL3936327 & 6 & 6.9245 & 133 & \\
\hline AEMBL3 & 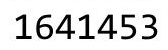 & 342 & & \\
\hline HEMBL & & 899 & 426 & \\
\hline HEMBL3 & 164 & 8.0 & 517 & \\
\hline AEMBL3 & & 633 & 479 & \\
\hline AEMBL3 & 64 & 7.4318 & 15 & \\
\hline HEMBL & 3 & 861 & 15 & \\
\hline HEMBL & & 27 & 21 & \\
\hline HEMBL; & 3 & 208 & 3641 & \\
\hline AEMBL3 & & 383 & & \\
\hline AEMBL3 & 64 & 7.0195 & 91 & \\
\hline HEMBL3 & 6 & & 38 & \\
\hline HEMBL & & & 17 & \\
\hline 32 & & 229 & & \\
\hline IEMBL: & & & & \\
\hline AEMBL3 & 62 & 6.4976 & 38 & \\
\hline AEMBL & & 376 & 52 & \\
\hline 82 & & & & \\
\hline & & & & \\
\hline HEMBL3 & 3 & & & \\
\hline AEMBL3904438 & 64 & 9.0605 & 63 & \\
\hline AEMBL & 6 & 496 & 54 & \\
\hline & & & & \\
\hline HEMBL3 & & & & \\
\hline HEMBL3921212 & 3 & 6.2388 & & \\
\hline AEMBL & 6 & 6.8861 & & \\
\hline HEMBL3 & & 7.3665 & 96 & \\
\hline & & 5.2518 & & \\
\hline HEMBL3905422 & & 7.2076 & & \\
\hline HEMBL3973889 & 16 & 7.7959 & 206 & \\
\hline 81 & & 7.2581 & & \\
\hline CHEMBL3920732 & & 8.0969 & 7.2638 & \\
\hline CHEMBL3957556 & 16 & 7.1487 & 7.7441 & \\
\hline CHEMBL3980894 & 1641453 & 7.1331 & 7.1285 & \\
\hline
\end{tabular}


Supplemental Table S2.txt

\begin{tabular}{|c|c|c|c|c|}
\hline - & נהדגדי & & & \\
\hline HEMBL3963410 & & 7.4815 & 7.3302 & \\
\hline 36 & & & & \\
\hline HEMBL & & 3098 & 9962 & 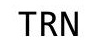 \\
\hline AEMBL39 & מ & 7.2125 & 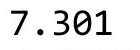 & \\
\hline HEMBL3915529 & 641453 & 7.0132 & .7588 & \\
\hline HEMBL3968817 & & & 2177 & \\
\hline 996 & & & 6771 & \\
\hline HEMBL3971569 & & & 1724 & \\
\hline HEMBL3924137 & 64 & 5.0778 & 8834 & \\
\hline HEMBL3935940 & 62 & 8.8539 & 5159 & \\
\hline IEMBL3C & $0<$ & 39 & 671 & \\
\hline AEMBL3 & & & & \\
\hline HEMBL 39 & & & 5.8579 & \\
\hline AEMBL39 & 62 & 72 & & \\
\hline AEMBL3901695 & 6 & 18 & 45 & \\
\hline AEMBL3\& & 0 & & 588 & \\
\hline HEMBL3S & & & & \\
\hline HEMBL 3898955 & & 12 & 7.2272 & \\
\hline AEMBL39 & & & & \\
\hline HEIMBLSS & 6 & & 51 & I RIV \\
\hline HEMBL3 & & & 17 & RN \\
\hline HEMBL3S & & & & \\
\hline 3384 & & & & \\
\hline AEMBL39 & & & & I RIV \\
\hline 30808 & 6 & & 36 & RN \\
\hline HEMBL & & & 02 & (1) \\
\hline$H F M B I=$ & & & & \\
\hline HEMBL3S & & & & in \\
\hline HEMBL3955892 & & & & IRN \\
\hline HEMBL3S & 6 & 6 & 23 & RN \\
\hline HEMBL; & & & 22 & RN \\
\hline AEMBL3 & & & 14 & ג \\
\hline HEMBL3924515 & 62 & & 729 & IRN \\
\hline HEMBL3957027 & & & $\partial 68$ & TRN \\
\hline HEMBL3S & & 88 & 573 & TST \\
\hline HFMRI 3 & & & 74 & TRN \\
\hline HEMBL3 & & & 328 & TRN \\
\hline HEMBL3968912 & 6 & & & TRN \\
\hline IEMBL39 & & & 95 & TRN \\
\hline HEMBL3964122 & 6 & & 67 & \\
\hline CHEMBL3925462 & & & & ST \\
\hline HEMBL3968711 & 53 & $7.2 \varepsilon$ & .7043 & TST \\
\hline HEMBL3969211 & 6 & 5.1232 & .1343 & TS \\
\hline$M B L 3$ & & & 5331 & TR \\
\hline HEMBL39 & & & 7.5868 & \\
\hline CHEMBL 3901027 & & .9281 & .2058 & \\
\hline CHEMBL3900111 & 1641453 & 5.6038 & 7.0412 & \\
\hline
\end{tabular}

Page 8626 
Supplemental Table S2.txt

\begin{tabular}{|c|c|c|c|c|c|}
\hline CHEMBL 3903880 & 1641453 & 7.2815 & 7.3348 & TRN & \\
\hline CHEMBL 3921416 & 1641453 & 5.8041 & 5.4233 & TRN & \\
\hline CHEMBL3965056 & 1641453 & 7.301 & 7.0807 & TRN & \\
\hline CHEMBL 3942282 & 1641453 & 6.426 & 6.6163 & TST & \\
\hline CHEMBL 3966600 & 1641453 & 7.1415 & 7.3512 & TRN & \\
\hline CHEMBL 3894342 & 1641453 & 4.6253 & 6.0068 & TST & \\
\hline CHEMBL 3916872 & 1641453 & 7.5229 & 7.7381 & TRN & \\
\hline CHEMBL3910073 & 1641453 & 7.6576 & 7.7271 & TRN & \\
\hline CHEMBL3915849 & 1641453 & 5.2314 & 5.7766 & TRN & \\
\hline CHEMBL3913544 & 1641453 & 7.3468 & 7.3118 & TRN & \\
\hline CHEMBL 3904149 & 1641453 & 9.0 & 8.3792 & TRN & \\
\hline CHEMBL 3925020 & 1641453 & 6.7258 & 6.7577 & TST & \\
\hline CHEMBL 3930667 & 1641453 & 5.7747 & 6.2867 & TST & \\
\hline CHEMBL 3927002 & 1641453 & 7.2076 & 6.9928 & TRN & \\
\hline CHEMBL 3926914 & 1641453 & 7.5376 & 7.315 & TRN & \\
\hline CHEMBL3976045 & 1641453 & 7.7825 & 7.4768 & TRN & \\
\hline CHEMBL3899615 & 1641453 & 3.3979 & 4.5983 & TST & \\
\hline CHEMBL 3902829 & 1641453 & 6.9872 & 6.8751 & TRN & \\
\hline CHEMBL 3965566 & 1641453 & 3.3979 & 4.8736 & TRN & \\
\hline CHEMBL3985831 & 1641453 & 6.2411 & 6.6329 & TST & \\
\hline CHEMBL3896886 & 1641453 & 7.5229 & 7.3711 & TRN & \\
\hline CHEMBL3961329 & 1641453 & 7.1308 & 7.157999 & 99999999995 & TRN \\
\hline CHEMBL 3939821 & 1641453 & 6.9914 & 7.2121 & TRN & \\
\hline CHEMBL 3952431 & 1641453 & 5.6576 & 5.8629 & TST & \\
\hline CHEMBL 3986682 & 1641453 & 6.2518 & 5.56 & TRN & \\
\hline CHEMBL3972614 & 1641453 & 7.2441 & 7.4639 & TRN & \\
\hline CHEMBL3911790 & 1641453 & 4.5622 & 5.0823 & TST & \\
\hline CHEMBL 3945149 & 1641453 & 7.7258 & 7.7293 & TRN & \\
\hline CHEMBL3974975 & 1641453 & 6.0 & 6.7709 & TRN & \\
\hline CHEMBL 3935479 & 1641453 & 6.8069 & 7.0175 & TRN & \\
\hline CHEMBL 3940163 & 1641453 & 7.8539 & 7.9338 & TRN & \\
\hline CHEMBL 3893892 & 1641453 & 9.1549 & 9.4522 & TRN & \\
\hline CHEMBL3969602 & 1641453 & 7.6198 & 6.9286 & TST & \\
\hline CHEMBL 3909660 & 1641453 & 3.3979 & 5.3569 & TST & \\
\hline CHEMBL 3934414 & 1641453 & 6.5952 & 7.0181 & TRN & \\
\hline CHEMBL3933535 & 1641453 & 7.9586 & 7.5049 & TRN & \\
\hline CHEMBL 3941417 & 1641453 & 8.4559 & 8.266 & TRN & \\
\hline CHEMBL 3911484 & 1641453 & 6.7496 & 6.5009 & TST & \\
\hline CHEMBL 3977392 & 1641453 & 7.3788 & 7.3287 & TRN & \\
\hline CHEMBL 3939374 & 1641453 & 8.6383 & 9.2305 & TRN & \\
\hline CHEMBL 3985595 & 1641453 & 5.0013 & 4.8833 & TRN & \\
\hline CHEMBL3915277 & 1641453 & 7.3143 & 6.7753 & TRN & \\
\hline CHEMBL 3986014 & 1641453 & 5.4672 & 5.5319 & TRN & \\
\hline CHEMBL 3940796 & 1641453 & 7.3098 & 7.3873 & TRN & \\
\hline CHEMBL 3940730 & 1641453 & 5.5287 & 5.9436 & TST & \\
\hline CHEMBL 3908739 & 1641453 & 4.2534 & 5.9974 & TST & \\
\hline CHEMBL3927382 & 1641453 & 7.1024 & 6.6655 & TRN & \\
\hline CHEMBL 3961045 & 1641453 & 7.8539 & 7.4259 & TRN & \\
\hline
\end{tabular}


Supplemental Table S2.txt

\begin{tabular}{|c|c|c|c|c|}
\hline CHEMBL3957970 & 641453 & 7.5376 & 7.5072 & TRN \\
\hline HEMBL3915749 & 641453 & 3.3979 & 5.077 & TCT \\
\hline HEMBL3985686 & 641453 & 7.3565 & 6.9925 & TRN \\
\hline HEMBL 258488 & 472938 & 3.3979 & 6446 & ST \\
\hline HEMBL 261411 & 472938 & 3.0 & 3.3197 & RN \\
\hline HEMBL193416 & 472938 & 3.0 & .7129 & \\
\hline HEMBL 260894 & 72938 & 3.0 & .9692 & \\
\hline HEMBL 259903 & 472938 & 3.0 & .5763 & RN \\
\hline HEMBL429856 & 472938 & 3.0 & 3.3327 & RN \\
\hline HEMBL407150 & 472938 & 3.0 & .4695 & $\mathrm{RN}$ \\
\hline HEMBL409924 & 472938 & 4.1135 & 3.6595 & \\
\hline HEMBL 259109 & 472 & 4.2291 & 3.4401 & \\
\hline HEMBL 265201 & 472 & 5.1549 & 4.109 & RN \\
\hline HEMBL 259904 & 472 & 3.0 & 3.736 & RN \\
\hline HEMBL407036 & 472 & 3.0 & 3.0797 & \\
\hline HEMBL407149 & 472938 & 3.0 & 3.6373 & RN \\
\hline HEMBL411929 & 472 & 3.7447 & 3.8965 & RN \\
\hline HEMBL259318 & 472 & 4.4202 & 3.886 & \\
\hline HEMBL258692 & 472 & 3.0 & 2.6658 & TRN \\
\hline HEMBL258833 & 472 & 612 & 3.8332 & TRN \\
\hline HEMBL564201 & 472 & 3.60 & 2.6652 & ISI \\
\hline HEMBL406970 & 472 & 3 . & 2.7138 & ST \\
\hline HEMBL 259586 & 472 & 3.0 & 3.6246 & TRN \\
\hline HEMBL408910 & 472 & 3.2596 & 3.6587 & TRN \\
\hline HEMBL382756 & 472 & 3.0 & 2.6602 & IRN \\
\hline HEMBL259346 & 472 & 5.0969 & 4.2448 & IRIN \\
\hline HEMBL410669 & 47 & 3. & 3.1021 & TRN \\
\hline HEMBL 258971 & 47 & 3.0 & 3.4886 & TST \\
\hline HEMBL408837 & 472 & 3.0 & 3.2357 & TRN \\
\hline HEMBL407805 & 472 & 3.61 & 3.6379 & TRN \\
\hline HEMBL 259606 & 47 & 4.2147 & 3.4181 & ГRN \\
\hline HEMBL41 & 47 & 3 . & 3.1999 & TRN \\
\hline CHEMBL418 & 47 & 979 & 2.8252 & TST \\
\hline CHEMBL405461 & 472 & 3.0 & 3.2767 & TRN \\
\hline HEMBL 259495 & 472 & 3.1739 & 3.6395 & TST \\
\hline CHEMBL406452 & & 3 & 2.9904 & TRN \\
\hline CHEMBL 258 & 47 & 3 . & 3.7054 & TST \\
\hline CHEMBL259369 & 472 & 3.3188 & 3.1752 & TRN \\
\hline CHEMBL260181 & 472 & 3.0 & 3.1293 & TRN \\
\hline CHEMBL 259531 & & 3. & 3.1987 & TRN \\
\hline CHEMBL428256 & 472 & 3 . & 3.4017 & TST \\
\hline CHEMBL259497 & 472 & 3.0605 & 3.7297 & TST \\
\hline CHEMBL265458 & 472938 & 3.0 & 3.8908 & TST \\
\hline CHEMBL261412 & 472938 & 4.5686 & 4.6688 & TRN \\
\hline CHEMBL408223 & 472 & 3 . & 3.5462 & TRN \\
\hline CHEMBL258847 & & 4.699 & 4.1604 & $T R$ \\
\hline CHEMBL406413 & 472938 & 3.0 & 3.333 & TRN \\
\hline CHEMBL259932 & 472938 & 4.7212 & 4.1943 & TRN \\
\hline
\end{tabular}

Page 8628 


\begin{tabular}{|c|c|c|c|c|c|}
\hline \multicolumn{6}{|c|}{ Supplemental Table S2.txt } \\
\hline CHEMBL258835 & 472938 & 3.2924 & 2.9889 & TRN & \\
\hline CHEMBL 261888 & 472938 & 3.0 & 3.8535 & TRN & \\
\hline CHEMBL260182 & 472938 & 3.0 & 2.9094 & TRN & \\
\hline CHEMBL409923 & 472938 & 3.2924 & 3.5095 & TST & \\
\hline CHEMBL 259391 & 472938 & 3.0 & 3.05899 & 99999999997 & TRN \\
\hline CHEMBL409287 & 472938 & 3.5528 & 3.20899 & 99999999996 & TRN \\
\hline CHEMBL 259348 & 472938 & 4.1249 & 3.2487 & TRN & \\
\hline CHEMBL261446 & 472938 & 3.0 & 3.3135 & TST & \\
\hline CHEMBL409307 & 472938 & 4.1079 & 3.4265 & TRN & \\
\hline CHEMBL 261889 & 472938 & 3.0 & 2.9438 & TRN & \\
\hline CHEMBL259915 & 472938 & 3.0 & 2.9891 & TST & \\
\hline CHEMBL 261448 & 472938 & 3.0655 & 3.0662 & TST & \\
\hline CHEMBL428087 & 472938 & 4.8239 & 4.49 & TRN & \\
\hline CHEMBL407721 & 472938 & 3.2441 & 3.4509 & TST & \\
\hline CHEMBL 265457 & 472938 & 3.1938 & 3.6104 & TST & \\
\hline CHEMBL 260484 & 472938 & 3.0 & 3.9145 & TRN & \\
\hline CHEMBL407081 & 472938 & 3.0 & 2.935 & TRN & \\
\hline CHEMBL 259110 & 472938 & 3.0 & 3.4874 & TRN & \\
\hline CHEMBL261414 & 472938 & 3.0 & 2.98 & TRN & \\
\hline CHEMBL 287602 & 31889 & 4.2175 & 4.5371 & TRN & \\
\hline CHEMBL 37408 & 31889 & 4.9586 & 5.0209 & TRN & \\
\hline CHEMBL37074 & 31889 & 4.9508 & 4.3291 & TST & \\
\hline CHEMBL36790 & 31889 & 5.1805 & 5.1923 & TRN & \\
\hline CHEMBL448777 & 31889 & 4.7447 & 4.3962 & TRN & \\
\hline CHEMBL40107 & 31889 & 3.7959 & 4.0174 & TRN & \\
\hline CHEMBL35488 & 31889 & 7.0 & 6.9386 & TRN & \\
\hline CHEMBL287365 & 31889 & 4.6778 & 4.6008 & TRN & \\
\hline CHEMBL37910 & 31889 & 5.3188 & 5.1759 & TST & \\
\hline CHEMBL288909 & 31889 & 5.0915 & 4.8242 & TRN & \\
\hline CHEMBL38256 & 31889 & 3.7696 & 3.2988 & TRN & \\
\hline CHEMBL36636 & 31889 & 6.6576 & 6.4671 & TRN & \\
\hline CHEMBL430742 & 31889 & 7.1549 & 6.4018 & TRN & \\
\hline CHEMBL37305 & 31889 & 6.3188 & 6.0069 & TRN & \\
\hline CHEMBL39554 & 31889 & 7.2218 & 7.1166 & TRN & \\
\hline CHEMBL418056 & 31889 & 4.8761 & 5.1642 & TST & \\
\hline CHEMBL288607 & 31889 & 4.4214 & 4.7952 & TRN & \\
\hline CHEMBL290030 & 31889 & 4.4855 & 4.9082 & TRN & \\
\hline CHEMBL35730 & 31889 & 6.5376 & 6.6785 & TRN & \\
\hline CHEMBL 38038 & 31889 & 5.5686 & 5.4705 & TRN & \\
\hline CHEMBL 35777 & 31889 & 5.7959 & 4.9995 & TRN & \\
\hline CHEMBL36699 & 31889 & 4.0334 & 3.8494 & TRN & \\
\hline CHEMBL289027 & 31889 & 4.8539 & 5.1611 & TRN & \\
\hline CHEMBL288157 & 31889 & 6.7212 & 6.7903 & TRN & \\
\hline CHEMBL34859 & 31889 & 4.9208 & 4.9596 & TRN & \\
\hline CHEMBL 37181 & 31889 & 5.0809 & 5.1662 & TRN & \\
\hline CHEMBL287891 & 31889 & 2.9031 & 3.3124 & TRN & \\
\hline CHEMBL290619 & 31889 & 5.6576 & 6.0567 & TST & \\
\hline CHEMBL290157 & 31889 & 4.3556 & 4.8007 & TRN & \\
\hline
\end{tabular}




\begin{tabular}{|c|c|c|c|c|c|c|}
\hline & & \multicolumn{5}{|c|}{ Supplemental Table S2.txt } \\
\hline CHEMBL288819 & 31889 & 4.9281 & 5.0576 & TRN & & \\
\hline CHEMBL39391 & 31889 & 5.3468 & 4.9063 & TRN & & \\
\hline CHEMBL290381 & 31889 & 4.6144 & 4.4368 & TRN & & \\
\hline CHEMBL284779 & 31889 & 6.4559 & 6.9245 & TRN & & \\
\hline CHEMBL35724 & 31889 & 5.8239 & 5.939 & TRN & & \\
\hline CHEMBL285253 & 31889 & 2.9031 & 4.2828 & TST & & \\
\hline CHEMBL38128 & 31889 & 4.7959 & 4.6982 & TRN & & \\
\hline CHEMBL37750 & 31889 & 5.284 & 5.0322 & TRN & & \\
\hline CHEMBL36750 & 31889 & 6.7959 & 6.8631 & TRN & & \\
\hline CHEMBL290770 & 31889 & 4.2774 & 4.3211 & TRN & & \\
\hline CHEMBL288017 & 31889 & 4.0804 & 4.1444 & TRN & & \\
\hline CHEMBL39924 & 31889 & 4.6198 & 4.8422 & TRN & & \\
\hline CHEMBL39430 & 31889 & 4.9031 & 4.9417 & TRN & & \\
\hline CHEMBL39565 & 31889 & 2.9031 & 3.2085 & TRN & & \\
\hline CHEMBL 37027 & 31889 & 4.8539 & 4.2072 & TRN & & \\
\hline CHEMBL 37090 & 31889 & 4.7986 & 3.6862 & TST & & \\
\hline CHEMBL290111 & 31889 & 4.4202 & 4.5562 & TRN & & \\
\hline CHEMBL37183 & 31889 & 4.6576 & 4.9885 & TRN & & \\
\hline CHEMBL 288414 & 31889 & 4.5045 & 4.5009 & TRN & & \\
\hline CHEMBL 35524 & 31889 & 6.2924 & 6.4921 & TRN & & \\
\hline CHEMBL37559 & 31889 & 5.3768 & 5.7175 & TRN & & \\
\hline CHEMBL37296 & 31889 & 6.7212 & 6.676 & TRN & & \\
\hline CHEMBL431512 & 31889 & 4.6289 & 4.5865 & TRN & & \\
\hline CHEMBL37494 & 31889 & 5.0223 & 5.626 & TST & & \\
\hline CHEMBL288013 & 31889 & 6.2441 & 5.7245 & TST & & \\
\hline CHEMBL289788 & 31889 & 7.0969 & 7.5179 & TST & & \\
\hline CHEMBL37071 & 31889 & 7.0969 & 6.78 & TST & & \\
\hline CHEMBL39456 & 31889 & 4.0353 & 3.7784 & TST & & \\
\hline CHEMBL39694 & 31889 & 5.0458 & 6.3834 & TST & & \\
\hline CHEMBL36860 & 31889 & 4.4976 & 4.3148 & TST & & \\
\hline CHEMBL288184 & 31889 & 6.7447 & 6.472 & TST & & \\
\hline CHEMBL36385 & 31889 & 4.1427 & 4.5267 & TST & & \\
\hline CHEMBL39389 & 31889 & 5.2007 & 5.4018 & TST & & \\
\hline CHEMBL292891 & 543133 & 2.699 & 2.9444 & TRN & & \\
\hline CHEMBL52068 & 543133 & 1.83599 & 99999999 & 999 & 2.0954 & TRN \\
\hline CHEMBL292464 & 543133 & 2.367 & 2.74 & TST & & \\
\hline CHEMBL51738 & 543133 & 2.222 & 2.3547 & TRN & & \\
\hline CHEMBL299014 & 543133 & 1.796 & 1.8993 & TST & & \\
\hline CHEMBL 296376 & 543133 & 2.215 & 2.2799 & TRN & & \\
\hline CHEMBL51912 & 543133 & 0.93900 & 00000000 & 001 & 1.5282 & TRN \\
\hline CHEMBL300757 & 543133 & 2.387 & 1.9856 & TST & & \\
\hline CHEMBL55599 & 543133 & 2.131 & 2.0886 & TRN & & \\
\hline CHEMBL54793 & 543133 & 1.52300 & 00000000 & 001 & 1.7702 & TST \\
\hline CHEMBL56465 & 543133 & 2.292 & 2.0212 & TRN & & \\
\hline CHEMBL449041 & 543133 & 2.009 & 1.8134 & TRN & & \\
\hline CHEMBL293806 & 543133 & 2.762 & 2.2272 & TRN & & \\
\hline CHEMBL56841 & 543133 & 1.359 & 1.0622 & TRN & & \\
\hline CHEMBL293963 & 543133 & 1.893 & 1.9886 & TRN & & \\
\hline
\end{tabular}




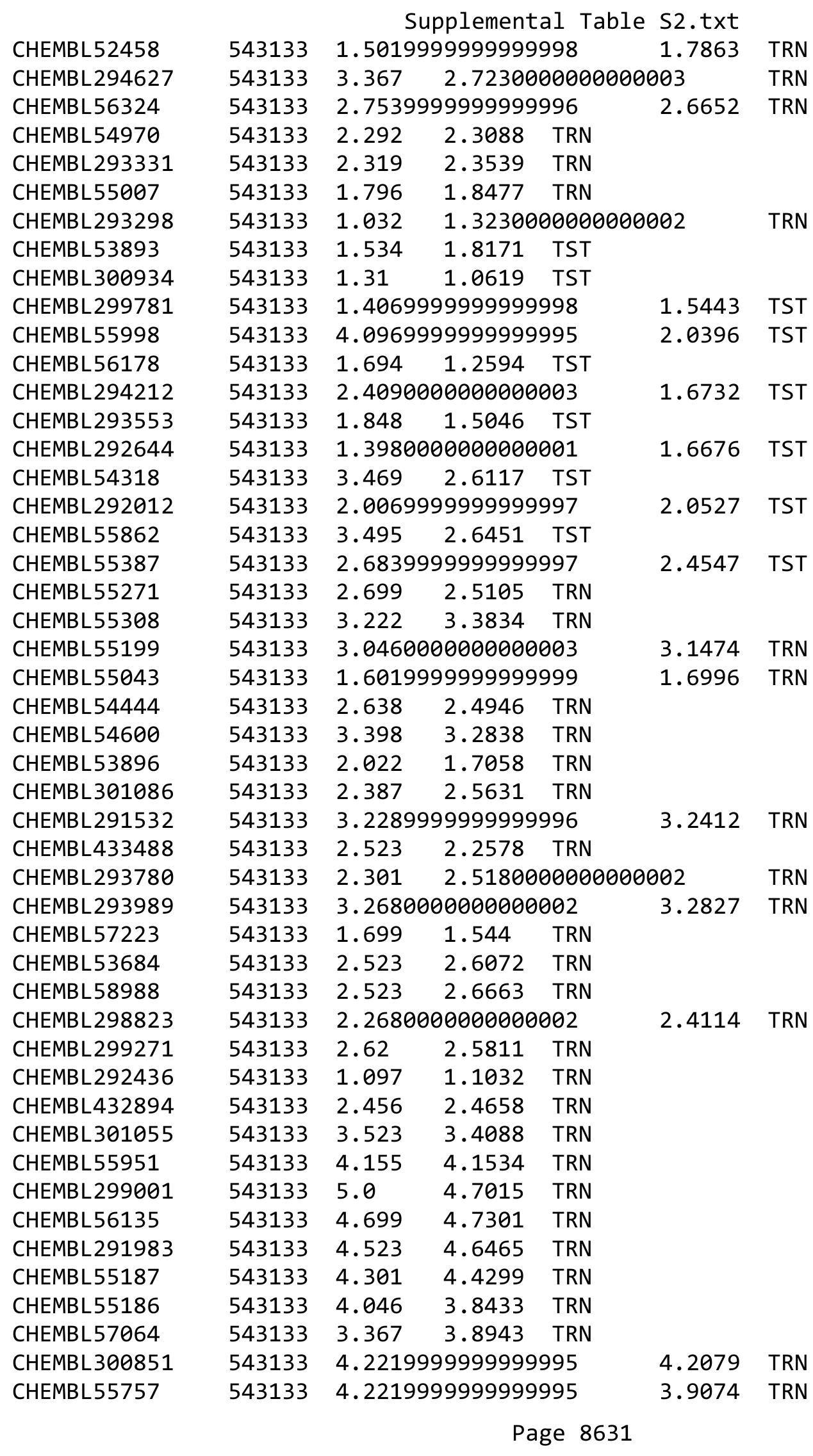




\begin{tabular}{|c|c|c|c|c|c|}
\hline & & \multicolumn{4}{|c|}{ Supplemental Table S2.txt } \\
\hline CHEMBL55997 & 543133 & 3.222 & 3.4184 & TRN & \\
\hline CHEMBL1683138 & 728291 & 4.7447 & 4.5454 & TRN & \\
\hline CHEMBL1683140 & 728291 & 4.4559 & 4.4589 & TRN & \\
\hline CHEMBL1683135 & 728291 & 4.7212 & 4.7968 & TRN & \\
\hline CHEMBL1683103 & 728291 & 3.0 & 2.7221 & TRN & \\
\hline CHEMBL1683127 & 728291 & 4.1192 & 3.6898 & TRN & \\
\hline CHEMBL1683109 & 728291 & 3.0 & 3.1151 & TRN & \\
\hline CHEMBL1683089 & 728291 & 4.2076 & 3.4251 & TST & \\
\hline CHEMBL1683112 & 728291 & 3.0 & 2.7549 & TRN & \\
\hline CHEMBL1683145 & 728291 & 4.2366 & 4.0689 & TST & \\
\hline CHEMBL1683105 & 728291 & 4.1549 & 3.6699 & TRN & \\
\hline CHEMBL1683122 & 728291 & 4.2366 & 3.9333 & TST & \\
\hline CHEMBL1683087 & 728291 & 3.0 & 3.0168 & TRN & \\
\hline CHEMBL 25211 & 728291 & 6.0315 & 4.0952 & TST & \\
\hline CHEMBL1683086 & 728291 & 4.1487 & 3.7176 & TRN & \\
\hline CHEMBL1683142 & 728291 & 4.585 & 4.4721 & TRN & \\
\hline CHEMBL1682977 & 728291 & 3.1612 & 3.4224 & TRN & \\
\hline CHEMBL1683094 & 728291 & 3.0 & 2.6416 & TRN & \\
\hline CHEMBL1683088 & 728291 & 3.0 & 3.2509 & TRN & \\
\hline CHEMBL1682984 & 728291 & 4.1192 & 3.8009 & TRN & \\
\hline CHEMBL1683093 & 728291 & 3.0 & 2.96199 & 99999999997 & TRN \\
\hline CHEMBL1683108 & 728291 & 4.2366 & 3.5497 & TRN & \\
\hline CHEMBL1683131 & 728291 & 4.5376 & 4.6655 & TRN & \\
\hline CHEMBL1683133 & 728291 & 5.2596 & 4.4859 & TST & \\
\hline CHEMBL1683096 & 728291 & 3.0 & 3.2183 & TRN & \\
\hline CHEMBL1683134 & 728291 & 4.3372 & 4.0887 & TST & \\
\hline CHEMBL1682983 & 728291 & 4.2596 & 4.0842 & TRN & \\
\hline CHEMBL1683097 & 728291 & 3.0 & 2.801 & TRN & \\
\hline CHEMBL1682979 & 728291 & 4.1612 & 4.0024 & TRN & \\
\hline CHEMBL1683137 & 728291 & 4.4318 & 4.4554 & TST & \\
\hline CHEMBL1683126 & 728291 & 3.0 & 3.1434 & TRN & \\
\hline CHEMBL1683129 & 728291 & 3.0 & 3.2691 & TRN & \\
\hline CHEMBL1683106 & 728291 & 3.0 & 3.002 & TRN & \\
\hline CHEMBL1683130 & 728291 & 4.0223 & 3.9924 & TRN & \\
\hline CHEMBL1683132 & 728291 & 4.5229 & 4.1491 & TST & \\
\hline CHEMBL1682985 & 728291 & 3.0 & 3.6851 & TRN & \\
\hline CHEMBL1683095 & 728291 & 3.0 & 3.1652 & TRN & \\
\hline CHEMBL1683111 & 728291 & 3.0 & 3.1274 & TRN & \\
\hline CHEMBL1683110 & 728291 & 3.0 & 2.8757 & TRN & \\
\hline CHEMBL1683144 & 728291 & 4.1427 & 4.2295 & TST & \\
\hline CHEMBL1683143 & 728291 & 4.4089 & 3.8444 & TST & \\
\hline CHEMBL1683141 & 728291 & 4.3279 & 4.4151 & TST & \\
\hline CHEMBL1683092 & 728291 & 3.0 & 3.0127 & TRN & \\
\hline CHEMBL1683124 & 728291 & 4.1249 & 3.9222 & TST & \\
\hline CHEMBL1682976 & 728291 & 4.1871 & 4.2751 & TRN & \\
\hline CHEMBL1683102 & 728291 & 3.0 & 3.1048 & TRN & \\
\hline CHEMBL1682978 & 728291 & 3.0 & 3.2931 & TRN & \\
\hline CHEMBL1682981 & 728291 & 4.4685 & 4.4904 & TRN & \\
\hline
\end{tabular}




\begin{tabular}{|c|c|c|c|c|c|c|}
\hline \multicolumn{7}{|c|}{ Supplemental Table s2.txt } \\
\hline CHEMBL1683090 & 728291 & 3.0 & 3.2392 & TRN & & \\
\hline CHEMBL1683091 & 728291 & 3.0 & 3.12899 & 9999999999 & 96 & TRN \\
\hline CHEMBL1683128 & 728291 & 3.0 & 3.4541 & TRN & & \\
\hline CHEMBL1683123 & 728291 & 4.4815 & 4.1621 & TST & & \\
\hline CHEMBL1683136 & 728291 & 4.4949 & 4.5261 & TST & & \\
\hline CHEMBL1682974 & 728291 & 6.7696 & 4.5171 & TST & & \\
\hline CHEMBL1683125 & 728291 & 3.0 & 2.9816 & TRN & & \\
\hline CHEMBL1683101 & 728291 & 4.301 & 3.7908 & TRN & & \\
\hline CHEMBL1683104 & 728291 & 3.0 & 3.1844 & TRN & & \\
\hline CHEMBL1682982 & 728291 & 4.1871 & 4.3122 & TRN & & \\
\hline CHEMBL1682980 & 728291 & 3.0 & 3.2744 & TRN & & \\
\hline CHEMBL1682975 & 728291 & 4.2147 & 4.0732 & TRN & & \\
\hline CHEMBL1683139 & 728291 & 4.5086 & 4.3748 & TST & & \\
\hline CHEMBL1683107 & 728291 & 4.4559 & 4.7984 & TRN & & \\
\hline CHEMBL1683100 & 728291 & 3.0 & 3.21 & TRN & & \\
\hline CHEMBL3976549 & 1642361 & 6.0132 & 5.9338 & TRN & & \\
\hline CHEMBL3906051 & 1642361 & 6.6696 & 6.8147 & TRN & & \\
\hline CHEMBL3908940 & 1642361 & 6.5654 & 6.731 & TRN & & \\
\hline CHEMBL3962437 & 1642361 & 7.6904 & 7.5785 & TRN & & \\
\hline CHEMBL3927059 & 1642361 & 7.1246 & 6.9524 & TRN & & \\
\hline CHEMBL3951269 & 1642361 & 6.6421 & 6.6126 & TRN & & \\
\hline CHEMBL3892761 & 1642361 & 7.2218 & 7.4786 & TRN & & \\
\hline CHEMBL3969144 & 1642361 & 5.8097 & 6.2154 & TRN & & \\
\hline CHEMBL3967401 & 1642361 & 6.4437 & 6.3321 & TRN & & \\
\hline CHEMBL3900133 & 1642361 & 7.27 & 7.1428 & TRN & & \\
\hline CHEMBL3941986 & 1642361 & 6.1772 & 6.9458 & TST & & \\
\hline CHEMBL3906058 & 1642361 & 5.4895 & 6.329 & TST & & \\
\hline CHEMBL 3910484 & 1642361 & 6.5361 & 6.5954 & TRN & & \\
\hline CHEMBL 3973221 & 1642361 & 6.2581 & 6.4303 & TRN & & \\
\hline CHEMBL3916655 & 1642361 & 7.2628 & 7.1476 & TRN & & \\
\hline CHEMBL3961768 & 1642361 & 6.1838 & 6.1941 & TRN & & \\
\hline CHEMBL3934554 & 1642361 & 6.2741 & 6.3207 & TRN & & \\
\hline CHEMBL3930161 & 1642361 & 6.8794 & 7.1683 & TRN & & \\
\hline CHEMBL 3974221 & 1642361 & 5.9957 & 6.0009 & TRN & & \\
\hline CHEMBL3918191 & 1642361 & 7.5544 & 7.3979 & TRN & & \\
\hline CHEMBL3941189 & 1642361 & 7.3372 & 7.2399 & TRN & & \\
\hline CHEMBL3930595 & 1642361 & 7.091 & 6.5025 & TST & & \\
\hline CHEMBL3907721 & 1642361 & 6.5735 & 6.5961 & TRN & & \\
\hline CHEMBL3951895 & 1642361 & 6.76200 & 00000000 & 205 & 6.8233 & TRN \\
\hline CHEMBL3895257 & 1642361 & 7.3737 & 7.6321 & TRN & & \\
\hline CHEMBL3937556 & 1642361 & 6.9957 & 6.9577 & TRN & & \\
\hline CHEMBL3938532 & 1642361 & 7.0106 & 7.0797 & TRN & & \\
\hline CHEMBL3911239 & 1642361 & 6.8125 & 6.46200 & 0000000001 & & TRN \\
\hline CHEMBL3902226 & 1642361 & 6.4473 & 6.5642 & TRN & & \\
\hline CHEMBL3916144 & 1642361 & 6.025 & 5.9786 & TRN & & \\
\hline CHEMBL3980571 & 1642361 & 6.4672 & 6.5767 & TRN & & \\
\hline CHEMBL3923510 & 1642361 & 6.0994 & 6.2867 & TRN & & \\
\hline CHEMBL3907175 & 1642361 & 6.3851 & 6.2221 & TRN & & \\
\hline
\end{tabular}


Supplemental Table S2.txt

\begin{tabular}{|c|c|c|c|c|c|c|}
\hline CHEMBL3969361 & 1642361 & 6.0191 & 6.2088 & TRN & & \\
\hline CHEMBL3947132 & 1642361 & 6.7545 & 7.3432 & TST & & \\
\hline CHEMBL3968043 & 1642361 & 6.8386 & 6.4376 & TRN & & \\
\hline CHEMBL3908841 & 1642361 & 6.2457 & 6.3374 & TRN & & \\
\hline CHEMBL3951766 & 1642361 & 6.4001 & 6.2373 & TRN & & \\
\hline CHEMBL3971066 & 1642361 & 5.7905 & 7.3463 & TST & & \\
\hline CHEMBL3905553 & 1642361 & 5.9172 & 7.3599 & TST & & \\
\hline CHEMBL3977772 & 1642361 & 7.5452 & 7.3737 & TRN & & \\
\hline CHEMBL3945612 & 1642361 & 6.4647 & 6.7653 & TRN & & \\
\hline CHEMBL3917789 & 1642361 & 7.6861 & 7.6194 & TRN & & \\
\hline CHEMBL3905819 & 1642361 & 6.8633 & 6.5932 & TRN & & \\
\hline CHEMBL3953676 & 1642361 & 6.4685 & 6.4626 & TRN & & \\
\hline CHEMBL 3899367 & 1642361 & 7.2976 & 7.1443 & TRN & & \\
\hline CHEMBL3960725 & 1642361 & 7.2211 & 7.4502 & TRN & & \\
\hline CHEMBL3976107 & 1642361 & 6.6402 & 6.7436 & TRN & & \\
\hline CHEMBL3926432 & 1642361 & 7.9136 & 8.0131 & TRN & & \\
\hline CHEMBL3957026 & 1642361 & 6.4271 & 6.5076 & TST & & \\
\hline CHEMBL3945113 & 1642361 & 7.2933 & 7.1828 & TRN & & \\
\hline CHEMBL3889611 & 1642361 & 5.8386 & 7.0498 & TST & & \\
\hline CHEMBL3939590 & 1642361 & 6.6556 & 6.6784 & TST & & \\
\hline CHEMBL3910048 & 1642361 & 7.5436 & 7.5923 & TRN & & \\
\hline CHEMBL3939194 & 1642361 & 6.4401 & 6.5415 & TRN & & \\
\hline CHEMBL3947939 & 1642361 & 7.5482 & 6.8063 & TST & & \\
\hline CHEMBL3920047 & 1642361 & 6.4045 & 6.4095 & TRN & & \\
\hline CHEMBL3944958 & 1642361 & 7.2204 & 6.8223 & TST & & \\
\hline CHEMBL 3923223 & 1642361 & 7.3645 & 7.0487 & TRN & & \\
\hline CHEMBL 3893409 & 1642361 & 6.2581 & 6.4485 & TST & & \\
\hline CHEMBL3926686 & 1642361 & 7.5591 & 7.1091 & TST & & \\
\hline CHEMBL3891650 & 1642361 & \multicolumn{3}{|c|}{6.752000000000001} & 6.9766 & TRN \\
\hline CHEMBL3932173 & 1642361 & 6.1618 & 6.1167 & TST & & \\
\hline CHEMBL 3984048 & 1642361 & 7.2 & 7.1171 & TST & & \\
\hline CHEMBL 3910483 & 1642361 & 7.6392 & 7.4466 & TRN & & \\
\hline CHEMBL3979166 & 1642361 & 6.0942 & 6.2044 & TST & & \\
\hline CHEMBL3923319 & 1642361 & 6.3904 & 6.2854 & TRN & & \\
\hline CHEMBL 3898625 & 1642361 & 7.3487 & 6.6146 & TST & & \\
\hline CHEMBL3920876 & 1642361 & 5.9586 & 5.9819 & TRN & & \\
\hline CHEMBL 3970250 & 1642361 & 7.3468 & 7.1028 & TRN & & \\
\hline CHEMBL3982381 & 1642361 & 6.9031 & 6.2862 & TST & & \\
\hline CHEMBL3955892 & 1641455 & 5.4248 & 5.3709 & TRN & & \\
\hline CHEMBL3970713 & 1641455 & 5.9914 & 5.9806 & TRN & & \\
\hline CHEMBL3968711 & 1641455 & 7.5086 & 7.6547 & TRN & & \\
\hline CHEMBL3935512 & 1641455 & 8.6021 & 8.5764 & TRN & & \\
\hline CHEMBL3983343 & 1641455 & 5.7825 & 6.0301 & TRN & & \\
\hline CHEMBL3957027 & 1641455 & 7.5528 & 7.4857 & TRN & & \\
\hline CHEMBL3929911 & 1641455 & 7.8239 & 7.2271 & TRN & & \\
\hline CHEMBL3929456 & 1641455 & 6.0 & 7.2436 & TRN & & \\
\hline CHEMBL3908985 & 1641455 & 7.7212 & 7.3799 & TRN & & \\
\hline CHEMBL3957556 & 1641455 & 7.9586 & 7.7023 & TRN & & \\
\hline
\end{tabular}

Page 8634 
Supplemental Table S2.txt

\begin{tabular}{|c|c|c|c|c|}
\hline CHEMBL3977981 & 1641455 & 7.4078 & 7.5795 & TRN \\
\hline CHEMBL3895405 & 1641455 & 7.7696 & 7.8335 & TRN \\
\hline CHEMBL3966080 & 1641455 & 6.4881 & 6.9 & TRN \\
\hline CHEMBL3937663 & 1641455 & 7.4237 & 7.3376 & TRN \\
\hline CHEMBL3952431 & 1641455 & 5.5086 & 5.7953 & TST \\
\hline CHEMBL3900583 & 1641455 & 7.6198 & 7.5469 & TRN \\
\hline CHEMBL3985831 & 1641455 & 6.1203 & 5.8918 & TRN \\
\hline CHEMBL 3898408 & 1641455 & 5.289 & 5.50299 & 9999999999 \\
\hline CHEMBL3909033 & 1641455 & 6.9245 & 6.8475 & TST \\
\hline CHEMBL3954148 & 1641455 & 7.2644 & 7.3787 & TRN \\
\hline CHEMBL3904438 & 1641455 & 8.4353 & 8.6178 & TRN \\
\hline CHEMBL3915529 & 1641455 & 6.2604 & 6.7307 & TRN \\
\hline CHEMBL3940730 & 1641455 & 5.6091 & 5.1972 & TST \\
\hline CHEMBL3896202 & 1641455 & 7.4949 & 7.1233 & TRN \\
\hline CHEMBL3958521 & 1641455 & 7.1931 & 6.825 & TRN \\
\hline CHEMBL3916241 & 1641455 & 5.2233 & 4.9579 & TST \\
\hline CHEMBL3952931 & 1641455 & 6.2933 & 5.9671 & TST \\
\hline CHEMBL3971100 & 1641455 & 5.4855 & 5.1775 & TRN \\
\hline CHEMBL3943009 & 1641455 & 8.1549 & 7.8022 & TRN \\
\hline CHEMBL3915277 & 1641455 & 7.5969 & 7.5767 & TRN \\
\hline CHEMBL3898955 & 1641455 & 7.0915 & 7.3871 & TRN \\
\hline CHEMBL3961630 & 1641455 & 6.0419 & 6.0417 & TST \\
\hline CHEMBL3901216 & 1641455 & 6.8996 & 7.0462 & TRN \\
\hline CHEMBL3966149 & 1641455 & 7.4202 & 6.7623 & TRN \\
\hline CHEMBL3934911 & 1641455 & 5.4145 & 5.2862 & TST \\
\hline CHEMBL3963645 & 1641455 & 7.4559 & 7.9849 & TRN \\
\hline CHEMBL3956399 & 1641455 & 6.5317 & 6.4838 & TRN \\
\hline CHEMBL3979325 & 1641455 & 6.4214 & 6.5319 & TRN \\
\hline CHEMBL3899615 & 1641455 & 3.8069 & 3.6255 & TST \\
\hline CHEMBL 3986646 & 1641455 & 7.5768 & 7.5235 & TRN \\
\hline CHEMBL3951561 & 1641455 & 7.1681 & 7.2899 & TRN \\
\hline CHEMBL3940322 & 1641455 & 6.2581 & 6.6811 & TRN \\
\hline CHEMBL3930009 & 1641455 & 8.1549 & 8.182 & TRN \\
\hline CHEMBL 3896886 & 1641455 & 7.6383 & 7.4756 & TRN \\
\hline CHEMBL3938609 & 1641455 & 5.3372 & 5.6053 & TST \\
\hline CHEMBL3926156 & 1641455 & 7.3098 & 7.3165 & TRN \\
\hline CHEMBL3973889 & 1641455 & 7.8861 & 7.5635 & TRN \\
\hline CHEMBL3940796 & 1641455 & 7.2441 & 7.0747 & TRN \\
\hline CHEMBL3926258 & 1641455 & 8.2218 & 8.0773 & TRN \\
\hline CHEMBL3913544 & 1641455 & 7.8239 & 7.6312 & TRN \\
\hline CHEMBL3924515 & 1641455 & 8.5229 & 8.3021 & TRN \\
\hline CHEMBL 3943888 & 1641455 & 5.5513 & 5.4146 & TST \\
\hline CHEMBL3899306 & 1641455 & 6.6198 & 6.4361 & TRN \\
\hline CHEMBL3979143 & 1641455 & 9.0 & 9.4466 & TRN \\
\hline CHEMBL3957666 & 1641455 & 7.2596 & 7.1868 & TRN \\
\hline CHEMBL3943162 & 1641455 & 6.7167 & 7.1706 & TRN \\
\hline CHEMBL3901695 & 1641455 & 6.8125 & 7.0132 & TRN \\
\hline CHEMBL3975091 & 1641455 & 7.1972 & 6.8658 & TRN \\
\hline
\end{tabular}


Supplemental Table S2.txt

\begin{tabular}{|c|c|c|c|c|}
\hline HEMB I & נחדעד & 7.7212 & & \\
\hline & & 5.8239 & 5.9025 & \\
\hline 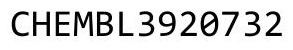 & & 086 & & \\
\hline HEMBL390 & 5 & 5302 & 5342 & \\
\hline AEMBL3894342 & - & 351 & 1119 & \\
\hline HEMBL3930808 & 641455 & 7.6596 & . 9157 & \\
\hline HEMBL3960028 & & & .2654 & \\
\hline AEMBL3901 & & & & \\
\hline HEMBL3964 & & $\partial 516$ & 6.2645 & \\
\hline HEMBL3937600 & 64 & 599 & .347 & \\
\hline AEMBL3966313 & 64 & 6.0 & .5931 & \\
\hline AEMBL39117 & 6 & & 2722 & \\
\hline HEMBL 394 & & & & \\
\hline HEMBL3933535 & & 089 & 8.0647 & \\
\hline AEMBL3955707 & 62 & 861 & 8936 & \\
\hline AEMBL3954714 & 6 & 6. & .0268 & \\
\hline HEMBL390 & o & $\partial 3$ & 24 & KIV \\
\hline HEMBL397! & & 77 & & \\
\hline HEMBL3908807 & & 747 & 95 & \\
\hline AEMBL 394 & & 39 & & \\
\hline HEMBL 394 & 64 & 47 & 992 & Niv \\
\hline HEMBL391: & & 16 & 06 & וזנה \\
\hline HEMBL391: & & 25 & 86 & \\
\hline HEMBL3963410 & & 208 & 1079 & \\
\hline AEMBL39773 & & 921 & & I RIV \\
\hline HEMBL 3906 & 6 & & 54 & SI \\
\hline HEMBL39 & & & 17 & RN \\
\hline HFMBI 3927 & & 66 & 41 & \\
\hline HEMBL3905422 & & 279 & 7.2586 & in \\
\hline HEMBL39523 & & 69 & 236 & ISI \\
\hline HEMBL 3911 & & 248 & 89 & RN \\
\hline HEMBL3 & & 78 & 98 & ST \\
\hline HEMBL3 & & 21 & 879 & TRN \\
\hline HEMBL3939817 & 62 & & 8.2002 & $\mathrm{IR}$ \\
\hline HEMBL 3965056 & 6 & & 2574 & TRN \\
\hline HEMBL3972 & & & 22 & TRN \\
\hline HFMRI 3 & & & 01 & \\
\hline HEMBL390 & & & 5.8986 & TST \\
\hline HEMBL3961045 & & 37 & 6342 & TRN \\
\hline EMBL3985 & & 069 & 5655 & TST \\
\hline HEMBL23471 & $6<$ & 686 & 9838 & \\
\hline CHEMBL 3927936 & & 6.1945 & & TRN \\
\hline HEMBL3966981 & & 8.5229 & 7.9406 & TRN \\
\hline HEMBL $39082 \varepsilon$ & למ & 8.0757 & .2047 & TR \\
\hline MBL391 & & & 6.0922 & 13 \\
\hline HEMBL39838 & & & .0258 & \\
\hline CHEMBL 38945 & & .2612 & 6.3179 & \\
\hline CHEMBL3926112 & 1641455 & 8.3188 & 7.8787 & \\
\hline
\end{tabular}

Page 8636 
Supplemental Table S2.txt

\begin{tabular}{|c|c|c|c|c|}
\hline - & נהדגדס & & & \\
\hline & & 3.8069 & 3.515 & \\
\hline$=0$ & & & & \\
\hline AEMBL3971 & & & & \\
\hline AEMBL3981436 & - & 858 & 1971 & \\
\hline HEMBL3945149 & 641455 & 8.3468 & . 1559 & \\
\hline 525 & & 55 & 969 & \\
\hline AEMBL 393 & & & & \\
\hline HEMBL3985686 & & & 725 & \\
\hline HEMBL3925020 & 64 & & .7037 & \\
\hline HEMBL3903960 & 62 & 6.5 & 9531 & \\
\hline IEMBL395 & $.0<$ & 229 & 533 & \\
\hline AEMBL39 & & & & RN \\
\hline HEMBL 390 & & 607 & 7.0077 & \\
\hline HEMBL396 & 6 & & 3883 & \\
\hline AEMBL3905256 & & 06 & 6251 & \\
\hline HEMBL396 & o & 55 & 597 & \\
\hline HEMBL 393 & & & 3772 & \\
\hline HEMBL3926914 & & 379 & 7.0558 & \\
\hline AEMBL393 & & & 3686 & \\
\hline AEMBL39 & 6 & 98 & 3216 & NIV \\
\hline HEMBL39 & & & 75 & הות \\
\hline HEMBL39 & & & 973 & \\
\hline HFMRI 380 & & & 1745 & \\
\hline HEMBL 39 & & & & I RIV \\
\hline HEMBL39e & 6 & & 863 & | \\
\hline HEMBL3S & & & 09 & ST \\
\hline HFMBI 30 & & 41 & 423 & $\mathrm{RN}$ \\
\hline HEMBL 39 & & & 5901 & 15 \\
\hline HEMBL3930667 & & & & ISI \\
\hline HEMBL39 & & & 584 & ГST \\
\hline HEMBL3 & & 19 & 193 & ST \\
\hline HEMBL3 & & 52 & 389 & RN \\
\hline HEMBL3972899 & & & 338 & IRN \\
\hline HEMBL3911790 & & 59 & 737 & TST \\
\hline HEMBL392 & & 3 & 3556 & TST \\
\hline HEMRI 3 & & 6 & 397 & $\Gamma \mathrm{RN}$ \\
\hline HEMBL39 & & & 717 & IRN \\
\hline HEMBL3980634 & & 7.5376 & $\partial 131$ & TRN \\
\hline HEMBL 396 & & & & TRN \\
\hline HEMBL3909660 & & 69 & 1809 & $|S|$ \\
\hline CHEMBL 3958391 & & & 7.6599 & TRN \\
\hline HEMBL3976045 & & 16 & 2039 & TRN \\
\hline HEMBL3969602 & 16 & 7.5086 & 0659 & TR \\
\hline$\partial \theta$ & & & 8967 & $\mathrm{~N}$ \\
\hline HEMBL 392 & & & & \\
\hline CHEMBL3979965 & & .3625 & .159 & \\
\hline CHEMBL3953730 & 1641455 & 7.0315 & 6.9535 & ГRN \\
\hline
\end{tabular}


Supplemental Table S2.txt

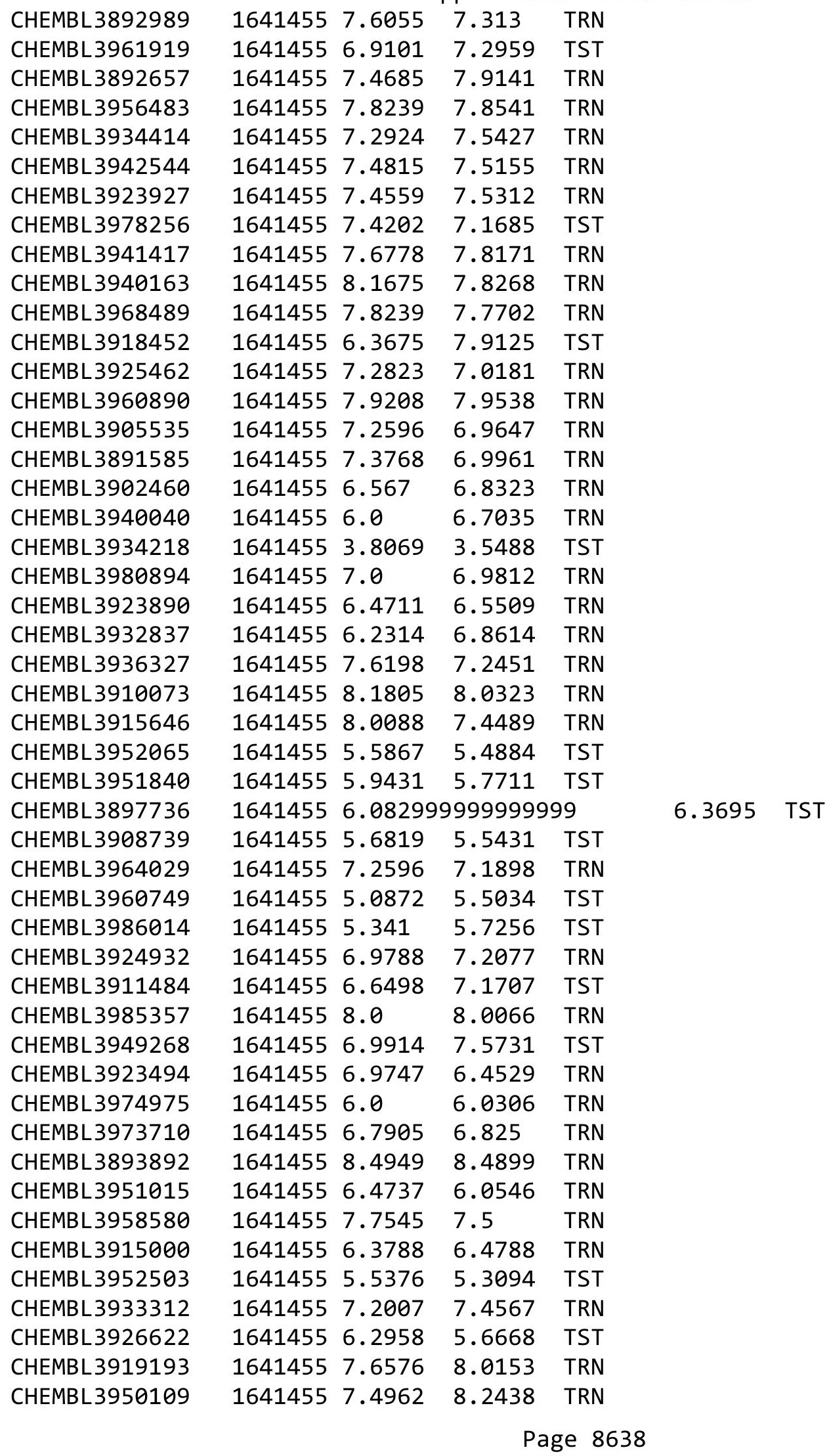




\begin{tabular}{|c|c|c|c|c|c|c|}
\hline CHEMBL3969211 & 1641455 & \multicolumn{4}{|c|}{ Supplemental Table S2.txt } & TST \\
\hline CHEMBL3957970 & 1641455 & 7.7055 & 7.4009 & TRN & & \\
\hline CHEMBL3924137 & 1641455 & 3.8069 & 3.8835 & TST & & \\
\hline CHEMBL3986682 & 1641455 & 5.6757 & 6.3958 & TST & & \\
\hline CHEMBL3984203 & 1641455 & 7.2441 & 7.2759 & TST & & \\
\hline CHEMBL3945996 & 1641455 & 7.699 & 8.0718 & TRN & & \\
\hline CHEMBL3953251 & 1641455 & 7.3768 & 7.5046 & TST & & \\
\hline CHEMBL3917242 & 1641455 & 7.7305 & 7.3681 & TRN & & \\
\hline CHEMBL3969182 & 1641455 & 6.9136 & 6.3778 & TRN & & \\
\hline CHEMBL3962299 & 1641455 & 3.8069 & 5.1961 & TST & & \\
\hline CHEMBL3939821 & 1641455 & 7.5086 & 7.2911 & TRN & & \\
\hline CHEMBL3968817 & 1641455 & 7.0605 & 7.1431 & TRN & & \\
\hline CHEMBL3923394 & 1641455 & 7.9957 & 7.9455 & TRN & & \\
\hline CHEMBL3961673 & 1641455 & 7.4101 & 7.4875 & TRN & & \\
\hline CHEMBL3897411 & 1641455 & 6.58 & 6.8401 & TRN & & \\
\hline CHEMBL3982006 & 1641455 & 7.04 & 6.9427 & TRN & & \\
\hline CHEMBL3965566 & 1641455 & 5.0878 & 4.5085 & TST & & \\
\hline CHEMBL3931128 & 1641455 & 8.28399 & 999999999 & 99 & 7.8511 & TRN \\
\hline CHEMBL3948355 & 1641455 & 7.5376 & 7.3539 & TRN & & \\
\hline CHEMBL3935940 & 1641455 & 8.0177 & 8.2918 & TRN & & \\
\hline CHEMBL1096243 & 628628 & 9.22 & 9.2387 & TST & & \\
\hline CHEMBL1096244 & 628628 & 9.22 & 8.9052 & TST & & \\
\hline CHEMBL1096245 & 628628 & 9.3 & 9.1164 & TRN & & \\
\hline CHEMBL1096569 & 628628 & 8.62 & 8.8093 & TRN & & \\
\hline CHEMBL1096570 & 628628 & 9.22 & 8.99 & TRN & & \\
\hline CHEMBL1096571 & 628628 & 9.0 & 8.9233 & TRN & & \\
\hline CHEMBL1096572 & 628628 & 8.92 & 9.0729 & TRN & & \\
\hline CHEMBL1096573 & 628628 & 8.82 & 8.8306 & TRN & & \\
\hline CHEMBL1096574 & 628628 & 9.15 & 8.9462 & TRN & & \\
\hline CHEMBL1096575 & 628628 & 8.72 & 8.9264 & TRN & & \\
\hline CHEMBL1199269 & 628628 & 8.52 & 8.6041 & TRN & & \\
\hline CHEMBL1096577 & 628628 & 7.8 & 8.7622 & TST & & \\
\hline CHEMBL1096578 & 628628 & 8.29 & 8.9044 & TST & & \\
\hline CHEMBL1096579 & 628628 & 7.55 & 8.6782 & TST & & \\
\hline CHEMBL1096580 & 628628 & 8.38 & 9.5459 & TST & & \\
\hline CHEMBL1096581 & 628628 & 8.82 & 9.2397 & TST & & \\
\hline CHEMBL1096582 & 628628 & 8.48 & 9.3357 & TST & & \\
\hline CHEMBL1096583 & 628628 & 8.89 & 9.4229 & TST & & \\
\hline CHEMBL1096584 & 628628 & 8.42 & 9.2979 & TST & & \\
\hline CHEMBL1096585 & 628628 & 8.32 & 8.9967 & TST & & \\
\hline CHEMBL263804 & 628628 & 10.86 & 10.3177 & TRN & & \\
\hline CHEMBL284085 & 628628 & 9.47 & 10.4832 & TRN & & \\
\hline CHEMBL284083 & 628628 & 10.98 & 11.4191 & TRN & & \\
\hline CHEMBL30855 & 628628 & 11.18 & 11.4285 & TRN & & \\
\hline CHEMBL282148 & 628628 & 12.73 & 12.3291 & TRN & & \\
\hline CHEMBL30496 & 628628 & 12.11 & 12.2061 & TRN & & \\
\hline CHEMBL430733 & 628628 & 12.02 & 11.3593 & TRN & & \\
\hline CHEMBL284084 & 628628 & 11.76 & 11.8438 & TRN & & \\
\hline
\end{tabular}




\begin{tabular}{|c|c|c|c|c|c|}
\hline \multicolumn{6}{|c|}{ Supplemental Table S2.txt } \\
\hline CHEMBL33016 & 628628 & 11.57 & 11.3376 & TRN & \\
\hline CHEMBL34734 & 628628 & 11.22 & 11.1419 & TRN & \\
\hline CHEMBL 290566 & 628628 & 10.87 & 10.8894 & TRN & \\
\hline CHEMBL540215 & 628628 & 9.28 & 9.1982 & TRN & \\
\hline CHEMBL540690 & 628628 & 9.23 & 9.3002 & TRN & \\
\hline CHEMBL537956 & 628628 & 9.37 & 9.4888 & TRN & \\
\hline CHEMBL539890 & 628628 & 9.36 & 9.3217 & TRN & \\
\hline CHEMBL554560 & 628628 & 9.46 & 9.0715 & TRN & \\
\hline CHEMBL556741 & 628628 & 9.07 & 9.2053 & TRN & \\
\hline CHEMBL551331 & 628628 & 9.46 & 9.3619 & TRN & \\
\hline CHEMBL555197 & 628628 & 9.37 & 9.2336 & TRN & \\
\hline CHEMBL555945 & 628628 & 8.71 & 9.2298 & TRN & \\
\hline CHEMBL537955 & 628628 & 9.37 & 9.3424 & TRN & \\
\hline CHEMBL553933 & 628628 & 9.24 & 9.5352 & TRN & \\
\hline CHEMBL564422 & 628628 & 9.54 & 9.3913 & TRN & \\
\hline CHEMBL556740 & 628628 & 9.24 & 9.4279 & TRN & \\
\hline CHEMBL553932 & 628628 & 9.43 & 9.5597 & TRN & \\
\hline CHEMBL538133 & 628628 & 9.4 & 9.6993 & TRN & \\
\hline CHEMBL538439 & 628628 & 9.44 & 9.5676 & TRN & \\
\hline CHEMBL555946 & 628628 & 9.16 & 8.9423 & TRN & \\
\hline CHEMBL539196 & 628628 & 9.27 & 9.0695 & TRN & \\
\hline CHEMBL555198 & 628628 & 9.17 & 9.222000 & 0000000001 & TRN \\
\hline CHEMBL555142 & 628628 & 9.28 & 9.0803 & TRN & \\
\hline CHEMBL553661 & 628628 & 8.95 & 8.8012 & TRN & \\
\hline CHEMBL554540 & 628628 & 8.94 & 8.9426 & TRN & \\
\hline CHEMBL538440 & 628628 & 9.12 & 9.0891 & TRN & \\
\hline CHEMBL554777 & 628628 & 9.07 & 8.9743 & TRN & \\
\hline CHEMBL552529 & 628628 & 9.07 & 8.97 & TRN & \\
\hline CHEMBL553898 & 628628 & 8.95 & 9.0984 & TRN & \\
\hline CHEMBL541440 & 628628 & 9.35 & 9.2817 & TRN & \\
\hline CHEMBL553662 & 628628 & 9.17 & 9.1288 & TRN & \\
\hline CHEMBL556742 & 628628 & 9.3 & 9.1625 & TST & \\
\hline CHEMBL1096586 & 628628 & 9.4 & 8.9955 & TST & \\
\hline CHEMBL554776 & 628628 & 9.3 & 9.4278 & TST & \\
\hline CHEMBL540216 & 628628 & 9.4 & 9.3137 & TST & \\
\hline CHEMBL1096587 & 628628 & 9.15 & 9.5265 & TST & \\
\hline CHEMBL334020 & 47661 & 7.08 & 6.5634 & TRN & \\
\hline CHEMBL330773 & 47661 & 8.13 & 7.8676 & TRN & \\
\hline CHEMBL120031 & 47661 & 6.6 & 6.3282 & TRN & \\
\hline CHEMBL120793 & 47661 & 6.66 & 6.6979 & TRN & \\
\hline CHEMBL121267 & 47661 & 7.32 & 7.2932 & TRN & \\
\hline CHEMBL332601 & 47661 & 6.66 & 6.1628 & TRN & \\
\hline CHEMBL120363 & 47661 & 6.2 & 6.1588 & TRN & \\
\hline CHEMBL338278 & 47661 & 7.33 & 7.081 & TST & \\
\hline CHEMBL121331 & 47661 & 7.65 & 7.3727 & TRN & \\
\hline CHEMBL121703 & 47661 & 6.95 & 7.4672 & TRN & \\
\hline CHEMBL420728 & 47661 & 6.95 & 7.172999 & 9999999999 & TRN \\
\hline CHEMBL340107 & 47661 & 6.18 & 6.5461 & TRN & \\
\hline
\end{tabular}




\begin{tabular}{|c|c|c|c|c|}
\hline & & & pplement & $\mathrm{a} \perp \mathrm{T}$ \\
\hline CHEMBL120657 & 47661 & 6.0 & 5.7699 & TRN \\
\hline CHEMBL331244 & 47661 & 5.8 & 5.9943 & TRN \\
\hline CHEMBL332595 & 47661 & 6.94 & 6.6981 & TST \\
\hline CHEMBL120296 & 47661 & 7.0 & 6.5967 & TRN \\
\hline CHEMBL333517 & 47661 & 5.95 & 6.0059 & TRN \\
\hline CHEMBL121624 & 47661 & 6.6 & 6.9341 & TRN \\
\hline CHEMBL333930 & 47661 & 7.2 & 6.9659 & TRN \\
\hline CHEMBL339879 & 47661 & 6.91 & 6.8044 & TST \\
\hline CHEMBL118622 & 47661 & 7.01 & 7.4565 & TRN \\
\hline CHEMBL331929 & 47661 & 6.57 & 6.5096 & TRN \\
\hline CHEMBL119608 & 47661 & 6.09 & 6.1356 & TRN \\
\hline CHEMBL332646 & 47661 & 6.71 & 6.8201 & TRN \\
\hline CHEMBL331971 & 47661 & 7.15 & 7.194 & TRN \\
\hline CHEMBL415240 & 47661 & 5.67 & 5.9294 & TRN \\
\hline CHEMBL278018 & 47661 & 6.6 & 6.6146 & TRN \\
\hline CHEMBL331651 & 47661 & 7.11 & 6.555 & TST \\
\hline CHEMBL332403 & 47661 & 7.93 & 7.9124 & TRN \\
\hline CHEMBL331872 & 47661 & 6.92 & 6.9957 & TRN \\
\hline CHEMBL402702 & 47661 & 6.47 & 6.2458 & TRN \\
\hline CHEMBL331975 & 47661 & 7.65 & 7.4977 & TRN \\
\hline CHEMBL331405 & 47661 & 6.52 & 6.3365 & TRN \\
\hline CHEMBL118189 & 47661 & 5.46 & 5.6369 & TRN \\
\hline CHEMBL120168 & 47661 & 7.31 & 7.4551 & TST \\
\hline CHEMBL331688 & 47661 & 7.01 & 7.0493 & TRN \\
\hline CHEMBL121021 & 47661 & 7.44 & 7.5342 & TRN \\
\hline CHEMBL332128 & 47661 & 6.53 & 6.5707 & TRN \\
\hline CHEMBL421271 & 47661 & 7.32 & 7.0129 & TRN \\
\hline CHEMBL120021 & 47661 & 6.35 & 6.2129 & TRN \\
\hline CHEMBL331468 & 47661 & 5.39 & 5.8753 & TRN \\
\hline CHEMBL331119 & 47661 & 5.82 & 6.1021 & TRN \\
\hline CHEMBL433028 & 47661 & 6.0 & 5.8186 & TST \\
\hline CHEMBL120015 & 47661 & 6.85 & 7.1088 & TST \\
\hline CHEMBL330854 & 47661 & 6.26 & 6.7294 & TST \\
\hline CHEMBL332568 & 47661 & 7.71 & 7.5445 & TST \\
\hline CHEMBL118954 & 47661 & 4.69 & 5.5267 & TST \\
\hline CHEMBL331262 & 47661 & 7.35 & 7.0219 & TST \\
\hline CHEMBL332850 & 47661 & 4.7 & 6.1212 & TST \\
\hline CHEMBL332902 & 47661 & 7.64 & 7.5269 & TST \\
\hline CHEMBL311354 & 50316 & 1.284 & 1.2727 & TRN \\
\hline CHEMBL310271 & 50316 & 3.6383 & 3.6279 & TRN \\
\hline CHEMBL80701 & 50316 & 2.8861 & 2.875 & TRN \\
\hline CHEMBL309978 & 50316 & 3.3979 & 3.407 & TRN \\
\hline CHEMBL77155 & 50316 & 4.3468 & 1.8566 & TST \\
\hline CHEMBL311228 & 50316 & 3.6576 & 1.8351 & TST \\
\hline CHEMBL80213 & 50316 & 3.4437 & 3.4301 & TRN \\
\hline CHEMBL 78227 & 50316 & 2.1549 & 2.1385 & TRN \\
\hline CHEMBL80203 & 50316 & 2.0 & 3.6447 & TST \\
\hline CHEMBL309495 & 50316 & 2.3565 & 2.3835 & TRN \\
\hline
\end{tabular}

Page 8641 


\begin{tabular}{|c|c|c|c|c|c|}
\hline \multicolumn{6}{|c|}{ Supplemental Table S2.txt } \\
\hline CHEMBL80755 & 50316 & 2.301 & 3.448 & TST & \\
\hline CHEMBL76670 & 50316 & 3.6198 & 3.6332 & TRN & \\
\hline CHEMBL77369 & 50316 & 3.2076 & 3.2344 & TRN & \\
\hline CHEMBL415270 & 50316 & 3.5376 & 3.5119 & TRN & \\
\hline CHEMBL75809 & 50316 & 2.301 & 2.3228 & TRN & \\
\hline CHEMBL77145 & 50316 & 6.0 & 2.719 & TST & \\
\hline CHEMBL311488 & 50316 & 2.301 & 2.3072 & TRN & \\
\hline CHEMBL80402 & 50316 & 2.1549 & 3.0749 & TST & \\
\hline CHEMBL80713 & 50316 & 3.4815 & 3.4736 & TRN & \\
\hline CHEMBL311571 & 50316 & 6.0 & 5.9736 & TRN & \\
\hline CHEMBL76784 & 50316 & 2.3979 & 2.3982 & TRN & \\
\hline CHEMBL 307891 & 50316 & 2.0 & 2.024 & TRN & \\
\hline CHEMBL80693 & 50316 & 2.8539 & 2.7939 & TRN & \\
\hline CHEMBL 309227 & 50316 & 3.301 & 3.3105 & TRN & \\
\hline CHEMBL80859 & 50316 & 2.8861 & 2.8957 & TRN & \\
\hline CHEMBL80562 & 50316 & 3.0 & 3.0046 & TRN & \\
\hline CHEMBL 78223 & 50316 & 4.5229 & 4.5244 & TRN & \\
\hline CHEMBL312078 & 50316 & 4.3979 & 4.4162 & TRN & \\
\hline CHEMBL 77291 & 50316 & 2.5229 & 2.5173 & TRN & \\
\hline CHEMBL 80168 & 50316 & 0.3665 & 0.3387 & TRN & \\
\hline CHEMBL 311741 & 50316 & 3.3979 & 3.4058 & TRN & \\
\hline CHEMBL540188 & 50316 & 2.6383 & 2.64600 & 00000000004 & TRN \\
\hline CHEMBL80225 & 50316 & 3.6021 & 3.6248 & TRN & \\
\hline CHEMBL 76917 & 50316 & 2.9208 & 2.9319 & TRN & \\
\hline CHEMBL 78214 & 50316 & 1.4815 & 1.5061 & TRN & \\
\hline CHEMBL 76592 & 50316 & 3.7959 & 3.7817 & TRN & \\
\hline CHEMBL 77126 & 50316 & 2.2218 & 2.2252 & TRN & \\
\hline CHEMBL 74799 & 50316 & 4.0 & 4.0009 & TRN & \\
\hline CHEMBL 312530 & 50316 & 2.8861 & 2.8779 & TRN & \\
\hline CHEMBL75795 & 50316 & 3.2518 & 3.2336 & TRN & \\
\hline CHEMBL 307367 & 50316 & 2.3665 & 2.3653 & TRN & \\
\hline CHEMBL 77064 & 50316 & 3.6383 & 3.261 & TST & \\
\hline CHEMBL 77122 & 50316 & 2.301 & 3.0916 & TST & \\
\hline CHEMBL75319 & 50316 & 2.5528 & 2.5407 & TRN & \\
\hline CHEMBL23254 & 50316 & 4.699 & 4.7157 & TRN & \\
\hline CHEMBL 77732 & 50316 & 4.0 & 4.0041 & TRN & \\
\hline CHEMBL 80916 & 50316 & 3.5686 & 3.57 & TRN & \\
\hline CHEMBL 305823 & 50316 & 3.301 & 3.2951 & TRN & \\
\hline CHEMBL 77610 & 50316 & 3.6576 & 3.1257 & TST & \\
\hline CHEMBL419830 & 50316 & 2.7959 & 2.8046 & TRN & \\
\hline CHEMBL76761 & 50316 & 3.7696 & 1.9052 & TST & \\
\hline CHEMBL 77365 & 50316 & 3.301 & 3.2983 & TRN & \\
\hline CHEMBL76921 & 50316 & 1.9666 & 1.962 & TRN & \\
\hline CHEMBL 80754 & 50316 & 3.1549 & 3.1587 & TRN & \\
\hline CHEMBL 308714 & 50316 & 3.8861 & 3.8956 & TRN & \\
\hline CHEMBL 276120 & 50316 & 2.0 & 3.9751 & TST & \\
\hline CHEMBL 77413 & 50316 & 2.9208 & 3.4193 & TST & \\
\hline CHEMBL420571 & 50316 & 2.5528 & 3.0098 & TST & \\
\hline
\end{tabular}




\begin{tabular}{|c|c|c|c|c|}
\hline \multicolumn{5}{|c|}{ Supplemental Table S2.txt } \\
\hline CHEMBL75973 & 50316 & 2.0458 & 2.0231 & TRN \\
\hline CHEMBL77262 & 50316 & 4.0969 & 4.0473 & TRN \\
\hline CHEMBL80674 & 50316 & 3.6778 & 3.6973 & TRN \\
\hline CHEMBL79491 & 50316 & 2.8239 & 2.8093 & TRN \\
\hline CHEMBL 80920 & 50316 & 2.9208 & 3.6156 & TST \\
\hline CHEMBL445311 & 50316 & 2.301 & 3.3593 & TST \\
\hline CHEMBL80758 & 50316 & 2.0458 & 2.0557 & TRN \\
\hline CHEMBL 310590 & 50316 & 3.8861 & 3.9683 & TST \\
\hline CHEMBL80586 & 50316 & 3.2757 & 3.3025 & TRN \\
\hline CHEMBL77119 & 50316 & 2.2757 & 2.4277 & TST \\
\hline CHEMBL419094 & 50316 & 3.1024 & 3.1384 & TRN \\
\hline CHEMBL75633 & 50316 & 2.5686 & 2.5863 & TRN \\
\hline CHEMBL 306783 & 50316 & 3.5229 & 3.5108 & TRN \\
\hline CHEMBL 306288 & 50316 & 2.3979 & 2.9166 & TST \\
\hline CHEMBL79329 & 50316 & 3.3768 & 3.3633 & TRN \\
\hline CHEMBL312406 & 50316 & 2.301 & 3.6597 & TST \\
\hline CHEMBL 306183 & 50316 & 3.3468 & 3.455 & TST \\
\hline CHEMBL75924 & 50316 & 2.1871 & 2.1731 & TRN \\
\hline CHEMBL80895 & 50316 & 3.0458 & 3.0507 & TRN \\
\hline CHEMBL1518369 & 688763 & 4.3 & 4.3567 & TRN \\
\hline CHEMBL462576 & 688763 & 6.0 & 4.4654 & TST \\
\hline CHEMBL167423 & 688763 & 4.1 & 4.2225 & TRN \\
\hline CHEMBL1430204 & 688763 & 4.3 & 4.3983 & TRN \\
\hline CHEMBL1492884 & 688763 & 4.4 & 4.3631 & TRN \\
\hline CHEMBL440287 & 688763 & 4.3 & 4.3912 & TRN \\
\hline CHEMBL144530 & 688763 & 4.4 & 4.3273 & TRN \\
\hline CHEMBL509531 & 688763 & 4.6 & 4.5557 & TST \\
\hline CHEMBL1447588 & 688763 & 5.0 & 4.8805 & TST \\
\hline CHEMBL1338613 & 688763 & 4.3 & 4.1915 & TRN \\
\hline CHEMBL1602699 & 688763 & 5.2 & 5.2075 & TRN \\
\hline CHEMBL1526319 & 688763 & 4.3 & 4.2732 & TRN \\
\hline CHEMBL1561876 & 688763 & 4.3 & 4.2886 & TRN \\
\hline CHEMBL224282 & 688763 & 4.1 & 4.1841 & TRN \\
\hline CHEMBL1489064 & 688763 & 4.1 & 4.2769 & TRN \\
\hline CHEMBL443949 & 688763 & 4.3 & 4.1863 & TRN \\
\hline CHEMBL 242080 & 688763 & 4.3 & 4.4147 & TRN \\
\hline CHEMBL1565705 & 688763 & 4.1 & 4.2363 & TRN \\
\hline CHEMBL36296 & 688763 & 4.1 & 4.1123 & TRN \\
\hline CHEMBL1308088 & 688763 & 4.9 & 4.8899 & TRN \\
\hline CHEMBL1495381 & 688763 & 5.9 & 4.9999 & TST \\
\hline CHEMBL1414154 & 688763 & 4.1 & 4.0452 & TRN \\
\hline CHEMBL1331245 & 688763 & 4.3 & 4.2201 & TRN \\
\hline CHEMBL1524617 & 688763 & 5.2 & 5.0189 & TRN \\
\hline CHEMBL1304981 & 688763 & 4.1 & 4.1022 & TRN \\
\hline CHEMBL1549844 & 688763 & 4.6 & 4.689 & TST \\
\hline CHEMBL1530684 & 688763 & 4.4 & 4.3672 & TRN \\
\hline CHEMBL1612246 & 688763 & 4.3 & 4.3426 & TRN \\
\hline CHEMBL195953 & 688763 & 4.1 & 4.2896 & TST \\
\hline
\end{tabular}




\begin{tabular}{|c|c|c|c|c|c|}
\hline \\
\hline CHEMBL1408847 & 688763 & 5.1 & 5.1879 & TRN & \\
\hline CHEMBL1496957 & 688763 & 4.6 & 4.6382 & TRN & \\
\hline CHEMBL44072 & 688763 & 4.4 & 4.3503 & TST & \\
\hline CHEMBL1558796 & 688763 & 4.3 & 4.3506 & TRN & \\
\hline CHEMBL402063 & 688763 & 4.3 & 5.0652 & TST & \\
\hline CHEMBL1527567 & 688763 & 4.4 & 4.2771 & TRN & \\
\hline CHEMBL418068 & 688763 & 4.2 & 4.1986 & TRN & \\
\hline CHEMBL1609459 & 688763 & 5.0 & 5.001 & TRN & \\
\hline CHEMBL1366408 & 688763 & 4.4 & 4.296 & TRN & \\
\hline CHEMBL 8320 & 688763 & 4.3 & 4.5204 & TST & \\
\hline CHEMBL1309179 & 688763 & 4.9 & 4.7255 & TRN & \\
\hline CHEMBL1569226 & 688763 & 5.2 & 5.2746 & TRN & \\
\hline CHEMBL1499545 & 688763 & 5.1 & 5.0896 & TRN & \\
\hline CHEMBL230156 & 688763 & 4.3 & 4.2766 & TRN & \\
\hline CHEMBL1517425 & 688763 & 4.1 & 4.0782 & TRN & \\
\hline CHEMBL1452158 & 688763 & 4.3 & 4.1144 & TRN & \\
\hline CHEMBL1579130 & 688763 & 6.0 & 5.2495 & TST & \\
\hline CHEMBL1559341 & 688763 & 4.6 & 4.5411 & TRN & \\
\hline CHEMBL192627 & 688763 & 4.6 & 4.6959 & TST & \\
\hline CHEMBL1450607 & 688763 & 4.7 & 4.5458 & TST & \\
\hline CHEMBL8739 & 688763 & 4.1 & 4.1085 & TRN & \\
\hline CHEMBL1569493 & 688763 & 5.9 & 5.7164 & TRN & \\
\hline CHEMBL1545634 & 688763 & 6.4 & 6.2711 & TRN & \\
\hline CHEMBL1526721 & 688763 & 5.3 & 5.0154 & TST & \\
\hline CHEMBL1522486 & 688763 & 4.6 & 4.6593 & TRN & \\
\hline CHEMBL1303139 & 688763 & 5.1 & 5.13200 & 0000000001 & TRN \\
\hline CHEMBL1451833 & 688763 & 4.4 & 4.3687 & TRN & \\
\hline CHEMBL1407826 & 688763 & 4.4 & 4.7019 & TST & \\
\hline CHEMBL1576086 & 688763 & 4.3 & 4.3106 & TRN & \\
\hline CHEMBL1566504 & 688763 & 4.3 & 4.3925 & TST & \\
\hline CHEMBL162598 & 688763 & 4.3 & 4.2119 & TST & \\
\hline CHEMBL1600998 & 688763 & 5.2 & 5.3006 & TRN & \\
\hline CHEMBL1484480 & 688763 & 4.4 & 4.2132 & TRN & \\
\hline CHEMBL1471289 & 688763 & 4.5 & 4.5489 & TRN & \\
\hline CHEMBL289277 & 688763 & 4.3 & 4.298 & TRN & \\
\hline CHEMBL1535689 & 688763 & 4.4 & 4.3409 & TRN & \\
\hline CHEMBL140 & 688763 & 4.3 & 4.2649 & TRN & \\
\hline CHEMBL486193 & 688763 & 4.1 & 4.5326 & TST & \\
\hline CHEMBL1462419 & 688763 & 4.1 & 4.3051 & TRN & \\
\hline CHEMBL1142 & 688763 & 4.3 & 4.3368 & TRN & \\
\hline CHEMBL1448387 & 688763 & 4.3 & 4.3328 & TRN & \\
\hline CHEMBL1409985 & 688763 & 5.2 & 5.1227 & TRN & \\
\hline CHEMBL1200471 & 688763 & 6.4 & 6.5893 & TRN & \\
\hline CHEMBL196537 & 688763 & 4.3 & 4.2836 & TST & \\
\hline CHEMBL334255 & 688763 & 4.4 & 4.6387 & TRN & \\
\hline CHEMBL1492104 & 688763 & 4.7 & 4.7577 & TST & \\
\hline CHEMBL1562104 & 688763 & 5.2 & 5.2375 & TRN & \\
\hline CHEMBL220845 & 688763 & 4.1 & 4.1185 & TRN & \\
\hline
\end{tabular}




\begin{tabular}{|c|c|c|c|c|c|}
\hline CHEMBL1519327 & 688763 & 6.3 & 6.2112 & TRN & \\
\hline CHEMBL1449018 & 688763 & 4.4 & 4.4086 & TRN & \\
\hline CHEMBL1485360 & 688763 & 4.6 & 4.5109 & TST & \\
\hline CHEMBL105712 & 688763 & 4.9 & 4.9715 & TST & \\
\hline CHEMBL1498444 & 688752 & 4.4509 & 3.4996 & TRN & \\
\hline CHEMBL1568508 & 688752 & 4.808 & 4.051 & TRN & \\
\hline CHEMBL1349621 & 688752 & 5.6082 & 5.5874 & TST & \\
\hline CHEMBL1604975 & 688752 & 5.2783 & 5.2373 & TRN & \\
\hline CHEMBL1322190 & 688752 & 3.1003 & 3.1746 & TRN & \\
\hline CHEMBL1499411 & 688752 & 4.8914 & 3.7111 & TRN & \\
\hline CHEMBL1456701 & 688752 & 4.9551 & 4.9517 & TRN & \\
\hline CHEMBL1604196 & 688752 & 4.5855 & 4.4674 & TRN & \\
\hline CHEMBL1491688 & 688752 & 3.1003 & 3.7285 & TST & \\
\hline CHEMBL1547204 & 688752 & 4.2431 & 3.6552 & TRN & \\
\hline CHEMBL1501928 & 688752 & 4.8345 & 3.9457 & TRN & \\
\hline CHEMBL1515768 & 688752 & 3.7333 & 3.1953 & TRN & \\
\hline CHEMBL3199401 & 688752 & 4.5429 & 4.8028 & TRN & \\
\hline CHEMBL1568260 & 688752 & 5.0838 & 4.9021 & TRN & \\
\hline CHEMBL1331930 & 688752 & 5.6676 & \multicolumn{2}{|c|}{5.7010000000000005} & TST \\
\hline CHEMBL1385904 & 688752 & 5.0791 & 4.8792 & TRN & \\
\hline CHEMBL1337652 & 688752 & 5.0863 & 4.5632 & TRN & \\
\hline CHEMBL1385747 & 688752 & 4.9551 & 4.7695 & TRN & \\
\hline CHEMBL1528299 & 688752 & 3.1003 & 3.7177 & TST & \\
\hline CHEMBL1412417 & 688752 & 3.6258 & 3.8031 & TRN & \\
\hline CHEMBL1530807 & 688752 & 4.9694 & 5.0041 & TRN & \\
\hline CHEMBL1363571 & 688752 & 5.2354 & 5.0636 & TRN & \\
\hline CHEMBL1601252 & 688752 & 3.5774 & \multicolumn{2}{|c|}{3.6260000000000003} & TRN \\
\hline CHEMBL1418633 & 688752 & 4.7051 & 4.7058 & TRN & \\
\hline CHEMBL1164316 & 688752 & 5.0915 & 4.8619 & TRN & \\
\hline CHEMBL1497668 & 688752 & 4.658 & 4.8472 & TRN & \\
\hline CHEMBL1416266 & 688752 & 5.1002 & 5.3247 & TRN & \\
\hline CHEMBL1305201 & 688752 & 3.1003 & 3.2797 & TRN & \\
\hline CHEMBL1568611 & 688752 & 3.1003 & 3.7083 & TRN & \\
\hline CHEMBL 1380526 & 688752 & 4.8952 & 4.4263 & TRN & \\
\hline CHEMBL1580375 & 688752 & 5.1852 & 5.1122 & TRN & \\
\hline CHEMBL1604626 & 688752 & 3.1003 & 3.1613 & TRN & \\
\hline CHEMBL1489863 & 688752 & 4.5393 & 4.7726 & TRN & \\
\hline CHEMBL1548720 & 688752 & 3.1003 & 3.1733 & TRN & \\
\hline CHEMBL1470505 & 688752 & 3.1003 & 3.1948 & TRN & \\
\hline CHEMBL1365146 & 688752 & 5.1009 & 5.3736 & TRN & \\
\hline CHEMBL1306312 & 688752 & 4.4026 & 4.448 & TRN & \\
\hline CHEMBL1349902 & 688752 & 3.1003 & 3.1991 & TRN & \\
\hline CHEMBL1399754 & 688752 & 4.0546 & 4.8494 & TRN & \\
\hline CHEMBL1500449 & 688752 & 4.9747 & 5.1207 & TRN & \\
\hline CHEMBL1403983 & 688752 & 3.1003 & 3.6738 & TRN & \\
\hline CHEMBL1416815 & 688752 & 5.32 & 5.3219 & TRN & \\
\hline CHEMBL1579464 & 688752 & 5.0922 & 5.3745 & TRN & \\
\hline CHEMBL3199612 & 688752 & 4.3221 & 3.6852 & TRN & \\
\hline
\end{tabular}


Supplemental Table S2.txt

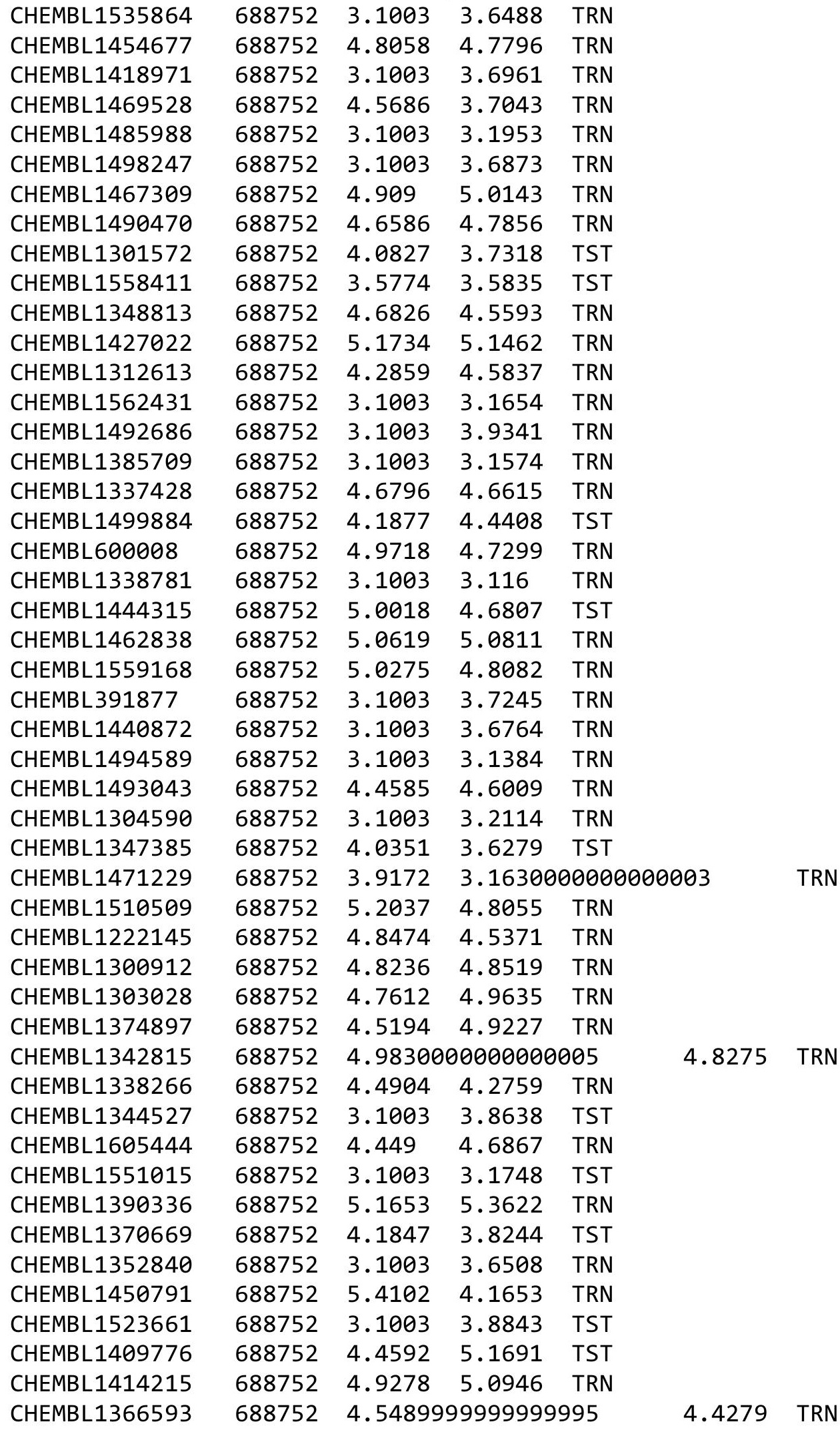

Page 8646 
Supplemental Table S2.txt

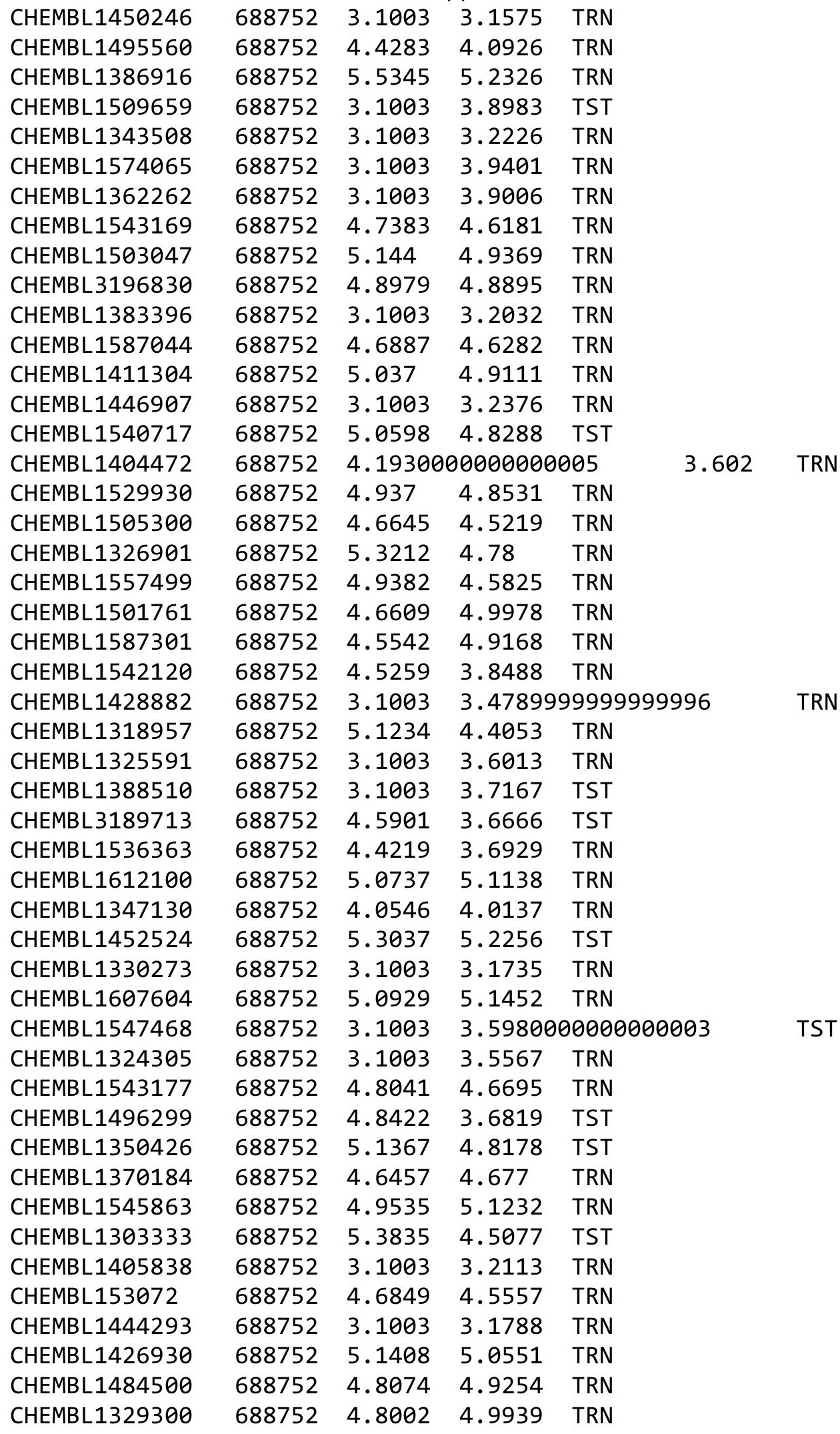


Supplemental Table S2.txt

\begin{tabular}{|c|c|c|c|c|c|}
\hline CHEMBL1494982 & 688752 & 3.1003 & 3.1757 & TRN & \\
\hline CHEMBL1359009 & 688752 & 4.6243 & 4.3507 & TRN & \\
\hline CHEMBL1448094 & 688752 & 4.3691 & 4.3083 & TRN & \\
\hline CHEMBL1432472 & 688752 & 3.5774 & 3.8265 & TRN & \\
\hline CHEMBL1364957 & 688752 & 4.4946 & 3.5979 & TRN & \\
\hline CHEMBL1427304 & 688752 & 3.1003 & 3.2483 & TRN & \\
\hline CHEMBL1503060 & 688752 & 5.3708 & 4.7994 & TRN & \\
\hline CHEMBL1351418 & 688752 & 4.9654 & 5.1281 & TRN & \\
\hline CHEMBL1528008 & 688752 & 3.1003 & 3.7189 & TRN & \\
\hline CHEMBL1603238 & 688752 & 4.387 & 3.7319 & TST & \\
\hline CHEMBL1375544 & 688752 & 3.1003 & \multicolumn{2}{|c|}{ 3. 2039999999999997} & TRN \\
\hline CHEMBL1417231 & 688752 & 5.4002 & 5.2366 & TRN & \\
\hline CHEMBL1327088 & 688752 & 3.1003 & 3.2341 & TRN & \\
\hline CHEMBL1497688 & 688752 & 3.1003 & 3.2071 & TRN & \\
\hline CHEMBL1491062 & 688752 & 4.6536 & 4.6921 & TRN & \\
\hline CHEMBL1450163 & 688752 & 4.543 & 4.3561 & TRN & \\
\hline CHEMBL1309837 & 688752 & 4.9289 & 4.8824 & TRN & \\
\hline CHEMBL1587518 & 688752 & 5.6284 & 3.9536 & TST & \\
\hline CHEMBL1575003 & 688752 & 4.4508 & 4.1555 & TRN & \\
\hline CHEMBL1585275 & 688752 & 4.3466 & 3.7647 & TRN & \\
\hline CHEMBL1587890 & 688752 & 3.1003 & 3.1952 & TRN & \\
\hline CHEMBL1380640 & 688752 & 3.1003 & 3.8279 & TST & \\
\hline CHEMBL1582392 & 688752 & 3.1003 & 3.3864 & TRN & \\
\hline CHEMBL1442411 & 688752 & 3.9465 & 3.5437 & TRN & \\
\hline CHEMBL1596518 & 688752 & 3.1003 & \multicolumn{2}{|c|}{3.1460000000000004} & TRN \\
\hline CHEMBL3197060 & 688752 & 5.069 & 5.2562 & TST & \\
\hline CHEMBL1485384 & 688752 & 4.5577 & 3.6119 & TRN & \\
\hline CHEMBL1347350 & 688752 & 3.1003 & 3.2015 & TRN & \\
\hline CHEMBL1302000 & 688752 & 3.1003 & 3.1164 & TRN & \\
\hline CHEMBL1368099 & 688752 & 4.3609 & 3.4935 & TRN & \\
\hline CHEMBL1318943 & 688752 & 4.8419 & 4.8944 & TST & \\
\hline CHEMBL1412448 & 688752 & 4.1799 & 3.4931 & TRN & \\
\hline CHEMBL1332040 & 688752 & 4.5355 & 4.6133 & TST & \\
\hline CHEMBL3198706 & 688752 & 4.6398 & 4.7477 & TST & \\
\hline CHEMBL1380276 & 688752 & 3.5774 & 3.6459 & TRN & \\
\hline CHEMBL1543903 & 688752 & 3.1003 & 3.1687 & TRN & \\
\hline CHEMBL1547272 & 688752 & 3.1003 & 3.5857 & TRN & \\
\hline CHEMBL1484562 & 688752 & 5.2579 & 4.8617 & TST & \\
\hline CHEMBL1354197 & 688752 & 3.1003 & 3.7633 & TST & \\
\hline CHEMBL1351746 & 688752 & 4.6753 & 3.5765 & TST & \\
\hline CHEMBL1495948 & 688752 & 4.7138 & 3.9688 & TRN & \\
\hline CHEMBL1414671 & 688752 & 4.7775 & 3.8595 & TRN & \\
\hline CHEMBL1451957 & 688752 & 3.5774 & 3.5947 & TRN & \\
\hline CHEMBL1528753 & 688752 & 3.1003 & 3.1722 & TRN & \\
\hline CHEMBL1494683 & 688752 & 3.5774 & 3.656 & TRN & \\
\hline CHEMBL1605635 & 688752 & 4.0495 & 3.6488 & TRN & \\
\hline CHEMBL 3198000 & 688752 & 5.5478 & 5.2588 & TRN & \\
\hline CHEMBL1426396 & 688752 & 3.1003 & 3.2757 & TRN & \\
\hline
\end{tabular}


Supplemental Table S2.txt

\begin{tabular}{|c|c|c|c|c|c|}
\hline CHEMBL1573867 & 688752 & 3.1003 & 3.7692 & TRN & \\
\hline CHEMBL1399076 & 688752 & 3.1003 & 3.1933 & TRN & \\
\hline CHEMBL1459745 & 688752 & 3.8633 & 3.5378 & TRN & \\
\hline CHEMBL1322491 & 688752 & 3.5774 & 3.8742 & TRN & \\
\hline CHEMBL1321356 & 688752 & 5.48799 & 79999999 & 995 & 5.2337 \\
\hline CHEMBL1580338 & 688752 & 3.1003 & 3.193 & TRN & \\
\hline CHEMBL504791 & 688752 & 4.9219 & 5.0482 & TST & \\
\hline CHEMBL1486010 & 688752 & 3.1003 & 3.5651 & TRN & \\
\hline CHEMBL1586211 & 688752 & 4.3969 & 4.4876 & TRN & \\
\hline CHEMBL1561641 & 688752 & 4.9259 & 4.7052 & TRN & \\
\hline CHEMBL1572461 & 688752 & 3.1003 & 3.406 & TRN & \\
\hline CHEMBL1413736 & 688752 & 3.1003 & 3.722 & TRN & \\
\hline CHEMBL1388862 & 688752 & 5.2485 & 5.0048 & TST & \\
\hline CHEMBL1301494 & 688752 & 3.1003 & 3.5011 & TRN & \\
\hline CHEMBL1431563 & 688752 & 3.1003 & 3.7413 & TRN & \\
\hline CHEMBL 1484186 & 688752 & 4.9996 & 4.7986 & TST & \\
\hline CHEMBL1587764 & 688752 & 4.5814 & 3.9001 & TRN & \\
\hline CHEMBL1575051 & 688752 & 4.0701 & 3.6234 & TRN & \\
\hline CHEMBL1305732 & 688752 & 3.1003 & 3.573 & TRN & \\
\hline CHEMBL1508025 & 688752 & 4.0546 & 4.0446 & TRN & \\
\hline CHEMBL1589053 & 688752 & 4.8589 & 4.7351 & TRN & \\
\hline CHEMBL1359775 & 688752 & 5.3254 & 4.8991 & TRN & \\
\hline CHEMBL1447245 & 688752 & 4.934 & 4.9744 & TRN & \\
\hline CHEMBL405110 & 688752 & 6.1296 & 5.6247 & TST & \\
\hline CHEMBL1462764 & 688752 & 5.2997 & 4.8449 & TRN & \\
\hline CHEMBL1601197 & 688752 & 4.5032 & 4.3628 & TRN & \\
\hline CHEMBL1503781 & 688752 & 3.1003 & 3.1508 & TRN & \\
\hline CHEMBL1603319 & 688752 & 3.1003 & 4.8515 & TRN & \\
\hline CHEMBL1313532 & 688752 & 3.1003 & 3.1441 & TRN & \\
\hline CHEMBL1607932 & 688752 & 4.8857 & 5.121 & TRN & \\
\hline CHEMBL1611123 & 688752 & 4.9763 & 5.0731 & TRN & \\
\hline CHEMBL1336564 & 688752 & 3.1003 & 3.5036 & TRN & \\
\hline CHEMBL1414033 & 688752 & 3.1003 & 3.1528 & TRN & \\
\hline CHEMBL1538790 & 688752 & 5.4864 & 5.6131 & TRN & \\
\hline CHEMBL1393172 & 688752 & 5.1404 & 5.324 & TRN & \\
\hline CHEMBL1588950 & 688752 & 4.2279 & 4.248 & TRN & \\
\hline CHEMBL1556602 & 688752 & 4.9219 & 5.0934 & TST & \\
\hline CHEMBL1510408 & 688752 & 5.3741 & 5.3502 & TST & \\
\hline CHEMBL1488394 & 688752 & 3.1003 & 3.1613 & TRN & \\
\hline CHEMBL1537230 & 688752 & 3.5774 & 3.5587 & TRN & \\
\hline CHEMBL1494018 & 688752 & 3.1003 & 3.1551 & TRN & \\
\hline CHEMBL1330383 & 688752 & 5.4187 & 3.5209 & TRN & \\
\hline CHEMBL1481844 & 688752 & 3.5774 & 3.5235 & TRN & \\
\hline CHEMBL1464093 & 688752 & 4.6857 & 4.7684 & TRN & \\
\hline CHEMBL1328113 & 688752 & 3.1003 & 3.1181 & TRN & \\
\hline CHEMBL1392806 & 688752 & 4.4219 & 4.6741 & TRN & \\
\hline CHEMBL1449640 & 688752 & 4.7359 & 4.6011 & TRN & \\
\hline CHEMBL1546820 & 688752 & 4.4127 & 3.8569 & TST & \\
\hline
\end{tabular}




\begin{tabular}{|c|c|c|c|c|c|c|}
\hline & & \multicolumn{5}{|c|}{ Supplemental Table S2.txt } \\
\hline CHEMBL1465040 & 688752 & 3.1003 & 3.8677 & TRN & & \\
\hline CHEMBL1408514 & 688752 & 3.5774 & 4.5536 & TRN & & \\
\hline CHEMBL1380232 & 688752 & 5.472 & 5.4578 & TRN & & \\
\hline CHEMBL3192653 & 688752 & 4.7293 & 4.7118 & TRN & & \\
\hline CHEMBL3195488 & 688752 & 5.1358 & 4.8094 & TST & & \\
\hline CHEMBL1382865 & 688752 & 4.9427 & 5.0613 & TRN & & \\
\hline CHEMBL1328473 & 688752 & 5.0923 & 5.2014 & TRN & & \\
\hline CHEMBL1515913 & 688752 & 3.1003 & 3.7314 & TRN & & \\
\hline CHEMBL1547257 & 688752 & 5.2871 & 5.1046 & TRN & & \\
\hline CHEMBL1409912 & 688752 & 3.5774 & 3.1603 & TRN & & \\
\hline CHEMBL1578127 & 688752 & 4.8788 & 4.6881 & TST & & \\
\hline CHEMBL1417249 & 688752 & 5.0124 & 4.8344 & TST & & \\
\hline CHEMBL1556424 & 688752 & 3.1003 & 3.2113 & TRN & & \\
\hline CHEMBL1420204 & 688752 & 3.1003 & 3.2066 & TRN & & \\
\hline CHEMBL1545051 & 688752 & 4.937 & 4.5485 & TST & & \\
\hline CHEMBL1507312 & 688752 & 4.6207 & 4.6799 & TRN & & \\
\hline CHEMBL1374054 & 688752 & 5.4688 & 5.2908 & TRN & & \\
\hline CHEMBL1556190 & 688752 & 5.3394 & 5.0612 & TRN & & \\
\hline CHEMBL1603373 & 688752 & 4.5569 & 4.7875 & TRN & & \\
\hline CHEMBL1501406 & 688752 & 5.1026 & 4.0415 & TRN & & \\
\hline CHEMBL1398596 & 688752 & 4.7073 & 3.6646 & TRN & & \\
\hline CHEMBL1340538 & 688752 & 3.1003 & 3.3298 & TRN & & \\
\hline CHEMBL1271059 & 688752 & 4.9367 & 5.2097 & TRN & & \\
\hline CHEMBL1564280 & 688752 & 4.9115 & 5.1042 & TRN & & \\
\hline CHEMBL1351686 & 688752 & 5.09399 & 999999999 & 99 & 5.1078 & TRN \\
\hline CHEMBL1531023 & 688752 & 3.1003 & 3.1684 & TRN & & \\
\hline CHEMBL1546847 & 688752 & 3.1003 & 3.4108 & TRN & & \\
\hline CHEMBL1408111 & 688752 & 4.8523 & 5.0526 & TRN & & \\
\hline CHEMBL1464872 & 688752 & 3.5774 & 3.7178 & TRN & & \\
\hline CHEMBL1299762 & 688752 & 4.9031 & 5.0029 & TST & & \\
\hline CHEMBL1389338 & 688752 & 4.4466 & 3.5952 & TRN & & \\
\hline CHEMBL1613238 & 688752 & 5.8582 & 5.388999 & 9999999999 & & TST \\
\hline CHEMBL1563062 & 688752 & 3.1003 & 3.0705 & TRN & & \\
\hline CHEMBL1348824 & 688752 & 3.1003 & 3.1635 & TRN & & \\
\hline CHEMBL1424191 & 688752 & 3.1003 & 3.5078 & TRN & & \\
\hline CHEMBL1589567 & 688752 & $5.4970 e$ & 000000000 & 01 & 5.2611 & TRN \\
\hline CHEMBL1304062 & 688752 & 4.4184 & 4.1463 & TRN & & \\
\hline CHEMBL1417458 & 688752 & 3.1003 & 3.9618 & TRN & & \\
\hline CHEMBL1583741 & 688752 & 3.1003 & 3.4086 & TRN & & \\
\hline CHEMBL1386873 & 688752 & 3.1003 & 3.5934 & TRN & & \\
\hline CHEMBL1521813 & 688752 & 4.6164 & 4.2723 & TST & & \\
\hline CHEMBL1352830 & 688752 & 3.1003 & 3.8343 & TRN & & \\
\hline CHEMBL1312424 & 688752 & 4.9014 & 5.2891 & TRN & & \\
\hline CHEMBL1409901 & 688752 & 4.3013 & 3.9786 & TRN & & \\
\hline CHEMBL1428640 & 688752 & 4.787 & 4.838 & TST & & \\
\hline CHEMBL3194658 & 688752 & 4.8996 & 4.7948 & TRN & & \\
\hline CHEMBL1576788 & 688752 & 4.6582 & 3.8051 & TRN & & \\
\hline CHEMBL1412520 & 688752 & 4.8297 & 4.8559 & TRN & & \\
\hline
\end{tabular}




\begin{tabular}{|c|c|c|c|c|c|}
\hline & & \multicolumn{4}{|c|}{ Supplemental Table S2.txt } \\
\hline CHEMBL1471189 & 688752 & 3.1003 & 5.5248 & TST & \\
\hline CHEMBL1978236 & 688752 & 5.064 & 5.3293 & TST & \\
\hline CHEMBL1517409 & 688752 & 3.1003 & 3.7761 & TRN & \\
\hline CHEMBL1376488 & 688752 & 4.8453 & 4.7577 & TRN & \\
\hline CHEMBL1600188 & 688752 & 4.4505 & 4.1573 & TRN & \\
\hline CHEMBL 3196468 & 688752 & 4.7113 & 4.5392 & TRN & \\
\hline CHEMBL1423537 & 688752 & 4.0546 & 4.6908 & TRN & \\
\hline CHEMBL1505452 & 688752 & 3.1003 & 3.1546 & TRN & \\
\hline CHEMBL1485914 & 688752 & 4.2691 & 3.3718 & TRN & \\
\hline CHEMBL1461424 & 688752 & 3.1003 & 3.2357 & TRN & \\
\hline CHEMBL1542650 & 688752 & 3.1003 & 3.5285 & TST & \\
\hline CHEMBL1582769 & 688752 & 4.9045 & 4.6972 & TRN & \\
\hline CHEMBL1312234 & 688752 & 4.4931 & 4.3611 & TRN & \\
\hline CHEMBL1405142 & 688752 & 5.1419 & 4.5991 & TRN & \\
\hline CHEMBL1567568 & 688752 & 4.8005 & 4.5823 & TST & \\
\hline CHEMBL1485010 & 688752 & 4.141 & 3.7672 & TRN & \\
\hline CHEMBL1597383 & 688752 & 4.2847 & 3.7614 & TRN & \\
\hline CHEMBL1480380 & 688752 & 3.1003 & 3.2009 & TRN & \\
\hline CHEMBL1490285 & 688752 & 3.1003 & 3.1368 & TRN & \\
\hline CHEMBL1398693 & 688752 & 3.1003 & 3.7568 & TST & \\
\hline CHEMBL1448856 & 688752 & 4.6981 & 4.6035 & TRN & \\
\hline CHEMBL1382616 & 688752 & 3.1003 & 3.7306 & TRN & \\
\hline CHEMBL1568732 & 688752 & 4.1179 & 3.2667 & TRN & \\
\hline CHEMBL1543192 & 688752 & 3.1003 & 3.7747 & TRN & \\
\hline CHEMBL1335392 & 688752 & 5.0306 & 4.9225 & TRN & \\
\hline CHEMBL1492585 & 688752 & 5.0523 & 5.0137 & TST & \\
\hline CHEMBL1305440 & 688752 & 3.1003 & 3.6027 & TRN & \\
\hline CHEMBL1452842 & 688752 & 3.1003 & 3.3557 & TRN & \\
\hline CHEMBL1425009 & 688752 & 3.1003 & 3.54699 & 99999999997 & TRN \\
\hline CHEMBL1490437 & 688752 & 3.1003 & 3.2048 & TRN & \\
\hline CHEMBL1494694 & 688752 & 5.026 & 4.9419 & TRN & \\
\hline CHEMBL3213646 & 688752 & 3.1003 & 3.6391 & TRN & \\
\hline CHEMBL1564547 & 688752 & 4.7397 & 4.3615 & TRN & \\
\hline CHEMBL1418881 & 688752 & 4.6844 & 4.7268 & TST & \\
\hline CHEMBL3198489 & 688752 & 3.1003 & 3.739 & TRN & \\
\hline CHEMBL1370794 & 688752 & 4.0546 & 4.6109 & TRN & \\
\hline CHEMBL1557028 & 688752 & 3.1003 & 3.8705 & TRN & \\
\hline CHEMBL1369067 & 688752 & 3.1003 & 3.1892 & TRN & \\
\hline CHEMBL1426003 & 688752 & 5.4076 & 5.4589 & TRN & \\
\hline CHEMBL1525902 & 688752 & 5.0136 & 4.5902 & TRN & \\
\hline CHEMBL1350581 & 688752 & 5.2515 & 5.0073 & TRN & \\
\hline CHEMBL1371949 & 688752 & 3.1003 & 3.2982 & TRN & \\
\hline CHEMBL1417090 & 688752 & 3.1003 & 3.1483 & TRN & \\
\hline CHEMBL3194616 & 688752 & 4.5435 & 3.8614 & TRN & \\
\hline CHEMBL1511437 & 688752 & 5.2011 & 5.2012 & TRN & \\
\hline CHEMBL1307254 & 688752 & 3.1003 & 3.6225 & TRN & \\
\hline CHEMBL1466134 & 688752 & 3.1003 & 3.7279 & TST & \\
\hline CHEMBL1526553 & 688752 & 5.0333 & 5.0476 & TRN & \\
\hline
\end{tabular}


Supplemental Table S2.txt

\begin{tabular}{|c|c|c|c|c|}
\hline CHEMBL1583070 & 688752 & 3.1003 & 3.1864 & TRN \\
\hline CHEMBL1360098 & 688752 & 3.5774 & 4.0421 & TRN \\
\hline CHEMBL1402874 & 688752 & 4.4473 & 3.5794 & TRN \\
\hline CHEMBL1389774 & 688752 & 3.1003 & 3.2014 & TRN \\
\hline CHEMBL1404376 & 688752 & 3.1003 & 3.6034 & TRN \\
\hline CHEMBL1345018 & 688752 & 3.1003 & 3.2235 & TRN \\
\hline CHEMBL1529744 & 688752 & 5.1479 & 5.0752 & TRN \\
\hline CHEMBL1569119 & 688752 & 3.1003 & 3.5487 & TRN \\
\hline CHEMBL1324024 & 688752 & 5.1731 & 5.3399 & TRN \\
\hline CHEMBL1521960 & 688752 & 5.0867 & 4.7346 & TST \\
\hline CHEMBL1454187 & 688752 & 3.1003 & 4.6784 & TRN \\
\hline CHEMBL1310248 & 688752 & 4.6402 & 3.4903 & TRN \\
\hline CHEMBL602163 & 688752 & 4.2208 & 4.1334 & TRN \\
\hline CHEMBL1535724 & 688752 & 3.1003 & 3.7734 & TRN \\
\hline CHEMBL1362149 & 688752 & 3.1003 & 3.3229 & TRN \\
\hline CHEMBL1467138 & 688752 & 3.1003 & 3.61899 & 99999999998 \\
\hline CHEMBL1428877 & 688752 & 3.1003 & 3.1594 & TRN \\
\hline CHEMBL1567207 & 688752 & 4.7277 & 4.4551 & TRN \\
\hline CHEMBL1423531 & 688752 & 4.5827 & 3.661 & TRN \\
\hline CHEMBL1608905 & 688752 & 3.1003 & 3.2222 & TRN \\
\hline CHEMBL1362711 & 688752 & 4.6338 & 4.5748 & TRN \\
\hline CHEMBL1587683 & 688752 & 4.4431 & 3.7627 & TRN \\
\hline CHEMBL1506268 & 688752 & 3.1003 & 3.6387 & TST \\
\hline CHEMBL1448422 & 688752 & 3.1003 & 3.1702 & TRN \\
\hline CHEMBL1449966 & 688752 & 4.523 & 4.8405 & TST \\
\hline CHEMBL1304332 & 688752 & 4.9682 & 4.8374 & TRN \\
\hline CHEMBL1401856 & 688752 & 3.1003 & 3.262 & TRN \\
\hline CHEMBL1535116 & 688752 & 3.1003 & 3.5626 & TRN \\
\hline CHEMBL1587976 & 688752 & 5.2864 & 5.4302 & TST \\
\hline CHEMBL1427926 & 688752 & 5.7133 & 5.4088 & TST \\
\hline CHEMBL1583996 & 688752 & 3.1003 & 3.4448 & TST \\
\hline CHEMBL1530194 & 688752 & 4.4907 & 4.729 & TST \\
\hline CHEMBL1378944 & 688752 & 3.1003 & 3.4769 & TST \\
\hline CHEMBL1441823 & 688752 & 4.9547 & 4.9473 & TST \\
\hline CHEMBL1588879 & 688752 & 3.1003 & 3.6879 & TST \\
\hline CHEMBL1366942 & 688752 & 4.7696 & 4.8859 & TST \\
\hline CHEMBL1526978 & 688752 & 3.1003 & 3.4883 & TST \\
\hline CHEMBL1488460 & 688752 & 4.8074 & 5.1713 & TST \\
\hline CHEMBL1571111 & 688752 & 4.7169 & 3.7737 & TST \\
\hline CHEMBL417727 & 688752 & 4.9176 & 4.9017 & TST \\
\hline CHEMBL1351361 & 688752 & 4.3521 & 4.452 & TST \\
\hline CHEMBL1966612 & 688752 & 4.9735 & 4.9082 & TST \\
\hline CHEMBL3196920 & 688752 & 4.5158 & 4.4242 & TST \\
\hline CHEMBL1388589 & 688752 & 5.7582 & 5.3414 & TST \\
\hline CHEMBL1498284 & 688752 & 4.5738 & 4.1839 & TST \\
\hline CHEMBL1569232 & 688752 & 4.614 & 3.6553 & TST \\
\hline CHEMBL1380975 & 688752 & 5.0069 & 4.2804 & TST \\
\hline CHEMBL1403337 & 688752 & 3.1003 & 3.8059 & TST \\
\hline
\end{tabular}




\begin{tabular}{|c|c|c|c|c|c|c|}
\hline & & \multicolumn{5}{|c|}{ Supplemental Table S2.txt } \\
\hline CHEMBL1381564 & 688752 & 4.2305 & 4.0575 & TST & & \\
\hline CHEMBL1505364 & 688752 & 3.1003 & 3.8386 & TST & & \\
\hline CHEMBL1366562 & 688752 & 5.0429 & 4.7742 & TST & & \\
\hline CHEMBL1331978 & 688752 & 5.3831 & 5.1539 & TST & & \\
\hline CHEMBL1384431 & 688752 & 4.9867 & 5.0344 & TST & & \\
\hline CHEMBL1604187 & 688752 & 3.1003 & 3.6374 & TST & & \\
\hline CHEMBL1606315 & 688752 & 4.6377 & 3.6877 & TST & & \\
\hline CHEMBL1431341 & 688752 & 4.7118 & 4.7608 & TST & & \\
\hline CHEMBL1491054 & 688752 & 4.8407 & 4.7799 & TST & & \\
\hline CHEMBL1556161 & 688752 & 5.4662 & 5.6151 & TST & & \\
\hline CHEMBL1586131 & 688752 & 3.1003 & 3.8707 & TST & & \\
\hline CHEMBL 3193785 & 688752 & 5.059 & 5.2207 & TST & & \\
\hline CHEMBL1510387 & 688752 & 3.1003 & 3.1023 & TST & & \\
\hline CHEMBL1596917 & 688752 & 3.1003 & 3.8002 & TST & & \\
\hline CHEMBL1448603 & 688752 & 4.561 & 4.8375 & TST & & \\
\hline CHEMBL1480312 & 688752 & 3.5774 & 3.2149 & TST & & \\
\hline CHEMBL1594622 & 688752 & 3.5774 & 3.1962 & TST & & \\
\hline CHEMBL1471965 & 688752 & 3.1003 & 3.8576 & TST & & \\
\hline CHEMBL1539264 & 688752 & 4.5819 & 4.4505 & TST & & \\
\hline CHEMBL1412367 & 688752 & 3.1003 & 3.6768 & TST & & \\
\hline CHEMBL445522 & 566087 & 9.301 & 9.4406 & TRN & & \\
\hline CHEMBL492946 & 566087 & 6.0213 & 4.4841 & TRN & & \\
\hline CHEMBL494225 & 566087 & 9.4559 & 9.024 & TRN & & \\
\hline CHEMBL523021 & 566087 & 5.301 & 6.3992 & TRN & & \\
\hline CHEMBL492948 & 566087 & 6.4831 & 5.3418 & TRN & & \\
\hline CHEMBL524010 & 566087 & 7.6757 & 6.7026 & TRN & & \\
\hline CHEMBL495182 & 566087 & 5.301 & 8.6524 & TRN & & \\
\hline CHEMBL522010 & 566087 & 4.696006 & 00000000 & 01 & 6.1122 & TRN \\
\hline CHEMBL492345 & 566087 & 3.9189 & 5.6067 & TST & & \\
\hline CHEMBL493942 & 566087 & 5.9625 & 5.7399 & TRN & & \\
\hline CHEMBL522154 & 566087 & 5.301 & 6.7314 & TRN & & \\
\hline CHEMBL494358 & 566087 & 8.3098 & 7.8363 & TRN & & \\
\hline CHEMBL494164 & 566087 & 7.6364 & 7.6488 & TST & & \\
\hline CHEMBL494349 & 566087 & 7.6162 & 8.0923 & TRN & & \\
\hline CHEMBL522022 & 566087 & 9.8861 & 9.2065 & TRN & & \\
\hline CHEMBL492937 & 566087 & 8.3468 & 7.2108 & TRN & & \\
\hline CHEMBL495032 & 566087 & 7.0482 & 7.0019 & TRN & & \\
\hline CHEMBL495004 & 566087 & 8.7212 & 9.3093 & TRN & & \\
\hline CHEMBL493738 & 566087 & 9.3468 & 8.4407 & TRN & & \\
\hline CHEMBL493838 & 566087 & 7.3686 & 8.6897 & TRN & & \\
\hline CHEMBL494357 & 566087 & 5.5376 & 6.3729 & TRN & & \\
\hline CHEMBL492951 & 566087 & 4.6045 & 6.6312 & TRN & & \\
\hline CHEMBL523362 & 566087 & 10.2218 & 9.9088 & TRN & & \\
\hline CHEMBL493000 & 566087 & 8.7696 & 8.3563 & TRN & & \\
\hline CHEMBL521524 & 566087 & 5.301 & 7.1276 & TRN & & \\
\hline CHEMBL 336293 & 566087 & 6.8154 & 6.1732 & TRN & & \\
\hline CHEMBL495019 & 566087 & 9.3768 & 7.8768 & TRN & & \\
\hline CHEMBL523372 & 566087 & 8.1805 & 8.2187 & TRN & & \\
\hline
\end{tabular}




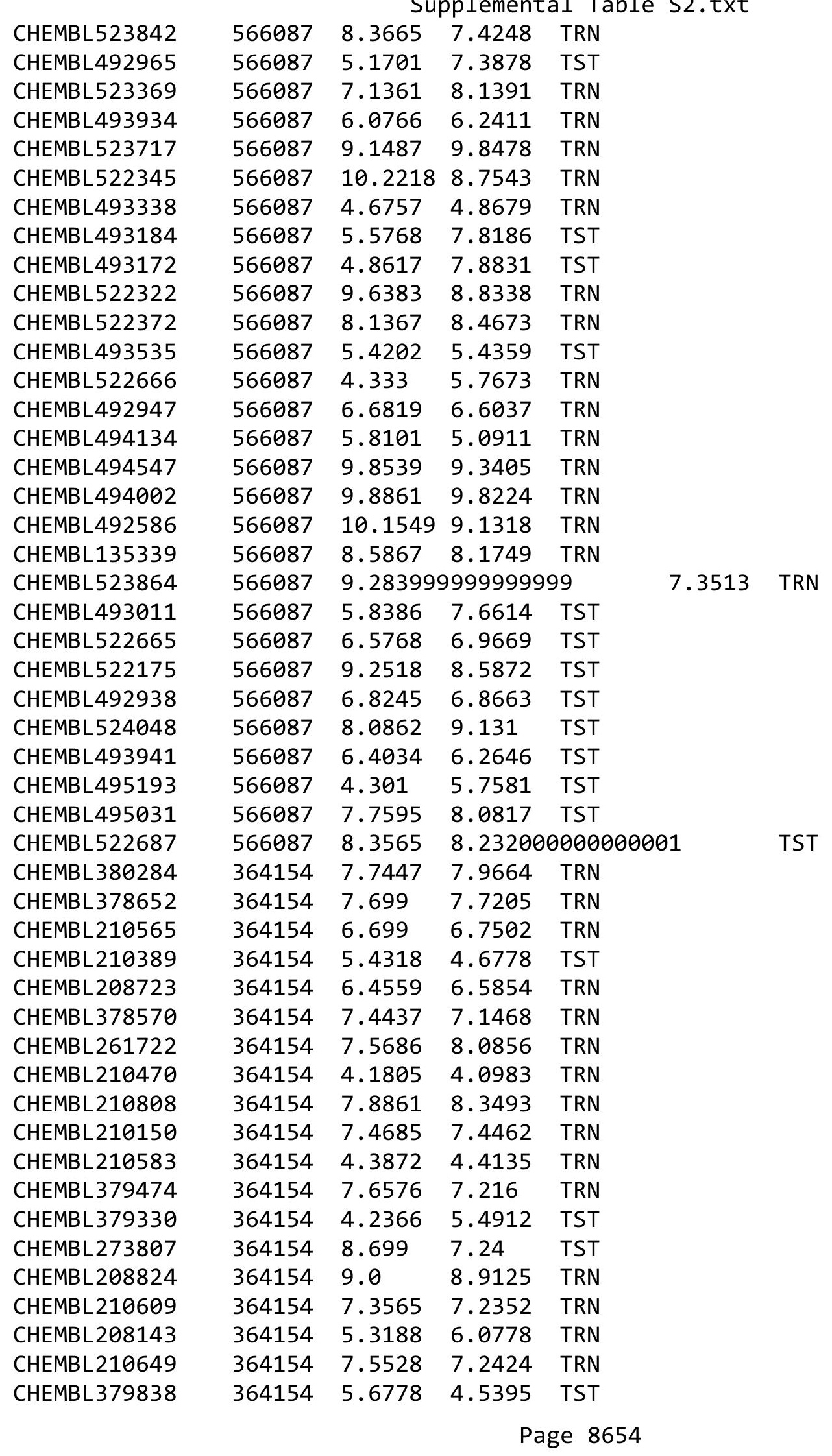


Supplemental Table S2.txt

\begin{tabular}{|c|c|c|c|c|}
\hline CHEMBL211038 & 364154 & 6.3872 & 6.2619 & TRN \\
\hline CHEMBL378598 & 364154 & 7.6576 & 7.1754 & TRN \\
\hline CHEMBL383201 & 364154 & 6.0088 & 6.1837 & TRN \\
\hline CHEMBL210319 & 364154 & 7.0 & 6.7667 & TRN \\
\hline CHEMBL441530 & 364154 & 5.9031 & 6.1131 & TRN \\
\hline CHEMBL209217 & 364154 & 7.1308 & 7.2568 & TRN \\
\hline CHEMBL210271 & 364154 & 7.7212 & 7.95299 & 9999999999 \\
\hline CHEMBL210614 & 364154 & 6.4437 & 6.1148 & TRN \\
\hline CHEMBL 207524 & 364154 & 7.3979 & 7.46899 & 9999999999 \\
\hline CHEMBL378743 & 364154 & 6.0044 & 5.9986 & TRN \\
\hline CHEMBL 210683 & 364154 & 7.4318 & 7.5231 & TRN \\
\hline CHEMBL210213 & 364154 & 7.2366 & 7.3237 & TRN \\
\hline CHEMBL 210686 & 364154 & 4.1805 & 4.3128 & TRN \\
\hline CHEMBL210890 & 364154 & 6.4089 & 6.6667 & TRN \\
\hline CHEMBL210747 & 364154 & 7.4815 & 7.5287 & TRN \\
\hline CHEMBL 210938 & 364154 & 7.7447 & 7.7938 & TRN \\
\hline CHEMBL210212 & 364154 & 7.4559 & 7.3947 & TRN \\
\hline CHEMBL426504 & 364154 & 8.301 & 7.8449 & TRN \\
\hline CHEMBL 380219 & 364154 & 7.4318 & 7.1853 & TRN \\
\hline CHEMBL 254725 & 364154 & 7.9586 & 7.6502 & TRN \\
\hline CHEMBL 209512 & 364154 & 4.1805 & 4.2724 & TRN \\
\hline CHEMBL 251870 & 364154 & 7.8539 & 8.0484 & TRN \\
\hline CHEMBL 210584 & 364154 & 4.2366 & 5.9419 & TST \\
\hline CHEMBL 210482 & 364154 & 6.1938 & 6.2318 & TRN \\
\hline CHEMBL209831 & 364154 & 6.5086 & 6.5188 & TRN \\
\hline CHEMBL207434 & 364154 & 7.699 & 7.7905 & TRN \\
\hline CHEMBL 207482 & 364154 & 6.6198 & 6.8574 & TRN \\
\hline CHEMBL379032 & 364154 & 6.1549 & 5.8653 & TRN \\
\hline CHEMBL 209174 & 364154 & 7.5376 & 7.1056 & TRN \\
\hline CHEMBL210534 & 364154 & 4.2366 & 5.8264 & TST \\
\hline CHEMBL380176 & 364154 & 8.0458 & 5.3705 & TST \\
\hline CHEMBL378020 & 364154 & 6.1871 & 6.0775 & TST \\
\hline CHEMBL437301 & 364154 & 5.6383 & 8.4773 & TST \\
\hline CHEMBL 251869 & 364154 & 7.8539 & 7.4412 & TST \\
\hline CHEMBL 208110 & 364154 & 7.4318 & 6.3215 & TST \\
\hline CHEMBL 210738 & 364154 & 5.9586 & 4.8191 & TST \\
\hline CHEMBL408186 & 364154 & 7.4202 & 6.0819 & TST \\
\hline CHEMBL 208920 & 364154 & 6.5229 & 6.5961 & TST \\
\hline CHEMBL183 & 364154 & 7.2518 & 5.6006 & TST \\
\hline CHEMBL3917787 & 1642209 & 7.5229 & 7.5397 & TRN \\
\hline CHEMBL3890831 & 1642209 & 7.3665 & 7.3618 & TRN \\
\hline CHEMBL3962570 & 1642209 & 8.0458 & 7.9595 & TRN \\
\hline CHEMBL3952658 & 1642209 & 6.3809 & 7.3014 & TST \\
\hline CHEMBL3931439 & 1642209 & 6.9208 & 7.5981 & TST \\
\hline CHEMBL3984792 & 1642209 & 7.9208 & 7.8808 & TRN \\
\hline CHEMBL3984795 & 1642209 & 7.2518 & 7.1811 & TRN \\
\hline CHEMBL3040442 & 1642209 & 7.6576 & 7.7447 & TRN \\
\hline CHEMBL3923222 & 1642209 & 6.7471 & 6.7592 & TRN \\
\hline
\end{tabular}


Supplemental Table S2.txt

\begin{tabular}{|c|c|c|c|c|}
\hline CHEMBL3929408 & 1642209 & 6.7235 & 7.7382 & TST \\
\hline CHEMBL 3941838 & 1642209 & 7.7696 & 7.7345 & TRN \\
\hline CHEMBL3902543 & 1642209 & 7.7959 & 7.8034 & TRN \\
\hline CHEMBL 3040589 & 1642209 & 7.5686 & 7.4032 & TRN \\
\hline CHEMBL 3945572 & 1642209 & 8.0 & 8.1131 & TRN \\
\hline CHEMBL 3985856 & 1642209 & 7.1249 & 7.2482 & TRN \\
\hline CHEMBL 3922751 & 1642209 & 8.2218 & 8.3003 & TRN \\
\hline CHEMBL 3970030 & 1642209 & \multicolumn{3}{|c|}{6.4510000000000005} \\
\hline CHEMBL3959167 & 1642209 & 8.2218 & 8.2106 & TRN \\
\hline CHEMBL 3959682 & 1642209 & 6.3915 & 7.5501 & TST \\
\hline CHEMBL 3040492 & 1642209 & 7.2366 & 7.294 & TRN \\
\hline CHEMBL 3961346 & 1642209 & 6.9031 & 7.6797 & TST \\
\hline CHEMBL 3971427 & 1642209 & 8.301 & 8.2118 & TRN \\
\hline CHEMBL3945201 & 1642209 & 8.5229 & 8.4286 & TRN \\
\hline CHEMBL 3944632 & 1642209 & 8.0458 & 8.0959 & TRN \\
\hline CHEMBL 3970731 & 1642209 & 8.301 & 8.3174 & TRN \\
\hline CHEMBL3976707 & 1642209 & 7.8861 & 7.8812 & TRN \\
\hline CHEMBL 3040594 & 1642209 & 6.7399 & 7.227 & TST \\
\hline CHEMBL3933238 & 1642209 & 7.3565 & 7.3822 & TST \\
\hline CHEMBL 3897050 & 1642209 & 7.7696 & 7.8815 & TRN \\
\hline CHEMBL 3040493 & 1642209 & 7.0809 & 7.2814 & TST \\
\hline CHEMBL 3934552 & 1642209 & 7.9586 & 7.9238 & TRN \\
\hline CHEMBL 3950782 & 1642209 & 7.5528 & 7.5413 & TRN \\
\hline CHEMBL3960618 & 1642209 & 7.4815 & 7.516 & TST \\
\hline CHEMBL 3040443 & 1642209 & 7.3372 & 7.29700 & 0000000001 \\
\hline CHEMBL3908839 & 1642209 & 7.2596 & 7.2422 & TRN \\
\hline CHEMBL 3959594 & 1642209 & 7.6383 & 7.606 & TRN \\
\hline CHEMBL 3040527 & 1642209 & 8.0 & 7.9342 & TRN \\
\hline CHEMBL3940477 & 1642209 & 6.6308 & 7.6513 & TST \\
\hline CHEMBL 3950467 & 1642209 & 7.9208 & 7.7119 & TST \\
\hline CHEMBL3040491 & 1642209 & 7.7212 & 7.7898 & TRN \\
\hline CHEMBL 3953687 & 1642209 & 7.8239 & 7.789 & TRN \\
\hline CHEMBL3932171 & 1642209 & 7.2676 & 7.3069 & TRN \\
\hline CHEMBL3913602 & 1642209 & 8.0 & 8.0676 & TRN \\
\hline CHEMBL3892361 & 1642209 & 7.3665 & 7.3956 & TRN \\
\hline CHEMBL3040460 & 1642209 & 7.4949 & 7.4941 & TST \\
\hline CHEMBL 3911548 & 1642209 & 7.7447 & 7.7207 & TRN \\
\hline CHEMBL3939041 & 1642209 & 7.5376 & 7.579 & TRN \\
\hline CHEMBL 3957186 & 1642209 & 7.6383 & 7.5921 & TRN \\
\hline CHEMBL 3040528 & 1642209 & 8.0458 & 8.043 & TRN \\
\hline CHEMBL3935189 & 1642209 & 7.8861 & 7.9909 & TRN \\
\hline CHEMBL 3963534 & 1642209 & 7.9208 & 7.7515 & TST \\
\hline CHEMBL 3976627 & 1642209 & 7.4685 & 7.5055 & TRN \\
\hline CHEMBL 3040504 & 1642209 & 8.0 & 7.8489 & TRN \\
\hline CHEMBL3933158 & 1642209 & 7.6383 & 7.6392 & TRN \\
\hline CHEMBL118863 & 215007 & 7.6576 & 7.6304 & TRN \\
\hline CHEMBL 323802 & 215007 & 7.6021 & 8.0238 & TRN \\
\hline CHEMBL119591 & 215007 & 6.8239 & 6.9395 & TRN \\
\hline
\end{tabular}


Supplemental Table S2.txt

\begin{tabular}{|c|c|c|c|c|}
\hline CHEMBL118562 & 215007 & 6.3979 & 6.4973 & TRN \\
\hline CHEMBL324935 & 215007 & 5.0915 & 4.7894 & TRN \\
\hline CHEMBL333055 & 215007 & 6.2757 & 5.9927 & TRN \\
\hline CHEMBL333652 & 215007 & 6.7696 & 6.6759 & TRN \\
\hline CHEMBL118595 & 215007 & 4.3979 & 5.3017 & TRN \\
\hline CHEMBL116820 & 215007 & 5.3872 & 6.7595 & TST \\
\hline CHEMBL119291 & 215007 & 4.6576 & 5.4307 & TST \\
\hline CHEMBL120449 & 215007 & 7.0177 & 7.3589 & TRN \\
\hline CHEMBL118933 & 215007 & 5.1192 & 5.2159 & TRN \\
\hline CHEMBL324251 & 215007 & 7.8861 & 8.2252 & TRN \\
\hline CHEMBL118829 & 215007 & 6.3979 & 6.6457 & TRN \\
\hline CHEMBL331424 & 215007 & 6.1192 & 6.0581 & TRN \\
\hline CHEMBL333597 & 215007 & 7.1487 & 7.454 & TRN \\
\hline CHEMBL118271 & 215007 & 7.5376 & 7.6131 & TRN \\
\hline CHEMBL118805 & 215007 & 6.0 & 7.2044 & TST \\
\hline CHEMBL118387 & 215007 & 7.5376 & 7.6758 & TRN \\
\hline CHEMBL332090 & 215007 & 5.8539 & 5.7125 & TRN \\
\hline CHEMBL332685 & 215007 & 7.8539 & 7.1203 & TRN \\
\hline CHEMBL331164 & 215007 & 6.699 & 6.3525 & TRN \\
\hline CHEMBL118878 & 215007 & 6.7212 & 7.4404 & TST \\
\hline CHEMBL119730 & 215007 & 6.0 & 5.5479 & TRN \\
\hline CHEMBL420880 & 215007 & 7.4949 & 7.48799 & 99999999995 \\
\hline CHEMBL115853 & 215007 & 7.3565 & 7.2783 & TST \\
\hline CHEMBL332450 & 215007 & 6.7447 & 6.7686 & TRN \\
\hline CHEMBL119840 & 215007 & 3.0 & 2.782 & TRN \\
\hline CHEMBL331098 & 215007 & 7.8539 & 8.0575 & TST \\
\hline CHEMBL333201 & 215007 & 7.1549 & 7.0566 & TRN \\
\hline CHEMBL117566 & 215007 & 6.6778 & 6.48799 & 99999999995 \\
\hline CHEMBL333135 & 215007 & 6.5229 & 6.4837 & TRN \\
\hline CHEMBL331647 & 215007 & 5.1871 & 5.1326 & TRN \\
\hline CHEMBL333139 & 215007 & 6.0088 & 5.8122 & TRN \\
\hline CHEMBL115434 & 215007 & 5.1487 & 4.4665 & TRN \\
\hline CHEMBL118660 & 215007 & 6.3768 & 6.7723 & TRN \\
\hline CHEMBL119806 & 215007 & 7.5528 & 7.6019 & TRN \\
\hline CHEMBL332060 & 215007 & 6.9586 & 6.9973 & TST \\
\hline CHEMBL119793 & 215007 & 7.7447 & 7.5897 & TRN \\
\hline CHEMBL118922 & 215007 & 7.5376 & 7.0578 & TRN \\
\hline CHEMBL333340 & 215007 & 3.0 & 3.3171 & TRN \\
\hline CHEMBL 324488 & 215007 & 7.6198 & 7.5089 & TRN \\
\hline CHEMBL119651 & 215007 & 7.0862 & 6.3694 & TRN \\
\hline CHEMBL331956 & 215007 & 3.0 & 4.3251 & TRN \\
\hline CHEMBL118244 & 215007 & 5.7959 & 6.2939 & TST \\
\hline CHEMBL334225 & 215007 & 7.5686 & 7.222 & TST \\
\hline CHEMBL118892 & 215007 & 5.1938 & 5.6758 & TST \\
\hline CHEMBL118220 & 215007 & 6.1675 & 6.485 & TRN \\
\hline CHEMBL118609 & 215007 & 7.301 & 7.0322 & TRN \\
\hline CHEMBL119534 & 215007 & 5.7447 & 5.4114 & TRN \\
\hline CHEMBL119087 & 215007 & 6.6021 & 6.2948 & TRN \\
\hline
\end{tabular}




\begin{tabular}{|c|c|c|c|c|c|}
\hline \multicolumn{6}{|c|}{ Supplemental Table S2.txt } \\
\hline CHEMBL119638 & 215007 & 7.8861 & 8.0224 & TST & \\
\hline CHEMBL119442 & 215007 & 5.6778 & 6.109 & TRN & \\
\hline CHEMBL121455 & 215007 & 6.699 & 6.7628 & TRN & \\
\hline CHEMBL331173 & 215007 & 7.5376 & 7.6465 & TRN & \\
\hline CHEMBL325819 & 215007 & 6.1938 & 6.9879 & TST & \\
\hline CHEMBL119671 & 215007 & 6.8539 & 7.8237 & TST & \\
\hline CHEMBL334009 & 215007 & 5.7696 & 5.6206 & TRN & \\
\hline CHEMBL118128 & 215007 & 5.9208 & 5.8559 & TRN & \\
\hline CHEMBL118270 & 215007 & 7.5686 & 8.1018 & TST & \\
\hline CHEMBL334082 & 215007 & 7.1135 & 7.5391 & TST & \\
\hline CHEMBL332757 & 215007 & 5.2147 & 5.3794 & TRN & \\
\hline CHEMBL119551 & 215007 & 5.7212 & 5.95200 & 0000000001 & TRN \\
\hline CHEMBL119318 & 215007 & 7.699 & 7.8258 & TST & \\
\hline CHEMBL1595403 & 737000 & 5.5021 & 5.8695 & TRN & \\
\hline CHEMBL1487872 & 737000 & 5.7852 & 5.9647 & TRN & \\
\hline CHEMBL1313229 & 737000 & 6.5016 & 6.3475 & TST & \\
\hline CHEMBL1342119 & 737000 & 5.4881 & 5.6782 & TRN & \\
\hline CHEMBL1464571 & 737000 & 5.2619 & 5.2131 & TRN & \\
\hline CHEMBL1496820 & 737000 & 5.4385 & 5.7102 & TRN & \\
\hline CHEMBL1301892 & 737000 & 6.3796 & 6.3267 & TRN & \\
\hline CHEMBL1571807 & 737000 & 5.1774 & 5.2559 & TRN & \\
\hline CHEMBL1375038 & 737000 & 6.4511 & 6.8424 & TRN & \\
\hline CHEMBL1565236 & 737000 & 6.0726 & 5.9277 & TRN & \\
\hline CHEMBL1388463 & 737000 & 5.5465 & 5.0859 & TRN & \\
\hline CHEMBL1540610 & 737000 & 6.3906 & 5.9867 & TRN & \\
\hline CHEMBL1491556 & 737000 & 5.3854 & 5.6721 & TST & \\
\hline CHEMBL1331281 & 737000 & 7.2614 & 7.1209 & TRN & \\
\hline CHEMBL1372776 & 737000 & 5.8931 & 5.8645 & TRN & \\
\hline CHEMBL1724205 & 737000 & 4.5704 & 4.6572 & TRN & \\
\hline CHEMBL1399289 & 737000 & 5.6126 & 5.2664 & TRN & \\
\hline CHEMBL1493746 & 737000 & 5.9045 & 5.7196 & TRN & \\
\hline CHEMBL1335116 & 737000 & 6.4682 & 6.3097 & TRN & \\
\hline CHEMBL1440341 & 737000 & 5.9477 & 5.6925 & TRN & \\
\hline CHEMBL1582357 & 737000 & 6.7355 & 6.1515 & TRN & \\
\hline CHEMBL1440953 & 737000 & 5.8435 & 6.428 & TRN & \\
\hline CHEMBL1571574 & 737000 & 6.0549 & 6.1627 & TRN & \\
\hline CHEMBL1476308 & 737000 & 5.5761 & 6.3677 & TST & \\
\hline CHEMBL1401331 & 737000 & 5.5698 & 5.6901 & TRN & \\
\hline CHEMBL1520702 & 737000 & 5.5669 & 5.1689 & TRN & \\
\hline CHEMBL1575559 & 737000 & 5.3518 & 5.6769 & TRN & \\
\hline CHEMBL1302355 & 737000 & 6.1129 & 6.4746 & TRN & \\
\hline CHEMBL1461147 & 737000 & 4.6935 & 5.3173 & TRN & \\
\hline CHEMBL1977808 & 737000 & 5.9458 & 5.6705 & TRN & \\
\hline CHEMBL1507474 & 737000 & 5.5261 & 5.8827 & TRN & \\
\hline CHEMBL1577537 & 737000 & 5.5018 & 5.8478 & TST & \\
\hline CHEMBL1384723 & 737000 & 6.2436 & 6.2481 & TRN & \\
\hline CHEMBL1336039 & 737000 & 5.7042 & 5.6605 & TRN & \\
\hline CHEMBL1418095 & 737000 & 6.2568 & 6.3984 & TRN & \\
\hline
\end{tabular}




\begin{tabular}{|c|c|c|c|c|c|c|}
\hline \multirow[b]{2}{*}{ CHEMBL1485217 } & & \multicolumn{5}{|c|}{ Supplemental Table S2.txt } \\
\hline & 737000 & 4.8144 & 5.0347 & TRN & & \\
\hline CHEMBL1553774 & 737000 & 5.2153 & 5.4799 & TRN & & \\
\hline CHEMBL1576843 & 737000 & 5.9205 & 5.5215 & TRN & & \\
\hline CHEMBL1588229 & 737000 & 4.8758 & 5.5561 & TST & & \\
\hline CHEMBL1355104 & 737000 & 6.3845 & 6.6816 & TRN & & \\
\hline CHEMBL1365949 & 737000 & 5.1731 & 5.8207 & TRN & & \\
\hline CHEMBL1402931 & 737000 & 6.7601 & 5.6502 & TST & & \\
\hline CHEMBL1342888 & 737000 & 6.0985 & 5.8644 & TST & & \\
\hline CHEMBL1460004 & 737000 & 4.2003 & 5.7296 & TST & & \\
\hline CHEMBL1421498 & 737000 & 5.3411 & 5.8704 & TRN & & \\
\hline CHEMBL1970286 & 737000 & \multicolumn{3}{|c|}{5.757000000000001} & 5.4206 & TRN \\
\hline CHEMBL1612190 & 737000 & 5.9646 & 5.4995 & TRN & & \\
\hline CHEMBL1351110 & 737000 & 6.0106 & 5.407 & TRN & & \\
\hline CHEMBL1479657 & 737000 & 6.0367 & 5.6134 & TRN & & \\
\hline CHEMBL1438621 & 737000 & 5.1989 & 5.6021 & TRN & & \\
\hline CHEMBL1722206 & 737000 & 3.179 & 4.8395 & TRN & & \\
\hline CHEMBL1498924 & 737000 & 6.3927 & 5.4555 & TST & & \\
\hline CHEMBL1966472 & 737000 & 5.0926 & 4.9319 & TRN & & \\
\hline CHEMBL1304258 & 737000 & 6.3372 & 5.9412 & TRN & & \\
\hline CHEMBL1978193 & 737000 & 6.2328 & 5.1091 & TRN & & \\
\hline CHEMBL1585859 & 737000 & 6.3233 & 6.78799 & 9999999999 & & TRN \\
\hline CHEMBL1557141 & 737000 & 5.6745 & 5.6265 & TRN & & \\
\hline CHEMBL1342815 & 737000 & 5.4761 & 5.6599 & TRN & & \\
\hline CHEMBL1344555 & 737000 & 5.4455 & 5.2815 & TRN & & \\
\hline CHEMBL1308855 & 737000 & 5.6805 & 5.3763 & TST & & \\
\hline CHEMBL1508525 & 737000 & 5.6428 & 5.7544 & TRN & & \\
\hline CHEMBL1709502 & 737000 & 6.4539 & 6.4064 & TRN & & \\
\hline CHEMBL1556254 & 737000 & 5.2722 & 5.3005 & TRN & & \\
\hline CHEMBL1979844 & 737000 & 5.6897 & 5.6755 & TRN & & \\
\hline CHEMBL1967103 & 737000 & 6.1409 & 6.0335 & TRN & & \\
\hline CHEMBL1430677 & 737000 & 6.822 & 6.0927 & TRN & & \\
\hline CHEMBL1988282 & 737000 & 6.2896 & 5.9129 & TRN & & \\
\hline CHEMBL1354074 & 737000 & 4.6103 & 5.0621 & TRN & & \\
\hline CHEMBL1482828 & 737000 & 5.9112 & 5.8771 & TRN & & \\
\hline CHEMBL1532928 & 737000 & 5.9566 & 6.0823 & TRN & & \\
\hline CHEMBL1466856 & 737000 & 5.9201 & 5.9692 & TRN & & \\
\hline CHEMBL1556270 & 737000 & 5.1322 & 4.7353 & TRN & & \\
\hline CHEMBL 2007173 & 737000 & 5.5243 & 5.3102 & TRN & & \\
\hline CHEMBL1541192 & 737000 & 6.816 & 6.6364 & TRN & & \\
\hline CHEMBL1597288 & 737000 & 4.9829 & 5.3507 & TRN & & \\
\hline CHEMBL1337585 & 737000 & 7.149 & 6.7235 & TRN & & \\
\hline CHEMBL1409773 & 737000 & 5.6878 & 5.6082 & TRN & & \\
\hline CHEMBL1594672 & 737000 & 6.5778 & 6.5673 & TRN & & \\
\hline CHEMBL1406761 & 737000 & 5.7022 & 5.4286 & TRN & & \\
\hline CHEMBL 1713886 & 737000 & 5.26399 & 79999999 & & 5.5036 & TRN \\
\hline CHEMBL1706285 & 737000 & 5.6103 & 5.5702 & TRN & & \\
\hline CHEMBL1590005 & 737000 & 5.9252 & 6.2563 & TRN & & \\
\hline CHEMBL1995726 & 737000 & 5.13700 & 30000000 & 205 & 5.2411 & TRN \\
\hline & & & & 865 & & \\
\hline
\end{tabular}


Supplemental Table S2.txt

\begin{tabular}{|c|c|c|c|c|c|}
\hline CHEMBL1463349 & 737000 & 5.5737 & 5.8383 & TRN & \\
\hline CHEMBL1546895 & 737000 & 5.7185 & 5.6407 & TRN & \\
\hline CHEMBL1518032 & 737000 & 5.4866 & 5.5334 & TRN & \\
\hline CHEMBL1721724 & 737000 & 5.8052 & 5.9843 & TRN & \\
\hline CHEMBL1367648 & 737000 & 5.6133 & 5.5513 & TRN & \\
\hline CHEMBL1466997 & 737000 & 6.0205 & 5.5656 & TRN & \\
\hline CHEMBL1516768 & 737000 & 5.4018 & 5.7104 & TRN & \\
\hline CHEMBL1560993 & 737000 & 7.4802 & 6.528 & TRN & \\
\hline CHEMBL1491374 & 737000 & 3.1789 & 4.7279 & TRN & \\
\hline CHEMBL 2003606 & 737000 & 6.4991 & 5.8604 & TRN & \\
\hline CHEMBL1978117 & 737000 & 5.5249 & 5.5201 & TRN & \\
\hline CHEMBL1494796 & 737000 & 5.6844 & 6.4641 & TST & \\
\hline CHEMBL1400350 & 737000 & 6.0601 & 5.3298 & TRN & \\
\hline CHEMBL1448743 & 737000 & 5.6556 & 6.0076 & TRN & \\
\hline CHEMBL1476869 & 737000 & \multicolumn{3}{|c|}{5.997000000000001} & TST \\
\hline CHEMBL1973904 & 737000 & 5.4835 & 5.4149 & TRN & \\
\hline CHEMBL1583293 & 737000 & 5.1746 & 5.3557 & TRN & \\
\hline CHEMBL1344470 & 737000 & 3.179 & 4.898 & TRN & \\
\hline CHEMBL1501952 & 737000 & 6.3582 & 6.1585 & TRN & \\
\hline CHEMBL1341758 & 737000 & 5.1523 & 5.8065 & TST & \\
\hline CHEMBL1727586 & 737000 & 3.1789 & 5.526 & TST & \\
\hline CHEMBL1360282 & 737000 & 5.7696 & 6.4085 & TRN & \\
\hline CHEMBL1528787 & 737000 & 5.2629 & 5.5961 & TRN & \\
\hline CHEMBL1983843 & 737000 & 5.6702 & 5.4574 & TRN & \\
\hline CHEMBL1536921 & 737000 & 5.9948 & 5.3327 & TRN & \\
\hline CHEMBL1518566 & 737000 & 6.4769 & 6.0928 & TRN & \\
\hline CHEMBL1579404 & 737000 & 5.7937 & 6.235 & TRN & \\
\hline CHEMBL1524484 & 737000 & 5.5701 & 5.9889 & TRN & \\
\hline CHEMBL1335338 & 737000 & 5.3847 & 5.8196 & TRN & \\
\hline CHEMBL1330781 & 737000 & 4.6369 & 5.7019 & TST & \\
\hline CHEMBL1399190 & 737000 & 4.2445 & 5.622000 & 0000000001 & TST \\
\hline CHEMBL1520346 & 737000 & 5.9427 & 6.3514 & TRN & \\
\hline CHEMBL1562279 & 737000 & 6.596 & 6.4318 & TRN & \\
\hline CHEMBL1502109 & 737000 & 5.1985 & 5.1984 & TRN & \\
\hline CHEMBL1493493 & 737000 & 5.1894 & 5.6908 & TRN & \\
\hline CHEMBL1364699 & 737000 & 5.6137 & 5.3739 & TRN & \\
\hline CHEMBL1572480 & 737000 & 5.5456 & 5.3984 & TRN & \\
\hline CHEMBL1270809 & 737000 & 6.2959 & 5.5267 & TRN & \\
\hline CHEMBL1539105 & 737000 & 5.9485 & 6.1865 & TRN & \\
\hline CHEMBL1964878 & 737000 & 6.3831 & 5.8876 & TST & \\
\hline CHEMBL1540815 & 737000 & 5.8139 & 6.1996 & TRN & \\
\hline CHEMBL1418678 & 737000 & 5.33799 & 999999999 & 6.0371 & 1 \\
\hline CHEMBL1720286 & 737000 & 5.7997 & 5.6265 & TST & \\
\hline CHEMBL1581581 & 737000 & 4.3743 & 5.3005 & TRN & \\
\hline CHEMBL1418004 & 737000 & 5.4897 & 5.3018 & TRN & \\
\hline CHEMBL1478565 & 737000 & 5.9978 & 5.2387 & TRN & \\
\hline CHEMBL1521046 & 737000 & 5.6868 & 5.6515 & TRN & \\
\hline CHEMBL1526729 & 737000 & 5.4362 & 5.8859 & TRN & \\
\hline
\end{tabular}




\begin{tabular}{|c|c|c|c|c|c|c|}
\hline & & \multicolumn{4}{|c|}{ Supplemental Table s2.txt } & \\
\hline CHEMBL1422276 & 737000 & 5.33299 & 99999999 & 99 & 5.5942 & TRN \\
\hline CHEMBL1714761 & 737000 & 6.3153 & 6.1147 & TRN & & \\
\hline CHEMBL1434457 & 737000 & 5.9519 & 5.5963 & TRN & & \\
\hline CHEMBL1722330 & 737000 & 5.3815 & 5.7859 & TRN & & \\
\hline CHEMBL1572758 & 737000 & 5.6254 & 5.4797 & TRN & & \\
\hline CHEMBL1343392 & 737000 & 4.7605 & 5.9067 & TRN & & \\
\hline CHEMBL1493516 & 737000 & 5.5996 & 5.795 & TRN & & \\
\hline CHEMBL1501678 & 737000 & 6.9741 & 6.5385 & TRN & & \\
\hline CHEMBL1588363 & 737000 & 5.83799 & 99999999 & 99 & 5.9084 & TRN \\
\hline CHEMBL1416951 & 737000 & 6.5576 & 5.9106 & TRN & & \\
\hline CHEMBL1456018 & 737000 & 6.2329 & 5.8959 & TRN & & \\
\hline CHEMBL3199892 & 737000 & 5.983 & 5.6958 & TRN & & \\
\hline CHEMBL1514800 & 737000 & 5.8239 & 6.3904 & TRN & & \\
\hline CHEMBL1485238 & 737000 & 6.185 & 5.7177 & TRN & & \\
\hline CHEMBL1328144 & 737000 & 6.8641 & 6.4234 & TRN & & \\
\hline CHEMBL1552334 & 737000 & 6.2838 & 5.8293 & TRN & & \\
\hline CHEMBL1348119 & 737000 & 5.2109 & 4.878 & TRN & & \\
\hline CHEMBL1966014 & 737000 & 5.7986 & 5.902 & TRN & & \\
\hline CHEMBL1715597 & 737000 & 6.816 & 6.4724 & TRN & & \\
\hline CHEMBL1716146 & 737000 & 6.0353 & 5.9129 & TRN & & \\
\hline CHEMBL1327720 & 737000 & 5.2439 & 5.2298 & TRN & & \\
\hline CHEMBL1380649 & 737000 & 6.6119 & 6.7257 & TRN & & \\
\hline CHEMBL1511752 & 737000 & 6.0386 & 5.1526 & TRN & & \\
\hline CHEMBL1512619 & 737000 & 5.791 & 5.511 & TRN & & \\
\hline CHEMBL1699081 & 737000 & 4.9202 & 4.9803 & TRN & & \\
\hline CHEMBL1565349 & 737000 & 5.4443 & 5.3705 & TRN & & \\
\hline CHEMBL1595012 & 737000 & 5.9322 & 5.8819 & TRN & & \\
\hline CHEMBL1558506 & 737000 & 5.5704 & 6.0606 & TRN & & \\
\hline CHEMBL1357156 & 737000 & 6.4135 & 6.0616 & TRN & & \\
\hline CHEMBL1503548 & 737000 & 6.0391 & 6.1589 & TRN & & \\
\hline CHEMBL1714525 & 737000 & 6.1445 & 5.4943 & TRN & & \\
\hline CHEMBL1733477 & 737000 & 7.4802 & 5.9086 & TRN & & \\
\hline CHEMBL 2006840 & 737000 & 5.5358 & 6.0525 & TRN & & \\
\hline CHEMBL1465216 & 737000 & 5.6515 & 6.0951 & TST & & \\
\hline CHEMBL1555841 & 737000 & 5.4307 & 5.3476 & TST & & \\
\hline CHEMBL1386871 & 737000 & 5.4407 & 5.7603 & TRN & & \\
\hline CHEMBL1334210 & 737000 & 5.9763 & 5.5489 & TRN & & \\
\hline CHEMBL1727648 & 737000 & 6.7575 & 6.3339 & TRN & & \\
\hline CHEMBL1377656 & 737000 & 5.2125 & 5.0307 & TRN & & \\
\hline CHEMBL1980584 & 737000 & 5.2914 & 5.6877 & TRN & & \\
\hline CHEMBL1590375 & 737000 & 5.3647 & 5.7609 & TST & & \\
\hline CHEMBL1588256 & 737000 & 6.1622 & 5.9493 & TRN & & \\
\hline CHEMBL1333148 & 737000 & 6.4694 & 6.9098 & TRN & & \\
\hline CHEMBL1542157 & 737000 & 5.4664 & 5.7126 & TRN & & \\
\hline CHEMBL1363571 & 737000 & 5.6094 & 5.4173 & TRN & & \\
\hline CHEMBL1512498 & 737000 & 5.8775 & 6.0769 & TRN & & \\
\hline CHEMBL1481716 & 737000 & 5.7533 & 5.9967 & TRN & & \\
\hline CHEMBL1583817 & 737000 & 4.8263 & 5.7648 & TRN & & \\
\hline
\end{tabular}




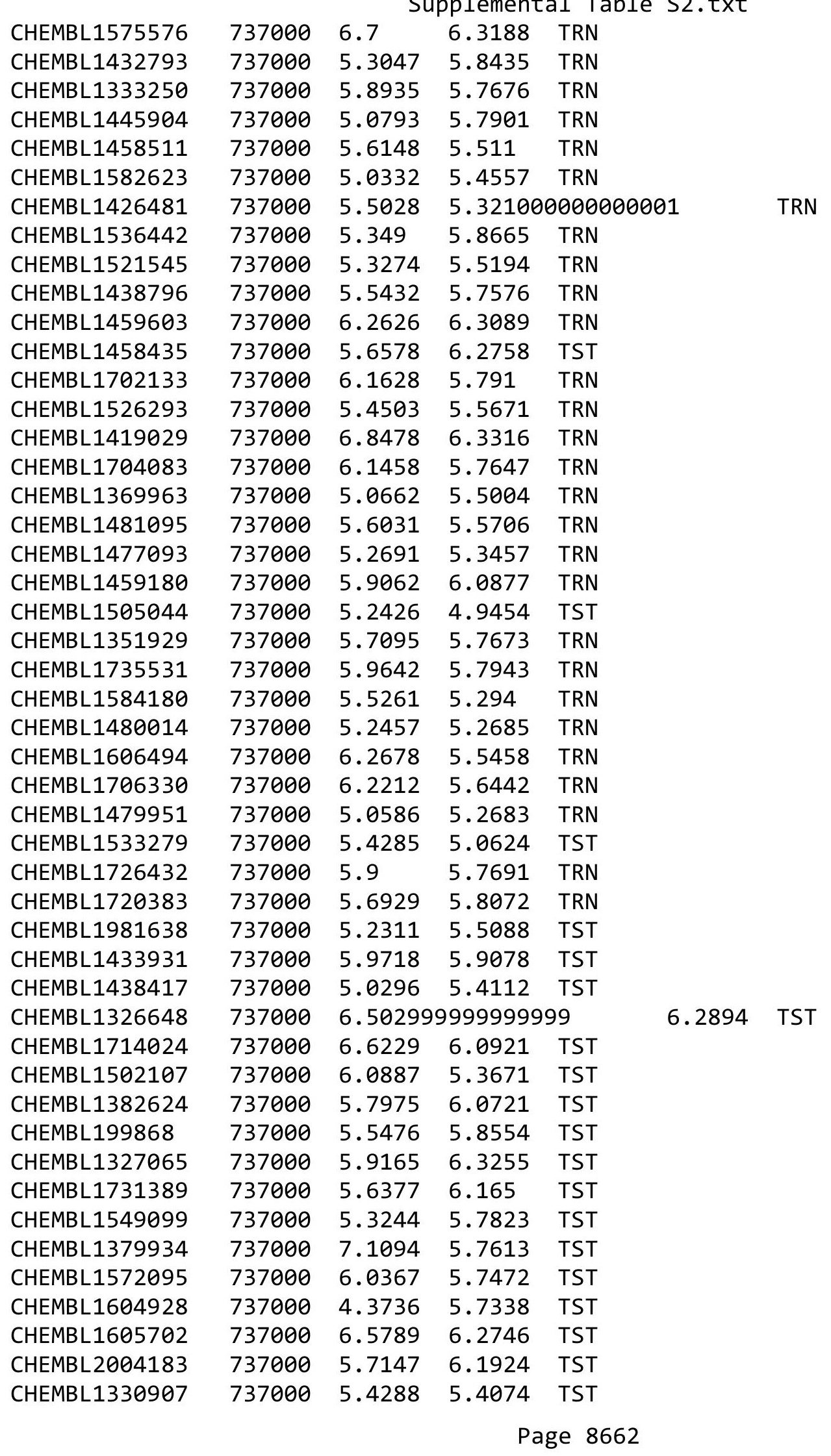


Supplemental Table S2.txt

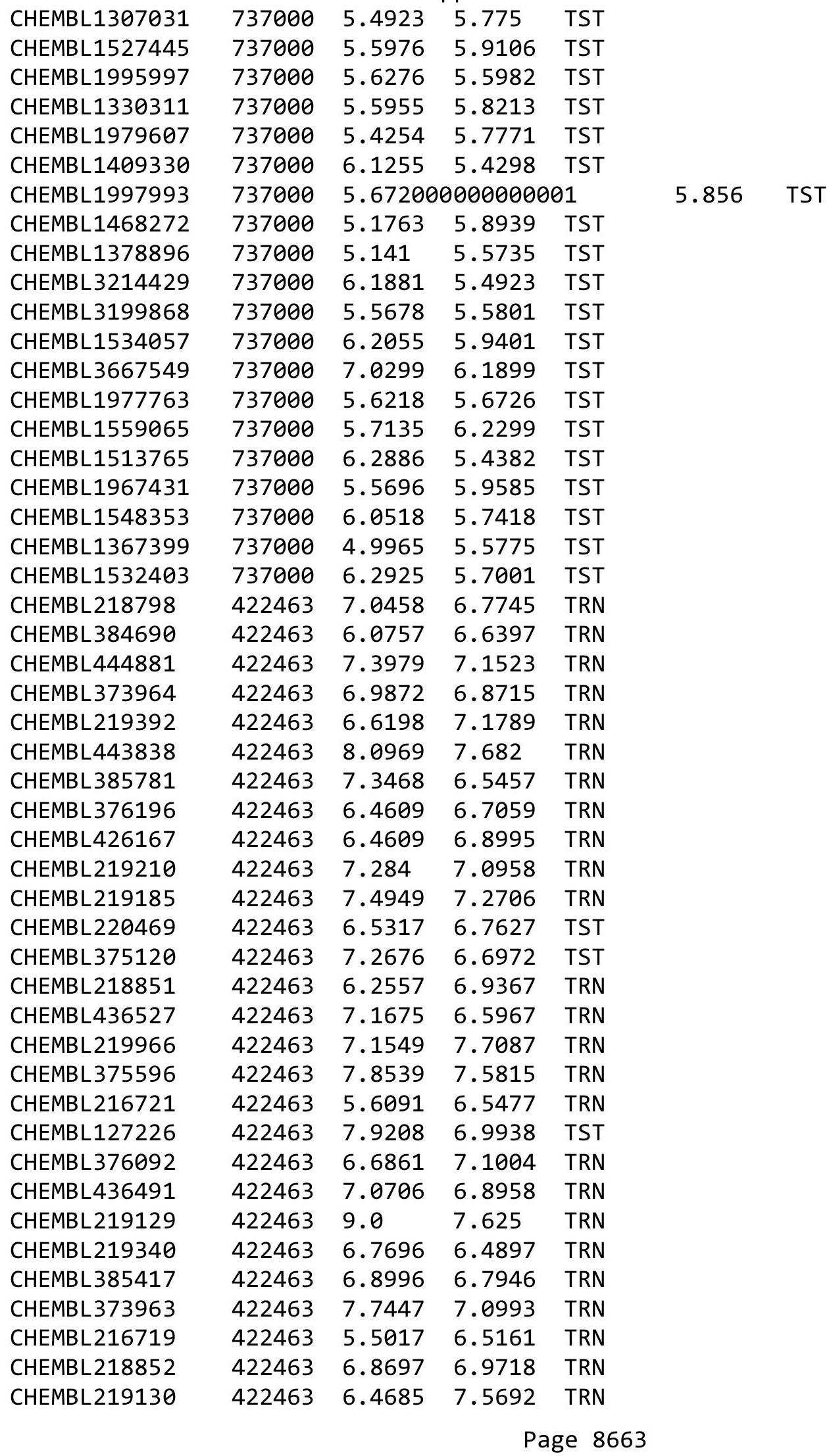




\begin{tabular}{|c|c|c|c|c|c|}
\hline \multicolumn{6}{|c|}{ supplemental lable S2 } \\
\hline CHEMBL219564 & 422463 & 6.7447 & 6.6524 & TRN & \\
\hline CHEMBL386917 & 422463 & 5.8894 & 6.4829 & TRN & \\
\hline CHEMBL216922 & 422463 & 9.0 & 7.6701 & TRN & \\
\hline CHEMBL218797 & 422463 & 6.8386 & 7.0411 & TRN & \\
\hline CHEMBL218761 & 422463 & 6.3768 & 7.4913 & TRN & \\
\hline CHEMBL216393 & 422463 & 6.7696 & 7.541 & TRN & \\
\hline CHEMBL425288 & 422463 & 6.7959 & 6.8213 & TRN & \\
\hline CHEMBL373516 & 422463 & 6.2907 & 7.5971 & TRN & \\
\hline CHEMBL219566 & 422463 & 7.4202 & 6.6532 & TRN & \\
\hline CHEMBL219181 & 422463 & 6.3251 & 6.6587 & TRN & \\
\hline CHEMBL219570 & 422463 & 7.0 & 7.072 & TRN & \\
\hline CHEMBL220083 & 422463 & 8.0088 & 7.2194 & TST & \\
\hline CHEMBL216450 & 422463 & 8.0969 & 7.57799 & 9999999999 & TRN \\
\hline CHEMBL220015 & 422463 & 6.9393 & 6.598 & TRN & \\
\hline CHEMBL219261 & 422463 & 7.2218 & 6.9069 & TRN & \\
\hline CHEMBL219426 & 422463 & 6.2741 & 6.5078 & TRN & \\
\hline CHEMBL216921 & 422463 & 8.4202 & 7.7153 & TRN & \\
\hline CHEMBL440687 & 422463 & 7.9066 & 6.9715 & TST & \\
\hline CHEMBL219551 & 422463 & 6.4895 & 6.6409 & TRN & \\
\hline CHEMBL218757 & 422463 & 6.1643 & 6.6438 & TST & \\
\hline CHEMBL219263 & 422463 & 7.2007 & 6.5669 & TRN & \\
\hline CHEMBL219182 & 422463 & 7.0506 & 6.8242 & TRN & \\
\hline CHEMBL220192 & 422463 & 6.7986 & 6.4814 & TRN & \\
\hline CHEMBL45244 & 422463 & 8.0809 & 7.1245 & TST & \\
\hline CHEMBL219389 & 422463 & 7.0223 & 7.0375 & TRN & \\
\hline CHEMBL219186 & 422463 & 7.301 & 6.7265 & TRN & \\
\hline CHEMBL219417 & 422463 & 6.7959 & 7.0335 & TRN & \\
\hline CHEMBL414706 & 422463 & 7.2076 & 6.9449 & TRN & \\
\hline CHEMBL385418 & 422463 & 7.4437 & 7.6736 & TRN & \\
\hline CHEMBL264286 & 422463 & 7.1192 & 6.9887 & TRN & \\
\hline CHEMBL219179 & 422463 & 8.6198 & 7.0456 & TST & \\
\hline CHEMBL220139 & 422463 & 6.8729 & 6.7605 & TST & \\
\hline CHEMBL219565 & 422463 & 6.4685 & 6.8513 & TST & \\
\hline CHEMBL219567 & 422463 & 6.9547 & 7.1987 & TST & \\
\hline CHEMBL374326 & 422463 & 6.5686 & 6.8436 & TST & \\
\hline CHEMBL216215 & 422463 & 7.0706 & 6.54299 & 9999999999 & TST \\
\hline CHEMBL425793 & 422463 & 6.4437 & 6.9488 & TST & \\
\hline CHEMBL219211 & 422463 & 7.1805 & 7.0105 & TST & \\
\hline CHEMBL219394 & 422463 & 7.2218 & 7.0933 & TST & \\
\hline CHEMBL216794 & 422463 & 8.0458 & 7.1324 & TST & \\
\hline CHEMBL129885 & 62181 & 8.2291 & 8.0826 & TRN & \\
\hline CHEMBL130372 & 62181 & 7.0605 & 6.4777 & TRN & \\
\hline CHEMBL336624 & 62181 & 5.1612 & 5.7695 & TRN & \\
\hline CHEMBL133760 & 62181 & 5.7212 & 4.3375 & TST & \\
\hline CHEMBL131969 & 62181 & 5.4559 & 4.1584 & TST & \\
\hline CHEMBL130394 & 62181 & 8.2007 & 8.1789 & TRN & \\
\hline CHEMBL130092 & 62181 & 5.5528 & 4.8957 & TST & \\
\hline CHEMBL132781 & 62181 & 5.3665 & 3.9863 & TST & \\
\hline
\end{tabular}




\begin{tabular}{|c|c|c|c|c|c|}
\hline \multicolumn{6}{|c|}{ Supplemental Table S2.txt } \\
\hline CHEMBL337052 & 62181 & 8.2366 & 8.2162 & TRN & \\
\hline CHEMBL130747 & 62181 & 6.1938 & 6.2598 & TRN & \\
\hline CHEMBL134217 & 62181 & 5.6576 & 5.4733 & TST & \\
\hline CHEMBL339841 & 62181 & 6.5376 & 6.6602 & TRN & \\
\hline CHEMBL340392 & 62181 & 6.1427 & 5.9418 & TRN & \\
\hline CHEMBL130668 & 62181 & 8.4685 & 8.4315 & TRN & \\
\hline CHEMBL133287 & 62181 & 6.6383 & 6.5034 & TRN & \\
\hline CHEMBL132955 & 62181 & 7.8539 & 7.8284 & TRN & \\
\hline CHEMBL442765 & 62181 & 7.2441 & 7.1937 & TRN & \\
\hline CHEMBL133901 & 62181 & 5.0315 & 5.3851 & TST & \\
\hline CHEMBL336510 & 62181 & 5.3979 & 5.4862 & TST & \\
\hline CHEMBL335870 & 62181 & 5.4559 & 5.5507 & TRN & \\
\hline CHEMBL336654 & 62181 & 8.4949 & 8.6075 & TRN & \\
\hline CHEMBL133646 & 62181 & 7.7959 & 7.5466 & TRN & \\
\hline CHEMBL334577 & 62181 & 7.4318 & 8.1101 & TRN & \\
\hline CHEMBL340281 & 62181 & 7.4202 & 7.22 & TRN & \\
\hline CHEMBL133786 & 62181 & 9.0 & 8.9831 & TRN & \\
\hline CHEMBL132241 & 62181 & 8.3665 & 8.2707 & TRN & \\
\hline CHEMBL134098 & 62181 & 7.3768 & 7.3487 & TRN & \\
\hline CHEMBL334535 & 62181 & 7.4685 & 7.8881 & TST & \\
\hline CHEMBL337299 & 62181 & 7.301 & 7.1705 & TRN & \\
\hline CHEMBL132198 & 62181 & 8.585 & 8.5822 & TRN & \\
\hline CHEMBL424640 & 62181 & 7.0 & 7.0326 & TRN & \\
\hline CHEMBL130477 & 62181 & 9.0 & 8.9146 & TRN & \\
\hline CHEMBL336547 & 62181 & 6.2518 & 4.7773 & TST & \\
\hline CHEMBL132630 & 62181 & 6.4949 & 6.7098 & TST & \\
\hline CHEMBL134247 & 62181 & 4.7212 & 4.6854 & TRN & \\
\hline CHEMBL131637 & 62181 & 6.5376 & 6.6449 & TRN & \\
\hline CHEMBL130983 & 62181 & 5.1367 & 6.1047 & TST & \\
\hline CHEMBL339648 & 62181 & 7.0315 & 7.0438 & TRN & \\
\hline CHEMBL133355 & 62181 & 7.8861 & 7.8213 & TRN & \\
\hline CHEMBL134196 & 62181 & 4.1739 & 4.1844 & TRN & \\
\hline CHEMBL336820 & 62181 & 5.0223 & 4.9934 & TRN & \\
\hline CHEMBL133812 & 62181 & 5.5086 & 5.2981 & TST & \\
\hline CHEMBL132988 & 62181 & 5.4318 & 5.36700 & 0000000001 & TRN \\
\hline CHEMBL133336 & 62181 & 5.1871 & 6.0985 & TST & \\
\hline CHEMBL133795 & 62181 & 8.699 & 8.7617 & TRN & \\
\hline CHEMBL132419 & 62181 & 5.4815 & 5.3527 & TRN & \\
\hline CHEMBL129962 & 62181 & 5.9208 & 5.8731 & TRN & \\
\hline CHEMBL 337004 & 62181 & 5.7959 & 5.1442 & TST & \\
\hline CHEMBL336413 & 62181 & 8.1871 & 7.9064 & TRN & \\
\hline CHEMBL336761 & 62181 & 7.2007 & 7.2244 & TRN & \\
\hline CHEMBL134006 & 62181 & 5.3098 & 5.4276 & TRN & \\
\hline CHEMBL129899 & 62181 & 8.6021 & 8.4111 & TRN & \\
\hline CHEMBL339169 & 62181 & 7.2757 & 7.2822 & TRN & \\
\hline CHEMBL130255 & 62181 & 8.8239 & 8.7836 & TRN & \\
\hline CHEMBL132180 & 62181 & 5.5528 & 5.6915 & TRN & \\
\hline CHEMBL337510 & 62181 & 8.7696 & 9.0054 & TRN & \\
\hline
\end{tabular}




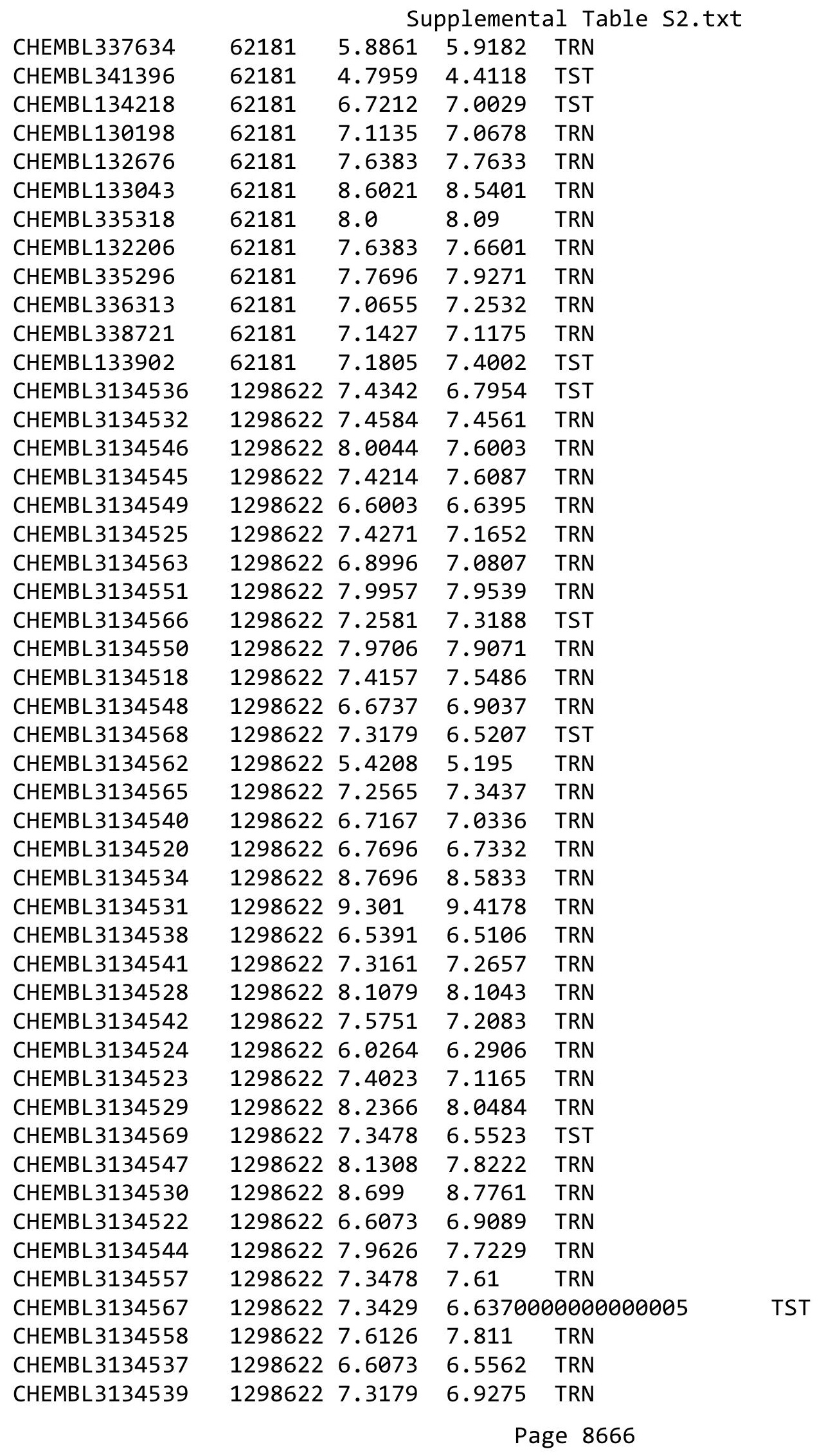


Supplemental Table S2.txt

\begin{tabular}{|c|c|c|c|c|}
\hline CHEMBL 3134527 & 1298622 & 8.1192 & 7.6047 & TST \\
\hline CHEMBL3134560 & 1298622 & 7.6326 & 7.8166 & TRN \\
\hline CHEMBL1951577 & 1298622 & 8.0044 & 7.7381 & TRN \\
\hline CHEMBL 3134554 & 1298622 & 7.4776 & 7.8309 & TRN \\
\hline CHEMBL 3134543 & 1298622 & 7.3468 & 7.5687 & TRN \\
\hline CHEMBL3134519 & 1298622 & 8.7447 & 8.6701 & TRN \\
\hline CHEMBL3134556 & 1298622 & 8.0177 & 7.9395 & TRN \\
\hline CHEMBL3134517 & 1298622 & 7.1688 & 7.2866 & TRN \\
\hline CHEMBL3134553 & 1298622 & 7.3478 & 7.4694 & TRN \\
\hline CHEMBL3134564 & 1298622 & 5.0559 & 6.2031 & TST \\
\hline CHEMBL 3134533 & 1298622 & 7.3947 & 6.84200 & 00000000005 \\
\hline CHEMBL 3134555 & 1298622 & 7.9136 & 7.8736 & TRN \\
\hline CHEMBL 3134521 & 1298622 & 6.7305 & 6.9314 & TRN \\
\hline CHEMBL3134552 & 1298622 & 7.3947 & 7.5685 & TST \\
\hline CHEMBL 3134570 & 1298622 & 7.3893 & 6.8264 & TST \\
\hline CHEMBL 3134526 & 1298622 & 7.9957 & 7.1531 & TST \\
\hline CHEMBL3134561 & 1298622 & 8.0969 & 8.1098 & TST \\
\hline CHEMBL 3134535 & 1298622 & 7.3716 & 7.3553 & TST \\
\hline CHEMBL3134559 & 1298622 & 7.1101 & 6.603 & TST \\
\hline CHEMBL3700137 & 1528111 & 6.7696 & 6.4811 & TRN \\
\hline CHEMBL3700156 & 1528111 & 6.2441 & 6.3175 & TRN \\
\hline CHEMBL3703512 & 1528111 & 5.7959 & 5.9991 & TRN \\
\hline CHEMBL 3700141 & 1528111 & 6.6778 & 6.7756 & TRN \\
\hline CHEMBL3703534 & 1528111 & 8.7959 & 8.6931 & TRN \\
\hline CHEMBL3700116 & 1528111 & 7.3188 & 7.1527 & TRN \\
\hline CHEMBL3700123 & 1528111 & 7.1675 & 7.1809 & TRN \\
\hline CHEMBL3703511 & 1528111 & 5.7959 & 6.1118 & TRN \\
\hline CHEMBL3703563 & 1528111 & 8.8861 & 8.6852 & TST \\
\hline CHEMBL3700147 & 1528111 & 6.585 & 6.7699 & TRN \\
\hline CHEMBL3703538 & 1528111 & 7.8239 & 7.9223 & TRN \\
\hline CHEMBL3703519 & 1528111 & 8.0915 & 8.5554 & TRN \\
\hline CHEMBL3700115 & 1528111 & 7.4685 & 7.5245 & TRN \\
\hline CHEMBL 3700109 & 1528111 & 8.2676 & 8.1522 & TRN \\
\hline CHEMBL3700110 & 1528111 & 8.041 & 7.8608 & TRN \\
\hline CHEMBL3700155 & 1528111 & 6.3188 & 6.9937 & TRN \\
\hline CHEMBL3700117 & 1528111 & 7.284 & 7.0949 & TRN \\
\hline CHEMBL3700146 & 1528111 & 6.6021 & 6.5493 & TRN \\
\hline CHEMBL3703507 & 1528111 & 5.8239 & 5.9068 & TRN \\
\hline CHEMBL3700152 & 1528111 & 6.3768 & 6.3541 & TRN \\
\hline CHEMBL3700160 & 1528111 & 6.0757 & 6.4131 & TST \\
\hline CHEMBL3703560 & 1528111 & 8.5528 & 8.0336 & TRN \\
\hline CHEMBL3700131 & 1528111 & 7.0362 & 7.2434 & TRN \\
\hline CHEMBL3703556 & 1528111 & 9.0315 & 9.2137 & TRN \\
\hline CHEMBL3700145 & 1528111 & 6.6021 & 6.8339 & TRN \\
\hline CHEMBL3703550 & 1528111 & 6.9208 & 7.1095 & TRN \\
\hline CHEMBL 3700158 & 1528111 & 6.0915 & 6.2876 & TRN \\
\hline CHEMBL 3700129 & 1528111 & 7.041 & 6.3277 & TST \\
\hline CHEMBL3703559 & 1528111 & 8.0915 & 8.2607 & TRN \\
\hline
\end{tabular}


Supplemental Table S2.txt

\begin{tabular}{|c|c|c|c|c|c|}
\hline CHEMBL3703517 & 1528111 & 7.9208 & 7.6006 & TRN & \\
\hline CHEMBL 3703542 & 1528111 & 6.9208 & 7.3211 & TRN & \\
\hline CHEMBL 3703526 & 1528111 & 7.585 & 8.2068 & TRN & \\
\hline CHEMBL 3703541 & 1528111 & 8.1249 & 8.0091 & TRN & \\
\hline CHEMBL 3703523 & 1528111 & 7.8239 & 7.5144 & TST & \\
\hline CHEMBL 3703527 & 1528111 & 8.2757 & 7.8613 & TST & \\
\hline CHEMBL 3700143 & 1528111 & 6.6383 & 6.7868 & TRN & \\
\hline CHEMBL 2180411 & 1528111 & 9.4949 & 9.3291 & TRN & \\
\hline CHEMBL 3703554 & 1528111 & 7.5376 & 7.7569 & TST & \\
\hline CHEMBL 2180414 & 1528111 & 8.7447 & 8.8988 & TRN & \\
\hline CHEMBL 3703555 & 1528111 & 7.8239 & 7.7885 & TRN & \\
\hline CHEMBL 3703545 & 1528111 & 8.4685 & 7.9887 & TRN & \\
\hline CHEMBL 3700112 & 1528111 & 7.699 & 7.0888 & TRN & \\
\hline CHEMBL3700151 & 1528111 & 6.3872 & 6.5094 & TRN & \\
\hline CHEMBL 3703530 & 1528111 & 8.5528 & 7.8881 & TST & \\
\hline CHEMBL 3703558 & 1528111 & 7.7696 & 7.5917 & TST & \\
\hline CHEMBL3703535 & 1528111 & 7.6383 & 8.013 & TRN & \\
\hline CHEMBL 3700124 & 1528111 & 7.1612 & 7.0327 & TRN & \\
\hline CHEMBL3700133 & 1528111 & 7.0 & 7.1521 & TRN & \\
\hline CHEMBL 3703516 & 1528111 & 6.3279 & \multicolumn{2}{|c|}{6.446000000000001} & TRN \\
\hline CHEMBL3703528 & 1528111 & 7.6198 & 7.5932 & TST & \\
\hline CHEMBL3703529 & 1528111 & 7.6021 & 7.8006 & TRN & \\
\hline CHEMBL 3703536 & 1528111 & 7.3979 & 6.8328 & TST & \\
\hline CHEMBL3700114 & 1528111 & 7.585 & 7.358 & TRN & \\
\hline CHEMBL 3700148 & 1528111 & 6.4815 & \multicolumn{2}{|c|}{6.5920000000000005} & TRN \\
\hline CHEMBL3700161 & 1528111 & 6.0506 & 6.2106 & TRN & \\
\hline CHEMBL3700122 & 1528111 & 7.1675 & 7.1811 & TRN & \\
\hline CHEMBL 3703532 & 1528111 & 8.301 & 8.3804 & TRN & \\
\hline CHEMBL3703524 & 1528111 & 7.9208 & \multicolumn{2}{|c|}{7.917999999999999} & TRN \\
\hline CHEMBL 3703513 & 1528111 & 5.7447 & 6.8042 & TST & \\
\hline CHEMBL3700144 & 1528111 & 6.6198 & 6.624 & TRN & \\
\hline CHEMBL 3703533 & 1528111 & 8.1612 & 8.1578 & TRN & \\
\hline CHEMBL3703514 & 1528111 & 5.5376 & 5.7944 & TRN & \\
\hline CHEMBL 3703562 & 1528111 & 8.1367 & 8.384 & TRN & \\
\hline CHEMBL3703552 & 1528111 & 6.7959 & 7.1326 & TRN & \\
\hline CHEMBL3700113 & 1528111 & 7.6576 & 7.7019 & TRN & \\
\hline CHEMBL 3703544 & 1528111 & 8.8861 & 8.7837 & TRN & \\
\hline CHEMBL3700119 & 1528111 & 7.2147 & 6.8793 & TRN & \\
\hline CHEMBL 3700127 & 1528111 & 7.0757 & 7.0968 & TRN & \\
\hline CHEMBL3700128 & 1528111 & 7.0605 & 6.6801 & TST & \\
\hline CHEMBL3700135 & 1528111 & 6.8539 & 6.6516 & TRN & \\
\hline CHEMBL3703518 & 1528111 & 7.8539 & 7.87299 & 9999999999 & TRN \\
\hline CHEMBL3703570 & 1528111 & 8.9586 & 8.7771 & TRN & \\
\hline CHEMBL3700111 & 1528111 & 7.9208 & 7.4215 & TRN & \\
\hline CHEMBL3700154 & 1528111 & 6.3665 & 6.5005 & TST & \\
\hline CHEMBL3703553 & 1528111 & 8.3188 & 8.4045 & TRN & \\
\hline CHEMBL 3703549 & 1528111 & 8.6021 & 8.3092 & TRN & \\
\hline CHEMBL3703543 & 1528111 & 8.5686 & 8.708 & TRN & \\
\hline
\end{tabular}


Supplemental Table S2.txt

\begin{tabular}{|c|c|c|c|c|}
\hline CHEMBL3703522 & 1528111 & 7.7212 & 7.4637 & TRN \\
\hline CHEMBL3703510 & 1528111 & 5.8239 & 5.9719 & TRN \\
\hline CHEMBL 3640024 & 1528111 & 9.1612 & 8.6603 & TRN \\
\hline CHEMBL3703551 & 1528111 & 8.4437 & 8.3484 & TRN \\
\hline CHEMBL 3700140 & 1528111 & 6.6778 & 6.5515 & TRN \\
\hline CHEMBL 3703547 & 1528111 & 8.8539 & 8.5959 & TRN \\
\hline CHEMBL3700157 & 1528111 & 6.2366 & 6.865 & TST \\
\hline CHEMBL3703520 & 1528111 & 7.4815 & 7.7725 & TST \\
\hline CHEMBL3703561 & 1528111 & 7.6021 & 8.5425 & TST \\
\hline CHEMBL3703557 & 1528111 & 7.4815 & 7.7737 & TRN \\
\hline CHEMBL 3700139 & 1528111 & 6.7447 & 6.7261 & TRN \\
\hline CHEMBL3700138 & 1528111 & 6.7447 & 6.8102 & TRN \\
\hline CHEMBL3700142 & 1528111 & 6.6576 & 6.5632 & TRN \\
\hline CHEMBL3700134 & 1528111 & 6.9586 & 6.9251 & TRN \\
\hline CHEMBL 3700159 & 1528111 & 6.0809 & 5.564 & TRN \\
\hline CHEMBL 3703540 & 1528111 & 7.0969 & 6.9917 & TRN \\
\hline CHEMBL3700126 & 1528111 & 7.1249 & 6.4283 & TRN \\
\hline CHEMBL3703537 & 1528111 & 7.6021 & 7.9547 & TRN \\
\hline CHEMBL3703567 & 1528111 & 7.5376 & 7.7095 & TRN \\
\hline CHEMBL 3700121 & 1528111 & 7.1805 & 7.1372 & TRN \\
\hline CHEMBL 3703525 & 1528111 & 7.4437 & 7.6561 & TRN \\
\hline CHEMBL3703521 & 1528111 & 8.2218 & 8.1932 & TRN \\
\hline CHEMBL 2180413 & 1528111 & 7.7696 & 7.5062 & TRN \\
\hline CHEMBL 3700149 & 1528111 & 6.4437 & 6.1764 & TRN \\
\hline CHEMBL 3703508 & 1528111 & 5.8239 & 6.1264 & TST \\
\hline CHEMBL 3700153 & 1528111 & 6.3665 & 6.4291 & TRN \\
\hline CHEMBL3700163 & 1528111 & 5.9208 & 5.9351 & TRN \\
\hline CHEMBL3700136 & 1528111 & 6.7696 & 6.5937 & TRN \\
\hline CHEMBL 3700118 & 1528111 & 7.2291 & 7.4144 & TRN \\
\hline CHEMBL 3700120 & 1528111 & 7.1938 & 7.273 & TST \\
\hline CHEMBL3703515 & 1528111 & 6.4318 & 6.4995 & TRN \\
\hline CHEMBL3703531 & 1528111 & 8.3768 & 8.5089 & TST \\
\hline CHEMBL3700125 & 1528111 & 7.1549 & 7.1973 & TST \\
\hline CHEMBL 3700132 & 1528111 & 7.0 & 6.9825 & TST \\
\hline CHEMBL 3703564 & 1528111 & 8.3565 & 8.145 & TST \\
\hline CHEMBL3703568 & 1528111 & 7.1024 & 7.5688 & TST \\
\hline CHEMBL 3700150 & 1528111 & 6.4202 & 6.7358 & TST \\
\hline CHEMBL3703539 & 1528111 & 8.5528 & 8.0584 & TST \\
\hline CHEMBL 2180412 & 1528111 & 8.1427 & 8.6119 & TST \\
\hline CHEMBL 3700130 & 1528111 & 7.0362 & 6.2879 & TST \\
\hline CHEMBL 3703509 & 1528111 & 5.8239 & 5.78700 & 0000000001 \\
\hline CHEMBL 3703546 & 1528111 & 8.0605 & 8.4679 & TST \\
\hline CHEMBL3703569 & 1528111 & 7.4949 & 7.5573 & TST \\
\hline CHEMBL 3700162 & 1528111 & 5.9586 & 6.1696 & TST \\
\hline CHEMBL 3666357 & 1528895 & 6.0899 & 6.3861 & TRN \\
\hline CHEMBL 3661499 & 1528895 & 7.5918 & 7.6413 & TRN \\
\hline CHEMBL 3661532 & 1528895 & 5.0804 & 5.6012 & TRN \\
\hline CHEMBL 3661489 & 1528895 & 7.2612 & 7.4663 & TRN \\
\hline
\end{tabular}

Page 8669 
Supplemental Table S2.txt

\begin{tabular}{|c|c|c|c|c|c|c|}
\hline CHEMBL 3671467 & 1528895 & 8.3335 & 6.6296 & TST & & \\
\hline CHEMBL3661494 & 1528895 & 7.5918 & 6.9582 & TRN & & \\
\hline CHEMBL3666305 & 1528895 & 6.2277 & 7.5297 & TST & & \\
\hline CHEMBL3666287 & 1528895 & 7.3655 & 6.9521 & TRN & & \\
\hline CHEMBL3666421 & 1528895 & 7.6478 & 5.4116 & TST & & \\
\hline CHEMBL3666257 & 1528895 & 8.4067 & 8.4922 & TRN & & \\
\hline CHEMBL 3661467 & 1528895 & 7.1986 & 7.01 & TRN & & \\
\hline CHEMBL3671473 & 1528895 & 5.9431 & 6.5675 & TRN & & \\
\hline CHEMBL 3671440 & 1528895 & 7.9172 & 7.4788 & TRN & & \\
\hline CHEMBL3666344 & 1528895 & 6.0195 & 6.2613 & TRN & & \\
\hline CHEMBL 3671408 & 1528895 & 7.9547 & 7.7731 & TRN & & \\
\hline CHEMBL3666423 & 1528895 & 5.0762 & 5.7898 & TRN & & \\
\hline CHEMBL3661563 & 1528895 & 5.5086 & 5.9384 & TRN & & \\
\hline CHEMBL3666430 & 1528895 & 6.5654 & 6.6152 & TRN & & \\
\hline CHEMBL3666330 & 1528895 & 6.6003 & 7.0317 & TRN & & \\
\hline CHEMBL 3671404 & 1528895 & 8.6478 & 7.3546 & TST & & \\
\hline CHEMBL3671401 & 1528895 & 7.9431 & 7.4788 & TRN & & \\
\hline CHEMBL 3666342 & 1528895 & 5.0088 & 5.5614 & TRN & & \\
\hline CHEMBL3661514 & 1528895 & 7.2757 & 7.0109 & TRN & & \\
\hline CHEMBL3661601 & 1528895 & 6.8894 & 6.5212 & TRN & & \\
\hline CHEMBL3666428 & 1528895 & 6.0904 & 6.3021 & TRN & & \\
\hline CHEMBL3661529 & 1528895 & 6.5058 & 6.3777 & TRN & & \\
\hline CHEMBL 3661603 & 1528895 & 6.7328 & 6.4672 & TRN & & \\
\hline CHEMBL3671395 & 1528895 & 5.3575 & 5.4896 & TST & & \\
\hline CHEMBL3661496 & 1528895 & 7.3675 & 7.2757 & TRN & & \\
\hline CHEMBL3671468 & 1528895 & \multicolumn{3}{|c|}{8.091000000000001} & 7.528 & TRN \\
\hline CHEMBL3661464 & 1528895 & 7.9626 & 7.4523 & TRN & & \\
\hline CHEMBL 3661490 & 1528895 & 8.2636 & 7.6806 & TRN & & \\
\hline CHEMBL3666248 & 1528895 & 8.3288 & 8.1414 & TRN & & \\
\hline CHEMBL3666356 & 1528895 & 5.0088 & 5.3086 & TRN & & \\
\hline CHEMBL3661627 & 1528895 & 8.0287 & 7.4911 & TRN & & \\
\hline CHEMBL3671414 & 1528895 & 8.821 & 9.3161 & TRN & & \\
\hline CHEMBL3666335 & 1528895 & 6.5969 & 6.7532 & TRN & & \\
\hline CHEMBL3661564 & 1528895 & 5.5086 & 5.2918 & TRN & & \\
\hline CHEMBL3671437 & 1528895 & 8.8041 & 7.2198 & TRN & & \\
\hline CHEMBL3666443 & 1528895 & 5.8794 & 5.8219 & TRN & & \\
\hline CHEMBL 3671462 & 1528895 & 7.3696 & 7.5459 & TRN & & \\
\hline CHEMBL3666311 & 1528895 & 7.4078 & 7.2933 & TRN & & \\
\hline CHEMBL3661535 & 1528895 & 7.2255 & 7.6596 & TRN & & \\
\hline CHEMBL3666293 & 1528895 & 7.2118 & 7.311 & TRN & & \\
\hline CHEMBL3671391 & 1528895 & 6.8416 & 5.8075 & TRN & & \\
\hline CHEMBL3661483 & 1528895 & 7.2472 & 7.3767 & TRN & & \\
\hline CHEMBL3666314 & 1528895 & 5.5086 & 5.8036 & TRN & & \\
\hline CHEMBL3671415 & 1528895 & 8.3893 & 8.254 & TRN & & \\
\hline CHEMBL3661572 & 1528895 & 5.5086 & 6.1419 & TRN & & \\
\hline CHEMBL3661551 & 1528895 & 6.7595 & 6.5691 & TST & & \\
\hline CHEMBL3661571 & 1528895 & 5.5086 & 5.2894 & TRN & & \\
\hline CHEMBL3666270 & 1528895 & 6.2541 & 6.7013 & TRN & & \\
\hline
\end{tabular}

Page 8670 
Supplemental Table S2.txt

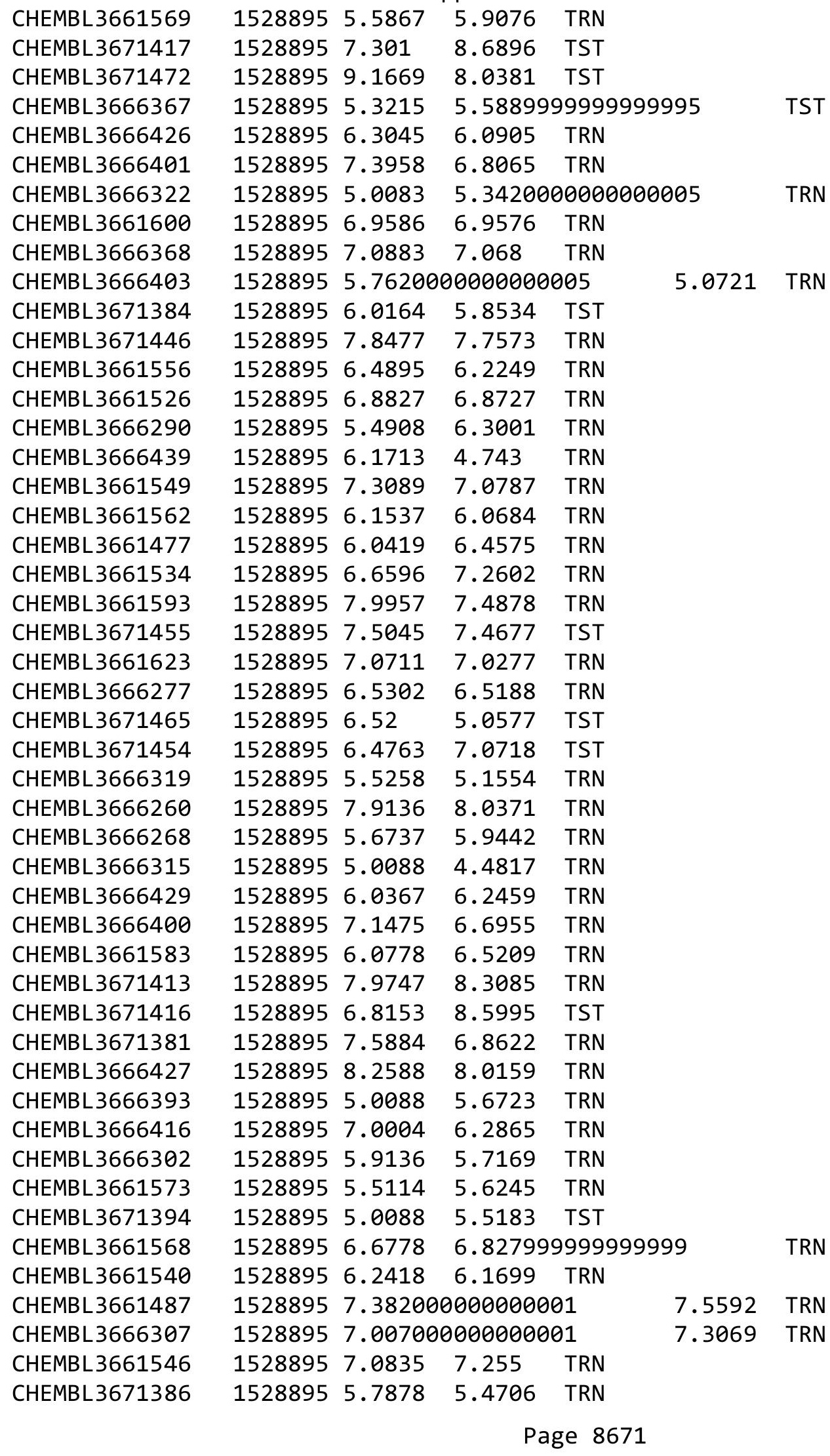


Supplemental Table S2.txt

\begin{tabular}{|c|c|c|c|c|c|}
\hline CHEMBL 3671456 & 1528895 & 7.1475 & 7.6578 & TST & \\
\hline CHEMBL 3661488 & 1528895 & 7.9066 & 8.2241 & TRN & \\
\hline CHEMBL 3671445 & 1528895 & 7.7471 & 7.6653 & TRN & \\
\hline CHEMBL3661516 & 1528895 & 5.2336 & \multicolumn{2}{|c|}{5.736000000000001} & TST \\
\hline CHEMBL 3661498 & 1528895 & 7.699 & 7.3895 & TRN & \\
\hline CHEMBL 3661624 & 1528895 & 7.1518 & 7.0203 & TRN & \\
\hline CHEMBL3661482 & 1528895 & 7.1993 & 6.721 & TRN & \\
\hline CHEMBL3666276 & 1528895 & 5.2924 & 6.0958 & TRN & \\
\hline CHEMBL3661470 & 1528895 & 6.2464 & 6.6099 & TRN & \\
\hline CHEMBL3666409 & 1528895 & 7.0297 & 6.8542 & TRN & \\
\hline CHEMBL 3671426 & 1528895 & 8.118 & 8.3729 & TRN & \\
\hline CHEMBL 3671372 & 1528895 & 5.8508 & \multicolumn{2}{|c|}{5.9270000000000005} & TRN \\
\hline CHEMBL 3666411 & 1528895 & 5.5622 & 5.7145 & TRN & \\
\hline CHEMBL3661486 & 1528895 & 5.9872 & 6.4058 & TRN & \\
\hline CHEMBL 3671464 & 1528895 & 5.0088 & 5.4352 & TRN & \\
\hline CHEMBL 3661508 & 1528895 & 6.0106 & 6.5179 & TRN & \\
\hline CHEMBL 3666255 & 1528895 & 7.4802 & 7.41 & TRN & \\
\hline CHEMBL 3666458 & 1528895 & 5.5186 & 5.9619 & TRN & \\
\hline CHEMBL 3666377 & 1528895 & 5.1475 & 4.9024 & TRN & \\
\hline CHEMBL 3666390 & 1528895 & 5.585 & 5.2245 & TRN & \\
\hline CHEMBL 3666304 & 1528895 & 5.5784 & 6.0284 & TRN & \\
\hline CHEMBL 3666340 & 1528895 & 7.2034 & 7.2264 & TRN & \\
\hline CHEMBL 3671453 & 1528895 & 7.6882 & 7.7372 & TRN & \\
\hline CHEMBL 3661521 & 1528895 & 5.8761 & 5.681 & TRN & \\
\hline CHEMBL 3661576 & 1528895 & 6.2652 & 6.8001 & TRN & \\
\hline CHEMBL3661536 & 1528895 & 5.8601 & 6.2757 & TRN & \\
\hline CHEMBL 3666294 & 1528895 & 7.4962 & \multicolumn{2}{|c|}{7.577000000000001} & TRN \\
\hline CHEMBL 3666312 & 1528895 & 6.7258 & 6.2831 & TRN & \\
\hline CHEMBL 3661512 & 1528895 & 5.5935 & 5.5943 & TRN & \\
\hline CHEMBL3661608 & 1528895 & 5.9172 & 5.6941 & TRN & \\
\hline CHEMBL3661585 & 1528895 & 6.059 & 6.0702 & TRN & \\
\hline CHEMBL 3671371 & 1528895 & 5.0088 & 4.9072 & TRN & \\
\hline CHEMBL 3671427 & 1528895 & 8.3565 & 8.576 & TST & \\
\hline CHEMBL3666327 & 1528895 & 5.0088 & 6.3861 & TST & \\
\hline CHEMBL 3661570 & 1528895 & 6.7825 & 6.9512 & TRN & \\
\hline CHEMBL3666343 & 1528895 & 5.0088 & 4.9069 & TRN & \\
\hline CHEMBL3666392 & 1528895 & 7.1524 & 7.3447 & TRN & \\
\hline CHEMBL3661511 & 1528895 & 7.1649 & 7.235 & TRN & \\
\hline CHEMBL 3666346 & 1528895 & \multicolumn{3}{|c|}{5.718999999999999} & TRN \\
\hline CHEMBL 3666415 & 1528895 & 6.6091 & 7.0142 & TRN & \\
\hline CHEMBL3671405 & 1528895 & 8.4056 & 8.7695 & TRN & \\
\hline CHEMBL 3671402 & 1528895 & 8.3439 & 7.9553 & TRN & \\
\hline CHEMBL 3671470 & 1528895 & 8.4935 & 7.9015 & TRN & \\
\hline CHEMBL 3671392 & 1528895 & 7.8996 & 6.5135 & TST & \\
\hline CHEMBL 3661604 & 1528895 & 6.0 & 6.5527 & TRN & \\
\hline CHEMBL 3671432 & 1528895 & 8.2549 & 7.0282 & TST & \\
\hline CHEMBL 3661548 & 1528895 & 7.0264 & 6.773 & TRN & \\
\hline CHEMBL 3666247 & 1528895 & 7.4157 & 7.4885 & TRN & \\
\hline
\end{tabular}


Supplemental Table S2.txt

\begin{tabular}{|c|c|c|c|c|}
\hline CHEMBL3661517 & 1528895 & 6.8447 & 7.0295 & TRN \\
\hline CHEMBL3666388 & 1528895 & 5.7878 & 5.5336 & TRN \\
\hline CHEMBL3666465 & 1528895 & 6.7167 & 5.8316 & TRN \\
\hline CHEMBL3661485 & 1528895 & 8.055 & 8.3257 & TRN \\
\hline CHEMBL3661621 & 1528895 & 6.5622 & 6.7955 & TRN \\
\hline CHEMBL3666436 & 1528895 & 6.1986 & 5.233 & TRN \\
\hline CHEMBL3666455 & 1528895 & 5.3546 & 5.13899 & 9999999999 \\
\hline CHEMBL3661492 & 1528895 & 8.2874 & 7.6272 & TRN \\
\hline CHEMBL3661560 & 1528895 & 6.9586 & 7.2414 & TRN \\
\hline CHEMBL3666446 & 1528895 & 5.6716 & 5.8246 & TRN \\
\hline CHEMBL 3666447 & 1528895 & 6.3979 & 6.7682 & TRN \\
\hline CHEMBL3666271 & 1528895 & 6.4647 & 6.2176 & TRN \\
\hline CHEMBL 3671443 & 1528895 & 8.5346 & 7.9888 & TRN \\
\hline CHEMBL3666369 & 1528895 & 5.0088 & 5.1987 & TRN \\
\hline CHEMBL3661565 & 1528895 & 5.8928 & 5.3493 & TRN \\
\hline CHEMBL3666404 & 1528895 & 6.3458 & 5.9585 & TRN \\
\hline CHEMBL3666339 & 1528895 & 7.6757 & 7.8317 & TRN \\
\hline CHEMBL3666362 & 1528895 & 6.1451 & 5.3126 & TRN \\
\hline CHEMBL3666317 & 1528895 & 5.5086 & 5.5309 & TRN \\
\hline CHEMBL3666283 & 1528895 & 5.9957 & 6.3893 & TRN \\
\hline CHEMBL3661618 & 1528895 & 7.8268 & 7.4927 & TRN \\
\hline CHEMBL3666309 & 1528895 & 6.7799 & 7.1184 & TRN \\
\hline CHEMBL3661522 & 1528895 & 6.6861 & 6.6963 & TRN \\
\hline CHEMBL 3666420 & 1528895 & 7.5058 & 6.9197 & TST \\
\hline CHEMBL3661595 & 1528895 & 6.3851 & 7.322 & TRN \\
\hline CHEMBL3661616 & 1528895 & 8.4425 & 8.0911 & TRN \\
\hline CHEMBL3666381 & 1528895 & 6.8601 & 7.0427 & TRN \\
\hline CHEMBL3639702 & 1528895 & 5.0088 & 5.5865 & TRN \\
\hline CHEMBL 3661557 & 1528895 & 5.7352 & 6.5104 & TST \\
\hline CHEMBL3666333 & 1528895 & 6.4868 & 6.2487 & TRN \\
\hline CHEMBL3671448 & 1528895 & 6.5287 & 7.9291 & TRN \\
\hline CHEMBL3661462 & 1528895 & 8.382 & 7.8904 & TRN \\
\hline CHEMBL3639652 & 1528895 & 6.52 & 6.1341 & TST \\
\hline CHEMBL 3666288 & 1528895 & 5.8633 & 6.8804 & TRN \\
\hline CHEMBL 3671431 & 1528895 & 8.0237 & 7.9084 & TRN \\
\hline CHEMBL3661520 & 1528895 & 7.0191 & 7.0736 & TRN \\
\hline CHEMBL 3666245 & 1528895 & 7.3439 & 7.4293 & TRN \\
\hline CHEMBL3666300 & 1528895 & 6.3686 & 6.7167 & TRN \\
\hline CHEMBL 3671434 & 1528895 & 5.7932 & 6.2816 & TRN \\
\hline CHEMBL3661561 & 1528895 & 5.4597 & 6.2059 & TRN \\
\hline CHEMBL3671403 & 1528895 & 8.0232 & 7.7724 & TRN \\
\hline CHEMBL3666398 & 1528895 & 5.5867 & 5.4156 & TRN \\
\hline CHEMBL3666371 & 1528895 & 6.7825 & 6.9449 & TRN \\
\hline CHEMBL3666370 & 1528895 & 5.1624 & 6.041 & TST \\
\hline CHEMBL3661592 & 1528895 & 7.6556 & 7.6689 & TST \\
\hline CHEMBL3661509 & 1528895 & 6.9914 & 6.8268 & TRN \\
\hline CHEMBL3666402 & 1528895 & 5.0088 & 5.0517 & TRN \\
\hline CHEMBL3666349 & 1528895 & 5.6904 & 5.9157 & TRN \\
\hline
\end{tabular}


Supplemental Table S2.txt

\begin{tabular}{|c|c|c|c|c|c|}
\hline CHEMBL3661460 & 1528895 & 7.2549 & 7.2529 & TRN & \\
\hline CHEMBL3671385 & 1528895 & 5.9914 & 6.2756 & TRN & \\
\hline CHEMBL3666394 & 1528895 & 5.0088 & 5.3899 & TRN & \\
\hline CHEMBL3666438 & 1528895 & 5.1574 & 5.2207 & TRN & \\
\hline CHEMBL 3666441 & 1528895 & 5.0088 & 4.3976 & TRN & \\
\hline CHEMBL3671382 & 1528895 & 6.6968 & 7.6026 & TRN & \\
\hline CHEMBL3671447 & 1528895 & 8.51 & 8.1242 & TRN & \\
\hline CHEMBL3661580 & 1528895 & 6.1433 & 6.1708 & TRN & \\
\hline CHEMBL3666372 & 1528895 & 7.0742 & 6.6576 & TRN & \\
\hline CHEMBL3661513 & 1528895 & 6.6326 & 6.7457 & TRN & \\
\hline CHEMBL3666252 & 1528895 & 7.6253 & 7.7852 & TRN & \\
\hline CHEMBL3661555 & 1528895 & 5.2027 & 5.7837 & TRN & \\
\hline CHEMBL3666457 & 1528895 & 7.1871 & 7.0618 & TRN & \\
\hline CHEMBL3666376 & 1528895 & 5.8665 & 5.8516 & TRN & \\
\hline CHEMBL 3666328 & 1528895 & 5.3686 & 5.5496 & TST & \\
\hline CHEMBL3661622 & 1528895 & 7.0155 & 6.7847 & TRN & \\
\hline CHEMBL3661502 & 1528895 & 8.1175 & 6.4008 & TRN & \\
\hline CHEMBL3666264 & 1528895 & 7.1331 & 6.9197 & TRN & \\
\hline CHEMBL3661552 & 1528895 & 6.6383 & 6.3347 & TRN & \\
\hline CHEMBL 3671377 & 1528895 & 6.7011 & 7.3334 & TRN & \\
\hline CHEMBL3661537 & 1528895 & 5.3251 & 5.3699 & TRN & \\
\hline CHEMBL3666298 & 1528895 & 6.2684 & 6.5925 & TRN & \\
\hline CHEMBL3666448 & 1528895 & 6.2692 & 7.0174 & TRN & \\
\hline CHEMBL3666323 & 1528895 & 5.5086 & 5.9294 & TRN & \\
\hline CHEMBL 3666431 & 1528895 & 6.8097 & 6.5243 & TRN & \\
\hline CHEMBL3666249 & 1528895 & 8.3279 & 8.0361 & TRN & \\
\hline CHEMBL3671373 & 1528895 & 5.7721 & 6.8097 & TST & \\
\hline CHEMBL3661588 & 1528895 & 6.9957 & 7.0105 & TRN & \\
\hline CHEMBL3666380 & 1528895 & 5.0088 & 5.4313 & TRN & \\
\hline CHEMBL 3666375 & 1528895 & 6.8697 & 6.7126 & TRN & \\
\hline CHEMBL3666265 & 1528895 & 7.0716 & 7.3362 & TRN & \\
\hline CHEMBL3666281 & 1528895 & 6.3028 & 6.7593 & TRN & \\
\hline CHEMBL3671418 & 1528895 & 7.5003 & \multicolumn{2}{|c|}{8.716000000000001} & TST \\
\hline CHEMBL 3661475 & 1528895 & 6.4067 & 6.4529 & TRN & \\
\hline CHEMBL 3671387 & 1528895 & 7.1739 & 7.6054 & TRN & \\
\hline CHEMBL3661554 & 1528895 & 5.9666 & 5.0608 & TRN & \\
\hline CHEMBL3661547 & 1528895 & 7.1457 & 7.3232 & TRN & \\
\hline CHEMBL3666325 & 1528895 & 5.6615 & 5.6456 & TRN & \\
\hline CHEMBL3671399 & 1528895 & 7.0329 & 7.1782 & TRN & \\
\hline CHEMBL3666364 & 1528895 & 5.556 & 5.6748 & TRN & \\
\hline CHEMBL3661599 & 1528895 & 6.9101 & 7.1037 & TRN & \\
\hline CHEMBL3661581 & 1528895 & 5.58 & 5.7508 & TRN & \\
\hline CHEMBL3666360 & 1528895 & 5.2924 & 5.5368 & TRN & \\
\hline CHEMBL3661541 & 1528895 & 7.1169 & 7.2645 & TRN & \\
\hline CHEMBL3666399 & 1528895 & 7.284 & 6.2512 & TST & \\
\hline CHEMBL3661472 & 1528895 & 7.1918 & 7.2646 & TRN & \\
\hline CHEMBL3666395 & 1528895 & 8.2857 & 6.3706 & TST & \\
\hline CHEMBL 3661471 & 1528895 & $6.7620 e$ & $\partial 000000$ & 6.5494 & RN \\
\hline
\end{tabular}


Supplemental Table S2.txt

\begin{tabular}{|c|c|c|c|c|c|}
\hline CHEMBL3671367 & 1528895 & 6.0942 & 6.7381 & TRN & \\
\hline CHEMBL3666269 & 1528895 & 6.2373 & 5.3438 & TRN & \\
\hline CHEMBL3661626 & 1528895 & 7.1314 & 7.1169 & TRN & \\
\hline CHEMBL3666452 & 1528895 & 6.1244 & 5.5805 & TST & \\
\hline CHEMBL 3666284 & 1528895 & 6.5272 & 6.6144 & TRN & \\
\hline CHEMBL3661505 & 1528895 & 7.3354 & 6.8433 & TRN & \\
\hline CHEMBL3661589 & 1528895 & 6.1018 & 6.8489 & TRN & \\
\hline CHEMBL3666382 & 1528895 & 6.8153 & 6.3272 & TST & \\
\hline CHEMBL3661566 & 1528895 & 5.4157 & 5.8687 & TRN & \\
\hline CHEMBL3661531 & 1528895 & 6.3045 & 6.5852 & TST & \\
\hline CHEMBL3666266 & 1528895 & 7.1612 & 6.3596 & TRN & \\
\hline CHEMBL3661590 & 1528895 & 6.3665 & 6.3827 & TRN & \\
\hline CHEMBL3661625 & 1528895 & 7.5986 & 7.3195 & TRN & \\
\hline CHEMBL3661620 & 1528895 & 7.1959 & 7.4406 & TRN & \\
\hline CHEMBL3666296 & 1528895 & 6.5243 & 8.068 & TST & \\
\hline CHEMBL3666407 & 1528895 & 6.0991 & 6.8409 & TRN & \\
\hline CHEMBL3661539 & 1528895 & 7.4271 & 7.1086 & TRN & \\
\hline CHEMBL3666366 & 1528895 & 6.8861 & 7.0632 & TRN & \\
\hline CHEMBL3671366 & 1528895 & 7.699 & \multicolumn{2}{|c|}{6.5520000000000005} & TRN \\
\hline CHEMBL3639653 & 1528895 & 6.6716 & 6.7671 & TST & \\
\hline CHEMBL3666258 & 1528895 & 7.279 & 7.2637 & TRN & \\
\hline CHEMBL3666306 & 1528895 & 7.2684 & 7.4271 & TRN & \\
\hline CHEMBL3666424 & 1528895 & 7.4365 & 6.7829 & TST & \\
\hline CHEMBL3666332 & 1528895 & 7.2684 & 7.0586 & TRN & \\
\hline CHEMBL3666373 & 1528895 & 5.0088 & \multicolumn{2}{|c|}{5.9639999999999995} & TRN \\
\hline CHEMBL3666440 & 1528895 & 8.3915 & \multicolumn{2}{|c|}{7.212000000000001} & TST \\
\hline CHEMBL3666433 & 1528895 & 5.1445 & 4.6208 & TRN & \\
\hline CHEMBL3666378 & 1528895 & 5.8697 & 6.0738 & TRN & \\
\hline CHEMBL3666308 & 1528895 & 6.6234 & \multicolumn{2}{|c|}{7.638999999999999} & TRN \\
\hline CHEMBL3666273 & 1528895 & 6.1568 & 5.9098 & TRN & \\
\hline CHEMBL3661510 & 1528895 & 6.9872 & 6.4579 & TRN & \\
\hline CHEMBL3666291 & 1528895 & 7.4237 & 7.3657 & TRN & \\
\hline CHEMBL3666365 & 1528895 & 7.3401 & 6.05 & TST & \\
\hline CHEMBL3666313 & 1528895 & 5.5086 & 5.9863 & TRN & \\
\hline CHEMBL3666384 & 1528895 & 6.8794 & 6.7117 & TRN & \\
\hline CHEMBL3666386 & 1528895 & 5.9136 & 6.4238 & TST & \\
\hline CHEMBL3666419 & 1528895 & 6.9706 & 6.8754 & TRN & \\
\hline CHEMBL3661476 & 1528895 & 6.7055 & 6.8777 & TRN & \\
\hline CHEMBL3661542 & 1528895 & 7.0297 & 7.0149 & TRN & \\
\hline CHEMBL3666417 & 1528895 & 5.2604 & 6.0737 & TST & \\
\hline CHEMBL3671449 & 1528895 & 8.7212 & 8.2854 & TRN & \\
\hline CHEMBL 3666347 & 1528895 & 5.9872 & 6.6976 & TRN & \\
\hline CHEMBL3671428 & 1528895 & 6.5686 & 6.6604 & TST & \\
\hline CHEMBL3666345 & 1528895 & 5.1169 & 5.2782 & TRN & \\
\hline CHEMBL3666267 & 1528895 & 5.5302 & 5.5606 & TRN & \\
\hline CHEMBL3661574 & 1528895 & 5.5086 & 5.8037 & TRN & \\
\hline CHEMBL3661479 & 1528895 & 5.5436 & 7.8807 & TST & \\
\hline CHEMBL3671439 & 1528895 & 7.6819 & 8.0403 & TRN & \\
\hline
\end{tabular}


Supplemental Table S2.txt

\begin{tabular}{|c|c|c|c|c|c|c|}
\hline CHEMBL 3661553 & 1528895 & 6.6308 & 6.2692 & TRN & & \\
\hline CHEMBL 3666329 & 1528895 & 5.5638 & 6.693 & TST & & \\
\hline CHEMBL 3666250 & 1528895 & 7.4486 & 7.6205 & TRN & & \\
\hline CHEMBL 3671433 & 1528895 & 6.4271 & 6.9859 & TRN & & \\
\hline CHEMBL3671369 & 1528895 & 7.1898 & 6.1414 & TST & & \\
\hline CHEMBL 3666454 & 1528895 & 5.1379 & 5.4257 & TRN & & \\
\hline CHEMBL 3671400 & 1528895 & 7.3595 & 7.1242 & TRN & & \\
\hline CHEMBL3666425 & 1528895 & 7.3215 & 6.1646 & TRN & & \\
\hline CHEMBL 3666272 & 1528895 & 7.4089 & 7.1057 & TRN & & \\
\hline CHEMBL3661582 & 1528895 & 6.5575 & 6.2252 & TRN & & \\
\hline CHEMBL 3671396 & 1528895 & 8.1367 & 7.3016 & TRN & & \\
\hline CHEMBL 3666289 & 1528895 & 6.7773 & 7.1113 & TRN & & \\
\hline CHEMBL 3661497 & 1528895 & 7.3799 & 8.1353 & TRN & & \\
\hline CHEMBL 3661605 & 1528895 & 6.0 & 6.8226 & TRN & & \\
\hline CHEMBL3666379 & 1528895 & 6.75200 & 000000000 & 1 & 7.0525 & TRN \\
\hline CHEMBL 3671409 & 1528895 & 7.5045 & 6.2084 & TST & & \\
\hline CHEMBL3661518 & 1528895 & 6.6126 & 6.7266 & TRN & & \\
\hline CHEMBL 3666324 & 1528895 & 5.0083 & 5.291 & TRN & & \\
\hline CHEMBL 3661484 & 1528895 & 7.6635 & 7.4048 & TRN & & \\
\hline CHEMBL3661610 & 1528895 & 6.3354 & 6.013 & TRN & & \\
\hline CHEMBL 3671374 & 1528895 & 6.0716 & 6.2812 & TRN & & \\
\hline CHEMBL3661596 & 1528895 & 6.5003 & 6.7135 & TRN & & \\
\hline CHEMBL 3666450 & 1528895 & 6.2815 & 6.4692 & TRN & & \\
\hline CHEMBL 3666444 & 1528895 & 6.7305 & 6.1114 & TRN & & \\
\hline CHEMBL 3639603 & 1528895 & 8.4034 & 7.6764 & TRN & & \\
\hline CHEMBL 3661528 & 1528895 & 6.4815 & 6.3552 & TST & & \\
\hline CHEMBL 3661558 & 1528895 & 6.8761 & 6.8651 & TRN & & \\
\hline CHEMBL 3661533 & 1528895 & 7.1824 & 7.6449 & TRN & & \\
\hline CHEMBL 3661578 & 1528895 & 6.2373 & 5.5399 & TRN & & \\
\hline CHEMBL 3666451 & 1528895 & 6.7799 & 7.0579 & TST & & \\
\hline CHEMBL 3666350 & 1528895 & \multicolumn{3}{|c|}{6.4510000000000005} & 6.9495 & TRN \\
\hline CHEMBL 3661543 & 1528895 & 5.4473 & 5.8065 & TRN & & \\
\hline CHEMBL 3666353 & 1528895 & 5.5229 & 5.9324 & TRN & & \\
\hline CHEMBL 3671376 & 1528895 & 5.0088 & 4.9359 & TRN & & \\
\hline CHEMBL 3666414 & 1528895 & 5.5544 & 5.8421 & TRN & & \\
\hline CHEMBL 3661461 & 1528895 & 8.4498 & 7.9359 & TRN & & \\
\hline CHEMBL 3661613 & 1528895 & 5.7799 & 5.6226 & TRN & & \\
\hline CHEMBL 3666297 & 1528895 & 5.8356 & 7.7621 & TST & & \\
\hline CHEMBL 3666410 & 1528895 & 6.0177 & 5.9366 & TRN & & \\
\hline CHEMBL 3666253 & 1528895 & 7.4461 & 7.5788 & TRN & & \\
\hline CHEMBL 3666254 & 1528895 & 8.4584 & 7.745 & TRN & & \\
\hline CHEMBL 3666352 & 1528895 & 6.1232 & 6.0182 & TRN & & \\
\hline CHEMBL 3661614 & 1528895 & 5.5086 & 5.4902 & TST & & \\
\hline CHEMBL 3671451 & 1528895 & 7.4353 & 7.9252 & TST & & \\
\hline CHEMBL 3671407 & 1528895 & 7.2807 & 6.5352 & TRN & & \\
\hline CHEMBL 3661463 & 1528895 & 7.9172 & 7.7147 & TRN & & \\
\hline CHEMBL 3661611 & 1528895 & 5.5086 & 5.6655 & TRN & & \\
\hline CHEMBL 3666442 & 1528895 & 5.0088 & 5.0879 & TST & & \\
\hline
\end{tabular}


Supplemental Table S2.txt

\begin{tabular}{|c|c|c|c|c|}
\hline S & & & & \\
\hline & & & 8.5704 & \\
\hline 58 & & & & \\
\hline IEMBL & & 088 & & S \\
\hline AEMBL & 528895 & 2636 & & \\
\hline HEMBL3671419 & 528895 & 8.5302 & .1033 & \\
\hline 5331 & (n) & 458 & 66 & \\
\hline 474 & 8895 & & & \\
\hline AEMBL3661480 & 528895 & & 5.3718 & \\
\hline HEMBL3671457 & 528895 & 477 & .2738 & \\
\hline AEMBL3666262 & 528895 & 8.0645 & 7.7 & \\
\hline IEMBL & 8895 & 98 & 81 & \\
\hline IEMBL: & & & & \\
\hline HEMBL3 & 528895 & 088 & & \\
\hline AEMBL3 & 5 & 088 & & \\
\hline AEMBL36 & 04 & 072 & 37 & \\
\hline AEMBL & 2 & 086 & & \\
\hline HEMBL & & 95 & & \\
\hline AEMBL3 & 528805 & 289 & & \\
\hline IEMBL3 & & 34 & & \\
\hline AEIMBL. & 28 & 51 & 35 & RIN \\
\hline AEMBL & & 52 & & (1) \\
\hline AEMBL & & & & \\
\hline 456 & & 18 & & \\
\hline IEMBL36 & & & & N \\
\hline HEMBL & 52 & & & 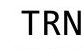 \\
\hline HEMBL & & & & ST \\
\hline HFMRI & J & 47 & & \\
\hline HEMBL36 & & 269 & & TIV \\
\hline HEMBL 367 & & -0.9912 & & I RIV \\
\hline HEMBL3 & 2 & 89 & 48 & RN \\
\hline HEMBL & & 12 & & RN \\
\hline AEMBL & 95 & 32 & & RN \\
\hline HEMBL3666278 & I000 & 6 . & & IRN \\
\hline HEMBL3661602 & 5288 & 654 & 6. & TRN \\
\hline HEMBL3 & 288 & 924 & & RN \\
\hline HCMDI & & & & RIV \\
\hline HEMBL; & & 5. & & IST \\
\hline HEMBL3661507 & 5288 & 229 & 11 & $\Gamma \mathrm{RN}$ \\
\hline AEMBL36 & 5288 & & & RN \\
\hline HEMBL36 & 5288 & 82 & 64 & \\
\hline HEMBL36 & & & & II \\
\hline HEMBL3 & 528895 & 101 & & RN \\
\hline AEMBL3666363 & 52889 & 747 & 73 & TRN \\
\hline $1=$ & & & & $\mathrm{N}$ \\
\hline HEMBL36 & & & & \\
\hline HEMBL3661500 & & .8297 & 7.2236 & \\
\hline CHEMBL3661523 & 15288 & 5.4134 & 6.2861 & RN \\
\hline
\end{tabular}


Supplemental Table S2.txt

\begin{tabular}{|c|c|c|c|c|c|c|}
\hline CHEMBL 3661577 & 1528895 & 5.7328 & 5.4015 & TRN & & \\
\hline CHEMBL 3671425 & 1528895 & 8.55600 & 00000000 & 01 & 8.8286 & TRN \\
\hline CHEMBL3666263 & 1528895 & 7.7747 & 7.8424 & TRN & & \\
\hline CHEMBL3661465 & 1528895 & 7.6421 & 7.2863 & TRN & & \\
\hline CHEMBL3666461 & 1528895 & 6.2749 & 6.6052 & TRN & & \\
\hline CHEMBL3661474 & 1528895 & 5.8013 & 5.8876 & TRN & & \\
\hline CHEMBL3666337 & 1528895 & 7.4365 & 7.4515 & TRN & & \\
\hline CHEMBL3666299 & 1528895 & 7.2823 & 7.2628 & TRN & & \\
\hline CHEMBL3661525 & 1528895 & 6.0804 & 5.2235 & TRN & & \\
\hline CHEMBL3661617 & 1528895 & 7.9031 & 8.4397 & TRN & & \\
\hline CHEMBL3666326 & 1528895 & 5.8097 & 5.6973 & TRN & & \\
\hline CHEMBL3671458 & 1528895 & 6.8928 & 6.4953 & TRN & & \\
\hline CHEMBL 3666274 & 1528895 & 6.466 & 6.7317 & TRN & & \\
\hline CHEMBL3661559 & 1528895 & 5.4685 & 5.7658 & TRN & & \\
\hline CHEMBL3666435 & 1528895 & 6.1979 & 5.186 & TST & & \\
\hline CHEMBL 3666320 & 1528895 & 5.5086 & 5.6387 & TRN & & \\
\hline CHEMBL3666361 & 1528895 & 5.58 & 5.3124 & TRN & & \\
\hline CHEMBL 3666280 & 1528895 & 6.3575 & \multicolumn{3}{|c|}{6.832000000000001} & TRN \\
\hline CHEMBL3671430 & 1528895 & 8.5003 & 7.9496 & TRN & & \\
\hline CHEMBL 3671410 & 1528895 & 7.6925 & 7.2334 & TRN & & \\
\hline CHEMBL3661493 & 1528895 & 7.71 & 8.002 & TRN & & \\
\hline CHEMBL3661481 & 1528895 & 7.02 & 6.4263 & TRN & & \\
\hline CHEMBL3666406 & 1528895 & 5.3655 & 5.6009 & TRN & & \\
\hline CHEMBL3661527 & 1528895 & 6.1669 & 5.9495 & TRN & & \\
\hline CHEMBL3666389 & 1528895 & 5.5784 & 6.4674 & TRN & & \\
\hline CHEMBL3666408 & 1528895 & 6.6421 & 5.4263 & TST & & \\
\hline CHEMBL3661524 & 1528895 & 6.5467 & \multicolumn{3}{|c|}{6.2410000000000005} & TRN \\
\hline CHEMBL3671422 & 1528895 & 7.6737 & 8.3225 & TRN & & \\
\hline CHEMBL3666437 & 1528895 & 5.9706 & 6.8501 & TST & & \\
\hline CHEMBL3671442 & 1528895 & 5.1568 & 7.2395 & TST & & \\
\hline CHEMBL3671429 & 1528895 & 6.8239 & 6.4114 & TRN & & \\
\hline CHEMBL3661579 & 1528895 & 7.1713 & 6.6688 & TRN & & \\
\hline CHEMBL3671378 & 1528895 & 7.3615 & 7.2334 & TST & & \\
\hline CHEMBL3661619 & 1528895 & 6.8601 & 7.0565 & TRN & & \\
\hline CHEMBL3666374 & 1528895 & 6.6091 & 6.2094 & TRN & & \\
\hline CHEMBL3666397 & 1528895 & 6.8013 & 5.7877 & TST & & \\
\hline CHEMBL3671461 & 1528895 & 8.2168 & 7.8668 & TST & & \\
\hline CHEMBL3666434 & 1528895 & 6.266 & 6.2679 & TRN & & \\
\hline CHEMBL3671379 & 1528895 & 5.6308 & 6.0784 & TST & & \\
\hline CHEMBL 3666445 & 1528895 & 5.5214 & 5.4555 & TRN & & \\
\hline CHEMBL3666412 & 1528895 & 6.5272 & 5.8287 & TRN & & \\
\hline CHEMBL3666334 & 1528895 & 6.4413 & 6.6354 & TRN & & \\
\hline CHEMBL3671406 & 1528895 & 8.2291 & 8.1046 & TRN & & \\
\hline CHEMBL3671375 & 1528895 & 5.5901 & 5.4777 & TRN & & \\
\hline CHEMBL3661586 & 1528895 & 6.76200 & 00000000 & 005 & 6.716 & TRN \\
\hline CHEMBL3661519 & 1528895 & 6.8297 & 6.5573 & TRN & & \\
\hline CHEMBL 3666275 & 1528895 & 7.4134 & 6.8319 & TRN & & \\
\hline CHEMBL3671452 & 1528895 & 6.0 & 7.2051 & TST & & \\
\hline
\end{tabular}


Supplemental Table S2.txt

\begin{tabular}{|c|c|c|c|c|}
\hline $\mathrm{HEN}$ & 528895 & 8.821 & & 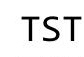 \\
\hline & 528895 & 5.5086 & & \\
\hline & & & & \\
\hline AEMB & זם0חת & 78 & & \\
\hline AEMBL & 528895 & 01 & & \\
\hline HEMBL3661567 & 528895 & 5.0083 & 9461 & \\
\hline 348 & 2889 & 76 & & \\
\hline |FMRI & 8805 & & & \\
\hline HEMBL & 528895 & 575 & .5228 & \\
\hline HEMBL 366 & 528895 & 8.9626 & .0829 & \\
\hline AEMBL3 & 528895 & 6.5436 & 91 & \\
\hline IEMBL: & 889 & 088 & .4279 & \\
\hline AEMBL & & & & \\
\hline HEMBL & 528895 & 2381 & 7.2477 & \\
\hline AEMBL3 & 895 & 925 & .0639 & \\
\hline AEMBL3 & 200 & 086 & .0544 & \\
\hline AEMBL & 2 & 46 & 52 & \\
\hline HEMBL; & & 07 & & \\
\hline HEMBL & r & 634 & 7.2369 & \\
\hline AEMBL: & 528895 & 6 . & & \\
\hline AEMIBL & 2 & & 49 & \\
\hline AEMBL & $2<$ & 83 & & \\
\hline AEMBL & & 81 & & \\
\hline 550 & & & & \\
\hline AEMBL3 & 0288 & 7. & & ST \\
\hline HEMBL & 2 & 87 & .77 & \\
\hline AEMBL & & & 17 & \\
\hline FMB & 528895 & 35 & & \\
\hline HEMBL3 & & & & \\
\hline HEMBL3 & 5288 & 5. & 395 & 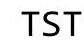 \\
\hline HEMBL & 38 & 45 & 7.0544 & ST \\
\hline HFMBI & & 52 & 33 & ST \\
\hline 0 & & & 64 & ST \\
\hline HEMBL36 & & & 34 & $\mid$ \\
\hline HEMBL 3671397 & 5288 & 7. & 0967 & IST \\
\hline HEMBL3 & 5288 & 33 & 98 & \\
\hline HCMDI & & & & ST \\
\hline HEMBL3 & & & & ST \\
\hline HEMBL3666338 & 5288 & 6 . & 7.6952 & TST \\
\hline AEMBL & 5288 & & 5.7832 & TS \\
\hline HEMBL3 & 5288 & 045 & 6.0424 & \\
\hline CHEMBL3 & & & & I \\
\hline HEMBL3 & 528895 & & 6.8467 & TST \\
\hline AEMBL3661587 & 52889 & 5.4473 & 5.9198 & TST \\
\hline EMBL & $=1$ & & 5.0359 & TS \\
\hline CHEMBL3661612 & & & 5.7968 & \\
\hline HEN & Г & 3069 & 7.0581 & \\
\hline HEMBL367142 & 1528895 & 7.7932 & 8.0321 & ГST \\
\hline
\end{tabular}

Page 8679 
Supplemental Table S2.txt

\begin{tabular}{|c|c|c|c|c|c|}
\hline CHEMBL 3661495 & 1528895 & 6.6904 & 7.7889 & TST & \\
\hline CHEMBL 3666449 & 1528895 & 5.2924 & 5.0387 & TST & \\
\hline CHEMBL 3666460 & 1528895 & 5.6655 & 5.8369 & TST & \\
\hline CHEMBL 3666336 & 1528895 & 6.8097 & 6.5393 & TST & \\
\hline CHEMBL 3671420 & 1528895 & 8.2725 & 7.9294 & TST & \\
\hline CHEMBL 3671466 & 1528895 & \multicolumn{3}{|c|}{7.821000000000001} & TST \\
\hline CHEMBL 3661503 & 1528895 & 7.1864 & 6.3092 & TST & \\
\hline CHEMBL 3666246 & 1528895 & 8.06 & 7.7357 & TST & \\
\hline CHEMBL 3666432 & 1528895 & 5.5017 & 6.3665 & TST & \\
\hline CHEMBL 3671383 & 1528895 & \multicolumn{3}{|c|}{5.202000000000001} & TST \\
\hline CHEMBL 3666464 & 1528895 & 6.9281 & 6.4233 & TST & \\
\hline CHEMBL 3661607 & 1528895 & 7.0794 & 6.2917 & TST & \\
\hline CHEMBL 3661530 & 1528895 & 6.4763 & 6.2117 & TST & \\
\hline CHEMBL 3666354 & 1528895 & \multicolumn{3}{|c|}{5.4510000000000005} & TST \\
\hline CHEMBL 3671423 & 1528895 & 8.4921 & 8.4879 & TST & \\
\hline CHEMBL 3666459 & 1528895 & 6.2314 & 6.0517 & TST & \\
\hline CHEMBL3661469 & 1528895 & 5.9172 & 6.4977 & TST & \\
\hline CHEMBL 2372512 & 210407 & 6.44 & 5.5864 & TST & \\
\hline CHEMBL263059 & 210407 & 2.47 & 2.8146 & TRN & \\
\hline CHEMBL38873 & 210407 & 8.82 & 7.4985 & TST & \\
\hline CHEMBL 38405 & 210407 & 5.64 & 3.5525 & TST & \\
\hline CHEMBL43228 & 210407 & 7.78 & 7.4846 & TRN & \\
\hline CHEMBL41913 & 210407 & 5.05 & 4.5306 & TRN & \\
\hline CHEMBL44309 & 210407 & 3.66 & 3.1542 & TRN & \\
\hline CHEMBL 2372453 & 210407 & 2.47 & 2.2123 & TRN & \\
\hline CHEMBL41500 & 210407 & 7.72 & 6.7381 & TRN & \\
\hline CHEMBL40208 & 210407 & 7.73 & 7.6138 & TRN & \\
\hline CHEMBL 2372522 & 210407 & 2.51 & 3.0765 & TRN & \\
\hline CHEMBL 25048 & 210407 & 3.29 & 3.826 & TRN & \\
\hline CHEMBL289509 & 210407 & 6.12 & 5.8723 & TRN & \\
\hline CHEMBL1161037 & 210407 & 4.06 & 5.8265 & TST & \\
\hline CHEMBL10247 & 210407 & 5.74 & 5.8879 & TRN & \\
\hline CHEMBL43353 & 210407 & 3.46 & 3.288999 & 99999999997 & rRN \\
\hline CHEMBL413073 & 210407 & 5.84 & 5.4909 & TST & \\
\hline CHEMBL41492 & 210407 & 4.14 & 5.1511 & TRN & \\
\hline CHEMBL43233 & 210407 & 2.79 & 2.8805 & TRN & \\
\hline CHEMBL442732 & 210407 & 6.37 & 6.4306 & TRN & \\
\hline CHEMBL 287723 & 210407 & 4.89 & 4.3307 & TRN & \\
\hline CHEMBL 2372439 & 210407 & 6.18 & 5.3057 & TRN & \\
\hline CHEMBL41376 & 210407 & 6.74 & 7.7301 & TRN & \\
\hline CHEMBL42377 & 210407 & 3.64 & 3.7271 & TRN & \\
\hline CHEMBL 2372434 & 210407 & 6.18 & 6.1934 & TRN & \\
\hline CHEMBL418619 & 210407 & 4.7 & 4.8327 & TRN & \\
\hline CHEMBL40858 & 210407 & 0.52 & 5.1042 & TST & \\
\hline CHEMBL 2372429 & 210407 & 5.16 & 5.1366 & TRN & \\
\hline CHEMBL40510 & 210407 & 4.1 & 4.1998 & TST & \\
\hline CHEMBL40654 & 210407 & 3.03 & 2.5486 & TRN & \\
\hline CHEMBL41693 & 210407 & 5.57 & 5.9479 & TRN & \\
\hline
\end{tabular}




\begin{tabular}{|c|c|c|c|c|}
\hline \multicolumn{5}{|c|}{ Supplemental Table S2.txt } \\
\hline CHEMBL288359 & 210407 & 6.66 & 5.8704 & TRN \\
\hline CHEMBL40641 & 210407 & 5.59 & 5.4072 & TRN \\
\hline CHEMBL40871 & 210407 & 6.07 & 6.2822 & TRN \\
\hline CHEMBL290692 & 210407 & 7.12 & 7.8634 & TRN \\
\hline CHEMBL38354 & 210407 & 0.52 & 2.6513 & TST \\
\hline CHEMBL2372452 & 210407 & 0.52 & 2.2732 & TRN \\
\hline CHEMBL131931 & 210407 & 2.96 & 3.8994 & TRN \\
\hline CHEMBL133783 & 210407 & 1.68 & 1.9552 & TRN \\
\hline CHEMBL 2372445 & 210407 & 2.51 & 1.6567 & TRN \\
\hline CHEMBL 2372437 & 210407 & 6.32 & 5.2032 & TRN \\
\hline CHEMBL436544 & 210407 & 7.18 & 7.7086 & TRN \\
\hline CHEMBL296747 & 210407 & 3.18 & 2.7478 & TRN \\
\hline CHEMBL38496 & 210407 & 4.27 & 4.5803 & TRN \\
\hline CHEMBL 287773 & 210407 & 5.77 & 5.4011 & TRN \\
\hline CHEMBL 287912 & 210407 & 2.65 & 2.6353 & TRN \\
\hline CHEMBL 290023 & 210407 & 6.52 & 6.6084 & TRN \\
\hline CHEMBL2372446 & 210407 & 6.12 & 5.1788 & TRN \\
\hline CHEMBL289503 & 210407 & 6.22 & 5.224 & TRN \\
\hline CHEMBL41348 & 210407 & 7.96 & 7.8678 & TRN \\
\hline CHEMBL 289703 & 210407 & 7.28 & 6.9144 & TST \\
\hline CHEMBL319299 & 210407 & 7.47 & 6.8307 & TRN \\
\hline CHEMBL42966 & 210407 & 2.42 & 3.9837 & TRN \\
\hline CHEMBL 2372449 & 210407 & 3.38 & 3.4591 & TRN \\
\hline CHEMBL2372438 & 210407 & 2.54 & 2.1853 & TRN \\
\hline CHEMBL41772 & 210407 & 3.72 & 4.3865 & TST \\
\hline CHEMBL41289 & 210407 & 7.55 & 8.1524 & TRN \\
\hline CHEMBL43849 & 210407 & 3.42 & 3.7808 & TRN \\
\hline CHEMBL43692 & 210407 & 5.85 & 5.4766 & TST \\
\hline CHEMBL42922 & 210407 & 6.57 & 7.1197 & TST \\
\hline CHEMBL 289084 & 210407 & 5.55 & 4.9686 & TST \\
\hline CHEMBL43176 & 210407 & 8.04 & 7.5713 & TST \\
\hline CHEMBL432673 & 210407 & 6.39 & 5.176 & TST \\
\hline CHEMBL 2372428 & 210407 & 2.37 & 2.3106 & TST \\
\hline CHEMBL2006909 & 688444 & 5.7894 & 5.8318 & TRN \\
\hline CHEMBL1323744 & 688444 & 4.8813 & 4.6679 & TRN \\
\hline CHEMBL518252 & 688444 & 6.8794 & 5.7674 & TST \\
\hline CHEMBL1575594 & 688444 & 6.6596 & 5.5987 & TST \\
\hline CHEMBL1483825 & 688444 & 5.6415 & 5.1555 & TRN \\
\hline CHEMBL3210051 & 688444 & 5.1881 & 5.109 & TRN \\
\hline CHEMBL1609759 & 688444 & 7.9208 & 6.1234 & TRN \\
\hline CHEMBL1544114 & 688444 & 6.2967 & 6.3403 & TRN \\
\hline CHEMBL1315921 & 688444 & 2.8239 & 6.4379 & TRN \\
\hline CHEMBL1563714 & 688444 & 6.1811 & 5.8524 & TRN \\
\hline CHEMBL1385118 & 688444 & 4.7239 & 3.8341 & TRN \\
\hline CHEMBL393287 & 688444 & 5.9318 & 5.355 & TRN \\
\hline CHEMBL1336526 & 688444 & 4.7489 & 4.7504 & TST \\
\hline CHEMBL1447307 & 688444 & 2.8239 & 4.2893 & TRN \\
\hline CHEMBL1542349 & 688444 & 5.1313 & 4.3705 & TRN \\
\hline
\end{tabular}




\begin{tabular}{|c|c|c|c|c|c|c|}
\hline & & \multicolumn{5}{|c|}{ Supplemental Table S2.txt } \\
\hline CHEMBL3198496 & 688444 & 4.8381 & 4.3196 & TRN & & \\
\hline CHEMBL 3212288 & 688444 & 5.4627 & 4.0381 & TRN & & \\
\hline CHEMBL1499893 & 688444 & 5.6096 & 5.4477 & TRN & & \\
\hline CHEMBL1310713 & 688444 & 6.0625 & 5.8011 & TRN & & \\
\hline CHEMBL3195688 & 688444 & 6.1911 & 5.7276 & TRN & & \\
\hline CHEMBL1484332 & 688444 & 6.8153 & 5.9463 & TRN & & \\
\hline CHEMBL1409695 & 688444 & 2.7959 & 3.9361 & TRN & & \\
\hline CHEMBL1584524 & 688444 & 5.6662 & 5.7737 & TRN & & \\
\hline CHEMBL1548613 & 688444 & 6.0168 & 5.4814 & TST & & \\
\hline CHEMBL1541425 & 688444 & 4.5539 & 4.8588 & TRN & & \\
\hline CHEMBL1308502 & 688444 & 2.8239 & 3.9225 & TRN & & \\
\hline CHEMBL3194752 & 688444 & 5.7547 & 4.3056 & TRN & & \\
\hline CHEMBL1365988 & 688444 & 6.0757 & 6.2797 & TRN & & \\
\hline CHEMBL1546005 & 688444 & 2.7959 & 4.9563 & TRN & & \\
\hline CHEMBL1587043 & 688444 & 2.8239 & 4.4762 & TRN & & \\
\hline CHEMBL1414734 & 688444 & 5.7459 & 4.9544 & TST & & \\
\hline CHEMBL1301999 & 688444 & 2.7959 & 4.3426 & TRN & & \\
\hline CHEMBL1549060 & 688444 & 4.789 & 4.3493 & TST & & \\
\hline CHEMBL1340519 & 688444 & 6.3979 & 6.0122 & TRN & & \\
\hline CHEMBL1312953 & 688444 & $5.5020 e$ & j00000006 & 01 & 5.8394 & TRN \\
\hline CHEMBL1372734 & 688444 & 6.066 & 5.7917 & TRN & & \\
\hline CHEMBL3190322 & 688444 & 5.0339 & 4.0356 & TRN & & \\
\hline CHEMBL1427508 & 688444 & 5.2495 & 3.945 & TRN & & \\
\hline CHEMBL1428287 & 688444 & 4.4965 & 4.3412 & TRN & & \\
\hline CHEMBL1502020 & 688444 & 5.6728 & 5.4914 & TRN & & \\
\hline CHEMBL3189966 & 688444 & 6.1226 & 5.9197 & TRN & & \\
\hline CHEMBL1538232 & 688444 & 2.8239 & 5.5851 & TRN & & \\
\hline CHEMBL1350245 & 688444 & 6.0 & 5.4977 & TST & & \\
\hline CHEMBL1602534 & 688444 & 2.7959 & 3.8427 & TRN & & \\
\hline CHEMBL1581627 & 688444 & 5.9767 & 5.4274 & TRN & & \\
\hline CHEMBL1570025 & 688444 & 2.8239 & 3.7658 & TRN & & \\
\hline CHEMBL1583292 & 688444 & 5.5084 & 5.8356 & TST & & \\
\hline CHEMBL1613016 & 688444 & 2.8239 & 3.8042 & TST & & \\
\hline CHEMBL1547347 & 688444 & 5.8091 & 5.6844 & TRN & & \\
\hline CHEMBL1492078 & 688444 & 5.3716 & 5.2834 & TST & & \\
\hline CHEMBL1386774 & 688444 & 5.9446 & 5.9797 & TRN & & \\
\hline CHEMBL193872 & 688444 & 7.9208 & 6.7634 & TRN & & \\
\hline CHEMBL1404493 & 688444 & 7.9208 & 7.3853 & TRN & & \\
\hline CHEMBL1460522 & 688444 & 5.0314 & 5.5945 & TRN & & \\
\hline CHEMBL1375226 & 688444 & 2.8239 & 5.4452 & TRN & & \\
\hline CHEMBL1379894 & 688444 & 2.8239 & 5.6988 & TRN & & \\
\hline CHEMBL1345820 & 688444 & 5.6488 & 5.3246 & TRN & & \\
\hline CHEMBL1977678 & 688444 & 5.2716 & 5.2537 & TRN & & \\
\hline CHEMBL1337614 & 688444 & 5.6164 & 5.3383 & TRN & & \\
\hline CHEMBL1603036 & 688444 & 2.8239 & 3.9025 & TRN & & \\
\hline CHEMBL1503874 & 688444 & 2.7959 & 4.0466 & TRN & & \\
\hline CHEMBL1412068 & 688444 & 5.4752 & 5.3724 & TRN & & \\
\hline CHEMBL1587031 & 688444 & 4.9422 & 4.1741 & TST & & \\
\hline
\end{tabular}




\begin{tabular}{|c|c|c|c|c|c|}
\hline & & \multicolumn{4}{|c|}{ Supplemental Table S2.txt } \\
\hline CHEMBL1528975 & 688444 & 5.1229 & 5.0218 & TRN & \\
\hline CHEMBL1340678 & 688444 & 6.0467 & 5.5512 & TRN & \\
\hline CHEMBL1599337 & 688444 & 2.7959 & 3.8444 & TRN & \\
\hline CHEMBL1544679 & 688444 & 5.7011 & 5.7853 & TRN & \\
\hline CHEMBL1584449 & 688444 & 6.0209 & 4.8957 & TRN & \\
\hline CHEMBL1556805 & 688444 & 7.9208 & 7.2434 & TRN & \\
\hline CHEMBL1301513 & 688444 & 6.1118 & 5.3888 & TRN & \\
\hline CHEMBL1430893 & 688444 & 5.5433 & 5.5721 & TRN & \\
\hline CHEMBL1417624 & 688444 & 2.7959 & 3.8366 & TST & \\
\hline CHEMBL1328053 & 688444 & 6.0048 & 5.3907 & TRN & \\
\hline CHEMBL1504569 & 688444 & 6.05399 & 99999999 & 6.0002 & TRN \\
\hline CHEMBL1498830 & 688444 & 5.6498 & 5.2621 & TRN & \\
\hline CHEMBL1407420 & 688444 & 2.8239 & 4.67399 & 99999999995 & TST \\
\hline CHEMBL3210589 & 688444 & 2.7959 & 4.0316 & TRN & \\
\hline CHEMBL578675 & 688444 & 2.8239 & 4.202 & TRN & \\
\hline CHEMBL1334557 & 688444 & 5.7018 & 6.4288 & TST & \\
\hline CHEMBL1301505 & 688444 & 4.7224 & 4.0403 & TRN & \\
\hline CHEMBL1348582 & 688444 & 5.9678 & 6.4497 & TRN & \\
\hline CHEMBL1537650 & 688444 & 2.7959 & 3.7867 & TST & \\
\hline CHEMBL1337528 & 688444 & 5.3984 & 5.13899 & 9999999999 & TRN \\
\hline CHEMBL1312909 & 688444 & 5.5825 & 5.4305 & TRN & \\
\hline CHEMBL3213305 & 688444 & 6.0721 & 4.2557 & TRN & \\
\hline CHEMBL1484777 & 688444 & 7.9208 & 6.3735 & TRN & \\
\hline CHEMBL1431710 & 688444 & 6.8729 & 5.6997 & TRN & \\
\hline CHEMBL1509327 & 688444 & 5.5327 & 4.0284 & TRN & \\
\hline CHEMBL1351158 & 688444 & 5.704 & 5.1769 & TRN & \\
\hline CHEMBL1422453 & 688444 & 2.7959 & 6.1658 & TST & \\
\hline CHEMBL 3191808 & 688444 & 6.0419 & 6.2265 & TRN & \\
\hline CHEMBL1492246 & 688444 & 5.4785 & 3.8605 & TRN & \\
\hline CHEMBL1510332 & 688444 & 5.4804 & 5.6317 & TRN & \\
\hline CHEMBL1305918 & 688444 & 2.7959 & 4.34699 & 99999999995 & TRN \\
\hline CHEMBL590947 & 688444 & 5.3213 & 5.6256 & TRN & \\
\hline CHEMBL 3197628 & 688444 & 6.0535 & 5.6522 & TRN & \\
\hline CHEMBL1460249 & 688444 & 6.1945 & 5.1404 & TRN & \\
\hline CHEMBL1479557 & 688444 & 6.1385 & 5.8833 & TRN & \\
\hline CHEMBL479107 & 688444 & 5.1964 & 4.2494 & TRN & \\
\hline CHEMBL1377705 & 688444 & 6.1457 & 5.4978 & TRN & \\
\hline CHEMBL1539860 & 688444 & 5.2153 & 4.4769 & TRN & \\
\hline CHEMBL1361307 & 688444 & 6.0205 & 5.5512 & TRN & \\
\hline CHEMBL1311826 & 688444 & 6.1831 & 6.3451 & TRN & \\
\hline CHEMBL3192181 & 688444 & 6.2069 & 5.6838 & TRN & \\
\hline CHEMBL1541536 & 688444 & 5.5588 & 4.4563 & TRN & \\
\hline CHEMBL1372207 & 688444 & 4.7891 & 3.9981 & TST & \\
\hline CHEMBL1319778 & 688444 & 5.315 & 4.51399 & 9999999999 & TRN \\
\hline CHEMBL 3197024 & 688444 & 5.9223 & 6.1463 & TRN & \\
\hline CHEMBL1506216 & 688444 & 5.3856 & 5.7478 & TRN & \\
\hline CHEMBL1502943 & 688444 & 5.8447 & 4.3447 & TST & \\
\hline CHEMBL547285 & 688444 & 6.1457 & 6.5525 & TRN & \\
\hline
\end{tabular}




\begin{tabular}{|c|c|c|c|c|c|c|}
\hline & & \multicolumn{5}{|c|}{ Supplemental Table S2.txt } \\
\hline CHEMBL1472489 & 688444 & 2.8239 & 4.3046 & TRN & & \\
\hline CHEMBL1427969 & 688444 & 2.8239 & 4.2243 & TRN & & \\
\hline CHEMBL1505070 & 688444 & 4.8074 & 3.964 & TRN & & \\
\hline CHEMBL595700 & 688444 & 5.4752 & 5.3528 & TRN & & \\
\hline CHEMBL 3190138 & 688444 & 2.7959 & 3.8676 & TRN & & \\
\hline CHEMBL1585527 & 688444 & 5.9041 & 5.8917 & TRN & & \\
\hline CHEMBL1599610 & 688444 & 5.5891 & 5.46200 & 0000000001 & & TRN \\
\hline CHEMBL1499342 & 688444 & 5.694 & 5.6072 & TRN & & \\
\hline CHEMBL1419305 & 688444 & 4.8578 & 4.1676 & TRN & & \\
\hline CHEMBL1418430 & 688444 & \multicolumn{3}{|c|}{4.968999999999999} & 4.2029 & TRN \\
\hline CHEMBL1375925 & 688444 & 5.565 & 5.3503 & TRN & & \\
\hline CHEMBL1387387 & 688444 & 6.091 & 4.7704 & TRN & & \\
\hline CHEMBL1383706 & 688444 & 5.8925 & 5.3836 & TRN & & \\
\hline CHEMBL1304402 & 688444 & 5.9326 & 5.9853 & TRN & & \\
\hline CHEMBL3193547 & 688444 & 2.7959 & 5.1422 & TRN & & \\
\hline CHEMBL 2000750 & 688444 & 5.8016 & 5.8768 & TRN & & \\
\hline CHEMBL1470259 & 688444 & 4.3482 & 4.313 & TRN & & \\
\hline CHEMBL1572031 & 688444 & 5.5761 & 5.8209 & TRN & & \\
\hline CHEMBL1419772 & 688444 & 6.0372 & 5.6106 & TST & & \\
\hline CHEMBL1505028 & 688444 & 5.9355 & 5.3486 & TST & & \\
\hline CHEMBL1334286 & 688444 & 2.8239 & 5.1398 & TRN & & \\
\hline CHEMBL1368802 & 688444 & 4.9252 & 4.511 & TRN & & \\
\hline CHEMBL3191182 & 688444 & 5.9187 & 4.5178 & TRN & & \\
\hline CHEMBL 3214345 & 688444 & 2.8239 & 4.1457 & TRN & & \\
\hline CHEMBL1576976 & 688444 & 5.5 & 5.3829 & TST & & \\
\hline CHEMBL1521380 & 688444 & 5.1812 & 5.2852 & TST & & \\
\hline CHEMBL1612493 & 688444 & 5.5677 & 4.5355 & TRN & & \\
\hline CHEMBL1562545 & 688444 & 2.8239 & 4.126 & TRN & & \\
\hline CHEMBL1538399 & 688444 & 5.5834 & 5.0293 & TRN & & \\
\hline CHEMBL1504220 & 688444 & 5.5756 & 4.8519 & TRN & & \\
\hline CHEMBL1302028 & 688444 & 2.7959 & 5.1944 & TRN & & \\
\hline CHEMBL1425238 & 688444 & 5.2261 & 5.3505 & TRN & & \\
\hline CHEMBL1426430 & 688444 & 2.8239 & 4.9289 & TRN & & \\
\hline CHEMBL1555271 & 688444 & 6.2874 & 6.4677 & TRN & & \\
\hline CHEMBL1490866 & 688444 & 2.7959 & 3.8775 & TRN & & \\
\hline CHEMBL1568545 & 688444 & 2.8239 & 4.1941 & TST & & \\
\hline CHEMBL1995715 & 688444 & 5.4156 & 5.351 & TRN & & \\
\hline CHEMBL1538392 & 688444 & 5.5947 & 3.7275 & TRN & & \\
\hline CHEMBL590665 & 688444 & 6.3904 & 6.5932 & TRN & & \\
\hline CHEMBL1338258 & 688444 & 2.8239 & 4.5756 & TRN & & \\
\hline CHEMBL1547329 & 688444 & 2.7959 & 4.0417 & TST & & \\
\hline CHEMBL391877 & 688444 & 4.8176 & 4.3253 & TRN & & \\
\hline CHEMBL590927 & 688444 & 6.0491 & 6.5134 & TRN & & \\
\hline CHEMBL1422696 & 688444 & 5.4401 & 3.7649 & TRN & & \\
\hline CHEMBL1542861 & 688444 & 5.1799 & 5.1957 & TRN & & \\
\hline CHEMBL3199752 & 688444 & 2.7959 & 5.0155 & TRN & & \\
\hline CHEMBL1460056 & 688444 & 6.3585 & 5.3106 & TST & & \\
\hline CHEMBL1323553 & 688444 & 5.2499 & 5.1538 & TRN & & \\
\hline
\end{tabular}




\begin{tabular}{|c|c|c|c|c|c|}
\hline & & & & & \\
\hline CHEMBL1594475 & 688444 & 5.7627 & 6.1468 & TRN & \\
\hline CHEMBL1379535 & 688444 & 5.5143 & 4.3925 & TRN & \\
\hline CHEMBL1414580 & 688444 & 5.3824 & 4.1942 & TRN & \\
\hline CHEMBL1471157 & 688444 & 5.6966 & 4.9154 & TRN & \\
\hline CHEMBL455284 & 688444 & 5.6381 & 6.1291 & TRN & \\
\hline CHEMBL3193134 & 688444 & 5.3958 & 5.2654 & TRN & \\
\hline CHEMBL1495072 & 688444 & 5.8365 & 5.8957 & TRN & \\
\hline CHEMBL1366140 & 688444 & 5.2183 & 4.6001 & TST & \\
\hline CHEMBL1498022 & 688444 & 5.7902 & 5.5595 & TST & \\
\hline CHEMBL1997747 & 688444 & 5.9144 & 5.6876 & TRN & \\
\hline CHEMBL1362077 & 688444 & 6.0953 & 5.0767 & TRN & \\
\hline CHEMBL3195142 & 688444 & 5.9876 & 6.0716 & TRN & \\
\hline CHEMBL1323428 & 688444 & 5.4828 & 5.4793 & TRN & \\
\hline CHEMBL1377316 & 688444 & 6.109 & 6.58299 & 9999999999 & TRN \\
\hline CHEMBL1441467 & 688444 & 5.8277 & 5.1118 & TRN & \\
\hline CHEMBL1366656 & 688444 & 2.7959 & 4.3513 & TRN & \\
\hline CHEMBL1310341 & 688444 & 5.9739 & 5.1654 & TRN & \\
\hline CHEMBL1307271 & 688444 & 5.5615 & 4.7136 & TRN & \\
\hline CHEMBL3199286 & 688444 & 6.3261 & 6.015 & TRN & \\
\hline CHEMBL1549472 & 688444 & 5.2556 & 5.1777 & TRN & \\
\hline CHEMBL1369893 & 688444 & 6.1986 & 6.6184 & TRN & \\
\hline CHEMBL3193326 & 688444 & 5.8005 & 5.3209 & TRN & \\
\hline CHEMBL1347962 & 688444 & 5.09399 & 99999999 & 4.0419 & TRN \\
\hline CHEMBL1424999 & 688444 & 5.7817 & 4.191 & TRN & \\
\hline CHEMBL1471845 & 688444 & 5.0166 & 5.6679 & TRN & \\
\hline CHEMBL1339626 & 688444 & 2.8239 & 5.825 & TRN & \\
\hline CHEMBL1363032 & 688444 & 5.9252 & 5.3693 & TRN & \\
\hline CHEMBL1542594 & 688444 & 5.7258 & 5.86600 & 00000000005 & TRN \\
\hline CHEMBL1510020 & 688444 & 6.1302 & 5.2048 & TRN & \\
\hline CHEMBL3192165 & 688444 & 6.0386 & 5.6644 & TRN & \\
\hline CHEMBL1488279 & 688444 & 6.4962 & 5.7799 & TRN & \\
\hline CHEMBL1491815 & 688444 & 6.2111 & 5.7694 & TRN & \\
\hline CHEMBL1483252 & 688444 & 6.1524 & 6.4539 & TRN & \\
\hline CHEMBL1577971 & 688444 & 2.8239 & 4.1692 & TST & \\
\hline CHEMBL1344321 & 688444 & 2.7959 & 3.9544 & TRN & \\
\hline CHEMBL1393700 & 688444 & 6.1851 & 5.45799 & 9999999999 & TRN \\
\hline CHEMBL1567865 & 688444 & 6.0794 & 4.2336 & TRN & \\
\hline CHEMBL571501 & 688444 & 4.6879 & 4.6686 & TRN & \\
\hline CHEMBL1402715 & 688444 & 2.7959 & 4.0264 & TRN & \\
\hline CHEMBL1549128 & 688444 & 5.0394 & 5.5356 & TST & \\
\hline CHEMBL1310527 & 688444 & 5.3565 & 4.9514 & TRN & \\
\hline CHEMBL1591171 & 688444 & 5.1444 & 4.2157 & TST & \\
\hline CHEMBL1789998 & 688444 & 7.9208 & 6.5154 & TST & \\
\hline CHEMBL1566955 & 688444 & 2.7959 & 3.8603 & TRN & \\
\hline CHEMBL1467755 & 688444 & 5.3454 & 4.9083 & TRN & \\
\hline CHEMBL1598222 & 688444 & 5.4535 & 5.1393 & TRN & \\
\hline CHEMBL1536869 & 688444 & 4.7286 & 4.2812 & TRN & \\
\hline CHEMBL1349146 & 688444 & 5.7817 & 5.6966 & TRN & \\
\hline
\end{tabular}




\begin{tabular}{|c|c|c|c|c|c|}
\hline \multirow[b]{2}{*}{ CHEMBL1334608 } & & \multicolumn{4}{|c|}{ Supplemental Table s2.txt } \\
\hline & 688444 & 6.1124 & 5.1607 & TRN & \\
\hline CHEMBL1304361 & 688444 & 5.278 & 5.0937 & TRN & \\
\hline CHEMBL1705092 & 688444 & 2.8239 & 4.3219 & TRN & \\
\hline CHEMBL3198729 & 688444 & 5.9115 & 5.70799 & 9999999999 & TRN \\
\hline CHEMBL1389335 & 688444 & 6.2041 & 5.2673 & TRN & \\
\hline CHEMBL1582831 & 688444 & 6.1637 & 6.6006 & TRN & \\
\hline CHEMBL1472105 & 688444 & 6.4547 & 5.664 & TST & \\
\hline CHEMBL1564599 & 688444 & 2.7959 & 6.0331 & TRN & \\
\hline CHEMBL1327205 & 688444 & 5.8368 & 5.6577 & TRN & \\
\hline CHEMBL1462375 & 688444 & 6.75700 & 00000000 & 5.6835 & TRN \\
\hline CHEMBL1558285 & 688444 & 6.0747 & 5.7758 & TRN & \\
\hline CHEMBL3207925 & 688444 & 4.8214 & 4.4069 & TRN & \\
\hline CHEMBL3196754 & 688444 & 5.9248 & 5.8688 & TRN & \\
\hline CHEMBL1350865 & 688444 & 2.8239 & 3.7413 & TRN & \\
\hline CHEMBL1390645 & 688444 & 4.9527 & 3.6681 & TRN & \\
\hline CHEMBL600862 & 688444 & 6.3298 & 6.5052 & TRN & \\
\hline CHEMBL1557243 & 688444 & 5.5102 & 5.6968 & TRN & \\
\hline CHEMBL1339997 & 688444 & 6.153 & 4.9461 & TRN & \\
\hline CHEMBL1609654 & 688444 & 2.7959 & 4.1687 & TRN & \\
\hline CHEMBL1421854 & 688444 & 2.8239 & 5.3915 & TRN & \\
\hline CHEMBL1563219 & 688444 & 5.5096 & 4.298 & TRN & \\
\hline CHEMBL1383805 & 688444 & 5.3094 & 5.2761 & TRN & \\
\hline CHEMBL1310438 & 688444 & 6.1051 & 5.3602 & TRN & \\
\hline CHEMBL1347211 & 688444 & 2.7959 & 5.2964 & TRN & \\
\hline CHEMBL3189997 & 688444 & 2.8239 & 5.38399 & 99999999995 & TRN \\
\hline CHEMBL1360037 & 688444 & 2.7959 & 4.3913 & TRN & \\
\hline CHEMBL1985664 & 688444 & 5.8428 & 5.2888 & TRN & \\
\hline CHEMBL1516797 & 688444 & 2.7959 & 4.8614 & TRN & \\
\hline CHEMBL1450648 & 688444 & 2.8239 & 4.4006 & TRN & \\
\hline CHEMBL1307453 & 688444 & 5.8739 & 5.2757 & TRN & \\
\hline CHEMBL1454012 & 688444 & 2.7959 & 4.5568 & TRN & \\
\hline CHEMBL1522807 & 688444 & 6.0177 & 5.8252 & TRN & \\
\hline CHEMBL3197625 & 688444 & 4.913 & 5.3464 & TRN & \\
\hline CHEMBL1440899 & 688444 & 2.7959 & 3.9504 & TRN & \\
\hline CHEMBL3195643 & 688444 & 5.8687 & 3.97 & TRN & \\
\hline CHEMBL3208133 & 688444 & 2.7959 & 3.8344 & TRN & \\
\hline CHEMBL1501268 & 688444 & 2.7959 & 3.9104 & TST & \\
\hline CHEMBL1478041 & 688444 & 5.9367 & 5.9253 & TRN & \\
\hline CHEMBL1491740 & 688444 & 2.7959 & 4.796 & TRN & \\
\hline CHEMBL1463934 & 688444 & 5.763 & 5.4507 & TRN & \\
\hline CHEMBL1305499 & 688444 & 2.7959 & 4.0172 & TRN & \\
\hline CHEMBL1484139 & 688444 & 2.8239 & 4.1875 & TST & \\
\hline CHEMBL1578164 & 688444 & 5.2302 & 3.9734 & TRN & \\
\hline CHEMBL1341697 & 688444 & 6.0241 & 5.5339 & TRN & \\
\hline CHEMBL1360446 & 688444 & 4.6448 & 4.0605 & TRN & \\
\hline CHEMBL3191432 & 688444 & 6.0348 & 4.4061 & TRN & \\
\hline CHEMBL1372914 & 688444 & 5.6649 & 5.6787 & TRN & \\
\hline CHEMBL1432784 & 688444 & 2.7959 & 5.7021 & TRN & \\
\hline
\end{tabular}




\begin{tabular}{|c|c|c|c|c|c|}
\hline \multicolumn{6}{|c|}{ Supplemental Table S2.txt } \\
\hline CHEMBL1364010 & 688444 & 4.7484 & 5.3822 & TRN & \\
\hline CHEMBL1329507 & 688444 & 6.0799 & 5.9014 & TRN & \\
\hline CHEMBL1541582 & 688444 & 6.0516 & 5.1939 & TRN & \\
\hline CHEMBL3191385 & 688444 & 2.8239 & 4.0987 & TRN & \\
\hline CHEMBL1448895 & 688444 & 5.7742 & 4.7879 & TST & \\
\hline CHEMBL3193305 & 688444 & 5.7637 & 5.1556 & TRN & \\
\hline CHEMBL3190720 & 688444 & 5.755 & 5.7815 & TRN & \\
\hline CHEMBL3189613 & 688444 & 5.3005 & 5.6183 & TRN & \\
\hline CHEMBL1425575 & 688444 & 2.8239 & 3.6621 & TRN & \\
\hline CHEMBL1392500 & 688444 & 5.1137 & 5.268 & TRN & \\
\hline CHEMBL527584 & 688444 & 4.7236 & 3.9151 & TRN & \\
\hline CHEMBL1451169 & 688444 & 6.1385 & 5.6106 & TRN & \\
\hline CHEMBL1594071 & 688444 & 5.8983 & 5.3798 & TRN & \\
\hline CHEMBL1501432 & 688444 & 5.2002 & 5.2497 & TRN & \\
\hline CHEMBL1429632 & 688444 & 5.7217 & 4.521 & TRN & \\
\hline CHEMBL251055 & 688444 & 2.7959 & 5.3935 & TST & \\
\hline CHEMBL1466593 & 688444 & 5.7786 & 5.4066 & TST & \\
\hline CHEMBL1606685 & 688444 & 6.3536 & 6.53 & TRN & \\
\hline CHEMBL1391588 & 688444 & 2.8239 & 5.1144 & TRN & \\
\hline CHEMBL1443836 & 688444 & 2.8239 & 3.9158 & TRN & \\
\hline CHEMBL1607404 & 688444 & 4.84399 & 99999999 & 5.4876 & TRN \\
\hline CHEMBL1327372 & 688444 & 5.6558 & 5.1721 & TRN & \\
\hline CHEMBL1528603 & 688444 & 5.0732 & 3.9717 & TRN & \\
\hline CHEMBL1399543 & 688444 & 6.0119 & 5.7711 & TRN & \\
\hline CHEMBL1519958 & 688444 & 4.8548 & 5.0612 & TST & \\
\hline CHEMBL1461811 & 688444 & 2.8239 & 3.7261 & TRN & \\
\hline CHEMBL1565454 & 688444 & 5.567 & 4.9814 & TRN & \\
\hline CHEMBL1451977 & 688444 & 5.7467 & 5.88299 & 9999999999 & TRN \\
\hline CHEMBL1471948 & 688444 & 5.0372 & 4.0797 & TRN & \\
\hline CHEMBL1423611 & 688444 & 5.7016 & 5.2498 & TRN & \\
\hline CHEMBL1455405 & 688444 & 2.7959 & 4.3549 & TRN & \\
\hline CHEMBL1597208 & 688444 & 2.8239 & 3.9105 & TRN & \\
\hline CHEMBL1500363 & 688444 & 4.6949 & 4.9676 & TRN & \\
\hline CHEMBL1595088 & 688444 & 6.2111 & 5.6203 & TRN & \\
\hline CHEMBL1577590 & 688444 & 5.7251 & 5.7853 & TRN & \\
\hline CHEMBL1569267 & 688444 & 2.8239 & 5.8069 & TRN & \\
\hline CHEMBL1511757 & 688444 & 2.7959 & 4.0114 & TRN & \\
\hline CHEMBL1538246 & 688444 & 6.2534 & 5.4211 & TST & \\
\hline CHEMBL1361917 & 688444 & 2.8239 & 5.3518 & TRN & \\
\hline CHEMBL1419381 & 688444 & 6.0083 & 5.4035 & TRN & \\
\hline CHEMBL1319294 & 688444 & 2.8239 & 4.0156 & TRN & \\
\hline CHEMBL1256876 & 688444 & 5.4731 & 5.2096 & TST & \\
\hline CHEMBL581880 & 688444 & 2.7959 & 6.1215 & TST & \\
\hline CHEMBL1587453 & 688444 & 6.1701 & 5.1625 & TRN & \\
\hline CHEMBL1432888 & 688444 & 5.3812 & 5.3528 & TRN & \\
\hline CHEMBL1307923 & 688444 & 2.7959 & 4.6957 & TRN & \\
\hline CHEMBL1472418 & 688444 & 5.8422 & 5.6641 & TRN & \\
\hline CHEMBL3194214 & 688444 & 5.4891 & 5.4364 & TRN & \\
\hline
\end{tabular}




\begin{tabular}{|c|c|c|c|c|c|}
\hline & & \multicolumn{4}{|c|}{ Supplemental Table S2.txt } \\
\hline CHEMBL1560928 & 688444 & 5.8204 & 4.8053 & TRN & \\
\hline CHEMBL1324985 & 688444 & 2.8239 & 3.9161 & TRN & \\
\hline CHEMBL1428240 & 688444 & 6.3507 & 5.3358 & TRN & \\
\hline CHEMBL1299903 & 688444 & 6.4045 & 5.678 & TRN & \\
\hline CHEMBL469036 & 688444 & 2.8239 & 5.7824 & TST & \\
\hline CHEMBL1439734 & 688444 & 5.7547 & 3.9184 & TRN & \\
\hline CHEMBL1611301 & 688444 & 6.4868 & 5.5253 & TRN & \\
\hline CHEMBL3196181 & 688444 & 6.0334 & 5.9055 & TRN & \\
\hline CHEMBL1436213 & 688444 & 5.7011 & 5.7563 & TRN & \\
\hline CHEMBL1564030 & 688444 & 4.9952 & 4.2485 & TST & \\
\hline CHEMBL1530097 & 688444 & 5.3132 & 4.6007 & TRN & \\
\hline CHEMBL1346822 & 688444 & 5.9809 & 6.3038 & TRN & \\
\hline CHEMBL3198627 & 688444 & 5.3985 & 4.1731 & TRN & \\
\hline CHEMBL578944 & 688444 & 2.7959 & 5.854 & TST & \\
\hline CHEMBL3191519 & 688444 & 2.8239 & 4.5552 & TST & \\
\hline CHEMBL1448722 & 688444 & 5.1735 & 5.3197 & TRN & \\
\hline CHEMBL1502711 & 688444 & 2.7959 & 5.0298 & TRN & \\
\hline CHEMBL1373688 & 688444 & 2.8239 & 4.0263 & TRN & \\
\hline CHEMBL 2359911 & 688444 & 6.4449 & 6.36799 & 9999999999 & TRN \\
\hline CHEMBL1405150 & 688444 & 6.4295 & 6.4248 & TRN & \\
\hline CHEMBL1467211 & 688444 & 6.6216 & 5.5072 & TRN & \\
\hline CHEMBL1430800 & 688444 & 5.9389 & 5.0748 & TRN & \\
\hline CHEMBL 3209306 & 688444 & 5.6486 & 5.604 & TRN & \\
\hline CHEMBL3191763 & 688444 & 2.7959 & 5.5925 & TRN & \\
\hline CHEMBL1503114 & 688444 & 2.7959 & 3.7262 & TRN & \\
\hline CHEMBL586031 & 688444 & 6.6108 & 5.1848 & TRN & \\
\hline CHEMBL1380557 & 688444 & 5.1858 & 5.8123 & TRN & \\
\hline CHEMBL3192659 & 688444 & 5.5914 & 4.9529 & TRN & \\
\hline CHEMBL1520556 & 688444 & 5.5658 & 5.2387 & TRN & \\
\hline CHEMBL1464385 & 688444 & 5.8557 & 5.3207 & TRN & \\
\hline CHEMBL1582088 & 688444 & 5.0663 & 4.2632 & TRN & \\
\hline CHEMBL1430319 & 688444 & 5.3674 & 5.3062 & TRN & \\
\hline CHEMBL3209142 & 688444 & 5.7231 & 4.2224 & TRN & \\
\hline CHEMBL 2006545 & 688444 & 2.8239 & 5.4543 & TRN & \\
\hline CHEMBL3196364 & 688444 & 5.8383 & 4.5174 & TRN & \\
\hline CHEMBL1350460 & 688444 & 4.9252 & 4.0207 & TRN & \\
\hline CHEMBL1506750 & 688444 & 5.5089 & 4.0194 & TRN & \\
\hline CHEMBL1609004 & 688444 & 4.7954 & 4.1477 & TST & \\
\hline CHEMBL1344283 & 688444 & 2.7959 & 4.178 & TRN & \\
\hline CHEMBL1464894 & 688444 & 2.7959 & 3.9931 & TRN & \\
\hline CHEMBL1993746 & 688444 & 2.7959 & 4.3414 & TRN & \\
\hline CHEMBL1463750 & 688444 & 5.6757 & 5.8569 & TRN & \\
\hline CHEMBL1537190 & 688444 & 6.1494 & 5.0487 & TRN & \\
\hline CHEMBL3145303 & 688444 & 5.5738 & 5.3822 & TRN & \\
\hline CHEMBL1524956 & 688444 & 6.7328 & 6.0043 & TRN & \\
\hline CHEMBL1501041 & 688444 & 2.8239 & 4.3767 & TRN & \\
\hline CHEMBL1439020 & 688444 & 5.8697 & 5.2097 & TRN & \\
\hline CHEMBL1328566 & 688444 & 4.7713 & 4.4 & TRN & \\
\hline
\end{tabular}




\begin{tabular}{|c|c|c|c|c|c|c|}
\hline & & \multicolumn{5}{|c|}{ Supplemental Table S2.txt } \\
\hline CHEMBL1586201 & 688444 & 5.8259 & 5.6378 & TRN & & \\
\hline CHEMBL1496096 & 688444 & 5.4305 & 4.0324 & TRN & & \\
\hline CHEMBL1390963 & 688444 & \multicolumn{3}{|c|}{5.9079999999999995} & 5.7081 & TRN \\
\hline CHEMBL1548257 & 688444 & 5.1665 & 4.9426 & TRN & & \\
\hline CHEMBL1607272 & 688444 & 5.6078 & 4.0022 & TRN & & \\
\hline CHEMBL1995550 & 688444 & 5.6392 & 5.2415 & TRN & & \\
\hline CHEMBL1566967 & 688444 & 4.6354 & 4.1463 & TST & & \\
\hline CHEMBL1595551 & 688444 & 2.7959 & 3.8759 & TRN & & \\
\hline CHEMBL1368410 & 688444 & 5.6819 & 5.38899 & 9999999999 & & TRN \\
\hline CHEMBL1566224 & 688444 & 5.0467 & 4.0121 & TRN & & \\
\hline CHEMBL1505039 & 688444 & 5.724 & 5.5855 & TST & & \\
\hline CHEMBL1305864 & 688444 & 6.3979 & 5.0612 & TRN & & \\
\hline CHEMBL1333095 & 688444 & 6.1141 & 5.2627 & TST & & \\
\hline CHEMBL3193084 & 688444 & 5.8336 & 4.2056 & TRN & & \\
\hline CHEMBL1567688 & 688444 & 5.9038 & 5.3329 & TRN & & \\
\hline CHEMBL1966798 & 688444 & 5.7251 & 4.308 & TRN & & \\
\hline CHEMBL3194528 & 688444 & 5.4454 & 5.7249 & TRN & & \\
\hline CHEMBL1581042 & 688444 & 5.8508 & 5.4722 & TRN & & \\
\hline CHEMBL1352234 & 688444 & 5.1319 & 5.1437 & TST & & \\
\hline CHEMBL3213808 & 688444 & 2.8239 & 3.9635 & TRN & & \\
\hline CHEMBL1442280 & 688444 & 6.4828 & 6.4141 & TRN & & \\
\hline CHEMBL1349566 & 688444 & 6.0477 & 5.4112 & TRN & & \\
\hline CHEMBL1376904 & 688444 & 5.5763 & 5.1335 & TRN & & \\
\hline CHEMBL1391974 & 688444 & 5.2791 & 5.1281 & TRN & & \\
\hline CHEMBL1526793 & 688444 & 2.7959 & 3.8699 & TRN & & \\
\hline CHEMBL1330616 & 688444 & 4.3802 & 3.9541 & TRN & & \\
\hline CHEMBL187263 & 688444 & 5.8732 & 5.1973 & TRN & & \\
\hline CHEMBL1520537 & 688444 & 6.7721 & 4.8758 & TRN & & \\
\hline CHEMBL1487576 & 688444 & 2.8239 & 4.4417 & TRN & & \\
\hline CHEMBL1371877 & 688444 & 6.4034 & 5.3328 & TRN & & \\
\hline CHEMBL1390196 & 688444 & 4.644 & 4.0427 & TRN & & \\
\hline CHEMBL140425 & 688444 & 6.4634 & 6.8527 & TRN & & \\
\hline CHEMBL1563623 & 688444 & 5.9252 & 5.6977 & TRN & & \\
\hline CHEMBL3191080 & 688444 & 5.4368 & 5.2899 & TST & & \\
\hline CHEMBL1528049 & 688444 & 5.4141 & 4.1456 & TRN & & \\
\hline CHEMBL1412223 & 688444 & 2.7959 & 5.9371 & TRN & & \\
\hline CHEMBL1544423 & 688444 & 5.6231 & 5.0992 & TRN & & \\
\hline CHEMBL1424665 & 688444 & 6.475 & 6.5051 & TRN & & \\
\hline CHEMBL1348012 & 688444 & 4.9054 & 5.3244 & TST & & \\
\hline CHEMBL1538671 & 688444 & 2.7959 & 4.2868 & TRN & & \\
\hline CHEMBL1583101 & 688444 & 5.4025 & 4.2889 & TRN & & \\
\hline CHEMBL1447697 & 688444 & 6.1599 & 5.2348 & TRN & & \\
\hline CHEMBL1572967 & 688444 & 2.7959 & 4.0536 & TRN & & \\
\hline CHEMBL1426383 & 688444 & 5.9169 & 5.42200 & 0000000001 & & TRN \\
\hline CHEMBL492115 & 688444 & 4.756 & 4.0346 & TRN & & \\
\hline CHEMBL1403085 & 688444 & 6.0301 & 4.2534 & TRN & & \\
\hline CHEMBL1525526 & 688444 & 2.7959 & 5.3792 & TRN & & \\
\hline CHEMBL1467876 & 688444 & 5.8821 & 5.2658 & TRN & & \\
\hline
\end{tabular}




\begin{tabular}{|c|c|c|c|c|c|}
\hline & & \multicolumn{4}{|c|}{ Supplemental Table S2.txt } \\
\hline CHEMBL1386049 & 688444 & 5.7693 & 4.9436 & TRN & \\
\hline CHEMBL1337224 & 688444 & 5.4928 & 5.3257 & TRN & \\
\hline CHEMBL1987461 & 688444 & 5.9367 & 5.5829 & TRN & \\
\hline CHEMBL1484456 & 688444 & 2.8239 & 4.194 & TRN & \\
\hline CHEMBL591412 & 688444 & 5.9851 & 6.3852 & TRN & \\
\hline CHEMBL1454827 & 688444 & 5.7215 & 4.2745 & TRN & \\
\hline CHEMBL1329232 & 688444 & 5.0211 & 4.0388 & TRN & \\
\hline CHEMBL1345665 & 688444 & 5.3407 & 4.9539 & TRN & \\
\hline CHEMBL1331633 & 688444 & 2.7959 & 3.7713 & TRN & \\
\hline CHEMBL1556838 & 688444 & 5.5756 & 5.1115 & TRN & \\
\hline CHEMBL3197761 & 688444 & 6.1925 & 5.8661 & TRN & \\
\hline CHEMBL1605966 & 688444 & 2.8239 & 4.8698 & TRN & \\
\hline CHEMBL1600749 & 688444 & 6.3391 & 4.9038 & TRN & \\
\hline CHEMBL1359020 & 688444 & 2.8239 & 3.6429 & TRN & \\
\hline CHEMBL1534309 & 688444 & 2.8239 & 4.1339 & TRN & \\
\hline CHEMBL3196726 & 688444 & 6.2055 & 6.04899 & 99999999995 & TRN \\
\hline CHEMBL1404163 & 688444 & 2.8239 & 4.1916 & TRN & \\
\hline CHEMBL1349480 & 688444 & 6.0809 & 5.8298 & TRN & \\
\hline CHEMBL1352227 & 688444 & 2.8239 & 4.5489 & TRN & \\
\hline CHEMBL1420598 & 688444 & 4.888 & 5.2729 & TRN & \\
\hline CHEMBL1420535 & 688444 & 5.1801 & 3.8969 & TRN & \\
\hline CHEMBL1305011 & 688444 & 5.1318 & 4.2443 & TRN & \\
\hline CHEMBL1716494 & 688444 & 4.7232 & 5.401 & TRN & \\
\hline CHEMBL3198720 & 688444 & 6.058 & 5.7182 & TRN & \\
\hline CHEMBL3190974 & 688444 & 6.0535 & 5.6301 & TRN & \\
\hline CHEMBL1601830 & 688444 & 5.7547 & 5.2655 & TRN & \\
\hline CHEMBL1489113 & 688444 & 5.6985 & 5.2984 & TRN & \\
\hline CHEMBL1333987 & 688444 & 5.9658 & 6.1981 & TRN & \\
\hline CHEMBL1604864 & 688444 & 2.7959 & 4.4923 & TRN & \\
\hline CHEMBL1566205 & 688444 & 5.5986 & 5.3324 & TRN & \\
\hline CHEMBL1336535 & 688444 & 6.6091 & 6.0925 & TRN & \\
\hline CHEMBL1566084 & 688444 & 5.4215 & 4.7519 & TRN & \\
\hline CHEMBL1367086 & 688444 & 6.3372 & 6.4564 & TRN & \\
\hline CHEMBL1506580 & 688444 & 5.9893 & 5.8835 & TRN & \\
\hline CHEMBL1479804 & 688444 & 6.0128 & 5.314 & TRN & \\
\hline CHEMBL3191817 & 688444 & 5.2105 & 5.4416 & TRN & \\
\hline CHEMBL1483620 & 688444 & 5.8965 & 5.1697 & TRN & \\
\hline CHEMBL1438970 & 688444 & 5.9183 & 5.5488 & TRN & \\
\hline CHEMBL3193092 & 688444 & 2.8239 & 4.0653 & TRN & \\
\hline CHEMBL86104 & 688444 & 5.5865 & 5.9307 & TRN & \\
\hline CHEMBL1490555 & 688444 & 6.7144 & 5.6724 & TRN & \\
\hline CHEMBL1579999 & 688444 & 6.1858 & 5.4727 & TST & \\
\hline CHEMBL1392918 & 688444 & $5.4510 e$ & 300000006 & 4.7401 & T \\
\hline CHEMBL3145381 & 688444 & 5.0231 & 4.1463 & TRN & \\
\hline CHEMBL1454030 & 688444 & 4.2654 & 4.2386 & TRN & \\
\hline CHEMBL3198754 & 688444 & 5.8911 & 5.9505 & TRN & \\
\hline CHEMBL1527022 & 688444 & 5.9626 & 5.2445 & TRN & \\
\hline CHEMBL1503173 & 688444 & 4.8738 & 4.9152 & TRN & \\
\hline
\end{tabular}




\begin{tabular}{|c|c|c|c|c|c|c|}
\hline \multirow[b]{2}{*}{ CHEMBL1370536 } & & \multicolumn{5}{|c|}{ Supplemental Table S2.txt } \\
\hline & 688444 & 6.1824 & 5.6358 & TST & & \\
\hline CHEMBL1612201 & 688444 & 5.2195 & 4.9068 & TST & & \\
\hline CHEMBL1424331 & 688444 & $5.6720 e$ & 00000000 & & 5.4795 & TRN \\
\hline CHEMBL1605026 & 688444 & 5.1774 & 5.3334 & TRN & & \\
\hline CHEMBL1589335 & 688444 & 6.0173 & 5.4745 & TST & & \\
\hline CHEMBL1468668 & 688444 & 5.8887 & 5.4024 & TST & & \\
\hline CHEMBL1348119 & 688444 & 6.0453 & 5.813 & TRN & & \\
\hline CHEMBL1366992 & 688444 & 5.4459 & 5.1476 & TST & & \\
\hline CHEMBL1585127 & 688444 & 6.0752 & 5.351 & TRN & & \\
\hline CHEMBL1300225 & 688444 & 2.8239 & 3.8366 & TRN & & \\
\hline CHEMBL1382011 & 688444 & 5.7615 & 3.9138 & TRN & & \\
\hline CHEMBL1576945 & 688444 & 5.3977 & 5.4551 & TRN & & \\
\hline CHEMBL1477212 & 688444 & 6.3152 & 5.7253 & TRN & & \\
\hline CHEMBL1420556 & 688444 & $6.0820 e$ & 0000000 & & 5.7081 & TRN \\
\hline CHEMBL1391837 & 688444 & 2.8239 & 3.8684 & TRN & & \\
\hline CHEMBL1570176 & 688444 & 5.9488 & 5.188 & TRN & & \\
\hline CHEMBL1987472 & 688444 & 5.7319 & 4.6277 & TRN & & \\
\hline CHEMBL1572286 & 688444 & 2.8239 & 4.0067 & TRN & & \\
\hline CHEMBL1372492 & 688444 & 5.5921 & 5.5612 & TRN & & \\
\hline CHEMBL 2004417 & 688444 & 5.2063 & 5.6626 & TRN & & \\
\hline CHEMBL601768 & 688444 & 6.2652 & 6.6566 & TRN & & \\
\hline CHEMBL1489956 & 688444 & 5.6876 & 5.3849 & TRN & & \\
\hline CHEMBL3193010 & 688444 & 6.3947 & 6.1028 & TRN & & \\
\hline CHEMBL1994877 & 688444 & 5.6645 & 4.8929 & TRN & & \\
\hline CHEMBL3189193 & 688444 & 5.9194 & 5.5216 & TRN & & \\
\hline CHEMBL1502929 & 688444 & 5.7924 & 5.2334 & TRN & & \\
\hline CHEMBL483768 & 688444 & 6.1918 & 5.2421 & TRN & & \\
\hline CHEMBL512366 & 688444 & 6.0168 & 5.352 & TRN & & \\
\hline CHEMBL1517490 & 688444 & 2.7959 & 3.9194 & TST & & \\
\hline CHEMBL1334791 & 688444 & 5.4626 & 3.9643 & TRN & & \\
\hline CHEMBL1537127 & 688444 & 2.7959 & 4.0461 & TRN & & \\
\hline CHEMBL585656 & 688444 & 6.4815 & 5.4917 & TRN & & \\
\hline CHEMBL1326523 & 688444 & 4.6023 & 3.9501 & TRN & & \\
\hline CHEMBL1318350 & 688444 & 7.9208 & 7.1786 & TRN & & \\
\hline CHEMBL1874620 & 688444 & 5.7291 & 5.7519 & TRN & & \\
\hline CHEMBL3193652 & 688444 & 2.7959 & 5.3706 & TRN & & \\
\hline CHEMBL 1307255 & 688444 & 6.4698 & 5.5882 & TRN & & \\
\hline CHEMBL3397122 & 688444 & 5.3962 & 4.1824 & TRN & & \\
\hline CHEMBL1460823 & 688444 & 4.8735 & 4.2004 & TRN & & \\
\hline CHEMBL1543255 & 688444 & 5.9281 & 5.1662 & TRN & & \\
\hline CHEMBL3196430 & 688444 & 4.9252 & 4.166 & TRN & & \\
\hline CHEMBL1426244 & 688444 & 4.3242 & 4.0232 & TRN & & \\
\hline CHEMBL1505071 & 688444 & 5.919 & 5.2442 & TRN & & \\
\hline CHEMBL1502351 & 688444 & 6.0443 & 5.6314 & TRN & & \\
\hline CHEMBL1538652 & 688444 & 5.0046 & 4.7576 & TRN & & \\
\hline CHEMBL1459101 & 688444 & 2.8239 & 5.6342 & TRN & & \\
\hline CHEMBL1391547 & 688444 & 4.7515 & 4.1601 & TST & & \\
\hline CHEMBL1492474 & 688444 & 2.8239 & 4.1775 & TRN & & \\
\hline
\end{tabular}




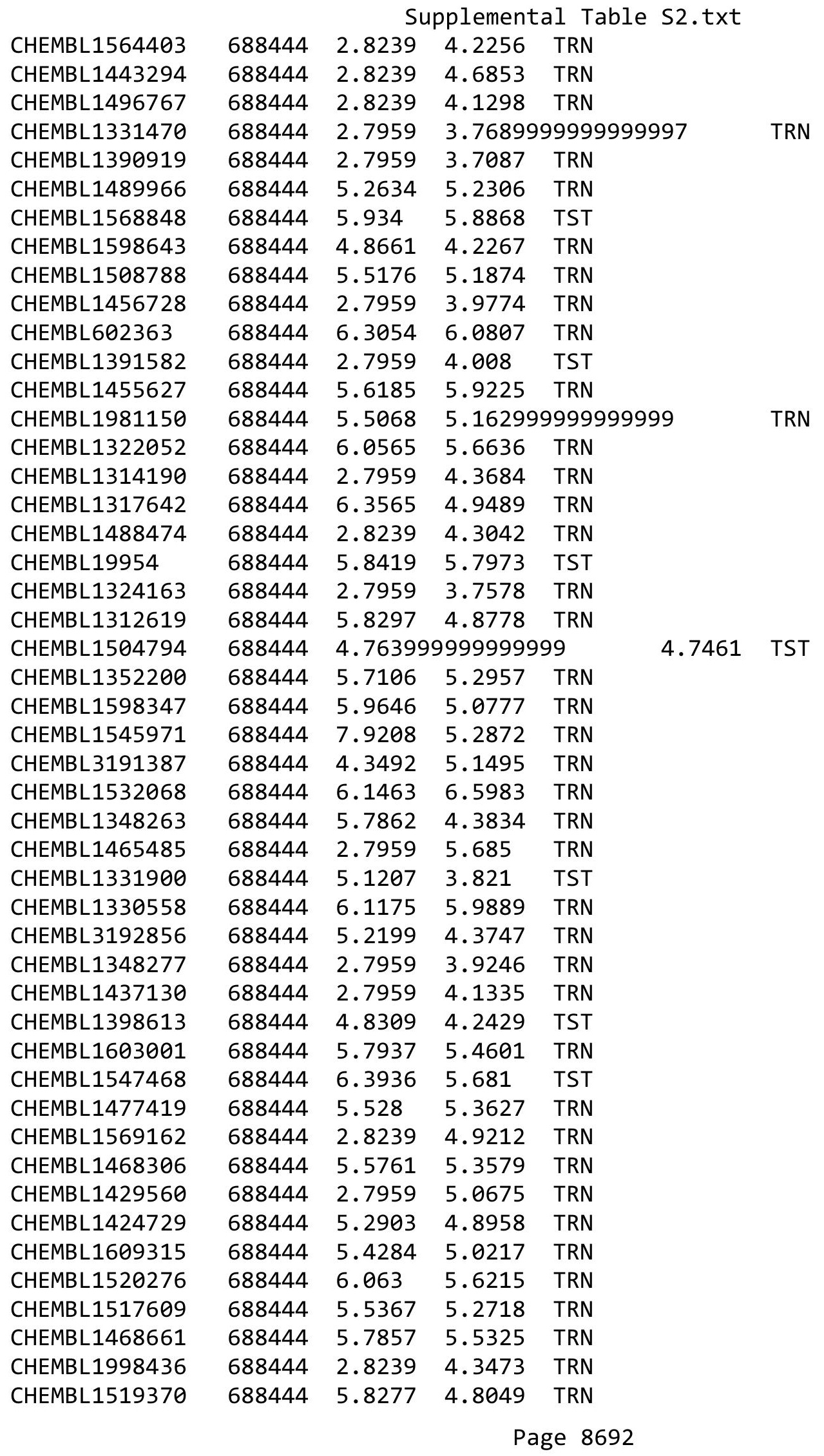


Supplemental Table S2.txt

\begin{tabular}{|c|c|c|c|c|c|}
\hline CHEMBL1397742 & 688444 & 5.6407 & 5.3083 & TRN & \\
\hline CHEMBL1365660 & 688444 & 2.7959 & 4.396 & TST & \\
\hline CHEMBL1608579 & 688444 & 5.1099 & 5.2139 & TRN & \\
\hline CHEMBL1367316 & 688444 & 2.8239 & 5.1506 & TRN & \\
\hline CHEMBL1306949 & 688444 & 6.0625 & 4.7145 & TRN & \\
\hline CHEMBL1990174 & 688444 & 5.8377 & 5.7676 & TRN & \\
\hline CHEMBL1485259 & 688444 & 6.1024 & 6.2716 & TRN & \\
\hline CHEMBL580955 & 688444 & 6.1811 & 6.5255 & TRN & \\
\hline CHEMBL3194699 & 688444 & 4.7878 & 4.3729 & TRN & \\
\hline CHEMBL1481697 & 688444 & 5.9108 & 5.3411 & TRN & \\
\hline CHEMBL1481740 & 688444 & 4.5114 & 4.0044 & TRN & \\
\hline CHEMBL3192707 & 688444 & 5.1417 & 5.2096 & TST & \\
\hline CHEMBL1494743 & 688444 & 2.8239 & 3.87600 & 30000000003 & TST \\
\hline CHEMBL1408965 & 688444 & 6.6737 & 5.37700 & 0000000001 & \\
\hline CHEMBL1439576 & 688444 & 5.1662 & 4.2022 & TRN & \\
\hline CHEMBL1341308 & 688444 & 5.7838 & 5.4123 & TRN & \\
\hline CHEMBL1345042 & 688444 & \multicolumn{3}{|c|}{4.6419999999999995} & TRN \\
\hline CHEMBL1452779 & 688444 & 6.6904 & 4.857 & TRN & \\
\hline CHEMBL1582044 & 688444 & 5.0124 & 3.9257 & TRN & \\
\hline CHEMBL1544560 & 688444 & 2.7959 & 3.7615 & TRN & \\
\hline CHEMBL1312049 & 688444 & 6.8297 & 5.7823 & TRN & \\
\hline CHEMBL1967081 & 688444 & 6.1791 & 5.7208 & TRN & \\
\hline CHEMBL 2005246 & 688444 & 6.8761 & 6.1259 & TRN & \\
\hline CHEMBL1351171 & 688444 & 4.6075 & 3.9393 & TRN & \\
\hline CHEMBL 300389 & 688444 & 6.0273 & 5.5081 & TST & \\
\hline CHEMBL 3195177 & 688444 & 2.8239 & 4.2758 & TRN & \\
\hline CHEMBL548615 & 688444 & 5.9991 & 5.8234 & TRN & \\
\hline CHEMBL1537417 & 688444 & 6.4802 & 5.5685 & TST & \\
\hline CHEMBL1465367 & 688444 & 2.7959 & 3.818 & TRN & \\
\hline CHEMBL1478465 & 688444 & 5.3263 & 4.0724 & TRN & \\
\hline CHEMBL3196186 & 688444 & 4.8552 & 5.33 & TRN & \\
\hline CHEMBL1489407 & 688444 & 5.6844 & 4.6809 & TRN & \\
\hline CHEMBL1519558 & 688444 & 5.3024 & 5.3115 & TRN & \\
\hline CHEMBL1529553 & 688444 & 5.6594 & 4.9248 & TST & \\
\hline CHEMBL1995152 & 688444 & 2.8239 & 5.0912 & TRN & \\
\hline CHEMBL1562633 & 688444 & 2.8239 & 3.9894 & TRN & \\
\hline CHEMBL1326457 & 688444 & 2.8239 & 4.0678 & TRN & \\
\hline CHEMBL1385760 & 688444 & 6.2899 & 5.7335 & TRN & \\
\hline CHEMBL3192779 & 688444 & 5.2412 & 4.1547 & TRN & \\
\hline CHEMBL1524400 & 688444 & 5.1009 & 4.2857 & TRN & \\
\hline CHEMBL1510925 & 688444 & 5.4192 & 4.9526 & TRN & \\
\hline CHEMBL1491222 & 688444 & 6.2426 & 6.0982 & TRN & \\
\hline CHEMBL1587683 & 688444 & 7.9208 & 6.3226 & TRN & \\
\hline CHEMBL 1278181 & 688444 & 6.098 & 5.2014 & TRN & \\
\hline CHEMBL 3211050 & 688444 & 6.0975 & 5.9201 & TRN & \\
\hline CHEMBL1347598 & 688444 & 5.0864 & 4.8183 & TST & \\
\hline CHEMBL1582488 & 688444 & 5.5875 & 4.0941 & TRN & \\
\hline CHEMBL1502530 & 688444 & 5.9821 & 5.3169 & TRN & \\
\hline
\end{tabular}

Page 8693 


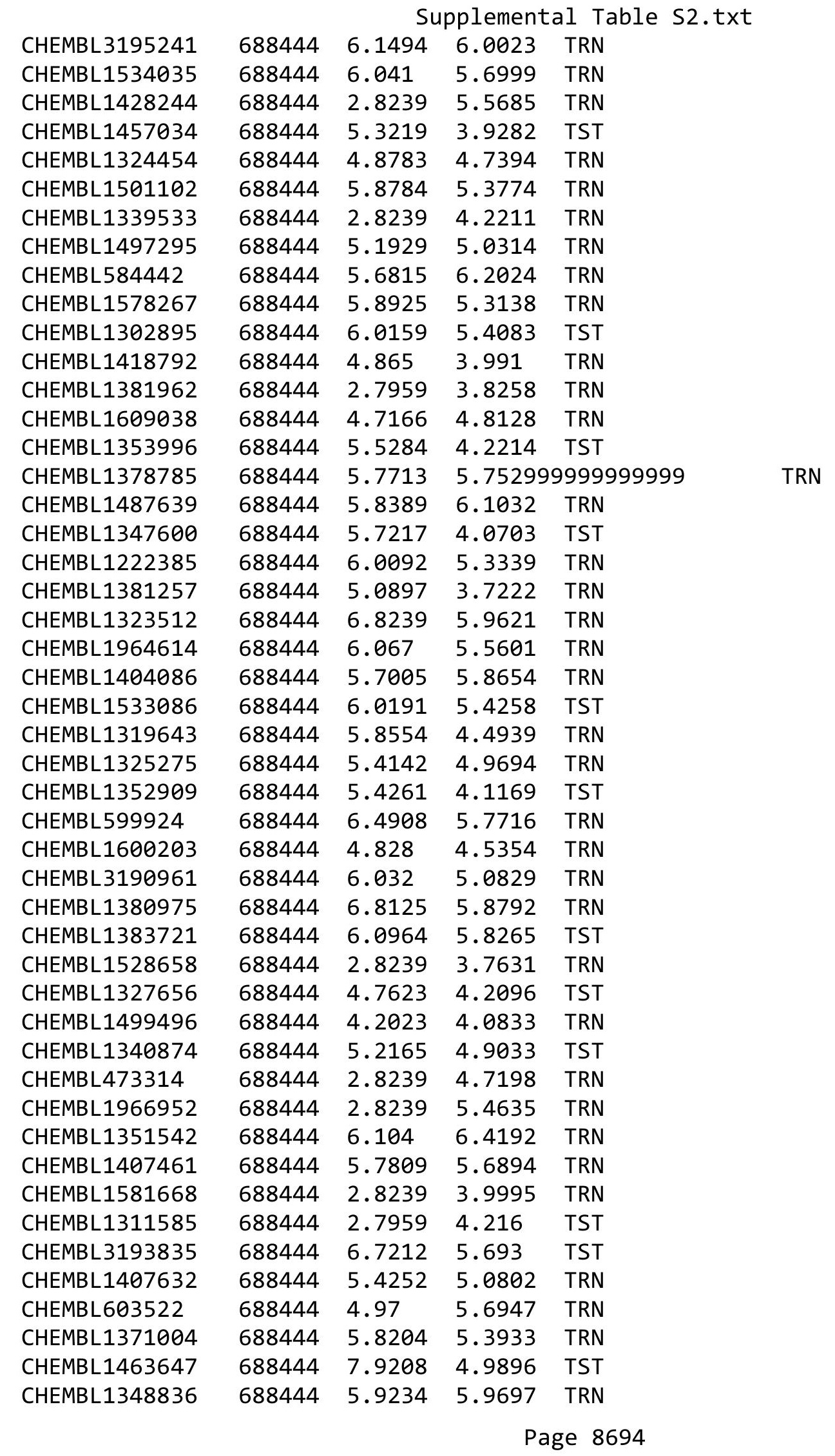




\begin{tabular}{|c|c|c|c|c|c|c|}
\hline \multirow{3}{*}{$\begin{array}{l}\text { CHEMBL1601193 } \\
\text { CHFMBI 1484227 }\end{array}$} & & \multicolumn{5}{|c|}{ Supplemental Table S2.txt } \\
\hline & 688444 & 2.8239 & \multicolumn{3}{|c|}{3.9130000000000003} & TRN \\
\hline & 688444 & 6.3556 & 5.6783 & TST & & \\
\hline CHEMBL3190648 & 688444 & 6.2269 & 6.1007 & TRN & & \\
\hline CHEMBL1414068 & 688444 & 5.5862 & 5.4318 & TRN & & \\
\hline CHEMBL1321271 & 688444 & 5.7844 & 5.2513 & TRN & & \\
\hline CHEMBL1471206 & 688444 & 5.4942 & 5.6995 & TRN & & \\
\hline CHEMBL1520187 & 688444 & 4.8309 & 4.9088 & TST & & \\
\hline CHEMBL1347784 & 688444 & 2.8239 & 4.612 & TRN & & \\
\hline CHEMBL1576118 & 688444 & 6.0482 & 5.3616 & TST & & \\
\hline CHEMBL1416456 & 688444 & 4.8395 & 4.3357 & TRN & & \\
\hline CHEMBL1789993 & 688444 & 5.45299 & 99999999 & 99 & .3721 & TST \\
\hline CHEMBL1583585 & 688444 & 5.7807 & 5.9742 & TRN & & \\
\hline CHEMBL1431312 & 688444 & 4.8753 & 4.0633 & TRN & & \\
\hline CHEMBL1328182 & 688444 & 6.0128 & 5.2988 & TRN & & \\
\hline CHEMBL1545499 & 688444 & 4.9635 & 3.9699 & TRN & & \\
\hline CHEMBL1603456 & 688444 & 5.2061 & 4.0393 & TRN & & \\
\hline CHEMBL1426337 & 688444 & 5.8901 & 5.0236 & TRN & & \\
\hline CHEMBL1443454 & 688444 & 2.7959 & 5.6132 & TRN & & \\
\hline CHEMBL1567963 & 688444 & 2.8239 & 5.0965 & TST & & \\
\hline CHEMBL1330113 & 688444 & 6.0 & 5.5837 & TRN & & \\
\hline CHEMBL1563766 & 688444 & 5.7194 & 5.5671 & TRN & & \\
\hline CHEMBL1547746 & 688444 & 4.627 & 3.9906 & TRN & & \\
\hline CHEMBL1475477 & 688444 & 5.5918 & 4.1222 & TRN & & \\
\hline CHEMBL1417242 & 688444 & 5.2194 & $5.45200 t$ & 0000000001 & & TRN \\
\hline CHEMBL 225963 & 688444 & 6.4895 & 5.7883 & TRN & & \\
\hline CHEMBL 3184468 & 688444 & 5.5058 & 5.1327 & TST & & \\
\hline CHEMBL1306256 & 688444 & 2.8239 & 5.7958 & TRN & & \\
\hline CHEMBL1353757 & 688444 & 6.0501 & 4.3566 & TRN & & \\
\hline CHEMBL 3210642 & 688444 & 5.4523 & 5.5463 & TRN & & \\
\hline CHEMBL1447219 & 688444 & 6.2211 & 6.1567 & TRN & & \\
\hline CHEMBL1481132 & 688444 & 6.0159 & 5.5841 & TRN & & \\
\hline CHEMBL3191534 & 688444 & 2.8239 & 4.2285 & TRN & & \\
\hline CHEMBL1469379 & 688444 & 5.4925 & 4.6876 & TRN & & \\
\hline CHEMBL325841 & 688444 & 5.4523 & 5.4461 & TRN & & \\
\hline CHEMBL1382821 & 688444 & 2.7959 & 5.947 & TRN & & \\
\hline CHEMBL1905194 & 688444 & 4.676 & 4.9311 & TST & & \\
\hline CHEMBL1486827 & 688444 & 5.0759 & 4.1229 & TRN & & \\
\hline CHEMBL1390303 & 688444 & 5.49299 & 99999999 & & .6166 & TRN \\
\hline CHEMBL1335117 & 688444 & 2.7959 & 3.9977 & TST & & \\
\hline CHEMBL1389542 & 688444 & 6.5361 & 5.5967 & TRN & & \\
\hline CHEMBL1349470 & 688444 & 2.8239 & 3.7993 & TRN & & \\
\hline CHEMBL1313518 & 688444 & 2.7959 & 5.2788 & TRN & & \\
\hline CHEMBL1462215 & 688444 & 6.5391 & 6.3865 & TRN & & \\
\hline CHEMBL1434756 & 688444 & 2.8239 & 4.2212 & TST & & \\
\hline CHEMBL1993194 & 688444 & 6.5544 & 6.2507 & TRN & & \\
\hline CHEMBL1995800 & 688444 & 2.8239 & 4.903006 & 3000000000 & & TST \\
\hline CHEMBL1578484 & 688444 & 5.6737 & 5.2113 & TST & & \\
\hline CHEMBL1606097 & 688444 & 6.4437 & 5.8622 & TRN & & \\
\hline
\end{tabular}


Supplemental Table S2.txt

\begin{tabular}{|c|c|c|c|c|c|}
\hline CHEMBL1613503 & 688444 & 5.269 & 4.8101 & TRN & \\
\hline CHEMBL3211998 & 688444 & 6.0605 & \multicolumn{2}{|c|}{4.2330000000000005} & TRN \\
\hline CHEMBL1389836 & 688444 & 4.8488 & 4.2343 & TRN & \\
\hline CHEMBL3194066 & 688444 & 4.7604 & 5.1602 & TRN & \\
\hline CHEMBL1408094 & 688444 & 6.8356 & 5.1809 & TRN & \\
\hline CHEMBL1303401 & 688444 & 5.4884 & 5.2139 & TRN & \\
\hline CHEMBL1401188 & 688444 & 2.8239 & 4.6347 & TRN & \\
\hline CHEMBL1408342 & 688444 & 5.5078 & 4.9334 & TRN & \\
\hline CHEMBL1610180 & 688444 & 2.8239 & 4.0459 & TRN & \\
\hline CHEMBL1602947 & 688444 & 5.7375 & 5.3795 & TRN & \\
\hline CHEMBL1979784 & 688444 & 6.2899 & 5.681 & TRN & \\
\hline CHEMBL1352172 & 688444 & 4.5758 & 4.2372 & TRN & \\
\hline CHEMBL3208391 & 688444 & 2.8239 & 4.0709 & TRN & \\
\hline CHEMBL 3213054 & 688444 & 2.7959 & 4.8811 & TST & \\
\hline CHEMBL1447039 & 688444 & 2.8239 & 4.0224 & TRN & \\
\hline CHEMBL1994094 & 688444 & 5.3181 & 4.2807 & TRN & \\
\hline CHEMBL1550442 & 688444 & 5.7775 & 6.1102 & TRN & \\
\hline CHEMBL1553408 & 688444 & 6.224 & 5.5848 & TRN & \\
\hline CHEMBL1401668 & 688444 & 2.7959 & 5.2752 & TST & \\
\hline CHEMBL 380184 & 688444 & 5.4621 & \multicolumn{2}{|c|}{5.303999999999999} & TRN \\
\hline CHEMBL1481555 & 688444 & 2.8239 & 4.0427 & TRN & \\
\hline CHEMBL3194481 & 688444 & 2.8239 & 4.3632 & TRN & \\
\hline CHEMBL1582218 & 688444 & 2.8239 & 4.7723 & TST & \\
\hline CHEMBL1545105 & 688444 & 5.9948 & 5.8273 & TRN & \\
\hline CHEMBL3193008 & 688444 & 2.8239 & 4.1638 & TRN & \\
\hline CHEMBL1611574 & 688444 & 4.3072 & 4.1723 & TRN & \\
\hline CHEMBL1379888 & 688444 & 6.4789 & 5.263 & TST & \\
\hline CHEMBL1359871 & 688444 & 5.8066 & 6.1303 & TRN & \\
\hline CHEMBL1559931 & 688444 & 2.7959 & 3.9229 & TST & \\
\hline CHEMBL1500960 & 688444 & 5.0079 & 5.2535 & TRN & \\
\hline CHEMBL1469362 & 688444 & 6.4306 & 5.1097 & TRN & \\
\hline CHEMBL1503033 & 688444 & 5.7652 & 5.5277 & TRN & \\
\hline CHEMBL1458478 & 688444 & 2.7959 & 4.0118 & TST & \\
\hline CHEMBL405927 & 688444 & 5.9201 & 5.4201 & TRN & \\
\hline CHEMBL1377364 & 688444 & 2.8239 & 4.4747 & TRN & \\
\hline CHEMBL1386593 & 688444 & 4.7641 & 4.8119 & TST & \\
\hline CHEMBL1383777 & 688444 & 2.7959 & 5.629 & TRN & \\
\hline CHEMBL 2006418 & 688444 & 5.0832 & 4.2813 & TRN & \\
\hline CHEMBL1301784 & 688444 & 6.3936 & 4.1545 & TRN & \\
\hline CHEMBL1391737 & 688444 & 6.0232 & \multicolumn{2}{|c|}{5.542000000000001} & TRN \\
\hline CHEMBL1500144 & 688444 & 5.2134 & 4.282 & TRN & \\
\hline CHEMBL1566358 & 688444 & 6.3575 & 5.3842 & TRN & \\
\hline CHEMBL3145287 & 688444 & 5.4859 & 4.4903 & TRN & \\
\hline CHEMBL1532413 & 688444 & 2.8239 & 4.3829 & TST & \\
\hline CHEMBL1382884 & 688444 & 5.2057 & 4.4984 & TST & \\
\hline CHEMBL3197902 & 688444 & 4.724 & 5.6232 & TRN & \\
\hline CHEMBL1481390 & 688444 & 4.9272 & 4.152 & TRN & \\
\hline CHEMBL1306690 & 688444 & 5.5376 & 5.2406 & TST & \\
\hline
\end{tabular}




\begin{tabular}{|c|c|c|c|c|c|}
\hline \multicolumn{6}{|c|}{ Supplemental Table S2.txt } \\
\hline CHEMBL1536493 & 688444 & 5.4516 & 5.8672 & TRN & \\
\hline CHEMBL1303524 & 688444 & 6.0947 & 4.8173 & TRN & \\
\hline CHEMBL1390658 & 688444 & 5.6977 & 5.1177 & TRN & \\
\hline CHEMBL1429980 & 688444 & 5.9151 & 5.2543 & TST & \\
\hline CHEMBL 3208002 & 688444 & 5.5161 & 5.0935 & TRN & \\
\hline CHEMBL1304950 & 688444 & 5.9731 & 5.0816 & TRN & \\
\hline CHEMBL1087588 & 688444 & 4.6673 & 4.9154 & TRN & \\
\hline CHEMBL1351099 & 688444 & 2.8239 & 4.021 & TST & \\
\hline CHEMBL1487498 & 688444 & 6.5003 & 5.2155 & TRN & \\
\hline CHEMBL1563898 & 688444 & 5.8176 & 5.6469 & TST & \\
\hline CHEMBL1519688 & 688444 & 2.8239 & 4.0161 & TRN & \\
\hline CHEMBL600734 & 688444 & 6.2248 & 5.6396 & TRN & \\
\hline CHEMBL1452116 & 688444 & 6.2668 & 5.8117 & TST & \\
\hline CHEMBL1569989 & 688444 & 6.0164 & 5.8588 & TRN & \\
\hline CHEMBL1612613 & 688444 & 2.8239 & 3.9604 & TRN & \\
\hline CHEMBL1494713 & 688444 & 2.8239 & 4.131 & TST & \\
\hline CHEMBL3212271 & 688444 & 5.739 & 6.2047 & TRN & \\
\hline CHEMBL1529521 & 688444 & 5.6297 & 5.1114 & TRN & \\
\hline CHEMBL3198692 & 688444 & 2.8239 & 4.4184 & TRN & \\
\hline CHEMBL3199724 & 688444 & 4.9618 & 4.7508 & TRN & \\
\hline CHEMBL1419335 & 688444 & 4.9656 & 4.9997 & TRN & \\
\hline CHEMBL3209845 & 688444 & 5.6659 & 5.609 & TRN & \\
\hline CHEMBL1306749 & 688444 & 5.153 & 5.1119 & TRN & \\
\hline CHEMBL1443898 & 688444 & 5.7484 & 5.2122 & TST & \\
\hline CHEMBL1541834 & 688444 & 6.0711 & 5.9835 & TRN & \\
\hline CHEMBL1569124 & 688444 & 4.9334 & 4.3259 & TRN & \\
\hline CHEMBL3199737 & 688444 & 5.2521 & 4.1837 & TST & \\
\hline CHEMBL1336054 & 688444 & 5.9003 & 5.7814 & TRN & \\
\hline CHEMBL1490887 & 688444 & 5.3782 & 3.9288 & TST & \\
\hline CHEMBL1333504 & 688444 & 5.8719 & 5.2053 & TST & \\
\hline CHEMBL1480135 & 688444 & 5.7194 & 4.8805 & TRN & \\
\hline CHEMBL1991779 & 688444 & 5.7442 & 5.7652 & TRN & \\
\hline CHEMBL1442895 & 688444 & 4.7663 & 3.6636 & TRN & \\
\hline CHEMBL1444022 & 688444 & 2.8239 & 5.7184 & TRN & \\
\hline CHEMBL1538428 & 688444 & 5.3648 & 5.2056 & TST & \\
\hline CHEMBL1518057 & 688444 & 5.2293 & 5.4272 & TRN & \\
\hline CHEMBL 1378218 & 688444 & 2.7959 & 3.987 & TRN & \\
\hline CHEMBL1305001 & 688444 & 6.2062 & 5.3155 & TRN & \\
\hline CHEMBL1400007 & 688444 & 2.7959 & 3.8183 & TRN & \\
\hline CHEMBL1600678 & 688444 & 5.5158 & 5.5055 & TST & \\
\hline CHEMBL1309091 & 688444 & 2.8239 & 6.5212 & TRN & \\
\hline CHEMBL1483291 & 688444 & 4.9757 & 4.497 & TST & \\
\hline CHEMBL3198207 & 688444 & 5.9686 & 5.3992 & TRN & \\
\hline CHEMBL1329129 & 688444 & 5.9465 & 5.7854 & TRN & \\
\hline CHEMBL1422472 & 688444 & 5.581 & 5.3087 & TRN & \\
\hline CHEMBL1401645 & 688444 & 5.439 & $5.61600 t$ & 00000000005 & TRN \\
\hline CHEMBL1472773 & 688444 & 2.7959 & 5.9386 & TST & \\
\hline CHEMBL1462295 & 688444 & 2.8239 & 4.5774 & TRN & \\
\hline
\end{tabular}


Supplemental Table S2.txt

\begin{tabular}{|c|c|c|c|c|}
\hline - & & & & \\
\hline HEMBL1449883 & 88444 & .0106 & 6.1828 & \\
\hline & & & & \\
\hline FMRI 3 & 84 & 673 & 05 & \\
\hline IEMBL1401057 & 88444 & 3963 & 8155 & \\
\hline JEMBL459022 & 88444 & .8403 & 3356 & \\
\hline HEMBL1580272 & 88444 & .3526 & 3215 & \\
\hline HEMBL 319 & 38444 & & & \\
\hline IEMBL609027 & 884 & & & \\
\hline HEMBL1582221 & 88444 & 255 & 3488 & \\
\hline HEMBL1491555 & 88444 & 39 & 3272 & \\
\hline IEMBL1468811 & 88444 & 46 & 5124 & \\
\hline AEMBL152 & 8444 & & & \\
\hline HEMBL13 & 88444 & 56 & 1257 & \\
\hline AEMBL1345299 & 88444 & 39 & 5975 & \\
\hline AEMBL1383916 & 88444 & & 0074 & \\
\hline HEMBL196 & 88444 & & 547 & \\
\hline HEMBL 319 & 38444 & & 329 & \\
\hline HEMBL 154 & 14 & & 358 & \\
\hline AEMBL1381 & 884 & & & RN \\
\hline IEMBL1389047 & 38444 & & 393 & וכ \\
\hline HEMBL1992 & 38444 & & 557 & \\
\hline HEM & 38444 & & 167 & \\
\hline 40 & 4 & & & RN \\
\hline AEMBL150 & 884 & 1 & & RIN \\
\hline L199. & 8444 & & 158 & RN \\
\hline AEMBL142e & 38444 & & 618 & NIV \\
\hline 7 & 8444 & & 381 & RN \\
\hline 132 & 4 & & & RN \\
\hline AEMBL19980 & 88444 & & & SI \\
\hline IEMBL14026] & 38444 & & 33 & $\mathrm{RN}$ \\
\hline AFMBI 1578 & & & 43 & RN \\
\hline 0 & 4 & & 663 & RN \\
\hline HEMBL1530274 & & & & SI \\
\hline AEMBL14904 & 88444 & & 82 & RN \\
\hline AEMBL31 & 88444 & & 56 & \\
\hline $45 M D I 5$ & & & & RN \\
\hline HEMBL1535759 & & & 223 & RN \\
\hline HEMBL3209395 & 884 & & 571 & RN \\
\hline AEMBL3199 & 884 & $\partial 1$ & 731 & RN \\
\hline HEMBL1348093 & 88444 & 39 & 457 & 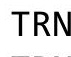 \\
\hline HEMBL1996971 & & & & RN \\
\hline HEMBL1574132 & 4 & . 3152 & 3436 & RN \\
\hline AEMBL3199526 & 884 & 33 & 214 & RN \\
\hline EMBL15 & $881+2,+2>$ & & & $\mathrm{K}$ \\
\hline HEMBL135 & 688444 & & 878 & \\
\hline HEIIDLI & 688444 & 5.6092 & 188 & \\
\hline HEMBL1362096 & 688444 & 5.5452 & 5.3264 & \\
\hline
\end{tabular}

Page 8698 


\begin{tabular}{|c|c|c|c|c|c|c|}
\hline & & \multicolumn{5}{|c|}{ Supplemental Table S2.txt } \\
\hline CHEMBL1320281 & 688444 & 5.8834 & 5.3891 & TRN & & \\
\hline CHEMBL461820 & 688444 & 4.8864 & 4.2927 & TST & & \\
\hline CHEMBL1406348 & 688444 & 2.7959 & 5.1593 & TRN & & \\
\hline CHEMBL 3856090 & 688444 & 5.5479 & 4.8928 & TRN & & \\
\hline CHEMBL1545677 & 688444 & 5.8145 & 5.6291 & TRN & & \\
\hline CHEMBL1516976 & 688444 & 5.8128 & 4.0488 & TST & & \\
\hline CHEMBL3189344 & 688444 & 5.7662 & 5.7772 & TRN & & \\
\hline CHEMBL1341995 & 688444 & \multicolumn{3}{|c|}{5.468999999999999} & 5.559 & TRN \\
\hline CHEMBL1549308 & 688444 & 5.6728 & 4.0905 & TRN & & \\
\hline CHEMBL1421670 & 688444 & 5.8771 & 5.4801 & TST & & \\
\hline CHEMBL1499658 & 688444 & 5.246 & 4.1935 & TRN & & \\
\hline CHEMBL1464110 & 688444 & \multicolumn{3}{|c|}{5.013999999999999} & 4.3745 & TRN \\
\hline CHEMBL1451060 & 688444 & 6.3809 & 6.1167 & TRN & & \\
\hline CHEMBL1575613 & 688444 & 2.8239 & 3.8658 & TRN & & \\
\hline CHEMBL3190585 & 688444 & 5.8911 & 5.1407 & TRN & & \\
\hline CHEMBL1305208 & 688444 & 2.7959 & 4.029 & TST & & \\
\hline CHEMBL1608901 & 688444 & 2.8239 & 3.8722 & TRN & & \\
\hline CHEMBL1352766 & 688444 & 2.7959 & 3.8108 & TRN & & \\
\hline CHEMBL1391911 & 688444 & 5.9562 & 5.7584 & TRN & & \\
\hline CHEMBL1486934 & 688444 & 2.8239 & 5.1028 & TRN & & \\
\hline CHEMBL1549103 & 688444 & 5.1101 & 5.0027 & TRN & & \\
\hline CHEMBL1417809 & 688444 & 5.0185 & 5.2865 & TRN & & \\
\hline CHEMBL1390391 & 688444 & 2.7959 & 4.0224 & TRN & & \\
\hline CHEMBL1535900 & 688444 & 5.7875 & 5.4229 & TST & & \\
\hline CHEMBL1985582 & 688444 & 5.6312 & 5.5338 & TRN & & \\
\hline CHEMBL1311007 & 688444 & 6.1561 & 5.3666 & TRN & & \\
\hline CHEMBL1528425 & 688444 & 6.3325 & 6.4321 & TRN & & \\
\hline CHEMBL1519902 & 688444 & 5.9404 & 6.3356 & TRN & & \\
\hline CHEMBL 1405220 & 688444 & 5.8033 & 5.3573 & TRN & & \\
\hline CHEMBL1353042 & 688444 & 6.1844 & 5.939 & TST & & \\
\hline CHEMBL1458975 & 688444 & 5.5249 & 4.9981 & TRN & & \\
\hline CHEMBL1352575 & 688444 & 4.8521 & 4.8537 & TRN & & \\
\hline CHEMBL1561050 & 688444 & 6.4921 & 5.7089 & TRN & & \\
\hline CHEMBL1497549 & 688444 & 5.9813 & 5.7916 & TRN & & \\
\hline CHEMBL1333088 & 688444 & 2.7959 & 5.2353 & TST & & \\
\hline CHEMBL1332555 & 688444 & 6.0205 & 4.1315 & TRN & & \\
\hline CHEMBL1568337 & 688444 & 6.0846 & 5.0328 & TRN & & \\
\hline CHEMBL 3198723 & 688444 & 5.5119 & 4.3441 & TRN & & \\
\hline CHEMBL1332450 & 688444 & 5.9108 & 6.193 & TRN & & \\
\hline CHEMBL1493512 & 688444 & 5.1898 & 4.0085 & TRN & & \\
\hline CHEMBL1389295 & 688444 & 2.7959 & 3.6485 & TRN & & \\
\hline CHEMBL1574024 & 688444 & 2.8239 & 5.3478 & TRN & & \\
\hline CHEMBL1422542 & 688444 & 2.8239 & 3.6647 & TRN & & \\
\hline CHEMBL1470587 & 688444 & 5.5114 & 5.0056 & TRN & & \\
\hline CHEMBL1411342 & 688444 & 2.7959 & 4.0802 & TRN & & \\
\hline CHEMBL602718 & 688444 & 6.0004 & 6.1229 & TRN & & \\
\hline CHEMBL1370871 & 688444 & 2.7959 & 4.0777 & TRN & & \\
\hline CHEMBL530499 & 688444 & 6.1373 & 6.4092 & TRN & & \\
\hline
\end{tabular}




\begin{tabular}{|c|c|c|c|c|c|c|}
\hline & & \multicolumn{5}{|c|}{ Supplemental Table s2.txt } \\
\hline CHEMBL1540525 & 688444 & 4.9741 & 5.6542 & TRN & & \\
\hline CHEMBL3191233 & 688444 & 2.7959 & 4.2664 & TRN & & \\
\hline CHEMBL1581275 & 688444 & 5.2087 & 4.1158 & TRN & & \\
\hline CHEMBL 3189845 & 688444 & \multicolumn{3}{|c|}{6.1579999999999995} & 5.6084 & TRN \\
\hline CHEMBL1380406 & 688444 & 5.7203 & 5.3671 & TRN & & \\
\hline CHEMBL3392051 & 688444 & 6.8697 & 5.6817 & TST & & \\
\hline CHEMBL1483964 & 688444 & 7.9208 & 5.1222 & TRN & & \\
\hline CHEMBL1597174 & 688444 & 5.5064 & 5.275 & TRN & & \\
\hline CHEMBL 2028186 & 688444 & 5.1237 & 4.5368 & TST & & \\
\hline CHEMBL1330453 & 688444 & 6.1599 & 5.5984 & TRN & & \\
\hline CHEMBL1385558 & 688444 & 6.0665 & 6.0837 & TRN & & \\
\hline CHEMBL1499914 & 688444 & 5.0684 & 4.5234 & TRN & & \\
\hline CHEMBL1390492 & 688444 & 6.1524 & 5.5459 & TRN & & \\
\hline CHEMBL1421997 & 688444 & 2.8239 & 3.9379 & TRN & & \\
\hline CHEMBL1302439 & 688444 & 5.7809 & 5.4979 & TRN & & \\
\hline CHEMBL1609663 & 688444 & \multicolumn{3}{|c|}{6.382000000000001} & 5.5926 & TRN \\
\hline CHEMBL1392963 & 688444 & 2.7959 & 5.6735 & TRN & & \\
\hline CHEMBL537692 & 688444 & 2.8239 & 3.9509 & TRN & & \\
\hline CHEMBL1362788 & 688444 & 6.1273 & 5.649 & TRN & & \\
\hline CHEMBL1505060 & 688444 & 4.9039 & 4.2019 & TRN & & \\
\hline CHEMBL1313101 & 688444 & 5.9462 & 5.2338 & TRN & & \\
\hline CHEMBL1242180 & 688444 & 6.4318 & 6.874 & TRN & & \\
\hline CHEMBL1420064 & 688444 & 6.2048 & 5.7336 & TRN & & \\
\hline CHEMBL1338986 & 688444 & 2.7959 & 3.7591 & TRN & & \\
\hline CHEMBL1375251 & 688444 & 5.7275 & 5.3617 & TRN & & \\
\hline CHEMBL1583911 & 688444 & 2.8239 & 5.1988 & TRN & & \\
\hline CHEMBL1550278 & 688444 & 6.2175 & \multicolumn{3}{|c|}{5.7170000000000005} & TRN \\
\hline CHEMBL3145366 & 688444 & 6.025 & 5.0889 & TRN & & \\
\hline CHEMBL1470382 & 688444 & 6.2343 & 5.9831 & TRN & & \\
\hline CHEMBL1328184 & 688444 & 5.9606 & 5.9765 & TRN & & \\
\hline CHEMBL1438619 & 688444 & 2.8239 & 4.2826 & TRN & & \\
\hline CHEMBL1300301 & 688444 & 4.8571 & 4.7796 & TRN & & \\
\hline CHEMBL1519338 & 688444 & 4.7928 & 4.3657 & TRN & & \\
\hline CHEMBL1557142 & 688444 & 6.4841 & 5.6381 & TRN & & \\
\hline CHEMBL3145245 & 688444 & 5.1807 & 5.1312 & TRN & & \\
\hline CHEMBL1377849 & 688444 & 7.9208 & 5.9128 & TRN & & \\
\hline CHEMBL3191022 & 688444 & 6.0048 & 5.41700 & 0000000001 & & TRN \\
\hline CHEMBL1404792 & 688444 & 7.9208 & 7.4648 & TRN & & \\
\hline CHEMBL1613178 & 688444 & 2.7959 & 3.9912 & TST & & \\
\hline CHEMBL1433075 & 688444 & 5.8551 & 5.8227 & TST & & \\
\hline CHEMBL1790008 & 688444 & 6.6478 & 6.1184 & TST & & \\
\hline CHEMBL3192541 & 688444 & \multicolumn{3}{|c|}{5.5729999999999995} & 4.2893 & TRN \\
\hline CHEMBL1388803 & 688444 & 5.803 & 5.2057 & TRN & & \\
\hline CHEMBL1595820 & 688444 & 6.7144 & 6.407 & TRN & & \\
\hline CHEMBL1420684 & 688444 & 5.4821 & 5.1807 & TST & & \\
\hline CHEMBL1455850 & 688444 & 2.8239 & 4.0998 & TRN & & \\
\hline CHEMBL1322595 & 688444 & 4.787 & 3.9932 & TRN & & \\
\hline CHEMBL1441218 & 688444 & 6.4237 & 5.0699 & TRN & & \\
\hline
\end{tabular}




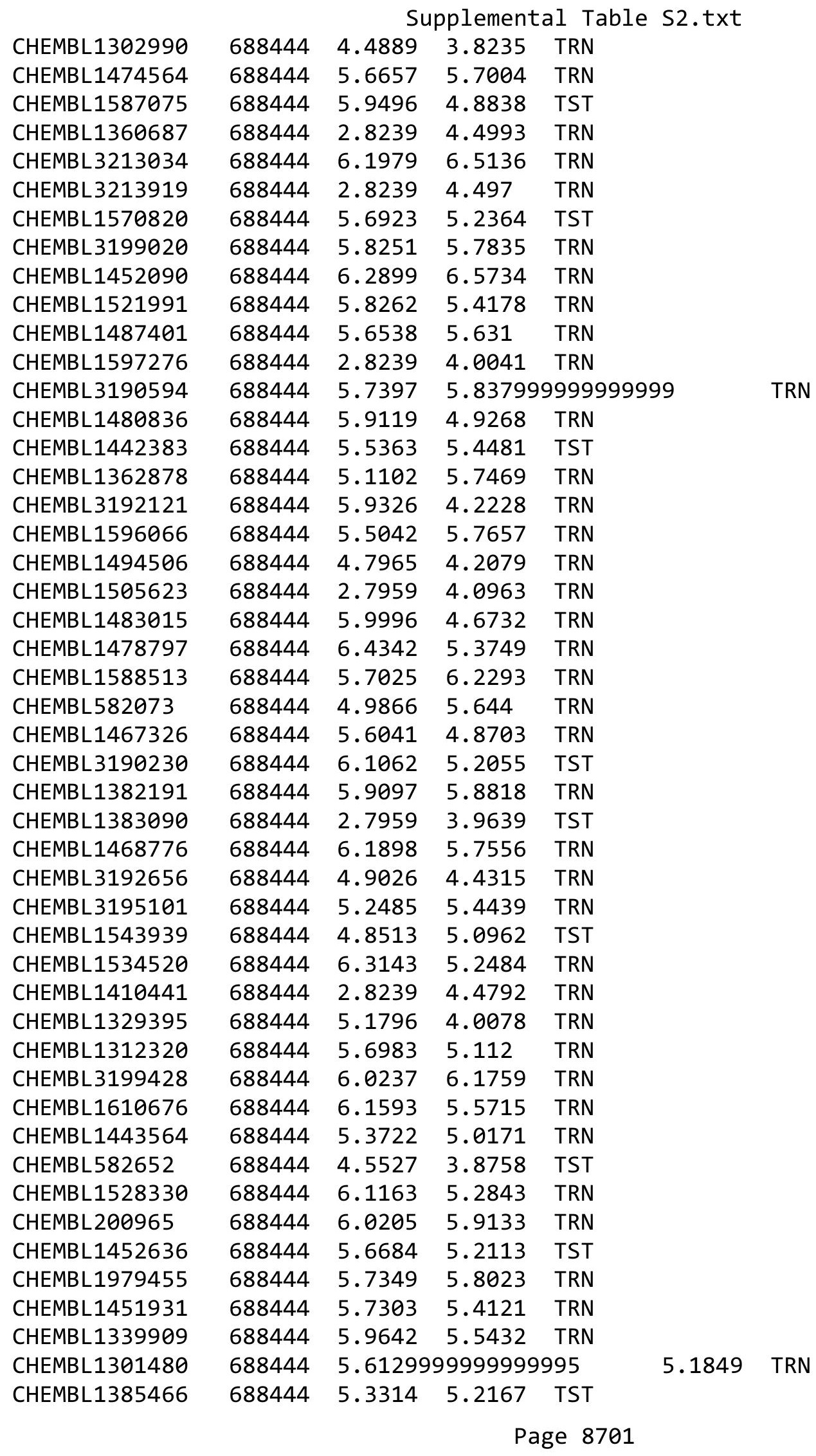




\begin{tabular}{|c|c|c|c|c|c|}
\hline & & \multicolumn{4}{|c|}{ Supplemental Table S2.txt } \\
\hline CHEMBL1608990 & 688444 & 5.0019 & 5.1939 & TRN & \\
\hline CHEMBL1463257 & 688444 & 4.9778 & 3.7951 & TST & \\
\hline CHEMBL3197343 & 688444 & 6.0931 & 5.825 & TRN & \\
\hline CHEMBL1519744 & 688444 & 2.7959 & 5.204 & TRN & \\
\hline CHEMBL1500188 & 688444 & 6.7144 & 6.4987 & TRN & \\
\hline CHEMBL1971033 & 688444 & 5.8116 & 5.6311 & TRN & \\
\hline CHEMBL1342141 & 688444 & 2.8239 & 5.192 & TRN & \\
\hline CHEMBL599255 & 688444 & 6.0315 & 6.1342 & TRN & \\
\hline CHEMBL1318943 & 688444 & 6.1249 & 5.3812 & TST & \\
\hline CHEMBL1483724 & 688444 & 2.8239 & 4.8229 & TRN & \\
\hline CHEMBL1366055 & 688444 & 2.8239 & 6.0648 & TRN & \\
\hline CHEMBL1378479 & 688444 & 6.6383 & 5.4658 & TST & \\
\hline CHEMBL598263 & 688444 & 5.8294 & 5.4126 & TRN & \\
\hline CHEMBL1469827 & 688444 & 5.466 & 5.9358 & TRN & \\
\hline CHEMBL580727 & 688444 & 6.1035 & 6.2769 & TRN & \\
\hline CHEMBL1348448 & 688444 & 5.8041 & 5.6908 & TRN & \\
\hline CHEMBL1560221 & 688444 & 6.3215 & 5.0742 & TRN & \\
\hline CHEMBL1508474 & 688444 & 5.9863 & 5.6041 & TRN & \\
\hline CHEMBL1520111 & 688444 & 5.7296 & 4.9281 & TRN & \\
\hline CHEMBL1486311 & 688444 & 2.8239 & 4.1754 & TRN & \\
\hline CHEMBL1348654 & 688444 & 5.9935 & 5.4349 & TRN & \\
\hline CHEMBL3190095 & 688444 & 5.8038 & 5.3903 & TST & \\
\hline CHEMBL3212148 & 688444 & 2.7959 & 4.0981 & TRN & \\
\hline CHEMBL1335030 & 688444 & 6.06 & 6.1973 & TRN & \\
\hline CHEMBL313163 & 688444 & 5.54700 & 000000000 & 5.2993 & TST \\
\hline CHEMBL3195271 & 688444 & 5.9382 & 4.403000 & 00000000005 & TRN \\
\hline CHEMBL1309987 & 688444 & 5.0344 & 4.1702 & TST & \\
\hline CHEMBL1518873 & 688444 & 7.9208 & 6.1186 & TST & \\
\hline CHEMBL1322883 & 688444 & 4.9607 & 5.0696 & TRN & \\
\hline CHEMBL1346781 & 688444 & 4.6648 & 3.7969 & TST & \\
\hline CHEMBL1548429 & 688444 & 5.9219 & 5.545 & TST & \\
\hline CHEMBL1393007 & 688444 & 5.791 & 5.3174 & TRN & \\
\hline CHEMBL1548492 & 688444 & 6.2027 & 6.4969 & TRN & \\
\hline CHEMBL3210143 & 688444 & 2.8239 & 4.1276 & TRN & \\
\hline CHEMBL1993613 & 688444 & 4.8641 & 5.4025 & TRN & \\
\hline CHEMBL1456701 & 688444 & 2.7959 & 5.54899 & 99999999995 & וد \\
\hline CHEMBL1462283 & 688444 & 7.9208 & 5.0109 & TRN & \\
\hline CHEMBL3198503 & 688444 & 5.8611 & 5.9286 & TRN & \\
\hline CHEMBL1355133 & 688444 & 5.6517 & 5.5218 & TRN & \\
\hline CHEMBL1522592 & 688444 & 4.6057 & 4.1915 & TRN & \\
\hline CHEMBL1353862 & 688444 & 2.8239 & 4.4441 & TRN & \\
\hline CHEMBL 1405070 & 688444 & 2.7959 & 4.0801 & TRN & \\
\hline CHEMBL579322 & 688444 & 5.8502 & 5.7618 & TRN & \\
\hline CHEMBL3197978 & 688444 & 6.301 & 5.8311 & TRN & \\
\hline CHEMBL1388882 & 688444 & 2.8239 & 4.0229 & TST & \\
\hline CHEMBL3195273 & 688444 & 5.9539 & 5.466 & TRN & \\
\hline CHEMBL3211846 & 688444 & 6.3655 & 5.3934 & TRN & \\
\hline CHEMBL1574748 & 688444 & 5.9212 & 4.1074 & TRN & \\
\hline
\end{tabular}


Supplemental Table S2.txt

\begin{tabular}{|c|c|c|c|c|c|}
\hline CHEMBL1346226 & 688444 & 6.2774 & 5.1743 & TRN & \\
\hline CHEMBL1585777 & 688444 & 6.0794 & 5.8316 & TRN & \\
\hline CHEMBL1310176 & 688444 & 5.1097 & 4.9969 & TRN & \\
\hline CHEMBL1375220 & 688444 & 4.6123 & 4.0326 & TRN & \\
\hline CHEMBL1453929 & 688444 & 5.9031 & 5.4639 & TRN & \\
\hline CHEMBL36654 & 688444 & 2.8239 & 4.0151 & TST & \\
\hline CHEMBL1413859 & 688444 & 5.1767 & 4.5839 & TRN & \\
\hline CHEMBL1425019 & 688444 & 5.4656 & 5.2669 & TRN & \\
\hline CHEMBL1587766 & 688444 & 6.066 & 4.0923 & TRN & \\
\hline CHEMBL1393266 & 688444 & 5.1223 & 4.8558 & TRN & \\
\hline CHEMBL1349793 & 688444 & 5.0259 & 5.2982 & TRN & \\
\hline CHEMBL1578670 & 688444 & 2.7959 & 5.0154 & TRN & \\
\hline CHEMBL1503392 & 688444 & 5.9594 & 4.9454 & TRN & \\
\hline CHEMBL1349378 & 688444 & 2.7959 & 4.407 & TRN & \\
\hline CHEMBL1580472 & 688444 & 7.9208 & 5.9531 & TRN & \\
\hline CHEMBL1416096 & 688444 & 5.8557 & 5.7125 & TRN & \\
\hline CHEMBL1392455 & 688444 & 7.9208 & 6.0232 & TST & \\
\hline CHEMBL3189582 & 688444 & 6.0182 & 5.091 & TRN & \\
\hline CHEMBL1408577 & 688444 & 5.9101 & 4.4104 & TRN & \\
\hline CHEMBL1576754 & 688444 & 5.2372 & 4.1875 & TRN & \\
\hline CHEMBL3195036 & 688444 & 6.1593 & 6.0474 & TRN & \\
\hline CHEMBL1318693 & 688444 & 6.0325 & 6.2264 & TRN & \\
\hline CHEMBL3194042 & 688444 & 5.1067 & 4.228 & TRN & \\
\hline CHEMBL1584387 & 688444 & 5.5547 & 5.3966 & TRN & \\
\hline CHEMBL1326221 & 688444 & 2.7959 & 3.6485 & TRN & \\
\hline CHEMBL1488035 & 688444 & 6.05399 & 99999999 & 5.7869 & TRN \\
\hline CHEMBL1309890 & 688444 & 6.6968 & 6.5798 & TRN & \\
\hline CHEMBL1328054 & 688444 & 2.7959 & 5.1229 & TST & \\
\hline CHEMBL1442155 & 688444 & 5.1178 & 5.5758 & TRN & \\
\hline CHEMBL3190697 & 688444 & 5.9884 & 5.6156 & TRN & \\
\hline CHEMBL1578482 & 688444 & 6.2749 & 6.5139 & TRN & \\
\hline CHEMBL1429917 & 688444 & 5.7865 & 5.2652 & TRN & \\
\hline CHEMBL1457320 & 688444 & 2.8239 & 3.6856 & TST & \\
\hline CHEMBL3190558 & 688444 & 5.477 & 5.2214 & TRN & \\
\hline CHEMBL1458812 & 688444 & 4.6222 & 4.876 & TST & \\
\hline CHEMBL3198836 & 688444 & 5.3917 & 5.5533 & TRN & \\
\hline CHEMBL1420309 & 688444 & 2.7959 & 4.2086 & TRN & \\
\hline CHEMBL193627 & 688444 & 7.9208 & 6.6939 & TRN & \\
\hline CHEMBL1463847 & 688444 & 6.1979 & 5.1224 & TST & \\
\hline CHEMBL1583801 & 688444 & 6.1931 & 4.4158 & TRN & \\
\hline CHEMBL1336675 & 688444 & 5.5916 & 5.6331 & TRN & \\
\hline CHEMBL1486894 & 688444 & 5.4391 & 4.0717 & TRN & \\
\hline CHEMBL453974 & 688444 & 6.6308 & 6.367999 & 7999999999 & TST \\
\hline CHEMBL1529188 & 688444 & 6.4711 & 4.3146 & TRN & \\
\hline CHEMBL1447974 & 688444 & 5.0583 & 4.5864 & TRN & \\
\hline CHEMBL3144960 & 688444 & 5.0742 & 4.784 & TRN & \\
\hline CHEMBL1325209 & 688444 & 4.1217 & 4.0533 & TST & \\
\hline CHEMBL1503006 & 688444 & 6.1267 & 6.3683 & TRN & \\
\hline
\end{tabular}

Page 8703 


\begin{tabular}{|c|c|c|c|c|c|}
\hline \multirow[b]{2}{*}{ CHEMBL1351838 } & \multicolumn{5}{|c|}{ Supplemental Table S2.txt } \\
\hline & 688444 & 2.7959 & 4.3229 & TRN & \\
\hline CHEMBL1379187 & 688444 & 5.9223 & 5.4171 & TRN & \\
\hline CHEMBL1338502 & 688444 & 2.8239 & 4.7069 & TRN & \\
\hline CHEMBL1562664 & 688444 & 6.1158 & 6.1982 & TST & \\
\hline CHEMBL1504407 & 688444 & 5.3769 & 5.4394 & TST & \\
\hline CHEMBL1461196 & 688444 & 2.8239 & 5.6264 & TRN & \\
\hline CHEMBL 3199324 & 688444 & 5.8401 & 4.4017 & TRN & \\
\hline CHEMBL1447186 & 688444 & 5.5621 & 4.6985 & TRN & \\
\hline CHEMBL87285 & 688444 & 6.0 & 5.5695 & TST & \\
\hline CHEMBL1606978 & 688444 & 5.5959 & 5.7483 & TRN & \\
\hline CHEMBL1372534 & 688444 & 5.401 & 5.1857 & TST & \\
\hline CHEMBL1365796 & 688444 & 5.7846 & 5.16299 & 9999999999 & TRN \\
\hline CHEMBL1443697 & 688444 & 2.8239 & 3.81 & TRN & \\
\hline CHEMBL1310309 & 688444 & 2.7959 & 3.9555 & TRN & \\
\hline CHEMBL1366561 & 688444 & 4.9657 & 4.1058 & TRN & \\
\hline CHEMBL1511594 & 688444 & 2.8239 & 3.792 & TRN & \\
\hline CHEMBL1362036 & 688444 & 5.8271 & 5.0653 & TRN & \\
\hline CHEMBL1460705 & 688444 & 6.3125 & 5.8262 & TRN & \\
\hline CHEMBL1470712 & 688444 & 4.9056 & 4.5507 & TRN & \\
\hline CHEMBL1455523 & 688444 & 6.1284 & 5.2501 & TRN & \\
\hline CHEMBL1986418 & 688444 & 6.4179 & 6.2708 & TRN & \\
\hline CHEMBL 2095095 & 688444 & 5.4756 & 5.9577 & TRN & \\
\hline CHEMBL1452795 & 688444 & 2.8239 & 5.896 & TST & \\
\hline CHEMBL3195031 & 688444 & 2.7959 & 4.23300 & 00000000005 & TRN \\
\hline CHEMBL1417569 & 688444 & 2.8239 & 4.8707 & TST & \\
\hline CHEMBL1343568 & 688444 & 5.6336 & 4.3358 & TRN & \\
\hline CHEMBL1987742 & 688444 & 4.9246 & 4.2977 & TST & \\
\hline CHEMBL1578007 & 688444 & 2.8239 & 4.0537 & TST & \\
\hline CHEMBL1463786 & 688444 & 6.2048 & 5.8292 & TRN & \\
\hline CHEMBL1545223 & 688444 & 4.7203 & 4.8556 & TRN & \\
\hline CHEMBL1389225 & 688444 & 5.1892 & 5.2191 & TST & \\
\hline CHEMBL1430488 & 688444 & 2.7959 & 3.8871 & TRN & \\
\hline CHEMBL1364999 & 688444 & 6.71 & 6.2398 & TRN & \\
\hline CHEMBL 2006840 & 688444 & 7.9208 & 6.1383 & TRN & \\
\hline CHEMBL1391743 & 688444 & 5.76399 & 99999999 & 5.5891 & TRN \\
\hline CHEMBL3193869 & 688444 & 5.1326 & 5.3368 & TRN & \\
\hline CHEMBL1469579 & 688444 & 5.5662 & 5.8403 & TRN & \\
\hline CHEMBL1499233 & 688444 & 6.2041 & 6.3329 & TRN & \\
\hline CHEMBL1514530 & 688444 & 6.2993 & 6.6463 & TRN & \\
\hline CHEMBL1406031 & 688444 & 5.9582 & 4.8811 & TST & \\
\hline CHEMBL1328504 & 688444 & 5.4065 & 5.4201 & TRN & \\
\hline CHEMBL1998184 & 688444 & 5.2548 & 5.0501 & TRN & \\
\hline CHEMBL1525081 & 688444 & 5.8551 & 5.3398 & TRN & \\
\hline CHEMBL1327172 & 688444 & 5.8327 & 6.1762 & TRN & \\
\hline CHEMBL1304603 & 688444 & 5.6419 & 5.2278 & TRN & \\
\hline CHEMBL1386508 & 688444 & 2.7959 & 5.2898 & TRN & \\
\hline CHEMBL1582111 & 688444 & 5.1948 & 4.5119 & TRN & \\
\hline CHEMBL1387894 & 688444 & 4.5247 & 3.8364 & TRN & \\
\hline
\end{tabular}




\begin{tabular}{|c|c|c|c|c|c|}
\hline & & \multicolumn{4}{|c|}{ Supplemental Table S2.txt } \\
\hline CHEMBL1989683 & 688444 & 2.8239 & 4.1739 & TRN & \\
\hline CHEMBL1385356 & 688444 & 2.7959 & 5.5349 & TST & \\
\hline CHEMBL1468024 & 688444 & 5.2672 & 5.2865 & TRN & \\
\hline CHEMBL1445436 & 688444 & 2.8239 & 4.4006 & TRN & \\
\hline CHEMBL1409333 & 688444 & 5.3337 & 5.32799 & 9999999999 & TRN \\
\hline CHEMBL1533308 & 688444 & 5.4239 & 5.3603 & TRN & \\
\hline CHEMBL1587027 & 688444 & 5.3271 & 4.4092 & TRN & \\
\hline CHEMBL1519450 & 688444 & 6.0958 & 6.1248 & TRN & \\
\hline CHEMBL 1317657 & 688444 & 6.341 & 5.5103 & TRN & \\
\hline CHEMBL1467782 & 688444 & 4.4598 & 3.9243 & TRN & \\
\hline CHEMBL588804 & 688444 & 6.2233 & 6.2543 & TRN & \\
\hline CHEMBL1464485 & 688444 & 6.4012 & 5.785 & TRN & \\
\hline CHEMBL1306283 & 688444 & 6.0947 & 6.3032 & TRN & \\
\hline CHEMBL1605988 & 688444 & 5.7245 & 5.0463 & TRN & \\
\hline CHEMBL1565403 & 688444 & 5.5815 & 5.3835 & TRN & \\
\hline CHEMBL3209453 & 688444 & 5.1852 & 5.0714 & TST & \\
\hline CHEMBL1535361 & 688444 & 5.6128 & 5.5925 & TRN & \\
\hline CHEMBL1492376 & 688444 & 4.9097 & 4.6131 & TRN & \\
\hline CHEMBL1969712 & 688444 & 5.4043 & 4.3368 & TRN & \\
\hline CHEMBL1331790 & 688444 & 5.8794 & 5.6421 & TRN & \\
\hline CHEMBL478791 & 688444 & 5.4675 & 4.4138 & TRN & \\
\hline CHEMBL1485579 & 688444 & 5.4949 & 5.2218 & TRN & \\
\hline CHEMBL1604425 & 688444 & 6.0969 & 5.0095 & TRN & \\
\hline CHEMBL1427734 & 688444 & 5.862 & 4.0471 & TRN & \\
\hline CHEMBL1377176 & 688444 & 2.7959 & 5.3688 & TST & \\
\hline CHEMBL1306983 & 688444 & 5.4309 & 5.4878 & TRN & \\
\hline CHEMBL1448700 & 688444 & 2.7959 & 5.689 & TRN & \\
\hline CHEMBL1453521 & 688444 & 5.8989 & 4.8039 & TRN & \\
\hline CHEMBL1505875 & 688444 & 5.7062 & 5.0853 & TRN & \\
\hline CHEMBL1457949 & 688444 & 5.4531 & 4.8714 & TRN & \\
\hline CHEMBL1493533 & 688444 & 2.7959 & 4.0561 & TRN & \\
\hline CHEMBL1459813 & 688444 & 5.2252 & 5.5626 & TRN & \\
\hline CHEMBL1418460 & 688444 & 4.9603 & 4.91 & TST & \\
\hline CHEMBL1988042 & 688444 & 6.6162 & 6.1685 & TRN & \\
\hline CHEMBL1522211 & 688444 & 6.0283 & 6.2099 & TRN & \\
\hline CHEMBL1585075 & 688444 & 5.7645 & 3.9699 & TRN & \\
\hline CHEMBL1517325 & 688444 & 5.76 & 6.4012 & TRN & \\
\hline CHEMBL1387847 & 688444 & 2.7959 & 3.8435 & TRN & \\
\hline CHEMBL1324371 & 688444 & 5.4473 & 5.6808 & TRN & \\
\hline CHEMBL1373577 & 688444 & 6.3458 & 5.7202 & TRN & \\
\hline CHEMBL1426693 & 688444 & 6.0214 & 5.1888 & TRN & \\
\hline CHEMBL1460270 & 688444 & 2.8239 & 4.0271 & TRN & \\
\hline CHEMBL1985667 & 688444 & 5.5611 & 5.7 & TRN & \\
\hline CHEMBL1456703 & 688444 & 5.4161 & 3.9562 & TRN & \\
\hline CHEMBL1369209 & 688444 & 2.8239 & 4.4452 & TRN & \\
\hline CHEMBL1524515 & 688444 & 5.2842 & 4.4773 & TRN & \\
\hline CHEMBL3194161 & 688444 & 2.7959 & 4.3572 & TRN & \\
\hline CHEMBL 22062 & 688444 & 5.2232 & 5.2876 & TRN & \\
\hline
\end{tabular}


Supplemental Table S2.txt

\begin{tabular}{|c|c|c|c|c|}
\hline 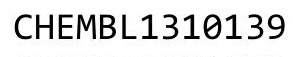 & & & & \\
\hline HEMBL1320059 & 88444 & 8239 & 1768 & \\
\hline AEMBL1443478 & 8444 & 52 & 17 & \\
\hline AEMBL1312275 & 444 & & & \\
\hline AEMBL1976839 & 3444 & & & \\
\hline AEMBL1599674 & 88444 & 076 & 3491 & \\
\hline AEMBL1563323 & 88444 & 074 & 3902 & \\
\hline HEMBL3197825 & 88444 & & 2851 & \\
\hline AEMBL1308332 & 88444 & & 472 & \\
\hline AEMBL1444553 & & & 69 & \\
\hline AEMBL585591 & 688444 & & 9586 & \\
\hline AEMBL1337045 & 688444 & & 253 & \\
\hline AEMBL1376224 & 588444 & & & \\
\hline IEMBL147 & 44 & & 53 & \\
\hline HEMBL1578908 & & & & \\
\hline AEMBL1504321 & 688444 & & 78 & \\
\hline AEMBL1544131 & & & & \\
\hline HEMBL1342332 & 688444 & & 93 & \\
\hline HEMBL 240329 & 44 & & & \\
\hline AEMBL1388595 & & & & \\
\hline AEMBL1594485 & & & 87 & \\
\hline AEMBL1313174 & & & & \\
\hline AEMBL1598581 & 68 & & & \\
\hline JEMBL14 & 44 & & & \\
\hline HEMBL 19 & & & & \\
\hline AEMBL1511029 & & & & \\
\hline IEMBL1502352 & & & & \\
\hline IEMBL13132ع & & & 22 & \\
\hline HEM & & & & \\
\hline 132 & & & & \\
\hline AEMBL1409296 & & & & \\
\hline HEMBL1500854 & & & & \\
\hline $3 \mathrm{~L} 31$ & & & & \\
\hline 9 & & & 71 & \\
\hline AEMBL1524 & & & & ST \\
\hline AEMBL1594897 & & & & 「R』 \\
\hline AEMBL1602503 & & & 24 & $F$ \\
\hline & & & 49 & $S$ \\
\hline 2 & & & 43 & RN \\
\hline HEMBL1341726 & & & & RN \\
\hline AEMBL1419066 & & & 85 & $\mathrm{TR}$ \\
\hline HEMBL581872 & & & & TS \\
\hline HEMBL1594242 & & & & \\
\hline CHEMBL1442500 & & & & $1 \mathrm{~s}$ \\
\hline AEMBL1392617 & & & 4.1182 & $\mathrm{R}$ \\
\hline AEMBL1334044 & 68 & 4.887 & 89 & TR \\
\hline 305 & & 2.8239 & 5.1604 & S \\
\hline & & & & \\
\hline
\end{tabular}

Page 8706

4.3294 TRN 


\begin{tabular}{|c|c|c|c|c|c|}
\hline \multicolumn{6}{|c|}{ Supplemental Table S2.txt } \\
\hline CHEMBL1431928 & 688444 & 5.5627 & 5.2491 & TRN & \\
\hline CHEMBL1605956 & 688444 & 6.0487 & 5.3741 & TRN & \\
\hline CHEMBL1347084 & 688444 & 6.0991 & 5.0359 & TRN & \\
\hline CHEMBL 3189255 & 688444 & 5.6615 & 5.1659 & TRN & \\
\hline CHEMBL1299925 & 688444 & 5.1161 & 3.9633 & TRN & \\
\hline CHEMBL1970872 & 688444 & 5.5547 & 5.5498 & TRN & \\
\hline CHEMBL1300319 & 688444 & 6.3757 & 5.5788 & TRN & \\
\hline CHEMBL1547450 & 688444 & 5.0108 & 5.0356 & TRN & \\
\hline CHEMBL591361 & 688444 & 6.1169 & 6.3773 & TRN & \\
\hline CHEMBL1381627 & 688444 & 5.3575 & 4.09399 & 9999999999 & TRN \\
\hline CHEMBL586135 & 688444 & 7.9208 & 7.4632 & TRN & \\
\hline CHEMBL1476264 & 688444 & 5.7435 & 6.8965 & TRN & \\
\hline CHEMBL1437579 & 688444 & 5.8545 & 5.901 & TST & \\
\hline CHEMBL 3213942 & 688444 & 2.7959 & 4.2732 & TRN & \\
\hline CHEMBL199868 & 688444 & 5.6164 & 5.8083 & TRN & \\
\hline CHEMBL1995280 & 688444 & 2.7959 & 4.8689 & TRN & \\
\hline CHEMBL3197232 & 688444 & 5.2127 & 5.2929 & TRN & \\
\hline CHEMBL1364071 & 688444 & 5.8262 & 5.1511 & TRN & \\
\hline CHEMBL1416601 & 688444 & 5.9462 & 5.5605 & TRN & \\
\hline CHEMBL1440514 & 688444 & 5.9397 & 5.665 & TRN & \\
\hline CHEMBL1416961 & 688444 & 5.9801 & 5.1632 & TRN & \\
\hline CHEMBL1360400 & 688444 & 5.6702 & 4.9474 & TRN & \\
\hline CHEMBL1426078 & 688444 & 5.6142 & 5.29700 & 3000000001 & TST \\
\hline CHEMBL1580695 & 688444 & 5.5974 & 5.1149 & TRN & \\
\hline CHEMBL1481746 & 688444 & 5.2774 & 4.1892 & TST & \\
\hline CHEMBL1442114 & 688444 & 5.7178 & 5.3262 & TRN & \\
\hline CHEMBL1469885 & 688444 & 5.0494 & 5.5239 & TRN & \\
\hline CHEMBL1444424 & 688444 & 2.8239 & 5.0326 & TRN & \\
\hline CHEMBL1310989 & 688444 & 2.8239 & 3.8263 & TRN & \\
\hline CHEMBL1327278 & 688444 & 2.7959 & 4.0434 & TRN & \\
\hline CHEMBL1603092 & 688444 & 4.9776 & 5.5553 & TRN & \\
\hline CHEMBL1346637 & 688444 & 6.1911 & 4.1348 & TRN & \\
\hline CHEMBL1422799 & 688444 & 4.6507 & 5.0228 & TRN & \\
\hline CHEMBL1429789 & 688444 & 5.359 & 4.2949 & TRN & \\
\hline CHEMBL1978354 & 688444 & 5.2029 & 5.2778 & TRN & \\
\hline CHEMBL1523281 & 688444 & 2.8239 & 3.8978 & TRN & \\
\hline CHEMBL1300080 & 688444 & 7.9208 & 5.9342 & TRN & \\
\hline CHEMBL254576 & 688444 & 5.7552 & 4.385 & TST & \\
\hline CHEMBL1483387 & 688444 & 2.8239 & 3.9804 & TRN & \\
\hline CHEMBL1497750 & 688444 & 2.7959 & 5.5471 & TRN & \\
\hline CHEMBL1349173 & 688444 & 2.8239 & 4.708 & TRN & \\
\hline CHEMBL1602088 & 688444 & 5.9496 & 5.9007 & TRN & \\
\hline CHEMBL1320542 & 688444 & 5.7395 & 5.2765 & TRN & \\
\hline CHEMBL1369698 & 688444 & 5.1692 & 5.2925 & TRN & \\
\hline CHEMBL1468055 & 688444 & 5.5782 & 3.9735 & TRN & \\
\hline CHEMBL1446034 & 688444 & 6.6345 & 5.4429 & TRN & \\
\hline CHEMBL1471627 & 688444 & 2.8239 & 3.9434 & TRN & \\
\hline CHEMBL1977301 & 688444 & 6.0391 & 5.8116 & TRN & \\
\hline
\end{tabular}


Supplemental Table S2.txt

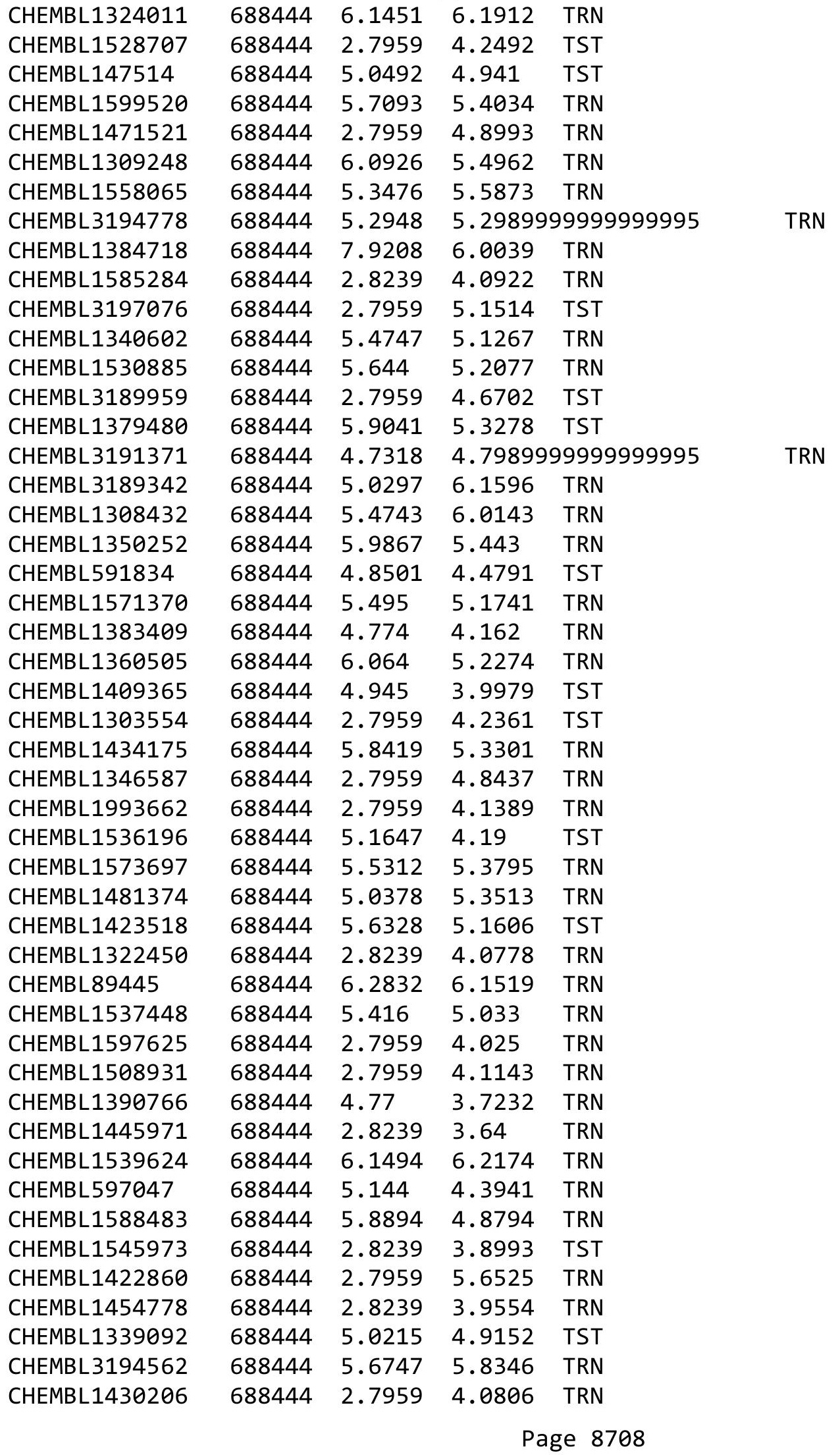




\begin{tabular}{|c|c|c|c|c|c|c|}
\hline CHEMBL1450261 & 688444 & \multicolumn{4}{|c|}{ Supplemental Table s2.txt } & TRN \\
\hline CHEMBL1400950 & 688444 & 2.7959 & 4.1728 & TRN & & \\
\hline CHEMBL3193098 & 688444 & 6.6234 & 6.3713 & TRN & & \\
\hline CHEMBL1452711 & 688444 & 5.6637 & 5.78799 & 999999999؟ & 99 & TRN \\
\hline CHEMBL1403955 & 688444 & 5.2871 & 4.2109 & TRN & & \\
\hline CHEMBL1601133 & 688444 & 5.7131 & 6.0818 & TST & & \\
\hline CHEMBL1373038 & 688444 & 2.8239 & 3.8431 & TST & & \\
\hline CHEMBL1535533 & 688444 & 4.8951 & 3.968 & TST & & \\
\hline CHEMBL1602841 & 688444 & 5.8199 & 5.1883 & TST & & \\
\hline CHEMBL1390521 & 688444 & 5.0635 & 4.3028 & TST & & \\
\hline CHEMBL1350780 & 688444 & 6.3665 & 6.2815 & TST & & \\
\hline CHEMBL1589420 & 688444 & 2.8239 & 3.8454 & TST & & \\
\hline CHEMBL1545702 & 688444 & 6.1858 & 5.9004 & TST & & \\
\hline CHEMBL1405204 & 688444 & 6.4179 & 5.5239 & TST & & \\
\hline CHEMBL1335817 & 688444 & 2.8239 & 4.9635 & TST & & \\
\hline CHEMBL1352025 & 688444 & 6.153 & 5.6522 & TST & & \\
\hline CHEMBL1301892 & 688444 & 5.6003 & 3.989 & TST & & \\
\hline CHEMBL1373678 & 688444 & 6.7144 & 5.2402 & TST & & \\
\hline CHEMBL1561540 & 688444 & 5.4833 & 5.3567 & TST & & \\
\hline CHEMBL1598391 & 688444 & 2.7959 & 4.8862 & TST & & \\
\hline CHEMBL1455396 & 688444 & 5.7361 & 5.1575 & TST & & \\
\hline CHEMBL1388684 & 688444 & 5.6297 & 5.0556 & TST & & \\
\hline CHEMBL1326194 & 688444 & 2.7959 & 5.2222 & TST & & \\
\hline CHEMBL1458786 & 688444 & 2.8239 & 5.3129 & TST & & \\
\hline CHEMBL1342295 & 688444 & 2.7959 & 3.8638 & TST & & \\
\hline CHEMBL585502 & 688444 & 6.8268 & 7.2182 & TST & & \\
\hline CHEMBL1369060 & 688444 & 2.7959 & 3.924 & TST & & \\
\hline CHEMBL334707 & 688444 & 6.5361 & 6.7804 & TST & & \\
\hline CHEMBL1588660 & 688444 & 6.0057 & 5.8112 & TST & & \\
\hline CHEMBL1453766 & 688444 & 2.8239 & 3.8932 & TST & & \\
\hline CHEMBL1536073 & 688444 & 5.4968 & 5.6497 & TST & & \\
\hline CHEMBL1610563 & 688444 & 6.1296 & 5.2512 & TST & & \\
\hline CHEMBL602218 & 688444 & 5.8438 & 6.0566 & TST & & \\
\hline CHEMBL1466179 & 688444 & 6.5272 & 5.4446 & TST & & \\
\hline CHEMBL3198912 & 688444 & 6.0482 & 5.6802 & TST & & \\
\hline CHEMBL1347656 & 688444 & 5.6735 & 4.9457 & TST & & \\
\hline CHEMBL1519576 & 688444 & 5.5 & 4.2445 & TST & & \\
\hline CHEMBL1603982 & 688444 & 5.6445 & 5.2372 & TST & & \\
\hline CHEMBL1497325 & 688444 & 6.1261 & 5.0806 & TST & & \\
\hline CHEMBL1350258 & 688444 & 5.66700 & 0000000 & 01 & 5.8774 & \\
\hline CHEMBL1352732 & 688444 & 2.7959 & 4.658 & TST & & \\
\hline CHEMBL3194039 & 688444 & 2.7959 & 4.5209 & TST & & \\
\hline CHEMBL1508647 & 688444 & 5.9901 & 5.6382 & TST & & \\
\hline CHEMBL1450615 & 688444 & 6.1152 & 5.6253 & TST & & \\
\hline CHEMBL 3194368 & 688444 & 2.7959 & 4.1849 & TST & & \\
\hline CHEMBL528181 & 688444 & 5.2872 & 5.2567 & TST & & \\
\hline CHEMBL3193419 & 688444 & 6.1618 & 6.3977 & TST & & \\
\hline CHEMBL1964389 & 688444 & 2.7959 & 4.3104 & TST & & \\
\hline
\end{tabular}




\begin{tabular}{|c|c|c|c|c|c|}
\hline & & \multicolumn{4}{|c|}{ Supplemental Table s2.txt } \\
\hline CHEMBL1601709 & 688444 & 2.7959 & 3.7596 & TST & \\
\hline CHEMBL1393829 & 688444 & 6.062 & 6.2896 & TST & \\
\hline CHEMBL461579 & 688444 & 5.9226 & 6.0598 & TST & \\
\hline CHEMBL1588832 & 688444 & 5.3849 & 5.33 & TST & \\
\hline CHEMBL1422400 & 688444 & 4.8861 & 4.7421 & TST & \\
\hline CHEMBL1558160 & 688444 & 5.1326 & 5.6099 & TST & \\
\hline CHEMBL1492918 & 688444 & 2.7959 & 4.1035 & TST & \\
\hline CHEMBL1387710 & 688444 & 5.721 & 5.7699 & TST & \\
\hline CHEMBL1518827 & 688444 & 5.3684 & 5.2151 & TST & \\
\hline CHEMBL1455776 & 688444 & 2.8239 & 3.9314 & TST & \\
\hline CHEMBL1342833 & 688444 & 2.7959 & 5.9077 & TST & \\
\hline CHEMBL600315 & 688444 & 5.8008 & 5.2795 & TST & \\
\hline CHEMBL1412002 & 688444 & 6.1506 & 6.4512 & TST & \\
\hline CHEMBL1340417 & 688444 & 6.1884 & 5.3241 & TST & \\
\hline CHEMBL1369425 & 688444 & 6.15799 & 99999999 & 5.6088 & TST \\
\hline CHEMBL1380634 & 688444 & 2.8239 & 3.9069 & TST & \\
\hline CHEMBL1503699 & 688444 & 5.6821 & 5.7404 & TST & \\
\hline CHEMBL1595934 & 688444 & 5.574 & 5.7868 & TST & \\
\hline CHEMBL 221190 & 688444 & 5.6552 & 5.159 & TST & \\
\hline CHEMBL3213908 & 688444 & 2.8239 & 4.2414 & TST & \\
\hline CHEMBL1609233 & 688444 & 2.7959 & 4.0603 & TST & \\
\hline CHEMBL1308052 & 688444 & 5.9809 & 6.0178 & TST & \\
\hline CHEMBL1484231 & 688444 & 5.6119 & 5.2848 & TST & \\
\hline CHEMBL560919 & 688444 & 5.5608 & 5.2781 & TST & \\
\hline CHEMBL1348468 & 688444 & 6.3391 & 5.5871 & TST & \\
\hline CHEMBL1319079 & 688444 & 6.0191 & 5.78299 & 99999999995 & ГST \\
\hline CHEMBL1449892 & 688444 & 5.2037 & 4.8859 & TST & \\
\hline CHEMBL1546228 & 688444 & 6.056 & 5.7816 & TST & \\
\hline CHEMBL 1300956 & 688444 & 5.3915 & 5.0971 & TST & \\
\hline CHEMBL1389318 & 688444 & 7.9208 & 5.7976 & TST & \\
\hline CHEMBL1505192 & 688444 & 2.7959 & 7.0798 & TST & \\
\hline CHEMBL1408075 & 688444 & 2.8239 & 5.3842 & TST & \\
\hline CHEMBL3192747 & 688444 & 5.5065 & 4.9003 & TST & \\
\hline CHEMBL1309909 & 688444 & 5.2725 & 5.0734 & TST & \\
\hline CHEMBL3190873 & 688444 & 6.0386 & 5.7252 & TST & \\
\hline CHEMBL1987579 & 688444 & 5.3637 & 5.7292 & TST & \\
\hline CHEMBL1371081 & 688444 & 5.9731 & 5.4109 & TST & \\
\hline CHEMBL1464569 & 688444 & 2.7959 & 4.2001 & TST & \\
\hline CHEMBL585827 & 688444 & 6.1238 & 6.5275 & TST & \\
\hline CHEMBL1338492 & 688444 & 5.8413 & 5.3335 & TST & \\
\hline CHEMBL1329076 & 688444 & 2.8239 & 4.122 & TST & \\
\hline CHEMBL 1453870 & 688444 & 5.2703 & 4.0692 & TST & \\
\hline CHEMBL1433124 & 688444 & 5.1395 & 5.7179 & TST & \\
\hline CHEMBL1370513 & 688444 & 5.8207 & 6.2533 & TST & \\
\hline CHEMBL1392564 & 688444 & 6.1481 & 5.5766 & TST & \\
\hline CHEMBL1374462 & 688444 & 7.9208 & 6.7658 & TST & \\
\hline CHEMBL389162 & 688444 & 6.1057 & 5.0653 & TST & \\
\hline CHEMBL1521297 & 688444 & 6.8356 & 5.6302 & TST & \\
\hline
\end{tabular}


Supplemental Table S2.txt

\begin{tabular}{|c|c|c|c|c|}
\hline . & & & & \\
\hline HEMBL1587133 & 38444 & 8851 & 1385 & \\
\hline HEMBL1488696 & 3444 & & 5962 & \\
\hline 585 & & & & \\
\hline EMBL15 & & & & \\
\hline AEMBL1370113 & 88444 & 578 & 2977 & \\
\hline AEMBL1352792 & 88444 & 697 & 2514 & \\
\hline HEMBL1449523 & & & & \\
\hline EMBL14 & 444 & & 359 & \\
\hline EMBL13 & & & 825 & \\
\hline AEMBL1994988 & 88444 & & 3952 & \\
\hline AEMBL1330913 & & & 805 & \\
\hline AEMBL1581503 & & & 112 & \\
\hline HEMBL3208223 & & & & \\
\hline IEMBL1598785 & & & & \\
\hline AEMBL1407169 & & & 333 & \\
\hline AEMBL1497081 & & & & \\
\hline IEMBL1309156 & & & & \\
\hline HEMBL1989897 & & & & \\
\hline AEMBL1509727 & & & & \\
\hline AEMBL1465297 & & & 96 & \\
\hline AEMBL1374970 & & & & \\
\hline AEMBL319 & & & & \\
\hline AFMRI 152 & & & & \\
\hline 523 & & & & \\
\hline AEMBL1524829 & & & & \\
\hline IEMBL145 & & & & \\
\hline EMBL1458210 & & & 49 & \\
\hline 53 & & & & \\
\hline 328 & & & & \\
\hline AEMBL1546039 & & & & \\
\hline IEMBL1997827 & & & & 5 \\
\hline & & & & \\
\hline 30 & & & & \\
\hline & & & & \\
\hline AEMBL1887153 & & & 31 & 5 \\
\hline AEMBL1522797 & & & 98 & $\mathrm{~s}$ \\
\hline & & & 79 & \\
\hline 50 & & & & \\
\hline HEMBL1496313 & & & & S \\
\hline AEMBL1612118 & & & 675 & TS \\
\hline AEMBL1426155 & & & 545 & 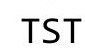 \\
\hline HEMBL1451747 & & & .9421 & \\
\hline HEMBL1366104 & & & & \\
\hline AEMBL1314125 & & & 1766 & TS \\
\hline IEMBL1465741 & & & 482 & TS \\
\hline 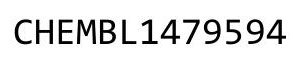 & & & & \\
\hline & & & 4.0291 & \\
\hline
\end{tabular}

Page 8711 


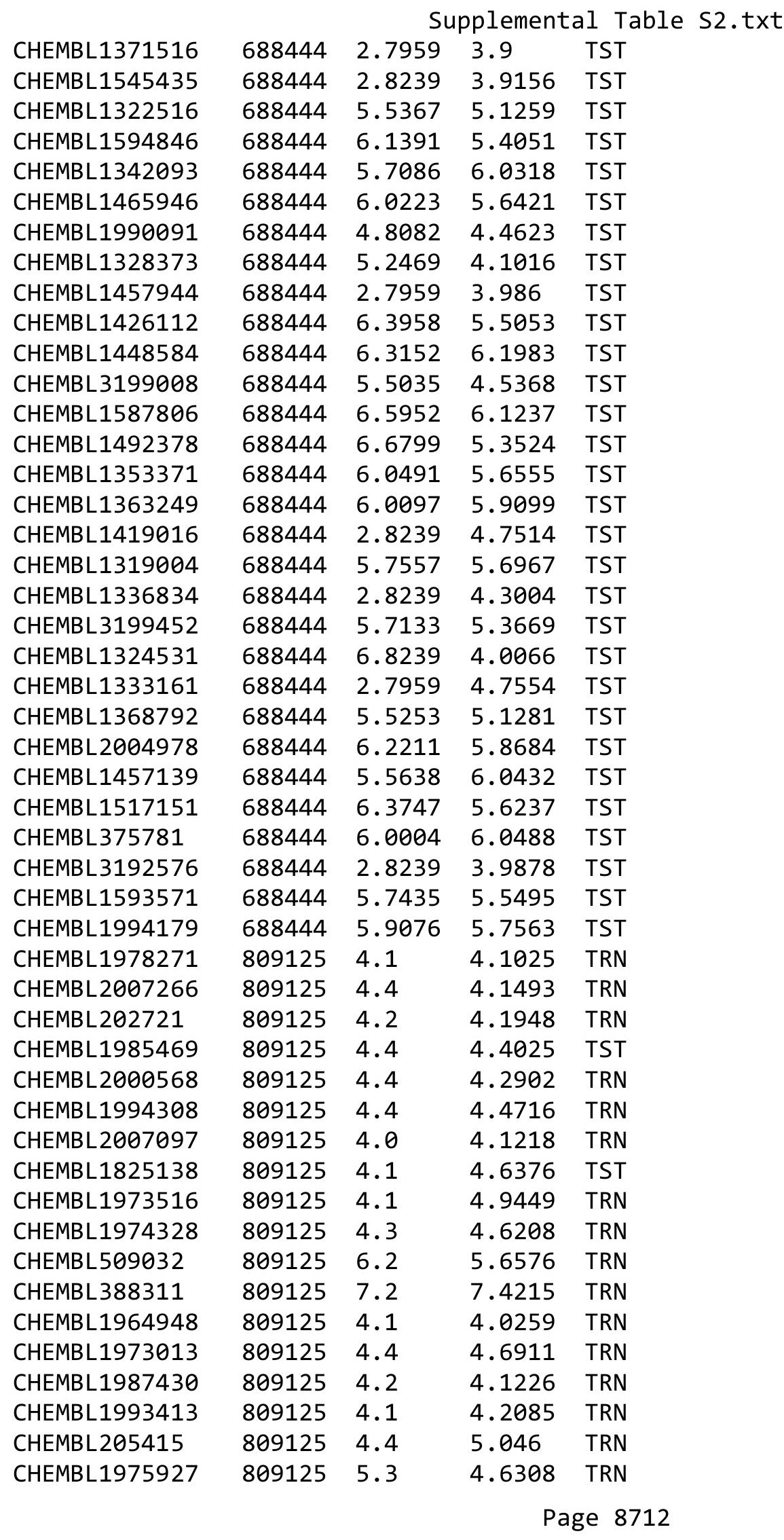




\begin{tabular}{|c|c|c|c|c|}
\hline \\
\hline CHEMBL1986943 & 809125 & 6.8 & 6.0547 & TRN \\
\hline CHEMBL1977138 & 809125 & 6.6 & 5.6948 & TRN \\
\hline CHEMBL1978448 & 809125 & 4.4 & 4.4221 & TST \\
\hline CHEMBL1980329 & 809125 & 5.6 & 5.7524 & TRN \\
\hline CHEMBL 2004515 & 809125 & 5.0 & 4.6812 & TRN \\
\hline CHEMBL1992042 & 809125 & 4.4 & 5.1727 & TRN \\
\hline CHEMBL1986265 & 809125 & 4.4 & 4.2114 & TRN \\
\hline CHEMBL1991734 & 809125 & 6.3 & 5.8331 & TRN \\
\hline CHEMBL 21156 & 809125 & 4.4 & 4.8885 & TRN \\
\hline CHEMBL1994724 & 809125 & 4.4 & 4.3845 & TRN \\
\hline CHEMBL1989267 & 809125 & 4.4 & 5.1308 & TRN \\
\hline CHEMBL1991782 & 809125 & 3.1 & 3.1265 & TRN \\
\hline CHEMBL1983348 & 809125 & 4.4 & 5.2147 & TRN \\
\hline CHEMBL1974574 & 809125 & 4.4 & 4.5798 & TRN \\
\hline CHEMBL1970290 & 809125 & 5.4 & 4.7675 & TRN \\
\hline CHEMBL1993877 & 809125 & 4.4 & 4.8071 & TRN \\
\hline CHEMBL1974480 & 809125 & 5.7 & 5.0271 & TRN \\
\hline CHEMBL1996500 & 809125 & 4.4 & 4.3245 & TRN \\
\hline CHEMBL1980671 & 809125 & 4.4 & 4.0576 & TRN \\
\hline CHEMBL1986177 & 809125 & 4.4 & 4.1825 & TRN \\
\hline CHEMBL1989708 & 809125 & 4.4 & 4.5115 & TRN \\
\hline CHEMBL1976420 & 809125 & 4.1 & 3.8954 & TRN \\
\hline CHEMBL1998253 & 809125 & 4.4 & 4.4684 & TST \\
\hline CHEMBL1981744 & 809125 & 4.1 & 4.1245 & TRN \\
\hline CHEMBL1985367 & 809125 & 4.4 & 4.5305 & TRN \\
\hline CHEMBL1996510 & 809125 & 6.3 & 5.6176 & TRN \\
\hline CHEMBL 2000029 & 809125 & 6.0 & 5.4073 & TRN \\
\hline CHEMBL1995172 & 809125 & 4.4 & 3.9054 & TST \\
\hline CHEMBL 2001584 & 809125 & 4.4 & 4.0649 & TRN \\
\hline CHEMBL1973961 & 809125 & 4.4 & 4.6831 & TRN \\
\hline CHEMBL1967998 & 809125 & 5.4 & 5.5791 & TRN \\
\hline CHEMBL1978562 & 809125 & 4.4 & 4.6888 & TRN \\
\hline CHEMBL1994977 & 809125 & 4.1 & 4.1407 & TRN \\
\hline CHEMBL 2001149 & 809125 & 4.4 & 4.7385 & TRN \\
\hline CHEMBL1974875 & 809125 & 4.5 & 4.1549 & TST \\
\hline CHEMBL 2005478 & 809125 & 4.4 & 4.7286 & TRN \\
\hline CHEMBL1996646 & 809125 & 5.5 & 5.169 & TRN \\
\hline CHEMBL1979773 & 809125 & 4.1 & 4.0675 & TRN \\
\hline CHEMBL1989471 & 809125 & 4.4 & 4.6813 & TST \\
\hline CHEMBL1996702 & 809125 & 5.8 & 5.314 & TRN \\
\hline CHEMBL 2007124 & 809125 & 4.4 & 4.2121 & TRN \\
\hline CHEMBL1978195 & 809125 & 4.4 & 4.757 & TRN \\
\hline CHEMBL 2006439 & 809125 & 5.5 & 5.1647 & TRN \\
\hline CHEMBL1985681 & 809125 & 4.4 & 4.8809 & TRN \\
\hline CHEMBL 2002660 & 809125 & 4.1 & 4.1439 & TRN \\
\hline CHEMBL1991674 & 809125 & 4.5 & 5.1137 & TRN \\
\hline CHEMBL1982711 & 809125 & 6.1 & 5.3395 & TRN \\
\hline CHEMBL262623 & 809125 & 4.5 & 4.2333 & TRN \\
\hline
\end{tabular}




\begin{tabular}{|c|c|c|c|c|}
\hline \multicolumn{5}{|r|}{11 Table } \\
\hline CHEMBL1984842 & 809125 & 4.4 & 4.399 & TRN \\
\hline CHEMBL 2004118 & 809125 & 4.4 & 4.4261 & TRN \\
\hline CHEMBL1996345 & 809125 & 4.4 & 4.2645 & TRN \\
\hline CHEMBL 2004025 & 809125 & 6.0 & 5.1821 & TRN \\
\hline CHEMBL1996048 & 809125 & 4.2 & 4.607 & TRN \\
\hline CHEMBL50894 & 809125 & 4.4 & 4.4556 & TRN \\
\hline CHEMBL1976158 & 809125 & 4.7 & 4.7501 & TRN \\
\hline CHEMBL1995211 & 809125 & 5.8 & 4.9342 & TRN \\
\hline CHEMBL1965033 & 809125 & 4.4 & 4.2561 & TRN \\
\hline CHEMBL461876 & 809125 & 4.4 & 4.5753 & TRN \\
\hline CHEMBL1982753 & 809125 & 4.5 & 4.7782 & TRN \\
\hline CHEMBL 2006299 & 809125 & 4.1 & 4.2576 & TRN \\
\hline CHEMBL1972346 & 809125 & 6.1 & 4.743 & TST \\
\hline CHEMBL1971519 & 809125 & 4.6 & 4.2369 & TRN \\
\hline CHEMBL1997335 & 809125 & 4.4 & 5.3427 & TRN \\
\hline CHEMBL1965169 & 809125 & 4.1 & 4.2186 & TRN \\
\hline CHEMBL1991818 & 809125 & 4.4 & 4.8459 & TRN \\
\hline CHEMBL1081312 & 809125 & 4.2 & 4.5895 & TRN \\
\hline CHEMBL1971132 & 809125 & 4.4 & 4.121 & TRN \\
\hline CHEMBL1965170 & 809125 & 4.4 & 4.5736 & TRN \\
\hline CHEMBL 2005792 & 809125 & 4.4 & 4.3692 & TRN \\
\hline CHEMBL1991867 & 809125 & 4.2 & 4.0764 & TST \\
\hline CHEMBL1986503 & 809125 & 4.4 & 4.3986 & TST \\
\hline CHEMBL1972355 & 809125 & 6.0 & 5.78700 & 0000000001 \\
\hline CHEMBL1997892 & 809125 & 4.4 & 4.3946 & TRN \\
\hline CHEMBL 2001641 & 809125 & 4.2 & 4.2893 & TRN \\
\hline CHEMBL1991377 & 809125 & 4.1 & 4.1811 & TRN \\
\hline CHEMBL1997193 & 809125 & 5.8 & 4.7459 & TST \\
\hline CHEMBL1964902 & 809125 & 4.4 & 4.0419 & TRN \\
\hline CHEMBL1973868 & 809125 & 4.4 & 4.5401 & TRN \\
\hline CHEMBL1972462 & 809125 & 4.4 & 4.3125 & TRN \\
\hline CHEMBL1983715 & 809125 & 5.7 & 5.6127 & TRN \\
\hline CHEMBL1984500 & 809125 & 3.1 & 3.1522 & TRN \\
\hline CHEMBL 2002992 & 809125 & 5.4 & 4.8687 & TRN \\
\hline CHEMBL1982700 & 809125 & 4.4 & 4.2494 & TRN \\
\hline CHEMBL10 & 809125 & 4.4 & 4.2421 & TRN \\
\hline CHEMBL1980763 & 809125 & 4.4 & 4.4543 & TRN \\
\hline CHEMBL1977634 & 809125 & 4.4 & 4.0085 & TRN \\
\hline CHEMBL1977931 & 809125 & 4.1 & 4.1371 & TRN \\
\hline CHEMBL 2007479 & 809125 & 4.2 & 4.5053 & TRN \\
\hline CHEMBL1998953 & 809125 & 5.7 & 4.6521 & TRN \\
\hline CHEMBL1971606 & 809125 & 4.1 & 4.1822 & TRN \\
\hline CHEMBL1971223 & 809125 & 4.1 & 4.3387 & TRN \\
\hline CHEMBL1999120 & 809125 & 4.2 & 4.019 & TST \\
\hline CHEMBL1972220 & 809125 & 4.4 & 4.7311 & TRN \\
\hline CHEMBL1981215 & 809125 & 4.2 & 4.0852 & TRN \\
\hline CHEMBL1973720 & 809125 & 6.7 & 6.1415 & TRN \\
\hline CHEMBL1999414 & 809125 & 4.1 & 4.374 & TRN \\
\hline
\end{tabular}

TRN 


\begin{tabular}{|c|c|c|c|c|}
\hline \multicolumn{5}{|c|}{ Supplemental Table S2.txt } \\
\hline CHEMBL1967336 & 809125 & 4.1 & 4.2448 & TRN \\
\hline CHEMBL 2001923 & 809125 & 4.1 & 4.521 & TRN \\
\hline CHEMBL1983070 & 809125 & 4.1 & 4.2999 & TRN \\
\hline CHEMBL 2003514 & 809125 & 4.1 & 4.2247 & TRN \\
\hline CHEMBL1970340 & 809125 & 4.3 & 4.2622 & TRN \\
\hline CHEMBL1967992 & 809125 & 4.4 & 4.7333 & TRN \\
\hline CHEMBL1989043 & 809125 & 4.4 & 4.6621 & TRN \\
\hline CHEMBL1981671 & 809125 & 4.4 & 4.4705 & TRN \\
\hline CHEMBL 2006450 & 809125 & 4.1 & 4.2511 & TRN \\
\hline CHEMBL 2001987 & 809125 & 4.1 & 4.0378 & TRN \\
\hline CHEMBL1994555 & 809125 & 4.1 & 4.0221 & TRN \\
\hline CHEMBL1164180 & 809125 & 4.4 & 4.8473 & TST \\
\hline CHEMBL1975121 & 809125 & 4.1 & 4.2792 & TRN \\
\hline CHEMBL1983640 & 809125 & 4.4 & 4.399 & TRN \\
\hline CHEMBL1997611 & 809125 & 5.4 & 4.863 & TRN \\
\hline CHEMBL1971943 & 809125 & 4.1 & 4.2813 & TRN \\
\hline CHEMBL 2002723 & 809125 & 5.9 & 4.9147 & TRN \\
\hline CHEMBL1984686 & 809125 & 4.4 & 4.2103 & TST \\
\hline CHEMBL1973793 & 809125 & 4.4 & 4.1525 & TRN \\
\hline CHEMBL1992073 & 809125 & 5.6 & 4.41 & TRN \\
\hline CHEMBL1992334 & 809125 & 4.1 & 4.3388 & TRN \\
\hline CHEMBL1990254 & 809125 & 4.4 & 4.6543 & TRN \\
\hline CHEMBL1986143 & 809125 & 4.1 & 4.3358 & TRN \\
\hline CHEMBL1972934 & 809125 & 4.2 & 4.1188 & TRN \\
\hline CHEMBL 2007559 & 809125 & 4.4 & 4.1432 & TRN \\
\hline CHEMBL1992581 & 809125 & 5.4 & 4.7174 & TRN \\
\hline CHEMBL 2004290 & 809125 & 4.4 & 4.3117 & TRN \\
\hline CHEMBL1975923 & 809125 & 4.7 & 4.7843 & TST \\
\hline CHEMBL1984847 & 809125 & 4.1 & 4.255 & TRN \\
\hline CHEMBL 2005449 & 809125 & 4.4 & 4.6087 & TRN \\
\hline CHEMBL1996576 & 809125 & 4.4 & 4.3812 & TST \\
\hline CHEMBL1991678 & 809125 & 4.4 & 4.3639 & TRN \\
\hline CHEMBL1987998 & 809125 & 4.4 & 4.2205 & TRN \\
\hline CHEMBL1971534 & 809125 & 4.1 & 4.4205 & TRN \\
\hline CHEMBL1990496 & 809125 & 4.3 & 4.5459 & TRN \\
\hline CHEMBL242865 & 809125 & 4.4 & 4.6118 & TRN \\
\hline CHEMBL235157 & 809125 & 4.1 & 4.1937 & TRN \\
\hline CHEMBL1983884 & 809125 & 3.1 & 4.0229 & TRN \\
\hline CHEMBL2004159 & 809125 & 4.1 & 4.1963 & TRN \\
\hline CHEMBL1978371 & 809125 & 5.5 & 5.1732 & TST \\
\hline CHEMBL440084 & 809125 & 4.1 & 4.266 & TRN \\
\hline CHEMBL1998110 & 809125 & 4.4 & 4.0195 & TRN \\
\hline CHEMBL1978166 & 809125 & 5.8 & 5.1516 & TRN \\
\hline CHEMBL 2001451 & 809125 & 4.1 & 4.2629 & TRN \\
\hline CHEMBL1990590 & 809125 & 4.1 & 4.3706 & TRN \\
\hline CHEMBL1977814 & 809125 & 4.4 & 4.5265 & TST \\
\hline CHEMBL1974617 & 809125 & 4.1 & 4.5375 & TRN \\
\hline CHEMBL1965660 & 809125 & 4.1 & 4.6213 & TRN \\
\hline
\end{tabular}




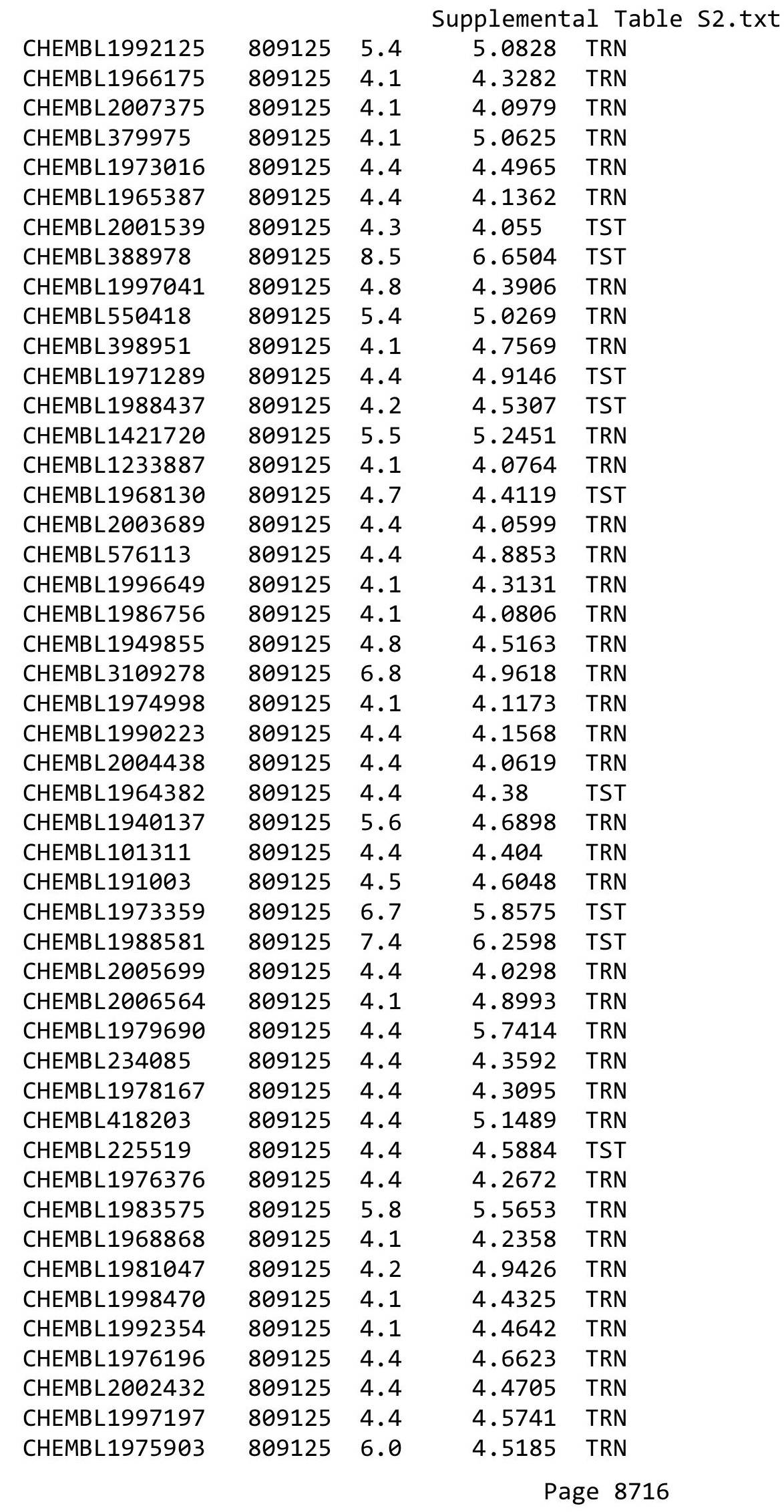




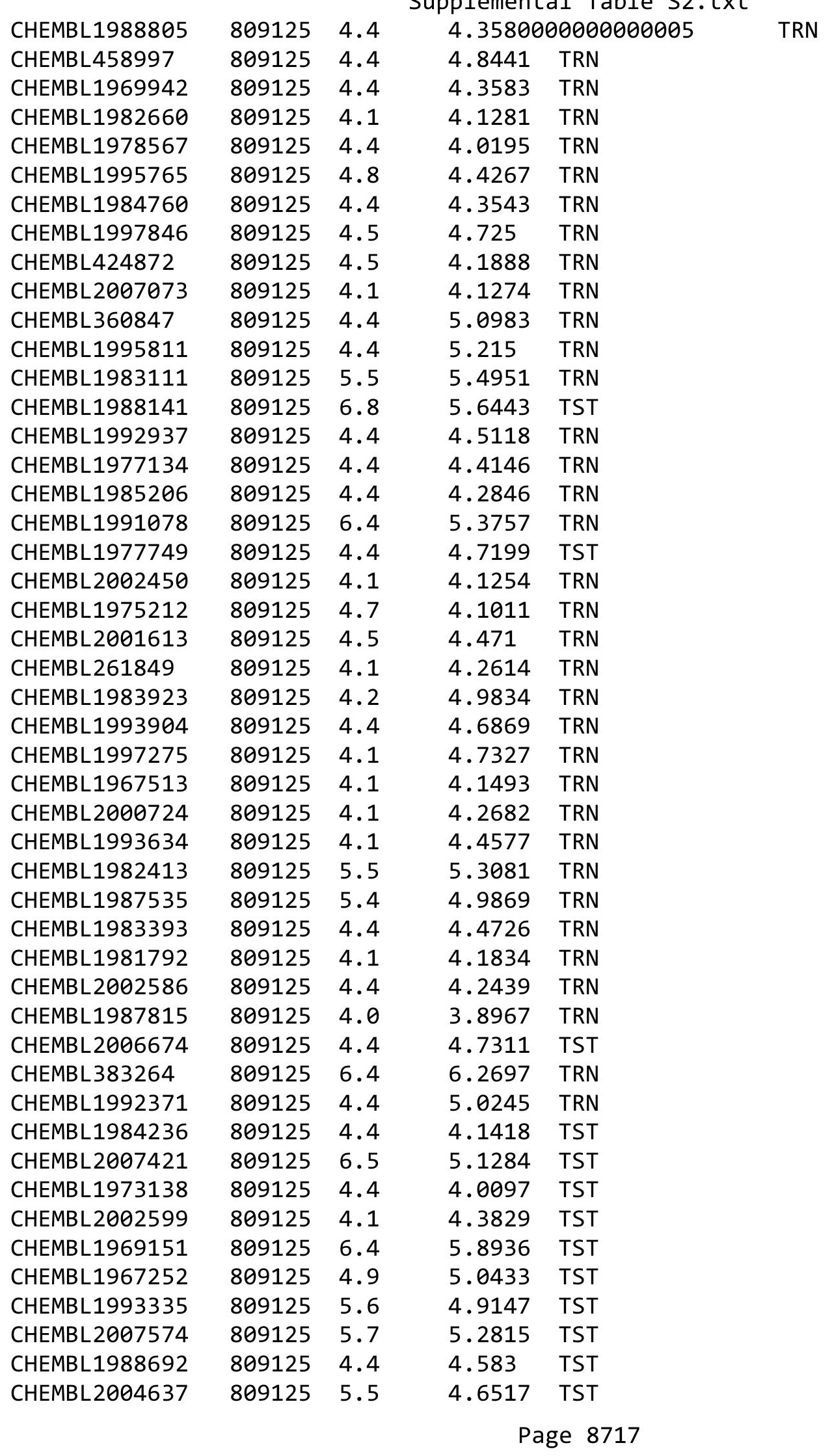




\begin{tabular}{|c|c|c|c|c|c|}
\hline \multicolumn{6}{|c|}{ Supplemental Table S2.txt } \\
\hline CHEMBL1993374 & 809125 & 4.4 & 4.3987 & TST & \\
\hline CHEMBL1994318 & 809125 & 4.1 & 4.4211 & TST & \\
\hline CHEMBL1998680 & 809125 & 4.4 & 4.1369 & TST & \\
\hline CHEMBL592030 & 809125 & 4.3 & 4.6968 & TST & \\
\hline CHEMBL1999506 & 809125 & 4.1 & 4.1401 & TST & \\
\hline CHEMBL1605605 & 809125 & 4.1 & 4.5322 & TST & \\
\hline CHEMBL1996208 & 809125 & 4.1 & 4.6089 & TST & \\
\hline CHEMBL 2002736 & 809125 & 4.1 & 4.4664 & TST & \\
\hline CHEMBL1997007 & 809125 & 4.4 & 4.3399 & TST & \\
\hline CHEMBL1970352 & 809125 & 4.4 & 4.9748 & TST & \\
\hline CHEMBL 2002690 & 809125 & 4.4 & 4.2089 & TST & \\
\hline CHEMBL1980167 & 809125 & 5.7 & 5.1608 & TST & \\
\hline CHEMBL377408 & 809125 & 4.5 & 4.3148 & TST & \\
\hline CHEMBL278041 & 809125 & 4.4 & 4.383 & TST & \\
\hline CHEMBL215152 & 809125 & 4.2 & 4.24100 & 00000000005 & TST \\
\hline CHEMBL 2006765 & 809125 & 4.1 & 4.958 & TST & \\
\hline CHEMBL1986590 & 809125 & 4.4 & 4.7566 & TST & \\
\hline CHEMBL1870106 & 809125 & 4.1 & 5.0243 & TST & \\
\hline CHEMBL406845 & 809125 & 4.3 & 4.2431 & TST & \\
\hline CHEMBL1980246 & 809125 & 4.4 & 4.4199 & TST & \\
\hline CHEMBL1983980 & 809125 & 6.0 & 5.334 & TST & \\
\hline CHEMBL482538 & 809125 & 5.0 & 4.4068 & TST & \\
\hline CHEMBL1999484 & 809125 & 4.4 & 5.6535 & TST & \\
\hline CHEMBL1984296 & 809125 & 5.5 & 5.2004 & TST & \\
\hline CHEMBL1986899 & 809125 & 4.4 & 4.3094 & TST & \\
\hline CHEMBL1984038 & 809125 & 4.4 & 4.3442 & TST & \\
\hline CHEMBL1968606 & 809125 & 4.1 & 4.2586 & TST & \\
\hline CHEMBL1964718 & 809125 & 4.2 & 4.0408 & TST & \\
\hline CHEMBL1993661 & 809125 & 6.2 & 5.7903 & TST & \\
\hline CHEMBL1968705 & 809125 & 4.1 & 4.5037 & TST & \\
\hline CHEMBL1964441 & 809125 & 4.4 & 4.2833 & TST & \\
\hline CHEMBL1991410 & 809125 & 4.1 & 4.0956 & TST & \\
\hline CHEMBL546797 & 809125 & 5.5 & 4.6175 & TST & \\
\hline CHEMBL1090424 & 615505 & 4.0 & 4.0006 & TRN & \\
\hline CHEMBL1085444 & 615505 & 5.1739 & 4.716 & TST & \\
\hline CHEMBL1086149 & 615505 & 5.2218 & 5.2244 & TRN & \\
\hline CHEMBL1089053 & 615505 & 3.699 & 3.6997 & TRN & \\
\hline CHEMBL1089387 & 615505 & 4.8861 & 4.8847 & TRN & \\
\hline CHEMBL1089396 & 615505 & 6.3979 & 6.3947 & TRN & \\
\hline CHEMBL1078496 & 615505 & 6.2218 & 6.2236 & TRN & \\
\hline CHEMBL1084137 & 615505 & 5.7696 & 5.768 & TRN & \\
\hline CHEMBL1085928 & 615505 & 4.0 & 4.0005 & TRN & \\
\hline CHEMBL1085441 & 615505 & 4.0 & 3.9995 & TRN & \\
\hline CHEMBL1089725 & 615505 & 5.9586 & 5.9584 & TRN & \\
\hline CHEMBL1089734 & 615505 & 7.2218 & 7.225 & TRN & \\
\hline CHEMBL1078394 & 615505 & 3.699 & 3.7028 & TRN & \\
\hline CHEMBL1077273 & 615505 & 6.2218 & 5.0172 & TST & \\
\hline CHEMBL1095042 & 615505 & 3.699 & 3.6998 & TRN & \\
\hline
\end{tabular}




\begin{tabular}{|c|c|c|c|c|}
\hline \multicolumn{5}{|c|}{ Supplemental Table S2.txt } \\
\hline CHEMBL1084138 & 615505 & 4.0 & 3.9976 & TRN \\
\hline CHEMBL1078695 & 615505 & 7.0 & 6.9989 & TRN \\
\hline CHEMBL1091816 & 615505 & 3.699 & 3.6998 & TRN \\
\hline CHEMBL1085897 & 615505 & 3.699 & 3.6966 & TRN \\
\hline CHEMBL1091478 & 615505 & 3.699 & 3.4597 & TST \\
\hline CHEMBL1090746 & 615505 & 5.7696 & 5.7744 & TRN \\
\hline CHEMBL1085929 & 615505 & 3.699 & 3.5394 & TST \\
\hline CHEMBL1083831 & 615505 & 3.699 & 3.6981 & TRN \\
\hline CHEMBL1085442 & 615505 & 4.0 & 3.9975 & TRN \\
\hline CHEMBL1093086 & 615505 & 3.699 & 3.7048 & TRN \\
\hline CHEMBL1083216 & 615505 & 5.4437 & 5.4452 & TRN \\
\hline CHEMBL1078465 & 615505 & 5.7696 & 5.7658 & TRN \\
\hline CHEMBL1083832 & 615505 & 5.5229 & 4.7645 & TST \\
\hline CHEMBL1078576 & 615505 & 6.3979 & 6.3961 & TRN \\
\hline CHEMBL1089395 & 615505 & 3.699 & 3.7036 & TRN \\
\hline CHEMBL1085898 & 615505 & 4.0 & 3.9978 & TRN \\
\hline CHEMBL1084145 & 615505 & 5.1079 & 5.1053 & TRN \\
\hline CHEMBL1078395 & 615505 & 5.1612 & 5.1662 & TRN \\
\hline CHEMBL1077199 & 615505 & 3.699 & 3.7008 & TRN \\
\hline CHEMBL1084144 & 615505 & 4.0 & 3.9979 & TRN \\
\hline CHEMBL1094715 & 615505 & 3.699 & 3.6934 & TRN \\
\hline CHEMBL1078749 & 615505 & 6.3979 & 6.4009 & TRN \\
\hline CHEMBL1085694 & 615505 & 3.699 & 3.7002 & TRN \\
\hline CHEMBL1089386 & 615505 & 4.0 & 4.0002 & TRN \\
\hline CHEMBL1077238 & 615505 & 4.0 & 4.001 & TRN \\
\hline CHEMBL1088076 & 615505 & 3.699 & 3.6968 & TRN \\
\hline CHEMBL1092502 & 615505 & 4.8239 & 4.8238 & TRN \\
\hline CHEMBL1078495 & 615505 & 5.3279 & 5.3215 & TRN \\
\hline CHEMBL1091479 & 615505 & 3.699 & 3.699 & TRN \\
\hline CHEMBL1078876 & 615505 & 4.7959 & 4.7975 & TRN \\
\hline CHEMBL1089052 & 615505 & 4.7959 & 4.7953 & TRN \\
\hline CHEMBL1078696 & 615505 & 4.8239 & 4.822 & TRN \\
\hline CHEMBL1085693 & 615505 & 5.9586 & 5.1526 & TST \\
\hline CHEMBL1090416 & 615505 & 3.699 & 4.6523 & TST \\
\hline CHEMBL111201 & 615505 & 5.6383 & 5.7497 & TST \\
\hline CHEMBL1078575 & 615505 & 4.0 & 4.4576 & TST \\
\hline CHEMBL1090425 & 615505 & 5.0605 & 4.6417 & TST \\
\hline CHEMBL1084136 & 615505 & 4.0 & 4.7073 & TST \\
\hline CHEMBL1086411 & 615505 & 3.699 & 3.6952 & TST \\
\hline CHEMBL1093387 & 615505 & 3.699 & 3.8633 & TST \\
\hline CHEMBL1089735 & 615505 & 5.2757 & 4.8241 & TST \\
\hline CHEMBL1084667 & 615505 & 4.0 & 4.0178 & TST \\
\hline CHEMBL3344021 & 1436310 & 5.2132 & 5.3496 & TRN \\
\hline CHEMBL 3344030 & 1436310 & 5.5051 & 5.4565 & TRN \\
\hline CHEMBL3344008 & 1436310 & 5.2129 & 5.4283 & TRN \\
\hline CHEMBL3344025 & 1436310 & 4.9469 & 5.0892 & TRN \\
\hline CHEMBL3344003 & 1436310 & 3.301 & 4.2467 & TRN \\
\hline CHEMBL3344036 & 1436310 & 5.5376 & 5.1956 & TRN \\
\hline
\end{tabular}


Supplemental Table S2.txt

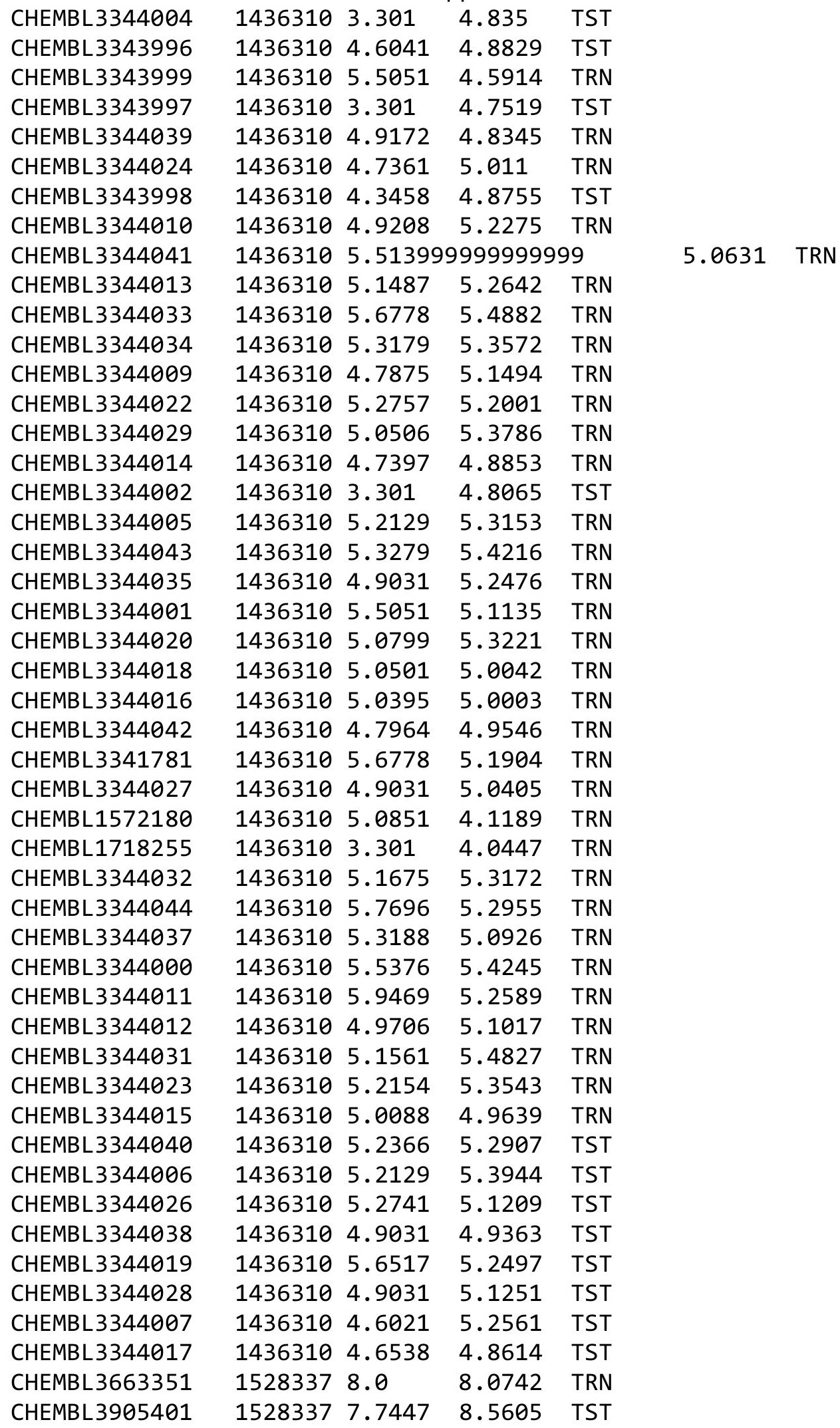

Page 8720 
Supplemental Table S2.txt

\begin{tabular}{|c|c|c|c|c|c|}
\hline CHEMBL3663373 & 1528337 & 7.8239 & 8.0319 & TRN & \\
\hline CHEMBL3663367 & 1528337 & 9.2218 & 7.0918 & TST & \\
\hline CHEMBL3667945 & 1528337 & 9.301 & 9.2402 & TRN & \\
\hline CHEMBL 3667925 & 1528337 & 8.0 & 7.7685 & TRN & \\
\hline CHEMBL3663321 & 1528337 & 10.2596 & 10.2296 & TRN & \\
\hline CHEMBL 3663320 & 1528337 & 10.2596 & 10.2464 & TRN & \\
\hline CHEMBL3663331 & 1528337 & 9.8386 & 9.7959 & TRN & \\
\hline CHEMBL3663317 & 1528337 & 8.5229 & 8.7864 & TRN & \\
\hline CHEMBL3663346 & 1528337 & 8.3979 & 8.3124 & TRN & \\
\hline CHEMBL3667943 & 1528337 & 9.1249 & 8.5859 & TRN & \\
\hline CHEMBL3667933 & 1528337 & 8.5229 & 8.6788 & TRN & \\
\hline CHEMBL 3663340 & 1528337 & 9.3468 & 8.2223 & TST & \\
\hline CHEMBL3663350 & 1528337 & 8.1549 & 8.16 & TRN & \\
\hline CHEMBL3667922 & 1528337 & 8.5229 & 8.4811 & TRN & \\
\hline CHEMBL3663333 & 1528337 & 8.699 & 8.7762 & TRN & \\
\hline CHEMBL 3663324 & 1528337 & 7.1249 & 7.0657 & TRN & \\
\hline CHEMBL3667957 & 1528337 & 8.3979 & 8.339 & TRN & \\
\hline CHEMBL3663323 & 1528337 & 9.0794 & 9.031 & TRN & \\
\hline CHEMBL3917269 & 1528337 & 9.0 & 6.415 & TST & \\
\hline CHEMBL3663335 & 1528337 & 9.3979 & 9.3088 & TRN & \\
\hline CHEMBL3667949 & 1528337 & 7.1079 & 8.1232 & TST & \\
\hline CHEMBL3667944 & 1528337 & 9.1249 & 9.1789 & TRN & \\
\hline CHEMBL3639622 & 1528337 & 7.699 & 8.1363 & TRN & \\
\hline CHEMBL3667934 & 1528337 & 8.301 & 8.3902 & TST & \\
\hline CHEMBL3663341 & 1528337 & 7.4559 & 7.5443 & TRN & \\
\hline CHEMBL3667931 & 1528337 & 7.1938 & 7.1191 & TRN & \\
\hline CHEMBL3667926 & 1528337 & 8.1549 & 8.0229 & TRN & \\
\hline CHEMBL3667956 & 1528337 & 8.2218 & 8.4822 & TRN & \\
\hline CHEMBL3667961 & 1528337 & 8.1549 & 8.0742 & TRN & \\
\hline CHEMBL3663377 & 1528337 & 8.0458 & 7.9568 & TRN & \\
\hline CHEMBL3663371 & 1528337 & 7.9586 & 8.1813 & TRN & \\
\hline CHEMBL3663325 & 1528337 & 9.1549 & 8.8629 & TRN & \\
\hline CHEMBL 3663374 & 1528337 & 8.1549 & 8.347006 & 0000000001 & TRN \\
\hline CHEMBL 3667921 & 1528337 & 8.301 & 8.4221 & TRN & \\
\hline CHEMBL3945171 & 1528337 & 7.9586 & 7.8979 & TST & \\
\hline CHEMBL3946840 & 1528337 & 8.5229 & 7.0397 & TST & \\
\hline CHEMBL3663363 & 1528337 & 9.5229 & 7.7226 & TST & \\
\hline CHEMBL3899884 & 1528337 & 8.699 & 7.1147 & TST & \\
\hline CHEMBL3667941 & 1528337 & 8.5229 & 8.6792 & TRN & \\
\hline CHEMBL3663339 & 1528337 & 9.1549 & 7.1167 & TST & \\
\hline CHEMBL3663365 & 1528337 & 8.0969 & 7.9345 & TRN & \\
\hline CHEMBL3663342 & 1528337 & 9.5229 & 9.2695 & TRN & \\
\hline CHEMBL3667959 & 1528337 & 8.0969 & 8.3795 & TRN & \\
\hline CHEMBL3667955 & 1528337 & 8.301 & 8.3216 & TRN & \\
\hline CHEMBL3663359 & 1528337 & 8.301 & 8.1363 & TRN & \\
\hline CHEMBL3663381 & 1528337 & 8.2218 & 8.4548 & TST & \\
\hline CHEMBL3667918 & 1528337 & 8.0458 & 8.1059 & TRN & \\
\hline CHEMBL3663318 & 1528337 & 9.1249 & 9.1408 & TRN & \\
\hline
\end{tabular}


Supplemental Table S2.txt

\begin{tabular}{|c|c|c|c|c|}
\hline 7 & & & & ..... \\
\hline & & & & \\
\hline$E M$ & 337 & & & \\
\hline IEMBL L & 37 & 891 & & \\
\hline AEMBL3663328 & 528337 & 7.3468 & 3633 & \\
\hline HEMBL 366 & 37 & 8.1549 & 51 & \\
\hline 54 & & 2218 & & \\
\hline HEMBL; & & 229 & 934 & \\
\hline HEMBL3663357 & 528337 & 8.5229 & 4718 & \\
\hline HEMBL3667948 & 337 & 8.3979 & 3792 & \\
\hline HEMBL3667946 & 337 & 8.3979 & 3847 & \\
\hline IEME & 37 & 9.0 & 584 & \\
\hline AEMBL: & & 69 & 9637 & \\
\hline HEMBL3667954 & 337 & 5.9626 & 0108 & \\
\hline AEMBL3639667 & & 969 & & \\
\hline HEMBL3 & 31 & 8.0 & גב & RIN \\
\hline HEMBL & & 9.2218 & 9521 & ו \\
\hline AEMBL. & & 0706 & .1245 & \\
\hline HEMBL3 & & 9.1871 & 2203 & ונ \\
\hline AEMBL3663376 & & 8 . & & KIV \\
\hline HEMBL & 1 & 49 & & ST \\
\hline IEM & & 79 & & RN \\
\hline AEMBL & 37 & 979 & & ST \\
\hline HEMBL & & 2218 & & RN \\
\hline AEMBL3 & $3 /$ & 8.0 & 43 & RIN \\
\hline HEMBL & & & & RN \\
\hline 17 & & 29 & & KIN \\
\hline 62 & & 79 & 275 & RN \\
\hline HEMBL & & 9 . & & IRN \\
\hline HEMBL3663344 & $\boldsymbol{I}$ & 7. & 3634 & RN \\
\hline 58 & & 8 & 342 & RN \\
\hline 0 & & & 51 & RN \\
\hline 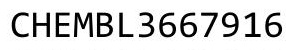 & & 229 & & RN \\
\hline HEMBL3 & & 9.60 & & RN \\
\hline AEMBL3663366 & 37 & 9 & 028 & ST \\
\hline 15 & & & 31 & $\mathrm{RN}$ \\
\hline 6 & & & & RN \\
\hline HEMBL3 & & & & TRN \\
\hline HEMBL 366 & & 0969 & 118 & $\mathrm{TR}$ \\
\hline 9 & & & & RN \\
\hline HFMRI = & & 8. & 25 & RN \\
\hline & & 7.3188 & 954 & RN \\
\hline HEMBL3663334 & & 9.301 & & $\mathrm{RN}$ \\
\hline HEMBL 3663 & 3 & 239 & & s \\
\hline I. & & & & \\
\hline HEMBL3 & & 3.699 & & \\
\hline HEMBL 3967705 & & 9.0 & 7.3664 & $\mathrm{~T}$ \\
\hline HEMBL 3663370 & 1528337 & 9.6021 & 7.4991 & ST \\
\hline
\end{tabular}

Page 8722 
Supplemental Table S2.txt

\begin{tabular}{|c|c|c|c|c|}
\hline-5 & & & & \\
\hline HEMBL3667923 & 528337 & 7.699 & 7569 & \\
\hline & & & & \\
\hline 29099 & 37 & 9.4559 & 4664 & \\
\hline AEMBL3663330 & 528337 & 9.0223 & 9099 & \\
\hline AEMBL3667952 & 528337 & 5.1896 & 1867 & \\
\hline HEMBL366 & 528337 & 6.8928 & .8876 & \\
\hline HEMBL: & 528 & 9.0 & 98 & \\
\hline AEMBL & 528 & 7.3979 & .5563 & \\
\hline HEMBL3663322 & 528337 & 7.4815 & .4574 & \\
\hline HEMBL 3663329 & 528337 & 9.2218 & .0326 & \\
\hline HEMBL 392 & 528337 & 8.699 & .3863 & \\
\hline HEMBL & & 979 & & \\
\hline HEMBL. & 37 & 549 & .1291 & \\
\hline HEMBL366 & 528 & 586 & 1694 & \\
\hline AEMBL1760130 & 39425 & 4.699 & 28 & \\
\hline AEMBL17 & 394 & 979 & 401 & \\
\hline HEMBL17 & 3 & 239 & & \\
\hline HEMBL1 & 30 & 5021 & 717 & \\
\hline AEMBL176e & 39 & 5.301 & 18 & $\omega_{2}$ \\
\hline AEMBL598784 & 39 & 301 & 3303 & RIV \\
\hline HEMBL4 & 39 & 021 & 421 & \\
\hline HEMBL5 & & 21 & & \\
\hline HEMBL599 & 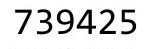 & 021 & 8737 & \\
\hline AEMBL176 & 5 & 3 & 3.6775 & RIV \\
\hline IEMBL1 & 39 & 0. & 392 & ST \\
\hline AEMBL59 & 39 & & 884 & RN \\
\hline HEM & 5 & & 34 & RN \\
\hline HEMBL17 & 30 & & & $\mathrm{RN}$ \\
\hline AEMBL17 & 39 & 3. & 987 & RN \\
\hline AEMBL59 & 39 & 021 & 818 & RN \\
\hline AFMBI 1 & 5 & 1 & 552 & RN \\
\hline 7 & & & 554 & RN \\
\hline HEMBL176 & - & & & ST \\
\hline HEMBL17 & 39 & 3.6021 & 009 & ST \\
\hline HEMBL59 & 5 & 021 & 732 & RN \\
\hline 1 & & 8 & & RN \\
\hline HEMBL489. & 25 & 3. & 259 & RN \\
\hline HEMBL1760128 & 39425 & 3.6021 & & RN \\
\hline IEMBL610 & 5 & 021 & 4.7033 & RN \\
\hline HEMBL 602 & 39 & 01 & .2022 & RN \\
\hline & & & 4.1794 & RN \\
\hline HEMBL611 & 39425 & 3.6021 & 4.2393 & $\mathrm{RN}$ \\
\hline HEMBL17602 & 39425 & 3.6021 & 4.1984 & RN \\
\hline L1 & 35 & 1 & 3.4202 & \\
\hline HEMBL17 & - & . & 4.4063 & \\
\hline CHEMBL599 & 739425 & 3.6021 & 3.5852 & \\
\hline CHEMBL176000 & 739425 & 5.301 & 4.9463 & RN \\
\hline
\end{tabular}

Page 8723 


\begin{tabular}{|c|c|c|c|c|c|}
\hline & & \multicolumn{4}{|c|}{ Supplemental Table S2.txt } \\
\hline CHEMBL1760131 & 739425 & 3.6021 & 4.1552 & TRN & \\
\hline CHEMBL1760148 & 739425 & 5.0 & 4.3914 & TRN & \\
\hline CHEMBL1760284 & 739425 & 5.1549 & 5.9373 & TRN & \\
\hline CHEMBL605984 & 739425 & 3.6021 & 3.9043 & TRN & \\
\hline CHEMBL1760280 & 739425 & 3.6021 & 3.9948 & TRN & \\
\hline CHEMBL599820 & 739425 & 3.6021 & 3.8899 & TST & \\
\hline CHEMBL1760281 & 739425 & 3.6021 & 3.8771 & TRN & \\
\hline CHEMBL605767 & 739425 & 5.301 & 4.2917 & TRN & \\
\hline CHEMBL596749 & 739425 & 5.0 & 5.0019 & TRN & \\
\hline CHEMBL1760137 & 739425 & 3.6021 & 3.7373 & TRN & \\
\hline CHEMBL1760139 & 739425 & 4.9208 & 4.9077 & TRN & \\
\hline CHEMBL605985 & 739425 & 3.6021 & 3.7209 & TRN & \\
\hline CHEMBL591464 & 739425 & 3.6021 & 4.1721 & TST & \\
\hline CHEMBL1760138 & 739425 & 3.6021 & 5.0485 & TST & \\
\hline CHEMBL598580 & 739425 & 3.6021 & 4.15600 & 0000000001 & TST \\
\hline CHEMBL596748 & 739425 & 3.6021 & 3.833 & TST & \\
\hline CHEMBL1760152 & 739425 & 3.6021 & 4.3678 & TST & \\
\hline CHEMBL598600 & 739425 & 3.6021 & 3.9226 & TST & \\
\hline CHEMBL 1760140 & 739425 & 5.0 & 5.17299 & 9999999999 & TST \\
\hline CHEMBL1964290 & 809186 & 4.2 & 5.1157 & TRN & \\
\hline CHEMBL 2003768 & 809186 & 4.2 & 4.1869 & TRN & \\
\hline CHEMBL213505 & 809186 & 4.2 & 4.0725 & TRN & \\
\hline CHEMBL1987034 & 809186 & 6.9 & 6.9535 & TRN & \\
\hline CHEMBL1993941 & 809186 & 4.2 & 4.4582 & TRN & \\
\hline CHEMBL1980435 & 809186 & 5.7 & 5.0629 & TRN & \\
\hline CHEMBL377383 & 809186 & 4.2 & 4.0539 & TRN & \\
\hline CHEMBL 2005886 & 809186 & 6.0 & 6.494 & TRN & \\
\hline CHEMBL481491 & 809186 & 5.4 & 5.2572 & TST & \\
\hline CHEMBL1973142 & 809186 & 5.6 & 5.7373 & TRN & \\
\hline CHEMBL1973145 & 809186 & 4.2 & 4.3276 & TRN & \\
\hline CHEMBL1982924 & 809186 & 5.9 & 5.7554 & TRN & \\
\hline CHEMBL 2005936 & 809186 & 5.6 & 5.6024 & TRN & \\
\hline CHEMBL1971141 & 809186 & 4.2 & 4.3921 & TRN & \\
\hline CHEMBL1995813 & 809186 & 7.4 & 6.49700 & 0000000001 & TRN \\
\hline CHEMBL206236 & 809186 & 4.2 & 4.8802 & TRN & \\
\hline CHEMBL244378 & 809186 & 6.6 & 6.3556 & TRN & \\
\hline CHEMBL 2001957 & 809186 & 4.2 & 4.1394 & TRN & \\
\hline CHEMBL1969372 & 809186 & 4.2 & 4.3385 & TRN & \\
\hline CHEMBL1993413 & 809186 & 4.5 & 4.5711 & TRN & \\
\hline CHEMBL1986943 & 809186 & 7.2 & 6.4631 & TRN & \\
\hline CHEMBL 2006263 & 809186 & 6.0 & 5.0133 & TST & \\
\hline CHEMBL1993584 & 809186 & 5.5 & 4.2977 & TRN & \\
\hline CHEMBL1986263 & 809186 & 6.3 & 5.8916 & TRN & \\
\hline CHEMBL 2000114 & 809186 & 5.4 & 5.6004 & TRN & \\
\hline CHEMBL210618 & 809186 & 4.2 & 3.9309 & TRN & \\
\hline CHEMBL1971172 & 809186 & 6.1 & 6.064 & TRN & \\
\hline CHEMBL1975647 & 809186 & 4.2 & 4.5112 & TRN & \\
\hline CHEMBL1968380 & 809186 & 6.8 & 6.4084 & TRN & \\
\hline
\end{tabular}




\begin{tabular}{|c|c|c|c|c|c|}
\hline \\
\hline CHEMBL1964644 & 809186 & 4.2 & 4.3334 & TRN & \\
\hline CHEMBL1981782 & 809186 & 4.2 & 4.2822 & TRN & \\
\hline CHEMBL1977681 & 809186 & 5.7 & 5.3751 & TRN & \\
\hline CHEMBL1970142 & 809186 & 4.2 & 4.1755 & TRN & \\
\hline CHEMBL1990912 & 809186 & 4.2 & 4.543 & TRN & \\
\hline CHEMBL1988163 & 809186 & 6.7 & 6.6827 & TRN & \\
\hline CHEMBL1975128 & 809186 & 5.9 & 5.3634 & TRN & \\
\hline CHEMBL 2006493 & 809186 & 4.2 & 4.2258 & TST & \\
\hline CHEMBL1996923 & 809186 & 4.2 & 4.1353 & TST & \\
\hline CHEMBL1983449 & 809186 & 4.2 & 3.9623 & TRN & \\
\hline CHEMBL1992323 & 809186 & 4.2 & 4.0434 & TRN & \\
\hline CHEMBL1969735 & 809186 & 4.2 & 4.1303 & TRN & \\
\hline CHEMBL 2002649 & 809186 & 5.8 & 6.0663 & TRN & \\
\hline CHEMBL1983589 & 809186 & 4.5 & 5.3338 & TRN & \\
\hline CHEMBL 2005718 & 809186 & 6.1 & 6.0988 & TRN & \\
\hline CHEMBL1995172 & 809186 & 4.2 & 4.1298 & TST & \\
\hline CHEMBL1994321 & 809186 & 4.2 & 4.9343 & TRN & \\
\hline CHEMBL1984788 & 809186 & 4.2 & 4.1874 & TRN & \\
\hline CHEMBL 2000508 & 809186 & 4.2 & 4.3217 & TRN & \\
\hline CHEMBL1971694 & 809186 & 4.2 & 4.5135 & TST & \\
\hline CHEMBL 2001547 & 809186 & 4.2 & 4.0654 & TRN & \\
\hline CHEMBL210928 & 809186 & 4.2 & 4.03600 & 00000000005 & TRN \\
\hline CHEMBL1986603 & 809186 & 4.2 & 4.4075 & TST & \\
\hline CHEMBL1977148 & 809186 & 4.2 & 4.3064 & TRN & \\
\hline CHEMBL 2003286 & 809186 & 5.2 & 4.8947 & TRN & \\
\hline CHEMBL1992306 & 809186 & 4.2 & 4.0162 & TRN & \\
\hline CHEMBL 2002165 & 809186 & 5.3 & 4.6225 & TRN & \\
\hline CHEMBL2001668 & 809186 & 4.2 & 4.6672 & TST & \\
\hline CHEMBL1979318 & 809186 & 4.2 & 4.2037 & TST & \\
\hline CHEMBL206382 & 809186 & 4.2 & 4.7204 & TRN & \\
\hline CHEMBL1998585 & 809186 & 5.5 & 5.2683 & TRN & \\
\hline CHEMBL127898 & 809186 & 4.2 & 4.0812 & TST & \\
\hline CHEMBL519697 & 809186 & 4.2 & 5.4093 & TST & \\
\hline CHEMBL 2004934 & 809186 & 4.2 & 3.9321 & TRN & \\
\hline CHEMBL1987261 & 809186 & 6.4 & 6.1423 & TRN & \\
\hline CHEMBL1970369 & 809186 & 4.2 & 4.3128 & TRN & \\
\hline CHEMBL 2001485 & 809186 & 4.2 & 4.2715 & TRN & \\
\hline CHEMBL1966425 & 809186 & 6.1 & 5.5498 & TRN & \\
\hline CHEMBL1984363 & 809186 & 4.2 & 4.7376 & TRN & \\
\hline CHEMBL1978099 & 809186 & 5.8 & 5.9115 & TRN & \\
\hline CHEMBL1988608 & 809186 & 4.2 & 4.3603 & TRN & \\
\hline CHEMBL184847 & 809186 & 4.2 & 4.0396 & TRN & \\
\hline CHEMBL1984367 & 809186 & 4.2 & 4.3205 & TRN & \\
\hline CHEMBL1985723 & 809186 & 6.3 & 6.5047 & TRN & \\
\hline CHEMBL178737 & 809186 & 5.2 & 5.1002 & TST & \\
\hline CHEMBL226898 & 809186 & 8.3 & 8.0897 & TRN & \\
\hline CHEMBL1982563 & 809186 & 4.2 & 4.1459 & TRN & \\
\hline CHEMBL539474 & 809186 & 5.9 & 4.6049 & TST & \\
\hline & & & & 8725 & \\
\hline
\end{tabular}




\begin{tabular}{|c|c|c|c|c|}
\hline & & & pमeme & al Ta \\
\hline CHEMBL575824 & 809186 & 5.6 & 5.6685 & TRN \\
\hline CHEMBL1988387 & 809186 & 5.3 & 4.2515 & TRN \\
\hline CHEMBL1977128 & 809186 & 4.5 & 4.5413 & TRN \\
\hline CHEMBL1990288 & 809186 & 4.2 & 4.0389 & TRN \\
\hline CHEMBL1989708 & 809186 & 4.2 & 4.6426 & TRN \\
\hline CHEMBL1974803 & 809186 & 5.9 & 5.1025 & TST \\
\hline CHEMBL1970074 & 809186 & 4.2 & 4.0921 & TRN \\
\hline CHEMBL1965702 & 809186 & 5.7 & 6.2157 & TRN \\
\hline CHEMBL1986970 & 809186 & 4.2 & 4.4062 & TRN \\
\hline CHEMBL 2005112 & 809186 & 4.2 & 4.4546 & TST \\
\hline CHEMBL1958401 & 809186 & 4.2 & 4.0395 & TRN \\
\hline CHEMBL1984044 & 809186 & 4.2 & 4.5781 & TRN \\
\hline CHEMBL 2003456 & 809186 & 5.3 & 4.6106 & TRN \\
\hline CHEMBL1966816 & 809186 & 5.3 & 4.5841 & TRN \\
\hline CHEMBL1972584 & 809186 & 5.4 & 5.0725 & TRN \\
\hline CHEMBL 2002992 & 809186 & 5.5 & 4.9633 & TRN \\
\hline CHEMBL560813 & 809186 & 5.2 & 4.4259 & TRN \\
\hline CHEMBL1990635 & 809186 & 5.2 & 5.0017 & TST \\
\hline CHEMBL1968791 & 809186 & 5.8 & 5.5744 & TRN \\
\hline CHEMBL 2002682 & 809186 & 5.7 & 5.4923 & TST \\
\hline CHEMBL1971186 & 809186 & 4.2 & 4.0096 & TRN \\
\hline CHEMBL 2003482 & 809186 & 4.2 & 4.0376 & TRN \\
\hline CHEMBL 2006456 & 809186 & 6.0 & 6.3234 & TRN \\
\hline CHEMBL1973211 & 809186 & 5.5 & 5.5722 & TRN \\
\hline CHEMBL1984700 & 809186 & 4.2 & 4.0587 & TRN \\
\hline CHEMBL1972125 & 809186 & 4.4 & 4.7665 & TRN \\
\hline CHEMBL1461728 & 809186 & 4.2 & 4.1692 & TRN \\
\hline CHEMBL1976134 & 809186 & 5.6 & 5.0695 & TRN \\
\hline CHEMBL1965131 & 809186 & 5.5 & 5.8758 & TRN \\
\hline CHEMBL1972158 & 809186 & 6.3 & 5.8818 & TRN \\
\hline CHEMBL 2006580 & 809186 & 4.2 & 4.2814 & TRN \\
\hline CHEMBL 2006481 & 809186 & 4.2 & 4.1047 & TRN \\
\hline CHEMBL1979855 & 809186 & 4.2 & 4.2563 & TRN \\
\hline CHEMBL1970340 & 809186 & 5.6 & 4.6985 & TRN \\
\hline CHEMBL 2005186 & 809186 & 4.2 & 4.4341 & TRN \\
\hline CHEMBL1995927 & 809186 & 4.2 & 4.418 & TST \\
\hline CHEMBL 2006450 & 809186 & 4.5 & 4.5032 & TRN \\
\hline CHEMBL1975534 & 809186 & 5.4 & 5.4931 & TRN \\
\hline CHEMBL1993424 & 809186 & 6.3 & 6.4802 & TRN \\
\hline CHEMBL1966703 & 809186 & 4.2 & 4.4564 & TST \\
\hline CHEMBL1969561 & 809186 & 4.2 & 4.5103 & TRN \\
\hline CHEMBL1975121 & 809186 & 4.2 & 4.0976 & TRN \\
\hline CHEMBL1997023 & 809186 & 4.2 & 4.7981 & TST \\
\hline CHEMBL1964687 & 809186 & 4.2 & 4.1865 & TRN \\
\hline CHEMBL1971943 & 809186 & 5.4 & 4.775 & TRN \\
\hline CHEMBL1974254 & 809186 & 4.2 & 4.4853 & TRN \\
\hline CHEMBL1988537 & 809186 & 6.7 & 6.0619 & TST \\
\hline CHEMBL1969049 & 809186 & 4.2 & 3.9607 & TRN \\
\hline
\end{tabular}




\begin{tabular}{|c|c|c|c|c|}
\hline & & & & \\
\hline CHEMBL 2005828 & 809186 & 4.2 & 4.368 & TRN \\
\hline CHEMBL 2002240 & 809186 & 4.2 & 4.0742 & TRN \\
\hline CHEMBL2003405 & 809186 & 5.4 & 4.7107 & TST \\
\hline CHEMBL1991143 & 809186 & 4.2 & 4.0075 & TST \\
\hline CHEMBL1980178 & 809186 & 6.2 & 5.9245 & TRN \\
\hline CHEMBL1998611 & 809186 & 5.8 & 6.0804 & TRN \\
\hline CHEMBL1975900 & 809186 & 4.2 & 4.3312 & TRN \\
\hline CHEMBL255822 & 809186 & 5.6 & 5.4243 & TRN \\
\hline CHEMBL1972221 & 809186 & 4.2 & 4.3633 & TRN \\
\hline CHEMBL 2006778 & 809186 & 5.2 & 5.1799 & TRN \\
\hline CHEMBL378627 & 809186 & 4.2 & 3.8859 & TRN \\
\hline CHEMBL1996979 & 809186 & 6.2 & 6.0635 & TRN \\
\hline CHEMBL1997025 & 809186 & 4.2 & 4.33 & TRN \\
\hline CHEMBL1968406 & 809186 & 4.2 & 4.0044 & TRN \\
\hline CHEMBL1984274 & 809186 & 5.4 & 4.5686 & TST \\
\hline CHEMBL1998545 & 809186 & 4.2 & 4.3522 & TRN \\
\hline CHEMBL1986869 & 809186 & 4.2 & 4.1903 & TRN \\
\hline CHEMBL 2006010 & 809186 & 4.2 & 3.9306 & TRN \\
\hline CHEMBL1682558 & 809186 & 4.2 & 4.1281 & TRN \\
\hline CHEMBL1990496 & 809186 & 5.2 & 4.9666 & TRN \\
\hline CHEMBL 2002479 & 809186 & 5.6 & 5.7519 & TRN \\
\hline CHEMBL1967094 & 809186 & 4.2 & 4.1266 & TRN \\
\hline CHEMBL1966035 & 809186 & 4.2 & 4.3416 & TRN \\
\hline CHEMBL 2003341 & 809186 & 4.2 & 4.3326 & TRN \\
\hline CHEMBL1982992 & 809186 & 5.6 & 5.0596 & TRN \\
\hline CHEMBL1999590 & 809186 & 4.2 & 4.5025 & TST \\
\hline CHEMBL1981079 & 809186 & 4.5 & 4.2144 & TRN \\
\hline CHEMBL1972276 & 809186 & 4.2 & 4.1258 & TRN \\
\hline CHEMBL1980489 & 809186 & 4.2 & 3.8309 & TRN \\
\hline CHEMBL 2000832 & 809186 & 6.0 & 5.9669 & TRN \\
\hline CHEMBL1967116 & 809186 & 4.2 & 4.8694 & TRN \\
\hline CHEMBL513846 & 809186 & 4.2 & 4.5637 & TRN \\
\hline CHEMBL1970709 & 809186 & 4.2 & 3.9753 & TRN \\
\hline CHEMBL1965660 & 809186 & 4.5 & 4.3215 & TRN \\
\hline CHEMBL1998112 & 809186 & 4.2 & 4.0321 & TRN \\
\hline CHEMBL1972290 & 809186 & 6.0 & 6.3191 & TRN \\
\hline CHEMBL1969126 & 809186 & 4.2 & 4.2852 & TRN \\
\hline CHEMBL1980896 & 809186 & 5.5 & 5.0892 & TRN \\
\hline CHEMBL1975208 & 809186 & 4.2 & 3.7588 & TST \\
\hline CHEMBL1970104 & 809186 & 5.3 & 5.4289 & TRN \\
\hline CHEMBL1991429 & 809186 & 4.2 & 4.4296 & TRN \\
\hline CHEMBL1964777 & 809186 & 5.3 & 4.83 & TST \\
\hline CHEMBL1971149 & 809186 & 4.2 & 4.0379 & TRN \\
\hline CHEMBL1999714 & 809186 & 4.2 & 4.4167 & TRN \\
\hline CHEMBL1987533 & 809186 & 5.2 & 4.5589 & TRN \\
\hline CHEMBL1994040 & 809186 & 4.2 & 4.05399 & 9999999999 \\
\hline CHEMBL1984548 & 809186 & 7.0 & 6.6265 & TRN \\
\hline CHEMBL579246 & 809186 & 6.0 & 6.0256 & TRN \\
\hline & & & Pa & e 8727 \\
\hline
\end{tabular}

TRN 


\begin{tabular}{|c|c|c|c|c|}
\hline & & & pplement & al $\mathrm{Ta}$ \\
\hline CHEMBL398951 & 809186 & 6.9 & 4.9529 & TST \\
\hline CHEMBL1982506 & 809186 & 4.2 & 4.452 & TST \\
\hline CHEMBL2004716 & 809186 & 5.9 & 5.8383 & TRN \\
\hline CHEMBL1968127 & 809186 & 4.2 & 4.1717 & TRN \\
\hline CHEMBL1975233 & 809186 & 4.2 & 4.4542 & TRN \\
\hline CHEMBL1985406 & 809186 & 4.2 & 4.9805 & TRN \\
\hline CHEMBL 207400 & 809186 & 4.2 & 3.9905 & TST \\
\hline CHEMBL 2000894 & 809186 & 5.8 & 5.6858 & TST \\
\hline CHEMBL1982135 & 809186 & 4.2 & 4.2046 & TRN \\
\hline CHEMBL1976090 & 809186 & 5.6 & 5.5965 & TRN \\
\hline CHEMBL1993243 & 809186 & 4.2 & 4.4963 & TRN \\
\hline CHEMBL1992922 & 809186 & 7.1 & 6.6969 & TRN \\
\hline CHEMBL2004771 & 809186 & 4.2 & 4.4932 & TRN \\
\hline CHEMBL1997597 & 809186 & 4.2 & 4.8084 & TRN \\
\hline CHEMBL1969537 & 809186 & 6.7 & 5.3316 & TST \\
\hline CHEMBL1976093 & 809186 & 4.2 & 4.2641 & TRN \\
\hline CHEMBL210032 & 809186 & 4.2 & 4.4221 & TRN \\
\hline CHEMBL1975256 & 809186 & 4.2 & 3.946 & TST \\
\hline CHEMBL508928 & 809186 & 5.5 & 4.9405 & TRN \\
\hline CHEMBL1991356 & 809186 & 4.2 & 4.6966 & TRN \\
\hline CHEMBL1983309 & 809186 & 4.2 & 4.3552 & TRN \\
\hline CHEMBL 2004892 & 809186 & 5.4 & 5.1173 & TRN \\
\hline CHEMBL1999126 & 809186 & 4.2 & 4.4654 & TST \\
\hline CHEMBL1997503 & 809186 & 4.2 & 4.382 & TST \\
\hline CHEMBL1972339 & 809186 & 6.6 & 5.7693 & TRN \\
\hline CHEMBL116070 & 809186 & 4.2 & 4.5232 & TST \\
\hline CHEMBL1990821 & 809186 & 5.2 & 4.835 & TST \\
\hline CHEMBL1970314 & 809186 & 4.2 & 4.4088 & TRN \\
\hline CHEMBL 2004871 & 809186 & 4.2 & 4.1569 & TRN \\
\hline CHEMBL 2004872 & 809186 & 4.2 & 4.0824 & TRN \\
\hline CHEMBL1727312 & 809186 & 4.2 & 4.3372 & TRN \\
\hline CHEMBL1969879 & 809186 & 4.2 & 4.4982 & TRN \\
\hline CHEMBL1981720 & 809186 & 4.2 & 4.7608 & TRN \\
\hline CHEMBL419932 & 809186 & 5.3 & 4.9484 & TRN \\
\hline CHEMBL 262433 & 809186 & 4.2 & 4.3358 & TRN \\
\hline CHEMBL 306380 & 809186 & 4.2 & 4.7165 & TRN \\
\hline CHEMBL1966722 & 809186 & 5.6 & 5.6117 & TRN \\
\hline CHEMBL1983595 & 809186 & 4.5 & 4.5874 & TRN \\
\hline CHEMBL1975500 & 809186 & 6.3 & 6.1444 & TRN \\
\hline CHEMBL394619 & 809186 & 5.4 & 5.3053 & TRN \\
\hline CHEMBL1996831 & 809186 & 6.1 & 5.0665 & TST \\
\hline CHEMBL411903 & 809186 & 5.3 & 4.9205 & TRN \\
\hline CHEMBL1980253 & 809186 & 6.4 & 6.0739 & TRN \\
\hline CHEMBL1965988 & 809186 & 5.8 & 5.6415 & TRN \\
\hline CHEMBL418203 & 809186 & 5.7 & 5.5114 & TST \\
\hline CHEMBL1989646 & 809186 & 5.2 & 5.285 & TRN \\
\hline CHEMBL225519 & 809186 & 4.8 & 4.6976 & TRN \\
\hline CHEMBL1978200 & 809186 & 4.2 & 4.1362 & TRN \\
\hline
\end{tabular}




\begin{tabular}{|c|c|c|c|c|c|}
\hline \\
\hline CHEMBL1970522 & 809186 & 5.7 & 5.6601 & TRN & \\
\hline CHEMBL402846 & 809186 & 4.2 & 3.8275 & TRN & \\
\hline CHEMBL1990415 & 809186 & 5.8 & 4.9834 & TRN & \\
\hline CHEMBL1966087 & 809186 & 4.2 & 4.3917 & TRN & \\
\hline CHEMBL1964692 & 809186 & 4.2 & 3.6293 & TRN & \\
\hline CHEMBL1996931 & 809186 & 4.2 & 4.2857 & TRN & \\
\hline CHEMBL1973483 & 809186 & 4.2 & 4.2565 & TRN & \\
\hline CHEMBL1998470 & 809186 & 4.5 & 4.8539 & TRN & \\
\hline CHEMBL1996980 & 809186 & 6.4 & 6.4857 & TRN & \\
\hline CHEMBL1970735 & 809186 & 4.2 & 4.213 & TRN & \\
\hline CHEMBL1997340 & 809186 & 4.2 & 4.2513 & TRN & \\
\hline CHEMBL1994669 & 809186 & 7.5 & 6.6506 & TRN & \\
\hline CHEMBL 2004365 & 809186 & 4.2 & 4.5807 & TST & \\
\hline CHEMBL1522508 & 809186 & 4.2 & 4.0077 & TRN & \\
\hline CHEMBL1989474 & 809186 & 4.2 & 4.1036 & TRN & \\
\hline CHEMBL1090360 & 809186 & 4.2 & 4.2542 & TRN & \\
\hline CHEMBL210887 & 809186 & 4.2 & 5.33700 & 0000000001 & TST \\
\hline CHEMBL458997 & 809186 & 6.5 & 6.3954 & TRN & \\
\hline CHEMBL1971021 & 809186 & 4.2 & 4.0123 & TRN & \\
\hline CHEMBL 227271 & 809186 & 7.6 & 7.6231 & TRN & \\
\hline CHEMBL583144 & 809186 & 5.3 & 5.2884 & TRN & \\
\hline CHEMBL1974310 & 809186 & 5.5 & 5.4559 & TST & \\
\hline CHEMBL1982660 & 809186 & 4.2 & 4.4275 & TRN & \\
\hline CHEMBL1994693 & 809186 & 4.2 & 4.3946 & TRN & \\
\hline CHEMBL1982957 & 809186 & 7.2 & 6.7767 & TRN & \\
\hline CHEMBL1725279 & 809186 & 6.0 & 5.4794 & TST & \\
\hline CHEMBL1975138 & 809186 & 5.7 & 5.771 & TRN & \\
\hline CHEMBL424872 & 809186 & 4.2 & 3.9626 & TRN & \\
\hline CHEMBL2006836 & 809186 & 4.2 & 4.4437 & TST & \\
\hline CHEMBL412142 & 809186 & 4.2 & 3.9947 & TST & \\
\hline CHEMBL1980704 & 809186 & 4.2 & 4.5081 & TST & \\
\hline CHEMBL 2003271 & 809186 & 5.6 & 5.9858 & TRN & \\
\hline CHEMBL1966808 & 809186 & 4.2 & 3.7394 & TST & \\
\hline CHEMBL 2004447 & 809186 & 4.2 & 4.0695 & TST & \\
\hline CHEMBL1992231 & 809186 & 4.5 & 4.2562 & TRN & \\
\hline CHEMBL1983111 & 809186 & 6.7 & 6.6805 & TST & \\
\hline CHEMBL1973860 & 809186 & 5.2 & 5.0826 & TRN & \\
\hline CHEMBL260135 & 809186 & 4.2 & 4.4591 & TRN & \\
\hline CHEMBL220241 & 809186 & 4.2 & 4.3549 & TRN & \\
\hline CHEMBL 2004544 & 809186 & 5.8 & 4.7443 & TST & \\
\hline CHEMBL1982610 & 809186 & 4.2 & 4.7375 & TST & \\
\hline CHEMBL1999496 & 809186 & 4.2 & 4.0902 & TRN & \\
\hline CHEMBL1988300 & 809186 & 5.6 & 4.2321 & TRN & \\
\hline CHEMBL1991078 & 809186 & 6.1 & 5.32600 & 00000000005 & TRN \\
\hline CHEMBL1987359 & 809186 & 4.2 & 4.1805 & TST & \\
\hline CHEMBL1994438 & 809186 & 4.5 & 6.1021 & TRN & \\
\hline CHEMBL1989265 & 809186 & 4.2 & 4.2147 & TST & \\
\hline CHEMBL1969502 & 809186 & 5.3 & 5.2187 & TRN & \\
\hline
\end{tabular}




\begin{tabular}{|c|c|c|c|c|c|}
\hline \\
\hline CHEMBL1682553 & 809186 & 4.2 & 4.3527 & TRN & \\
\hline CHEMBL1971430 & 809186 & 4.2 & 4.6466 & TRN & \\
\hline CHEMBL1983963 & 809186 & 4.2 & 4.4963 & TRN & \\
\hline CHEMBL1997764 & 809186 & 5.9 & 5.8969 & TRN & \\
\hline CHEMBL1985092 & 809186 & 5.3 & 5.5287 & TST & \\
\hline CHEMBL 2004692 & 809186 & 4.2 & 4.0081 & TST & \\
\hline CHEMBL1981410 & 809186 & 4.2 & 4.3147 & TRN & \\
\hline CHEMBL1996234 & 809186 & 4.2 & 4.0006 & TRN & \\
\hline CHEMBL1991434 & 809186 & 4.2 & 4.5422 & TRN & \\
\hline CHEMBL1967544 & 809186 & 5.5 & 5.1999 & TRN & \\
\hline CHEMBL340384 & 809186 & 5.9 & 6.1653 & TST & \\
\hline CHEMBL1969151 & 809186 & 5.9 & 6.3504 & TRN & \\
\hline CHEMBL1996587 & 809186 & 4.2 & 4.4638 & TRN & \\
\hline CHEMBL1964804 & 809186 & 5.3 & 4.7923 & TRN & \\
\hline CHEMBL443962 & 809186 & 4.2 & 4.4384 & TST & \\
\hline CHEMBL 2000354 & 809186 & 5.9 & 5.71899 & 9999999999 & TRN \\
\hline CHEMBL1965507 & 809186 & 6.7 & 6.00299 & 9999999999 & TRN \\
\hline CHEMBL1967564 & 809186 & 4.2 & 4.1879 & TRN & \\
\hline CHEMBL592030 & 809186 & 6.8 & 6.00899 & 99999999995 & TST \\
\hline CHEMBL 2000071 & 809186 & 6.8 & 6.7129 & TRN & \\
\hline CHEMBL1979176 & 809186 & 4.2 & 4.5306 & TRN & \\
\hline CHEMBL 2002613 & 809186 & 5.8 & 5.0583 & TRN & \\
\hline CHEMBL 2000408 & 809186 & 4.2 & 4.2363 & TRN & \\
\hline CHEMBL1978014 & 809186 & 4.2 & 4.1782 & TRN & \\
\hline CHEMBL1994538 & 809186 & 4.2 & 4.4575 & TRN & \\
\hline CHEMBL1983195 & 809186 & 5.7 & 4.8796 & TST & \\
\hline CHEMBL1975490 & 809186 & 5.3 & 5.5924 & TRN & \\
\hline CHEMBL1964444 & 809186 & 4.2 & 4.2814 & TRN & \\
\hline CHEMBL1986139 & 809186 & 4.2 & 4.5301 & TRN & \\
\hline CHEMBL1980540 & 809186 & 4.2 & 4.2407 & TRN & \\
\hline CHEMBL1979883 & 809186 & 5.6 & 5.6318 & TRN & \\
\hline CHEMBL1984162 & 809186 & 5.4 & 4.88 & TRN & \\
\hline CHEMBL1998432 & 809186 & 6.6 & 6.5326 & TRN & \\
\hline CHEMBL491758 & 809186 & 5.4 & 4.8555 & TRN & \\
\hline CHEMBL549730 & 809186 & 4.2 & 4.49100 & 00000000005 & TRN \\
\hline CHEMBL1970189 & 809186 & 4.2 & 4.2129 & TST & \\
\hline CHEMBL1996791 & 809186 & 4.2 & 4.2448 & TRN & \\
\hline CHEMBL371206 & 809186 & 5.7 & 5.3789 & TRN & \\
\hline CHEMBL1974664 & 809186 & 4.2 & 4.5156 & TRN & \\
\hline CHEMBL1974288 & 809186 & 4.2 & 4.3269 & TRN & \\
\hline CHEMBL196363 & 809186 & 5.5 & 5.4596 & TRN & \\
\hline CHEMBL1190711 & 809186 & 4.2 & 4.706 & TRN & \\
\hline CHEMBL1968705 & 809186 & 6.0 & 5.0264 & TRN & \\
\hline CHEMBL1991410 & 809186 & 4.5 & 4.4661 & TRN & \\
\hline CHEMBL404367 & 809186 & 4.2 & 4.2066 & TRN & \\
\hline CHEMBL1966343 & 809186 & 5.6 & 5.6138 & TRN & \\
\hline CHEMBL1967887 & 809186 & 6.8 & 6.3296 & TRN & \\
\hline CHEMBL 2000568 & 809186 & 4.2 & 4.6347 & TRN & \\
\hline
\end{tabular}




\begin{tabular}{|c|c|c|c|c|c|}
\hline \\
\hline CHEMBL2000335 & 809186 & 6.1 & 5.6619 & TRN & \\
\hline CHEMBL1977604 & 809186 & 4.2 & 4.2056 & TST & \\
\hline CHEMBL1988717 & 809186 & 4.2 & 4.3194 & TRN & \\
\hline CHEMBL1974328 & 809186 & 6.4 & 6.2657 & TRN & \\
\hline CHEMBL509032 & 809186 & 8.4 & 8.2248 & TRN & \\
\hline CHEMBL243298 & 809186 & 4.5 & 5.2243 & TRN & \\
\hline CHEMBL1973808 & 809186 & 4.2 & 4.3395 & TRN & \\
\hline CHEMBL 2000429 & 809186 & 4.2 & 4.0398 & TRN & \\
\hline CHEMBL1972576 & 809186 & 6.1 & 5.9215 & TRN & \\
\hline CHEMBL1992555 & 809186 & 4.2 & 4.2023 & TST & \\
\hline CHEMBL1992342 & 809186 & 4.2 & 5.1575 & TRN & \\
\hline CHEMBL1988173 & 809186 & 6.2 & 6.03 & TRN & \\
\hline CHEMBL535331 & 809186 & 4.2 & 4.3055 & TRN & \\
\hline CHEMBL1989805 & 809186 & 6.1 & 5.1217 & TST & \\
\hline CHEMBL1966204 & 809186 & 4.5 & 5.1187 & TRN & \\
\hline CHEMBL1965423 & 809186 & 5.2 & 4.8918 & TRN & \\
\hline CHEMBL1982980 & 809186 & 5.7 & 4.9465 & TST & \\
\hline CHEMBL1983025 & 809186 & 5.3 & 5.2404 & TRN & \\
\hline CHEMBL205415 & 809186 & 5.6 & 5.2899 & TRN & \\
\hline CHEMBL1977135 & 809186 & 4.2 & 4.3617 & TRN & \\
\hline CHEMBL 2001920 & 809186 & 5.9 & 6.2701 & TRN & \\
\hline CHEMBL1978448 & 809186 & 6.6 & 5.4157 & TST & \\
\hline CHEMBL1972258 & 809186 & 4.2 & 4.6699 & TRN & \\
\hline CHEMBL 2001257 & 809186 & 5.6 & 5.33299 & 999999999 & TRN \\
\hline CHEMBL1992536 & 809186 & 4.2 & 3.9016 & TRN & \\
\hline CHEMBL1987793 & 809186 & 5.6 & 5.2843 & TST & \\
\hline CHEMBL439340 & 809186 & 4.2 & 4.2301 & TRN & \\
\hline CHEMBL 2002373 & 809186 & 4.2 & 4.4406 & TRN & \\
\hline CHEMBL 2006188 & 809186 & 4.2 & 4.0697 & TRN & \\
\hline CHEMBL1967531 & 809186 & 5.4 & 5.3748 & TRN & \\
\hline CHEMBL1970913 & 809186 & 4.2 & 4.2853 & TRN & \\
\hline CHEMBL1973893 & 809186 & 4.2 & 4.4853 & TRN & \\
\hline CHEMBL1995736 & 809186 & 5.4 & 4.4161 & TRN & \\
\hline CHEMBL1997534 & 809186 & 5.3 & 5.2799 & TRN & \\
\hline CHEMBL1996500 & 809186 & 4.2 & 3.9594 & TRN & \\
\hline CHEMBL1985095 & 809186 & 5.5 & 5.8265 & TST & \\
\hline CHEMBL1998551 & 809186 & 4.2 & 4.2075 & TRN & \\
\hline CHEMBL1977374 & 809186 & 4.2 & 4.297 & TRN & \\
\hline CHEMBL1682540 & 809186 & 4.2 & 4.1694 & TRN & \\
\hline CHEMBL1976420 & 809186 & 4.2 & 4.9046 & TST & \\
\hline CHEMBL1994864 & 809186 & 4.2 & 3.8635 & TRN & \\
\hline CHEMBL 2002446 & 809186 & 5.9 & 5.0431 & TST & \\
\hline CHEMBL497151 & 809186 & 5.6 & 5.0404 & TST & \\
\hline CHEMBL1973961 & 809186 & 4.5 & 5.0046 & TRN & \\
\hline CHEMBL246970 & 809186 & 6.2 & 6.0773 & TST & \\
\hline CHEMBL340921 & 809186 & 5.5 & 5.7555 & TST & \\
\hline CHEMBL1999718 & 809186 & 4.2 & 4.0181 & TRN & \\
\hline CHEMBL1987073 & 809186 & 4.5 & 4.3723 & TRN & \\
\hline & & & & 8731 & \\
\hline
\end{tabular}




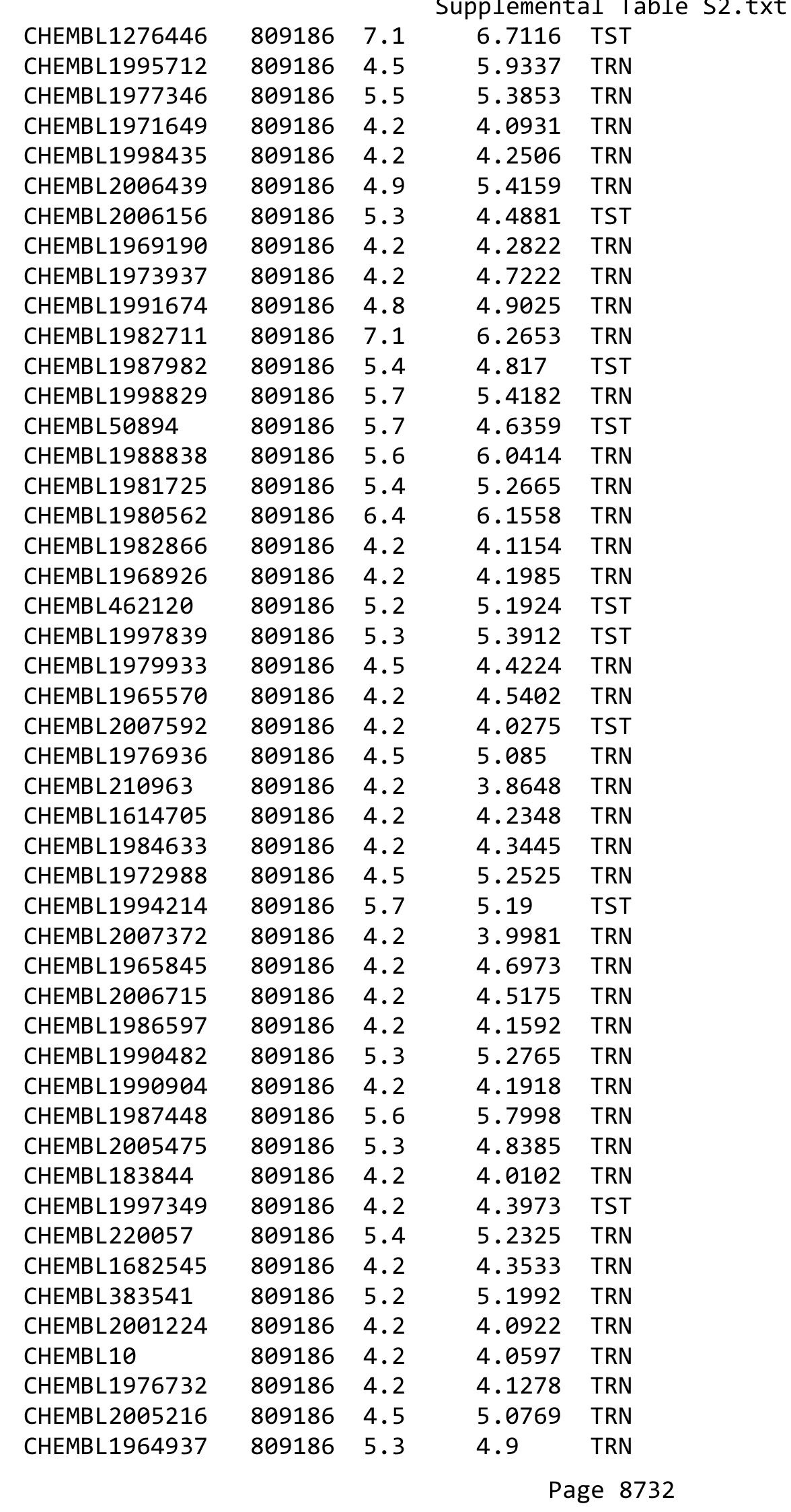




\begin{tabular}{|c|c|c|c|c|c|}
\hline & & & & & \\
\hline CHEMBL1969506 & 809186 & 4.2 & 4.4162 & TRN & \\
\hline CHEMBL1980163 & 809186 & 4.2 & 4.1898 & TRN & \\
\hline CHEMBL 2005899 & 809186 & 4.2 & 4.4608 & TRN & \\
\hline CHEMBL1682552 & 809186 & 4.2 & 4.1626 & TRN & \\
\hline CHEMBL1972568 & 809186 & 4.2 & 4.4899 & TRN & \\
\hline CHEMBL105739 & 809186 & 6.2 & 6.0405 & TRN & \\
\hline CHEMBL 379300 & 809186 & 7.8 & 8.0884 & TRN & \\
\hline CHEMBL1973720 & 809186 & 6.6 & 6.76206 & 00000000005 & TRN \\
\hline CHEMBL1988995 & 809186 & 4.2 & 4.2467 & TRN & \\
\hline CHEMBL1986781 & 809186 & 4.2 & 3.9623 & TRN & \\
\hline CHEMBL526133 & 809186 & 4.2 & 4.3167 & TRN & \\
\hline CHEMBL387971 & 809186 & 5.4 & 4.7886 & TST & \\
\hline CHEMBL1979057 & 809186 & 4.2 & 4.2865 & TRN & \\
\hline CHEMBL1164180 & 809186 & 4.5 & 5.2278 & TST & \\
\hline CHEMBL1999428 & 809186 & 4.2 & 4.1911 & TRN & \\
\hline CHEMBL1967560 & 809186 & 4.2 & 4.8168 & TRN & \\
\hline CHEMBL211378 & 809186 & 4.2 & 4.387 & TRN & \\
\hline CHEMBL1516890 & 809186 & 5.4 & 5.6409 & TRN & \\
\hline CHEMBL1982465 & 809186 & 5.2 & 5.3436 & TRN & \\
\hline CHEMBL 2001751 & 809186 & 7.8 & 7.4819 & TRN & \\
\hline CHEMBL 2003420 & 809186 & 4.2 & 4.4326 & TRN & \\
\hline CHEMBL1984586 & 809186 & 4.2 & 4.4403 & TRN & \\
\hline CHEMBL1972659 & 809186 & 4.2 & 4.3805 & TST & \\
\hline CHEMBL 272453 & 809186 & 4.2 & 3.9509 & TRN & \\
\hline CHEMBL1970217 & 809186 & 4.2 & 4.1156 & TRN & \\
\hline CHEMBL 2005528 & 809186 & 4.2 & 4.6364 & TST & \\
\hline CHEMBL185569 & 809186 & 4.2 & 4.4686 & TRN & \\
\hline CHEMBL1969843 & 809186 & 4.2 & 3.9715 & TRN & \\
\hline CHEMBL 2007002 & 809186 & 5.2 & 5.3101 & TRN & \\
\hline CHEMBL1987007 & 809186 & 5.4 & 5.0361 & TRN & \\
\hline CHEMBL1969588 & 809186 & 7.1 & 6.705 & TRN & \\
\hline CHEMBL1984711 & 809186 & 4.2 & 4.8337 & TRN & \\
\hline CHEMBL484390 & 809186 & 4.2 & 5.4499 & TST & \\
\hline CHEMBL1983255 & 809186 & 5.3 & 5.1114 & TST & \\
\hline CHEMBL1979252 & 809186 & 4.2 & 4.5529 & TRN & \\
\hline CHEMBL 2004290 & 809186 & 4.2 & 4.0382 & TRN & \\
\hline CHEMBL1986499 & 809186 & 5.7 & 5.6162 & TRN & \\
\hline CHEMBL1972937 & 809186 & 4.2 & 4.6592 & TRN & \\
\hline CHEMBL 2000393 & 809186 & 6.4 & 6.1945 & TST & \\
\hline CHEMBL 2004311 & 809186 & 4.2 & 3.9868 & TRN & \\
\hline CHEMBL1992634 & 809186 & 6.5 & 6.7912 & TRN & \\
\hline CHEMBL1242373 & 809186 & 4.2 & 4.1622 & TRN & \\
\hline CHEMBL56543 & 809186 & 4.2 & 4.5401 & TRN & \\
\hline CHEMBL1988075 & 809186 & 4.2 & 4.2929 & TRN & \\
\hline CHEMBL316264 & 809186 & 4.2 & 4.2496 & TRN & \\
\hline CHEMBL1991678 & 809186 & 4.2 & 4.0685 & TRN & \\
\hline CHEMBL 2001239 & 809186 & 5.7 & 5.4583 & TST & \\
\hline CHEMBL1988594 & 809186 & 5.7 & 6.0602 & TRN & \\
\hline & & & & e 8733 & \\
\hline
\end{tabular}




\begin{tabular}{|c|c|c|c|c|}
\hline \multicolumn{5}{|c|}{ emental T } \\
\hline CHEMBL 2001288 & 809186 & 4.2 & 4.5634 & TRN \\
\hline CHEMBL1992363 & 809186 & 4.5 & 5.3254 & TRN \\
\hline CHEMBL1999811 & 809186 & 5.4 & 4.7018 & TST \\
\hline CHEMBL1985074 & 809186 & 4.2 & 4.7057 & TST \\
\hline CHEMBL1982874 & 809186 & 4.2 & 4.5494 & TRN \\
\hline CHEMBL 2000481 & 809186 & 4.2 & 4.7941 & TRN \\
\hline CHEMBL1991725 & 809186 & 4.2 & 4.3809 & TRN \\
\hline CHEMBL1992242 & 809186 & 4.2 & 4.183 & TRN \\
\hline CHEMBL1982271 & 809186 & 6.2 & 6.415 & TRN \\
\hline CHEMBL 2007296 & 809186 & 4.2 & 4.3205 & TRN \\
\hline CHEMBL 396523 & 809186 & 6.2 & 6.0332 & TRN \\
\hline CHEMBL208637 & 809186 & 4.2 & 4.2678 & TRN \\
\hline CHEMBL1970203 & 809186 & 4.2 & 5.0526 & TRN \\
\hline CHEMBL1986530 & 809186 & 4.2 & 4.6278 & TST \\
\hline CHEMBL1999321 & 809186 & 4.2 & 4.0018 & TRN \\
\hline CHEMBL1968590 & 809186 & 4.2 & 4.566 & TRN \\
\hline CHEMBL 2005375 & 809186 & 5.3 & 5.7531 & TRN \\
\hline CHEMBL1984191 & 809186 & 4.2 & 4.3787 & TRN \\
\hline CHEMBL1972183 & 809186 & 4.2 & 4.4121 & TST \\
\hline CHEMBL 394790 & 809186 & 5.3 & 4.9964 & TRN \\
\hline CHEMBL226471 & 809186 & 4.2 & 4.6875 & TRN \\
\hline CHEMBL1974702 & 809186 & 5.5 & 5.2523 & TRN \\
\hline CHEMBL1996111 & 809186 & 4.2 & 4.3034 & TRN \\
\hline CHEMBL1965589 & 809186 & 4.2 & 4.2693 & TRN \\
\hline CHEMBL1998193 & 809186 & 4.2 & 4.1942 & TRN \\
\hline CHEMBL379975 & 809186 & 6.4 & 5.1501 & TST \\
\hline CHEMBL474432 & 809186 & 4.2 & 5.7966 & TST \\
\hline CHEMBL1988153 & 809186 & 5.4 & 3.9029 & TST \\
\hline CHEMBL1986666 & 809186 & 4.5 & 5.3682 & TRN \\
\hline CHEMBL1988437 & 809186 & 5.3 & 5.1766 & TST \\
\hline CHEMBL1998121 & 809186 & 5.7 & 5.2513 & TRN \\
\hline CHEMBL1979577 & 809186 & 5.8 & 5.7383 & TRN \\
\hline CHEMBL52387 & 809186 & 4.2 & 4.311 & TST \\
\hline CHEMBL379835 & 809186 & 4.2 & 4.0737 & TST \\
\hline CHEMBL1979357 & 809186 & 4.2 & 4.4585 & TRN \\
\hline CHEMBL1996817 & 809186 & 7.4 & 7.0494 & TRN \\
\hline CHEMBL3197315 & 809186 & 4.2 & 4.1416 & TST \\
\hline CHEMBL468280 & 809186 & 4.2 & 4.3437 & TST \\
\hline CHEMBL1990884 & 809186 & 4.2 & 4.212 & TRN \\
\hline CHEMBL 3109278 & 809186 & 7.6 & 7.0704 & TRN \\
\hline CHEMBL256835 & 809186 & 4.2 & 4.2219 & TRN \\
\hline CHEMBL1980142 & 809186 & 4.2 & 3.9875 & TRN \\
\hline CHEMBL41783 & 809186 & 4.2 & 4.0459 & TRN \\
\hline CHEMBL 2006276 & 809186 & 4.2 & 4.5332 & TRN \\
\hline CHEMBL271381 & 809186 & 4.2 & 4.505 & TRN \\
\hline CHEMBL 2006785 & 809186 & 4.2 & 4.3841 & TRN \\
\hline CHEMBL1982466 & 809186 & 4.2 & 4.2355 & TRN \\
\hline CHEMBL1995740 & 809186 & 5.8 & 4.702 & TRN \\
\hline
\end{tabular}




\begin{tabular}{|c|c|c|c|c|c|}
\hline \\
\hline CHEMBL1990162 & 809186 & 4.5 & 4.6518 & TRN & \\
\hline CHEMBL1992220 & 809186 & 6.8 & 6.3297 & TRN & \\
\hline CHEMBL234085 & 809186 & 5.9 & 4.5403 & TRN & \\
\hline CHEMBL1995832 & 809186 & 4.2 & 4.2463 & TRN & \\
\hline CHEMBL1998414 & 809186 & 4.2 & 4.1067 & TRN & \\
\hline CHEMBL1969042 & 809186 & 5.9 & 5.345 & TST & \\
\hline CHEMBL1999931 & 809186 & 6.3 & 5.5047 & TRN & \\
\hline CHEMBL1375418 & 809186 & 4.2 & 4.5563 & TRN & \\
\hline CHEMBL 2007064 & 809186 & 5.9 & 6.1337 & TRN & \\
\hline CHEMBL1981047 & 809186 & 5.8 & 6.157 & TRN & \\
\hline CHEMBL 229968 & 809186 & 7.9 & 8.3406 & TRN & \\
\hline CHEMBL1976240 & 809186 & 4.2 & 4.4885 & TRN & \\
\hline CHEMBL1987948 & 809186 & 6.2 & 5.8662 & TRN & \\
\hline CHEMBL1979093 & 809186 & 4.2 & 4.7047 & TRN & \\
\hline CHEMBL1968151 & 809186 & 4.2 & 4.1079 & TST & \\
\hline CHEMBL1987009 & 809186 & 5.2 & 4.5213 & TRN & \\
\hline CHEMBL379218 & 809186 & 8.0 & 7.7728 & TRN & \\
\hline CHEMBL2003817 & 809186 & 4.2 & 4.3043 & TRN & \\
\hline CHEMBL1994830 & 809186 & 4.2 & 3.8386 & TST & \\
\hline CHEMBL226403 & 809186 & 6.1 & 5.2232 & TRN & \\
\hline CHEMBL 2005631 & 809186 & 4.2 & 4.7277 & TRN & \\
\hline CHEMBL1994938 & 809186 & 5.2 & 4.8574 & TRN & \\
\hline CHEMBL1966279 & 809186 & 4.2 & 4.4425 & TRN & \\
\hline CHEMBL1997846 & 809186 & 4.5 & 4.2877 & TRN & \\
\hline CHEMBL 2004419 & 809186 & 4.2 & 4.94600 & 0000000001 & TRN \\
\hline CHEMBL1995811 & 809186 & 4.5 & 4.4708 & TRN & \\
\hline CHEMBL1972489 & 809186 & 4.2 & 4.1961 & TRN & \\
\hline CHEMBL1994074 & 809186 & 4.2 & 5.2318 & TRN & \\
\hline CHEMBL1992937 & 809186 & 5.3 & 4.2417 & TST & \\
\hline CHEMBL1968930 & 809186 & 6.5 & 6.4382 & TRN & \\
\hline CHEMBL1972119 & 809186 & 4.2 & 4.4354 & TRN & \\
\hline CHEMBL1090356 & 809186 & 4.2 & 4.2728 & TRN & \\
\hline CHEMBL95692 & 809186 & 4.2 & 4.2988 & TRN & \\
\hline CHEMBL1986328 & 809186 & 5.9 & 4.7471 & TST & \\
\hline CHEMBL1976455 & 809186 & 4.2 & 4.5828 & TRN & \\
\hline CHEMBL1983923 & 809186 & 4.2 & 4.963 & TST & \\
\hline CHEMBL1983534 & 809186 & 4.2 & 4.3895 & TRN & \\
\hline CHEMBL1982361 & 809186 & 4.2 & 4.5887 & TRN & \\
\hline CHEMBL1999112 & 809186 & 4.2 & 4.8452 & TST & \\
\hline CHEMBL1982122 & 809186 & 4.2 & 4.0063 & TRN & \\
\hline CHEMBL 2000801 & 809186 & 5.3 & 4.1034 & TRN & \\
\hline CHEMBL1682546 & 809186 & 4.2 & 3.9955 & TRN & \\
\hline CHEMBL1991395 & 809186 & 4.2 & 4.2477 & TRN & \\
\hline CHEMBL1971245 & 809186 & 4.2 & 4.4563 & TRN & \\
\hline CHEMBL1972142 & 809186 & 4.2 & 4.3722 & TRN & \\
\hline CHEMBL1966514 & 809186 & 4.2 & 4.6113 & TRN & \\
\hline CHEMBL 2003638 & 809186 & 6.3 & 5.1123 & TST & \\
\hline CHEMBL1996066 & 809186 & 4.2 & 4.4759 & TST & \\
\hline
\end{tabular}




\begin{tabular}{|c|c|c|c|c|}
\hline \multicolumn{5}{|c|}{ Supplemental Table S2.txt } \\
\hline CHEMBL1993722 & 809186 & 4.2 & 4.8348 & TST \\
\hline CHEMBL1970806 & 809186 & 4.2 & 3.8768 & TST \\
\hline CHEMBL1375640 & 809186 & 4.2 & 5.1855 & TST \\
\hline CHEMBL1979970 & 809186 & 4.2 & 3.8902 & TST \\
\hline CHEMBL 2006237 & 809186 & 4.2 & 4.4006 & TST \\
\hline CHEMBL1967720 & 809186 & 5.3 & 4.8708 & TST \\
\hline CHEMBL 2005509 & 809186 & 6.9 & 6.3126 & TST \\
\hline CHEMBL1572266 & 809186 & 4.2 & 4.1212 & TST \\
\hline CHEMBL1991138 & 809186 & 4.2 & 4.3546 & TST \\
\hline CHEMBL1969755 & 809186 & 4.2 & 4.175 & TST \\
\hline CHEMBL1979516 & 809186 & 4.2 & 4.4612 & TST \\
\hline CHEMBL1605605 & 809186 & 4.2 & 4.5441 & TST \\
\hline CHEMBL1972820 & 809186 & 4.2 & 4.3489 & TST \\
\hline CHEMBL1996208 & 809186 & 4.2 & 4.3893 & TST \\
\hline CHEMBL1989029 & 809186 & 4.2 & 4.9035 & TST \\
\hline CHEMBL392642 & 809186 & 6.1 & 6.1015 & TST \\
\hline CHEMBL514499 & 809186 & 4.2 & 5.315 & TST \\
\hline CHEMBL1980144 & 809186 & 4.2 & 5.3542 & TST \\
\hline CHEMBL1991188 & 809186 & 4.2 & 3.9611 & TST \\
\hline CHEMBL1972849 & 809186 & 4.2 & 4.1928 & TST \\
\hline CHEMBL1986855 & 809186 & 6.5 & 5.8797 & TST \\
\hline CHEMBL 231209 & 809186 & 5.4 & 4.8925 & TST \\
\hline CHEMBL1976220 & 809186 & 5.4 & 5.2586 & TST \\
\hline CHEMBL 259922 & 809186 & 4.2 & 4.146 & TST \\
\hline CHEMBL1997617 & 809186 & 5.6 & 5.4677 & TST \\
\hline CHEMBL1982383 & 809186 & 4.2 & 3.9879 & TST \\
\hline CHEMBL1969301 & 809186 & 4.2 & 5.6892 & TST \\
\hline CHEMBL17370 & 809186 & 4.2 & 4.0816 & TST \\
\hline CHEMBL1987910 & 809186 & 4.2 & 4.4196 & TST \\
\hline CHEMBL1983932 & 809186 & 4.2 & 4.319 & TST \\
\hline CHEMBL1997822 & 809186 & 4.2 & 4.3958 & TST \\
\hline CHEMBL1991285 & 809186 & 4.2 & 4.5668 & TST \\
\hline CHEMBL1985690 & 809186 & 5.2 & 5.1755 & TST \\
\hline CHEMBL 243088 & 809186 & 5.9 & 5.6733 & TST \\
\hline CHEMBL1984038 & 809186 & 4.2 & 4.3657 & TST \\
\hline CHEMBL1993661 & 809186 & 7.7 & 6.9436 & TST \\
\hline CHEMBL1974416 & 809186 & 5.9 & 5.9368 & TST \\
\hline CHEMBL 2004615 & 809186 & 5.9 & 5.414 & TST \\
\hline CHEMBL1984039 & 809186 & 5.2 & 4.8535 & TST \\
\hline CHEMBL1997872 & 809186 & 4.2 & 4.053 & TST \\
\hline CHEMBL 3670518 & 1527633 & 5.0 & 5.1557 & TRN \\
\hline CHEMBL3670508 & 1527633 & 6.5622 & 6.5469 & TRN \\
\hline CHEMBL3665623 & 1527633 & 6.7471 & 6.4006 & TRN \\
\hline CHEMBL 3670574 & 1527633 & 7.1427 & 6.8966 & TRN \\
\hline CHEMBL 3670524 & 1527633 & 6.3063 & 6.4227 & TRN \\
\hline CHEMBL 3670533 & 1527633 & 7.0362 & 7.2768 & TRN \\
\hline CHEMBL3670555 & 1527633 & 7.041 & 7.1717 & TRN \\
\hline CHEMBL 3670608 & 1527633 & 8.0 & 8.1252 & TRN \\
\hline
\end{tabular}


Supplemental Table S2.txt

\begin{tabular}{|c|c|c|c|c|}
\hline HEMBL36 & & 6.4067 & 73 & \\
\hline HFMRI 3679576 & 527623 & 6.1308 & 6353 & \\
\hline HEMBI & & 4815 & 67 & \\
\hline AEMBL & $52 / 633$ & .284 & 2266 & \\
\hline HEMBL3670526 & 527633 & 7.5528 & .7639 & \\
\hline HEMBL & 533 & 5.8539 & .9239 & \\
\hline AEMBL. & & 6.9101 & & \\
\hline HEMBL; & 533 & 1696 & 5834 & \\
\hline HEMBL3670556 & 527633 & 7.4437 & .4575 & \\
\hline HEMBL3670507 & 527633 & 5.8897 & .2395 & \\
\hline HEMBL3 & 33 & 6.7258 & 853 & \\
\hline HEMBL; & & 6.3768 & & RN \\
\hline HEMBL & 33 & 268 & 9494 & \\
\hline AEMBL3 & 33 & 467 & & \\
\hline HEMBL $367 €$ & 33 & 7.8239 & 595 & \\
\hline AEMBL & & 585 & & \\
\hline AEMBL & & & & RN \\
\hline HEMBL & 33 & 799 & 734 & \\
\hline HEMBL3 & & 431 & & \\
\hline AEMBL36 & 33 & 7. & 946 & KIV \\
\hline AEMBL & 33 & 328 & 63 & $\mathrm{RN}$ \\
\hline AEMBL & & 78 & & RIV \\
\hline HEMBL & 33 & 528 & & RN \\
\hline HEMBL & & 239 & & 「RN \\
\hline AEMBL 3 & 33 & 6.7167 & & RN \\
\hline IEMBL & & 586 & & RN \\
\hline AEM & & & & RN \\
\hline 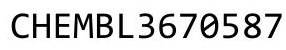 & & 71 & & ST \\
\hline IEMBL: & & & & IRN \\
\hline AEMBL36 & 33 & 167 & 54 & ГST \\
\hline IEMBL & & 96 & & RN \\
\hline$I 5 M$ & & & & RN \\
\hline & & & & RN \\
\hline AEMBL3 & & & & 「RN \\
\hline HEMBL3 & 33 & 549 & 656 & 「RN \\
\hline AFMRI : & & 5 & 26 & RN \\
\hline & & & & RN \\
\hline HEMBL; & & & 576 & TRN \\
\hline AEMBL36705 & 33 & 7.5086 & & $\Gamma R$ \\
\hline AEMBL3 & 533 & 979 & 528 & RN \\
\hline HEMBL3 & & 383 & 571 & \\
\hline & & 5.9586 & 877 & $\mathrm{RN}$ \\
\hline HEMBL36 & & 6.6517 & & 「RN \\
\hline AEMBL36 & 33 & 549 & 315 & TR \\
\hline . & & & & \\
\hline HEMBL 3670635 & & 7.8239 & & \\
\hline CHEMBL3670548 & & 5.6819 & 6.5944 & \\
\hline CHEMBL3670627 & 1527633 & 7.7959 & 7.4442 & \\
\hline
\end{tabular}

Page 8737 
Supplemental Table S2.txt

\begin{tabular}{|c|c|c|c|c|c|}
\hline CHEMBL 3670551 & 1527633 & 5.0458 & 5.3057 & TRN & \\
\hline CHEMBL 3665647 & 1527633 & 6.6576 & 6.526 & TRN & \\
\hline CHEMBL 3670513 & 1527633 & 6.4437 & 6.5592 & TRN & \\
\hline CHEMBL 3665616 & 1527633 & 6.8539 & 6.9411 & TST & \\
\hline CHEMBL 3670543 & 1527633 & 7.7959 & 8.0233 & TRN & \\
\hline CHEMBL 3670532 & 1527633 & 7.3468 & 7.2542 & TST & \\
\hline CHEMBL3670515 & 1527633 & 5.0 & 5.4647 & TRN & \\
\hline CHEMBL3670636 & 1527633 & 7.9586 & 7.3707 & TRN & \\
\hline CHEMBL 3670566 & 1527633 & 6.7696 & 6.4002 & TRN & \\
\hline CHEMBL 3670538 & 1527633 & 7.4437 & 7.4635 & TRN & \\
\hline CHEMBL 3670623 & 1527633 & 7.8861 & 7.7325 & TRN & \\
\hline CHEMBL 3665651 & 1527633 & 7.6383 & 7.6642 & TRN & \\
\hline CHEMBL 3670580 & 1527633 & 7.2076 & 6.9532 & TST & \\
\hline CHEMBL 3670529 & 1527633 & 7.585 & 7.5852 & TST & \\
\hline CHEMBL3670602 & 1527633 & 7.8539 & 7.6521 & TST & \\
\hline CHEMBL 3670550 & 1527633 & 6.1343 & 5.8771 & TRN & \\
\hline CHEMBL3670629 & 1527633 & 7.041 & 6.96899 & 9999999999 & TRN \\
\hline CHEMBL3665632 & 1527633 & 7.5376 & 7.2959 & TRN & \\
\hline CHEMBL 3670563 & 1527633 & 7.2441 & 7.5372 & TRN & \\
\hline CHEMBL 3665627 & 1527633 & 6.8633 & 7.1824 & TST & \\
\hline CHEMBL 3670514 & 1527633 & 6.466 & 6.5336 & TRN & \\
\hline CHEMBL 3670534 & 1527633 & 7.1367 & 7.2877 & TRN & \\
\hline CHEMBL3670596 & 1527633 & 6.9586 & 6.5702 & TRN & \\
\hline CHEMBL 3670510 & 1527633 & 6.699 & 6.6288 & TRN & \\
\hline CHEMBL 3670519 & 1527633 & 5.0 & 5.4074 & TRN & \\
\hline CHEMBL 3670527 & 1527633 & 7.7447 & 7.9117 & TRN & \\
\hline CHEMBL 3670541 & 1527633 & 5.0 & 5.4432 & TRN & \\
\hline CHEMBL 3670520 & 1527633 & 6.6576 & 6.7639 & TRN & \\
\hline CHEMBL 3670537 & 1527633 & 7.585 & 7.3487 & TRN & \\
\hline CHEMBL 3670583 & 1527633 & 5.8861 & 5.8771 & TRN & \\
\hline CHEMBL 3665626 & 1527633 & 6.3002 & 6.7763 & TST & \\
\hline CHEMBL 3670509 & 1527633 & 7.0177 & 6.4297 & TRN & \\
\hline CHEMBL3670611 & 1527633 & 6.8416 & 6.5446 & TRN & \\
\hline CHEMBL 3670525 & 1527633 & 7.2218 & 7.1053 & TRN & \\
\hline CHEMBL 3670528 & 1527633 & 7.7696 & 7.4609 & TST & \\
\hline CHEMBL 3665622 & 1527633 & 6.8794 & 6.8767 & TRN & \\
\hline CHEMBL 3670626 & 1527633 & 7.6198 & 7.6489 & TRN & \\
\hline CHEMBL 3670557 & 1527633 & 6.7212 & 6.7916 & TRN & \\
\hline CHEMBL 3665628 & 1527633 & 5.7418 & 5.851 & TRN & \\
\hline CHEMBL 3670562 & 1527633 & 6.8539 & 6.5394 & TRN & \\
\hline CHEMBL 3670531 & 1527633 & 7.2291 & 7.0764 & TST & \\
\hline CHEMBL 3670616 & 1527633 & 8.2218 & 6.859 & TST & \\
\hline CHEMBL3665633 & 1527633 & 5.9784 & 5.7092 & TRN & \\
\hline CHEMBL3639694 & 1527633 & 6.6383 & 6.2976 & TRN & \\
\hline CHEMBL 3665640 & 1527633 & 7.3768 & 6.0333 & TST & \\
\hline CHEMBL 3670547 & 1527633 & 7.1549 & 7.2571 & TRN & \\
\hline CHEMBL 3670588 & 1527633 & 5.8861 & 5.92700 & 00000000005 & TRN \\
\hline CHEMBL 3670577 & 1527633 & 7.2291 & 7.2672 & TRN & \\
\hline
\end{tabular}


Supplemental Table S2.txt

\begin{tabular}{|c|c|c|c|c|}
\hline CHEMBL3670615 & 1527633 & 7.699 & 7.5145 & TRN \\
\hline CHEMBL3670553 & 1527633 & 6.9586 & 6.9178 & TRN \\
\hline CHEMBL3670558 & 1527633 & 6.2741 & 6.0503 & TRN \\
\hline CHEMBL3665618 & 1527633 & 6.5901 & 6.6467 & TST \\
\hline CHEMBL3670605 & 1527633 & 8.3979 & 8.3791 & TRN \\
\hline CHEMBL3665645 & 1527633 & 5.8539 & 5.8876 & TST \\
\hline CHEMBL3670568 & 1527633 & 6.4318 & 6.5954 & TRN \\
\hline CHEMBL3670634 & 1527633 & 6.9245 & 6.9492 & TRN \\
\hline CHEMBL 3670540 & 1527633 & 6.6021 & 6.6904 & TRN \\
\hline CHEMBL3670619 & 1527633 & 7.8239 & 7.9224 & TRN \\
\hline CHEMBL3670631 & 1527633 & 7.4685 & 7.3983 & TRN \\
\hline CHEMBL3670593 & 1527633 & 6.1675 & 6.2273 & TRN \\
\hline CHEMBL3670617 & 1527633 & 7.8861 & 8.2549 & TRN \\
\hline CHEMBL3670632 & 1527633 & 7.0458 & 7.2554 & TRN \\
\hline CHEMBL 3670614 & 1527633 & 7.5376 & 7.4511 & TRN \\
\hline CHEMBL3665650 & 1527633 & 6.4318 & 6.9401 & TRN \\
\hline CHEMBL3670600 & 1527633 & 6.1871 & 5.8402 & TRN \\
\hline CHEMBL3670633 & 1527633 & 7.1367 & 7.254 & TRN \\
\hline CHEMBL3665620 & 1527633 & 5.9722 & 6.1052 & TST \\
\hline CHEMBL 3670570 & 1527633 & 6.4202 & 6.3533 & TRN \\
\hline CHEMBL3665634 & 1527633 & 5.0305 & 5.4109 & TRN \\
\hline CHEMBL 2413511 & 1527633 & 7.3979 & 7.4892 & TRN \\
\hline CHEMBL3670620 & 1527633 & 7.6778 & 7.5137 & TRN \\
\hline CHEMBL3665639 & 1527633 & 6.9626 & 5.5353 & TST \\
\hline CHEMBL 3670572 & 1527633 & 6.7212 & 6.7279 & TRN \\
\hline CHEMBL3670603 & 1527633 & 5.5086 & 6.1286 & TST \\
\hline CHEMBL3670545 & 1527633 & 5.0 & 5.8425 & TST \\
\hline CHEMBL3670567 & 1527633 & 6.2676 & 6.3626 & TRN \\
\hline CHEMBL3670523 & 1527633 & 6.7932 & 6.9082 & TRN \\
\hline CHEMBL 3670595 & 1527633 & 7.4559 & 7.6286 & TRN \\
\hline CHEMBL3670590 & 1527633 & 6.699 & 6.5575 & TRN \\
\hline CHEMBL 3670594 & 1527633 & 6.5086 & 6.522 & TRN \\
\hline CHEMBL3670582 & 1527633 & 6.3116 & 6.1272 & TST \\
\hline CHEMBL 3670624 & 1527633 & 7.2924 & 7.2657 & TRN \\
\hline CHEMBL3670546 & 1527633 & 6.5607 & 6.0013 & TST \\
\hline CHEMBL3670622 & 1527633 & 7.8861 & 7.5423 & TRN \\
\hline CHEMBL3670613 & 1527633 & 5.6753 & 5.8659 & TRN \\
\hline CHEMBL 3670554 & 1527633 & 6.5243 & 6.597 & TRN \\
\hline CHEMBL 3670575 & 1527633 & 7.2596 & 7.5544 & TRN \\
\hline CHEMBL3670610 & 1527633 & 7.3565 & 7.4847 & TRN \\
\hline CHEMBL3670599 & 1527633 & 6.1079 & 6.2406 & TRN \\
\hline CHEMBL3665649 & 1527633 & 6.6383 & 6.4656 & TRN \\
\hline CHEMBL3670592 & 1527633 & 7.2518 & 7.0526 & TRN \\
\hline CHEMBL3665621 & 1527633 & 5.4225 & 5.5159 & TST \\
\hline CHEMBL3670585 & 1527633 & 6.8996 & 6.00899 & 99999999995 \\
\hline CHEMBL3670586 & 1527633 & 5.9586 & 6.0045 & TST \\
\hline CHEMBL 3665642 & 1527633 & 6.8069 & 6.96399 & 99999999995 \\
\hline CHEMBL3670536 & 1527633 & 6.6778 & 6.4564 & TRN \\
\hline
\end{tabular}


Supplemental Table S2.txt

\begin{tabular}{|c|c|c|c|c|}
\hline CHEMBL 3670561 & 1527633 & 7.0862 & 6.7604 & TRN \\
\hline CHEMBL 3670552 & 1527633 & 5.5511 & 5.9429 & TST \\
\hline CHEMBL 3670542 & 1527633 & 7.4437 & 7.6977 & TST \\
\hline CHEMBL 3670569 & 1527633 & 6.5528 & 6.318 & TST \\
\hline CHEMBL3931064 & 1527633 & 5.0458 & 5.7288 & TST \\
\hline CHEMBL 3670516 & 1527633 & 5.0 & 5.591 & TST \\
\hline CHEMBL 3670601 & 1527633 & 7.5528 & 7.6193 & TST \\
\hline CHEMBL 3670530 & 1527633 & 7.1249 & 7.1776 & TST \\
\hline CHEMBL 3670628 & 1527633 & 7.699 & 7.6773 & TST \\
\hline CHEMBL 3670511 & 1527633 & 6.7212 & 6.7651 & TST \\
\hline CHEMBL 3670630 & 1527633 & 7.9208 & 7.8119 & TST \\
\hline CHEMBL 3670579 & 1527633 & 7.3188 & 7.4605 & TST \\
\hline CHEMBL 3670606 & 1527633 & 6.0 & 7.3263 & TST \\
\hline CHEMBL 3670522 & 1527633 & 6.9393 & 7.1029 & TST \\
\hline CHEMBL 3670581 & 1527633 & 5.2219 & 6.2872 & TST \\
\hline CHEMBL 3665648 & 1527633 & 7.0757 & 7.1087 & TST \\
\hline CHEMBL 3670591 & 1527633 & 8.0458 & 7.6475 & TST \\
\hline CHEMBL1590308 & 954789 & 3.5839 & 3.7363 & TST \\
\hline CHEMBL512504 & 954789 & 4.3144 & 4.1308 & TRN \\
\hline CHEMBL 1186585 & 954789 & 4.0364 & 3.9585 & TRN \\
\hline CHEMBL65 & 954789 & 8.2836 & 7.5578 & TRN \\
\hline CHEMBL135561 & 954789 & 4.7382 & 4.6942 & TRN \\
\hline CHEMBL191334 & 954789 & 3.5291 & 4.1749 & TRN \\
\hline CHEMBL1256459 & 954789 & 6.5758 & 7.0577 & TRN \\
\hline CHEMBL213100 & 954789 & 7.3297 & 8.0339 & TRN \\
\hline CHEMBL 222102 & 954789 & 3.4253 & 3.7341 & TRN \\
\hline CHEMBL393929 & 954789 & 3.4411 & 3.6896 & TRN \\
\hline CHEMBL 220241 & 954789 & 6.2017 & 5.4257 & TRN \\
\hline CHEMBL 240954 & 954789 & 3.0682 & 3.5811 & TST \\
\hline CHEMBL577784 & 954789 & 5.3661 & 5.3201 & TRN \\
\hline CHEMBL 202721 & 954789 & 4.7175 & 4.9057 & TRN \\
\hline CHEMBL 3186408 & 954789 & 4.2774 & 3.96 & TST \\
\hline CHEMBL509032 & 954789 & 6.1793 & 6.0816 & TRN \\
\hline CHEMBL1242367 & 954789 & 5.1855 & 4.7476 & TRN \\
\hline CHEMBL1970879 & 954789 & 6.6732 & 6.4862 & TRN \\
\hline CHEMBL412142 & 954789 & 6.0725 & 4.6503 & TRN \\
\hline CHEMBL 2005886 & 954789 & 6.0596 & 5.9576 & TRN \\
\hline CHEMBL 2144069 & 954789 & 4.4691 & 5.282999 & 99999999995 \\
\hline CHEMBL1643959 & 954789 & 5.09699 & 999999999 & 4.5922 \\
\hline CHEMBL 399530 & 954789 & 4.8059 & 4.3665 & TRN \\
\hline CHEMBL514499 & 954789 & 6.2989 & 6.6851 & TRN \\
\hline CHEMBL188678 & 954789 & 4.7004 & 4.2303 & TRN \\
\hline CHEMBL483847 & 954789 & 5.1226 & 4.8986 & TRN \\
\hline CHEMBL1230020 & 954789 & 3.2242 & 3.8269 & TRN \\
\hline CHEMBL 3392440 & 954789 & 3.7728 & 4.0014 & TRN \\
\hline CHEMBL 2137530 & 954789 & 4.868 & 4.7187 & TRN \\
\hline CHEMBL1516890 & 954789 & 3.7929 & 3.8626 & TRN \\
\hline CHEMBL 258844 & 954789 & 4.2012 & 4.5528 & TRN \\
\hline
\end{tabular}




\begin{tabular}{|c|c|c|c|c|c|}
\hline & & \multicolumn{4}{|c|}{ Supplemental Table S2.txt } \\
\hline CHEMBL585951 & 954789 & 5.9943 & 6.0926 & TRN & \\
\hline CHEMBL515416 & 954789 & 4.2017 & 4.6556 & TRN & \\
\hline CHEMBL189584 & 954789 & 5.3499 & 4.7164 & TRN & \\
\hline CHEMBL573107 & 954789 & 4.3654 & 4.9249 & TRN & \\
\hline CHEMBL300389 & 954789 & 6.9619 & 6.9376 & TRN & \\
\hline CHEMBL9470 & 954789 & $5.7570 e$ & 00000000 & 5.7139 & TST \\
\hline CHEMBL 2134202 & 954789 & 3.9284 & 4.0463 & TRN & \\
\hline CHEMBL 217354 & 954789 & 6.0188 & 5.9473 & TRN & \\
\hline CHEMBL373751 & 954789 & 3.326 & 3.8542 & TRN & \\
\hline CHEMBL392695 & 954789 & 4.5876 & 4.9327 & TRN & \\
\hline CHEMBL379975 & 954789 & 4.7851 & 4.3822 & TRN & \\
\hline CHEMBL379300 & 954789 & 6.3753 & 6.2622 & TRN & \\
\hline CHEMBL92309 & 954789 & 2.1725 & 3.2909 & TST & \\
\hline CHEMBL483849 & 954789 & 0.7828 & 2.2204 & TST & \\
\hline CHEMBL209148 & 954789 & 5.1685 & 4.8701 & TST & \\
\hline CHEMBL180127 & 954789 & 4.8206 & 4.3564 & TST & \\
\hline CHEMBL1404918 & 954789 & 2.8775 & 2.9209 & TST & \\
\hline CHEMBL 210618 & 954789 & 3.1071 & 3.4336 & TST & \\
\hline CHEMBL1673039 & 954789 & 6.1141 & 5.3002 & TST & \\
\hline CHEMBL 255342 & 954789 & 3.7264 & 3.45300 & 00000000003 & TST \\
\hline CHEMBL102714 & 954789 & 3.9724 & 3.4019 & TST & \\
\hline CHEMBL1767132 & 744057 & 3.6021 & 3.6751 & TRN & \\
\hline CHEMBL1767273 & 744057 & 5.1938 & 5.2145 & TRN & \\
\hline CHEMBL1767244 & 744057 & 5.5686 & 5.0997 & TRN & \\
\hline CHEMBL1767281 & 744057 & 5.0132 & 5.2306 & TRN & \\
\hline CHEMBL1767297 & 744057 & 5.3098 & 4.9759 & TST & \\
\hline CHEMBL1767263 & 744057 & 5.4685 & 4.5883 & TRN & \\
\hline CHEMBL1767280 & 744057 & 4.9914 & 5.3808 & TRN & \\
\hline CHEMBL1767250 & 744057 & 3.6021 & 4.2766 & TRN & \\
\hline CHEMBL1767256 & 744057 & 5.585 & 5.1466 & TRN & \\
\hline CHEMBL1767129 & 744057 & 3.0 & 3.5128 & TRN & \\
\hline CHEMBL1767276 & 744057 & 5.4685 & 5.2269 & TRN & \\
\hline CHEMBL1767131 & 744057 & 3.6021 & 3.5987 & TRN & \\
\hline CHEMBL1767283 & 744057 & 5.2366 & 5.2384 & TRN & \\
\hline CHEMBL1767298 & 744057 & 5.6021 & 4.6542 & TST & \\
\hline CHEMBL1767293 & 744057 & 5.1192 & 4.8428 & TST & \\
\hline CHEMBL1767265 & 744057 & 4.9245 & 4.3984 & TRN & \\
\hline CHEMBL1767274 & 744057 & 5.2366 & 5.2143 & TRN & \\
\hline CHEMBL1767294 & 744057 & 4.0783 & 4.9973 & TST & \\
\hline CHEMBL1767237 & 744057 & 5.4437 & 4.5315 & TRN & \\
\hline CHEMBL1767128 & 744057 & 3.0 & 3.4372 & TRN & \\
\hline CHEMBL1767289 & 744057 & 3.301 & 4.3838 & TRN & \\
\hline CHEMBL1767279 & 744057 & 5.0862 & 5.2485 & TRN & \\
\hline CHEMBL1767247 & 744057 & 5.5686 & 5.3668 & TRN & \\
\hline CHEMBL1767286 & 744057 & 5.5086 & 4.9988 & TRN & \\
\hline CHEMBL1767264 & 744057 & 5.7447 & 4.9972 & TRN & \\
\hline CHEMBL1767300 & 744057 & 5.6021 & 5.0262 & TST & \\
\hline CHEMBL1767126 & 744057 & 4.585 & 3.6901 & TRN & \\
\hline
\end{tabular}




\begin{tabular}{|c|c|c|c|c|c|}
\hline & & \multicolumn{4}{|c|}{ Supplemental Table S2.txt } \\
\hline CHEMBL1767255 & 744057 & 5.8539 & 4.7954 & TRN & \\
\hline CHEMBL1767295 & 744057 & 5.4437 & 5.2707 & TRN & \\
\hline CHEMBL1767238 & 744057 & 5.2291 & 4.5539 & TRN & \\
\hline CHEMBL1767248 & 744057 & 5.7447 & 5.3817 & TRN & \\
\hline CHEMBL1767296 & 744057 & 5.6021 & 5.2797 & TRN & \\
\hline CHEMBL1767266 & 744057 & 5.585 & 4.8427 & TRN & \\
\hline CHEMBL1767257 & 744057 & 4.7282 & 5.3763 & TRN & \\
\hline CHEMBL1767288 & 744057 & 5.0915 & 4.8941 & TRN & \\
\hline CHEMBL1734241 & 744057 & 4.1244 & 4.7168 & TST & \\
\hline CHEMBL1767291 & 744057 & 3.301 & 5.0446 & TST & \\
\hline CHEMBL1767245 & 744057 & 3.301 & 4.1549 & TRN & \\
\hline CHEMBL1767258 & 744057 & 5.0809 & 4.7395 & TRN & \\
\hline CHEMBL1767270 & 744057 & 5.3665 & 5.0537 & TRN & \\
\hline CHEMBL1767299 & 744057 & 5.7212 & 5.4863 & TRN & \\
\hline CHEMBL1767249 & 744057 & 3.6021 & 4.8692 & TRN & \\
\hline CHEMBL1767290 & 744057 & 5.0269 & 4.2499 & TRN & \\
\hline CHEMBL1767241 & 744057 & 3.6021 & 4.2979 & TRN & \\
\hline CHEMBL1767246 & 744057 & 3.6021 & 4.7127 & TST & \\
\hline CHEMBL1767239 & 744057 & 3.0 & 4.4857 & TST & \\
\hline CHEMBL1767260 & 744057 & 5.5376 & 4.5489 & TRN & \\
\hline CHEMBL1767284 & 744057 & 4.9031 & 5.1476 & TRN & \\
\hline CHEMBL1767127 & 744057 & 3.0 & 3.4575 & TRN & \\
\hline CHEMBL1767240 & 744057 & 3.6021 & 4.4757 & TRN & \\
\hline CHEMBL1767285 & 744057 & 3.6021 & 4.9327 & TRN & \\
\hline CHEMBL1767261 & 744057 & 5.7447 & 4.9237 & TRN & \\
\hline CHEMBL1767278 & 744057 & 5.7212 & 5.13700 & 00000000005 & TRN \\
\hline CHEMBL1567347 & 744057 & 3.0 & 4.4698 & TRN & \\
\hline CHEMBL1767252 & 744057 & 3.6021 & 4.3259 & TRN & \\
\hline CHEMBL 1767287 & 744057 & 3.301 & 5.0252 & TRN & \\
\hline CHEMBL1767271 & 744057 & 3.6021 & 4.7992 & TRN & \\
\hline CHEMBL1767275 & 744057 & 4.6799 & 5.0624 & TRN & \\
\hline CHEMBL1767251 & 744057 & 5.6383 & 4.8919 & TRN & \\
\hline CHEMBL1767292 & 744057 & 4.1851 & 5.008 & TST & \\
\hline CHEMBL1584161 & 744057 & 5.5376 & 5.0241 & TRN & \\
\hline CHEMBL1767267 & 744057 & 5.2441 & 4.8547 & TRN & \\
\hline CHEMBL1767236 & 744057 & 5.2676 & 3.8265 & TRN & \\
\hline CHEMBL1767235 & 744057 & 3.0 & 3.61 & TST & \\
\hline CHEMBL1767277 & 744057 & 3.6021 & 4.9264 & TRN & \\
\hline CHEMBL1767262 & 744057 & 3.6021 & 5.0341 & TRN & \\
\hline CHEMBL1767253 & 744057 & 3.6021 & 4.3919 & TST & \\
\hline CHEMBL1767272 & 744057 & 5.1192 & 5.0277 & TRN & \\
\hline CHEMBL1767254 & 744057 & 5.8861 & 4.3095 & TRN & \\
\hline CHEMBL1767242 & 744057 & 3.6021 & 4.3901 & TST & \\
\hline CHEMBL1767243 & 744057 & 5.4949 & 4.9548 & TST & \\
\hline CHEMBL1767130 & 744057 & 3.0 & 3.7633 & TST & \\
\hline CHEMBL1767282 & 744057 & 5.1308 & 4.9111 & TST & \\
\hline CHEMBL1765112 & 744057 & 5.0269 & 5.0691 & TST & \\
\hline CHEMBL1767268 & 744057 & 5.2218 & 4.4956 & TST & \\
\hline
\end{tabular}


Supplemental Table S2.txt

\begin{tabular}{|c|c|c|c|c|c|c|}
\hline CHEMBL1767269 & 744057 & 5.2676 & 4.9369 & TST & & \\
\hline CHEMBL1767259 & 744057 & 5.2924 & 5.2128 & TST & & \\
\hline CHEMBL220912 & 1527732 & 6.6126 & 6.6977 & TRN & & \\
\hline CHEMBL 3648058 & 1527732 & 7.75700 & 000000000 & 01 & 7.5401 & TST \\
\hline CHEMBL3651216 & 1527732 & 6.8477 & 6.9219 & TRN & & \\
\hline CHEMBL3648051 & 1527732 & 7.7545 & 7.9087 & TST & & \\
\hline CHEMBL 231338 & 1527732 & 7.1772 & 7.3192 & TRN & & \\
\hline CHEMBL437004 & 1527732 & 8.2518 & 7.9553 & TRN & & \\
\hline CHEMBL376860 & 1527732 & 4.0 & 3.8552 & TRN & & \\
\hline CHEMBL231524 & 1527732 & 7.2924 & 7.2216 & TRN & & \\
\hline CHEMBL3648036 & 1527732 & 7.4101 & 7.4375 & TRN & & \\
\hline CHEMBL 218551 & 1527732 & 4.0 & 3.6453 & TRN & & \\
\hline CHEMBL 3648028 & 1527732 & 6.7235 & 6.4977 & TRN & & \\
\hline CHEMBL 218597 & 1527732 & 6.8447 & 6.8428 & TRN & & \\
\hline CHEMBL3651249 & 1527732 & 8.1675 & 8.1243 & TST & & \\
\hline CHEMBL397691 & 1527732 & 7.6904 & 7.5951 & TRN & & \\
\hline CHEMBL250821 & 1527732 & 9.1549 & 9.2277 & TRN & & \\
\hline CHEMBL 3651279 & 1527732 & 8.8239 & 8.5661 & TST & & \\
\hline CHEMBL3651257 & 1527732 & 8.3768 & 8.5888 & TRN & & \\
\hline CHEMBL221431 & 1527732 & 6.9666 & 6.9413 & TRN & & \\
\hline CHEMBL3648009 & 1527732 & 7.1427 & 7.1473 & TST & & \\
\hline CHEMBL3648011 & 1527732 & 4.0 & 4.5422 & TRN & & \\
\hline CHEMBL 218598 & 1527732 & 5.7447 & 5.3024 & TST & & \\
\hline CHEMBL3651235 & 1527732 & 7.5719 & 7.6208 & TST & & \\
\hline CHEMBL268825 & 1527732 & 7.4584 & 7.0439 & TRN & & \\
\hline CHEMBL3651291 & 1527732 & 8.4202 & 8.6504 & TRN & & \\
\hline CHEMBL 250218 & 1527732 & 8.3188 & 8.2185 & TRN & & \\
\hline CHEMBL3648068 & 1527732 & 7.7375 & 7.5042 & TST & & \\
\hline CHEMBL 3648061 & 1527732 & 7.8356 & 7.6154 & TST & & \\
\hline CHEMBL 3648017 & 1527732 & 3.0 & 4.0934 & TRN & & \\
\hline CHEMBL 218160 & 1527732 & 4.0 & 3.5033 & TRN & & \\
\hline CHEMBL3651286 & 1527732 & 9.0 & 9.09 & TRN & & \\
\hline CHEMBL3651200 & 1527732 & 7.4949 & 7.6339 & TST & & \\
\hline CHEMBL3651239 & 1527732 & 7.2774 & 7.1666 & TRN & & \\
\hline CHEMBL 3648006 & 1527732 & 5.0 & 3.8586 & TRN & & \\
\hline CHEMBL3651278 & 1527732 & 8.3665 & 8.3359 & TRN & & \\
\hline CHEMBL3651195 & 1527732 & 7.9245 & 8.0592 & TRN & & \\
\hline CHEMBL 230685 & 1527732 & 6.4672 & 6.2234 & TRN & & \\
\hline CHEMBL 3651292 & 1527732 & 8.9208 & 9.0611 & TRN & & \\
\hline CHEMBL 3651283 & 1527732 & 8.4318 & 8.4335 & TRN & & \\
\hline CHEMBL3651220 & 1527732 & 7.5243 & 7.567 & TRN & & \\
\hline CHEMBL3648067 & 1527732 & 7.5346 & 7.7086 & TRN & & \\
\hline CHEMBL3651256 & 1527732 & 5.0 & 5.4994 & TRN & & \\
\hline CHEMBL 230614 & 1527732 & 7.6778 & 7.7058 & TRN & & \\
\hline CHEMBL 3648016 & 1527732 & 4.0 & 4.5258 & TRN & & \\
\hline CHEMBL250625 & 1527732 & 8.28399 & 999999999 & 99 & 8.2979 & TRN \\
\hline CHEMBL231219 & 1527732 & 7.8539 & 7.8482 & TRN & & \\
\hline CHEMBL440963 & 1527732 & 8.5086 & 8.6359 & TRN & & \\
\hline
\end{tabular}


Supplemental Table S2.txt

\begin{tabular}{|c|c|c|c|c|c|}
\hline CHEMBL3651284 & 1527732 & 8.7959 & 8.7296 & TRN & \\
\hline CHEMBL231525 & 1527732 & 6.5498 & 6.407 & TRN & \\
\hline CHEMBL3651221 & 1527732 & 7.466 & 7.4343 & TRN & \\
\hline CHEMBL397998 & 1527732 & 4.0 & 4.3718 & TRN & \\
\hline CHEMBL394518 & 1527732 & 6.6819 & 6.7866 & TRN & \\
\hline CHEMBL374868 & 1527732 & 4.0 & 3.56 & TRN & \\
\hline CHEMBL3651281 & 1527732 & 6.8069 & 6.8093 & TRN & \\
\hline CHEMBL3651230 & 1527732 & 6.9318 & 7.1716 & TRN & \\
\hline CHEMBL3651265 & 1527732 & 7.644 & 7.3917 & TRN & \\
\hline CHEMBL218109 & 1527732 & 5.0 & 4.4493 & TRN & \\
\hline CHEMBL231316 & 1527732 & 7.5986 & 7.6091 & TRN & \\
\hline CHEMBL230830 & 1527732 & 7.9747 & 8.1683 & TRN & \\
\hline CHEMBL3651288 & 1527732 & 9.02 & 8.9289 & TRN & \\
\hline CHEMBL3648065 & 1527732 & 7.5622 & 7.5074 & TST & \\
\hline CHEMBL3651259 & 1527732 & 7.9872 & 8.0759 & TST & \\
\hline CHEMBL3648053 & 1527732 & 7.6778 & 7.5397 & TRN & \\
\hline CHEMBL3651246 & 1527732 & 8.7959 & 8.566 & TRN & \\
\hline CHEMBL3651269 & 1527732 & 6.5513 & 6.5006 & TRN & \\
\hline CHEMBL3651238 & 1527732 & 7.9508 & 7.7986 & TST & \\
\hline CHEMBL230615 & 1527732 & 7.4034 & 7.6541 & TRN & \\
\hline CHEMBL3651266 & 1527732 & 7.9914 & 7.9481 & TRN & \\
\hline CHEMBL249820 & 1527732 & 7.153 & 7.3722 & TRN & \\
\hline CHEMBL230793 & 1527732 & 5.9208 & 5.7336 & TRN & \\
\hline CHEMBL3648013 & 1527732 & 4.0 & 3.787 & TRN & \\
\hline CHEMBL3648055 & 1527732 & 7.0269 & 6.6601 & TST & \\
\hline CHEMBL3648070 & 1527732 & 4.0 & 4.2933 & TRN & \\
\hline CHEMBL 3651280 & 1527732 & 8.28399 & 999999999 & 99 & 8.1658 \\
\hline CHEMBL249819 & 1527732 & 8.5229 & 8.6452 & TRN & \\
\hline CHEMBL374248 & 1527732 & 6.5317 & 6.4594 & TRN & \\
\hline CHEMBL3651227 & 1527732 & 8.0 & 8.2329 & TRN & \\
\hline CHEMBL3648015 & 1527732 & 4.0 & 3.8635 & TST & \\
\hline CHEMBL3651295 & 1527732 & 8.4437 & 8.5948 & TRN & \\
\hline CHEMBL3651294 & 1527732 & 6.8761 & 6.8164 & TRN & \\
\hline CHEMBL3651212 & 1527732 & 8.1805 & 8.2388 & TRN & \\
\hline CHEMBL3651234 & 1527732 & 6.9208 & 6.9543 & TST & \\
\hline CHEMBL3648049 & 1527732 & 6.0 & 5.476 & TST & \\
\hline CHEMBL3648046 & 1527732 & 7.5406 & 7.4365 & TRN & \\
\hline CHEMBL3651207 & 1527732 & 5.301 & 5.4871 & TRN & \\
\hline CHEMBL3648056 & 1527732 & 6.9281 & 6.6835 & TRN & \\
\hline CHEMBL3651260 & 1527732 & 8.7447 & 8.5356 & TST & \\
\hline CHEMBL3651268 & 1527732 & 7.3546 & 7.3997 & TRN & \\
\hline CHEMBL 3651247 & 1527732 & 7.3325 & 7.7044 & TST & \\
\hline CHEMBL3651276 & 1527732 & 8.4685 & 8.4648 & TRN & \\
\hline CHEMBL3651232 & 1527732 & 6.8633 & 6.9272 & TST & \\
\hline CHEMBL3648062 & 1527732 & 7.8153 & 7.7921 & TRN & \\
\hline CHEMBL 3651285 & 1527732 & 8.9586 & 8.9879 & TRN & \\
\hline CHEMBL3651211 & 1527732 & 6.5654 & 7.1317 & TRN & \\
\hline CHEMBL3651215 & 1527732 & 4.0 & 4.4685 & TST & \\
\hline
\end{tabular}


Supplemental Table S2.txt

\begin{tabular}{|c|c|c|c|c|c|c|}
\hline CHEMBL 3651267 & 1527732 & 5.6544 & 5.8059 & TRN & & \\
\hline CHEMBL394765 & 1527732 & 6.1035 & 5.9061 & TRN & & \\
\hline CHEMBL3651245 & 1527732 & 5.8386 & 5.3036 & TST & & \\
\hline CHEMBL3651229 & 1527732 & \multicolumn{3}{|c|}{5.7620000000000005} & 5.5482 & TRN \\
\hline CHEMBL3648060 & 1527732 & 7.8356 & 8.0189 & TST & & \\
\hline CHEMBL3648007 & 1527732 & 5.0 & 4.0443 & TRN & & \\
\hline CHEMBL3651236 & 1527732 & 7.6655 & 7.904 & TST & & \\
\hline CHEMBL3648023 & 1527732 & 3.0 & 2.9948 & TRN & & \\
\hline CHEMBL3651226 & 1527732 & 5.0969 & 5.2687 & TRN & & \\
\hline CHEMBL3639468 & 1527732 & 3.0 & 3.3689 & TRN & & \\
\hline CHEMBL3648052 & 1527732 & 5.8239 & 5.5758 & TST & & \\
\hline CHEMBL3648027 & 1527732 & 3.0 & 3.2485 & TRN & & \\
\hline CHEMBL230815 & 1527732 & 5.5376 & 5.3001 & TRN & & \\
\hline CHEMBL3651201 & 1527732 & 5.0 & 5.0185 & TRN & & \\
\hline CHEMBL3651199 & 1527732 & 7.4584 & 7.5196 & TRN & & \\
\hline CHEMBL3651205 & 1527732 & 7.3536 & 7.4831 & TRN & & \\
\hline CHEMBL218281 & 1527732 & 6.8928 & 7.0186 & TRN & & \\
\hline CHEMBL 3651225 & 1527732 & 7.9136 & 7.6987 & TST & & \\
\hline CHEMBL 3651228 & 1527732 & 8.3188 & 8.5304 & TST & & \\
\hline CHEMBL3651231 & 1527732 & 8.2441 & 8.0102 & TST & & \\
\hline CHEMBL3651287 & 1527732 & 8.6198 & 8.6379 & TRN & & \\
\hline CHEMBL250019 & 1527732 & 8.5229 & 8.498 & TRN & & \\
\hline CHEMBL250214 & 1527732 & 8.4437 & 8.5797 & TRN & & \\
\hline CHEMBL270490 & 1527732 & 4.0 & 3.966 & TRN & & \\
\hline CHEMBL3648037 & 1527732 & 7.4461 & 7.3765 & TRN & & \\
\hline CHEMBL3651241 & 1527732 & 8.0706 & 8.0795 & TRN & & \\
\hline CHEMBL221975 & 1527732 & 6.8861 & 6.7439 & TST & & \\
\hline CHEMBL 3648048 & 1527732 & 7.7932 & 7.9083 & TST & & \\
\hline CHEMBL3648066 & 1527732 & 7.8827 & 7.9923 & TST & & \\
\hline CHEMBL231251 & 1527732 & 8.1675 & 8.1882 & TRN & & \\
\hline CHEMBL 3651250 & 1527732 & 8.7447 & 8.7744 & TRN & & \\
\hline CHEMBL3648039 & 1527732 & 8.0506 & 8.058 & TRN & & \\
\hline CHEMBL3651261 & 1527732 & 6.3635 & 6.2806 & TRN & & \\
\hline CHEMBL218742 & 1527732 & 6.7496 & 6.4025 & TRN & & \\
\hline CHEMBL3651251 & 1527732 & 5.0 & 4.4062 & TST & & \\
\hline CHEMBL250021 & 1527732 & 8.4949 & 8.3487 & TRN & & \\
\hline CHEMBL3651290 & 1527732 & 8.6778 & 8.7866 & TRN & & \\
\hline CHEMBL3648047 & 1527732 & 7.0173 & 7.2494 & TST & & \\
\hline CHEMBL 3651224 & 1527732 & 5.3458 & 5.1394 & TST & & \\
\hline CHEMBL3651237 & 1527732 & 6.9266 & 6.9847 & TST & & \\
\hline CHEMBL218042 & 1527732 & 5.8182 & 6.2122 & TRN & & \\
\hline CHEMBL230509 & 1527732 & 7.1415 & 6.9236 & TRN & & \\
\hline CHEMBL3651255 & 1527732 & 8.4815 & 8.3392 & TST & & \\
\hline CHEMBL221739 & 1527732 & 5.0 & 3.9693 & TST & & \\
\hline CHEMBL3648014 & 1527732 & 3.0 & 4.4237 & TST & & \\
\hline CHEMBL3651217 & 1527732 & 7.75200 & 00000000 & 01 & 7.744 & TRN \\
\hline CHEMBL3651242 & 1527732 & 7.5654 & 7.4058 & TRN & & \\
\hline CHEMBL400303 & 1527732 & 8.8239 & 8.9201 & TRN & & \\
\hline
\end{tabular}


Supplemental Table S2.txt

\begin{tabular}{|c|c|c|c|c|}
\hline CHEMBL 3651248 & 1527732 & 4.0 & 4.5096 & TRN \\
\hline CHEMBL 3648032 & 1527732 & 7.4828 & 7.6015 & TRN \\
\hline CHEMBL 3648043 & 1527732 & 7.5622 & 7.5642 & TRN \\
\hline CHEMBL230829 & 1527732 & 8.0132 & \multicolumn{2}{|c|}{8.267000000000001} \\
\hline CHEMBL 3648035 & 1527732 & 7.1249 & 7.2546 & TRN \\
\hline CHEMBL 3651264 & 1527732 & 7.2182 & 7.24100 & 00000000005 \\
\hline CHEMBL 3648022 & 1527732 & 3.0 & 3.2619 & TRN \\
\hline CHEMBL 3648045 & 1527732 & 7.5986 & 7.3429 & TRN \\
\hline CHEMBL 218102 & 1527732 & 7.9914 & 8.0803 & TRN \\
\hline CHEMBL 3651223 & 1527732 & 6.0555 & 5.8464 & TRN \\
\hline CHEMBL250623 & 1527732 & 8.1805 & 8.0113 & TRN \\
\hline CHEMBL436516 & 1527732 & 6.4921 & 6.4954 & TRN \\
\hline CHEMBL 230918 & 1527732 & 6.5017 & 6.5331 & TRN \\
\hline CHEMBL 3648057 & 1527732 & 6.6345 & 6.318 & TRN \\
\hline CHEMBL441545 & 1527732 & 4.0 & 3.54 & TRN \\
\hline CHEMBL 3648069 & 1527732 & 6.5436 & 6.8049 & TST \\
\hline CHEMBL3651222 & 1527732 & 6.9547 & 6.6186 & TRN \\
\hline CHEMBL 231218 & 1527732 & 8.041 & 8.0612 & TRN \\
\hline CHEMBL 3651273 & 1527732 & 7.1979 & 7.2291 & TRN \\
\hline CHEMBL 3648008 & 1527732 & 5.0458 & 4.7062 & TST \\
\hline CHEMBL399268 & 1527732 & 8.301 & 8.2567 & TRN \\
\hline CHEMBL230271 & 1527732 & 6.9172 & 7.0516 & TRN \\
\hline CHEMBL 3648025 & 1527732 & 3.0 & 3.3224 & TRN \\
\hline CHEMBL390479 & 1527732 & 7.6904 & 7.6937 & TRN \\
\hline CHEMBL3651206 & 1527732 & 8.1024 & 7.6267 & TRN \\
\hline CHEMBL249821 & 1527732 & 8.4437 & 8.5161 & TRN \\
\hline CHEMBL 3648034 & 1527732 & 6.4672 & 6.3167 & TRN \\
\hline CHEMBL 230898 & 1527732 & 6.684 & 6.2746 & TRN \\
\hline CHEMBL 3651218 & 1527732 & 6.3575 & 6.0582 & TRN \\
\hline CHEMBL3651293 & 1527732 & 7.0443 & 7.079 & TST \\
\hline CHEMBL 3648019 & 1527732 & 3.0 & 3.2654 & TRN \\
\hline CHEMBL 3651213 & 1527732 & 7.1192 & 7.1203 & TST \\
\hline CHEMBL 3949485 & 1527732 & 7.4248 & 7.3154 & TST \\
\hline CHEMBL 3648005 & 1527732 & 5.2366 & 5.2776 & TST \\
\hline CHEMBL 3651194 & 1527732 & 7.5935 & 7.6276 & TRN \\
\hline CHEMBL 3651263 & 1527732 & 5.4004 & 5.392 & TRN \\
\hline CHEMBL 250423 & 1527732 & 8.1805 & 8.1914 & TRN \\
\hline CHEMBL 3648012 & 1527732 & 4.0 & 4.4116 & TRN \\
\hline CHEMBL 3648018 & 1527732 & 3.0 & 3.427 & TRN \\
\hline CHEMBL 3651274 & 1527732 & 7.6655 & 7.5804 & TRN \\
\hline CHEMBL 3648063 & 1527732 & 7.5986 & 7.5875 & TRN \\
\hline CHEMBL 3651277 & 1527732 & 8.3665 & 8.3018 & TST \\
\hline CHEMBL 3651240 & 1527732 & 7.8633 & 8.0805 & TRN \\
\hline CHEMBL397692 & 1527732 & 7.8996 & 7.9063 & TRN \\
\hline CHEMBL 3651254 & 1527732 & 5.7515 & 5.6726 & TST \\
\hline CHEMBL 3651214 & 1527732 & 6.4698 & 7.0415 & TRN \\
\hline CHEMBL 3651198 & 1527732 & 7.9136 & 7.7822 & TRN \\
\hline CHEMBL 218738 & 1527732 & 4.0 & 4.0922 & TST \\
\hline
\end{tabular}


Supplemental Table S2.txt

\begin{tabular}{|c|c|c|c|c|c|}
\hline CHEMBL218049 & 1527732 & 7.317 & 7.2128 & TRN & \\
\hline CHEMBL 3651271 & 1527732 & 7.1624 & 7.0748 & TST & \\
\hline CHEMBL 220480 & 1527732 & 6.0191 & 5.7806 & TRN & \\
\hline CHEMBL 3639501 & 1527732 & 9.266 & 9.3906 & TRN & \\
\hline CHEMBL 3648054 & 1527732 & 7.5784 & 7.7213 & TRN & \\
\hline CHEMBL220798 & 1527732 & 6.8539 & 6.4625 & TRN & \\
\hline CHEMBL 3651275 & 1527732 & 7.1096 & 6.9485 & TRN & \\
\hline CHEMBL 3651253 & 1527732 & 8.3768 & 8.3479 & TST & \\
\hline CHEMBL 3651252 & 1527732 & 5.0 & 4.6382 & TST & \\
\hline CHEMBL 230272 & 1527732 & 7.9101 & 8.206 & TRN & \\
\hline CHEMBL398279 & 1527732 & 8.3872 & 8.4784 & TRN & \\
\hline CHEMBL3651209 & 1527732 & 7.2168 & 7.3228 & TRN & \\
\hline CHEMBL 3651282 & 1527732 & 6.9101 & 7.1322 & TRN & \\
\hline CHEMBL 3651289 & 1527732 & 7.1013 & 6.8382 & TRN & \\
\hline CHEMBL446951 & 1527732 & 6.8633 & 6.8551 & TRN & \\
\hline CHEMBL3651272 & 1527732 & 6.4377 & 6.4645 & TRN & \\
\hline CHEMBL3651258 & 1527732 & 8.585 & 8.5196 & TST & \\
\hline CHEMBL 3648044 & 1527732 & 7.6345 & 7.4932 & TRN & \\
\hline CHEMBL 3651244 & 1527732 & 5.0969 & 5.2528 & TRN & \\
\hline CHEMBL218656 & 1527732 & 8.0146 & 8.068 & TRN & \\
\hline CHEMBL 3648042 & 1527732 & 4.1249 & 4.1564 & TRN & \\
\hline CHEMBL 3651210 & 1527732 & 8.4685 & 8.3482 & TRN & \\
\hline CHEMBL3651270 & 1527732 & 6.4168 & 6.0585 & TST & \\
\hline CHEMBL 3651208 & 1527732 & 7.0372 & 7.1947 & TRN & \\
\hline CHEMBL3648064 & 1527732 & 7.7375 & 7.7039 & TST & \\
\hline CHEMBL399246 & 1527732 & 8.5376 & 8.5201 & TRN & \\
\hline CHEMBL3651204 & 1527732 & 7.3261 & 7.2296 & TRN & \\
\hline CHEMBL230999 & 1527732 & 7.8239 & 7.9832 & TRN & \\
\hline CHEMBL 3651262 & 1527732 & 8.9208 & 8.9208 & TRN & \\
\hline CHEMBL3648031 & 1527732 & 7.5686 & 7.4479 & TRN & \\
\hline CHEMBL 230686 & 1527732 & 8.0269 & 7.8785 & TRN & \\
\hline CHEMBL 230792 & 1527732 & 6.2967 & 6.3529 & TRN & \\
\hline CHEMBL3651233 & 1527732 & 4.0 & 4.7486 & TST & \\
\hline CHEMBL 3648021 & 1527732 & 3.0 & 3.2277 & TRN & \\
\hline CHEMBL3651196 & 1527732 & 7.5406 & 7.5905 & TRN & \\
\hline CHEMBL230816 & 1527732 & 7.9788 & 7.9104 & TRN & \\
\hline CHEMBL3648038 & 1527732 & 4.9318 & 4.6416 & TST & \\
\hline CHEMBL3651203 & 1527732 & 5.0 & 5.4782 & TRN & \\
\hline CHEMBL 3648041 & 1527732 & 6.2147 & 5.8655 & TRN & \\
\hline CHEMBL 3651243 & 1527732 & 7.5834 & 7.86299 & 99999999995 & TRN \\
\hline CHEMBL 272233 & 1527732 & 5.0 & 4.9268 & TRN & \\
\hline CHEMBL395984 & 1527732 & 7.9101 & 7.8021 & TRN & \\
\hline CHEMBL3651202 & 1527732 & 6.2518 & 6.2535 & TRN & \\
\hline CHEMBL3651197 & 1527732 & 7.0526 & 7.2423 & TRN & \\
\hline CHEMBL 218842 & 1527732 & 3.0 & 4.0771 & TRN & \\
\hline CHEMBL400402 & 1527732 & 8.7959 & 8.6221 & TRN & \\
\hline CHEMBL 3648010 & 1527732 & 7.1169 & 7.0076 & TST & \\
\hline CHEMBL 3648040 & 1527732 & 6.2581 & 6.2232 & TRN & \\
\hline
\end{tabular}


Supplemental Table S2.txt

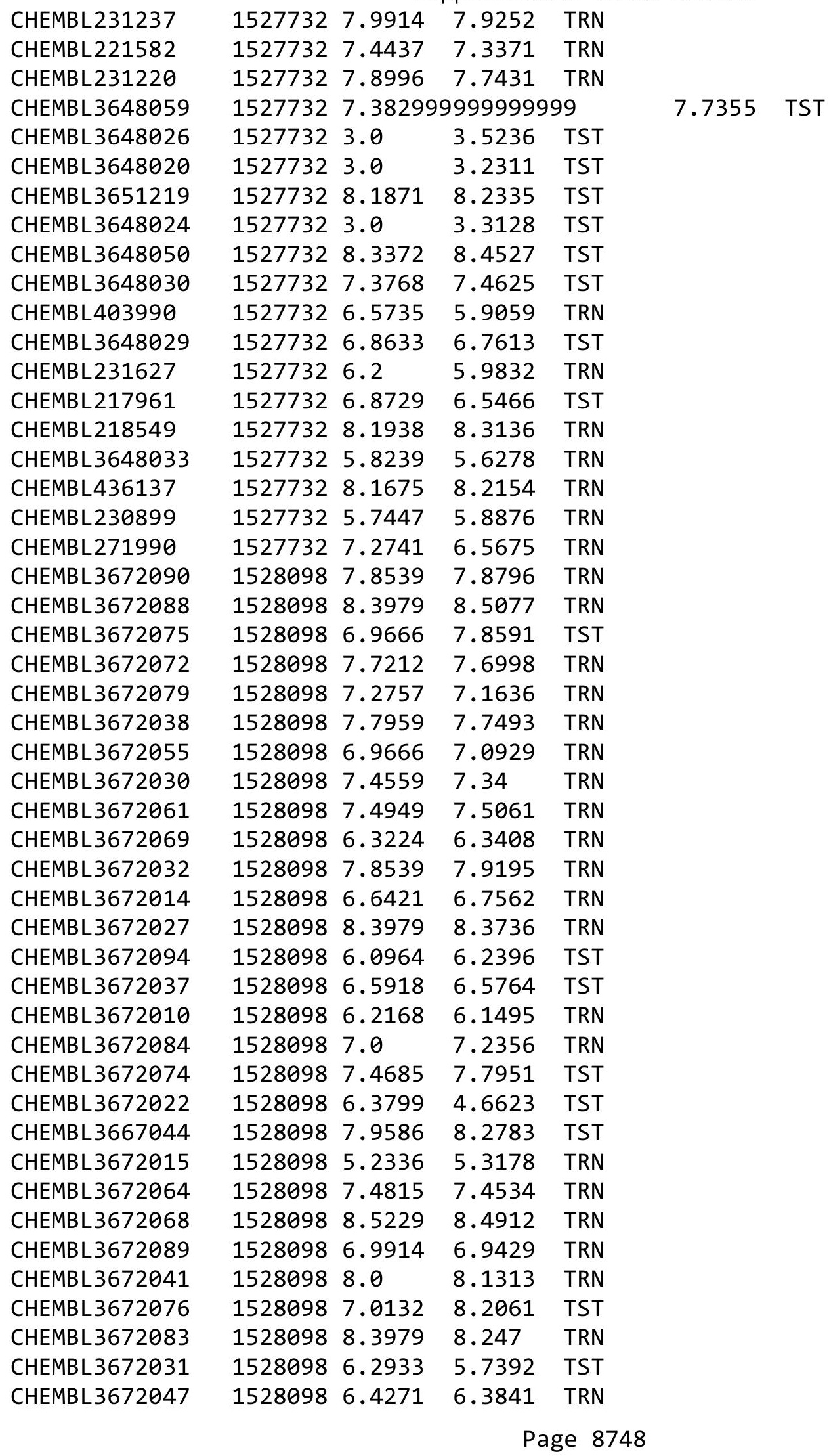


Supplemental Table S2.txt

\begin{tabular}{|c|c|c|c|c|c|}
\hline CHEMBL 3667045 & 1528098 & 5.9136 & 5.8332 & TRN & \\
\hline CHEMBL 3672070 & 1528098 & 6.8928 & 6.9164 & TRN & \\
\hline CHEMBL3672011 & 1528098 & 6.3706 & 6.4072 & TRN & \\
\hline CHEMBL3672062 & 1528098 & 5.8416 & 5.8461 & TRN & \\
\hline CHEMBL3672018 & 1528098 & 5.9626 & 5.8478 & TRN & \\
\hline CHEMBL3672067 & 1528098 & 7.3279 & 7.3324 & TRN & \\
\hline CHEMBL3672092 & 1528098 & 6.9066 & 6.8835 & TRN & \\
\hline CHEMBL 3672060 & 1528098 & 7.7696 & 7.8586 & TRN & \\
\hline CHEMBL 3672080 & 1528098 & 6.8386 & 6.7462 & TRN & \\
\hline CHEMBL3672048 & 1528098 & 7.6778 & 7.731 & TRN & \\
\hline CHEMBL3672050 & 1528098 & 7.0862 & 7.1559 & TST & \\
\hline CHEMBL3639709 & 1528098 & 8.301 & 8.2406 & TRN & \\
\hline CHEMBL 3672042 & 1528098 & 7.7212 & 7.989 & TST & \\
\hline CHEMBL 3667043 & 1528098 & 8.301 & 7.8559 & TST & \\
\hline CHEMBL3672086 & 1528098 & 6.6536 & 6.6881 & TRN & \\
\hline CHEMBL3672036 & 1528098 & 7.3768 & 7.3502 & TRN & \\
\hline CHEMBL3672044 & 1528098 & 7.9586 & 8.0374 & TRN & \\
\hline CHEMBL3672035 & 1528098 & 5.6402 & 5.25 & TST & \\
\hline CHEMBL 3672065 & 1528098 & 7.7696 & 7.6483 & TRN & \\
\hline CHEMBL3672019 & 1528098 & 6.4789 & 4.8193 & TST & \\
\hline CHEMBL3672078 & 1528098 & 7.4437 & 7.46399 & 99999999995 & TRN \\
\hline CHEMBL3672059 & 1528098 & 6.7825 & 6.7123 & TRN & \\
\hline CHEMBL3672063 & 1528098 & 8.1549 & 8.169 & TRN & \\
\hline CHEMBL 3672066 & 1528098 & 7.8539 & 7.9035 & TRN & \\
\hline CHEMBL3672073 & 1528098 & 6.9281 & 7.6058 & TST & \\
\hline CHEMBL3672016 & 1528098 & 5.9666 & 6.0799 & TRN & \\
\hline CHEMBL 3672077 & 1528098 & 7.4089 & 7.494 & TRN & \\
\hline CHEMBL3672028 & 1528098 & 6.9393 & 6.6702 & TST & \\
\hline CHEMBL 3672023 & 1528098 & 6.1198 & 6.1423 & TRN & \\
\hline CHEMBL3672051 & 1528098 & 6.6925 & 7.5149 & TST & \\
\hline CHEMBL3672081 & 1528098 & 7.0555 & 7.1269 & TRN & \\
\hline CHEMBL 3672025 & 1528098 & 5.0052 & 5.2853 & TST & \\
\hline CHEMBL 3672024 & 1528098 & 6.3615 & 6.3176 & TRN & \\
\hline CHEMBL 3672085 & 1528098 & 7.9208 & 7.6801 & TRN & \\
\hline CHEMBL3672056 & 1528098 & 5.9586 & 5.8383 & TRN & \\
\hline CHEMBL3672054 & 1528098 & 7.0132 & 7.0831 & TRN & \\
\hline CHEMBL3672082 & 1528098 & 7.7959 & 7.8377 & TRN & \\
\hline CHEMBL3667042 & 1528098 & 7.1871 & 7.6741 & TST & \\
\hline CHEMBL 3672017 & 1528098 & 3.699 & 3.8577 & TRN & \\
\hline CHEMBL 3672040 & 1528098 & 6.5638 & 6.4184 & TST & \\
\hline CHEMBL3672013 & 1528098 & 6.5003 & 6.4497 & TRN & \\
\hline CHEMBL3672058 & 1528098 & 7.1612 & 7.3424 & TRN & \\
\hline CHEMBL3672071 & 1528098 & 7.2596 & 7.25899 & 99999999995 & TRN \\
\hline CHEMBL 3667041 & 1528098 & 7.301 & 7.7234 & TST & \\
\hline CHEMBL 3672020 & 1528098 & 5.9957 & 6.0024 & TRN & \\
\hline CHEMBL3672087 & 1528098 & 7.0969 & 7.1734 & TRN & \\
\hline CHEMBL3672093 & 1528098 & 6.8125 & 6.8704 & TRN & \\
\hline CHEMBL3672033 & 1528098 & 6.6696 & 7.2622 & TST & \\
\hline
\end{tabular}


Supplemental Table S2.txt

\begin{tabular}{|c|c|c|c|c|}
\hline 9 & & & 6.7373 & \\
\hline HEMBL3672039 & 528098 & 7.5686 & 7.5399 & \\
\hline 045 & 28098 & & & \\
\hline 2034 & 28098 & 69 & 487 & \\
\hline AEMBL 3672021 & 528098 & 021 & 1156 & \\
\hline AEMBL3672052 & 528098 & 4318 & 3891 & \\
\hline AEMBL. & 528098 & 696 & 7479 & \\
\hline 2046 & 28098 & & & \\
\hline 72053 & 528098 & 894 & 9102 & \\
\hline AEMBL3672057 & 528098 & 7.3372 & 1618 & \\
\hline HEMBL3672026 & 528098 & 7.7447 & 7302 & \\
\hline AEMBL & 542191 & 565 & 7114 & \\
\hline 292 & & & & \\
\hline HEMBL; & 191 & & 1615 & \\
\hline AEMBL3 & 542191 & 88 & 9534 & \\
\hline AEMBL3986760 & 191 & 56 & 9164 & \\
\hline HEMBL & 191 & 26 & 392 & \\
\hline HEMBL & & & & \\
\hline HEMBL & 191 & & 44 & \\
\hline AEMBL3906356 & 91 & 96 & & 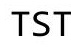 \\
\hline 3849 & 91 & 44 & 67 & RIN \\
\hline AEMBL & 91 & 12 & 962 & \\
\hline AEMBL & & & & \\
\hline 9987 & 191 & & & $3 \mu$ \\
\hline AEMBL3 & 91 & & 52 & SI \\
\hline 080 & & & 19 & ST \\
\hline 815 & & & & RN \\
\hline 1 & & & & RN \\
\hline 318 & & & & RIN \\
\hline AEMBL & 91 & & 34 & RN \\
\hline AEMBL & 91 & 4 & & ST \\
\hline$A F M B \mid=$ & & & & RN \\
\hline & & & & RN \\
\hline HEMBL3S & & & 092 & RN \\
\hline AEMBL3 & 642191 & 59 & 7627 & RN \\
\hline AEMBL3 & 191 & 89 & 99 & \\
\hline 83 & & & & ST \\
\hline & & & & ST \\
\hline HEMBL3985645 & 642191 & 6.5686 & 081 & RN \\
\hline AEMBL3 & 642191 & 08 & 899 & RN \\
\hline HEMBL3S & 164 & 29 & 3222 & 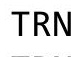 \\
\hline HEMBL3S & & & 5276 & RN \\
\hline HEMBL3923100 & 642191 & & 9552 & $\mathrm{RN}$ \\
\hline IEMBL3934761 & 642191 & 7.1675 & 8055 & ST \\
\hline & & & 4677 & \\
\hline HEMBL 3918042 & 1642191 & 073 & 5073 & \\
\hline 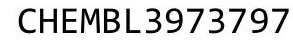 & 104 & & 8.6545 & \\
\hline HEMBL 390357 & 1642191 & 8.4089 & 8.4304 & \\
\hline
\end{tabular}

Page 8750 
Supplemental Table S2.txt

\begin{tabular}{|c|c|c|c|c|}
\hline CHEMBL3928041 & 1642191 & 8.0 & 7.904 & TRN \\
\hline CHEMBL3959554 & 1642191 & 8.2441 & 8.1437 & TRN \\
\hline CHEMBL3949670 & 1642191 & 8.4318 & 8.3586 & TRN \\
\hline CHEMBL 3969218 & 1642191 & 6.0182 & 6.0277 & TRN \\
\hline CHEMBL3901303 & 1642191 & 7.5086 & 7.2167 & TST \\
\hline CHEMBL3930419 & 1642191 & 5.0212 & 6.2921 & TST \\
\hline CHEMBL3910228 & 1642191 & 9.2007 & 9.2648 & TRN \\
\hline CHEMBL 3965570 & 1642191 & 6.1537 & 5.9942 & TRN \\
\hline CHEMBL 3942915 & 1642191 & 9.5528 & 9.2694 & TRN \\
\hline CHEMBL3894568 & 1642191 & 7.5229 & 7.5378 & TRN \\
\hline CHEMBL3935385 & 1642191 & 6.6596 & 7.0052 & TST \\
\hline CHEMBL 3961454 & 1642191 & 8.9586 & 8.9205 & TRN \\
\hline CHEMBL 3898837 & 1642191 & 5.7924 & \multicolumn{2}{|c|}{5.781000000000001} \\
\hline CHEMBL3891425 & 1642191 & 8.8539 & 9.2603 & TRN \\
\hline CHEMBL3921002 & 1642191 & 6.4724 & 6.5839 & TRN \\
\hline CHEMBL3955239 & 1642191 & 5.6925 & 4.0531 & TST \\
\hline CHEMBL3982458 & 1642191 & 5.7854 & 5.7671 & TRN \\
\hline CHEMBL 3945940 & 1642191 & 7.1938 & 7.0681 & TRN \\
\hline CHEMBL 3944720 & 1642191 & 8.6021 & 8.546 & TRN \\
\hline CHEMBL3944761 & 1642191 & 8.7959 & 8.5655 & TRN \\
\hline CHEMBL 3962846 & 1642191 & 9.5086 & 9.088 & TRN \\
\hline CHEMBL3901897 & 1642191 & 8.3768 & 8.387 & TRN \\
\hline CHEMBL3947414 & 1642191 & 8.4437 & 8.3969 & TRN \\
\hline CHEMBL3933178 & 1642191 & 9.4559 & 9.4594 & TRN \\
\hline CHEMBL3907681 & 1642191 & 6.8297 & 6.8477 & TST \\
\hline CHEMBL 3914118 & 1642191 & 8.3768 & 8.2715 & TRN \\
\hline CHEMBL3952769 & 1642191 & 9.6198 & 9.4047 & TRN \\
\hline CHEMBL 3914820 & 1642191 & 7.1612 & 7.1111 & TRN \\
\hline CHEMBL 3944146 & 1642191 & 8.0044 & 8.2125 & TRN \\
\hline CHEMBL3920356 & 1642191 & 7.3768 & 7.3586 & TRN \\
\hline CHEMBL3939857 & 1642191 & 9.3872 & 9.5048 & TRN \\
\hline CHEMBL3921775 & 1642191 & 5.0212 & \multicolumn{2}{|c|}{5.446000000000001} \\
\hline CHEMBL 3917252 & 1642191 & 7.6576 & 7.5818 & TRN \\
\hline CHEMBL 3893436 & 1642191 & 8.3279 & 8.559 & TRN \\
\hline CHEMBL 3930408 & 1642191 & 5.9817 & 6.0385 & TRN \\
\hline CHEMBL 3914234 & 1642191 & 6.5735 & 6.6605 & TRN \\
\hline CHEMBL3969459 & 1642191 & 7.5229 & 7.4547 & TRN \\
\hline CHEMBL3909833 & 1642191 & 6.6615 & 6.7437 & TRN \\
\hline CHEMBL3962552 & 1642191 & 7.6383 & 7.5527 & TRN \\
\hline CHEMBL 3977411 & 1642191 & 5.7657 & 6.0539 & TST \\
\hline CHEMBL 3933481 & 1642191 & 5.8687 & \multicolumn{2}{|c|}{5.502000000000001} \\
\hline CHEMBL3894278 & 1642191 & 6.7595 & 6.5906 & TRN \\
\hline CHEMBL 3891075 & 1642191 & 7.9586 & 7.9796 & TRN \\
\hline CHEMBL3908395 & 1642191 & 6.9136 & 6.9698 & TRN \\
\hline CHEMBL 3945243 & 1642191 & 6.9101 & 6.9958 & TRN \\
\hline CHEMBL 3968289 & 1642191 & 8.0223 & 7.8345 & TRN \\
\hline CHEMBL3893733 & 1642191 & 6.3799 & 6.3201 & TRN \\
\hline CHEMBL 3913634 & 1642191 & 8.8861 & 8.8642 & TRN \\
\hline
\end{tabular}


Supplemental Table S2.txt

\begin{tabular}{|c|c|c|c|c|}
\hline 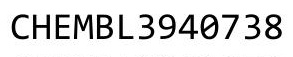 & & & 39 & \\
\hline HEMBL3961870 & 542191 & 6.5986 & 6737 & \\
\hline HEMBL3913054 & 542191 & 3188 & 3175 & \\
\hline & & & 404 & \\
\hline EMBL3978589 & 91 & & 1211 & \\
\hline HEMBL3908329 & 642191 & 9.4685 & 3186 & \\
\hline HEMBL3954775 & 642191 & 7.4437 & .3813 & \\
\hline HEMBL3935818 & 91 & & & \\
\hline EMBL 390 & 1 & 729 & .87 & \\
\hline EMBL: & 91 & 559 & 3459 & \\
\hline HEMBL3921432 & 91 & 3372 & 5254 & \\
\hline HEMBL 3917414 & 91 & & 6038 & \\
\hline HEMBL3936335 & 1 & 59 & 5849 & \\
\hline IEMBL39e & $\sigma^{2}+2 x+2$ & & 3676 & \\
\hline AEMBL & 1 & 07 & 1074 & \\
\hline HEMBL3985839 & 91 & 86 & 2249 & \\
\hline HEMBL3905209 & $\vartheta 1$ & 9.0 & 1812 & \\
\hline HEMBL 391 & 6 & $\partial 1$ & 233 & \\
\hline HEM & & & 343 & \\
\hline HEME & 1 & & 415 & \\
\hline HEMBL3983409 & 1 & & .045 & \\
\hline HEMBL3895439 & & & & \\
\hline HEMBL 39 & 62 & & 81 & RIV \\
\hline HEMBL 39 & & & 82 & niv \\
\hline 35 & 1 & & 27 & [ST \\
\hline HEMBL 398 & & & & SI \\
\hline AEMBL3972435 & 1 & & 727 & TST \\
\hline HEMBL39 & 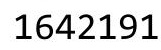 & & 303 & SI \\
\hline HEM & 1 & & 324 & RN \\
\hline 60 & 1 & 38 & 433 & RN \\
\hline HEMBL3898839 & & & & ГST \\
\hline HEMBL 3939748 & & & 795 & ГR \\
\hline HEMBL3S & & & & I RN \\
\hline 6 & & & & 「RN \\
\hline HEMBL2164384 & & & & TRN \\
\hline HEMBL2164376 & & & 3504 & TST \\
\hline HEMBL 2164387 & $\theta$ & & 5094 & TRN \\
\hline 4 & & & 426 & TRN \\
\hline 12 21 & & & 25 & TRN \\
\hline HEMBL2164386 & & & 7052 & 「RN \\
\hline HEMBL2164040 & $\theta$ & & 542 & $\Gamma R$ \\
\hline HEMBL 216 & $\theta$ & & 827 & R \\
\hline 7 & & & 252 & $C T$ \\
\hline HEMBL 2164362 & & & 9332 & TRN \\
\hline HEMBL2164397 & & 4.7212 & $\partial 082$ & TRN \\
\hline HEMBL 216 & 366 & 5. & 984 & $\mathrm{~N}$ \\
\hline$\llcorner 2$ & & & & $T$ \\
\hline בר יסטזו & & & & \\
\hline
\end{tabular}

Page 8752 
Supplemental Table S2.txt

\begin{tabular}{|c|c|c|c|c|c|}
\hline CHEMBL2164042 & 860770 & 3.7959 & 4.4129 & TRN & \\
\hline CHEMBL2164368 & 860770 & 6.0915 & 5.1907 & TRN & \\
\hline CHEMBL2164395 & 860770 & 3.4815 & 3.9903 & TRN & \\
\hline CHEMBL 2164041 & 860770 & 6.0269 & 5.0988 & TRN & \\
\hline CHEMBL2164381 & 860770 & 3.585 & 4.7898 & TRN & \\
\hline CHEMBL2164379 & 860770 & 3.4815 & 4.6479 & TRN & \\
\hline CHEMBL2164046 & 860770 & 5.2147 & 5.1933 & TRN & \\
\hline CHEMBL2164038 & 860770 & 3.4815 & 5.0807 & TRN & \\
\hline CHEMBL2164392 & 860770 & 5.0506 & 4.5413 & TRN & \\
\hline CHEMBL2164366 & 860770 & 4.7212 & 4.6157 & TRN & \\
\hline CHEMBL 2164363 & 860770 & 5.7212 & 4.9949 & TRN & \\
\hline CHEMBL2164388 & 860770 & 3.6383 & 4.3964 & TRN & \\
\hline CHEMBL2164385 & 860770 & 4.9208 & 4.0474 & TRN & \\
\hline CHEMBL2164390 & 860770 & 5.5528 & 4.8742 & TRN & \\
\hline CHEMBL2164372 & 860770 & 3.4815 & 4.872 & TST & \\
\hline CHEMBL2164039 & 860770 & 4.7696 & 5.2203 & TRN & \\
\hline CHEMBL2163357 & 860770 & 5.2147 & 4.8571 & TST & \\
\hline CHEMBL2164045 & 860770 & 4.0 & 4.6516 & TRN & \\
\hline CHEMBL2164044 & 860770 & 3.6021 & 3.6004 & TRN & \\
\hline CHEMBL2164358 & 860770 & 5.0132 & 4.76399 & 9999999999 & TRN \\
\hline CHEMBL2164037 & 860770 & 4.7959 & 5.0872 & TRN & \\
\hline CHEMBL2164396 & 860770 & 3.4815 & 3.9343 & TRN & \\
\hline CHEMBL 2164394 & 860770 & 3.4815 & 3.7708 & TRN & \\
\hline CHEMBL2164043 & 860770 & 4.7696 & 4.0689 & TRN & \\
\hline CHEMBL2164365 & 860770 & 4.9208 & 4.9775 & TRN & \\
\hline CHEMBL2164361 & 860770 & 4.8861 & 4.9607 & TRN & \\
\hline CHEMBL 2164375 & 860770 & 5.3565 & 4.9211 & TST & \\
\hline CHEMBL2164382 & 860770 & 5.585 & 5.0521 & TRN & \\
\hline CHEMBL2164356 & 860770 & 5.7212 & 5.0719 & TRN & \\
\hline CHEMBL2164359 & 860770 & 5.3665 & 4.965 & TST & \\
\hline CHEMBL2164374 & 860770 & 5.3468 & 4.8802 & TST & \\
\hline CHEMBL2164393 & 860770 & 5.4318 & 4.2959 & TST & \\
\hline CHEMBL2164391 & 860770 & 5.3565 & 4.3169 & TST & \\
\hline CHEMBL2164380 & 860770 & 3.5086 & 4.6114 & TST & \\
\hline CHEMBL2164369 & 860770 & 5.3279 & 5.1572 & TST & \\
\hline CHEMBL2164360 & 860770 & 5.3979 & 4.808 & TST & \\
\hline CHEMBL54131 & 39938 & 6.2218 & 5.9406 & TRN & \\
\hline CHEMBL51529 & 39938 & 4.6576 & 5.7917 & TST & \\
\hline CHEMBL2372883 & 39938 & 6.0458 & 6.1306 & TRN & \\
\hline CHEMBL301179 & 39938 & 6.0 & 5.8184 & TRN & \\
\hline CHEMBL301793 & 39938 & 5.0969 & 5.5492 & TRN & \\
\hline CHEMBL51948 & 39938 & 6.0 & 5.6629 & TST & \\
\hline CHEMBL2372854 & 39938 & 6.1549 & 6.1575 & TRN & \\
\hline CHEMBL54154 & 39938 & 6.0 & 5.7134 & TST & \\
\hline CHEMBL51322 & 39938 & 5.9586 & 5.8914 & TRN & \\
\hline CHEMBL300663 & 39938 & 5.4437 & 5.7187 & TST & \\
\hline CHEMBL2372881 & 39938 & 6.0458 & 6.1296 & TRN & \\
\hline CHEMBL2372874 & 39938 & 6.1549 & 6.1463 & TRN & \\
\hline
\end{tabular}

Page 8753 


\begin{tabular}{|c|c|c|c|c|c|}
\hline & & \multicolumn{4}{|c|}{ Supplemental Table S2.txt } \\
\hline CHEMBL 2372892 & 39938 & 5.7212 & 6.1326 & TRN & \\
\hline CHEMBL51314 & 39938 & 6.699 & 5.8402 & TRN & \\
\hline CHEMBL 2372891 & 39938 & 5.699 & 6.03700 & 0000000001 & TRN \\
\hline CHEMBL52347 & 39938 & 5.5229 & 5.5596 & TST & \\
\hline CHEMBL50505 & 39938 & 5.8239 & 6.017 & TRN & \\
\hline CHEMBL 2372862 & 39938 & 5.8539 & 6.0627 & TRN & \\
\hline CHEMBL 2372875 & 39938 & 6.0 & 6.1674 & TRN & \\
\hline CHEMBL 2372880 & 39938 & 6.0 & 6.1302 & TRN & \\
\hline CHEMBL54164 & 39938 & 4.8894 & 5.6583 & TST & \\
\hline CHEMBL50878 & 39938 & 6.2218 & 5.8626 & TRN & \\
\hline CHEMBL 2372885 & 39938 & 6.1549 & 6.08700 & 0000000001 & TRN \\
\hline CHEMBL51583 & 39938 & 6.0969 & 5.6233 & TST & \\
\hline CHEMBL51447 & 39938 & 5.301 & 5.5797 & TRN & \\
\hline CHEMBL417021 & 39938 & 6.0 & 5.819 & TRN & \\
\hline CHEMBL 298183 & 39938 & 5.6383 & 5.6043 & TRN & \\
\hline CHEMBL51257 & 39938 & 6.1549 & 5.8971 & TRN & \\
\hline CHEMBL300241 & 39938 & 6.0969 & 5.9257 & TRN & \\
\hline CHEMBL50846 & 39938 & 6.0969 & 5.8982 & TRN & \\
\hline CHEMBL 2372867 & 39938 & 6.2218 & 6.1057 & TRN & \\
\hline CHEMBL295267 & 39938 & 3.5229 & 5.7845 & TST & \\
\hline CHEMBL298582 & 39938 & 5.2596 & 5.5519 & TRN & \\
\hline CHEMBL51781 & 39938 & 6.3979 & 5.9199 & TRN & \\
\hline CHEMBL50973 & 39938 & 6.301 & 5.5324 & TRN & \\
\hline CHEMBL417727 & 39938 & 6.3979 & 5.5954 & TRN & \\
\hline CHEMBL49236 & 39938 & 6.0969 & 5.5803 & TRN & \\
\hline CHEMBL54165 & 39938 & 5.1135 & 5.5545 & TRN & \\
\hline CHEMBL51636 & 39938 & 5.1549 & 5.7975 & TST & \\
\hline CHEMBL 2372868 & 39938 & 6.0969 & 6.1575 & TRN & \\
\hline CHEMBL52491 & 39938 & 6.3979 & 5.5968 & TRN & \\
\hline CHEMBL 2372864 & 39938 & 6.1549 & 6.1306 & TRN & \\
\hline CHEMBL299154 & 39938 & 5.5376 & 5.6156 & TRN & \\
\hline CHEMBL52388 & 39938 & 5.8239 & 5.5983 & TRN & \\
\hline CHEMBL 2372858 & 39938 & 6.1549 & 6.1399 & TRN & \\
\hline CHEMBL 2372871 & 39938 & 6.2218 & 6.126 & TRN & \\
\hline CHEMBL53966 & 39938 & 6.301 & 5.9119 & TRN & \\
\hline CHEMBL51547 & 39938 & 5.9586 & 5.9696 & TRN & \\
\hline CHEMBL51931 & 39938 & 6.1549 & 5.5611 & TRN & \\
\hline CHEMBL50187 & 39938 & 5.1024 & 5.5185 & TRN & \\
\hline CHEMBL 2372898 & 39938 & 5.9208 & 6.1039 & TRN & \\
\hline CHEMBL51637 & 39938 & 4.9586 & 5.731 & TST & \\
\hline CHEMBL 2372848 & 39938 & 6.0458 & 6.1397 & TRN & \\
\hline CHEMBL52047 & 39938 & 3.5229 & 5.572 & TRN & \\
\hline CHEMBL298384 & 39938 & 6.1549 & 5.9414 & TRN & \\
\hline CHEMBL 2372866 & 39938 & 6.0458 & 6.1114 & TRN & \\
\hline CHEMBL51235 & 39938 & 5.3098 & 5.6431 & TST & \\
\hline CHEMBL50627 & 39938 & 6.0 & 5.6178 & TRN & \\
\hline CHEMBL 2372863 & 39938 & 5.7447 & 6.0453 & TRN & \\
\hline CHEMBL 299853 & 39938 & 3.5229 & 5.6616 & TST & \\
\hline
\end{tabular}




\begin{tabular}{|c|c|c|c|c|}
\hline & & & pplement & al Table S \\
\hline CHEMBL2372865 & 39938 & 6.2218 & 6.1292 & TRN \\
\hline CHEMBL51880 & 39938 & 5.4318 & 5.5982 & TRN \\
\hline CHEMBL51317 & 39938 & 5.9208 & 5.8633 & TRN \\
\hline CHEMBL295944 & 39938 & 5.2676 & 5.7969 & TRN \\
\hline CHEMBL3144419 & 39938 & 6.0458 & 6.1449 & TRN \\
\hline CHEMBL50149 & 39938 & 6.301 & 5.5201 & TRN \\
\hline CHEMBL51007 & 39938 & 5.9208 & 5.6341 & TST \\
\hline CHEMBL52162 & 39938 & 5.0605 & 5.5669 & TRN \\
\hline CHEMBL2372870 & 39938 & 6.0 & 6.1575 & TRN \\
\hline CHEMBL2372849 & 39938 & 6.2218 & 6.1575 & TRN \\
\hline CHEMBL49990 & 39938 & 5.301 & 5.6313 & TST \\
\hline CHEMBL 300260 & 39938 & 3.5229 & 5.5012 & TRN \\
\hline CHEMBL 2372888 & 39938 & 5.9586 & 6.1125 & TRN \\
\hline CHEMBL3144418 & 39938 & 5.8861 & 6.1363 & TRN \\
\hline CHEMBL301801 & 39938 & 6.301 & 5.9265 & TRN \\
\hline CHEMBL300664 & 39938 & 6.0969 & 5.61 & TST \\
\hline CHEMBL2372878 & 39938 & 6.1549 & 6.1399 & TRN \\
\hline CHEMBL300680 & 39938 & 5.3872 & 5.5065 & TRN \\
\hline CHEMBL 2372889 & 39938 & 6.1549 & 6.1223 & TRN \\
\hline CHEMBL433282 & 39938 & 5.6198 & 5.5313 & TRN \\
\hline CHEMBL50347 & 39938 & 6.301 & 5.9402 & TRN \\
\hline CHEMBL2372873 & 39938 & 5.9586 & 6.1249 & TRN \\
\hline CHEMBL50161 & 39938 & 6.0969 & 5.9313 & TRN \\
\hline CHEMBL51776 & 39938 & 6.301 & 5.8968 & TRN \\
\hline CHEMBL2372872 & 39938 & 6.0969 & 6.1674 & TRN \\
\hline CHEMBL2372879 & 39938 & 5.9586 & 6.12 & TRN \\
\hline CHEMBL2372869 & 39938 & 5.8539 & 6.1462 & TRN \\
\hline CHEMBL38066 & 39938 & 5.9586 & 5.6032 & TRN \\
\hline CHEMBL2372882 & 39938 & 5.9586 & 6.1292 & TRN \\
\hline CHEMBL49992 & 39938 & 6.2218 & 5.9397 & TRN \\
\hline CHEMBL2372876 & 39938 & 5.8539 & 6.1575 & TST \\
\hline CHEMBL299374 & 39938 & 5.4318 & 5.6345 & TST \\
\hline CHEMBL50620 & 39938 & 5.699 & 5.6598 & TST \\
\hline CHEMBL51579 & 39938 & 6.3979 & 5.8386 & TST \\
\hline CHEMBL2372893 & 39938 & 6.0458 & 6.1463 & TST \\
\hline CHEMBL2372877 & 39938 & 5.9586 & 6.1227 & TST \\
\hline CHEMBL 2372894 & 39938 & 5.8539 & 6.1109 & TST \\
\hline CHEMBL2372886 & 39938 & 5.9586 & 6.1057 & TST \\
\hline CHEMBL 300002 & 39938 & 3.5229 & 5.7939 & TST \\
\hline CHEMBL51039 & 39938 & 6.0 & 5.6618 & TST \\
\hline CHEMBL3408202 & 1469079 & 3.5229 & 6.2762 & TRN \\
\hline CHEMBL3408169 & 1469079 & 3.5229 & 5.19600 & 0000000001 \\
\hline CHEMBL3408166 & 1469079 & 4.9031 & 5.1005 & TRN \\
\hline CHEMBL3408170 & 1469079 & 4.3507 & 5.1175 & TST \\
\hline CHEMBL3408213 & 1469079 & 8.301 & 7.6151 & TRN \\
\hline CHEMBL3408173 & 1469079 & 4.5544 & 4.724 & TRN \\
\hline CHEMBL3408193 & 1469079 & 6.1273 & 7.2402 & TRN \\
\hline CHEMBL3408167 & 1469079 & 4.585 & 5.2618 & TRN \\
\hline
\end{tabular}


Supplemental Table S2.txt

\begin{tabular}{|c|c|c|c|c|c|}
\hline CHEMBL3408186 & 1469079 & 7.0605 & 6.5568 & TRN & \\
\hline CHEMBL3408198 & 1469079 & 6.9469 & 6.8269 & TRN & \\
\hline CHEMBL 3408175 & 1469079 & 4.6383 & 5.1041 & TRN & \\
\hline CHEMBL 3408181 & 1469079 & 7.3979 & 5.721 & TRN & \\
\hline CHEMBL 3408189 & 1469079 & 7.3768 & 6.294 & TRN & \\
\hline CHEMBL 3408216 & 1469079 & 8.0 & 7.6126 & TRN & \\
\hline CHEMBL3408215 & 1469079 & 7.5528 & 7.5816 & TRN & \\
\hline CHEMBL3408208 & 1469079 & 7.6198 & 7.4296 & TRN & \\
\hline CHEMBL3408206 & 1469079 & 6.3665 & 7.3887 & TRN & \\
\hline CHEMBL 3408185 & 1469079 & 6.9101 & 6.5325 & TRN & \\
\hline CHEMBL 3408174 & 1469079 & 3.5229 & 4.7664 & TST & \\
\hline CHEMBL3408204 & 1469079 & 6.8508 & 7.2197 & TRN & \\
\hline CHEMBL 3408183 & 1469079 & 6.1379 & 6.1138 & TRN & \\
\hline CHEMBL 3408171 & 1469079 & 3.5229 & 5.4576 & TST & \\
\hline CHEMBL3408218 & 1469079 & 8.699 & 7.5661 & TRN & \\
\hline CHEMBL 3408168 & 1469079 & 3.5229 & 4.4981 & TRN & \\
\hline CHEMBL3408188 & 1469079 & 6.51 & 5.9555 & TRN & \\
\hline CHEMBL 3408212 & 1469079 & 7.6576 & 7.4686 & TRN & \\
\hline CHEMBL3408210 & 1469079 & 7.4437 & 7.532 & TRN & \\
\hline CHEMBL1673059 & 1469079 & 5.7545 & 5.1749 & TRN & \\
\hline CHEMBL3408191 & 1469079 & 7.0605 & 6.70200 & 0000000001 & TRN \\
\hline CHEMBL3408203 & 1469079 & 5.9208 & 7.1091 & TRN & \\
\hline CHEMBL 3408190 & 1469079 & 7.1549 & 6.6445 & TRN & \\
\hline CHEMBL 3408207 & 1469079 & 7.7959 & 7.4753 & TRN & \\
\hline CHEMBL 3408179 & 1469079 & 5.7696 & 6.1259 & TRN & \\
\hline CHEMBL3408209 & 1469079 & 6.6478 & 7.4097 & TRN & \\
\hline CHEMBL3408177 & 1469079 & 7.0555 & 5.5314 & TRN & \\
\hline CHEMBL 3408211 & 1469079 & 7.301 & 7.4514 & TRN & \\
\hline CHEMBL3408172 & 1469079 & 5.0 & 5.5177 & TST & \\
\hline CHEMBL3408196 & 1469079 & 7.2596 & 7.2778 & TRN & \\
\hline CHEMBL 3408180 & 1469079 & 6.109 & 6.2228 & TRN & \\
\hline CHEMBL3408192 & 1469079 & 7.5229 & 7.2243 & TRN & \\
\hline CHEMBL 3408200 & 1469079 & 7.1079 & 6.9436 & TRN & \\
\hline CHEMBL3408184 & 1469079 & 7.4318 & 6.4987 & TRN & \\
\hline CHEMBL 3408205 & 1469079 & 6.8125 & 7.1555 & TRN & \\
\hline CHEMBL3408194 & 1469079 & 6.1457 & 6.9688 & TRN & \\
\hline CHEMBL3408187 & 1469079 & 5.7773 & 6.3916 & TST & \\
\hline CHEMBL 3408178 & 1469079 & 5.4868 & 4.875 & TST & \\
\hline CHEMBL 3408201 & 1469079 & 6.0 & 6.7737 & TST & \\
\hline CHEMBL 3408195 & 1469079 & 5.2441 & 7.2099 & TST & \\
\hline CHEMBL3408199 & 1469079 & 7.9208 & 6.7983 & TST & \\
\hline CHEMBL3408176 & 1469079 & 6.4437 & 4.8965 & TST & \\
\hline CHEMBL3408197 & 1469079 & 8.2218 & 7.2366 & TST & \\
\hline CHEMBL3408214 & 1469079 & 7.8239 & 7.47 & TST & \\
\hline CHEMBL 3408182 & 1469079 & 5.9586 & 5.914 & TST & \\
\hline CHEMBL249899 & 456313 & 6.0706 & 4.2813 & TST & \\
\hline CHEMBL250539 & 456313 & 4.5229 & 4.4171 & TST & \\
\hline CHEMBL250336 & 456313 & 4.8729 & 4.4424 & TRN & \\
\hline
\end{tabular}




\begin{tabular}{|c|c|c|c|c|c|c|}
\hline & & \multicolumn{5}{|c|}{ Supplemental Table S2.txt } \\
\hline CHEMBL398514 & 456313 & 4.2248 & 4.2631 & TRN & & \\
\hline CHEMBL249720 & 456313 & 5.2418 & 4.3086 & TRN & & \\
\hline CHEMBL250337 & 456313 & 5.1445 & 4.4199 & TRN & & \\
\hline CHEMBL251724 & 456313 & 5.9788 & 5.7719 & TRN & & \\
\hline CHEMBL249901 & 456313 & 3.0 & 4.2346 & TRN & & \\
\hline CHEMBL249682 & 456313 & 4.4486 & 4.707 & TRN & & \\
\hline CHEMBL249073 & 456313 & 3.5229 & 4.4705 & TST & & \\
\hline CHEMBL250335 & 456313 & 4.9914 & 4.502 & TRN & & \\
\hline CHEMBL398253 & 456313 & 5.7423 & 5.8562 & TRN & & \\
\hline CHEMBL399383 & 456313 & 4.7696 & 3.8755 & TRN & & \\
\hline CHEMBL399688 & 456313 & 6.0915 & 5.8837 & TRN & & \\
\hline CHEMBL249681 & 456313 & 5.7212 & 5.8664 & TRN & & \\
\hline CHEMBL400078 & 456313 & 6.4685 & 5.8611 & TRN & & \\
\hline CHEMBL249515 & 456313 & 6.0223 & 5.3716 & TRN & & \\
\hline CHEMBL249719 & 456313 & 5.8697 & 4.5398 & TRN & & \\
\hline CHEMBL249900 & 456313 & 3.0 & 4.1102 & TST & & \\
\hline CHEMBL437586 & 456313 & $5.1720 e$ & 00000000 & 01 & 5.6203 & TRN \\
\hline CHEMBL249697 & 456313 & 4.8761 & 3.9358 & TST & & \\
\hline CHEMBL 249280 & 456313 & 6.5686 & 6.0952 & TRN & & \\
\hline CHEMBL249104 & 456313 & 5.6198 & 5.2896 & TRN & & \\
\hline CHEMBL398511 & 456313 & 4.7305 & 4.2306 & TRN & & \\
\hline CHEMBL 250106 & 456313 & 5.0958 & 4.319 & TRN & & \\
\hline CHEMBL250131 & 456313 & 5.5003 & 4.435 & TRN & & \\
\hline CHEMBL249508 & 456313 & 4.3883 & 4.753 & TRN & & \\
\hline CHEMBL249103 & 456313 & 3.5229 & 3.9243 & TRN & & \\
\hline CHEMBL249482 & 456313 & 6.0362 & 6.0969 & TRN & & \\
\hline CHEMBL 249929 & 456313 & 3.0 & 4.1446 & TRN & & \\
\hline CHEMBL249516 & 456313 & 3.0 & 3.4455 & TRN & & \\
\hline CHEMBL249480 & 456313 & 5.7055 & 5.9277 & TRN & & \\
\hline CHEMBL249886 & 456313 & 3.0 & 5.6815 & TRN & & \\
\hline CHEMBL401301 & 456313 & 4.1824 & 4.7423 & TRN & & \\
\hline CHEMBL 248899 & 456313 & 3.0 & 3.6411 & TRN & & \\
\hline CHEMBL400077 & 456313 & 5.2306 & 5.5855 & TRN & & \\
\hline CHEMBL 250107 & 456313 & 4.5302 & 4.2252 & TRN & & \\
\hline CHEMBL398512 & 456313 & 3.0 & 4.1776 & TRN & & \\
\hline CHEMBL400389 & 456313 & 4.8069 & 4.2798 & TRN & & \\
\hline CHEMBL399368 & 456313 & 6.3279 & 5.8416 & TRN & & \\
\hline CHEMBL398513 & 456313 & 3.0 & 3.9636 & TRN & & \\
\hline CHEMBL 249102 & 456313 & 4.5346 & 4.2165 & TRN & & \\
\hline CHEMBL249279 & 456313 & 5.6326 & 5.8058 & TST & & \\
\hline CHEMBL249683 & 456313 & 5.3045 & 5.8492 & TST & & \\
\hline CHEMBL428754 & 456313 & 5.5834 & 5.7514 & TST & & \\
\hline CHEMBL249721 & 456313 & 3.5229 & 4.3538 & TST & & \\
\hline CHEMBL 249481 & 456313 & 6.2596 & 5.9466 & TST & & \\
\hline CHEMBL399486 & 456313 & 6.4437 & 5.6815 & TST & & \\
\hline CHEMBL250105 & 456313 & 5.0991 & 4.2717 & TST & & \\
\hline CHEMBL 249902 & 456313 & 5.3439 & 4.4225 & TST & & \\
\hline CHEMBL 2392169 & 982934 & 6.8928 & 6.9307 & TRN & & \\
\hline
\end{tabular}


Supplemental Table S2.txt

\begin{tabular}{|c|c|c|c|c|c|c|}
\hline CHEMBL 2392158 & 982934 & 6.6326 & 6.6089 & TRN & & \\
\hline CHEMBL1517986 & 982934 & 7.9393 & 7.9553 & TRN & & \\
\hline CHEMBL 2392155 & 982934 & 6.1568 & 5.8285 & TRN & & \\
\hline CHEMBL 2392161 & 982934 & 7.9393 & 7.9804 & TRN & & \\
\hline CHEMBL 2392145 & 982934 & 4.7328 & 4.8569 & TRN & & \\
\hline CHEMBL 2425820 & 982934 & 8.7852 & 8.4608 & TRN & & \\
\hline CHEMBL 2425825 & 982934 & 7.2941 & 5.4425 & TST & & \\
\hline CHEMBL 2392172 & 982934 & 8.6615 & 8.6201 & TRN & & \\
\hline CHEMBL 2392177 & 982934 & 6.6421 & 6.9907 & TRN & & \\
\hline CHEMBL 2425823 & 982934 & 7.6882 & 7.522 & TRN & & \\
\hline CHEMBL 2392173 & 982934 & 6.8297 & 6.8711 & TRN & & \\
\hline CHEMBL 2392152 & 982934 & 6.1605 & 6.1535 & TRN & & \\
\hline CHEMBL 2392165 & 982934 & 6.6021 & 6.6003 & TRN & & \\
\hline CHEMBL 2392150 & 982934 & 5.5654 & 5.4481 & TRN & & \\
\hline CHEMBL 2392162 & 982934 & 7.5952 & 7.7531 & TRN & & \\
\hline CHEMBL 299155 & 982934 & 3.8633 & 3.6948 & TRN & & \\
\hline CHEMBL 2392170 & 982934 & 8.3197 & 8.6604 & TRN & & \\
\hline CHEMBL 2392180 & 982934 & 5.4306 & 5.4869 & TRN & & \\
\hline CHEMBL 2392176 & 982934 & 6.4802 & 6.6412 & TRN & & \\
\hline CHEMBL 2392157 & 982934 & 6.6556 & 6.6027 & TRN & & \\
\hline CHEMBL 2392154 & 982934 & 5.3575 & 5.4529 & TRN & & \\
\hline CHEMBL 2392156 & 982934 & 4.9872 & 5.0621 & TRN & & \\
\hline CHEMBL 2392160 & 982934 & 8.3851 & 8.2275 & TRN & & \\
\hline CHEMBL 2392148 & 982934 & 5.4461 & 5.4534 & TRN & & \\
\hline CHEMBL 2425822 & 982934 & 7.3686 & 7.3473 & TRN & & \\
\hline CHEMBL 2392178 & 982934 & 7.8239 & 8.0264 & TRN & & \\
\hline CHEMBL 2425824 & 982934 & 8.7167 & 8.7151 & TRN & & \\
\hline CHEMBL443738 & 982934 & 5.0061 & 6.6795 & TST & & \\
\hline CHEMBL 2392179 & 982934 & 8.9508 & 8.7284 & TRN & & \\
\hline CHEMBL 2425819 & 982934 & 8.8633 & 9.0339 & TRN & & \\
\hline CHEMBL 2392167 & 982934 & 8.2596 & 8.0257 & TRN & & \\
\hline CHEMBL 2392175 & 982934 & 7.00700 & 000000000 & 31 & 6.9454 & TRN \\
\hline CHEMBL 2392146 & 982934 & 5.1694 & 5.1996 & TRN & & \\
\hline CHEMBL 2392153 & 982934 & 5.3206 & 5.5808 & TRN & & \\
\hline CHEMBL 2425821 & 982934 & 9.2299 & 9.1924 & TRN & & \\
\hline CHEMBL 2392149 & 982934 & 5.4828 & 5.4371 & TRN & & \\
\hline CHEMBL 2392174 & 982934 & 8.2857 & 8.3721 & TRN & & \\
\hline CHEMBL 2392159 & 982934 & 6.9245 & 6.9144 & TRN & & \\
\hline CHEMBL 2392166 & 982934 & 6.7375 & 6.6563 & TRN & & \\
\hline CHEMBL 2392163 & 982934 & 6.7033 & 6.7157 & TRN & & \\
\hline CHEMBL 2392168 & 982934 & 7.0883 & 6.9276 & TRN & & \\
\hline CHEMBL 1914576 & 982934 & 6.1838 & 6.6012 & TST & & \\
\hline CHEMBL 2392151 & 982934 & 6.1463 & 6.3992 & TST & & \\
\hline CHEMBL 2392182 & 982934 & 7.2457 & 8.0459 & TST & & \\
\hline CHEMBL 2392183 & 982934 & 7.5901 & 7.5819 & TST & & \\
\hline CHEMBL 2392144 & 982934 & 5.5214 & 7.1032 & TST & & \\
\hline CHEMBL 2392147 & 982934 & 4.7305 & 5.5098 & TST & & \\
\hline CHEMBL 2392171 & 982934 & 9.0278 & 8.8106 & TST & & \\
\hline
\end{tabular}




\begin{tabular}{|c|c|c|c|c|c|}
\hline & & \multicolumn{4}{|c|}{ Supplemental Table S2.txt } \\
\hline CHEMBL2392142 & 982934 & 4.8665 & 5.2778 & TST & \\
\hline CHEMBL2392181 & 982934 & 5.0937 & 5.42399 & 99999999995 & TST \\
\hline CHEMBL2392164 & 982934 & 6.8601 & 6.6217 & TST & \\
\hline CHEMBL1708510 & 982934 & 7.3747 & 7.3266 & TST & \\
\hline CHEMBL1384502 & 982934 & 8.0575 & 6.5227 & TST & \\
\hline CHEMBL509531 & 688586 & 4.7 & 4.705 & TST & \\
\hline CHEMBL1492104 & 688586 & 4.6 & 4.9065 & TST & \\
\hline CHEMBL462576 & 688586 & 4.1 & 4.28100 & 0000000001 & TRN \\
\hline CHEMBL1612246 & 688586 & 4.3 & 4.3809 & TRN & \\
\hline CHEMBL1418603 & 688586 & 4.1 & 3.9796 & TRN & \\
\hline CHEMBL1528479 & 688586 & 4.1 & 4.0903 & TRN & \\
\hline CHEMBL1585396 & 688586 & 4.3 & 4.3984 & TRN & \\
\hline CHEMBL1471289 & 688586 & 4.5 & 4.2648 & TRN & \\
\hline CHEMBL 220845 & 688586 & 4.4 & 4.5881 & TRN & \\
\hline CHEMBL1489064 & 688586 & 4.3 & 4.4196 & TRN & \\
\hline CHEMBL1565705 & 688586 & 4.2 & 4.103 & TRN & \\
\hline CHEMBL1447588 & 688586 & 4.7 & 5.013 & TST & \\
\hline CHEMBL1499545 & 688586 & 5.1 & 5.1151 & TRN & \\
\hline CHEMBL153062 & 688586 & 4.1 & 4.3039 & TRN & \\
\hline CHEMBL1530684 & 688586 & 4.4 & 4.2226 & TRN & \\
\hline CHEMBL1579130 & 688586 & 6.0 & 5.6808 & TST & \\
\hline CHEMBL1330518 & 688586 & 4.3 & 4.2541 & TRN & \\
\hline CHEMBL1407826 & 688586 & 4.4 & 4.7667 & TST & \\
\hline CHEMBL175193 & 688586 & 4.1 & 3.9944 & TRN & \\
\hline CHEMBL1580759 & 688586 & 4.3 & 4.2696 & TRN & \\
\hline CHEMBL1545634 & 688586 & 6.3 & 6.1661 & TRN & \\
\hline CHEMBL105712 & 688586 & 4.8 & 4.7784 & TRN & \\
\hline CHEMBL1526721 & 688586 & 5.2 & 4.9707 & TRN & \\
\hline CHEMBL1562104 & 688586 & 4.8 & 4.9835 & TRN & \\
\hline CHEMBL1338613 & 688586 & 4.3 & 4.2011 & TST & \\
\hline CHEMBL1409985 & 688586 & 5.2 & 5.1099 & TRN & \\
\hline CHEMBL28517 & 688586 & 4.1 & 4.4161 & TST & \\
\hline CHEMBL440287 & 688586 & 4.3 & 4.5189 & TRN & \\
\hline CHEMBL1303139 & 688586 & 5.2 & 5.2101 & TRN & \\
\hline CHEMBL1535689 & 688586 & 4.3 & 4.3468 & TRN & \\
\hline CHEMBL1462419 & 688586 & 4.3 & 4.5664 & TRN & \\
\hline CHEMBL1549844 & 688586 & 4.5 & 4.6945 & TST & \\
\hline CHEMBL1413383 & 688586 & 4.1 & 4.0797 & TRN & \\
\hline CHEMBL1456906 & 688586 & 4.3 & 4.4249 & TST & \\
\hline CHEMBL1408847 & 688586 & 5.2 & 5.1684 & TRN & \\
\hline CHEMBL1524617 & 688586 & 5.2 & 5.2501 & TRN & \\
\hline CHEMBL1569226 & 688586 & 5.1 & 4.9291 & TRN & \\
\hline CHEMBL8739 & 688586 & 4.1 & 4.0687 & TRN & \\
\hline CHEMBL 224282 & 688586 & 4.1 & 4.2444 & TRN & \\
\hline CHEMBL486193 & 688586 & 4.1 & 4.6896 & TST & \\
\hline CHEMBL1308088 & 688586 & 4.9 & 4.7054 & TRN & \\
\hline CHEMBL1452158 & 688586 & 4.3 & 4.1396 & TRN & \\
\hline CHEMBL167423 & 688586 & 4.1 & 4.1291 & TRN & \\
\hline
\end{tabular}




\begin{tabular}{|c|c|c|c|c|c|}
\hline \multirow{2}{*}{ CHEMBL1393325 } & \multirow{2}{*}{688586} & \multirow[b]{2}{*}{4.3} & \\
\hline & & & 4.2113 & TRN & \\
\hline CHEMBL 242080 & 688586 & 6.0 & 5.4932 & TRN & \\
\hline CHEMBL192627 & 688586 & 4.5 & 4.5964 & TRN & \\
\hline CHEMBL1485974 & 688586 & 4.3 & 4.2008 & TRN & \\
\hline CHEMBL162598 & 688586 & 4.4 & 4.3906 & TST & \\
\hline CHEMBL445957 & 688586 & 4.3 & 4.2768 & TRN & \\
\hline CHEMBL194400 & 688586 & 4.3 & 4.2252 & TRN & \\
\hline CHEMBL1430204 & 688586 & 4.3 & 4.4518 & TRN & \\
\hline CHEMBL1448387 & 688586 & 4.5 & 4.6367 & TRN & \\
\hline CHEMBL935 & 688586 & 4.3 & 4.2731 & TRN & \\
\hline CHEMBL1304981 & 688586 & 4.1 & 4.1969 & TST & \\
\hline CHEMBL1522486 & 688586 & 4.6 & 4.5874 & TRN & \\
\hline CHEMBL1526319 & 688586 & 4.5 & 4.7178 & TRN & \\
\hline CHEMBL1527567 & 688586 & 4.3 & 4.0862 & TRN & \\
\hline CHEMBL1449018 & 688586 & 4.5 & 4.4278 & TRN & \\
\hline CHEMBL195953 & 688586 & 4.3 & 4.2834 & TRN & \\
\hline CHEMBL 28 & 688586 & 4.1 & 4.3876 & TRN & \\
\hline CHEMBL230156 & 688586 & 4.3 & \multicolumn{2}{|c|}{4.0680000000000005} & TRN \\
\hline CHEMBL1200471 & 688586 & 6.6 & 6.7397 & TRN & \\
\hline CHEMBL144530 & 688586 & 4.4 & 4.3647 & TRN & \\
\hline CHEMBL1484480 & 688586 & 4.1 & 4.0419 & TRN & \\
\hline CHEMBL1609459 & 688586 & 4.9 & 4.9966 & TRN & \\
\hline CHEMBL1450607 & 688586 & 4.6 & 4.6208 & TRN & \\
\hline CHEMBL1569493 & 688586 & 5.8 & 5.7007 & TRN & \\
\hline CHEMBL1331245 & 688586 & 4.1 & 4.1675 & TRN & \\
\hline CHEMBL1517425 & 688586 & 4.1 & 3.9431 & TRN & \\
\hline CHEMBL 280998 & 688586 & 4.4 & 4.4078 & TRN & \\
\hline CHEMBL1492884 & 688586 & 4.4 & 4.2474 & TRN & \\
\hline CHEMBL1414154 & 688586 & 4.1 & \multicolumn{2}{|c|}{4.0089999999999995} & TRN \\
\hline CHEMBL1309179 & 688586 & 4.9 & 4.7735 & TRN & \\
\hline CHEMBL1600998 & 688586 & 5.0 & 5.0912 & TRN & \\
\hline CHEMBL 8320 & 688586 & 4.4 & 4.298 & TRN & \\
\hline CHEMBL1561876 & 688586 & 4.3 & 4.5433 & TRN & \\
\hline CHEMBL 36296 & 688586 & 4.1 & 4.1168 & TRN & \\
\hline CHEMBL1559341 & 688586 & 4.4 & 4.4472 & TRN & \\
\hline CHEMBL1518369 & 688586 & 4.2 & 4.4624 & TRN & \\
\hline CHEMBL1566504 & 688586 & 4.3 & 4.3305 & TRN & \\
\hline CHEMBL1451833 & 688586 & 4.4 & 4.5902 & TRN & \\
\hline CHEMBL1496957 & 688586 & 4.6 & 4.6221 & TRN & \\
\hline CHEMBL1602699 & 688586 & 5.3 & 5.3339 & TRN & \\
\hline CHEMBL1366408 & 688586 & 4.5 & 4.4646 & TRN & \\
\hline CHEMBL1485360 & 688586 & 4.7 & 4.7464 & TRN & \\
\hline CHEMBL1519327 & 688586 & 6.5 & 6.4273 & TRN & \\
\hline CHEMBL418068 & 688586 & 4.1 & 4.2597 & TRN & \\
\hline CHEMBL1142 & 688586 & 4.3 & 4.4079 & TST & \\
\hline CHEMBL 289277 & 688586 & 4.1 & 4.587 & TST & \\
\hline CHEMBL443949 & 688586 & 4.3 & 4.2707 & TST & \\
\hline CHEMBL140 & 688586 & 4.3 & 4.4941 & TST & \\
\hline & & & & 8760 & \\
\hline
\end{tabular}




\begin{tabular}{|c|c|c|c|c|c|}
\hline & & \\
\hline CHEMBL1319452 & 688586 & 4.4 & 4.3936 & TST & \\
\hline CHEMBL1558796 & 688586 & 4.3 & 4.359 & TST & \\
\hline CHEMBL334255 & 688586 & 4.6 & 4.7797 & TST & \\
\hline CHEMBL57394 & 688586 & 4.1 & 4.1631 & TST & \\
\hline CHEMBL58835 & 688586 & 4.3 & 4.2951 & TST & \\
\hline CHEMBL402063 & 688586 & 6.0 & 5.3136 & TST & \\
\hline CHEMBL44072 & 688586 & 4.4 & 4.3305 & TST & \\
\hline CHEMBL1576086 & 688586 & 4.4 & 4.4417 & TST & \\
\hline CHEMBL 70582 & 688586 & 4.4 & 4.2585 & TST & \\
\hline CHEMBL380047 & 363879 & 3.6383 & 3.5534 & TRN & \\
\hline CHEMBL 314532 & 363879 & 2.9586 & 2.9533 & TRN & \\
\hline CHEMBL91777 & 363879 & 4.3979 & 4.338 & TRN & \\
\hline CHEMBL 210490 & 363879 & 3.3279 & 3.3136 & TRN & \\
\hline CHEMBL90452 & 363879 & 3.5528 & 3.6122 & TRN & \\
\hline CHEMBL91241 & 363879 & 3.284 & 3.2467 & TRN & \\
\hline CHEMBL54552 & 363879 & 4.1549 & 4.0169 & TRN & \\
\hline CHEMBL438960 & 363879 & 4.0 & 3.8804 & TRN & \\
\hline CHEMBL89956 & 363879 & 3.6198 & 3.6658 & TRN & \\
\hline CHEMBL209083 & 363879 & 2.7959 & 1.9668 & TST & \\
\hline CHEMBL299889 & 363879 & 3.8861 & 3.7559 & TRN & \\
\hline CHEMBL429950 & 363879 & 3.9586 & 3.9819 & TRN & \\
\hline CHEMBL188866 & 363879 & 4.0 & 4.0601 & TRN & \\
\hline CHEMBL421171 & 363879 & 3.3565 & 3.1731 & TRN & \\
\hline CHEMBL39159 & 363879 & 4.301 & 4.2393 & TRN & \\
\hline CHEMBL208094 & 363879 & 3.8539 & 3.786 & TRN & \\
\hline CHEMBL378907 & 363879 & 4.5229 & 4.5856 & TRN & \\
\hline CHEMBL3321985 & 363879 & 3.7212 & 3.4712 & TST & \\
\hline CHEMBL191057 & 363879 & 3.6576 & 3.7153 & TRN & \\
\hline CHEMBL95286 & 363879 & 4.2218 & 4.2067 & TRN & \\
\hline CHEMBL299759 & 363879 & 3.4815 & 3.6093 & TRN & \\
\hline CHEMBL57338 & 363879 & 4.0969 & 4.21899 & 9999999999 & TRN \\
\hline CHEMBL17171 & 363879 & 3.0044 & 3.1834 & TRN & \\
\hline CHEMBL190704 & 363879 & 1.301 & 2.1113 & TST & \\
\hline CHEMBL371194 & 363879 & 3.1549 & 2.9383 & TST & \\
\hline CHEMBL441685 & 363879 & 3.1612 & 3.25699 & 99999999997 & TRN \\
\hline CHEMBL91392 & 363879 & 3.2596 & 3.2504 & TRN & \\
\hline CHEMBL53400 & 363879 & 3.8539 & 3.8376 & TRN & \\
\hline CHEMBL318315 & 363879 & 3.0 & 3.1939 & TRN & \\
\hline CHEMBL54933 & 363879 & 4.0969 & 3.9758 & TRN & \\
\hline CHEMBL421361 & 363879 & 3.2924 & 3.3146 & TRN & \\
\hline CHEMBL209765 & 363879 & 3.7212 & 3.718 & TRN & \\
\hline CHEMBL175737 & 363879 & 3.2676 & 2.9514 & TST & \\
\hline CHEMBL380174 & 363879 & 3.6778 & 3.9503 & TRN & \\
\hline CHEMBL54278 & 363879 & 3.2366 & 3.1787 & TST & \\
\hline CHEMBL209670 & 363879 & 3.5528 & 3.5017 & TRN & \\
\hline CHEMBL209341 & 363879 & 3.6778 & 3.7168 & TRN & \\
\hline CHEMBL190361 & 363879 & 3.5086 & 3.293 & TRN & \\
\hline CHEMBL316103 & 363879 & 4.0 & 3.9307 & TRN & \\
\hline
\end{tabular}




\begin{tabular}{|c|c|c|c|c|c|}
\hline \multicolumn{6}{|c|}{ Supplemental Table S2.txt } \\
\hline CHEMBL56119 & 363879 & 3.7696 & 3.888 & TRN & \\
\hline CHEMBL 379810 & 363879 & 3.8539 & 3.9368 & TRN & \\
\hline CHEMBL210850 & 363879 & 3.3768 & 3.4269 & TRN & \\
\hline CHEMBL210616 & 363879 & 3.0706 & 3.0552 & TRN & \\
\hline CHEMBL52461 & 363879 & 4.0969 & 3.9651 & TRN & \\
\hline CHEMBL382777 & 363879 & 3.5686 & 3.4974 & TRN & \\
\hline CHEMBL417979 & 363879 & 3.9586 & 3.8628 & TRN & \\
\hline CHEMBL365790 & 363879 & 3.2757 & 3.2362 & TRN & \\
\hline CHEMBL91792 & 363879 & 4.0969 & 4.1078 & TRN & \\
\hline CHEMBL80548 & 363879 & 3.8861 & 3.3069 & TST & \\
\hline CHEMBL91561 & 363879 & 3.4948 & 3.6276 & TRN & \\
\hline CHEMBL420061 & 363879 & 3.1249 & 3.1253 & TRN & \\
\hline CHEMBL108438 & 363879 & 4.5229 & 4.3455 & TST & \\
\hline CHEMBL93127 & 363879 & 3.3979 & 3.0628 & TST & \\
\hline CHEMBL94016 & 363879 & 4.2218 & 4.0711 & TST & \\
\hline CHEMBL327588 & 363879 & 3.585 & 3.7828 & TST & \\
\hline CHEMBL 293494 & 363879 & 3.6021 & 2.9083 & TST & \\
\hline CHEMBL190027 & 363879 & 1.301 & 1.8673 & TST & \\
\hline CHEMBL 377872 & 363879 & 3.4318 & 3.6439 & TST & \\
\hline CHEMBL 292467 & 363879 & 3.3188 & 3.2438 & TST & \\
\hline CHEMBL1773575 & 745548 & 7.1192 & 7.9373 & TST & \\
\hline CHEMBL1773735 & 745548 & 10.0 & 9.8571 & TRN & \\
\hline CHEMBL1773559 & 745548 & 7.7447 & 7.8775 & TRN & \\
\hline CHEMBL1773573 & 745548 & 5.5045 & 7.3442 & TST & \\
\hline CHEMBL1773603 & 745548 & 8.9208 & 8.9539 & TRN & \\
\hline CHEMBL1773566 & 745548 & 6.9431 & 6.9626 & TRN & \\
\hline CHEMBL1773582 & 745548 & 7.4202 & 7.721 & TST & \\
\hline CHEMBL1773734 & 745548 & 10.0 & 9.9901 & TRN & \\
\hline CHEMBL1773730 & 745548 & 10.0 & 9.9151 & TRN & \\
\hline CHEMBL1773558 & 745548 & 7.8861 & 8.1401 & TST & \\
\hline CHEMBL1773596 & 745548 & 7.2291 & 7.5543 & TRN & \\
\hline CHEMBL1773602 & 745548 & 8.8539 & 8.9347 & TRN & \\
\hline CHEMBL1773598 & 745548 & 7.3188 & 7.66100 & 00000000005 & TRN \\
\hline CHEMBL1773733 & 745548 & 10.0 & 9.991 & TRN & \\
\hline CHEMBL1773561 & 745548 & 7.3279 & 7.4282 & TRN & \\
\hline CHEMBL1773731 & 745548 & 10.0 & 9.7397 & TRN & \\
\hline CHEMBL1773578 & 745548 & 7.1871 & 7.7353 & TST & \\
\hline CHEMBL1773562 & 745548 & 6.8508 & 6.9641 & TRN & \\
\hline CHEMBL1773077 & 745548 & 7.7447 & 7.4626 & TRN & \\
\hline CHEMBL1773588 & 745548 & 7.0706 & 6.6724 & TRN & \\
\hline CHEMBL1773605 & 745548 & 8.8539 & 9.1185 & TRN & \\
\hline CHEMBL1773563 & 745548 & 7.2366 & 7.421 & TRN & \\
\hline CHEMBL1773579 & 745548 & 7.0757 & 7.3296 & TST & \\
\hline CHEMBL1773576 & 745548 & 7.2076 & 7.8193 & TST & \\
\hline CHEMBL1773577 & 745548 & 7.3872 & 7.686 & TST & \\
\hline CHEMBL1773571 & 745548 & 6.4776 & 6.9305 & TRN & \\
\hline CHEMBL1773597 & 745548 & 6.8416 & 7.2338 & TRN & \\
\hline CHEMBL1773570 & 745548 & 5.8097 & 6.7397 & TST & \\
\hline
\end{tabular}




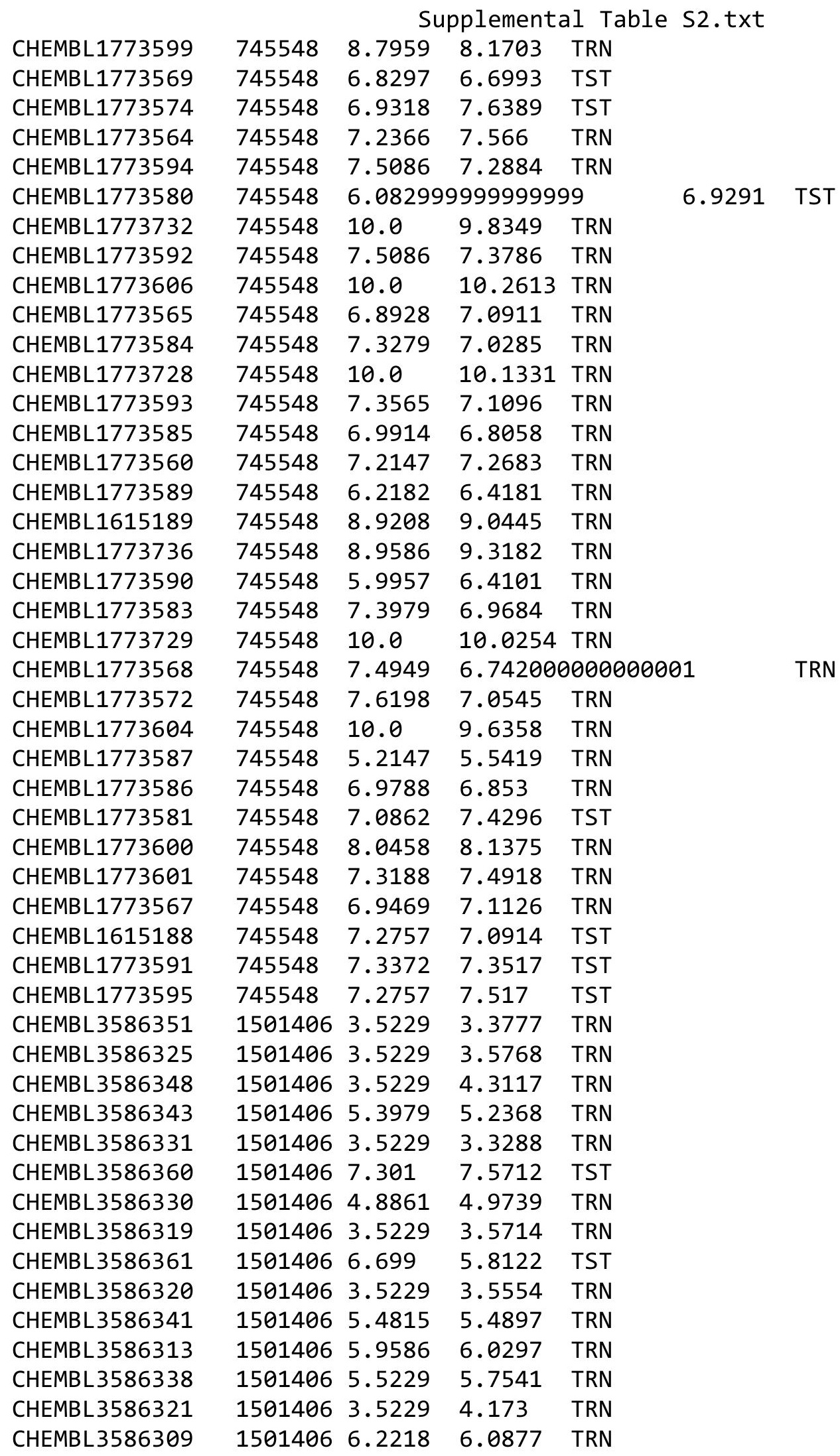

Page 8763 
Supplemental Table S2.txt

\begin{tabular}{|c|c|c|c|c|c|}
\hline CHEMBL3586317 & 1501406 & 3.5229 & 2.9942 & TRN & \\
\hline CHEMBL 3586347 & 1501406 & 7.2218 & 6.0073 & TST & \\
\hline CHEMBL3586339 & 1501406 & 5.6021 & 5.4508 & TRN & \\
\hline CHEMBL3586333 & 1501406 & 5.7212 & 5.5717 & TRN & \\
\hline CHEMBL 3586326 & 1501406 & 5.3188 & 5.3294 & TRN & \\
\hline CHEMBL 3586345 & 1501406 & 6.699 & 6.2356 & TRN & \\
\hline CHEMBL3586335 & 1501406 & 6.2218 & 6.2475 & TRN & \\
\hline CHEMBL3586334 & 1501406 & 3.5229 & 3.3602 & TRN & \\
\hline CHEMBL3586346 & 1501406 & 7.3979 & 7.2372 & TRN & \\
\hline CHEMBL 3586344 & 1501406 & 3.5229 & 4.8752 & TST & \\
\hline CHEMBL3586356 & 1501406 & 3.5229 & 4.1007 & TST & \\
\hline CHEMBL 3586314 & 1501406 & 5.8239 & 5.956 & TRN & \\
\hline CHEMBL 3586349 & 1501406 & 5.4202 & 5.4884 & TRN & \\
\hline CHEMBL 3586354 & 1501406 & 3.5229 & 3.9962 & TST & \\
\hline CHEMBL 3586311 & 1501406 & 6.0458 & 6.0488 & TRN & \\
\hline CHEMBL 3586352 & 1501406 & 6.0 & 5.7732 & TRN & \\
\hline CHEMBL 3586342 & 1501406 & 6.1549 & 6.1695 & TST & \\
\hline CHEMBL 3586327 & 1501406 & 3.5229 & 3.8036 & TRN & \\
\hline CHEMBL3586324 & 1501406 & 6.0 & 5.6199 & TRN & \\
\hline CHEMBL 3586336 & 1501406 & 4.8239 & 5.277 & TST & \\
\hline CHEMBL 3586357 & 1501406 & 3.5229 & 3.6448 & TRN & \\
\hline CHEMBL 3586340 & 1501406 & 6.0458 & 5.9422 & TST & \\
\hline CHEMBL 3586337 & 1501406 & 6.0 & 6.0499 & TST & \\
\hline CHEMBL 3586362 & 1501406 & 8.0 & 7.4371 & TST & \\
\hline CHEMBL 3586310 & 1501406 & 5.5229 & 5.8272 & TRN & \\
\hline CHEMBL3586353 & 1501406 & 5.6021 & 5.5019 & TRN & \\
\hline CHEMBL 3586328 & 1501406 & 5.6021 & 5.7988 & TRN & \\
\hline CHEMBL3586318 & 1501406 & 3.5229 & 3.3679 & TRN & \\
\hline CHEMBL 3586350 & 1501406 & 3.5229 & 3.8082 & TRN & \\
\hline CHEMBL 3586316 & 1501406 & 3.5229 & 3.5123 & TRN & \\
\hline CHEMBL 3586358 & 1501406 & 3.5229 & 3.1972 & TRN & \\
\hline CHEMBL3586329 & 1501406 & 3.5229 & 3.5633 & TRN & \\
\hline CHEMBL3586359 & 1501406 & 6.699 & 6.2082 & TST & \\
\hline CHEMBL 3586312 & 1501406 & 7.0969 & 7.338999 & 99999999995 & TRN \\
\hline CHEMBL3586315 & 1501406 & 6.301 & 6.0617 & TRN & \\
\hline CHEMBL3586332 & 1501406 & 3.5229 & 3.5281 & TRN & \\
\hline CHEMBL 3586355 & 1501406 & 3.5229 & 3.8109 & TST & \\
\hline CHEMBL1784566 & 1528476 & 6.2147 & 6.211 & TRN & \\
\hline CHEMBL1784574 & 1528476 & 7.2218 & 7.2331 & TRN & \\
\hline CHEMBL1784590 & 1528476 & 6.2147 & 6.2036 & TRN & \\
\hline CHEMBL3689094 & 1528476 & 5.9208 & 5.9271 & TRN & \\
\hline CHEMBL 3689084 & 1528476 & 5.9208 & 5.9163 & TRN & \\
\hline CHEMBL 3289671 & 1528476 & 7.699 & 7.6648 & TRN & \\
\hline CHEMBL1956265 & 1528476 & 6.8239 & 6.8114 & TRN & \\
\hline CHEMBL1784575 & 1528476 & 6.2924 & 6.3203 & TRN & \\
\hline CHEMBL1784591 & 1528476 & 6.0044 & 6.0123 & TRN & \\
\hline CHEMBL1738786 & 1528476 & 7.4202 & 7.432 & TRN & \\
\hline CHEMBL1956279 & 1528476 & 7.0315 & 7.0208 & TRN & \\
\hline
\end{tabular}


Supplemental Table S2.txt

\begin{tabular}{|c|c|c|c|c|}
\hline 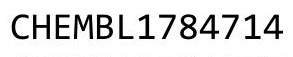 & & - & & \\
\hline HEMBL1784577 & 528476 & 6.7212 & 7379 & \\
\hline HEMBL3289670 & 528476 & 7.4559 & 4087 & \\
\hline & & 458 & 057 & \\
\hline EMBL1 & 28476 & 861 & 9249 & \\
\hline HEMBL1784715 & 528476 & 5.4989 & 4063 & \\
\hline HEMBL1956283 & 528476 & 7.5528 & .5946 & \\
\hline HEMBL17 & 8476 & 458 & $\partial 317$ & \\
\hline 083 & 528476 & 3665 & .3647 & \\
\hline HEMBLI & 528476 & 073 & .6125 & \\
\hline HEMBL1956290 & 528476 & 7.4559 & . 4617 & \\
\hline HEMBL1956288 & 528476 & 6.7212 & .7404 & \\
\hline HEMBL1956285 & 528476 & 7.5229 & 5505 & \\
\hline HEME & 528476 & 354 & 1338 & \\
\hline HEMBL36 & 528476 & 924 & 2955 & \\
\hline HEMBL17 & 528476 & 6.301 & 8535 & \\
\hline HEMBL17 & 528476 & 2676 & 2665 & \\
\hline HEMBL36 & 16 & 37 & 006 & \\
\hline HEMBL3 & 76 & & 848 & \\
\hline HEMBL3 & 528476 & 6. & 5836 & \\
\hline HEMBL2C & 528476 & 76 & 5581 & \\
\hline HEMBL 2172226 & 76 & & 2683 & \\
\hline HEMBL1S & 76 & & 011 & 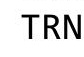 \\
\hline HEMBL1 & 76 & & 9871 & RN \\
\hline HEME & 76 & & 5789 & RN \\
\hline HEMBL1 & 76 & & & RIN \\
\hline HEMBL17 & 76 & & 676 & 151 \\
\hline HEMBL1 & 6 & 19 & 027 & RIV \\
\hline HEM & 76 & & 99 & \\
\hline HEMBL3 & 76 & & 297 & IRN \\
\hline HEMBL17 & 76 & & 583 & 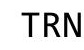 \\
\hline HEMBL36 & 76 & 6.8539 & 8852 & TRN \\
\hline HEMBL3 & & 68 & 855 & Niv \\
\hline 7 & 6 & & 63 & ST \\
\hline HEMBL3 & & & 2576 & RN \\
\hline HEMBL54 & 5284 & 861 & 3942 & $\Gamma R$ \\
\hline HEMBL17 & 528476 & 739 & 5174 & TST \\
\hline HEMBL36 & 6 & & 264 & $\mathrm{RN}$ \\
\hline 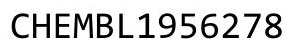 & & & 691 & RN \\
\hline HEMBL1 & & 5.7696 & 3682 & TST \\
\hline HEMBL17 & 76 & 6.301 & 109 & IST \\
\hline HEMBL5 & כ & 207 & 961 & TRN \\
\hline 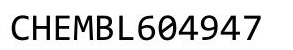 & & & 509 & \\
\hline HEMBL 6 & & & 3078 & 「RN \\
\hline HEMBL6 6 & & 6.4815 & .4282 & RN \\
\hline HEMBL6C & 10565 & 198 & 239 & RN \\
\hline & & & & \\
\hline 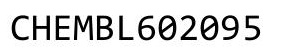 & & & & \\
\hline
\end{tabular}

Page 8765 


\begin{tabular}{|c|c|c|c|c|c|}
\hline & & \multicolumn{4}{|c|}{ Supplemental Table s2.txt } \\
\hline CHEMBL600613 & 610565 & 6.3372 & 6.4336 & TRN & \\
\hline CHEMBL601436 & 610565 & 4.0 & 4.2136 & TRN & \\
\hline CHEMBL600005 & 610565 & 6.4202 & 6.1961 & TRN & \\
\hline CHEMBL605578 & 610565 & 4.0 & 3.8479 & TRN & \\
\hline CHEMBL602063 & 610565 & 5.6383 & 5.5959 & TRN & \\
\hline CHEMBL602267 & 610565 & 6.2218 & 6.4925 & TRN & \\
\hline CHEMBL178126 & 610565 & 5.8539 & 5.7749 & TRN & \\
\hline CHEMBL599557 & 610565 & 6.2366 & 6.08299 & 9999999999 & TRN \\
\hline CHEMBL605557 & 610565 & 6.3565 & 6.03600 & 00000000005 & TRN \\
\hline CHEMBL599556 & 610565 & 6.3372 & 6.0713 & TRN & \\
\hline CHEMBL179532 & 610565 & 6.1549 & 6.2312 & TRN & \\
\hline CHEMBL600406 & 610565 & 6.0 & 6.3691 & TRN & \\
\hline CHEMBL603237 & 610565 & 6.0862 & 5.7974 & TRN & \\
\hline CHEMBL600204 & 610565 & 5.9208 & 6.1434 & TRN & \\
\hline CHEMBL601031 & 610565 & 6.0809 & 6.0976 & TRN & \\
\hline CHEMBL603918 & 610565 & 5.8239 & 5.7067 & TRN & \\
\hline CHEMBL606202 & 610565 & 6.2218 & 6.1207 & TRN & \\
\hline CHEMBL 216000 & 610565 & 5.1739 & 4.007 & TST & \\
\hline CHEMBL601677 & 610565 & 5.699 & 5.1312 & TRN & \\
\hline CHEMBL600427 & 610565 & 6.4815 & 6.3724 & TRN & \\
\hline CHEMBL602142 & 610565 & 6.3468 & 6.1239 & TRN & \\
\hline CHEMBL600223 & 610565 & 6.1079 & 6.0299 & TRN & \\
\hline CHEMBL190558 & 610565 & 6.0969 & 5.5674 & TRN & \\
\hline CHEMBL600206 & 610565 & 5.0 & 6.0947 & TST & \\
\hline CHEMBL602876 & 610565 & 5.6021 & 5.7373 & TRN & \\
\hline CHEMBL600222 & 610565 & 6.4202 & 6.0299 & TRN & \\
\hline CHEMBL610921 & 610565 & 6.0969 & 5.9178 & TRN & \\
\hline CHEMBL605366 & 610565 & 5.4685 & 5.5297 & TRN & \\
\hline CHEMBL600425 & 610565 & 5.8861 & 6.1594 & TRN & \\
\hline CHEMBL604336 & 610565 & 5.8239 & 5.9665 & TRN & \\
\hline CHEMBL601239 & 610565 & 4.0 & 4.3119 & TRN & \\
\hline CHEMBL594318 & 610565 & 7.301 & 5.3013 & TST & \\
\hline CHEMBL602877 & 610565 & 6.0 & 6.2229 & TRN & \\
\hline CHEMBL600673 & 610565 & 5.8861 & 5.7878 & TRN & \\
\hline CHEMBL601437 & 610565 & 4.0 & 4.1178 & TRN & \\
\hline CHEMBL601030 & 610565 & 6.3872 & 5.9896 & TRN & \\
\hline CHEMBL604956 & 610565 & 3.0269 & 5.6834 & TRN & \\
\hline CHEMBL610631 & 610565 & 5.7696 & 5.9208 & TST & \\
\hline CHEMBL601010 & 610565 & 5.8861 & 6.0261 & TST & \\
\hline CHEMBL386508 & 610565 & 5.3768 & 4.1712 & TST & \\
\hline CHEMBL604945 & 610565 & 6.8861 & 5.8529 & TST & \\
\hline CHEMBL604760 & 610565 & 5.699 & 5.78100 & $\partial 000000001$ & TST \\
\hline CHEMBL589140 & 610565 & 6.0 & 6.1293 & TST & \\
\hline CHEMBL601435 & 610565 & 5.9586 & 6.2167 & TST & \\
\hline CHEMBL604128 & 610565 & 6.1938 & 5.9518 & TST & \\
\hline CHEMBL3191474 & 688266 & 5.7096 & 5.3088 & TRN & \\
\hline CHEMBL1424694 & 688266 & 5.5708 & 5.1832 & TRN & \\
\hline CHEMBL1547501 & 688266 & 5.5442 & 5.2897 & TST & \\
\hline
\end{tabular}




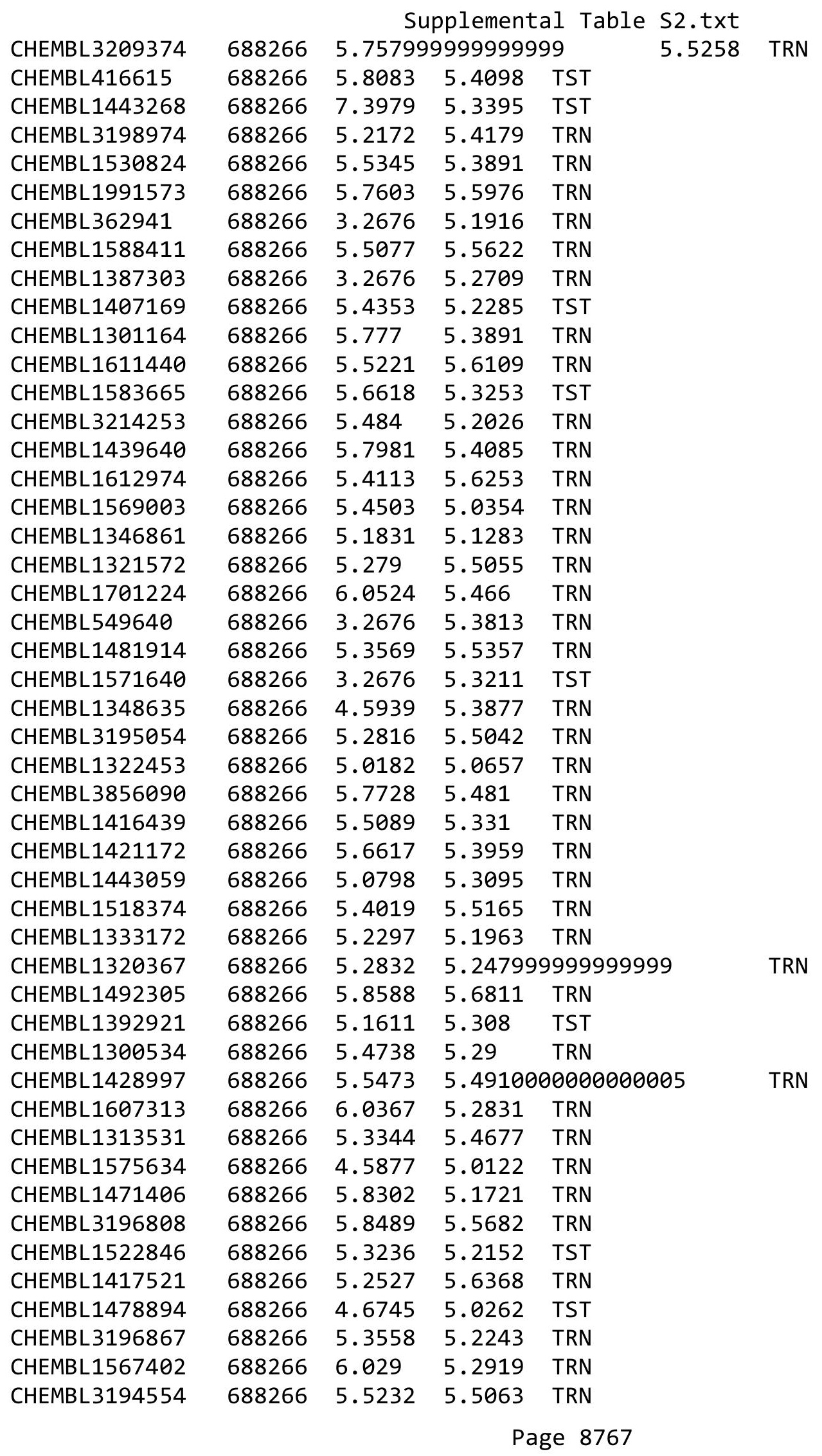




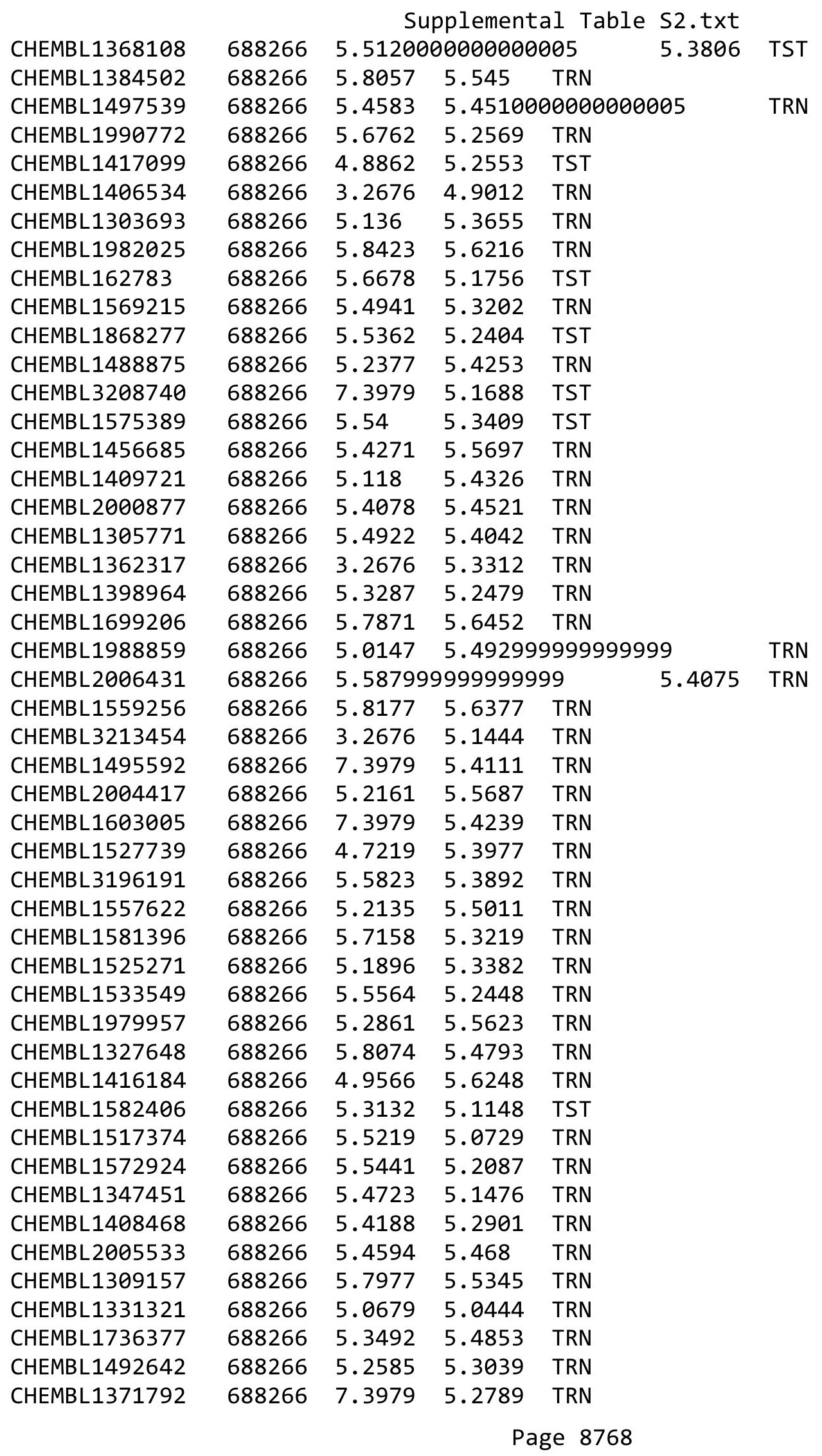




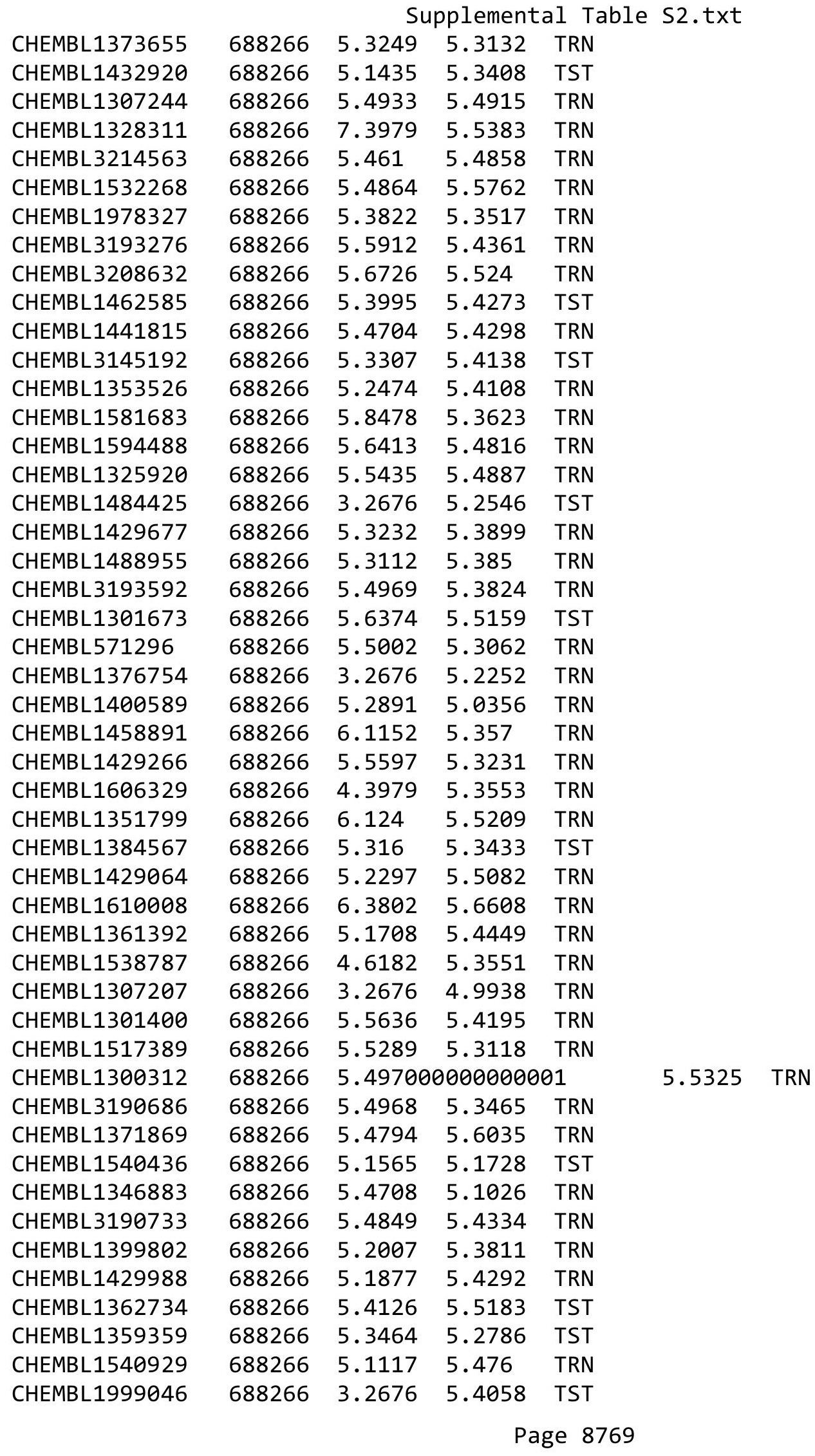




\begin{tabular}{|c|c|c|c|c|c|}
\hline \multicolumn{6}{|c|}{ Supplemental Table S2.txt } \\
\hline CHEMBL1487834 & 688266 & 5.1433 & 5.3273 & TRN & \\
\hline CHEMBL483531 & 688266 & 5.3822 & 5.1023 & TRN & \\
\hline CHEMBL1387404 & 688266 & 5.0807 & 5.2262 & TRN & \\
\hline CHEMBL1349382 & 688266 & 5.7411 & 5.535 & TRN & \\
\hline CHEMBL1542433 & 688266 & 3.2676 & 5.3133 & TRN & \\
\hline CHEMBL1367191 & 688266 & 4.9877 & 5.3327 & TRN & \\
\hline CHEMBL1419792 & 688266 & 5.1857 & 5.3538 & TRN & \\
\hline CHEMBL1309385 & 688266 & 5.4974 & 5.0396 & TRN & \\
\hline CHEMBL1540246 & 688266 & 5.8998 & 5.1662 & TRN & \\
\hline CHEMBL1416348 & 688266 & 5.8229 & 5.3464 & TRN & \\
\hline CHEMBL1485126 & 688266 & 5.9613 & 5.6197 & TRN & \\
\hline CHEMBL1499658 & 688266 & 5.5657 & 5.5256 & TRN & \\
\hline CHEMBL1448854 & 688266 & 5.5254 & 5.4292 & TRN & \\
\hline CHEMBL1565557 & 688266 & 5.0192 & 5.2795 & TRN & \\
\hline CHEMBL1580295 & 688266 & 5.4814 & 5.3948 & TRN & \\
\hline CHEMBL1382279 & 688266 & 5.5456 & 5.3069 & TRN & \\
\hline CHEMBL1424580 & 688266 & 5.2366 & 5.1462 & TRN & \\
\hline CHEMBL1965471 & 688266 & 5.4222 & 5.6678 & TRN & \\
\hline CHEMBL1443570 & 688266 & 5.7747 & 5.3242 & TRN & \\
\hline CHEMBL1443791 & 688266 & 5.9455 & 5.4049 & TRN & \\
\hline CHEMBL1313227 & 688266 & 5.3305 & 5.1635 & TRN & \\
\hline CHEMBL1468811 & 688266 & 6.1046 & 5.4244 & TRN & \\
\hline CHEMBL1332402 & 688266 & 5.6873 & 5.5789 & TRN & \\
\hline CHEMBL1526855 & 688266 & 4.8401 & 4.9488 & TRN & \\
\hline CHEMBL1373454 & 688266 & 4.9435 & 5.5399 & TRN & \\
\hline CHEMBL1389588 & 688266 & 4.8508 & 5.6181 & TRN & \\
\hline CHEMBL3195383 & 688266 & 5.21399 & 99999999 & 5.7382 & TRN \\
\hline CHEMBL1994988 & 688266 & 5.4603 & 5.3714 & TRN & \\
\hline CHEMBL1333773 & 688266 & 3.2676 & 5.0683 & TRN & \\
\hline CHEMBL1427047 & 688266 & 5.0489 & 5.4759 & TRN & \\
\hline CHEMBL3193670 & 688266 & 5.4255 & 5.3314 & TRN & \\
\hline CHEMBL484640 & 688266 & 5.4041 & 5.2212 & TST & \\
\hline CHEMBL1390703 & 688266 & 5.0987 & 5.29799 & 9999999999 & TRN \\
\hline CHEMBL1381627 & 688266 & 5.4239 & 5.4765 & TRN & \\
\hline CHEMBL1606696 & 688266 & 3.2676 & 5.2574 & TRN & \\
\hline CHEMBL1353229 & 688266 & 4.8095 & 5.5088 & TRN & \\
\hline CHEMBL1311453 & 688266 & 5.6348 & 5.181 & TRN & \\
\hline CHEMBL1387240 & 688266 & 5.5576 & 5.4716 & TRN & \\
\hline CHEMBL1561215 & 688266 & 5.1611 & 5.5541 & TST & \\
\hline CHEMBL1580173 & 688266 & 5.2946 & 5.4038 & TRN & \\
\hline CHEMBL1391063 & 688266 & 5.8174 & 5.4856 & TST & \\
\hline CHEMBL1361957 & 688266 & 5.2088 & 5.2967 & TRN & \\
\hline CHEMBL1308055 & 688266 & 5.7312 & 5.3125 & TRN & \\
\hline CHEMBL1534795 & 688266 & 5.1509 & 5.3993 & TRN & \\
\hline CHEMBL1579632 & 688266 & 5.4981 & 5.3132 & TRN & \\
\hline CHEMBL1491456 & 688266 & 3.2676 & 5.1865 & TST & \\
\hline CHEMBL1416382 & 688266 & 5.2786 & 5.1795 & TRN & \\
\hline CHEMBL1399331 & 688266 & 5.6645 & 5.3182 & TRN & \\
\hline
\end{tabular}




\begin{tabular}{|c|c|c|c|c|c|}
\hline \multicolumn{6}{|c|}{ supple } \\
\hline CHEMBL1426676 & 688266 & 5.4566 & 5.3827 & TRN & \\
\hline CHEMBL1496516 & 688266 & 7.3979 & 5.3951 & TRN & \\
\hline CHEMBL1493936 & 688266 & 6.1278 & 5.5512 & TRN & \\
\hline CHEMBL1496585 & 688266 & 5.3137 & 5.2571 & TRN & \\
\hline CHEMBL1599175 & 688266 & 5.0016 & 5.3627 & TRN & \\
\hline CHEMBL1329974 & 688266 & 4.8664 & 5.4768 & TRN & \\
\hline CHEMBL1466965 & 688266 & 4.7077 & 5.3265 & TST & \\
\hline CHEMBL1576220 & 688266 & 5.5573 & 5.266 & TRN & \\
\hline CHEMBL3197153 & 688266 & 6.3651 & 5.3071 & TRN & \\
\hline CHEMBL1562987 & 688266 & 5.1402 & 5.5595 & TRN & \\
\hline CHEMBL469424 & 688266 & 5.6162 & 5.2445 & TRN & \\
\hline CHEMBL1555894 & 688266 & 5.2332 & 5.3731 & TRN & \\
\hline CHEMBL3193664 & 688266 & 5.3255 & 5.2922 & TRN & \\
\hline CHEMBL463175 & 688266 & 5.8263 & 5.0956 & TST & \\
\hline CHEMBL 246446 & 688266 & 3.2676 & 5.3084 & TRN & \\
\hline CHEMBL1487331 & 688266 & 5.1859 & 5.2979 & TRN & \\
\hline CHEMBL1366942 & 688266 & 5.3333 & 5.2971 & TRN & \\
\hline CHEMBL1331231 & 688266 & 5.0348 & 5.3688 & TRN & \\
\hline CHEMBL1465176 & 688266 & 7.3979 & 5.29799 & 9999999999 & TST \\
\hline CHEMBL1490692 & 688266 & 5.7996 & 5.4563 & TRN & \\
\hline CHEMBL1574857 & 688266 & 4.7139 & 5.4074 & TRN & \\
\hline CHEMBL1458441 & 688266 & 5.4801 & 5.2996 & TRN & \\
\hline CHEMBL1454808 & 688266 & 5.2892 & 5.7378 & TRN & \\
\hline CHEMBL1381318 & 688266 & 5.4364 & 5.1923 & TRN & \\
\hline CHEMBL1532909 & 688266 & 5.5519 & 5.0818 & TRN & \\
\hline CHEMBL1573731 & 688266 & 5.8155 & 5.6171 & TRN & \\
\hline CHEMBL1467222 & 688266 & 5.1419 & 5.4871 & TRN & \\
\hline CHEMBL221415 & 688266 & 5.3833 & 5.4167 & TRN & \\
\hline CHEMBL1375569 & 688266 & 5.2949 & 5.2836 & TRN & \\
\hline CHEMBL1499053 & 688266 & 5.0558 & 5.4277 & TRN & \\
\hline CHEMBL1976049 & 688266 & 5.1554 & 5.4218 & TRN & \\
\hline CHEMBL1509707 & 688266 & 6.0446 & 5.6751 & TRN & \\
\hline CHEMBL1438240 & 688266 & 5.5702 & 5.181 & TRN & \\
\hline CHEMBL1588524 & 688266 & 5.6709 & 5.3006 & TRN & \\
\hline CHEMBL1471932 & 688266 & 5.732 & 5.4819 & TRN & \\
\hline CHEMBL1589385 & 688266 & 3.2676 & 5.1511 & TST & \\
\hline CHEMBL 3195280 & 688266 & 5.437 & 5.57100 & 0000000001 & TRN \\
\hline CHEMBL1402473 & 688266 & 5.3154 & 5.4046 & TRN & \\
\hline CHEMBL69612 & 688266 & 5.7165 & 5.465 & TRN & \\
\hline CHEMBL1503050 & 688266 & 5.3124 & 5.1816 & TST & \\
\hline CHEMBL1578345 & 688266 & 5.4222 & 5.4055 & TRN & \\
\hline CHEMBL1459778 & 688266 & 5.5052 & 5.4486 & TST & \\
\hline CHEMBL3197450 & 688266 & 5.4155 & 5.2369 & TRN & \\
\hline CHEMBL1462469 & 688266 & 5.1072 & 5.4532 & TRN & \\
\hline CHEMBL1504470 & 688266 & 5.8542 & 5.42899 & 9999999999 & TRN \\
\hline CHEMBL1488072 & 688266 & 5.5482 & 5.4604 & TRN & \\
\hline CHEMBL1362867 & 688266 & 5.4035 & 5.3523 & TRN & \\
\hline CHEMBL3191831 & 688266 & 5.6542 & 5.4682 & TRN & \\
\hline
\end{tabular}


Supplemental Table S2.txt

\begin{tabular}{|c|c|c|c|c|c|}
\hline CHEMBL1321933 & 688266 & 4.7272 & 5.1767 & TRN & \\
\hline CHEMBL1460436 & 688266 & 5.3043 & 5.3673 & TST & \\
\hline CHEMBL1984240 & 688266 & 5.7965 & 5.6406 & TRN & \\
\hline CHEMBL1975746 & 688266 & 5.939 & 5.454 & TST & \\
\hline CHEMBL1348645 & 688266 & 5.4265 & 5.2466 & TRN & \\
\hline CHEMBL1531377 & 688266 & 5.483 & 5.4391 & TST & \\
\hline CHEMBL1362566 & 688266 & 5.932 & 5.3903 & TRN & \\
\hline CHEMBL1575547 & 688266 & 5.4584 & 5.5273 & TRN & \\
\hline CHEMBL1373107 & 688266 & 5.5967 & 5.2593 & TRN & \\
\hline CHEMBL1414863 & 688266 & 3.2676 & 5.2265 & TST & \\
\hline CHEMBL523844 & 688266 & 4.8725 & 5.362 & TRN & \\
\hline CHEMBL1303916 & 688266 & 4.8738 & 5.7159 & TRN & \\
\hline CHEMBL1382760 & 688266 & 5.2225 & 5.1349 & TRN & \\
\hline CHEMBL1530437 & 688266 & 5.4862 & 5.5734 & TRN & \\
\hline CHEMBL1408125 & 688266 & 5.605 & 5.6226 & TRN & \\
\hline CHEMBL1526918 & 688266 & 3.2676 & 5.5185 & TST & \\
\hline CHEMBL 3195241 & 688266 & 5.8338 & 5.4136 & TRN & \\
\hline CHEMBL1304684 & 688266 & 5.2976 & 5.2455 & TRN & \\
\hline CHEMBL1449333 & 688266 & 7.3979 & 5.2526 & TRN & \\
\hline CHEMBL1491441 & 688266 & 5.4118 & 5.6798 & TST & \\
\hline CHEMBL1352080 & 688266 & 7.3979 & 5.4004 & TRN & \\
\hline CHEMBL1374841 & 688266 & 5.5308 & 5.6136 & TRN & \\
\hline CHEMBL1510164 & 688266 & 5.4172 & 5.3616 & TRN & \\
\hline CHEMBL1595235 & 688266 & 5.2511 & 5.3491 & TRN & \\
\hline CHEMBL1337694 & 688266 & 4.5963 & 5.501 & TRN & \\
\hline CHEMBL1391256 & 688266 & 5.4947 & 5.2385 & TST & \\
\hline CHEMBL1423032 & 688266 & 5.7673 & 5.442 & TRN & \\
\hline CHEMBL1306856 & 688266 & 5.4774 & 5.5521 & TRN & \\
\hline CHEMBL560919 & 688266 & 4.9305 & 5.3308 & TRN & \\
\hline CHEMBL1333283 & 688266 & 4.8916 & 5.2725 & TRN & \\
\hline CHEMBL1390559 & 688266 & 5.024 & 5.12200 & 0000000001 & TRN \\
\hline CHEMBL1342843 & 688266 & 3.2676 & 5.2751 & TRN & \\
\hline CHEMBL1538244 & 688266 & 5.5615 & 5.1025 & TRN & \\
\hline CHEMBL1099177 & 688266 & 5.6029 & 5.2424 & TRN & \\
\hline CHEMBL1560608 & 688266 & 5.2417 & 5.3859 & TST & \\
\hline CHEMBL1607846 & 688266 & 7.3979 & 5.5382 & TRN & \\
\hline CHEMBL1332449 & 688266 & 5.1714 & 5.2273 & TRN & \\
\hline CHEMBL578585 & 688266 & 5.8006 & 5.2424 & TRN & \\
\hline CHEMBL1400145 & 688266 & 5.7572 & 5.7131 & TRN & \\
\hline CHEMBL1507308 & 688266 & 5.3572 & 5.5134 & TRN & \\
\hline CHEMBL1386096 & 688266 & 5.6161 & 5.0582 & TRN & \\
\hline CHEMBL1353221 & 688266 & 4.996 & 5.2808 & TST & \\
\hline CHEMBL1461928 & 688266 & 5.5157 & 5.4315 & TRN & \\
\hline CHEMBL1994635 & 688266 & 5.7855 & 5.3189 & TST & \\
\hline CHEMBL1430473 & 688266 & 3.2676 & 5.1914 & TRN & \\
\hline CHEMBL 2000340 & 688266 & 5.3038 & 5.2903 & TRN & \\
\hline CHEMBL1359806 & 688266 & 5.4332 & 5.4248 & TRN & \\
\hline CHEMBL1346172 & 688266 & 5.6425 & 5.489 & TRN & \\
\hline
\end{tabular}




\begin{tabular}{|c|c|c|c|c|c|}
\hline \multirow{2}{*}{ CHEMBL1541894 } & \multirow{2}{*}{688266} & \multicolumn{4}{|l|}{ U } \\
\hline & & 5.3573 & 5.4021 & TRN & \\
\hline CHEMBL1446626 & 688266 & 5.4318 & 5.4248 & TRN & \\
\hline CHEMBL1972621 & 688266 & 5.3531 & 5.3068 & TRN & \\
\hline CHEMBL1482554 & 688266 & 5.3288 & 5.5204 & TRN & \\
\hline CHEMBL1407474 & 688266 & 5.7942 & 5.1213 & TST & \\
\hline CHEMBL1411383 & 688266 & 6.0 & 5.5933 & TRN & \\
\hline CHEMBL1323000 & 688266 & 5.2894 & 5.1745 & TRN & \\
\hline CHEMBL1335522 & 688266 & 5.2652 & 5.1527 & TRN & \\
\hline CHEMBL1334919 & 688266 & 3.2676 & 5.3616 & TRN & \\
\hline CHEMBL1469742 & 688266 & 5.1145 & 5.5127 & TRN & \\
\hline CHEMBL256098 & 688266 & 3.2676 & \multicolumn{2}{|c|}{5.3839999999999995} & TRN \\
\hline CHEMBL1972470 & 688266 & 5.2338 & 5.5107 & TRN & \\
\hline CHEMBL1406667 & 688266 & 5.5505 & 5.45 & TRN & \\
\hline CHEMBL1462613 & 688266 & 5.5249 & 5.4055 & TRN & \\
\hline CHEMBL1304429 & 688266 & 3.2676 & 5.2478 & TST & \\
\hline CHEMBL1412105 & 688266 & 5.9535 & 5.415 & TRN & \\
\hline CHEMBL1499653 & 688266 & 5.3355 & 5.3595 & TRN & \\
\hline CHEMBL1303508 & 688266 & 5.3039 & 5.2418 & TRN & \\
\hline CHEMBL1426009 & 688266 & 5.151 & \multicolumn{2}{|c|}{5.0280000000000005} & TRN \\
\hline CHEMBL66953 & 688266 & 3.2676 & 5.0665 & TRN & \\
\hline CHEMBL 3213107 & 688266 & 5.7878 & 5.7644 & TRN & \\
\hline CHEMBL1340633 & 688266 & 5.8174 & 5.231 & TRN & \\
\hline CHEMBL1987928 & 688266 & 5.9301 & 5.2979 & TRN & \\
\hline CHEMBL1522663 & 688266 & 5.2215 & 5.0125 & TST & \\
\hline CHEMBL1530511 & 688266 & 6.1433 & 4.9208 & TST & \\
\hline CHEMBL3191876 & 688266 & 5.4472 & 5.4291 & TRN & \\
\hline CHEMBL223453 & 688266 & 5.4688 & 5.296 & TST & \\
\hline CHEMBL 3145049 & 688266 & 5.7684 & 5.254 & TST & \\
\hline CHEMBL63354 & 688266 & 5.7867 & 5.4407 & TST & \\
\hline CHEMBL1460107 & 688266 & 5.3354 & 5.143 & TRN & \\
\hline CHEMBL1409603 & 688266 & 5.4623 & 5.4775 & TRN & \\
\hline CHEMBL1529285 & 688266 & 5.5877 & 5.1886 & TRN & \\
\hline CHEMBL3191780 & 688266 & 5.5652 & 5.3845 & TRN & \\
\hline CHEMBL1542128 & 688266 & 5.4981 & 5.5627 & TRN & \\
\hline CHEMBL1301169 & 688266 & 5.6026 & 5.5808 & TRN & \\
\hline CHEMBL1568684 & 688266 & 5.4888 & 5.0558 & TRN & \\
\hline CHEMBL242358 & 688266 & 5.5463 & 5.1774 & TRN & \\
\hline CHEMBL1450049 & 688266 & 5.3118 & 5.3906 & TRN & \\
\hline CHEMBL1326167 & 688266 & 5.8132 & 5.75700 & 0000000001 & TRN \\
\hline CHEMBL1461772 & 688266 & 4.9137 & 5.3267 & TRN & \\
\hline CHEMBL1497894 & 688266 & 5.5801 & 5.6422 & TRN & \\
\hline CHEMBL1476264 & 688266 & 4.8519 & 5.4948 & TRN & \\
\hline CHEMBL1457311 & 688266 & 5.0881 & 5.0875 & TST & \\
\hline CHEMBL1339695 & 688266 & 5.5834 & 5.26399 & 9999999999 & TRN \\
\hline CHEMBL1371504 & 688266 & 5.3486 & 5.1875 & TRN & \\
\hline CHEMBL1506994 & 688266 & 5.027 & 5.0571 & TST & \\
\hline CHEMBL1460793 & 688266 & 5.6204 & 5.1683 & TST & \\
\hline CHEMBL1447467 & 688266 & 5.0561 & 5.3091 & TST & \\
\hline
\end{tabular}




\begin{tabular}{|c|c|c|c|c|c|}
\hline \\
\hline CHEMBL1310030 & 688266 & 5.8428 & 5.2101 & TRN & \\
\hline CHEMBL1604793 & 688266 & 5.8308 & 5.2465 & TST & \\
\hline CHEMBL1518767 & 688266 & 5.6577 & 5.3059 & TRN & \\
\hline CHEMBL1550812 & 688266 & 5.3598 & 5.5174 & TST & \\
\hline CHEMBL1568305 & 688266 & 5.6002 & 5.4545 & TRN & \\
\hline CHEMBL3192541 & 688266 & 5.9313 & 5.4414 & TRN & \\
\hline CHEMBL1536896 & 688266 & 5.9076 & 5.6387 & TRN & \\
\hline CHEMBL1399191 & 688266 & 4.9645 & 5.1327 & TST & \\
\hline CHEMBL1989426 & 688266 & 5.0945 & 5.3233 & TRN & \\
\hline CHEMBL1480877 & 688266 & 5.2099 & 5.45799 & 9999999999 & TRN \\
\hline CHEMBL1342337 & 688266 & 4.9799 & 5.3149 & TRN & \\
\hline CHEMBL2028179 & 688266 & 5.5504 & 5.182 & TST & \\
\hline CHEMBL1400203 & 688266 & 5.3789 & 5.3078 & TRN & \\
\hline CHEMBL1499111 & 688266 & 5.7941 & 5.604 & TRN & \\
\hline CHEMBL1402807 & 688266 & 5.2516 & 5.4414 & TRN & \\
\hline CHEMBL3214598 & 688266 & 5.9321 & 5.6341 & TRN & \\
\hline CHEMBL3191557 & 688266 & 5.4881 & 5.5578 & TRN & \\
\hline CHEMBL1549883 & 688266 & 5.6641 & 5.5099 & TRN & \\
\hline CHEMBL1519068 & 688266 & 5.2716 & 4.9789 & TRN & \\
\hline CHEMBL1377333 & 688266 & 5.4914 & 5.2179 & TRN & \\
\hline CHEMBL1464420 & 688266 & 3.2676 & 5.1822 & TST & \\
\hline CHEMBL1448387 & 688266 & 5.4635 & 5.2341 & TST & \\
\hline CHEMBL591135 & 688266 & 5.0916 & 5.4926 & TRN & \\
\hline CHEMBL1372387 & 688266 & 5.4809 & 5.4373 & TRN & \\
\hline CHEMBL1585538 & 688266 & 5.3541 & 5.3176 & TRN & \\
\hline CHEMBL 3856088 & 688266 & 5.8431 & 5.3892 & TRN & \\
\hline CHEMBL1423705 & 688266 & 5.5163 & 5.2554 & TRN & \\
\hline CHEMBL1487945 & 688266 & 3.2676 & 5.4237 & TST & \\
\hline CHEMBL1562029 & 688266 & 5.2694 & 5.1192 & TRN & \\
\hline CHEMBL1595724 & 688266 & 5.2465 & 5.3641 & TRN & \\
\hline CHEMBL1318937 & 688266 & 3.2676 & 5.1768 & TRN & \\
\hline CHEMBL1342736 & 688266 & 5.7172 & 5.6688 & TRN & \\
\hline CHEMBL1366367 & 688266 & 5.5542 & 5.4271 & TRN & \\
\hline CHEMBL1467719 & 688266 & 5.5429 & 5.3548 & TRN & \\
\hline CHEMBL1566010 & 688266 & 5.6195 & 5.2122 & TST & \\
\hline CHEMBL1487767 & 688266 & 5.461 & 5.1114 & TRN & \\
\hline CHEMBL1336922 & 688266 & 5.4461 & 5.6525 & TRN & \\
\hline CHEMBL1415045 & 688266 & 5.4888 & 5.2732 & TST & \\
\hline CHEMBL3189251 & 688266 & 5.308 & 5.3745 & TRN & \\
\hline CHEMBL1310886 & 688266 & 5.2747 & 5.3805 & TRN & \\
\hline CHEMBL1968732 & 688266 & 4.7048 & 5.4522 & TRN & \\
\hline CHEMBL1421330 & 688266 & 5.4283 & 5.32700 & $\partial 000000001$ & TST \\
\hline CHEMBL1429158 & 688266 & 5.3811 & 5.2612 & TRN & \\
\hline CHEMBL1588263 & 688266 & 5.2509 & 5.3794 & TST & \\
\hline CHEMBL1449334 & 688266 & 5.0961 & 5.3111 & TRN & \\
\hline CHEMBL 2000253 & 688266 & 5.1915 & 5.4875 & TRN & \\
\hline CHEMBL1575303 & 688266 & 5.3303 & 5.73600 & 3000000001 & TRN \\
\hline CHEMBL3190974 & 688266 & 5.2483 & 5.3532 & TRN & \\
\hline
\end{tabular}




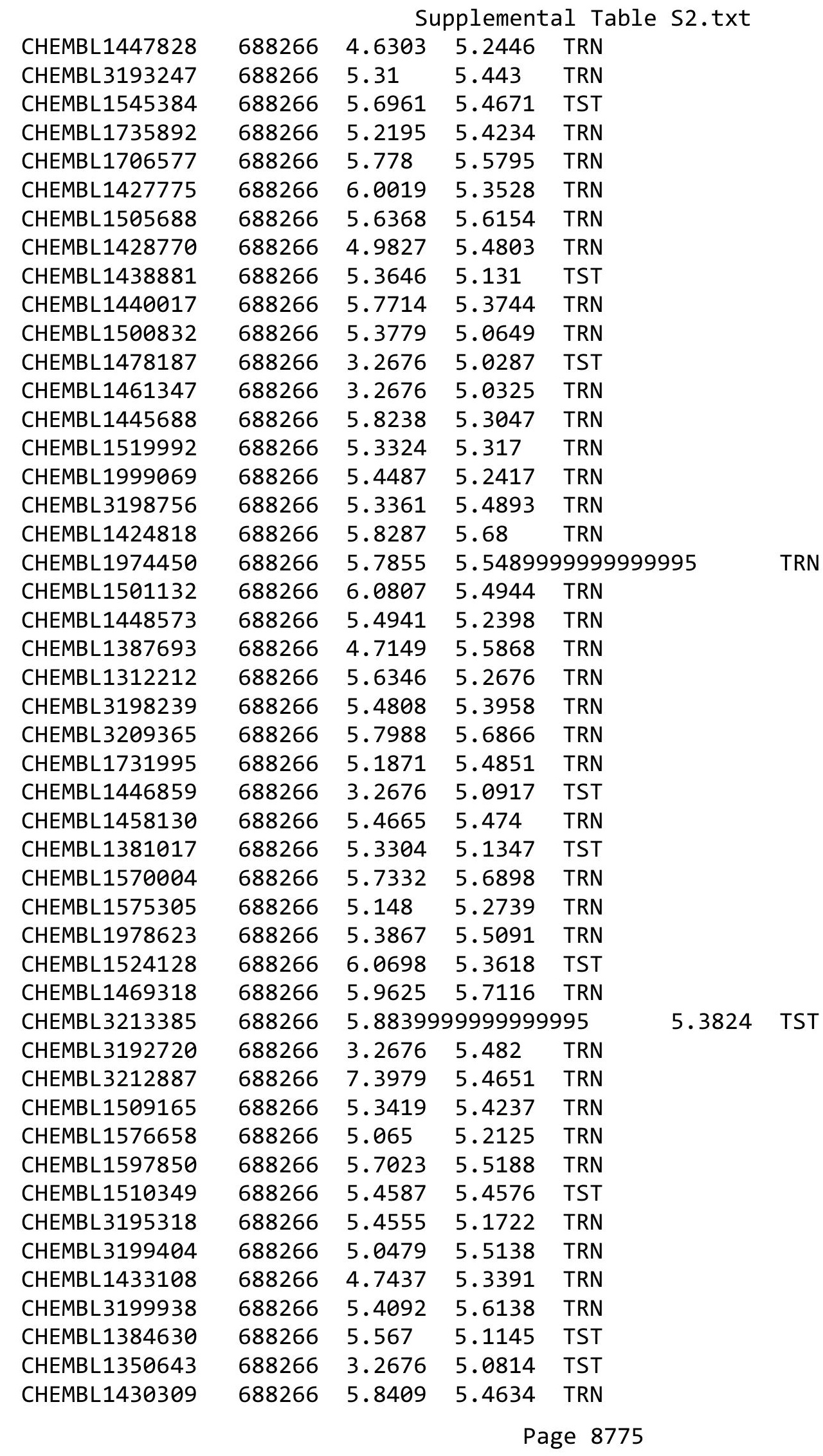




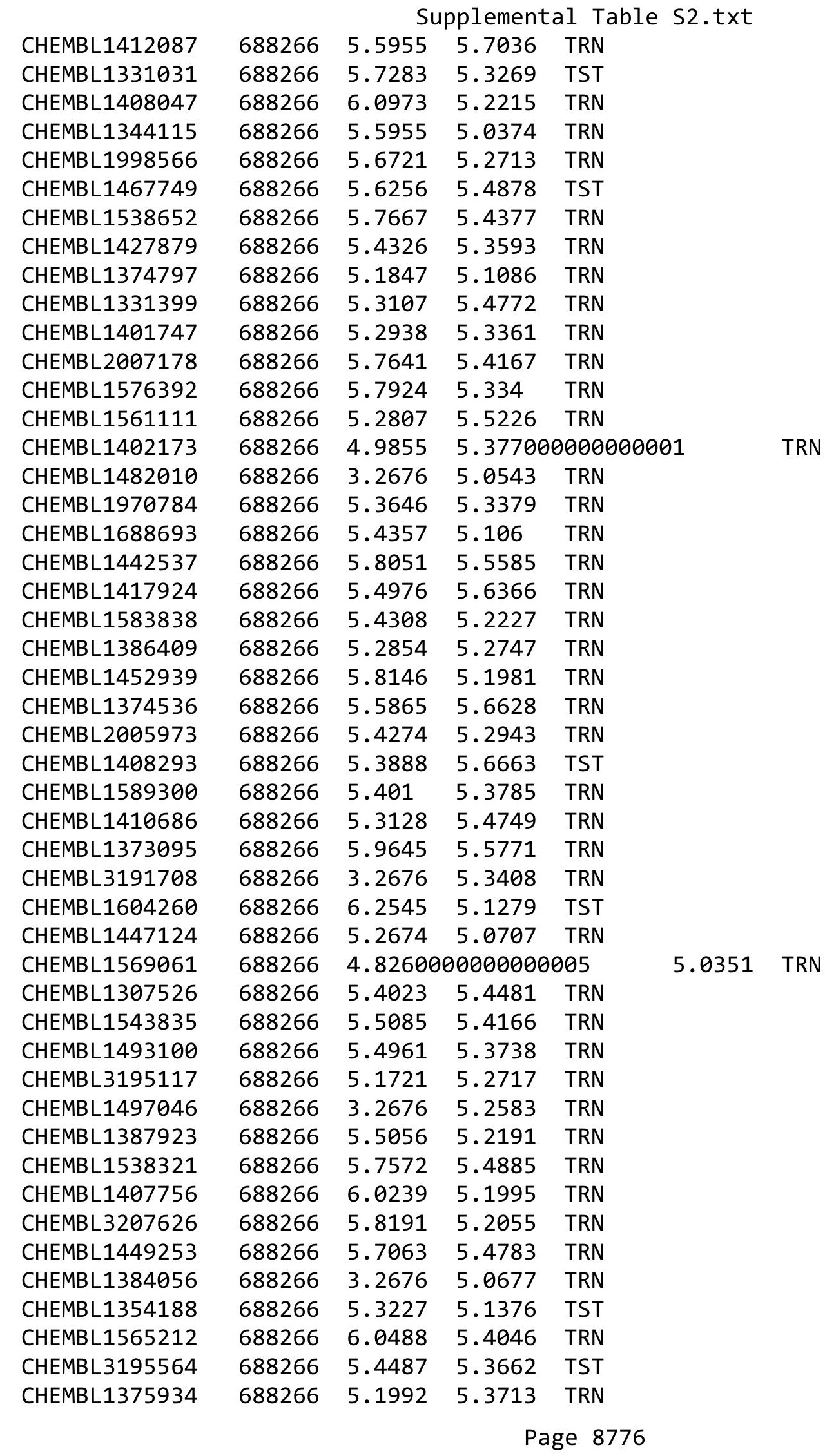




\begin{tabular}{|c|c|c|c|c|c|c|}
\hline & & & & & & \\
\hline CHEMBL3199870 & 688266 & 4.7785 & 5.3822 & TRN & & \\
\hline CHEMBL1560068 & 688266 & 5.0636 & 5.0865 & TST & & \\
\hline CHEMBL1319682 & 688266 & 5.841 & 5.3069 & TRN & & \\
\hline CHEMBL1472502 & 688266 & 5.5889 & 5.0058 & TRN & & \\
\hline CHEMBL1546396 & 688266 & 7.3979 & 5.5288 & TRN & & \\
\hline CHEMBL1309643 & 688266 & 5.5542 & 5.6191 & TRN & & \\
\hline CHEMBL1998302 & 688266 & 5.7833 & 5.3073 & TRN & & \\
\hline CHEMBL1336701 & 688266 & 5.1748 & 5.4225 & TRN & & \\
\hline CHEMBL1399979 & 688266 & 5.7996 & 5.5445 & TRN & & \\
\hline CHEMBL1432791 & 688266 & 4.548 & 5.3667 & TST & & \\
\hline CHEMBL1312836 & 688266 & 5.309 & 5.2251 & TRN & & \\
\hline CHEMBL3199823 & 688266 & 3.2676 & 5.0536 & TST & & \\
\hline CHEMBL1600380 & 688266 & 5.0298 & 5.4371 & TRN & & \\
\hline CHEMBL1353738 & 688266 & 5.8254 & 5.5014 & TRN & & \\
\hline CHEMBL1404216 & 688266 & 3.2676 & 5.5306 & TST & & \\
\hline CHEMBL1335988 & 688266 & 4.6186 & 5.0911 & TST & & \\
\hline CHEMBL1541862 & 688266 & 5.3642 & 5.5488 & TRN & & \\
\hline CHEMBL3196247 & 688266 & 5.2217 & 5.5376 & TRN & & \\
\hline CHEMBL1410616 & 688266 & 5.9275 & 5.8189 & TRN & & \\
\hline CHEMBL1594787 & 688266 & 5.675 & 5.4104 & TRN & & \\
\hline CHEMBL 3214263 & 688266 & 7.3979 & 5.3344 & TST & & \\
\hline CHEMBL1311844 & 688266 & 5.4781 & 5.1225 & TRN & & \\
\hline CHEMBL1976499 & 688266 & 5.3367 & 5.4733 & TRN & & \\
\hline CHEMBL1425483 & 688266 & 5.1622 & 5.5947 & TRN & & \\
\hline CHEMBL1336283 & 688266 & 5.5238 & 5.54299 & 9999999999 & TRN & \\
\hline CHEMBL1468919 & 688266 & 5.3273 & 5.1992 & TRN & & \\
\hline CHEMBL1964407 & 688266 & 4.9798 & 5.3344 & TRN & & \\
\hline CHEMBL1406864 & 688266 & 5.3348 & 5.6028 & TRN & & \\
\hline CHEMBL3212652 & 688266 & 5.0697 & 5.441 & TRN & & \\
\hline CHEMBL1408741 & 688266 & 5.3417 & 5.1613 & TRN & & \\
\hline CHEMBL1557043 & 688266 & 5.2873 & 5.4501 & TRN & & \\
\hline CHEMBL1415108 & 688266 & 4.9292 & 5.3882 & TRN & & \\
\hline CHEMBL1327469 & 688266 & 5.20799 & 99999999 & 5.3 & 000000001 & TRN \\
\hline CHEMBL1304974 & 688266 & 5.2462 & 5.5712 & TRN & & \\
\hline CHEMBL1377466 & 688266 & 5.3024 & 5.2619 & TRN & & \\
\hline CHEMBL1359782 & 688266 & 5.4944 & 5.7138 & TRN & & \\
\hline CHEMBL3392069 & 688266 & 5.7446 & 5.0528 & TRN & & \\
\hline CHEMBL1347080 & 688266 & 5.6345 & 5.638 & TRN & & \\
\hline CHEMBL1478140 & 688266 & 5.0713 & $5.55200 t$ & 00000000005 & TRN & \\
\hline CHEMBL1431490 & 688266 & 5.5066 & 5.4121 & TRN & & \\
\hline CHEMBL1416093 & 688266 & 5.449 & 5.4286 & TRN & & \\
\hline CHEMBL3199516 & 688266 & 5.7882 & 5.4203 & TRN & & \\
\hline CHEMBL1575652 & 688266 & 5.7778 & 5.3694 & TRN & & \\
\hline CHEMBL1992631 & 688266 & 5.4651 & 5.4327 & TRN & & \\
\hline CHEMBL1443726 & 688266 & 5.4554 & 5.2021 & TRN & & \\
\hline CHEMBL1484139 & 688266 & 5.3058 & 5.0707 & TST & & \\
\hline CHEMBL592124 & 688266 & 5.229 & 5.4878 & TRN & & \\
\hline CHEMBL1495977 & 688266 & 5.9538 & 5.3924 & TRN & & \\
\hline
\end{tabular}




\begin{tabular}{|c|c|c|c|c|c|c|}
\hline \multirow[b]{2}{*}{ CHEMBL1570659 } & \multicolumn{6}{|c|}{ Supplemental Table S2.txt } \\
\hline & 688266 & 5.5558 & 5.16 & TRN & & \\
\hline CHEMBL1526036 & 688266 & 5.314 & 5.29700 & 000000000 & & TRN \\
\hline CHEMBL1994371 & 688266 & 5.1742 & 5.82700 & 000000000 & & TRN \\
\hline CHEMBL1471907 & 688266 & 5.4638 & 5.4377 & TRN & & \\
\hline CHEMBL1393615 & 688266 & 5.2688 & 5.2051 & TRN & & \\
\hline CHEMBL3198811 & 688266 & 5.5196 & 5.5725 & TRN & & \\
\hline CHEMBL1612116 & 688266 & 5.5132 & 5.4316 & TRN & & \\
\hline CHEMBL1546527 & 688266 & 5.5914 & 5.5061 & TRN & & \\
\hline CHEMBL1511931 & 688266 & 5.4504 & 5.4156 & TRN & & \\
\hline CHEMBL3191716 & 688266 & 5.8411 & 5.3921 & TRN & & \\
\hline CHEMBL1530167 & 688266 & 5.4656 & 5.5326 & TRN & & \\
\hline CHEMBL1404349 & 688266 & 5.6083 & 5.6101 & TRN & & \\
\hline CHEMBL2006418 & 688266 & 5.5261 & 5.5405 & TRN & & \\
\hline CHEMBL 245087 & 688266 & 4.6152 & 5.2148 & TST & & \\
\hline CHEMBL1470602 & 688266 & 3.2676 & 5.1038 & TST & & \\
\hline CHEMBL1594634 & 688266 & 5.4536 & 5.308 & TRN & & \\
\hline CHEMBL1985664 & 688266 & 5.3657 & 5.6396 & TRN & & \\
\hline CHEMBL1305014 & 688266 & 4.9445 & 5.3666 & TRN & & \\
\hline CHEMBL3196164 & 688266 & 5.4239 & 5.2245 & TRN & & \\
\hline CHEMBL1546949 & 688266 & 5.1971 & 5.3524 & TRN & & \\
\hline CHEMBL1544178 & 688266 & 5.3344 & 5.4979 & TRN & & \\
\hline CHEMBL3198434 & 688266 & 4.8191 & 5.5535 & TRN & & \\
\hline CHEMBL1390647 & 688266 & 5.6641 & 5.4001 & TRN & & \\
\hline CHEMBL1546921 & 688266 & 5.7872 & 5.5588 & TRN & & \\
\hline CHEMBL1428264 & 688266 & 5.15600 & 00000000 & 01 & 5.3011 & TRN \\
\hline CHEMBL1428254 & 688266 & 5.4383 & 5.1917 & TRN & & \\
\hline CHEMBL1384716 & 688266 & 5.4766 & 5.4445 & TRN & & \\
\hline CHEMBL1346515 & 688266 & 3.2676 & 5.4053 & TRN & & \\
\hline CHEMBL1540071 & 688266 & 6.3251 & 5.2806 & TRN & & \\
\hline CHEMBL1601846 & 688266 & 3.2676 & 5.1662 & TRN & & \\
\hline CHEMBL1374241 & 688266 & 6.0674 & 5.2846 & TRN & & \\
\hline CHEMBL1430335 & 688266 & 5.74100 & 20000000 & 005 & 5.2113 & TRN \\
\hline CHEMBL1524050 & 688266 & 5.6102 & 5.4985 & TRN & & \\
\hline CHEMBL1381152 & 688266 & 7.3979 & 5.2402 & TRN & & \\
\hline CHEMBL1560366 & 688266 & 5.3476 & 5.2082 & TST & & \\
\hline CHEMBL1549333 & 688266 & 5.8083 & 5.3728 & TRN & & \\
\hline CHEMBL1573230 & 688266 & 5.7454 & 5.3522 & TRN & & \\
\hline CHEMBL1990571 & 688266 & 5.6005 & 5.5744 & TST & & \\
\hline CHEMBL1320975 & 688266 & 5.3725 & 5.5517 & TRN & & \\
\hline CHEMBL1376200 & 688266 & 5.1748 & 5.2336 & TRN & & \\
\hline CHEMBL1495778 & 688266 & 5.71700 & 00000000 & 205 & 5.2496 & TRN \\
\hline CHEMBL1447211 & 688266 & 5.5327 & 5.5827 & TRN & & \\
\hline CHEMBL602969 & 688266 & 5.0368 & 5.1727 & TST & & \\
\hline CHEMBL1405311 & 688266 & 5.8086 & 5.3131 & TRN & & \\
\hline CHEMBL1422845 & 688266 & 4.6173 & 5.3672 & TRN & & \\
\hline CHEMBL1494973 & 688266 & 5.8333 & 5.1641 & TRN & & \\
\hline CHEMBL1520133 & 688266 & 5.6437 & 5.6675 & TRN & & \\
\hline CHEMBL3144970 & 688266 & 5.0612 & 5.2631 & TST & & \\
\hline
\end{tabular}




\begin{tabular}{|c|c|c|c|c|c|}
\hline \multicolumn{6}{|c|}{ Supplemental Table S2.txt } \\
\hline CHEMBL1336615 & 688266 & 5.5626 & 5.5901 & TRN & \\
\hline CHEMBL3192400 & 688266 & 5.135 & 5.3991 & TRN & \\
\hline CHEMBL498373 & 688266 & 5.2404 & 5.2235 & TRN & \\
\hline CHEMBL1486265 & 688266 & 5.3585 & 5.2623 & TRN & \\
\hline CHEMBL1381419 & 688266 & 5.7685 & 5.5404 & TRN & \\
\hline CHEMBL1269084 & 688266 & 5.1932 & 5.4578 & TRN & \\
\hline CHEMBL1421256 & 688266 & 5.2884 & 5.5253 & TRN & \\
\hline CHEMBL1488371 & 688266 & 5.6758 & 5.1329 & TRN & \\
\hline CHEMBL1388790 & 688266 & 5.2117 & 5.3302 & TRN & \\
\hline CHEMBL1579066 & 688266 & 5.6212 & 5.0303 & TRN & \\
\hline CHEMBL3194876 & 688266 & 4.7108 & 5.369 & TRN & \\
\hline CHEMBL1494713 & 688266 & 5.6347 & 5.3534 & TRN & \\
\hline CHEMBL1567396 & 688266 & 5.2919 & 5.1046 & TRN & \\
\hline CHEMBL1546414 & 688266 & 5.8389 & 5.4217 & TRN & \\
\hline CHEMBL1360981 & 688266 & 5.5029 & 5.2892 & TRN & \\
\hline CHEMBL1309568 & 688266 & 5.3313 & 5.3953 & TRN & \\
\hline CHEMBL1362333 & 688266 & 5.6048 & 5.4592 & TRN & \\
\hline CHEMBL1429019 & 688266 & 5.5643 & 5.3618 & TRN & \\
\hline CHEMBL1444565 & 688266 & 5.6939 & 5.3385 & TRN & \\
\hline CHEMBL1510676 & 688266 & 5.4406 & 5.3685 & TRN & \\
\hline CHEMBL1416266 & 688266 & 3.2676 & 5.138 & TRN & \\
\hline CHEMBL1721986 & 688266 & 5.8695 & 5.45700 & 0000000001 & TRN \\
\hline CHEMBL1416169 & 688266 & 5.7856 & 5.6142 & TRN & \\
\hline CHEMBL1594376 & 688266 & 5.9123 & 5.5708 & TRN & \\
\hline CHEMBL1303756 & 688266 & 5.3576 & 5.2815 & TRN & \\
\hline CHEMBL1533561 & 688266 & 5.3643 & 5.3416 & TST & \\
\hline CHEMBL599255 & 688266 & 5.4751 & 5.3227 & TRN & \\
\hline CHEMBL1586973 & 688266 & 5.3329 & 5.5161 & TRN & \\
\hline CHEMBL3193692 & 688266 & 5.466 & 5.61299 & 99999999995 & TRN \\
\hline CHEMBL1366030 & 688266 & 6.3474 & 5.7089 & TRN & \\
\hline CHEMBL1978607 & 688266 & 5.8053 & 5.2966 & TST & \\
\hline CHEMBL28626 & 688266 & 5.5246 & 5.2207 & TST & \\
\hline CHEMBL19954 & 688266 & 3.2676 & 5.20799 & 9999999999 & TRN \\
\hline CHEMBL3190701 & 688266 & 5.3592 & 5.232 & TST & \\
\hline CHEMBL1429570 & 688266 & 5.4114 & 5.5319 & TRN & \\
\hline CHEMBL1308848 & 688266 & 5.4274 & 5.3957 & TRN & \\
\hline CHEMBL1408705 & 688266 & 5.6849 & 5.1834 & TRN & \\
\hline CHEMBL1992702 & 688266 & 5.1219 & 5.7006 & TRN & \\
\hline CHEMBL1584150 & 688266 & 5.296 & 5.1726 & TST & \\
\hline CHEMBL1445086 & 688266 & 5.3227 & 5.2534 & TRN & \\
\hline CHEMBL1570257 & 688266 & 5.4196 & 5.5708 & TRN & \\
\hline CHEMBL1384399 & 688266 & 5.6351 & 5.0499 & TST & \\
\hline CHEMBL3197936 & 688266 & 4.4432 & 5.2512 & TRN & \\
\hline CHEMBL1307778 & 688266 & 3.2676 & 5.4516 & TST & \\
\hline CHEMBL1376308 & 688266 & 5.3607 & 5.5799 & TRN & \\
\hline CHEMBL1378869 & 688266 & 5.3665 & 5.3374 & TRN & \\
\hline CHEMBL1472249 & 688266 & 5.3584 & 5.3668 & TST & \\
\hline CHEMBL3214495 & 688266 & 5.7822 & 5.3183 & TST & \\
\hline
\end{tabular}




\begin{tabular}{|c|c|c|c|c|c|c|}
\hline \multicolumn{7}{|c|}{ Supplemental Table S2.txt } \\
\hline CHEMBL 2006909 & 688266 & 5.3394 & 5.5885 & TRN & & \\
\hline CHEMBL1452254 & 688266 & 5.8155 & 5.2671 & TRN & & \\
\hline CHEMBL1428001 & 688266 & 5.7226 & 5.2796 & TRN & & \\
\hline CHEMBL1559883 & 688266 & 5.4028 & 5.4109 & TRN & & \\
\hline CHEMBL1584828 & 688266 & 5.107 & 5.4221 & TRN & & \\
\hline CHEMBL3197096 & 688266 & 5.2994 & 5.5037 & TRN & & \\
\hline CHEMBL119171 & 688266 & 5.13399 & 99999999 & 995 & 5.138 & TST \\
\hline CHEMBL1410609 & 688266 & 5.2653 & 5.4543 & TRN & & \\
\hline CHEMBL1446202 & 688266 & 7.3979 & 5.4476 & TRN & & \\
\hline CHEMBL 3145364 & 688266 & 5.218 & 5.4055 & TRN & & \\
\hline CHEMBL1489368 & 688266 & 5.4925 & 5.1797 & TRN & & \\
\hline CHEMBL1508127 & 688266 & 3.2676 & 5.0474 & TRN & & \\
\hline CHEMBL117813 & 688266 & 5.1498 & 5.4022 & TRN & & \\
\hline CHEMBL1413956 & 688266 & 5.7017 & 5.5451 & TRN & & \\
\hline CHEMBL1586107 & 688266 & 5.5331 & 5.5147 & TRN & & \\
\hline CHEMBL1417159 & 688266 & 5.2875 & 5.0923 & TST & & \\
\hline CHEMBL1438294 & 688266 & 4.748 & 4.965 & TRN & & \\
\hline CHEMBL1363505 & 688266 & 5.4848 & 4.9516 & TRN & & \\
\hline CHEMBL1340514 & 688266 & 5.58899 & 79999999 & 995 & 5.4039 & TRN \\
\hline CHEMBL 3197494 & 688266 & 4.3956 & 5.2583 & TRN & & \\
\hline CHEMBL1722566 & 688266 & 5.8426 & 5.6508 & TRN & & \\
\hline CHEMBL1547684 & 688266 & 5.7992 & 5.0484 & TRN & & \\
\hline CHEMBL1609550 & 688266 & 5.5003 & 5.4031 & TRN & & \\
\hline CHEMBL1543865 & 688266 & 5.5795 & 5.3203 & TRN & & \\
\hline CHEMBL1340228 & 688266 & 5.2583 & 5.36799 & 9999999999 & & TRN \\
\hline CHEMBL1493705 & 688266 & 5.5984 & 5.4075 & TRN & & \\
\hline CHEMBL1346724 & 688266 & 5.3717 & 5.4137 & TRN & & \\
\hline CHEMBL1400512 & 688266 & 5.6111 & 5.3218 & TST & & \\
\hline CHEMBL305978 & 688266 & 7.3979 & 5.2497 & TRN & & \\
\hline CHEMBL1542453 & 688266 & 5.8121 & 5.3136 & TST & & \\
\hline CHEMBL1532453 & 688266 & 5.9521 & 5.3435 & TRN & & \\
\hline CHEMBL1968789 & 688266 & 5.5506 & 5.63 & TRN & & \\
\hline CHEMBL1351274 & 688266 & 5.7761 & 5.3412 & TRN & & \\
\hline CHEMBL1310972 & 688266 & 5.1895 & 5.4507 & TRN & & \\
\hline CHEMBL1987106 & 688266 & 5.8118 & 5.4924 & TRN & & \\
\hline CHEMBL1339475 & 688266 & 5.3161 & 5.1269 & TRN & & \\
\hline CHEMBL1354004 & 688266 & 5.1949 & 5.1787 & TST & & \\
\hline CHEMBL1504817 & 688266 & 5.1447 & 5.2537 & TRN & & \\
\hline CHEMBL1370375 & 688266 & 5.4324 & 5.471 & TST & & \\
\hline CHEMBL1528792 & 688266 & 7.3979 & 5.239 & TRN & & \\
\hline CHEMBL1313324 & 688266 & 5.8166 & 5.6477 & TRN & & \\
\hline CHEMBL3195827 & 688266 & 5.6428 & 5.2243 & TRN & & \\
\hline CHEMBL1448985 & 688266 & 5.5001 & 5.3603 & TRN & & \\
\hline CHEMBL1369136 & 688266 & 4.5799 & 5.1539 & TRN & & \\
\hline CHEMBL1604163 & 688266 & 5.0236 & 5.292006 & 0000000001 & & TRN \\
\hline CHEMBL1548111 & 688266 & 5.4084 & 5.3925 & TST & & \\
\hline CHEMBL1360585 & 688266 & 4.6267 & 5.4319 & TST & & \\
\hline CHEMBL1413078 & 688266 & 5.0302 & 5.1009 & TST & & \\
\hline
\end{tabular}




\begin{tabular}{|c|c|c|c|c|c|}
\hline \multicolumn{6}{|c|}{ Supplemental Table S2.txt } \\
\hline CHEMBL1381495 & 688266 & 5.188 & 5.1401 & TST & \\
\hline CHEMBL1567869 & 688266 & 5.7543 & 5.56 & TRN & \\
\hline CHEMBL1546633 & 688266 & 5.5754 & 5.3035 & TST & \\
\hline CHEMBL1986081 & 688266 & 6.0764 & 5.41200 & 0000000001 & TRN \\
\hline CHEMBL1340308 & 688266 & 5.7636 & 5.3478 & TRN & \\
\hline CHEMBL3210158 & 688266 & 6.3631 & 5.3363 & TST & \\
\hline CHEMBL1438722 & 688266 & 5.4258 & 5.2603 & TRN & \\
\hline CHEMBL1386015 & 688266 & 5.5212 & 5.3946 & TRN & \\
\hline CHEMBL1563823 & 688266 & 3.2676 & 5.2014 & TRN & \\
\hline CHEMBL1560760 & 688266 & 5.0151 & 5.2015 & TRN & \\
\hline CHEMBL1459786 & 688266 & 5.3883 & 5.29200 & 0000000001 & TRN \\
\hline CHEMBL1606403 & 688266 & 5.9223 & 5.5309 & TRN & \\
\hline CHEMBL 2003564 & 688266 & 5.6599 & 5.3496 & TRN & \\
\hline CHEMBL1303152 & 688266 & 5.5693 & 5.3872 & TRN & \\
\hline CHEMBL 1460352 & 688266 & 5.274 & 5.5236 & TRN & \\
\hline CHEMBL1447158 & 688266 & 5.8987 & 5.4357 & TRN & \\
\hline CHEMBL1421509 & 688266 & 5.5128 & 5.4841 & TRN & \\
\hline CHEMBL1452301 & 688266 & 5.5491 & 5.4331 & TRN & \\
\hline CHEMBL 3207893 & 688266 & 5.4092 & 5.4854 & TRN & \\
\hline CHEMBL233531 & 688266 & 5.1654 & 5.563 & TRN & \\
\hline CHEMBL1506692 & 688266 & 3.2676 & 5.2873 & TRN & \\
\hline CHEMBL1311605 & 688266 & 5.3027 & 5.1646 & TRN & \\
\hline CHEMBL1450534 & 688266 & 5.3629 & 5.3349 & TRN & \\
\hline CHEMBL1381676 & 688266 & 5.5307 & 5.7261 & TRN & \\
\hline CHEMBL1370989 & 688266 & 5.1787 & 5.118 & TST & \\
\hline CHEMBL3199590 & 688266 & 5.3189 & 5.4509 & TRN & \\
\hline CHEMBL1309432 & 688266 & 5.9274 & 5.5626 & TRN & \\
\hline CHEMBL1464373 & 688266 & 5.5104 & 5.4376 & TRN & \\
\hline CHEMBL1588707 & 688266 & 5.2997 & 5.276 & TRN & \\
\hline CHEMBL515252 & 688266 & 5.5645 & 5.36700 & $\partial 000000001$ & TST \\
\hline CHEMBL1414652 & 688266 & 5.8771 & 5.2376 & TST & \\
\hline CHEMBL1423071 & 688266 & 5.4158 & 5.4103 & TRN & \\
\hline CHEMBL3199908 & 688266 & 5.33 & 5.3976 & TST & \\
\hline CHEMBL1415999 & 688266 & 3.2676 & 5.6009 & TRN & \\
\hline CHEMBL1350157 & 688266 & 5.5043 & 5.2545 & TRN & \\
\hline CHEMBL1367790 & 688266 & 7.3979 & 5.3188 & TRN & \\
\hline CHEMBL1967185 & 688266 & 5.8086 & 5.4738 & TRN & \\
\hline CHEMBL1447137 & 688266 & 5.5414 & 5.5672 & TRN & \\
\hline CHEMBL3189821 & 688266 & 5.1625 & 5.5024 & TRN & \\
\hline CHEMBL1340363 & 688266 & 5.5889 & 5.5395 & TRN & \\
\hline CHEMBL1424878 & 688266 & 5.6878 & 5.4696 & TRN & \\
\hline CHEMBL1386032 & 688266 & 5.3083 & 5.4996 & TRN & \\
\hline CHEMBL3193134 & 688266 & 5.1813 & 5.3158 & TRN & \\
\hline CHEMBL1392551 & 688266 & 5.9264 & 5.3286 & TST & \\
\hline CHEMBL1587409 & 688266 & 4.5847 & 5.2068 & TRN & \\
\hline CHEMBL1376870 & 688266 & 3.2676 & 5.0285 & TRN & \\
\hline CHEMBL1477770 & 688266 & 5.8894 & 5.3252 & TRN & \\
\hline CHEMBL1413735 & 688266 & 6.2021 & 5.2299 & TRN & \\
\hline
\end{tabular}




\begin{tabular}{|c|c|c|c|c|c|c|}
\hline \multicolumn{7}{|c|}{ Supplemental Table S2.txt } \\
\hline CHEMBL1319609 & 688266 & 5.3389 & 5.1192 & TST & & \\
\hline CHEMBL2000619 & 688266 & 4.9732 & 5.3499 & TRN & & \\
\hline CHEMBL1595221 & 688266 & 5.9361 & 5.4172 & TRN & & \\
\hline CHEMBL1597979 & 688266 & 5.6345 & 5.1209 & TST & & \\
\hline CHEMBL1407483 & 688266 & 5.5388 & 5.1298 & TST & & \\
\hline CHEMBL1465297 & 688266 & 5.4517 & 5.7421 & TRN & & \\
\hline CHEMBL1450853 & 688266 & 5.8386 & 5.2213 & TST & & \\
\hline CHEMBL1524206 & 688266 & 3.2676 & 5.1669 & TRN & & \\
\hline CHEMBL1387491 & 688266 & 5.9737 & 5.5914 & TRN & & \\
\hline CHEMBL1334633 & 688266 & 6.0011 & 5.186 & TRN & & \\
\hline CHEMBL3213353 & 688266 & 5.1125 & 5.32600 & 00000000005 & TRN & \\
\hline CHEMBL3144984 & 688266 & 5.2384 & 5.1003 & TRN & & \\
\hline CHEMBL1565738 & 688266 & 5.8852 & 5.5644 & TRN & & \\
\hline CHEMBL1451059 & 688266 & 5.8007 & 5.0985 & TST & & \\
\hline CHEMBL1597758 & 688266 & 5.3704 & 5.4601 & TST & & \\
\hline CHEMBL131037 & 688266 & 4.6058 & 5.0312 & TST & & \\
\hline CHEMBL1461513 & 688266 & 5.1471 & 5.2535 & TRN & & \\
\hline CHEMBL1987510 & 688266 & 5.8264 & 5.5245 & TRN & & \\
\hline CHEMBL1362829 & 688266 & 5.8422 & 5.1249 & TST & & \\
\hline CHEMBL1539720 & 688266 & 5.5596 & 5.0076 & TRN & & \\
\hline CHEMBL3191969 & 688266 & 5.4001 & 5.4368 & TRN & & \\
\hline CHEMBL1532031 & 688266 & 5.4531 & 5.1901 & TST & & \\
\hline CHEMBL1418005 & 688266 & 5.2038 & 5.5361 & TRN & & \\
\hline CHEMBL3197060 & 688266 & 5.5878 & 5.3643 & TRN & & \\
\hline CHEMBL3209490 & 688266 & 4.6748 & 5.2134 & TRN & & \\
\hline CHEMBL1491229 & 688266 & 5.6346 & 5.5938 & TRN & & \\
\hline CHEMBL1584969 & 688266 & 5.1954 & 5.2925 & TRN & & \\
\hline CHEMBL1372624 & 688266 & 7.3979 & 5.1252 & TRN & & \\
\hline CHEMBL1971611 & 688266 & 7.3979 & 5.4411 & TRN & & \\
\hline CHEMBL1586658 & 688266 & 6.0967 & 5.5256 & TRN & & \\
\hline CHEMBL1984298 & 688266 & 5.3309 & 5.2615 & TRN & & \\
\hline CHEMBL1463964 & 688266 & 5.4243 & 5.2596 & TRN & & \\
\hline CHEMBL1578306 & 688266 & 5.1165 & 5.5297 & TRN & & \\
\hline CHEMBL1332626 & 688266 & 5.1534 & 5.1293 & TRN & & \\
\hline CHEMBL1330946 & 688266 & 5.175 & 5.1118 & TRN & & \\
\hline CHEMBL1350435 & 688266 & 5.6768 & 5.2955 & TRN & & \\
\hline CHEMBL3856092 & 688266 & 4.6347 & 5.4291 & TRN & & \\
\hline CHEMBL1570875 & 688266 & 7.3979 & 5.2983 & TST & & \\
\hline CHEMBL1546136 & 688266 & 5.2232 & 5.3634 & TRN & & \\
\hline CHEMBL1587224 & 688266 & 3.2676 & 5.1738 & TRN & & \\
\hline CHEMBL1597427 & 688266 & 5.6151 & 5.1635 & TRN & & \\
\hline CHEMBL1502600 & 688266 & 5.2498 & 5.2019 & TRN & & \\
\hline CHEMBL1603565 & 688266 & 3.2676 & 4.9635 & TST & & \\
\hline CHEMBL1984703 & 688266 & 5.1321 & 5.5951 & TRN & & \\
\hline CHEMBL3194633 & 688266 & 5.2784 & 5.4801 & TRN & & \\
\hline CHEMBL1980737 & 688266 & 5.2584 & 5.2273 & TRN & & \\
\hline CHEMBL1461574 & 688266 & 3.2676 & 5.2988 & TST & & \\
\hline
\end{tabular}




\begin{tabular}{|c|c|c|c|c|c|c|}
\hline \\
\hline CHEMBL1379570 & 688266 & 5.1684 & 5.2649 & TRN & & \\
\hline CHEMBL1983142 & 688266 & 5.5521 & 5.4752 & TRN & & \\
\hline CHEMBL1372447 & 688266 & 5.9587 & 5.2792 & TRN & & \\
\hline CHEMBL1550597 & 688266 & 5.1219 & 5.2804 & TST & & \\
\hline CHEMBL1536878 & 688266 & 5.1898 & 5.3711 & TRN & & \\
\hline CHEMBL1375499 & 688266 & 4.96899 & 99999999 & 99 & 5.6952 & TRN \\
\hline CHEMBL1500884 & 688266 & 5.315 & 5.4112 & TRN & & \\
\hline CHEMBL3190756 & 688266 & 5.8259 & 5.3856 & TST & & \\
\hline CHEMBL1985327 & 688266 & 5.6593 & 5.3551 & TRN & & \\
\hline CHEMBL1446929 & 688266 & 5.36799 & 99999999 & 99 & 4.922 & TST \\
\hline CHEMBL1402056 & 688266 & 5.7969 & 5.2734 & TRN & & \\
\hline CHEMBL1587715 & 688266 & 5.5796 & 5.273 & TRN & & \\
\hline CHEMBL1539579 & 688266 & 3.2676 & 5.4872 & TRN & & \\
\hline CHEMBL3856095 & 688266 & 3.2676 & 5.3014 & TRN & & \\
\hline CHEMBL2003806 & 688266 & 5.5128 & 5.4841 & TRN & & \\
\hline CHEMBL1979530 & 688266 & 4.783 & 5.3503 & TRN & & \\
\hline CHEMBL3198500 & 688266 & 7.3979 & 5.6916 & TRN & & \\
\hline CHEMBL1346055 & 688266 & 5.19799 & 99999999 & 995 & 5.1806 & TRN \\
\hline CHEMBL1325664 & 688266 & 5.5514 & 5.38399 & 9999999999 & 95 & TRN \\
\hline CHEMBL1540453 & 688266 & 7.3979 & 5.3116 & TRN & & \\
\hline CHEMBL1421887 & 688266 & 5.3525 & 5.2235 & TRN & & \\
\hline CHEMBL1608929 & 688266 & 3.2676 & 5.0587 & TRN & & \\
\hline CHEMBL1510086 & 688266 & 5.8404 & 5.3824 & TRN & & \\
\hline CHEMBL1373994 & 688266 & 5.9416 & 5.0302 & TRN & & \\
\hline CHEMBL1409835 & 688266 & 5.255 & 5.3211 & TRN & & \\
\hline CHEMBL1334484 & 688266 & 5.3847 & 5.4344 & TRN & & \\
\hline CHEMBL3191871 & 688266 & 5.6644 & 5.2669 & TRN & & \\
\hline CHEMBL1518952 & 688266 & 3.2676 & 5.224 & TRN & & \\
\hline CHEMBL1596745 & 688266 & 5.3619 & 5.2934 & TRN & & \\
\hline CHEMBL1422133 & 688266 & 5.3128 & 5.296 & TST & & \\
\hline CHEMBL1350484 & 688266 & 5.0408 & 5.2888 & TST & & \\
\hline CHEMBL2000167 & 688266 & 5.9581 & 5.6988 & TRN & & \\
\hline CHEMBL1361582 & 688266 & 5.523 & 5.3304 & TRN & & \\
\hline CHEMBL490355 & 688266 & 5.814 & 5.3774 & TRN & & \\
\hline CHEMBL1969593 & 688266 & 5.2901 & 5.1653 & TRN & & \\
\hline CHEMBL1493191 & 688266 & 5.7634 & 5.3638 & TRN & & \\
\hline CHEMBL3190772 & 688266 & 5.3316 & 5.4167 & TRN & & \\
\hline CHEMBL605747 & 688266 & 5.4476 & 5.356 & TRN & & \\
\hline CHEMBL1520703 & 688266 & 3.2676 & 5.2092 & TST & & \\
\hline CHEMBL1505816 & 688266 & 5.5241 & 5.2392 & TST & & \\
\hline CHEMBL1348345 & 688266 & 5.1774 & 5.4582 & TRN & & \\
\hline CHEMBL3197099 & 688266 & 5.0926 & 5.2191 & TRN & & \\
\hline CHEMBL1346456 & 688266 & 5.7106 & 5.2426 & TST & & \\
\hline CHEMBL1310336 & 688266 & 5.3965 & 5.5744 & TRN & & \\
\hline CHEMBL1381264 & 688266 & 5.4024 & 5.5406 & TRN & & \\
\hline CHEMBL1454884 & 688266 & 5.6045 & 5.2294 & TRN & & \\
\hline CHEMBL1327418 & 688266 & 5.7731 & 5.5663 & TRN & & \\
\hline CHEMBL1978193 & 688266 & 5.2185 & 5.274 & TRN & & \\
\hline
\end{tabular}




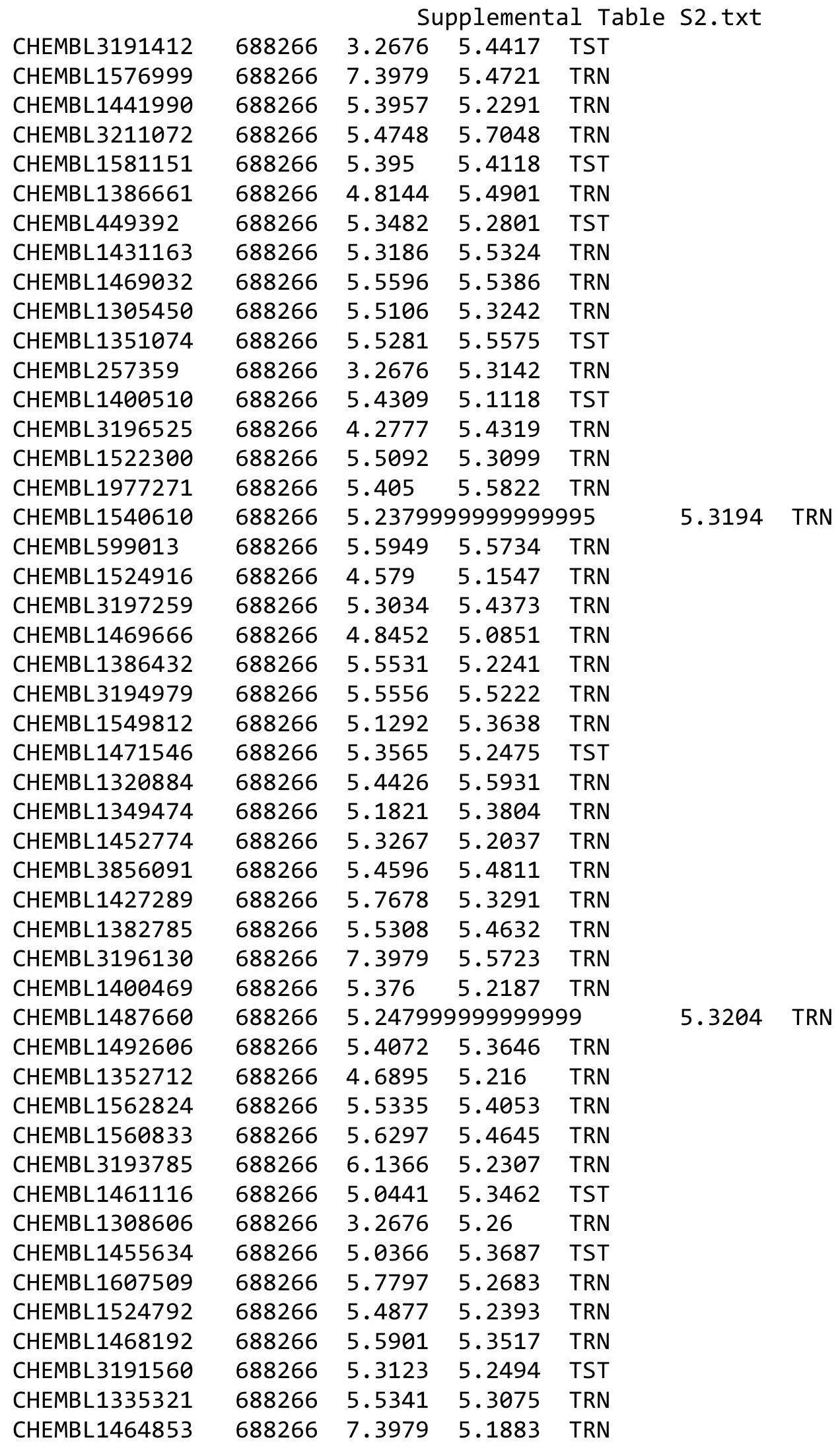




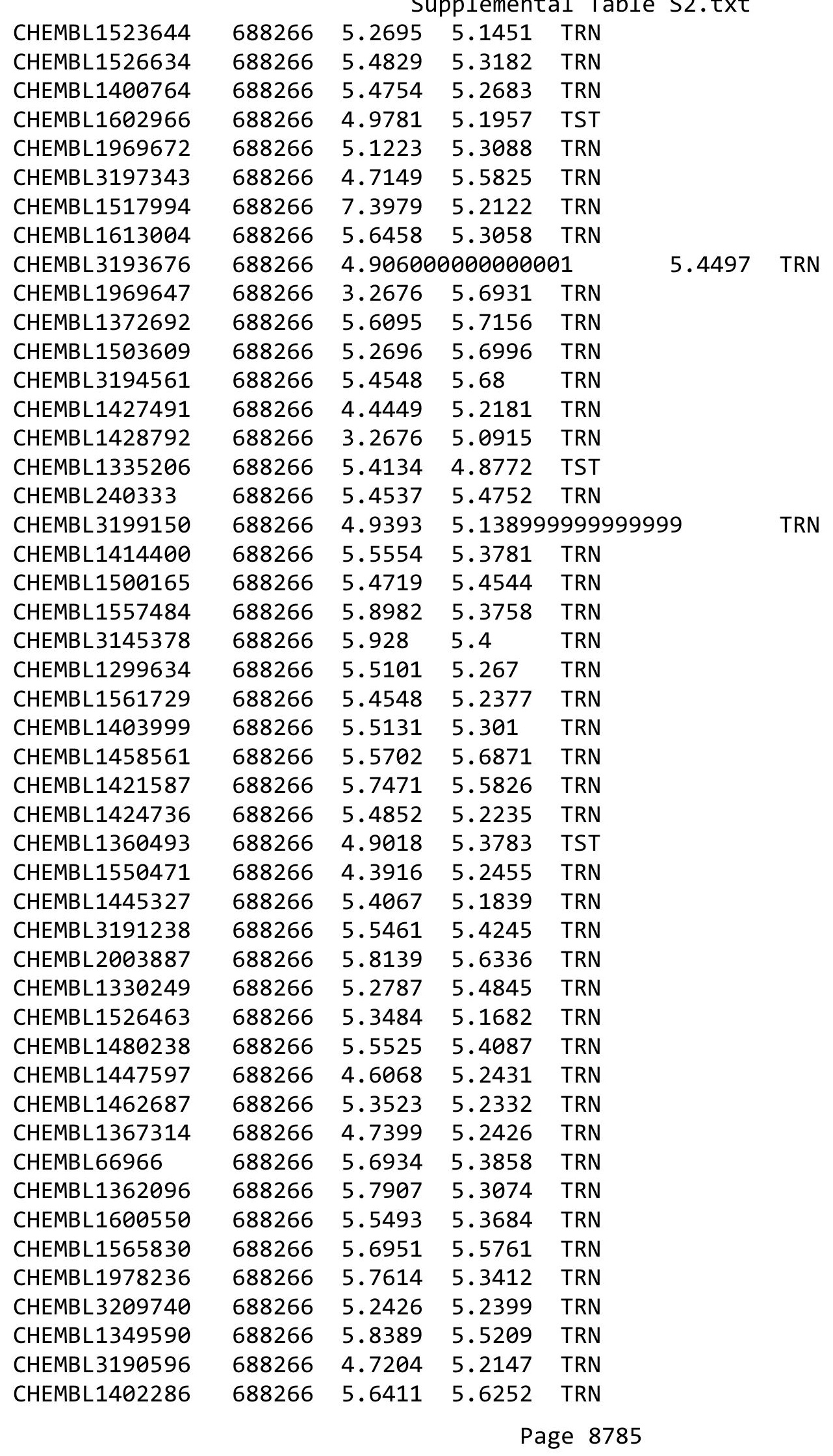


Supplemental Table S2.txt

\begin{tabular}{|c|c|c|c|c|c|}
\hline CHEMBL3191627 & 688266 & 5.5072 & 5.2087 & TRN & \\
\hline CHEMBL1572113 & 688266 & 3.2676 & 5.2515 & TRN & \\
\hline CHEMBL116548 & 688266 & 3.2676 & 5.2467 & TRN & \\
\hline CHEMBL1576601 & 688266 & 7.3979 & 5.3813 & TRN & \\
\hline CHEMBL1508086 & 688266 & 5.4782 & 5.3724 & TRN & \\
\hline CHEMBL 3212922 & 688266 & 5.2465 & 5.3925 & TRN & \\
\hline CHEMBL 3190558 & 688266 & 5.8148 & 5.74 & TRN & \\
\hline CHEMBL1522351 & 688266 & 5.8033 & 5.3284 & TRN & \\
\hline CHEMBL1415426 & 688266 & 5.2837 & 5.3543 & TRN & \\
\hline CHEMBL1335844 & 688266 & 4.9323 & 5.4047 & TRN & \\
\hline CHEMBL1454848 & 688266 & 5.2534 & 5.6078 & TRN & \\
\hline CHEMBL1464721 & 688266 & 5.436 & 5.1571 & TRN & \\
\hline CHEMBL1572386 & 688266 & 3.2676 & 5.3712 & TST & \\
\hline CHEMBL1323245 & 688266 & 5.5723 & 5.5395 & TRN & \\
\hline CHEMBL1572923 & 688266 & 4.7102 & 4.9966 & TRN & \\
\hline CHEMBL1505563 & 688266 & 5.3564 & 5.4338 & TRN & \\
\hline CHEMBL1565652 & 688266 & 3.2676 & 5.24200 & 0000000001 & TRN \\
\hline CHEMBL1310969 & 688266 & 5.187 & 5.2747 & TRN & \\
\hline CHEMBL1468800 & 688266 & 5.029 & 5.4325 & TRN & \\
\hline CHEMBL1360564 & 688266 & 5.4629 & 5.0425 & TRN & \\
\hline CHEMBL 3192328 & 688266 & 5.6041 & 5.4585 & TRN & \\
\hline CHEMBL1353879 & 688266 & 5.3631 & 5.3096 & TRN & \\
\hline CHEMBL1428894 & 688266 & 5.2411 & 5.4514 & TRN & \\
\hline CHEMBL1422304 & 688266 & 5.2565 & 5.4005 & TRN & \\
\hline CHEMBL1607399 & 688266 & 5.3221 & 5.2672 & TRN & \\
\hline CHEMBL1405834 & 688266 & 5.815 & 5.4142 & TRN & \\
\hline CHEMBL1471865 & 688266 & 5.8006 & 5.6537 & TRN & \\
\hline CHEMBL3199060 & 688266 & 5.015 & 5.6147 & TRN & \\
\hline CHEMBL1361703 & 688266 & 5.6901 & 5.5914 & TRN & \\
\hline CHEMBL1330018 & 688266 & 6.3419 & 5.3214 & TRN & \\
\hline CHEMBL1546240 & 688266 & 5.2318 & 5.3382 & TRN & \\
\hline CHEMBL1421400 & 688266 & 5.8613 & 5.4146 & TRN & \\
\hline CHEMBL1482585 & 688266 & 5.2325 & 5.4479 & TRN & \\
\hline CHEMBL1429479 & 688266 & 5.315 & 5.1669 & TRN & \\
\hline CHEMBL1540172 & 688266 & 5.9204 & 5.4416 & TRN & \\
\hline CHEMBL1426947 & 688266 & 5.3532 & 5.1482 & TRN & \\
\hline CHEMBL 3212590 & 688266 & 5.4285 & 5.4699 & TRN & \\
\hline CHEMBL1334452 & 688266 & 7.3979 & 5.4194 & TRN & \\
\hline CHEMBL1598639 & 688266 & 5.0226 & 5.1277 & TRN & \\
\hline CHEMBL1566005 & 688266 & 5.2193 & 5.3851 & TRN & \\
\hline CHEMBL1577730 & 688266 & 5.4103 & 5.4329 & TRN & \\
\hline CHEMBL1364584 & 688266 & 5.5197 & 5.3834 & TRN & \\
\hline CHEMBL1301315 & 688266 & 5.3772 & 5.3902 & TRN & \\
\hline CHEMBL1582121 & 688266 & 6.1367 & 5.3991 & TRN & \\
\hline CHEMBL1466329 & 688266 & 5.5484 & 5.6902 & TST & \\
\hline CHEMBL1966366 & 688266 & 5.7138 & 5.1356 & TRN & \\
\hline CHEMBL 3194109 & 688266 & 5.4273 & 5.5302 & TRN & \\
\hline CHEMBL 3194218 & 688266 & 4.8732 & 5.225 & TRN & \\
\hline
\end{tabular}




\begin{tabular}{|c|c|c|c|c|c|c|}
\hline & & & & & & \\
\hline CHEMBL1302721 & 688266 & 5.2907 & 5.4616 & TRN & & \\
\hline CHEMBL1995904 & 688266 & 5.7352 & 5.6617 & TRN & & \\
\hline CHEMBL1384281 & 688266 & 5.1828 & 5.3787 & TST & & \\
\hline CHEMBL1572262 & 688266 & 4.9374 & 5.1979 & TST & & \\
\hline CHEMBL1347373 & 688266 & 5.6208 & 5.4343 & TRN & & \\
\hline CHEMBL1351018 & 688266 & 6.0304 & 5.0929 & TRN & & \\
\hline CHEMBL1470905 & 688266 & 5.7918 & 5.1339 & TRN & & \\
\hline CHEMBL1559061 & 688266 & 5.1378 & 5.3475 & TRN & & \\
\hline CHEMBL1307317 & 688266 & 5.7027 & 5.5007 & TRN & & \\
\hline CHEMBL1348336 & 688266 & 5.7789 & 5.3711 & TRN & & \\
\hline CHEMBL1446668 & 688266 & 5.3707 & 5.3545 & TRN & & \\
\hline CHEMBL1424819 & 688266 & 5.3823 & 5.6852 & TRN & & \\
\hline CHEMBL1418360 & 688266 & 5.3205 & 5.2588 & TST & & \\
\hline CHEMBL1420642 & 688266 & 5.8555 & 5.5806 & TST & & \\
\hline CHEMBL1470539 & 688266 & 5.46399 & 99999999 & 995 & 5.5271 & $T c$ \\
\hline CHEMBL1411862 & 688266 & 6.2375 & 5.4528 & TST & & \\
\hline CHEMBL3209644 & 688266 & 5.71299 & 99999999 & 99 & 5.5055 & TST \\
\hline CHEMBL1430983 & 688266 & 5.1419 & 5.41700 & 0000000001 & & TST \\
\hline CHEMBL1587620 & 688266 & 5.3632 & 5.2497 & TST & & \\
\hline CHEMBL1400828 & 688266 & 5.5106 & 5.3983 & TST & & \\
\hline CHEMBL1581251 & 688266 & 5.3077 & 5.3396 & TST & & \\
\hline CHEMBL1509648 & 688266 & 5.6731 & 5.5062 & TST & & \\
\hline CHEMBL1972722 & 688266 & 5.1419 & 5.3313 & TST & & \\
\hline CHEMBL1996954 & 688266 & 5.1682 & 5.461 & TST & & \\
\hline CHEMBL1558216 & 688266 & 5.8199 & 5.1359 & TST & & \\
\hline CHEMBL1365333 & 688266 & 3.2676 & 5.1948 & TST & & \\
\hline CHEMBL1973626 & 688266 & 5.4657 & 5.6119 & TST & & \\
\hline CHEMBL1600058 & 688266 & 5.5353 & 5.5261 & TST & & \\
\hline CHEMBL1529201 & 688266 & 5.3823 & 5.295 & TST & & \\
\hline CHEMBL241768 & 688266 & 4.755 & 5.3659 & TST & & \\
\hline CHEMBL1519374 & 688266 & 5.2042 & 5.2589 & TST & & \\
\hline CHEMBL1498047 & 688266 & 5.2797 & 5.3464 & TST & & \\
\hline CHEMBL1526171 & 688266 & 5.8367 & 5.4099 & TST & & \\
\hline CHEMBL1539886 & 688266 & 5.4357 & 5.4636 & TST & & \\
\hline CHEMBL3198496 & 688266 & 5.1497 & 5.4979 & TST & & \\
\hline CHEMBL1529677 & 688266 & 3.2676 & 4.90300 & 0000000000 & & TST \\
\hline CHEMBL1537847 & 688266 & 5.3078 & 5.3302 & TST & & \\
\hline CHEMBL1320230 & 688266 & 5.6163 & 5.4008 & TST & & \\
\hline CHEMBL1550566 & 688266 & 5.4593 & 5.3673 & TST & & \\
\hline CHEMBL1500249 & 688266 & 5.3432 & 5.1352 & TST & & \\
\hline CHEMBL1459125 & 688266 & 5.3942 & 5.5588 & TST & & \\
\hline CHEMBL1463686 & 688266 & 3.2676 & 5.2509 & TST & & \\
\hline CHEMBL605959 & 688266 & 5.1858 & 5.273 & TST & & \\
\hline CHEMBL3189657 & 688266 & 5.6421 & 5.3018 & TST & & \\
\hline CHEMBL1581784 & 688266 & 5.5233 & 5.2816 & TST & & \\
\hline CHEMBL1323518 & 688266 & 4.8905 & 5.3283 & TST & & \\
\hline CHEMBL1416554 & 688266 & 4.9692 & 5.1369 & TST & & \\
\hline CHEMBL1578127 & 688266 & 5.4868 & 5.3388 & TST & & \\
\hline
\end{tabular}




\begin{tabular}{|c|c|c|c|c|}
\hline & & & 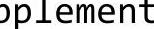 & \\
\hline CHEMBL1343178 & 688266 & 5.4403 & 5.3934 & TST \\
\hline CHEMBL1381658 & 688266 & 5.2263 & 5.3427 & TST \\
\hline CHEMBL3199715 & 688266 & 5.0785 & 5.7024 & TST \\
\hline CHEMBL1318884 & 688266 & 5.4812 & 5.2336 & TST \\
\hline CHEMBL1548872 & 688266 & 4.3748 & 5.4027 & TST \\
\hline CHEMBL1424468 & 688266 & 5.2159 & 5.2915 & TST \\
\hline CHEMBL1585999 & 688266 & 5.7089 & 5.3392 & TST \\
\hline CHEMBL1408074 & 688266 & 5.5109 & 5.3577 & TST \\
\hline CHEMBL1557913 & 688266 & 7.3979 & 5.3323 & TST \\
\hline CHEMBL1342859 & 688266 & 5.8103 & 5.3587 & TST \\
\hline CHEMBL1464107 & 688266 & 5.02 & 5.3603 & TST \\
\hline CHEMBL381033 & 688266 & 4.6861 & 5.2826 & TST \\
\hline CHEMBL1452952 & 688266 & 5.4205 & 5.229 & TST \\
\hline CHEMBL1443464 & 688266 & 5.8962 & 5.4065 & TST \\
\hline CHEMBL1488898 & 688266 & 5.4496 & 5.1799 & TST \\
\hline CHEMBL1500226 & 688266 & 5.7699 & 5.2153 & TST \\
\hline CHEMBL1404683 & 688266 & 5.2796 & 5.267 & TST \\
\hline CHEMBL1472210 & 688266 & 5.0441 & 5.336 & TST \\
\hline CHEMBL1522133 & 688266 & 5.4684 & 5.3408 & TST \\
\hline CHEMBL1482308 & 688266 & 5.3515 & 5.4777 & TST \\
\hline CHEMBL1431996 & 688266 & 5.4715 & 5.374 & TST \\
\hline CHEMBL1389667 & 688266 & 3.2676 & 5.2653 & TST \\
\hline CHEMBL1966224 & 688266 & 5.3522 & 5.2735 & TST \\
\hline CHEMBL1547154 & 688266 & 5.2362 & 5.37799 & 9999999999 \\
\hline CHEMBL1377130 & 688266 & 5.2997 & 5.2459 & TST \\
\hline CHEMBL1421530 & 688266 & 5.1871 & 5.4469 & TST \\
\hline CHEMBL3192197 & 688266 & 3.2676 & 5.3397 & TST \\
\hline CHEMBL1502716 & 688266 & 5.5655 & 5.4294 & TST \\
\hline CHEMBL1420321 & 688266 & 5.8459 & 5.32700 & 0000000001 \\
\hline CHEMBL1411344 & 688266 & 5.3515 & 5.2551 & TST \\
\hline CHEMBL1447034 & 688266 & 5.4989 & 5.0231 & TST \\
\hline CHEMBL1546596 & 688266 & 5.2134 & 5.1949 & TST \\
\hline CHEMBL1505859 & 688266 & 5.0572 & 5.2516 & TST \\
\hline CHEMBL1324382 & 688266 & 5.3563 & 5.1378 & TST \\
\hline CHEMBL1981657 & 688266 & 5.4133 & 5.6677 & TST \\
\hline CHEMBL1603056 & 688266 & 5.1505 & 5.4176 & TST \\
\hline CHEMBL1300251 & 688266 & 5.6613 & 5.3357 & TST \\
\hline CHEMBL1478490 & 688266 & 5.4305 & 5.2306 & TST \\
\hline CHEMBL1342410 & 688266 & 4.8597 & 5.2392 & TST \\
\hline CHEMBL399293 & 688266 & 5.6008 & 5.3266 & TST \\
\hline CHEMBL1330042 & 688266 & 5.5252 & 5.3367 & TST \\
\hline CHEMBL1721937 & 688266 & 5.2887 & 5.2263 & TST \\
\hline CHEMBL1339527 & 688266 & 5.5026 & 5.3133 & TST \\
\hline CHEMBL1353630 & 688266 & 5.1748 & 5.0532 & TST \\
\hline CHEMBL3196993 & 688266 & 5.4529 & 5.4248 & TST \\
\hline CHEMBL1502381 & 688266 & 5.8162 & 5.1132 & TST \\
\hline CHEMBL1603637 & 688266 & 5.7726 & 5.4485 & TST \\
\hline CHEMBL1368362 & 688266 & 5.4899 & 5.5714 & TST \\
\hline
\end{tabular}





\begin{tabular}{|c|c|c|c|c|c|}
\hline \\
\hline CHEMBL 7909 & 430786 & 7.2 & 5.8298 & TST & \\
\hline CHEMBL 7113 & 430786 & 7.1 & 7.9222 & TST & \\
\hline CHEMBL388969 & 430786 & 7.3 & 7.3152 & TRN & \\
\hline CHEMBL387870 & 430786 & 7.0 & 7.0026 & TRN & \\
\hline CHEMBL16715 & 430786 & 7.1 & 7.0997 & TRN & \\
\hline CHEMBL224453 & 430786 & 8.3 & 8.0067 & TST & \\
\hline CHEMBL389039 & 430786 & 7.3 & 7.3168 & TST & \\
\hline CHEMBL16416 & 430786 & 6.5 & 6.4746 & TRN & \\
\hline CHEMBL16774 & 430786 & 9.0 & 8.9592 & TRN & \\
\hline CHEMBL276321 & 430786 & 8.9 & 8.9549 & TRN & \\
\hline CHEMBL279870 & 430786 & 8.3 & 8.3185 & TRN & \\
\hline CHEMBL275421 & 430786 & 8.4 & 8.3207 & TRN & \\
\hline CHEMBL16643 & 430786 & 7.5 & 7.3972 & TRN & \\
\hline CHEMBL416537 & 430786 & 7.7 & 7.6703 & TRN & \\
\hline CHEMBL273578 & 430786 & 7.7 & 7.7959 & TRN & \\
\hline CHEMBL280278 & 430786 & 9.4 & 9.4504 & TRN & \\
\hline CHEMBL274267 & 430786 & 8.8 & 8.7913 & TRN & \\
\hline CHEMBL278197 & 430786 & 8.0 & 8.051 & TRN & \\
\hline CHEMBL97037 & 430786 & 7.8 & 8.7774 & TST & \\
\hline CHEMBL96576 & 430786 & 6.1 & 6.11299 & 99999999995 & TRN \\
\hline CHEMBL224569 & 430786 & 6.5 & 6.4621 & TRN & \\
\hline CHEMBL328214 & 430786 & 5.3 & 7.065 & TST & \\
\hline CHEMBL103588 & 430786 & 6.7 & 7.6289 & TST & \\
\hline CHEMBL103150 & 430786 & 7.3 & 7.2843 & TST & \\
\hline CHEMBL321330 & 430786 & 5.0 & 7.0427 & TST & \\
\hline CHEMBL441815 & 430786 & 5.0 & 6.8162 & TST & \\
\hline CHEMBL103553 & 430786 & 5.1 & 6.91100 & 30000000005 & TST \\
\hline CHEMBL103796 & 430786 & 5.7 & 6.8542 & TST & \\
\hline CHEMBL323303 & 430786 & 7.6 & 7.6996 & TRN & \\
\hline CHEMBL104999 & 430786 & 8.2 & 8.1467 & TRN & \\
\hline CHEMBL102974 & 430786 & 6.5 & 6.5141 & TRN & \\
\hline CHEMBL103559 & 430786 & 7.3 & 7.2727 & TRN & \\
\hline CHEMBL418797 & 430786 & 7.1 & 7.7486 & TST & \\
\hline CHEMBL102429 & 430786 & 9.2 & 9.2908 & TRN & \\
\hline CHEMBL94538 & 430786 & 7.0 & 6.9813 & TRN & \\
\hline CHEMBL98227 & 430786 & 5.9 & 5.1154 & TST & \\
\hline CHEMBL 329294 & 430786 & 8.8 & 8.8931 & TRN & \\
\hline CHEMBL97895 & 430786 & 8.3 & 8.2863 & TRN & \\
\hline CHEMBL97896 & 430786 & 7.6 & 7.6012 & TRN & \\
\hline CHEMBL97760 & 430786 & 9.8 & 9.7686 & TRN & \\
\hline CHEMBL97687 & 430786 & 9.1 & 9.0766 & TRN & \\
\hline CHEMBL313864 & 430786 & 8.3 & 8.3065 & TRN & \\
\hline CHEMBL97624 & 430786 & 7.5 & 7.5587 & TRN & \\
\hline CHEMBL97337 & 430786 & 7.8 & 7.7256 & TRN & \\
\hline CHEMBL319580 & 430786 & 5.2 & 5.1351 & TRN & \\
\hline CHEMBL97778 & 430786 & 6.0 & 6.0625 & TRN & \\
\hline CHEMBL415697 & 430786 & 6.3 & 6.4631 & TST & \\
\hline CHEMBL97549 & 430786 & 8.3 & 8.2267 & TRN & \\
\hline
\end{tabular}




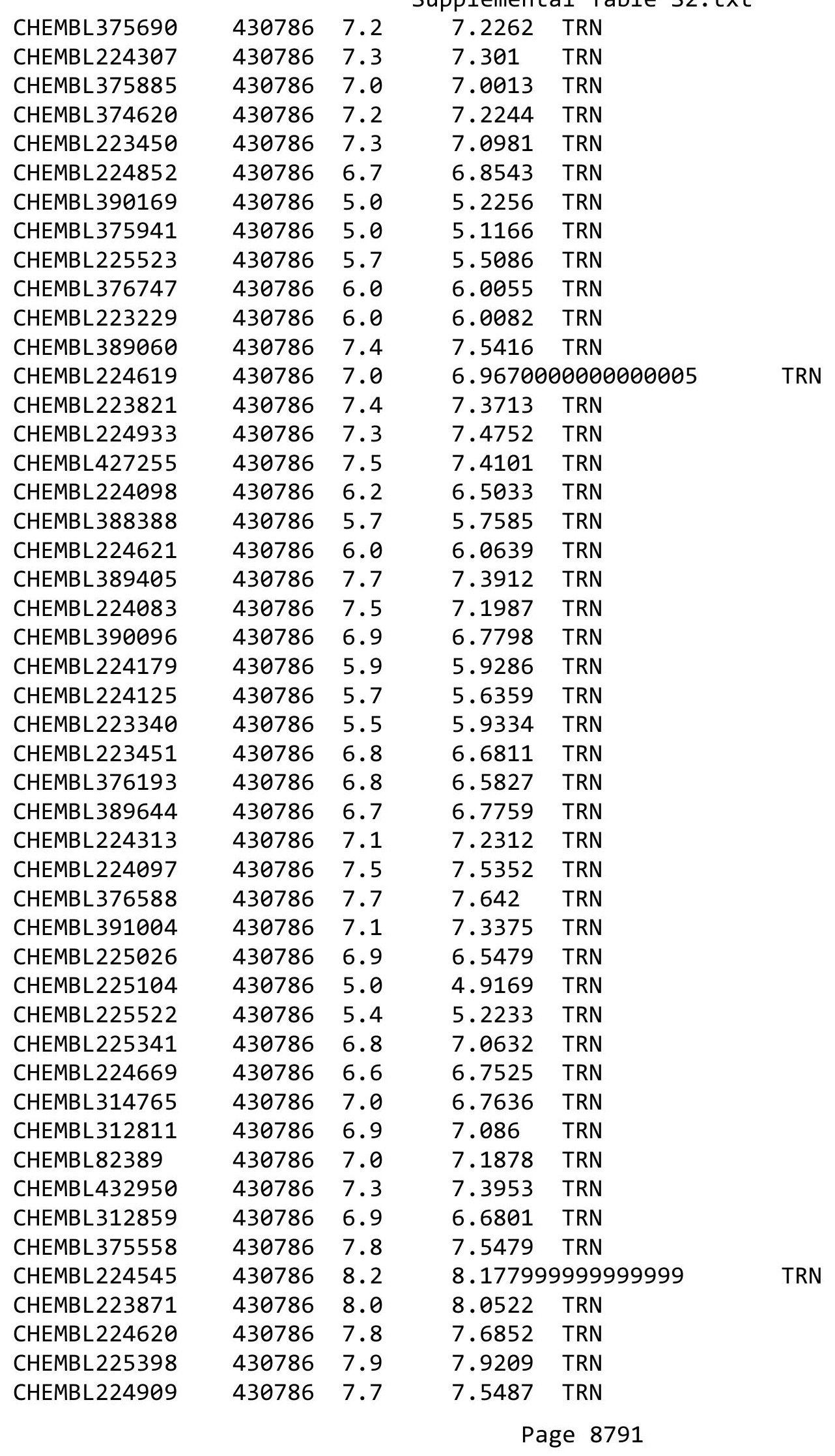




\begin{tabular}{|c|c|c|c|c|c|c|}
\hline \multicolumn{7}{|c|}{ seriter } \\
\hline CHEMBL375154 & 430786 & 8.1 & 8.1185 & TRN & & \\
\hline CHEMBL1086411 & 615503 & 6.767 & 7.1365 & TRN & & \\
\hline CHEMBL1091479 & 615503 & 5.8526 & 5.9044 & TRN & & \\
\hline CHEMBL1078394 & 615503 & 7.0655 & 6.9117 & TRN & & \\
\hline CHEMBL1078465 & 615503 & 7.4949 & 7.4844 & TRN & & \\
\hline CHEMBL1084145 & 615503 & 7.7959 & 7.934 & TRN & & \\
\hline CHEMBL1084138 & 615503 & 8.0969 & 8.1244 & TRN & & \\
\hline CHEMBL1093086 & 615503 & 6.1593 & 6.2615 & TRN & & \\
\hline CHEMBL1078395 & 615503 & 7.6198 & 8.047 & TRN & & \\
\hline CHEMBL1078695 & 615503 & 6.9788 & 6.8063 & TRN & & \\
\hline CHEMBL1085441 & 615503 & \multicolumn{3}{|c|}{7.117999999999999} & 0000000001 & TRN \\
\hline CHEMBL1089734 & 615503 & 6.7282 & 6.6344 & TRN & & \\
\hline CHEMBL111201 & 615503 & 8.4437 & 7.4746 & TST & & \\
\hline CHEMBL1085898 & 615503 & 6.6478 & 6.9056 & TRN & & \\
\hline CHEMBL1078749 & 615503 & 7.4318 & 7.3984 & TRN & & \\
\hline CHEMBL1089395 & 615503 & 6.7471 & 6.8369 & TRN & & \\
\hline CHEMBL1085693 & 615503 & 6.5482 & 6.6433 & TRN & & \\
\hline CHEMBL1083831 & 615503 & 7.4437 & 7.5511 & TRN & & \\
\hline CHEMBL1089387 & 615503 & 7.6198 & 7.3413 & TRN & & \\
\hline CHEMBL1085442 & 615503 & 7.6778 & 7.6604 & TRN & & \\
\hline CHEMBL1091816 & 615503 & 8.7212 & 8.5515 & TRN & & \\
\hline CHEMBL1085928 & 615503 & 7.0 & 7.2093 & TRN & & \\
\hline CHEMBL1078496 & 615503 & 8.1612 & 7.8344 & TRN & & \\
\hline CHEMBL1090416 & 615503 & 6.9101 & 6.6643 & TRN & & \\
\hline CHEMBL1090425 & 615503 & 8.1675 & 8.1834 & TRN & & \\
\hline CHEMBL1095042 & 615503 & \multicolumn{3}{|c|}{6.617999999999999} & TRN & \\
\hline CHEMBL1089725 & 615503 & 7.6778 & 7.8787 & TRN & & \\
\hline CHEMBL1089386 & 615503 & 7.8539 & 7.7956 & TRN & & \\
\hline CHEMBL1085897 & 615503 & 7.0223 & 6.9284 & TRN & & \\
\hline CHEMBL1088076 & 615503 & 6.2366 & 6.366006 & $\partial 0000000005$ & TRN & \\
\hline CHEMBL1077199 & 615503 & 6.5272 & 6.7689 & TRN & & \\
\hline CHEMBL1084144 & 615503 & 7.7212 & 7.7623 & TRN & & \\
\hline CHEMBL1077238 & 615503 & 7.7212 & 7.8632 & TRN & & \\
\hline CHEMBL1094715 & 615503 & 6.6615 & 6.5044 & TRN & & \\
\hline CHEMBL1090746 & 615503 & 6.7595 & 6.9383 & TRN & & \\
\hline CHEMBL1078575 & 615503 & 7.4559 & 7.5774 & TRN & & \\
\hline CHEMBL1086149 & 615503 & 8.0555 & 7.343 & TRN & & \\
\hline CHEMBL1085929 & 615503 & 6.3429 & 6.414 & TST & & \\
\hline CHEMBL1083216 & 615503 & 6.3028 & 6.2609 & TRN & & \\
\hline CHEMBL1089052 & 615503 & 6.0097 & 5.9446 & TRN & & \\
\hline CHEMBL1093387 & 615503 & 7.6576 & 7.6573 & TRN & & \\
\hline CHEMBL1089396 & 615503 & 6.7352 & 6.7916 & TRN & & \\
\hline CHEMBL1092502 & 615503 & 7.3188 & 7.2259 & TRN & & \\
\hline CHEMBL1085694 & 615503 & 5.5772 & 5.8823 & TRN & & \\
\hline CHEMBL1089735 & 615503 & 7.1739 & 7.0479 & TRN & & \\
\hline CHEMBL1078495 & 615503 & 7.3279 & 7.7459 & TST & & \\
\hline CHEMBL1083832 & 615503 & 7.3768 & 7.00799 & 9999999999 & TST & \\
\hline CHEMBL1077273 & 615503 & 6.5834 & 6.6861 & TST & & \\
\hline
\end{tabular}




\begin{tabular}{|c|c|c|c|c|c|}
\hline & & & & & \\
\hline CHEMBL1078576 & 615503 & 8.0 & 7.4379 & TST & \\
\hline CHEMBL1091478 & 615503 & 5.4239 & 6.0994 & TST & \\
\hline CHEMBL1078876 & 615503 & 7.1192 & 6.9157 & TST & \\
\hline CHEMBL1084137 & 615503 & 7.0655 & 7.2021 & TST & \\
\hline CHEMBL1085444 & 615503 & 7.1938 & 6.8303 & TST & \\
\hline CHEMBL1084136 & 615503 & 7.1308 & 7.1168 & TST & \\
\hline CHEMBL1084667 & 615503 & 7.7212 & 7.1532 & TST & \\
\hline CHEMBL1090424 & 615503 & 6.9872 & 6.7074 & TST & \\
\hline CHEMBL1078696 & 615503 & 7.1367 & 7.0259 & TST & \\
\hline CHEMBL1089053 & 615503 & 7.4318 & 7.1743 & TST & \\
\hline CHEMBL119221 & 155946 & 5.7959 & 6.2122 & TRN & \\
\hline CHEMBL118902 & 155946 & 3.1871 & 4.1233 & TST & \\
\hline CHEMBL117619 & 155946 & 6.0757 & 6.0786 & TRN & \\
\hline CHEMBL115530 & 155946 & 3.0969 & 3.5472 & TST & \\
\hline CHEMBL118311 & 155946 & 3.5229 & 6.2122 & TRN & \\
\hline CHEMBL22463 & 155946 & 2.0 & 3.3382 & TST & \\
\hline CHEMBL116428 & 155946 & 6.6778 & 6.4325 & TRN & \\
\hline CHEMBL116707 & 155946 & 5.8861 & 6.1581 & TRN & \\
\hline CHEMBL119482 & 155946 & 3.2218 & 3.4104 & TRN & \\
\hline CHEMBL118235 & 155946 & 2.9208 & 3.4462 & TST & \\
\hline CHEMBL324402 & 155946 & 6.9586 & 6.307 & TRN & \\
\hline CHEMBL118227 & 155946 & 3.4559 & 3.4247 & TST & \\
\hline CHEMBL118705 & 155946 & 2.0 & 3.3603 & TST & \\
\hline CHEMBL118765 & 155946 & 3.8861 & 4.1318 & TRN & \\
\hline CHEMBL333552 & 155946 & 1.699 & 3.9458 & TST & \\
\hline CHEMBL118745 & 155946 & 5.6778 & 6.2122 & TRN & \\
\hline CHEMBL1182 & 155946 & 1.0969 & 3.4017 & TST & \\
\hline CHEMBL116470 & 155946 & 2.3161 & 3.35699 & 99999999998 & TST \\
\hline CHEMBL118539 & 155946 & 3.699 & 3.6328 & TRN & \\
\hline CHEMBL109873 & 155946 & 6.301 & 6.2122 & TRN & \\
\hline CHEMBL122581 & 155946 & 3.3768 & 3.3709 & TST & \\
\hline CHEMBL1135 & 155946 & 2.8861 & 3.3001 & TRN & \\
\hline CHEMBL421897 & 155946 & 6.8239 & 6.2969 & TRN & \\
\hline CHEMBL120782 & 155946 & 6.1549 & 6.2122 & TRN & \\
\hline CHEMBL119701 & 155946 & 7.0458 & 4.4979 & TRN & \\
\hline CHEMBL116600 & 155946 & 2.699 & 3.412 & TST & \\
\hline CHEMBL119327 & 155946 & 6.2924 & 5.8011 & TRN & \\
\hline CHEMBL3350840 & 155946 & 2.9208 & 3.409 & TST & \\
\hline CHEMBL116663 & 155946 & 3.5229 & 3.4118 & TRN & \\
\hline CHEMBL122587 & 155946 & 4.9208 & 4.4979 & TRN & \\
\hline CHEMBL119296 & 155946 & 2.699 & 3.9742 & TST & \\
\hline CHEMBL118950 & 155946 & 5.699 & 4.8243 & TRN & \\
\hline CHEMBL119073 & 155946 & 6.8239 & 4.1233 & TST & \\
\hline CHEMBL120462 & 155946 & 3.9586 & 3.9248 & TRN & \\
\hline CHEMBL327032 & 155946 & 4.0969 & 3.5344 & TRN & \\
\hline CHEMBL119520 & 155946 & 6.3188 & 6.1581 & TRN & \\
\hline CHEMBL116834 & 155946 & 4.301 & 3.3266 & TRN & \\
\hline CHEMBL122184 & 155946 & 3.3468 & 3.5159 & TRN & \\
\hline
\end{tabular}




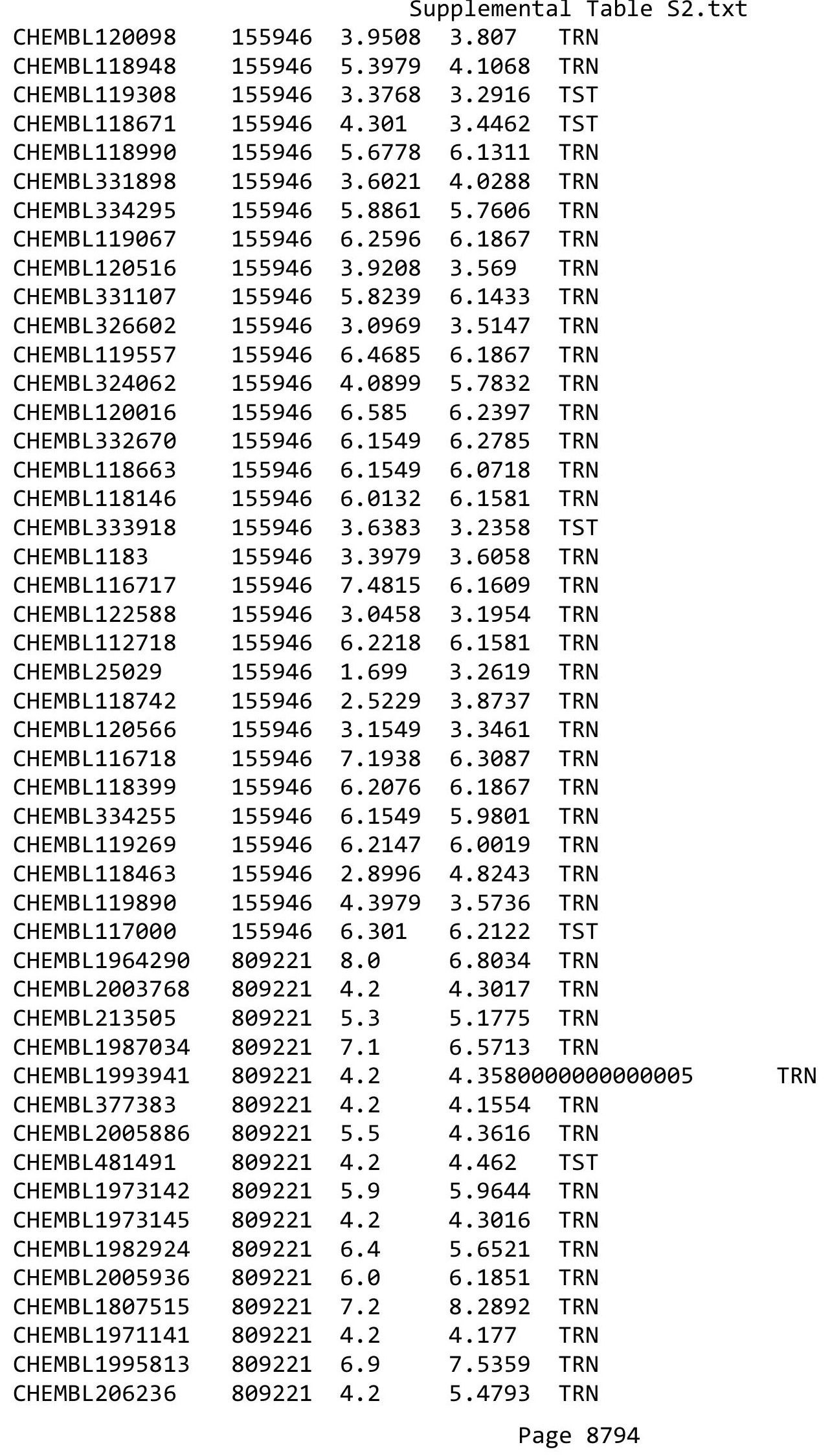




\begin{tabular}{|c|c|c|c|c|c|}
\hline & & & & & \\
\hline CHEMBL 244378 & 809221 & 6.5 & 6.9616 & TRN & \\
\hline CHEMBL 2001957 & 809221 & 4.2 & 4.2214 & TRN & \\
\hline CHEMBL1969372 & 809221 & 5.5 & 4.5306 & TRN & \\
\hline CHEMBL1986943 & 809221 & 8.3 & 7.9547 & TRN & \\
\hline CHEMBL 2006263 & 809221 & 5.7 & 4.8055 & TRN & \\
\hline CHEMBL1993584 & 809221 & 5.9 & 5.6702 & TRN & \\
\hline CHEMBL1986263 & 809221 & 6.0 & 6.5376 & TRN & \\
\hline CHEMBL 2000114 & 809221 & 4.2 & 4.9404 & TRN & \\
\hline CHEMBL210618 & 809221 & 4.2 & 3.78800 & 20000000003 & TRN \\
\hline CHEMBL1975647 & 809221 & 4.2 & 5.1741 & TRN & \\
\hline CHEMBL1968380 & 809221 & 4.2 & 4.5839 & TRN & \\
\hline CHEMBL1964644 & 809221 & 4.2 & 4.0561 & TRN & \\
\hline CHEMBL1981782 & 809221 & 5.6 & 5.3795 & TRN & \\
\hline CHEMBL1977681 & 809221 & 6.2 & 5.2019 & TRN & \\
\hline CHEMBL1990912 & 809221 & 6.2 & 5.4036 & TRN & \\
\hline CHEMBL 2006493 & 809221 & 4.2 & 4.4227 & TST & \\
\hline CHEMBL1996923 & 809221 & 4.2 & 4.527 & TST & \\
\hline CHEMBL1983449 & 809221 & 4.2 & 4.285 & TRN & \\
\hline CHEMBL1992323 & 809221 & 5.3 & 5.2538 & TRN & \\
\hline CHEMBL1969735 & 809221 & 4.2 & 4.2346 & TRN & \\
\hline CHEMBL1995172 & 809221 & 4.2 & 4.1848 & TST & \\
\hline CHEMBL1994321 & 809221 & 5.5 & 4.8327 & TRN & \\
\hline CHEMBL1997129 & 809221 & 8.1 & 7.0753 & TRN & \\
\hline CHEMBL1984788 & 809221 & 4.2 & 5.232 & TRN & \\
\hline CHEMBL 2000508 & 809221 & 4.2 & 4.3716 & TRN & \\
\hline CHEMBL1971694 & 809221 & 4.2 & 4.8049 & TST & \\
\hline CHEMBL 2001547 & 809221 & 4.2 & 4.0999 & TRN & \\
\hline CHEMBL210928 & 809221 & 4.2 & 4.0604 & TRN & \\
\hline CHEMBL1986603 & 809221 & 6.3 & 5.0564 & TST & \\
\hline CHEMBL1977148 & 809221 & 4.2 & 4.04899 & 99999999995 & TRN \\
\hline CHEMBL 2003286 & 809221 & 7.0 & 6.7288 & TRN & \\
\hline CHEMBL1992306 & 809221 & 4.2 & 4.5635 & TRN & \\
\hline CHEMBL 2002165 & 809221 & 4.2 & 4.79899 & 99999999995 & TRN \\
\hline CHEMBL 2001668 & 809221 & 4.2 & 4.7927 & TST & \\
\hline CHEMBL1979318 & 809221 & 4.2 & 4.4202 & TST & \\
\hline CHEMBL 206382 & 809221 & 5.9 & 5.2778 & TRN & \\
\hline CHEMBL1998585 & 809221 & 5.6 & 5.385 & TRN & \\
\hline CHEMBL127898 & 809221 & 4.2 & 4.8427 & TST & \\
\hline CHEMBL519697 & 809221 & 4.2 & 5.12200 & 3000000001 & TRN \\
\hline CHEMBL1981947 & 809221 & 6.0 & 4.7016 & TST & \\
\hline CHEMBL1975128 & 809221 & 6.0 & 6.5142 & TRN & \\
\hline CHEMBL1970369 & 809221 & 4.2 & 4.4289 & TRN & \\
\hline CHEMBL1966425 & 809221 & 4.2 & 4.3249 & TRN & \\
\hline CHEMBL1984363 & 809221 & 5.5 & 5.1106 & TRN & \\
\hline CHEMBL1988608 & 809221 & 5.6 & 5.3357 & TRN & \\
\hline CHEMBL184847 & 809221 & 4.2 & 4.7007 & TRN & \\
\hline CHEMBL1984367 & 809221 & 4.2 & 4.758 & TRN & \\
\hline CHEMBL1982563 & 809221 & 4.2 & 4.3146 & TRN & \\
\hline & & & & 8795 & \\
\hline
\end{tabular}




\begin{tabular}{|c|c|c|c|c|c|}
\hline & & & & & \\
\hline CHEMBL539474 & 809221 & 5.6 & 4.8606 & TST & \\
\hline CHEMBL575824 & 809221 & 6.4 & 6.7017 & TRN & \\
\hline CHEMBL1989708 & 809221 & 4.2 & 4.7984 & TRN & \\
\hline CHEMBL1990288 & 809221 & 4.2 & 4.3134 & TRN & \\
\hline CHEMBL1974803 & 809221 & 5.3 & 5.1716 & TRN & \\
\hline CHEMBL1970074 & 809221 & 4.2 & 4.6601 & TRN & \\
\hline CHEMBL1986970 & 809221 & 4.2 & 5.268 & TRN & \\
\hline CHEMBL 2005112 & 809221 & 4.2 & 5.29299 & 9999999999 & TST \\
\hline CHEMBL1958401 & 809221 & 6.1 & 5.9474 & TRN & \\
\hline CHEMBL1984044 & 809221 & 4.2 & 5.1872 & TRN & \\
\hline CHEMBL 2003456 & 809221 & 4.2 & 4.3641 & TRN & \\
\hline CHEMBL1966816 & 809221 & 4.2 & 4.4896 & TRN & \\
\hline CHEMBL1972584 & 809221 & 4.2 & 4.1302 & TRN & \\
\hline CHEMBL 2002992 & 809221 & 4.2 & 4.7249 & TRN & \\
\hline CHEMBL560813 & 809221 & 5.6 & 5.0333 & TRN & \\
\hline CHEMBL1968791 & 809221 & 5.6 & 4.4847 & TRN & \\
\hline CHEMBL1971186 & 809221 & 4.2 & 4.59399 & 9999999999 & TRN \\
\hline CHEMBL 2003482 & 809221 & 4.2 & 3.9404 & TRN & \\
\hline CHEMBL1973211 & 809221 & 5.5 & 4.9366 & TRN & \\
\hline CHEMBL1984700 & 809221 & 4.2 & 4.1298 & TRN & \\
\hline CHEMBL1972125 & 809221 & 5.4 & 5.63700 & 00000000005 & TRN \\
\hline CHEMBL1461728 & 809221 & 6.0 & 4.9286 & TRN & \\
\hline CHEMBL1976134 & 809221 & 5.9 & 5.4403 & TRN & \\
\hline CHEMBL1965131 & 809221 & 5.5 & 5.9854 & TRN & \\
\hline CHEMBL 2006580 & 809221 & 5.9 & 5.2999 & TRN & \\
\hline CHEMBL 2006481 & 809221 & 4.2 & 4.4993 & TRN & \\
\hline CHEMBL1979855 & 809221 & 5.9 & 4.1354 & TRN & \\
\hline CHEMBL1970340 & 809221 & 4.2 & 4.6054 & TRN & \\
\hline CHEMBL1975534 & 809221 & 6.1 & 5.3054 & TRN & \\
\hline CHEMBL1966703 & 809221 & 4.2 & 4.0144 & TST & \\
\hline CHEMBL1969561 & 809221 & 4.2 & 4.9881 & TRN & \\
\hline CHEMBL1997023 & 809221 & 4.2 & 4.6265 & TST & \\
\hline CHEMBL1964687 & 809221 & 4.2 & 4.8544 & TRN & \\
\hline CHEMBL1971943 & 809221 & 7.1 & 5.0468 & TST & \\
\hline CHEMBL1974254 & 809221 & 4.2 & 4.3235 & TRN & \\
\hline CHEMBL1988537 & 809221 & 4.4 & 5.0273 & TST & \\
\hline CHEMBL 2005828 & 809221 & 5.7 & 4.8413 & TRN & \\
\hline CHEMBL 2002240 & 809221 & 4.2 & 4.463 & TRN & \\
\hline CHEMBL1991143 & 809221 & 4.2 & 4.1648 & TST & \\
\hline CHEMBL1998611 & 809221 & 4.3 & 5.3558 & TRN & \\
\hline CHEMBL1975900 & 809221 & 4.2 & 4.9949 & TRN & \\
\hline CHEMBL 255822 & 809221 & 8.0 & 7.165 & TRN & \\
\hline CHEMBL1972221 & 809221 & 5.3 & 4.5721 & TRN & \\
\hline CHEMBL 2006778 & 809221 & 4.2 & 5.0529 & TRN & \\
\hline CHEMBL 378627 & 809221 & 4.2 & 4.1906 & TRN & \\
\hline CHEMBL1996979 & 809221 & 5.5 & 5.0365 & TRN & \\
\hline CHEMBL1997025 & 809221 & 5.8 & 5.4262 & TRN & \\
\hline CHEMBL1968406 & 809221 & 5.3 & 5.3658 & TRN & \\
\hline & & & & 8796 & \\
\hline
\end{tabular}




\begin{tabular}{|c|c|c|c|c|c|}
\hline \multicolumn{6}{|c|}{ Supplemental Table S2.txt } \\
\hline CHEMBL1984274 & 809221 & 4.2 & 4.175 & TST & \\
\hline CHEMBL1998545 & 809221 & 4.2 & 4.0787 & TRN & \\
\hline CHEMBL 2006010 & 809221 & 4.2 & 4.0219 & TRN & \\
\hline CHEMBL1682558 & 809221 & 4.2 & 4.3961 & TRN & \\
\hline CHEMBL1990496 & 809221 & 4.2 & 4.5239 & TRN & \\
\hline CHEMBL 2002479 & 809221 & 6.2 & 5.2084 & TRN & \\
\hline CHEMBL1967094 & 809221 & 5.4 & 5.3869 & TRN & \\
\hline CHEMBL1966035 & 809221 & 4.2 & 4.253 & TRN & \\
\hline CHEMBL 2003341 & 809221 & 4.2 & 4.2958 & TRN & \\
\hline CHEMBL1982992 & 809221 & 5.9 & 5.3214 & TRN & \\
\hline CHEMBL1999590 & 809221 & 4.2 & 4.2636 & TST & \\
\hline CHEMBL1981079 & 809221 & 7.8 & 7.2857 & TRN & \\
\hline CHEMBL1972276 & 809221 & 4.2 & 5.0635 & TRN & \\
\hline CHEMBL1980489 & 809221 & 4.2 & 4.512 & TRN & \\
\hline CHEMBL1967116 & 809221 & 6.0 & 5.0079 & TRN & \\
\hline CHEMBL 2000832 & 809221 & 6.2 & 4.8499 & TRN & \\
\hline CHEMBL513846 & 809221 & 4.2 & 4.8456 & TRN & \\
\hline CHEMBL1970709 & 809221 & 4.2 & 4.5176 & TRN & \\
\hline CHEMBL1965660 & 809221 & 8.0 & 7.6794 & TRN & \\
\hline CHEMBL1969126 & 809221 & 4.2 & 4.3784 & TRN & \\
\hline CHEMBL1980896 & 809221 & 5.7 & 4.749 & TRN & \\
\hline CHEMBL1975208 & 809221 & 5.2 & 4.4888 & TST & \\
\hline CHEMBL1970104 & 809221 & 4.2 & 5.4938 & TRN & \\
\hline CHEMBL1964777 & 809221 & 5.5 & 5.4124 & TST & \\
\hline CHEMBL1999714 & 809221 & 4.2 & 4.0193 & TRN & \\
\hline CHEMBL1971149 & 809221 & 4.2 & 4.1697 & TRN & \\
\hline CHEMBL1987533 & 809221 & 4.2 & 4.3501 & TRN & \\
\hline CHEMBL1994040 & 809221 & 4.2 & 4.1837 & TRN & \\
\hline CHEMBL579246 & 809221 & 6.6 & 6.8115 & TRN & \\
\hline CHEMBL398951 & 809221 & 4.2 & 3.8986 & TRN & \\
\hline CHEMBL1982506 & 809221 & 4.2 & 4.4977 & TST & \\
\hline CHEMBL1968127 & 809221 & 4.2 & 4.1796 & TRN & \\
\hline CHEMBL1975233 & 809221 & 4.2 & 4.21 & TRN & \\
\hline CHEMBL1985406 & 809221 & 4.2 & 4.94300 & 00000000005 & TRN \\
\hline CHEMBL 207400 & 809221 & 5.3 & 4.3808 & TST & \\
\hline CHEMBL 2000894 & 809221 & 6.8 & 4.7207 & TST & \\
\hline CHEMBL1982135 & 809221 & 5.5 & 5.4153 & TRN & \\
\hline CHEMBL1976090 & 809221 & 6.5 & 6.0696 & TRN & \\
\hline CHEMBL1993243 & 809221 & 4.2 & 4.5291 & TRN & \\
\hline CHEMBL1992922 & 809221 & 6.0 & 5.6696 & TRN & \\
\hline CHEMBL 2004771 & 809221 & 4.2 & 4.3899 & TRN & \\
\hline CHEMBL1997597 & 809221 & 5.9 & 5.0826 & TRN & \\
\hline CHEMBL1969537 & 809221 & 5.3 & 5.3797 & TST & \\
\hline CHEMBL1976093 & 809221 & 4.2 & 3.9695 & TRN & \\
\hline CHEMBL 210032 & 809221 & 4.2 & 4.0798 & TRN & \\
\hline CHEMBL1975256 & 809221 & 4.2 & 4.3445 & TST & \\
\hline CHEMBL508928 & 809221 & 6.5 & 4.9333 & TRN & \\
\hline CHEMBL1991356 & 809221 & 4.2 & 4.3823 & TRN & \\
\hline
\end{tabular}




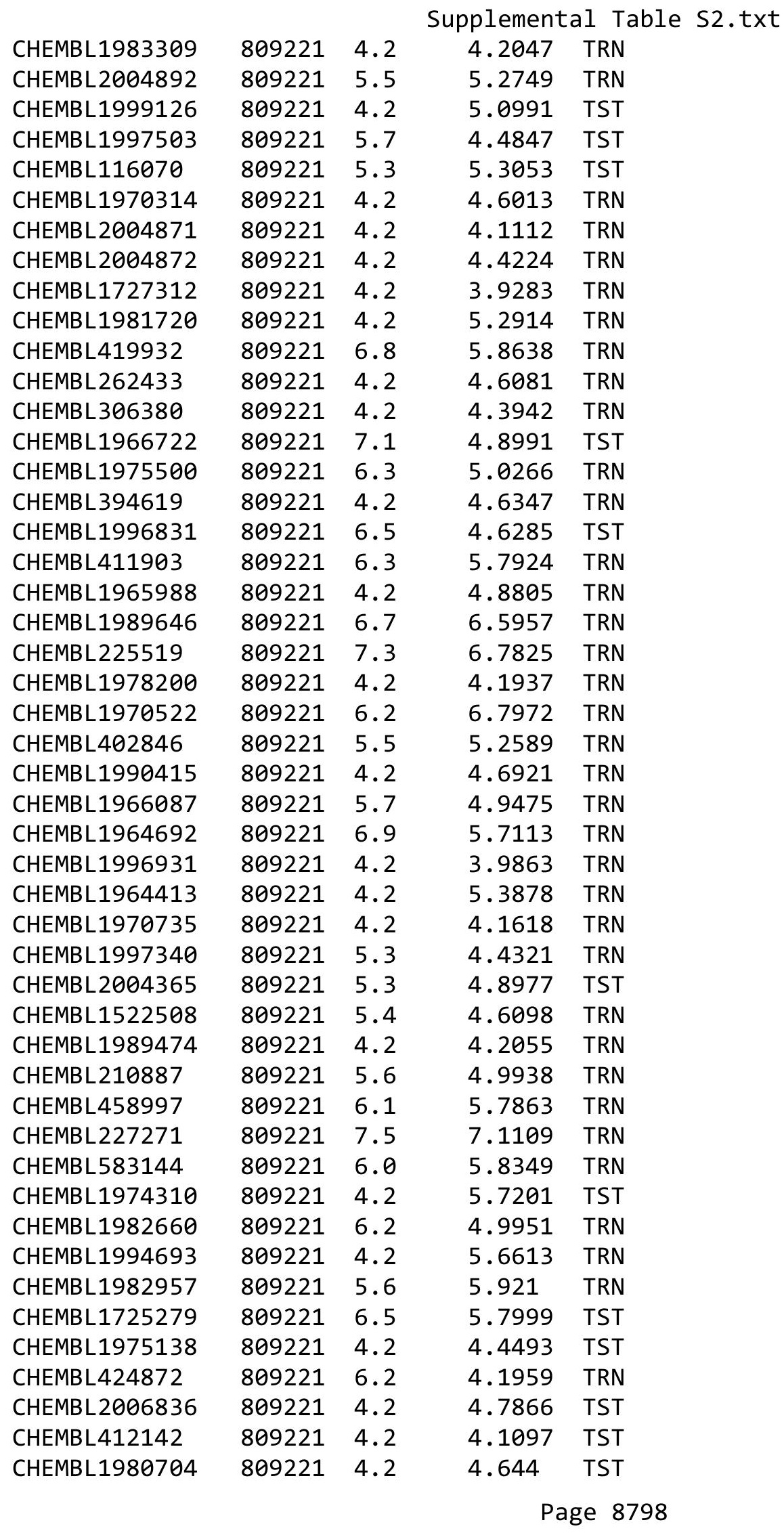




\begin{tabular}{|c|c|c|c|c|}
\hline \multicolumn{5}{|c|}{ lemental T } \\
\hline CHEMBL 2003271 & 809221 & 5.8 & 5.9559 & TRN \\
\hline CHEMBL 2004447 & 809221 & 4.2 & 4.1245 & TST \\
\hline CHEMBL1983111 & 809221 & 5.3 & 5.6726 & TST \\
\hline CHEMBL1973860 & 809221 & 5.9 & 5.175 & TRN \\
\hline CHEMBL 260135 & 809221 & 4.2 & 4.7106 & TRN \\
\hline CHEMBL 2004544 & 809221 & 5.7 & 5.1544 & TST \\
\hline CHEMBL1982610 & 809221 & 5.4 & 5.3308 & TST \\
\hline CHEMBL1989569 & 809221 & 5.5 & 5.3229 & TRN \\
\hline CHEMBL1999496 & 809221 & 4.2 & 4.2583 & TRN \\
\hline CHEMBL1988300 & 809221 & 4.2 & 4.7782 & TRN \\
\hline CHEMBL1991078 & 809221 & 6.2 & 7.2764 & TRN \\
\hline CHEMBL1987359 & 809221 & 7.4 & 4.1724 & TST \\
\hline CHEMBL1989265 & 809221 & 4.2 & 4.824 & TST \\
\hline CHEMBL1969502 & 809221 & 4.2 & 5.0174 & TRN \\
\hline CHEMBL1682553 & 809221 & 7.3 & 6.4612 & TRN \\
\hline CHEMBL1971430 & 809221 & 4.2 & 4.4334 & TRN \\
\hline CHEMBL1997764 & 809221 & 5.6 & 5.4229 & TRN \\
\hline CHEMBL1983963 & 809221 & 4.2 & 4.8242 & TRN \\
\hline CHEMBL1985092 & 809221 & 6.0 & 5.146 & TST \\
\hline CHEMBL 2004692 & 809221 & 4.2 & 4.0543 & TST \\
\hline CHEMBL1981410 & 809221 & 4.2 & 5.3426 & TRN \\
\hline CHEMBL1991434 & 809221 & 4.2 & 4.7952 & TRN \\
\hline CHEMBL1967544 & 809221 & 6.7 & 5.4816 & TRN \\
\hline CHEMBL 223367 & 809221 & 4.2 & 3.8794 & TST \\
\hline CHEMBL 340384 & 809221 & 7.4 & 5.724 & TST \\
\hline CHEMBL1964804 & 809221 & 6.6 & 5.7109 & TRN \\
\hline CHEMBL443962 & 809221 & 6.0 & 4.6969 & TST \\
\hline CHEMBL 2000354 & 809221 & 6.8 & 6.9572 & TRN \\
\hline CHEMBL1965507 & 809221 & 4.2 & 4.2747 & TRN \\
\hline CHEMBL 274064 & 809221 & 5.7 & 4.7526 & TRN \\
\hline CHEMBL1967564 & 809221 & 4.2 & 4.2973 & TRN \\
\hline CHEMBL592030 & 809221 & 7.0 & 5.9195 & TST \\
\hline CHEMBL 2000071 & 809221 & 5.5 & 5.6939 & TRN \\
\hline CHEMBL 2000408 & 809221 & 4.2 & 4.3002 & TRN \\
\hline CHEMBL 248757 & 809221 & 4.2 & 4.3113 & TST \\
\hline CHEMBL1978014 & 809221 & 5.5 & 5.0104 & TRN \\
\hline CHEMBL1994538 & 809221 & 6.0 & 4.9212 & TRN \\
\hline CHEMBL1983195 & 809221 & 5.8 & 4.9736 & TST \\
\hline CHEMBL1975490 & 809221 & 4.2 & 4.5759 & TRN \\
\hline CHEMBL1964444 & 809221 & 4.2 & 4.3073 & TRN \\
\hline CHEMBL1986139 & 809221 & 5.6 & 4.8957 & TRN \\
\hline CHEMBL1980540 & 809221 & 4.2 & 3.9996 & TRN \\
\hline CHEMBL1979883 & 809221 & 5.7 & 4.872 & TRN \\
\hline CHEMBL1984162 & 809221 & 4.2 & 4.6857 & TRN \\
\hline CHEMBL491758 & 809221 & 4.2 & 4.0191 & TRN \\
\hline CHEMBL549730 & 809221 & 4.2 & 4.3866 & TRN \\
\hline CHEMBL1970189 & 809221 & 4.2 & 4.3289 & TST \\
\hline CHEMBL371206 & 809221 & 6.2 & 5.2599 & TRN \\
\hline
\end{tabular}




\begin{tabular}{|c|c|c|c|c|c|}
\hline \\
\hline CHEMBL1996791 & 809221 & 6.1 & 5.5122 & TRN & \\
\hline CHEMBL1974664 & 809221 & 4.2 & 4.3711 & TRN & \\
\hline CHEMBL1974288 & 809221 & 4.2 & 4.5232 & TRN & \\
\hline CHEMBL196363 & 809221 & 4.2 & 4.8365 & TRN & \\
\hline CHEMBL1190711 & 809221 & 6.3 & 5.7456 & TRN & \\
\hline CHEMBL1968705 & 809221 & 4.2 & 4.5674 & TRN & \\
\hline CHEMBL1966343 & 809221 & 5.9 & 5.9943 & TRN & \\
\hline CHEMBL404367 & 809221 & 5.5 & 5.3373 & TRN & \\
\hline CHEMBL1967887 & 809221 & 7.6 & 6.6313 & TRN & \\
\hline CHEMBL2000568 & 809221 & 4.2 & 4.5933 & TRN & \\
\hline CHEMBL2000335 & 809221 & 4.2 & 5.2434 & TRN & \\
\hline CHEMBL1977604 & 809221 & 4.2 & 4.5709 & TST & \\
\hline CHEMBL1988717 & 809221 & 4.2 & 4.6337 & TRN & \\
\hline CHEMBL1974328 & 809221 & 5.4 & 5.6758 & TRN & \\
\hline CHEMBL509032 & 809221 & 4.2 & 5.0345 & TRN & \\
\hline CHEMBL1973808 & 809221 & 4.2 & 5.0373 & TRN & \\
\hline CHEMBL 2000429 & 809221 & 4.2 & 4.1692 & TRN & \\
\hline CHEMBL1972576 & 809221 & 4.2 & 4.3939 & TRN & \\
\hline CHEMBL1992555 & 809221 & 4.2 & 4.4061 & TRN & \\
\hline CHEMBL1992342 & 809221 & 6.2 & 5.2638 & TRN & \\
\hline CHEMBL1988173 & 809221 & 6.9 & 5.5274 & TST & \\
\hline CHEMBL535331 & 809221 & 4.2 & 4.4827 & TRN & \\
\hline CHEMBL1989805 & 809221 & 4.4 & 4.9963 & TST & \\
\hline CHEMBL1965423 & 809221 & 6.7 & 4.9508 & TRN & \\
\hline CHEMBL1983025 & 809221 & 5.3 & 4.7461 & TRN & \\
\hline CHEMBL205415 & 809221 & 6.3 & 5.5135 & TRN & \\
\hline CHEMBL1977135 & 809221 & 4.2 & 4.3718 & TRN & \\
\hline CHEMBL 2001920 & 809221 & 4.2 & 5.3887 & TRN & \\
\hline CHEMBL1241473 & 809221 & 6.4 & 6.6347 & TRN & \\
\hline CHEMBL1978448 & 809221 & 6.8 & 5.1217 & TST & \\
\hline CHEMBL1972258 & 809221 & 5.8 & 5.0611 & TRN & \\
\hline CHEMBL 2001257 & 809221 & 4.2 & 4.4092 & TRN & \\
\hline CHEMBL1992536 & 809221 & 4.2 & 4.5134 & TRN & \\
\hline CHEMBL1992740 & 809221 & 4.2 & 5.1072 & TRN & \\
\hline CHEMBL439340 & 809221 & 5.8 & 4.987 & TRN & \\
\hline CHEMBL 2002373 & 809221 & 4.2 & 4.2061 & TRN & \\
\hline CHEMBL 2006188 & 809221 & 4.2 & 4.5961 & TRN & \\
\hline CHEMBL1967531 & 809221 & 5.8 & 5.3531 & TRN & \\
\hline CHEMBL1973893 & 809221 & 4.2 & 4.4938 & TRN & \\
\hline CHEMBL1970913 & 809221 & 4.2 & 4.2071 & TRN & \\
\hline CHEMBL1995736 & 809221 & 4.4 & 5.06800 & j0000000005 & TRN \\
\hline CHEMBL1997534 & 809221 & 4.2 & 4.7089 & TRN & \\
\hline CHEMBL1996500 & 809221 & 4.2 & 4.1322 & TRN & \\
\hline CHEMBL1985095 & 809221 & 6.2 & 5.8144 & TST & \\
\hline CHEMBL1682540 & 809221 & 6.1 & 6.164 & TRN & \\
\hline CHEMBL1976420 & 809221 & 4.2 & 4.0972 & TST & \\
\hline CHEMBL1994864 & 809221 & 4.2 & 4.477 & TRN & \\
\hline CHEMBL 2002446 & 809221 & 4.2 & 4.3353 & TRN & \\
\hline
\end{tabular}




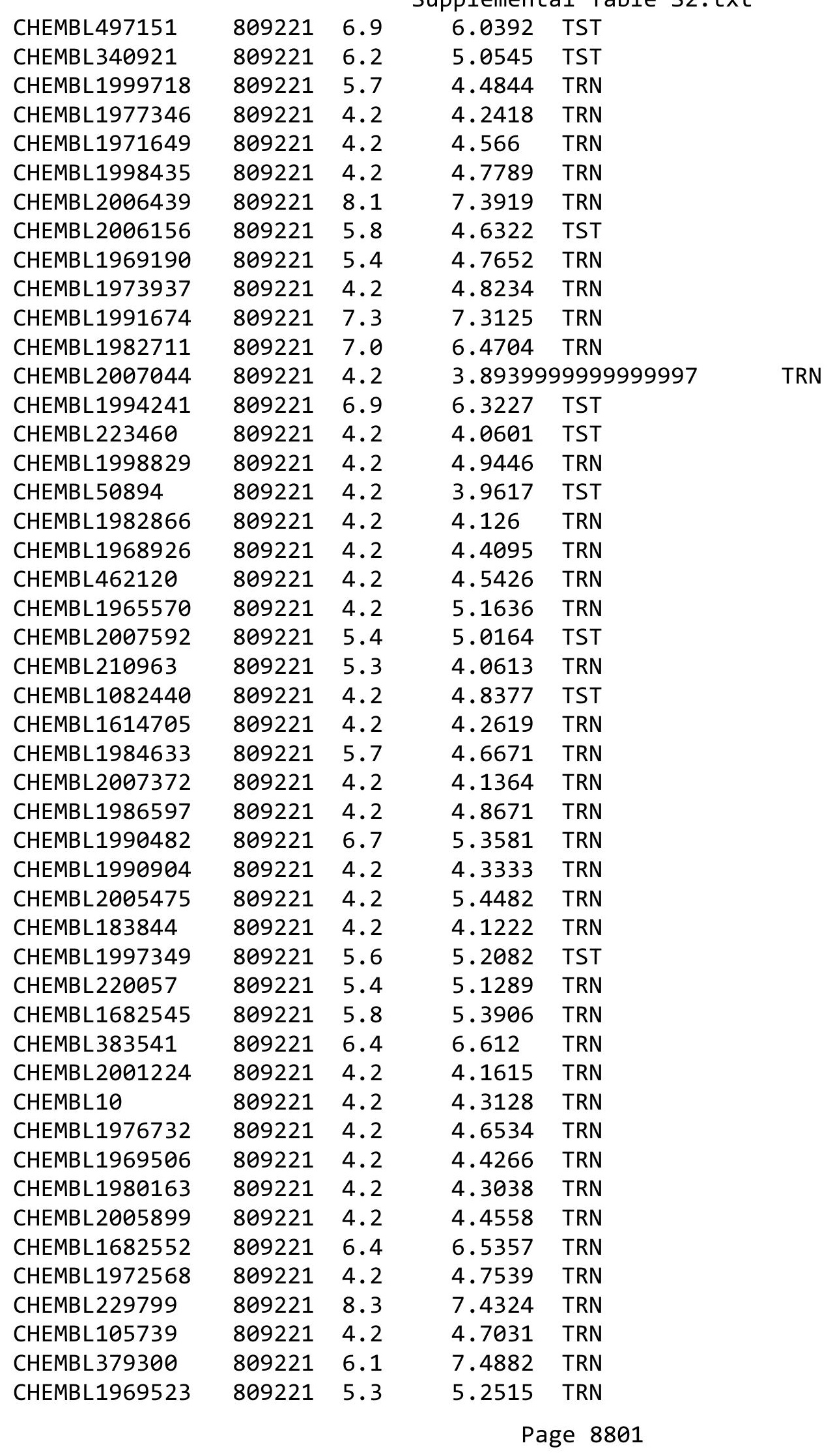




\begin{tabular}{|c|c|c|c|c|}
\hline & & & ent & \\
\hline CHEMBL1988995 & 809221 & 4.2 & 4.309 & TRN \\
\hline CHEMBL1986781 & 809221 & 4.2 & 4.2488 & TRN \\
\hline CHEMBL387971 & 809221 & 4.2 & 4.3245 & TRN \\
\hline CHEMBL1979057 & 809221 & 4.2 & 4.8854 & TRN \\
\hline CHEMBL1999428 & 809221 & 4.2 & 3.9888 & TRN \\
\hline CHEMBL1967560 & 809221 & 4.2 & 4.2421 & TRN \\
\hline CHEMBL211378 & 809221 & 4.2 & 4.5682 & TRN \\
\hline CHEMBL1982465 & 809221 & 5.3 & 4.7648 & TRN \\
\hline CHEMBL 2001751 & 809221 & 8.1 & 7.6204 & TRN \\
\hline CHEMBL 2003420 & 809221 & 4.2 & 4.2444 & TRN \\
\hline CHEMBL1984586 & 809221 & 4.2 & 4.9032 & TRN \\
\hline CHEMBL1972659 & 809221 & 4.2 & 4.418 & TST \\
\hline CHEMBL272453 & 809221 & 4.2 & 4.5722 & TRN \\
\hline CHEMBL 2005528 & 809221 & 5.3 & 5.1907 & TST \\
\hline CHEMBL1969843 & 809221 & 5.8 & 5.4109 & TRN \\
\hline CHEMBL185569 & 809221 & 4.2 & 4.2745 & TRN \\
\hline CHEMBL 2007002 & 809221 & 5.3 & 5.3382 & TRN \\
\hline CHEMBL1987007 & 809221 & 4.2 & 4.5594 & TRN \\
\hline CHEMBL1969588 & 809221 & 7.2 & 7.7876 & TRN \\
\hline CHEMBL1984711 & 809221 & 4.2 & 5.0146 & TRN \\
\hline CHEMBL484390 & 809221 & 4.2 & 5.0008 & TRN \\
\hline CHEMBL1979252 & 809221 & 4.2 & 4.5827 & TRN \\
\hline CHEMBL1986499 & 809221 & 6.2 & 6.5627 & TRN \\
\hline CHEMBL 2004290 & 809221 & 4.2 & 4.0698 & TRN \\
\hline CHEMBL1972937 & 809221 & 5.3 & 5.2309 & TRN \\
\hline CHEMBL 2000393 & 809221 & 4.2 & 4.8939 & TST \\
\hline CHEMBL1992634 & 809221 & 4.2 & 5.6419 & TRN \\
\hline CHEMBL1242373 & 809221 & 4.2 & 5.5234 & TRN \\
\hline CHEMBL56543 & 809221 & 4.2 & 4.5597 & TRN \\
\hline CHEMBL1988075 & 809221 & 4.2 & 4.8369 & TRN \\
\hline CHEMBL316264 & 809221 & 4.2 & 4.1822 & TRN \\
\hline CHEMBL1991678 & 809221 & 4.2 & 4.2593 & TRN \\
\hline CHEMBL 2001239 & 809221 & 4.2 & 4.6415 & TST \\
\hline CHEMBL1988594 & 809221 & 5.5 & 4.6852 & TRN \\
\hline CHEMBL 2001288 & 809221 & 5.9 & 4.9821 & TRN \\
\hline CHEMBL1999811 & 809221 & 6.0 & 6.3722 & TST \\
\hline CHEMBL1985074 & 809221 & 6.2 & 4.6414 & TST \\
\hline CHEMBL1982874 & 809221 & 4.2 & 4.9466 & TRN \\
\hline CHEMBL 2000481 & 809221 & 4.2 & 4.2163 & TRN \\
\hline CHEMBL1991725 & 809221 & 6.6 & 5.9883 & TRN \\
\hline CHEMBL1992242 & 809221 & 4.2 & 4.1228 & TRN \\
\hline CHEMBL 2007296 & 809221 & 6.1 & 4.0036 & TRN \\
\hline CHEMBL396523 & 809221 & 6.8 & 7.0737 & TRN \\
\hline CHEMBL208637 & 809221 & 4.2 & 4.0898 & TRN \\
\hline CHEMBL1970203 & 809221 & 4.2 & 4.2854 & TRN \\
\hline CHEMBL1999321 & 809221 & 4.2 & 4.1432 & TRN \\
\hline CHEMBL1968590 & 809221 & 4.2 & 4.4616 & TRN \\
\hline CHEMBL2005375 & 809221 & 4.2 & 4.5293 & TRN \\
\hline
\end{tabular}




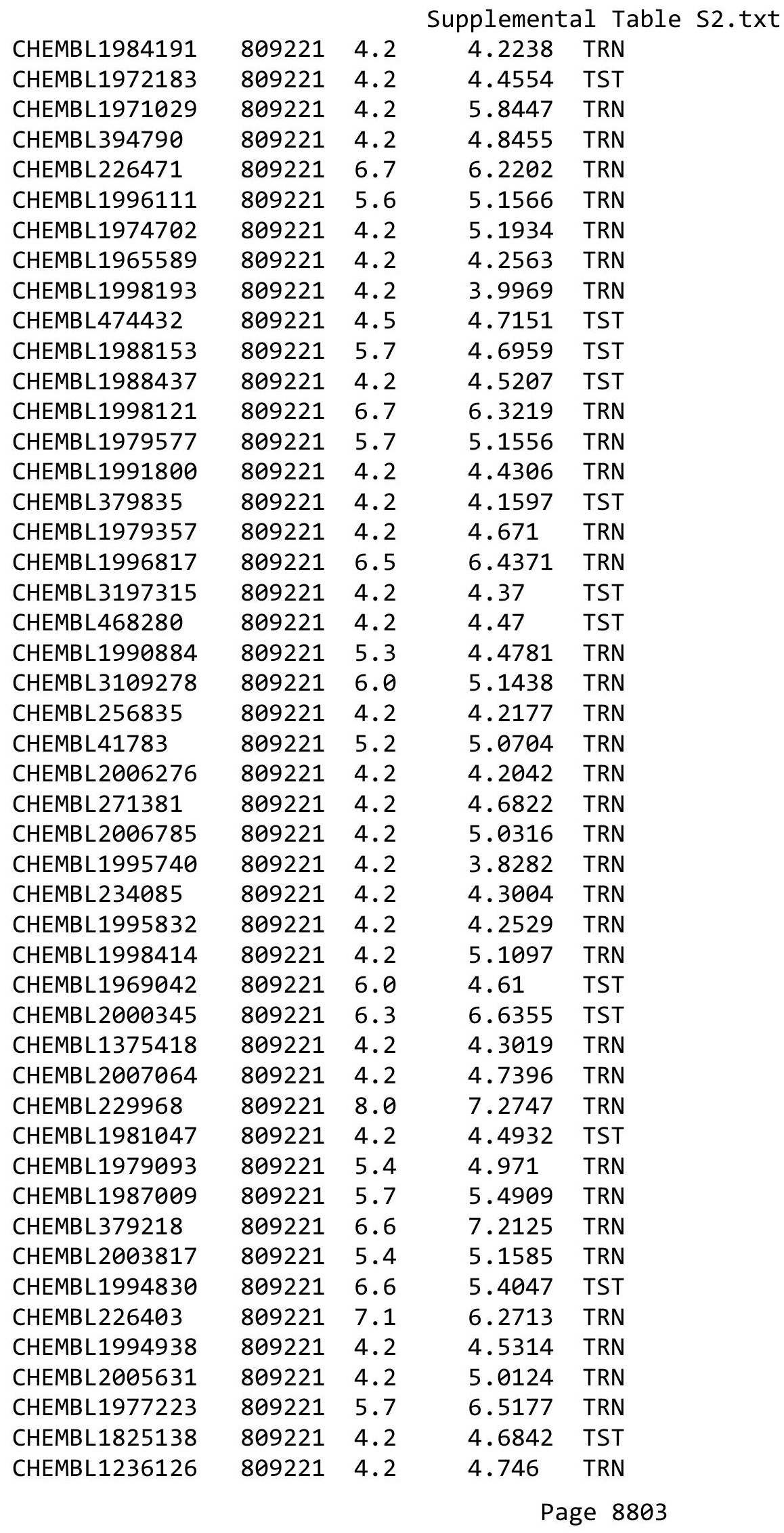




\begin{tabular}{|c|c|c|c|c|}
\hline & & & & e S2 \\
\hline CHEMBL1966279 & 809221 & 4.2 & 4.0888 & TRN \\
\hline CHEMBL1997846 & 809221 & 7.0 & 6.892 & TRN \\
\hline CHEMBL2004419 & 809221 & 4.2 & 4.8788 & TRN \\
\hline CHEMBL1972489 & 809221 & 4.2 & 4.6423 & TRN \\
\hline CHEMBL1994074 & 809221 & 4.2 & 4.9526 & TRN \\
\hline CHEMBL1992937 & 809221 & 6.9 & 5.4211 & TRN \\
\hline CHEMBL1090356 & 809221 & 4.2 & 4.2807 & TRN \\
\hline CHEMBL95692 & 809221 & 4.2 & 4.1954 & TRN \\
\hline CHEMBL1986328 & 809221 & 5.6 & 4.998 & TST \\
\hline CHEMBL1976455 & 809221 & 7.1 & 5.4602 & TRN \\
\hline CHEMBL1982361 & 809221 & 4.2 & 4.7397 & TRN \\
\hline CHEMBL1983923 & 809221 & 4.2 & 4.8052 & TST \\
\hline CHEMBL 2000801 & 809221 & 4.2 & 4.1158 & TRN \\
\hline CHEMBL1999112 & 809221 & 4.2 & 4.602 & TST \\
\hline CHEMBL1682546 & 809221 & 4.2 & 4.9525 & TRN \\
\hline CHEMBL1991395 & 809221 & 4.2 & 4.1732 & TRN \\
\hline CHEMBL1972142 & 809221 & 4.2 & 4.4687 & TRN \\
\hline CHEMBL1966514 & 809221 & 5.8 & 4.8942 & TRN \\
\hline CHEMBL 2003638 & 809221 & 6.9 & 7.8716 & TST \\
\hline CHEMBL1993722 & 809221 & 5.6 & 5.2528 & TST \\
\hline CHEMBL1970806 & 809221 & 4.2 & 4.9934 & TST \\
\hline CHEMBL1979970 & 809221 & 4.5 & 4.9522 & TST \\
\hline CHEMBL1375640 & 809221 & 6.3 & 6.0897 & TST \\
\hline CHEMBL 249282 & 809221 & 4.2 & 3.9419 & TST \\
\hline CHEMBL2006237 & 809221 & 4.2 & 5.2065 & TST \\
\hline CHEMBL1967720 & 809221 & 4.2 & 4.8012 & TST \\
\hline CHEMBL1572266 & 809221 & 4.2 & 4.3373 & TST \\
\hline CHEMBL1969755 & 809221 & 4.2 & 4.1881 & TST \\
\hline CHEMBL1979516 & 809221 & 4.2 & 4.3368 & TST \\
\hline CHEMBL1991138 & 809221 & 4.2 & 4.3773 & TST \\
\hline CHEMBL1605605 & 809221 & 4.2 & 4.3367 & TST \\
\hline CHEMBL1972820 & 809221 & 4.2 & 4.4997 & TST \\
\hline CHEMBL1996208 & 809221 & 4.2 & 4.8627 & TST \\
\hline CHEMBL1989029 & 809221 & 4.2 & 5.117 & TST \\
\hline CHEMBL514499 & 809221 & 4.2 & 4.5573 & TST \\
\hline CHEMBL1965631 & 809221 & 5.3 & 6.1461 & TST \\
\hline CHEMBL1980144 & 809221 & 4.2 & 4.4815 & TST \\
\hline CHEMBL1991188 & 809221 & 4.2 & 4.6548 & TST \\
\hline CHEMBL1972849 & 809221 & 4.2 & 4.25899 & 99999999995 \\
\hline CHEMBL 377408 & 809221 & 5.3 & 4.3646 & TST \\
\hline CHEMBL231209 & 809221 & 4.2 & 4.9133 & TST \\
\hline CHEMBL1976220 & 809221 & 4.2 & 4.867 & TST \\
\hline CHEMBL1997617 & 809221 & 4.2 & 4.5733 & TST \\
\hline CHEMBL 259922 & 809221 & 7.5 & 4.282 & TST \\
\hline CHEMBL1982383 & 809221 & 4.2 & 4.2591 & TST \\
\hline CHEMBL1969301 & 809221 & 4.2 & 4.9336 & TST \\
\hline CHEMBL17370 & 809221 & 4.2 & 4.2024 & TST \\
\hline CHEMBL1997822 & 809221 & 5.7 & 4.9876 & TST \\
\hline
\end{tabular}




\begin{tabular}{|c|c|c|c|c|c|}
\hline \multicolumn{6}{|c|}{ plemental } \\
\hline CHEMBL1991285 & 809221 & 4.2 & 4.4134 & TST & \\
\hline CHEMBL1984038 & 809221 & 4.2 & 4.0268 & TST & \\
\hline CHEMBL243088 & 809221 & 6.6 & 6.8171 & TST & \\
\hline CHEMBL1993661 & 809221 & 5.4 & 5.9755 & TST & \\
\hline CHEMBL1974416 & 809221 & 5.4 & 5.2968 & TST & \\
\hline CHEMBL 2004615 & 809221 & 4.2 & 5.4008 & TST & \\
\hline CHEMBL1997872 & 809221 & 4.2 & 4.4399 & TST & \\
\hline CHEMBL191823 & 306073 & 4.8539 & 4.9074 & TRN & \\
\hline CHEMBL370072 & 306073 & 5.9586 & 5.8864 & TST & \\
\hline CHEMBL365575 & 306073 & 4.6383 & 4.4609 & TRN & \\
\hline CHEMBL192781 & 306073 & 5.2441 & 5.2314 & TRN & \\
\hline CHEMBL364057 & 306073 & 6.0809 & 5.6421 & TST & \\
\hline CHEMBL195443 & 306073 & 6.4815 & 6.3184 & TRN & \\
\hline CHEMBL194489 & 306073 & 5.284 & 5.2153 & TRN & \\
\hline CHEMBL370734 & 306073 & 5.2518 & 5.2615 & TST & \\
\hline CHEMBL195862 & 306073 & 4.3372 & 5.0839 & TST & \\
\hline CHEMBL263326 & 306073 & 6.6021 & 6.4172 & TRN & \\
\hline CHEMBL365996 & 306073 & 4.3188 & 4.4498 & TRN & \\
\hline CHEMBL193887 & 306073 & 5.7447 & 5.817 & TRN & \\
\hline CHEMBL191933 & 306073 & 5.5229 & 5.4718 & TRN & \\
\hline CHEMBL 362973 & 306073 & 4.2291 & 4.2436 & TRN & \\
\hline CHEMBL192425 & 306073 & 6.3098 & 6.4174 & TRN & \\
\hline CHEMBL425375 & 306073 & 5.6021 & 5.5824 & TRN & \\
\hline CHEMBL363175 & 306073 & 6.9208 & 6.7802 & TRN & \\
\hline CHEMBL195270 & 306073 & 5.1079 & 5.0142 & TRN & \\
\hline CHEMBL195905 & 306073 & 5.9586 & 5.71 & TST & \\
\hline CHEMBL190454 & 306073 & 5.2291 & 5.2464 & TRN & \\
\hline CHEMBL192365 & 306073 & 5.2291 & 5.23 & TRN & \\
\hline CHEMBL195755 & 306073 & 5.0362 & 4.94300 & 00000000005 & TRN \\
\hline CHEMBL372472 & 306073 & 5.6021 & 5.579 & TRN & \\
\hline CHEMBL195378 & 306073 & 5.5376 & 5.4818 & TST & \\
\hline CHEMBL363584 & 306073 & 5.6021 & 5.5457 & TRN & \\
\hline CHEMBL195739 & 306073 & 6.0605 & 5.6959 & TST & \\
\hline CHEMBL191652 & 306073 & 3.0 & 4.4232 & TST & \\
\hline CHEMBL 278729 & 306073 & 5.8861 & 5.8201 & TRN & \\
\hline CHEMBL192117 & 306073 & 5.8861 & 5.9756 & TRN & \\
\hline CHEMBL191858 & 306073 & 5.3372 & 5.3254 & TRN & \\
\hline CHEMBL192396 & 306073 & 6.1427 & 5.4413 & TST & \\
\hline CHEMBL369888 & 306073 & 4.8539 & 5.1196 & TRN & \\
\hline CHEMBL 370033 & 306073 & 7.0177 & 5.7615 & TST & \\
\hline CHEMBL 362976 & 306073 & 4.7212 & 4.9211 & TST & \\
\hline CHEMBL366031 & 306073 & 5.4437 & 5.4129 & TRN & \\
\hline CHEMBL552788 & 306073 & 5.8239 & 4.7566 & TST & \\
\hline CHEMBL192421 & 306073 & 6.0862 & 6.1381 & TRN & \\
\hline CHEMBL195667 & 306073 & 6.0177 & 5.8864 & TST & \\
\hline CHEMBL 370079 & 306073 & 4.4437 & 4.522 & TRN & \\
\hline CHEMBL195205 & 306073 & 5.3188 & 5.2755 & TRN & \\
\hline CHEMBL189881 & 306073 & 5.5686 & 5.6223 & TRN & \\
\hline
\end{tabular}




\begin{tabular}{|c|c|c|c|c|}
\hline & & & oplement & al $\mathrm{T}$ \\
\hline CHEMBL191354 & 306073 & 5.4437 & 5.4463 & TRN \\
\hline CHEMBL 364093 & 306073 & 5.284 & 5.2726 & TRN \\
\hline CHEMBL370240 & 306073 & 5.9586 & 6.0511 & TRN \\
\hline CHEMBL190979 & 306073 & 6.4559 & 5.6623 & TST \\
\hline CHEMBL191769 & 306073 & 6.4202 & 6.4738 & TRN \\
\hline CHEMBL371846 & 306073 & 5.5086 & 5.483 & TRN \\
\hline CHEMBL362930 & 306073 & 4.5528 & 4.5379 & TRN \\
\hline CHEMBL192449 & 306073 & 5.0 & 4.9504 & TRN \\
\hline CHEMBL191906 & 306073 & 5.0655 & 5.121 & TRN \\
\hline CHEMBL192980 & 306073 & 6.1739 & 6.3538 & TRN \\
\hline CHEMBL365953 & 306073 & 5.4202 & 5.4409 & TRN \\
\hline CHEMBL191514 & 306073 & 5.9586 & 5.9205 & TRN \\
\hline CHEMBL194437 & 306073 & 5.9208 & 5.7594 & TRN \\
\hline CHEMBL 366173 & 306073 & 4.9586 & 4.8797 & TRN \\
\hline CHEMBL191812 & 306073 & 5.699 & 5.8914 & TRN \\
\hline CHEMBL 365780 & 306073 & 5.5376 & 5.6208 & TRN \\
\hline CHEMBL195173 & 306073 & 5.699 & 6.1861 & TST \\
\hline CHEMBL569338 & 787658 & 4.0586 & 4.0964 & TRN \\
\hline CHEMBL1917661 & 787658 & 4.2526 & 4.4059 & TRN \\
\hline CHEMBL569115 & 787658 & 6.6198 & 6.4642 & TRN \\
\hline CHEMBL1917667 & 787658 & 3.0 & 3.8364 & TRN \\
\hline CHEMBL1917662 & 787658 & 4.0598 & 3.0926 & TRN \\
\hline CHEMBL1917669 & 787658 & 3.0 & 2.7583 & TRN \\
\hline CHEMBL576070 & 787658 & 5.4283 & 5.1899 & TRN \\
\hline CHEMBL569557 & 787658 & 3.0 & 3.2546 & TRN \\
\hline CHEMBL1917660 & 787658 & 4.9851 & 5.1376 & TRN \\
\hline CHEMBL1917656 & 787658 & 4.167 & 4.9579 & TRN \\
\hline CHEMBL1917839 & 787658 & 3.0 & 1.3822 & TST \\
\hline CHEMBL1917829 & 787658 & 3.0 & 2.7431 & TST \\
\hline CHEMBL1917670 & 787658 & 3.0 & 3.6481 & TRN \\
\hline CHEMBL570466 & 787658 & 5.4921 & 4.7234 & TRN \\
\hline CHEMBL572024 & 787658 & 5.7825 & 5.8036 & TRN \\
\hline CHEMBL1917834 & 787658 & 3.0 & 2.1507 & TST \\
\hline CHEMBL1917835 & 787658 & 4.6637 & 1.9477 & TST \\
\hline CHEMBL1917655 & 787658 & 5.3706 & 5.4484 & TRN \\
\hline CHEMBL1917659 & 787658 & 5.1972 & 5.0107 & TRN \\
\hline CHEMBL572236 & 787658 & 3.0 & 3.1589 & TRN \\
\hline CHEMBL1917828 & 787658 & 3.0 & 2.952 & TRN \\
\hline CHEMBL1917833 & 787658 & 4.6313 & 4.3964 & TST \\
\hline CHEMBL569558 & 787658 & 3.0 & 4.1354 & TRN \\
\hline CHEMBL571359 & 787658 & 5.1226 & 4.1354 & TRN \\
\hline CHEMBL1917663 & 787658 & 4.9884 & 5.0907 & TRN \\
\hline CHEMBL1917654 & 787658 & 5.9066 & 6.0548 & TRN \\
\hline CHEMBL570465 & 787658 & 3.0 & 2.907 & TRN \\
\hline CHEMBL1917830 & 787658 & 3.0 & 2.7354 & TST \\
\hline CHEMBL571146 & 787658 & 5.3675 & 5.1043 & TRN \\
\hline CHEMBL1917831 & 787658 & 3.0 & 2.0829 & TST \\
\hline CHEMBL578814 & 787658 & 5.8386 & 5.5304 & TRN \\
\hline
\end{tabular}




\begin{tabular}{|c|c|c|c|c|c|}
\hline \multicolumn{6}{|c|}{ 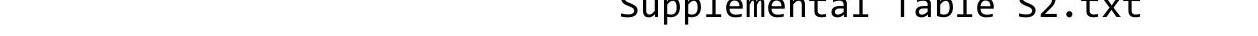 } \\
\hline CHEMBL570511 & 787658 & 3.0 & 3.5444 & TRN & \\
\hline CHEMBL1917836 & 787658 & 3.0 & 3.2939 & TST & \\
\hline CHEMBL1917827 & 787658 & 3.0 & 2.7633 & TRN & \\
\hline CHEMBL1917832 & 787658 & 4.7414 & 3.7208 & TST & \\
\hline CHEMBL1917837 & 787658 & 3.0 & 2.4275 & TST & \\
\hline CHEMBL1917666 & 787658 & 3.0 & 2.9408 & TRN & \\
\hline CHEMBL584953 & 787658 & 4.0994 & 3.9908 & TRN & \\
\hline CHEMBL1914493 & 787658 & 5.1746 & 4.0348 & TST & \\
\hline CHEMBL1917657 & 787658 & 5.5986 & 5.5563 & TRN & \\
\hline CHEMBL1917665 & 787658 & 3.0 & 3.0909 & TRN & \\
\hline CHEMBL570510 & 787658 & 4.8371 & 4.122 & TRN & \\
\hline CHEMBL1917668 & 787658 & 3.0 & 3.0773 & TRN & \\
\hline CHEMBL1917838 & 787658 & 3.0 & 1.5726 & TST & \\
\hline CHEMBL1917671 & 787658 & 4.8716 & 4.2707 & TRN & \\
\hline CHEMBL1917658 & 787658 & 3.0 & 3.0785 & TRN & \\
\hline CHEMBL572026 & 787658 & 3.0 & 3.3153 & TRN & \\
\hline CHEMBL1917664 & 787658 & 3.0 & 3.4153 & TST & \\
\hline CHEMBL570059 & 787658 & 5.3655 & 5.6739 & TRN & \\
\hline CHEMBL583335 & 787658 & 4.841 & 4.9293 & TRN & \\
\hline CHEMBL1452391 & 688644 & 5.8016 & 5.0305 & TRN & \\
\hline CHEMBL1334442 & 688644 & 4.8592 & 4.1551 & TRN & \\
\hline CHEMBL1467646 & 688644 & 4.046 & 3.6277 & TRN & \\
\hline CHEMBL1979574 & 688644 & 5.2781 & 5.2242 & TRN & \\
\hline CHEMBL1301700 & 688644 & 5.0728 & 4.6426 & TST & \\
\hline CHEMBL1975487 & 688644 & 4.9737 & 5.2162 & TRN & \\
\hline CHEMBL1403675 & 688644 & 2.9208 & 4.8493 & TRN & \\
\hline CHEMBL1505799 & 688644 & 2.9208 & 4.9004 & TRN & \\
\hline CHEMBL1540519 & 688644 & 3.2218 & 3.7961 & TRN & \\
\hline CHEMBL1374715 & 688644 & 8.0 & 6.3657 & TRN & \\
\hline CHEMBL3197055 & 688644 & 2.9208 & 3.2258 & TRN & \\
\hline CHEMBL1569450 & 688644 & 3.9706 & 5.1043 & TST & \\
\hline CHEMBL1432711 & 688644 & 4.8639 & 4.8084 & TRN & \\
\hline CHEMBL1255733 & 688644 & 6.9914 & 7.3309 & TST & \\
\hline CHEMBL3196324 & 688644 & 6.34200 & 000000000 & 6.5673 & TRN \\
\hline CHEMBL3190974 & 688644 & 4.5727 & 5.2992 & TRN & \\
\hline CHEMBL1312166 & 688644 & 2.9208 & 3.512 & TRN & \\
\hline CHEMBL1332395 & 688644 & 2.9208 & 4.2429 & TRN & \\
\hline CHEMBL1413355 & 688644 & 2.9208 & 3.958999 & 9999999996 & TRN \\
\hline CHEMBL1493942 & 688644 & 5.33799 & 999999999 & 5.3169 & TRN \\
\hline CHEMBL1341290 & 688644 & 4.88899 & 999999999 & 5.5549 & TRN \\
\hline CHEMBL1594680 & 688644 & 4.6703 & 4.0226 & TRN & \\
\hline CHEMBL1563201 & 688644 & 8.0 & 5.6538 & TRN & \\
\hline CHEMBL1542833 & 688644 & 5.6033 & 5.4686 & TRN & \\
\hline CHEMBL1384253 & 688644 & 6.5952 & 5.9158 & TRN & \\
\hline CHEMBL1388529 & 688644 & 5.26399 & 999999999 & 5.4422 & TRN \\
\hline CHEMBL578502 & 688644 & 5.1113 & 4.8899 & TRN & \\
\hline CHEMBL1303835 & 688644 & 5.0513 & 4.4061 & TRN & \\
\hline CHEMBL1579258 & 688644 & 8.0 & 6.8443 & TST & \\
\hline
\end{tabular}




\begin{tabular}{|c|c|c|c|c|}
\hline & & & oplement & al $\mathrm{T}$ \\
\hline CHEMBL1388595 & 688644 & 5.0907 & 4.8042 & TRN \\
\hline CHEMBL1472341 & 688644 & 2.9208 & 3.4963 & TRN \\
\hline CHEMBL1329349 & 688644 & 6.2211 & 5.6871 & TRN \\
\hline CHEMBL1977930 & 688644 & 5.0924 & 3.7116 & TRN \\
\hline CHEMBL1453673 & 688644 & 2.9208 & 4.4619 & TRN \\
\hline CHEMBL1306460 & 688644 & 8.0 & 5.1674 & TRN \\
\hline CHEMBL1409113 & 688644 & 2.9208 & 5.07 & TRN \\
\hline CHEMBL1306095 & 688644 & 2.9208 & 3.471 & TST \\
\hline CHEMBL1506791 & 688644 & 2.9208 & 3.1628 & TST \\
\hline CHEMBL1573902 & 688644 & 2.9208 & 3.787 & TRN \\
\hline CHEMBL1547760 & 688644 & 6.9547 & 6.4819 & TRN \\
\hline CHEMBL1384368 & 688644 & 4.9986 & 4.6786 & TRN \\
\hline CHEMBL1477200 & 688644 & 2.9208 & 3.1768 & TRN \\
\hline CHEMBL 3197250 & 688644 & 4.9875 & 5.2407 & TRN \\
\hline CHEMBL1455468 & 688644 & 8.0 & 7.7628 & TRN \\
\hline CHEMBL1365398 & 688644 & 5.1398 & 3.9665 & TRN \\
\hline CHEMBL3196364 & 688644 & 5.0518 & 5.5354 & TRN \\
\hline CHEMBL3185655 & 688644 & 8.0 & 7.7813 & TRN \\
\hline CHEMBL1466833 & 688644 & 2.9208 & 3.2926 & TRN \\
\hline CHEMBL1338349 & 688644 & 2.9208 & 3.3344 & TST \\
\hline CHEMBL189584 & 688644 & 5.0342 & 4.0213 & TST \\
\hline CHEMBL1500168 & 688644 & 2.9208 & 2.7311 & TRN \\
\hline CHEMBL1427106 & 688644 & 4.8578 & 3.253 & TRN \\
\hline CHEMBL53260 & 688644 & 2.9208 & 3.6476 & TST \\
\hline CHEMBL1304897 & 688644 & 2.9208 & 4.0616 & TST \\
\hline CHEMBL1612177 & 688644 & 5.0496 & 4.9227 & TRN \\
\hline CHEMBL1487901 & 688644 & 4.9639 & 5.1196 & TRN \\
\hline CHEMBL1471360 & 688644 & 2.9208 & 4.1602 & TRN \\
\hline CHEMBL1517147 & 688644 & 2.9208 & 4.6664 & TRN \\
\hline CHEMBL1451921 & 688644 & 8.0 & 7.2681 & TRN \\
\hline CHEMBL1444874 & 688644 & 4.7969 & 4.0414 & TST \\
\hline CHEMBL1322272 & 688644 & 8.0 & 5.6972 & TRN \\
\hline CHEMBL1314284 & 688644 & 6.9586 & 5.1169 & TRN \\
\hline CHEMBL1598196 & 688644 & 2.9208 & 3.2802 & TRN \\
\hline CHEMBL1609807 & 688644 & 2.9208 & 3.8694 & TST \\
\hline CHEMBL1329398 & 688644 & 6.7328 & 4.6753 & TRN \\
\hline CHEMBL1344346 & 688644 & 5.7894 & 5.4701 & TST \\
\hline CHEMBL1506436 & 688644 & 4.8276 & 4.0588 & TRN \\
\hline CHEMBL1483593 & 688644 & 8.0 & 7.3787 & TRN \\
\hline CHEMBL1569549 & 688644 & 2.9208 & 3.7402 & TRN \\
\hline CHEMBL 2028186 & 688644 & 4.8288 & 5.1119 & TST \\
\hline CHEMBL3199157 & 688644 & 2.9208 & 4.9084 & TRN \\
\hline CHEMBL1537509 & 688644 & 8.0 & 7.4911 & TST \\
\hline CHEMBL1588846 & 688644 & 4.9071 & 3.5466 & TRN \\
\hline CHEMBL1341097 & 688644 & 2.9208 & 3.6255 & TST \\
\hline CHEMBL1420837 & 688644 & 5.0203 & 5.1067 & TRN \\
\hline CHEMBL1539440 & 688644 & 2.9208 & 4.367 & TST \\
\hline CHEMBL1539531 & 688644 & 2.9208 & 3.787 & TRN \\
\hline
\end{tabular}


Supplemental Table S2.txt

\begin{tabular}{|c|c|c|c|c|c|}
\hline CHEMBL1535546 & 688644 & 5.0372 & 4.1628 & TRN & \\
\hline CHEMBL1488001 & 688644 & 4.9675 & 4.0401 & TRN & \\
\hline CHEMBL1334550 & 688644 & 4.9222 & 3.9488 & TRN & \\
\hline CHEMBL587801 & 688644 & 5.1109 & 4.3795 & TRN & \\
\hline CHEMBL1412184 & 688644 & 3.2218 & 4.2015 & TRN & \\
\hline CHEMBL1331851 & 688644 & 5.1718 & 6.0925 & TRN & \\
\hline CHEMBL1361196 & 688644 & 4.8299 & 4.477 & TRN & \\
\hline CHEMBL1375094 & 688644 & 2.9208 & 4.0699 & TRN & \\
\hline CHEMBL1452409 & 688644 & 5.01399 & 79999999 & 5.6858 & TRN \\
\hline CHEMBL1484547 & 688644 & 5.841 & 6.0662 & TRN & \\
\hline CHEMBL1484632 & 688644 & 5.3061 & 5.6228 & TST & \\
\hline CHEMBL1310439 & 688644 & 2.9208 & 3.1977 & TRN & \\
\hline CHEMBL1339694 & 688644 & 4.9824 & 4.9734 & TRN & \\
\hline CHEMBL1572266 & 688644 & 2.9208 & 4.1564 & TST & \\
\hline CHEMBL1486267 & 688644 & 4.9163 & 3.5549 & TST & \\
\hline CHEMBL1485890 & 688644 & 5.4023 & 4.9205 & TRN & \\
\hline CHEMBL1484558 & 688644 & 4.9856 & 4.4765 & TST & \\
\hline CHEMBL 3213574 & 688644 & 6.7258 & 6.0107 & TRN & \\
\hline CHEMBL1341849 & 688644 & 2.9208 & 4.5298 & TRN & \\
\hline CHEMBL1584226 & 688644 & 4.8607 & 5.2598 & TRN & \\
\hline CHEMBL1422978 & 688644 & 2.9208 & 4.7851 & TST & \\
\hline CHEMBL3190189 & 688644 & 5.05699 & 99999999 & 5.3605 & TST \\
\hline CHEMBL1507600 & 688644 & 4.604 & 4.3472 & TRN & \\
\hline CHEMBL1359890 & 688644 & 4.9744 & 3.4046 & TRN & \\
\hline CHEMBL1525080 & 688644 & 5.1063 & 3.9003 & TRN & \\
\hline CHEMBL1525789 & 688644 & 6.8861 & 7.3335 & TRN & \\
\hline CHEMBL591404 & 688644 & 2.9208 & 3.6545 & TRN & \\
\hline CHEMBL1403048 & 688644 & 5.0808 & 5.1978 & TRN & \\
\hline CHEMBL1528487 & 688644 & 5.0172 & 3.93 & TRN & \\
\hline CHEMBL 3190257 & 688644 & 5.0313 & 4.6148 & TRN & \\
\hline CHEMBL1985479 & 688644 & 5.0681 & 4.9533 & TRN & \\
\hline CHEMBL1320542 & 688644 & 4.9761 & 4.0349 & TRN & \\
\hline CHEMBL1303404 & 688644 & 5.0295 & 5.4018 & TRN & \\
\hline CHEMBL1418823 & 688644 & 2.9208 & 3.7702 & TRN & \\
\hline CHEMBL1503359 & 688644 & 5.3704 & 5.5274 & TRN & \\
\hline CHEMBL1366268 & 688644 & 5.0635 & 4.1462 & TRN & \\
\hline CHEMBL1503659 & 688644 & 6.3233 & 5.2438 & TRN & \\
\hline CHEMBL606532 & 688644 & 2.9208 & 5.7123 & TRN & \\
\hline CHEMBL1594286 & 688644 & 5.0495 & 4.9107 & TRN & \\
\hline CHEMBL3196217 & 688644 & 2.9208 & 4.5029 & TRN & \\
\hline CHEMBL1485010 & 688644 & 2.9208 & 4.5159 & TST & \\
\hline CHEMBL1480024 & 688644 & 2.9208 & 3.7326 & TRN & \\
\hline CHEMBL1413629 & 688644 & 5.4352 & 5.1072 & TRN & \\
\hline CHEMBL1466243 & 688644 & 5.0811 & 4.5742 & TRN & \\
\hline CHEMBL1613639 & 688644 & 6.9626 & \multicolumn{2}{|c|}{6.9510000000000005} & I \\
\hline CHEMBL 3210088 & 688644 & 5.0287 & 5.4902 & TRN & \\
\hline CHEMBL1452941 & 688644 & 2.9208 & 3.3838 & TRN & \\
\hline CHEMBL261115 & 688644 & 8.0 & 5.5197 & TRN & \\
\hline
\end{tabular}




\begin{tabular}{|c|c|c|c|c|c|c|}
\hline & & \multicolumn{5}{|c|}{ Supplemental Table S2.txt } \\
\hline CHEMBL1301665 & 688644 & 4.0803 & 4.0178 & TRN & & \\
\hline CHEMBL1705518 & 688644 & 3.2218 & 5.3106 & TRN & & \\
\hline CHEMBL1335149 & 688644 & 4.8132 & 4.3159 & TST & & \\
\hline CHEMBL1574553 & 688644 & 6.9031 & 6.1512 & TST & & \\
\hline CHEMBL1351143 & 688644 & 2.9208 & 3.4872 & TRN & & \\
\hline CHEMBL579318 & 688644 & 8.0 & 7.0749 & TRN & & \\
\hline CHEMBL6742 & 688644 & 5.7905 & 4.4137 & TRN & & \\
\hline CHEMBL1978901 & 688644 & 5.1175 & 5.2025 & TRN & & \\
\hline CHEMBL486504 & 688644 & 8.0 & 8.5183 & TST & & \\
\hline CHEMBL1368875 & 688644 & 2.9208 & 3.0039 & TRN & & \\
\hline CHEMBL1480952 & 688644 & 2.9208 & 3.9457 & TRN & & \\
\hline CHEMBL1506640 & 688644 & 4.8884 & 4.1272 & TRN & & \\
\hline CHEMBL1448448 & 688644 & 2.9208 & 3.298 & TST & & \\
\hline CHEMBL 3211308 & 688644 & 8.0 & 6.1042 & TST & & \\
\hline CHEMBL1407787 & 688644 & 5.1615 & 4.3803 & TRN & & \\
\hline CHEMBL1556805 & 688644 & 6.1765 & 5.2975 & TRN & & \\
\hline CHEMBL1459440 & 688644 & 2.9208 & 3.0676 & TRN & & \\
\hline CHEMBL1483913 & 688644 & 4.3022 & 4.805 & TST & & \\
\hline CHEMBL1350777 & 688644 & 4.907 & 5.2351 & TRN & & \\
\hline CHEMBL3210628 & 688644 & \multicolumn{3}{|c|}{4.8919999999999995} & 5.2828 & TRN \\
\hline CHEMBL1402171 & 688644 & 2.9208 & 4.2162 & TRN & & \\
\hline CHEMBL3208398 & 688644 & 4.8065 & 3.7508 & TRN & & \\
\hline CHEMBL1983311 & 688644 & 5.0658 & 4.3047 & TRN & & \\
\hline CHEMBL1988416 & 688644 & 5.0191 & 3.7437 & TST & & \\
\hline CHEMBL1414850 & 688644 & 2.9208 & 4.2677 & TRN & & \\
\hline CHEMBL1406301 & 688644 & 4.8282 & 4.1412 & TST & & \\
\hline CHEMBL1572375 & 688644 & 4.8925 & 4.0421 & TRN & & \\
\hline CHEMBL3196105 & 688644 & 4.7284 & 3.7984 & TRN & & \\
\hline CHEMBL1371056 & 688644 & 8.0 & 6.2996 & TRN & & \\
\hline CHEMBL1352668 & 688644 & 2.9208 & 3.7579 & TRN & & \\
\hline CHEMBL1589670 & 688644 & 4.9877 & 4.872 & TRN & & \\
\hline CHEMBL1404086 & 688644 & 4.8959 & 3.8163 & TRN & & \\
\hline CHEMBL1569984 & 688644 & 2.9208 & 5.1282 & TRN & & \\
\hline CHEMBL1367759 & 688644 & 5.6983 & 5.9492 & TRN & & \\
\hline CHEMBL1989673 & 688644 & 4.9195 & 4.9472 & TRN & & \\
\hline CHEMBL1325856 & 688644 & 6.8633 & 7.2783 & TRN & & \\
\hline CHEMBL1531681 & 688644 & 4.8936 & 5.0494 & TST & & \\
\hline CHEMBL1499698 & 688644 & 4.9928 & 4.0368 & TRN & & \\
\hline CHEMBL1612884 & 688644 & 2.9208 & 3.852 & TRN & & \\
\hline CHEMBL1576132 & 688644 & 5.3629 & 5.9596 & TRN & & \\
\hline CHEMBL1572746 & 688644 & 6.7773 & 7.1285 & TRN & & \\
\hline CHEMBL1407294 & 688644 & 2.9208 & 3.0923 & TRN & & \\
\hline CHEMBL1549357 & 688644 & 6.4976 & 4.4322 & TRN & & \\
\hline CHEMBL1590547 & 688644 & 5.1492 & 5.1935 & TST & & \\
\hline CHEMBL1522803 & 688644 & 5.5299 & 4.9908 & TST & & \\
\hline CHEMBL1320755 & 688644 & 2.9208 & 4.5387 & TRN & & \\
\hline CHEMBL1515483 & 688644 & 2.9208 & 3.2493 & TRN & & \\
\hline CHEMBL1459117 & 688644 & 2.9208 & 3.1836 & TRN & & \\
\hline
\end{tabular}




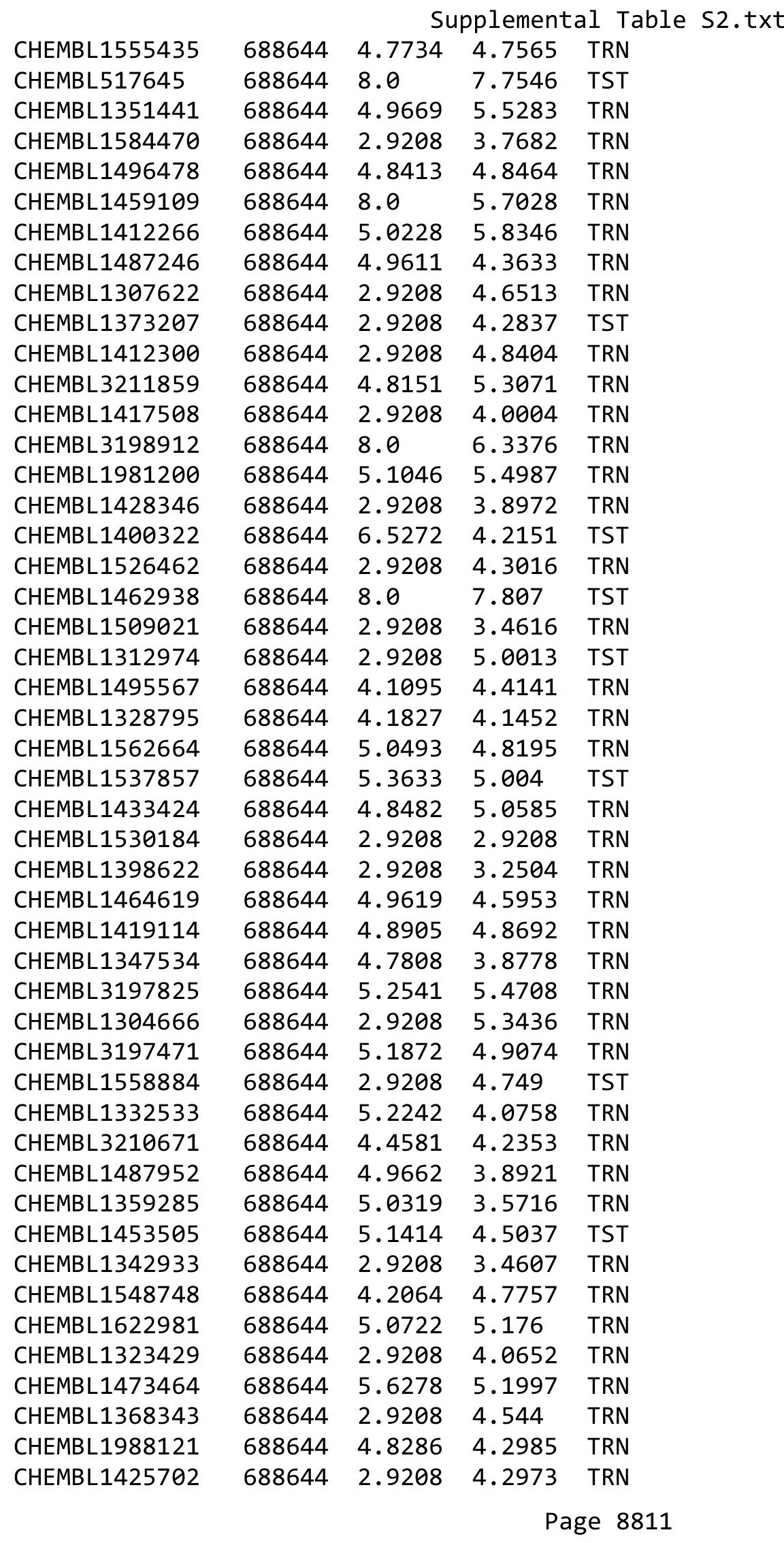




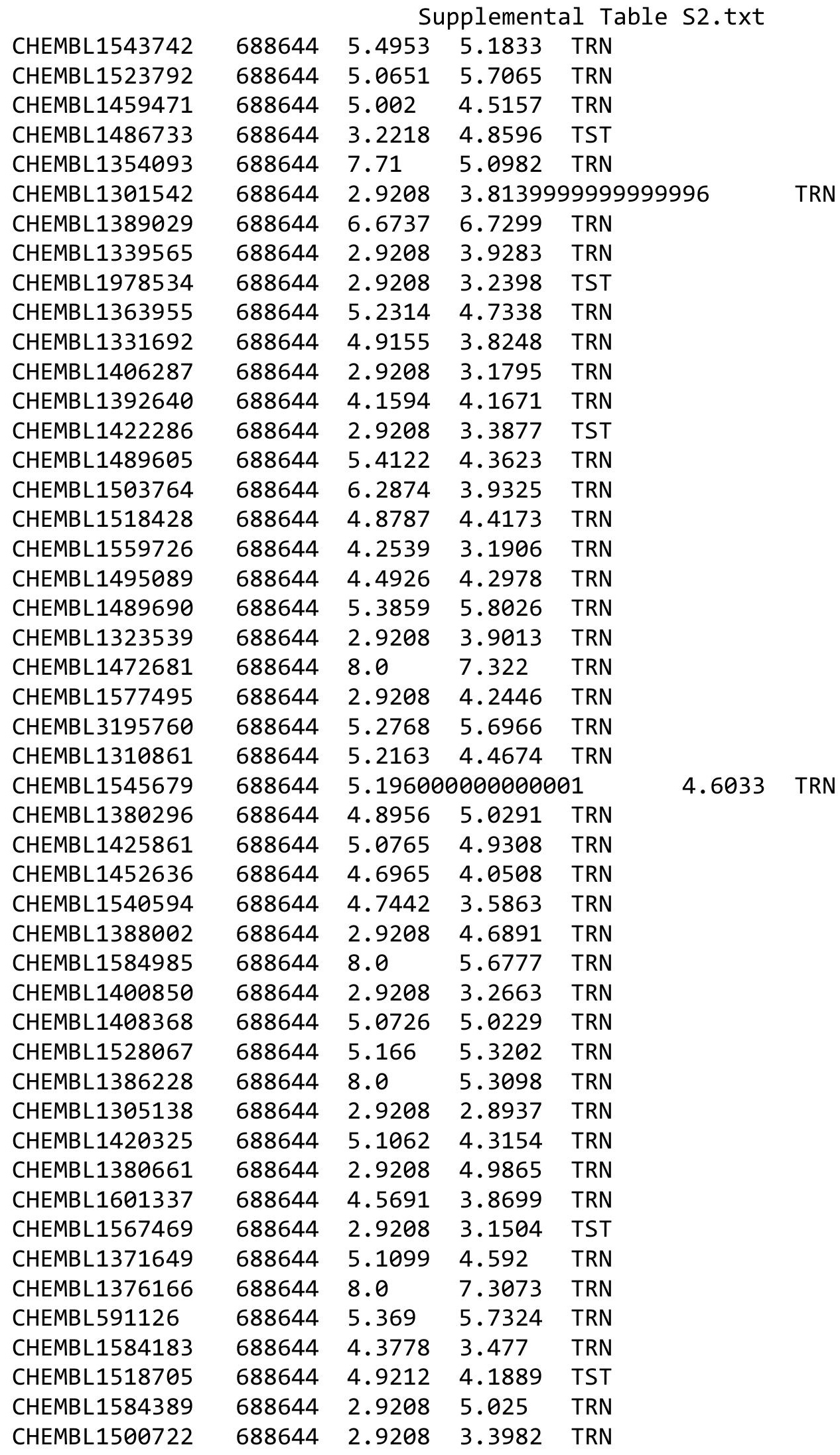


Supplemental Table S2.txt

\begin{tabular}{|c|c|c|c|c|}
\hline 6569 & & 5.0279 & & \\
\hline & & 2.9208 & & \\
\hline 73 & & & & \\
\hline EMBL13 & & & & \\
\hline IEMBL: & 88644 & & & \\
\hline HEMBL 304291 & 88644 & 8.0 & 2727 & \\
\hline 61738 & 88644 & & 366 & \\
\hline 626 & & & & \\
\hline IEMBL: & 88644 & & & \\
\hline AEMBL1 & 88644 & 208 & 475 & \\
\hline AEMBL1545422 & 88644 & 208 & 495 & \\
\hline EMBL & 38644 & & 533 & \\
\hline 170 & 14 & & & \\
\hline 4436 & 88644 & & & \\
\hline IEMBL: & 88644 & & 506 & \\
\hline IEMBL & 88644 & 4.8 & 24 & \\
\hline IEMBL & 88644 & & 62 & \\
\hline AEMBL & 88644 & & & RN \\
\hline 9181 & 88644 & & & \\
\hline 428 & 88644 & & 98 & \\
\hline 4030 & 88644 & & 268 & ונ \\
\hline 8414 & 88644 & 5 . & 52 & R \\
\hline 1037 & 88644 & & & . \\
\hline 292 & 14 & & & \\
\hline EMBL & 14 & & & \\
\hline 06 & 88644 & & 83 & RI \\
\hline 091 & 88644 & 8. & 524 & $\mathrm{R}$ \\
\hline 404 & 44 & & 88 & TIV \\
\hline 36 & 44 & & 77 & \\
\hline 3835 & 44 & & & RI \\
\hline 866 & 88644 & 5 . & 58 & RI \\
\hline 8647 & 88644 & 2 . & 16 & \\
\hline 795 & 14 & & & RIV \\
\hline & & & & RN \\
\hline 06300 & 88644 & & 22 & $S$ \\
\hline 3931 & 88644 & & 85 & $\mathrm{R}$ \\
\hline 2601 & 88644 & 5 & & 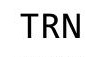 \\
\hline & 14 & & & RN \\
\hline & & & & RI \\
\hline 89393 & 88644 & & & \\
\hline 120 & 88644 & & 89 & K \\
\hline AEMBL & 88644 & & & R \\
\hline & & & & RI \\
\hline IEMBL: & 88644 & & 194 & $S$ \\
\hline$M B L$ & 88644 & 88 & 162 & $\mathrm{R}$ \\
\hline & & & & \\
\hline & & 4.8592 & 3.2936 & \\
\hline 43124 & . & 5.0157 & 4.1838 & \\
\hline
\end{tabular}

Page 8813 
Supplemental Table S2.txt

\begin{tabular}{|c|c|c|c|c|c|}
\hline CHEMBL1592251 & 688644 & 4.9883 & 4.8314 & TRN & \\
\hline CHEMBL533226 & 688644 & 5.7807 & 5.8214 & TRN & \\
\hline CHEMBL1972651 & 688644 & 5.0262 & 5.5995 & TRN & \\
\hline CHEMBL1447563 & 688644 & 5.0957 & 4.5925 & TST & \\
\hline CHEMBL1438877 & 688644 & 4.9376 & 4.9895 & TRN & \\
\hline CHEMBL525103 & 688644 & 4.4198 & 4.7644 & TRN & \\
\hline CHEMBL1374384 & 688644 & 4.9908 & 5.2929 & TRN & \\
\hline CHEMBL1349403 & 688644 & 5.0656 & 4.5516 & TRN & \\
\hline CHEMBL1506283 & 688644 & 4.5044 & 4.0162 & TRN & \\
\hline CHEMBL166209 & 688644 & 5.6105 & 5.7426 & TRN & \\
\hline CHEMBL1387011 & 688644 & 4.9853 & 5.0074 & TRN & \\
\hline CHEMBL1463463 & 688644 & 4.6176 & 4.6013 & TRN & \\
\hline CHEMBL1515627 & 688644 & 5.2453 & 4.9347 & TRN & \\
\hline CHEMBL1509380 & 688644 & 2.9208 & 4.9532 & TST & \\
\hline CHEMBL 259784 & 688644 & 6.4353 & \multicolumn{2}{|c|}{5.9879999999999995} & TRN \\
\hline CHEMBL222409 & 688644 & 8.0 & 7.8552 & TRN & \\
\hline CHEMBL1558285 & 688644 & 5.0229 & 5.0463 & TRN & \\
\hline CHEMBL1546084 & 688644 & 2.9208 & 3.9879 & TRN & \\
\hline CHEMBL1500138 & 688644 & 5.2338 & 4.9828 & TRN & \\
\hline CHEMBL1569783 & 688644 & 6.8962 & 5.6922 & TRN & \\
\hline CHEMBL1312906 & 688644 & 4.6887 & 4.6517 & TRN & \\
\hline CHEMBL1506879 & 688644 & 2.9208 & 3.7109 & TST & \\
\hline CHEMBL3192156 & 688644 & 2.9208 & 4.7433 & TRN & \\
\hline CHEMBL1384869 & 688644 & 2.9208 & \multicolumn{2}{|c|}{3.7960000000000003} & TRN \\
\hline CHEMBL1495788 & 688644 & 5.0431 & 4.2233 & TRN & \\
\hline CHEMBL1560901 & 688644 & 2.9208 & 4.5547 & TRN & \\
\hline CHEMBL 236353 & 688644 & 2.9208 & 3.4271 & TRN & \\
\hline CHEMBL1312101 & 688644 & 2.9208 & 3.6051 & TRN & \\
\hline CHEMBL1602800 & 688644 & 4.864 & 4.2214 & TRN & \\
\hline CHEMBL1369231 & 688644 & 6.3089 & 6.8063 & TRN & \\
\hline CHEMBL581225 & 688644 & 5.4685 & 4.2563 & TST & \\
\hline CHEMBL1352812 & 688644 & 2.9208 & 3.3961 & TRN & \\
\hline CHEMBL1326102 & 688644 & 4.6736 & 3.148 & TRN & \\
\hline CHEMBL599255 & 688644 & 2.9208 & 5.2328 & TRN & \\
\hline CHEMBL1525098 & 688644 & 5.0099 & 4.3493 & TRN & \\
\hline CHEMBL1608402 & 688644 & 5.0297 & 4.7255 & TRN & \\
\hline CHEMBL1593562 & 688644 & 4.8566 & 4.7542 & TRN & \\
\hline CHEMBL1490392 & 688644 & 4.7885 & 5.0486 & TRN & \\
\hline CHEMBL1468961 & 688644 & 2.9208 & 3.0521 & TRN & \\
\hline CHEMBL1416406 & 688644 & 4.919 & 4.3133 & TRN & \\
\hline CHEMBL1386044 & 688644 & 4.945 & 3.0551 & TRN & \\
\hline CHEMBL1464973 & 688644 & 4.8467 & 3.9285 & TRN & \\
\hline CHEMBL1538336 & 688644 & 2.9208 & 3.4918 & TRN & \\
\hline CHEMBL1997659 & 688644 & 2.9208 & 3.5369 & TRN & \\
\hline CHEMBL1970422 & 688644 & 8.0 & 8.2875 & TST & \\
\hline CHEMBL1480997 & 688644 & 2.9208 & 3.4051 & TRN & \\
\hline CHEMBL1467993 & 688644 & 2.9208 & 4.261 & TST & \\
\hline CHEMBL1499388 & 688644 & 2.9208 & 3.3063 & TRN & \\
\hline
\end{tabular}




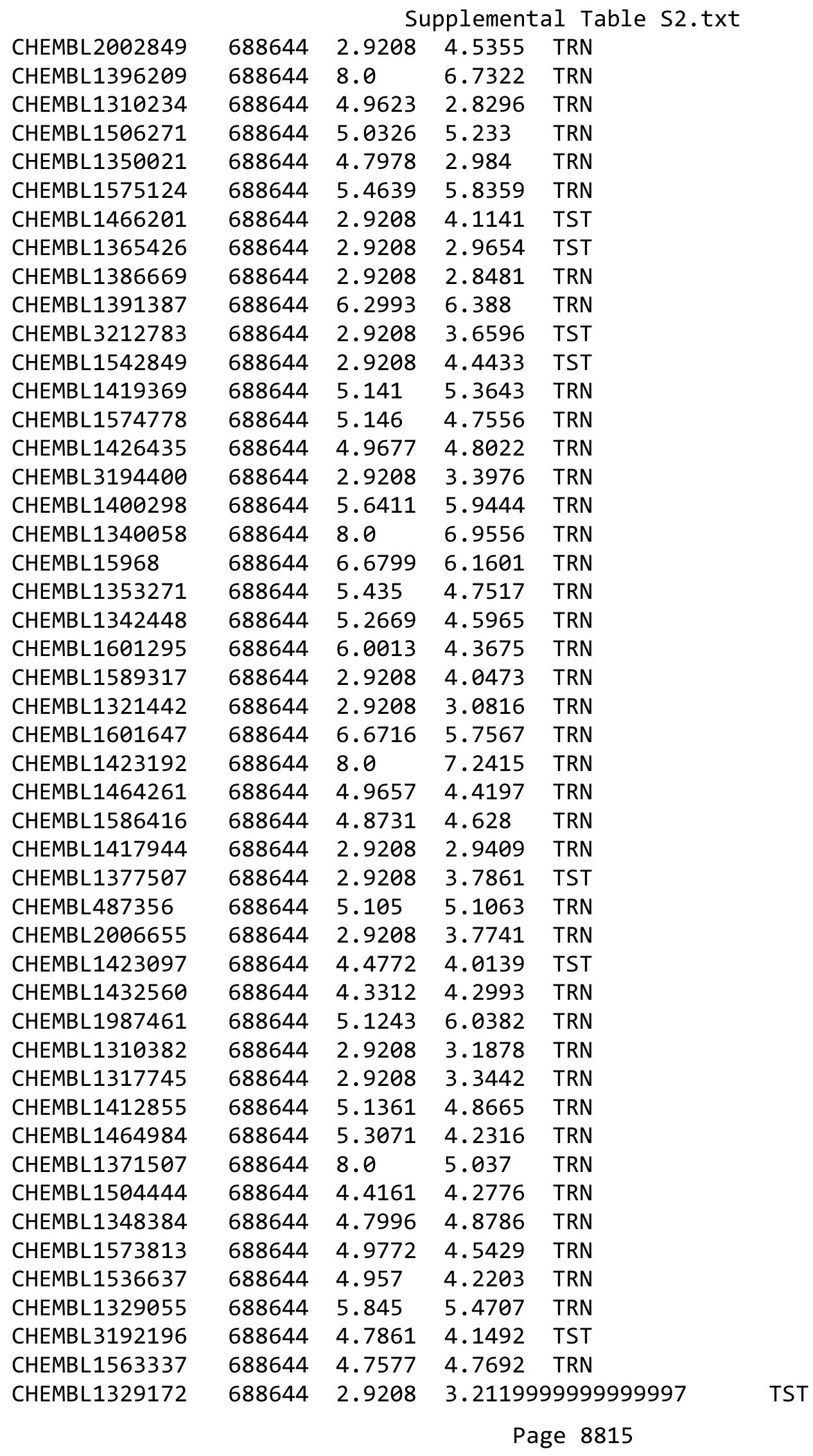




\begin{tabular}{|c|c|c|c|c|}
\hline & & & pplement & al $\mathrm{Tc}$ \\
\hline CHEMBL1500043 & 688644 & 2.9208 & 3.5296 & TST \\
\hline CHEMBL1984876 & 688644 & 8.0 & 5.8508 & TRN \\
\hline CHEMBL1605919 & 688644 & 5.0411 & 5.3792 & TRN \\
\hline CHEMBL1467399 & 688644 & 2.9208 & 3.6854 & TRN \\
\hline CHEMBL1579708 & 688644 & 2.9208 & 4.624 & TRN \\
\hline CHEMBL1459795 & 688644 & 4.9345 & 4.7084 & TRN \\
\hline CHEMBL1423970 & 688644 & 4.9581 & 4.0802 & TST \\
\hline CHEMBL1582086 & 688644 & 4.8373 & 2.9797 & TRN \\
\hline CHEMBL1588275 & 688644 & 5.0429 & 5.0504 & TRN \\
\hline CHEMBL1316831 & 688644 & 8.0 & 7.1443 & TST \\
\hline CHEMBL1338639 & 688644 & 2.9208 & 3.9472 & TST \\
\hline CHEMBL1488730 & 688644 & 6.8013 & 7.1177 & TRN \\
\hline CHEMBL1477773 & 688644 & 5.0211 & 4.6635 & TRN \\
\hline CHEMBL 260451 & 688644 & 5.1425 & 5.4533 & TRN \\
\hline CHEMBL1362507 & 688644 & 5.039 & 7.9473 & TRN \\
\hline CHEMBL1497230 & 688644 & 2.9208 & 4.6871 & TRN \\
\hline CHEMBL1545086 & 688644 & 5.059 & 4.0256 & TRN \\
\hline CHEMBL1601627 & 688644 & 4.4083 & 4.0535 & TRN \\
\hline CHEMBL1453996 & 688644 & 8.0 & 7.7673 & TRN \\
\hline CHEMBL1368066 & 688644 & 2.9208 & 4.6197 & TRN \\
\hline CHEMBL1341999 & 688644 & 4.2286 & 4.2987 & TRN \\
\hline CHEMBL1487444 & 688644 & 5.1667 & 5.265 & TRN \\
\hline CHEMBL3191011 & 688644 & 4.8243 & 4.9249 & TRN \\
\hline CHEMBL 3212546 & 688644 & 4.1707 & 3.6147 & TRN \\
\hline CHEMBL1514790 & 688644 & 5.1055 & 4.3764 & TST \\
\hline CHEMBL3211386 & 688644 & 2.9208 & 3.7248 & TRN \\
\hline CHEMBL1382716 & 688644 & 3.971 & 3.2678 & TRN \\
\hline CHEMBL1327749 & 688644 & 8.0 & 6.4208 & TRN \\
\hline CHEMBL1583256 & 688644 & 5.0025 & 5.1484 & TRN \\
\hline CHEMBL1306196 & 688644 & 4.3191 & 2.7629 & TRN \\
\hline CHEMBL1523552 & 688644 & 4.8075 & 4.8919 & TRN \\
\hline CHEMBL1441391 & 688644 & 4.8001 & 4.0907 & TRN \\
\hline CHEMBL1580124 & 688644 & 4.7996 & 4.3953 & TRN \\
\hline CHEMBL1324569 & 688644 & 4.9478 & 4.3456 & TRN \\
\hline CHEMBL1427089 & 688644 & 4.4173 & 4.527 & TRN \\
\hline CHEMBL1525220 & 688644 & 5.117 & 4.8866 & TRN \\
\hline CHEMBL1301056 & 688644 & 2.9208 & 4.9085 & TRN \\
\hline CHEMBL1399388 & 688644 & 5.5842 & 4.489 & TRN \\
\hline CHEMBL1403718 & 688644 & 2.9208 & 3.3698 & TRN \\
\hline CHEMBL 3195551 & 688644 & 5.0237 & 5.3091 & TRN \\
\hline CHEMBL1498952 & 688644 & 2.9208 & 3.5625 & TRN \\
\hline CHEMBL1504565 & 688644 & 2.9208 & 3.6837 & TRN \\
\hline CHEMBL1375406 & 688644 & 2.9208 & 4.3607 & TST \\
\hline CHEMBL1560772 & 688644 & 4.3833 & 3.0132 & TRN \\
\hline CHEMBL1585777 & 688644 & 4.8096 & 3.9206 & TRN \\
\hline CHEMBL1408486 & 688644 & 8.0 & 5.9977 & TRN \\
\hline CHEMBL3191713 & 688644 & 6.9706 & 7.4316 & TRN \\
\hline CHEMBL1507800 & 688644 & 2.9208 & 4.3928 & TRN \\
\hline
\end{tabular}


Supplemental Table S2.txt

\begin{tabular}{|c|c|c|c|c|}
\hline HEM & & 2.9208 & 4.7762 & \\
\hline & & .9208 & 3.535 & \\
\hline AEMPI 2 & 4 & & & \\
\hline IEMBL & 4 & & 17 & \\
\hline AEMBL1454819 & 38644 & & 7888 & \\
\hline HEMBL1303364 & 88644 & $\partial 8$ & 5554 & \\
\hline$\partial 21$ & 8644 & & 5642 & \\
\hline AEMBL155 & 8644 & 8 & 8885 & \\
\hline HEMBL1392176 & 88644 & 656 & 9774 & \\
\hline HEMBL1478486 & 88644 & 86 & 9899 & \\
\hline HEMBL1520718 & 88644 & & 9163 & \\
\hline 355 & 644 & & 822 & \\
\hline AEMBL1 & & & 548 & \\
\hline HEMBL1369106 & 38644 & & 5015 & \\
\hline AEMBL3192555 & 3644 & & & \\
\hline AEMBL1 & 44 & 28 & 1091 & \\
\hline HEMBL1 & & & 254 & RN \\
\hline AEMBL1 & 44 & . & 19 & \\
\hline HEMBL1305287 & 3644 & & 3761 & \\
\hline AEMBL1436557 & & & & I nIV \\
\hline AEMBL1 & 44 & & 63 & RN \\
\hline IEM & & & & TIV \\
\hline AEMBL & 14 & & 017 & RN \\
\hline AEMBL1 & 14 & & 241 & \\
\hline AEMBL1434686 & 644 & & 85 & I RN \\
\hline AEMBL1 & 644 & & 195 & RN \\
\hline 72 & 14 & & 11 & KIV \\
\hline 34 & & & & $\mathrm{RN}$ \\
\hline IEMBL1 & & & & IRN \\
\hline AEMBL1354582 & 3644 & & 309 & TST \\
\hline AEMBL: & 44 & & 461 & IST \\
\hline 4 & & & 363 & ГST \\
\hline 9 & & & 179 & 「RN \\
\hline HEMBL154C & & & 927 & TST \\
\hline AEMBL1597706 & 3644 & & 113 & ГRN \\
\hline 83 & 4 & & 399 & TRN \\
\hline 9 & & & & RN \\
\hline HEMBL1391418 & & & 638 & TRN \\
\hline HEMBL131 & 4 & & 124 & $\Gamma R$ \\
\hline-1 & & & 246 & RN \\
\hline HEMBL1 & 44 & & 288 & TRN \\
\hline HEMBL1 & 44 & & 454 & 「RN \\
\hline HEMBL1582334 & & & 5178 & RN \\
\hline HEMBL154. & 14 & & 184 & TR \\
\hline CHEMPI 15856 & & & & \\
\hline HEMBL1. & & & 2546 & \\
\hline CHEMBL1460757 & 644 & 2.9208 & 3.2833 & RN \\
\hline CHEMBL267099 & 688644 & 8.0 & 7.0686 & - \\
\hline
\end{tabular}

Page 8817 


\begin{tabular}{|c|c|c|c|c|c|c|}
\hline & & \multicolumn{5}{|c|}{ Supplemental Table S2.txt } \\
\hline CHEMBL1322293 & 688644 & 4.1958 & 4.4226 & TRN & & \\
\hline CHEMBL1316506 & 688644 & 4.9551 & 3.8886 & TRN & & \\
\hline CHEMBL1383331 & 688644 & 2.9208 & 3.8882 & TRN & & \\
\hline CHEMBL1428004 & 688644 & 4.5927 & 4.5926 & TRN & & \\
\hline CHEMBL1544823 & 688644 & 5.0616 & 4.6723 & TRN & & \\
\hline CHEMBL1585345 & 688644 & 6.1739 & 6.5277 & TRN & & \\
\hline CHEMBL1300558 & 688644 & 8.0 & 4.6019 & TRN & & \\
\hline CHEMBL1098875 & 688644 & 5.0534 & 4.60800 & 00000000 & 205 & TRN \\
\hline CHEMBL1973906 & 688644 & 4.7414 & 4.5115 & TST & & \\
\hline CHEMBL1471899 & 688644 & 5.8545 & 5.8054 & TRN & & \\
\hline CHEMBL1457139 & 688644 & 5.0182 & 5.5787 & TRN & & \\
\hline CHEMBL1533541 & 688644 & 4.3429 & 4.1642 & TRN & & \\
\hline CHEMBL1392894 & 688644 & 2.9208 & 4.5778 & TST & & \\
\hline CHEMBL1335176 & 688644 & 5.1339 & 5.2321 & TST & & \\
\hline CHEMBL1509721 & 688644 & 4.6006 & 4.1008 & TRN & & \\
\hline CHEMBL1526910 & 688644 & 4.6966 & 5.0899 & TRN & & \\
\hline CHEMBL1420056 & 688644 & 2.9208 & 4.0543 & TST & & \\
\hline CHEMBL1334578 & 688644 & 2.9208 & 2.9604 & TRN & & \\
\hline CHEMBL1379401 & 688644 & 2.9208 & 4.8816 & TRN & & \\
\hline CHEMBL1547470 & 688644 & 2.9208 & 4.2611 & TRN & & \\
\hline CHEMBL1610999 & 688644 & 4.3711 & 3.3433 & TST & & \\
\hline CHEMBL3214332 & 688644 & 4.6212 & 4.6193 & TRN & & \\
\hline CHEMBL1928491 & 688644 & 5.432 & 5.5953 & TRN & & \\
\hline CHEMBL1428986 & 688644 & 4.2364 & 4.1992 & TRN & & \\
\hline CHEMBL1428850 & 688644 & 5.1617 & 3.8538 & TRN & & \\
\hline CHEMBL1318866 & 688644 & 2.9208 & 3.9362 & TRN & & \\
\hline CHEMBL1995692 & 688644 & 6.7878 & 6.955 & TRN & & \\
\hline CHEMBL3193593 & 688644 & 4.7047 & 4.8605 & TRN & & \\
\hline CHEMBL1456320 & 688644 & 2.9208 & 4.1684 & TRN & & \\
\hline CHEMBL1491004 & 688644 & 5.2772 & 5.0575 & TRN & & \\
\hline CHEMBL1466102 & 688644 & 5.3561 & 5.2652 & TRN & & \\
\hline CHEMBL1581158 & 688644 & 5.2287 & 3.8856 & TST & & \\
\hline CHEMBL1600769 & 688644 & 2.9208 & 4.0319 & TRN & & \\
\hline CHEMBL1517243 & 688644 & 4.3464 & 3.7356 & TRN & & \\
\hline CHEMBL1576851 & 688644 & 6.0841 & 5.2713 & TRN & & \\
\hline CHEMBL2006168 & 688644 & 5.092 & 3.9067 & TST & & \\
\hline CHEMBL1511653 & 688644 & 2.9208 & 3.0716 & TRN & & \\
\hline CHEMBL1333035 & 688644 & 5.36799 & 99999999 & 99 & 4.5806 & TRN \\
\hline CHEMBL1458390 & 688644 & 4.9539 & 3.6004 & TRN & & \\
\hline CHEMBL1613644 & 688644 & 4.7402 & 3.6236 & TRN & & \\
\hline CHEMBL1452295 & 688644 & 5.0038 & 4.9843 & TRN & & \\
\hline CHEMBL1386622 & 688644 & 5.2553 & 5.4961 & TRN & & \\
\hline CHEMBL1394270 & 688644 & 2.9208 & 4.2175 & TRN & & \\
\hline CHEMBL1340220 & 688644 & 4.894 & 4.5834 & TRN & & \\
\hline CHEMBL1602808 & 688644 & 5.4954 & 5.3619 & TRN & & \\
\hline CHEMBL1468313 & 688644 & 2.9208 & 3.8868 & TRN & & \\
\hline CHEMBL3192890 & 688644 & 2.9208 & 4.3083 & TRN & & \\
\hline CHEMBL1416089 & 688644 & 5.24299 & 79999999 & & 4.4705 & TRN \\
\hline
\end{tabular}


Supplemental Table S2.txt

\begin{tabular}{|c|c|c|c|c|}
\hline CHEMBL1499914 & 688644 & 2.9208 & 4.2991 & TRN \\
\hline CHEMBL1466222 & 688644 & 4.7896 & 5.1104 & TRN \\
\hline CHEMBL470881 & 688644 & 5.1548 & 4.4077 & TST \\
\hline CHEMBL1603662 & 688644 & 6.3947 & 5.0279 & TRN \\
\hline CHEMBL1540112 & 688644 & 5.5303 & 5.7674 & TRN \\
\hline CHEMBL1466656 & 688644 & 2.9208 & \multicolumn{2}{|c|}{2.8569999999999998} \\
\hline CHEMBL1351309 & 688644 & 4.9086 & 5.3841 & TRN \\
\hline CHEMBL1415650 & 688644 & 2.9208 & 3.5159 & TST \\
\hline CHEMBL1503756 & 688644 & 2.9208 & 3.0178 & TRN \\
\hline CHEMBL1594613 & 688644 & 2.9208 & 3.4697 & TRN \\
\hline CHEMBL1389427 & 688644 & 5.0936 & 5.0488 & TRN \\
\hline CHEMBL1309839 & 688644 & 4.81 & 3.233 & TRN \\
\hline CHEMBL1343269 & 688644 & 2.9208 & 3.1247 & TST \\
\hline CHEMBL3195189 & 688644 & 6.7167 & 7.0422 & TRN \\
\hline CHEMBL1584186 & 688644 & 4.6752 & 4.5852 & TRN \\
\hline CHEMBL1545881 & 688644 & 4.1104 & 3.1985 & TRN \\
\hline CHEMBL1406361 & 688644 & 8.0 & 4.8671 & TRN \\
\hline CHEMBL1999965 & 688644 & 4.8972 & 5.2214 & TRN \\
\hline CHEMBL1536753 & 688644 & 2.9208 & 3.1015 & TRN \\
\hline CHEMBL1451109 & 688644 & 4.1638 & 3.2511 & TRN \\
\hline CHEMBL1974613 & 688644 & 2.9208 & 4.5963 & TRN \\
\hline CHEMBL1485785 & 688644 & 2.9208 & 3.5353 & TRN \\
\hline CHEMBL1425426 & 688644 & 4.4678 & 4.2266 & TRN \\
\hline CHEMBL1576166 & 688644 & 5.1033 & 5.4763 & TRN \\
\hline CHEMBL1494050 & 688644 & 4.0718 & 4.0198 & TRN \\
\hline CHEMBL1464011 & 688644 & 4.4245 & 4.1332 & TRN \\
\hline CHEMBL1364056 & 688644 & 4.8935 & 3.1237 & TST \\
\hline CHEMBL1996189 & 688644 & 8.0 & 6.3072 & TRN \\
\hline CHEMBL1520497 & 688644 & 2.9208 & 3.4071 & TRN \\
\hline CHEMBL1535730 & 688644 & 4.7956 & 3.4325 & TRN \\
\hline CHEMBL1304245 & 688644 & 2.9208 & 3.3598 & TRN \\
\hline CHEMBL1544095 & 688644 & 2.9208 & 3.4515 & TRN \\
\hline CHEMBL 3199362 & 688644 & 5.0977 & 4.9089 & TRN \\
\hline CHEMBL192984 & 688644 & 5.001 & 5.3023 & TRN \\
\hline CHEMBL1307769 & 688644 & 8.0 & 7.1987 & TRN \\
\hline CHEMBL1340423 & 688644 & 5.0038 & 4.0712 & TRN \\
\hline CHEMBL1534781 & 688644 & 2.9208 & 5.516 & TRN \\
\hline CHEMBL1602637 & 688644 & 6.8894 & 7.4057 & TRN \\
\hline CHEMBL1415306 & 688644 & 2.9208 & 4.4424 & TRN \\
\hline CHEMBL1452595 & 688644 & 2.9208 & 3.0125 & TRN \\
\hline CHEMBL1313684 & 688644 & 2.9208 & 3.3252 & TRN \\
\hline CHEMBL1576605 & 688644 & 2.9208 & 4.2431 & TRN \\
\hline CHEMBL1309796 & 688644 & 2.9208 & 4.0856 & TRN \\
\hline CHEMBL1496396 & 688644 & 5.0686 & 4.476 & TRN \\
\hline CHEMBL1581343 & 688644 & 2.9208 & 3.3803 & TST \\
\hline CHEMBL1463373 & 688644 & 2.9208 & 4.6791 & TRN \\
\hline CHEMBL1503006 & 688644 & 6.857 & 6.8395 & TRN \\
\hline CHEMBL1508788 & 688644 & 5.4684 & 5.6347 & TRN \\
\hline
\end{tabular}




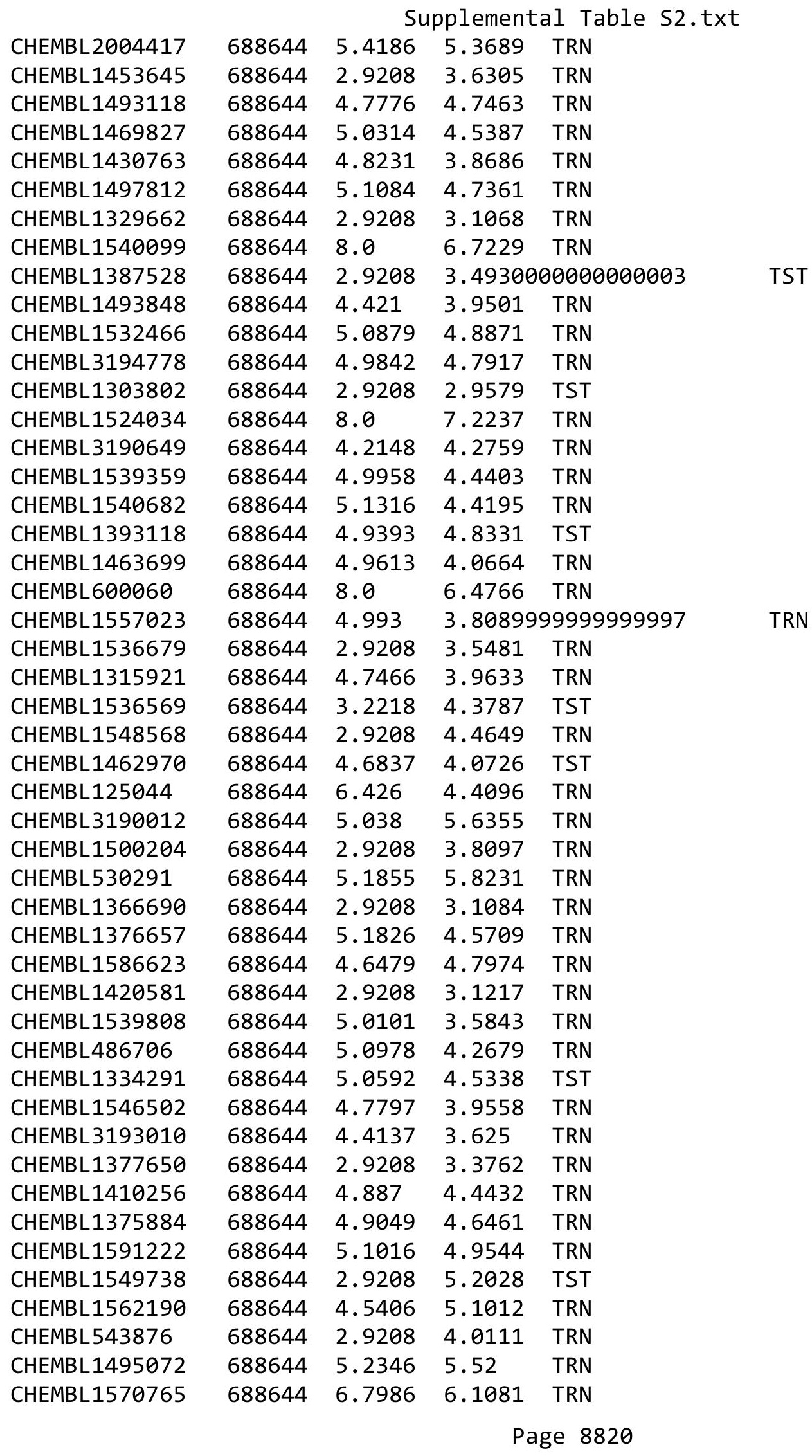




\begin{tabular}{|c|c|c|c|c|c|}
\hline & & \multicolumn{4}{|c|}{ Supplemental Table S2.txt } \\
\hline CHEMBL1535225 & 688644 & 5.225 & 5.7609 & TRN & \\
\hline CHEMBL1463234 & 688644 & 2.9208 & 3.5338 & TRN & \\
\hline CHEMBL1332931 & 688644 & 2.9208 & 5.2461 & TRN & \\
\hline CHEMBL1470614 & 688644 & 2.9208 & 4.7883 & TRN & \\
\hline CHEMBL1344340 & 688644 & 2.9208 & 3.5129 & TRN & \\
\hline CHEMBL1513325 & 688644 & 8.0 & 5.9416 & TRN & \\
\hline CHEMBL1587117 & 688644 & 8.0 & 8.2851 & TRN & \\
\hline CHEMBL1555681 & 688644 & 2.9208 & 3.176 & TRN & \\
\hline CHEMBL1537246 & 688644 & 5.0075 & 4.0259 & TRN & \\
\hline CHEMBL1385414 & 688644 & 2.9208 & 3.5285 & TRN & \\
\hline CHEMBL3210018 & 688644 & 4.8713 & 4.369 & TRN & \\
\hline CHEMBL1314195 & 688644 & 4.2345 & 4.0104 & TST & \\
\hline CHEMBL1495451 & 688644 & 4.8623 & 3.6302 & TST & \\
\hline CHEMBL1329507 & 688644 & 5.1802 & 5.006 & TRN & \\
\hline CHEMBL1491402 & 688644 & 5.3243 & 4.8001 & TRN & \\
\hline CHEMBL1557372 & 688644 & 4.7406 & 4.5667 & TRN & \\
\hline CHEMBL1481849 & 688644 & 5.1056 & 4.3347 & TST & \\
\hline CHEMBL77064 & 688644 & 5.0304 & 5.0854 & TRN & \\
\hline CHEMBL1978354 & 688644 & 5.3468 & 5.5527 & TRN & \\
\hline CHEMBL 2001216 & 688644 & 2.9208 & 4.5684 & TRN & \\
\hline CHEMBL1325168 & 688644 & 4.6428 & 4.7273 & TST & \\
\hline CHEMBL1555935 & 688644 & 8.0 & 7.572 & TST & \\
\hline CHEMBL1563022 & 688644 & 2.9208 & 3.8964 & TRN & \\
\hline CHEMBL1375248 & 688644 & 2.9208 & 3.7768 & TRN & \\
\hline CHEMBL1326180 & 688644 & 2.9208 & 4.7965 & TRN & \\
\hline CHEMBL1349151 & 688644 & 5.0853 & 3.9009 & TRN & \\
\hline CHEMBL1510156 & 688644 & 2.9208 & 5.0245 & TRN & \\
\hline CHEMBL1364172 & 688644 & 4.9711 & 4.016999 & & TRN \\
\hline CHEMBL 2000750 & 688644 & 5.0457 & 5.5291 & TRN & \\
\hline CHEMBL1510690 & 688644 & $6.3820 e$ & 200000000 & 5.5223 & TRN \\
\hline CHEMBL3196703 & 688644 & 5.1737 & 5.2041 & TRN & \\
\hline CHEMBL1469689 & 688644 & 2.9208 & 3.1853 & TRN & \\
\hline CHEMBL460601 & 688644 & 8.0 & 7.6574 & TRN & \\
\hline CHEMBL1495001 & 688644 & 2.9208 & 4.1382 & TRN & \\
\hline CHEMBL1465741 & 688644 & 4.793 & 4.6181 & TRN & \\
\hline CHEMBL1565969 & 688644 & 4.7944 & 3.634 & TRN & \\
\hline CHEMBL1461192 & 688644 & 2.9208 & 3.1473 & TRN & \\
\hline CHEMBL1981103 & 688644 & 5.0145 & 4.4841 & TST & \\
\hline CHEMBL1366573 & 688644 & 4.8338 & 3.0269 & TRN & \\
\hline CHEMBL1576754 & 688644 & 2.9208 & 4.518 & TRN & \\
\hline CHEMBL3199401 & 688644 & 4.9317 & 4.7497 & TRN & \\
\hline CHEMBL1308497 & 688644 & 2.9208 & 3.1706 & TRN & \\
\hline CHEMBL1442791 & 688644 & 2.9208 & 4.2609 & TST & \\
\hline CHEMBL1605138 & 688644 & 2.9208 & 4.186 & TST & \\
\hline CHEMBL1542868 & 688644 & 2.9208 & 3.3272 & TRN & \\
\hline CHEMBL1582355 & 688644 & 4.8748 & 4.9848 & TRN & \\
\hline CHEMBL1408311 & 688644 & 4.8549 & 4.785 & TRN & \\
\hline CHEMBL1375903 & 688644 & 4.1097 & 4.3354 & TST & \\
\hline
\end{tabular}


Supplemental Table S2.txt

\begin{tabular}{|c|c|c|c|c|}
\hline CHEMBL1306265 & 688644 & 4.8903 & 3.3869 & TRN \\
\hline CHEMBL1382128 & 688644 & 4.9502 & 3.3819 & TRN \\
\hline CHEMBL1597748 & 688644 & 2.9208 & 4.0721 & TRN \\
\hline CHEMBL1593640 & 688644 & 4.0133 & 3.2118 & TRN \\
\hline CHEMBL1425176 & 688644 & 4.8793 & 4.3205 & TST \\
\hline CHEMBL484744 & 688644 & 4.9256 & 3.6557 & TRN \\
\hline CHEMBL1429312 & 688644 & 5.013 & 4.6247 & TRN \\
\hline CHEMBL 2360527 & 688644 & 6.3947 & 6.2726 & TRN \\
\hline CHEMBL1302099 & 688644 & 4.6159 & 3.5298 & TRN \\
\hline CHEMBL1381585 & 688644 & 2.9208 & 3.6182 & TRN \\
\hline CHEMBL1530743 & 688644 & 5.1904 & 5.8996 & TRN \\
\hline CHEMBL1601997 & 688644 & 4.4759 & 4.7946 & TST \\
\hline CHEMBL261123 & 688644 & 5.0078 & 5.8414 & TRN \\
\hline CHEMBL1404781 & 688644 & 2.9208 & 4.0451 & TRN \\
\hline CHEMBL1989858 & 688644 & 5.4139 & 5.5681 & TST \\
\hline CHEMBL1521023 & 688644 & 8.0 & 7.5898 & TRN \\
\hline CHEMBL1459841 & 688644 & 8.0 & 6.8531 & TRN \\
\hline CHEMBL1449243 & 688644 & 4.9673 & 3.928 & TRN \\
\hline CHEMBL1336402 & 688644 & 2.9208 & 3.97 & TRN \\
\hline CHEMBL1534592 & 688644 & 2.9208 & 3.7875 & TRN \\
\hline CHEMBL1547706 & 688644 & 6.3565 & 6.4393 & TRN \\
\hline CHEMBL1496771 & 688644 & 2.9208 & 3.9937 & TRN \\
\hline CHEMBL1470245 & 688644 & 2.9208 & 3.9246 & TRN \\
\hline CHEMBL1315704 & 688644 & 2.9208 & 4.9202 & TRN \\
\hline CHEMBL1495417 & 688644 & 5.5725 & 5.3263 & TST \\
\hline CHEMBL1570797 & 688644 & 4.9532 & 4.9204 & TRN \\
\hline CHEMBL1578975 & 688644 & 5.0608 & 4.7006 & TRN \\
\hline CHEMBL1324921 & 688644 & 2.9208 & 3.2173 & TST \\
\hline CHEMBL1420319 & 688644 & 8.0 & 6.9656 & TRN \\
\hline CHEMBL1422586 & 688644 & 5.1019 & 3.938 & TRN \\
\hline CHEMBL1365689 & 688644 & 5.4099 & 5.3377 & TRN \\
\hline CHEMBL1320019 & 688644 & 4.9851 & 3.7741 & TRN \\
\hline CHEMBL1454614 & 688644 & 5.0754 & 4.1963 & TRN \\
\hline CHEMBL586602 & 688644 & 5.4541 & 5.8728 & TRN \\
\hline CHEMBL1370849 & 688644 & 4.6156 & 4.9774 & TRN \\
\hline CHEMBL1487099 & 688644 & 6.4559 & 6.87799 & 9999999999 \\
\hline CHEMBL1450354 & 688644 & 2.9208 & 3.8623 & TRN \\
\hline CHEMBL3191808 & 688644 & 8.0 & 4.7398 & TRN \\
\hline CHEMBL1467877 & 688644 & 8.0 & 6.2609 & TST \\
\hline CHEMBL3195226 & 688644 & 2.9208 & 5.3971 & TRN \\
\hline CHEMBL1335915 & 688644 & 4.7526 & 4.3666 & TRN \\
\hline CHEMBL1423270 & 688644 & 2.9208 & 4.7218 & TRN \\
\hline CHEMBL 2006221 & 688644 & 4.8953 & 5.2909 & TRN \\
\hline CHEMBL1385210 & 688644 & 5.022 & 4.0318 & TRN \\
\hline CHEMBL1333294 & 688644 & 8.0 & 6.9553 & TRN \\
\hline CHEMBL1343081 & 688644 & 2.9208 & 4.1205 & TRN \\
\hline CHEMBL1496138 & 688644 & 4.9045 & 3.8676 & TRN \\
\hline CHEMBL1998521 & 688644 & 8.0 & 8.0903 & TRN \\
\hline
\end{tabular}




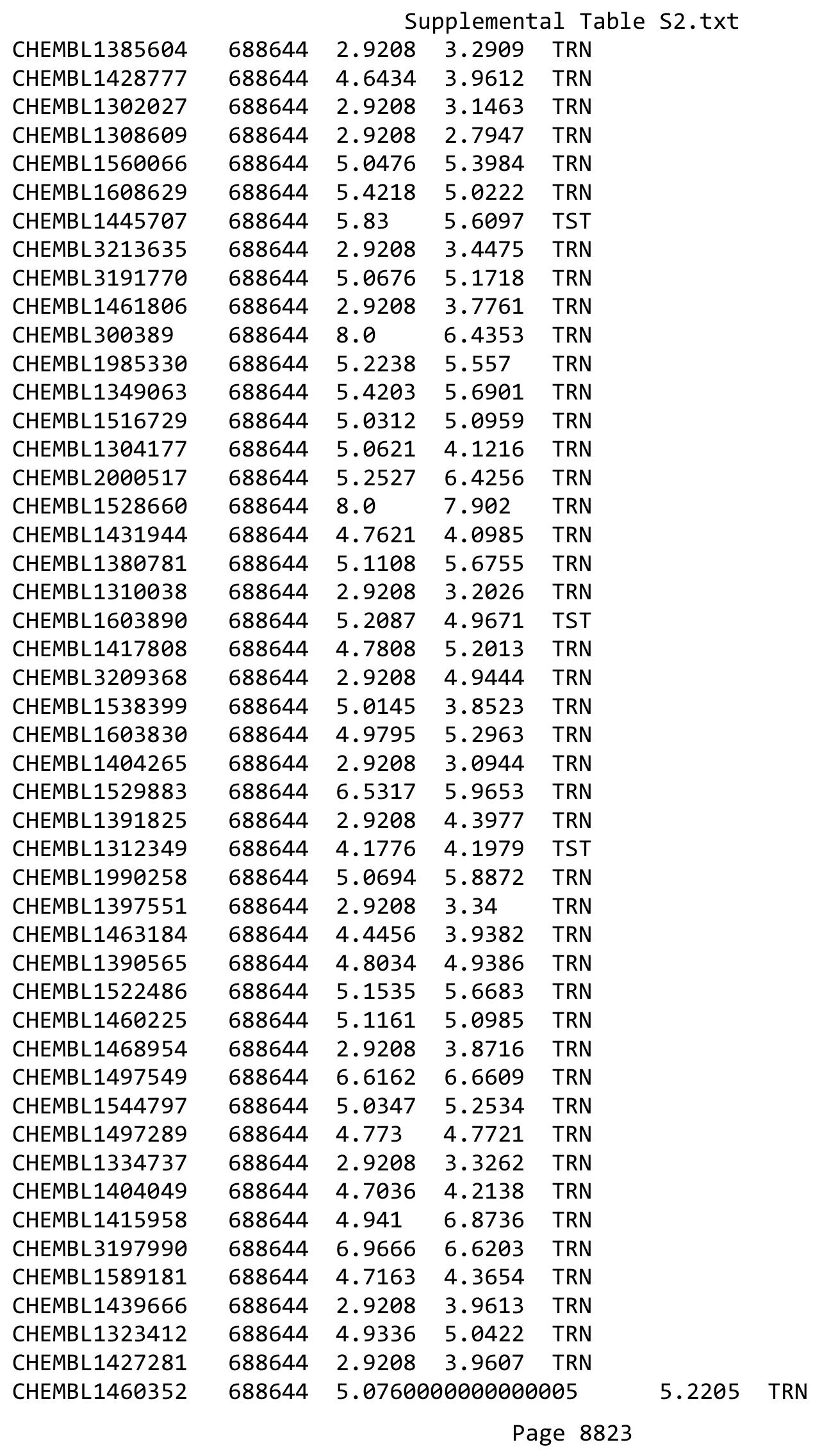




\begin{tabular}{|c|c|c|c|c|c|}
\hline & & \multicolumn{4}{|c|}{ Supplemental Table S2.txt } \\
\hline CHEMBL1463050 & 688644 & 5.98799 & 9999999 & 5.2744 & TRN \\
\hline CHEMBL1312738 & 688644 & 8.0 & 7.5032 & TST & \\
\hline CHEMBL600734 & 688644 & 5.0861 & 4.2487 & TRN & \\
\hline CHEMBL1535361 & 688644 & 5.0259 & 5.3115 & TRN & \\
\hline CHEMBL1576167 & 688644 & 2.9208 & 3.9462 & TST & \\
\hline CHEMBL1330027 & 688644 & 4.1175 & 3.8387 & TRN & \\
\hline CHEMBL3190651 & 688644 & 5.0286 & 4.8009 & TRN & \\
\hline CHEMBL1353133 & 688644 & 4.8708 & 5.1127 & TRN & \\
\hline CHEMBL1505277 & 688644 & 2.9208 & 3.2325 & TRN & \\
\hline CHEMBL3189156 & 688644 & 5.1613 & 4.2534 & TRN & \\
\hline CHEMBL1608301 & 688644 & 5.0096 & 4.8357 & TRN & \\
\hline CHEMBL1443802 & 688644 & 5.0507 & 4.3914 & TRN & \\
\hline CHEMBL1600065 & 688644 & 4.8984 & 4.9319 & TRN & \\
\hline CHEMBL1361206 & 688644 & 2.9208 & 4.3657 & TRN & \\
\hline CHEMBL1352257 & 688644 & 4.4794 & 5.1582 & TRN & \\
\hline CHEMBL1407961 & 688644 & 5.0139 & 5.0825 & TRN & \\
\hline CHEMBL3198239 & 688644 & 2.9208 & 4.6473 & TRN & \\
\hline CHEMBL1360028 & 688644 & 5.0393 & 5.0902 & TRN & \\
\hline CHEMBL532160 & 688644 & 2.9208 & 3.463 & TRN & \\
\hline CHEMBL1404578 & 688644 & 4.9372 & 4.2556 & TRN & \\
\hline CHEMBL3199311 & 688644 & 8.0 & 6.3825 & TRN & \\
\hline CHEMBL1526298 & 688644 & 2.9208 & 4.0992 & TRN & \\
\hline CHEMBL1487074 & 688644 & 2.9208 & 3.2703 & TST & \\
\hline CHEMBL1463249 & 688644 & 4.9671 & 5.0015 & TST & \\
\hline CHEMBL1420309 & 688644 & 4.5829 & 4.1343 & TRN & \\
\hline CHEMBL1597655 & 688644 & 6.2774 & 6.6776 & TRN & \\
\hline CHEMBL1990919 & 688644 & 6.9431 & 7.1108 & TRN & \\
\hline CHEMBL1499095 & 688644 & 2.9208 & 2.9519 & TRN & \\
\hline CHEMBL1494423 & 688644 & 4.9673 & 3.7037 & TRN & \\
\hline CHEMBL1334376 & 688644 & 2.9208 & 3.43600 & 00000000004 & TRN \\
\hline CHEMBL1602717 & 688644 & 5.2037 & 4.6 & TRN & \\
\hline CHEMBL1507833 & 688644 & 2.9208 & 3.5783 & TST & \\
\hline CHEMBL3191879 & 688644 & 5.1258 & 5.2466 & TRN & \\
\hline CHEMBL1428616 & 688644 & 2.9208 & 3.3921 & TST & \\
\hline CHEMBL1487609 & 688644 & 5.0926 & 4.3413 & TRN & \\
\hline CHEMBL1422078 & 688644 & 5.6921 & 5.9219 & TRN & \\
\hline CHEMBL3190805 & 688644 & 5.2566 & 5.5601 & TRN & \\
\hline CHEMBL1451935 & 688644 & 6.6326 & 6.5132 & TRN & \\
\hline CHEMBL1323569 & 688644 & 4.6534 & 4.7265 & TRN & \\
\hline CHEMBL3190445 & 688644 & 2.9208 & 4.4365 & TRN & \\
\hline CHEMBL1569107 & 688644 & 2.9208 & 4.0702 & TRN & \\
\hline CHEMBL1511841 & 688644 & 2.9208 & 3.3648 & TRN & \\
\hline CHEMBL1418632 & 688644 & 5.4295 & 3.9535 & TRN & \\
\hline CHEMBL1497019 & 688644 & 6.5243 & 6.3798 & TRN & \\
\hline CHEMBL1441228 & 688644 & 5.0678 & 4.1665 & TRN & \\
\hline CHEMBL1575284 & 688644 & 4.6404 & 4.7292 & TRN & \\
\hline CHEMBL1606328 & 688644 & 5.011 & 4.7048 & TRN & \\
\hline CHEMBL1382361 & 688644 & 4.6535 & 4.7106 & TRN & \\
\hline
\end{tabular}




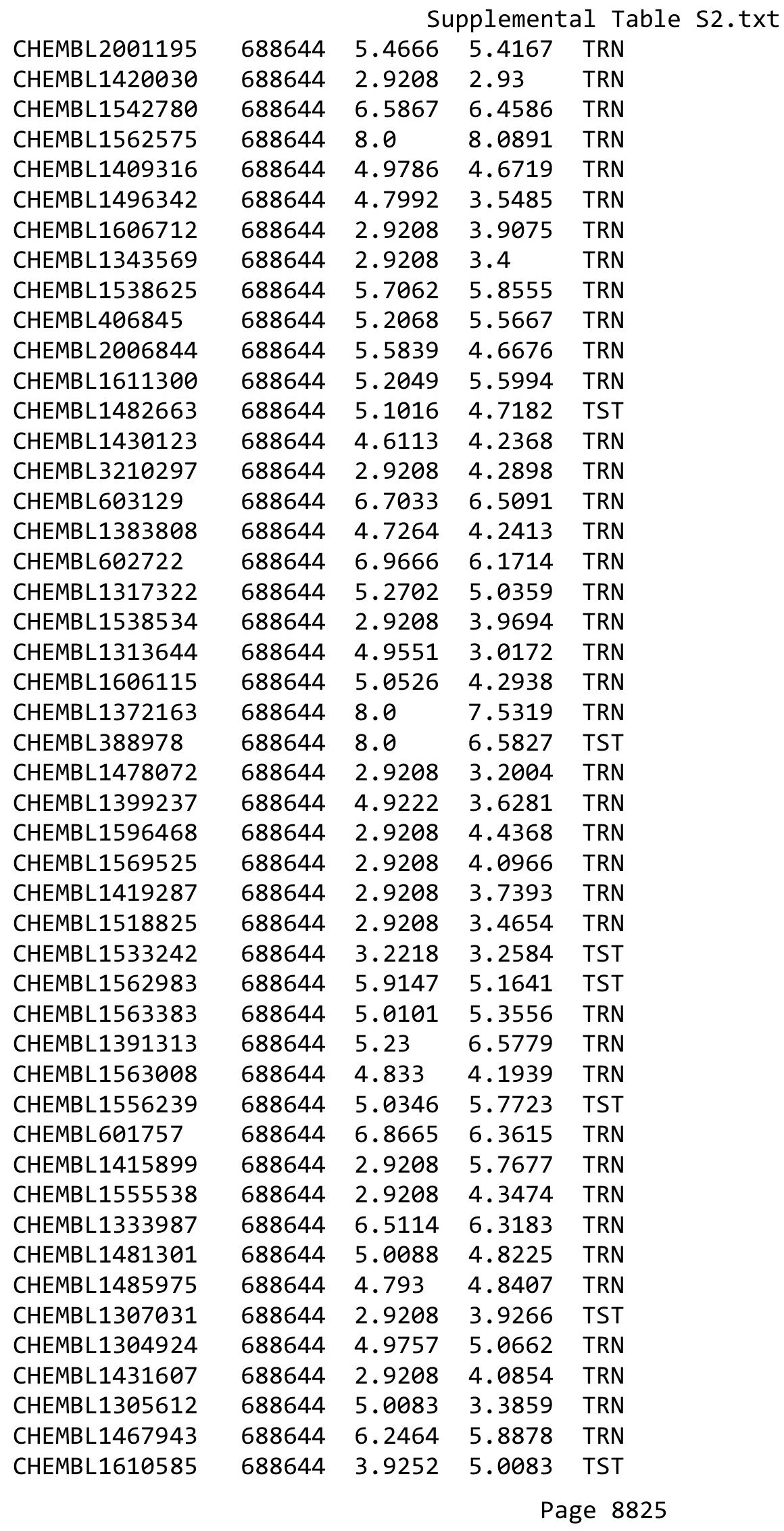




\begin{tabular}{|c|c|c|c|c|c|}
\hline & & \multicolumn{4}{|c|}{ Supplemental Table S2.txt } \\
\hline CHEMBL1365210 & 688644 & 4.954 & 4.7877 & TRN & \\
\hline CHEMBL1305566 & 688644 & 5.4339 & 5.4155 & TRN & \\
\hline CHEMBL1439222 & 688644 & 2.9208 & 3.2869 & TST & \\
\hline CHEMBL1466170 & 688644 & 2.9208 & 4.0081 & TRN & \\
\hline CHEMBL1602385 & 688644 & 8.0 & 7.629 & TRN & \\
\hline CHEMBL1412543 & 688644 & 2.9208 & 3.2813 & TRN & \\
\hline CHEMBL1313520 & 688644 & 8.0 & 7.7261 & TRN & \\
\hline CHEMBL1505866 & 688644 & 5.0129 & 3.1693 & TRN & \\
\hline CHEMBL 3208365 & 688644 & 5.1395 & 5.9859 & TRN & \\
\hline CHEMBL1542001 & 688644 & 4.8524 & 4.7024 & TRN & \\
\hline CHEMBL1452379 & 688644 & 5.126 & 3.8912 & TRN & \\
\hline CHEMBL1572214 & 688644 & 8.0 & 6.3627 & TST & \\
\hline CHEMBL3198554 & 688644 & 4.9904 & 5.1002 & TRN & \\
\hline CHEMBL1299644 & 688644 & 4.7039 & 3.6037 & TST & \\
\hline CHEMBL1571005 & 688644 & 4.5194 & 4.5376 & TRN & \\
\hline CHEMBL1991327 & 688644 & 5.0405 & 4.9636 & TRN & \\
\hline CHEMBL1527210 & 688644 & 2.9208 & 4.1341 & TST & \\
\hline CHEMBL1329255 & 688644 & 4.8719 & 2.7459 & TRN & \\
\hline CHEMBL1386838 & 688644 & 4.9778 & 4.2932 & TST & \\
\hline CHEMBL600336 & 688644 & 6.5607 & 5.682 & TRN & \\
\hline CHEMBL1430581 & 688644 & 4.8226 & 3.9033 & TRN & \\
\hline CHEMBL1456768 & 688644 & 5.0378 & 4.2998 & TRN & \\
\hline CHEMBL1544655 & 688644 & 4.6544 & 3.2999 & TRN & \\
\hline CHEMBL3192670 & 688644 & 4.918 & 4.5922 & TRN & \\
\hline CHEMBL1421347 & 688644 & 4.8209 & 4.7504 & TST & \\
\hline CHEMBL1349428 & 688644 & 5.1445 & 6.9451 & TRN & \\
\hline CHEMBL1457567 & 688644 & 5.3891 & 4.5741 & TRN & \\
\hline CHEMBL1388404 & 688644 & 4.8316 & 4.2034 & TST & \\
\hline CHEMBL1489894 & 688644 & 4.0302 & 2.9517 & TRN & \\
\hline CHEMBL1382960 & 688644 & 2.9208 & 3.4844 & TST & \\
\hline CHEMBL1379405 & 688644 & 2.9208 & 3.1968 & TRN & \\
\hline CHEMBL1494220 & 688644 & 2.9208 & 3.2351 & TRN & \\
\hline CHEMBL1495092 & 688644 & 8.0 & 6.3216 & TST & \\
\hline CHEMBL1341553 & 688644 & 4.4348 & 4.4498 & TRN & \\
\hline CHEMBL1379081 & 688644 & 6.0223 & 6.8274 & TRN & \\
\hline CHEMBL1462745 & 688644 & 6.5452 & 6.5374 & TRN & \\
\hline CHEMBL1412303 & 688644 & 5.2272 & 4.59699 & 99999999995 & TRN \\
\hline CHEMBL1583778 & 688644 & 4.8622 & 3.5687 & TST & \\
\hline CHEMBL1360539 & 688644 & 5.4724 & 4.9955 & TRN & \\
\hline CHEMBL1976786 & 688644 & 8.0 & 5.9508 & TRN & \\
\hline CHEMBL1609770 & 688644 & 6.6073 & 5.774 & TRN & \\
\hline CHEMBL1472085 & 688644 & 4.209 & 4.8123 & TST & \\
\hline CHEMBL3212551 & 688644 & 5.1001 & 5.2854 & TRN & \\
\hline CHEMBL3198341 & 688644 & 5.1515 & 5.3835 & TRN & \\
\hline CHEMBL3196726 & 688644 & 2.9208 & 4.228 & TRN & \\
\hline CHEMBL1445776 & 688644 & 2.9208 & 3.8454 & TRN & \\
\hline CHEMBL1509754 & 688644 & 3.2218 & 4.3462 & TRN & \\
\hline CHEMBL3199752 & 688644 & 4.9044 & 5.1935 & TRN & \\
\hline
\end{tabular}


Supplemental Table S2.txt

\begin{tabular}{|c|c|c|c|c|}
\hline CHEMBL1554602 & 688644 & 4.8349 & 4.4886 & TRN \\
\hline CHEMBL3194229 & 688644 & 2.9208 & 3.5321 & TRN \\
\hline CHEMBL1516044 & 688644 & 2.9208 & 3.9353 & TRN \\
\hline CHEMBL1564524 & 688644 & 2.9208 & 3.268999 & \\
\hline CHEMBL1483161 & 688644 & 4.7446 & 3.8046 & TST \\
\hline CHEMBL1392228 & 688644 & 8.0 & 7.6648 & TRN \\
\hline CHEMBL1979047 & 688644 & 5.02 & 4.8146 & TRN \\
\hline CHEMBL1493861 & 688644 & 2.9208 & 4.8768 & TRN \\
\hline CHEMBL1356472 & 688644 & 2.9208 & 5.3575 & TRN \\
\hline CHEMBL1386760 & 688644 & 4.8166 & 3.5907 & TRN \\
\hline CHEMBL1386546 & 688644 & 5.0693 & 5.0389 & TRN \\
\hline CHEMBL1603615 & 688644 & 5.2157 & 4.9605 & TRN \\
\hline CHEMBL1561111 & 688644 & 2.9208 & 5.2759 & TRN \\
\hline CHEMBL601351 & 688644 & 2.9208 & 3.3279 & TST \\
\hline CHEMBL1536119 & 688644 & 2.9208 & 3.2242 & TRN \\
\hline CHEMBL1606583 & 688644 & 8.0 & 6.1408 & TRN \\
\hline CHEMBL1523392 & 688644 & 2.9208 & 3.0057 & TRN \\
\hline CHEMBL1348251 & 688644 & 4.8754 & 3.6689 & TRN \\
\hline CHEMBL3189245 & 688644 & 5.2461 & 5.7011 & TRN \\
\hline CHEMBL1300239 & 688644 & 6.5058 & 4.438 & TRN \\
\hline CHEMBL1324061 & 688644 & 8.0 & 5.3979 & TST \\
\hline CHEMBL1497910 & 688644 & 2.9208 & 4.7313 & TRN \\
\hline CHEMBL1311547 & 688644 & 4.9342 & 5.0597 & TRN \\
\hline CHEMBL1519703 & 688644 & 4.2618 & 4.623 & TST \\
\hline CHEMBL1471211 & 688644 & 2.9208 & 4.6144 & TRN \\
\hline CHEMBL1999193 & 688644 & 2.9208 & 3.4031 & TRN \\
\hline CHEMBL1342336 & 688644 & 8.0 & 8.4688 & TRN \\
\hline CHEMBL1598445 & 688644 & 5.0065 & 4.7449 & TRN \\
\hline CHEMBL1337301 & 688644 & 2.9208 & 3.1986 & TRN \\
\hline CHEMBL1580848 & 688644 & 8.0 & 7.1327 & TRN \\
\hline CHEMBL1328529 & 688644 & 2.9208 & 4.1016 & TST \\
\hline CHEMBL1567841 & 688644 & 8.0 & 5.4908 & TRN \\
\hline CHEMBL3194214 & 688644 & 4.9101 & 4.8131 & TST \\
\hline CHEMBL1515202 & 688644 & 2.9208 & 5.0465 & TST \\
\hline CHEMBL1374907 & 688644 & 4.9401 & 4.7216 & TRN \\
\hline CHEMBL1517849 & 688644 & 2.9208 & 3.5948 & TRN \\
\hline CHEMBL1588263 & 688644 & 2.9208 & 4.9883 & TST \\
\hline CHEMBL1426636 & 688644 & 4.7843 & 4.662 & TRN \\
\hline CHEMBL1602344 & 688644 & 4.9157 & 3.1276 & TRN \\
\hline CHEMBL492468 & 688644 & 5.0426 & 3.8804 & TRN \\
\hline CHEMBL1442176 & 688644 & 4.0692 & 3.9179 & TRN \\
\hline CHEMBL1423927 & 688644 & 8.0 & 6.0602 & TRN \\
\hline CHEMBL1477197 & 688644 & 2.9208 & 5.1532 & TRN \\
\hline CHEMBL3191831 & 688644 & 5.0421 & 5.3765 & TRN \\
\hline CHEMBL1595706 & 688644 & 5.0842 & 3.478 & TRN \\
\hline CHEMBL1486078 & 688644 & 2.9208 & 3.9481 & TRN \\
\hline CHEMBL1599796 & 688644 & 4.7956 & 4.5466 & TRN \\
\hline CHEMBL1545747 & 688644 & 2.9208 & 4.6554 & TRN \\
\hline
\end{tabular}




\begin{tabular}{|c|c|c|c|c|c|c|}
\hline & & \multicolumn{5}{|c|}{ Supplemental Table S2.txt } \\
\hline CHEMBL1349509 & 688644 & 2.9208 & 3.3971 & TRN & & \\
\hline CHEMBL 259103 & 688644 & 8.0 & 7.0524 & TRN & & \\
\hline CHEMBL1557615 & 688644 & 5.0676 & 5.0151 & TRN & & \\
\hline CHEMBL1550442 & 688644 & 5.0101 & 4.9732 & TRN & & \\
\hline CHEMBL405914 & 688644 & 6.5129 & 5.7191 & TRN & & \\
\hline CHEMBL1481574 & 688644 & 2.9208 & 3.94199 & 99999999 & 997 & TRN \\
\hline CHEMBL1470712 & 688644 & 5.9219 & 6.0269 & TRN & & \\
\hline CHEMBL1345685 & 688644 & 5.0985 & 5.1821 & TRN & & \\
\hline CHEMBL1460047 & 688644 & 2.9208 & 3.9443 & TRN & & \\
\hline CHEMBL1504982 & 688644 & 5.0457 & 4.5835 & TRN & & \\
\hline CHEMBL 2138014 & 688644 & 5.0062 & 3.8092 & TRN & & \\
\hline CHEMBL1539642 & 688644 & 2.9208 & 3.4448 & TRN & & \\
\hline CHEMBL1518206 & 688644 & 5.2801 & 5.0304 & TRN & & \\
\hline CHEMBL1493561 & 688644 & 4.8342 & 3.3975 & TRN & & \\
\hline CHEMBL1422597 & 688644 & 5.2308 & 5.6692 & TRN & & \\
\hline CHEMBL1600709 & 688644 & 2.9208 & 3.9936 & TRN & & \\
\hline CHEMBL1363982 & 688644 & 2.9208 & 3.6798 & TRN & & \\
\hline CHEMBL1599438 & 688644 & 5.0299 & 5.2234 & TRN & & \\
\hline CHEMBL606675 & 688644 & 4.8755 & 4.6365 & TST & & \\
\hline CHEMBL1576251 & 688644 & 8.0 & 8.1592 & TRN & & \\
\hline CHEMBL1504859 & 688644 & 4.6981 & 5.2938 & TRN & & \\
\hline CHEMBL1352854 & 688644 & 6.9355 & 6.5267 & TST & & \\
\hline CHEMBL1352348 & 688644 & 5.3051 & 5.2919 & TRN & & \\
\hline CHEMBL1329221 & 688644 & 8.0 & 6.6319 & TRN & & \\
\hline CHEMBL1299210 & 688644 & 4.5872 & 3.4333 & TRN & & \\
\hline CHEMBL1569989 & 688644 & 5.37299 & 99999999 & 99 & 5.5407 & TRN \\
\hline CHEMBL1311021 & 688644 & 2.9208 & 3.0121 & TRN & & \\
\hline CHEMBL1490532 & 688644 & 5.1547 & 4.6858 & TRN & & \\
\hline CHEMBL1396519 & 688644 & 5.1998 & 4.0495 & TRN & & \\
\hline CHEMBL1572498 & 688644 & 4.9538 & 4.0339 & TRN & & \\
\hline CHEMBL1491019 & 688644 & 5.0784 & 3.4689 & TRN & & \\
\hline CHEMBL1558822 & 688644 & 4.59699 & 79999999ऽ & 995 & 3.9596 & TRN \\
\hline CHEMBL1437623 & 688644 & 4.8154 & 3.9881 & TRN & & \\
\hline CHEMBL355496 & 688644 & 5.03100 & 000000006 & 01 & 4.665 & t \\
\hline CHEMBL3211755 & 688644 & 2.9208 & 4.3456 & TST & & \\
\hline CHEMBL1302495 & 688644 & 4.7666 & 3.9424 & TRN & & \\
\hline CHEMBL1399858 & 688644 & 4.5706 & 3.073 & TRN & & \\
\hline CHEMBL 3145088 & 688644 & 5.67299 & 99999999 & 99 & 5.5244 & t \\
\hline CHEMBL1332955 & 688644 & 4.9908 & 3.5782 & TRN & & \\
\hline CHEMBL602997 & 688644 & 5.1091 & 4.2414 & TRN & & \\
\hline CHEMBL3197126 & 688644 & 6.0424 & 6.0009 & TRN & & \\
\hline CHEMBL1403315 & 688644 & 5.0156 & 3.8262 & TRN & & \\
\hline CHEMBL1332013 & 688644 & 5.1164 & 5.4787 & TRN & & \\
\hline CHEMBL1329237 & 688644 & 8.0 & 6.6049 & TRN & & \\
\hline CHEMBL1608722 & 688644 & 5.0447 & 6.4125 & TRN & & \\
\hline CHEMBL1345123 & 688644 & 2.9208 & 2.8481 & TRN & & \\
\hline CHEMBL1306565 & 688644 & 5.0187 & 5.0641 & TST & & \\
\hline CHEMBL1377889 & 688644 & 2.9208 & 3.4322 & TRN & & \\
\hline
\end{tabular}




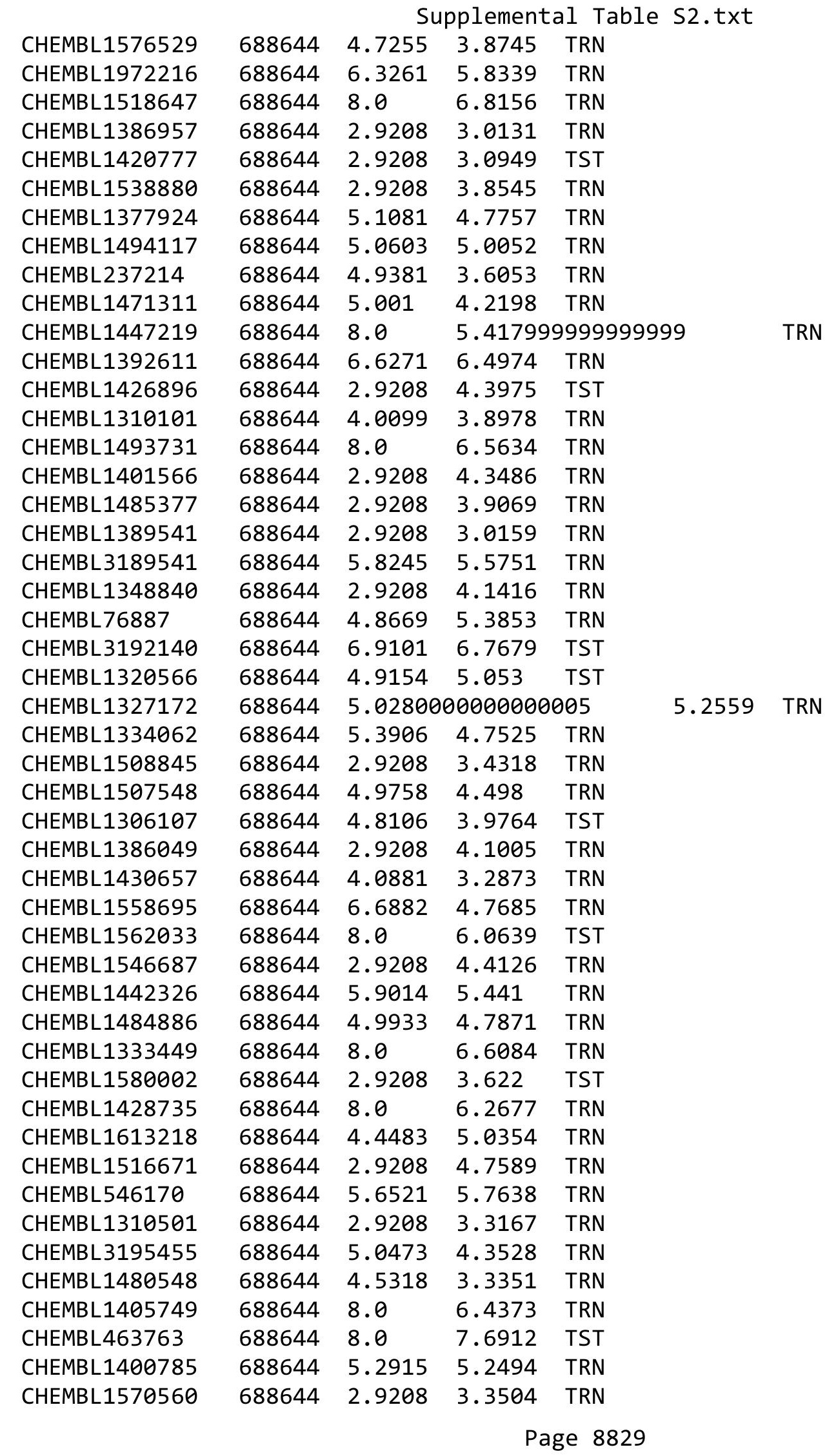


Supplemental Table S2.txt

\begin{tabular}{|c|c|c|c|c|c|}
\hline CHEMBL1430182 & 688644 & 2.9208 & 3.7356 & TST & \\
\hline CHEMBL1412554 & 688644 & 2.9208 & 3.5212 & TRN & \\
\hline CHEMBL1487794 & 688644 & 2.9208 & 3.2338 & TRN & \\
\hline CHEMBL1530673 & 688644 & 8.0 & 5.9558 & TST & \\
\hline CHEMBL3189810 & 688644 & 5.0186 & 4.1989 & TRN & \\
\hline CHEMBL1584336 & 688644 & 2.9208 & 3.2825 & TST & \\
\hline CHEMBL1319204 & 688644 & 4.0246 & 3.4692 & TRN & \\
\hline CHEMBL1560324 & 688644 & 5.085 & 4.5087 & TST & \\
\hline CHEMBL1535351 & 688644 & 6.7471 & 6.4023 & TRN & \\
\hline CHEMBL1558095 & 688644 & 2.9208 & 3.0369 & TRN & \\
\hline CHEMBL1986678 & 688644 & 4.9901 & 5.5437 & TRN & \\
\hline CHEMBL1574752 & 688644 & 2.9208 & 4.0922 & TST & \\
\hline CHEMBL1552929 & 688644 & 5.0786 & 4.2144 & TRN & \\
\hline CHEMBL1488757 & 688644 & 4.3502 & 3.9762 & TRN & \\
\hline CHEMBL1562367 & 688644 & 2.9208 & 4.0486 & TRN & \\
\hline CHEMBL1448054 & 688644 & 6.3288 & 6.3109 & TRN & \\
\hline CHEMBL1369768 & 688644 & 5.0931 & 4.306 & TRN & \\
\hline CHEMBL1589009 & 688644 & 2.9208 & 3.14399 & 99999999997 & TRN \\
\hline CHEMBL1412667 & 688644 & 5.4559 & 3.4456 & TRN & \\
\hline CHEMBL1521660 & 688644 & 4.7654 & 3.6655 & TRN & \\
\hline CHEMBL1570491 & 688644 & 5.2983 & 5.22 & TRN & \\
\hline CHEMBL1527380 & 688644 & 8.0 & 4.9751 & TRN & \\
\hline CHEMBL1341384 & 688644 & 4.5657 & 4.0706 & TRN & \\
\hline CHEMBL1401272 & 688644 & 6.0605 & 4.7458 & TRN & \\
\hline CHEMBL1426865 & 688644 & 4.9618 & 5.6346 & TST & \\
\hline CHEMBL1583804 & 688644 & 2.9208 & 2.8121 & TRN & \\
\hline CHEMBL1361507 & 688644 & 5.0448 & 5.079 & TRN & \\
\hline CHEMBL1403940 & 688644 & 4.9911 & 5.1907 & TRN & \\
\hline CHEMBL1558947 & 688644 & 2.9208 & 2.9357 & TRN & \\
\hline CHEMBL1452898 & 688644 & 2.9208 & 3.6102 & TRN & \\
\hline CHEMBL1421670 & 688644 & 4.9904 & 5.322 & TRN & \\
\hline CHEMBL1560034 & 688644 & 2.9208 & 3.7753 & TRN & \\
\hline CHEMBL1577399 & 688644 & 4.751 & 3.9347 & TRN & \\
\hline CHEMBL1502189 & 688644 & \multicolumn{3}{|c|}{5.196000000000001} & TRN \\
\hline CHEMBL3194303 & 688644 & 4.7778 & 4.7156 & TRN & \\
\hline CHEMBL1303463 & 688644 & 5.0015 & 4.5794 & TRN & \\
\hline CHEMBL290077 & 688644 & 8.0 & 8.0591 & TST & \\
\hline CHEMBL1496165 & 688644 & 4.99 & 4.2388 & TRN & \\
\hline CHEMBL1989817 & 688644 & 2.9208 & 4.2962 & TRN & \\
\hline CHEMBL3189613 & 688644 & 5.2408 & 5.4101 & TRN & \\
\hline CHEMBL1312291 & 688644 & 4.5698 & 4.0369 & TRN & \\
\hline CHEMBL1571181 & 688644 & 2.9208 & 2.9437 & TRN & \\
\hline CHEMBL1546566 & 688644 & 2.9208 & 5.0834 & TRN & \\
\hline CHEMBL 2001739 & 688644 & \multicolumn{3}{|c|}{5.0360000000000005} & TRN \\
\hline CHEMBL1330113 & 688644 & 5.0053 & 4.7754 & TST & \\
\hline CHEMBL1996263 & 688644 & 4.085 & 4.4516 & TRN & \\
\hline CHEMBL1302266 & 688644 & 5.1687 & 5.1195 & TRN & \\
\hline CHEMBL1403276 & 688644 & 6.38399 & 99999999 & 6.4594 & TRN \\
\hline
\end{tabular}




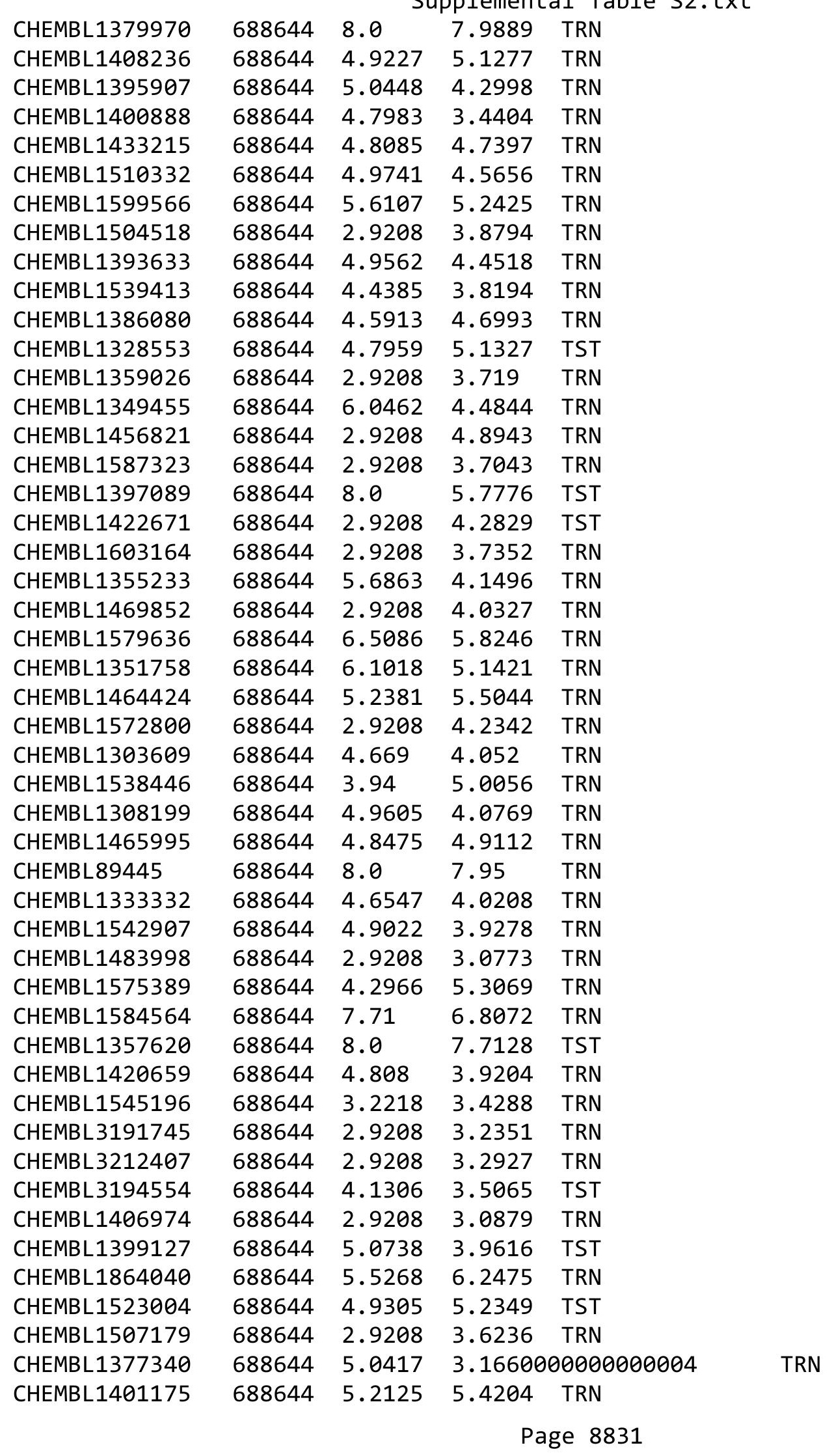


Supplemental Table S2.txt

\begin{tabular}{|c|c|c|c|c|c|}
\hline CHEMBL1347191 & 688644 & 2.9208 & 3.7669 & TRN & \\
\hline CHEMBL1550934 & 688644 & 5.0557 & 5.2526 & TRN & \\
\hline CHEMBL1456009 & 688644 & 4.8286 & 3.1524 & TRN & \\
\hline CHEMBL 3189161 & 688644 & 4.9742 & 4.9643 & TRN & \\
\hline CHEMBL1572558 & 688644 & 6.699 & 5.8647 & TRN & \\
\hline CHEMBL1440659 & 688644 & 5.2355 & 3.9074 & TRN & \\
\hline CHEMBL1452116 & 688644 & 5.1698 & 5.0248 & TRN & \\
\hline CHEMBL1370024 & 688644 & 5.3564 & 5.3491 & TRN & \\
\hline CHEMBL1539710 & 688644 & 2.9208 & 5.0393 & TST & \\
\hline CHEMBL1967497 & 688644 & 5.11 & 3.87 & TRN & \\
\hline CHEMBL1609140 & 688644 & 5.1826 & 5.2161 & TRN & \\
\hline CHEMBL1598052 & 688644 & 4.0397 & 4.2992 & TRN & \\
\hline CHEMBL1305436 & 688644 & 2.9208 & 3.8809 & TRN & \\
\hline CHEMBL1362687 & 688644 & 6.1403 & 6.1268 & TRN & \\
\hline CHEMBL1430866 & 688644 & 2.9208 & 4.6089 & TRN & \\
\hline CHEMBL 2004794 & 688644 & 4.8837 & 4.6044 & TRN & \\
\hline CHEMBL1567663 & 688644 & 5.0641 & 4.8782 & TRN & \\
\hline CHEMBL1321622 & 688644 & 6.983 & 6.7367 & TRN & \\
\hline CHEMBL 3212655 & 688644 & 4.9205 & 4.939 & TRN & \\
\hline CHEMBL1523348 & 688644 & 2.9208 & 3.6508 & TRN & \\
\hline CHEMBL1347556 & 688644 & 4.8538 & 5.1154 & TRN & \\
\hline CHEMBL1984454 & 688644 & 4.8565 & 4.6839 & TRN & \\
\hline CHEMBL1545701 & 688644 & 5.0218 & 4.9857 & TRN & \\
\hline CHEMBL1995314 & 688644 & 2.9208 & 3.5036 & TRN & \\
\hline CHEMBL1363371 & 688644 & 2.9208 & 4.05699 & 99999999995 & TRN \\
\hline CHEMBL1583503 & 688644 & 4.2103 & 4.6671 & TRN & \\
\hline CHEMBL1612880 & 688644 & 5.1059 & 3.4939 & TRN & \\
\hline CHEMBL 3197771 & 688644 & 4.6949 & 5.2203 & TRN & \\
\hline CHEMBL 3196824 & 688644 & 2.9208 & 4.4794 & TRN & \\
\hline CHEMBL1591171 & 688644 & 4.9372 & 3.9091 & TST & \\
\hline CHEMBL1588363 & 688644 & 3.2218 & 4.1981 & TRN & \\
\hline CHEMBL1332878 & 688644 & 8.0 & 7.5071 & TRN & \\
\hline CHEMBL1443177 & 688644 & 5.2863 & 5.8151 & TRN & \\
\hline CHEMBL1966867 & 688644 & 5.1091 & 5.2495 & TRN & \\
\hline CHEMBL1508668 & 688644 & 4.6382 & 4.8805 & TRN & \\
\hline CHEMBL1490356 & 688644 & 2.9208 & 3.2993 & TRN & \\
\hline CHEMBL1985582 & 688644 & 5.7263 & 5.7045 & TRN & \\
\hline CHEMBL1546607 & 688644 & 4.7428 & 3.9456 & TRN & \\
\hline CHEMBL1327056 & 688644 & 4.0806 & 4.5976 & TRN & \\
\hline CHEMBL1431314 & 688644 & 2.9208 & 4.3333 & TRN & \\
\hline CHEMBL1350432 & 688644 & 5.1129 & 5.0569 & TST & \\
\hline CHEMBL1309980 & 688644 & 4.4994 & 4.2085 & TRN & \\
\hline CHEMBL1553215 & 688644 & 2.9208 & 3.2229 & TST & \\
\hline CHEMBL1504509 & 688644 & 5.1577 & 4.7575 & TRN & \\
\hline CHEMBL1324125 & 688644 & 8.0 & 6.9731 & TRN & \\
\hline CHEMBL1578880 & 688644 & 4.7646 & 4.5764 & TRN & \\
\hline CHEMBL1980322 & 688644 & 5.0738 & 4.1366 & TRN & \\
\hline CHEMBL1424697 & 688644 & 5.7342 & 5.0247 & TRN & \\
\hline
\end{tabular}




\begin{tabular}{|c|c|c|c|c|c|c|}
\hline & & \multicolumn{5}{|c|}{ Supplemental Table S2.txt } \\
\hline CHEMBL1587516 & 688644 & 4.7925 & 4.6658 & TRN & & \\
\hline CHEMBL1454029 & 688644 & 5.3016 & 6.0936 & TRN & & \\
\hline CHEMBL1604761 & 688644 & 4.8668 & 4.8282 & TRN & & \\
\hline CHEMBL1466676 & 688644 & 2.9208 & 3.6152 & TRN & & \\
\hline CHEMBL3192625 & 688644 & 2.9208 & 5.4811 & TRN & & \\
\hline CHEMBL1389609 & 688644 & 2.9208 & 3.0873 & TRN & & \\
\hline CHEMBL1537552 & 688644 & 2.9208 & 3.5589 & TRN & & \\
\hline CHEMBL1379817 & 688644 & 4.8205 & 4.6296 & TST & & \\
\hline CHEMBL1525695 & 688644 & 4.7872 & 5.3902 & TRN & & \\
\hline CHEMBL1603253 & 688644 & \multicolumn{3}{|c|}{5.422000000000001} & 5.6486 & TRN \\
\hline CHEMBL1310844 & 688644 & 2.9208 & 3.9103 & TRN & & \\
\hline CHEMBL373137 & 688644 & 8.0 & 7.2055 & TRN & & \\
\hline CHEMBL1559204 & 688644 & 4.9223 & 4.859 & TRN & & \\
\hline CHEMBL3193702 & 688644 & 5.0179 & 4.4342 & TRN & & \\
\hline CHEMBL1609081 & 688644 & 4.7702 & 4.7388 & TRN & & \\
\hline CHEMBL1426049 & 688644 & 4.5018 & 3.2193 & TST & & \\
\hline CHEMBL1541017 & 688644 & 8.0 & 6.312 & TRN & & \\
\hline CHEMBL3191416 & 688644 & 5.3212 & 6.3276 & TRN & & \\
\hline CHEMBL1424164 & 688644 & 2.9208 & 4.0795 & TRN & & \\
\hline CHEMBL3198763 & 688644 & 5.5296 & 6.0524 & TRN & & \\
\hline CHEMBL1592917 & 688644 & 5.3674 & 4.4772 & TST & & \\
\hline CHEMBL1601912 & 688644 & 8.0 & 7.3396 & TRN & & \\
\hline CHEMBL1461400 & 688644 & 6.4737 & 5.9623 & TRN & & \\
\hline CHEMBL1335978 & 688644 & \multicolumn{3}{|c|}{4.8919999999999995} & 3.7034 & TRN \\
\hline CHEMBL1561676 & 688644 & 5.1499 & 4.8609 & TRN & & \\
\hline CHEMBL3207792 & 688644 & 4.9231 & 4.1551 & TRN & & \\
\hline CHEMBL1329006 & 688644 & 3.9427 & 3.2353 & TRN & & \\
\hline CHEMBL 267160 & 688644 & 4.8775 & 5.3287 & TRN & & \\
\hline CHEMBL1302164 & 688644 & 5.0284 & 4.8189 & TRN & & \\
\hline CHEMBL1516767 & 688644 & 2.9208 & 3.9375 & TRN & & \\
\hline CHEMBL1363839 & 688644 & 5.0706 & 4.5954 & TRN & & \\
\hline CHEMBL1565674 & 688644 & 2.9208 & 4.8998 & TRN & & \\
\hline CHEMBL1500296 & 688644 & 2.9208 & 3.0965 & TRN & & \\
\hline CHEMBL1484622 & 688644 & 5.1674 & 5.1619 & TRN & & \\
\hline CHEMBL1554240 & 688644 & 5.0862 & 5.02800 & 0000000000 & & TRN \\
\hline CHEMBL1383414 & 688644 & 2.9208 & 4.834 & TRN & & \\
\hline CHEMBL3194887 & 688644 & 2.9208 & 3.70600 & 0000000000 & & TRN \\
\hline CHEMBL1464595 & 688644 & 4.4149 & 3.9467 & TST & & \\
\hline CHEMBL1570624 & 688644 & 5.0894 & 5.9155 & TST & & \\
\hline CHEMBL1574374 & 688644 & 5.8508 & 6.0424 & TST & & \\
\hline CHEMBL1450165 & 688644 & 2.9208 & 3.7709 & TST & & \\
\hline CHEMBL1573187 & 688644 & 4.735 & 5.0702 & TRN & & \\
\hline CHEMBL1331514 & 688644 & 8.0 & 7.3714 & TRN & & \\
\hline CHEMBL1439210 & 688644 & 2.9208 & 3.9134 & TRN & & \\
\hline CHEMBL1525719 & 688644 & 2.9208 & 4.4603 & TRN & & \\
\hline CHEMBL3195389 & 688644 & 8.0 & 8.1453 & TRN & & \\
\hline CHEMBL1611686 & 688644 & 4.9705 & 3.8408 & TRN & & \\
\hline CHEMBL1497562 & 688644 & 4.9541 & 5.8994 & TRN & & \\
\hline
\end{tabular}




\begin{tabular}{|c|c|c|c|c|c|}
\hline & & \multicolumn{4}{|c|}{ Supplemental Table S2.txt } \\
\hline CHEMBL1481780 & 688644 & 4.5909 & 3.2614 & TRN & \\
\hline CHEMBL1393195 & 688644 & 6.5287 & 6.7686 & TRN & \\
\hline CHEMBL1989090 & 688644 & 5.2349 & 5.8066 & TRN & \\
\hline CHEMBL1542614 & 688644 & 4.6393 & 3.9105 & TRN & \\
\hline CHEMBL1890591 & 688644 & 5.2925 & 5.1254 & TRN & \\
\hline CHEMBL1404987 & 688644 & 5.0401 & 4.6275 & TRN & \\
\hline CHEMBL1572139 & 688644 & 8.0 & 5.1267 & TRN & \\
\hline CHEMBL 251785 & 688644 & 8.0 & 7.1941 & TRN & \\
\hline CHEMBL 1372738 & 688644 & 2.9208 & 3.2596 & TRN & \\
\hline CHEMBL1376031 & 688644 & 2.9208 & 3.2717 & TRN & \\
\hline CHEMBL1541251 & 688644 & 5.0069 & 5.20299 & 9999999999 & TRN \\
\hline CHEMBL1305052 & 688644 & 2.9208 & 4.2383 & TRN & \\
\hline CHEMBL585591 & 688644 & 8.0 & 7.9335 & TST & \\
\hline CHEMBL1575194 & 688644 & 2.9208 & 3.7935 & TRN & \\
\hline CHEMBL1444941 & 688644 & 4.2485 & 3.66399 & 99999999997 & TRN \\
\hline CHEMBL1441086 & 688644 & 3.972 & 3.142 & TRN & \\
\hline CHEMBL1538920 & 688644 & 2.9208 & 3.8712 & TRN & \\
\hline CHEMBL3197908 & 688644 & 5.0318 & 4.7877 & TRN & \\
\hline CHEMBL1511499 & 688644 & 2.9208 & 3.792 & TST & \\
\hline CHEMBL1993501 & 688644 & 5.0347 & 4.4437 & TRN & \\
\hline CHEMBL1301576 & 688644 & 4.7505 & 5.1869 & TRN & \\
\hline CHEMBL1414867 & 688644 & 4.9064 & 4.5556 & TRN & \\
\hline CHEMBL1407086 & 688644 & 2.9208 & 2.589 & TRN & \\
\hline CHEMBL1506317 & 688644 & 5.2781 & 5.3727 & TRN & \\
\hline CHEMBL1278035 & 688644 & 5.0495 & 5.2097 & TRN & \\
\hline CHEMBL1376974 & 688644 & 8.0 & 6.0479 & TST & \\
\hline CHEMBL1572510 & 688644 & 5.0496 & 4.8342 & TRN & \\
\hline CHEMBL1539864 & 688644 & 4.9069 & 4.3861 & TRN & \\
\hline CHEMBL1496714 & 688644 & 4.35 & 3.687 & TST & \\
\hline CHEMBL1603905 & 688644 & 2.9208 & 4.1852 & TRN & \\
\hline CHEMBL1576248 & 688644 & 4.7605 & 4.1008 & TRN & \\
\hline CHEMBL1384729 & 688644 & 4.7052 & 5.0282 & TRN & \\
\hline CHEMBL1476556 & 688644 & 2.9208 & 5.4151 & TRN & \\
\hline CHEMBL1450889 & 688644 & 4.5509 & 3.5642 & TRN & \\
\hline CHEMBL1352168 & 688644 & 5.3582 & 5.3091 & TRN & \\
\hline CHEMBL1522618 & 688644 & 3.2218 & 3.3021 & TRN & \\
\hline CHEMBL1464180 & 688644 & 5.5701 & 5.1235 & TRN & \\
\hline CHEMBL1494106 & 688644 & 2.9208 & 3.4095 & TRN & \\
\hline CHEMBL1321427 & 688644 & 8.0 & 8.3445 & TRN & \\
\hline CHEMBL1311981 & 688644 & 2.9208 & 3.1431 & TST & \\
\hline CHEMBL1469224 & 688644 & 5.1348 & 4.9405 & TRN & \\
\hline CHEMBL1500397 & 688644 & 4.8222 & 3.989 & TRN & \\
\hline CHEMBL417727 & 688644 & 2.9208 & 4.8082 & TRN & \\
\hline CHEMBL259507 & 688644 & 2.9208 & 4.481 & TRN & \\
\hline CHEMBL1446892 & 688644 & 4.074 & 3.5928 & TRN & \\
\hline CHEMBL1385847 & 688644 & 2.9208 & 4.6261 & TRN & \\
\hline CHEMBL1491327 & 688644 & 5.7217 & 5.2436 & TRN & \\
\hline CHEMBL1366838 & 688644 & 5.0865 & 4.8979 & TRN & \\
\hline
\end{tabular}


Supplemental Table S2.txt

\begin{tabular}{|c|c|c|c|c|}
\hline CHEMBL1585423 & 688644 & 3.9771 & 4.7801 & TST \\
\hline CHEMBL1403165 & 688644 & 2.9208 & 3.3605 & TRN \\
\hline CHEMBL1403919 & 688644 & 4.30399 & 79999999 & 4.1685 \\
\hline CHEMBL1341301 & 688644 & 2.9208 & 3.3649 & TRN \\
\hline CHEMBL1560092 & 688644 & 2.9208 & 3.9594 & TRN \\
\hline CHEMBL1580220 & 688644 & 4.3294 & 4.2107 & TRN \\
\hline CHEMBL1583867 & 688644 & 2.9208 & 3.8888 & TRN \\
\hline CHEMBL1345528 & 688644 & 2.9208 & 4.1614 & TRN \\
\hline CHEMBL1492289 & 688644 & 2.9208 & 4.6995 & TRN \\
\hline CHEMBL1353180 & 688644 & 4.7581 & 3.0888 & TST \\
\hline CHEMBL1611644 & 688644 & 2.9208 & 4.328 & TRN \\
\hline CHEMBL1418432 & 688644 & 5.2 & 4.9407 & TRN \\
\hline CHEMBL1312568 & 688644 & 5.4456 & 4.9508 & TRN \\
\hline CHEMBL1578216 & 688644 & 4.8002 & 4.6333 & TRN \\
\hline CHEMBL1311879 & 688644 & 5.1272 & 5.5234 & TRN \\
\hline CHEMBL3197793 & 688644 & 2.9208 & 3.7363 & TRN \\
\hline CHEMBL1497927 & 688644 & 2.9208 & 5.1582 & TRN \\
\hline CHEMBL1406488 & 688644 & 2.9208 & 4.0007 & TRN \\
\hline CHEMBL1441866 & 688644 & 4.9052 & 5.1159 & TRN \\
\hline CHEMBL1490905 & 688644 & 2.9208 & 4.3524 & TRN \\
\hline CHEMBL1487635 & 688644 & 4.9394 & 4.7456 & TRN \\
\hline CHEMBL1541717 & 688644 & 2.9208 & 3.0656 & TRN \\
\hline CHEMBL1497821 & 688644 & 2.9208 & 3.1455 & TRN \\
\hline CHEMBL1532762 & 688644 & 2.9208 & 4.5132 & TRN \\
\hline CHEMBL1564302 & 688644 & 4.0022 & 3.8751 & TST \\
\hline CHEMBL405110 & 688644 & 5.2629 & 5.4233 & TST \\
\hline CHEMBL1470919 & 688644 & 2.9208 & 4.1078 & TRN \\
\hline CHEMBL1423060 & 688644 & 5.0808 & 5.1149 & TRN \\
\hline CHEMBL1467220 & 688644 & 2.9208 & 3.3908 & TST \\
\hline CHEMBL1568933 & 688644 & 4.934 & 5.1946 & TRN \\
\hline CHEMBL1372889 & 688644 & 8.0 & 7.3842 & TRN \\
\hline CHEMBL1563424 & 688644 & 2.9208 & 3.9796 & TRN \\
\hline CHEMBL1525771 & 688644 & 5.0344 & 4.8511 & TRN \\
\hline CHEMBL1557333 & 688644 & 4.7757 & 4.4392 & TRN \\
\hline CHEMBL3211923 & 688644 & 4.9452 & 5.295 & TRN \\
\hline CHEMBL3039774 & 688644 & 2.9208 & 3.7434 & TST \\
\hline CHEMBL1432186 & 688644 & 2.9208 & 4.0654 & TRN \\
\hline CHEMBL1529404 & 688644 & 6.3036 & 5.98600 & 0000000001 \\
\hline CHEMBL1537098 & 688644 & 8.0 & 6.3042 & TRN \\
\hline CHEMBL1594171 & 688644 & 4.9431 & 5.3111 & TRN \\
\hline CHEMBL1466251 & 688644 & 2.9208 & 3.84 & TRN \\
\hline CHEMBL1540713 & 688644 & 2.9208 & 3.5241 & TRN \\
\hline CHEMBL1508373 & 688644 & 2.9208 & 3.2359 & TRN \\
\hline CHEMBL3211050 & 688644 & 5.0007 & 4.1561 & TRN \\
\hline CHEMBL1590016 & 688644 & 6.3778 & 5.0284 & TRN \\
\hline CHEMBL1491222 & 688644 & 6.7167 & 6.8259 & TRN \\
\hline CHEMBL1446095 & 688644 & 2.9208 & 4.6681 & TRN \\
\hline CHEMBL1447284 & 688644 & 8.0 & 5.8784 & TRN \\
\hline
\end{tabular}




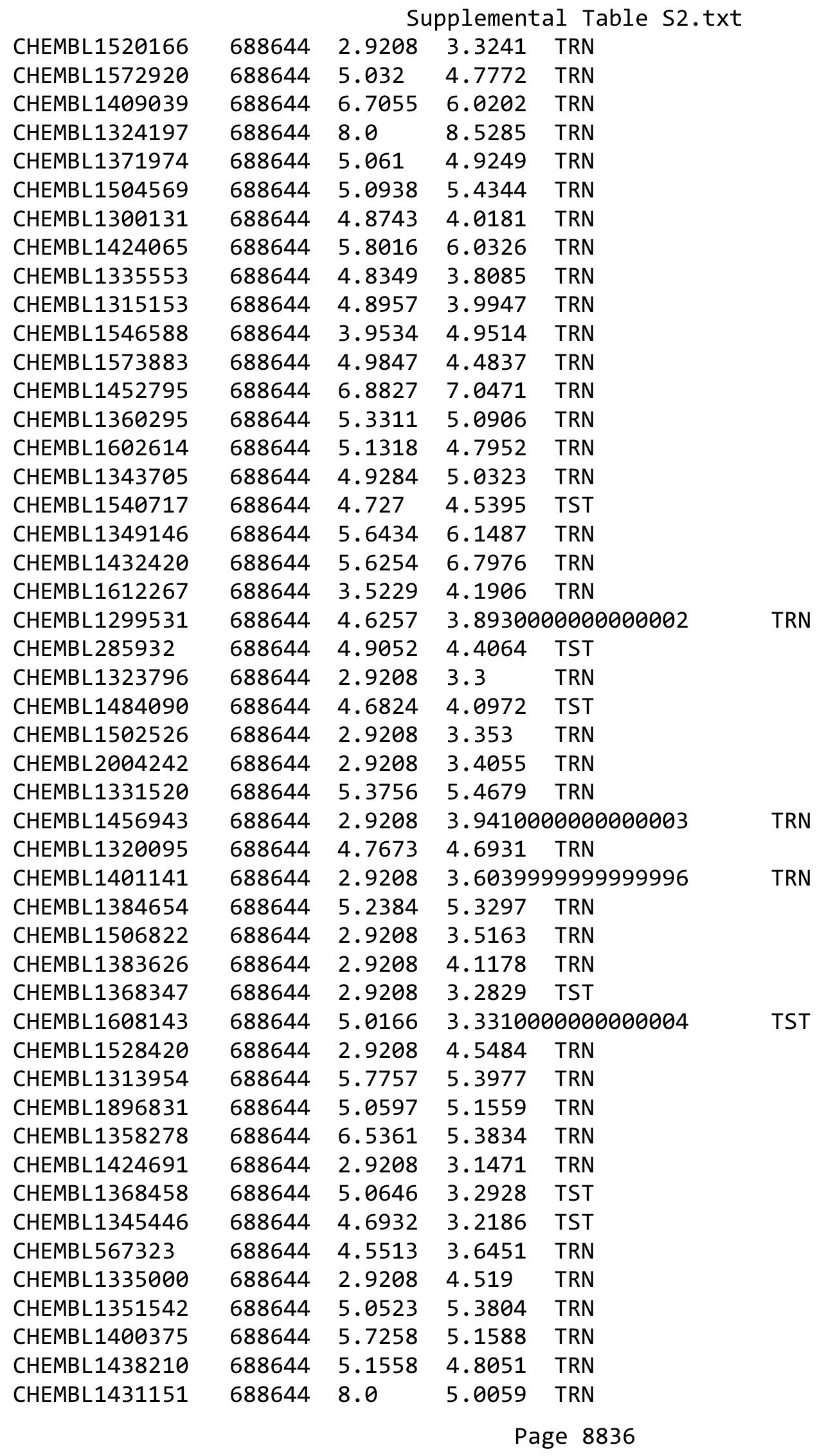




\begin{tabular}{|c|c|c|c|c|c|}
\hline & & \multicolumn{4}{|c|}{ Supplemental Table S2.txt } \\
\hline CHEMBL3209663 & 688644 & 4.843 & 4.9564 & TST & \\
\hline CHEMBL1522827 & 688644 & 5.4464 & 5.7016 & TRN & \\
\hline CHEMBL1333962 & 688644 & 2.9208 & 4.8288 & TRN & \\
\hline CHEMBL1502608 & 688644 & 2.9208 & 3.46100 & 00000000003 & TRN \\
\hline CHEMBL1421255 & 688644 & 5.3517 & 5.6446 & TRN & \\
\hline CHEMBL1371395 & 688644 & 5.2244 & 5.0314 & TRN & \\
\hline CHEMBL1505057 & 688644 & 5.0135 & 3.8752 & TRN & \\
\hline CHEMBL1364877 & 688644 & 4.4643 & 4.1857 & TRN & \\
\hline CHEMBL1559811 & 688644 & 6.8182 & 6.8514 & TRN & \\
\hline CHEMBL1349834 & 688644 & 2.9208 & 3.5102 & TRN & \\
\hline CHEMBL1417651 & 688644 & 2.9208 & 4.1165 & TRN & \\
\hline CHEMBL1467873 & 688644 & 4.817 & 4.0233 & TST & \\
\hline CHEMBL1546992 & 688644 & 2.9208 & 3.4593 & TST & \\
\hline CHEMBL1490339 & 688644 & 7.71 & 7.3446 & TRN & \\
\hline CHEMBL1528118 & 688644 & 6.4318 & 5.055 & TRN & \\
\hline CHEMBL1887153 & 688644 & 6.0106 & 6.4626 & TRN & \\
\hline CHEMBL1325260 & 688644 & 4.5445 & 4.8375 & TRN & \\
\hline CHEMBL1386406 & 688644 & 2.9208 & 3.2855 & TRN & \\
\hline CHEMBL1417099 & 688644 & 5.159 & 5.5567 & TST & \\
\hline CHEMBL3193600 & 688644 & 5.0007 & 5.3067 & TRN & \\
\hline CHEMBL1561380 & 688644 & 3.9244 & 3.7569 & TST & \\
\hline CHEMBL1475302 & 688644 & 4.8701 & 3.853 & TRN & \\
\hline CHEMBL1377218 & 688644 & 4.2266 & 3.1776 & TRN & \\
\hline CHEMBL1526855 & 688644 & 2.9208 & 5.0122 & TRN & \\
\hline CHEMBL3191594 & 688644 & 5.0952 & 5.5315 & TRN & \\
\hline CHEMBL1496595 & 688644 & 4.9094 & 4.79899 & 99999999995 & TRN \\
\hline CHEMBL1336728 & 688644 & 2.9208 & 4.2253 & TRN & \\
\hline CHEMBL1586266 & 688644 & 4.9913 & 4.0284 & TRN & \\
\hline CHEMBL1319679 & 688644 & 5.1358 & 5.1418 & TRN & \\
\hline CHEMBL3192251 & 688644 & 5.1134 & 5.435 & TRN & \\
\hline CHEMBL1566664 & 688644 & 4.8552 & 3.3242 & TRN & \\
\hline CHEMBL579322 & 688644 & 4.9815 & 5.1276 & TRN & \\
\hline CHEMBL1471345 & 688644 & 2.9208 & 4.2834 & TRN & \\
\hline CHEMBL1419031 & 688644 & 6.556 & 6.0627 & TRN & \\
\hline CHEMBL1420007 & 688644 & 4.8698 & 5.4023 & TST & \\
\hline CHEMBL1299526 & 688644 & 2.9208 & 4.6771 & TRN & \\
\hline CHEMBL1507107 & 688644 & 2.9208 & 4.6092 & TRN & \\
\hline CHEMBL1427494 & 688644 & 4.71 & 4.6337 & TRN & \\
\hline CHEMBL1576489 & 688644 & 4.94600 & 00000000 & 3.3653 & TRN \\
\hline CHEMBL1464327 & 688644 & 4.8326 & 4.8812 & TST & \\
\hline CHEMBL1320575 & 688644 & 2.9208 & 4.0076 & TRN & \\
\hline CHEMBL1387436 & 688644 & 5.4666 & 5.1745 & TRN & \\
\hline CHEMBL1477635 & 688644 & 2.9208 & 3.4717 & TRN & \\
\hline CHEMBL1567944 & 688644 & 8.0 & 7.7934 & TST & \\
\hline CHEMBL1332529 & 688644 & 4.6236 & 3.9379 & TRN & \\
\hline CHEMBL1570761 & 688644 & 4.7765 & 4.0398 & TRN & \\
\hline CHEMBL3190911 & 688644 & 5.0094 & 4.5805 & TRN & \\
\hline CHEMBL1585682 & 688644 & 6.7986 & 6.7114 & TRN & \\
\hline
\end{tabular}


Supplemental Table S2.txt

\begin{tabular}{|c|c|c|c|c|c|}
\hline CHEMBL1378991 & 688644 & 2.9208 & 3.8634 & TRN & \\
\hline CHEMBL1457419 & 688644 & 3.9234 & 5.0651 & TST & \\
\hline CHEMBL1587732 & 688644 & 2.9208 & 3.56699 & 9999999997 & TRN \\
\hline CHEMBL1576870 & 688644 & 8.0 & 6.9699 & TRN & \\
\hline CHEMBL1548803 & 688644 & 2.9208 & 5.2546 & TRN & \\
\hline CHEMBL1417732 & 688644 & 5.1641 & 5.0249 & TRN & \\
\hline CHEMBL1313968 & 688644 & 6.4802 & 4.7851 & TRN & \\
\hline CHEMBL1399543 & 688644 & 6.8861 & 5.0951 & TRN & \\
\hline CHEMBL1453067 & 688644 & 4.914 & 4.6472 & TRN & \\
\hline CHEMBL1468277 & 688644 & 5.0106 & 5.1737 & TRN & \\
\hline CHEMBL1526550 & 688644 & 2.9208 & 3.7174 & TRN & \\
\hline CHEMBL1986425 & 688644 & 5.0743 & 5.012 & TRN & \\
\hline CHEMBL1315224 & 688644 & 4.9412 & 5.1853 & TRN & \\
\hline CHEMBL1556891 & 688644 & 5.0781 & 4.2906 & TRN & \\
\hline CHEMBL1383035 & 688644 & 2.9208 & 4.2043 & TRN & \\
\hline CHEMBL1603001 & 688644 & 2.9208 & 3.6231 & TRN & \\
\hline CHEMBL1506364 & 688644 & 2.9208 & 4.2241 & TST & \\
\hline CHEMBL1492266 & 688644 & 4.0456 & 4.6255 & TRN & \\
\hline CHEMBL1305809 & 688644 & 2.9208 & 3.746006 & 0000000004 & TRN \\
\hline CHEMBL1318757 & 688644 & 2.9208 & 4.4366 & TRN & \\
\hline CHEMBL1355327 & 688644 & 2.9208 & 3.1139 & TRN & \\
\hline CHEMBL3212029 & 688644 & 6.341 & 5.78100 & 000000001 & TRN \\
\hline CHEMBL1333534 & 688644 & 6.4634 & 3.2219 & TRN & \\
\hline CHEMBL1334514 & 688644 & 6.8447 & 6.2579 & TRN & \\
\hline CHEMBL1310144 & 688644 & 6.3958 & 5.7329 & TRN & \\
\hline CHEMBL1484169 & 688644 & 2.9208 & 4.3357 & TST & \\
\hline CHEMBL1389184 & 688644 & 2.9208 & 3.2348 & TRN & \\
\hline CHEMBL1582620 & 688644 & 2.9208 & 3.3247 & TRN & \\
\hline CHEMBL1401973 & 688644 & 2.9208 & 4.4312 & TRN & \\
\hline CHEMBL1305304 & 688644 & 8.0 & 6.8756 & TRN & \\
\hline CHEMBL1386429 & 688644 & 4.5804 & 4.8441 & TRN & \\
\hline CHEMBL 270605 & 688644 & 2.9208 & 4.7736 & TRN & \\
\hline CHEMBL1566335 & 688644 & 2.9208 & 3.9731 & TRN & \\
\hline CHEMBL1421941 & 688644 & 6.0521 & 5.4582 & TRN & \\
\hline CHEMBL1488346 & 688644 & 4.4114 & 3.9715 & TRN & \\
\hline CHEMBL 248654 & 688644 & 4.4728 & 3.2039 & TRN & \\
\hline CHEMBL1471808 & 688644 & 5.0737 & 4.6264 & TRN & \\
\hline CHEMBL1546279 & 688644 & 5.0914 & 4.9053 & TRN & \\
\hline CHEMBL1437052 & 688644 & 5.0891 & 4.3384 & TRN & \\
\hline CHEMBL1604735 & 688644 & 5.0727 & 3.2088 & TRN & \\
\hline CHEMBL1312371 & 688644 & 2.9208 & 3.3085 & TST & \\
\hline CHEMBL1485659 & 688644 & 2.9208 & 3.341 & TRN & \\
\hline CHEMBL1377352 & 688644 & 2.9208 & 3.2659 & TRN & \\
\hline CHEMBL1377699 & 688644 & 6.6021 & 5.0819 & TRN & \\
\hline CHEMBL1322645 & 688644 & 2.9208 & 4.8811 & TRN & \\
\hline CHEMBL1390428 & 688644 & 2.9208 & 4.0656 & TRN & \\
\hline CHEMBL590706 & 688644 & 4.8287 & 4.8195 & TRN & \\
\hline CHEMBL1432507 & 688644 & 8.0 & 6.1446 & TRN & \\
\hline
\end{tabular}


Supplemental Table S2.txt

\begin{tabular}{|c|c|c|c|c|}
\hline & & & & \\
\hline CHEMBL1523206 & 88644 & .4675 & 5.6321 & \\
\hline HEMBL 225963 & 644 & 9208 & & \\
\hline 9196 & 3644 & & & \\
\hline IEMBL1545660 & 8644 & & & \\
\hline HEMBL269881 & 88644 & 8632 & & \\
\hline HEMBL1994623 & 88644 & 8.0 & 569 & \\
\hline HEMBL1597705 & 88644 & 9572 & & \\
\hline EMBL1472773 & 38644 & .023 & & \\
\hline EMBL17639 & 38644 & & & \\
\hline AEMBL1455309 & 88644 & 9208 & & \\
\hline HEMBL1375597 & 88644 & 1.959 & & \\
\hline HEMBL1358906 & 88644 & & & \\
\hline IEMBL32 & 38644 & 2.9208 & & \\
\hline AEMBL] & 88644 & & & \\
\hline AEMBL1579084 & 88644 & 5.1584 & & \\
\hline HEMBL1600977 & 88644 & & & \\
\hline HEMBL13 & 88644 & 4. & & \\
\hline EMMBL1 & 88644 & 43 & & \\
\hline HEMBL] & 88644 & & & \\
\hline IEMBL321 & 88644 & 746 & & \\
\hline AEMBL1333491 & 644 & 4. & & \\
\hline HEMBL1C & 588644 & 5.267 & & \\
\hline AEMBL5: & 88644 & $+\perp$ & & \\
\hline AEMB & 88644 & & & \\
\hline 5792 & 88644 & 3508 & & \\
\hline AEMBL1389225 & 88644 & 28 & & ST \\
\hline IEMBL46 & 38644 & 8 & & \\
\hline IEMB & 44 & 98 & & \\
\hline 31 & 88644 & 82 & & RIV \\
\hline 243 & 88644 & & & \\
\hline HEMBL1978733 & 88644 & 5.0963 & & \\
\hline AEMBL: & 4 & & & RI \\
\hline 6 & 4 & & & \\
\hline 5 & 44 & 8 & & RN \\
\hline EMBL1491827 & 88644 & 3.92 & & \\
\hline AEMBL1402510 & 88644 & & & \\
\hline 5 & & & & $\mathrm{RI}$ \\
\hline 2 & 4 & 8 & & \\
\hline & & & & $\mathrm{RN}$ \\
\hline IEMBL1418885 & 88644 & .9208 & & \\
\hline AEMBL] & 88644 & 08 & & \\
\hline CHEME & & & & \\
\hline HEMBLI & 88644 & & & \\
\hline HEMBL13 & & & & $\mathrm{R}$ \\
\hline AEMBL1S & 38644 & .1948 & & \\
\hline HEMBL $]$ & & 4.42 & & \\
\hline CHEMBL148103 & & & 4.3088 & \\
\hline
\end{tabular}

Page 8839 
Supplemental Table S2.txt

\begin{tabular}{|c|c|c|c|c|}
\hline CHEMBL1334041 & 688644 & 2.9208 & 4.6908 & TST \\
\hline CHEMBL1353693 & 688644 & 4.2943 & 5.1367 & TRN \\
\hline CHEMBL1392356 & 688644 & 2.9208 & 4.152 & TRN \\
\hline CHEMBL1370744 & 688644 & 5.2095 & 5.2118 & TRN \\
\hline CHEMBL1417061 & 688644 & 2.9208 & 2.6703 & TRN \\
\hline CHEMBL1490480 & 688644 & 5.5501 & 3.3488 & TRN \\
\hline CHEMBL1352489 & 688644 & 6.8861 & \multicolumn{2}{|c|}{6.4910000000000005} \\
\hline CHEMBL1425823 & 688644 & 5.5109 & 5.7752 & TRN \\
\hline CHEMBL1321166 & 688644 & 4.5103 & 4.1927 & TST \\
\hline CHEMBL1343052 & 688644 & 2.9208 & 3.2024 & TRN \\
\hline CHEMBL1537452 & 688644 & 8.0 & 6.7667 & TRN \\
\hline CHEMBL181930 & 688644 & 2.9208 & 3.7152 & TRN \\
\hline CHEMBL1371264 & 688644 & 5.504 & 5.6902 & TRN \\
\hline CHEMBL1522352 & 688644 & 4.1571 & 4.303 & TRN \\
\hline CHEMBL1979536 & 688644 & 6.7799 & 6.199 & TRN \\
\hline CHEMBL1430043 & 688644 & 4.761 & 5.5577 & TRN \\
\hline CHEMBL1336644 & 688644 & 4.5748 & 4.6874 & TRN \\
\hline CHEMBL1380594 & 688644 & 2.9208 & 3.758 & TRN \\
\hline CHEMBL1321333 & 688644 & 4.0716 & 3.5773 & TRN \\
\hline CHEMBL1498913 & 688644 & 2.9208 & 3.3499 & TRN \\
\hline CHEMBL1368103 & 688644 & 8.0 & 6.3473 & TRN \\
\hline CHEMBL1384920 & 688644 & 5.021 & 4.5342 & TRN \\
\hline CHEMBL1381920 & 688644 & 4.7373 & 4.0776 & TST \\
\hline CHEMBL1307022 & 688644 & 2.9208 & 3.963 & TRN \\
\hline CHEMBL1349613 & 688644 & 2.9208 & 3.6138 & TRN \\
\hline CHEMBL1416020 & 688644 & 2.9208 & 3.2486 & TRN \\
\hline CHEMBL1521456 & 688644 & 2.9208 & 3.8128 & TRN \\
\hline CHEMBL1986081 & 688644 & 5.294 & 4.7564 & TRN \\
\hline CHEMBL1402745 & 688644 & 4.9135 & 3.9846 & TRN \\
\hline CHEMBL581152 & 688644 & 2.9208 & 3.471 & TRN \\
\hline CHEMBL1995152 & 688644 & 4.9843 & 4.8034 & TRN \\
\hline CHEMBL 2369309 & 688644 & 4.9106 & 3.5043 & TRN \\
\hline CHEMBL1319615 & 688644 & 5.0818 & 4.8196 & TRN \\
\hline CHEMBL 3190648 & 688644 & 5.3118 & \multicolumn{2}{|c|}{5.4639999999999995} \\
\hline CHEMBL1608635 & 688644 & 5.3694 & 5.3261 & TRN \\
\hline CHEMBL1468700 & 688644 & 4.8028 & 3.2333 & TRN \\
\hline CHEMBL1541657 & 688644 & 4.9252 & 3.6022 & TST \\
\hline CHEMBL1343773 & 688644 & 2.9208 & 4.4762 & TRN \\
\hline CHEMBL1454000 & 688644 & 5.1075 & \multicolumn{2}{|c|}{5.321000000000001} \\
\hline CHEMBL1467927 & 688644 & 2.9208 & 3.392 & TRN \\
\hline CHEMBL3199915 & 688644 & 5.1127 & 4.8129 & TST \\
\hline CHEMBL1403917 & 688644 & 5.0608 & 4.8854 & TRN \\
\hline CHEMBL1340698 & 688644 & 5.0539 & 5.5284 & TRN \\
\hline CHEMBL1320068 & 688644 & 4.2699 & 4.2572 & TRN \\
\hline CHEMBL1476264 & 688644 & 8.0 & 4.5352 & TRN \\
\hline CHEMBL1341889 & 688644 & 5.011 & 4.1638 & TRN \\
\hline CHEMBL1506641 & 688644 & 5.0983 & 5.2308 & TRN \\
\hline CHEMBL1304082 & 688644 & 2.9208 & 3.2259 & TRN \\
\hline
\end{tabular}




\begin{tabular}{|c|c|c|c|c|c|c|}
\hline & & \multicolumn{5}{|c|}{ Supplemental Table S2.txt } \\
\hline CHEMBL1411830 & 688644 & 4.5028 & 3.8021 & TRN & & \\
\hline CHEMBL1478639 & 688644 & 4.9592 & 4.8764 & TRN & & \\
\hline CHEMBL1321326 & 688644 & 6.8861 & 5.5088 & TRN & & \\
\hline CHEMBL1564569 & 688644 & 4.4799 & 4.4097 & TST & & \\
\hline CHEMBL1559574 & 688644 & 4.7123 & 3.2928 & TRN & & \\
\hline CHEMBL1429850 & 688644 & 6.5735 & 6.3177 & TRN & & \\
\hline CHEMBL1402900 & 688644 & \multicolumn{3}{|c|}{5.2620000000000005} & 5.1548 & TRN \\
\hline CHEMBL1477279 & 688644 & 8.0 & 7.6063 & TRN & & \\
\hline CHEMBL1334861 & 688644 & 2.9208 & 3.0616 & TRN & & \\
\hline CHEMBL1490293 & 688644 & 8.0 & 7.1062 & TRN & & \\
\hline CHEMBL1500185 & 688644 & 2.9208 & 4.1088 & TRN & & \\
\hline CHEMBL1319510 & 688644 & 2.9208 & 4.7117 & TRN & & \\
\hline CHEMBL 3190314 & 688644 & 5.2318 & 5.1077 & TRN & & \\
\hline CHEMBL1491927 & 688644 & 4.8189 & 5.0732 & TRN & & \\
\hline CHEMBL1548023 & 688644 & 2.9208 & 3.4727 & TST & & \\
\hline CHEMBL1300952 & 688644 & 6.8041 & 6.1433 & TRN & & \\
\hline CHEMBL1339546 & 688644 & 6.2175 & 5.5159 & TRN & & \\
\hline CHEMBL1497323 & 688644 & 4.8891 & 4.8878 & TRN & & \\
\hline CHEMBL1307395 & 688644 & 2.9208 & 3.1302 & TRN & & \\
\hline CHEMBL1595934 & 688644 & 5.2797 & 5.2744 & TRN & & \\
\hline CHEMBL1525939 & 688644 & 4.8397 & 5.0073 & TRN & & \\
\hline CHEMBL1543387 & 688644 & 6.4908 & 5.9744 & TRN & & \\
\hline CHEMBL589238 & 688644 & 5.0947 & 5.3889 & TRN & & \\
\hline CHEMBL1319810 & 688644 & 4.9739 & 4.7037 & TRN & & \\
\hline CHEMBL1451168 & 688644 & 2.9208 & 3.9475 & TRN & & \\
\hline CHEMBL1591302 & 688644 & 2.9208 & 3.2281 & TRN & & \\
\hline CHEMBL1407046 & 688644 & 2.9208 & 2.9968 & TRN & & \\
\hline CHEMBL1505555 & 688644 & 2.9208 & 4.275 & TRN & & \\
\hline CHEMBL1391811 & 688644 & 2.9208 & 3.9233 & TRN & & \\
\hline CHEMBL1300237 & 688644 & 6.8268 & 4.7257 & TRN & & \\
\hline CHEMBL1380880 & 688644 & 2.9208 & 3.427 & TST & & \\
\hline CHEMBL1570396 & 688644 & 2.9208 & 3.3989 & TRN & & \\
\hline CHEMBL1467326 & 688644 & \multicolumn{3}{|c|}{ 4.968999999999999 } & 4.3525 & TRN \\
\hline CHEMBL1359973 & 688644 & 2.9208 & 3.4624 & TST & & \\
\hline CHEMBL64391 & 688644 & 2.9208 & 3.9059 & TST & & \\
\hline CHEMBL3189599 & 688644 & 5.0044 & 5.6247 & TRN & & \\
\hline CHEMBL1560237 & 688644 & 8.0 & 5.6078 & TST & & \\
\hline CHEMBL1592159 & 688644 & 2.9208 & 3.4823 & TST & & \\
\hline CHEMBL1507852 & 688644 & 4.7735 & 4.0696 & TRN & & \\
\hline CHEMBL1390471 & 688644 & 2.9208 & 4.092 & TRN & & \\
\hline CHEMBL1418158 & 688644 & 2.9208 & 5.3291 & TRN & & \\
\hline CHEMBL1349435 & 688644 & 4.9219 & 4.0888 & TRN & & \\
\hline CHEMBL1557954 & 688644 & 4.7826 & 3.9978 & TRN & & \\
\hline CHEMBL1335177 & 688644 & 5.1701 & 5.1263 & TRN & & \\
\hline CHEMBL3196936 & 688644 & 5.29 & 5.5664 & TRN & & \\
\hline CHEMBL1409963 & 688644 & 5.0538 & 5.3195 & TST & & \\
\hline CHEMBL1586489 & 688644 & 8.0 & 5.5685 & TRN & & \\
\hline CHEMBL1380862 & 688644 & 4.3829 & 3.9489 & TRN & & \\
\hline
\end{tabular}




\begin{tabular}{|c|c|c|c|c|}
\hline & & & pplement & al $\mathrm{T}$ \\
\hline CHEMBL1301968 & 688644 & 4.7835 & 4.2209 & TRN \\
\hline CHEMBL1488229 & 688644 & 5.0988 & 5.558 & TRN \\
\hline CHEMBL3209229 & 688644 & 4.0186 & 5.3681 & TRN \\
\hline CHEMBL1384963 & 688644 & 2.9208 & 3.6919 & TRN \\
\hline CHEMBL607309 & 688644 & 5.0319 & 4.9969 & TRN \\
\hline CHEMBL1728993 & 688644 & 2.9208 & 3.5219 & TST \\
\hline CHEMBL1572212 & 688644 & 2.9208 & 3.3438 & TRN \\
\hline CHEMBL1469597 & 688644 & 2.9208 & 3.0875 & TRN \\
\hline CHEMBL935 & 688644 & 5.0042 & 5.1377 & TRN \\
\hline CHEMBL1360484 & 688644 & 8.0 & 6.45 & TRN \\
\hline CHEMBL1610036 & 688644 & 5.9638 & 4.7161 & TRN \\
\hline CHEMBL1563221 & 688644 & 5.07 & 4.9121 & TRN \\
\hline CHEMBL1497865 & 688644 & 2.9208 & 3.3078 & TST \\
\hline CHEMBL1300069 & 688644 & 2.9208 & 4.4703 & TRN \\
\hline CHEMBL1558903 & 688644 & 2.9208 & 3.6242 & TRN \\
\hline CHEMBL1348888 & 688644 & 5.075 & 4.1405 & TRN \\
\hline CHEMBL1563001 & 688644 & 2.9208 & 4.7546 & TRN \\
\hline CHEMBL1466145 & 688644 & 4.6998 & 3.7318 & TST \\
\hline CHEMBL1468683 & 688644 & 2.9208 & 4.224 & TRN \\
\hline CHEMBL1310617 & 688644 & 5.7303 & 5.876 & TRN \\
\hline CHEMBL1448808 & 688644 & 2.9208 & 4.479 & TRN \\
\hline CHEMBL1586806 & 688644 & 2.9208 & 3.3943 & TST \\
\hline CHEMBL1379178 & 688644 & 5.0363 & 5.2729 & TST \\
\hline CHEMBL1316074 & 688644 & 5.063 & 5.0473 & TRN \\
\hline CHEMBL1430024 & 688644 & 4.5727 & 3.38 & TRN \\
\hline CHEMBL3189243 & 688644 & 5.6568 & 4.944 & TRN \\
\hline CHEMBL34137 & 688644 & 5.0082 & 4.936 & TRN \\
\hline CHEMBL3145296 & 688644 & 6.0511 & 5.3043 & TRN \\
\hline CHEMBL1313978 & 688644 & 4.9552 & 3.865 & TRN \\
\hline CHEMBL 3210051 & 688644 & 5.0151 & 5.2499 & TRN \\
\hline CHEMBL1559622 & 688644 & 4.9823 & 4.521 & TRN \\
\hline CHEMBL1362250 & 688644 & 2.9208 & 3.7915 & TST \\
\hline CHEMBL1467233 & 688644 & 2.9208 & 4.0769 & TRN \\
\hline CHEMBL1548478 & 688644 & 2.9208 & 4.1629 & TRN \\
\hline CHEMBL1410483 & 688644 & 2.9208 & 4.7937 & TRN \\
\hline CHEMBL1429267 & 688644 & 2.9208 & 4.2893 & TRN \\
\hline CHEMBL1457201 & 688644 & 5.2931 & 5.3156 & TRN \\
\hline CHEMBL1323461 & 688644 & 4.8048 & 4.9557 & TRN \\
\hline CHEMBL3192855 & 688644 & 8.0 & 6.5498 & TRN \\
\hline CHEMBL1575038 & 688644 & 2.9208 & 4.0286 & TRN \\
\hline CHEMBL1394212 & 688644 & 4.7661 & 4.9891 & TST \\
\hline CHEMBL1353980 & 688644 & 4.9323 & 4.4159 & TST \\
\hline CHEMBL1528280 & 688644 & 4.3182 & 3.7827 & TRN \\
\hline CHEMBL580918 & 688644 & 5.1436 & 5.8728 & TRN \\
\hline CHEMBL1485006 & 688644 & 2.9208 & 3.2681 & TRN \\
\hline CHEMBL1543238 & 688644 & 6.6308 & 6.9815 & TRN \\
\hline CHEMBL1513553 & 688644 & 2.9208 & 3.7565 & TST \\
\hline CHEMBL3190770 & 688644 & 4.8619 & 3.7008 & TRN \\
\hline
\end{tabular}




\begin{tabular}{|c|c|c|c|c|c|}
\hline \multicolumn{6}{|c|}{ Supplemental Table S2.txt } \\
\hline CHEMBL1392142 & 688644 & 8.0 & 7.9467 & TRN & \\
\hline CHEMBL1578539 & 688644 & 2.9208 & 3.4511 & TST & \\
\hline CHEMBL1967256 & 688644 & 4.3683 & 4.8383 & TRN & \\
\hline CHEMBL1519030 & 688644 & 2.9208 & 3.5051 & TST & \\
\hline CHEMBL 3213030 & 688644 & 2.9208 & 2.7761 & TRN & \\
\hline CHEMBL1600993 & 688644 & 2.9208 & 3.3244 & TRN & \\
\hline CHEMBL1611614 & 688644 & 6.7447 & 6.7986 & TRN & \\
\hline CHEMBL1473676 & 688644 & 8.0 & 7.0559 & TST & \\
\hline CHEMBL1460783 & 688644 & 2.9208 & 3.7802 & TST & \\
\hline CHEMBL1480291 & 688644 & 2.9208 & 3.1557 & TRN & \\
\hline CHEMBL1603960 & 688644 & 5.0101 & 6.0241 & TRN & \\
\hline CHEMBL3209509 & 688644 & 4.3185 & 4.1558 & TRN & \\
\hline CHEMBL3213208 & 688644 & 2.9208 & 4.2436 & TRN & \\
\hline CHEMBL3198929 & 688644 & 4.8392 & 3.7287 & TRN & \\
\hline CHEMBL1611191 & 688644 & 6.4634 & 6.1225 & TRN & \\
\hline CHEMBL1455409 & 688644 & 4.8348 & 4.0676 & TRN & \\
\hline CHEMBL1542839 & 688644 & 2.9208 & 3.463 & TRN & \\
\hline CHEMBL1524994 & 688644 & 5.0522 & 5.0424 & TRN & \\
\hline CHEMBL1361645 & 688644 & 2.9208 & 3.9309 & TRN & \\
\hline CHEMBL1503983 & 688644 & 2.9208 & 4.1881 & TRN & \\
\hline CHEMBL1430097 & 688644 & 2.9208 & 4.1703 & TRN & \\
\hline CHEMBL1502410 & 688644 & 5.0436 & 4.1323 & TRN & \\
\hline CHEMBL1461934 & 688644 & 5.0173 & 4.1225 & TRN & \\
\hline CHEMBL1498999 & 688644 & 5.141 & 5.4992 & TRN & \\
\hline CHEMBL1607180 & 688644 & 4.9739 & 4.6377 & TRN & \\
\hline CHEMBL3209921 & 688644 & 2.9208 & 3.5609 & TRN & \\
\hline CHEMBL1442185 & 688644 & 3.2218 & 3.3947 & TRN & \\
\hline CHEMBL1588626 & 688644 & 2.9208 & 4.188 & TRN & \\
\hline CHEMBL1367134 & 688644 & 2.9208 & 3.2434 & TST & \\
\hline CHEMBL1306018 & 688644 & 2.9208 & 3.18899 & 99999999996 & TRN \\
\hline CHEMBL1348885 & 688644 & 4.4044 & 4.2068 & TRN & \\
\hline CHEMBL1573496 & 688644 & 2.9208 & 4.0221 & TRN & \\
\hline CHEMBL1470428 & 688644 & 4.8835 & 4.0639 & TRN & \\
\hline CHEMBL1438978 & 688644 & 4.8259 & 3.7972 & TRN & \\
\hline CHEMBL1367325 & 688644 & 4.8673 & 5.5561 & TRN & \\
\hline CHEMBL1468323 & 688644 & 8.0 & 7.4889 & TRN & \\
\hline CHEMBL175434 & 688644 & 5.0729 & 4.2773 & TRN & \\
\hline CHEMBL1992394 & 688644 & 2.9208 & 5.255 & TRN & \\
\hline CHEMBL1332139 & 688644 & 8.0 & 7.7113 & TRN & \\
\hline CHEMBL1518680 & 688644 & 2.9208 & 3.9839 & TST & \\
\hline CHEMBL1368526 & 688644 & 5.7612 & 5.9983 & TRN & \\
\hline CHEMBL1347378 & 688644 & 2.9208 & 3.22300 & 00000000003 & TRN \\
\hline CHEMBL1523369 & 688644 & 5.2986 & 5.1771 & TRN & \\
\hline CHEMBL1572256 & 688644 & 4.9608 & 5.4155 & TRN & \\
\hline CHEMBL1992943 & 688644 & 4.82 & 4.3191 & TST & \\
\hline CHEMBL1522289 & 688644 & 7.71 & 5.1657 & TRN & \\
\hline CHEMBL1451300 & 688644 & 4.1395 & 3.1734 & TRN & \\
\hline CHEMBL1501511 & 688644 & 2.9208 & 4.1583 & TRN & \\
\hline
\end{tabular}


Supplemental Table S2.txt

\begin{tabular}{|c|c|c|c|c|c|}
\hline CHEMBL1562712 & 688644 & 6.7932 & 6.9401 & TRN & \\
\hline CHEMBL1563176 & 688644 & 5.1007 & 4.279 & TRN & \\
\hline CHEMBL1416848 & 688644 & 5.3299 & 5.2744 & TRN & \\
\hline CHEMBL1416108 & 688644 & 4.7766 & 3.2041 & TRN & \\
\hline CHEMBL1999480 & 688644 & 5.1354 & 5.7866 & TRN & \\
\hline CHEMBL 3193098 & 688644 & 8.0 & 6.6622 & TRN & \\
\hline CHEMBL1422740 & 688644 & 5.0082 & 5.2379 & TRN & \\
\hline CHEMBL1412984 & 688644 & 2.9208 & 4.5494 & TRN & \\
\hline CHEMBL1310865 & 688644 & 2.9208 & 3.5291 & TRN & \\
\hline CHEMBL3193076 & 688644 & 4.8704 & 5.1873 & TST & \\
\hline CHEMBL1486465 & 688644 & 5.5075 & \multicolumn{2}{|c|}{5.553999999999999} & TRN \\
\hline CHEMBL1557240 & 688644 & 2.9208 & 3.5051 & TRN & \\
\hline CHEMBL1471010 & 688644 & 2.9208 & 3.2057 & TRN & \\
\hline CHEMBL1547087 & 688644 & 4.962 & 3.7741 & TRN & \\
\hline CHEMBL19980 & 688644 & 8.0 & 7.9115 & TST & \\
\hline CHEMBL1443472 & 688644 & 2.9208 & 3.3259 & TST & \\
\hline CHEMBL1309679 & 688644 & 4.7485 & 2.9298 & TRN & \\
\hline CHEMBL1312298 & 688644 & 4.8161 & 3.9999 & TRN & \\
\hline CHEMBL1331836 & 688644 & 6.8013 & \multicolumn{2}{|c|}{4.9430000000000005} & TST \\
\hline CHEMBL1330626 & 688644 & 4.6331 & 4.805 & TRN & \\
\hline CHEMBL1427989 & 688644 & 2.9208 & 3.8309 & TRN & \\
\hline CHEMBL3191453 & 688644 & 8.0 & 5.0033 & TRN & \\
\hline CHEMBL547101 & 688644 & 5.1535 & 4.0191 & TRN & \\
\hline CHEMBL1595938 & 688644 & 2.9208 & 5.3172 & TRN & \\
\hline CHEMBL1311526 & 688644 & 4.0931 & 5.5349 & TRN & \\
\hline CHEMBL1594756 & 688644 & 5.0683 & 5.4276 & TRN & \\
\hline CHEMBL1412681 & 688644 & 2.9208 & 2.8217 & TRN & \\
\hline CHEMBL1309450 & 688644 & 4.9144 & 4.665 & TRN & \\
\hline CHEMBL1600782 & 688644 & 2.9208 & 3.3647 & TRN & \\
\hline CHEMBL581872 & 688644 & 5.065 & 5.2204 & TST & \\
\hline CHEMBL1608294 & 688644 & 4.4933 & 3.9507 & TRN & \\
\hline CHEMBL1586352 & 688644 & 2.9208 & 3.2257 & TRN & \\
\hline CHEMBL1601488 & 688644 & 4.7625 & 4.1956 & TRN & \\
\hline CHEMBL1488591 & 688644 & 5.0956 & 4.0616 & TST & \\
\hline CHEMBL1995169 & 688644 & 4.8065 & 3.5655 & TRN & \\
\hline CHEMBL1611593 & 688644 & 2.9208 & 4.0691 & TRN & \\
\hline CHEMBL1400593 & 688644 & 2.9208 & 4.7939 & TRN & \\
\hline CHEMBL1405413 & 688644 & 4.9525 & 3.9657 & TRN & \\
\hline CHEMBL1606524 & 688644 & 4.7144 & 4.3618 & TRN & \\
\hline CHEMBL1323668 & 688644 & 8.0 & 6.3232 & TRN & \\
\hline CHEMBL1520880 & 688644 & 2.9208 & 4.2594 & TRN & \\
\hline CHEMBL1611223 & 688644 & 2.9208 & 4.3329 & TRN & \\
\hline CHEMBL 3197102 & 688644 & 5.1138 & 5.0842 & TRN & \\
\hline CHEMBL1578124 & 688644 & 2.9208 & 3.4448 & TST & \\
\hline CHEMBL1335117 & 688644 & 6.3036 & 6.9261 & TRN & \\
\hline CHEMBL3211971 & 688644 & 4.5137 & 4.5749 & TRN & \\
\hline CHEMBL1585663 & 688644 & 2.9208 & 4.6587 & TRN & \\
\hline CHEMBL1506428 & 688644 & 2.9208 & 4.0884 & TRN & \\
\hline
\end{tabular}


Supplemental Table S2.txt

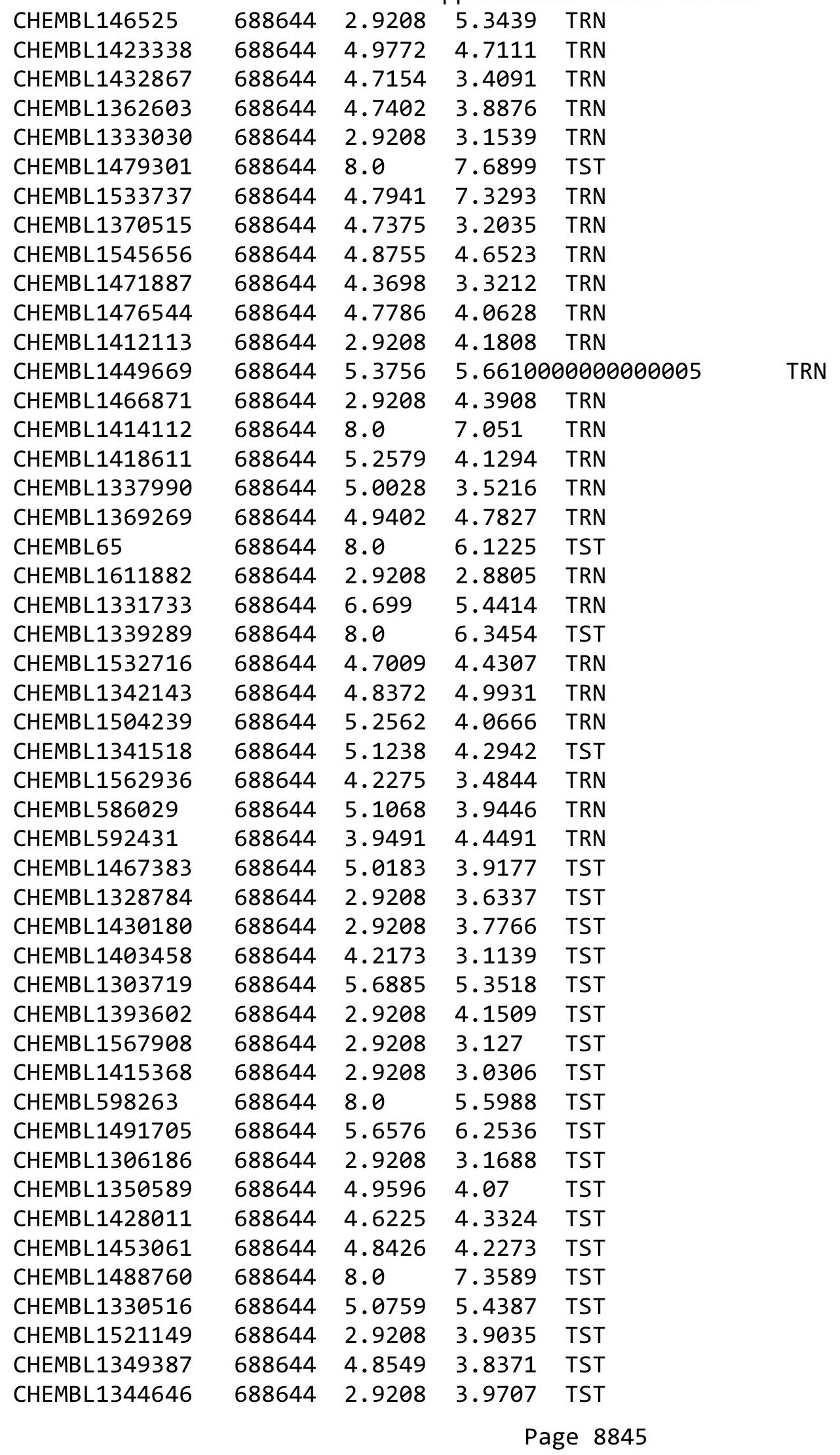




\begin{tabular}{|c|c|c|c|c|}
\hline & & & pplement & al $\mathrm{T}$ \\
\hline CHEMBL1429906 & 688644 & 4.7247 & 3.0023 & TST \\
\hline CHEMBL1495991 & 688644 & 2.9208 & 3.1264 & TST \\
\hline CHEMBL1308576 & 688644 & 4.7744 & 3.1075 & TST \\
\hline CHEMBL1465671 & 688644 & 4.9169 & 4.4776 & TST \\
\hline CHEMBL1426800 & 688644 & 2.9208 & 4.9343 & TST \\
\hline CHEMBL1415903 & 688644 & 2.9208 & 3.6515 & TST \\
\hline CHEMBL1415642 & 688644 & 2.9208 & 4.2455 & TST \\
\hline CHEMBL1441654 & 688644 & 2.9208 & 3.5935 & TST \\
\hline CHEMBL3195273 & 688644 & 6.5072 & 6.5431 & TST \\
\hline CHEMBL1365411 & 688644 & 5.0524 & 4.7231 & TST \\
\hline CHEMBL1594961 & 688644 & 5.0268 & 5.6831 & TST \\
\hline CHEMBL1533981 & 688644 & 2.9208 & 3.3731 & TST \\
\hline CHEMBL1392046 & 688644 & 2.9208 & 4.5327 & TST \\
\hline CHEMBL1581013 & 688644 & 5.0666 & 5.2607 & TST \\
\hline CHEMBL1452890 & 688644 & 2.9208 & 3.782 & TST \\
\hline CHEMBL1536942 & 688644 & 2.9208 & 3.2941 & TST \\
\hline CHEMBL1338885 & 688644 & 2.9208 & 3.2563 & TST \\
\hline CHEMBL1460639 & 688644 & 5.4647 & 5.6964 & TST \\
\hline CHEMBL1550378 & 688644 & 4.9104 & 4.0394 & TST \\
\hline CHEMBL 3190786 & 688644 & 5.0611 & 5.4467 & TST \\
\hline CHEMBL1994068 & 688644 & 4.9593 & 5.2141 & TST \\
\hline CHEMBL1464513 & 688644 & 2.9208 & 3.2126 & TST \\
\hline CHEMBL1533271 & 688644 & 2.9208 & 3.2428 & TST \\
\hline CHEMBL3197433 & 688644 & 5.0822 & 5.8884 & TST \\
\hline CHEMBL1378768 & 688644 & 4.8903 & 3.7335 & TST \\
\hline CHEMBL505209 & 688644 & 4.9364 & 5.1539 & TST \\
\hline CHEMBL1469553 & 688644 & 2.9208 & 3.1199 & TST \\
\hline CHEMBL1533711 & 688644 & 5.1414 & 4.8988 & TST \\
\hline CHEMBL1345432 & 688644 & 2.9208 & 3.2037 & TST \\
\hline CHEMBL1416171 & 688644 & 4.9491 & 4.28 & TST \\
\hline CHEMBL1500581 & 688644 & 8.0 & 6.0 & TST \\
\hline CHEMBL1462215 & 688644 & 6.2083 & 5.869 & TST \\
\hline CHEMBL1500190 & 688644 & 8.0 & 4.5393 & TST \\
\hline CHEMBL1359872 & 688644 & 8.0 & 7.5472 & TST \\
\hline CHEMBL1505359 & 688644 & 2.9208 & 5.1079 & TST \\
\hline CHEMBL1312088 & 688644 & 4.492 & 3.28 & TST \\
\hline CHEMBL1459916 & 688644 & 5.0942 & 3.9442 & TST \\
\hline CHEMBL1390234 & 688644 & 2.9208 & 3.3806 & TST \\
\hline CHEMBL1327580 & 688644 & 4.7575 & 3.9332 & TST \\
\hline CHEMBL1600287 & 688644 & 2.9208 & 3.9512 & TST \\
\hline CHEMBL1351052 & 688644 & 5.0322 & 4.8564 & TST \\
\hline CHEMBL1305231 & 688644 & 4.6582 & 3.5651 & TST \\
\hline CHEMBL1374644 & 688644 & 4.8558 & 4.5634 & TST \\
\hline CHEMBL1504403 & 688644 & 5.0219 & 5.1132 & TST \\
\hline CHEMBL3194826 & 688644 & 5.32 & 5.3927 & TST \\
\hline CHEMBL1602639 & 688644 & 2.9208 & 4.3641 & TST \\
\hline CHEMBL1331904 & 688644 & 8.0 & 5.7823 & TST \\
\hline CHEMBL1337227 & 688644 & 2.9208 & 5.2239 & TST \\
\hline
\end{tabular}


Supplemental Table S2.txt

\begin{tabular}{|c|c|c|c|c|}
\hline CHEMBL1310414 & 688644 & 4.7263 & 3.4596 & TST \\
\hline CHEMBL1609361 & 688644 & 2.9208 & 2.9729 & TST \\
\hline CHEMBL1405648 & 688644 & 2.9208 & 3.4692 & TST \\
\hline CHEMBL3199325 & 688644 & 2.9208 & 5.4244 & TST \\
\hline CHEMBL1569506 & 688644 & 4.2408 & 4.1811 & TST \\
\hline CHEMBL1440954 & 688644 & 8.0 & 7.6796 & TST \\
\hline CHEMBL1384373 & 688644 & 2.9208 & 3.8028 & TST \\
\hline CHEMBL1344206 & 688644 & 4.7944 & 3.2558 & TST \\
\hline CHEMBL1573212 & 688644 & 2.9208 & 3.12 & TST \\
\hline CHEMBL1550359 & 688644 & 4.8436 & \multicolumn{2}{|c|}{4.5760000000000005} \\
\hline CHEMBL1516860 & 688644 & 2.9208 & 3.8832 & TST \\
\hline CHEMBL1572624 & 688644 & 6.7212 & 6.0237 & TST \\
\hline CHEMBL1362086 & 688644 & 4.6387 & 3.4263 & TST \\
\hline CHEMBL1595516 & 688644 & 2.9208 & 3.1491 & TST \\
\hline CHEMBL1453857 & 688644 & 2.9208 & 4.6281 & TST \\
\hline CHEMBL1884996 & 688644 & 8.0 & 4.9278 & TST \\
\hline CHEMBL1300405 & 688644 & 2.9208 & 3.8041 & TST \\
\hline CHEMBL1377992 & 688644 & 5.5482 & 5.7204 & TST \\
\hline CHEMBL1447556 & 688644 & 2.9208 & 3.8229 & TST \\
\hline CHEMBL1383790 & 688644 & 2.9208 & 3.0874 & TST \\
\hline CHEMBL193627 & 688644 & 8.0 & 6.3969 & TST \\
\hline CHEMBL1442323 & 688644 & 2.9208 & 3.4416 & TST \\
\hline CHEMBL1532099 & 688644 & 4.6506 & 3.8379 & TST \\
\hline CHEMBL1329450 & 688644 & 4.8585 & 2.7975 & TST \\
\hline CHEMBL1560708 & 688644 & 2.9208 & 3.6732 & TST \\
\hline CHEMBL1421193 & 688644 & 4.2199 & 3.3184 & TST \\
\hline CHEMBL1450690 & 688644 & 2.9208 & 4.4636 & TST \\
\hline CHEMBL1548907 & 688644 & 4.7913 & 4.4868 & TST \\
\hline CHEMBL1419582 & 688644 & 2.9208 & 3.7958 & TST \\
\hline CHEMBL1503892 & 688644 & 4.8035 & \multicolumn{2}{|c|}{4.361000000000001} \\
\hline CHEMBL1506962 & 688644 & 4.8123 & 5.4849 & TST \\
\hline CHEMBL3191765 & 688644 & 5.075 & 6.5867 & TST \\
\hline CHEMBL1412636 & 688644 & 2.9208 & 3.7129 & TST \\
\hline CHEMBL3189905 & 688644 & 2.9208 & 3.7422 & TST \\
\hline CHEMBL1332356 & 688644 & 2.9208 & 3.3787 & TST \\
\hline CHEMBL1308451 & 688644 & 5.4316 & 4.8828 & TST \\
\hline CHEMBL1327496 & 688644 & 8.0 & 6.9818 & TST \\
\hline CHEMBL1424729 & 688644 & 5.0933 & 4.9745 & TST \\
\hline CHEMBL1989897 & 688644 & 5.5809 & 5.3127 & TST \\
\hline CHEMBL1567269 & 688644 & 8.0 & 5.2326 & TST \\
\hline CHEMBL1504701 & 688644 & 6.3478 & 6.6054 & TST \\
\hline CHEMBL1967697 & 688644 & 5.0504 & 5.0531 & TST \\
\hline CHEMBL1333930 & 688644 & 8.0 & 7.6269 & TST \\
\hline CHEMBL1361820 & 688644 & 5.0849 & 4.0228 & TST \\
\hline CHEMBL1336914 & 688644 & 4.9911 & 3.5133 & TST \\
\hline CHEMBL1478187 & 688644 & 2.9208 & 3.5675 & TST \\
\hline CHEMBL1422161 & 688644 & 8.0 & 4.4822 & TST \\
\hline CHEMBL1522194 & 688644 & 2.9208 & 4.1303 & TST \\
\hline
\end{tabular}




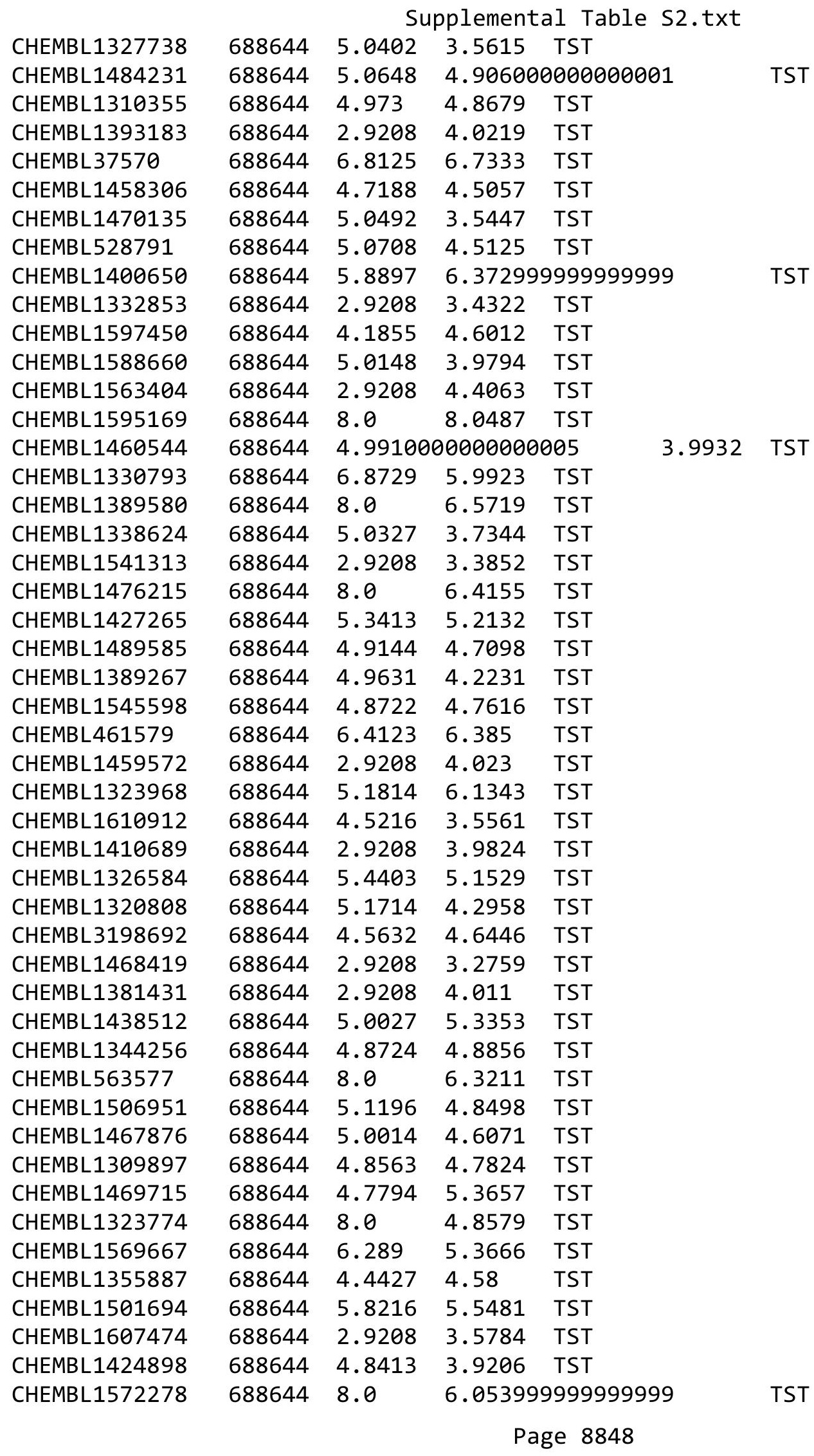


Supplemental Table S2.txt

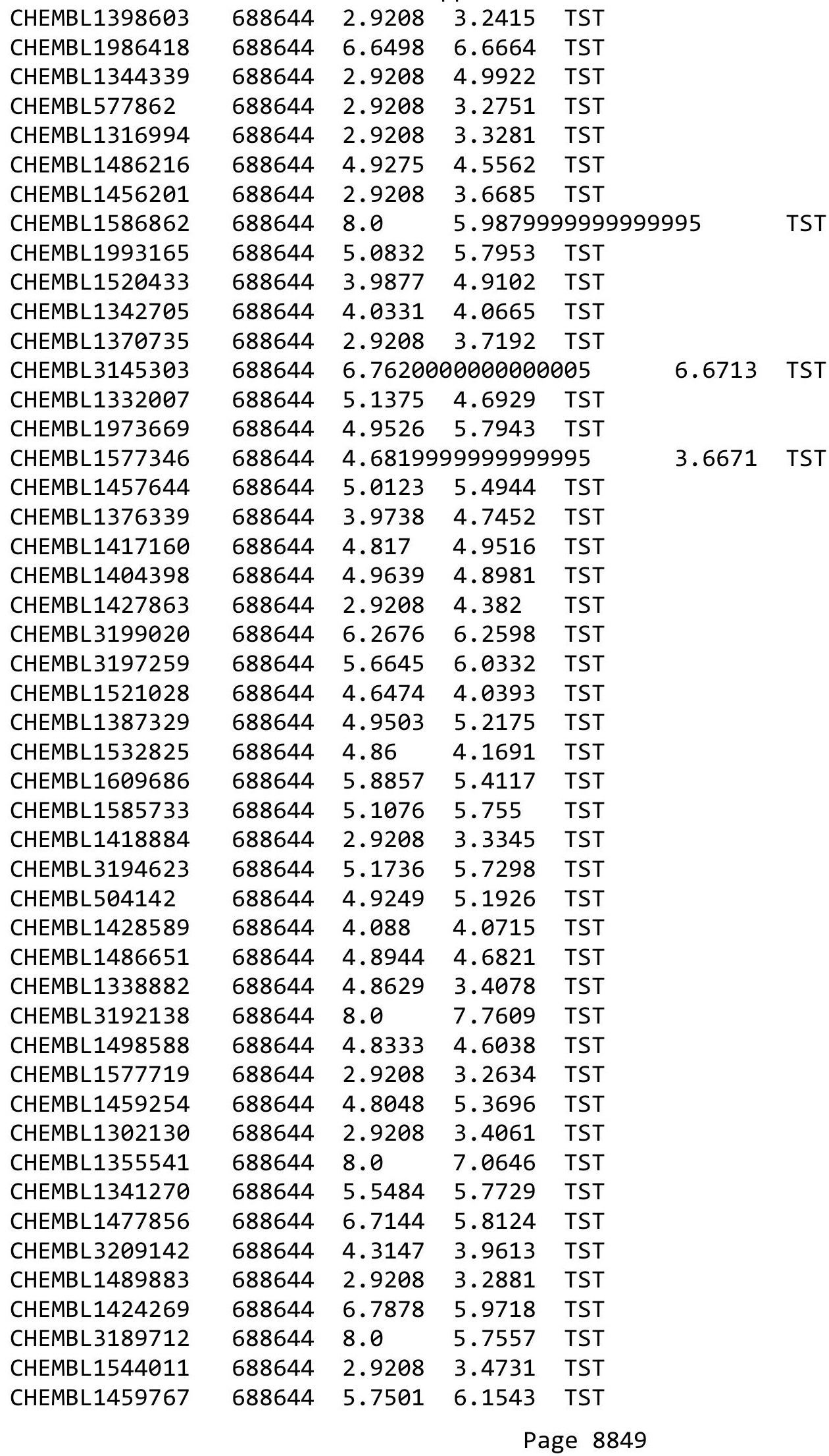


Supplemental Table S2.txt

\begin{tabular}{|c|c|c|c|c|c|}
\hline CHEMBL1531769 & 688644 & 2.9208 & 3.2108 & TST & \\
\hline CHEMBL1407944 & 688644 & 6.4855 & 5.9742 & TST & \\
\hline CHEMBL1462204 & 688644 & 2.9208 & 4.5233 & TST & \\
\hline CHEMBL1456751 & 688644 & 5.4104 & 5.7013 & TST & \\
\hline CHEMBL3192181 & 688644 & 5.5787 & 6.0468 & TST & \\
\hline CHEMBL1561439 & 688644 & 5.1005 & 4.7203 & TST & \\
\hline CHEMBL1324224 & 688644 & 4.8975 & 4.1635 & TST & \\
\hline CHEMBL1347346 & 688644 & 8.0 & 7.1873 & TST & \\
\hline CHEMBL1586200 & 688644 & 4.8208 & 3.347 & TST & \\
\hline CHEMBL1613695 & 688644 & 5.2297 & 5.3285 & TST & \\
\hline CHEMBL1598769 & 688644 & 5.9133 & 6.2452 & TST & \\
\hline CHEMBL3198754 & 688644 & 5.3325 & 5.5918 & TST & \\
\hline CHEMBL1365261 & 688644 & 2.9208 & 3.3179 & TST & \\
\hline CHEMBL1450526 & 688644 & 5.3851 & 5.8629 & TST & \\
\hline CHEMBL1429139 & 688644 & 2.9208 & 4.1327 & TST & \\
\hline CHEMBL1579505 & 688644 & 2.9208 & 4.5553 & TST & \\
\hline CHEMBL1429868 & 688644 & 2.9208 & 4.1593 & TST & \\
\hline CHEMBL1213281 & 688644 & 4.742 & 5.0009 & TST & \\
\hline CHEMBL1557894 & 688644 & 2.9208 & 3.3937 & TST & \\
\hline CHEMBL1301573 & 688644 & 5.1502 & 5.9488 & TST & \\
\hline CHEMBL1348389 & 688644 & 4.8631 & 5.4635 & TST & \\
\hline CHEMBL1483475 & 688644 & 4.9419 & 4.5199 & TST & \\
\hline CHEMBL1461748 & 688644 & 2.9208 & 3.7467 & TST & \\
\hline CHEMBL1333209 & 688644 & 2.9208 & 2.9741 & TST & \\
\hline CHEMBL1572961 & 688644 & 2.9208 & 3.2846 & TST & \\
\hline CHEMBL1301556 & 688644 & 2.9208 & 2.9571 & TST & \\
\hline CHEMBL1301260 & 688644 & 4.5768 & 4.7864 & TST & \\
\hline CHEMBL1435056 & 688644 & 4.995 & 4.86600 & 00000000005 & TST \\
\hline CHEMBL1366321 & 688644 & 5.1439 & 5.1914 & TST & \\
\hline CHEMBL1379115 & 688644 & 4.9791 & 5.1433 & TST & \\
\hline CHEMBL1536437 & 688644 & 4.5995 & 5.5479 & TST & \\
\hline CHEMBL1573311 & 688644 & 4.97199 & 99999999 & 4.4024 & TST \\
\hline CHEMBL1496096 & 688644 & 6.3143 & 5.3069 & TST & \\
\hline CHEMBL1520802 & 688644 & 2.9208 & 4.104 & TST & \\
\hline CHEMBL1362117 & 688644 & 4.7926 & 5.1947 & TST & \\
\hline CHEMBL1339433 & 688644 & 2.9208 & 3.4077 & TST & \\
\hline CHEMBL1935024 & 794421 & 3.0 & 3.0061 & TRN & \\
\hline CHEMBL1935037 & 794421 & 3.0 & 2.9436 & TRN & \\
\hline CHEMBL1935067 & 794421 & 3.0 & 3.4675 & TRN & \\
\hline CHEMBL1935057 & 794421 & 3.0 & 3.2039 & TRN & \\
\hline CHEMBL1935050 & 794421 & 3.0 & 3.2889 & TRN & \\
\hline CHEMBL1935169 & 794421 & 4.8814 & 3.2467 & TST & \\
\hline CHEMBL1935023 & 794421 & 3.0 & 2.9168 & TRN & \\
\hline CHEMBL1935017 & 794421 & 3.0 & 2.9482 & TST & \\
\hline CHEMBL1935055 & 794421 & 3.0 & 3.3839 & TRN & \\
\hline CHEMBL1935029 & 794421 & 3.0 & 3.02 & TRN & \\
\hline CHEMBL1935052 & 794421 & 4.4992 & 3.4982 & TRN & \\
\hline CHEMBL1933087 & 794421 & 3.0 & 3.0604 & TRN & \\
\hline
\end{tabular}




\begin{tabular}{|c|c|c|c|c|c|}
\hline \multicolumn{6}{|c|}{ Supplemental Table s2.txt } \\
\hline CHEMBL1935049 & 794421 & 3.0 & 3.2704 & TRN & \\
\hline CHEMBL1935040 & 794421 & 3.0 & 3.1526 & TRN & \\
\hline CHEMBL1935028 & 794421 & 3.0 & 2.9181 & TRN & \\
\hline CHEMBL1935038 & 794421 & 3.0 & 2.9472 & TST & \\
\hline CHEMBL1935058 & 794421 & 3.0 & 3.2252 & TRN & \\
\hline CHEMBL1935065 & 794421 & 4.3457 & 3.2723 & TRN & \\
\hline CHEMBL1935069 & 794421 & 4.7183 & 3.3424 & TST & \\
\hline CHEMBL1935046 & 794421 & 3.0 & 3.2857 & TRN & \\
\hline CHEMBL1935056 & 794421 & 3.0 & 3.2422 & TRN & \\
\hline CHEMBL1935021 & 794421 & 3.0 & 2.8935 & TRN & \\
\hline CHEMBL1935019 & 794421 & 3.0 & 3.3501 & TRN & \\
\hline CHEMBL1935047 & 794421 & 3.0 & 3.2444 & TRN & \\
\hline CHEMBL1935170 & 794421 & 3.0 & 3.2199 & TST & \\
\hline CHEMBL1935031 & 794421 & 3.0 & 2.9481 & TRN & \\
\hline CHEMBL1935022 & 794421 & 3.0 & 2.8738 & TRN & \\
\hline CHEMBL1935048 & 794421 & 3.0 & 3.29600 & 00000000003 & TRN \\
\hline CHEMBL1935043 & 794421 & 4.56 & 3.2431 & TRN & \\
\hline CHEMBL1935072 & 794421 & 4.6017 & 3.2847 & TST & \\
\hline CHEMBL1935051 & 794421 & 4.4037 & 3.4513 & TRN & \\
\hline CHEMBL1935042 & 794421 & 3.0 & 3.2137 & TRN & \\
\hline CHEMBL1935033 & 794421 & 3.0 & 3.1244 & TRN & \\
\hline CHEMBL1935068 & 794421 & 3.0 & 3.37 & TRN & \\
\hline CHEMBL1935171 & 794421 & 3.0 & 3.097 & TST & \\
\hline CHEMBL1935025 & 794421 & 3.0 & 2.98199 & 99999999998 & TRN \\
\hline CHEMBL1935062 & 794421 & 3.0 & 3.4225 & TRN & \\
\hline CHEMBL1935045 & 794421 & 3.0 & 3.1474 & TST & \\
\hline CHEMBL1935064 & 794421 & 3.0 & 3.3379 & TST & \\
\hline CHEMBL1935063 & 794421 & 3.0 & 3.3327 & TRN & \\
\hline CHEMBL1935070 & 794421 & 3.0 & 3.3823 & TRN & \\
\hline CHEMBL1935039 & 794421 & 3.0 & 3.085 & TRN & \\
\hline CHEMBL1935168 & 794421 & 4.3551 & 3.2816 & TST & \\
\hline CHEMBL1935172 & 794421 & 4.534 & 3.2253 & TST & \\
\hline CHEMBL1935036 & 794421 & 3.0 & 3.0463 & TRN & \\
\hline CHEMBL1935026 & 794421 & 3.0 & 3.11 & TRN & \\
\hline CHEMBL1935027 & 794421 & 3.0 & 3.2449 & TRN & \\
\hline CHEMBL1935030 & 794421 & 4.4443 & 3.0728 & TRN & \\
\hline CHEMBL1935041 & 794421 & 3.0 & 3.2496 & TRN & \\
\hline CHEMBL1935018 & 794421 & 3.0 & 3.1471 & TST & \\
\hline CHEMBL1935054 & 794421 & 3.0 & 3.2028 & TRN & \\
\hline CHEMBL1935020 & 794421 & 3.0 & 3.3325 & TRN & \\
\hline CHEMBL1935059 & 794421 & 3.0 & 3.3742 & TRN & \\
\hline CHEMBL1935035 & 794421 & 3.0 & 3.013 & TRN & \\
\hline CHEMBL1935060 & 794421 & 3.0 & 3.3583 & TST & \\
\hline CHEMBL1935053 & 794421 & 4.87 & 3.5539 & TRN & \\
\hline CHEMBL1935032 & 794421 & 3.0 & 2.9856 & TRN & \\
\hline CHEMBL1935034 & 794421 & 3.0 & 2.967 & TST & \\
\hline CHEMBL1935044 & 794421 & 3.0 & 3.1436 & TRN & \\
\hline CHEMBL1935066 & 794421 & 3.0 & 3.4249 & TRN & \\
\hline
\end{tabular}




\begin{tabular}{|c|c|c|c|c|c|c|}
\hline \multicolumn{7}{|c|}{ Supplemental Table S2.txt } \\
\hline CHEMBL1935061 & 794421 & 3.0 & 3.4043 & TST & & \\
\hline CHEMBL1935071 & 794421 & 3.0 & 3.2742 & TST & & \\
\hline CHEMBL564979 & 954282 & 4.4597 & 4.2382 & TRN & & \\
\hline CHEMBL1894615 & 954282 & 5.3635 & 5.1441 & TRN & & \\
\hline CHEMBL1727999 & 954282 & 3.284 & 3.7913 & TRN & & \\
\hline CHEMBL1420829 & 954282 & 3.284 & 3.6752 & TRN & & \\
\hline CHEMBL1731349 & 954282 & 5.8539 & 5.2638 & TRN & & \\
\hline CHEMBL1310969 & 954282 & 4.9658 & 4.3173 & TRN & & \\
\hline CHEMBL 2145116 & 954282 & 3.284 & 3.5926 & TRN & & \\
\hline CHEMBL1713163 & 954282 & 5.1925 & 4.4193 & TRN & & \\
\hline CHEMBL1409256 & 954282 & 3.284 & 3.5522 & TRN & & \\
\hline CHEMBL1302645 & 954282 & 3.284 & 4.1271 & TRN & & \\
\hline CHEMBL1980369 & 954282 & 4.4066 & 4.6474 & TRN & & \\
\hline CHEMBL1549928 & 954282 & 4.2971 & 4.3167 & TRN & & \\
\hline CHEMBL1724648 & 954282 & 4.7428 & 4.4373 & TRN & & \\
\hline CHEMBL1507339 & 954282 & 3.284 & 3.8437 & TRN & & \\
\hline CHEMBL1608989 & 954282 & 4.5091 & 4.4352 & TRN & & \\
\hline CHEMBL1578386 & 954282 & 4.8645 & 4.8382 & TRN & & \\
\hline CHEMBL1396351 & 954282 & 4.9274 & 5.439 & TRN & & \\
\hline CHEMBL1540891 & 954282 & 3.284 & 4.7368 & TST & & \\
\hline CHEMBL1387110 & 954282 & 5.1385 & 4.6101 & TRN & & \\
\hline CHEMBL1559129 & 954282 & 4.3538 & 4.512 & TRN & & \\
\hline CHEMBL1498700 & 954282 & 5.0835 & 4.1787 & TRN & & \\
\hline CHEMBL1341584 & 954282 & 3.284 & 4.4884 & TST & & \\
\hline CHEMBL1553387 & 954282 & 4.4259 & 4.0963 & TRN & & \\
\hline CHEMBL1597510 & 954282 & 3.284 & 4.7455 & TST & & \\
\hline CHEMBL1880137 & 954282 & 4.575 & 4.2831 & TST & & \\
\hline CHEMBL1465899 & 954282 & 4.9348 & 4.7427 & TRN & & \\
\hline CHEMBL1734162 & 954282 & 4.6328 & 4.4455 & TRN & & \\
\hline CHEMBL1542686 & 954282 & 4.4475 & 3.8275 & TRN & & \\
\hline CHEMBL1466979 & 954282 & 4.6276 & 4.6893 & TRN & & \\
\hline CHEMBL1307737 & 954282 & 3.284 & 3.7883 & TRN & & \\
\hline CHEMBL1906256 & 954282 & 3.284 & 4.1272 & TRN & & \\
\hline CHEMBL133283 & 954282 & 4.5799 & 4.2988 & TRN & & \\
\hline CHEMBL1418656 & 954282 & 4.5805 & 5.2019 & TRN & & \\
\hline CHEMBL1371774 & 954282 & 4.8811 & 5.4226 & TRN & & \\
\hline CHEMBL1393202 & 954282 & 4.4574 & 4.2063 & TRN & & \\
\hline CHEMBL600336 & 954282 & 4.6371 & 4.7388 & TRN & & \\
\hline CHEMBL1572375 & 954282 & 4.671 & 3.9707 & TRN & & \\
\hline CHEMBL1870296 & 954282 & 4.5575 & 4.2551 & TST & & \\
\hline CHEMBL1733762 & 954282 & 3.284 & 3.8762 & TRN & & \\
\hline CHEMBL1725406 & 954282 & 3.284 & 3.6324 & TRN & & \\
\hline CHEMBL1429543 & 954282 & 4.4177 & 4.5582 & TRN & & \\
\hline CHEMBL1578407 & 954282 & 4.3021 & 4.1505 & TRN & & \\
\hline CHEMBL1591662 & 954282 & 4.40600 & 00000000 & 01 & 3.6619 & TRN \\
\hline CHEMBL1419822 & 954282 & 5.3449 & 4.5367 & TST & & \\
\hline CHEMBL1385193 & 954282 & 4.4208 & 4.5843 & TRN & & \\
\hline CHEMBL1384419 & 954282 & 4.7582 & 4.083 & TRN & & \\
\hline
\end{tabular}




\begin{tabular}{|c|c|c|c|c|c|}
\hline \multirow[b]{2}{*}{ CHEMBL1557820 } & \multicolumn{5}{|c|}{ Supplemental Table S2.txt } \\
\hline & 954282 & 4.9658 & 5.1194 & TRN & \\
\hline CHEMBL1489605 & 954282 & 3.284 & 4.2765 & TRN & \\
\hline CHEMBL 2006607 & 954282 & 5.7721 & 4.79899 & 99999999995 & TRN \\
\hline CHEMBL1489194 & 954282 & 4.4851 & 4.0883 & TRN & \\
\hline CHEMBL1580254 & 954282 & 3.284 & 3.8131 & TRN & \\
\hline CHEMBL1573905 & 954282 & 4.3885 & 3.6676 & TRN & \\
\hline CHEMBL1346587 & 954282 & 5.433 & 5.4591 & TRN & \\
\hline CHEMBL18115 & 954282 & 4.8592 & 4.7132 & TRN & \\
\hline CHEMBL1484622 & 954282 & 4.533 & 4.2 & TRN & \\
\hline CHEMBL46703 & 954282 & 4.6546 & 4.8844 & TRN & \\
\hline CHEMBL1433926 & 954282 & 4.988 & 5.2576 & TRN & \\
\hline CHEMBL1326110 & 954282 & 5.3478 & 4.9608 & TST & \\
\hline CHEMBL1715016 & 954282 & 3.284 & 4.0238 & TRN & \\
\hline CHEMBL1598986 & 954282 & 3.284 & 4.0845 & TRN & \\
\hline CHEMBL1337622 & 954282 & 4.5854 & 4.1112 & TRN & \\
\hline CHEMBL1365476 & 954282 & 4.813 & 3.7738 & TST & \\
\hline CHEMBL1430947 & 954282 & 4.4171 & 3.858 & TST & \\
\hline CHEMBL1483252 & 954282 & 3.284 & 4.3372 & TST & \\
\hline CHEMBL1305054 & 954282 & 3.284 & 3.8453 & TST & \\
\hline CHEMBL1364747 & 954282 & 4.5432 & 4.1536 & TST & \\
\hline CHEMBL1303719 & 954282 & 4.8055 & 4.1591 & TST & \\
\hline CHEMBL1513040 & 954282 & 4.7286 & 4.6123 & TST & \\
\hline CHEMBL1544797 & 954282 & 5.2807 & 4.5547 & TST & \\
\hline CHEMBL1524734 & 954282 & 3.284 & 4.0747 & TST & \\
\hline CHEMBL1483768 & 954282 & 4.8336 & 4.5609 & TST & \\
\hline CHEMBL1466614 & 954282 & 3.284 & 3.802 & TST & \\
\hline CHEMBL1290507 & 687187 & 6.1549 & 5.8974 & TRN & \\
\hline CHEMBL1289186 & 687187 & 7.0969 & 7.1301 & TRN & \\
\hline CHEMBL1289070 & 687187 & 6.2596 & 6.1105 & TST & \\
\hline CHEMBL1290281 & 687187 & 3.301 & 3.9865 & TRN & \\
\hline CHEMBL1289071 & 687187 & 5.9393 & 5.7109 & TRN & \\
\hline CHEMBL1290398 & 687187 & 5.8996 & 5.8308 & TRN & \\
\hline CHEMBL1290064 & 687187 & 5.5918 & 5.5614 & TST & \\
\hline CHEMBL1289639 & 687187 & 6.4559 & 6.6075 & TRN & \\
\hline CHEMBL1290508 & 687187 & 6.2757 & 5.8184 & TRN & \\
\hline CHEMBL1290618 & 687187 & 6.5229 & 6.4021 & TRN & \\
\hline CHEMBL1289744 & 687187 & 6.4437 & 6.6847 & TRN & \\
\hline CHEMBL1290621 & 687187 & 6.2676 & 6.3772 & TRN & \\
\hline CHEMBL1289300 & 687187 & 6.699 & 6.8003 & TRN & \\
\hline CHEMBL1289416 & 687187 & 6.8539 & 6.5593 & TRN & \\
\hline CHEMBL1290739 & 687187 & 6.1249 & 6.3269 & TRN & \\
\hline CHEMBL1290396 & 687187 & 6.1549 & 5.8917 & TRN & \\
\hline CHEMBL1289530 & 687187 & 7.0458 & 7.2807 & TRN & \\
\hline CHEMBL1290171 & 687187 & 5.2291 & 5.2967 & TRN & \\
\hline CHEMBL1289968 & 687187 & 6.0757 & 6.404 & TRN & \\
\hline CHEMBL1289417 & 687187 & 6.699 & 6.4596 & TRN & \\
\hline CHEMBL1289851 & 687187 & 5.8697 & 6.1672 & TRN & \\
\hline CHEMBL1289068 & 687187 & 6.5528 & 5.96399 & 999999 & TRN \\
\hline & & & & 88 & \\
\hline
\end{tabular}




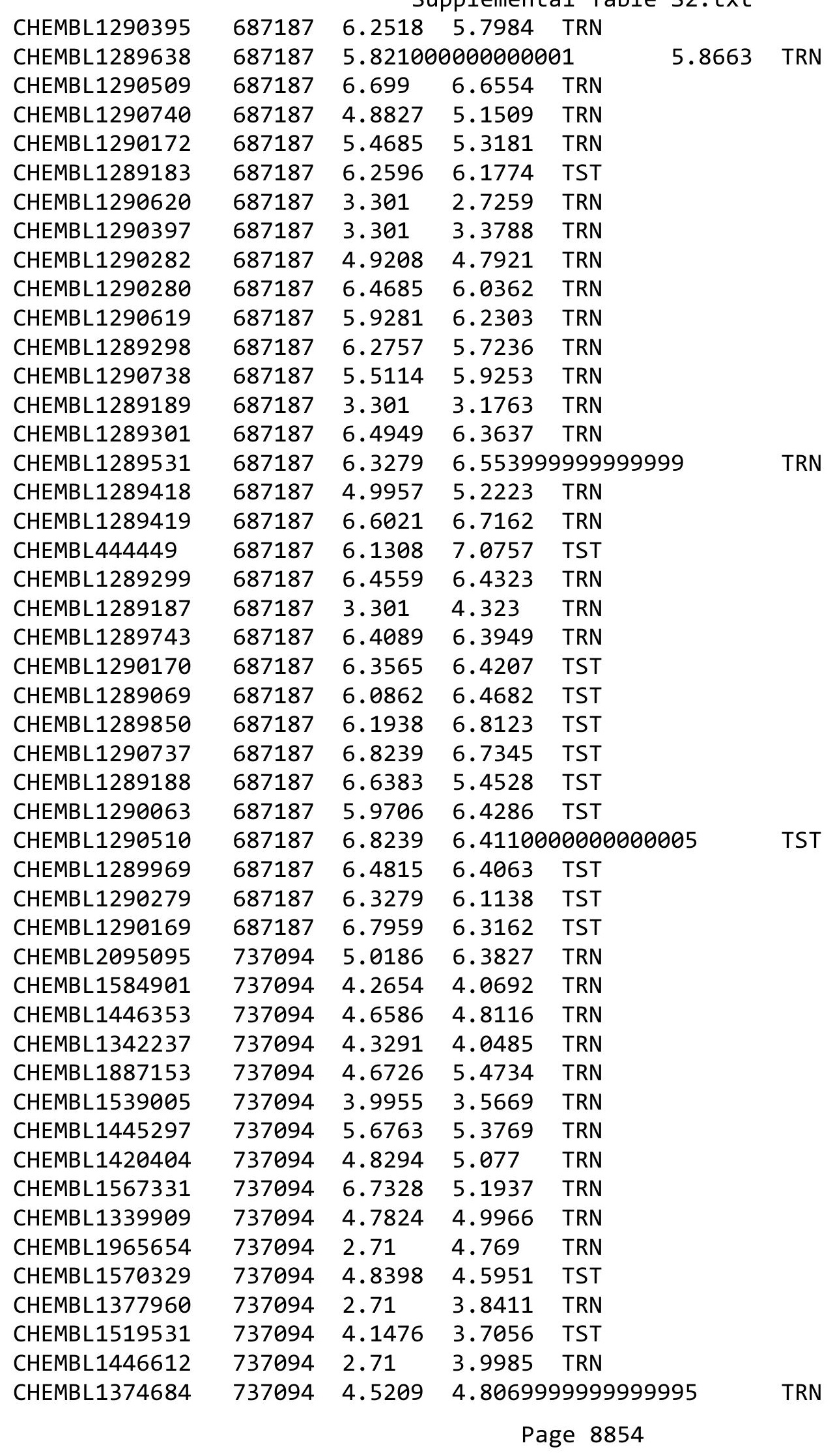




\begin{tabular}{|c|c|c|c|c|c|c|}
\hline \multicolumn{7}{|c|}{ Supplemental Table S2.txt } \\
\hline CHEMBL1459746 & 737094 & 5.7442 & 5.0646 & TRN & & \\
\hline CHEMBL1519673 & 737094 & 4.0615 & 4.4978 & TRN & & \\
\hline CHEMBL518292 & 737094 & 4.7468 & 5.1896 & TST & & \\
\hline CHEMBL1372134 & 737094 & 3.9883 & 4.2343 & TRN & & \\
\hline CHEMBL267099 & 737094 & 5.4984 & 5.21899 & 999999999 & & TST \\
\hline CHEMBL1364655 & 737094 & 4.8769 & 4.6248 & TRN & & \\
\hline CHEMBL1534182 & 737094 & 4.56 & 4.1123 & TRN & & \\
\hline CHEMBL1524433 & 737094 & 4.5908 & 3.5912 & TRN & & \\
\hline CHEMBL1327551 & 737094 & 4.3342 & 4.0353 & TRN & & \\
\hline CHEMBL567529 & 737094 & 2.71 & 3.3823 & TRN & & \\
\hline CHEMBL1369478 & 737094 & 4.7259 & 3.9433 & TST & & \\
\hline CHEMBL1517813 & 737094 & 4.0491 & 4.0971 & TRN & & \\
\hline CHEMBL1355541 & 737094 & 4.1579 & 5.87200 & 000000000 & & C \\
\hline CHEMBL1573331 & 737094 & 3.9175 & 4.4313 & TRN & & \\
\hline CHEMBL1499127 & 737094 & 4.7613 & 4.0962 & TRN & & \\
\hline CHEMBL1502300 & 737094 & 4.6376 & 4.3237 & TRN & & \\
\hline CHEMBL175434 & 737094 & 4.67399 & 99999999 & 995 & 4.9885 & \\
\hline CHEMBL 3193922 & 737094 & 6.7399 & 5.3959 & TRN & & \\
\hline CHEMBL1389474 & 737094 & 2.71 & 3.68899 & 999999999 & 96 & iv \\
\hline CHEMBL1389311 & 737094 & 4.0779 & 3.9826 & TRN & & \\
\hline CHEMBL1384904 & 737094 & 4.1654 & 4.2102 & TRN & & \\
\hline CHEMBL1482740 & 737094 & 4.2896 & 4.4227 & TRN & & \\
\hline CHEMBL1437979 & 737094 & 4.0823 & 4.4716 & TRN & & \\
\hline CHEMBL1387688 & 737094 & 5.3073 & 4.9193 & TRN & & \\
\hline CHEMBL1403959 & 737094 & 4.3789 & 3.5037 & TRN & & \\
\hline CHEMBL1428445 & 737094 & 2.71 & 3.9591 & TRN & & \\
\hline CHEMBL1301042 & 737094 & 4.5608 & 4.7695 & TRN & & \\
\hline CHEMBL1485025 & 737094 & 2.71 & 4.3966 & TRN & & \\
\hline CHEMBL 3192555 & 737094 & 5.8213 & 6.2109 & TRN & & \\
\hline CHEMBL1585742 & 737094 & 4.792 & 4.3255 & TRN & & \\
\hline CHEMBL1348808 & 737094 & 4.57100 & 00000000 & $\partial 1$ & 4.3745 & 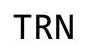 \\
\hline CHEMBL1600909 & 737094 & 3.8021 & 3.8805 & TRN & & \\
\hline CHEMBL1451228 & 737094 & 4.6633 & 4.2695 & TRN & & \\
\hline CHEMBL 3208426 & 737094 & 2.71 & 3.7762 & TRN & & \\
\hline CHEMBL1539054 & 737094 & 4.1562 & 4.824 & TRN & & \\
\hline CHEMBL3190941 & 737094 & 4.7135 & 4.6753 & TST & & \\
\hline CHEMBL1456461 & 737094 & 4.0821 & 3.5978 & TRN & & \\
\hline CHEMBL1506429 & 737094 & 2.71 & 4.3156 & TRN & & \\
\hline CHEMBL1384253 & 737094 & 5.9714 & 5.6171 & TRN & & \\
\hline CHEMBL1376120 & 737094 & 5.1696 & 4.4612 & TRN & & \\
\hline CHEMBL1497520 & 737094 & 4.5521 & 4.2709 & TRN & & \\
\hline CHEMBL1322078 & 737094 & 6.3152 & 4.5977 & TST & & \\
\hline CHEMBL1352208 & 737094 & 4.4577 & 4.4577 & TRN & & \\
\hline CHEMBL1612251 & 737094 & 2.71 & 4.1835 & TRN & & \\
\hline CHEMBL 3144830 & 737094 & 5.38399 & 99999999 & 995 & 4.4657 & $\mathrm{TH}$ \\
\hline CHEMBL1423079 & 737094 & 3.762 & 3.5541 & TRN & & \\
\hline CHEMBL1425400 & 737094 & 3.9896 & 3.8361 & TRN & & \\
\hline CHEMBL 3191749 & 737094 & 4.5726 & 4.0421 & TRN & & \\
\hline
\end{tabular}




\begin{tabular}{|c|c|c|c|c|c|c|}
\hline & & \multicolumn{5}{|c|}{ Supplemental Table S2.txt } \\
\hline CHEMBL1330717 & 737094 & 2.71 & 3.5756 & TRN & & \\
\hline CHEMBL1325900 & 737094 & 2.71 & 3.5514 & TRN & & \\
\hline CHEMBL1565115 & 737094 & 6.3487 & 5.2692 & TRN & & \\
\hline CHEMBL1400472 & 737094 & 3.7256 & 4.2727 & TRN & & \\
\hline CHEMBL1482152 & 737094 & 3.7124 & 4.0322 & TRN & & \\
\hline CHEMBL1361876 & 737094 & 4.0069 & 3.4079 & TRN & & \\
\hline CHEMBL1604712 & 737094 & 3.8151 & 3.1478 & TRN & & \\
\hline CHEMBL1415265 & 737094 & 3.8773 & 4.2275 & TRN & & \\
\hline CHEMBL1351633 & 737094 & 4.4203 & 4.0138 & TRN & & \\
\hline CHEMBL1448374 & 737094 & 4.3762 & 4.2142 & TRN & & \\
\hline CHEMBL3192358 & 737094 & 2.71 & 4.0167 & TRN & & \\
\hline CHEMBL1497165 & 737094 & 4.6449 & 4.8811 & TRN & & \\
\hline CHEMBL1987894 & 737094 & 5.7373 & 6.1106 & TRN & & \\
\hline CHEMBL1491705 & 737094 & 4.3184 & 5.0062 & TRN & & \\
\hline CHEMBL1417881 & 737094 & 3.8227 & 3.7858 & TRN & & \\
\hline CHEMBL1332524 & 737094 & 4.394 & 4.6433 & TRN & & \\
\hline CHEMBL1354126 & 737094 & 4.5831 & 4.3868 & TRN & & \\
\hline CHEMBL1494295 & 737094 & 4.4591 & 4.5414 & TRN & & \\
\hline CHEMBL1452795 & 737094 & 5.71899 & 99999999 & 99 & 5.2898 & TRN \\
\hline CHEMBL1471839 & 737094 & 4.0662 & 3.9203 & TRN & & \\
\hline CHEMBL1544131 & 737094 & 4.7372 & 4.4281 & TRN & & \\
\hline CHEMBL1313953 & 737094 & 3.778 & 3.4378 & TRN & & \\
\hline CHEMBL1510859 & 737094 & 4.3853 & 4.4534 & TST & & \\
\hline CHEMBL1370276 & 737094 & 4.5154 & 4.0798 & TRN & & \\
\hline CHEMBL1353696 & 737094 & 4.5661 & 4.848 & TRN & & \\
\hline CHEMBL1584874 & 737094 & 2.71 & 4.3301 & TST & & \\
\hline CHEMBL1338304 & 737094 & 4.7908 & 5.1396 & TRN & & \\
\hline CHEMBL1583965 & 737094 & 4.6574 & 4.0692 & TRN & & \\
\hline CHEMBL1558065 & 737094 & 3.8885 & 4.8057 & TRN & & \\
\hline CHEMBL1328336 & 737094 & 4.3812 & 3.9893 & TRN & & \\
\hline CHEMBL1974856 & 737094 & 4.6409 & 4.5911 & TST & & \\
\hline CHEMBL1334484 & 737094 & 4.0291 & 4.3402 & TRN & & \\
\hline CHEMBL473106 & 737094 & 4.3302 & 4.0404 & TST & & \\
\hline CHEMBL1595026 & 737094 & 4.3684 & 3.7485 & TRN & & \\
\hline CHEMBL1607115 & 737094 & 5.5864 & 3.6992 & TRN & & \\
\hline CHEMBL1302575 & 737094 & 4.079 & 4.2127 & TRN & & \\
\hline CHEMBL1331971 & 737094 & 4.5414 & 4.1723 & TRN & & \\
\hline CHEMBL1330617 & 737094 & 3.7927 & 4.0497 & TST & & \\
\hline CHEMBL261055 & 737094 & 4.3692 & 4.3005 & TRN & & \\
\hline CHEMBL1362709 & 737094 & 2.71 & 3.6873 & TST & & \\
\hline CHEMBL1496549 & 737094 & 4.6099 & 4.4275 & TRN & & \\
\hline CHEMBL1408647 & 737094 & 4.1169 & 4.165 & TRN & & \\
\hline CHEMBL1488050 & 737094 & 4.5786 & 4.7842 & TRN & & \\
\hline CHEMBL1471943 & 737094 & 4.5114 & 4.7048 & TST & & \\
\hline CHEMBL3190911 & 737094 & 6.0857 & 5.8178 & TRN & & \\
\hline CHEMBL1345979 & 737094 & 5.6091 & 4.3555 & TST & & \\
\hline CHEMBL1326249 & 737094 & 4.5221 & 5.0294 & TST & & \\
\hline CHEMBL1585086 & 737094 & 4.488 & 3.9793 & TRN & & \\
\hline
\end{tabular}




\begin{tabular}{|c|c|c|c|c|c|}
\hline \multicolumn{6}{|c|}{ Supplemental Table S2.txt } \\
\hline CHEMBL1549565 & 737094 & 3.7147 & 3.3172 & TRN & \\
\hline CHEMBL3195883 & 737094 & 4.7821 & 4.8717 & TST & \\
\hline CHEMBL1579260 & 737094 & 4.6015 & 4.3403 & TRN & \\
\hline CHEMBL1588068 & 737094 & 4.0251 & 3.70399 & 99999999997 & TRN \\
\hline CHEMBL1303557 & 737094 & 3.8695 & 4.1448 & TST & \\
\hline CHEMBL1523387 & 737094 & 4.5291 & 4.3636 & TST & \\
\hline CHEMBL1610875 & 737094 & 4.4252 & 4.7794 & TRN & \\
\hline CHEMBL1603858 & 737094 & 4.2419 & 4.5917 & TRN & \\
\hline CHEMBL1340084 & 737094 & 2.71 & 3.4148 & TRN & \\
\hline CHEMBL1534883 & 737094 & 2.71 & 3.8077 & TRN & \\
\hline CHEMBL1506355 & 737094 & 4.0486 & 4.004 & TRN & \\
\hline CHEMBL1360097 & 737094 & 4.1811 & 4.2362 & TRN & \\
\hline CHEMBL 3194789 & 737094 & 4.6331 & 3.9703 & TRN & \\
\hline CHEMBL 3211745 & 737094 & 4.4893 & 4.7869 & TRN & \\
\hline CHEMBL1461236 & 737094 & 3.9039 & 4.5951 & TRN & \\
\hline CHEMBL1300136 & 737094 & 4.654 & 4.545 & TRN & \\
\hline CHEMBL1496413 & 737094 & 4.6873 & 5.0947 & TRN & \\
\hline CHEMBL1497798 & 737094 & 3.9823 & 4.0985 & TRN & \\
\hline CHEMBL1311015 & 737094 & 4.6268 & 4.2512 & TRN & \\
\hline CHEMBL3198239 & 737094 & 4.583 & 4.7385 & TRN & \\
\hline CHEMBL1343775 & 737094 & 3.9947 & 4.2512 & TRN & \\
\hline CHEMBL1556638 & 737094 & 3.9929 & 3.9435 & TRN & \\
\hline CHEMBL1314730 & 737094 & 3.8187 & 3.99600 & 00000000004 & TRN \\
\hline CHEMBL1389407 & 737094 & 2.71 & 3.5191 & TRN & \\
\hline CHEMBL1351908 & 737094 & 2.71 & 4.0721 & TRN & \\
\hline CHEMBL1427757 & 737094 & 2.71 & 4.0141 & TRN & \\
\hline CHEMBL1309878 & 737094 & 4.6181 & 4.5607 & TRN & \\
\hline CHEMBL1468610 & 737094 & 4.5406 & 4.3435 & TRN & \\
\hline CHEMBL1371387 & 737094 & 3.7747 & 3.9693 & TRN & \\
\hline CHEMBL1544285 & 737094 & 4.6494 & 4.1939 & TRN & \\
\hline CHEMBL1346431 & 737094 & 2.71 & 4.0098 & TRN & \\
\hline CHEMBL1425525 & 737094 & 4.4846 & 5.2661 & TST & \\
\hline CHEMBL1406454 & 737094 & 4.1182 & 4.5986 & TRN & \\
\hline CHEMBL1610049 & 737094 & 5.2685 & 5.6292 & TRN & \\
\hline CHEMBL1409113 & 737094 & 6.15 & 4.7887 & TST & \\
\hline CHEMBL1544051 & 737094 & 2.71 & 3.8129 & TRN & \\
\hline CHEMBL1485676 & 737094 & 4.492 & 4.5165 & TRN & \\
\hline CHEMBL1307035 & 737094 & 3.8977 & 4.1019 & TRN & \\
\hline CHEMBL261681 & 737094 & 4.2765 & 4.2364 & TRN & \\
\hline CHEMBL1525675 & 737094 & 4.4513 & 4.4946 & TRN & \\
\hline CHEMBL1508309 & 737094 & 3.8728 & 3.7582 & TRN & \\
\hline CHEMBL1364999 & 737094 & 4.808 & 4.3059 & TRN & \\
\hline CHEMBL1505266 & 737094 & 2.71 & 4.553 & TRN & \\
\hline CHEMBL1498275 & 737094 & 3.8133 & 3.4555 & TRN & \\
\hline CHEMBL1480598 & 737094 & 4.2727 & 4.2109 & TRN & \\
\hline CHEMBL3195447 & 737094 & 4.5513 & 4.4749 & TRN & \\
\hline CHEMBL1576908 & 737094 & 3.7166 & 3.4408 & TRN & \\
\hline CHEMBL1612633 & 737094 & 4.6452 & 5.0345 & TRN & \\
\hline
\end{tabular}


Supplemental Table S2.txt

\begin{tabular}{|c|c|c|c|c|}
\hline CHEMBL1595744 & 737094 & 4.6777 & 3.8724 & TRN \\
\hline CHEMBL1303746 & 737094 & 4.4874 & 4.2341 & TRN \\
\hline CHEMBL1525118 & 737094 & 2.71 & 3.8419 & TRN \\
\hline CHEMBL1386072 & 737094 & 4.064 & 4.1988 & TRN \\
\hline CHEMBL1452379 & 737094 & 4.7589 & 4.4522 & TRN \\
\hline CHEMBL1304754 & 737094 & 4.5328 & 4.425 & TRN \\
\hline CHEMBL1410443 & 737094 & 2.71 & 3.5241 & TRN \\
\hline CHEMBL1453299 & 737094 & 4.8362 & 4.0594 & TRN \\
\hline CHEMBL1364498 & 737094 & 4.4709 & 4.6598 & TST \\
\hline CHEMBL131037 & 737094 & 5.6392 & 4.6567 & TRN \\
\hline CHEMBL1457961 & 737094 & 4.4915 & 4.3884 & TRN \\
\hline CHEMBL1379842 & 737094 & 4.2243 & 3.4919 & TRN \\
\hline CHEMBL1338438 & 737094 & 4.052 & 3.9176 & TRN \\
\hline CHEMBL1483306 & 737094 & 4.3499 & 4.3185 & TRN \\
\hline CHEMBL1373833 & 737094 & 4.2563 & 3.7453 & TRN \\
\hline CHEMBL1430935 & 737094 & 4.0563 & 4.1409 & TST \\
\hline CHEMBL1560894 & 737094 & 4.4431 & 3.9188 & TRN \\
\hline CHEMBL1462352 & 737094 & 5.8136 & 4.047 & TST \\
\hline CHEMBL1412273 & 737094 & 6.1713 & 4.8409 & TRN \\
\hline CHEMBL 273103 & 737094 & 4.3264 & 4.0088 & TRN \\
\hline CHEMBL1363796 & 737094 & 4.5872 & 4.5814 & TRN \\
\hline CHEMBL1299439 & 737094 & 4.7021 & 4.4106 & TRN \\
\hline CHEMBL1345625 & 737094 & 4.6803 & 5.1378 & TRN \\
\hline CHEMBL1509068 & 737094 & 4.5197 & 3.7277 & TRN \\
\hline CHEMBL1422749 & 737094 & 4.5612 & 4.2663 & TRN \\
\hline CHEMBL1521861 & 737094 & 4.2516 & 4.6569 & TST \\
\hline CHEMBL1492648 & 737094 & 5.7416 & 4.34399 & 9999999999 \\
\hline CHEMBL598263 & 737094 & 6.767 & 6.1475 & TRN \\
\hline CHEMBL1409544 & 737094 & 4.1214 & 4.1679 & TRN \\
\hline CHEMBL1499951 & 737094 & 4.9429 & 4.0631 & TRN \\
\hline CHEMBL1530859 & 737094 & 5.6496 & 4.6339 & TRN \\
\hline CHEMBL1469415 & 737094 & 6.0942 & 4.137 & TST \\
\hline CHEMBL1412396 & 737094 & 5.3957 & 4.5366 & TRN \\
\hline CHEMBL1520753 & 737094 & 4.7155 & 4.401 & TRN \\
\hline CHEMBL1539313 & 737094 & 2.71 & 4.1779 & TRN \\
\hline CHEMBL1504204 & 737094 & 6.3615 & 4.5098 & TRN \\
\hline CHEMBL1480112 & 737094 & 3.9157 & 4.2881 & TRN \\
\hline CHEMBL1373306 & 737094 & 4.5554 & 4.8529 & TRN \\
\hline CHEMBL1459140 & 737094 & 5.3218 & 4.6157 & TRN \\
\hline CHEMBL1484638 & 737094 & 4.1005 & 4.1356 & TRN \\
\hline CHEMBL1452484 & 737094 & 4.662 & 4.0656 & TRN \\
\hline CHEMBL1442804 & 737094 & 2.71 & 3.7553 & TRN \\
\hline CHEMBL1420145 & 737094 & 4.6185 & 4.5014 & TST \\
\hline CHEMBL1492196 & 737094 & 4.3292 & 3.8762 & TRN \\
\hline CHEMBL1415236 & 737094 & 4.6257 & 4.6085 & TRN \\
\hline CHEMBL1359575 & 737094 & 4.5289 & 4.4791 & TRN \\
\hline CHEMBL1309548 & 737094 & 5.7607 & 4.45 & TST \\
\hline CHEMBL1603156 & 737094 & 3.878 & 3.9458 & TRN \\
\hline
\end{tabular}


Supplemental Table S2.txt

\begin{tabular}{|c|c|c|c|c|c|c|}
\hline CHEMBL1403002 & 737094 & 4.1203 & 4.0379 & TRN & & \\
\hline CHEMBL1492542 & 737094 & 4.3113 & 4.244 & TRN & & \\
\hline CHEMBL1472133 & 737094 & 4.0786 & 4.0219 & TRN & & \\
\hline CHEMBL1371259 & 737094 & 4.6314 & 3.8391 & TRN & & \\
\hline CHEMBL1373574 & 737094 & 4.1029 & 3.9793 & TRN & & \\
\hline CHEMBL1549985 & 737094 & 4.8211 & 4.0434 & TRN & & \\
\hline CHEMBL1420048 & 737094 & 4.0607 & 4.1842 & TRN & & \\
\hline CHEMBL1442296 & 737094 & 4.0908 & 4.5923 & TRN & & \\
\hline CHEMBL1497562 & 737094 & 6.3936 & 5.8367 & TRN & & \\
\hline CHEMBL1304458 & 737094 & 3.9017 & 3.8631 & TRN & & \\
\hline CHEMBL1424968 & 737094 & 4.8837 & 4.0867 & TRN & & \\
\hline CHEMBL1588828 & 737094 & 2.71 & 3.572 & TRN & & \\
\hline CHEMBL1546764 & 737094 & 4.0442 & 4.015 & TRN & & \\
\hline CHEMBL1379276 & 737094 & 2.71 & 3.8477 & TRN & & \\
\hline CHEMBL1381424 & 737094 & 4.5763 & 3.5316 & TRN & & \\
\hline CHEMBL1461738 & 737094 & 5.7001 & 5.0095 & TRN & & \\
\hline CHEMBL1498509 & 737094 & 4.5848 & 4.9748 & TRN & & \\
\hline CHEMBL1460747 & 737094 & 4.2605 & 3.8052 & TRN & & \\
\hline CHEMBL1352313 & 737094 & 5.1568 & 4.8589 & TRN & & \\
\hline CHEMBL1373116 & 737094 & 4.7517 & 5.0249 & TRN & & \\
\hline CHEMBL1501680 & 737094 & 5.235 & 4.272 & TRN & & \\
\hline CHEMBL1078717 & 737094 & 2.71 & 3.1806 & TRN & & \\
\hline CHEMBL1271060 & 737094 & 4.7255 & 4.1251 & TRN & & \\
\hline CHEMBL1471123 & 737094 & $3.7910 e$ & j00000006 & 204 & 4.1833 & TS \\
\hline CHEMBL1597710 & 737094 & 3.7828 & 4.1459 & TRN & & \\
\hline CHEMBL1544067 & 737094 & 4.1434 & 3.6764 & TST & & \\
\hline CHEMBL1386484 & 737094 & 4.502 & 4.0154 & TRN & & \\
\hline CHEMBL1326371 & 737094 & 4.7482 & 5.1801 & TST & & \\
\hline CHEMBL1493620 & 737094 & 2.71 & 4.0569 & TRN & & \\
\hline CHEMBL1479920 & 737094 & 3.7161 & 4.2427 & TRN & & \\
\hline CHEMBL1424090 & 737094 & 4.2365 & 4.0536 & TRN & & \\
\hline CHEMBL1383630 & 737094 & 3.9943 & 4.2425 & TRN & & \\
\hline CHEMBL1509507 & 737094 & 3.7727 & 3.9007 & TRN & & \\
\hline CHEMBL1564577 & 737094 & 4.2212 & 4.0472 & TRN & & \\
\hline CHEMBL1300007 & 737094 & 4.4106 & 4.42 & TST & & \\
\hline CHEMBL1567944 & 737094 & 6.2604 & 6.1847 & TRN & & \\
\hline CHEMBL1347090 & 737094 & 4.7648 & 4.3089 & TRN & & \\
\hline CHEMBL1465560 & 737094 & 3.9206 & 4.0571 & TRN & & \\
\hline CHEMBL1413680 & 737094 & 4.8818 & 5.1429 & TST & & \\
\hline CHEMBL1443946 & 737094 & 5.3309 & 5.0102 & TRN & & \\
\hline CHEMBL1379782 & 737094 & 2.71 & 3.8286 & TRN & & \\
\hline CHEMBL1390074 & 737094 & 2.71 & 3.5712 & TRN & & \\
\hline CHEMBL1427778 & 737094 & 4.0085 & 4.2085 & TRN & & \\
\hline CHEMBL1310617 & 737094 & \multicolumn{3}{|c|}{6.4510000000000005} & 5.9892 & $\mathrm{TP}$ \\
\hline CHEMBL1347196 & 737094 & 4.5236 & 3.9872 & TRN & & \\
\hline CHEMBL1541037 & 737094 & 2.71 & 3.4639 & TRN & & \\
\hline CHEMBL 3194571 & 737094 & 5.7409 & 5.3831 & TST & & \\
\hline CHEMBL3197091 & 737094 & 5.3033 & 5.8722 & TRN & & \\
\hline
\end{tabular}




\begin{tabular}{|c|c|c|c|c|c|c|}
\hline \multirow[b]{2}{*}{ CHEMBL1326874 } & & \multicolumn{5}{|c|}{ Supplemental Table S2.txt } \\
\hline & 737094 & 4.6461 & 4.4568 & TRN & & \\
\hline CHEMBL1399287 & 737094 & 2.71 & 3.45899 & 99999999 & 996 & TRN \\
\hline CHEMBL1566498 & 737094 & 4.5716 & 3.7837 & TRN & & \\
\hline CHEMBL1450368 & 737094 & 3.9116 & 4.1363 & TRN & & \\
\hline CHEMBL1584852 & 737094 & 4.1908 & 4.0295 & TRN & & \\
\hline CHEMBL1403980 & 737094 & 4.6577 & 5.1671 & TRN & & \\
\hline CHEMBL1374545 & 737094 & 4.7663 & 4.3431 & TRN & & \\
\hline CHEMBL1533283 & 737094 & 3.9378 & 3.4212 & TRN & & \\
\hline CHEMBL1573883 & 737094 & 4.4424 & 4.3616 & TRN & & \\
\hline CHEMBL1495045 & 737094 & 4.6451 & 3.7677 & TRN & & \\
\hline CHEMBL1578997 & 737094 & 4.7313 & 5.1447 & TRN & & \\
\hline CHEMBL1564965 & 737094 & 2.71 & 4.2358 & TRN & & \\
\hline CHEMBL1466484 & 737094 & 4.2752 & 4.6732 & TRN & & \\
\hline CHEMBL1583576 & 737094 & 4.1449 & 4.5876 & TST & & \\
\hline CHEMBL1585441 & 737094 & 2.71 & 3.2589 & TRN & & \\
\hline CHEMBL1361720 & 737094 & 2.71 & 4.7185 & TST & & \\
\hline CHEMBL1403659 & 737094 & 4.4042 & 4.4159 & TRN & & \\
\hline CHEMBL1469311 & 737094 & 4.537 & 4.2389 & TRN & & \\
\hline CHEMBL1530126 & 737094 & 4.3454 & 3.9763 & TRN & & \\
\hline CHEMBL579318 & 737094 & 6.0501 & 5.5421 & TRN & & \\
\hline CHEMBL1388763 & 737094 & 3.0 & 4.1075 & TRN & & \\
\hline CHEMBL1545039 & 737094 & 4.6645 & 4.6328 & TST & & \\
\hline CHEMBL1322580 & 737094 & 4.6736 & 4.3775 & TRN & & \\
\hline CHEMBL1486523 & 737094 & 4.3997 & 3.8484 & TRN & & \\
\hline CHEMBL1542194 & 737094 & 4.3264 & 4.4514 & TST & & \\
\hline CHEMBL1470547 & 737094 & 2.71 & 3.7611 & TRN & & \\
\hline CHEMBL1458216 & 737094 & 4.5938 & 3.8411 & TRN & & \\
\hline CHEMBL1502138 & 737094 & 2.71 & 3.319 & TRN & & \\
\hline CHEMBL1343448 & 737094 & 4.0324 & 4.8884 & TRN & & \\
\hline CHEMBL1549128 & 737094 & 4.6551 & 4.4308 & TST & & \\
\hline CHEMBL1441868 & 737094 & 5.819 & 4.6802 & TST & & \\
\hline CHEMBL1378232 & 737094 & 4.1739 & 4.6786 & TRN & & \\
\hline CHEMBL1319020 & 737094 & 6.0511 & 4.5472 & TRN & & \\
\hline CHEMBL1537090 & 737094 & 4.3719 & 4.4904 & TRN & & \\
\hline CHEMBL1613451 & 737094 & 4.7935 & 3.8732 & TRN & & \\
\hline CHEMBL1407733 & 737094 & 4.5058 & 4.654 & TRN & & \\
\hline CHEMBL1492691 & 737094 & 4.9226 & 4.5314 & TRN & & \\
\hline CHEMBL1420507 & 737094 & 4.473 & 3.8529 & TRN & & \\
\hline CHEMBL1577355 & 737094 & 4.5855 & 4.6741 & TRN & & \\
\hline CHEMBL1503091 & 737094 & 4.8949 & 4.4446 & TRN & & \\
\hline CHEMBL1582137 & 737094 & 2.71 & 3.4627 & TRN & & \\
\hline CHEMBL1435056 & 737094 & 4.2331 & 3.8783 & TST & & \\
\hline CHEMBL1534698 & 737094 & 4.6385 & 4.1914 & TST & & \\
\hline CHEMBL1569034 & 737094 & 4.40300 & 00000000 & 005 & 3.9768 & TRN \\
\hline CHEMBL1448956 & 737094 & 4.493 & 4.6035 & TRN & & \\
\hline CHEMBL1389779 & 737094 & 4.575 & 4.1978 & TRN & & \\
\hline CHEMBL1337226 & 737094 & 4.7382 & 4.7559 & TRN & & \\
\hline CHEMBL1599251 & 737094 & 4.4411 & 3.438 & TRN & & \\
\hline
\end{tabular}




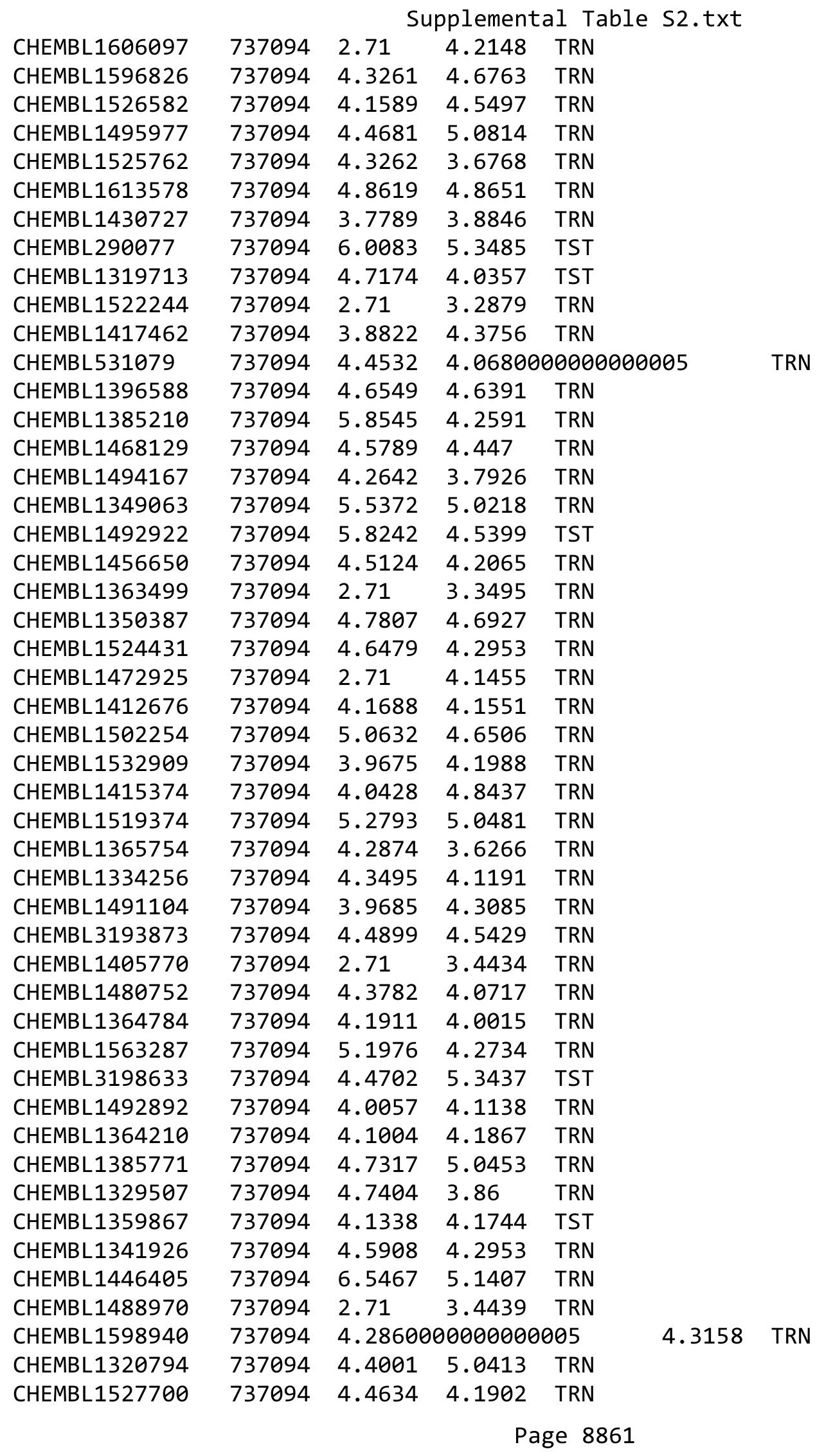




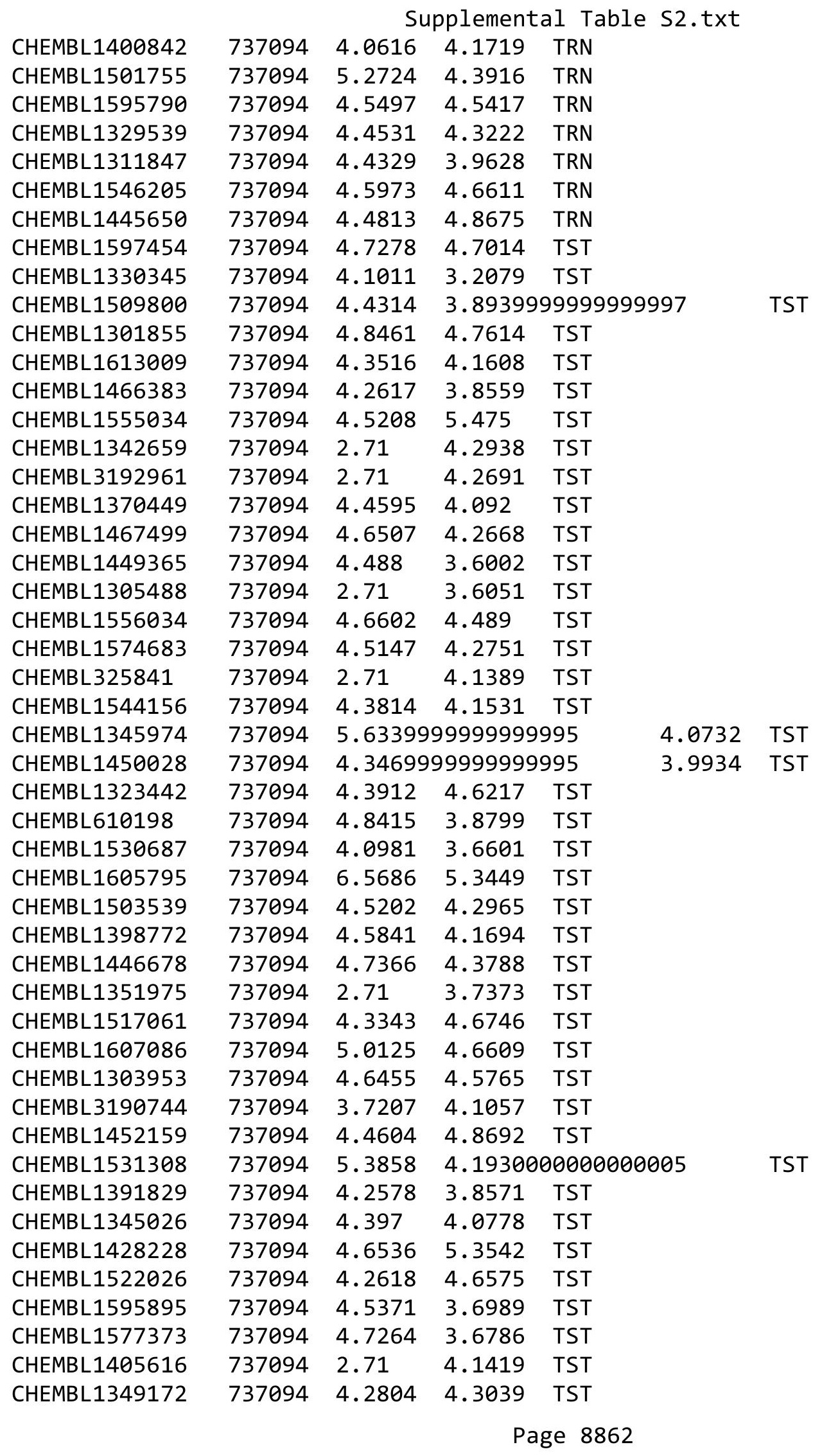




\begin{tabular}{|c|c|c|c|c|c|c|}
\hline & & \multicolumn{5}{|c|}{ Supplemental Table S2.txt } \\
\hline CHEMBL1340102 & 737094 & 3.9614 & 3.1927 & TST & & \\
\hline CHEMBL1531245 & 737094 & 4.7405 & 4.6881 & TST & & \\
\hline CHEMBL1302130 & 737094 & 6.4572 & 3.7935 & TST & & \\
\hline CHEMBL1595359 & 737094 & 3.8224 & 3.6887 & TST & & \\
\hline CHEMBL1484934 & 737094 & 4.6092 & 4.7784 & TST & & \\
\hline CHEMBL 2003964 & 737094 & 5.5219 & 4.6778 & TST & & \\
\hline CHEMBL1361821 & 737094 & 5.2497 & 4.6556 & TST & & \\
\hline CHEMBL1409883 & 737094 & 4.6728 & 4.6228 & TST & & \\
\hline CHEMBL1384702 & 737094 & 5.5393 & 5.1111 & TST & & \\
\hline CHEMBL1549202 & 737094 & 4.248 & 4.8704 & TST & & \\
\hline CHEMBL1503463 & 737094 & 4.4635 & 4.1781 & TST & & \\
\hline CHEMBL1399680 & 737094 & 4.4046 & 3.9918 & TST & & \\
\hline CHEMBL3191763 & 737094 & 6.0223 & 5.0123 & TST & & \\
\hline CHEMBL1480915 & 737094 & 3.9205 & 4.082 & TST & & \\
\hline CHEMBL1304228 & 737094 & 3.7324 & 4.2807 & TST & & \\
\hline CHEMBL 243111 & 444873 & 10.1549 & 9.9753 & TRN & & \\
\hline CHEMBL 242435 & 444873 & 9.8861 & 9.9963 & TRN & & \\
\hline CHEMBL243117 & 444873 & 8.7447 & 8.6906 & TRN & & \\
\hline CHEMBL243746 & 444873 & 8.8861 & 8.9653 & TRN & & \\
\hline CHEMBL396975 & 444873 & 7.1805 & 8.2638 & TST & & \\
\hline CHEMBL 242028 & 444873 & 9.3665 & 9.5464 & TRN & & \\
\hline CHEMBL 230637 & 444873 & 4.0 & 10.704 & TST & & \\
\hline CHEMBL 398002 & 444873 & 8.9208 & 9.0244 & TRN & & \\
\hline CHEMBL 395100 & 444873 & 8.8239 & 8.8233 & TRN & & \\
\hline CHEMBL 243305 & 444873 & 9.1249 & 9.1131 & TRN & & \\
\hline CHEMBL241829 & 444873 & 10.3979 & 10.3769 & TRN & & \\
\hline CHEMBL 395028 & 444873 & 8.3979 & 8.3202 & TRN & & \\
\hline CHEMBL 242050 & 444873 & 9.5229 & 9.5972 & TRN & & \\
\hline CHEMBL 243113 & 444873 & 4.0 & 4.2201 & TRN & & \\
\hline CHEMBL242891 & 444873 & 9.283999 & 99999999 & 99 & 9.2392 & TRN \\
\hline CHEMBL242051 & 444873 & 9.301 & 9.4191 & TRN & & \\
\hline CHEMBL 394818 & 444873 & 4.699 & 4.5943 & TRN & & \\
\hline CHEMBL 243745 & 444873 & 7.7447 & 7.3448 & TRN & & \\
\hline CHEMBL 242230 & 444873 & 8.0177 & 7.9296 & TRN & & \\
\hline CHEMBL 245022 & 444873 & 9.8239 & 9.7414 & TRN & & \\
\hline CHEMBL388715 & 444873 & 5.7696 & 5.7766 & TRN & & \\
\hline CHEMBL243306 & 444873 & 10.3979 & 10.3755 & TRN & & \\
\hline CHEMBL 242462 & 444873 & 9.2147 & 9.0354 & TRN & & \\
\hline CHEMBL 242447 & 444873 & 9.0458 & 9.1923 & TRN & & \\
\hline CHEMBL437011 & 444873 & 8.1079 & 8.122 & TRN & & \\
\hline CHEMBL396988 & 444873 & 9.0969 & 9.0149 & TRN & & \\
\hline CHEMBL 244620 & 444873 & 6.1871 & 6.7519 & TST & & \\
\hline CHEMBL242874 & 444873 & 8.0 & 8.1223 & TRN & & \\
\hline CHEMBL 245021 & 444873 & 8.4815 & 10.0973 & TST & & \\
\hline CHEMBL397452 & 444873 & 8.3979 & 8.2839 & TRN & & \\
\hline CHEMBL 242892 & 444873 & 8.3188 & 8.21600 & 0000000001 & & TRN \\
\hline CHEMBL 243303 & 444873 & 9.301 & 9.0506 & TRN & & \\
\hline CHEMBL 245228 & 444873 & 8.7696 & 9.0195 & TRN & & \\
\hline
\end{tabular}




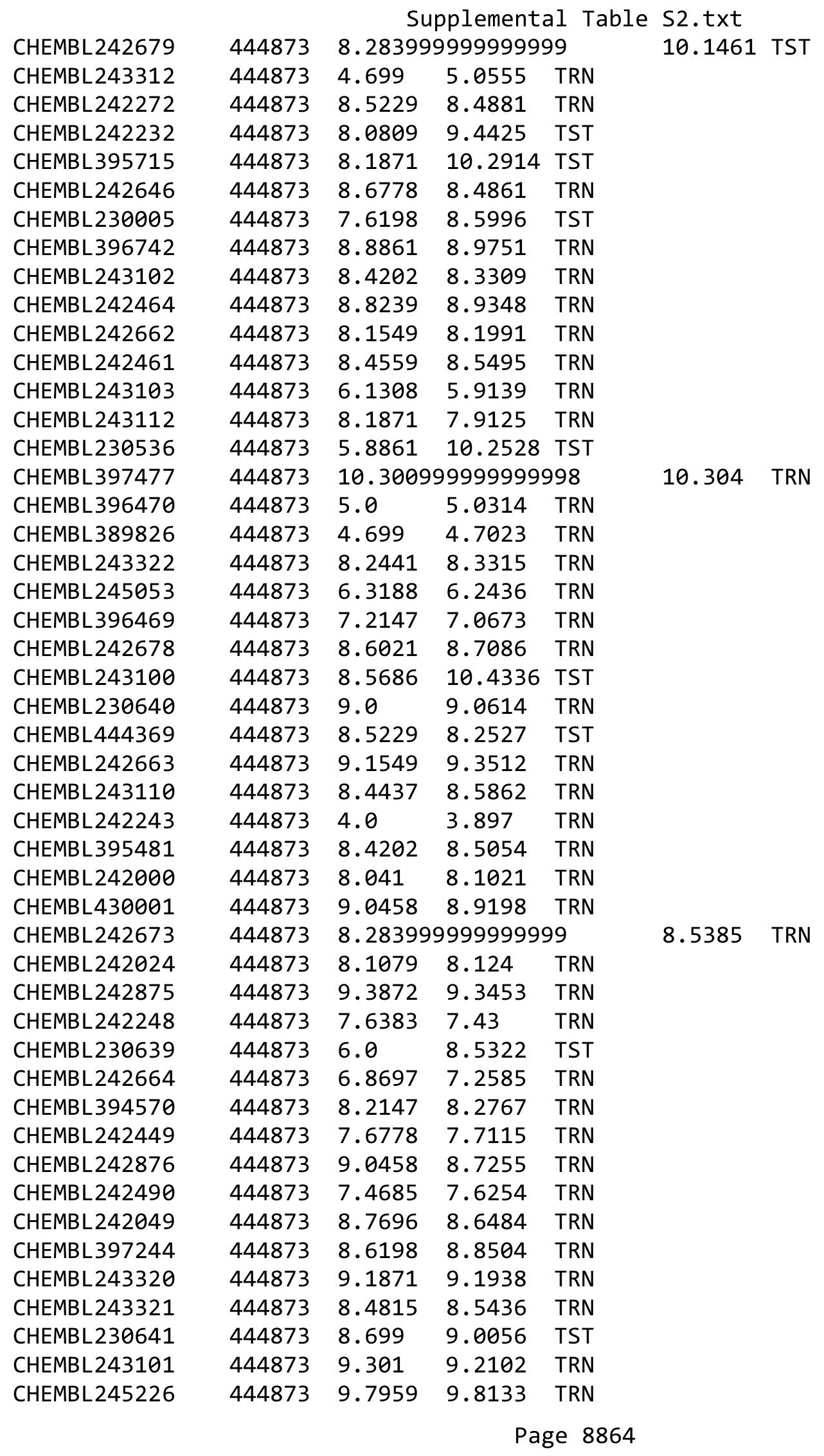




\begin{tabular}{|c|c|c|c|c|c|c|}
\hline & & \multicolumn{5}{|c|}{ Supplemental Table S2.txt } \\
\hline CHEMBL242446 & 444873 & 7.6198 & 7.6636 & TRN & & \\
\hline CHEMBL245227 & 444873 & 8.7959 & 8.4824 & TRN & & \\
\hline CHEMBL389087 & 444873 & 9.6383 & 10.2473 & TST & & \\
\hline CHEMBL243323 & 444873 & 7.0 & 9.7336 & TST & & \\
\hline CHEMBL388923 & 444873 & 7.7447 & 8.9035 & TST & & \\
\hline CHEMBL242052 & 444873 & 8.2441 & 8.7796 & TST & & \\
\hline CHEMBL245007 & 444873 & 8.5086 & 10.1919 & TST & & \\
\hline CHEMBL396468 & 444873 & 8.6021 & 8.0332 & TST & & \\
\hline CHEMBL430385 & 444873 & 4.699 & 5.7101 & TST & & \\
\hline CHEMBL230540 & 444873 & 7.8239 & 8.8573 & TST & & \\
\hline CHEMBL398228 & 444873 & 8.4318 & 8.2589 & TST & & \\
\hline CHEMBL424278 & 444873 & 9.0 & 9.1092 & TST & & \\
\hline CHEMBL446710 & 444873 & 6.4559 & 6.8524 & TST & & \\
\hline CHEMBL3891895 & 1637981 & 7.0 & 7.0385 & TRN & & \\
\hline CHEMBL3897567 & 1637981 & 7.0 & 7.0119 & TRN & & \\
\hline CHEMBL3915607 & 1637981 & 7.0 & 7.1154 & TRN & & \\
\hline CHEMBL3959310 & 1637981 & 7.0 & 7.0052 & TRN & & \\
\hline CHEMBL3915562 & 1637981 & 7.0 & 6.9352 & TRN & & \\
\hline CHEMBL3985867 & 1637981 & 7.0 & 7.0034 & TRN & & \\
\hline CHEMBL3955019 & 1637981 & 7.0 & 7.1022 & TRN & & \\
\hline CHEMBL3960801 & 1637981 & 8.0 & 8.0082 & TRN & & \\
\hline CHEMBL3901866 & 1637981 & 7.0 & 7.0255 & TRN & & \\
\hline CHEMBL3897763 & 1637981 & 8.1024 & 8.1638 & TRN & & \\
\hline CHEMBL3953227 & 1637981 & 8.28399 & 999999999 & 99 & 8.0009 & TRN \\
\hline CHEMBL3935733 & 1637981 & 7.0 & 6.3958 & TST & & \\
\hline CHEMBL3938388 & 1637981 & 8.3979 & 6.6823 & TST & & \\
\hline CHEMBL3984623 & 1637981 & 7.0 & 7.0196 & TRN & & \\
\hline CHEMBL3907423 & 1637981 & 7.0 & 7.1226 & TRN & & \\
\hline CHEMBL 3930485 & 1637981 & 8.0269 & 8.0001 & TRN & & \\
\hline CHEMBL3953791 & 1637981 & 8.6778 & 8.3196 & TRN & & \\
\hline CHEMBL3931953 & 1637981 & 8.2924 & 6.9663 & TST & & \\
\hline CHEMBL3907378 & 1637981 & 4.0 & 3.9173 & TRN & & \\
\hline CHEMBL3963146 & 1637981 & 7.0 & 6.9955 & TST & & \\
\hline CHEMBL3898428 & 1637981 & 7.0 & 7.0364 & TST & & \\
\hline CHEMBL3966821 & 1637981 & 7.9706 & 6.4557 & TST & & \\
\hline CHEMBL3948411 & 1637981 & 7.0 & 6.938 & TRN & & \\
\hline CHEMBL3899067 & 1637981 & 8.0269 & 8.015 & TRN & & \\
\hline CHEMBL3981871 & 1637981 & 8.3565 & 8.4206 & TRN & & \\
\hline CHEMBL3892583 & 1637981 & 8.4559 & 8.4719 & TRN & & \\
\hline CHEMBL3904228 & 1637981 & 7.0 & 6.9857 & TRN & & \\
\hline CHEMBL3954085 & 1637981 & 8.6778 & 7.0854 & TST & & \\
\hline CHEMBL3896103 & 1637981 & 7.0 & 7.2879 & TRN & & \\
\hline CHEMBL3922509 & 1637981 & 4.4202 & 4.4877 & TRN & & \\
\hline CHEMBL3915043 & 1637981 & 8.0706 & 8.3046 & TRN & & \\
\hline CHEMBL3951790 & 1637981 & 7.0 & 7.0233 & TRN & & \\
\hline CHEMBL3984370 & 1637981 & 8.4559 & 8.2059 & TRN & & \\
\hline CHEMBL3975092 & 1637981 & 7.0 & 6.9289 & TRN & & \\
\hline CHEMBL3956618 & 1637981 & 7.0 & 6.8776 & TRN & & \\
\hline
\end{tabular}


Supplemental Table S2.txt

\begin{tabular}{|c|c|c|c|c|}
\hline CHEMBL 3935569 & 1637981 & 8.3979 & 8.4247 & TRN \\
\hline CHEMBL 3914057 & 1637981 & 7.0 & 7.0718 & TRN \\
\hline CHEMBL 3960830 & 1637981 & 7.0 & 7.4316 & TST \\
\hline CHEMBL 3925855 & 1637981 & 8.0655 & 8.0307 & TRN \\
\hline CHEMBL 3959522 & 1637981 & 8.2441 & 8.2587 & TRN \\
\hline CHEMBL3972140 & 1637981 & 8.0969 & 6.8984 & TST \\
\hline CHEMBL 3963477 & 1637981 & 7.0 & 7.27 & TST \\
\hline CHEMBL 3938361 & 1637981 & 7.8239 & 6.2651 & TST \\
\hline CHEMBL 3906996 & 1637981 & 4.0 & 3.9896 & TRN \\
\hline CHEMBL 3891392 & 1637981 & 9.7447 & 5.9832 & TST \\
\hline CHEMBL 3923888 & 1637981 & 9.4559 & 6.2021 & TST \\
\hline CHEMBL 3898789 & 1637981 & 8.0177 & 7.5471 & TRN \\
\hline CHEMBL 3945318 & 1637981 & 8.5376 & 8.558 & TRN \\
\hline CHEMBL 3963347 & 1637981 & 7.0 & 8.1048 & TST \\
\hline CHEMBL 3942288 & 1637981 & 8.0706 & 8.1202 & TRN \\
\hline CHEMBL 3927752 & 1637981 & 8.2441 & 8.0395 & TRN \\
\hline CHEMBL 3889849 & 1637981 & 7.0 & 7.9286 & TST \\
\hline CHEMBL 3941907 & 1637981 & 8.3665 & 8.1595 & TRN \\
\hline CHEMBL 3954818 & 1637981 & 7.0 & 7.1312 & TRN \\
\hline CHEMBL 3912858 & 1637981 & 7.0 & 6.9781 & TRN \\
\hline CHEMBL 3952496 & 1637981 & 8.2596 & 8.2482 & TRN \\
\hline CHEMBL 3889841 & 1637981 & 8.0969 & 8.0749 & TRN \\
\hline CHEMBL 3944307 & 1637981 & 7.4949 & 8.0641 & TRN \\
\hline CHEMBL 3895731 & 1637981 & 9.2366 & 6.1973 & TST \\
\hline CHEMBL 3961315 & 1637981 & 8.2007 & 8.3436 & TRN \\
\hline CHEMBL 3956824 & 1637981 & 8.4089 & 8.5059 & TRN \\
\hline CHEMBL103553 & 27616 & 4.0 & 3.8609 & TST \\
\hline CHEMBL102491 & 27616 & 4.0 & 4.001 & TRN \\
\hline CHEMBL 328334 & 27616 & 4.0 & 3.958 & TRN \\
\hline CHEMBL97337 & 27616 & 6.3768 & 6.2796 & TRN \\
\hline CHEMBL 323303 & 27616 & 6.6383 & 6.6863 & TRN \\
\hline CHEMBL97760 & 27616 & 7.0 & 6.64 & TRN \\
\hline CHEMBL97549 & 27616 & 6.3372 & 6.2917 & TRN \\
\hline CHEMBL 97904 & 27616 & 4.0 & 4.2292 & TRN \\
\hline CHEMBL105000 & 27616 & 5.0 & 5.3887 & TRN \\
\hline CHEMBL103278 & 27616 & 4.0 & 3.6941 & TRN \\
\hline CHEMBL 97895 & 27616 & 4.0 & 4.5849 & TRN \\
\hline CHEMBL102974 & 27616 & 4.0 & 3.4811 & TRN \\
\hline CHEMBL103150 & 27616 & 6.0458 & 5.4845 & TRN \\
\hline CHEMBL96576 & 27616 & 4.0 & 4.3661 & TRN \\
\hline CHEMBL 97624 & 27616 & 6.0809 & 6.2575 & TRN \\
\hline CHEMBL104998 & 27616 & 5.6383 & 5.4298 & TRN \\
\hline CHEMBL441815 & 27616 & 4.0 & 3.8442 & TRN \\
\hline CHEMBL 95384 & 27616 & 6.3279 & 6.809 & TRN \\
\hline CHEMBL316630 & 27616 & 6.3372 & 5.8911 & TRN \\
\hline CHEMBL 97757 & 27616 & 6.7696 & 6.332000 & 0000000001 \\
\hline CHEMBL 97778 & 27616 & 4.0 & 4.548999 & 99999999995 \\
\hline CHEMBL102753 & 27616 & 4.0 & 3.8388 & TST \\
\hline
\end{tabular}




\begin{tabular}{|c|c|c|c|c|c|}
\hline \multicolumn{6}{|c|}{ Supplemental Table S2.txt } \\
\hline CHEMBL104999 & 27616 & 6.301 & 6.5119 & TRN & \\
\hline CHEMBL329294 & 27616 & 5.8539 & 5.8975 & TRN & \\
\hline CHEMBL102178 & 27616 & 4.0 & 4.3185 & TRN & \\
\hline CHEMBL97037 & 27616 & 4.0 & 4.1451 & TRN & \\
\hline CHEMBL329293 & 27616 & 5.9031 & 5.7874 & TRN & \\
\hline CHEMBL183 & 27616 & 6.699 & 6.4238 & TST & \\
\hline CHEMBL415697 & 27616 & 4.0 & 3.7737 & TST & \\
\hline CHEMBL102017 & 27616 & 4.0 & 3.7777 & TRN & \\
\hline CHEMBL103588 & 27616 & 4.0 & 4.5848 & TRN & \\
\hline CHEMBL94538 & 27616 & 5.7447 & 5.6477 & TRN & \\
\hline CHEMBL103559 & 27616 & 5.5376 & 5.3223 & TRN & \\
\hline CHEMBL97896 & 27616 & 5.7212 & 5.1813 & TRN & \\
\hline CHEMBL317411 & 27616 & 4.0 & 4.0464 & TRN & \\
\hline CHEMBL98227 & 27616 & 4.0 & 3.65100 & 00000000002 & TST \\
\hline CHEMBL97665 & 27616 & 5.1549 & 4.7015 & TRN & \\
\hline CHEMBL97687 & 27616 & 7.1805 & 7.2891 & TRN & \\
\hline CHEMBL103796 & 27616 & 4.0 & 4.1821 & TRN & \\
\hline CHEMBL102429 & 27616 & 5.6383 & 6.1116 & TRN & \\
\hline CHEMBL100121 & 27616 & 4.0 & 4.0954 & TRN & \\
\hline CHEMBL321769 & 27616 & 6.2366 & 6.0851 & TRN & \\
\hline CHEMBL328214 & 27616 & 4.0 & 4.0778 & TST & \\
\hline CHEMBL313864 & 27616 & 6.2007 & 6.2116 & TRN & \\
\hline CHEMBL97344 & 27616 & 4.0 & 3.9295 & TRN & \\
\hline CHEMBL323288 & 27616 & 5.1427 & 3.2419 & TST & \\
\hline CHEMBL102126 & 27616 & 4.0 & 3.7744 & TST & \\
\hline CHEMBL319580 & 27616 & 4.0 & 4.1215 & TST & \\
\hline CHEMBL102430 & 27616 & 5.2291 & 5.6157 & TST & \\
\hline CHEMBL418797 & 27616 & 5.6021 & 5.6673 & TST & \\
\hline CHEMBL17127 & 27616 & 8.699 & 5.1927 & TST & \\
\hline CHEMBL96617 & 27616 & 4.0 & 4.1211 & TST & \\
\hline CHEMBL427792 & 304278 & 6.3516 & 7.2241 & TST & \\
\hline CHEMBL429069 & 304278 & 5.0 & 6.9965 & TST & \\
\hline CHEMBL414711 & 304278 & 7.0177 & 6.2503 & TRN & \\
\hline CHEMBL438948 & 304278 & 7.1965 & 7.1606 & TRN & \\
\hline CHEMBL411590 & 304278 & 7.1979 & 7.4202 & TST & \\
\hline CHEMBL429719 & 304278 & 6.2175 & 5.8105 & TRN & \\
\hline CHEMBL412026 & 304278 & 7.1681 & 6.7163 & TRN & \\
\hline CHEMBL427923 & 304278 & 6.9747 & 6.2503 & TRN & \\
\hline CHEMBL429970 & 304278 & 6.0 & 6.2695 & TST & \\
\hline CHEMBL436912 & 304278 & 7.0921 & 7.8371 & TST & \\
\hline CHEMBL411961 & 304278 & 5.0 & 5.8702 & TRN & \\
\hline CHEMBL414568 & 304278 & 5.0 & 6.146 & TST & \\
\hline CHEMBL438760 & 304278 & 6.3497 & 6.2503 & TRN & \\
\hline CHEMBL410568 & 304278 & 6.7247 & 6.7163 & TRN & \\
\hline CHEMBL428824 & 304278 & 7.1057 & 6.9681 & TRN & \\
\hline CHEMBL429547 & 304278 & 6.2503 & 6.146 & TST & \\
\hline CHEMBL427811 & 304278 & 6.9686 & 7.0239 & TRN & \\
\hline CHEMBL428809 & 304278 & 6.4151 & 5.9973 & TRN & \\
\hline
\end{tabular}




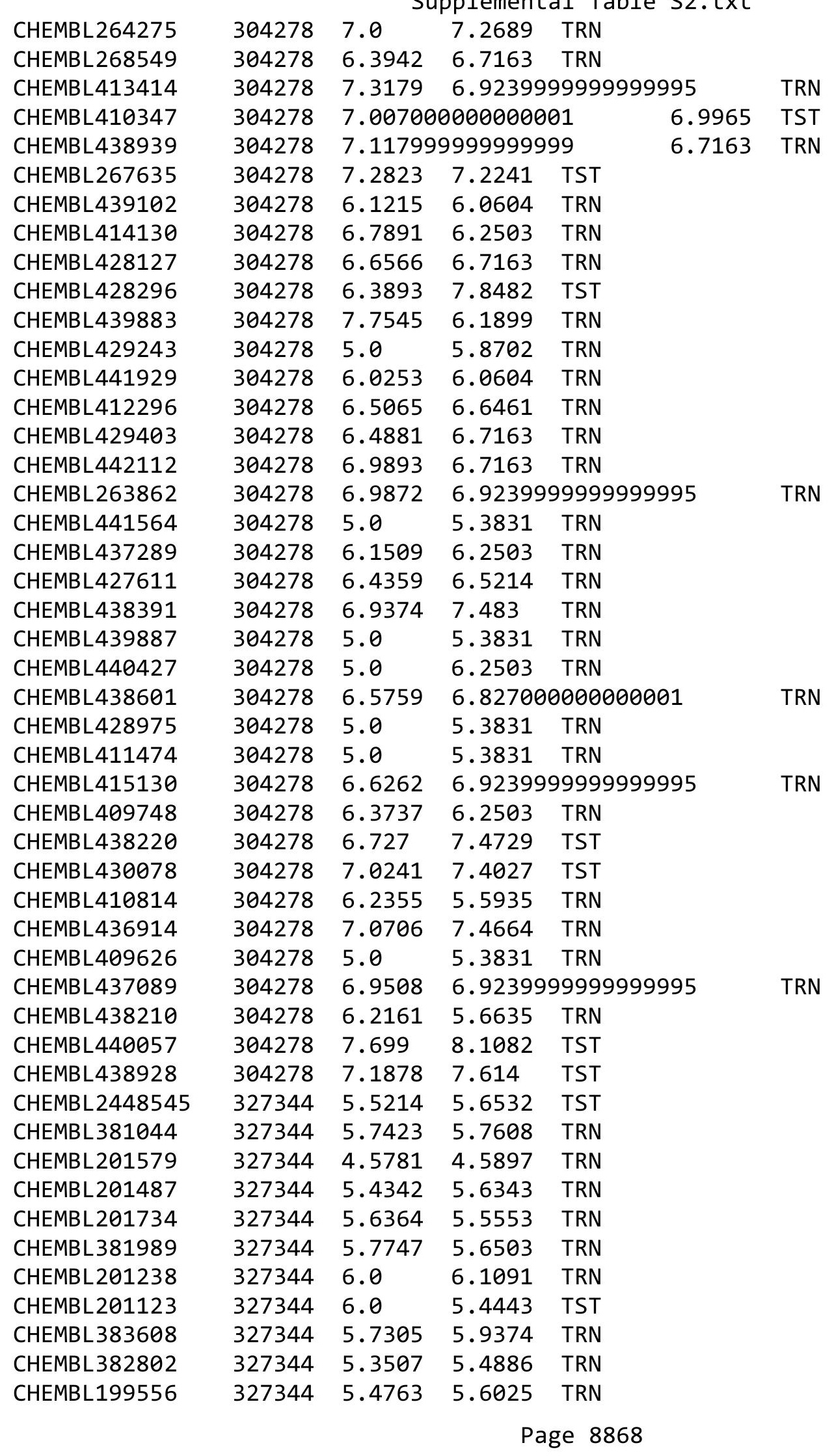




\begin{tabular}{|c|c|c|c|c|c|}
\hline \\
\hline CHEMBL202379 & 327344 & 5.7122 & 5.7362 & TRN & \\
\hline CHEMBL202975 & 327344 & 5.6055 & 5.5733 & TRN & \\
\hline CHEMBL199332 & 327344 & 6.3468 & 6.1533 & TRN & \\
\hline CHEMBL383534 & 327344 & 5.2984 & 5.0027 & TRN & \\
\hline CHEMBL383649 & 327344 & 6.1367 & 5.8878 & TRN & \\
\hline CHEMBL201319 & 327344 & 5.3279 & 5.4964 & TRN & \\
\hline CHEMBL201590 & 327344 & 5.9547 & 5.8655 & TRN & \\
\hline CHEMBL202778 & 327344 & 5.4547 & 5.5471 & TRN & \\
\hline CHEMBL202976 & 327344 & 5.5544 & 5.5087 & TRN & \\
\hline CHEMBL198407 & 327344 & 5.7122 & 5.7304 & TRN & \\
\hline CHEMBL201545 & 327344 & 5.767 & 5.7583 & TRN & \\
\hline CHEMBL201503 & 327344 & 3.2596 & 4.3793 & TST & \\
\hline CHEMBL197594 & 327344 & 4.9144 & 4.8788 & TRN & \\
\hline CHEMBL 203140 & 327344 & 5.6459 & 5.4531 & TST & \\
\hline CHEMBL382849 & 327344 & 5.51 & 5.592006 & 00000000005 & TRN \\
\hline CHEMBL201637 & 327344 & 4.959 & 5.0773 & TST & \\
\hline CHEMBL 380413 & 327344 & 4.2793 & 4.4487 & TST & \\
\hline CHEMBL201380 & 327344 & 6.284 & 6.2614 & TRN & \\
\hline CHEMBL380657 & 327344 & 6.0269 & 6.0544 & TRN & \\
\hline CHEMBL199942 & 327344 & 5.6345 & 5.6958 & TRN & \\
\hline CHEMBL 202978 & 327344 & 6.1135 & 6.0789 & TRN & \\
\hline CHEMBL199953 & 327344 & 5.9508 & 5.8751 & TRN & \\
\hline CHEMBL370376 & 327344 & 5.4597 & 5.6195 & TRN & \\
\hline CHEMBL440759 & 327344 & 5.4461 & 5.6181 & TRN & \\
\hline CHEMBL201682 & 327344 & 6.0862 & 5.4887 & TRN & \\
\hline CHEMBL 200132 & 327344 & 6.3372 & 6.2001 & TRN & \\
\hline CHEMBL437138 & 327344 & 5.4101 & 5.6468 & TRN & \\
\hline CHEMBL382137 & 327344 & 5.4868 & 5.8222 & TRN & \\
\hline CHEMBL437511 & 327344 & 4.9974 & 5.0687 & TRN & \\
\hline CHEMBL199889 & 327344 & 5.6478 & 5.6002 & TRN & \\
\hline CHEMBL383494 & 327344 & 3.2291 & 4.341 & TST & \\
\hline CHEMBL 201356 & 327344 & 5.8041 & 5.6738 & TRN & \\
\hline CHEMBL380751 & 327344 & 5.3585 & 5.5314 & TRN & \\
\hline CHEMBL 202664 & 327344 & 5.3468 & 5.5386 & TRN & \\
\hline CHEMBL381737 & 327344 & 5.1945 & 5.0731 & TRN & \\
\hline CHEMBL201704 & 327344 & 6.1675 & 5.9522 & TRN & \\
\hline CHEMBL199601 & 327344 & 6.1249 & 6.1676 & TRN & \\
\hline CHEMBL 380823 & 327344 & 6.3098 & 6.1799 & TRN & \\
\hline CHEMBL 201078 & 327344 & 5.3625 & 5.5718 & TST & \\
\hline CHEMBL413570 & 327344 & 5.8069 & 5.7425 & TST & \\
\hline CHEMBL377948 & 327344 & 5.4112 & 5.5559 & TST & \\
\hline CHEMBL201345 & 327344 & 5.7645 & 5.86 & TST & \\
\hline CHEMBL201134 & 327344 & 5.6861 & 5.5019 & TST & \\
\hline CHEMBL369978 & 327344 & 5.2899 & 5.6005 & TST & \\
\hline CHEMBL199604 & 327344 & 6.0757 & 5.9478 & TST & \\
\hline CHEMBL 3967549 & 1640802 & 5.3706 & 5.395 & TRN & \\
\hline CHEMBL 2419699 & 1640802 & 3.7212 & 3.7766 & TRN & \\
\hline CHEMBL3978546 & 1640802 & 5.51 & 5.182 & TST & \\
\hline
\end{tabular}


Supplemental Table S2.txt

\begin{tabular}{|c|c|c|c|c|c|}
\hline CHEMBL3955426 & 1640802 & 3.7212 & 3.7034 & TRN & \\
\hline CHEMBL3933577 & 1640802 & 3.7212 & 3.7609 & TRN & \\
\hline CHEMBL3903427 & 1640802 & 5.5467 & 5.5877 & TRN & \\
\hline CHEMBL3903965 & 1640802 & 5.4949 & 5.5028 & TRN & \\
\hline CHEMBL 2419698 & 1640802 & 3.7212 & 3.7869 & TRN & \\
\hline CHEMBL2419702 & 1640802 & 3.7212 & 3.75399 & 99999999996 & TRN \\
\hline CHEMBL3892864 & 1640802 & 3.7212 & 3.6798 & TRN & \\
\hline CHEMBL3898270 & 1640802 & 3.7212 & 3.7326 & TRN & \\
\hline CHEMBL 2419701 & 1640802 & 3.7212 & 3.7112 & TRN & \\
\hline CHEMBL3956527 & 1640802 & 5.6253 & 5.6341 & TRN & \\
\hline CHEMBL 3986246 & 1640802 & 5.4389 & 5.386 & TRN & \\
\hline CHEMBL3928915 & 1640802 & 5.7055 & 5.7361 & TRN & \\
\hline CHEMBL 2419700 & 1640802 & 3.7212 & 3.6809 & TRN & \\
\hline CHEMBL3935111 & 1640802 & 3.7212 & 3.7128 & TRN & \\
\hline CHEMBL 3943283 & 1640802 & 5.6383 & 5.6162 & TRN & \\
\hline CHEMBL3965278 & 1640802 & 3.7212 & 3.7175 & TRN & \\
\hline CHEMBL3966085 & 1640802 & 6.1549 & 6.1254 & TRN & \\
\hline CHEMBL 3986804 & 1640802 & 3.7212 & 3.7285 & TRN & \\
\hline CHEMBL3964642 & 1640802 & 3.7212 & 3.7038 & TRN & \\
\hline CHEMBL 3941313 & 1640802 & 3.7212 & 3.7492 & TRN & \\
\hline CHEMBL 2419705 & 1640802 & 3.7212 & 3.5621 & TRN & \\
\hline CHEMBL3959094 & 1640802 & 3.7212 & 3.741 & TRN & \\
\hline CHEMBL3946798 & 1640802 & 3.7212 & 3.7362 & TRN & \\
\hline CHEMBL3919581 & 1640802 & 3.7212 & 3.6792 & TRN & \\
\hline CHEMBL3946751 & 1640802 & 5.9393 & 5.4142 & TST & \\
\hline CHEMBL 3985156 & 1640802 & 3.7212 & 3.7385 & TRN & \\
\hline CHEMBL3983088 & 1640802 & 3.7212 & 3.8342 & TRN & \\
\hline CHEMBL3961412 & 1640802 & 5.0391 & 3.7122 & TST & \\
\hline CHEMBL3940683 & 1640802 & 3.7212 & 3.6396 & TRN & \\
\hline CHEMBL3955207 & 1640802 & 3.7212 & 5.2821 & TST & \\
\hline CHEMBL3987175 & 1640802 & 3.7212 & 3.7565 & TRN & \\
\hline CHEMBL3933931 & 1640802 & 6.6144 & 6.0855 & TST & \\
\hline CHEMBL3956490 & 1640802 & 3.7212 & 3.6897 & TRN & \\
\hline CHEMBL3975140 & 1640802 & 4.9296 & 4.8467 & TRN & \\
\hline CHEMBL3938947 & 1640802 & 3.7212 & 3.6891 & TRN & \\
\hline CHEMBL3914416 & 1640802 & 3.7212 & 3.68600 & 00000000004 & TRN \\
\hline CHEMBL 3925030 & 1640802 & 5.5867 & 5.5343 & TST & \\
\hline CHEMBL3907294 & 1640802 & 3.7212 & 3.716 & TRN & \\
\hline CHEMBL3891789 & 1640802 & 3.7212 & 3.8064 & TRN & \\
\hline CHEMBL3913243 & 1640802 & 3.7212 & 3.741 & TRN & \\
\hline CHEMBL3944401 & 1640802 & 6.0362 & 5.9159 & TST & \\
\hline CHEMBL2419697 & 1640802 & 5.5086 & 5.0622 & TST & \\
\hline CHEMBL3906833 & 1640802 & 5.6716 & 5.7491 & TST & \\
\hline CHEMBL3939009 & 1640802 & 5.3439 & 5.2003 & TST & \\
\hline CHEMBL3932754 & 1640802 & 5.3354 & 5.899 & TST & \\
\hline CHEMBL3937250 & 1640802 & 3.7212 & 3.7056 & TRN & \\
\hline CHEMBL3929923 & 1640802 & 3.7212 & 3.7279 & TRN & \\
\hline CHEMBL3902386 & 1640802 & 5.5376 & 5.3546 & TST & \\
\hline
\end{tabular}


Supplemental Table S2.txt

\begin{tabular}{|c|c|c|c|c|}
\hline W & & 7212 & & \\
\hline UГMDI 2019054 & 640802 & 6.0531 & 5.9316 & \\
\hline 174 & 302 & & & \\
\hline AEMBL3901978 & $\partial 802$ & 7212 & & \\
\hline AEMBL2419706 & 540802 & 3.7212 & & \\
\hline HEMBL3922251 & 640802 & 3.7212 & 6969 & \\
\hline 618 & 802 & 7212 & 7221 & \\
\hline 715 & 384 & 5.6055 & & \\
\hline AEMBL3601237 & 509384 & 5.6048 & 5386 & \\
\hline HEMBL3601704 & 509384 & 5.4008 & 3924 & \\
\hline AEMBL3601712 & 509384 & 5.5445 & 5382 & \\
\hline IEMBL36e & 384 & 36 & 158 & \\
\hline AEMBL 36 & & & & \\
\hline HEMBL 360 & 384 & 3.301 & 8353 & \\
\hline AEMBL36e & 384 & 73 & & \\
\hline AEMBL360 & 509384 & 3 & 68 & \\
\hline HEMBL36 & 84 & 74 & 61 & \\
\hline HEMBL36 & & 81 & & \\
\hline HEMBL36e & 384 & 1832 & 1811 & \\
\hline AEMBL36 & 84 & 85 & & \\
\hline AEMBL36 & 34 & 19 & & NIV \\
\hline AEMBL: & 34 & 42 & & 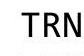 \\
\hline HEMBL & & 29 & & \\
\hline 728 & 384 & 698 & 391 & \\
\hline AEMBL $36 \ell$ & & 38 & & v \\
\hline HEMBL36 & 84 & 87 & 073 & I RN \\
\hline HEMBL & & 41 & 31 & ונכ \\
\hline$H F M B I=$ & 34 & 77 & 44 & \\
\hline HEMBL36€ & & 312 & & 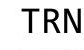 \\
\hline HEMBL 360 & & & & $\cdots$ \\
\hline HEMBL36 & 34 & 4 & 98 & SI \\
\hline HEMBL & & & 28 & ST \\
\hline HEMBL3 & & 92 & 724 & RN \\
\hline HEMBL360 & & & 08 & IRN \\
\hline HEMBL 360 & CaO & 5.4985 & 1011 & TRN \\
\hline HEMBL36e & & 897 & 736 & \\
\hline HFMRI 3 & & 31 & 59 & RN \\
\hline HEMBL3 & & & 869 & IRN \\
\hline HEMBL360 & 50 & 035 & 5616 & TRN \\
\hline AEMBL $36 e$ & 509 & 389 & 993 & ГRN \\
\hline HEMBL36 & T & 97 & 797 & \\
\hline CHEMBL36e & & & & RN \\
\hline HEMBL36 & 84 & 67 & 5467 & TST \\
\hline HEMBL36e & 509384 & 5.4552 & 1965 & TRN \\
\hline 93 & & & & \\
\hline HEMBL36 & & & 5658 & \\
\hline CHEMBL36e & & & 4.5559 & \\
\hline LHEMBL3601239 & 150938 & 4.7585 & 4.846 & ГST \\
\hline
\end{tabular}

Page 8871 
Supplemental Table S2.txt

\begin{tabular}{|c|c|c|c|c|c|}
\hline CHEMBL3601713 & 1509384 & 5.4572 & 5.5067 & TST & \\
\hline CHEMBL3601233 & 1509384 & 5.2844 & 4.9614 & TRN & \\
\hline CHEMBL3601706 & 1509384 & 5.6972 & 5.7027 & TRN & \\
\hline CHEMBL3601708 & 1509384 & 5.5063 & 5.5733 & TRN & \\
\hline CHEMBL3601228 & 1509384 & 6.4225 & 6.4366 & TRN & \\
\hline CHEMBL3601114 & 1509384 & 5.4607 & \multicolumn{2}{|c|}{5.617999999999999} & TRN \\
\hline CHEMBL3601113 & 1509384 & 5.5046 & 5.7108 & TRN & \\
\hline CHEMBL 3601234 & 1509384 & 3.301 & 3.4638 & TRN & \\
\hline CHEMBL3601227 & 1509384 & 6.0857 & 6.3211 & TRN & \\
\hline CHEMBL 3601226 & 1509384 & 6.2899 & 6.3187 & TRN & \\
\hline CHEMBL3601108 & 1509384 & 5.669 & 5.5077 & TRN & \\
\hline CHEMBL3601122 & 1509384 & 5.3056 & 5.1817 & TRN & \\
\hline CHEMBL3601117 & 1509384 & 5.6253 & 5.6443 & TRN & \\
\hline CHEMBL3601705 & 1509384 & 6.1543 & 6.0025 & TST & \\
\hline CHEMBL 3601121 & 1509384 & 5.2408 & \multicolumn{2}{|c|}{5.707000000000001} & TST \\
\hline CHEMBL3601714 & 1509384 & 4.9259 & 5.2631 & TST & \\
\hline CHEMBL3601120 & 1509384 & 5.425 & 5.6908 & TST & \\
\hline CHEMBL 3601107 & 1509384 & 5.7496 & 5.9303 & TST & \\
\hline CHEMBL3601127 & 1509384 & 5.4408 & 5.6059 & TST & \\
\hline CHEMBL 3601723 & 1509384 & 5.8811 & 5.7095 & TST & \\
\hline CHEMBL3601111 & 1509384 & 5.3417 & 5.3143 & TST & \\
\hline CHEMBL1604822 & 688721 & 4.7 & 4.9294 & TRN & \\
\hline CHEMBL1598997 & 688721 & 7.4001 & 4.8257 & TST & \\
\hline CHEMBL1372899 & 688721 & 4.6 & 4.9456 & TRN & \\
\hline CHEMBL1602127 & 688721 & 4.4 & 5.3194 & TRN & \\
\hline CHEMBL1366846 & 688721 & 4.5 & 5.1629 & TST & \\
\hline CHEMBL1552051 & 688721 & 4.5 & 5.2535 & TRN & \\
\hline CHEMBL1486706 & 688721 & 4.4 & 4.9797 & TRN & \\
\hline CHEMBL1517796 & 688721 & 4.6 & 5.1346 & TRN & \\
\hline CHEMBL1520417 & 688721 & 4.8 & 4.9879 & TRN & \\
\hline CHEMBL1483600 & 688721 & 4.9 & 5.0087 & TRN & \\
\hline CHEMBL1523735 & 688721 & 5.5 & 4.8752 & TRN & \\
\hline CHEMBL1311470 & 688721 & 4.7 & 5.0795 & TRN & \\
\hline CHEMBL1496951 & 688721 & 4.8 & 4.9212 & TST & \\
\hline CHEMBL1346218 & 688721 & 5.4 & 4.9497 & TRN & \\
\hline CHEMBL1542927 & 688721 & 5.4 & 5.0002 & TRN & \\
\hline CHEMBL466545 & 688721 & 5.1 & 5.3382 & TST & \\
\hline CHEMBL1587552 & 688721 & 4.6 & 5.1972 & TRN & \\
\hline CHEMBL1568117 & 688721 & 5.9 & 4.8962 & TRN & \\
\hline CHEMBL1595336 & 688721 & 4.7 & 4.8906 & TRN & \\
\hline CHEMBL1527556 & 688721 & 4.8 & 5.2611 & TST & \\
\hline CHEMBL492127 & 688721 & 4.6 & 5.0164 & TRN & \\
\hline CHEMBL1380020 & 688721 & 5.2 & 4.9776 & TRN & \\
\hline CHEMBL1351261 & 688721 & 4.4 & 4.8892 & TRN & \\
\hline CHEMBL1200450 & 688721 & 6.0 & 4.824 & TST & \\
\hline CHEMBL1604589 & 688721 & 4.6 & 5.0243 & TRN & \\
\hline CHEMBL1348905 & 688721 & 5.1 & 4.8859 & TST & \\
\hline CHEMBL1484854 & 688721 & 4.4 & 4.8729 & TRN & \\
\hline
\end{tabular}




\begin{tabular}{|c|c|c|c|c|c|}
\hline \\
\hline CHEMBL1420350 & 688721 & 5.2 & 5.0694 & TST & \\
\hline CHEMBL1585075 & 688721 & 4.8 & 4.9824 & TRN & \\
\hline CHEMBL1568116 & 688721 & 4.8 & 5.0233 & TRN & \\
\hline CHEMBL1568806 & 688721 & 4.5 & 4.9812 & TRN & \\
\hline CHEMBL1338573 & 688721 & 4.6 & 4.8784 & TRN & \\
\hline CHEMBL1539677 & 688721 & 6.4 & 5.0123 & TRN & \\
\hline CHEMBL1611298 & 688721 & 4.9 & 4.8188 & TRN & \\
\hline CHEMBL1377727 & 688721 & 5.2 & 4.965 & TRN & \\
\hline CHEMBL1531135 & 688721 & 5.5 & 5.0555 & TRN & \\
\hline CHEMBL1380509 & 688721 & 4.4 & 4.8437 & TRN & \\
\hline CHEMBL1412035 & 688721 & 4.6 & 5.0761 & TRN & \\
\hline CHEMBL1535791 & 688721 & 4.8 & 4.9586 & TRN & \\
\hline CHEMBL1528296 & 688721 & 4.7 & 4.7726 & TRN & \\
\hline CHEMBL1338229 & 688721 & 5.2 & 4.944 & TST & \\
\hline CHEMBL1372275 & 688721 & 4.6 & 4.9453 & TRN & \\
\hline CHEMBL1485777 & 688721 & 6.0 & 4.9096 & TRN & \\
\hline CHEMBL1607105 & 688721 & 5.3 & 4.9963 & TRN & \\
\hline CHEMBL1331873 & 688721 & 5.0 & 4.8901 & TRN & \\
\hline CHEMBL1312427 & 688721 & 4.4 & 4.8601 & TST & \\
\hline CHEMBL119841 & 688721 & 4.6 & 5.0223 & TRN & \\
\hline CHEMBL1442558 & 688721 & 5.3 & 5.0477 & TST & \\
\hline CHEMBL1532640 & 688721 & 4.5 & 4.9046 & TRN & \\
\hline CHEMBL1306099 & 688721 & 4.8 & 4.8947 & TRN & \\
\hline CHEMBL1486887 & 688721 & 4.5 & 4.7523 & TRN & \\
\hline CHEMBL1424407 & 688721 & 5.1 & 4.8976 & TST & \\
\hline CHEMBL1384385 & 688721 & 4.4 & 5.0177 & TRN & \\
\hline CHEMBL1373711 & 688721 & 4.8 & 4.8471 & TRN & \\
\hline CHEMBL1603191 & 688721 & 4.7 & 4.9389 & TRN & \\
\hline CHEMBL1363951 & 688721 & 4.6 & 4.9317 & TRN & \\
\hline CHEMBL1430185 & 688721 & 4.6 & 4.9125 & TRN & \\
\hline CHEMBL1497266 & 688721 & 4.5 & 4.8978 & TRN & \\
\hline CHEMBL1322549 & 688721 & 5.8 & 5.185 & TST & \\
\hline CHEMBL1304477 & 688721 & 4.6 & 4.98300 & 30000000005 & TRN \\
\hline CHEMBL1482753 & 688721 & 4.7 & 4.8923 & TRN & \\
\hline CHEMBL1370372 & 688721 & 5.1 & 4.8145 & TRN & \\
\hline CHEMBL1456698 & 688721 & 5.2 & 5.0064 & TRN & \\
\hline CHEMBL1597310 & 688721 & 4.4 & 4.825 & TST & \\
\hline CHEMBL1514782 & 688721 & 5.2 & 5.1035 & TRN & \\
\hline CHEMBL3210485 & 688721 & 5.0 & 5.0139 & TRN & \\
\hline CHEMBL3212680 & 688721 & 5.8 & 5.0032 & TST & \\
\hline CHEMBL1498167 & 688721 & 5.0 & 5.0952 & TRN & \\
\hline CHEMBL1430524 & 688721 & 5.0 & 4.7875 & TRN & \\
\hline CHEMBL1333939 & 688721 & 5.5 & 4.9673 & TRN & \\
\hline CHEMBL1603638 & 688721 & 4.6 & 4.9523 & TST & \\
\hline CHEMBL1532465 & 688721 & 4.4 & 4.8554 & TRN & \\
\hline CHEMBL1381404 & 688721 & 5.6 & 5.0321 & TRN & \\
\hline CHEMBL1594411 & 688721 & 5.4 & 4.9306 & TST & \\
\hline CHEMBL1510563 & 688721 & 5.2 & 4.9013 & TRN & \\
\hline
\end{tabular}




\begin{tabular}{|c|c|c|c|c|c|}
\hline \multicolumn{6}{|c|}{ Supplemental Table s2.txt } \\
\hline CHEMBL1523923 & 688721 & 4.9 & 4.992 & TRN & \\
\hline CHEMBL1460951 & 688721 & 4.6 & 5.0476 & TRN & \\
\hline CHEMBL1432760 & 688721 & 4.6 & 4.7432 & TRN & \\
\hline CHEMBL1478509 & 688721 & 5.5 & 4.7882 & TRN & \\
\hline CHEMBL1504324 & 688721 & 4.5 & 4.9698 & TRN & \\
\hline CHEMBL1466923 & 688721 & 4.6 & 4.8116 & TRN & \\
\hline CHEMBL1379374 & 688721 & 4.7 & 5.0228 & TRN & \\
\hline CHEMBL1516068 & 688721 & 4.9 & 4.7954 & TRN & \\
\hline CHEMBL1345437 & 688721 & 4.7 & 4.8178 & TRN & \\
\hline CHEMBL1403882 & 688721 & 4.5 & 4.8852 & TRN & \\
\hline CHEMBL1405306 & 688721 & 4.7 & 4.7392 & TRN & \\
\hline CHEMBL1488842 & 688721 & 4.4 & 4.9334 & TRN & \\
\hline CHEMBL1458475 & 688721 & 4.6 & 4.897 & TRN & \\
\hline CHEMBL1589502 & 688721 & 4.6 & 5.1615 & TRN & \\
\hline CHEMBL1525272 & 688721 & 5.2 & 5.0586 & TST & \\
\hline CHEMBL1534503 & 688721 & 4.4 & 4.94 & TST & \\
\hline CHEMBL1499501 & 688721 & 5.5 & 4.9728 & TRN & \\
\hline CHEMBL1414526 & 688721 & 5.1 & 4.7661 & TST & \\
\hline CHEMBL1380598 & 688721 & 4.5 & 4.9143 & TRN & \\
\hline CHEMBL1555899 & 688721 & 4.5 & 4.9415 & TRN & \\
\hline CHEMBL1490804 & 688721 & 4.6 & 4.8654 & TRN & \\
\hline CHEMBL1414430 & 688721 & 5.0 & 4.7898 & TRN & \\
\hline CHEMBL1394533 & 688721 & 5.4 & 4.9254 & TRN & \\
\hline CHEMBL1565908 & 688721 & 4.4 & 4.894 & TRN & \\
\hline CHEMBL1300721 & 688721 & 4.7 & 4.9573 & TRN & \\
\hline CHEMBL317757 & 688721 & 4.5 & 5.0509 & TRN & \\
\hline CHEMBL1511272 & 688721 & 5.2 & 4.8799 & TRN & \\
\hline CHEMBL1301702 & 688721 & 5.5 & 5.1542 & TRN & \\
\hline CHEMBL1554976 & 688721 & 4.6 & 5.1228 & TRN & \\
\hline CHEMBL1461109 & 688721 & 5.2 & 4.9323 & TRN & \\
\hline CHEMBL1444946 & 688721 & 4.5 & 4.8695 & TRN & \\
\hline CHEMBL1412228 & 688721 & 5.2 & 4.8777 & TRN & \\
\hline CHEMBL1463091 & 688721 & 4.4 & 4.7968 & TRN & \\
\hline CHEMBL1455462 & 688721 & 7.5003 & 5.1377 & TRN & \\
\hline CHEMBL1427136 & 688721 & 4.5 & 4.9057 & TRN & \\
\hline CHEMBL1517842 & 688721 & 5.5 & 4.7609 & TRN & \\
\hline CHEMBL1494407 & 688721 & 6.0 & 4.8988 & TST & \\
\hline CHEMBL1602568 & 688721 & 4.4 & 5.19 & TRN & \\
\hline CHEMBL1572857 & 688721 & 5.1 & 4.8758 & TRN & \\
\hline CHEMBL1415198 & 688721 & 4.7 & 4.8328 & TRN & \\
\hline CHEMBL1451386 & 688721 & 5.9 & 4.9781 & TST & \\
\hline CHEMBL1608561 & 688721 & 4.4 & 5.10800 & 00000000005 & TRN \\
\hline CHEMBL1535764 & 688721 & 4.4 & 5.1182 & TST & \\
\hline CHEMBL1312261 & 688721 & 4.5 & 4.8799 & TRN & \\
\hline CHEMBL1411551 & 688721 & 4.5 & 4.9089 & TRN & \\
\hline CHEMBL1422307 & 688721 & 4.4 & 4.7943 & TRN & \\
\hline CHEMBL1407762 & 688721 & 4.6 & 4.9807 & TRN & \\
\hline CHEMBL500812 & 688721 & 5.4 & 4.9886 & TRN & \\
\hline
\end{tabular}




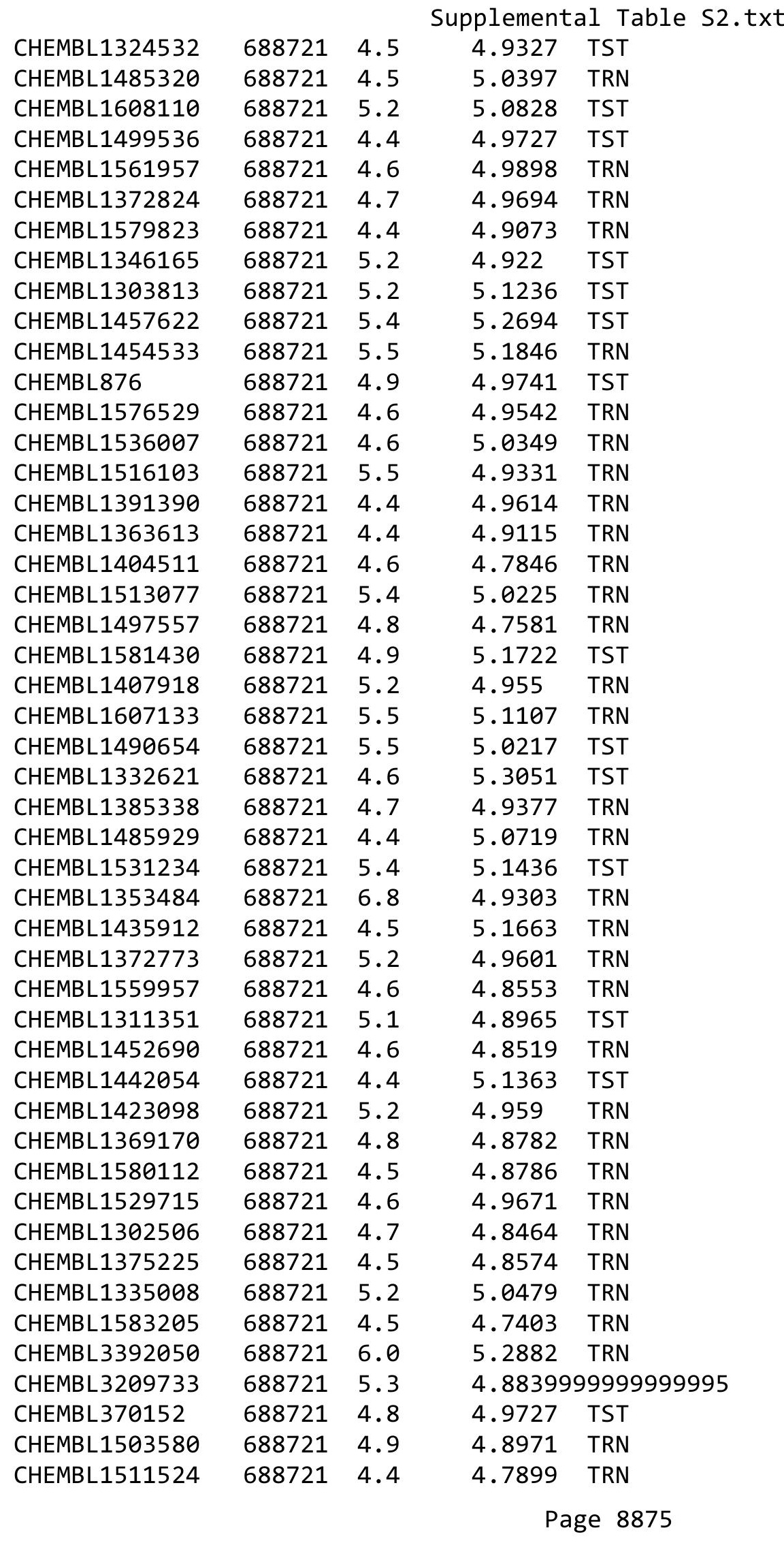




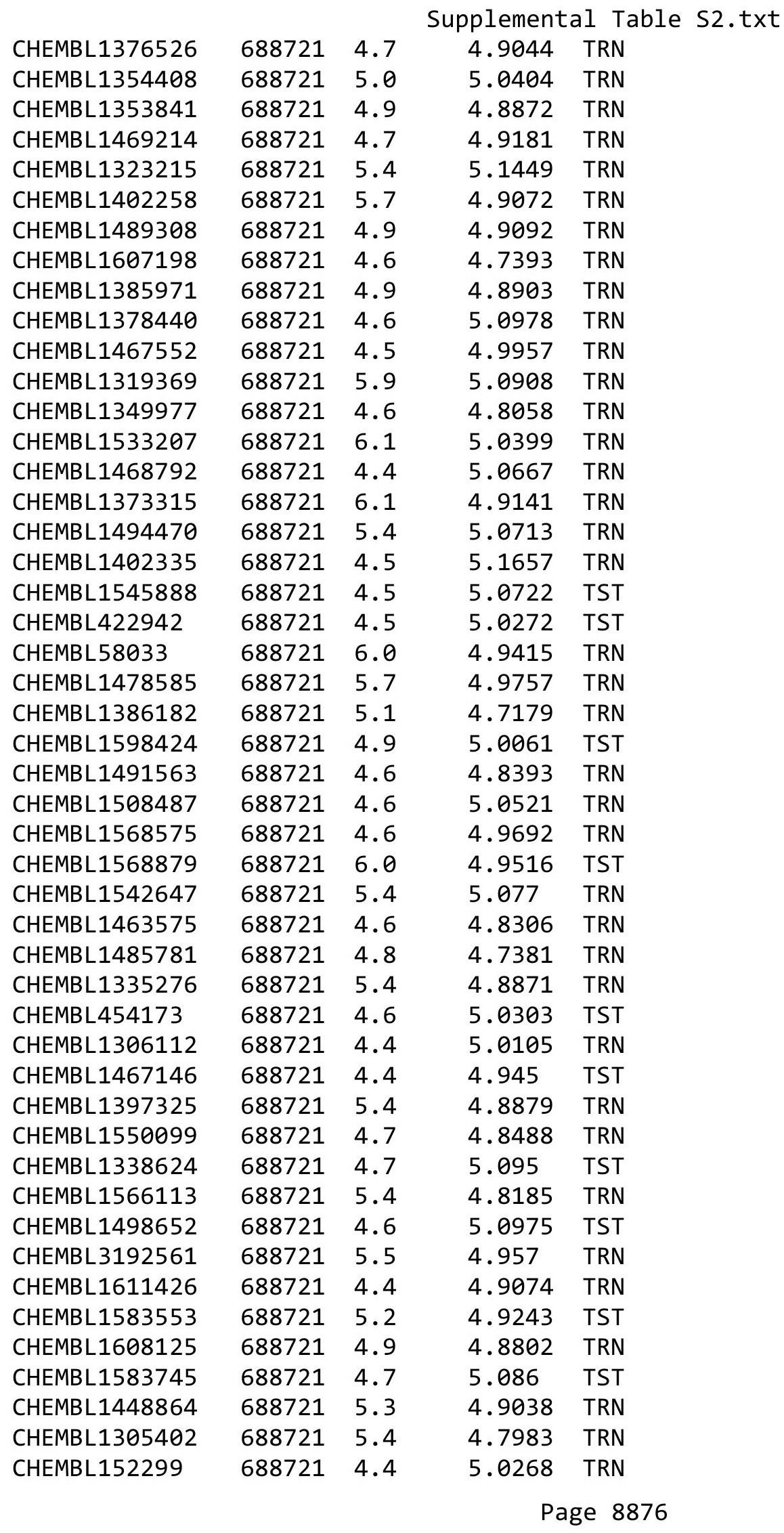




\begin{tabular}{|c|c|c|c|c|}
\hline & & & Supplement & \\
\hline CHEMBL1532206 & 688721 & 4.6 & 5.0303 & TRN \\
\hline CHEMBL1411088 & 688721 & 4.6 & 4.9393 & TRN \\
\hline CHEMBL1528265 & 688721 & 4.6 & 4.981 & TRN \\
\hline CHEMBL1355387 & 688721 & 4.9 & 4.8946 & TRN \\
\hline CHEMBL1352463 & 688721 & 5.2 & 5.2066 & TST \\
\hline CHEMBL1365332 & 688721 & 4.9 & 5.0408 & TRN \\
\hline CHEMBL1478252 & 688721 & 4.8 & 4.9966 & TST \\
\hline CHEMBL1310499 & 688721 & 4.5 & 4.9038 & TRN \\
\hline CHEMBL3193695 & 688721 & 4.5 & 4.8802 & TST \\
\hline CHEMBL1377816 & 688721 & 5.2 & 4.9698 & TST \\
\hline CHEMBL1456924 & 688721 & 4.7 & 5.0117 & TRN \\
\hline CHEMBL1548667 & 688721 & 4.8 & 4.9063 & TRN \\
\hline CHEMBL1496161 & 688721 & 6.0 & 4.9291 & TRN \\
\hline CHEMBL1390478 & 688721 & 4.4 & 4.9705 & TST \\
\hline CHEMBL1498877 & 688721 & 4.4 & 4.8475 & TRN \\
\hline CHEMBL1506375 & 688721 & 5.3 & 4.7738 & TRN \\
\hline CHEMBL63154 & 688721 & 6.0 & 4.9007 & TST \\
\hline CHEMBL1346847 & 688721 & 5.4 & 4.9343 & TRN \\
\hline CHEMBL1427751 & 688721 & 4.5 & 5.0438 & TRN \\
\hline CHEMBL1369491 & 688721 & 4.5 & 5.0365 & TST \\
\hline CHEMBL1430277 & 688721 & 4.4 & 4.8293 & TRN \\
\hline CHEMBL1365281 & 688721 & 4.4 & 4.9937 & TST \\
\hline CHEMBL1528648 & 688721 & 5.4 & 5.0707 & TRN \\
\hline CHEMBL1318635 & 688721 & 5.5 & 5.0613 & TST \\
\hline CHEMBL1332646 & 688721 & 4.6 & 4.8977 & TRN \\
\hline CHEMBL3197221 & 688721 & 4.4 & 5.2464 & TST \\
\hline CHEMBL1480874 & 688721 & 4.4 & 4.9723 & TRN \\
\hline CHEMBL1500401 & 688721 & 4.4 & 4.7934 & TRN \\
\hline CHEMBL3213638 & 688721 & 5.4 & 4.9978 & TST \\
\hline CHEMBL1318752 & 688721 & 5.5 & 5.2346 & TRN \\
\hline CHEMBL1495392 & 688721 & 5.0 & 4.7685 & TRN \\
\hline CHEMBL1485276 & 688721 & 4.4 & 4.8682 & TRN \\
\hline CHEMBL1396773 & 688721 & 4.9 & 5.1483 & TRN \\
\hline CHEMBL1583650 & 688721 & 4.5 & 4.8549 & TRN \\
\hline CHEMBL1489378 & 688721 & 4.4 & 5.0496 & TST \\
\hline CHEMBL1451408 & 688721 & 4.8 & 4.9528 & TRN \\
\hline CHEMBL1597696 & 688721 & 5.3 & 4.953 & TRN \\
\hline CHEMBL1421442 & 688721 & 4.8 & 5.0981 & TRN \\
\hline CHEMBL1390147 & 688721 & 4.7 & 5.1304 & TRN \\
\hline CHEMBL1413938 & 688721 & 4.8 & 4.9412 & TRN \\
\hline CHEMBL1548839 & 688721 & 5.0 & 4.9539 & TRN \\
\hline CHEMBL1540830 & 688721 & 4.4 & 5.0203 & TRN \\
\hline CHEMBL1384525 & 688721 & 4.5 & 4.8977 & TST \\
\hline CHEMBL1391259 & 688721 & 5.3 & 4.9736 & TRN \\
\hline CHEMBL1542619 & 688721 & 4.7 & 4.9753 & TRN \\
\hline CHEMBL1559014 & 688721 & 4.4 & 4.9022 & TRN \\
\hline CHEMBL1312051 & 688721 & 5.2 & 5.0155 & TRN \\
\hline CHEMBL1475688 & 688721 & 5.2 & 5.2624 & TST \\
\hline
\end{tabular}




\begin{tabular}{|c|c|c|c|c|c|}
\hline \multicolumn{6}{|c|}{ Supplemental Table S2.txt } \\
\hline CHEMBL1586442 & 688721 & 4.4 & 4.7476 & TRN & \\
\hline CHEMBL1598490 & 688721 & 4.5 & 4.8782 & TRN & \\
\hline CHEMBL1542938 & 688721 & 4.4 & 4.9384 & TST & \\
\hline CHEMBL1464568 & 688721 & 6.2 & 5.1223 & TST & \\
\hline CHEMBL1569193 & 688721 & 4.5 & 4.7779 & TRN & \\
\hline CHEMBL1606550 & 688721 & 4.4 & 5.1164 & TRN & \\
\hline CHEMBL1436715 & 688721 & 4.4 & 4.8207 & TRN & \\
\hline CHEMBL1548581 & 688721 & 5.2 & 4.8787 & TST & \\
\hline CHEMBL1367453 & 688721 & 4.8 & 4.9698 & TRN & \\
\hline CHEMBL1551925 & 688721 & 5.3 & 5.096 & TRN & \\
\hline CHEMBL1459840 & 688721 & 4.7 & 5.0098 & TRN & \\
\hline CHEMBL1406078 & 688721 & 4.4 & 5.0486 & TRN & \\
\hline CHEMBL1255866 & 688721 & 6.9 & 4.897 & TST & \\
\hline CHEMBL1484944 & 688721 & 4.7 & 5.1321 & TRN & \\
\hline CHEMBL1433384 & 688721 & 4.6 & 4.7682 & TRN & \\
\hline CHEMBL1444123 & 688721 & 4.8 & 4.9071 & TRN & \\
\hline CHEMBL1566955 & 688721 & 6.4 & 4.8959 & TRN & \\
\hline CHEMBL1519692 & 688721 & 4.5 & 4.73600 & 0000000001 & TRN \\
\hline CHEMBL1406427 & 688721 & 4.7 & 4.8052 & TST & \\
\hline CHEMBL1303518 & 688721 & 5.3 & 4.8641 & TRN & \\
\hline CHEMBL1399466 & 688721 & 4.7 & 4.8561 & TRN & \\
\hline CHEMBL3209440 & 688721 & 4.9 & 4.9029 & TRN & \\
\hline CHEMBL1322373 & 688721 & 4.5 & 5.0709 & TST & \\
\hline CHEMBL1603515 & 688721 & 4.5 & 4.7616 & TRN & \\
\hline CHEMBL1489152 & 688721 & 4.8 & 4.8856 & TRN & \\
\hline CHEMBL1575923 & 688721 & 6.0 & 5.0578 & TRN & \\
\hline CHEMBL3193930 & 688721 & 6.2 & 4.904 & TST & \\
\hline CHEMBL414400 & 688721 & 5.1 & 5.269 & TST & \\
\hline CHEMBL1330853 & 688721 & 5.6 & 4.8075 & TRN & \\
\hline CHEMBL1413819 & 688721 & 4.7 & 4.8618 & TRN & \\
\hline CHEMBL1374585 & 688721 & 4.8 & 4.9088 & TRN & \\
\hline CHEMBL1595155 & 688721 & 4.8 & 4.995 & TST & \\
\hline CHEMBL1503853 & 688721 & 4.4 & 5.0526 & TRN & \\
\hline CHEMBL1366282 & 688721 & 5.7 & 5.0181 & TST & \\
\hline CHEMBL1495212 & 688721 & 4.9 & 4.9692 & TST & \\
\hline CHEMBL271023 & 688721 & 4.4 & 5.0573 & TST & \\
\hline CHEMBL1344981 & 688721 & 4.7 & 4.8153 & TRN & \\
\hline CHEMBL1450899 & 688721 & 4.5 & 4.8716 & TRN & \\
\hline CHEMBL1465781 & 688721 & 4.5 & 4.9459 & TRN & \\
\hline CHEMBL1530878 & 688721 & 5.5 & 4.7572 & TRN & \\
\hline CHEMBL1430092 & 688721 & 4.5 & 4.849 & TRN & \\
\hline CHEMBL1426529 & 688721 & 4.4 & 4.994 & TRN & \\
\hline CHEMBL1527174 & 688721 & 7.5003 & 5.1627 & TST & \\
\hline CHEMBL1409369 & 688721 & 6.3 & 5.0597 & TRN & \\
\hline CHEMBL1448568 & 688721 & 4.5 & 5.0548 & TST & \\
\hline CHEMBL1502286 & 688721 & 5.4 & 4.9442 & TST & \\
\hline CHEMBL1340593 & 688721 & 5.0 & 5.0552 & TRN & \\
\hline CHEMBL1491655 & 688721 & 5.2 & 4.873 & TST & \\
\hline
\end{tabular}




\begin{tabular}{|c|c|c|c|c|c|}
\hline \multicolumn{6}{|c|}{ Supplemental Table s2.txt } \\
\hline CHEMBL1498803 & 688721 & 4.7 & 4.9066 & TST & \\
\hline CHEMBL1511154 & 688721 & 4.4 & 4.8741 & TRN & \\
\hline CHEMBL1465539 & 688721 & 5.5 & 4.8808 & TRN & \\
\hline CHEMBL1430561 & 688721 & 5.1 & 4.7815 & TRN & \\
\hline CHEMBL1516054 & 688721 & 5.1 & 4.8678 & TRN & \\
\hline CHEMBL1588101 & 688721 & 4.5 & 4.8977 & TRN & \\
\hline CHEMBL1507108 & 688721 & 5.1 & 4.9629 & TRN & \\
\hline CHEMBL1304055 & 688721 & 5.4 & 4.9235 & TST & \\
\hline CHEMBL1542906 & 688721 & 4.7 & 5.0647 & TRN & \\
\hline CHEMBL1500019 & 688721 & 4.4 & 4.8838 & TST & \\
\hline CHEMBL1311841 & 688721 & 4.7 & 4.9272 & TRN & \\
\hline CHEMBL1390474 & 688721 & 4.7 & 4.9402 & TRN & \\
\hline CHEMBL1613331 & 688721 & 4.6 & 4.8199 & TRN & \\
\hline CHEMBL1357192 & 688721 & 5.5 & 5.1322 & TST & \\
\hline CHEMBL1468635 & 688721 & 4.8 & 4.9264 & TRN & \\
\hline CHEMBL1352496 & 688721 & 4.9 & 4.8611 & TST & \\
\hline CHEMBL1568714 & 688721 & 4.7 & 4.8379 & TRN & \\
\hline CHEMBL259615 & 688721 & 4.4 & 4.7946 & TRN & \\
\hline CHEMBL1558761 & 688721 & 4.4 & 4.8954 & TRN & \\
\hline CHEMBL1466849 & 688721 & 4.7 & 4.7783 & TRN & \\
\hline CHEMBL1481288 & 688721 & 5.2 & 4.895 & TRN & \\
\hline CHEMBL1384120 & 688721 & 6.5 & 4.886 & TST & \\
\hline CHEMBL1517721 & 688721 & 4.9 & 5.1431 & TRN & \\
\hline CHEMBL1520062 & 688721 & 4.4 & 4.9691 & TRN & \\
\hline CHEMBL1451617 & 688721 & 5.3 & 4.9859 & TRN & \\
\hline CHEMBL1408175 & 688721 & 4.4 & 5.0849 & TST & \\
\hline CHEMBL1380496 & 688721 & 4.7 & 4.9283 & TRN & \\
\hline CHEMBL1436049 & 688721 & 4.8 & 4.8761 & TRN & \\
\hline CHEMBL1085162 & 688721 & 5.2 & 5.1291 & TRN & \\
\hline CHEMBL1353486 & 688721 & 6.5 & 5.0441 & TRN & \\
\hline CHEMBL1371232 & 688721 & 4.6 & 4.8208 & TRN & \\
\hline CHEMBL1335202 & 688721 & 4.4 & 4.8788 & TRN & \\
\hline CHEMBL1524703 & 688721 & 5.2 & 4.8754 & TST & \\
\hline CHEMBL1369268 & 688721 & 5.2 & 5.0352 & TRN & \\
\hline CHEMBL1390074 & 688721 & 4.5 & 5.0264 & TST & \\
\hline CHEMBL409695 & 688721 & 4.7 & 5.0967 & TRN & \\
\hline CHEMBL1424914 & 688721 & 4.5 & 4.9906 & TRN & \\
\hline CHEMBL1575609 & 688721 & 4.6 & 5.0344 & TST & \\
\hline CHEMBL1346880 & 688721 & 4.7 & 5.099 & TRN & \\
\hline CHEMBL1518015 & 688721 & 5.2 & 5.066 & TST & \\
\hline CHEMBL1596241 & 688721 & 4.5 & 4.9567 & TRN & \\
\hline CHEMBL1428499 & 688721 & 4.4 & 4.92399 & 99999999995 & TRN \\
\hline CHEMBL1603639 & 688721 & 5.9 & 4.9415 & TRN & \\
\hline CHEMBL1604159 & 688721 & 5.0 & 4.8918 & TRN & \\
\hline CHEMBL 364900 & 688721 & 4.4 & 5.029 & TRN & \\
\hline CHEMBL1433135 & 688721 & 4.4 & 4.8918 & TRN & \\
\hline CHEMBL1391062 & 688721 & 4.5 & 4.8163 & TRN & \\
\hline CHEMBL1450903 & 688721 & 4.8 & 5.1032 & TRN & \\
\hline
\end{tabular}




\begin{tabular}{|c|c|c|c|c|c|}
\hline & & & & & \\
\hline CHEMBL1345977 & 688721 & 4.4 & 4.9067 & TRN & \\
\hline CHEMBL1494655 & 688721 & 5.3 & 4.9674 & TRN & \\
\hline CHEMBL1378255 & 688721 & 4.7 & 4.7332 & TRN & \\
\hline CHEMBL1590980 & 688721 & 4.8 & 4.8707 & TRN & \\
\hline CHEMBL1442785 & 688721 & 5.8 & 5.1725 & TRN & \\
\hline CHEMBL1524813 & 688721 & 4.7 & 4.6636 & TRN & \\
\hline CHEMBL1519955 & 688721 & 4.7 & 4.93199 & 99999999995 & TRN \\
\hline CHEMBL1470488 & 688721 & 4.6 & 4.9268 & TRN & \\
\hline CHEMBL1304887 & 688721 & 4.4 & 4.8843 & TRN & \\
\hline CHEMBL1321961 & 688721 & 5.3 & 4.855 & TST & \\
\hline CHEMBL1513488 & 688721 & 4.5 & 5.04899 & 99999999995 & TST \\
\hline CHEMBL1330922 & 688721 & 4.8 & 4.7359 & TRN & \\
\hline CHEMBL 228862 & 688721 & 5.7 & 5.16299 & 9999999999 & TST \\
\hline CHEMBL1379558 & 688721 & 4.7 & 5.0755 & TRN & \\
\hline CHEMBL1487166 & 688721 & 7.0 & 5.0476 & TST & \\
\hline CHEMBL1541513 & 688721 & 5.7 & 4.8604 & TRN & \\
\hline CHEMBL1418088 & 688721 & 5.2 & 5.0451 & TRN & \\
\hline CHEMBL1327697 & 688721 & 5.4 & 5.1741 & TRN & \\
\hline CHEMBL 1571020 & 688721 & 5.9 & 4.8791 & TRN & \\
\hline CHEMBL1542786 & 688721 & 4.4 & 4.9416 & TRN & \\
\hline CHEMBL1453103 & 688721 & 5.7 & 5.0891 & TST & \\
\hline CHEMBL1588930 & 688721 & 4.5 & 4.836 & TRN & \\
\hline CHEMBL1443255 & 688721 & 4.6 & 4.8911 & TRN & \\
\hline CHEMBL1330028 & 688721 & 5.1 & 4.9661 & TST & \\
\hline CHEMBL1557609 & 688721 & 6.3 & 4.8663 & TRN & \\
\hline CHEMBL1532900 & 688721 & 5.2 & 4.9272 & TRN & \\
\hline CHEMBL1525354 & 688721 & 4.9 & 4.8524 & TRN & \\
\hline CHEMBL1446909 & 688721 & 4.6 & 4.7672 & TRN & \\
\hline CHEMBL1497235 & 688721 & 4.6 & 4.9669 & TRN & \\
\hline CHEMBL1442153 & 688721 & 5.5 & 5.4031 & TRN & \\
\hline CHEMBL1526413 & 688721 & 5.2 & 4.9645 & TST & \\
\hline CHEMBL1557303 & 688721 & 4.6 & 4.7532 & TRN & \\
\hline CHEMBL1518249 & 688721 & 4.5 & 5.1631 & TRN & \\
\hline CHEMBL1471901 & 688721 & 4.6 & 4.9955 & TRN & \\
\hline CHEMBL1525187 & 688721 & 4.8 & 5.1134 & TRN & \\
\hline CHEMBL1367420 & 688721 & 4.7 & 4.8965 & TRN & \\
\hline CHEMBL1386228 & 688721 & 5.5 & 4.817 & TRN & \\
\hline CHEMBL1562316 & 688721 & 4.5 & 4.8982 & TRN & \\
\hline CHEMBL1319715 & 688721 & 4.6 & 4.8161 & TRN & \\
\hline CHEMBL1383741 & 688721 & 6.8 & 4.9905 & TRN & \\
\hline CHEMBL1600842 & 688721 & 6.2 & 4.976 & TST & \\
\hline CHEMBL1429270 & 688721 & 4.9 & 4.8317 & TRN & \\
\hline CHEMBL1588567 & 688721 & 4.5 & 5.0045 & TRN & \\
\hline CHEMBL1517649 & 688721 & 5.2 & 4.8868 & TRN & \\
\hline CHEMBL1493173 & 688721 & 4.5 & 4.8321 & TRN & \\
\hline CHEMBL1337451 & 688721 & 4.7 & 4.9596 & TRN & \\
\hline CHEMBL1460019 & 688721 & 4.6 & 5.0889 & TRN & \\
\hline CHEMBL1579983 & 688721 & 4.9 & 4.879 & TST & \\
\hline
\end{tabular}




\begin{tabular}{|c|c|c|c|c|}
\hline \multicolumn{5}{|c|}{ Supplemental Table S2.txt } \\
\hline CHEMBL1531716 & 688721 & 4.4 & 5.1076 & TST \\
\hline CHEMBL1302419 & 688721 & 5.2 & 5.0289 & TST \\
\hline CHEMBL1317761 & 688721 & 5.1 & 4.7701 & TRN \\
\hline CHEMBL1408042 & 688721 & 4.5 & 5.0108 & TRN \\
\hline CHEMBL1483442 & 688721 & 4.9 & 4.7892 & TRN \\
\hline CHEMBL1351263 & 688721 & 4.8 & 5.0686 & TST \\
\hline CHEMBL1612324 & 688721 & 5.7 & 4.931 & TRN \\
\hline CHEMBL1603894 & 688721 & 5.6 & 4.8805 & TRN \\
\hline CHEMBL1464099 & 688721 & 4.5 & 4.9346 & TRN \\
\hline CHEMBL1344033 & 688721 & 5.2 & 4.9958 & TRN \\
\hline CHEMBL1425853 & 688721 & 4.6 & 4.8018 & TRN \\
\hline CHEMBL1362377 & 688721 & 5.3 & 4.9431 & TRN \\
\hline CHEMBL1604833 & 688721 & 6.0 & 4.8367 & TRN \\
\hline CHEMBL1594781 & 688721 & 4.8 & 4.88 & TRN \\
\hline CHEMBL44 & 688721 & 6.0 & 5.0489 & TRN \\
\hline CHEMBL1349999 & 688721 & 4.4 & 4.9323 & TST \\
\hline CHEMBL1256759 & 688721 & 6.0 & 5.1714 & TRN \\
\hline CHEMBL1487937 & 688721 & 5.4 & 5.1652 & TRN \\
\hline CHEMBL1257014 & 688721 & 4.8 & 4.916 & TRN \\
\hline CHEMBL1427719 & 688721 & 4.4 & 4.8239 & TRN \\
\hline CHEMBL1586215 & 688721 & 5.0 & 4.9899 & TST \\
\hline CHEMBL1503361 & 688721 & 4.7 & 4.9985 & TST \\
\hline CHEMBL1339054 & 688721 & 4.9 & 4.8514 & TRN \\
\hline CHEMBL1563812 & 688721 & 5.3 & 4.8651 & TST \\
\hline CHEMBL1570016 & 688721 & 4.9 & 4.9201 & TRN \\
\hline CHEMBL3213067 & 688721 & 4.4 & 4.8833 & TRN \\
\hline CHEMBL1325339 & 688721 & 4.7 & 4.9285 & TRN \\
\hline CHEMBL1504664 & 688721 & 4.5 & 4.9006 & TRN \\
\hline CHEMBL1430992 & 688721 & 4.7 & 4.968 & TRN \\
\hline CHEMBL1372747 & 688721 & 4.4 & 5.0071 & TRN \\
\hline CHEMBL1610422 & 688721 & 5.4 & 4.8097 & TRN \\
\hline CHEMBL1598939 & 688721 & 4.4 & 5.2621 & TST \\
\hline CHEMBL1573611 & 688721 & 4.6 & 5.0584 & TRN \\
\hline CHEMBL1372976 & 688721 & 6.0 & 4.9122 & TRN \\
\hline CHEMBL1510218 & 688721 & 7.699 & 4.7667 & TRN \\
\hline CHEMBL1256360 & 688721 & 6.0 & 5.1921 & TRN \\
\hline CHEMBL1447020 & 688721 & 4.5 & 4.8031 & TRN \\
\hline CHEMBL1530526 & 688721 & 4.6 & 4.9305 & TST \\
\hline CHEMBL1501180 & 688721 & 4.4 & 4.881 & TRN \\
\hline CHEMBL1560230 & 688721 & 4.5 & 4.954 & TST \\
\hline CHEMBL115121 & 688721 & 4.4 & 4.8882 & TST \\
\hline CHEMBL1420531 & 688721 & 4.8 & 5.0199 & TRN \\
\hline CHEMBL1348407 & 688721 & 4.6 & 4.9557 & TRN \\
\hline CHEMBL1599249 & 688721 & 4.5 & 4.744 & TRN \\
\hline CHEMBL1377800 & 688721 & 4.9 & 4.9311 & TST \\
\hline CHEMBL1399235 & 688721 & 4.4 & 4.8627 & TST \\
\hline CHEMBL1417018 & 688721 & 4.5 & 5.0044 & TST \\
\hline CHEMBL1425658 & 688721 & 4.6 & 4.7764 & TRN \\
\hline
\end{tabular}




\begin{tabular}{|c|c|c|c|c|}
\hline \multicolumn{5}{|c|}{ pplemental T } \\
\hline CHEMBL1540891 & 688721 & 4.7 & 5.0561 & TST \\
\hline CHEMBL1566386 & 688721 & 4.6 & 4.7546 & TRN \\
\hline CHEMBL1531197 & 688721 & 5.2 & 5.0232 & TRN \\
\hline CHEMBL1338900 & 688721 & 6.1 & 5.2653 & TST \\
\hline CHEMBL 285843 & 688721 & 5.2 & 5.419 & TRN \\
\hline CHEMBL 1487840 & 688721 & 4.4 & 4.9564 & TRN \\
\hline CHEMBL1430222 & 688721 & 4.4 & 4.7914 & TRN \\
\hline CHEMBL1507227 & 688721 & 4.4 & 4.8814 & TRN \\
\hline CHEMBL1522278 & 688721 & 5.2 & 4.925 & TRN \\
\hline CHEMBL1583506 & 688721 & 4.5 & 5.086 & TST \\
\hline CHEMBL1598228 & 688721 & 5.4 & 5.1224 & TST \\
\hline CHEMBL1527442 & 688721 & 6.9 & 5.0005 & TST \\
\hline CHEMBL1438566 & 688721 & 6.0 & 5.0942 & TRN \\
\hline CHEMBL1608618 & 688721 & 4.6 & 4.7699 & TRN \\
\hline CHEMBL83552 & 688721 & 4.9 & 5.0318 & TST \\
\hline CHEMBL1347264 & 688721 & 4.7 & 4.9594 & TRN \\
\hline CHEMBL1553114 & 688721 & 4.8 & 4.9047 & TRN \\
\hline CHEMBL1314647 & 688721 & 6.6 & 5.3124 & TRN \\
\hline CHEMBL1489064 & 688721 & 5.9 & 5.0723 & TST \\
\hline CHEMBL88621 & 688721 & 4.4 & 5.4246 & TRN \\
\hline CHEMBL1460710 & 688721 & 5.0 & 4.7768 & TRN \\
\hline CHEMBL556001 & 688721 & 6.0 & 4.9265 & TRN \\
\hline CHEMBL1475142 & 688721 & 4.9 & 4.8229 & TRN \\
\hline CHEMBL1422370 & 688721 & 4.4 & 4.9368 & TST \\
\hline CHEMBL1419137 & 688721 & 4.6 & 4.9351 & TRN \\
\hline CHEMBL1523141 & 688721 & 4.4 & 5.0181 & TRN \\
\hline CHEMBL1316595 & 688721 & 4.4 & 4.8659 & TST \\
\hline CHEMBL1549010 & 688721 & 4.4 & 4.9156 & TRN \\
\hline CHEMBL1418551 & 688721 & 5.1 & 4.8682 & TRN \\
\hline CHEMBL1386803 & 688721 & 5.1 & 4.8793 & TRN \\
\hline CHEMBL1255737 & 688721 & 5.2 & 5.0441 & TST \\
\hline CHEMBL1499094 & 688721 & 4.7 & 4.9251 & TRN \\
\hline CHEMBL1353408 & 688721 & 4.6 & 4.9209 & TRN \\
\hline CHEMBL1542303 & 688721 & 5.9 & 5.053 & TRN \\
\hline CHEMBL1447431 & 688721 & 4.8 & 4.7792 & TRN \\
\hline CHEMBL1595002 & 688721 & 4.9 & 5.024 & TRN \\
\hline CHEMBL1332706 & 688721 & 5.4 & 4.8808 & TRN \\
\hline CHEMBL1452413 & 688721 & 4.7 & 5.0231 & TRN \\
\hline CHEMBL1412893 & 688721 & 5.2 & 5.1273 & TRN \\
\hline CHEMBL1375405 & 688721 & 4.4 & 4.967 & TRN \\
\hline CHEMBL1271881 & 688721 & 5.4 & 5.0396 & TRN \\
\hline CHEMBL1405692 & 688721 & 5.2 & 4.8973 & TST \\
\hline CHEMBL1461912 & 688721 & 4.6 & 5.0126 & TST \\
\hline CHEMBL1439844 & 688721 & 4.6 & 4.9238 & TRN \\
\hline CHEMBL1535402 & 688721 & 4.8 & 5.0851 & TST \\
\hline CHEMBL1533059 & 688721 & 4.4 & 4.888 & TRN \\
\hline CHEMBL1453299 & 688721 & 4.5 & 4.6823 & TRN \\
\hline CHEMBL375126 & 688721 & 4.4 & 4.8252 & TST \\
\hline
\end{tabular}




\begin{tabular}{|c|c|c|c|c|c|}
\hline \\
\hline CHEMBL1580735 & 688721 & 5.4 & 5.1288 & TST & \\
\hline CHEMBL1373408 & 688721 & 4.5 & 5.0326 & TST & \\
\hline CHEMBL1546958 & 688721 & 4.6 & 4.7888 & TRN & \\
\hline CHEMBL1515614 & 688721 & 4.4 & 5.1833 & TRN & \\
\hline CHEMBL1480787 & 688721 & 4.8 & 4.8747 & TRN & \\
\hline CHEMBL1562710 & 688721 & 5.2 & 4.8273 & TRN & \\
\hline CHEMBL1509066 & 688721 & 4.6 & 4.8743 & TRN & \\
\hline CHEMBL1440784 & 688721 & 4.4 & 5.072 & TRN & \\
\hline CHEMBL1471421 & 688721 & 4.5 & 4.742 & TRN & \\
\hline CHEMBL1576755 & 688721 & 4.4 & 4.9359 & TRN & \\
\hline CHEMBL1420389 & 688721 & 4.4 & 4.9454 & TRN & \\
\hline CHEMBL1428767 & 688721 & 4.6 & 4.8361 & TRN & \\
\hline CHEMBL1483086 & 688721 & 6.1 & 5.0047 & TRN & \\
\hline CHEMBL1550771 & 688721 & 4.8 & 4.9549 & TST & \\
\hline CHEMBL1598575 & 688721 & 5.2 & 5.3031 & TRN & \\
\hline CHEMBL1548592 & 688721 & 4.4 & 5.1547 & TRN & \\
\hline CHEMBL1541154 & 688721 & 5.0 & 4.8363 & TRN & \\
\hline CHEMBL1368406 & 688721 & 7.699 & 4.9841 & TRN & \\
\hline CHEMBL1601412 & 688721 & 4.6 & 5.0457 & TRN & \\
\hline CHEMBL1482317 & 688721 & 5.5 & 4.7269 & TRN & \\
\hline CHEMBL1307843 & 688721 & 5.4 & 4.8137 & TST & \\
\hline CHEMBL1595573 & 688721 & 4.5 & 4.9061 & TRN & \\
\hline CHEMBL1448658 & 688721 & 5.5 & 4.9912 & TST & \\
\hline CHEMBL1318988 & 688721 & 4.4 & 4.8604 & TST & \\
\hline CHEMBL1449118 & 688721 & 5.2 & 4.9003 & TRN & \\
\hline CHEMBL1494666 & 688721 & 4.7 & 4.923 & TRN & \\
\hline CHEMBL1335080 & 688721 & 5.4 & 4.9122 & TRN & \\
\hline CHEMBL3191913 & 688721 & 5.2 & 4.8016 & TST & \\
\hline CHEMBL1321357 & 688721 & 5.9 & 5.0945 & TRN & \\
\hline CHEMBL1559311 & 688721 & 4.4 & 4.9222 & TST & \\
\hline CHEMBL1482654 & 688721 & 4.4 & 4.9806 & TRN & \\
\hline CHEMBL1319378 & 688721 & 4.5 & 4.8257 & TST & \\
\hline CHEMBL1349971 & 688721 & 5.5 & 4.8733 & TRN & \\
\hline CHEMBL1569877 & 688721 & 4.7 & 4.9438 & TRN & \\
\hline CHEMBL1599605 & 688721 & 4.7 & 4.8186 & TRN & \\
\hline CHEMBL1444431 & 688721 & 4.5 & 4.8312 & TRN & \\
\hline CHEMBL1532948 & 688721 & 5.2 & 5.02800 & 00000000005 & TST \\
\hline CHEMBL1521169 & 688721 & 4.8 & 5.0994 & TRN & \\
\hline CHEMBL1345294 & 688721 & 5.1 & 4.8277 & TRN & \\
\hline CHEMBL1608755 & 688721 & 4.4 & 4.8036 & TRN & \\
\hline CHEMBL1340202 & 688721 & 6.0 & 4.9969 & TRN & \\
\hline CHEMBL1534495 & 688721 & 4.5 & 5.0388 & TRN & \\
\hline CHEMBL1431783 & 688721 & 4.4 & 4.7752 & TRN & \\
\hline CHEMBL1581555 & 688721 & 4.9 & 4.8492 & TRN & \\
\hline CHEMBL1531690 & 688721 & 6.4 & 5.0462 & TRN & \\
\hline CHEMBL1377176 & 688721 & 4.5 & 4.8867 & TST & \\
\hline CHEMBL1560250 & 688721 & 4.7 & 5.0343 & TRN & \\
\hline CHEMBL1451308 & 688721 & 5.3 & 4.7503 & TRN & \\
\hline & & & & 3883 & \\
\hline
\end{tabular}




\begin{tabular}{|c|c|c|c|c|}
\hline & & & pplement & al $\mathrm{Ta}$ \\
\hline CHEMBL1311973 & 688721 & 4.6 & 4.9742 & TRN \\
\hline CHEMBL1453052 & 688721 & 4.5 & 4.8092 & TST \\
\hline CHEMBL1331521 & 688721 & 4.4 & 4.7995 & TRN \\
\hline CHEMBL1491697 & 688721 & 4.9 & 4.9777 & TRN \\
\hline CHEMBL1378817 & 688721 & 4.5 & 5.0584 & TRN \\
\hline CHEMBL1326304 & 688721 & 4.8 & 5.0829 & TRN \\
\hline CHEMBL1594171 & 688721 & 4.4 & 4.9035 & TRN \\
\hline CHEMBL1548006 & 688721 & 4.4 & 4.8833 & TRN \\
\hline CHEMBL1598539 & 688721 & 4.4 & 4.9547 & TRN \\
\hline CHEMBL1473990 & 688721 & 5.0 & 5.0282 & TRN \\
\hline CHEMBL1305217 & 688721 & 4.6 & 4.9025 & TRN \\
\hline CHEMBL1301118 & 688721 & 5.3 & 4.8717 & TRN \\
\hline CHEMBL1555438 & 688721 & 4.5 & 5.0265 & TST \\
\hline CHEMBL1603924 & 688721 & 4.4 & 5.0495 & TST \\
\hline CHEMBL1456804 & 688721 & 4.4 & 4.9745 & TRN \\
\hline CHEMBL1574269 & 688721 & 4.4 & 4.925 & TRN \\
\hline CHEMBL1308667 & 688721 & 5.2 & 4.8896 & TST \\
\hline CHEMBL1427702 & 688721 & 4.4 & 4.8094 & TRN \\
\hline CHEMBL1575772 & 688721 & 4.7 & 4.8998 & TRN \\
\hline CHEMBL1372646 & 688721 & 4.6 & 4.7568 & TRN \\
\hline CHEMBL1567128 & 688721 & 4.5 & 4.809 & TRN \\
\hline CHEMBL1550528 & 688721 & 4.6 & 4.9269 & TRN \\
\hline CHEMBL1308716 & 688721 & 4.8 & 4.9695 & TRN \\
\hline CHEMBL1568449 & 688721 & 5.9 & 4.852 & TRN \\
\hline CHEMBL1311328 & 688721 & 5.4 & 4.7944 & TRN \\
\hline CHEMBL1585355 & 688721 & 4.8 & 4.9689 & TST \\
\hline CHEMBL1425039 & 688721 & 4.6 & 4.7583 & TRN \\
\hline CHEMBL1306095 & 688721 & 5.3 & 4.8133 & TRN \\
\hline CHEMBL1549248 & 688721 & 4.4 & 5.1224 & TST \\
\hline CHEMBL1580903 & 688721 & 4.6 & 4.7758 & TRN \\
\hline CHEMBL1468039 & 688721 & 5.4 & 5.0201 & TRN \\
\hline CHEMBL1538593 & 688721 & 4.9 & 5.0453 & TRN \\
\hline CHEMBL1367109 & 688721 & 5.2 & 5.1079 & TST \\
\hline CHEMBL1540341 & 688721 & 5.8 & 4.7273 & TRN \\
\hline CHEMBL1529625 & 688721 & 5.3 & 5.3257 & TST \\
\hline CHEMBL1402105 & 688721 & 5.5 & 4.7811 & TST \\
\hline CHEMBL3212021 & 688721 & 4.5 & 4.8985 & TRN \\
\hline CHEMBL1594951 & 688721 & 5.2 & 4.8299 & TRN \\
\hline CHEMBL1539718 & 688721 & 4.5 & 4.9547 & TRN \\
\hline CHEMBL1448969 & 688721 & 4.6 & 4.8282 & TST \\
\hline CHEMBL1334895 & 688721 & 4.6 & 4.928 & TST \\
\hline CHEMBL1508633 & 688721 & 4.6 & 5.0479 & TRN \\
\hline CHEMBL1414129 & 688721 & 6.0 & 5.0515 & TRN \\
\hline CHEMBL1416940 & 688721 & 4.6 & 4.9131 & TRN \\
\hline CHEMBL1362370 & 688721 & 6.8 & 4.8359 & TRN \\
\hline CHEMBL1609044 & 688721 & 5.2 & 4.8675 & TRN \\
\hline CHEMBL1467186 & 688721 & 4.6 & 4.9112 & TRN \\
\hline CHEMBL1313504 & 688721 & 4.6 & 4.9994 & TRN \\
\hline
\end{tabular}




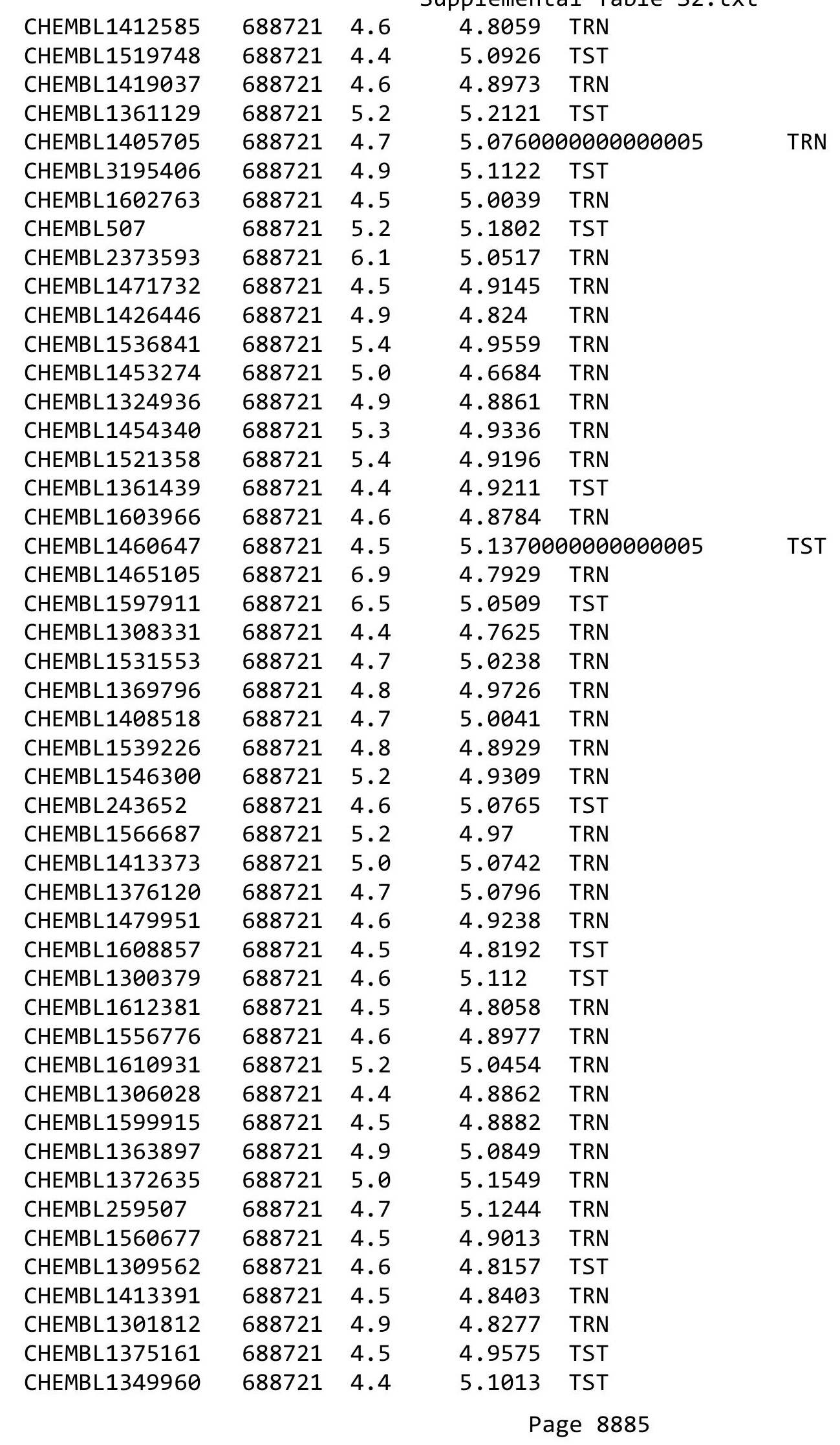




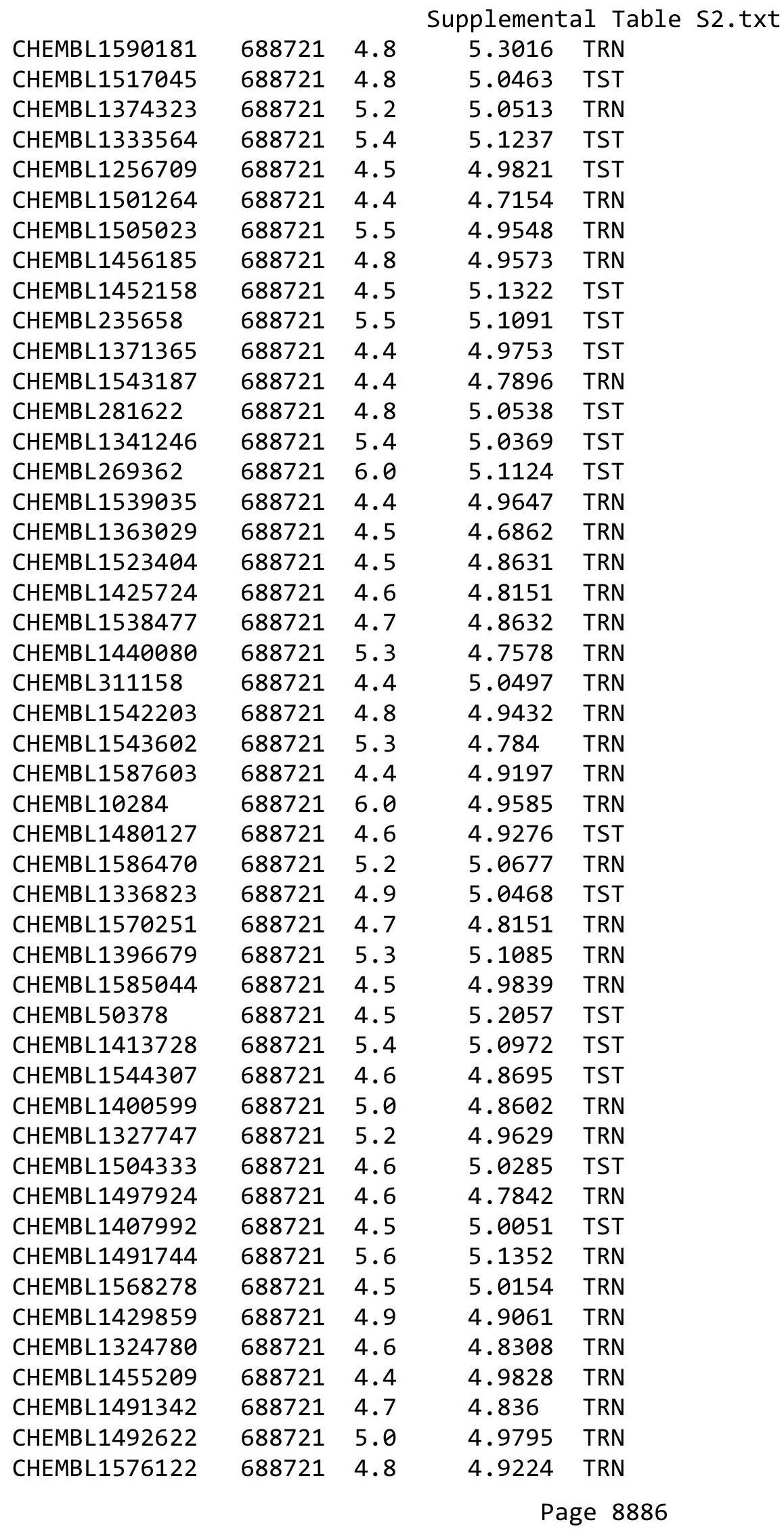




\begin{tabular}{|c|c|c|c|c|}
\hline \multicolumn{5}{|c|}{ lemental T } \\
\hline CHEMBL1583268 & 688721 & 4.8 & 5.0115 & TRN \\
\hline CHEMBL1344963 & 688721 & 6.8 & 5.0359 & TRN \\
\hline CHEMBL1329814 & 688721 & 5.1 & 5.2733 & TST \\
\hline CHEMBL1537764 & 688721 & 4.7 & 5.0271 & TST \\
\hline CHEMBL1571018 & 688721 & 4.5 & 4.8644 & TRN \\
\hline CHEMBL1424680 & 688721 & 4.6 & 4.9424 & TST \\
\hline CHEMBL1568217 & 688721 & 4.8 & 4.8399 & TRN \\
\hline CHEMBL1430213 & 688721 & 4.4 & 4.8717 & TST \\
\hline CHEMBL1559904 & 688721 & 4.6 & 4.8925 & TRN \\
\hline CHEMBL1316496 & 688721 & 4.4 & 5.0741 & TST \\
\hline CHEMBL1585598 & 688721 & 4.9 & 5.0277 & TST \\
\hline CHEMBL1607363 & 688721 & 4.5 & 4.957 & TRN \\
\hline CHEMBL1441337 & 688721 & 4.8 & 4.8745 & TRN \\
\hline CHEMBL1606549 & 688721 & 4.6 & 4.8834 & TRN \\
\hline CHEMBL1493898 & 688721 & 6.4 & 5.0103 & TRN \\
\hline CHEMBL1474695 & 688721 & 4.9 & 5.0941 & TRN \\
\hline CHEMBL1391342 & 688721 & 5.4 & 5.0623 & TST \\
\hline CHEMBL1576351 & 688721 & 4.6 & 4.8235 & TST \\
\hline CHEMBL1437428 & 688721 & 5.2 & 5.0637 & TST \\
\hline CHEMBL1421179 & 688721 & 5.0 & 4.877 & TRN \\
\hline CHEMBL1513812 & 688721 & 4.6 & 5.0946 & TRN \\
\hline CHEMBL448966 & 688721 & 4.6 & 5.0556 & TRN \\
\hline CHEMBL1364720 & 688721 & 4.7 & 4.7774 & TRN \\
\hline CHEMBL1586326 & 688721 & 6.0 & 4.9524 & TST \\
\hline CHEMBL1314255 & 688721 & 4.8 & 4.8879 & TRN \\
\hline CHEMBL1389757 & 688721 & 5.0 & 4.7779 & TRN \\
\hline CHEMBL1436355 & 688721 & 4.9 & 4.8193 & TRN \\
\hline CHEMBL1587441 & 688721 & 5.1 & 4.9102 & TST \\
\hline CHEMBL1371260 & 688721 & 4.7 & 4.9491 & TRN \\
\hline CHEMBL1530814 & 688721 & 4.4 & 4.87 & TRN \\
\hline CHEMBL1366194 & 688721 & 4.4 & 4.9586 & TRN \\
\hline CHEMBL1522303 & 688721 & 4.4 & 5.1004 & TST \\
\hline CHEMBL157427 & 688721 & 4.8 & 5.2902 & TST \\
\hline CHEMBL1549473 & 688721 & 5.2 & 5.1305 & TST \\
\hline CHEMBL1611449 & 688721 & 5.3 & 4.919 & TRN \\
\hline CHEMBL1542758 & 688721 & 4.6 & 4.907 & TRN \\
\hline CHEMBL1319055 & 688721 & 4.6 & 5.0096 & TRN \\
\hline CHEMBL1346589 & 688721 & 4.7 & 4.9939 & TRN \\
\hline CHEMBL1408077 & 688721 & 5.4 & 5.1462 & TST \\
\hline CHEMBL1398607 & 688721 & 5.4 & 4.9595 & TST \\
\hline CHEMBL1472338 & 688721 & 4.5 & 4.6773 & TRN \\
\hline CHEMBL1531439 & 688721 & 5.3 & 4.8646 & TRN \\
\hline CHEMBL1391187 & 688721 & 4.7 & 4.9536 & TRN \\
\hline CHEMBL1404169 & 688721 & 4.4 & 4.992 & TST \\
\hline CHEMBL1401753 & 688721 & 4.9 & 4.8788 & TST \\
\hline CHEMBL1452251 & 688721 & 5.6 & 4.9321 & TRN \\
\hline CHEMBL1448360 & 688721 & 4.7 & 4.8892 & TST \\
\hline CHEMBL1448607 & 688721 & 5.9 & 4.8684 & TRN \\
\hline
\end{tabular}




\begin{tabular}{|c|c|c|c|c|c|}
\hline \\
\hline CHEMBL1256776 & 688721 & 4.6 & 5.0928 & TRN & \\
\hline CHEMBL1374117 & 688721 & 4.6 & 4.9476 & TRN & \\
\hline CHEMBL1603347 & 688721 & 4.5 & 4.9585 & TRN & \\
\hline CHEMBL1300798 & 688721 & 4.4 & 4.877 & TST & \\
\hline CHEMBL1430822 & 688721 & 4.4 & 4.6986 & TRN & \\
\hline CHEMBL1498356 & 688721 & 4.7 & 4.887 & TRN & \\
\hline CHEMBL1488738 & 688721 & 4.6 & 4.842 & TRN & \\
\hline CHEMBL1452199 & 688721 & 5.5 & 5.2048 & TRN & \\
\hline CHEMBL1599409 & 688721 & 5.9 & 4.9814 & TRN & \\
\hline CHEMBL1318831 & 688721 & 4.6 & 5.0247 & TST & \\
\hline CHEMBL1611439 & 688721 & 5.4 & 4.8786 & TST & \\
\hline CHEMBL1338424 & 688721 & 5.4 & 5.0571 & TST & \\
\hline CHEMBL1609614 & 688721 & 4.7 & 5.0978 & TRN & \\
\hline CHEMBL1387227 & 688721 & 4.9 & 4.9009 & TRN & \\
\hline CHEMBL1326920 & 688721 & 4.6 & 4.9464 & TRN & \\
\hline CHEMBL1419868 & 688721 & 4.5 & 5.0647 & TRN & \\
\hline CHEMBL1430324 & 688721 & 4.6 & 4.9973 & TRN & \\
\hline CHEMBL1384184 & 688721 & 4.7 & 5.0402 & TRN & \\
\hline CHEMBL1411543 & 688721 & 6.0 & 5.1408 & TRN & \\
\hline CHEMBL14276 & 688721 & 6.0 & 4.9773 & TST & \\
\hline CHEMBL1598686 & 688721 & 4.6 & 4.8629 & TRN & \\
\hline CHEMBL1352138 & 688721 & 4.5 & 5.0101 & TST & \\
\hline CHEMBL1528917 & 688721 & 4.4 & 4.9769 & TRN & \\
\hline CHEMBL1379130 & 688721 & 4.8 & 4.8787 & TRN & \\
\hline CHEMBL1372584 & 688721 & 4.8 & 4.9274 & TRN & \\
\hline CHEMBL1475083 & 688721 & 5.3 & 5.1305 & TRN & \\
\hline CHEMBL1317039 & 688721 & 5.1 & 5.1141 & TRN & \\
\hline CHEMBL1522003 & 688721 & 5.0 & 4.8114 & TRN & \\
\hline CHEMBL1345206 & 688721 & 4.7 & 4.9505 & TRN & \\
\hline CHEMBL1352070 & 688721 & 5.5 & 4.8785 & TRN & \\
\hline CHEMBL1606761 & 688721 & 4.6 & 4.9443 & TRN & \\
\hline CHEMBL1495827 & 688721 & 4.6 & 4.8588 & TRN & \\
\hline CHEMBL1608509 & 688721 & 5.2 & 4.776 & TRN & \\
\hline CHEMBL1509430 & 688721 & 5.1 & 4.8626 & TRN & \\
\hline CHEMBL1529181 & 688721 & 4.5 & 4.8993 & TRN & \\
\hline CHEMBL1521602 & 688721 & 4.4 & 4.9576 & TRN & \\
\hline CHEMBL175193 & 688721 & 5.7 & 5.1211 & TST & \\
\hline CHEMBL1305846 & 688721 & 4.5 & 5.0902 & TST & \\
\hline CHEMBL1331312 & 688721 & 6.0 & 5.0028 & TRN & \\
\hline CHEMBL1500874 & 688721 & 4.4 & 4.8679 & TST & \\
\hline CHEMBL1462372 & 688721 & 6.2 & 4.9541 & TST & \\
\hline CHEMBL1413294 & 688721 & 5.5 & 5.1137 & TRN & \\
\hline CHEMBL1539444 & 688721 & 6.0 & 4.9118 & TRN & \\
\hline CHEMBL1427968 & 688721 & 4.5 & 4.7772 & TRN & \\
\hline CHEMBL1457118 & 688721 & 5.2 & 5.0255 & TRN & \\
\hline CHEMBL1533004 & 688721 & 4.5 & 4.9574 & TRN & \\
\hline CHEMBL1312478 & 688721 & 5.1 & 4.8538 & TRN & \\
\hline CHEMBL1358988 & 688721 & 4.6 & $4.9460 e$ & 0000000001 & TRN \\
\hline & & & & e 8888 & \\
\hline
\end{tabular}




\begin{tabular}{|c|c|c|c|c|c|}
\hline \multicolumn{6}{|c|}{ Supplemental Table S2.txt } \\
\hline CHEMBL1482692 & 688721 & 4.9 & 4.7465 & TRN & \\
\hline CHEMBL1466238 & 688721 & 4.8 & 4.7928 & TRN & \\
\hline CHEMBL532641 & 688721 & 4.8 & 5.0639 & TST & \\
\hline CHEMBL45591 & 688721 & 8.7959 & 5.0499 & TRN & \\
\hline CHEMBL1302237 & 688721 & 4.8 & 4.7287 & TRN & \\
\hline CHEMBL1395862 & 688721 & 5.0 & 4.9247 & TST & \\
\hline CHEMBL1506771 & 688721 & 4.8 & 4.9027 & TST & \\
\hline CHEMBL1425463 & 688721 & 6.0 & 4.8835 & TRN & \\
\hline CHEMBL1609660 & 688721 & 5.1 & 4.8485 & TRN & \\
\hline CHEMBL1463736 & 688721 & 5.2 & 5.0854 & TST & \\
\hline CHEMBL1358989 & 688721 & 4.6 & 4.8089 & TST & \\
\hline CHEMBL1342658 & 688721 & 4.4 & 4.8966 & TST & \\
\hline CHEMBL1407696 & 688721 & 5.2 & 5.0455 & TRN & \\
\hline CHEMBL1608471 & 688721 & 4.6 & 4.8257 & TRN & \\
\hline CHEMBL1325488 & 688721 & 4.8 & 4.8483 & TRN & \\
\hline CHEMBL1516884 & 688721 & 4.5 & 4.9342 & TST & \\
\hline CHEMBL1321633 & 688721 & 4.8 & 4.6394 & TRN & \\
\hline CHEMBL592106 & 688721 & 4.8 & 5.0228 & TRN & \\
\hline CHEMBL1304063 & 688721 & 6.9 & 4.942 & TRN & \\
\hline CHEMBL1441425 & 688721 & 4.8 & 4.9574 & TRN & \\
\hline CHEMBL1401963 & 688721 & 4.5 & 4.9746 & TRN & \\
\hline CHEMBL1594144 & 688721 & 5.5 & 4.8968 & TST & \\
\hline CHEMBL1569631 & 688721 & 5.1 & 4.9956 & TRN & \\
\hline CHEMBL1570165 & 688721 & 4.9 & 4.9028 & TRN & \\
\hline CHEMBL1478570 & 688721 & 4.8 & 4.8237 & TRN & \\
\hline CHEMBL1337025 & 688721 & 4.8 & 4.94300 & 00000000005 & TRN \\
\hline CHEMBL1452984 & 688721 & 4.6 & 4.8777 & TRN & \\
\hline CHEMBL1508544 & 688721 & 4.9 & 4.8163 & TRN & \\
\hline CHEMBL1346528 & 688721 & 4.5 & 4.7875 & TST & \\
\hline CHEMBL454761 & 688721 & 5.3 & 5.3606 & TST & \\
\hline CHEMBL1317344 & 688721 & 4.6 & 4.9929 & TRN & \\
\hline CHEMBL1599855 & 688721 & 5.2 & 5.0036 & TRN & \\
\hline CHEMBL1593288 & 688721 & 5.8 & 4.8713 & TRN & \\
\hline CHEMBL1536811 & 688721 & 4.8 & 4.8346 & TRN & \\
\hline CHEMBL1610064 & 688721 & 4.4 & 4.9642 & TRN & \\
\hline CHEMBL1600521 & 688721 & 5.5 & 5.0677 & TST & \\
\hline CHEMBL1455789 & 688721 & 4.5 & 4.8548 & TRN & \\
\hline CHEMBL1505338 & 688721 & 4.6 & 5.0286 & TST & \\
\hline CHEMBL1440748 & 688721 & 4.4 & 4.8868 & TRN & \\
\hline CHEMBL1389864 & 688721 & 4.6 & 4.793 & TRN & \\
\hline CHEMBL1319292 & 688721 & 4.4 & 5.0915 & TRN & \\
\hline CHEMBL1469625 & 688721 & 4.5 & 4.8359 & TRN & \\
\hline CHEMBL1419263 & 688721 & 7.1002 & 4.8436 & TRN & \\
\hline CHEMBL1541653 & 688721 & 4.5 & 4.8526 & TRN & \\
\hline CHEMBL1388808 & 688721 & 6.1 & 5.0692 & TST & \\
\hline CHEMBL1355963 & 688721 & 7.5003 & 5.3547 & TST & \\
\hline CHEMBL1516118 & 688721 & 4.9 & 4.9285 & TRN & \\
\hline CHEMBL1371779 & 688721 & 5.2 & 5.0807 & TST & \\
\hline
\end{tabular}




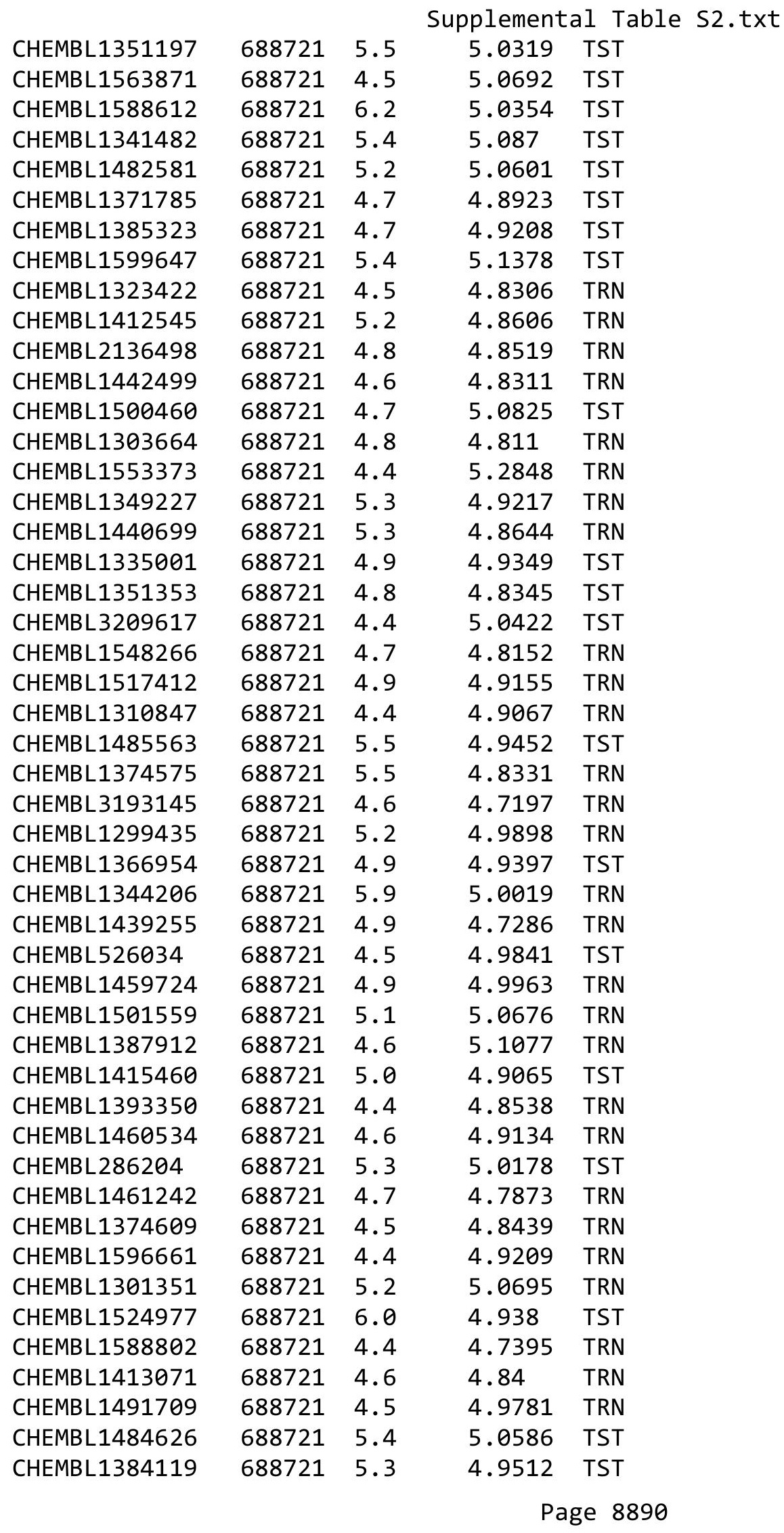




\begin{tabular}{|c|c|c|c|c|c|}
\hline \\
\hline CHEMBL1421478 & 688721 & 4.5 & 5.0089 & TRN & \\
\hline CHEMBL1609075 & 688721 & 6.5 & 4.9877 & TST & \\
\hline CHEMBL1365271 & 688721 & 4.9 & 5.1075 & TRN & \\
\hline CHEMBL1369764 & 688721 & 4.7 & 4.8429 & TRN & \\
\hline CHEMBL1441970 & 688721 & 4.4 & 4.9029 & TST & \\
\hline CHEMBL1577024 & 688721 & 4.9 & 4.7596 & TRN & \\
\hline CHEMBL373940 & 688721 & 5.4 & 5.0414 & TST & \\
\hline CHEMBL1376664 & 688721 & 4.8 & 4.8704 & TRN & \\
\hline CHEMBL1541021 & 688721 & 4.8 & 4.8958 & TRN & \\
\hline CHEMBL1502359 & 688721 & 4.5 & 4.7242 & TRN & \\
\hline CHEMBL1358263 & 688721 & 7.0 & 5.1944 & TRN & \\
\hline CHEMBL1613104 & 688721 & 4.9 & 5.1425 & TRN & \\
\hline CHEMBL1429079 & 688721 & 4.5 & 4.9141 & TRN & \\
\hline CHEMBL1606107 & 688721 & 5.7 & 5.2237 & TRN & \\
\hline CHEMBL1327903 & 688721 & 5.3 & 4.9582 & TRN & \\
\hline CHEMBL1509566 & 688721 & 5.4 & 4.8769 & TRN & \\
\hline CHEMBL1355186 & 688721 & 5.9 & 4.9431 & TRN & \\
\hline CHEMBL1605275 & 688721 & 4.8 & 4.8896 & TRN & \\
\hline CHEMBL1486659 & 688721 & 5.5 & 5.0623 & TST & \\
\hline CHEMBL1569640 & 688721 & 4.7 & 4.8402 & TRN & \\
\hline CHEMBL1535610 & 688721 & 4.6 & 4.723 & TRN & \\
\hline CHEMBL1334336 & 688721 & 4.6 & 5.0305 & TST & \\
\hline CHEMBL1406241 & 688721 & 4.6 & 4.6604 & TRN & \\
\hline CHEMBL1541091 & 688721 & 6.8 & 4.834 & TRN & \\
\hline CHEMBL1315374 & 688721 & 7.5003 & 4.9791 & TST & \\
\hline CHEMBL69710 & 688721 & 4.5 & 5.249 & TST & \\
\hline CHEMBL1459290 & 688721 & 4.8 & 4.8771 & TRN & \\
\hline CHEMBL1363345 & 688721 & 4.4 & 4.9852 & TRN & \\
\hline CHEMBL1365994 & 688721 & 5.0 & 5.1407 & TRN & \\
\hline CHEMBL286721 & 688721 & 4.9 & 5.1827 & TRN & \\
\hline CHEMBL1495845 & 688721 & 5.5 & 4.8118 & TRN & \\
\hline CHEMBL1565782 & 688721 & 4.6 & 4.9009 & TRN & \\
\hline CHEMBL1301656 & 688721 & 5.8 & 5.0152 & TST & \\
\hline CHEMBL1577538 & 688721 & 4.8 & 4.6936 & TRN & \\
\hline CHEMBL1319185 & 688721 & 5.1 & 4.9177 & TRN & \\
\hline CHEMBL1370522 & 688721 & 4.8 & 4.8189 & TRN & \\
\hline CHEMBL1464695 & 688721 & 4.6 & 5.059 & TRN & \\
\hline CHEMBL1334211 & 688721 & 5.5 & 4.8702 & TRN & \\
\hline CHEMBL1346808 & 688721 & 4.4 & 5.0073 & TRN & \\
\hline CHEMBL1453579 & 688721 & 5.1 & 5.0279 & TRN & \\
\hline CHEMBL1605298 & 688721 & 5.2 & 4.9689 & TRN & \\
\hline CHEMBL1424150 & 688721 & 4.5 & 4.8132 & TRN & \\
\hline CHEMBL1497343 & 688721 & 4.7 & 4.92899 & 9999999999 & TRN \\
\hline CHEMBL1380327 & 688721 & 4.4 & 4.9696 & TRN & \\
\hline CHEMBL1318375 & 688721 & 5.8 & 4.9445 & TST & \\
\hline CHEMBL1594761 & 688721 & 5.2 & 5.1206 & TRN & \\
\hline CHEMBL1360924 & 688721 & 5.4 & 5.0505 & TRN & \\
\hline CHEMBL1511366 & 688721 & 6.0 & 4.9504 & TRN & \\
\hline
\end{tabular}




\begin{tabular}{|c|c|c|c|c|}
\hline \multicolumn{5}{|c|}{ Supplemental Table S2.txt } \\
\hline CHEMBL1589175 & 688721 & 4.5 & 5.0764 & TST \\
\hline CHEMBL1483992 & 688721 & 4.5 & 4.7445 & TRN \\
\hline CHEMBL1389266 & 688721 & 5.2 & 4.992 & TRN \\
\hline CHEMBL1540513 & 688721 & 4.6 & 4.7975 & TRN \\
\hline CHEMBL1488436 & 688721 & 4.6 & 4.8962 & TRN \\
\hline CHEMBL1446896 & 688721 & 4.5 & 4.8396 & TRN \\
\hline CHEMBL1567257 & 688721 & 4.4 & 4.8558 & TRN \\
\hline CHEMBL1570073 & 688721 & 4.8 & 4.9065 & TRN \\
\hline CHEMBL1582791 & 688721 & 5.6 & 4.8482 & TRN \\
\hline CHEMBL1336703 & 688721 & 5.2 & 4.8997 & TST \\
\hline CHEMBL1534577 & 688721 & 4.6 & 4.8263 & TRN \\
\hline CHEMBL1502745 & 688721 & 7.4001 & 4.9332 & TRN \\
\hline CHEMBL1498403 & 688721 & 5.1 & 4.9479 & TRN \\
\hline CHEMBL1363513 & 688721 & 4.5 & 5.1206 & TRN \\
\hline CHEMBL1407298 & 688721 & 4.6 & 4.8627 & TRN \\
\hline CHEMBL1346206 & 688721 & 4.4 & 4.8433 & TRN \\
\hline CHEMBL1583083 & 688721 & 5.2 & 5.0225 & TRN \\
\hline CHEMBL1492346 & 688721 & 5.0 & 5.0072 & TRN \\
\hline CHEMBL1494575 & 688721 & 4.8 & 5.021 & TRN \\
\hline CHEMBL33171 & 688721 & 5.3 & 5.0926 & TRN \\
\hline CHEMBL1515691 & 688721 & 5.4 & 5.1333 & TST \\
\hline CHEMBL1435086 & 688721 & 4.5 & 4.9487 & TRN \\
\hline CHEMBL1546327 & 688721 & 4.5 & 5.0277 & TRN \\
\hline CHEMBL1571139 & 688721 & 6.8 & 4.99 & TRN \\
\hline CHEMBL1577187 & 688721 & 4.8 & 4.9001 & TRN \\
\hline CHEMBL1393774 & 688721 & 4.4 & 5.0806 & TST \\
\hline CHEMBL1565412 & 688721 & 4.5 & 4.9022 & TRN \\
\hline CHEMBL1531535 & 688721 & 5.4 & 5.0746 & TST \\
\hline CHEMBL1256178 & 688721 & 5.8 & 5.2363 & TST \\
\hline CHEMBL1576934 & 688721 & 4.4 & 4.9745 & TST \\
\hline CHEMBL1474989 & 688721 & 4.6 & 4.9089 & TRN \\
\hline CHEMBL1315528 & 688721 & 5.2 & 5.093 & TRN \\
\hline CHEMBL1412569 & 688721 & 4.4 & 4.819 & TRN \\
\hline CHEMBL1383218 & 688721 & 5.2 & 4.9554 & TRN \\
\hline CHEMBL1542605 & 688721 & 4.5 & 4.9312 & TRN \\
\hline CHEMBL1481953 & 688721 & 5.9 & 4.8831 & TST \\
\hline CHEMBL1565364 & 688721 & 4.7 & 4.6841 & TRN \\
\hline CHEMBL1553506 & 688721 & 5.5 & 5.3414 & TRN \\
\hline CHEMBL1324335 & 688721 & 5.9 & 4.8669 & TRN \\
\hline CHEMBL1369827 & 688721 & 4.4 & 5.16799 & 9999999999 \\
\hline CHEMBL1432540 & 688721 & 4.7 & 4.8454 & TRN \\
\hline CHEMBL1597410 & 688721 & 4.8 & 5.1978 & TRN \\
\hline CHEMBL1305038 & 688721 & 4.6 & 5.015 & TRN \\
\hline CHEMBL1313689 & 688721 & 4.5 & 4.9663 & TRN \\
\hline CHEMBL1307894 & 688721 & 4.6 & 4.9959 & TST \\
\hline CHEMBL1583957 & 688721 & 4.4 & 5.1144 & TRN \\
\hline CHEMBL1437088 & 688721 & 5.6 & 5.1825 & TRN \\
\hline CHEMBL1407952 & 688721 & 4.8 & 5.0041 & TST \\
\hline
\end{tabular}




\begin{tabular}{|c|c|c|c|c|c|}
\hline \multicolumn{6}{|c|}{ Supplemental Table S2.txt } \\
\hline CHEMBL1454544 & 688721 & 4.8 & 4.9685 & TRN & \\
\hline CHEMBL1394302 & 688721 & 4.5 & 4.9129 & TRN & \\
\hline CHEMBL1458607 & 688721 & 5.4 & 4.9852 & TRN & \\
\hline CHEMBL1336256 & 688721 & 4.5 & 4.8678 & TRN & \\
\hline CHEMBL1532770 & 688721 & 4.4 & 4.904 & TRN & \\
\hline CHEMBL1419647 & 688721 & 4.7 & 4.9134 & TST & \\
\hline CHEMBL1384347 & 688721 & 5.4 & 5.0011 & TST & \\
\hline CHEMBL 3193722 & 688721 & 4.6 & 5.16700 & 0000000001 & TRN \\
\hline CHEMBL1558676 & 688721 & 4.7 & 4.9324 & TRN & \\
\hline CHEMBL1506316 & 688721 & 5.9 & 5.0838 & TST & \\
\hline CHEMBL1568288 & 688721 & 5.5 & 4.8049 & TRN & \\
\hline CHEMBL1555463 & 688721 & 4.6 & 4.8961 & TRN & \\
\hline CHEMBL1360891 & 688721 & 5.2 & 4.8726 & TRN & \\
\hline CHEMBL1522698 & 688721 & 5.1 & 4.9822 & TRN & \\
\hline CHEMBL1330272 & 688721 & 4.5 & 5.0752 & TRN & \\
\hline CHEMBL1446604 & 688721 & 5.4 & 4.9528 & TRN & \\
\hline CHEMBL1515508 & 688721 & 5.2 & 4.8512 & TRN & \\
\hline CHEMBL1600224 & 688721 & 4.8 & 5.0486 & TRN & \\
\hline CHEMBL1342238 & 688721 & 4.5 & 4.8965 & TST & \\
\hline CHEMBL1493496 & 688721 & 5.5 & 5.199 & TRN & \\
\hline CHEMBL1303331 & 688721 & 6.8 & 4.8756 & TRN & \\
\hline CHEMBL3210205 & 688721 & 6.5 & 5.2954 & TST & \\
\hline CHEMBL1299374 & 688721 & 4.9 & 4.6872 & TRN & \\
\hline CHEMBL1337702 & 688721 & 4.7 & 4.7361 & TRN & \\
\hline CHEMBL1384828 & 688721 & 6.9 & 5.1519 & TRN & \\
\hline CHEMBL1978488 & 688721 & 4.4 & 4.7956 & TRN & \\
\hline CHEMBL1423740 & 688721 & 5.4 & 4.9343 & TRN & \\
\hline CHEMBL1330566 & 688721 & 5.2 & 5.037 & TRN & \\
\hline CHEMBL16656 & 688721 & 7.6003 & 5.0113 & TRN & \\
\hline CHEMBL1518275 & 688721 & 4.5 & 4.8401 & TRN & \\
\hline CHEMBL1371340 & 688721 & 4.5 & 5.0197 & TRN & \\
\hline CHEMBL23094 & 688721 & 4.9 & 5.3165 & TST & \\
\hline CHEMBL1340152 & 688721 & 4.5 & 5.0291 & TRN & \\
\hline CHEMBL1437883 & 688721 & 4.9 & 4.8912 & TST & \\
\hline CHEMBL1371147 & 688721 & 4.5 & 4.9053 & TRN & \\
\hline CHEMBL1430754 & 688721 & 5.0 & 4.8925 & TRN & \\
\hline CHEMBL1509745 & 688721 & 6.0 & 5.1622 & TRN & \\
\hline CHEMBL1453713 & 688721 & 6.1 & 5.1018 & TRN & \\
\hline CHEMBL1609241 & 688721 & 4.5 & 5.1245 & TRN & \\
\hline CHEMBL1381589 & 688721 & 4.6 & 4.8433 & TRN & \\
\hline CHEMBL1587160 & 688721 & 5.0 & 4.9651 & TRN & \\
\hline CHEMBL1301089 & 688721 & 5.2 & 5.0348 & TRN & \\
\hline CHEMBL3207337 & 688721 & 5.5 & 4.9553 & TRN & \\
\hline CHEMBL1529478 & 688721 & 6.8 & 5.088 & TRN & \\
\hline CHEMBL1352710 & 688721 & 4.5 & 4.8662 & TRN & \\
\hline CHEMBL293349 & 688721 & 6.6 & 5.1009 & TST & \\
\hline CHEMBL1410773 & 688721 & 4.4 & 4.939 & TRN & \\
\hline CHEMBL1492649 & 688721 & 7.0 & 5.0659 & TRN & \\
\hline
\end{tabular}


Supplemental Table S2.txt

\begin{tabular}{|c|c|c|c|c|}
\hline CHEMBL1369719 & 688721 & 7.5003 & 5.0818 & TRN \\
\hline CHEMBL1585190 & 688721 & 6.3 & 4.8856 & \\
\hline CHEMBL1545100 & 688721 & 4.8 & 4.6937 & \\
\hline CHEMBL1564034 & 688721 & 5.3 & 5.0282 & \\
\hline CHEMBL1542674 & 688721 & 5.0 & 4.9534 & \\
\hline CHEMBL1490991 & 688721 & 4.7 & 4.8793 & \\
\hline CHEMBL1341581 & 688721 & 4.6 & 4.9164 & \\
\hline CHEMBL1589098 & 688721 & 4.4 & 4.9093 & \\
\hline CHEMBL1606749 & 688721 & 5.2 & 4.9364 & \\
\hline CHEMBL1563407 & 688721 & 5.0 & 4.7869 & \\
\hline CHEMBL1327143 & 688721 & 5.8 & 5.3097 & \\
\hline CHEMBL1574231 & 688721 & 5.9 & 5.0881 & \\
\hline CHEMBL1409804 & 688721 & 4.4 & 4.8645 & \\
\hline CHEMBL1471203 & 688721 & 4.4 & 4.7013 & \\
\hline CHEMBL1382628 & 688721 & 4.7 & 4.9163 & \\
\hline CHEMBL1503929 & 688721 & 4.4 & 4.8434 & \\
\hline CHEMBL1599138 & 688721 & 4.5 & 4.9088 & \\
\hline CHEMBL1344721 & 688721 & 4.5 & 5.1102 & \\
\hline CHEMBL1509894 & 688721 & 4.7 & 4.9991 & \\
\hline CHEMBL1437294 & 688721 & 6.0 & 5.1375 & \\
\hline CHEMBL1520584 & 688721 & 4.5 & 4.9057 & \\
\hline CHEMBL1455689 & 688721 & 4.6 & 4.7516 & \\
\hline CHEMBL1443360 & 688721 & 4.7 & 5.0673 & \\
\hline CHEMBL1611308 & 688721 & 5.9 & 5.3299 & \\
\hline CHEMBL1407106 & 688721 & 5.5 & 5.0643 & \\
\hline CHEMBL1344571 & 688721 & 4.9 & 5.1674 & \\
\hline CHEMBL41172 & 688721 & 5.8 & 5.0445 & \\
\hline CHEMBL1340479 & 688721 & 4.5 & 4.968 & \\
\hline CHEMBL1487974 & 688721 & 4.8 & 4.8586 & \\
\hline CHEMBL1525524 & 688721 & 4.8 & 4.7816 & \\
\hline CHEMBL1597217 & 688721 & 5.2 & 4.8799 & \\
\hline CHEMBL1585428 & 688721 & 4.6 & 5.0734 & \\
\hline CHEMBL1320183 & 688721 & 4.7 & 4.7833 & \\
\hline CHEMBL1415385 & 688721 & 4.8 & 4.8352 & \\
\hline CHEMBL1560552 & 688721 & 4.6 & 4.8046 & \\
\hline CHEMBL1422696 & 688721 & 4.4 & 5.0493 & \\
\hline CHEMBL1348748 & 688721 & 4.5 & 4.8563 & \\
\hline CHEMBL1520889 & 688721 & 4.5 & 5.0716 & \\
\hline CHEMBL1479470 & 688721 & 5.2 & 4.9686 & \\
\hline CHEMBL1412931 & 688721 & 5.2 & 5.0009 & \\
\hline CHEMBL1359256 & 688721 & 7.0 & 4.9909 & \\
\hline CHEMBL1487873 & 688721 & 4.4 & 5.0905 & \\
\hline CHEMBL1426073 & 688721 & 4.5 & 4.9609 & \\
\hline CHEMBL1605198 & 688721 & 4.5 & 5.1296 & \\
\hline CHEMBL1325250 & 688721 & 5.3 & 4.8846 & \\
\hline CHEMBL1382977 & 688721 & 4.5 & 4.7647 & \\
\hline CHEMBL1552194 & 688721 & 5.7 & 4.9562 & \\
\hline CHEMBL1526135 & 688721 & 4.8 & 4.7939 & \\
\hline
\end{tabular}

Page 8894 


\begin{tabular}{|c|c|c|c|c|}
\hline \multicolumn{5}{|c|}{ plemental T } \\
\hline CHEMBL1505212 & 688721 & 5.3 & 4.8742 & TST \\
\hline CHEMBL1550137 & 688721 & 5.9 & 4.7966 & TRN \\
\hline CHEMBL1550521 & 688721 & 5.2 & 4.9744 & TST \\
\hline CHEMBL1311555 & 688721 & 4.6 & 5.0958 & TRN \\
\hline CHEMBL1556428 & 688721 & 5.1 & 4.8809 & TRN \\
\hline CHEMBL1411418 & 688721 & 4.5 & 4.8197 & TRN \\
\hline CHEMBL1612145 & 688721 & 5.0 & 4.8007 & TRN \\
\hline CHEMBL1444802 & 688721 & 5.0 & 4.8211 & TRN \\
\hline CHEMBL1322531 & 688721 & 4.4 & 4.9175 & TST \\
\hline CHEMBL1355831 & 688721 & 5.0 & 5.0729 & TRN \\
\hline CHEMBL 1408520 & 688721 & 5.3 & 5.0903 & TRN \\
\hline CHEMBL1581290 & 688721 & 4.9 & 4.8201 & TRN \\
\hline CHEMBL1548013 & 688721 & 5.1 & 4.9132 & TRN \\
\hline CHEMBL1578595 & 688721 & 7.2 & 4.8579 & TRN \\
\hline CHEMBL1371693 & 688721 & 4.9 & 4.7823 & TST \\
\hline CHEMBL 1603357 & 688721 & 4.7 & 4.9207 & TST \\
\hline CHEMBL1448138 & 688721 & 4.8 & 5.2158 & TRN \\
\hline CHEMBL1344736 & 688721 & 4.7 & 4.9211 & TRN \\
\hline CHEMBL1390578 & 688721 & 4.4 & 4.92 & TRN \\
\hline CHEMBL1580616 & 688721 & 4.9 & 4.8372 & TRN \\
\hline CHEMBL 1978564 & 688721 & 4.5 & 4.9807 & TRN \\
\hline CHEMBL1345135 & 688721 & 5.3 & 4.8103 & TRN \\
\hline CHEMBL1584646 & 688721 & 4.6 & 5.0682 & TST \\
\hline CHEMBL1593663 & 688721 & 6.0 & 5.2823 & TRN \\
\hline CHEMBL1421004 & 688721 & 4.5 & 4.8058 & TRN \\
\hline CHEMBL1585062 & 688721 & 4.6 & 4.7883 & TRN \\
\hline CHEMBL1303548 & 688721 & 4.8 & 4.8677 & TRN \\
\hline CHEMBL1476526 & 688721 & 5.6 & 4.9704 & TRN \\
\hline CHEMBL1317900 & 688721 & 4.8 & 5.1938 & TRN \\
\hline CHEMBL1461098 & 688721 & 4.6 & 4.8125 & TRN \\
\hline CHEMBL1386202 & 688721 & 4.4 & 4.95 & TRN \\
\hline CHEMBL1326806 & 688721 & 5.5 & 4.9622 & TRN \\
\hline CHEMBL1448764 & 688721 & 4.5 & 4.7016 & TRN \\
\hline CHEMBL1533639 & 688721 & 4.5 & 4.8714 & TST \\
\hline CHEMBL1563235 & 688721 & 5.4 & 4.9078 & TST \\
\hline CHEMBL1317537 & 688721 & 4.6 & 4.8682 & TRN \\
\hline CHEMBL1554960 & 688721 & 4.5 & 4.89 & TRN \\
\hline CHEMBL1368175 & 688721 & 4.8 & 4.7538 & TRN \\
\hline CHEMBL1378997 & 688721 & 4.6 & 4.9213 & TRN \\
\hline CHEMBL1558496 & 688721 & 4.6 & 4.9321 & TRN \\
\hline CHEMBL224214 & 688721 & 6.2 & 5.1549 & TST \\
\hline CHEMBL1358085 & 688721 & 5.2 & 4.873 & TRN \\
\hline CHEMBL 1470063 & 688721 & 4.8 & 4.7925 & TRN \\
\hline CHEMBL1410374 & 688721 & 4.5 & 4.9786 & TRN \\
\hline CHEMBL1585445 & 688721 & 5.2 & 4.7754 & TRN \\
\hline CHEMBL1612885 & 688721 & 5.4 & 4.9901 & TRN \\
\hline CHEMBL1508863 & 688721 & 5.5 & 4.9234 & TRN \\
\hline CHEMBL1548451 & 688721 & 5.1 & 4.6493 & TRN \\
\hline
\end{tabular}




\begin{tabular}{|c|c|c|c|c|c|}
\hline \multicolumn{6}{|c|}{ Supplemental Table S2.txt } \\
\hline CHEMBL1496100 & 688721 & 4.4 & 4.9184 & TRN & \\
\hline CHEMBL1561241 & 688721 & 5.4 & 4.9537 & TRN & \\
\hline CHEMBL126077 & 688721 & 6.0 & 5.0446 & TST & \\
\hline CHEMBL3216654 & 688721 & 4.8 & 4.937 & TST & \\
\hline CHEMBL1340294 & 688721 & 4.9 & 4.9187 & TRN & \\
\hline CHEMBL1371515 & 688721 & 4.7 & 4.8098 & TRN & \\
\hline CHEMBL1468353 & 688721 & 4.7 & 4.8886 & TRN & \\
\hline CHEMBL1495320 & 688721 & 5.2 & 4.9274 & TRN & \\
\hline CHEMBL1584470 & 688721 & 5.2 & 4.909 & TRN & \\
\hline CHEMBL1326553 & 688721 & 4.8 & 5.0905 & TRN & \\
\hline CHEMBL1509281 & 688721 & 4.8 & 4.6824 & TRN & \\
\hline CHEMBL559612 & 688721 & 6.0 & 5.32600 & 00000000005 & TST \\
\hline CHEMBL1488376 & 688721 & 5.0 & 4.9694 & TRN & \\
\hline CHEMBL1367384 & 688721 & 4.8 & 5.069 & TST & \\
\hline CHEMBL1577162 & 688721 & 4.5 & 4.8463 & TRN & \\
\hline CHEMBL1563972 & 688721 & 4.4 & 4.8975 & TRN & \\
\hline CHEMBL1307791 & 688721 & 4.9 & 4.7373 & TRN & \\
\hline CHEMBL1443397 & 688721 & 5.2 & 4.9411 & TST & \\
\hline CHEMBL1543716 & 688721 & 4.8 & 4.9952 & TRN & \\
\hline CHEMBL34155 & 688721 & 5.2 & 5.3136 & TST & \\
\hline CHEMBL1422059 & 688721 & 4.4 & 4.8541 & TRN & \\
\hline CHEMBL1587814 & 688721 & 4.6 & 4.8567 & TRN & \\
\hline CHEMBL1533320 & 688721 & 5.4 & 5.081 & TRN & \\
\hline CHEMBL1380935 & 688721 & 6.7001 & 4.96899 & 9999999999 & TRN \\
\hline CHEMBL1413056 & 688721 & 5.0 & 4.7977 & TRN & \\
\hline CHEMBL1558480 & 688721 & 5.1 & 5.0575 & TRN & \\
\hline CHEMBL1425970 & 688721 & 8.2007 & 4.9544 & TST & \\
\hline CHEMBL1453749 & 688721 & 4.5 & 5.0943 & TRN & \\
\hline CHEMBL1475358 & 688721 & 4.4 & 5.1261 & TRN & \\
\hline CHEMBL1521893 & 688721 & 5.5 & 4.857 & TRN & \\
\hline CHEMBL1543231 & 688721 & 4.5 & 4.9217 & TRN & \\
\hline CHEMBL1317998 & 688721 & 4.9 & 5.1405 & TRN & \\
\hline CHEMBL402477 & 688721 & 4.4 & 5.0843 & TRN & \\
\hline CHEMBL1336826 & 688721 & 5.1 & 5.0717 & TRN & \\
\hline CHEMBL1481743 & 688721 & 4.5 & 4.93 & TRN & \\
\hline CHEMBL1506881 & 688721 & 5.3 & 4.8299 & TRN & \\
\hline CHEMBL1457593 & 688721 & 4.6 & 4.922 & TRN & \\
\hline CHEMBL1341352 & 688721 & 6.1 & 5.027 & TRN & \\
\hline CHEMBL1513643 & 688721 & 5.4 & 5.1233 & TST & \\
\hline CHEMBL3189937 & 688721 & 4.7 & 5.0778 & TRN & \\
\hline CHEMBL1565972 & 688721 & 4.5 & 4.9025 & TRN & \\
\hline CHEMBL1540347 & 688721 & 4.6 & 4.7624 & TRN & \\
\hline CHEMBL1353911 & 688721 & 4.4 & 5.0894 & TST & \\
\hline CHEMBL1333530 & 688721 & 4.9 & 4.8925 & TST & \\
\hline CHEMBL1593219 & 688721 & 5.9 & 5.2266 & TRN & \\
\hline CHEMBL1574707 & 688721 & 4.4 & 4.8211 & TRN & \\
\hline CHEMBL1256996 & 688721 & 4.4 & 5.1668 & TRN & \\
\hline CHEMBL1543382 & 688721 & 4.6 & 4.8719 & TRN & \\
\hline
\end{tabular}




\begin{tabular}{|c|c|c|c|c|}
\hline & & & ient & $a \perp 1 a$ \\
\hline CHEMBL1600325 & 688721 & 5.3 & 5.3905 & TRN \\
\hline CHEMBL1342745 & 688721 & 4.5 & 4.8511 & TRN \\
\hline CHEMBL1335981 & 688721 & 4.6 & 4.9877 & TRN \\
\hline CHEMBL1588470 & 688721 & 4.8 & 4.8046 & TRN \\
\hline CHEMBL1490809 & 688721 & 4.6 & 4.8705 & TRN \\
\hline CHEMBL1511537 & 688721 & 4.9 & 4.8883 & TRN \\
\hline CHEMBL1367765 & 688721 & 5.9 & 4.91 & TRN \\
\hline CHEMBL1391482 & 688721 & 5.0 & 5.0073 & TST \\
\hline CHEMBL1525929 & 688721 & 4.6 & 4.9145 & TRN \\
\hline CHEMBL1444257 & 688721 & 4.8 & 4.9395 & TRN \\
\hline CHEMBL1312907 & 688721 & 4.4 & 5.0703 & TRN \\
\hline CHEMBL1450106 & 688721 & 5.2 & 5.0931 & TRN \\
\hline CHEMBL1567616 & 688721 & 4.4 & 4.9981 & TRN \\
\hline CHEMBL1326896 & 688721 & 4.6 & 4.8622 & TRN \\
\hline CHEMBL1344112 & 688721 & 4.7 & 4.8805 & TRN \\
\hline CHEMBL1611799 & 688721 & 4.6 & 4.9937 & TST \\
\hline CHEMBL1422129 & 688721 & 6.1 & 5.0774 & TRN \\
\hline CHEMBL1442704 & 688721 & 5.3 & 4.9789 & TRN \\
\hline CHEMBL1412667 & 688721 & 4.4 & 4.9163 & TST \\
\hline CHEMBL1378138 & 688721 & 4.9 & 4.747 & TRN \\
\hline CHEMBL1332883 & 688721 & 4.5 & 4.9252 & TRN \\
\hline CHEMBL1499880 & 688721 & 4.7 & 4.9789 & TRN \\
\hline CHEMBL1466032 & 688721 & 5.2 & 4.8398 & TRN \\
\hline CHEMBL1588639 & 688721 & 4.8 & 4.9404 & TRN \\
\hline CHEMBL1559368 & 688721 & 5.4 & 4.8813 & TRN \\
\hline CHEMBL1501431 & 688721 & 4.7 & 4.7295 & TRN \\
\hline CHEMBL1520663 & 688721 & 4.6 & 4.8769 & TRN \\
\hline CHEMBL1451974 & 688721 & 4.7 & 4.8157 & TST \\
\hline CHEMBL1428889 & 688721 & 5.1 & 4.9632 & TST \\
\hline CHEMBL1485559 & 688721 & 5.0 & 4.9336 & TRN \\
\hline CHEMBL1372991 & 688721 & 4.9 & 4.8745 & TRN \\
\hline CHEMBL1438811 & 688721 & 5.2 & 5.0176 & TST \\
\hline CHEMBL1368892 & 688721 & 5.4 & 5.1369 & TRN \\
\hline CHEMBL1360735 & 688721 & 4.6 & 4.8687 & TST \\
\hline CHEMBL1568834 & 688721 & 5.7 & 4.7688 & TST \\
\hline CHEMBL1429074 & 688721 & 4.8 & 4.9695 & TRN \\
\hline CHEMBL76589 & 688721 & 6.9 & 5.153 & TRN \\
\hline CHEMBL1480497 & 688721 & 5.5 & 4.9823 & TRN \\
\hline CHEMBL1355146 & 688721 & 5.2 & 5.005 & TRN \\
\hline CHEMBL1360485 & 688721 & 4.6 & 4.7472 & TRN \\
\hline CHEMBL1500867 & 688721 & 4.8 & 4.7663 & TRN \\
\hline CHEMBL1328771 & 688721 & 4.9 & 4.9983 & TRN \\
\hline CHEMBL1478772 & 688721 & 4.5 & 5.1624 & TRN \\
\hline CHEMBL1575613 & 688721 & 5.4 & 4.7252 & TRN \\
\hline CHEMBL1427512 & 688721 & 4.4 & 5.0608 & TRN \\
\hline CHEMBL1473875 & 688721 & 5.1 & 4.9132 & TRN \\
\hline CHEMBL1376143 & 688721 & 4.7 & 5.0036 & TRN \\
\hline CHEMBL1604288 & 688721 & 4.7 & 5.1555 & TRN \\
\hline
\end{tabular}




\begin{tabular}{|c|c|c|c|c|}
\hline & & & CII & al Ta \\
\hline CHEMBL1370049 & 688721 & 4.8 & 5.0403 & TRN \\
\hline CHEMBL1172977 & 688721 & 5.2 & 5.0455 & TST \\
\hline CHEMBL1598001 & 688721 & 4.9 & 4.9042 & TRN \\
\hline CHEMBL1318878 & 688721 & 4.5 & 4.8983 & TST \\
\hline CHEMBL1549879 & 688721 & 5.0 & 4.9433 & TRN \\
\hline CHEMBL1303002 & 688721 & 4.6 & 4.863 & TRN \\
\hline CHEMBL1565273 & 688721 & 4.4 & 4.9755 & TRN \\
\hline CHEMBL1574881 & 688721 & 4.5 & 5.041 & TRN \\
\hline CHEMBL1406976 & 688721 & 4.6 & 4.8909 & TRN \\
\hline CHEMBL1407022 & 688721 & 4.4 & 4.8003 & TRN \\
\hline CHEMBL1387781 & 688721 & 6.0 & 4.8053 & TRN \\
\hline CHEMBL1403437 & 688721 & 5.3 & 4.9688 & TRN \\
\hline CHEMBL1529009 & 688721 & 4.4 & 4.7279 & TST \\
\hline CHEMBL1318668 & 688721 & 5.2 & 5.0086 & TST \\
\hline CHEMBL 208484 & 688721 & 4.4 & 4.8645 & TST \\
\hline CHEMBL1529248 & 688721 & 5.1 & 4.9787 & TRN \\
\hline CHEMBL1461039 & 688721 & 5.0 & 4.8344 & TST \\
\hline CHEMBL1526319 & 688721 & 4.4 & 5.0996 & TST \\
\hline CHEMBL582444 & 688721 & 5.1 & 5.1959 & TST \\
\hline CHEMBL1568197 & 688721 & 5.3 & 4.895 & TRN \\
\hline CHEMBL1446084 & 688721 & 4.8 & 5.0777 & TRN \\
\hline CHEMBL1324699 & 688721 & 4.6 & 5.0502 & TST \\
\hline CHEMBL1517593 & 688721 & 4.4 & 4.8632 & TST \\
\hline CHEMBL1529330 & 688721 & 4.8 & 5.1327 & TRN \\
\hline CHEMBL1482207 & 688721 & 5.3 & 4.9044 & TRN \\
\hline CHEMBL1545523 & 688721 & 4.6 & 4.8218 & TST \\
\hline CHEMBL3196079 & 688721 & 4.4 & 5.0911 & TST \\
\hline CHEMBL1464287 & 688721 & 6.5 & 4.9749 & TST \\
\hline CHEMBL1324794 & 688721 & 5.3 & 4.8162 & TRN \\
\hline CHEMBL1395355 & 688721 & 5.0 & 5.0297 & TRN \\
\hline CHEMBL1502259 & 688721 & 4.6 & 4.9244 & TST \\
\hline CHEMBL1328884 & 688721 & 4.6 & 4.7563 & TRN \\
\hline CHEMBL1431729 & 688721 & 5.3 & 5.0354 & TRN \\
\hline CHEMBL1440908 & 688721 & 4.6 & 4.8706 & TRN \\
\hline CHEMBL1559473 & 688721 & 4.5 & 4.8469 & TRN \\
\hline CHEMBL1231330 & 688721 & 4.4 & 5.358 & TRN \\
\hline CHEMBL1465860 & 688721 & 4.6 & 4.7344 & TRN \\
\hline CHEMBL1326841 & 688721 & 4.4 & 4.8755 & TST \\
\hline CHEMBL1307897 & 688721 & 4.7 & 5.2442 & TST \\
\hline CHEMBL1309248 & 688721 & 5.2 & 4.8573 & TRN \\
\hline CHEMBL1478839 & 688721 & 4.7 & 4.7712 & TRN \\
\hline CHEMBL1524852 & 688721 & 4.4 & 5.2495 & TRN \\
\hline CHEMBL1528112 & 688721 & 4.6 & 4.7238 & TRN \\
\hline CHEMBL1454912 & 688721 & 4.4 & 5.1767 & TRN \\
\hline CHEMBL1412984 & 688721 & 5.5 & 4.8144 & TRN \\
\hline CHEMBL1572607 & 688721 & 5.5 & 5.0499 & TRN \\
\hline CHEMBL1299531 & 688721 & 4.4 & 4.8728 & TRN \\
\hline CHEMBL1466163 & 688721 & 4.5 & 5.1919 & TST \\
\hline
\end{tabular}




\begin{tabular}{|c|c|c|c|c|c|}
\hline \multicolumn{6}{|c|}{ Supplemental Table S2.txt } \\
\hline CHEMBL1444065 & 688721 & 4.8 & 4.9177 & TRN & \\
\hline CHEMBL1446829 & 688721 & 5.4 & 4.9155 & TRN & \\
\hline CHEMBL1477595 & 688721 & 4.6 & 4.7477 & TST & \\
\hline CHEMBL1406204 & 688721 & 5.3 & 4.8663 & TST & \\
\hline CHEMBL1390006 & 688721 & 5.4 & 4.7522 & TRN & \\
\hline CHEMBL1593837 & 688721 & 4.4 & 5.3407 & TRN & \\
\hline CHEMBL1494256 & 688721 & 4.6 & 4.7849 & TST & \\
\hline CHEMBL1544298 & 688721 & 4.9 & 4.8919 & TRN & \\
\hline CHEMBL1447120 & 688721 & 5.1 & 4.8577 & TRN & \\
\hline CHEMBL1480560 & 688721 & 4.5 & 4.7993 & TRN & \\
\hline CHEMBL1554018 & 688721 & 5.2 & 5.3117 & TST & \\
\hline CHEMBL63426 & 688721 & 5.0 & 5.0947 & TST & \\
\hline CHEMBL1502489 & 688721 & 4.8 & 4.8952 & TRN & \\
\hline CHEMBL118765 & 688721 & 5.7 & 5.2595 & TST & \\
\hline CHEMBL1481904 & 688721 & 6.4 & 5.129 & TRN & \\
\hline CHEMBL1612359 & 688721 & 4.5 & 4.7703 & TRN & \\
\hline CHEMBL1525033 & 688721 & 4.5 & 4.6803 & TRN & \\
\hline CHEMBL1469464 & 688721 & 4.5 & 4.9887 & TRN & \\
\hline CHEMBL1511760 & 688721 & 4.5 & 4.9307 & TRN & \\
\hline CHEMBL1385393 & 688721 & 4.6 & 5.0075 & TRN & \\
\hline CHEMBL1339515 & 688721 & 5.2 & 4.9616 & TST & \\
\hline CHEMBL1539505 & 688721 & 5.5 & 5.0152 & TRN & \\
\hline CHEMBL1354547 & 688721 & 5.3 & 5.07606 & 00000000005 & TRN \\
\hline CHEMBL1537166 & 688721 & 4.4 & 4.9452 & TRN & \\
\hline CHEMBL164290 & 688721 & 7.3002 & $5.2120 €$ & 0000000001 & TST \\
\hline CHEMBL1352761 & 688721 & 5.3 & 5.0396 & TST & \\
\hline CHEMBL1443966 & 688721 & 4.5 & 4.8634 & TRN & \\
\hline CHEMBL1385546 & 688721 & 5.0 & 4.9123 & TRN & \\
\hline CHEMBL1519056 & 688721 & 4.5 & 4.9243 & TRN & \\
\hline CHEMBL1589409 & 688721 & 5.4 & 4.9038 & TRN & \\
\hline CHEMBL1530572 & 688721 & 4.4 & 5.0845 & TST & \\
\hline CHEMBL3196509 & 688721 & 4.4 & 4.9212 & TST & \\
\hline CHEMBL298461 & 688721 & 5.1 & 4.8882 & TRN & \\
\hline CHEMBL1592481 & 688721 & 4.9 & 5.091 & TST & \\
\hline CHEMBL1501096 & 688721 & 5.2 & 4.9891 & TST & \\
\hline CHEMBL1325506 & 688721 & 4.7 & 4.8919 & 99999999995 & TRN \\
\hline CHEMBL1392180 & 688721 & 4.4 & 4.9115 & TRN & \\
\hline CHEMBL1389037 & 688721 & 4.4 & 4.8408 & TRN & \\
\hline CHEMBL1526454 & 688721 & 5.3 & 5.0793 & TRN & \\
\hline CHEMBL1387603 & 688721 & 4.5 & 4.8837 & TST & \\
\hline CHEMBL1342878 & 688721 & 4.5 & 4.8184 & TRN & \\
\hline CHEMBL1563032 & 688721 & 5.1 & 5.1422 & TRN & \\
\hline CHEMBL1332535 & 688721 & 5.2 & 4.974 & TRN & \\
\hline CHEMBL1420530 & 688721 & 4.7 & 4.9446 & TRN & \\
\hline CHEMBL1606289 & 688721 & 5.1 & 5.0815 & TRN & \\
\hline CHEMBL1556299 & 688721 & 4.5 & 4.8837 & TRN & \\
\hline CHEMBL1538493 & 688721 & 4.7 & 4.7845 & TST & \\
\hline CHEMBL1466720 & 688721 & 5.3 & 5.0167 & TRN & \\
\hline
\end{tabular}




\begin{tabular}{|c|c|c|c|c|}
\hline & & & plement & \\
\hline CHEMBL1515555 & 688721 & 4.9 & 4.9154 & TRN \\
\hline CHEMBL1447714 & 688721 & 4.4 & 4.8506 & TRN \\
\hline CHEMBL1424372 & 688721 & 4.9 & 4.9677 & TRN \\
\hline CHEMBL1486368 & 688721 & 4.4 & 4.9064 & TRN \\
\hline CHEMBL1334439 & 688721 & 4.8 & 4.8042 & TRN \\
\hline CHEMBL1384832 & 688721 & 5.2 & 5.0084 & TST \\
\hline CHEMBL1471890 & 688721 & 4.4 & 4.8387 & TRN \\
\hline CHEMBL1452910 & 688721 & 4.7 & 5.0705 & TRN \\
\hline CHEMBL1560093 & 688721 & 5.1 & 4.9097 & TRN \\
\hline CHEMBL284028 & 688721 & 4.4 & 5.0472 & TST \\
\hline CHEMBL1433062 & 688721 & 5.3 & 4.8475 & TRN \\
\hline CHEMBL1435520 & 688721 & 5.4 & 5.3078 & TRN \\
\hline CHEMBL1572214 & 688721 & 4.8 & 4.9585 & TST \\
\hline CHEMBL1299486 & 688721 & 4.4 & 4.9756 & TRN \\
\hline CHEMBL1465132 & 688721 & 4.8 & 4.9562 & TRN \\
\hline CHEMBL1580002 & 688721 & 4.7 & 4.8996 & TST \\
\hline CHEMBL1467315 & 688721 & 6.1 & 5.1379 & TST \\
\hline CHEMBL1525177 & 688721 & 4.8 & 4.9299 & TRN \\
\hline CHEMBL1419096 & 688721 & 4.8 & 4.8291 & TRN \\
\hline CHEMBL1552403 & 688721 & 6.0 & 5.1825 & TST \\
\hline CHEMBL1365000 & 688721 & 4.6 & 4.8001 & TRN \\
\hline CHEMBL1565954 & 688721 & 5.3 & 4.9988 & TRN \\
\hline CHEMBL1531586 & 688721 & 4.7 & 5.0497 & TRN \\
\hline CHEMBL1488031 & 688721 & 4.7 & 5.0038 & TST \\
\hline CHEMBL1607192 & 688721 & 5.4 & 5.1707 & TST \\
\hline CHEMBL1503791 & 688721 & 4.8 & 4.945 & TST \\
\hline CHEMBL1596063 & 688721 & 4.8 & 4.9482 & TST \\
\hline CHEMBL1341897 & 688721 & 5.4 & 4.9512 & TRN \\
\hline CHEMBL1321339 & 688721 & 4.9 & 5.004 & TRN \\
\hline CHEMBL 2261860 & 688721 & 5.9 & 5.0535 & TRN \\
\hline CHEMBL1411871 & 688721 & 4.4 & 5.021 & TRN \\
\hline CHEMBL1549739 & 688721 & 5.3 & 4.9351 & TST \\
\hline CHEMBL1441711 & 688721 & 4.4 & 4.8456 & TRN \\
\hline CHEMBL1412181 & 688721 & 4.4 & 5.0485 & TST \\
\hline CHEMBL1422233 & 688721 & 4.4 & 4.8901 & TRN \\
\hline CHEMBL1343806 & 688721 & 4.5 & 4.8809 & TRN \\
\hline CHEMBL1553990 & 688721 & 5.6 & 5.1558 & TRN \\
\hline CHEMBL1362467 & 688721 & 4.4 & 5.0602 & TRN \\
\hline CHEMBL1533687 & 688721 & 4.8 & 4.7602 & TRN \\
\hline CHEMBL1312942 & 688721 & 5.5 & 4.9435 & TRN \\
\hline CHEMBL1555675 & 688721 & 4.6 & 4.9192 & TRN \\
\hline CHEMBL1595709 & 688721 & 5.0 & 5.0563 & TST \\
\hline CHEMBL1545939 & 688721 & 4.9 & 4.9294 & TRN \\
\hline CHEMBL1345225 & 688721 & 4.6 & 4.9337 & TRN \\
\hline CHEMBL1382694 & 688721 & 4.6 & 4.855 & TST \\
\hline CHEMBL1483132 & 688721 & 4.6 & 4.731 & TST \\
\hline CHEMBL1556539 & 688721 & 4.6 & 4.9397 & TRN \\
\hline CHEMBL1365444 & 688721 & 4.4 & 4.9346 & TRN \\
\hline
\end{tabular}




\begin{tabular}{|c|c|c|c|c|c|}
\hline \\
\hline CHEMBL1371726 & 688721 & 6.0 & 5.1527 & TRN & \\
\hline CHEMBL1383057 & 688721 & 4.5 & 4.9225 & TRN & \\
\hline CHEMBL1312589 & 688721 & 5.9 & 4.945 & TST & \\
\hline CHEMBL1531294 & 688721 & 5.2 & 5.1489 & TRN & \\
\hline CHEMBL1456533 & 688721 & 5.5 & 5.0734 & TRN & \\
\hline CHEMBL1391377 & 688721 & 4.8 & 4.9578 & TRN & \\
\hline CHEMBL1321221 & 688721 & 4.6 & 5.0179 & TRN & \\
\hline CHEMBL1579937 & 688721 & 6.7001 & 4.9401 & TRN & \\
\hline CHEMBL1525622 & 688721 & 4.7 & 4.9589 & TRN & \\
\hline CHEMBL1612736 & 688721 & 4.5 & 4.8194 & TRN & \\
\hline CHEMBL1595842 & 688721 & 4.8 & 4.9601 & TRN & \\
\hline CHEMBL1459169 & 688721 & 5.2 & 5.0797 & TST & \\
\hline CHEMBL1347532 & 688721 & 5.6 & 4.744 & TRN & \\
\hline CHEMBL1362615 & 688721 & 4.4 & 4.8678 & TRN & \\
\hline CHEMBL18104 & 688721 & 5.1 & 5.2735 & TRN & \\
\hline CHEMBL1312768 & 688721 & 4.7 & 4.9618 & TRN & \\
\hline CHEMBL1393244 & 688721 & 5.2 & 5.0485 & TRN & \\
\hline CHEMBL1572550 & 688721 & 4.5 & 5.0766 & TRN & \\
\hline CHEMBL179024 & 688721 & 4.5 & 4.9532 & TST & \\
\hline CHEMBL1346709 & 688721 & 4.4 & 4.8734 & TRN & \\
\hline CHEMBL1417221 & 688721 & 4.7 & 4.8333 & TRN & \\
\hline CHEMBL1451520 & 688721 & 4.6 & 4.9989 & TRN & \\
\hline CHEMBL1410949 & 688721 & 5.1 & 4.8874 & TRN & \\
\hline CHEMBL1380571 & 688721 & 4.6 & 4.9518 & TST & \\
\hline CHEMBL1348129 & 688721 & 5.0 & 4.8967 & TRN & \\
\hline CHEMBL1353546 & 688721 & 5.1 & 4.8629 & TRN & \\
\hline CHEMBL1387978 & 688721 & 4.6 & 5.0524 & TST & \\
\hline CHEMBL1426257 & 688721 & 5.5 & 5.0493 & TRN & \\
\hline CHEMBL1339536 & 688721 & 5.5 & 4.7233 & TRN & \\
\hline CHEMBL1430921 & 688721 & 4.4 & 4.9062 & TRN & \\
\hline CHEMBL1300232 & 688721 & 6.1 & 5.0078 & TRN & \\
\hline CHEMBL1443218 & 688721 & 4.6 & 5.0018 & TST & \\
\hline CHEMBL1392591 & 688721 & 4.6 & 4.8253 & TRN & \\
\hline CHEMBL1587569 & 688721 & 5.6 & 4.879 & TRN & \\
\hline CHEMBL1328164 & 688721 & 5.8 & 4.76699 & 99999999995 & TRN \\
\hline CHEMBL1487121 & 688721 & 4.5 & 4.894 & TRN & \\
\hline CHEMBL399761 & 688721 & 4.5 & 4.7858 & TRN & \\
\hline CHEMBL1577745 & 688721 & 5.2 & 4.8563 & TRN & \\
\hline CHEMBL1529766 & 688721 & 4.5 & 5.0907 & TST & \\
\hline CHEMBL1594527 & 688721 & 5.2 & 5.0153 & TST & \\
\hline CHEMBL1419294 & 688721 & 4.8 & 5.0179 & TST & \\
\hline CHEMBL1356764 & 688721 & 5.3 & 5.152 & TRN & \\
\hline CHEMBL1332629 & 688721 & 4.6 & 4.8072 & TRN & \\
\hline CHEMBL1332721 & 688721 & 6.8 & 5.0456 & TRN & \\
\hline CHEMBL1503882 & 688721 & 4.7 & 4.8267 & TRN & \\
\hline CHEMBL1608526 & 688721 & 4.6 & 4.8459 & TRN & \\
\hline CHEMBL1594626 & 688721 & 4.6 & 5.4336 & TST & \\
\hline CHEMBL1354432 & 688721 & 5.4 & 5.1178 & TST & \\
\hline
\end{tabular}




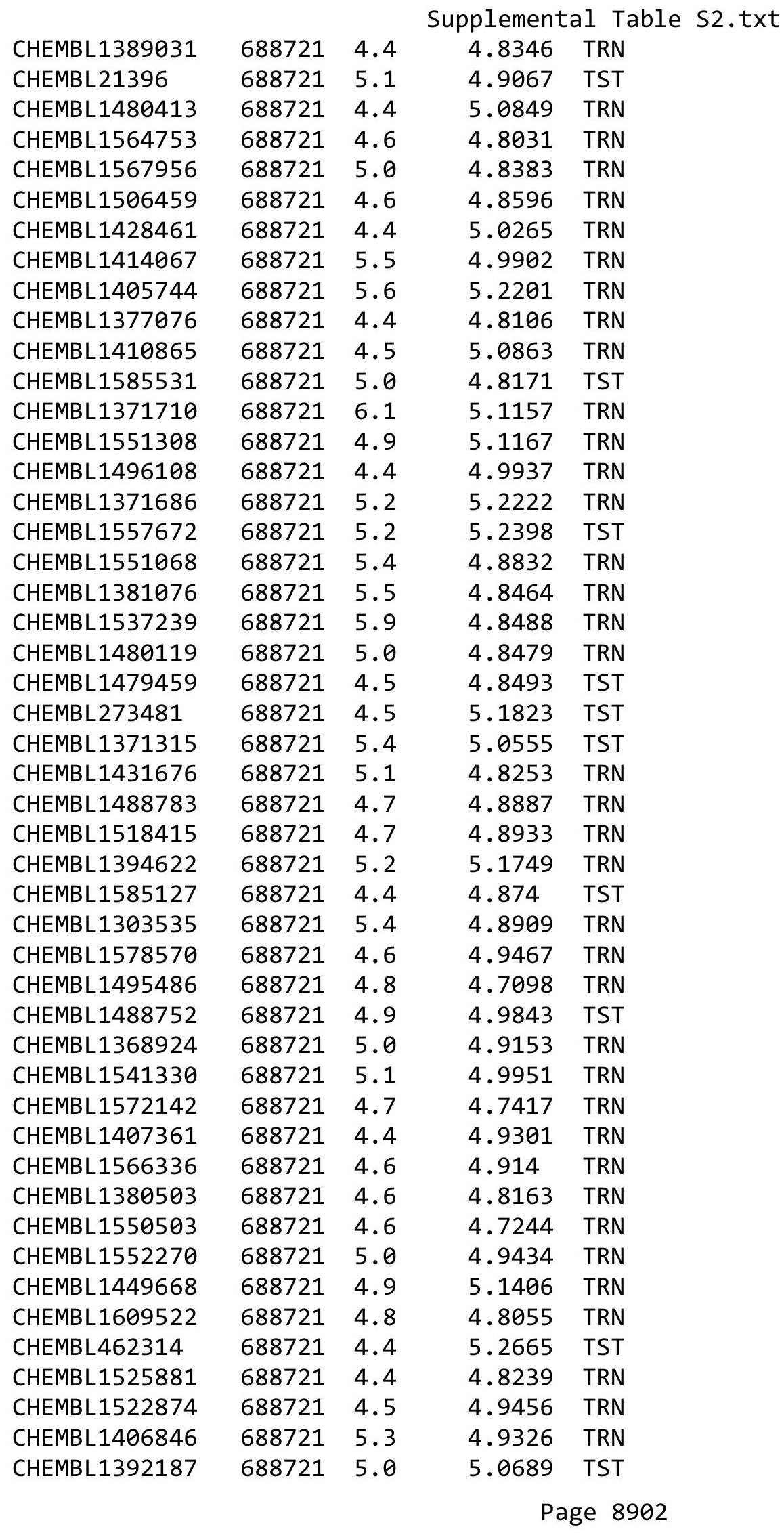




\begin{tabular}{|c|c|c|c|c|}
\hline & & & Supplement & \\
\hline CHEMBL1333512 & 688721 & 4.8 & 5.1746 & TRN \\
\hline CHEMBL3210451 & 688721 & 7.0 & 4.975 & TRN \\
\hline CHEMBL1603717 & 688721 & 5.0 & 4.9504 & TST \\
\hline CHEMBL1439066 & 688721 & 4.6 & 4.8494 & TRN \\
\hline CHEMBL1385522 & 688721 & 5.0 & 4.8604 & TRN \\
\hline CHEMBL1319097 & 688721 & 5.4 & 5.0377 & TST \\
\hline CHEMBL1428838 & 688721 & 4.9 & 4.8104 & TRN \\
\hline CHEMBL1498744 & 688721 & 4.5 & 5.1239 & TRN \\
\hline CHEMBL1381727 & 688721 & 4.6 & 5.1352 & TRN \\
\hline CHEMBL1302669 & 688721 & 5.4 & 4.9106 & TRN \\
\hline CHEMBL1538626 & 688721 & 4.8 & 4.8971 & TRN \\
\hline CHEMBL1595175 & 688721 & 4.5 & 4.7705 & TRN \\
\hline CHEMBL1565991 & 688721 & 4.6 & 4.723 & TRN \\
\hline CHEMBL3191413 & 688721 & 5.2 & 4.8934 & TST \\
\hline CHEMBL1609356 & 688721 & 5.9 & 4.9456 & TRN \\
\hline CHEMBL1523894 & 688721 & 4.6 & 5.1524 & TST \\
\hline CHEMBL1488251 & 688721 & 4.4 & 4.8148 & TRN \\
\hline CHEMBL1445009 & 688721 & 4.5 & 4.9804 & TRN \\
\hline CHEMBL1409032 & 688721 & 5.2 & 5.0562 & TST \\
\hline CHEMBL1561648 & 688721 & 4.5 & 4.9436 & TRN \\
\hline CHEMBL3196987 & 688721 & 4.6 & 4.8076 & TRN \\
\hline CHEMBL1409672 & 688721 & 4.6 & 4.9181 & TRN \\
\hline CHEMBL1533390 & 688721 & 4.6 & 4.8715 & TRN \\
\hline CHEMBL1370299 & 688721 & 4.5 & 4.7145 & TRN \\
\hline CHEMBL1414675 & 688721 & 6.9 & 4.9795 & TRN \\
\hline CHEMBL1401324 & 688721 & 4.9 & 4.92 & TST \\
\hline CHEMBL1556666 & 688721 & 4.8 & 4.8117 & TRN \\
\hline CHEMBL1442469 & 688721 & 5.4 & 4.9396 & TRN \\
\hline CHEMBL1465799 & 688721 & 5.2 & 4.9864 & TRN \\
\hline CHEMBL556489 & 688721 & 6.2 & 5.2748 & TRN \\
\hline CHEMBL1373868 & 688721 & 4.7 & 4.8651 & TRN \\
\hline CHEMBL1470770 & 688721 & 4.6 & 4.8274 & TRN \\
\hline CHEMBL1351991 & 688721 & 5.3 & 4.9167 & TRN \\
\hline CHEMBL1414084 & 688721 & 4.7 & 4.8683 & TRN \\
\hline CHEMBL1352800 & 688721 & 4.5 & 4.8489 & TST \\
\hline CHEMBL1455336 & 688721 & 5.3 & 4.8645 & TRN \\
\hline CHEMBL1607028 & 688721 & 4.5 & 4.9988 & TRN \\
\hline CHEMBL1387832 & 688721 & 4.7 & 4.8924 & TRN \\
\hline CHEMBL1413855 & 688721 & 4.4 & 4.8528 & TRN \\
\hline CHEMBL600060 & 688721 & 4.7 & 4.9974 & TRN \\
\hline CHEMBL1471728 & 688721 & 4.6 & 5.0749 & TRN \\
\hline CHEMBL1373724 & 688721 & 4.4 & 4.7663 & TRN \\
\hline CHEMBL1486450 & 688721 & 5.3 & 5.118 & TST \\
\hline CHEMBL1460295 & 688721 & 5.5 & 4.6967 & TRN \\
\hline CHEMBL1427637 & 688721 & 4.8 & 5.0309 & TST \\
\hline CHEMBL1528656 & 688721 & 4.8 & 4.9346 & TRN \\
\hline CHEMBL1450956 & 688721 & 4.6 & 4.7259 & TRN \\
\hline CHEMBL1342777 & 688721 & 5.2 & 4.8868 & TRN \\
\hline
\end{tabular}




\begin{tabular}{|c|c|c|c|c|}
\hline & & & pplement & al lable s \\
\hline CHEMBL1478609 & 688721 & 4.6 & 4.9264 & TRN \\
\hline CHEMBL1315913 & 688721 & 4.9 & 4.9075 & TRN \\
\hline CHEMBL1306295 & 688721 & 4.8 & 4.88899 & 9999999999 \\
\hline CHEMBL1544507 & 688721 & 5.9 & 4.9982 & TST \\
\hline CHEMBL1547831 & 688721 & 4.5 & 4.9844 & TST \\
\hline CHEMBL1409547 & 688721 & 4.6 & 4.8633 & TST \\
\hline CHEMBL1601181 & 688721 & 4.9 & 4.8682 & TRN \\
\hline CHEMBL1601135 & 688721 & 4.8 & 4.9117 & TRN \\
\hline CHEMBL1407548 & 688721 & 5.0 & 5.1148 & TRN \\
\hline CHEMBL1479324 & 688721 & 4.7 & 5.0884 & TRN \\
\hline CHEMBL1439741 & 688721 & 4.6 & 5.1058 & TST \\
\hline CHEMBL1553766 & 688721 & 5.8 & 5.1934 & TRN \\
\hline CHEMBL1408789 & 688721 & 4.5 & 4.8222 & TST \\
\hline CHEMBL1469819 & 688721 & 4.5 & 4.9255 & TRN \\
\hline CHEMBL1540207 & 688721 & 4.6 & 4.8856 & TRN \\
\hline CHEMBL1421244 & 688721 & 4.8 & 5.0526 & TRN \\
\hline CHEMBL1369929 & 688721 & 4.7 & 4.9525 & TRN \\
\hline CHEMBL1552957 & 688721 & 4.4 & 5.0743 & TRN \\
\hline CHEMBL1516342 & 688721 & 5.5 & 5.1654 & TRN \\
\hline CHEMBL177611 & 688721 & 6.0 & 5.1284 & TST \\
\hline CHEMBL1557386 & 688721 & 4.4 & 4.7718 & TRN \\
\hline CHEMBL1312961 & 688721 & 4.6 & 4.7958 & TRN \\
\hline CHEMBL1549400 & 688721 & 5.2 & 5.0547 & TST \\
\hline CHEMBL1382568 & 688721 & 4.6 & 4.8529 & TST \\
\hline CHEMBL1564478 & 688721 & 4.5 & 4.8381 & TRN \\
\hline CHEMBL1439272 & 688721 & 5.5 & 4.8869 & TRN \\
\hline CHEMBL1543025 & 688721 & 5.4 & 5.0033 & TST \\
\hline CHEMBL1406133 & 688721 & 4.4 & 4.735 & TRN \\
\hline CHEMBL1374825 & 688721 & 4.4 & 4.935 & TRN \\
\hline CHEMBL1612859 & 688721 & 4.5 & 4.8958 & TRN \\
\hline CHEMBL1603030 & 688721 & 4.5 & 4.7774 & TST \\
\hline CHEMBL1565292 & 688721 & 4.8 & 5.0362 & TST \\
\hline CHEMBL1581772 & 688721 & 4.5 & 4.8707 & TST \\
\hline CHEMBL1306955 & 688721 & 4.9 & 4.9141 & TST \\
\hline CHEMBL1592819 & 688721 & 4.8 & 4.9045 & TRN \\
\hline CHEMBL1429530 & 688721 & 4.9 & 4.8631 & TRN \\
\hline CHEMBL1524804 & 688721 & 5.4 & 4.9168 & TRN \\
\hline CHEMBL1566132 & 688721 & 4.4 & 5.273 & TST \\
\hline CHEMBL1300640 & 688721 & 5.2 & 4.8967 & TRN \\
\hline CHEMBL1587968 & 688721 & 5.9 & 4.9225 & TRN \\
\hline CHEMBL1605791 & 688721 & 4.6 & 4.7554 & TRN \\
\hline CHEMBL 78150 & 688721 & 6.1 & 5.2421 & TRN \\
\hline CHEMBL1420564 & 688721 & 4.6 & 4.852 & TRN \\
\hline CHEMBL3196169 & 688721 & 5.2 & 5.1665 & TST \\
\hline CHEMBL1572139 & 688721 & 4.6 & 4.8825 & TRN \\
\hline CHEMBL1377287 & 688721 & 4.5 & 5.1072 & TRN \\
\hline CHEMBL1540534 & 688721 & 4.6 & 4.8821 & TST \\
\hline CHEMBL1546102 & 688721 & 4.6 & 4.7333 & TRN \\
\hline
\end{tabular}

TRN 


\begin{tabular}{|c|c|c|c|c|c|}
\hline \multicolumn{6}{|c|}{ Supplemental Table S2.txt } \\
\hline CHEMBL1353803 & 688721 & 4.7 & 4.7641 & TRN & \\
\hline CHEMBL1256576 & 688721 & 7.8996 & 5.2618 & TST & \\
\hline CHEMBL1542023 & 688721 & 4.5 & 4.9546 & TRN & \\
\hline CHEMBL1308895 & 688721 & 4.5 & 4.9443 & TST & \\
\hline CHEMBL1302993 & 688721 & 4.6 & 4.8813 & TRN & \\
\hline CHEMBL1427586 & 688721 & 4.6 & 4.8957 & TRN & \\
\hline CHEMBL510009 & 688721 & 5.8 & 5.0902 & TRN & \\
\hline CHEMBL1468652 & 688721 & 5.4 & 4.9714 & TRN & \\
\hline CHEMBL1392143 & 688721 & 5.4 & 5.1193 & TST & \\
\hline CHEMBL1335205 & 688721 & 5.4 & 4.8611 & TRN & \\
\hline CHEMBL1570885 & 688721 & 5.1 & 4.7972 & TRN & \\
\hline CHEMBL1556307 & 688721 & 5.4 & 5.0578 & TRN & \\
\hline CHEMBL1438160 & 688721 & 5.2 & 5.0445 & TST & \\
\hline CHEMBL1531037 & 688721 & 4.7 & 4.7871 & TRN & \\
\hline CHEMBL1391567 & 688721 & 5.2 & 4.908 & TRN & \\
\hline CHEMBL1200471 & 688721 & 5.2 & 5.1569 & TST & \\
\hline CHEMBL1335290 & 688721 & 5.6 & 4.9334 & TRN & \\
\hline CHEMBL1319049 & 688721 & 5.0 & 5.1319 & TRN & \\
\hline CHEMBL1380671 & 688721 & 4.4 & 5.0986 & TRN & \\
\hline CHEMBL1373723 & 688721 & 4.9 & 5.1154 & TRN & \\
\hline CHEMBL1545295 & 688721 & 5.1 & 4.7756 & TRN & \\
\hline CHEMBL1522144 & 688721 & 5.3 & 4.9537 & TRN & \\
\hline CHEMBL 1561370 & 688721 & 5.2 & 5.0654 & TRN & \\
\hline CHEMBL1389510 & 688721 & 7.0 & 4.9828 & TST & \\
\hline CHEMBL1467754 & 688721 & 4.6 & 5.112 & TRN & \\
\hline CHEMBL1486905 & 688721 & 5.2 & 4.8812 & TRN & \\
\hline CHEMBL1478384 & 688721 & 5.2 & 4.9571 & TST & \\
\hline CHEMBL1486127 & 688721 & 4.4 & 4.89199 & 99999999995 & TRN \\
\hline CHEMBL1484727 & 688721 & 4.9 & 4.8513 & TRN & \\
\hline CHEMBL1300263 & 688721 & 5.3 & 5.2488 & TST & \\
\hline CHEMBL1610741 & 688721 & 4.7 & 4.9902 & TRN & \\
\hline CHEMBL1409166 & 688721 & 4.6 & 4.846 & TRN & \\
\hline CHEMBL1479129 & 688721 & 5.2 & 5.1035 & TRN & \\
\hline CHEMBL1332591 & 688721 & 5.8 & 5.1265 & TRN & \\
\hline CHEMBL1402656 & 688721 & 4.9 & 4.9584 & TRN & \\
\hline CHEMBL1500198 & 688721 & 4.4 & 4.9816 & TRN & \\
\hline CHEMBL1500847 & 688721 & 5.1 & 5.0608 & TST & \\
\hline CHEMBL1324817 & 688721 & 6.2 & 5.0892 & TST & \\
\hline CHEMBL498770 & 688721 & 4.4 & 5.1767 & TST & \\
\hline CHEMBL1478804 & 688721 & 4.7 & 4.8372 & TRN & \\
\hline CHEMBL1609183 & 688721 & 5.1 & 4.864 & TRN & \\
\hline CHEMBL1568215 & 688721 & 4.6 & 5.0809 & TST & \\
\hline CHEMBL1549972 & 688721 & 5.1 & 4.9755 & TST & \\
\hline CHEMBL 1483602 & 688721 & 4.6 & 4.7091 & TST & \\
\hline CHEMBL1387949 & 688721 & 4.4 & 4.9103 & TST & \\
\hline CHEMBL1531515 & 688721 & 5.4 & 4.9506 & TRN & \\
\hline CHEMBL1528250 & 688721 & 4.5 & 4.783 & TRN & \\
\hline CHEMBL1405511 & 688721 & 4.7 & 4.9684 & TRN & \\
\hline
\end{tabular}




\begin{tabular}{|c|c|c|c|c|c|}
\hline \multicolumn{6}{|c|}{ Supplemental Table S2.txt } \\
\hline CHEMBL1412531 & 688721 & 4.5 & 4.7993 & TST & \\
\hline CHEMBL1407119 & 688721 & 5.1 & 4.9818 & TRN & \\
\hline CHEMBL1464595 & 688721 & 4.6 & 4.9547 & TRN & \\
\hline CHEMBL1478445 & 688721 & 5.4 & 4.9942 & TRN & \\
\hline CHEMBL1438593 & 688721 & 6.9 & 4.9683 & TRN & \\
\hline CHEMBL1409917 & 688721 & 5.0 & 4.9082 & TRN & \\
\hline CHEMBL1445522 & 688721 & 4.8 & 5.1922 & TRN & \\
\hline CHEMBL1463134 & 688721 & 5.1 & 4.9027 & TRN & \\
\hline CHEMBL1361422 & 688721 & 5.2 & 5.0247 & TST & \\
\hline CHEMBL1525470 & 688721 & 4.8 & 4.922 & TST & \\
\hline CHEMBL1574187 & 688721 & 4.4 & 4.8518 & TST & \\
\hline CHEMBL1402898 & 688721 & 4.4 & 4.8377 & TRN & \\
\hline CHEMBL1610951 & 688721 & 4.5 & 5.0976 & TRN & \\
\hline CHEMBL1538109 & 688721 & 4.7 & 4.8811 & TRN & \\
\hline CHEMBL1585567 & 688721 & 5.6 & 4.7626 & TRN & \\
\hline CHEMBL1524567 & 688721 & 4.5 & 5.01 & TRN & \\
\hline CHEMBL1455998 & 688721 & 4.6 & 4.7674 & TRN & \\
\hline CHEMBL1603786 & 688721 & 5.1 & 5.0117 & TST & \\
\hline CHEMBL1309506 & 688721 & 6.9 & 4.9332 & TRN & \\
\hline CHEMBL1333818 & 688721 & 5.2 & 4.8217 & TRN & \\
\hline CHEMBL1316714 & 688721 & 4.4 & 5.0085 & TRN & \\
\hline CHEMBL1399767 & 688721 & 5.4 & 5.1517 & TST & \\
\hline CHEMBL1358416 & 688721 & 5.5 & 5.1805 & TST & \\
\hline CHEMBL1415094 & 688721 & 4.7 & 4.9101 & TRN & \\
\hline CHEMBL1459934 & 688721 & 4.5 & 4.8696 & TRN & \\
\hline CHEMBL1459937 & 688721 & 4.7 & 4.9591 & TRN & \\
\hline CHEMBL1386297 & 688721 & 4.6 & 4.8741 & TRN & \\
\hline CHEMBL1346712 & 688721 & 5.3 & 4.9635 & TRN & \\
\hline CHEMBL1403666 & 688721 & 4.6 & 4.829 & TRN & \\
\hline CHEMBL1572599 & 688721 & 5.2 & 4.8461 & TRN & \\
\hline CHEMBL1597037 & 688721 & 4.7 & 4.9698 & TRN & \\
\hline CHEMBL1534227 & 688721 & 5.1 & 4.9255 & TRN & \\
\hline CHEMBL1533258 & 688721 & 5.2 & 4.9663 & TRN & \\
\hline CHEMBL1440311 & 688721 & 4.5 & 4.7558 & TRN & \\
\hline CHEMBL1410920 & 688721 & 5.0 & 4.88399 & 99999999995 & TRN \\
\hline CHEMBL1429566 & 688721 & 4.5 & 4.7623 & TRN & \\
\hline CHEMBL1453717 & 688721 & 5.2 & 5.0807 & TRN & \\
\hline CHEMBL1366732 & 688721 & 4.7 & 4.9127 & TRN & \\
\hline CHEMBL1605043 & 688721 & 5.3 & 4.7598 & TRN & \\
\hline CHEMBL1305020 & 688721 & 4.8 & 4.9756 & TRN & \\
\hline CHEMBL1607125 & 688721 & 4.5 & 4.9872 & TST & \\
\hline CHEMBL1410007 & 688721 & 4.4 & 4.8584 & TRN & \\
\hline CHEMBL1366144 & 688721 & 4.8 & 4.7774 & TRN & \\
\hline CHEMBL1366423 & 688721 & 4.6 & 5.0494 & TST & \\
\hline CHEMBL1461765 & 688721 & 5.4 & 4.9362 & TRN & \\
\hline CHEMBL1445142 & 688721 & 4.6 & 4.8672 & TST & \\
\hline CHEMBL1393368 & 688721 & 4.5 & 4.9512 & TRN & \\
\hline CHEMBL1386325 & 688721 & 4.5 & 4.9121 & TRN & \\
\hline
\end{tabular}




\begin{tabular}{|c|c|c|c|c|}
\hline \multicolumn{5}{|c|}{ Supplemental Table S2.txt } \\
\hline CHEMBL1333260 & 688721 & 4.4 & 4.7847 & TRN \\
\hline CHEMBL1592186 & 688721 & 4.6 & 5.0694 & TRN \\
\hline CHEMBL1348137 & 688721 & 4.9 & 4.9854 & TRN \\
\hline CHEMBL1333283 & 688721 & 4.5 & 4.8227 & TRN \\
\hline CHEMBL1418014 & 688721 & 4.5 & 4.9552 & TRN \\
\hline CHEMBL1447889 & 688721 & 4.9 & 4.9653 & TRN \\
\hline CHEMBL1601761 & 688721 & 5.1 & 4.9999 & TRN \\
\hline CHEMBL1301849 & 688721 & 4.4 & 4.9104 & TRN \\
\hline CHEMBL1595277 & 688721 & 5.2 & 4.8203 & TRN \\
\hline CHEMBL1503565 & 688721 & 4.4 & 5.0601 & TRN \\
\hline CHEMBL1373673 & 688721 & 4.9 & 5.1088 & TRN \\
\hline CHEMBL1413571 & 688721 & 4.5 & 4.9332 & TRN \\
\hline CHEMBL1579414 & 688721 & 5.8 & 4.9961 & TRN \\
\hline CHEMBL1534995 & 688721 & 6.2 & 4.8352 & TRN \\
\hline CHEMBL1301325 & 688721 & 4.6 & 4.914 & TRN \\
\hline CHEMBL1365705 & 688721 & 4.7 & 5.2405 & TRN \\
\hline CHEMBL1552864 & 688721 & 4.5 & 5.065 & TRN \\
\hline CHEMBL1351764 & 688721 & 4.8 & 4.8169 & TRN \\
\hline CHEMBL1491136 & 688721 & 4.4 & 4.8909 & TST \\
\hline CHEMBL1346140 & 688721 & 4.5 & 4.9793 & TRN \\
\hline CHEMBL1490320 & 688721 & 5.2 & 4.9133 & TRN \\
\hline CHEMBL1603902 & 688721 & 4.8 & 4.7359 & TRN \\
\hline CHEMBL1352639 & 688721 & 4.4 & 4.9516 & TRN \\
\hline CHEMBL1570734 & 688721 & 4.5 & 4.9101 & TST \\
\hline CHEMBL1355307 & 688721 & 4.8 & 4.8223 & TRN \\
\hline CHEMBL1486836 & 688721 & 5.2 & 5.0585 & TST \\
\hline CHEMBL1300475 & 688721 & 4.4 & 5.1258 & TST \\
\hline CHEMBL1488661 & 688721 & 4.8 & 4.9409 & TRN \\
\hline CHEMBL1306196 & 688721 & 4.6 & 4.8417 & TRN \\
\hline CHEMBL 1418843 & 688721 & 4.6 & 4.928 & TRN \\
\hline CHEMBL1485974 & 688721 & 6.0 & 5.2588 & TRN \\
\hline CHEMBL1522209 & 688721 & 4.8 & 4.8817 & TRN \\
\hline CHEMBL1422210 & 688721 & 4.4 & 4.8436 & TRN \\
\hline CHEMBL1488168 & 688721 & 5.5 & 4.7626 & TST \\
\hline CHEMBL1532984 & 688721 & 4.4 & 4.938 & TRN \\
\hline CHEMBL1379880 & 688721 & 5.4 & 5.086 & TST \\
\hline CHEMBL1478067 & 688721 & 4.8 & 4.9199 & TRN \\
\hline CHEMBL1548222 & 688721 & 4.4 & 5.088 & TST \\
\hline CHEMBL1608942 & 688721 & 5.0 & 4.9805 & TST \\
\hline CHEMBL1389039 & 688721 & 5.5 & 5.0083 & TRN \\
\hline CHEMBL1469177 & 688721 & 7.1002 & 4.8907 & TST \\
\hline CHEMBL1545764 & 688721 & 4.8 & 4.8308 & TRN \\
\hline CHEMBL1331128 & 688721 & 4.8 & 5.0472 & TST \\
\hline CHEMBL1375377 & 688721 & 4.8 & 4.9824 & TRN \\
\hline CHEMBL1448163 & 688721 & 5.3 & 4.9422 & TRN \\
\hline CHEMBL1310198 & 688721 & 4.9 & 4.8185 & TRN \\
\hline CHEMBL1537100 & 688721 & 5.1 & 4.8379 & TRN \\
\hline CHEMBL 3214013 & 688721 & 4.7 & 4.9629 & TRN \\
\hline
\end{tabular}




\begin{tabular}{|c|c|c|c|c|c|}
\hline \multicolumn{6}{|c|}{ Supplemental Table S2.txt } \\
\hline CHEMBL1999738 & 688721 & 4.8 & 4.9046 & TST & \\
\hline CHEMBL1430804 & 688721 & 5.0 & 4.7883 & TRN & \\
\hline CHEMBL1560366 & 688721 & 4.5 & 5.0433 & TST & \\
\hline CHEMBL1451195 & 688721 & 4.5 & 4.909 & TRN & \\
\hline CHEMBL1462195 & 688721 & 4.6 & 4.8985 & TRN & \\
\hline CHEMBL1450404 & 688721 & 6.1 & 4.8892 & TST & \\
\hline CHEMBL9843 & 688721 & 6.0 & 4.8683 & TRN & \\
\hline CHEMBL1527688 & 688721 & 5.2 & 5.0196 & TRN & \\
\hline CHEMBL1549600 & 688721 & 5.2 & 5.1034 & TRN & \\
\hline CHEMBL1534028 & 688721 & 4.9 & 4.8314 & TRN & \\
\hline CHEMBL1536211 & 688721 & 4.8 & 4.8464 & TST & \\
\hline CHEMBL1496838 & 688721 & 5.4 & 4.8404 & TRN & \\
\hline CHEMBL1347468 & 688721 & 4.7 & 4.7983 & TRN & \\
\hline CHEMBL1453542 & 688721 & 4.5 & 5.1844 & TRN & \\
\hline CHEMBL1417789 & 688721 & 4.9 & 5.07600 & 00000000005 & TRN \\
\hline CHEMBL1308058 & 688721 & 5.0 & 4.9637 & TRN & \\
\hline CHEMBL1421615 & 688721 & 4.4 & 5.0025 & TRN & \\
\hline CHEMBL1312282 & 688721 & 8.0 & 4.9105 & TRN & \\
\hline CHEMBL1377856 & 688721 & 8.2007 & 4.8942 & TRN & \\
\hline CHEMBL1384007 & 688721 & 5.4 & 4.926 & TRN & \\
\hline CHEMBL1359009 & 688721 & 4.8 & 4.8569 & TRN & \\
\hline CHEMBL1443226 & 688721 & 4.6 & 4.8977 & TRN & \\
\hline CHEMBL1375370 & 688721 & 4.4 & 5.0816 & TST & \\
\hline CHEMBL1448062 & 688721 & 5.4 & 4.9328 & TRN & \\
\hline CHEMBL1574074 & 688721 & 4.5 & 4.7701 & TRN & \\
\hline CHEMBL1605525 & 688721 & 7.4001 & 4.7438 & TRN & \\
\hline CHEMBL1568019 & 688721 & 5.0 & 5.1871 & TRN & \\
\hline CHEMBL1377929 & 688721 & 5.4 & 5.0045 & TRN & \\
\hline CHEMBL1427065 & 688721 & 6.1 & 5.1447 & TRN & \\
\hline CHEMBL1312517 & 688721 & 5.2 & 4.9926 & TRN & \\
\hline CHEMBL1581643 & 688721 & 4.6 & 5.0572 & TRN & \\
\hline CHEMBL1364184 & 688721 & 4.6 & 5.0525 & TST & \\
\hline CHEMBL1499745 & 688721 & 4.4 & 4.9213 & TRN & \\
\hline CHEMBL1536202 & 688721 & 6.0 & 5.0001 & TRN & \\
\hline CHEMBL1609915 & 688721 & 4.9 & 5.1025 & TST & \\
\hline CHEMBL1340753 & 688721 & 5.4 & 4.8419 & TRN & \\
\hline CHEMBL1511312 & 688721 & 5.0 & 4.8384 & TRN & \\
\hline CHEMBL1310609 & 688721 & 4.6 & 4.8465 & TRN & \\
\hline CHEMBL1327508 & 688721 & 4.7 & 5.0112 & TST & \\
\hline CHEMBL1469467 & 688721 & 5.0 & 4.8388 & TRN & \\
\hline CHEMBL1319407 & 688721 & 4.5 & 4.7891 & TRN & \\
\hline CHEMBL1603115 & 688721 & 4.7 & 5.0063 & TRN & \\
\hline CHEMBL1577646 & 688721 & 4.7 & 4.7418 & TST & \\
\hline CHEMBL1351900 & 688721 & 4.9 & 4.8977 & TRN & \\
\hline CHEMBL1342370 & 688721 & 4.4 & 4.8883 & TRN & \\
\hline CHEMBL1414319 & 688721 & 5.3 & 5.2682 & TST & \\
\hline CHEMBL1380000 & 688721 & 4.4 & 5.2306 & TRN & \\
\hline CHEMBL1528358 & 688721 & 4.4 & 4.9025 & TST & \\
\hline
\end{tabular}




\begin{tabular}{|c|c|c|c|c|c|}
\hline \multicolumn{6}{|c|}{ Supplemental Table S2.txt } \\
\hline CHEMBL1458256 & 688721 & 5.0 & 4.8321 & TRN & \\
\hline CHEMBL1483503 & 688721 & 4.7 & 4.7672 & TRN & \\
\hline CHEMBL 2062344 & 688721 & 5.1 & 4.7751 & TST & \\
\hline CHEMBL1349856 & 688721 & 6.3 & 4.9601 & TRN & \\
\hline CHEMBL1416584 & 688721 & 4.6 & 4.9813 & TRN & \\
\hline CHEMBL1431636 & 688721 & 5.4 & 4.9262 & TRN & \\
\hline CHEMBL1312038 & 688721 & 4.5 & 4.8031 & TRN & \\
\hline CHEMBL1528385 & 688721 & 4.8 & 4.8862 & TST & \\
\hline CHEMBL1570715 & 688721 & 4.6 & 4.9513 & TST & \\
\hline CHEMBL1366334 & 688721 & 4.6 & 4.823 & TRN & \\
\hline CHEMBL1517793 & 688721 & 4.8 & 5.1631 & TST & \\
\hline CHEMBL1565446 & 688721 & 6.9 & 4.9046 & TRN & \\
\hline CHEMBL1410980 & 688721 & 4.7 & 5.0833 & TST & \\
\hline CHEMBL1591893 & 688721 & 5.2 & 4.9944 & TRN & \\
\hline CHEMBL1303172 & 688721 & 4.4 & 4.8939 & TRN & \\
\hline CHEMBL1515355 & 688721 & 4.9 & 5.0788 & TRN & \\
\hline CHEMBL1499405 & 688721 & 4.6 & 4.8791 & TST & \\
\hline CHEMBL1404107 & 688721 & 4.7 & 4.8164 & TRN & \\
\hline CHEMBL1367427 & 688721 & 5.4 & 4.9366 & TRN & \\
\hline CHEMBL1430139 & 688721 & 4.5 & 4.8884 & TRN & \\
\hline CHEMBL1594325 & 688721 & 4.5 & 5.0228 & TRN & \\
\hline CHEMBL1353568 & 688721 & 4.6 & 4.9045 & TST & \\
\hline CHEMBL1463769 & 688721 & 4.8 & 5.0839 & TRN & \\
\hline CHEMBL1364836 & 688721 & 6.5 & 5.0931 & TRN & \\
\hline CHEMBL1466031 & 688721 & 4.6 & 4.8709 & TRN & \\
\hline CHEMBL1989464 & 688721 & 4.8 & 4.9849 & TRN & \\
\hline CHEMBL1504234 & 688721 & 4.7 & 4.83899 & 99999999995 & TRN \\
\hline CHEMBL1514512 & 688721 & 6.0 & 5.1828 & TST & \\
\hline CHEMBL1448971 & 688721 & 5.2 & 4.8642 & TRN & \\
\hline CHEMBL1555368 & 688721 & 5.1 & 5.1858 & TRN & \\
\hline CHEMBL1566863 & 688721 & 4.5 & 4.7946 & TRN & \\
\hline CHEMBL1531130 & 688721 & 4.4 & 5.0231 & TRN & \\
\hline CHEMBL1328707 & 688721 & 4.6 & 4.9002 & TRN & \\
\hline CHEMBL1369097 & 688721 & 4.4 & 4.7944 & TRN & \\
\hline CHEMBL1515986 & 688721 & 5.4 & 5.0369 & TRN & \\
\hline CHEMBL1331618 & 688721 & 5.2 & 5.1129 & TRN & \\
\hline CHEMBL1419858 & 688721 & 4.4 & 4.9107 & TST & \\
\hline CHEMBL1528624 & 688721 & 4.4 & 4.8561 & TST & \\
\hline CHEMBL1538398 & 688721 & 4.6 & 4.7134 & TRN & \\
\hline CHEMBL1310211 & 688721 & 4.5 & 4.8051 & TRN & \\
\hline CHEMBL618 & 688721 & 4.4 & 5.1276 & TRN & \\
\hline CHEMBL1414762 & 688721 & 4.5 & 4.7532 & TST & \\
\hline CHEMBL1540280 & 688721 & 4.8 & 4.8509 & TRN & \\
\hline CHEMBL1472384 & 688721 & 5.2 & 5.2544 & TRN & \\
\hline CHEMBL1255733 & 688721 & 4.6 & 5.4195 & TST & \\
\hline CHEMBL1368301 & 688721 & 5.2 & 4.8953 & TRN & \\
\hline CHEMBL1496957 & 688721 & 5.1 & 5.3143 & TRN & \\
\hline CHEMBL1353729 & 688721 & 8.301 & 4.9204 & TRN & \\
\hline
\end{tabular}




\begin{tabular}{|c|c|c|c|c|}
\hline \multicolumn{5}{|c|}{ ipplemental T } \\
\hline CHEMBL1306942 & 688721 & 4.6 & 4.9387 & TST \\
\hline CHEMBL1335688 & 688721 & 5.3 & 4.7429 & TRN \\
\hline CHEMBL1581719 & 688721 & 4.5 & 4.7922 & TRN \\
\hline CHEMBL1390762 & 688721 & 4.6 & 5.0434 & TST \\
\hline CHEMBL1974308 & 688721 & 5.4 & 4.7922 & TST \\
\hline CHEMBL1564635 & 688721 & 5.7 & 4.9732 & TRN \\
\hline CHEMBL261693 & 688721 & 5.3 & 4.725 & TST \\
\hline CHEMBL1481561 & 688721 & 4.7 & 4.8624 & TRN \\
\hline CHEMBL1568463 & 688721 & 4.5 & 4.7509 & TRN \\
\hline CHEMBL1566148 & 688721 & 4.5 & 4.9152 & TST \\
\hline CHEMBL1350280 & 688721 & 4.4 & 4.8631 & TRN \\
\hline CHEMBL1591677 & 688721 & 4.8 & 5.0761 & TRN \\
\hline CHEMBL1339753 & 688721 & 5.4 & 5.1045 & TRN \\
\hline CHEMBL1567983 & 688721 & 5.0 & 4.8393 & TRN \\
\hline CHEMBL1526828 & 688721 & 5.5 & 5.0455 & TST \\
\hline CHEMBL1543224 & 688721 & 4.4 & 4.871 & TRN \\
\hline CHEMBL1448545 & 688721 & 4.6 & 4.928 & TST \\
\hline CHEMBL1531249 & 688721 & 4.5 & 4.9498 & TRN \\
\hline CHEMBL1583259 & 688721 & 4.5 & 4.6516 & TRN \\
\hline CHEMBL1449846 & 688721 & 4.9 & 4.8499 & TRN \\
\hline CHEMBL1367252 & 688721 & 4.5 & 4.9053 & TRN \\
\hline CHEMBL1424468 & 688721 & 4.5 & 4.9591 & TRN \\
\hline CHEMBL 1305646 & 688721 & 5.1 & 4.9743 & TRN \\
\hline CHEMBL1424628 & 688721 & 4.8 & 4.8217 & TRN \\
\hline CHEMBL1424313 & 688721 & 5.4 & 4.8234 & TRN \\
\hline CHEMBL460515 & 688721 & 4.5 & 4.8683 & TST \\
\hline CHEMBL1567080 & 688721 & 4.5 & 4.6844 & TRN \\
\hline CHEMBL1436644 & 688721 & 4.6 & 5.1253 & TRN \\
\hline CHEMBL1508089 & 688721 & 4.5 & 4.9382 & TRN \\
\hline CHEMBL1370308 & 688721 & 4.6 & 5.1805 & TST \\
\hline CHEMBL1429805 & 688721 & 6.0 & 4.9402 & TRN \\
\hline CHEMBL1470858 & 688721 & 5.2 & 5.1869 & TST \\
\hline CHEMBL1346650 & 688721 & 4.6 & 4.9741 & TRN \\
\hline CHEMBL1563735 & 688721 & 4.5 & 4.9442 & TRN \\
\hline CHEMBL1446316 & 688721 & 4.6 & 4.8327 & TRN \\
\hline CHEMBL1411040 & 688721 & 5.5 & 4.9307 & TRN \\
\hline CHEMBL1421632 & 688721 & 4.8 & 4.9656 & TRN \\
\hline CHEMBL227726 & 688721 & 5.5 & 4.8589 & TRN \\
\hline CHEMBL1391082 & 688721 & 4.5 & 5.0463 & TST \\
\hline CHEMBL1507642 & 688721 & 5.3 & 5.1036 & TRN \\
\hline CHEMBL1548567 & 688721 & 4.6 & 5.0127 & TRN \\
\hline CHEMBL1372827 & 688721 & 5.4 & 4.9231 & TST \\
\hline CHEMBL1372115 & 688721 & 4.9 & 4.8619 & TRN \\
\hline CHEMBL1558379 & 688721 & 4.5 & 5.0061 & TRN \\
\hline CHEMBL1442736 & 688721 & 4.6 & 4.9872 & TRN \\
\hline CHEMBL1384685 & 688721 & 4.7 & 4.8215 & TRN \\
\hline CHEMBL1501400 & 688721 & 4.6 & 4.9701 & TRN \\
\hline CHEMBL239673 & 688721 & 4.9 & 4.9851 & TRN \\
\hline
\end{tabular}




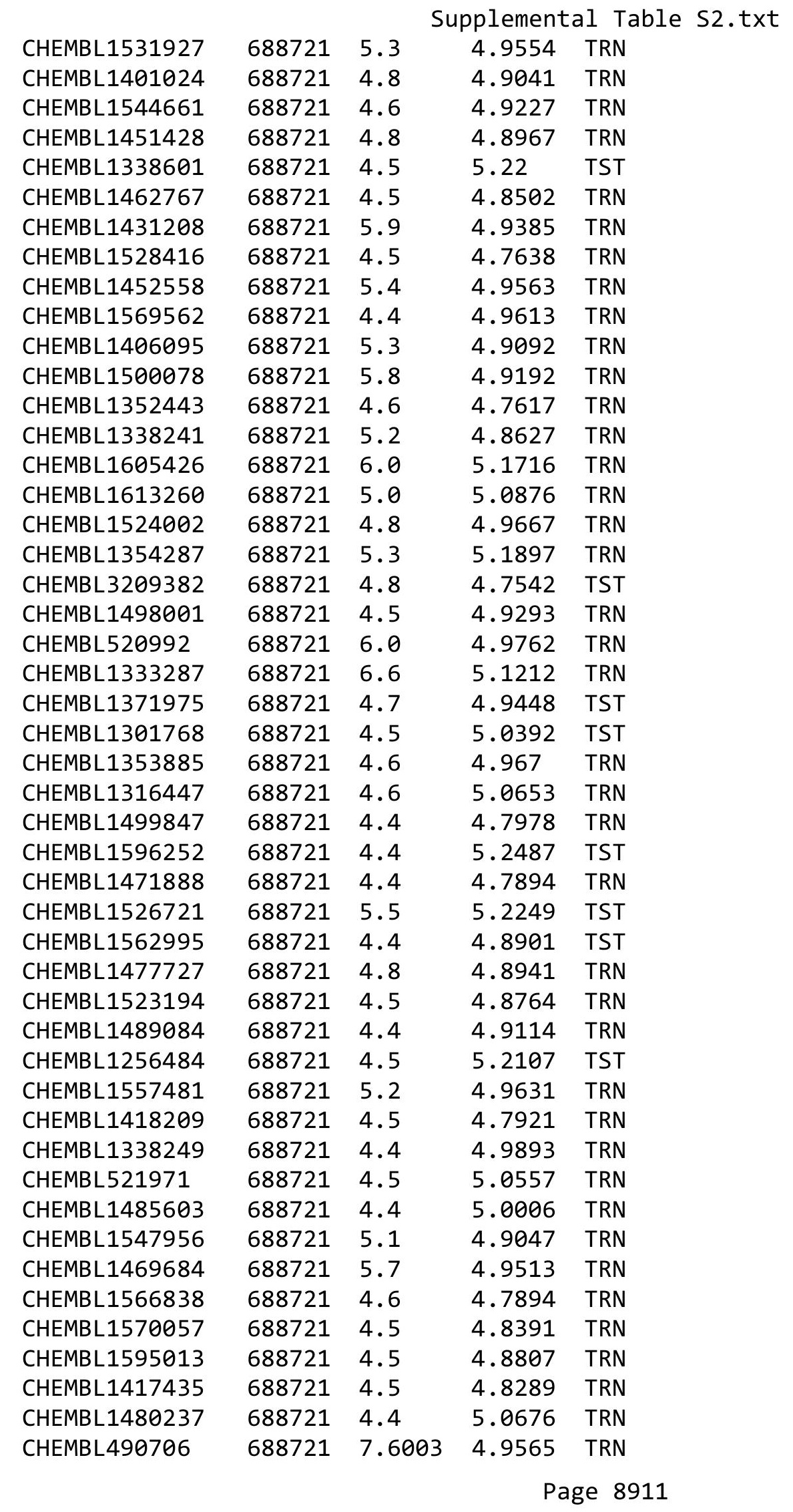




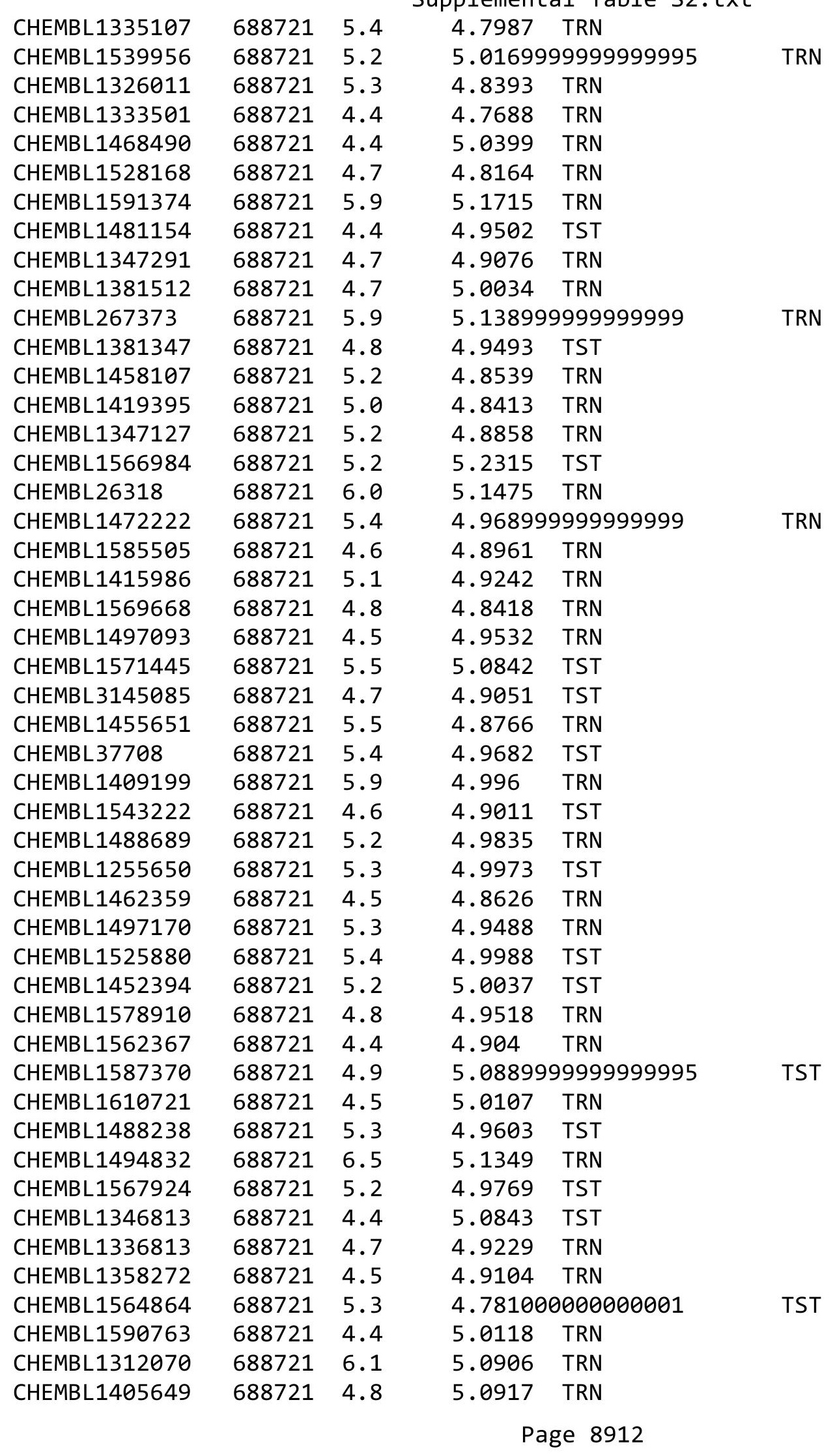




\begin{tabular}{|c|c|c|c|c|}
\hline & & & 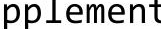 & al Ta \\
\hline CHEMBL1600998 & 688721 & 5.1 & 5.1964 & TRN \\
\hline CHEMBL1427033 & 688721 & 4.8 & 4.92 & TRN \\
\hline CHEMBL1364009 & 688721 & 5.0 & 4.8367 & TRN \\
\hline CHEMBL1439401 & 688721 & 4.5 & 4.8962 & TRN \\
\hline CHEMBL 299683 & 688721 & 5.4 & 5.2335 & TRN \\
\hline CHEMBL1557057 & 688721 & 4.4 & 5.0409 & TST \\
\hline CHEMBL1605632 & 688721 & 6.5 & 5.1751 & TRN \\
\hline CHEMBL1349610 & 688721 & 5.3 & 4.8328 & TRN \\
\hline CHEMBL1551090 & 688721 & 5.3 & 5.0717 & TRN \\
\hline CHEMBL1382372 & 688721 & 4.4 & 5.0165 & TRN \\
\hline CHEMBL1612390 & 688721 & 4.4 & 4.9768 & TST \\
\hline CHEMBL1442142 & 688721 & 5.1 & 4.7965 & TRN \\
\hline CHEMBL1527262 & 688721 & 4.4 & 4.9385 & TST \\
\hline CHEMBL1520347 & 688721 & 4.9 & 5.0376 & TRN \\
\hline CHEMBL1593108 & 688721 & 5.0 & 5.1852 & TRN \\
\hline CHEMBL1365427 & 688721 & 4.7 & 5.2196 & TRN \\
\hline CHEMBL1364366 & 688721 & 4.5 & 5.1343 & TRN \\
\hline CHEMBL1548408 & 688721 & 4.8 & 4.8162 & TRN \\
\hline CHEMBL1601200 & 688721 & 4.4 & 4.9013 & TRN \\
\hline CHEMBL1581798 & 688721 & 4.4 & 4.8577 & TRN \\
\hline CHEMBL1521144 & 688721 & 5.1 & 5.0424 & TRN \\
\hline CHEMBL1580761 & 688721 & 4.6 & 4.7261 & TRN \\
\hline CHEMBL1569175 & 688721 & 4.9 & 5.0136 & TRN \\
\hline CHEMBL1417197 & 688721 & 4.7 & 4.9631 & TRN \\
\hline CHEMBL1390680 & 688721 & 4.4 & 5.003 & TST \\
\hline CHEMBL1324146 & 688721 & 4.4 & 4.9922 & TRN \\
\hline CHEMBL3209071 & 688721 & 4.4 & 4.8391 & TST \\
\hline CHEMBL1543652 & 688721 & 4.5 & 4.9118 & TRN \\
\hline CHEMBL1389657 & 688721 & 4.6 & 4.8937 & TRN \\
\hline CHEMBL1466728 & 688721 & 6.1 & 4.9397 & TRN \\
\hline CHEMBL1558361 & 688721 & 4.5 & 4.8909 & TRN \\
\hline CHEMBL1556511 & 688721 & 5.2 & 4.9942 & TRN \\
\hline CHEMBL235586 & 688721 & 4.7 & 5.1258 & TRN \\
\hline CHEMBL1341087 & 688721 & 4.6 & 4.8908 & TRN \\
\hline CHEMBL1607661 & 688721 & 5.0 & 4.7946 & TST \\
\hline CHEMBL1443694 & 688721 & 5.4 & 4.9504 & TST \\
\hline CHEMBL1548607 & 688721 & 4.4 & 5.0215 & TRN \\
\hline CHEMBL1331317 & 688721 & 5.1 & 4.9649 & TST \\
\hline CHEMBL1529176 & 688721 & 4.4 & 4.867 & TRN \\
\hline CHEMBL1447663 & 688721 & 5.8 & 5.0396 & TRN \\
\hline CHEMBL1462869 & 688721 & 4.4 & 5.0863 & TST \\
\hline CHEMBL1455375 & 688721 & 4.4 & 4.7456 & TRN \\
\hline CHEMBL1370120 & 688721 & 5.1 & 4.8851 & TRN \\
\hline CHEMBL1443480 & 688721 & 4.7 & 5.1076 & TRN \\
\hline CHEMBL1424916 & 688721 & 4.6 & 4.8138 & TRN \\
\hline CHEMBL1368282 & 688721 & 5.4 & 5.1041 & TST \\
\hline CHEMBL1478963 & 688721 & 4.5 & 5.1335 & TRN \\
\hline CHEMBL1542555 & 688721 & 5.1 & 5.0035 & TRN \\
\hline
\end{tabular}




\begin{tabular}{|c|c|c|c|c|}
\hline \multicolumn{5}{|c|}{ Supplemental Table S2.txt } \\
\hline CHEMBL 3208804 & 688721 & 5.1 & 5.0213 & TST \\
\hline CHEMBL1371615 & 688721 & 4.5 & 4.9144 & TRN \\
\hline CHEMBL1594540 & 688721 & 5.1 & 4.9165 & TRN \\
\hline CHEMBL1518035 & 688721 & 5.2 & 4.875 & TRN \\
\hline CHEMBL1343941 & 688721 & 4.8 & 4.8217 & TRN \\
\hline CHEMBL1506373 & 688721 & 5.0 & 4.8154 & TRN \\
\hline CHEMBL 1407488 & 688721 & 4.8 & 4.8671 & TRN \\
\hline CHEMBL56 & 688721 & 4.8 & 5.1172 & TRN \\
\hline CHEMBL1421334 & 688721 & 4.7 & 4.6575 & TRN \\
\hline CHEMBL1606077 & 688721 & 4.4 & 4.9392 & TST \\
\hline CHEMBL1349241 & 688721 & 5.5 & 5.0035 & TST \\
\hline CHEMBL1525467 & 688721 & 4.4 & 4.9 & TRN \\
\hline CHEMBL1544478 & 688721 & 5.4 & 4.8259 & TRN \\
\hline CHEMBL1421382 & 688721 & 4.7 & 4.825 & TRN \\
\hline CHEMBL1336812 & 688721 & 5.8 & 5.2224 & TST \\
\hline CHEMBL1585938 & 688721 & 4.4 & 4.794 & TST \\
\hline CHEMBL1311510 & 688721 & 6.1 & 4.9977 & TRN \\
\hline CHEMBL1592556 & 688721 & 5.5 & 5.0175 & TRN \\
\hline CHEMBL1563147 & 688721 & 4.9 & 5.0314 & TRN \\
\hline CHEMBL1543294 & 688721 & 4.9 & 4.944 & TST \\
\hline CHEMBL1423551 & 688721 & 4.4 & 4.8747 & TRN \\
\hline CHEMBL 22075 & 688721 & 4.8 & 5.0454 & TST \\
\hline CHEMBL1566251 & 688721 & 4.7 & 4.8394 & TRN \\
\hline CHEMBL1502184 & 688721 & 4.5 & 4.8021 & TRN \\
\hline CHEMBL1377909 & 688721 & 4.4 & 5.0644 & TST \\
\hline CHEMBL1463339 & 688721 & 4.6 & 4.7815 & TRN \\
\hline CHEMBL1392532 & 688721 & 4.5 & 4.8716 & TRN \\
\hline CHEMBL1539715 & 688721 & 5.5 & 5.2994 & TST \\
\hline CHEMBL1520783 & 688721 & 5.4 & 5.0284 & TST \\
\hline CHEMBL1370957 & 688721 & 4.6 & 4.8311 & TRN \\
\hline CHEMBL1423574 & 688721 & 7.5003 & 4.9394 & TRN \\
\hline CHEMBL1408559 & 688721 & 4.4 & 5.0118 & TRN \\
\hline CHEMBL1590789 & 688721 & 4.9 & 5.3546 & TRN \\
\hline CHEMBL1533981 & 688721 & 5.5 & 4.9438 & TRN \\
\hline CHEMBL 1495740 & 688721 & 4.6 & 4.7182 & TRN \\
\hline CHEMBL1580182 & 688721 & 4.8 & 5.051 & TST \\
\hline CHEMBL1303383 & 688721 & 5.4 & 4.8525 & TRN \\
\hline CHEMBL1352388 & 688721 & 4.4 & 5.1262 & TST \\
\hline CHEMBL1366072 & 688721 & 5.2 & 4.7643 & TRN \\
\hline CHEMBL1569821 & 688721 & 4.4 & 4.8891 & TST \\
\hline CHEMBL1532543 & 688721 & 4.4 & 4.909 & TRN \\
\hline CHEMBL1522249 & 688721 & 4.6 & 4.7723 & TRN \\
\hline CHEMBL1415790 & 688721 & 5.0 & 4.8986 & TRN \\
\hline CHEMBL1401872 & 688721 & 5.2 & 4.7165 & TRN \\
\hline CHEMBL1308779 & 688721 & 4.6 & 4.8083 & TRN \\
\hline CHEMBL1373766 & 688721 & 4.6 & 4.9561 & TRN \\
\hline CHEMBL1554577 & 688721 & 4.6 & 4.9849 & TRN \\
\hline CHEMBL1338767 & 688721 & 5.8 & 5.0759 & TRN \\
\hline
\end{tabular}




\begin{tabular}{|c|c|c|c|c|}
\hline \multicolumn{5}{|c|}{ Supplemental Table S2.txt } \\
\hline CHEMBL1399091 & 688721 & 4.6 & 4.7267 & TRN \\
\hline CHEMBL1559033 & 688721 & 5.2 & 4.9281 & TST \\
\hline CHEMBL1507411 & 688721 & 5.4 & 4.9375 & TRN \\
\hline CHEMBL1449998 & 688721 & 6.1 & 5.0239 & TRN \\
\hline CHEMBL1502395 & 688721 & 4.7 & 4.8912 & TST \\
\hline CHEMBL1347350 & 688721 & 4.4 & 4.8906 & TRN \\
\hline CHEMBL1507418 & 688721 & 4.8 & 4.9891 & TRN \\
\hline CHEMBL1599966 & 688721 & 4.4 & 4.9084 & TRN \\
\hline CHEMBL 1458690 & 688721 & 5.1 & 4.9033 & TRN \\
\hline CHEMBL18238 & 688721 & 5.1 & 5.1761 & TRN \\
\hline CHEMBL1465198 & 688721 & 5.0 & 4.8902 & TRN \\
\hline CHEMBL1569585 & 688721 & 5.4 & 5.2072 & TST \\
\hline CHEMBL1303091 & 688721 & 4.6 & 4.8496 & TRN \\
\hline CHEMBL1318045 & 688721 & 7.8013 & 4.9786 & TRN \\
\hline CHEMBL1522577 & 688721 & 5.4 & 4.9471 & TRN \\
\hline CHEMBL1329718 & 688721 & 7.4001 & 4.9182 & TST \\
\hline CHEMBL1551841 & 688721 & 4.9 & 5.1906 & TRN \\
\hline CHEMBL1448326 & 688721 & 6.9 & 5.0928 & TRN \\
\hline CHEMBL1453980 & 688721 & 4.9 & 5.1949 & TRN \\
\hline CHEMBL1403263 & 688721 & 4.4 & 4.9293 & TRN \\
\hline CHEMBL1548546 & 688721 & 4.4 & 5.0202 & TST \\
\hline CHEMBL1388153 & 688721 & 5.3 & 4.9668 & TRN \\
\hline CHEMBL1562133 & 688721 & 5.4 & 4.9125 & TRN \\
\hline CHEMBL1609951 & 688721 & 4.4 & 4.8493 & TRN \\
\hline CHEMBL1535074 & 688721 & 4.7 & 5.1042 & TRN \\
\hline CHEMBL1420150 & 688721 & 4.9 & 4.9779 & TRN \\
\hline CHEMBL1309851 & 688721 & 4.6 & 4.9207 & TRN \\
\hline CHEMBL 261663 & 688721 & 4.4 & 5.3254 & TST \\
\hline CHEMBL1556888 & 688721 & 4.6 & 4.8903 & TRN \\
\hline CHEMBL1303411 & 688721 & 4.5 & 5.0102 & TRN \\
\hline CHEMBL1373334 & 688721 & 6.2 & 5.0053 & TRN \\
\hline CHEMBL1554745 & 688721 & 5.5 & 4.8787 & TRN \\
\hline CHEMBL1371354 & 688721 & 5.5 & 5.0413 & TRN \\
\hline CHEMBL1574201 & 688721 & 4.9 & 4.8685 & TST \\
\hline CHEMBL1405461 & 688721 & 4.6 & 4.8459 & TRN \\
\hline CHEMBL1440226 & 688721 & 4.4 & 5.0724 & TST \\
\hline CHEMBL1384664 & 688721 & 4.8 & 5.0059 & TRN \\
\hline CHEMBL1433290 & 688721 & 5.1 & 4.7865 & TRN \\
\hline CHEMBL1304205 & 688721 & 5.1 & 5.0311 & TRN \\
\hline CHEMBL1475810 & 688721 & 5.1 & 5.1819 & TRN \\
\hline CHEMBL1344681 & 688721 & 5.1 & 4.8571 & TRN \\
\hline CHEMBL1568937 & 688721 & 4.7 & 4.8119 & TRN \\
\hline CHEMBL1334477 & 688721 & 5.4 & 5.0237 & TRN \\
\hline CHEMBL1470619 & 688721 & 4.8 & 4.9221 & TRN \\
\hline CHEMBL1347816 & 688721 & 4.5 & 4.8949 & TRN \\
\hline CHEMBL1319506 & 688721 & 5.5 & 5.2806 & TRN \\
\hline CHEMBL1318943 & 688721 & 4.6 & 5.1272 & TST \\
\hline CHEMBL1459856 & 688721 & 4.4 & 4.8639 & TRN \\
\hline
\end{tabular}




\begin{tabular}{|c|c|c|c|c|c|}
\hline & & & & & \\
\hline CHEMBL1575688 & 688721 & 4.8 & 4.9384 & TRN & \\
\hline CHEMBL1412261 & 688721 & 4.5 & 5.1635 & TST & \\
\hline CHEMBL1402729 & 688721 & 5.5 & 4.8268 & TRN & \\
\hline CHEMBL1391623 & 688721 & 4.8 & 4.8487 & TRN & \\
\hline CHEMBL1471783 & 688721 & 5.2 & 5.0637 & TRN & \\
\hline CHEMBL1978773 & 688721 & 5.4 & 4.7942 & TRN & \\
\hline CHEMBL1576613 & 688721 & 4.8 & 5.0089 & TRN & \\
\hline CHEMBL1594186 & 688721 & 5.2 & 4.9647 & TRN & \\
\hline CHEMBL1490953 & 688721 & 4.9 & 4.7905 & TRN & \\
\hline CHEMBL1507422 & 688721 & 4.5 & 4.7745 & TRN & \\
\hline CHEMBL1570853 & 688721 & 4.6 & 4.8769 & TRN & \\
\hline CHEMBL1456462 & 688721 & 4.6 & 4.9504 & TRN & \\
\hline CHEMBL1412697 & 688721 & 4.5 & 4.909 & TRN & \\
\hline CHEMBL1459185 & 688721 & 4.4 & 4.84399 & & TST \\
\hline CHEMBL1381147 & 688721 & 5.4 & 4.8356 & TRN & \\
\hline CHEMBL1554194 & 688721 & 5.9 & 4.8826 & TRN & \\
\hline CHEMBL1349169 & 688721 & 4.4 & 4.9822 & TRN & \\
\hline CHEMBL1423205 & 688721 & 4.5 & 5.0287 & TRN & \\
\hline CHEMBL1385623 & 688721 & 4.6 & 4.90300 & 00000000005 & TRN \\
\hline CHEMBL1590197 & 688721 & 4.8 & 4.921 & TRN & \\
\hline CHEMBL1420677 & 688721 & 4.6 & 4.8291 & TRN & \\
\hline CHEMBL1471814 & 688721 & 5.4 & 5.0308 & TST & \\
\hline CHEMBL1460443 & 688721 & 4.6 & 4.8873 & TST & \\
\hline CHEMBL42485 & 688721 & 4.8 & 4.9036 & TST & \\
\hline CHEMBL3194605 & 688721 & 5.7 & 4.9354 & TRN & \\
\hline CHEMBL428814 & 688721 & 6.2 & 4.9526 & TRN & \\
\hline CHEMBL1456994 & 688721 & 4.6 & 5.1051 & TST & \\
\hline CHEMBL1326228 & 688721 & 5.3 & 5.1221 & TST & \\
\hline CHEMBL1493669 & 688721 & 4.6 & 4.8937 & TRN & \\
\hline CHEMBL1331723 & 688721 & 4.6 & 4.8904 & TRN & \\
\hline CHEMBL1348747 & 688721 & 4.7 & 4.8274 & TRN & \\
\hline CHEMBL1423537 & 688721 & 4.8 & 4.7761 & TRN & \\
\hline CHEMBL1534466 & 688721 & 5.2 & 4.9997 & TRN & \\
\hline CHEMBL1381393 & 688721 & 4.4 & 4.8102 & TRN & \\
\hline CHEMBL1511000 & 688721 & 4.5 & 5.0883 & TST & \\
\hline CHEMBL1411260 & 688721 & 5.2 & 4.9421 & TST & \\
\hline CHEMBL1376888 & 688721 & 4.5 & 4.618 & TRN & \\
\hline CHEMBL1536838 & 688721 & 4.5 & 5.0158 & TRN & \\
\hline CHEMBL1392144 & 688721 & 5.2 & 5.0741 & TRN & \\
\hline CHEMBL1495167 & 688721 & 4.7 & 4.8844 & TRN & \\
\hline CHEMBL1368894 & 688721 & 5.2 & 5.2199 & TRN & \\
\hline CHEMBL1607512 & 688721 & 4.4 & 4.9177 & TRN & \\
\hline CHEMBL1463381 & 688721 & 4.6 & 4.9046 & TST & \\
\hline CHEMBL1465612 & 688721 & 4.4 & 5.4003 & TST & \\
\hline CHEMBL1494965 & 688721 & 4.7 & 4.8544 & TRN & \\
\hline CHEMBL1457725 & 688721 & 6.9 & 4.9944 & TRN & \\
\hline CHEMBL1400603 & 688721 & 5.2 & 4.9056 & TRN & \\
\hline CHEMBL1382739 & 688721 & 5.2 & 4.9197 & TRN & \\
\hline
\end{tabular}




\begin{tabular}{|c|c|c|c|c|c|}
\hline CHEMBL1354353 & 688721 & 5.6 & 5.2932 & TRN & \\
\hline CHEMBL1379798 & 688721 & 4.7 & 4.85 & TRN & \\
\hline CHEMBL1584048 & 688721 & 5.1 & 4.8808 & TRN & \\
\hline CHEMBL1549683 & 688721 & 4.9 & 4.8007 & TRN & \\
\hline CHEMBL1371501 & 688721 & 4.5 & 4.9158 & TRN & \\
\hline CHEMBL1305086 & 688721 & 5.5 & 4.8815 & TRN & \\
\hline CHEMBL1607364 & 688721 & 4.6 & 4.8376 & TRN & \\
\hline CHEMBL1516381 & 688721 & 5.3 & 4.7836 & TRN & \\
\hline CHEMBL1338177 & 688721 & 5.4 & 4.9815 & TST & \\
\hline CHEMBL1514923 & 688721 & 5.0 & 5.1754 & TRN & \\
\hline CHEMBL503254 & 688721 & 5.4 & 5.1673 & TST & \\
\hline CHEMBL1507610 & 688721 & 4.5 & 4.9226 & TRN & \\
\hline CHEMBL1401452 & 688721 & 5.4 & 5.043 & TRN & \\
\hline CHEMBL1484841 & 688721 & 5.5 & 4.9822 & TRN & \\
\hline CHEMBL1581280 & 688721 & 5.1 & 4.7863 & TRN & \\
\hline CHEMBL 2374058 & 688721 & 5.9 & 5.2312 & TST & \\
\hline CHEMBL1594460 & 688721 & 6.1 & 4.88399 & 99999999995 & TRN \\
\hline CHEMBL1317275 & 688721 & 4.8 & 4.8311 & TRN & \\
\hline CHEMBL1586332 & 688721 & 4.4 & 4.7543 & TRN & \\
\hline CHEMBL1338917 & 688721 & 4.7 & 4.8863 & TRN & \\
\hline CHEMBL3195734 & 688721 & 6.2 & 5.0899 & TRN & \\
\hline CHEMBL1526767 & 688721 & 4.7 & 4.8526 & TST & \\
\hline CHEMBL1418463 & 688721 & 4.5 & 4.7603 & TST & \\
\hline CHEMBL1381484 & 688721 & 5.3 & 4.9002 & TRN & \\
\hline CHEMBL1309092 & 688721 & 4.7 & 5.0404 & TRN & \\
\hline CHEMBL1300270 & 688721 & 4.8 & 4.8423 & TRN & \\
\hline CHEMBL1385618 & 688721 & 4.4 & 4.9093 & TST & \\
\hline CHEMBL1446659 & 688721 & 5.1 & 4.996 & TRN & \\
\hline CHEMBL1512817 & 688721 & 6.0 & 5.0483 & TRN & \\
\hline CHEMBL1303125 & 688721 & 5.0 & 4.8479 & TRN & \\
\hline CHEMBL1394113 & 688721 & 6.1 & 4.8865 & TRN & \\
\hline CHEMBL1438974 & 688721 & 5.0 & 5.0403 & TRN & \\
\hline CHEMBL1368887 & 688721 & 6.0 & 4.953 & TRN & \\
\hline CHEMBL1577514 & 688721 & 5.4 & 4.9227 & TRN & \\
\hline CHEMBL3348970 & 688721 & 4.7 & 5.1414 & TRN & \\
\hline CHEMBL1361758 & 688721 & 4.8 & 5.0476 & TRN & \\
\hline CHEMBL1385086 & 688721 & 5.8 & 5.0707 & TRN & \\
\hline CHEMBL1367465 & 688721 & 4.4 & 5.0585 & TRN & \\
\hline CHEMBL1457192 & 688721 & 4.9 & 4.8695 & TRN & \\
\hline CHEMBL1353601 & 688721 & 4.8 & 4.9698 & TST & \\
\hline CHEMBL1373209 & 688721 & 4.5 & 4.9414 & TST & \\
\hline CHEMBL1538780 & 688721 & 5.2 & 4.8747 & TRN & \\
\hline CHEMBL1490721 & 688721 & 5.5 & 5.2114 & TRN & \\
\hline CHEMBL1602901 & 688721 & 4.6 & 4.8572 & TRN & \\
\hline CHEMBL1354388 & 688721 & 5.5 & 5.0836 & TRN & \\
\hline CHEMBL1378746 & 688721 & 4.6 & 4.8418 & TRN & \\
\hline CHEMBL1365324 & 688721 & 4.7 & 4.8449 & TST & \\
\hline CHEMBL1559212 & 688721 & 4.8 & 4.9013 & TRN & \\
\hline
\end{tabular}




\begin{tabular}{|c|c|c|c|c|c|}
\hline \multicolumn{6}{|c|}{ Supplemental Table S2.txt } \\
\hline CHEMBL1548952 & 688721 & 5.0 & 4.792 & TRN & \\
\hline CHEMBL1319718 & 688721 & 5.1 & 4.9228 & TRN & \\
\hline CHEMBL1610034 & 688721 & 4.5 & 4.9559 & TRN & \\
\hline CHEMBL1468103 & 688721 & 4.8 & 4.9271 & TRN & \\
\hline CHEMBL1414544 & 688721 & 4.6 & 4.899 & TRN & \\
\hline CHEMBL1446769 & 688721 & 4.8 & 4.9367 & TRN & \\
\hline CHEMBL1589687 & 688721 & 4.4 & 4.8287 & TRN & \\
\hline CHEMBL1612155 & 688721 & 4.8 & 5.0128 & TRN & \\
\hline CHEMBL1353834 & 688721 & 6.4 & 4.8226 & TST & \\
\hline CHEMBL273386 & 688721 & 5.1 & 5.2175 & TRN & \\
\hline CHEMBL1385331 & 688721 & 5.2 & 4.9488 & TRN & \\
\hline CHEMBL1457207 & 688721 & 4.6 & 4.8765 & TRN & \\
\hline CHEMBL1409287 & 688721 & 5.2 & 4.9184 & TRN & \\
\hline CHEMBL1459853 & 688721 & 4.6 & 4.7652 & TRN & \\
\hline CHEMBL467423 & 688721 & 6.5 & 5.0775 & TRN & \\
\hline CHEMBL1435381 & 688721 & 4.4 & 5.32600 & 00000000005 & TST \\
\hline CHEMBL1305681 & 688721 & 6.0 & 4.9657 & TST & \\
\hline CHEMBL1557584 & 688721 & 5.7 & 4.7158 & TRN & \\
\hline CHEMBL1419149 & 688721 & 4.4 & 4.7757 & TST & \\
\hline CHEMBL1609786 & 688721 & 4.5 & 4.8415 & TRN & \\
\hline CHEMBL1329994 & 688721 & 4.6 & 4.773 & TST & \\
\hline CHEMBL1606519 & 688721 & 4.5 & 4.7383 & TRN & \\
\hline CHEMBL1393149 & 688721 & 5.3 & 4.8964 & TRN & \\
\hline CHEMBL1582044 & 688721 & 4.6 & 4.9516 & TRN & \\
\hline CHEMBL1421763 & 688721 & 4.7 & 4.8871 & TRN & \\
\hline CHEMBL1365692 & 688721 & 5.3 & 5.0494 & TRN & \\
\hline CHEMBL1505672 & 688721 & 4.6 & 4.8536 & TRN & \\
\hline CHEMBL1336188 & 688721 & 4.6 & 4.8823 & TRN & \\
\hline CHEMBL1459221 & 688721 & 5.1 & 5.0276 & TRN & \\
\hline CHEMBL1384700 & 688721 & 4.8 & 5.0246 & TST & \\
\hline CHEMBL1463799 & 688721 & 4.6 & 4.9463 & TRN & \\
\hline CHEMBL1608647 & 688721 & 4.8 & 4.971 & TRN & \\
\hline CHEMBL1491746 & 688721 & 4.5 & 4.9698 & TRN & \\
\hline CHEMBL1585386 & 688721 & 5.8 & 4.9288 & TRN & \\
\hline CHEMBL1488218 & 688721 & 4.5 & 4.9357 & TRN & \\
\hline CHEMBL1342671 & 688721 & 4.4 & 5.084 & TST & \\
\hline CHEMBL1420119 & 688721 & 5.1 & 4.9147 & TST & \\
\hline CHEMBL1606662 & 688721 & 4.4 & 4.756 & TRN & \\
\hline CHEMBL1351455 & 688721 & 4.7 & 5.0287 & TRN & \\
\hline CHEMBL1489826 & 688721 & 5.3 & 4.9154 & TRN & \\
\hline CHEMBL1515324 & 688721 & 6.8 & 5.0421 & TRN & \\
\hline CHEMBL1348876 & 688721 & 4.5 & 4.6972 & TRN & \\
\hline CHEMBL1581187 & 688721 & 4.8 & 4.9503 & TST & \\
\hline CHEMBL1367979 & 688721 & 4.6 & 4.8494 & TRN & \\
\hline CHEMBL1607318 & 688721 & 4.8 & 4.828 & TRN & \\
\hline CHEMBL1329728 & 688721 & 4.5 & 4.8683 & TRN & \\
\hline CHEMBL1537868 & 688721 & 4.8 & 4.7553 & TRN & \\
\hline CHEMBL1438512 & 688721 & 4.5 & 4.6936 & TRN & \\
\hline
\end{tabular}




\begin{tabular}{|c|c|c|c|c|}
\hline \multicolumn{5}{|c|}{ Iemental I } \\
\hline CHEMBL1365057 & 688721 & 5.4 & 4.8293 & TRN \\
\hline CHEMBL1470122 & 688721 & 4.7 & 4.89199 & 99999999995 \\
\hline CHEMBL1412409 & 688721 & 5.4 & 4.8461 & TST \\
\hline CHEMBL1236602 & 688721 & 5.6 & 5.2111 & TST \\
\hline CHEMBL1332868 & 688721 & 4.5 & 4.9779 & TRN \\
\hline CHEMBL1430263 & 688721 & 6.0 & 4.8624 & TRN \\
\hline CHEMBL1387764 & 688721 & 4.4 & 4.9806 & TRN \\
\hline CHEMBL1478888 & 688721 & 5.0 & 4.7076 & TRN \\
\hline CHEMBL1540576 & 688721 & 4.4 & 4.8357 & TST \\
\hline CHEMBL1571308 & 688721 & 4.4 & 4.9014 & TRN \\
\hline CHEMBL1452728 & 688721 & 5.3 & 4.7598 & TST \\
\hline CHEMBL1572642 & 688721 & 4.5 & 4.8589 & TRN \\
\hline CHEMBL1332471 & 688721 & 5.5 & 5.182 & TRN \\
\hline CHEMBL1608457 & 688721 & 6.6 & 5.0225 & TRN \\
\hline CHEMBL1467611 & 688721 & 4.7 & 4.9963 & TRN \\
\hline CHEMBL1537424 & 688721 & 4.7 & 4.8811 & TST \\
\hline CHEMBL1456417 & 688721 & 4.7 & 5.0098 & TST \\
\hline CHEMBL1610464 & 688721 & 4.5 & 4.6571 & TRN \\
\hline CHEMBL1389694 & 688721 & 4.6 & 4.9887 & TRN \\
\hline CHEMBL1533869 & 688721 & 4.6 & 4.8342 & TRN \\
\hline CHEMBL1428659 & 688721 & 4.5 & 4.8278 & TRN \\
\hline CHEMBL1559946 & 688721 & 4.4 & 4.9534 & TRN \\
\hline CHEMBL1408420 & 688721 & 4.4 & 5.0134 & TST \\
\hline CHEMBL3210299 & 688721 & 5.2 & 5.1854 & TRN \\
\hline CHEMBL1545915 & 688721 & 4.6 & 4.8254 & TRN \\
\hline CHEMBL1416907 & 688721 & 4.4 & 4.9115 & TRN \\
\hline CHEMBL1342417 & 688721 & 4.6 & 4.9917 & TRN \\
\hline CHEMBL1508370 & 688721 & 4.4 & 4.9264 & TRN \\
\hline CHEMBL1359472 & 688721 & 5.2 & 5.2727 & TRN \\
\hline CHEMBL1535127 & 688721 & 4.6 & 5.0662 & TRN \\
\hline CHEMBL1417381 & 688721 & 4.5 & 4.8028 & TRN \\
\hline CHEMBL1472926 & 688721 & 4.6 & 4.971 & TRN \\
\hline CHEMBL1350944 & 688721 & 4.4 & 4.9581 & TRN \\
\hline CHEMBL1479425 & 688721 & 4.6 & 5.1117 & TRN \\
\hline CHEMBL1345361 & 688721 & 4.4 & 5.1308 & TST \\
\hline CHEMBL1389290 & 688721 & 6.0 & 4.8877 & TST \\
\hline CHEMBL1544930 & 688721 & 4.7 & 4.9984 & TRN \\
\hline CHEMBL1573220 & 688721 & 4.6 & 5.0405 & TRN \\
\hline CHEMBL1545971 & 688721 & 4.4 & 4.8196 & TRN \\
\hline CHEMBL77030 & 688721 & 5.1 & 5.2368 & TRN \\
\hline CHEMBL1407563 & 688721 & 5.2 & 4.8944 & TRN \\
\hline CHEMBL1425376 & 688721 & 4.4 & 4.9355 & TRN \\
\hline CHEMBL1376444 & 688721 & 5.4 & 4.773 & TRN \\
\hline CHEMBL492610 & 688721 & 4.5 & 5.047 & TRN \\
\hline CHEMBL1488071 & 688721 & 4.8 & 4.768 & TRN \\
\hline CHEMBL1440265 & 688721 & 5.4 & 5.0218 & TRN \\
\hline CHEMBL567531 & 688721 & 4.5 & 4.8053 & TRN \\
\hline CHEMBL1421873 & 688721 & 7.5003 & 5.175 & TRN \\
\hline
\end{tabular}

TRN 


\begin{tabular}{|c|c|c|c|c|c|}
\hline \multicolumn{6}{|c|}{ Supplemental Table S2.txt } \\
\hline CHEMBL1352374 & 688721 & 5.2 & 5.044 & TST & \\
\hline CHEMBL1306273 & 688721 & 6.1 & 4.9565 & TRN & \\
\hline CHEMBL1379766 & 688721 & 4.7 & 4.9499 & TRN & \\
\hline CHEMBL1346321 & 688721 & 4.8 & 4.8075 & TRN & \\
\hline CHEMBL1382980 & 688721 & 4.5 & 5.0453 & TRN & \\
\hline CHEMBL1572921 & 688721 & 4.4 & 4.8832 & TST & \\
\hline CHEMBL1415580 & 688721 & 4.6 & 4.7604 & TRN & \\
\hline CHEMBL1559578 & 688721 & 5.6 & 5.2642 & TRN & \\
\hline CHEMBL1370842 & 688721 & 4.4 & 5.0065 & TRN & \\
\hline CHEMBL3391990 & 688721 & 6.0 & 5.2886 & TST & \\
\hline CHEMBL1307406 & 688721 & 5.3 & 5.1206 & TRN & \\
\hline CHEMBL1430586 & 688721 & 4.4 & 5.1364 & TRN & \\
\hline CHEMBL1460400 & 688721 & 5.2 & 5.0368 & TRN & \\
\hline CHEMBL1329219 & 688721 & 5.0 & 5.04 & TRN & \\
\hline CHEMBL1537448 & 688721 & 5.2 & 4.9909 & TRN & \\
\hline CHEMBL1331229 & 688721 & 4.6 & 4.8221 & TRN & \\
\hline CHEMBL1317885 & 688721 & 4.7 & 5.1707 & TRN & \\
\hline CHEMBL143324 & 688721 & 7.6003 & 5.28700 & 0000000001 & TRN \\
\hline CHEMBL1505786 & 688721 & 6.1 & 4.9445 & TST & \\
\hline CHEMBL1492630 & 688721 & 4.5 & 5.0571 & TRN & \\
\hline CHEMBL1312118 & 688721 & 5.4 & 4.9828 & TST & \\
\hline CHEMBL1400435 & 688721 & 6.2 & 4.9531 & TRN & \\
\hline CHEMBL1351643 & 688721 & 4.4 & 5.0231 & TRN & \\
\hline CHEMBL1256866 & 688721 & 4.5 & 4.9284 & TRN & \\
\hline CHEMBL1375483 & 688721 & 4.6 & 4.7681 & TRN & \\
\hline CHEMBL1340715 & 688721 & 4.8 & 4.9571 & TRN & \\
\hline CHEMBL1452948 & 688721 & 4.8 & 4.8278 & TRN & \\
\hline CHEMBL1304045 & 688721 & 4.8 & 5.1028 & TRN & \\
\hline CHEMBL1563455 & 688721 & 4.6 & 4.744 & TRN & \\
\hline CHEMBL1578557 & 688721 & 4.6 & 4.9595 & TRN & \\
\hline CHEMBL1306108 & 688721 & 4.4 & 4.8195 & TRN & \\
\hline CHEMBL1395137 & 688721 & 4.4 & 5.2345 & TRN & \\
\hline CHEMBL1365166 & 688721 & 4.5 & 5.0373 & TRN & \\
\hline CHEMBL1483607 & 688721 & 4.4 & 4.8701 & TRN & \\
\hline CHEMBL39 & 688721 & 4.5 & 5.2088 & TRN & \\
\hline CHEMBL1309088 & 688721 & 4.8 & 4.711 & TRN & \\
\hline CHEMBL1399016 & 688721 & 4.6 & 4.9266 & TRN & \\
\hline CHEMBL1536421 & 688721 & 4.8 & 4.8392 & TST & \\
\hline CHEMBL1460030 & 688721 & 4.4 & 4.9087 & TRN & \\
\hline CHEMBL1330656 & 688721 & 4.7 & 4.977 & TST & \\
\hline CHEMBL1428511 & 688721 & 5.2 & 4.9751 & TRN & \\
\hline CHEMBL1351580 & 688721 & 4.6 & 4.6711 & TRN & \\
\hline CHEMBL1409436 & 688721 & 5.1 & 4.9941 & TST & \\
\hline CHEMBL1539848 & 688721 & 4.4 & 4.8189 & TRN & \\
\hline CHEMBL1450334 & 688721 & 4.8 & 4.9824 & TST & \\
\hline CHEMBL1379271 & 688721 & 5.3 & 4.9293 & TRN & \\
\hline CHEMBL1524127 & 688721 & 5.3 & 4.8935 & TRN & \\
\hline CHEMBL1462450 & 688721 & 4.8 & 4.8595 & TRN & \\
\hline
\end{tabular}




\begin{tabular}{|c|c|c|c|c|}
\hline & & & ient & al Ta \\
\hline CHEMBL1558886 & 688721 & 4.4 & 4.6958 & TRN \\
\hline CHEMBL1455993 & 688721 & 4.9 & 4.978 & TRN \\
\hline CHEMBL1415728 & 688721 & 4.9 & 5.0645 & TRN \\
\hline CHEMBL1532645 & 688721 & 4.6 & 4.9418 & TRN \\
\hline CHEMBL1593966 & 688721 & 4.4 & 5.1154 & TRN \\
\hline CHEMBL1381887 & 688721 & 4.6 & 4.8251 & TRN \\
\hline CHEMBL1516488 & 688721 & 4.8 & 4.8216 & TRN \\
\hline CHEMBL1538697 & 688721 & 5.2 & 4.7836 & TRN \\
\hline CHEMBL1577347 & 688721 & 5.7 & 4.8899 & TRN \\
\hline CHEMBL1256661 & 688721 & 4.5 & 4.795 & TST \\
\hline CHEMBL1428944 & 688721 & 4.6 & 4.9724 & TRN \\
\hline CHEMBL1587587 & 688721 & 5.0 & 4.9139 & TRN \\
\hline CHEMBL1328866 & 688721 & 4.4 & 4.8631 & TRN \\
\hline CHEMBL1359463 & 688721 & 4.5 & 4.9176 & TRN \\
\hline CHEMBL1377174 & 688721 & 5.2 & 4.9303 & TRN \\
\hline CHEMBL1525668 & 688721 & 5.1 & 4.8504 & TRN \\
\hline CHEMBL1584415 & 688721 & 4.5 & 4.8496 & TRN \\
\hline CHEMBL1370286 & 688721 & 4.7 & 4.9584 & TRN \\
\hline CHEMBL1395430 & 688721 & 5.0 & 5.2052 & TRN \\
\hline CHEMBL1485541 & 688721 & 4.6 & 4.909 & TRN \\
\hline CHEMBL1575147 & 688721 & 5.0 & 4.8054 & TRN \\
\hline CHEMBL1539941 & 688721 & 4.6 & 4.689 & TRN \\
\hline CHEMBL1404398 & 688721 & 4.4 & 4.9812 & TRN \\
\hline CHEMBL1556368 & 688721 & 4.6 & 5.0096 & TRN \\
\hline CHEMBL1471435 & 688721 & 5.4 & 4.9141 & TRN \\
\hline CHEMBL1597988 & 688721 & 4.4 & 4.9744 & TST \\
\hline CHEMBL1595205 & 688721 & 4.9 & 5.0099 & TRN \\
\hline CHEMBL1541527 & 688721 & 4.4 & 4.8231 & TRN \\
\hline CHEMBL1449386 & 688721 & 4.5 & 4.9574 & TRN \\
\hline CHEMBL1443697 & 688721 & 4.6 & 5.0444 & TRN \\
\hline CHEMBL1409889 & 688721 & 4.5 & 4.8444 & TRN \\
\hline CHEMBL1544235 & 688721 & 4.6 & 4.9199 & TRN \\
\hline CHEMBL1312692 & 688721 & 4.8 & 4.8771 & TRN \\
\hline CHEMBL1469094 & 688721 & 4.5 & 4.9564 & TRN \\
\hline CHEMBL1608733 & 688721 & 4.9 & 4.7949 & TST \\
\hline CHEMBL1368437 & 688721 & 5.2 & 4.8653 & TRN \\
\hline CHEMBL1458511 & 688721 & 4.4 & 4.9877 & TRN \\
\hline CHEMBL1448423 & 688721 & 4.4 & 4.891 & TRN \\
\hline CHEMBL1479620 & 688721 & 4.9 & 4.8241 & TRN \\
\hline CHEMBL1528970 & 688721 & 5.2 & 5.2235 & TRN \\
\hline CHEMBL1522904 & 688721 & 4.4 & 5.1427 & TRN \\
\hline CHEMBL509531 & 688721 & 6.3 & 5.442 & TST \\
\hline CHEMBL1457845 & 688721 & 6.0 & 4.9495 & TRN \\
\hline CHEMBL1504306 & 688721 & 4.4 & 4.8738 & TST \\
\hline CHEMBL1421710 & 688721 & 4.6 & 5.1885 & TST \\
\hline CHEMBL1532615 & 688721 & 6.9 & 5.2645 & TRN \\
\hline CHEMBL1563833 & 688721 & 5.4 & 4.8745 & TRN \\
\hline CHEMBL1388436 & 688721 & 5.5 & 5.0191 & TRN \\
\hline
\end{tabular}




\begin{tabular}{|c|c|c|c|c|}
\hline & & & 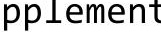 & \\
\hline CHEMBL3198180 & 688721 & 5.8 & 4.9107 & TRN \\
\hline CHEMBL334255 & 688721 & 5.2 & 5.2709 & TST \\
\hline CHEMBL1461973 & 688721 & 5.0 & 4.8701 & TRN \\
\hline CHEMBL1365075 & 688721 & 5.3 & 4.9505 & TRN \\
\hline CHEMBL1579943 & 688721 & 4.5 & 4.9987 & TRN \\
\hline CHEMBL3214200 & 688721 & 5.1 & 4.9356 & TST \\
\hline CHEMBL1590919 & 688721 & 4.9 & 5.1271 & TRN \\
\hline CHEMBL1346620 & 688721 & 5.4 & 5.0373 & TST \\
\hline CHEMBL1356138 & 688721 & 4.8 & 5.0217 & TRN \\
\hline CHEMBL1567201 & 688721 & 4.4 & 5.0244 & TRN \\
\hline CHEMBL1402455 & 688721 & 4.6 & 5.1132 & TRN \\
\hline CHEMBL1310535 & 688721 & 4.5 & 5.0079 & TRN \\
\hline CHEMBL1541906 & 688721 & 4.6 & 4.9454 & TRN \\
\hline CHEMBL1483438 & 688721 & 5.3 & 5.359 & TRN \\
\hline CHEMBL 3194764 & 688721 & 4.6 & 5.0023 & TRN \\
\hline CHEMBL1557407 & 688721 & 4.5 & 4.8691 & TRN \\
\hline CHEMBL1518144 & 688721 & 4.4 & 4.6779 & TRN \\
\hline CHEMBL1507944 & 688721 & 5.5 & 4.8192 & TRN \\
\hline CHEMBL398673 & 688721 & 5.4 & 5.0823 & TST \\
\hline CHEMBL1393347 & 688721 & 4.4 & 4.801 & TRN \\
\hline CHEMBL1505342 & 688721 & 4.7 & 4.8589 & TRN \\
\hline CHEMBL1491841 & 688721 & 5.8 & 5.0839 & TST \\
\hline CHEMBL1563840 & 688721 & 6.0 & 5.2025 & TRN \\
\hline CHEMBL1569816 & 688721 & 4.6 & 4.8227 & TRN \\
\hline CHEMBL1498484 & 688721 & 5.9 & 4.8962 & TRN \\
\hline CHEMBL1393325 & 688721 & 5.3 & 5.067 & TRN \\
\hline CHEMBL1357293 & 688721 & 4.4 & 4.8728 & TRN \\
\hline CHEMBL1502967 & 688721 & 4.4 & 4.97 & TRN \\
\hline CHEMBL1426807 & 688721 & 5.4 & 4.9628 & TRN \\
\hline CHEMBL1472293 & 688721 & 4.4 & 4.7433 & TRN \\
\hline CHEMBL1556632 & 688721 & 5.0 & 5.0971 & TRN \\
\hline CHEMBL1307312 & 688721 & 4.8 & 4.9019 & TST \\
\hline CHEMBL1487809 & 688721 & 4.4 & 4.9425 & TRN \\
\hline CHEMBL1510257 & 688721 & 4.5 & 4.8243 & TRN \\
\hline CHEMBL1462714 & 688721 & 5.8 & 4.9222 & TRN \\
\hline CHEMBL1255578 & 688721 & 4.4 & 5.3053 & TST \\
\hline CHEMBL1605550 & 688721 & 5.4 & 4.9547 & TRN \\
\hline CHEMBL1561335 & 688721 & 4.6 & 4.8654 & TRN \\
\hline CHEMBL1515310 & 688721 & 4.7 & 5.3443 & TST \\
\hline CHEMBL1370720 & 688721 & 4.5 & 5.0398 & TST \\
\hline CHEMBL259805 & 688721 & 4.8 & 4.744 & TRN \\
\hline CHEMBL1609248 & 688721 & 4.7 & 4.936 & TRN \\
\hline CHEMBL1543601 & 688721 & 6.5 & 4.9717 & TRN \\
\hline CHEMBL1521714 & 688721 & 5.2 & 5.2466 & TST \\
\hline CHEMBL1393329 & 688721 & 4.5 & 4.7611 & TRN \\
\hline CHEMBL1500043 & 688721 & 4.6 & 5.0402 & TST \\
\hline CHEMBL1326618 & 688721 & 5.0 & 4.9716 & TRN \\
\hline CHEMBL1256646 & 688721 & 4.5 & 5.1507 & TST \\
\hline
\end{tabular}




\begin{tabular}{|c|c|c|c|c|}
\hline & & & 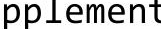 & al Ta \\
\hline CHEMBL1328097 & 688721 & 5.2 & 5.0133 & TRN \\
\hline CHEMBL408653 & 688721 & 4.5 & 4.8812 & TRN \\
\hline CHEMBL1575456 & 688721 & 5.1 & 4.9342 & TRN \\
\hline CHEMBL1423242 & 688721 & 4.6 & 4.8668 & TRN \\
\hline CHEMBL159096 & 688721 & 4.7 & 4.8148 & TST \\
\hline CHEMBL1369020 & 688721 & 5.2 & 4.9657 & TRN \\
\hline CHEMBL1379324 & 688721 & 4.8 & 5.0947 & TST \\
\hline CHEMBL1306395 & 688721 & 4.9 & 4.8849 & TRN \\
\hline CHEMBL1532193 & 688721 & 5.8 & 4.9283 & TST \\
\hline CHEMBL 27403 & 688721 & 4.5 & 5.0338 & TST \\
\hline CHEMBL1576658 & 688721 & 4.5 & 5.0954 & TST \\
\hline CHEMBL1311617 & 688721 & 4.8 & 5.0201 & TRN \\
\hline CHEMBL1413413 & 688721 & 4.5 & 4.9761 & TRN \\
\hline CHEMBL1395054 & 688721 & 5.2 & 5.1525 & TRN \\
\hline CHEMBL1497672 & 688721 & 5.1 & 4.8969 & TRN \\
\hline CHEMBL1337095 & 688721 & 5.5 & 5.078 & TRN \\
\hline CHEMBL1610403 & 688721 & 4.4 & 4.8058 & TRN \\
\hline CHEMBL1422166 & 688721 & 6.8 & 4.8304 & TRN \\
\hline CHEMBL3212505 & 688721 & 6.2 & 4.9201 & TST \\
\hline CHEMBL1408603 & 688721 & 5.2 & 5.0822 & TST \\
\hline CHEMBL1584919 & 688721 & 4.4 & 4.997 & TRN \\
\hline CHEMBL 3211877 & 688721 & 5.4 & 4.9213 & TRN \\
\hline CHEMBL1511747 & 688721 & 5.1 & 4.9244 & TRN \\
\hline CHEMBL1450716 & 688721 & 4.4 & 5.0033 & TRN \\
\hline CHEMBL1510376 & 688721 & 5.2 & 4.9639 & TRN \\
\hline CHEMBL1564965 & 688721 & 4.6 & 4.9653 & TST \\
\hline CHEMBL1472170 & 688721 & 4.7 & 4.9816 & TRN \\
\hline CHEMBL1395417 & 688721 & 4.5 & 4.8065 & TRN \\
\hline CHEMBL1342633 & 688721 & 5.4 & 5.0046 & TRN \\
\hline CHEMBL1494934 & 688721 & 4.6 & 4.9935 & TRN \\
\hline CHEMBL1606325 & 688721 & 4.7 & 4.7907 & TRN \\
\hline CHEMBL1417471 & 688721 & 4.4 & 5.0203 & TRN \\
\hline CHEMBL320361 & 688721 & 4.4 & 5.1271 & TRN \\
\hline CHEMBL1580694 & 688721 & 4.7 & 4.9386 & TRN \\
\hline CHEMBL1496514 & 688721 & 6.0 & 5.103 & TST \\
\hline CHEMBL1356346 & 688721 & 4.5 & 4.9016 & TST \\
\hline CHEMBL1386248 & 688721 & 4.6 & 4.8983 & TST \\
\hline CHEMBL1351054 & 688721 & 4.9 & 4.9248 & TRN \\
\hline CHEMBL1518244 & 688721 & 4.6 & 5.041 & TRN \\
\hline CHEMBL1319229 & 688721 & 4.6 & 4.8722 & TRN \\
\hline CHEMBL1595282 & 688721 & 5.4 & 5.1691 & TRN \\
\hline CHEMBL1511675 & 688721 & 4.6 & 4.9353 & TST \\
\hline CHEMBL1323436 & 688721 & 5.1 & 4.9085 & TRN \\
\hline CHEMBL1448347 & 688721 & 4.9 & 4.9022 & TST \\
\hline CHEMBL1339485 & 688721 & 4.4 & 4.8855 & TRN \\
\hline CHEMBL85728 & 688721 & 4.4 & 5.1842 & TST \\
\hline CHEMBL1411940 & 688721 & 4.4 & 4.9645 & TST \\
\hline CHEMBL1583655 & 688721 & 5.2 & 4.8202 & TRN \\
\hline
\end{tabular}




\begin{tabular}{|c|c|c|c|c|}
\hline & & & & \\
\hline CHEMBL1409939 & 688721 & 4.4 & 5.0934 & TST \\
\hline CHEMBL1447701 & 688721 & 4.9 & 5.1197 & TRN \\
\hline CHEMBL1333019 & 688721 & 6.9 & 4.9398 & TST \\
\hline CHEMBL1327354 & 688721 & 5.8 & 4.8423 & TST \\
\hline CHEMBL1480574 & 688721 & 5.4 & 5.1304 & TRN \\
\hline CHEMBL1376416 & 688721 & 4.8 & 4.883 & TRN \\
\hline CHEMBL1571693 & 688721 & 4.6 & 4.7564 & TRN \\
\hline CHEMBL1489529 & 688721 & 6.8 & 5.0451 & TRN \\
\hline CHEMBL1533594 & 688721 & 5.2 & 4.8925 & TRN \\
\hline CHEMBL1401720 & 688721 & 4.8 & 4.8312 & TRN \\
\hline CHEMBL1420491 & 688721 & 5.6 & 4.8763 & TRN \\
\hline CHEMBL1497485 & 688721 & 4.4 & 4.8597 & TRN \\
\hline CHEMBL1453168 & 688721 & 5.3 & 4.8797 & TST \\
\hline CHEMBL1492205 & 688721 & 4.5 & 5.1021 & TRN \\
\hline CHEMBL1361095 & 688721 & 4.8 & 5.0702 & TST \\
\hline CHEMBL1388190 & 688721 & 4.6 & 4.8592 & TRN \\
\hline CHEMBL1500190 & 688721 & 4.9 & 4.8121 & TRN \\
\hline CHEMBL1584770 & 688721 & 4.6 & 4.763 & TRN \\
\hline CHEMBL1321322 & 688721 & 4.4 & 4.8765 & TRN \\
\hline CHEMBL1603879 & 688721 & 5.4 & 4.8738 & TRN \\
\hline CHEMBL1559024 & 688721 & 4.5 & 4.8312 & TRN \\
\hline CHEMBL1530269 & 688721 & 4.8 & 4.9486 & TST \\
\hline CHEMBL1478458 & 688721 & 4.4 & 4.9685 & TRN \\
\hline CHEMBL1534925 & 688721 & 4.8 & 5.0442 & TST \\
\hline CHEMBL1535468 & 688721 & 4.5 & 4.958 & TRN \\
\hline CHEMBL1368940 & 688721 & 4.6 & 4.7304 & TRN \\
\hline CHEMBL1567255 & 688721 & 5.2 & 4.965 & TRN \\
\hline CHEMBL1333487 & 688721 & 5.2 & 5.0227 & TST \\
\hline CHEMBL1370036 & 688721 & 4.6 & 4.9015 & TRN \\
\hline CHEMBL1539824 & 688721 & 4.6 & 4.6664 & TRN \\
\hline CHEMBL1386323 & 688721 & 4.8 & 4.8906 & TRN \\
\hline CHEMBL1348399 & 688721 & 4.8 & 4.7628 & TRN \\
\hline CHEMBL1601228 & 688721 & 4.5 & 5.1226 & TRN \\
\hline CHEMBL1496747 & 688721 & 4.8 & 4.8722 & TRN \\
\hline CHEMBL1473755 & 688721 & 4.7 & 5.0366 & TST \\
\hline CHEMBL1306761 & 688721 & 4.9 & 5.0442 & TRN \\
\hline CHEMBL1469331 & 688721 & 4.6 & 4.8464 & TRN \\
\hline CHEMBL283196 & 688721 & 4.5 & 4.8471 & TST \\
\hline CHEMBL1415575 & 688721 & 4.5 & 5.0781 & TST \\
\hline CHEMBL483137 & 688721 & 4.6 & 4.8868 & TRN \\
\hline CHEMBL1417368 & 688721 & 4.6 & 4.8721 & TRN \\
\hline CHEMBL1569970 & 688721 & 4.4 & 4.7792 & TRN \\
\hline CHEMBL1496215 & 688721 & 4.6 & 5.0271 & TRN \\
\hline CHEMBL1517147 & 688721 & 4.5 & 4.7679 & TRN \\
\hline CHEMBL1449005 & 688721 & 5.1 & 5.0146 & TRN \\
\hline CHEMBL1327910 & 688721 & 6.4 & 4.9062 & TST \\
\hline CHEMBL1466977 & 688721 & 4.6 & 4.9504 & TRN \\
\hline CHEMBL1406630 & 688721 & 5.2 & 4.7382 & TRN \\
\hline
\end{tabular}




\begin{tabular}{|c|c|c|c|c|}
\hline \multicolumn{5}{|c|}{ Supplemental Table S2.txt } \\
\hline CHEMBL1467944 & 688721 & 6.1 & 5.024 & TRN \\
\hline CHEMBL1305957 & 688721 & 6.2 & 5.1546 & TRN \\
\hline CHEMBL1498785 & 688721 & 4.4 & 4.9128 & TRN \\
\hline CHEMBL1503781 & 688721 & 6.1 & 4.9069 & TRN \\
\hline CHEMBL1526803 & 688721 & 4.9 & 4.8708 & TRN \\
\hline CHEMBL 225257 & 688721 & 7.4001 & 5.0277 & TST \\
\hline CHEMBL3191455 & 688721 & 4.6 & 4.9135 & TRN \\
\hline CHEMBL1311969 & 688721 & 4.4 & 4.6863 & TRN \\
\hline CHEMBL1597687 & 688721 & 4.6 & 4.7984 & TRN \\
\hline CHEMBL1362477 & 688721 & 5.2 & 5.1197 & TST \\
\hline CHEMBL1439534 & 688721 & 4.5 & 5.0175 & TRN \\
\hline CHEMBL1364348 & 688721 & 4.6 & 4.894 & TRN \\
\hline CHEMBL1323534 & 688721 & 5.4 & 4.9341 & TST \\
\hline CHEMBL1589103 & 688721 & 5.1 & 4.8656 & TRN \\
\hline CHEMBL1400538 & 688721 & 4.9 & 4.9466 & TRN \\
\hline CHEMBL1452066 & 688721 & 4.7 & 4.9676 & TRN \\
\hline CHEMBL1453552 & 688721 & 4.9 & 4.7792 & TRN \\
\hline CHEMBL1561913 & 688721 & 5.5 & 5.0669 & TRN \\
\hline CHEMBL1419317 & 688721 & 4.5 & 5.0492 & TST \\
\hline CHEMBL98398 & 688721 & 5.2 & 4.8965 & TST \\
\hline CHEMBL1507299 & 688721 & 4.8 & 4.9439 & TRN \\
\hline CHEMBL1409920 & 688721 & 6.2 & 5.0105 & TST \\
\hline CHEMBL1530469 & 688721 & 4.6 & 4.9309 & TRN \\
\hline CHEMBL1573425 & 688721 & 4.6 & 5.0933 & TRN \\
\hline CHEMBL1299399 & 688721 & 4.5 & 4.954 & TRN \\
\hline CHEMBL1482370 & 688721 & 5.8 & 5.1319 & TRN \\
\hline CHEMBL1498324 & 688721 & 4.6 & 4.9266 & TRN \\
\hline CHEMBL1472056 & 688721 & 4.6 & 5.079 & TST \\
\hline CHEMBL1300405 & 688721 & 4.9 & 4.9193 & TRN \\
\hline CHEMBL1393545 & 688721 & 5.9 & 4.9286 & TRN \\
\hline CHEMBL1516524 & 688721 & 4.5 & 4.9173 & TST \\
\hline CHEMBL1363566 & 688721 & 4.4 & 4.9251 & TRN \\
\hline CHEMBL1347066 & 688721 & 7.5003 & 4.871 & TST \\
\hline CHEMBL1613092 & 688721 & 4.6 & 4.7455 & TRN \\
\hline CHEMBL1341707 & 688721 & 4.8 & 4.9756 & TRN \\
\hline CHEMBL1560725 & 688721 & 5.0 & 4.9171 & TRN \\
\hline CHEMBL1525381 & 688721 & 4.7 & 4.8525 & TRN \\
\hline CHEMBL1300519 & 688721 & 4.9 & 4.8588 & TRN \\
\hline CHEMBL1576662 & 688721 & 4.5 & 4.9478 & TST \\
\hline CHEMBL1358955 & 688721 & 5.1 & 4.8004 & TRN \\
\hline CHEMBL1525110 & 688721 & 4.5 & 4.9975 & TRN \\
\hline CHEMBL1321716 & 688721 & 4.7 & 4.7786 & TRN \\
\hline CHEMBL1565666 & 688721 & 4.6 & 5.0095 & TST \\
\hline CHEMBL1346299 & 688721 & 5.2 & 4.9965 & TRN \\
\hline CHEMBL481577 & 688721 & 5.1 & 4.9212 & TRN \\
\hline CHEMBL1408943 & 688721 & 5.8 & 4.8988 & TRN \\
\hline CHEMBL3211852 & 688721 & 4.5 & 4.7802 & TST \\
\hline CHEMBL1560213 & 688721 & 4.4 & 4.9806 & TST \\
\hline
\end{tabular}




\begin{tabular}{|c|c|c|c|c|}
\hline \multicolumn{5}{|c|}{ plemental I } \\
\hline CHEMBL1589228 & 688721 & 4.5 & 4.8306 & TRN \\
\hline CHEMBL1505110 & 688721 & 4.4 & 5.1381 & TST \\
\hline CHEMBL1324314 & 688721 & 4.8 & 5.1422 & TST \\
\hline CHEMBL1310573 & 688721 & 4.4 & 5.0533 & TST \\
\hline CHEMBL1499272 & 688721 & 4.4 & 4.8674 & TRN \\
\hline CHEMBL3211012 & 688721 & 6.0 & 4.9637 & TRN \\
\hline CHEMBL1484715 & 688721 & 4.8 & 4.7937 & TRN \\
\hline CHEMBL1425059 & 688721 & 4.8 & 4.8657 & TRN \\
\hline CHEMBL1367376 & 688721 & 4.4 & 5.0937 & TRN \\
\hline CHEMBL1578133 & 688721 & 4.8 & 4.9414 & TST \\
\hline CHEMBL1508009 & 688721 & 4.7 & 4.7964 & TST \\
\hline CHEMBL1603026 & 688721 & 4.4 & 4.8816 & TST \\
\hline CHEMBL1579840 & 688721 & 5.4 & 4.8399 & TRN \\
\hline CHEMBL1435077 & 688721 & 4.5 & 4.9324 & TRN \\
\hline CHEMBL1427175 & 688721 & 4.6 & 5.0203 & TRN \\
\hline CHEMBL1332761 & 688721 & 5.4 & 4.9304 & TRN \\
\hline CHEMBL1476604 & 688721 & 4.6 & 5.189 & TRN \\
\hline CHEMBL1371950 & 688721 & 5.8 & 5.0209 & TST \\
\hline CHEMBL1160709 & 688721 & 4.4 & 5.1626 & TRN \\
\hline CHEMBL1439569 & 688721 & 5.2 & 5.0696 & TST \\
\hline CHEMBL1464142 & 688721 & 5.2 & 4.8888 & TST \\
\hline CHEMBL1529105 & 688721 & 5.2 & 4.8022 & TRN \\
\hline CHEMBL1507983 & 688721 & 4.7 & 4.7288 & TST \\
\hline CHEMBL1447514 & 688721 & 4.4 & 4.9467 & TRN \\
\hline CHEMBL1459729 & 688721 & 4.4 & 4.8381 & TRN \\
\hline CHEMBL1334959 & 688721 & 5.5 & 4.9821 & TRN \\
\hline CHEMBL10347 & 688721 & 6.0 & 5.1296 & TRN \\
\hline CHEMBL1362669 & 688721 & 4.5 & 4.8935 & TRN \\
\hline CHEMBL1349280 & 688721 & 4.8 & 5.0832 & TRN \\
\hline CHEMBL1318400 & 688721 & 5.0 & 5.1231 & TRN \\
\hline CHEMBL1601830 & 688721 & 5.5 & 5.046 & TRN \\
\hline CHEMBL1405487 & 688721 & 4.4 & 4.9094 & TST \\
\hline CHEMBL1456809 & 688721 & 4.4 & 4.7149 & TRN \\
\hline CHEMBL1443347 & 688721 & 4.5 & 4.8454 & TRN \\
\hline CHEMBL1570429 & 688721 & 4.7 & 5.0169 & TRN \\
\hline CHEMBL395269 & 688721 & 5.2 & 5.0386 & TST \\
\hline CHEMBL1547253 & 688721 & 4.7 & 4.9969 & TRN \\
\hline CHEMBL1570378 & 688721 & 6.1 & 4.9006 & TST \\
\hline CHEMBL1454779 & 688721 & 5.5 & 4.9974 & TRN \\
\hline CHEMBL 3197797 & 688721 & 5.3 & 5.1357 & TST \\
\hline CHEMBL1522929 & 688721 & 5.2 & 5.1116 & TRN \\
\hline CHEMBL1423013 & 688721 & 4.4 & 4.97199 & 99999999995 \\
\hline CHEMBL1568316 & 688721 & 4.4 & 4.9 & TRN \\
\hline CHEMBL1496594 & 688721 & 4.6 & 5.0717 & TST \\
\hline CHEMBL1606798 & 688721 & 4.6 & 5.0083 & TRN \\
\hline CHEMBL1602336 & 688721 & 4.4 & 4.9957 & TRN \\
\hline CHEMBL1489638 & 688721 & 4.4 & 4.9014 & TST \\
\hline CHEMBL1592268 & 688721 & 4.5 & 5.3004 & TRN \\
\hline
\end{tabular}




\begin{tabular}{|c|c|c|c|c|}
\hline \multicolumn{5}{|c|}{ Supplemental Table S2.txt } \\
\hline CHEMBL1533155 & 688721 & 4.6 & 4.7543 & TRN \\
\hline CHEMBL1445946 & 688721 & 5.4 & 5.0994 & TRN \\
\hline CHEMBL1305742 & 688721 & 7.0 & 5.1928 & TST \\
\hline CHEMBL1437997 & 688721 & 4.7 & 4.8168 & TST \\
\hline CHEMBL1536852 & 688721 & 4.6 & 4.9296 & TRN \\
\hline CHEMBL1360489 & 688721 & 4.5 & 5.0852 & TRN \\
\hline CHEMBL1541679 & 688721 & 4.9 & 4.9117 & TST \\
\hline CHEMBL1256940 & 688721 & 7.5003 & 5.0755 & TST \\
\hline CHEMBL1493381 & 688721 & 5.3 & 4.9146 & TRN \\
\hline CHEMBL1427360 & 688721 & 4.8 & 5.0568 & TRN \\
\hline CHEMBL1498011 & 688721 & 4.6 & 4.9967 & TRN \\
\hline CHEMBL1548983 & 688721 & 4.6 & 5.0047 & TRN \\
\hline CHEMBL1369069 & 688721 & 4.8 & 4.8098 & TRN \\
\hline CHEMBL1607300 & 688721 & 4.5 & 5.0294 & TRN \\
\hline CHEMBL3209402 & 688721 & 4.5 & 5.0525 & TRN \\
\hline CHEMBL1612824 & 688721 & 4.8 & 4.8805 & TRN \\
\hline CHEMBL1315318 & 688721 & 5.0 & 4.8327 & TRN \\
\hline CHEMBL1478311 & 688721 & 4.5 & 5.3414 & TRN \\
\hline CHEMBL1436763 & 688721 & 5.2 & 4.9887 & TRN \\
\hline CHEMBL1318954 & 688721 & 4.4 & 5.1255 & TST \\
\hline CHEMBL1540158 & 688721 & 5.1 & 5.0605 & TRN \\
\hline CHEMBL1524318 & 688721 & 4.8 & 5.0322 & TRN \\
\hline CHEMBL1302201 & 688721 & 5.4 & 4.8261 & TST \\
\hline CHEMBL1512444 & 688721 & 5.7 & 5.1543 & TRN \\
\hline CHEMBL1547250 & 688721 & 4.9 & 4.8631 & TRN \\
\hline CHEMBL1455817 & 688721 & 5.4 & 4.9992 & TST \\
\hline CHEMBL1588426 & 688721 & 4.6 & 4.864 & TRN \\
\hline CHEMBL1522462 & 688721 & 4.4 & 5.0595 & TST \\
\hline CHEMBL1529029 & 688721 & 4.7 & 4.737 & TRN \\
\hline CHEMBL1580299 & 688721 & 4.5 & 5.1031 & TRN \\
\hline CHEMBL1447160 & 688721 & 5.3 & 4.978 & TST \\
\hline CHEMBL1173475 & 688721 & 6.0 & 5.1068 & TRN \\
\hline CHEMBL1537325 & 688721 & 5.2 & 4.9423 & TRN \\
\hline CHEMBL1611450 & 688721 & 4.6 & 4.9491 & TRN \\
\hline CHEMBL1465416 & 688721 & 4.6 & 5.0838 & TRN \\
\hline CHEMBL1325054 & 688721 & 4.7 & 4.8752 & TRN \\
\hline CHEMBL1369405 & 688721 & 5.2 & 5.0205 & TST \\
\hline CHEMBL1545577 & 688721 & 4.6 & 4.9257 & TRN \\
\hline CHEMBL1550834 & 688721 & 5.0 & 4.9592 & TRN \\
\hline CHEMBL1361557 & 688721 & 4.7 & 4.8302 & TRN \\
\hline CHEMBL1613268 & 688721 & 4.8 & 4.968 & TRN \\
\hline CHEMBL1374558 & 688721 & 4.6 & 5.0254 & TRN \\
\hline CHEMBL1607988 & 688721 & 7.3002 & 5.0752 & TRN \\
\hline CHEMBL1444361 & 688721 & 4.9 & 4.9475 & TRN \\
\hline CHEMBL1410921 & 688721 & 4.9 & 4.8113 & TRN \\
\hline CHEMBL1453467 & 688721 & 4.8 & 4.7858 & TRN \\
\hline CHEMBL1343722 & 688721 & 4.8 & 5.0011 & TRN \\
\hline CHEMBL1594961 & 688721 & 4.7 & 5.0023 & TST \\
\hline
\end{tabular}




\begin{tabular}{|c|c|c|c|c|}
\hline \multicolumn{5}{|c|}{ Supplemental Table S2.txt } \\
\hline CHEMBL1593371 & 688721 & 4.8 & 5.1431 & TRN \\
\hline CHEMBL1319745 & 688721 & 4.4 & 4.7772 & TST \\
\hline CHEMBL1334041 & 688721 & 5.0 & 5.07 & TRN \\
\hline CHEMBL1606292 & 688721 & 5.4 & 5.1878 & TRN \\
\hline CHEMBL1571250 & 688721 & 5.5 & 4.9826 & TST \\
\hline CHEMBL1369874 & 688721 & 6.0 & 5.091 & TRN \\
\hline CHEMBL1464858 & 688721 & 6.2 & 5.0027 & TST \\
\hline CHEMBL1504719 & 688721 & 4.5 & 5.1239 & TRN \\
\hline CHEMBL1395415 & 688721 & 4.8 & 5.0173 & TRN \\
\hline CHEMBL1609357 & 688721 & 5.1 & 5.0081 & TRN \\
\hline CHEMBL1407145 & 688721 & 4.6 & 5.1033 & TRN \\
\hline CHEMBL1526065 & 688721 & 5.1 & 5.1064 & TRN \\
\hline CHEMBL1506315 & 688721 & 4.4 & 5.2576 & TST \\
\hline CHEMBL1578196 & 688721 & 4.4 & 4.8569 & TRN \\
\hline CHEMBL1456204 & 688721 & 4.6 & 4.867 & TRN \\
\hline CHEMBL1491624 & 688721 & 5.4 & 4.8314 & TRN \\
\hline CHEMBL1453119 & 688721 & 4.9 & 4.6794 & TRN \\
\hline CHEMBL1579483 & 688721 & 4.6 & 4.8996 & TRN \\
\hline CHEMBL1369683 & 688721 & 4.8 & 5.0369 & TRN \\
\hline CHEMBL1501637 & 688721 & 4.7 & 4.9939 & TST \\
\hline CHEMBL1435079 & 688721 & 5.6 & 5.0023 & TRN \\
\hline CHEMBL1362854 & 688721 & 4.7 & 4.9988 & TRN \\
\hline CHEMBL1347128 & 688721 & 4.5 & 4.9434 & TST \\
\hline CHEMBL1349386 & 688721 & 4.4 & 4.9612 & TST \\
\hline CHEMBL1519575 & 688721 & 7.699 & 5.0955 & TST \\
\hline CHEMBL1361733 & 688721 & 4.5 & 4.9589 & TST \\
\hline CHEMBL1549430 & 688721 & 4.8 & 4.8465 & TRN \\
\hline CHEMBL1306528 & 688721 & 5.0 & 4.5895 & TRN \\
\hline CHEMBL1374501 & 688721 & 5.4 & 5.0619 & TRN \\
\hline CHEMBL169233 & 688721 & 4.4 & 5.145 & TST \\
\hline CHEMBL1314434 & 688721 & 6.1 & 5.0245 & TRN \\
\hline CHEMBL1449890 & 688721 & 5.2 & 5.0397 & TRN \\
\hline CHEMBL1541369 & 688721 & 5.4 & 5.0812 & TRN \\
\hline CHEMBL1451932 & 688721 & 4.6 & 4.8115 & TRN \\
\hline CHEMBL1399130 & 688721 & 5.1 & 4.8458 & TRN \\
\hline CHEMBL1471846 & 688721 & 4.5 & 4.9234 & TRN \\
\hline CHEMBL1488599 & 688721 & 4.8 & 5.1305 & TRN \\
\hline CHEMBL1531843 & 688721 & 4.4 & 4.9711 & TRN \\
\hline CHEMBL1507444 & 688721 & 4.4 & 4.9335 & TRN \\
\hline CHEMBL1318041 & 688721 & 5.0 & 5.0588 & TRN \\
\hline CHEMBL1312242 & 688721 & 4.6 & 4.8453 & TRN \\
\hline CHEMBL1319199 & 688721 & 4.4 & 4.8741 & TRN \\
\hline CHEMBL1338280 & 688721 & 5.1 & 4.8404 & TRN \\
\hline CHEMBL1375365 & 688721 & 4.4 & 4.7524 & TRN \\
\hline CHEMBL560073 & 688721 & 4.6 & 4.7418 & TRN \\
\hline CHEMBL1448941 & 688721 & 4.5 & 5.0789 & TRN \\
\hline CHEMBL470671 & 688721 & 4.9 & 4.9586 & TST \\
\hline CHEMBL1610769 & 688721 & 5.2 & 5.0128 & TRN \\
\hline
\end{tabular}




\begin{tabular}{|c|c|c|c|c|c|}
\hline \multicolumn{6}{|c|}{ Supplemental Table S2.txt } \\
\hline CHEMBL1521391 & 688721 & 4.8 & 5.1808 & TRN & \\
\hline CHEMBL1351715 & 688721 & 4.5 & 4.7532 & TRN & \\
\hline CHEMBL1311759 & 688721 & 4.5 & 5.1216 & TST & \\
\hline CHEMBL1549271 & 688721 & 4.7 & 4.8347 & TRN & \\
\hline CHEMBL1561554 & 688721 & 4.9 & 4.885 & TRN & \\
\hline CHEMBL1569619 & 688721 & 4.7 & 5.1394 & TST & \\
\hline CHEMBL1464879 & 688721 & 5.2 & 4.8738 & TRN & \\
\hline CHEMBL1400836 & 688721 & 4.8 & 4.9308 & TRN & \\
\hline CHEMBL93496 & 688721 & 5.2 & 4.9969 & TST & \\
\hline CHEMBL1498570 & 688721 & 5.0 & 5.1349 & TRN & \\
\hline CHEMBL1551139 & 688721 & 5.6 & 4.9901 & TRN & \\
\hline CHEMBL1583907 & 688721 & 5.0 & 4.7216 & TRN & \\
\hline CHEMBL1529657 & 688721 & 4.4 & 4.8957 & TRN & \\
\hline CHEMBL1353259 & 688721 & 4.6 & 4.7992 & TRN & \\
\hline CHEMBL1493423 & 688721 & 5.0 & 4.7356 & TRN & \\
\hline CHEMBL1349712 & 688721 & 5.0 & 4.8161 & TST & \\
\hline CHEMBL1529094 & 688721 & 4.4 & 4.8722 & TRN & \\
\hline CHEMBL1460048 & 688721 & 4.7 & 5.0704 & TRN & \\
\hline CHEMBL1440653 & 688721 & 4.6 & 5.0814 & TRN & \\
\hline CHEMBL409906 & 688721 & 7.6003 & 4.86600 & 00000000005 & TRN \\
\hline CHEMBL1443585 & 688721 & 5.7 & 5.3618 & TRN & \\
\hline CHEMBL1532389 & 688721 & 5.5 & 4.9932 & TST & \\
\hline CHEMBL1392265 & 688721 & 4.9 & 4.752 & TST & \\
\hline CHEMBL1381267 & 688721 & 4.5 & 5.0145 & TST & \\
\hline CHEMBL1398223 & 688721 & 4.6 & 5.2938 & TRN & \\
\hline CHEMBL1342845 & 688721 & 5.3 & 4.9011 & TRN & \\
\hline CHEMBL1424548 & 688721 & 4.8 & 4.9089 & TRN & \\
\hline CHEMBL1451119 & 688721 & 5.0 & 5.1259 & TRN & \\
\hline CHEMBL1457733 & 688721 & 5.2 & 4.7276 & TST & \\
\hline CHEMBL1354614 & 688721 & 5.2 & 5.0635 & TRN & \\
\hline CHEMBL1428033 & 688721 & 5.4 & 5.0007 & TRN & \\
\hline CHEMBL1354563 & 688721 & 4.6 & 5.0604 & TST & \\
\hline CHEMBL38934 & 688721 & 5.1 & 5.0257 & TRN & \\
\hline CHEMBL1461715 & 688721 & 4.6 & 4.8582 & TRN & \\
\hline CHEMBL1476430 & 688721 & 4.7 & 4.8954 & TRN & \\
\hline CHEMBL1970272 & 688721 & 4.5 & 4.8564 & TST & \\
\hline CHEMBL1466775 & 688721 & 5.1 & 5.0205 & TRN & \\
\hline CHEMBL1567922 & 688721 & 4.6 & 4.8517 & TST & \\
\hline CHEMBL1480334 & 688721 & 4.5 & 4.7235 & TRN & \\
\hline CHEMBL1611746 & 688721 & 4.8 & 4.8817 & TRN & \\
\hline CHEMBL1362501 & 688721 & 6.1 & 5.1919 & TST & \\
\hline CHEMBL1583736 & 688721 & 4.6 & 4.7215 & TRN & \\
\hline CHEMBL1360934 & 688721 & 5.3 & 4.9232 & TST & \\
\hline CHEMBL1327038 & 688721 & 4.7 & 5.0485 & TRN & \\
\hline CHEMBL1380354 & 688721 & 4.7 & 4.8131 & TRN & \\
\hline CHEMBL1301763 & 688721 & 4.8 & 4.8676 & TRN & \\
\hline CHEMBL1537739 & 688721 & 4.4 & 4.8625 & TRN & \\
\hline CHEMBL1329093 & 688721 & 4.4 & 4.8996 & TRN & \\
\hline
\end{tabular}




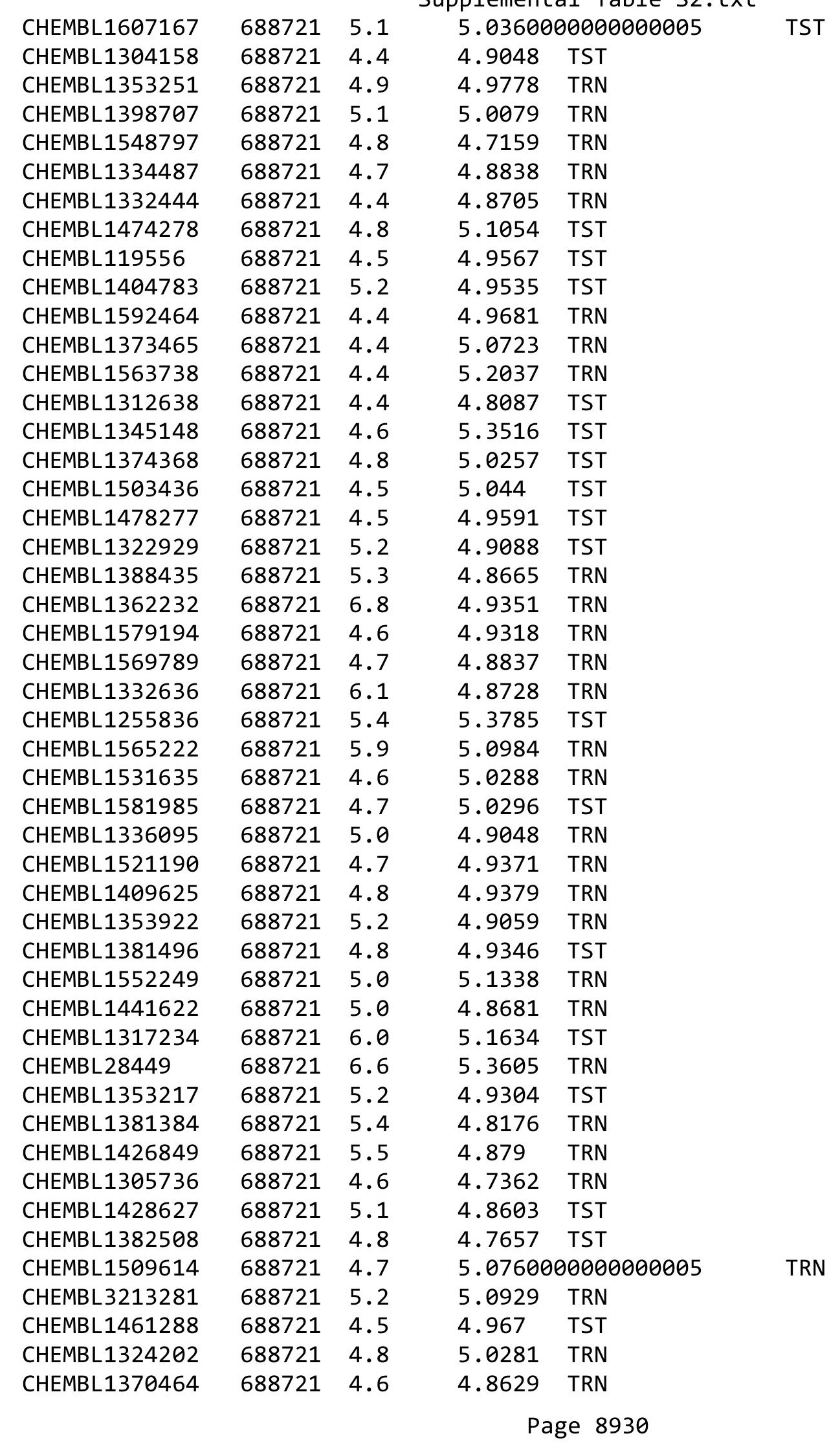




\begin{tabular}{|c|c|c|c|c|c|}
\hline & & \\
\hline CHEMBL1561850 & 688721 & 4.5 & 4.7517 & TST & \\
\hline CHEMBL1393359 & 688721 & 5.9 & 4.9197 & TRN & \\
\hline CHEMBL1501050 & 688721 & 4.4 & 4.8228 & TRN & \\
\hline CHEMBL1578190 & 688721 & 5.3 & 4.8267 & TRN & \\
\hline CHEMBL1374812 & 688721 & 4.7 & 4.8379 & TRN & \\
\hline CHEMBL1547182 & 688721 & 6.0 & 5.118 & TST & \\
\hline CHEMBL1450025 & 688721 & 4.5 & 5.0223 & TRN & \\
\hline CHEMBL1524343 & 688721 & 4.4 & 4.6871 & TST & \\
\hline CHEMBL1559866 & 688721 & 4.5 & 4.7637 & TRN & \\
\hline CHEMBL1415207 & 688721 & 4.7 & \multicolumn{2}{|c|}{5.0889999999999995} & TRN \\
\hline CHEMBL1394874 & 688721 & 4.7 & 5.0215 & TRN & \\
\hline CHEMBL1450856 & 688721 & 5.4 & 5.0654 & TRN & \\
\hline CHEMBL1371199 & 688721 & 5.4 & 4.9205 & TRN & \\
\hline CHEMBL1447719 & 688721 & 4.6 & 4.8061 & TST & \\
\hline CHEMBL1575755 & 688721 & 6.1 & 4.7496 & TRN & \\
\hline CHEMBL1457788 & 688721 & 4.5 & 4.9936 & TRN & \\
\hline CHEMBL1568684 & 688721 & 4.5 & 5.0393 & TST & \\
\hline CHEMBL1312088 & 688721 & 4.9 & 5.0147 & TST & \\
\hline CHEMBL247879 & 688721 & 5.9 & \multicolumn{2}{|c|}{4.888999999999999} & TST \\
\hline CHEMBL1381145 & 688721 & 6.1 & 5.0617 & TST & \\
\hline CHEMBL1380269 & 688721 & 4.4 & 4.7883 & TRN & \\
\hline CHEMBL1516548 & 688721 & 4.5 & 4.8359 & TRN & \\
\hline CHEMBL1331367 & 688721 & 5.3 & 5.1551 & TST & \\
\hline CHEMBL1466777 & 688721 & 4.8 & 5.1354 & TRN & \\
\hline CHEMBL1418427 & 688721 & 4.6 & 4.9932 & TST & \\
\hline CHEMBL1461375 & 688721 & 4.7 & 4.7844 & TRN & \\
\hline CHEMBL1477847 & 688721 & 6.5 & 4.7798 & TRN & \\
\hline CHEMBL1408236 & 688721 & 5.5 & 4.8164 & TRN & \\
\hline CHEMBL1411201 & 688721 & 5.1 & \multicolumn{2}{|c|}{5.1979999999999995} & TRN \\
\hline CHEMBL1537955 & 688721 & 4.7 & 4.9134 & TRN & \\
\hline CHEMBL1467168 & 688721 & 4.7 & 4.9587 & TRN & \\
\hline CHEMBL1353317 & 688721 & 4.4 & 4.8131 & TRN & \\
\hline CHEMBL1581337 & 688721 & 4.6 & \multicolumn{2}{|c|}{4.9030000000000005} & TRN \\
\hline CHEMBL1302694 & 688721 & 4.7 & 4.7706 & TRN & \\
\hline CHEMBL1395605 & 688721 & 5.2 & 5.0507 & TRN & \\
\hline CHEMBL1455219 & 688721 & 4.5 & 5.3212 & TST & \\
\hline CHEMBL1342209 & 688721 & 5.2 & 4.8174 & TST & \\
\hline CHEMBL1308277 & 688721 & 6.1 & 4.9036 & TRN & \\
\hline CHEMBL1593153 & 688721 & 5.4 & 5.1496 & TRN & \\
\hline CHEMBL 277120 & 688721 & 7.8013 & 5.0305 & TST & \\
\hline CHEMBL1370296 & 688721 & 4.5 & 4.921 & TRN & \\
\hline CHEMBL1460497 & 688721 & 4.5 & 4.8243 & TRN & \\
\hline CHEMBL1380311 & 688721 & 4.4 & 4.7981 & TRN & \\
\hline CHEMBL1381570 & 688721 & 4.4 & 4.9181 & TST & \\
\hline CHEMBL1431730 & 688721 & 4.4 & 4.9848 & TST & \\
\hline CHEMBL1368995 & 688721 & 4.6 & 4.6056 & TRN & \\
\hline CHEMBL1349741 & 688721 & 6.8 & 4.992 & TRN & \\
\hline CHEMBL1498229 & 688721 & 6.7001 & 5.0074 & TST & \\
\hline & & & & 8931 & \\
\hline
\end{tabular}




\begin{tabular}{|c|c|c|c|c|c|}
\hline \\
\hline CHEMBL1350628 & 688721 & 5.6 & 5.0278 & TRN & \\
\hline CHEMBL1519116 & 688721 & 5.1 & 4.7231 & TRN & \\
\hline CHEMBL1446563 & 688721 & 4.5 & 5.0876 & TRN & \\
\hline CHEMBL1305334 & 688721 & 4.6 & 4.8457 & TRN & \\
\hline CHEMBL1612696 & 688721 & 5.9 & 5.0256 & TRN & \\
\hline CHEMBL3211966 & 688721 & 7.8996 & 4.7888 & TST & \\
\hline CHEMBL 8747 & 688721 & 4.7 & 4.9578 & TST & \\
\hline CHEMBL1603418 & 688721 & 4.9 & 4.9978 & TRN & \\
\hline CHEMBL1443987 & 688721 & 5.2 & 4.8836 & TST & \\
\hline CHEMBL1498682 & 688721 & 4.4 & 4.8914 & TRN & \\
\hline CHEMBL1457763 & 688721 & 5.4 & 4.9685 & TRN & \\
\hline CHEMBL1545183 & 688721 & 5.1 & 4.7639 & TRN & \\
\hline CHEMBL1488030 & 688721 & 4.6 & 4.8547 & TRN & \\
\hline CHEMBL1465194 & 688721 & 4.6 & 4.8121 & TST & \\
\hline CHEMBL177809 & 688721 & 4.4 & 5.1193 & TST & \\
\hline CHEMBL1344299 & 688721 & 5.1 & 4.9085 & TRN & \\
\hline CHEMBL1317921 & 688721 & 5.1 & 5.1989 & TST & \\
\hline CHEMBL1346825 & 688721 & 4.6 & 5.0962 & TRN & \\
\hline CHEMBL1335973 & 688721 & 4.7 & 5.0716 & TRN & \\
\hline CHEMBL1331051 & 688721 & 6.1 & 4.7202 & TRN & \\
\hline CHEMBL3198936 & 688721 & 5.2 & 5.0901 & TRN & \\
\hline CHEMBL1465632 & 688721 & 4.4 & 5.0854 & TRN & \\
\hline CHEMBL1559029 & 688721 & 4.4 & 5.0133 & TRN & \\
\hline CHEMBL1517453 & 688721 & 5.6 & 5.0707 & TRN & \\
\hline CHEMBL1577108 & 688721 & 4.8 & 5.0724 & TRN & \\
\hline CHEMBL1450354 & 688721 & 5.2 & 4.742 & TRN & \\
\hline CHEMBL1385762 & 688721 & 4.8 & 4.8556 & TRN & \\
\hline CHEMBL1421028 & 688721 & 4.9 & 5.0293 & TST & \\
\hline CHEMBL1454025 & 688721 & 4.6 & 4.9545 & TRN & \\
\hline CHEMBL1393919 & 688721 & 4.5 & 4.7762 & TRN & \\
\hline CHEMBL1418675 & 688721 & 4.7 & 4.80699 & 99999999995 & TRN \\
\hline CHEMBL1455972 & 688721 & 5.7 & 5.2914 & TST & \\
\hline CHEMBL1301641 & 688721 & 4.8 & 4.7102 & TRN & \\
\hline CHEMBL1431188 & 688721 & 4.9 & 5.0288 & TRN & \\
\hline CHEMBL1362384 & 688721 & 5.3 & 4.9346 & TRN & \\
\hline CHEMBL1506646 & 688721 & 4.6 & 4.8779 & TRN & \\
\hline CHEMBL1561070 & 688721 & 4.6 & 5.0873 & TRN & \\
\hline CHEMBL1392260 & 688721 & 5.2 & 4.8813 & TRN & \\
\hline CHEMBL1447561 & 688721 & 5.1 & 4.8512 & TRN & \\
\hline CHEMBL1366238 & 688721 & 4.6 & 4.7957 & TRN & \\
\hline CHEMBL1397766 & 688721 & 4.5 & 5.0533 & TST & \\
\hline CHEMBL1542946 & 688721 & 4.6 & 4.9104 & TRN & \\
\hline CHEMBL1389704 & 688721 & 6.2 & 4.9288 & TRN & \\
\hline CHEMBL1425173 & 688721 & 4.5 & 4.9254 & TRN & \\
\hline CHEMBL1491886 & 688721 & 4.5 & 4.8867 & TRN & \\
\hline CHEMBL1476206 & 688721 & 4.6 & 5.20200 & 2000000001 & TRN \\
\hline CHEMBL1496752 & 688721 & 5.5 & 5.1751 & TRN & \\
\hline CHEMBL1488010 & 688721 & 5.3 & 5.0487 & TRN & \\
\hline
\end{tabular}


Supplemental Table S2.txt

\begin{tabular}{|c|c|c|c|c|}
\hline CHEMBL1311151 & 688721 & 6.7001 & 5.0204 & TRN \\
\hline CHEMBL1365616 & 688721 & 6.3 & 5.0723 & TRN \\
\hline CHEMBL1388948 & 88721 & 4.8 & 5.1033 & TRN \\
\hline CHEMBL1457966 & 688721 & 5.1 & 5.0493 & TST \\
\hline CHEMBL1445178 & 88721 & 4.5 & 4.8821 & IRIV \\
\hline CHEMBL581194 & 688721 & 4.6 & 4.8357 & TST \\
\hline HEMBL108766 & 588721 & 6.0 & 5.3616 & TRN \\
\hline CHEMBL1435188 & 688721 & 5.0 & 5.183 & ГST \\
\hline CHEMBL1531939 & 688721 & 4.7 & 4.9352 & TRN \\
\hline CHEMBL142735 & 688721 & 8.0 & 5.2863 & TST \\
\hline CHEMBL1506583 & 688721 & 5.3 & 4.8143 & TST \\
\hline CHEMBL1457138 & 688721 & 4.4 & 5.0692 & RN \\
\hline CHEMBL1308921 & 688721 & 4.4 & 4.9724 & RN \\
\hline CHEMBL1312622 & 688721 & 4.4 & 4.9165 & TRN \\
\hline CHEMBL1364372 & 688721 & 5.4 & 4.8853 & TST \\
\hline CHEMBL170781 & 688721 & 5.1 & 5.1155 & I RIV \\
\hline CHEMBL1599014 & 688721 & 5.5 & 5.1506 & TRN \\
\hline CHEMBL1608226 & 688721 & 4.4 & 4.8093 & ГST \\
\hline CHEMBL 1420570 & 688721 & 4.7 & 4.856 & TST \\
\hline CHEMBL1300645 & 688721 & 4.6 & 4.8872 & TST \\
\hline CHEMBL1415738 & 688721 & 5 . & 4.8725 & TST \\
\hline CHEMBL1471824 & 688721 & 4.7 & 5.0502 & TST \\
\hline CHEMBL1366831 & 688721 & 4.8 & 5.0151 & TST \\
\hline CHEMBL1475015 & 688721 & 4.5 & 5.0956 & TST \\
\hline CHEMBL1432983 & 688721 & 4.6 & 4.9309 & TRN \\
\hline CHEMBL1489766 & 688721 & 4.5 & 4.9705 & TRN \\
\hline CHEMBL1350075 & 688721 & 5.1 & 4.8273 & TRN \\
\hline CHEMBL1342646 & 688721 & 5.0 & 4.9742 & TRN \\
\hline CHEMBL1577032 & 688721 & 4.5 & 5.0634 & TST \\
\hline CHEMBL1500666 & 688721 & 4.4 & 4.9869 & TRN \\
\hline CHEMBL1332937 & 688721 & 4.8 & 5.1465 & TRN \\
\hline CHEMBL1373190 & 688721 & 5.0 & 5.0178 & TRN \\
\hline CHEMBL1583207 & 688721 & 4.5 & 5.0328 & TRN \\
\hline CHEMBL1331245 & 688721 & 5.1 & 5.0675 & TST \\
\hline CHEMBL1554486 & 688721 & 4.5 & 5.355 & TRN \\
\hline CHEMBL1607731 & 688721 & 5.1 & 5.1179 & TST \\
\hline CHEMBL 1506800 & 688721 & 5.2 & 4.9219 & TRN \\
\hline CHEMBL1507358 & 688721 & 4.4 & 4.9835 & TRN \\
\hline CHEMBL1365345 & 688721 & 4.5 & 5.0042 & TRN \\
\hline CHEMBL1383400 & 688721 & 4.6 & 4.9703 & TRN \\
\hline CHEMBL1417724 & 688721 & 4.8 & 4.7771 & TRN \\
\hline CHEMBL1443713 & 688721 & 5.2 & 5.2074 & TRN \\
\hline CHEMBL1459239 & 688721 & 4.9 & 4.6843 & TST \\
\hline CHEMBL1468924 & 688721 & 5.3 & 4.8034 & TRN \\
\hline CHEMBL1395196 & 688721 & 5.3 & 5.2121 & TST \\
\hline CHEMBL1547450 & 688721 & 4.7 & 4.8577 & TRN \\
\hline CHEMBL1346994 & 688721 & 4.4 & 5.0934 & IRI \\
\hline CHEMBL1528060 & 688721 & 4.4 & 4.9438 & TRN \\
\hline
\end{tabular}

Page 8933 


\begin{tabular}{|c|c|c|c|c|c|}
\hline \multicolumn{6}{|c|}{ Supplemental Table S2.txt } \\
\hline CHEMBL1431956 & 688721 & 4.5 & 4.9089 & TRN & \\
\hline CHEMBL1597656 & 688721 & 4.6 & 4.8295 & TRN & \\
\hline CHEMBL1368191 & 688721 & 4.4 & 5.19799 & 99999999995 & TST \\
\hline CHEMBL1404353 & 688721 & 4.5 & 4.9405 & TST & \\
\hline CHEMBL1534864 & 688721 & 4.7 & 4.8228 & TRN & \\
\hline CHEMBL1375753 & 688721 & 4.8 & 5.0848 & TRN & \\
\hline CHEMBL1377526 & 688721 & 6.1 & 5.0245 & TRN & \\
\hline CHEMBL1586234 & 688721 & 4.5 & 4.7782 & TRN & \\
\hline CHEMBL1428387 & 688721 & 5.9 & 4.9378 & TRN & \\
\hline CHEMBL1589243 & 688721 & 4.5 & 4.8955 & TRN & \\
\hline CHEMBL491747 & 688721 & 4.5 & 5.1135 & TRN & \\
\hline CHEMBL1521104 & 688721 & 4.5 & 4.9968 & TRN & \\
\hline CHEMBL1492738 & 688721 & 4.8 & 4.7588 & TRN & \\
\hline CHEMBL561936 & 688721 & 4.4 & 4.6962 & TRN & \\
\hline CHEMBL1500549 & 688721 & 4.4 & 4.7314 & TRN & \\
\hline CHEMBL1374573 & 688721 & 4.5 & 4.9564 & TRN & \\
\hline CHEMBL1595250 & 688721 & 4.4 & 4.9593 & TRN & \\
\hline CHEMBL1358568 & 688721 & 4.8 & 5.0435 & TRN & \\
\hline CHEMBL1405366 & 688721 & 4.5 & 4.9908 & TRN & \\
\hline CHEMBL1369619 & 688721 & 4.6 & 4.8172 & TRN & \\
\hline CHEMBL1548680 & 688721 & 4.5 & 4.6656 & TRN & \\
\hline CHEMBL1380133 & 688721 & 5.9 & 5.0398 & TST & \\
\hline CHEMBL1518481 & 688721 & 4.6 & 4.8803 & TRN & \\
\hline CHEMBL1407941 & 688721 & 5.1 & 4.8782 & TRN & \\
\hline CHEMBL1322921 & 688721 & 4.7 & 4.77800 & 00000000005 & TRN \\
\hline CHEMBL1522938 & 688721 & 4.5 & 5.1164 & TST & \\
\hline CHEMBL1342725 & 688721 & 4.6 & 5.0155 & TRN & \\
\hline CHEMBL98350 & 688721 & 6.0 & 4.882 & TST & \\
\hline CHEMBL1476580 & 688721 & 5.4 & 5.1271 & TRN & \\
\hline CHEMBL3198987 & 688721 & 5.3 & 4.8898 & TST & \\
\hline CHEMBL1399445 & 688721 & 4.8 & 4.7646 & TRN & \\
\hline CHEMBL1400768 & 688721 & 4.8 & 4.8456 & TRN & \\
\hline CHEMBL1548618 & 688721 & 4.6 & 5.0655 & TST & \\
\hline CHEMBL 2373666 & 688721 & 4.4 & 5.0874 & TRN & \\
\hline CHEMBL1320669 & 688721 & 5.0 & 4.9014 & TRN & \\
\hline CHEMBL1361034 & 688721 & 4.6 & 4.9931 & TST & \\
\hline CHEMBL1378372 & 688721 & 4.7 & 5.0023 & TRN & \\
\hline CHEMBL1315083 & 688721 & 5.4 & 5.0131 & TRN & \\
\hline CHEMBL1366606 & 688721 & 4.4 & 4.899 & TRN & \\
\hline CHEMBL1405678 & 688721 & 4.4 & 4.6832 & TST & \\
\hline CHEMBL1309361 & 688721 & 4.5 & 4.8625 & TRN & \\
\hline CHEMBL1317498 & 688721 & 7.1002 & 5.2117 & TRN & \\
\hline CHEMBL1452857 & 688721 & 4.7 & 4.9778 & TST & \\
\hline CHEMBL1486171 & 688721 & 4.5 & 5.0091 & TRN & \\
\hline CHEMBL1462034 & 688721 & 4.4 & 4.9424 & TRN & \\
\hline CHEMBL1452716 & 688721 & 6.0 & 5.0651 & TRN & \\
\hline CHEMBL1413584 & 688721 & 6.1 & 4.8702 & TRN & \\
\hline CHEMBL1370386 & 688721 & 4.5 & 5.0335 & TRN & \\
\hline
\end{tabular}




\begin{tabular}{|c|c|c|c|c|c|}
\hline \\
\hline CHEMBL1491477 & 688721 & 6.2 & 5.0329 & TST & \\
\hline CHEMBL517444 & 688721 & 4.4 & 4.8829 & TST & \\
\hline CHEMBL1586438 & 688721 & 4.6 & 5.0273 & TRN & \\
\hline CHEMBL1333581 & 688721 & 5.3 & 4.6718 & TRN & \\
\hline CHEMBL1383467 & 688721 & 5.2 & 4.9791 & TRN & \\
\hline CHEMBL1537876 & 688721 & 4.5 & 4.9049 & TST & \\
\hline CHEMBL1373771 & 688721 & 4.5 & 4.9261 & TRN & \\
\hline CHEMBL1487686 & 688721 & 4.7 & 4.7292 & TRN & \\
\hline CHEMBL1323883 & 688721 & 4.4 & 5.4162 & TST & \\
\hline CHEMBL1369049 & 688721 & 4.6 & 4.9009 & TRN & \\
\hline CHEMBL1602394 & 688721 & 5.8 & 4.9598 & TRN & \\
\hline CHEMBL584905 & 688721 & 4.5 & 4.9611 & TST & \\
\hline CHEMBL1489965 & 688721 & 4.4 & 4.9628 & TST & \\
\hline CHEMBL1256718 & 688721 & 4.5 & 5.1275 & TST & \\
\hline CHEMBL3195416 & 688721 & 4.7 & 5.0342 & TST & \\
\hline CHEMBL1483601 & 688721 & 4.4 & 5.246 & TRN & \\
\hline CHEMBL1338220 & 688721 & 4.7 & 4.8357 & TRN & \\
\hline CHEMBL1507975 & 688721 & 5.2 & 4.9218 & TRN & \\
\hline CHEMBL1349492 & 688721 & 5.0 & 4.9473 & TST & \\
\hline CHEMBL1392853 & 688721 & 4.5 & 4.8649 & TRN & \\
\hline CHEMBL1501491 & 688721 & 5.6 & 5.1222 & TRN & \\
\hline CHEMBL1330103 & 688721 & 4.5 & 4.9422 & TST & \\
\hline CHEMBL1486233 & 688721 & 4.4 & 4.9155 & TST & \\
\hline CHEMBL1309461 & 688721 & 6.1 & 4.7216 & TRN & \\
\hline CHEMBL1517329 & 688721 & 4.5 & 5.2386 & TRN & \\
\hline CHEMBL1576495 & 688721 & 7.699 & 4.9634 & TRN & \\
\hline CHEMBL1560296 & 688721 & 4.5 & 4.9717 & TST & \\
\hline CHEMBL1454658 & 688721 & 5.4 & 4.8441 & TRN & \\
\hline CHEMBL1403744 & 688721 & 4.5 & 4.9902 & TST & \\
\hline CHEMBL1486993 & 688721 & 4.4 & 5.0025 & TRN & \\
\hline CHEMBL1342092 & 688721 & 4.6 & 4.9814 & TST & \\
\hline CHEMBL1557313 & 688721 & 4.8 & 4.8249 & TRN & \\
\hline CHEMBL1563507 & 688721 & 5.4 & 5.09399 & 9999999999 & TRN \\
\hline CHEMBL1443205 & 688721 & 4.8 & 4.8946 & TRN & \\
\hline CHEMBL1409060 & 688721 & 4.4 & 5.0735 & TST & \\
\hline CHEMBL1593601 & 688721 & 4.8 & 5.1797 & TRN & \\
\hline CHEMBL1442919 & 688721 & 4.4 & 4.7709 & TRN & \\
\hline CHEMBL1605366 & 688721 & 4.4 & 5.0426 & TRN & \\
\hline CHEMBL1558902 & 688721 & 4.6 & 4.8451 & TRN & \\
\hline CHEMBL1421476 & 688721 & 4.7 & 4.9615 & TST & \\
\hline CHEMBL1389769 & 688721 & 4.4 & 4.8301 & TRN & \\
\hline CHEMBL1610872 & 688721 & 5.8 & 5.1071 & TST & \\
\hline CHEMBL1410509 & 688721 & 4.4 & 4.8987 & TRN & \\
\hline CHEMBL585081 & 688721 & 5.6 & 4.6781 & TRN & \\
\hline CHEMBL1521999 & 688721 & 4.6 & 5.0117 & TRN & \\
\hline CHEMBL1585074 & 688721 & 4.4 & 4.8892 & TRN & \\
\hline CHEMBL1449438 & 688721 & 7.0 & 5.2338 & TRN & \\
\hline CHEMBL1568024 & 688721 & 4.4 & 5.0614 & TRN & \\
\hline
\end{tabular}




\begin{tabular}{|c|c|c|c|c|}
\hline & & & pplement & al $\mathrm{Ta}$ \\
\hline CHEMBL1533840 & 688721 & 4.7 & 4.8769 & TRN \\
\hline CHEMBL72631 & 688721 & 4.4 & 4.8393 & TRN \\
\hline CHEMBL1533050 & 688721 & 5.4 & 4.8332 & TRN \\
\hline CHEMBL1549705 & 688721 & 4.4 & 4.8103 & TRN \\
\hline CHEMBL3214457 & 688721 & 4.9 & 4.8492 & TRN \\
\hline CHEMBL1399958 & 688721 & 5.2 & 5.2056 & TST \\
\hline CHEMBL1422108 & 688721 & 5.1 & 5.3225 & TRN \\
\hline CHEMBL1507132 & 688721 & 4.6 & 4.9689 & TRN \\
\hline CHEMBL1425267 & 688721 & 5.6 & 4.978 & TRN \\
\hline CHEMBL424581 & 688721 & 5.2 & 4.9464 & TRN \\
\hline CHEMBL1307951 & 688721 & 5.0 & 4.69 & TRN \\
\hline CHEMBL1416209 & 688721 & 6.0 & 4.8459 & TRN \\
\hline CHEMBL1341764 & 688721 & 4.6 & 4.8498 & TST \\
\hline CHEMBL1472168 & 688721 & 6.1 & 4.8143 & TRN \\
\hline CHEMBL1430269 & 688721 & 4.5 & 4.9304 & TRN \\
\hline CHEMBL1394258 & 688721 & 4.8 & 4.9799 & TRN \\
\hline CHEMBL1578267 & 688721 & 4.8 & 4.8971 & TRN \\
\hline CHEMBL1396310 & 688721 & 5.2 & 5.1907 & TRN \\
\hline CHEMBL1374761 & 688721 & 4.6 & 4.9005 & TRN \\
\hline CHEMBL1586641 & 688721 & 4.5 & 4.8103 & TRN \\
\hline CHEMBL1600993 & 688721 & 4.6 & 4.9353 & TRN \\
\hline CHEMBL1545613 & 688721 & 4.4 & 4.7863 & TST \\
\hline CHEMBL1602353 & 688721 & 5.4 & 5.0398 & TRN \\
\hline CHEMBL1602512 & 688721 & 4.6 & 4.9269 & TRN \\
\hline CHEMBL1371459 & 688721 & 4.6 & 4.8291 & TRN \\
\hline CHEMBL1308227 & 688721 & 4.7 & 4.7711 & TRN \\
\hline CHEMBL1530033 & 688721 & 5.5 & 4.8896 & TRN \\
\hline CHEMBL1340876 & 688721 & 5.5 & 4.8291 & TRN \\
\hline CHEMBL1379364 & 688721 & 4.5 & 4.9018 & TRN \\
\hline CHEMBL1393339 & 688721 & 4.7 & 4.6616 & TRN \\
\hline CHEMBL1527601 & 688721 & 4.7 & 5.0489 & TST \\
\hline CHEMBL1345131 & 688721 & 5.4 & 5.0037 & TRN \\
\hline CHEMBL1377745 & 688721 & 5.2 & 4.9845 & TRN \\
\hline CHEMBL1602566 & 688721 & 4.8 & 4.9669 & TST \\
\hline CHEMBL1324882 & 688721 & 5.6 & 5.2564 & TRN \\
\hline CHEMBL1372617 & 688721 & 5.4 & 4.9143 & TRN \\
\hline CHEMBL1333515 & 688721 & 4.5 & 4.942 & TRN \\
\hline CHEMBL1561474 & 688721 & 5.4 & 5.3727 & TRN \\
\hline CHEMBL1594649 & 688721 & 4.6 & 4.8926 & TRN \\
\hline CHEMBL1414511 & 688721 & 4.4 & 5.1658 & TST \\
\hline CHEMBL1362640 & 688721 & 5.2 & 5.0787 & TST \\
\hline CHEMBL1598438 & 688721 & 4.5 & 4.9684 & TRN \\
\hline CHEMBL1475004 & 688721 & 5.2 & 5.1964 & TRN \\
\hline CHEMBL404313 & 688721 & 4.4 & 5.4101 & TST \\
\hline CHEMBL1400009 & 688721 & 5.4 & 4.8497 & TRN \\
\hline CHEMBL526952 & 688721 & 6.0 & 4.9011 & TRN \\
\hline CHEMBL1436272 & 688721 & 5.0 & 5.1101 & TRN \\
\hline CHEMBL1429998 & 688721 & 4.8 & 4.9397 & TRN \\
\hline
\end{tabular}




\begin{tabular}{|c|c|c|c|c|}
\hline \multicolumn{5}{|c|}{ Supplemental Table S2.txt } \\
\hline CHEMBL1491272 & 688721 & 4.5 & 4.7765 & TRN \\
\hline CHEMBL1388788 & 688721 & 5.5 & 4.8222 & TRN \\
\hline CHEMBL1336191 & 688721 & 6.0 & 4.8132 & TRN \\
\hline CHEMBL1384647 & 688721 & 4.6 & 4.8672 & TRN \\
\hline CHEMBL1387861 & 688721 & 5.3 & 4.9743 & TST \\
\hline CHEMBL1493313 & 688721 & 4.4 & 5.0385 & TRN \\
\hline CHEMBL1513568 & 688721 & 5.4 & 5.1569 & TRN \\
\hline CHEMBL1500715 & 688721 & 4.7 & 4.8905 & TST \\
\hline CHEMBL1326702 & 688721 & 5.4 & 4.955 & TRN \\
\hline CHEMBL1589519 & 688721 & 6.7001 & 4.8633 & TRN \\
\hline CHEMBL1374329 & 688721 & 4.8 & 4.8108 & TRN \\
\hline CHEMBL1476762 & 688721 & 6.2 & 5.2957 & TRN \\
\hline CHEMBL1573269 & 688721 & 5.3 & 4.7994 & TRN \\
\hline CHEMBL1307189 & 688721 & 4.5 & 5.059 & TRN \\
\hline CHEMBL1494982 & 688721 & 4.8 & 4.8784 & TRN \\
\hline CHEMBL1563638 & 688721 & 4.4 & 4.9492 & TRN \\
\hline CHEMBL1380574 & 688721 & 4.6 & 4.8696 & TRN \\
\hline CHEMBL1530274 & 688721 & 4.6 & 4.9789 & TRN \\
\hline CHEMBL1340190 & 688721 & 4.9 & 4.6897 & TST \\
\hline CHEMBL1384891 & 688721 & 4.4 & 4.9122 & TRN \\
\hline CHEMBL1573069 & 688721 & 4.4 & 5.2557 & TST \\
\hline CHEMBL1399328 & 688721 & 4.5 & 4.9104 & TRN \\
\hline CHEMBL3211146 & 688721 & 4.5 & 4.7955 & TRN \\
\hline CHEMBL1429539 & 688721 & 5.7 & 4.9525 & TRN \\
\hline CHEMBL1448422 & 688721 & 6.9 & 4.8604 & TRN \\
\hline CHEMBL1395088 & 688721 & 5.8 & 5.0347 & TRN \\
\hline CHEMBL1423014 & 688721 & 4.9 & 4.8226 & TRN \\
\hline CHEMBL1449408 & 688721 & 4.4 & 4.9834 & TST \\
\hline CHEMBL1520432 & 688721 & 7.1002 & 4.9719 & TRN \\
\hline CHEMBL289431 & 688721 & 5.5 & 5.1117 & TST \\
\hline CHEMBL1302713 & 688721 & 4.8 & 4.8371 & TRN \\
\hline CHEMBL1396898 & 688721 & 4.9 & 5.0287 & TRN \\
\hline CHEMBL1387000 & 688721 & 4.5 & 4.7493 & TRN \\
\hline CHEMBL1606247 & 688721 & 4.5 & 4.8174 & TRN \\
\hline CHEMBL1394923 & 688721 & 5.0 & 5.01 & TRN \\
\hline CHEMBL1606433 & 688721 & 4.4 & 4.9521 & TST \\
\hline CHEMBL1339659 & 688721 & 4.5 & 4.8011 & TRN \\
\hline CHEMBL1337829 & 688721 & 8.1024 & 5.2659 & TRN \\
\hline CHEMBL1450521 & 688721 & 4.6 & 5.1515 & TRN \\
\hline CHEMBL1538893 & 688721 & 4.5 & 4.8039 & TRN \\
\hline CHEMBL1418858 & 688721 & 5.1 & 5.1438 & TST \\
\hline CHEMBL1549565 & 688721 & 4.6 & 4.7895 & TST \\
\hline CHEMBL1338237 & 688721 & 4.7 & 4.9892 & TRN \\
\hline CHEMBL1307610 & 688721 & 4.4 & 4.8857 & TRN \\
\hline CHEMBL1552890 & 688721 & 4.6 & 4.9365 & TST \\
\hline CHEMBL1552680 & 688721 & 4.6 & 5.0386 & TRN \\
\hline CHEMBL1530580 & 688721 & 4.4 & 4.9954 & TRN \\
\hline CHEMBL1585261 & 688721 & 6.1 & 5.0097 & TST \\
\hline
\end{tabular}




\begin{tabular}{|c|c|c|c|c|}
\hline & & & ppone & \\
\hline CHEMBL1454439 & 688721 & 5.1 & 5.081 & TST \\
\hline CHEMBL1379048 & 688721 & 4.8 & 4.9525 & TST \\
\hline CHEMBL279998 & 688721 & 5.2 & 5.3011 & TST \\
\hline CHEMBL1384351 & 688721 & 4.5 & 5.0494 & TRN \\
\hline CHEMBL1387162 & 688721 & 4.7 & 4.966 & TRN \\
\hline CHEMBL1589006 & 688721 & 4.4 & 4.9131 & TST \\
\hline CHEMBL1534524 & 688721 & 4.7 & 4.8731 & TRN \\
\hline CHEMBL1372547 & 688721 & 4.7 & 4.9154 & TRN \\
\hline CHEMBL1444035 & 688721 & 4.7 & 4.8626 & TST \\
\hline CHEMBL1406804 & 688721 & 5.3 & 4.9973 & TRN \\
\hline CHEMBL1416537 & 688721 & 5.3 & 4.958 & TRN \\
\hline CHEMBL1595866 & 688721 & 5.0 & 4.9599 & TST \\
\hline CHEMBL1362861 & 688721 & 5.1 & 4.9666 & TRN \\
\hline CHEMBL1454327 & 688721 & 4.6 & 4.917 & TRN \\
\hline CHEMBL1256177 & 688721 & 5.2 & 5.2049 & TST \\
\hline CHEMBL1393191 & 688721 & 4.5 & 4.8948 & TRN \\
\hline CHEMBL1577570 & 688721 & 5.0 & 4.8305 & TRN \\
\hline CHEMBL1340393 & 688721 & 4.4 & 4.6123 & TRN \\
\hline CHEMBL1417716 & 688721 & 5.4 & 4.9704 & TRN \\
\hline CHEMBL1581914 & 688721 & 5.2 & 4.8134 & TRN \\
\hline CHEMBL1485069 & 688721 & 5.2 & 5.1453 & TRN \\
\hline CHEMBL1566365 & 688721 & 4.8 & 4.8355 & TRN \\
\hline CHEMBL1507052 & 688721 & 4.7 & 4.8884 & TRN \\
\hline CHEMBL1390434 & 688721 & 4.6 & 5.0873 & TRN \\
\hline CHEMBL1321518 & 688721 & 5.2 & 4.891 & TST \\
\hline CHEMBL1578407 & 688721 & 4.9 & 4.9028 & TST \\
\hline CHEMBL1546398 & 688721 & 4.5 & 5.0943 & TRN \\
\hline CHEMBL1421762 & 688721 & 4.8 & 4.8299 & TRN \\
\hline CHEMBL1606443 & 688721 & 5.3 & 4.9284 & TRN \\
\hline CHEMBL1452934 & 688721 & 4.8 & 4.8946 & TRN \\
\hline CHEMBL1348071 & 688721 & 4.6 & 5.0352 & TST \\
\hline CHEMBL1305536 & 688721 & 4.4 & 4.8924 & TRN \\
\hline CHEMBL1545426 & 688721 & 4.6 & 4.8884 & TRN \\
\hline CHEMBL1470661 & 688721 & 5.4 & 5.0356 & TST \\
\hline CHEMBL1566472 & 688721 & 4.8 & 4.9999 & TRN \\
\hline CHEMBL1405369 & 688721 & 4.5 & 5.0963 & TST \\
\hline CHEMBL481537 & 688721 & 6.0 & 4.8344 & TST \\
\hline CHEMBL1462823 & 688721 & 4.5 & 4.8456 & TRN \\
\hline CHEMBL1469736 & 688721 & 4.4 & 4.7302 & TRN \\
\hline CHEMBL1311633 & 688721 & 4.7 & 4.8937 & TRN \\
\hline CHEMBL1466437 & 688721 & 4.4 & 4.9574 & TRN \\
\hline CHEMBL1544202 & 688721 & 5.4 & 4.9388 & TRN \\
\hline CHEMBL1425475 & 688721 & 4.8 & 4.6834 & TRN \\
\hline CHEMBL1548088 & 688721 & 4.6 & 4.8291 & TRN \\
\hline CHEMBL1494881 & 688721 & 4.6 & 5.1121 & TST \\
\hline CHEMBL1367220 & 688721 & 7.0 & 5.0091 & TRN \\
\hline CHEMBL1306116 & 688721 & 5.2 & 4.9356 & TRN \\
\hline CHEMBL1488407 & 688721 & 4.8 & 4.8714 & TRN \\
\hline
\end{tabular}




\begin{tabular}{|c|c|c|c|c|c|}
\hline \multicolumn{6}{|c|}{ oplemental Table S } \\
\hline CHEMBL1583079 & 688721 & 4.6 & 4.8791 & TRN & \\
\hline CHEMBL3207830 & 688721 & 4.8 & 4.81 & TST & \\
\hline CHEMBL1402372 & 688721 & 4.6 & 4.9059 & TRN & \\
\hline CHEMBL1584466 & 688721 & 5.2 & 5.0305 & TST & \\
\hline CHEMBL1366393 & 688721 & 4.5 & 4.8645 & TRN & \\
\hline CHEMBL1400176 & 688721 & 4.5 & 4.7002 & TRN & \\
\hline CHEMBL1384133 & 688721 & 4.8 & 4.9374 & TRN & \\
\hline CHEMBL1344893 & 688721 & 4.4 & 5.1206 & TRN & \\
\hline CHEMBL1462234 & 688721 & 4.6 & 4.7333 & TRN & \\
\hline CHEMBL1527407 & 688721 & 5.6 & 4.9716 & TRN & \\
\hline CHEMBL1608801 & 688721 & 4.6 & 5.0525 & TRN & \\
\hline CHEMBL1470050 & 688721 & 4.5 & 4.987 & TRN & \\
\hline CHEMBL1450387 & 688721 & 5.0 & 4.7753 & TRN & \\
\hline CHEMBL1534430 & 688721 & 5.2 & 5.0066 & TRN & \\
\hline CHEMBL1569417 & 688721 & 5.0 & 4.8282 & TRN & \\
\hline CHEMBL1608831 & 688721 & 5.2 & 4.8875 & TST & \\
\hline CHEMBL1318908 & 688721 & 4.9 & 4.8736 & TRN & \\
\hline CHEMBL1502182 & 688721 & 5.1 & 4.9501 & TRN & \\
\hline CHEMBL1611225 & 688721 & 4.4 & 5.1779 & TST & \\
\hline CHEMBL1359750 & 688721 & 4.7 & 4.9712 & TRN & \\
\hline CHEMBL1300634 & 688721 & 4.5 & 4.8636 & TRN & \\
\hline CHEMBL1595142 & 688721 & 6.1 & 5.2436 & TRN & \\
\hline CHEMBL1421666 & 688721 & 6.8 & 4.9391 & TRN & \\
\hline CHEMBL1570523 & 688721 & 5.3 & 4.9792 & TRN & \\
\hline CHEMBL1284 & 688721 & 4.4 & 5.2351 & TRN & \\
\hline CHEMBL1368623 & 688721 & 5.3 & 4.9592 & TST & \\
\hline CHEMBL1398683 & 688721 & 4.4 & 5.0359 & TST & \\
\hline CHEMBL1350377 & 688721 & 7.1002 & 5.0298 & TRN & \\
\hline CHEMBL1366168 & 688721 & 4.4 & 4.9379 & TRN & \\
\hline CHEMBL1182 & 688721 & 8.3979 & 5.2646 & TST & \\
\hline CHEMBL1439291 & 688721 & 4.8 & 4.9696 & TST & \\
\hline CHEMBL1458159 & 688721 & 5.9 & 4.8912 & TRN & \\
\hline CHEMBL1524252 & 688721 & 4.5 & 4.9481 & TST & \\
\hline CHEMBL1447806 & 688721 & 4.6 & 4.8998 & TRN & \\
\hline CHEMBL1543973 & 688721 & 5.9 & 5.01399 & 9999999999 & TRN \\
\hline CHEMBL1344817 & 688721 & 4.5 & 5.0529 & TRN & \\
\hline CHEMBL1599321 & 688721 & 5.3 & 4.9601 & TRN & \\
\hline CHEMBL1344102 & 688721 & 7.6003 & 5.0145 & TST & \\
\hline CHEMBL 8080 & 688721 & 4.4 & 5.2783 & TST & \\
\hline CHEMBL1609528 & 688721 & 5.8 & 5.0686 & TRN & \\
\hline CHEMBL1484743 & 688721 & 4.8 & 4.9953 & TRN & \\
\hline CHEMBL1557211 & 688721 & 4.4 & 4.7657 & TRN & \\
\hline CHEMBL1491183 & 688721 & 5.5 & 4.9543 & TRN & \\
\hline CHEMBL491952 & 688721 & 4.9 & 5.0075 & TRN & \\
\hline CHEMBL1383992 & 688721 & 4.4 & 5.1051 & TRN & \\
\hline CHEMBL1353034 & 688721 & 5.4 & 4.9532 & TRN & \\
\hline CHEMBL1579821 & 688721 & 4.8 & 4.9274 & TST & \\
\hline CHEMBL1576757 & 688721 & 4.9 & 4.8266 & TRN & \\
\hline
\end{tabular}




\begin{tabular}{|c|c|c|c|c|c|}
\hline \multicolumn{6}{|c|}{ Supplemental Table S2.txt } \\
\hline CHEMBL1601416 & 688721 & 4.8 & 5.0142 & TRN & \\
\hline CHEMBL1497269 & 688721 & 4.9 & 4.8538 & TRN & \\
\hline CHEMBL1522688 & 688721 & 4.7 & 4.7057 & TRN & \\
\hline CHEMBL1570735 & 688721 & 5.0 & 5.119 & TRN & \\
\hline CHEMBL1514779 & 688721 & 4.4 & 5.2081 & TRN & \\
\hline CHEMBL1408541 & 688721 & 4.6 & 4.8144 & TRN & \\
\hline CHEMBL1576341 & 688721 & 4.4 & 4.9992 & TST & \\
\hline CHEMBL1456621 & 688721 & 4.8 & 4.7912 & TRN & \\
\hline CHEMBL68230 & 688721 & 5.0 & 4.8191 & TST & \\
\hline CHEMBL1342902 & 688721 & 5.4 & 5.0947 & TRN & \\
\hline CHEMBL1330692 & 688721 & 5.7 & 4.9621 & TRN & \\
\hline CHEMBL1331476 & 688721 & 7.1002 & 5.1134 & TST & \\
\hline CHEMBL1452869 & 688721 & 5.2 & 4.9438 & TRN & \\
\hline CHEMBL1568051 & 688721 & 4.5 & 5.0307 & TST & \\
\hline CHEMBL1346075 & 688721 & 5.5 & 4.8824 & TRN & \\
\hline CHEMBL1369212 & 688721 & 5.1 & 5.0283 & TRN & \\
\hline CHEMBL1560567 & 688721 & 4.8 & 4.9342 & TST & \\
\hline CHEMBL1370907 & 688721 & 4.7 & 4.8556 & TRN & \\
\hline CHEMBL1421883 & 688721 & 5.4 & 4.9378 & TRN & \\
\hline CHEMBL1471577 & 688721 & 5.5 & 4.8636 & TST & \\
\hline CHEMBL1390131 & 688721 & 5.0 & 4.7962 & TRN & \\
\hline CHEMBL1582536 & 688721 & 5.2 & 4.8438 & TRN & \\
\hline CHEMBL1596384 & 688721 & 5.3 & 4.9086 & TRN & \\
\hline CHEMBL1500025 & 688721 & 5.1 & 4.9189 & TRN & \\
\hline CHEMBL1511152 & 688721 & 4.6 & 4.9617 & TRN & \\
\hline CHEMBL1520601 & 688721 & 4.7 & 4.8976 & TST & \\
\hline CHEMBL1605878 & 688721 & 5.0 & 4.9119 & TRN & \\
\hline CHEMBL3195844 & 688721 & 4.5 & 4.891 & TST & \\
\hline CHEMBL1351093 & 688721 & 6.5 & 5.074 & TST & \\
\hline CHEMBL1422866 & 688721 & 4.7 & 4.7793 & TRN & \\
\hline CHEMBL1502467 & 688721 & 4.6 & 4.6361 & TRN & \\
\hline CHEMBL1550596 & 688721 & 4.5 & 5.0345 & TST & \\
\hline CHEMBL1361021 & 688721 & 5.3 & 5.04899 & 99999999995 & TRN \\
\hline CHEMBL1350617 & 688721 & 4.9 & 5.1045 & TRN & \\
\hline CHEMBL1581244 & 688721 & 4.5 & 4.8076 & TRN & \\
\hline CHEMBL1581085 & 688721 & 4.4 & 4.7361 & TRN & \\
\hline CHEMBL1300414 & 688721 & 5.3 & 4.9498 & TST & \\
\hline CHEMBL1546788 & 688721 & 5.1 & 4.8489 & TRN & \\
\hline CHEMBL1565242 & 688721 & 5.4 & 4.8899 & TST & \\
\hline CHEMBL1570042 & 688721 & 7.0 & 4.7438 & TRN & \\
\hline CHEMBL 2002776 & 688721 & 4.8 & 4.8445 & TRN & \\
\hline CHEMBL1342678 & 688721 & 4.7 & 5.0084 & TRN & \\
\hline CHEMBL1495071 & 688721 & 4.4 & 4.9327 & TST & \\
\hline CHEMBL1400094 & 688721 & 7.6003 & 5.0532 & TRN & \\
\hline CHEMBL1256695 & 688721 & 4.5 & 5.0609 & TST & \\
\hline CHEMBL1538037 & 688721 & 4.9 & 4.7346 & TRN & \\
\hline CHEMBL 3212480 & 688721 & 4.8 & 5.0424 & TRN & \\
\hline CHEMBL1505210 & 688721 & 5.4 & 4.9022 & TRN & \\
\hline
\end{tabular}




\begin{tabular}{|c|c|c|c|c|}
\hline \multicolumn{5}{|c|}{ Supplemental Tab } \\
\hline CHEMBL1608168 & 688721 & 4.7 & 4.6349 & TRN \\
\hline CHEMBL1472444 & 688721 & 4.6 & 4.8316 & TRN \\
\hline CHEMBL1390677 & 688721 & 4.6 & 4.975 & TRN \\
\hline CHEMBL1519704 & 688721 & 4.7 & 4.9199 & TST \\
\hline CHEMBL1386805 & 688721 & 4.4 & 4.9627 & TRN \\
\hline CHEMBL1340404 & 688721 & 5.3 & 5.1542 & TST \\
\hline CHEMBL1579038 & 688721 & 4.6 & 5.1029 & TRN \\
\hline CHEMBL1438930 & 688721 & 5.2 & 5.0159 & TRN \\
\hline CHEMBL1386004 & 688721 & 4.6 & 4.8174 & TST \\
\hline CHEMBL1440166 & 688721 & 4.4 & 4.6773 & TRN \\
\hline CHEMBL 1353545 & 688721 & 5.2 & 4.8527 & TRN \\
\hline CHEMBL1338528 & 688721 & 4.7 & 4.9074 & TST \\
\hline CHEMBL1313522 & 688721 & 5.3 & 4.8227 & TRN \\
\hline CHEMBL1304738 & 688721 & 4.6 & 4.7127 & TRN \\
\hline CHEMBL1438048 & 688721 & 4.4 & 4.9434 & TRN \\
\hline CHEMBL1369815 & 688721 & 4.8 & 4.9549 & TST \\
\hline CHEMBL1463280 & 688721 & 4.6 & 4.8719 & TRN \\
\hline CHEMBL1532219 & 688721 & 4.4 & 4.8804 & TRN \\
\hline CHEMBL1320847 & 688721 & 4.5 & 4.9396 & TRN \\
\hline CHEMBL1500931 & 688721 & 4.7 & 4.9545 & TRN \\
\hline CHEMBL 1505662 & 688721 & 5.5 & 5.0647 & TRN \\
\hline CHEMBL1302088 & 688721 & 5.2 & 5.0749 & TRN \\
\hline CHEMBL1509744 & 688721 & 4.6 & 4.9468 & TRN \\
\hline CHEMBL1412651 & 688721 & 5.2 & 4.9353 & TRN \\
\hline CHEMBL1431034 & 688721 & 5.1 & 4.8846 & TRN \\
\hline CHEMBL1347430 & 688721 & 4.4 & 4.9082 & TRN \\
\hline CHEMBL1524953 & 688721 & 5.2 & 4.8572 & TRN \\
\hline CHEMBL1407294 & 688721 & 4.8 & 4.8425 & TRN \\
\hline CHEMBL1322756 & 688721 & 4.8 & 4.9896 & TRN \\
\hline CHEMBL1466679 & 688721 & 4.5 & 4.925 & TRN \\
\hline CHEMBL1431172 & 688721 & 4.7 & 4.7468 & TST \\
\hline CHEMBL1434334 & 688721 & 4.4 & 5.3764 & TST \\
\hline CHEMBL1376926 & 688721 & 4.6 & 4.9367 & TST \\
\hline CHEMBL1466951 & 688721 & 4.8 & 4.927 & TRN \\
\hline CHEMBL1272096 & 688721 & 4.7 & 4.8286 & TRN \\
\hline CHEMBL513116 & 688721 & 4.5 & 5.1302 & TRN \\
\hline CHEMBL1589088 & 688721 & 4.8 & 4.9392 & TST \\
\hline CHEMBL1442912 & 688721 & 6.2 & 5.0139 & TRN \\
\hline CHEMBL1429819 & 688721 & 4.5 & 4.7937 & TRN \\
\hline CHEMBL1465588 & 688721 & 5.4 & 4.9439 & TRN \\
\hline CHEMBL1605605 & 688721 & 6.0 & 5.0541 & TST \\
\hline CHEMBL1567121 & 688721 & 4.4 & 4.9533 & TRN \\
\hline CHEMBL1403333 & 688721 & 4.7 & 4.9986 & TRN \\
\hline CHEMBL1449244 & 688721 & 4.5 & 5.0365 & TRN \\
\hline CHEMBL1316516 & 688721 & 4.6 & 5.1946 & TRN \\
\hline CHEMBL1440656 & 688721 & 4.4 & 4.8878 & TRN \\
\hline CHEMBL1368561 & 688721 & 4.4 & 5.0691 & TRN \\
\hline CHEMBL1528446 & 688721 & 4.5 & 5.0437 & TST \\
\hline
\end{tabular}




\begin{tabular}{|c|c|c|c|c|}
\hline \multicolumn{5}{|c|}{ ptemetras } \\
\hline CHEMBL1502880 & 688721 & 6.3 & 4.9946 & TST \\
\hline CHEMBL1440688 & 688721 & 4.8 & 4.9481 & TRN \\
\hline CHEMBL7162 & 688721 & 4.4 & 5.0339 & TST \\
\hline CHEMBL1563783 & 688721 & 4.7 & 5.0418 & TRN \\
\hline CHEMBL1606151 & 688721 & 5.3 & 4.9577 & TRN \\
\hline CHEMBL1612774 & 688721 & 4.5 & 4.9749 & TST \\
\hline CHEMBL1605795 & 688721 & 4.9 & 4.9326 & TRN \\
\hline CHEMBL1404612 & 688721 & 4.4 & 4.9545 & TST \\
\hline CHEMBL1300731 & 688721 & 4.8 & 4.8067 & TRN \\
\hline CHEMBL1590645 & 688721 & 4.4 & 5.1834 & TRN \\
\hline CHEMBL1325660 & 688721 & 4.6 & 4.9811 & TRN \\
\hline CHEMBL1394698 & 688721 & 4.5 & 5.0099 & TRN \\
\hline CHEMBL1379111 & 688721 & 4.4 & 5.0513 & TST \\
\hline CHEMBL1382260 & 688721 & 4.7 & 5.0383 & TST \\
\hline CHEMBL1522662 & 688721 & 4.4 & 4.8659 & TRN \\
\hline CHEMBL1334208 & 688721 & 4.4 & 4.8419 & TRN \\
\hline CHEMBL1568476 & 688721 & 4.4 & 4.9539 & TRN \\
\hline CHEMBL1521379 & 688721 & 4.6 & 4.9138 & TRN \\
\hline CHEMBL1324970 & 688721 & 5.3 & 4.7928 & TRN \\
\hline CHEMBL1547953 & 688721 & 4.8 & 4.8322 & TRN \\
\hline CHEMBL1342687 & 688721 & 5.2 & 4.8147 & TRN \\
\hline CHEMBL1532597 & 688721 & 6.0 & 5.1371 & TRN \\
\hline CHEMBL1590663 & 688721 & 4.4 & 5.1399 & TRN \\
\hline CHEMBL3194619 & 688721 & 5.4 & 4.9488 & TRN \\
\hline CHEMBL1447630 & 688721 & 5.9 & 5.0442 & TST \\
\hline CHEMBL1425011 & 688721 & 4.4 & 5.0917 & TST \\
\hline CHEMBL1392276 & 688721 & 5.2 & 4.8989 & TRN \\
\hline CHEMBL1449457 & 688721 & 5.4 & 5.1577 & TST \\
\hline CHEMBL1484134 & 688721 & 6.4 & 5.0992 & TRN \\
\hline CHEMBL602481 & 688721 & 5.1 & 5.0004 & TST \\
\hline CHEMBL1529669 & 688721 & 4.8 & 4.8342 & TRN \\
\hline CHEMBL1436925 & 688721 & 5.2 & 4.8198 & TRN \\
\hline CHEMBL1504386 & 688721 & 4.8 & 4.8078 & TRN \\
\hline CHEMBL1547047 & 688721 & 4.4 & 4.8192 & TRN \\
\hline CHEMBL1423124 & 688721 & 4.9 & 5.0828 & TRN \\
\hline CHEMBL1351095 & 688721 & 4.7 & 4.7315 & TRN \\
\hline CHEMBL1449584 & 688721 & 5.4 & 4.731 & TST \\
\hline CHEMBL1591140 & 688721 & 4.5 & 4.9168 & TRN \\
\hline CHEMBL1373893 & 688721 & 4.4 & 5.0584 & TST \\
\hline CHEMBL1337450 & 688721 & 5.2 & 4.729 & TRN \\
\hline CHEMBL1326512 & 688721 & 5.0 & 4.9895 & TRN \\
\hline CHEMBL1423146 & 688721 & 4.9 & 4.974 & TRN \\
\hline CHEMBL1582263 & 688721 & 4.5 & 4.9212 & TRN \\
\hline CHEMBL1402593 & 688721 & 5.3 & 4.8819 & TRN \\
\hline CHEMBL492719 & 688721 & 4.4 & 4.9808 & TRN \\
\hline CHEMBL1586875 & 688721 & 4.5 & 4.8372 & TRN \\
\hline CHEMBL1479715 & 688721 & 5.4 & 4.9214 & TRN \\
\hline CHEMBL1304951 & 688721 & 4.7 & 4.9026 & TRN \\
\hline
\end{tabular}




\begin{tabular}{|c|c|c|c|c|c|}
\hline \multicolumn{6}{|c|}{ Supplemental Table s2.txt } \\
\hline CHEMBL1523881 & 688721 & 4.9 & 5.0363 & TRN & \\
\hline CHEMBL1604212 & 688721 & 4.4 & 4.8663 & TRN & \\
\hline CHEMBL164841 & 688721 & 4.5 & 4.7876 & TRN & \\
\hline CHEMBL1510406 & 688721 & 7.8996 & 5.1809 & TST & \\
\hline CHEMBL1380859 & 688721 & 4.8 & 4.7469 & TRN & \\
\hline CHEMBL1560952 & 688721 & 4.5 & 5.0863 & TST & \\
\hline CHEMBL1467444 & 688721 & 4.9 & 4.7861 & TRN & \\
\hline CHEMBL1501066 & 688721 & 4.9 & 4.9809 & TRN & \\
\hline CHEMBL1398965 & 688721 & 5.4 & 4.9247 & TRN & \\
\hline CHEMBL1539698 & 688721 & 4.7 & 4.7934 & TRN & \\
\hline CHEMBL1599783 & 688721 & 5.2 & 4.8986 & TST & \\
\hline CHEMBL1378030 & 688721 & 4.8 & 4.9958 & TRN & \\
\hline CHEMBL1490602 & 688721 & 5.3 & 4.9413 & TRN & \\
\hline CHEMBL1361725 & 688721 & 4.9 & 5.0562 & TRN & \\
\hline CHEMBL1323038 & 688721 & 4.6 & 5.0214 & TST & \\
\hline CHEMBL3210187 & 688721 & 4.4 & 5.0642 & TST & \\
\hline CHEMBL1601133 & 688721 & 4.8 & 4.99100 & 00000000005 & TST \\
\hline CHEMBL1595944 & 688721 & 4.9 & 4.9615 & TRN & \\
\hline CHEMBL1489445 & 688721 & 4.6 & 5.1693 & TST & \\
\hline CHEMBL1507334 & 688721 & 4.9 & 4.8951 & TRN & \\
\hline CHEMBL1449282 & 688721 & 4.6 & 4.9923 & TRN & \\
\hline CHEMBL1353585 & 688721 & 4.5 & 5.0883 & TRN & \\
\hline CHEMBL1468865 & 688721 & 4.9 & 4.7673 & TRN & \\
\hline CHEMBL263116 & 688721 & 4.9 & 4.9844 & TRN & \\
\hline CHEMBL1544491 & 688721 & 5.4 & 5.059 & TRN & \\
\hline CHEMBL1363006 & 688721 & 4.9 & 4.999 & TRN & \\
\hline CHEMBL1351330 & 688721 & 5.1 & 5.1405 & TRN & \\
\hline CHEMBL1507842 & 688721 & 5.2 & 4.9241 & TRN & \\
\hline CHEMBL1366106 & 688721 & 5.5 & 5.1088 & TRN & \\
\hline CHEMBL1483354 & 688721 & 7.0 & 5.2082 & TRN & \\
\hline CHEMBL1341055 & 688721 & 4.6 & 4.8068 & TRN & \\
\hline CHEMBL185885 & 688721 & 5.1 & 5.0927 & TST & \\
\hline CHEMBL1574400 & 688721 & 4.9 & 4.9986 & TRN & \\
\hline CHEMBL1352741 & 688721 & 4.4 & 4.7828 & TRN & \\
\hline CHEMBL1503046 & 688721 & 4.8 & 4.9236 & TRN & \\
\hline CHEMBL1583499 & 688721 & 4.7 & 4.8652 & TRN & \\
\hline CHEMBL347862 & 688721 & 4.5 & 5.2583 & TST & \\
\hline CHEMBL1353297 & 688721 & 4.7 & 4.843 & TST & \\
\hline CHEMBL1439356 & 688721 & 4.8 & 4.8699 & TRN & \\
\hline CHEMBL1441317 & 688721 & 4.4 & 4.9065 & TRN & \\
\hline CHEMBL1535332 & 688721 & 4.7 & 4.8662 & TRN & \\
\hline CHEMBL1471344 & 688721 & 5.0 & 4.8174 & TRN & \\
\hline CHEMBL1333783 & 688721 & 5.2 & 5.0609 & TRN & \\
\hline CHEMBL1391265 & 688721 & 4.6 & 4.8135 & TRN & \\
\hline CHEMBL1980844 & 688721 & 5.1 & 5.1832 & TST & \\
\hline CHEMBL1533014 & 688721 & 6.2 & 4.9245 & TRN & \\
\hline CHEMBL3211670 & 688721 & 4.7 & 5.0043 & TST & \\
\hline CHEMBL1327501 & 688721 & 5.0 & 4.8268 & TST & \\
\hline
\end{tabular}




\begin{tabular}{|c|c|c|c|c|c|}
\hline \multirow{2}{*}{ CHEMBL1603246 } & \multirow[b]{2}{*}{688721} & \multicolumn{4}{|c|}{ Supplemental Table S2.txt } \\
\hline & & 4.7 & 4.8256 & TST & \\
\hline CHEMBL1546956 & 688721 & 4.5 & 4.8433 & TRN & \\
\hline CHEMBL1541257 & 688721 & 4.7 & 4.90300 & 00000000005 & TST \\
\hline CHEMBL1351431 & 688721 & 5.3 & 4.7697 & TRN & \\
\hline CHEMBL1413793 & 688721 & 5.5 & 4.913 & TRN & \\
\hline CHEMBL1418726 & 688721 & 5.5 & 5.1759 & TRN & \\
\hline CHEMBL1353146 & 688721 & 4.9 & 4.9611 & TST & \\
\hline CHEMBL1336243 & 688721 & 5.2 & 4.8922 & TRN & \\
\hline CHEMBL1538857 & 688721 & 5.4 & 5.0024 & TST & \\
\hline CHEMBL1488786 & 688721 & 4.5 & 4.9265 & TST & \\
\hline CHEMBL1606181 & 688721 & 4.4 & 4.888 & TST & \\
\hline CHEMBL1419608 & 688721 & 6.3 & 4.7748 & TRN & \\
\hline CHEMBL1488451 & 688721 & 4.6 & 5.0358 & TRN & \\
\hline CHEMBL 3189828 & 688721 & 4.5 & 5.0229 & TRN & \\
\hline CHEMBL1372207 & 688721 & 4.6 & 5.0931 & TST & \\
\hline CHEMBL1507290 & 688721 & 4.8 & 4.7703 & TRN & \\
\hline CHEMBL1495244 & 688721 & 4.6 & 4.8352 & TRN & \\
\hline CHEMBL 293341 & 688721 & 4.5 & 4.8588 & TST & \\
\hline CHEMBL1529399 & 688721 & 4.5 & 5.0222 & TRN & \\
\hline CHEMBL1408055 & 688721 & 5.2 & 4.8989 & TRN & \\
\hline CHEMBL1582753 & 688721 & 6.4 & 4.8284 & TRN & \\
\hline CHEMBL1313315 & 688721 & 7.5003 & 5.0215 & TST & \\
\hline CHEMBL1576586 & 688721 & 5.5 & 4.9778 & TRN & \\
\hline CHEMBL 2002522 & 688721 & 4.4 & 4.9404 & TST & \\
\hline CHEMBL1469518 & 688721 & 4.6 & 4.9056 & TRN & \\
\hline CHEMBL1335166 & 688721 & 4.6 & 4.7959 & TRN & \\
\hline CHEMBL1566219 & 688721 & 5.2 & 5.1336 & TST & \\
\hline CHEMBL1356094 & 688721 & 4.4 & 5.1062 & TRN & \\
\hline CHEMBL1607024 & 688721 & 4.8 & 4.7141 & TRN & \\
\hline CHEMBL1334962 & 688721 & 4.5 & 4.7171 & TST & \\
\hline CHEMBL1416450 & 688721 & 5.9 & 5.0208 & TRN & \\
\hline CHEMBL1600878 & 688721 & 5.1 & 4.912 & TST & \\
\hline CHEMBL1365382 & 688721 & 5.9 & 4.8162 & TRN & \\
\hline CHEMBL1448726 & 688721 & 4.7 & 5.1799 & TRN & \\
\hline CHEMBL1586929 & 688721 & 4.9 & 4.808 & TST & \\
\hline CHEMBL1507850 & 688721 & 4.5 & 4.9359 & TRN & \\
\hline CHEMBL1471031 & 688721 & 4.4 & 4.8364 & TRN & \\
\hline CHEMBL1563352 & 688721 & 4.4 & 5.2871 & TST & \\
\hline CHEMBL1373595 & 688721 & 5.9 & 4.8471 & TRN & \\
\hline CHEMBL1456892 & 688721 & 5.0 & 5.2322 & TST & \\
\hline CHEMBL1444186 & 688721 & 4.4 & 5.0878 & TRN & \\
\hline CHEMBL1481034 & 688721 & 4.4 & 4.9264 & TST & \\
\hline CHEMBL1430610 & 688721 & 4.8 & 4.9467 & TRN & \\
\hline CHEMBL1499801 & 688721 & 4.4 & 4.9017 & TRN & \\
\hline CHEMBL1415251 & 688721 & 5.1 & 4.9353 & TRN & \\
\hline CHEMBL1476266 & 688721 & 5.9 & 5.0698 & TRN & \\
\hline CHEMBL1487748 & 688721 & 5.0 & 5.1023 & TRN & \\
\hline CHEMBL1343186 & 688721 & 4.8 & 4.82100 & $\partial 000000001$ & TRN \\
\hline & & & & e 8944 & \\
\hline
\end{tabular}




\begin{tabular}{|c|c|c|c|c|}
\hline & & & oplement & al lable s \\
\hline CHEMBL1426683 & 688721 & 4.4 & 4.9191 & TRN \\
\hline CHEMBL1528419 & 688721 & 4.6 & 5.1337 & TST \\
\hline CHEMBL1427602 & 688721 & 5.0 & 4.8434 & TRN \\
\hline CHEMBL1495677 & 688721 & 4.5 & 4.8034 & TST \\
\hline CHEMBL1323134 & 688721 & 4.5 & 4.7928 & TRN \\
\hline CHEMBL1502861 & 688721 & 4.4 & 4.86100 & 0000000001 \\
\hline CHEMBL206483 & 688721 & 4.6 & 4.9911 & TRN \\
\hline CHEMBL1527727 & 688721 & 4.8 & 4.8842 & TRN \\
\hline CHEMBL1491790 & 688721 & 5.4 & 4.9466 & TRN \\
\hline CHEMBL3190178 & 688721 & 5.5 & 4.791 & TRN \\
\hline CHEMBL1309335 & 688721 & 4.6 & 4.7725 & TRN \\
\hline CHEMBL1331872 & 688721 & 4.5 & 4.7249 & TRN \\
\hline CHEMBL1379776 & 688721 & 4.6 & 4.8216 & TRN \\
\hline CHEMBL1442918 & 688721 & 4.5 & 4.8308 & TRN \\
\hline CHEMBL1486250 & 688721 & 4.5 & 4.998 & TRN \\
\hline CHEMBL1571785 & 688721 & 4.9 & 5.1168 & TST \\
\hline CHEMBL1497393 & 688721 & 5.5 & 4.9552 & TST \\
\hline CHEMBL1413172 & 688721 & 4.6 & 4.8336 & TRN \\
\hline CHEMBL1423050 & 688721 & 5.0 & 4.9276 & TRN \\
\hline CHEMBL1504303 & 688721 & 4.7 & 4.8388 & TRN \\
\hline CHEMBL1557919 & 688721 & 4.5 & 4.8762 & TRN \\
\hline CHEMBL1581943 & 688721 & 4.5 & 4.7774 & TRN \\
\hline CHEMBL1398863 & 688721 & 4.4 & 5.1291 & TST \\
\hline CHEMBL1557265 & 688721 & 4.5 & 4.9375 & TRN \\
\hline CHEMBL1338378 & 688721 & 4.9 & 4.9904 & TRN \\
\hline CHEMBL1583032 & 688721 & 4.4 & 4.7585 & TRN \\
\hline CHEMBL1309175 & 688721 & 4.6 & 4.9077 & TRN \\
\hline CHEMBL1467942 & 688721 & 5.1 & 4.8644 & TST \\
\hline CHEMBL1503621 & 688721 & 4.4 & 4.9161 & TRN \\
\hline CHEMBL1504843 & 688721 & 4.8 & 5.1205 & TRN \\
\hline CHEMBL1480347 & 688721 & 4.4 & 4.923 & TST \\
\hline CHEMBL1311410 & 688721 & 5.3 & 4.9734 & TRN \\
\hline CHEMBL1464245 & 688721 & 4.6 & 4.9314 & TRN \\
\hline CHEMBL1567345 & 688721 & 4.9 & 5.0136 & TST \\
\hline CHEMBL1332958 & 688721 & 4.4 & 4.8149 & TST \\
\hline CHEMBL1433225 & 688721 & 4.6 & 4.9425 & TRN \\
\hline CHEMBL1517935 & 688721 & 4.6 & 5.2024 & TRN \\
\hline CHEMBL1438772 & 688721 & 4.6 & 4.9261 & TRN \\
\hline CHEMBL1576463 & 688721 & 4.9 & 4.8606 & TRN \\
\hline CHEMBL1478450 & 688721 & 4.4 & 4.7735 & TRN \\
\hline CHEMBL1565342 & 688721 & 4.8 & 4.9729 & TRN \\
\hline CHEMBL1377576 & 688721 & 4.7 & 4.8769 & TRN \\
\hline CHEMBL1444544 & 688721 & 5.4 & 4.949 & TRN \\
\hline CHEMBL1310871 & 688721 & 5.4 & 4.9376 & TST \\
\hline CHEMBL1481374 & 688721 & 4.5 & 4.7012 & TRN \\
\hline CHEMBL1365850 & 688721 & 4.4 & 4.9555 & TST \\
\hline CHEMBL1370759 & 688721 & 4.6 & 4.851 & TRN \\
\hline CHEMBL1578769 & 688721 & 6.1 & 4.9128 & TRN \\
\hline
\end{tabular}

TRN 


\begin{tabular}{|c|c|c|c|c|c|}
\hline \multicolumn{6}{|c|}{ plemental labıe S2 } \\
\hline CHEMBL1569099 & 688721 & 4.9 & 4.8214 & TRN & \\
\hline CHEMBL1513115 & 688721 & 5.9 & 5.0696 & TRN & \\
\hline CHEMBL1389863 & 688721 & 4.5 & 4.943006 & 00000000005 & TST \\
\hline CHEMBL1313249 & 688721 & 4.5 & 4.9204 & TRN & \\
\hline CHEMBL1555657 & 688721 & 4.5 & 4.7734 & TRN & \\
\hline CHEMBL1573243 & 688721 & 5.1 & 4.7843 & TRN & \\
\hline CHEMBL1365959 & 688721 & 4.8 & 4.7695 & TRN & \\
\hline CHEMBL1543813 & 688721 & 4.6 & 4.867 & TRN & \\
\hline CHEMBL1506228 & 688721 & 7.8996 & 5.2416 & TST & \\
\hline CHEMBL1329152 & 688721 & 4.4 & 5.0061 & TRN & \\
\hline CHEMBL1321642 & 688721 & 4.9 & 4.9784 & TST & \\
\hline CHEMBL1470593 & 688721 & 4.5 & 4.907 & TST & \\
\hline CHEMBL 290426 & 688721 & 5.4 & 5.1425 & TRN & \\
\hline CHEMBL1381306 & 688721 & 4.6 & 4.9472 & TST & \\
\hline CHEMBL1319702 & 688721 & 4.5 & 4.9043 & TRN & \\
\hline CHEMBL1566764 & 688721 & 4.5 & 4.9268 & TRN & \\
\hline CHEMBL1422602 & 688721 & 4.6 & 4.8931 & TRN & \\
\hline CHEMBL1382618 & 688721 & 5.4 & 4.9419 & TRN & \\
\hline CHEMBL1334578 & 688721 & 4.6 & 4.9394 & TST & \\
\hline CHEMBL1502576 & 688721 & 4.6 & 4.7961 & TRN & \\
\hline CHEMBL1358796 & 688721 & 5.9 & 4.9347 & TRN & \\
\hline CHEMBL1566382 & 688721 & 4.4 & 4.91100 & 00000000005 & TRN \\
\hline CHEMBL1330440 & 688721 & 4.6 & 5.1963 & TST & \\
\hline CHEMBL1562961 & 688721 & 4.5 & 5.0329 & TST & \\
\hline CHEMBL1491012 & 688721 & 4.5 & 5.0251 & TRN & \\
\hline CHEMBL1420707 & 688721 & 5.2 & 4.8543 & TRN & \\
\hline CHEMBL1377338 & 688721 & 4.4 & 5.1034 & TRN & \\
\hline CHEMBL1387942 & 688721 & 4.7 & 4.9544 & TRN & \\
\hline CHEMBL1402559 & 688721 & 4.9 & 5.0078 & TRN & \\
\hline CHEMBL1489704 & 688721 & 4.5 & 4.9336 & TRN & \\
\hline CHEMBL1319393 & 688721 & 5.2 & 4.9308 & TRN & \\
\hline CHEMBL1444971 & 688721 & 4.8 & 4.9659 & TRN & \\
\hline CHEMBL1608197 & 688721 & 5.9 & 5.2502 & TST & \\
\hline CHEMBL1446306 & 688721 & 4.6 & 4.8708 & TRN & \\
\hline CHEMBL1583976 & 688721 & 4.7 & 4.9092 & TRN & \\
\hline CHEMBL1374715 & 688721 & 4.4 & 4.8211 & TRN & \\
\hline CHEMBL1386945 & 688721 & 4.6 & 4.8267 & TRN & \\
\hline CHEMBL3197840 & 688721 & 4.5 & 5.0257 & TRN & \\
\hline CHEMBL1607693 & 688721 & 5.0 & 4.8682 & TRN & \\
\hline CHEMBL44228 & 688721 & 4.9 & 5.1015 & TST & \\
\hline CHEMBL1477636 & 688721 & 5.3 & 4.9062 & TRN & \\
\hline CHEMBL1499181 & 688721 & 4.5 & 5.0476 & TRN & \\
\hline CHEMBL1419613 & 688721 & 4.5 & 4.8191 & TRN & \\
\hline CHEMBL1394464 & 688721 & 4.6 & 4.9922 & TST & \\
\hline CHEMBL1325100 & 688721 & 6.8 & 4.9821 & TRN & \\
\hline CHEMBL1390787 & 688721 & 5.4 & 4.8987 & TST & \\
\hline CHEMBL1541866 & 688721 & 5.5 & 4.8825 & TRN & \\
\hline CHEMBL1421962 & 688721 & 4.7 & 4.9601 & TRN & \\
\hline
\end{tabular}




\begin{tabular}{|c|c|c|c|c|c|}
\hline \\
\hline CHEMBL1317461 & 688721 & 4.7 & 4.9495 & TRN & \\
\hline CHEMBL1540900 & 688721 & 4.4 & 4.89199 & 99999999995 & TRN \\
\hline CHEMBL1571364 & 688721 & 4.8 & 4.8659 & TRN & \\
\hline CHEMBL257856 & 688721 & 4.6 & 4.7368 & TRN & \\
\hline CHEMBL1448862 & 688721 & 4.4 & 4.9135 & TRN & \\
\hline CHEMBL1465349 & 688721 & 5.1 & 5.0832 & TRN & \\
\hline CHEMBL1555925 & 688721 & 4.9 & 4.916 & TRN & \\
\hline CHEMBL1600727 & 688721 & 4.5 & 4.6867 & TRN & \\
\hline CHEMBL1431063 & 688721 & 5.1 & 4.9346 & TRN & \\
\hline CHEMBL1499247 & 688721 & 4.4 & 4.7262 & TRN & \\
\hline CHEMBL1441062 & 688721 & 5.1 & 4.7893 & TRN & \\
\hline CHEMBL1399493 & 688721 & 4.7 & 5.0409 & TRN & \\
\hline CHEMBL1357347 & 688721 & 4.8 & 4.9172 & TRN & \\
\hline CHEMBL1503235 & 688721 & 5.1 & 5.1704 & TST & \\
\hline CHEMBL1311267 & 688721 & 4.5 & 5.037 & TRN & \\
\hline CHEMBL1385428 & 688721 & 4.8 & 4.8296 & TRN & \\
\hline CHEMBL1529898 & 688721 & 4.6 & 4.788 & TRN & \\
\hline CHEMBL1323587 & 688721 & 4.4 & 4.9427 & TRN & \\
\hline CHEMBL1256647 & 688721 & 6.2 & 4.9235 & TST & \\
\hline CHEMBL1572198 & 688721 & 4.7 & 5.0002 & TRN & \\
\hline CHEMBL1316292 & 688721 & 4.7 & 4.9291 & TRN & \\
\hline CHEMBL1300285 & 688721 & 5.1 & 4.9512 & TRN & \\
\hline CHEMBL1332305 & 688721 & 4.4 & 4.8225 & TRN & \\
\hline CHEMBL1373569 & 688721 & 5.5 & 4.8256 & TRN & \\
\hline CHEMBL1534480 & 688721 & 5.1 & 5.0253 & TST & \\
\hline CHEMBL1361411 & 688721 & 4.4 & 4.9061 & TST & \\
\hline CHEMBL1534639 & 688721 & 4.5 & 4.9024 & TST & \\
\hline CHEMBL1491836 & 688721 & 4.5 & 5.0548 & TRN & \\
\hline CHEMBL1494329 & 688721 & 4.6 & 4.8918 & TRN & \\
\hline CHEMBL1460741 & 688721 & 4.4 & 4.7873 & TRN & \\
\hline CHEMBL1487963 & 688721 & 4.5 & 4.745 & TRN & \\
\hline CHEMBL1563284 & 688721 & 4.8 & 4.8166 & TRN & \\
\hline CHEMBL1598952 & 688721 & 6.5 & 4.9788 & TRN & \\
\hline CHEMBL1488392 & 688721 & 4.5 & 4.8845 & TRN & \\
\hline CHEMBL1461122 & 688721 & 6.0 & 5.0518 & TRN & \\
\hline CHEMBL1453232 & 688721 & 4.6 & 4.8192 & TRN & \\
\hline CHEMBL1612873 & 688721 & 4.8 & 4.7308 & TRN & \\
\hline CHEMBL1569907 & 688721 & 4.7 & 4.7409 & TRN & \\
\hline CHEMBL1331148 & 688721 & 4.4 & 5.1302 & TRN & \\
\hline CHEMBL1570351 & 688721 & 4.6 & 4.8916 & TRN & \\
\hline CHEMBL1402143 & 688721 & 5.3 & 4.9884 & TRN & \\
\hline CHEMBL1397322 & 688721 & 4.8 & 5.1613 & TRN & \\
\hline CHEMBL1339079 & 688721 & 4.9 & 4.8115 & TRN & \\
\hline CHEMBL1421386 & 688721 & 5.0 & 4.8654 & TRN & \\
\hline CHEMBL34450 & 688721 & 4.5 & 4.92 & TST & \\
\hline CHEMBL1515001 & 688721 & 6.0 & 5.056 & TST & \\
\hline CHEMBL1576783 & 688721 & 4.4 & 4.8337 & TST & \\
\hline CHEMBL1407527 & 688721 & 4.7 & 5.1304 & TRN & \\
\hline
\end{tabular}




\begin{tabular}{|c|c|c|c|c|c|}
\hline \\
\hline CHEMBL1387314 & 688721 & 4.6 & 4.7843 & TRN & \\
\hline CHEMBL1504749 & 688721 & 4.8 & 5.0731 & TRN & \\
\hline CHEMBL1522189 & 688721 & 4.4 & 5.3253 & TST & \\
\hline CHEMBL1304255 & 688721 & 4.9 & 4.8875 & TRN & \\
\hline CHEMBL235260 & 688721 & 4.5 & 4.853 & TST & \\
\hline CHEMBL1558607 & 688721 & 4.4 & 4.9327 & TRN & \\
\hline CHEMBL1526813 & 688721 & 5.8 & 5.0042 & TST & \\
\hline CHEMBL1498363 & 688721 & 6.1 & 4.9851 & TST & \\
\hline CHEMBL1380395 & 688721 & 5.0 & 4.9999 & TRN & \\
\hline CHEMBL1383479 & 688721 & 5.5 & 5.0332 & TRN & \\
\hline CHEMBL1520230 & 688721 & 5.3 & 5.1022 & TST & \\
\hline CHEMBL1533636 & 688721 & 5.4 & 4.8352 & TST & \\
\hline CHEMBL1364507 & 688721 & 4.6 & 4.827 & TST & \\
\hline CHEMBL 3208324 & 688721 & 4.6 & 4.7433 & TRN & \\
\hline CHEMBL1460378 & 688721 & 5.4 & 5.09 & TRN & \\
\hline CHEMBL1347536 & 688721 & 4.6 & 4.9774 & TST & \\
\hline CHEMBL1331105 & 688721 & 4.9 & 5.2175 & TST & \\
\hline CHEMBL1350615 & 688721 & 5.4 & 4.94306 & 20000000005 & TRN \\
\hline CHEMBL1443543 & 688721 & 5.2 & 4.9516 & TRN & \\
\hline CHEMBL1341867 & 688721 & 4.6 & 4.9655 & TRN & \\
\hline CHEMBL1451248 & 688721 & 5.1 & 4.9836 & TST & \\
\hline CHEMBL3208870 & 688721 & 5.2 & 4.8631 & TST & \\
\hline CHEMBL1408013 & 688721 & 6.0 & 4.9821 & TRN & \\
\hline CHEMBL1577559 & 688721 & 4.4 & 5.0482 & TST & \\
\hline CHEMBL1594554 & 688721 & 4.7 & 4.8691 & TRN & \\
\hline CHEMBL137648 & 688721 & 4.4 & 5.025 & TST & \\
\hline CHEMBL1441799 & 688721 & 5.3 & 5.0848 & TST & \\
\hline CHEMBL1409381 & 688721 & 4.6 & 4.8661 & TRN & \\
\hline CHEMBL1374799 & 688721 & 5.4 & 5.1211 & TRN & \\
\hline CHEMBL1611870 & 688721 & 4.7 & 4.7769 & TRN & \\
\hline CHEMBL1303389 & 688721 & 4.9 & 4.829 & TRN & \\
\hline CHEMBL1588151 & 688721 & 4.6 & 4.9787 & TRN & \\
\hline CHEMBL1327473 & 688721 & 5.1 & 4.8294 & TST & \\
\hline CHEMBL1437885 & 688721 & 4.8 & 4.9426 & TRN & \\
\hline CHEMBL1545746 & 688721 & 5.4 & 4.9354 & TRN & \\
\hline CHEMBL1375399 & 688721 & 4.5 & 4.7596 & TRN & \\
\hline CHEMBL1427982 & 688721 & 4.6 & 4.9904 & TRN & \\
\hline CHEMBL1550081 & 688721 & 4.5 & 4.7763 & TRN & \\
\hline CHEMBL1453696 & 688721 & 5.5 & 4.8737 & TRN & \\
\hline CHEMBL1454183 & 688721 & 4.8 & 5.0751 & TST & \\
\hline CHEMBL1468236 & 688721 & 5.3 & 4.9681 & TRN & \\
\hline CHEMBL1500235 & 688721 & 6.2 & 4.9001 & TRN & \\
\hline CHEMBL1363322 & 688721 & 4.7 & 4.8873 & TRN & \\
\hline CHEMBL1537788 & 688721 & 4.5 & 4.9918 & TST & \\
\hline CHEMBL1498811 & 688721 & 4.7 & 5.0655 & TRN & \\
\hline CHEMBL1528626 & 688721 & 5.5 & 4.7914 & TRN & \\
\hline CHEMBL1567336 & 688721 & 5.3 & 5.0519 & TRN & \\
\hline CHEMBL1480680 & 688721 & 5.4 & 4.9166 & TRN & \\
\hline
\end{tabular}




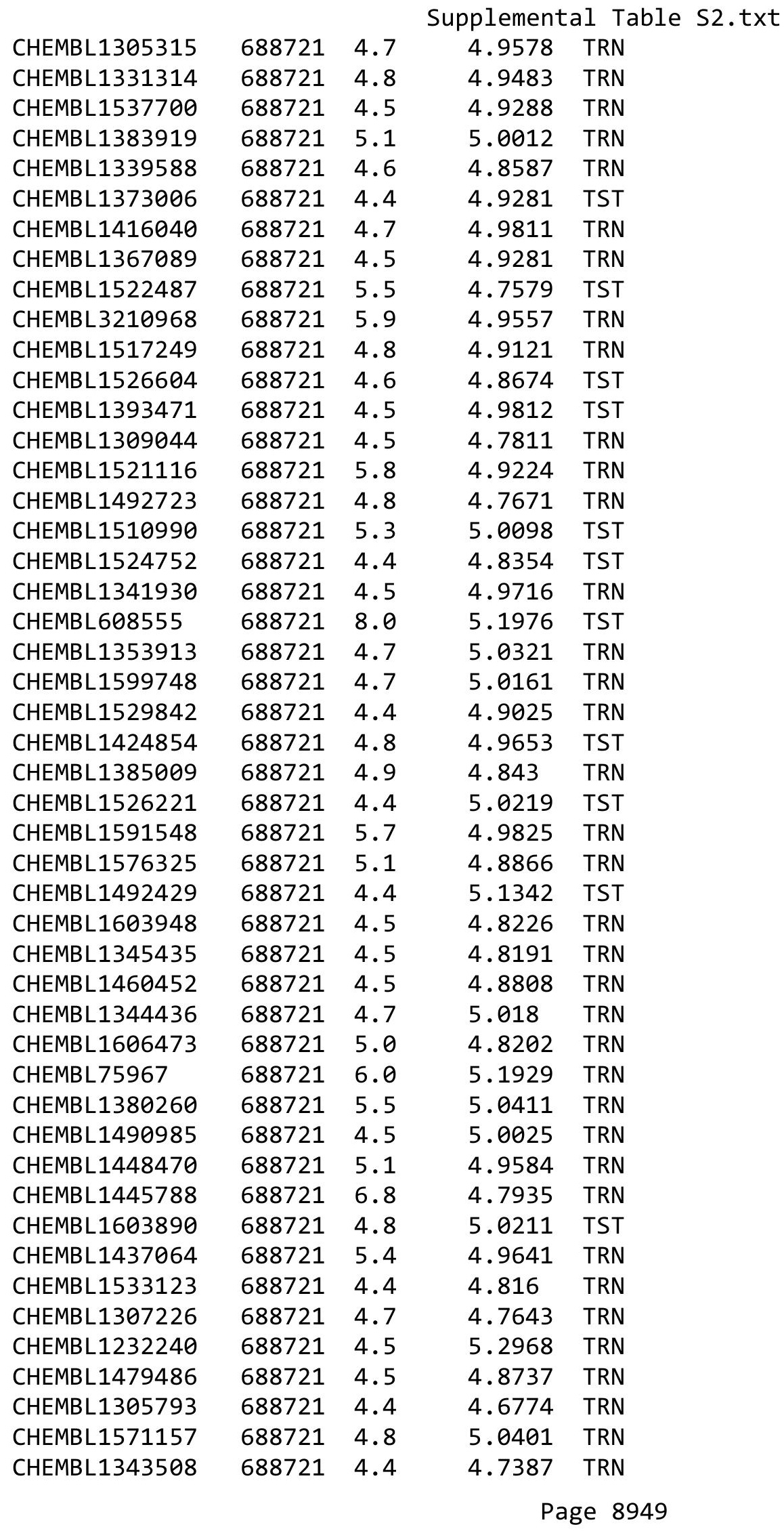




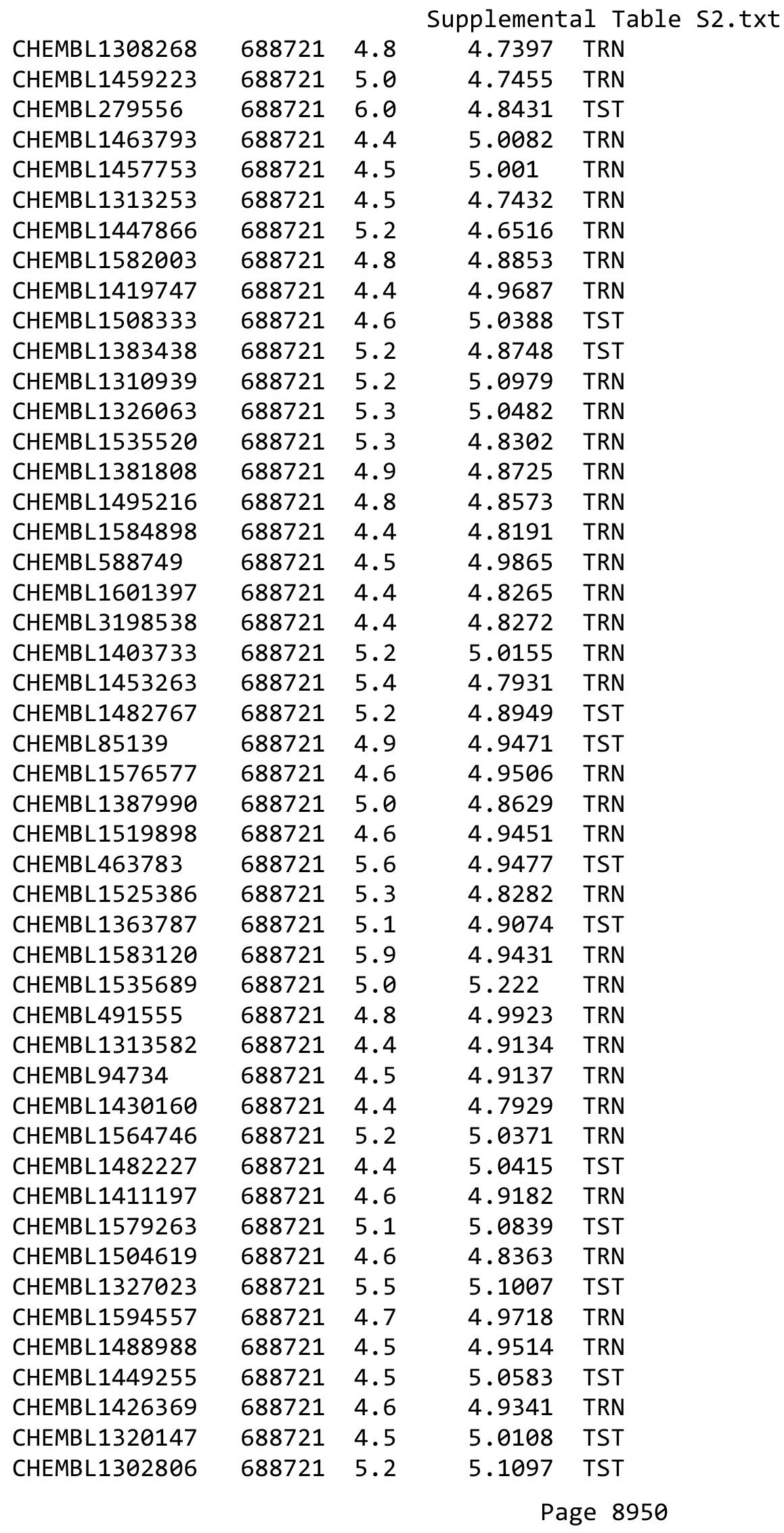




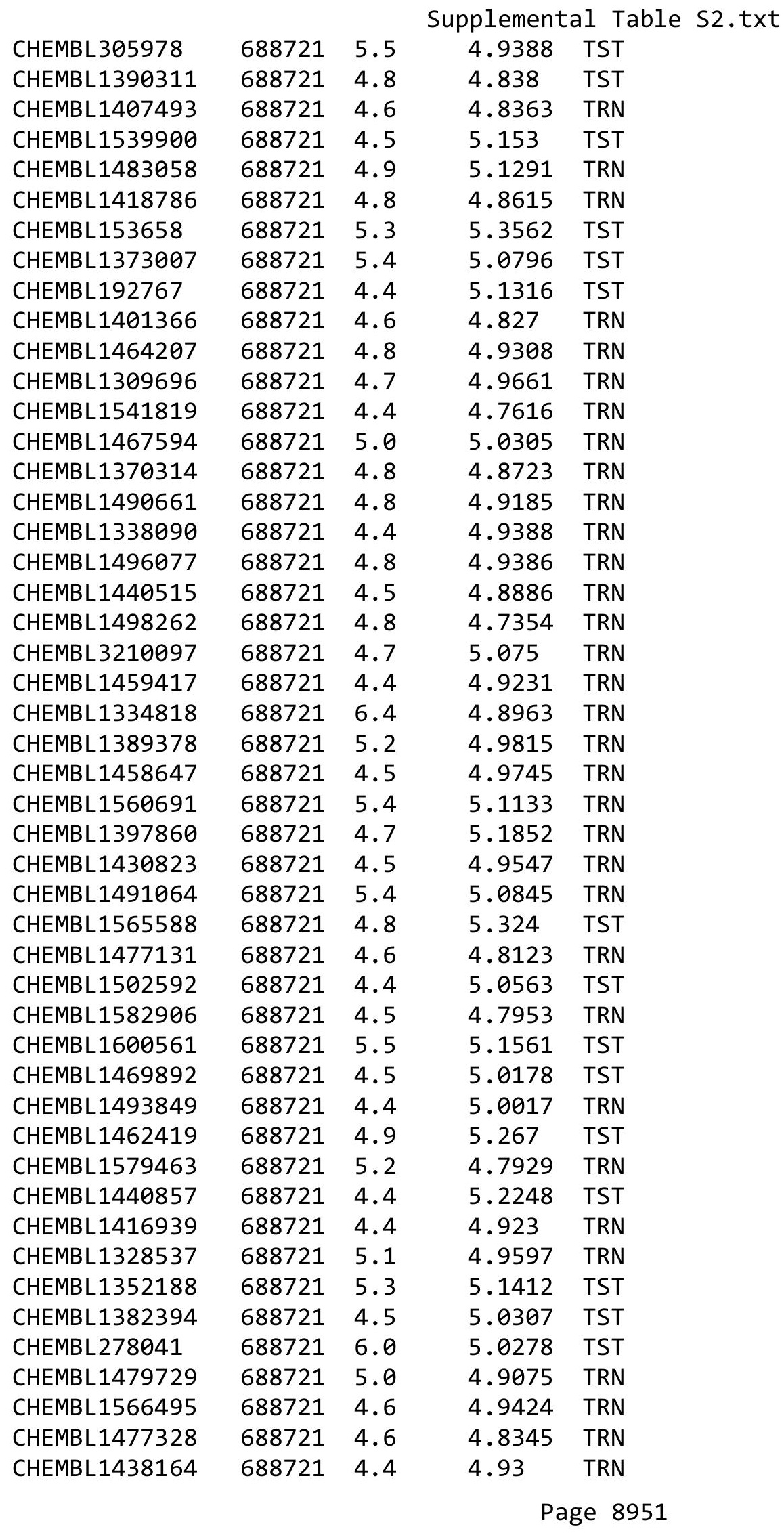




\begin{tabular}{|c|c|c|c|c|c|}
\hline \multirow{2}{*}{ CHEMBL1369152 } & \multirow[b]{2}{*}{688721} & \\
\hline & & 5.0 & 4.9443 & TRN & \\
\hline CHEMBL1332745 & 688721 & 6.1 & 4.9995 & TST & \\
\hline CHEMBL1501962 & 688721 & 4.7 & 4.8236 & TRN & \\
\hline CHEMBL1549873 & 688721 & 4.4 & 5.0193 & TRN & \\
\hline CHEMBL1312240 & 688721 & 5.5 & 4.9662 & TRN & \\
\hline CHEMBL1398066 & 688721 & 4.9 & 5.1649 & TRN & \\
\hline CHEMBL1530697 & 688721 & 4.4 & 5.021 & TRN & \\
\hline CHEMBL1453130 & 688721 & 4.9 & 4.94 & TRN & \\
\hline CHEMBL1306623 & 688721 & 4.4 & 4.9446 & TST & \\
\hline CHEMBL1606991 & 688721 & 5.4 & 5.2038 & TST & \\
\hline CHEMBL1441216 & 688721 & 4.7 & 5.1634 & TRN & \\
\hline CHEMBL1575906 & 688721 & 4.6 & 4.9368 & TRN & \\
\hline CHEMBL 1256727 & 688721 & 5.4 & 4.8127 & TST & \\
\hline CHEMBL1576049 & 688721 & 4.4 & 4.9434 & TRN & \\
\hline CHEMBL1589310 & 688721 & 4.8 & 4.7042 & TRN & \\
\hline CHEMBL1566986 & 688721 & 5.2 & 4.8114 & TRN & \\
\hline CHEMBL1383499 & 688721 & 5.5 & 4.7792 & TST & \\
\hline CHEMBL1518386 & 688721 & 4.4 & 4.76699 & 99999999995 & TRN \\
\hline CHEMBL1341211 & 688721 & 6.5 & 4.8005 & TRN & \\
\hline CHEMBL1541876 & 688721 & 4.6 & 4.9088 & TST & \\
\hline CHEMBL1493235 & 688721 & 5.9 & 4.9754 & TRN & \\
\hline CHEMBL1334320 & 688721 & 4.6 & 4.941 & TRN & \\
\hline CHEMBL1439427 & 688721 & 4.4 & 4.8055 & TRN & \\
\hline CHEMBL1497036 & 688721 & 4.5 & 4.7823 & TRN & \\
\hline CHEMBL1338330 & 688721 & 5.5 & 5.0211 & TST & \\
\hline CHEMBL1588238 & 688721 & 4.6 & 4.9299 & TST & \\
\hline CHEMBL1430566 & 688721 & 4.9 & 4.8017 & TST & \\
\hline CHEMBL1437981 & 688721 & 4.7 & 4.7472 & TRN & \\
\hline CHEMBL1475787 & 688721 & 4.5 & 4.851 & TRN & \\
\hline CHEMBL1597209 & 688721 & 5.3 & 5.0595 & TRN & \\
\hline CHEMBL1364079 & 688721 & 4.7 & 4.7217 & TRN & \\
\hline CHEMBL1328319 & 688721 & 5.2 & 5.2501 & TRN & \\
\hline CHEMBL1601591 & 688721 & 4.5 & 5.01 & TRN & \\
\hline CHEMBL1478221 & 688721 & 4.6 & 5.1171 & TRN & \\
\hline CHEMBL1399589 & 688721 & 6.8 & 4.7891 & TRN & \\
\hline CHEMBL1577637 & 688721 & 4.8 & 4.908 & TST & \\
\hline CHEMBL1476134 & 688721 & 4.7 & 5.0043 & TRN & \\
\hline CHEMBL1477697 & 688721 & 4.5 & 4.8394 & TRN & \\
\hline CHEMBL1543996 & 688721 & 4.9 & 5.0698 & TRN & \\
\hline CHEMBL1576645 & 688721 & 4.6 & 5.1761 & TST & \\
\hline CHEMBL1323851 & 688721 & 5.4 & 5.0378 & TST & \\
\hline CHEMBL1490005 & 688721 & 4.5 & 5.0441 & TRN & \\
\hline CHEMBL1413105 & 688721 & 5.0 & 5.0154 & TRN & \\
\hline CHEMBL1586623 & 688721 & 4.4 & 4.8241 & TRN & \\
\hline CHEMBL1318799 & 688721 & 5.9 & 5.2501 & TRN & \\
\hline CHEMBL1500578 & 688721 & 4.4 & 5.1221 & TRN & \\
\hline CHEMBL1302366 & 688721 & 4.6 & 4.6699 & TRN & \\
\hline CHEMBL1328156 & 688721 & 4.4 & 5.1701 & TRN & \\
\hline & & & & 8952 & \\
\hline
\end{tabular}




\begin{tabular}{|c|c|c|c|c|c|}
\hline \multicolumn{6}{|c|}{ Supplemental Table S2.txt } \\
\hline CHEMBL1447639 & 688721 & 4.4 & 4.9523 & TRN & \\
\hline CHEMBL1496189 & 688721 & 4.8 & 4.923 & TRN & \\
\hline CHEMBL1306618 & 688721 & 4.4 & 4.9145 & TRN & \\
\hline CHEMBL1521729 & 688721 & 5.2 & 4.9182 & TRN & \\
\hline CHEMBL1403351 & 688721 & 5.4 & 4.9205 & TRN & \\
\hline CHEMBL1570956 & 688721 & 5.1 & 4.8461 & TRN & \\
\hline CHEMBL1585852 & 688721 & 5.2 & 4.939 & TRN & \\
\hline CHEMBL1532840 & 688721 & 4.4 & 5.013 & TRN & \\
\hline CHEMBL1328930 & 688721 & 4.8 & 4.6942 & TRN & \\
\hline CHEMBL1563858 & 688721 & 4.4 & 4.8305 & TRN & \\
\hline CHEMBL1558396 & 688721 & 5.3 & 5.1981 & TRN & \\
\hline CHEMBL1463759 & 688721 & 5.4 & 5.1986 & TST & \\
\hline CHEMBL1460206 & 688721 & 5.8 & 4.9366 & TRN & \\
\hline CHEMBL1604222 & 688721 & 5.0 & 4.853 & TRN & \\
\hline CHEMBL1370544 & 688721 & 4.5 & 5.0492 & TRN & \\
\hline CHEMBL1428002 & 688721 & 4.4 & 4.9781 & TRN & \\
\hline CHEMBL1299476 & 688721 & 4.6 & 4.8812 & TRN & \\
\hline CHEMBL1591459 & 688721 & 5.6 & 4.9792 & TRN & \\
\hline CHEMBL1422843 & 688721 & 5.4 & 4.923 & TST & \\
\hline CHEMBL1347289 & 688721 & 4.5 & 5.0856 & TRN & \\
\hline CHEMBL1489100 & 688721 & 4.6 & 4.9014 & TST & \\
\hline CHEMBL1450210 & 688721 & 5.1 & 4.9552 & TRN & \\
\hline CHEMBL1307376 & 688721 & 5.2 & 5.1257 & TRN & \\
\hline CHEMBL1571520 & 688721 & 4.9 & 5.0624 & TST & \\
\hline CHEMBL1571324 & 688721 & 4.7 & 4.7771 & TRN & \\
\hline CHEMBL1565582 & 688721 & 4.7 & 5.0257 & TST & \\
\hline CHEMBL1396301 & 688721 & 4.4 & 4.8418 & TRN & \\
\hline CHEMBL1585166 & 688721 & 5.3 & 4.9284 & TRN & \\
\hline CHEMBL1484463 & 688721 & 4.4 & 5.1713 & TST & \\
\hline CHEMBL1491582 & 688721 & 4.7 & 4.7618 & TRN & \\
\hline CHEMBL1325008 & 688721 & 4.5 & 4.9457 & TST & \\
\hline CHEMBL1559998 & 688721 & 5.2 & 5.21700 & 00000000005 & TST \\
\hline CHEMBL1472933 & 688721 & 6.0 & 5.2716 & TRN & \\
\hline CHEMBL1522983 & 688721 & 7.0 & 4.8399 & TRN & \\
\hline CHEMBL1589750 & 688721 & 4.7 & 4.7756 & TRN & \\
\hline CHEMBL1256020 & 688721 & 4.6 & 5.1729 & TRN & \\
\hline CHEMBL1438275 & 688721 & 6.0 & 5.2062 & TRN & \\
\hline CHEMBL1463699 & 688721 & 4.8 & 4.9139 & TRN & \\
\hline CHEMBL1551962 & 688721 & 5.6 & 5.1198 & TRN & \\
\hline CHEMBL1609337 & 688721 & 4.5 & 5.16 & TST & \\
\hline CHEMBL1546117 & 688721 & 5.9 & 5.0056 & TRN & \\
\hline CHEMBL1498004 & 688721 & 4.5 & 4.8881 & TRN & \\
\hline CHEMBL1548760 & 688721 & 4.8 & 4.9192 & TRN & \\
\hline CHEMBL1375205 & 688721 & 4.6 & 4.7862 & TRN & \\
\hline CHEMBL1402637 & 688721 & 4.6 & 4.9687 & TRN & \\
\hline CHEMBL1452923 & 688721 & 5.2 & 4.9476 & TRN & \\
\hline CHEMBL1324151 & 688721 & 7.5003 & 5.0063 & TRN & \\
\hline CHEMBL1519940 & 688721 & 5.4 & 4.7638 & TRN & \\
\hline
\end{tabular}




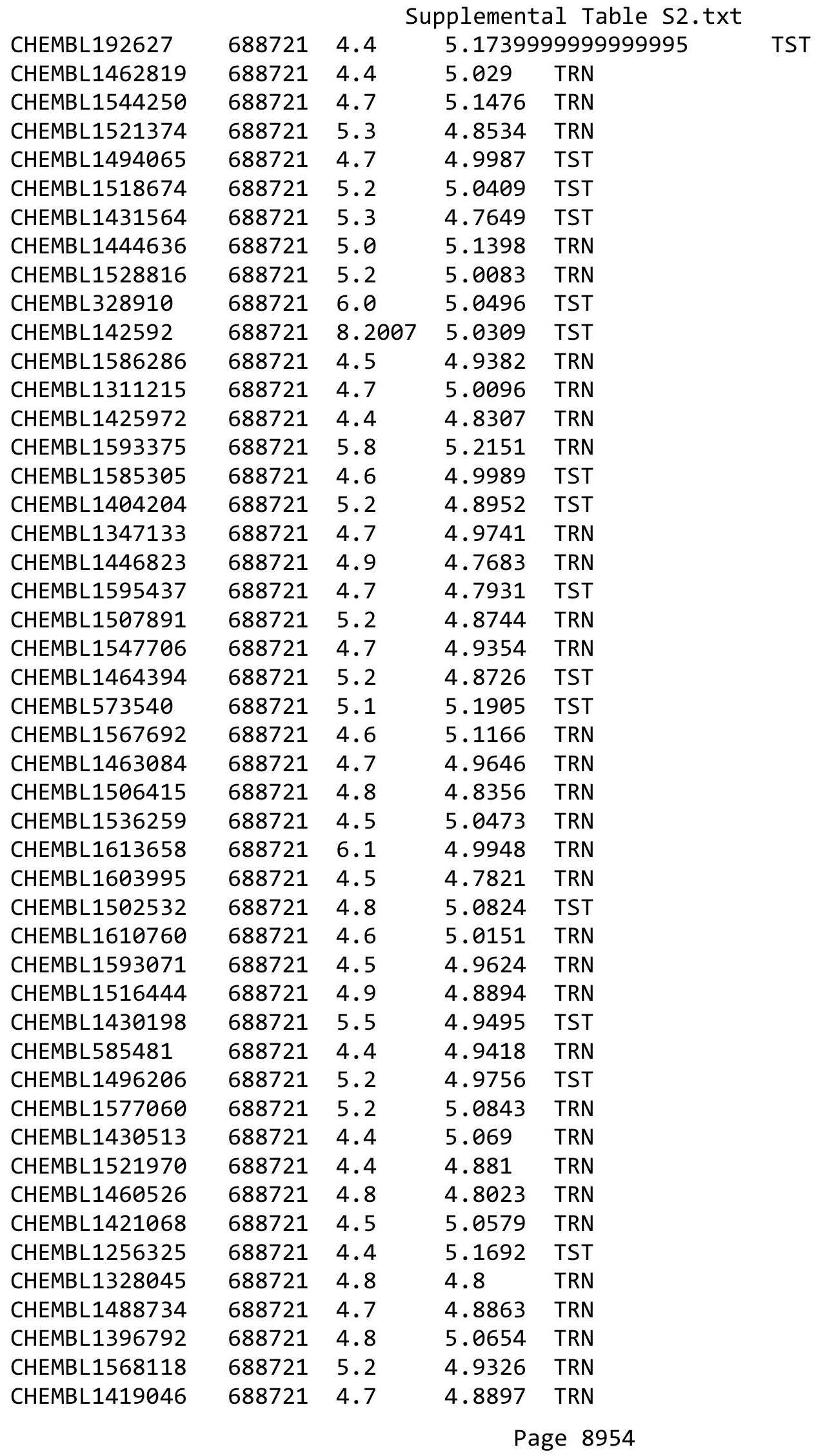




\begin{tabular}{|c|c|c|c|c|c|}
\hline \multirow[b]{2}{*}{ CHEMBL1449857 } & \multirow{2}{*}{688721} & \\
\hline & & 4.6 & 4.7894 & TRN & \\
\hline CHEMBL1381308 & 688721 & 5.2 & 5.0569 & TST & \\
\hline CHEMBL1469677 & 688721 & 5.4 & 4.7554 & TRN & \\
\hline CHEMBL1520424 & 688721 & 5.0 & 4.8644 & TRN & \\
\hline CHEMBL1330357 & 688721 & 6.0 & 5.2789 & TRN & \\
\hline CHEMBL1305287 & 688721 & 4.9 & 4.8928 & TRN & \\
\hline CHEMBL1536615 & 688721 & 4.8 & 4.8193 & TRN & \\
\hline CHEMBL1319485 & 688721 & 4.6 & 4.963 & TRN & \\
\hline CHEMBL1327616 & 688721 & 5.5 & 5.092 & TRN & \\
\hline CHEMBL1536809 & 688721 & 5.3 & 5.0367 & TST & \\
\hline CHEMBL1393221 & 688721 & 4.6 & 4.9167 & TRN & \\
\hline CHEMBL1498658 & 688721 & 5.8 & 5.0159 & TRN & \\
\hline CHEMBL1338206 & 688721 & 4.5 & 5.004 & TRN & \\
\hline CHEMBL1311756 & 688721 & 4.5 & 4.9202 & TRN & \\
\hline CHEMBL1413701 & 688721 & 4.9 & 5.0885 & TST & \\
\hline CHEMBL1440767 & 688721 & 4.6 & 4.9503 & TRN & \\
\hline CHEMBL1316760 & 688721 & 5.0 & 5.0995 & TRN & \\
\hline CHEMBL1504076 & 688721 & 4.4 & 4.792 & TRN & \\
\hline CHEMBL1508109 & 688721 & 4.4 & 4.9068 & TRN & \\
\hline CHEMBL1340795 & 688721 & 4.7 & 4.9359 & TRN & \\
\hline CHEMBL1496487 & 688721 & 4.4 & 4.8405 & TRN & \\
\hline CHEMBL1613619 & 688721 & 5.4 & 5.1915 & TST & \\
\hline CHEMBL1538120 & 688721 & 4.6 & 4.7481 & TST & \\
\hline CHEMBL1580880 & 688721 & 4.7 & 4.8813 & TRN & \\
\hline CHEMBL1571505 & 688721 & 4.4 & 5.1133 & TRN & \\
\hline CHEMBL1462921 & 688721 & 4.4 & 4.8405 & TST & \\
\hline CHEMBL1613499 & 688721 & 4.6 & 4.8269 & TRN & \\
\hline CHEMBL1329790 & 688721 & 4.4 & 5.1454 & TST & \\
\hline CHEMBL1575679 & 688721 & 5.4 & 4.8572 & TRN & \\
\hline CHEMBL1362221 & 688721 & 5.3 & 5.0218 & TRN & \\
\hline CHEMBL429711 & 688721 & 5.4 & 4.9719 & TRN & \\
\hline CHEMBL1559924 & 688721 & 5.2 & 4.8536 & TST & \\
\hline CHEMBL1584686 & 688721 & 4.4 & 4.8643 & TST & \\
\hline CHEMBL1483593 & 688721 & 4.6 & 4.6653 & TRN & \\
\hline CHEMBL489941 & 688721 & 4.5 & 4.9101 & TRN & \\
\hline CHEMBL1430632 & 688721 & 4.6 & 4.9028 & TST & \\
\hline CHEMBL1387406 & 688721 & 5.5 & 5.0039 & TST & \\
\hline CHEMBL1356115 & 688721 & 5.1 & 5.36299 & & TST \\
\hline CHEMBL1435809 & 688721 & 5.0 & 5.081 & TRN & \\
\hline CHEMBL1462977 & 688721 & 5.2 & 4.8908 & TRN & \\
\hline CHEMBL1556608 & 688721 & 4.6 & 5.0268 & TRN & \\
\hline CHEMBL1526230 & 688721 & 5.2 & 4.7414 & TRN & \\
\hline CHEMBL452894 & 688721 & 4.6 & 4.9644 & TRN & \\
\hline CHEMBL1429250 & 688721 & 4.7 & 4.824 & TRN & \\
\hline CHEMBL1477796 & 688721 & 4.5 & 4.9143 & TRN & \\
\hline CHEMBL1585164 & 688721 & 4.8 & 4.9337 & TRN & \\
\hline CHEMBL1409043 & 688721 & 6.4 & 5.1579 & TRN & \\
\hline CHEMBL3213714 & 688721 & 4.4 & 4.7713 & TRN & \\
\hline & & & & 8955 & \\
\hline
\end{tabular}




\begin{tabular}{|c|c|c|c|c|c|}
\hline \\
\hline CHEMBL1472779 & 688721 & 5.4 & 5.1057 & TRN & \\
\hline CHEMBL45005 & 688721 & 4.9 & 4.8958 & TRN & \\
\hline CHEMBL1611971 & 688721 & 5.4 & 4.8448 & TRN & \\
\hline CHEMBL3197234 & 688721 & 4.5 & 4.9369 & TRN & \\
\hline CHEMBL1391476 & 688721 & 5.5 & 5.0838 & TRN & \\
\hline CHEMBL1482751 & 688721 & 4.8 & 5.0027 & TRN & \\
\hline CHEMBL1468756 & 688721 & 4.6 & 4.9494 & TST & \\
\hline CHEMBL1430571 & 688721 & 5.2 & 4.7854 & TRN & \\
\hline CHEMBL1504424 & 688721 & 4.5 & 4.7539 & TRN & \\
\hline CHEMBL1303320 & 688721 & 4.6 & 4.8472 & TRN & \\
\hline CHEMBL1529360 & 688721 & 4.4 & 4.9659 & TRN & \\
\hline CHEMBL1486992 & 688721 & 4.5 & 4.9558 & TRN & \\
\hline CHEMBL1398721 & 688721 & 5.0 & 4.8708 & TRN & \\
\hline CHEMBL1558035 & 688721 & 5.6 & 4.9194 & TRN & \\
\hline CHEMBL1451534 & 688721 & 5.2 & 5.2033 & TST & \\
\hline CHEMBL1340568 & 688721 & 5.2 & 4.8795 & TRN & \\
\hline CHEMBL1438743 & 688721 & 4.4 & 4.9513 & TRN & \\
\hline CHEMBL1521895 & 688721 & 5.0 & 5.0691 & TRN & \\
\hline CHEMBL1419849 & 688721 & 4.6 & 4.9774 & TST & \\
\hline CHEMBL1304930 & 688721 & 4.5 & 4.9739 & TRN & \\
\hline CHEMBL600976 & 688721 & 4.5 & 4.7157 & TST & \\
\hline CHEMBL1471921 & 688721 & 5.0 & 4.9485 & TRN & \\
\hline CHEMBL362919 & 688721 & 4.4 & 4.9775 & TST & \\
\hline CHEMBL1459161 & 688721 & 5.3 & 4.8597 & TRN & \\
\hline CHEMBL1413998 & 688721 & 7.4001 & 5.0728 & TRN & \\
\hline CHEMBL1501336 & 688721 & 4.5 & 4.8251 & TST & \\
\hline CHEMBL1299446 & 688721 & 4.4 & 4.9905 & TST & \\
\hline CHEMBL1469050 & 688721 & 4.6 & 4.9074 & TRN & \\
\hline CHEMBL1303731 & 688721 & 5.2 & 4.9376 & TST & \\
\hline CHEMBL1486411 & 688721 & 4.6 & 4.83899 & 99999999995 & TST \\
\hline CHEMBL1600935 & 688721 & 4.7 & 4.8427 & TRN & \\
\hline CHEMBL1492729 & 688721 & 6.0 & 5.3143 & TRN & \\
\hline CHEMBL1409062 & 688721 & 4.4 & 5.0001 & TRN & \\
\hline CHEMBL1506237 & 688721 & 6.6 & 4.8887 & TRN & \\
\hline CHEMBL1381437 & 688721 & 5.3 & 5.0143 & TRN & \\
\hline CHEMBL576997 & 688721 & 7.0 & 5.0598 & TRN & \\
\hline CHEMBL1495011 & 688721 & 5.4 & 4.935 & TRN & \\
\hline CHEMBL1569408 & 688721 & 5.4 & 4.9201 & TST & \\
\hline CHEMBL1457020 & 688721 & 4.8 & 5.0411 & TRN & \\
\hline CHEMBL1306907 & 688721 & 4.4 & 4.9834 & TST & \\
\hline CHEMBL1466563 & 688721 & 4.5 & 4.794 & TRN & \\
\hline CHEMBL1448625 & 688721 & 5.2 & 5.0219 & TRN & \\
\hline CHEMBL1555538 & 688721 & 4.5 & 4.83 & TRN & \\
\hline CHEMBL3211124 & 688721 & 4.4 & 5.2207 & TST & \\
\hline CHEMBL1434817 & 688721 & 4.6 & 4.8798 & TRN & \\
\hline CHEMBL1352160 & 688721 & 4.5 & 4.732 & TRN & \\
\hline CHEMBL1404076 & 688721 & 4.6 & 4.7543 & TRN & \\
\hline CHEMBL1450461 & 688721 & 4.7 & 4.8923 & TRN & \\
\hline
\end{tabular}




\begin{tabular}{|c|c|c|c|c|}
\hline \multicolumn{5}{|c|}{ Supplemental Table S2.txt } \\
\hline CHEMBL1431772 & 688721 & 4.4 & 4.8562 & TRN \\
\hline CHEMBL1455551 & 688721 & 4.7 & 5.1453 & TRN \\
\hline CHEMBL1501207 & 688721 & 4.6 & 4.8835 & TRN \\
\hline CHEMBL1488893 & 688721 & 4.9 & 4.7182 & TRN \\
\hline CHEMBL1412222 & 688721 & 4.7 & 4.9443 & TST \\
\hline CHEMBL1445400 & 688721 & 4.5 & 4.8592 & TST \\
\hline CHEMBL1257081 & 688721 & 5.2 & 5.0926 & TST \\
\hline CHEMBL1400051 & 688721 & 5.4 & 5.0093 & TRN \\
\hline CHEMBL 1444583 & 688721 & 4.9 & 4.8467 & TRN \\
\hline CHEMBL1521691 & 688721 & 4.5 & 4.8688 & TRN \\
\hline CHEMBL1519586 & 688721 & 5.1 & 5.1036 & TRN \\
\hline CHEMBL1612520 & 688721 & 6.1 & 4.819 & TRN \\
\hline CHEMBL1558599 & 688721 & 5.8 & 5.2912 & TST \\
\hline CHEMBL1352096 & 688721 & 5.4 & 5.1481 & TRN \\
\hline CHEMBL1533633 & 688721 & 5.3 & 5.062 & TRN \\
\hline CHEMBL1499767 & 688721 & 4.5 & 4.8955 & TRN \\
\hline CHEMBL1363255 & 688721 & 4.7 & 4.9989 & TRN \\
\hline CHEMBL429023 & 688721 & 6.0 & 5.0673 & TST \\
\hline CHEMBL1448539 & 688721 & 4.5 & 4.9294 & TST \\
\hline CHEMBL1554717 & 688721 & 4.5 & 4.927 & TRN \\
\hline CHEMBL1469169 & 688721 & 4.8 & 4.7462 & TRN \\
\hline CHEMBL1510902 & 688721 & 7.6003 & 4.8404 & TST \\
\hline CHEMBL1470966 & 688721 & 4.6 & 4.6715 & TRN \\
\hline CHEMBL1256659 & 688721 & 5.1 & 5.0749 & TST \\
\hline CHEMBL1467277 & 688721 & 4.5 & 4.8798 & TRN \\
\hline CHEMBL1443163 & 688721 & 4.4 & 5.0502 & TRN \\
\hline CHEMBL1553941 & 688721 & 4.7 & 5.0555 & TRN \\
\hline CHEMBL1342405 & 688721 & 4.8 & 4.9994 & TRN \\
\hline CHEMBL1408041 & 688721 & 4.7 & 4.7903 & TRN \\
\hline CHEMBL471397 & 688721 & 5.9 & 4.9706 & TST \\
\hline CHEMBL1313841 & 688721 & 4.4 & 4.9903 & TRN \\
\hline CHEMBL1301390 & 688721 & 4.7 & 4.9586 & TRN \\
\hline CHEMBL1498567 & 688721 & 4.7 & 4.7782 & TRN \\
\hline CHEMBL1323068 & 688721 & 4.5 & 4.9272 & TRN \\
\hline CHEMBL1328112 & 688721 & 6.7001 & 4.9569 & TRN \\
\hline CHEMBL1561879 & 688721 & 4.7 & 5.0072 & TRN \\
\hline CHEMBL1414899 & 688721 & 4.7 & 5.059 & TRN \\
\hline CHEMBL82949 & 688721 & 4.6 & 5.0724 & TST \\
\hline CHEMBL1320071 & 688721 & 4.8 & 4.9712 & TRN \\
\hline CHEMBL1570390 & 688721 & 4.6 & 4.9055 & TRN \\
\hline CHEMBL1425390 & 688721 & 4.8 & 5.0264 & TRN \\
\hline CHEMBL1499986 & 688721 & 4.8 & 4.9345 & TRN \\
\hline CHEMBL1346815 & 688721 & 4.6 & 5.0381 & TRN \\
\hline CHEMBL1333531 & 688721 & 5.4 & 5.0506 & TRN \\
\hline CHEMBL1604272 & 688721 & 4.4 & 4.8393 & TST \\
\hline CHEMBL1373256 & 688721 & 4.6 & 4.8543 & TRN \\
\hline CHEMBL16857 & 688721 & 4.4 & 5.0697 & TRN \\
\hline CHEMBL1509814 & 688721 & 4.9 & 4.9576 & TST \\
\hline
\end{tabular}




\begin{tabular}{|c|c|c|c|c|}
\hline & & & & \\
\hline CHEMBL1491454 & 688721 & 5.2 & 5.0383 & TST \\
\hline CHEMBL1427520 & 688721 & 4.5 & 4.9973 & TST \\
\hline CHEMBL1433464 & 688721 & 5.6 & 4.8807 & TRN \\
\hline CHEMBL1426897 & 688721 & 6.9 & 4.8263 & TRN \\
\hline CHEMBL1300161 & 688721 & 4.5 & 4.7619 & TST \\
\hline CHEMBL1482002 & 688721 & 5.0 & 4.8624 & TRN \\
\hline CHEMBL1521535 & 688721 & 4.6 & 4.9585 & TRN \\
\hline CHEMBL1388763 & 688721 & 4.4 & 4.9043 & TST \\
\hline CHEMBL497170 & 688721 & 4.4 & 4.7715 & TRN \\
\hline CHEMBL389885 & 688721 & 4.4 & 5.0139 & TRN \\
\hline CHEMBL1303423 & 688721 & 4.5 & 5.0594 & TRN \\
\hline CHEMBL1576582 & 688721 & 4.4 & 5.0155 & TRN \\
\hline CHEMBL1612228 & 688721 & 5.2 & 4.9181 & TRN \\
\hline CHEMBL1397406 & 688721 & 5.4 & 5.1039 & TRN \\
\hline CHEMBL1322206 & 688721 & 5.4 & 4.8721 & TRN \\
\hline CHEMBL1491678 & 688721 & 4.4 & 4.883 & TRN \\
\hline CHEMBL1568030 & 688721 & 5.0 & 4.8823 & TRN \\
\hline CHEMBL 3209274 & 688721 & 4.6 & 4.8771 & TST \\
\hline CHEMBL1433152 & 688721 & 5.4 & 5.0696 & TRN \\
\hline CHEMBL1353893 & 688721 & 4.6 & 5.0037 & TST \\
\hline CHEMBL1403178 & 688721 & 5.3 & 4.864 & TRN \\
\hline CHEMBL1563066 & 688721 & 5.3 & 4.9742 & TRN \\
\hline CHEMBL1531516 & 688721 & 4.5 & 4.9996 & TRN \\
\hline CHEMBL1406011 & 688721 & 7.0 & 4.9245 & TRN \\
\hline CHEMBL1464645 & 688721 & 4.7 & 4.7751 & TRN \\
\hline CHEMBL1508997 & 688721 & 4.8 & 4.8501 & TRN \\
\hline CHEMBL3209674 & 688721 & 4.6 & 4.8391 & TST \\
\hline CHEMBL1480516 & 688721 & 4.8 & 5.1225 & TRN \\
\hline CHEMBL1461832 & 688721 & 4.7 & 5.0405 & TST \\
\hline CHEMBL1480952 & 688721 & 4.6 & 4.8323 & TRN \\
\hline CHEMBL1522136 & 688721 & 5.4 & 4.9412 & TRN \\
\hline CHEMBL1444899 & 688721 & 4.5 & 4.9664 & TRN \\
\hline CHEMBL199194 & 688721 & 4.6 & 4.7971 & TST \\
\hline CHEMBL1439525 & 688721 & 4.4 & 4.8501 & TRN \\
\hline CHEMBL1490713 & 688721 & 5.8 & 4.9298 & TRN \\
\hline CHEMBL1361262 & 688721 & 5.1 & 4.9647 & TRN \\
\hline CHEMBL1519571 & 688721 & 4.7 & 4.9364 & TST \\
\hline CHEMBL1388233 & 688721 & 4.8 & 4.8289 & TST \\
\hline CHEMBL1412945 & 688721 & 4.7 & 4.9122 & TRN \\
\hline CHEMBL1369599 & 688721 & 4.4 & 4.8924 & TRN \\
\hline CHEMBL1584884 & 688721 & 4.4 & 5.1267 & TST \\
\hline CHEMBL1369303 & 688721 & 4.4 & 4.8607 & TRN \\
\hline CHEMBL1611489 & 688721 & 5.4 & 4.8442 & TRN \\
\hline CHEMBL1434266 & 688721 & 5.4 & 5.1068 & TRN \\
\hline CHEMBL1570874 & 688721 & 5.0 & 4.7638 & TRN \\
\hline CHEMBL1362068 & 688721 & 5.4 & 5.2244 & TRN \\
\hline CHEMBL1545690 & 688721 & 4.5 & 4.9316 & TRN \\
\hline CHEMBL1490337 & 688721 & 6.9 & 4.8904 & TRN \\
\hline
\end{tabular}




\begin{tabular}{|c|c|c|c|c|}
\hline & & & EI & al Ta \\
\hline CHEMBL1386411 & 688721 & 5.2 & 5.0475 & TRN \\
\hline CHEMBL1441920 & 688721 & 6.0 & 5.1284 & TST \\
\hline CHEMBL1455570 & 688721 & 5.0 & 5.1334 & TRN \\
\hline CHEMBL1463679 & 688721 & 5.3 & 5.0602 & TST \\
\hline CHEMBL1454093 & 688721 & 5.1 & 4.9138 & TST \\
\hline CHEMBL1501776 & 688721 & 4.6 & 5.1204 & TRN \\
\hline CHEMBL1588491 & 688721 & 5.3 & 4.7156 & TRN \\
\hline CHEMBL1504033 & 688721 & 4.4 & 4.963 & TST \\
\hline CHEMBL1456914 & 688721 & 7.0 & 5.1004 & TST \\
\hline CHEMBL1452503 & 688721 & 5.6 & 4.93 & TRN \\
\hline CHEMBL1526979 & 688721 & 5.1 & 4.9709 & TRN \\
\hline CHEMBL1596966 & 688721 & 4.9 & 4.9603 & TRN \\
\hline CHEMBL1493660 & 688721 & 4.9 & 4.9178 & TRN \\
\hline CHEMBL1326251 & 688721 & 4.6 & 5.2565 & TRN \\
\hline CHEMBL1414822 & 688721 & 5.1 & 5.0282 & TRN \\
\hline CHEMBL1333303 & 688721 & 4.5 & 4.9243 & TRN \\
\hline CHEMBL1528877 & 688721 & 4.6 & 5.0231 & TST \\
\hline CHEMBL1362711 & 688721 & 4.8 & 4.8489 & TRN \\
\hline CHEMBL1501225 & 688721 & 4.4 & 5.011 & TRN \\
\hline CHEMBL1406306 & 688721 & 4.5 & 4.7229 & TRN \\
\hline CHEMBL1361446 & 688721 & 6.0 & 5.4241 & TST \\
\hline CHEMBL1393241 & 688721 & 4.9 & 4.7536 & TRN \\
\hline CHEMBL1451172 & 688721 & 5.4 & 5.1116 & TRN \\
\hline CHEMBL598270 & 688721 & 4.8 & 5.1091 & TST \\
\hline CHEMBL1597058 & 688721 & 4.5 & 5.0102 & TRN \\
\hline CHEMBL1315922 & 688721 & 4.4 & 5.3569 & TRN \\
\hline CHEMBL1442709 & 688721 & 4.7 & 4.995 & TRN \\
\hline CHEMBL145725 & 688721 & 5.0 & 5.0622 & TST \\
\hline CHEMBL1369583 & 688721 & 4.7 & 4.8914 & TRN \\
\hline CHEMBL1585194 & 688721 & 5.2 & 5.0485 & TST \\
\hline CHEMBL1533567 & 688721 & 5.3 & 4.8879 & TRN \\
\hline CHEMBL1333833 & 688721 & 4.4 & 4.9121 & TRN \\
\hline CHEMBL1448402 & 688721 & 4.8 & 4.8411 & TRN \\
\hline CHEMBL1440936 & 688721 & 4.6 & 4.8659 & TRN \\
\hline CHEMBL1492764 & 688721 & 4.7 & 5.0988 & TST \\
\hline CHEMBL1569095 & 688721 & 4.8 & 4.8935 & TRN \\
\hline CHEMBL1491274 & 688721 & 4.6 & 4.8863 & TRN \\
\hline CHEMBL1307942 & 688721 & 4.4 & 4.7772 & TRN \\
\hline CHEMBL1569974 & 688721 & 4.7 & 4.9297 & TRN \\
\hline CHEMBL1382787 & 688721 & 5.3 & 4.927 & TRN \\
\hline CHEMBL1451728 & 688721 & 4.5 & 4.9652 & TRN \\
\hline CHEMBL1466391 & 688721 & 4.9 & 4.8609 & TRN \\
\hline CHEMBL1491009 & 688721 & 5.8 & 5.0274 & TRN \\
\hline CHEMBL1599572 & 688721 & 4.9 & 4.9106 & TRN \\
\hline CHEMBL1564194 & 688721 & 4.9 & 4.9107 & TRN \\
\hline CHEMBL1450253 & 688721 & 4.6 & 4.7893 & TRN \\
\hline CHEMBL1518987 & 688721 & 4.5 & 4.6459 & TRN \\
\hline CHEMBL1454799 & 688721 & 5.2 & 4.8206 & TRN \\
\hline
\end{tabular}




\begin{tabular}{|c|c|c|c|c|}
\hline \multicolumn{5}{|c|}{ plemental } \\
\hline CHEMBL1305863 & 688721 & 4.4 & 4.8686 & TRN \\
\hline CHEMBL1467937 & 688721 & 4.5 & 4.8762 & TRN \\
\hline CHEMBL1528102 & 688721 & 4.6 & 4.8318 & TRN \\
\hline CHEMBL1419223 & 688721 & 4.6 & 4.7606 & TRN \\
\hline CHEMBL388054 & 688721 & 6.0 & 4.973 & TST \\
\hline CHEMBL1404123 & 688721 & 4.4 & 4.8897 & TRN \\
\hline CHEMBL1508494 & 688721 & 5.4 & 4.949 & TRN \\
\hline CHEMBL1595979 & 688721 & 4.6 & 4.7921 & TRN \\
\hline CHEMBL1510400 & 688721 & 4.8 & 4.8745 & TST \\
\hline CHEMBL1321624 & 688721 & 5.4 & 5.3622 & TRN \\
\hline CHEMBL1411204 & 688721 & 5.2 & 5.0308 & TST \\
\hline CHEMBL1560223 & 688721 & 5.3 & 5.0685 & TRN \\
\hline CHEMBL1609686 & 688721 & 5.6 & 4.7951 & TRN \\
\hline CHEMBL3192857 & 688721 & 5.5 & 4.8907 & TRN \\
\hline CHEMBL1345044 & 688721 & 4.9 & 4.9134 & TST \\
\hline CHEMBL1427061 & 688721 & 4.4 & 4.9361 & TST \\
\hline CHEMBL3190253 & 688721 & 5.2 & 4.9102 & TST \\
\hline CHEMBL1489840 & 688721 & 5.9 & 4.9228 & TRN \\
\hline CHEMBL1506364 & 688721 & 4.8 & 4.9879 & TRN \\
\hline CHEMBL1435276 & 688721 & 5.0 & 5.069 & TRN \\
\hline CHEMBL1507262 & 688721 & 4.6 & 5.0975 & TST \\
\hline CHEMBL 3212141 & 688721 & 4.6 & 5.0813 & TST \\
\hline CHEMBL1545834 & 688721 & 4.4 & 4.9131 & TRN \\
\hline CHEMBL1532448 & 688721 & 5.4 & 5.2945 & TST \\
\hline CHEMBL1582406 & 688721 & 5.3 & 4.8752 & TRN \\
\hline CHEMBL1369528 & 688721 & 4.7 & 4.923 & TRN \\
\hline CHEMBL1581427 & 688721 & 4.4 & 4.9814 & TRN \\
\hline CHEMBL1571817 & 688721 & 4.6 & 4.8246 & TRN \\
\hline CHEMBL1335497 & 688721 & 4.5 & 4.824 & TRN \\
\hline CHEMBL1344858 & 688721 & 5.2 & 4.9777 & TST \\
\hline CHEMBL1357167 & 688721 & 4.7 & 4.9261 & TRN \\
\hline CHEMBL1608381 & 688721 & 4.6 & 5.1351 & TST \\
\hline CHEMBL1372415 & 688721 & 4.6 & 5.0167 & TRN \\
\hline CHEMBL1411875 & 688721 & 4.6 & 4.8211 & TRN \\
\hline CHEMBL1485328 & 688721 & 4.8 & 4.9333 & TRN \\
\hline CHEMBL1602599 & 688721 & 4.4 & 4.9456 & TRN \\
\hline CHEMBL1444441 & 688721 & 4.4 & 4.7675 & TRN \\
\hline CHEMBL1374260 & 688721 & 4.6 & 5.0408 & TRN \\
\hline CHEMBL1530100 & 688721 & 4.4 & 5.0027 & TRN \\
\hline CHEMBL1549742 & 688721 & 4.5 & 5.1871 & TRN \\
\hline CHEMBL1425134 & 688721 & 4.6 & 4.9388 & TRN \\
\hline CHEMBL1472085 & 688721 & 4.6 & 5.033 & TST \\
\hline CHEMBL1360195 & 688721 & 5.9 & 4.7532 & TRN \\
\hline CHEMBL1360874 & 688721 & 4.5 & 4.888 & TRN \\
\hline CHEMBL261642 & 688721 & 6.0 & 5.2704 & TRN \\
\hline CHEMBL1487947 & 688721 & 4.4 & 4.961 & TRN \\
\hline CHEMBL1445418 & 688721 & 5.0 & 4.8929 & TRN \\
\hline CHEMBL104264 & 688721 & 4.6 & 5.1618 & TST \\
\hline
\end{tabular}




\begin{tabular}{|c|c|c|c|c|c|}
\hline \multicolumn{6}{|c|}{ Supplemental Table S2.txt } \\
\hline CHEMBL 399760 & 688721 & 5.5 & 4.7257 & TRN & \\
\hline CHEMBL1372133 & 688721 & 5.1 & 4.9907 & TRN & \\
\hline CHEMBL1462904 & 688721 & 5.3 & 5.0975 & TRN & \\
\hline CHEMBL1562814 & 688721 & 5.3 & 4.8975 & TRN & \\
\hline CHEMBL1411424 & 688721 & 4.4 & 5.1755 & TRN & \\
\hline CHEMBL1441016 & 688721 & 5.3 & 4.9719 & TRN & \\
\hline CHEMBL1361588 & 688721 & 5.2 & 4.8924 & TST & \\
\hline CHEMBL1526475 & 688721 & 4.5 & 4.7443 & TST & \\
\hline CHEMBL1369631 & 688721 & 5.0 & 5.1358 & TRN & \\
\hline CHEMBL1547072 & 688721 & 4.5 & 4.9958 & TRN & \\
\hline CHEMBL1492495 & 688721 & 4.4 & 4.7328 & TRN & \\
\hline CHEMBL1306161 & 688721 & 4.5 & 4.8672 & TRN & \\
\hline CHEMBL363554 & 688721 & 6.8 & 5.3005 & TRN & \\
\hline CHEMBL1353575 & 688721 & 4.6 & 4.871 & TRN & \\
\hline CHEMBL1539765 & 688721 & 4.6 & 4.90600 & 0000000001 & TST \\
\hline CHEMBL1585676 & 688721 & 6.9 & 4.88 & TRN & \\
\hline CHEMBL233896 & 688721 & 4.9 & 4.8149 & TST & \\
\hline CHEMBL1540125 & 688721 & 4.9 & 4.8479 & TRN & \\
\hline CHEMBL553751 & 688721 & 4.9 & 5.2078 & TST & \\
\hline CHEMBL1489774 & 688721 & 4.4 & 4.963 & TRN & \\
\hline CHEMBL1570212 & 688721 & 5.4 & 4.7469 & TST & \\
\hline CHEMBL1502354 & 688721 & 4.4 & 4.8347 & TST & \\
\hline CHEMBL1414671 & 688721 & 4.4 & 4.8391 & TST & \\
\hline CHEMBL1372322 & 688721 & 4.6 & 4.8587 & TRN & \\
\hline CHEMBL320247 & 688721 & 4.5 & 4.8656 & TRN & \\
\hline CHEMBL1364368 & 688721 & 4.8 & 4.98 & TST & \\
\hline CHEMBL1441030 & 688721 & 4.6 & 5.0168 & TST & \\
\hline CHEMBL 267458 & 688721 & 4.8 & 4.9834 & TRN & \\
\hline CHEMBL1479239 & 688721 & 4.8 & 4.9639 & TRN & \\
\hline CHEMBL1236104 & 688721 & 5.3 & 5.2547 & TRN & \\
\hline CHEMBL1605211 & 688721 & 4.8 & 4.9427 & TRN & \\
\hline CHEMBL1510615 & 688721 & 4.6 & 4.948 & TRN & \\
\hline CHEMBL1402528 & 688721 & 4.7 & 4.8875 & TRN & \\
\hline CHEMBL1578918 & 688721 & 5.2 & 5.0996 & TST & \\
\hline CHEMBL1479514 & 688721 & 4.6 & 4.9152 & TRN & \\
\hline CHEMBL1482532 & 688721 & 4.4 & 4.7399 & TRN & \\
\hline CHEMBL567130 & 688721 & 4.8 & 4.9094 & TRN & \\
\hline CHEMBL1597936 & 688721 & 4.7 & 5.0678 & TRN & \\
\hline CHEMBL1344453 & 688721 & 5.0 & 5.1861 & TST & \\
\hline CHEMBL1335360 & 688721 & 4.4 & 4.984 & TRN & \\
\hline CHEMBL1416540 & 688721 & 4.7 & 4.8574 & TRN & \\
\hline CHEMBL1432238 & 688721 & 4.5 & 4.9683 & TRN & \\
\hline CHEMBL1363298 & 688721 & 5.2 & 5.0917 & TRN & \\
\hline CHEMBL1413396 & 688721 & 5.2 & 4.9846 & TRN & \\
\hline CHEMBL1517617 & 688721 & 4.9 & 5.0958 & TRN & \\
\hline CHEMBL1478833 & 688721 & 5.8 & 5.1047 & TRN & \\
\hline CHEMBL1385925 & 688721 & 4.5 & 4.9956 & TST & \\
\hline CHEMBL1612854 & 688721 & 4.9 & 4.86 & TRN & \\
\hline
\end{tabular}




\begin{tabular}{|c|c|c|c|c|c|}
\hline \\
\hline CHEMBL1440326 & 688721 & 5.0 & 4.9386 & TST & \\
\hline CHEMBL1541509 & 688721 & 4.4 & 4.8366 & TRN & \\
\hline CHEMBL1479675 & 688721 & 4.7 & 4.9142 & TST & \\
\hline CHEMBL50267 & 688721 & 5.2 & 5.1022 & TST & \\
\hline CHEMBL1335952 & 688721 & 4.5 & 5.0701 & TRN & \\
\hline CHEMBL1513654 & 688721 & 4.4 & 5.0743 & TST & \\
\hline CHEMBL1521490 & 688721 & 5.2 & 5.1302 & TRN & \\
\hline CHEMBL1545575 & 688721 & 4.8 & 4.79899 & 99999999995 & TRN \\
\hline CHEMBL1374649 & 688721 & 4.6 & 4.9483 & TRN & \\
\hline CHEMBL1418264 & 688721 & 4.6 & 4.7831 & TST & \\
\hline CHEMBL1355002 & 688721 & 5.4 & 5.0677 & TRN & \\
\hline CHEMBL1408965 & 688721 & 4.6 & 4.9732 & TRN & \\
\hline CHEMBL1603680 & 688721 & 4.9 & 4.8902 & TRN & \\
\hline CHEMBL1370636 & 688721 & 4.5 & 4.7641 & TRN & \\
\hline CHEMBL1345685 & 688721 & 4.4 & 4.7698 & TRN & \\
\hline CHEMBL 1256750 & 688721 & 5.7 & 4.85 & TRN & \\
\hline CHEMBL1335635 & 688721 & 5.2 & 4.9973 & TST & \\
\hline CHEMBL1353458 & 688721 & 4.4 & 5.0745 & TRN & \\
\hline CHEMBL1588844 & 688721 & 4.4 & 4.8882 & TRN & \\
\hline CHEMBL1431888 & 688721 & 4.6 & 5.0368 & TRN & \\
\hline CHEMBL1447657 & 688721 & 4.6 & 5.0048 & TRN & \\
\hline CHEMBL3191796 & 688721 & 5.5 & 5.039 & TST & \\
\hline CHEMBL1459708 & 688721 & 4.5 & 4.7817 & TRN & \\
\hline CHEMBL1460830 & 688721 & 4.8 & 4.9522 & TRN & \\
\hline CHEMBL1483908 & 688721 & 4.5 & 4.881 & TRN & \\
\hline CHEMBL1322272 & 688721 & 4.5 & 4.7975 & TRN & \\
\hline CHEMBL1540307 & 688721 & 4.5 & 5.0173 & TRN & \\
\hline CHEMBL1392205 & 688721 & 4.4 & 4.8828 & TST & \\
\hline CHEMBL1350144 & 688721 & 5.0 & 5.0133 & TRN & \\
\hline CHEMBL1605823 & 688721 & 4.8 & 4.9262 & TRN & \\
\hline CHEMBL29757 & 688721 & 5.1 & 5.4008 & TRN & \\
\hline CHEMBL489940 & 688721 & 4.6 & 4.9024 & TRN & \\
\hline CHEMBL1611258 & 688721 & 4.5 & 4.8315 & TRN & \\
\hline CHEMBL1350339 & 688721 & 4.6 & 5.1501 & TRN & \\
\hline CHEMBL1505912 & 688721 & 4.5 & 4.8361 & TST & \\
\hline CHEMBL1583209 & 688721 & 5.4 & 4.6892 & TST & \\
\hline CHEMBL1325691 & 688721 & 5.2 & 5.0436 & TST & \\
\hline CHEMBL1613110 & 688721 & 4.6 & 5.0679 & TST & \\
\hline CHEMBL1602606 & 688721 & 4.6 & 4.8671 & TRN & \\
\hline CHEMBL1398960 & 688721 & 4.6 & 4.8277 & TRN & \\
\hline CHEMBL1418235 & 688721 & 4.4 & 4.8429 & TRN & \\
\hline CHEMBL1480581 & 688721 & 4.6 & 5.2062 & TST & \\
\hline CHEMBL1319909 & 688721 & 5.1 & 4.9284 & TST & \\
\hline CHEMBL 222808 & 688721 & 5.5 & 4.9497 & TST & \\
\hline CHEMBL1525591 & 688721 & 4.6 & 4.8034 & TRN & \\
\hline CHEMBL1373568 & 688721 & 4.4 & 5.1157 & TST & \\
\hline CHEMBL1541064 & 688721 & 5.1 & 4.9869 & TRN & \\
\hline CHEMBL1456165 & 688721 & 4.9 & 5.1496 & TRN & \\
\hline
\end{tabular}




\begin{tabular}{|c|c|c|c|c|c|}
\hline \multicolumn{6}{|c|}{ Supplemental Table s2.txt } \\
\hline CHEMBL1418747 & 688721 & 5.4 & 5.0462 & TST & \\
\hline CHEMBL1346066 & 688721 & 5.2 & 5.1544 & TRN & \\
\hline CHEMBL1604796 & 688721 & 7.5003 & 5.069 & TRN & \\
\hline CHEMBL1503456 & 688721 & 5.0 & 5.2632 & TST & \\
\hline CHEMBL1527622 & 688721 & 5.3 & 4.8721 & TST & \\
\hline CHEMBL1302766 & 688721 & 4.9 & 5.0634 & TRN & \\
\hline CHEMBL1484176 & 688721 & 5.3 & 4.8174 & TRN & \\
\hline CHEMBL1348896 & 688721 & 4.6 & 4.8817 & TST & \\
\hline CHEMBL1596847 & 688721 & 5.1 & 4.8966 & TST & \\
\hline CHEMBL1537053 & 688721 & 4.4 & 4.8142 & TRN & \\
\hline CHEMBL1469620 & 688721 & 4.5 & 4.7564 & TRN & \\
\hline CHEMBL1505683 & 688721 & 4.6 & 4.9867 & TRN & \\
\hline CHEMBL1537383 & 688721 & 4.7 & 5.05699 & 99999999995 & TRN \\
\hline CHEMBL1418494 & 688721 & 4.4 & 4.8217 & TST & \\
\hline CHEMBL1466097 & 688721 & 4.6 & 4.9107 & TRN & \\
\hline CHEMBL1479781 & 688721 & 5.0 & 4.8418 & TRN & \\
\hline CHEMBL1488642 & 688721 & 4.5 & 4.9036 & TRN & \\
\hline CHEMBL1450327 & 688721 & 4.8 & 4.9398 & TRN & \\
\hline CHEMBL1455056 & 688721 & 4.6 & 4.933 & TST & \\
\hline CHEMBL1573063 & 688721 & 4.6 & 5.1354 & TRN & \\
\hline CHEMBL1353164 & 688721 & 4.8 & 4.9534 & TRN & \\
\hline CHEMBL1606698 & 688721 & 4.4 & 5.0256 & TRN & \\
\hline CHEMBL1327901 & 688721 & 4.4 & 5.0406 & TRN & \\
\hline CHEMBL1600732 & 688721 & 4.4 & 4.9987 & TRN & \\
\hline CHEMBL1329998 & 688721 & 4.8 & 4.726 & TRN & \\
\hline CHEMBL1402233 & 688721 & 4.4 & 4.8407 & TRN & \\
\hline CHEMBL1411684 & 688721 & 4.6 & 4.9838 & TRN & \\
\hline CHEMBL1430548 & 688721 & 5.4 & 4.9379 & TRN & \\
\hline CHEMBL1402096 & 688721 & 5.0 & 5.047 & TRN & \\
\hline CHEMBL1299949 & 688721 & 4.8 & 5.255 & TST & \\
\hline CHEMBL1502229 & 688721 & 4.8 & 5.0177 & TST & \\
\hline CHEMBL1527995 & 688721 & 4.7 & 4.9185 & TST & \\
\hline CHEMBL1372742 & 688721 & 4.4 & 5.1518 & TST & \\
\hline CHEMBL1408076 & 688721 & 5.5 & 5.0316 & TRN & \\
\hline CHEMBL1449135 & 688721 & 4.6 & 4.9111 & TST & \\
\hline CHEMBL1531970 & 688721 & 5.8 & 4.9052 & TRN & \\
\hline CHEMBL1595774 & 688721 & 4.6 & 4.9369 & TRN & \\
\hline CHEMBL1372596 & 688721 & 4.5 & 4.9263 & TRN & \\
\hline CHEMBL1433117 & 688721 & 4.9 & 4.8572 & TRN & \\
\hline CHEMBL1331544 & 688721 & 4.4 & 5.018 & TRN & \\
\hline CHEMBL1353157 & 688721 & 4.8 & 4.7734 & TRN & \\
\hline CHEMBL1538993 & 688721 & 4.8 & 4.8801 & TRN & \\
\hline CHEMBL1522160 & 688721 & 4.7 & 5.0499 & TRN & \\
\hline CHEMBL1568586 & 688721 & 4.5 & 4.8112 & TRN & \\
\hline CHEMBL1461878 & 688721 & 4.6 & 5.0692 & TRN & \\
\hline CHEMBL1419142 & 688721 & 4.6 & 4.7944 & TRN & \\
\hline CHEMBL1520748 & 688721 & 4.7 & 4.9413 & TRN & \\
\hline CHEMBL1509641 & 688721 & 4.6 & 5.2002 & TRN & \\
\hline
\end{tabular}




\begin{tabular}{|c|c|c|c|c|c|}
\hline \\
\hline CHEMBL1318480 & 688721 & 4.5 & 5.1345 & TRN & \\
\hline CHEMBL1477557 & 688721 & 4.8 & 5.1165 & TRN & \\
\hline CHEMBL1566487 & 688721 & 4.7 & 4.8366 & TRN & \\
\hline CHEMBL1485979 & 688721 & 4.4 & 4.9506 & TRN & \\
\hline CHEMBL1473761 & 688721 & 4.7 & 5.051 & TRN & \\
\hline CHEMBL1490638 & 688721 & 5.0 & 4.945 & TRN & \\
\hline CHEMBL1352410 & 688721 & 4.7 & 4.8809 & TRN & \\
\hline CHEMBL1387988 & 688721 & 6.0 & 4.9595 & TRN & \\
\hline CHEMBL1358487 & 688721 & 5.2 & 5.095 & TST & \\
\hline CHEMBL1548645 & 688721 & 4.6 & 4.9199 & TST & \\
\hline CHEMBL1396611 & 688721 & 7.0 & 4.9186 & TRN & \\
\hline CHEMBL1588857 & 688721 & 5.1 & 4.928 & TST & \\
\hline CHEMBL1608446 & 688721 & 4.4 & 4.7868 & TRN & \\
\hline CHEMBL1540342 & 688721 & 4.4 & 4.7181 & TRN & \\
\hline CHEMBL1408230 & 688721 & 5.3 & 5.1058 & TRN & \\
\hline CHEMBL1502655 & 688721 & 5.1 & 5.04899 & 99999999995 & TRN \\
\hline CHEMBL1425555 & 688721 & 4.6 & 4.8769 & TST & \\
\hline CHEMBL1361490 & 688721 & 5.3 & 4.9361 & TST & \\
\hline CHEMBL1413156 & 688721 & 5.2 & 5.0889 & TRN & \\
\hline CHEMBL1376987 & 688721 & 4.4 & 5.1525 & TRN & \\
\hline CHEMBL1578473 & 688721 & 5.5 & 4.8869 & TST & \\
\hline CHEMBL1491574 & 688721 & 4.5 & 5.1611 & TRN & \\
\hline CHEMBL1333071 & 688721 & 4.6 & 5.0745 & TRN & \\
\hline CHEMBL1570557 & 688721 & 4.4 & 4.7642 & TST & \\
\hline CHEMBL1477858 & 688721 & 4.5 & 4.8296 & TRN & \\
\hline CHEMBL1400183 & 688721 & 4.5 & 5.0421 & TRN & \\
\hline CHEMBL1505042 & 688721 & 5.4 & 4.9492 & TRN & \\
\hline CHEMBL1480648 & 688721 & 4.8 & 4.8767 & TRN & \\
\hline CHEMBL1524023 & 688721 & 4.5 & 4.7839 & TRN & \\
\hline CHEMBL1359872 & 688721 & 5.3 & 5.01399 & 9999999999 & TRN \\
\hline CHEMBL1327823 & 688721 & 5.1 & 5.303 & TST & \\
\hline CHEMBL1607964 & 688721 & 5.2 & 5.0108 & TST & \\
\hline CHEMBL1543833 & 688721 & 4.6 & 4.8119 & TRN & \\
\hline CHEMBL1341030 & 688721 & 4.9 & 5.1002 & TST & \\
\hline CHEMBL1481022 & 688721 & 4.6 & 4.8255 & TRN & \\
\hline CHEMBL1307241 & 688721 & 5.2 & 4.852 & TRN & \\
\hline CHEMBL1560343 & 688721 & 4.6 & 4.933 & TRN & \\
\hline CHEMBL1413655 & 688721 & 5.3 & 4.9245 & TRN & \\
\hline CHEMBL1505867 & 688721 & 4.8 & 4.9853 & TST & \\
\hline CHEMBL1565756 & 688721 & 4.5 & 4.8332 & TRN & \\
\hline CHEMBL1334387 & 688721 & 4.4 & 4.9997 & TRN & \\
\hline CHEMBL1586127 & 688721 & 4.5 & 4.8064 & TRN & \\
\hline CHEMBL3211627 & 688721 & 4.4 & 5.1896 & TST & \\
\hline CHEMBL567332 & 688721 & 4.8 & 4.9843 & TRN & \\
\hline CHEMBL1566504 & 688721 & 4.4 & 5.2477 & TST & \\
\hline CHEMBL1607362 & 688721 & 4.4 & 5.0208 & TRN & \\
\hline CHEMBL1409230 & 688721 & 4.6 & 4.8872 & TST & \\
\hline CHEMBL1597968 & 688721 & 4.6 & 5.0453 & TRN & \\
\hline
\end{tabular}




\begin{tabular}{|c|c|c|c|c|c|}
\hline \multicolumn{6}{|c|}{ Supplemental Table S2.txt } \\
\hline CHEMBL1464055 & 688721 & 5.1 & 5.0887 & TRN & \\
\hline CHEMBL1487131 & 688721 & 5.5 & 4.6776 & TRN & \\
\hline CHEMBL1538612 & 688721 & 4.4 & 4.8944 & TST & \\
\hline CHEMBL1312650 & 688721 & 4.6 & 5.0381 & TRN & \\
\hline CHEMBL1309451 & 688721 & 4.6 & 4.7949 & TST & \\
\hline CHEMBL1468832 & 688721 & 6.1 & 5.0256 & TST & \\
\hline CHEMBL1583283 & 688721 & 7.5003 & 5.0064 & TRN & \\
\hline CHEMBL1412443 & 688721 & 5.1 & 4.9272 & TRN & \\
\hline CHEMBL405317 & 688721 & 4.4 & 4.8839 & TRN & \\
\hline CHEMBL1427685 & 688721 & 4.5 & 4.8877 & TST & \\
\hline CHEMBL1483541 & 688721 & 4.6 & 5.0184 & TRN & \\
\hline CHEMBL1542915 & 688721 & 4.6 & 4.784 & TRN & \\
\hline CHEMBL1528249 & 688721 & 4.4 & 4.8529 & TRN & \\
\hline CHEMBL1499872 & 688721 & 5.3 & 4.8631 & TRN & \\
\hline CHEMBL1449162 & 688721 & 4.5 & 4.9045 & TRN & \\
\hline CHEMBL1423701 & 688721 & 5.2 & 4.8648 & TRN & \\
\hline CHEMBL1422354 & 688721 & 4.4 & 4.9208 & TRN & \\
\hline CHEMBL397209 & 688721 & 5.2 & 5.2047 & TST & \\
\hline CHEMBL1496378 & 688721 & 6.0 & 5.0349 & TRN & \\
\hline CHEMBL1365888 & 688721 & 4.4 & 4.9934 & TRN & \\
\hline CHEMBL1353725 & 688721 & 4.4 & 4.9007 & TRN & \\
\hline CHEMBL1373183 & 688721 & 4.8 & 4.7365 & TRN & \\
\hline CHEMBL1370413 & 688721 & 4.6 & 4.8255 & TRN & \\
\hline CHEMBL1492494 & 688721 & 5.9 & 4.85800 & 00000000005 & TRN \\
\hline CHEMBL1539964 & 688721 & 4.7 & 5.0727 & TRN & \\
\hline CHEMBL1581648 & 688721 & 5.9 & 4.971 & TRN & \\
\hline CHEMBL1410723 & 688721 & 4.9 & 4.8896 & TRN & \\
\hline CHEMBL1471052 & 688721 & 5.2 & 5.0409 & TST & \\
\hline CHEMBL1540509 & 688721 & 5.2 & 4.9884 & TRN & \\
\hline CHEMBL3186408 & 688721 & 5.1 & 5.1207 & TST & \\
\hline CHEMBL1531441 & 688721 & 4.4 & 5.1041 & TRN & \\
\hline CHEMBL1575573 & 688721 & 6.0 & 5.2481 & TRN & \\
\hline CHEMBL1321173 & 688721 & 4.4 & 4.9411 & TRN & \\
\hline CHEMBL1492029 & 688721 & 7.0 & 5.0154 & TRN & \\
\hline CHEMBL1500687 & 688721 & 5.2 & 4.817 & TRN & \\
\hline CHEMBL1609526 & 688721 & 4.7 & 4.7728 & TRN & \\
\hline CHEMBL1498918 & 688721 & 6.8 & 4.9296 & TRN & \\
\hline CHEMBL1331426 & 688721 & 5.2 & 5.0357 & TST & \\
\hline CHEMBL1320408 & 688721 & 5.4 & 5.0161 & TST & \\
\hline CHEMBL1405969 & 688721 & 4.9 & 4.9149 & TST & \\
\hline CHEMBL1444141 & 688721 & 5.0 & 5.0794 & TRN & \\
\hline CHEMBL1542974 & 688721 & 4.7 & 5.0 & TRN & \\
\hline CHEMBL1347981 & 688721 & 5.2 & 5.1765 & TRN & \\
\hline CHEMBL1319809 & 688721 & 5.4 & 4.9269 & TRN & \\
\hline CHEMBL1413287 & 688721 & 5.1 & 5.1148 & TRN & \\
\hline CHEMBL1523911 & 688721 & 4.7 & 4.9771 & TRN & \\
\hline CHEMBL1398443 & 688721 & 4.8 & 5.3239 & TST & \\
\hline CHEMBL1340880 & 688721 & 4.8 & 4.7921 & TRN & \\
\hline
\end{tabular}




\begin{tabular}{|c|c|c|c|c|}
\hline \multicolumn{5}{|c|}{ Supplemental Table S2.txt } \\
\hline CHEMBL1442979 & 688721 & 4.8 & 4.8541 & TRN \\
\hline CHEMBL1344207 & 688721 & 4.7 & 4.9498 & TST \\
\hline CHEMBL1476851 & 688721 & 5.9 & 5.1025 & TRN \\
\hline CHEMBL1536768 & 688721 & 4.5 & 4.9864 & TRN \\
\hline CHEMBL1350093 & 688721 & 4.4 & 4.8635 & TRN \\
\hline CHEMBL1581088 & 688721 & 4.8 & 4.7959 & TST \\
\hline CHEMBL1586847 & 688721 & 4.9 & 4.795 & TRN \\
\hline CHEMBL1490268 & 688721 & 4.8 & 4.9911 & TRN \\
\hline CHEMBL551883 & 688721 & 5.8 & 5.0434 & TST \\
\hline CHEMBL 1478376 & 688721 & 4.4 & 5.06 & TST \\
\hline CHEMBL326967 & 688721 & 5.1 & 4.9975 & TST \\
\hline CHEMBL1408176 & 688721 & 5.4 & 5.0275 & TRN \\
\hline CHEMBL1437733 & 688721 & 4.5 & 5.3073 & TRN \\
\hline CHEMBL1482368 & 688721 & 6.9 & 4.7047 & TRN \\
\hline CHEMBL1423070 & 688721 & 4.6 & 4.7946 & TRN \\
\hline CHEMBL1372336 & 688721 & 4.9 & 4.9895 & TST \\
\hline CHEMBL1310694 & 688721 & 4.5 & 4.9528 & TRN \\
\hline CHEMBL1607565 & 688721 & 4.7 & 4.8351 & TRN \\
\hline CHEMBL1309613 & 688721 & 6.9 & 4.898 & TRN \\
\hline CHEMBL1453475 & 688721 & 4.6 & 4.7608 & TRN \\
\hline CHEMBL1449867 & 688721 & 8.2007 & 4.9869 & TST \\
\hline CHEMBL 267014 & 688721 & 6.0 & 5.0701 & TRN \\
\hline CHEMBL1566161 & 688721 & 4.8 & 4.7267 & TRN \\
\hline CHEMBL1352829 & 688721 & 5.0 & 5.0438 & TRN \\
\hline CHEMBL1521189 & 688721 & 5.5 & 4.9512 & TST \\
\hline CHEMBL1371789 & 688721 & 4.8 & 4.7589 & TRN \\
\hline CHEMBL1579627 & 688721 & 4.5 & 5.1256 & TST \\
\hline CHEMBL1445388 & 688721 & 5.2 & 4.9669 & TRN \\
\hline CHEMBL1414021 & 688721 & 4.9 & 4.915 & TRN \\
\hline CHEMBL1359428 & 688721 & 4.8 & 4.8918 & TRN \\
\hline CHEMBL1489351 & 688721 & 4.4 & 4.8526 & TRN \\
\hline CHEMBL1303738 & 688721 & 4.4 & 4.8945 & TRN \\
\hline CHEMBL1471467 & 688721 & 4.4 & 4.8797 & TST \\
\hline CHEMBL1372821 & 688721 & 4.4 & 4.9044 & TST \\
\hline CHEMBL1521261 & 688721 & 4.5 & 4.9416 & TST \\
\hline CHEMBL1500252 & 688721 & 4.6 & 4.9725 & TRN \\
\hline CHEMBL1570215 & 688721 & 6.7001 & 4.8388 & TRN \\
\hline CHEMBL 344127 & 688721 & 6.7001 & 5.1572 & TST \\
\hline CHEMBL1486577 & 688721 & 5.9 & 5.3595 & TRN \\
\hline CHEMBL1585399 & 688721 & 5.2 & 5.1019 & TRN \\
\hline CHEMBL1379819 & 688721 & 4.6 & 4.8992 & TRN \\
\hline CHEMBL1506998 & 688721 & 4.5 & 4.9321 & TRN \\
\hline CHEMBL1329391 & 688721 & 4.4 & 4.9445 & TRN \\
\hline CHEMBL1383574 & 688721 & 4.9 & 4.9398 & TRN \\
\hline CHEMBL1583614 & 688721 & 5.2 & 4.9887 & TRN \\
\hline CHEMBL1330128 & 688721 & 5.3 & 4.9409 & TRN \\
\hline CHEMBL1544552 & 688721 & 5.6 & 5.0343 & TRN \\
\hline CHEMBL1300779 & 688721 & 4.9 & 4.9425 & TST \\
\hline
\end{tabular}




\begin{tabular}{|c|c|c|c|c|}
\hline \multicolumn{5}{|c|}{ Supplemental Table S2.txt } \\
\hline CHEMBL1516618 & 688721 & 4.4 & 4.8739 & TRN \\
\hline CHEMBL1484186 & 688721 & 4.6 & 4.8886 & TST \\
\hline CHEMBL534084 & 688721 & 6.0 & 5.0929 & TST \\
\hline CHEMBL1539925 & 688721 & 4.7 & 4.9289 & TRN \\
\hline CHEMBL1401431 & 688721 & 4.5 & 4.9394 & TRN \\
\hline CHEMBL1570167 & 688721 & 4.6 & 4.7726 & TRN \\
\hline CHEMBL1307179 & 688721 & 5.2 & 4.9475 & TRN \\
\hline CHEMBL1589780 & 688721 & 4.6 & 5.013 & TST \\
\hline CHEMBL16370 & 688721 & 4.8 & 5.2593 & TST \\
\hline CHEMBL1598873 & 688721 & 4.8 & 4.7852 & TRN \\
\hline CHEMBL1331836 & 688721 & 5.1 & 4.8862 & TRN \\
\hline CHEMBL1371755 & 688721 & 5.6 & 5.001 & TRN \\
\hline CHEMBL1391435 & 688721 & 6.7001 & 5.0712 & TRN \\
\hline CHEMBL 3208453 & 688721 & 5.4 & 5.1693 & TST \\
\hline CHEMBL1368672 & 688721 & 4.4 & 4.8507 & TRN \\
\hline CHEMBL1471444 & 688721 & 4.5 & 4.8454 & TRN \\
\hline CHEMBL1490139 & 688721 & 4.6 & 5.1594 & TRN \\
\hline CHEMBL582081 & 688721 & 4.6 & 4.8873 & TRN \\
\hline CHEMBL1488213 & 688721 & 5.0 & 4.7956 & TRN \\
\hline CHEMBL1437713 & 688721 & 5.5 & 5.1893 & TRN \\
\hline CHEMBL1317056 & 688721 & 5.3 & 5.1429 & TRN \\
\hline CHEMBL1401457 & 688721 & 4.8 & 5.1011 & TRN \\
\hline CHEMBL1607113 & 688721 & 4.5 & 4.9985 & TRN \\
\hline CHEMBL1481186 & 688721 & 4.6 & 4.9123 & TRN \\
\hline CHEMBL1457342 & 688721 & 4.7 & 4.7224 & TRN \\
\hline CHEMBL1390831 & 688721 & 4.8 & 4.8065 & TRN \\
\hline CHEMBL1469396 & 688721 & 4.6 & 4.873 & TRN \\
\hline CHEMBL1551643 & 688721 & 5.4 & 5.3495 & TST \\
\hline CHEMBL389516 & 688721 & 5.3 & 4.9147 & TST \\
\hline CHEMBL1459571 & 688721 & 4.6 & 4.923 & TRN \\
\hline CHEMBL1557284 & 688721 & 4.6 & 4.8608 & TRN \\
\hline CHEMBL1443681 & 688721 & 4.6 & 4.947 & TRN \\
\hline CHEMBL1328437 & 688721 & 4.5 & 5.0211 & TRN \\
\hline CHEMBL1603137 & 688721 & 4.6 & 4.8551 & TRN \\
\hline CHEMBL3436365 & 688721 & 4.8 & 5.0552 & TST \\
\hline CHEMBL1324529 & 688721 & 6.3 & 5.1882 & TRN \\
\hline CHEMBL1549367 & 688721 & 4.6 & 4.6836 & TRN \\
\hline CHEMBL1549209 & 688721 & 4.6 & 4.7237 & TRN \\
\hline CHEMBL284104 & 688721 & 5.8 & 5.0668 & TRN \\
\hline CHEMBL1567013 & 688721 & 4.4 & 4.7562 & TRN \\
\hline CHEMBL1451315 & 688721 & 4.6 & 5.0387 & TRN \\
\hline CHEMBL1587583 & 688721 & 4.6 & 4.7599 & TRN \\
\hline CHEMBL1325831 & 688721 & 4.5 & 4.9061 & TST \\
\hline CHEMBL1593547 & 688721 & 5.4 & 5.0996 & TRN \\
\hline CHEMBL1565192 & 688721 & 5.0 & 5.0893 & TRN \\
\hline CHEMBL1305512 & 688721 & 4.6 & 4.8818 & TRN \\
\hline CHEMBL1407576 & 688721 & 6.1 & 5.3856 & TRN \\
\hline CHEMBL1349348 & 688721 & 5.9 & 4.9986 & TRN \\
\hline
\end{tabular}




\begin{tabular}{|c|c|c|c|c|c|}
\hline \\
\hline CHEMBL1559388 & 688721 & 5.0 & 4.9344 & TRN & \\
\hline CHEMBL1313319 & 688721 & 5.0 & 4.9792 & TRN & \\
\hline CHEMBL1367977 & 688721 & 7.0 & 4.905 & TRN & \\
\hline CHEMBL1320349 & 688721 & 4.6 & 4.86600 & 00000000005 & TRN \\
\hline CHEMBL1595350 & 688721 & 4.7 & 4.8818 & TRN & \\
\hline CHEMBL1390422 & 688721 & 5.1 & 5.0677 & TRN & \\
\hline CHEMBL1374352 & 688721 & 4.5 & 4.8891 & TRN & \\
\hline CHEMBL1492874 & 688721 & 5.1 & 5.1746 & TST & \\
\hline CHEMBL1372823 & 688721 & 5.2 & 4.9353 & TST & \\
\hline CHEMBL1529166 & 688721 & 4.6 & 4.885 & TRN & \\
\hline CHEMBL1566928 & 688721 & 4.6 & 4.9651 & TST & \\
\hline CHEMBL1450655 & 688721 & 4.4 & 4.9189 & TRN & \\
\hline CHEMBL1370480 & 688721 & 5.9 & 5.2317 & TRN & \\
\hline CHEMBL1433760 & 688721 & 6.3 & 5.1343 & TRN & \\
\hline CHEMBL1570436 & 688721 & 4.4 & 4.8515 & TRN & \\
\hline CHEMBL1412373 & 688721 & 4.7 & 4.7457 & TRN & \\
\hline CHEMBL1488264 & 688721 & 6.8 & 4.9505 & TRN & \\
\hline CHEMBL1302017 & 688721 & 4.4 & 4.9685 & TRN & \\
\hline CHEMBL1525511 & 688721 & 4.5 & 5.0724 & TRN & \\
\hline CHEMBL1461993 & 688721 & 5.4 & 4.9669 & TST & \\
\hline CHEMBL1415706 & 688721 & 4.4 & 5.0291 & TRN & \\
\hline CHEMBL1528542 & 688721 & 4.4 & 4.899 & TRN & \\
\hline CHEMBL1334872 & 688721 & 5.3 & 4.8152 & TRN & \\
\hline CHEMBL1449269 & 688721 & 5.4 & 4.85800 & 00000000005 & TRN \\
\hline CHEMBL1611064 & 688721 & 4.5 & 4.8599 & TST & \\
\hline CHEMBL1578323 & 688721 & 5.2 & 4.8797 & TRN & \\
\hline CHEMBL1343333 & 688721 & 4.5 & 4.9163 & TRN & \\
\hline CHEMBL335231 & 688721 & 4.4 & 5.2185 & TST & \\
\hline CHEMBL1299783 & 688721 & 5.1 & 4.713 & TRN & \\
\hline CHEMBL1320223 & 688721 & 4.4 & 4.8985 & TRN & \\
\hline CHEMBL1488675 & 688721 & 4.6 & 4.8391 & TST & \\
\hline CHEMBL1484810 & 688721 & 4.7 & 4.9499 & TRN & \\
\hline CHEMBL1449327 & 688721 & 4.5 & 4.8122 & TRN & \\
\hline CHEMBL1484080 & 688721 & 4.5 & 4.9585 & TRN & \\
\hline CHEMBL1599919 & 688721 & 5.1 & 5.0627 & TRN & \\
\hline CHEMBL1519435 & 688721 & 4.6 & 4.94300 & 20000000005 & TRN \\
\hline CHEMBL1486613 & 688721 & 5.2 & 4.9503 & TRN & \\
\hline CHEMBL1441866 & 688721 & 4.6 & 4.8719 & TST & \\
\hline CHEMBL1543317 & 688721 & 6.1 & 4.8569 & TRN & \\
\hline CHEMBL1313785 & 688721 & 4.4 & 4.8318 & TST & \\
\hline CHEMBL1402435 & 688721 & 4.7 & 5.1386 & TST & \\
\hline CHEMBL1459111 & 688721 & 4.7 & 4.8498 & TRN & \\
\hline CHEMBL1425169 & 688721 & 4.6 & 4.925 & TRN & \\
\hline CHEMBL1544586 & 688721 & 5.2 & 5.0269 & TST & \\
\hline CHEMBL1494408 & 688721 & 6.5 & 5.225 & TRN & \\
\hline CHEMBL1443080 & 688721 & 5.5 & 4.8947 & TST & \\
\hline CHEMBL1380940 & 688721 & 4.9 & 4.7861 & TRN & \\
\hline CHEMBL1379011 & 688721 & 4.4 & 4.9646 & TST & \\
\hline
\end{tabular}




\begin{tabular}{|c|c|c|c|c|c|}
\hline \multicolumn{6}{|c|}{ Supplemental Table s2.txt } \\
\hline CHEMBL1330392 & 688721 & 5.3 & 4.9122 & TST & \\
\hline CHEMBL1445901 & 688721 & 4.6 & 5.0372 & TRN & \\
\hline CHEMBL1394640 & 688721 & 6.8 & 5.0905 & TRN & \\
\hline CHEMBL1491885 & 688721 & 5.5 & 5.0308 & TST & \\
\hline CHEMBL1521658 & 688721 & 4.6 & 4.8522 & TST & \\
\hline CHEMBL1334509 & 688721 & 4.8 & 5.0093 & TRN & \\
\hline CHEMBL1612085 & 688721 & 5.4 & 4.8915 & TRN & \\
\hline CHEMBL1492317 & 688721 & 4.7 & 4.8632 & TST & \\
\hline CHEMBL1586897 & 688721 & 7.699 & 5.0878 & TRN & \\
\hline CHEMBL1607095 & 688721 & 4.8 & 5.0032 & TST & \\
\hline CHEMBL1599971 & 688721 & 4.5 & 4.8631 & TST & \\
\hline CHEMBL1311124 & 688721 & 4.4 & 4.7656 & TRN & \\
\hline CHEMBL1400251 & 688721 & 5.6 & 5.0872 & TST & \\
\hline CHEMBL1483301 & 688721 & 4.4 & 4.8653 & TST & \\
\hline CHEMBL1354112 & 688721 & 5.5 & 5.1673 & TST & \\
\hline CHEMBL1589435 & 688721 & 4.6 & 5.1244 & TRN & \\
\hline CHEMBL1613622 & 688721 & 7.5003 & 5.1624 & TRN & \\
\hline CHEMBL1416498 & 688721 & 4.8 & 4.853 & TRN & \\
\hline CHEMBL1347603 & 688721 & 4.6 & 4.7715 & TRN & \\
\hline CHEMBL1495577 & 688721 & 5.2 & 5.0017 & TRN & \\
\hline CHEMBL1371349 & 688721 & 4.4 & 4.7485 & TRN & \\
\hline CHEMBL1386080 & 688721 & 4.4 & 4.5979 & TRN & \\
\hline CHEMBL1563807 & 688721 & 4.6 & 5.0894 & TRN & \\
\hline CHEMBL1310517 & 688721 & 4.8 & 4.9795 & TRN & \\
\hline CHEMBL1506109 & 688721 & 5.2 & 4.86600 & 00000000005 & TRN \\
\hline CHEMBL1418677 & 688721 & 4.6 & 4.9321 & TST & \\
\hline CHEMBL1448287 & 688721 & 4.4 & 4.9682 & TRN & \\
\hline CHEMBL1382898 & 688721 & 5.3 & 4.9592 & TRN & \\
\hline CHEMBL1524299 & 688721 & 4.6 & 4.7842 & TRN & \\
\hline CHEMBL1597467 & 688721 & 4.6 & 4.815 & TRN & \\
\hline CHEMBL552741 & 688721 & 4.8 & 5.0993 & TST & \\
\hline CHEMBL1585260 & 688721 & 6.0 & 4.8884 & TRN & \\
\hline CHEMBL1381883 & 688721 & 5.3 & 5.0056 & TRN & \\
\hline CHEMBL1367007 & 688721 & 4.7 & 4.8678 & TRN & \\
\hline CHEMBL1478073 & 688721 & 5.9 & 4.8145 & TRN & \\
\hline CHEMBL1529503 & 688721 & 4.6 & 5.0578 & TST & \\
\hline CHEMBL1354294 & 688721 & 5.9 & 5.2494 & TRN & \\
\hline CHEMBL1384213 & 688721 & 5.0 & 4.9945 & TRN & \\
\hline CHEMBL1457429 & 688721 & 4.6 & 5.018 & TST & \\
\hline CHEMBL1558206 & 688721 & 4.4 & 4.8785 & TRN & \\
\hline CHEMBL1510784 & 688721 & 4.5 & 5.0079 & TRN & \\
\hline CHEMBL1389097 & 688721 & 5.4 & 4.9494 & TRN & \\
\hline CHEMBL1561644 & 688721 & 5.3 & 4.9427 & TRN & \\
\hline CHEMBL1370000 & 688721 & 5.2 & 5.0471 & TST & \\
\hline CHEMBL1449082 & 688721 & 5.7 & 5.1316 & TRN & \\
\hline CHEMBL1432848 & 688721 & 4.8 & 4.85800 & 00000000005 & TRN \\
\hline CHEMBL1564368 & 688721 & 4.7 & 5.0647 & TRN & \\
\hline CHEMBL1320948 & 688721 & 4.7 & 4.77 & TRN & \\
\hline
\end{tabular}




\begin{tabular}{|c|c|c|c|c|c|}
\hline \multicolumn{6}{|c|}{ Supplemental Table S2.txt } \\
\hline CHEMBL1361294 & 688721 & 4.4 & 4.7054 & TRN & \\
\hline CHEMBL1481119 & 688721 & 4.4 & 5.0176 & TST & \\
\hline CHEMBL1507131 & 688721 & 5.3 & 4.854 & TRN & \\
\hline CHEMBL1606723 & 688721 & 5.3 & 4.837 & TRN & \\
\hline CHEMBL1388307 & 688721 & 5.0 & 4.7727 & TRN & \\
\hline CHEMBL1393207 & 688721 & 4.5 & 5.1849 & TST & \\
\hline CHEMBL1580189 & 688721 & 5.2 & 4.7969 & TRN & \\
\hline CHEMBL1415248 & 688721 & 4.5 & 4.9771 & TRN & \\
\hline CHEMBL1379209 & 688721 & 4.5 & 4.9732 & TST & \\
\hline CHEMBL1497763 & 688721 & 5.2 & 5.0263 & TRN & \\
\hline CHEMBL1450089 & 688721 & 4.8 & 4.9393 & TRN & \\
\hline CHEMBL1603624 & 688721 & 5.3 & 5.1087 & TST & \\
\hline CHEMBL1593019 & 688721 & 5.1 & 5.1297 & TRN & \\
\hline CHEMBL1310209 & 688721 & 4.5 & 4.7678 & TRN & \\
\hline CHEMBL1347363 & 688721 & 5.2 & 5.0962 & TST & \\
\hline CHEMBL1583101 & 688721 & 4.4 & 4.9842 & TST & \\
\hline CHEMBL1560016 & 688721 & 4.7 & 4.897 & TRN & \\
\hline CHEMBL1579228 & 688721 & 4.6 & 4.8746 & TRN & \\
\hline CHEMBL1508308 & 688721 & 4.4 & 5.0393 & TRN & \\
\hline CHEMBL1310408 & 688721 & 4.4 & 5.2179 & TST & \\
\hline CHEMBL1318674 & 688721 & 5.2 & 5.1649 & TRN & \\
\hline CHEMBL1611267 & 688721 & 5.3 & 4.9028 & TST & \\
\hline CHEMBL1371160 & 688721 & 5.1 & 4.8418 & TST & \\
\hline CHEMBL1429669 & 688721 & 4.5 & 5.0067 & TRN & \\
\hline CHEMBL1457497 & 688721 & 4.6 & 5.1573 & TST & \\
\hline CHEMBL1596156 & 688721 & 5.3 & 4.8212 & TRN & \\
\hline CHEMBL1507474 & 688721 & 4.4 & 4.824 & TRN & \\
\hline CHEMBL1508794 & 688721 & 4.6 & 4.8941 & TRN & \\
\hline CHEMBL1448750 & 688721 & 5.2 & 4.806 & TRN & \\
\hline CHEMBL1493069 & 688721 & 5.0 & 4.857 & TRN & \\
\hline CHEMBL1322377 & 688721 & 4.7 & 4.965 & TRN & \\
\hline CHEMBL1414083 & 688721 & 4.4 & 5.0173 & TST & \\
\hline CHEMBL1444379 & 688721 & 4.4 & 4.7741 & TST & \\
\hline CHEMBL1430037 & 688721 & 5.1 & 5.0067 & TRN & \\
\hline CHEMBL1428217 & 688721 & 5.4 & 4.8168 & TRN & \\
\hline CHEMBL1492536 & 688721 & 4.6 & 5.2017 & TST & \\
\hline CHEMBL1301964 & 688721 & 5.2 & 5.0018 & TST & \\
\hline CHEMBL1404988 & 688721 & 4.4 & 4.9024 & TST & \\
\hline CHEMBL1554911 & 688721 & 5.9 & 5.335 & TST & \\
\hline CHEMBL611207 & 688721 & 5.3 & 4.8589 & TST & \\
\hline CHEMBL1468300 & 688721 & 5.2 & 4.9181 & TRN & \\
\hline CHEMBL12252 & 688721 & 4.8 & 4.9793 & TRN & \\
\hline CHEMBL1476712 & 688721 & 4.9 & 4.8419 & TRN & \\
\hline CHEMBL1307824 & 688721 & 6.0 & 4.9877 & TST & \\
\hline CHEMBL1556227 & 688721 & 4.6 & 4.8321 & TRN & \\
\hline CHEMBL1433339 & 688721 & 4.7 & 5.1454 & TRN & \\
\hline CHEMBL1494177 & 688721 & 5.5 & 5.12200 & 0000000001 & TRN \\
\hline CHEMBL565654 & 688721 & 5.1 & 4.8675 & TRN & \\
\hline
\end{tabular}




\begin{tabular}{|c|c|c|c|c|c|}
\hline & & & & & \\
\hline CHEMBL1323451 & 688721 & 4.4 & 4.7728 & TST & \\
\hline CHEMBL1367594 & 688721 & 4.6 & 4.859 & TRN & \\
\hline CHEMBL1429438 & 688721 & 4.6 & 5.0635 & TRN & \\
\hline CHEMBL1445714 & 688721 & 4.6 & 4.9815 & TRN & \\
\hline CHEMBL1566950 & 688721 & 4.4 & 4.7319 & TRN & \\
\hline CHEMBL1323385 & 688721 & 5.4 & 5.1925 & TRN & \\
\hline CHEMBL1465461 & 688721 & 4.8 & 4.9198 & TRN & \\
\hline CHEMBL1453592 & 688721 & 5.0 & 4.7964 & TRN & \\
\hline CHEMBL1468779 & 688721 & 4.5 & 4.7676 & TRN & \\
\hline CHEMBL1373834 & 688721 & 4.5 & 4.9211 & TRN & \\
\hline CHEMBL1306007 & 688721 & 4.6 & 4.9851 & TRN & \\
\hline CHEMBL1493017 & 688721 & 5.2 & 4.9394 & TRN & \\
\hline CHEMBL1369340 & 688721 & 4.4 & 4.9568 & TRN & \\
\hline CHEMBL1399014 & 688721 & 5.4 & 5.2412 & TRN & \\
\hline CHEMBL1426925 & 688721 & 4.8 & 5.0083 & TRN & \\
\hline CHEMBL1556116 & 688721 & 4.7 & 4.8895 & TST & \\
\hline CHEMBL1322828 & 688721 & 4.6 & 4.90300 & 00000000005 & TRN \\
\hline CHEMBL13670 & 688721 & 6.1 & 4.9542 & TST & \\
\hline CHEMBL1429506 & 688721 & 4.4 & 5.2721 & TST & \\
\hline CHEMBL1385337 & 688721 & 4.4 & 4.8571 & TRN & \\
\hline CHEMBL1596996 & 688721 & 4.5 & 4.9884 & TRN & \\
\hline CHEMBL1530348 & 688721 & 4.5 & 4.8296 & TRN & \\
\hline CHEMBL1256959 & 688721 & 6.0 & 5.0997 & TST & \\
\hline CHEMBL1343167 & 688721 & 4.8 & 4.8756 & TRN & \\
\hline CHEMBL1428840 & 688721 & 6.4 & 4.8174 & TRN & \\
\hline CHEMBL1462322 & 688721 & 4.5 & 4.8507 & TST & \\
\hline CHEMBL1329528 & 688721 & 4.6 & 4.7997 & TRN & \\
\hline CHEMBL1486391 & 688721 & 5.2 & 4.7878 & TRN & \\
\hline CHEMBL1417030 & 688721 & 4.5 & 4.9889 & TST & \\
\hline CHEMBL1310329 & 688721 & 5.2 & 4.8556 & TST & \\
\hline CHEMBL1526397 & 688721 & 5.4 & 4.8625 & TRN & \\
\hline CHEMBL1361935 & 688721 & 4.6 & 4.886 & TRN & \\
\hline CHEMBL1408158 & 688721 & 4.4 & 4.8579 & TST & \\
\hline CHEMBL489534 & 688721 & 4.6 & 4.9643 & TRN & \\
\hline CHEMBL1571922 & 688721 & 5.5 & 4.9885 & TRN & \\
\hline CHEMBL1482174 & 688721 & 6.8 & 5.0042 & TST & \\
\hline CHEMBL1431961 & 688721 & 4.5 & 4.8309 & TST & \\
\hline CHEMBL1384822 & 688721 & 4.8 & 4.8573 & TRN & \\
\hline CHEMBL1397427 & 688721 & 5.5 & 5.1728 & TRN & \\
\hline CHEMBL1449586 & 688721 & 4.6 & 4.7223 & TRN & \\
\hline CHEMBL512649 & 688721 & 4.4 & 4.9329 & TST & \\
\hline CHEMBL1373061 & 688721 & 5.4 & 4.8277 & TRN & \\
\hline CHEMBL1382721 & 688721 & 4.6 & 4.9393 & TST & \\
\hline CHEMBL1456320 & 688721 & 4.6 & 4.8911 & TRN & \\
\hline CHEMBL1387713 & 688721 & 4.4 & 4.9354 & TRN & \\
\hline CHEMBL 1459050 & 688721 & 4.6 & 4.8334 & TRN & \\
\hline CHEMBL1331651 & 688721 & 4.4 & 5.007 & TRN & \\
\hline CHEMBL1496718 & 688721 & 5.2 & 4.8217 & TST & \\
\hline
\end{tabular}




\begin{tabular}{|c|c|c|c|c|c|}
\hline \\
\hline CHEMBL1454438 & 688721 & 4.4 & 4.8552 & TRN & \\
\hline CHEMBL1406097 & 688721 & 4.5 & 4.7969 & TRN & \\
\hline CHEMBL1507611 & 688721 & 6.0 & 4.9091 & TST & \\
\hline CHEMBL1609322 & 688721 & 4.7 & 4.7677 & TRN & \\
\hline CHEMBL1507969 & 688721 & 5.2 & 4.8804 & TRN & \\
\hline CHEMBL1407012 & 688721 & 5.3 & 5.0705 & TRN & \\
\hline CHEMBL1399069 & 688721 & 6.5 & 5.3054 & TST & \\
\hline CHEMBL1517685 & 688721 & 4.5 & 4.7988 & TRN & \\
\hline CHEMBL1512540 & 688721 & 4.9 & 5.0932 & TRN & \\
\hline CHEMBL1346295 & 688721 & 4.6 & 5.0385 & TRN & \\
\hline CHEMBL1589670 & 688721 & 4.8 & 4.7556 & TRN & \\
\hline CHEMBL1356834 & 688721 & 4.8 & 5.08899 & 99999999995 & TRN \\
\hline CHEMBL1336386 & 688721 & 4.6 & 4.8613 & TRN & \\
\hline CHEMBL1557653 & 688721 & 5.5 & 4.9593 & TRN & \\
\hline CHEMBL1532408 & 688721 & 5.4 & 4.779 & TRN & \\
\hline CHEMBL1355010 & 688721 & 5.6 & 5.1696 & TRN & \\
\hline CHEMBL97760 & 688721 & 5.5 & 4.8906 & TST & \\
\hline CHEMBL1455586 & 688721 & 5.1 & 4.8248 & TRN & \\
\hline CHEMBL1580917 & 688721 & 4.7 & 4.8046 & TRN & \\
\hline CHEMBL1469785 & 688721 & 5.5 & 5.0262 & TRN & \\
\hline CHEMBL1537753 & 688721 & 4.5 & 4.9944 & TRN & \\
\hline CHEMBL1562288 & 688721 & 5.4 & 5.0344 & TST & \\
\hline CHEMBL1581148 & 688721 & 4.4 & 4.8632 & TRN & \\
\hline CHEMBL1556251 & 688721 & 5.1 & 4.8971 & TRN & \\
\hline CHEMBL1407551 & 688721 & 4.6 & 4.9838 & TRN & \\
\hline CHEMBL1320485 & 688721 & 4.4 & 5.109 & TST & \\
\hline CHEMBL1529039 & 688721 & 4.4 & 4.8357 & TST & \\
\hline CHEMBL1384006 & 688721 & 4.6 & 4.7909 & TRN & \\
\hline CHEMBL1376286 & 688721 & 4.9 & 5.1651 & TST & \\
\hline CHEMBL1332898 & 688721 & 4.6 & 4.8079 & TRN & \\
\hline CHEMBL3193842 & 688721 & 4.5 & 4.784 & TST & \\
\hline CHEMBL1384617 & 688721 & 4.4 & 4.9959 & TST & \\
\hline CHEMBL1583911 & 688721 & 4.9 & 4.8267 & TST & \\
\hline CHEMBL1590095 & 688721 & 5.0 & 4.8958 & TRN & \\
\hline CHEMBL1599089 & 688721 & 5.9 & 4.9268 & TRN & \\
\hline CHEMBL1590360 & 688721 & 4.4 & 4.7607 & TRN & \\
\hline CHEMBL1415196 & 688721 & 4.6 & 4.89199 & 99999999995 & TRN \\
\hline CHEMBL1452838 & 688721 & 4.4 & 5.1128 & TST & \\
\hline CHEMBL1320713 & 688721 & 4.8 & 4.9181 & TRN & \\
\hline CHEMBL1416454 & 688721 & 4.6 & 4.8896 & TRN & \\
\hline CHEMBL1492058 & 688721 & 5.5 & 5.0536 & TRN & \\
\hline CHEMBL15819 & 688721 & 5.2 & 5.1288 & TST & \\
\hline CHEMBL1565310 & 688721 & 5.2 & 4.9552 & TST & \\
\hline CHEMBL1580188 & 688721 & 4.6 & 5.0372 & TRN & \\
\hline CHEMBL1590270 & 688721 & 5.0 & 5.3127 & TRN & \\
\hline CHEMBL1349667 & 688721 & 4.9 & 4.896 & TRN & \\
\hline CHEMBL1520633 & 688721 & 6.1 & 4.9848 & TRN & \\
\hline CHEMBL1461096 & 688721 & 4.5 & 4.9197 & TRN & \\
\hline
\end{tabular}




\begin{tabular}{|c|c|c|c|c|c|}
\hline \\
\hline CHEMBL1557795 & 688721 & 5.6 & 5.0193 & TST & \\
\hline CHEMBL1530521 & 688721 & 4.9 & 4.9159 & TRN & \\
\hline CHEMBL1535790 & 688721 & 5.3 & 4.9753 & TRN & \\
\hline CHEMBL1557553 & 688721 & 5.4 & 5.0304 & TRN & \\
\hline CHEMBL1440494 & 688721 & 4.4 & 4.98 & TST & \\
\hline CHEMBL1603373 & 688721 & 4.6 & 4.7082 & TRN & \\
\hline CHEMBL1346894 & 688721 & 4.7 & 4.7592 & TRN & \\
\hline CHEMBL1476146 & 688721 & 5.4 & 5.1928 & TRN & \\
\hline CHEMBL1518915 & 688721 & 4.6 & 5.0816 & TRN & \\
\hline CHEMBL1606835 & 688721 & 4.7 & 5.0122 & TST & \\
\hline CHEMBL1302365 & 688721 & 4.6 & 4.9485 & TST & \\
\hline CHEMBL1558881 & 688721 & 5.4 & 4.7582 & TRN & \\
\hline CHEMBL1490272 & 688721 & 5.2 & 4.7668 & TRN & \\
\hline CHEMBL1325130 & 688721 & 4.6 & 4.9059 & TST & \\
\hline CHEMBL1536373 & 688721 & 4.6 & 4.854 & TRN & \\
\hline CHEMBL1558130 & 688721 & 5.5 & 4.836 & TRN & \\
\hline CHEMBL1416931 & 688721 & 5.1 & 4.9216 & TRN & \\
\hline CHEMBL142630 & 688721 & 4.9 & 4.9044 & TRN & \\
\hline CHEMBL1535652 & 688721 & 4.4 & 4.77800 & 00000000005 & TRN \\
\hline CHEMBL1446065 & 688721 & 4.9 & 4.8675 & TRN & \\
\hline CHEMBL1314152 & 688721 & 4.5 & 4.8925 & TRN & \\
\hline CHEMBL1572747 & 688721 & 4.8 & 4.9817 & TRN & \\
\hline CHEMBL1593504 & 688721 & 5.2 & 5.1898 & TRN & \\
\hline CHEMBL292477 & 688721 & 4.5 & 4.9506 & TST & \\
\hline CHEMBL1350721 & 688721 & 4.6 & 4.8648 & TRN & \\
\hline CHEMBL1445151 & 688721 & 4.4 & 4.9037 & TRN & \\
\hline CHEMBL1366201 & 688721 & 5.4 & 5.0057 & TST & \\
\hline CHEMBL1494165 & 688721 & 4.4 & 4.8748 & TRN & \\
\hline CHEMBL1444923 & 688721 & 4.5 & 4.9785 & TRN & \\
\hline CHEMBL1367337 & 688721 & 5.2 & 5.0735 & TRN & \\
\hline CHEMBL1358962 & 688721 & 4.5 & 4.8648 & TRN & \\
\hline CHEMBL1512511 & 688721 & 5.4 & 5.0879 & TST & \\
\hline CHEMBL1602135 & 688721 & 6.1 & 4.8922 & TRN & \\
\hline CHEMBL1403311 & 688721 & 4.5 & 4.9509 & TST & \\
\hline CHEMBL1594560 & 688721 & 4.4 & 4.7943 & TRN & \\
\hline CHEMBL1336840 & 688721 & 4.8 & 5.051 & TRN & \\
\hline CHEMBL1538217 & 688721 & 4.8 & 4.9248 & TRN & \\
\hline CHEMBL1361518 & 688721 & 4.8 & 4.89199 & 99999999995 & TRN \\
\hline CHEMBL1514804 & 688721 & 4.7 & 5.1231 & TRN & \\
\hline CHEMBL1365120 & 688721 & 4.5 & 4.9849 & TRN & \\
\hline CHEMBL1307165 & 688721 & 4.6 & 4.7685 & TRN & \\
\hline CHEMBL1411907 & 688721 & 4.6 & 4.8922 & TST & \\
\hline CHEMBL1370553 & 688721 & 4.8 & 5.0738 & TRN & \\
\hline CHEMBL1340259 & 688721 & 5.5 & 4.9408 & TST & \\
\hline CHEMBL1572245 & 688721 & 4.5 & 4.8334 & TRN & \\
\hline CHEMBL1607076 & 688721 & 5.2 & 5.0863 & TRN & \\
\hline CHEMBL1369008 & 688721 & 4.6 & 5.1922 & TRN & \\
\hline CHEMBL1423100 & 688721 & 4.5 & 4.9285 & TRN & \\
\hline & & & & 8973 & \\
\hline
\end{tabular}




\begin{tabular}{|c|c|c|c|c|}
\hline & & & ient & $a \perp 1 a$ \\
\hline CHEMBL1376494 & 688721 & 5.4 & 4.8795 & TRN \\
\hline CHEMBL1441690 & 688721 & 4.6 & 4.8696 & TRN \\
\hline CHEMBL1257125 & 688721 & 4.7 & 5.0471 & TRN \\
\hline CHEMBL1450380 & 688721 & 4.4 & 4.8056 & TST \\
\hline CHEMBL1448844 & 688721 & 4.8 & 4.897 & TRN \\
\hline CHEMBL1462467 & 688721 & 4.5 & 4.8668 & TRN \\
\hline CHEMBL1335678 & 688721 & 4.6 & 4.7817 & TRN \\
\hline CHEMBL1451583 & 688721 & 4.6 & 4.967 & TRN \\
\hline CHEMBL1595761 & 688721 & 4.6 & 4.9796 & TRN \\
\hline CHEMBL1425896 & 688721 & 5.2 & 4.7869 & TRN \\
\hline CHEMBL3192945 & 688721 & 4.5 & 4.8626 & TST \\
\hline CHEMBL1417243 & 688721 & 4.5 & 4.7897 & TRN \\
\hline CHEMBL1598862 & 688721 & 4.5 & 4.8896 & TST \\
\hline CHEMBL1346244 & 688721 & 4.5 & 4.9665 & TRN \\
\hline CHEMBL1323935 & 688721 & 4.9 & 4.8786 & TRN \\
\hline CHEMBL1518003 & 688721 & 6.0 & 5.0242 & TRN \\
\hline CHEMBL1374125 & 688721 & 4.9 & 4.9409 & TRN \\
\hline CHEMBL1570435 & 688721 & 4.5 & 4.7785 & TRN \\
\hline CHEMBL1324163 & 688721 & 4.7 & 4.7969 & TRN \\
\hline CHEMBL1509159 & 688721 & 4.6 & 4.7584 & TRN \\
\hline CHEMBL1411078 & 688721 & 4.5 & 4.8126 & TRN \\
\hline CHEMBL1508452 & 688721 & 5.7 & 4.846 & TRN \\
\hline CHEMBL1405769 & 688721 & 4.6 & 4.752 & TRN \\
\hline CHEMBL1395737 & 688721 & 5.9 & 5.3194 & TRN \\
\hline CHEMBL1500466 & 688721 & 4.5 & 4.8671 & TRN \\
\hline CHEMBL1448923 & 688721 & 4.4 & 5.0925 & TRN \\
\hline CHEMBL1509253 & 688721 & 4.4 & 4.8116 & TRN \\
\hline CHEMBL1507941 & 688721 & 4.7 & 4.8801 & TRN \\
\hline CHEMBL1299327 & 688721 & 4.6 & 4.9275 & TRN \\
\hline CHEMBL1383901 & 688721 & 4.8 & 4.9733 & TST \\
\hline CHEMBL1515777 & 688721 & 6.5 & 5.1701 & TRN \\
\hline CHEMBL1506307 & 688721 & 4.5 & 4.921 & TRN \\
\hline CHEMBL1335460 & 688721 & 4.7 & 5.0179 & TRN \\
\hline CHEMBL1527239 & 688721 & 5.0 & 4.8546 & TRN \\
\hline CHEMBL3209543 & 688721 & 4.9 & 5.0203 & TRN \\
\hline CHEMBL1424630 & 688721 & 4.5 & 5.0469 & TST \\
\hline CHEMBL1383345 & 688721 & 4.9 & 5.1154 & TRN \\
\hline CHEMBL1442987 & 688721 & 4.8 & 5.1066 & TRN \\
\hline CHEMBL1736239 & 688721 & 5.5 & 4.9668 & TRN \\
\hline CHEMBL1503009 & 688721 & 5.1 & 4.9065 & TRN \\
\hline CHEMBL1418640 & 688721 & 4.6 & 4.7987 & TRN \\
\hline CHEMBL1330520 & 688721 & 4.4 & 5.1193 & TST \\
\hline CHEMBL1444367 & 688721 & 5.1 & 5.0348 & TRN \\
\hline CHEMBL1256191 & 688721 & 4.5 & 5.0971 & TST \\
\hline CHEMBL1380865 & 688721 & 6.1 & 5.0067 & TST \\
\hline CHEMBL3351064 & 688721 & 5.1 & 5.0281 & TST \\
\hline CHEMBL1543940 & 688721 & 5.0 & 4.8093 & TST \\
\hline CHEMBL1372697 & 688721 & 5.9 & 5.1234 & TRN \\
\hline
\end{tabular}




\begin{tabular}{|c|c|c|c|c|c|}
\hline \multicolumn{6}{|c|}{ Supplemental Table S2.txt } \\
\hline CHEMBL1467469 & 688721 & 4.8 & 5.0682 & TRN & \\
\hline CHEMBL1609198 & 688721 & 6.7001 & 5.0974 & TRN & \\
\hline CHEMBL376103 & 688721 & 6.0 & 5.0384 & TRN & \\
\hline CHEMBL1379677 & 688721 & 4.6 & 4.9955 & TST & \\
\hline CHEMBL1533836 & 688721 & 4.4 & 4.7245 & TRN & \\
\hline CHEMBL1304250 & 688721 & 5.3 & 4.9178 & TRN & \\
\hline CHEMBL1610827 & 688721 & 4.5 & 4.9952 & TRN & \\
\hline CHEMBL1437871 & 688721 & 6.8 & 4.8743 & TRN & \\
\hline CHEMBL1351658 & 688721 & 4.7 & 4.8794 & TRN & \\
\hline CHEMBL1372685 & 688721 & 4.8 & 4.8685 & TRN & \\
\hline CHEMBL1311916 & 688721 & 4.4 & 4.8236 & TRN & \\
\hline CHEMBL1365284 & 688721 & 5.2 & 5.0289 & TST & \\
\hline CHEMBL1335363 & 688721 & 4.8 & 5.0257 & TRN & \\
\hline CHEMBL148296 & 688721 & 4.4 & 4.9248 & TRN & \\
\hline CHEMBL1392448 & 688721 & 4.9 & 4.8468 & TRN & \\
\hline CHEMBL1347017 & 688721 & 4.5 & 4.8256 & TRN & \\
\hline CHEMBL1560829 & 688721 & 4.8 & 5.0699 & TRN & \\
\hline CHEMBL1309238 & 688721 & 4.5 & 5.0159 & TST & \\
\hline CHEMBL1442355 & 688721 & 6.9 & 5.3227 & TRN & \\
\hline CHEMBL1490744 & 688721 & 4.5 & 4.7997 & TRN & \\
\hline CHEMBL1342134 & 688721 & 4.4 & 4.9689 & TRN & \\
\hline CHEMBL1363228 & 688721 & 4.9 & 4.93199 & 99999999995 & TRN \\
\hline CHEMBL1527029 & 688721 & 6.8 & 4.9957 & TRN & \\
\hline CHEMBL1322479 & 688721 & 4.6 & 4.9696 & TST & \\
\hline CHEMBL1336605 & 688721 & 4.5 & 4.6789 & TRN & \\
\hline CHEMBL1388003 & 688721 & 5.9 & 4.9334 & TRN & \\
\hline CHEMBL1370876 & 688721 & 5.5 & 4.8851 & TST & \\
\hline CHEMBL1972755 & 688721 & 5.0 & 4.939 & TST & \\
\hline CHEMBL 1547533 & 688721 & 4.5 & 4.9969 & TST & \\
\hline CHEMBL1603323 & 688721 & 4.4 & 5.0127 & TRN & \\
\hline CHEMBL1468900 & 688721 & 4.8 & 4.8972 & TRN & \\
\hline CHEMBL1586936 & 688721 & 5.2 & 4.9452 & TRN & \\
\hline CHEMBL1486463 & 688721 & 5.0 & 5.1201 & TST & \\
\hline CHEMBL1562926 & 688721 & 4.6 & 4.9384 & TRN & \\
\hline CHEMBL1305544 & 688721 & 6.4 & 5.0401 & TRN & \\
\hline CHEMBL1314956 & 688721 & 5.5 & 5.1323 & TRN & \\
\hline CHEMBL1558817 & 688721 & 5.2 & 4.8047 & TRN & \\
\hline CHEMBL1455653 & 688721 & 4.5 & 5.102 & TST & \\
\hline CHEMBL1370307 & 688721 & 4.4 & 4.8427 & TST & \\
\hline CHEMBL1489708 & 688721 & 5.2 & 5.1992 & TRN & \\
\hline CHEMBL1323563 & 688721 & 5.0 & 4.9794 & TRN & \\
\hline CHEMBL1344551 & 688721 & 4.8 & 4.8655 & TRN & \\
\hline CHEMBL1499271 & 688721 & 4.7 & 4.868 & TRN & \\
\hline CHEMBL1417895 & 688721 & 4.9 & 4.8447 & TRN & \\
\hline CHEMBL1572276 & 688721 & 4.7 & 5.1576 & TRN & \\
\hline CHEMBL1354123 & 688721 & 5.4 & 4.8121 & TRN & \\
\hline CHEMBL1517099 & 688721 & 4.8 & 4.9745 & TST & \\
\hline CHEMBL18602 & 688721 & 4.4 & 5.2563 & TRN & \\
\hline
\end{tabular}




\begin{tabular}{|c|c|c|c|c|c|}
\hline \\
\hline CHEMBL1547578 & 688721 & 5.4 & 5.2734 & TRN & \\
\hline CHEMBL1501346 & 688721 & 4.4 & 4.8487 & TRN & \\
\hline CHEMBL1341971 & 688721 & 4.9 & 5.0852 & TRN & \\
\hline CHEMBL1483757 & 688721 & 5.4 & 5.1309 & TRN & \\
\hline CHEMBL1507697 & 688721 & 5.2 & 4.9808 & TST & \\
\hline CHEMBL1404413 & 688721 & 4.7 & 4.8873 & TRN & \\
\hline CHEMBL1520427 & 688721 & 4.9 & 4.7958 & TRN & \\
\hline CHEMBL1346648 & 688721 & 4.6 & 4.7523 & TRN & \\
\hline CHEMBL1402689 & 688721 & 7.3002 & 5.1071 & TRN & \\
\hline CHEMBL1579227 & 688721 & 4.6 & 4.9897 & TRN & \\
\hline CHEMBL1374718 & 688721 & 4.9 & 4.8429 & TRN & \\
\hline CHEMBL1593981 & 688721 & 5.2 & 5.1082 & TST & \\
\hline CHEMBL1310238 & 688721 & 4.6 & 4.9004 & TST & \\
\hline CHEMBL1559560 & 688721 & 4.4 & 4.8957 & TRN & \\
\hline CHEMBL1352315 & 688721 & 4.5 & 5.0371 & TST & \\
\hline CHEMBL1529114 & 688721 & 4.5 & 4.6472 & TRN & \\
\hline CHEMBL1533003 & 688721 & 4.9 & 4.8971 & TRN & \\
\hline CHEMBL1411746 & 688721 & 6.0 & 4.9125 & TST & \\
\hline CHEMBL1333556 & 688721 & 4.5 & 4.8954 & TST & \\
\hline CHEMBL1569610 & 688721 & 4.9 & 5.2272 & TST & \\
\hline CHEMBL1309139 & 688721 & 4.8 & 4.7329 & TRN & \\
\hline CHEMBL1553930 & 688721 & 5.4 & 5.1586 & TRN & \\
\hline CHEMBL1334817 & 688721 & 6.0 & 5.206 & TST & \\
\hline CHEMBL1421029 & 688721 & 4.5 & 4.8099 & TST & \\
\hline CHEMBL1325152 & 688721 & 5.3 & 4.9326 & TRN & \\
\hline CHEMBL1323378 & 688721 & 4.6 & 5.0142 & TST & \\
\hline CHEMBL1449060 & 688721 & 4.5 & 4.9044 & TRN & \\
\hline CHEMBL1601923 & 688721 & 6.1 & 5.0991 & TST & \\
\hline CHEMBL1427121 & 688721 & 4.6 & 5.0102 & TRN & \\
\hline CHEMBL1575737 & 688721 & 5.5 & 4.9104 & TST & \\
\hline CHEMBL1594647 & 688721 & 5.4 & 5.20299 & 9999999999 & TRN \\
\hline CHEMBL1432753 & 688721 & 5.9 & 5.0496 & TST & \\
\hline CHEMBL1586884 & 688721 & 5.2 & 4.869 & TRN & \\
\hline CHEMBL1605780 & 688721 & 5.2 & 4.8086 & TRN & \\
\hline CHEMBL1343985 & 688721 & 4.4 & 5.0942 & TRN & \\
\hline CHEMBL1610924 & 688721 & 5.4 & 4.8909 & TRN & \\
\hline CHEMBL1429745 & 688721 & 4.5 & 4.8688 & TRN & \\
\hline CHEMBL1460359 & 688721 & 4.6 & 4.8494 & TRN & \\
\hline CHEMBL1485696 & 688721 & 4.5 & 5.1126 & TRN & \\
\hline CHEMBL1353501 & 688721 & 4.7 & 4.8821 & TRN & \\
\hline CHEMBL1303405 & 688721 & 4.7 & 4.8766 & TRN & \\
\hline CHEMBL1546388 & 688721 & 4.7 & 5.2605 & TRN & \\
\hline CHEMBL1496902 & 688721 & 5.2 & 4.9321 & TRN & \\
\hline CHEMBL1530653 & 688721 & 4.4 & 4.5843 & TRN & \\
\hline CHEMBL1483855 & 688721 & 5.6 & 5.0362 & TRN & \\
\hline CHEMBL1497433 & 688721 & 5.2 & 4.9068 & TRN & \\
\hline CHEMBL1373773 & 688721 & 5.6 & 5.2098 & TRN & \\
\hline CHEMBL1334521 & 688721 & 4.6 & 4.8781 & TRN & \\
\hline
\end{tabular}




\begin{tabular}{|c|c|c|c|c|c|}
\hline \multicolumn{6}{|c|}{ Supplemental Table S2.txt } \\
\hline CHEMBL1391474 & 688721 & 4.5 & 4.9779 & TRN & \\
\hline CHEMBL1601159 & 688721 & 4.4 & 5.1174 & TRN & \\
\hline CHEMBL1582273 & 688721 & 4.5 & 5.1745 & TST & \\
\hline CHEMBL1549988 & 688721 & 5.2 & 4.97 & TST & \\
\hline CHEMBL1484835 & 688721 & 4.6 & 4.8028 & TRN & \\
\hline CHEMBL397442 & 688721 & 5.5 & 5.1159 & TST & \\
\hline CHEMBL1566556 & 688721 & 4.8 & 5.0865 & TRN & \\
\hline CHEMBL1493981 & 688721 & 5.3 & 5.0212 & TRN & \\
\hline CHEMBL1378892 & 688721 & 6.7001 & 4.8538 & TRN & \\
\hline CHEMBL131199 & 688721 & 6.7001 & 5.0142 & TST & \\
\hline CHEMBL1527826 & 688721 & 5.2 & 4.9041 & TRN & \\
\hline CHEMBL1442655 & 688721 & 5.9 & 5.047 & TRN & \\
\hline CHEMBL1608296 & 688721 & 4.4 & 4.8108 & TRN & \\
\hline CHEMBL1489867 & 688721 & 5.1 & 5.1168 & TRN & \\
\hline CHEMBL1333669 & 688721 & 4.6 & 5.0886 & TRN & \\
\hline CHEMBL1477471 & 688721 & 5.3 & 4.8783 & TRN & \\
\hline CHEMBL1383119 & 688721 & 4.4 & 4.9829 & TRN & \\
\hline CHEMBL1574811 & 688721 & 5.4 & 5.1065 & TRN & \\
\hline CHEMBL1462133 & 688721 & 4.8 & 4.7773 & TRN & \\
\hline CHEMBL1586648 & 688721 & 4.8 & 4.73300 & 00000000005 & TRN \\
\hline CHEMBL1530999 & 688721 & 4.4 & 4.9171 & TRN & \\
\hline CHEMBL1344319 & 688721 & 6.0 & 5.2532 & TRN & \\
\hline CHEMBL1304625 & 688721 & 5.4 & 5.0161 & TRN & \\
\hline CHEMBL1480833 & 688721 & 5.4 & 5.1137 & TRN & \\
\hline CHEMBL1347024 & 688721 & 5.0 & 4.8884 & TRN & \\
\hline CHEMBL1300586 & 688721 & 4.9 & 4.9208 & TRN & \\
\hline CHEMBL1561205 & 688721 & 5.3 & 4.8193 & TRN & \\
\hline CHEMBL1396358 & 688721 & 4.6 & 5.0148 & TRN & \\
\hline CHEMBL1501851 & 688721 & 4.5 & 4.9365 & TRN & \\
\hline CHEMBL 269630 & 688721 & 5.0 & 5.2205 & TST & \\
\hline CHEMBL1421681 & 688721 & 4.6 & 4.855 & TRN & \\
\hline CHEMBL1333156 & 688721 & 5.1 & 4.9479 & TRN & \\
\hline CHEMBL1505952 & 688721 & 4.5 & 4.9544 & TRN & \\
\hline CHEMBL433238 & 688721 & 7.1002 & 5.434 & TRN & \\
\hline CHEMBL1580618 & 688721 & 5.9 & 5.0645 & TRN & \\
\hline CHEMBL587714 & 688721 & 4.4 & 5.1667 & TRN & \\
\hline CHEMBL1495854 & 688721 & 4.6 & 4.9063 & TRN & \\
\hline CHEMBL1306935 & 688721 & 4.4 & 4.9509 & TRN & \\
\hline CHEMBL1481252 & 688721 & 5.6 & 4.9257 & TRN & \\
\hline CHEMBL1403985 & 688721 & 4.6 & 4.7342 & TRN & \\
\hline CHEMBL1425782 & 688721 & 7.8013 & 5.024 & TST & \\
\hline CHEMBL1447678 & 688721 & 5.4 & 4.9344 & TRN & \\
\hline CHEMBL1417374 & 688721 & 4.8 & 5.032 & TRN & \\
\hline CHEMBL1411772 & 688721 & 4.6 & 4.9197 & TRN & \\
\hline CHEMBL1567849 & 688721 & 4.4 & 4.9679 & TRN & \\
\hline CHEMBL1486459 & 688721 & 4.8 & 5.0204 & TRN & \\
\hline CHEMBL1517051 & 688721 & 4.5 & 5.118 & TRN & \\
\hline CHEMBL1586056 & 688721 & 4.5 & 4.8715 & TRN & \\
\hline
\end{tabular}




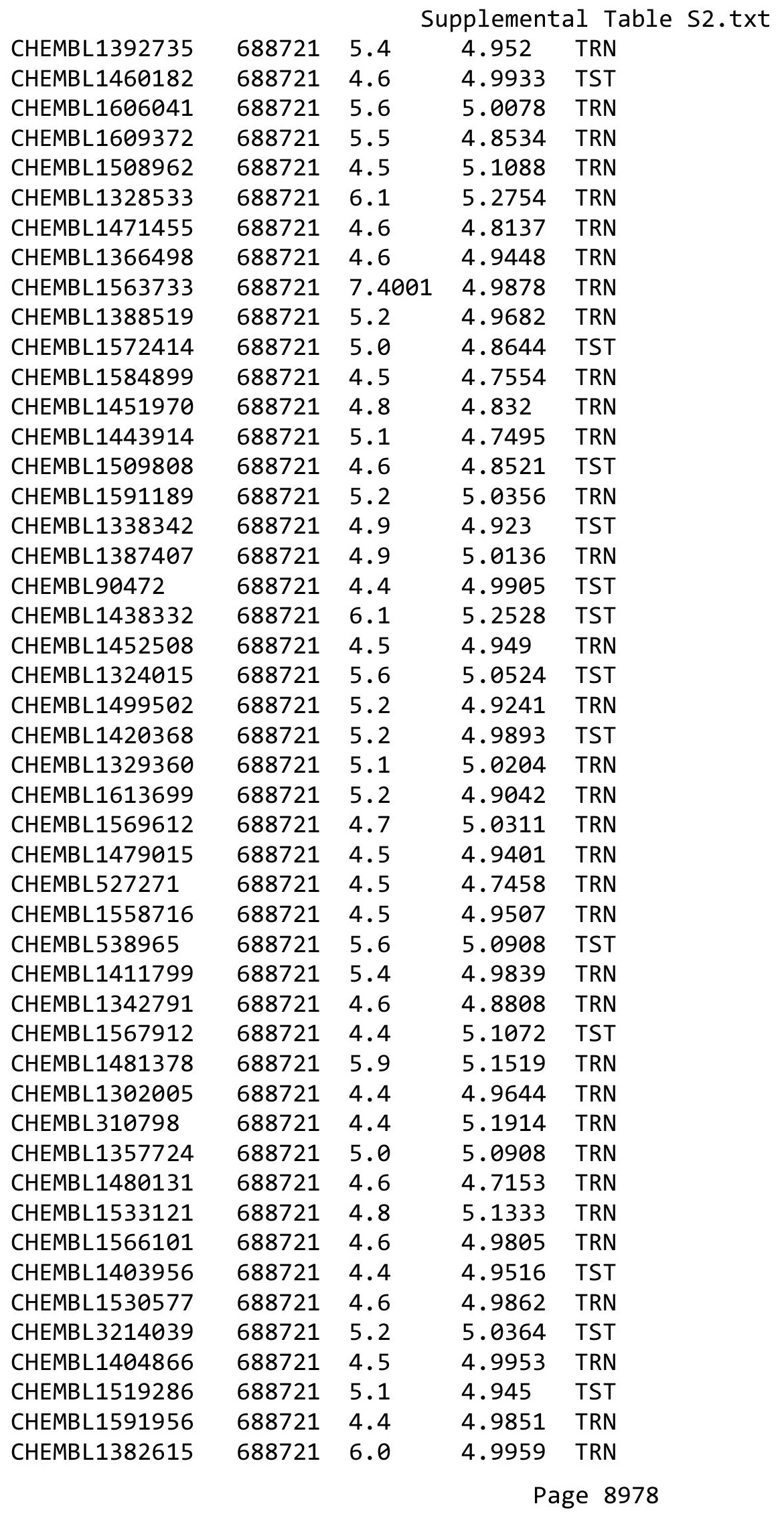




\begin{tabular}{|c|c|c|c|c|c|}
\hline & & & & & \\
\hline CHEMBL1510800 & 688721 & 4.8 & 4.9497 & TRN & \\
\hline CHEMBL1381205 & 688721 & 4.8 & 4.754 & TRN & \\
\hline CHEMBL1507391 & 688721 & 4.6 & 4.8501 & TRN & \\
\hline CHEMBL1371834 & 688721 & 4.6 & 4.9574 & TRN & \\
\hline CHEMBL1350771 & 688721 & 5.4 & 4.9353 & TRN & \\
\hline CHEMBL1378837 & 688721 & 4.5 & 4.97199 & 99999999995 & TST \\
\hline CHEMBL1404565 & 688721 & 5.0 & 4.9535 & TRN & \\
\hline CHEMBL1508182 & 688721 & 5.2 & 5.1386 & TRN & \\
\hline CHEMBL1511671 & 688721 & 5.2 & 5.0043 & TRN & \\
\hline CHEMBL1578060 & 688721 & 4.9 & 4.8736 & TRN & \\
\hline CHEMBL1513149 & 688721 & 5.2 & 5.3256 & TST & \\
\hline CHEMBL3196148 & 688721 & 6.0 & 4.9272 & TST & \\
\hline CHEMBL1445449 & 688721 & 4.6 & 4.81800 & 00000000005 & TRN \\
\hline CHEMBL1380287 & 688721 & 5.1 & 4.7578 & TRN & \\
\hline CHEMBL1310700 & 688721 & 5.4 & 4.8332 & TST & \\
\hline CHEMBL1323793 & 688721 & 5.5 & 5.3646 & TRN & \\
\hline CHEMBL1605301 & 688721 & 4.7 & 4.9112 & TRN & \\
\hline CHEMBL3207935 & 688721 & 4.4 & 4.984 & TRN & \\
\hline CHEMBL1547520 & 688721 & 4.6 & 4.7848 & TST & \\
\hline CHEMBL1373040 & 688721 & 4.6 & 4.8887 & TRN & \\
\hline CHEMBL1438144 & 688721 & 5.9 & 4.9109 & TRN & \\
\hline CHEMBL3191002 & 688721 & 5.2 & 4.71899 & & TST \\
\hline CHEMBL1589387 & 688721 & 4.9 & 4.8847 & TST & \\
\hline CHEMBL1443953 & 688721 & 5.1 & 4.9574 & TST & \\
\hline CHEMBL1428963 & 688721 & 5.4 & 4.8424 & TST & \\
\hline CHEMBL1381595 & 688721 & 5.0 & 4.9275 & TRN & \\
\hline CHEMBL1489461 & 688721 & 4.4 & 5.0636 & TRN & \\
\hline CHEMBL1499 & 688721 & 5.4 & 5.2883 & TRN & \\
\hline CHEMBL1310712 & 688721 & 6.0 & 4.917 & TRN & \\
\hline CHEMBL1350672 & 688721 & 4.5 & 4.8572 & TRN & \\
\hline CHEMBL1413521 & 688721 & 4.7 & 4.7876 & TRN & \\
\hline CHEMBL1376569 & 688721 & 5.9 & 5.1857 & TRN & \\
\hline CHEMBL1522715 & 688721 & 4.6 & 4.9326 & TRN & \\
\hline CHEMBL1570547 & 688721 & 5.0 & 4.9809 & TRN & \\
\hline CHEMBL1474272 & 688721 & 4.7 & 4.9456 & TRN & \\
\hline CHEMBL1311037 & 688721 & 6.0 & 4.9761 & TST & \\
\hline CHEMBL1346525 & 688721 & 4.6 & 4.803 & TRN & \\
\hline CHEMBL1399595 & 688721 & 4.6 & 5.0561 & TRN & \\
\hline CHEMBL1567236 & 688721 & 5.4 & 5.1903 & TRN & \\
\hline CHEMBL1388493 & 688721 & 6.1 & 4.9345 & TRN & \\
\hline CHEMBL1422003 & 688721 & 6.5 & 4.9713 & TRN & \\
\hline CHEMBL1599628 & 688721 & 4.4 & 4.9469 & TRN & \\
\hline CHEMBL1383968 & 688721 & 4.6 & 5.0083 & TST & \\
\hline CHEMBL1300887 & 688721 & 5.9 & 5.0845 & TST & \\
\hline CHEMBL1503933 & 688721 & 4.8 & 4.8628 & TST & \\
\hline CHEMBL1400900 & 688721 & 5.2 & 5.1617 & TRN & \\
\hline CHEMBL1348211 & 688721 & 5.5 & 4.9743 & TST & \\
\hline CHEMBL1515287 & 688721 & 5.2 & 5.3063 & TRN & \\
\hline
\end{tabular}




\begin{tabular}{|c|c|c|c|c|}
\hline & & & 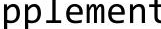 & al Ta \\
\hline CHEMBL1408183 & 688721 & 4.6 & 5.0035 & TRN \\
\hline CHEMBL540303 & 688721 & 4.6 & 5.1777 & TST \\
\hline CHEMBL1422504 & 688721 & 6.8 & 5.0836 & TRN \\
\hline CHEMBL1359040 & 688721 & 4.6 & 4.8312 & TRN \\
\hline CHEMBL1600956 & 688721 & 4.6 & 4.8549 & TRN \\
\hline CHEMBL1318895 & 688721 & 6.4 & 5.0469 & TRN \\
\hline CHEMBL1482920 & 688721 & 4.7 & 5.0133 & TRN \\
\hline CHEMBL1381946 & 688721 & 4.8 & 4.9422 & TRN \\
\hline CHEMBL1518599 & 688721 & 4.9 & 4.9182 & TST \\
\hline CHEMBL1480357 & 688721 & 4.8 & 4.8921 & TRN \\
\hline CHEMBL1419530 & 688721 & 4.9 & 4.9109 & TRN \\
\hline CHEMBL1467832 & 688721 & 4.7 & 4.8222 & TST \\
\hline CHEMBL1426279 & 688721 & 5.4 & 4.8378 & TRN \\
\hline CHEMBL1454323 & 688721 & 4.5 & 4.9866 & TRN \\
\hline CHEMBL1507739 & 688721 & 4.9 & 4.9604 & TST \\
\hline CHEMBL1451755 & 688721 & 5.4 & 4.9977 & TRN \\
\hline CHEMBL1300068 & 688721 & 4.5 & 4.9321 & TRN \\
\hline CHEMBL1442960 & 688721 & 4.5 & 4.7833 & TRN \\
\hline CHEMBL1487795 & 688721 & 4.5 & 4.8614 & TRN \\
\hline CHEMBL1353241 & 688721 & 4.9 & 4.7877 & TRN \\
\hline CHEMBL1397079 & 688721 & 4.8 & 5.1959 & TRN \\
\hline CHEMBL3197779 & 688721 & 5.5 & 4.7896 & TRN \\
\hline CHEMBL1353549 & 688721 & 4.7 & 4.9977 & TRN \\
\hline CHEMBL1366874 & 688721 & 4.6 & 5.026 & TRN \\
\hline CHEMBL1370253 & 688721 & 4.8 & 4.8579 & TRN \\
\hline CHEMBL1396664 & 688721 & 4.7 & 5.1151 & TRN \\
\hline CHEMBL1364995 & 688721 & 5.5 & 5.0795 & TRN \\
\hline CHEMBL1492379 & 688721 & 5.5 & 5.17 & TST \\
\hline CHEMBL1504346 & 688721 & 5.3 & 4.8784 & TRN \\
\hline CHEMBL1338095 & 688721 & 4.6 & 4.9558 & TRN \\
\hline CHEMBL1503483 & 688721 & 5.8 & 4.7415 & TRN \\
\hline CHEMBL1407524 & 688721 & 5.5 & 4.92 & TRN \\
\hline CHEMBL1458962 & 688721 & 7.0 & 4.8825 & TST \\
\hline CHEMBL3210845 & 688721 & 4.6 & 4.8716 & TST \\
\hline CHEMBL1413557 & 688721 & 5.4 & 4.7832 & TRN \\
\hline CHEMBL1415001 & 688721 & 5.4 & 4.9278 & TRN \\
\hline CHEMBL1413959 & 688721 & 4.4 & 4.9449 & TRN \\
\hline CHEMBL1453357 & 688721 & 6.0 & 4.8713 & TRN \\
\hline CHEMBL1597471 & 688721 & 4.7 & 4.9786 & TST \\
\hline CHEMBL1479248 & 688721 & 5.9 & 5.0478 & TRN \\
\hline CHEMBL1308000 & 688721 & 4.5 & 5.0853 & TRN \\
\hline CHEMBL1609464 & 688721 & 5.0 & 4.9234 & TRN \\
\hline CHEMBL1604705 & 688721 & 5.2 & 5.0569 & TRN \\
\hline CHEMBL3207670 & 688721 & 5.3 & 5.023 & TST \\
\hline CHEMBL1559433 & 688721 & 4.4 & 5.0015 & TRN \\
\hline CHEMBL1469872 & 688721 & 4.5 & 4.8244 & TRN \\
\hline CHEMBL1331817 & 688721 & 4.8 & 5.056 & TRN \\
\hline CHEMBL1322401 & 688721 & 4.5 & 4.9537 & TRN \\
\hline
\end{tabular}




\begin{tabular}{|c|c|c|c|c|}
\hline \multicolumn{5}{|c|}{ Supplemental Table S2.txt } \\
\hline CHEMBL1521075 & 688721 & 4.7 & 4.8312 & TRN \\
\hline CHEMBL1418350 & 688721 & 4.9 & 4.8895 & TRN \\
\hline CHEMBL1310906 & 688721 & 4.8 & 4.7235 & TRN \\
\hline CHEMBL1328091 & 688721 & 4.8 & 4.8855 & TST \\
\hline CHEMBL1575288 & 688721 & 4.4 & 4.9038 & TRN \\
\hline CHEMBL 664 & 688721 & 7.6003 & 5.0817 & TST \\
\hline CHEMBL1565867 & 688721 & 4.5 & 4.8948 & TRN \\
\hline CHEMBL1598064 & 688721 & 4.5 & 4.8885 & TRN \\
\hline CHEMBL1301055 & 688721 & 5.4 & 4.8996 & TRN \\
\hline CHEMBL1371652 & 688721 & 5.2 & 4.8429 & TRN \\
\hline CHEMBL1318560 & 688721 & 4.5 & 5.0296 & TRN \\
\hline CHEMBL1412063 & 688721 & 5.1 & 4.8164 & TRN \\
\hline CHEMBL1601055 & 688721 & 4.4 & 5.0607 & TRN \\
\hline CHEMBL1306139 & 688721 & 4.8 & 4.9021 & TRN \\
\hline CHEMBL3213062 & 688721 & 5.5 & 4.9817 & TRN \\
\hline CHEMBL1603533 & 688721 & 6.0 & 4.8899 & TST \\
\hline CHEMBL1418024 & 688721 & 4.5 & 5.1036 & TST \\
\hline CHEMBL1309684 & 688721 & 4.8 & 4.907 & TRN \\
\hline CHEMBL1538675 & 688721 & 6.0 & 4.9669 & TRN \\
\hline CHEMBL1491627 & 688721 & 5.4 & 5.0966 & TRN \\
\hline CHEMBL1588325 & 688721 & 4.5 & 5.0312 & TRN \\
\hline CHEMBL1484095 & 688721 & 5.0 & 4.8232 & TRN \\
\hline CHEMBL1311002 & 688721 & 4.7 & 4.9161 & TRN \\
\hline CHEMBL1580759 & 688721 & 4.8 & 5.0686 & TST \\
\hline CHEMBL1546412 & 688721 & 4.8 & 4.7972 & TRN \\
\hline CHEMBL1445003 & 688721 & 7.6003 & 5.0493 & TRN \\
\hline CHEMBL1450001 & 688721 & 4.6 & 4.955 & TRN \\
\hline CHEMBL579219 & 688721 & 4.4 & 4.8612 & TRN \\
\hline CHEMBL3192589 & 688721 & 4.5 & 4.8361 & TRN \\
\hline CHEMBL1312919 & 688721 & 4.8 & 4.8175 & TRN \\
\hline CHEMBL1527710 & 688721 & 4.8 & 4.8117 & TRN \\
\hline CHEMBL1425567 & 688721 & 4.7 & 4.8722 & TST \\
\hline CHEMBL1419443 & 688721 & 4.7 & 4.8254 & TRN \\
\hline CHEMBL1585079 & 688721 & 4.7 & 4.7676 & TRN \\
\hline CHEMBL1552985 & 688721 & 5.0 & 4.9684 & TRN \\
\hline CHEMBL418971 & 688721 & 4.4 & 5.2187 & TST \\
\hline CHEMBL1565363 & 688721 & 4.7 & 4.8809 & TRN \\
\hline CHEMBL1464163 & 688721 & 4.9 & 4.8113 & TRN \\
\hline CHEMBL1597022 & 688721 & 4.6 & 4.7516 & TRN \\
\hline CHEMBL1457150 & 688721 & 4.7 & 4.8424 & TRN \\
\hline CHEMBL1602873 & 688721 & 5.1 & 4.8431 & TRN \\
\hline CHEMBL1609324 & 688721 & 4.6 & 4.9596 & TRN \\
\hline CHEMBL1374420 & 688721 & 4.6 & 5.1867 & TRN \\
\hline CHEMBL1524817 & 688721 & 4.6 & 4.848 & TST \\
\hline CHEMBL1559347 & 688721 & 5.0 & 4.9203 & TRN \\
\hline CHEMBL1570158 & 688721 & 5.5 & 4.9371 & TRN \\
\hline CHEMBL1319723 & 688721 & 5.1 & 5.0739 & TRN \\
\hline CHEMBL1609879 & 688721 & 5.2 & 4.8946 & TRN \\
\hline
\end{tabular}




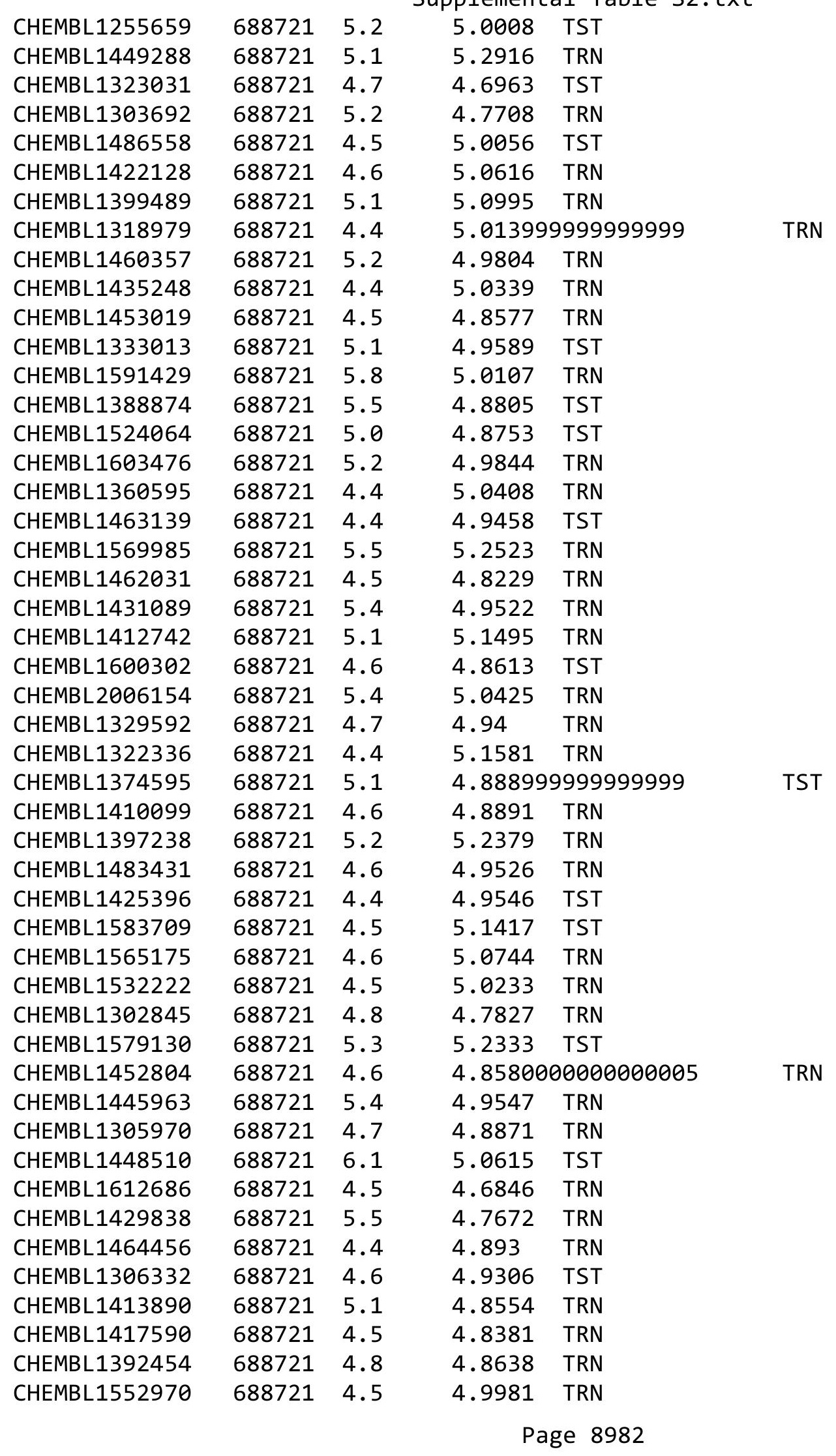




\begin{tabular}{|c|c|c|c|c|}
\hline \multicolumn{5}{|c|}{ Supplemental Table S2.txt } \\
\hline CHEMBL1347110 & 688721 & 5.4 & 4.916 & TRN \\
\hline CHEMBL1613481 & 688721 & 4.6 & 4.9653 & TRN \\
\hline CHEMBL1593765 & 688721 & 4.4 & 4.8399 & TRN \\
\hline CHEMBL1515295 & 688721 & 5.0 & 5.0226 & TRN \\
\hline CHEMBL1548741 & 688721 & 5.3 & 4.9576 & TST \\
\hline CHEMBL1415830 & 688721 & 4.8 & 4.7039 & TRN \\
\hline CHEMBL903 & 688721 & 5.4 & 5.3088 & TST \\
\hline CHEMBL1599734 & 688721 & 6.7001 & 4.9215 & TRN \\
\hline CHEMBL1447573 & 688721 & 4.8 & 5.0393 & TST \\
\hline CHEMBL1578372 & 688721 & 4.6 & 4.9044 & TRN \\
\hline CHEMBL1540503 & 688721 & 5.5 & 4.9163 & TST \\
\hline CHEMBL1592936 & 688721 & 4.9 & 5.2524 & TRN \\
\hline CHEMBL1401548 & 688721 & 5.9 & 4.9638 & TRN \\
\hline CHEMBL587772 & 688721 & 4.7 & 5.0526 & TST \\
\hline CHEMBL1502097 & 688721 & 7.1002 & 5.1633 & TST \\
\hline CHEMBL1540099 & 688721 & 4.9 & 5.0639 & TRN \\
\hline CHEMBL1475036 & 688721 & 4.6 & 5.11 & TRN \\
\hline CHEMBL1597519 & 688721 & 4.6 & 4.8712 & TRN \\
\hline CHEMBL1416381 & 688721 & 4.5 & 4.8622 & TRN \\
\hline CHEMBL1387247 & 688721 & 4.7 & 4.9338 & TRN \\
\hline CHEMBL1558938 & 688721 & 4.4 & 4.9213 & TRN \\
\hline CHEMBL1459411 & 688721 & 4.6 & 4.9899 & TRN \\
\hline CHEMBL1383593 & 688721 & 4.9 & 4.849 & TRN \\
\hline CHEMBL1348073 & 688721 & 5.5 & 4.9677 & TST \\
\hline CHEMBL1550630 & 688721 & 4.4 & 4.9798 & TST \\
\hline CHEMBL1370506 & 688721 & 5.0 & 4.9496 & TST \\
\hline CHEMBL1485783 & 688721 & 4.6 & 4.9925 & TRN \\
\hline CHEMBL1305740 & 688721 & 4.8 & 4.8977 & TRN \\
\hline CHEMBL1452824 & 688721 & 4.7 & 4.959 & TRN \\
\hline CHEMBL1408309 & 688721 & 5.9 & 5.1027 & TRN \\
\hline CHEMBL1425076 & 688721 & 5.1 & 4.8917 & TRN \\
\hline CHEMBL1384654 & 688721 & 5.2 & 4.8454 & TRN \\
\hline CHEMBL1605922 & 688721 & 4.6 & 4.8478 & TST \\
\hline CHEMBL1430907 & 688721 & 5.5 & 4.9051 & TRN \\
\hline CHEMBL1602291 & 688721 & 4.4 & 4.7611 & TRN \\
\hline CHEMBL1370535 & 688721 & 4.9 & 5.0655 & TRN \\
\hline CHEMBL1602357 & 688721 & 4.6 & 4.9842 & TRN \\
\hline CHEMBL1523614 & 688721 & 4.5 & 5.025 & TRN \\
\hline CHEMBL1493328 & 688721 & 4.6 & 4.8281 & TRN \\
\hline CHEMBL1455786 & 688721 & 4.7 & 4.9775 & TST \\
\hline CHEMBL1456269 & 688721 & 4.5 & 4.8497 & TRN \\
\hline CHEMBL1314451 & 688721 & 5.2 & 5.0075 & TST \\
\hline CHEMBL1553123 & 688721 & 4.9 & 4.9218 & TRN \\
\hline CHEMBL1575158 & 688721 & 4.8 & 5.0226 & TRN \\
\hline CHEMBL1509385 & 688721 & 5.0 & 5.0275 & TST \\
\hline CHEMBL1527209 & 688721 & 4.8 & 5.2599 & TRN \\
\hline CHEMBL1429038 & 688721 & 4.6 & 4.8469 & TRN \\
\hline CHEMBL1470649 & 688721 & 4.5 & 4.8822 & TRN \\
\hline
\end{tabular}




\begin{tabular}{|c|c|c|c|c|}
\hline & & & & \\
\hline CHEMBL1594997 & 688721 & 4.6 & 4.9817 & TST \\
\hline CHEMBL1348062 & 688721 & 4.6 & 4.6682 & TRN \\
\hline CHEMBL1374550 & 688721 & 4.5 & 4.9009 & TRN \\
\hline CHEMBL29027 & 688721 & 5.4 & 4.8811 & TRN \\
\hline CHEMBL1364669 & 688721 & 5.0 & 4.8813 & TST \\
\hline CHEMBL491910 & 688721 & 4.6 & 5.1786 & TRN \\
\hline CHEMBL1467064 & 688721 & 5.3 & 4.7122 & TRN \\
\hline CHEMBL1454479 & 688721 & 4.4 & 4.793 & TST \\
\hline CHEMBL1496623 & 688721 & 4.6 & 4.9468 & TRN \\
\hline CHEMBL1385888 & 688721 & 4.5 & 5.0817 & TRN \\
\hline CHEMBL1593096 & 688721 & 4.8 & 4.8663 & TRN \\
\hline CHEMBL1603264 & 688721 & 4.8 & 5.015 & TST \\
\hline CHEMBL1596922 & 688721 & 5.2 & 4.8416 & TST \\
\hline CHEMBL1480919 & 688721 & 5.0 & 4.7694 & TRN \\
\hline CHEMBL1587071 & 688721 & 4.9 & 4.9992 & TST \\
\hline CHEMBL1520845 & 688721 & 4.5 & 4.8536 & TST \\
\hline CHEMBL1445104 & 688721 & 4.7 & 4.9623 & TRN \\
\hline CHEMBL1397914 & 688721 & 4.4 & 5.1461 & TRN \\
\hline CHEMBL1378854 & 688721 & 5.2 & 4.8755 & TST \\
\hline CHEMBL1597481 & 688721 & 4.6 & 4.8856 & TRN \\
\hline CHEMBL1431620 & 688721 & 4.5 & 4.8841 & TST \\
\hline CHEMBL1394223 & 688721 & 4.8 & 5.1894 & TRN \\
\hline CHEMBL1321297 & 688721 & 5.0 & 4.7102 & TRN \\
\hline CHEMBL1593269 & 688721 & 5.5 & 5.1068 & TRN \\
\hline CHEMBL1327906 & 688721 & 4.6 & 4.7893 & TRN \\
\hline CHEMBL589123 & 688721 & 4.4 & 4.9842 & TRN \\
\hline CHEMBL1528437 & 688721 & 6.0 & 4.8003 & TRN \\
\hline CHEMBL1382904 & 688721 & 4.4 & 4.8516 & TRN \\
\hline CHEMBL1487860 & 688721 & 5.1 & 5.4892 & TST \\
\hline CHEMBL1411002 & 688721 & 5.0 & 4.9259 & TST \\
\hline CHEMBL1452252 & 688721 & 4.8 & 4.9229 & TRN \\
\hline CHEMBL1516845 & 688721 & 5.1 & 5.1092 & TRN \\
\hline CHEMBL1570793 & 688721 & 5.2 & 4.9214 & TRN \\
\hline CHEMBL1600408 & 688721 & 5.8 & 5.1 & TRN \\
\hline CHEMBL1320619 & 688721 & 4.8 & 5.03 & TRN \\
\hline CHEMBL1322145 & 688721 & 5.4 & 4.8138 & TRN \\
\hline CHEMBL1545113 & 688721 & 5.4 & 4.9369 & TRN \\
\hline CHEMBL1564263 & 688721 & 4.4 & 4.8434 & TRN \\
\hline CHEMBL1497175 & 688721 & 6.0 & 4.8909 & TRN \\
\hline CHEMBL1349003 & 688721 & 4.8 & 4.9378 & TRN \\
\hline CHEMBL1549053 & 688721 & 4.6 & 4.8177 & TRN \\
\hline CHEMBL1302575 & 688721 & 5.2 & 4.8713 & TRN \\
\hline CHEMBL1465767 & 688721 & 7.2 & 4.8784 & TRN \\
\hline CHEMBL1417577 & 688721 & 4.9 & 4.8908 & TRN \\
\hline CHEMBL1566730 & 688721 & 5.9 & 4.9302 & TST \\
\hline CHEMBL1567161 & 688721 & 4.8 & 4.7482 & TRN \\
\hline CHEMBL1332918 & 688721 & 4.5 & 4.9121 & TRN \\
\hline CHEMBL1349721 & 688721 & 5.9 & 4.9301 & TST \\
\hline
\end{tabular}




\begin{tabular}{|c|c|c|c|c|c|}
\hline \multicolumn{6}{|c|}{ Supplemental Table S2.txt } \\
\hline CHEMBL1353987 & 688721 & 4.6 & 4.9665 & TRN & \\
\hline CHEMBL1571634 & 688721 & 5.1 & 5.2475 & TST & \\
\hline CHEMBL1373177 & 688721 & 5.2 & 5.0316 & TST & \\
\hline CHEMBL1310954 & 688721 & 4.4 & 4.9246 & TST & \\
\hline CHEMBL1379889 & 688721 & 5.2 & 4.8357 & TST & \\
\hline CHEMBL1369281 & 688721 & 4.9 & 4.9976 & TRN & \\
\hline CHEMBL14085 & 688721 & 7.8996 & 5.3018 & TRN & \\
\hline CHEMBL437061 & 688721 & 4.4 & 4.7878 & TST & \\
\hline CHEMBL1497019 & 688721 & 4.6 & 4.7423 & TST & \\
\hline CHEMBL1510985 & 688721 & 4.4 & 4.987 & TRN & \\
\hline CHEMBL1529042 & 688721 & 5.4 & 4.8934 & TRN & \\
\hline CHEMBL1501221 & 688721 & 4.5 & 4.9072 & TRN & \\
\hline CHEMBL1427319 & 688721 & 4.7 & 4.8384 & TRN & \\
\hline CHEMBL1413962 & 688721 & 4.6 & 5.1995 & TRN & \\
\hline CHEMBL1598717 & 688721 & 5.3 & 5.1831 & TRN & \\
\hline CHEMBL1541708 & 688721 & 4.8 & 4.8802 & TRN & \\
\hline CHEMBL1365652 & 688721 & 4.8 & 4.7618 & TRN & \\
\hline CHEMBL1402888 & 688721 & 5.0 & 4.9486 & TST & \\
\hline CHEMBL1392428 & 688721 & 4.7 & 5.0061 & TST & \\
\hline CHEMBL1532093 & 688721 & 4.8 & 4.8755 & TST & \\
\hline CHEMBL1358631 & 688721 & 4.8 & 5.1832 & TRN & \\
\hline CHEMBL1435384 & 688721 & 4.7 & 5.15 & TRN & \\
\hline CHEMBL1551479 & 688721 & 5.7 & 5.115 & TRN & \\
\hline CHEMBL1445255 & 688721 & 6.9 & 4.8228 & TST & \\
\hline CHEMBL1576376 & 688721 & 4.5 & 4.882 & TST & \\
\hline CHEMBL1566540 & 688721 & 4.6 & 5.0496 & TST & \\
\hline CHEMBL1400703 & 688721 & 4.6 & 4.9371 & TRN & \\
\hline CHEMBL1367957 & 688721 & 4.6 & 4.9576 & TRN & \\
\hline CHEMBL196590 & 688721 & 4.4 & 5.0833 & TRN & \\
\hline CHEMBL1491373 & 688721 & 7.5003 & 4.9174 & TRN & \\
\hline CHEMBL1555815 & 688721 & 4.4 & 4.8094 & TRN & \\
\hline CHEMBL1333915 & 688721 & 4.6 & 4.9772 & TRN & \\
\hline CHEMBL1536064 & 688721 & 5.1 & 5.0892 & TRN & \\
\hline CHEMBL1574279 & 688721 & 4.4 & 4.9607 & TST & \\
\hline CHEMBL1469705 & 688721 & 4.8 & 4.859 & TST & \\
\hline CHEMBL1461535 & 688721 & 7.1002 & 4.7797 & TRN & \\
\hline CHEMBL1354864 & 688721 & 4.8 & 5.1565 & TRN & \\
\hline CHEMBL1305990 & 688721 & 6.0 & 4.8055 & TRN & \\
\hline CHEMBL1422189 & 688721 & 4.5 & 5.1271 & TST & \\
\hline CHEMBL1580103 & 688721 & 4.5 & 4.82600 & 00000000005 & TRN \\
\hline CHEMBL491578 & 688721 & 4.5 & 4.9437 & TRN & \\
\hline CHEMBL1558310 & 688721 & 4.8 & 4.8231 & TST & \\
\hline CHEMBL1342930 & 688721 & 4.8 & 4.8238 & TRN & \\
\hline CHEMBL1580655 & 688721 & 4.9 & 4.952 & TRN & \\
\hline CHEMBL1423577 & 688721 & 4.5 & 4.9406 & TST & \\
\hline CHEMBL1318977 & 688721 & 4.4 & 4.7296 & TRN & \\
\hline CHEMBL1360333 & 688721 & 4.5 & 4.9405 & TRN & \\
\hline CHEMBL1341031 & 688721 & 5.0 & 5.1925 & TRN & \\
\hline
\end{tabular}




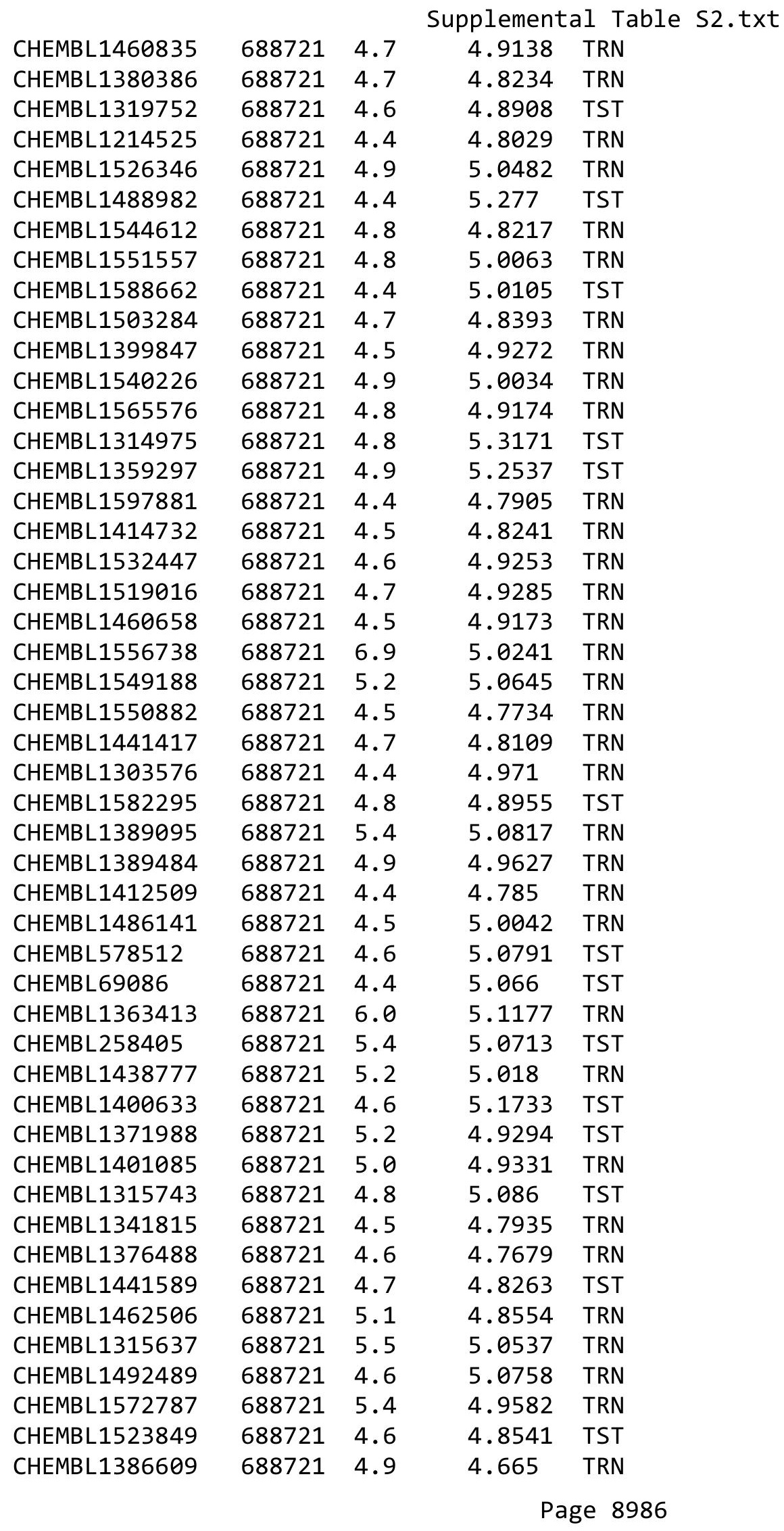




\begin{tabular}{|c|c|c|c|c|}
\hline & & & & $a \perp 1 a$ \\
\hline CHEMBL1446323 & 688721 & 5.3 & 4.9645 & TRN \\
\hline CHEMBL1542572 & 688721 & 4.9 & 5.0003 & TRN \\
\hline CHEMBL1415472 & 688721 & 4.8 & 4.88 & TST \\
\hline CHEMBL1448790 & 688721 & 4.9 & 4.9171 & TRN \\
\hline CHEMBL1555913 & 688721 & 4.6 & 4.9031 & TST \\
\hline CHEMBL1329440 & 688721 & 5.2 & 5.0537 & TRN \\
\hline CHEMBL1488939 & 688721 & 4.5 & 4.9795 & TRN \\
\hline CHEMBL1517241 & 688721 & 4.6 & 4.9823 & TRN \\
\hline CHEMBL30193 & 688721 & 4.5 & 4.9874 & TST \\
\hline CHEMBL1425956 & 688721 & 4.8 & 4.7446 & TST \\
\hline CHEMBL1596120 & 688721 & 4.4 & 5.3814 & TRN \\
\hline CHEMBL1359556 & 688721 & 4.8 & 4.7993 & TRN \\
\hline CHEMBL1571725 & 688721 & 5.0 & 4.8723 & TRN \\
\hline CHEMBL1525051 & 688721 & 4.7 & 4.8487 & TRN \\
\hline CHEMBL1414753 & 688721 & 4.5 & 4.9227 & TRN \\
\hline CHEMBL1548726 & 688721 & 4.6 & 5.2336 & TRN \\
\hline CHEMBL1495824 & 688721 & 4.8 & 4.8288 & TRN \\
\hline CHEMBL1585499 & 688721 & 4.8 & 4.9617 & TRN \\
\hline CHEMBL1601694 & 688721 & 4.5 & 4.864 & TRN \\
\hline CHEMBL1331748 & 688721 & 4.5 & 5.0754 & TRN \\
\hline CHEMBL1339424 & 688721 & 4.9 & 4.9703 & TRN \\
\hline CHEMBL1458387 & 688721 & 5.1 & 4.9458 & TST \\
\hline CHEMBL1562870 & 688721 & 5.3 & 4.7909 & TRN \\
\hline CHEMBL1443070 & 688721 & 5.2 & 4.8212 & TRN \\
\hline CHEMBL1467289 & 688721 & 4.5 & 4.8677 & TRN \\
\hline CHEMBL1577343 & 688721 & 4.4 & 4.902 & TST \\
\hline CHEMBL1343705 & 688721 & 4.4 & 4.9587 & TRN \\
\hline CHEMBL1471591 & 688721 & 4.5 & 4.9232 & TRN \\
\hline CHEMBL3210295 & 688721 & 6.0 & 4.8957 & TRN \\
\hline CHEMBL1349521 & 688721 & 4.8 & 4.8125 & TRN \\
\hline CHEMBL1410508 & 688721 & 4.5 & 4.8215 & TRN \\
\hline CHEMBL1452111 & 688721 & 4.6 & 5.1293 & TRN \\
\hline CHEMBL1472402 & 688721 & 4.5 & 4.7181 & TRN \\
\hline CHEMBL1432868 & 688721 & 4.4 & 4.9754 & TRN \\
\hline CHEMBL1493939 & 688721 & 5.6 & 5.0995 & TRN \\
\hline CHEMBL1361741 & 688721 & 4.7 & 4.8637 & TRN \\
\hline CHEMBL1344952 & 688721 & 5.0 & 5.1356 & TRN \\
\hline CHEMBL1426455 & 688721 & 4.6 & 4.8865 & TRN \\
\hline CHEMBL1446297 & 688721 & 4.5 & 4.8392 & TRN \\
\hline CHEMBL1375000 & 688721 & 5.4 & 4.9167 & TRN \\
\hline CHEMBL1429186 & 688721 & 4.4 & 4.9911 & TST \\
\hline CHEMBL1463833 & 688721 & 5.9 & 5.0898 & TST \\
\hline CHEMBL1578130 & 688721 & 5.8 & 4.8081 & TRN \\
\hline CHEMBL1492811 & 688721 & 5.2 & 4.9748 & TRN \\
\hline CHEMBL1447876 & 688721 & 4.6 & 4.9855 & TRN \\
\hline CHEMBL1359836 & 688721 & 5.4 & 5.4144 & TST \\
\hline CHEMBL1304094 & 688721 & 5.4 & 4.8953 & TRN \\
\hline CHEMBL1382421 & 688721 & 4.5 & 4.9605 & TRN \\
\hline
\end{tabular}




\begin{tabular}{|c|c|c|c|c|c|}
\hline \multicolumn{6}{|c|}{ Supplemental Table S2.txt } \\
\hline CHEMBL1393096 & 688721 & 4.4 & 4.8668 & TRN & \\
\hline CHEMBL1581345 & 688721 & 4.6 & 4.785 & TRN & \\
\hline CHEMBL1600736 & 688721 & 4.5 & 4.9506 & TRN & \\
\hline CHEMBL1612273 & 688721 & 4.7 & 4.8946 & TRN & \\
\hline CHEMBL1500691 & 688721 & 4.9 & 4.8689 & TST & \\
\hline CHEMBL1465620 & 688721 & 4.8 & 4.994 & TST & \\
\hline CHEMBL1454785 & 688721 & 5.6 & 4.8631 & TRN & \\
\hline CHEMBL1351402 & 688721 & 4.5 & 4.8471 & TRN & \\
\hline CHEMBL1606727 & 688721 & 4.8 & 5.0931 & TRN & \\
\hline CHEMBL355014 & 688721 & 4.4 & 4.9644 & TRN & \\
\hline CHEMBL1491899 & 688721 & 4.7 & 5.0173 & TRN & \\
\hline CHEMBL1339814 & 688721 & 5.5 & 4.9201 & TRN & \\
\hline CHEMBL1535422 & 688721 & 4.7 & 5.0805 & TST & \\
\hline CHEMBL1578539 & 688721 & 4.9 & 4.8056 & TST & \\
\hline CHEMBL1560374 & 688721 & 4.5 & 4.9356 & TRN & \\
\hline CHEMBL1437095 & 688721 & 4.5 & 4.9654 & TRN & \\
\hline CHEMBL1384300 & 688721 & 5.4 & 5.1737 & TRN & \\
\hline CHEMBL1394353 & 688721 & 4.4 & 5.0851 & TRN & \\
\hline CHEMBL1375628 & 688721 & 4.7 & 4.8547 & TRN & \\
\hline CHEMBL1414912 & 688721 & 5.2 & 4.9037 & TRN & \\
\hline CHEMBL1437408 & 688721 & 4.6 & 5.1341 & TRN & \\
\hline CHEMBL221300 & 688721 & 5.6 & 5.0036 & TST & \\
\hline CHEMBL1257013 & 688721 & 4.6 & 5.3436 & TRN & \\
\hline CHEMBL1491231 & 688721 & 5.2 & 4.7707 & TRN & \\
\hline CHEMBL62 & 688721 & 6.0 & 5.0029 & TRN & \\
\hline CHEMBL1492025 & 688721 & 4.6 & 4.8755 & TST & \\
\hline CHEMBL1530686 & 688721 & 4.9 & 4.8258 & TRN & \\
\hline CHEMBL1480205 & 688721 & 5.3 & 4.8187 & TST & \\
\hline CHEMBL1448473 & 688721 & 4.4 & 4.9334 & TRN & \\
\hline CHEMBL1542833 & 688721 & 5.2 & 4.9131 & TRN & \\
\hline CHEMBL1511227 & 688721 & 5.4 & 4.95100 & 00000000005 & TRN \\
\hline CHEMBL1344965 & 688721 & 4.6 & 4.9606 & TRN & \\
\hline CHEMBL1520318 & 688721 & 5.7 & 4.8885 & TRN & \\
\hline CHEMBL1581061 & 688721 & 5.0 & 4.8297 & TRN & \\
\hline CHEMBL1430717 & 688721 & 4.4 & 5.1675 & TST & \\
\hline CHEMBL1320662 & 688721 & 7.0 & 5.1066 & TRN & \\
\hline CHEMBL1535635 & 688721 & 4.5 & 5.1026 & TRN & \\
\hline CHEMBL1574931 & 688721 & 4.7 & 5.0408 & TST & \\
\hline CHEMBL1302466 & 688721 & 5.3 & 4.9632 & TRN & \\
\hline CHEMBL1419066 & 688721 & 4.8 & 4.7896 & TRN & \\
\hline CHEMBL1562139 & 688721 & 4.5 & 4.8439 & TRN & \\
\hline CHEMBL1420552 & 688721 & 4.4 & 4.8361 & TRN & \\
\hline CHEMBL1539702 & 688721 & 4.6 & 4.9987 & TRN & \\
\hline CHEMBL1305046 & 688721 & 4.5 & 4.9455 & TRN & \\
\hline CHEMBL1565435 & 688721 & 4.5 & 5.0323 & TST & \\
\hline CHEMBL1373741 & 688721 & 5.2 & 4.9665 & TST & \\
\hline CHEMBL1331931 & 688721 & 5.7 & 4.8468 & TRN & \\
\hline CHEMBL1565842 & 688721 & 4.7 & 4.8905 & TRN & \\
\hline
\end{tabular}




\begin{tabular}{|c|c|c|c|c|}
\hline \multicolumn{5}{|c|}{ Supplemental Tab } \\
\hline CHEMBL1373513 & 688721 & 6.1 & 4.9892 & TRN \\
\hline CHEMBL1575766 & 688721 & 4.6 & 4.9191 & TRN \\
\hline CHEMBL1585451 & 688721 & 5.2 & 4.9494 & TRN \\
\hline CHEMBL1414091 & 688721 & 4.8 & 4.8472 & TRN \\
\hline CHEMBL1426233 & 688721 & 4.8 & 4.8305 & TST \\
\hline CHEMBL1583200 & 688721 & 4.5 & 4.7617 & TRN \\
\hline CHEMBL1557008 & 688721 & 4.5 & 4.8729 & TRN \\
\hline CHEMBL1359452 & 688721 & 4.5 & 5.0903 & TRN \\
\hline CHEMBL86676 & 688721 & 4.4 & 4.9975 & TST \\
\hline CHEMBL1349038 & 688721 & 5.1 & 4.9261 & TST \\
\hline CHEMBL 1538533 & 688721 & 4.4 & 4.8448 & TRN \\
\hline CHEMBL1578928 & 688721 & 5.9 & 5.3225 & TRN \\
\hline CHEMBL1599007 & 688721 & 4.6 & 4.7862 & TST \\
\hline CHEMBL1380402 & 688721 & 4.7 & 4.8128 & TRN \\
\hline CHEMBL1301299 & 688721 & 4.8 & 4.8484 & TRN \\
\hline CHEMBL1562453 & 688721 & 4.5 & 5.0771 & TRN \\
\hline CHEMBL1531365 & 688721 & 5.1 & 4.8845 & TRN \\
\hline CHEMBL1314165 & 688721 & 4.7 & 4.8102 & TRN \\
\hline CHEMBL1541656 & 688721 & 5.4 & 4.941 & TRN \\
\hline CHEMBL1511595 & 688721 & 6.8 & 5.055 & TRN \\
\hline CHEMBL 259388 & 688721 & 6.0 & 4.8538 & TST \\
\hline CHEMBL1527876 & 688721 & 5.3 & 5.0736 & TRN \\
\hline CHEMBL1998234 & 688721 & 5.1 & 4.9227 & TRN \\
\hline CHEMBL1599856 & 688721 & 4.6 & 4.7994 & TRN \\
\hline CHEMBL1491478 & 688721 & 5.2 & 4.9695 & TRN \\
\hline CHEMBL1565468 & 688721 & 4.8 & 4.9382 & TRN \\
\hline CHEMBL1498589 & 688721 & 4.5 & 4.995 & TRN \\
\hline CHEMBL1351861 & 688721 & 4.7 & 4.8643 & TRN \\
\hline CHEMBL1535324 & 688721 & 4.9 & 4.8149 & TRN \\
\hline CHEMBL1426154 & 688721 & 4.6 & 5.0705 & TRN \\
\hline CHEMBL1529807 & 688721 & 5.1 & 4.9615 & TRN \\
\hline CHEMBL1605841 & 688721 & 4.8 & 4.965 & TST \\
\hline CHEMBL1572253 & 688721 & 4.4 & 5.0515 & TRN \\
\hline CHEMBL1360472 & 688721 & 4.4 & 4.8076 & TRN \\
\hline CHEMBL1562810 & 688721 & 4.9 & 4.9505 & TRN \\
\hline CHEMBL1377207 & 688721 & 4.6 & 5.2629 & TST \\
\hline CHEMBL1610823 & 688721 & 4.7 & 5.0067 & TRN \\
\hline CHEMBL1438788 & 688721 & 5.3 & 4.8638 & TRN \\
\hline CHEMBL3194566 & 688721 & 4.4 & 5.033 & TRN \\
\hline CHEMBL1424736 & 688721 & 5.8 & 5.0928 & TRN \\
\hline CHEMBL1465276 & 688721 & 4.6 & 4.8837 & TRN \\
\hline CHEMBL3191187 & 688721 & 5.0 & 5.0566 & TRN \\
\hline CHEMBL1470816 & 688721 & 4.4 & 4.9073 & TRN \\
\hline CHEMBL1343808 & 688721 & 5.4 & 4.8988 & TRN \\
\hline CHEMBL1413869 & 688721 & 4.6 & 4.8851 & TRN \\
\hline CHEMBL1344065 & 688721 & 4.7 & 4.8448 & TRN \\
\hline CHEMBL1611316 & 688721 & 4.4 & 5.0369 & TST \\
\hline CHEMBL1343554 & 688721 & 4.7 & 5.1815 & TRN \\
\hline
\end{tabular}




\begin{tabular}{|c|c|c|c|c|}
\hline \multicolumn{5}{|c|}{ Supplemental Table S2.txt } \\
\hline CHEMBL1480179 & 688721 & 5.4 & 4.7616 & TST \\
\hline CHEMBL1569508 & 688721 & 4.4 & 4.8755 & TRN \\
\hline CHEMBL1586333 & 688721 & 5.2 & 4.7299 & TRN \\
\hline CHEMBL1406319 & 688721 & 4.6 & 4.8376 & TRN \\
\hline CHEMBL1345583 & 688721 & 4.4 & 4.5721 & TRN \\
\hline CHEMBL1324022 & 688721 & 4.9 & 5.0682 & TST \\
\hline CHEMBL1346788 & 688721 & 4.4 & 4.9798 & TRN \\
\hline CHEMBL1571573 & 688721 & 4.4 & 4.8121 & TRN \\
\hline CHEMBL1491699 & 688721 & 5.2 & 5.0762 & TRN \\
\hline CHEMBL1593545 & 688721 & 5.2 & 5.2339 & TRN \\
\hline CHEMBL1583433 & 688721 & 5.3 & 4.8724 & TRN \\
\hline CHEMBL1598887 & 688721 & 6.0 & 5.0507 & TST \\
\hline CHEMBL1440469 & 688721 & 4.6 & 4.8492 & TRN \\
\hline CHEMBL606166 & 688721 & 5.7 & 4.9945 & TST \\
\hline CHEMBL1415458 & 688721 & 4.4 & 4.8864 & TRN \\
\hline CHEMBL1435544 & 688721 & 4.7 & 5.0075 & TRN \\
\hline CHEMBL1379936 & 688721 & 4.4 & 5.0227 & TRN \\
\hline CHEMBL1369023 & 688721 & 4.6 & 4.8694 & TRN \\
\hline CHEMBL1536044 & 688721 & 4.7 & 4.8124 & TRN \\
\hline CHEMBL1309624 & 688721 & 4.5 & 5.0265 & TRN \\
\hline CHEMBL1428574 & 688721 & 4.6 & 4.8569 & TST \\
\hline CHEMBL1527940 & 688721 & 5.2 & 5.0066 & TRN \\
\hline CHEMBL1509562 & 688721 & 4.5 & 4.8694 & TRN \\
\hline CHEMBL1448717 & 688721 & 4.9 & 4.9636 & TST \\
\hline CHEMBL1321714 & 688721 & 4.8 & 4.7523 & TRN \\
\hline CHEMBL1312730 & 688721 & 4.7 & 5.0464 & TRN \\
\hline CHEMBL1537629 & 688721 & 4.6 & 4.9572 & TRN \\
\hline CHEMBL1384456 & 688721 & 5.2 & 4.8594 & TRN \\
\hline CHEMBL577195 & 688721 & 5.2 & 5.0053 & TRN \\
\hline CHEMBL 1350590 & 688721 & 4.6 & 4.8233 & TRN \\
\hline CHEMBL1382994 & 688721 & 5.4 & 4.9249 & TRN \\
\hline CHEMBL 1438560 & 688721 & 5.8 & 4.8439 & TRN \\
\hline CHEMBL1352593 & 688721 & 5.5 & 4.9642 & TRN \\
\hline CHEMBL193888 & 688721 & 4.5 & 5.0253 & TRN \\
\hline CHEMBL1608868 & 688721 & 5.0 & 4.7251 & TRN \\
\hline CHEMBL3209033 & 688721 & 4.6 & 4.9863 & TST \\
\hline CHEMBL1449987 & 688721 & 5.1 & 5.188 & TST \\
\hline CHEMBL1349311 & 688721 & 4.4 & 4.8868 & TST \\
\hline CHEMBL1299505 & 688721 & 4.5 & 4.726 & TRN \\
\hline CHEMBL1510629 & 688721 & 5.1 & 4.9469 & TRN \\
\hline CHEMBL1491679 & 688721 & 7.6003 & 4.8495 & TRN \\
\hline CHEMBL1416319 & 688721 & 4.6 & 4.8419 & TRN \\
\hline CHEMBL1372993 & 688721 & 4.4 & 5.002 & TRN \\
\hline CHEMBL1491094 & 688721 & 4.8 & 4.9719 & TRN \\
\hline CHEMBL1571980 & 688721 & 4.8 & 4.8626 & TST \\
\hline CHEMBL1496758 & 688721 & 4.9 & 5.0651 & TRN \\
\hline CHEMBL1510273 & 688721 & 4.5 & 4.8733 & TRN \\
\hline CHEMBL1576456 & 688721 & 4.5 & 4.968 & TST \\
\hline
\end{tabular}




\begin{tabular}{|c|c|c|c|c|c|}
\hline \multicolumn{6}{|c|}{ Supplemental Table S2.txt } \\
\hline CHEMBL1577619 & 688721 & 4.4 & 4.9562 & TRN & \\
\hline CHEMBL1575994 & 688721 & 4.4 & 4.8752 & TRN & \\
\hline CHEMBL1302217 & 688721 & 4.6 & 4.8898 & TRN & \\
\hline CHEMBL1591731 & 688721 & 6.9 & 5.3633 & TST & \\
\hline CHEMBL1493283 & 688721 & 4.8 & 4.6919 & TRN & \\
\hline CHEMBL1424106 & 688721 & 5.0 & 4.8914 & TRN & \\
\hline CHEMBL1403715 & 688721 & 5.5 & 4.9186 & TST & \\
\hline CHEMBL1427611 & 688721 & 4.6 & 5.0191 & TST & \\
\hline CHEMBL1306076 & 688721 & 5.2 & 4.9854 & TST & \\
\hline CHEMBL1573058 & 688721 & 4.6 & 4.9387 & TRN & \\
\hline CHEMBL1612074 & 688721 & 5.3 & 4.8445 & TRN & \\
\hline CHEMBL1577274 & 688721 & 4.8 & 4.999 & TRN & \\
\hline CHEMBL1443110 & 688721 & 4.4 & 4.732 & TRN & \\
\hline CHEMBL1444504 & 688721 & 4.5 & 5.0101 & TST & \\
\hline CHEMBL1448695 & 688721 & 5.0 & 5.085 & TRN & \\
\hline CHEMBL1598208 & 688721 & 5.4 & 4.9589 & TRN & \\
\hline CHEMBL1436024 & 688721 & 4.5 & 4.9486 & TRN & \\
\hline CHEMBL1516148 & 688721 & 5.4 & 5.2554 & TST & \\
\hline CHEMBL1610511 & 688721 & 4.6 & 4.9482 & TRN & \\
\hline CHEMBL 2373595 & 688721 & 4.6 & 4.9762 & TRN & \\
\hline CHEMBL1448281 & 688721 & 5.0 & 4.9349 & TRN & \\
\hline CHEMBL1350634 & 688721 & 4.5 & 4.96 & TRN & \\
\hline CHEMBL1597046 & 688721 & 8.3979 & 4.8517 & TST & \\
\hline CHEMBL1304672 & 688721 & 4.4 & 4.8133 & TRN & \\
\hline CHEMBL1504007 & 688721 & 4.6 & 4.8143 & TRN & \\
\hline CHEMBL1510755 & 688721 & 5.2 & 4.9566 & TST & \\
\hline CHEMBL1345784 & 688721 & 4.6 & 4.9233 & TST & \\
\hline CHEMBL1338369 & 688721 & 4.5 & 4.6546 & TRN & \\
\hline CHEMBL1580954 & 688721 & 5.0 & 4.8121 & TRN & \\
\hline CHEMBL1466638 & 688721 & 4.6 & 4.9325 & TRN & \\
\hline CHEMBL1418567 & 688721 & 4.4 & 4.8035 & TRN & \\
\hline CHEMBL1497983 & 688721 & 5.3 & 4.9335 & TST & \\
\hline CHEMBL1385628 & 688721 & 6.9 & 4.9546 & TRN & \\
\hline CHEMBL1162293 & 688721 & 6.9 & 5.2445 & TRN & \\
\hline CHEMBL1313496 & 688721 & 4.7 & 4.7624 & TRN & \\
\hline CHEMBL1440679 & 688721 & 5.2 & 4.9157 & TST & \\
\hline CHEMBL1330055 & 688721 & 5.3 & 4.9918 & TRN & \\
\hline CHEMBL1429994 & 688721 & 4.7 & 5.1714 & TRN & \\
\hline CHEMBL1319775 & 688721 & 5.5 & 4.9698 & TRN & \\
\hline CHEMBL1334823 & 688721 & 4.8 & 4.7102 & TRN & \\
\hline CHEMBL1504823 & 688721 & 5.2 & 5.063 & TST & \\
\hline CHEMBL1387519 & 688721 & 4.9 & 4.95100 & 00000000005 & TRN \\
\hline CHEMBL1458663 & 688721 & 4.7 & 4.7119 & TRN & \\
\hline CHEMBL3198096 & 688721 & 5.4 & 4.9591 & TRN & \\
\hline CHEMBL1557806 & 688721 & 5.3 & 4.9599 & TRN & \\
\hline CHEMBL1580280 & 688721 & 6.2 & 4.9933 & TRN & \\
\hline CHEMBL1499079 & 688721 & 4.4 & 4.8165 & TRN & \\
\hline CHEMBL1318963 & 688721 & 4.6 & 4.7084 & TRN & \\
\hline
\end{tabular}




\begin{tabular}{|c|c|c|c|c|}
\hline & & & Supplement & \\
\hline CHEMBL1469086 & 688721 & 4.9 & 4.8091 & TRN \\
\hline CHEMBL259849 & 688721 & 4.4 & 4.9566 & TRN \\
\hline CHEMBL1541000 & 688721 & 4.4 & 4.9885 & TRN \\
\hline CHEMBL1383488 & 688721 & 4.8 & 5.0723 & TST \\
\hline CHEMBL1585719 & 688721 & 4.6 & 4.8905 & TST \\
\hline CHEMBL354663 & 688721 & 5.9 & 5.1588 & TRN \\
\hline CHEMBL1599850 & 688721 & 4.8 & 4.7649 & TST \\
\hline CHEMBL1512190 & 688721 & 4.5 & 5.0049 & TRN \\
\hline CHEMBL1493519 & 688721 & 4.8 & 4.8688 & TRN \\
\hline CHEMBL1484447 & 688721 & 4.6 & 4.9334 & TRN \\
\hline CHEMBL1348233 & 688721 & 4.5 & 4.8929 & TST \\
\hline CHEMBL1559035 & 688721 & 4.5 & 4.7835 & TRN \\
\hline CHEMBL1497662 & 688721 & 5.0 & 4.9152 & TRN \\
\hline CHEMBL1409084 & 688721 & 5.9 & 4.9235 & TRN \\
\hline CHEMBL3213949 & 688721 & 5.2 & 4.973 & TRN \\
\hline CHEMBL1427588 & 688721 & 5.3 & 5.1463 & TRN \\
\hline CHEMBL1429915 & 688721 & 4.6 & 4.9167 & TRN \\
\hline CHEMBL1374613 & 688721 & 4.6 & 4.7822 & TRN \\
\hline CHEMBL1334391 & 688721 & 4.5 & 4.9213 & TRN \\
\hline CHEMBL1385895 & 688721 & 4.6 & 4.8794 & TRN \\
\hline CHEMBL1532016 & 688721 & 4.8 & 5.2615 & TRN \\
\hline CHEMBL1495657 & 688721 & 5.4 & 5.0598 & TST \\
\hline CHEMBL1579872 & 688721 & 4.5 & 4.7513 & TRN \\
\hline CHEMBL1367565 & 688721 & 4.8 & 5.1442 & TST \\
\hline CHEMBL1552588 & 688721 & 5.3 & 5.2659 & TRN \\
\hline CHEMBL1478904 & 688721 & 4.6 & 4.9804 & TRN \\
\hline CHEMBL1364519 & 688721 & 4.5 & 4.836 & TRN \\
\hline CHEMBL1307081 & 688721 & 4.4 & 4.9758 & TST \\
\hline CHEMBL1484276 & 688721 & 4.8 & 4.8902 & TRN \\
\hline CHEMBL1341608 & 688721 & 5.9 & 4.9858 & TRN \\
\hline CHEMBL1414002 & 688721 & 6.1 & 5.1278 & TRN \\
\hline CHEMBL1604551 & 688721 & 4.4 & 4.9532 & TST \\
\hline CHEMBL1564665 & 688721 & 4.7 & 4.872 & TRN \\
\hline CHEMBL1477475 & 688721 & 5.1 & 4.8427 & TST \\
\hline CHEMBL1393376 & 688721 & 4.5 & 5.0516 & TRN \\
\hline CHEMBL1532340 & 688721 & 5.0 & 4.8966 & TST \\
\hline CHEMBL1613574 & 688721 & 5.7 & 4.9559 & TRN \\
\hline CHEMBL1424022 & 688721 & 4.7 & 5.0434 & TRN \\
\hline CHEMBL1439783 & 688721 & 4.7 & 4.7604 & TST \\
\hline CHEMBL1587097 & 688721 & 4.4 & 5.0265 & TRN \\
\hline CHEMBL1583734 & 688721 & 5.1 & 4.7295 & TRN \\
\hline CHEMBL1372348 & 688721 & 4.7 & 4.8468 & TRN \\
\hline CHEMBL1426762 & 688721 & 4.5 & 5.0727 & TST \\
\hline CHEMBL1569584 & 688721 & 5.5 & 4.9516 & TST \\
\hline CHEMBL1362008 & 688721 & 5.1 & 5.0451 & TST \\
\hline CHEMBL1430161 & 688721 & 4.4 & 4.8795 & TRN \\
\hline CHEMBL1322920 & 688721 & 5.2 & 4.7637 & TRN \\
\hline CHEMBL1371894 & 688721 & 4.4 & 4.9843 & TRN \\
\hline
\end{tabular}




\begin{tabular}{|c|c|c|c|c|c|}
\hline \multicolumn{6}{|c|}{ Supplemental Table S2.txt } \\
\hline CHEMBL1399289 & 688721 & 4.5 & 4.6149 & TRN & \\
\hline CHEMBL1330207 & 688721 & 4.9 & 4.9502 & TRN & \\
\hline CHEMBL1613639 & 688721 & 4.5 & 4.908 & TRN & \\
\hline CHEMBL1307264 & 688721 & 5.5 & 4.9304 & TRN & \\
\hline CHEMBL1406206 & 688721 & 5.3 & 5.1048 & TRN & \\
\hline CHEMBL1496600 & 688721 & 4.5 & 4.7396 & TST & \\
\hline CHEMBL1570665 & 688721 & 4.5 & 4.8984 & TRN & \\
\hline CHEMBL1368020 & 688721 & 4.4 & 4.9549 & TRN & \\
\hline CHEMBL13790 & 688721 & 6.9 & 5.1178 & TST & \\
\hline CHEMBL1530457 & 688721 & 6.9 & 4.8985 & TRN & \\
\hline CHEMBL1359041 & 688721 & 4.4 & 4.9692 & TST & \\
\hline CHEMBL1498817 & 688721 & 5.8 & 5.0222 & TST & \\
\hline CHEMBL1482304 & 688721 & 5.0 & 4.8989 & TRN & \\
\hline CHEMBL1302494 & 688721 & 5.4 & 4.8495 & TRN & \\
\hline CHEMBL1366920 & 688721 & 4.7 & 4.9512 & TRN & \\
\hline CHEMBL1491667 & 688721 & 4.4 & 5.0032 & TRN & \\
\hline CHEMBL1386806 & 688721 & 4.6 & 5.0424 & TRN & \\
\hline CHEMBL1508029 & 688721 & 4.4 & 5.02800 & 00000000005 & TRN \\
\hline CHEMBL1376702 & 688721 & 4.8 & 4.8303 & TRN & \\
\hline CHEMBL1589042 & 688721 & 4.6 & 4.8711 & TRN & \\
\hline CHEMBL1200765 & 688721 & 4.6 & 5.0502 & TST & \\
\hline CHEMBL1419718 & 688721 & 4.6 & 4.905 & TST & \\
\hline CHEMBL1478074 & 688721 & 4.4 & 4.6115 & TRN & \\
\hline CHEMBL1375233 & 688721 & 7.5003 & 4.9752 & TRN & \\
\hline CHEMBL1456982 & 688721 & 5.2 & 5.0202 & TST & \\
\hline CHEMBL1313676 & 688721 & 4.4 & 4.927 & TRN & \\
\hline CHEMBL1491128 & 688721 & 4.6 & 4.9371 & TST & \\
\hline CHEMBL1360235 & 688721 & 4.6 & 4.8183 & TRN & \\
\hline CHEMBL1322959 & 688721 & 5.6 & 5.2242 & TST & \\
\hline CHEMBL194400 & 688721 & 4.4 & 5.1444 & TST & \\
\hline CHEMBL1310051 & 688721 & 4.5 & 4.9056 & TRN & \\
\hline CHEMBL1594711 & 688721 & 5.2 & 5.1902 & TST & \\
\hline CHEMBL1522603 & 688721 & 4.6 & 4.831 & TRN & \\
\hline CHEMBL1327614 & 688721 & 5.4 & 4.9186 & TRN & \\
\hline CHEMBL1459751 & 688721 & 4.4 & 4.9483 & TST & \\
\hline CHEMBL1333797 & 688721 & 4.8 & 5.0023 & TRN & \\
\hline CHEMBL1493739 & 688721 & 4.5 & 4.8809 & TRN & \\
\hline CHEMBL1508159 & 688721 & 6.0 & 4.99 & TST & \\
\hline CHEMBL1441821 & 688721 & 4.9 & 5.0045 & TRN & \\
\hline CHEMBL1501233 & 688721 & 4.5 & 4.8527 & TRN & \\
\hline CHEMBL1440508 & 688721 & 5.6 & 4.7511 & TRN & \\
\hline CHEMBL375629 & 688721 & 4.4 & 5.0454 & TRN & \\
\hline CHEMBL1599419 & 688721 & 5.3 & 4.7658 & TRN & \\
\hline CHEMBL1425092 & 688721 & 4.5 & 4.897 & TRN & \\
\hline CHEMBL1302503 & 688721 & 4.7 & 5.1152 & TST & \\
\hline CHEMBL1360103 & 688721 & 5.2 & 5.1256 & TST & \\
\hline CHEMBL1534287 & 688721 & 5.5 & 4.963 & TRN & \\
\hline CHEMBL1332662 & 688721 & 5.9 & 4.8097 & TRN & \\
\hline
\end{tabular}




\begin{tabular}{|c|c|c|c|c|}
\hline \multicolumn{5}{|c|}{ Supplemental Table S2.txt } \\
\hline CHEMBL1466192 & 688721 & 5.0 & 4.9022 & TRN \\
\hline CHEMBL1440067 & 688721 & 4.4 & 4.8859 & TRN \\
\hline CHEMBL1571750 & 688721 & 4.5 & 4.8188 & TRN \\
\hline CHEMBL3199612 & 688721 & 4.5 & 4.9769 & TRN \\
\hline CHEMBL1471105 & 688721 & 5.5 & 5.0054 & TST \\
\hline CHEMBL1575489 & 688721 & 4.9 & 5.0019 & TST \\
\hline CHEMBL1604283 & 688721 & 4.6 & 5.1573 & TRN \\
\hline CHEMBL1333420 & 688721 & 4.4 & 5.1723 & TRN \\
\hline CHEMBL1256396 & 688721 & 4.4 & 5.0486 & TRN \\
\hline CHEMBL1330706 & 688721 & 5.3 & 4.9342 & TRN \\
\hline CHEMBL1608295 & 688721 & 6.2 & 5.1649 & TRN \\
\hline CHEMBL1574741 & 688721 & 4.7 & 4.8611 & TRN \\
\hline CHEMBL1606898 & 688721 & 4.5 & 4.9317 & TST \\
\hline CHEMBL1564518 & 688721 & 4.9 & 4.8741 & TRN \\
\hline CHEMBL1506218 & 688721 & 4.7 & 4.8173 & TRN \\
\hline CHEMBL1542307 & 688721 & 5.7 & 4.7185 & TRN \\
\hline CHEMBL1416630 & 688721 & 4.4 & 4.7733 & TRN \\
\hline CHEMBL1361731 & 688721 & 4.9 & 5.0812 & TRN \\
\hline CHEMBL1492497 & 688721 & 4.7 & 4.8238 & TRN \\
\hline CHEMBL1373469 & 688721 & 4.7 & 4.9756 & TRN \\
\hline CHEMBL1451968 & 688721 & 4.7 & 4.7703 & TRN \\
\hline CHEMBL1360959 & 688721 & 4.9 & 5.0592 & TST \\
\hline CHEMBL1559171 & 688721 & 5.3 & 5.0349 & TRN \\
\hline CHEMBL1450757 & 688721 & 4.4 & 4.9584 & TRN \\
\hline CHEMBL1328413 & 688721 & 4.6 & 4.8554 & TRN \\
\hline CHEMBL1363381 & 688721 & 6.6 & 5.0885 & TRN \\
\hline CHEMBL1430979 & 688721 & 5.2 & 4.7674 & TRN \\
\hline CHEMBL1332003 & 688721 & 5.5 & 4.873 & TRN \\
\hline CHEMBL1359569 & 688721 & 5.4 & 4.7812 & TRN \\
\hline CHEMBL1445595 & 688721 & 5.3 & 4.9693 & TRN \\
\hline CHEMBL1464849 & 688721 & 5.7 & 4.9367 & TST \\
\hline CHEMBL1325852 & 688721 & 4.6 & 4.8713 & TRN \\
\hline CHEMBL1564386 & 688721 & 4.6 & 4.6983 & TST \\
\hline CHEMBL1370583 & 688721 & 4.8 & 4.8821 & TST \\
\hline CHEMBL362223 & 688721 & 6.0 & 5.0447 & TST \\
\hline CHEMBL1428481 & 688721 & 5.5 & 4.8387 & TRN \\
\hline CHEMBL1595964 & 688721 & 4.9 & 4.8518 & TST \\
\hline CHEMBL1364058 & 688721 & 4.5 & 4.8197 & TRN \\
\hline CHEMBL1326360 & 688721 & 5.9 & 5.2834 & TRN \\
\hline CHEMBL1362430 & 688721 & 4.5 & 4.9285 & TRN \\
\hline CHEMBL503470 & 688721 & 4.8 & 4.8255 & TST \\
\hline CHEMBL1417287 & 688721 & 4.7 & 4.8216 & TST \\
\hline CHEMBL1612353 & 688721 & 5.3 & 5.0002 & TRN \\
\hline CHEMBL3197066 & 688721 & 5.2 & 4.7919 & TST \\
\hline CHEMBL1307695 & 688721 & 4.5 & 5.0804 & TST \\
\hline CHEMBL1306516 & 688721 & 4.8 & 4.9718 & TRN \\
\hline CHEMBL1309441 & 688721 & 4.4 & 4.9019 & TRN \\
\hline CHEMBL1505070 & 688721 & 7.4001 & 4.7648 & TRN \\
\hline
\end{tabular}




\begin{tabular}{|c|c|c|c|c|}
\hline & & & pplement & al Table \\
\hline CHEMBL1451690 & 688721 & 4.7 & 4.8704 & TRN \\
\hline CHEMBL1471289 & 688721 & 5.2 & 4.9879 & TST \\
\hline CHEMBL1368866 & 688721 & 4.4 & 4.9526 & TRN \\
\hline CHEMBL1460322 & 688721 & 4.5 & 4.9494 & TRN \\
\hline CHEMBL1566246 & 688721 & 5.0 & 4.8463 & TRN \\
\hline CHEMBL1368309 & 688721 & 5.3 & 4.9722 & TST \\
\hline CHEMBL1467886 & 688721 & 4.8 & 4.8409 & TRN \\
\hline CHEMBL1460488 & 688721 & 4.6 & 5.026 & TRN \\
\hline CHEMBL35482 & 688721 & 5.2 & 4.8221 & TRN \\
\hline CHEMBL1389608 & 688721 & 4.5 & 4.8278 & TRN \\
\hline CHEMBL1326411 & 688721 & 5.9 & 5.0648 & TRN \\
\hline CHEMBL1311753 & 688721 & 4.6 & 4.965 & TST \\
\hline CHEMBL1598520 & 688721 & 5.0 & 4.9721 & TRN \\
\hline CHEMBL1542189 & 688721 & 4.9 & 4.7862 & TRN \\
\hline CHEMBL1360749 & 688721 & 5.4 & 5.0187 & TST \\
\hline CHEMBL1340727 & 688721 & 4.5 & 4.7931 & TRN \\
\hline CHEMBL1601002 & 688721 & 4.5 & 4.7626 & TRN \\
\hline CHEMBL1412251 & 688721 & 5.0 & 5.0722 & TRN \\
\hline CHEMBL1401418 & 688721 & 6.1 & 4.8278 & TRN \\
\hline CHEMBL1465162 & 688721 & 4.4 & 4.8228 & TRN \\
\hline CHEMBL1451823 & 688721 & 6.0 & 5.1691 & TRN \\
\hline CHEMBL1572103 & 688721 & 5.3 & 4.7903 & TRN \\
\hline CHEMBL1490963 & 688721 & 4.8 & 4.8395 & TRN \\
\hline CHEMBL1480089 & 688721 & 4.8 & 5.0 & TRN \\
\hline CHEMBL1422535 & 688721 & 5.1 & 5.0357 & TST \\
\hline CHEMBL1529769 & 688721 & 5.1 & 5.106 & TRN \\
\hline CHEMBL1546719 & 688721 & 5.4 & 4.8771 & TRN \\
\hline CHEMBL1414950 & 688721 & 7.1002 & 5.3092 & TRN \\
\hline CHEMBL1381609 & 688721 & 8.301 & 4.8995 & TST \\
\hline CHEMBL1386675 & 688721 & 4.7 & 4.8297 & TRN \\
\hline CHEMBL1465532 & 688721 & 6.3 & 5.0757 & TRN \\
\hline CHEMBL1342419 & 688721 & 4.7 & 4.8665 & TRN \\
\hline CHEMBL1568850 & 688721 & 4.4 & 5.0448 & TRN \\
\hline CHEMBL1403106 & 688721 & 4.6 & 4.8232 & TRN \\
\hline CHEMBL1311376 & 688721 & 4.8 & 4.8378 & TRN \\
\hline CHEMBL1372935 & 688721 & 7.699 & 4.982 & TRN \\
\hline CHEMBL1586148 & 688721 & 4.5 & 4.8513 & TST \\
\hline CHEMBL1537605 & 688721 & 4.6 & 4.9065 & TRN \\
\hline CHEMBL1522235 & 688721 & 4.4 & 4.8052 & TRN \\
\hline CHEMBL1338891 & 688721 & 5.1 & 4.9168 & TRN \\
\hline CHEMBL1469134 & 688721 & 5.1 & 4.9474 & TRN \\
\hline CHEMBL1472379 & 688721 & 4.7 & 4.863 & TRN \\
\hline CHEMBL1451494 & 688721 & 4.5 & 4.9443 & TRN \\
\hline CHEMBL1403616 & 688721 & 5.4 & 4.9168 & TRN \\
\hline CHEMBL329673 & 688721 & 4.4 & 4.8923 & TRN \\
\hline CHEMBL1546362 & 688721 & 5.4 & 5.1153 & TST \\
\hline CHEMBL1367356 & 688721 & 4.4 & 4.8996 & TST \\
\hline CHEMBL1565591 & 688721 & 7.5003 & 4.9506 & TRN \\
\hline
\end{tabular}




\begin{tabular}{|c|c|c|c|c|c|}
\hline \multicolumn{6}{|c|}{ Supplemental Table S2.txt } \\
\hline CHEMBL1570047 & 688721 & 5.4 & 4.8404 & TRN & \\
\hline CHEMBL1550946 & 688721 & 4.6 & 5.0878 & TST & \\
\hline CHEMBL1568299 & 688721 & 4.8 & 4.9139 & TRN & \\
\hline CHEMBL1411249 & 688721 & 7.5003 & 4.8472 & TRN & \\
\hline CHEMBL1576666 & 688721 & 4.5 & 4.8629 & TST & \\
\hline CHEMBL1486556 & 688721 & 4.6 & 4.7667 & TRN & \\
\hline CHEMBL1380864 & 688721 & 5.3 & 5.03 & TRN & \\
\hline CHEMBL1304213 & 688721 & 5.4 & 4.9579 & TRN & \\
\hline CHEMBL1504219 & 688721 & 4.9 & 4.9123 & TRN & \\
\hline CHEMBL1600468 & 688721 & 5.0 & 4.8931 & TRN & \\
\hline CHEMBL1474801 & 688721 & 5.3 & 4.9582 & TST & \\
\hline CHEMBL1412427 & 688721 & 4.6 & 4.8552 & TRN & \\
\hline CHEMBL1341417 & 688721 & 4.9 & 5.0373 & TRN & \\
\hline CHEMBL1377961 & 688721 & 4.4 & 5.0874 & TRN & \\
\hline CHEMBL1592493 & 688721 & 4.5 & 4.9783 & TRN & \\
\hline CHEMBL1573763 & 688721 & 5.0 & 4.9756 & TRN & \\
\hline CHEMBL529939 & 688721 & 4.5 & 4.7611 & TRN & \\
\hline CHEMBL1557018 & 688721 & 4.8 & 4.8679 & TRN & \\
\hline CHEMBL1330662 & 688721 & 4.5 & 4.8295 & TRN & \\
\hline CHEMBL1424804 & 688721 & 5.2 & 4.9628 & TST & \\
\hline CHEMBL1587996 & 688721 & 5.2 & 4.9325 & TRN & \\
\hline CHEMBL1400290 & 688721 & 4.6 & 4.9162 & TRN & \\
\hline CHEMBL1434783 & 688721 & 4.4 & 5.1684 & TRN & \\
\hline CHEMBL1584551 & 688721 & 5.2 & 4.9002 & TST & \\
\hline CHEMBL1506932 & 688721 & 5.1 & 5.0412 & TST & \\
\hline CHEMBL1303943 & 688721 & 4.5 & 4.9175 & TST & \\
\hline CHEMBL1363801 & 688721 & 5.1 & 5.015 & TRN & \\
\hline CHEMBL1535530 & 688721 & 4.9 & 4.8437 & TRN & \\
\hline CHEMBL1400521 & 688721 & 5.3 & 5.29700 & 0000000001 & TRN \\
\hline CHEMBL1380708 & 688721 & 4.8 & 4.9596 & TRN & \\
\hline CHEMBL1256573 & 688721 & 6.9 & 5.2533 & TST & \\
\hline CHEMBL1503409 & 688721 & 5.3 & 4.9024 & TST & \\
\hline CHEMBL1514748 & 688721 & 5.2 & 4.9115 & TRN & \\
\hline CHEMBL1555895 & 688721 & 5.3 & 4.7282 & TST & \\
\hline CHEMBL1304524 & 688721 & 4.6 & 4.9785 & TST & \\
\hline CHEMBL1439673 & 688721 & 4.4 & 5.0454 & TRN & \\
\hline CHEMBL1320092 & 688721 & 4.7 & 4.7954 & TST & \\
\hline CHEMBL1318837 & 688721 & 4.5 & 5.0062 & TRN & \\
\hline CHEMBL1502175 & 688721 & 4.5 & 4.8676 & TRN & \\
\hline CHEMBL1300194 & 688721 & 4.4 & 4.96399 & 99999999995 & TRN \\
\hline CHEMBL1312349 & 688721 & 5.2 & 5.0051 & TST & \\
\hline CHEMBL1607413 & 688721 & 5.7 & 4.7681 & TST & \\
\hline CHEMBL1335771 & 688721 & 5.2 & 4.7105 & TRN & \\
\hline CHEMBL1442091 & 688721 & 4.7 & 4.9217 & TRN & \\
\hline CHEMBL1383317 & 688721 & 5.3 & 4.7055 & TRN & \\
\hline CHEMBL1485893 & 688721 & 4.6 & 4.8314 & TRN & \\
\hline CHEMBL1508619 & 688721 & 5.3 & 4.9183 & TRN & \\
\hline CHEMBL1317124 & 688721 & 6.0 & 5.0623 & TST & \\
\hline
\end{tabular}




\begin{tabular}{|c|c|c|c|c|}
\hline & & & pplement & al $\mathrm{Ta}$ \\
\hline CHEMBL1481551 & 688721 & 6.0 & 5.0958 & TRN \\
\hline CHEMBL517986 & 688721 & 4.7 & 5.0995 & TRN \\
\hline CHEMBL 20377 & 688721 & 4.8 & 4.8525 & TRN \\
\hline CHEMBL1347113 & 688721 & 4.6 & 5.0757 & TST \\
\hline CHEMBL1495846 & 688721 & 4.4 & 5.0676 & TRN \\
\hline CHEMBL1432647 & 688721 & 5.3 & 5.1021 & TRN \\
\hline CHEMBL1514307 & 688721 & 5.5 & 5.1006 & TRN \\
\hline CHEMBL1580580 & 688721 & 4.9 & 4.9268 & TRN \\
\hline CHEMBL1489098 & 688721 & 4.5 & 4.8118 & TRN \\
\hline CHEMBL137035 & 688721 & 8.0 & 5.1037 & TST \\
\hline CHEMBL1368895 & 688721 & 4.8 & 5.1528 & TRN \\
\hline CHEMBL 1503540 & 688721 & 5.2 & 5.1067 & TRN \\
\hline CHEMBL1524954 & 688721 & 4.8 & 5.0967 & TRN \\
\hline CHEMBL1535630 & 688721 & 5.5 & 4.9671 & TRN \\
\hline CHEMBL1405426 & 688721 & 5.2 & 4.9696 & TRN \\
\hline CHEMBL1329153 & 688721 & 4.7 & 4.9232 & TRN \\
\hline CHEMBL1393673 & 688721 & 4.8 & 4.8869 & TRN \\
\hline CHEMBL1551913 & 688721 & 4.5 & 4.9616 & TRN \\
\hline CHEMBL1515221 & 688721 & 4.6 & 4.9195 & TRN \\
\hline CHEMBL1448042 & 688721 & 5.3 & 5.0017 & TRN \\
\hline CHEMBL1523277 & 688721 & 4.6 & 4.9687 & TRN \\
\hline CHEMBL1437954 & 688721 & 4.5 & 4.8919 & TST \\
\hline CHEMBL1469025 & 688721 & 5.3 & 4.9421 & TRN \\
\hline CHEMBL1446178 & 688721 & 4.9 & 4.7503 & TRN \\
\hline CHEMBL1578159 & 688721 & 5.4 & 4.9887 & TRN \\
\hline CHEMBL1470367 & 688721 & 4.6 & 5.1933 & TST \\
\hline CHEMBL1533260 & 688721 & 4.4 & 4.8893 & TRN \\
\hline CHEMBL1328639 & 688721 & 5.6 & 4.8386 & TRN \\
\hline CHEMBL1529174 & 688721 & 4.4 & 4.9081 & TRN \\
\hline CHEMBL1610343 & 688721 & 4.4 & 4.8808 & TST \\
\hline CHEMBL1464836 & 688721 & 5.8 & 4.8765 & TRN \\
\hline CHEMBL1336879 & 688721 & 5.0 & 5.0587 & TRN \\
\hline CHEMBL1256869 & 688721 & 5.1 & 4.8035 & TST \\
\hline CHEMBL1577664 & 688721 & 4.7 & 4.7955 & TRN \\
\hline CHEMBL1311011 & 688721 & 5.4 & 4.8349 & TST \\
\hline CHEMBL1341301 & 688721 & 5.1 & 4.8395 & TRN \\
\hline CHEMBL1448054 & 688721 & 5.5 & 4.9727 & TRN \\
\hline CHEMBL1544371 & 688721 & 4.7 & 4.9527 & TST \\
\hline CHEMBL1482912 & 688721 & 4.5 & 4.9914 & TRN \\
\hline CHEMBL1472995 & 688721 & 4.6 & 4.9024 & TRN \\
\hline CHEMBL1374656 & 688721 & 4.6 & 4.9247 & TRN \\
\hline CHEMBL1537905 & 688721 & 4.6 & 4.8738 & TRN \\
\hline CHEMBL1490452 & 688721 & 4.6 & 4.9531 & TRN \\
\hline CHEMBL1452243 & 688721 & 5.2 & 4.8723 & TRN \\
\hline CHEMBL1376387 & 688721 & 5.1 & 4.995 & TST \\
\hline CHEMBL1353131 & 688721 & 5.2 & 5.0228 & TST \\
\hline CHEMBL1426789 & 688721 & 5.4 & 4.917 & TRN \\
\hline CHEMBL1354626 & 688721 & 5.6 & 5.0024 & TST \\
\hline
\end{tabular}




\begin{tabular}{|c|c|c|c|c|c|}
\hline \multirow{2}{*}{\multicolumn{6}{|c|}{ CHFMRI 1471112}} \\
\hline CHEMBL1471112 & 688721 & 4.6 & & & \\
\hline CHEMBL1545440 & 688721 & 4.6 & 4.7752 & TRN & \\
\hline CHEMBL3198078 & 688721 & 5.3 & 4.9814 & TRN & \\
\hline CHEMBL1363042 & 688721 & 4.4 & 4.9636 & TRN & \\
\hline CHEMBL1337250 & 688721 & 4.6 & 4.8694 & TRN & \\
\hline CHEMBL1551235 & 688721 & 5.1 & 5.4027 & TST & \\
\hline CHEMBL1326186 & 688721 & 4.5 & 4.8288 & TRN & \\
\hline CHEMBL1518063 & 688721 & 4.4 & 4.9059 & TRN & \\
\hline CHEMBL1461435 & 688721 & 4.7 & 4.8291 & TST & \\
\hline CHEMBL1420766 & 688721 & 4.4 & 4.8487 & TRN & \\
\hline CHEMBL1372426 & 688721 & 5.2 & 4.9438 & TRN & \\
\hline CHEMBL1570402 & 688721 & 4.8 & 4.8051 & TRN & \\
\hline CHEMBL1368596 & 688721 & 4.6 & 4.7435 & TST & \\
\hline CHEMBL1468996 & 688721 & 4.9 & 4.8161 & TRN & \\
\hline CHEMBL1548799 & 688721 & 5.2 & 5.1 & TST & \\
\hline CHEMBL1543264 & 688721 & 5.2 & 4.8662 & TST & \\
\hline CHEMBL1498631 & 688721 & 5.5 & 4.9255 & TRN & \\
\hline CHEMBL1413767 & 688721 & 4.4 & 4.8478 & TRN & \\
\hline CHEMBL1413787 & 688721 & 4.9 & 5.0445 & TRN & \\
\hline CHEMBL1566731 & 688721 & 4.9 & 4.7993 & TRN & \\
\hline CHEMBL1565379 & 688721 & 4.4 & 4.718 & TRN & \\
\hline CHEMBL1378199 & 688721 & 5.1 & 5.2088 & TRN & \\
\hline CHEMBL1403474 & 688721 & 4.7 & 4.8487 & TRN & \\
\hline CHEMBL1597208 & 688721 & 4.6 & 5.0549 & TRN & \\
\hline CHEMBL1570685 & 688721 & 5.0 & 5.0844 & TST & \\
\hline CHEMBL1559160 & 688721 & 5.9 & 4.8761 & TRN & \\
\hline CHEMBL1494829 & 688721 & 4.7 & 4.8812 & TRN & \\
\hline CHEMBL1400807 & 688721 & 4.5 & 4.8689 & TRN & \\
\hline CHEMBL1567569 & 688721 & 4.5 & 5.019 & TRN & \\
\hline CHEMBL1321146 & 688721 & 4.7 & 5.285 & TST & \\
\hline CHEMBL1572973 & 688721 & 4.4 & 4.8954 & TST & \\
\hline CHEMBL1533139 & 688721 & 4.5 & 5.0617 & TRN & \\
\hline CHEMBL1325637 & 688721 & 5.3 & 4.8751 & TST & \\
\hline CHEMBL1452976 & 688721 & 4.6 & 5.0305 & TRN & \\
\hline CHEMBL1333103 & 688721 & 4.5 & 4.8849 & TRN & \\
\hline CHEMBL1443442 & 688721 & 4.4 & 4.8893 & TRN & \\
\hline CHEMBL1453358 & 688721 & 4.9 & 5.0711 & TRN & \\
\hline CHEMBL1353359 & 688721 & 4.6 & 4.7928 & TRN & \\
\hline CHEMBL1459444 & 688721 & 4.7 & 4.84699 & 99999999995 & TRN \\
\hline CHEMBL1578713 & 688721 & 4.6 & 4.978 & TRN & \\
\hline CHEMBL3211367 & 688721 & 4.6 & 5.0456 & TST & \\
\hline CHEMBL1339856 & 688721 & 4.4 & 5.0423 & TRN & \\
\hline CHEMBL1378123 & 688721 & 4.6 & 4.8744 & TRN & \\
\hline CHEMBL1401293 & 688721 & 5.0 & 4.8134 & TRN & \\
\hline CHEMBL351769 & 688721 & 4.4 & 5.2431 & TST & \\
\hline CHEMBL1439896 & 688721 & 5.4 & 4.9106 & TRN & \\
\hline CHEMBL1434646 & 688721 & 4.9 & 4.8889 & TRN & \\
\hline CHEMBL1363197 & 688721 & 5.5 & 5.0359 & TST & \\
\hline
\end{tabular}




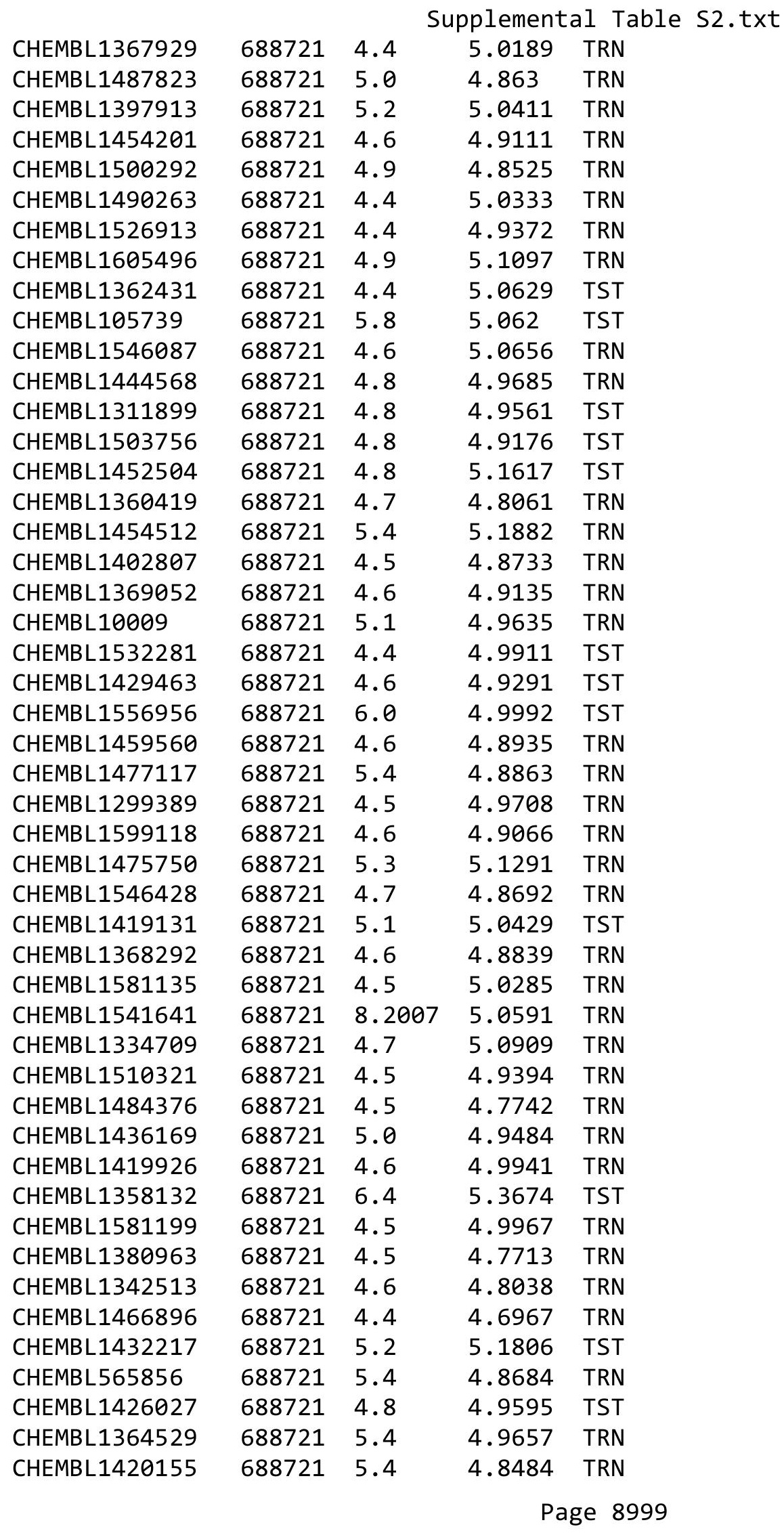




\begin{tabular}{|c|c|c|c|c|}
\hline & & & & \\
\hline CHEMBL1511158 & 688721 & 4.6 & 5.0119 & TRN \\
\hline CHEMBL1423849 & 688721 & 5.8 & 4.6573 & TRN \\
\hline CHEMBL1553179 & 688721 & 5.0 & 5.0736 & TRN \\
\hline CHEMBL1470305 & 688721 & 4.4 & 4.9481 & TRN \\
\hline CHEMBL1432368 & 688721 & 4.8 & 4.8495 & TRN \\
\hline CHEMBL1516762 & 688721 & 5.5 & 4.8153 & TST \\
\hline CHEMBL1427284 & 688721 & 4.6 & 4.8884 & TRN \\
\hline CHEMBL1389382 & 688721 & 5.2 & 5.2702 & TRN \\
\hline CHEMBL1554098 & 688721 & 7.4001 & 5.1691 & TST \\
\hline CHEMBL1587145 & 688721 & 4.7 & 4.8183 & TRN \\
\hline CHEMBL1609955 & 688721 & 5.2 & 4.9589 & TST \\
\hline CHEMBL1405731 & 688721 & 4.6 & 5.037 & TRN \\
\hline CHEMBL1500440 & 688721 & 6.3 & 4.8917 & TST \\
\hline CHEMBL1374863 & 688721 & 5.7 & 5.1824 & TRN \\
\hline CHEMBL11348 & 688721 & 4.4 & 4.9504 & TRN \\
\hline CHEMBL1371447 & 688721 & 5.2 & 4.976 & TRN \\
\hline CHEMBL1299880 & 688721 & 4.9 & 4.9418 & TST \\
\hline CHEMBL1536618 & 688721 & 5.4 & 4.814 & TRN \\
\hline CHEMBL1555480 & 688721 & 4.6 & 5.1694 & TRN \\
\hline CHEMBL1582286 & 688721 & 5.2 & 5.0479 & TST \\
\hline CHEMBL1560193 & 688721 & 5.9 & 5.1022 & TRN \\
\hline CHEMBL1480417 & 688721 & 4.8 & 4.8473 & TRN \\
\hline CHEMBL1372798 & 688721 & 4.5 & 5.1665 & TST \\
\hline CHEMBL1508989 & 688721 & 4.6 & 4.8843 & TRN \\
\hline CHEMBL1411170 & 688721 & 5.2 & 4.8638 & TRN \\
\hline CHEMBL1532856 & 688721 & 5.4 & 4.9135 & TRN \\
\hline CHEMBL1543055 & 688721 & 4.6 & 4.7965 & TRN \\
\hline CHEMBL1549074 & 688721 & 6.1 & 4.9755 & TRN \\
\hline CHEMBL1344473 & 688721 & 5.1 & 4.9386 & TRN \\
\hline CHEMBL1507992 & 688721 & 4.8 & 4.8548 & TRN \\
\hline CHEMBL1444844 & 688721 & 5.1 & 4.9917 & TST \\
\hline CHEMBL1586489 & 688721 & 4.4 & 4.7012 & TRN \\
\hline CHEMBL86962 & 688721 & 4.4 & 5.0427 & TRN \\
\hline CHEMBL1369828 & 688721 & 4.6 & 4.9618 & TRN \\
\hline CHEMBL1541343 & 688721 & 4.6 & 4.7315 & TRN \\
\hline CHEMBL1589419 & 688721 & 4.7 & 4.8832 & TRN \\
\hline CHEMBL1380778 & 688721 & 4.5 & 4.9972 & TST \\
\hline CHEMBL1358591 & 688721 & 4.7 & 5.0509 & TRN \\
\hline CHEMBL1334728 & 688721 & 4.8 & 4.9403 & TRN \\
\hline CHEMBL1608662 & 688721 & 5.2 & 4.934 & TRN \\
\hline CHEMBL1612504 & 688721 & 4.4 & 4.9311 & TRN \\
\hline CHEMBL1375885 & 688721 & 4.6 & 4.9672 & TRN \\
\hline CHEMBL1497978 & 688721 & 4.7 & 4.8468 & TRN \\
\hline CHEMBL1402518 & 688721 & 5.4 & 4.9981 & TRN \\
\hline CHEMBL1607736 & 688721 & 4.6 & 4.9053 & TST \\
\hline CHEMBL1450197 & 688721 & 4.5 & 5.0651 & TRN \\
\hline CHEMBL1535418 & 688721 & 4.7 & 4.8381 & TRN \\
\hline CHEMBL1443979 & 688721 & 4.6 & 4.9971 & TRN \\
\hline
\end{tabular}




\begin{tabular}{|c|c|c|c|c|}
\hline & & & & \\
\hline CHEMBL1573821 & 688721 & 4.6 & 4.9547 & TRN \\
\hline CHEMBL1539958 & 688721 & 6.1 & 5.0592 & TRN \\
\hline CHEMBL555689 & 688721 & 5.5 & 4.84 & TST \\
\hline CHEMBL1447214 & 688721 & 6.0 & 5.279 & TST \\
\hline CHEMBL1522067 & 688721 & 4.4 & 4.9078 & TRN \\
\hline CHEMBL1256656 & 688721 & 5.2 & 4.7788 & TST \\
\hline CHEMBL1488677 & 688721 & 4.5 & 5.1317 & TST \\
\hline CHEMBL1608621 & 688721 & 6.3 & 5.1056 & TST \\
\hline CHEMBL1501795 & 688721 & 4.5 & 4.9809 & TRN \\
\hline CHEMBL1423407 & 688721 & 4.4 & 4.9683 & TRN \\
\hline CHEMBL1360632 & 688721 & 4.7 & 4.919 & TRN \\
\hline CHEMBL1565528 & 688721 & 4.5 & 4.9507 & TST \\
\hline CHEMBL1558652 & 688721 & 5.9 & 5.1027 & TST \\
\hline CHEMBL1519163 & 688721 & 6.0 & 5.072 & TRN \\
\hline CHEMBL1597366 & 688721 & 4.6 & 5.2504 & TRN \\
\hline CHEMBL1479618 & 688721 & 4.5 & 4.7946 & TST \\
\hline CHEMBL1344621 & 688721 & 4.9 & 4.8374 & TRN \\
\hline CHEMBL1452139 & 688721 & 6.0 & 4.9564 & TRN \\
\hline CHEMBL1496007 & 688721 & 4.8 & 4.9628 & TRN \\
\hline CHEMBL1469018 & 688721 & 4.7 & 4.9778 & TRN \\
\hline CHEMBL1492559 & 688721 & 5.0 & 4.8255 & TRN \\
\hline CHEMBL1417443 & 688721 & 5.4 & 5.1374 & TST \\
\hline CHEMBL1425916 & 688721 & 4.4 & 4.9568 & TRN \\
\hline CHEMBL1531299 & 688721 & 4.5 & 5.1837 & TRN \\
\hline CHEMBL1372895 & 688721 & 4.5 & 5.0453 & TRN \\
\hline CHEMBL1369861 & 688721 & 5.4 & 4.7687 & TRN \\
\hline CHEMBL1376431 & 688721 & 5.9 & 5.0276 & TRN \\
\hline CHEMBL1341760 & 688721 & 5.0 & 4.9599 & TST \\
\hline CHEMBL1588993 & 688721 & 4.8 & 5.0983 & TRN \\
\hline CHEMBL1426936 & 688721 & 4.5 & 4.8689 & TRN \\
\hline CHEMBL1521232 & 688721 & 5.2 & 4.8993 & TRN \\
\hline CHEMBL1570043 & 688721 & 4.6 & 4.9374 & TRN \\
\hline CHEMBL1460257 & 688721 & 5.5 & 4.9338 & TST \\
\hline CHEMBL1408083 & 688721 & 5.2 & 4.7522 & TRN \\
\hline CHEMBL1425223 & 688721 & 5.2 & 5.1535 & TST \\
\hline CHEMBL1534514 & 688721 & 5.0 & 4.752 & TRN \\
\hline CHEMBL1347958 & 688721 & 4.6 & 4.9635 & TRN \\
\hline CHEMBL1335023 & 688721 & 5.2 & 4.8422 & TRN \\
\hline CHEMBL1594803 & 688721 & 4.6 & 4.8931 & TRN \\
\hline CHEMBL1303052 & 688721 & 4.4 & 4.7935 & TRN \\
\hline CHEMBL1380655 & 688721 & 4.4 & 4.749 & TRN \\
\hline CHEMBL1543331 & 688721 & 4.4 & 4.9224 & TST \\
\hline CHEMBL1300788 & 688721 & 5.0 & 4.868 & TRN \\
\hline CHEMBL1548243 & 688721 & 5.2 & 5.0738 & TST \\
\hline CHEMBL1606397 & 688721 & 5.4 & 4.8215 & TRN \\
\hline CHEMBL1499224 & 688721 & 5.1 & 4.9765 & TRN \\
\hline CHEMBL1405602 & 688721 & 4.4 & 4.9233 & TRN \\
\hline CHEMBL1303003 & 688721 & 4.6 & 4.6756 & TRN \\
\hline
\end{tabular}




\begin{tabular}{|c|c|c|c|c|}
\hline & & & pplement & al Ta \\
\hline CHEMBL1362793 & 688721 & 4.5 & 5.0108 & TST \\
\hline CHEMBL1463782 & 688721 & 4.6 & 4.9108 & TRN \\
\hline CHEMBL1448251 & 688721 & 5.3 & 4.7836 & TRN \\
\hline CHEMBL1349378 & 688721 & 4.6 & 5.0055 & TST \\
\hline CHEMBL1500452 & 688721 & 4.5 & 5.1286 & TST \\
\hline CHEMBL 268855 & 688721 & 4.7 & 5.0134 & TRN \\
\hline CHEMBL1477186 & 688721 & 5.7 & 4.7751 & TST \\
\hline CHEMBL1502398 & 688721 & 4.7 & 4.8597 & TRN \\
\hline CHEMBL1551518 & 688721 & 5.0 & 4.9398 & TRN \\
\hline CHEMBL1548533 & 688721 & 4.6 & 5.0629 & TRN \\
\hline CHEMBL1537729 & 688721 & 4.6 & 5.025 & TRN \\
\hline CHEMBL1612363 & 688721 & 5.5 & 5.1421 & TRN \\
\hline CHEMBL1327010 & 688721 & 5.4 & 4.8078 & TRN \\
\hline CHEMBL1430533 & 688721 & 4.8 & 4.9963 & TRN \\
\hline CHEMBL1407869 & 688721 & 4.9 & 5.0123 & TRN \\
\hline CHEMBL1557396 & 688721 & 5.5 & 4.9613 & TRN \\
\hline CHEMBL1534861 & 688721 & 4.8 & 5.0405 & TST \\
\hline CHEMBL1508731 & 688721 & 4.4 & 5.0835 & TST \\
\hline CHEMBL1352568 & 688721 & 6.1 & 4.9163 & TRN \\
\hline CHEMBL1411094 & 688721 & 6.2 & 5.2514 & TRN \\
\hline CHEMBL1326611 & 688721 & 4.6 & 4.8192 & TRN \\
\hline CHEMBL1398837 & 688721 & 4.4 & 4.8435 & TRN \\
\hline CHEMBL1358807 & 688721 & 4.8 & 5.1359 & TRN \\
\hline CHEMBL3191258 & 688721 & 4.6 & 5.1346 & TST \\
\hline CHEMBL1596228 & 688721 & 5.5 & 4.7532 & TRN \\
\hline CHEMBL1603766 & 688721 & 4.6 & 4.8083 & TRN \\
\hline CHEMBL1477373 & 688721 & 5.2 & 4.827 & TRN \\
\hline CHEMBL1403306 & 688721 & 4.5 & 4.9553 & TST \\
\hline CHEMBL1411207 & 688721 & 4.4 & 4.8914 & TRN \\
\hline CHEMBL1583556 & 688721 & 4.5 & 4.8609 & TRN \\
\hline CHEMBL1428621 & 688721 & 4.8 & 5.1047 & TRN \\
\hline CHEMBL1256139 & 688721 & 5.2 & 5.3323 & TRN \\
\hline CHEMBL1451996 & 688721 & 4.5 & 4.9544 & TRN \\
\hline CHEMBL1567251 & 688721 & 5.2 & 5.1272 & TRN \\
\hline CHEMBL1587997 & 688721 & 5.2 & 4.956 & TST \\
\hline CHEMBL1475255 & 688721 & 4.9 & 4.9014 & TRN \\
\hline CHEMBL1536510 & 688721 & 6.8 & 5.0534 & TRN \\
\hline CHEMBL1328049 & 688721 & 4.9 & 5.0129 & TRN \\
\hline CHEMBL1533680 & 688721 & 4.9 & 5.1179 & TRN \\
\hline CHEMBL1492136 & 688721 & 5.8 & 5.0435 & TRN \\
\hline CHEMBL1441605 & 688721 & 5.5 & 4.8825 & TRN \\
\hline CHEMBL1577511 & 688721 & 5.0 & 5.1143 & TRN \\
\hline CHEMBL570383 & 688721 & 4.5 & 5.4103 & TST \\
\hline CHEMBL1256147 & 688721 & 5.3 & 5.3792 & TST \\
\hline CHEMBL1329612 & 688721 & 4.9 & 4.8139 & TRN \\
\hline CHEMBL1310445 & 688721 & 4.5 & 4.9272 & TRN \\
\hline CHEMBL1331632 & 688721 & 4.7 & 4.8408 & TST \\
\hline CHEMBL1573112 & 688721 & 5.0 & 4.9349 & TST \\
\hline
\end{tabular}




\begin{tabular}{|c|c|c|c|c|c|}
\hline \\
\hline CHEMBL1313452 & 688721 & 5.4 & 5.1776 & TST & \\
\hline CHEMBL1517982 & 688721 & 4.7 & 5.1044 & TRN & \\
\hline CHEMBL1461249 & 688721 & 4.6 & 4.8527 & TRN & \\
\hline CHEMBL1523566 & 688721 & 4.5 & 4.7771 & TRN & \\
\hline CHEMBL1407352 & 688721 & 4.5 & 4.9211 & TRN & \\
\hline CHEMBL1374191 & 688721 & 6.9 & 4.9479 & TST & \\
\hline CHEMBL1542646 & 688721 & 5.4 & 4.9262 & TST & \\
\hline CHEMBL1337654 & 688721 & 4.5 & 5.0729 & TRN & \\
\hline CHEMBL1489325 & 688721 & 5.5 & 4.7993 & TRN & \\
\hline CHEMBL1393846 & 688721 & 4.4 & 4.8431 & TRN & \\
\hline CHEMBL1537195 & 688721 & 4.8 & 4.9307 & TRN & \\
\hline CHEMBL1448461 & 688721 & 5.1 & 4.9204 & TST & \\
\hline CHEMBL1326113 & 688721 & 4.9 & 5.0344 & TRN & \\
\hline CHEMBL1368302 & 688721 & 5.2 & 5.0799 & TRN & \\
\hline CHEMBL1536946 & 688721 & 4.4 & 4.90300 & 00000000005 & TRN \\
\hline CHEMBL1510421 & 688721 & 5.6 & 4.8149 & TRN & \\
\hline CHEMBL1360064 & 688721 & 4.4 & 4.9012 & TST & \\
\hline CHEMBL1400517 & 688721 & 4.7 & 4.765 & TRN & \\
\hline CHEMBL1375361 & 688721 & 4.9 & 4.8114 & TRN & \\
\hline CHEMBL1450654 & 688721 & 4.8 & 4.8028 & TRN & \\
\hline CHEMBL1441397 & 688721 & 4.9 & 4.79 & TRN & \\
\hline CHEMBL1574179 & 688721 & 4.8 & 5.2431 & TST & \\
\hline CHEMBL1302705 & 688721 & 4.5 & 4.8395 & TRN & \\
\hline CHEMBL1541166 & 688721 & 4.9 & 5.0952 & TST & \\
\hline CHEMBL1569892 & 688721 & 4.9 & 4.9411 & TST & \\
\hline CHEMBL1583165 & 688721 & 5.3 & 4.9334 & TRN & \\
\hline CHEMBL1441891 & 688721 & 4.6 & 4.8719 & TRN & \\
\hline CHEMBL1461990 & 688721 & 6.1 & 4.9043 & TRN & \\
\hline CHEMBL1360455 & 688721 & 4.9 & 4.9732 & TRN & \\
\hline CHEMBL1448082 & 688721 & 4.4 & 4.8816 & TRN & \\
\hline CHEMBL1471361 & 688721 & 4.4 & 4.8154 & TRN & \\
\hline CHEMBL1389438 & 688721 & 4.6 & 4.8942 & TST & \\
\hline CHEMBL1538382 & 688721 & 5.9 & 4.8965 & TRN & \\
\hline CHEMBL1543009 & 688721 & 4.7 & 5.0312 & TRN & \\
\hline CHEMBL1515246 & 688721 & 4.7 & 5.15 & TRN & \\
\hline CHEMBL1514016 & 688721 & 4.4 & 5.1185 & TRN & \\
\hline CHEMBL1371715 & 688721 & 6.8 & 4.973 & TST & \\
\hline CHEMBL1396936 & 688721 & 4.6 & 4.9854 & TRN & \\
\hline CHEMBL1318118 & 688721 & 4.4 & 4.942 & TRN & \\
\hline CHEMBL1351484 & 688721 & 4.4 & 4.9214 & TRN & \\
\hline CHEMBL1310359 & 688721 & 4.9 & 4.9632 & TRN & \\
\hline CHEMBL1320835 & 688721 & 4.4 & 4.8581 & TRN & \\
\hline CHEMBL1464597 & 688721 & 4.5 & 4.8816 & TRN & \\
\hline CHEMBL1540230 & 688721 & 4.7 & 4.9531 & TRN & \\
\hline CHEMBL1577504 & 688721 & 4.8 & 4.7385 & TRN & \\
\hline CHEMBL1606128 & 688721 & 4.8 & 4.8442 & TRN & \\
\hline CHEMBL1464939 & 688721 & 5.0 & 4.7774 & TRN & \\
\hline CHEMBL1332463 & 688721 & 4.8 & 4.9842 & TRN & \\
\hline
\end{tabular}




\begin{tabular}{|c|c|c|c|c|c|}
\hline \multicolumn{6}{|c|}{ Supplemental Table S2.txt } \\
\hline CHEMBL1421485 & 688721 & 5.9 & 4.7531 & TRN & \\
\hline CHEMBL409902 & 688721 & 4.8 & 4.9681 & TRN & \\
\hline CHEMBL1402865 & 688721 & 4.9 & 4.7597 & TRN & \\
\hline CHEMBL1381039 & 688721 & 4.4 & 4.8763 & TRN & \\
\hline CHEMBL1419387 & 688721 & 4.8 & 4.7602 & TRN & \\
\hline CHEMBL1415937 & 688721 & 5.1 & 4.7268 & TRN & \\
\hline CHEMBL1469425 & 688721 & 5.2 & 4.9961 & TRN & \\
\hline CHEMBL1586626 & 688721 & 5.2 & 4.974 & TRN & \\
\hline CHEMBL1534654 & 688721 & 4.4 & 5.0564 & TST & \\
\hline CHEMBL1324061 & 688721 & 4.6 & 4.848 & TRN & \\
\hline CHEMBL1334396 & 688721 & 5.5 & 5.1063 & TRN & \\
\hline CHEMBL1312094 & 688721 & 5.2 & 4.9948 & TST & \\
\hline CHEMBL1576798 & 688721 & 7.6003 & 5.1172 & TST & \\
\hline CHEMBL1432701 & 688721 & 4.8 & 4.9263 & TRN & \\
\hline CHEMBL1546487 & 688721 & 4.4 & 5.1321 & TRN & \\
\hline CHEMBL1388344 & 688721 & 5.3 & 4.88899 & 9999999999 & TRN \\
\hline CHEMBL1448069 & 688721 & 4.8 & 5.0194 & TRN & \\
\hline CHEMBL1518889 & 688721 & 4.4 & 4.9887 & TST & \\
\hline CHEMBL1422012 & 688721 & 4.6 & 5.0655 & TRN & \\
\hline CHEMBL1571331 & 688721 & 4.5 & 5.0108 & TRN & \\
\hline CHEMBL1335726 & 688721 & 4.6 & 4.8862 & TRN & \\
\hline CHEMBL1357148 & 688721 & 4.9 & 4.935 & TRN & \\
\hline CHEMBL1410294 & 688721 & 4.5 & 4.9588 & TRN & \\
\hline CHEMBL1327130 & 688721 & 5.0 & 4.8023 & TRN & \\
\hline CHEMBL1327766 & 688721 & 5.4 & 4.7342 & TRN & \\
\hline CHEMBL1436174 & 688721 & 4.5 & 4.9173 & TRN & \\
\hline CHEMBL1440808 & 688721 & 5.5 & 4.8464 & TST & \\
\hline CHEMBL250053 & 688721 & 4.4 & 5.0331 & TST & \\
\hline CHEMBL1326826 & 688721 & 5.2 & 4.9999 & TRN & \\
\hline CHEMBL1372997 & 688721 & 7.0 & 5.01 & TST & \\
\hline CHEMBL1580537 & 688721 & 4.5 & 4.8931 & TRN & \\
\hline CHEMBL1431659 & 688721 & 4.5 & 4.9246 & TRN & \\
\hline CHEMBL1517172 & 688721 & 4.4 & 4.9656 & TRN & \\
\hline CHEMBL1392231 & 688721 & 4.9 & 4.8796 & TRN & \\
\hline CHEMBL3208554 & 688721 & 5.4 & 5.1913 & TST & \\
\hline CHEMBL1522582 & 688721 & 4.7 & 4.8622 & TRN & \\
\hline CHEMBL1324425 & 688721 & 4.4 & 4.865 & TST & \\
\hline CHEMBL1482962 & 688721 & 4.7 & 4.9659 & TRN & \\
\hline CHEMBL1418570 & 688721 & 4.6 & 5.0152 & TRN & \\
\hline CHEMBL1347926 & 688721 & 4.4 & 4.9627 & TRN & \\
\hline CHEMBL1460466 & 688721 & 5.2 & 4.9382 & TST & \\
\hline CHEMBL1332117 & 688721 & 4.6 & 4.8458 & TST & \\
\hline CHEMBL1363440 & 688721 & 5.2 & 5.0595 & TRN & \\
\hline CHEMBL1579416 & 688721 & 4.5 & 4.6591 & TRN & \\
\hline CHEMBL1353220 & 688721 & 4.7 & 4.7752 & TRN & \\
\hline CHEMBL1527910 & 688721 & 4.4 & 4.9152 & TST & \\
\hline CHEMBL 288998 & 688721 & 7.1002 & 5.2778 & TST & \\
\hline CHEMBL1565027 & 688721 & 4.6 & 4.9718 & TST & \\
\hline
\end{tabular}




\begin{tabular}{|c|c|c|c|c|c|}
\hline \multicolumn{6}{|c|}{ Supplemental Table S2.txt } \\
\hline CHEMBL1311993 & 688721 & 4.5 & 4.9476 & TRN & \\
\hline CHEMBL1369930 & 688721 & 4.7 & 4.9664 & TRN & \\
\hline CHEMBL1573277 & 688721 & 5.4 & 4.8665 & TRN & \\
\hline CHEMBL1404154 & 688721 & 6.9 & 5.09399 & 9999999999 & TRN \\
\hline CHEMBL 374400 & 688721 & 4.5 & 5.0673 & TST & \\
\hline CHEMBL1474468 & 688721 & 8.2007 & 4.9809 & TRN & \\
\hline CHEMBL1421160 & 688721 & 4.5 & 4.8548 & TST & \\
\hline CHEMBL1340054 & 688721 & 5.4 & 4.9276 & TRN & \\
\hline CHEMBL1494758 & 688721 & 4.6 & 5.0249 & TRN & \\
\hline CHEMBL1584791 & 688721 & 4.6 & 5.0926 & TST & \\
\hline CHEMBL1464984 & 688721 & 4.8 & 5.0232 & TRN & \\
\hline CHEMBL1611341 & 688721 & 4.6 & 5.125 & TRN & \\
\hline CHEMBL1569981 & 688721 & 4.6 & 4.9021 & TRN & \\
\hline CHEMBL1375173 & 688721 & 4.5 & 4.7465 & TRN & \\
\hline CHEMBL1476280 & 688721 & 4.8 & 5.1599 & TRN & \\
\hline CHEMBL1332298 & 688721 & 4.5 & 4.9706 & TRN & \\
\hline CHEMBL1521868 & 688721 & 6.1 & 4.8969 & TRN & \\
\hline CHEMBL1334723 & 688721 & 5.2 & 5.0641 & TST & \\
\hline CHEMBL1349043 & 688721 & 5.4 & 5.0663 & TST & \\
\hline CHEMBL1388110 & 688721 & 5.5 & 4.8287 & TST & \\
\hline CHEMBL1587264 & 688721 & 4.5 & 4.7649 & TRN & \\
\hline CHEMBL1351425 & 688721 & 5.4 & 4.86600 & 00000000005 & TRN \\
\hline CHEMBL1324971 & 688721 & 5.9 & 5.0767 & TST & \\
\hline CHEMBL1375509 & 688721 & 4.9 & 5.0027 & TRN & \\
\hline CHEMBL1456916 & 688721 & 4.5 & 5.0934 & TST & \\
\hline CHEMBL1526643 & 688721 & 4.5 & 5.07100 & 0000000001 & TRN \\
\hline CHEMBL1588974 & 688721 & 4.7 & 4.9287 & TRN & \\
\hline CHEMBL1521640 & 688721 & 4.8 & 5.0578 & TRN & \\
\hline CHEMBL547833 & 688721 & 4.5 & 4.9916 & TRN & \\
\hline CHEMBL1445348 & 688721 & 4.5 & 4.9298 & TRN & \\
\hline CHEMBL1537855 & 688721 & 5.2 & 5.0503 & TST & \\
\hline CHEMBL1527132 & 688721 & 4.7 & 5.12299 & 9999999999 & TRN \\
\hline CHEMBL1490816 & 688721 & 4.5 & 4.7912 & TRN & \\
\hline CHEMBL1428759 & 688721 & 4.9 & 5.0465 & TRN & \\
\hline CHEMBL1379259 & 688721 & 5.2 & 4.962 & TRN & \\
\hline CHEMBL1423482 & 688721 & 4.5 & 5.0248 & TRN & \\
\hline CHEMBL1461818 & 688721 & 4.4 & 4.8085 & TRN & \\
\hline CHEMBL1370437 & 688721 & 4.9 & 4.7816 & TST & \\
\hline CHEMBL1382882 & 688721 & 5.3 & 4.9482 & TST & \\
\hline CHEMBL1449969 & 688721 & 4.6 & 4.9248 & TRN & \\
\hline CHEMBL1612133 & 688721 & 5.3 & 4.8529 & TRN & \\
\hline CHEMBL1511785 & 688721 & 4.8 & 4.9446 & TST & \\
\hline CHEMBL1570537 & 688721 & 4.6 & 4.9 & TRN & \\
\hline CHEMBL 3214172 & 688721 & 4.4 & 5.1053 & TST & \\
\hline CHEMBL1454859 & 688721 & 5.4 & 4.8517 & TST & \\
\hline CHEMBL1303668 & 688721 & 5.5 & 4.8601 & TRN & \\
\hline CHEMBL1563566 & 688721 & 5.9 & 5.0957 & TRN & \\
\hline CHEMBL1472244 & 688721 & 5.3 & 4.7356 & TRN & \\
\hline
\end{tabular}




\begin{tabular}{|c|c|c|c|c|}
\hline \multicolumn{5}{|c|}{ pıemental } \\
\hline CHEMBL1506962 & 688721 & 5.4 & 4.9002 & TRN \\
\hline CHEMBL1556679 & 688721 & 5.8 & 5.1118 & TRN \\
\hline CHEMBL462576 & 688721 & 6.0 & 5.2809 & TST \\
\hline CHEMBL1391432 & 688721 & 5.3 & 4.9497 & TST \\
\hline CHEMBL1402481 & 688721 & 4.5 & 5.0061 & TRN \\
\hline CHEMBL1459575 & 688721 & 4.6 & 4.994 & TST \\
\hline CHEMBL1448655 & 688721 & 4.6 & 5.1657 & TST \\
\hline CHEMBL1554693 & 688721 & 5.5 & 5.3057 & TRN \\
\hline CHEMBL1462683 & 688721 & 4.4 & 4.971 & TRN \\
\hline CHEMBL1372838 & 688721 & 6.5 & 5.1046 & TRN \\
\hline CHEMBL1468358 & 688721 & 4.4 & 5.1275 & TST \\
\hline CHEMBL1408710 & 688721 & 4.4 & 4.9474 & TRN \\
\hline CHEMBL1454781 & 688721 & 6.4 & 4.9768 & TRN \\
\hline CHEMBL1582811 & 688721 & 5.2 & 4.9247 & TRN \\
\hline CHEMBL1353833 & 688721 & 4.9 & 4.9359 & TRN \\
\hline CHEMBL1406645 & 688721 & 4.4 & 5.1482 & TST \\
\hline CHEMBL1451427 & 688721 & 4.7 & 4.9013 & TST \\
\hline CHEMBL1448856 & 688721 & 6.4 & 4.8263 & TRN \\
\hline CHEMBL1585095 & 688721 & 5.4 & 4.9762 & TRN \\
\hline CHEMBL1441793 & 688721 & 4.8 & 4.7129 & TRN \\
\hline CHEMBL1534970 & 688721 & 4.5 & 4.9105 & TRN \\
\hline CHEMBL1611200 & 688721 & 5.0 & 4.976 & TST \\
\hline CHEMBL1446489 & 688721 & 4.4 & 4.87 & TRN \\
\hline CHEMBL1489212 & 688721 & 4.8 & 5.1037 & TST \\
\hline CHEMBL1476670 & 688721 & 5.5 & 5.1574 & TRN \\
\hline CHEMBL1544013 & 688721 & 4.4 & 5.1246 & TST \\
\hline CHEMBL1594885 & 688721 & 4.7 & 4.8118 & TRN \\
\hline CHEMBL1412263 & 688721 & 4.7 & 4.8992 & TRN \\
\hline CHEMBL1447777 & 688721 & 4.7 & 4.8204 & TRN \\
\hline CHEMBL1365941 & 688721 & 4.5 & 4.8119 & TRN \\
\hline CHEMBL1578760 & 688721 & 4.7 & 4.8359 & TRN \\
\hline CHEMBL1570765 & 688721 & 5.3 & 4.9052 & TST \\
\hline CHEMBL1494289 & 688721 & 5.5 & 5.0374 & TRN \\
\hline CHEMBL1307002 & 688721 & 4.7 & 5.0013 & TRN \\
\hline CHEMBL1345233 & 688721 & 5.3 & 4.9346 & TRN \\
\hline CHEMBL1338301 & 688721 & 4.8 & 4.9763 & TRN \\
\hline CHEMBL1374999 & 688721 & 5.9 & 5.1448 & TST \\
\hline CHEMBL1501141 & 688721 & 4.4 & 4.9425 & TRN \\
\hline CHEMBL409024 & 688721 & 4.6 & 5.2081 & TST \\
\hline CHEMBL538 & 688721 & 5.9 & 5.1201 & TST \\
\hline CHEMBL1541290 & 688721 & 5.4 & 4.965 & TRN \\
\hline CHEMBL1544301 & 688721 & 4.4 & 5.2358 & TST \\
\hline CHEMBL1580498 & 688721 & 4.8 & 4.7042 & TRN \\
\hline CHEMBL1365133 & 688721 & 4.6 & 4.7731 & TRN \\
\hline CHEMBL1386667 & 688721 & 5.1 & 4.98 & TRN \\
\hline CHEMBL1366573 & 688721 & 4.6 & 4.9813 & TRN \\
\hline CHEMBL1589014 & 688721 & 4.5 & 4.8843 & TRN \\
\hline CHEMBL1466714 & 688721 & 4.7 & 4.6792 & TRN \\
\hline
\end{tabular}




\begin{tabular}{|c|c|c|c|c|}
\hline & & & Supplement & \\
\hline CHEMBL1481585 & 688721 & 4.7 & 4.8695 & TRN \\
\hline CHEMBL1462316 & 688721 & 4.5 & 4.9178 & TRN \\
\hline CHEMBL1601114 & 688721 & 5.4 & 4.9008 & TRN \\
\hline CHEMBL1375563 & 688721 & 4.8 & 4.9296 & TRN \\
\hline CHEMBL1363764 & 688721 & 5.6 & 5.0038 & TRN \\
\hline CHEMBL1387002 & 688721 & 4.4 & 4.8353 & TRN \\
\hline CHEMBL1367064 & 688721 & 4.6 & 4.8721 & TRN \\
\hline CHEMBL1393881 & 688721 & 4.5 & 4.9825 & TRN \\
\hline CHEMBL1433051 & 688721 & 4.8 & 4.8592 & TRN \\
\hline CHEMBL1338358 & 688721 & 4.4 & 4.8044 & TST \\
\hline CHEMBL1535801 & 688721 & 4.6 & 4.9269 & TRN \\
\hline CHEMBL1585299 & 688721 & 4.7 & 4.7484 & TRN \\
\hline CHEMBL1576563 & 688721 & 4.6 & 4.7895 & TRN \\
\hline CHEMBL1342585 & 688721 & 4.6 & 4.9571 & TST \\
\hline CHEMBL1404498 & 688721 & 4.4 & 5.0541 & TST \\
\hline CHEMBL1235551 & 688721 & 5.4 & 4.9921 & TST \\
\hline CHEMBL598663 & 688721 & 4.7 & 4.9419 & TRN \\
\hline CHEMBL1587683 & 688721 & 5.8 & 4.7287 & TRN \\
\hline CHEMBL1331889 & 688721 & 5.9 & 4.9861 & TST \\
\hline CHEMBL1568969 & 688721 & 4.5 & 4.7975 & TRN \\
\hline CHEMBL220087 & 688721 & 4.5 & 5.1059 & TRN \\
\hline CHEMBL1302867 & 688721 & 4.6 & 5.0115 & TST \\
\hline CHEMBL1594995 & 688721 & 4.8 & 4.9622 & TRN \\
\hline CHEMBL1533843 & 688721 & 5.3 & 5.1535 & TRN \\
\hline CHEMBL1547225 & 688721 & 5.4 & 4.8199 & TRN \\
\hline CHEMBL1527671 & 688721 & 4.7 & 4.9344 & TST \\
\hline CHEMBL1561030 & 688721 & 4.6 & 4.8438 & TRN \\
\hline CHEMBL1324598 & 688721 & 4.6 & 4.8353 & TRN \\
\hline CHEMBL1432952 & 688721 & 4.8 & 5.1124 & TST \\
\hline CHEMBL1386385 & 688721 & 5.2 & 4.9415 & TRN \\
\hline CHEMBL1408856 & 688721 & 4.8 & 4.9134 & TRN \\
\hline CHEMBL3211953 & 688721 & 5.5 & 5.0072 & TST \\
\hline CHEMBL597246 & 688721 & 4.6 & 5.0862 & TRN \\
\hline CHEMBL1507852 & 688721 & 4.5 & 4.94 & TRN \\
\hline CHEMBL1554183 & 688721 & 4.5 & 5.2805 & TST \\
\hline CHEMBL1326155 & 688721 & 5.2 & 4.9758 & TRN \\
\hline CHEMBL1532056 & 688721 & 4.8 & 4.7715 & TRN \\
\hline CHEMBL1409676 & 688721 & 5.1 & 4.8701 & TRN \\
\hline CHEMBL1554131 & 688721 & 4.8 & 5.3908 & TRN \\
\hline CHEMBL1520860 & 688721 & 4.8 & 5.0443 & TRN \\
\hline CHEMBL1329135 & 688721 & 4.5 & 4.8838 & TRN \\
\hline CHEMBL1433742 & 688721 & 5.4 & 5.1729 & TST \\
\hline CHEMBL1342502 & 688721 & 5.4 & 4.9046 & TST \\
\hline CHEMBL1413010 & 688721 & 5.3 & 5.1033 & TRN \\
\hline CHEMBL1538165 & 688721 & 4.7 & 4.8929 & TRN \\
\hline CHEMBL1563201 & 688721 & 5.9 & 4.8453 & TRN \\
\hline CHEMBL1328934 & 688721 & 4.6 & 4.7469 & TRN \\
\hline CHEMBL1403626 & 688721 & 4.9 & 5.1688 & TRN \\
\hline
\end{tabular}




\begin{tabular}{|c|c|c|c|c|c|}
\hline \multicolumn{6}{|c|}{ Supplemental Table S2.txt } \\
\hline CHEMBL1336909 & 688721 & 4.9 & 4.971 & TRN & \\
\hline CHEMBL1442735 & 688721 & 4.4 & 5.0137 & TRN & \\
\hline CHEMBL1567964 & 688721 & 4.6 & 4.9829 & TRN & \\
\hline CHEMBL1568601 & 688721 & 4.6 & 4.9287 & TRN & \\
\hline CHEMBL1565345 & 688721 & 4.6 & 4.8991 & TRN & \\
\hline CHEMBL1533335 & 688721 & 4.8 & 4.947 & TRN & \\
\hline CHEMBL1573701 & 688721 & 4.5 & 4.8042 & TRN & \\
\hline CHEMBL1596627 & 688721 & 5.2 & 5.24799 & 9999999999 & TRN \\
\hline CHEMBL3213620 & 688721 & 5.2 & 5.0328 & TST & \\
\hline CHEMBL1513478 & 688721 & 5.2 & 5.1303 & TRN & \\
\hline CHEMBL1372521 & 688721 & 4.4 & 5.0571 & TST & \\
\hline CHEMBL1320057 & 688721 & 4.7 & 5.0435 & TST & \\
\hline CHEMBL259073 & 688721 & 4.6 & 4.9369 & TRN & \\
\hline CHEMBL1367114 & 688721 & 5.0 & 4.8416 & TRN & \\
\hline CHEMBL1497861 & 688721 & 5.0 & 4.9777 & TRN & \\
\hline CHEMBL1592470 & 688721 & 5.3 & 5.1312 & TRN & \\
\hline CHEMBL1456547 & 688721 & 4.4 & 4.8871 & TRN & \\
\hline CHEMBL1327014 & 688721 & 5.1 & 5.0763 & TRN & \\
\hline CHEMBL1564730 & 688721 & 5.0 & 4.9215 & TST & \\
\hline CHEMBL1528050 & 688721 & 5.4 & 5.1106 & TRN & \\
\hline CHEMBL3196797 & 688721 & 5.5 & 5.1162 & TRN & \\
\hline CHEMBL1338672 & 688721 & 4.6 & 4.8489 & TRN & \\
\hline CHEMBL30131 & 688721 & 4.8 & 5.0992 & TST & \\
\hline CHEMBL1379345 & 688721 & 4.4 & 4.8713 & TRN & \\
\hline CHEMBL1311278 & 688721 & 4.4 & 4.7915 & TST & \\
\hline CHEMBL1525750 & 688721 & 4.9 & 4.7258 & TRN & \\
\hline CHEMBL1441858 & 688721 & 4.4 & 4.966 & TRN & \\
\hline CHEMBL1463079 & 688721 & 4.9 & 5.0481 & TRN & \\
\hline CHEMBL1378152 & 688721 & 4.5 & 4.9399 & TRN & \\
\hline CHEMBL1382217 & 688721 & 4.4 & 5.0441 & TST & \\
\hline CHEMBL1421754 & 688721 & 4.6 & 4.9624 & TST & \\
\hline CHEMBL1336031 & 688721 & 4.7 & 4.8684 & TST & \\
\hline CHEMBL1321223 & 688721 & 5.4 & 5.1461 & TRN & \\
\hline CHEMBL3197105 & 688721 & 4.5 & 5.0908 & TST & \\
\hline CHEMBL1313221 & 688721 & 5.1 & 5.0202 & TST & \\
\hline CHEMBL1256693 & 688721 & 5.2 & 5.2018 & TST & \\
\hline CHEMBL1428555 & 688721 & 5.1 & 4.8391 & TRN & \\
\hline CHEMBL1588916 & 688721 & 4.5 & 4.9331 & TRN & \\
\hline CHEMBL1534825 & 688721 & 4.6 & 5.0407 & TRN & \\
\hline CHEMBL1338530 & 688721 & 5.2 & 4.9507 & TRN & \\
\hline CHEMBL1448444 & 688721 & 4.7 & 4.8975 & TRN & \\
\hline CHEMBL1509961 & 688721 & 4.5 & 4.8254 & TST & \\
\hline CHEMBL1607888 & 688721 & 5.7 & 4.9288 & TRN & \\
\hline CHEMBL1491676 & 688721 & 4.5 & 4.8365 & TRN & \\
\hline CHEMBL1468716 & 688721 & 5.2 & 5.0191 & TRN & \\
\hline CHEMBL1589801 & 688721 & 4.7 & 4.9677 & TRN & \\
\hline CHEMBL1311861 & 688721 & 5.3 & 5.1169 & TRN & \\
\hline CHEMBL1605850 & 688721 & 5.9 & 4.86 & TRN & \\
\hline
\end{tabular}




\begin{tabular}{|c|c|c|c|c|c|}
\hline \multicolumn{6}{|c|}{ Supplemental Table S2.txt } \\
\hline CHEMBL1539584 & 688721 & 4.5 & 4.9793 & TRN & \\
\hline CHEMBL1371130 & 688721 & 4.5 & 4.7804 & TRN & \\
\hline CHEMBL1469822 & 688721 & 4.6 & 4.8181 & TRN & \\
\hline CHEMBL1589269 & 688721 & 4.6 & 4.8837 & TRN & \\
\hline CHEMBL1452142 & 688721 & 4.5 & 5.0419 & TRN & \\
\hline CHEMBL1541633 & 688721 & 4.5 & 4.831 & TRN & \\
\hline CHEMBL1575430 & 688721 & 4.6 & 4.9867 & TRN & \\
\hline CHEMBL1438452 & 688721 & 4.7 & 4.8274 & TRN & \\
\hline CHEMBL1342608 & 688721 & 4.7 & 5.019 & TRN & \\
\hline CHEMBL1306887 & 688721 & 5.5 & 4.8389 & TRN & \\
\hline CHEMBL1517068 & 688721 & 4.6 & 4.6498 & TRN & \\
\hline CHEMBL1453446 & 688721 & 4.4 & 4.9545 & TRN & \\
\hline CHEMBL1402196 & 688721 & 5.2 & 4.9459 & TST & \\
\hline CHEMBL1339727 & 688721 & 4.6 & 4.9132 & TRN & \\
\hline CHEMBL1379151 & 688721 & 4.4 & 4.9022 & TRN & \\
\hline CHEMBL1504734 & 688721 & 4.6 & 5.20799 & 9999999999 & TST \\
\hline CHEMBL1398981 & 688721 & 4.6 & 4.8935 & TRN & \\
\hline CHEMBL1536407 & 688721 & 6.1 & 4.8579 & TRN & \\
\hline CHEMBL1474302 & 688721 & 5.0 & 5.1308 & TRN & \\
\hline CHEMBL1335130 & 688721 & 4.9 & 4.7417 & TRN & \\
\hline CHEMBL1520172 & 688721 & 4.8 & 4.9207 & TRN & \\
\hline CHEMBL1388126 & 688721 & 4.5 & 5.0429 & TRN & \\
\hline CHEMBL1369085 & 688721 & 5.7 & 4.9787 & TRN & \\
\hline CHEMBL1441152 & 688721 & 5.5 & 4.8983 & TRN & \\
\hline CHEMBL1488815 & 688721 & 5.4 & 4.9478 & TRN & \\
\hline CHEMBL1413235 & 688721 & 4.7 & 4.7985 & TRN & \\
\hline CHEMBL258893 & 688721 & 4.6 & 4.9726 & TST & \\
\hline CHEMBL1332439 & 688721 & 6.9 & 5.1068 & TRN & \\
\hline CHEMBL1305204 & 688721 & 4.9 & 4.9787 & TST & \\
\hline CHEMBL1595251 & 688721 & 4.9 & 4.9052 & TRN & \\
\hline CHEMBL1450269 & 688721 & 4.6 & 5.073 & TRN & \\
\hline CHEMBL1463231 & 688721 & 4.8 & 4.8029 & TRN & \\
\hline CHEMBL1540271 & 688721 & 5.2 & 4.7399 & TST & \\
\hline CHEMBL1404884 & 688721 & 7.6003 & 5.1589 & TRN & \\
\hline CHEMBL1549610 & 688721 & 4.5 & 4.8865 & TRN & \\
\hline CHEMBL1325336 & 688721 & 5.0 & 4.7615 & TRN & \\
\hline CHEMBL1431882 & 688721 & 4.4 & 4.7502 & TST & \\
\hline CHEMBL394930 & 688721 & 5.2 & 5.0819 & TST & \\
\hline CHEMBL1408026 & 688721 & 4.6 & 4.9087 & TST & \\
\hline CHEMBL1521625 & 688721 & 5.9 & 5.012 & TRN & \\
\hline CHEMBL1559938 & 688721 & 5.5 & 5.0796 & TRN & \\
\hline CHEMBL1505567 & 688721 & 4.6 & 4.8644 & TRN & \\
\hline CHEMBL1413265 & 688721 & 4.6 & 4.8061 & TRN & \\
\hline CHEMBL1561561 & 688721 & 4.4 & 5.0125 & TRN & \\
\hline CHEMBL1340360 & 688721 & 5.3 & 4.7766 & TRN & \\
\hline CHEMBL1303167 & 688721 & 5.2 & 4.9838 & TRN & \\
\hline CHEMBL1437138 & 688721 & 4.4 & 5.0725 & TRN & \\
\hline CHEMBL1580274 & 688721 & 4.5 & 4.8301 & TRN & \\
\hline
\end{tabular}




\begin{tabular}{|c|c|c|c|c|c|}
\hline & & & & & \\
\hline CHEMBL1325751 & 688721 & 5.2 & 5.034 & TRN & \\
\hline CHEMBL1561293 & 688721 & 4.9 & 4.7818 & TRN & \\
\hline CHEMBL1491292 & 688721 & 4.5 & 4.9234 & TRN & \\
\hline CHEMBL1550700 & 688721 & 4.4 & 4.9483 & TRN & \\
\hline CHEMBL1552677 & 688721 & 4.7 & 5.1945 & TRN & \\
\hline CHEMBL1489659 & 688721 & 4.9 & 5.2086 & TRN & \\
\hline CHEMBL1330336 & 688721 & 5.0 & 4.9775 & TRN & \\
\hline CHEMBL1479661 & 688721 & 5.8 & 4.9831 & TRN & \\
\hline CHEMBL1373790 & 688721 & 4.5 & 4.7359 & TRN & \\
\hline CHEMBL1459673 & 688721 & 4.6 & 5.1322 & TRN & \\
\hline CHEMBL1364005 & 688721 & 4.5 & 5.0425 & TRN & \\
\hline CHEMBL1389322 & 688721 & 4.6 & 4.7964 & TRN & \\
\hline CHEMBL1336044 & 688721 & 5.5 & 5.1349 & TRN & \\
\hline CHEMBL1586877 & 688721 & 5.2 & 4.9742 & TRN & \\
\hline CHEMBL1562688 & 688721 & 4.4 & 4.9463 & TST & \\
\hline CHEMBL1552154 & 688721 & 5.2 & 5.16100 & 00000000005 & TRN \\
\hline CHEMBL1595565 & 688721 & 4.4 & 4.7909 & TRN & \\
\hline CHEMBL1444764 & 688721 & 5.4 & 5.07 & TRN & \\
\hline CHEMBL1552720 & 688721 & 4.7 & 5.0056 & TRN & \\
\hline CHEMBL1476362 & 688721 & 4.6 & 5.2321 & TST & \\
\hline CHEMBL1489926 & 688721 & 4.4 & 4.9409 & TRN & \\
\hline CHEMBL1523465 & 688721 & 4.4 & 5.0706 & TRN & \\
\hline CHEMBL1413339 & 688721 & 4.5 & 4.9886 & TRN & \\
\hline CHEMBL1581922 & 688721 & 4.5 & 4.7952 & TRN & \\
\hline CHEMBL1340087 & 688721 & 5.2 & 4.9872 & TRN & \\
\hline CHEMBL1379266 & 688721 & 4.8 & 4.933 & TRN & \\
\hline CHEMBL1408032 & 688721 & 5.1 & 4.8836 & TRN & \\
\hline CHEMBL1324618 & 688721 & 5.4 & 4.9495 & TRN & \\
\hline CHEMBL1470718 & 688721 & 5.1 & 4.9723 & TRN & \\
\hline CHEMBL3191553 & 688721 & 5.4 & 5.1723 & TRN & \\
\hline CHEMBL1313009 & 688721 & 4.9 & 4.8204 & TRN & \\
\hline CHEMBL1488418 & 688721 & 4.7 & 4.8384 & TRN & \\
\hline CHEMBL1490863 & 688721 & 5.2 & 5.0934 & TRN & \\
\hline CHEMBL1354013 & 688721 & 5.4 & 4.9249 & TRN & \\
\hline CHEMBL1380879 & 688721 & 5.9 & 5.0828 & TRN & \\
\hline CHEMBL1329526 & 688721 & 5.8 & 4.84399 & 9999999999 & TRN \\
\hline CHEMBL45462 & 688721 & 5.1 & 5.2099 & TST & \\
\hline CHEMBL1468639 & 688721 & 5.7 & 4.9425 & TRN & \\
\hline CHEMBL1480895 & 688721 & 5.2 & 5.0343 & TRN & \\
\hline CHEMBL1346315 & 688721 & 4.6 & 4.76 & TRN & \\
\hline CHEMBL1379280 & 688721 & 4.4 & 4.9204 & TRN & \\
\hline CHEMBL1322983 & 688721 & 4.9 & 4.7251 & TRN & \\
\hline CHEMBL1564908 & 688721 & 4.7 & 4.9686 & TRN & \\
\hline CHEMBL3209065 & 688721 & 4.5 & 4.8951 & TRN & \\
\hline CHEMBL1559225 & 688721 & 4.7 & 4.8462 & TRN & \\
\hline CHEMBL1427882 & 688721 & 4.8 & 4.7644 & TRN & \\
\hline CHEMBL1598120 & 688721 & 4.8 & 4.7833 & TRN & \\
\hline CHEMBL1562088 & 688721 & 5.0 & 4.9833 & TST & \\
\hline & & & & 9010 & \\
\hline
\end{tabular}




\begin{tabular}{|c|c|c|c|c|c|}
\hline \multicolumn{6}{|c|}{ Supplemental Table S2.txt } \\
\hline CHEMBL1481730 & 688721 & 4.8 & 4.992 & TRN & \\
\hline CHEMBL1498980 & 688721 & 4.8 & 4.8216 & TRN & \\
\hline CHEMBL1511071 & 688721 & 5.4 & 5.0949 & TRN & \\
\hline CHEMBL1357247 & 688721 & 4.7 & 5.1513 & TST & \\
\hline CHEMBL1310898 & 688721 & 4.8 & 5.1015 & TRN & \\
\hline CHEMBL1350654 & 688721 & 4.5 & 4.8217 & TRN & \\
\hline CHEMBL1358197 & 688721 & 5.4 & 5.2305 & TRN & \\
\hline CHEMBL1448958 & 688721 & 4.6 & 4.9899 & TST & \\
\hline CHEMBL1330080 & 688721 & 5.4 & 4.9262 & TRN & \\
\hline CHEMBL1393461 & 688721 & 4.6 & 4.9453 & TST & \\
\hline CHEMBL1594723 & 688721 & 4.5 & 4.9022 & TST & \\
\hline CHEMBL1400272 & 688721 & 4.4 & 4.9382 & TRN & \\
\hline CHEMBL489935 & 688721 & 4.8 & 5.0831 & TRN & \\
\hline CHEMBL1452312 & 688721 & 4.5 & 4.9275 & TRN & \\
\hline CHEMBL1570162 & 688721 & 4.7 & 4.9564 & TRN & \\
\hline CHEMBL1594090 & 688721 & 4.6 & 5.0613 & TST & \\
\hline CHEMBL491771 & 688721 & 4.8 & 4.9804 & TRN & \\
\hline CHEMBL1464027 & 688721 & 4.6 & 4.9001 & TRN & \\
\hline CHEMBL1458258 & 688721 & 4.4 & 5.0814 & TRN & \\
\hline CHEMBL1485434 & 688721 & 4.4 & 5.0523 & TRN & \\
\hline CHEMBL1493493 & 688721 & 4.8 & 5.1117 & TRN & \\
\hline CHEMBL1392604 & 688721 & 5.4 & 5.015 & TRN & \\
\hline CHEMBL1442100 & 688721 & 5.0 & 5.1053 & TST & \\
\hline CHEMBL1561543 & 688721 & 4.8 & 4.9206 & TRN & \\
\hline CHEMBL1602253 & 688721 & 6.1 & 4.9422 & TRN & \\
\hline CHEMBL1415927 & 688721 & 4.6 & 4.9754 & TST & \\
\hline CHEMBL1302294 & 688721 & 4.4 & 4.934 & TST & \\
\hline CHEMBL1307208 & 688721 & 5.4 & 5.0354 & TRN & \\
\hline CHEMBL1311399 & 688721 & 4.5 & 4.9345 & TRN & \\
\hline CHEMBL1465099 & 688721 & 6.8 & 5.0486 & TRN & \\
\hline CHEMBL1508221 & 688721 & 4.6 & 4.8523 & TRN & \\
\hline CHEMBL1421412 & 688721 & 5.5 & 4.9505 & TRN & \\
\hline CHEMBL1521690 & 688721 & 4.5 & 4.9047 & TRN & \\
\hline CHEMBL170408 & 688721 & 4.2 & 5.1122 & TRN & \\
\hline CHEMBL1439429 & 688721 & 4.4 & 4.9171 & TRN & \\
\hline CHEMBL1569493 & 688721 & 8.0 & 5.1252 & TRN & \\
\hline CHEMBL1399222 & 688721 & 5.1 & 4.8895 & TRN & \\
\hline CHEMBL1331017 & 688721 & 5.2 & 5.1102 & TST & \\
\hline CHEMBL1333148 & 688721 & 4.6 & 4.8218 & TST & \\
\hline CHEMBL 286615 & 688721 & 4.4 & 5.1648 & TST & \\
\hline CHEMBL1529835 & 688721 & 4.5 & 4.8905 & TRN & \\
\hline CHEMBL1319957 & 688721 & 5.5 & 4.7808 & TRN & \\
\hline CHEMBL1458230 & 688721 & 4.5 & 4.85800 & 00000000005 & TRN \\
\hline CHEMBL1375436 & 688721 & 4.4 & 4.7892 & TRN & \\
\hline CHEMBL1531251 & 688721 & 6.7001 & 4.9828 & TRN & \\
\hline CHEMBL1543144 & 688721 & 6.0 & 4.9109 & TRN & \\
\hline CHEMBL1391121 & 688721 & 4.4 & 4.8547 & TST & \\
\hline CHEMBL1303944 & 688721 & 6.1 & 5.2017 & TRN & \\
\hline
\end{tabular}




\begin{tabular}{|c|c|c|c|c|c|}
\hline \multicolumn{6}{|c|}{ Supplemental Table S2.txt } \\
\hline CHEMBL1394477 & 688721 & 5.6 & 5.2688 & TRN & \\
\hline CHEMBL1458917 & 688721 & 4.4 & 5.0122 & TST & \\
\hline CHEMBL1485999 & 688721 & 5.2 & 5.0685 & TST & \\
\hline CHEMBL1391643 & 688721 & 4.5 & 4.9278 & TRN & \\
\hline CHEMBL1598711 & 688721 & 4.7 & 4.9164 & TRN & \\
\hline CHEMBL1405153 & 688721 & 4.7 & 4.9942 & TRN & \\
\hline CHEMBL 1383720 & 688721 & 4.9 & 4.9145 & TRN & \\
\hline CHEMBL1488462 & 688721 & 5.2 & 4.8994 & TRN & \\
\hline CHEMBL1581410 & 688721 & 4.6 & 4.9864 & TRN & \\
\hline CHEMBL1404301 & 688721 & 5.3 & 4.8616 & TRN & \\
\hline CHEMBL1468271 & 688721 & 4.4 & 4.9603 & TRN & \\
\hline CHEMBL1558175 & 688721 & 4.4 & 4.8602 & TST & \\
\hline CHEMBL1590059 & 688721 & 7.4001 & 5.1774 & TRN & \\
\hline CHEMBL1400140 & 688721 & 4.9 & 5.12 & TRN & \\
\hline CHEMBL1497693 & 688721 & 4.5 & 4.9367 & TST & \\
\hline CHEMBL1459368 & 688721 & 4.8 & 4.8229 & TRN & \\
\hline CHEMBL1362542 & 688721 & 4.9 & 4.8431 & TRN & \\
\hline CHEMBL1469431 & 688721 & 4.6 & 4.877 & TRN & \\
\hline CHEMBL539947 & 688721 & 5.5 & 5.2526 & TRN & \\
\hline CHEMBL1383638 & 688721 & 5.3 & 4.9337 & TRN & \\
\hline CHEMBL1425168 & 688721 & 7.8996 & 5.0487 & TRN & \\
\hline CHEMBL1482431 & 688721 & 4.5 & 4.8509 & TRN & \\
\hline CHEMBL1476904 & 688721 & 5.4 & 4.8376 & TRN & \\
\hline CHEMBL1525066 & 688721 & 4.8 & 4.9899 & TRN & \\
\hline CHEMBL1484713 & 688721 & 4.5 & 4.8284 & TRN & \\
\hline CHEMBL1553034 & 688721 & 5.2 & 5.0534 & TRN & \\
\hline CHEMBL1538360 & 688721 & 4.8 & 4.7925 & TST & \\
\hline CHEMBL1531191 & 688721 & 4.7 & 4.8165 & TRN & \\
\hline CHEMBL1611830 & 688721 & 4.8 & 4.8611 & TRN & \\
\hline CHEMBL1414219 & 688721 & 6.1 & 5.16200 & 0000000001 & TST \\
\hline CHEMBL1477182 & 688721 & 5.1 & 5.4099 & TRN & \\
\hline CHEMBL1595870 & 688721 & 4.4 & 4.7696 & TRN & \\
\hline CHEMBL1374849 & 688721 & 4.9 & 5.0824 & TRN & \\
\hline CHEMBL1402799 & 688721 & 4.6 & 4.9633 & TRN & \\
\hline CHEMBL1576399 & 688721 & 4.5 & 4.8571 & TRN & \\
\hline CHEMBL1444360 & 688721 & 5.7 & 4.9112 & TRN & \\
\hline CHEMBL1592500 & 688721 & 6.0 & 4.9926 & TRN & \\
\hline CHEMBL1349211 & 688721 & 5.2 & 5.0675 & TRN & \\
\hline CHEMBL1425498 & 688721 & 4.5 & 4.8088 & TRN & \\
\hline CHEMBL1602476 & 688721 & 6.1 & 5.12200 & 0000000001 & TST \\
\hline CHEMBL1316628 & 688721 & 4.5 & 5.1477 & TRN & \\
\hline CHEMBL1453430 & 688721 & 4.7 & 4.9431 & TST & \\
\hline CHEMBL1507393 & 688721 & 4.6 & 4.9566 & TRN & \\
\hline CHEMBL1418697 & 688721 & 4.6 & 4.881 & TST & \\
\hline CHEMBL1611354 & 688721 & 5.5 & 4.8544 & TRN & \\
\hline CHEMBL1535173 & 688721 & 4.7 & 4.9595 & TRN & \\
\hline CHEMBL1363472 & 688721 & 4.6 & 4.9382 & TRN & \\
\hline CHEMBL1594499 & 688721 & 5.0 & 4.7715 & TST & \\
\hline
\end{tabular}




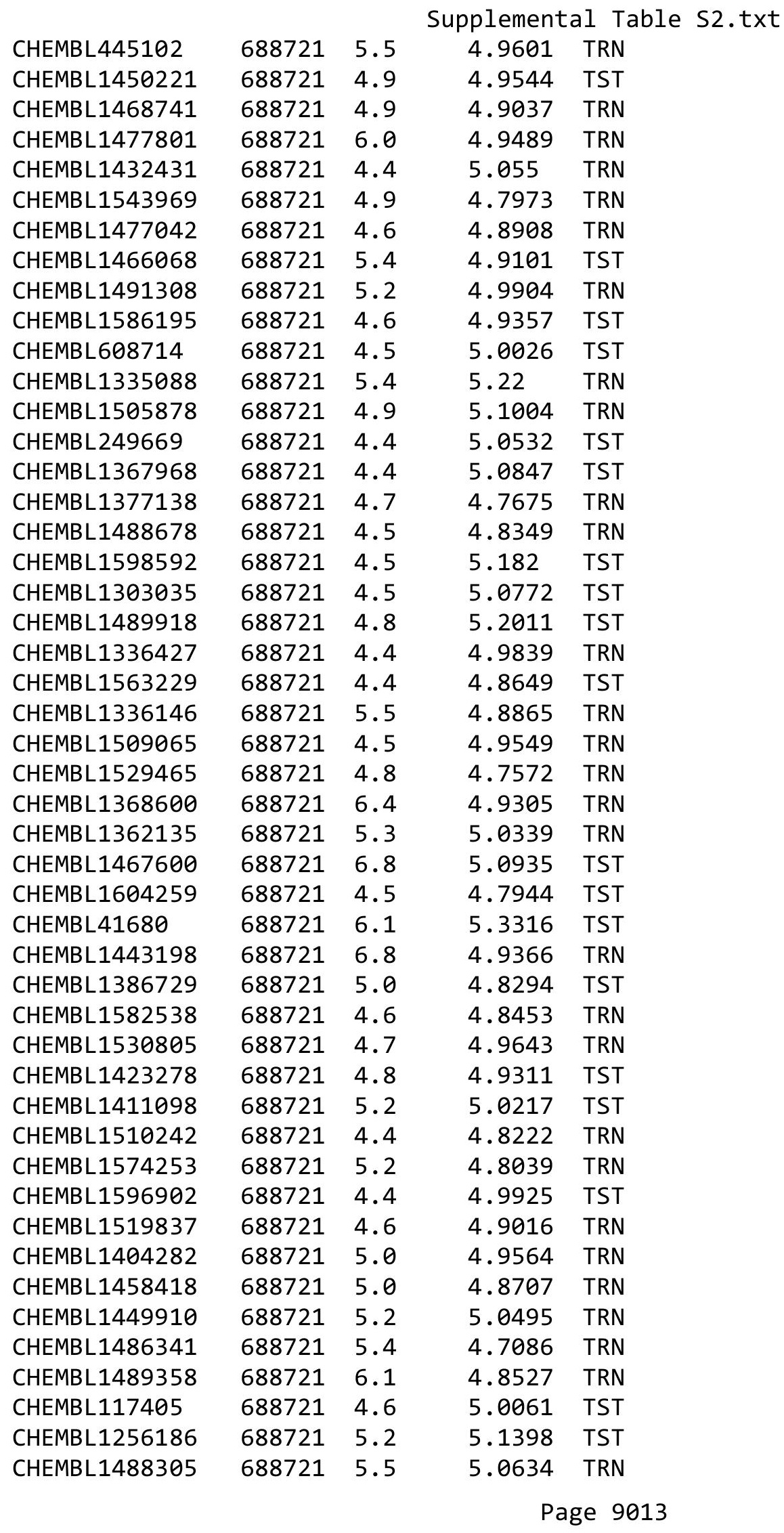




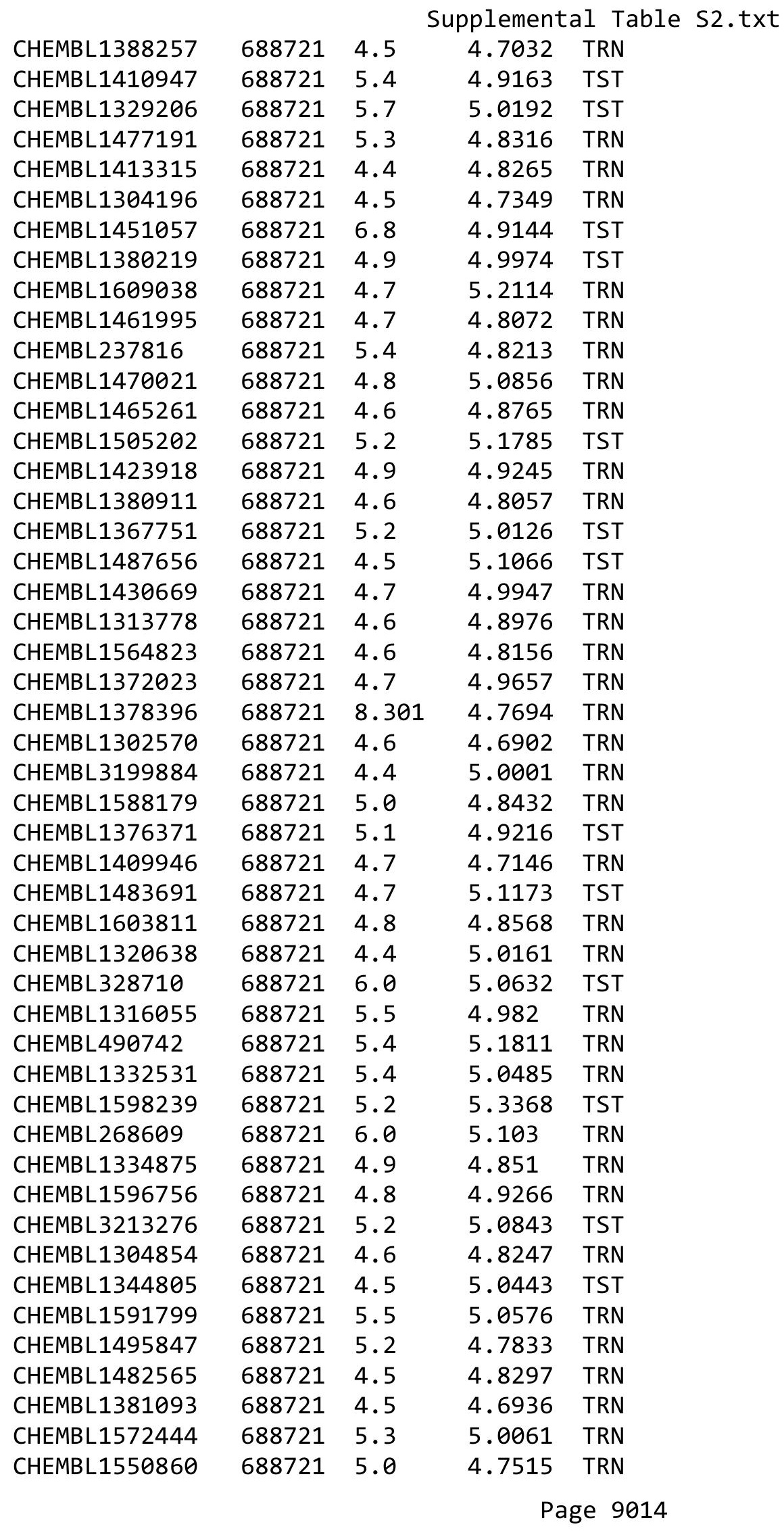




\begin{tabular}{|c|c|c|c|c|c|}
\hline \multicolumn{6}{|c|}{ Supplemental Table S2.txt } \\
\hline CHEMBL1576221 & 688721 & 4.8 & 4.9974 & TRN & \\
\hline CHEMBL1301904 & 688721 & 5.2 & 4.9091 & TRN & \\
\hline CHEMBL1403121 & 688721 & 5.1 & 4.9469 & TRN & \\
\hline CHEMBL1545624 & 688721 & 4.5 & 4.8075 & TRN & \\
\hline CHEMBL1352752 & 688721 & 4.4 & 4.753 & TRN & \\
\hline CHEMBL1506523 & 688721 & 5.3 & 5.1031 & TST & \\
\hline CHEMBL1321801 & 688721 & 4.8 & 4.9205 & TRN & \\
\hline CHEMBL1518701 & 688721 & 4.5 & 4.9924 & TST & \\
\hline CHEMBL1580154 & 688721 & 4.4 & 4.965 & TRN & \\
\hline CHEMBL1524520 & 688721 & 4.5 & 4.9938 & TRN & \\
\hline CHEMBL1347061 & 688721 & 4.8 & 5.2139 & TST & \\
\hline CHEMBL1383582 & 688721 & 5.0 & 4.8972 & TRN & \\
\hline CHEMBL1484159 & 688721 & 5.2 & 4.9514 & TRN & \\
\hline CHEMBL1510877 & 688721 & 4.4 & 4.9205 & TST & \\
\hline CHEMBL1433010 & 688721 & 4.7 & 4.6858 & TRN & \\
\hline CHEMBL1302174 & 688721 & 5.4 & 5.0226 & TRN & \\
\hline CHEMBL1491100 & 688721 & 4.7 & 4.9071 & TRN & \\
\hline CHEMBL1343376 & 688721 & 6.8 & 5.0114 & TRN & \\
\hline CHEMBL1552272 & 688721 & 5.3 & 5.2422 & TRN & \\
\hline CHEMBL1611371 & 688721 & 4.4 & 4.84699 & 99999999995 & TRN \\
\hline CHEMBL1543707 & 688721 & 4.7 & 4.8063 & TRN & \\
\hline CHEMBL1440590 & 688721 & 6.0 & 4.9782 & TRN & \\
\hline CHEMBL1584016 & 688721 & 5.0 & 4.9146 & TRN & \\
\hline CHEMBL1440586 & 688721 & 4.8 & 5.0713 & TST & \\
\hline CHEMBL1610780 & 688721 & 4.6 & 4.9147 & TRN & \\
\hline CHEMBL1337169 & 688721 & 4.9 & 5.0806 & TRN & \\
\hline CHEMBL1386366 & 688721 & 4.9 & 4.8561 & TRN & \\
\hline CHEMBL1365373 & 688721 & 5.2 & 5.0455 & TRN & \\
\hline CHEMBL1608522 & 688721 & 4.6 & 4.9655 & TRN & \\
\hline CHEMBL1326516 & 688721 & 4.5 & 4.6706 & TRN & \\
\hline CHEMBL1413296 & 688721 & 4.4 & 4.9274 & TRN & \\
\hline CHEMBL1365031 & 688721 & 4.4 & 5.079 & TRN & \\
\hline CHEMBL1349706 & 688721 & 8.2007 & 4.9502 & TST & \\
\hline CHEMBL1522182 & 688721 & 4.4 & 4.8058 & TRN & \\
\hline CHEMBL1481566 & 688721 & 4.6 & 4.7644 & TRN & \\
\hline CHEMBL452370 & 688721 & 4.4 & 5.274 & TST & \\
\hline CHEMBL1341291 & 688721 & 4.6 & 4.9203 & TRN & \\
\hline CHEMBL1492905 & 688721 & 4.6 & 4.9231 & TRN & \\
\hline CHEMBL1482184 & 688721 & 6.0 & 5.15799 & 99999999995 & TST \\
\hline CHEMBL1601573 & 688721 & 4.7 & 4.8862 & TRN & \\
\hline CHEMBL1304100 & 688721 & 4.8 & 4.8431 & TRN & \\
\hline CHEMBL1352633 & 688721 & 4.4 & 4.9432 & TRN & \\
\hline CHEMBL1360805 & 688721 & 5.4 & 4.9194 & TST & \\
\hline CHEMBL1309352 & 688721 & 4.7 & 4.8798 & TST & \\
\hline CHEMBL1509699 & 688721 & 4.5 & 4.9339 & TST & \\
\hline CHEMBL1558539 & 688721 & 5.2 & 5.1634 & TST & \\
\hline CHEMBL1320496 & 688721 & 4.6 & 4.9806 & TRN & \\
\hline CHEMBL1318349 & 688721 & 4.4 & 5.1064 & TRN & \\
\hline
\end{tabular}




\begin{tabular}{|c|c|c|c|c|}
\hline & & & ient & $a \perp 1 a$ \\
\hline CHEMBL1327833 & 688721 & 5.3 & 4.8672 & TRN \\
\hline CHEMBL1554683 & 688721 & 4.8 & 4.9181 & TRN \\
\hline CHEMBL1363858 & 688721 & 6.0 & 4.916 & TRN \\
\hline CHEMBL1450653 & 688721 & 4.5 & 4.9271 & TST \\
\hline CHEMBL1528278 & 688721 & 5.2 & 5.1425 & TRN \\
\hline CHEMBL1485141 & 688721 & 4.6 & 5.0935 & TST \\
\hline CHEMBL1543167 & 688721 & 5.2 & 5.1486 & TRN \\
\hline CHEMBL1464734 & 688721 & 4.4 & 5.0767 & TRN \\
\hline CHEMBL1461667 & 688721 & 4.7 & 4.8218 & TRN \\
\hline CHEMBL1386383 & 688721 & 4.4 & 5.0082 & TRN \\
\hline CHEMBL1540058 & 688721 & 4.7 & 5.0791 & TRN \\
\hline CHEMBL1307070 & 688721 & 5.3 & 5.0324 & TRN \\
\hline CHEMBL1547724 & 688721 & 5.2 & 5.1701 & TST \\
\hline CHEMBL1494079 & 688721 & 5.0 & 4.8251 & TRN \\
\hline CHEMBL1473450 & 688721 & 4.6 & 4.84 & TST \\
\hline CHEMBL1594549 & 688721 & 5.2 & 4.9346 & TRN \\
\hline CHEMBL1405986 & 688721 & 4.4 & 5.2641 & TST \\
\hline CHEMBL1520918 & 688721 & 5.0 & 5.2174 & TRN \\
\hline CHEMBL1550302 & 688721 & 4.5 & 5.066 & TRN \\
\hline CHEMBL1564357 & 688721 & 4.4 & 4.8242 & TRN \\
\hline CHEMBL 299613 & 688721 & 4.5 & 5.1797 & TST \\
\hline CHEMBL1338439 & 688721 & 4.6 & 4.9775 & TRN \\
\hline CHEMBL1605470 & 688721 & 5.0 & 5.0411 & TRN \\
\hline CHEMBL1467999 & 688721 & 4.4 & 4.8173 & TRN \\
\hline CHEMBL1401648 & 688721 & 5.2 & 4.9681 & TRN \\
\hline CHEMBL1331193 & 688721 & 4.6 & 4.9772 & TRN \\
\hline CHEMBL1535796 & 688721 & 4.5 & 5.0237 & TRN \\
\hline CHEMBL261687 & 688721 & 6.8 & 4.9974 & TRN \\
\hline CHEMBL1372634 & 688721 & 5.3 & 4.8054 & TRN \\
\hline CHEMBL1404701 & 688721 & 4.6 & 4.9052 & TRN \\
\hline CHEMBL 255027 & 688721 & 5.1 & 5.1336 & TST \\
\hline CHEMBL3207451 & 688721 & 4.4 & 5.1671 & TST \\
\hline CHEMBL1443318 & 688721 & 5.2 & 4.9267 & TRN \\
\hline CHEMBL1549529 & 688721 & 4.5 & 4.8322 & TRN \\
\hline CHEMBL1498205 & 688721 & 5.5 & 4.8536 & TRN \\
\hline CHEMBL1474875 & 688721 & 5.1 & 5.0799 & TRN \\
\hline CHEMBL1301871 & 688721 & 4.5 & 4.8459 & TRN \\
\hline CHEMBL1488720 & 688721 & 4.4 & 4.9263 & TRN \\
\hline CHEMBL1414605 & 688721 & 4.8 & 4.9053 & TRN \\
\hline CHEMBL1403459 & 688721 & 4.6 & 4.8409 & TRN \\
\hline CHEMBL1444217 & 688721 & 5.3 & 4.982 & TRN \\
\hline CHEMBL1571899 & 688721 & 5.3 & 4.8214 & TST \\
\hline CHEMBL1513188 & 688721 & 5.5 & 5.1142 & TRN \\
\hline CHEMBL1417671 & 688721 & 5.2 & 5.0009 & TST \\
\hline CHEMBL1494756 & 688721 & 4.8 & 4.8783 & TRN \\
\hline CHEMBL1372378 & 688721 & 4.6 & 4.8671 & TRN \\
\hline CHEMBL1319284 & 688721 & 4.9 & 4.838 & TRN \\
\hline CHEMBL1532659 & 688721 & 4.6 & 4.9888 & TRN \\
\hline
\end{tabular}




\begin{tabular}{|c|c|c|c|c|}
\hline \multicolumn{5}{|c|}{ plementa } \\
\hline CHEMBL1412076 & 688721 & 5.4 & 4.9948 & TST \\
\hline CHEMBL1499336 & 688721 & 4.8 & 4.8931 & TST \\
\hline CHEMBL1334437 & 688721 & 5.1 & 4.8572 & TST \\
\hline CHEMBL1587479 & 688721 & 4.7 & 4.9765 & TRN \\
\hline CHEMBL1320893 & 688721 & 4.4 & 5.1193 & TRN \\
\hline CHEMBL261919 & 688721 & 6.0 & 5.1513 & TST \\
\hline CHEMBL1520292 & 688721 & 7.0 & 5.0522 & TRN \\
\hline CHEMBL1447902 & 688721 & 4.6 & 4.8736 & TRN \\
\hline CHEMBL1565902 & 688721 & 6.4 & 4.9045 & TST \\
\hline CHEMBL1532486 & 688721 & 4.9 & 4.8456 & TRN \\
\hline CHEMBL1350082 & 688721 & 4.7 & 4.9275 & TRN \\
\hline CHEMBL1566264 & 688721 & 4.8 & 5.0042 & TRN \\
\hline CHEMBL1510889 & 688721 & 4.5 & 4.9674 & TST \\
\hline CHEMBL1359317 & 688721 & 4.4 & 5.1184 & TST \\
\hline CHEMBL1482398 & 688721 & 4.6 & 4.7712 & TRN \\
\hline CHEMBL1435120 & 688721 & 4.6 & 5.2745 & TRN \\
\hline CHEMBL1394499 & 688721 & 5.4 & 4.9668 & TRN \\
\hline CHEMBL1488813 & 688721 & 4.4 & 4.9164 & TST \\
\hline CHEMBL1590397 & 688721 & 6.4 & 4.9741 & TRN \\
\hline CHEMBL1369149 & 688721 & 4.5 & 4.8698 & TRN \\
\hline CHEMBL1468530 & 688721 & 5.0 & 5.0357 & TRN \\
\hline CHEMBL1319286 & 688721 & 5.0 & 5.1007 & TRN \\
\hline CHEMBL1437667 & 688721 & 4.5 & 5.1868 & TRN \\
\hline CHEMBL1608269 & 688721 & 5.4 & 5.0835 & TRN \\
\hline CHEMBL525239 & 688721 & 4.7 & 5.2646 & TST \\
\hline CHEMBL1525948 & 688721 & 4.9 & 4.9465 & TRN \\
\hline CHEMBL85251 & 688721 & 4.5 & 5.0522 & TST \\
\hline CHEMBL1546010 & 688721 & 4.6 & 4.9403 & TST \\
\hline CHEMBL1385108 & 688721 & 5.2 & 5.0022 & TST \\
\hline CHEMBL1388983 & 688721 & 4.6 & 4.8108 & TRN \\
\hline CHEMBL1543453 & 688721 & 4.8 & 4.7985 & TRN \\
\hline CHEMBL1566983 & 688721 & 4.4 & 4.8653 & TRN \\
\hline CHEMBL1299267 & 688721 & 4.8 & 4.8996 & TRN \\
\hline CHEMBL1559267 & 688721 & 4.5 & 4.8791 & TRN \\
\hline CHEMBL1333157 & 688721 & 4.5 & 5.0134 & TRN \\
\hline CHEMBL1479822 & 688721 & 4.6 & 4.6791 & TRN \\
\hline CHEMBL1345818 & 688721 & 6.1 & 5.0558 & TST \\
\hline CHEMBL1372766 & 688721 & 4.9 & 4.8331 & TRN \\
\hline CHEMBL1334194 & 688721 & 4.6 & 5.1187 & TST \\
\hline CHEMBL1538552 & 688721 & 6.0 & 5.0402 & TRN \\
\hline CHEMBL1492009 & 688721 & 5.3 & 5.01 & TRN \\
\hline CHEMBL1406721 & 688721 & 4.6 & 4.8996 & TRN \\
\hline CHEMBL1385437 & 688721 & 4.6 & 4.7633 & TRN \\
\hline CHEMBL1443098 & 688721 & 4.6 & 4.9464 & TRN \\
\hline CHEMBL1255660 & 688721 & 4.4 & 5.2819 & TST \\
\hline CHEMBL1607407 & 688721 & 4.5 & 4.877 & TRN \\
\hline CHEMBL1491558 & 688721 & 4.8 & 4.9727 & TRN \\
\hline CHEMBL1542313 & 688721 & 4.6 & 4.875 & TRN \\
\hline
\end{tabular}




\begin{tabular}{|c|c|c|c|c|}
\hline \multicolumn{5}{|c|}{ Supplemental Table S2.txt } \\
\hline CHEMBL1348265 & 688721 & 4.5 & 5.1535 & TRN \\
\hline CHEMBL1343699 & 688721 & 4.7 & 4.9308 & TRN \\
\hline CHEMBL1527251 & 688721 & 4.5 & 4.8791 & TRN \\
\hline CHEMBL1499837 & 688721 & 4.6 & 5.0002 & TRN \\
\hline CHEMBL1496844 & 688721 & 4.5 & 4.7591 & TRN \\
\hline CHEMBL1363889 & 688721 & 4.7 & 4.7334 & TRN \\
\hline CHEMBL1200462 & 688721 & 8.699 & 5.0243 & TST \\
\hline CHEMBL1562269 & 688721 & 4.9 & 4.8603 & TRN \\
\hline CHEMBL1362638 & 688721 & 5.0 & 4.9612 & TRN \\
\hline CHEMBL1447386 & 688721 & 4.7 & 4.8913 & TRN \\
\hline CHEMBL1362314 & 688721 & 4.5 & 4.8897 & TRN \\
\hline CHEMBL1540079 & 688721 & 4.4 & 4.815 & TST \\
\hline CHEMBL1447658 & 688721 & 4.7 & 5.1933 & TRN \\
\hline CHEMBL1306078 & 688721 & 6.8 & 4.9908 & TRN \\
\hline CHEMBL1377510 & 688721 & 4.5 & 4.8883 & TST \\
\hline CHEMBL1478935 & 688721 & 5.3 & 5.0394 & TST \\
\hline CHEMBL1497863 & 688721 & 4.5 & 4.9913 & TRN \\
\hline CHEMBL1499656 & 688721 & 4.8 & 4.9867 & TRN \\
\hline CHEMBL1379445 & 688721 & 6.6 & 4.8161 & TST \\
\hline CHEMBL1388289 & 688721 & 4.5 & 5.0105 & TST \\
\hline CHEMBL1557390 & 688721 & 4.6 & 4.8888 & TRN \\
\hline CHEMBL1328850 & 688721 & 5.6 & 4.7901 & TRN \\
\hline CHEMBL1356721 & 688721 & 5.5 & 5.1385 & TRN \\
\hline CHEMBL1529320 & 688721 & 6.0 & 5.0127 & TST \\
\hline CHEMBL1369517 & 688721 & 5.2 & 4.9492 & TST \\
\hline CHEMBL1348591 & 688721 & 4.4 & 4.8256 & TRN \\
\hline CHEMBL1576787 & 688721 & 4.5 & 4.8308 & TST \\
\hline CHEMBL1310309 & 688721 & 6.0 & 4.816 & TRN \\
\hline CHEMBL1565215 & 688721 & 4.4 & 4.8691 & TRN \\
\hline CHEMBL1429185 & 688721 & 4.6 & 4.9301 & TRN \\
\hline CHEMBL1548028 & 688721 & 5.6 & 5.0572 & TRN \\
\hline CHEMBL1409923 & 688721 & 4.8 & 4.7738 & TRN \\
\hline CHEMBL1385800 & 688721 & 4.8 & 4.8831 & TRN \\
\hline CHEMBL1531362 & 688721 & 4.8 & 4.9555 & TST \\
\hline CHEMBL1559199 & 688721 & 4.5 & 4.8921 & TRN \\
\hline CHEMBL1461491 & 688721 & 5.3 & 5.1802 & TST \\
\hline CHEMBL1500242 & 688721 & 4.8 & 5.0252 & TST \\
\hline CHEMBL1376225 & 688721 & 4.8 & 4.878 & TRN \\
\hline CHEMBL1339050 & 688721 & 7.5003 & 4.8488 & TRN \\
\hline CHEMBL1573819 & 688721 & 5.2 & 4.9569 & TRN \\
\hline CHEMBL1347867 & 688721 & 5.4 & 5.1318 & TRN \\
\hline CHEMBL1411686 & 688721 & 4.4 & 4.868 & TRN \\
\hline CHEMBL1558569 & 688721 & 4.8 & 5.1017 & TRN \\
\hline CHEMBL276679 & 688721 & 5.8 & 5.1498 & TST \\
\hline CHEMBL1595337 & 688721 & 5.8 & 4.9743 & TST \\
\hline CHEMBL1402026 & 688721 & 4.6 & 5.0717 & TST \\
\hline CHEMBL1580762 & 688721 & 4.6 & 4.7421 & TRN \\
\hline CHEMBL1391424 & 688721 & 4.5 & 4.9276 & TST \\
\hline
\end{tabular}




\begin{tabular}{|c|c|c|c|c|c|}
\hline \\
\hline CHEMBL1474461 & 688721 & 4.5 & 5.0791 & TRN & \\
\hline CHEMBL266459 & 688721 & 4.4 & 5.0256 & TST & \\
\hline CHEMBL1441404 & 688721 & 4.9 & 4.83899 & 99999999995 & TRN \\
\hline CHEMBL1606660 & 688721 & 4.6 & 5.1957 & TRN & \\
\hline CHEMBL1475805 & 688721 & 5.8 & 5.3009 & TRN & \\
\hline CHEMBL1551284 & 688721 & 4.8 & 5.231 & TRN & \\
\hline CHEMBL1412842 & 688721 & 6.0 & 4.9517 & TRN & \\
\hline CHEMBL1522974 & 688721 & 4.4 & 4.8066 & TRN & \\
\hline CHEMBL1561421 & 688721 & 4.6 & 4.7554 & TST & \\
\hline CHEMBL1526284 & 688721 & 4.5 & 5.0996 & TST & \\
\hline CHEMBL1351630 & 688721 & 5.0 & 4.8295 & TRN & \\
\hline CHEMBL1496479 & 688721 & 4.5 & 4.9787 & TRN & \\
\hline CHEMBL1459097 & 688721 & 4.7 & 4.7552 & TRN & \\
\hline CHEMBL3199819 & 688721 & 4.6 & 5.0991 & TRN & \\
\hline CHEMBL1361083 & 688721 & 4.9 & 4.864 & TST & \\
\hline CHEMBL1550830 & 688721 & 4.5 & 4.9058 & TRN & \\
\hline CHEMBL1453764 & 688721 & 4.5 & 5.0523 & TRN & \\
\hline CHEMBL1435158 & 688721 & 5.4 & 5.4193 & TST & \\
\hline CHEMBL1401204 & 688721 & 4.9 & 4.9562 & TST & \\
\hline CHEMBL1485295 & 688721 & 4.4 & 5.0229 & TRN & \\
\hline CHEMBL1507555 & 688721 & 4.5 & 5.0603 & TST & \\
\hline CHEMBL1330947 & 688721 & 4.6 & 4.8677 & TRN & \\
\hline CHEMBL1581857 & 688721 & 5.2 & 5.0166 & TRN & \\
\hline CHEMBL1430166 & 688721 & 4.9 & 4.9283 & TRN & \\
\hline CHEMBL1334657 & 688721 & 4.9 & 5.1837 & TRN & \\
\hline CHEMBL1411999 & 688721 & 5.4 & 4.8972 & TRN & \\
\hline CHEMBL1383513 & 688721 & 5.2 & 4.9667 & TRN & \\
\hline CHEMBL1465737 & 688721 & 4.9 & 4.8713 & TRN & \\
\hline CHEMBL1507733 & 688721 & 5.2 & 4.9723 & TRN & \\
\hline CHEMBL1518469 & 688721 & 4.8 & 5.0402 & TST & \\
\hline CHEMBL1346548 & 688721 & 4.5 & 4.9622 & TRN & \\
\hline CHEMBL1325576 & 688721 & 4.9 & 4.8743 & TRN & \\
\hline CHEMBL1428273 & 688721 & 8.301 & 5.0222 & TST & \\
\hline CHEMBL1428970 & 688721 & 4.5 & 4.9933 & TRN & \\
\hline CHEMBL1387022 & 688721 & 4.9 & 5.0525 & TRN & \\
\hline CHEMBL1432721 & 688721 & 4.9 & 4.8025 & TRN & \\
\hline CHEMBL1595629 & 688721 & 4.6 & 4.8277 & TRN & \\
\hline CHEMBL1372193 & 688721 & 4.8 & 4.9151 & TRN & \\
\hline CHEMBL1529060 & 688721 & 5.2 & 4.9636 & TST & \\
\hline CHEMBL1419017 & 688721 & 4.5 & 4.8719 & TRN & \\
\hline CHEMBL1398114 & 688721 & 4.8 & 5.1629 & TST & \\
\hline CHEMBL1528477 & 688721 & 5.6 & 4.9597 & TST & \\
\hline CHEMBL1559522 & 688721 & 5.2 & 4.8297 & TRN & \\
\hline CHEMBL1527563 & 688721 & 5.4 & 4.8577 & TRN & \\
\hline CHEMBL1341122 & 688721 & 4.5 & 4.9031 & TST & \\
\hline CHEMBL1327690 & 688721 & 5.1 & 4.8422 & TRN & \\
\hline CHEMBL1547130 & 688721 & 5.5 & 4.773 & TRN & \\
\hline CHEMBL1584254 & 688721 & 4.6 & 4.8903 & TRN & \\
\hline
\end{tabular}




\begin{tabular}{|c|c|c|c|c|c|}
\hline & & \multicolumn{4}{|c|}{ Supplemental Table S2.txt } \\
\hline CHEMBL1358252 & 688721 & 5.5 & \multicolumn{2}{|c|}{5.1979999999999995} & TRN \\
\hline CHEMBL1381499 & 688721 & 5.2 & 5.0576 & TRN & \\
\hline CHEMBL1474890 & 688721 & 5.9 & 4.9025 & TRN & \\
\hline CHEMBL1329204 & 688721 & 4.6 & 5.001 & TRN & \\
\hline CHEMBL1490835 & 688721 & 4.7 & 4.9328 & TRN & \\
\hline CHEMBL1485835 & 688721 & 4.6 & 4.9718 & TST & \\
\hline CHEMBL1602276 & 688721 & 7.8013 & 5.0228 & TST & \\
\hline CHEMBL1345974 & 688721 & 4.7 & 4.9375 & TST & \\
\hline CHEMBL1612527 & 688721 & 4.8 & 4.7512 & TRN & \\
\hline CHEMBL1479887 & 688721 & 4.4 & 4.8325 & TRN & \\
\hline CHEMBL1462547 & 688721 & 4.5 & 4.9477 & TRN & \\
\hline CHEMBL1399218 & 688721 & 4.8 & 4.9582 & TRN & \\
\hline CHEMBL1497999 & 688721 & 5.0 & 4.8185 & TRN & \\
\hline CHEMBL1509433 & 688721 & 4.9 & 5.0128 & TRN & \\
\hline CHEMBL1529932 & 688721 & 5.4 & 4.8745 & TST & \\
\hline CHEMBL1234848 & 688721 & 6.0 & 5.2838 & TST & \\
\hline CHEMBL1496691 & 688721 & 5.5 & 5.2096 & TRN & \\
\hline CHEMBL1571088 & 688721 & 4.6 & 5.0623 & TST & \\
\hline CHEMBL 3191505 & 688721 & 5.3 & 5.0439 & TST & \\
\hline CHEMBL1523123 & 688721 & 4.8 & 5.0083 & TRN & \\
\hline CHEMBL1312114 & 688721 & 4.7 & 5.0123 & TRN & \\
\hline CHEMBL1598840 & 688721 & 5.1 & 4.9558 & TST & \\
\hline CHEMBL1530586 & 688721 & 4.4 & 4.851 & TST & \\
\hline CHEMBL 3190014 & 688721 & 4.6 & 4.8953 & TST & \\
\hline CHEMBL1388125 & 688721 & 6.4 & 4.745 & TRN & \\
\hline CHEMBL1386925 & 688721 & 4.4 & 5.0675 & TST & \\
\hline CHEMBL1405043 & 688721 & 5.2 & 4.9087 & TRN & \\
\hline CHEMBL1477411 & 688721 & 4.7 & 5.06 & TRN & \\
\hline CHEMBL1602620 & 688721 & 7.8996 & 4.9849 & TRN & \\
\hline CHEMBL1578233 & 688721 & 4.6 & 4.88399 & 99999999995 & TRN \\
\hline CHEMBL1605916 & 688721 & 6.8 & 5.3837 & TST & \\
\hline CHEMBL1574552 & 688721 & 5.3 & 5.3422 & TRN & \\
\hline CHEMBL1554659 & 688721 & 4.6 & 5.1829 & TRN & \\
\hline CHEMBL1366313 & 688721 & 4.7 & 4.9451 & TST & \\
\hline CHEMBL1533537 & 688721 & 4.8 & 4.994 & TRN & \\
\hline CHEMBL1305911 & 688721 & 4.6 & 4.9386 & TRN & \\
\hline CHEMBL1390050 & 688721 & 4.6 & 4.8759 & TRN & \\
\hline CHEMBL1590259 & 688721 & 5.5 & 5.2242 & TRN & \\
\hline CHEMBL1531750 & 688721 & 4.4 & 4.8248 & TRN & \\
\hline CHEMBL3196967 & 688721 & 5.8 & 4.9273 & TRN & \\
\hline CHEMBL1412483 & 688721 & 4.8 & 4.9322 & TRN & \\
\hline CHEMBL1326130 & 688721 & 4.6 & 4.8776 & TST & \\
\hline CHEMBL1423123 & 688721 & 4.8 & 4.8302 & TST & \\
\hline CHEMBL1561273 & 688721 & 4.4 & 4.8838 & TRN & \\
\hline CHEMBL3189575 & 688721 & 4.7 & 5.1336 & TST & \\
\hline CHEMBL1561366 & 688721 & 4.6 & 4.883 & TRN & \\
\hline CHEMBL1465671 & 688721 & 5.4 & 5.1341 & TST & \\
\hline CHEMBL1437056 & 688721 & 5.3 & 4.8804 & TRN & \\
\hline
\end{tabular}




\begin{tabular}{|c|c|c|c|c|}
\hline & & & Supplement & \\
\hline CHEMBL563294 & 688721 & 4.6 & 4.9411 & TRN \\
\hline CHEMBL1450744 & 688721 & 4.8 & 4.8062 & TRN \\
\hline CHEMBL1531471 & 688721 & 4.4 & 5.0418 & TRN \\
\hline CHEMBL1575123 & 688721 & 6.9 & 5.0214 & TRN \\
\hline CHEMBL1397558 & 688721 & 4.8 & 5.1132 & TRN \\
\hline CHEMBL1342481 & 688721 & 4.7 & 4.7964 & TRN \\
\hline CHEMBL1524355 & 688721 & 4.7 & 4.9035 & TRN \\
\hline CHEMBL1505359 & 688721 & 4.5 & 4.8602 & TRN \\
\hline CHEMBL1492779 & 688721 & 4.4 & 5.1135 & TRN \\
\hline CHEMBL1552286 & 688721 & 4.7 & 4.8764 & TRN \\
\hline CHEMBL1595467 & 688721 & 5.2 & 4.6756 & TRN \\
\hline CHEMBL1336496 & 688721 & 4.6 & 4.8776 & TRN \\
\hline CHEMBL1422712 & 688721 & 5.5 & 4.8654 & TRN \\
\hline CHEMBL1512434 & 688721 & 6.0 & 5.1211 & TRN \\
\hline CHEMBL1526429 & 688721 & 6.0 & 5.0646 & TRN \\
\hline CHEMBL1312972 & 688721 & 4.7 & 4.9964 & TRN \\
\hline CHEMBL1504385 & 688721 & 5.1 & 4.9492 & TRN \\
\hline CHEMBL1533923 & 688721 & 6.1 & 5.1082 & TRN \\
\hline CHEMBL1537512 & 688721 & 4.4 & 4.9516 & TRN \\
\hline CHEMBL1390465 & 688721 & 4.5 & 4.8166 & TRN \\
\hline CHEMBL1454689 & 688721 & 4.6 & 4.9247 & TST \\
\hline CHEMBL1516772 & 688721 & 4.6 & 4.9215 & TRN \\
\hline CHEMBL1393750 & 688721 & 4.4 & 4.851 & TRN \\
\hline CHEMBL1431748 & 688721 & 4.7 & 4.882 & TRN \\
\hline CHEMBL1369089 & 688721 & 5.3 & 5.0023 & TST \\
\hline CHEMBL1369486 & 688721 & 4.5 & 4.7999 & TRN \\
\hline CHEMBL1489460 & 688721 & 4.7 & 4.8243 & TRN \\
\hline CHEMBL1348974 & 688721 & 4.4 & 4.9604 & TRN \\
\hline CHEMBL1502475 & 688721 & 5.5 & 5.1135 & TRN \\
\hline CHEMBL1360723 & 688721 & 4.5 & 4.9555 & TRN \\
\hline CHEMBL1393650 & 688721 & 5.9 & 4.901 & TRN \\
\hline CHEMBL1528840 & 688721 & 4.6 & 4.8296 & TRN \\
\hline CHEMBL1307565 & 688721 & 5.2 & 5.1771 & TRN \\
\hline CHEMBL1333773 & 688721 & 5.1 & 4.875 & TRN \\
\hline CHEMBL1555156 & 688721 & 5.4 & 5.0594 & TRN \\
\hline CHEMBL1340651 & 688721 & 5.2 & 5.053 & TRN \\
\hline CHEMBL1503472 & 688721 & 4.4 & 4.8783 & TRN \\
\hline CHEMBL1558891 & 688721 & 4.4 & 4.7641 & TST \\
\hline CHEMBL1611297 & 688721 & 4.6 & 5.0237 & TRN \\
\hline CHEMBL1417004 & 688721 & 5.2 & 4.9473 & TRN \\
\hline CHEMBL1257234 & 688721 & 4.6 & 4.7171 & TRN \\
\hline CHEMBL1505637 & 688721 & 4.5 & 5.1624 & TRN \\
\hline CHEMBL1609115 & 688721 & 5.6 & 5.1079 & TRN \\
\hline CHEMBL1402457 & 688721 & 4.4 & 4.9673 & TRN \\
\hline CHEMBL1407269 & 688721 & 5.5 & 5.1497 & TST \\
\hline CHEMBL1531499 & 688721 & 6.0 & 5.3696 & TST \\
\hline CHEMBL1388969 & 688721 & 5.0 & 4.8151 & TRN \\
\hline CHEMBL1453144 & 688721 & 5.4 & 5.0949 & TRN \\
\hline
\end{tabular}




\begin{tabular}{|c|c|c|c|c|}
\hline \multicolumn{5}{|c|}{ Supplemental Tab } \\
\hline CHEMBL1329084 & 688721 & 6.8 & 4.9574 & TRN \\
\hline CHEMBL1310293 & 688721 & 4.5 & 4.8549 & TRN \\
\hline CHEMBL1505375 & 688721 & 5.0 & 5.1305 & TRN \\
\hline CHEMBL1343239 & 688721 & 4.5 & 4.6827 & TRN \\
\hline CHEMBL1483679 & 688721 & 4.8 & 4.784 & TRN \\
\hline CHEMBL1317913 & 688721 & 4.9 & 5.2126 & TRN \\
\hline CHEMBL1550728 & 688721 & 4.5 & 4.9968 & TRN \\
\hline CHEMBL1459963 & 688721 & 4.5 & 4.9875 & TST \\
\hline CHEMBL1559680 & 688721 & 5.2 & 5.0464 & TST \\
\hline CHEMBL1517022 & 688721 & 5.2 & 5.0323 & TRN \\
\hline CHEMBL 1378383 & 688721 & 5.0 & 4.9706 & TRN \\
\hline CHEMBL1490528 & 688721 & 4.5 & 5.1736 & TRN \\
\hline CHEMBL1358122 & 688721 & 5.9 & 5.0791 & TRN \\
\hline CHEMBL1300521 & 688721 & 5.0 & 4.7507 & TRN \\
\hline CHEMBL1533785 & 688721 & 4.6 & 4.8481 & TRN \\
\hline CHEMBL 1497987 & 688721 & 4.8 & 5.3596 & TST \\
\hline CHEMBL1337547 & 688721 & 4.5 & 5.0188 & TRN \\
\hline CHEMBL1449197 & 688721 & 5.2 & 4.9396 & TRN \\
\hline CHEMBL1549200 & 688721 & 5.4 & 4.9675 & TRN \\
\hline CHEMBL1499269 & 688721 & 5.2 & 5.0788 & TST \\
\hline CHEMBL3207598 & 688721 & 5.2 & 4.9203 & TRN \\
\hline CHEMBL1490895 & 688721 & 6.3 & 5.1865 & TRN \\
\hline CHEMBL1483350 & 688721 & 4.6 & 4.8801 & TRN \\
\hline CHEMBL1450576 & 688721 & 5.2 & 4.7534 & TRN \\
\hline CHEMBL1301620 & 688721 & 4.5 & 4.998 & TRN \\
\hline CHEMBL1585118 & 688721 & 4.5 & 5.0228 & TRN \\
\hline CHEMBL1548458 & 688721 & 4.4 & 4.8282 & TRN \\
\hline CHEMBL1531727 & 688721 & 5.2 & 5.0593 & TST \\
\hline CHEMBL1566602 & 688721 & 4.4 & 4.8534 & TRN \\
\hline CHEMBL1574575 & 688721 & 4.4 & 4.9479 & TRN \\
\hline CHEMBL1588850 & 688721 & 4.4 & 5.0512 & TRN \\
\hline CHEMBL1472104 & 688721 & 4.8 & 5.0687 & TRN \\
\hline CHEMBL1568408 & 688721 & 4.8 & 4.789 & TRN \\
\hline CHEMBL1488216 & 688721 & 5.2 & 4.6526 & TRN \\
\hline CHEMBL1422470 & 688721 & 4.5 & 4.805 & TRN \\
\hline CHEMBL1330293 & 688721 & 4.5 & 4.9733 & TRN \\
\hline CHEMBL1372974 & 688721 & 4.6 & 5.0359 & TRN \\
\hline CHEMBL1588072 & 688721 & 4.4 & 4.9215 & TST \\
\hline CHEMBL1400043 & 688721 & 5.4 & 5.0759 & TRN \\
\hline CHEMBL1545766 & 688721 & 6.0 & 4.9967 & TRN \\
\hline CHEMBL1587663 & 688721 & 4.5 & 4.8854 & TRN \\
\hline CHEMBL1452282 & 688721 & 4.6 & 4.7941 & TRN \\
\hline CHEMBL 1300020 & 688721 & 5.0 & 4.9814 & TST \\
\hline CHEMBL1449581 & 688721 & 4.6 & 4.8719 & TRN \\
\hline CHEMBL18840 & 688721 & 5.2 & 5.2052 & TRN \\
\hline CHEMBL1566790 & 688721 & 4.8 & 4.876 & TRN \\
\hline CHEMBL1311728 & 688721 & 4.4 & 5.02 & TRN \\
\hline CHEMBL1534126 & 688721 & 4.5 & 4.8699 & TST \\
\hline
\end{tabular}




\begin{tabular}{|c|c|c|c|c|c|}
\hline \\
\hline CHEMBL1356336 & 688721 & 6.6 & 5.1321 & TRN & \\
\hline CHEMBL1431486 & 688721 & 5.2 & 4.9811 & TRN & \\
\hline CHEMBL1347594 & 688721 & 4.9 & 4.8577 & TRN & \\
\hline CHEMBL1302716 & 688721 & 4.4 & 4.9464 & TRN & \\
\hline CHEMBL1504242 & 688721 & 4.8 & 4.9134 & TRN & \\
\hline CHEMBL1419399 & 688721 & 5.2 & 4.8378 & TRN & \\
\hline CHEMBL1462804 & 688721 & 5.2 & 4.7306 & TRN & \\
\hline CHEMBL1356870 & 688721 & 6.0 & 5.0034 & TRN & \\
\hline CHEMBL1564361 & 688721 & 4.8 & 4.9795 & TST & \\
\hline CHEMBL1438188 & 688721 & 4.7 & 4.7965 & TRN & \\
\hline CHEMBL1583513 & 688721 & 4.6 & 4.8827 & TRN & \\
\hline CHEMBL1455514 & 688721 & 5.2 & 4.9098 & TRN & \\
\hline CHEMBL266158 & 688721 & 4.8 & 5.1344 & TST & \\
\hline CHEMBL3208361 & 688721 & 5.9 & 4.8337 & TRN & \\
\hline CHEMBL1393021 & 688721 & 4.4 & 4.8983 & TST & \\
\hline CHEMBL1362853 & 688721 & 4.4 & 4.8845 & TST & \\
\hline CHEMBL1320287 & 688721 & 5.2 & 5.01399 & 9999999999 & TRN \\
\hline CHEMBL1310750 & 688721 & 4.6 & 5.0335 & TST & \\
\hline CHEMBL1528479 & 688721 & 4.4 & 5.1306 & TRN & \\
\hline CHEMBL29726 & 688721 & 4.4 & 5.3324 & TST & \\
\hline CHEMBL1581465 & 688721 & 4.5 & 4.9242 & TRN & \\
\hline CHEMBL1406024 & 688721 & 4.8 & 4.9739 & TRN & \\
\hline CHEMBL1460235 & 688721 & 4.6 & 5.11100 & 0000000001 & TRN \\
\hline CHEMBL1358033 & 688721 & 4.4 & 5.0541 & TRN & \\
\hline CHEMBL1391856 & 688721 & 6.7001 & 5.1642 & TST & \\
\hline CHEMBL1432734 & 688721 & 4.4 & 4.8184 & TRN & \\
\hline CHEMBL1607475 & 688721 & 4.8 & 4.9764 & TRN & \\
\hline CHEMBL82224 & 688721 & 6.5 & 4.9785 & TST & \\
\hline CHEMBL1442997 & 688721 & 4.4 & 5.0985 & TRN & \\
\hline CHEMBL1437325 & 688721 & 4.7 & 5.0499 & TRN & \\
\hline CHEMBL1596379 & 688721 & 5.2 & 4.928 & TRN & \\
\hline CHEMBL1412915 & 688721 & 4.5 & 4.789 & TRN & \\
\hline CHEMBL1584435 & 688721 & 5.8 & 4.9027 & TST & \\
\hline CHEMBL1342590 & 688721 & 4.4 & 4.9567 & TRN & \\
\hline CHEMBL1346885 & 688721 & 4.6 & 4.9339 & TRN & \\
\hline CHEMBL1485377 & 688721 & 4.6 & 4.94300 & 00000000005 & TRN \\
\hline CHEMBL1441608 & 688721 & 4.5 & 5.1959 & TRN & \\
\hline CHEMBL1314371 & 688721 & 5.6 & 5.0708 & TRN & \\
\hline CHEMBL1348753 & 688721 & 5.3 & 4.9241 & TST & \\
\hline CHEMBL123 & 688721 & 4.6 & 4.9899 & TST & \\
\hline CHEMBL1351680 & 688721 & 4.7 & 5.0358 & TRN & \\
\hline CHEMBL1305728 & 688721 & 5.7 & 4.937 & TST & \\
\hline CHEMBL1588088 & 688721 & 5.0 & 4.9144 & TST & \\
\hline CHEMBL1482982 & 688721 & 4.5 & 4.8672 & TRN & \\
\hline CHEMBL323356 & 688721 & 4.4 & 4.9345 & TST & \\
\hline CHEMBL1447188 & 688721 & 4.8 & 4.7385 & TRN & \\
\hline CHEMBL1457774 & 688721 & 4.6 & 4.9371 & TRN & \\
\hline CHEMBL1487346 & 688721 & 4.9 & 5.0063 & TRN & \\
\hline
\end{tabular}




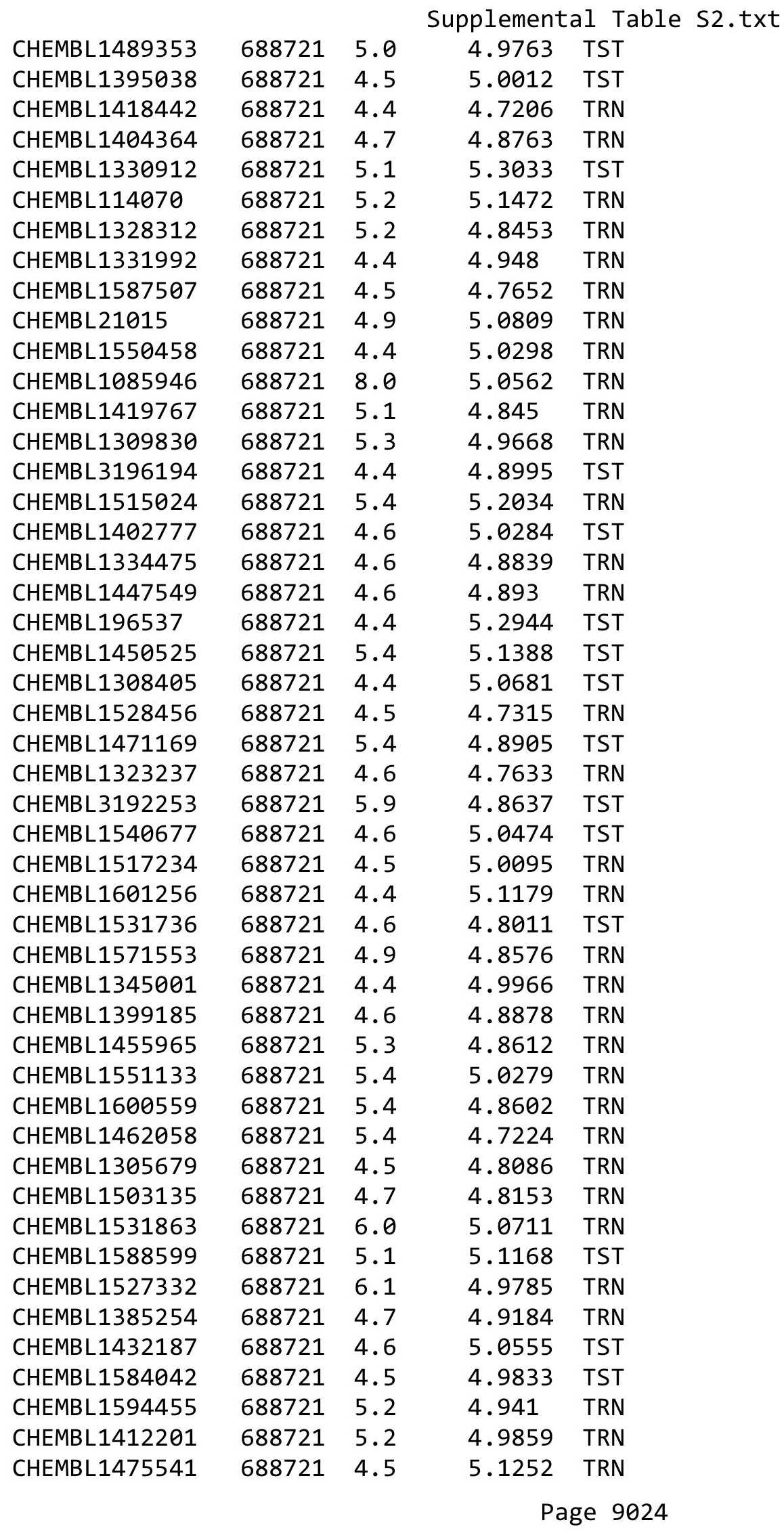




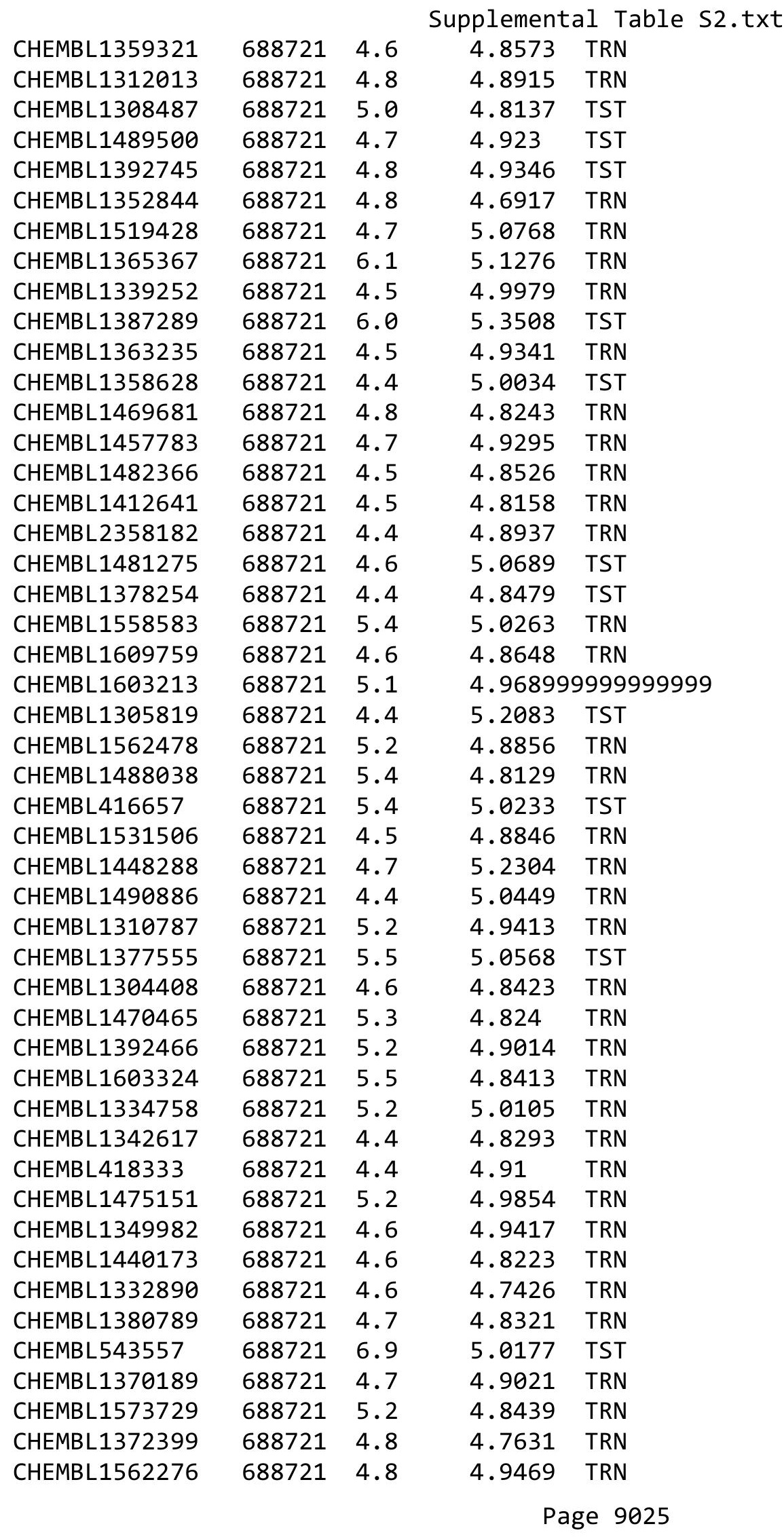




\begin{tabular}{|c|c|c|c|c|c|}
\hline & & \multicolumn{4}{|c|}{ Supplemental Table S2.txt } \\
\hline CHEMBL1310188 & 688721 & 5.1 & 4.9663 & TRN & \\
\hline CHEMBL1546642 & 688721 & 4.5 & 5.0381 & TRN & \\
\hline CHEMBL1432802 & 688721 & 5.0 & 5.0382 & TRN & \\
\hline CHEMBL1605192 & 688721 & 5.0 & 4.8566 & TST & \\
\hline CHEMBL1313141 & 688721 & 4.5 & 5.0568 & TRN & \\
\hline CHEMBL1321627 & 688721 & 4.8 & 4.8329 & TRN & \\
\hline CHEMBL453019 & 688721 & 4.9 & 4.9451 & TST & \\
\hline CHEMBL1502228 & 688721 & 4.4 & 4.7561 & TST & \\
\hline CHEMBL1458299 & 688721 & 4.7 & 5.0867 & TST & \\
\hline CHEMBL545523 & 688721 & 4.6 & 5.0193 & TRN & \\
\hline CHEMBL1305371 & 688721 & 6.0 & 4.9512 & TRN & \\
\hline CHEMBL1256024 & 688721 & 5.2 & 5.3418 & TST & \\
\hline CHEMBL1502549 & 688721 & 5.1 & 4.8372 & TRN & \\
\hline CHEMBL1485361 & 688721 & 4.9 & 5.1411 & TRN & \\
\hline CHEMBL1415180 & 688721 & 4.7 & 5.2446 & TRN & \\
\hline CHEMBL1392776 & 688721 & 4.5 & 4.9036 & TRN & \\
\hline CHEMBL1335327 & 688721 & 4.7 & 4.8726 & TRN & \\
\hline CHEMBL1391230 & 688721 & 4.7 & 4.7985 & TRN & \\
\hline CHEMBL1498248 & 688721 & 5.6 & 4.8496 & TRN & \\
\hline CHEMBL1576580 & 688721 & 4.5 & 4.8635 & TRN & \\
\hline CHEMBL1598164 & 688721 & 5.1 & 4.8834 & TRN & \\
\hline CHEMBL1605942 & 688721 & 4.7 & 4.8582 & TRN & \\
\hline CHEMBL1525346 & 688721 & 4.5 & 4.9501 & TRN & \\
\hline CHEMBL1411953 & 688721 & 5.5 & 4.8545 & TRN & \\
\hline CHEMBL1474318 & 688721 & 4.4 & 5.2091 & TRN & \\
\hline CHEMBL1392280 & 688721 & 5.5 & 5.0602 & TRN & \\
\hline CHEMBL1556175 & 688721 & 4.8 & 4.9081 & TRN & \\
\hline CHEMBL1408404 & 688721 & 4.5 & 4.8805 & TST & \\
\hline CHEMBL1422946 & 688721 & 4.4 & 5.048 & TST & \\
\hline CHEMBL1364030 & 688721 & 4.6 & 4.8243 & TRN & \\
\hline CHEMBL1378258 & 688721 & 4.7 & 4.8097 & TRN & \\
\hline CHEMBL1606983 & 688721 & 4.9 & 5.0802 & TRN & \\
\hline CHEMBL1420993 & 688721 & 5.2 & 4.8406 & TRN & \\
\hline CHEMBL491909 & 688721 & 4.6 & 5.1461 & TRN & \\
\hline CHEMBL1544119 & 688721 & 4.9 & 4.7444 & TRN & \\
\hline CHEMBL1578356 & 688721 & 5.7 & 4.96899 & 9999999999 & TRN \\
\hline CHEMBL1605078 & 688721 & 4.5 & 4.832 & TRN & \\
\hline CHEMBL1480270 & 688721 & 5.4 & 5.1191 & TRN & \\
\hline CHEMBL1524009 & 688721 & 4.5 & 4.9265 & TRN & \\
\hline CHEMBL1491068 & 688721 & 4.7 & 4.8329 & TRN & \\
\hline CHEMBL1432948 & 688721 & 4.4 & 4.8048 & TRN & \\
\hline CHEMBL1498944 & 688721 & 4.4 & 5.0202 & TRN & \\
\hline CHEMBL1570622 & 688721 & 4.4 & 5.0521 & TRN & \\
\hline CHEMBL1413972 & 688721 & 5.4 & 4.8153 & TRN & \\
\hline CHEMBL1539840 & 688721 & 5.4 & 4.8437 & TRN & \\
\hline CHEMBL1507725 & 688721 & 4.4 & 4.8946 & TRN & \\
\hline CHEMBL1556815 & 688721 & 4.8 & 4.9213 & TRN & \\
\hline CHEMBL1327752 & 688721 & 4.4 & 5.0779 & TRN & \\
\hline
\end{tabular}




\begin{tabular}{|c|c|c|c|c|}
\hline & & & & $a \perp 1 a$ \\
\hline CHEMBL1333370 & 688721 & 6.3 & 4.9414 & TRN \\
\hline CHEMBL1454049 & 688721 & 4.9 & 4.916 & TRN \\
\hline CHEMBL1514517 & 688721 & 4.4 & 5.1797 & TRN \\
\hline CHEMBL1525960 & 688721 & 4.9 & 4.9562 & TRN \\
\hline CHEMBL1509305 & 688721 & 5.1 & 4.7478 & TRN \\
\hline CHEMBL1448617 & 688721 & 5.5 & 4.9597 & TRN \\
\hline CHEMBL1344383 & 688721 & 5.4 & 4.8199 & TST \\
\hline CHEMBL1462871 & 688721 & 5.8 & 4.8533 & TRN \\
\hline CHEMBL1608228 & 688721 & 4.5 & 5.0168 & TRN \\
\hline CHEMBL1429383 & 688721 & 4.4 & 4.9452 & TRN \\
\hline CHEMBL1446130 & 688721 & 4.6 & 4.9026 & TRN \\
\hline CHEMBL1579029 & 688721 & 5.2 & 5.0912 & TST \\
\hline CHEMBL1568782 & 688721 & 4.4 & 4.8108 & TRN \\
\hline CHEMBL1415399 & 688721 & 4.7 & 4.8003 & TRN \\
\hline CHEMBL45281 & 688721 & 5.8 & 5.0355 & TST \\
\hline CHEMBL1508135 & 688721 & 4.4 & 4.8473 & TRN \\
\hline CHEMBL1468477 & 688721 & 4.6 & 5.0147 & TRN \\
\hline CHEMBL1471414 & 688721 & 4.6 & 5.005 & TST \\
\hline CHEMBL7033 & 688721 & 6.1 & 4.899 & TRN \\
\hline CHEMBL1456688 & 688721 & 5.0 & 5.0374 & TRN \\
\hline CHEMBL1577877 & 688721 & 4.4 & 4.8321 & TRN \\
\hline CHEMBL1335122 & 688721 & 5.4 & 5.1197 & TST \\
\hline CHEMBL1571387 & 688721 & 5.5 & 4.8492 & TRN \\
\hline CHEMBL1388832 & 688721 & 5.4 & 5.0429 & TRN \\
\hline CHEMBL1587216 & 688721 & 4.5 & 4.9152 & TST \\
\hline CHEMBL1583952 & 688721 & 6.1 & 4.9111 & TST \\
\hline CHEMBL1557436 & 688721 & 4.4 & 5.0502 & TST \\
\hline CHEMBL1386674 & 688721 & 4.7 & 4.8477 & TST \\
\hline CHEMBL1714574 & 688721 & 4.8 & 5.1906 & TST \\
\hline CHEMBL1605493 & 688721 & 4.9 & 5.0609 & TST \\
\hline CHEMBL1483215 & 688721 & 4.6 & 4.6383 & TRN \\
\hline CHEMBL1353727 & 688721 & 4.4 & 4.9688 & TRN \\
\hline CHEMBL1313013 & 688721 & 4.5 & 4.7611 & TRN \\
\hline CHEMBL1570953 & 688721 & 5.2 & 5.1049 & TRN \\
\hline CHEMBL1361267 & 688721 & 4.4 & 5.1329 & TRN \\
\hline CHEMBL1369034 & 688721 & 4.7 & 4.8879 & TRN \\
\hline CHEMBL1578963 & 688721 & 4.4 & 5.1511 & TST \\
\hline CHEMBL1529618 & 688721 & 5.4 & 5.1047 & TST \\
\hline CHEMBL1437804 & 688721 & 4.8 & 5.1672 & TST \\
\hline CHEMBL1488221 & 688721 & 4.9 & 5.1128 & TRN \\
\hline CHEMBL1605778 & 688721 & 4.6 & 4.8026 & TRN \\
\hline CHEMBL1437046 & 688721 & 5.5 & 5.1344 & TRN \\
\hline CHEMBL1367842 & 688721 & 4.7 & 4.9369 & TST \\
\hline CHEMBL1200488 & 688721 & 4.7 & 5.2794 & TRN \\
\hline CHEMBL1369831 & 688721 & 4.4 & 4.9704 & TRN \\
\hline CHEMBL1446593 & 688721 & 4.6 & 4.9151 & TRN \\
\hline CHEMBL1409619 & 688721 & 4.4 & 4.7018 & TST \\
\hline CHEMBL1525434 & 688721 & 4.6 & 4.7915 & TRN \\
\hline
\end{tabular}




\begin{tabular}{|c|c|c|c|c|c|}
\hline \multicolumn{6}{|c|}{ Supplemental Table s2.txt } \\
\hline CHEMBL1463041 & 688721 & 4.6 & 4.8313 & TST & \\
\hline CHEMBL1431655 & 688721 & 4.6 & 5.0333 & TST & \\
\hline CHEMBL1312719 & 688721 & 4.6 & 4.9739 & TRN & \\
\hline CHEMBL1552133 & 688721 & 8.301 & 5.4124 & TRN & \\
\hline CHEMBL1401352 & 688721 & 5.2 & 5.0314 & TRN & \\
\hline CHEMBL1572490 & 688721 & 4.4 & 5.0002 & TRN & \\
\hline CHEMBL309917 & 688721 & 4.4 & 5.1015 & TRN & \\
\hline CHEMBL1342654 & 688721 & 4.7 & 4.7215 & TRN & \\
\hline CHEMBL1570558 & 688721 & 7.1002 & 4.9654 & TRN & \\
\hline CHEMBL1608360 & 688721 & 4.8 & 5.0263 & TST & \\
\hline CHEMBL530115 & 688721 & 4.4 & 4.904 & TRN & \\
\hline CHEMBL1346059 & 688721 & 5.3 & 4.9004 & TRN & \\
\hline CHEMBL1402708 & 688721 & 4.9 & 4.8507 & TRN & \\
\hline CHEMBL1444033 & 688721 & 7.3002 & 5.1701 & TRN & \\
\hline CHEMBL1488374 & 688721 & 4.6 & 4.8137 & TRN & \\
\hline CHEMBL1422320 & 688721 & 4.9 & 4.8718 & TRN & \\
\hline CHEMBL1372392 & 688721 & 4.7 & 4.8425 & TST & \\
\hline CHEMBL1588463 & 688721 & 4.6 & 4.7491 & TST & \\
\hline CHEMBL1486291 & 688721 & 5.1 & 5.0559 & TST & \\
\hline CHEMBL1597889 & 688721 & 4.6 & 5.0111 & TRN & \\
\hline CHEMBL1585845 & 688721 & 5.5 & 4.6671 & TRN & \\
\hline CHEMBL1333153 & 688721 & 4.4 & 4.976 & TRN & \\
\hline CHEMBL1580240 & 688721 & 4.9 & 4.8389 & TRN & \\
\hline CHEMBL1479028 & 688721 & 5.2 & 4.9728 & TRN & \\
\hline CHEMBL1525784 & 688721 & 5.0 & 4.8646 & TRN & \\
\hline CHEMBL1577977 & 688721 & 4.4 & 4.7154 & TRN & \\
\hline CHEMBL1321055 & 688721 & 4.9 & 4.8353 & TRN & \\
\hline CHEMBL1451622 & 688721 & 4.5 & 4.9659 & TRN & \\
\hline CHEMBL1596825 & 688721 & 5.5 & 5.0308 & TRN & \\
\hline CHEMBL1591107 & 688721 & 4.8 & 4.9034 & TRN & \\
\hline CHEMBL1455212 & 688721 & 5.2 & 4.922 & TRN & \\
\hline CHEMBL1583859 & 688721 & 4.4 & 5.01699 & 99999999995 & TRN \\
\hline CHEMBL1612890 & 688721 & 4.6 & 4.8495 & TRN & \\
\hline CHEMBL1351321 & 688721 & 4.8 & 4.8487 & TRN & \\
\hline CHEMBL1530061 & 688721 & 4.7 & 4.9177 & TRN & \\
\hline CHEMBL1375780 & 688721 & 5.9 & 5.1814 & TST & \\
\hline CHEMBL1591779 & 688721 & 5.3 & 4.895 & TRN & \\
\hline CHEMBL1462315 & 688721 & 4.5 & 4.9983 & TST & \\
\hline CHEMBL1338864 & 688721 & 5.3 & 4.7672 & TRN & \\
\hline CHEMBL1521269 & 688721 & 4.4 & 4.7589 & TRN & \\
\hline CHEMBL1508507 & 688721 & 4.9 & 4.9779 & TST & \\
\hline CHEMBL1604679 & 688721 & 4.8 & 4.7864 & TRN & \\
\hline CHEMBL1544055 & 688721 & 4.6 & 4.9434 & TRN & \\
\hline CHEMBL1494695 & 688721 & 4.5 & 5.0162 & TRN & \\
\hline CHEMBL1607228 & 688721 & 6.0 & 5.0833 & TRN & \\
\hline CHEMBL1427201 & 688721 & 4.5 & 4.8784 & TRN & \\
\hline CHEMBL1544334 & 688721 & 5.6 & 4.8221 & TRN & \\
\hline CHEMBL1345018 & 688721 & 4.5 & 4.8159 & TST & \\
\hline
\end{tabular}




\begin{tabular}{|c|c|c|c|c|}
\hline & & & plemen & \\
\hline CHEMBL1535429 & 688721 & 4.8 & 4.8415 & TRN \\
\hline CHEMBL1492840 & 688721 & 4.6 & 4.9025 & TST \\
\hline CHEMBL1520589 & 688721 & 4.6 & 4.9233 & TST \\
\hline CHEMBL1421453 & 688721 & 4.5 & 4.8967 & TRN \\
\hline CHEMBL1609896 & 688721 & 4.8 & 5.1812 & TRN \\
\hline CHEMBL1558843 & 688721 & 4.6 & 4.8662 & TRN \\
\hline CHEMBL1388407 & 688721 & 4.6 & 4.8412 & TRN \\
\hline CHEMBL1330096 & 688721 & 5.1 & 4.955 & TRN \\
\hline CHEMBL1383033 & 688721 & 4.8 & 4.7096 & TRN \\
\hline CHEMBL1307106 & 688721 & 6.5 & 5.0438 & TRN \\
\hline CHEMBL1428942 & 688721 & 5.8 & 4.9782 & TRN \\
\hline CHEMBL1523322 & 688721 & 5.5 & 5.0004 & TRN \\
\hline CHEMBL1482437 & 688721 & 4.4 & 4.869 & TRN \\
\hline CHEMBL1338618 & 688721 & 4.5 & 4.8135 & TRN \\
\hline CHEMBL1309053 & 688721 & 4.4 & 4.8807 & TRN \\
\hline CHEMBL1499582 & 688721 & 6.4 & 5.0276 & TRN \\
\hline CHEMBL542493 & 688721 & 6.9 & 5.0966 & TST \\
\hline CHEMBL1323050 & 688721 & 5.3 & 5.1166 & TRN \\
\hline CHEMBL1522912 & 688721 & 5.2 & 4.8784 & TRN \\
\hline CHEMBL1517981 & 688721 & 5.2 & 4.9681 & TST \\
\hline CHEMBL1507689 & 688721 & 4.6 & 4.9895 & TRN \\
\hline CHEMBL3191368 & 688721 & 5.8 & 4.9616 & TRN \\
\hline CHEMBL1329020 & 688721 & 4.6 & 5.1587 & TST \\
\hline CHEMBL1299268 & 688721 & 4.9 & 4.7697 & TRN \\
\hline CHEMBL 544348 & 688721 & 4.6 & 4.9949 & TRN \\
\hline CHEMBL1504894 & 688721 & 4.5 & 4.7194 & TRN \\
\hline CHEMBL1460095 & 688721 & 4.6 & 5.0079 & TRN \\
\hline CHEMBL1322077 & 688721 & 5.2 & 5.0931 & TST \\
\hline CHEMBL1452914 & 688721 & 4.8 & 4.7958 & TRN \\
\hline CHEMBL1362214 & 688721 & 4.4 & 4.9879 & TST \\
\hline CHEMBL1550293 & 688721 & 5.1 & 4.8672 & TRN \\
\hline CHEMBL1424438 & 688721 & 5.2 & 4.8282 & TRN \\
\hline CHEMBL1368192 & 688721 & 5.0 & 4.7303 & TRN \\
\hline CHEMBL1392518 & 688721 & 4.8 & 4.9917 & TRN \\
\hline CHEMBL1524674 & 688721 & 7.0 & 5.0344 & TRN \\
\hline CHEMBL1545632 & 688721 & 4.6 & 4.8374 & TRN \\
\hline CHEMBL1579098 & 688721 & 5.0 & 4.7497 & TRN \\
\hline CHEMBL1365587 & 688721 & 5.5 & 4.8292 & TST \\
\hline CHEMBL1585470 & 688721 & 4.4 & 4.9178 & TRN \\
\hline CHEMBL1337319 & 688721 & 4.6 & 4.8208 & TRN \\
\hline CHEMBL1318616 & 688721 & 4.7 & 5.1262 & TRN \\
\hline CHEMBL1533575 & 688721 & 5.2 & 5.1114 & TRN \\
\hline CHEMBL1520586 & 688721 & 4.6 & 5.0049 & TRN \\
\hline CHEMBL1415858 & 688721 & 4.7 & 4.8853 & TRN \\
\hline CHEMBL1399703 & 688721 & 5.4 & 5.0157 & TRN \\
\hline CHEMBL1480219 & 688721 & 5.3 & 5.0479 & TRN \\
\hline CHEMBL1493101 & 688721 & 4.6 & 5.0053 & TRN \\
\hline CHEMBL1475207 & 688721 & 5.6 & 5.1494 & TRN \\
\hline
\end{tabular}




\begin{tabular}{|c|c|c|c|c|c|}
\hline \multirow{3}{*}{ CHEMBL 1396737} & \multirow{2}{*}{688721} & \\
\hline & & 5.2 & 4.965 & \multicolumn{2}{|l|}{ TRN } \\
\hline & 688721 & 4.6 & 4.8924 & \multicolumn{2}{|l|}{ TRN } \\
\hline CHEMBL1483770 & 688721 & 4.8 & 4.9195 & \multicolumn{2}{|l|}{ TRN } \\
\hline CHEMBL2141452 & 688721 & 4.4 & 4.9046 & \multicolumn{2}{|l|}{ TRN } \\
\hline CHEMBL1610380 & 688721 & 5.2 & 5.0832 & \multicolumn{2}{|l|}{ TST } \\
\hline CHEMBL1530542 & 688721 & 4.4 & 4.8261 & \multicolumn{2}{|l|}{ TRN } \\
\hline CHEMBL1351164 & 688721 & 4.5 & 4.8148 & \multicolumn{2}{|l|}{ TRN } \\
\hline CHEMBL1419182 & 688721 & 4.5 & 4.8585 & \multicolumn{2}{|l|}{ TRN } \\
\hline CHEMBL1579117 & 688721 & 5.8 & 5.0072 & \multicolumn{2}{|l|}{ TRN } \\
\hline CHEMBL1391460 & 688721 & 4.5 & 4.9038 & \multicolumn{2}{|l|}{ TRN } \\
\hline CHEMBL1480806 & 688721 & 4.8 & 4.9575 & \multicolumn{2}{|l|}{ TRN } \\
\hline CHEMBL1525939 & 688721 & 4.4 & 4.7779 & \multicolumn{2}{|l|}{ TRN } \\
\hline CHEMBL1361135 & 688721 & 5.0 & \multicolumn{2}{|c|}{4.7410000000000005} & TRN \\
\hline CHEMBL1500317 & 688721 & 4.4 & \multicolumn{2}{|c|}{4.9030000000000005} & TRN \\
\hline CHEMBL1395049 & 688721 & 4.7 & 5.1842 & TRN & \\
\hline CHEMBL1582033 & 688721 & 5.8 & 4.8836 & \multicolumn{2}{|l|}{ TST } \\
\hline CHEMBL1510838 & 688721 & 5.4 & 4.9158 & \multicolumn{2}{|l|}{ TRN } \\
\hline CHEMBL1374432 & 688721 & 4.5 & 4.8564 & \multicolumn{2}{|l|}{ TRN } \\
\hline CHEMBL194399 & 688721 & 4.4 & 5.2031 & TST & \\
\hline CHEMBL1591275 & 688721 & 5.0 & 5.24799 & 9999999999 & TRN \\
\hline CHEMBL540848 & 688721 & 4.6 & 5.0451 & TST & \\
\hline CHEMBL1404295 & 688721 & 4.4 & 4.8997 & TRN & \\
\hline CHEMBL1367482 & 688721 & 4.8 & 5.0485 & TRN & \\
\hline CHEMBL1316492 & 688721 & 6.0 & 5.2271 & TRN & \\
\hline CHEMBL1542820 & 688721 & 4.6 & 4.9169 & TRN & \\
\hline CHEMBL1577160 & 688721 & 4.5 & 4.9869 & TRN & \\
\hline CHEMBL1575590 & 688721 & 4.7 & 4.9256 & TRN & \\
\hline CHEMBL1399058 & 688721 & 4.9 & 5.0485 & TRN & \\
\hline CHEMBL1478761 & 688721 & 5.2 & 4.9737 & TRN & \\
\hline CHEMBL1201091 & 688721 & 4.6 & 5.0275 & TRN & \\
\hline CHEMBL1370530 & 688721 & 4.6 & 4.8945 & TRN & \\
\hline CHEMBL1301314 & 688721 & 5.2 & 4.9616 & TRN & \\
\hline CHEMBL1558511 & 688721 & 5.2 & 5.0207 & TRN & \\
\hline CHEMBL1544046 & 688721 & 4.4 & 4.822 & TRN & \\
\hline CHEMBL1409985 & 688721 & 4.9 & 5.1063 & TST & \\
\hline CHEMBL1322376 & 688721 & 4.8 & 4.9035 & TST & \\
\hline CHEMBL1308630 & 688721 & 5.2 & 5.1699 & TRN & \\
\hline CHEMBL1469243 & 688721 & 4.5 & 4.8048 & TRN & \\
\hline CHEMBL1592958 & 688721 & 5.5 & 5.1745 & TRN & \\
\hline CHEMBL3214098 & 688721 & 4.4 & 4.8242 & TRN & \\
\hline CHEMBL1309006 & 688721 & 4.6 & 4.6875 & TRN & \\
\hline CHEMBL1446935 & 688721 & 4.4 & 4.8217 & TRN & \\
\hline CHEMBL1432306 & 688721 & 4.8 & 4.8295 & TRN & \\
\hline CHEMBL1463629 & 688721 & 4.6 & 4.9823 & TRN & \\
\hline CHEMBL1301940 & 688721 & 4.6 & 4.901 & TST & \\
\hline CHEMBL1360484 & 688721 & 4.7 & 4.9338 & TRN & \\
\hline CHEMBL1418229 & 688721 & 4.6 & 4.9619 & TRN & \\
\hline CHEMBL1456906 & 688721 & 5.0 & 5.11100 & 0000000001 & TRN \\
\hline & & & & e 9030 & \\
\hline
\end{tabular}




\begin{tabular}{|c|c|c|c|c|c|}
\hline & & & & & \\
\hline CHEMBL1415594 & 688721 & 4.6 & 4.8268 & TST & \\
\hline CHEMBL1382656 & 688721 & 5.0 & 4.8868 & TRN & \\
\hline CHEMBL1379270 & 688721 & 4.7 & 4.6469 & TRN & \\
\hline CHEMBL1532417 & 688721 & 4.4 & 5.0597 & TRN & \\
\hline CHEMBL1594502 & 688721 & 5.2 & 4.9115 & TRN & \\
\hline CHEMBL1558865 & 688721 & 4.6 & 4.8067 & TRN & \\
\hline CHEMBL1328466 & 688721 & 4.8 & 4.8633 & TRN & \\
\hline CHEMBL319244 & 688721 & 5.3 & 5.1849 & TRN & \\
\hline CHEMBL1517889 & 688721 & 4.5 & 4.859 & TRN & \\
\hline CHEMBL1493896 & 688721 & 5.2 & 4.9264 & TRN & \\
\hline CHEMBL1610147 & 688721 & 4.5 & 4.9877 & TRN & \\
\hline CHEMBL1597719 & 688721 & 4.5 & 4.8429 & TRN & \\
\hline CHEMBL1402400 & 688721 & 4.6 & 4.6264 & TRN & \\
\hline CHEMBL1322464 & 688721 & 4.6 & 4.9629 & TRN & \\
\hline CHEMBL1411082 & 688721 & 4.7 & 4.8027 & TRN & \\
\hline CHEMBL1352660 & 688721 & 4.6 & 4.8416 & TRN & \\
\hline CHEMBL1403656 & 688721 & 6.1 & 5.0467 & TRN & \\
\hline CHEMBL1527558 & 688721 & 4.6 & 4.7961 & TRN & \\
\hline CHEMBL1578555 & 688721 & 4.4 & 4.8633 & TRN & \\
\hline CHEMBL1590223 & 688721 & 5.1 & 5.06800 & 00000000005 & TRN \\
\hline CHEMBL1341857 & 688721 & 4.8 & 4.8674 & TRN & \\
\hline CHEMBL1335866 & 688721 & 4.6 & 4.8937 & TRN & \\
\hline CHEMBL1420270 & 688721 & 6.6 & 5.0136 & TRN & \\
\hline CHEMBL1384158 & 688721 & 4.5 & 5.0055 & TRN & \\
\hline CHEMBL1501813 & 688721 & 5.0 & 4.9044 & TRN & \\
\hline CHEMBL1427992 & 688721 & 5.4 & 4.8414 & TRN & \\
\hline CHEMBL1474534 & 688721 & 5.4 & 5.1198 & TST & \\
\hline CHEMBL1375453 & 688721 & 5.2 & 4.9644 & TRN & \\
\hline CHEMBL1449121 & 688721 & 4.4 & 5.1509 & TST & \\
\hline CHEMBL1433249 & 688721 & 4.5 & 4.8249 & TST & \\
\hline CHEMBL1481930 & 688721 & 5.4 & 4.8152 & TST & \\
\hline CHEMBL1501719 & 688721 & 5.3 & 5.1264 & TRN & \\
\hline CHEMBL1477642 & 688721 & 4.7 & 5.0011 & TRN & \\
\hline CHEMBL1340701 & 688721 & 4.9 & 4.8065 & TST & \\
\hline CHEMBL1376088 & 688721 & 4.5 & 4.9683 & TST & \\
\hline CHEMBL1521689 & 688721 & 5.2 & 4.919 & TRN & \\
\hline CHEMBL1586416 & 688721 & 5.1 & 5.1153 & TST & \\
\hline CHEMBL1455249 & 688721 & 4.6 & 5.0657 & TST & \\
\hline CHEMBL1352363 & 688721 & 4.4 & 4.9961 & TRN & \\
\hline CHEMBL1553145 & 688721 & 5.1 & 5.2233 & TRN & \\
\hline CHEMBL1364362 & 688721 & 5.2 & 4.9624 & TRN & \\
\hline CHEMBL1569309 & 688721 & 5.9 & 4.9788 & TRN & \\
\hline CHEMBL1543893 & 688721 & 5.0 & 4.7316 & TRN & \\
\hline CHEMBL1574220 & 688721 & 4.5 & 4.8921 & TRN & \\
\hline CHEMBL1483419 & 688721 & 5.2 & 4.9259 & TRN & \\
\hline CHEMBL1527444 & 688721 & 4.7 & 4.9019 & TRN & \\
\hline CHEMBL1591556 & 688721 & 6.0 & 5.45299 & 9999999999 & TST \\
\hline CHEMBL1427049 & 688721 & 4.6 & 4.9643 & TRN & \\
\hline
\end{tabular}




\begin{tabular}{|c|c|c|c|c|}
\hline \multicolumn{5}{|c|}{ splemental T } \\
\hline CHEMBL1548834 & 688721 & 5.5 & 4.9983 & TRN \\
\hline CHEMBL1479377 & 688721 & 4.5 & 4.7588 & TRN \\
\hline CHEMBL1457597 & 688721 & 5.0 & 4.8642 & TST \\
\hline CHEMBL1391316 & 688721 & 5.1 & 5.0579 & TRN \\
\hline CHEMBL1392033 & 688721 & 4.9 & 5.0734 & TRN \\
\hline CHEMBL1591205 & 688721 & 6.1 & 5.3889 & TRN \\
\hline CHEMBL1507550 & 688721 & 4.4 & 4.7824 & TST \\
\hline CHEMBL1347516 & 688721 & 4.9 & 5.12 & TRN \\
\hline CHEMBL1508377 & 688721 & 5.2 & 4.7738 & TST \\
\hline CHEMBL1409996 & 688721 & 4.9 & 5.18 & TRN \\
\hline CHEMBL1409533 & 688721 & 4.4 & 4.8953 & TST \\
\hline CHEMBL1532424 & 688721 & 4.9 & 4.7274 & TST \\
\hline CHEMBL1530275 & 688721 & 5.4 & 5.0774 & TRN \\
\hline CHEMBL1349765 & 688721 & 5.0 & 5.0222 & TRN \\
\hline CHEMBL1489771 & 688721 & 5.2 & 4.8478 & TRN \\
\hline CHEMBL1505797 & 688721 & 4.4 & 4.9977 & TRN \\
\hline CHEMBL1386306 & 688721 & 5.2 & 4.8729 & TRN \\
\hline CHEMBL1524790 & 688721 & 4.5 & 4.7853 & TRN \\
\hline CHEMBL1332429 & 688721 & 4.4 & 4.8631 & TRN \\
\hline CHEMBL1552277 & 688721 & 4.4 & 5.0198 & TRN \\
\hline CHEMBL1518814 & 688721 & 4.5 & 4.8594 & TRN \\
\hline CHEMBL1478232 & 688721 & 4.6 & 5.0017 & TRN \\
\hline CHEMBL1319919 & 688721 & 4.7 & 4.8123 & TRN \\
\hline CHEMBL1472099 & 688721 & 4.6 & 4.7663 & TRN \\
\hline CHEMBL1563878 & 688721 & 5.2 & 4.9904 & TRN \\
\hline CHEMBL1377245 & 688721 & 4.4 & 4.9824 & TRN \\
\hline CHEMBL1580131 & 688721 & 4.7 & 4.7143 & TRN \\
\hline CHEMBL1453820 & 688721 & 4.4 & 4.8972 & TRN \\
\hline CHEMBL1355089 & 688721 & 5.4 & 5.0465 & TRN \\
\hline CHEMBL1466554 & 688721 & 4.6 & 4.9492 & TRN \\
\hline CHEMBL1355896 & 688721 & 5.2 & 4.9697 & TRN \\
\hline CHEMBL1322056 & 688721 & 4.5 & 4.8839 & TST \\
\hline CHEMBL1496533 & 688721 & 4.4 & 4.9709 & TST \\
\hline CHEMBL1344734 & 688721 & 4.4 & 4.9788 & TST \\
\hline CHEMBL 288174 & 688721 & 4.7 & 4.7899 & TST \\
\hline CHEMBL1310208 & 688721 & 6.0 & 4.9368 & TST \\
\hline CHEMBL1418483 & 688721 & 4.6 & 4.8335 & TST \\
\hline CHEMBL1453558 & 688721 & 5.2 & 4.9976 & TRN \\
\hline CHEMBL1444884 & 688721 & 4.4 & 4.7028 & TRN \\
\hline CHEMBL1337635 & 688721 & 4.5 & 4.8179 & TRN \\
\hline CHEMBL1448997 & 688721 & 5.1 & 5.0524 & TST \\
\hline CHEMBL1356808 & 688721 & 4.4 & 4.9741 & TRN \\
\hline CHEMBL331372 & 688721 & 7.1002 & 5.4703 & TRN \\
\hline CHEMBL1591384 & 688721 & 5.2 & 5.1857 & TRN \\
\hline CHEMBL1574328 & 688721 & 5.6 & 5.2878 & TRN \\
\hline CHEMBL1379850 & 688721 & 4.4 & 4.965 & TST \\
\hline CHEMBL1526290 & 688721 & 5.2 & 5.04 & TRN \\
\hline CHEMBL1321887 & 688721 & 4.6 & 5.2193 & TRN \\
\hline
\end{tabular}




\begin{tabular}{|c|c|c|c|c|c|}
\hline \multicolumn{6}{|c|}{ Supplemental Table S2.txt } \\
\hline CHEMBL1383533 & 688721 & 4.4 & 4.7564 & TRN & \\
\hline CHEMBL1451644 & 688721 & 4.5 & 4.9052 & TRN & \\
\hline CHEMBL1471721 & 688721 & 5.2 & 5.0248 & TST & \\
\hline CHEMBL1521069 & 688721 & 4.7 & 4.8826 & TST & \\
\hline CHEMBL1495725 & 688721 & 5.2 & 4.855 & TRN & \\
\hline CHEMBL1475484 & 688721 & 5.1 & 5.1713 & TRN & \\
\hline CHEMBL1462264 & 688721 & 4.5 & 4.8446 & TST & \\
\hline CHEMBL1499393 & 688721 & 4.4 & 4.9031 & TRN & \\
\hline CHEMBL1382086 & 688721 & 4.7 & 4.9282 & TRN & \\
\hline CHEMBL1400519 & 688721 & 5.0 & 4.9443 & TRN & \\
\hline CHEMBL1547429 & 688721 & 4.6 & 4.7727 & TRN & \\
\hline CHEMBL1509221 & 688721 & 6.0 & 5.1665 & TRN & \\
\hline CHEMBL1396949 & 688721 & 5.5 & 5.0244 & TRN & \\
\hline CHEMBL1441288 & 688721 & 5.4 & 4.831 & TRN & \\
\hline CHEMBL1450262 & 688721 & 5.2 & 4.9135 & TRN & \\
\hline CHEMBL1431278 & 688721 & 7.4001 & 4.9455 & TRN & \\
\hline CHEMBL1411212 & 688721 & 4.5 & 4.8022 & TRN & \\
\hline CHEMBL1336173 & 688721 & 5.2 & 4.9642 & TST & \\
\hline CHEMBL3209348 & 688721 & 4.8 & 4.7929 & TRN & \\
\hline CHEMBL1422899 & 688721 & 6.1 & 4.7766 & TRN & \\
\hline CHEMBL99408 & 688721 & 5.2 & 5.0927 & TST & \\
\hline CHEMBL1361945 & 688721 & 4.5 & 5.3197 & TRN & \\
\hline CHEMBL1372515 & 688721 & 5.4 & 4.8007 & TRN & \\
\hline CHEMBL1492916 & 688721 & 4.5 & 5.0252 & TST & \\
\hline CHEMBL1598549 & 688721 & 4.6 & 4.9048 & TRN & \\
\hline CHEMBL215195 & 688721 & 4.6 & 4.881 & TRN & \\
\hline CHEMBL1547738 & 688721 & 4.7 & 4.9449 & TST & \\
\hline CHEMBL1365786 & 688721 & 4.5 & 5.0708 & TRN & \\
\hline CHEMBL1301130 & 688721 & 6.7001 & 4.8699 & TRN & \\
\hline CHEMBL1399394 & 688721 & 4.8 & 5.0011 & TRN & \\
\hline CHEMBL1326346 & 688721 & 5.9 & 4.93199 & 99999999995 & TST \\
\hline CHEMBL1606088 & 688721 & 5.5 & 4.8988 & TRN & \\
\hline CHEMBL1499016 & 688721 & 4.6 & 4.8238 & TRN & \\
\hline CHEMBL1341214 & 688721 & 5.4 & 4.9865 & TRN & \\
\hline CHEMBL1486781 & 688721 & 4.4 & 4.878 & TRN & \\
\hline CHEMBL1489663 & 688721 & 5.5 & 4.8671 & TRN & \\
\hline CHEMBL1562745 & 688721 & 4.5 & 4.9195 & TRN & \\
\hline CHEMBL1444107 & 688721 & 6.6 & 5.03100 & 0000000001 & TRN \\
\hline CHEMBL1333895 & 688721 & 4.6 & 5.0152 & TRN & \\
\hline CHEMBL1378735 & 688721 & 4.8 & 4.8606 & TRN & \\
\hline CHEMBL1557009 & 688721 & 4.5 & 4.8346 & TRN & \\
\hline CHEMBL1376345 & 688721 & 4.5 & 4.8802 & TRN & \\
\hline CHEMBL1605370 & 688721 & 4.5 & 5.0357 & TRN & \\
\hline CHEMBL1583865 & 688721 & 4.6 & 4.8016 & TRN & \\
\hline CHEMBL1335554 & 688721 & 4.4 & 4.8921 & TRN & \\
\hline CHEMBL1329068 & 688721 & 5.1 & 4.9296 & TRN & \\
\hline CHEMBL1451867 & 688721 & 4.6 & 4.8672 & TRN & \\
\hline CHEMBL1606249 & 688721 & 4.7 & 5.0818 & TST & \\
\hline
\end{tabular}




\begin{tabular}{|c|c|c|c|c|c|}
\hline CHEMBL1353950 & 688721 & 4.6 & \multicolumn{2}{|c|}{5.031000000000001} & TRN \\
\hline CHEMBL1546342 & 688721 & 4.8 & 4.7104 & TRN & \\
\hline CHEMBL1428792 & 688721 & 5.4 & 5.1455 & TRN & \\
\hline CHEMBL1584888 & 688721 & 5.1 & 4.9035 & TRN & \\
\hline CHEMBL1565286 & 688721 & 4.5 & 4.8347 & TRN & \\
\hline CHEMBL1424448 & 688721 & 6.9 & 5.067 & TST & \\
\hline CHEMBL1462412 & 688721 & 4.6 & 4.9022 & TST & \\
\hline CHEMBL1275984 & 688721 & 5.5 & 4.8554 & TRN & \\
\hline CHEMBL1377511 & 688721 & 4.8 & 4.7198 & TRN & \\
\hline CHEMBL1366983 & 688721 & 4.7 & 4.9764 & TRN & \\
\hline CHEMBL1401672 & 688721 & 5.5 & 4.9799 & TRN & \\
\hline CHEMBL1302808 & 688721 & 4.8 & 5.0442 & TST & \\
\hline CHEMBL1568293 & 688721 & 4.7 & \multicolumn{2}{|c|}{4.928999999999999} & TRN \\
\hline CHEMBL1341329 & 688721 & 8.0 & 5.2739 & TST & \\
\hline CHEMBL1318454 & 688721 & 5.2 & 5.1458 & TRN & \\
\hline CHEMBL1363939 & 688721 & 4.9 & 4.8452 & TRN & \\
\hline CHEMBL1423004 & 688721 & 5.2 & 5.0222 & TST & \\
\hline CHEMBL1577245 & 688721 & 5.1 & 5.0715 & TST & \\
\hline CHEMBL1349430 & 688721 & 4.8 & 4.9143 & TRN & \\
\hline CHEMBL1428019 & 688721 & 4.8 & 4.999 & TRN & \\
\hline CHEMBL1367330 & 688721 & 5.2 & 4.9247 & TRN & \\
\hline CHEMBL1560787 & 688721 & 6.2 & 4.9253 & TST & \\
\hline CHEMBL1462132 & 688721 & 5.2 & 5.1927 & TST & \\
\hline CHEMBL1371551 & 688721 & 5.4 & 4.9088 & TST & \\
\hline CHEMBL1391258 & 688721 & 4.7 & 4.7172 & TRN & \\
\hline CHEMBL1491648 & 688721 & 4.9 & 5.1955 & TRN & \\
\hline CHEMBL1320591 & 688721 & 4.5 & 4.791 & TRN & \\
\hline CHEMBL3208367 & 688721 & 4.7 & 4.9699 & TRN & \\
\hline CHEMBL1380225 & 688721 & 4.5 & 5.1476 & TRN & \\
\hline CHEMBL1406686 & 688721 & 4.5 & 5.0235 & TST & \\
\hline CHEMBL426123 & 688721 & 5.4 & 5.0372 & TST & \\
\hline CHEMBL1507538 & 688721 & 5.5 & 4.808 & TRN & \\
\hline CHEMBL1612194 & 688721 & 4.8 & 4.9476 & TST & \\
\hline CHEMBL1391519 & 688721 & 5.0 & 5.01 & TRN & \\
\hline CHEMBL1510539 & 688721 & 5.1 & 4.9896 & TST & \\
\hline CHEMBL1378208 & 688721 & 5.5 & 5.0843 & TRN & \\
\hline CHEMBL1522257 & 688721 & 4.8 & 4.987 & TRN & \\
\hline CHEMBL1425932 & 688721 & 4.6 & 4.7628 & TRN & \\
\hline CHEMBL1353215 & 688721 & 4.7 & 4.7849 & TRN & \\
\hline CHEMBL1525497 & 688721 & 4.6 & 4.8359 & TRN & \\
\hline CHEMBL1332074 & 688721 & 4.4 & 4.9293 & TRN & \\
\hline CHEMBL1600726 & 688721 & 4.7 & 4.7199 & TRN & \\
\hline CHEMBL1594676 & 688721 & 4.8 & 5.1925 & TRN & \\
\hline CHEMBL1347655 & 688721 & 4.4 & 5.0196 & TST & \\
\hline CHEMBL1508888 & 688721 & 4.6 & 4.8791 & TRN & \\
\hline CHEMBL1578457 & 688721 & 6.2 & 4.9767 & TRN & \\
\hline CHEMBL1444530 & 688721 & 4.7 & 4.9766 & TRN & \\
\hline CHEMBL1430829 & 688721 & 4.6 & 4.917 & TRN & \\
\hline
\end{tabular}




\begin{tabular}{|c|c|c|c|c|c|}
\hline \multicolumn{6}{|c|}{ Supplemental Table S2.txt } \\
\hline CHEMBL1503262 & 688721 & 4.8 & 4.8701 & TRN & \\
\hline CHEMBL1347996 & 688721 & 6.7001 & 5.0482 & TRN & \\
\hline CHEMBL1988679 & 688721 & 5.8 & 4.9614 & TRN & \\
\hline CHEMBL1450205 & 688721 & 5.2 & 4.9806 & TST & \\
\hline CHEMBL1480223 & 688721 & 5.2 & 4.8414 & TRN & \\
\hline CHEMBL1563657 & 688721 & 4.4 & 5.0765 & TRN & \\
\hline CHEMBL1452094 & 688721 & 4.7 & 4.8861 & TRN & \\
\hline CHEMBL1541009 & 688721 & 4.6 & 4.7742 & TRN & \\
\hline CHEMBL3190916 & 688721 & 4.5 & 4.9657 & TST & \\
\hline CHEMBL1389124 & 688721 & 4.9 & 4.8444 & TRN & \\
\hline CHEMBL1331471 & 688721 & 4.5 & 4.91100 & 00000000005 & TRN \\
\hline CHEMBL1361621 & 688721 & 4.5 & 4.7741 & TRN & \\
\hline CHEMBL1588207 & 688721 & 4.4 & 4.841 & TRN & \\
\hline CHEMBL1610943 & 688721 & 4.7 & 4.8487 & TRN & \\
\hline CHEMBL455491 & 688721 & 4.4 & 5.42899 & 9999999999 & TST \\
\hline CHEMBL1323622 & 688721 & 4.8 & 4.8262 & TRN & \\
\hline CHEMBL1905194 & 688721 & 5.4 & 4.9792 & TRN & \\
\hline CHEMBL1587608 & 688721 & 4.4 & 4.7001 & TRN & \\
\hline CHEMBL1604134 & 688721 & 4.9 & 4.6849 & TRN & \\
\hline CHEMBL1336521 & 688721 & 4.4 & 5.0799 & TST & \\
\hline CHEMBL1453097 & 688721 & 4.5 & 4.7795 & TRN & \\
\hline CHEMBL1567004 & 688721 & 4.5 & 5.0298 & TRN & \\
\hline CHEMBL80941 & 688721 & 4.5 & 5.1723 & TST & \\
\hline CHEMBL1301462 & 688721 & 4.7 & 5.0289 & TRN & \\
\hline CHEMBL 254348 & 688721 & 4.8 & 5.0289 & TST & \\
\hline CHEMBL1444187 & 688721 & 4.5 & 4.8275 & TRN & \\
\hline CHEMBL1451562 & 688721 & 4.7 & 5.0999 & TRN & \\
\hline CHEMBL1386618 & 688721 & 4.9 & 4.8648 & TRN & \\
\hline CHEMBL1348949 & 688721 & 4.5 & 4.8428 & TST & \\
\hline CHEMBL1439172 & 688721 & 6.9 & 5.1651 & TST & \\
\hline CHEMBL1559875 & 688721 & 4.4 & 4.8129 & TRN & \\
\hline CHEMBL1358983 & 688721 & 4.6 & 4.9061 & TRN & \\
\hline CHEMBL1492558 & 688721 & 4.8 & 5.1327 & TST & \\
\hline CHEMBL1523215 & 688721 & 5.2 & 5.129 & TRN & \\
\hline CHEMBL170365 & 688721 & 4.4 & 5.2413 & TST & \\
\hline CHEMBL1511217 & 688721 & 4.4 & 4.8945 & TST & \\
\hline CHEMBL1318565 & 688721 & 5.4 & 5.0649 & TRN & \\
\hline CHEMBL1369607 & 688721 & 5.9 & 4.9672 & TRN & \\
\hline CHEMBL1490558 & 688721 & 5.2 & 4.8829 & TST & \\
\hline CHEMBL1431585 & 688721 & 4.4 & 4.8258 & TRN & \\
\hline CHEMBL1332784 & 688721 & 4.7 & 5.0264 & TRN & \\
\hline CHEMBL1330391 & 688721 & 4.9 & 4.9185 & TRN & \\
\hline CHEMBL1606718 & 688721 & 4.8 & 4.9542 & TRN & \\
\hline CHEMBL1392483 & 688721 & 5.5 & 4.9099 & TST & \\
\hline CHEMBL1487702 & 688721 & 5.3 & 4.9986 & TST & \\
\hline CHEMBL1573090 & 688721 & 4.9 & 5.0144 & TRN & \\
\hline CHEMBL1393963 & 688721 & 5.1 & 4.8895 & TST & \\
\hline CHEMBL1412113 & 688721 & 4.5 & 4.9493 & TRN & \\
\hline
\end{tabular}




\begin{tabular}{|c|c|c|c|c|c|}
\hline \multicolumn{6}{|c|}{ Supplemental Table S2.txt } \\
\hline CHEMBL68253 & 688721 & 5.2 & 5.3073 & TRN & \\
\hline CHEMBL1321459 & 688721 & 4.8 & 5.1333 & TRN & \\
\hline CHEMBL1451908 & 688721 & 5.1 & 4.9249 & TRN & \\
\hline CHEMBL1399914 & 688721 & 5.2 & 5.0141 & TRN & \\
\hline CHEMBL1526622 & 688721 & 4.9 & 4.7488 & TRN & \\
\hline CHEMBL1451255 & 688721 & 4.4 & 4.9169 & TRN & \\
\hline CHEMBL1529543 & 688721 & 5.4 & 5.1291 & TRN & \\
\hline CHEMBL1360234 & 688721 & 4.6 & 4.8266 & TRN & \\
\hline CHEMBL1350196 & 688721 & 5.2 & 5.0647 & TRN & \\
\hline CHEMBL1539572 & 688721 & 4.5 & 5.0634 & TRN & \\
\hline CHEMBL1394719 & 688721 & 4.4 & 5.1242 & TRN & \\
\hline CHEMBL1424677 & 688721 & 5.1 & 4.7573 & TRN & \\
\hline CHEMBL1357558 & 688721 & 4.4 & 4.7961 & TST & \\
\hline CHEMBL1418145 & 688721 & 4.8 & 4.753 & TST & \\
\hline CHEMBL1603817 & 688721 & 4.8 & 4.7558 & TRN & \\
\hline CHEMBL1434882 & 688721 & 4.8 & 4.9146 & TRN & \\
\hline CHEMBL1482566 & 688721 & 4.5 & 5.0033 & TRN & \\
\hline CHEMBL1425864 & 688721 & 4.4 & 4.9661 & TRN & \\
\hline CHEMBL1389856 & 688721 & 4.6 & 4.7563 & TRN & \\
\hline CHEMBL1540916 & 688721 & 4.7 & 5.073 & TRN & \\
\hline CHEMBL1451286 & 688721 & 4.6 & 4.7641 & TRN & \\
\hline CHEMBL1386105 & 688721 & 4.8 & 4.9204 & TRN & \\
\hline CHEMBL1506196 & 688721 & 4.4 & 4.89199 & 99999999995 & TRN \\
\hline CHEMBL1541867 & 688721 & 4.7 & 4.9071 & TRN & \\
\hline CHEMBL1432278 & 688721 & 5.2 & 4.9489 & TRN & \\
\hline CHEMBL1459464 & 688721 & 4.8 & 4.9878 & TST & \\
\hline CHEMBL1349820 & 688721 & 5.5 & 4.8297 & TRN & \\
\hline CHEMBL1360180 & 688721 & 4.5 & 4.9239 & TRN & \\
\hline CHEMBL1471211 & 688721 & 4.6 & 4.8986 & TST & \\
\hline CHEMBL1386457 & 688721 & 4.7 & 4.846 & TRN & \\
\hline CHEMBL1587325 & 688721 & 4.7 & 5.1022 & TST & \\
\hline CHEMBL1499308 & 688721 & 4.7 & 4.8642 & TRN & \\
\hline CHEMBL1533560 & 688721 & 7.0 & 5.4102 & TST & \\
\hline CHEMBL1405085 & 688721 & 4.9 & 4.8742 & TRN & \\
\hline CHEMBL513678 & 688721 & 4.4 & 5.1685 & TST & \\
\hline CHEMBL1491606 & 688721 & 5.4 & 5.2307 & TST & \\
\hline CHEMBL562192 & 688721 & 5.0 & 4.7525 & TRN & \\
\hline CHEMBL1331778 & 688721 & 5.5 & 4.9867 & TST & \\
\hline CHEMBL1341340 & 688721 & 4.6 & 4.9553 & TRN & \\
\hline CHEMBL1586093 & 688721 & 5.0 & 4.9375 & TRN & \\
\hline CHEMBL1592672 & 688721 & 4.7 & 5.0375 & TRN & \\
\hline CHEMBL1305880 & 688721 & 4.5 & 4.8882 & TST & \\
\hline CHEMBL1472383 & 688721 & 5.2 & 4.978 & TRN & \\
\hline CHEMBL1506526 & 688721 & 4.6 & 4.942 & TRN & \\
\hline CHEMBL1554158 & 688721 & 6.2 & 5.0004 & TRN & \\
\hline CHEMBL1448518 & 688721 & 6.2 & 4.90300 & 00000000005 & TST \\
\hline CHEMBL1331615 & 688721 & 5.0 & 4.8044 & TRN & \\
\hline CHEMBL516075 & 688721 & 4.9 & 4.9213 & TRN & \\
\hline
\end{tabular}




\begin{tabular}{|c|c|c|c|c|c|}
\hline \\
\hline CHEMBL1468759 & 688721 & 5.5 & 5.1235 & TRN & \\
\hline CHEMBL1400280 & 688721 & 5.3 & 5.0915 & TST & \\
\hline CHEMBL1548548 & 688721 & 4.8 & 4.9935 & TRN & \\
\hline CHEMBL1345872 & 688721 & 4.9 & 4.8232 & TRN & \\
\hline CHEMBL1423429 & 688721 & 4.6 & 4.817 & TRN & \\
\hline CHEMBL1401490 & 688721 & 4.5 & 4.8724 & TRN & \\
\hline CHEMBL1470413 & 688721 & 5.5 & 5.0355 & TRN & \\
\hline CHEMBL1612035 & 688721 & 5.2 & 4.8603 & TRN & \\
\hline CHEMBL1575943 & 688721 & 5.4 & 5.1201 & TRN & \\
\hline CHEMBL1424620 & 688721 & 4.8 & 5.084 & TRN & \\
\hline CHEMBL1333508 & 688721 & 4.6 & 4.8893 & TRN & \\
\hline CHEMBL1457700 & 688721 & 4.6 & 4.9332 & TST & \\
\hline CHEMBL1328870 & 688721 & 5.4 & 4.998 & TRN & \\
\hline CHEMBL1526446 & 688721 & 4.9 & 4.961 & TRN & \\
\hline CHEMBL1310614 & 688721 & 4.4 & 4.9649 & TRN & \\
\hline CHEMBL1428218 & 688721 & 4.5 & 4.939 & TST & \\
\hline CHEMBL1301508 & 688721 & 4.5 & 4.9894 & TRN & \\
\hline CHEMBL1388759 & 688721 & 4.6 & 4.88899 & 9999999999 & TRN \\
\hline CHEMBL1445423 & 688721 & 4.6 & 4.9183 & TRN & \\
\hline CHEMBL1348847 & 688721 & 4.8 & 4.9287 & TRN & \\
\hline CHEMBL490744 & 688721 & 4.4 & 5.0525 & TRN & \\
\hline CHEMBL1568570 & 688721 & 4.8 & 4.9562 & TRN & \\
\hline CHEMBL1388477 & 688721 & 4.9 & 4.8835 & TRN & \\
\hline CHEMBL15625 & 688721 & 4.8 & 5.2472 & TST & \\
\hline CHEMBL1312087 & 688721 & 4.6 & 4.8382 & TRN & \\
\hline CHEMBL1465638 & 688721 & 4.5 & 4.9969 & TST & \\
\hline CHEMBL1408398 & 688721 & 4.5 & 4.8087 & TRN & \\
\hline CHEMBL1564471 & 688721 & 4.5 & 4.9144 & TRN & \\
\hline CHEMBL1337092 & 688721 & 5.2 & 5.0399 & TRN & \\
\hline CHEMBL1376434 & 688721 & 4.4 & 4.9536 & TRN & \\
\hline CHEMBL1255664 & 688721 & 5.2 & 5.0618 & TST & \\
\hline CHEMBL1396661 & 688721 & 4.4 & 5.24200 & 3000000001 & TRN \\
\hline CHEMBL1375326 & 688721 & 4.4 & 4.8761 & TRN & \\
\hline CHEMBL1459968 & 688721 & 4.8 & 4.9657 & TRN & \\
\hline CHEMBL1525343 & 688721 & 5.4 & 4.9624 & TRN & \\
\hline CHEMBL1610313 & 688721 & 4.6 & 4.8993 & TST & \\
\hline CHEMBL1381207 & 688721 & 5.4 & 5.0602 & TST & \\
\hline CHEMBL1565890 & 688721 & 4.9 & 5.0398 & TRN & \\
\hline CHEMBL1494136 & 688721 & 4.6 & 4.8278 & TRN & \\
\hline CHEMBL1460779 & 688721 & 5.2 & 4.7514 & TRN & \\
\hline CHEMBL1597970 & 688721 & 4.6 & 4.7773 & TRN & \\
\hline CHEMBL491748 & 688721 & 4.4 & 5.0109 & TRN & \\
\hline CHEMBL1399443 & 688721 & 5.5 & 4.9505 & TRN & \\
\hline CHEMBL1483537 & 688721 & 4.5 & 4.8643 & TRN & \\
\hline CHEMBL1453244 & 688721 & 5.5 & 5.1842 & TRN & \\
\hline CHEMBL1310502 & 688721 & 4.4 & 4.9623 & TRN & \\
\hline CHEMBL1500116 & 688721 & 4.9 & 4.9581 & TRN & \\
\hline CHEMBL1605006 & 688721 & 4.7 & 5.019 & TRN & \\
\hline
\end{tabular}




\begin{tabular}{|c|c|c|c|c|}
\hline \multicolumn{5}{|c|}{ Supplemental Table S2.txt } \\
\hline CHEMBL1342974 & 688721 & 4.8 & 4.6785 & TRN \\
\hline CHEMBL398363 & 688721 & 5.2 & 4.9955 & TST \\
\hline CHEMBL1364367 & 688721 & 5.2 & 5.0643 & TRN \\
\hline CHEMBL1358570 & 688721 & 6.0 & 5.135 & TST \\
\hline CHEMBL1577213 & 688721 & 4.8 & 5.1034 & TRN \\
\hline CHEMBL1377459 & 688721 & 5.0 & 4.7289 & TRN \\
\hline CHEMBL1549910 & 688721 & 4.6 & 4.8644 & TRN \\
\hline CHEMBL1451329 & 688721 & 4.6 & 4.8487 & TRN \\
\hline CHEMBL1522650 & 688721 & 5.3 & 4.9056 & TRN \\
\hline CHEMBL1372989 & 688721 & 4.4 & 4.8903 & TST \\
\hline CHEMBL1535088 & 688721 & 5.4 & 5.2077 & TRN \\
\hline CHEMBL1373923 & 688721 & 5.6 & 4.9247 & TRN \\
\hline CHEMBL1324414 & 688721 & 7.4001 & 4.9321 & TRN \\
\hline CHEMBL1489456 & 688721 & 4.5 & 4.8957 & TRN \\
\hline CHEMBL1535453 & 688721 & 5.0 & 4.9154 & TRN \\
\hline CHEMBL1407220 & 688721 & 4.5 & 4.9321 & TST \\
\hline CHEMBL1393365 & 688721 & 4.8 & 4.7338 & TRN \\
\hline CHEMBL1414010 & 688721 & 4.7 & 4.9973 & TRN \\
\hline CHEMBL 3190100 & 688721 & 4.4 & 5.044 & TRN \\
\hline CHEMBL1453905 & 688721 & 5.5 & 4.7231 & TRN \\
\hline CHEMBL1553555 & 688721 & 4.5 & 5.0873 & TRN \\
\hline CHEMBL1386982 & 688721 & 4.4 & 5.0349 & TRN \\
\hline CHEMBL1509077 & 688721 & 4.5 & 4.8284 & TRN \\
\hline CHEMBL1369241 & 688721 & 6.9 & 4.8803 & TRN \\
\hline CHEMBL1369350 & 688721 & 4.5 & 5.0479 & TRN \\
\hline CHEMBL1356497 & 688721 & 5.9 & 5.1008 & TRN \\
\hline CHEMBL1383693 & 688721 & 4.6 & 4.9995 & TST \\
\hline CHEMBL1574544 & 688721 & 4.5 & 4.9418 & TRN \\
\hline CHEMBL1486638 & 688721 & 4.4 & 5.1777 & TST \\
\hline CHEMBL1435444 & 688721 & 4.5 & 5.0307 & TST \\
\hline CHEMBL1490740 & 688721 & 4.9 & 4.9711 & TRN \\
\hline CHEMBL1567185 & 688721 & 4.6 & 4.8838 & TST \\
\hline CHEMBL1510439 & 688721 & 5.8 & 4.9465 & TRN \\
\hline CHEMBL1340832 & 688721 & 5.2 & 4.8702 & TRN \\
\hline CHEMBL1518187 & 688721 & 5.8 & 5.0655 & TRN \\
\hline CHEMBL1457243 & 688721 & 5.2 & 5.0611 & TRN \\
\hline CHEMBL1599394 & 688721 & 4.4 & 5.0764 & TRN \\
\hline CHEMBL1407874 & 688721 & 5.3 & 5.0168 & TST \\
\hline CHEMBL1338297 & 688721 & 5.1 & 5.061 & TRN \\
\hline CHEMBL1586662 & 688721 & 4.4 & 4.9726 & TRN \\
\hline CHEMBL1556932 & 688721 & 5.5 & 4.9035 & TRN \\
\hline CHEMBL1602608 & 688721 & 4.4 & 4.8751 & TST \\
\hline CHEMBL1507580 & 688721 & 5.2 & 4.9466 & TRN \\
\hline CHEMBL1491091 & 688721 & 4.4 & 5.0389 & TRN \\
\hline CHEMBL1575051 & 688721 & 4.5 & 4.718 & TRN \\
\hline CHEMBL1421806 & 688721 & 4.4 & 4.9673 & TRN \\
\hline CHEMBL1578311 & 688721 & 5.2 & 4.9914 & TRN \\
\hline CHEMBL1578301 & 688721 & 4.8 & 4.8725 & TRN \\
\hline
\end{tabular}




\begin{tabular}{|c|c|c|c|c|}
\hline \multicolumn{5}{|c|}{ Supplemental Table S2.txt } \\
\hline CHEMBL1509507 & 688721 & 5.2 & 4.9084 & TRN \\
\hline CHEMBL1300106 & 688721 & 5.4 & 4.974 & TRN \\
\hline CHEMBL1404611 & 688721 & 4.8 & 4.7788 & TRN \\
\hline CHEMBL1436536 & 688721 & 5.4 & 5.1021 & TRN \\
\hline CHEMBL1302307 & 688721 & 5.4 & 4.9052 & TST \\
\hline CHEMBL1380693 & 688721 & 5.0 & 5.0017 & TRN \\
\hline CHEMBL1407442 & 688721 & 4.4 & 5.0376 & TST \\
\hline CHEMBL1567597 & 688721 & 4.5 & 4.8956 & TRN \\
\hline CHEMBL1339869 & 688721 & 4.5 & 5.0163 & TRN \\
\hline CHEMBL1560329 & 688721 & 4.6 & 4.7009 & TRN \\
\hline CHEMBL1308063 & 688721 & 6.1 & 5.1426 & TRN \\
\hline CHEMBL1487138 & 688721 & 5.2 & 4.9351 & TRN \\
\hline CHEMBL1544605 & 688721 & 4.5 & 4.9705 & TRN \\
\hline CHEMBL1468309 & 688721 & 4.8 & 4.9042 & TRN \\
\hline CHEMBL1455031 & 688721 & 4.8 & 4.738 & TRN \\
\hline CHEMBL1306727 & 688721 & 4.5 & 4.8102 & TRN \\
\hline CHEMBL1424566 & 688721 & 4.5 & 4.908 & TRN \\
\hline CHEMBL1390377 & 688721 & 4.8 & 4.6908 & TRN \\
\hline CHEMBL1454000 & 688721 & 4.6 & 4.8113 & TRN \\
\hline CHEMBL1479246 & 688721 & 5.5 & 4.9722 & TRN \\
\hline CHEMBL1600472 & 688721 & 4.7 & 4.8021 & TRN \\
\hline CHEMBL1420158 & 688721 & 4.5 & 4.9278 & TRN \\
\hline CHEMBL1376974 & 688721 & 6.7001 & 5.2703 & TST \\
\hline CHEMBL1421600 & 688721 & 5.2 & 4.9744 & TST \\
\hline CHEMBL1519798 & 688721 & 4.6 & 4.9296 & TRN \\
\hline CHEMBL1397225 & 688721 & 4.4 & 5.1552 & TRN \\
\hline CHEMBL1484064 & 688721 & 5.0 & 4.9778 & TRN \\
\hline CHEMBL12327 & 688721 & 5.4 & 5.0315 & TST \\
\hline CHEMBL1501110 & 688721 & 5.0 & 4.8168 & TRN \\
\hline CHEMBL1370322 & 688721 & 4.8 & 4.9539 & TST \\
\hline CHEMBL1421831 & 688721 & 5.5 & 4.8995 & TST \\
\hline CHEMBL1570469 & 688721 & 5.0 & 5.0248 & TST \\
\hline CHEMBL1422415 & 688721 & 4.5 & 4.7236 & TST \\
\hline CHEMBL1517432 & 688721 & 4.6 & 4.9322 & TRN \\
\hline CHEMBL1972735 & 688721 & 4.7 & 4.9564 & TRN \\
\hline CHEMBL1477492 & 688721 & 4.7 & 5.0556 & TRN \\
\hline CHEMBL1523429 & 688721 & 4.6 & 4.7862 & TRN \\
\hline CHEMBL3197959 & 688721 & 5.4 & 5.1344 & TST \\
\hline CHEMBL1443823 & 688721 & 4.4 & 4.8616 & TRN \\
\hline CHEMBL1562663 & 688721 & 5.2 & 5.1382 & TRN \\
\hline CHEMBL1605210 & 688721 & 4.4 & 4.8945 & TST \\
\hline CHEMBL1411716 & 688721 & 4.7 & 5.064 & TST \\
\hline CHEMBL10 & 688721 & 4.4 & 5.0825 & TST \\
\hline CHEMBL1424593 & 688721 & 4.4 & 5.0861 & TRN \\
\hline CHEMBL1349172 & 688721 & 4.4 & 4.9001 & TRN \\
\hline CHEMBL1476711 & 688721 & 4.8 & 5.1086 & TRN \\
\hline CHEMBL1350579 & 688721 & 4.4 & 4.7008 & TRN \\
\hline CHEMBL1412386 & 688721 & 5.9 & 5.0802 & TST \\
\hline
\end{tabular}




\begin{tabular}{|c|c|c|c|c|}
\hline \multicolumn{5}{|c|}{ plemental } \\
\hline CHEMBL1527275 & 688721 & 4.4 & 4.9792 & TST \\
\hline CHEMBL1611841 & 688721 & 5.7 & 4.8885 & TRN \\
\hline CHEMBL1437128 & 688721 & 5.4 & 5.1661 & TST \\
\hline CHEMBL1301692 & 688721 & 4.4 & 4.8419 & TST \\
\hline CHEMBL1425067 & 688721 & 4.6 & 5.0123 & TST \\
\hline CHEMBL1431485 & 688721 & 4.4 & 5.0016 & TRN \\
\hline CHEMBL1305310 & 688721 & 4.5 & 4.9039 & TST \\
\hline CHEMBL1404146 & 688721 & 4.6 & 4.7995 & TRN \\
\hline CHEMBL538595 & 688721 & 4.4 & 5.1643 & TRN \\
\hline CHEMBL1411413 & 688721 & 4.8 & 4.842 & TRN \\
\hline CHEMBL1517855 & 688721 & 4.5 & 4.8754 & TRN \\
\hline CHEMBL1477509 & 688721 & 5.1 & 5.0562 & TST \\
\hline CHEMBL541543 & 688721 & 6.0 & 5.1035 & TST \\
\hline CHEMBL1377385 & 688721 & 4.7 & 5.1856 & TRN \\
\hline CHEMBL1369067 & 688721 & 5.5 & 4.7789 & TRN \\
\hline CHEMBL1432842 & 688721 & 4.8 & 4.7725 & TST \\
\hline CHEMBL1387047 & 688721 & 4.4 & 4.8539 & TRN \\
\hline CHEMBL1515918 & 688721 & 4.5 & 4.9219 & TRN \\
\hline CHEMBL1484660 & 688721 & 6.0 & 4.8693 & TRN \\
\hline CHEMBL1591876 & 688721 & 5.3 & 4.9344 & TRN \\
\hline CHEMBL1361042 & 688721 & 4.4 & 4.8122 & TRN \\
\hline CHEMBL1363718 & 688721 & 6.8 & 5.1471 & TRN \\
\hline CHEMBL1596743 & 688721 & 5.5 & 5.2474 & TRN \\
\hline CHEMBL1580791 & 688721 & 4.6 & 4.956 & TST \\
\hline CHEMBL1305649 & 688721 & 4.7 & 5.0112 & TRN \\
\hline CHEMBL1305455 & 688721 & 4.9 & 4.833 & TRN \\
\hline CHEMBL1579518 & 688721 & 4.6 & 4.8021 & TRN \\
\hline CHEMBL197014 & 688721 & 4.6 & 5.0251 & TRN \\
\hline CHEMBL1462110 & 688721 & 4.4 & 4.8356 & TRN \\
\hline CHEMBL1610411 & 688721 & 5.5 & 5.3219 & TRN \\
\hline CHEMBL1419459 & 688721 & 5.7 & 4.8548 & TRN \\
\hline CHEMBL1455926 & 688721 & 4.4 & 5.153 & TRN \\
\hline CHEMBL1468448 & 688721 & 6.0 & 4.9717 & TRN \\
\hline CHEMBL1335045 & 688721 & 5.2 & 4.8616 & TST \\
\hline CHEMBL1542305 & 688721 & 5.2 & 4.9169 & TRN \\
\hline CHEMBL1369782 & 688721 & 4.6 & 4.835 & TRN \\
\hline CHEMBL1545220 & 688721 & 4.5 & 5.0491 & TRN \\
\hline CHEMBL1313851 & 688721 & 4.7 & 4.8266 & TRN \\
\hline CHEMBL1585575 & 688721 & 4.4 & 4.8442 & TRN \\
\hline CHEMBL1565834 & 688721 & 4.6 & 4.9847 & TRN \\
\hline CHEMBL1419737 & 688721 & 5.7 & 4.8918 & TRN \\
\hline CHEMBL87285 & 688721 & 6.0 & 5.3545 & TRN \\
\hline CHEMBL1344341 & 688721 & 5.0 & 4.9542 & TRN \\
\hline CHEMBL1362547 & 688721 & 5.2 & 4.8142 & TRN \\
\hline CHEMBL1440157 & 688721 & 4.8 & 4.8828 & TRN \\
\hline CHEMBL1548353 & 688721 & 7.0 & 4.9588 & TRN \\
\hline CHEMBL1401480 & 688721 & 4.7 & 5.3711 & TST \\
\hline CHEMBL1603812 & 688721 & 4.6 & 4.8443 & TRN \\
\hline
\end{tabular}




\begin{tabular}{|c|c|c|c|c|}
\hline \multicolumn{5}{|c|}{ Supplemental Table S2.txt } \\
\hline CHEMBL1366476 & 688721 & 5.4 & 5.0231 & TRN \\
\hline CHEMBL1463711 & 688721 & 4.4 & 4.8971 & TRN \\
\hline CHEMBL1394137 & 688721 & 4.9 & 5.1031 & TRN \\
\hline CHEMBL1518808 & 688721 & 7.6003 & 5.0744 & TRN \\
\hline CHEMBL1485686 & 688721 & 5.1 & 5.2382 & TRN \\
\hline CHEMBL1543101 & 688721 & 5.4 & 4.8864 & TRN \\
\hline CHEMBL1372733 & 688721 & 5.4 & 4.9931 & TRN \\
\hline CHEMBL1302244 & 688721 & 4.8 & 4.7169 & TRN \\
\hline CHEMBL1352062 & 688721 & 4.5 & 4.9149 & TRN \\
\hline CHEMBL1347752 & 688721 & 4.9 & 4.7879 & TRN \\
\hline CHEMBL1378019 & 688721 & 6.8 & 4.8296 & TST \\
\hline CHEMBL1337941 & 688721 & 4.9 & 4.9267 & TRN \\
\hline CHEMBL1370078 & 688721 & 4.6 & 4.8444 & TRN \\
\hline CHEMBL1562553 & 688721 & 4.4 & 5.3075 & TST \\
\hline CHEMBL1389972 & 688721 & 4.6 & 4.9937 & TRN \\
\hline CHEMBL1605322 & 688721 & 4.8 & 4.8347 & TRN \\
\hline CHEMBL1597935 & 688721 & 4.7 & 4.9877 & TRN \\
\hline CHEMBL1503927 & 688721 & 5.2 & 4.9175 & TRN \\
\hline CHEMBL1602438 & 688721 & 4.5 & 5.0727 & TST \\
\hline CHEMBL1335760 & 688721 & 4.6 & 4.7781 & TRN \\
\hline CHEMBL1522425 & 688721 & 4.4 & 4.9697 & TRN \\
\hline CHEMBL1524249 & 688721 & 4.5 & 5.0931 & TRN \\
\hline CHEMBL1436865 & 688721 & 5.8 & 5.2315 & TRN \\
\hline CHEMBL1550057 & 688721 & 6.0 & 5.0378 & TRN \\
\hline CHEMBL1550164 & 688721 & 4.6 & 5.0967 & TRN \\
\hline CHEMBL1531018 & 688721 & 6.3 & 4.9868 & TRN \\
\hline CHEMBL1547990 & 688721 & 5.0 & 4.9285 & TRN \\
\hline CHEMBL1607830 & 688721 & 5.2 & 4.8862 & TST \\
\hline CHEMBL1540621 & 688721 & 4.5 & 4.7746 & TRN \\
\hline CHEMBL1484253 & 688721 & 6.5 & 5.0215 & TRN \\
\hline CHEMBL1471765 & 688721 & 4.8 & 4.908 & TRN \\
\hline CHEMBL467623 & 688721 & 4.9 & 5.1346 & TST \\
\hline CHEMBL1497021 & 688721 & 4.6 & 5.0398 & TRN \\
\hline CHEMBL1333376 & 688721 & 5.1 & 5.0723 & TST \\
\hline CHEMBL1396384 & 688721 & 4.6 & 4.852 & TRN \\
\hline CHEMBL1455983 & 688721 & 4.6 & 5.3354 & TST \\
\hline CHEMBL1372624 & 688721 & 5.4 & 4.9941 & TRN \\
\hline CHEMBL1402225 & 688721 & 4.6 & 4.873 & TRN \\
\hline CHEMBL1460401 & 688721 & 4.5 & 4.8641 & TST \\
\hline CHEMBL1344483 & 688721 & 5.2 & 4.8137 & TST \\
\hline CHEMBL1330994 & 688721 & 4.8 & 5.0145 & TRN \\
\hline CHEMBL1399546 & 688721 & 4.4 & 4.7972 & TRN \\
\hline CHEMBL1343003 & 688721 & 4.4 & 4.9169 & TRN \\
\hline CHEMBL1389688 & 688721 & 4.5 & 4.98 & TRN \\
\hline CHEMBL1569630 & 688721 & 4.5 & 5.2109 & TST \\
\hline CHEMBL1338163 & 688721 & 4.8 & 5.0199 & TRN \\
\hline CHEMBL1522996 & 688721 & 4.4 & 4.7763 & TRN \\
\hline CHEMBL1568097 & 688721 & 7.5003 & 5.2359 & TRN \\
\hline
\end{tabular}




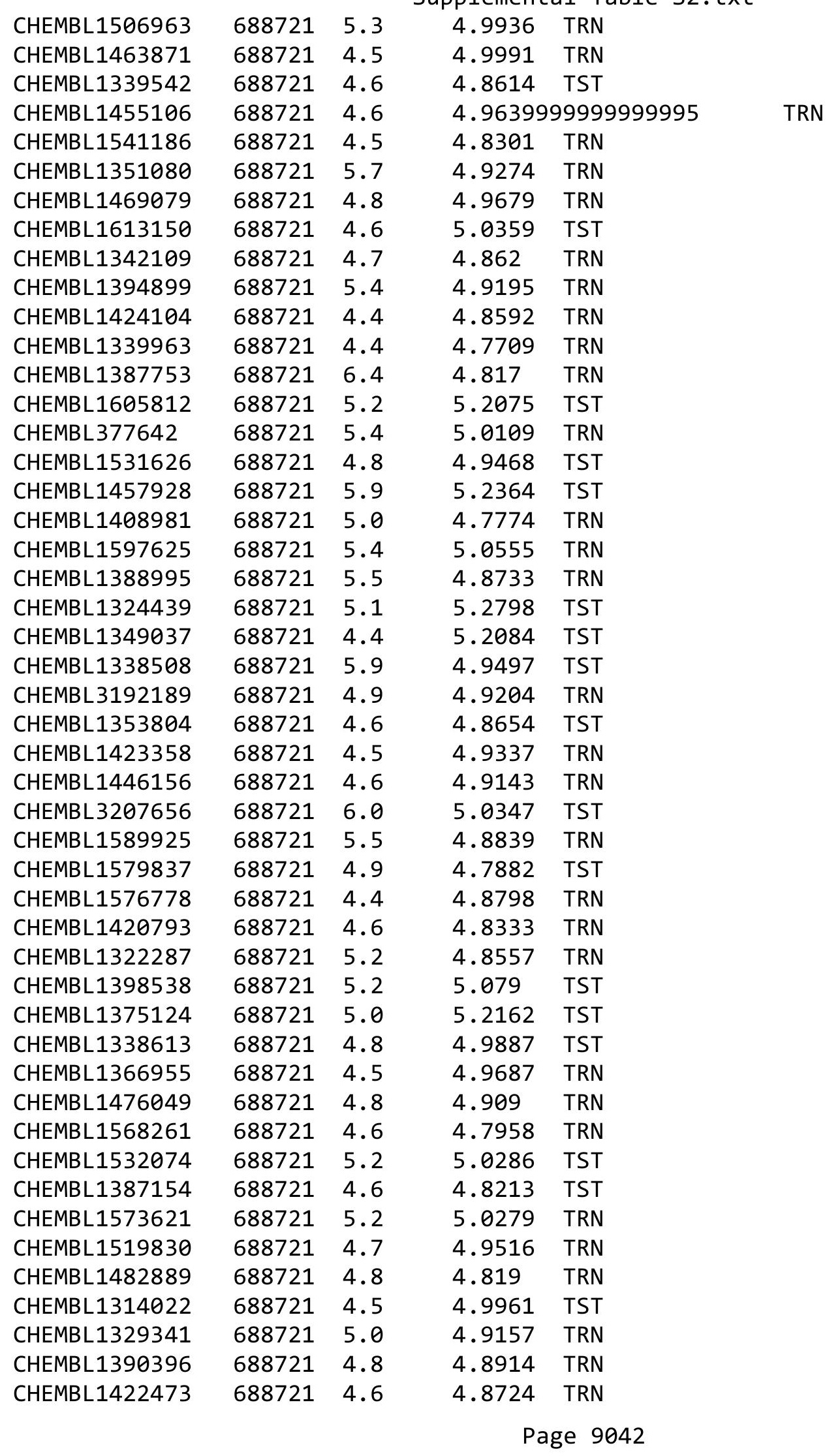




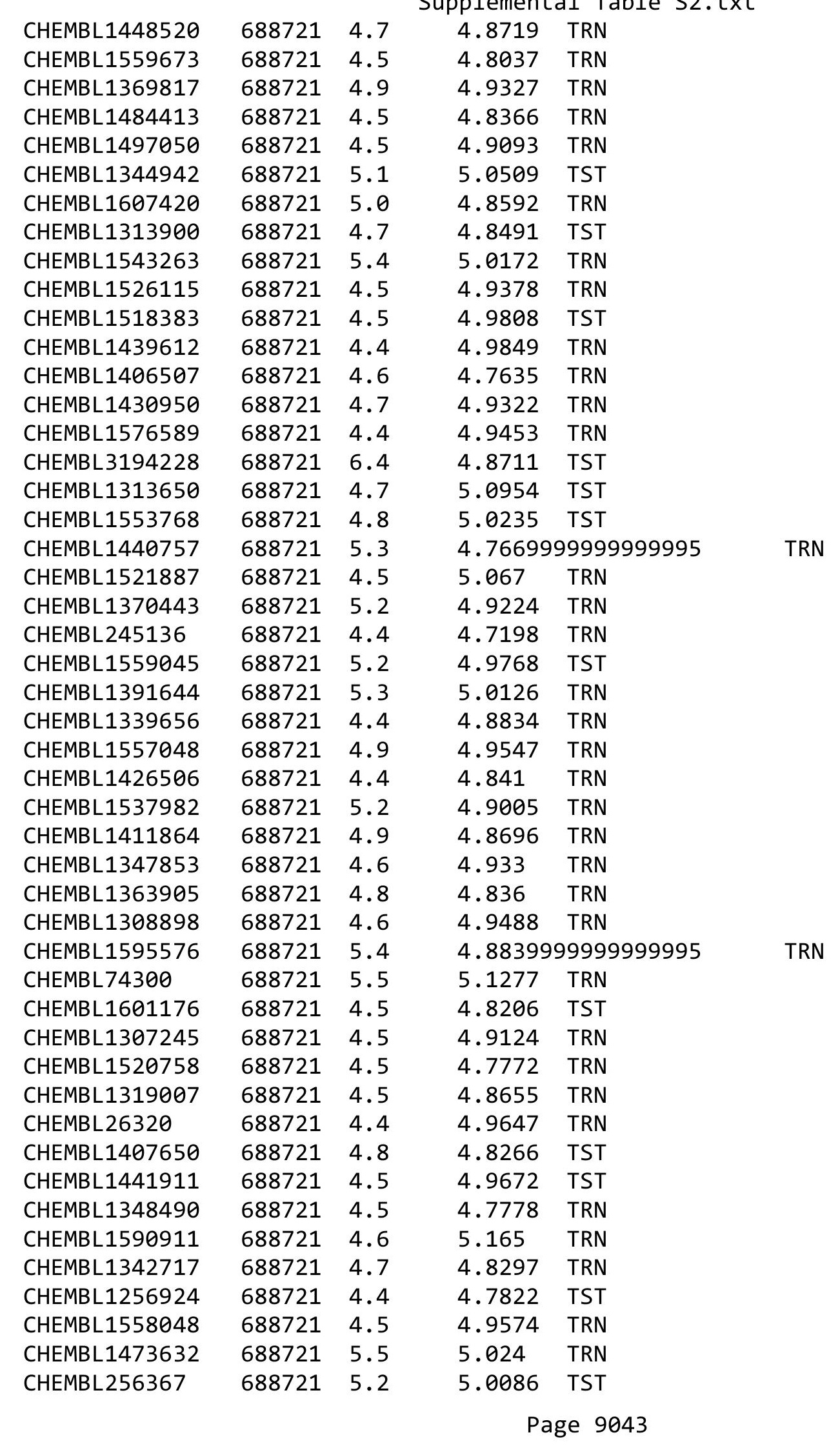




\begin{tabular}{|c|c|c|c|c|c|}
\hline \\
\hline CHEMBL1372088 & 688721 & 6.0 & 5.0582 & TRN & \\
\hline CHEMBL88147 & 688721 & 4.4 & 4.9681 & TST & \\
\hline CHEMBL1466047 & 688721 & 7.0 & 5.1161 & TRN & \\
\hline CHEMBL1484824 & 688721 & 5.4 & 5.051 & TRN & \\
\hline CHEMBL1350068 & 688721 & 5.2 & 4.8417 & TRN & \\
\hline CHEMBL1444078 & 688721 & 4.4 & 5.2515 & TST & \\
\hline CHEMBL1362471 & 688721 & 4.5 & 4.9767 & TST & \\
\hline CHEMBL1340822 & 688721 & 5.1 & 4.8421 & TRN & \\
\hline CHEMBL1548183 & 688721 & 5.3 & 4.8768 & TRN & \\
\hline CHEMBL1408259 & 688721 & 4.4 & 5.0284 & TRN & \\
\hline CHEMBL1459568 & 688721 & 5.2 & 4.963 & TRN & \\
\hline CHEMBL1543759 & 688721 & 4.4 & 5.1075 & TRN & \\
\hline CHEMBL1329965 & 688721 & 4.5 & 4.7692 & TRN & \\
\hline CHEMBL1353533 & 688721 & 4.5 & 5.0833 & TRN & \\
\hline CHEMBL1505553 & 688721 & 4.9 & 5.026 & TRN & \\
\hline CHEMBL1302225 & 688721 & 4.4 & 4.8327 & TRN & \\
\hline CHEMBL1385123 & 688721 & 4.7 & 4.8861 & TRN & \\
\hline CHEMBL1304204 & 688721 & 6.8 & 5.02800 & 30000000005 & TRN \\
\hline CHEMBL1313467 & 688721 & 5.2 & 4.8683 & TRN & \\
\hline CHEMBL1519957 & 688721 & 4.6 & 4.8686 & TRN & \\
\hline CHEMBL1531818 & 688721 & 4.9 & 4.9685 & TST & \\
\hline CHEMBL 79824 & 688721 & 5.7 & 5.2151 & TST & \\
\hline CHEMBL1575967 & 688721 & 4.5 & 4.9655 & TST & \\
\hline CHEMBL1370174 & 688721 & 5.3 & 4.8337 & TRN & \\
\hline CHEMBL1441818 & 688721 & 5.5 & 4.8098 & TRN & \\
\hline CHEMBL1439619 & 688721 & 4.6 & 4.8331 & TRN & \\
\hline CHEMBL1452812 & 688721 & 5.8 & 4.9245 & TRN & \\
\hline CHEMBL1339120 & 688721 & 4.6 & 4.7886 & TRN & \\
\hline CHEMBL1447333 & 688721 & 8.0 & 5.1157 & TST & \\
\hline CHEMBL1443614 & 688721 & 4.7 & 5.1565 & TRN & \\
\hline CHEMBL1325380 & 688721 & 5.2 & 5.1297 & TST & \\
\hline CHEMBL1322030 & 688721 & 5.3 & 4.9687 & TST & \\
\hline CHEMBL1482983 & 688721 & 4.4 & 4.9566 & TST & \\
\hline CHEMBL1310350 & 688721 & 5.2 & 4.9396 & TRN & \\
\hline CHEMBL1454735 & 688721 & 4.6 & 5.0902 & TST & \\
\hline CHEMBL1519736 & 688721 & 4.6 & 4.7691 & TRN & \\
\hline CHEMBL1545249 & 688721 & 4.6 & 5.0516 & TST & \\
\hline CHEMBL1363103 & 688721 & 4.8 & 4.8265 & TST & \\
\hline CHEMBL1582382 & 688721 & 5.1 & 4.8453 & TRN & \\
\hline CHEMBL1375946 & 688721 & 5.2 & 4.9361 & TRN & \\
\hline CHEMBL1374411 & 688721 & 4.4 & 4.8716 & TST & \\
\hline CHEMBL1540890 & 688721 & 4.5 & 4.9029 & TRN & \\
\hline CHEMBL1368002 & 688721 & 5.2 & 5.1109 & TST & \\
\hline CHEMBL1368871 & 688721 & 4.5 & 4.9459 & TST & \\
\hline CHEMBL1527667 & 688721 & 4.8 & 4.8718 & TRN & \\
\hline CHEMBL1415957 & 688721 & 5.6 & 5.0741 & TRN & \\
\hline CHEMBL1544968 & 688721 & 5.4 & 4.8757 & TRN & \\
\hline CHEMBL1392302 & 688721 & 4.6 & 4.8339 & TRN & \\
\hline
\end{tabular}




\begin{tabular}{|c|c|c|c|c|}
\hline & & & plem & \\
\hline CHEMBL1386065 & 688721 & 4.6 & 4.8666 & TRN \\
\hline CHEMBL1563604 & 688721 & 4.8 & 5.1161 & TRN \\
\hline CHEMBL1408469 & 688721 & 6.6 & 4.9954 & TST \\
\hline CHEMBL1488198 & 688721 & 4.6 & 4.8436 & TRN \\
\hline CHEMBL1382384 & 688721 & 6.2 & 5.1235 & TRN \\
\hline CHEMBL1335540 & 688721 & 5.2 & 4.8885 & TRN \\
\hline CHEMBL1380170 & 688721 & 4.5 & 4.9815 & TST \\
\hline CHEMBL1488183 & 688721 & 4.4 & 4.8998 & TRN \\
\hline CHEMBL1432773 & 688721 & 5.1 & 4.8572 & TRN \\
\hline CHEMBL1610232 & 688721 & 4.4 & 4.7248 & TRN \\
\hline CHEMBL1499344 & 688721 & 4.6 & 5.0166 & TST \\
\hline CHEMBL1352687 & 688721 & 4.8 & 4.8443 & TRN \\
\hline CHEMBL1577452 & 688721 & 4.5 & 4.7993 & TRN \\
\hline CHEMBL1418959 & 688721 & 5.2 & 4.8245 & TRN \\
\hline CHEMBL1335889 & 688721 & 4.9 & 5.0066 & TRN \\
\hline CHEMBL1454280 & 688721 & 5.4 & 5.0155 & TRN \\
\hline CHEMBL1566696 & 688721 & 4.6 & 4.9006 & TRN \\
\hline CHEMBL1516077 & 688721 & 4.8 & 5.0252 & TST \\
\hline CHEMBL1568385 & 688721 & 4.6 & 4.9951 & TRN \\
\hline CHEMBL1342271 & 688721 & 4.6 & 5.02 & TST \\
\hline CHEMBL1561170 & 688721 & 4.8 & 4.7691 & TRN \\
\hline CHEMBL1550272 & 688721 & 5.5 & 5.1413 & TST \\
\hline CHEMBL1589639 & 688721 & 5.4 & 4.849 & TRN \\
\hline CHEMBL1493859 & 688721 & 4.6 & 4.9541 & TRN \\
\hline CHEMBL1527460 & 688721 & 4.7 & 4.9852 & TST \\
\hline CHEMBL1477394 & 688721 & 4.6 & 5.1075 & TRN \\
\hline CHEMBL1452532 & 688721 & 4.7 & 4.8395 & TRN \\
\hline CHEMBL1470214 & 688721 & 4.6 & 4.9186 & TRN \\
\hline CHEMBL1453087 & 688721 & 5.1 & 5.2643 & TRN \\
\hline CHEMBL1510261 & 688721 & 5.1 & 4.8428 & TST \\
\hline CHEMBL1484230 & 688721 & 4.7 & 4.757 & TRN \\
\hline CHEMBL1485204 & 688721 & 4.7 & 4.8425 & TST \\
\hline CHEMBL1603782 & 688721 & 4.4 & 5.0644 & TST \\
\hline CHEMBL1308461 & 688721 & 4.6 & 4.7801 & TRN \\
\hline CHEMBL1528604 & 688721 & 5.3 & 4.8898 & TRN \\
\hline CHEMBL227496 & 688721 & 4.8 & 4.8998 & TRN \\
\hline CHEMBL1448542 & 688721 & 4.4 & 5.0099 & TRN \\
\hline CHEMBL1477366 & 688721 & 4.4 & 4.8809 & TRN \\
\hline CHEMBL1420106 & 688721 & 4.6 & 4.9305 & TRN \\
\hline CHEMBL1544757 & 688721 & 4.4 & 4.9591 & TRN \\
\hline CHEMBL1529087 & 688721 & 6.4 & 4.6906 & TRN \\
\hline CHEMBL1540098 & 688721 & 4.7 & 4.7137 & TST \\
\hline CHEMBL3191869 & 688721 & 4.4 & 5.0945 & TST \\
\hline CHEMBL1476480 & 688721 & 5.3 & 4.9636 & TRN \\
\hline CHEMBL1308490 & 688721 & 6.5 & 4.9527 & TRN \\
\hline CHEMBL1369033 & 688721 & 4.9 & 4.8735 & TRN \\
\hline CHEMBL1460848 & 688721 & 4.6 & 4.7137 & TRN \\
\hline CHEMBL1571126 & 688721 & 4.4 & 4.926 & TST \\
\hline
\end{tabular}




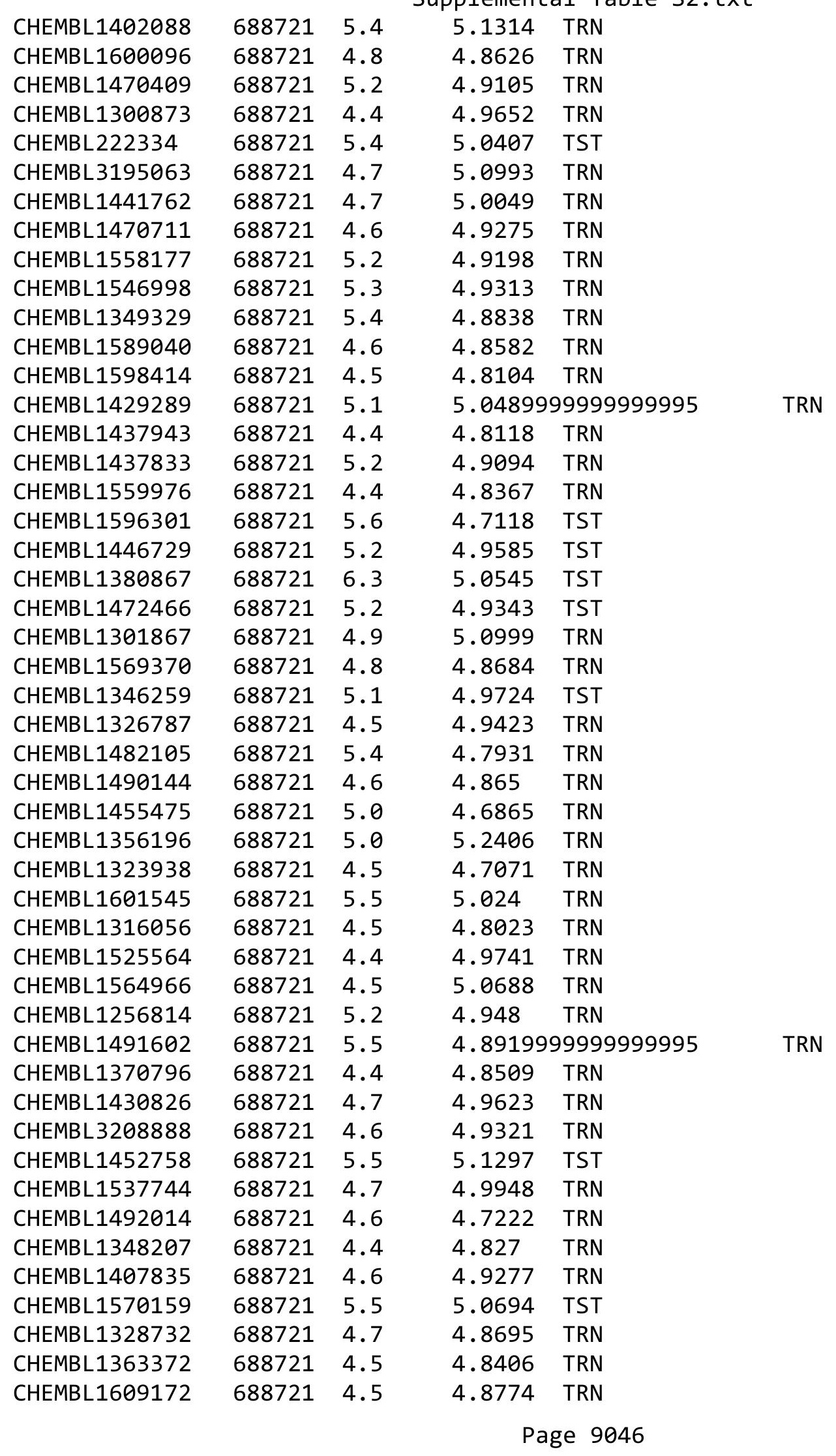




\begin{tabular}{|c|c|c|c|c|c|}
\hline \multicolumn{6}{|c|}{ Supplemental Table S2.txt } \\
\hline CHEMBL1490297 & 688721 & 4.6 & 5.0221 & TST & \\
\hline CHEMBL259140 & 688721 & 4.5 & 5.0663 & TRN & \\
\hline CHEMBL1508605 & 688721 & 5.4 & 5.09699 & 99999999995 & TRN \\
\hline CHEMBL1348771 & 688721 & 4.9 & 4.8591 & TRN & \\
\hline CHEMBL1561200 & 688721 & 5.3 & 4.9576 & TRN & \\
\hline CHEMBL1351619 & 688721 & 6.1 & 5.144 & TST & \\
\hline CHEMBL1392784 & 688721 & 4.9 & 5.0357 & TST & \\
\hline CHEMBL1366219 & 688721 & 5.5 & 4.9042 & TST & \\
\hline CHEMBL1520757 & 688721 & 4.5 & 4.8579 & TRN & \\
\hline CHEMBL1418584 & 688721 & 5.1 & 4.941 & TST & \\
\hline CHEMBL1389629 & 688721 & 4.4 & 4.8618 & TST & \\
\hline CHEMBL1371512 & 688721 & 4.4 & 4.8213 & TRN & \\
\hline CHEMBL1595404 & 688721 & 5.2 & 5.2399 & TRN & \\
\hline CHEMBL1448019 & 688721 & 4.7 & 4.9179 & TRN & \\
\hline CHEMBL1306917 & 688721 & 4.5 & 4.9984 & TST & \\
\hline CHEMBL1332055 & 688721 & 5.2 & 5.0101 & TST & \\
\hline CHEMBL1430893 & 688721 & 4.5 & 4.8267 & TRN & \\
\hline CHEMBL1349134 & 688721 & 4.5 & 4.6893 & TRN & \\
\hline CHEMBL1315991 & 688721 & 4.4 & 5.1722 & TRN & \\
\hline CHEMBL1372090 & 688721 & 6.2 & 4.97 & TRN & \\
\hline CHEMBL1466795 & 688721 & 4.7 & 4.968 & TST & \\
\hline CHEMBL1317009 & 688721 & 5.0 & 4.8019 & TRN & \\
\hline CHEMBL1556862 & 688721 & 4.5 & 5.0024 & TRN & \\
\hline CHEMBL1546451 & 688721 & 4.5 & 4.8251 & TRN & \\
\hline CHEMBL1499741 & 688721 & 4.8 & 4.8676 & TRN & \\
\hline CHEMBL1449447 & 688721 & 4.9 & 5.0152 & TRN & \\
\hline CHEMBL1517264 & 688721 & 4.4 & 4.9713 & TRN & \\
\hline CHEMBL1307116 & 688721 & 4.6 & 4.9521 & TRN & \\
\hline CHEMBL3198100 & 688721 & 4.5 & 4.907 & TST & \\
\hline CHEMBL1528383 & 688721 & 4.8 & 4.7385 & TRN & \\
\hline CHEMBL23832 & 688721 & 4.6 & 5.0796 & TRN & \\
\hline CHEMBL1423151 & 688721 & 5.4 & 5.0771 & TRN & \\
\hline CHEMBL3196650 & 688721 & 4.7 & 4.9392 & TST & \\
\hline CHEMBL1490260 & 688721 & 5.2 & 5.0601 & TST & \\
\hline CHEMBL1420813 & 688721 & 8.301 & 5.0584 & TST & \\
\hline CHEMBL1520559 & 688721 & 4.4 & 4.647 & TRN & \\
\hline CHEMBL1389179 & 688721 & 4.6 & 4.8383 & TRN & \\
\hline CHEMBL1353055 & 688721 & 4.4 & 4.8505 & TRN & \\
\hline CHEMBL1454746 & 688721 & 5.4 & 4.8436 & TRN & \\
\hline CHEMBL1559507 & 688721 & 5.3 & 4.9931 & TRN & \\
\hline CHEMBL1572173 & 688721 & 7.5003 & 5.2104 & TRN & \\
\hline CHEMBL1511625 & 688721 & 5.0 & 4.9766 & TST & \\
\hline CHEMBL1539477 & 688721 & 4.5 & 5.0095 & TRN & \\
\hline CHEMBL1522486 & 688721 & 6.0 & 5.033 & TST & \\
\hline CHEMBL1421241 & 688721 & 4.8 & 4.8173 & TRN & \\
\hline CHEMBL1594329 & 688721 & 5.5 & 5.1883 & TRN & \\
\hline CHEMBL1441750 & 688721 & 4.5 & 5.025 & TRN & \\
\hline CHEMBL1420689 & 688721 & 5.4 & 4.7414 & TRN & \\
\hline
\end{tabular}




\begin{tabular}{|c|c|c|c|c|}
\hline \multicolumn{5}{|c|}{ Supplemental Table S2.txt } \\
\hline CHEMBL3192608 & 688721 & 4.4 & 4.8651 & TRN \\
\hline CHEMBL1613288 & 688721 & 4.6 & 4.7288 & TRN \\
\hline CHEMBL 3190124 & 688721 & 5.2 & 5.0472 & TST \\
\hline CHEMBL1372780 & 688721 & 4.6 & 4.8559 & TRN \\
\hline CHEMBL 263893 & 688721 & 4.4 & 5.0878 & TRN \\
\hline CHEMBL1402444 & 688721 & 5.4 & 5.0419 & TRN \\
\hline CHEMBL1460876 & 688721 & 4.5 & 4.9577 & TST \\
\hline CHEMBL1580978 & 688721 & 4.6 & 4.6822 & TRN \\
\hline CHEMBL1430855 & 688721 & 6.0 & 4.7802 & TRN \\
\hline CHEMBL1608678 & 688721 & 4.8 & 5.0599 & TRN \\
\hline CHEMBL6567 & 688721 & 6.9 & 5.2415 & TST \\
\hline CHEMBL1496934 & 688721 & 4.7 & 5.0036 & TST \\
\hline CHEMBL1302376 & 688721 & 4.9 & 4.904 & TRN \\
\hline CHEMBL1605515 & 688721 & 7.6003 & 5.2014 & TRN \\
\hline CHEMBL1344053 & 688721 & 4.9 & 4.6356 & TRN \\
\hline CHEMBL1495107 & 688721 & 5.9 & 4.9408 & TRN \\
\hline CHEMBL 261123 & 688721 & 4.5 & 4.7446 & TRN \\
\hline CHEMBL1611210 & 688721 & 4.7 & 4.6853 & TRN \\
\hline CHEMBL1544164 & 688721 & 5.2 & 4.9539 & TST \\
\hline CHEMBL1604912 & 688721 & 4.9 & 4.9083 & TRN \\
\hline CHEMBL1490031 & 688721 & 4.6 & 4.7885 & TRN \\
\hline CHEMBL1574848 & 688721 & 4.5 & 4.749 & TRN \\
\hline CHEMBL1422446 & 688721 & 5.7 & 5.0063 & TRN \\
\hline CHEMBL1488082 & 688721 & 4.4 & 4.8071 & TRN \\
\hline CHEMBL1076555 & 688721 & 4.8 & 4.9234 & TST \\
\hline CHEMBL1456465 & 688721 & 4.8 & 4.9621 & TST \\
\hline CHEMBL3210745 & 688721 & 4.4 & 4.8963 & TST \\
\hline CHEMBL1407308 & 688721 & 4.5 & 4.7318 & TRN \\
\hline CHEMBL1305172 & 688721 & 4.7 & 5.0895 & TRN \\
\hline CHEMBL1612246 & 688721 & 5.5 & 5.0818 & TST \\
\hline CHEMBL1392655 & 688721 & 4.8 & 4.8529 & TRN \\
\hline CHEMBL1405659 & 688721 & 4.6 & 5.0018 & TRN \\
\hline CHEMBL1378995 & 688721 & 4.9 & 4.7014 & TRN \\
\hline CHEMBL1562425 & 688721 & 4.5 & 4.8043 & TRN \\
\hline CHEMBL1348692 & 688721 & 6.0 & 4.8158 & TST \\
\hline CHEMBL1424982 & 688721 & 4.6 & 4.9387 & TRN \\
\hline CHEMBL1369522 & 688721 & 5.2 & 4.9508 & TRN \\
\hline CHEMBL1574632 & 688721 & 4.4 & 4.9045 & TRN \\
\hline CHEMBL1570525 & 688721 & 6.0 & 5.1032 & TRN \\
\hline CHEMBL1327772 & 688721 & 5.3 & 5.0896 & TRN \\
\hline CHEMBL1497427 & 688721 & 5.0 & 4.8024 & TRN \\
\hline CHEMBL1569825 & 688721 & 4.6 & 4.8677 & TRN \\
\hline CHEMBL1421059 & 688721 & 5.4 & 4.8186 & TRN \\
\hline CHEMBL1605152 & 688721 & 5.4 & 4.8915 & TST \\
\hline CHEMBL1599609 & 688721 & 4.8 & 4.8048 & TRN \\
\hline CHEMBL1540153 & 688721 & 6.1 & 4.8831 & TRN \\
\hline CHEMBL1314422 & 688721 & 4.4 & 4.9655 & TRN \\
\hline CHEMBL1530024 & 688721 & 4.5 & 5.0174 & TRN \\
\hline
\end{tabular}




\begin{tabular}{|c|c|c|c|c|c|}
\hline \multirow[b]{2}{*}{ CHEMBL1428821 } & \multicolumn{5}{|c|}{ able s2. } \\
\hline & 688721 & 4.6 & 5.0506 & TRN & \\
\hline CHEMBL1461856 & 688721 & 4.4 & 4.8772 & TRN & \\
\hline CHEMBL1543554 & 688721 & 4.6 & 4.94600 & 0000000001 & TRN \\
\hline CHEMBL1494059 & 688721 & 4.4 & 5.1129 & TRN & \\
\hline CHEMBL1413782 & 688721 & 5.3 & 4.9832 & TST & \\
\hline CHEMBL1572127 & 688721 & 4.7 & 4.8492 & TRN & \\
\hline CHEMBL1606174 & 688721 & 6.1 & 4.9287 & TRN & \\
\hline CHEMBL1408061 & 688721 & 4.5 & 4.7751 & TRN & \\
\hline CHEMBL1536269 & 688721 & 5.2 & 4.9434 & TRN & \\
\hline CHEMBL1517378 & 688721 & 5.5 & 5.0502 & TST & \\
\hline CHEMBL1362304 & 688721 & 4.7 & 4.9804 & TRN & \\
\hline CHEMBL1516005 & 688721 & 5.4 & 4.93199 & 99999999995 & TRN \\
\hline CHEMBL1489035 & 688721 & 4.8 & 4.9075 & TRN & \\
\hline CHEMBL1521930 & 688721 & 4.7 & 4.8434 & TRN & \\
\hline CHEMBL1304586 & 688721 & 4.4 & 4.7316 & TRN & \\
\hline CHEMBL1412140 & 688721 & 4.4 & 4.9233 & TRN & \\
\hline CHEMBL1453826 & 688721 & 4.5 & 5.0735 & TRN & \\
\hline CHEMBL1480405 & 688721 & 4.5 & 4.8012 & TRN & \\
\hline CHEMBL1564741 & 688721 & 4.6 & 4.8792 & TST & \\
\hline CHEMBL1362247 & 688721 & 4.5 & 4.81 & TRN & \\
\hline CHEMBL1452952 & 688721 & 4.5 & 4.7018 & TRN & \\
\hline CHEMBL1568982 & 688721 & 4.4 & 4.86100 & 0000000001 & TRN \\
\hline CHEMBL1363809 & 688721 & 4.6 & 4.9311 & TRN & \\
\hline CHEMBL1528564 & 688721 & 4.6 & 4.9302 & TRN & \\
\hline CHEMBL1438992 & 688721 & 6.0 & 5.0228 & TRN & \\
\hline CHEMBL1414481 & 688721 & 4.9 & 4.9273 & TST & \\
\hline CHEMBL1365783 & 688721 & 4.7 & 4.9711 & TRN & \\
\hline CHEMBL1424954 & 688721 & 5.1 & 4.7374 & TRN & \\
\hline CHEMBL1407030 & 688721 & 4.4 & 5.1016 & TRN & \\
\hline CHEMBL1530831 & 688721 & 4.6 & 4.9473 & TRN & \\
\hline CHEMBL1510342 & 688721 & 4.8 & 4.9246 & TRN & \\
\hline CHEMBL1500854 & 688721 & 4.5 & 5.0771 & TST & \\
\hline CHEMBL1523854 & 688721 & 5.4 & 5.0301 & TST & \\
\hline CHEMBL1321686 & 688721 & 5.6 & 4.8946 & TRN & \\
\hline CHEMBL1302133 & 688721 & 5.3 & 4.8596 & TRN & \\
\hline CHEMBL1572836 & 688721 & 5.0 & 4.8457 & TRN & \\
\hline CHEMBL1466317 & 688721 & 4.5 & 5.12200 & 0000000001 & TST \\
\hline CHEMBL1359108 & 688721 & 6.7001 & 5.2623 & TRN & \\
\hline CHEMBL1468626 & 688721 & 5.2 & 4.8384 & TRN & \\
\hline CHEMBL1413050 & 688721 & 4.8 & 4.9293 & TST & \\
\hline CHEMBL1541174 & 688721 & 5.9 & 4.8752 & TST & \\
\hline CHEMBL1470953 & 688721 & 4.6 & 4.8258 & TRN & \\
\hline CHEMBL1340364 & 688721 & 4.7 & 4.707 & TRN & \\
\hline CHEMBL1565927 & 688721 & 4.7 & 4.9022 & TRN & \\
\hline CHEMBL1520349 & 688721 & 4.8 & 4.9622 & TRN & \\
\hline CHEMBL1432334 & 688721 & 4.6 & 4.7678 & TRN & \\
\hline CHEMBL1323791 & 688721 & 5.5 & 4.9807 & TRN & \\
\hline CHEMBL3207743 & 688721 & 4.5 & 5.3578 & TST & \\
\hline
\end{tabular}




\begin{tabular}{|c|c|c|c|c|}
\hline & & & pplement & al $\mathrm{Ta}$ \\
\hline CHEMBL1312163 & 688721 & 6.2 & 4.9127 & TRN \\
\hline CHEMBL1577485 & 688721 & 4.8 & 4.8494 & TST \\
\hline CHEMBL1420897 & 688721 & 4.8 & 4.9379 & TRN \\
\hline CHEMBL1368032 & 688721 & 4.8 & 4.837 & TRN \\
\hline CHEMBL1365303 & 688721 & 4.4 & 4.9615 & TST \\
\hline CHEMBL1546824 & 688721 & 4.5 & 4.7697 & TRN \\
\hline CHEMBL1427147 & 688721 & 4.6 & 4.9102 & TRN \\
\hline CHEMBL1319881 & 688721 & 4.4 & 4.9978 & TRN \\
\hline CHEMBL3197487 & 688721 & 4.6 & 4.8392 & TRN \\
\hline CHEMBL1332033 & 688721 & 4.8 & 4.9443 & TRN \\
\hline CHEMBL1570200 & 688721 & 4.5 & 4.9532 & TRN \\
\hline CHEMBL3207708 & 688721 & 5.0 & 4.8454 & TST \\
\hline CHEMBL1432013 & 688721 & 5.7 & 5.3379 & TRN \\
\hline CHEMBL1520346 & 688721 & 6.9 & 4.7697 & TST \\
\hline CHEMBL1453955 & 688721 & 4.4 & 4.8467 & TRN \\
\hline CHEMBL1352094 & 688721 & 5.2 & 4.9345 & TRN \\
\hline CHEMBL1346584 & 688721 & 4.6 & 4.8632 & TRN \\
\hline CHEMBL1526789 & 688721 & 4.7 & 4.8238 & TRN \\
\hline CHEMBL1428601 & 688721 & 5.5 & 4.9949 & TRN \\
\hline CHEMBL1532602 & 688721 & 5.4 & 4.9668 & TRN \\
\hline CHEMBL1301017 & 688721 & 5.5 & 4.8405 & TRN \\
\hline CHEMBL1384522 & 688721 & 4.8 & 5.0599 & TRN \\
\hline CHEMBL1583225 & 688721 & 5.2 & 4.9699 & TST \\
\hline CHEMBL1432209 & 688721 & 4.5 & 4.9641 & TRN \\
\hline CHEMBL1365186 & 688721 & 4.5 & 4.9654 & TRN \\
\hline CHEMBL1582353 & 688721 & 4.4 & 4.8636 & TST \\
\hline CHEMBL1451209 & 688721 & 4.5 & 4.8135 & TRN \\
\hline CHEMBL1489547 & 688721 & 4.7 & 5.0393 & TST \\
\hline CHEMBL1377212 & 688721 & 5.3 & 4.8962 & TRN \\
\hline CHEMBL1496350 & 688721 & 5.3 & 5.0591 & TRN \\
\hline CHEMBL1376312 & 688721 & 4.7 & 4.9543 & TRN \\
\hline CHEMBL1478751 & 688721 & 5.4 & 4.8964 & TRN \\
\hline CHEMBL1385011 & 688721 & 4.9 & 4.7316 & TRN \\
\hline CHEMBL1411381 & 688721 & 4.5 & 4.9573 & TRN \\
\hline CHEMBL1502260 & 688721 & 4.4 & 4.7247 & TRN \\
\hline CHEMBL1429577 & 688721 & 4.5 & 4.9345 & TRN \\
\hline CHEMBL1591635 & 688721 & 5.3 & 5.3058 & TRN \\
\hline CHEMBL1366061 & 688721 & 5.4 & 5.1415 & TRN \\
\hline CHEMBL1565405 & 688721 & 5.1 & 4.9048 & TRN \\
\hline CHEMBL1593430 & 688721 & 4.5 & 5.0903 & TRN \\
\hline CHEMBL1502546 & 688721 & 4.4 & 5.0322 & TRN \\
\hline CHEMBL1390916 & 688721 & 5.9 & 4.7668 & TRN \\
\hline CHEMBL1527157 & 688721 & 5.2 & 5.1077 & TST \\
\hline CHEMBL1569116 & 688721 & 5.2 & 5.3914 & TRN \\
\hline CHEMBL1609128 & 688721 & 4.4 & 4.9675 & TST \\
\hline CHEMBL1489204 & 688721 & 5.4 & 4.8405 & TRN \\
\hline CHEMBL1463766 & 688721 & 4.8 & 4.9254 & TRN \\
\hline CHEMBL1437718 & 688721 & 5.9 & 5.0785 & TRN \\
\hline
\end{tabular}




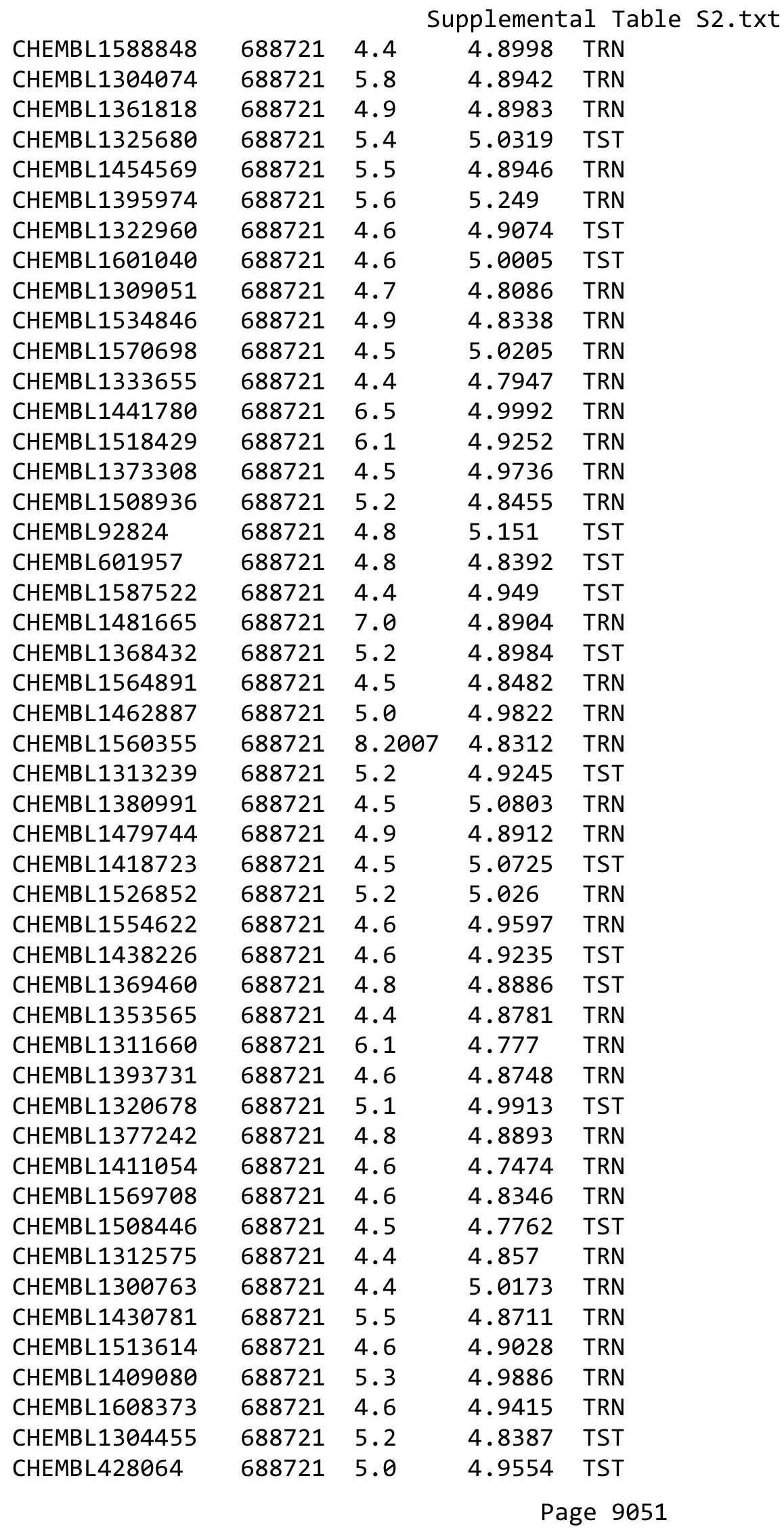




\begin{tabular}{|c|c|c|c|c|}
\hline \multicolumn{5}{|c|}{ Supplemental Table s2.txt } \\
\hline CHEMBL1360603 & 688721 & 4.5 & 4.9134 & TRN \\
\hline CHEMBL1586792 & 688721 & 5.4 & 4.981 & TRN \\
\hline CHEMBL1344791 & 688721 & 4.6 & 4.9494 & TRN \\
\hline CHEMBL1450713 & 688721 & 5.2 & 4.795 & TRN \\
\hline CHEMBL1550065 & 688721 & 4.6 & 5.1086 & TST \\
\hline CHEMBL1437968 & 688721 & 4.4 & 5.0682 & TST \\
\hline CHEMBL1379420 & 688721 & 5.2 & 4.899 & TRN \\
\hline CHEMBL1389851 & 688721 & 4.7 & 4.8756 & TRN \\
\hline CHEMBL1412471 & 688721 & 4.6 & 4.9919 & TRN \\
\hline CHEMBL1315802 & 688721 & 5.2 & 5.1709 & TRN \\
\hline CHEMBL1448511 & 688721 & 5.4 & 5.0976 & TST \\
\hline CHEMBL1483034 & 688721 & 5.5 & 4.7308 & TST \\
\hline CHEMBL1504506 & 688721 & 5.0 & 4.9374 & TRN \\
\hline CHEMBL1521879 & 688721 & 5.4 & 5.0279 & TRN \\
\hline CHEMBL1586833 & 688721 & 4.4 & 4.8805 & TRN \\
\hline CHEMBL1424988 & 688721 & 4.8 & 5.0425 & TST \\
\hline CHEMBL1329067 & 688721 & 6.5 & 5.0891 & TRN \\
\hline CHEMBL1497853 & 688721 & 4.4 & 4.8581 & TRN \\
\hline CHEMBL1516187 & 688721 & 5.9 & 5.1054 & TST \\
\hline CHEMBL1357157 & 688721 & 5.9 & 4.9898 & TRN \\
\hline CHEMBL1608558 & 688721 & 7.6003 & 5.24 & TST \\
\hline CHEMBL1569176 & 688721 & 4.5 & 5.0243 & TST \\
\hline CHEMBL1326700 & 688721 & 4.6 & 4.9166 & TRN \\
\hline CHEMBL1609468 & 688721 & 4.7 & 5.0199 & TST \\
\hline CHEMBL1546033 & 688721 & 4.6 & 4.86 & TRN \\
\hline CHEMBL270299 & 688721 & 4.6 & 5.2443 & TST \\
\hline CHEMBL110739 & 688721 & 6.9 & 5.4526 & TRN \\
\hline CHEMBL1320751 & 688721 & 5.3 & 4.823 & TRN \\
\hline CHEMBL1465985 & 688721 & 5.0 & 4.893 & TRN \\
\hline CHEMBL 302213 & 688721 & 5.4 & 5.1995 & TST \\
\hline CHEMBL1301505 & 688721 & 5.0 & 4.8551 & TRN \\
\hline CHEMBL1506593 & 688721 & 4.6 & 4.9617 & TRN \\
\hline CHEMBL1436817 & 688721 & 4.8 & 5.0451 & TRN \\
\hline CHEMBL1606811 & 688721 & 4.4 & 4.961 & TST \\
\hline CHEMBL1432711 & 688721 & 4.7 & 5.0562 & TRN \\
\hline CHEMBL1451251 & 688721 & 5.1 & 4.8694 & TST \\
\hline CHEMBL1398467 & 688721 & 4.9 & 5.105 & TRN \\
\hline CHEMBL1413443 & 688721 & 5.1 & 4.9336 & TRN \\
\hline CHEMBL1419082 & 688721 & 4.6 & 4.8286 & TRN \\
\hline CHEMBL3208814 & 688721 & 5.5 & 4.9367 & TRN \\
\hline CHEMBL1346439 & 688721 & 4.4 & 4.8516 & TRN \\
\hline CHEMBL1443931 & 688721 & 4.6 & 5.1095 & TST \\
\hline CHEMBL1528664 & 688721 & 4.7 & 4.8253 & TRN \\
\hline CHEMBL1331011 & 688721 & 4.6 & 5.0193 & TRN \\
\hline CHEMBL1344369 & 688721 & 6.1 & 4.7934 & TRN \\
\hline CHEMBL1425857 & 688721 & 6.1 & 5.0034 & TRN \\
\hline CHEMBL1449992 & 688721 & 4.6 & 4.78100 & 0000000001 \\
\hline CHEMBL1568018 & 688721 & 4.6 & 4.8998 & TST \\
\hline
\end{tabular}

TRN 


\begin{tabular}{|c|c|c|c|c|}
\hline & & & pplement & al $\mathrm{Ta}$ \\
\hline CHEMBL1207889 & 688721 & 6.0 & 5.2458 & TRN \\
\hline CHEMBL1444396 & 688721 & 5.6 & 5.0903 & TRN \\
\hline CHEMBL1562171 & 688721 & 6.0 & 4.8487 & TST \\
\hline CHEMBL1581217 & 688721 & 5.4 & 4.9642 & TRN \\
\hline CHEMBL336467 & 688721 & 4.8 & 5.0317 & TST \\
\hline CHEMBL1399151 & 688721 & 5.8 & 5.2989 & TST \\
\hline CHEMBL1442026 & 688721 & 4.8 & 4.8541 & TRN \\
\hline CHEMBL1385459 & 688721 & 4.4 & 5.0095 & TRN \\
\hline CHEMBL1452784 & 688721 & 4.5 & 4.8858 & TRN \\
\hline CHEMBL1451672 & 688721 & 4.5 & 5.1497 & TRN \\
\hline CHEMBL1461811 & 688721 & 4.5 & 4.8648 & TRN \\
\hline CHEMBL1385215 & 688721 & 4.5 & 4.8873 & TRN \\
\hline CHEMBL1557024 & 688721 & 4.8 & 4.9284 & TRN \\
\hline CHEMBL1370718 & 688721 & 5.3 & 5.1271 & TRN \\
\hline CHEMBL1447026 & 688721 & 4.7 & 4.956 & TRN \\
\hline CHEMBL1462422 & 688721 & 4.4 & 4.9225 & TST \\
\hline CHEMBL1448192 & 688721 & 5.2 & 5.1329 & TST \\
\hline CHEMBL1325183 & 688721 & 5.3 & 5.0946 & TST \\
\hline CHEMBL1484692 & 688721 & 4.8 & 4.84 & TRN \\
\hline CHEMBL1395869 & 688721 & 5.4 & 5.1462 & TRN \\
\hline CHEMBL1450088 & 688721 & 4.7 & 4.8046 & TRN \\
\hline CHEMBL1610522 & 688721 & 4.4 & 5.011 & TRN \\
\hline CHEMBL1373035 & 688721 & 5.9 & 4.9583 & TRN \\
\hline CHEMBL585059 & 688721 & 4.8 & 4.8827 & TRN \\
\hline CHEMBL1404934 & 688721 & 4.4 & 5.0164 & TRN \\
\hline CHEMBL1359211 & 688721 & 4.6 & 4.7968 & TRN \\
\hline CHEMBL1343526 & 688721 & 5.4 & 4.9392 & TRN \\
\hline CHEMBL1603155 & 688721 & 4.5 & 4.9256 & TST \\
\hline CHEMBL1538259 & 688721 & 4.8 & 4.9027 & TST \\
\hline CHEMBL 1606030 & 688721 & 4.4 & 4.7696 & TRN \\
\hline CHEMBL1428021 & 688721 & 4.9 & 4.7409 & TRN \\
\hline CHEMBL1574543 & 688721 & 5.5 & 5.0721 & TRN \\
\hline CHEMBL1416650 & 688721 & 4.7 & 4.7606 & TRN \\
\hline CHEMBL1415139 & 688721 & 5.6 & 5.011 & TRN \\
\hline CHEMBL1312236 & 688721 & 5.4 & 4.5954 & TRN \\
\hline CHEMBL1387225 & 688721 & 4.4 & 5.0187 & TST \\
\hline CHEMBL1458079 & 688721 & 4.9 & 4.9384 & TRN \\
\hline CHEMBL1411288 & 688721 & 4.7 & 4.8675 & TRN \\
\hline CHEMBL1533378 & 688721 & 5.1 & 4.9678 & TRN \\
\hline CHEMBL1391416 & 688721 & 5.3 & 4.8208 & TRN \\
\hline CHEMBL1530982 & 688721 & 5.2 & 5.317 & TRN \\
\hline CHEMBL1496920 & 688721 & 5.4 & 4.8152 & TRN \\
\hline CHEMBL1441246 & 688721 & 5.9 & 4.6467 & TRN \\
\hline CHEMBL1608266 & 688721 & 4.6 & 4.86 & TRN \\
\hline CHEMBL1584754 & 688721 & 4.7 & 4.9604 & TST \\
\hline CHEMBL1547144 & 688721 & 4.7 & 4.8229 & TRN \\
\hline CHEMBL1405376 & 688721 & 4.5 & 4.8054 & TRN \\
\hline CHEMBL1578584 & 688721 & 4.7 & 4.819 & TRN \\
\hline
\end{tabular}




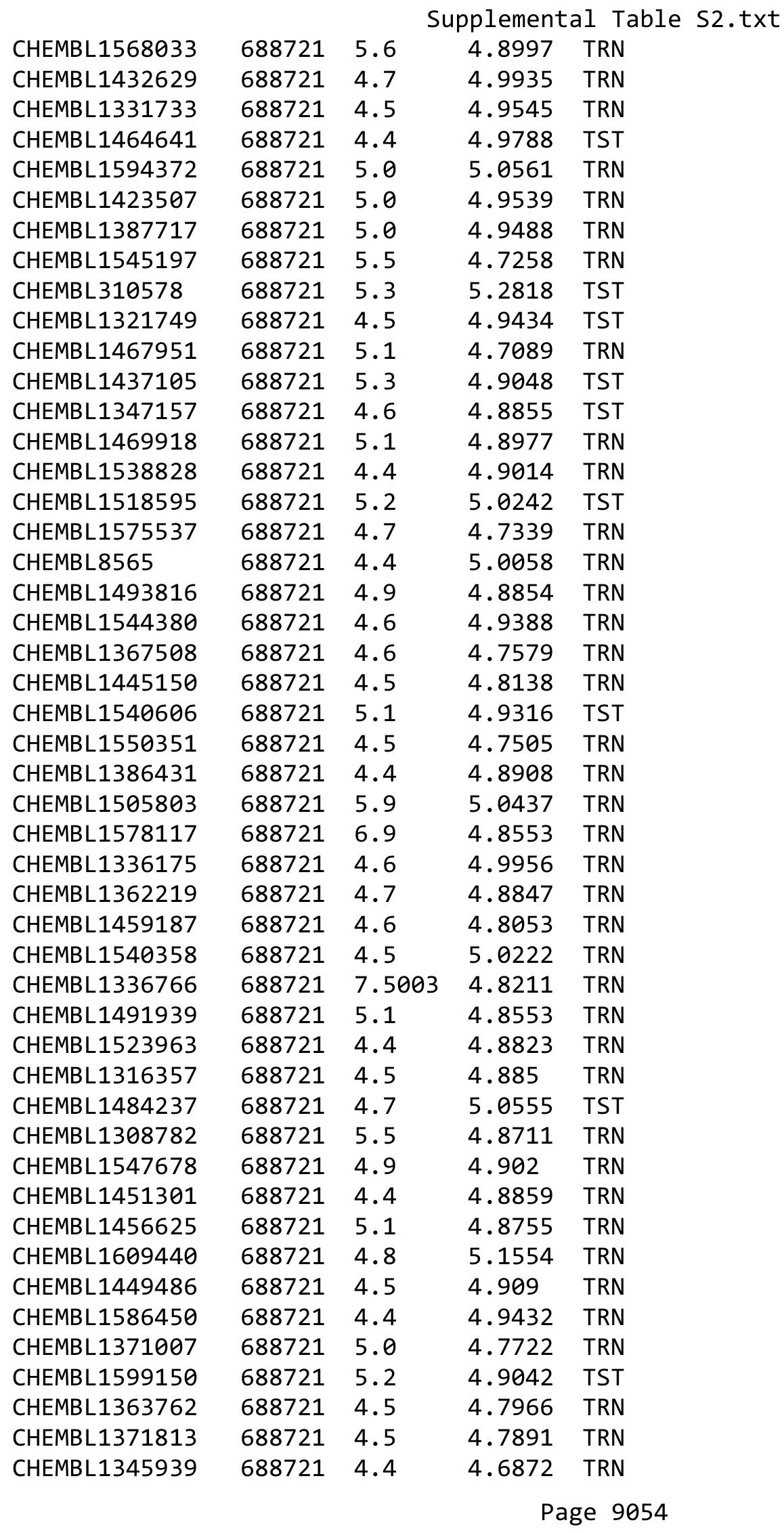




\begin{tabular}{|c|c|c|c|c|}
\hline \multicolumn{5}{|c|}{ Supplemental Table S2.txt } \\
\hline CHEMBL1489755 & 688721 & 4.4 & 4.8516 & TRN \\
\hline CHEMBL1326803 & 688721 & 4.6 & 5.0878 & TRN \\
\hline CHEMBL 285235 & 688721 & 5.7 & 5.1067 & TST \\
\hline CHEMBL1546572 & 688721 & 4.7 & 4.9313 & TRN \\
\hline CHEMBL1435654 & 688721 & 5.6 & 5.0762 & TRN \\
\hline CHEMBL1566094 & 688721 & 4.7 & 4.7627 & TST \\
\hline CHEMBL1335140 & 688721 & 5.4 & 5.0131 & TRN \\
\hline CHEMBL1533903 & 688721 & 4.9 & 4.8431 & TST \\
\hline CHEMBL1417482 & 688721 & 4.5 & 4.9974 & TST \\
\hline CHEMBL 275938 & 688721 & 5.5 & 5.1852 & TST \\
\hline CHEMBL1561429 & 688721 & 5.4 & 5.0917 & TST \\
\hline CHEMBL1435259 & 688721 & 5.6 & 5.2041 & TRN \\
\hline CHEMBL1435252 & 688721 & 4.8 & 4.8969 & TRN \\
\hline CHEMBL1335389 & 688721 & 4.4 & 4.8729 & TRN \\
\hline CHEMBL1536604 & 688721 & 5.2 & 4.7948 & TRN \\
\hline CHEMBL1535147 & 688721 & 4.5 & 4.8343 & TRN \\
\hline CHEMBL1581913 & 688721 & 5.4 & 5.106 & TRN \\
\hline CHEMBL1329280 & 688721 & 4.4 & 5.1295 & TRN \\
\hline CHEMBL1570238 & 688721 & 4.5 & 4.9367 & TRN \\
\hline CHEMBL1344973 & 688721 & 4.5 & 4.9046 & TRN \\
\hline CHEMBL1426183 & 688721 & 4.6 & 4.8373 & TRN \\
\hline CHEMBL1534832 & 688721 & 4.7 & 4.9806 & TRN \\
\hline CHEMBL1444983 & 688721 & 4.5 & 4.8757 & TRN \\
\hline CHEMBL1407494 & 688721 & 4.9 & 4.8158 & TRN \\
\hline CHEMBL1374696 & 688721 & 4.6 & 5.1212 & TRN \\
\hline CHEMBL1356794 & 688721 & 4.5 & 4.9203 & TRN \\
\hline CHEMBL1467595 & 688721 & 4.4 & 5.0094 & TRN \\
\hline CHEMBL1434198 & 688721 & 4.8 & 4.8928 & TRN \\
\hline CHEMBL1604803 & 688721 & 4.4 & 4.8312 & TRN \\
\hline CHEMBL1323522 & 688721 & 4.6 & 4.8088 & TRN \\
\hline CHEMBL1372230 & 688721 & 4.8 & 4.9494 & TRN \\
\hline CHEMBL3199301 & 688721 & 4.8 & 4.7189 & TRN \\
\hline CHEMBL1557465 & 688721 & 4.6 & 5.0678 & TST \\
\hline CHEMBL1575530 & 688721 & 4.9 & 4.9329 & TRN \\
\hline CHEMBL1305869 & 688721 & 4.8 & 5.0392 & TRN \\
\hline CHEMBL1579292 & 688721 & 5.2 & 5.0828 & TRN \\
\hline CHEMBL1393537 & 688721 & 5.2 & 5.0217 & TST \\
\hline CHEMBL1479506 & 688721 & 5.7 & 4.9732 & TRN \\
\hline CHEMBL1595747 & 688721 & 4.5 & 5.0246 & TST \\
\hline CHEMBL1402112 & 688721 & 4.7 & 5.0534 & TRN \\
\hline CHEMBL1558074 & 688721 & 7.5003 & 5.2447 & TST \\
\hline CHEMBL1417000 & 688721 & 5.2 & 5.0938 & TST \\
\hline CHEMBL1541318 & 688721 & 4.5 & 4.8834 & TRN \\
\hline CHEMBL1393501 & 688721 & 4.4 & 5.1163 & TST \\
\hline CHEMBL1529067 & 688721 & 4.4 & 4.7418 & TST \\
\hline CHEMBL1461504 & 688721 & 5.9 & 5.084 & TRN \\
\hline CHEMBL1570832 & 688721 & 4.4 & 4.895 & TRN \\
\hline CHEMBL1422671 & 688721 & 4.8 & 4.9413 & TRN \\
\hline
\end{tabular}




\begin{tabular}{|c|c|c|c|c|}
\hline \multicolumn{5}{|c|}{ plemental } \\
\hline CHEMBL1299373 & 688721 & 4.4 & 4.8605 & TST \\
\hline CHEMBL1426615 & 688721 & 4.8 & 5.0992 & TRN \\
\hline CHEMBL1322827 & 688721 & 4.8 & 4.9821 & TRN \\
\hline CHEMBL1506982 & 688721 & 4.7 & 4.9413 & TST \\
\hline CHEMBL1301166 & 688721 & 4.8 & 4.9183 & TRN \\
\hline CHEMBL1487209 & 688721 & 5.2 & 4.9071 & TRN \\
\hline CHEMBL1308088 & 688721 & 4.4 & 5.0373 & TRN \\
\hline CHEMBL1487036 & 688721 & 4.9 & 4.8577 & TRN \\
\hline CHEMBL1604123 & 688721 & 5.2 & 4.8924 & TRN \\
\hline CHEMBL1397548 & 688721 & 4.6 & 4.9483 & TRN \\
\hline CHEMBL1459858 & 688721 & 4.8 & 5.0243 & TRN \\
\hline CHEMBL1408062 & 688721 & 4.5 & 4.7236 & TRN \\
\hline CHEMBL1523206 & 688721 & 4.5 & 4.8862 & TST \\
\hline CHEMBL1603946 & 688721 & 4.6 & 4.9703 & TST \\
\hline CHEMBL1368777 & 688721 & 4.6 & 4.9847 & TRN \\
\hline CHEMBL1303068 & 688721 & 5.1 & 4.8099 & TRN \\
\hline CHEMBL1541506 & 688721 & 4.4 & 4.9058 & TST \\
\hline CHEMBL1304744 & 688721 & 4.4 & 5.1934 & TST \\
\hline CHEMBL1574897 & 688721 & 5.2 & 5.0677 & TRN \\
\hline CHEMBL2000175 & 688721 & 4.5 & 4.8375 & TST \\
\hline CHEMBL1414426 & 688721 & 4.4 & 4.9369 & TRN \\
\hline CHEMBL1328092 & 688721 & 5.3 & 5.0913 & TRN \\
\hline CHEMBL1363710 & 688721 & 4.5 & 4.9952 & TRN \\
\hline CHEMBL1530543 & 688721 & 5.2 & 4.9363 & TRN \\
\hline CHEMBL1345948 & 688721 & 5.2 & 5.0115 & TRN \\
\hline CHEMBL1582589 & 688721 & 4.5 & 4.8437 & TRN \\
\hline CHEMBL1313167 & 688721 & 5.8 & 4.9812 & TRN \\
\hline CHEMBL3208298 & 688721 & 4.4 & 4.923 & TST \\
\hline CHEMBL1320934 & 688721 & 5.5 & 5.0829 & TRN \\
\hline CHEMBL1546479 & 688721 & 4.6 & 4.8424 & TRN \\
\hline CHEMBL1454868 & 688721 & 4.6 & 4.7072 & TRN \\
\hline CHEMBL1501608 & 688721 & 4.8 & 4.9115 & TST \\
\hline CHEMBL1590048 & 688721 & 4.8 & 5.0152 & TST \\
\hline CHEMBL1544058 & 688721 & 5.5 & 4.8365 & TST \\
\hline CHEMBL1322263 & 688721 & 4.6 & 4.8167 & TRN \\
\hline CHEMBL1586784 & 688721 & 4.5 & 4.7708 & TRN \\
\hline CHEMBL1506370 & 688721 & 4.4 & 5.1736 & TST \\
\hline CHEMBL1535714 & 688721 & 5.2 & 5.1139 & TST \\
\hline CHEMBL1437226 & 688721 & 4.5 & 4.9533 & TRN \\
\hline CHEMBL1452870 & 688721 & 4.8 & 4.9203 & TRN \\
\hline CHEMBL1333102 & 688721 & 4.7 & 4.933 & TRN \\
\hline CHEMBL1352224 & 688721 & 4.4 & 5.0287 & TRN \\
\hline CHEMBL1539966 & 688721 & 4.6 & 5.1479 & TRN \\
\hline CHEMBL1607188 & 688721 & 4.8 & 4.8842 & TRN \\
\hline CHEMBL1610323 & 688721 & 5.2 & 4.8291 & TRN \\
\hline CHEMBL1421178 & 688721 & 5.0 & 4.795 & TRN \\
\hline CHEMBL1535521 & 688721 & 4.5 & 5.0053 & TRN \\
\hline CHEMBL1443212 & 688721 & 4.4 & 4.8211 & TRN \\
\hline
\end{tabular}




\begin{tabular}{|c|c|c|c|c|c|}
\hline \multicolumn{6}{|c|}{ Supplemental Table S2.txt } \\
\hline CHEMBL1612525 & 688721 & 4.8 & 4.9075 & TST & \\
\hline CHEMBL1344593 & 688721 & 6.6 & 4.9772 & TRN & \\
\hline CHEMBL 375270 & 688721 & 5.3 & 5.0698 & TRN & \\
\hline CHEMBL1388179 & 688721 & 4.5 & 4.8466 & TRN & \\
\hline CHEMBL1442642 & 688721 & 4.8 & 4.8324 & TRN & \\
\hline CHEMBL1352525 & 688721 & 4.6 & 4.8768 & TRN & \\
\hline CHEMBL3208430 & 688721 & 4.5 & 4.9397 & TST & \\
\hline CHEMBL1571422 & 688721 & 5.0 & 4.8186 & TRN & \\
\hline CHEMBL1321719 & 688721 & 4.6 & 5.1553 & TRN & \\
\hline CHEMBL 252901 & 688721 & 4.8 & 4.7545 & TRN & \\
\hline CHEMBL1492992 & 688721 & 4.5 & 4.8909 & TRN & \\
\hline CHEMBL1561287 & 688721 & 4.5 & 4.8711 & TRN & \\
\hline CHEMBL1565158 & 688721 & 5.3 & 4.7591 & TRN & \\
\hline CHEMBL1364693 & 688721 & 4.7 & 4.9206 & TRN & \\
\hline CHEMBL1537862 & 688721 & 5.2 & 4.9015 & TST & \\
\hline CHEMBL1360824 & 688721 & 4.5 & 4.984 & TRN & \\
\hline CHEMBL1313675 & 688721 & 5.5 & 5.0193 & TST & \\
\hline CHEMBL1395138 & 688721 & 5.5 & 5.0947 & TRN & \\
\hline CHEMBL1577238 & 688721 & 4.8 & 4.8824 & TRN & \\
\hline CHEMBL1330587 & 688721 & 5.4 & 5.1004 & TRN & \\
\hline CHEMBL1500717 & 688721 & 4.4 & 5.0791 & TST & \\
\hline CHEMBL1324727 & 688721 & 4.6 & 5.0261 & TRN & \\
\hline CHEMBL1503155 & 688721 & 4.8 & 4.8644 & TRN & \\
\hline CHEMBL1325376 & 688721 & 4.5 & 4.7808 & TRN & \\
\hline CHEMBL1343083 & 688721 & 6.2 & 4.8665 & TST & \\
\hline CHEMBL1587174 & 688721 & 5.2 & 4.9651 & TRN & \\
\hline CHEMBL1326451 & 688721 & 4.9 & 4.9277 & TRN & \\
\hline CHEMBL1369753 & 688721 & 6.0 & 4.9939 & TRN & \\
\hline CHEMBL1393465 & 688721 & 4.7 & 4.9101 & TRN & \\
\hline CHEMBL1320865 & 688721 & 4.4 & 4.8038 & TRN & \\
\hline CHEMBL1581304 & 688721 & 4.5 & 4.7666 & TRN & \\
\hline CHEMBL1463238 & 688721 & 5.6 & 4.8533 & TST & \\
\hline CHEMBL1390766 & 688721 & 6.0 & 4.9423 & TRN & \\
\hline CHEMBL473736 & 688721 & 4.9 & 4.7752 & TRN & \\
\hline CHEMBL1503603 & 688721 & 4.8 & 4.8832 & TST & \\
\hline CHEMBL1326090 & 688721 & 4.6 & 4.8339 & TRN & \\
\hline CHEMBL3210742 & 688721 & 4.7 & 5.0559 & TST & \\
\hline CHEMBL225230 & 688721 & 6.7001 & 5.0575 & TST & \\
\hline CHEMBL1339031 & 688721 & 4.5 & 4.8713 & TST & \\
\hline CHEMBL1354018 & 688721 & 5.2 & 5.0694 & TRN & \\
\hline CHEMBL1569712 & 688721 & 4.6 & 4.864 & TRN & \\
\hline CHEMBL1410321 & 688721 & 5.4 & 5.0195 & TRN & \\
\hline CHEMBL1521440 & 688721 & 4.6 & 5.2162 & TRN & \\
\hline CHEMBL1447180 & 688721 & 4.4 & 5.19600 & 0000000001 & TRN \\
\hline CHEMBL1587049 & 688721 & 5.8 & 5.2273 & TST & \\
\hline CHEMBL1492580 & 688721 & 5.4 & 4.8495 & TRN & \\
\hline CHEMBL1518842 & 688721 & 4.6 & 4.7179 & TRN & \\
\hline CHEMBL1445298 & 688721 & 4.5 & 4.8571 & TRN & \\
\hline
\end{tabular}




\begin{tabular}{|c|c|c|c|c|}
\hline & & & & al Table S \\
\hline CHEMBL1461406 & 688721 & 4.4 & 4.9186 & TRN \\
\hline CHEMBL1558773 & 688721 & 4.7 & 4.9502 & TRN \\
\hline CHEMBL1569406 & 688721 & 6.1 & 4.7937 & TRN \\
\hline CHEMBL1401214 & 688721 & 4.8 & 5.2156 & TRN \\
\hline CHEMBL1382951 & 688721 & 4.4 & 4.8062 & TRN \\
\hline CHEMBL1473430 & 688721 & 6.1 & 5.0139 & TRN \\
\hline CHEMBL1579385 & 688721 & 4.9 & 4.8302 & TRN \\
\hline CHEMBL1401442 & 688721 & 4.6 & 5.034 & TRN \\
\hline CHEMBL1610807 & 688721 & 4.4 & 5.2125 & TST \\
\hline CHEMBL1524617 & 688721 & 4.9 & 5.2611 & TST \\
\hline CHEMBL1574475 & 688721 & 4.9 & 4.9616 & TST \\
\hline CHEMBL1550242 & 688721 & 4.8 & 4.8903 & TRN \\
\hline CHEMBL1561625 & 688721 & 4.4 & 4.8481 & TRN \\
\hline CHEMBL491960 & 688721 & 5.6 & 4.9755 & TST \\
\hline CHEMBL1443695 & 688721 & 4.8 & 5.1098 & TRN \\
\hline CHEMBL1402025 & 688721 & 4.6 & 4.8631 & TRN \\
\hline CHEMBL1602729 & 688721 & 6.4 & 5.0491 & TST \\
\hline CHEMBL1555931 & 688721 & 4.6 & 4.832 & TRN \\
\hline CHEMBL1299357 & 688721 & 4.6 & 4.9701 & TRN \\
\hline CHEMBL1474633 & 688721 & 4.5 & 5.1648 & TRN \\
\hline CHEMBL1535917 & 688721 & 4.7 & 5.0616 & TRN \\
\hline CHEMBL1498032 & 688721 & 4.4 & 4.8691 & TRN \\
\hline CHEMBL1567815 & 688721 & 4.5 & 4.84399 & 9999999999 \\
\hline CHEMBL1386440 & 688721 & 5.3 & 4.8809 & TRN \\
\hline CHEMBL1416476 & 688721 & 5.4 & 4.9721 & TRN \\
\hline CHEMBL1323569 & 688721 & 4.6 & 4.7397 & TST \\
\hline CHEMBL1561236 & 688721 & 4.9 & 4.9376 & TRN \\
\hline CHEMBL1370379 & 688721 & 4.4 & 4.9625 & TST \\
\hline CHEMBL1329866 & 688721 & 5.2 & 4.8809 & TRN \\
\hline CHEMBL1412662 & 688721 & 4.8 & 4.9087 & TRN \\
\hline CHEMBL1446277 & 688721 & 4.9 & 4.9554 & TRN \\
\hline CHEMBL1359848 & 688721 & 4.8 & 4.7832 & TRN \\
\hline CHEMBL1579942 & 688721 & 4.9 & 4.927 & TRN \\
\hline CHEMBL1527162 & 688721 & 5.4 & 4.9864 & TRN \\
\hline CHEMBL1466856 & 688721 & 4.4 & 4.8769 & TRN \\
\hline CHEMBL363207 & 688721 & 6.0 & 5.1232 & TST \\
\hline CHEMBL1571789 & 688721 & 4.5 & 4.9004 & TRN \\
\hline CHEMBL1358629 & 688721 & 5.2 & 5.0418 & TST \\
\hline CHEMBL 3212845 & 688721 & 5.1 & 5.1172 & TST \\
\hline CHEMBL1485627 & 688721 & 5.4 & 4.835 & TRN \\
\hline CHEMBL1563315 & 688721 & 6.9 & 4.9839 & TRN \\
\hline CHEMBL1500553 & 688721 & 5.4 & 5.2237 & TST \\
\hline CHEMBL1339052 & 688721 & 4.4 & 5.0211 & TST \\
\hline CHEMBL1425968 & 688721 & 4.8 & 5.0376 & TRN \\
\hline CHEMBL1312369 & 688721 & 4.8 & 4.8653 & TRN \\
\hline CHEMBL1565244 & 688721 & 5.0 & 4.849 & TST \\
\hline CHEMBL1462042 & 688721 & 6.2 & 4.9746 & TRN \\
\hline CHEMBL1511677 & 688721 & 4.8 & 4.8687 & TST \\
\hline
\end{tabular}

TRN 


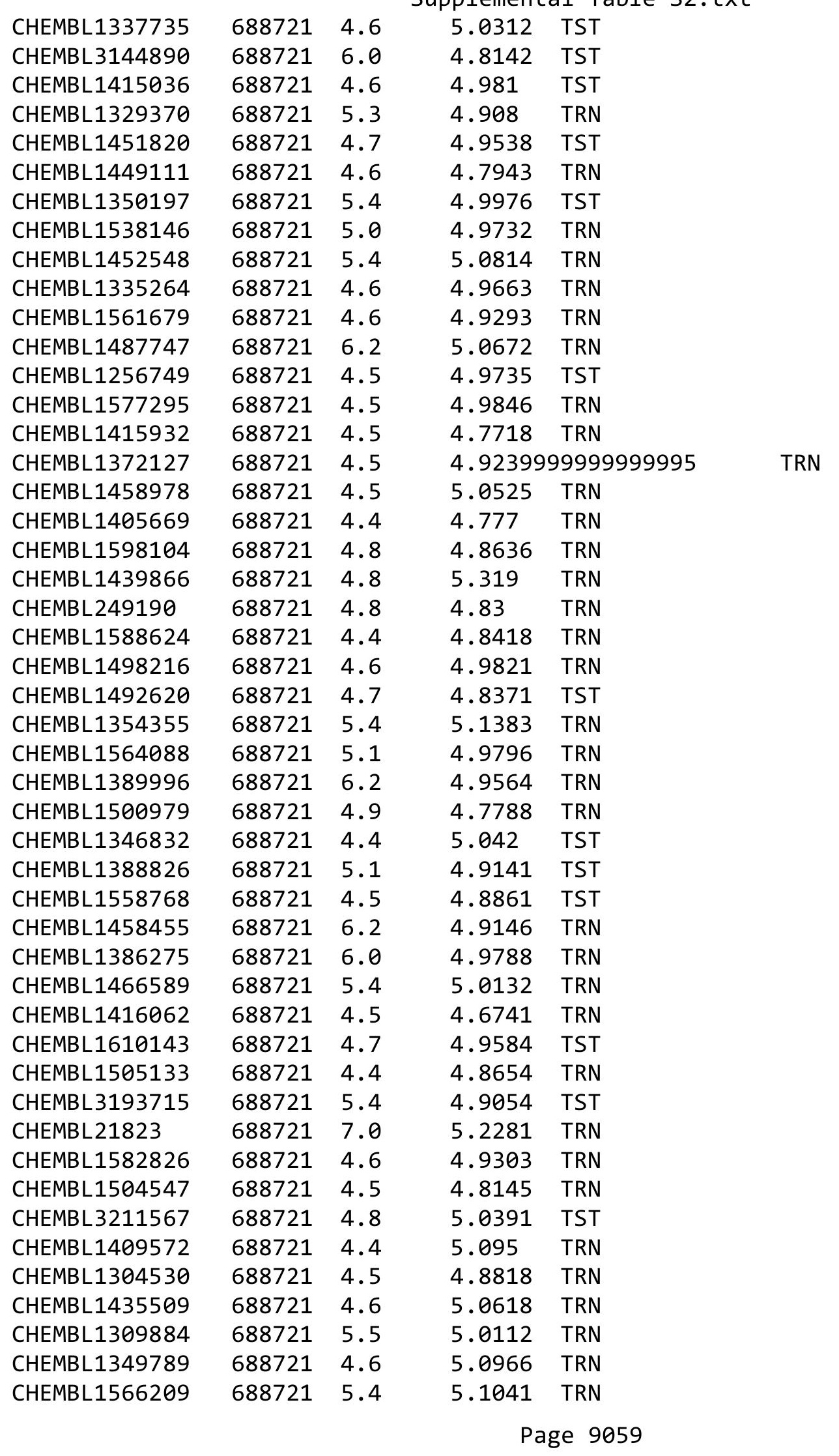




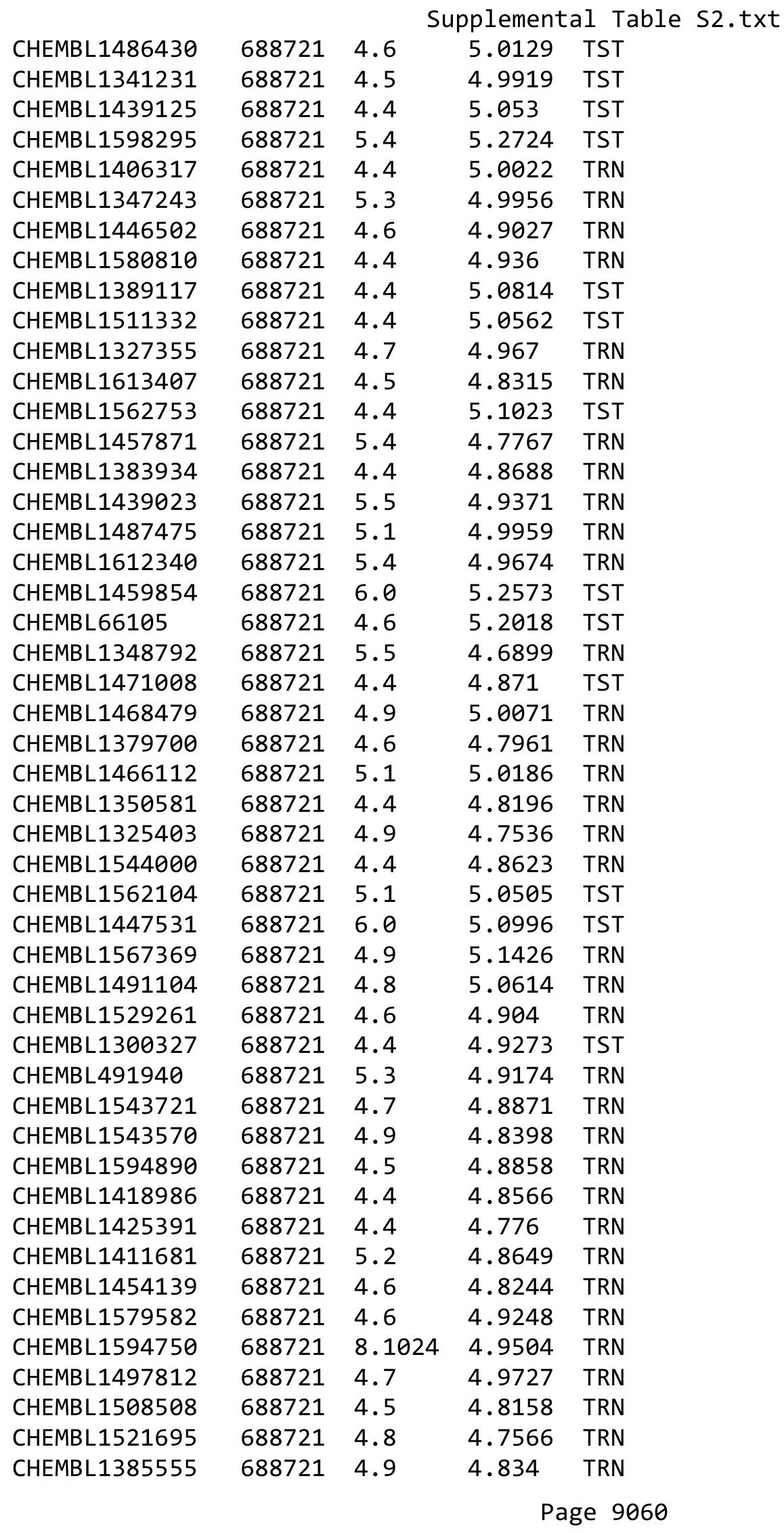




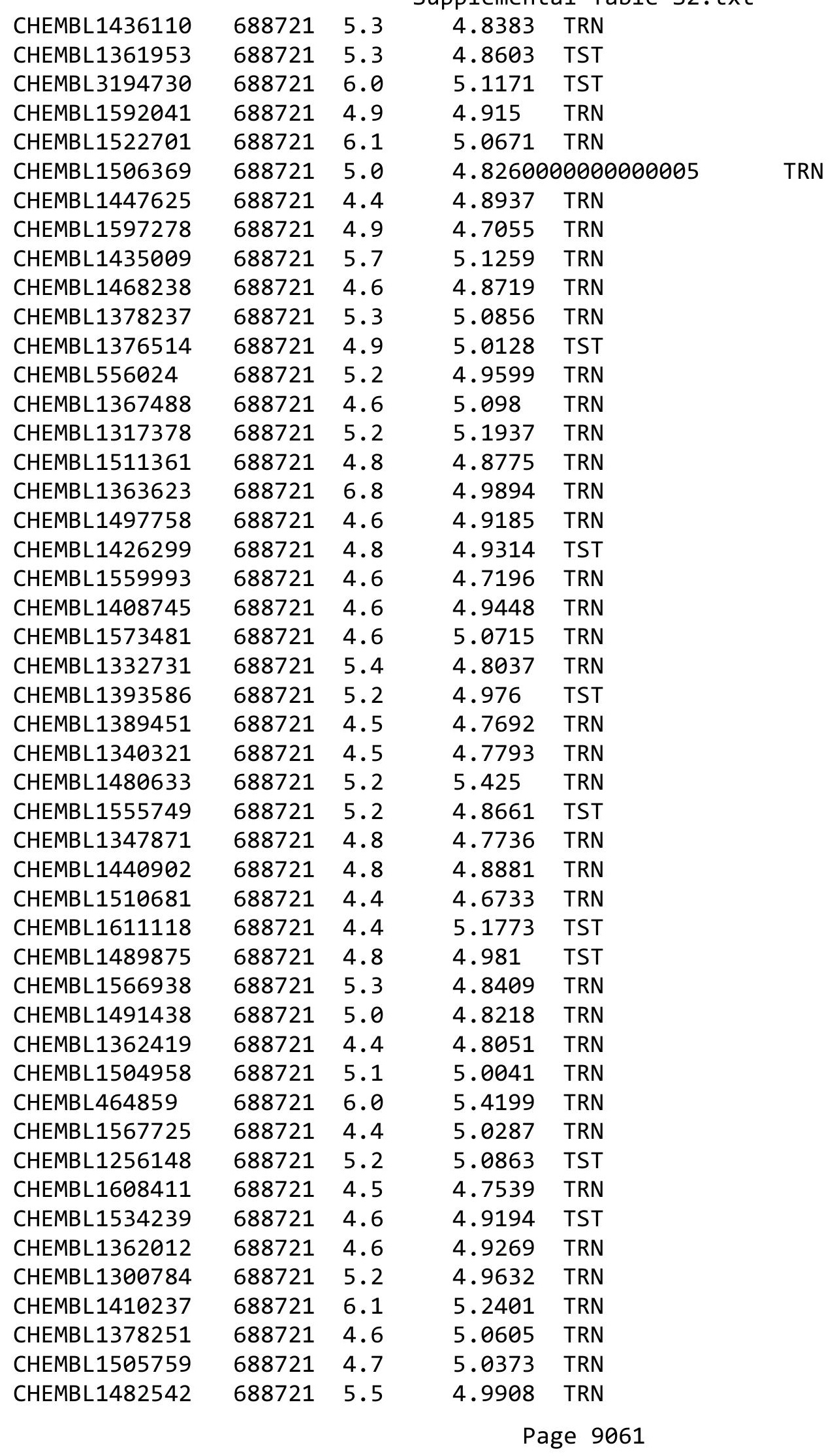




\begin{tabular}{|c|c|c|c|c|}
\hline & & & pplement & al $\mathrm{Ta}$ \\
\hline CHEMBL1524650 & 688721 & 5.5 & 5.1857 & TRN \\
\hline CHEMBL1576902 & 688721 & 4.6 & 5.0186 & TRN \\
\hline CHEMBL1489221 & 688721 & 4.6 & 4.7475 & TST \\
\hline CHEMBL111545 & 688721 & 4.5 & 4.9909 & TST \\
\hline CHEMBL1341471 & 688721 & 4.6 & 4.8853 & TRN \\
\hline CHEMBL1373587 & 688721 & 5.5 & 5.2318 & TST \\
\hline CHEMBL1306920 & 688721 & 6.0 & 5.1549 & TRN \\
\hline CHEMBL1598408 & 688721 & 4.6 & 4.9886 & TRN \\
\hline CHEMBL338567 & 688721 & 5.8 & 5.2291 & TRN \\
\hline CHEMBL1568268 & 688721 & 4.7 & 4.7465 & TRN \\
\hline CHEMBL1355216 & 688721 & 4.7 & 4.8929 & TRN \\
\hline CHEMBL1410470 & 688721 & 5.4 & 4.6971 & TRN \\
\hline CHEMBL1477172 & 688721 & 5.0 & 4.7154 & TRN \\
\hline CHEMBL1404149 & 688721 & 4.4 & 4.9423 & TRN \\
\hline CHEMBL1566459 & 688721 & 5.0 & 4.9401 & TST \\
\hline CHEMBL1487678 & 688721 & 4.4 & 4.8133 & TST \\
\hline CHEMBL1579561 & 688721 & 4.6 & 4.9288 & TRN \\
\hline CHEMBL1529561 & 688721 & 5.8 & 5.1583 & TST \\
\hline CHEMBL1494592 & 688721 & 5.4 & 5.1696 & TRN \\
\hline CHEMBL1604707 & 688721 & 4.6 & 4.7272 & TRN \\
\hline CHEMBL1469840 & 688721 & 5.4 & 5.0906 & TST \\
\hline CHEMBL1611004 & 688721 & 4.7 & 4.7768 & TRN \\
\hline CHEMBL1449514 & 688721 & 4.6 & 4.8343 & TRN \\
\hline CHEMBL1562750 & 688721 & 4.8 & 4.9675 & TRN \\
\hline CHEMBL1373561 & 688721 & 4.8 & 5.1611 & TST \\
\hline CHEMBL1459280 & 688721 & 4.4 & 4.9661 & TST \\
\hline CHEMBL1396065 & 688721 & 5.9 & 5.0 & TST \\
\hline CHEMBL1532132 & 688721 & 4.5 & 4.7242 & TRN \\
\hline CHEMBL1427182 & 688721 & 5.1 & 5.2248 & TRN \\
\hline CHEMBL1422735 & 688721 & 6.9 & 5.041 & TST \\
\hline CHEMBL1485253 & 688721 & 4.4 & 4.8842 & TRN \\
\hline CHEMBL1495160 & 688721 & 6.5 & 4.8331 & TRN \\
\hline CHEMBL3211543 & 688721 & 4.8 & 5.0393 & TST \\
\hline CHEMBL1526339 & 688721 & 4.9 & 4.8465 & TRN \\
\hline CHEMBL1577121 & 688721 & 4.4 & 4.8941 & TRN \\
\hline CHEMBL1462049 & 688721 & 4.6 & 4.8096 & TRN \\
\hline CHEMBL 247378 & 688721 & 4.4 & 5.1797 & TST \\
\hline CHEMBL1353661 & 688721 & 6.0 & 4.8031 & TRN \\
\hline CHEMBL1353855 & 688721 & 4.4 & 4.8468 & TRN \\
\hline CHEMBL1518689 & 688721 & 5.0 & 5.1047 & TRN \\
\hline CHEMBL1350474 & 688721 & 4.8 & 4.9941 & TST \\
\hline CHEMBL1553322 & 688721 & 4.5 & 4.8618 & TRN \\
\hline CHEMBL1466345 & 688721 & 6.5 & 5.034 & TRN \\
\hline CHEMBL1541546 & 688721 & 4.9 & 4.8659 & TRN \\
\hline CHEMBL1582240 & 688721 & 5.5 & 4.7789 & TST \\
\hline CHEMBL1367173 & 688721 & 4.9 & 4.9098 & TRN \\
\hline CHEMBL1329764 & 688721 & 4.6 & 4.717 & TST \\
\hline CHEMBL3198389 & 688721 & 5.2 & 4.9108 & TST \\
\hline
\end{tabular}




\begin{tabular}{|c|c|c|c|c|c|}
\hline \multicolumn{6}{|c|}{ Supplemental Table S2.txt } \\
\hline CHEMBL1342795 & 688721 & 4.5 & 4.9268 & TRN & \\
\hline CHEMBL1323029 & 688721 & 4.8 & 5.0166 & TRN & \\
\hline CHEMBL1487422 & 688721 & 4.4 & 4.8024 & TRN & \\
\hline CHEMBL1579608 & 688721 & 4.5 & 4.9243 & TST & \\
\hline CHEMBL1563855 & 688721 & 4.7 & 5.0282 & TRN & \\
\hline CHEMBL1346153 & 688721 & 5.2 & 4.9935 & TRN & \\
\hline CHEMBL1581955 & 688721 & 5.2 & 4.9511 & TRN & \\
\hline CHEMBL1560437 & 688721 & 5.5 & 4.881 & TRN & \\
\hline CHEMBL1574652 & 688721 & 5.4 & 4.9301 & TRN & \\
\hline CHEMBL1547376 & 688721 & 5.1 & 4.99 & TST & \\
\hline CHEMBL1472303 & 688721 & 4.7 & 4.8214 & TRN & \\
\hline CHEMBL1299985 & 688721 & 4.5 & 5.1547 & TRN & \\
\hline CHEMBL1538344 & 688721 & 6.0 & 4.9631 & TST & \\
\hline CHEMBL1480712 & 688721 & 4.4 & 4.7985 & TRN & \\
\hline CHEMBL1445162 & 688721 & 4.4 & 4.8903 & TRN & \\
\hline CHEMBL1335639 & 688721 & 6.0 & 4.901 & TRN & \\
\hline CHEMBL1338028 & 688721 & 5.1 & 4.8137 & TRN & \\
\hline CHEMBL1501390 & 688721 & 6.0 & 4.9374 & TRN & \\
\hline CHEMBL1374181 & 688721 & 5.2 & 4.8413 & TRN & \\
\hline CHEMBL1393088 & 688721 & 4.4 & 4.9766 & TST & \\
\hline CHEMBL1417871 & 688721 & 5.2 & 5.1378 & TST & \\
\hline CHEMBL1469528 & 688721 & 5.2 & 4.8264 & TRN & \\
\hline CHEMBL1361174 & 688721 & 4.6 & 4.8121 & TRN & \\
\hline CHEMBL1516589 & 688721 & 4.5 & 4.7927 & TRN & \\
\hline CHEMBL1550204 & 688721 & 4.4 & 4.8122 & TRN & \\
\hline CHEMBL1432468 & 688721 & 4.5 & 4.8185 & TRN & \\
\hline CHEMBL1511573 & 688721 & 4.8 & 4.9927 & TRN & \\
\hline CHEMBL1362051 & 688721 & 4.6 & 4.7021 & TST & \\
\hline CHEMBL1472271 & 688721 & 4.8 & 4.7751 & TRN & \\
\hline CHEMBL1337075 & 688721 & 4.7 & 4.8039 & TRN & \\
\hline CHEMBL1578839 & 688721 & 4.5 & 5.1601 & TRN & \\
\hline CHEMBL1565262 & 688721 & 4.4 & 4.8833 & TST & \\
\hline CHEMBL1360047 & 688721 & 6.9 & 4.9754 & TRN & \\
\hline CHEMBL1424579 & 688721 & 4.8 & 4.9779 & TRN & \\
\hline CHEMBL152557 & 688721 & 4.6 & 5.211 & TST & \\
\hline CHEMBL1491808 & 688721 & 6.3 & 4.9692 & TRN & \\
\hline CHEMBL512090 & 688721 & 4.4 & 5.0389 & TST & \\
\hline CHEMBL1497143 & 688721 & 6.5 & 4.9082 & TST & \\
\hline CHEMBL1344576 & 688721 & 4.4 & 4.7892 & TRN & \\
\hline CHEMBL1550751 & 688721 & 5.5 & 4.902 & TRN & \\
\hline CHEMBL 24510 & 688721 & 4.6 & 5.1371 & TST & \\
\hline CHEMBL1488097 & 688721 & 4.6 & 4.7891 & TRN & \\
\hline CHEMBL1414024 & 688721 & 5.3 & 5.0344 & TST & \\
\hline CHEMBL1340419 & 688721 & 4.6 & 4.8605 & TRN & \\
\hline CHEMBL1414507 & 688721 & 4.8 & 4.96899 & 9999999999 & TRN \\
\hline CHEMBL1601477 & 688721 & 4.4 & 5.1343 & TRN & \\
\hline CHEMBL1350157 & 688721 & 4.5 & 5.1128 & TRN & \\
\hline CHEMBL1483862 & 688721 & 4.8 & 5.3157 & TST & \\
\hline
\end{tabular}




\begin{tabular}{|c|c|c|c|c|}
\hline \multirow[b]{2}{*}{ CHEMBL1325740 } & \multicolumn{4}{|c|}{$=11$} \\
\hline & 688721 & 5.9 & 4.9275 & TRN \\
\hline CHEMBL1351157 & 688721 & 4.8 & 4.9312 & TRN \\
\hline CHEMBL1606704 & 688721 & 5.6 & 4.9132 & TRN \\
\hline CHEMBL1547762 & 688721 & 5.4 & 4.9406 & TRN \\
\hline CHEMBL1352314 & 688721 & 5.7 & 4.9721 & TRN \\
\hline CHEMBL1374143 & 688721 & 5.5 & 5.2117 & TST \\
\hline CHEMBL1557383 & 688721 & 5.1 & 5.2303 & TRN \\
\hline CHEMBL1305658 & 688721 & 4.4 & 4.8949 & TRN \\
\hline CHEMBL1477287 & 688721 & 4.8 & 5.0518 & TRN \\
\hline CHEMBL1356372 & 688721 & 5.1 & 5.1903 & TRN \\
\hline CHEMBL1489620 & 688721 & 4.5 & 4.8679 & TRN \\
\hline CHEMBL1486645 & 688721 & 6.3 & 4.9557 & TRN \\
\hline CHEMBL293749 & 688721 & 4.4 & 5.2754 & TRN \\
\hline CHEMBL1502328 & 688721 & 4.4 & 5.0426 & TRN \\
\hline CHEMBL1518110 & 688721 & 4.8 & 4.9846 & TRN \\
\hline CHEMBL1456015 & 688721 & 5.0 & 4.9916 & TRN \\
\hline CHEMBL1488197 & 688721 & 6.0 & 5.1 & TRN \\
\hline CHEMBL1504090 & 688721 & 4.6 & 4.9471 & TST \\
\hline CHEMBL1256760 & 688721 & 5.2 & 5.5237 & TRN \\
\hline CHEMBL1525740 & 688721 & 4.7 & 4.942 & TRN \\
\hline CHEMBL1601160 & 688721 & 4.7 & 4.9135 & TRN \\
\hline CHEMBL1462403 & 688721 & 4.5 & 5.1741 & TRN \\
\hline CHEMBL1325659 & 688721 & 4.4 & 4.8452 & TST \\
\hline CHEMBL1419981 & 688721 & 4.5 & 5.1994 & TST \\
\hline CHEMBL1450125 & 688721 & 4.8 & 5.0521 & TRN \\
\hline CHEMBL1495025 & 688721 & 4.8 & 4.8414 & TST \\
\hline CHEMBL1606551 & 688721 & 4.9 & 4.8822 & TRN \\
\hline CHEMBL1597576 & 688721 & 4.6 & 4.8833 & TRN \\
\hline CHEMBL1595253 & 688721 & 4.4 & 4.9309 & TRN \\
\hline CHEMBL1402227 & 688721 & 4.8 & 4.977 & TRN \\
\hline CHEMBL1347957 & 688721 & 4.4 & 4.9329 & TRN \\
\hline CHEMBL1308334 & 688721 & 5.0 & 5.2675 & TST \\
\hline CHEMBL1380910 & 688721 & 4.6 & 4.8667 & TST \\
\hline CHEMBL1389592 & 688721 & 4.5 & 4.8874 & TRN \\
\hline CHEMBL1483555 & 688721 & 4.7 & 4.8177 & TRN \\
\hline CHEMBL1309292 & 688721 & 4.7 & 4.9676 & TRN \\
\hline CHEMBL1505253 & 688721 & 4.5 & 4.8305 & TRN \\
\hline CHEMBL1345867 & 688721 & 4.4 & 4.8647 & TRN \\
\hline CHEMBL1376874 & 688721 & 4.4 & 4.7908 & TRN \\
\hline CHEMBL1349019 & 688721 & 4.4 & 4.9156 & TRN \\
\hline CHEMBL1568071 & 688721 & 4.8 & 5.2426 & TRN \\
\hline CHEMBL1305963 & 688721 & 4.6 & 4.6872 & TRN \\
\hline CHEMBL1482582 & 688721 & 4.5 & 5.0566 & TRN \\
\hline CHEMBL1334230 & 688721 & 4.4 & 5.1327 & TRN \\
\hline CHEMBL1424575 & 688721 & 4.4 & 4.8716 & TRN \\
\hline CHEMBL1310587 & 688721 & 5.2 & 5.0063 & TRN \\
\hline CHEMBL530149 & 688721 & 5.2 & 5.0287 & TRN \\
\hline CHEMBL1462190 & 688721 & 6.7001 & 4.8287 & TRN \\
\hline
\end{tabular}




\begin{tabular}{|c|c|c|c|c|c|}
\hline \multicolumn{6}{|c|}{ Supplemental Table S2.txt } \\
\hline CHEMBL1530630 & 688721 & 4.8 & 4.7932 & TRN & \\
\hline CHEMBL1507042 & 688721 & 4.7 & 5.0467 & TRN & \\
\hline CHEMBL1603676 & 688721 & 4.5 & 4.827 & TRN & \\
\hline CHEMBL1309837 & 688721 & 4.6 & 4.8241 & TST & \\
\hline CHEMBL1433762 & 688721 & 8.8861 & 5.0946 & TST & \\
\hline CHEMBL1491397 & 688721 & 5.1 & 4.9714 & TRN & \\
\hline CHEMBL1413465 & 688721 & 4.5 & 4.8383 & TRN & \\
\hline CHEMBL1300290 & 688721 & 7.4001 & 5.0116 & TRN & \\
\hline CHEMBL1468007 & 688721 & 4.6 & 4.9146 & TST & \\
\hline CHEMBL1537545 & 688721 & 4.8 & 4.9571 & TRN & \\
\hline CHEMBL1323105 & 688721 & 6.3 & 4.8366 & TRN & \\
\hline CHEMBL1353398 & 688721 & 6.0 & 4.9256 & TRN & \\
\hline CHEMBL1365169 & 688721 & 4.8 & 4.867 & TRN & \\
\hline CHEMBL 279564 & 688721 & 4.9 & $5.0280 e$ & 00000000005 & TRN \\
\hline CHEMBL1384330 & 688721 & 4.5 & 5.0577 & TRN & \\
\hline CHEMBL1380347 & 688721 & 4.8 & 4.9302 & TRN & \\
\hline CHEMBL1333857 & 688721 & 4.8 & 5.0826 & TRN & \\
\hline CHEMBL1591190 & 688721 & 5.4 & 5.042 & TRN & \\
\hline CHEMBL1560551 & 688721 & 4.7 & 4.9959 & TRN & \\
\hline CHEMBL1585807 & 688721 & 4.7 & 5.0237 & TRN & \\
\hline CHEMBL1312599 & 688721 & 5.5 & 4.9327 & TRN & \\
\hline CHEMBL1326664 & 688721 & 5.9 & 4.8805 & TRN & \\
\hline CHEMBL1601858 & 688721 & 4.5 & 4.9968 & TRN & \\
\hline CHEMBL1507557 & 688721 & 4.7 & 4.9364 & TRN & \\
\hline CHEMBL1427650 & 688721 & 5.4 & 4.9718 & TRN & \\
\hline CHEMBL3192965 & 688721 & 4.5 & 5.0028 & TRN & \\
\hline CHEMBL1563782 & 688721 & 4.4 & 5.0016 & TST & \\
\hline CHEMBL1336301 & 688721 & 5.4 & 5.0083 & TRN & \\
\hline CHEMBL 3212662 & 688721 & 5.2 & 4.9378 & TST & \\
\hline CHEMBL1502958 & 688721 & 5.5 & 4.8806 & TRN & \\
\hline CHEMBL1333517 & 688721 & 5.1 & 4.6414 & TST & \\
\hline CHEMBL1396583 & 688721 & 5.4 & 5.0563 & TRN & \\
\hline CHEMBL1378282 & 688721 & 4.6 & 5.043 & TRN & \\
\hline CHEMBL1311477 & 688721 & 5.2 & 4.7575 & TRN & \\
\hline CHEMBL1313957 & 688721 & 4.4 & 5.1087 & TRN & \\
\hline CHEMBL3212042 & 688721 & 5.5 & 5.0586 & TST & \\
\hline CHEMBL1562297 & 688721 & 4.6 & 4.8686 & TRN & \\
\hline CHEMBL1303566 & 688721 & 4.6 & 4.9057 & TRN & \\
\hline CHEMBL1449234 & 688721 & 4.6 & 4.9503 & TRN & \\
\hline CHEMBL1431877 & 688721 & 4.7 & 4.8082 & TRN & \\
\hline CHEMBL1549160 & 688721 & 4.9 & 4.9051 & TRN & \\
\hline CHEMBL1397177 & 688721 & 5.4 & 5.1024 & TRN & \\
\hline CHEMBL1610043 & 688721 & 6.4 & 4.9897 & TRN & \\
\hline CHEMBL1593443 & 688721 & 4.8 & 4.9721 & TRN & \\
\hline CHEMBL1442166 & 688721 & 5.4 & 4.7674 & TRN & \\
\hline CHEMBL1494768 & 688721 & 4.5 & 5.1447 & TST & \\
\hline CHEMBL1472090 & 688721 & 4.7 & 4.7267 & TRN & \\
\hline CHEMBL1468599 & 688721 & 4.5 & 4.8575 & TRN & \\
\hline
\end{tabular}




\begin{tabular}{|c|c|c|c|c|}
\hline \multicolumn{5}{|c|}{ Iementa1 } \\
\hline CHEMBL3209110 & 688721 & 5.1 & 4.8919 & TRN \\
\hline CHEMBL1489674 & 688721 & 4.8 & 4.82 & TRN \\
\hline CHEMBL1300062 & 688721 & 4.4 & 5.0645 & TRN \\
\hline CHEMBL1464442 & 688721 & 6.2 & 4.9637 & TRN \\
\hline CHEMBL1428087 & 688721 & 4.8 & 4.8824 & TRN \\
\hline CHEMBL1544342 & 688721 & 4.6 & 4.9374 & TRN \\
\hline CHEMBL1309571 & 688721 & 5.3 & 5.0064 & TRN \\
\hline CHEMBL1508336 & 688721 & 5.5 & 4.9445 & TRN \\
\hline CHEMBL1607373 & 688721 & 4.4 & 4.9726 & TRN \\
\hline CHEMBL1449573 & 688721 & 4.6 & 5.1443 & TST \\
\hline CHEMBL1482430 & 688721 & 4.8 & 4.9288 & TRN \\
\hline CHEMBL1492834 & 688721 & 4.4 & 4.8722 & TRN \\
\hline CHEMBL1573419 & 688721 & 6.0 & 4.9583 & TRN \\
\hline CHEMBL475198 & 688721 & 4.8 & 4.9814 & TRN \\
\hline CHEMBL1572056 & 688721 & 4.5 & 4.7408 & TRN \\
\hline CHEMBL1611839 & 688721 & 4.6 & 4.9417 & TRN \\
\hline CHEMBL1464638 & 688721 & 4.5 & 4.9801 & TRN \\
\hline CHEMBL1570135 & 688721 & 4.5 & 4.9513 & TRN \\
\hline CHEMBL1332378 & 688721 & 5.4 & 4.8908 & TST \\
\hline CHEMBL118752 & 688721 & 4.5 & 4.9715 & TRN \\
\hline CHEMBL1554654 & 688721 & 5.5 & 4.9854 & TRN \\
\hline CHEMBL1533928 & 688721 & 4.4 & 4.7087 & TRN \\
\hline CHEMBL3212191 & 688721 & 4.8 & 4.8062 & TST \\
\hline CHEMBL1554937 & 688721 & 4.5 & 4.9604 & TRN \\
\hline CHEMBL1355185 & 688721 & 5.5 & 5.1736 & TRN \\
\hline CHEMBL200309 & 688721 & 4.8 & 5.2303 & TST \\
\hline CHEMBL395915 & 688721 & 5.5 & 5.1496 & TRN \\
\hline CHEMBL1539070 & 688721 & 5.2 & 4.7468 & TRN \\
\hline CHEMBL3198790 & 688721 & 4.7 & 4.7651 & TRN \\
\hline CHEMBL1384368 & 688721 & 5.2 & 4.8538 & TRN \\
\hline CHEMBL1517765 & 688721 & 4.8 & 5.0692 & TRN \\
\hline CHEMBL1453502 & 688721 & 6.2 & 4.9216 & TRN \\
\hline CHEMBL1529294 & 688721 & 5.3 & 4.9746 & TRN \\
\hline CHEMBL1517261 & 688721 & 6.1 & 4.9418 & TRN \\
\hline CHEMBL1357857 & 688721 & 4.5 & 5.0384 & TRN \\
\hline CHEMBL1358806 & 688721 & 6.0 & 5.1141 & TRN \\
\hline CHEMBL1387100 & 688721 & 4.8 & 4.9343 & TRN \\
\hline CHEMBL1437047 & 688721 & 4.4 & 5.2196 & TST \\
\hline CHEMBL1371626 & 688721 & 5.4 & 4.8371 & TRN \\
\hline CHEMBL1454506 & 688721 & 4.6 & 5.1516 & TST \\
\hline CHEMBL1386786 & 688721 & 4.6 & 4.7543 & TRN \\
\hline CHEMBL1577419 & 688721 & 4.9 & 5.0267 & TRN \\
\hline CHEMBL1532177 & 688721 & 4.5 & 4.6376 & TRN \\
\hline CHEMBL1490572 & 688721 & 5.2 & 4.9776 & TST \\
\hline CHEMBL1299387 & 688721 & 5.2 & 5.1605 & TST \\
\hline CHEMBL1317626 & 688721 & 4.7 & 5.0599 & TRN \\
\hline CHEMBL1364980 & 688721 & 4.9 & 5.0899 & TRN \\
\hline CHEMBL1459623 & 688721 & 5.3 & 4.8999 & TRN \\
\hline
\end{tabular}




\begin{tabular}{|c|c|c|c|c|c|}
\hline & & & & & \\
\hline CHEMBL1451788 & 688721 & 5.2 & 5.255 & TRN & \\
\hline CHEMBL1562130 & 688721 & 5.3 & 4.9792 & TRN & \\
\hline CHEMBL1351038 & 688721 & 5.1 & 4.8362 & TRN & \\
\hline CHEMBL1346069 & 688721 & 4.9 & 4.9659 & TRN & \\
\hline CHEMBL1450384 & 688721 & 4.8 & 4.9287 & TRN & \\
\hline CHEMBL1548659 & 688721 & 5.5 & 4.9929 & TRN & \\
\hline CHEMBL1490226 & 688721 & 4.6 & 4.794 & TRN & \\
\hline CHEMBL1306058 & 688721 & 4.6 & 4.7926 & TRN & \\
\hline CHEMBL1302741 & 688721 & 4.4 & 4.8274 & TST & \\
\hline CHEMBL1573699 & 688721 & 4.4 & 4.9442 & TRN & \\
\hline CHEMBL1482852 & 688721 & 4.8 & 4.7575 & TRN & \\
\hline CHEMBL1571735 & 688721 & 5.1 & 4.8656 & TRN & \\
\hline CHEMBL 20667 & 688721 & 5.2 & 5.3464 & TRN & \\
\hline CHEMBL1424127 & 688721 & 4.6 & 4.8552 & TRN & \\
\hline CHEMBL1457544 & 688721 & 4.6 & $5.2420 e$ & 0000000001 & TRN \\
\hline CHEMBL1361956 & 688721 & 4.5 & 4.8226 & TRN & \\
\hline CHEMBL1605746 & 688721 & 4.5 & 5.0611 & TRN & \\
\hline CHEMBL1387598 & 688721 & 4.8 & 4.7159 & TRN & \\
\hline CHEMBL1602916 & 688721 & 4.7 & 4.9037 & TRN & \\
\hline CHEMBL1537129 & 688721 & 4.6 & 4.8506 & TRN & \\
\hline CHEMBL 244693 & 688721 & 5.2 & 5.1009 & TST & \\
\hline CHEMBL 263376 & 688721 & 5.3 & 5.1624 & TRN & \\
\hline CHEMBL1409830 & 688721 & 5.3 & 5.0549 & TRN & \\
\hline CHEMBL1339679 & 688721 & 4.8 & 4.9105 & TRN & \\
\hline CHEMBL1473270 & 688721 & 4.4 & 5.2731 & TST & \\
\hline CHEMBL1301018 & 688721 & 4.7 & 4.9723 & TRN & \\
\hline CHEMBL1579809 & 688721 & 5.2 & 4.8691 & TRN & \\
\hline CHEMBL1483427 & 688721 & 4.5 & 4.9809 & TRN & \\
\hline CHEMBL1542493 & 688721 & 4.9 & 5.0218 & TST & \\
\hline CHEMBL1383780 & 688721 & 5.3 & 5.0377 & TRN & \\
\hline CHEMBL1452253 & 688721 & 4.6 & 4.8912 & TRN & \\
\hline CHEMBL1545132 & 688721 & 5.3 & 5.0394 & TRN & \\
\hline CHEMBL1548294 & 688721 & 4.5 & 5.0084 & TST & \\
\hline CHEMBL182786 & 688721 & 5.5 & 5.0142 & TST & \\
\hline CHEMBL1581045 & 688721 & 4.7 & 4.7322 & TRN & \\
\hline CHEMBL1537651 & 688721 & 4.5 & 4.7934 & TRN & \\
\hline CHEMBL1506356 & 688721 & 4.8 & 4.8983 & TST & \\
\hline CHEMBL1380507 & 688721 & 5.1 & 4.8522 & TRN & \\
\hline CHEMBL1522074 & 688721 & 5.1 & 4.8598 & TRN & \\
\hline CHEMBL1536244 & 688721 & 4.6 & 4.8098 & TRN & \\
\hline CHEMBL1344195 & 688721 & 4.5 & 4.9218 & TRN & \\
\hline CHEMBL 272005 & 688721 & 4.4 & 4.803 & TRN & \\
\hline CHEMBL1488467 & 688721 & 4.8 & 5.1799 & TST & \\
\hline CHEMBL1355396 & 688721 & 4.7 & 5.1959 & TRN & \\
\hline CHEMBL1466337 & 688721 & 4.6 & 5.3737 & TST & \\
\hline CHEMBL1426403 & 688721 & 4.6 & 4.9182 & TRN & \\
\hline CHEMBL1457931 & 688721 & 4.5 & 4.8404 & TST & \\
\hline CHEMBL1586677 & 688721 & 4.6 & 5.157 & TRN & \\
\hline & & & & 9067 & \\
\hline
\end{tabular}




\begin{tabular}{|c|c|c|c|c|}
\hline \multicolumn{5}{|c|}{ Supplemental Table S2.txt } \\
\hline CHEMBL1411009 & 688721 & 4.6 & 5.1063 & TRN \\
\hline CHEMBL1468529 & 688721 & 4.8 & 4.9511 & TRN \\
\hline CHEMBL1409129 & 688721 & 5.7 & 5.0014 & TRN \\
\hline CHEMBL1411130 & 688721 & 5.0 & 4.8294 & TRN \\
\hline CHEMBL1547516 & 688721 & 4.7 & 4.9164 & TRN \\
\hline CHEMBL1350850 & 688721 & 4.9 & 4.8504 & TRN \\
\hline CHEMBL1511133 & 688721 & 4.4 & 4.8741 & TRN \\
\hline CHEMBL1317066 & 688721 & 4.5 & 4.9436 & TRN \\
\hline CHEMBL1487887 & 688721 & 5.5 & 4.8297 & TRN \\
\hline CHEMBL1462161 & 688721 & 5.0 & 4.8249 & TRN \\
\hline CHEMBL1299969 & 688721 & 4.5 & 4.9349 & TRN \\
\hline CHEMBL1492765 & 688721 & 5.3 & 4.9674 & TRN \\
\hline CHEMBL1526960 & 688721 & 5.5 & 4.8308 & TRN \\
\hline CHEMBL1448909 & 688721 & 4.4 & 4.9292 & TST \\
\hline CHEMBL1308867 & 688721 & 4.5 & 5.0745 & TST \\
\hline CHEMBL1455181 & 688721 & 5.1 & 4.8672 & TRN \\
\hline CHEMBL1588307 & 688721 & 4.5 & 4.9655 & TST \\
\hline CHEMBL1374178 & 688721 & 4.7 & 4.8663 & TRN \\
\hline CHEMBL167869 & 688721 & 4.8 & 5.1696 & TRN \\
\hline CHEMBL603028 & 688721 & 4.8 & 4.7562 & TRN \\
\hline CHEMBL1425045 & 688721 & 5.6 & 5.0712 & TST \\
\hline CHEMBL1429787 & 688721 & 5.2 & 5.1263 & TRN \\
\hline CHEMBL1531699 & 688721 & 4.9 & 5.1446 & TRN \\
\hline CHEMBL1331442 & 688721 & 4.9 & 4.7117 & TST \\
\hline CHEMBL1613220 & 688721 & 5.1 & 5.003 & TST \\
\hline CHEMBL1589629 & 688721 & 4.9 & 4.8411 & TRN \\
\hline CHEMBL1417433 & 688721 & 4.6 & 4.8848 & TST \\
\hline CHEMBL1535022 & 688721 & 4.4 & 5.1298 & TRN \\
\hline CHEMBL1368613 & 688721 & 5.1 & 4.9695 & TRN \\
\hline CHEMBL1363915 & 688721 & 5.1 & 4.8087 & TRN \\
\hline CHEMBL1537719 & 688721 & 4.8 & 4.9626 & TST \\
\hline CHEMBL1407307 & 688721 & 5.0 & 5.0404 & TRN \\
\hline CHEMBL1606198 & 688721 & 4.7 & 4.7953 & TRN \\
\hline CHEMBL1550403 & 688721 & 4.5 & 4.8199 & TRN \\
\hline CHEMBL1480855 & 688721 & 4.4 & 5.099 & TRN \\
\hline CHEMBL1542271 & 688721 & 4.5 & 5.0098 & TST \\
\hline CHEMBL1381353 & 688721 & 4.6 & 4.7807 & TRN \\
\hline CHEMBL1504503 & 688721 & 4.5 & 4.8286 & TRN \\
\hline CHEMBL1406037 & 688721 & 4.4 & 5.0965 & TRN \\
\hline CHEMBL1520065 & 688721 & 5.4 & 4.834 & TRN \\
\hline CHEMBL1558184 & 688721 & 5.4 & 4.9078 & TRN \\
\hline CHEMBL1568085 & 688721 & 4.7 & 4.8606 & TRN \\
\hline CHEMBL1572741 & 688721 & 4.9 & 4.9061 & TRN \\
\hline CHEMBL1534353 & 688721 & 6.0 & 4.8838 & TRN \\
\hline CHEMBL1565064 & 688721 & 4.5 & 4.7188 & TRN \\
\hline CHEMBL1570154 & 688721 & 5.5 & 4.9375 & TRN \\
\hline CHEMBL1527638 & 688721 & 6.1 & 5.0285 & TRN \\
\hline CHEMBL1595166 & 688721 & 4.4 & 5.1689 & TRN \\
\hline
\end{tabular}




\begin{tabular}{|c|c|c|c|c|c|}
\hline \multicolumn{6}{|c|}{ Supplemental Table S2.txt } \\
\hline CHEMBL1380900 & 688721 & 5.1 & 4.8593 & TRN & \\
\hline CHEMBL1470266 & 688721 & 4.6 & 4.8841 & TRN & \\
\hline CHEMBL1420241 & 688721 & 5.4 & 4.8189 & TRN & \\
\hline CHEMBL1576567 & 688721 & 4.5 & 4.9834 & TRN & \\
\hline CHEMBL1477659 & 688721 & 4.7 & 4.8784 & TRN & \\
\hline CHEMBL1422120 & 688721 & 4.4 & 5.0896 & TRN & \\
\hline CHEMBL1541899 & 688721 & 4.9 & 5.0199 & TRN & \\
\hline CHEMBL1354122 & 688721 & 4.8 & 4.8958 & TRN & \\
\hline CHEMBL3207899 & 688721 & 5.4 & 5.10800 & 00000000005 & TRN \\
\hline CHEMBL1433798 & 688721 & 4.4 & 4.9798 & TRN & \\
\hline CHEMBL1462741 & 688721 & 4.4 & 5.09399 & 9999999999 & TST \\
\hline CHEMBL1404682 & 688721 & 5.1 & 4.8532 & TRN & \\
\hline CHEMBL1488104 & 688721 & 4.7 & 4.7213 & TRN & \\
\hline CHEMBL1531742 & 688721 & 4.4 & 4.9465 & TRN & \\
\hline CHEMBL1342664 & 688721 & 4.9 & 4.7855 & TRN & \\
\hline CHEMBL1339255 & 688721 & 6.4 & 4.8871 & TRN & \\
\hline CHEMBL1488918 & 688721 & 5.3 & 5.2344 & TRN & \\
\hline CHEMBL268291 & 688721 & 7.4001 & 5.2433 & TST & \\
\hline CHEMBL1403905 & 688721 & 5.9 & 5.2967 & TRN & \\
\hline CHEMBL1407077 & 688721 & 4.4 & 4.917 & TRN & \\
\hline CHEMBL1590855 & 688721 & 4.7 & 4.9408 & TRN & \\
\hline CHEMBL1576558 & 688721 & 5.2 & 4.9504 & TRN & \\
\hline CHEMBL1569001 & 688721 & 4.5 & 4.8677 & TRN & \\
\hline CHEMBL1431184 & 688721 & 5.1 & 4.9745 & TRN & \\
\hline CHEMBL1383022 & 688721 & 5.3 & 4.8915 & TST & \\
\hline CHEMBL1457228 & 688721 & 4.6 & 4.9147 & TRN & \\
\hline CHEMBL1543543 & 688721 & 4.5 & 4.7641 & TRN & \\
\hline CHEMBL1493623 & 688721 & 5.7 & 4.9973 & TST & \\
\hline CHEMBL1088937 & 688721 & 5.7 & 4.9458 & TRN & \\
\hline CHEMBL1392762 & 688721 & 4.7 & 4.69 & TRN & \\
\hline CHEMBL1330979 & 688721 & 4.8 & 4.7899 & TRN & \\
\hline CHEMBL1530588 & 688721 & 5.0 & 5.2235 & TST & \\
\hline CHEMBL140220 & 688721 & 5.1 & 4.9623 & TST & \\
\hline CHEMBL1411415 & 688721 & 4.7 & 4.9741 & TRN & \\
\hline CHEMBL1414269 & 688721 & 4.5 & 4.9469 & TRN & \\
\hline CHEMBL1323474 & 688721 & 5.4 & 5.0893 & TRN & \\
\hline CHEMBL1304794 & 688721 & 4.5 & 4.9677 & TRN & \\
\hline CHEMBL1378722 & 688721 & 5.0 & 4.7919 & TRN & \\
\hline CHEMBL564664 & 688721 & 4.7 & 4.8627 & TRN & \\
\hline CHEMBL1492783 & 688721 & 4.5 & 4.9259 & TRN & \\
\hline CHEMBL1491247 & 688721 & 4.6 & 4.9164 & TRN & \\
\hline CHEMBL1358276 & 688721 & 4.4 & 5.2569 & TRN & \\
\hline CHEMBL1573874 & 688721 & 6.3 & 4.9041 & TRN & \\
\hline CHEMBL1506214 & 688721 & 4.8 & 4.873 & TRN & \\
\hline CHEMBL1477529 & 688721 & 4.4 & 4.8744 & TRN & \\
\hline CHEMBL1323778 & 688721 & 4.5 & 5.0705 & TRN & \\
\hline CHEMBL1312693 & 688721 & 4.7 & 5.0544 & TRN & \\
\hline CHEMBL1566939 & 688721 & 4.8 & 4.7821 & TRN & \\
\hline
\end{tabular}




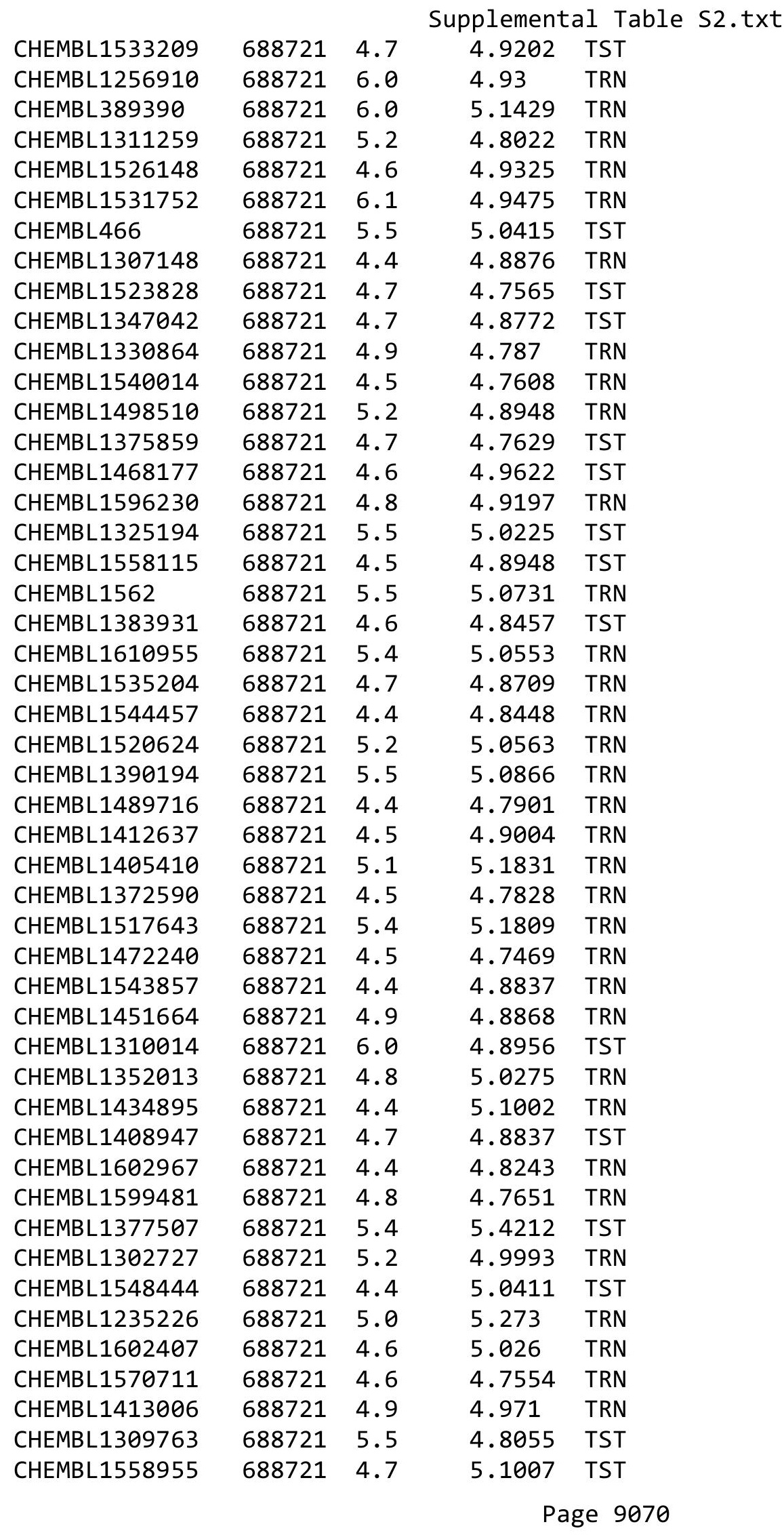




\begin{tabular}{|c|c|c|c|c|c|}
\hline \multicolumn{6}{|c|}{ splemental } \\
\hline CHEMBL1569529 & 688721 & 4.4 & 5.0184 & TRN & \\
\hline CHEMBL1526736 & 688721 & 5.0 & 5.1125 & TRN & \\
\hline CHEMBL1340749 & 688721 & 4.5 & 4.7505 & TRN & \\
\hline CHEMBL1417829 & 688721 & 4.7 & 4.8778 & TST & \\
\hline CHEMBL1597856 & 688721 & 5.3 & 5.0989 & TST & \\
\hline CHEMBL1393136 & 688721 & 4.9 & 4.8255 & TST & \\
\hline CHEMBL1520596 & 688721 & 5.1 & 4.9603 & TRN & \\
\hline CHEMBL1601782 & 688721 & 5.5 & 4.9239 & TRN & \\
\hline CHEMBL1311095 & 688721 & 5.0 & 4.9846 & TST & \\
\hline CHEMBL1555985 & 688721 & 4.5 & 4.8255 & TRN & \\
\hline CHEMBL1446384 & 688721 & 4.7 & 5.2015 & TST & \\
\hline CHEMBL1374594 & 688721 & 4.8 & 4.8314 & TRN & \\
\hline CHEMBL1515305 & 688721 & 4.8 & 5.3255 & TST & \\
\hline CHEMBL183 & 688721 & 5.2 & 5.0121 & TST & \\
\hline CHEMBL1583310 & 688721 & 4.4 & 5.0949 & TRN & \\
\hline CHEMBL1452308 & 688721 & 4.6 & 5.0083 & TST & \\
\hline CHEMBL2374259 & 688721 & 7.8013 & 5.21399 & 99999999995 & TRN \\
\hline CHEMBL1381896 & 688721 & 4.6 & 5.0218 & TRN & \\
\hline CHEMBL1510397 & 688721 & 6.8 & 4.9971 & TRN & \\
\hline CHEMBL1373894 & 688721 & 5.5 & 4.8009 & TRN & \\
\hline CHEMBL1345304 & 688721 & 6.6 & 4.987 & TRN & \\
\hline CHEMBL348107 & 688721 & 4.4 & 5.3253 & TST & \\
\hline CHEMBL1592202 & 688721 & 5.4 & 4.9869 & TRN & \\
\hline CHEMBL1342128 & 688721 & 4.6 & 4.7739 & TRN & \\
\hline CHEMBL1472133 & 688721 & 4.9 & 4.8991 & TRN & \\
\hline CHEMBL1484266 & 688721 & 5.4 & 4.9036 & TRN & \\
\hline CHEMBL1524331 & 688721 & 5.2 & 5.1664 & TRN & \\
\hline CHEMBL1381236 & 688721 & 4.8 & 4.9402 & TST & \\
\hline CHEMBL1479610 & 688721 & 4.5 & 5.0154 & TST & \\
\hline CHEMBL1310020 & 688721 & 4.7 & 5.0068 & TRN & \\
\hline CHEMBL523283 & 688721 & 4.9 & 5.0034 & TRN & \\
\hline CHEMBL1355242 & 688721 & 4.4 & 4.9242 & TRN & \\
\hline CHEMBL1306731 & 688721 & 4.7 & 5.00899 & 99999999995 & TST \\
\hline CHEMBL1412878 & 688721 & 4.4 & 4.9564 & TRN & \\
\hline CHEMBL552272 & 688721 & 5.3 & 4.8402 & TRN & \\
\hline CHEMBL1370540 & 688721 & 4.7 & 4.9893 & TRN & \\
\hline CHEMBL1515717 & 688721 & 4.6 & 4.8736 & TRN & \\
\hline CHEMBL1582649 & 688721 & 4.4 & 5.0417 & TST & \\
\hline CHEMBL1304910 & 688721 & 4.4 & 4.8056 & TRN & \\
\hline CHEMBL1313201 & 688721 & 4.4 & 4.9098 & TRN & \\
\hline CHEMBL1539839 & 688721 & 5.4 & 4.7037 & TRN & \\
\hline CHEMBL1586100 & 688721 & 4.8 & 4.8486 & TRN & \\
\hline CHEMBL1480019 & 688721 & 4.6 & 4.7682 & TRN & \\
\hline CHEMBL1340657 & 688721 & 4.4 & 4.8438 & TRN & \\
\hline CHEMBL1569485 & 688721 & 7.8013 & 5.2817 & TRN & \\
\hline CHEMBL1993170 & 688721 & 4.7 & 4.9375 & TRN & \\
\hline CHEMBL1319971 & 688721 & 4.5 & 4.926 & TST & \\
\hline CHEMBL1535838 & 688721 & 5.0 & 4.9684 & TST & \\
\hline
\end{tabular}




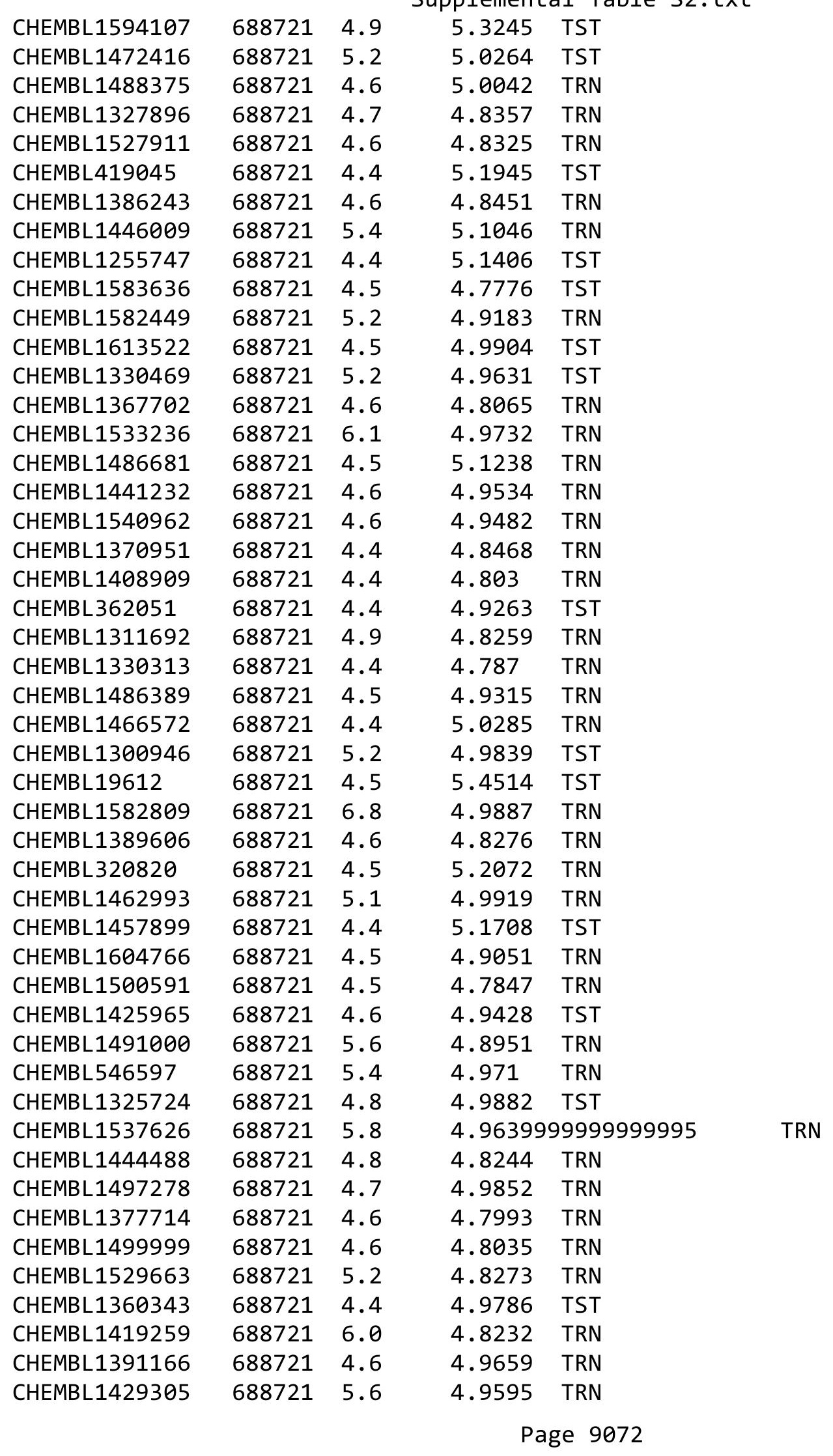




\begin{tabular}{|c|c|c|c|c|}
\hline \multicolumn{5}{|c|}{ plemen } \\
\hline CHEMBL1314158 & 688721 & 5.7 & 5.0348 & TRN \\
\hline CHEMBL1375697 & 688721 & 6.1 & 4.9211 & TRN \\
\hline CHEMBL1562406 & 688721 & 5.2 & 4.9022 & TRN \\
\hline CHEMBL1322651 & 688721 & 4.4 & 4.8096 & TRN \\
\hline CHEMBL1521000 & 688721 & 4.4 & 4.7242 & TRN \\
\hline CHEMBL1579738 & 688721 & 5.3 & 4.9745 & TRN \\
\hline CHEMBL1365142 & 688721 & 4.4 & 4.9101 & TRN \\
\hline CHEMBL1490276 & 688721 & 5.0 & 4.8079 & TST \\
\hline CHEMBL1543320 & 688721 & 4.6 & 4.837 & TRN \\
\hline CHEMBL1557696 & 688721 & 5.2 & 5.0203 & TRN \\
\hline CHEMBL1375193 & 688721 & 5.2 & 4.8575 & TRN \\
\hline CHEMBL1527835 & 688721 & 5.8 & 4.7995 & TRN \\
\hline CHEMBL1309269 & 688721 & 5.2 & 4.8337 & TST \\
\hline CHEMBL1424345 & 688721 & 4.9 & 4.9504 & TST \\
\hline CHEMBL1351687 & 688721 & 4.9 & 4.9697 & TRN \\
\hline CHEMBL1466790 & 688721 & 4.7 & 5.0318 & TST \\
\hline CHEMBL1406267 & 688721 & 4.8 & 4.9139 & TRN \\
\hline CHEMBL1303906 & 688721 & 5.2 & 5.0376 & TRN \\
\hline CHEMBL445612 & 688721 & 4.4 & 5.2854 & TST \\
\hline CHEMBL1566117 & 688721 & 4.4 & 4.9472 & TRN \\
\hline CHEMBL1612292 & 688721 & 4.5 & 4.8564 & TRN \\
\hline CHEMBL1365776 & 688721 & 4.8 & 5.1892 & TRN \\
\hline CHEMBL1514149 & 688721 & 4.8 & 4.9746 & TRN \\
\hline CHEMBL1578945 & 688721 & 4.6 & 4.8748 & TRN \\
\hline CHEMBL1419836 & 688721 & 4.6 & 4.9567 & TRN \\
\hline CHEMBL1346737 & 688721 & 4.5 & 4.8599 & TRN \\
\hline CHEMBL1078384 & 688721 & 5.6 & 5.1039 & TST \\
\hline CHEMBL568379 & 688721 & 4.5 & 4.9763 & TRN \\
\hline CHEMBL1451621 & 688721 & 4.7 & 4.9588 & TRN \\
\hline CHEMBL1325975 & 688721 & 4.4 & 4.899 & TRN \\
\hline CHEMBL1542340 & 688721 & 4.7 & 4.8201 & TRN \\
\hline CHEMBL1339447 & 688721 & 7.2 & 4.8998 & TRN \\
\hline CHEMBL1453856 & 688721 & 5.3 & 4.8317 & TRN \\
\hline CHEMBL1366185 & 688721 & 4.9 & 4.6687 & TRN \\
\hline CHEMBL1563333 & 688721 & 4.5 & 4.8233 & TRN \\
\hline CHEMBL1601960 & 688721 & 4.8 & 5.1625 & TRN \\
\hline CHEMBL1551979 & 688721 & 5.7 & 4.9306 & TRN \\
\hline CHEMBL1599268 & 688721 & 5.5 & 4.9127 & TST \\
\hline CHEMBL2373626 & 688721 & 4.5 & 5.0844 & TST \\
\hline CHEMBL1566137 & 688721 & 4.9 & 4.9351 & TRN \\
\hline CHEMBL1488574 & 688721 & 5.0 & 5.3074 & TRN \\
\hline CHEMBL1608888 & 688721 & 4.4 & 4.763 & TRN \\
\hline CHEMBL1574041 & 688721 & 4.6 & 4.933 & TRN \\
\hline CHEMBL1509016 & 688721 & 5.0 & 4.9762 & TRN \\
\hline CHEMBL1415852 & 688721 & 4.4 & 4.9835 & TST \\
\hline CHEMBL1451927 & 688721 & 4.5 & 4.8764 & TRN \\
\hline CHEMBL1349278 & 688721 & 5.3 & 4.7509 & TRN \\
\hline CHEMBL1306954 & 688721 & 4.6 & 4.8352 & TRN \\
\hline
\end{tabular}




\begin{tabular}{|c|c|c|c|c|}
\hline \\
\hline CHEMBL1382107 & 688721 & 4.4 & 4.8974 & TRN \\
\hline CHEMBL72365 & 688721 & 6.0 & 5.1451 & TST \\
\hline CHEMBL1407376 & 688721 & 5.2 & 4.9414 & TRN \\
\hline CHEMBL1439266 & 688721 & 4.9 & 4.8375 & TRN \\
\hline CHEMBL1321135 & 688721 & 4.6 & 4.9641 & TRN \\
\hline CHEMBL1399680 & 688721 & 4.5 & 4.7673 & TST \\
\hline CHEMBL1478134 & 688721 & 4.6 & 4.6221 & TRN \\
\hline CHEMBL1351195 & 688721 & 6.8 & 5.013 & TRN \\
\hline CHEMBL1508747 & 688721 & 4.9 & 5.0924 & TRN \\
\hline CHEMBL1435296 & 688721 & 4.8 & 5.1279 & TRN \\
\hline CHEMBL1432979 & 688721 & 5.6 & \multicolumn{2}{|c|}{4.928999999999999} \\
\hline CHEMBL1488337 & 688721 & 5.1 & 4.7474 & TST \\
\hline CHEMBL1346120 & 688721 & 4.5 & 4.7406 & TRN \\
\hline CHEMBL1462712 & 688721 & 4.4 & 5.1657 & TST \\
\hline CHEMBL1560938 & 688721 & 4.7 & 4.7843 & TRN \\
\hline CHEMBL1478465 & 688721 & 4.6 & 4.7255 & TRN \\
\hline CHEMBL1549022 & 688721 & 5.5 & 4.9193 & TRN \\
\hline CHEMBL1534716 & 688721 & 4.8 & 4.8951 & TRN \\
\hline CHEMBL1725279 & 688721 & 4.4 & 5.1206 & TST \\
\hline CHEMBL1363362 & 688721 & 4.4 & 4.8677 & TRN \\
\hline CHEMBL1604421 & 688721 & 5.2 & 5.2556 & TRN \\
\hline CHEMBL399121 & 688721 & 5.6 & 4.9955 & TST \\
\hline CHEMBL1574021 & 688721 & 4.9 & 4.8209 & TRN \\
\hline CHEMBL1256660 & 688721 & 4.5 & \multicolumn{2}{|c|}{4.906000000000001} \\
\hline CHEMBL1527567 & 688721 & 7.2 & 5.1905 & TRN \\
\hline CHEMBL1425548 & 688721 & 4.6 & 5.0385 & TST \\
\hline CHEMBL1490542 & 688721 & 4.5 & 4.9273 & TRN \\
\hline CHEMBL1612242 & 688721 & 4.9 & 5.0077 & TRN \\
\hline CHEMBL1584535 & 688721 & 4.8 & 4.8708 & TRN \\
\hline CHEMBL1605465 & 688721 & 5.7 & 4.9513 & TRN \\
\hline CHEMBL1356842 & 688721 & 5.0 & 5.1137 & TRN \\
\hline CHEMBL1385709 & 688721 & 4.4 & 4.9151 & TRN \\
\hline CHEMBL1448278 & 688721 & 4.4 & 4.8638 & TRN \\
\hline CHEMBL1626274 & 688721 & 5.3 & 4.9429 & TST \\
\hline CHEMBL1562837 & 688721 & 5.4 & 4.8417 & TRN \\
\hline CHEMBL1477417 & 688721 & 5.0 & 5.07 & TRN \\
\hline CHEMBL1409798 & 688721 & 4.5 & 4.8 & TRN \\
\hline CHEMBL1432234 & 688721 & 4.4 & 4.7367 & TRN \\
\hline CHEMBL1604109 & 688721 & 4.4 & 4.8849 & TRN \\
\hline CHEMBL1332098 & 688721 & 4.5 & 4.8527 & TRN \\
\hline CHEMBL1499736 & 688721 & 4.9 & 4.8788 & TST \\
\hline CHEMBL1438105 & 688721 & 4.4 & 5.1456 & TRN \\
\hline CHEMBL1520491 & 688721 & 4.5 & 4.9272 & TST \\
\hline CHEMBL1599277 & 688721 & 4.5 & 4.8975 & TST \\
\hline CHEMBL1347299 & 688721 & 4.8 & 5.0031 & TST \\
\hline CHEMBL1563164 & 688721 & 4.4 & 4.8838 & TRN \\
\hline CHEMBL1478630 & 688721 & 4.4 & 4.8686 & TRN \\
\hline CHEMBL1327644 & 688721 & 4.5 & 5.126 & TST \\
\hline
\end{tabular}


Supplemental Table S2.txt

\begin{tabular}{|c|c|c|c|c|c|}
\hline CHEMBL1406901 & 688721 & 7.5003 & 4.9859 & TST & \\
\hline CHEMBL1377781 & 688721 & 4.6 & 5.1291 & TRN & \\
\hline CHEMBL1477421 & 688721 & 4.6 & 4.8891 & TRN & \\
\hline CHEMBL1406919 & 688721 & 4.9 & 4.8497 & TRN & \\
\hline CHEMBL1490024 & 688721 & 4.8 & 5.0362 & TRN & \\
\hline CHEMBL1582114 & 688721 & 4.5 & 4.9221 & TRN & \\
\hline CHEMBL1412804 & 688721 & 4.4 & 4.7572 & TST & \\
\hline CHEMBL265686 & 688721 & 4.4 & 4.8501 & TRN & \\
\hline CHEMBL1492780 & 688721 & 5.6 & 5.0046 & TRN & \\
\hline CHEMBL1319667 & 688721 & 5.4 & 4.9737 & TRN & \\
\hline CHEMBL1583898 & 688721 & 4.9 & 4.9748 & TRN & \\
\hline CHEMBL1544965 & 688721 & 5.8 & 4.9561 & TRN & \\
\hline CHEMBL1369878 & 688721 & 4.8 & 5.0473 & TRN & \\
\hline CHEMBL1310815 & 688721 & 4.5 & 4.9188 & TRN & \\
\hline CHEMBL1490223 & 688721 & 6.0 & 4.9364 & TRN & \\
\hline CHEMBL1583564 & 688721 & 5.2 & 4.753 & TRN & \\
\hline CHEMBL1565664 & 688721 & 4.6 & 5.0125 & TRN & \\
\hline CHEMBL1379520 & 688721 & 4.5 & 4.7452 & TRN & \\
\hline CHEMBL544713 & 688721 & 5.3 & 4.9068 & TRN & \\
\hline CHEMBL1409247 & 688721 & 4.9 & 5.0635 & TRN & \\
\hline CHEMBL1325541 & 688721 & 4.4 & 4.7859 & TRN & \\
\hline CHEMBL1451224 & 688721 & 5.5 & 5.1435 & TRN & \\
\hline CHEMBL1419352 & 688721 & 5.2 & 4.8351 & TRN & \\
\hline CHEMBL1544295 & 688721 & 4.6 & 4.8632 & TST & \\
\hline CHEMBL1528170 & 688721 & 6.0 & 5.0106 & TRN & \\
\hline CHEMBL1460072 & 688721 & 4.9 & 4.7581 & TRN & \\
\hline CHEMBL3209957 & 688721 & 4.7 & 5.2295 & TST & \\
\hline CHEMBL1553694 & 688721 & 5.4 & 4.9728 & TRN & \\
\hline CHEMBL1334308 & 688721 & 4.5 & 4.798 & TRN & \\
\hline CHEMBL1452123 & 688721 & 4.6 & 4.9228 & TRN & \\
\hline CHEMBL1380735 & 688721 & 4.5 & 5.0987 & TRN & \\
\hline CHEMBL1324772 & 688721 & 4.6 & 4.784 & TRN & \\
\hline CHEMBL1523217 & 688721 & 5.4 & 4.9782 & TRN & \\
\hline CHEMBL1539012 & 688721 & 4.4 & 4.9384 & TRN & \\
\hline CHEMBL1463911 & 688721 & 4.9 & 4.8889 & TRN & \\
\hline CHEMBL1450507 & 688721 & 4.4 & 4.75899 & 99999999995 & TRN \\
\hline CHEMBL1321325 & 688721 & 4.4 & 4.9555 & TRN & \\
\hline CHEMBL1354561 & 688721 & 4.7 & 5.051 & TRN & \\
\hline CHEMBL1565369 & 688721 & 5.2 & 4.9091 & TRN & \\
\hline CHEMBL1306250 & 688721 & 4.6 & 4.8587 & TRN & \\
\hline CHEMBL1527977 & 688721 & 4.9 & 4.9282 & TRN & \\
\hline CHEMBL1512744 & 688721 & 4.6 & 5.1888 & TRN & \\
\hline CHEMBL1526851 & 688721 & 4.4 & 4.8788 & TST & \\
\hline CHEMBL1330684 & 688721 & 4.7 & 5.0694 & TRN & \\
\hline CHEMBL1352906 & 688721 & 5.3 & 4.9166 & TRN & \\
\hline CHEMBL1606581 & 688721 & 4.4 & 4.8337 & TRN & \\
\hline CHEMBL1437488 & 688721 & 6.0 & 5.0387 & TRN & \\
\hline CHEMBL1533694 & 688721 & 5.1 & 4.7881 & TRN & \\
\hline
\end{tabular}


Supplemental Table S2.txt

\begin{tabular}{|c|c|c|c|c|}
\hline CHEMBL1451198 & 688721 & 7.5003 & 4.8995 & TRN \\
\hline CHEMBL1351058 & 688721 & 4.8 & 4.9427 & TRN \\
\hline CHEMBL1517382 & 688721 & 5.2 & 5.0344 & TST \\
\hline CHEMBL1532909 & 688721 & 4.9 & 4.9264 & TST \\
\hline CHEMBL1490562 & 688721 & 4.6 & 4.9705 & TST \\
\hline CHEMBL1483348 & 688721 & 4.6 & 4.773 & TRN \\
\hline CHEMBL1446413 & 688721 & 4.5 & 4.8854 & TRN \\
\hline CHEMBL1542361 & 688721 & 5.1 & 4.9508 & TST \\
\hline CHEMBL1584751 & 688721 & 4.4 & 4.836 & TRN \\
\hline CHEMBL1367129 & 688721 & 5.2 & 4.92899 & 7999999999 \\
\hline CHEMBL1404206 & 688721 & 4.6 & 4.7879 & TRN \\
\hline CHEMBL1501868 & 688721 & 4.9 & 5.1079 & TRN \\
\hline CHEMBL1571614 & 688721 & 5.9 & 4.8737 & TRN \\
\hline CHEMBL1406410 & 688721 & 5.4 & 5.0104 & TRN \\
\hline CHEMBL1364682 & 688721 & 4.5 & 4.898 & TRN \\
\hline CHEMBL1419235 & 688721 & 4.9 & 4.8995 & TRN \\
\hline CHEMBL520107 & 688721 & 4.4 & 4.8583 & TST \\
\hline CHEMBL1409131 & 688721 & 5.2 & 4.984 & TRN \\
\hline CHEMBL1344905 & 688721 & 5.4 & 5.1733 & TRN \\
\hline CHEMBL1530185 & 688721 & 5.1 & 4.9069 & TRN \\
\hline CHEMBL1518167 & 688721 & 4.5 & 4.9155 & TRN \\
\hline CHEMBL1462451 & 688721 & 4.6 & 5.1307 & TRN \\
\hline CHEMBL1573862 & 688721 & 4.4 & 4.9677 & TRN \\
\hline CHEMBL1474681 & 688721 & 5.5 & 5.008 & TRN \\
\hline CHEMBL1364596 & 688721 & 4.6 & 4.9214 & TRN \\
\hline CHEMBL1505732 & 688721 & 4.4 & 4.895 & TST \\
\hline CHEMBL1447244 & 688721 & 4.4 & 4.7889 & TRN \\
\hline CHEMBL1455814 & 688721 & 4.6 & 4.8913 & TST \\
\hline CHEMBL1456679 & 688721 & 4.4 & 5.0395 & TST \\
\hline CHEMBL1331659 & 688721 & 5.5 & 4.8481 & TST \\
\hline CHEMBL1336469 & 688721 & 5.4 & 5.2007 & TST \\
\hline CHEMBL1578087 & 688721 & 4.4 & 4.71 & TRN \\
\hline CHEMBL1456266 & 688721 & 4.5 & 5.0789 & TRN \\
\hline CHEMBL1608161 & 688721 & 4.5 & 4.9369 & TRN \\
\hline CHEMBL1421370 & 688721 & 4.5 & 4.9799 & TST \\
\hline CHEMBL1456076 & 688721 & 5.4 & 5.1672 & TRN \\
\hline CHEMBL1331691 & 688721 & 5.0 & 4.7726 & TRN \\
\hline CHEMBL1613088 & 688721 & 4.9 & 4.8614 & TRN \\
\hline CHEMBL1517925 & 688721 & 4.6 & 4.791 & TRN \\
\hline CHEMBL1570633 & 688721 & 4.5 & 4.9772 & TRN \\
\hline CHEMBL1489993 & 688721 & 5.3 & 5.0653 & TST \\
\hline CHEMBL1437448 & 688721 & 4.5 & 5.0477 & TRN \\
\hline CHEMBL1300448 & 688721 & 4.7 & 4.9667 & TRN \\
\hline CHEMBL1308738 & 688721 & 4.5 & 4.8666 & TRN \\
\hline CHEMBL1508671 & 688721 & 4.5 & 4.8898 & TRN \\
\hline CHEMBL1557224 & 688721 & 4.6 & 5.0382 & TST \\
\hline CHEMBL1406408 & 688721 & 5.0 & 5.0572 & TRN \\
\hline CHEMBL1400868 & 688721 & 4.6 & 4.8665 & TRN \\
\hline
\end{tabular}




\begin{tabular}{|c|c|c|c|c|}
\hline & & & CIIL & al Ta \\
\hline CHEMBL1394348 & 688721 & 6.0 & 5.3797 & TRN \\
\hline CHEMBL1503426 & 688721 & 5.1 & 4.9199 & TRN \\
\hline CHEMBL1339697 & 688721 & 4.6 & 4.7244 & TRN \\
\hline CHEMBL1601557 & 688721 & 5.1 & 4.9111 & TRN \\
\hline CHEMBL1586975 & 688721 & 4.8 & \multicolumn{2}{|c|}{5.0760000000000005} \\
\hline CHEMBL500996 & 688721 & 5.8 & 5.0851 & TRN \\
\hline CHEMBL1576743 & 688721 & 4.5 & 4.8229 & TRN \\
\hline CHEMBL1484261 & 688721 & 5.3 & 5.0231 & TRN \\
\hline CHEMBL1587360 & 688721 & 5.3 & 5.0144 & TST \\
\hline CHEMBL1412825 & 688721 & 4.7 & 4.9486 & TRN \\
\hline CHEMBL1462011 & 688721 & 4.5 & 4.9239 & TRN \\
\hline CHEMBL1405991 & 688721 & 4.9 & 5.1251 & TRN \\
\hline CHEMBL1084625 & 688721 & 4.5 & 4.9374 & TST \\
\hline CHEMBL1577450 & 688721 & 4.6 & 4.9614 & TRN \\
\hline CHEMBL1435823 & 688721 & 5.5 & 5.21 & TRN \\
\hline CHEMBL1411234 & 688721 & 4.8 & 4.8923 & TRN \\
\hline CHEMBL1371176 & 688721 & 4.9 & 4.7856 & TRN \\
\hline CHEMBL1457043 & 688721 & 4.4 & 5.5053 & TRN \\
\hline CHEMBL1331252 & 688721 & 4.5 & 5.0454 & TST \\
\hline CHEMBL1538411 & 688721 & 5.0 & 4.7283 & TRN \\
\hline CHEMBL3210268 & 688721 & 5.7 & 5.0221 & TRN \\
\hline CHEMBL1551445 & 688721 & 4.8 & 5.1114 & TRN \\
\hline CHEMBL1432702 & 688721 & 4.4 & 4.9781 & TST \\
\hline CHEMBL1582133 & 688721 & 4.5 & 4.8405 & TRN \\
\hline CHEMBL1501933 & 688721 & 4.5 & 4.8587 & TRN \\
\hline CHEMBL1499784 & 688721 & 5.9 & 4.8063 & TRN \\
\hline CHEMBL1525780 & 688721 & 4.6 & 4.9143 & TST \\
\hline CHEMBL1482072 & 688721 & 4.5 & 4.8411 & TST \\
\hline CHEMBL388676 & 688721 & 6.0 & 5.2193 & TST \\
\hline CHEMBL1365624 & 688721 & 4.7 & 5.0097 & TRN \\
\hline CHEMBL1329873 & 688721 & 5.2 & 5.4223 & TST \\
\hline CHEMBL1335115 & 688721 & 4.9 & 4.9777 & TRN \\
\hline CHEMBL1342346 & 688721 & 5.2 & 4.8732 & TRN \\
\hline CHEMBL1489360 & 688721 & 4.5 & 4.8395 & TRN \\
\hline CHEMBL1525602 & 688721 & 4.6 & 4.9484 & TRN \\
\hline CHEMBL1548217 & 688721 & 5.1 & 4.7468 & TRN \\
\hline CHEMBL1339553 & 688721 & 4.9 & 4.9491 & TRN \\
\hline CHEMBL1572689 & 688721 & 4.6 & 4.9286 & TRN \\
\hline CHEMBL1537116 & 688721 & 5.4 & 4.995 & TRN \\
\hline CHEMBL1408486 & 688721 & 5.3 & 4.83 & TRN \\
\hline CHEMBL1589897 & 688721 & 4.4 & 5.0869 & TRN \\
\hline CHEMBL1433180 & 688721 & 6.8 & 4.8143 & TRN \\
\hline CHEMBL1307769 & 688721 & 4.6 & 4.6494 & TRN \\
\hline CHEMBL1514075 & 688721 & 6.4 & 5.1819 & TRN \\
\hline CHEMBL1361389 & 688721 & 4.8 & 5.1097 & TST \\
\hline CHEMBL1524501 & 688721 & 6.3 & 4.9783 & TRN \\
\hline CHEMBL1612675 & 688721 & 4.7 & 5.1037 & TST \\
\hline CHEMBL1464511 & 688721 & 4.5 & 4.8733 & TST \\
\hline
\end{tabular}




\begin{tabular}{|c|c|c|c|c|c|}
\hline & & & & & \\
\hline CHEMBL1525855 & 688721 & 4.4 & 5.0364 & TRN & \\
\hline CHEMBL1429375 & 688721 & 4.9 & 4.8935 & TRN & \\
\hline CHEMBL1407267 & 688721 & 4.7 & 4.8604 & TRN & \\
\hline CHEMBL1548487 & 688721 & 4.4 & 5.0583 & TRN & \\
\hline CHEMBL1399664 & 688721 & 4.6 & 4.8227 & TRN & \\
\hline CHEMBL1500633 & 688721 & 5.0 & 4.8849 & TST & \\
\hline CHEMBL1336011 & 688721 & 4.5 & 5.1397 & TRN & \\
\hline CHEMBL1364509 & 688721 & 5.4 & 4.9681 & TST & \\
\hline CHEMBL1446591 & 688721 & 5.4 & 4.7373 & TRN & \\
\hline CHEMBL475376 & 688721 & 4.9 & 4.9691 & TRN & \\
\hline CHEMBL1450455 & 688721 & 4.5 & 5.1026 & TRN & \\
\hline CHEMBL1386292 & 688721 & 5.0 & 5.0447 & TST & \\
\hline CHEMBL348856 & 688721 & 6.0 & 5.1806 & TST & \\
\hline CHEMBL1331926 & 688721 & 4.6 & 4.8819 & TRN & \\
\hline CHEMBL1553808 & 688721 & 4.4 & 5.1964 & TRN & \\
\hline CHEMBL1563779 & 688721 & 4.8 & 4.8075 & TRN & \\
\hline CHEMBL1387077 & 688721 & 4.6 & 4.816 & TRN & \\
\hline CHEMBL1450413 & 688721 & 4.8 & 5.1803 & TRN & \\
\hline CHEMBL1395165 & 688721 & 4.5 & 5.0109 & TRN & \\
\hline CHEMBL1420464 & 688721 & 4.6 & 4.9794 & TRN & \\
\hline CHEMBL1366834 & 688721 & 4.5 & 4.9426 & TRN & \\
\hline CHEMBL1576436 & 688721 & 4.7 & 5.098 & TRN & \\
\hline CHEMBL1600236 & 688721 & 4.4 & 4.7923 & TRN & \\
\hline CHEMBL1550849 & 688721 & 4.5 & 5.0428 & TRN & \\
\hline CHEMBL1317041 & 688721 & 5.3 & 5.05699 & 99999999995 & TRN \\
\hline CHEMBL1347734 & 688721 & 4.7 & 4.7493 & TST & \\
\hline CHEMBL584031 & 688721 & 4.6 & 4.8552 & TRN & \\
\hline CHEMBL1460426 & 688721 & 4.4 & 5.0504 & TRN & \\
\hline CHEMBL1457637 & 688721 & 4.6 & 4.92 & TRN & \\
\hline CHEMBL1419176 & 688721 & 4.4 & 4.942 & TST & \\
\hline CHEMBL1588354 & 688721 & 4.4 & 4.8641 & TST & \\
\hline CHEMBL1353944 & 688721 & 4.6 & 5.0652 & TRN & \\
\hline CHEMBL1485902 & 688721 & 4.4 & 4.8393 & TST & \\
\hline CHEMBL1398792 & 688721 & 4.4 & 5.0824 & TST & \\
\hline CHEMBL1433783 & 688721 & 4.5 & 5.0362 & TRN & \\
\hline CHEMBL1323417 & 688721 & 4.6 & 4.9155 & TRN & \\
\hline CHEMBL1441675 & 688721 & 4.7 & 4.8373 & TST & \\
\hline CHEMBL1378110 & 688721 & 4.4 & 4.7489 & TRN & \\
\hline CHEMBL1556084 & 688721 & 5.3 & 4.9686 & TRN & \\
\hline CHEMBL1421517 & 688721 & 4.6 & 4.9397 & TRN & \\
\hline CHEMBL1367444 & 688721 & 4.6 & 4.7872 & TRN & \\
\hline CHEMBL1599179 & 688721 & 4.8 & 4.8103 & TRN & \\
\hline CHEMBL1407940 & 688721 & 4.7 & 5.0078 & TST & \\
\hline CHEMBL1582416 & 688721 & 4.5 & 5.0326 & TST & \\
\hline CHEMBL472931 & 688721 & 5.2 & 4.8916 & TRN & \\
\hline CHEMBL1354644 & 688721 & 5.6 & 4.8933 & TST & \\
\hline CHEMBL15766 & 688721 & 4.7 & 5.1104 & TST & \\
\hline CHEMBL1321193 & 688721 & 4.8 & 4.7611 & TRN & \\
\hline & & & & 9078 & \\
\hline
\end{tabular}




\begin{tabular}{|c|c|c|c|c|}
\hline & & & pplement & al Ta \\
\hline CHEMBL1257012 & 688721 & 6.2 & 4.8861 & TST \\
\hline CHEMBL1450307 & 688721 & 6.2 & 5.1054 & TRN \\
\hline CHEMBL1613233 & 688721 & 4.9 & 5.0253 & TRN \\
\hline CHEMBL1415894 & 688721 & 4.4 & 5.0844 & TST \\
\hline CHEMBL1499606 & 688721 & 5.2 & 5.0371 & TRN \\
\hline CHEMBL1334597 & 688721 & 5.4 & 5.0023 & TRN \\
\hline CHEMBL1255662 & 688721 & 6.0 & 5.1325 & TST \\
\hline CHEMBL1481265 & 688721 & 6.0 & 4.9582 & TRN \\
\hline CHEMBL1479267 & 688721 & 4.4 & 4.9864 & TRN \\
\hline CHEMBL1513324 & 688721 & 5.1 & 4.9591 & TRN \\
\hline CHEMBL1542500 & 688721 & 4.5 & 4.9762 & TRN \\
\hline CHEMBL1502008 & 688721 & 4.8 & 4.7343 & TRN \\
\hline CHEMBL1526480 & 688721 & 4.4 & 5.0394 & TRN \\
\hline CHEMBL1610904 & 688721 & 4.7 & 4.8281 & TRN \\
\hline CHEMBL1505008 & 688721 & 6.6 & 5.0174 & TRN \\
\hline CHEMBL1537941 & 688721 & 5.2 & 5.0215 & TRN \\
\hline CHEMBL1324004 & 688721 & 4.4 & 4.9805 & TRN \\
\hline CHEMBL1539530 & 688721 & 4.9 & 4.8727 & TRN \\
\hline CHEMBL1300006 & 688721 & 4.6 & 4.8533 & TRN \\
\hline CHEMBL1350829 & 688721 & 4.6 & 5.038 & TRN \\
\hline CHEMBL1595845 & 688721 & 4.4 & 5.2246 & TST \\
\hline CHEMBL3212549 & 688721 & 4.5 & 5.0695 & TST \\
\hline CHEMBL1352072 & 688721 & 4.6 & 4.8661 & TST \\
\hline CHEMBL31970 & 688721 & 4.9 & 5.2393 & TST \\
\hline CHEMBL1452793 & 688721 & 4.7 & 4.8552 & TRN \\
\hline CHEMBL1420459 & 688721 & 5.4 & 5.0958 & TST \\
\hline CHEMBL1359923 & 688721 & 4.6 & 4.7194 & TRN \\
\hline CHEMBL1441415 & 688721 & 4.5 & 4.9335 & TRN \\
\hline CHEMBL1486138 & 688721 & 4.6 & 4.8428 & TRN \\
\hline CHEMBL1459717 & 688721 & 4.8 & 4.9027 & TRN \\
\hline CHEMBL1320820 & 688721 & 4.8 & 5.1204 & TRN \\
\hline CHEMBL1550298 & 688721 & 4.9 & 4.8071 & TRN \\
\hline CHEMBL1429698 & 688721 & 4.4 & 4.9389 & TRN \\
\hline CHEMBL1353598 & 688721 & 5.3 & 4.8825 & TRN \\
\hline CHEMBL1532542 & 688721 & 4.4 & 5.1297 & TST \\
\hline CHEMBL1300639 & 688721 & 4.6 & 4.9945 & TRN \\
\hline CHEMBL1538221 & 688721 & 5.2 & 4.7815 & TRN \\
\hline CHEMBL1591757 & 688721 & 5.5 & 5.0213 & TRN \\
\hline CHEMBL1410544 & 688721 & 4.4 & 4.8537 & TST \\
\hline CHEMBL1516719 & 688721 & 5.0 & 4.8051 & TRN \\
\hline CHEMBL1497732 & 688721 & 5.4 & 4.8486 & TRN \\
\hline CHEMBL1510672 & 688721 & 4.4 & 4.6185 & TRN \\
\hline CHEMBL1491716 & 688721 & 4.4 & 4.8267 & TRN \\
\hline CHEMBL1609807 & 688721 & 4.5 & 4.8857 & TST \\
\hline CHEMBL1345052 & 688721 & 5.5 & 5.0333 & TST \\
\hline CHEMBL1583308 & 688721 & 5.0 & 4.9493 & TRN \\
\hline CHEMBL1604051 & 688721 & 5.0 & 4.9682 & TRN \\
\hline CHEMBL1496523 & 688721 & 4.5 & 4.7695 & TRN \\
\hline
\end{tabular}




\begin{tabular}{|c|c|c|c|c|}
\hline \multicolumn{5}{|c|}{ Iemental } \\
\hline CHEMBL1348441 & 688721 & 5.4 & 5.0301 & TRN \\
\hline CHEMBL1446139 & 688721 & 4.8 & 5.2059 & TRN \\
\hline CHEMBL1578920 & 688721 & 5.2 & 4.8818 & TRN \\
\hline CHEMBL1603446 & 688721 & 5.0 & 5.0469 & TRN \\
\hline CHEMBL1594779 & 688721 & 5.3 & 4.8402 & TRN \\
\hline CHEMBL1436179 & 688721 & 5.4 & 5.2085 & TRN \\
\hline CHEMBL1573134 & 688721 & 4.8 & 4.8307 & TST \\
\hline CHEMBL1512470 & 688721 & 5.4 & 5.3252 & TRN \\
\hline CHEMBL1333917 & 688721 & 4.6 & 4.7883 & TRN \\
\hline CHEMBL1560696 & 688721 & 4.6 & 4.9047 & TRN \\
\hline CHEMBL1299284 & 688721 & 4.6 & 4.99 & TST \\
\hline CHEMBL1365274 & 688721 & 5.4 & 4.8368 & TRN \\
\hline CHEMBL1450320 & 688721 & 5.3 & 5.0387 & TRN \\
\hline CHEMBL1575911 & 688721 & 4.9 & 4.7825 & TRN \\
\hline CHEMBL1458134 & 688721 & 4.4 & 4.7821 & TRN \\
\hline CHEMBL1334650 & 688721 & 4.8 & 5.1447 & TRN \\
\hline CHEMBL1510847 & 688721 & 5.2 & 4.8704 & TST \\
\hline CHEMBL474415 & 688721 & 4.4 & 4.9898 & TRN \\
\hline CHEMBL1328127 & 688721 & 4.8 & 4.9379 & TST \\
\hline CHEMBL1559163 & 688721 & 5.2 & 4.8792 & TST \\
\hline CHEMBL 3207522 & 688721 & 5.4 & 4.9954 & TRN \\
\hline CHEMBL1344249 & 688721 & 4.4 & 4.8081 & TRN \\
\hline CHEMBL1350100 & 688721 & 5.7 & 4.9593 & TST \\
\hline CHEMBL1491241 & 688721 & 4.7 & 4.7613 & TRN \\
\hline CHEMBL1485710 & 688721 & 4.5 & 4.8557 & TST \\
\hline CHEMBL1496268 & 688721 & 4.6 & 4.754 & TRN \\
\hline CHEMBL1310739 & 688721 & 4.8 & 5.0235 & TRN \\
\hline CHEMBL1462945 & 688721 & 5.3 & 4.8901 & TRN \\
\hline CHEMBL1499726 & 688721 & 4.5 & 5.1096 & TST \\
\hline CHEMBL1462055 & 688721 & 4.6 & 4.8911 & TST \\
\hline CHEMBL1430716 & 688721 & 5.3 & 4.8921 & TST \\
\hline CHEMBL1568539 & 688721 & 4.8 & 4.9681 & TRN \\
\hline CHEMBL1554088 & 688721 & 5.6 & 5.18 & TRN \\
\hline CHEMBL1445618 & 688721 & 5.9 & 5.0441 & TRN \\
\hline CHEMBL1337997 & 688721 & 5.7 & 4.8008 & TRN \\
\hline CHEMBL1482056 & 688721 & 6.0 & 4.9686 & TRN \\
\hline CHEMBL1459795 & 688721 & 5.0 & 4.828 & TRN \\
\hline CHEMBL1388566 & 688721 & 4.5 & 4.9111 & TRN \\
\hline CHEMBL1429690 & 688721 & 4.4 & 5.0541 & TST \\
\hline CHEMBL1584948 & 688721 & 4.4 & 4.8562 & TRN \\
\hline CHEMBL1366796 & 688721 & 4.4 & 5.0588 & TRN \\
\hline CHEMBL1541747 & 688721 & 4.5 & 4.9296 & TRN \\
\hline CHEMBL1412938 & 688721 & 5.2 & 5.1297 & TRN \\
\hline CHEMBL1451905 & 688721 & 6.2 & 4.8838 & TST \\
\hline CHEMBL1352852 & 688721 & 4.8 & 4.8996 & TRN \\
\hline CHEMBL1512210 & 688721 & 5.4 & 5.1827 & TRN \\
\hline CHEMBL1344803 & 688721 & 4.8 & 5.1382 & TRN \\
\hline CHEMBL1392862 & 688721 & 4.8 & 4.8533 & TRN \\
\hline
\end{tabular}




\begin{tabular}{|c|c|c|c|c|c|}
\hline \\
\hline CHEMBL1571314 & 688721 & 5.5 & 4.7976 & TRN & \\
\hline CHEMBL1445850 & 688721 & 5.3 & 4.8686 & TST & \\
\hline CHEMBL1420478 & 688721 & 5.2 & 4.8199 & TRN & \\
\hline CHEMBL1516418 & 688721 & 4.6 & 4.9425 & TRN & \\
\hline CHEMBL1365455 & 688721 & 6.0 & 5.0366 & TRN & \\
\hline CHEMBL1306607 & 688721 & 4.6 & 4.8563 & TRN & \\
\hline CHEMBL1510006 & 688721 & 5.1 & 4.8512 & TRN & \\
\hline CHEMBL1543323 & 688721 & 4.4 & 4.8605 & TST & \\
\hline CHEMBL1602710 & 688721 & 5.4 & 5.1482 & TST & \\
\hline CHEMBL1538584 & 688721 & 4.4 & 5.3074 & TST & \\
\hline CHEMBL1596952 & 688721 & 4.8 & 5.04899 & 99999999995 & TRN \\
\hline CHEMBL1388023 & 688721 & 4.8 & 4.8375 & TRN & \\
\hline CHEMBL83294 & 688721 & 4.7 & 4.9221 & TRN & \\
\hline CHEMBL1527443 & 688721 & 4.7 & 5.1071 & TRN & \\
\hline CHEMBL1438621 & 688721 & 5.4 & 4.8543 & TST & \\
\hline CHEMBL1319665 & 688721 & 5.1 & 4.9551 & TRN & \\
\hline CHEMBL1410245 & 688721 & 4.7 & 5.2039 & TRN & \\
\hline CHEMBL1372254 & 688721 & 5.6 & 5.1941 & TST & \\
\hline CHEMBL1479761 & 688721 & 4.8 & 4.8739 & TRN & \\
\hline CHEMBL1400190 & 688721 & 5.3 & 5.0947 & TRN & \\
\hline CHEMBL1358161 & 688721 & 4.4 & 5.1006 & TRN & \\
\hline CHEMBL1327675 & 688721 & 5.1 & 4.9345 & TRN & \\
\hline CHEMBL 1448775 & 688721 & 5.5 & 4.9298 & TRN & \\
\hline CHEMBL1332904 & 688721 & 4.5 & 4.8228 & TRN & \\
\hline CHEMBL1321112 & 688721 & 4.8 & 4.84 & TRN & \\
\hline CHEMBL1470060 & 688721 & 5.9 & 4.8092 & TRN & \\
\hline CHEMBL1385826 & 688721 & 4.7 & 4.7672 & TRN & \\
\hline CHEMBL1365748 & 688721 & 4.4 & 4.705 & TRN & \\
\hline CHEMBL1608512 & 688721 & 5.7 & 4.8899 & TRN & \\
\hline CHEMBL2369312 & 688721 & 5.2 & 5.0052 & TST & \\
\hline CHEMBL1335406 & 688721 & 4.4 & 4.9963 & TST & \\
\hline CHEMBL1606998 & 688721 & 5.0 & 4.9539 & TRN & \\
\hline CHEMBL1554789 & 688721 & 6.0 & 5.004 & TRN & \\
\hline CHEMBL1597397 & 688721 & 4.9 & 5.0785 & TRN & \\
\hline CHEMBL1564549 & 688721 & 4.4 & 5.2733 & TST & \\
\hline CHEMBL1361477 & 688721 & 4.5 & 4.7901 & TRN & \\
\hline CHEMBL1352569 & 688721 & 4.6 & 4.9395 & TRN & \\
\hline CHEMBL1421504 & 688721 & 5.4 & 4.9972 & TRN & \\
\hline CHEMBL1509309 & 688721 & 6.4 & 5.0804 & TST & \\
\hline CHEMBL1483828 & 688721 & 4.6 & 5.0062 & TST & \\
\hline CHEMBL1523366 & 688721 & 4.7 & 4.883 & TRN & \\
\hline CHEMBL1564209 & 688721 & 4.7 & 4.8286 & TRN & \\
\hline CHEMBL428768 & 688721 & 4.8 & 4.9284 & TRN & \\
\hline CHEMBL1527393 & 688721 & 4.8 & 4.7707 & TRN & \\
\hline CHEMBL1335759 & 688721 & 4.5 & 5.0247 & TRN & \\
\hline CHEMBL1408124 & 688721 & 6.0 & 5.0617 & TRN & \\
\hline CHEMBL 20866 & 688721 & 5.2 & 5.1052 & TST & \\
\hline CHEMBL1529798 & 688721 & 4.5 & 4.8648 & TRN & \\
\hline
\end{tabular}




\begin{tabular}{|c|c|c|c|c|c|}
\hline \\
\hline CHEMBL3212119 & 688721 & 4.4 & 4.9759 & TST & \\
\hline CHEMBL1505854 & 688721 & 4.4 & 4.9031 & TRN & \\
\hline CHEMBL1319748 & 688721 & 4.4 & 4.8462 & TRN & \\
\hline CHEMBL554041 & 688721 & 4.8 & 5.3132 & TST & \\
\hline CHEMBL1312004 & 688721 & 4.7 & 4.9058 & TST & \\
\hline CHEMBL1607966 & 688721 & 5.6 & 4.8471 & TRN & \\
\hline CHEMBL1454545 & 688721 & 5.9 & 4.8419 & TRN & \\
\hline CHEMBL1327203 & 688721 & 4.8 & 4.9221 & TRN & \\
\hline CHEMBL1582160 & 688721 & 4.5 & 4.9298 & TRN & \\
\hline CHEMBL1608758 & 688721 & 4.6 & 4.8435 & TST & \\
\hline CHEMBL1487112 & 688721 & 6.1 & 4.9653 & TRN & \\
\hline CHEMBL1467967 & 688721 & 5.3 & 5.0639 & TRN & \\
\hline CHEMBL1395523 & 688721 & 5.5 & 5.1892 & TRN & \\
\hline CHEMBL1380357 & 688721 & 4.4 & 4.848 & TRN & \\
\hline CHEMBL1353786 & 688721 & 4.6 & 4.8109 & TRN & \\
\hline CHEMBL1490515 & 688721 & 7.0 & 4.8186 & TRN & \\
\hline CHEMBL1362088 & 688721 & 5.1 & 5.1211 & TST & \\
\hline CHEMBL1306249 & 688721 & 4.7 & 4.6707 & TRN & \\
\hline CHEMBL1391395 & 688721 & 4.7 & 4.8069 & TRN & \\
\hline CHEMBL1390468 & 688721 & 4.6 & 4.86600 & 00000000005 & TST \\
\hline CHEMBL 230056 & 688721 & 6.0 & 5.1652 & TST & \\
\hline CHEMBL1523920 & 688721 & 6.1 & 4.7616 & TRN & \\
\hline CHEMBL1308140 & 688721 & 4.8 & 4.7603 & TRN & \\
\hline CHEMBL1511200 & 688721 & 4.4 & 4.8157 & TRN & \\
\hline CHEMBL1388883 & 688721 & 4.5 & 4.8128 & TRN & \\
\hline CHEMBL1351516 & 688721 & 4.9 & 4.9235 & TRN & \\
\hline CHEMBL1425136 & 688721 & 5.2 & 5.0043 & TRN & \\
\hline CHEMBL1577394 & 688721 & 4.4 & 4.7889 & TRN & \\
\hline CHEMBL1487314 & 688721 & 4.6 & 4.9622 & TRN & \\
\hline CHEMBL1536855 & 688721 & 5.2 & 4.9362 & TRN & \\
\hline CHEMBL1569972 & 688721 & 5.5 & 5.0899 & TRN & \\
\hline CHEMBL1345035 & 688721 & 4.6 & 4.9949 & TRN & \\
\hline CHEMBL1424299 & 688721 & 4.5 & 4.7766 & TRN & \\
\hline CHEMBL216504 & 688721 & 5.2 & 5.1429 & TST & \\
\hline CHEMBL1371724 & 688721 & 5.8 & 4.9814 & TST & \\
\hline CHEMBL1449322 & 688721 & 5.0 & 5.0931 & TRN & \\
\hline CHEMBL1534811 & 688721 & 4.9 & 5.1979 & TRN & \\
\hline CHEMBL589439 & 688721 & 6.0 & 5.0995 & TRN & \\
\hline CHEMBL1304641 & 688721 & 5.2 & 4.9978 & TST & \\
\hline CHEMBL1716991 & 688721 & 6.3 & 4.9601 & TRN & \\
\hline CHEMBL1382524 & 688721 & 5.3 & 4.9667 & TRN & \\
\hline CHEMBL1526075 & 688721 & 5.5 & 5.051 & TRN & \\
\hline CHEMBL1393845 & 688721 & 4.4 & 5.0813 & TST & \\
\hline CHEMBL1419896 & 688721 & 5.2 & 4.9265 & TRN & \\
\hline CHEMBL1611402 & 688721 & 6.2 & 4.7646 & TRN & \\
\hline CHEMBL1579490 & 688721 & 4.6 & 4.9103 & TRN & \\
\hline CHEMBL1412538 & 688721 & 4.6 & 4.9139 & TST & \\
\hline CHEMBL1363561 & 688721 & 4.6 & 5.0168 & TRN & \\
\hline
\end{tabular}




\begin{tabular}{|c|c|c|c|c|}
\hline \multirow[b]{2}{*}{ CHEMBL1441145 } & \multicolumn{4}{|c|}{ Supplemental Table S2.txt } \\
\hline & 688721 & 4.4 & 4.9778 & TST \\
\hline CHEMBL1555592 & 688721 & 4.8 & 4.7706 & TST \\
\hline CHEMBL1440005 & 688721 & 5.8 & 5.0792 & TST \\
\hline CHEMBL1320190 & 688721 & 4.7 & 5.0051 & TRN \\
\hline CHEMBL1469299 & 688721 & 4.6 & 4.8404 & TRN \\
\hline CHEMBL1371510 & 688721 & 5.3 & 5.1195 & TST \\
\hline CHEMBL1353238 & 688721 & 5.4 & 4.9365 & TRN \\
\hline CHEMBL1367917 & 688721 & 4.4 & 4.8954 & TRN \\
\hline CHEMBL1607965 & 688721 & 4.9 & 4.9299 & TRN \\
\hline CHEMBL1371371 & 688721 & 5.2 & 4.8977 & TST \\
\hline CHEMBL1494373 & 688721 & 4.9 & 4.9657 & TRN \\
\hline CHEMBL1369911 & 688721 & 5.0 & 4.9452 & TRN \\
\hline CHEMBL1418737 & 688721 & 4.6 & 4.9708 & TRN \\
\hline CHEMBL1435834 & 688721 & 5.1 & 5.0277 & TRN \\
\hline CHEMBL1501372 & 688721 & 4.5 & 4.8169 & TRN \\
\hline CHEMBL1328576 & 688721 & 4.8 & 5.3886 & TST \\
\hline CHEMBL3211314 & 688721 & 4.5 & 5.0252 & TST \\
\hline CHEMBL1313055 & 688721 & 5.8 & 5.0562 & TRN \\
\hline CHEMBL1509725 & 688721 & 5.6 & 4.7966 & TRN \\
\hline CHEMBL1471275 & 688721 & 5.2 & 4.9227 & TST \\
\hline CHEMBL1359612 & 688721 & 4.5 & 4.9661 & TRN \\
\hline CHEMBL22373 & 688721 & 4.8 & 5.1589 & TST \\
\hline CHEMBL1472108 & 688721 & 4.4 & 4.8861 & TRN \\
\hline CHEMBL1412548 & 688721 & 4.6 & 4.8753 & TST \\
\hline CHEMBL1564765 & 688721 & 4.6 & 4.9479 & TRN \\
\hline CHEMBL1357520 & 688721 & 5.4 & 4.9827 & TRN \\
\hline CHEMBL1377436 & 688721 & 4.4 & 4.8648 & TRN \\
\hline CHEMBL1318789 & 688721 & 6.0 & 5.3965 & TST \\
\hline CHEMBL1418995 & 688721 & 4.4 & 4.8927 & TRN \\
\hline CHEMBL1475860 & 688721 & 5.0 & 5.039 & TRN \\
\hline CHEMBL1460403 & 688721 & 4.4 & 4.9247 & TRN \\
\hline CHEMBL1378382 & 688721 & 4.9 & 4.8628 & TRN \\
\hline CHEMBL1520649 & 688721 & 4.4 & 5.1522 & TST \\
\hline CHEMBL1503016 & 688721 & 5.3 & 5.0026 & TRN \\
\hline CHEMBL1413159 & 688721 & 5.1 & 5.0491 & TRN \\
\hline CHEMBL1602150 & 688721 & 4.5 & 5.0956 & TRN \\
\hline CHEMBL1304227 & 688721 & 4.6 & 4.9461 & TRN \\
\hline CHEMBL1407710 & 688721 & 6.9 & 4.921 & TRN \\
\hline CHEMBL1446444 & 688721 & 4.6 & 5.0852 & TRN \\
\hline CHEMBL1519220 & 688721 & 4.6 & 4.8768 & TRN \\
\hline CHEMBL1417409 & 688721 & 4.7 & 4.831 & TRN \\
\hline CHEMBL1329927 & 688721 & 6.0 & 4.9631 & TST \\
\hline CHEMBL1393509 & 688721 & 4.8 & 4.8397 & TRN \\
\hline CHEMBL171145 & 688721 & 4.4 & 5.1639 & TST \\
\hline CHEMBL1491677 & 688721 & 4.5 & 4.8894 & TST \\
\hline CHEMBL1507753 & 688721 & 4.4 & 4.8385 & TRN \\
\hline CHEMBL1600131 & 688721 & 4.6 & 4.8752 & TRN \\
\hline CHEMBL1439956 & 688721 & 4.8 & 4.8574 & TRN \\
\hline
\end{tabular}




\begin{tabular}{|c|c|c|c|c|c|}
\hline \multicolumn{6}{|c|}{ Supplemental Table S2.txt } \\
\hline CHEMBL1431259 & 688721 & 5.5 & 4.684 & TRN & \\
\hline CHEMBL1544736 & 688721 & 5.3 & 4.9444 & TST & \\
\hline CHEMBL1506136 & 688721 & 4.4 & 4.8022 & TRN & \\
\hline CHEMBL541847 & 688721 & 4.5 & 4.9546 & TRN & \\
\hline CHEMBL1568129 & 688721 & 5.0 & 5.0477 & TRN & \\
\hline CHEMBL1485646 & 688721 & 4.5 & 4.6821 & TRN & \\
\hline CHEMBL1609391 & 688721 & 4.8 & 4.81800 & 00000000005 & TRN \\
\hline CHEMBL1455098 & 688721 & 4.7 & 4.7832 & TRN & \\
\hline CHEMBL1572088 & 688721 & 4.5 & 5.05399 & 9999999999 & TST \\
\hline CHEMBL1485898 & 688721 & 4.7 & 4.833 & TRN & \\
\hline CHEMBL1368090 & 688721 & 5.5 & 5.053 & TST & \\
\hline CHEMBL1256754 & 688721 & 4.9 & 5.16299 & 9999999999 & TRN \\
\hline CHEMBL1372481 & 688721 & 4.6 & 4.9902 & TST & \\
\hline CHEMBL1580426 & 688721 & 4.8 & 4.851 & TST & \\
\hline CHEMBL1375082 & 688721 & 5.2 & 4.9073 & TRN & \\
\hline CHEMBL1527466 & 688721 & 5.2 & 5.1158 & TRN & \\
\hline CHEMBL1478530 & 688721 & 7.8996 & 5.1935 & TST & \\
\hline CHEMBL1583062 & 688721 & 5.2 & 4.9424 & TRN & \\
\hline CHEMBL1353300 & 688721 & 8.1024 & 5.1408 & TRN & \\
\hline CHEMBL1444887 & 688721 & 4.6 & 4.7998 & TST & \\
\hline CHEMBL1362254 & 688721 & 4.4 & 4.8292 & TRN & \\
\hline CHEMBL1583810 & 688721 & 4.7 & 4.8837 & TST & \\
\hline CHEMBL1430777 & 688721 & 4.5 & 4.7755 & TRN & \\
\hline CHEMBL1611906 & 688721 & 5.7 & 5.0708 & TST & \\
\hline CHEMBL1306181 & 688721 & 4.6 & 4.9768 & TRN & \\
\hline CHEMBL1418459 & 688721 & 4.8 & 4.9132 & TRN & \\
\hline CHEMBL1347057 & 688721 & 4.6 & 5.204 & TST & \\
\hline CHEMBL1338384 & 688721 & 4.5 & 4.9655 & TRN & \\
\hline CHEMBL1536690 & 688721 & 4.7 & 4.8799 & TRN & \\
\hline CHEMBL1574934 & 688721 & 4.9 & 4.9301 & TRN & \\
\hline CHEMBL1577546 & 688721 & 5.0 & 4.9588 & TRN & \\
\hline CHEMBL1589326 & 688721 & 5.2 & 4.854 & TST & \\
\hline CHEMBL1411785 & 688721 & 4.4 & 5.0132 & TST & \\
\hline CHEMBL1336516 & 688721 & 5.9 & 4.9421 & TST & \\
\hline CHEMBL1574849 & 688721 & 4.5 & 4.9999 & TRN & \\
\hline CHEMBL1454765 & 688721 & 4.8 & 4.9627 & TRN & \\
\hline CHEMBL1467957 & 688721 & 4.5 & 4.8146 & TRN & \\
\hline CHEMBL1474483 & 688721 & 6.7001 & 5.0819 & TRN & \\
\hline CHEMBL1490373 & 688721 & 4.5 & 4.8781 & TST & \\
\hline CHEMBL1585404 & 688721 & 4.8 & 4.8051 & TRN & \\
\hline CHEMBL1605627 & 688721 & 4.7 & 4.92 & TRN & \\
\hline CHEMBL1447059 & 688721 & 4.7 & 4.84699 & 99999999995 & TRN \\
\hline CHEMBL1525199 & 688721 & 5.2 & 4.8625 & TST & \\
\hline CHEMBL1572696 & 688721 & 4.9 & 5.0789 & TST & \\
\hline CHEMBL1449702 & 688721 & 5.5 & 4.8464 & TRN & \\
\hline CHEMBL1509510 & 688721 & 5.2 & 4.9781 & TST & \\
\hline CHEMBL1389692 & 688721 & 4.6 & 4.8049 & TRN & \\
\hline CHEMBL1601678 & 688721 & 5.3 & 4.9149 & TRN & \\
\hline
\end{tabular}




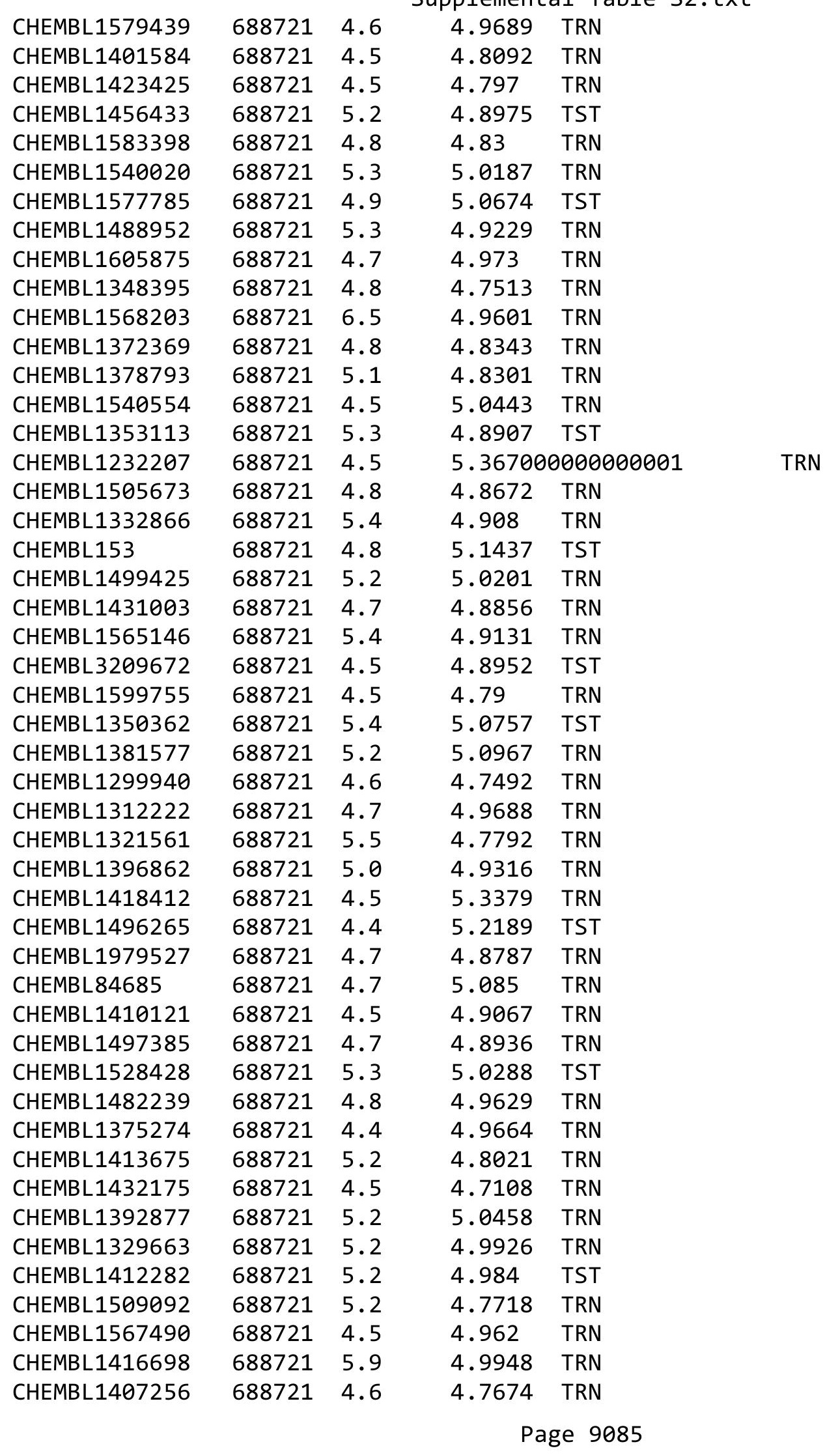




\begin{tabular}{|c|c|c|c|c|}
\hline \multicolumn{5}{|c|}{ Supplemental Table S2.txt } \\
\hline CHEMBL1371427 & 688721 & 4.7 & 4.8607 & TRN \\
\hline CHEMBL1512708 & 688721 & 5.2 & 5.0111 & TRN \\
\hline CHEMBL1538241 & 688721 & 4.6 & 4.945 & TST \\
\hline CHEMBL1430495 & 688721 & 5.4 & 4.8349 & TST \\
\hline CHEMBL1384748 & 688721 & 4.6 & 4.7987 & TRN \\
\hline CHEMBL1577615 & 688721 & 5.5 & 5.2608 & TRN \\
\hline CHEMBL1455083 & 688721 & 5.2 & 4.8685 & TRN \\
\hline CHEMBL1356998 & 688721 & 6.2 & 5.1049 & TRN \\
\hline CHEMBL1304290 & 688721 & 4.5 & 4.7689 & TRN \\
\hline CHEMBL1359422 & 688721 & 4.4 & 4.8943 & TRN \\
\hline CHEMBL1597330 & 688721 & 5.9 & 5.1078 & TST \\
\hline CHEMBL1456811 & 688721 & 5.5 & 5.096 & TRN \\
\hline CHEMBL1342113 & 688721 & 4.6 & 4.8857 & TST \\
\hline CHEMBL1322862 & 688721 & 4.6 & 4.8457 & TRN \\
\hline CHEMBL1343147 & 688721 & 4.4 & 5.147 & TST \\
\hline CHEMBL1596096 & 688721 & 5.4 & 4.9931 & TST \\
\hline CHEMBL1583862 & 688721 & 4.5 & 5.0747 & TRN \\
\hline CHEMBL1545552 & 688721 & 4.5 & 4.9245 & TST \\
\hline CHEMBL1480756 & 688721 & 5.2 & 4.9628 & TRN \\
\hline CHEMBL1327908 & 688721 & 4.6 & 4.8155 & TRN \\
\hline CHEMBL1607824 & 688721 & 4.5 & 4.8494 & TRN \\
\hline CHEMBL1545169 & 688721 & 5.0 & 4.8633 & TST \\
\hline CHEMBL1382502 & 688721 & 6.1 & 4.9702 & TRN \\
\hline CHEMBL1596783 & 688721 & 4.4 & 5.152 & TST \\
\hline CHEMBL1256911 & 688721 & 4.8 & 5.1368 & TRN \\
\hline CHEMBL1585639 & 688721 & 4.5 & 5.0942 & TST \\
\hline CHEMBL1380257 & 688721 & 4.9 & 4.9311 & TST \\
\hline CHEMBL1559474 & 688721 & 4.7 & 4.8131 & TRN \\
\hline CHEMBL407874 & 688721 & 5.3 & 5.1118 & TST \\
\hline CHEMBL1332220 & 688721 & 4.5 & 4.8665 & TRN \\
\hline CHEMBL1569310 & 688721 & 4.5 & 4.9377 & TRN \\
\hline CHEMBL1358525 & 688721 & 4.9 & 4.9322 & TST \\
\hline CHEMBL1344409 & 688721 & 4.5 & 4.8935 & TRN \\
\hline CHEMBL1545534 & 688721 & 4.5 & 4.6605 & TRN \\
\hline CHEMBL1301494 & 688721 & 6.1 & 4.9927 & TST \\
\hline CHEMBL1590123 & 688721 & 4.8 & 5.0106 & TRN \\
\hline CHEMBL3210360 & 688721 & 5.2 & 4.9461 & TRN \\
\hline CHEMBL1517687 & 688721 & 4.4 & 4.9329 & TST \\
\hline CHEMBL1457162 & 688721 & 4.6 & 4.9849 & TRN \\
\hline CHEMBL1453889 & 688721 & 5.2 & 4.8989 & TRN \\
\hline CHEMBL1575331 & 688721 & 4.5 & 4.8957 & TRN \\
\hline CHEMBL1469374 & 688721 & 4.4 & 4.9104 & TRN \\
\hline CHEMBL1463698 & 688721 & 5.5 & 4.944 & TRN \\
\hline CHEMBL1416666 & 688721 & 4.5 & 4.8049 & TRN \\
\hline CHEMBL1416250 & 688721 & 5.7 & 5.1728 & TRN \\
\hline CHEMBL1537596 & 688721 & 4.4 & 5.1467 & TST \\
\hline CHEMBL1408022 & 688721 & 4.4 & 4.7815 & TRN \\
\hline CHEMBL1372412 & 688721 & 5.3 & 4.9413 & TRN \\
\hline
\end{tabular}




\begin{tabular}{|c|c|c|c|c|c|}
\hline \multicolumn{6}{|c|}{ Supplemental Table S2.txt } \\
\hline CHEMBL1484899 & 688721 & 5.5 & 4.9773 & TST & \\
\hline CHEMBL1458653 & 688721 & 4.9 & 4.9982 & TRN & \\
\hline CHEMBL1388879 & 688721 & 4.5 & 4.8428 & TST & \\
\hline CHEMBL1483857 & 688721 & 5.8 & 4.9206 & TRN & \\
\hline CHEMBL1447497 & 688721 & 4.4 & 4.968 & TST & \\
\hline CHEMBL1390598 & 688721 & 6.1 & 4.8706 & TRN & \\
\hline CHEMBL1519978 & 688721 & 4.8 & 5.0976 & TRN & \\
\hline CHEMBL1563134 & 688721 & 4.5 & 4.7587 & TRN & \\
\hline CHEMBL1535571 & 688721 & 4.5 & 4.8662 & TST & \\
\hline CHEMBL1495568 & 688721 & 4.6 & 4.9109 & TST & \\
\hline CHEMBL1568990 & 688721 & 4.9 & 4.9244 & TST & \\
\hline CHEMBL1401523 & 688721 & 4.5 & 4.8465 & TRN & \\
\hline CHEMBL1581249 & 688721 & 4.8 & 4.9079 & TRN & \\
\hline CHEMBL1594281 & 688721 & 4.4 & 5.0551 & TRN & \\
\hline CHEMBL1256746 & 688721 & 4.5 & 5.2266 & TRN & \\
\hline CHEMBL1543548 & 688721 & 4.6 & 4.9282 & TRN & \\
\hline CHEMBL1573454 & 688721 & 5.8 & 4.8819 & TRN & \\
\hline CHEMBL1556061 & 688721 & 5.1 & 4.8811 & TRN & \\
\hline CHEMBL1372820 & 688721 & 5.7 & 4.9923 & TRN & \\
\hline CHEMBL1508020 & 688721 & 4.9 & 4.9002 & TRN & \\
\hline CHEMBL1364867 & 688721 & 4.5 & 4.9928 & TRN & \\
\hline CHEMBL1603919 & 688721 & 5.4 & 4.7551 & TRN & \\
\hline CHEMBL1533464 & 688721 & 5.2 & 5.1457 & TST & \\
\hline CHEMBL1321018 & 688721 & 4.6 & 4.7415 & TRN & \\
\hline CHEMBL1577497 & 688721 & 4.5 & 4.8637 & TST & \\
\hline CHEMBL1351497 & 688721 & 4.8 & 4.8414 & TRN & \\
\hline CHEMBL25236 & 688721 & 4.8 & 4.8972 & TRN & \\
\hline CHEMBL1408782 & 688721 & 4.4 & 4.8345 & TRN & \\
\hline CHEMBL1360647 & 688721 & 4.9 & 5.0177 & TRN & \\
\hline CHEMBL1465732 & 688721 & 6.4 & 5.0847 & TRN & \\
\hline CHEMBL1528820 & 688721 & 5.2 & 5.1309 & TRN & \\
\hline CHEMBL1405325 & 688721 & 5.5 & 4.6555 & TRN & \\
\hline CHEMBL1493587 & 688721 & 4.8 & 4.9495 & TRN & \\
\hline CHEMBL1455566 & 688721 & 4.8 & 4.8908 & TRN & \\
\hline CHEMBL1471335 & 688721 & 5.0 & 4.8923 & TRN & \\
\hline CHEMBL1574460 & 688721 & 4.6 & 5.06800 & 00000000005 & TRN \\
\hline CHEMBL1440362 & 688721 & 7.5003 & 5.3349 & TRN & \\
\hline CHEMBL1547388 & 688721 & 5.2 & 5.0242 & TRN & \\
\hline CHEMBL 3211120 & 688721 & 4.4 & 4.8424 & TRN & \\
\hline CHEMBL1331288 & 688721 & 5.3 & 5.0767 & TRN & \\
\hline CHEMBL1308032 & 688721 & 4.5 & 5.0003 & TRN & \\
\hline CHEMBL1506225 & 688721 & 6.1 & 5.2237 & TRN & \\
\hline CHEMBL1488286 & 688721 & 4.6 & 5.047 & TST & \\
\hline CHEMBL 25048 & 688721 & 6.3 & 5.12200 & 0000000001 & TRN \\
\hline CHEMBL1368233 & 688721 & 5.1 & 4.9439 & TRN & \\
\hline CHEMBL1504865 & 688721 & 4.8 & 4.8268 & TRN & \\
\hline CHEMBL1451089 & 688721 & 4.6 & 5.0342 & TST & \\
\hline CHEMBL1374179 & 688721 & 4.5 & 5.1356 & TST & \\
\hline
\end{tabular}




\begin{tabular}{|c|c|c|c|c|c|}
\hline \multicolumn{6}{|c|}{ Supplemental Table s2.txt } \\
\hline CHEMBL1445873 & 688721 & 5.0 & 4.8715 & TRN & \\
\hline CHEMBL1608659 & 688721 & 5.9 & 4.974 & TRN & \\
\hline CHEMBL1451333 & 688721 & 4.6 & 4.9113 & TRN & \\
\hline CHEMBL1325688 & 688721 & 4.5 & 5.0449 & TRN & \\
\hline CHEMBL1487303 & 688721 & 5.5 & 5.1646 & TST & \\
\hline CHEMBL1553404 & 688721 & 5.2 & 5.0653 & TRN & \\
\hline CHEMBL1386265 & 688721 & 4.4 & 4.8983 & TRN & \\
\hline CHEMBL282433 & 688721 & 4.8 & 4.9575 & TRN & \\
\hline CHEMBL1331447 & 688721 & 4.7 & 4.9685 & TRN & \\
\hline CHEMBL1484572 & 688721 & 4.5 & 5.0757 & TST & \\
\hline CHEMBL1517718 & 688721 & 4.9 & 5.1783 & TRN & \\
\hline CHEMBL1332712 & 688721 & 5.2 & 4.9053 & TRN & \\
\hline CHEMBL1318765 & 688721 & 5.5 & 5.0175 & TRN & \\
\hline CHEMBL 3207580 & 688721 & 5.2 & \multicolumn{2}{|c|}{ 5.013999999999999 } & TRN \\
\hline CHEMBL577420 & 688721 & 4.8 & 4.965 & TST & \\
\hline CHEMBL1333934 & 688721 & 4.5 & 5.1242 & TRN & \\
\hline CHEMBL1566074 & 688721 & 6.0 & 5.1426 & TST & \\
\hline CHEMBL1465690 & 688721 & 6.7001 & 5.1468 & TRN & \\
\hline CHEMBL1394088 & 688721 & 4.8 & 5.2171 & TST & \\
\hline CHEMBL1373151 & 688721 & 4.5 & 5.1583 & TRN & \\
\hline CHEMBL151 & 688721 & 4.4 & 5.0201 & TRN & \\
\hline CHEMBL1342446 & 688721 & 4.9 & 4.9721 & TRN & \\
\hline CHEMBL1528486 & 688721 & 4.4 & 4.8717 & TRN & \\
\hline CHEMBL1327867 & 688721 & 4.8 & 4.8909 & TRN & \\
\hline CHEMBL1413928 & 688721 & 4.8 & 4.882 & TRN & \\
\hline CHEMBL1452755 & 688721 & 4.4 & 5.0004 & TRN & \\
\hline CHEMBL1366616 & 688721 & 7.5003 & 5.0469 & TST & \\
\hline CHEMBL1419908 & 688721 & 4.4 & \multicolumn{2}{|c|}{5.172000000000001} & TST \\
\hline CHEMBL1574587 & 688721 & 4.7 & 4.8577 & TST & \\
\hline CHEMBL1568508 & 688721 & 4.5 & 4.8445 & TRN & \\
\hline CHEMBL1312797 & 688721 & 5.8 & 5.0217 & TRN & \\
\hline CHEMBL1468382 & 688721 & 5.0 & 4.9779 & TRN & \\
\hline CHEMBL1476108 & 688721 & 4.4 & 5.169 & TST & \\
\hline CHEMBL1309919 & 688721 & 4.8 & 4.8012 & TRN & \\
\hline CHEMBL1359774 & 688721 & 4.8 & 4.8733 & TST & \\
\hline CHEMBL1446523 & 688721 & 4.6 & 4.9533 & TRN & \\
\hline CHEMBL1547542 & 688721 & 5.4 & 5.0809 & TST & \\
\hline CHEMBL1561092 & 688721 & 4.4 & 4.7514 & TRN & \\
\hline CHEMBL1514375 & 688721 & 4.7 & 4.8546 & TST & \\
\hline CHEMBL1402397 & 688721 & 4.6 & 4.9703 & TST & \\
\hline CHEMBL1359157 & 688721 & 4.9 & 5.0478 & TRN & \\
\hline CHEMBL1497038 & 688721 & 4.4 & 5.2171 & TST & \\
\hline CHEMBL1590492 & 688721 & 5.2 & 4.8362 & TST & \\
\hline CHEMBL1408742 & 688721 & 4.4 & 4.796 & TRN & \\
\hline CHEMBL1577408 & 688721 & 4.6 & 5.0118 & TRN & \\
\hline CHEMBL1409865 & 688721 & 6.3 & 4.9113 & TRN & \\
\hline CHEMBL1355970 & 688721 & 4.4 & 5.1515 & TRN & \\
\hline CHEMBL1257078 & 688721 & 5.4 & 4.9037 & TST & \\
\hline
\end{tabular}




\begin{tabular}{|c|c|c|c|c|}
\hline \multicolumn{5}{|c|}{ Supplemental Table S2.txt } \\
\hline CHEMBL1497370 & 688721 & 4.6 & 4.8412 & TRN \\
\hline CHEMBL1363204 & 688721 & 5.5 & 4.7214 & TRN \\
\hline CHEMBL1322501 & 688721 & 4.6 & 5.1523 & TST \\
\hline CHEMBL1538053 & 688721 & 5.3 & 4.9975 & TRN \\
\hline CHEMBL278751 & 688721 & 4.5 & 5.0167 & TST \\
\hline CHEMBL1336686 & 688721 & 4.6 & 4.8044 & TRN \\
\hline CHEMBL1605356 & 688721 & 5.5 & 5.1676 & TRN \\
\hline CHEMBL1414552 & 688721 & 4.4 & 5.0102 & TRN \\
\hline CHEMBL1386394 & 688721 & 4.7 & 4.8868 & TRN \\
\hline CHEMBL1368965 & 688721 & 4.9 & 5.1549 & TRN \\
\hline CHEMBL1459777 & 688721 & 5.2 & 4.9685 & TRN \\
\hline CHEMBL1458268 & 688721 & 4.9 & 4.9117 & TRN \\
\hline CHEMBL1338673 & 688721 & 4.8 & 4.9654 & TRN \\
\hline CHEMBL1341119 & 688721 & 4.6 & 4.7074 & TRN \\
\hline CHEMBL1472594 & 688721 & 4.7 & 4.9436 & TRN \\
\hline CHEMBL1373679 & 688721 & 4.7 & 5.0658 & TST \\
\hline CHEMBL1561750 & 688721 & 5.2 & 5.0313 & TRN \\
\hline CHEMBL1494878 & 688721 & 5.1 & 4.9024 & TST \\
\hline CHEMBL1496529 & 688721 & 4.7 & 4.8392 & TRN \\
\hline CHEMBL1342625 & 688721 & 4.5 & 4.8442 & TST \\
\hline CHEMBL1574982 & 688721 & 5.1 & 5.193 & TST \\
\hline CHEMBL1313927 & 688721 & 4.5 & 4.9212 & TST \\
\hline CHEMBL1500033 & 688721 & 4.8 & 4.9612 & TRN \\
\hline CHEMBL1532224 & 688721 & 5.2 & 5.0159 & TRN \\
\hline CHEMBL1529151 & 688721 & 4.8 & 5.0396 & TRN \\
\hline CHEMBL1538798 & 688721 & 4.6 & 4.8119 & TRN \\
\hline CHEMBL1325279 & 688721 & 5.3 & 4.8996 & TRN \\
\hline CHEMBL1450869 & 688721 & 5.4 & 5.052 & TRN \\
\hline CHEMBL1485536 & 688721 & 6.9 & 5.0069 & TRN \\
\hline CHEMBL1532928 & 688721 & 4.4 & 4.7515 & TST \\
\hline CHEMBL1515698 & 688721 & 5.3 & 5.2502 & TRN \\
\hline CHEMBL1414261 & 688721 & 6.6 & 4.9179 & TRN \\
\hline CHEMBL1539969 & 688721 & 4.8 & 4.9207 & TRN \\
\hline CHEMBL1530963 & 688721 & 5.5 & 4.9547 & TRN \\
\hline CHEMBL1430700 & 688721 & 6.7001 & 4.9026 & TRN \\
\hline CHEMBL1582216 & 688721 & 4.4 & 4.885 & TST \\
\hline CHEMBL1459561 & 688721 & 4.4 & 4.9353 & TST \\
\hline CHEMBL1583670 & 688721 & 4.8 & 4.9627 & TRN \\
\hline CHEMBL1364670 & 688721 & 4.7 & 5.0241 & TRN \\
\hline CHEMBL1606245 & 688721 & 5.2 & 5.0547 & TST \\
\hline CHEMBL1341427 & 688721 & 4.7 & 4.898 & TRN \\
\hline CHEMBL18132 & 688721 & 4.5 & 4.9712 & TST \\
\hline CHEMBL192293 & 688721 & 4.5 & 4.9873 & TRN \\
\hline CHEMBL3192316 & 688721 & 5.3 & 5.0752 & TST \\
\hline CHEMBL1484309 & 688721 & 4.9 & 4.7806 & TRN \\
\hline CHEMBL1370093 & 688721 & 4.6 & 5.0342 & TST \\
\hline CHEMBL1456771 & 688721 & 4.6 & 4.7156 & TRN \\
\hline CHEMBL1447064 & 688721 & 5.2 & 5.0731 & TST \\
\hline
\end{tabular}




\begin{tabular}{|c|c|c|c|c|}
\hline \multicolumn{5}{|c|}{ Supplemental Table S2.txt } \\
\hline CHEMBL1346186 & 688721 & 4.5 & 5.0989 & TRN \\
\hline CHEMBL17468 & 688721 & 5.2 & 5.0197 & TST \\
\hline CHEMBL1382685 & 688721 & 4.9 & 5.0069 & TST \\
\hline CHEMBL1387526 & 688721 & 5.4 & 4.9168 & TRN \\
\hline CHEMBL 1413340 & 688721 & 4.6 & 5.121 & TRN \\
\hline CHEMBL1311714 & 688721 & 4.4 & 4.8382 & TRN \\
\hline CHEMBL1326236 & 688721 & 4.9 & 4.7568 & TRN \\
\hline CHEMBL1580259 & 688721 & 8.301 & 4.8035 & TST \\
\hline CHEMBL1499961 & 688721 & 4.5 & 4.9066 & TRN \\
\hline CHEMBL1300070 & 688721 & 4.4 & 4.8309 & TRN \\
\hline CHEMBL50112 & 688721 & 5.1 & 5.0064 & TRN \\
\hline CHEMBL1584572 & 688721 & 7.5003 & 4.8504 & TRN \\
\hline CHEMBL1412240 & 688721 & 4.4 & 4.9275 & TST \\
\hline CHEMBL1604435 & 688721 & 4.4 & 4.9278 & TRN \\
\hline CHEMBL1553173 & 688721 & 4.5 & 4.9624 & TRN \\
\hline CHEMBL1466652 & 688721 & 4.6 & 4.8634 & TST \\
\hline CHEMBL1385227 & 688721 & 5.0 & 4.8129 & TRN \\
\hline CHEMBL1361066 & 688721 & 5.2 & 5.1401 & TRN \\
\hline CHEMBL1574894 & 688721 & 5.5 & 4.7713 & TRN \\
\hline CHEMBL1413982 & 688721 & 4.6 & 4.7797 & TRN \\
\hline CHEMBL1436438 & 688721 & 6.0 & 5.3261 & TRN \\
\hline CHEMBL1610260 & 688721 & 4.9 & 4.9854 & TRN \\
\hline CHEMBL1525007 & 688721 & 5.0 & 4.9836 & TRN \\
\hline CHEMBL1394118 & 688721 & 5.4 & 5.2359 & TRN \\
\hline CHEMBL1390926 & 688721 & 4.9 & 5.0779 & TRN \\
\hline CHEMBL1578304 & 688721 & 4.6 & 4.8531 & TRN \\
\hline CHEMBL1381551 & 688721 & 4.5 & 4.9568 & TST \\
\hline CHEMBL57394 & 688721 & 4.4 & 5.0288 & TRN \\
\hline CHEMBL1450211 & 688721 & 5.2 & 4.7611 & TRN \\
\hline CHEMBL1302590 & 688721 & 4.5 & 5.0887 & TRN \\
\hline CHEMBL1373348 & 688721 & 4.8 & 4.7986 & TST \\
\hline CHEMBL1541805 & 688721 & 6.9 & 5.0116 & TRN \\
\hline CHEMBL1352121 & 688721 & 4.4 & 4.9073 & TRN \\
\hline CHEMBL1544839 & 688721 & 4.7 & 5.1655 & TRN \\
\hline CHEMBL1579456 & 688721 & 4.6 & 4.9374 & TRN \\
\hline CHEMBL1608077 & 688721 & 4.5 & 4.9133 & TRN \\
\hline CHEMBL1328534 & 688721 & 4.6 & 5.0066 & TRN \\
\hline CHEMBL1525774 & 688721 & 4.6 & 5.0538 & TRN \\
\hline CHEMBL1479591 & 688721 & 4.4 & 4.9428 & TST \\
\hline CHEMBL1341829 & 688721 & 4.7 & 4.8935 & TST \\
\hline CHEMBL1487111 & 688721 & 5.3 & 5.0841 & TRN \\
\hline CHEMBL1498013 & 688721 & 4.9 & 4.8854 & TRN \\
\hline CHEMBL1524735 & 688721 & 4.5 & 4.9402 & TRN \\
\hline CHEMBL1346960 & 688721 & 4.6 & 4.8871 & TRN \\
\hline CHEMBL1488671 & 688721 & 4.5 & 4.9713 & TRN \\
\hline CHEMBL1505758 & 688721 & 5.4 & 5.0196 & TRN \\
\hline CHEMBL1564036 & 688721 & 4.8 & 4.8393 & TRN \\
\hline CHEMBL1399402 & 688721 & 4.5 & 4.8976 & TRN \\
\hline
\end{tabular}




\begin{tabular}{|c|c|c|c|c|c|}
\hline \\
\hline CHEMBL1459889 & 688721 & 4.6 & 4.9091 & TRN & \\
\hline CHEMBL1584360 & 688721 & 5.2 & 5.0397 & TRN & \\
\hline CHEMBL1353416 & 688721 & 4.4 & 5.0616 & TRN & \\
\hline CHEMBL1378375 & 688721 & 4.8 & 4.7239 & TRN & \\
\hline CHEMBL1326338 & 688721 & 5.3 & 5.1037 & TST & \\
\hline CHEMBL1444917 & 688721 & 4.7 & 4.8795 & TRN & \\
\hline CHEMBL1538503 & 688721 & 5.1 & 4.8719 & TRN & \\
\hline CHEMBL2374027 & 688721 & 4.5 & 5.1392 & TRN & \\
\hline CHEMBL539648 & 688721 & 7.5003 & 5.2941 & TRN & \\
\hline CHEMBL1464123 & 688721 & 5.5 & 4.9852 & TST & \\
\hline CHEMBL15134 & 688721 & 5.0 & 5.0645 & TRN & \\
\hline CHEMBL1322129 & 688721 & 4.9 & 5.0324 & TRN & \\
\hline CHEMBL1535626 & 688721 & 5.2 & 5.0037 & TST & \\
\hline CHEMBL1373631 & 688721 & 7.5003 & 4.8983 & TST & \\
\hline CHEMBL1449674 & 688721 & 5.4 & 4.9499 & TRN & \\
\hline CHEMBL1489512 & 688721 & 5.5 & 5.0141 & TRN & \\
\hline CHEMBL1509355 & 688721 & 6.0 & 4.8412 & TRN & \\
\hline CHEMBL1594030 & 688721 & 5.4 & 4.895 & TST & \\
\hline CHEMBL1520775 & 688721 & 5.6 & 4.9674 & TRN & \\
\hline CHEMBL1305209 & 688721 & 5.4 & 4.9158 & TRN & \\
\hline CHEMBL1455578 & 688721 & 4.7 & 4.8373 & TRN & \\
\hline CHEMBL1589376 & 688721 & 4.5 & 5.0396 & TST & \\
\hline CHEMBL1490770 & 688721 & 5.5 & 5.0437 & TRN & \\
\hline CHEMBL1313479 & 688721 & 5.2 & 5.0737 & TRN & \\
\hline CHEMBL1482064 & 688721 & 5.0 & 4.9685 & TRN & \\
\hline CHEMBL1314453 & 688721 & 5.3 & 5.0061 & TRN & \\
\hline CHEMBL1414761 & 688721 & 4.5 & 4.9056 & TRN & \\
\hline CHEMBL1535709 & 688721 & 4.4 & 4.7521 & TRN & \\
\hline CHEMBL1500506 & 688721 & 6.3 & 4.8497 & TRN & \\
\hline CHEMBL1351793 & 688721 & 4.6 & 4.9424 & TRN & \\
\hline CHEMBL1331929 & 688721 & 5.8 & 4.9869 & TRN & \\
\hline CHEMBL1415281 & 688721 & 5.3 & 4.68199 & 99999999995 & TRN \\
\hline CHEMBL1378939 & 688721 & 4.4 & 4.9022 & TST & \\
\hline CHEMBL1531944 & 688721 & 4.6 & 4.8593 & TRN & \\
\hline CHEMBL1607716 & 688721 & 4.4 & 4.8478 & TST & \\
\hline CHEMBL1569606 & 688721 & 4.6 & 4.8384 & TRN & \\
\hline CHEMBL1586993 & 688721 & 4.6 & 4.8645 & TRN & \\
\hline CHEMBL370458 & 688721 & 6.3 & 5.0987 & TRN & \\
\hline CHEMBL1597435 & 688721 & 4.5 & 4.9671 & TRN & \\
\hline CHEMBL1567517 & 688721 & 5.2 & 4.9211 & TRN & \\
\hline CHEMBL1411937 & 688721 & 4.6 & 4.7671 & TRN & \\
\hline CHEMBL1322468 & 688721 & 5.5 & 5.0087 & TRN & \\
\hline CHEMBL1463712 & 688721 & 4.4 & 4.9225 & TRN & \\
\hline CHEMBL1479805 & 688721 & 5.2 & 5.3304 & TST & \\
\hline CHEMBL1569358 & 688721 & 6.5 & 5.1376 & TRN & \\
\hline CHEMBL1446112 & 688721 & 5.1 & 5.0264 & TRN & \\
\hline CHEMBL1329182 & 688721 & 4.5 & 4.9062 & TST & \\
\hline CHEMBL1349677 & 688721 & 4.8 & 4.9604 & TRN & \\
\hline
\end{tabular}




\begin{tabular}{|c|c|c|c|c|}
\hline \multicolumn{5}{|c|}{ Supplemental Table S2.txt } \\
\hline CHEMBL1323790 & 688721 & 4.6 & 4.9004 & TRN \\
\hline CHEMBL1532758 & 688721 & 4.4 & 4.8234 & TRN \\
\hline CHEMBL1347524 & 688721 & 6.7001 & 5.006 & TRN \\
\hline CHEMBL1454529 & 688721 & 4.6 & 4.6535 & TRN \\
\hline CHEMBL1544110 & 688721 & 4.7 & 4.9448 & TRN \\
\hline CHEMBL1324769 & 688721 & 4.5 & 4.9186 & TRN \\
\hline CHEMBL1309814 & 688721 & 4.4 & 4.9057 & TRN \\
\hline CHEMBL3213581 & 688721 & 5.9 & 5.2638 & TST \\
\hline CHEMBL1439027 & 688721 & 6.5 & 5.1672 & TRN \\
\hline CHEMBL1499013 & 688721 & 4.7 & 4.9376 & TRN \\
\hline CHEMBL1457994 & 688721 & 4.4 & 4.9952 & TRN \\
\hline CHEMBL1462825 & 688721 & 4.4 & 4.7969 & TRN \\
\hline CHEMBL1491726 & 688721 & 4.6 & 4.9215 & TRN \\
\hline CHEMBL1374496 & 688721 & 4.9 & 4.9995 & TRN \\
\hline CHEMBL1527923 & 688721 & 5.1 & 5.2076 & TRN \\
\hline CHEMBL1472039 & 688721 & 4.6 & 4.8868 & TRN \\
\hline CHEMBL1538347 & 688721 & 4.6 & 4.8572 & TRN \\
\hline CHEMBL1426146 & 688721 & 4.8 & 4.9831 & TRN \\
\hline CHEMBL1601244 & 688721 & 4.5 & 4.8613 & TRN \\
\hline CHEMBL1519735 & 688721 & 4.5 & 5.1067 & TRN \\
\hline CHEMBL1604755 & 688721 & 4.6 & 5.0116 & TRN \\
\hline CHEMBL1318448 & 688721 & 4.7 & 5.1231 & TRN \\
\hline CHEMBL1372129 & 688721 & 4.5 & 4.9093 & TRN \\
\hline CHEMBL1606336 & 688721 & 4.8 & 5.1356 & TST \\
\hline CHEMBL1413002 & 688721 & 4.8 & 5.1317 & TRN \\
\hline CHEMBL1475788 & 688721 & 5.1 & 4.9403 & TRN \\
\hline CHEMBL1489464 & 688721 & 4.4 & 5.0827 & TRN \\
\hline CHEMBL1562069 & 688721 & 4.6 & 4.9813 & TRN \\
\hline CHEMBL1524085 & 688721 & 5.1 & 5.0891 & TST \\
\hline CHEMBL1435907 & 688721 & 4.6 & 4.959 & TRN \\
\hline CHEMBL1337188 & 688721 & 4.5 & 4.9447 & TRN \\
\hline CHEMBL1412390 & 688721 & 4.6 & 5.043 & TRN \\
\hline CHEMBL1442487 & 688721 & 4.8 & 4.7586 & TRN \\
\hline CHEMBL 272942 & 688721 & 5.2 & 4.919 & TRN \\
\hline CHEMBL1446998 & 688721 & 4.7 & 5.1863 & TRN \\
\hline CHEMBL1610286 & 688721 & 5.2 & 4.9446 & TRN \\
\hline CHEMBL1559776 & 688721 & 4.4 & 5.0653 & TST \\
\hline CHEMBL1445619 & 688721 & 4.6 & 4.8278 & TRN \\
\hline CHEMBL1422817 & 688721 & 6.0 & 4.9007 & TRN \\
\hline CHEMBL1541127 & 688721 & 5.2 & 4.9724 & TST \\
\hline CHEMBL1403558 & 688721 & 4.7 & 4.9872 & TST \\
\hline CHEMBL1308349 & 688721 & 5.0 & 4.873 & TRN \\
\hline CHEMBL1429699 & 688721 & 4.5 & 4.9548 & TRN \\
\hline CHEMBL1555744 & 688721 & 4.5 & 4.8103 & TRN \\
\hline CHEMBL1483527 & 688721 & 4.9 & 5.0914 & TRN \\
\hline CHEMBL1349379 & 688721 & 4.4 & 4.8691 & TRN \\
\hline CHEMBL1448387 & 688721 & 5.5 & 5.1524 & TST \\
\hline CHEMBL1512454 & 688721 & 5.5 & 5.0999 & TRN \\
\hline
\end{tabular}




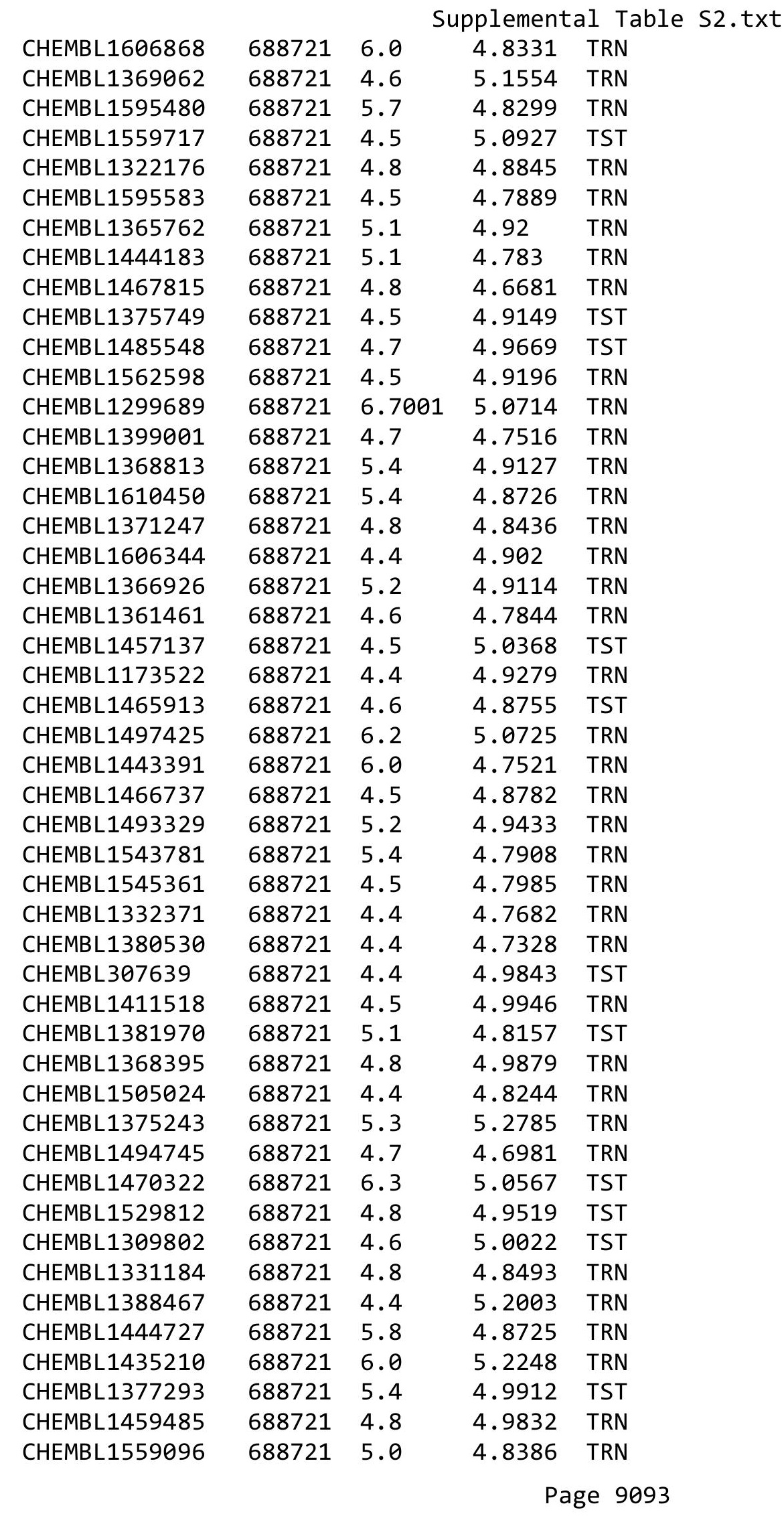




\begin{tabular}{|c|c|c|c|c|c|}
\hline \\
\hline CHEMBL1603113 & 688721 & 5.1 & 5.0763 & TRN & \\
\hline CHEMBL1356256 & 688721 & 5.0 & 5.2646 & TRN & \\
\hline CHEMBL1430299 & 688721 & 5.8 & 5.0439 & TRN & \\
\hline CHEMBL321691 & 688721 & 5.1 & 5.2433 & TST & \\
\hline CHEMBL1528661 & 688721 & 4.6 & 5.0272 & TRN & \\
\hline CHEMBL1414282 & 688721 & 4.7 & 4.7932 & TRN & \\
\hline CHEMBL1354736 & 688721 & 5.4 & 5.3211 & TRN & \\
\hline CHEMBL1344731 & 688721 & 5.2 & 4.8813 & TRN & \\
\hline CHEMBL1346683 & 688721 & 5.1 & 4.7901 & TRN & \\
\hline CHEMBL1469710 & 688721 & 4.9 & 4.9542 & TRN & \\
\hline CHEMBL1485313 & 688721 & 4.6 & 4.8027 & TRN & \\
\hline CHEMBL1379147 & 688721 & 4.7 & 4.88399 & 99999999995 & TRN \\
\hline CHEMBL1528058 & 688721 & 4.8 & 4.7459 & TRN & \\
\hline CHEMBL1483214 & 688721 & 4.6 & 4.9664 & TRN & \\
\hline CHEMBL1613109 & 688721 & 4.5 & 4.9511 & TRN & \\
\hline CHEMBL1564572 & 688721 & 4.5 & 4.6939 & TRN & \\
\hline CHEMBL1486217 & 688721 & 4.4 & 4.8989 & TRN & \\
\hline CHEMBL1484422 & 688721 & 5.0 & 4.8999 & TRN & \\
\hline CHEMBL1303987 & 688721 & 4.5 & 5.0729 & TRN & \\
\hline CHEMBL1307475 & 688721 & 4.8 & 5.0775 & TRN & \\
\hline CHEMBL1447799 & 688721 & 4.5 & 4.9542 & TRN & \\
\hline CHEMBL1546369 & 688721 & 5.2 & 4.8356 & TRN & \\
\hline CHEMBL 1354272 & 688721 & 5.0 & 5.0372 & TRN & \\
\hline CHEMBL1336432 & 688721 & 4.7 & 4.9078 & TST & \\
\hline CHEMBL1596872 & 688721 & 4.4 & 4.8862 & TRN & \\
\hline CHEMBL1508148 & 688721 & 4.6 & 4.7965 & TRN & \\
\hline CHEMBL1556743 & 688721 & 5.4 & 4.97 & TRN & \\
\hline CHEMBL1568520 & 688721 & 4.4 & 5.0897 & TRN & \\
\hline CHEMBL1352766 & 688721 & 5.3 & 5.0137 & TST & \\
\hline CHEMBL1417558 & 688721 & 5.1 & 4.914 & TRN & \\
\hline CHEMBL1577505 & 688721 & 5.5 & 4.8386 & TRN & \\
\hline CHEMBL1364873 & 688721 & 4.6 & 5.0464 & TRN & \\
\hline CHEMBL1374979 & 688721 & 4.7 & 5.1194 & TST & \\
\hline CHEMBL1591381 & 688721 & 4.8 & 5.0875 & TRN & \\
\hline CHEMBL1379708 & 688721 & 4.6 & 4.8671 & TRN & \\
\hline CHEMBL1503851 & 688721 & 4.6 & 4.9866 & TRN & \\
\hline CHEMBL1415226 & 688721 & 4.8 & 4.8301 & TRN & \\
\hline CHEMBL1547931 & 688721 & 4.8 & 5.0863 & TRN & \\
\hline CHEMBL1420058 & 688721 & 5.9 & 4.9213 & TST & \\
\hline CHEMBL1462601 & 688721 & 4.5 & 4.9501 & TST & \\
\hline CHEMBL1355263 & 688721 & 4.6 & 5.1588 & TRN & \\
\hline CHEMBL1473707 & 688721 & 5.4 & 5.0986 & TST & \\
\hline CHEMBL1526697 & 688721 & 4.9 & 4.9373 & TRN & \\
\hline CHEMBL1572907 & 688721 & 4.6 & 4.8169 & TRN & \\
\hline CHEMBL1336167 & 688721 & 4.6 & 4.8413 & TRN & \\
\hline CHEMBL1416762 & 688721 & 5.2 & 5.05699 & 99999999995 & TRN \\
\hline CHEMBL1445650 & 688721 & 4.5 & 4.7657 & TRN & \\
\hline CHEMBL1351942 & 688721 & 4.6 & 4.7424 & TRN & \\
\hline
\end{tabular}




\begin{tabular}{|c|c|c|c|c|}
\hline \multicolumn{5}{|c|}{ Supplemental Table S2.txt } \\
\hline CHEMBL1460392 & 688721 & 5.0 & 4.9901 & TRN \\
\hline CHEMBL1565441 & 688721 & 4.5 & 5.0732 & TRN \\
\hline CHEMBL1574591 & 688721 & 5.9 & 4.8744 & TRN \\
\hline CHEMBL1525408 & 688721 & 4.5 & 4.8157 & TRN \\
\hline CHEMBL1483013 & 688721 & 5.2 & 5.1344 & TRN \\
\hline CHEMBL1403254 & 688721 & 4.6 & 4.9206 & TRN \\
\hline CHEMBL1390164 & 688721 & 4.5 & 5.046 & TRN \\
\hline CHEMBL1579401 & 688721 & 4.9 & 4.8577 & TRN \\
\hline CHEMBL1352257 & 688721 & 4.6 & 4.8546 & TRN \\
\hline CHEMBL1467517 & 688721 & 4.4 & 5.1117 & TRN \\
\hline CHEMBL1307805 & 688721 & 5.3 & 4.8544 & TST \\
\hline CHEMBL1367539 & 688721 & 5.3 & 5.1496 & TRN \\
\hline CHEMBL1421826 & 688721 & 4.6 & 5.0346 & TRN \\
\hline CHEMBL1468425 & 688721 & 4.9 & 5.2997 & TST \\
\hline CHEMBL1542797 & 688721 & 4.4 & 4.8828 & TRN \\
\hline CHEMBL1372302 & 688721 & 5.2 & 5.0498 & TST \\
\hline CHEMBL1386458 & 688721 & 4.4 & 4.825 & TST \\
\hline CHEMBL1359135 & 688721 & 5.2 & 5.0961 & TST \\
\hline CHEMBL1481401 & 688721 & 5.1 & 4.842 & TRN \\
\hline CHEMBL1367076 & 688721 & 4.8 & 5.0802 & TST \\
\hline CHEMBL1538508 & 688721 & 4.4 & 4.8449 & TRN \\
\hline CHEMBL1552187 & 688721 & 4.7 & 5.2401 & TRN \\
\hline CHEMBL1256480 & 688721 & 5.2 & 5.3656 & TST \\
\hline CHEMBL453388 & 688721 & 4.9 & 5.1214 & TST \\
\hline CHEMBL 3212640 & 688721 & 4.5 & 4.944 & TST \\
\hline CHEMBL1443976 & 688721 & 4.6 & 4.9414 & TRN \\
\hline CHEMBL1517078 & 688721 & 4.4 & 5.2086 & TRN \\
\hline CHEMBL1377095 & 688721 & 4.6 & 4.7766 & TRN \\
\hline CHEMBL1491570 & 688721 & 6.0 & 4.8051 & TRN \\
\hline CHEMBL1447769 & 688721 & 6.8 & 5.1095 & TST \\
\hline CHEMBL1473133 & 688721 & 4.5 & 4.9807 & TRN \\
\hline CHEMBL1480687 & 688721 & 5.2 & 5.0109 & TRN \\
\hline CHEMBL1444534 & 688721 & 4.8 & 4.8378 & TRN \\
\hline CHEMBL1530468 & 688721 & 5.3 & 4.8262 & TRN \\
\hline CHEMBL1538446 & 688721 & 6.7001 & 4.9481 & TRN \\
\hline CHEMBL1462474 & 688721 & 5.1 & 5.1828 & TST \\
\hline CHEMBL1340617 & 688721 & 5.4 & 4.7806 & TRN \\
\hline CHEMBL1350515 & 688721 & 5.2 & 4.8951 & TST \\
\hline CHEMBL1389999 & 688721 & 6.3 & 4.9841 & TRN \\
\hline CHEMBL1408255 & 688721 & 5.4 & 4.8765 & TRN \\
\hline CHEMBL1434098 & 688721 & 4.5 & 4.9954 & TRN \\
\hline CHEMBL1441778 & 688721 & 4.7 & 5.0536 & TST \\
\hline CHEMBL1338194 & 688721 & 4.7 & 4.888 & TRN \\
\hline CHEMBL1540738 & 688721 & 4.6 & 5.0145 & TRN \\
\hline CHEMBL1424385 & 688721 & 5.3 & 4.8855 & TRN \\
\hline CHEMBL1527775 & 688721 & 4.7 & 4.9338 & TRN \\
\hline CHEMBL1582818 & 688721 & 4.5 & 4.9202 & TST \\
\hline CHEMBL1364784 & 688721 & 5.2 & 4.7878 & TRN \\
\hline
\end{tabular}




\begin{tabular}{|c|c|c|c|c|c|}
\hline \multicolumn{6}{|c|}{ Supplemental Table S2.txt } \\
\hline CHEMBL1534772 & 688721 & 4.5 & 4.8664 & TRN & \\
\hline CHEMBL1345542 & 688721 & 5.2 & 4.9393 & TRN & \\
\hline CHEMBL1504635 & 688721 & 5.6 & 4.8227 & TRN & \\
\hline CHEMBL1529744 & 688721 & 5.5 & 4.9047 & TRN & \\
\hline CHEMBL1377893 & 688721 & 4.8 & 5.0454 & TRN & \\
\hline CHEMBL1607274 & 688721 & 4.6 & 4.8129 & TRN & \\
\hline CHEMBL1371805 & 688721 & 4.6 & 4.8152 & TST & \\
\hline CHEMBL1532033 & 688721 & 5.2 & 5.0557 & TST & \\
\hline CHEMBL1503542 & 688721 & 5.2 & 4.9069 & TRN & \\
\hline CHEMBL1315373 & 688721 & 4.6 & 4.8752 & TST & \\
\hline CHEMBL1349063 & 688721 & 4.7 & 4.8719 & TRN & \\
\hline CHEMBL1499545 & 688721 & 4.8 & 5.2905 & TRN & \\
\hline CHEMBL1316592 & 688721 & 5.5 & 5.1659 & TST & \\
\hline CHEMBL1343524 & 688721 & 4.4 & 4.9858 & TRN & \\
\hline CHEMBL1504889 & 688721 & 4.5 & 4.8528 & TRN & \\
\hline CHEMBL1341351 & 688721 & 5.4 & 4.9354 & TRN & \\
\hline CHEMBL1594612 & 688721 & 4.5 & 4.902 & TRN & \\
\hline CHEMBL1447042 & 688721 & 5.5 & 5.0407 & TST & \\
\hline CHEMBL1428337 & 688721 & 4.4 & 4.8589 & TST & \\
\hline CHEMBL1449253 & 688721 & 4.6 & 4.8427 & TRN & \\
\hline CHEMBL1344666 & 688721 & 4.4 & 4.8345 & TRN & \\
\hline CHEMBL491976 & 688721 & 4.7 & 4.9644 & TRN & \\
\hline CHEMBL1487225 & 688721 & 5.0 & 5.0209 & TST & \\
\hline CHEMBL1593335 & 688721 & 4.8 & 4.871 & TRN & \\
\hline CHEMBL1362198 & 688721 & 4.6 & 5.0761 & TRN & \\
\hline CHEMBL1506830 & 688721 & 4.8 & 4.9826 & TST & \\
\hline CHEMBL1372908 & 688721 & 4.4 & 4.8618 & TST & \\
\hline CHEMBL1365592 & 688721 & 6.0 & 5.119 & TST & \\
\hline CHEMBL3209093 & 688721 & 5.4 & 5.0555 & TRN & \\
\hline CHEMBL1424211 & 688721 & 4.6 & 4.9111 & TRN & \\
\hline CHEMBL1536904 & 688721 & 5.9 & 4.9273 & TRN & \\
\hline CHEMBL1603540 & 688721 & 4.6 & 4.7955 & TRN & \\
\hline CHEMBL1410507 & 688721 & 4.5 & 4.755 & TRN & \\
\hline CHEMBL1442757 & 688721 & 5.1 & 5.02800 & 00000000005 & TRN \\
\hline CHEMBL1438138 & 688721 & 5.7 & 5.0838 & TST & \\
\hline CHEMBL1525493 & 688721 & 4.7 & 4.8945 & TRN & \\
\hline CHEMBL1360032 & 688721 & 4.9 & 4.9517 & TRN & \\
\hline CHEMBL1321901 & 688721 & 4.5 & 4.9024 & TRN & \\
\hline CHEMBL1595950 & 688721 & 5.2 & 4.7149 & TRN & \\
\hline CHEMBL1365506 & 688721 & 4.6 & 4.9324 & TRN & \\
\hline CHEMBL1487852 & 688721 & 4.6 & 5.0698 & TRN & \\
\hline CHEMBL1470784 & 688721 & 4.8 & 4.8812 & TST & \\
\hline CHEMBL1596183 & 688721 & 5.1 & 5.0027 & TRN & \\
\hline CHEMBL1500970 & 688721 & 5.2 & 4.9113 & TRN & \\
\hline CHEMBL3210617 & 688721 & 5.4 & 4.9664 & TST & \\
\hline CHEMBL1522245 & 688721 & 4.7 & 4.8052 & TRN & \\
\hline CHEMBL1502922 & 688721 & 4.5 & 4.8454 & TRN & \\
\hline CHEMBL1503158 & 688721 & 4.8 & 5.2388 & TST & \\
\hline
\end{tabular}




\begin{tabular}{|c|c|c|c|c|}
\hline & & & pplement & al $\mathrm{T}$ \\
\hline CHEMBL1496811 & 688721 & 4.6 & 4.8872 & TRN \\
\hline CHEMBL1479727 & 688721 & 4.7 & 4.9441 & TRN \\
\hline CHEMBL1374755 & 688721 & 5.4 & 4.8597 & TRN \\
\hline CHEMBL1324703 & 688721 & 4.7 & 5.1686 & TRN \\
\hline CHEMBL1500473 & 688721 & 4.8 & 4.7771 & TRN \\
\hline CHEMBL1360272 & 688721 & 4.6 & 4.7662 & TRN \\
\hline CHEMBL1555238 & 688721 & 5.0 & 5.2539 & TRN \\
\hline CHEMBL1511039 & 688721 & 4.4 & 4.8763 & TRN \\
\hline CHEMBL1598189 & 688721 & 4.8 & 4.9969 & TRN \\
\hline CHEMBL1547267 & 688721 & 4.7 & 4.9531 & TST \\
\hline CHEMBL1609952 & 688721 & 5.2 & 4.9334 & TRN \\
\hline CHEMBL1324487 & 688721 & 4.4 & 4.8955 & TRN \\
\hline CHEMBL1613659 & 688721 & 4.4 & 4.8813 & TRN \\
\hline CHEMBL1587720 & 688721 & 4.4 & 4.9568 & TRN \\
\hline CHEMBL1374243 & 688721 & 4.5 & 4.9175 & TRN \\
\hline CHEMBL1518710 & 688721 & 4.8 & 4.8714 & TRN \\
\hline CHEMBL1366325 & 688721 & 5.5 & 5.1014 & TRN \\
\hline CHEMBL1412478 & 688721 & 4.6 & 4.8694 & TRN \\
\hline CHEMBL1535565 & 688721 & 5.8 & 4.9998 & TRN \\
\hline CHEMBL1555832 & 688721 & 4.4 & 4.9125 & TRN \\
\hline CHEMBL1372301 & 688721 & 4.4 & 5.0299 & TRN \\
\hline CHEMBL1325891 & 688721 & 4.4 & 4.872 & TRN \\
\hline CHEMBL1582991 & 688721 & 5.3 & 4.977 & TST \\
\hline CHEMBL1331237 & 688721 & 4.6 & 5.1776 & TST \\
\hline CHEMBL1408529 & 688721 & 4.6 & 5.1365 & TST \\
\hline CHEMBL1326691 & 688721 & 4.7 & 4.8844 & TRN \\
\hline CHEMBL1464080 & 688721 & 4.6 & 4.863 & TRN \\
\hline CHEMBL1507626 & 688721 & 5.1 & 4.9573 & TRN \\
\hline CHEMBL1359940 & 688721 & 4.4 & 4.7345 & TRN \\
\hline CHEMBL1404920 & 688721 & 4.8 & 4.7873 & TRN \\
\hline CHEMBL1465151 & 688721 & 4.8 & 4.7992 & TRN \\
\hline CHEMBL1299672 & 688721 & 4.6 & 5.0076 & TRN \\
\hline CHEMBL1479969 & 688721 & 5.9 & 5.0951 & TRN \\
\hline CHEMBL1432517 & 688721 & 7.699 & 4.9958 & TRN \\
\hline CHEMBL1353986 & 688721 & 4.5 & 4.8638 & TRN \\
\hline CHEMBL1575635 & 688721 & 4.4 & 4.9378 & TST \\
\hline CHEMBL1362550 & 688721 & 4.6 & 5.0185 & TST \\
\hline CHEMBL1490788 & 688721 & 4.8 & 4.9692 & TRN \\
\hline CHEMBL1596686 & 688721 & 4.5 & 4.6264 & TRN \\
\hline CHEMBL1411402 & 688721 & 4.4 & 4.8645 & TRN \\
\hline CHEMBL1328749 & 688721 & 5.2 & 4.979 & TRN \\
\hline CHEMBL1607196 & 688721 & 4.5 & 5.0179 & TST \\
\hline CHEMBL1562302 & 688721 & 5.2 & 5.1198 & TST \\
\hline CHEMBL1422539 & 688721 & 4.4 & 4.9293 & TST \\
\hline CHEMBL1597692 & 688721 & 5.2 & 5.1181 & TRN \\
\hline CHEMBL1474970 & 688721 & 6.0 & 5.0816 & TRN \\
\hline CHEMBL1577354 & 688721 & 6.2 & 5.0048 & TST \\
\hline CHEMBL1472132 & 688721 & 4.7 & 5.0333 & TRN \\
\hline
\end{tabular}




\begin{tabular}{|c|c|c|c|c|c|}
\hline \multicolumn{6}{|c|}{ Supplemental Table S2.txt } \\
\hline CHEMBL1575621 & 688721 & 4.6 & 4.7919 & TRN & \\
\hline CHEMBL1459960 & 688721 & 5.3 & 5.0922 & TST & \\
\hline CHEMBL1521352 & 688721 & 5.5 & 4.8989 & TRN & \\
\hline CHEMBL1541302 & 688721 & 4.4 & 5.1568 & TST & \\
\hline CHEMBL1468159 & 688721 & 4.6 & 4.9802 & TRN & \\
\hline CHEMBL1518892 & 688721 & 4.5 & 5.0076 & TRN & \\
\hline CHEMBL1555164 & 688721 & 5.4 & 4.8261 & TRN & \\
\hline CHEMBL1595905 & 688721 & 4.6 & 4.7658 & TRN & \\
\hline CHEMBL1332702 & 688721 & 4.5 & 4.9234 & TRN & \\
\hline CHEMBL1592117 & 688721 & 4.5 & 5.0476 & TRN & \\
\hline CHEMBL1301165 & 688721 & 4.6 & 4.9536 & TRN & \\
\hline CHEMBL1386271 & 688721 & 4.8 & 5.024 & TRN & \\
\hline CHEMBL1558122 & 688721 & 4.4 & 4.8654 & TRN & \\
\hline CHEMBL1451711 & 688721 & 4.5 & 4.9124 & TRN & \\
\hline CHEMBL1361939 & 688721 & 5.0 & 4.9904 & TRN & \\
\hline CHEMBL1488603 & 688721 & 4.4 & 5.1002 & TRN & \\
\hline CHEMBL1488204 & 688721 & 4.4 & 4.8411 & TRN & \\
\hline CHEMBL1610601 & 688721 & 5.0 & 4.9125 & TRN & \\
\hline CHEMBL1404605 & 688721 & 4.5 & 5.0509 & TST & \\
\hline CHEMBL1571533 & 688721 & 4.7 & 4.934 & TRN & \\
\hline CHEMBL1556896 & 688721 & 5.2 & 5.0238 & TST & \\
\hline CHEMBL354676 & 688721 & 4.4 & 5.1106 & TRN & \\
\hline CHEMBL1363332 & 688721 & 5.3 & 4.7999 & TRN & \\
\hline CHEMBL1554070 & 688721 & 5.9 & 4.9795 & TST & \\
\hline CHEMBL1979306 & 688721 & 4.8 & 5.1051 & TST & \\
\hline CHEMBL1477929 & 688721 & 7.5003 & 5.0191 & TRN & \\
\hline CHEMBL1441900 & 688721 & 4.5 & 5.0483 & TRN & \\
\hline CHEMBL1533466 & 688721 & 4.5 & 5.0286 & TRN & \\
\hline CHEMBL1392363 & 688721 & 5.2 & 5.0985 & TRN & \\
\hline CHEMBL1406648 & 688721 & 4.5 & 4.9766 & TRN & \\
\hline CHEMBL1465165 & 688721 & 4.4 & 4.9503 & TRN & \\
\hline CHEMBL1272150 & 688721 & 4.6 & 4.8592 & TRN & \\
\hline CHEMBL1307361 & 688721 & 4.7 & 4.9742 & TRN & \\
\hline CHEMBL1143 & 688721 & 4.8 & 5.0606 & TRN & \\
\hline CHEMBL1315268 & 688721 & 5.6 & 5.1 & TRN & \\
\hline CHEMBL1363603 & 688721 & 4.6 & 5.007 & TST & \\
\hline CHEMBL1486590 & 688721 & 4.5 & 5.08899 & 99999999995 & TST \\
\hline CHEMBL1595181 & 688721 & 4.5 & 5.0196 & TRN & \\
\hline CHEMBL1539939 & 688721 & 4.8 & 4.8642 & TRN & \\
\hline CHEMBL1306802 & 688721 & 4.6 & 4.7592 & TRN & \\
\hline CHEMBL1349601 & 688721 & 4.5 & 4.7643 & TRN & \\
\hline CHEMBL1560982 & 688721 & 4.4 & 5.0363 & TST & \\
\hline CHEMBL1320632 & 688721 & 4.4 & 4.9202 & TRN & \\
\hline CHEMBL1487093 & 688721 & 4.9 & 5.0235 & TST & \\
\hline CHEMBL1604540 & 688721 & 5.4 & 5.067 & TST & \\
\hline CHEMBL1319364 & 688721 & 6.7001 & 5.0716 & TRN & \\
\hline CHEMBL1582419 & 688721 & 4.5 & 4.8305 & TRN & \\
\hline CHEMBL1403535 & 688721 & 5.5 & 4.9088 & TRN & \\
\hline
\end{tabular}




\begin{tabular}{|c|c|c|c|c|}
\hline & & & & $a \perp 1 a$ \\
\hline CHEMBL1503585 & 688721 & 4.4 & 5.0321 & TRN \\
\hline CHEMBL1498591 & 688721 & 5.2 & 4.81 & TRN \\
\hline CHEMBL1524508 & 688721 & 4.7 & 4.8982 & TRN \\
\hline CHEMBL1529220 & 688721 & 4.5 & 4.8246 & TRN \\
\hline CHEMBL1534365 & 688721 & 4.5 & 5.0306 & TST \\
\hline CHEMBL1490516 & 688721 & 5.0 & 4.9347 & TRN \\
\hline CHEMBL1434762 & 688721 & 4.6 & 5.0857 & TRN \\
\hline CHEMBL1606892 & 688721 & 4.5 & 5.0007 & TST \\
\hline CHEMBL1429652 & 688721 & 5.2 & 5.1332 & TRN \\
\hline CHEMBL1526213 & 688721 & 4.9 & 5.0044 & TRN \\
\hline CHEMBL1384825 & 688721 & 4.6 & 4.8559 & TRN \\
\hline CHEMBL1373704 & 688721 & 5.2 & 4.9519 & TRN \\
\hline CHEMBL131171 & 688721 & 4.8 & 5.0761 & TST \\
\hline CHEMBL1458566 & 688721 & 5.5 & 4.8146 & TST \\
\hline CHEMBL1309048 & 688721 & 4.5 & 4.9197 & TRN \\
\hline CHEMBL1606087 & 688721 & 4.8 & 4.7353 & TRN \\
\hline CHEMBL1411550 & 688721 & 4.6 & 4.8301 & TRN \\
\hline CHEMBL1303059 & 688721 & 5.1 & 4.7132 & TRN \\
\hline CHEMBL1307517 & 688721 & 5.2 & 4.9462 & TRN \\
\hline CHEMBL1579827 & 688721 & 4.5 & 5.0827 & TST \\
\hline CHEMBL3190658 & 688721 & 4.4 & 4.8464 & TRN \\
\hline CHEMBL1481412 & 688721 & 4.5 & 4.9528 & TRN \\
\hline CHEMBL1392777 & 688721 & 5.3 & 5.0233 & TST \\
\hline CHEMBL1609283 & 688721 & 4.8 & 4.9939 & TRN \\
\hline CHEMBL1316081 & 688721 & 6.1 & 5.381 & TRN \\
\hline CHEMBL1508280 & 688721 & 4.5 & 5.063 & TST \\
\hline CHEMBL1588150 & 688721 & 4.8 & 4.7996 & TRN \\
\hline CHEMBL1385896 & 688721 & 4.4 & 5.1792 & TST \\
\hline CHEMBL1498959 & 688721 & 4.6 & 5.0549 & TST \\
\hline CHEMBL284588 & 688721 & 6.0 & 5.2232 & TRN \\
\hline CHEMBL1600690 & 688721 & 4.8 & 5.1064 & TST \\
\hline CHEMBL 259067 & 688721 & 4.6 & 4.902 & TRN \\
\hline CHEMBL3212537 & 688721 & 5.2 & 4.9044 & TRN \\
\hline CHEMBL1300588 & 688721 & 5.3 & 5.0063 & TRN \\
\hline CHEMBL1508328 & 688721 & 5.2 & 4.8836 & TRN \\
\hline CHEMBL1548428 & 688721 & 4.5 & 4.927 & TRN \\
\hline CHEMBL1387744 & 688721 & 5.2 & 4.8679 & TRN \\
\hline CHEMBL1526273 & 688721 & 4.6 & 4.9353 & TRN \\
\hline CHEMBL1585014 & 688721 & 4.6 & 4.8745 & TRN \\
\hline CHEMBL3192087 & 688721 & 5.0 & 4.9052 & TRN \\
\hline CHEMBL1537884 & 688721 & 4.4 & 4.8992 & TRN \\
\hline CHEMBL1594178 & 688721 & 5.4 & 4.8908 & TRN \\
\hline CHEMBL1367995 & 688721 & 4.4 & 5.0339 & TRN \\
\hline CHEMBL1560917 & 688721 & 4.5 & 4.9081 & TRN \\
\hline CHEMBL1402358 & 688721 & 4.6 & 4.8222 & TRN \\
\hline CHEMBL1308659 & 688721 & 4.4 & 4.9842 & TRN \\
\hline CHEMBL1395661 & 688721 & 5.3 & 5.0399 & TRN \\
\hline CHEMBL1580342 & 688721 & 5.2 & 4.8023 & TRN \\
\hline
\end{tabular}




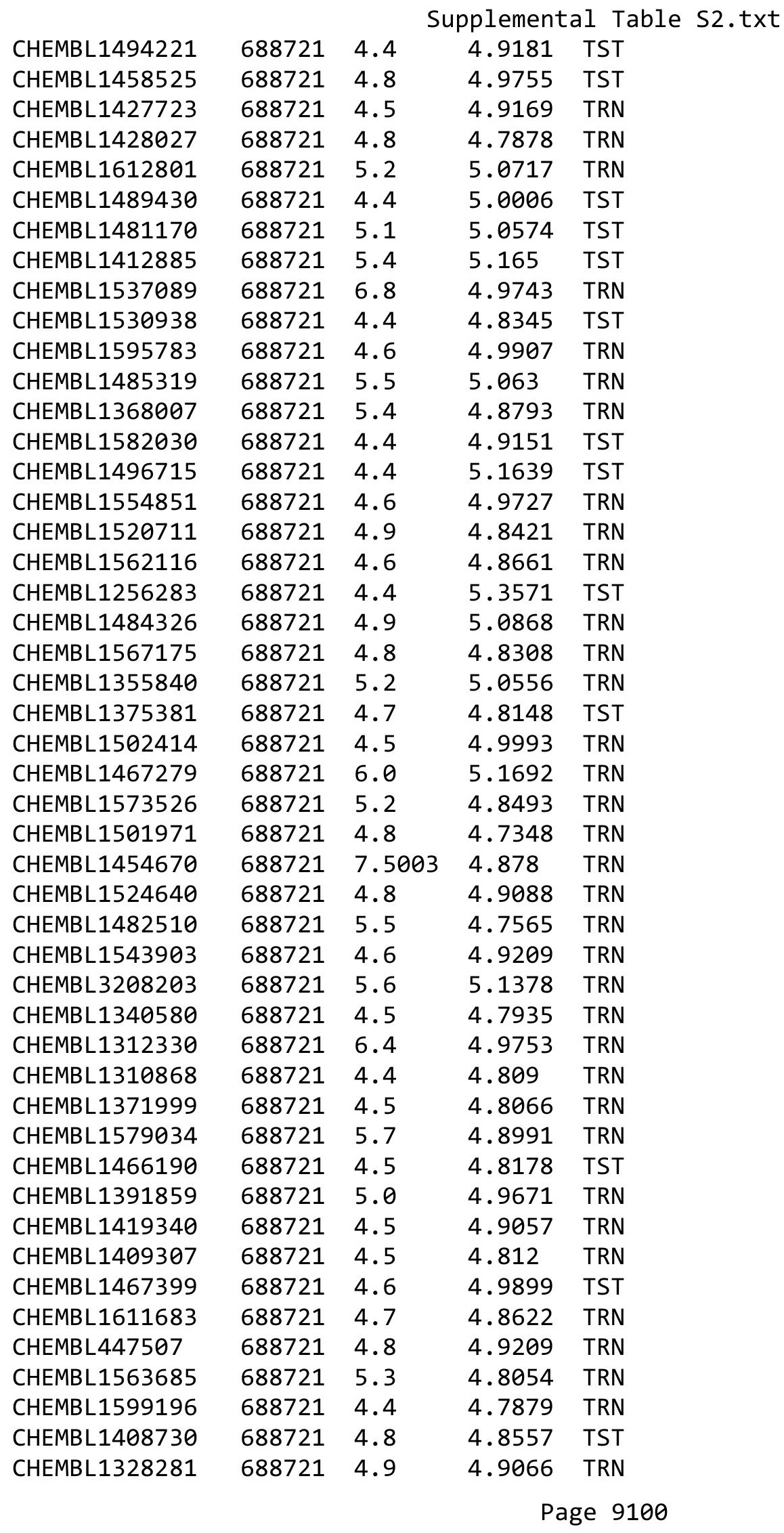




\begin{tabular}{|c|c|c|c|c|c|}
\hline & & & & & \\
\hline CHEMBL508779 & 688721 & 4.4 & 5.1134 & TST & \\
\hline CHEMBL1488280 & 688721 & 6.1 & 4.7324 & TRN & \\
\hline CHEMBL1585541 & 688721 & 5.5 & 5.1086 & TRN & \\
\hline CHEMBL1472091 & 688721 & 4.7 & 4.877 & TRN & \\
\hline CHEMBL1419335 & 688721 & 4.7 & 4.8504 & TST & \\
\hline CHEMBL1342186 & 688721 & 5.2 & 4.9259 & TST & \\
\hline CHEMBL475541 & 688721 & 5.3 & 4.9172 & TST & \\
\hline CHEMBL1322449 & 688721 & 4.6 & 4.8297 & TRN & \\
\hline CHEMBL1528449 & 688721 & 4.6 & 4.7533 & TRN & \\
\hline CHEMBL1371533 & 688721 & 4.4 & 4.7386 & TRN & \\
\hline CHEMBL1369694 & 688721 & 4.5 & 4.9646 & TST & \\
\hline CHEMBL1480503 & 688721 & 4.8 & 4.8325 & TRN & \\
\hline CHEMBL1352378 & 688721 & 4.4 & 4.8197 & TST & \\
\hline CHEMBL1530364 & 688721 & 4.5 & 4.7417 & TRN & \\
\hline CHEMBL1527868 & 688721 & 4.7 & 4.92899 & 9999999999 & TST \\
\hline CHEMBL1437172 & 688721 & 4.4 & 5.0954 & TRN & \\
\hline CHEMBL1419548 & 688721 & 4.5 & 4.9519 & TRN & \\
\hline CHEMBL1338997 & 688721 & 4.8 & 4.958 & TRN & \\
\hline CHEMBL1363056 & 688721 & 4.8 & 4.8178 & TRN & \\
\hline CHEMBL1313066 & 688721 & 4.5 & 4.7682 & TRN & \\
\hline CHEMBL1423336 & 688721 & 4.9 & 4.7735 & TST & \\
\hline CHEMBL3214190 & 688721 & 4.5 & 4.9142 & TRN & \\
\hline CHEMBL1591600 & 688721 & 4.4 & 5.2205 & TRN & \\
\hline CHEMBL1579239 & 688721 & 4.6 & 4.9468 & TRN & \\
\hline CHEMBL1604062 & 688721 & 5.5 & 4.9969 & TRN & \\
\hline CHEMBL3210248 & 688721 & 5.2 & 4.9339 & TRN & \\
\hline CHEMBL1406119 & 688721 & 4.4 & 4.7289 & TRN & \\
\hline CHEMBL1380091 & 688721 & 4.9 & 4.7029 & TRN & \\
\hline CHEMBL1366497 & 688721 & 4.4 & 4.9337 & TRN & \\
\hline CHEMBL1500041 & 688721 & 4.4 & 4.8576 & TRN & \\
\hline CHEMBL1464607 & 688721 & 4.4 & 4.8466 & TRN & \\
\hline CHEMBL 29197 & 688721 & 4.4 & 4.9844 & TST & \\
\hline CHEMBL1384793 & 688721 & 4.5 & 4.8019 & TST & \\
\hline CHEMBL1455980 & 688721 & 5.4 & 4.7917 & TST & \\
\hline CHEMBL1441375 & 688721 & 4.7 & 4.8722 & TRN & \\
\hline CHEMBL1407268 & 688721 & 4.6 & 4.9731 & TRN & \\
\hline CHEMBL1487371 & 688721 & 5.2 & 5.1187 & TST & \\
\hline CHEMBL45891 & 688721 & 4.6 & 5.2674 & TRN & \\
\hline CHEMBL1305665 & 688721 & 4.7 & 4.8076 & TRN & \\
\hline CHEMBL23507 & 688721 & 5.2 & 5.0845 & TST & \\
\hline CHEMBL1495020 & 688721 & 4.8 & 4.8953 & TRN & \\
\hline CHEMBL1515559 & 688721 & 6.8 & 5.0098 & TRN & \\
\hline CHEMBL1406418 & 688721 & 4.5 & 4.9035 & TRN & \\
\hline CHEMBL1374710 & 688721 & 4.4 & 4.9826 & TRN & \\
\hline CHEMBL1408033 & 688721 & 4.4 & 5.1744 & TST & \\
\hline CHEMBL1510819 & 688721 & 4.5 & 4.7671 & TRN & \\
\hline CHEMBL1509822 & 688721 & 4.4 & 4.9835 & TRN & \\
\hline CHEMBL1352335 & 688721 & 4.4 & 4.9177 & TRN & \\
\hline & & & & 9101 & \\
\hline
\end{tabular}




\begin{tabular}{|c|c|c|c|c|}
\hline \\
\hline CHEMBL1574468 & 688721 & 4.4 & 4.8307 & TRN \\
\hline CHEMBL1402673 & 688721 & 5.3 & 5.0277 & TST \\
\hline CHEMBL1508690 & 688721 & 4.6 & 4.9138 & TRN \\
\hline CHEMBL1463829 & 688721 & 5.2 & 4.7904 & TRN \\
\hline CHEMBL1611505 & 688721 & 5.1 & 4.9072 & TRN \\
\hline CHEMBL1509502 & 688721 & 5.3 & 5.0435 & TRN \\
\hline CHEMBL1483413 & 688721 & 5.2 & 4.849 & TRN \\
\hline CHEMBL1383421 & 688721 & 4.7 & 4.8871 & TRN \\
\hline CHEMBL1344156 & 688721 & 4.7 & 4.89 & TRN \\
\hline CHEMBL1318739 & 688721 & 5.1 & 5.1945 & TRN \\
\hline CHEMBL1367862 & 688721 & 5.5 & 4.9846 & TST \\
\hline CHEMBL1427293 & 688721 & 5.0 & 5.2116 & TST \\
\hline CHEMBL1459570 & 688721 & 4.7 & 4.9149 & TST \\
\hline CHEMBL1611756 & 688721 & 5.2 & 4.9469 & TST \\
\hline CHEMBL1612609 & 688721 & 4.5 & 4.7186 & TRN \\
\hline CHEMBL1319684 & 688721 & 4.6 & 4.8798 & TRN \\
\hline CHEMBL1364473 & 688721 & 5.2 & 5.1068 & TRN \\
\hline CHEMBL 222409 & 688721 & 4.5 & 5.1042 & TRN \\
\hline CHEMBL1606169 & 688721 & 6.0 & 4.9895 & TRN \\
\hline CHEMBL1363142 & 688721 & 5.9 & 5.1803 & TRN \\
\hline CHEMBL1536945 & 688721 & 4.6 & 4.9961 & TRN \\
\hline CHEMBL1410698 & 688721 & 4.7 & 4.7069 & TST \\
\hline CHEMBL1368372 & 688721 & 4.9 & 4.9278 & TRN \\
\hline CHEMBL1511191 & 688721 & 5.4 & 4.8636 & TRN \\
\hline CHEMBL1603235 & 688721 & 4.4 & 4.8421 & TST \\
\hline CHEMBL1393345 & 688721 & 4.4 & 4.8967 & TRN \\
\hline CHEMBL1339493 & 688721 & 4.8 & 4.9808 & TRN \\
\hline CHEMBL1607456 & 688721 & 4.8 & 4.7949 & TRN \\
\hline CHEMBL1311882 & 688721 & 5.0 & 5.2005 & TST \\
\hline CHEMBL1394181 & 688721 & 5.2 & 5.2184 & TRN \\
\hline CHEMBL1521370 & 688721 & 5.3 & 4.9233 & TRN \\
\hline CHEMBL1494319 & 688721 & 4.5 & 4.958 & TRN \\
\hline CHEMBL1379012 & 688721 & 5.2 & 5.0796 & TST \\
\hline CHEMBL3195620 & 688721 & 4.5 & 4.9952 & TRN \\
\hline CHEMBL1327738 & 688721 & 4.6 & 4.8271 & TRN \\
\hline CHEMBL1561843 & 688721 & 6.0 & 4.9805 & TRN \\
\hline CHEMBL1422256 & 688721 & 5.0 & 4.7708 & TST \\
\hline CHEMBL1403787 & 688721 & 5.2 & 4.9454 & TRN \\
\hline CHEMBL1546324 & 688721 & 4.6 & 4.9336 & TRN \\
\hline CHEMBL1406292 & 688721 & 4.5 & 5.25 & TST \\
\hline CHEMBL1612219 & 688721 & 4.4 & 4.7533 & TRN \\
\hline CHEMBL1563839 & 688721 & 5.2 & 4.8216 & TRN \\
\hline CHEMBL1525398 & 688721 & 4.7 & 4.9477 & TST \\
\hline CHEMBL1557508 & 688721 & 6.3 & 4.773 & TRN \\
\hline CHEMBL1550430 & 688721 & 5.2 & 4.74100 & 3000000000 \\
\hline CHEMBL1489967 & 688721 & 5.1 & 5.1138 & TRN \\
\hline CHEMBL1327079 & 688721 & 4.7 & 4.8141 & TRN \\
\hline CHEMBL521970 & 688721 & 4.9 & 4.9855 & TRN \\
\hline
\end{tabular}




\begin{tabular}{|c|c|c|c|c|c|}
\hline \multicolumn{6}{|c|}{ Supplemental Table S2.txt } \\
\hline CHEMBL198759 & 688721 & 4.7 & 4.7737 & TST & \\
\hline CHEMBL1305132 & 688721 & 4.7 & 4.8026 & TRN & \\
\hline CHEMBL1559230 & 688721 & 5.0 & 4.8575 & TRN & \\
\hline CHEMBL1361406 & 688721 & 5.0 & 5.1607 & TRN & \\
\hline CHEMBL1333081 & 688721 & 8.1024 & 5.0446 & TST & \\
\hline CHEMBL1568892 & 688721 & 5.1 & 4.8942 & TRN & \\
\hline CHEMBL1416282 & 688721 & 5.3 & 4.9291 & TRN & \\
\hline CHEMBL1461649 & 688721 & 4.8 & 4.9183 & TST & \\
\hline CHEMBL1419977 & 688721 & 4.7 & 4.8745 & TRN & \\
\hline CHEMBL1451476 & 688721 & 5.9 & 4.7403 & TRN & \\
\hline CHEMBL1338722 & 688721 & 5.9 & 4.9612 & TRN & \\
\hline CHEMBL1303767 & 688721 & 4.6 & 4.7788 & TST & \\
\hline CHEMBL1448929 & 688721 & 4.4 & 4.919 & TRN & \\
\hline CHEMBL1531194 & 688721 & 4.8 & 4.9052 & TRN & \\
\hline CHEMBL1319813 & 688721 & 6.1 & 5.0737 & TST & \\
\hline CHEMBL1604757 & 688721 & 4.5 & 4.997 & TRN & \\
\hline CHEMBL1568497 & 688721 & 4.9 & 4.691 & TRN & \\
\hline CHEMBL1560323 & 688721 & 4.6 & 5.0474 & TRN & \\
\hline CHEMBL1430402 & 688721 & 4.5 & 4.8046 & TRN & \\
\hline CHEMBL1314037 & 688721 & 4.6 & 4.98300 & 00000000005 & TRN \\
\hline CHEMBL1476831 & 688721 & 6.2 & 5.1242 & TRN & \\
\hline CHEMBL1607690 & 688721 & 4.8 & 4.7876 & TRN & \\
\hline CHEMBL1485018 & 688721 & 4.8 & 4.9577 & TRN & \\
\hline CHEMBL1528773 & 688721 & 4.5 & 4.9655 & TST & \\
\hline CHEMBL1342249 & 688721 & 4.8 & 4.8881 & TRN & \\
\hline CHEMBL1405411 & 688721 & 4.4 & 4.9928 & TRN & \\
\hline CHEMBL1446926 & 688721 & 4.6 & 4.7876 & TRN & \\
\hline CHEMBL1306807 & 688721 & 4.6 & 4.9359 & TST & \\
\hline CHEMBL1313855 & 688721 & 6.0 & 4.9736 & TRN & \\
\hline CHEMBL1312225 & 688721 & 4.8 & 4.9473 & TRN & \\
\hline CHEMBL1452360 & 688721 & 4.4 & 5.1013 & TST & \\
\hline CHEMBL1406467 & 688721 & 5.1 & 4.9217 & TST & \\
\hline CHEMBL1600866 & 688721 & 6.4 & 4.8249 & TRN & \\
\hline CHEMBL1369207 & 688721 & 4.6 & 4.9005 & TRN & \\
\hline CHEMBL1465045 & 688721 & 5.1 & 4.8245 & TRN & \\
\hline CHEMBL1499659 & 688721 & 4.6 & 4.8598 & TRN & \\
\hline CHEMBL3211349 & 688721 & 4.4 & 5.0395 & TST & \\
\hline CHEMBL1389599 & 688721 & 6.0 & 4.9149 & TST & \\
\hline CHEMBL1315618 & 688721 & 7.0 & 5.1052 & TST & \\
\hline CHEMBL1576762 & 688721 & 4.8 & 4.7865 & TRN & \\
\hline CHEMBL591836 & 688721 & 4.7 & 4.9837 & TRN & \\
\hline CHEMBL 1417180 & 688721 & 4.6 & 4.9767 & TRN & \\
\hline CHEMBL1529847 & 688721 & 4.9 & 4.9362 & TST & \\
\hline CHEMBL1504192 & 688721 & 4.6 & 4.7899 & TRN & \\
\hline CHEMBL1322979 & 688721 & 7.3002 & 5.0529 & TST & \\
\hline CHEMBL1380581 & 688721 & 7.5003 & 5.0094 & TST & \\
\hline CHEMBL1411502 & 688721 & 4.4 & 4.8804 & TST & \\
\hline CHEMBL1438793 & 688721 & 5.3 & 4.9967 & TRN & \\
\hline
\end{tabular}




\begin{tabular}{|c|c|c|c|c|c|}
\hline \multicolumn{6}{|c|}{ Supplemental Table S2.txt } \\
\hline CHEMBL1564974 & 688721 & 5.2 & 5.0947 & TRN & \\
\hline CHEMBL3194743 & 688721 & 4.4 & 5.0313 & TRN & \\
\hline CHEMBL1323061 & 688721 & 5.2 & 4.9671 & TRN & \\
\hline CHEMBL250969 & 688721 & 5.2 & 5.0572 & TRN & \\
\hline CHEMBL3196534 & 688721 & 4.6 & 5.0913 & TST & \\
\hline CHEMBL1471973 & 688721 & 4.9 & 5.0397 & TST & \\
\hline CHEMBL1312834 & 688721 & 4.6 & 5.0439 & TST & \\
\hline CHEMBL1524646 & 688721 & 4.6 & 4.7627 & TRN & \\
\hline CHEMBL1352398 & 688721 & 4.7 & 4.7585 & TRN & \\
\hline CHEMBL1517762 & 688721 & 5.8 & 5.0261 & TST & \\
\hline CHEMBL1333958 & 688721 & 4.5 & 5.0291 & TST & \\
\hline CHEMBL3209603 & 688721 & 4.8 & 4.8622 & TRN & \\
\hline CHEMBL1421271 & 688721 & 4.5 & 4.8499 & TRN & \\
\hline CHEMBL1466416 & 688721 & 4.6 & 5.0218 & TST & \\
\hline CHEMBL1595597 & 688721 & 4.7 & 4.8159 & TST & \\
\hline CHEMBL1400168 & 688721 & 5.0 & 4.6995 & TST & \\
\hline CHEMBL1330386 & 688721 & 4.8 & 4.7088 & TRN & \\
\hline CHEMBL1336298 & 688721 & 8.2007 & 5.136 & TST & \\
\hline CHEMBL1432458 & 688721 & 4.4 & 4.7572 & TRN & \\
\hline CHEMBL1514276 & 688721 & 4.8 & 4.9462 & TST & \\
\hline CHEMBL1338470 & 688721 & 4.8 & 4.9023 & TST & \\
\hline CHEMBL1379297 & 688721 & 4.4 & 4.9691 & TRN & \\
\hline CHEMBL1563877 & 688721 & 5.2 & 5.0456 & TRN & \\
\hline CHEMBL1459370 & 688721 & 4.8 & 4.836 & TST & \\
\hline CHEMBL1443317 & 688721 & 4.6 & 4.8752 & TRN & \\
\hline CHEMBL1407669 & 688721 & 4.9 & 4.9108 & TRN & \\
\hline CHEMBL1391275 & 688721 & 4.5 & 4.8794 & TRN & \\
\hline CHEMBL1480512 & 688721 & 4.4 & 4.8829 & TRN & \\
\hline CHEMBL1492727 & 688721 & 4.5 & 5.1653 & TRN & \\
\hline CHEMBL1609246 & 688721 & 5.4 & 4.9276 & TRN & \\
\hline CHEMBL1416951 & 688721 & 5.0 & 4.953 & TRN & \\
\hline CHEMBL1321566 & 688721 & 4.6 & 4.8416 & TRN & \\
\hline CHEMBL189438 & 688721 & 6.0 & 5.1408 & TRN & \\
\hline CHEMBL1480854 & 688721 & 5.1 & 5.006 & TRN & \\
\hline CHEMBL1602505 & 688721 & 4.7 & 4.9836 & TRN & \\
\hline CHEMBL1506202 & 688721 & 4.6 & 4.94600 & 0000000001 & TRN \\
\hline CHEMBL1350957 & 688721 & 5.4 & 4.8531 & TRN & \\
\hline CHEMBL1255936 & 688721 & 4.4 & 5.0373 & TST & \\
\hline CHEMBL1580109 & 688721 & 5.2 & 4.8391 & TST & \\
\hline CHEMBL1381863 & 688721 & 4.9 & 4.8151 & TRN & \\
\hline CHEMBL1532568 & 688721 & 4.6 & 4.9384 & TRN & \\
\hline CHEMBL1320442 & 688721 & 4.9 & 4.9479 & TRN & \\
\hline CHEMBL1302003 & 688721 & 4.5 & 4.7111 & TRN & \\
\hline CHEMBL1568191 & 688721 & 4.5 & 4.9953 & TRN & \\
\hline CHEMBL1561433 & 688721 & 5.3 & 4.7118 & TRN & \\
\hline CHEMBL1584314 & 688721 & 6.0 & 5.0621 & TRN & \\
\hline CHEMBL1417733 & 688721 & 4.7 & 4.9687 & TRN & \\
\hline CHEMBL1448614 & 688721 & 4.7 & 4.8321 & TRN & \\
\hline
\end{tabular}




\begin{tabular}{|c|c|c|c|c|}
\hline & & & Supplement & \\
\hline CHEMBL1308116 & 688721 & 4.8 & 4.7031 & TRN \\
\hline CHEMBL1439839 & 688721 & 4.7 & 5.2183 & TRN \\
\hline CHEMBL1371711 & 688721 & 5.8 & 5.0133 & TRN \\
\hline CHEMBL1549130 & 688721 & 4.5 & 4.9388 & TRN \\
\hline CHEMBL1592327 & 688721 & 4.8 & 4.9246 & TRN \\
\hline CHEMBL1532657 & 688721 & 4.9 & 4.9268 & TRN \\
\hline CHEMBL1308043 & 688721 & 5.0 & 4.6976 & TRN \\
\hline CHEMBL1431076 & 688721 & 5.2 & 4.9466 & TRN \\
\hline CHEMBL1158 & 688721 & 4.4 & 5.0784 & TST \\
\hline CHEMBL1607795 & 688721 & 4.6 & 5.0937 & TST \\
\hline CHEMBL1374765 & 688721 & 4.5 & 4.9383 & TRN \\
\hline CHEMBL1442992 & 688721 & 5.7 & 5.5057 & TRN \\
\hline CHEMBL1462396 & 688721 & 5.7 & 4.9302 & TRN \\
\hline CHEMBL1256291 & 688721 & 4.7 & 5.0589 & TST \\
\hline CHEMBL1543611 & 688721 & 4.8 & 4.8571 & TST \\
\hline CHEMBL1466018 & 688721 & 4.8 & 5.0543 & TRN \\
\hline CHEMBL1324862 & 688721 & 4.9 & 4.9854 & TRN \\
\hline CHEMBL1173823 & 688721 & 5.2 & 4.9533 & TRN \\
\hline CHEMBL1300336 & 688721 & 4.4 & 4.9495 & TRN \\
\hline CHEMBL1299659 & 688721 & 6.3 & 5.0919 & TST \\
\hline CHEMBL1487757 & 688721 & 4.5 & 4.8967 & TST \\
\hline CHEMBL1564619 & 688721 & 4.5 & 4.8351 & TST \\
\hline CHEMBL1386745 & 688721 & 5.0 & 4.8108 & TRN \\
\hline CHEMBL1600572 & 688721 & 5.5 & 4.8142 & TRN \\
\hline CHEMBL1527886 & 688721 & 5.4 & 5.1038 & TRN \\
\hline CHEMBL1356113 & 688721 & 5.4 & 5.0993 & TRN \\
\hline CHEMBL1477399 & 688721 & 6.2 & 4.8988 & TRN \\
\hline CHEMBL1454696 & 688721 & 5.4 & 4.9236 & TRN \\
\hline CHEMBL1356628 & 688721 & 4.6 & 4.9077 & TRN \\
\hline CHEMBL1588609 & 688721 & 6.9 & 4.9472 & TST \\
\hline CHEMBL1315145 & 688721 & 5.0 & 5.3332 & TRN \\
\hline CHEMBL1601824 & 688721 & 5.3 & 5.0185 & TRN \\
\hline CHEMBL3211074 & 688721 & 4.4 & 5.0069 & TST \\
\hline CHEMBL1433055 & 688721 & 4.6 & 4.824 & TRN \\
\hline CHEMBL1355351 & 688721 & 5.4 & 5.1544 & TST \\
\hline CHEMBL1535589 & 688721 & 5.4 & 4.9455 & TST \\
\hline CHEMBL1476897 & 688721 & 5.1 & 5.0301 & TST \\
\hline CHEMBL1487532 & 688721 & 5.1 & 5.2791 & TST \\
\hline CHEMBL1304199 & 688721 & 5.0 & 4.8809 & TRN \\
\hline CHEMBL1355778 & 688721 & 4.8 & 5.0085 & TRN \\
\hline CHEMBL1370797 & 688721 & 4.5 & 5.0047 & TRN \\
\hline CHEMBL1323893 & 688721 & 5.2 & 4.9839 & TRN \\
\hline CHEMBL1604539 & 688721 & 4.7 & 4.8907 & TRN \\
\hline CHEMBL3192733 & 688721 & 5.2 & 5.1874 & TRN \\
\hline CHEMBL1432443 & 688721 & 4.8 & 4.6919 & TRN \\
\hline CHEMBL1384931 & 688721 & 5.1 & 4.8762 & TRN \\
\hline CHEMBL1603859 & 688721 & 5.3 & 5.0551 & TRN \\
\hline CHEMBL1391020 & 688721 & 5.3 & 5.043 & TRN \\
\hline
\end{tabular}




\begin{tabular}{|c|c|c|c|c|}
\hline \multicolumn{5}{|c|}{ Supplemental Table S2.txt } \\
\hline CHEMBL1438309 & 688721 & 5.0 & 4.8009 & TRN \\
\hline CHEMBL3213875 & 688721 & 5.5 & 5.1712 & TST \\
\hline CHEMBL1487638 & 688721 & 5.5 & 4.959 & TRN \\
\hline CHEMBL1539432 & 688721 & 4.6 & 4.9137 & TRN \\
\hline CHEMBL1342825 & 688721 & 4.5 & 5.0927 & TRN \\
\hline CHEMBL1392067 & 688721 & 5.0 & 4.9004 & TRN \\
\hline CHEMBL260876 & 688721 & 6.4 & 5.2938 & TST \\
\hline CHEMBL1500830 & 688721 & 4.8 & 4.7853 & TRN \\
\hline CHEMBL1539307 & 688721 & 4.4 & 4.8899 & TRN \\
\hline CHEMBL1504353 & 688721 & 4.7 & 4.8476 & TRN \\
\hline CHEMBL1517096 & 688721 & 4.9 & 4.7988 & TST \\
\hline CHEMBL1609019 & 688721 & 4.6 & 4.8295 & TRN \\
\hline CHEMBL1520647 & 688721 & 5.2 & 4.9187 & TST \\
\hline CHEMBL1337579 & 688721 & 4.5 & 4.8597 & TRN \\
\hline CHEMBL1403280 & 688721 & 5.4 & 4.8983 & TRN \\
\hline CHEMBL1527748 & 688721 & 4.5 & 4.9641 & TRN \\
\hline CHEMBL1574209 & 688721 & 4.5 & 4.9409 & TST \\
\hline CHEMBL1540520 & 688721 & 4.5 & 4.8579 & TRN \\
\hline CHEMBL1504367 & 688721 & 4.6 & 4.9866 & TRN \\
\hline CHEMBL1309379 & 688721 & 4.9 & 4.9878 & TRN \\
\hline CHEMBL1551066 & 688721 & 4.6 & 5.1745 & TRN \\
\hline CHEMBL1504299 & 688721 & 5.6 & 4.7693 & TRN \\
\hline CHEMBL1596296 & 688721 & 4.4 & 4.9478 & TST \\
\hline CHEMBL1409119 & 688721 & 4.7 & 4.8796 & TRN \\
\hline CHEMBL1597359 & 688721 & 4.8 & 4.8231 & TRN \\
\hline CHEMBL1488990 & 688721 & 4.6 & 5.0216 & TRN \\
\hline CHEMBL1591543 & 688721 & 5.0 & 4.9596 & TRN \\
\hline CHEMBL1565677 & 688721 & 4.5 & 4.8706 & TRN \\
\hline CHEMBL1317148 & 688721 & 5.5 & 5.4352 & TRN \\
\hline CHEMBL1425637 & 688721 & 4.5 & 4.7777 & TRN \\
\hline CHEMBL1400541 & 688721 & 5.2 & 5.1061 & TRN \\
\hline CHEMBL1574497 & 688721 & 6.4 & 4.9666 & TRN \\
\hline CHEMBL1563323 & 688721 & 4.8 & 4.7509 & TRN \\
\hline CHEMBL1439079 & 688721 & 4.8 & 4.8892 & TRN \\
\hline CHEMBL1547444 & 688721 & 4.4 & 4.8514 & TST \\
\hline CHEMBL1352291 & 688721 & 5.1 & 4.9193 & TRN \\
\hline CHEMBL1471463 & 688721 & 7.0 & 5.085 & TST \\
\hline CHEMBL1533465 & 688721 & 4.9 & 4.9555 & TST \\
\hline CHEMBL1321885 & 688721 & 4.5 & 4.9748 & TRN \\
\hline CHEMBL1419272 & 688721 & 4.8 & 4.9119 & TRN \\
\hline CHEMBL1331982 & 688721 & 5.1 & 4.954 & TRN \\
\hline CHEMBL1304765 & 688721 & 4.4 & 4.8892 & TRN \\
\hline CHEMBL1486501 & 688721 & 4.8 & 4.708 & TRN \\
\hline CHEMBL1571456 & 688721 & 5.9 & 4.9602 & TRN \\
\hline CHEMBL1337157 & 688721 & 4.7 & 4.8745 & TRN \\
\hline CHEMBL1466779 & 688721 & 6.5 & 4.9842 & TRN \\
\hline CHEMBL1384108 & 688721 & 4.6 & 4.9268 & TRN \\
\hline CHEMBL1358652 & 688721 & 5.3 & 5.1245 & TRN \\
\hline
\end{tabular}




\begin{tabular}{|c|c|c|c|c|}
\hline & & & & at \\
\hline CHEMBL1410889 & 688721 & 4.4 & 5.1058 & TST \\
\hline CHEMBL1431084 & 688721 & 4.5 & 4.9305 & TRN \\
\hline CHEMBL1376357 & 688721 & 4.6 & 4.9788 & TRN \\
\hline CHEMBL1302606 & 688721 & 4.4 & 4.8765 & TRN \\
\hline CHEMBL163970 & 688721 & 4.4 & 5.0631 & TRN \\
\hline CHEMBL3191783 & 688721 & 4.4 & 4.9686 & TST \\
\hline CHEMBL1469806 & 688721 & 4.8 & 4.9965 & TRN \\
\hline CHEMBL1347778 & 688721 & 4.4 & 5.0135 & TRN \\
\hline CHEMBL1560517 & 688721 & 4.7 & 4.8257 & TRN \\
\hline CHEMBL1473448 & 688721 & 4.4 & 5.1742 & TRN \\
\hline CHEMBL1484889 & 688721 & 5.0 & 4.9542 & TRN \\
\hline CHEMBL1528644 & 688721 & 4.5 & 4.9505 & TRN \\
\hline CHEMBL1493491 & 688721 & 5.2 & 5.1524 & TST \\
\hline CHEMBL1580052 & 688721 & 4.7 & 5.0005 & TRN \\
\hline CHEMBL1481813 & 688721 & 4.6 & 4.8545 & TRN \\
\hline CHEMBL1413218 & 688721 & 6.1 & 5.1316 & TRN \\
\hline CHEMBL1334094 & 688721 & 5.3 & 4.8176 & TRN \\
\hline CHEMBL1592651 & 688721 & 5.6 & 5.022 & TRN \\
\hline CHEMBL 250428 & 688721 & 4.4 & 4.8679 & TRN \\
\hline CHEMBL1378711 & 688721 & 5.6 & 4.8086 & TRN \\
\hline CHEMBL1431735 & 688721 & 4.7 & 4.9606 & TRN \\
\hline CHEMBL1599469 & 688721 & 4.6 & 5.2759 & TST \\
\hline CHEMBL1380031 & 688721 & 4.5 & 4.9735 & TST \\
\hline CHEMBL1582310 & 688721 & 6.1 & 5.2479 & TST \\
\hline CHEMBL1493369 & 688721 & 4.4 & 5.0318 & TST \\
\hline CHEMBL1386368 & 688721 & 5.4 & 5.029 & TST \\
\hline CHEMBL 252332 & 688721 & 4.5 & 4.8541 & TST \\
\hline CHEMBL1301207 & 688721 & 6.0 & 4.9869 & TRN \\
\hline CHEMBL1408872 & 688721 & 4.4 & 5.1123 & TST \\
\hline CHEMBL1506437 & 688721 & 7.0 & 4.6904 & TRN \\
\hline CHEMBL1349069 & 688721 & 4.6 & 4.9153 & TRN \\
\hline CHEMBL1586886 & 688721 & 4.4 & 5.2615 & TST \\
\hline CHEMBL3392072 & 688721 & 4.5 & 5.2882 & TRN \\
\hline CHEMBL1338829 & 688721 & 4.9 & 5.0045 & TRN \\
\hline CHEMBL1339798 & 688721 & 5.2 & 5.0431 & TRN \\
\hline CHEMBL1300983 & 688721 & 4.4 & 4.9557 & TRN \\
\hline CHEMBL1382640 & 688721 & 4.9 & 4.8606 & TRN \\
\hline CHEMBL1566620 & 688721 & 5.2 & 5.0008 & TST \\
\hline CHEMBL1403868 & 688721 & 5.5 & 4.8956 & TRN \\
\hline CHEMBL1331786 & 688721 & 4.6 & 5.0516 & TST \\
\hline CHEMBL1473123 & 688721 & 5.3 & 4.9805 & TRN \\
\hline CHEMBL1400916 & 688721 & 4.4 & 4.8182 & TST \\
\hline CHEMBL1611235 & 688721 & 5.4 & 5.0676 & TRN \\
\hline CHEMBL1349350 & 688721 & 5.1 & 4.9023 & TRN \\
\hline CHEMBL1385071 & 688721 & 6.0 & 5.0591 & TRN \\
\hline CHEMBL1521481 & 688721 & 4.6 & 4.692 & TRN \\
\hline CHEMBL1361552 & 688721 & 4.5 & 5.0594 & TRN \\
\hline CHEMBL1567805 & 688721 & 4.4 & 4.9567 & TRN \\
\hline
\end{tabular}




\begin{tabular}{|c|c|c|c|c|c|}
\hline \multicolumn{6}{|c|}{ Supplemental Table S2.txt } \\
\hline CHEMBL1567100 & 688721 & 4.6 & 4.8414 & TRN & \\
\hline CHEMBL1325964 & 688721 & 4.4 & 5.0135 & TRN & \\
\hline CHEMBL1601710 & 688721 & 4.5 & 4.8674 & TRN & \\
\hline CHEMBL1600662 & 688721 & 4.6 & 4.94600 & 2000000001 & TRN \\
\hline CHEMBL1305828 & 688721 & 4.6 & 4.8747 & TRN & \\
\hline CHEMBL1347369 & 688721 & 4.8 & 4.782 & TST & \\
\hline CHEMBL1438937 & 688721 & 4.4 & 5.3637 & TST & \\
\hline CHEMBL488803 & 688721 & 4.5 & 5.002 & TST & \\
\hline CHEMBL1561675 & 688721 & 4.4 & 4.9955 & TRN & \\
\hline CHEMBL1549782 & 688721 & 5.6 & 5.0436 & TRN & \\
\hline CHEMBL1533993 & 688721 & 4.4 & 5.0072 & TRN & \\
\hline CHEMBL1587512 & 688721 & 7.8996 & 5.2773 & TST & \\
\hline CHEMBL1605730 & 688721 & 4.4 & 5.0457 & TRN & \\
\hline CHEMBL1468116 & 688721 & 4.5 & 4.9409 & TRN & \\
\hline CHEMBL1499261 & 688721 & 7.8996 & 5.0391 & TRN & \\
\hline CHEMBL1325833 & 688721 & 5.3 & 5.0979 & TRN & \\
\hline CHEMBL1393168 & 688721 & 4.6 & 4.9848 & TRN & \\
\hline CHEMBL579224 & 688721 & 4.4 & 5.0424 & TST & \\
\hline CHEMBL1379948 & 688721 & 4.7 & 4.8386 & TRN & \\
\hline CHEMBL1482795 & 688721 & 5.1 & 4.9416 & TRN & \\
\hline CHEMBL1425032 & 688721 & 4.5 & 4.8663 & TRN & \\
\hline CHEMBL1419900 & 688721 & 7.1002 & 5.0923 & TRN & \\
\hline CHEMBL1434715 & 688721 & 4.6 & 4.8163 & TRN & \\
\hline CHEMBL1521829 & 688721 & 4.6 & 4.8454 & TRN & \\
\hline CHEMBL1305409 & 688721 & 4.5 & 4.6938 & TRN & \\
\hline CHEMBL1581007 & 688721 & 4.7 & 4.8644 & TRN & \\
\hline CHEMBL1503193 & 688721 & 4.7 & 4.6584 & TRN & \\
\hline CHEMBL1481598 & 688721 & 5.1 & 5.0007 & TRN & \\
\hline CHEMBL1336727 & 688721 & 4.5 & 4.8731 & TST & \\
\hline CHEMBL1440170 & 688721 & 4.4 & 4.8136 & TRN & \\
\hline CHEMBL1531948 & 688721 & 4.6 & 4.6803 & TRN & \\
\hline CHEMBL1389449 & 688721 & 4.8 & 4.7278 & TRN & \\
\hline CHEMBL1498604 & 688721 & 7.4001 & 4.8948 & TRN & \\
\hline CHEMBL1507911 & 688721 & 4.5 & 4.975 & TRN & \\
\hline CHEMBL1459021 & 688721 & 4.4 & 4.8343 & TRN & \\
\hline CHEMBL1452405 & 688721 & 4.5 & 4.9696 & TST & \\
\hline CHEMBL1485190 & 688721 & 5.0 & 5.0093 & TRN & \\
\hline CHEMBL1576324 & 688721 & 4.5 & 4.9201 & TRN & \\
\hline CHEMBL1352641 & 688721 & 6.1 & 5.03 & TRN & \\
\hline CHEMBL1572655 & 688721 & 4.7 & 4.9996 & TRN & \\
\hline CHEMBL1609093 & 688721 & 4.8 & 4.9688 & TST & \\
\hline CHEMBL1510642 & 688721 & 5.0 & 4.8973 & TRN & \\
\hline CHEMBL1447920 & 688721 & 5.8 & 5.2873 & TST & \\
\hline CHEMBL1398537 & 688721 & 4.9 & 5.2086 & TRN & \\
\hline CHEMBL1370662 & 688721 & 4.4 & 4.9159 & TRN & \\
\hline CHEMBL1332661 & 688721 & 4.4 & 5.12799 & 9999999999 & TST \\
\hline CHEMBL1579219 & 688721 & 5.2 & 4.917 & TST & \\
\hline CHEMBL1346720 & 688721 & 4.9 & 4.9342 & TRN & \\
\hline
\end{tabular}




\begin{tabular}{|c|c|c|c|c|c|}
\hline & & \multicolumn{4}{|c|}{ Supplemental Table S2.txt } \\
\hline CHEMBL1455133 & 688721 & 4.8 & 4.9204 & TRN & \\
\hline CHEMBL1459569 & 688721 & 5.0 & 4.9016 & TRN & \\
\hline CHEMBL1432163 & 688721 & 4.6 & 4.8478 & TRN & \\
\hline CHEMBL1457897 & 688721 & 4.6 & 4.9053 & TRN & \\
\hline CHEMBL1566888 & 688721 & 4.8 & 5.1303 & TRN & \\
\hline CHEMBL1499254 & 688721 & 6.3 & 5.4201 & TST & \\
\hline CHEMBL1506743 & 688721 & 6.1 & 4.7768 & TRN & \\
\hline CHEMBL1479741 & 688721 & 4.6 & 4.8738 & TRN & \\
\hline CHEMBL1599258 & 688721 & 4.7 & 4.9478 & TRN & \\
\hline CHEMBL1431534 & 688721 & 4.7 & 5.0883 & TRN & \\
\hline CHEMBL1394983 & 688721 & 5.5 & 5.2502 & TRN & \\
\hline CHEMBL1431517 & 688721 & 4.4 & 5.1944 & TST & \\
\hline CHEMBL1522900 & 688721 & 5.2 & 5.0776 & TST & \\
\hline CHEMBL1603107 & 688721 & 4.6 & 4.8849 & TRN & \\
\hline CHEMBL1484152 & 688721 & 5.1 & 5.03600 & 00000000005 & TRN \\
\hline CHEMBL1489236 & 688721 & 4.6 & 4.9072 & TRN & \\
\hline CHEMBL1438341 & 688721 & 4.7 & 4.9016 & TST & \\
\hline CHEMBL1500805 & 688721 & 5.5 & 4.8914 & TRN & \\
\hline CHEMBL1564709 & 688721 & 4.9 & 5.082 & TRN & \\
\hline CHEMBL1503521 & 688721 & 5.4 & 5.0251 & TST & \\
\hline CHEMBL144530 & 688721 & 5.3 & 5.2545 & TST & \\
\hline CHEMBL1572043 & 688721 & 5.2 & 4.7634 & TRN & \\
\hline CHEMBL1417509 & 688721 & 5.1 & 4.9635 & TST & \\
\hline CHEMBL1347353 & 688721 & 4.6 & 4.9449 & TRN & \\
\hline CHEMBL589207 & 688721 & 4.8 & 4.8818 & TST & \\
\hline CHEMBL1434535 & 688721 & 5.2 & 5.0704 & TRN & \\
\hline CHEMBL1500636 & 688721 & 4.8 & 4.6967 & TRN & \\
\hline CHEMBL1429693 & 688721 & 5.0 & 4.9506 & TRN & \\
\hline CHEMBL418068 & 688721 & 4.8 & 5.1309 & TRN & \\
\hline CHEMBL1330374 & 688721 & 4.8 & 4.8221 & TRN & \\
\hline CHEMBL1352993 & 688721 & 5.1 & 4.8396 & TRN & \\
\hline CHEMBL1488179 & 688721 & 5.9 & 5.1241 & TRN & \\
\hline CHEMBL1436037 & 688721 & 5.7 & 5.0538 & TRN & \\
\hline CHEMBL3196107 & 688721 & 4.5 & 4.9789 & TST & \\
\hline CHEMBL1336204 & 688721 & 4.4 & 4.9111 & TRN & \\
\hline CHEMBL1606720 & 688721 & 4.6 & 4.7954 & TRN & \\
\hline CHEMBL1320069 & 688721 & 4.5 & 4.8167 & TRN & \\
\hline CHEMBL1374544 & 688721 & 4.8 & 4.9189 & TRN & \\
\hline CHEMBL1409056 & 688721 & 4.7 & 4.8633 & TRN & \\
\hline CHEMBL1491628 & 688721 & 5.8 & 4.849 & TST & \\
\hline CHEMBL1463057 & 688721 & 5.3 & 4.8516 & TRN & \\
\hline CHEMBL1442668 & 688721 & 4.8 & 4.7781 & TRN & \\
\hline CHEMBL334378 & 688721 & 4.4 & 5.0002 & TST & \\
\hline CHEMBL1353929 & 688721 & 4.8 & 4.7398 & TRN & \\
\hline CHEMBL1384381 & 688721 & 6.1 & 4.9275 & TST & \\
\hline CHEMBL1327204 & 688721 & 4.6 & 5.2896 & TRN & \\
\hline CHEMBL1494405 & 688721 & 4.6 & 4.9171 & TRN & \\
\hline CHEMBL1613159 & 688721 & 5.4 & 5.1442 & TRN & \\
\hline
\end{tabular}




\begin{tabular}{|c|c|c|c|c|}
\hline & & & ient & $a \perp 1 a$ \\
\hline CHEMBL1549773 & 688721 & 4.4 & 5.0182 & TRN \\
\hline CHEMBL1611618 & 688721 & 5.2 & 4.8134 & TRN \\
\hline CHEMBL1589768 & 688721 & 4.7 & 4.841 & TST \\
\hline CHEMBL343822 & 688721 & 6.6 & 5.023 & TST \\
\hline CHEMBL1332292 & 688721 & 4.4 & 4.9558 & TRN \\
\hline CHEMBL1391847 & 688721 & 4.6 & 5.0627 & TRN \\
\hline CHEMBL1347306 & 688721 & 4.5 & 4.914 & TRN \\
\hline CHEMBL1341221 & 688721 & 4.7 & 4.8723 & TST \\
\hline CHEMBL1363643 & 688721 & 6.0 & 4.9706 & TRN \\
\hline CHEMBL1396261 & 688721 & 5.1 & 5.0536 & TRN \\
\hline CHEMBL1488302 & 688721 & 5.0 & 4.9705 & TRN \\
\hline CHEMBL262347 & 688721 & 4.4 & 4.8819 & TRN \\
\hline CHEMBL1399995 & 688721 & 4.4 & 4.8747 & TRN \\
\hline CHEMBL1495722 & 688721 & 5.2 & 5.2033 & TST \\
\hline CHEMBL1471165 & 688721 & 6.3 & 4.9682 & TRN \\
\hline CHEMBL1391401 & 688721 & 4.4 & 4.7802 & TRN \\
\hline CHEMBL1570475 & 688721 & 4.8 & 4.8782 & TRN \\
\hline CHEMBL1373217 & 688721 & 4.6 & 4.6935 & TRN \\
\hline CHEMBL1451986 & 688721 & 5.9 & 5.2142 & TST \\
\hline CHEMBL1303206 & 688721 & 6.4 & 4.9584 & TRN \\
\hline CHEMBL1407556 & 688721 & 4.5 & 4.7792 & TRN \\
\hline CHEMBL1389201 & 688721 & 4.5 & 4.753 & TRN \\
\hline CHEMBL1560320 & 688721 & 4.6 & 4.898 & TRN \\
\hline CHEMBL1455310 & 688721 & 4.6 & 4.9389 & TRN \\
\hline CHEMBL1566188 & 688721 & 5.3 & 5.1048 & TST \\
\hline CHEMBL1533733 & 688721 & 4.9 & 5.0119 & TRN \\
\hline CHEMBL1512111 & 688721 & 5.3 & 5.421 & TRN \\
\hline CHEMBL1565793 & 688721 & 4.5 & 4.8095 & TRN \\
\hline CHEMBL1533513 & 688721 & 4.5 & 4.9767 & TST \\
\hline CHEMBL1607450 & 688721 & 5.2 & 4.9754 & TRN \\
\hline CHEMBL1305447 & 688721 & 6.1 & 4.9962 & TST \\
\hline CHEMBL1483130 & 688721 & 4.5 & 5.0187 & TRN \\
\hline CHEMBL1341789 & 688721 & 4.5 & 5.0311 & TRN \\
\hline CHEMBL1323670 & 688721 & 4.5 & 4.824 & TRN \\
\hline CHEMBL3212608 & 688721 & 4.6 & 5.0227 & TST \\
\hline CHEMBL1503548 & 688721 & 4.6 & 4.9109 & TRN \\
\hline CHEMBL1481127 & 688721 & 5.3 & 5.2137 & TRN \\
\hline CHEMBL1440675 & 688721 & 6.0 & 4.9487 & TRN \\
\hline CHEMBL1537789 & 688721 & 4.8 & 4.9978 & TRN \\
\hline CHEMBL1550510 & 688721 & 4.6 & 4.7374 & TRN \\
\hline CHEMBL1502625 & 688721 & 4.7 & 4.9964 & TRN \\
\hline CHEMBL1468242 & 688721 & 5.2 & 5.0573 & TRN \\
\hline CHEMBL1478628 & 688721 & 5.2 & 4.8843 & TRN \\
\hline CHEMBL1491959 & 688721 & 5.0 & 4.8931 & TRN \\
\hline CHEMBL1459919 & 688721 & 4.6 & 4.9466 & TRN \\
\hline CHEMBL1270169 & 688721 & 5.2 & 5.1795 & TST \\
\hline CHEMBL1442247 & 688721 & 6.0 & 4.9749 & TRN \\
\hline CHEMBL1305634 & 688721 & 5.2 & 5.0182 & TRN \\
\hline
\end{tabular}




\begin{tabular}{|c|c|c|c|c|c|}
\hline \multicolumn{6}{|c|}{ Supplemental Table S2.txt } \\
\hline CHEMBL1555859 & 688721 & 5.3 & 5.1804 & TST & \\
\hline CHEMBL1336716 & 688721 & 4.7 & 4.8883 & TRN & \\
\hline CHEMBL295212 & 688721 & 4.4 & 5.2379 & TST & \\
\hline CHEMBL1360056 & 688721 & 5.2 & 4.8785 & TRN & \\
\hline CHEMBL1506477 & 688721 & 4.4 & 4.8789 & TRN & \\
\hline CHEMBL1384324 & 688721 & 5.3 & 4.7735 & TST & \\
\hline CHEMBL1466198 & 688721 & 4.6 & 4.8491 & TRN & \\
\hline CHEMBL1438667 & 688721 & 4.7 & 4.9127 & TRN & \\
\hline CHEMBL1311707 & 688721 & 4.7 & 4.808 & TST & \\
\hline CHEMBL1508361 & 688721 & 4.8 & 4.9738 & TRN & \\
\hline CHEMBL1568082 & 688721 & 6.0 & 4.8614 & TRN & \\
\hline CHEMBL1355176 & 688721 & 4.6 & 4.9722 & TRN & \\
\hline CHEMBL1581095 & 688721 & 4.5 & 4.851 & TRN & \\
\hline CHEMBL1567313 & 688721 & 7.1002 & 5.0895 & TST & \\
\hline CHEMBL1590213 & 688721 & 4.6 & 5.1094 & TRN & \\
\hline CHEMBL1347558 & 688721 & 5.1 & 4.9164 & TST & \\
\hline CHEMBL1507777 & 688721 & 5.2 & 5.0616 & TST & \\
\hline CHEMBL1360981 & 688721 & 4.4 & 4.7531 & TRN & \\
\hline CHEMBL1530548 & 688721 & 4.8 & 4.9674 & TRN & \\
\hline CHEMBL1502211 & 688721 & 5.0 & 4.8753 & TST & \\
\hline CHEMBL1333445 & 688721 & 4.6 & 5.2403 & TRN & \\
\hline CHEMBL1417256 & 688721 & 5.8 & 4.9396 & TST & \\
\hline CHEMBL1489494 & 688721 & 4.5 & 4.9051 & TRN & \\
\hline CHEMBL1499886 & 688721 & 4.9 & 4.9171 & TRN & \\
\hline CHEMBL1432678 & 688721 & 5.1 & 4.7752 & TST & \\
\hline CHEMBL1353199 & 688721 & 4.4 & 5.01699 & 99999999995 & TRN \\
\hline CHEMBL1441572 & 688721 & 4.9 & 4.8944 & TST & \\
\hline CHEMBL1453923 & 688721 & 4.5 & 4.9149 & TRN & \\
\hline CHEMBL1372349 & 688721 & 4.6 & 4.8149 & TRN & \\
\hline CHEMBL1554725 & 688721 & 4.4 & 5.1927 & TRN & \\
\hline CHEMBL1347822 & 688721 & 4.7 & 4.9622 & TRN & \\
\hline CHEMBL1559098 & 688721 & 4.4 & 5.0966 & TRN & \\
\hline CHEMBL1544846 & 688721 & 4.9 & 4.9161 & TRN & \\
\hline CHEMBL1491519 & 688721 & 5.5 & 4.8204 & TRN & \\
\hline CHEMBL1378194 & 688721 & 4.5 & 4.8423 & TRN & \\
\hline CHEMBL1307858 & 688721 & 4.5 & 4.9616 & TRN & \\
\hline CHEMBL1590081 & 688721 & 6.1 & 5.1941 & TRN & \\
\hline CHEMBL1371597 & 688721 & 4.5 & 4.9983 & TRN & \\
\hline CHEMBL1493825 & 688721 & 4.7 & 5.0752 & TRN & \\
\hline CHEMBL1412993 & 688721 & 4.4 & 4.8376 & TRN & \\
\hline CHEMBL1324051 & 688721 & 4.6 & 4.8408 & TST & \\
\hline CHEMBL1447405 & 688721 & 4.5 & 4.913 & TRN & \\
\hline CHEMBL1494309 & 688721 & 4.5 & 4.9224 & TRN & \\
\hline CHEMBL1465543 & 688721 & 5.4 & 4.8347 & TST & \\
\hline CHEMBL1479572 & 688721 & 6.8 & 4.7903 & TRN & \\
\hline CHEMBL1463591 & 688721 & 6.8 & 4.8673 & TRN & \\
\hline CHEMBL1454920 & 688721 & 6.1 & 4.97 & TRN & \\
\hline CHEMBL1322270 & 688721 & 5.2 & 4.7955 & TRN & \\
\hline
\end{tabular}




\begin{tabular}{|c|c|c|c|c|}
\hline & & & ipplement & al $\mathrm{T}$ \\
\hline CHEMBL1565462 & 688721 & 5.0 & 4.7588 & TST \\
\hline CHEMBL1549825 & 688721 & 4.5 & 4.8362 & TRN \\
\hline CHEMBL516029 & 688721 & 4.5 & 4.8807 & TRN \\
\hline CHEMBL372227 & 688721 & 4.5 & 5.0109 & TRN \\
\hline CHEMBL1584015 & 688721 & 4.7 & 4.7459 & TRN \\
\hline CHEMBL1463264 & 688721 & 4.8 & 4.922 & TRN \\
\hline CHEMBL1232474 & 688721 & 4.8 & 4.9489 & TRN \\
\hline CHEMBL1526331 & 688721 & 4.4 & 4.9366 & TST \\
\hline CHEMBL1554677 & 688721 & 5.2 & 5.0898 & TRN \\
\hline CHEMBL1542398 & 688721 & 4.4 & 4.8256 & TRN \\
\hline CHEMBL1507490 & 688721 & 5.6 & 4.9567 & TRN \\
\hline CHEMBL1596496 & 688721 & 4.8 & 4.888 & TRN \\
\hline CHEMBL1596460 & 688721 & 4.9 & 4.9401 & TRN \\
\hline CHEMBL1454477 & 688721 & 4.9 & 5.0463 & TRN \\
\hline CHEMBL1413124 & 688721 & 4.4 & 4.9973 & TRN \\
\hline CHEMBL1321899 & 688721 & 4.5 & 5.1086 & TRN \\
\hline CHEMBL1536993 & 688721 & 4.9 & 5.0366 & TRN \\
\hline CHEMBL1538802 & 688721 & 4.4 & 4.8431 & TRN \\
\hline CHEMBL1387489 & 688721 & 5.0 & 4.8833 & TRN \\
\hline CHEMBL1544761 & 688721 & 4.5 & 4.9151 & TRN \\
\hline CHEMBL1348895 & 688721 & 5.0 & 4.8862 & TRN \\
\hline CHEMBL565755 & 688721 & 4.6 & 4.9551 & TRN \\
\hline CHEMBL1584781 & 688721 & 5.6 & 5.0325 & TRN \\
\hline CHEMBL1386456 & 688721 & 4.4 & 4.9518 & TRN \\
\hline CHEMBL1417665 & 688721 & 4.8 & 4.7835 & TRN \\
\hline CHEMBL1514607 & 688721 & 4.4 & 5.1439 & TRN \\
\hline CHEMBL1430390 & 688721 & 5.4 & 5.0036 & TRN \\
\hline CHEMBL1422775 & 688721 & 4.5 & 5.0541 & TRN \\
\hline CHEMBL1465755 & 688721 & 4.4 & 4.8289 & TRN \\
\hline CHEMBL1557170 & 688721 & 5.9 & 4.7928 & TRN \\
\hline CHEMBL1545114 & 688721 & 4.8 & 4.7453 & TRN \\
\hline CHEMBL1505633 & 688721 & 4.6 & 4.9757 & TST \\
\hline CHEMBL1324405 & 688721 & 6.0 & 4.9442 & TST \\
\hline CHEMBL1303450 & 688721 & 4.9 & 5.0329 & TST \\
\hline CHEMBL166050 & 688721 & 5.0 & 5.1406 & TRN \\
\hline CHEMBL1329110 & 688721 & 5.2 & 5.0187 & TRN \\
\hline CHEMBL 1453530 & 688721 & 5.9 & 4.9968 & TRN \\
\hline CHEMBL1533672 & 688721 & 5.5 & 4.9994 & TRN \\
\hline CHEMBL1581724 & 688721 & 5.2 & 5.0635 & TST \\
\hline CHEMBL52387 & 688721 & 4.5 & 5.0521 & TRN \\
\hline CHEMBL1555369 & 688721 & 4.6 & 5.0165 & TRN \\
\hline CHEMBL1582760 & 688721 & 4.6 & 5.0817 & TRN \\
\hline CHEMBL1563767 & 688721 & 6.8 & 4.6004 & TRN \\
\hline CHEMBL1609519 & 688721 & 5.2 & 4.9582 & TST \\
\hline CHEMBL1355712 & 688721 & 4.7 & 4.8006 & TRN \\
\hline CHEMBL1501053 & 688721 & 4.6 & 4.8343 & TRN \\
\hline CHEMBL 1470100 & 688721 & 4.6 & 4.9005 & TRN \\
\hline CHEMBL1320841 & 688721 & 4.6 & 4.8572 & TRN \\
\hline
\end{tabular}




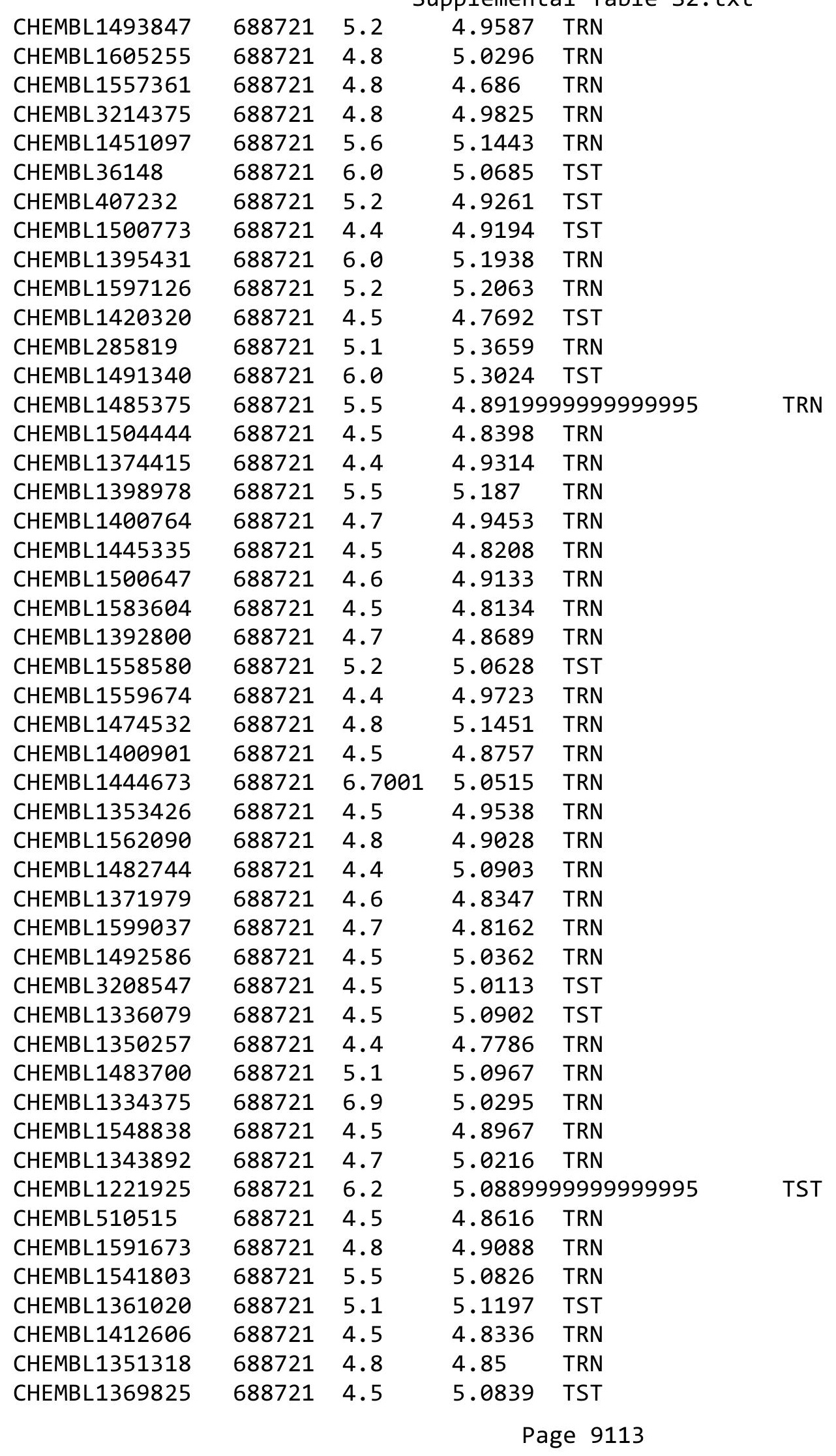




\begin{tabular}{|c|c|c|c|c|}
\hline \multicolumn{5}{|c|}{ Supplemental Table S2.txt } \\
\hline CHEMBL1605035 & 688721 & 5.2 & 4.8131 & TST \\
\hline CHEMBL1981833 & 688721 & 6.8 & 4.9389 & TRN \\
\hline CHEMBL1464322 & 688721 & 5.3 & 4.8865 & TRN \\
\hline CHEMBL1572007 & 688721 & 4.5 & 4.8772 & TRN \\
\hline CHEMBL1475079 & 688721 & 4.7 & 5.0262 & TRN \\
\hline CHEMBL1388545 & 688721 & 5.5 & 4.9422 & TRN \\
\hline CHEMBL1536796 & 688721 & 4.6 & 5.0464 & TRN \\
\hline CHEMBL1404553 & 688721 & 4.7 & 4.9734 & TRN \\
\hline CHEMBL1538915 & 688721 & 5.9 & 4.8256 & TRN \\
\hline CHEMBL1462693 & 688721 & 4.4 & 4.8568 & TRN \\
\hline CHEMBL1546310 & 688721 & 4.5 & 4.9626 & TRN \\
\hline CHEMBL1342672 & 688721 & 5.4 & 5.1082 & TRN \\
\hline CHEMBL1612861 & 688721 & 4.6 & 4.9193 & TST \\
\hline CHEMBL1449017 & 688721 & 4.6 & 4.8687 & TRN \\
\hline CHEMBL1362418 & 688721 & 5.3 & 5.1236 & TST \\
\hline CHEMBL1545010 & 688721 & 5.1 & 4.7898 & TRN \\
\hline CHEMBL1359146 & 688721 & 5.4 & 4.8102 & TRN \\
\hline CHEMBL1507657 & 688721 & 4.8 & 4.8969 & TST \\
\hline CHEMBL1452608 & 688721 & 4.6 & 4.9013 & TRN \\
\hline CHEMBL1493020 & 688721 & 4.7 & 4.9752 & TRN \\
\hline CHEMBL1388809 & 688721 & 5.0 & 4.8214 & TRN \\
\hline CHEMBL1582756 & 688721 & 4.6 & 4.9153 & TST \\
\hline CHEMBL1317386 & 688721 & 5.9 & 5.1576 & TST \\
\hline CHEMBL1399833 & 688721 & 5.0 & 4.8628 & TRN \\
\hline CHEMBL23957 & 688721 & 6.0 & 5.2228 & TST \\
\hline CHEMBL1441291 & 688721 & 4.4 & 4.8274 & TRN \\
\hline CHEMBL1596172 & 688721 & 4.7 & 4.8486 & TRN \\
\hline CHEMBL1160509 & 688721 & 7.8013 & 5.3568 & TRN \\
\hline CHEMBL1330463 & 688721 & 4.6 & 4.864 & TRN \\
\hline CHEMBL1570447 & 688721 & 4.4 & 4.9436 & TST \\
\hline CHEMBL1430379 & 688721 & 6.5 & 4.9136 & TRN \\
\hline CHEMBL1503244 & 688721 & 4.4 & 4.7595 & TRN \\
\hline CHEMBL1530940 & 688721 & 4.6 & 4.7937 & TRN \\
\hline CHEMBL1368776 & 688721 & 4.4 & 4.9368 & TST \\
\hline CHEMBL12014 & 688721 & 4.6 & 4.9165 & TST \\
\hline CHEMBL1391741 & 688721 & 4.5 & 4.9397 & TST \\
\hline CHEMBL1544623 & 688721 & 4.9 & 4.8974 & TRN \\
\hline CHEMBL1574779 & 688721 & 5.1 & 4.8151 & TRN \\
\hline CHEMBL1566660 & 688721 & 5.2 & 5.1033 & TST \\
\hline CHEMBL1454421 & 688721 & 4.5 & 4.8081 & TRN \\
\hline CHEMBL1572383 & 688721 & 4.5 & 4.9015 & TST \\
\hline CHEMBL1308419 & 688721 & 4.6 & 5.0135 & TRN \\
\hline CHEMBL1341401 & 688721 & 4.6 & 5.0668 & TRN \\
\hline CHEMBL1413831 & 688721 & 4.6 & 4.8846 & TRN \\
\hline CHEMBL1561828 & 688721 & 5.0 & 4.795 & TRN \\
\hline CHEMBL1303180 & 688721 & 5.2 & 4.8692 & TRN \\
\hline CHEMBL1473073 & 688721 & 4.8 & 4.9191 & TRN \\
\hline CHEMBL1308843 & 688721 & 4.7 & 4.9084 & TRN \\
\hline
\end{tabular}




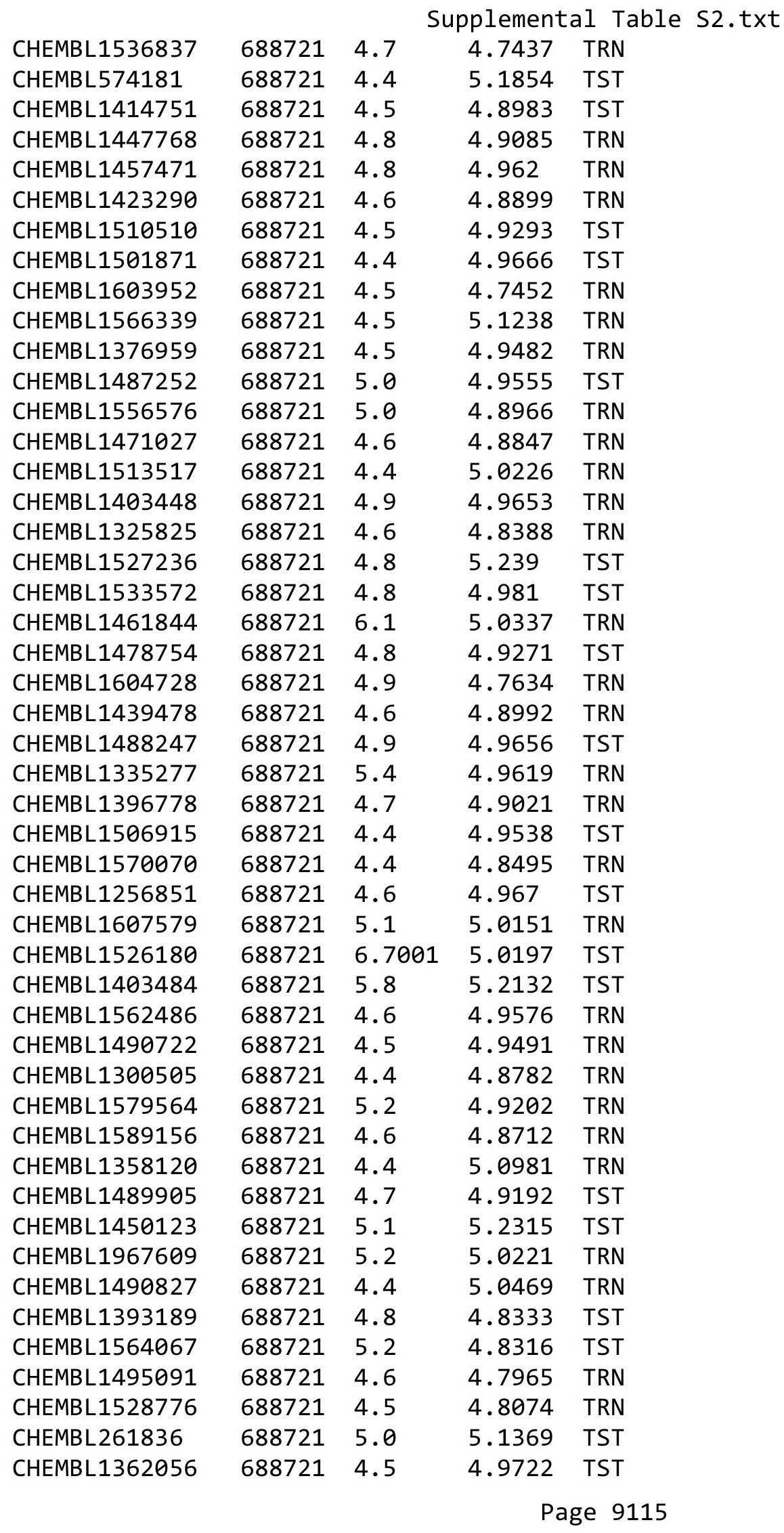




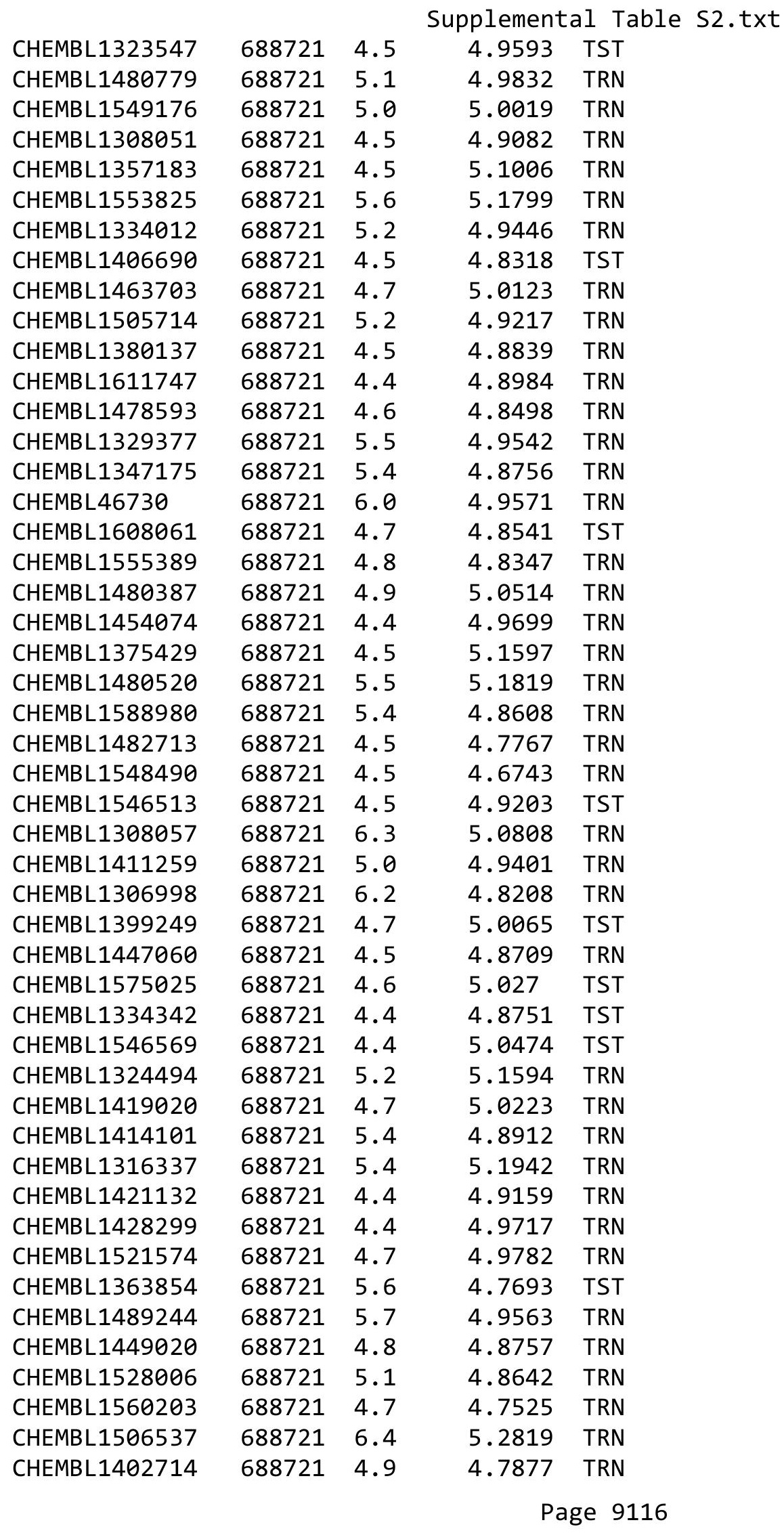




\begin{tabular}{|c|c|c|c|c|c|}
\hline & & & & & \\
\hline CHEMBL1549880 & 688721 & 4.6 & 4.8063 & TRN & \\
\hline CHEMBL1496055 & 688721 & 4.6 & 4.8409 & TRN & \\
\hline CHEMBL1422838 & 688721 & 4.8 & 4.7702 & TRN & \\
\hline CHEMBL1334369 & 688721 & 5.1 & 4.8806 & TRN & \\
\hline CHEMBL1441101 & 688721 & 5.1 & 4.7829 & TRN & \\
\hline CHEMBL1379136 & 688721 & 4.6 & 4.8612 & TST & \\
\hline CHEMBL1299495 & 688721 & 4.8 & 4.9609 & TRN & \\
\hline CHEMBL1575759 & 688721 & 4.7 & 5.0049 & TRN & \\
\hline CHEMBL1529824 & 688721 & 4.6 & 4.7928 & TST & \\
\hline CHEMBL1477833 & 688721 & 6.0 & 5.1061 & TRN & \\
\hline CHEMBL1334106 & 688721 & 5.2 & 5.0888 & TRN & \\
\hline CHEMBL1361276 & 688721 & 4.4 & 4.915 & TST & \\
\hline CHEMBL1602633 & 688721 & 4.5 & 5.2906 & TRN & \\
\hline CHEMBL1425624 & 688721 & 4.5 & 4.9249 & TRN & \\
\hline CHEMBL1401242 & 688721 & 4.6 & 4.9523 & TRN & \\
\hline CHEMBL1329661 & 688721 & 4.5 & 4.8448 & TRN & \\
\hline CHEMBL1336638 & 688721 & 4.5 & 4.7742 & TRN & \\
\hline CHEMBL1566108 & 688721 & 4.7 & 4.8963 & TRN & \\
\hline CHEMBL1467490 & 688721 & 4.7 & 4.8306 & TRN & \\
\hline CHEMBL1439530 & 688721 & 6.0 & 4.9051 & TRN & \\
\hline CHEMBL1367222 & 688721 & 5.5 & 5.0765 & TRN & \\
\hline CHEMBL1475667 & 688721 & 4.5 & 4.8627 & TRN & \\
\hline CHEMBL464135 & 688721 & 5.2 & 5.0157 & TST & \\
\hline CHEMBL1373518 & 688721 & 6.4 & 4.8673 & TRN & \\
\hline CHEMBL1445325 & 688721 & 5.5 & 4.9713 & TRN & \\
\hline CHEMBL1460318 & 688721 & 4.4 & 5.1295 & TST & \\
\hline CHEMBL1419889 & 688721 & 4.7 & 4.8901 & TRN & \\
\hline CHEMBL1529272 & 688721 & 5.2 & 4.9219 & TST & \\
\hline CHEMBL1346978 & 688721 & 6.8 & 5.1461 & TST & \\
\hline CHEMBL1441877 & 688721 & 4.4 & 4.9323 & TRN & \\
\hline CHEMBL1588811 & 688721 & 5.4 & 5.0609 & TST & \\
\hline CHEMBL1610903 & 688721 & 4.8 & 4.7716 & TRN & \\
\hline CHEMBL1493594 & 688721 & 5.6 & 4.7983 & TRN & \\
\hline CHEMBL1401044 & 688721 & 5.0 & 4.7511 & TRN & \\
\hline CHEMBL1492010 & 688721 & 6.0 & 4.8891 & TST & \\
\hline CHEMBL1466691 & 688721 & 4.7 & 5.1766 & TST & \\
\hline CHEMBL1494495 & 688721 & 4.4 & 4.7559 & TRN & \\
\hline CHEMBL1430871 & 688721 & 4.4 & 4.9098 & TRN & \\
\hline CHEMBL1596976 & 688721 & 4.5 & 5.1062 & TST & \\
\hline CHEMBL1541839 & 688721 & 4.7 & 4.9645 & TRN & \\
\hline CHEMBL1583117 & 688721 & 4.7 & 5.03 & TRN & \\
\hline CHEMBL600572 & 688721 & 4.5 & 4.9795 & TRN & \\
\hline CHEMBL1576394 & 688721 & 4.7 & 4.8827 & TRN & \\
\hline CHEMBL1393786 & 688721 & 4.5 & 5.1007 & TRN & \\
\hline CHEMBL1595887 & 688721 & 7.5003 & 4.7553 & TRN & \\
\hline CHEMBL1504683 & 688721 & 5.2 & 5.0974 & TRN & \\
\hline CHEMBL1498956 & 688721 & 5.7 & 4.7679 & TRN & \\
\hline CHEMBL1465546 & 688721 & 4.6 & $4.8180 e$ & 20000000005 & TRN \\
\hline & & & & e 9117 & \\
\hline
\end{tabular}




\begin{tabular}{|c|c|c|c|c|}
\hline & & & 11 & \\
\hline CHEMBL1392663 & 688721 & 5.5 & 4.9294 & TRN \\
\hline CHEMBL1364557 & 688721 & 5.0 & 4.856 & TRN \\
\hline CHEMBL1465319 & 688721 & 4.6 & 4.7486 & TRN \\
\hline CHEMBL1428525 & 688721 & 4.5 & 4.6931 & TRN \\
\hline CHEMBL1389139 & 688721 & 4.9 & 4.9029 & TRN \\
\hline CHEMBL1160730 & 688721 & 4.8 & 5.0106 & TRN \\
\hline CHEMBL1341699 & 688721 & 5.0 & 4.8769 & TRN \\
\hline CHEMBL1503228 & 688721 & 4.5 & 4.8527 & TST \\
\hline CHEMBL1323531 & 688721 & 4.8 & 4.9702 & TRN \\
\hline CHEMBL504791 & 688721 & 5.9 & 4.897 & TST \\
\hline CHEMBL1501282 & 688721 & 4.8 & 4.7859 & TRN \\
\hline CHEMBL1308361 & 688721 & 4.5 & 4.8111 & TST \\
\hline CHEMBL1453601 & 688721 & 6.0 & 5.1252 & TST \\
\hline CHEMBL1574689 & 688721 & 4.8 & 4.7805 & TRN \\
\hline CHEMBL1511444 & 688721 & 5.5 & 4.9024 & TRN \\
\hline CHEMBL1479082 & 688721 & 4.4 & 5.0101 & TRN \\
\hline CHEMBL1307319 & 688721 & 4.6 & 4.9509 & TST \\
\hline CHEMBL1447446 & 688721 & 4.6 & 5.1728 & TST \\
\hline CHEMBL1330487 & 688721 & 4.8 & 4.7669 & TRN \\
\hline CHEMBL1580452 & 688721 & 4.7 & 4.8967 & TRN \\
\hline CHEMBL1362517 & 688721 & 5.2 & 5.0166 & TRN \\
\hline CHEMBL1336328 & 688721 & 5.5 & 5.1352 & TRN \\
\hline CHEMBL1338487 & 688721 & 4.4 & 5.1821 & TST \\
\hline CHEMBL1329944 & 688721 & 4.4 & 4.802 & TST \\
\hline CHEMBL1316828 & 688721 & 4.5 & 5.0818 & TRN \\
\hline CHEMBL1592974 & 688721 & 4.6 & 4.934 & TRN \\
\hline CHEMBL1322432 & 688721 & 4.7 & 4.8369 & TRN \\
\hline CHEMBL1569486 & 688721 & 6.4 & 5.0124 & TST \\
\hline CHEMBL1355701 & 688721 & 4.6 & 5.0056 & TRN \\
\hline CHEMBL1605185 & 688721 & 4.4 & 4.9429 & TRN \\
\hline CHEMBL1493770 & 688721 & 4.9 & 4.8795 & TST \\
\hline CHEMBL1335523 & 688721 & 4.6 & 5.0205 & TRN \\
\hline CHEMBL1328465 & 688721 & 4.8 & 4.9551 & TRN \\
\hline CHEMBL1577801 & 688721 & 4.9 & 4.8743 & TRN \\
\hline CHEMBL1423046 & 688721 & 4.8 & 4.8886 & TRN \\
\hline CHEMBL1515280 & 688721 & 4.4 & 5.0831 & TRN \\
\hline CHEMBL1518145 & 688721 & 6.6 & 4.9231 & TRN \\
\hline CHEMBL490749 & 688721 & 5.8 & 4.9532 & TRN \\
\hline CHEMBL1567094 & 688721 & 4.5 & 4.9425 & TRN \\
\hline CHEMBL1322513 & 688721 & 4.6 & 4.8652 & TRN \\
\hline CHEMBL1447946 & 688721 & 4.7 & 5.1063 & TRN \\
\hline CHEMBL1417771 & 688721 & 4.9 & 4.9509 & TRN \\
\hline CHEMBL1372818 & 688721 & 4.8 & 4.819 & TRN \\
\hline CHEMBL1440690 & 688721 & 5.4 & 4.865 & TRN \\
\hline CHEMBL573214 & 688721 & 5.4 & 5.1577 & TRN \\
\hline CHEMBL1613671 & 688721 & 4.5 & 4.9628 & TST \\
\hline CHEMBL1589307 & 688721 & 4.5 & 4.8475 & TRN \\
\hline CHEMBL1428582 & 688721 & 4.9 & 4.609 & TRN \\
\hline
\end{tabular}




\begin{tabular}{|c|c|c|c|c|c|}
\hline \multicolumn{6}{|c|}{ Supplemental Table S2.txt } \\
\hline CHEMBL1375169 & 688721 & 4.5 & 4.7586 & TRN & \\
\hline CHEMBL1354154 & 688721 & 5.4 & 5.2266 & TRN & \\
\hline CHEMBL1335077 & 688721 & 5.3 & 4.8428 & TRN & \\
\hline CHEMBL1453691 & 688721 & 4.4 & 4.8157 & TRN & \\
\hline CHEMBL1469101 & 688721 & 6.7001 & 4.8862 & TST & \\
\hline CHEMBL1475137 & 688721 & 4.4 & 5.0902 & TST & \\
\hline CHEMBL1408815 & 688721 & 4.7 & 4.915 & TRN & \\
\hline CHEMBL1300857 & 688721 & 7.0 & 4.6623 & TRN & \\
\hline CHEMBL1445473 & 688721 & 4.5 & 5.2488 & TRN & \\
\hline CHEMBL1331935 & 688721 & 7.5003 & 4.8398 & TST & \\
\hline CHEMBL1570175 & 688721 & 5.3 & 4.9569 & TST & \\
\hline CHEMBL1389576 & 688721 & 5.2 & 5.2663 & TRN & \\
\hline CHEMBL1414773 & 688721 & 4.6 & 4.9818 & TST & \\
\hline CHEMBL1602058 & 688721 & 4.5 & 4.872 & TST & \\
\hline CHEMBL26915 & 688721 & 4.7 & 4.9534 & TST & \\
\hline CHEMBL1328353 & 688721 & 4.4 & 4.9264 & TST & \\
\hline CHEMBL1493367 & 688721 & 6.0 & 4.9577 & TST & \\
\hline CHEMBL1469332 & 688721 & 4.9 & 4.8941 & TRN & \\
\hline CHEMBL405616 & 688721 & 4.7 & 4.8757 & TRN & \\
\hline CHEMBL1511584 & 688721 & 5.8 & 4.8403 & TRN & \\
\hline CHEMBL1482007 & 688721 & 4.5 & 4.7414 & TRN & \\
\hline CHEMBL1426650 & 688721 & 5.5 & 4.8249 & TRN & \\
\hline CHEMBL1383630 & 688721 & 4.5 & 4.9488 & TRN & \\
\hline CHEMBL1432354 & 688721 & 5.2 & 4.9781 & TRN & \\
\hline CHEMBL1594744 & 688721 & 4.4 & 4.8211 & TRN & \\
\hline CHEMBL1444838 & 688721 & 4.7 & 4.909 & TRN & \\
\hline CHEMBL1347418 & 688721 & 4.6 & 4.9612 & TRN & \\
\hline CHEMBL1593866 & 688721 & 4.4 & 4.8454 & TRN & \\
\hline CHEMBL1583163 & 688721 & 4.9 & 5.0395 & TRN & \\
\hline CHEMBL1378350 & 688721 & 4.4 & 5.0196 & TRN & \\
\hline CHEMBL1414123 & 688721 & 5.2 & 4.9432 & TRN & \\
\hline CHEMBL1514560 & 688721 & 5.2 & 5.1907 & TRN & \\
\hline CHEMBL1539540 & 688721 & 4.5 & 4.869 & TRN & \\
\hline CHEMBL1445749 & 688721 & 4.8 & 5.0054 & TRN & \\
\hline CHEMBL1597894 & 688721 & 4.5 & 4.997 & TRN & \\
\hline CHEMBL 310310 & 688721 & 6.0 & 5.03100 & 0000000001 & TRN \\
\hline CHEMBL3192909 & 688721 & 5.2 & 5.0268 & TRN & \\
\hline CHEMBL1589559 & 688721 & 4.5 & 5.0002 & TRN & \\
\hline CHEMBL1537144 & 688721 & 4.4 & 4.9632 & TRN & \\
\hline CHEMBL1459254 & 688721 & 4.6 & 5.0844 & TST & \\
\hline CHEMBL1551415 & 688721 & 5.2 & 5.018 & TRN & \\
\hline CHEMBL1305701 & 688721 & 4.5 & 4.8655 & TRN & \\
\hline CHEMBL1379438 & 688721 & 4.8 & 4.7696 & TRN & \\
\hline CHEMBL1345307 & 688721 & 4.5 & 5.0659 & TRN & \\
\hline CHEMBL1315716 & 688721 & 4.4 & 4.9547 & TRN & \\
\hline CHEMBL1588302 & 688721 & 4.4 & 5.0452 & TRN & \\
\hline CHEMBL1532189 & 688721 & 4.6 & 4.9056 & TRN & \\
\hline CHEMBL1391602 & 688721 & 5.6 & 4.8021 & TRN & \\
\hline
\end{tabular}




\begin{tabular}{|c|c|c|c|c|c|}
\hline \multicolumn{6}{|c|}{ Supplemental Table S2.txt } \\
\hline CHEMBL1380628 & 688721 & 4.7 & 4.9419 & TRN & \\
\hline CHEMBL1334167 & 688721 & 4.4 & 4.7767 & TRN & \\
\hline CHEMBL489738 & 688721 & 5.2 & 4.9934 & TRN & \\
\hline CHEMBL1342819 & 688721 & 4.4 & 4.8409 & TRN & \\
\hline CHEMBL1590261 & 688721 & 5.5 & 5.1469 & TRN & \\
\hline CHEMBL1519612 & 688721 & 4.7 & \multicolumn{2}{|c|}{4.9639999999999995} & TST \\
\hline CHEMBL1599012 & 688721 & 5.3 & 4.9544 & TST & \\
\hline CHEMBL 3196041 & 688721 & 4.8 & 4.8179 & TRN & \\
\hline CHEMBL1429782 & 688721 & 4.6 & 4.8896 & TRN & \\
\hline CHEMBL1603868 & 688721 & 5.2 & 5.0047 & TRN & \\
\hline CHEMBL1608674 & 688721 & 5.2 & 5.1773 & TRN & \\
\hline CHEMBL489934 & 688721 & 4.7 & 4.9769 & TRN & \\
\hline CHEMBL1385388 & 688721 & 4.4 & 4.8747 & TRN & \\
\hline CHEMBL1399505 & 688721 & 4.8 & 5.0644 & TRN & \\
\hline CHEMBL1337295 & 688721 & 4.7 & 4.8501 & TRN & \\
\hline CHEMBL1446905 & 688721 & 4.8 & 5.0277 & TRN & \\
\hline CHEMBL1256697 & 688721 & 4.4 & 5.2257 & TRN & \\
\hline CHEMBL3211706 & 688721 & 5.5 & 5.1162 & TST & \\
\hline CHEMBL1334105 & 688721 & 4.4 & 4.9362 & TST & \\
\hline CHEMBL1482916 & 688721 & 5.4 & 4.8874 & TRN & \\
\hline CHEMBL1333400 & 688721 & 5.2 & 5.2333 & TST & \\
\hline CHEMBL1577611 & 688721 & 4.5 & 4.7117 & TST & \\
\hline CHEMBL1396986 & 688721 & 4.5 & \multicolumn{2}{|c|}{5.132000000000001} & TRN \\
\hline CHEMBL1494574 & 688721 & 4.9 & 4.8675 & TRN & \\
\hline CHEMBL1528790 & 688721 & 4.9 & 4.9571 & TRN & \\
\hline CHEMBL1457257 & 688721 & 4.9 & 4.7135 & TST & \\
\hline CHEMBL1554325 & 688721 & 4.4 & 4.7892 & TRN & \\
\hline CHEMBL1587717 & 688721 & 4.5 & 4.8374 & TRN & \\
\hline CHEMBL1409783 & 688721 & 7.0 & 5.0685 & TRN & \\
\hline CHEMBL1520880 & 688721 & 4.6 & 4.9363 & TST & \\
\hline CHEMBL1610545 & 688721 & 4.8 & 4.8784 & TRN & \\
\hline CHEMBL 3209757 & 688721 & 4.6 & 4.7951 & TRN & \\
\hline CHEMBL1412344 & 688721 & 4.5 & 4.7084 & TRN & \\
\hline CHEMBL1381824 & 688721 & 4.7 & 4.7486 & TRN & \\
\hline CHEMBL1373907 & 688721 & 5.7 & 5.1215 & TRN & \\
\hline CHEMBL450493 & 688721 & 7.6003 & 5.0687 & TRN & \\
\hline CHEMBL1595593 & 688721 & 4.5 & 4.9353 & TRN & \\
\hline CHEMBL 3212438 & 688721 & 4.8 & 4.9432 & TRN & \\
\hline CHEMBL410873 & 688721 & 5.7 & 5.3715 & TRN & \\
\hline CHEMBL1451787 & 688721 & 5.4 & 4.9614 & TRN & \\
\hline CHEMBL1566946 & 688721 & 5.2 & 4.9583 & TST & \\
\hline CHEMBL1350559 & 688721 & 4.8 & 4.7131 & TRN & \\
\hline CHEMBL1370696 & 688721 & 5.2 & 4.9834 & TRN & \\
\hline CHEMBL1457373 & 688721 & 4.5 & 4.9037 & TST & \\
\hline CHEMBL1312002 & 688721 & 4.4 & 4.7307 & TRN & \\
\hline CHEMBL1598680 & 688721 & 6.0 & 5.1588 & TRN & \\
\hline CHEMBL1426235 & 688721 & 5.0 & 4.7082 & TRN & \\
\hline CHEMBL1388319 & 688721 & 4.4 & 4.8731 & TRN & \\
\hline
\end{tabular}




\begin{tabular}{|c|c|c|c|c|c|}
\hline \\
\hline CHEMBL1489830 & 688721 & 4.7 & 4.7626 & TRN & \\
\hline CHEMBL1382146 & 688721 & 4.7 & 4.925 & TST & \\
\hline CHEMBL1455931 & 688721 & 4.6 & 4.6505 & TRN & \\
\hline CHEMBL1304515 & 688721 & 6.1 & 4.9869 & TRN & \\
\hline CHEMBL1378666 & 688721 & 4.6 & 5.1878 & TST & \\
\hline CHEMBL1436761 & 688721 & 4.8 & 5.12700 & 0000000001 & TRN \\
\hline CHEMBL444376 & 688721 & 4.5 & 4.9349 & TRN & \\
\hline CHEMBL1490113 & 688721 & 5.5 & 5.0822 & TST & \\
\hline CHEMBL1510303 & 688721 & 4.6 & 4.998 & TST & \\
\hline CHEMBL1453646 & 688721 & 5.5 & 4.8909 & TRN & \\
\hline CHEMBL1440030 & 688721 & 5.2 & 4.834 & TRN & \\
\hline CHEMBL1378498 & 688721 & 4.5 & 4.9435 & TRN & \\
\hline CHEMBL1345142 & 688721 & 4.5 & 5.1623 & TRN & \\
\hline CHEMBL1560035 & 688721 & 5.7 & 4.7542 & TRN & \\
\hline CHEMBL1359493 & 688721 & 4.4 & 4.9952 & TRN & \\
\hline CHEMBL1369822 & 688721 & 4.8 & 5.20200 & 0000000001 & TRN \\
\hline CHEMBL1439901 & 688721 & 4.7 & 4.9108 & TRN & \\
\hline CHEMBL1414901 & 688721 & 4.6 & 5.0757 & TST & \\
\hline CHEMBL1598994 & 688721 & 4.5 & 5.0385 & TRN & \\
\hline CHEMBL1414184 & 688721 & 4.6 & 4.8241 & TRN & \\
\hline CHEMBL1318544 & 688721 & 5.7 & 5.2623 & TRN & \\
\hline CHEMBL1422801 & 688721 & 5.3 & 4.8947 & TST & \\
\hline CHEMBL1454082 & 688721 & 4.5 & 4.8201 & TRN & \\
\hline CHEMBL1407005 & 688721 & 5.8 & 5.34399 & 9999999999 & TST \\
\hline CHEMBL1360725 & 688721 & 4.6 & 4.9813 & TST & \\
\hline CHEMBL1580636 & 688721 & 4.7 & 4.8398 & TRN & \\
\hline CHEMBL1342999 & 688721 & 4.8 & 4.9779 & TRN & \\
\hline CHEMBL1339818 & 688721 & 4.8 & 4.998 & TRN & \\
\hline CHEMBL1302259 & 688721 & 4.4 & 4.9338 & TRN & \\
\hline CHEMBL1606690 & 688721 & 4.5 & 4.9096 & TST & \\
\hline CHEMBL1525468 & 688721 & 4.8 & 4.7759 & TRN & \\
\hline CHEMBL1420841 & 688721 & 5.0 & 4.8401 & TST & \\
\hline CHEMBL1430852 & 688721 & 4.6 & 4.853 & TRN & \\
\hline CHEMBL1511410 & 688721 & 5.4 & 5.069 & TRN & \\
\hline CHEMBL1301322 & 688721 & 5.4 & 4.8739 & TRN & \\
\hline CHEMBL1439292 & 688721 & 4.4 & 4.9213 & TST & \\
\hline CHEMBL1359989 & 688721 & 5.5 & 4.8478 & TRN & \\
\hline CHEMBL1342504 & 688721 & 4.5 & 5.0676 & TRN & \\
\hline CHEMBL1485957 & 688721 & 4.8 & 4.8423 & TRN & \\
\hline CHEMBL1448249 & 688721 & 5.2 & 5.0652 & TRN & \\
\hline CHEMBL1358837 & 688721 & 4.5 & 5.0715 & TRN & \\
\hline CHEMBL1455186 & 688721 & 4.4 & 4.9997 & TRN & \\
\hline CHEMBL1510613 & 688721 & 4.4 & 4.8846 & TRN & \\
\hline CHEMBL1592289 & 688721 & 5.5 & 5.092 & TRN & \\
\hline CHEMBL1488055 & 688721 & 7.0 & 4.8373 & TRN & \\
\hline CHEMBL1499044 & 688721 & 5.2 & 4.9137 & TRN & \\
\hline CHEMBL1600612 & 688721 & 5.3 & 5.0839 & TRN & \\
\hline CHEMBL1467135 & 688721 & 4.4 & 4.9972 & TST & \\
\hline
\end{tabular}




\begin{tabular}{|c|c|c|c|c|}
\hline & & & & al Ta \\
\hline CHEMBL1501331 & 688721 & 6.8 & 5.002 & TRN \\
\hline CHEMBL1445973 & 688721 & 4.6 & 4.7522 & TRN \\
\hline CHEMBL1602322 & 688721 & 4.8 & 4.8855 & TRN \\
\hline CHEMBL1460670 & 688721 & 4.9 & 4.961 & TST \\
\hline CHEMBL1575586 & 688721 & 4.5 & 4.8429 & TRN \\
\hline CHEMBL1310661 & 688721 & 5.2 & 4.8705 & TRN \\
\hline CHEMBL1602975 & 688721 & 4.8 & 4.8223 & TRN \\
\hline CHEMBL1563443 & 688721 & 4.4 & 4.9082 & TRN \\
\hline CHEMBL1591219 & 688721 & 6.9 & 5.4704 & TRN \\
\hline CHEMBL1568562 & 688721 & 6.8 & 5.0032 & TST \\
\hline CHEMBL1312239 & 688721 & 4.7 & 4.9147 & TST \\
\hline CHEMBL1451493 & 688721 & 6.1 & 5.0499 & TRN \\
\hline CHEMBL1341689 & 688721 & 5.5 & 5.0035 & TST \\
\hline CHEMBL1364243 & 688721 & 6.0 & 5.0261 & TRN \\
\hline CHEMBL1583701 & 688721 & 4.7 & 4.8283 & TRN \\
\hline CHEMBL1567017 & 688721 & 4.6 & 4.9459 & TRN \\
\hline CHEMBL1323648 & 688721 & 6.0 & 5.11100 & 0000000001 \\
\hline CHEMBL1433289 & 688721 & 4.8 & 4.935 & TST \\
\hline CHEMBL1372166 & 688721 & 4.5 & 4.935 & TRN \\
\hline CHEMBL1420830 & 688721 & 4.4 & 5.0795 & TST \\
\hline CHEMBL1447825 & 688721 & 4.6 & 5.0335 & TRN \\
\hline CHEMBL1488210 & 688721 & 5.1 & 5.001 & TRN \\
\hline CHEMBL1332509 & 688721 & 5.4 & 4.835 & TRN \\
\hline CHEMBL1381730 & 688721 & 4.6 & 4.8785 & TRN \\
\hline CHEMBL1573605 & 688721 & 4.6 & 4.8516 & TRN \\
\hline CHEMBL1381518 & 688721 & 4.7 & 4.8206 & TRN \\
\hline CHEMBL1400207 & 688721 & 4.4 & 4.9482 & TRN \\
\hline CHEMBL1442216 & 688721 & 4.4 & 4.9285 & TRN \\
\hline CHEMBL1412990 & 688721 & 4.6 & 4.894 & TRN \\
\hline CHEMBL1608159 & 688721 & 6.1 & 5.3293 & TRN \\
\hline CHEMBL1409553 & 688721 & 5.0 & 4.9503 & TRN \\
\hline CHEMBL1513699 & 688721 & 4.4 & 5.1066 & TRN \\
\hline CHEMBL1564428 & 688721 & 4.4 & 4.8698 & TST \\
\hline CHEMBL1610082 & 688721 & 4.6 & 4.8792 & TRN \\
\hline CHEMBL1464918 & 688721 & 4.6 & 4.845 & TRN \\
\hline CHEMBL1536861 & 688721 & 4.6 & 4.7521 & TRN \\
\hline CHEMBL1524432 & 688721 & 4.7 & 4.7956 & TRN \\
\hline CHEMBL274438 & 688721 & 5.1 & 4.9794 & TST \\
\hline CHEMBL153036 & 688721 & 6.0 & 5.1967 & TST \\
\hline CHEMBL1558384 & 688721 & 7.0 & 5.1661 & TRN \\
\hline CHEMBL1606924 & 688721 & 4.6 & 5.0123 & TST \\
\hline CHEMBL1503334 & 688721 & 4.9 & 5.3818 & TST \\
\hline CHEMBL1438070 & 688721 & 4.7 & 4.9124 & TRN \\
\hline CHEMBL1432339 & 688721 & 4.7 & 4.8428 & TRN \\
\hline CHEMBL1580319 & 688721 & 4.9 & 4.9543 & TST \\
\hline CHEMBL1471350 & 688721 & 4.4 & 4.8224 & TST \\
\hline CHEMBL1533805 & 688721 & 4.8 & 4.7043 & TRN \\
\hline CHEMBL 3209201 & 688721 & 5.2 & 5.2882 & TST \\
\hline
\end{tabular}




\begin{tabular}{|c|c|c|c|c|c|}
\hline \multirow{3}{*}{$\begin{array}{l}\text { CHEMBL1467582 } \\
\text { CHEMBL } 1473379\end{array}$} & \multirow[b]{2}{*}{688721} & \multicolumn{4}{|c|}{ Supplemental Table S2.txt } \\
\hline & & 4.4 & 4.8039 & 9999999999 & TRN \\
\hline & 688721 & 6.5 & 5.0767 & TRN & \\
\hline CHEMBL1477367 & 688721 & 4.4 & 5.3459 & TRN & \\
\hline CHEMBL1599276 & 688721 & 5.3 & 4.9313 & TRN & \\
\hline CHEMBL1547605 & 688721 & 4.8 & 4.7781 & TRN & \\
\hline CHEMBL32307 & 688721 & 5.1 & 5.3688 & TRN & \\
\hline CHEMBL1557460 & 688721 & 5.2 & 4.9067 & TST & \\
\hline CHEMBL1363940 & 688721 & 4.8 & 4.8943 & TRN & \\
\hline CHEMBL1550750 & 688721 & 4.6 & 4.8588 & TRN & \\
\hline CHEMBL1525767 & 688721 & 4.8 & 4.9984 & TRN & \\
\hline CHEMBL1449935 & 688721 & 4.8 & 4.6937 & TRN & \\
\hline CHEMBL1454662 & 688721 & 4.4 & 4.6913 & TRN & \\
\hline CHEMBL1337619 & 688721 & 4.5 & 4.9665 & TRN & \\
\hline CHEMBL1485700 & 688721 & 4.4 & 4.8874 & TRN & \\
\hline CHEMBL1537275 & 688721 & 4.9 & 4.988 & TST & \\
\hline CHEMBL1332841 & 688721 & 4.4 & 4.8738 & TRN & \\
\hline CHEMBL1311673 & 688721 & 5.9 & 4.9351 & TRN & \\
\hline CHEMBL1472880 & 688721 & 5.8 & 5.1463 & TRN & \\
\hline CHEMBL1463919 & 688721 & 4.8 & 4.9868 & TRN & \\
\hline CHEMBL1417302 & 688721 & 4.7 & 4.9262 & TRN & \\
\hline CHEMBL1530687 & 688721 & 4.5 & 4.8791 & TRN & \\
\hline CHEMBL1456714 & 688721 & 4.4 & 4.8632 & TRN & \\
\hline CHEMBL1538288 & 688721 & 6.1 & 5.1121 & TST & \\
\hline CHEMBL1414417 & 688721 & 5.1 & 4.8033 & TRN & \\
\hline CHEMBL1335392 & 688721 & 5.5 & 4.8061 & TRN & \\
\hline CHEMBL1606763 & 688721 & 4.5 & 5.1147 & TST & \\
\hline CHEMBL1566779 & 688721 & 5.5 & 5.0834 & TST & \\
\hline CHEMBL 721 & 688721 & 4.4 & 5.2538 & TST & \\
\hline CHEMBL1305660 & 688721 & 4.5 & 4.6201 & TRN & \\
\hline CHEMBL1312848 & 688721 & 5.4 & 5.2075 & TRN & \\
\hline CHEMBL1565741 & 688721 & 5.1 & 5.1707 & TRN & \\
\hline CHEMBL1491453 & 688721 & 4.5 & 4.7838 & TST & \\
\hline CHEMBL1563656 & 688721 & 5.4 & 5.149 & TRN & \\
\hline CHEMBL1464550 & 688721 & 4.6 & 4.9104 & TRN & \\
\hline CHEMBL1572017 & 688721 & 4.7 & 4.8989 & TST & \\
\hline CHEMBL290943 & 688721 & 4.4 & 5.3258 & TST & \\
\hline CHEMBL1359027 & 688721 & 4.9 & 4.8227 & TRN & \\
\hline CHEMBL1405122 & 688721 & 6.0 & 5.2926 & TST & \\
\hline CHEMBL1344285 & 688721 & 4.6 & 4.9479 & TRN & \\
\hline CHEMBL1554982 & 688721 & 4.8 & 5.1418 & TRN & \\
\hline CHEMBL1400095 & 688721 & 4.6 & 4.8692 & TRN & \\
\hline CHEMBL1524448 & 688721 & 4.6 & 4.9203 & TRN & \\
\hline CHEMBL1361543 & 688721 & 4.5 & 5.0564 & TRN & \\
\hline CHEMBL1574882 & 688721 & 6.9 & 5.2745 & TRN & \\
\hline CHEMBL1530777 & 688721 & 4.9 & 5.1136 & TST & \\
\hline CHEMBL1490232 & 688721 & 4.8 & 4.7471 & TRN & \\
\hline CHEMBL1504411 & 688721 & 4.4 & 4.8803 & TRN & \\
\hline CHEMBL1413914 & 688721 & 6.8 & 5.0633 & TRN & \\
\hline
\end{tabular}




\begin{tabular}{|c|c|c|c|c|c|}
\hline \\
\hline CHEMBL1426084 & 688721 & 5.4 & 5.025 & TRN & \\
\hline CHEMBL1463777 & 688721 & 4.6 & 5.0003 & TRN & \\
\hline CHEMBL1607465 & 688721 & 5.3 & 5.1383 & TRN & \\
\hline CHEMBL1542929 & 688721 & 5.2 & 4.9858 & TST & \\
\hline CHEMBL1409217 & 688721 & 5.1 & 4.9644 & TRN & \\
\hline CHEMBL1572658 & 688721 & 4.8 & 4.783 & TRN & \\
\hline CHEMBL1321143 & 688721 & 5.0 & 4.7456 & TST & \\
\hline CHEMBL1334256 & 688721 & 5.2 & 4.9048 & TST & \\
\hline CHEMBL3190009 & 688721 & 4.5 & 4.8738 & TRN & \\
\hline CHEMBL1609150 & 688721 & 4.6 & 4.9471 & TRN & \\
\hline CHEMBL1549341 & 688721 & 4.4 & 4.8984 & TRN & \\
\hline CHEMBL1459324 & 688721 & 4.8 & 4.9015 & TRN & \\
\hline CHEMBL1373113 & 688721 & 5.2 & 4.8054 & TRN & \\
\hline CHEMBL1334425 & 688721 & 4.5 & 4.8559 & TRN & \\
\hline CHEMBL1568484 & 688721 & 4.6 & 4.8883 & TRN & \\
\hline CHEMBL1611224 & 688721 & 4.6 & 5.2562 & TRN & \\
\hline CHEMBL1550335 & 688721 & 4.6 & 4.9114 & TRN & \\
\hline CHEMBL1592754 & 688721 & 5.5 & 5.1544 & TRN & \\
\hline CHEMBL1589673 & 688721 & 4.8 & 4.9629 & TRN & \\
\hline CHEMBL1428859 & 688721 & 5.0 & 4.80699 & 99999999995 & TRN \\
\hline CHEMBL1526228 & 688721 & 4.4 & 5.1442 & TST & \\
\hline CHEMBL1496947 & 688721 & 5.1 & 4.9679 & TRN & \\
\hline CHEMBL1567516 & 688721 & 5.9 & 5.085 & TST & \\
\hline CHEMBL1427957 & 688721 & 4.8 & 4.9813 & TRN & \\
\hline CHEMBL1313005 & 688721 & 4.5 & 4.8632 & TST & \\
\hline CHEMBL1600661 & 688721 & 4.4 & 5.0473 & TST & \\
\hline CHEMBL1428587 & 688721 & 5.1 & 5.1073 & TRN & \\
\hline CHEMBL1317373 & 688721 & 5.5 & 5.1192 & TRN & \\
\hline CHEMBL1530122 & 688721 & 4.5 & 4.6771 & TRN & \\
\hline CHEMBL1568200 & 688721 & 4.5 & 4.8862 & TRN & \\
\hline CHEMBL1453703 & 688721 & 5.3 & 4.7201 & TRN & \\
\hline CHEMBL1526198 & 688721 & 4.7 & 4.962 & TRN & \\
\hline CHEMBL1324246 & 688721 & 5.8 & 5.1126 & TRN & \\
\hline CHEMBL1341754 & 688721 & 4.4 & 4.9875 & TRN & \\
\hline CHEMBL1430875 & 688721 & 4.5 & 4.7143 & TRN & \\
\hline CHEMBL1468909 & 688721 & 4.6 & 4.9114 & TRN & \\
\hline CHEMBL1372803 & 688721 & 7.0 & 4.9413 & TRN & \\
\hline CHEMBL1328096 & 688721 & 4.6 & 5.0083 & TST & \\
\hline CHEMBL1496062 & 688721 & 4.8 & 4.7714 & TRN & \\
\hline CHEMBL1343279 & 688721 & 4.7 & 4.7617 & TRN & \\
\hline CHEMBL1504998 & 688721 & 5.3 & 5.0944 & TRN & \\
\hline CHEMBL1517237 & 688721 & 5.2 & 4.8594 & TRN & \\
\hline CHEMBL1550634 & 688721 & 5.2 & 4.9879 & TRN & \\
\hline CHEMBL1606472 & 688721 & 4.6 & 4.9972 & TRN & \\
\hline CHEMBL1540094 & 688721 & 4.4 & 4.9213 & TRN & \\
\hline CHEMBL3208830 & 688721 & 4.8 & 4.9838 & TST & \\
\hline CHEMBL1443948 & 688721 & 4.5 & 5.0415 & TRN & \\
\hline CHEMBL1414327 & 688721 & 4.5 & 4.7401 & TRN & \\
\hline
\end{tabular}




\begin{tabular}{|c|c|c|c|c|}
\hline & & & & al Table \\
\hline CHEMBL1513740 & 688721 & 5.1 & 5.1915 & TRN \\
\hline CHEMBL1335579 & 688721 & 5.3 & 4.8983 & TST \\
\hline CHEMBL1371286 & 688721 & 4.6 & 4.8239 & TST \\
\hline CHEMBL1369854 & 688721 & 4.5 & 4.9369 & TRN \\
\hline CHEMBL1371362 & 688721 & 5.0 & 5.0124 & TST \\
\hline CHEMBL1301227 & 688721 & 5.4 & 4.712 & TRN \\
\hline CHEMBL1603195 & 688721 & 4.4 & 4.9112 & TRN \\
\hline CHEMBL1585192 & 688721 & 4.6 & 5.1288 & TST \\
\hline CHEMBL1351186 & 688721 & 4.7 & 4.8559 & TRN \\
\hline CHEMBL1413954 & 688721 & 5.0 & 4.7921 & TRN \\
\hline CHEMBL1313439 & 688721 & 5.2 & 5.1313 & TST \\
\hline CHEMBL1510910 & 688721 & 6.2 & 5.0931 & TST \\
\hline CHEMBL277498 & 688721 & 6.9 & 5.2411 & TST \\
\hline CHEMBL1501628 & 688721 & 5.0 & 4.9208 & TRN \\
\hline CHEMBL1497581 & 688721 & 5.0 & 4.8648 & TRN \\
\hline CHEMBL1486399 & 688721 & 4.8 & 5.0913 & TRN \\
\hline CHEMBL1584639 & 688721 & 4.4 & 4.9203 & TRN \\
\hline CHEMBL1540416 & 688721 & 5.6 & 5.0915 & TST \\
\hline CHEMBL60718 & 688721 & 4.5 & 4.9492 & TRN \\
\hline CHEMBL1376210 & 688721 & 4.4 & 5.0218 & TRN \\
\hline CHEMBL1354011 & 688721 & 4.7 & 4.8145 & TRN \\
\hline CHEMBL1609957 & 688721 & 4.7 & 4.981 & TRN \\
\hline CHEMBL 225510 & 688721 & 4.5 & 5.01399 & 9999999999 \\
\hline CHEMBL1343980 & 688721 & 4.6 & 4.9525 & TRN \\
\hline CHEMBL1485770 & 688721 & 5.0 & 4.9015 & TRN \\
\hline CHEMBL3208967 & 688721 & 5.1 & 4.8534 & TST \\
\hline CHEMBL1300881 & 688721 & 4.8 & 4.8039 & TRN \\
\hline CHEMBL1323759 & 688721 & 4.6 & 5.0301 & TRN \\
\hline CHEMBL1467483 & 688721 & 4.4 & 4.9599 & TRN \\
\hline CHEMBL1508526 & 688721 & 5.2 & 5.1233 & TRN \\
\hline CHEMBL1564003 & 688721 & 4.5 & 4.9138 & TRN \\
\hline CHEMBL1340251 & 688721 & 4.6 & 4.9273 & TRN \\
\hline CHEMBL1335502 & 688721 & 4.7 & 4.8873 & TRN \\
\hline CHEMBL1598623 & 688721 & 4.4 & 4.8797 & TRN \\
\hline CHEMBL1352501 & 688721 & 4.7 & 4.8885 & TRN \\
\hline CHEMBL1479912 & 688721 & 5.5 & 5.1846 & TRN \\
\hline CHEMBL1368279 & 688721 & 4.6 & 4.939 & TRN \\
\hline CHEMBL1565612 & 688721 & 4.5 & 5.1166 & TRN \\
\hline CHEMBL1557377 & 688721 & 4.5 & 4.9792 & TRN \\
\hline CHEMBL65063 & 688721 & 5.3 & 5.2408 & TRN \\
\hline CHEMBL1565209 & 688721 & 4.9 & 4.7871 & TRN \\
\hline CHEMBL1604968 & 688721 & 4.4 & 4.8279 & TRN \\
\hline CHEMBL1338478 & 688721 & 4.6 & 5.0755 & TST \\
\hline CHEMBL1501260 & 688721 & 4.4 & 4.9593 & TRN \\
\hline CHEMBL1335471 & 688721 & 5.4 & 5.1276 & TRN \\
\hline CHEMBL1484189 & 688721 & 4.6 & 4.9795 & TST \\
\hline CHEMBL467085 & 688721 & 4.5 & 4.9088 & TST \\
\hline CHEMBL1535482 & 688721 & 5.2 & 4.9144 & TRN \\
\hline
\end{tabular}




\begin{tabular}{|c|c|c|c|c|c|}
\hline \multicolumn{6}{|c|}{ Supplemental Table S2.txt } \\
\hline CHEMBL1302158 & 688721 & 4.8 & 4.8013 & TRN & \\
\hline CHEMBL1390658 & 688721 & 4.7 & 4.8596 & TRN & \\
\hline CHEMBL1360179 & 688721 & 4.8 & 4.8139 & TRN & \\
\hline CHEMBL1491101 & 688721 & 4.5 & 4.9067 & TRN & \\
\hline CHEMBL1517745 & 688721 & 5.2 & 5.1007 & TST & \\
\hline CHEMBL1461777 & 688721 & 4.4 & 4.9491 & TST & \\
\hline CHEMBL1535373 & 688721 & 5.5 & 4.9791 & TST & \\
\hline CHEMBL1584211 & 688721 & 5.0 & 4.9407 & TRN & \\
\hline CHEMBL1401860 & 688721 & 4.7 & 4.9501 & TST & \\
\hline CHEMBL1328444 & 688721 & 4.6 & 5.0623 & TRN & \\
\hline CHEMBL1399316 & 688721 & 6.3 & 4.9207 & TST & \\
\hline CHEMBL1332851 & 688721 & 4.5 & 4.8469 & TRN & \\
\hline CHEMBL1477519 & 688721 & 4.6 & 4.8504 & TST & \\
\hline CHEMBL1477524 & 688721 & 4.6 & 4.8436 & TST & \\
\hline CHEMBL1480481 & 688721 & 5.5 & 4.9465 & TRN & \\
\hline CHEMBL1355256 & 688721 & 4.7 & 4.944 & TRN & \\
\hline CHEMBL1305908 & 688721 & 4.6 & 4.9867 & TST & \\
\hline CHEMBL1514272 & 688721 & 4.6 & 5.0143 & TRN & \\
\hline CHEMBL1321132 & 688721 & 4.6 & 4.8981 & TRN & \\
\hline CHEMBL1590616 & 688721 & 4.5 & 5.062 & TRN & \\
\hline CHEMBL271624 & 688721 & 4.6 & 4.76 & TRN & \\
\hline CHEMBL1585431 & 688721 & 5.5 & 5.0415 & TRN & \\
\hline CHEMBL1551899 & 688721 & 4.8 & 5.0738 & TST & \\
\hline CHEMBL1527225 & 688721 & 6.0 & 5.1183 & TRN & \\
\hline CHEMBL1366420 & 688721 & 4.8 & 4.8646 & TRN & \\
\hline CHEMBL1580575 & 688721 & 4.5 & 4.9506 & TRN & \\
\hline CHEMBL1416812 & 688721 & 4.6 & 5.0994 & TRN & \\
\hline CHEMBL1478515 & 688721 & 4.8 & 4.9343 & TRN & \\
\hline CHEMBL1352304 & 688721 & 4.8 & 4.8271 & TRN & \\
\hline CHEMBL1586297 & 688721 & 5.9 & 5.2201 & TST & \\
\hline CHEMBL1379255 & 688721 & 5.5 & 4.9361 & TST & \\
\hline CHEMBL1524095 & 688721 & 4.6 & 4.7617 & TRN & \\
\hline CHEMBL1578528 & 688721 & 4.5 & 4.8536 & TRN & \\
\hline CHEMBL1300058 & 688721 & 4.4 & 5.03600 & 00000000005 & TRN \\
\hline CHEMBL1379075 & 688721 & 5.4 & 5.1087 & TRN & \\
\hline CHEMBL1468928 & 688721 & 4.7 & 4.8851 & TRN & \\
\hline CHEMBL1564190 & 688721 & 4.5 & 5.0816 & TST & \\
\hline CHEMBL1381853 & 688721 & 4.5 & 5.1987 & TRN & \\
\hline CHEMBL1611386 & 688721 & 4.5 & 5.0007 & TST & \\
\hline CHEMBL1347227 & 688721 & 4.6 & 4.7211 & TRN & \\
\hline CHEMBL1335634 & 688721 & 6.0 & 5.3383 & TRN & \\
\hline CHEMBL1360433 & 688721 & 4.5 & 4.8278 & TST & \\
\hline CHEMBL1532973 & 688721 & 4.6 & 4.9227 & TST & \\
\hline CHEMBL1484000 & 688721 & 4.4 & 4.7691 & TRN & \\
\hline CHEMBL1408153 & 688721 & 4.5 & 4.8924 & TST & \\
\hline CHEMBL1606694 & 688721 & 5.2 & 5.1138 & TRN & \\
\hline CHEMBL1364116 & 688721 & 4.5 & 4.949 & TST & \\
\hline CHEMBL1567274 & 688721 & 5.1 & 4.8757 & TRN & \\
\hline
\end{tabular}




\begin{tabular}{|c|c|c|c|c|c|}
\hline \multicolumn{6}{|c|}{ Supplemental Table S2.txt } \\
\hline CHEMBL1574079 & 688721 & 4.8 & 4.976 & TRN & \\
\hline CHEMBL578112 & 688721 & 5.4 & 4.976 & TRN & \\
\hline CHEMBL1393744 & 688721 & 5.5 & 4.9868 & TRN & \\
\hline CHEMBL1490042 & 688721 & 5.9 & 4.9199 & TRN & \\
\hline CHEMBL1378104 & 688721 & 5.2 & 4.9065 & TRN & \\
\hline CHEMBL1569400 & 688721 & 4.6 & 5.1153 & TRN & \\
\hline CHEMBL1508369 & 688721 & 4.4 & 4.9331 & TST & \\
\hline CHEMBL1334682 & 688721 & 4.5 & 5.1025 & TST & \\
\hline CHEMBL1348060 & 688721 & 4.7 & 4.7983 & TRN & \\
\hline CHEMBL1453739 & 688721 & 4.4 & 4.96899 & 9999999999 & TRN \\
\hline CHEMBL1503330 & 688721 & 4.4 & 4.9895 & TRN & \\
\hline CHEMBL1475737 & 688721 & 6.3 & 5.0685 & TRN & \\
\hline CHEMBL1505296 & 688721 & 4.6 & 4.8962 & TRN & \\
\hline CHEMBL1330729 & 688721 & 7.8996 & 5.2895 & TST & \\
\hline CHEMBL1594964 & 688721 & 5.1 & 4.8937 & TRN & \\
\hline CHEMBL1607499 & 688721 & 4.4 & 5.0137 & TST & \\
\hline CHEMBL1457969 & 688721 & 4.5 & 5.0127 & TST & \\
\hline CHEMBL1360852 & 688721 & 4.9 & 4.7724 & TRN & \\
\hline CHEMBL1596231 & 688721 & 4.4 & 4.8337 & TRN & \\
\hline CHEMBL1384956 & 688721 & 4.5 & 4.8257 & TRN & \\
\hline CHEMBL1401483 & 688721 & 4.5 & 5.07100 & 0000000001 & TRN \\
\hline CHEMBL1256667 & 688721 & 4.5 & 5.2356 & TST & \\
\hline CHEMBL1480990 & 688721 & 5.9 & 5.0507 & TRN & \\
\hline CHEMBL1495747 & 688721 & 4.4 & 5.0124 & TRN & \\
\hline CHEMBL1403858 & 688721 & 4.8 & 4.9277 & TRN & \\
\hline CHEMBL1568825 & 688721 & 5.1 & 4.9742 & TRN & \\
\hline CHEMBL3189905 & 688721 & 4.4 & 4.9257 & TRN & \\
\hline CHEMBL1372076 & 688721 & 4.7 & 4.9792 & TST & \\
\hline CHEMBL1424702 & 688721 & 4.5 & 4.8335 & TRN & \\
\hline CHEMBL1520976 & 688721 & 5.2 & 5.2474 & TST & \\
\hline CHEMBL1385229 & 688721 & 7.1002 & 5.1922 & TST & \\
\hline CHEMBL1415442 & 688721 & 4.7 & 4.8653 & TRN & \\
\hline CHEMBL1410385 & 688721 & 6.4 & 4.8665 & TRN & \\
\hline CHEMBL3194890 & 688721 & 5.9 & 4.9139 & TRN & \\
\hline CHEMBL1574558 & 688721 & 4.5 & 4.8245 & TRN & \\
\hline CHEMBL1575066 & 688721 & 4.6 & 4.7704 & TRN & \\
\hline CHEMBL1304272 & 688721 & 4.4 & 4.851 & TST & \\
\hline CHEMBL1525732 & 688721 & 4.5 & 4.8326 & TRN & \\
\hline CHEMBL1543990 & 688721 & 4.4 & 5.0009 & TRN & \\
\hline CHEMBL1573712 & 688721 & 4.7 & 4.95100 & 00000000005 & TRN \\
\hline CHEMBL1373610 & 688721 & 4.6 & 5.1183 & TRN & \\
\hline CHEMBL1335362 & 688721 & 4.9 & 4.8776 & TRN & \\
\hline CHEMBL1470269 & 688721 & 4.9 & 4.8677 & TRN & \\
\hline CHEMBL1369845 & 688721 & 4.4 & 4.8432 & TRN & \\
\hline CHEMBL1456346 & 688721 & 4.5 & 5.3512 & TRN & \\
\hline CHEMBL1509520 & 688721 & 4.7 & 4.9439 & TRN & \\
\hline CHEMBL1459188 & 688721 & 4.7 & 4.9753 & TST & \\
\hline CHEMBL1455866 & 688721 & 4.6 & 5.0446 & TRN & \\
\hline
\end{tabular}




\begin{tabular}{|c|c|c|c|c|c|}
\hline \multicolumn{6}{|c|}{ Supplemental Table S2.txt } \\
\hline CHEMBL1489568 & 688721 & 4.8 & 5.0257 & TRN & \\
\hline CHEMBL1496141 & 688721 & 5.5 & 4.958 & TRN & \\
\hline CHEMBL1445094 & 688721 & 5.5 & 4.874 & TRN & \\
\hline CHEMBL1339329 & 688721 & 4.6 & 5.05699 & 99999999995 & TRN \\
\hline CHEMBL1324334 & 688721 & 5.5 & 5.2677 & TRN & \\
\hline CHEMBL1475924 & 688721 & 5.1 & 5.21200 & 0000000001 & TRN \\
\hline CHEMBL1601980 & 688721 & 5.2 & 4.7742 & TRN & \\
\hline CHEMBL1602481 & 688721 & 4.8 & 4.7569 & TRN & \\
\hline CHEMBL1412163 & 688721 & 4.4 & 4.8923 & TST & \\
\hline CHEMBL1482739 & 688721 & 5.5 & 4.9409 & TRN & \\
\hline CHEMBL1382175 & 688721 & 5.1 & 4.9601 & TRN & \\
\hline CHEMBL1333664 & 688721 & 5.4 & 5.0814 & TRN & \\
\hline CHEMBL1315457 & 688721 & 7.5003 & 5.1409 & TST & \\
\hline CHEMBL1499245 & 688721 & 4.8 & 5.1191 & TST & \\
\hline CHEMBL1559558 & 688721 & 4.4 & 4.7774 & TST & \\
\hline CHEMBL1529534 & 688721 & 4.9 & 4.8195 & TRN & \\
\hline CHEMBL1378036 & 688721 & 4.6 & 4.8814 & TST & \\
\hline CHEMBL3193600 & 688721 & 4.8 & 4.7677 & TST & \\
\hline CHEMBL1575532 & 688721 & 5.4 & 4.9049 & TRN & \\
\hline CHEMBL1500436 & 688721 & 4.6 & 4.7514 & TRN & \\
\hline CHEMBL1517243 & 688721 & 4.6 & 4.7729 & TRN & \\
\hline CHEMBL1524613 & 688721 & 5.2 & 5.0224 & TRN & \\
\hline CHEMBL1539531 & 688721 & 7.5003 & 4.9296 & TST & \\
\hline CHEMBL1538076 & 688721 & 4.7 & 5.1464 & TST & \\
\hline CHEMBL1554170 & 688721 & 4.8 & 5.2206 & TRN & \\
\hline CHEMBL1466937 & 688721 & 4.8 & 4.9857 & TST & \\
\hline CHEMBL1356624 & 688721 & 7.0 & 5.0581 & TRN & \\
\hline CHEMBL1563607 & 688721 & 4.4 & 4.9238 & TRN & \\
\hline CHEMBL1496527 & 688721 & 4.4 & 4.9059 & TRN & \\
\hline CHEMBL1353698 & 688721 & 4.5 & 4.9102 & TRN & \\
\hline CHEMBL1304008 & 688721 & 4.8 & 4.7376 & TRN & \\
\hline CHEMBL1437139 & 688721 & 7.6003 & 5.2733 & TRN & \\
\hline CHEMBL1540676 & 688721 & 5.2 & 5.0518 & TST & \\
\hline CHEMBL1381929 & 688721 & 5.9 & 4.9985 & TRN & \\
\hline CHEMBL1487133 & 688721 & 5.0 & 4.8673 & TRN & \\
\hline CHEMBL1417922 & 688721 & 4.6 & 4.8128 & TRN & \\
\hline CHEMBL1405544 & 688721 & 4.5 & 4.8482 & TRN & \\
\hline CHEMBL1507273 & 688721 & 4.9 & 5.0733 & TST & \\
\hline CHEMBL1343906 & 688721 & 4.7 & 4.846 & TST & \\
\hline CHEMBL1451347 & 688721 & 4.6 & 4.9437 & TRN & \\
\hline CHEMBL1347975 & 688721 & 5.6 & 5.0632 & TST & \\
\hline CHEMBL1384728 & 688721 & 5.0 & 4.8586 & TRN & \\
\hline CHEMBL1419106 & 688721 & 4.6 & 4.9218 & TRN & \\
\hline CHEMBL1366718 & 688721 & 4.5 & 4.8817 & TRN & \\
\hline CHEMBL1348213 & 688721 & 5.2 & 4.9376 & TST & \\
\hline CHEMBL1612410 & 688721 & 4.4 & 5.1185 & TRN & \\
\hline CHEMBL1538628 & 688721 & 5.5 & 4.9372 & TRN & \\
\hline CHEMBL1299992 & 688721 & 4.6 & 4.7989 & TRN & \\
\hline
\end{tabular}




\begin{tabular}{|c|c|c|c|c|c|}
\hline \multicolumn{6}{|c|}{ Supplemental Table S2.txt } \\
\hline CHEMBL1534361 & 688721 & 6.0 & 4.9533 & TRN & \\
\hline CHEMBL1437747 & 688721 & 4.6 & 5.2341 & TRN & \\
\hline CHEMBL1579276 & 688721 & 5.3 & 4.9437 & TRN & \\
\hline CHEMBL1600269 & 688721 & 5.7 & 5.0433 & TRN & \\
\hline CHEMBL37312 & 688721 & 4.4 & 4.9551 & TST & \\
\hline CHEMBL1323628 & 688721 & 4.7 & 5.0008 & TRN & \\
\hline CHEMBL1467636 & 688721 & 4.5 & 4.8084 & TRN & \\
\hline CHEMBL1333083 & 688721 & 4.7 & 4.9512 & TRN & \\
\hline CHEMBL1548600 & 688721 & 4.9 & 4.8975 & TRN & \\
\hline CHEMBL1442458 & 688721 & 4.6 & 4.9978 & TRN & \\
\hline CHEMBL1612536 & 688721 & 4.4 & 4.9644 & TRN & \\
\hline CHEMBL491953 & 688721 & 5.6 & 4.9648 & TRN & \\
\hline CHEMBL1446372 & 688721 & 5.2 & 5.0726 & TRN & \\
\hline CHEMBL1570597 & 688721 & 5.5 & 4.7827 & TRN & \\
\hline CHEMBL1570863 & 688721 & 4.8 & 4.6937 & TRN & \\
\hline CHEMBL1532701 & 688721 & 5.0 & 4.9143 & TST & \\
\hline CHEMBL1547865 & 688721 & 4.4 & 4.9194 & TRN & \\
\hline CHEMBL1587649 & 688721 & 4.8 & 4.6904 & TRN & \\
\hline CHEMBL1479264 & 688721 & 5.6 & 4.9508 & TRN & \\
\hline CHEMBL1321786 & 688721 & 4.5 & 4.8055 & TST & \\
\hline CHEMBL1510097 & 688721 & 4.6 & 4.9709 & TRN & \\
\hline CHEMBL164747 & 688721 & 5.4 & 5.0504 & TST & \\
\hline CHEMBL1409297 & 688721 & 5.1 & 4.9257 & TST & \\
\hline CHEMBL1409763 & 688721 & 4.4 & 4.8808 & TRN & \\
\hline CHEMBL1577715 & 688721 & 4.7 & 4.7729 & TRN & \\
\hline CHEMBL1415887 & 688721 & 4.4 & 5.0921 & TRN & \\
\hline CHEMBL1547159 & 688721 & 7.0 & 5.0591 & TST & \\
\hline CHEMBL1382121 & 688721 & 4.5 & 4.8244 & TRN & \\
\hline CHEMBL1411560 & 688721 & 4.5 & 4.7576 & TRN & \\
\hline CHEMBL1470847 & 688721 & 4.4 & 4.7053 & TRN & \\
\hline CHEMBL1443043 & 688721 & 4.4 & 4.974 & TRN & \\
\hline CHEMBL 267476 & 688721 & 4.5 & 5.3508 & TRN & \\
\hline CHEMBL1379250 & 688721 & 4.5 & 5.0181 & TRN & \\
\hline CHEMBL1550861 & 688721 & 4.4 & 5.0444 & TRN & \\
\hline CHEMBL1471148 & 688721 & 4.4 & 4.9002 & TRN & \\
\hline CHEMBL1358860 & 688721 & 5.9 & 5.0358 & TST & \\
\hline CHEMBL1522315 & 688721 & 4.5 & 4.9827 & TRN & \\
\hline CHEMBL1398927 & 688721 & 5.3 & 5.0291 & TRN & \\
\hline CHEMBL1478951 & 688721 & 4.5 & 5.084 & TRN & \\
\hline CHEMBL1470340 & 688721 & 4.8 & 4.7447 & TRN & \\
\hline CHEMBL1527961 & 688721 & 4.7 & 4.8828 & TRN & \\
\hline CHEMBL1322017 & 688721 & 4.7 & 4.84699 & 99999999995 & TRN \\
\hline CHEMBL1564653 & 688721 & 6.4 & 5.1903 & TRN & \\
\hline CHEMBL1412847 & 688721 & 4.9 & 5.0774 & TRN & \\
\hline CHEMBL1414719 & 688721 & 4.5 & 4.8454 & TRN & \\
\hline CHEMBL1380462 & 688721 & 5.1 & 5.0967 & TRN & \\
\hline CHEMBL1373401 & 688721 & 4.5 & 4.9423 & TRN & \\
\hline CHEMBL1426209 & 688721 & 4.5 & 5.1125 & TRN & \\
\hline
\end{tabular}




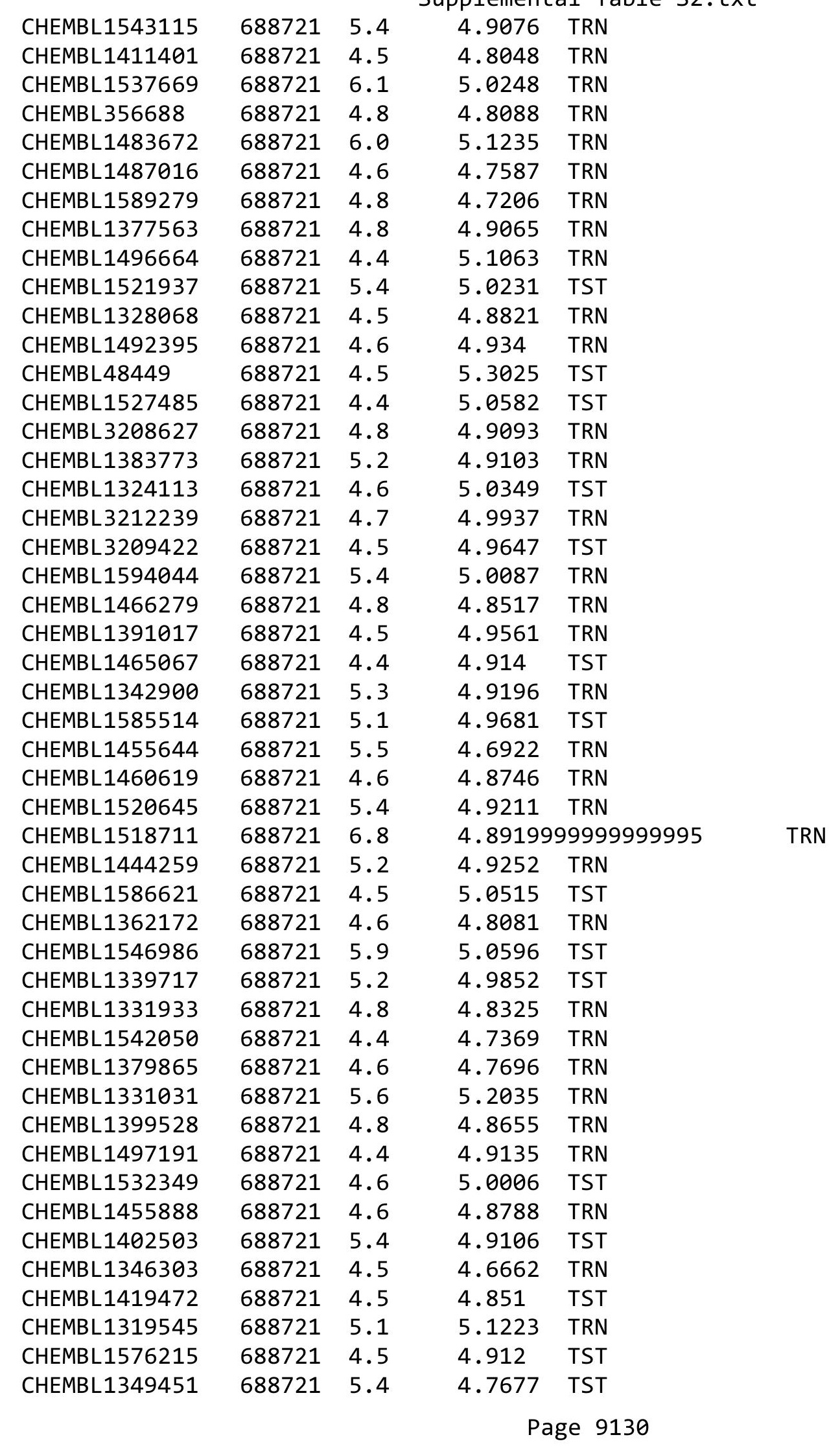




\begin{tabular}{|c|c|c|c|c|c|}
\hline \multicolumn{6}{|c|}{ Supplemental Table S2.txt } \\
\hline CHEMBL1164301 & 688721 & 4.4 & 5.0414 & TRN & \\
\hline CHEMBL1427976 & 688721 & 4.7 & 4.9283 & TRN & \\
\hline CHEMBL1487022 & 688721 & 4.6 & 4.9562 & TRN & \\
\hline CHEMBL1411000 & 688721 & 7.6003 & 5.0577 & TRN & \\
\hline CHEMBL1577194 & 688721 & 4.4 & 4.8442 & TST & \\
\hline CHEMBL1525388 & 688721 & 6.6 & 5.3138 & TRN & \\
\hline CHEMBL1612923 & 688721 & 4.6 & 4.9119 & TST & \\
\hline CHEMBL1599147 & 688721 & 5.1 & 5.1368 & TRN & \\
\hline CHEMBL1421053 & 688721 & 4.5 & 4.8874 & TRN & \\
\hline CHEMBL1326066 & 688721 & 4.5 & 4.7435 & TRN & \\
\hline CHEMBL1453742 & 688721 & 4.7 & 4.9066 & TRN & \\
\hline CHEMBL1412045 & 688721 & 5.6 & 4.9114 & TRN & \\
\hline CHEMBL1300164 & 688721 & 4.5 & 5.0158 & TRN & \\
\hline CHEMBL1307720 & 688721 & 4.4 & 4.8372 & TRN & \\
\hline CHEMBL1460749 & 688721 & 4.5 & 4.8794 & TST & \\
\hline CHEMBL1516573 & 688721 & 4.4 & 5.1271 & TST & \\
\hline CHEMBL1383762 & 688721 & 5.5 & 4.8366 & TRN & \\
\hline CHEMBL1520949 & 688721 & 4.4 & 5.0487 & TST & \\
\hline CHEMBL1497417 & 688721 & 6.5 & 4.9721 & TRN & \\
\hline CHEMBL1521693 & 688721 & 4.4 & 5.0341 & TRN & \\
\hline CHEMBL1509527 & 688721 & 6.1 & 5.0049 & TRN & \\
\hline CHEMBL1463780 & 688721 & 4.5 & 4.7897 & TRN & \\
\hline CHEMBL1609622 & 688721 & 4.7 & 4.8645 & TRN & \\
\hline CHEMBL1546497 & 688721 & 4.8 & 4.7421 & TRN & \\
\hline CHEMBL375107 & 688721 & 4.4 & 5.2693 & TST & \\
\hline CHEMBL 7463 & 688721 & 4.8 & 4.9769 & TST & \\
\hline CHEMBL1316745 & 688721 & 5.2 & 5.1465 & TRN & \\
\hline CHEMBL1532531 & 688721 & 4.7 & 5.0118 & TRN & \\
\hline CHEMBL1550387 & 688721 & 4.4 & 4.9278 & TRN & \\
\hline CHEMBL1576851 & 688721 & 4.4 & 4.8081 & TRN & \\
\hline CHEMBL1562334 & 688721 & 5.2 & 5.2901 & TST & \\
\hline CHEMBL1336201 & 688721 & 4.6 & 5.0699 & TRN & \\
\hline CHEMBL1604981 & 688721 & 6.0 & 5.17899 & 9999999999 & TRN \\
\hline CHEMBL1334907 & 688721 & 5.5 & 4.9187 & TRN & \\
\hline CHEMBL1473188 & 688721 & 5.1 & 5.0231 & TRN & \\
\hline CHEMBL1489357 & 688721 & 5.4 & 5.2908 & TST & \\
\hline CHEMBL1445893 & 688721 & 4.4 & 4.9516 & TRN & \\
\hline CHEMBL1584144 & 688721 & 5.3 & 4.8693 & TRN & \\
\hline CHEMBL1352896 & 688721 & 4.7 & 4.9986 & TST & \\
\hline CHEMBL1559999 & 688721 & 4.6 & 4.7827 & TRN & \\
\hline CHEMBL1305232 & 688721 & 4.4 & 4.9593 & TRN & \\
\hline CHEMBL1549992 & 688721 & 4.4 & 4.8194 & TRN & \\
\hline CHEMBL1587226 & 688721 & 4.8 & 4.923 & TST & \\
\hline CHEMBL1528992 & 688721 & 4.8 & 4.8054 & TRN & \\
\hline CHEMBL1479372 & 688721 & 5.6 & 5.1045 & TRN & \\
\hline CHEMBL1387014 & 688721 & 4.6 & 4.7963 & TRN & \\
\hline CHEMBL1549201 & 688721 & 5.2 & 5.0408 & TST & \\
\hline CHEMBL1557369 & 688721 & 4.4 & 5.0471 & TRN & \\
\hline
\end{tabular}




\begin{tabular}{|c|c|c|c|c|c|}
\hline \multicolumn{6}{|c|}{ Supplemental Table S2.txt } \\
\hline CHEMBL1323268 & 688721 & 4.6 & 4.8307 & TRN & \\
\hline CHEMBL1547012 & 688721 & 4.5 & 5.1219 & TST & \\
\hline CHEMBL1401387 & 688721 & 5.2 & 5.0153 & TRN & \\
\hline CHEMBL1521677 & 688721 & 5.4 & 5.0266 & TST & \\
\hline CHEMBL1463540 & 688721 & 4.4 & 4.9318 & TRN & \\
\hline CHEMBL1417338 & 688721 & 4.8 & 4.8423 & TRN & \\
\hline CHEMBL1476789 & 688721 & 5.1 & 5.0987 & TRN & \\
\hline CHEMBL1501108 & 688721 & 4.5 & 4.8101 & TRN & \\
\hline CHEMBL1557817 & 688721 & 5.4 & 5.0272 & TRN & \\
\hline CHEMBL1559653 & 688721 & 4.6 & 5.0444 & TRN & \\
\hline CHEMBL1608349 & 688721 & 5.5 & 5.0832 & TRN & \\
\hline CHEMBL1540090 & 688721 & 4.5 & 4.9416 & TST & \\
\hline CHEMBL1315820 & 688721 & 5.5 & 5.0715 & TRN & \\
\hline CHEMBL1482847 & 688721 & 5.2 & 5.0986 & TRN & \\
\hline CHEMBL1368545 & 688721 & 4.8 & 5.2978 & TST & \\
\hline CHEMBL1488420 & 688721 & 5.4 & 4.8798 & TST & \\
\hline CHEMBL3208184 & 688721 & 5.2 & 4.85800 & 00000000005 & TRN \\
\hline CHEMBL340807 & 688721 & 6.0 & 4.8826 & TST & \\
\hline CHEMBL1432976 & 688721 & 4.8 & 4.9213 & TRN & \\
\hline CHEMBL1362301 & 688721 & 5.3 & 4.922 & TRN & \\
\hline CHEMBL1370398 & 688721 & 4.5 & 4.851 & TST & \\
\hline CHEMBL1319905 & 688721 & 5.0 & 4.9824 & TST & \\
\hline CHEMBL1501415 & 688721 & 5.4 & 4.902 & TRN & \\
\hline CHEMBL1337117 & 688721 & 4.6 & 5.0105 & TRN & \\
\hline CHEMBL1312533 & 688721 & 4.4 & 5.197 & TST & \\
\hline CHEMBL1415693 & 688721 & 4.6 & 4.8249 & TRN & \\
\hline CHEMBL1499215 & 688721 & 4.5 & 4.8587 & TRN & \\
\hline CHEMBL1342690 & 688721 & 4.6 & 4.9955 & TRN & \\
\hline CHEMBL1401360 & 688721 & 5.4 & 4.9737 & TRN & \\
\hline CHEMBL1388275 & 688721 & 4.8 & 4.87 & TRN & \\
\hline CHEMBL73711 & 688721 & 5.0 & 4.7822 & TST & \\
\hline CHEMBL1367658 & 688721 & 4.7 & 4.7993 & TRN & \\
\hline CHEMBL1555567 & 688721 & 5.5 & 5.1666 & TRN & \\
\hline CHEMBL1546387 & 688721 & 4.8 & 4.9725 & TRN & \\
\hline CHEMBL 234926 & 688721 & 4.9 & 5.3038 & TST & \\
\hline CHEMBL1332964 & 688721 & 5.3 & 5.206 & TRN & \\
\hline CHEMBL1444831 & 688721 & 5.3 & 5.2113 & TRN & \\
\hline CHEMBL1415675 & 688721 & 5.3 & 4.7922 & TRN & \\
\hline CHEMBL1370582 & 688721 & 4.8 & 4.7401 & TST & \\
\hline CHEMBL1440392 & 688721 & 4.9 & 5.0749 & TRN & \\
\hline CHEMBL1327950 & 688721 & 5.7 & 4.9327 & TRN & \\
\hline CHEMBL1592517 & 688721 & 4.5 & 5.0845 & TRN & \\
\hline CHEMBL1372884 & 688721 & 4.8 & 5.0234 & TST & \\
\hline CHEMBL1331623 & 688721 & 4.8 & 4.8863 & TRN & \\
\hline CHEMBL1393875 & 688721 & 4.9 & 4.8264 & TRN & \\
\hline CHEMBL1582763 & 688721 & 4.6 & 4.88899 & 9999999999 & TRN \\
\hline CHEMBL1612846 & 688721 & 4.6 & 4.8679 & TRN & \\
\hline CHEMBL1495289 & 688721 & 5.4 & 5.3225 & TRN & \\
\hline
\end{tabular}




\begin{tabular}{|c|c|c|c|c|c|}
\hline \multicolumn{6}{|c|}{ Supplemental Table S2.txt } \\
\hline CHEMBL1544315 & 688721 & 4.8 & 5.015 & TRN & \\
\hline CHEMBL1478 & 688721 & 4.4 & 5.4775 & TRN & \\
\hline CHEMBL1470726 & 688721 & 4.7 & 4.8965 & TRN & \\
\hline CHEMBL1409196 & 688721 & 5.0 & 4.9198 & TRN & \\
\hline CHEMBL1569157 & 688721 & 5.3 & 5.0558 & TST & \\
\hline CHEMBL1609912 & 688721 & 5.2 & 4.8833 & TRN & \\
\hline CHEMBL1302290 & 688721 & 4.6 & 5.1229 & TRN & \\
\hline CHEMBL 335900 & 688721 & 5.5 & 5.2577 & TRN & \\
\hline CHEMBL1584441 & 688721 & 4.9 & 4.9076 & TRN & \\
\hline CHEMBL1494024 & 688721 & 4.6 & 4.967 & TST & \\
\hline CHEMBL1336101 & 688721 & 4.9 & 4.8195 & TST & \\
\hline CHEMBL1488711 & 688721 & 4.6 & 4.8467 & TRN & \\
\hline CHEMBL1442663 & 688721 & 5.6 & 4.9737 & TRN & \\
\hline CHEMBL1321695 & 688721 & 4.7 & 4.9127 & TRN & \\
\hline CHEMBL1340509 & 688721 & 4.4 & 4.7557 & TRN & \\
\hline CHEMBL1430017 & 688721 & 5.1 & 4.9179 & TRN & \\
\hline CHEMBL1449548 & 688721 & 5.8 & 4.8685 & TRN & \\
\hline CHEMBL1613338 & 688721 & 5.2 & 5.1555 & TRN & \\
\hline CHEMBL1343205 & 688721 & 4.5 & 4.9302 & TRN & \\
\hline CHEMBL1327559 & 688721 & 4.5 & 4.7967 & TRN & \\
\hline CHEMBL1587001 & 688721 & 4.5 & 4.7885 & TRN & \\
\hline CHEMBL1387850 & 688721 & 4.4 & 4.9838 & TRN & \\
\hline CHEMBL1386257 & 688721 & 4.8 & 4.9407 & TST & \\
\hline CHEMBL1576161 & 688721 & 4.4 & 5.0276 & TRN & \\
\hline CHEMBL1610181 & 688721 & 4.7 & 5.0288 & TST & \\
\hline CHEMBL1334279 & 688721 & 5.2 & 4.9432 & TRN & \\
\hline CHEMBL1372513 & 688721 & 4.5 & 4.979 & TRN & \\
\hline CHEMBL1321134 & 688721 & 4.5 & 4.942 & TST & \\
\hline CHEMBL1335042 & 688721 & 6.7001 & 5.1219 & TST & \\
\hline CHEMBL1369588 & 688721 & 4.4 & 4.9151 & TST & \\
\hline CHEMBL1554479 & 688721 & 4.8 & 5.4644 & TST & \\
\hline CHEMBL1372043 & 688721 & 5.2 & 4.8866 & TST & \\
\hline CHEMBL1464213 & 688721 & 5.3 & 5.0762 & TST & \\
\hline CHEMBL1463533 & 688721 & 4.4 & 5.16700 & 2000000001 & TRN \\
\hline CHEMBL1407481 & 688721 & 4.6 & 4.8617 & TRN & \\
\hline CHEMBL1483338 & 688721 & 4.6 & 4.8411 & TRN & \\
\hline CHEMBL1519622 & 688721 & 4.6 & 4.8679 & TRN & \\
\hline CHEMBL1309339 & 688721 & 4.9 & 4.8661 & TRN & \\
\hline CHEMBL591834 & 688721 & 5.4 & 5.0098 & TST & \\
\hline CHEMBL1497169 & 688721 & 4.8 & 4.897 & TRN & \\
\hline CHEMBL1575717 & 688721 & 4.4 & 4.8556 & TRN & \\
\hline CHEMBL1555898 & 688721 & 4.6 & 4.8385 & TRN & \\
\hline CHEMBL1417190 & 688721 & 4.8 & 4.9067 & TRN & \\
\hline CHEMBL1401280 & 688721 & 4.5 & 5.1667 & TRN & \\
\hline CHEMBL1558155 & 688721 & 4.8 & 4.9573 & TST & \\
\hline CHEMBL1520982 & 688721 & 5.2 & 5.1025 & TRN & \\
\hline CHEMBL1401209 & 688721 & 4.7 & 4.9048 & TRN & \\
\hline CHEMBL609030 & 688721 & 4.6 & 5.106 & TST & \\
\hline
\end{tabular}




\begin{tabular}{|c|c|c|c|c|c|}
\hline \multicolumn{6}{|c|}{ Supplemental Table S2.txt } \\
\hline CHEMBL1601662 & 688721 & 5.0 & 4.923 & TRN & \\
\hline CHEMBL1465487 & 688721 & 6.1 & 5.0313 & TRN & \\
\hline CHEMBL1594970 & 688721 & 5.7 & 4.9416 & TRN & \\
\hline CHEMBL1402961 & 688721 & 5.2 & 4.7931 & TRN & \\
\hline CHEMBL1495651 & 688721 & 4.9 & 4.9627 & TRN & \\
\hline CHEMBL1362562 & 688721 & 5.4 & 4.9784 & TRN & \\
\hline CHEMBL1606407 & 688721 & 4.6 & 5.2509 & TST & \\
\hline CHEMBL1309821 & 688721 & 4.4 & 4.8832 & TST & \\
\hline CHEMBL1412900 & 688721 & 4.9 & 5.1078 & TRN & \\
\hline CHEMBL1300775 & 688721 & 4.5 & 5.0433 & TST & \\
\hline CHEMBL1429150 & 688721 & 4.9 & 4.8223 & TRN & \\
\hline CHEMBL1467437 & 688721 & 5.3 & 4.80399 & 9999999999 & TRN \\
\hline CHEMBL1316775 & 688721 & 4.4 & 5.1229 & TRN & \\
\hline CHEMBL1546083 & 688721 & 4.9 & 4.8766 & TST & \\
\hline CHEMBL1561943 & 688721 & 6.2 & 4.873 & TRN & \\
\hline CHEMBL1487188 & 688721 & 5.4 & 5.1613 & TRN & \\
\hline CHEMBL1520681 & 688721 & 4.7 & 5.1707 & TRN & \\
\hline CHEMBL1371499 & 688721 & 4.8 & 4.838 & TRN & \\
\hline CHEMBL441282 & 688721 & 6.0 & 5.0965 & TST & \\
\hline CHEMBL1376094 & 688721 & 5.4 & 4.9325 & TRN & \\
\hline CHEMBL1513241 & 688721 & 6.1 & 5.306 & TRN & \\
\hline CHEMBL1378869 & 688721 & 4.5 & 4.9009 & TRN & \\
\hline CHEMBL1350844 & 688721 & 4.4 & 4.97199 & 99999999995 & TRN \\
\hline CHEMBL1523844 & 688721 & 4.6 & 4.8552 & TRN & \\
\hline CHEMBL604119 & 688721 & 5.2 & 5.0068 & TST & \\
\hline CHEMBL1537665 & 688721 & 5.2 & 5.1303 & TST & \\
\hline CHEMBL1518722 & 688721 & 5.2 & 4.9471 & TST & \\
\hline CHEMBL1605585 & 688721 & 4.5 & 4.9153 & TRN & \\
\hline CHEMBL1404781 & 688721 & 4.7 & 4.725 & TRN & \\
\hline CHEMBL1471969 & 688721 & 5.5 & 4.8967 & TST & \\
\hline CHEMBL1256019 & 688721 & 5.4 & 5.3035 & TST & \\
\hline CHEMBL1487087 & 688721 & 4.6 & 4.9511 & TST & \\
\hline CHEMBL1306234 & 688721 & 4.5 & 4.8532 & TRN & \\
\hline CHEMBL1503512 & 688721 & 4.4 & 4.8801 & TRN & \\
\hline CHEMBL 87310 & 688721 & 8.301 & 5.2272 & TST & \\
\hline CHEMBL1520615 & 688721 & 5.3 & 5.1009 & TST & \\
\hline CHEMBL1461480 & 688721 & 4.6 & 5.0079 & TRN & \\
\hline CHEMBL602807 & 688721 & 4.4 & 4.8722 & TRN & \\
\hline CHEMBL1490842 & 688721 & 4.8 & 4.9959 & TRN & \\
\hline CHEMBL1308495 & 688721 & 5.2 & 4.9541 & TRN & \\
\hline CHEMBL1393510 & 688721 & 4.6 & 5.0352 & TRN & \\
\hline CHEMBL1505711 & 688721 & 4.8 & 4.6976 & TRN & \\
\hline CHEMBL1499300 & 688721 & 4.8 & 4.9356 & TRN & \\
\hline CHEMBL1608949 & 688721 & 4.7 & 4.9192 & TRN & \\
\hline CHEMBL1305160 & 688721 & 4.4 & 5.232 & TST & \\
\hline CHEMBL1318310 & 688721 & 4.8 & 4.8332 & TRN & \\
\hline CHEMBL1308944 & 688721 & 4.5 & 5.0317 & TRN & \\
\hline CHEMBL1352954 & 688721 & 6.4 & 4.9853 & TRN & \\
\hline
\end{tabular}




\begin{tabular}{|c|c|c|c|c|c|}
\hline & & & & & \\
\hline CHEMBL1450981 & 688721 & 5.6 & 4.8498 & TRN & \\
\hline CHEMBL402063 & 688721 & 4.8 & 5.3472 & TRN & \\
\hline CHEMBL1414710 & 688721 & 5.0 & 4.8885 & TRN & \\
\hline CHEMBL1469929 & 688721 & 5.2 & 5.0373 & TRN & \\
\hline CHEMBL1456526 & 688721 & 5.8 & 4.8261 & TRN & \\
\hline CHEMBL1308012 & 688721 & 4.5 & 5.0704 & TRN & \\
\hline CHEMBL1424962 & 688721 & 4.6 & 4.84 & TRN & \\
\hline CHEMBL1399977 & 688721 & 4.6 & 4.8871 & TRN & \\
\hline CHEMBL1587831 & 688721 & 4.4 & 4.9976 & TST & \\
\hline CHEMBL1534422 & 688721 & 4.4 & 4.90600 & 0000000001 & TRN \\
\hline CHEMBL1302222 & 688721 & 4.7 & 4.7744 & TST & \\
\hline CHEMBL1447880 & 688721 & 4.4 & 5.0437 & TST & \\
\hline CHEMBL1335318 & 688721 & 4.8 & 4.8555 & TRN & \\
\hline CHEMBL1437851 & 688721 & 4.5 & 5.0316 & TRN & \\
\hline CHEMBL1498172 & 688721 & 4.6 & 4.797 & TRN & \\
\hline CHEMBL1385434 & 688721 & 4.4 & 4.9455 & TRN & \\
\hline CHEMBL1345862 & 688721 & 5.0 & 4.851 & TRN & \\
\hline CHEMBL1520338 & 688721 & 5.3 & 4.9488 & TRN & \\
\hline CHEMBL1471099 & 688721 & 5.5 & 4.7328 & TRN & \\
\hline CHEMBL1482575 & 688721 & 5.6 & 5.1702 & TRN & \\
\hline CHEMBL1364538 & 688721 & 4.6 & 4.9438 & TRN & \\
\hline CHEMBL1475990 & 688721 & 4.4 & 4.9201 & TRN & \\
\hline CHEMBL1369959 & 688721 & 5.5 & 4.9475 & TST & \\
\hline CHEMBL1320983 & 688721 & 4.6 & 4.6965 & TRN & \\
\hline CHEMBL1571862 & 688721 & 6.1 & 5.0383 & TRN & \\
\hline CHEMBL1484196 & 688721 & 4.8 & 5.1176 & TRN & \\
\hline CHEMBL1445455 & 688721 & 6.2 & 5.0656 & TRN & \\
\hline CHEMBL1429456 & 688721 & 4.4 & 4.832 & TRN & \\
\hline CHEMBL1331292 & 688721 & 4.4 & 4.9845 & TST & \\
\hline CHEMBL1525663 & 688721 & 5.8 & 4.8941 & TRN & \\
\hline CHEMBL1405782 & 688721 & 4.9 & 4.7724 & TRN & \\
\hline CHEMBL1528513 & 688721 & 4.6 & 4.9974 & TRN & \\
\hline CHEMBL 1406020 & 688721 & 5.3 & 4.9297 & TRN & \\
\hline CHEMBL1336509 & 688721 & 4.5 & 4.8715 & TRN & \\
\hline CHEMBL2373579 & 688721 & 4.6 & 5.2096 & TRN & \\
\hline CHEMBL1419334 & 688721 & 4.6 & 4.9433 & TRN & \\
\hline CHEMBL1362390 & 688721 & 4.8 & 5.1479 & TST & \\
\hline CHEMBL1312641 & 688721 & 6.1 & 4.9839 & TRN & \\
\hline CHEMBL1569541 & 688721 & 4.5 & 4.8873 & TRN & \\
\hline CHEMBL1410827 & 688721 & 5.0 & 5.0927 & TST & \\
\hline CHEMBL1339942 & 688721 & 4.7 & 4.7716 & TRN & \\
\hline CHEMBL1479899 & 688721 & 4.4 & 4.9228 & TRN & \\
\hline CHEMBL1417025 & 688721 & 6.1 & 5.1448 & TRN & \\
\hline CHEMBL1386350 & 688721 & 4.7 & 4.8709 & TST & \\
\hline CHEMBL1526723 & 688721 & 4.5 & 4.9907 & TRN & \\
\hline CHEMBL1442619 & 688721 & 4.6 & 4.7459 & TRN & \\
\hline CHEMBL1444847 & 688721 & 5.2 & 4.8087 & TRN & \\
\hline CHEMBL1576517 & 688721 & 5.5 & 5.0252 & TST & \\
\hline
\end{tabular}




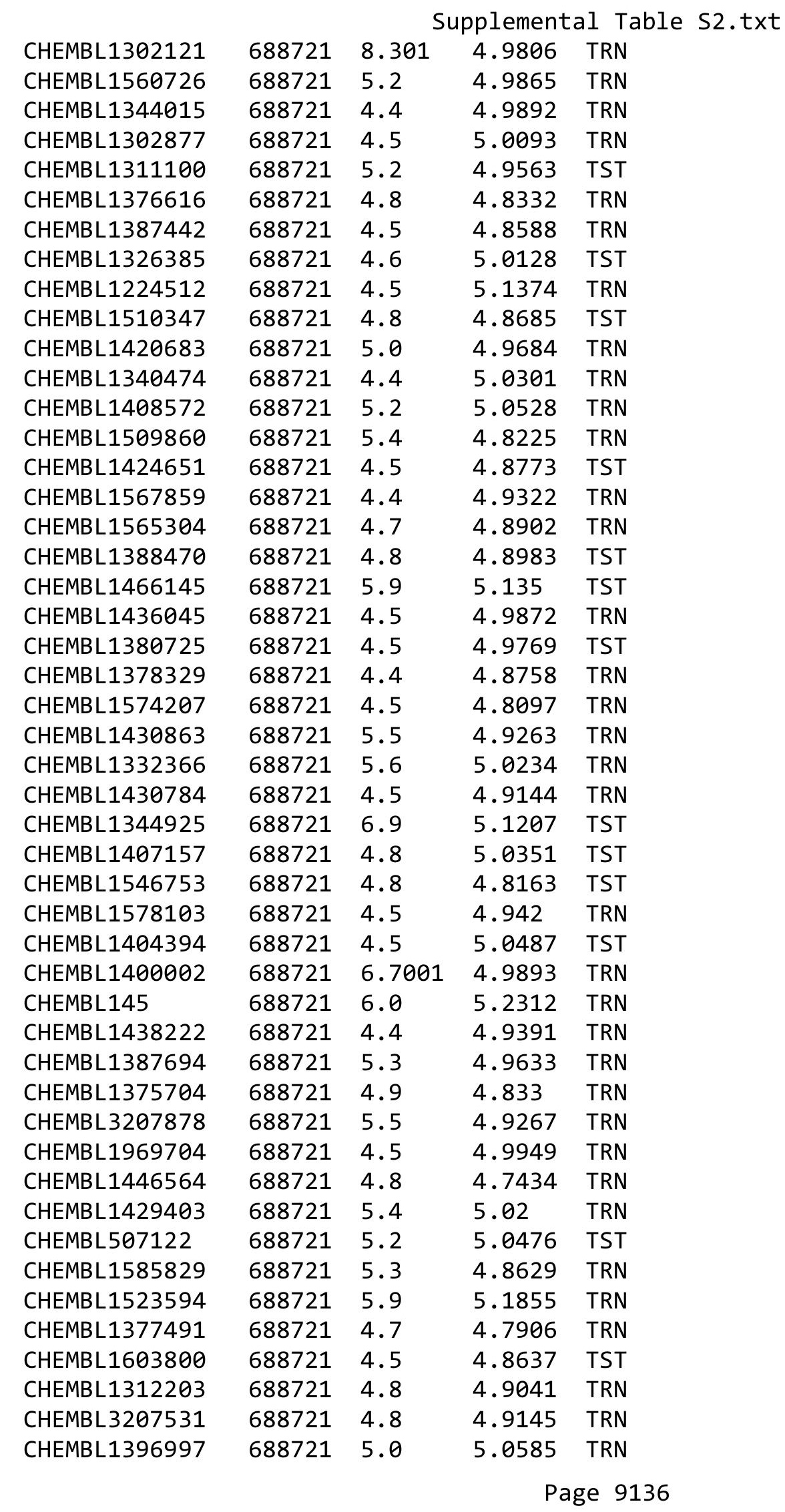




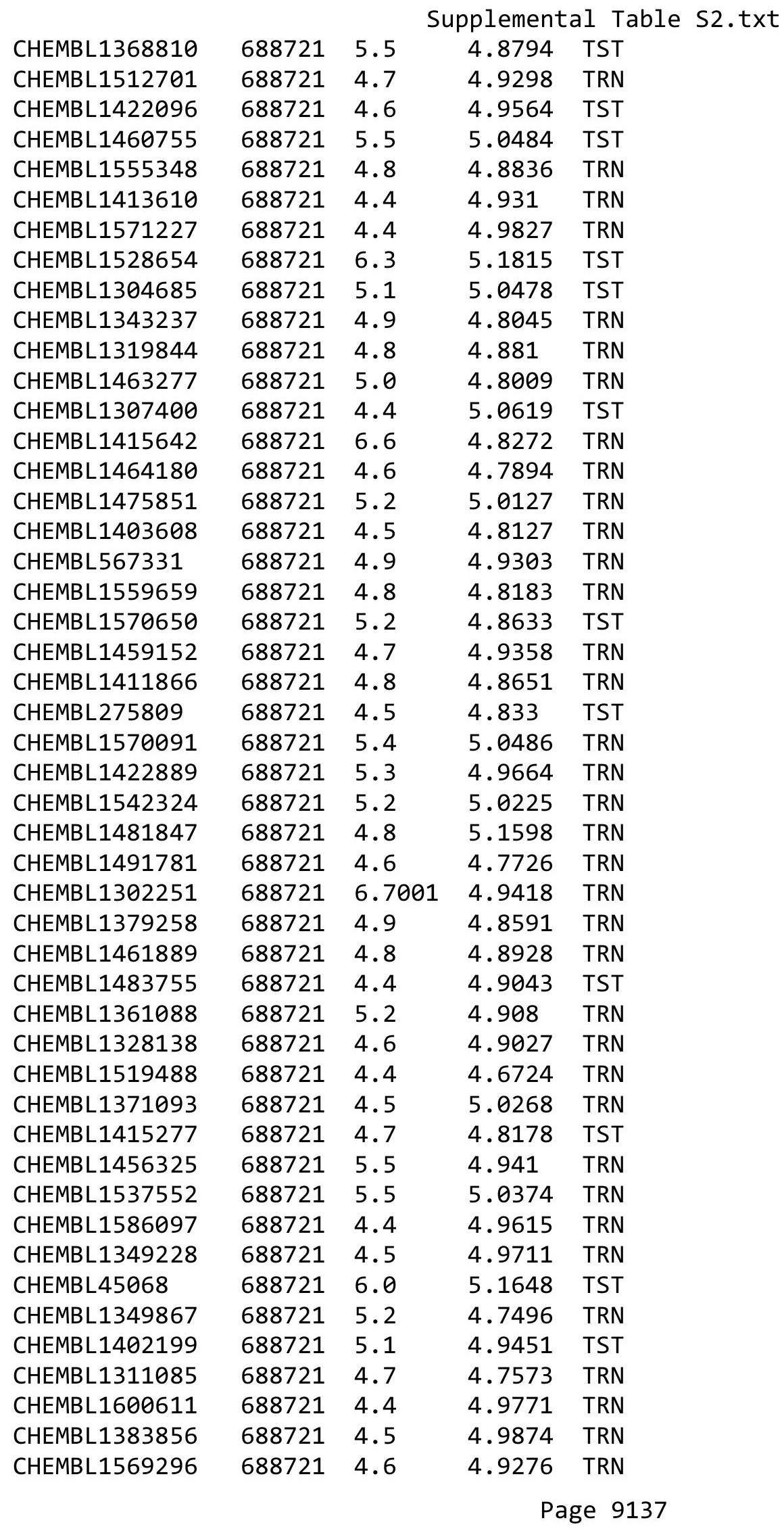




\begin{tabular}{|c|c|c|c|c|}
\hline & & & & al Table \\
\hline CHEMBL1610228 & 688721 & 4.4 & 4.9006 & TRN \\
\hline CHEMBL1393071 & 688721 & 4.9 & 5.033 & TRN \\
\hline CHEMBL1333952 & 688721 & 4.4 & 4.9436 & TRN \\
\hline CHEMBL46703 & 688721 & 4.5 & 5.37299 & 9999999999 \\
\hline CHEMBL1353059 & 688721 & 5.2 & 4.9963 & TRN \\
\hline CHEMBL1368934 & 688721 & 4.5 & 4.8787 & TRN \\
\hline CHEMBL1308632 & 688721 & 4.4 & 4.8409 & TRN \\
\hline CHEMBL1308901 & 688721 & 5.4 & 4.912 & TRN \\
\hline CHEMBL1578763 & 688721 & 4.9 & 4.8032 & TRN \\
\hline CHEMBL1359568 & 688721 & 4.7 & 4.8271 & TRN \\
\hline CHEMBL1384903 & 688721 & 4.6 & 4.9965 & TST \\
\hline CHEMBL1577735 & 688721 & 4.4 & 5.0146 & TRN \\
\hline CHEMBL1533655 & 688721 & 4.6 & 4.7628 & TRN \\
\hline CHEMBL1321251 & 688721 & 4.4 & 5.0815 & TRN \\
\hline CHEMBL1375285 & 688721 & 5.0 & 5.0363 & TRN \\
\hline CHEMBL1401655 & 688721 & 4.5 & 4.8638 & TRN \\
\hline CHEMBL1352405 & 688721 & 5.2 & 4.8667 & TRN \\
\hline CHEMBL105457 & 688721 & 5.5 & 5.2134 & TRN \\
\hline CHEMBL1306878 & 688721 & 4.5 & 5.0047 & TRN \\
\hline CHEMBL1608653 & 688721 & 4.6 & 4.745 & TRN \\
\hline CHEMBL1600800 & 688721 & 4.7 & 4.7136 & TRN \\
\hline CHEMBL 3208465 & 688721 & 4.4 & 4.9667 & TRN \\
\hline CHEMBL1485196 & 688721 & 4.8 & 4.9276 & TRN \\
\hline CHEMBL1537077 & 688721 & 5.2 & 4.9024 & TRN \\
\hline CHEMBL1546085 & 688721 & 6.1 & 4.8759 & TST \\
\hline CHEMBL1514634 & 688721 & 5.0 & 5.2471 & TST \\
\hline CHEMBL3214590 & 688721 & 4.5 & 5.0253 & TST \\
\hline CHEMBL1595442 & 688721 & 4.6 & 5.0571 & TST \\
\hline CHEMBL1301531 & 688721 & 4.6 & 4.936 & TRN \\
\hline CHEMBL1305671 & 688721 & 4.6 & 4.7512 & TRN \\
\hline CHEMBL1346091 & 688721 & 4.4 & 4.8251 & TST \\
\hline CHEMBL1575289 & 688721 & 4.5 & 4.9116 & TRN \\
\hline CHEMBL 3214326 & 688721 & 4.7 & 5.0018 & TST \\
\hline CHEMBL1311716 & 688721 & 4.6 & 4.7412 & TRN \\
\hline CHEMBL1330121 & 688721 & 4.7 & 4.7885 & TRN \\
\hline CHEMBL1559297 & 688721 & 4.6 & 4.9878 & TRN \\
\hline CHEMBL1574426 & 688721 & 4.6 & 4.7683 & TRN \\
\hline CHEMBL1454271 & 688721 & 6.0 & 4.8491 & TRN \\
\hline CHEMBL1423766 & 688721 & 5.2 & 4.9078 & TRN \\
\hline CHEMBL1602645 & 688721 & 5.4 & 4.8867 & TRN \\
\hline CHEMBL1368742 & 688721 & 4.5 & 4.8496 & TRN \\
\hline CHEMBL1332529 & 688721 & 4.6 & 5.0663 & TST \\
\hline CHEMBL1510411 & 688721 & 5.3 & 4.9188 & TRN \\
\hline CHEMBL1545696 & 688721 & 4.6 & 4.6596 & TRN \\
\hline CHEMBL1434235 & 688721 & 5.2 & 5.1362 & TRN \\
\hline CHEMBL1442998 & 688721 & 4.5 & 4.9658 & TRN \\
\hline CHEMBL1334564 & 688721 & 5.3 & 4.8512 & TRN \\
\hline CHEMBL1334204 & 688721 & 4.8 & 4.9878 & TRN \\
\hline
\end{tabular}

TRN 


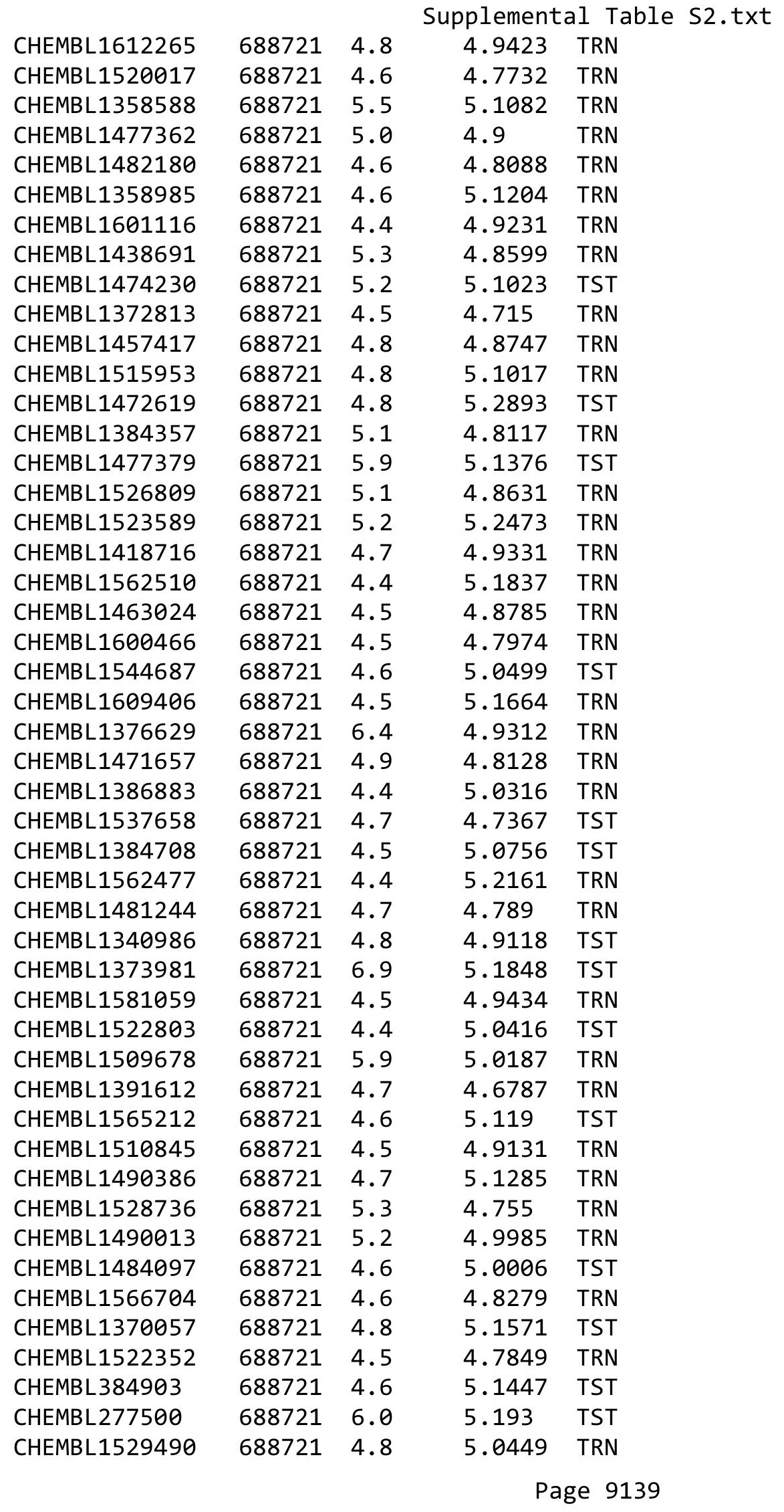




\begin{tabular}{|c|c|c|c|c|}
\hline \multicolumn{5}{|c|}{ Supplemental Table S2.txt } \\
\hline CHEMBL437450 & 688721 & 4.7 & 4.9114 & TRN \\
\hline CHEMBL1559745 & 688721 & 5.4 & 5.0448 & TRN \\
\hline CHEMBL1416858 & 688721 & 4.5 & 4.8841 & TRN \\
\hline CHEMBL1477856 & 688721 & 4.6 & 4.7001 & TRN \\
\hline CHEMBL1595300 & 688721 & 4.4 & 4.9932 & TRN \\
\hline CHEMBL16102 & 688721 & 7.0 & 5.2253 & TRN \\
\hline CHEMBL1538960 & 688721 & 5.2 & 5.1128 & TRN \\
\hline CHEMBL1496517 & 688721 & 4.7 & 4.9509 & TRN \\
\hline CHEMBL1343744 & 688721 & 5.2 & 4.8615 & TRN \\
\hline CHEMBL1535629 & 688721 & 4.4 & 4.8341 & TRN \\
\hline CHEMBL1419549 & 688721 & 4.7 & 4.8891 & TRN \\
\hline CHEMBL1303634 & 688721 & 4.7 & 4.7908 & TRN \\
\hline CHEMBL1501614 & 688721 & 4.4 & 5.0277 & TST \\
\hline CHEMBL1490957 & 688721 & 4.8 & 4.8379 & TRN \\
\hline CHEMBL1609553 & 688721 & 5.0 & 4.8086 & TRN \\
\hline CHEMBL1462331 & 688721 & 5.5 & 4.9187 & TRN \\
\hline CHEMBL1543740 & 688721 & 4.5 & 4.8011 & TRN \\
\hline CHEMBL1432038 & 688721 & 5.6 & 4.9824 & TRN \\
\hline CHEMBL1541660 & 688721 & 4.7 & 4.9299 & TST \\
\hline CHEMBL1567205 & 688721 & 4.5 & 4.9629 & TRN \\
\hline CHEMBL1497777 & 688721 & 5.1 & 5.0254 & TST \\
\hline CHEMBL1446651 & 688721 & 5.1 & 5.0156 & TRN \\
\hline CHEMBL1602112 & 688721 & 5.5 & 5.2254 & TRN \\
\hline CHEMBL1353590 & 688721 & 4.5 & 4.6205 & TRN \\
\hline CHEMBL1523544 & 688721 & 5.3 & 5.025 & TRN \\
\hline CHEMBL1466002 & 688721 & 4.6 & 4.8818 & TRN \\
\hline CHEMBL1310311 & 688721 & 4.5 & 4.7287 & TRN \\
\hline CHEMBL1357089 & 688721 & 5.2 & 4.9123 & TRN \\
\hline CHEMBL1330712 & 688721 & 4.6 & 5.0196 & TRN \\
\hline CHEMBL382541 & 688721 & 7.5003 & 4.8889 & TRN \\
\hline CHEMBL1422850 & 688721 & 4.7 & 4.7466 & TRN \\
\hline CHEMBL1612279 & 688721 & 4.7 & 4.8439 & TST \\
\hline CHEMBL1508897 & 688721 & 4.8 & 4.8072 & TRN \\
\hline CHEMBL1378726 & 688721 & 5.2 & 5.0344 & TST \\
\hline CHEMBL1481853 & 688721 & 5.4 & 4.775 & TRN \\
\hline CHEMBL1407829 & 688721 & 4.4 & 4.8411 & TRN \\
\hline CHEMBL1353231 & 688721 & 4.4 & 4.8182 & TRN \\
\hline CHEMBL1421346 & 688721 & 4.5 & 5.0359 & TRN \\
\hline CHEMBL1549342 & 688721 & 4.5 & 4.9163 & TRN \\
\hline CHEMBL1417852 & 688721 & 6.6 & 5.1687 & TRN \\
\hline CHEMBL1530565 & 688721 & 5.0 & 4.9401 & TRN \\
\hline CHEMBL1498941 & 688721 & 4.8 & 4.8861 & TRN \\
\hline CHEMBL1523254 & 688721 & 4.7 & 5.0432 & TRN \\
\hline CHEMBL1363536 & 688721 & 4.9 & 4.9249 & TRN \\
\hline CHEMBL 330320 & 688721 & 6.9 & 5.0695 & TST \\
\hline CHEMBL1495197 & 688721 & 5.2 & 5.048 & TRN \\
\hline CHEMBL1370669 & 688721 & 5.4 & 5.0635 & TST \\
\hline CHEMBL1396049 & 688721 & 4.5 & 5.3915 & TRN \\
\hline
\end{tabular}




\begin{tabular}{|c|c|c|c|c|c|}
\hline \\
\hline CHEMBL1361955 & 688721 & 5.3 & 4.9455 & TRN & \\
\hline CHEMBL1518770 & 688721 & 4.8 & 5.001 & TRN & \\
\hline CHEMBL1397088 & 688721 & 5.3 & 5.1642 & TRN & \\
\hline CHEMBL1540995 & 688721 & 5.3 & 4.9304 & TRN & \\
\hline CHEMBL1478528 & 688721 & 5.3 & 5.0005 & TRN & \\
\hline CHEMBL1609209 & 688721 & 4.6 & 5.0349 & TRN & \\
\hline CHEMBL1427142 & 688721 & 4.9 & 4.7997 & TRN & \\
\hline CHEMBL1430099 & 688721 & 6.1 & 5.0043 & TRN & \\
\hline CHEMBL1458374 & 688721 & 4.9 & 4.7753 & TRN & \\
\hline CHEMBL1362579 & 688721 & 5.4 & 4.8629 & TRN & \\
\hline CHEMBL1581164 & 688721 & 4.8 & 4.8011 & TRN & \\
\hline CHEMBL1483233 & 688721 & 4.6 & 4.907 & TRN & \\
\hline CHEMBL1604542 & 688721 & 4.4 & 4.7548 & TRN & \\
\hline CHEMBL1368554 & 688721 & 5.3 & 5.0189 & TRN & \\
\hline CHEMBL1348476 & 688721 & 4.6 & 5.1481 & TST & \\
\hline CHEMBL3212799 & 688721 & 4.6 & 5.1945 & TST & \\
\hline CHEMBL1506445 & 688721 & 4.8 & 4.9348 & TRN & \\
\hline CHEMBL1440708 & 688721 & 4.9 & 4.676 & TRN & \\
\hline CHEMBL327919 & 688721 & 4.4 & 5.0098 & TST & \\
\hline CHEMBL1487085 & 688721 & 5.2 & 4.9225 & TRN & \\
\hline CHEMBL1505801 & 688721 & 5.3 & 5.0416 & TRN & \\
\hline CHEMBL1484216 & 688721 & 4.7 & 4.9502 & TRN & \\
\hline CHEMBL1623028 & 688721 & 4.6 & $5.1370 e$ & 00000000005 & TST \\
\hline CHEMBL1469378 & 688721 & 4.5 & 4.843 & TRN & \\
\hline CHEMBL1429220 & 688721 & 4.7 & 4.8571 & TRN & \\
\hline CHEMBL1557636 & 688721 & 4.6 & 5.0838 & TRN & \\
\hline CHEMBL1435293 & 688721 & 5.7 & 5.1944 & TRN & \\
\hline CHEMBL1583480 & 688721 & 4.6 & $4.9430 e$ & 00000000005 & TST \\
\hline CHEMBL1410095 & 688721 & 4.4 & 4.8978 & TST & \\
\hline CHEMBL1389724 & 688721 & 5.9 & 4.788 & TRN & \\
\hline CHEMBL38576 & 688721 & 4.5 & 4.7933 & TRN & \\
\hline CHEMBL1602718 & 688721 & 5.0 & 4.8233 & TRN & \\
\hline CHEMBL1340896 & 688721 & 4.5 & 4.8716 & TST & \\
\hline CHEMBL1412133 & 688721 & 6.3 & 4.8234 & TRN & \\
\hline CHEMBL1449117 & 688721 & 4.7 & 4.8936 & TRN & \\
\hline CHEMBL1497762 & 688721 & 4.4 & 4.9678 & TRN & \\
\hline CHEMBL1521192 & 688721 & 5.3 & 4.9609 & TRN & \\
\hline CHEMBL1588598 & 688721 & 4.5 & 4.9609 & TRN & \\
\hline CHEMBL1347450 & 688721 & 5.0 & 4.899 & TRN & \\
\hline CHEMBL3207738 & 688721 & 4.6 & 4.7992 & TRN & \\
\hline CHEMBL1503415 & 688721 & 4.5 & 4.9679 & TST & \\
\hline CHEMBL1464482 & 688721 & 4.6 & 4.9138 & TST & \\
\hline CHEMBL1377250 & 688721 & 4.8 & 4.6979 & TRN & \\
\hline CHEMBL1338147 & 688721 & 4.5 & 4.7712 & TRN & \\
\hline CHEMBL1363615 & 688721 & 4.5 & 4.9957 & TRN & \\
\hline CHEMBL1314279 & 688721 & 5.7 & 4.8218 & TRN & \\
\hline CHEMBL1461647 & 688721 & 4.4 & 5.2283 & TST & \\
\hline CHEMBL1488663 & 688721 & 4.8 & 5.0558 & TRN & \\
\hline
\end{tabular}




\begin{tabular}{|c|c|c|c|c|c|}
\hline \\
\hline CHEMBL1328607 & 688721 & 6.0 & 5.1056 & TST & \\
\hline CHEMBL1507719 & 688721 & 4.5 & 4.7365 & TRN & \\
\hline CHEMBL1525205 & 688721 & 4.6 & 4.9556 & TRN & \\
\hline CHEMBL1607905 & 688721 & 4.4 & 5.0472 & TST & \\
\hline CHEMBL1458198 & 688721 & 5.2 & 4.9841 & TRN & \\
\hline CHEMBL1318982 & 688721 & 4.8 & 4.9043 & TRN & \\
\hline CHEMBL1581377 & 688721 & 5.0 & 4.989 & TRN & \\
\hline CHEMBL1350174 & 688721 & 4.4 & 4.9025 & TRN & \\
\hline CHEMBL1437848 & 688721 & 5.0 & 4.9151 & TRN & \\
\hline CHEMBL1612117 & 688721 & 4.7 & 4.9074 & TRN & \\
\hline CHEMBL1351393 & 688721 & 4.8 & 5.0156 & TRN & \\
\hline CHEMBL1403650 & 688721 & 5.7 & 4.8087 & TRN & \\
\hline CHEMBL1402000 & 688721 & 4.6 & 4.849 & TRN & \\
\hline CHEMBL1469635 & 688721 & 4.4 & 5.169 & TST & \\
\hline CHEMBL1577916 & 688721 & 4.6 & 5.0417 & TRN & \\
\hline CHEMBL1371870 & 688721 & 4.8 & 4.9048 & TRN & \\
\hline CHEMBL1329645 & 688721 & 4.9 & 4.9518 & TRN & \\
\hline CHEMBL1540498 & 688721 & 4.6 & 4.8697 & TRN & \\
\hline CHEMBL1396010 & 688721 & 5.0 & 5.0025 & TRN & \\
\hline CHEMBL1499996 & 688721 & 5.1 & 5.03600 & 00000000005 & TST \\
\hline CHEMBL1530839 & 688721 & 5.9 & 4.9948 & TST & \\
\hline CHEMBL1551321 & 688721 & 5.2 & 5.1412 & TRN & \\
\hline CHEMBL1332611 & 688721 & 5.3 & 4.8551 & TRN & \\
\hline CHEMBL1332486 & 688721 & 4.7 & 4.927 & TRN & \\
\hline CHEMBL444309 & 688721 & 4.5 & 4.8529 & TST & \\
\hline CHEMBL1348783 & 688721 & 7.0 & 5.0036 & TST & \\
\hline CHEMBL1333631 & 688721 & 5.2 & 4.9078 & TST & \\
\hline CHEMBL1380776 & 688721 & 5.4 & 4.9816 & TRN & \\
\hline CHEMBL1363189 & 688721 & 4.5 & 4.6902 & TRN & \\
\hline CHEMBL1390841 & 688721 & 5.2 & 4.962 & TRN & \\
\hline CHEMBL1368497 & 688721 & 4.4 & 5.12700 & 3000000001 & TRN \\
\hline CHEMBL1609167 & 688721 & 4.8 & 4.8234 & TRN & \\
\hline CHEMBL1521637 & 688721 & 4.7 & 4.8333 & TRN & \\
\hline CHEMBL1438073 & 688721 & 4.6 & 4.702 & TRN & \\
\hline CHEMBL1505091 & 688721 & 4.7 & 4.9541 & TRN & \\
\hline CHEMBL1532651 & 688721 & 4.7 & 4.9585 & TRN & \\
\hline CHEMBL1480494 & 688721 & 4.5 & 4.8099 & TST & \\
\hline CHEMBL1604646 & 688721 & 4.8 & 4.8217 & TRN & \\
\hline CHEMBL1363446 & 688721 & 4.8 & 4.81800 & 00000000005 & TRN \\
\hline CHEMBL1402802 & 688721 & 4.8 & 5.2888 & TST & \\
\hline CHEMBL1440905 & 688721 & 4.7 & 4.8625 & TST & \\
\hline CHEMBL1521325 & 688721 & 4.8 & 5.0213 & TST & \\
\hline CHEMBL1433273 & 688721 & 4.5 & 4.738 & TRN & \\
\hline CHEMBL1546137 & 688721 & 4.7 & 4.9204 & TRN & \\
\hline CHEMBL1390170 & 688721 & 4.9 & 5.0388 & TST & \\
\hline CHEMBL1446696 & 688721 & 4.5 & 4.7774 & TRN & \\
\hline CHEMBL1452881 & 688721 & 6.0 & 5.4083 & TRN & \\
\hline CHEMBL1458777 & 688721 & 4.6 & 5.204 & TST & \\
\hline
\end{tabular}




\begin{tabular}{|c|c|c|c|c|c|}
\hline \multicolumn{6}{|c|}{ Supplemental Table S2.txt } \\
\hline CHEMBL45079 & 688721 & 5.0 & 5.1673 & TST & \\
\hline CHEMBL1491830 & 688721 & 4.8 & 4.8856 & TRN & \\
\hline CHEMBL1406161 & 688721 & 5.0 & 4.765 & TRN & \\
\hline CHEMBL1563063 & 688721 & 4.5 & 4.914 & TST & \\
\hline CHEMBL1364435 & 688721 & 4.6 & 4.9106 & TRN & \\
\hline CHEMBL1332244 & 688721 & 4.8 & 4.7996 & TRN & \\
\hline CHEMBL1447708 & 688721 & 4.4 & 5.2247 & TST & \\
\hline CHEMBL1548195 & 688721 & 4.9 & 4.9552 & TRN & \\
\hline CHEMBL1385946 & 688721 & 5.2 & 4.9679 & TRN & \\
\hline CHEMBL1441618 & 688721 & 4.5 & 4.8487 & TRN & \\
\hline CHEMBL554311 & 688721 & 5.3 & 5.3341 & TRN & \\
\hline CHEMBL1429413 & 688721 & 5.2 & 4.8562 & TRN & \\
\hline CHEMBL1339545 & 688721 & 5.4 & 4.8878 & TST & \\
\hline CHEMBL1333711 & 688721 & 4.9 & 4.9608 & TRN & \\
\hline CHEMBL1579268 & 688721 & 5.2 & 4.9811 & TRN & \\
\hline CHEMBL1409252 & 688721 & 4.4 & 4.9844 & TRN & \\
\hline CHEMBL1322572 & 688721 & 4.4 & 4.8147 & TRN & \\
\hline CHEMBL1312793 & 688721 & 5.1 & 5.0446 & TRN & \\
\hline CHEMBL1443468 & 688721 & 4.8 & 5.0634 & TST & \\
\hline CHEMBL1525407 & 688721 & 5.4 & 5.0495 & TST & \\
\hline CHEMBL1322757 & 688721 & 4.7 & 4.9082 & TRN & \\
\hline CHEMBL1439610 & 688721 & 6.7001 & 4.8475 & TRN & \\
\hline CHEMBL1502717 & 688721 & 4.5 & 4.813 & TST & \\
\hline CHEMBL1454903 & 688721 & 6.0 & 4.9267 & TRN & \\
\hline CHEMBL1314041 & 688721 & 5.2 & 5.1719 & TST & \\
\hline CHEMBL1471303 & 688721 & 4.7 & 4.9164 & TRN & \\
\hline CHEMBL1374388 & 688721 & 4.6 & 4.8719 & TRN & \\
\hline CHEMBL1555132 & 688721 & 5.2 & 4.9778 & TRN & \\
\hline CHEMBL1603858 & 688721 & 4.6 & 4.9818 & TRN & \\
\hline CHEMBL1411672 & 688721 & 4.5 & 4.773 & TRN & \\
\hline CHEMBL1531836 & 688721 & 5.2 & 5.0128 & TRN & \\
\hline CHEMBL1470303 & 688721 & 5.1 & 5.0558 & TRN & \\
\hline CHEMBL1345275 & 688721 & 5.3 & 5.1053 & TRN & \\
\hline CHEMBL1460076 & 688721 & 5.1 & 5.1022 & TST & \\
\hline CHEMBL1360650 & 688721 & 4.8 & 5.17899 & 9999999999 & TRN \\
\hline CHEMBL1524660 & 688721 & 4.4 & 4.7041 & TRN & \\
\hline CHEMBL1401086 & 688721 & 5.2 & 4.8119 & TRN & \\
\hline CHEMBL1490409 & 688721 & 5.5 & 5.0981 & TRN & \\
\hline CHEMBL1528116 & 688721 & 5.7 & 4.97 & TRN & \\
\hline CHEMBL1327534 & 688721 & 4.5 & 4.8489 & TRN & \\
\hline CHEMBL1465681 & 688721 & 4.4 & 5.0666 & TST & \\
\hline CHEMBL1491107 & 688721 & 5.1 & 4.8905 & TRN & \\
\hline CHEMBL1385395 & 688721 & 4.6 & 4.9364 & TRN & \\
\hline CHEMBL1591971 & 688721 & 4.6 & 4.971 & TRN & \\
\hline CHEMBL1371633 & 688721 & 4.4 & 4.9204 & TRN & \\
\hline CHEMBL1385390 & 688721 & 5.4 & 5.2663 & TST & \\
\hline CHEMBL1471531 & 688721 & 5.2 & 4.9602 & TRN & \\
\hline CHEMBL1422823 & 688721 & 4.6 & 4.9949 & TRN & \\
\hline
\end{tabular}




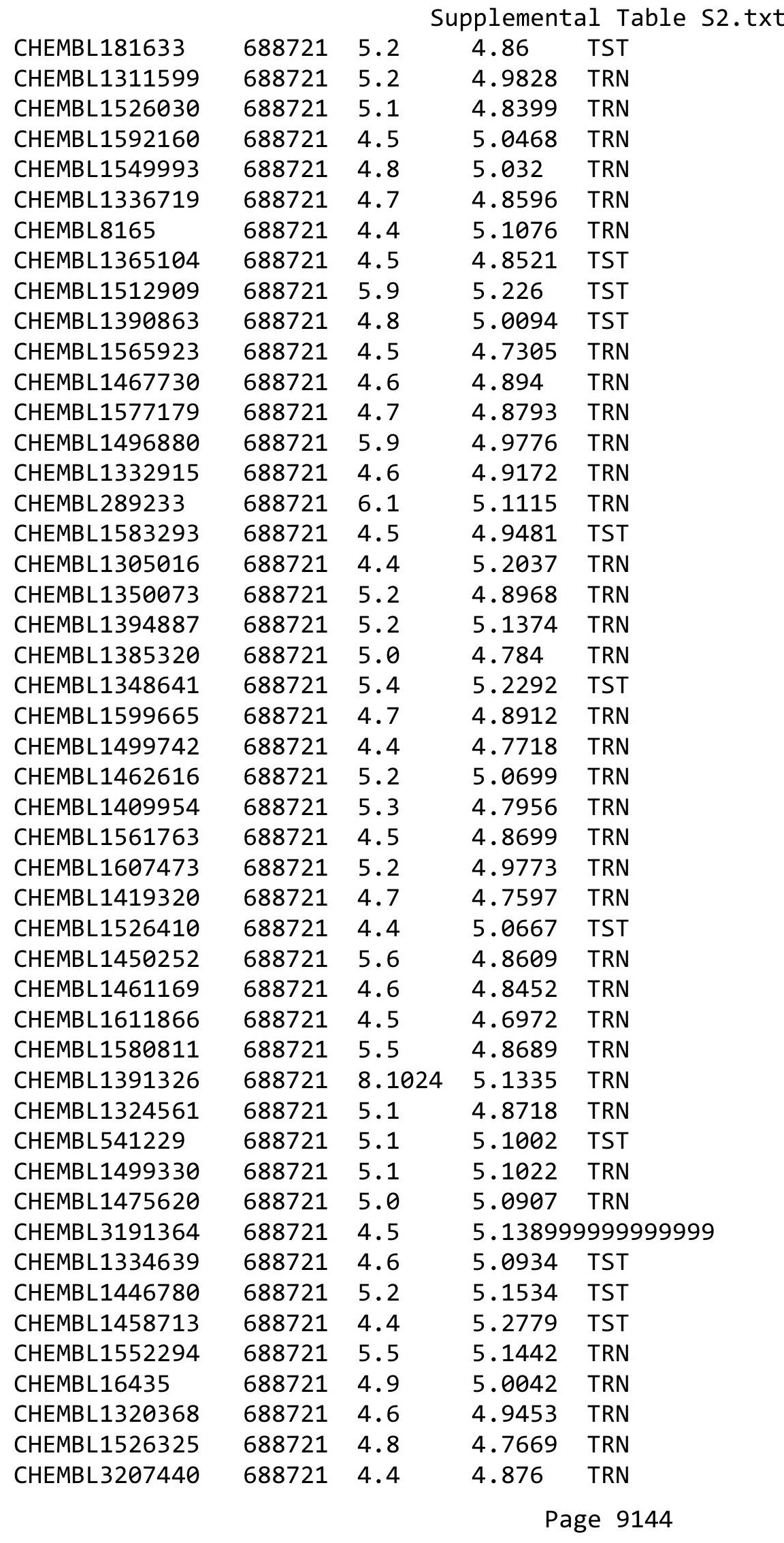




\begin{tabular}{|c|c|c|c|c|c|}
\hline \multicolumn{6}{|c|}{ Supplemental Table S2.txt } \\
\hline CHEMBL1369940 & 688721 & 4.8 & 5.1021 & TRN & \\
\hline CHEMBL1369316 & 688721 & 4.6 & 4.9771 & TRN & \\
\hline CHEMBL1373648 & 688721 & 4.6 & 5.0381 & TRN & \\
\hline CHEMBL1310466 & 688721 & 5.3 & 4.8222 & TRN & \\
\hline CHEMBL1336166 & 688721 & 4.6 & 4.9672 & TRN & \\
\hline CHEMBL1454052 & 688721 & 5.0 & 5.0773 & TRN & \\
\hline CHEMBL1563391 & 688721 & 5.3 & 4.9414 & TRN & \\
\hline CHEMBL21260 & 688721 & 6.0 & 5.0961 & TST & \\
\hline CHEMBL1321919 & 688721 & 5.4 & 5.1386 & TST & \\
\hline CHEMBL1537779 & 688721 & 4.5 & 4.8067 & TRN & \\
\hline CHEMBL1610686 & 688721 & 5.2 & 4.883 & TRN & \\
\hline CHEMBL1450313 & 688721 & 5.2 & 4.9805 & TRN & \\
\hline CHEMBL1578622 & 688721 & 4.5 & 4.958 & TST & \\
\hline CHEMBL1372318 & 688721 & 4.6 & 4.888 & TRN & \\
\hline CHEMBL1335213 & 688721 & 5.0 & 5.0266 & TRN & \\
\hline CHEMBL1322500 & 688721 & 4.6 & 5.1015 & TST & \\
\hline CHEMBL1603744 & 688721 & 5.2 & 4.8197 & TRN & \\
\hline CHEMBL1499097 & 688721 & 7.8013 & 4.8788 & TST & \\
\hline CHEMBL1364976 & 688721 & 5.9 & 5.1737 & TST & \\
\hline CHEMBL1425842 & 688721 & 5.4 & 4.8975 & TST & \\
\hline CHEMBL1299942 & 688721 & 4.4 & 4.817 & TRN & \\
\hline CHEMBL1580282 & 688721 & 5.1 & 4.8991 & TRN & \\
\hline CHEMBL1575442 & 688721 & 4.4 & 4.8203 & TST & \\
\hline CHEMBL1429242 & 688721 & 5.1 & 4.667 & TRN & \\
\hline CHEMBL1255648 & 688721 & 5.3 & 4.8638 & TRN & \\
\hline CHEMBL1362206 & 688721 & 4.6 & 4.9329 & TRN & \\
\hline CHEMBL1526215 & 688721 & 4.4 & 4.8238 & TRN & \\
\hline CHEMBL1490659 & 688721 & 5.3 & 4.9541 & TST & \\
\hline CHEMBL1435235 & 688721 & 4.8 & 5.0734 & TRN & \\
\hline CHEMBL 313493 & 688721 & 4.7 & 5.1803 & TST & \\
\hline CHEMBL1607984 & 688721 & 4.5 & 5.1035 & TRN & \\
\hline CHEMBL1422852 & 688721 & 5.6 & 4.9853 & TRN & \\
\hline CHEMBL1509861 & 688721 & 4.5 & 4.8414 & TRN & \\
\hline CHEMBL1337740 & 688721 & 6.0 & 4.8633 & TST & \\
\hline CHEMBL1336503 & 688721 & 4.4 & 4.8808 & TRN & \\
\hline CHEMBL1566378 & 688721 & 4.6 & 4.8782 & TRN & \\
\hline CHEMBL1183 & 688721 & 4.9 & 5.2344 & TST & \\
\hline CHEMBL1299291 & 688721 & 4.4 & 4.7672 & TRN & \\
\hline CHEMBL1423860 & 688721 & 4.5 & 5.1342 & TST & \\
\hline CHEMBL1586738 & 688721 & 4.5 & 4.746 & TRN & \\
\hline CHEMBL1380881 & 688721 & 4.8 & 4.758 & TRN & \\
\hline CHEMBL1533461 & 688721 & 4.5 & 4.74100 & 00000000005 & TRN \\
\hline CHEMBL1608513 & 688721 & 4.8 & 4.7732 & TRN & \\
\hline CHEMBL1478447 & 688721 & 4.5 & 5.0242 & TRN & \\
\hline CHEMBL1489067 & 688721 & 4.6 & 5.2437 & TRN & \\
\hline CHEMBL1574446 & 688721 & 5.3 & 4.9851 & TST & \\
\hline CHEMBL1550141 & 688721 & 4.5 & 5.0519 & TST & \\
\hline CHEMBL1538485 & 688721 & 4.9 & 4.945 & TRN & \\
\hline
\end{tabular}




\begin{tabular}{|c|c|c|c|c|c|}
\hline & & & & & \\
\hline CHEMBL1507882 & 688721 & 4.4 & 4.8974 & TST & \\
\hline CHEMBL77456 & 688721 & 5.0 & 5.0168 & TST & \\
\hline CHEMBL1584001 & 688721 & 4.5 & 4.9568 & TRN & \\
\hline CHEMBL1303712 & 688721 & 4.4 & 5.0152 & TRN & \\
\hline CHEMBL1567179 & 688721 & 4.4 & 4.90300 & 00000000005 & TRN \\
\hline CHEMBL1502290 & 688721 & 4.4 & 4.7564 & TRN & \\
\hline CHEMBL1603672 & 688721 & 4.8 & 4.8327 & TRN & \\
\hline CHEMBL1485744 & 688721 & 4.5 & 4.9103 & TRN & \\
\hline CHEMBL1578861 & 688721 & 4.7 & 4.9498 & TRN & \\
\hline CHEMBL1462076 & 688721 & 5.1 & 5.0867 & TRN & \\
\hline CHEMBL1442367 & 688721 & 4.6 & 5.0635 & TRN & \\
\hline CHEMBL1486652 & 688721 & 5.4 & 4.973 & TRN & \\
\hline CHEMBL1441883 & 688721 & 4.6 & 4.8633 & TRN & \\
\hline CHEMBL1393449 & 688721 & 5.2 & 4.8791 & TRN & \\
\hline CHEMBL1568916 & 688721 & 4.5 & 4.8435 & TRN & \\
\hline CHEMBL1334442 & 688721 & 4.9 & 4.9205 & TRN & \\
\hline CHEMBL1483763 & 688721 & 4.6 & 5.096 & TST & \\
\hline CHEMBL1392171 & 688721 & 5.5 & 4.9494 & TRN & \\
\hline CHEMBL1322883 & 688721 & 4.6 & 4.942 & TRN & \\
\hline CHEMBL1531643 & 688721 & 4.6 & 4.7819 & TRN & \\
\hline CHEMBL8918 & 688721 & 5.4 & 5.0163 & TRN & \\
\hline CHEMBL1335245 & 688721 & 4.7 & 5.1918 & TRN & \\
\hline CHEMBL1453158 & 688721 & 5.2 & 4.8771 & TRN & \\
\hline CHEMBL1422314 & 688721 & 5.3 & 4.832 & TRN & \\
\hline CHEMBL1366433 & 688721 & 4.4 & 4.9917 & TRN & \\
\hline CHEMBL1321807 & 688721 & 5.2 & 5.2283 & TST & \\
\hline CHEMBL1611300 & 688721 & 4.8 & 4.8107 & TRN & \\
\hline CHEMBL1372808 & 688721 & 4.5 & 4.8976 & TST & \\
\hline CHEMBL1603491 & 688721 & 4.4 & 4.8986 & TRN & \\
\hline CHEMBL3190774 & 688721 & 4.8 & 4.8105 & TRN & \\
\hline CHEMBL1402122 & 688721 & 5.6 & 4.9312 & TRN & \\
\hline CHEMBL1307845 & 688721 & 4.8 & 4.9106 & TRN & \\
\hline CHEMBL1435604 & 688721 & 5.3 & 5.1029 & TRN & \\
\hline CHEMBL1414453 & 688721 & 5.0 & 4.7412 & TRN & \\
\hline CHEMBL1349707 & 688721 & 5.1 & 5.21 & TRN & \\
\hline CHEMBL1573636 & 688721 & 5.4 & 4.9326 & TRN & \\
\hline CHEMBL1315417 & 688721 & 4.4 & 4.9956 & TST & \\
\hline CHEMBL1600483 & 688721 & 4.7 & 5.2114 & TST & \\
\hline CHEMBL1317950 & 688721 & 4.8 & 4.902 & TRN & \\
\hline CHEMBL1303178 & 688721 & 5.2 & 4.8171 & TRN & \\
\hline CHEMBL1555208 & 688721 & 4.8 & 5.08899 & 99999999995 & TRN \\
\hline CHEMBL1328248 & 688721 & 4.8 & 4.8449 & TRN & \\
\hline CHEMBL1511081 & 688721 & 5.1 & 5.0291 & TRN & \\
\hline CHEMBL1519579 & 688721 & 4.9 & 4.9594 & TST & \\
\hline CHEMBL1305316 & 688721 & 4.4 & 4.9558 & TRN & \\
\hline CHEMBL1255655 & 688721 & 4.5 & 5.1048 & TST & \\
\hline CHEMBL1390759 & 688721 & 4.5 & 4.9352 & TRN & \\
\hline CHEMBL1589856 & 688721 & 4.9 & 4.9649 & TRN & \\
\hline & & & & 9146 & \\
\hline
\end{tabular}




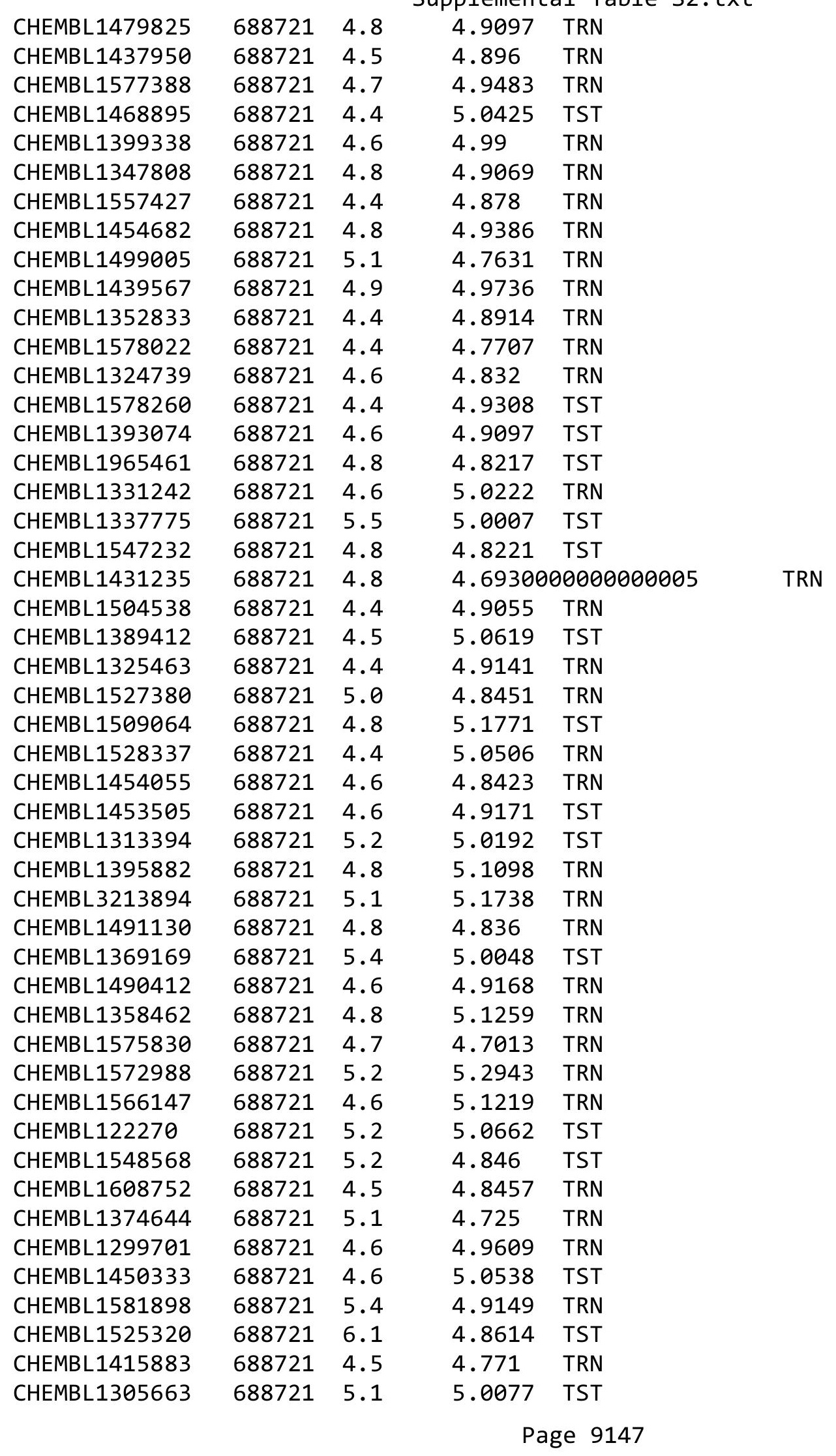




\begin{tabular}{|c|c|c|c|c|c|}
\hline \multicolumn{6}{|c|}{ Supplemental Table S2.txt } \\
\hline CHEMBL1370495 & 688721 & 4.5 & 4.9079 & TST & \\
\hline CHEMBL1196026 & 688721 & 4.8 & 5.0706 & TST & \\
\hline CHEMBL1462696 & 688721 & 4.5 & 4.7598 & TRN & \\
\hline CHEMBL1504052 & 688721 & 5.6 & 4.9452 & TRN & \\
\hline CHEMBL1557857 & 688721 & 4.6 & 4.837 & TRN & \\
\hline CHEMBL1561876 & 688721 & 5.0 & 5.2781 & TST & \\
\hline CHEMBL1353065 & 688721 & 4.8 & 4.80399 & 9999999999 & TRN \\
\hline CHEMBL1456650 & 688721 & 4.5 & 4.7474 & TRN & \\
\hline CHEMBL1573374 & 688721 & 4.5 & 4.8251 & TRN & \\
\hline CHEMBL1486808 & 688721 & 6.0 & 5.0912 & TRN & \\
\hline CHEMBL1572608 & 688721 & 4.6 & 4.9741 & TST & \\
\hline CHEMBL1383379 & 688721 & 6.8 & 4.8467 & TRN & \\
\hline CHEMBL1394020 & 688721 & 5.0 & 4.9627 & TRN & \\
\hline CHEMBL1585000 & 688721 & 4.4 & 4.9309 & TRN & \\
\hline CHEMBL1410702 & 688721 & 4.4 & 5.1727 & TST & \\
\hline CHEMBL1484774 & 688721 & 4.5 & 5.0461 & TST & \\
\hline CHEMBL1529024 & 688721 & 5.3 & 4.8267 & TRN & \\
\hline CHEMBL1505650 & 688721 & 4.5 & 5.1423 & TST & \\
\hline CHEMBL1446542 & 688721 & 5.0 & 4.9403 & TRN & \\
\hline CHEMBL84963 & 688721 & 6.3 & 4.957 & TST & \\
\hline CHEMBL1577717 & 688721 & 5.2 & 5.1051 & TRN & \\
\hline CHEMBL1444266 & 688721 & 4.9 & 5.0167 & TRN & \\
\hline CHEMBL1330219 & 688721 & 4.6 & 4.9292 & TRN & \\
\hline CHEMBL1362994 & 688721 & 5.1 & 4.7139 & TST & \\
\hline CHEMBL1508316 & 688721 & 5.5 & 4.7651 & TRN & \\
\hline CHEMBL1578490 & 688721 & 4.8 & 4.897 & TRN & \\
\hline CHEMBL1611820 & 688721 & 6.0 & 5.1558 & TRN & \\
\hline CHEMBL1547645 & 688721 & 4.6 & 5.0247 & TRN & \\
\hline CHEMBL1442312 & 688721 & 4.6 & 4.893 & TRN & \\
\hline CHEMBL1309955 & 688721 & 4.4 & 4.9454 & TRN & \\
\hline CHEMBL1493835 & 688721 & 4.5 & 5.3021 & TST & \\
\hline CHEMBL1412517 & 688721 & 5.2 & 5.056 & TST & \\
\hline CHEMBL1344130 & 688721 & 5.5 & 4.9929 & TRN & \\
\hline CHEMBL1609067 & 688721 & 4.5 & 4.9168 & TRN & \\
\hline CHEMBL171064 & 688721 & 4.5 & 5.1889 & TST & \\
\hline CHEMBL1556843 & 688721 & 5.0 & 4.7925 & TRN & \\
\hline CHEMBL1453216 & 688721 & 4.7 & 5.135 & TRN & \\
\hline CHEMBL1429011 & 688721 & 4.4 & 4.6952 & TRN & \\
\hline CHEMBL1471400 & 688721 & 6.0 & 4.9681 & TST & \\
\hline CHEMBL1304639 & 688721 & 4.6 & 4.9747 & TRN & \\
\hline CHEMBL1449350 & 688721 & 4.4 & 4.958 & TRN & \\
\hline CHEMBL1443012 & 688721 & 4.6 & 4.9032 & TRN & \\
\hline CHEMBL1597960 & 688721 & 5.8 & 4.8119 & TRN & \\
\hline CHEMBL1495008 & 688721 & 5.5 & 4.8095 & TST & \\
\hline CHEMBL1417270 & 688721 & 4.6 & 5.0362 & TRN & \\
\hline CHEMBL1525237 & 688721 & 7.4001 & 5.1331 & TST & \\
\hline CHEMBL1460105 & 688721 & 5.0 & 4.8689 & TRN & \\
\hline CHEMBL1358950 & 688721 & 4.9 & 4.6743 & TRN & \\
\hline
\end{tabular}




\begin{tabular}{|c|c|c|c|c|}
\hline & & & ement & al Ta \\
\hline CHEMBL3196267 & 688721 & 5.3 & 4.8704 & TRN \\
\hline CHEMBL1372330 & 688721 & 6.0 & 5.0206 & TRN \\
\hline CHEMBL1603393 & 688721 & 4.5 & 5.2564 & TRN \\
\hline CHEMBL1377189 & 688721 & 4.8 & 5.1656 & TST \\
\hline CHEMBL1509967 & 688721 & 4.5 & 4.7594 & TRN \\
\hline CHEMBL1577502 & 688721 & 4.9 & 4.9637 & TST \\
\hline CHEMBL1336489 & 688721 & 4.4 & 4.8633 & TRN \\
\hline CHEMBL116600 & 688721 & 5.1 & 5.2689 & TRN \\
\hline CHEMBL1574813 & 688721 & 4.6 & 4.9316 & TRN \\
\hline CHEMBL1413382 & 688721 & 5.0 & 4.8796 & TRN \\
\hline CHEMBL1333774 & 688721 & 4.7 & 4.9346 & TRN \\
\hline CHEMBL1420172 & 688721 & 4.8 & 4.6852 & TRN \\
\hline CHEMBL1556152 & 688721 & 4.6 & 4.9485 & TST \\
\hline CHEMBL1400452 & 688721 & 4.6 & 4.9599 & TST \\
\hline CHEMBL1452644 & 688721 & 5.5 & 4.8478 & TST \\
\hline CHEMBL1360448 & 688721 & 5.0 & 4.8037 & TRN \\
\hline CHEMBL1365911 & 688721 & 4.5 & 5.0385 & TRN \\
\hline CHEMBL1388839 & 688721 & 5.3 & 4.8299 & TRN \\
\hline CHEMBL1529470 & 688721 & 4.5 & 5.0269 & TRN \\
\hline CHEMBL1463288 & 688721 & 4.6 & 4.843 & TRN \\
\hline CHEMBL1449909 & 688721 & 5.8 & 4.8562 & TST \\
\hline CHEMBL1599779 & 688721 & 4.5 & 5.0375 & TRN \\
\hline CHEMBL1487400 & 688721 & 4.8 & 4.9934 & TRN \\
\hline CHEMBL1320607 & 688721 & 4.9 & 4.9018 & TRN \\
\hline CHEMBL295337 & 688721 & 5.5 & 5.1968 & TRN \\
\hline CHEMBL1351703 & 688721 & 5.2 & 5.211 & TRN \\
\hline CHEMBL1574534 & 688721 & 4.8 & 5.126 & TRN \\
\hline CHEMBL1570373 & 688721 & 4.8 & 4.7618 & TRN \\
\hline CHEMBL1443125 & 688721 & 5.1 & 5.2501 & TST \\
\hline CHEMBL60851 & 688721 & 5.3 & 5.3454 & TST \\
\hline CHEMBL1549692 & 688721 & 4.6 & 4.9429 & TST \\
\hline CHEMBL1306110 & 688721 & 4.8 & 4.9283 & TRN \\
\hline CHEMBL1539450 & 688721 & 4.4 & 5.0736 & TST \\
\hline CHEMBL1352262 & 688721 & 7.699 & 5.0466 & TRN \\
\hline CHEMBL1390484 & 688721 & 4.4 & 5.14 & TST \\
\hline CHEMBL1537491 & 688721 & 5.1 & 5.0578 & TST \\
\hline CHEMBL1454850 & 688721 & 4.6 & 4.955 & TRN \\
\hline CHEMBL 2373281 & 688721 & 5.1 & 5.1204 & TST \\
\hline CHEMBL1302390 & 688721 & 5.0 & 5.0052 & TRN \\
\hline CHEMBL1466669 & 688721 & 6.1 & 4.9554 & TST \\
\hline CHEMBL1374152 & 688721 & 4.4 & 5.1037 & TRN \\
\hline CHEMBL1522687 & 688721 & 4.8 & 4.7726 & TRN \\
\hline CHEMBL1531513 & 688721 & 5.0 & 4.9859 & TRN \\
\hline CHEMBL1315939 & 688721 & 4.8 & 5.1392 & TST \\
\hline CHEMBL1528712 & 688721 & 5.7 & 4.9704 & TRN \\
\hline CHEMBL1577182 & 688721 & 4.8 & 4.7551 & TRN \\
\hline CHEMBL1370533 & 688721 & 4.5 & 4.9016 & TRN \\
\hline CHEMBL1454146 & 688721 & 5.4 & 5.0158 & TRN \\
\hline
\end{tabular}




\begin{tabular}{|c|c|c|c|c|c|}
\hline \multicolumn{6}{|c|}{ Supplemental Table S2.txt } \\
\hline CHEMBL1564794 & 688721 & 5.2 & 5.0522 & TRN & \\
\hline CHEMBL1486698 & 688721 & 4.4 & 4.8554 & TRN & \\
\hline CHEMBL1350094 & 688721 & 5.0 & 4.9656 & TRN & \\
\hline CHEMBL1361840 & 688721 & 4.9 & 4.9726 & TRN & \\
\hline CHEMBL1583061 & 688721 & 5.5 & 5.0159 & TRN & \\
\hline CHEMBL1601019 & 688721 & 4.7 & 5.0986 & TRN & \\
\hline CHEMBL1331504 & 688721 & 5.2 & 4.9024 & TRN & \\
\hline CHEMBL1458209 & 688721 & 4.8 & 4.8838 & TRN & \\
\hline CHEMBL1443380 & 688721 & 4.5 & 4.9705 & TRN & \\
\hline CHEMBL1417865 & 688721 & 4.9 & 5.1732 & TST & \\
\hline CHEMBL1559765 & 688721 & 4.5 & \multicolumn{2}{|c|}{4.9110000000000005} & TST \\
\hline CHEMBL1552753 & 688721 & 5.4 & 5.0761 & TRN & \\
\hline CHEMBL1512602 & 688721 & 7.4001 & 5.3211 & TRN & \\
\hline CHEMBL1475377 & 688721 & 4.7 & 5.1405 & TRN & \\
\hline CHEMBL1477600 & 688721 & 4.6 & 4.8066 & TRN & \\
\hline CHEMBL1599370 & 688721 & 4.6 & 4.9409 & TST & \\
\hline CHEMBL1585876 & 688721 & 5.9 & 5.0589 & TST & \\
\hline CHEMBL1526750 & 688721 & 4.6 & 4.8314 & TST & \\
\hline CHEMBL1575570 & 688721 & 4.7 & 4.812 & TRN & \\
\hline CHEMBL1363385 & 688721 & 5.3 & 4.8627 & TRN & \\
\hline CHEMBL1340103 & 688721 & 5.3 & 4.8129 & TST & \\
\hline CHEMBL1536819 & 688721 & 5.1 & 4.8032 & TRN & \\
\hline CHEMBL1608542 & 688721 & 4.5 & 4.8652 & TRN & \\
\hline CHEMBL1470796 & 688721 & 5.0 & 4.7744 & TST & \\
\hline CHEMBL1366590 & 688721 & 5.4 & 5.1097 & TRN & \\
\hline CHEMBL1518538 & 688721 & 5.1 & 5.0649 & TST & \\
\hline CHEMBL1569363 & 688721 & 6.1 & 5.056 & TRN & \\
\hline CHEMBL1496315 & 688721 & 4.8 & 4.9901 & TRN & \\
\hline CHEMBL1404793 & 688721 & 5.3 & 4.9904 & TST & \\
\hline CHEMBL1560914 & 688721 & 4.8 & 4.8519 & TRN & \\
\hline CHEMBL1505564 & 688721 & 4.9 & 4.8156 & TRN & \\
\hline CHEMBL1378764 & 688721 & 5.6 & 5.1369 & TRN & \\
\hline CHEMBL1312343 & 688721 & 4.4 & 4.7795 & TRN & \\
\hline CHEMBL16200 & 688721 & 6.9 & 5.0091 & TST & \\
\hline CHEMBL1488115 & 688721 & 4.7 & 4.9535 & TRN & \\
\hline CHEMBL1497897 & 688721 & 4.5 & 4.7706 & TRN & \\
\hline CHEMBL1377686 & 688721 & 5.3 & 5.0464 & TRN & \\
\hline CHEMBL3208302 & 688721 & 4.5 & 4.936 & TRN & \\
\hline CHEMBL1483878 & 688721 & 4.8 & 5.0786 & TST & \\
\hline CHEMBL1579151 & 688721 & 5.6 & 4.8613 & TRN & \\
\hline CHEMBL1443200 & 688721 & 4.5 & 4.8241 & TRN & \\
\hline CHEMBL1458885 & 688721 & 5.0 & 4.9108 & TRN & \\
\hline CHEMBL1494205 & 688721 & 6.1 & 4.859 & TRN & \\
\hline CHEMBL1313190 & 688721 & 4.8 & 4.9716 & TRN & \\
\hline CHEMBL1504797 & 688721 & 5.0 & 4.7613 & TRN & \\
\hline CHEMBL1390986 & 688721 & 5.4 & 4.8593 & TRN & \\
\hline CHEMBL15897 & 688721 & 5.2 & 5.1548 & TRN & \\
\hline \multirow[t]{2}{*}{ CHEMBL1482759 } & 688721 & 5.8 & 5.17200 & 2000000001 & TRN \\
\hline & & \multicolumn{4}{|c|}{ Page 9150} \\
\hline
\end{tabular}




\begin{tabular}{|c|c|c|c|c|}
\hline \multicolumn{5}{|c|}{ Supplemental Table S2.txt } \\
\hline CHEMBL1392879 & 688721 & 4.9 & 4.6929 & TRN \\
\hline CHEMBL1525504 & 688721 & 4.7 & 5.0534 & TRN \\
\hline CHEMBL1359102 & 688721 & 4.5 & 4.8348 & TRN \\
\hline CHEMBL1357551 & 688721 & 5.1 & 5.0072 & TRN \\
\hline CHEMBL1347645 & 688721 & 4.6 & 4.9172 & TRN \\
\hline CHEMBL1390086 & 688721 & 4.5 & 4.8098 & TRN \\
\hline CHEMBL1550476 & 688721 & 5.5 & 4.9349 & TRN \\
\hline CHEMBL1549470 & 688721 & 5.2 & 5.0392 & TRN \\
\hline CHEMBL1585481 & 688721 & 4.5 & 4.9491 & TST \\
\hline CHEMBL1402406 & 688721 & 4.5 & 4.9444 & TST \\
\hline CHEMBL338743 & 688721 & 5.2 & 5.3451 & TST \\
\hline CHEMBL1458225 & 688721 & 4.9 & 4.7014 & TRN \\
\hline CHEMBL493698 & 688721 & 4.8 & 4.848 & TRN \\
\hline CHEMBL1516028 & 688721 & 4.5 & 4.91 & TRN \\
\hline CHEMBL1302584 & 688721 & 4.8 & 4.9298 & TRN \\
\hline CHEMBL1372200 & 688721 & 5.1 & 5.0214 & TST \\
\hline CHEMBL1413240 & 688721 & 4.5 & 4.8991 & TRN \\
\hline CHEMBL1601630 & 688721 & 5.2 & 5.1636 & TRN \\
\hline CHEMBL1412094 & 688721 & 4.5 & 4.8318 & TRN \\
\hline CHEMBL1537094 & 688721 & 4.4 & 5.1267 & TRN \\
\hline CHEMBL1424395 & 688721 & 4.6 & 4.8818 & TRN \\
\hline CHEMBL1577864 & 688721 & 4.4 & 4.8383 & TRN \\
\hline CHEMBL3190407 & 688721 & 5.9 & 5.0384 & TRN \\
\hline CHEMBL15712 & 688721 & 7.5003 & 5.2925 & TRN \\
\hline CHEMBL1538976 & 688721 & 4.5 & 4.7844 & TRN \\
\hline CHEMBL1545920 & 688721 & 5.0 & 5.024 & TRN \\
\hline CHEMBL41794 & 688721 & 4.7 & 5.0724 & TRN \\
\hline CHEMBL1506872 & 688721 & 5.3 & 4.9264 & TST \\
\hline CHEMBL 3211086 & 688721 & 4.8 & 5.0031 & TRN \\
\hline CHEMBL1566752 & 688721 & 4.6 & 4.8518 & TST \\
\hline CHEMBL1539084 & 688721 & 4.5 & 4.8401 & TST \\
\hline CHEMBL1457199 & 688721 & 4.7 & 4.9464 & TRN \\
\hline CHEMBL1455273 & 688721 & 5.3 & 4.8472 & TST \\
\hline CHEMBL1539788 & 688721 & 5.5 & 4.7995 & TRN \\
\hline CHEMBL1326366 & 688721 & 5.4 & 4.8989 & TRN \\
\hline CHEMBL1325766 & 688721 & 5.7 & 4.9533 & TRN \\
\hline CHEMBL1311758 & 688721 & 4.6 & 4.9594 & TRN \\
\hline CHEMBL1563909 & 688721 & 4.4 & 4.7515 & TRN \\
\hline CHEMBL1453160 & 688721 & 4.9 & 4.7218 & TST \\
\hline CHEMBL 3212348 & 688721 & 5.0 & 4.8552 & TST \\
\hline CHEMBL1425887 & 688721 & 4.5 & 4.8613 & TRN \\
\hline CHEMBL1530123 & 688721 & 4.8 & 4.97 & TRN \\
\hline CHEMBL1346587 & 688721 & 6.1 & 4.8342 & TST \\
\hline CHEMBL1326154 & 688721 & 4.7 & 5.0038 & TRN \\
\hline CHEMBL1445500 & 688721 & 4.8 & 4.7516 & TRN \\
\hline CHEMBL1399652 & 688721 & 5.9 & 5.118 & TRN \\
\hline CHEMBL1330137 & 688721 & 5.2 & 5.0028 & TRN \\
\hline CHEMBL1309404 & 688721 & 5.4 & 4.9122 & TST \\
\hline
\end{tabular}




\begin{tabular}{|c|c|c|c|c|c|}
\hline \multicolumn{6}{|c|}{ Supplemental Table S2.txt } \\
\hline CHEMBL1532681 & 688721 & 4.9 & 4.9648 & TRN & \\
\hline CHEMBL490913 & 688721 & 4.5 & 5.0394 & TRN & \\
\hline CHEMBL1354281 & 688721 & 5.0 & 5.1905 & TRN & \\
\hline CHEMBL1501158 & 688721 & 5.5 & 4.8566 & TRN & \\
\hline CHEMBL1318909 & 688721 & 4.4 & 4.9494 & TRN & \\
\hline CHEMBL1605688 & 688721 & 4.8 & 4.9136 & TRN & \\
\hline CHEMBL1453510 & 688721 & 5.7 & 4.8691 & TRN & \\
\hline CHEMBL1360349 & 688721 & 5.2 & 4.9595 & TST & \\
\hline CHEMBL1481323 & 688721 & 5.4 & 4.8634 & TRN & \\
\hline CHEMBL1352360 & 688721 & 6.8 & 4.9431 & TRN & \\
\hline CHEMBL1583517 & 688721 & 4.6 & 4.9953 & TST & \\
\hline CHEMBL1537155 & 688721 & 5.1 & 5.0093 & TST & \\
\hline CHEMBL275084 & 688721 & 4.9 & 5.0482 & TST & \\
\hline CHEMBL1609459 & 688721 & 4.9 & 5.188 & TST & \\
\hline CHEMBL1590857 & 688721 & 4.6 & 4.9476 & TRN & \\
\hline CHEMBL1348638 & 688721 & 4.9 & 4.882 & TRN & \\
\hline CHEMBL1330302 & 688721 & 4.4 & 4.8415 & TRN & \\
\hline CHEMBL1346609 & 688721 & 4.6 & 4.7656 & TRN & \\
\hline CHEMBL1490103 & 688721 & 5.3 & 4.7609 & TST & \\
\hline CHEMBL1479224 & 688721 & 4.7 & 4.8087 & TRN & \\
\hline CHEMBL1446827 & 688721 & 4.4 & 4.9286 & TRN & \\
\hline CHEMBL516702 & 688721 & 4.8 & 5.2513 & TST & \\
\hline CHEMBL1308582 & 688721 & 4.7 & 5.0725 & TRN & \\
\hline CHEMBL1550356 & 688721 & 4.8 & 4.9517 & TRN & \\
\hline CHEMBL14090 & 688721 & 4.5 & 5.3191 & TST & \\
\hline CHEMBL1377730 & 688721 & 5.1 & 4.909 & TRN & \\
\hline CHEMBL1410636 & 688721 & 4.4 & 4.7471 & TRN & \\
\hline CHEMBL1409445 & 688721 & 4.9 & 5.164 & TRN & \\
\hline CHEMBL1597718 & 688721 & 4.5 & 5.0775 & TRN & \\
\hline CHEMBL1569522 & 688721 & 4.7 & 4.9001 & TRN & \\
\hline CHEMBL1568579 & 688721 & 4.6 & 4.939 & TRN & \\
\hline CHEMBL1504663 & 688721 & 4.5 & 5.3038 & TRN & \\
\hline CHEMBL1466769 & 688721 & 4.7 & 4.8632 & TST & \\
\hline CHEMBL1603994 & 688721 & 5.0 & 5.0168 & TST & \\
\hline CHEMBL1476741 & 688721 & 4.4 & 4.8765 & TRN & \\
\hline CHEMBL1592584 & 688721 & 5.9 & $5.2920 e$ & 0000000001 & TRN \\
\hline CHEMBL1323414 & 688721 & 4.6 & 5.002 & TST & \\
\hline CHEMBL1553498 & 688721 & 4.5 & 5.059 & TRN & \\
\hline CHEMBL1479807 & 688721 & 4.5 & 4.84399 & 9999999999 & TRN \\
\hline CHEMBL1538927 & 688721 & 4.8 & 4.9442 & TRN & \\
\hline CHEMBL1519870 & 688721 & 4.6 & 4.7927 & TRN & \\
\hline CHEMBL1488598 & 688721 & 4.5 & 4.7697 & TRN & \\
\hline CHEMBL1414994 & 688721 & 4.6 & 4.9864 & TST & \\
\hline CHEMBL1410437 & 688721 & 4.4 & 4.6751 & TST & \\
\hline CHEMBL1603208 & 688721 & 4.5 & 4.9487 & TRN & \\
\hline CHEMBL1386928 & 688721 & 5.5 & 4.8698 & TRN & \\
\hline CHEMBL318275 & 688721 & 7.0 & 5.1591 & TRN & \\
\hline CHEMBL1351825 & 688721 & 6.0 & 4.9107 & TST & \\
\hline
\end{tabular}




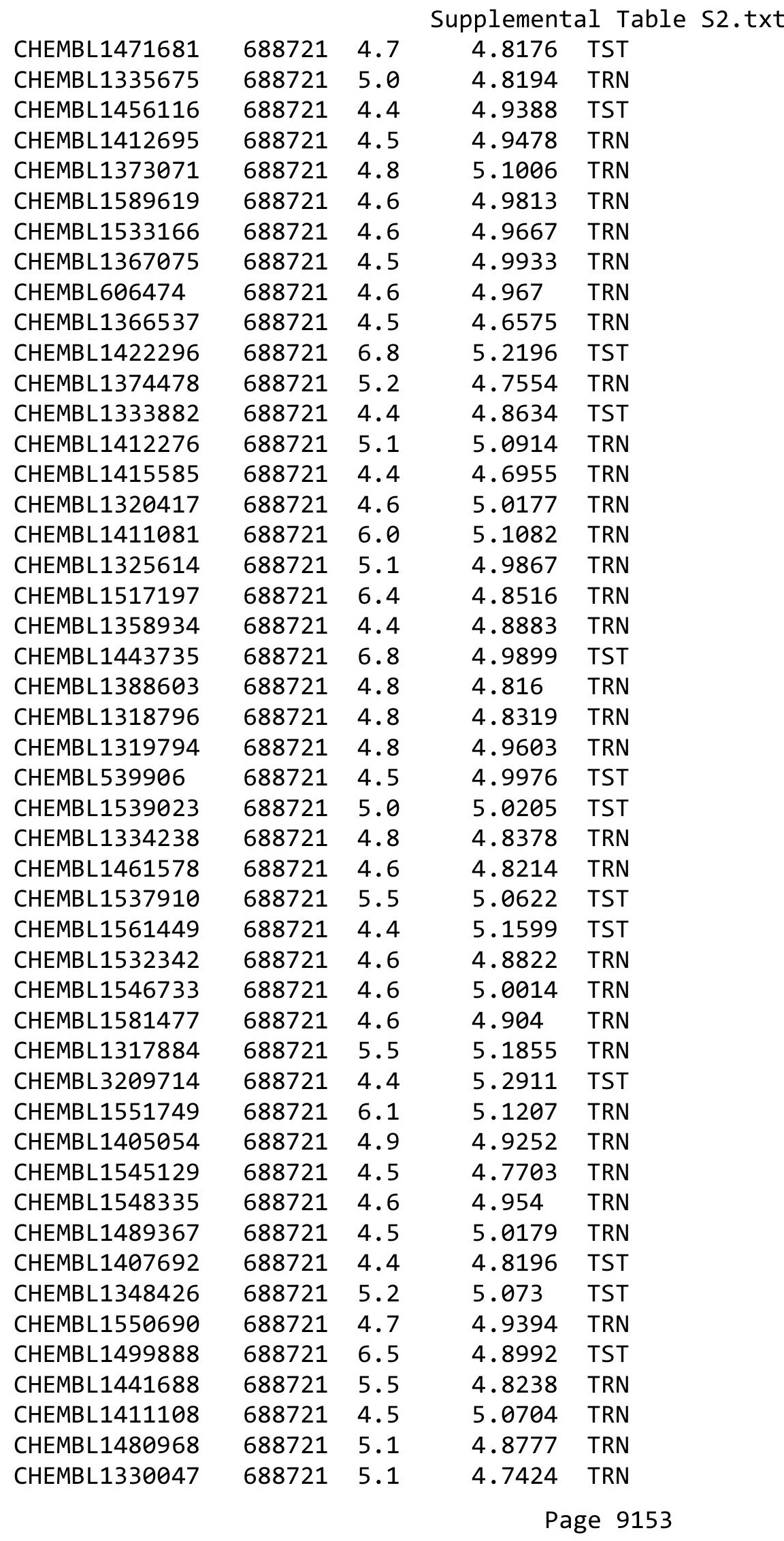




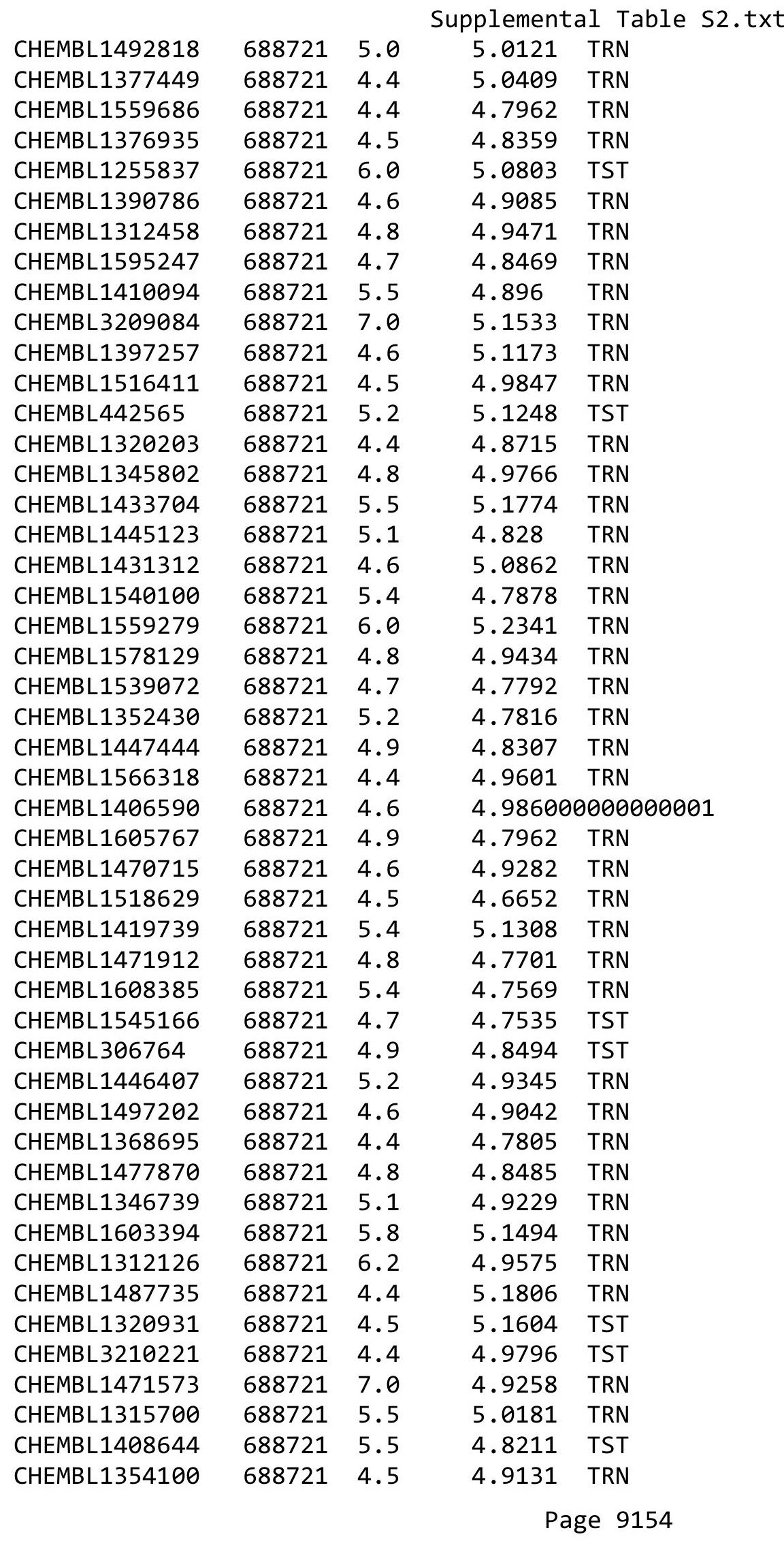




\begin{tabular}{|c|c|c|c|c|c|}
\hline \multicolumn{6}{|c|}{ Supplemental Table S2.txt } \\
\hline CHEMBL1408322 & 688721 & 4.6 & 4.928 & TRN & \\
\hline CHEMBL1608220 & 688721 & 4.6 & 4.7662 & TRN & \\
\hline CHEMBL1389979 & 688721 & 5.5 & 4.9246 & TST & \\
\hline CHEMBL1368396 & 688721 & 4.4 & 4.7928 & TRN & \\
\hline CHEMBL1454751 & 688721 & 4.8 & 5.2226 & TRN & \\
\hline CHEMBL1307167 & 688721 & 5.2 & 4.8547 & TRN & \\
\hline CHEMBL1506570 & 688721 & 4.5 & 4.8568 & TRN & \\
\hline CHEMBL1417800 & 688721 & 4.6 & 5.0722 & TST & \\
\hline CHEMBL1479046 & 688721 & 5.2 & 4.9698 & TRN & \\
\hline CHEMBL1604556 & 688721 & 5.2 & 4.7861 & TRN & \\
\hline CHEMBL1607099 & 688721 & 4.8 & 4.768 & TRN & \\
\hline CHEMBL1484081 & 688721 & 4.8 & 4.7494 & TRN & \\
\hline CHEMBL1401859 & 688721 & 4.6 & 4.8967 & TRN & \\
\hline CHEMBL1420563 & 688721 & 4.5 & 4.9207 & TRN & \\
\hline CHEMBL1300658 & 688721 & 5.8 & 4.7468 & TRN & \\
\hline CHEMBL3209285 & 688721 & 5.5 & 4.9068 & TST & \\
\hline CHEMBL1351965 & 688721 & 4.5 & 4.6796 & TRN & \\
\hline CHEMBL1506458 & 688721 & 4.7 & 4.9812 & TRN & \\
\hline CHEMBL1324415 & 688721 & 4.7 & 4.80399 & 9999999999 & TRN \\
\hline CHEMBL1498283 & 688721 & 4.4 & 4.9071 & TRN & \\
\hline CHEMBL1352447 & 688721 & 4.5 & 4.9773 & TRN & \\
\hline CHEMBL1374687 & 688721 & 4.7 & 4.9395 & TST & \\
\hline CHEMBL1611789 & 688721 & 5.0 & 5.0836 & TRN & \\
\hline CHEMBL1468932 & 688721 & 4.7 & 5.0538 & TST & \\
\hline CHEMBL1330877 & 688721 & 6.4 & 4.9913 & TRN & \\
\hline CHEMBL1488668 & 688721 & 4.4 & 5.0662 & TRN & \\
\hline CHEMBL1467877 & 688721 & 4.6 & 4.8377 & TRN & \\
\hline CHEMBL1411438 & 688721 & 5.6 & 5.0768 & TRN & \\
\hline CHEMBL1417726 & 688721 & 4.5 & 4.9445 & TRN & \\
\hline CHEMBL1383035 & 688721 & 4.7 & 4.9309 & TST & \\
\hline CHEMBL1594330 & 688721 & 5.2 & 5.0374 & TRN & \\
\hline CHEMBL1370445 & 688721 & 4.8 & 4.8425 & TRN & \\
\hline CHEMBL1482597 & 688721 & 4.7 & 4.9213 & TRN & \\
\hline CHEMBL1546620 & 688721 & 4.6 & 4.8537 & TRN & \\
\hline CHEMBL1457981 & 688721 & 4.4 & 4.9193 & TRN & \\
\hline CHEMBL1583467 & 688721 & 8.2007 & 4.8501 & TRN & \\
\hline CHEMBL1321863 & 688721 & 6.2 & 4.9318 & TRN & \\
\hline CHEMBL1376242 & 688721 & 4.4 & 5.1644 & TRN & \\
\hline CHEMBL1419704 & 688721 & 5.9 & 5.1893 & TST & \\
\hline CHEMBL1523579 & 688721 & 4.7 & 5.0001 & TRN & \\
\hline CHEMBL1444271 & 688721 & 4.6 & 4.8161 & TST & \\
\hline CHEMBL1568722 & 688721 & 4.4 & 4.8297 & TST & \\
\hline CHEMBL1563143 & 688721 & 4.9 & 4.973 & TRN & \\
\hline CHEMBL1442580 & 688721 & 5.4 & 4.8033 & TRN & \\
\hline CHEMBL1582006 & 688721 & 4.9 & 4.8568 & TRN & \\
\hline CHEMBL1552953 & 688721 & 5.7 & 4.9959 & TST & \\
\hline CHEMBL1360748 & 688721 & 4.5 & 4.8532 & TST & \\
\hline CHEMBL1393143 & 688721 & 4.7 & 4.88399 & 99999999995 & TRN \\
\hline & & & & 9155 & \\
\hline
\end{tabular}




\begin{tabular}{|c|c|c|c|c|}
\hline \multicolumn{5}{|c|}{ pıemental } \\
\hline CHEMBL1529692 & 688721 & 5.2 & 4.9363 & TRN \\
\hline CHEMBL1383270 & 688721 & 5.5 & 5.176 & TRN \\
\hline CHEMBL1380424 & 688721 & 4.4 & 5.0519 & TRN \\
\hline CHEMBL1611216 & 688721 & 4.4 & 4.9637 & TST \\
\hline CHEMBL1351456 & 688721 & 5.3 & 5.0335 & TST \\
\hline CHEMBL1421118 & 688721 & 4.5 & 4.9166 & TRN \\
\hline CHEMBL2001481 & 688721 & 4.6 & 4.931 & TST \\
\hline CHEMBL600342 & 688721 & 4.4 & 4.8529 & TRN \\
\hline CHEMBL1328745 & 688721 & 4.5 & 4.7899 & TRN \\
\hline CHEMBL1548237 & 688721 & 5.9 & 5.0448 & TRN \\
\hline CHEMBL1563090 & 688721 & 4.8 & 4.8549 & TRN \\
\hline CHEMBL1343424 & 688721 & 4.8 & 4.8058 & TRN \\
\hline CHEMBL1496744 & 688721 & 5.5 & 5.1638 & TRN \\
\hline CHEMBL1596984 & 688721 & 4.6 & 4.8451 & TRN \\
\hline CHEMBL3193247 & 688721 & 4.5 & 4.8869 & TRN \\
\hline CHEMBL1396374 & 688721 & 5.5 & 4.7878 & TRN \\
\hline CHEMBL1489438 & 688721 & 4.4 & 5.0253 & TRN \\
\hline CHEMBL1489891 & 688721 & 4.5 & 4.9046 & TRN \\
\hline CHEMBL1300359 & 688721 & 4.5 & 4.8418 & TRN \\
\hline CHEMBL1546483 & 688721 & 4.4 & 4.9513 & TRN \\
\hline CHEMBL1571568 & 688721 & 6.8 & 4.8981 & TRN \\
\hline CHEMBL1598028 & 688721 & 4.6 & 4.9668 & TRN \\
\hline CHEMBL1441012 & 688721 & 6.1 & 5.1682 & TRN \\
\hline CHEMBL1352703 & 688721 & 4.4 & 4.7661 & TRN \\
\hline CHEMBL3207615 & 688721 & 4.7 & 4.9443 & TST \\
\hline CHEMBL1346967 & 688721 & 4.6 & 4.9035 & TRN \\
\hline CHEMBL1489374 & 688721 & 4.4 & 4.9765 & TRN \\
\hline CHEMBL1566213 & 688721 & 4.4 & 5.1521 & TRN \\
\hline CHEMBL1596209 & 688721 & 5.5 & 4.9077 & TRN \\
\hline CHEMBL1359105 & 688721 & 5.4 & 4.9486 & TRN \\
\hline CHEMBL1464513 & 688721 & 4.5 & 5.1167 & TRN \\
\hline CHEMBL1370155 & 688721 & 4.6 & 4.9048 & TRN \\
\hline CHEMBL1565048 & 688721 & 4.9 & 4.8278 & TRN \\
\hline CHEMBL1370498 & 688721 & 4.6 & 4.6607 & TRN \\
\hline CHEMBL1378365 & 688721 & 4.5 & 5.0732 & TRN \\
\hline CHEMBL1359713 & 688721 & 4.9 & 5.0077 & TRN \\
\hline CHEMBL1362939 & 688721 & 4.5 & 4.8583 & TRN \\
\hline CHEMBL1343646 & 688721 & 5.2 & 4.9792 & TRN \\
\hline CHEMBL1546372 & 688721 & 4.6 & 4.6349 & TRN \\
\hline CHEMBL1366586 & 688721 & 4.8 & 5.1954 & TRN \\
\hline CHEMBL1500640 & 688721 & 4.9 & 4.7624 & TRN \\
\hline CHEMBL1558167 & 688721 & 4.4 & 4.8239 & TRN \\
\hline CHEMBL1502400 & 688721 & 4.4 & 4.9404 & TRN \\
\hline CHEMBL1423539 & 688721 & 5.2 & 4.8454 & TRN \\
\hline CHEMBL1512780 & 688721 & 4.5 & 5.0844 & TRN \\
\hline CHEMBL1455269 & 688721 & 4.6 & 4.8753 & TRN \\
\hline CHEMBL1583040 & 688721 & 5.8 & 4.9606 & TRN \\
\hline CHEMBL1449018 & 688721 & 5.3 & 5.0942 & TRN \\
\hline
\end{tabular}




\begin{tabular}{|c|c|c|c|c|c|}
\hline \multicolumn{6}{|c|}{ Supplemental Table S2.txt } \\
\hline CHEMBL1615433 & 688721 & 5.1 & 5.1454 & TRN & \\
\hline CHEMBL1565645 & 688721 & 4.6 & 4.8079 & TRN & \\
\hline CHEMBL1473523 & 688721 & 4.8 & 5.2629 & TST & \\
\hline CHEMBL1494386 & 688721 & 4.5 & 4.9626 & TRN & \\
\hline CHEMBL1430687 & 688721 & 5.0 & 4.833 & TRN & \\
\hline CHEMBL1345798 & 688721 & 4.6 & 4.9996 & TRN & \\
\hline CHEMBL492267 & 688721 & 4.4 & 4.9334 & TST & \\
\hline CHEMBL1515975 & 688721 & 4.7 & 5.0936 & TRN & \\
\hline CHEMBL1502203 & 688721 & 4.7 & 4.9316 & TST & \\
\hline CHEMBL1368942 & 688721 & 5.8 & 5.1163 & TRN & \\
\hline CHEMBL1406820 & 688721 & 6.5 & 4.8576 & TRN & \\
\hline CHEMBL1523780 & 688721 & 4.5 & 4.8308 & TRN & \\
\hline CHEMBL1331593 & 688721 & 4.6 & 4.9415 & TRN & \\
\hline CHEMBL448841 & 688721 & 4.5 & 4.8878 & TST & \\
\hline CHEMBL1395226 & 688721 & 5.1 & 5.2708 & TRN & \\
\hline CHEMBL1602993 & 688721 & 5.5 & 4.8116 & TRN & \\
\hline CHEMBL1565681 & 688721 & 4.5 & 4.9486 & TRN & \\
\hline CHEMBL1594935 & 688721 & 5.2 & 5.33799 & 9999999999 & TST \\
\hline CHEMBL1483759 & 688721 & 4.6 & 4.9597 & TST & \\
\hline CHEMBL1331525 & 688721 & 6.8 & 4.9601 & TRN & \\
\hline CHEMBL1434111 & 688721 & 6.0 & 5.1797 & TRN & \\
\hline CHEMBL1427864 & 688721 & 4.5 & 5.0202 & TST & \\
\hline CHEMBL1415950 & 688721 & 5.0 & 4.92399 & 99999999995 & TRN \\
\hline CHEMBL1448275 & 688721 & 4.6 & 4.7781 & TRN & \\
\hline CHEMBL1611622 & 688721 & 4.8 & 4.8625 & TRN & \\
\hline CHEMBL1497927 & 688721 & 4.4 & 4.8546 & TRN & \\
\hline CHEMBL1305755 & 688721 & 5.0 & 5.0857 & TST & \\
\hline CHEMBL1419723 & 688721 & 4.4 & 4.8377 & TRN & \\
\hline CHEMBL1365949 & 688721 & 4.4 & 4.9844 & TRN & \\
\hline CHEMBL1589056 & 688721 & 5.4 & 4.8853 & TST & \\
\hline CHEMBL1256362 & 688721 & 4.4 & 5.2702 & TST & \\
\hline CHEMBL1236872 & 688721 & 4.6 & 5.4459 & TRN & \\
\hline CHEMBL1428517 & 688721 & 4.4 & 4.7789 & TRN & \\
\hline CHEMBL1400050 & 688721 & 6.0 & 4.9683 & TRN & \\
\hline CHEMBL1550840 & 688721 & 4.5 & 4.8655 & TRN & \\
\hline CHEMBL1418247 & 688721 & 4.6 & 4.9054 & TRN & \\
\hline CHEMBL1608615 & 688721 & 4.4 & 4.7958 & TRN & \\
\hline CHEMBL1310339 & 688721 & 4.6 & 4.692 & TRN & \\
\hline CHEMBL 325238 & 688721 & 5.4 & 5.0192 & TRN & \\
\hline CHEMBL1378783 & 688721 & 4.6 & 4.9652 & TRN & \\
\hline CHEMBL1965138 & 688721 & 7.5003 & 5.2054 & TST & \\
\hline CHEMBL1560702 & 688721 & 4.8 & 4.8486 & TRN & \\
\hline CHEMBL1311188 & 688721 & 4.5 & 4.9367 & TRN & \\
\hline CHEMBL1419368 & 688721 & 6.6 & 5.0861 & TRN & \\
\hline CHEMBL1337531 & 688721 & 5.0 & 5.1181 & TRN & \\
\hline CHEMBL251785 & 688721 & 5.0 & 4.7122 & TRN & \\
\hline CHEMBL1597691 & 688721 & 4.4 & 4.7611 & TRN & \\
\hline CHEMBL1570109 & 688721 & 4.8 & 4.961 & TST & \\
\hline
\end{tabular}




\begin{tabular}{|c|c|c|c|c|c|}
\hline \multirow{2}{*}{ CHEMBL1451509 } & \multirow{2}{*}{688721} & \\
\hline & & 5.1 & 4.9809 & TRN & \\
\hline CHEMBL1313118 & 688721 & 5.2 & 5.1474 & TRN & \\
\hline CHEMBL1374217 & 688721 & 5.9 & 4.9573 & TST & \\
\hline CHEMBL1361805 & 688721 & 4.6 & 4.7155 & TRN & \\
\hline CHEMBL1412260 & 688721 & 4.5 & 4.8268 & TRN & \\
\hline CHEMBL1460617 & 688721 & 4.4 & 4.9548 & TRN & \\
\hline CHEMBL1398488 & 688721 & 5.0 & 5.2496 & TRN & \\
\hline CHEMBL1454922 & 688721 & 6.0 & 4.8965 & TRN & \\
\hline CHEMBL1370613 & 688721 & 5.4 & \multicolumn{2}{|c|}{5.252000000000001} & TST \\
\hline CHEMBL 77971 & 688721 & 4.7 & 5.0094 & TST & \\
\hline CHEMBL1583045 & 688721 & 5.0 & 4.9977 & TRN & \\
\hline CHEMBL1488009 & 688721 & 5.2 & 5.0965 & TRN & \\
\hline CHEMBL1607264 & 688721 & 5.2 & 5.0365 & TRN & \\
\hline CHEMBL1386716 & 688721 & 5.2 & 4.9123 & TRN & \\
\hline CHEMBL1351718 & 688721 & 4.4 & 5.0856 & TRN & \\
\hline CHEMBL1444343 & 688721 & 4.5 & 5.0124 & TST & \\
\hline CHEMBL1367636 & 688721 & 5.4 & 4.8774 & TRN & \\
\hline CHEMBL1538849 & 688721 & 7.1002 & 4.8659 & TRN & \\
\hline CHEMBL1561581 & 688721 & 6.4 & 5.0363 & TST & \\
\hline CHEMBL1462097 & 688721 & 4.6 & 4.6673 & TRN & \\
\hline CHEMBL1407739 & 688721 & 4.7 & 5.0157 & TRN & \\
\hline CHEMBL1491547 & 688721 & 4.4 & 4.9525 & TRN & \\
\hline CHEMBL89295 & 688721 & 5.3 & 5.2791 & TST & \\
\hline CHEMBL1486572 & 688721 & 4.4 & 4.8249 & TRN & \\
\hline CHEMBL1405342 & 688721 & 5.3 & 4.7953 & TRN & \\
\hline CHEMBL 9113 & 688721 & 4.9 & 4.8893 & TRN & \\
\hline CHEMBL1431949 & 688721 & 4.5 & 4.8849 & TRN & \\
\hline CHEMBL1578085 & 688721 & 4.6 & 5.0364 & TRN & \\
\hline CHEMBL1380550 & 688721 & 6.2 & 4.8472 & TRN & \\
\hline CHEMBL1473705 & 688721 & 5.2 & 5.4752 & TRN & \\
\hline CHEMBL1488200 & 688721 & 4.6 & 4.801 & TRN & \\
\hline CHEMBL1389701 & 688721 & 4.5 & 4.8978 & TST & \\
\hline CHEMBL1366020 & 688721 & 4.4 & 4.938 & TRN & \\
\hline CHEMBL1406595 & 688721 & 4.6 & 4.8385 & TRN & \\
\hline CHEMBL1569346 & 688721 & 4.4 & \multicolumn{2}{|c|}{4.9430000000000005} & TRN \\
\hline CHEMBL1492526 & 688721 & 4.5 & 4.8594 & TRN & \\
\hline CHEMBL1459135 & 688721 & 4.5 & 4.8792 & TST & \\
\hline CHEMBL1505290 & 688721 & 5.4 & 4.7221 & TST & \\
\hline CHEMBL1345487 & 688721 & 4.4 & 4.9205 & TRN & \\
\hline CHEMBL1599620 & 688721 & 4.5 & 4.8744 & TRN & \\
\hline CHEMBL1394964 & 688721 & 5.1 & 5.2555 & TRN & \\
\hline CHEMBL1547078 & 688721 & 5.2 & 5.2383 & TST & \\
\hline CHEMBL1562633 & 688721 & 4.6 & 4.8647 & TRN & \\
\hline CHEMBL1373357 & 688721 & 4.5 & 4.9008 & TRN & \\
\hline CHEMBL 1490010 & 688721 & 6.0 & 5.1905 & TST & \\
\hline CHEMBL1346928 & 688721 & 4.9 & 4.9855 & TRN & \\
\hline CHEMBL 1492950 & 688721 & 4.8 & 4.9292 & TRN & \\
\hline \multirow[t]{2}{*}{ CHEMBL1493138 } & 688721 & 4.8 & 4.8671 & TRN & \\
\hline & & \multicolumn{4}{|c|}{ Page 9158} \\
\hline
\end{tabular}




\begin{tabular}{|c|c|c|c|c|}
\hline \multicolumn{5}{|c|}{ iental lable S2. } \\
\hline CHEMBL1344424 & 688721 & 5.4 & 4.923 & TRN \\
\hline CHEMBL1365088 & 688721 & 4.5 & 4.912 & TRN \\
\hline CHEMBL1517062 & 688721 & 5.8 & 4.8278 & TRN \\
\hline CHEMBL1330913 & 688721 & 6.2 & 5.1293 & TST \\
\hline CHEMBL1329725 & 688721 & 4.6 & 4.9319 & TRN \\
\hline CHEMBL1340774 & 688721 & 4.8 & 4.8273 & TRN \\
\hline CHEMBL1595907 & 688721 & 5.2 & 5.0753 & TRN \\
\hline CHEMBL1393097 & 688721 & 5.6 & 4.8015 & TRN \\
\hline CHEMBL1508186 & 688721 & 7.1002 & 4.8611 & TRN \\
\hline CHEMBL1409496 & 688721 & 4.6 & 5.1634 & TRN \\
\hline CHEMBL1497046 & 688721 & 5.2 & 4.9422 & TRN \\
\hline CHEMBL1345083 & 688721 & 4.8 & 4.7908 & TRN \\
\hline CHEMBL1611982 & 688721 & 4.8 & 5.0665 & TRN \\
\hline CHEMBL1415404 & 688721 & 4.6 & 4.9888 & TRN \\
\hline CHEMBL1572237 & 688721 & 4.4 & 4.8078 & TRN \\
\hline CHEMBL1333817 & 688721 & 5.2 & 4.9582 & TST \\
\hline CHEMBL1450975 & 688721 & 4.9 & 4.8339 & TRN \\
\hline CHEMBL1319482 & 688721 & 4.8 & 4.7701 & TRN \\
\hline CHEMBL1603769 & 688721 & 4.7 & 4.9123 & TRN \\
\hline CHEMBL1524731 & 688721 & 4.8 & 4.6784 & TRN \\
\hline CHEMBL 1400060 & 688721 & 4.4 & 5.0161 & TST \\
\hline CHEMBL1256740 & 688721 & 6.0 & 5.0986 & TST \\
\hline CHEMBL1460654 & 688721 & 4.8 & 4.912 & TRN \\
\hline CHEMBL1333421 & 688721 & 5.9 & 5.04 & TRN \\
\hline CHEMBL1569975 & 688721 & 4.8 & 4.9632 & TRN \\
\hline CHEMBL1594327 & 688721 & 5.3 & 4.9574 & TRN \\
\hline CHEMBL1530684 & 688721 & 5.6 & 5.3441 & TRN \\
\hline CHEMBL1468815 & 688721 & 5.3 & 4.7272 & TRN \\
\hline CHEMBL1413371 & 688721 & 6.1 & 5.1367 & TST \\
\hline CHEMBL1522073 & 688721 & 4.5 & 4.8506 & TST \\
\hline CHEMBL1565052 & 688721 & 4.7 & 4.8142 & TRN \\
\hline CHEMBL3213925 & 688721 & 4.6 & 4.8421 & TRN \\
\hline CHEMBL411492 & 688721 & 4.5 & 4.9277 & TRN \\
\hline CHEMBL1313395 & 688721 & 4.7 & 4.9013 & TRN \\
\hline CHEMBL1376266 & 688721 & 4.7 & 4.9199 & TRN \\
\hline CHEMBL1455799 & 688721 & 4.5 & 4.8527 & TRN \\
\hline CHEMBL1454793 & 688721 & 5.0 & 5.1316 & TRN \\
\hline CHEMBL1470737 & 688721 & 4.5 & 4.8563 & TST \\
\hline CHEMBL1475562 & 688721 & 4.7 & 4.9008 & TRN \\
\hline CHEMBL 82870 & 688721 & 5.2 & $5.1620 e$ & 0000000001 \\
\hline CHEMBL1501864 & 688721 & 4.4 & 4.8846 & TRN \\
\hline CHEMBL1316735 & 688721 & 5.5 & 5.1723 & TRN \\
\hline CHEMBL1401831 & 688721 & 4.6 & 5.0965 & TRN \\
\hline CHEMBL1470713 & 688721 & 6.3 & 4.9965 & TRN \\
\hline CHEMBL1503554 & 688721 & 4.6 & 4.8257 & TRN \\
\hline CHEMBL1353210 & 688721 & 5.1 & 5.1488 & TST \\
\hline CHEMBL1540345 & 688721 & 5.4 & 5.0903 & TST \\
\hline CHEMBL1377572 & 688721 & 4.8 & 5.1904 & TST \\
\hline
\end{tabular}




\begin{tabular}{|c|c|c|c|c|}
\hline & & & plem & \\
\hline CHEMBL1347327 & 688721 & 4.5 & 4.8122 & TRN \\
\hline CHEMBL1502807 & 688721 & 5.2 & 4.9953 & TRN \\
\hline CHEMBL1322199 & 688721 & 4.7 & 4.9475 & TRN \\
\hline CHEMBL1513278 & 688721 & 4.7 & 4.936 & TRN \\
\hline CHEMBL1539473 & 688721 & 6.6 & 4.8314 & TST \\
\hline CHEMBL1494697 & 688721 & 4.6 & 5.0416 & TRN \\
\hline CHEMBL1502071 & 688721 & 4.6 & 5.189 & TST \\
\hline CHEMBL1483983 & 688721 & 5.4 & 4.9659 & TRN \\
\hline CHEMBL1327184 & 688721 & 5.0 & 5.0891 & TRN \\
\hline CHEMBL1466746 & 688721 & 4.7 & 4.9377 & TRN \\
\hline CHEMBL1344260 & 688721 & 4.8 & 4.9379 & TST \\
\hline CHEMBL1455257 & 688721 & 4.6 & 4.9718 & TRN \\
\hline CHEMBL1343779 & 688721 & 6.0 & 4.998 & TRN \\
\hline CHEMBL12998 & 688721 & 4.7 & 5.0831 & TST \\
\hline CHEMBL1373505 & 688721 & 4.6 & 4.8985 & TRN \\
\hline CHEMBL1316779 & 688721 & 5.9 & 5.2743 & TRN \\
\hline CHEMBL365739 & 688721 & 6.0 & 5.0256 & TST \\
\hline CHEMBL1569965 & 688721 & 4.7 & 5.0003 & TRN \\
\hline CHEMBL1458972 & 688721 & 4.5 & 4.7858 & TRN \\
\hline CHEMBL1317620 & 688721 & 4.9 & 4.9243 & TRN \\
\hline CHEMBL1309392 & 688721 & 4.7 & 4.9138 & TRN \\
\hline CHEMBL1462652 & 688721 & 5.8 & 4.7972 & TRN \\
\hline CHEMBL1462954 & 688721 & 4.4 & 4.9813 & TST \\
\hline CHEMBL1376939 & 688721 & 4.9 & 4.8676 & TRN \\
\hline CHEMBL1564098 & 688721 & 5.1 & 4.8815 & TRN \\
\hline CHEMBL592712 & 688721 & 4.8 & 4.9696 & TST \\
\hline CHEMBL1557431 & 688721 & 4.5 & 4.7986 & TRN \\
\hline CHEMBL1328380 & 688721 & 5.5 & 4.9579 & TRN \\
\hline CHEMBL1346330 & 688721 & 4.5 & 4.9533 & TST \\
\hline CHEMBL1613204 & 688721 & 4.6 & 4.913 & TST \\
\hline CHEMBL1326487 & 688721 & 5.9 & 5.032 & TST \\
\hline CHEMBL1591460 & 688721 & 5.1 & 4.9806 & TRN \\
\hline CHEMBL1400566 & 688721 & 4.6 & 5.0264 & TST \\
\hline CHEMBL1504816 & 688721 & 4.6 & 5.0535 & TRN \\
\hline CHEMBL1429139 & 688721 & 4.5 & 5.0713 & TST \\
\hline CHEMBL1322512 & 688721 & 4.5 & 5.0715 & TRN \\
\hline CHEMBL1369249 & 688721 & 4.4 & 4.7828 & TRN \\
\hline CHEMBL1523699 & 688721 & 4.7 & 5.1315 & TRN \\
\hline CHEMBL1508573 & 688721 & 5.4 & 4.8347 & TRN \\
\hline CHEMBL1324684 & 688721 & 4.7 & 4.8322 & TRN \\
\hline CHEMBL1354648 & 688721 & 5.9 & 5.02 & TST \\
\hline CHEMBL1334474 & 688721 & 4.4 & 4.901 & TRN \\
\hline CHEMBL1565563 & 688721 & 5.4 & 4.7431 & TRN \\
\hline CHEMBL1516562 & 688721 & 4.5 & 5.0617 & TRN \\
\hline CHEMBL1501892 & 688721 & 4.4 & 4.9183 & TRN \\
\hline CHEMBL1595195 & 688721 & 5.4 & 5.0377 & TRN \\
\hline CHEMBL1484947 & 688721 & 4.3 & 5.2783 & TST \\
\hline CHEMBL1448561 & 688721 & 4.4 & 5.2079 & TST \\
\hline
\end{tabular}




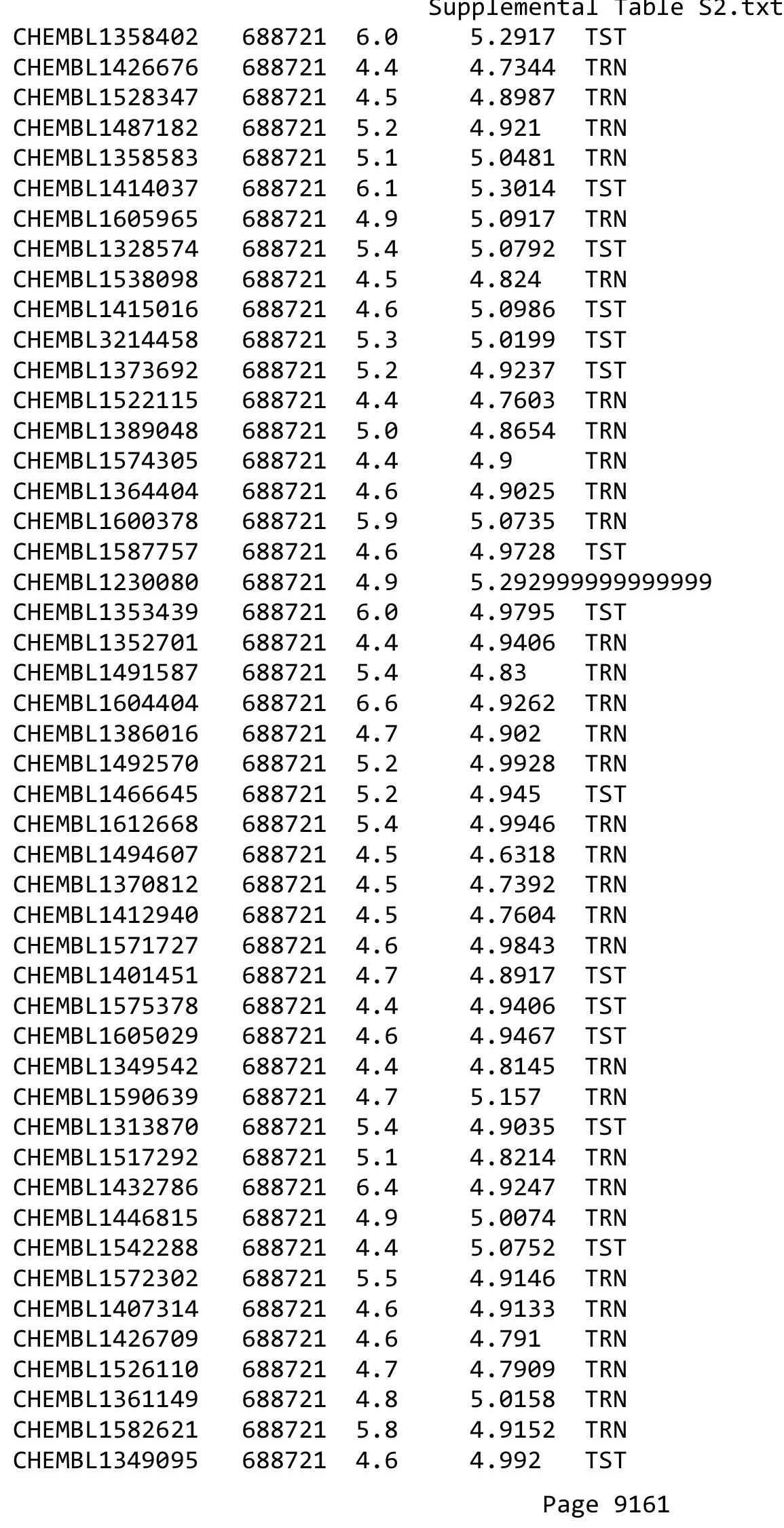




\begin{tabular}{|c|c|c|c|c|c|}
\hline \multicolumn{6}{|c|}{ Supplemental Table S2.txt } \\
\hline CHEMBL1605497 & 688721 & 4.6 & 5.1065 & TRN & \\
\hline CHEMBL1461412 & 688721 & 4.8 & 4.7087 & TRN & \\
\hline CHEMBL442956 & 688721 & 5.1 & 5.083 & TST & \\
\hline CHEMBL1566037 & 688721 & 4.5 & 4.9266 & TRN & \\
\hline CHEMBL1404693 & 688721 & 4.7 & 4.842 & TST & \\
\hline CHEMBL1607385 & 688721 & 7.5003 & 4.9378 & TRN & \\
\hline CHEMBL3214589 & 688721 & 4.8 & 4.8918 & TST & \\
\hline CHEMBL1405348 & 688721 & 4.5 & 4.9526 & TRN & \\
\hline CHEMBL1508547 & 688721 & 4.6 & 4.8294 & TRN & \\
\hline CHEMBL1360322 & 688721 & 5.4 & 4.9608 & TRN & \\
\hline CHEMBL1341986 & 688721 & 5.1 & 5.0575 & TST & \\
\hline CHEMBL1550952 & 688721 & 4.5 & 4.7588 & TRN & \\
\hline CHEMBL1424785 & 688721 & 4.5 & 4.8948 & TRN & \\
\hline CHEMBL1440238 & 688721 & 4.5 & 4.7418 & TRN & \\
\hline CHEMBL1607832 & 688721 & 4.4 & 4.8496 & TRN & \\
\hline CHEMBL1322600 & 688721 & 4.6 & 4.9221 & TRN & \\
\hline CHEMBL1604588 & 688721 & 4.9 & 4.9876 & TRN & \\
\hline CHEMBL1468806 & 688721 & 4.6 & 4.7385 & TRN & \\
\hline CHEMBL1468709 & 688721 & 5.1 & 4.9849 & TRN & \\
\hline CHEMBL1413328 & 688721 & 5.1 & 5.0175 & TRN & \\
\hline CHEMBL1542000 & 688721 & 4.4 & 4.9911 & TST & \\
\hline CHEMBL1332759 & 688721 & 4.8 & 5.1793 & TRN & \\
\hline CHEMBL1307107 & 688721 & 4.5 & 5.1743 & TST & \\
\hline CHEMBL1549597 & 688721 & 4.6 & 4.8654 & TRN & \\
\hline CHEMBL1562623 & 688721 & 4.9 & 4.8423 & TRN & \\
\hline CHEMBL1400430 & 688721 & 4.7 & 5.0034 & TRN & \\
\hline CHEMBL1376163 & 688721 & 4.5 & 4.9324 & TST & \\
\hline CHEMBL1597178 & 688721 & 4.8 & 5.3629 & TRN & \\
\hline CHEMBL1470846 & 688721 & 5.5 & 4.9129 & TRN & \\
\hline CHEMBL1391429 & 688721 & 4.6 & 5.1345 & TST & \\
\hline CHEMBL1317055 & 688721 & 6.0 & 5.0578 & TRN & \\
\hline CHEMBL1323987 & 688721 & 5.2 & 4.8201 & TRN & \\
\hline CHEMBL1565567 & 688721 & 6.8 & 5.0355 & TST & \\
\hline CHEMBL1322019 & 688721 & 5.3 & 4.9554 & TRN & \\
\hline CHEMBL1571692 & 688721 & 4.4 & 5.052 & TST & \\
\hline CHEMBL1518825 & 688721 & 5.7 & 4.7064 & TRN & \\
\hline CHEMBL1459678 & 688721 & 4.6 & 4.9936 & TRN & \\
\hline CHEMBL1397782 & 688721 & 4.6 & 5.0311 & TRN & \\
\hline CHEMBL1605980 & 688721 & 5.1 & 4.76699 & 99999999995 & TRN \\
\hline CHEMBL1429381 & 688721 & 4.6 & 4.8383 & TRN & \\
\hline CHEMBL1360572 & 688721 & 4.4 & 4.8101 & TRN & \\
\hline CHEMBL1468280 & 688721 & 5.1 & 4.8184 & TRN & \\
\hline CHEMBL1573271 & 688721 & 4.7 & 5.0662 & TRN & \\
\hline CHEMBL1512895 & 688721 & 5.2 & 5.2448 & TRN & \\
\hline CHEMBL1355227 & 688721 & 4.7 & 5.1328 & TRN & \\
\hline CHEMBL1549414 & 688721 & 4.6 & 4.8707 & TRN & \\
\hline CHEMBL1520634 & 688721 & 4.5 & 4.8326 & TRN & \\
\hline CHEMBL368473 & 688721 & 5.2 & 4.985 & TRN & \\
\hline
\end{tabular}




\begin{tabular}{|c|c|c|c|c|c|}
\hline \multicolumn{6}{|c|}{ Supplemental Table s2.txt } \\
\hline CHEMBL1432074 & 688721 & 4.8 & 4.8633 & TRN & \\
\hline CHEMBL1442201 & 688721 & 4.4 & 5.0043 & TRN & \\
\hline CHEMBL1533755 & 688721 & 4.4 & 4.9779 & TRN & \\
\hline CHEMBL1376783 & 688721 & 4.8 & 4.7243 & TRN & \\
\hline CHEMBL1327326 & 688721 & 4.5 & 4.8303 & TRN & \\
\hline CHEMBL1415465 & 688721 & 5.5 & 5.1662 & TRN & \\
\hline CHEMBL1398800 & 688721 & 4.6 & 5.21 & TRN & \\
\hline CHEMBL1486744 & 688721 & 4.4 & 4.9052 & TRN & \\
\hline CHEMBL1508142 & 688721 & 4.9 & 4.9213 & TRN & \\
\hline CHEMBL1415721 & 688721 & 5.5 & 4.8602 & TRN & \\
\hline CHEMBL1490627 & 688721 & 4.5 & 4.8633 & TRN & \\
\hline CHEMBL1507268 & 688721 & 6.0 & 4.9527 & TRN & \\
\hline CHEMBL3211174 & 688721 & 4.7 & 4.8167 & TRN & \\
\hline CHEMBL1357812 & 688721 & 5.4 & 4.9258 & TRN & \\
\hline CHEMBL3198071 & 688721 & 4.4 & 4.7698 & TRN & \\
\hline CHEMBL1458707 & 688721 & 4.8 & 5.0552 & TRN & \\
\hline CHEMBL228511 & 688721 & 7.1002 & 5.17200 & 0000000001 & TST \\
\hline CHEMBL1471745 & 688721 & 4.5 & 4.8615 & TRN & \\
\hline CHEMBL1495792 & 688721 & 4.8 & 5.1737 & TST & \\
\hline CHEMBL1410075 & 688721 & 5.0 & 4.9968 & TRN & \\
\hline CHEMBL1402717 & 688721 & 5.1 & 4.8217 & TRN & \\
\hline CHEMBL1413152 & 688721 & 5.4 & 4.9572 & TRN & \\
\hline CHEMBL1580467 & 688721 & 4.4 & 4.8032 & TRN & \\
\hline CHEMBL605747 & 688721 & 4.7 & 4.8353 & TRN & \\
\hline CHEMBL1451260 & 688721 & 4.4 & 4.9982 & TST & \\
\hline CHEMBL1333484 & 688721 & 5.1 & 4.8809 & TRN & \\
\hline CHEMBL1521328 & 688721 & 4.4 & 5.0704 & TRN & \\
\hline CHEMBL1458509 & 688721 & 5.3 & 4.8995 & TST & \\
\hline CHEMBL1408760 & 688721 & 5.1 & 5.0986 & TRN & \\
\hline CHEMBL157351 & 688721 & 5.3 & 4.8865 & TST & \\
\hline CHEMBL1437650 & 688721 & 5.2 & 5.1489 & TRN & \\
\hline CHEMBL1605399 & 688721 & 5.1 & 5.0745 & TRN & \\
\hline CHEMBL1601163 & 688721 & 4.7 & 4.9999 & TRN & \\
\hline CHEMBL1592371 & 688721 & 4.9 & 5.0356 & TRN & \\
\hline CHEMBL1389029 & 688721 & 4.9 & 4.9822 & TRN & \\
\hline CHEMBL1492122 & 688721 & 4.9 & 4.9116 & TRN & \\
\hline CHEMBL1484051 & 688721 & 5.2 & 5.0703 & TST & \\
\hline CHEMBL1424574 & 688721 & 5.4 & 4.8176 & TRN & \\
\hline CHEMBL1355090 & 688721 & 8.301 & 5.2428 & TRN & \\
\hline CHEMBL1439424 & 688721 & 4.5 & 4.8534 & TRN & \\
\hline CHEMBL3197516 & 688721 & 4.6 & 4.8275 & TST & \\
\hline CHEMBL1341220 & 688721 & 5.3 & 4.9616 & TRN & \\
\hline CHEMBL1415734 & 688721 & 4.6 & 5.0114 & TRN & \\
\hline CHEMBL1321338 & 688721 & 4.9 & 5.1165 & TRN & \\
\hline CHEMBL1425084 & 688721 & 4.5 & 4.9776 & TST & \\
\hline CHEMBL1708832 & 688721 & 4.7 & 4.9816 & TST & \\
\hline CHEMBL1401929 & 688721 & 4.4 & 5.0089 & TRN & \\
\hline CHEMBL1545864 & 688721 & 4.5 & 4.8849 & TRN & \\
\hline
\end{tabular}




\begin{tabular}{|c|c|c|c|c|c|}
\hline \multicolumn{6}{|c|}{ Supplemental Table S2.txt } \\
\hline CHEMBL1598058 & 688721 & 4.4 & 4.9159 & TRN & \\
\hline CHEMBL1427907 & 688721 & 4.4 & 5.1288 & TRN & \\
\hline CHEMBL1333962 & 688721 & 4.8 & 4.779 & TRN & \\
\hline CHEMBL1613188 & 688721 & 4.6 & 4.8298 & TRN & \\
\hline CHEMBL1366257 & 688721 & 6.2 & 4.9719 & TRN & \\
\hline CHEMBL1442411 & 688721 & 4.5 & 4.8588 & TRN & \\
\hline CHEMBL1393514 & 688721 & 5.3 & 4.7709 & TRN & \\
\hline CHEMBL1494142 & 688721 & 4.5 & 4.7634 & TRN & \\
\hline CHEMBL1412576 & 688721 & 4.4 & 5.0132 & TST & \\
\hline CHEMBL1576552 & 688721 & 4.8 & 4.8611 & TRN & \\
\hline CHEMBL1412889 & 688721 & 7.5003 & 4.8546 & TST & \\
\hline CHEMBL1358208 & 688721 & 4.5 & 4.8516 & TST & \\
\hline CHEMBL519344 & 688721 & 4.5 & 5.0215 & TRN & \\
\hline CHEMBL1406810 & 688721 & 4.8 & 4.9217 & TRN & \\
\hline CHEMBL1256943 & 688721 & 4.4 & 4.9261 & TRN & \\
\hline CHEMBL 273103 & 688721 & 4.5 & 4.7494 & TRN & \\
\hline CHEMBL1537558 & 688721 & 5.5 & 4.7957 & TRN & \\
\hline CHEMBL1606327 & 688721 & 5.2 & 4.8751 & TRN & \\
\hline CHEMBL1532637 & 688721 & 4.8 & 4.7222 & TRN & \\
\hline CHEMBL1560110 & 688721 & 5.5 & 4.7429 & TRN & \\
\hline CHEMBL1413178 & 688721 & 5.1 & 5.0814 & TST & \\
\hline CHEMBL1332316 & 688721 & 5.2 & 5.0729 & TST & \\
\hline CHEMBL1450292 & 688721 & 5.2 & 4.9324 & TRN & \\
\hline CHEMBL1408476 & 688721 & 4.5 & 4.9196 & TST & \\
\hline CHEMBL1416177 & 688721 & 4.6 & 4.6752 & TRN & \\
\hline CHEMBL1470856 & 688721 & 5.4 & 5.13899 & 9999999999 & TRN \\
\hline CHEMBL391997 & 688721 & 6.0 & 5.093 & TST & \\
\hline CHEMBL1354678 & 688721 & 6.0 & 5.1814 & TRN & \\
\hline CHEMBL1334035 & 688721 & 5.4 & 5.0845 & TST & \\
\hline CHEMBL1490629 & 688721 & 4.7 & 4.9413 & TRN & \\
\hline CHEMBL322970 & 688721 & 7.4001 & 5.1477 & TST & \\
\hline CHEMBL1521011 & 688721 & 4.6 & 4.9717 & TRN & \\
\hline CHEMBL1587527 & 688721 & 4.7 & 4.8302 & TRN & \\
\hline CHEMBL1491493 & 688721 & 5.2 & 4.9125 & TRN & \\
\hline CHEMBL1481491 & 688721 & 4.9 & 4.8988 & TRN & \\
\hline CHEMBL1344838 & 688721 & 4.7 & 4.9073 & TST & \\
\hline CHEMBL1591294 & 688721 & 5.7 & 5.2551 & TST & \\
\hline CHEMBL1511490 & 688721 & 4.6 & 4.9036 & TRN & \\
\hline CHEMBL1365694 & 688721 & 4.7 & 4.9145 & TRN & \\
\hline CHEMBL1486333 & 688721 & 4.4 & 4.9017 & TRN & \\
\hline CHEMBL1359579 & 688721 & 6.7001 & 4.9637 & TRN & \\
\hline CHEMBL1372549 & 688721 & 4.7 & 5.1524 & TRN & \\
\hline CHEMBL1545511 & 688721 & 6.7001 & 4.9054 & TST & \\
\hline CHEMBL1353637 & 688721 & 5.0 & 4.8323 & TRN & \\
\hline CHEMBL1544585 & 688721 & 5.1 & 4.9839 & TRN & \\
\hline CHEMBL1575829 & 688721 & 5.6 & 4.8875 & TRN & \\
\hline CHEMBL1557360 & 688721 & 4.6 & 4.8184 & TRN & \\
\hline CHEMBL1485514 & 688721 & 4.4 & 4.937 & TST & \\
\hline
\end{tabular}




\begin{tabular}{|c|c|c|c|c|c|}
\hline \multicolumn{6}{|c|}{ Supplemental Table S2.txt } \\
\hline CHEMBL434063 & 688721 & 6.0 & 5.0525 & TST & \\
\hline CHEMBL1598999 & 688721 & 4.6 & 4.9456 & TRN & \\
\hline CHEMBL1608918 & 688721 & 5.6 & 4.9636 & TRN & \\
\hline CHEMBL1236251 & 688721 & 5.7 & 5.1604 & TST & \\
\hline CHEMBL1606419 & 688721 & 4.5 & 4.948 & TRN & \\
\hline CHEMBL1330394 & 688721 & 4.8 & 5.1246 & TRN & \\
\hline CHEMBL1551980 & 688721 & 4.9 & 5.0724 & TRN & \\
\hline CHEMBL1335417 & 688721 & 4.4 & 4.8614 & TRN & \\
\hline CHEMBL1400018 & 688721 & 4.6 & 4.9114 & TRN & \\
\hline CHEMBL1606513 & 688721 & 5.4 & 4.9633 & TRN & \\
\hline CHEMBL1482442 & 688721 & 4.9 & 4.8709 & TST & \\
\hline CHEMBL1525610 & 688721 & 5.9 & 5.0929 & TRN & \\
\hline CHEMBL1318419 & 688721 & 4.7 & 4.9145 & TRN & \\
\hline CHEMBL1496009 & 688721 & 5.2 & 4.84699 & 99999999995 & TST \\
\hline CHEMBL1390886 & 688721 & 5.2 & 4.8568 & TST & \\
\hline CHEMBL1505053 & 688721 & 4.4 & 5.0467 & TRN & \\
\hline CHEMBL1561002 & 688721 & 4.5 & 4.8592 & TRN & \\
\hline CHEMBL1491210 & 688721 & 4.5 & 4.8156 & TRN & \\
\hline CHEMBL1489478 & 688721 & 4.6 & 4.9352 & TRN & \\
\hline CHEMBL1511986 & 688721 & 4.6 & 5.1164 & TRN & \\
\hline CHEMBL1332989 & 688721 & 4.4 & 4.898 & TRN & \\
\hline CHEMBL1340418 & 688721 & 4.4 & 4.8524 & TRN & \\
\hline CHEMBL1609405 & 688721 & 4.9 & 5.099 & TRN & \\
\hline CHEMBL1418832 & 688721 & 4.4 & 5.0194 & TRN & \\
\hline CHEMBL1369863 & 688721 & 4.6 & 5.0474 & TRN & \\
\hline CHEMBL1438166 & 688721 & 5.5 & 4.9325 & TRN & \\
\hline CHEMBL1503684 & 688721 & 7.699 & 4.9206 & TST & \\
\hline CHEMBL1407945 & 688721 & 4.5 & 4.7268 & TRN & \\
\hline CHEMBL1612563 & 688721 & 5.5 & 4.9531 & TRN & \\
\hline CHEMBL1733652 & 688721 & 4.6 & 5.024 & TRN & \\
\hline CHEMBL1516373 & 688721 & 5.4 & 4.9574 & TRN & \\
\hline CHEMBL1583730 & 688721 & 4.7 & 4.9131 & TST & \\
\hline CHEMBL1441523 & 688721 & 4.5 & 4.744 & TRN & \\
\hline CHEMBL1430798 & 688721 & 4.4 & 5.0475 & TRN & \\
\hline CHEMBL1487898 & 688721 & 5.5 & 5.2228 & TRN & \\
\hline CHEMBL1604319 & 688721 & 4.9 & 4.8787 & TRN & \\
\hline CHEMBL1310281 & 688721 & 5.2 & 4.8017 & TRN & \\
\hline CHEMBL1370534 & 688721 & 4.4 & 5.087 & TRN & \\
\hline CHEMBL1452841 & 688721 & 6.1 & 4.9079 & TST & \\
\hline CHEMBL1592506 & 688721 & 7.3002 & 5.13700 & 00000000005 & TRN \\
\hline CHEMBL1528097 & 688721 & 4.5 & 4.8619 & TRN & \\
\hline CHEMBL1362137 & 688721 & 4.6 & 4.9079 & TST & \\
\hline CHEMBL1549184 & 688721 & 4.4 & 4.8649 & TRN & \\
\hline CHEMBL602424 & 688721 & 5.2 & 4.7919 & TRN & \\
\hline CHEMBL1559728 & 688721 & 5.2 & 5.2065 & TST & \\
\hline CHEMBL1603249 & 688721 & 4.4 & 4.8933 & TRN & \\
\hline CHEMBL1583131 & 688721 & 4.5 & 4.916 & TRN & \\
\hline CHEMBL1451229 & 688721 & 5.4 & 4.7695 & TST & \\
\hline
\end{tabular}




\begin{tabular}{|c|c|c|c|c|}
\hline \multicolumn{5}{|c|}{ Supplemental Table S2.txt } \\
\hline CHEMBL1410187 & 688721 & 4.7 & 4.9535 & TRN \\
\hline CHEMBL1361257 & 688721 & 4.8 & 5.043 & TST \\
\hline CHEMBL1315521 & 688721 & 7.2 & 5.0554 & TRN \\
\hline CHEMBL184450 & 688721 & 6.0 & 5.2445 & TRN \\
\hline CHEMBL1576354 & 688721 & 5.9 & 5.0011 & TRN \\
\hline CHEMBL1338787 & 688721 & 5.4 & 5.1085 & TST \\
\hline CHEMBL1475789 & 688721 & 4.5 & 5.0782 & TRN \\
\hline CHEMBL1493179 & 688721 & 4.9 & 5.012 & TRN \\
\hline CHEMBL1446861 & 688721 & 4.4 & 4.7868 & TRN \\
\hline CHEMBL1372859 & 688721 & 4.6 & 4.9136 & TRN \\
\hline CHEMBL1367593 & 688721 & 4.7 & 4.8426 & TST \\
\hline CHEMBL1557810 & 688721 & 4.7 & 5.1025 & TRN \\
\hline CHEMBL1610341 & 688721 & 4.4 & 4.9898 & TST \\
\hline CHEMBL6291 & 688721 & 4.8 & 5.0042 & TST \\
\hline CHEMBL1430602 & 688721 & 4.8 & 4.7924 & TRN \\
\hline CHEMBL113830 & 688721 & 6.0 & 4.9527 & TST \\
\hline CHEMBL1380880 & 688721 & 6.7001 & 5.1581 & TST \\
\hline CHEMBL1376677 & 688721 & 5.3 & 5.2545 & TRN \\
\hline CHEMBL1319534 & 688721 & 4.7 & 4.9555 & TRN \\
\hline CHEMBL1417580 & 688721 & 4.9 & 4.8777 & TRN \\
\hline CHEMBL1340053 & 688721 & 5.4 & 4.8865 & TRN \\
\hline CHEMBL479014 & 688721 & 4.4 & 5.0133 & TST \\
\hline CHEMBL1336258 & 688721 & 5.1 & 5.1056 & TRN \\
\hline CHEMBL1549968 & 688721 & 5.2 & 4.8589 & TRN \\
\hline CHEMBL1354426 & 688721 & 4.5 & 5.0839 & TRN \\
\hline CHEMBL1602790 & 688721 & 4.8 & 4.7127 & TRN \\
\hline CHEMBL 1537440 & 688721 & 4.5 & 4.8968 & TRN \\
\hline CHEMBL3191143 & 688721 & 5.0 & 4.8686 & TST \\
\hline CHEMBL1521154 & 688721 & 6.1 & 4.7605 & TRN \\
\hline CHEMBL1391167 & 688721 & 4.8 & 4.8854 & TRN \\
\hline CHEMBL1498271 & 688721 & 5.4 & 4.9745 & TST \\
\hline CHEMBL1603006 & 688721 & 4.7 & 4.8831 & TRN \\
\hline CHEMBL1464187 & 688721 & 5.2 & 5.0403 & TRN \\
\hline CHEMBL1338533 & 688721 & 4.7 & 4.7839 & TRN \\
\hline CHEMBL1394956 & 688721 & 5.1 & 5.0379 & TRN \\
\hline CHEMBL1558283 & 688721 & 5.2 & 4.84 & TST \\
\hline CHEMBL 1420358 & 688721 & 4.6 & 4.8827 & TRN \\
\hline CHEMBL1382401 & 688721 & 5.5 & 5.1399 & TRN \\
\hline CHEMBL1566158 & 688721 & 4.4 & 4.9421 & TRN \\
\hline CHEMBL1603598 & 688721 & 6.4 & 5.0181 & TST \\
\hline CHEMBL1567889 & 688721 & 4.4 & 5.0179 & TST \\
\hline CHEMBL1441745 & 688721 & 5.8 & 4.9146 & TRN \\
\hline CHEMBL1506172 & 688721 & 4.4 & 5.0708 & TRN \\
\hline CHEMBL1585724 & 688721 & 4.5 & 4.9403 & TRN \\
\hline CHEMBL1528118 & 688721 & 4.6 & 4.9587 & TRN \\
\hline CHEMBL259358 & 688721 & 4.7 & 5.0307 & TRN \\
\hline CHEMBL1316897 & 688721 & 5.1 & 4.9531 & TRN \\
\hline CHEMBL1613623 & 688721 & 4.8 & 5.1565 & TRN \\
\hline
\end{tabular}




\begin{tabular}{|c|c|c|c|c|}
\hline & & & ient & al Ta \\
\hline CHEMBL1480465 & 688721 & 4.5 & 4.8788 & TRN \\
\hline CHEMBL1587878 & 688721 & 4.9 & 4.8685 & TRN \\
\hline CHEMBL109095 & 688721 & 4.4 & 5.1106 & TRN \\
\hline CHEMBL530049 & 688721 & 4.5 & 5.0228 & TST \\
\hline CHEMBL1413816 & 688721 & 7.0 & 5.0508 & TST \\
\hline CHEMBL 262083 & 688721 & 4.4 & 5.319 & TRN \\
\hline CHEMBL1416966 & 688721 & 4.6 & 4.9897 & TRN \\
\hline CHEMBL1311755 & 688721 & 4.8 & 4.9783 & TRN \\
\hline CHEMBL1535974 & 688721 & 4.5 & 4.8247 & TRN \\
\hline CHEMBL1547879 & 688721 & 4.5 & 4.9093 & TRN \\
\hline CHEMBL1571377 & 688721 & 4.8 & 4.939 & TRN \\
\hline CHEMBL1400654 & 688721 & 5.0 & 4.9305 & TRN \\
\hline CHEMBL3196905 & 688721 & 5.1 & 4.8025 & TRN \\
\hline CHEMBL1373288 & 688721 & 4.5 & 4.953 & TRN \\
\hline CHEMBL1460558 & 688721 & 4.8 & 5.0981 & TST \\
\hline CHEMBL1347695 & 688721 & 4.8 & 4.916 & TRN \\
\hline CHEMBL1345725 & 688721 & 4.7 & 4.8311 & TRN \\
\hline CHEMBL1308429 & 688721 & 4.8 & 5.0603 & TRN \\
\hline CHEMBL1523777 & 688721 & 4.6 & 4.7553 & TST \\
\hline CHEMBL1484896 & 688721 & 5.3 & 5.1719 & TRN \\
\hline CHEMBL1533904 & 688721 & 4.8 & 4.8804 & TRN \\
\hline CHEMBL1343484 & 688721 & 4.7 & 5.0312 & TRN \\
\hline CHEMBL1468840 & 688721 & 5.3 & 5.1309 & TST \\
\hline CHEMBL1312521 & 688721 & 4.8 & 4.7907 & TRN \\
\hline CHEMBL457504 & 688721 & 6.2 & 5.2629 & TST \\
\hline CHEMBL1418595 & 688721 & 4.8 & 4.8451 & TRN \\
\hline CHEMBL1325335 & 688721 & 5.2 & 5.1631 & TRN \\
\hline CHEMBL1352278 & 688721 & 5.4 & 4.8493 & TST \\
\hline CHEMBL1337580 & 688721 & 5.6 & 5.1245 & TRN \\
\hline CHEMBL1610126 & 688721 & 5.2 & 4.7862 & TRN \\
\hline CHEMBL1387387 & 688721 & 4.5 & 4.9426 & TRN \\
\hline CHEMBL578276 & 688721 & 5.7 & 4.8595 & TRN \\
\hline CHEMBL490756 & 688721 & 4.6 & 4.9845 & TRN \\
\hline CHEMBL1377706 & 688721 & 5.5 & 5.1721 & TRN \\
\hline CHEMBL1481683 & 688721 & 4.4 & 4.8337 & TRN \\
\hline CHEMBL1309150 & 688721 & 4.7 & 4.7054 & TRN \\
\hline CHEMBL1391220 & 688721 & 4.6 & 5.1797 & TST \\
\hline CHEMBL1537751 & 688721 & 4.5 & 4.8078 & TRN \\
\hline CHEMBL1320838 & 688721 & 4.6 & 4.9026 & TRN \\
\hline CHEMBL1371243 & 688721 & 4.6 & 4.7711 & TRN \\
\hline CHEMBL1606283 & 688721 & 4.4 & 4.9863 & TRN \\
\hline CHEMBL1301413 & 688721 & 5.2 & 4.9215 & TRN \\
\hline CHEMBL1449270 & 688721 & 4.9 & 4.9198 & TRN \\
\hline CHEMBL1411468 & 688721 & 5.2 & 4.9263 & TRN \\
\hline CHEMBL1383994 & 688721 & 5.4 & 4.8773 & TRN \\
\hline CHEMBL1397040 & 688721 & 5.4 & 5.2434 & TST \\
\hline CHEMBL1337908 & 688721 & 4.8 & 4.7511 & TRN \\
\hline CHEMBL1511506 & 688721 & 4.4 & 5.1285 & TST \\
\hline
\end{tabular}




\begin{tabular}{|c|c|c|c|c|c|}
\hline & & & & & \\
\hline CHEMBL1312247 & 688721 & 5.3 & 4.9008 & TST & \\
\hline CHEMBL1319220 & 688721 & 4.5 & 4.9824 & TRN & \\
\hline CHEMBL1431579 & 688721 & 4.5 & 4.8925 & TRN & \\
\hline CHEMBL1367286 & 688721 & 5.4 & 4.8485 & TRN & \\
\hline CHEMBL1440487 & 688721 & 4.6 & 4.9229 & TRN & \\
\hline CHEMBL1527459 & 688721 & 5.9 & 4.9905 & TRN & \\
\hline CHEMBL1417622 & 688721 & 4.5 & 5.1171 & TRN & \\
\hline CHEMBL1483913 & 688721 & 5.3 & 5.0581 & TRN & \\
\hline CHEMBL1423291 & 688721 & 4.8 & 4.7115 & TRN & \\
\hline CHEMBL1356690 & 688721 & 4.6 & 5.2149 & TRN & \\
\hline CHEMBL1444987 & 688721 & 5.2 & 4.9332 & TRN & \\
\hline CHEMBL1602323 & 688721 & 4.6 & 4.7207 & TRN & \\
\hline CHEMBL1563162 & 688721 & 4.8 & 4.7778 & TST & \\
\hline CHEMBL1404633 & 688721 & 5.8 & 4.9541 & TRN & \\
\hline CHEMBL1332732 & 688721 & 5.3 & 4.6411 & TRN & \\
\hline CHEMBL1548931 & 688721 & 5.1 & 4.7397 & TRN & \\
\hline CHEMBL1469915 & 688721 & 4.8 & 5.1357 & TRN & \\
\hline CHEMBL1371071 & 688721 & 5.3 & 4.8595 & TRN & \\
\hline CHEMBL1555046 & 688721 & 4.5 & 5.4373 & TRN & \\
\hline CHEMBL1490295 & 688721 & 5.0 & 4.7819 & TRN & \\
\hline CHEMBL1589288 & 688721 & 4.7 & 4.9193 & TRN & \\
\hline CHEMBL1568220 & 688721 & 4.6 & 4.7192 & TRN & \\
\hline CHEMBL1321713 & 688721 & 4.8 & $4.6610 e$ & 00000000005 & TRN \\
\hline CHEMBL1560871 & 688721 & 4.8 & 4.9644 & TRN & \\
\hline CHEMBL1330317 & 688721 & 4.9 & 4.8668 & TRN & \\
\hline CHEMBL1516882 & 688721 & 5.6 & 5.0685 & TRN & \\
\hline CHEMBL1490703 & 688721 & 4.8 & 4.9346 & TRN & \\
\hline CHEMBL1601483 & 688721 & 4.5 & 4.8707 & TST & \\
\hline CHEMBL489943 & 688721 & 4.5 & 5.1299 & TRN & \\
\hline CHEMBL1502818 & 688721 & 4.6 & 4.9544 & TRN & \\
\hline CHEMBL 289277 & 688721 & 6.0 & 5.0368 & TRN & \\
\hline CHEMBL1467086 & 688721 & 5.6 & 5.0246 & TST & \\
\hline CHEMBL1549688 & 688721 & 5.2 & 4.769 & TRN & \\
\hline CHEMBL411085 & 688721 & 4.4 & 4.7117 & TRN & \\
\hline CHEMBL1599435 & 688721 & 6.3 & 4.8993 & TRN & \\
\hline CHEMBL1487393 & 688721 & 4.7 & 4.9779 & TRN & \\
\hline CHEMBL1320262 & 688721 & 6.3 & 4.9357 & TRN & \\
\hline CHEMBL1338854 & 688721 & 5.5 & 4.7695 & TRN & \\
\hline CHEMBL1581806 & 688721 & 4.5 & 5.0971 & TRN & \\
\hline CHEMBL1328827 & 688721 & 4.5 & 4.718 & TRN & \\
\hline CHEMBL411502 & 688721 & 4.6 & 5.0077 & TRN & \\
\hline CHEMBL1609282 & 688721 & 4.6 & 4.8413 & TRN & \\
\hline CHEMBL1359994 & 688721 & 4.6 & 4.8774 & TRN & \\
\hline CHEMBL1539112 & 688721 & 4.7 & 4.9556 & TRN & \\
\hline CHEMBL1339537 & 688721 & 4.4 & 4.848 & TRN & \\
\hline CHEMBL1482262 & 688721 & 4.7 & 4.8507 & TRN & \\
\hline CHEMBL1596599 & 688721 & 4.5 & 5.0284 & TRN & \\
\hline CHEMBL1415855 & 688721 & 4.9 & 4.9787 & TRN & \\
\hline
\end{tabular}




\begin{tabular}{|c|c|c|c|c|}
\hline & & & pplement & al $\mathrm{Ta}$ \\
\hline CHEMBL1587280 & 688721 & 5.2 & 4.7659 & TRN \\
\hline CHEMBL1445585 & 688721 & 4.8 & 5.0932 & TST \\
\hline CHEMBL1554910 & 688721 & 5.4 & 5.1597 & TRN \\
\hline CHEMBL1366456 & 688721 & 5.0 & 4.7762 & TRN \\
\hline CHEMBL1597211 & 688721 & 4.5 & 5.0788 & TST \\
\hline CHEMBL1352543 & 688721 & 4.7 & 4.8727 & TRN \\
\hline CHEMBL1434272 & 688721 & 4.4 & 5.1045 & TRN \\
\hline CHEMBL1587498 & 688721 & 4.9 & 4.7977 & TRN \\
\hline CHEMBL1549348 & 688721 & 4.6 & 5.0389 & TST \\
\hline CHEMBL1488590 & 688721 & 4.5 & 4.8106 & TRN \\
\hline CHEMBL1549580 & 688721 & 4.8 & 4.8772 & TRN \\
\hline CHEMBL1470943 & 688721 & 4.4 & 4.8426 & TRN \\
\hline CHEMBL1321470 & 688721 & 5.1 & 5.1452 & TRN \\
\hline CHEMBL1408858 & 688721 & 4.6 & 5.0101 & TST \\
\hline CHEMBL1302395 & 688721 & 5.4 & 4.9072 & TRN \\
\hline CHEMBL1357982 & 688721 & 5.2 & 5.3156 & TRN \\
\hline CHEMBL1359025 & 688721 & 4.5 & 4.8936 & TRN \\
\hline CHEMBL1437886 & 688721 & 4.7 & 4.8508 & TRN \\
\hline CHEMBL1411400 & 688721 & 5.4 & 4.9114 & TST \\
\hline CHEMBL1334939 & 688721 & 4.5 & 4.8858 & TRN \\
\hline CHEMBL1367583 & 688721 & 4.5 & 4.945 & TRN \\
\hline CHEMBL1610964 & 688721 & 6.8 & 4.699 & TRN \\
\hline CHEMBL1362342 & 688721 & 4.4 & 4.9843 & TRN \\
\hline CHEMBL1409484 & 688721 & 5.2 & 5.0628 & TST \\
\hline CHEMBL1484049 & 688721 & 4.9 & 4.9544 & TRN \\
\hline CHEMBL1570641 & 688721 & 4.5 & 4.8896 & TST \\
\hline CHEMBL1466718 & 688721 & 5.4 & 4.9049 & TRN \\
\hline CHEMBL1586661 & 688721 & 4.8 & 4.9242 & TRN \\
\hline CHEMBL541585 & 688721 & 5.2 & 5.0572 & TRN \\
\hline CHEMBL93655 & 688721 & 4.4 & 4.9951 & TST \\
\hline CHEMBL1378168 & 688721 & 4.6 & 5.0159 & TRN \\
\hline CHEMBL1503110 & 688721 & 4.6 & 4.704 & TRN \\
\hline CHEMBL1550363 & 688721 & 4.9 & 4.775 & TRN \\
\hline CHEMBL1490334 & 688721 & 5.2 & 4.7645 & TRN \\
\hline CHEMBL1527287 & 688721 & 4.5 & 4.7762 & TRN \\
\hline CHEMBL1465372 & 688721 & 5.4 & 4.7475 & TRN \\
\hline CHEMBL1436125 & 688721 & 4.7 & 4.8955 & TRN \\
\hline CHEMBL1442547 & 688721 & 4.6 & 4.8492 & TRN \\
\hline CHEMBL1399701 & 688721 & 4.9 & 4.8264 & TRN \\
\hline CHEMBL1334461 & 688721 & 4.7 & 4.876 & TRN \\
\hline CHEMBL1606591 & 688721 & 4.9 & 5.1802 & TRN \\
\hline CHEMBL1608915 & 688721 & 4.6 & 5.0406 & TRN \\
\hline CHEMBL1572010 & 688721 & 5.4 & 5.0261 & TST \\
\hline CHEMBL1388322 & 688721 & 6.1 & 4.8673 & TRN \\
\hline CHEMBL1313158 & 688721 & 5.2 & 5.1301 & TST \\
\hline CHEMBL1331905 & 688721 & 4.6 & 4.8162 & TST \\
\hline CHEMBL1606185 & 688721 & 7.0 & 4.9722 & TRN \\
\hline CHEMBL1537246 & 688721 & 4.7 & 4.9669 & TRN \\
\hline
\end{tabular}




\begin{tabular}{|c|c|c|c|c|}
\hline & & & 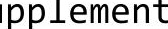 & al Table \\
\hline CHEMBL1480194 & 688721 & 4.5 & 5.0147 & TST \\
\hline CHEMBL1411337 & 688721 & 4.6 & 5.24799 & 9999999999 \\
\hline CHEMBL1473331 & 688721 & 4.6 & 5.2825 & TRN \\
\hline CHEMBL1300705 & 688721 & 4.9 & 4.9445 & TRN \\
\hline CHEMBL1448725 & 688721 & 4.7 & 4.9919 & TRN \\
\hline CHEMBL1325427 & 688721 & 4.7 & 4.9072 & TRN \\
\hline CHEMBL1312829 & 688721 & 5.5 & 5.0798 & TRN \\
\hline CHEMBL1389906 & 688721 & 4.6 & 4.8315 & TRN \\
\hline CHEMBL 3145067 & 688721 & 4.6 & 4.9423 & TST \\
\hline CHEMBL1383589 & 688721 & 4.5 & 4.9339 & TRN \\
\hline CHEMBL 28 & 688721 & 5.4 & 4.9553 & TRN \\
\hline CHEMBL1381557 & 688721 & 5.4 & 4.979 & TRN \\
\hline CHEMBL1519225 & 688721 & 5.1 & 5.2061 & TRN \\
\hline CHEMBL1465879 & 688721 & 5.4 & 4.8978 & TRN \\
\hline CHEMBL1605499 & 688721 & 4.6 & 4.8707 & TRN \\
\hline CHEMBL1447004 & 688721 & 5.2 & 4.8026 & TRN \\
\hline CHEMBL1572220 & 688721 & 5.0 & 5.0417 & TRN \\
\hline CHEMBL1600003 & 688721 & 5.4 & 4.7157 & TRN \\
\hline CHEMBL1579377 & 688721 & 4.8 & 4.9793 & TRN \\
\hline CHEMBL1422872 & 688721 & 4.4 & 4.8969 & TRN \\
\hline CHEMBL1349835 & 688721 & 4.9 & 4.8951 & TRN \\
\hline CHEMBL 3195130 & 688721 & 4.8 & 5.0652 & TRN \\
\hline CHEMBL1450227 & 688721 & 6.0 & 4.9278 & TRN \\
\hline CHEMBL1322495 & 688721 & 4.4 & 5.3125 & TST \\
\hline CHEMBL1421057 & 688721 & 4.8 & 4.7449 & TRN \\
\hline CHEMBL1561607 & 688721 & 5.0 & 4.9978 & TST \\
\hline CHEMBL1412475 & 688721 & 5.3 & 4.8611 & TST \\
\hline CHEMBL1396109 & 688721 & 4.7 & 4.8169 & TRN \\
\hline CHEMBL1378707 & 688721 & 4.8 & 4.8455 & TRN \\
\hline CHEMBL1344490 & 688721 & 5.3 & 4.8855 & TRN \\
\hline CHEMBL577764 & 688721 & 4.5 & 5.0643 & TST \\
\hline CHEMBL522600 & 688721 & 4.9 & 4.9829 & TRN \\
\hline CHEMBL1576107 & 688721 & 5.2 & 4.7566 & TRN \\
\hline CHEMBL1535669 & 688721 & 5.2 & 4.9791 & TRN \\
\hline CHEMBL1510100 & 688721 & 4.6 & 4.7875 & TRN \\
\hline CHEMBL1510576 & 688721 & 4.6 & 4.8969 & TRN \\
\hline CHEMBL1446115 & 688721 & 4.5 & 4.9718 & TRN \\
\hline CHEMBL1528639 & 688721 & 4.6 & 4.9692 & TST \\
\hline CHEMBL1440095 & 688721 & 4.7 & 5.0319 & TRN \\
\hline CHEMBL1353824 & 688721 & 5.0 & 4.7528 & TST \\
\hline CHEMBL1311514 & 688721 & 4.8 & 4.8486 & TRN \\
\hline CHEMBL1341771 & 688721 & 6.0 & 5.0062 & TRN \\
\hline CHEMBL1500081 & 688721 & 4.5 & 4.8925 & TST \\
\hline CHEMBL1388070 & 688721 & 4.4 & 4.8874 & TRN \\
\hline CHEMBL1255583 & 688721 & 4.6 & 5.2827 & TST \\
\hline CHEMBL 20730 & 688721 & 6.0 & 5.0848 & TST \\
\hline CHEMBL1539314 & 688721 & 5.1 & 5.0596 & TRN \\
\hline CHEMBL1443016 & 688721 & 4.8 & 4.9358 & TRN \\
\hline
\end{tabular}




\begin{tabular}{|c|c|c|c|c|c|}
\hline \multicolumn{6}{|c|}{ Supplemental Table S2.txt } \\
\hline CHEMBL1601967 & 688721 & 5.4 & 5.0787 & TRN & \\
\hline CHEMBL1432289 & 688721 & 4.4 & 4.8848 & TRN & \\
\hline CHEMBL1332208 & 688721 & 6.2 & 4.9893 & TST & \\
\hline CHEMBL1561796 & 688721 & 4.5 & 4.9682 & TRN & \\
\hline CHEMBL23327 & 688721 & 7.8996 & 5.1117 & TRN & \\
\hline CHEMBL1447484 & 688721 & 4.7 & 4.8893 & TRN & \\
\hline CHEMBL1364705 & 688721 & 7.2 & 4.9957 & TST & \\
\hline CHEMBL1360059 & 688721 & 4.4 & 5.0272 & TST & \\
\hline CHEMBL1402468 & 688721 & 4.8 & 4.8218 & TRN & \\
\hline CHEMBL1325934 & 688721 & 4.5 & 4.8887 & TRN & \\
\hline CHEMBL1410347 & 688721 & 5.8 & 5.0668 & TST & \\
\hline CHEMBL1537051 & 688721 & 4.6 & 4.9813 & TRN & \\
\hline CHEMBL1477559 & 688721 & 4.6 & 4.7957 & TRN & \\
\hline CHEMBL1354090 & 688721 & 4.6 & 5.2034 & TRN & \\
\hline CHEMBL1571828 & 688721 & 4.6 & 4.8595 & TRN & \\
\hline CHEMBL1612744 & 688721 & 5.2 & 4.956 & TST & \\
\hline CHEMBL1521449 & 688721 & 6.1 & 4.7481 & TRN & \\
\hline CHEMBL1330034 & 688721 & 4.7 & 4.8358 & TRN & \\
\hline CHEMBL1594156 & 688721 & 4.6 & 4.8561 & TRN & \\
\hline CHEMBL1444064 & 688721 & 4.9 & 4.9411 & TRN & \\
\hline CHEMBL1420834 & 688721 & 4.4 & 4.9562 & TRN & \\
\hline CHEMBL1548388 & 688721 & 4.5 & 5.1438 & TST & \\
\hline CHEMBL1503397 & 688721 & 4.4 & 4.9135 & TST & \\
\hline CHEMBL1341254 & 688721 & 4.4 & 4.7632 & TRN & \\
\hline CHEMBL1583860 & 688721 & 4.9 & 5.007 & TRN & \\
\hline CHEMBL1452250 & 688721 & 4.6 & 4.9167 & TRN & \\
\hline CHEMBL1415596 & 688721 & 4.5 & 4.8453 & TRN & \\
\hline CHEMBL1427254 & 688721 & 4.5 & 4.9517 & TST & \\
\hline CHEMBL1466155 & 688721 & 5.0 & 4.8592 & TRN & \\
\hline CHEMBL1328431 & 688721 & 5.1 & 4.9524 & TST & \\
\hline CHEMBL1460192 & 688721 & 4.4 & 5.1536 & TST & \\
\hline CHEMBL1541929 & 688721 & 4.5 & 4.923 & TRN & \\
\hline CHEMBL1373571 & 688721 & 5.6 & 4.8628 & TRN & \\
\hline CHEMBL1475428 & 688721 & 4.6 & 4.9301 & TRN & \\
\hline CHEMBL1349743 & 688721 & 4.8 & 4.9229 & TRN & \\
\hline CHEMBL1348248 & 688721 & 4.7 & 5.0893 & TST & \\
\hline CHEMBL1302187 & 688721 & 5.6 & 4.803 & TRN & \\
\hline CHEMBL1418470 & 688721 & 6.0 & 4.79 & TRN & \\
\hline CHEMBL1565338 & 688721 & 4.5 & 4.9445 & TRN & \\
\hline CHEMBL1388432 & 688721 & 4.6 & 4.8185 & TRN & \\
\hline CHEMBL571295 & 688721 & 5.7 & 4.9542 & TST & \\
\hline CHEMBL1566288 & 688721 & 4.9 & 4.9028 & TRN & \\
\hline CHEMBL1491432 & 688721 & 5.2 & 4.942 & TST & \\
\hline CHEMBL1519490 & 688721 & 5.5 & 5.0851 & TRN & \\
\hline CHEMBL1270217 & 688721 & 5.5 & 4.8784 & TRN & \\
\hline CHEMBL1465195 & 688721 & 4.6 & 4.90300 & 00000000005 & TRN \\
\hline CHEMBL1345202 & 688721 & 4.9 & 4.8053 & TRN & \\
\hline CHEMBL1423568 & 688721 & 4.5 & 4.9397 & TRN & \\
\hline
\end{tabular}




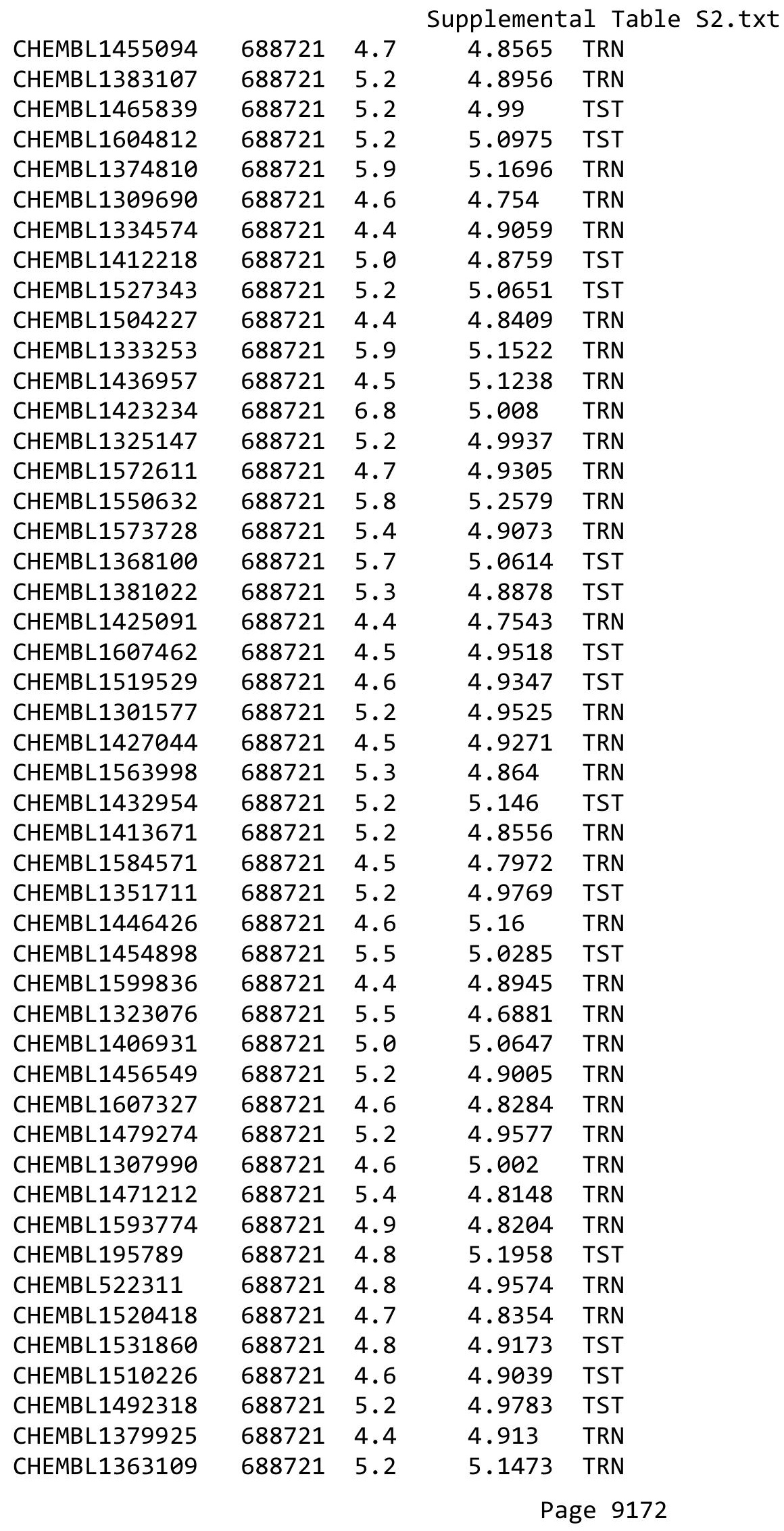




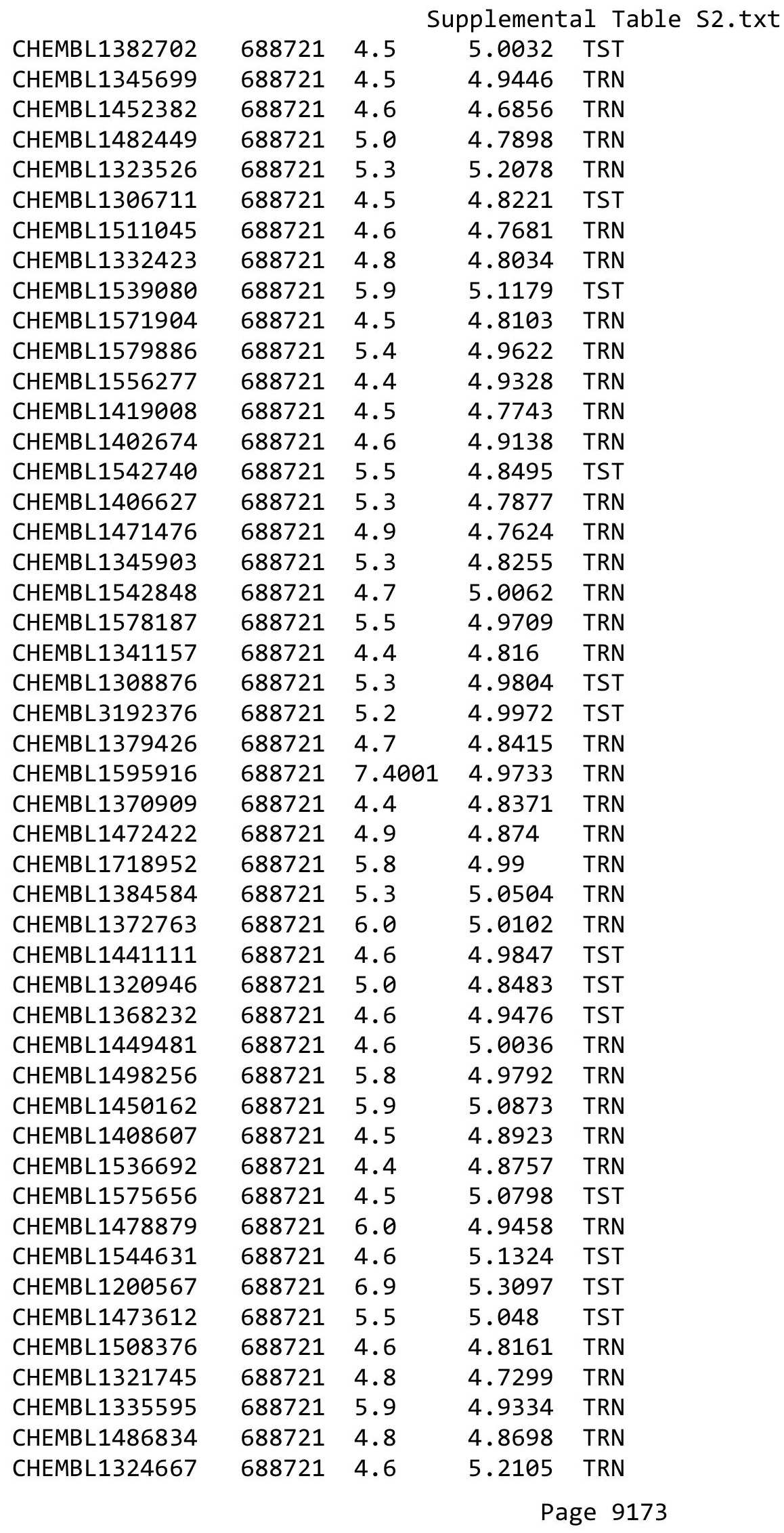




\begin{tabular}{|c|c|c|c|c|c|}
\hline \multicolumn{6}{|c|}{ Supplemental Table S2.txt } \\
\hline CHEMBL1331004 & 688721 & 4.7 & 5.2888 & TRN & \\
\hline CHEMBL1562893 & 688721 & 4.4 & 4.9575 & TST & \\
\hline CHEMBL1581071 & 688721 & 4.8 & 5.0585 & TST & \\
\hline CHEMBL1311108 & 688721 & 4.7 & 4.9387 & TRN & \\
\hline CHEMBL1464985 & 688721 & 6.1 & 4.8154 & TRN & \\
\hline CHEMBL1420950 & 688721 & 4.4 & 4.745 & TRN & \\
\hline CHEMBL1494334 & 688721 & 4.7 & 4.9313 & TST & \\
\hline CHEMBL1563242 & 688721 & 4.7 & 4.878 & TST & \\
\hline CHEMBL1526555 & 688721 & 4.5 & 4.9526 & TRN & \\
\hline CHEMBL1481160 & 688721 & 5.4 & 4.9706 & TST & \\
\hline CHEMBL1572410 & 688721 & 4.8 & 4.98300 & 00000000005 & TRN \\
\hline CHEMBL1310190 & 688721 & 4.7 & 4.8882 & TRN & \\
\hline CHEMBL1411270 & 688721 & 4.8 & 4.9662 & TRN & \\
\hline CHEMBL1485366 & 688721 & 4.4 & 4.9348 & TRN & \\
\hline CHEMBL1562185 & 688721 & 5.3 & 5.0327 & TRN & \\
\hline CHEMBL1373432 & 688721 & 4.9 & 4.7808 & TRN & \\
\hline CHEMBL1608709 & 688721 & 4.4 & 5.0154 & TRN & \\
\hline CHEMBL1473849 & 688721 & 4.8 & 5.0138 & TRN & \\
\hline CHEMBL1375046 & 688721 & 6.0 & 5.1372 & TRN & \\
\hline CHEMBL1409737 & 688721 & 4.5 & 4.9199 & TRN & \\
\hline CHEMBL1483962 & 688721 & 5.2 & 5.1626 & TRN & \\
\hline CHEMBL1310283 & 688721 & 4.5 & 4.9385 & TST & \\
\hline CHEMBL1518866 & 688721 & 4.9 & 5.1715 & TRN & \\
\hline CHEMBL1570851 & 688721 & 5.1 & 5.0906 & TST & \\
\hline CHEMBL1606137 & 688721 & 4.5 & 4.8867 & TRN & \\
\hline CHEMBL1459294 & 688721 & 4.6 & 5.08899 & 99999999995 & TST \\
\hline CHEMBL1414155 & 688721 & 5.2 & 4.9766 & TST & \\
\hline CHEMBL1401037 & 688721 & 5.2 & 4.9032 & TST & \\
\hline CHEMBL1428162 & 688721 & 4.5 & 4.9704 & TRN & \\
\hline CHEMBL1387087 & 688721 & 5.2 & 4.9109 & TST & \\
\hline CHEMBL1402796 & 688721 & 4.4 & 4.9122 & TRN & \\
\hline CHEMBL1422682 & 688721 & 5.3 & 4.9332 & TRN & \\
\hline CHEMBL1342643 & 688721 & 5.7 & 4.8976 & TRN & \\
\hline CHEMBL1584027 & 688721 & 5.2 & 4.9797 & TRN & \\
\hline CHEMBL1475689 & 688721 & 6.3 & 4.9796 & TRN & \\
\hline CHEMBL1413764 & 688721 & 5.4 & 4.9069 & TRN & \\
\hline CHEMBL1558729 & 688721 & 4.8 & 5.0183 & TRN & \\
\hline CHEMBL1503818 & 688721 & 4.6 & 4.8397 & TST & \\
\hline CHEMBL1391221 & 688721 & 5.3 & 5.1488 & TRN & \\
\hline CHEMBL1585897 & 688721 & 5.3 & 5.2146 & TRN & \\
\hline CHEMBL1475941 & 688721 & 5.0 & 5.1215 & TRN & \\
\hline CHEMBL1370770 & 688721 & 5.7 & 5.1606 & TRN & \\
\hline CHEMBL1384025 & 688721 & 4.9 & 5.0059 & TRN & \\
\hline CHEMBL1350630 & 688721 & 5.2 & 4.9346 & TRN & \\
\hline CHEMBL1453047 & 688721 & 4.6 & 4.9629 & TRN & \\
\hline CHEMBL1468417 & 688721 & 4.6 & 5.2151 & TRN & \\
\hline CHEMBL1522697 & 688721 & 6.7001 & 5.1363 & TST & \\
\hline CHEMBL1410255 & 688721 & 4.5 & 5.0285 & TRN & \\
\hline
\end{tabular}




\begin{tabular}{|c|c|c|c|c|}
\hline & & & prome & al Ta \\
\hline CHEMBL1370164 & 688721 & 5.9 & 5.1731 & TST \\
\hline CHEMBL1406865 & 688721 & 6.4 & 5.2468 & TRN \\
\hline CHEMBL1451594 & 688721 & 5.2 & 4.9846 & TRN \\
\hline CHEMBL1527817 & 688721 & 4.4 & 4.7824 & TST \\
\hline CHEMBL1417805 & 688721 & 5.5 & 4.9349 & TRN \\
\hline CHEMBL1609626 & 688721 & 4.4 & 5.2902 & TRN \\
\hline CHEMBL1532795 & 688721 & 5.2 & 4.8841 & TST \\
\hline CHEMBL1575730 & 688721 & 5.5 & 4.8609 & TRN \\
\hline CHEMBL1303643 & 688721 & 5.2 & 4.9262 & TST \\
\hline CHEMBL1430587 & 688721 & 4.5 & 4.9087 & TRN \\
\hline CHEMBL1365201 & 688721 & 4.5 & 4.8452 & TRN \\
\hline CHEMBL1361559 & 688721 & 6.0 & 4.8996 & TRN \\
\hline CHEMBL1373552 & 688721 & 5.0 & 4.9464 & TRN \\
\hline CHEMBL1541520 & 688721 & 5.6 & 4.8596 & TRN \\
\hline CHEMBL1496763 & 688721 & 4.5 & 5.0419 & TST \\
\hline CHEMBL1495381 & 688721 & 4.8 & 5.1437 & TST \\
\hline CHEMBL1419418 & 688721 & 4.7 & 4.8167 & TRN \\
\hline CHEMBL1406513 & 688721 & 4.4 & 5.2513 & TST \\
\hline CHEMBL1522663 & 688721 & 5.9 & 4.9684 & TST \\
\hline CHEMBL1490993 & 688721 & 4.6 & 4.9021 & TRN \\
\hline CHEMBL1550093 & 688721 & 4.5 & 4.8035 & TRN \\
\hline CHEMBL1256816 & 688721 & 4.4 & 4.9899 & TST \\
\hline CHEMBL1519188 & 688721 & 5.2 & 5.0435 & TST \\
\hline CHEMBL1598986 & 688721 & 5.5 & 4.9731 & TRN \\
\hline CHEMBL1419090 & 688721 & 4.5 & 4.942 & TST \\
\hline CHEMBL1338349 & 688721 & 4.6 & 5.0457 & TST \\
\hline CHEMBL1348557 & 688721 & 5.3 & 4.9226 & TRN \\
\hline CHEMBL1421221 & 688721 & 4.5 & 4.9061 & TRN \\
\hline CHEMBL1481297 & 688721 & 5.3 & 4.8307 & TST \\
\hline CHEMBL1408016 & 688721 & 4.4 & 5.0976 & TRN \\
\hline CHEMBL1519010 & 688721 & 4.7 & 4.9698 & TST \\
\hline CHEMBL1562706 & 688721 & 4.7 & 4.9441 & TST \\
\hline CHEMBL1535563 & 688721 & 5.3 & 5.0019 & TRN \\
\hline CHEMBL1410810 & 688721 & 5.4 & 4.8939 & TRN \\
\hline CHEMBL1554360 & 688721 & 4.4 & 5.1956 & TRN \\
\hline CHEMBL1375229 & 688721 & 4.4 & 5.119 & TRN \\
\hline CHEMBL1457262 & 688721 & 4.5 & 4.9813 & TRN \\
\hline CHEMBL1329102 & 688721 & 5.2 & 5.012 & TST \\
\hline CHEMBL3213950 & 688721 & 4.4 & 4.8395 & TRN \\
\hline CHEMBL1587384 & 688721 & 4.6 & 4.8256 & TRN \\
\hline CHEMBL1572146 & 688721 & 5.2 & 4.79 & TRN \\
\hline CHEMBL1327767 & 688721 & 4.4 & 5.0157 & TRN \\
\hline CHEMBL1327119 & 688721 & 4.5 & 4.8543 & TRN \\
\hline CHEMBL1411519 & 688721 & 4.6 & 5.1294 & TRN \\
\hline CHEMBL1564986 & 688721 & 4.4 & 4.822 & TRN \\
\hline CHEMBL1608147 & 688721 & 5.1 & 4.9772 & TRN \\
\hline CHEMBL1371768 & 688721 & 4.6 & 4.8994 & TRN \\
\hline CHEMBL1479088 & 688721 & 5.8 & 5.2358 & TRN \\
\hline
\end{tabular}




\begin{tabular}{|c|c|c|c|c|}
\hline & & & 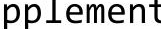 & al Ta \\
\hline CHEMBL1303824 & 688721 & 5.3 & 5.0115 & TRN \\
\hline CHEMBL475375 & 688721 & 4.4 & 5.0168 & TRN \\
\hline CHEMBL1512023 & 688721 & 4.9 & 5.2242 & TRN \\
\hline CHEMBL1426347 & 688721 & 4.5 & 4.9589 & TRN \\
\hline CHEMBL1538664 & 688721 & 5.4 & 4.8345 & TRN \\
\hline CHEMBL1545307 & 688721 & 5.2 & 5.0761 & TRN \\
\hline CHEMBL1454182 & 688721 & 4.4 & 4.9908 & TRN \\
\hline CHEMBL1600210 & 688721 & 5.2 & 5.0026 & TRN \\
\hline CHEMBL1373761 & 688721 & 4.6 & 4.907 & TRN \\
\hline CHEMBL282489 & 688721 & 5.2 & 5.0788 & TST \\
\hline CHEMBL1472448 & 688721 & 5.2 & 5.0558 & TRN \\
\hline CHEMBL1336216 & 688721 & 4.5 & 4.8586 & TRN \\
\hline CHEMBL1524034 & 688721 & 4.4 & 4.8674 & TRN \\
\hline CHEMBL1387820 & 688721 & 4.4 & 4.9235 & TRN \\
\hline CHEMBL1532755 & 688721 & 4.6 & 4.9656 & TRN \\
\hline CHEMBL1491207 & 688721 & 5.2 & 4.7971 & TRN \\
\hline CHEMBL1532243 & 688721 & 5.1 & 4.9587 & TST \\
\hline CHEMBL1499667 & 688721 & 4.8 & 4.8996 & TRN \\
\hline CHEMBL1335371 & 688721 & 4.6 & 4.9648 & TRN \\
\hline CHEMBL1412864 & 688721 & 5.9 & 5.2303 & TRN \\
\hline CHEMBL1591336 & 688721 & 4.8 & 4.9481 & TRN \\
\hline CHEMBL1387164 & 688721 & 5.9 & 4.9564 & TST \\
\hline CHEMBL1339993 & 688721 & 4.4 & 4.7716 & TRN \\
\hline CHEMBL1410995 & 688721 & 5.9 & 4.9202 & TRN \\
\hline CHEMBL1547558 & 688721 & 4.8 & 4.845 & TRN \\
\hline CHEMBL60518 & 688721 & 4.6 & 5.0952 & TRN \\
\hline CHEMBL1405339 & 688721 & 4.8 & 5.1053 & TRN \\
\hline CHEMBL1410798 & 688721 & 4.8 & 4.9029 & TRN \\
\hline CHEMBL1443810 & 688721 & 5.4 & 4.8603 & TRN \\
\hline CHEMBL 258767 & 688721 & 6.0 & 5.1248 & TRN \\
\hline CHEMBL1555814 & 688721 & 5.5 & 4.8185 & TRN \\
\hline CHEMBL1478464 & 688721 & 4.5 & 4.8885 & TST \\
\hline CHEMBL1584720 & 688721 & 5.0 & 4.9731 & TRN \\
\hline CHEMBL1480041 & 688721 & 4.6 & 4.9052 & TRN \\
\hline CHEMBL1447207 & 688721 & 5.1 & 4.9453 & TRN \\
\hline CHEMBL1508674 & 688721 & 6.0 & 5.0039 & TRN \\
\hline CHEMBL1451720 & 688721 & 4.5 & 5.0982 & TRN \\
\hline CHEMBL1523346 & 688721 & 4.5 & 4.7775 & TRN \\
\hline CHEMBL1608250 & 688721 & 4.5 & 5.0369 & TST \\
\hline CHEMBL1482818 & 688721 & 4.5 & 5.234 & TST \\
\hline CHEMBL1603174 & 688721 & 5.2 & 4.9323 & TRN \\
\hline CHEMBL1538833 & 688721 & 5.4 & 4.809 & TRN \\
\hline CHEMBL1451340 & 688721 & 4.8 & 5.0054 & TRN \\
\hline CHEMBL1351496 & 688721 & 4.5 & 5.0204 & TRN \\
\hline CHEMBL3198094 & 688721 & 4.4 & 4.9043 & TRN \\
\hline CHEMBL1568363 & 688721 & 4.6 & 4.6868 & TRN \\
\hline CHEMBL1505360 & 688721 & 5.2 & 4.9713 & TST \\
\hline CHEMBL1307842 & 688721 & 4.4 & 4.7205 & TRN \\
\hline
\end{tabular}




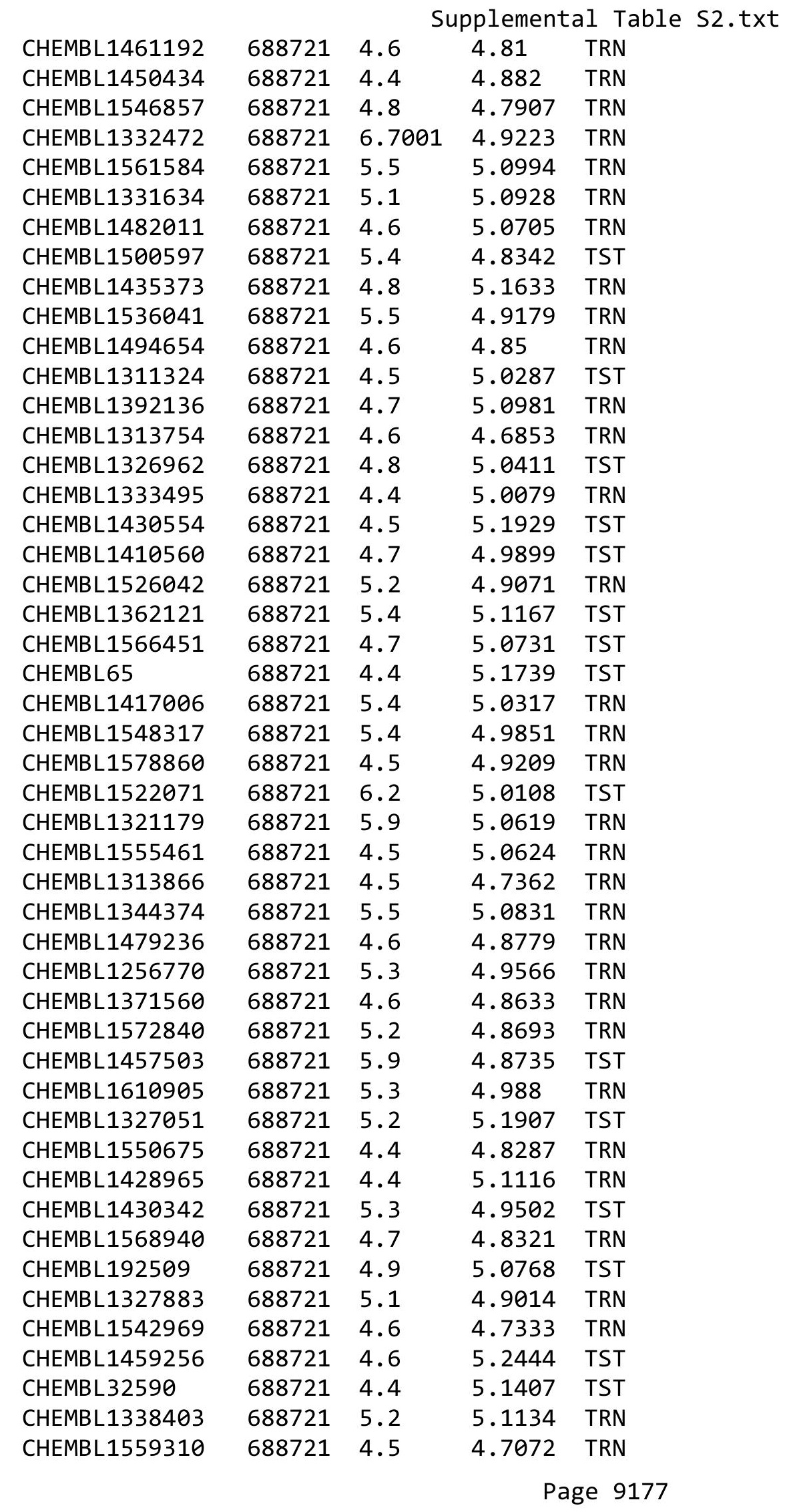




\begin{tabular}{|c|c|c|c|c|}
\hline \multicolumn{5}{|c|}{ Supplemental Table S2.txt } \\
\hline CHEMBL1314247 & 688721 & 4.6 & 4.9806 & TRN \\
\hline CHEMBL1344631 & 688721 & 4.5 & 5.034 & TST \\
\hline CHEMBL489737 & 688721 & 6.0 & 5.0142 & TRN \\
\hline CHEMBL1439779 & 688721 & 5.2 & 4.8976 & TRN \\
\hline CHEMBL1314473 & 688721 & 5.4 & 5.1019 & TRN \\
\hline CHEMBL1353692 & 688721 & 4.5 & 5.2093 & TRN \\
\hline CHEMBL1306305 & 688721 & 4.5 & 4.7436 & TRN \\
\hline CHEMBL1590974 & 688721 & 7.5003 & 5.1652 & TRN \\
\hline CHEMBL1588215 & 688721 & 6.0 & 5.001 & TRN \\
\hline CHEMBL1372293 & 688721 & 5.0 & 4.9944 & TRN \\
\hline CHEMBL1422641 & 688721 & 4.4 & 5.0068 & TRN \\
\hline CHEMBL1531599 & 688721 & 4.8 & 4.8962 & TRN \\
\hline CHEMBL1539736 & 688721 & 4.4 & 4.9008 & TRN \\
\hline CHEMBL1380742 & 688721 & 5.2 & 5.0535 & TST \\
\hline CHEMBL1609182 & 688721 & 4.8 & 4.939 & TRN \\
\hline CHEMBL1310994 & 688721 & 6.0 & 5.011 & TRN \\
\hline CHEMBL1352318 & 688721 & 4.6 & 4.8759 & TRN \\
\hline CHEMBL1332688 & 688721 & 4.6 & 4.8052 & TRN \\
\hline CHEMBL1546751 & 688721 & 5.6 & 4.8687 & TRN \\
\hline CHEMBL1591238 & 688721 & 4.9 & 5.1465 & TRN \\
\hline CHEMBL1454728 & 688721 & 4.6 & 4.8003 & TRN \\
\hline CHEMBL1561768 & 688721 & 4.8 & 4.7509 & TRN \\
\hline CHEMBL1589171 & 688721 & 4.5 & 4.9275 & TRN \\
\hline CHEMBL1464871 & 688721 & 5.3 & 4.7833 & TRN \\
\hline CHEMBL1506979 & 688721 & 4.5 & 4.9429 & TRN \\
\hline CHEMBL1510580 & 688721 & 4.6 & 4.915 & TRN \\
\hline CHEMBL1514458 & 688721 & 5.6 & 5.1381 & TRN \\
\hline CHEMBL1386337 & 688721 & 4.6 & 4.8375 & TRN \\
\hline CHEMBL1505394 & 688721 & 4.5 & 4.9453 & TRN \\
\hline CHEMBL1413966 & 688721 & 6.4 & 4.9633 & TST \\
\hline CHEMBL1439247 & 688721 & 4.8 & 4.7705 & TRN \\
\hline CHEMBL1365446 & 688721 & 5.2 & 4.9269 & TRN \\
\hline CHEMBL1305152 & 688721 & 4.9 & 4.9726 & TST \\
\hline CHEMBL1503073 & 688721 & 5.4 & 5.1055 & TRN \\
\hline CHEMBL1560999 & 688721 & 5.0 & 4.8097 & TRN \\
\hline CHEMBL1400275 & 688721 & 4.5 & 4.9319 & TST \\
\hline CHEMBL 1437873 & 688721 & 4.6 & 4.8541 & TRN \\
\hline CHEMBL1554680 & 688721 & 4.6 & 4.9067 & TRN \\
\hline CHEMBL1564920 & 688721 & 4.7 & 5.1661 & TST \\
\hline CHEMBL1531255 & 688721 & 5.8 & 5.3496 & TST \\
\hline CHEMBL1524664 & 688721 & 4.4 & 5.0258 & TRN \\
\hline CHEMBL1318622 & 688721 & 5.6 & 5.1472 & TRN \\
\hline CHEMBL1256995 & 688721 & 4.7 & 5.0583 & TST \\
\hline CHEMBL1559853 & 688721 & 4.6 & 4.8525 & TRN \\
\hline CHEMBL1596944 & 688721 & 4.6 & 4.7485 & TRN \\
\hline CHEMBL13888 & 688721 & 4.4 & 5.1479 & TRN \\
\hline CHEMBL1391156 & 688721 & 4.4 & 4.9254 & TRN \\
\hline CHEMBL1559601 & 688721 & 4.8 & 4.9182 & TRN \\
\hline
\end{tabular}




\begin{tabular}{|c|c|c|c|c|c|}
\hline \\
\hline CHEMBL1564940 & 688721 & 4.7 & 4.7335 & TRN & \\
\hline CHEMBL546257 & 688721 & 6.0 & 5.0099 & TST & \\
\hline CHEMBL1478563 & 688721 & 5.7 & 4.7296 & TRN & \\
\hline CHEMBL1348507 & 688721 & 5.7 & 4.7477 & TRN & \\
\hline CHEMBL1512277 & 688721 & 4.8 & 4.9078 & TRN & \\
\hline CHEMBL1407511 & 688721 & 5.4 & 5.29200 & 0000000001 & TRN \\
\hline CHEMBL1546666 & 688721 & 4.5 & 5.0846 & TST & \\
\hline CHEMBL1365415 & 688721 & 4.7 & 4.7711 & TRN & \\
\hline CHEMBL1310041 & 688721 & 4.5 & 4.7815 & TRN & \\
\hline CHEMBL1563874 & 688721 & 4.8 & 4.7907 & TRN & \\
\hline CHEMBL1594075 & 688721 & 7.0 & 5.2308 & TRN & \\
\hline CHEMBL1486100 & 688721 & 4.4 & 5.1125 & TRN & \\
\hline CHEMBL1405209 & 688721 & 4.6 & 4.7632 & TRN & \\
\hline CHEMBL1500745 & 688721 & 4.4 & 4.9853 & TRN & \\
\hline CHEMBL1383719 & 688721 & 5.4 & 4.851 & TRN & \\
\hline CHEMBL1439987 & 688721 & 4.7 & 4.9902 & TRN & \\
\hline CHEMBL1509449 & 688721 & 5.4 & 4.8962 & TRN & \\
\hline CHEMBL1605110 & 688721 & 5.4 & 4.9472 & TRN & \\
\hline CHEMBL1508906 & 688721 & 4.4 & 4.9542 & TST & \\
\hline CHEMBL1528867 & 688721 & 4.8 & 4.9496 & TRN & \\
\hline CHEMBL1359819 & 688721 & 5.5 & 4.9234 & TRN & \\
\hline CHEMBL1540596 & 688721 & 4.8 & 4.9211 & TRN & \\
\hline CHEMBL1429881 & 688721 & 4.6 & 4.9165 & TRN & \\
\hline CHEMBL296586 & 688721 & 4.4 & 5.0781 & TST & \\
\hline CHEMBL1378650 & 688721 & 5.3 & 5.1169 & TRN & \\
\hline CHEMBL1371944 & 688721 & 5.8 & 5.2722 & TRN & \\
\hline CHEMBL1537142 & 688721 & 5.5 & 4.9571 & TRN & \\
\hline CHEMBL1484912 & 688721 & 6.5 & 4.9951 & TRN & \\
\hline CHEMBL1311570 & 688721 & 4.4 & 4.8087 & TRN & \\
\hline CHEMBL1423898 & 688721 & 6.1 & 4.9015 & TRN & \\
\hline CHEMBL1334270 & 688721 & 4.6 & 4.9689 & TST & \\
\hline CHEMBL1369819 & 688721 & 5.1 & 4.9643 & TST & \\
\hline CHEMBL1563743 & 688721 & 5.1 & 4.8267 & TRN & \\
\hline CHEMBL1421619 & 688721 & 4.6 & 5.0847 & TRN & \\
\hline CHEMBL1309735 & 688721 & 5.0 & 4.748 & TRN & \\
\hline CHEMBL1442113 & 688721 & 4.4 & 5.1437 & TST & \\
\hline CHEMBL1409415 & 688721 & 5.2 & 5.039 & TRN & \\
\hline CHEMBL1329755 & 688721 & 4.8 & 5.1629 & TST & \\
\hline CHEMBL1479211 & 688721 & 4.7 & 4.7795 & TRN & \\
\hline CHEMBL1499033 & 688721 & 4.7 & 5.144 & TRN & \\
\hline CHEMBL1324690 & 688721 & 4.6 & 4.8765 & TST & \\
\hline CHEMBL1345387 & 688721 & 4.5 & 4.8225 & TST & \\
\hline CHEMBL599705 & 688721 & 4.5 & 4.9775 & TRN & \\
\hline CHEMBL1384306 & 688721 & 4.7 & 4.8882 & TRN & \\
\hline CHEMBL1391120 & 688721 & 4.6 & 5.1302 & TRN & \\
\hline CHEMBL140 & 688721 & 6.0 & 5.1239 & TRN & \\
\hline CHEMBL1581028 & 688721 & 4.6 & 5.0141 & TRN & \\
\hline CHEMBL1500946 & 688721 & 4.4 & 4.9567 & TRN & \\
\hline
\end{tabular}




\begin{tabular}{|c|c|c|c|c|}
\hline & & & & \\
\hline CHEMBL1371350 & 688721 & 4.4 & 5.2284 & TST \\
\hline CHEMBL1587965 & 688721 & 5.2 & 4.961 & TST \\
\hline CHEMBL1526770 & 688721 & 5.5 & 5.2255 & TST \\
\hline CHEMBL44072 & 688721 & 4.6 & 5.1924 & TST \\
\hline CHEMBL1538118 & 688721 & 4.6 & 4.8726 & TRN \\
\hline CHEMBL1323764 & 688721 & 4.4 & 4.9054 & TRN \\
\hline CHEMBL1563799 & 688721 & 4.5 & 4.8624 & TRN \\
\hline CHEMBL1551834 & 688721 & 5.0 & 5.0788 & TRN \\
\hline CHEMBL1421019 & 688721 & 4.8 & 4.9547 & TRN \\
\hline CHEMBL1484153 & 688721 & 5.4 & 4.9968 & TRN \\
\hline CHEMBL1427297 & 688721 & 4.8 & 4.9766 & TST \\
\hline CHEMBL1602542 & 688721 & 4.6 & 4.7919 & TRN \\
\hline CHEMBL1362398 & 688721 & 4.6 & 4.7432 & TRN \\
\hline CHEMBL1307946 & 688721 & 4.4 & 4.8121 & TRN \\
\hline CHEMBL1310944 & 688721 & 4.7 & 4.8574 & TRN \\
\hline CHEMBL1431969 & 688721 & 4.7 & 4.9836 & TRN \\
\hline CHEMBL1519872 & 688721 & 4.6 & 4.9876 & TRN \\
\hline CHEMBL1401945 & 688721 & 4.7 & 4.7806 & TST \\
\hline CHEMBL1370467 & 688721 & 6.0 & 5.086 & TRN \\
\hline CHEMBL1527963 & 688721 & 4.9 & 4.8943 & TRN \\
\hline CHEMBL1472395 & 688721 & 4.7 & 4.8572 & TRN \\
\hline CHEMBL1395351 & 688721 & 4.9 & 5.0021 & TRN \\
\hline CHEMBL1442060 & 688721 & 4.5 & 4.7932 & TRN \\
\hline CHEMBL1503819 & 688721 & 4.6 & 4.8769 & TST \\
\hline CHEMBL1457512 & 688721 & 6.1 & 4.9993 & TRN \\
\hline CHEMBL1574687 & 688721 & 4.8 & 4.9748 & TRN \\
\hline CHEMBL3214565 & 688721 & 4.4 & 4.7788 & TST \\
\hline CHEMBL1522681 & 688721 & 5.9 & 5.2959 & TST \\
\hline CHEMBL1329708 & 688721 & 4.5 & 4.7461 & TRN \\
\hline CHEMBL1511225 & 688721 & 4.5 & 4.9557 & TRN \\
\hline CHEMBL1571220 & 688721 & 4.9 & 4.8283 & TRN \\
\hline CHEMBL1555508 & 688721 & 4.6 & 4.8522 & TST \\
\hline CHEMBL1594479 & 688721 & 4.4 & 4.832 & TRN \\
\hline CHEMBL1423060 & 688721 & 4.7 & 4.9167 & TRN \\
\hline CHEMBL1493096 & 688721 & 4.7 & 4.8682 & TRN \\
\hline CHEMBL1549356 & 688721 & 4.6 & 4.8285 & TRN \\
\hline CHEMBL3199263 & 688721 & 4.7 & 4.9346 & TST \\
\hline CHEMBL1491369 & 688721 & 4.6 & 4.8377 & TRN \\
\hline CHEMBL1359572 & 688721 & 4.7 & 4.9646 & TRN \\
\hline CHEMBL1421260 & 688721 & 5.4 & 4.9862 & TRN \\
\hline CHEMBL1560946 & 688721 & 4.4 & 4.9932 & TST \\
\hline CHEMBL1361777 & 688721 & 4.4 & 4.8244 & TRN \\
\hline CHEMBL1521545 & 688721 & 4.7 & 4.8954 & TRN \\
\hline CHEMBL1442250 & 688721 & 5.4 & 5.0126 & TRN \\
\hline CHEMBL1538542 & 688721 & 5.1 & 4.8958 & TRN \\
\hline CHEMBL1324586 & 688721 & 4.4 & 4.9842 & TRN \\
\hline CHEMBL1443757 & 688721 & 5.5 & 4.9259 & TRN \\
\hline CHEMBL1435744 & 688721 & 4.6 & 4.8436 & TRN \\
\hline
\end{tabular}




\begin{tabular}{|c|c|c|c|c|c|}
\hline \\
\hline CHEMBL1496903 & 688721 & 4.5 & 4.8301 & TRN & \\
\hline CHEMBL1577908 & 688721 & 4.8 & 4.8575 & TRN & \\
\hline CHEMBL1530410 & 688721 & 4.4 & 4.9166 & TRN & \\
\hline CHEMBL1338979 & 688721 & 4.6 & 4.9782 & TST & \\
\hline CHEMBL3211652 & 688721 & 4.4 & 5.1888 & TST & \\
\hline CHEMBL1483925 & 688721 & 4.8 & 4.9025 & TRN & \\
\hline CHEMBL1421872 & 688721 & 4.6 & 4.8582 & TRN & \\
\hline CHEMBL1335331 & 688721 & 6.1 & 5.039 & TRN & \\
\hline CHEMBL1411318 & 688721 & 5.1 & 4.9668 & TRN & \\
\hline CHEMBL1435477 & 688721 & 5.0 & 4.931 & TST & \\
\hline CHEMBL1309081 & 688721 & 5.0 & 4.9053 & TRN & \\
\hline CHEMBL1600077 & 688721 & 4.4 & 4.8887 & TRN & \\
\hline CHEMBL1311735 & 688721 & 4.6 & 4.832 & TRN & \\
\hline CHEMBL1303443 & 688721 & 4.6 & 4.9778 & TST & \\
\hline CHEMBL1479792 & 688721 & 4.5 & 4.91100 & 00000000005 & TRN \\
\hline CHEMBL1438642 & 688721 & 5.3 & 5.1258 & TST & \\
\hline CHEMBL1354079 & 688721 & 4.6 & 4.9758 & TRN & \\
\hline CHEMBL1368113 & 688721 & 5.3 & 5.051 & TST & \\
\hline CHEMBL1410589 & 688721 & 4.5 & 4.99100 & 00000000005 & TST \\
\hline CHEMBL1389834 & 688721 & 4.6 & 4.9812 & TRN & \\
\hline CHEMBL1303974 & 688721 & 4.5 & 4.9153 & TST & \\
\hline CHEMBL1384594 & 688721 & 4.4 & 4.7314 & TST & \\
\hline CHEMBL1567897 & 688721 & 4.4 & 4.887 & TRN & \\
\hline CHEMBL1429565 & 688721 & 4.8 & 5.0682 & TRN & \\
\hline CHEMBL1416386 & 688721 & 4.8 & 5.0948 & TRN & \\
\hline CHEMBL1575246 & 688721 & 6.5 & 4.9268 & TRN & \\
\hline CHEMBL1518906 & 688721 & 5.5 & 4.7277 & TRN & \\
\hline CHEMBL1327150 & 688721 & 4.4 & 4.9598 & TST & \\
\hline CHEMBL1501793 & 688721 & 4.7 & 4.9075 & TRN & \\
\hline CHEMBL1395247 & 688721 & 5.6 & 5.1421 & TRN & \\
\hline CHEMBL1707911 & 688721 & 4.7 & 4.961 & TRN & \\
\hline CHEMBL1609428 & 688721 & 4.5 & 4.856 & TRN & \\
\hline CHEMBL1511778 & 688721 & 6.4 & 4.9493 & TRN & \\
\hline CHEMBL1573292 & 688721 & 5.2 & 5.0212 & TST & \\
\hline CHEMBL1521099 & 688721 & 4.6 & 5.0564 & TRN & \\
\hline CHEMBL1587305 & 688721 & 5.1 & 4.8253 & TST & \\
\hline CHEMBL1572691 & 688721 & 4.7 & 4.8803 & TRN & \\
\hline CHEMBL1301192 & 688721 & 4.6 & 4.9954 & TRN & \\
\hline CHEMBL1505947 & 688721 & 4.6 & 4.7908 & TST & \\
\hline CHEMBL1359031 & 688721 & 4.6 & 4.8681 & TRN & \\
\hline CHEMBL1428991 & 688721 & 4.4 & 4.9821 & TRN & \\
\hline CHEMBL1366806 & 688721 & 4.6 & 4.8285 & TRN & \\
\hline CHEMBL1362521 & 688721 & 5.1 & 4.949 & TRN & \\
\hline CHEMBL1539118 & 688721 & 5.2 & 4.961 & TRN & \\
\hline CHEMBL1432507 & 688721 & 4.4 & 4.9479 & TRN & \\
\hline CHEMBL1334930 & 688721 & 4.4 & 4.822 & TRN & \\
\hline CHEMBL1594348 & 688721 & 4.6 & 4.9468 & TST & \\
\hline CHEMBL1460675 & 688721 & 4.7 & 4.9768 & TRN & \\
\hline
\end{tabular}




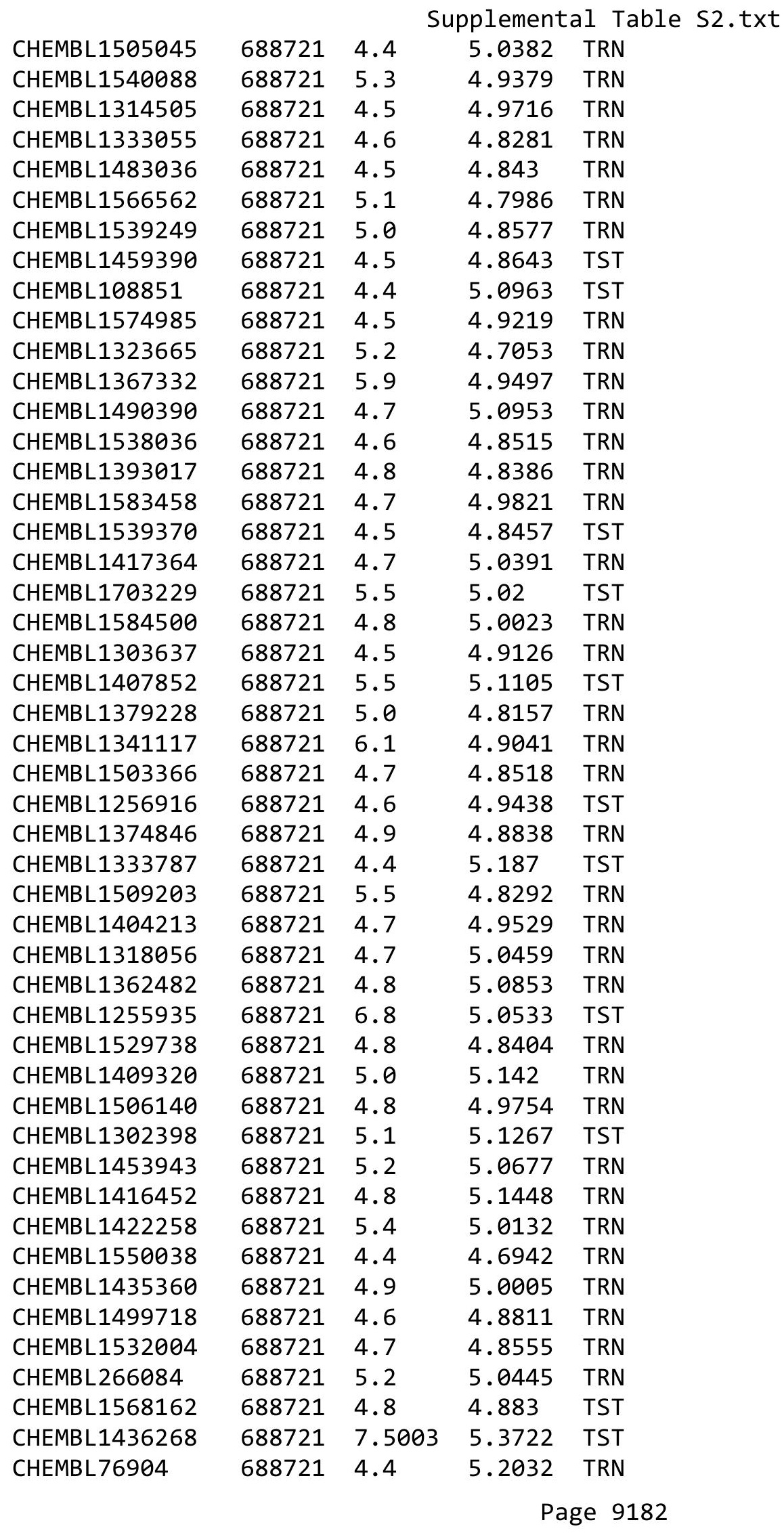




\begin{tabular}{|c|c|c|c|c|c|}
\hline \\
\hline CHEMBL1534254 & 688721 & 4.6 & 4.9454 & TRN & \\
\hline CHEMBL1402230 & 688721 & 4.6 & 4.8848 & TST & \\
\hline CHEMBL1371170 & 688721 & 4.6 & 5.0558 & TRN & \\
\hline CHEMBL1465613 & 688721 & 5.3 & 4.8833 & TST & \\
\hline CHEMBL3209774 & 688721 & 4.6 & 4.9588 & TST & \\
\hline CHEMBL1603962 & 688721 & 4.5 & 5.0026 & TRN & \\
\hline CHEMBL326958 & 688721 & 4.5 & 5.4154 & TRN & \\
\hline CHEMBL1348916 & 688721 & 4.9 & 4.9461 & TRN & \\
\hline CHEMBL1576363 & 688721 & 5.2 & 4.7448 & TRN & \\
\hline CHEMBL1329048 & 688721 & 6.2 & 4.8472 & TST & \\
\hline CHEMBL1418613 & 688721 & 4.6 & 4.887 & TRN & \\
\hline CHEMBL1446324 & 688721 & 4.5 & 5.164 & TRN & \\
\hline CHEMBL1302624 & 688721 & 4.5 & 4.9497 & TRN & \\
\hline CHEMBL258860 & 688721 & 4.6 & 4.9276 & TRN & \\
\hline CHEMBL1407754 & 688721 & 5.7 & 4.96899 & 9999999999 & TRN \\
\hline CHEMBL1409492 & 688721 & 4.9 & 4.8297 & TRN & \\
\hline CHEMBL1609081 & 688721 & 4.5 & 4.8562 & TRN & \\
\hline CHEMBL1585534 & 688721 & 4.7 & 4.7412 & TRN & \\
\hline CHEMBL1431939 & 688721 & 4.6 & 4.9506 & TRN & \\
\hline CHEMBL1412412 & 688721 & 4.8 & 4.808 & TRN & \\
\hline CHEMBL1558777 & 688721 & 5.2 & 4.8994 & TRN & \\
\hline CHEMBL3212057 & 688721 & 4.5 & 5.0736 & TST & \\
\hline CHEMBL1579658 & 688721 & 6.1 & 4.8924 & TRN & \\
\hline CHEMBL1593754 & 688721 & 6.0 & 5.204 & TST & \\
\hline CHEMBL1589751 & 688721 & 4.7 & 4.7549 & TST & \\
\hline CHEMBL1404747 & 688721 & 4.6 & 4.8711 & TRN & \\
\hline CHEMBL1584205 & 688721 & 4.6 & 4.9232 & TRN & \\
\hline CHEMBL1467677 & 688721 & 5.0 & 4.9109 & TST & \\
\hline CHEMBL1430570 & 688721 & 5.1 & 4.9359 & TRN & \\
\hline CHEMBL1457808 & 688721 & 5.1 & 4.8654 & TRN & \\
\hline CHEMBL1336572 & 688721 & 4.4 & 4.8502 & TST & \\
\hline CHEMBL1526693 & 688721 & 4.5 & 4.8775 & TRN & \\
\hline CHEMBL1529155 & 688721 & 4.4 & 4.9143 & TST & \\
\hline CHEMBL1329237 & 688721 & 4.5 & 4.7146 & TST & \\
\hline CHEMBL1380191 & 688721 & 4.4 & 4.8314 & TRN & \\
\hline CHEMBL1557078 & 688721 & 4.4 & 4.8427 & TRN & \\
\hline CHEMBL1329809 & 688721 & 5.6 & 4.9968 & TRN & \\
\hline CHEMBL1532325 & 688721 & 5.2 & 5.0709 & TRN & \\
\hline CHEMBL1460023 & 688721 & 4.5 & 5.0029 & TRN & \\
\hline CHEMBL106437 & 688721 & 5.2 & 4.9292 & TRN & \\
\hline CHEMBL1589428 & 688721 & 4.6 & 4.9032 & TRN & \\
\hline CHEMBL1492757 & 688721 & 5.0 & 4.9326 & TRN & \\
\hline CHEMBL1424034 & 688721 & 4.7 & 4.8111 & TRN & \\
\hline CHEMBL1192187 & 688721 & 6.0 & 5.2118 & TST & \\
\hline CHEMBL1362349 & 688721 & 4.5 & 5.0425 & TRN & \\
\hline CHEMBL1380274 & 688721 & 5.2 & 5.0378 & TST & \\
\hline CHEMBL1518075 & 688721 & 5.5 & 4.9704 & TRN & \\
\hline CHEMBL1545068 & 688721 & 4.7 & 4.9846 & TRN & \\
\hline & & & & 9183 & \\
\hline
\end{tabular}




\begin{tabular}{|c|c|c|c|c|c|}
\hline \multicolumn{6}{|c|}{ Supplemental Table S2.txt } \\
\hline CHEMBL287045 & 688721 & 6.4 & 4.9824 & TST & \\
\hline CHEMBL1301289 & 688721 & 4.6 & 4.8396 & TRN & \\
\hline CHEMBL1575931 & 688721 & 4.4 & 4.9557 & TRN & \\
\hline CHEMBL1556195 & 688721 & 4.6 & 4.8777 & TRN & \\
\hline CHEMBL1570008 & 688721 & 4.7 & 4.9306 & TRN & \\
\hline CHEMBL1398528 & 688721 & 4.9 & 5.2109 & TRN & \\
\hline CHEMBL1527170 & 688721 & 5.1 & 4.8083 & TRN & \\
\hline CHEMBL1370794 & 688721 & 4.4 & 4.7736 & TRN & \\
\hline CHEMBL1578030 & 688721 & 4.5 & 5.1866 & TRN & \\
\hline CHEMBL1405585 & 688721 & 5.9 & 5.0185 & TRN & \\
\hline CHEMBL1379304 & 688721 & 4.4 & 4.978 & TRN & \\
\hline CHEMBL1323579 & 688721 & 4.8 & 4.9924 & TRN & \\
\hline CHEMBL1489876 & 688721 & 5.4 & 4.8855 & TRN & \\
\hline CHEMBL1594058 & 688721 & 5.4 & 5.2053 & TRN & \\
\hline CHEMBL1551981 & 688721 & 4.6 & 4.9492 & TRN & \\
\hline CHEMBL1383540 & 688721 & 4.6 & 4.9319 & TRN & \\
\hline CHEMBL1311143 & 688721 & 5.4 & 4.9563 & TST & \\
\hline CHEMBL1382070 & 688721 & 4.4 & 5.04899 & 99999999995 & TST \\
\hline CHEMBL1478235 & 688721 & 5.2 & 5.0142 & TST & \\
\hline CHEMBL1335332 & 688721 & 4.8 & 4.9722 & TRN & \\
\hline CHEMBL1307028 & 688721 & 4.5 & 4.867 & TRN & \\
\hline CHEMBL1385148 & 688721 & 4.4 & 4.9271 & TRN & \\
\hline CHEMBL1369030 & 688721 & 4.5 & 5.1836 & TRN & \\
\hline CHEMBL1540699 & 688721 & 4.6 & 5.0152 & TST & \\
\hline CHEMBL1299504 & 688721 & 4.4 & 4.9233 & TST & \\
\hline CHEMBL1511205 & 688721 & 4.5 & 4.9473 & TST & \\
\hline CHEMBL1309212 & 688721 & 4.4 & 4.8116 & TRN & \\
\hline CHEMBL1547575 & 688721 & 4.5 & 4.8852 & TST & \\
\hline CHEMBL1519438 & 688721 & 5.5 & 5.0988 & TST & \\
\hline CHEMBL1605232 & 688721 & 4.8 & 4.9742 & TRN & \\
\hline CHEMBL1575033 & 688721 & 4.5 & 4.9377 & TST & \\
\hline CHEMBL1408228 & 688721 & 4.5 & 4.9805 & TRN & \\
\hline CHEMBL1579584 & 688721 & 6.5 & 4.8835 & TRN & \\
\hline CHEMBL1608034 & 688721 & 5.1 & 4.9227 & TRN & \\
\hline CHEMBL1365306 & 688721 & 4.9 & 4.9812 & TRN & \\
\hline CHEMBL1488613 & 688721 & 5.1 & 5.0354 & TRN & \\
\hline CHEMBL1373425 & 688721 & 4.9 & 4.8084 & TRN & \\
\hline CHEMBL1431257 & 688721 & 4.7 & 4.8655 & TRN & \\
\hline CHEMBL1558739 & 688721 & 4.4 & 5.0004 & TST & \\
\hline CHEMBL191750 & 688721 & 5.1 & 4.927 & TRN & \\
\hline CHEMBL1366292 & 688721 & 4.5 & 5.0144 & TRN & \\
\hline CHEMBL1377047 & 688721 & 4.6 & 4.9811 & TRN & \\
\hline CHEMBL1481844 & 688721 & 4.8 & 4.8474 & TRN & \\
\hline CHEMBL1520163 & 688721 & 5.2 & 4.9888 & TRN & \\
\hline CHEMBL1213406 & 688721 & 4.6 & 4.9108 & TST & \\
\hline CHEMBL1489528 & 688721 & 4.6 & 4.9639 & TRN & \\
\hline CHEMBL1523924 & 688721 & 6.8 & 4.8599 & TST & \\
\hline CHEMBL1564618 & 688721 & 5.1 & 4.8545 & TST & \\
\hline
\end{tabular}




\begin{tabular}{|c|c|c|c|c|c|}
\hline \\
\hline CHEMBL1508283 & 688721 & 4.5 & 4.9293 & TRN & \\
\hline CHEMBL1447959 & 688721 & 4.8 & 4.8833 & TRN & \\
\hline CHEMBL1410737 & 688721 & 5.1 & 4.9112 & TRN & \\
\hline CHEMBL1584930 & 688721 & 4.6 & 4.8975 & TRN & \\
\hline CHEMBL1606971 & 688721 & 5.1 & 4.8018 & TRN & \\
\hline CHEMBL1452335 & 688721 & 5.2 & 4.99 & TRN & \\
\hline CHEMBL1613725 & 688721 & 4.4 & 4.9932 & TRN & \\
\hline CHEMBL1308328 & 688721 & 4.7 & 4.867 & TRN & \\
\hline CHEMBL3213131 & 688721 & 5.5 & 4.9071 & TST & \\
\hline CHEMBL1585117 & 688721 & 4.5 & 4.887 & TRN & \\
\hline CHEMBL1510533 & 688721 & 4.8 & 4.7211 & TRN & \\
\hline CHEMBL1389959 & 688721 & 4.6 & 4.8627 & TRN & \\
\hline CHEMBL1499595 & 688721 & 4.5 & 4.785 & TRN & \\
\hline CHEMBL1444960 & 688721 & 4.8 & 5.0581 & TRN & \\
\hline CHEMBL1365081 & 688721 & 4.8 & 5.0145 & TRN & \\
\hline CHEMBL1410676 & 688721 & 4.8 & 4.9054 & TRN & \\
\hline CHEMBL1257003 & 688721 & 5.1 & 5.0652 & TST & \\
\hline CHEMBL1448873 & 688721 & 5.4 & 4.9212 & TRN & \\
\hline CHEMBL1361876 & 688721 & 5.9 & 4.8846 & TRN & \\
\hline CHEMBL1612543 & 688721 & 4.4 & 4.9537 & TRN & \\
\hline CHEMBL1502743 & 688721 & 4.9 & 5.0428 & TRN & \\
\hline CHEMBL1448538 & 688721 & 4.7 & 4.8509 & TRN & \\
\hline CHEMBL1568000 & 688721 & 5.6 & 4.9276 & TRN & \\
\hline CHEMBL1442106 & 688721 & 5.8 & 5.0937 & TRN & \\
\hline CHEMBL1467317 & 688721 & 4.8 & 4.8958 & TRN & \\
\hline CHEMBL1529722 & 688721 & 4.7 & 4.6597 & TRN & \\
\hline CHEMBL1361838 & 688721 & 4.6 & 4.8393 & TST & \\
\hline CHEMBL1470077 & 688721 & 4.4 & 5.2016 & TST & \\
\hline CHEMBL1370872 & 688721 & 4.7 & 4.8822 & TRN & \\
\hline CHEMBL1443654 & 688721 & 4.4 & 4.8322 & TST & \\
\hline CHEMBL1410513 & 688721 & 4.4 & 4.9406 & TRN & \\
\hline CHEMBL1465230 & 688721 & 4.4 & 5.0719 & TST & \\
\hline CHEMBL1448752 & 688721 & 4.4 & 4.8728 & TRN & \\
\hline CHEMBL592842 & 688721 & 4.4 & 5.084 & TRN & \\
\hline CHEMBL1370387 & 688721 & 4.4 & 4.8124 & TST & \\
\hline CHEMBL1351386 & 688721 & 4.6 & 5.0642 & TST & \\
\hline CHEMBL1483824 & 688721 & 4.5 & 4.8621 & TRN & \\
\hline CHEMBL1462482 & 688721 & 4.5 & 4.7651 & TST & \\
\hline CHEMBL1508379 & 688721 & 5.2 & 5.13399 & 99999999995 & TRN \\
\hline CHEMBL1598260 & 688721 & 4.8 & 5.1173 & TST & \\
\hline CHEMBL1321430 & 688721 & 4.6 & 4.9875 & TRN & \\
\hline CHEMBL1518072 & 688721 & 4.4 & 4.939 & TRN & \\
\hline CHEMBL1465199 & 688721 & 4.4 & 5.0868 & TST & \\
\hline CHEMBL1490892 & 688721 & 4.7 & 4.9567 & TRN & \\
\hline CHEMBL1331960 & 688721 & 4.5 & 4.7419 & TRN & \\
\hline CHEMBL1487536 & 688721 & 5.4 & 5.0113 & TRN & \\
\hline CHEMBL1332746 & 688721 & 4.7 & 4.8037 & TST & \\
\hline CHEMBL1594078 & 688721 & 4.8 & 5.1438 & TRN & \\
\hline
\end{tabular}




\begin{tabular}{|c|c|c|c|c|}
\hline \multicolumn{5}{|c|}{ Supplemental Table S2.txt } \\
\hline CHEMBL3190015 & 688721 & 4.4 & 5.109 & TRN \\
\hline CHEMBL1344408 & 688721 & 4.7 & 4.9366 & TRN \\
\hline CHEMBL1521445 & 688721 & 5.1 & 5.056 & TRN \\
\hline CHEMBL 3210620 & 688721 & 4.5 & 5.0089 & TRN \\
\hline CHEMBL1601711 & 688721 & 5.3 & 4.7238 & TRN \\
\hline CHEMBL1578194 & 688721 & 4.5 & 4.7559 & TRN \\
\hline CHEMBL1548825 & 688721 & 5.0 & 4.8635 & TST \\
\hline CHEMBL443949 & 688721 & 4.4 & 5.2863 & TST \\
\hline CHEMBL1493710 & 688721 & 5.2 & 4.9613 & TRN \\
\hline CHEMBL1543843 & 688721 & 4.8 & 4.9111 & TST \\
\hline CHEMBL1361677 & 688721 & 5.1 & 5.2452 & TRN \\
\hline CHEMBL1478115 & 688721 & 5.2 & 4.971 & TRN \\
\hline CHEMBL1481044 & 688721 & 4.4 & 4.814 & TRN \\
\hline CHEMBL1309521 & 688721 & 4.6 & 4.8019 & TRN \\
\hline CHEMBL1556134 & 688721 & 5.0 & 4.9016 & TRN \\
\hline CHEMBL1494650 & 688721 & 4.6 & 4.8843 & TST \\
\hline CHEMBL1549239 & 688721 & 4.4 & 4.9284 & TRN \\
\hline CHEMBL1498935 & 688721 & 4.6 & 4.8789 & TRN \\
\hline CHEMBL1521263 & 688721 & 4.9 & 4.9548 & TRN \\
\hline CHEMBL1525979 & 688721 & 4.7 & 4.6996 & TRN \\
\hline CHEMBL1319310 & 688721 & 4.7 & 4.8395 & TRN \\
\hline CHEMBL1482799 & 688721 & 5.0 & 4.8024 & TST \\
\hline CHEMBL1337381 & 688721 & 4.5 & 4.8446 & TRN \\
\hline CHEMBL405386 & 688721 & 5.4 & 4.9154 & TST \\
\hline CHEMBL1316956 & 688721 & 5.5 & 5.0183 & TRN \\
\hline CHEMBL1317943 & 688721 & 5.0 & 5.0145 & TRN \\
\hline CHEMBL1603400 & 688721 & 4.9 & 4.9842 & TRN \\
\hline CHEMBL1395567 & 688721 & 4.6 & 5.1779 & TRN \\
\hline CHEMBL1478700 & 688721 & 4.6 & 4.7704 & TRN \\
\hline CHEMBL1456745 & 688721 & 5.4 & 4.9841 & TRN \\
\hline CHEMBL1543818 & 688721 & 4.8 & 4.7775 & TRN \\
\hline CHEMBL1499165 & 688721 & 4.6 & 4.7832 & TRN \\
\hline CHEMBL1416977 & 688721 & 4.4 & 4.9025 & TRN \\
\hline CHEMBL1414984 & 688721 & 4.5 & 4.8664 & TRN \\
\hline CHEMBL1605491 & 688721 & 5.5 & 4.8885 & TRN \\
\hline CHEMBL1525418 & 688721 & 7.1002 & 4.9715 & TRN \\
\hline CHEMBL1417097 & 688721 & 6.8 & 4.6422 & TRN \\
\hline CHEMBL1364909 & 688721 & 4.5 & 4.9302 & TST \\
\hline CHEMBL192566 & 688721 & 5.3 & 5.3623 & TST \\
\hline CHEMBL1518739 & 688721 & 4.4 & 4.8088 & TRN \\
\hline CHEMBL1375619 & 688721 & 4.5 & 4.9716 & TRN \\
\hline CHEMBL1448182 & 688721 & 5.7 & 4.8418 & TRN \\
\hline CHEMBL1403786 & 688721 & 4.6 & 5.191 & TST \\
\hline CHEMBL1471171 & 688721 & 4.7 & 4.7277 & TRN \\
\hline CHEMBL1568767 & 688721 & 5.1 & 5.0344 & TRN \\
\hline CHEMBL1598747 & 688721 & 4.8 & 4.7402 & TRN \\
\hline CHEMBL1566340 & 688721 & 4.7 & 4.9001 & TRN \\
\hline CHEMBL1440253 & 688721 & 4.6 & 4.9718 & TRN \\
\hline
\end{tabular}




\begin{tabular}{|c|c|c|c|c|c|}
\hline \multicolumn{6}{|c|}{ Supplemental Table S2.txt } \\
\hline CHEMBL1347556 & 688721 & 5.9 & 4.8252 & TST & \\
\hline CHEMBL1400498 & 688721 & 5.1 & 4.95 & TRN & \\
\hline CHEMBL1457239 & 688721 & 4.6 & 4.8616 & TRN & \\
\hline CHEMBL41092 & 688721 & 4.8 & 4.9389 & TRN & \\
\hline CHEMBL1413572 & 688721 & 5.9 & 5.1057 & TRN & \\
\hline CHEMBL1496235 & 688721 & 6.8 & 4.8996 & TRN & \\
\hline CHEMBL1601790 & 688721 & 4.5 & 4.8409 & TRN & \\
\hline CHEMBL1256180 & 688721 & 4.4 & 5.1792 & TRN & \\
\hline CHEMBL1484411 & 688721 & 5.1 & 4.9201 & TST & \\
\hline CHEMBL1335770 & 688721 & 4.7 & 4.7806 & TRN & \\
\hline CHEMBL1424769 & 688721 & 4.7 & 4.9141 & TRN & \\
\hline CHEMBL1562638 & 688721 & 7.6003 & 5.0371 & TRN & \\
\hline CHEMBL1411691 & 688721 & 4.6 & 4.8879 & TRN & \\
\hline CHEMBL1304416 & 688721 & 5.2 & 4.7933 & TRN & \\
\hline CHEMBL1399619 & 688721 & 5.8 & 4.9165 & TST & \\
\hline CHEMBL1310511 & 688721 & 4.5 & 4.8086 & TRN & \\
\hline CHEMBL1367630 & 688721 & 5.9 & 4.88399 & 99999999995 & TRN \\
\hline CHEMBL1407483 & 688721 & 5.0 & 5.0624 & TST & \\
\hline CHEMBL1341609 & 688721 & 4.4 & 5.1071 & TRN & \\
\hline CHEMBL1324917 & 688721 & 6.1 & 4.8777 & TRN & \\
\hline CHEMBL1508175 & 688721 & 5.1 & 5.0266 & TST & \\
\hline CHEMBL1392463 & 688721 & 4.6 & 4.7767 & TST & \\
\hline CHEMBL1473753 & 688721 & 4.7 & 5.0215 & TRN & \\
\hline CHEMBL1466304 & 688721 & 4.4 & 5.06 & TST & \\
\hline CHEMBL1305411 & 688721 & 6.0 & 4.9453 & TST & \\
\hline CHEMBL1305326 & 688721 & 4.8 & 4.831 & TRN & \\
\hline CHEMBL1544230 & 688721 & 4.5 & 4.8525 & TRN & \\
\hline CHEMBL3210142 & 688721 & 5.4 & 5.1863 & TST & \\
\hline CHEMBL1418307 & 688721 & 4.6 & 5.1758 & TST & \\
\hline CHEMBL1456194 & 688721 & 4.4 & 4.809 & TRN & \\
\hline CHEMBL1485834 & 688721 & 4.8 & 4.852 & TRN & \\
\hline CHEMBL1409015 & 688721 & 5.2 & 4.7902 & TRN & \\
\hline CHEMBL1468505 & 688721 & 5.5 & 4.9002 & TRN & \\
\hline CHEMBL1609624 & 688721 & 4.5 & 5.0692 & TRN & \\
\hline CHEMBL1439593 & 688721 & 5.7 & 4.8818 & TRN & \\
\hline CHEMBL1594858 & 688721 & 4.9 & 4.8458 & TRN & \\
\hline CHEMBL1361716 & 688721 & 5.1 & 4.914 & TRN & \\
\hline CHEMBL1384652 & 688721 & 5.8 & 4.9589 & TRN & \\
\hline CHEMBL1497632 & 688721 & 4.9 & 4.9417 & TRN & \\
\hline CHEMBL1466946 & 688721 & 4.5 & 5.0717 & TST & \\
\hline CHEMBL1522604 & 688721 & 4.5 & 4.8962 & TRN & \\
\hline CHEMBL1413858 & 688721 & 4.7 & 5.1344 & TST & \\
\hline CHEMBL1354273 & 688721 & 5.0 & 5.0391 & TRN & \\
\hline CHEMBL1426192 & 688721 & 4.4 & 4.8926 & TRN & \\
\hline CHEMBL1496245 & 688721 & 5.2 & 4.7816 & TRN & \\
\hline CHEMBL1332051 & 688721 & 4.6 & 4.9624 & TRN & \\
\hline CHEMBL1399292 & 688721 & 4.6 & 5.1128 & TRN & \\
\hline CHEMBL1314291 & 688721 & 4.4 & 4.9061 & TRN & \\
\hline
\end{tabular}




\begin{tabular}{|c|c|c|c|c|}
\hline \multicolumn{5}{|c|}{ Supplemental Table S2.txt } \\
\hline CHEMBL1607968 & 688721 & 5.5 & 4.9755 & TRN \\
\hline CHEMBL1505750 & 688721 & 5.5 & 5.0794 & TRN \\
\hline CHEMBL1606432 & 688721 & 4.8 & 4.8768 & TST \\
\hline CHEMBL1324802 & 688721 & 5.4 & 4.842 & TRN \\
\hline CHEMBL1367690 & 688721 & 4.7 & 5.0539 & TST \\
\hline CHEMBL1551864 & 688721 & 5.4 & 5.1977 & TST \\
\hline CHEMBL1489120 & 688721 & 4.8 & 4.784 & TRN \\
\hline CHEMBL1486223 & 688721 & 5.0 & 5.0583 & TST \\
\hline CHEMBL1302653 & 688721 & 4.6 & 4.7897 & TRN \\
\hline CHEMBL1600522 & 688721 & 6.0 & 4.7964 & TRN \\
\hline CHEMBL1321086 & 688721 & 5.0 & 5.0113 & TRN \\
\hline CHEMBL1564425 & 688721 & 4.6 & 4.7971 & TRN \\
\hline CHEMBL1402412 & 688721 & 4.5 & 4.7837 & TRN \\
\hline CHEMBL1327185 & 688721 & 4.8 & 4.7874 & TRN \\
\hline CHEMBL342375 & 688721 & 5.5 & 5.0553 & TST \\
\hline CHEMBL1299561 & 688721 & 5.9 & 4.9423 & TRN \\
\hline CHEMBL1308152 & 688721 & 5.7 & 4.9908 & TRN \\
\hline CHEMBL1429196 & 688721 & 4.8 & 4.901 & TRN \\
\hline CHEMBL1460507 & 688721 & 4.8 & 4.9972 & TRN \\
\hline CHEMBL1584247 & 688721 & 4.9 & 4.8331 & TST \\
\hline CHEMBL1487601 & 688721 & 4.5 & 4.8738 & TRN \\
\hline CHEMBL1436507 & 688721 & 4.7 & 5.1764 & TRN \\
\hline CHEMBL1594349 & 688721 & 4.6 & 4.8425 & TRN \\
\hline CHEMBL1334175 & 688721 & 5.0 & 4.8253 & TRN \\
\hline CHEMBL1471355 & 688721 & 4.7 & 5.0666 & TRN \\
\hline CHEMBL1414483 & 688721 & 5.2 & 4.9815 & TRN \\
\hline CHEMBL1411213 & 688721 & 4.4 & 4.9262 & TRN \\
\hline CHEMBL1380300 & 688721 & 4.6 & 4.7632 & TRN \\
\hline CHEMBL1590909 & 688721 & 4.8 & 4.9337 & TRN \\
\hline CHEMBL1557564 & 688721 & 4.6 & 5.1444 & TRN \\
\hline CHEMBL1310155 & 688721 & 4.5 & 4.7964 & TRN \\
\hline CHEMBL1430579 & 688721 & 4.7 & 5.1073 & TST \\
\hline CHEMBL1332346 & 688721 & 5.0 & 5.2418 & TRN \\
\hline CHEMBL1590493 & 688721 & 4.4 & 4.9943 & TRN \\
\hline CHEMBL1387918 & 688721 & 4.5 & 4.907 & TRN \\
\hline CHEMBL1490807 & 688721 & 4.8 & 4.9215 & TRN \\
\hline CHEMBL1370066 & 688721 & 4.6 & 4.7306 & TRN \\
\hline CHEMBL1307365 & 688721 & 5.2 & 5.1098 & TST \\
\hline CHEMBL1481063 & 688721 & 5.2 & 4.9686 & TST \\
\hline CHEMBL1413909 & 688721 & 7.5003 & 4.9248 & TRN \\
\hline CHEMBL1488416 & 688721 & 4.7 & 4.8309 & TRN \\
\hline CHEMBL1428015 & 688721 & 4.9 & 4.9205 & TRN \\
\hline CHEMBL1408446 & 688721 & 5.3 & 5.0395 & TRN \\
\hline CHEMBL1457739 & 688721 & 4.8 & 4.9171 & TRN \\
\hline CHEMBL1349313 & 688721 & 4.6 & 4.9068 & TRN \\
\hline CHEMBL1536822 & 688721 & 4.6 & 4.8542 & TRN \\
\hline CHEMBL3195899 & 688721 & 4.5 & 5.12299 & 9999999999 \\
\hline CHEMBL1609757 & 688721 & 4.6 & 4.7983 & TRN \\
\hline
\end{tabular}




\begin{tabular}{|c|c|c|c|c|}
\hline \multicolumn{5}{|c|}{ Supplemental Table S2.txt } \\
\hline CHEMBL1536699 & 688721 & 4.5 & 4.8623 & TRN \\
\hline CHEMBL1567209 & 688721 & 5.4 & 4.9354 & TRN \\
\hline CHEMBL1472042 & 688721 & 4.8 & 4.7544 & TST \\
\hline CHEMBL1579944 & 688721 & 5.2 & 5.1443 & TRN \\
\hline CHEMBL1604342 & 688721 & 4.6 & 5.0317 & TST \\
\hline CHEMBL1607283 & 688721 & 4.5 & 4.96 & TST \\
\hline CHEMBL1429292 & 688721 & 4.4 & 4.7504 & TRN \\
\hline CHEMBL1315292 & 688721 & 6.8 & 5.0865 & TRN \\
\hline CHEMBL1483422 & 688721 & 5.6 & 5.1282 & TRN \\
\hline CHEMBL1437778 & 688721 & 5.4 & 5.0777 & TRN \\
\hline CHEMBL228792 & 688721 & 5.3 & 5.1051 & TRN \\
\hline CHEMBL1408712 & 688721 & 4.8 & 4.837 & TRN \\
\hline CHEMBL1346112 & 688721 & 4.4 & 4.6447 & TRN \\
\hline CHEMBL1513078 & 688721 & 5.4 & 5.077 & TRN \\
\hline CHEMBL1398910 & 688721 & 6.0 & 5.1211 & TRN \\
\hline CHEMBL1600620 & 688721 & 5.0 & 5.3551 & TRN \\
\hline CHEMBL1528209 & 688721 & 4.6 & 5.0194 & TRN \\
\hline CHEMBL1606451 & 688721 & 5.4 & 4.9625 & TRN \\
\hline CHEMBL1313196 & 688721 & 4.5 & 4.8367 & TRN \\
\hline CHEMBL1534533 & 688721 & 4.7 & 4.7857 & TRN \\
\hline CHEMBL1531644 & 688721 & 4.8 & 4.8551 & TRN \\
\hline CHEMBL1468993 & 688721 & 5.2 & 4.9763 & TST \\
\hline CHEMBL1598091 & 688721 & 4.5 & 4.7084 & TRN \\
\hline CHEMBL1568625 & 688721 & 4.5 & 4.8442 & TRN \\
\hline CHEMBL1612795 & 688721 & 4.4 & 4.9233 & TRN \\
\hline CHEMBL530361 & 688721 & 5.2 & 5.0079 & TRN \\
\hline CHEMBL1542779 & 688721 & 4.4 & 5.1151 & TRN \\
\hline CHEMBL1585322 & 688721 & 4.6 & 4.9461 & TRN \\
\hline CHEMBL1536892 & 688721 & 4.6 & 4.8732 & TRN \\
\hline CHEMBL1437863 & 688721 & 4.5 & 4.8149 & TRN \\
\hline CHEMBL 327708 & 688721 & 5.9 & 5.0342 & TRN \\
\hline CHEMBL1330422 & 688721 & 4.7 & 5.1773 & TRN \\
\hline CHEMBL1584777 & 688721 & 4.4 & 4.6607 & TRN \\
\hline CHEMBL280065 & 688721 & 6.0 & 5.3832 & TRN \\
\hline CHEMBL1397704 & 688721 & 4.5 & 5.0089 & TRN \\
\hline CHEMBL1574722 & 688721 & 4.5 & 5.0192 & TRN \\
\hline CHEMBL1418524 & 688721 & 4.7 & 4.8604 & TRN \\
\hline CHEMBL1299666 & 688721 & 4.8 & 4.8546 & TRN \\
\hline CHEMBL1586957 & 688721 & 4.8 & 4.9066 & TST \\
\hline CHEMBL1607673 & 688721 & 4.6 & 4.8565 & TRN \\
\hline CHEMBL1364408 & 688721 & 5.3 & 4.8581 & TRN \\
\hline CHEMBL1543322 & 688721 & 6.0 & 4.851 & TST \\
\hline CHEMBL1419895 & 688721 & 4.8 & 4.7854 & TRN \\
\hline CHEMBL1447057 & 688721 & 5.2 & 4.9984 & TRN \\
\hline CHEMBL1377901 & 688721 & 5.2 & 4.8639 & TRN \\
\hline CHEMBL1331619 & 688721 & 4.7 & 4.947 & TST \\
\hline CHEMBL105278 & 688721 & 7.5003 & 5.3011 & TST \\
\hline CHEMBL1482195 & 688721 & 5.6 & 5.0575 & TRN \\
\hline
\end{tabular}




\begin{tabular}{|c|c|c|c|c|c|}
\hline \multicolumn{6}{|c|}{ Supplemental Table S2.txt } \\
\hline CHEMBL1570222 & 688721 & 4.5 & 4.9765 & TRN & \\
\hline CHEMBL1380142 & 688721 & 4.8 & 4.918 & TRN & \\
\hline CHEMBL1522857 & 688721 & 4.6 & 5.1036 & TRN & \\
\hline CHEMBL1471950 & 688721 & 5.2 & 5.0299 & TRN & \\
\hline CHEMBL1488226 & 688721 & 5.0 & 5.0151 & TRN & \\
\hline CHEMBL1479771 & 688721 & 4.6 & 5.0087 & TRN & \\
\hline CHEMBL1324166 & 688721 & 4.5 & 4.9116 & TST & \\
\hline CHEMBL1501783 & 688721 & 5.2 & 5.1152 & TRN & \\
\hline CHEMBL1421864 & 688721 & 5.4 & 5.0199 & TST & \\
\hline CHEMBL1324493 & 688721 & 4.8 & 5.0844 & TRN & \\
\hline CHEMBL1427272 & 688721 & 4.9 & 4.8842 & TST & \\
\hline CHEMBL1589365 & 688721 & 4.5 & 4.882 & TRN & \\
\hline CHEMBL1445792 & 688721 & 5.5 & 5.1511 & TRN & \\
\hline CHEMBL1544192 & 688721 & 4.5 & 5.1094 & TRN & \\
\hline CHEMBL1439088 & 688721 & 4.8 & 5.0518 & TST & \\
\hline CHEMBL366489 & 688721 & 5.4 & 5.1843 & TST & \\
\hline CHEMBL1433080 & 688721 & 4.9 & 4.757 & TRN & \\
\hline CHEMBL1592212 & 688721 & 4.5 & 4.9534 & TRN & \\
\hline CHEMBL1602519 & 688721 & 4.4 & 5.0139 & TRN & \\
\hline CHEMBL1393779 & 688721 & 4.9 & 5.0137 & TRN & \\
\hline CHEMBL1605116 & 688721 & 4.4 & 5.0687 & TST & \\
\hline CHEMBL1307130 & 688721 & 4.5 & 4.8919 & TRN & \\
\hline CHEMBL1560562 & 688721 & 4.5 & 4.8561 & TRN & \\
\hline CHEMBL1331654 & 688721 & 5.5 & 4.9913 & TRN & \\
\hline CHEMBL1583671 & 688721 & 5.2 & 4.7368 & TRN & \\
\hline CHEMBL1412856 & 688721 & 4.7 & 4.91100 & 00000000005 & TRN \\
\hline CHEMBL1581103 & 688721 & 4.7 & 4.9091 & TRN & \\
\hline CHEMBL1576285 & 688721 & 4.4 & 5.0356 & TRN & \\
\hline CHEMBL1370693 & 688721 & 4.4 & 5.0684 & TST & \\
\hline CHEMBL1494499 & 688721 & 5.1 & 4.8183 & TST & \\
\hline CHEMBL1364572 & 688721 & 5.3 & 5.0882 & TST & \\
\hline CHEMBL1439004 & 688721 & 4.6 & 4.7347 & TRN & \\
\hline CHEMBL1390506 & 688721 & 4.7 & 4.8981 & TRN & \\
\hline CHEMBL1329054 & 688721 & 4.9 & 4.8991 & TRN & \\
\hline CHEMBL1342901 & 688721 & 5.4 & 4.9275 & TRN & \\
\hline CHEMBL1346311 & 688721 & 4.8 & 4.7745 & TRN & \\
\hline CHEMBL1456452 & 688721 & 7.0 & 4.9017 & TRN & \\
\hline CHEMBL1337502 & 688721 & 4.4 & 4.9266 & TST & \\
\hline CHEMBL1394840 & 688721 & 5.1 & 5.2126 & TRN & \\
\hline CHEMBL1540363 & 688721 & 4.6 & 5.169 & TRN & \\
\hline CHEMBL1440509 & 688721 & 4.5 & 5.0933 & TRN & \\
\hline CHEMBL1532161 & 688721 & 4.4 & 4.9676 & TRN & \\
\hline CHEMBL1469787 & 688721 & 4.6 & 5.1234 & TRN & \\
\hline CHEMBL1488942 & 688721 & 4.8 & 4.8494 & TRN & \\
\hline CHEMBL1407552 & 688721 & 5.2 & 4.8937 & TST & \\
\hline CHEMBL1434801 & 688721 & 6.2 & 5.3203 & TRN & \\
\hline CHEMBL1540450 & 688721 & 4.5 & 4.8052 & TRN & \\
\hline CHEMBL1464530 & 688721 & 4.8 & 4.8367 & TRN & \\
\hline
\end{tabular}




\begin{tabular}{|c|c|c|c|c|}
\hline \multicolumn{5}{|c|}{ Supplemental Table S2.txt } \\
\hline CHEMBL1544616 & 688721 & 4.6 & 4.8496 & TRN \\
\hline CHEMBL1456016 & 688721 & 4.6 & 4.8093 & TRN \\
\hline CHEMBL1441574 & 688721 & 4.8 & 4.9707 & TRN \\
\hline CHEMBL1318553 & 688721 & 4.5 & 5.0512 & TST \\
\hline CHEMBL1438748 & 688721 & 5.5 & 5.1172 & TRN \\
\hline CHEMBL1358012 & 688721 & 4.7 & 5.0707 & TST \\
\hline CHEMBL1384562 & 688721 & 4.4 & 5.0999 & TRN \\
\hline CHEMBL1327247 & 688721 & 4.5 & 5.1781 & TST \\
\hline CHEMBL1561971 & 688721 & 5.0 & 5.0382 & TST \\
\hline CHEMBL1416091 & 688721 & 4.8 & 4.9667 & TRN \\
\hline CHEMBL1412676 & 688721 & 4.6 & 4.8612 & TST \\
\hline CHEMBL1558796 & 688721 & 6.2 & 5.1085 & TRN \\
\hline CHEMBL1492229 & 688721 & 5.3 & 4.8772 & TRN \\
\hline CHEMBL1571264 & 688721 & 5.9 & 5.0038 & TRN \\
\hline CHEMBL1440648 & 688721 & 5.1 & 4.9763 & TST \\
\hline CHEMBL1544244 & 688721 & 8.2007 & 4.9836 & TRN \\
\hline CHEMBL1445084 & 688721 & 4.6 & 4.8453 & TRN \\
\hline CHEMBL1585266 & 688721 & 5.2 & 4.9903 & TRN \\
\hline CHEMBL1487744 & 688721 & 6.1 & 5.0226 & TRN \\
\hline CHEMBL1472753 & 688721 & 5.5 & 4.9882 & TRN \\
\hline CHEMBL1361119 & 688721 & 4.6 & 4.8856 & TRN \\
\hline CHEMBL1429064 & 688721 & 4.4 & 4.8498 & TRN \\
\hline CHEMBL1548181 & 688721 & 4.6 & 4.8925 & TRN \\
\hline CHEMBL1324032 & 688721 & 5.9 & 5.1183 & TST \\
\hline CHEMBL1561807 & 688721 & 4.5 & 4.9802 & TRN \\
\hline CHEMBL1371348 & 688721 & 5.4 & 5.1299 & TRN \\
\hline CHEMBL1310142 & 688721 & 4.4 & 4.9381 & TRN \\
\hline CHEMBL1606018 & 688721 & 6.1 & 5.3916 & TST \\
\hline CHEMBL1502012 & 688721 & 5.6 & 5.0467 & TST \\
\hline CHEMBL1335128 & 688721 & 4.6 & 4.9393 & TRN \\
\hline CHEMBL1538480 & 688721 & 5.7 & 4.7547 & TRN \\
\hline CHEMBL1560313 & 688721 & 4.5 & 4.7878 & TRN \\
\hline CHEMBL1528551 & 688721 & 7.5003 & 4.8053 & TRN \\
\hline CHEMBL1353230 & 688721 & 4.5 & 5.0211 & TST \\
\hline CHEMBL1577516 & 688721 & 4.4 & 4.8411 & TRN \\
\hline CHEMBL1416440 & 688721 & 4.9 & 4.8934 & TRN \\
\hline CHEMBL1371599 & 688721 & 4.7 & 4.9603 & TRN \\
\hline CHEMBL1448702 & 688721 & 4.6 & 4.8243 & TRN \\
\hline CHEMBL1585023 & 688721 & 4.4 & 4.8999 & TRN \\
\hline CHEMBL1572195 & 688721 & 5.5 & 5.0306 & TST \\
\hline CHEMBL1974818 & 688721 & 5.2 & 4.9044 & TST \\
\hline CHEMBL1457332 & 688721 & 5.4 & 5.0045 & TRN \\
\hline CHEMBL1452671 & 688721 & 4.5 & 4.8907 & TRN \\
\hline CHEMBL1548198 & 688721 & 5.3 & 4.8748 & TRN \\
\hline CHEMBL511207 & 688721 & 4.9 & 4.9911 & TRN \\
\hline CHEMBL1452221 & 688721 & 5.2 & 5.1347 & TRN \\
\hline CHEMBL1498135 & 688721 & 4.5 & 4.8595 & TRN \\
\hline CHEMBL1368827 & 688721 & 4.6 & 4.8623 & TST \\
\hline
\end{tabular}




\begin{tabular}{|c|c|c|c|c|c|}
\hline \multicolumn{6}{|c|}{ Supplemental Table S2.txt } \\
\hline CHEMBL1419284 & 688721 & 5.2 & 4.9698 & TRN & \\
\hline CHEMBL1612893 & 688721 & 5.1 & 4.9609 & TRN & \\
\hline CHEMBL1364852 & 688721 & 4.6 & 4.9087 & TRN & \\
\hline CHEMBL324642 & 688721 & 7.2 & 5.1232 & TRN & \\
\hline CHEMBL1376765 & 688721 & 5.0 & 4.9639 & TRN & \\
\hline CHEMBL1353497 & 688721 & 5.8 & 4.9013 & TST & \\
\hline CHEMBL1478987 & 688721 & 4.4 & 4.8563 & TRN & \\
\hline CHEMBL1605113 & 688721 & 4.4 & 4.7601 & TRN & \\
\hline CHEMBL1313600 & 688721 & 4.4 & 4.8841 & TRN & \\
\hline CHEMBL1426512 & 688721 & 4.5 & 4.7481 & TRN & \\
\hline CHEMBL1343907 & 688721 & 4.6 & 4.8985 & TRN & \\
\hline CHEMBL1322584 & 688721 & 7.4001 & 5.1201 & TRN & \\
\hline CHEMBL1417269 & 688721 & 4.8 & 4.91100 & 00000000005 & TST \\
\hline CHEMBL1502681 & 688721 & 5.8 & 4.8942 & TRN & \\
\hline CHEMBL1529629 & 688721 & 4.8 & 4.8641 & TRN & \\
\hline CHEMBL1408036 & 688721 & 4.8 & 4.8803 & TST & \\
\hline CHEMBL1373827 & 688721 & 5.0 & 4.7841 & TRN & \\
\hline CHEMBL1301013 & 688721 & 4.8 & 4.7817 & TST & \\
\hline CHEMBL1407088 & 688721 & 4.4 & 4.8949 & TRN & \\
\hline CHEMBL1588613 & 688721 & 5.0 & 4.8358 & TRN & \\
\hline CHEMBL1400266 & 688721 & 4.5 & 5.007 & TRN & \\
\hline CHEMBL1449973 & 688721 & 4.6 & 5.0143 & TRN & \\
\hline CHEMBL1564927 & 688721 & 5.4 & 5.0362 & TST & \\
\hline CHEMBL1471961 & 688721 & 5.0 & 5.256 & TST & \\
\hline CHEMBL1604529 & 688721 & 4.5 & 4.9066 & TRN & \\
\hline CHEMBL1483373 & 688721 & 4.5 & 4.9559 & TRN & \\
\hline CHEMBL3207553 & 688721 & 4.5 & 5.0177 & TRN & \\
\hline CHEMBL3193107 & 688721 & 5.4 & 5.0609 & TRN & \\
\hline CHEMBL1582162 & 688721 & 5.5 & 5.0276 & TRN & \\
\hline CHEMBL1411743 & 688721 & 6.3 & 5.1046 & TRN & \\
\hline CHEMBL1338367 & 688721 & 4.5 & 4.7834 & TRN & \\
\hline CHEMBL1322702 & 688721 & 6.1 & 5.0228 & TST & \\
\hline CHEMBL1547554 & 688721 & 5.4 & 5.0579 & TRN & \\
\hline CHEMBL1317633 & 688721 & 5.3 & 5.3671 & TRN & \\
\hline CHEMBL1309141 & 688721 & 4.7 & 4.9434 & TRN & \\
\hline CHEMBL1426886 & 688721 & 4.7 & 4.788 & TST & \\
\hline CHEMBL1330518 & 688721 & 5.1 & 5.3645 & TRN & \\
\hline CHEMBL1569029 & 688721 & 6.0 & 4.7795 & TRN & \\
\hline CHEMBL1348465 & 688721 & 4.6 & 4.8893 & TRN & \\
\hline CHEMBL1413213 & 688721 & 4.8 & 4.6886 & TRN & \\
\hline CHEMBL1448345 & 688721 & 4.7 & 5.0252 & TRN & \\
\hline CHEMBL1506257 & 688721 & 4.4 & 4.7109 & TST & \\
\hline CHEMBL1400181 & 688721 & 4.9 & 4.9205 & TST & \\
\hline CHEMBL1603257 & 688721 & 5.5 & 5.0833 & TRN & \\
\hline CHEMBL1364901 & 688721 & 4.6 & 4.8703 & TRN & \\
\hline CHEMBL1545045 & 688721 & 4.4 & 5.2429 & TST & \\
\hline CHEMBL1471717 & 688721 & 6.2 & 4.8421 & TRN & \\
\hline CHEMBL1421407 & 688721 & 4.7 & 5.0809 & TRN & \\
\hline
\end{tabular}




\begin{tabular}{|c|c|c|c|c|}
\hline \multicolumn{5}{|c|}{ Supplemental Table S2.txt } \\
\hline CHEMBL1395402 & 688721 & 5.5 & 5.2179 & TRN \\
\hline CHEMBL1545054 & 688721 & 4.8 & 4.8768 & TRN \\
\hline CHEMBL1357016 & 688721 & 6.1 & 4.8616 & TRN \\
\hline CHEMBL155265 & 688721 & 5.3 & 5.1893 & TST \\
\hline CHEMBL1324148 & 688721 & 5.3 & 5.0246 & TST \\
\hline CHEMBL1532679 & 688721 & 4.4 & 5.0314 & TRN \\
\hline CHEMBL1556507 & 688721 & 4.5 & 4.9435 & TRN \\
\hline CHEMBL1353393 & 688721 & 4.6 & 4.9387 & TST \\
\hline CHEMBL1305104 & 688721 & 6.0 & 4.9296 & TST \\
\hline CHEMBL1558705 & 688721 & 4.5 & 4.7834 & TRN \\
\hline CHEMBL1565777 & 688721 & 4.5 & 4.9461 & TRN \\
\hline CHEMBL 3197540 & 688721 & 4.4 & 5.0064 & TRN \\
\hline CHEMBL1339237 & 688721 & 4.7 & 4.8951 & TRN \\
\hline CHEMBL1463737 & 688721 & 4.5 & 4.8261 & TRN \\
\hline CHEMBL1545647 & 688721 & 4.4 & 4.9925 & TST \\
\hline CHEMBL1382529 & 688721 & 4.8 & 5.1006 & TRN \\
\hline CHEMBL1335472 & 688721 & 4.4 & 4.8245 & TRN \\
\hline CHEMBL1348159 & 688721 & 4.4 & 4.8947 & TRN \\
\hline CHEMBL1444296 & 688721 & 4.4 & 4.9056 & TST \\
\hline CHEMBL118902 & 688721 & 5.0 & 5.2456 & TST \\
\hline CHEMBL1449509 & 688721 & 4.5 & 4.9412 & TRN \\
\hline CHEMBL1503094 & 688721 & 4.7 & 4.9124 & TRN \\
\hline CHEMBL1514440 & 688721 & 7.4001 & 5.1168 & TRN \\
\hline CHEMBL405760 & 688721 & 4.4 & 4.8232 & TRN \\
\hline CHEMBL1489167 & 688721 & 6.1 & 4.8322 & TRN \\
\hline CHEMBL1495172 & 688721 & 4.5 & 4.7434 & TRN \\
\hline CHEMBL1367996 & 688721 & 4.7 & 4.9518 & TRN \\
\hline CHEMBL1500536 & 688721 & 5.3 & 5.0794 & TST \\
\hline CHEMBL1404128 & 688721 & 5.4 & 4.8037 & TRN \\
\hline CHEMBL1525781 & 688721 & 4.7 & 4.9374 & TRN \\
\hline CHEMBL1533734 & 688721 & 5.4 & 5.1118 & TST \\
\hline CHEMBL1365286 & 688721 & 4.6 & 5.0612 & TST \\
\hline CHEMBL1543571 & 688721 & 4.4 & 4.8238 & TRN \\
\hline CHEMBL1360019 & 688721 & 5.3 & 4.9816 & TRN \\
\hline CHEMBL1523742 & 688721 & 4.7 & 5.0037 & TRN \\
\hline CHEMBL1339504 & 688721 & 4.6 & 4.8033 & TRN \\
\hline CHEMBL1512385 & 688721 & 4.9 & 5.1527 & TRN \\
\hline CHEMBL1604866 & 688721 & 4.4 & 5.1213 & TRN \\
\hline CHEMBL1549959 & 688721 & 4.5 & 5.1045 & TRN \\
\hline CHEMBL1606610 & 688721 & 4.5 & 5.0188 & TST \\
\hline CHEMBL1341604 & 688721 & 4.4 & 4.8331 & TRN \\
\hline CHEMBL1490905 & 688721 & 4.8 & 4.8763 & TRN \\
\hline CHEMBL1371868 & 688721 & 5.5 & 4.9135 & TRN \\
\hline CHEMBL1463982 & 688721 & 5.4 & 4.8431 & TRN \\
\hline CHEMBL1342448 & 688721 & 5.5 & 4.8421 & TRN \\
\hline CHEMBL1301151 & 688721 & 4.5 & 5.0032 & TRN \\
\hline CHEMBL1317805 & 688721 & 5.1 & 5.081 & TRN \\
\hline CHEMBL1340214 & 688721 & 5.2 & 4.933 & TST \\
\hline
\end{tabular}




\begin{tabular}{|c|c|c|c|c|}
\hline & & & pplement & al lable s \\
\hline CHEMBL1605179 & 688721 & 4.4 & 5.1151 & TRN \\
\hline CHEMBL1439561 & 688721 & 4.6 & 4.8208 & TST \\
\hline CHEMBL1330355 & 688721 & 6.0 & 5.2856 & TST \\
\hline CHEMBL1556246 & 688721 & 5.5 & 5.0418 & TRN \\
\hline CHEMBL1517288 & 688721 & 5.2 & 4.6538 & TRN \\
\hline CHEMBL1352422 & 688721 & 4.4 & 4.9074 & TST \\
\hline CHEMBL1606828 & 688721 & 4.8 & $5.0310 e$ & 0000000001 \\
\hline CHEMBL1572697 & 688721 & 4.4 & 4.9251 & TST \\
\hline CHEMBL1450714 & 688721 & 5.2 & 4.8617 & TRN \\
\hline CHEMBL357625 & 688721 & 4.8 & 4.9686 & TST \\
\hline CHEMBL1333464 & 688721 & 4.8 & 4.8784 & TRN \\
\hline CHEMBL1378795 & 688721 & 5.2 & 4.9975 & TRN \\
\hline CHEMBL1464441 & 688721 & 4.5 & 5.0782 & TST \\
\hline CHEMBL1482054 & 688721 & 4.8 & 4.8204 & TRN \\
\hline CHEMBL1452005 & 688721 & 4.8 & 4.7998 & TST \\
\hline CHEMBL1388389 & 688721 & 4.8 & 4.9943 & TRN \\
\hline CHEMBL1318718 & 688721 & 5.2 & 4.8102 & TST \\
\hline CHEMBL3198962 & 688721 & 4.6 & 5.0707 & TRN \\
\hline CHEMBL1430958 & 688721 & 4.5 & 4.961 & TRN \\
\hline CHEMBL1612517 & 688721 & 5.0 & 4.8703 & TRN \\
\hline CHEMBL1326527 & 688721 & 6.9 & 4.7649 & TRN \\
\hline CHEMBL1599234 & 688721 & 4.8 & 4.8709 & TRN \\
\hline CHEMBL1300689 & 688721 & 4.4 & 4.7627 & TRN \\
\hline CHEMBL1611840 & 688721 & 4.5 & 5.1215 & TRN \\
\hline CHEMBL1377430 & 688721 & 4.6 & 4.8999 & TRN \\
\hline CHEMBL1543368 & 688721 & 5.2 & 5.0523 & TRN \\
\hline CHEMBL1528069 & 688721 & 4.5 & 5.1058 & TST \\
\hline CHEMBL1314144 & 688721 & 5.4 & 4.6486 & TRN \\
\hline CHEMBL1421424 & 688721 & 5.3 & 4.9539 & TRN \\
\hline CHEMBL1411051 & 688721 & 4.6 & 4.8191 & TRN \\
\hline CHEMBL1549796 & 688721 & 4.4 & 4.8996 & TRN \\
\hline CHEMBL1408019 & 688721 & 4.4 & 5.022 & TST \\
\hline CHEMBL1405470 & 688721 & 6.9 & 4.9307 & TST \\
\hline CHEMBL1539570 & 688721 & 5.5 & 4.9018 & TRN \\
\hline CHEMBL1492293 & 688721 & 4.7 & 4.8155 & TST \\
\hline CHEMBL1543469 & 688721 & 4.6 & 5.0469 & TRN \\
\hline CHEMBL1353522 & 688721 & 4.5 & 5.1372 & TST \\
\hline CHEMBL1474795 & 688721 & 5.5 & 5.2495 & TRN \\
\hline CHEMBL1346183 & 688721 & 5.2 & 4.8142 & TST \\
\hline CHEMBL1512208 & 688721 & 5.4 & 4.8383 & TRN \\
\hline CHEMBL1372627 & 688721 & 4.6 & 4.8991 & TRN \\
\hline CHEMBL1585956 & 688721 & 5.1 & 5.0981 & TRN \\
\hline CHEMBL1494033 & 688721 & 5.5 & 4.8963 & TST \\
\hline CHEMBL1407976 & 688721 & 4.6 & 4.8562 & TST \\
\hline CHEMBL1498839 & 688721 & 4.7 & 4.8305 & TRN \\
\hline CHEMBL1390617 & 688721 & 4.6 & 4.9988 & TRN \\
\hline CHEMBL1401243 & 688721 & 4.6 & 4.9946 & TRN \\
\hline CHEMBL1387217 & 688721 & 4.9 & 4.8347 & TRN \\
\hline
\end{tabular}

TRN 


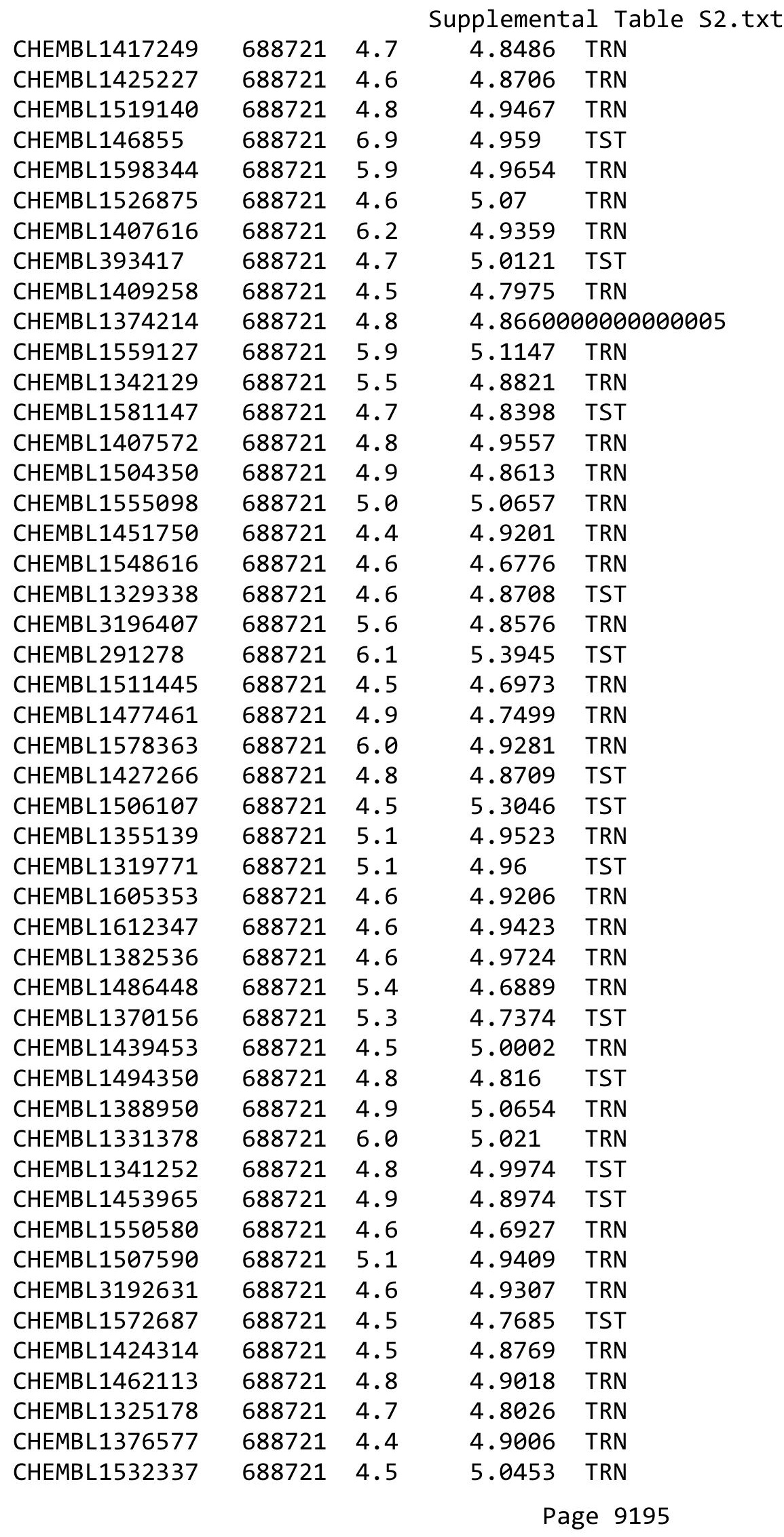




\begin{tabular}{|c|c|c|c|c|}
\hline & & & ipplement & al $\mathrm{T}$ \\
\hline CHEMBL1305344 & 688721 & 4.4 & 4.7851 & TST \\
\hline CHEMBL501701 & 688721 & 4.8 & 5.0237 & TRN \\
\hline CHEMBL1608455 & 688721 & 4.7 & 4.7075 & TRN \\
\hline CHEMBL1510023 & 688721 & 4.8 & 5.0351 & TRN \\
\hline CHEMBL1389752 & 688721 & 4.6 & 5.01 & TRN \\
\hline CHEMBL1572533 & 688721 & 6.5 & 5.0615 & TST \\
\hline CHEMBL1381120 & 688721 & 5.8 & 4.885 & TRN \\
\hline CHEMBL1482629 & 688721 & 5.0 & 5.0834 & TRN \\
\hline CHEMBL1345713 & 688721 & 5.9 & 4.8127 & TST \\
\hline CHEMBL1302058 & 688721 & 4.5 & 4.7432 & TST \\
\hline CHEMBL1395162 & 688721 & 4.4 & 5.0284 & TRN \\
\hline CHEMBL1386834 & 688721 & 4.4 & 4.6818 & TRN \\
\hline CHEMBL1583848 & 688721 & 4.7 & 4.6731 & TRN \\
\hline CHEMBL1501527 & 688721 & 5.2 & 4.9652 & TST \\
\hline CHEMBL1376741 & 688721 & 4.8 & 4.8572 & TRN \\
\hline CHEMBL3193785 & 688721 & 5.3 & 5.0263 & TST \\
\hline CHEMBL1587501 & 688721 & 4.7 & 4.8115 & TRN \\
\hline CHEMBL1367944 & 688721 & 4.9 & 5.0524 & TRN \\
\hline CHEMBL1566195 & 688721 & 4.7 & 4.9434 & TRN \\
\hline CHEMBL1481781 & 688721 & 6.4 & 5.0437 & TRN \\
\hline CHEMBL1586660 & 688721 & 4.7 & 4.8488 & TRN \\
\hline CHEMBL 28319 & 688721 & 5.0 & 5.0753 & TRN \\
\hline CHEMBL1426583 & 688721 & 5.2 & 4.8347 & TRN \\
\hline CHEMBL1567946 & 688721 & 5.5 & 4.9686 & TST \\
\hline CHEMBL1529415 & 688721 & 5.3 & 4.7502 & TRN \\
\hline CHEMBL1600166 & 688721 & 5.2 & 4.8455 & TRN \\
\hline CHEMBL1443514 & 688721 & 4.7 & 5.3097 & TRN \\
\hline CHEMBL1371606 & 688721 & 4.7 & 4.9307 & TST \\
\hline CHEMBL1542701 & 688721 & 4.9 & 5.0111 & TRN \\
\hline CHEMBL1583579 & 688721 & 4.6 & 4.9077 & TST \\
\hline CHEMBL1455355 & 688721 & 4.8 & 5.0013 & TRN \\
\hline CHEMBL1542677 & 688721 & 5.4 & 4.9436 & TST \\
\hline CHEMBL1488583 & 688721 & 4.4 & 4.8194 & TRN \\
\hline CHEMBL1436979 & 688721 & 4.5 & 4.9718 & TRN \\
\hline CHEMBL1359354 & 688721 & 5.4 & 4.7788 & TRN \\
\hline CHEMBL1608126 & 688721 & 4.5 & 4.875 & TRN \\
\hline CHEMBL1603371 & 688721 & 5.2 & 5.0695 & TRN \\
\hline CHEMBL464176 & 688721 & 4.4 & 5.362 & TST \\
\hline CHEMBL1367737 & 688721 & 5.7 & 4.8944 & TST \\
\hline CHEMBL1443192 & 688721 & 4.6 & 5.2201 & TST \\
\hline CHEMBL1365886 & 688721 & 4.6 & 4.7759 & TRN \\
\hline CHEMBL1332367 & 688721 & 4.6 & 4.8038 & TRN \\
\hline CHEMBL1307155 & 688721 & 4.7 & 5.0235 & TST \\
\hline CHEMBL1364357 & 688721 & 4.5 & 4.8915 & TST \\
\hline CHEMBL1450608 & 688721 & 5.1 & 4.9372 & TRN \\
\hline CHEMBL1332282 & 688721 & 4.6 & 4.9148 & TRN \\
\hline CHEMBL1453328 & 688721 & 4.4 & 5.0213 & TRN \\
\hline CHEMBL1336932 & 688721 & 5.5 & 5.1179 & TRN \\
\hline
\end{tabular}




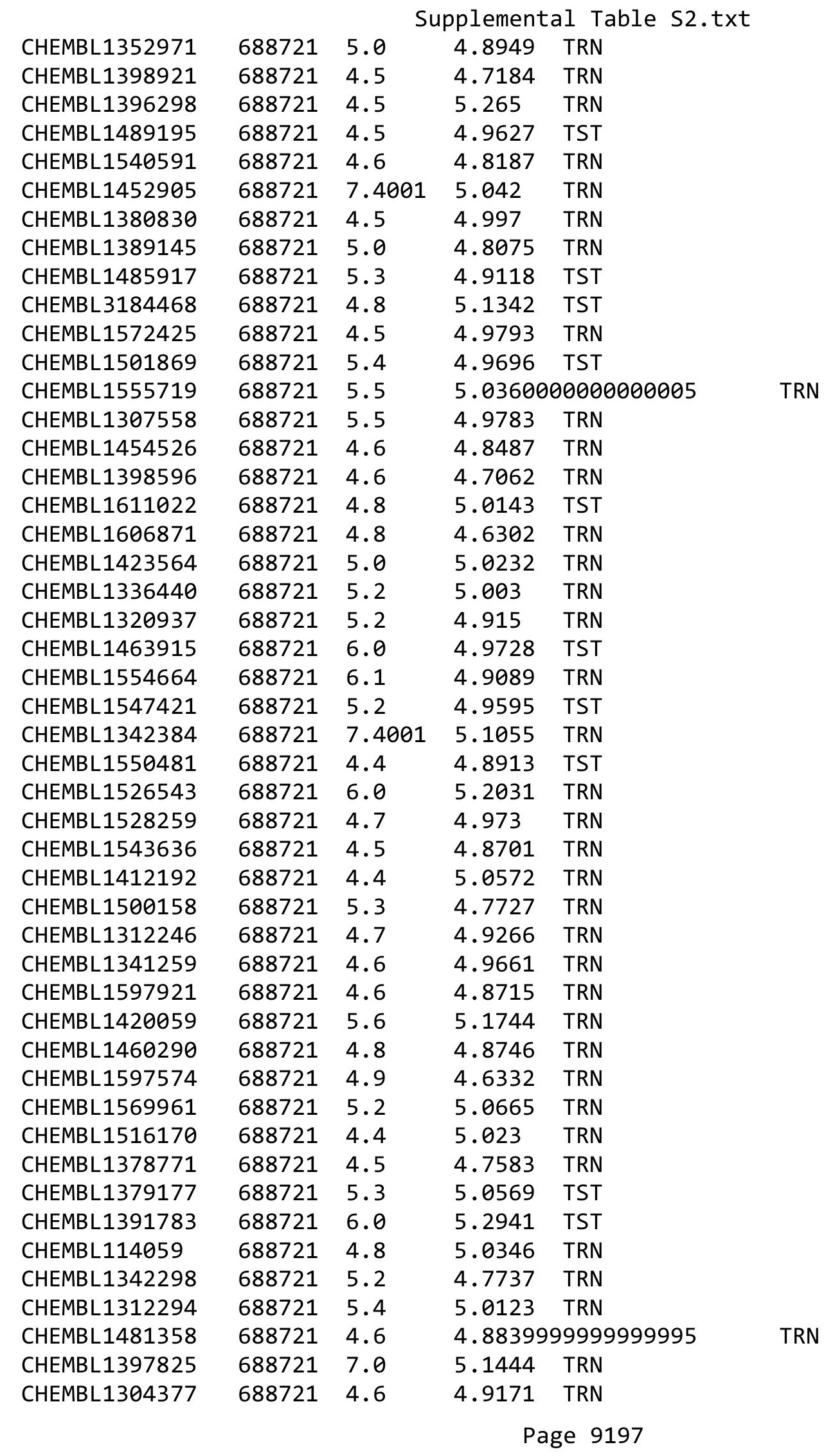




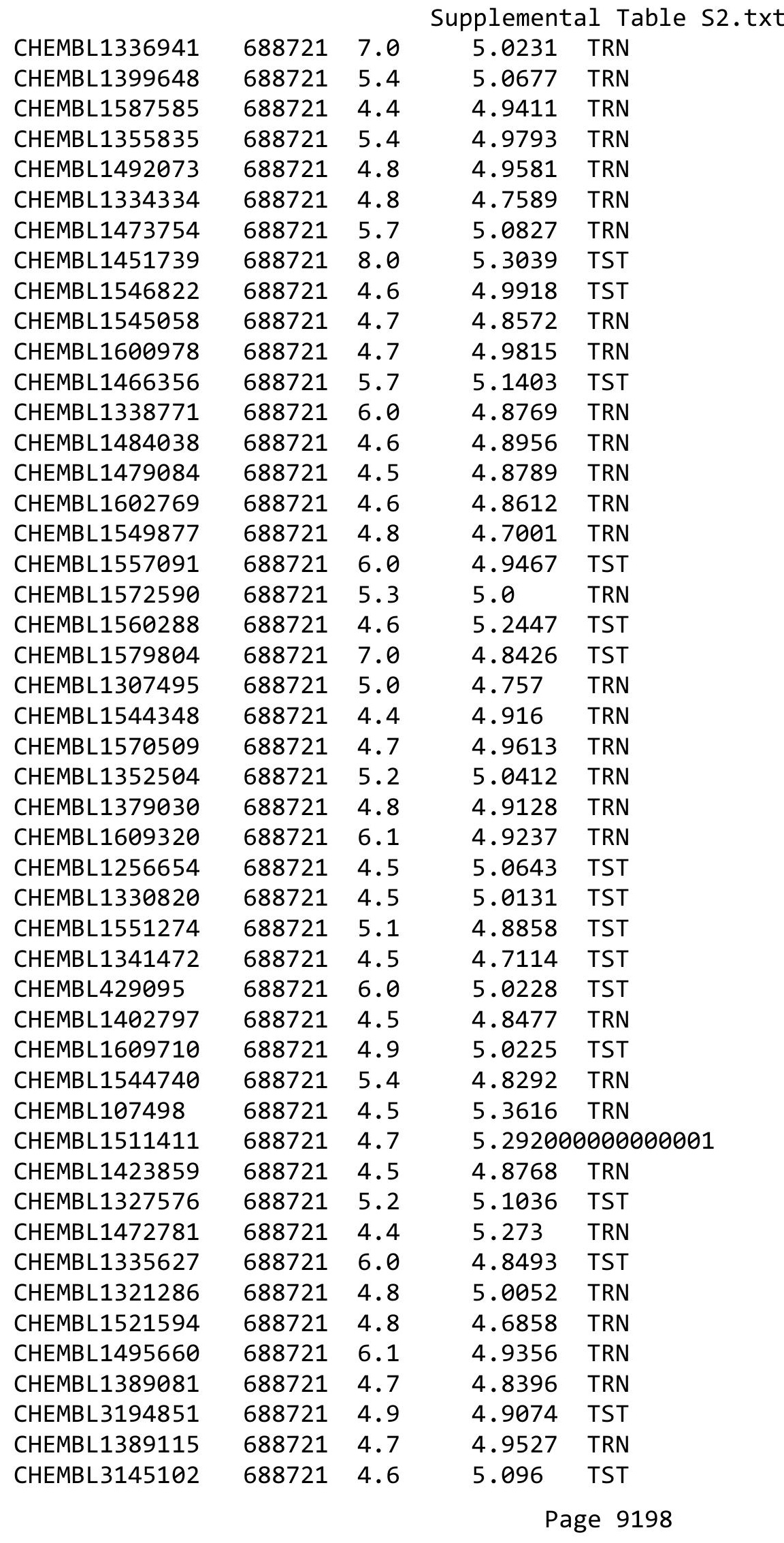




\begin{tabular}{|c|c|c|c|c|c|}
\hline \\
\hline CHEMBL1609846 & 688721 & 5.2 & 4.9518 & TRN & \\
\hline CHEMBL1535690 & 688721 & 4.4 & 4.945 & TRN & \\
\hline CHEMBL1473260 & 688721 & 5.8 & 5.1409 & TRN & \\
\hline CHEMBL1325495 & 688721 & 4.6 & 4.8003 & TRN & \\
\hline CHEMBL1420529 & 688721 & 4.4 & 4.819 & TRN & \\
\hline CHEMBL1528998 & 688721 & 4.6 & 5.0434 & TST & \\
\hline CHEMBL1299599 & 688721 & 4.5 & 5.0261 & TRN & \\
\hline CHEMBL1302967 & 688721 & 5.1 & 4.9252 & TRN & \\
\hline CHEMBL1548976 & 688721 & 4.7 & 4.7772 & TRN & \\
\hline CHEMBL1512567 & 688721 & 5.1 & 5.2188 & TST & \\
\hline CHEMBL1441874 & 688721 & 5.4 & 4.852 & TRN & \\
\hline CHEMBL1452034 & 688721 & 4.5 & 4.9357 & TRN & \\
\hline CHEMBL1337326 & 688721 & 6.8 & 4.9209 & TRN & \\
\hline CHEMBL1343438 & 688721 & 4.5 & 4.8459 & TRN & \\
\hline CHEMBL1422662 & 688721 & 4.7 & 4.9184 & TST & \\
\hline CHEMBL1536263 & 688721 & 5.5 & 5.1822 & TRN & \\
\hline CHEMBL1596703 & 688721 & 5.1 & 4.9651 & TST & \\
\hline CHEMBL1507728 & 688721 & 4.4 & 4.9167 & TRN & \\
\hline CHEMBL1598791 & 688721 & 4.8 & 4.9397 & TST & \\
\hline CHEMBL1604066 & 688721 & 6.3 & 4.9337 & TRN & \\
\hline CHEMBL1461076 & 688721 & 4.7 & 4.9927 & TRN & \\
\hline CHEMBL1304640 & 688721 & 4.4 & 4.9502 & TRN & \\
\hline CHEMBL1563397 & 688721 & 4.8 & 4.828 & TRN & \\
\hline CHEMBL1563648 & 688721 & 4.5 & 4.896 & TRN & \\
\hline CHEMBL1302264 & 688721 & 4.4 & 4.9773 & TST & \\
\hline CHEMBL1471693 & 688721 & 4.5 & 4.8527 & TRN & \\
\hline CHEMBL1560541 & 688721 & 5.1 & 5.0836 & TRN & \\
\hline CHEMBL1450174 & 688721 & 5.3 & 5.0452 & TRN & \\
\hline CHEMBL1563741 & 688721 & 4.8 & 5.0405 & TST & \\
\hline CHEMBL1578010 & 688721 & 4.4 & 4.9031 & TST & \\
\hline CHEMBL1608891 & 688721 & 6.0 & 5.03100 & 0000000001 & TRN \\
\hline CHEMBL1454473 & 688721 & 4.4 & 4.9452 & TRN & \\
\hline CHEMBL1433177 & 688721 & 4.5 & 4.8366 & TRN & \\
\hline CHEMBL1319109 & 688721 & 5.2 & 4.8827 & TRN & \\
\hline CHEMBL1314799 & 688721 & 4.8 & 4.94300 & 00000000005 & TRN \\
\hline CHEMBL1470094 & 688721 & 5.2 & 5.0199 & TRN & \\
\hline CHEMBL1382377 & 688721 & 5.4 & 5.0541 & TRN & \\
\hline CHEMBL1379472 & 688721 & 4.5 & 4.9457 & TRN & \\
\hline CHEMBL1592803 & 688721 & 5.3 & 4.9045 & TRN & \\
\hline CHEMBL1319074 & 688721 & 4.7 & 4.9368 & TRN & \\
\hline CHEMBL1310061 & 688721 & 5.4 & 5.0753 & TRN & \\
\hline CHEMBL1160544 & 688721 & 6.0 & 5.2604 & TRN & \\
\hline CHEMBL1559204 & 688721 & 4.5 & 4.7488 & TRN & \\
\hline CHEMBL1346094 & 688721 & 4.6 & 4.7855 & TRN & \\
\hline CHEMBL1389202 & 688721 & 4.4 & 4.8398 & TRN & \\
\hline CHEMBL1437018 & 688721 & 5.2 & 5.4802 & TRN & \\
\hline CHEMBL1547916 & 688721 & 4.7 & 4.8413 & TRN & \\
\hline CHEMBL1300034 & 688721 & 4.5 & 5.0198 & TST & \\
\hline
\end{tabular}




\begin{tabular}{|c|c|c|c|c|c|}
\hline \multicolumn{6}{|c|}{ Supplemental Table S2.txt } \\
\hline CHEMBL1573648 & 688721 & 4.5 & 4.9422 & TRN & \\
\hline CHEMBL1589018 & 688721 & 4.4 & 5.013 & TST & \\
\hline CHEMBL1595645 & 688721 & 4.8 & 5.0428 & TRN & \\
\hline CHEMBL1460147 & 688721 & 5.0 & 4.9642 & TRN & \\
\hline CHEMBL1506147 & 688721 & 4.6 & 4.8686 & TRN & \\
\hline CHEMBL1495571 & 688721 & 4.4 & 4.8858 & TRN & \\
\hline CHEMBL1356166 & 688721 & 4.8 & 5.1198 & TRN & \\
\hline CHEMBL1304985 & 688721 & 4.5 & 4.9291 & TST & \\
\hline CHEMBL1574160 & 688721 & 5.3 & 5.1667 & TRN & \\
\hline CHEMBL1570672 & 688721 & 4.7 & 4.9218 & TRN & \\
\hline CHEMBL1322742 & 688721 & 6.0 & 4.9789 & TST & \\
\hline CHEMBL1402573 & 688721 & 5.2 & 5.0908 & TST & \\
\hline CHEMBL1358092 & 688721 & 5.2 & 4.8994 & TRN & \\
\hline CHEMBL1582981 & 688721 & 4.7 & 4.7907 & TRN & \\
\hline CHEMBL1307299 & 688721 & 5.2 & 4.957 & TST & \\
\hline CHEMBL69367 & 688721 & 5.1 & 5.2034 & TST & \\
\hline CHEMBL1484127 & 688721 & 4.8 & 4.9243 & TRN & \\
\hline CHEMBL1570124 & 688721 & 5.3 & 5.0152 & TRN & \\
\hline CHEMBL1469093 & 688721 & 6.2 & 4.9195 & TST & \\
\hline CHEMBL1600973 & 688721 & 5.3 & 5.0086 & TRN & \\
\hline CHEMBL1449231 & 688721 & 4.5 & 4.8213 & TRN & \\
\hline CHEMBL1408257 & 688721 & 4.6 & 4.9102 & TRN & \\
\hline CHEMBL1568598 & 688721 & 4.6 & 4.9738 & TRN & \\
\hline CHEMBL1429811 & 688721 & 4.4 & 4.8782 & TRN & \\
\hline CHEMBL1441034 & 688721 & 5.0 & 5.0827 & TRN & \\
\hline CHEMBL1372078 & 688721 & 5.3 & 4.8929 & TRN & \\
\hline CHEMBL3189201 & 688721 & 4.8 & 4.7036 & TST & \\
\hline CHEMBL1305163 & 688721 & 5.5 & 5.2682 & TST & \\
\hline CHEMBL1457550 & 688721 & 5.8 & 5.0231 & TST & \\
\hline CHEMBL1334107 & 688721 & 4.4 & 5.0292 & TRN & \\
\hline CHEMBL1540323 & 688721 & 4.5 & 4.9863 & TST & \\
\hline CHEMBL1363049 & 688721 & 5.2 & 4.7389 & TRN & \\
\hline CHEMBL1542524 & 688721 & 5.2 & 4.9909 & TST & \\
\hline CHEMBL1582324 & 688721 & 4.4 & 4.931 & TRN & \\
\hline CHEMBL 302783 & 688721 & 6.0 & $5.4570 e$ & 0000000001 & TRN \\
\hline CHEMBL1326261 & 688721 & 4.6 & 5.1774 & TRN & \\
\hline CHEMBL 1447239 & 688721 & 4.5 & 5.0377 & TRN & \\
\hline CHEMBL1415382 & 688721 & 4.4 & 5.1009 & TRN & \\
\hline CHEMBL1339573 & 688721 & 5.2 & 4.8912 & TST & \\
\hline CHEMBL1330398 & 688721 & 5.1 & 5.197 & TST & \\
\hline CHEMBL1392054 & 688721 & 4.6 & 4.7581 & TRN & \\
\hline CHEMBL1486734 & 688721 & 4.8 & 4.9438 & TRN & \\
\hline CHEMBL1319533 & 688721 & 4.5 & 4.9567 & TRN & \\
\hline CHEMBL1530492 & 688721 & 4.4 & 4.9274 & TST & \\
\hline CHEMBL1426637 & 736948 & 4.4067 & 4.4067 & TRN & \\
\hline CHEMBL3192841 & 736948 & 3.0969 & 3.0974 & TRN & \\
\hline CHEMBL 1432378 & 736948 & 4.7328 & 4.7327 & TRN & \\
\hline CHEMBL1461738 & 736948 & 4.9872 & 4.9897 & TRN & \\
\hline
\end{tabular}




\begin{tabular}{|c|c|c|c|c|c|}
\hline & & \multicolumn{4}{|c|}{ Supplemental Table S2.txt } \\
\hline CHEMBL1975118 & 736948 & 3.0969 & 3.0959 & TRN & \\
\hline CHEMBL1420173 & 736948 & 3.0969 & 3.0951 & TRN & \\
\hline CHEMBL1371983 & 736948 & 4.3107 & 4.3086 & TRN & \\
\hline CHEMBL1706392 & 736948 & 4.8297 & 4.8285 & TRN & \\
\hline CHEMBL169811 & 736948 & 5.6596 & 5.65799 & 99999999995 & TRN \\
\hline CHEMBL263972 & 736948 & 4.6904 & 4.2734 & TST & \\
\hline CHEMBL1471715 & 736948 & 3.0969 & 3.097 & TRN & \\
\hline CHEMBL1299995 & 736948 & 4.71 & 4.7083 & TRN & \\
\hline CHEMBL1790033 & 736948 & 4.8477 & 4.3079 & TST & \\
\hline CHEMBL1502683 & 736948 & 4.2284 & 4.228 & TRN & \\
\hline CHEMBL1322745 & 736948 & 4.8665 & 4.8667 & TRN & \\
\hline CHEMBL1709153 & 736948 & 5.644 & 5.6442 & TRN & \\
\hline CHEMBL1706082 & 736948 & 5.0894 & 5.0896 & TRN & \\
\hline CHEMBL1444349 & 736948 & 3.0969 & 3.1706 & TST & \\
\hline CHEMBL1604990 & 736948 & 4.4191 & 4.0336 & TST & \\
\hline CHEMBL1325587 & 736948 & 4.6144 & 4.6159 & TRN & \\
\hline CHEMBL1454194 & 736948 & 4.8239 & 4.8218 & TRN & \\
\hline CHEMBL1728993 & 736948 & 4.2291 & 4.2295 & TRN & \\
\hline CHEMBL3195968 & 736948 & 3.0969 & 3.0971 & TRN & \\
\hline CHEMBL1545605 & 736948 & 4.4672 & 4.4658 & TRN & \\
\hline CHEMBL1704311 & 736948 & 5.041 & 5.0411 & TRN & \\
\hline CHEMBL1501771 & 736948 & 4.7122 & 4.7114 & TRN & \\
\hline CHEMBL1523347 & 736948 & 4.3307 & 4.331 & TRN & \\
\hline CHEMBL1527942 & 736948 & 4.4763 & 3.7463 & TST & \\
\hline CHEMBL1588820 & 736948 & 3.0969 & 3.9078 & TST & \\
\hline CHEMBL1734083 & 736948 & 3.0969 & 3.0971 & TRN & \\
\hline CHEMBL1401989 & 736948 & 5.6517 & 5.6516 & TRN & \\
\hline CHEMBL3145282 & 736948 & 3.0969 & 3.097 & TRN & \\
\hline CHEMBL1382826 & 736948 & 4.7959 & 4.7973 & TRN & \\
\hline CHEMBL 2000342 & 736948 & 4.2984 & 4.3008 & TRN & \\
\hline CHEMBL1491328 & 736948 & 3.0969 & 3.0963 & TRN & \\
\hline CHEMBL1312377 & 736948 & 5.0799 & 5.0791 & TRN & \\
\hline CHEMBL1434002 & 736948 & 4.3487 & 4.3486 & TRN & \\
\hline CHEMBL1482926 & 736948 & 4.9626 & 4.9632 & TRN & \\
\hline CHEMBL1589350 & 736948 & 5.0 & 5.0021 & TRN & \\
\hline CHEMBL1464186 & 736948 & 4.4067 & 4.4073 & TRN & \\
\hline CHEMBL1498652 & 736948 & 4.6073 & 4.6069 & TRN & \\
\hline CHEMBL75913 & 736948 & 4.2449 & 4.2453 & TRN & \\
\hline CHEMBL1385129 & 736948 & 3.0969 & 3.0962 & TRN & \\
\hline CHEMBL1339349 & 736948 & 4.6271 & 4.6268 & TRN & \\
\hline CHEMBL1470492 & 736948 & 3.0969 & 3.097 & TRN & \\
\hline CHEMBL1344977 & 736948 & 4.7423 & 4.7442 & TRN & \\
\hline CHEMBL1733942 & 736948 & 4.8761 & 4.8761 & TRN & \\
\hline CHEMBL3195322 & 736948 & 4.5768 & 4.5775 & TRN & \\
\hline CHEMBL1576392 & 736948 & 5.1013 & 5.1023 & TRN & \\
\hline CHEMBL1419292 & 736948 & 4.6021 & 4.6008 & TRN & \\
\hline CHEMBL1717079 & 736948 & 5.5186 & 5.5204 & TRN & \\
\hline CHEMBL1432648 & 736948 & 4.6073 & 4.6055 & TRN & \\
\hline
\end{tabular}




\begin{tabular}{|c|c|c|c|c|c|}
\hline \multirow[b]{2}{*}{ CHEMBL600862 } & \multicolumn{5}{|c|}{ Supplemental Table s2.txt } \\
\hline & 736948 & 4.8761 & 4.8764 & TRN & \\
\hline CHEMBL1478479 & 736948 & 5.0585 & 5.0568 & TRN & \\
\hline CHEMBL1338355 & 736948 & 4.4634 & 4.4647 & TRN & \\
\hline CHEMBL1497000 & 736948 & 3.0969 & 3.7822 & TST & \\
\hline CHEMBL1705535 & 736948 & 5.7375 & 5.73799 & 99999999995 & TRN \\
\hline CHEMBL51085 & 736948 & 4.4112 & 3.8726 & TST & \\
\hline CHEMBL1582527 & 736948 & 4.6216 & 4.6214 & TRN & \\
\hline CHEMBL1559226 & 736948 & 4.6946 & 4.6916 & TRN & \\
\hline CHEMBL1461181 & 736948 & 4.5686 & 4.5712 & TRN & \\
\hline CHEMBL1516663 & 736948 & 4.7375 & 4.7384 & TRN & \\
\hline CHEMBL1976317 & 736948 & 4.8097 & 4.8104 & TRN & \\
\hline CHEMBL1546933 & 736948 & 4.5952 & 4.5953 & TRN & \\
\hline CHEMBL1708020 & 736948 & 5.7932 & 5.7921 & TRN & \\
\hline CHEMBL 2000686 & 736948 & 4.5591 & 4.5579 & TRN & \\
\hline CHEMBL1430796 & 736948 & 3.0969 & 3.0983 & TRN & \\
\hline CHEMBL1409110 & 736948 & 3.0969 & 3.0975 & TRN & \\
\hline CHEMBL1587286 & 736948 & 4.4473 & 4.4477 & TRN & \\
\hline CHEMBL1318817 & 736948 & 4.5654 & 4.5643 & TRN & \\
\hline CHEMBL1345979 & 736948 & 4.7447 & 4.7436 & TRN & \\
\hline CHEMBL1528481 & 736948 & 4.8386 & 4.838 & TRN & \\
\hline CHEMBL1308783 & 736948 & 5.0339 & 5.0346 & TRN & \\
\hline CHEMBL1558692 & 736948 & 4.9318 & 4.9327 & TRN & \\
\hline CHEMBL1725990 & 736948 & 6.2111 & 6.2107 & TRN & \\
\hline CHEMBL1553908 & 736948 & 4.3089 & 4.3099 & TRN & \\
\hline CHEMBL1330332 & 736948 & 4.4976 & 4.4979 & TRN & \\
\hline CHEMBL1417967 & 736948 & 4.6345 & 4.6342 & TRN & \\
\hline CHEMBL1470212 & 736948 & 5.1163 & 5.1167 & TRN & \\
\hline CHEMBL1329129 & 736948 & 5.6576 & 5.6562 & TRN & \\
\hline CHEMBL1578997 & 736948 & 5.2503 & 5.2496 & TRN & \\
\hline CHEMBL1557023 & 736948 & 4.9393 & 4.9412 & TRN & \\
\hline CHEMBL1705697 & 736948 & 4.2874 & 4.2036 & TST & \\
\hline CHEMBL1343814 & 736948 & 3.0969 & 3.0974 & TRN & \\
\hline CHEMBL193627 & 736948 & 3.0969 & 3.8603 & TST & \\
\hline CHEMBL1301382 & 736948 & 3.0969 & 3.9257 & TST & \\
\hline CHEMBL1968355 & 736948 & 4.3655 & 4.3638 & TRN & \\
\hline CHEMBL1451037 & 736948 & 4.2874 & 4.2863 & TRN & \\
\hline CHEMBL1438779 & 736948 & 4.585 & 4.5869 & TRN & \\
\hline CHEMBL1724744 & 736948 & 4.556 & 5.1338 & TST & \\
\hline CHEMBL3145303 & 736948 & 5.1746 & 4.69600 & 0000000001 & TST \\
\hline CHEMBL1708343 & 736948 & 4.8386 & 4.91100 & 00000000005 & TST \\
\hline CHEMBL1550584 & 736948 & 5.4413 & 4.709 & TST & \\
\hline CHEMBL 2369189 & 736948 & 3.0969 & 3.3659 & TST & \\
\hline CHEMBL3192625 & 736948 & 4.5421 & 4.1861 & TST & \\
\hline CHEMBL1701797 & 736948 & 5.6498 & 5.2322 & TST & \\
\hline CHEMBL1708074 & 736948 & 4.4802 & 4.2944 & TST & \\
\hline CHEMBL1471660 & 736948 & 4.5058 & 4.3954 & TST & \\
\hline CHEMBL1721577 & 736948 & 3.0969 & 5.0259 & TST & \\
\hline CHEMBL1414923 & 736948 & 5.1818 & 4.2976 & TST & \\
\hline
\end{tabular}




\begin{tabular}{|c|c|c|c|c|}
\hline & & & & \\
\hline CHEMBL3199665 & טדילט & 4.7011 & 2.9271 & $1=$ \\
\hline CHEMBL1713955 & 736948 & 6.6737 & 4. 3751 & \\
\hline CHEMBL1375373 & 36948 & 6635 & 9101 & \\
\hline HEMBL1702026 & 36948 & 5.7496 & 3163 & \\
\hline CHEMBL 3143288 & 09254 & 5.4802 & 206 & \\
\hline HEMBL3143306 & 09254 & .1675 & 336 & \\
\hline CHEMBL 3143294 & 09254 & 0269 & 48 & \\
\hline HEMBL3143324 & 09254 & 1759 & 3139 & \\
\hline CHEMBL3143273 & 209254 & 7.3979 & 7.2637 & \\
\hline CHEMBL3143246 & 209254 & 528 & & \\
\hline HEMBL3143254 & 209254 & 212 & 54 & \\
\hline CHEMBL3143317 & 209254 & 596 & 57 & \\
\hline CHEMBL3143303 & 209254 & 229 & $\partial 11$ & \\
\hline CHEMBL3143275 & 09254 & 279 & 384 & \\
\hline CHEMBL3144093 & 209 & 12 & 47 & \\
\hline HEMBL: & 209 & 76 & & \\
\hline CHEMBL & $20 s$ & 38 & & \\
\hline CHEMBL3143274 & 209254 & 979 & 559 & \\
\hline CHEMBL3143255 & $20 s$ & 08 & & \\
\hline CHEMBL3 & $20 s$ & 96 & & \\
\hline CHEMBL: & $20 s$ & 78 & 36 & \\
\hline CHEMBL & $20 s$ & 55 & & \\
\hline CHEMBL3143290 & 209254 & 447 & & \\
\hline CHEMBL3143283 & 20 & & & \\
\hline CHEMBL3 & 209 & & 34 & \\
\hline CHEMBL & $20 s$ & 29 & 87 & \\
\hline CHEMBL & $20 s$ & 21 & & \\
\hline JEMBL3 & $20 s$ & & & \\
\hline CHEMBL3143326 & $20 s$ & 4.3279 & 567 & \\
\hline CHEMBL 3143268 & 209 & 192 & 772 & \\
\hline CHEMBL3 & $20 s$ & 21 & 369 & \\
\hline CHEMBL & 20 & 69 & 25 & \\
\hline CHEMBL3143304 & $20 s$ & 08 & 33 & TR \\
\hline CHEMBL3143313 & 209254 & 5 . & 53 & \\
\hline CHEMBL3 & 20 & & & $n$ \\
\hline CHEMBL & 54 & 59 & 4. & \\
\hline CHEMBL 3143284 & 209 & & 282 & $\mathrm{TR}$ \\
\hline CHEMBL3143684 & 209254 & 5.9245 & 6.3621 & TR \\
\hline CHEMBL3143272 & 209254 & 6.699 & & $\pi$ \\
\hline CHEMBL & $20 s$ & 3. & & $1 \pi$ \\
\hline CHEMBL3143301 & 209 & 4. & 56 & \\
\hline CHEMBL3143296 & 209254 & 5.4056 & 4.9275 & TRI \\
\hline CHEMBL3143271 & 209254 & 5.9469 & 074 & TR \\
\hline CHEMBL3143264 & 209254 & 925 & & 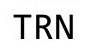 \\
\hline CHEMBL3143262 & 209254 & 106 & & $n$ \\
\hline CHEMBL 3143252 & 209254 & 7.0706 & 6.9878 & r \\
\hline CHEMBL3143316 & 209254 & 2.5229 & 2.7097 & $\mathrm{TR}$ \\
\hline CHEMBL3143295 & 209254 & 5.3307 & 5.1392 & $\mathrm{TR}$ \\
\hline
\end{tabular}

Page 9203 


\begin{tabular}{|c|c|c|c|c|c|c|}
\hline \multirow[b]{2}{*}{ CHEMBL3143281 } & \multicolumn{6}{|c|}{ Supplemental Table S2.txt } \\
\hline & 209254 & 7.301 & 6.5918 & TRN & & \\
\hline CHEMBL3143267 & 209254 & 6.6198 & 6.00799 & 9999999999 & & TRN \\
\hline CHEMBL3143308 & 209254 & 5.4123 & 4.5726 & TRN & & \\
\hline CHEMBL 3143300 & 209254 & 2.5229 & 3.827 & TRN & & \\
\hline CHEMBL3143291 & 209254 & 7.6778 & 7.0863 & TRN & & \\
\hline CHEMBL 3143321 & 209254 & 5.5638 & 6.0822 & TRN & & \\
\hline CHEMBL3143318 & 209254 & 2.5229 & 3.1637 & TRN & & \\
\hline CHEMBL3143305 & 209254 & 3.7144 & 3.7983 & TST & & \\
\hline CHEMBL 3143256 & 209254 & 4.4949 & 4.7617 & TRN & & \\
\hline CHEMBL3143307 & 209254 & 5.0044 & 5.2987 & TRN & & \\
\hline CHEMBL 3143292 & 209254 & 2.7959 & 3.8289 & TST & & \\
\hline CHEMBL3143311 & 209254 & 5.76200 & 30000000 & 005 & 5.2065 & TST \\
\hline CHEMBL 3143298 & 209254 & 5.699 & 6.1453 & TST & & \\
\hline CHEMBL3143319 & 209254 & 4.4559 & 4.7717 & TST & & \\
\hline CHEMBL 3143279 & 209254 & 3.8539 & 4.1657 & TST & & \\
\hline CHEMBL3143297 & 209254 & 5.5376 & 5.2384 & TST & & \\
\hline CHEMBL3143278 & 209254 & 7.2218 & 6.9226 & TST & & \\
\hline CHEMBL3143289 & 209254 & 5.059 & 4.8488 & TST & & \\
\hline CHEMBL 3143251 & 209254 & 6.4089 & 5.6515 & TST & & \\
\hline CHEMBL3287352 & 1365575 & 5.4935 & 5.5339 & TRN & & \\
\hline CHEMBL3287328 & 1365575 & 8.4685 & 8.4741 & TRN & & \\
\hline CHEMBL3287070 & 1365575 & 4.7258 & 4.6937 & TRN & & \\
\hline CHEMBL3287326 & 1365575 & 7.8239 & 7.8557 & TRN & & \\
\hline CHEMBL3287069 & 1365575 & 7.3665 & 7.2909 & TRN & & \\
\hline CHEMBL3287349 & 1365575 & 4.8097 & 4.9459 & TRN & & \\
\hline CHEMBL3287350 & 1365575 & 6.1024 & 6.2114 & TRN & & \\
\hline CHEMBL 3287334 & 1365575 & 6.3565 & 6.2375 & TRN & & \\
\hline CHEMBL3287346 & 1365575 & 3.0 & 3.5593 & TRN & & \\
\hline CHEMBL 3287337 & 1365575 & 5.4248 & 5.3427 & TRN & & \\
\hline CHEMBL3287329 & 1365575 & 7.8861 & 8.0082 & TRN & & \\
\hline CHEMBL3287071 & 1365575 & 3.0 & 2.7444 & TRN & & \\
\hline CHEMBL3287338 & 1365575 & 6.5331 & 6.6702 & TRN & & \\
\hline CHEMBL3287323 & 1365575 & 8.5376 & 8.1512 & TRN & & \\
\hline CHEMBL322610 & 1365575 & 7.284 & 7.3688 & TRN & & \\
\hline CHEMBL3287072 & 1365575 & 6.1675 & 6.2385 & TRN & & \\
\hline CHEMBL3287060 & 1365575 & 6.2676 & 6.2158 & TRN & & \\
\hline CHEMBL 275303 & 1365575 & 4.7467 & 4.8682 & TST & & \\
\hline CHEMBL3287356 & 1365575 & 5.9586 & 5.8478 & TRN & & \\
\hline CHEMBL 3287322 & 1365575 & 8.0 & 7.9648 & TRN & & \\
\hline CHEMBL 3287354 & 1365575 & 6.6676 & 6.6406 & TRN & & \\
\hline CHEMBL3287063 & 1365575 & 5.2048 & 5.2887 & TRN & & \\
\hline CHEMBL3287073 & 1365575 & 4.6383 & 4.5474 & TRN & & \\
\hline CHEMBL3287074 & 1365575 & 5.3686 & 5.5624 & TRN & & \\
\hline CHEMBL491870 & 1365575 & 7.3188 & 7.2073 & TST & & \\
\hline CHEMBL3287066 & 1365575 & 5.3063 & 5.3025 & TST & & \\
\hline CHEMBL 3287348 & 1365575 & 6.4202 & 6.54799 & 9999999999 & & TRN \\
\hline CHEMBL3287343 & 1365575 & 5.4989 & 5.8724 & TRN & & \\
\hline CHEMBL3287325 & 1365575 & 8.3565 & 8.1435 & TST & & \\
\hline
\end{tabular}


Supplemental Table S2.txt

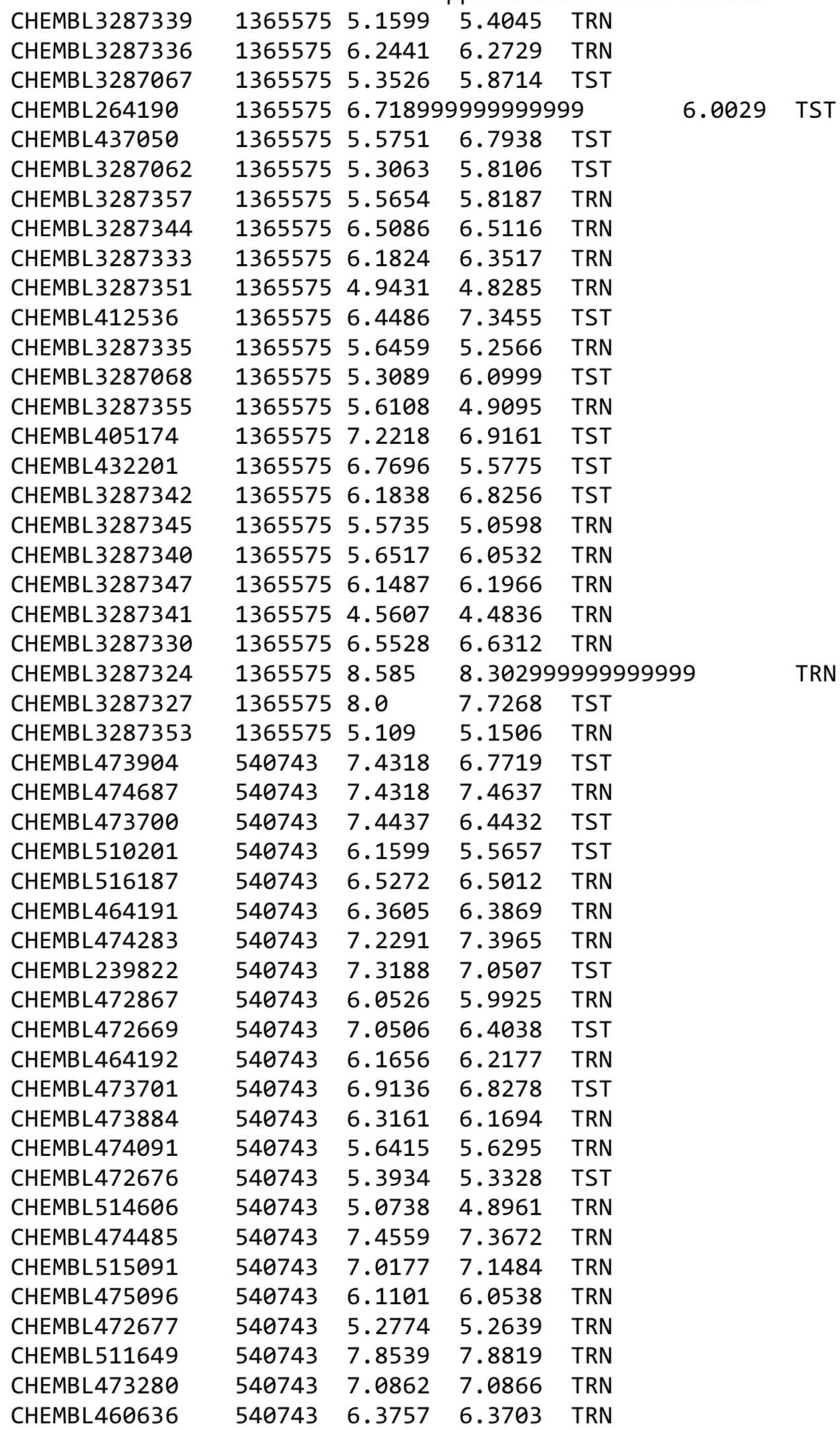


Supplemental Table S2.txt

\begin{tabular}{|c|c|c|c|c|c|}
\hline CHEMBL240215 & 540743 & 7.5376 & 6.4307 & TST & \\
\hline CHEMBL473279 & 540743 & 7.2147 & 7.1287 & TRN & \\
\hline CHEMBL501088 & 540743 & 5.7447 & 5.86299 & 99999999995 & TRN \\
\hline CHEMBL510745 & 540743 & 6.3979 & 6.2876 & TRN & \\
\hline CHEMBL514489 & 540743 & 7.1612 & 7.1431 & TRN & \\
\hline CHEMBL516024 & 540743 & 6.1391 & 6.1821 & TRN & \\
\hline CHEMBL514463 & 540743 & 6.9208 & 7.1162 & TRN & \\
\hline CHEMBL471882 & 540743 & 6.9914 & 6.8485 & TRN & \\
\hline CHEMBL517265 & 540743 & 6.0097 & 6.0966 & TRN & \\
\hline CHEMBL514662 & 540743 & 7.5528 & 6.5834 & TST & \\
\hline CHEMBL473068 & 540743 & 5.971 & 5.9935 & TRN & \\
\hline CHEMBL515142 & 540743 & 6.7773 & 6.5874 & TST & \\
\hline CHEMBL474092 & 540743 & 7.1938 & 7.1389 & TRN & \\
\hline CHEMBL475310 & 540743 & 7.585 & 6.5013 & TST & \\
\hline CHEMBL516389 & 540743 & 6.9508 & 6.7776 & TST & \\
\hline CHEMBL473278 & 540743 & 6.6216 & 6.7297 & TRN & \\
\hline CHEMBL475497 & 540743 & 4.8861 & 4.6942 & TRN & \\
\hline CHEMBL475308 & 540743 & 4.9298 & 5.1064 & TRN & \\
\hline CHEMBL511162 & 540743 & 6.857 & 6.8195 & TRN & \\
\hline CHEMBL514965 & 540743 & 4.2005 & 4.1877 & TRN & \\
\hline CHEMBL471262 & 540743 & 6.8477 & 6.8183 & TRN & \\
\hline CHEMBL456225 & 540743 & 6.2041 & 6.2693 & TRN & \\
\hline CHEMBL515575 & 540743 & 6.6904 & 6.7553 & TRN & \\
\hline CHEMBL518325 & 540743 & 6.1278 & 6.0121 & TRN & \\
\hline CHEMBL 240657 & 540743 & 6.3107 & 5.3877 & TST & \\
\hline CHEMBL473898 & 540743 & 7.1612 & 7.1951 & TRN & \\
\hline CHEMBL473272 & 540743 & 7.3665 & 7.2807 & TRN & \\
\hline CHEMBL457244 & 540743 & 5.8614 & 5.8584 & TRN & \\
\hline CHEMBL511161 & 540743 & 6.8508 & 6.7731 & TRN & \\
\hline CHEMBL499169 & 540743 & 5.7165 & 5.7486 & TRN & \\
\hline CHEMBL516077 & 540743 & 6.1656 & \multicolumn{2}{|c|}{6.167999999999999} & TRN \\
\hline CHEMBL241272 & 540743 & 5.2258 & 5.3979 & TST & \\
\hline CHEMBL475707 & 540743 & 6.8665 & 6.4988 & TST & \\
\hline CHEMBL474708 & 540743 & 5.3651 & 5.4039 & TRN & \\
\hline CHEMBL515829 & 540743 & 5.5941 & \multicolumn{2}{|c|}{5.712000000000001} & TRN \\
\hline CHEMBL457451 & 540743 & 6.3605 & 6.3627 & TRN & \\
\hline CHEMBL474096 & 540743 & 7.1805 & 7.0133 & TRN & \\
\hline CHEMBL517167 & 540743 & 6.8356 & 6.4498 & TST & \\
\hline CHEMBL475496 & 540743 & 4.4799 & 4.6782 & TRN & \\
\hline CHEMBL472086 & 540743 & 6.5143 & 6.572 & TRN & \\
\hline CHEMBL475094 & 540743 & 6.7033 & 6.6219 & TRN & \\
\hline CHEMBL471880 & 540743 & 7.301 & 6.5523 & TST & \\
\hline CHEMBL3920049 & 1637184 & 9.0 & 9.2722 & TRN & \\
\hline CHEMBL1923617 & 1637184 & 9.0 & 8.9253 & TRN & \\
\hline CHEMBL 3905987 & 1637184 & 7.0 & 7.2479 & TRN & \\
\hline CHEMBL 3958460 & 1637184 & 9.0 & 8.8782 & TRN & \\
\hline CHEMBL 3892517 & 1637184 & 5.0 & 4.3939 & TRN & \\
\hline CHEMBL1923631 & 1637184 & 6.0 & 6.3462 & TRN & \\
\hline
\end{tabular}


Supplemental Table S2.txt

\begin{tabular}{|c|c|c|c|c|}
\hline CHEMBL3910661 & 1637184 & 7.0 & 7.2034 & TRN \\
\hline CHEMBL3924192 & 1637184 & 7.0 & 7.4112 & TRN \\
\hline CHEMBL3931856 & 1637184 & 6.7878 & 6.942 & TRN \\
\hline CHEMBL 3898794 & 1637184 & 9.0 & 8.7226 & TRN \\
\hline CHEMBL3939196 & 1637184 & 6.5258 & 7.0317 & TRN \\
\hline CHEMBL3896536 & 1637184 & 7.0 & 8.2859 & TST \\
\hline CHEMBL3916659 & 1637184 & 9.0 & 7.2122 & TST \\
\hline CHEMBL3959108 & 1637184 & 9.0 & 8.2119 & TST \\
\hline CHEMBL3913855 & 1637184 & 9.0 & 8.1754 & TRN \\
\hline CHEMBL3898348 & 1637184 & 9.0 & 8.8791 & TRN \\
\hline CHEMBL3905791 & 1637184 & 9.0 & 8.8675 & TRN \\
\hline CHEMBL3973085 & 1637184 & 9.0 & 8.4028 & TRN \\
\hline CHEMBL3942642 & 1637184 & 7.0 & 6.7709 & TRN \\
\hline CHEMBL1923612 & 1637184 & 7.7799 & 7.8683 & TRN \\
\hline CHEMBL3893048 & 1637184 & 9.0 & 9.3101 & TRN \\
\hline CHEMBL1923512 & 1637184 & 9.0 & 9.0661 & TRN \\
\hline CHEMBL3918783 & 1637184 & 6.983 & 7.4779 & TRN \\
\hline CHEMBL 3932434 & 1637184 & 9.0 & 8.5217 & TRN \\
\hline CHEMBL3934561 & 1637184 & 6.8729 & 6.8976 & TRN \\
\hline CHEMBL3907497 & 1637184 & 9.0 & 9.0287 & TRN \\
\hline CHEMBL1923504 & 1637184 & 9.0 & 7.5038 & TRN \\
\hline CHEMBL 3918046 & 1637184 & 9.0 & 8.9376 & TRN \\
\hline CHEMBL3970499 & 1637184 & 9.0 & 8.096 & TST \\
\hline CHEMBL3938104 & 1637184 & 9.0 & 8.8869 & TST \\
\hline CHEMBL1923642 & 1637184 & 9.0 & 8.9596 & TRN \\
\hline CHEMBL3981072 & 1637184 & 7.0 & 7.0908 & TRN \\
\hline CHEMBL3921499 & 1637184 & 9.0 & 8.3009 & TRN \\
\hline CHEMBL3900284 & 1637184 & 9.0 & 8.8766 & TRN \\
\hline CHEMBL 3910300 & 1637184 & 9.0 & 9.055 & TRN \\
\hline CHEMBL1923626 & 1637184 & 9.0 & 9.088 & TRN \\
\hline CHEMBL3983626 & 1637184 & 5.0 & 7.3591 & TST \\
\hline CHEMBL3927481 & 1637184 & 9.0 & 8.0365 & TST \\
\hline CHEMBL3958451 & 1637184 & 7.0 & 7.3171 & TRN \\
\hline CHEMBL3932408 & 1637184 & 9.0 & 8.6197 & TRN \\
\hline CHEMBL3913052 & 1637184 & 9.0 & 8.7638 & TST \\
\hline CHEMBL3963078 & 1637184 & 7.0 & 7.5367 & TRN \\
\hline CHEMBL3922810 & 1637184 & 9.0 & 8.888 & TST \\
\hline CHEMBL3961696 & 1637184 & 5.0 & \multicolumn{2}{|c|}{8.107000000000001} \\
\hline CHEMBL1923638 & 1637184 & 9.0 & 9.1324 & TRN \\
\hline CHEMBL3961108 & 1637184 & 7.0 & 8.2717 & TRN \\
\hline CHEMBL1923609 & 1637184 & 9.0 & 8.0864 & TRN \\
\hline CHEMBL3903845 & 1637184 & 9.0 & 9.0843 & TRN \\
\hline CHEMBL3937924 & 1637184 & 7.0 & 7.6395 & TST \\
\hline CHEMBL1923636 & 1637184 & 7.0 & 7.0278 & TRN \\
\hline CHEMBL3922056 & 1637184 & 9.0 & 8.6539 & TST \\
\hline CHEMBL3913335 & 1637184 & 9.0 & 7.5844 & TST \\
\hline CHEMBL 3934402 & 1637184 & 9.0 & 8.6717 & TRN \\
\hline CHEMBL3967783 & 1637184 & 6.0 & 6.4628 & TRN \\
\hline
\end{tabular}




\begin{tabular}{|c|c|c|c|c|}
\hline \multicolumn{5}{|c|}{ Supplemental Table S2.txt } \\
\hline CHEMBL3889512 & 1637184 & 9.0 & 9.1653 & TST \\
\hline CHEMBL3978207 & 1637184 & 7.0 & 7.9067 & TRN \\
\hline CHEMBL1923610 & 1637184 & 9.0 & 8.3826 & TRN \\
\hline CHEMBL3915269 & 1637184 & 9.0 & 8.9687 & TST \\
\hline CHEMBL1923634 & 1637184 & 7.0 & 7.7869 & TRN \\
\hline CHEMBL3908264 & 1637184 & 7.0 & 8.5055 & TST \\
\hline CHEMBL3973940 & 1637184 & 7.0 & 6.7215 & TRN \\
\hline CHEMBL1923637 & 1637184 & 7.0 & 8.3527 & TRN \\
\hline CHEMBL3895776 & 1637184 & 9.0 & 8.9028 & TRN \\
\hline CHEMBL3909834 & 1637184 & 9.0 & 9.2376 & TRN \\
\hline CHEMBL 3937200 & 1637184 & 9.0 & 7.8938 & TRN \\
\hline CHEMBL3946348 & 1637184 & 9.0 & 8.7258 & TST \\
\hline CHEMBL3940705 & 1637184 & 9.0 & 9.1012 & TRN \\
\hline CHEMBL23459 & 55115 & 5.7212 & 5.5289 & TRN \\
\hline CHEMBL23382 & 55115 & 7.5376 & 7.4972 & TRN \\
\hline CHEMBL23963 & 55115 & 7.7696 & 7.6846 & TRN \\
\hline CHEMBL23569 & 55115 & 7.5086 & 7.6101 & TRN \\
\hline CHEMBL23383 & 55115 & 6.9208 & 6.7967 & TRN \\
\hline CHEMBL23584 & 55115 & 6.2596 & 6.1364 & TRN \\
\hline CHEMBL23844 & 55115 & 6.2757 & 6.2037 & TRN \\
\hline CHEMBL23532 & 55115 & 8.2676 & 8.3382 & TRN \\
\hline CHEMBL22434 & 55115 & 5.0862 & 5.0953 & TRN \\
\hline CHEMBL22543 & 55115 & 6.3279 & 6.3014 & TRN \\
\hline CHEMBL23021 & 55115 & 8.0 & 7.5063 & TRN \\
\hline CHEMBL282948 & 55115 & 6.8861 & 7.0216 & TRN \\
\hline CHEMBL 281131 & 55115 & 6.4949 & 6.5126 & TRN \\
\hline CHEMBL23286 & 55115 & 4.4401 & 4.3178 & TRN \\
\hline CHEMBL23705 & 55115 & 6.6383 & 6.5559 & TRN \\
\hline CHEMBL 279243 & 55115 & 3.6091 & 5.4085 & TST \\
\hline CHEMBL22924 & 55115 & 6.6383 & 6.8778 & TST \\
\hline CHEMBL23492 & 55115 & 6.1427 & 6.1137 & TST \\
\hline CHEMBL23466 & 55115 & 5.7212 & 5.8253 & TRN \\
\hline CHEMBL22677 & 55115 & 6.4318 & 6.4927 & TRN \\
\hline CHEMBL 279983 & 55115 & 7.2147 & 7.3287 & TRN \\
\hline CHEMBL 23402 & 55115 & 4.6402 & 4.8489 & TRN \\
\hline CHEMBL23211 & 55115 & 7.2596 & 6.9502 & TST \\
\hline CHEMBL23380 & 55115 & 5.1135 & 5.0458 & TST \\
\hline CHEMBL284544 & 55115 & 6.1135 & 6.0276 & TRN \\
\hline CHEMBL 23713 & 55115 & 6.8239 & 6.9257 & TRN \\
\hline CHEMBL 281648 & 55115 & 7.699 & 7.4878 & TRN \\
\hline CHEMBL 287511 & 55115 & 4.6345 & 4.5734 & TRN \\
\hline CHEMBL23919 & 55115 & 6.0555 & 5.9808 & TRN \\
\hline CHEMBL23146 & 55115 & 4.9914 & 4.5605 & TST \\
\hline CHEMBL26006 & 55115 & 5.8996 & 6.7638 & TST \\
\hline CHEMBL 276954 & 55115 & 4.2218 & 5.2059 & TST \\
\hline CHEMBL23560 & 55115 & 4.5229 & 4.5752 & TRN \\
\hline CHEMBL23911 & 55115 & 6.284 & 6.2407 & TRN \\
\hline CHEMBL22672 & 55115 & 6.5229 & 5.7972 & TST \\
\hline
\end{tabular}




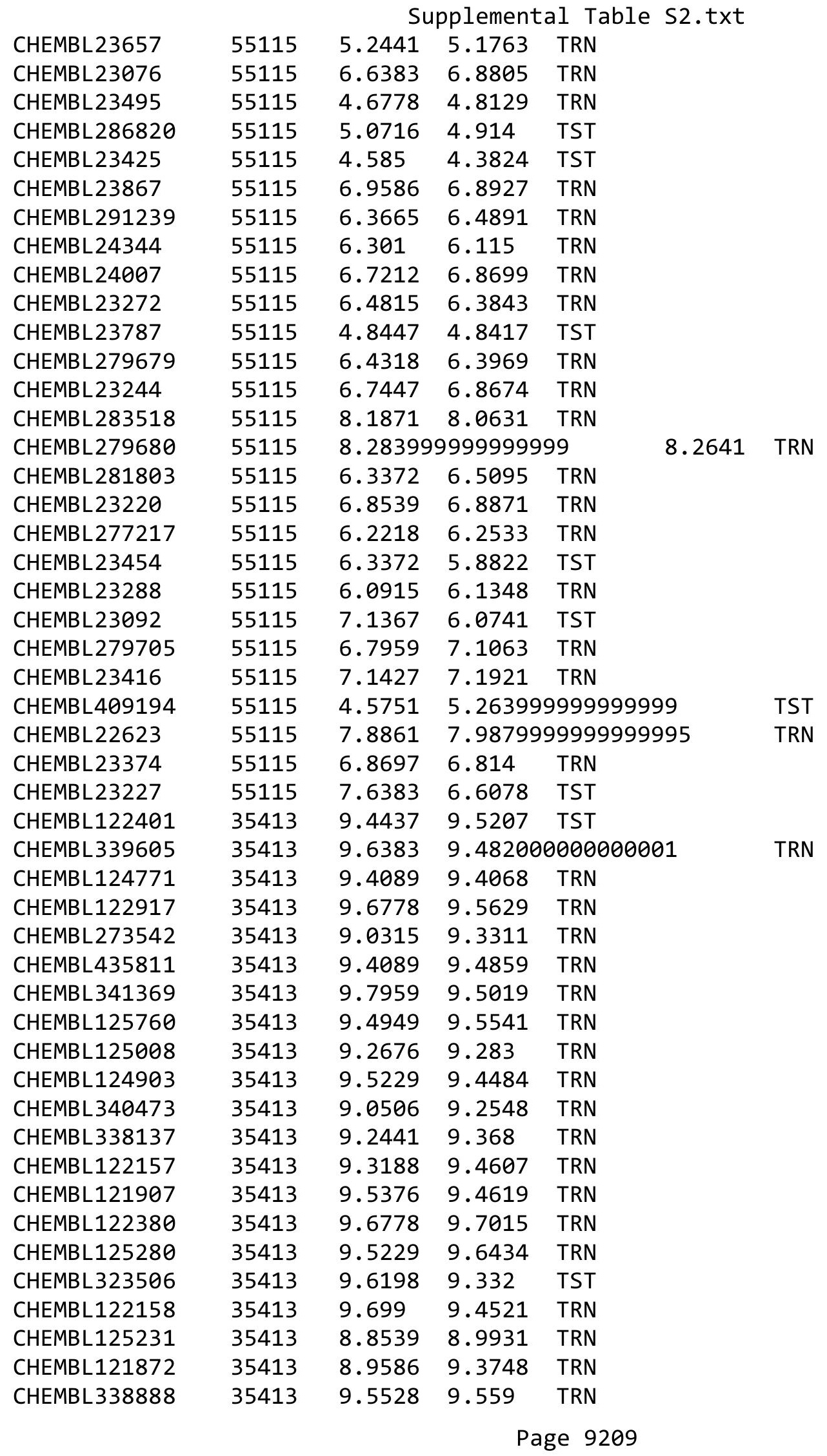




\begin{tabular}{|c|c|c|c|c|c|}
\hline \multicolumn{6}{|c|}{ Supplemental Table S2.txt } \\
\hline CHEMBL339256 & 35413 & 9.8239 & 9.6412 & TRN & \\
\hline CHEMBL338434 & 35413 & 9.6576 & 9.5229 & TRN & \\
\hline CHEMBL339672 & 35413 & 9.6778 & 9.5905 & TRN & \\
\hline CHEMBL331455 & 35413 & 9.5376 & 9.5049 & TRN & \\
\hline CHEMBL436396 & 35413 & 9.8539 & 9.4917 & TRN & \\
\hline CHEMBL 339040 & 35413 & 9.5686 & 9.4053 & TRN & \\
\hline CHEMBL331507 & 35413 & 9.3565 & 9.5882 & TRN & \\
\hline CHEMBL122273 & 35413 & 9.6021 & 9.6276 & TRN & \\
\hline CHEMBL 339004 & 35413 & 9.6021 & 9.4881 & TRN & \\
\hline CHEMBL339113 & 35413 & 9.5376 & 9.4882 & TRN & \\
\hline CHEMBL339806 & 35413 & 9.5376 & 9.3567 & TRN & \\
\hline CHEMBL338342 & 35413 & 9.6576 & 9.3633 & TRN & \\
\hline CHEMBL93907 & 35413 & 8.6021 & 8.6597 & TRN & \\
\hline CHEMBL338101 & 35413 & 8.6198 & 8.5667 & TRN & \\
\hline CHEMBL340078 & 35413 & 9.4318 & 9.6527 & TRN & \\
\hline CHEMBL 276674 & 35413 & 9.0 & 8.7237 & TRN & \\
\hline CHEMBL332576 & 35413 & 9.2366 & 9.4441 & TRN & \\
\hline CHEMBL421478 & 35413 & 9.0969 & 9.3356 & TRN & \\
\hline CHEMBL 333224 & 35413 & 8.8861 & 9.3731 & TRN & \\
\hline CHEMBL279629 & 35413 & 6.5229 & 8.5941 & TST & \\
\hline CHEMBL339722 & 35413 & 9.699 & 9.4981 & TRN & \\
\hline CHEMBL332909 & 35413 & 9.2518 & 9.4771 & TST & \\
\hline CHEMBL338889 & 35413 & 9.0915 & 9.5671 & TST & \\
\hline CHEMBL 340632 & 35413 & 9.7447 & 9.3872 & TST & \\
\hline CHEMBL338027 & 35413 & 9.9208 & 9.4839 & TST & \\
\hline CHEMBL 334300 & 35413 & 8.7959 & 8.575 & TST & \\
\hline CHEMBL444065 & 35413 & 9.3188 & 9.3921 & TST & \\
\hline CHEMBL338433 & 35413 & 9.6383 & 9.5047 & TST & \\
\hline CHEMBL331450 & 35413 & 9.7212 & 9.5091 & TST & \\
\hline CHEMBL 338687 & 35413 & 10.0 & 9.488 & TST & \\
\hline CHEMBL 302102 & 35413 & 9.1549 & 8.5255 & TST & \\
\hline CHEMBL 331632 & 35413 & 9.5376 & 9.4047 & TST & \\
\hline CHEMBL3718419 & 1536771 & 7.0 & 7.3803 & TST & \\
\hline CHEMBL 3718556 & 1536771 & 5.0 & 5.8684 & TRN & \\
\hline CHEMBL 3715773 & 1536771 & 7.0 & 7.0948 & TRN & \\
\hline CHEMBL 3717061 & 1536771 & 7.0 & 6.6983 & TRN & \\
\hline CHEMBL 3717787 & 1536771 & 7.0 & 6.78299 & 99999999995 & TRN \\
\hline CHEMBL3718967 & 1536771 & 7.0 & 6.9007 & TRN & \\
\hline CHEMBL 3715584 & 1536771 & 7.0 & 6.9794 & TRN & \\
\hline CHEMBL3716931 & 1536771 & 7.0 & 7.0493 & TRN & \\
\hline CHEMBL 3716513 & 1536771 & 7.0 & 6.4658 & TRN & \\
\hline CHEMBL3715269 & 1536771 & 7.0 & 7.2014 & TRN & \\
\hline CHEMBL3716943 & 1536771 & 7.0 & 6.1009 & TST & \\
\hline CHEMBL 3718339 & 1536771 & 7.0 & 6.779 & TRN & \\
\hline CHEMBL3718112 & 1536771 & 7.0 & 7.5448 & TST & \\
\hline CHEMBL 3716283 & 1536771 & 7.0 & 6.8219 & TRN & \\
\hline CHEMBL 3717577 & 1536771 & 7.0 & 7.1293 & TRN & \\
\hline CHEMBL 3717930 & 1536771 & 7.0 & 7.0041 & TRN & \\
\hline
\end{tabular}




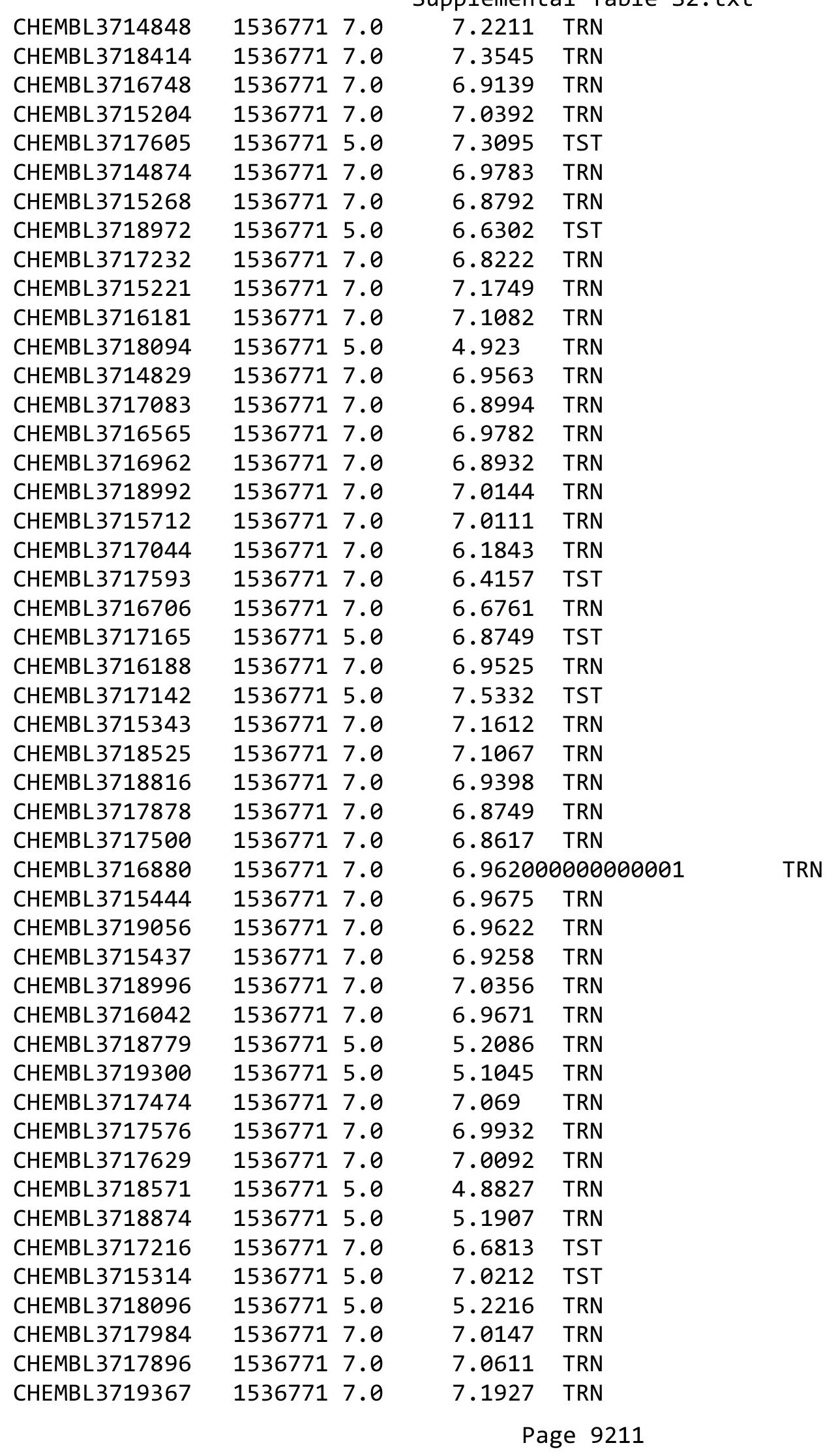




\begin{tabular}{|c|c|c|c|}
\hline & & & $a \perp 1 a$ \\
\hline CHEMBL3718326 & 15367717.0 & 6.7818 & TRN \\
\hline CHEMBL3718207 & 15367717.0 & 7.1002 & TRN \\
\hline CHEMBL3717501 & 15367717.0 & 6.9314 & TRN \\
\hline CHEMBL 3716345 & 15367715.0 & 5.8273 & TRN \\
\hline CHEMBL3715301 & 15367717.0 & 7.0251 & TRN \\
\hline CHEMBL3714868 & 15367717.0 & 7.1739 & TRN \\
\hline CHEMBL3716210 & 15367717.0 & 6.7125 & TRN \\
\hline CHEMBL3717826 & 15367715.0 & 4.9578 & TRN \\
\hline CHEMBL 3719171 & 15367715.0 & 6.6963 & TST \\
\hline CHEMBL3717408 & 15367715.0 & 4.6721 & TRN \\
\hline CHEMBL3715881 & 15367717.0 & 7.062 & TRN \\
\hline CHEMBL3714940 & 15367717.0 & 6.794 & TRN \\
\hline CHEMBL3717510 & 15367717.0 & 7.2442 & TRN \\
\hline CHEMBL 3715768 & 15367715.0 & 5.047 & TST \\
\hline CHEMBL3718089 & 15367717.0 & 7.0174 & TRN \\
\hline CHEMBL3715272 & 15367717.0 & 7.2453 & TRN \\
\hline CHEMBL3716331 & 15367717.0 & 7.0861 & TST \\
\hline CHEMBL 3718628 & 15367717.0 & 7.0695 & TRN \\
\hline CHEMBL 3717380 & 15367717.0 & 7.1271 & TRN \\
\hline CHEMBL3715324 & 15367717.0 & 7.0337 & TRN \\
\hline CHEMBL3715046 & 15367717.0 & 6.9865 & TRN \\
\hline CHEMBL3715981 & 15367717.0 & 6.8876 & TRN \\
\hline CHEMBL3719306 & 15367717.0 & 6.7277 & TRN \\
\hline CHEMBL3719221 & 15367717.0 & 7.0554 & TRN \\
\hline CHEMBL 3716651 & 15367717.0 & 7.0948 & TRN \\
\hline CHEMBL3719353 & 15367717.0 & 7.1461 & TRN \\
\hline CHEMBL3718270 & 15367717.0 & 6.5908 & TRN \\
\hline CHEMBL 3714794 & 15367717.0 & 6.9069 & TRN \\
\hline CHEMBL3718417 & 15367717.0 & 7.0594 & TRN \\
\hline CHEMBL 3716151 & 15367717.0 & 6.9183 & TRN \\
\hline CHEMBL 3717222 & 15367717.0 & 6.8442 & TRN \\
\hline CHEMBL3717223 & 15367717.0 & 7.0242 & TRN \\
\hline CHEMBL3717476 & 15367715.0 & 4.9802 & TRN \\
\hline CHEMBL3715422 & 15367715.0 & 5.1409 & TRN \\
\hline CHEMBL3716537 & 15367717.0 & 7.1157 & TRN \\
\hline CHEMBL3718056 & 15367717.0 & 6.965 & TST \\
\hline CHEMBL3714947 & 15367717.0 & 7.0323 & TRN \\
\hline CHEMBL3719283 & 15367717.0 & 7.0249 & TRN \\
\hline CHEMBL 3718911 & 15367717.0 & 6.9405 & TRN \\
\hline CHEMBL 3717057 & 15367717.0 & 7.0831 & TRN \\
\hline CHEMBL 3718694 & 15367717.0 & 6.8872 & TRN \\
\hline CHEMBL3719028 & 15367717.0 & 6.978 & TRN \\
\hline CHEMBL3715810 & 15367717.0 & 6.8073 & TRN \\
\hline CHEMBL 3717185 & 15367717.0 & 6.709 & TRN \\
\hline CHEMBL 3718238 & 15367717.0 & 7.2015 & TST \\
\hline CHEMBL 3717263 & 15367717.0 & 7.063 & TST \\
\hline CHEMBL3717495 & 15367717.0 & 7.0664 & TRN \\
\hline CHEMBL 3717177 & 15367717.0 & 6.8261 & TST \\
\hline
\end{tabular}




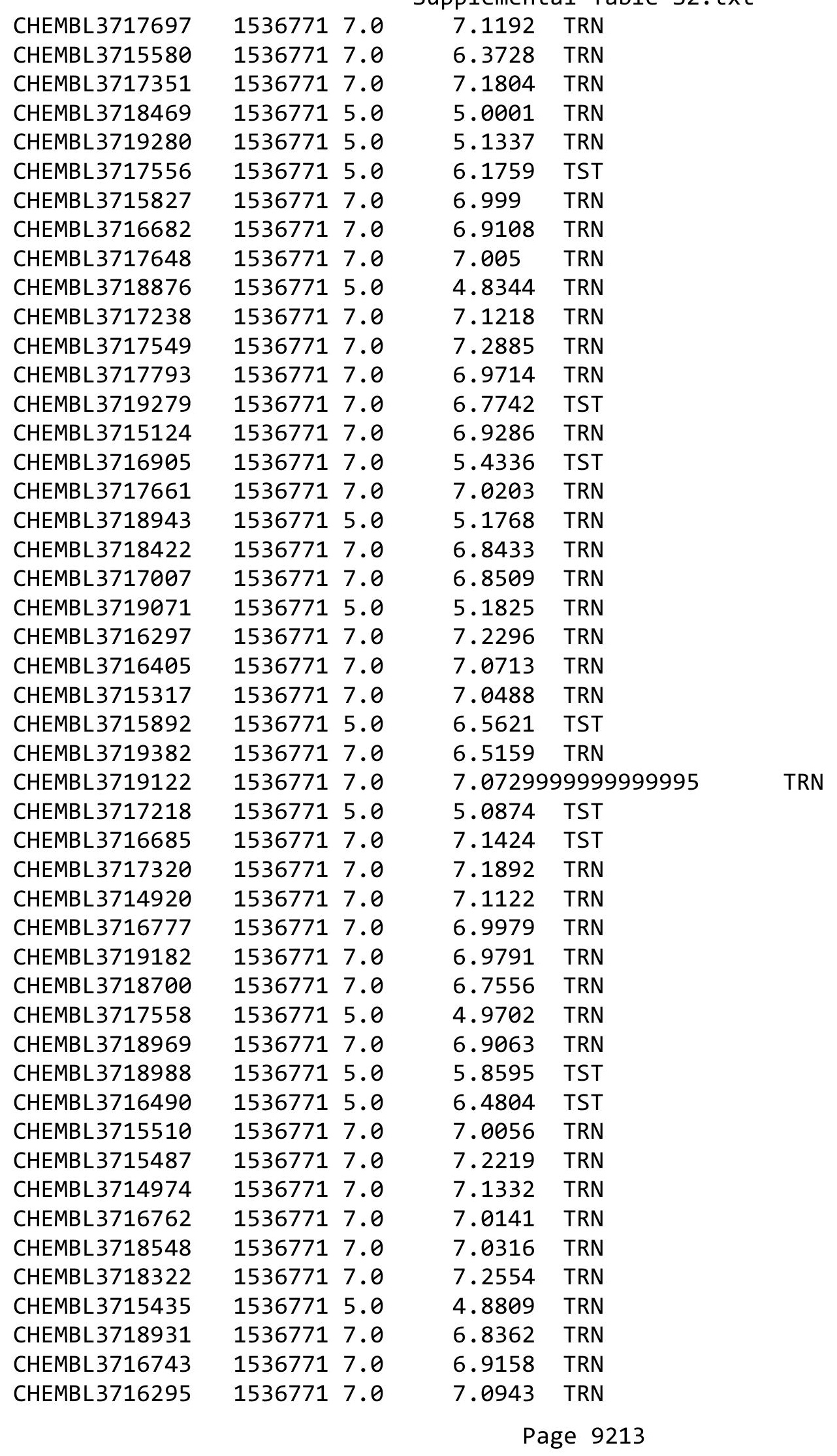




\begin{tabular}{|c|c|c|c|c|}
\hline \multicolumn{5}{|c|}{ Supplemental Table S2.txt } \\
\hline CHEMBL 3714975 & 1536771 & 5.0 & 5.0399 & TRN \\
\hline CHEMBL3715565 & 1536771 & 7.0 & 7.0513 & TRN \\
\hline CHEMBL3718394 & 1536771 & 7.0 & 6.9001 & TRN \\
\hline CHEMBL3717831 & 1536771 & 7.0 & 5.8629 & TST \\
\hline CHEMBL3716699 & 1536771 & 7.0 & 7.0605 & TRN \\
\hline CHEMBL3715134 & 1536771 & 5.0 & 5.4468 & TRN \\
\hline CHEMBL3718771 & 1536771 & 7.0 & 7.0143 & TRN \\
\hline CHEMBL 3717522 & 1536771 & 5.0 & 5.4698 & TRN \\
\hline CHEMBL3719199 & 1536771 & 7.0 & 6.8692 & TRN \\
\hline CHEMBL3719064 & 1536771 & 7.0 & 6.7205 & TRN \\
\hline CHEMBL3718370 & 1536771 & 7.0 & 7.1245 & TST \\
\hline CHEMBL3716851 & 1536771 & 7.0 & 6.8341 & TST \\
\hline CHEMBL 3718850 & 1536771 & 7.0 & 6.143 & TST \\
\hline CHEMBL3718738 & 1536771 & 5.0 & 6.1134 & TST \\
\hline CHEMBL3715636 & 1536771 & 7.0 & 6.9733 & TST \\
\hline CHEMBL3718134 & 1536771 & 7.0 & 7.0048 & TST \\
\hline CHEMBL3717340 & 1536771 & 5.0 & 5.6141 & TST \\
\hline CHEMBL3715585 & 1536771 & 7.0 & 7.3481 & TST \\
\hline CHEMBL 3714992 & 1536771 & 7.0 & 7.0644 & TST \\
\hline CHEMBL3717301 & 1536771 & 7.0 & 7.3293 & TST \\
\hline CHEMBL3714925 & 1536771 & 7.0 & 7.4734 & TST \\
\hline CHEMBL3716267 & 1536771 & 7.0 & 7.1836 & TST \\
\hline CHEMBL3717859 & 1536771 & 7.0 & 6.4169 & TST \\
\hline CHEMBL 3716303 & 1536771 & 5.0 & 5.4703 & TST \\
\hline CHEMBL3715287 & 1536771 & 7.0 & 6.9069 & TST \\
\hline CHEMBL3719098 & 1536771 & 7.0 & 7.0327 & TST \\
\hline CHEMBL3719075 & 1536771 & 7.0 & 6.3065 & TST \\
\hline CHEMBL3718191 & 1536771 & 5.0 & 5.3215 & TST \\
\hline CHEMBL 3719297 & 1536771 & 5.0 & 6.4801 & TST \\
\hline CHEMBL3716232 & 1536771 & 7.0 & 6.8476 & TST \\
\hline CHEMBL3718690 & 1536771 & 7.0 & 6.7937 & TST \\
\hline CHEMBL3717533 & 1536771 & 7.0 & 6.8183 & TST \\
\hline CHEMBL3792752 & 1572461 & 5.0 & 4.6158 & TRN \\
\hline CHEMBL3793154 & 1572461 & 4.5229 & 4.5597 & TRN \\
\hline CHEMBL3793399 & 1572461 & 3.4318 & 4.0354 & TST \\
\hline CHEMBL3793241 & 1572461 & 2.9547 & 4.1165 & TST \\
\hline CHEMBL3792579 & 1572461 & 2.9547 & 2.6445 & TRN \\
\hline CHEMBL3793459 & 1572461 & 4.7959 & 4.9912 & TRN \\
\hline CHEMBL3793616 & 1572461 & 5.3872 & 5.6966 & TRN \\
\hline CHEMBL 3794517 & 1572461 & 3.4318 & 4.2567 & TRN \\
\hline CHEMBL3793509 & 1572461 & 4.8861 & 4.5568 & TRN \\
\hline CHEMBL3793467 & 1572461 & 5.1192 & 4.6983 & TRN \\
\hline CHEMBL3793872 & 1572461 & 5.1938 & 5.2939 & TRN \\
\hline CHEMBL3794399 & 1572461 & 2.9547 & 3.8254 & TST \\
\hline CHEMBL3793606 & 1572461 & 4.7447 & 4.7594 & TRN \\
\hline CHEMBL3794008 & 1572461 & 4.4437 & 3.9375 & TRN \\
\hline CHEMBL3793508 & 1572461 & 2.9547 & 3.3969 & TRN \\
\hline CHEMBL3792897 & 1572461 & 5.3468 & 5.2428 & TRN \\
\hline
\end{tabular}


Supplemental Table S2.txt

\begin{tabular}{|c|c|c|c|c|}
\hline CHEMBL3793839 & 1572461 & 5.0 & 4.6703 & TRN \\
\hline CHEMBL3792554 & 1572461 & 4.3768 & 3.5111 & TRN \\
\hline CHEMBL3792475 & 1572461 & 5.5229 & 4.6246 & TRN \\
\hline CHEMBL3794519 & 1572461 & 3.4318 & 3.8304 & TRN \\
\hline CHEMBL3792917 & 1572461 & 5.0 & 5.5705 & TRN \\
\hline CHEMBL3794489 & 1572461 & 4.7959 & 4.3558 & TRN \\
\hline CHEMBL1210769 & 1572461 & 4.6021 & 3.8566 & TRN \\
\hline CHEMBL3793523 & 1572461 & 2.9547 & 3.7302 & TST \\
\hline CHEMBL3793974 & 1572461 & 4.8539 & 5.046 & TRN \\
\hline CHEMBL3793391 & 1572461 & 2.9547 & 3.913999 & 99999999997 \\
\hline CHEMBL3792448 & 1572461 & 5.4949 & 5.447 & TRN \\
\hline CHEMBL3794550 & 1572461 & 4.9586 & 5.244 & TRN \\
\hline CHEMBL3794044 & 1572461 & 5.0969 & 4.7367 & TRN \\
\hline CHEMBL3792741 & 1572461 & 4.8539 & 3.76 & TST \\
\hline CHEMBL3794036 & 1572461 & 4.9586 & 4.9458 & TRN \\
\hline CHEMBL3794329 & 1572461 & 4.8861 & 4.8052 & TRN \\
\hline CHEMBL3794248 & 1572461 & 5.2676 & 5.5382 & TRN \\
\hline CHEMBL3792519 & 1572461 & 5.1249 & 4.6781 & TST \\
\hline CHEMBL3793925 & 1572461 & 5.3468 & 4.9705 & TRN \\
\hline CHEMBL3794340 & 1572461 & 5.0088 & 4.9776 & TRN \\
\hline CHEMBL3794195 & 1572461 & 2.9547 & 2.7147 & TST \\
\hline CHEMBL3792592 & 1572461 & 5.1487 & 5.3726 & TRN \\
\hline CHEMBL3792845 & 1572461 & 4.7959 & 4.8419 & TRN \\
\hline CHEMBL3793472 & 1572461 & 2.9547 & 3.6356 & TST \\
\hline CHEMBL3792608 & 1572461 & 5.5229 & 5.2137 & TRN \\
\hline CHEMBL3793669 & 1572461 & 5.0315 & 5.1512 & TRN \\
\hline CHEMBL3792834 & 1572461 & 5.7212 & 5.4195 & TRN \\
\hline CHEMBL3793108 & 1572461 & 4.585 & 4.5745 & TRN \\
\hline CHEMBL3793043 & 1572461 & 5.2518 & 5.2138 & TRN \\
\hline CHEMBL3792890 & 1572461 & 4.9586 & 4.8213 & TRN \\
\hline CHEMBL3793579 & 1572461 & 2.9547 & 3.609 & TST \\
\hline CHEMBL3794268 & 1572461 & 4.699 & 5.1946 & TRN \\
\hline CHEMBL3794188 & 1572461 & 4.8239 & 4.7403 & TRN \\
\hline CHEMBL3793886 & 1572461 & 2.9547 & 3.7294 & TRN \\
\hline CHEMBL3793979 & 1572461 & 4.7212 & 5.0888 & TRN \\
\hline CHEMBL3793030 & 1572461 & 4.7212 & 4.8502 & TRN \\
\hline CHEMBL3792690 & 1572461 & 5.7696 & 5.3787 & TRN \\
\hline CHEMBL3793413 & 1572461 & 5.2924 & 5.1261 & TRN \\
\hline CHEMBL3792469 & 1572461 & 2.9547 & 3.9269 & TRN \\
\hline CHEMBL3793891 & 1572461 & 2.9547 & 3.7166 & TRN \\
\hline CHEMBL1928097 & 1572461 & 2.9547 & 3.5952 & TRN \\
\hline CHEMBL3793425 & 1572461 & 4.6778 & 4.1867 & TRN \\
\hline CHEMBL3793011 & 1572461 & 5.1549 & 4.943000 & 00000000005 \\
\hline CHEMBL1928103 & 1572461 & 2.9547 & 3.9904 & TST \\
\hline CHEMBL3793210 & 1572461 & 4.9586 & 4.9278 & TST \\
\hline CHEMBL3793861 & 1572461 & 4.6383 & 3.8759 & TST \\
\hline CHEMBL3793103 & 1572461 & 2.9547 & 3.1862 & TST \\
\hline CHEMBL3792520 & 1572461 & 5.2596 & 4.9636 & TST \\
\hline
\end{tabular}




\begin{tabular}{|c|c|c|c|c|c|c|}
\hline & & \multicolumn{5}{|c|}{ Supplemental Table S2.txt } \\
\hline CHEMBL1215597 & 649317 & 3.5781 & 3.6372 & TST & & \\
\hline CHEMBL1215528 & 649317 & 3.4816 & 3.6125 & TRN & & \\
\hline CHEMBL1214885 & 649317 & 4.3215 & 4.0435 & TRN & & \\
\hline CHEMBL1215459 & 649317 & 3.6203 & 3.6739 & TRN & & \\
\hline CHEMBL1215666 & 649317 & 4.0057 & 3.92 & TRN & & \\
\hline CHEMBL1215735 & 649317 & 3.6218 & 3.7185 & TRN & & \\
\hline CHEMBL1214822 & 649317 & 4.2168 & 4.0666 & TRN & & \\
\hline CHEMBL1215460 & 649317 & 3.6923 & 3.681 & TRN & & \\
\hline CHEMBL1215529 & 649317 & 3.6796 & 3.5778 & TST & & \\
\hline CHEMBL1215458 & 649317 & 3.6876 & 3.6705 & TRN & & \\
\hline CHEMBL1215308 & 649317 & 4.3979 & 4.4932 & TRN & & \\
\hline CHEMBL1215461 & 649317 & 5.0 & 4.7362 & TRN & & \\
\hline CHEMBL1214819 & 649317 & \multicolumn{3}{|c|}{3.6010000000000004} & 3.8212 & TRN \\
\hline CHEMBL1214743 & 649317 & 3.6975 & 3.6847 & TRN & & \\
\hline CHEMBL1215531 & 649317 & \multicolumn{3}{|c|}{3.6069999999999998} & 3.4768 & TST \\
\hline CHEMBL1215667 & 649317 & 3.7662 & 3.7673 & TRN & & \\
\hline CHEMBL1215534 & 649317 & 4.2336 & 4.1283 & TST & & \\
\hline CHEMBL1215307 & 649317 & 4.4225 & 4.4164 & TRN & & \\
\hline CHEMBL1214667 & 649317 & 3.6998 & 3.7361 & TRN & & \\
\hline CHEMBL1215386 & 649317 & 3.6459 & 3.7628 & TRN & & \\
\hline CHEMBL1212959 & 649317 & 3.4795 & 3.5069 & TRN & & \\
\hline CHEMBL1215737 & 649317 & 4.4522 & 4.4712 & TRN & & \\
\hline CHEMBL1214821 & 649317 & 3.6312 & 3.9528 & TRN & & \\
\hline CHEMBL1215671 & 649317 & 5.1367 & 5.1508 & TRN & & \\
\hline CHEMBL1215669 & 649317 & 4.4672 & 4.4957 & TRN & & \\
\hline CHEMBL1214741 & 649317 & 3.6786 & 3.6806 & TRN & & \\
\hline CHEMBL1215381 & 649317 & 4.5214 & 4.6266 & TST & & \\
\hline CHEMBL1215383 & 649317 & 4.4935 & 4.5529 & TST & & \\
\hline CHEMBL1214818 & 649317 & 3.6402 & 3.5714 & TRN & & \\
\hline CHEMBL1215734 & 649317 & 4.3893 & 4.343 & TRN & & \\
\hline CHEMBL1214669 & 649317 & 3.4333 & 3.4748 & TRN & & \\
\hline CHEMBL1214817 & 649317 & 3.8993 & 3.9207 & TRN & & \\
\hline CHEMBL1215600 & 649317 & 4.1891 & 4.1123 & TRN & & \\
\hline CHEMBL1214820 & 649317 & 4.2351 & 3.9348 & TRN & & \\
\hline CHEMBL1215598 & 649317 & 3.8614 & 4.0734 & TST & & \\
\hline CHEMBL1214742 & 649317 & 3.4991 & 3.6298 & TRN & & \\
\hline CHEMBL1215310 & 649317 & 4.4711 & 4.4248 & TST & & \\
\hline CHEMBL1214883 & 649317 & 3.852 & 4.0558 & TRN & & \\
\hline CHEMBL1215599 & 649317 & 3.5635 & 3.8782 & TST & & \\
\hline CHEMBL1215382 & 649317 & 4.3862 & 4.5003 & TST & & \\
\hline CHEMBL1214666 & 649317 & 5.4089 & 5.5544 & TRN & & \\
\hline CHEMBL1215668 & 649317 & 4.5768 & 4.6184 & TRN & & \\
\hline CHEMBL1215385 & 649317 & 3.7357 & 3.7116 & TRN & & \\
\hline CHEMBL1215602 & 649317 & 4.4776 & 4.34399 & 9999999999 & & TRN \\
\hline CHEMBL1215738 & 649317 & 4.0334 & 4.0816 & TRN & & \\
\hline CHEMBL1214670 & 649317 & 3.4333 & 3.5727 & TRN & & \\
\hline CHEMBL1215532 & 649317 & 3.6189 & 3.6546 & TST & & \\
\hline CHEMBL1214740 & 649317 & 3.74399 & 99999999 & 98 & 3.5825 & TRN \\
\hline
\end{tabular}




\begin{tabular}{|c|c|c|c|c|c|c|}
\hline & & \multicolumn{5}{|c|}{ Supplemental Table S2.txt } \\
\hline CHEMBL1214884 & 649317 & 4.2396 & 4.3042 & TRN & & \\
\hline CHEMBL1214668 & 649317 & 3.8136 & 3.7339 & TRN & & \\
\hline CHEMBL1215533 & 649317 & 3.5478 & 3.5186 & TST & & \\
\hline CHEMBL1215601 & 649317 & 3.415 & 3.4889 & TRN & & \\
\hline CHEMBL1215736 & 649317 & 4.3516 & 4.1528 & TRN & & \\
\hline CHEMBL1215457 & 649317 & 3.6463 & 3.5202 & TRN & & \\
\hline CHEMBL1215530 & 649317 & 3.7031 & 3.9477 & TST & & \\
\hline CHEMBL1215733 & 649317 & 3.6546 & 3.4971 & TRN & & \\
\hline CHEMBL164129 & 649317 & 4.3028 & 4.4491 & TST & & \\
\hline CHEMBL1214665 & 649317 & 5.0915 & 5.1732 & TRN & & \\
\hline CHEMBL1215309 & 649317 & 4.4123 & 4.4461 & TST & & \\
\hline CHEMBL1212969 & 649317 & 3.6645 & 3.6057 & TRN & & \\
\hline CHEMBL1215670 & 649317 & 5.2441 & 5.2617 & TRN & & \\
\hline CHEMBL1215456 & 649317 & 2.3936 & 2.4778 & TRN & & \\
\hline CHEMBL1215384 & 649317 & 4.6757 & 4.6931 & TST & & \\
\hline CHEMBL248018 & 456571 & 6.9318 & 6.8707 & TRN & & \\
\hline CHEMBL248234 & 456571 & 3.7167 & 5.2172 & TRN & & \\
\hline CHEMBL247219 & 456571 & 3.6091 & 4.5421 & TRN & & \\
\hline CHEMBL247221 & 456571 & 5.4318 & 5.2177 & TST & & \\
\hline CHEMBL247846 & 456571 & 7.7447 & 6.782 & TRN & & \\
\hline CHEMBL399053 & 456571 & 8.3979 & 8.3042 & TRN & & \\
\hline CHEMBL399233 & 456571 & 7.2441 & 8.4621 & TRN & & \\
\hline CHEMBL246832 & 456571 & 8.301 & 8.3013 & TRN & & \\
\hline CHEMBL399437 & 456571 & 6.2007 & 6.5491 & TRN & & \\
\hline CHEMBL246829 & 456571 & 4.6055 & 4.4798 & TRN & & \\
\hline CHEMBL246831 & 456571 & 7.5086 & 6.9519 & TRN & & \\
\hline CHEMBL247852 & 456571 & 8.699 & 6.9577 & TRN & & \\
\hline CHEMBL247845 & 456571 & $3.6180 e$ & 0000000 & 203 & 5.7004 & TST \\
\hline CHEMBL247851 & 456571 & 4.6655 & 6.1172 & TST & & \\
\hline CHEMBL246822 & 456571 & 3.6716 & 5.7429 & TST & & \\
\hline CHEMBL439402 & 456571 & 6.8729 & 5.0828 & TRN & & \\
\hline CHEMBL246841 & 456571 & 7.3279 & 6.4742 & TRN & & \\
\hline CHEMBL248021 & 456571 & 3.6478 & 6.2795 & TST & & \\
\hline CHEMBL 248023 & 456571 & 6.1397 & 6.3277 & TRN & & \\
\hline CHEMBL399051 & 456571 & 5.3635 & 6.8384 & TRN & & \\
\hline CHEMBL247854 & 456571 & 6.4401 & 6.1536 & TRN & & \\
\hline CHEMBL243876 & 456571 & 3.699 & 5.9696 & TST & & \\
\hline CHEMBL 99951 & 456571 & 4.0 & 7.8535 & TST & & \\
\hline CHEMBL246828 & 456571 & 6.7799 & 5.9583 & TRN & & \\
\hline CHEMBL247001 & 456571 & 6.9031 & 7.2545 & TRN & & \\
\hline CHEMBL248022 & 456571 & 6.2 & 5.6422 & TRN & & \\
\hline CHEMBL245992 & 456571 & 3.6234 & 2.1554 & TRN & & \\
\hline CHEMBL401052 & 456571 & 3.6308 & 5.9669 & TST & & \\
\hline CHEMBL247853 & 456571 & 7.2441 & 6.4545 & TRN & & \\
\hline CHEMBL246613 & 456571 & 3.7282 & 5.2827 & TRN & & \\
\hline CHEMBL246830 & 456571 & 8.0458 & 7.3076 & TRN & & \\
\hline CHEMBL398945 & 456571 & 7.3565 & 6.1025 & TRN & & \\
\hline CHEMBL246615 & 456571 & 5.1481 & 5.6774 & TRN & & \\
\hline
\end{tabular}


Supplemental Table S2.txt

\begin{tabular}{|c|c|c|c|c|c|}
\hline CHEMBL400847 & 456571 & 6.0862 & 5.1411 & TST & \\
\hline CHEMBL 246826 & 456571 & 6.7144 & 6.0853 & TRN & \\
\hline CHEMBL248235 & 456571 & 3.6383 & 4.2475 & TST & \\
\hline CHEMBL 247844 & 456571 & 3.6383 & 4.782 & TST & \\
\hline CHEMBL400489 & 456571 & 6.9547 & 6.9266 & TRN & \\
\hline CHEMBL246612 & 456571 & 7.0223 & 5.7752 & TRN & \\
\hline CHEMBL399129 & 456571 & 3.9101 & 4.6158 & TRN & \\
\hline CHEMBL248019 & 456571 & 3.5784 & 4.8362 & TRN & \\
\hline CHEMBL399052 & 456571 & 3.7375 & \multicolumn{2}{|c|}{5.4910000000000005} & TRN \\
\hline CHEMBL 248020 & 456571 & 3.6234 & 3.4451 & TRN & \\
\hline CHEMBL247850 & 456571 & 6.1599 & 6.3507 & TRN & \\
\hline CHEMBL418539 & 456571 & 8.3979 & 7.2242 & TRN & \\
\hline CHEMBL404853 & 456571 & 6.1457 & 5.7113 & TST & \\
\hline CHEMBL 247004 & 456571 & 7.301 & 6.2601 & TRN & \\
\hline CHEMBL400667 & 456571 & 3.6383 & 4.9887 & TRN & \\
\hline CHEMBL 247843 & 456571 & 5.1249 & 5.2625 & TST & \\
\hline CHEMBL399436 & 456571 & 6.7471 & 6.6961 & TRN & \\
\hline CHEMBL 248024 & 456571 & 6.1586 & 6.4468 & TRN & \\
\hline CHEMBL 248017 & 456571 & 5.5935 & 7.3382 & TRN & \\
\hline CHEMBL 247003 & 456571 & 7.7959 & 7.301 & TRN & \\
\hline CHEMBL 247847 & 456571 & 6.3224 & 7.2702 & TRN & \\
\hline CHEMBL 246614 & 456571 & 3.7399 & \multicolumn{2}{|c|}{ 4. 3469999999999995} & TRN \\
\hline CHEMBL400666 & 456571 & 3.6216 & 7.1099 & TST & \\
\hline CHEMBL 246820 & 456571 & 6.6383 & 5.8613 & TST & \\
\hline CHEMBL3676822 & 1528653 & 6.3979 & 5.4547 & TRN & \\
\hline CHEMBL 3671903 & 1528653 & 2.699 & 3.3283 & TRN & \\
\hline CHEMBL3671991 & 1528653 & 4.061 & 4.1004 & TRN & \\
\hline CHEMBL3671868 & 1528653 & 6.0315 & 6.3935 & TRN & \\
\hline CHEMBL3671989 & 1528653 & 4.9747 & 4.7236 & TRN & \\
\hline CHEMBL3671985 & 1528653 & 4.4685 & 4.4028 & TRN & \\
\hline CHEMBL3676789 & 1528653 & 4.7167 & 4.6395 & TRN & \\
\hline CHEMBL3671980 & 1528653 & 4.3098 & 4.7052 & TRN & \\
\hline CHEMBL3671960 & 1528653 & 5.699 & 6.0436 & TRN & \\
\hline CHEMBL 3671998 & 1528653 & 5.2441 & 4.9066 & TRN & \\
\hline CHEMBL3676842 & 1528653 & 5.0506 & 4.0845 & TST & \\
\hline CHEMBL3676782 & 1528653 & 4.8827 & 4.4162 & TRN & \\
\hline CHEMBL3671877 & 1528653 & 7.2218 & 6.4015 & TRN & \\
\hline CHEMBL3676797 & 1528653 & 6.0 & 4.1061 & TST & \\
\hline CHEMBL3671973 & 1528653 & 2.699 & 4.2119 & TST & \\
\hline CHEMBL3676825 & 1528653 & 3.699 & 4.0105 & TRN & \\
\hline CHEMBL3676799 & 1528653 & 5.3872 & 4.8403 & TRN & \\
\hline CHEMBL3676827 & 1528653 & 4.5086 & 4.6887 & TRN & \\
\hline CHEMBL3671987 & 1528653 & 4.9172 & 5.0619 & TRN & \\
\hline CHEMBL3671937 & 1528653 & 2.699 & 2.6231 & TRN & \\
\hline CHEMBL3671872 & 1528653 & 6.6576 & 5.9767 & TST & \\
\hline CHEMBL 3671886 & 1528653 & 2.699 & 4.3824 & TRN & \\
\hline CHEMBL3676836 & 1528653 & 5.0 & 5.2556 & TRN & \\
\hline CHEMBL 3671888 & 1528653 & 6.6576 & 7.9837 & TRN & \\
\hline
\end{tabular}

Page 9218 
Supplemental Table S2.txt

\begin{tabular}{|c|c|c|c|c|c|}
\hline CHEMBL 3671898 & 1528653 & 6.1871 & 5.6297 & TRN & \\
\hline CHEMBL 3672002 & 1528653 & 4.056 & 3.9279 & TRN & \\
\hline CHEMBL 3676821 & 1528653 & 3.8617 & 3.9447 & TRN & \\
\hline CHEMBL 3671990 & 1528653 & 4.1884 & 4.1315 & TRN & \\
\hline CHEMBL3671933 & 1528653 & 2.699 & 3.0888 & TST & \\
\hline CHEMBL3671922 & 1528653 & 3.752 & 3.8224 & TRN & \\
\hline CHEMBL3671983 & 1528653 & 4.1249 & 4.7242 & TST & \\
\hline CHEMBL 3671897 & 1528653 & 4.4949 & 4.9472 & TRN & \\
\hline CHEMBL 3676798 & 1528653 & 5.1612 & 4.6364 & TRN & \\
\hline CHEMBL3676837 & 1528653 & 4.585 & 4.4713 & TRN & \\
\hline CHEMBL 3676844 & 1528653 & 5.3468 & 4.353 & TRN & \\
\hline CHEMBL3671976 & 1528653 & 6.4559 & 5.8744 & TRN & \\
\hline CHEMBL 3676785 & 1528653 & 4.3458 & 4.4306 & TRN & \\
\hline CHEMBL3671936 & 1528653 & 5.1805 & 5.8538 & TST & \\
\hline CHEMBL 3676807 & 1528653 & 3.9722 & 4.9621 & TRN & \\
\hline CHEMBL3671930 & 1528653 & 6.4949 & 4.8474 & TST & \\
\hline CHEMBL3671938 & 1528653 & 2.699 & 5.5265 & TST & \\
\hline CHEMBL3671935 & 1528653 & 2.699 & 2.9057 & TRN & \\
\hline CHEMBL 3671924 & 1528653 & 3.7399 & 3.4633 & TST & \\
\hline CHEMBL3672006 & 1528653 & 5.1612 & 4.8157 & TRN & \\
\hline CHEMBL 3671964 & 1528653 & 5.0269 & 4.5722 & TRN & \\
\hline CHEMBL 3672000 & 1528653 & 5.0362 & 4.9524 & TRN & \\
\hline CHEMBL3671949 & 1528653 & 4.6021 & 4.2396 & TST & \\
\hline CHEMBL 3671944 & 1528653 & 3.8601 & 4.4393 & TST & \\
\hline CHEMBL3676811 & 1528653 & 4.9393 & 3.9695 & TST & \\
\hline CHEMBL3671916 & 1528653 & 3.7423 & 4.4799 & TST & \\
\hline CHEMBL3676809 & 1528653 & 4.1851 & 4.4525 & TRN & \\
\hline CHEMBL3671963 & 1528653 & 5.6198 & 5.9725 & TRN & \\
\hline CHEMBL 3676812 & 1528653 & 4.6498 & 5.03100 & 0000000001 & TRN \\
\hline CHEMBL 3671943 & 1528653 & 4.2924 & 4.3695 & TST & \\
\hline CHEMBL3676813 & 1528653 & 4.7055 & 4.7932 & TRN & \\
\hline CHEMBL 3671923 & 1528653 & 4.4685 & 4.1638 & TRN & \\
\hline CHEMBL3676806 & 1528653 & 3.7533 & 4.4632 & TRN & \\
\hline CHEMBL 3676810 & 1528653 & 4.6162 & 4.3483 & TRN & \\
\hline CHEMBL3671958 & 1528653 & 6.0458 & 6.0672 & TRN & \\
\hline CHEMBL 3676794 & 1528653 & 4.7258 & 4.4797 & TRN & \\
\hline CHEMBL 3671988 & 1528653 & 5.1739 & 4.9725 & TRN & \\
\hline CHEMBL3671997 & 1528653 & 4.3089 & 4.6831 & TRN & \\
\hline CHEMBL 3671902 & 1528653 & 4.8239 & 4.8282 & TRN & \\
\hline CHEMBL 3676832 & 1528653 & 4.4437 & 3.915 & TRN & \\
\hline CHEMBL 3671945 & 1528653 & 2.699 & 3.0977 & TRN & \\
\hline CHEMBL3671984 & 1528653 & 4.7212 & 4.9172 & TRN & \\
\hline CHEMBL3676831 & 1528653 & 3.699 & 4.3077 & TST & \\
\hline CHEMBL 3671955 & 1528653 & 4.1871 & 4.3935 & TST & \\
\hline CHEMBL 3676845 & 1528653 & 3.699 & 4.0601 & TRN & \\
\hline CHEMBL3671979 & 1528653 & 4.6383 & 4.8044 & TRN & \\
\hline CHEMBL 3671975 & 1528653 & 4.041 & 3.5589 & TRN & \\
\hline CHEMBL3671873 & 1528653 & 6.284 & 6.1179 & TRN & \\
\hline
\end{tabular}


Supplemental Table S2.txt

\begin{tabular}{|c|c|c|c|c|c|}
\hline CHEMBL 3676835 & 1528653 & 5.1249 & 5.5632 & TRN & \\
\hline CHEMBL3676786 & 1528653 & 4.7721 & 4.9275 & TRN & \\
\hline CHEMBL3676814 & 1528653 & 5.0555 & 5.0847 & TRN & \\
\hline CHEMBL3672004 & 1528653 & 5.3279 & 4.8917 & TRN & \\
\hline CHEMBL 3676787 & 1528653 & 4.0334 & 4.5344 & TRN & \\
\hline CHEMBL 3676820 & 1528653 & 3.7857 & 3.845 & TRN & \\
\hline CHEMBL 3676778 & 1528653 & 4.8996 & 5.3277 & TRN & \\
\hline CHEMBL3676839 & 1528653 & 5.0 & 5.2553 & TRN & \\
\hline CHEMBL3671894 & 1528653 & 6.0969 & 4.5942 & TRN & \\
\hline CHEMBL3671978 & 1528653 & 4.5686 & 4.1918 & TRN & \\
\hline CHEMBL3676815 & 1528653 & 4.8477 & 4.9344 & TRN & \\
\hline CHEMBL3671952 & 1528653 & 6.0 & 5.9626 & TRN & \\
\hline CHEMBL3671926 & 1528653 & 6.5528 & 7.6445 & TST & \\
\hline CHEMBL3671932 & 1528653 & 3.7773 & \multicolumn{2}{|c|}{ 4. 3839999999999995} & TST \\
\hline CHEMBL3671896 & 1528653 & 4.3979 & 5.4656 & TRN & \\
\hline CHEMBL3671925 & 1528653 & 6.301 & 4.7229 & TST & \\
\hline CHEMBL3671865 & 1528653 & 6.2007 & 6.7093 & TRN & \\
\hline CHEMBL3671885 & 1528653 & 4.6778 & 4.8033 & TRN & \\
\hline CHEMBL3671951 & 1528653 & 2.699 & 4.5777 & TRN & \\
\hline CHEMBL3671986 & 1528653 & 4.5086 & 4.7015 & TRN & \\
\hline CHEMBL3671927 & 1528653 & 6.6383 & 6.1044 & TST & \\
\hline CHEMBL3676792 & 1528653 & 4.1561 & \multicolumn{2}{|c|}{4.5360000000000005} & TRN \\
\hline CHEMBL 3676783 & 1528653 & 4.8386 & 4.1152 & TST & \\
\hline CHEMBL3671884 & 1528653 & 6.2147 & 6.1453 & TRN & \\
\hline CHEMBL 3671970 & 1528653 & 2.699 & 4.4723 & TRN & \\
\hline CHEMBL 3671950 & 1528653 & 2.699 & 3.117 & TST & \\
\hline CHEMBL3676826 & 1528653 & 4.4306 & 4.2801 & TRN & \\
\hline CHEMBL3671900 & 1528653 & 2.699 & 2.4016 & TRN & \\
\hline CHEMBL3671957 & 1528653 & 3.8633 & 3.7573 & TST & \\
\hline CHEMBL3671942 & 1528653 & 5.7212 & 5.6674 & TST & \\
\hline CHEMBL3671906 & 1528653 & 5.9586 & 5.4858 & TST & \\
\hline CHEMBL 3676788 & 1528653 & 4.3152 & 4.2522 & TRN & \\
\hline CHEMBL3671968 & 1528653 & 4.3979 & 4.2158 & TRN & \\
\hline CHEMBL3676830 & 1528653 & 4.4413 & 5.1443 & TRN & \\
\hline CHEMBL3676840 & 1528653 & 4.5686 & 4.3502 & TRN & \\
\hline CHEMBL3671880 & 1528653 & 7.0458 & 6.7375 & TRN & \\
\hline CHEMBL3671899 & 1528653 & 6.4089 & 5.0749 & TST & \\
\hline CHEMBL3676843 & 1528653 & 5.3098 & 5.2109 & TRN & \\
\hline CHEMBL3671882 & 1528653 & 5.6778 & 6.0975 & TRN & \\
\hline CHEMBL3671996 & 1528653 & 4.251 & 4.6101 & TRN & \\
\hline CHEMBL3672008 & 1528653 & 5.0458 & 4.6703 & TRN & \\
\hline CHEMBL3671931 & 1528653 & 5.4437 & 5.7665 & TST & \\
\hline CHEMBL3671921 & 1528653 & 2.699 & \multicolumn{2}{|c|}{3.6010000000000004} & TST \\
\hline CHEMBL3639708 & 1528653 & 4.7959 & 5.301 & TRN & \\
\hline CHEMBL3676828 & 1528653 & 3.699 & 4.224 & TRN & \\
\hline CHEMBL3672001 & 1528653 & 4.9788 & 4.4957 & TRN & \\
\hline CHEMBL 3671878 & 1528653 & 5.1675 & 4.9902 & TRN & \\
\hline CHEMBL3671895 & 1528653 & 5.1805 & 5.3346 & TRN & \\
\hline
\end{tabular}


Supplemental Table S2.txt

\begin{tabular}{|c|c|c|c|c|c|}
\hline CHEMBL3671912 & 1528653 & 2.699 & 2.9068 & TRN & \\
\hline CHEMBL 3671871 & 1528653 & 5.1871 & 5.6534 & TST & \\
\hline CHEMBL3676841 & 1528653 & 5.2596 & 4.238 & TST & \\
\hline CHEMBL3671967 & 1528653 & 2.699 & 4.0248 & TST & \\
\hline CHEMBL3676819 & 1528653 & 4.5528 & 4.3753 & TRN & \\
\hline CHEMBL3671947 & 1528653 & 6.0 & 6.3219 & TRN & \\
\hline CHEMBL3671875 & 1528653 & 6.6383 & 5.7479 & TRN & \\
\hline CHEMBL3671889 & 1528653 & 6.7447 & 6.3408 & TRN & \\
\hline CHEMBL3671911 & 1528653 & 4.0223 & 4.0818 & TRN & \\
\hline CHEMBL3671887 & 1528653 & 3.8268 & 3.721 & TRN & \\
\hline CHEMBL3671972 & 1528653 & 2.699 & 3.6779 & TST & \\
\hline CHEMBL3671869 & 1528653 & 7.0458 & 6.6829 & TRN & \\
\hline CHEMBL3671910 & 1528653 & 3.71 & 3.9084 & TRN & \\
\hline CHEMBL3671941 & 1528653 & 2.699 & 2.7244 & TST & \\
\hline CHEMBL3639707 & 1528653 & 5.0 & 4.8287 & TRN & \\
\hline CHEMBL3676823 & 1528653 & 6.0969 & 5.7129 & TRN & \\
\hline CHEMBL3671982 & 1528653 & 3.8794 & 4.8229 & TST & \\
\hline CHEMBL 3676804 & 1528653 & 4.8697 & 4.67399 & 99999999995 & TRN \\
\hline CHEMBL3671914 & 1528653 & 2.699 & 3.4658 & TRN & \\
\hline CHEMBL 3676780 & 1528653 & 4.7595 & 4.5306 & TRN & \\
\hline CHEMBL3671881 & 1528653 & 5.3468 & 5.3354 & TRN & \\
\hline CHEMBL 3676824 & 1528653 & 3.699 & 3.9841 & TRN & \\
\hline CHEMBL3676805 & 1528653 & 3.7014 & 3.5176 & TRN & \\
\hline CHEMBL3676833 & 1528653 & 4.2676 & 4.0387 & TRN & \\
\hline CHEMBL3676779 & 1528653 & 3.9884 & 4.3106 & TRN & \\
\hline CHEMBL3676838 & 1528653 & 4.7696 & 5.5033 & TRN & \\
\hline CHEMBL 3672005 & 1528653 & 5.0362 & 4.808 & TRN & \\
\hline CHEMBL3671934 & 1528653 & 4.5086 & 4.1832 & TST & \\
\hline CHEMBL 3671948 & 1528653 & 6.5376 & 6.193 & TST & \\
\hline CHEMBL3676795 & 1528653 & 5.2076 & 4.8044 & TRN & \\
\hline CHEMBL3671928 & 1528653 & 5.6198 & 3.5468 & TST & \\
\hline CHEMBL3671992 & 1528653 & 3.699 & 3.7352 & TRN & \\
\hline CHEMBL3671874 & 1528653 & 6.3872 & 6.9061 & TRN & \\
\hline CHEMBL3676829 & 1528653 & 5.3468 & 4.9973 & TRN & \\
\hline CHEMBL3671959 & 1528653 & 5.4318 & 5.0533 & TRN & \\
\hline CHEMBL3676790 & 1528653 & 3.699 & 4.2254 & TRN & \\
\hline CHEMBL 3676793 & 1528653 & 4.4815 & 4.5493 & TRN & \\
\hline CHEMBL3672003 & 1528653 & 5.1135 & 4.7414 & TRN & \\
\hline CHEMBL 3676784 & 1528653 & 4.8477 & 4.3013 & TST & \\
\hline CHEMBL3672007 & 1528653 & 4.9101 & 5.4005 & TRN & \\
\hline CHEMBL3671956 & 1528653 & 3.8729 & 3.783 & TST & \\
\hline CHEMBL3671879 & 1528653 & 6.6778 & 6.1452 & TRN & \\
\hline CHEMBL3671870 & 1528653 & 6.6576 & 6.3731 & TST & \\
\hline CHEMBL3671953 & 1528653 & 6.1612 & 5.9771 & TRN & \\
\hline CHEMBL3671962 & 1528653 & 5.7212 & 5.6385 & TRN & \\
\hline CHEMBL3671993 & 1528653 & 3.699 & 3.75100 & 00000000003 & TRN \\
\hline CHEMBL 3671971 & 1528653 & 3.699 & 3.8747 & TRN & \\
\hline CHEMBL 3671946 & 1528653 & 4.699 & 4.8443 & TRN & \\
\hline
\end{tabular}


Supplemental Table S2.txt

\begin{tabular}{|c|c|c|c|c|}
\hline CHEMBL3676816 & 1528653 & 4.2857 & 3.9644 & TRN \\
\hline CHEMBL3671994 & 1528653 & 3.699 & 3.918 & TRN \\
\hline CHEMBL3671954 & 1528653 & 6.2147 & 5.7388 & TRN \\
\hline CHEMBL 3671981 & 1528653 & 4.0555 & 4.3566 & TRN \\
\hline CHEMBL3671917 & 1528653 & 5.0315 & 5.8352 & TRN \\
\hline CHEMBL3671939 & 1528653 & 5.6383 & 5.2278 & TST \\
\hline CHEMBL3671915 & 1528653 & 4.3468 & 6.1083 & TST \\
\hline CHEMBL3671892 & 1528653 & 6.1805 & \multicolumn{2}{|c|}{5.718999999999999} \\
\hline CHEMBL3671904 & 1528653 & 6.0 & 4.5066 & TRN \\
\hline CHEMBL3671999 & 1528653 & 4.8013 & 5.109 & TRN \\
\hline CHEMBL3671965 & 1528653 & 5.8239 & 5.6985 & TRN \\
\hline CHEMBL3639757 & 1528653 & 4.9208 & 4.6 & TRN \\
\hline CHEMBL3676817 & 1528653 & 4.2581 & 3.8929 & TRN \\
\hline CHEMBL3671995 & 1528653 & 5.4437 & 4.7079 & TRN \\
\hline CHEMBL3671901 & 1528653 & 2.699 & 2.8149 & TRN \\
\hline CHEMBL3671940 & 1528653 & 2.699 & 5.8067 & TST \\
\hline CHEMBL3672009 & 1528653 & 4.8125 & 4.4205 & TST \\
\hline CHEMBL3671893 & 1528653 & 6.7212 & 6.0357 & TRN \\
\hline CHEMBL3671909 & 1528653 & 7.0 & 5.7143 & TRN \\
\hline CHEMBL3671969 & 1528653 & 3.699 & 4.0183 & TRN \\
\hline CHEMBL3676791 & 1528653 & 4.5376 & 4.3455 & TRN \\
\hline CHEMBL3676802 & 1528653 & 6.0 & 4.2218 & TRN \\
\hline CHEMBL3671966 & 1528653 & 2.699 & 3.5286 & TST \\
\hline CHEMBL 3671974 & 1528653 & 4.6576 & 4.8198 & TST \\
\hline CHEMBL3671883 & 1528653 & 4.4559 & 4.7026 & TRN \\
\hline CHEMBL3676834 & 1528653 & 5.2924 & 5.7151 & TRN \\
\hline CHEMBL3671908 & 1528653 & 5.8539 & 5.8002 & TST \\
\hline CHEMBL 3671867 & 1528653 & 6.585 & 6.4527 & TRN \\
\hline CHEMBL 3671876 & 1528653 & 6.5229 & 6.0835 & TRN \\
\hline CHEMBL3671977 & 1528653 & 6.3565 & 5.9981 & TRN \\
\hline CHEMBL3671907 & 1528653 & 6.4559 & 5.7582 & TST \\
\hline CHEMBL3671929 & 1528653 & 6.3565 & 6.3573 & TST \\
\hline CHEMBL3676808 & 1528653 & 4.2441 & 4.5903 & TRN \\
\hline CHEMBL 3676818 & 1528653 & 3.699 & 3.6193 & TRN \\
\hline CHEMBL3671890 & 1528653 & 5.7696 & 5.0893 & TST \\
\hline CHEMBL3671866 & 1528653 & 6.6383 & 6.7584 & TRN \\
\hline CHEMBL3671961 & 1528653 & 5.6576 & 5.5159 & TRN \\
\hline CHEMBL3671891 & 1528653 & 6.1192 & 6.1628 & TRN \\
\hline CHEMBL 3676781 & 1528653 & 4.7447 & 4.8299 & TRN \\
\hline CHEMBL 3671864 & 1528653 & 5.6778 & 6.8923 & TST \\
\hline CHEMBL1560870 & 1301767 & 5.0119 & 4.2508 & TST \\
\hline CHEMBL 2356442 & 1301767 & 4.5857 & 4.5488 & TRN \\
\hline CHEMBL1530866 & 1301767 & 4.7799 & 5.098 & TRN \\
\hline CHEMBL1350915 & 1301767 & 4.1615 & 4.4141 & TRN \\
\hline CHEMBL 2354788 & 1301767 & 4.4835 & 3.5971 & TRN \\
\hline CHEMBL 2362844 & 1301767 & 3.1549 & 4.0979 & TRN \\
\hline CHEMBL3182148 & 1301767 & 4.7435 & 4.4988 & TRN \\
\hline CHEMBL1390112 & 1301767 & 4.7385 & 4.9401 & TST \\
\hline
\end{tabular}


Supplemental Table S2.txt

\begin{tabular}{|c|c|c|c|c|c|}
\hline CHEMBL 3187821 & 1301767 & 4.3143 & 4.5068 & TRN & \\
\hline CHEMBL1375884 & 1301767 & 5.0996 & 5.2635 & TRN & \\
\hline CHEMBL1500469 & 1301767 & 4.7158 & 5.0023 & TST & \\
\hline CHEMBL1378851 & 1301767 & 4.3183 & 4.727 & TST & \\
\hline CHEMBL1904071 & 1301767 & 4.1094 & 4.1632 & TST & \\
\hline CHEMBL3182041 & 1301767 & 3.0 & 3.409 & TRN & \\
\hline CHEMBL 2355378 & 1301767 & 3.1549 & 4.8734 & TRN & \\
\hline CHEMBL 2357026 & 1301767 & 6.0 & 4.4886 & TRN & \\
\hline CHEMBL591363 & 1301767 & 5.1445 & 5.3936 & TRN & \\
\hline CHEMBL3183001 & 1301767 & 4.4387 & 4.0469 & TRN & \\
\hline CHEMBL1544186 & 1301767 & 4.9722 & 4.6504 & TRN & \\
\hline CHEMBL1551808 & 1301767 & 4.797 & 4.7678 & TRN & \\
\hline CHEMBL1622981 & 1301767 & 4.6741 & 4.4323 & TRN & \\
\hline CHEMBL1420472 & 1301767 & 4.5057 & 4.73 & TRN & \\
\hline CHEMBL1321427 & 1301767 & 5.6925 & 5.8876 & TST & \\
\hline CHEMBL1371507 & 1301767 & 3.0 & 4.5126 & TRN & \\
\hline CHEMBL1483562 & 1301767 & 5.2774 & 5.0407 & TRN & \\
\hline CHEMBL 2354712 & 1301767 & 6.0 & 5.6853 & TRN & \\
\hline CHEMBL1347023 & 1301767 & 4.3155 & 3.91 & TRN & \\
\hline CHEMBL1428095 & 1301767 & 4.6373 & 4.93 & TRN & \\
\hline CHEMBL 2358729 & 1301767 & 4.9727 & 5.0079 & TRN & \\
\hline CHEMBL1306900 & 1301767 & 4.8554 & 4.7724 & TRN & \\
\hline CHEMBL2359502 & 1301767 & 3.1549 & 4.5488 & TRN & \\
\hline CHEMBL2362650 & 1301767 & 5.4001 & 5.1974 & TRN & \\
\hline CHEMBL1337726 & 1301767 & 4.815 & 5.4912 & TRN & \\
\hline CHEMBL3185444 & 1301767 & 4.477 & 4.4762 & TRN & \\
\hline CHEMBL2359612 & 1301767 & 4.4165 & 4.606 & TRN & \\
\hline CHEMBL2359406 & 1301767 & 5.1296 & 5.0188 & TRN & \\
\hline CHEMBL3182281 & 1301767 & 4.3355 & 4.4452 & TRN & \\
\hline CHEMBL2359040 & 1301767 & 4.4535 & 4.9656 & TRN & \\
\hline CHEMBL2356002 & 1301767 & 4.7706 & 4.7848 & TRN & \\
\hline CHEMBL2355724 & 1301767 & 10.0565 & 6.54 & TRN & \\
\hline CHEMBL1487099 & 1301767 & 5.5638 & 5.6201 & TST & \\
\hline CHEMBL1418341 & 1301767 & 4.6916 & 4.8731 & TRN & \\
\hline CHEMBL1597245 & 1301767 & 4.1124 & 3.4061 & TRN & \\
\hline CHEMBL1489779 & 1301767 & 6.4365 & 6.2032 & TRN & \\
\hline CHEMBL1579170 & 1301767 & 4.4699 & 4.8588 & TRN & \\
\hline CHEMBL1379675 & 1301767 & 5.0752 & 5.0297 & TRN & \\
\hline CHEMBL2355735 & 1301767 & 4.5794 & 4.4821 & TRN & \\
\hline CHEMBL1544797 & 1301767 & 5.3625 & 5.3711 & TRN & \\
\hline CHEMBL2361659 & 1301767 & 4.3592 & 5.616006 & 00000000005 & TRN \\
\hline CHEMBL1321754 & 1301767 & 5.058 & 5.0756 & TRN & \\
\hline CHEMBL1584985 & 1301767 & 5.8477 & 6.045 & TST & \\
\hline CHEMBL1445297 & 1301767 & 6.9281 & 6.5177 & TRN & \\
\hline CHEMBL1378232 & 1301767 & 4.0711 & 4.8013 & TST & \\
\hline CHEMBL1488060 & 1301767 & 4.3734 & 4.6076 & TST & \\
\hline CHEMBL2359622 & 1301767 & 4.4284 & 6.6274 & TRN & \\
\hline CHEMBL1452421 & 1301767 & 5.1013 & 5.3157 & TRN & \\
\hline
\end{tabular}

Page 9223 
Supplemental Table S2.txt

\begin{tabular}{|c|c|c|c|c|}
\hline HEMBL 23 & & 4.6757 & $\partial 1$ & TR \\
\hline HFMBI 1345220 & 301767 & 5.5986 & 5.5887 & \\
\hline HEMBL 14726 & 01767 & 294 & & \\
\hline HEMBL1543417 & 301767 & 4.6036 & 5163 & \\
\hline HEMBL1459394 & 301767 & 4.5191 & .5473 & \\
\hline HEMBL1602637 & 767 & 5.3872 & 7278 & \\
\hline HEMBL1: & 767 & 8.9031 & 4.8354 & D. \\
\hline HEMBL1568022 & 767 & 4.8447 & 7464 & \\
\hline HEMBL1396619 & 301767 & 4.9901 & .9151 & \\
\hline HEMBL1578386 & 301767 & 4.6728 & 4.9261 & \\
\hline HEMBL171 & 767 & 4.694 & 423 & \\
\hline HEMBL 585 & & 5.4841 & & \\
\hline HEMBL213 & 767 & 5.4855 & 861 & \\
\hline HEMBL 140 & 767 & 6.3969 & 68 & \\
\hline HEMBL318 & 767 & 4.2118 & 06 & \\
\hline HEMBL1€ & 67 & 15 & 56 & ונס \\
\hline HEMBL3 & & 4 & & RN \\
\hline HEMBL 36 & 79 & 5. & 809 & $\mathrm{RN}$ \\
\hline HEMBL 367 & & 5 & & \\
\hline HEMBL 367 & 79 & 4 & 3064 & RIV \\
\hline AEMBL36 & 79 & 5 & 06 & $\mathrm{RN}$ \\
\hline HEMBL; & & & & ST \\
\hline HEMBL36 & & 5. & 452 & ST \\
\hline HEMBL 36 & & & & RN \\
\hline HEMBL 367 & 79 & 5 & 773 & RN \\
\hline AEMBL3 & & 5 & 52 & RN \\
\hline HEMBL & & & & $\mathrm{RN}$ \\
\hline HEMBL; & & 5. & 73 & RN \\
\hline HEMBL36 & & & & IRN \\
\hline HEMBL 367 & 79 & 5 & 093 & 「RN \\
\hline HEMBL3 & & 5 & & RN \\
\hline HEM & & & & ГRN \\
\hline HEMBL3 & & 5. & & $\mathrm{RN}$ \\
\hline HEMBL 36 & & 5. & & TRN \\
\hline HEMBL 367 & & & 3445 & TRN \\
\hline HEMBL36 & 99 & & 43 & TRN \\
\hline - חבMזו & & & & RN \\
\hline HEMBL36 & & 5 . & & TRN \\
\hline HEMBL 367 & & 6.407 & 48 & TRN \\
\hline IEMBL 36 & 79 & 5 & 391 & TST \\
\hline HEMBL 36 & & & 527 & TRN \\
\hline CHEMBL 367 & & 6.0585 & & RN \\
\hline HEMBL363 & & 5.0 & 5.5169 & TRN \\
\hline AEMBL367 & 79 & 5. & 42 & TS \\
\hline HEMBL 36 & & 4.30 & & TRN \\
\hline CHEMBL 3675551 & & 5.0 & 5.0633 & \\
\hline CHEMBL3675597 & & 4.36 & 4.234 & \\
\hline CHEMBL3670691 & 1535379 & 6.9208 & 6.6153 & rRN \\
\hline
\end{tabular}

Page 9224 


\begin{tabular}{|c|c|c|c|c|c|}
\hline \multicolumn{6}{|c|}{ Supplemental Table S2.txt } \\
\hline CHEMBL 3675570 & 1535379 & 5.0 & 5.0633 & TRN & \\
\hline CHEMBL3675562 & 1535379 & 4.301 & 4.2833 & TRN & \\
\hline CHEMBL3675571 & 1535379 & 5.0 & 4.4541 & TRN & \\
\hline CHEMBL3670703 & 1535379 & 5.0 & 5.2782 & TRN & \\
\hline CHEMBL 3675581 & 1535379 & 5.0 & 5.1437 & TRN & \\
\hline CHEMBL3670705 & 1535379 & 5.0 & 5.28299 & 99999999995 & TRN \\
\hline CHEMBL 3675584 & 1535379 & 5.0 & 4.8854 & TRN & \\
\hline CHEMBL 3675586 & 1535379 & 4.301 & 4.5812 & TRN & \\
\hline CHEMBL 3675580 & 1535379 & 3.0 & 3.5205 & TRN & \\
\hline CHEMBL 3675550 & 1535379 & 4.301 & 4.768 & TRN & \\
\hline CHEMBL1232489 & 1535379 & 5.0 & 5.4524 & TRN & \\
\hline CHEMBL 3675598 & 1535379 & 5.0 & 4.6216 & TRN & \\
\hline CHEMBL3675587 & 1535379 & 5.0 & 4.9807 & TRN & \\
\hline CHEMBL3675567 & 1535379 & 5.0 & 5.2189 & TRN & \\
\hline CHEMBL3675566 & 1535379 & 5.0 & 4.8271 & TRN & \\
\hline CHEMBL3675588 & 1535379 & 5.0 & 4.9307 & TRN & \\
\hline CHEMBL3675595 & 1535379 & 5.0 & 5.1718 & TRN & \\
\hline CHEMBL 3675573 & 1535379 & 6.1904 & 5.751 & TST & \\
\hline CHEMBL3670707 & 1535379 & 5.0 & 4.7917 & TRN & \\
\hline CHEMBL3675554 & 1535379 & 5.0 & 5.751 & TST & \\
\hline CHEMBL3675548 & 1535379 & 5.0 & 5.2189 & TRN & \\
\hline CHEMBL 3675572 & 1535379 & 4.301 & 5.5142 & TST & \\
\hline CHEMBL3670712 & 1535379 & 4.301 & 4.1017 & TST & \\
\hline CHEMBL 3675603 & 1535379 & 6.4023 & 5.3407 & TST & \\
\hline CHEMBL 3675547 & 1535379 & 4.301 & 4.3964 & TRN & \\
\hline CHEMBL3675592 & 1535379 & 6.6162 & 6.569 & TRN & \\
\hline CHEMBL3675569 & 1535379 & 5.0 & 4.768 & TRN & \\
\hline CHEMBL 3670720 & 1535379 & 6.7011 & 6.6033 & TRN & \\
\hline CHEMBL 3639744 & 1535379 & 5.0 & 4.8271 & TRN & \\
\hline CHEMBL3675605 & 1535379 & 5.0 & 5.0815 & TRN & \\
\hline CHEMBL3675582 & 1535379 & 5.0 & 5.1275 & TRN & \\
\hline CHEMBL 3675545 & 1535379 & 5.0 & 5.2933 & TRN & \\
\hline CHEMBL3670699 & 1535379 & 6.2182 & 6.2577 & TRN & \\
\hline CHEMBL 3670719 & 1535379 & 4.301 & 5.1773 & TST & \\
\hline CHEMBL3675579 & 1535379 & 4.301 & 4.4723 & TRN & \\
\hline CHEMBL3675557 & 1535379 & 6.1643 & 6.2441 & TRN & \\
\hline CHEMBL3670704 & 1535379 & 5.0 & 4.5908 & TRN & \\
\hline CHEMBL3670711 & 1535379 & 5.0 & 3.9349 & TST & \\
\hline CHEMBL 3675585 & 1535379 & 6.066 & 5.3792 & TRN & \\
\hline CHEMBL 3670700 & 1535379 & 5.0 & 5.6855 & TST & \\
\hline CHEMBL3675576 & 1535379 & 4.0 & 4.0967 & TRN & \\
\hline CHEMBL3675574 & 1535379 & 4.0 & 4.3964 & TRN & \\
\hline CHEMBL3675546 & 1535379 & 5.0 & 4.7122 & TRN & \\
\hline CHEMBL 3670710 & 1535379 & 4.301 & 5.2183 & TST & \\
\hline CHEMBL3670702 & 1535379 & 5.0 & 4.9341 & TST & \\
\hline CHEMBL3675561 & 1535379 & 4.301 & 4.2185 & TRN & \\
\hline CHEMBL3670708 & 1535379 & 5.0 & 5.1488 & TST & \\
\hline CHEMBL3675594 & 1535379 & 5.0 & 5.1912 & TRN & \\
\hline
\end{tabular}


Supplemental Table S2.txt

\begin{tabular}{|c|c|c|c|c|c|}
\hline CHEMBL 3675578 & 1535379 & 3.301 & 3.7062 & TRN & \\
\hline CHEMBL 3670721 & 1535379 & 5.0 & 5.0602 & TRN & \\
\hline CHEMBL3670695 & 1535379 & 5.0 & 5.9422 & TST & \\
\hline CHEMBL 3675601 & 1535379 & 4.301 & 4.6187 & TRN & \\
\hline CHEMBL 3675564 & 1535379 & 5.0 & 5.1769 & TRN & \\
\hline CHEMBL 3670706 & 1535379 & 5.0 & 5.282999 & 99999999995 & TST \\
\hline CHEMBL 3675549 & 1535379 & 5.0 & 4.4799 & TRN & \\
\hline CHEMBL 3670709 & 1535379 & 5.0 & 4.1877 & TST & \\
\hline CHEMBL3670714 & 1535379 & 5.0 & 4.8735 & TRN & \\
\hline CHEMBL3670698 & 1535379 & 5.0 & 6.0516 & TST & \\
\hline CHEMBL3675591 & 1535379 & 6.5467 & 5.7106 & TST & \\
\hline CHEMBL 3670697 & 1535379 & 4.0 & 5.6852 & TST & \\
\hline CHEMBL3670696 & 1535379 & 5.0 & 5.7905 & TST & \\
\hline CHEMBL3675590 & 1535379 & 5.0 & 5.4077 & TST & \\
\hline CHEMBL3670715 & 1535379 & 6.6289 & 6.6411 & TRN & \\
\hline CHEMBL3670701 & 1535379 & 5.0 & 5.8156 & TST & \\
\hline CHEMBL118458 & 41884 & 3.1192 & 3.3077 & TRN & \\
\hline CHEMBL432453 & 41884 & 5.1308 & 4.9337 & TRN & \\
\hline CHEMBL332070 & 41884 & 5.3872 & 4.4539 & TRN & \\
\hline CHEMBL118996 & 41884 & 5.5406 & 5.4408 & TRN & \\
\hline CHEMBL115688 & 41884 & 3.0862 & 3.5842 & TRN & \\
\hline CHEMBL118567 & 41884 & 6.3979 & 4.7103 & TRN & \\
\hline CHEMBL119099 & 41884 & 3.0458 & 3.7339 & TST & \\
\hline CHEMBL117560 & 41884 & 3.1675 & 3.2838 & TRN & \\
\hline CHEMBL334090 & 41884 & 3.0862 & 3.7215 & TRN & \\
\hline CHEMBL323724 & 41884 & 4.5482 & 4.7795 & TRN & \\
\hline CHEMBL326174 & 41884 & 4.9208 & 4.8104 & TRN & \\
\hline CHEMBL278493 & 41884 & 3.0757 & 4.4539 & TRN & \\
\hline CHEMBL115955 & 41884 & 4.5346 & 3.4481 & TRN & \\
\hline CHEMBL333293 & 41884 & 5.1024 & 3.5267 & TST & \\
\hline CHEMBL2111773 & 41884 & 6.1249 & 6.1597 & TRN & \\
\hline CHEMBL117497 & 41884 & 4.6108 & 5.3206 & TRN & \\
\hline CHEMBL116148 & 41884 & 3.1024 & 5.095 & TST & \\
\hline CHEMBL117709 & 41884 & 3.1079 & 4.5288 & TST & \\
\hline CHEMBL119451 & 41884 & 3.4948 & 4.0452 & TRN & \\
\hline CHEMBL118800 & 41884 & 5.284 & 5.6164 & TRN & \\
\hline CHEMBL119465 & 41884 & 3.0969 & 3.8121 & TST & \\
\hline CHEMBL119014 & 41884 & 5.8041 & 5.2598 & TRN & \\
\hline CHEMBL119177 & 41884 & 5.3335 & 5.025 & TRN & \\
\hline CHEMBL116534 & 41884 & 5.8539 & 5.6614 & TRN & \\
\hline CHEMBL117119 & 41884 & \multicolumn{3}{|c|}{ 4.76699999999999995 } & TRN \\
\hline CHEMBL 333292 & 41884 & 5.0969 & 4.2047 & TRN & \\
\hline CHEMBL119330 & 41884 & 3.0757 & 2.8496 & TRN & \\
\hline CHEMBL119115 & 41884 & 3.0862 & 3.6763 & TRN & \\
\hline CHEMBL117177 & 41884 & 6.4685 & 5.4512 & TRN & \\
\hline CHEMBL119305 & 41884 & 5.3188 & 5.5704 & TRN & \\
\hline CHEMBL332053 & 41884 & 3.699 & 3.506999 & 99999999997 & N \\
\hline CHEMBL116419 & 41884 & 5.1805 & 4.551 & TST & \\
\hline
\end{tabular}




\begin{tabular}{|c|c|c|c|c|c|}
\hline \multirow{3}{*}{$\begin{array}{l}\text { CHEMBL119381 } \\
\text { CHEMBL119813 }\end{array}$} & & \multicolumn{4}{|c|}{ Supplemental Table S2.txt } \\
\hline & 41884 & 6.0655 & \multicolumn{2}{|c|}{5.8629999999999995} & TRN \\
\hline & 41884 & 3.0969 & 4.0865 & TRN & \\
\hline CHEMBL119262 & 41884 & 5.3098 & 4.9998 & TRN & \\
\hline CHEMBL324152 & 41884 & 4.5918 & 5.0343 & TRN & \\
\hline CHEMBL119042 & 41884 & 5.6778 & 5.73 & TRN & \\
\hline CHEMBL326559 & 41884 & 5.1427 & 5.2019 & TRN & \\
\hline CHEMBL119419 & 41884 & 4.5272 & 5.0343 & TRN & \\
\hline CHEMBL331821 & 41884 & 3.1249 & 4.3676 & TRN & \\
\hline CHEMBL333434 & 41884 & 3.1079 & 4.0877 & TST & \\
\hline CHEMBL117685 & 41884 & 5.3565 & 5.9787 & TRN & \\
\hline CHEMBL116293 & 41884 & 4.7696 & 4.7646 & TRN & \\
\hline CHEMBL118774 & 41884 & 4.2336 & 4.4859 & TRN & \\
\hline CHEMBL117835 & 41884 & 5.9208 & 5.1326 & TRN & \\
\hline CHEMBL324966 & 41884 & 4.9355 & 5.4311 & TRN & \\
\hline CHEMBL117992 & 41884 & 3.0706 & 2.8928 & TRN & \\
\hline CHEMBL115846 & 41884 & 3.0757 & 2.8928 & TRN & \\
\hline CHEMBL324096 & 41884 & 5.5171 & 5.9787 & TRN & \\
\hline CHEMBL119344 & 41884 & 5.1427 & 5.2224 & TRN & \\
\hline CHEMBL118286 & 41884 & 3.1871 & 3.3892 & TST & \\
\hline CHEMBL265103 & 41884 & 3.0915 & 3.1958 & TST & \\
\hline CHEMBL119544 & 41884 & 4.4449 & 5.095 & TST & \\
\hline CHEMBL119176 & 41884 & 3.0555 & 3.5842 & TRN & \\
\hline CHEMBL412363 & 41884 & 4.752 & 4.7944 & TRN & \\
\hline CHEMBL435967 & 41884 & 3.1079 & 2.502 & TRN & \\
\hline CHEMBL325484 & 41884 & 3.0969 & 3.2069 & TRN & \\
\hline CHEMBL119364 & 41884 & 3.0862 & 3.5273 & TST & \\
\hline CHEMBL117927 & 41884 & 3.0915 & 3.5891 & TST & \\
\hline CHEMBL420702 & 41884 & 5.8601 & 5.4605 & TRN & \\
\hline CHEMBL119677 & 41884 & 5.4089 & 5.7423 & TRN & \\
\hline CHEMBL118732 & 41884 & 5.4202 & 5.7423 & TRN & \\
\hline CHEMBL333550 & 41884 & 3.1871 & 4.1332 & TRN & \\
\hline CHEMBL331593 & 41884 & 3.2007 & 3.3308 & TRN & \\
\hline CHEMBL119220 & 41884 & 3.1739 & 3.2838 & TRN & \\
\hline CHEMBL115973 & 41884 & 3.1675 & 3.4812 & TRN & \\
\hline CHEMBL117789 & 41884 & 5.3872 & 5.2224 & TRN & \\
\hline CHEMBL118301 & 41884 & 3.0757 & 3.5891 & TST & \\
\hline CHEMBL333278 & 41884 & 5.1024 & 4.9998 & TRN & \\
\hline CHEMBL119198 & 41884 & 3.1308 & 4.3638 & TST & \\
\hline CHEMBL116782 & 41884 & 4.5317 & 3.4478 & TST & \\
\hline CHEMBL119279 & 41884 & 5.7773 & 4.5976 & TRN & \\
\hline CHEMBL119897 & 41884 & 4.8955 & 4.3506 & TRN & \\
\hline CHEMBL117558 & 41884 & 5.0867 & 4.4859 & TRN & \\
\hline CHEMBL118579 & 41884 & 3.0757 & 3.7339 & TST & \\
\hline CHEMBL117498 & 41884 & 6.0605 & 5.9244 & TRN & \\
\hline CHEMBL119454 & 41884 & 3.2218 & 3.4206 & TRN & \\
\hline CHEMBL116925 & 41884 & 3.1024 & 3.9597 & TST & \\
\hline CHEMBL333217 & 41884 & 4.9872 & 5.2768 & TRN & \\
\hline CHEMBL115744 & 41884 & 5.301 & 4.9099 & TRN & \\
\hline & & & & 9227 & \\
\hline
\end{tabular}




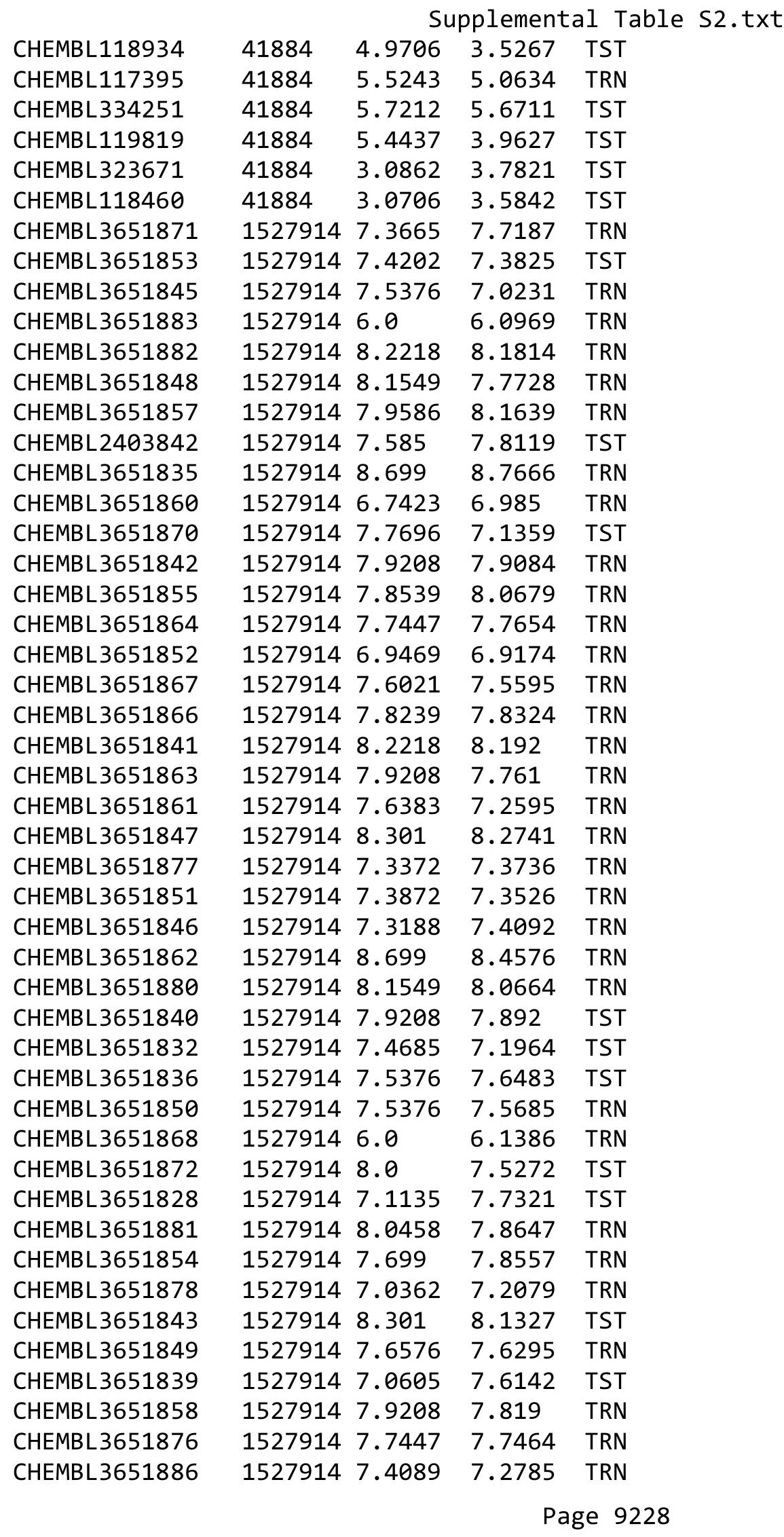


Supplemental Table S2.txt

\begin{tabular}{|c|c|c|c|c|c|}
\hline CHEMBL 3651833 & 1527914 & 8.2218 & 8.1336 & TST & \\
\hline CHEMBL3651875 & 1527914 & 8.2218 & 8.1775 & TRN & \\
\hline CHEMBL3651873 & 1527914 & 6.0 & 5.8139 & TRN & \\
\hline CHEMBL3651831 & 1527914 & 7.8861 & 7.2503 & TST & \\
\hline CHEMBL 3651844 & 1527914 & 7.8861 & 8.2279 & TRN & \\
\hline CHEMBL 3651834 & 1527914 & 7.4815 & 8.7408 & TST & \\
\hline CHEMBL3651827 & 1527914 & 8.0969 & 8.1631 & TST & \\
\hline CHEMBL 3651856 & 1527914 & 7.6778 & 7.7527 & TRN & \\
\hline CHEMBL 3651879 & 1527914 & 6.8097 & 7.1141 & TRN & \\
\hline CHEMBL3651859 & 1527914 & 6.2373 & 6.3982 & TRN & \\
\hline CHEMBL3651865 & 1527914 & 7.6778 & 7.5334 & TRN & \\
\hline CHEMBL3651885 & 1527914 & 7.3188 & 7.4004 & TRN & \\
\hline CHEMBL 3663866 & 1528831 & 7.0 & 6.4103 & TRN & \\
\hline CHEMBL3663864 & 1528831 & 4.301 & 6.2798 & TRN & \\
\hline CHEMBL3663877 & 1528831 & 7.0 & 6.6689 & TST & \\
\hline CHEMBL3960238 & 1528831 & 8.0 & 7.1605 & TST & \\
\hline CHEMBL3947504 & 1528831 & 6.0 & 6.41 & TRN & \\
\hline CHEMBL3968868 & 1528831 & 8.0 & 7.1936 & TRN & \\
\hline CHEMBL3663858 & 1528831 & 7.0 & 5.8867 & TRN & \\
\hline CHEMBL3663837 & 1528831 & 4.301 & 5.2397 & TRN & \\
\hline CHEMBL3665595 & 1528831 & 8.0 & 6.9518 & TST & \\
\hline CHEMBL3663865 & 1528831 & 6.0 & 6.4204 & TRN & \\
\hline CHEMBL3893789 & 1528831 & 7.0 & 7.0993 & TRN & \\
\hline CHEMBL3984442 & 1528831 & 7.0 & 7.1262 & TRN & \\
\hline CHEMBL3918314 & 1528831 & 7.0 & 7.1319 & TRN & \\
\hline CHEMBL3663818 & 1528831 & 6.0 & 5.2731 & TRN & \\
\hline CHEMBL3704484 & 1528831 & 6.699 & 6.6567 & TRN & \\
\hline CHEMBL3704485 & 1528831 & 7.0 & 7.1424 & TST & \\
\hline CHEMBL3663815 & 1528831 & 5.0 & 5.1625 & TRN & \\
\hline CHEMBL3663835 & 1528831 & 7.0 & \multicolumn{2}{|c|}{6.167000000000001} & TRN \\
\hline CHEMBL3918742 & 1528831 & 6.5229 & 7.0424 & TRN & \\
\hline CHEMBL3663838 & 1528831 & 7.0 & 6.2643 & TRN & \\
\hline CHEMBL3663814 & 1528831 & 4.0 & 4.476 & TRN & \\
\hline CHEMBL3980595 & 1528831 & 5.0 & 7.0076 & TST & \\
\hline CHEMBL3923430 & 1528831 & 7.301 & 7.0666 & TRN & \\
\hline CHEMBL3663816 & 1528831 & 4.301 & 4.4176 & TRN & \\
\hline CHEMBL3952698 & 1528831 & 7.0 & 7.2633 & TRN & \\
\hline CHEMBL3663809 & 1528831 & 5.0 & 5.2285 & TRN & \\
\hline CHEMBL3926016 & 1528831 & 7.0 & 7.0496 & TRN & \\
\hline CHEMBL3952433 & 1528831 & 7.0 & 6.876 & TRN & \\
\hline CHEMBL 3663811 & 1528831 & 6.0 & 5.9048 & TRN & \\
\hline CHEMBL3983089 & 1528831 & 8.0 & 7.1701 & TRN & \\
\hline CHEMBL3890230 & 1528831 & 8.0 & 7.2328 & TRN & \\
\hline CHEMBL3962018 & 1528831 & 6.5229 & 6.7254 & TST & \\
\hline CHEMBL3663862 & 1528831 & 6.5229 & 6.4742 & TRN & \\
\hline CHEMBL3665585 & 1528831 & 6.301 & 6.8878 & TST & \\
\hline CHEMBL3934862 & 1528831 & 6.5229 & 6.7969 & TRN & \\
\hline CHEMBL3892533 & 1528831 & 7.0 & 7.0797 & TST & \\
\hline
\end{tabular}




\begin{tabular}{|c|c|c|c|c|c|}
\hline \multicolumn{6}{|c|}{ Supplemental Table S2.txt } \\
\hline CHEMBL3928210 & 1528831 & 8.0 & 7.005 & TRN & \\
\hline CHEMBL3930694 & 1528831 & 6.0 & 6.8389 & TST & \\
\hline CHEMBL3663847 & 1528831 & 7.0 & 6.4317 & TST & \\
\hline CHEMBL3663849 & 1528831 & 7.0 & 6.8707 & TRN & \\
\hline CHEMBL3663820 & 1528831 & 6.301 & 5.6299 & TRN & \\
\hline CHEMBL3663859 & 1528831 & 4.5229 & 5.2846 & TST & \\
\hline CHEMBL3665598 & 1528831 & 8.0 & 6.7946 & TST & \\
\hline CHEMBL3975760 & 1528831 & 7.0 & 7.2119 & TRN & \\
\hline CHEMBL 3665587 & 1528831 & 6.5229 & 7.0433 & TST & \\
\hline CHEMBL3896983 & 1528831 & 6.5229 & 6.8828 & TRN & \\
\hline CHEMBL3965312 & 1528831 & 7.0 & 6.6313 & TRN & \\
\hline CHEMBL3915752 & 1528831 & 7.0 & 6.9204 & TRN & \\
\hline CHEMBL3974092 & 1528831 & 6.0 & 6.5644 & TRN & \\
\hline CHEMBL3663839 & 1528831 & 7.0 & 6.3762 & TRN & \\
\hline CHEMBL3894229 & 1528831 & 6.301 & 7.0274 & TST & \\
\hline CHEMBL3950747 & 1528831 & 7.0 & 6.7668 & TRN & \\
\hline CHEMBL3663812 & 1528831 & 6.301 & 5.466 & TRN & \\
\hline CHEMBL3981181 & 1528831 & 6.699 & 6.96399 & 99999999995 & TRN \\
\hline CHEMBL3663861 & 1528831 & 6.5229 & 6.5873 & TRN & \\
\hline CHEMBL3663840 & 1528831 & 5.0 & 5.2871 & TRN & \\
\hline CHEMBL3962400 & 1528831 & 7.0 & 6.9324 & TRN & \\
\hline CHEMBL3979126 & 1528831 & 7.301 & 6.9381 & TRN & \\
\hline CHEMBL3705041 & 1528831 & 4.0 & 6.05399 & 9999999999 & TST \\
\hline CHEMBL3665597 & 1528831 & 8.0 & 7.053 & TST & \\
\hline CHEMBL3986114 & 1528831 & 7.0 & 6.7201 & TRN & \\
\hline CHEMBL3983870 & 1528831 & 7.0 & 7.2592 & TRN & \\
\hline CHEMBL3663817 & 1528831 & 6.5229 & 5.9752 & TRN & \\
\hline CHEMBL3892878 & 1528831 & 8.0 & 7.1967 & TST & \\
\hline CHEMBL3665594 & 1528831 & 8.0 & 6.9485 & TST & \\
\hline CHEMBL3663827 & 1528831 & 7.0 & 6.3596 & TRN & \\
\hline CHEMBL3938694 & 1528831 & 6.0 & 6.6681 & TRN & \\
\hline CHEMBL3895445 & 1528831 & 7.301 & 6.8363 & TRN & \\
\hline CHEMBL3663867 & 1528831 & 6.301 & 5.41799 & 9999999999 & TRN \\
\hline CHEMBL 3663813 & 1528831 & 4.5229 & 5.4622 & TRN & \\
\hline CHEMBL3942156 & 1528831 & 7.0 & 7.0302 & TRN & \\
\hline CHEMBL3663831 & 1528831 & 6.301 & 5.432 & TRN & \\
\hline CHEMBL3906708 & 1528831 & 6.0 & 6.9066 & TST & \\
\hline CHEMBL3663829 & 1528831 & 6.301 & 5.3006 & TRN & \\
\hline CHEMBL3956957 & 1528831 & 6.5229 & 6.8814 & TRN & \\
\hline CHEMBL3977356 & 1528831 & 6.301 & 6.7546 & TST & \\
\hline CHEMBL3982406 & 1528831 & 7.0 & 7.0397 & TST & \\
\hline CHEMBL3901078 & 1528831 & 6.5229 & 6.5983 & TRN & \\
\hline CHEMBL3663810 & 1528831 & 6.0 & 5.7398 & TRN & \\
\hline CHEMBL 3663828 & 1528831 & 7.0 & 6.27 & TRN & \\
\hline CHEMBL3905926 & 1528831 & 7.0 & 7.1816 & TRN & \\
\hline CHEMBL3663852 & 1528831 & 4.301 & 6.6676 & TST & \\
\hline CHEMBL3938308 & 1528831 & 6.5229 & 6.9599 & TRN & \\
\hline CHEMBL3704482 & 1528831 & 7.0 & 6.7997 & TRN & \\
\hline
\end{tabular}




\begin{tabular}{|c|c|c|c|c|}
\hline \multicolumn{5}{|c|}{ Supplemental Table S2.txt } \\
\hline CHEMBL3944879 & 1528831 & 3.0 & 6.8675 & TST \\
\hline CHEMBL3978396 & 1528831 & 4.0 & 6.2257 & TST \\
\hline CHEMBL3704553 & 1528831 & 5.0 & 5.9447 & TRN \\
\hline CHEMBL 3663841 & 1528831 & 4.5229 & 5.3987 & TRN \\
\hline CHEMBL 3663855 & 1528831 & 6.0 & 6.5807 & TRN \\
\hline CHEMBL3976779 & 1528831 & 7.0 & 6.5419 & TRN \\
\hline CHEMBL3894231 & 1528831 & 6.301 & 7.2897 & TRN \\
\hline CHEMBL3969974 & 1528831 & 7.0 & 6.5966 & TRN \\
\hline CHEMBL3957534 & 1528831 & 7.0 & 7.2288 & TRN \\
\hline CHEMBL3966172 & 1528831 & 7.0 & 7.3432 & TRN \\
\hline CHEMBL 3663830 & 1528831 & 4.0 & 6.1788 & TRN \\
\hline CHEMBL 3663834 & 1528831 & 7.0 & 6.1711 & TRN \\
\hline CHEMBL3976715 & 1528831 & 7.0 & 6.2819 & TRN \\
\hline CHEMBL3911406 & 1528831 & 7.0 & 7.0734 & TRN \\
\hline CHEMBL 3902717 & 1528831 & 6.0 & 6.8916 & TST \\
\hline CHEMBL3929390 & 1528831 & 7.0 & 6.9473 & TRN \\
\hline CHEMBL3663819 & 1528831 & 4.0 & 4.5231 & TRN \\
\hline CHEMBL 3893571 & 1528831 & 7.0 & 7.1774 & TRN \\
\hline CHEMBL3959650 & 1528831 & 6.0 & 6.6138 & TRN \\
\hline CHEMBL3663836 & 1528831 & 5.0 & 5.2514 & TRN \\
\hline CHEMBL3663826 & 1528831 & 6.301 & 5.4399 & TRN \\
\hline CHEMBL3663848 & 1528831 & 7.0 & 6.8002 & TRN \\
\hline CHEMBL 3704487 & 1528831 & 7.0 & 6.6128 & TRN \\
\hline CHEMBL3663851 & 1528831 & 6.301 & 6.7736 & TRN \\
\hline CHEMBL3704486 & 1528831 & 6.699 & 6.5066 & TRN \\
\hline CHEMBL3915712 & 1528831 & 7.0 & 7.0162 & TRN \\
\hline CHEMBL3959463 & 1528831 & 6.5229 & 6.9412 & TRN \\
\hline CHEMBL 3935478 & 1528831 & 7.0 & 7.0797 & TRN \\
\hline CHEMBL 3663824 & 1528831 & 7.0 & 6.4744 & TRN \\
\hline CHEMBL3663876 & 1528831 & 7.0 & 6.5919 & TST \\
\hline CHEMBL3943710 & 1528831 & 6.5229 & 6.8723 & TRN \\
\hline CHEMBL3909310 & 1528831 & 7.0 & 6.7292 & TST \\
\hline CHEMBL3639627 & 1528831 & 7.0 & 6.56 & TRN \\
\hline CHEMBL3947481 & 1528831 & 7.0 & 6.8991 & TST \\
\hline CHEMBL3663857 & 1528831 & 6.301 & 6.3926 & TRN \\
\hline CHEMBL3940418 & 1528831 & 7.0 & 7.1631 & TST \\
\hline CHEMBL3971799 & 1528831 & 7.0 & 6.8407 & TRN \\
\hline CHEMBL3663856 & 1528831 & 6.0 & 6.5581 & TRN \\
\hline CHEMBL3928951 & 1528831 & 7.0 & 7.2968 & TRN \\
\hline CHEMBL 3948575 & 1528831 & 7.0 & 6.9725 & TRN \\
\hline CHEMBL3952156 & 1528831 & 7.0 & 6.9213 & TRN \\
\hline CHEMBL3704552 & 1528831 & 4.0 & 5.3415 & TRN \\
\hline CHEMBL3941207 & 1528831 & 7.0 & 7.0627 & TST \\
\hline CHEMBL3663846 & 1528831 & 4.0 & 6.0177 & TST \\
\hline CHEMBL 3937007 & 1528831 & 7.0 & 6.933 & TRN \\
\hline CHEMBL3665601 & 1528831 & 8.0 & 7.0676 & TST \\
\hline CHEMBL 3704554 & 1528831 & 5.0 & 5.2566 & TRN \\
\hline CHEMBL3896508 & 1528831 & 6.301 & 6.5538 & TST \\
\hline
\end{tabular}


Supplemental Table S2.txt

\begin{tabular}{|c|c|c|c|c|}
\hline CHEMBL3900109 & 1528831 & 7.0 & 6.68 & TST \\
\hline CHEMBL3663850 & 1528831 & 6.301 & 6.9473 & TRN \\
\hline CHEMBL3934326 & 1528831 & 7.0 & 6.88700 & 00000000005 \\
\hline CHEMBL 3897846 & 1528831 & 7.0 & 7.1329 & TST \\
\hline CHEMBL3704489 & 1528831 & 7.0 & 6.6937 & TRN \\
\hline CHEMBL3663853 & 1528831 & 6.301 & 6.7687 & TRN \\
\hline CHEMBL3958615 & 1528831 & 7.0 & 6.9865 & TRN \\
\hline CHEMBL3663832 & 1528831 & 7.0 & 6.4947 & TRN \\
\hline CHEMBL3663863 & 1528831 & 6.5229 & 6.3772 & TRN \\
\hline CHEMBL3663869 & 1528831 & 6.301 & 6.9048 & TST \\
\hline CHEMBL 384294 & 390501 & 7.7959 & 7.7712 & TRN \\
\hline CHEMBL 378831 & 390501 & 7.9208 & 7.9253 & TRN \\
\hline CHEMBL 377400 & 390501 & 6.9101 & 6.9204 & TRN \\
\hline CHEMBL212084 & 390501 & 6.8327 & 3.8802 & TST \\
\hline CHEMBL212986 & 390501 & 7.4685 & 7.4823 & TRN \\
\hline CHEMBL212499 & 390501 & 6.6737 & 6.6707 & TRN \\
\hline CHEMBL211464 & 390501 & 7.7212 & 7.7344 & TRN \\
\hline CHEMBL 213138 & 390501 & 5.5564 & 5.5764 & TRN \\
\hline CHEMBL211515 & 390501 & 4.9106 & 4.9135 & TRN \\
\hline CHEMBL215417 & 390501 & 5.5403 & 5.5411 & TRN \\
\hline CHEMBL384939 & 390501 & 4.6169 & 4.614 & TRN \\
\hline CHEMBL380068 & 390501 & 7.4559 & 7.465 & TRN \\
\hline CHEMBL380243 & 390501 & 7.6778 & 7.6811 & TRN \\
\hline CHEMBL379088 & 390501 & 7.5686 & 7.5601 & TRN \\
\hline CHEMBL213910 & 390501 & 7.9586 & 7.9513 & TRN \\
\hline CHEMBL 211567 & 390501 & 3.301 & 3.8503 & TST \\
\hline CHEMBL210070 & 390501 & 6.7852 & 6.7989 & TRN \\
\hline CHEMBL 209421 & 390501 & 6.9136 & 6.7861 & TRN \\
\hline CHEMBL443835 & 390501 & 3.301 & 3.0955 & TST \\
\hline CHEMBL 215563 & 390501 & 6.7447 & 6.7574 & TRN \\
\hline CHEMBL 213230 & 390501 & 4.6422 & 4.1478 & TST \\
\hline CHEMBL209971 & 390501 & 6.7447 & 6.8671 & TRN \\
\hline CHEMBL425615 & 390501 & 6.3526 & 6.4752 & TRN \\
\hline CHEMBL214109 & 390501 & 6.5867 & 6.5854 & TRN \\
\hline CHEMBL 225248 & 390501 & 6.7986 & 6.7978 & TRN \\
\hline CHEMBL 213743 & 390501 & 6.7447 & 4.3546 & TST \\
\hline CHEMBL213909 & 390501 & 6.5817 & 6.591 & TRN \\
\hline CHEMBL214161 & 390501 & 7.3188 & 7.4 & TRN \\
\hline CHEMBL212987 & 390501 & 5.1274 & 5.1526 & TRN \\
\hline CHEMBL415047 & 390501 & 6.5114 & 6.6003 & TRN \\
\hline CHEMBL 213430 & 390501 & 7.3468 & 7.3538 & TRN \\
\hline CHEMBL 209919 & 390501 & 7.2007 & 7.1998 & TRN \\
\hline CHEMBL209922 & 390501 & 6.7011 & 6.6074 & TRN \\
\hline CHEMBL 213270 & 390501 & 6.767 & 6.7467 & TRN \\
\hline CHEMBL 2096839 & 390501 & 6.983 & 6.9063 & TRN \\
\hline CHEMBL213507 & 390501 & 7.2147 & 7.0985 & TRN \\
\hline CHEMBL380397 & 390501 & 7.1024 & 7.1007 & TRN \\
\hline CHEMBL212932 & 390501 & 7.7696 & 7.7885 & TRN \\
\hline
\end{tabular}




\begin{tabular}{|c|c|c|c|c|}
\hline \multicolumn{5}{|c|}{ Supplementa } \\
\hline HEMBL 212985 & 390501 & 6.7986 & & TR \\
\hline HEMBL 213796 & 90501 & 6.3382 & 6.3168 & \\
\hline HEMBL425262 & 1 & 81 & .2923 & \\
\hline HEMBL 215948 & & & & \\
\hline HEMBL 214214 & 90501 & 201 & 2873 & \\
\hline HEMBL 212762 & 90501 & 5513 & 164 & \\
\hline HEMBL 211307 & 90501 & 9914 & 7.0384 & \\
\hline HEMBL 2 & & & 7.1204 & \\
\hline HEMBL 2 & 1 & .6778 & 3941 & \\
\hline HEMBL: & & & 68 & \\
\hline HEMBL210113 & 90501 & 5.7352 & 7.1418 & \\
\hline HEMBL 378895 & 01 & .699 & 7.4052 & \\
\hline HEMBL] & 3 & 4.75 & 4.5312 & \\
\hline HEMBL & 3 & 57 & 5.2 & \\
\hline HEMB & 3 & & & \\
\hline HEMBL & 23 & 4.5493 & 6.4595 & \\
\hline HEMBL3 & 23 & & & \\
\hline HEMBL: & 68 & 2. & 4 & \\
\hline HEMBL & 3 & & & \\
\hline HEME & 23 & & & \\
\hline 001 & 23 & & 621 & \\
\hline HEMBL: & 23 & & & \\
\hline HEMBL & 68 & 4. & 5. & \\
\hline HEME & 3 & & & \\
\hline 93 & 23 & & & \\
\hline 667 & & & & \\
\hline HEMBL: & 23 & & & \\
\hline HEMBL1 & 68 & & 32 & RN \\
\hline HEMI & 3 & & & \\
\hline 28 & 23 & 88 & 52 & \\
\hline 686 & & & & TRN \\
\hline CHEMBL 1 & 68 & 8 & & 11 \\
\hline CHEMBL & & & & TST \\
\hline 15 & 3 & & 26 & rRN \\
\hline 17 & 3 & 27 & 85 & RN \\
\hline HEMBL: & 23 & & 57 & Rs \\
\hline CHEMBL3 & 688 & & & \\
\hline 90 & & & & RIN \\
\hline HEMI & 3 & 8 & 4. & $\mathrm{RN}$ \\
\hline CHEME & & 3375 & 92 & rRN \\
\hline CHEMBL1 & 688 & & 6.1074 & TRA \\
\hline CHEMBL 1 & 688 & 4.77 & & \\
\hline CHEMI & & & & nI \\
\hline CHEMBL: & 3 & 2.9208 & 2.9103 & $\mathrm{RN}$ \\
\hline CHEMBL 1 & 23 & 3.2218 & 4.2646 & RN \\
\hline CHEMBL1 & 6886 & 2.9208 & 4.5352 & TRN \\
\hline CHEMBL3 & 6886 & 4.7526 & 4.8278 & \\
\hline CHEMBL1537452 & 688623 & 6.7852 & 5.9509 & RN \\
\hline
\end{tabular}

Page 9233 
Supplemental Table S2.txt

\begin{tabular}{|c|c|c|c|c|c|}
\hline CHEMBL1341872 & 688623 & 2.9208 & 3.0651 & TST & \\
\hline CHEMBL1558903 & 688623 & 2.9208 & 3.2524 & TRN & \\
\hline CHEMBL1368343 & 688623 & 2.9208 & 3.7915 & TRN & \\
\hline CHEMBL3196936 & 688623 & 5.1391 & 4.8655 & TRN & \\
\hline CHEMBL1489856 & 688623 & 4.416 & 4.1715 & TRN & \\
\hline CHEMBL1592917 & 688623 & 2.9208 & 4.5436 & TST & \\
\hline CHEMBL1471887 & 688623 & 2.9208 & 3.6522 & TRN & \\
\hline CHEMBL1450354 & 688623 & 2.9208 & 3.5751 & TRN & \\
\hline CHEMBL1986678 & 688623 & 4.9568 & 4.9012 & TRN & \\
\hline CHEMBL3198239 & 688623 & 4.8836 & 3.6962 & TRN & \\
\hline CHEMBL406845 & 688623 & 4.907 & 4.912 & TRN & \\
\hline CHEMBL1542839 & 688623 & 2.9208 & 3.2823 & TRN & \\
\hline CHEMBL1334291 & 688623 & 4.9196 & 4.3639 & TST & \\
\hline CHEMBL1493561 & 688623 & 2.9208 & 3.7525 & TRN & \\
\hline CHEMBL1398933 & 688623 & 6.4425 & 4.7011 & TRN & \\
\hline CHEMBL1332529 & 688623 & 2.9208 & 4.1825 & TRN & \\
\hline CHEMBL1367089 & 688623 & 4.6375 & 4.0195 & TRN & \\
\hline CHEMBL1464984 & 688623 & 5.0215 & 4.2447 & TRN & \\
\hline CHEMBL1391387 & 688623 & 5.4812 & 5.8762 & TRN & \\
\hline CHEMBL 76887 & 688623 & 4.8989 & 4.5973 & TRN & \\
\hline CHEMBL3196324 & 688623 & 6.2328 & 5.6746 & TRN & \\
\hline CHEMBL1306265 & 688623 & 2.9208 & 4.0205 & TRN & \\
\hline CHEMBL1420319 & 688623 & 5.2459 & 6.6953 & TRN & \\
\hline CHEMBL1539531 & 688623 & 2.9208 & 3.493006 & 20000000003 & TRN \\
\hline CHEMBL1542833 & 688623 & 5.082 & 4.8231 & TRN & \\
\hline CHEMBL1466871 & 688623 & 2.9208 & 3.72899 & 99999999996 & TRN \\
\hline CHEMBL1996189 & 688623 & 8.0 & 5.643 & TRN & \\
\hline CHEMBL1576754 & 688623 & 4.8247 & 3.5462 & TRN & \\
\hline CHEMBL1444941 & 688623 & 2.9208 & 3.8842 & TRN & \\
\hline CHEMBL1340220 & 688623 & 4.8881 & 4.3865 & TRN & \\
\hline CHEMBL1594171 & 688623 & 4.6888 & 4.5774 & TRN & \\
\hline CHEMBL1598196 & 688623 & 2.9208 & 3.0092 & TRN & \\
\hline CHEMBL1314284 & 688623 & 6.8962 & 5.0691 & TRN & \\
\hline CHEMBL1341442 & 688623 & 6.5361 & 4.6577 & TRN & \\
\hline CHEMBL1477773 & 688623 & 4.8556 & 4.378 & TRN & \\
\hline CHEMBL1302266 & 688623 & 5.0555 & 5.0902 & TRN & \\
\hline CHEMBL1395907 & 688623 & 5.0826 & 4.0096 & TRN & \\
\hline CHEMBL175434 & 688623 & 4.6133 & 3.9342 & TRN & \\
\hline CHEMBL 3196726 & 688623 & 4.9624 & 3.2734 & TRN & \\
\hline CHEMBL1991327 & 688623 & 4.8572 & 4.4584 & TRN & \\
\hline CHEMBL1335000 & 688623 & 4.8522 & 3.4473 & TRN & \\
\hline CHEMBL1333491 & 688623 & 4.7196 & 4.28 & TRN & \\
\hline CHEMBL1464180 & 688623 & 4.6073 & 4.721 & TRN & \\
\hline CHEMBL1430657 & 688623 & 2.9208 & 3.3775 & TRN & \\
\hline CHEMBL1492266 & 688623 & 2.9208 & 4.3119 & TRN & \\
\hline CHEMBL1213281 & 688623 & 4.636 & 4.643 & TRN & \\
\hline CHEMBL1340698 & 688623 & 4.8989 & 4.6896 & TRN & \\
\hline CHEMBL1590805 & 688623 & 4.4389 & 4.2879 & TRN & \\
\hline
\end{tabular}




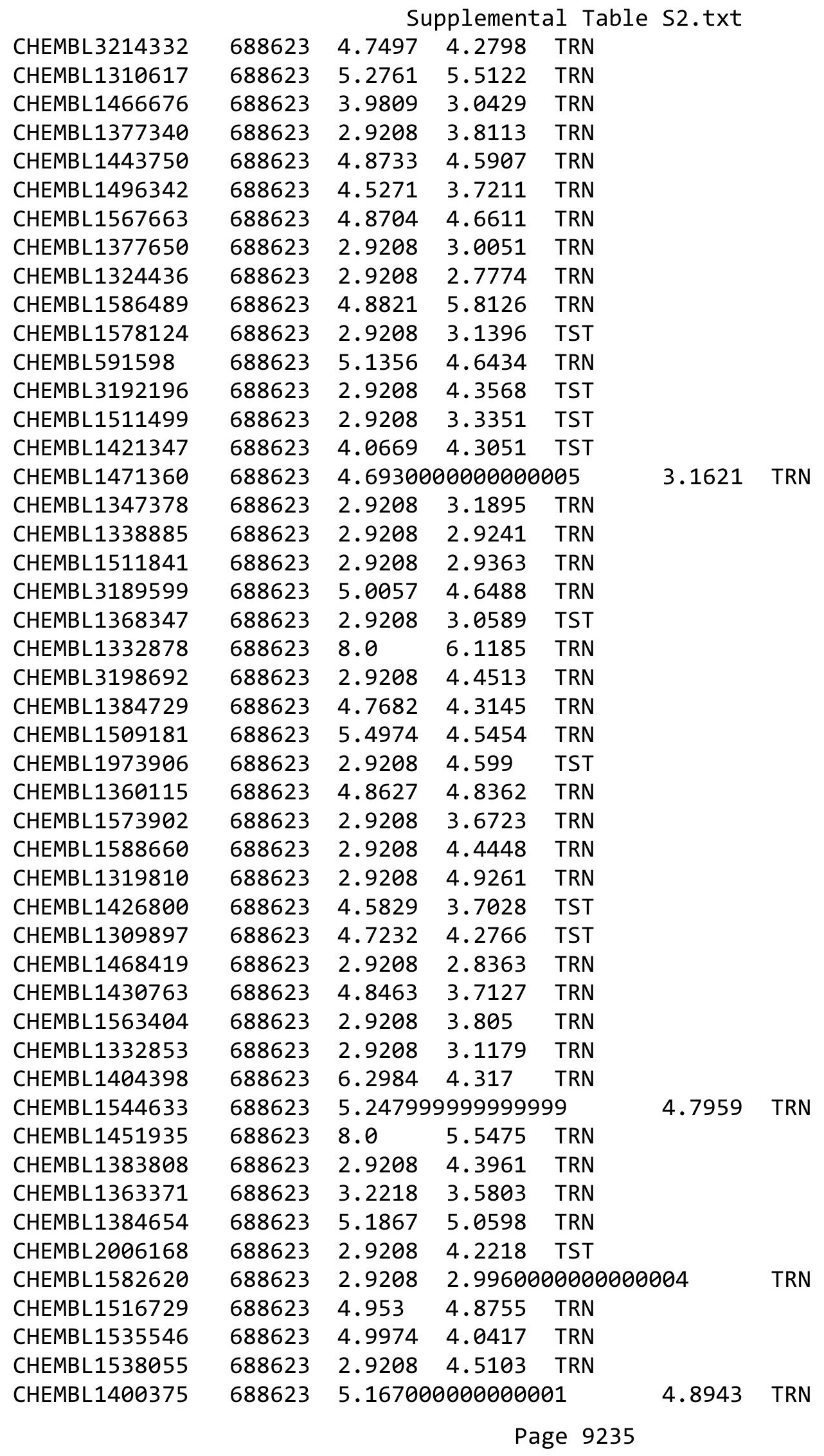




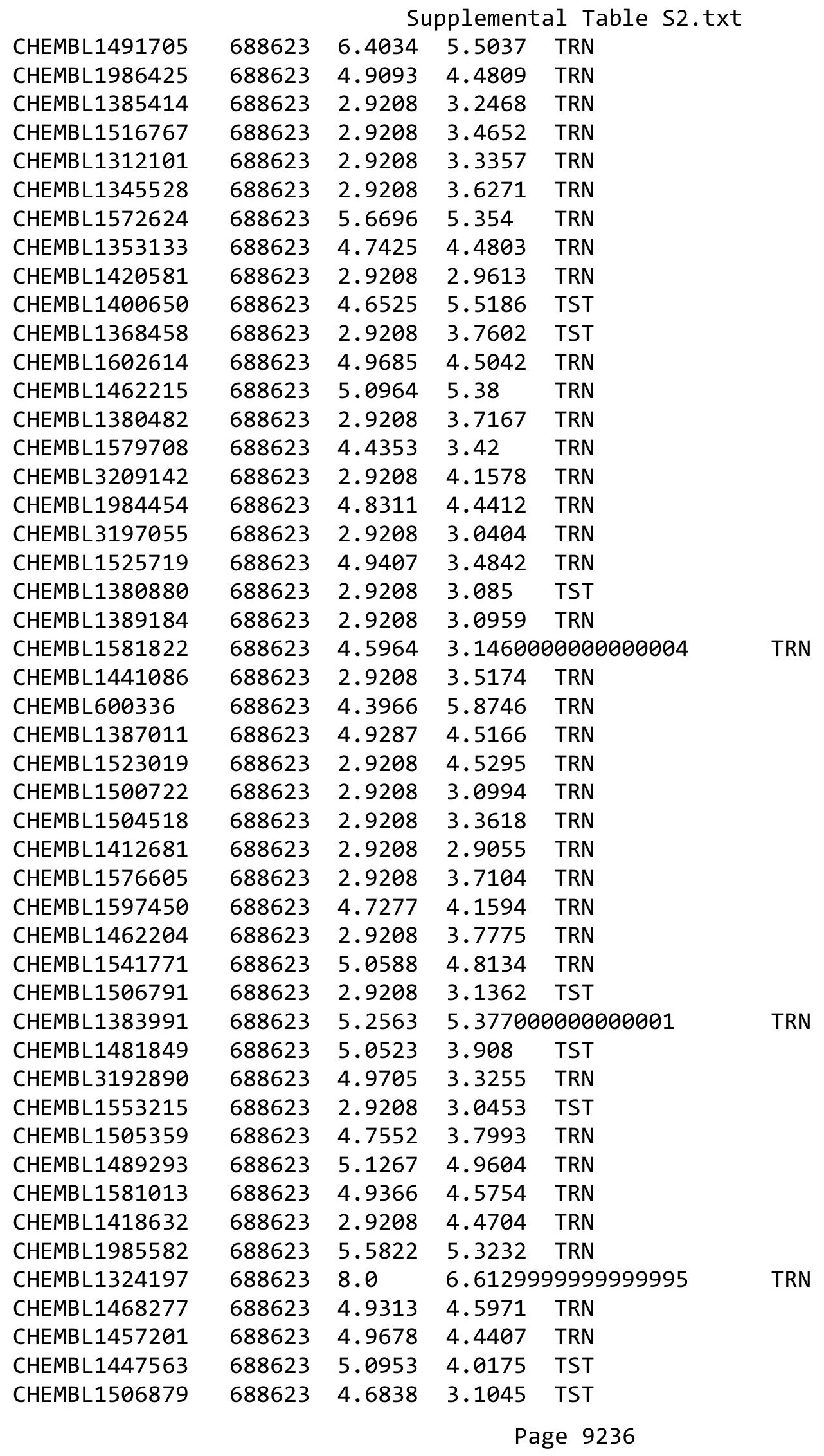


Supplemental Table S2.txt

\begin{tabular}{|c|c|c|c|c|c|}
\hline CHEMBL1445707 & 688623 & 5.697 & 5.0745 & TST & \\
\hline CHEMBL1313968 & 688623 & 4.9203 & 5.0689 & TRN & \\
\hline CHEMBL2002849 & 688623 & 5.0228 & 3.3953 & TRN & \\
\hline CHEMBL2369172 & 688623 & 2.9208 & 4.4336 & TRN & \\
\hline CHEMBL1586806 & 688623 & 2.9208 & 3.1671 & TST & \\
\hline CHEMBL1526550 & 688623 & 4.4728 & 3.0594 & TRN & \\
\hline CHEMBL1569107 & 688623 & 4.8778 & 3.1946 & TRN & \\
\hline CHEMBL1613695 & 688623 & 5.0882 & 4.5828 & TST & \\
\hline CHEMBL1486733 & 688623 & 4.9063 & 3.8277 & TST & \\
\hline CHEMBL1491827 & 688623 & 2.9208 & 4.0876 & TRN & \\
\hline CHEMBL1326584 & 688623 & 4.5598 & 4.7271 & TRN & \\
\hline CHEMBL1367325 & 688623 & 5.1237 & 4.9344 & TRN & \\
\hline CHEMBL1418611 & 688623 & 4.9171 & 4.1827 & TRN & \\
\hline CHEMBL1306565 & 688623 & 4.9437 & 4.4857 & TST & \\
\hline CHEMBL1343569 & 688623 & 2.9208 & 3.043999 & 79999999996 & TRN \\
\hline CHEMBL1375094 & 688623 & 2.9208 & 3.7193 & TRN & \\
\hline CHEMBL1565969 & 688623 & 2.9208 & 3.9621 & TRN & \\
\hline CHEMBL1317322 & 688623 & 5.3625 & 4.5483 & TRN & \\
\hline CHEMBL469036 & 688623 & 2.9208 & 3.7649 & TST & \\
\hline CHEMBL1490480 & 688623 & 2.9208 & 3.9804 & TRN & \\
\hline CHEMBL1380594 & 688623 & 2.9208 & 3.682 & TRN & \\
\hline CHEMBL1986081 & 688623 & 5.1003 & 4.651 & TRN & \\
\hline CHEMBL1609081 & 688623 & 4.7909 & 4.2436 & TRN & \\
\hline CHEMBL1523206 & 688623 & 5.2696 & 4.8782 & TRN & \\
\hline CHEMBL1560772 & 688623 & 2.9208 & 3.5391 & TRN & \\
\hline CHEMBL1360539 & 688623 & 5.13899 & 999999999 & 4.8912 & TRN \\
\hline CHEMBL1382361 & 688623 & 4.7232 & 4.1727 & TRN & \\
\hline CHEMBL1372163 & 688623 & 8.0 & 6.3092 & TRN & \\
\hline CHEMBL1590016 & 688623 & 5.1635 & 5.0049 & TRN & \\
\hline CHEMBL1432711 & 688623 & 4.5714 & 4.3292 & TRN & \\
\hline CHEMBL1495089 & 688623 & 2.9208 & 4.2586 & TRN & \\
\hline CHEMBL1378768 & 688623 & 4.3406 & 3.8908 & TST & \\
\hline CHEMBL1582086 & 688623 & 2.9208 & 3.7315 & TRN & \\
\hline CHEMBL1321333 & 688623 & 4.2033 & 3.3874 & TRN & \\
\hline CHEMBL1310101 & 688623 & 2.9208 & 3.8901 & TRN & \\
\hline CHEMBL1468954 & 688623 & 3.2218 & 3.2494 & TRN & \\
\hline CHEMBL470881 & 688623 & 5.0052 & 4.1005 & TST & \\
\hline CHEMBL1567908 & 688623 & 2.9208 & 2.8663 & TRN & \\
\hline CHEMBL1521660 & 688623 & 2.9208 & 3.8325 & TRN & \\
\hline CHEMBL3197771 & 688623 & 4.8827 & 4.5442 & TRN & \\
\hline CHEMBL1491327 & 688623 & 5.2773 & 5.0781 & TRN & \\
\hline CHEMBL1352854 & 688623 & 5.3606 & 6.1125 & TST & \\
\hline CHEMBL1533242 & 688623 & 2.9208 & 3.1551 & TST & \\
\hline CHEMBL1999193 & 688623 & 2.9208 & 3.3439 & TRN & \\
\hline CHEMBL1509721 & 688623 & 4.7679 & 3.8217 & TRN & \\
\hline CHEMBL1431241 & 688623 & 4.9718 & 3.8034 & TRN & \\
\hline CHEMBL1396209 & 688623 & 5.3561 & 6.1433 & TRN & \\
\hline CHEMBL1611686 & 688623 & 2.9208 & 4.0449 & TRN & \\
\hline
\end{tabular}

Page 9237 


\begin{tabular}{|c|c|c|c|c|}
\hline & & & oplement & al $\mathrm{T}$ \\
\hline CHEMBL 3213574 & 688623 & 5.8545 & 5.7065 & TRN \\
\hline CHEMBL1412184 & 688623 & 2.9208 & 3.7694 & TRN \\
\hline CHEMBL1497295 & 688623 & 4.8108 & 4.6757 & TRN \\
\hline CHEMBL1480548 & 688623 & 2.9208 & 3.7907 & TRN \\
\hline CHEMBL1500397 & 688623 & 4.7494 & 3.9497 & TRN \\
\hline CHEMBL1613639 & 688623 & 6.8729 & 5.5149 & TRN \\
\hline CHEMBL1323412 & 688623 & 4.7741 & 4.504 & TRN \\
\hline CHEMBL1321326 & 688623 & 6.644 & 5.375 & TRN \\
\hline CHEMBL1426636 & 688623 & 4.4569 & 4.3458 & TRN \\
\hline CHEMBL1320755 & 688623 & 4.7223 & 3.6182 & TRN \\
\hline CHEMBL1443472 & 688623 & 2.9208 & 3.0984 & TST \\
\hline CHEMBL1559811 & 688623 & 5.0404 & 6.6825 & TRN \\
\hline CHEMBL1333294 & 688623 & 6.5186 & 6.391 & TRN \\
\hline CHEMBL1570761 & 688623 & 2.9208 & 4.1957 & TRN \\
\hline CHEMBL1497821 & 688623 & 2.9208 & 3.036 & TRN \\
\hline CHEMBL1386669 & 688623 & 2.9208 & 2.8635 & TRN \\
\hline CHEMBL1487444 & 688623 & 5.2024 & 4.479 & TRN \\
\hline CHEMBL1464261 & 688623 & 4.5125 & 3.9953 & TRN \\
\hline CHEMBL1342336 & 688623 & 8.0 & 7.0072 & TRN \\
\hline CHEMBL1387528 & 688623 & 2.9208 & 3.1025 & TST \\
\hline CHEMBL1412554 & 688623 & 2.9208 & 3.0447 & TRN \\
\hline CHEMBL1450690 & 688623 & 2.9208 & 3.8557 & TRN \\
\hline CHEMBL1453061 & 688623 & 2.9208 & 4.3177 & TRN \\
\hline CHEMBL1575124 & 688623 & 5.2037 & 5.2307 & TRN \\
\hline CHEMBL1567317 & 688623 & 4.9676 & 5.0287 & TRN \\
\hline CHEMBL1535361 & 688623 & 4.8153 & 4.8404 & TRN \\
\hline CHEMBL1420056 & 688623 & 2.9208 & 3.5144 & TST \\
\hline CHEMBL1575284 & 688623 & 4.6974 & 4.2798 & TRN \\
\hline CHEMBL1595938 & 688623 & 4.7848 & 3.9623 & TRN \\
\hline CHEMBL1378991 & 688623 & 2.9208 & 3.3688 & TRN \\
\hline CHEMBL1606328 & 688623 & 4.9791 & 4.5386 & TRN \\
\hline CHEMBL1562936 & 688623 & 2.9208 & 3.715 & TRN \\
\hline CHEMBL1496138 & 688623 & 4.8484 & 3.9177 & TRN \\
\hline CHEMBL1438210 & 688623 & 4.9192 & 4.2509 & TRN \\
\hline CHEMBL1537857 & 688623 & 4.9337 & 4.6126 & TST \\
\hline CHEMBL1388404 & 688623 & 2.9208 & 4.3608 & TST \\
\hline CHEMBL1463463 & 688623 & 4.5486 & 4.2376 & TRN \\
\hline CHEMBL 2004242 & 688623 & 2.9208 & 3.2971 & TRN \\
\hline CHEMBL546170 & 688623 & 6.8996 & 4.9862 & TRN \\
\hline CHEMBL1540112 & 688623 & 5.2362 & 5.6748 & TRN \\
\hline CHEMBL1309980 & 688623 & 2.9208 & 3.9118 & TRN \\
\hline CHEMBL461579 & 688623 & 5.2428 & 5.8913 & TRN \\
\hline CHEMBL1347346 & 688623 & 6.7825 & 6.539 & TRN \\
\hline CHEMBL1420837 & 688623 & 4.8709 & 4.6086 & TRN \\
\hline CHEMBL1436569 & 688623 & 4.6821 & 4.3406 & TRN \\
\hline CHEMBL1310514 & 688623 & 2.9208 & 4.1155 & TRN \\
\hline CHEMBL3197126 & 688623 & 5.9957 & 5.2811 & TRN \\
\hline CHEMBL3208398 & 688623 & 2.9208 & 3.7609 & TRN \\
\hline
\end{tabular}


Supplemental Table S2.txt

\begin{tabular}{|c|c|c|c|c|c|}
\hline CHEMBL1604296 & 688623 & 5.0175 & 4.7164 & TRN & \\
\hline CHEMBL1609807 & 688623 & 2.9208 & 3.4554 & TST & \\
\hline CHEMBL1484558 & 688623 & 2.9208 & 4.5761 & TST & \\
\hline CHEMBL1303404 & 688623 & 5.2442 & 4.9602 & TRN & \\
\hline CHEMBL1320068 & 688623 & 2.9208 & 4.173 & TRN & \\
\hline CHEMBL1380781 & 688623 & 5.5462 & 4.8712 & TRN & \\
\hline CHEMBL1468700 & 688623 & 2.9208 & 3.8267 & TRN & \\
\hline CHEMBL1999480 & 688623 & 5.2363 & 4.8356 & TRN & \\
\hline CHEMBL1573212 & 688623 & 2.9208 & 2.96 & TRN & \\
\hline CHEMBL1367134 & 688623 & 2.9208 & 3.0989 & TST & \\
\hline CHEMBL1602637 & 688623 & 6.7905 & 5.9377 & TRN & \\
\hline CHEMBL1565674 & 688623 & 2.9208 & 3.9486 & TRN & \\
\hline CHEMBL1547706 & 688623 & 6.4698 & 5.2158 & TRN & \\
\hline CHEMBL1362086 & 688623 & 2.9208 & 3.796999 & 99999999997 & TRN \\
\hline CHEMBL1384292 & 688623 & 8.0 & 5.9892 & TRN & \\
\hline CHEMBL1300069 & 688623 & 5.0102 & 3.3142 & TRN & \\
\hline CHEMBL1561111 & 688623 & 4.8362 & 3.9254 & TRN & \\
\hline CHEMBL1506364 & 688623 & 2.9208 & 3.738 & TST & \\
\hline CHEMBL1397452 & 688623 & 4.9832 & 4.6916 & TRN & \\
\hline CHEMBL484744 & 688623 & 2.9208 & 3.9796 & TRN & \\
\hline CHEMBL1493118 & 688623 & 4.7081 & 4.2775 & TRN & \\
\hline CHEMBL1466102 & 688623 & 5.4388 & 4.9022 & TRN & \\
\hline CHEMBL1463699 & 688623 & 2.9208 & 4.365 & TRN & \\
\hline CHEMBL1466222 & 688623 & 4.6369 & 4.7344 & TRN & \\
\hline CHEMBL1562367 & 688623 & 2.9208 & 3.5297 & TRN & \\
\hline CHEMBL3193010 & 688623 & 2.9208 & 3.7192 & TRN & \\
\hline CHEMBL1359973 & 688623 & 2.9208 & 3.236 & TST & \\
\hline CHEMBL1563424 & 688623 & 2.9208 & 3.5208 & TRN & \\
\hline CHEMBL1389427 & 688623 & 4.9441 & 4.4872 & TRN & \\
\hline CHEMBL1466145 & 688623 & 4.7461 & 3.72 & TRN & \\
\hline CHEMBL1256686 & 688623 & 6.5735 & 5.6147 & TST & \\
\hline CHEMBL1485975 & 688623 & 5.1321 & 4.1784 & TRN & \\
\hline CHEMBL1456009 & 688623 & 2.9208 & 3.7213 & TRN & \\
\hline CHEMBL1535225 & 688623 & \multicolumn{2}{|c|}{5.388999999999999} & 5.1612 & TRN \\
\hline CHEMBL1972216 & 688623 & 5.3476 & 5.4353 & TRN & \\
\hline CHEMBL1342029 & 688623 & 2.9208 & 4.2652 & TRN & \\
\hline CHEMBL1452391 & 688623 & 2.9208 & 5.2668 & TRN & \\
\hline CHEMBL1306018 & 688623 & 2.9208 & 2.8545 & TRN & \\
\hline CHEMBL1333962 & 688623 & 4.8395 & 3.5587 & TRN & \\
\hline CHEMBL1416089 & 688623 & 5.0701 & 4.2091 & TRN & \\
\hline CHEMBL1585733 & 688623 & 5.522 & 4.8235 & TRN & \\
\hline CHEMBL1563201 & 688623 & \multicolumn{3}{|c|}{6.7620000000000005} & TRN \\
\hline CHEMBL1399858 & 688623 & 2.9208 & 3.661 & TRN & \\
\hline CHEMBL1489585 & 688623 & 4.7776 & 4.4589 & TRN & \\
\hline CHEMBL1332139 & 688623 & 6.9872 & 6.7936 & TRN & \\
\hline CHEMBL1557333 & 688623 & 4.7346 & 4.1909 & TRN & \\
\hline CHEMBL1558285 & 688623 & 4.5871 & 4.8475 & TRN & \\
\hline CHEMBL1344340 & 688623 & 2.9208 & 3.0303 & TRN & \\
\hline
\end{tabular}


Supplemental Table S2.txt

\begin{tabular}{|c|c|c|c|c|}
\hline IEMBL1542614 & & 9208 & 4.21 & \\
\hline & & & & \\
\hline MRI 1455499 & & & & \\
\hline EMBL & 8623 & & & \\
\hline IEMBL] & 8623 & & & \\
\hline AEMBL: & 38623 & 56 & 2 & \\
\hline 194 & 8623 & & & \\
\hline 622 & 8623 & & & \\
\hline IEMBL & 38623 & & & \\
\hline AEMBL: & 88623 & 4.8721 & & \\
\hline 716 & 88623 & & & \\
\hline 862 & 23 & & & \\
\hline 336 & & & & \\
\hline 6096 & 88623 & & & \\
\hline IEMBL & 88623 & & & \\
\hline IEMB| & 886 & & 8 & \\
\hline 508 & 23 & & & \\
\hline IEMBL & 8623 & & & \\
\hline 156 & 88623 & & & \\
\hline IEMBL & 23 & & & \\
\hline 29 & 88 & & & \\
\hline 19 & & & & RN \\
\hline 09 & 23 & & & \\
\hline 312 & 88623 & & & \\
\hline EMBL & 3 & & & \\
\hline 535 & 886 & & & ונ \\
\hline & & & & RN \\
\hline 19 & 23 & & & \\
\hline 361 & & & & RN \\
\hline 195 & 3 & & & \\
\hline & 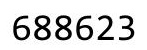 & & & RI \\
\hline & & & 4. & \\
\hline 12 & 3 & & 25 & RN \\
\hline 445 & & & & RN \\
\hline 391 & 886 & & & \\
\hline & & & & R \\
\hline & & & 3. & \\
\hline & & & & RI \\
\hline IEMBL: & 88623 & & & RI \\
\hline 206 & 88623 & & & \\
\hline & & & & RI \\
\hline 204 & 688623 & & 3.4249 & \\
\hline 095 & & & & RI \\
\hline 680 & 88623 & 2. & & $\mathrm{R}$ \\
\hline 639 & 000 & & 57 & $\mathrm{~S}$ \\
\hline 204 & 6886 & & & $\mathbf{R}$ \\
\hline 168 & 88623 & & 3.4771 & \\
\hline CHEMBL1987461 & 688623 & 5.3678 & 5.064 & \\
\hline
\end{tabular}

Page 9240 
Supplemental Table S2.txt

\begin{tabular}{|c|c|c|c|c|c|}
\hline CHEMBL1405648 & 688623 & 2.9208 & 3.2354 & TRN & \\
\hline CHEMBL1544095 & 688623 & 2.9208 & 3.133 & TRN & \\
\hline CHEMBL1403917 & 688623 & 4.9268 & 4.4294 & TRN & \\
\hline CHEMBL1560066 & 688623 & 4.9752 & 4.6988 & TRN & \\
\hline CHEMBL1458306 & 688623 & 2.9208 & 4.2781 & TRN & \\
\hline CHEMBL1613218 & 688623 & 4.3841 & 4.4816 & TRN & \\
\hline CHEMBL 2006844 & 688623 & 2.9208 & 4.7103 & TRN & \\
\hline CHEMBL1323461 & 688623 & 4.5737 & 4.3671 & TRN & \\
\hline CHEMBL1343081 & 688623 & 2.9208 & 3.4096 & TRN & \\
\hline CHEMBL1420659 & 688623 & 2.9208 & 4.2515 & TRN & \\
\hline CHEMBL1567469 & 688623 & 2.9208 & 3.1155 & TST & \\
\hline CHEMBL1323968 & 688623 & 6.4389 & 4.8695 & TST & \\
\hline CHEMBL1421170 & 688623 & 8.0 & 5.4596 & TRN & \\
\hline CHEMBL3211923 & 688623 & 4.8388 & 4.5528 & TRN & \\
\hline CHEMBL1546607 & 688623 & 4.8967 & 3.8922 & TRN & \\
\hline CHEMBL3190805 & 688623 & 5.0138 & 5.0547 & TRN & \\
\hline CHEMBL1493731 & 688623 & 5.0398 & 6.4241 & TRN & \\
\hline CHEMBL3196134 & 688623 & 5.0332 & 4.8753 & TRN & \\
\hline CHEMBL1464424 & 688623 & 5.3011 & 4.9937 & TRN & \\
\hline CHEMBL1425426 & 688623 & 2.9208 & 4.2672 & TRN & \\
\hline CHEMBL3195273 & 688623 & 6.1898 & 5.6604 & TRN & \\
\hline CHEMBL1306095 & 688623 & 2.9208 & 3.2197 & TRN & \\
\hline CHEMBL1611300 & 688623 & 5.092 & \multicolumn{2}{|c|}{5.281000000000001} & TRN \\
\hline CHEMBL1530743 & 688623 & 5.5488 & 4.9926 & TRN & \\
\hline CHEMBL1574778 & 688623 & 4.5552 & 4.9695 & TRN & \\
\hline CHEMBL3189613 & 688623 & 5.0369 & 4.7889 & TRN & \\
\hline CHEMBL1446341 & 688623 & 4.7287 & 3.5997 & TST & \\
\hline CHEMBL1547760 & 688623 & 6.8477 & 5.7373 & TRN & \\
\hline CHEMBL1343705 & 688623 & 5.1518 & 4.3513 & TRN & \\
\hline CHEMBL1563337 & 688623 & 4.3913 & 4.3852 & TRN & \\
\hline CHEMBL3213208 & 688623 & 4.7382 & 3.1788 & TRN & \\
\hline CHEMBL3196364 & 688623 & 5.0131 & 4.7168 & TRN & \\
\hline CHEMBL270605 & 688623 & 4.9343 & 3.7447 & TRN & \\
\hline CHEMBL1405413 & 688623 & 4.8674 & 4.0176 & TRN & \\
\hline CHEMBL1419114 & 688623 & 4.6481 & 4.455 & TRN & \\
\hline CHEMBL601757 & 688623 & 6.6003 & 5.5604 & TRN & \\
\hline CHEMBL1353693 & 688623 & 4.8471 & 4.6381 & TRN & \\
\hline CHEMBL3192625 & 688623 & 5.3782 & 3.7942 & TRN & \\
\hline CHEMBL1499388 & 688623 & 2.9208 & 3.1319 & TRN & \\
\hline CHEMBL1365210 & 688623 & 4.9462 & 4.4439 & TRN & \\
\hline CHEMBL1541313 & 688623 & 2.9208 & 3.0978 & TRN & \\
\hline CHEMBL3189712 & 688623 & 4.6872 & 6.0131 & TRN & \\
\hline CHEMBL1311547 & 688623 & 4.7726 & 4.6742 & TRN & \\
\hline CHEMBL3211971 & 688623 & 4.8972 & 4.3625 & TRN & \\
\hline CHEMBL1339694 & 688623 & 4.8967 & \multicolumn{2}{|c|}{4.6530000000000005} & TRN \\
\hline CHEMBL1525259 & 688623 & 4.6373 & 4.3574 & TRN & \\
\hline CHEMBL1330027 & 688623 & 4.578 & 3.4698 & TRN & \\
\hline CHEMBL1989897 & 688623 & 5.1229 & 4.9262 & TRN & \\
\hline
\end{tabular}


Supplemental Table S2.txt

\begin{tabular}{|c|c|c|c|c|c|c|}
\hline CHEMBL1604735 & 688623 & 2.9208 & \multicolumn{3}{|c|}{3.9219999999999997} & TRN \\
\hline CHEMBL1459572 & 688623 & 2.9208 & 3.2735 & TRN & & \\
\hline CHEMBL1497323 & 688623 & 4.8342 & 4.4305 & TRN & & \\
\hline CHEMBL1301556 & 688623 & 2.9208 & 3.1233 & TRN & & \\
\hline CHEMBL1521149 & 688623 & 4.8348 & 3.3255 & TRN & & \\
\hline CHEMBL1537552 & 688623 & 2.9208 & 3.1412 & TRN & & \\
\hline CHEMBL1594756 & 688623 & 5.0793 & 4.8483 & TRN & & \\
\hline CHEMBL1592159 & 688623 & 2.9208 & 3.00399 & 9999999 & 9996 & \\
\hline CHEMBL1393633 & 688623 & 4.9516 & 4.7168 & TRN & & \\
\hline CHEMBL1422286 & 688623 & 2.9208 & 3.1984 & TST & & \\
\hline CHEMBL1377699 & 688623 & 2.9208 & 5.5415 & TRN & & \\
\hline CHEMBL1491037 & 688623 & 4.3778 & 3.6053 & TRN & & \\
\hline CHEMBL2001216 & 688623 & 4.9301 & 3.5539 & TRN & & \\
\hline CHEMBL1323569 & 688623 & 4.8669 & 4.2325 & TRN & & \\
\hline CHEMBL1588275 & 688623 & $5.1610 t$ & 00000006 & 005 & 4.5268 & \\
\hline CHEMBL1452116 & 688623 & 4.8265 & 4.5267 & TRN & & \\
\hline CHEMBL1331836 & 688623 & 2.9208 & 5.6156 & TST & & \\
\hline CHEMBL1334578 & 688623 & 2.9208 & 3.1451 & TRN & & \\
\hline CHEMBL1410483 & 688623 & 4.7288 & 3.7191 & TRN & & \\
\hline CHEMBL1556891 & 688623 & 2.9208 & 4.3491 & TRN & & \\
\hline CHEMBL1299526 & 688623 & 5.0074 & 3.8171 & TRN & & \\
\hline CHEMBL1341384 & 688623 & 2.9208 & 4.1026 & TRN & & \\
\hline CHEMBL3194554 & 688623 & 2.9208 & 3.6978 & TST & & \\
\hline CHEMBL1470135 & 688623 & 2.9208 & 4.1628 & TRN & & \\
\hline CHEMBL1532762 & 688623 & 4.3994 & 3.5179 & TRN & & \\
\hline CHEMBL1583804 & 688623 & 2.9208 & 3.0187 & TRN & & \\
\hline CHEMBL1370515 & 688623 & 2.9208 & 3.6272 & TRN & & \\
\hline CHEMBL1413931 & 688623 & 4.9641 & 3.9954 & TRN & & \\
\hline CHEMBL1333332 & 688623 & 4.7789 & 3.8228 & TRN & & \\
\hline CHEMBL1301573 & 688623 & 6.6778 & 4.6742 & TRN & & \\
\hline CHEMBL1584564 & 688623 & 6.5884 & 6.1981 & TRN & & \\
\hline CHEMBL1518647 & 688623 & 5.1377 & 6.8873 & TRN & & \\
\hline CHEMBL193872 & 688623 & 5.7757 & 5.7899 & TRN & & \\
\hline CHEMBL1490356 & 688623 & 2.9208 & 3.2345 & TRN & & \\
\hline CHEMBL1300558 & 688623 & 2.9208 & 5.7032 & TRN & & \\
\hline CHEMBL1426435 & 688623 & 4.7409 & 4.5079 & TRN & & \\
\hline CHEMBL1864040 & 688623 & 5.1683 & 5.6734 & TRN & & \\
\hline CHEMBL3209659 & 688623 & 5.0297 & 4.7821 & TRN & & \\
\hline CHEMBL1349403 & 688623 & 2.9208 & 4.5216 & TRN & & \\
\hline CHEMBL1422978 & 688623 & 4.883 & 3.6513 & TST & & \\
\hline CHEMBL1385940 & 688623 & 5.0752 & 4.7137 & TRN & & \\
\hline CHEMBL1613644 & 688623 & 2.9208 & 4.1742 & TRN & & \\
\hline CHEMBL1305809 & 688623 & 2.9208 & 3.6958 & TRN & & \\
\hline CHEMBL1470919 & 688623 & 2.9208 & 3.6151 & TRN & & \\
\hline CHEMBL1576167 & 688623 & 2.9208 & 3.5032 & TST & & \\
\hline CHEMBL3193593 & 688623 & 4.6127 & 4.6325 & TRN & & \\
\hline CHEMBL1995169 & 688623 & 2.9208 & 4.0822 & TRN & & \\
\hline CHEMBL1409113 & 688623 & 5.1123 & 3.8109 & TRN & & \\
\hline
\end{tabular}

Page 9242 


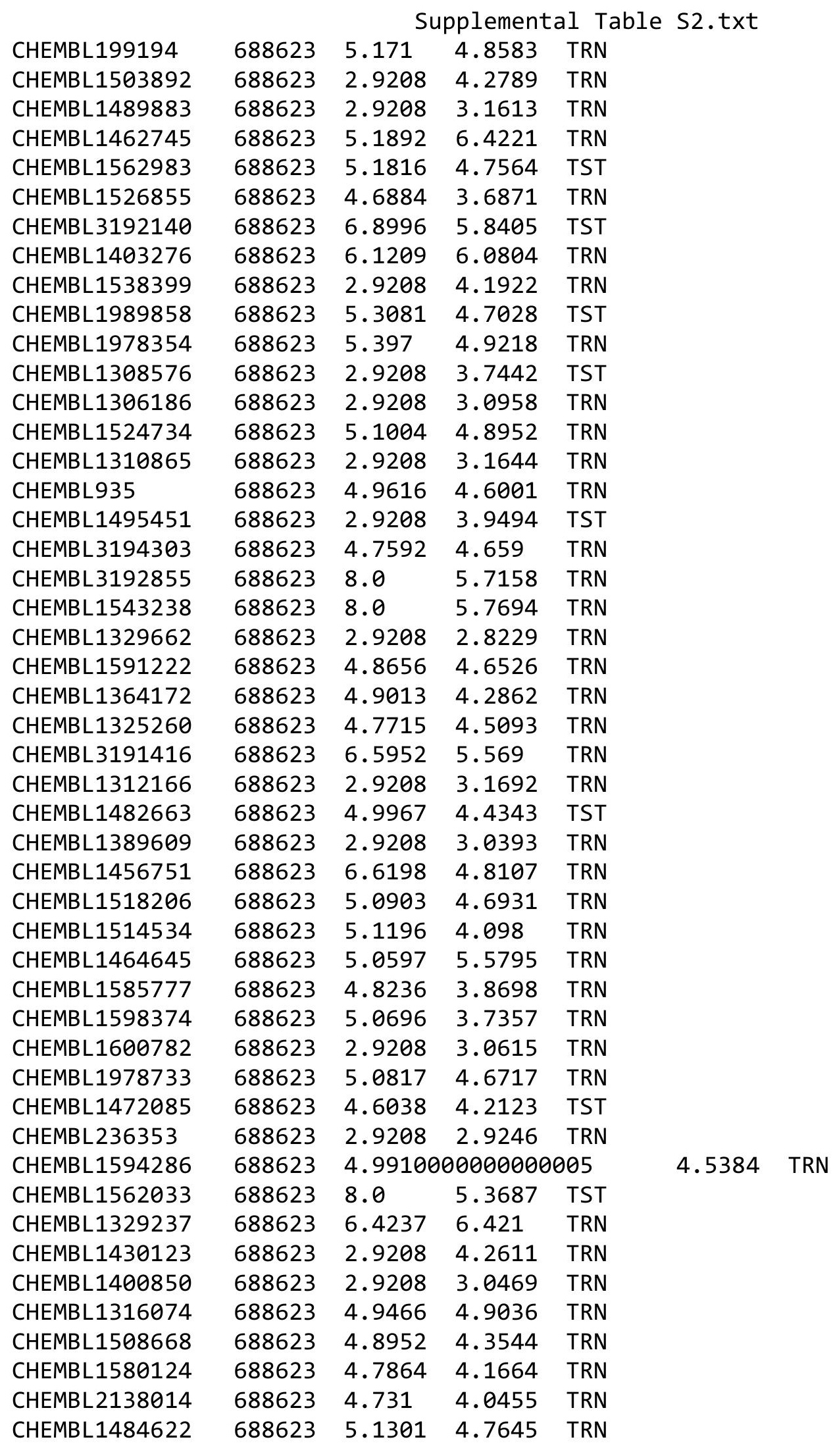




\begin{tabular}{|c|c|c|c|c|}
\hline & & & oplement & al Ta \\
\hline CHEMBL1404086 & 688623 & 2.9208 & 4.4341 & TRN \\
\hline CHEMBL3211859 & 688623 & 4.724 & 4.7373 & TRN \\
\hline CHEMBL1400322 & 688623 & 4.9769 & 4.6323 & TST \\
\hline CHEMBL1563001 & 688623 & 4.3666 & 3.6216 & TRN \\
\hline CHEMBL1301700 & 688623 & 4.9588 & 4.0789 & TST \\
\hline CHEMBL1499914 & 688623 & 5.0153 & 3.2998 & TRN \\
\hline CHEMBL1369231 & 688623 & 5.432 & 5.9994 & TRN \\
\hline CHEMBL1609140 & 688623 & 4.7519 & 4.7568 & TRN \\
\hline CHEMBL1329507 & 688623 & 5.0154 & 4.5168 & TRN \\
\hline CHEMBL1547785 & 688623 & 2.9208 & 3.7236 & TRN \\
\hline CHEMBL3213635 & 688623 & 2.9208 & 3.1205 & TRN \\
\hline CHEMBL1464973 & 688623 & 2.9208 & 4.3097 & TRN \\
\hline CHEMBL606532 & 688623 & 6.5272 & 3.8497 & TRN \\
\hline CHEMBL3195760 & 688623 & 4.9881 & 5.047 & TRN \\
\hline CHEMBL1359890 & 688623 & 2.9208 & 3.7158 & TRN \\
\hline CHEMBL1312974 & 688623 & 4.7981 & 3.6475 & TST \\
\hline CHEMBL3191770 & 688623 & 4.6422 & 4.5812 & TRN \\
\hline CHEMBL1601627 & 688623 & 2.9208 & 4.1564 & TRN \\
\hline CHEMBL1432420 & 688623 & 8.0 & 5.1323 & TRN \\
\hline CHEMBL1468323 & 688623 & 8.0 & 7.2617 & TRN \\
\hline CHEMBL1310414 & 688623 & 2.9208 & 3.8353 & TRN \\
\hline CHEMBL1408236 & 688623 & 4.5706 & 4.6622 & TRN \\
\hline CHEMBL225963 & 688623 & 2.9208 & 3.2373 & TST \\
\hline CHEMBL1308497 & 688623 & 2.9208 & 3.1684 & TRN \\
\hline CHEMBL1547087 & 688623 & 2.9208 & 4.3283 & TRN \\
\hline CHEMBL1345404 & 688623 & 4.677 & 4.4595 & TRN \\
\hline CHEMBL1988416 & 688623 & 2.9208 & 4.0636 & TST \\
\hline CHEMBL1967497 & 688623 & 2.9208 & 4.3299 & TRN \\
\hline CHEMBL3194887 & 688623 & 2.9208 & 3.3153 & TRN \\
\hline CHEMBL1323668 & 688623 & 8.0 & 5.9642 & TRN \\
\hline CHEMBL1424691 & 688623 & 2.9208 & 3.1179 & TRN \\
\hline CHEMBL1382128 & 688623 & 2.9208 & 3.8883 & TRN \\
\hline CHEMBL1362507 & 688623 & 8.0 & 5.6869 & TRN \\
\hline CHEMBL 290077 & 688623 & 8.0 & 6.6127 & TST \\
\hline CHEMBL1520880 & 688623 & 2.9208 & 3.7724 & TRN \\
\hline CHEMBL1310861 & 688623 & 5.0497 & 3.9347 & TRN \\
\hline CHEMBL1465995 & 688623 & 4.5874 & 4.3897 & TRN \\
\hline CHEMBL1320542 & 688623 & 4.9125 & 3.741 & TRN \\
\hline CHEMBL1600287 & 688623 & 2.9208 & 3.5739 & TRN \\
\hline CHEMBL1526298 & 688623 & 2.9208 & 3.787 & TRN \\
\hline CHEMBL536008 & 688623 & 2.9208 & 4.1278 & TRN \\
\hline CHEMBL3195226 & 688623 & 4.8834 & 4.2243 & TRN \\
\hline CHEMBL1609770 & 688623 & 5.1109 & 5.1034 & TRN \\
\hline CHEMBL586602 & 688623 & 5.2139 & 4.9894 & TRN \\
\hline CHEMBL1349455 & 688623 & 3.9846 & 4.797 & TRN \\
\hline CHEMBL1403048 & 688623 & 4.9272 & 4.793 & TRN \\
\hline CHEMBL1560901 & 688623 & 4.7572 & 3.9437 & TRN \\
\hline CHEMBL1494106 & 688623 & 2.9208 & 3.0184 & TRN \\
\hline
\end{tabular}


Supplemental Table S2.txt

\begin{tabular}{|c|c|c|c|c|c|c|}
\hline CHEMBL1523392 & 688623 & 2.9208 & 2.9725 & TRN & & \\
\hline CHEMBL1544655 & 688623 & 2.9208 & 3.6598 & TRN & & \\
\hline CHEMBL1316831 & 688623 & 6.9914 & 6.604 & TST & & \\
\hline CHEMBL1569450 & 688623 & 4.8265 & 4.1044 & TST & & \\
\hline CHEMBL1380296 & 688623 & 4.9475 & 4.4935 & TRN & & \\
\hline CHEMBL1576251 & 688623 & 8.0 & 6.4096 & TRN & & \\
\hline CHEMBL3198341 & 688623 & 4.9776 & 4.9397 & TRN & & \\
\hline CHEMBL1558822 & 688623 & 4.9011 & 3.6386 & TRN & & \\
\hline CHEMBL1334041 & 688623 & 4.6523 & 3.6834 & TST & & \\
\hline CHEMBL1470712 & 688623 & 5.5303 & 5.2861 & TRN & & \\
\hline CHEMBL1300952 & 688623 & 4.8175 & 6.1796 & TRN & & \\
\hline CHEMBL1488229 & 688623 & 4.8247 & 5.0624 & TRN & & \\
\hline CHEMBL1498913 & 688623 & 2.9208 & 2.9647 & TRN & & \\
\hline CHEMBL1583256 & 688623 & 5.0476 & 4.8264 & TRN & & \\
\hline CHEMBL1392640 & 688623 & 4.6641 & 3.8185 & TRN & & \\
\hline CHEMBL567323 & 688623 & 2.9208 & 3.9668 & TRN & & \\
\hline CHEMBL1518428 & 688623 & 4.8546 & 4.6689 & TRN & & \\
\hline CHEMBL1301542 & 688623 & 2.9208 & 3.5848 & TRN & & \\
\hline CHEMBL1572558 & 688623 & 5.0965 & 5.2285 & TRN & & \\
\hline CHEMBL1572256 & 688623 & 5.3988 & 4.6451 & TRN & & \\
\hline CHEMBL1338349 & 688623 & 2.9208 & 3.0225 & TST & & \\
\hline CHEMBL1432186 & 688623 & 4.766999 & 99999999 & 995 & 3.1604 & TRN \\
\hline CHEMBL1304997 & 688623 & 4.8897 & 3.2474 & TST & & \\
\hline CHEMBL1316994 & 688623 & 2.9208 & 3.3792 & TRN & & \\
\hline CHEMBL1352168 & 688623 & 5.5709 & 4.7225 & TRN & & \\
\hline CHEMBL1546588 & 688623 & 4.5155 & 4.1302 & TRN & & \\
\hline CHEMBL1539413 & 688623 & 4.4073 & 3.4827 & TRN & & \\
\hline CHEMBL1383331 & 688623 & 2.9208 & 3.5164 & TRN & & \\
\hline CHEMBL1546566 & 688623 & 4.5418 & 3.8395 & TRN & & \\
\hline CHEMBL1532099 & 688623 & 2.9208 & 4.0005 & TST & & \\
\hline CHEMBL1418884 & 688623 & 2.9208 & 3.2115 & TST & & \\
\hline CHEMBL1441654 & 688623 & 2.9208 & 3.2147 & TST & & \\
\hline CHEMBL 2004417 & 688623 & 4.9519 & 5.0488 & TRN & & \\
\hline CHEMBL1426049 & 688623 & 2.9208 & 3.6491 & TRN & & \\
\hline CHEMBL1327580 & 688623 & 2.9208 & 4.2813 & TRN & & \\
\hline CHEMBL192984 & 688623 & 4.9828 & 5.0111 & TRN & & \\
\hline CHEMBL1403165 & 688623 & 2.9208 & 3.2433 & TRN & & \\
\hline CHEMBL1501694 & 688623 & 5.2309 & 5.4477 & TST & & \\
\hline CHEMBL1312291 & 688623 & 4.8244 & 3.7983 & TRN & & \\
\hline CHEMBL3192156 & 688623 & 4.6753 & 3.813 & TRN & & \\
\hline CHEMBL589238 & 688623 & 5.0395 & 4.5464 & TRN & & \\
\hline CHEMBL355496 & 688623 & 2.9208 & 4.7656 & TRN & & \\
\hline CHEMBL1356472 & 688623 & 4.4527 & 4.2944 & TRN & & \\
\hline CHEMBL1546687 & 688623 & 4.6329 & 3.464 & TRN & & \\
\hline CHEMBL1487901 & 688623 & 4.9086 & 4.6066 & TST & & \\
\hline CHEMBL1520718 & 688623 & 2.9208 & 4.0878 & TRN & & \\
\hline CHEMBL1470614 & 688623 & 4.8825 & 3.5204 & TRN & & \\
\hline CHEMBL1561380 & 688623 & 4.6228 & 3.5018 & TST & & \\
\hline
\end{tabular}




\begin{tabular}{|c|c|c|c|c|c|c|}
\hline & & \multicolumn{5}{|c|}{ Supplemental Table S2.txt } \\
\hline CHEMBL1588363 & 688623 & 2.9208 & 3.89600 & 20000 & 204 & TRN \\
\hline CHEMBL1538534 & 688623 & 2.9208 & 3.4247 & TRN & & \\
\hline CHEMBL1469715 & 688623 & 5.1944 & 4.626 & TRN & & \\
\hline CHEMBL1399127 & 688623 & 2.9208 & 4.2675 & TST & & \\
\hline CHEMBL1502189 & 688623 & 5.0014 & 3.8734 & TRN & & \\
\hline CHEMBL3199157 & 688623 & 6.1726 & 3.3795 & TRN & & \\
\hline CHEMBL1472681 & 688623 & 8.0 & 6.6414 & TRN & & \\
\hline CHEMBL1606524 & 688623 & 4.1828 & 4.0469 & TRN & & \\
\hline CHEMBL1539642 & 688623 & 2.9208 & 3.1122 & TRN & & \\
\hline CHEMBL1997659 & 688623 & 3.2218 & 3.2987 & TRN & & \\
\hline CHEMBL1455309 & 688623 & 2.9208 & 3.1524 & TRN & & \\
\hline CHEMBL1333030 & 688623 & 2.9208 & 3.1212 & TRN & & \\
\hline CHEMBL222409 & 688623 & 8.0 & 6.6986 & TRN & & \\
\hline CHEMBL1543387 & 688623 & 6.4437 & 4.9014 & TRN & & \\
\hline CHEMBL1330516 & 688623 & 5.2073 & 4.7074 & TRN & & \\
\hline CHEMBL3194400 & 688623 & 2.9208 & 3.252 & TRN & & \\
\hline CHEMBL1322601 & 688623 & 2.9208 & 3.7397 & TRN & & \\
\hline CHEMBL1401973 & 688623 & 5.2183 & 3.1923 & TRN & & \\
\hline CHEMBL300389 & 688623 & 8.0 & 5.9624 & TRN & & \\
\hline CHEMBL123 & 688623 & 2.9208 & 4.7043 & TST & & \\
\hline CHEMBL1603905 & 688623 & 2.9208 & 3.6031 & TRN & & \\
\hline CHEMBL1478486 & 688623 & 4.8708 & 4.4151 & TRN & & \\
\hline CHEMBL1310844 & 688623 & 4.7573 & 3.1605 & TRN & & \\
\hline CHEMBL590706 & 688623 & 2.9208 & 4.6142 & TRN & & \\
\hline CHEMBL1585345 & 688623 & 5.1697 & 5.8651 & TRN & & \\
\hline CHEMBL1360295 & 688623 & 4.2996 & 5.254 & TRN & & \\
\hline CHEMBL1436557 & 688623 & 4.9248 & 4.5701 & TRN & & \\
\hline CHEMBL1466170 & 688623 & 4.5622 & 3.0151 & TRN & & \\
\hline CHEMBL1484632 & 688623 & 5.3898 & 5.0039 & TST & & \\
\hline CHEMBL1341889 & 688623 & 4.4766 & 3.8321 & TRN & & \\
\hline CHEMBL1524994 & 688623 & 4.8674 & 4.4815 & TRN & & \\
\hline CHEMBL1504239 & 688623 & 2.9208 & 4.7476 & TST & & \\
\hline CHEMBL1320575 & 688623 & 4.5564 & 3.7487 & TRN & & \\
\hline CHEMBL1425176 & 688623 & 4.76399 & 79999999 & 99 & 4.0374 & ST \\
\hline CHEMBL1329221 & 688623 & 6.6946 & 6.1425 & TRN & & \\
\hline CHEMBL1361206 & 688623 & 2.9208 & 3.8117 & TRN & & \\
\hline CHEMBL1375597 & 688623 & 2.9208 & 3.98 & TRN & & \\
\hline CHEMBL1460225 & 688623 & 5.022 & 4.5302 & TRN & & \\
\hline CHEMBL1506300 & 688623 & 2.9208 & 3.1822 & TST & & \\
\hline CHEMBL1491626 & 688623 & 2.9208 & 3.9536 & TRN & & \\
\hline CHEMBL1451921 & 688623 & 6.8962 & 6.1314 & TRN & & \\
\hline CHEMBL1315921 & 688623 & 2.9208 & 4.4109 & TRN & & \\
\hline CHEMBL 2369309 & 688623 & 2.9208 & 4.0998 & TRN & & \\
\hline CHEMBL1587323 & 688623 & 2.9208 & 3.5229 & TRN & & \\
\hline CHEMBL1304082 & 688623 & 2.9208 & 2.8487 & TRN & & \\
\hline CHEMBL1464619 & 688623 & 2.9208 & 4.5826 & TRN & & \\
\hline CHEMBL1582334 & 688623 & 2.9208 & 3.1878 & TRN & & \\
\hline CHEMBL3196824 & 688623 & 4.5949 & 3.431 & TRN & & \\
\hline
\end{tabular}




\begin{tabular}{|c|c|c|c|c|c|}
\hline \multirow[b]{2}{*}{ CHEMBL1993627 } & & \multicolumn{4}{|c|}{ Supplemental Table s2.txt } \\
\hline & 688623 & 5.1133 & 4.98300 & 00000000005 & TRN \\
\hline CHEMBL1391825 & 688623 & 2.9208 & 3.7693 & TRN & \\
\hline CHEMBL1370744 & 688623 & 4.9585 & 4.6216 & TRN & \\
\hline CHEMBL3190012 & 688623 & 4.9504 & 4.8451 & TRN & \\
\hline CHEMBL1345432 & 688623 & 2.9208 & 3.1148 & TRN & \\
\hline CHEMBL1408486 & 688623 & 5.3326 & 5.6028 & TRN & \\
\hline CHEMBL1397089 & 688623 & 4.8108 & 6.0899 & TST & \\
\hline CHEMBL1371056 & 688623 & 4.9009 & 6.1478 & TRN & \\
\hline CHEMBL 1341518 & 688623 & 2.9208 & 4.5483 & TST & \\
\hline CHEMBL1564522 & 688623 & 5.0768 & 4.6553 & TRN & \\
\hline CHEMBL1563022 & 688623 & 2.9208 & 3.3679 & TRN & \\
\hline CHEMBL1478412 & 688623 & 2.9208 & 2.9326 & TRN & \\
\hline CHEMBL1583503 & 688623 & 4.129 & 4.1086 & TRN & \\
\hline CHEMBL1504509 & 688623 & 4.8671 & 4.4225 & TRN & \\
\hline CHEMBL1306107 & 688623 & 2.9208 & 4.2522 & TST & \\
\hline CHEMBL3199243 & 688623 & 2.9208 & 3.27699 & 99999999997 & TRN \\
\hline CHEMBL1351309 & 688623 & 5.0078 & 4.6198 & TRN & \\
\hline CHEMBL1388529 & 688623 & 4.9993 & 5.1313 & TRN & \\
\hline CHEMBL 1385847 & 688623 & 4.4622 & 3.5493 & TRN & \\
\hline CHEMBL1521028 & 688623 & 2.9208 & 3.9653 & TRN & \\
\hline CHEMBL528791 & 688623 & 5.0625 & 4.0102 & TRN & \\
\hline CHEMBL1510332 & 688623 & 3.5229 & 4.5275 & TRN & \\
\hline CHEMBL1493848 & 688623 & 2.9208 & 3.8146 & TRN & \\
\hline CHEMBL532160 & 688623 & 2.9208 & 3.1001 & TRN & \\
\hline CHEMBL1471345 & 688623 & 2.9208 & 3.5689 & TRN & \\
\hline CHEMBL1510690 & 688623 & 5.4107 & 5.1808 & TRN & \\
\hline CHEMBL1433424 & 688623 & 4.9322 & 4.3672 & TRN & \\
\hline CHEMBL1513553 & 688623 & 4.3153 & 3.0603 & TST & \\
\hline CHEMBL1454614 & 688623 & 2.9208 & 4.371 & TRN & \\
\hline CHEMBL1417732 & 688623 & 5.0097 & 4.632 & TRN & \\
\hline CHEMBL1495417 & 688623 & 4.4632 & 4.9902 & TST & \\
\hline CHEMBL1589317 & 688623 & 2.9208 & 3.5714 & TRN & \\
\hline CHEMBL1307022 & 688623 & 4.3008 & 2.9829 & TRN & \\
\hline CHEMBL3212029 & 688623 & 5.9855 & 5.3656 & TRN & \\
\hline CHEMBL1422671 & 688623 & 2.9208 & 3.5992 & TST & \\
\hline CHEMBL3195189 & 688623 & 8.0 & 5.9828 & TRN & \\
\hline CHEMBL1338624 & 688623 & 4.4621 & 3.823 & TST & \\
\hline CHEMBL1375406 & 688623 & 3.9239 & 3.5262 & TST & \\
\hline CHEMBL1572375 & 688623 & 2.9208 & 4.3136 & TRN & \\
\hline CHEMBL1496714 & 688623 & 2.9208 & 3.7933 & TST & \\
\hline CHEMBL1388151 & 688623 & 2.9208 & 3.1999 & TST & \\
\hline CHEMBL1560034 & 688623 & 2.9208 & 3.3468 & TRN & \\
\hline CHEMBL1977930 & 688623 & 4.5392 & 3.9743 & TRN & \\
\hline CHEMBL1488757 & 688623 & 2.9208 & 4.0564 & TRN & \\
\hline CHEMBL1476215 & 688623 & 6.4498 & 5.809 & TRN & \\
\hline CHEMBL1427989 & 688623 & 4.6653 & 3.0399 & TRN & \\
\hline CHEMBL3194229 & 688623 & 2.9208 & 3.1376 & TRN & \\
\hline CHEMBL1581343 & 688623 & 2.9208 & 3.1459 & TST & \\
\hline
\end{tabular}




\begin{tabular}{|c|c|c|c|c|c|}
\hline \multicolumn{6}{|c|}{ Supplemental Table S2.txt } \\
\hline CHEMBL1416171 & 688623 & 4.7643 & 3.8811 & TRN & \\
\hline CHEMBL1548803 & 688623 & 4.9497 & 3.8925 & TRN & \\
\hline CHEMBL1428589 & 688623 & 2.9208 & 3.9615 & TRN & \\
\hline CHEMBL1353180 & 688623 & 2.9208 & 3.8941 & TST & \\
\hline CHEMBL1477635 & 688623 & 2.9208 & 3.0316 & TRN & \\
\hline CHEMBL1341849 & 688623 & 6.5229 & 3.2053 & TRN & \\
\hline CHEMBL1575636 & 688623 & 2.9208 & 3.088 & TRN & \\
\hline CHEMBL1967697 & 688623 & 4.7759 & 4.4583 & TRN & \\
\hline CHEMBL1983311 & 688623 & 2.9208 & 4.6312 & TRN & \\
\hline CHEMBL1576489 & 688623 & 2.9208 & 3.7888 & TRN & \\
\hline CHEMBL1503359 & 688623 & 5.0868 & 4.8601 & TRN & \\
\hline CHEMBL1595169 & 688623 & 8.0 & 6.7046 & TRN & \\
\hline CHEMBL1468683 & 688623 & 2.9208 & 3.6363 & TRN & \\
\hline CHEMBL1359872 & 688623 & 6.7212 & 6.5345 & TRN & \\
\hline CHEMBL1928491 & 688623 & 5.1985 & 5.0159 & TRN & \\
\hline CHEMBL1502526 & 688623 & 2.9208 & 3.0577 & TRN & \\
\hline CHEMBL1305052 & 688623 & 2.9208 & 3.9027 & TRN & \\
\hline CHEMBL1322645 & 688623 & 4.9577 & 3.6523 & TRN & \\
\hline CHEMBL1525080 & 688623 & 4.4258 & 3.99 & TRN & \\
\hline CHEMBL1572961 & 688623 & 2.9208 & 3.2152 & TRN & \\
\hline CHEMBL1523361 & 688623 & 2.9208 & 3.14600 & 00000000004 & TRN \\
\hline CHEMBL1310439 & 688623 & 2.9208 & 2.8209 & TRN & \\
\hline CHEMBL1345123 & 688623 & 2.9208 & 3.0901 & TRN & \\
\hline CHEMBL 6742 & 688623 & 4.8075 & 4.8707 & TRN & \\
\hline CHEMBL 3196703 & 688623 & 4.7353 & 4.875 & TRN & \\
\hline CHEMBL1508373 & 688623 & 2.9208 & 3.3075 & TRN & \\
\hline CHEMBL1349151 & 688623 & 2.9208 & 4.2234 & TRN & \\
\hline CHEMBL1478187 & 688623 & 2.9208 & 3.2006 & TST & \\
\hline CHEMBL1545881 & 688623 & 2.9208 & 3.3661 & TRN & \\
\hline CHEMBL 261123 & 688623 & 5.0794 & 5.4717 & TRN & \\
\hline CHEMBL517645 & 688623 & 8.0 & 6.9613 & TST & \\
\hline CHEMBL1432560 & 688623 & 2.9208 & 4.1213 & TRN & \\
\hline CHEMBL1364056 & 688623 & 2.9208 & 3.6912 & TST & \\
\hline CHEMBL591404 & 688623 & 2.9208 & 3.3294 & TRN & \\
\hline CHEMBL1601337 & 688623 & 2.9208 & 4.0213 & TRN & \\
\hline CHEMBL1427494 & 688623 & 2.9208 & 4.5032 & TRN & \\
\hline CHEMBL1540519 & 688623 & 2.9208 & 3.6439 & TRN & \\
\hline CHEMBL1326215 & 688623 & 4.7878 & 3.5534 & TRN & \\
\hline CHEMBL1974613 & 688623 & 4.9296 & 3.6852 & TRN & \\
\hline CHEMBL1402171 & 688623 & 2.9208 & 3.5792 & TRN & \\
\hline CHEMBL1349428 & 688623 & 8.0 & 5.1921 & TRN & \\
\hline CHEMBL1530184 & 688623 & 2.9208 & 3.1269 & TRN & \\
\hline CHEMBL3198912 & 688623 & 6.9914 & 5.9104 & TRN & \\
\hline CHEMBL1517849 & 688623 & 2.9208 & 3.2446 & TRN & \\
\hline CHEMBL1577719 & 688623 & 2.9208 & 3.2444 & TRN & \\
\hline CHEMBL1500185 & 688623 & 2.9208 & 3.5797 & TRN & \\
\hline CHEMBL1492289 & 688623 & 2.9208 & 3.9158 & TRN & \\
\hline CHEMBL1972651 & 688623 & 5.0174 & 4.836 & TRN & \\
\hline
\end{tabular}




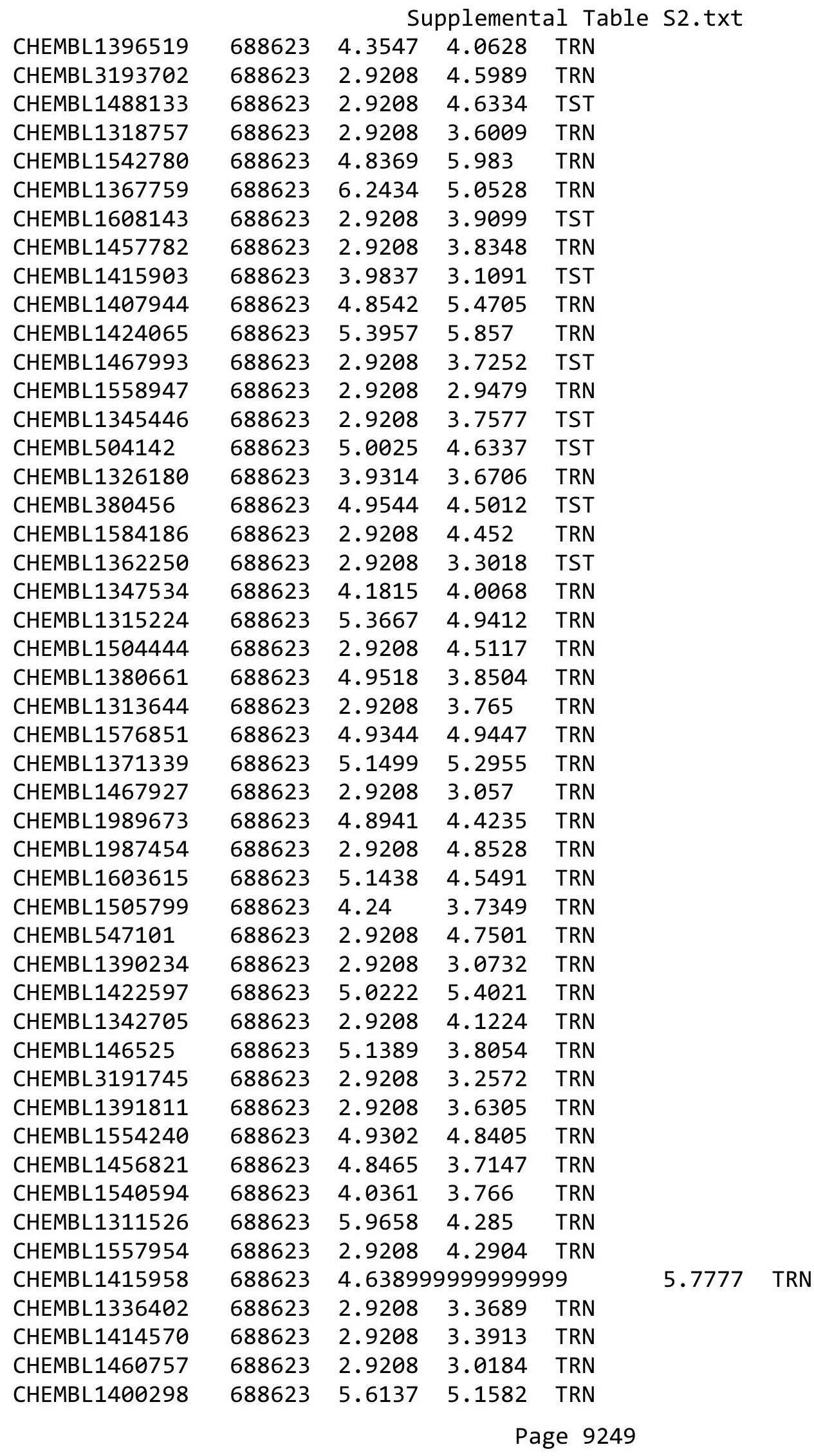




\begin{tabular}{|c|c|c|c|c|c|}
\hline & & \multicolumn{4}{|c|}{ Supplemental Table S2.txt } \\
\hline CHEMBL1601647 & 688623 & 6.4045 & 5.2059 & TRN & \\
\hline CHEMBL1348840 & 688623 & 2.9208 & 3.4866 & TRN & \\
\hline CHEMBL1337990 & 688623 & 2.9208 & 3.94199 & 99999999997 & TRN \\
\hline CHEMBL1540713 & 688623 & 2.9208 & 3.2339 & TRN & \\
\hline CHEMBL1558884 & 688623 & 4.4063 & 3.5741 & TST & \\
\hline CHEMBL1497927 & 688623 & 6.7447 & 3.9048 & TRN & \\
\hline CHEMBL1462970 & 688623 & 2.9208 & 4.1666 & TST & \\
\hline CHEMBL1500138 & 688623 & 4.9611 & 4.6091 & TRN & \\
\hline CHEMBL1376657 & 688623 & 4.8586 & 4.3852 & TRN & \\
\hline CHEMBL1554602 & 688623 & 4.7502 & 4.3663 & TRN & \\
\hline CHEMBL1562664 & 688623 & 5.0701 & 4.6142 & TRN & \\
\hline CHEMBL1348888 & 688623 & 2.9208 & 4.4471 & TRN & \\
\hline CHEMBL1386760 & 688623 & 2.9208 & 4.2478 & TRN & \\
\hline CHEMBL1496595 & 688623 & 2.9208 & 4.7656 & TRN & \\
\hline CHEMBL1533271 & 688623 & 2.9208 & 3.043 & TRN & \\
\hline CHEMBL1515627 & 688623 & 4.1738 & 4.6988 & TRN & \\
\hline CHEMBL1563176 & 688623 & 4.9763 & 3.8948 & TRN & \\
\hline CHEMBL1358906 & 688623 & 3.9363 & 3.7461 & TST & \\
\hline CHEMBL1423970 & 688623 & 4.8108 & 3.86899 & 99999999998 & TST \\
\hline CHEMBL1431314 & 688623 & 4.7832 & 3.437 & TRN & \\
\hline CHEMBL3210297 & 688623 & 2.9208 & 3.6793 & TRN & \\
\hline CHEMBL3192138 & 688623 & 8.0 & 6.8689 & TRN & \\
\hline CHEMBL189584 & 688623 & 4.8912 & 3.9714 & TST & \\
\hline CHEMBL1348384 & 688623 & 4.2655 & 4.5379 & TRN & \\
\hline CHEMBL1403718 & 688623 & 2.9208 & 3.4432 & TRN & \\
\hline CHEMBL405914 & 688623 & 4.5497 & 5.5782 & TRN & \\
\hline CHEMBL 2000517 & 688623 & 6.6271 & 5.2056 & TRN & \\
\hline CHEMBL1364877 & 688623 & 2.9208 & 4.302 & TRN & \\
\hline CHEMBL1315704 & 688623 & 4.1353 & 3.5676 & TRN & \\
\hline CHEMBL1469689 & 688623 & 2.9208 & 3.0757 & TRN & \\
\hline CHEMBL1426792 & 688623 & 4.9110 & 00000000 & 5.2868 & TST \\
\hline CHEMBL1331851 & 688623 & 5.5533 & 5.0695 & TRN & \\
\hline CHEMBL1489690 & 688623 & 5.353 & 5.2908 & TRN & \\
\hline CHEMBL1600709 & 688623 & 2.9208 & 3.4129 & TRN & \\
\hline CHEMBL1528280 & 688623 & 4.2152 & 3.6575 & TRN & \\
\hline CHEMBL1389541 & 688623 & 2.9208 & 2.8157 & TRN & \\
\hline CHEMBL1548748 & 688623 & 4.7917 & 4.3019 & TRN & \\
\hline CHEMBL1567944 & 688623 & 8.0 & 7.2601 & TST & \\
\hline CHEMBL1333209 & 688623 & 2.9208 & 2.9624 & TST & \\
\hline CHEMBL1478639 & 688623 & 4.8582 & 4.7348 & TRN & \\
\hline CHEMBL15968 & 688623 & 5.6265 & 5.5322 & TRN & \\
\hline CHEMBL237214 & 688623 & 2.9208 & 3.8889 & TRN & \\
\hline CHEMBL1306196 & 688623 & 2.9208 & 3.4377 & TRN & \\
\hline CHEMBL1589670 & 688623 & 4.8017 & 4.5282 & TRN & \\
\hline CHEMBL1606712 & 688623 & 2.9208 & 3.595 & TRN & \\
\hline CHEMBL64391 & 688623 & 4.3015 & 3.1825 & TST & \\
\hline CHEMBL1419287 & 688623 & 2.9208 & 3.2473 & TRN & \\
\hline CHEMBL1578850 & 688623 & 2.9208 & 3.1743 & TRN & \\
\hline
\end{tabular}


Supplemental Table S2.txt

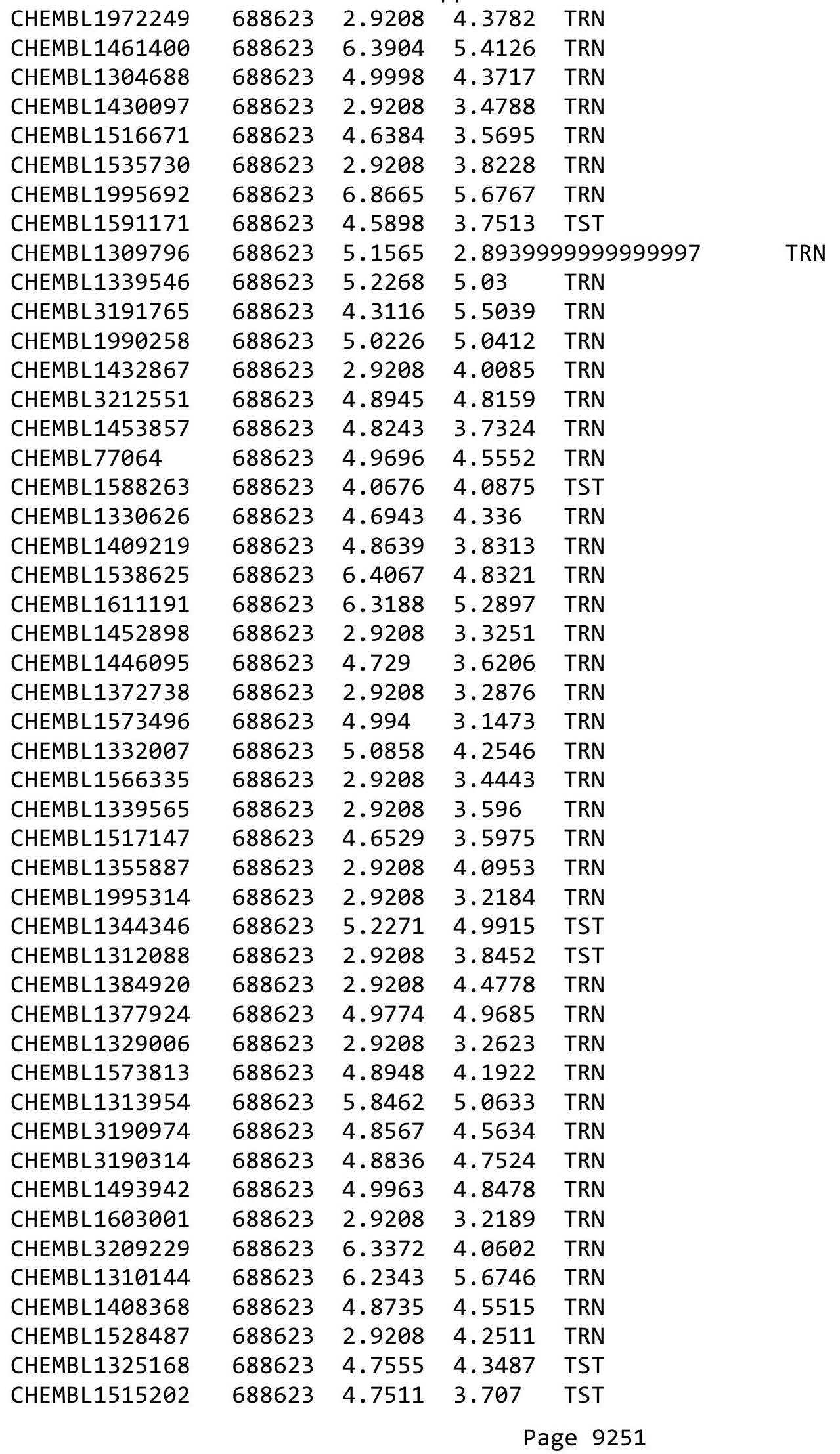


Supplemental Table S2.txt

\begin{tabular}{|c|c|c|c|c|}
\hline HEMBL13 & & 8 & 95 & TR \\
\hline HEMRI 3196693 & 38623 & 7209 & 38247 & \\
\hline AEMBL & & & & \\
\hline IEMBL1427106 & 8623 & 9208 & 7653 & \\
\hline HEMBL1338639 & 88623 & 2218 & 4039 & \\
\hline HEMBL1 & 8623 & 2383 & 906 & \\
\hline IEMBL1 & & & & \\
\hline AEMBL1374258 & 8623 & 9208 & 1803 & \\
\hline HEMBL1322272 & 88623 & 0 & 3606 & \\
\hline HEMBL1533737 & 88623 & 031 & 5401 & \\
\hline AEMBL1334550 & 8623 & 826 & 931 & \\
\hline AEMBL31 & & & & \\
\hline HEMBL1453067 & 8623 & 362 & 807 & \\
\hline AEMBL1427281 & 38623 & 208 & 5607 & \\
\hline AEMBL1423927 & 8623 & 3943 & 2691 & \\
\hline IEMBL1 & 623 & 208 & 352 & \\
\hline AEMBL1 & 23 & & & \\
\hline AEMBL1 & 3623 & 208 & 3672 & \\
\hline IEMBL14 & 8623 & 208 & & \\
\hline AEMBL1544797 & 23 & 08 & 059 & KIV \\
\hline EMBLC & 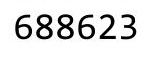 & 89 & 75 & RN \\
\hline IEM & 23 & 28 & & NIV \\
\hline HEMBL & 523 & 208 & 547 & RN \\
\hline AEMBL1S & 3 & & 715 & \\
\hline AEMBL13 & 8623 & 08 & 592 & RIV \\
\hline EMBL1 & 8623 & 15 & 357 & RN \\
\hline 7 & & 28 & 41 & $\mathrm{RN}$ \\
\hline 年 & & & & RN \\
\hline IEMBL1 & & & & IRN \\
\hline AEMBL 142 & 8623 & 68 & 081 & $\mathrm{RN}$ \\
\hline FMB 1 & 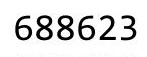 & & 039 & $\mathrm{RN}$ \\
\hline 9 & & & & RN \\
\hline & & & & RN \\
\hline IEMBL15 & & & & ГRN \\
\hline AEMBL15 & 86 & 208 & 485 & ГST \\
\hline FMRI 1 & 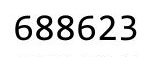 & 08 & 933 & 「RN \\
\hline & & & & ST \\
\hline HEMBL1: & & & & RN \\
\hline IEMBL1467233 & 100 & & 566 & $\Gamma R$ \\
\hline EMBL1 1 & 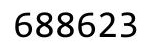 & 08 & 312 & RN \\
\hline HEMBL31 & - & 208 & 666 & \\
\hline & & & & RN \\
\hline HEMBL3191884 & & 2.9208 & & RN \\
\hline IEMBL14 & 8623 & 539 & 002 & $\mathrm{R}$ \\
\hline & & 687 & & \\
\hline HEMBL1327496 & 88623 & & 5.9684 & \\
\hline HEMBL3189243 & 88623 & & 4.7978 & \\
\hline CHEMBL1598052 & 688623 & 2.9208 & 4.053 & \\
\hline
\end{tabular}

Page 9252 


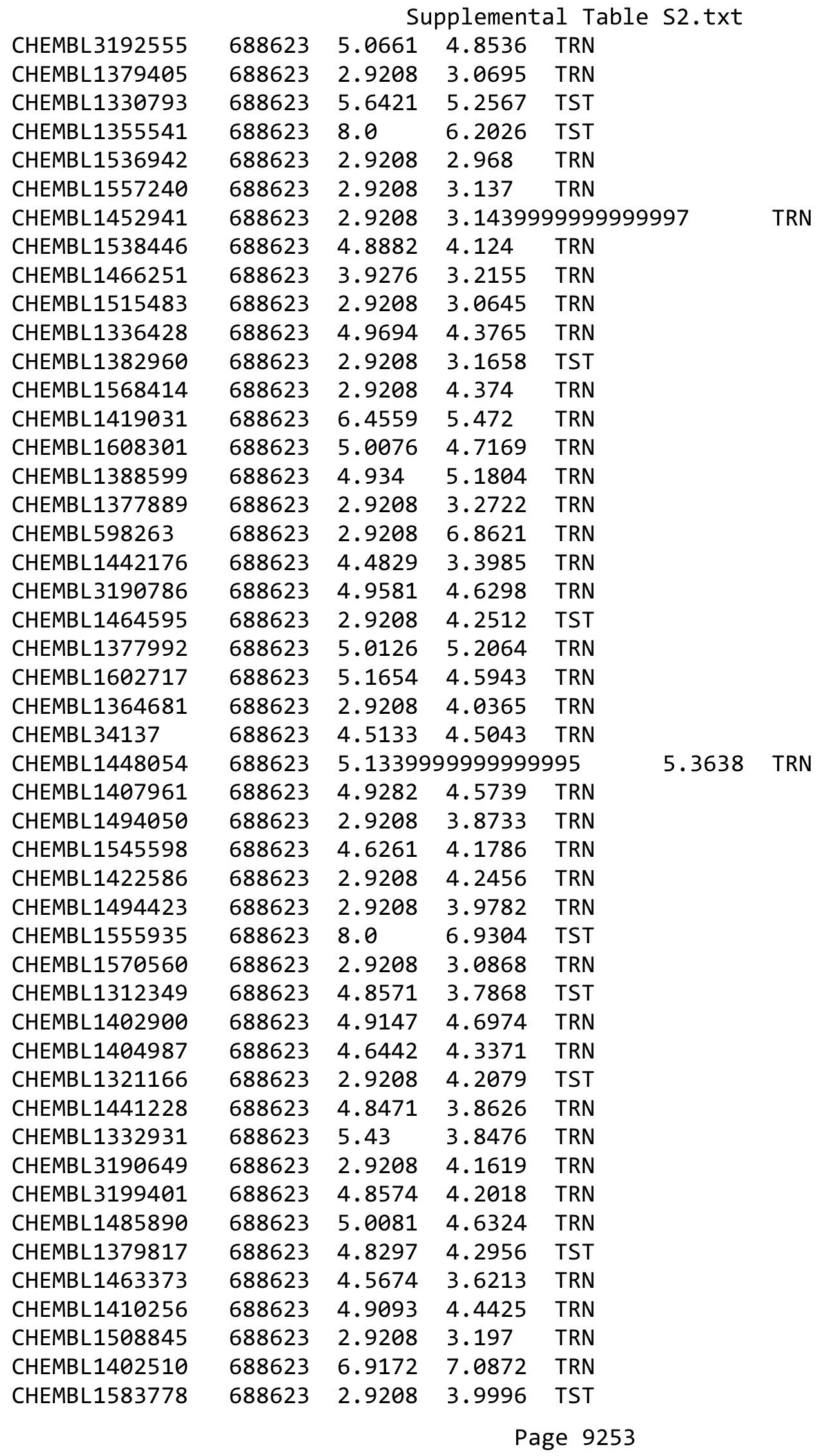




\begin{tabular}{|c|c|c|c|c|c|c|}
\hline & & \multicolumn{5}{|c|}{ Supplemental Table S2.txt } \\
\hline CHEMBL1496396 & 688623 & 4.8127 & 4.3907 & TRN & & \\
\hline CHEMBL581225 & 688623 & 4.8651 & 4.0027 & TST & & \\
\hline CHEMBL3145303 & 688623 & 6.8097 & 5.6014 & TRN & & \\
\hline CHEMBL1572294 & 688623 & 4.8991 & 3.9991 & TST & & \\
\hline CHEMBL1331904 & 688623 & 5.0234 & 5.6245 & TRN & & \\
\hline CHEMBL1313978 & 688623 & 4.8279 & 3.5256 & TRN & & \\
\hline CHEMBL1466656 & 688623 & 2.9208 & 3.082 & TRN & & \\
\hline CHEMBL1495072 & 688623 & 5.0916 & 4.9858 & TRN & & \\
\hline CHEMBL1496165 & 688623 & 2.9208 & 4.4277 & TRN & & \\
\hline CHEMBL3211050 & 688623 & 4.9661 & 3.8769 & TRN & & \\
\hline CHEMBL1309679 & 688623 & 2.9208 & 3.8079 & TRN & & \\
\hline CHEMBL1572746 & 688623 & 5.9974 & 6.057 & TRN & & \\
\hline CHEMBL1576166 & 688623 & 4.8954 & 4.7712 & TRN & & \\
\hline CHEMBL1331692 & 688623 & 4.4971 & 3.9762 & TRN & & \\
\hline CHEMBL1495788 & 688623 & 4.6682 & 3.9679 & TRN & & \\
\hline CHEMBL1507600 & 688623 & 4.1585 & 4.1737 & TRN & & \\
\hline CHEMBL1324921 & 688623 & 2.9208 & 3.0844 & TST & & \\
\hline CHEMBL1426896 & 688623 & 2.9208 & 3.8867 & TST & & \\
\hline CHEMBL1611614 & 688623 & 6.2993 & 5.5482 & TRN & & \\
\hline CHEMBL1489894 & 688623 & 2.9208 & 3.1764 & TRN & & \\
\hline CHEMBL1705518 & 688623 & 5.0057 & 3.8492 & TRN & & \\
\hline CHEMBL1488730 & 688623 & 8.0 & 5.8997 & TRN & & \\
\hline CHEMBL1416848 & 688623 & 5.029 & 5.143 & TRN & & \\
\hline CHEMBL1303609 & 688623 & 2.9208 & 4.238 & TRN & & \\
\hline CHEMBL1587117 & 688623 & 8.0 & 7.6884 & TRN & & \\
\hline CHEMBL1496478 & 688623 & 4.7693 & 4.4483 & TRN & & \\
\hline CHEMBL3194778 & 688623 & 4.6947 & 4.4988 & TRN & & \\
\hline CHEMBL1489605 & 688623 & 4.7887 & 4.3249 & TRN & & \\
\hline CHEMBL1544823 & 688623 & 5.0508 & 4.2001 & TRN & & \\
\hline CHEMBL3192251 & 688623 & 5.0685 & 4.7994 & TRN & & \\
\hline CHEMBL1307395 & 688623 & 2.9208 & 2.8502 & TRN & & \\
\hline CHEMBL1601295 & 688623 & 2.9208 & 4.8102 & TRN & & \\
\hline CHEMBL 3207792 & 688623 & 4.6592 & 3.9696 & TRN & & \\
\hline CHEMBL1430180 & 688623 & 4.7541 & 2.9549 & TRN & & \\
\hline CHEMBL1532466 & 688623 & 4.6221 & 4.5132 & TRN & & \\
\hline CHEMBL1496771 & 688623 & 2.9208 & 3.5886 & TRN & & \\
\hline CHEMBL1430182 & 688623 & 2.9208 & 3.3464 & TST & & \\
\hline CHEMBL1417651 & 688623 & 4.2263 & 3.4709 & TRN & & \\
\hline CHEMBL1523369 & 688623 & 5.38899 & 79999999 & 99 & 4.4959 & TRN \\
\hline CHEMBL1377507 & 688623 & 2.9208 & 3.7114 & TST & & \\
\hline CHEMBL1343823 & 688623 & 2.9208 & 4.7661 & TRN & & \\
\hline CHEMBL1594961 & 688623 & 4.9553 & 5.0461 & TRN & & \\
\hline CHEMBL1602385 & 688623 & 8.0 & 6.4966 & TRN & & \\
\hline CHEMBL1386838 & 688623 & 4.918 & 4.0092 & TST & & \\
\hline CHEMBL1307031 & 688623 & 2.9208 & 3.5089 & TST & & \\
\hline CHEMBL1349146 & 688623 & 4.913 & 5.2318 & TRN & & \\
\hline CHEMBL1500296 & 688623 & 2.9208 & 3.5237 & TRN & & \\
\hline CHEMBL1469827 & 688623 & 5.0096 & 4.5312 & TRN & & \\
\hline
\end{tabular}




\begin{tabular}{|c|c|c|c|c|c|}
\hline & & \multicolumn{4}{|c|}{ Supplemental Table S2.txt } \\
\hline CHEMBL1412266 & 688623 & 4.9743 & 5.3887 & TRN & \\
\hline CHEMBL1361820 & 688623 & 2.9208 & 4.4335 & TRN & \\
\hline CHEMBL1576383 & 688623 & 4.7857 & 3.44 & TRN & \\
\hline CHEMBL1300237 & 688623 & 3.2218 & 5.6569 & TRN & \\
\hline CHEMBL1338882 & 688623 & 2.9208 & 3.8107 & TRN & \\
\hline CHEMBL578502 & 688623 & 4.931 & 4.4514 & TRN & \\
\hline CHEMBL1487099 & 688623 & 6.1649 & 5.6469 & TST & \\
\hline CHEMBL1550934 & 688623 & 4.8343 & 4.6069 & TRN & \\
\hline CHEMBL1437052 & 688623 & 2.9208 & 4.5262 & TRN & \\
\hline CHEMBL1497562 & 688623 & 5.0268 & 5.0453 & TRN & \\
\hline CHEMBL486504 & 688623 & 8.0 & 6.4585 & TST & \\
\hline CHEMBL 3190189 & 688623 & 4.925 & 4.6973 & TST & \\
\hline CHEMBL1318866 & 688623 & 2.9208 & 3.4996 & TST & \\
\hline CHEMBL1376031 & 688623 & 2.9208 & 2.9663 & TRN & \\
\hline CHEMBL1457139 & 688623 & 5.0726 & 5.001 & TRN & \\
\hline CHEMBL1383626 & 688623 & 4.2815 & 3.3008 & TRN & \\
\hline CHEMBL1495567 & 688623 & 2.9208 & 4.0555 & TRN & \\
\hline CHEMBL1514790 & 688623 & 2.9208 & 4.5113 & TST & \\
\hline CHEMBL1328956 & 688623 & 3.2218 & 4.3761 & TRN & \\
\hline CHEMBL1477279 & 688623 & 8.0 & 6.4307 & TRN & \\
\hline CHEMBL17639 & 688623 & 5.4423 & 5.7579 & TST & \\
\hline CHEMBL1498999 & 688623 & 4.9705 & 5.0101 & TRN & \\
\hline CHEMBL1349063 & 688623 & 5.1087 & 4.8339 & TRN & \\
\hline CHEMBL 53260 & 688623 & 2.9208 & 3.4132 & TST & \\
\hline CHEMBL1526462 & 688623 & 2.9208 & 3.5622 & TRN & \\
\hline CHEMBL1426865 & 688623 & 6.6364 & 4.3757 & TST & \\
\hline CHEMBL1441866 & 688623 & 4.8519 & 4.6255 & TRN & \\
\hline CHEMBL1329055 & 688623 & 4.9437 & 4.9683 & TRN & \\
\hline CHEMBL1588846 & 688623 & 2.9208 & 4.2585 & TRN & \\
\hline CHEMBL338474 & 688623 & 5.0801 & 4.659 & TST & \\
\hline CHEMBL1352489 & 688623 & 4.9396 & 6.1388 & TST & \\
\hline CHEMBL1390565 & 688623 & 4.8646 & 4.442 & TRN & \\
\hline CHEMBL1406287 & 688623 & 2.9208 & 3.2138 & TRN & \\
\hline CHEMBL1428986 & 688623 & 3.9862 & 3.8455 & TRN & \\
\hline CHEMBL3211356 & 688623 & 4.8748 & 4.9466 & TRN & \\
\hline CHEMBL1570491 & 688623 & 5.0055 & 4.6872 & TRN & \\
\hline CHEMBL1563221 & 688623 & 4.8045 & 4.4758 & TRN & \\
\hline CHEMBL1414867 & 688623 & 4.7437 & 4.1005 & TRN & \\
\hline CHEMBL1393195 & 688623 & 5.90799 & 79999999 & 5.704 & TRN \\
\hline CHEMBL1387329 & 688623 & 4.8036 & 4.7191 & TRN & \\
\hline CHEMBL1556805 & 688623 & 4.9509 & 5.1412 & TRN & \\
\hline CHEMBL1611644 & 688623 & 2.9208 & 3.70399 & 99999999997 & TRN \\
\hline CHEMBL 2001739 & 688623 & 4.901 & 4.1491 & TRN & \\
\hline CHEMBL1487609 & 688623 & 4.915 & 4.1057 & TRN & \\
\hline CHEMBL1343052 & 688623 & 2.9208 & 3.0 & TRN & \\
\hline CHEMBL 3197793 & 688623 & 2.9208 & 3.3838 & TRN & \\
\hline CHEMBL248654 & 688623 & 2.9208 & 3.6213 & TRN & \\
\hline CHEMBL1560708 & 688623 & 4.4098 & 3.1988 & TST & \\
\hline
\end{tabular}




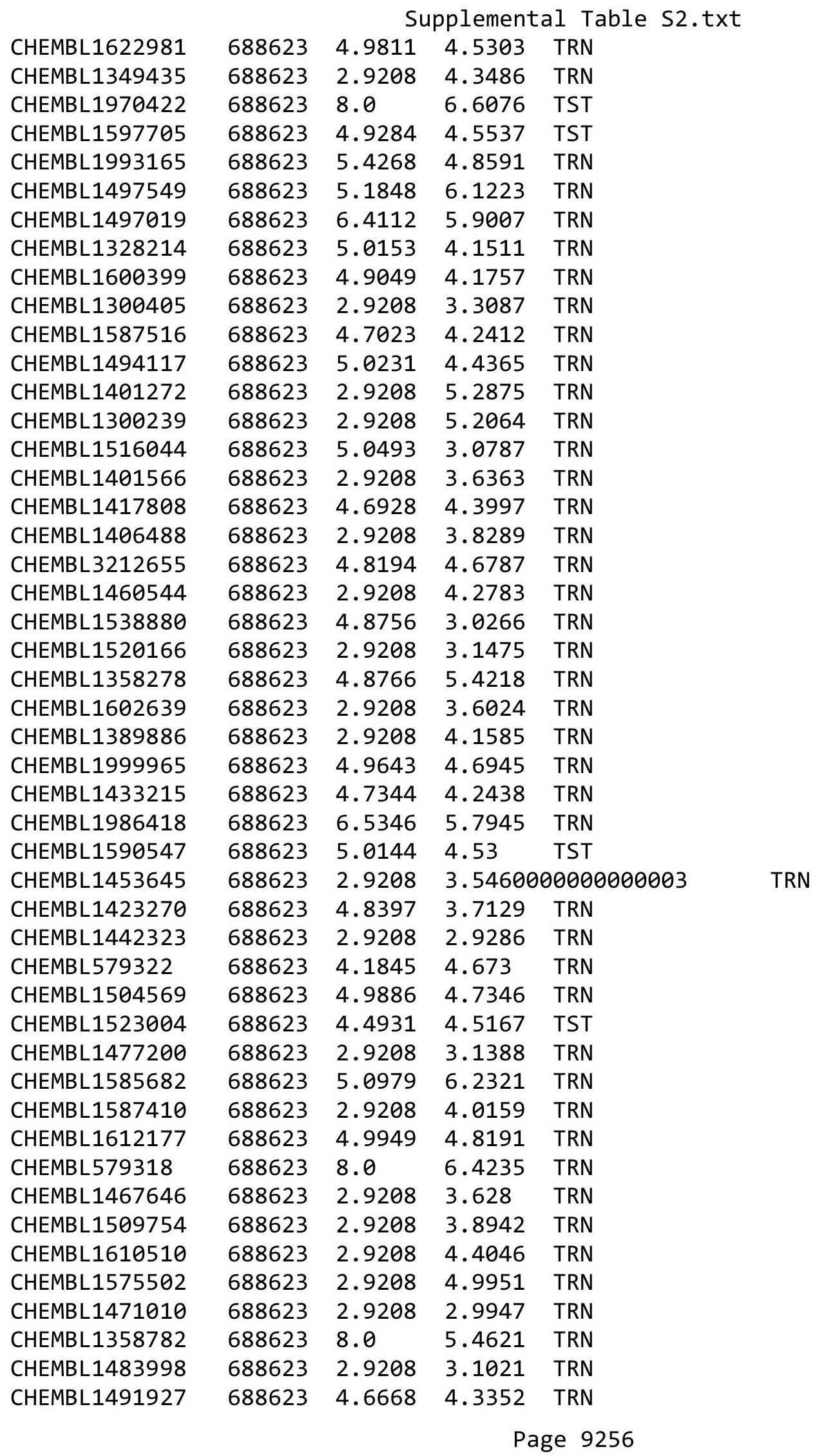


Supplemental Table S2.txt

\begin{tabular}{|c|c|c|c|c|}
\hline CHEMBL1347191 & 688623 & 2.9208 & 3.1896 & TRN \\
\hline CHEMBL1301968 & 688623 & 2.9208 & 4.3709 & TRN \\
\hline CHEMBL1501511 & 688623 & 2.9208 & 3.6921 & TRN \\
\hline CHEMBL1404578 & 688623 & 2.9208 & 4.476 & TRN \\
\hline CHEMBL1370735 & 688623 & 4.7742 & 3.0338 & TRN \\
\hline CHEMBL1544486 & 688623 & 5.0072 & 4.8164 & TRN \\
\hline CHEMBL3191011 & 688623 & 4.8516 & 4.5079 & TRN \\
\hline CHEMBL1998521 & 688623 & 8.0 & 6.7359 & TRN \\
\hline CHEMBL1989090 & 688623 & 5.8891 & 5.0265 & TRN \\
\hline CHEMBL1321442 & 688623 & 2.9208 & 2.9928 & TRN \\
\hline CHEMBL1352348 & 688623 & 5.0699 & 5.0891 & TRN \\
\hline CHEMBL1301260 & 688623 & 4.1864 & 4.2953 & TRN \\
\hline CHEMBL1584336 & 688623 & 2.9208 & 3.0318 & TST \\
\hline CHEMBL1347556 & 688623 & 4.7178 & 4.305 & TRN \\
\hline CHEMBL1495001 & 688623 & 2.9208 & 3.7024 & TRN \\
\hline CHEMBL1513325 & 688623 & 4.936 & 5.9515 & TRN \\
\hline CHEMBL1603826 & 688623 & 2.9208 & 4.0017 & TRN \\
\hline CHEMBL1578880 & 688623 & 2.9208 & 4.7884 & TRN \\
\hline CHEMBL1979106 & 688623 & 5.0879 & 4.26399 & э999999999 \\
\hline CHEMBL1568933 & 688623 & 4.9215 & 5.0233 & TRN \\
\hline CHEMBL1420309 & 688623 & 2.9208 & 4.1243 & TRN \\
\hline CHEMBL1546279 & 688623 & 4.978 & 4.4869 & TRN \\
\hline CHEMBL460601 & 688623 & 8.0 & 6.5455 & TRN \\
\hline CHEMBL1427265 & 688623 & 5.21299 & 9999999 & 5.0547 \\
\hline CHEMBL1607180 & 688623 & 4.6816 & 4.2597 & TRN \\
\hline CHEMBL1359285 & 688623 & 2.9208 & 3.9512 & TRN \\
\hline CHEMBL1412543 & 688623 & 2.9208 & 3.0588 & TRN \\
\hline CHEMBL1572498 & 688623 & 2.9208 & 4.3028 & TRN \\
\hline CHEMBL1434686 & 688623 & 2.9208 & 3.6072 & TRN \\
\hline CHEMBL1514474 & 688623 & 4.6978 & 4.0275 & TRN \\
\hline CHEMBL1476556 & 688623 & 6.6778 & 3.6094 & TRN \\
\hline CHEMBL1321427 & 688623 & 8.0 & 7.1163 & TRN \\
\hline CHEMBL1560324 & 688623 & 5.004 & 4.0766 & TRN \\
\hline CHEMBL1388595 & 688623 & 5.0121 & 4.4216 & TRN \\
\hline CHEMBL1320400 & 688623 & 2.9208 & 5.3575 & TRN \\
\hline CHEMBL1392356 & 688623 & 2.9208 & 3.6105 & TRN \\
\hline CHEMBL1548907 & 688623 & 4.7112 & 4.2481 & TRN \\
\hline CHEMBL1584389 & 688623 & 4.7245 & 4.2149 & TRN \\
\hline CHEMBL1300131 & 688623 & 4.8035 & 4.3687 & TRN \\
\hline CHEMBL1463050 & 688623 & 5.1045 & 5.4633 & TRN \\
\hline CHEMBL1577346 & 688623 & 2.9208 & 4.1404 & TRN \\
\hline CHEMBL1307769 & 688623 & 5.0486 & 6.8822 & TRN \\
\hline CHEMBL1600769 & 688623 & 2.9208 & 3.5481 & TRN \\
\hline CHEMBL1557701 & 688623 & 4.0786 & 3.0324 & TRN \\
\hline CHEMBL1311981 & 688623 & 2.9208 & 3.0141 & TST \\
\hline CHEMBL1305138 & 688623 & 2.9208 & 2.8473 & TRN \\
\hline CHEMBL1398622 & 688623 & 2.9208 & 3.1611 & TRN \\
\hline CHEMBL1459117 & 688623 & 2.9208 & 2.9943 & TRN \\
\hline
\end{tabular}


Supplemental Table S2.txt

\begin{tabular}{|c|c|c|c|c|c|}
\hline CHEMBL1383035 & 688623 & 2.9208 & 3.5734 & TRN & \\
\hline CHEMBL1548478 & 688623 & 2.9208 & 3.5822 & TRN & \\
\hline CHEMBL1427089 & 688623 & 3.9232 & 4.0409 & TRN & \\
\hline CHEMBL1401175 & 688623 & 5.0215 & 4.5694 & TRN & \\
\hline CHEMBL1463184 & 688623 & 2.9208 & 3.99899 & 99999999997 & TRN \\
\hline CHEMBL1572266 & 688623 & 4.8086 & 3.2606 & TST & \\
\hline CHEMBL1569984 & 688623 & 5.0227 & 4.4834 & TRN & \\
\hline CHEMBL1467383 & 688623 & 4.867 & 3.7888 & TRN & \\
\hline CHEMBL1612880 & 688623 & 2.9208 & 4.2282 & TRN & \\
\hline CHEMBL1533981 & 688623 & 2.9208 & 3.2951 & TRN & \\
\hline CHEMBL1505057 & 688623 & 4.6143 & 3.7955 & TRN & \\
\hline CHEMBL1366268 & 688623 & 2.9208 & 4.4465 & TRN & \\
\hline CHEMBL1409039 & 688623 & 5.4316 & 5.5111 & TRN & \\
\hline CHEMBL1386622 & 688623 & 5.5919 & 4.7015 & TRN & \\
\hline CHEMBL1354093 & 688623 & 2.9208 & 5.7772 & TRN & \\
\hline CHEMBL1570765 & 688623 & 5.0977 & 5.6722 & TRN & \\
\hline CHEMBL1351143 & 688623 & 2.9208 & 3.24 & TRN & \\
\hline CHEMBL1532825 & 688623 & 4.7525 & 3.8762 & TRN & \\
\hline CHEMBL1255733 & 688623 & 6.8794 & 6.0358 & TST & \\
\hline CHEMBL3210018 & 688623 & 2.9208 & 4.3096 & TRN & \\
\hline CHEMBL1397551 & 688623 & 2.9208 & 3.1321 & TRN & \\
\hline CHEMBL1468313 & 688623 & 2.9208 & 3.653 & TRN & \\
\hline CHEMBL1549357 & 688623 & 2.9208 & 5.0934 & TRN & \\
\hline CHEMBL1454000 & 688623 & 4.9856 & 4.6231 & TRN & \\
\hline CHEMBL1429868 & 688623 & 2.9208 & 3.5661 & TRN & \\
\hline CHEMBL1420007 & 688623 & 6.5654 & 4.4823 & TST & \\
\hline CHEMBL3209368 & 688623 & 4.8505 & 4.0062 & TRN & \\
\hline CHEMBL1423097 & 688623 & 4.7075 & 3.7031 & TST & \\
\hline CHEMBL 3212783 & 688623 & 2.9208 & 3.2154 & TST & \\
\hline CHEMBL1368066 & 688623 & 4.7348 & \multicolumn{2}{|c|}{3.5380000000000003} & TRN \\
\hline CHEMBL1605021 & 688623 & 6.8794 & 6.4087 & TST & \\
\hline CHEMBL1476264 & 688623 & 2.9208 & 6.0389 & TRN & \\
\hline CHEMBL1342933 & 688623 & 2.9208 & 3.1854 & TRN & \\
\hline CHEMBL1404049 & 688623 & 2.9208 & 4.3215 & TRN & \\
\hline CHEMBL1992394 & 688623 & 4.7252 & 3.9948 & TRN & \\
\hline CHEMBL1310355 & 688623 & 5.0521 & 4.5864 & TRN & \\
\hline CHEMBL1430866 & 688623 & 3.9645 & 3.5802 & TRN & \\
\hline CHEMBL1509021 & 688623 & 2.9208 & 3.1556 & TRN & \\
\hline CHEMBL3197471 & 688623 & 4.978 & 4.6 & TRN & \\
\hline CHEMBL3199752 & 688623 & 4.7874 & 4.7809 & TRN & \\
\hline CHEMBL1564569 & 688623 & 4.6609 & 3.9743 & TST & \\
\hline CHEMBL1315153 & 688623 & 2.9208 & 4.3449 & TRN & \\
\hline CHEMBL543876 & 688623 & 2.9208 & 3.4448 & TRN & \\
\hline CHEMBL1516860 & 688623 & 4.9 & 3.1418 & TRN & \\
\hline CHEMBL1318795 & 688623 & 2.9208 & 2.9295 & TRN & \\
\hline CHEMBL1452379 & 688623 & 3.2218 & 4.3124 & TRN & \\
\hline CHEMBL1498588 & 688623 & 4.5043 & 4.2653 & TRN & \\
\hline CHEMBL1317745 & 688623 & 2.9208 & 3.1954 & TRN & \\
\hline
\end{tabular}




\begin{tabular}{|c|c|c|c|c|c|}
\hline & & \multicolumn{4}{|c|}{ Supplemental Table S2.txt } \\
\hline CHEMBL1994068 & 688623 & 4.9192 & 4.5039 & TRN & \\
\hline CHEMBL1422078 & 688623 & 5.5391 & 5.3524 & TRN & \\
\hline CHEMBL1475128 & 688623 & 4.9272 & 4.5777 & TST & \\
\hline CHEMBL1415642 & 688623 & 2.9208 & 3.7653 & TRN & \\
\hline CHEMBL259103 & 688623 & 5.0575 & 6.9336 & TRN & \\
\hline CHEMBL1549738 & 688623 & 4.997 & 3.5832 & TST & \\
\hline CHEMBL1323539 & 688623 & 2.9208 & 3.4535 & TRN & \\
\hline CHEMBL1488760 & 688623 & 8.0 & 6.3619 & TRN & \\
\hline CHEMBL1539710 & 688623 & 4.8473 & 3.8306 & TST & \\
\hline CHEMBL1379970 & 688623 & 8.0 & 6.9778 & TST & \\
\hline CHEMBL1302099 & 688623 & 2.9208 & 4.008 & TRN & \\
\hline CHEMBL1345685 & 688623 & 5.074 & 4.4711 & TRN & \\
\hline CHEMBL1355327 & 688623 & 2.9208 & 2.9328 & TRN & \\
\hline CHEMBL1418158 & 688623 & 4.6678 & 4.1645 & TRN & \\
\hline CHEMBL1550378 & 688623 & 2.9208 & 4.1306 & TRN & \\
\hline CHEMBL1332533 & 688623 & 2.9208 & 4.6902 & TRN & \\
\hline CHEMBL 2000750 & 688623 & 4.9826 & 4.75899 & 99999999995 & TRN \\
\hline CHEMBL1555681 & 688623 & 2.9208 & 2.9812 & TRN & \\
\hline CHEMBL1331733 & 688623 & 4.939 & 5.1979 & TRN & \\
\hline CHEMBL1580002 & 688623 & 2.9208 & 3.158 & TST & \\
\hline CHEMBL1503659 & 688623 & 5.0869 & 5.4832 & TRN & \\
\hline CHEMBL1564524 & 688623 & 2.9208 & 3.0626 & TRN & \\
\hline CHEMBL1605138 & 688623 & 4.9916 & 3.0819 & TST & \\
\hline CHEMBL417727 & 688623 & 5.0616 & 3.431 & TRN & \\
\hline CHEMBL1429850 & 688623 & 6.2472 & 5.4767 & TRN & \\
\hline CHEMBL1469597 & 688623 & 2.9208 & 2.9812 & TRN & \\
\hline CHEMBL1505555 & 688623 & 2.9208 & 3.758 & TRN & \\
\hline CHEMBL1573311 & 688623 & 2.9208 & 4.4984 & TRN & \\
\hline CHEMBL1523792 & 688623 & 5.0371 & 4.888 & TRN & \\
\hline CHEMBL1449243 & 688623 & 3.2218 & 4.3613 & TRN & \\
\hline CHEMBL1459440 & 688623 & 2.9208 & 2.9147 & TRN & \\
\hline CHEMBL285932 & 688623 & 2.9208 & 4.4784 & TST & \\
\hline CHEMBL1451300 & 688623 & 2.9208 & 3.53899 & 99999999997 & TRN \\
\hline CHEMBL1520802 & 688623 & 2.9208 & 3.5799 & TRN & \\
\hline CHEMBL1303802 & 688623 & 2.9208 & 3.3872 & TST & \\
\hline CHEMBL1575389 & 688623 & 4.7824 & 4.4724 & TRN & \\
\hline CHEMBL1979574 & 688623 & 4.9645 & 4.8966 & TRN & \\
\hline CHEMBL1320414 & 688623 & 5.9706 & 5.4674 & TRN & \\
\hline CHEMBL259784 & 688623 & 6.2733 & 5.2939 & TRN & \\
\hline CHEMBL601351 & 688623 & 2.9208 & 3.0779 & TST & \\
\hline CHEMBL592431 & 688623 & 2.9208 & 4.1618 & TRN & \\
\hline CHEMBL3145296 & 688623 & 4.5757 & 5.1502 & TRN & \\
\hline CHEMBL3197433 & 688623 & 6.8962 & 4.6823 & TRN & \\
\hline CHEMBL1334062 & 688623 & 2.9208 & 4.763 & TRN & \\
\hline CHEMBL1463234 & 688623 & 2.9208 & 3.3213 & TRN & \\
\hline CHEMBL1548568 & 688623 & 4.738 & 3.3416 & TRN & \\
\hline CHEMBL3185655 & 688623 & 8.0 & 6.9335 & TRN & \\
\hline CHEMBL1543742 & 688623 & 5.2425 & 4.652 & TRN & \\
\hline
\end{tabular}





\begin{tabular}{|c|c|c|c|c|c|c|}
\hline & & \multicolumn{5}{|c|}{ Supplemental Table S2.txt } \\
\hline CHEMBL1506317 & 688623 & 4.9344 & 4.8355 & TRN & & \\
\hline CHEMBL1306460 & 688623 & 5.3051 & 5.7554 & TRN & & \\
\hline CHEMBL1572031 & 688623 & 4.9349 & 3.7949 & TRN & & \\
\hline CHEMBL1328553 & 688623 & 4.8349 & 4.3907 & TST & & \\
\hline CHEMBL1305231 & 688623 & 2.9208 & 3.8383 & TRN & & \\
\hline CHEMBL1522803 & 688623 & 3.2218 & 5.0954 & TRN & & \\
\hline CHEMBL1529883 & 688623 & 5.5727 & 5.4119 & TRN & & \\
\hline CHEMBL1491019 & 688623 & 2.9208 & 4.2514 & TRN & & \\
\hline CHEMBL1369768 & 688623 & 4.9635 & 4.0879 & TRN & & \\
\hline CHEMBL1335812 & 688623 & 2.9208 & 4.4426 & TRN & & \\
\hline CHEMBL1310382 & 688623 & 2.9208 & 3.1857 & TRN & & \\
\hline CHEMBL1542809 & 688623 & 5.04899 & 99999999 & 995 & 4.3519 & TRN \\
\hline CHEMBL1461192 & 688623 & 2.9208 & 3.0967 & TRN & & \\
\hline CHEMBL1545086 & 688623 & 2.9208 & 4.4421 & TRN & & \\
\hline CHEMBL1573563 & 688623 & 4.9296 & 5.3315 & TRN & & \\
\hline CHEMBL1360028 & 688623 & 4.9763 & 4.5853 & TRN & & \\
\hline CHEMBL1417944 & 688623 & 2.9208 & 2.9903 & TRN & & \\
\hline CHEMBL1348389 & 688623 & 4.7519 & 4.5295 & TRN & & \\
\hline CHEMBL1487074 & 688623 & 2.9208 & 2.9177 & TST & & \\
\hline CHEMBL1361645 & 688623 & 4.9398 & 3.2983 & TRN & & \\
\hline CHEMBL1400888 & 688623 & 2.9208 & 3.9051 & TRN & & \\
\hline CHEMBL1386546 & 688623 & 4.7279 & 4.8483 & TRN & & \\
\hline CHEMBL1328784 & 688623 & 2.9208 & 3.1412 & TST & & \\
\hline CHEMBL1611882 & 688623 & 2.9208 & 2.9009 & TRN & & \\
\hline CHEMBL1420777 & 688623 & 2.9208 & 3.0049 & TST & & \\
\hline CHEMBL1399543 & 688623 & 2.9208 & 5.4452 & TRN & & \\
\hline CHEMBL1368526 & 688623 & 5.1439 & 5.3151 & TRN & & \\
\hline CHEMBL1494220 & 688623 & 2.9208 & 3.1313 & TRN & & \\
\hline CHEMBL1379081 & 688623 & 5.3802 & 6.0945 & TRN & & \\
\hline CHEMBL1351542 & 688623 & 5.0316 & 4.7166 & TRN & & \\
\hline CHEMBL1375884 & 688623 & 4.6568 & 4.4235 & TRN & & \\
\hline CHEMBL1332356 & 688623 & 2.9208 & 3.0957 & TRN & & \\
\hline CHEMBL1472341 & 688623 & 2.9208 & 3.3688 & TRN & & \\
\hline CHEMBL1487635 & 688623 & 4.8184 & 4.4453 & TRN & & \\
\hline CHEMBL1567841 & 688623 & 5.1215 & 5.6309 & TRN & & \\
\hline CHEMBL1595706 & 688623 & 2.9208 & 3.807 & TRN & & \\
\hline CHEMBL1595516 & 688623 & 2.9208 & 3.0351 & TRN & & \\
\hline CHEMBL1332955 & 688623 & 2.9208 & 3.9777 & TRN & & \\
\hline CHEMBL3198554 & 688623 & 5.0167 & 4.5762 & TRN & & \\
\hline CHEMBL1336914 & 688623 & 2.9208 & 4.0404 & TRN & & \\
\hline CHEMBL1453505 & 688623 & 5.1013 & 4.3014 & TST & & \\
\hline CHEMBL1312738 & 688623 & 8.0 & 6.9434 & TST & & \\
\hline CHEMBL1299531 & 688623 & 2.9208 & 4.2068 & TRN & & \\
\hline CHEMBL1575194 & 688623 & 4.779 & 3.075 & TRN & & \\
\hline CHEMBL1602808 & 688623 & 5.1293 & 4.7117 & TRN & & \\
\hline CHEMBL1528118 & 688623 & 5.1353 & 5.0316 & TRN & & \\
\hline CHEMBL1546992 & 688623 & 2.9208 & 3.0718 & TST & & \\
\hline CHEMBL1564302 & 688623 & 2.9208 & 3.8768 & TST & & \\
\hline
\end{tabular}




\begin{tabular}{|c|c|c|c|c|c|}
\hline & & \multicolumn{4}{|c|}{ Supplemental Table S2.txt } \\
\hline CHEMBL1331520 & 688623 & 5.1536 & 5.0069 & TRN & \\
\hline CHEMBL1339289 & 688623 & 5.0535 & 6.159 & TST & \\
\hline CHEMBL1996263 & 688623 & 4.8055 & 3.9332 & TRN & \\
\hline CHEMBL505209 & 688623 & 4.6419 & 4.6159 & TRN & \\
\hline CHEMBL1523552 & 688623 & 4.6213 & 4.3156 & TRN & \\
\hline CHEMBL1608294 & 688623 & 2.9208 & 4.0691 & TRN & \\
\hline CHEMBL1462938 & 688623 & 8.0 & 6.6509 & TST & \\
\hline CHEMBL1499095 & 688623 & 2.9208 & 2.965 & TRN & \\
\hline CHEMBL1361866 & 688623 & 2.9208 & 4.7274 & TRN & \\
\hline CHEMBL1407046 & 688623 & 2.9208 & 3.016 & TRN & \\
\hline CHEMBL1302130 & 688623 & 2.9208 & 3.1902 & TST & \\
\hline CHEMBL1303463 & 688623 & 4.8312 & 4.2307 & TRN & \\
\hline CHEMBL1351052 & 688623 & 4.9482 & 4.4903 & TRN & \\
\hline CHEMBL1487246 & 688623 & 4.1305 & 4.2034 & TRN & \\
\hline CHEMBL1348251 & 688623 & 2.9208 & 4.1515 & TRN & \\
\hline CHEMBL1452295 & 688623 & 4.8092 & 4.4176 & TRN & \\
\hline CHEMBL1506641 & 688623 & 4.7855 & 4.6936 & TRN & \\
\hline CHEMBL1301576 & 688623 & 4.3052 & 4.6963 & TRN & \\
\hline CHEMBL 3198754 & 688623 & 5.0254 & 5.0382 & TRN & \\
\hline CHEMBL1572278 & 688623 & 6.5186 & 5.843 & TRN & \\
\hline CHEMBL1446892 & 688623 & 2.9208 & 3.5869 & TRN & \\
\hline CHEMBL1589009 & 688623 & 2.9208 & 2.9322 & TRN & \\
\hline CHEMBL1420325 & 688623 & 4.9860 & 0000000 & 4.0092 & I \\
\hline CHEMBL1328529 & 688623 & 4.0379 & 3.3577 & TST & \\
\hline CHEMBL1471311 & 688623 & 2.9208 & 4.5184 & TRN & \\
\hline CHEMBL3208365 & 688623 & 5.1648 & 4.92 & TRN & \\
\hline CHEMBL1326102 & 688623 & 2.9208 & 3.4918 & TRN & \\
\hline CHEMBL1370849 & 688623 & 4.8785 & 4.4032 & TRN & \\
\hline CHEMBL1522352 & 688623 & 4.1462 & 3.9062 & TRN & \\
\hline CHEMBL1490905 & 688623 & 2.9208 & 3.6874 & TRN & \\
\hline CHEMBL1506640 & 688623 & 4.7083 & 3.9225 & TRN & \\
\hline CHEMBL1609361 & 688623 & 2.9208 & 2.9527 & TRN & \\
\hline CHEMBL1585625 & 688623 & 2.9208 & 3.0492 & TRN & \\
\hline CHEMBL1430581 & 688623 & 4.4916 & 3.7819 & TRN & \\
\hline CHEMBL1399237 & 688623 & 4.4126 & 3.7549 & TRN & \\
\hline CHEMBL1383414 & 688623 & 4.9779 & 3.733 & TRN & \\
\hline CHEMBL586029 & 688623 & 4.7383 & 3.9129 & TRN & \\
\hline CHEMBL1409963 & 688623 & 5.0014 & 4.70100 & 00000000005 & TST \\
\hline CHEMBL1334376 & 688623 & 2.9208 & 3.1086 & TRN & \\
\hline CHEMBL1525695 & 688623 & 5.586 & 4.4804 & TST & \\
\hline CHEMBL1506951 & 688623 & 5.0481 & 4.4929 & TRN & \\
\hline CHEMBL1597706 & 688623 & 3.2218 & 3.1898 & TRN & \\
\hline CHEMBL3213030 & 688623 & 2.9208 & 3.2764 & TRN & \\
\hline CHEMBL1389225 & 688623 & 4.9416 & 4.4314 & TST & \\
\hline CHEMBL1525098 & 688623 & 2.9208 & 4.5276 & TRN & \\
\hline CHEMBL1312298 & 688623 & 2.9208 & 4.3417 & TRN & \\
\hline CHEMBL3191879 & 688623 & 5.0794 & 4.7547 & TRN & \\
\hline CHEMBL1575038 & 688623 & 2.9208 & 3.742 & TRN & \\
\hline
\end{tabular}




\begin{tabular}{|c|c|c|c|c|}
\hline & & & oplement & al Ta \\
\hline CHEMBL1310038 & 688623 & 2.9208 & 3.0832 & TRN \\
\hline CHEMBL1455468 & 688623 & 8.0 & 6.3425 & TRN \\
\hline CHEMBL1583867 & 688623 & 4.4056 & 3.0756 & TRN \\
\hline CHEMBL1302027 & 688623 & 2.9208 & 3.0367 & TRN \\
\hline CHEMBL606675 & 688623 & 3.9635 & 4.4389 & TST \\
\hline CHEMBL1379178 & 688623 & 5.0761 & 4.6989 & TST \\
\hline CHEMBL1500581 & 688623 & 6.0487 & 5.7433 & TST \\
\hline CHEMBL1601997 & 688623 & 4.052 & 4.2978 & TST \\
\hline CHEMBL1528660 & 688623 & 8.0 & 6.5686 & TRN \\
\hline CHEMBL1459254 & 688623 & 4.8878 & 4.5896 & TST \\
\hline CHEMBL1448448 & 688623 & 2.9208 & 3.0345 & TST \\
\hline CHEMBL1518705 & 688623 & 4.8823 & 3.9563 & TST \\
\hline CHEMBL1467220 & 688623 & 2.9208 & 3.2626 & TST \\
\hline CHEMBL1560237 & 688623 & 2.9208 & 6.5659 & TST \\
\hline CHEMBL1420030 & 688623 & 2.9208 & 3.1164 & TRN \\
\hline CHEMBL1468355 & 688623 & 5.0506 & 4.5788 & TRN \\
\hline CHEMBL1542001 & 688623 & 4.801 & 4.3738 & TRN \\
\hline CHEMBL1569783 & 688623 & 4.7922 & 5.5805 & TRN \\
\hline CHEMBL1542907 & 688623 & 4.7835 & 3.8361 & TRN \\
\hline CHEMBL 3189810 & 688623 & 4.7748 & 4.1819 & TRN \\
\hline CHEMBL1506962 & 688623 & 4.7804 & 4.9524 & TRN \\
\hline CHEMBL1457419 & 688623 & 4.4364 & 4.216 & TST \\
\hline CHEMBL1728993 & 688623 & 2.9208 & 3.2926 & TST \\
\hline CHEMBL1586266 & 688623 & 2.9208 & 4.3259 & TRN \\
\hline CHEMBL1400785 & 688623 & 5.5653 & 4.4704 & TRN \\
\hline CHEMBL1417160 & 688623 & 4.8365 & 4.3445 & TRN \\
\hline CHEMBL1304245 & 688623 & 2.9208 & 3.2407 & TRN \\
\hline CHEMBL1467399 & 688623 & 2.9208 & 3.3327 & TRN \\
\hline CHEMBL1319676 & 688623 & 5.4766 & 5.1965 & TRN \\
\hline CHEMBL1571005 & 688623 & 4.0784 & 4.3802 & TRN \\
\hline CHEMBL1558095 & 688623 & 2.9208 & 3.0315 & TRN \\
\hline CHEMBL1460352 & 688623 & 5.0806 & 4.5923 & TRN \\
\hline CHEMBL1525789 & 688623 & 8.0 & 6.4576 & TRN \\
\hline CHEMBL587801 & 688623 & 5.0383 & 4.0599 & TRN \\
\hline CHEMBL1480024 & 688623 & 2.9208 & 3.6197 & TRN \\
\hline CHEMBL1415306 & 688623 & 2.9208 & 3.8408 & TRN \\
\hline CHEMBL1476358 & 688623 & 4.9808 & 3.6898 & TRN \\
\hline CHEMBL1428777 & 688623 & 2.9208 & 4.2141 & TRN \\
\hline CHEMBL3212546 & 688623 & 2.9208 & 3.5024 & TRN \\
\hline CHEMBL269881 & 688623 & 4.8 & 4.3349 & TST \\
\hline CHEMBL1544011 & 688623 & 2.9208 & 3.2864 & TRN \\
\hline CHEMBL1990919 & 688623 & 6.6596 & 5.7971 & TRN \\
\hline CHEMBL1560092 & 688623 & 4.9296 & 3.3173 & TRN \\
\hline CHEMBL1539440 & 688623 & 3.9211 & 3.4267 & TST \\
\hline CHEMBL487356 & 688623 & 5.2843 & 4.605 & TRN \\
\hline CHEMBL1487952 & 688623 & 4.9874 & 3.9615 & TRN \\
\hline CHEMBL1490392 & 688623 & 4.8073 & 4.5233 & TRN \\
\hline CHEMBL1578216 & 688623 & 4.7731 & 4.2251 & TRN \\
\hline
\end{tabular}


Supplemental Table S2.txt

\begin{tabular}{|c|c|c|c|c|c|}
\hline CHEMBL1404030 & 688623 & 2.9208 & 3.1923 & TST & \\
\hline CHEMBL1377218 & 688623 & 2.9208 & 3.4293 & TRN & \\
\hline CHEMBL1541251 & 688623 & 5.0291 & 4.5487 & TRN & \\
\hline CHEMBL1540099 & 688623 & 5.0083 & 6.3563 & TRN & \\
\hline CHEMBL1374924 & 688623 & 4.7436 & 3.5303 & TRN & \\
\hline CHEMBL3190651 & 688623 & 2.9208 & 4.7734 & TRN & \\
\hline CHEMBL1600065 & 688623 & 4.6697 & 4.5871 & TRN & \\
\hline CHEMBL3189156 & 688623 & 5.0108 & 4.1209 & TRN & \\
\hline CHEMBL1470245 & 688623 & 2.9208 & 3.4768 & TRN & \\
\hline CHEMBL1506822 & 688623 & 2.9208 & 3.7947 & TRN & \\
\hline CHEMBL1444436 & 688623 & 6.7447 & 3.1781 & TRN & \\
\hline CHEMBL1363982 & 688623 & 2.9208 & 3.2577 & TRN & \\
\hline CHEMBL1567568 & 688623 & 8.0 & 4.4463 & TST & \\
\hline CHEMBL1323796 & 688623 & 2.9208 & 3.1056 & TRN & \\
\hline CHEMBL1503756 & 688623 & 2.9208 & 2.9653 & TRN & \\
\hline CHEMBL1461806 & 688623 & 2.9208 & 3.4307 & TRN & \\
\hline CHEMBL1980322 & 688623 & 2.9208 & 4.3351 & TRN & \\
\hline CHEMBL1517243 & 688623 & 2.9208 & 3.9334 & TRN & \\
\hline CHEMBL1585423 & 688623 & 4.7663 & 4.0278 & TST & \\
\hline CHEMBL1311021 & 688623 & 2.9208 & 2.8233 & TRN & \\
\hline CHEMBL1519703 & 688623 & 4.6347 & 4.10800 & 00000000005 & TRN \\
\hline CHEMBL602722 & 688623 & 5.4874 & 5.72 & TRN & \\
\hline CHEMBL1371264 & 688623 & 3.2218 & 5.2771 & TRN & \\
\hline CHEMBL1507833 & 688623 & 2.9208 & 3.0024 & TST & \\
\hline CHEMBL3191914 & 688623 & 4.9348 & 4.1203 & TRN & \\
\hline CHEMBL1505277 & 688623 & 2.9208 & 3.2488 & TRN & \\
\hline CHEMBL1577399 & 688623 & 2.9208 & 4.2348 & TRN & \\
\hline CHEMBL1440954 & 688623 & 8.0 & 6.6898 & TST & \\
\hline CHEMBL1587732 & 688623 & 2.9208 & 3.0331 & TRN & \\
\hline CHEMBL1510389 & 688623 & 6.5498 & 4.9039 & TRN & \\
\hline CHEMBL1497812 & 688623 & 4.8882 & 4.2436 & TRN & \\
\hline CHEMBL1301721 & 688623 & 4.8194 & 3.6937 & TRN & \\
\hline CHEMBL1365261 & 688623 & 2.9208 & 3.0824 & TRN & \\
\hline CHEMBL1407086 & 688623 & 2.9208 & 3.0898 & TRN & \\
\hline CHEMBL1603830 & 688623 & 4.9816 & 4.6347 & TRN & \\
\hline CHEMBL3196217 & 688623 & 4.9287 & 3.5747 & TRN & \\
\hline CHEMBL1537246 & 688623 & 2.9208 & 4.3279 & TRN & \\
\hline CHEMBL405110 & 688623 & 4.9561 & 5.0848 & TST & \\
\hline CHEMBL1384963 & 688623 & 2.9208 & 3.6743 & TRN & \\
\hline CHEMBL1534781 & 688623 & 5.1403 & 4.0595 & TRN & \\
\hline CHEMBL1402745 & 688623 & 2.9208 & 4.215 & TRN & \\
\hline CHEMBL1550442 & 688623 & 4.8489 & 4.3374 & TRN & \\
\hline CHEMBL1498834 & 688623 & 2.9208 & 3.5076 & TRN & \\
\hline CHEMBL1342448 & 688623 & 5.0352 & 4.1455 & TRN & \\
\hline CHEMBL1399388 & 688623 & 2.9208 & 4.4434 & TRN & \\
\hline CHEMBL1340058 & 688623 & 6.6144 & 6.0706 & TRN & \\
\hline CHEMBL1365411 & 688623 & 2.9208 & 4.6974 & TRN & \\
\hline CHEMBL1392894 & 688623 & 2.9208 & 3.9303 & TST & \\
\hline
\end{tabular}


Supplemental Table S2.txt

\begin{tabular}{|c|c|c|c|c|}
\hline HEM & & 376 & 5.2515 & \\
\hline & & .9208 & 3.548 & \\
\hline & & & & \\
\hline AEMBL1 & 3623 & & & \\
\hline IEMBL1370024 & 8623 & & 7998 & \\
\hline HEMBL1985479 & 88623 & 713 & 6471 & \\
\hline 944 & 23 & & & \\
\hline IEMBL603129 & & & & \\
\hline AEMBL1412300 & 88623 & & .0123 & \\
\hline AEMBL1353271 & 88623 & 08 & .7719 & \\
\hline HEMBL1594613 & 88623 & & 45 & \\
\hline EMBL15 & 8623 & & 4621 & \\
\hline IEMBL1 & & & & \\
\hline HEMBL1596468 & 88623 & & 3.843 & \\
\hline AEMBL1574879 & 38623 & & 36 & \\
\hline AEMBL1366690 & 88623 & 98 & 1767 & \\
\hline HEMBL13 & 23 & & 08 & \\
\hline HEMBL15 & & & & \\
\hline HEMBL160 & 88623 & 8.0 & 4.316 & \\
\hline IEMBL14 & 3 & & & \\
\hline $\mathrm{E} \in \mathrm{MB} \mathrm{B}$ & 8623 & & 1446 & MTV \\
\hline AEMBL14 & 3 & & & 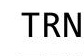 \\
\hline AEMBL13 & 3 & & & \\
\hline AEMBL1572212 & 3 & & & \\
\hline IEMBL14 & 3 & & & וכו \\
\hline HEMBL1C & 86 & & 346 & KIV \\
\hline HEMBL1 & & & & RN \\
\hline AFMBI 1 & 3 & & & \\
\hline HEMBL13 & 88623 & & & I KIV \\
\hline HEMBL1366838 & 386 & & & 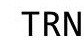 \\
\hline HEMBL16 & & & & RIV \\
\hline HEMBL1 & & & 53 & RN \\
\hline 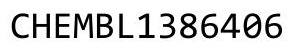 & 3 & & 25 & $\mathrm{RN}$ \\
\hline HEMBL1491222 & 88623 & & & $\mathrm{IR}$ \\
\hline HEMBL1546084 & 88623 & & 33 & TRN \\
\hline HEMBL1 & 886 & & & | \\
\hline AFMBI & 3 & & 35 & $\Gamma \mathrm{RN}$ \\
\hline & & & & TRN \\
\hline HEMBL3197259 & 88623 & & 155 & TRN \\
\hline IEMBL14 & 886 & & 746 & TST \\
\hline HEMBL31 & 886 & & 196 & $\Gamma \mathrm{RN}$ \\
\hline HEMBL14 & 88623 & & 5.0827 & TRN \\
\hline HEMBL577862 & & & 3.0723 & RN \\
\hline IEMBL135077 & 38623 & 53 & 4.8352 & TR \\
\hline MBL13 & 886 & 8 & 4.1942 & 2 \\
\hline HEMBL13 & 588623 & & 6.6555 & \\
\hline CHEMBL197 & 88623 & 6.56 & .665 & \\
\hline HEMBL 200479 & 688623 & 2.9208 & 4.6695 & \\
\hline
\end{tabular}

Page 9265 
Supplemental Table S2.txt

\begin{tabular}{|c|c|c|c|c|}
\hline CHEMBL1349387 & 688623 & 2.9208 & 4.7279 & TRN \\
\hline CHEMBL3210051 & 688623 & 4.9032 & 4.6573 & TRN \\
\hline CHEMBL1381920 & 688623 & 4.8669 & 3.8664 & TST \\
\hline CHEMBL1333987 & 688623 & 5.9646 & 5.7271 & TRN \\
\hline CHEMBL1352668 & 688623 & 4.5802 & 3.3491 & TRN \\
\hline CHEMBL1403315 & 688623 & 2.9208 & 4.4187 & TRN \\
\hline CHEMBL1355233 & 688623 & 2.9208 & 4.9305 & TRN \\
\hline CHEMBL1490339 & 688623 & 6.8477 & 6.1836 & TRN \\
\hline CHEMBL1471547 & 688623 & 2.9208 & 4.2599 & TRN \\
\hline CHEMBL1548023 & 688623 & 2.9208 & 3.2493 & TST \\
\hline CHEMBL1541657 & 688623 & 2.9208 & 3.9254 & TST \\
\hline CHEMBL1418432 & 688623 & 5.0091 & 4.5737 & TRN \\
\hline CHEMBL1569989 & 688623 & 5.2651 & 5.0816 & TRN \\
\hline CHEMBL1504403 & 688623 & 4.9278 & 4.3256 & TRN \\
\hline CHEMBL1514238 & 688623 & 3.2218 & 3.7453 & TRN \\
\hline CHEMBL1481301 & 688623 & 4.8604 & 4.3557 & TRN \\
\hline CHEMBL1386429 & 688623 & 4.6231 & 4.4034 & TRN \\
\hline CHEMBL1582355 & 688623 & 4.8925 & 4.4409 & TRN \\
\hline CHEMBL3211755 & 688623 & 4.6061 & 3.2118 & TST \\
\hline CHEMBL1994623 & 688623 & 6.5421 & 5.8561 & TRN \\
\hline CHEMBL1978534 & 688623 & 2.9208 & 2.9999 & TST \\
\hline CHEMBL1343269 & 688623 & 2.9208 & 3.1439 & TST \\
\hline CHEMBL3195551 & 688623 & 5.1378 & 4.6321 & TRN \\
\hline CHEMBL1483475 & 688623 & 4.4466 & 4.3642 & TRN \\
\hline CHEMBL1319510 & 688623 & 4.3997 & 3.5398 & TRN \\
\hline CHEMBL1988121 & 688623 & 4.9859 & 4.3168 & TRN \\
\hline CHEMBL3190257 & 688623 & 4.8358 & 4.3013 & TRN \\
\hline CHEMBL1533541 & 688623 & 5.3539 & 3.54399 & 99999999996 \\
\hline CHEMBL1464011 & 688623 & 2.9208 & 3.9129 & TRN \\
\hline CHEMBL1561439 & 688623 & 4.7397 & 4.4825 & TRN \\
\hline CHEMBL1301531 & 688623 & 2.9208 & 4.1615 & TRN \\
\hline CHEMBL1423060 & 688623 & 5.07600 & 00000000 & 4.7379 \\
\hline CHEMBL1341270 & 688623 & 5.4881 & 5.1471 & TRN \\
\hline CHEMBL1559622 & 688623 & 2.9208 & 4.5482 & TRN \\
\hline CHEMBL591126 & 688623 & 5.7883 & 4.9186 & TRN \\
\hline CHEMBL1439210 & 688623 & 2.9208 & 3.178 & TRN \\
\hline CHEMBL1424164 & 688623 & 4.1196 & 3.6015 & TRN \\
\hline CHEMBL1391313 & 688623 & 8.0 & 5.3721 & TRN \\
\hline CHEMBL1981103 & 688623 & 5.0528 & 4.0162 & TST \\
\hline CHEMBL1988883 & 688623 & 4.9593 & 5.0652 & TRN \\
\hline CHEMBL1559726 & 688623 & 2.9208 & 3.4915 & TRN \\
\hline CHEMBL1361507 & 688623 & 4.8994 & 4.1508 & TRN \\
\hline CHEMBL1299210 & 688623 & 2.9208 & 3.8235 & TRN \\
\hline CHEMBL1357620 & 688623 & 8.0 & 7.1164 & TST \\
\hline CHEMBL1415368 & 688623 & 2.9208 & 3.0299 & TRN \\
\hline CHEMBL1896831 & 688623 & 4.9168 & 4.5975 & TRN \\
\hline CHEMBL1407787 & 688623 & 4.9833 & 3.8325 & TRN \\
\hline CHEMBL3191713 & 688623 & 6.8125 & 6.2828 & TRN \\
\hline
\end{tabular}




\begin{tabular}{|c|c|c|c|c|c|}
\hline \multicolumn{6}{|c|}{ Supplemental Table S2.txt } \\
\hline CHEMBL1563383 & 688623 & 5.0267 & 4.8299 & TRN & \\
\hline CHEMBL181930 & 688623 & 2.9208 & 3.4852 & TRN & \\
\hline CHEMBL1456768 & 688623 & 2.9208 & 4.4206 & TRN & \\
\hline CHEMBL1375903 & 688623 & 2.9208 & 4.1869 & TST & \\
\hline CHEMBL3194623 & 688623 & 4.7665 & 4.9993 & TRN & \\
\hline CHEMBL1531769 & 688623 & 2.9208 & 2.9313 & TRN & \\
\hline CHEMBL1389029 & 688623 & 5.8248 & 5.8753 & TRN & \\
\hline CHEMBL1586416 & 688623 & 2.9208 & 4.6636 & TRN & \\
\hline CHEMBL1320019 & 688623 & 4.3429 & 3.741 & TRN & \\
\hline CHEMBL1376339 & 688623 & 3.9469 & 4.0903 & TST & \\
\hline CHEMBL1481780 & 688623 & 2.9208 & 3.6102 & TRN & \\
\hline CHEMBL1323429 & 688623 & 2.9208 & 3.5537 & TRN & \\
\hline CHEMBL1408311 & 688623 & 4.7901 & 4.5133 & TRN & \\
\hline CHEMBL1424269 & 688623 & 6.059 & 5.4438 & TRN & \\
\hline CHEMBL1329172 & 688623 & 2.9208 & 2.83600 & 00000000003 & TST \\
\hline CHEMBL1382716 & 688623 & 2.9208 & 3.8144 & TRN & \\
\hline CHEMBL1545701 & 688623 & 4.8081 & 4.3128 & TRN & \\
\hline CHEMBL1336644 & 688623 & 4.6998 & 4.1883 & TRN & \\
\hline CHEMBL1327172 & 688623 & 4.9641 & 4.7304 & TRN & \\
\hline CHEMBL563577 & 688623 & 4.9284 & 6.5324 & TRN & \\
\hline CHEMBL1327749 & 688623 & 4.9553 & 6.4099 & TRN & \\
\hline CHEMBL1362687 & 688623 & 6.1278 & 4.896 & TRN & \\
\hline CHEMBL1488346 & 688623 & 2.9208 & 4.0059 & TRN & \\
\hline CHEMBL1359026 & 688623 & 2.9208 & 3.5709 & TRN & \\
\hline CHEMBL1445776 & 688623 & 5.0491 & 3.0505 & TRN & \\
\hline CHEMBL1490532 & 688623 & 4.7552 & 4.391 & TRN & \\
\hline CHEMBL1412855 & 688623 & 4.9586 & 4.7551 & TRN & \\
\hline CHEMBL1569525 & 688623 & 4.5983 & 3.1844 & TRN & \\
\hline CHEMBL1327738 & 688623 & 2.9208 & 3.9343 & TRN & \\
\hline CHEMBL1379115 & 688623 & 4.8632 & 4.6569 & TRN & \\
\hline CHEMBL1319679 & 688623 & 4.9709 & 4.8184 & TRN & \\
\hline CHEMBL1365426 & 688623 & 2.9208 & 2.9521 & TST & \\
\hline CHEMBL1425702 & 688623 & 2.9208 & 3.56100 & 00000000004 & TRN \\
\hline CHEMBL1531681 & 688623 & 4.805 & 4.4012 & TST & \\
\hline CHEMBL1494829 & 688623 & 4.8009 & 4.5031 & TRN & \\
\hline CHEMBL1592251 & 688623 & 4.8853 & 4.5017 & TRN & \\
\hline CHEMBL1486078 & 688623 & 2.9208 & 3.5009 & TRN & \\
\hline CHEMBL1392228 & 688623 & 8.0 & 7.0962 & TRN & \\
\hline CHEMBL1332013 & 688623 & 5.2347 & 4.9321 & TRN & \\
\hline CHEMBL 3190648 & 688623 & 4.9295 & 4.8284 & TRN & \\
\hline CHEMBL1584470 & 688623 & 4.6877 & 2.8885 & TRN & \\
\hline CHEMBL1392142 & 688623 & 8.0 & 7.3203 & TRN & \\
\hline CHEMBL1428004 & 688623 & 4.8236 & 4.002 & TRN & \\
\hline CHEMBL1569549 & 688623 & 2.9208 & 3.3922 & TRN & \\
\hline CHEMBL1979047 & 688623 & 4.7727 & 4.5346 & TRN & \\
\hline CHEMBL1386044 & 688623 & 2.9208 & 3.5466 & TRN & \\
\hline CHEMBL3210628 & 688623 & 4.7314 & 4.6439 & TRN & \\
\hline CHEMBL1518680 & 688623 & 2.9208 & 3.6261 & TST & \\
\hline
\end{tabular}




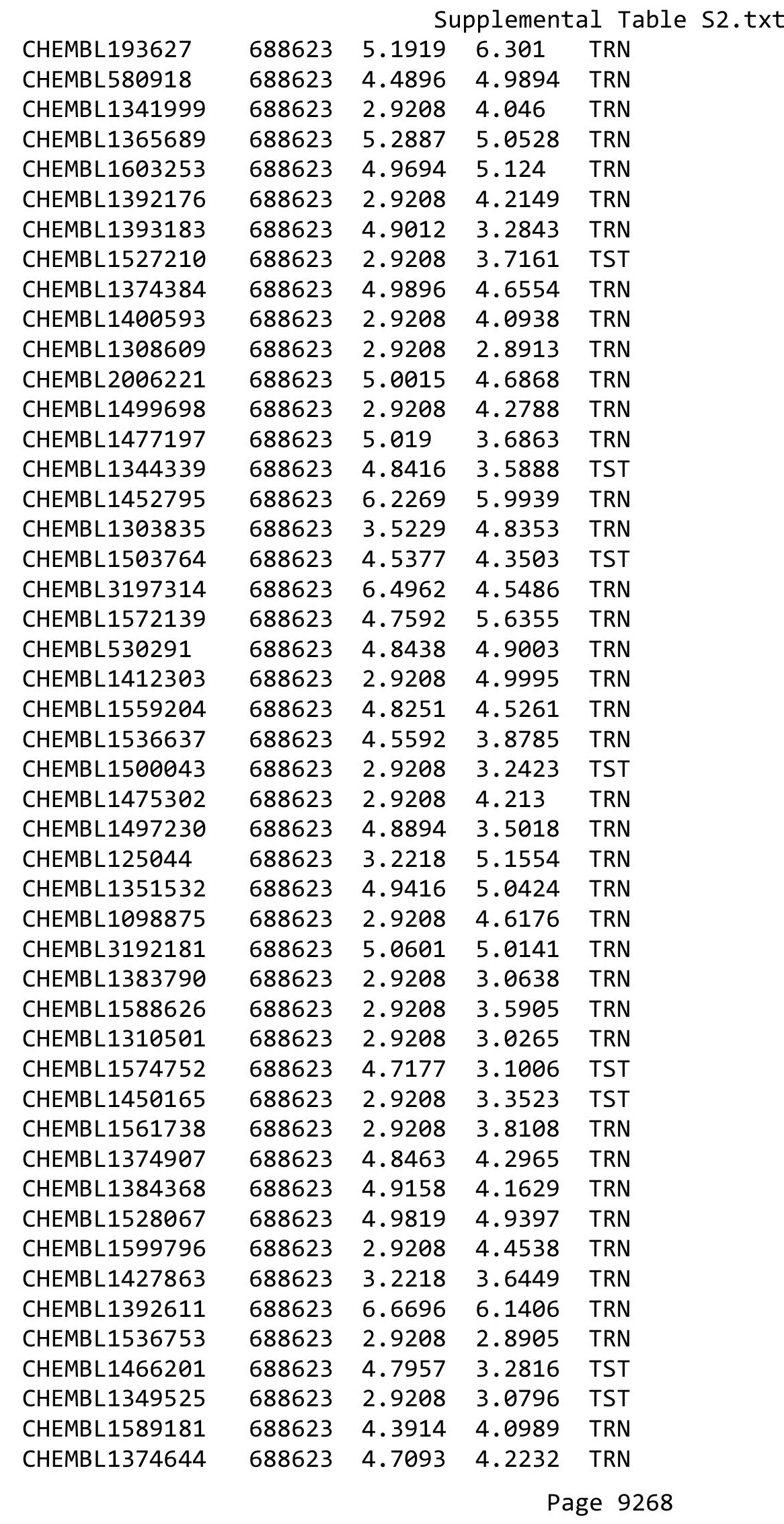




\begin{tabular}{|c|c|c|c|c|c|}
\hline & & \multicolumn{4}{|c|}{ Supplemental Table S2.txt } \\
\hline CHEMBL599255 & 688623 & 4.8635 & 3.8342 & TRN & \\
\hline CHEMBL1555435 & 688623 & 4.5251 & 4.36 & TRN & \\
\hline CHEMBL1497289 & 688623 & 4.6966 & 4.3154 & TRN & \\
\hline CHEMBL1304666 & 688623 & 4.8726 & 4.1013 & TRN & \\
\hline CHEMBL1610585 & 688623 & 4.6325 & 4.1251 & TST & \\
\hline CHEMBL1567326 & 688623 & 2.9208 & 4.4792 & TRN & \\
\hline CHEMBL1424729 & 688623 & 5.0767 & 4.5545 & TST & \\
\hline CHEMBL3198929 & 688623 & 2.9208 & 3.9973 & TRN & \\
\hline CHEMBL1416020 & 688623 & 2.9208 & 3.2313 & TRN & \\
\hline CHEMBL1533711 & 688623 & 4.9865 & 4.5333 & TRN & \\
\hline CHEMBL1585663 & 688623 & \multicolumn{3}{|c|}{4.1530000000000005} & TRN \\
\hline CHEMBL1600993 & 688623 & 2.9208 & 3.105 & TRN & \\
\hline CHEMBL3209663 & 688623 & 4.3157 & 4.7195 & TST & \\
\hline CHEMBL1478072 & 688623 & 2.9208 & \multicolumn{2}{|c|}{3.1010000000000004} & TRN \\
\hline CHEMBL1507179 & 688623 & 4.4909 & 2.8864 & TRN & \\
\hline CHEMBL1579258 & 688623 & 8.0 & 6.5162 & TST & \\
\hline CHEMBL1438877 & 688623 & 4.4075 & 4.5259 & TRN & \\
\hline CHEMBL1604761 & 688623 & 4.7862 & 4.1305 & TRN & \\
\hline CHEMBL1381431 & 688623 & 2.9208 & 3.3992 & TRN & \\
\hline CHEMBL1993501 & 688623 & 4.8922 & 4.1707 & TRN & \\
\hline CHEMBL1428850 & 688623 & 3.2218 & 4.4749 & TRN & \\
\hline CHEMBL1530011 & 688623 & 5.0834 & 4.6197 & TRN & \\
\hline CHEMBL1429312 & 688623 & 4.7791 & 4.3519 & TRN & \\
\hline CHEMBL1422740 & 688623 & 4.9685 & 4.5682 & TRN & \\
\hline CHEMBL1535351 & 688623 & 5.1042 & 5.8456 & TRN & \\
\hline CHEMBL1335553 & 688623 & 4.3685 & 3.708 & TRN & \\
\hline CHEMBL3197908 & 688623 & 2.9208 & 4.6795 & TRN & \\
\hline CHEMBL1304177 & 688623 & 4.9969 & 4.0467 & TRN & \\
\hline CHEMBL1468961 & 688623 & 2.9208 & 2.9958 & TRN & \\
\hline CHEMBL1498952 & 688623 & 4.4195 & \multicolumn{2}{|c|}{3.1460000000000004} & TRN \\
\hline CHEMBL1484090 & 688623 & 2.9208 & 4.1626 & TST & \\
\hline CHEMBL1384869 & 688623 & 2.9208 & 3.444 & TRN & \\
\hline CHEMBL1607474 & 688623 & 2.9208 & 3.2364 & TST & \\
\hline CHEMBL1337227 & 688623 & 5.1211 & 3.8214 & TRN & \\
\hline CHEMBL1483161 & 688623 & 4.1479 & 3.8118 & TST & \\
\hline CHEMBL1419582 & 688623 & 4.1209 & 3.1609 & TRN & \\
\hline CHEMBL1586352 & 688623 & 2.9208 & 3.1569 & TRN & \\
\hline CHEMBL600734 & 688623 & 2.9208 & 4.4303 & TRN & \\
\hline CHEMBL1423192 & 688623 & 8.0 & 6.5421 & TRN & \\
\hline CHEMBL1487794 & 688623 & 2.9208 & 3.1452 & TRN & \\
\hline CHEMBL1506436 & 688623 & 4.78 & 3.6822 & TRN & \\
\hline CHEMBL3193600 & 688623 & 4.9314 & 4.7026 & TRN & \\
\hline CHEMBL1508788 & 688623 & 5.3162 & 4.9554 & TRN & \\
\hline CHEMBL1507107 & 688623 & 5.4108 & 3.2412 & TRN & \\
\hline CHEMBL1453673 & 688623 & 2.9208 & 3.9152 & TRN & \\
\hline CHEMBL1381585 & 688623 & 2.9208 & 3.3226 & TRN & \\
\hline CHEMBL1337301 & 688623 & 2.9208 & 3.12 & TRN & \\
\hline CHEMBL1519030 & 688623 & 2.9208 & 3.3701 & TST & \\
\hline
\end{tabular}




\begin{tabular}{|c|c|c|c|c|}
\hline & & & oplement & al $\mathrm{T}$ \\
\hline CHEMBL1461934 & 688623 & 4.7287 & 4.0275 & TRN \\
\hline CHEMBL1595934 & 688623 & 5.0349 & 4.8401 & TRN \\
\hline CHEMBL588038 & 688623 & 5.0953 & 4.4335 & TST \\
\hline CHEMBL1439666 & 688623 & 2.9208 & 3.3807 & TRN \\
\hline CHEMBL1415899 & 688623 & 8.0 & 3.687 & TRN \\
\hline CHEMBL1351441 & 688623 & 2.9208 & 5.151 & TRN \\
\hline CHEMBL19980 & 688623 & 8.0 & 6.6085 & TST \\
\hline CHEMBL1463249 & 688623 & 4.651 & 4.474 & TST \\
\hline CHEMBL1312568 & 688623 & 5.5904 & 4.7662 & TRN \\
\hline CHEMBL3209921 & 688623 & 2.9208 & 3.2838 & TRN \\
\hline CHEMBL1322293 & 688623 & 4.1881 & 4.1024 & TRN \\
\hline CHEMBL1570396 & 688623 & 2.9208 & 3.2672 & TRN \\
\hline CHEMBL1603890 & 688623 & 4.9696 & 4.5188 & TST \\
\hline CHEMBL1491847 & 688623 & 2.9208 & 3.8776 & TST \\
\hline CHEMBL3191831 & 688623 & 4.9689 & 4.7892 & TRN \\
\hline CHEMBL1299644 & 688623 & 2.9208 & 3.7794 & TST \\
\hline CHEMBL1580220 & 688623 & 2.9208 & 3.9677 & TRN \\
\hline CHEMBL1601488 & 688623 & 2.9208 & 4.2994 & TRN \\
\hline CHEMBL1579505 & 688623 & 4.8773 & 3.5134 & TRN \\
\hline CHEMBL1341290 & 688623 & 6.9208 & 4.327 & TRN \\
\hline CHEMBL1526910 & 688623 & 4.8298 & 4.3016 & TRN \\
\hline CHEMBL1442326 & 688623 & 6.3089 & 4.7502 & TRN \\
\hline CHEMBL1460047 & 688623 & 2.9208 & 3.4589 & TRN \\
\hline CHEMBL1460440 & 688623 & 4.5543 & 4.2932 & TRN \\
\hline CHEMBL1987820 & 688623 & 2.9208 & 5.3224 & TRN \\
\hline CHEMBL1371649 & 688623 & 4.3235 & 4.6956 & TRN \\
\hline CHEMBL1305287 & 688623 & 6.4881 & 6.1719 & TRN \\
\hline CHEMBL1407294 & 688623 & 2.9208 & 2.9707 & TRN \\
\hline CHEMBL1471899 & 688623 & 6.1244 & 5.1039 & TRN \\
\hline CHEMBL1521456 & 688623 & 2.9208 & 3.4076 & TRN \\
\hline CHEMBL1467943 & 688623 & 6.3054 & 5.0333 & TRN \\
\hline CHEMBL1429139 & 688623 & 3.2218 & 3.4907 & TRN \\
\hline CHEMBL1403458 & 688623 & 2.9208 & 3.6595 & TRN \\
\hline CHEMBL3211386 & 688623 & 2.9208 & 3.3939 & TRN \\
\hline CHEMBL1597322 & 688623 & 2.9208 & 4.6103 & TRN \\
\hline CHEMBL1506283 & 688623 & 2.9208 & 3.9059 & TRN \\
\hline CHEMBL1329255 & 688623 & 2.9208 & 3.8755 & TRN \\
\hline CHEMBL1471211 & 688623 & 4.82 & 3.4612 & TRN \\
\hline CHEMBL1388002 & 688623 & 4.7423 & 3.6784 & TRN \\
\hline CHEMBL1989817 & 688623 & 5.0089 & 3.5306 & TRN \\
\hline CHEMBL1550359 & 688623 & 4.4544 & 4.2463 & TRN \\
\hline CHEMBL3199915 & 688623 & 5.0491 & 4.6554 & TST \\
\hline CHEMBL1387436 & 688623 & 5.1366 & 4.9306 & TRN \\
\hline CHEMBL3199325 & 688623 & 4.8698 & 3.8519 & TRN \\
\hline CHEMBL1602344 & 688623 & 2.9208 & 3.847 & TRN \\
\hline CHEMBL1597778 & 688623 & 8.0 & 5.2484 & TST \\
\hline CHEMBL1530673 & 688623 & 6.8069 & 5.7632 & TST \\
\hline CHEMBL1571181 & 688623 & 2.9208 & 2.9103 & TST \\
\hline
\end{tabular}


Supplemental Table S2.txt

\begin{tabular}{|c|c|c|c|c|c|}
\hline CHEMBL1398603 & 688623 & 2.9208 & 3.1558 & TST & \\
\hline CHEMBL1416108 & 688623 & 2.9208 & 3.6359 & TST & \\
\hline CHEMBL1442791 & 688623 & 2.9208 & 3.8081 & TST & \\
\hline CHEMBL1557894 & 688623 & 2.9208 & 3.1347 & TST & \\
\hline CHEMBL1469553 & 688623 & 2.9208 & 3.0612 & TST & \\
\hline CHEMBL1485659 & 688623 & 3.2218 & 3.1695 & TST & \\
\hline CHEMBL1477856 & 688623 & 6.0747 & 5.1432 & TST & \\
\hline CHEMBL1403940 & 688623 & 4.8594 & 4.5876 & TST & \\
\hline CHEMBL 3194214 & 688623 & 4.9153 & 4.5594 & TST & \\
\hline CHEMBL1537509 & 688623 & 8.0 & 6.4979 & TST & \\
\hline CHEMBL1343773 & 688623 & 2.9208 & 3.8077 & TST & \\
\hline CHEMBL 37570 & 688623 & 6.4976 & 5.7656 & TST & \\
\hline CHEMBL1608722 & 688623 & 4.0636 & 5.4801 & TST & \\
\hline CHEMBL1593562 & 688623 & 4.5786 & 4.3059 & TST & \\
\hline CHEMBL1584226 & 688623 & 4.712 & 4.6415 & TST & \\
\hline CHEMBL1471808 & 688623 & 5.2181 & 4.41100 & 00000000005 & TST \\
\hline CHEMBL1414850 & 688623 & 2.9208 & 3.56699 & 99999999997 & TST \\
\hline CHEMBL1334861 & 688623 & 2.9208 & 2.9169 & TST & \\
\hline CHEMBL 3193076 & 688623 & 4.6908 & 4.5585 & TST & \\
\hline CHEMBL1557023 & 688623 & 4.9384 & 3.948 & TST & \\
\hline CHEMBL1361196 & 688623 & 2.9208 & 4.6893 & TST & \\
\hline CHEMBL1497865 & 688623 & 2.9208 & 3.1524 & TST & \\
\hline CHEMBL1324125 & 688623 & 6.3645 & 6.4408 & TST & \\
\hline CHEMBL1542868 & 688623 & 2.9208 & 3.1861 & TST & \\
\hline CHEMBL1539864 & 688623 & 4.8304 & 4.1631 & TST & \\
\hline CHEMBL1462368 & 688623 & 2.9208 & 4.5727 & TST & \\
\hline CHEMBL1466833 & 688623 & 2.9208 & 3.0584 & TST & \\
\hline CHEMBL 3189245 & 688623 & 5.1913 & 4.9151 & TST & \\
\hline CHEMBL1392046 & 688623 & 4.1455 & 3.6451 & TST & \\
\hline CHEMBL1464513 & 688623 & 2.9208 & 3.0216 & TST & \\
\hline CHEMBL1460692 & 688623 & 6.585 & 4.3413 & TST & \\
\hline CHEMBL1545196 & 688623 & 4.4162 & 2.8913 & TST & \\
\hline CHEMBL581872 & 688623 & 4.9631 & 4.6283 & TST & \\
\hline CHEMBL1485785 & 688623 & 2.9208 & 3.1672 & TST & \\
\hline CHEMBL1504565 & 688623 & 2.9208 & 3.2847 & TST & \\
\hline CHEMBL1599566 & 688623 & 4.9779 & 4.6029 & TST & \\
\hline CHEMBL1975487 & 688623 & 4.8357 & 4.6229 & TST & \\
\hline CHEMBL1349834 & 688623 & 2.9208 & 3.2263 & TST & \\
\hline CHEMBL1336728 & 688623 & 2.9208 & 3.7004 & TST & \\
\hline CHEMBL1302495 & 688623 & 4.6271 & 3.7364 & TST & \\
\hline CHEMBL1313520 & 688623 & 8.0 & 7.1351 & TST & \\
\hline CHEMBL1610999 & 688623 & 2.9208 & 3.6594 & TST & \\
\hline CHEMBL1520433 & 688623 & 4.6149 & 4.2241 & TST & \\
\hline CHEMBL3199311 & 688623 & 6.5317 & 5.7027 & TST & \\
\hline CHEMBL1377352 & 688623 & 2.9208 & 2.9419 & TST & \\
\hline CHEMBL1578539 & 688623 & 2.9208 & 2.9706 & TST & \\
\hline CHEMBL1342143 & 688623 & 4.8473 & 4.3372 & TST & \\
\hline CHEMBL1303719 & 688623 & 5.3847 & 4.9515 & TST & \\
\hline
\end{tabular}




\begin{tabular}{|c|c|c|c|c|c|}
\hline & & \multicolumn{4}{|c|}{ Supplemental Table S2.txt } \\
\hline CHEMBL1549525 & 688623 & 6.6234 & 5.3911 & TST & \\
\hline CHEMBL1412984 & 688623 & 4.3122 & 3.4874 & TST & \\
\hline CHEMBL1452890 & 688623 & 4.4889 & 2.9601 & TST & \\
\hline CHEMBL1423338 & 688623 & 2.9208 & 4.5792 & TST & \\
\hline CHEMBL1973669 & 688623 & 4.9436 & 4.8111 & TST & \\
\hline CHEMBL1331514 & 688623 & 8.0 & 6.5577 & TST & \\
\hline CHEMBL1325856 & 688623 & 6.9172 & 6.7228 & TST & \\
\hline CHEMBL1544256 & 688623 & 4.8511 & 4.7273 & TST & \\
\hline CHEMBL1545656 & 688623 & 4.5553 & 4.3482 & TST & \\
\hline CHEMBL3212407 & 688623 & 2.9208 & 3.2012 & TST & \\
\hline CHEMBL1573883 & 688623 & 4.7945 & 4.5343 & TST & \\
\hline CHEMBL1562575 & 688623 & 8.0 & 7.5051 & TST & \\
\hline CHEMBL1415650 & 688623 & 2.9208 & 3.198 & TST & \\
\hline CHEMBL3194826 & 688623 & 5.3818 & 4.7316 & TST & \\
\hline CHEMBL1572920 & 688623 & 5.0803 & 4.4058 & TST & \\
\hline CHEMBL1480291 & 688623 & 2.9208 & 2.8733 & TST & \\
\hline CHEMBL1366321 & 688623 & 5.0842 & 4.6581 & TST & \\
\hline CHEMBL1459795 & 688623 & 4.8752 & 4.3251 & TST & \\
\hline CHEMBL1309839 & 688623 & 2.9208 & 3.7967 & TST & \\
\hline CHEMBL1579636 & 688623 & 5.4397 & 5.4929 & TST & \\
\hline CHEMBL1547470 & 688623 & 2.9208 & 3.6952 & TST & \\
\hline CHEMBL1341301 & 688623 & 2.9208 & 3.1271 & TST & \\
\hline CHEMBL1431151 & 688623 & 4.8946 & 5.975 & TST & \\
\hline CHEMBL1424898 & 688623 & 4.9505 & 3.8906 & TST & \\
\hline CHEMBL1394270 & 688623 & 2.9208 & 3.7344 & TST & \\
\hline CHEMBL1503983 & 688623 & 4.8811 & 3.0461 & TST & \\
\hline CHEMBL1429267 & 688623 & 2.9208 & 3.7563 & TST & \\
\hline CHEMBL1362603 & 688623 & 2.9208 & 4.2016 & TST & \\
\hline CHEMBL3196105 & 688623 & 2.9208 & 4.1493 & TST & \\
\hline CHEMBL1546502 & 688623 & 4.8028 & 3.7644 & TST & \\
\hline CHEMBL89445 & 688623 & 8.0 & 6.7464 & TST & \\
\hline CHEMBL1545747 & 688623 & 4.8256 & 3.4857 & TST & \\
\hline CHEMBL1431607 & 688623 & 2.9208 & 3.6304 & TST & \\
\hline CHEMBL1525771 & 688623 & 4.9883 & 4.4711 & TST & \\
\hline CHEMBL1442185 & 688623 & 2.9208 & 3.1681 & TST & \\
\hline CHEMBL1310553 & 688623 & 4.7062 & 3.7216 & TST & \\
\hline CHEMBL1576529 & 688623 & 2.9208 & 4.1814 & TST & \\
\hline CHEMBL3199020 & 688623 & 6.4685 & 5.5418 & TST & \\
\hline CHEMBL 1467873 & 688623 & 2.9208 & 4.3536 & TST & \\
\hline CHEMBL463763 & 688623 & 8.0 & 6.6609 & TST & \\
\hline CHEMBL1448808 & 688623 & 2.9208 & 3.76800 & 00000000002 & TST \\
\hline CHEMBL1453996 & 688623 & 8.0 & 7.0268 & TST & \\
\hline CHEMBL1522486 & 688623 & 5.24700 & 00000000 & 4.7486 & TST \\
\hline CHEMBL1418885 & 688623 & 2.9208 & 3.8695 & TST & \\
\hline CHEMBL1598769 & 688623 & 5.1776 & 6.0357 & TST & \\
\hline CHEMBL1459916 & 688623 & 2.9208 & 4.3899 & TST & \\
\hline CHEMBL1576132 & 688623 & 4.9744 & 5.2227 & TST & \\
\hline CHEMBL585591 & 688623 & 8.0 & 6.4448 & TST & \\
\hline
\end{tabular}


Supplemental Table S2.txt

\begin{tabular}{|c|c|c|c|c|c|}
\hline CHEMBL1328795 & 688623 & 2.9208 & 3.9258 & TST & \\
\hline CHEMBL1371974 & 688623 & 5.0666 & 4.4905 & TST & \\
\hline CHEMBL1442500 & 688623 & 5.0812 & 5.0135 & TST & \\
\hline CHEMBL1476544 & 688623 & 4.6071 & 3.9516 & TST & \\
\hline CHEMBL1386049 & 688623 & 4.9204 & 3.1387 & TST & \\
\hline CHEMBL581152 & 688623 & 2.9208 & 3.0471 & TST & \\
\hline CHEMBL1334514 & 688623 & 6.6517 & 5.6773 & TST & \\
\hline CHEMBL1333035 & 688623 & 4.9652 & 4.2929 & TST & \\
\hline CHEMBL1411830 & 688623 & 4.0783 & 3.6809 & TST & \\
\hline CHEMBL1406361 & 688623 & 5.0778 & 5.898 & TST & \\
\hline CHEMBL1412636 & 688623 & 2.9208 & 3.5105 & TST & \\
\hline CHEMBL1309450 & 688623 & 4.8047 & 4.3619 & TST & \\
\hline CHEMBL1404265 & 688623 & 2.9208 & 3.0863 & TST & \\
\hline CHEMBL1334442 & 688623 & 2.9208 & 4.2948 & TST & \\
\hline CHEMBL1465741 & 688623 & 4.8264 & 4.0628 & TST & \\
\hline CHEMBL1528120 & 688623 & 4.9834 & 5.3502 & TST & \\
\hline CHEMBL1393602 & 688623 & 2.9208 & 3.4169 & TST & \\
\hline CHEMBL1511653 & 688623 & 2.9208 & 2.8951 & TST & \\
\hline CHEMBL1320566 & 688623 & 4.8655 & 4.5514 & TST & \\
\hline CHEMBL1572800 & 688623 & 2.9208 & 3.5508 & TST & \\
\hline CHEMBL1612267 & 688623 & 4.8686 & 3.5767 & TST & \\
\hline CHEMBL1303364 & 688623 & 4.8685 & 3.4882 & TST & \\
\hline CHEMBL1545679 & 688623 & 2.9208 & 4.8903 & TST & \\
\hline CHEMBL1985330 & 688623 & 5.0601 & 4.8978 & TST & \\
\hline CHEMBL1524034 & 688623 & 6.8665 & 6.2764 & TST & \\
\hline CHEMBL3199362 & 688623 & 4.6175 & 4.4854 & TST & \\
\hline CHEMBL1385210 & 688623 & 4.9525 & 3.9186 & TST & \\
\hline CHEMBL1443177 & 688623 & 5.011 & 4.9132 & TST & \\
\hline CHEMBL1341097 & 688623 & 2.9208 & 3.1849 & TST & \\
\hline CHEMBL1481034 & 688623 & 2.9208 & 3.5937 & TST & \\
\hline CHEMBL3191594 & 688623 & 4.9301 & 5.1346 & TST & \\
\hline CHEMBL1981200 & 688623 & 5.0089 & 4.9699 & TST & \\
\hline CHEMBL1491004 & 688623 & 5.046 & 4.7216 & TST & \\
\hline CHEMBL1485006 & 688623 & 2.9208 & 3.2645 & TST & \\
\hline CHEMBL1362117 & 688623 & \multicolumn{4}{|c|}{4.8660000000000005} \\
\hline CHEMBL1437623 & 688623 & 2.9208 & 4.349 & TST & \\
\hline CHEMBL1461748 & 688623 & 4.6799 & 3.146006 & 20000000004 & TST \\
\hline CHEMBL1966867 & 688623 & 4.9556 & 4.8166 & TST & \\
\hline CHEMBL1428616 & 688623 & 2.9208 & 3.1691 & TST & \\
\hline CHEMBL1373927 & 688623 & 4.6699 & 4.3372 & TST & \\
\hline CHEMBL1353759 & 688623 & 4.9642 & 4.9153 & TST & \\
\hline CHEMBL1371395 & 688623 & 5.007 & 4.6301 & TST & \\
\hline CHEMBL1529404 & 688623 & 5.8745 & 5.581 & TST & \\
\hline CHEMBL1522827 & 688623 & 5.0833 & 4.8494 & TST & \\
\hline CHEMBL1417061 & 688623 & 2.9208 & 3.22 & TST & \\
\hline CHEMBL1428011 & 688623 & 2.9208 & 4.1662 & TST & \\
\hline CHEMBL1409316 & 688623 & 4.8646 & 4.4068 & TST & \\
\hline CHEMBL166209 & 688623 & 5.8807 & 4.9004 & TST & \\
\hline
\end{tabular}


Supplemental Table S2.txt

\begin{tabular}{|c|c|c|c|c|}
\hline CHEMBL1324224 & 688623 & 4.1392 & 4.2934 & TST \\
\hline CHEMBL3192670 & 688623 & 4.8884 & 4.4483 & TST \\
\hline CHEMBL3210088 & 688623 & 4.8944 & 5.2677 & TST \\
\hline CHEMBL1505866 & 688623 & 2.9208 & 3.9144 & TST \\
\hline CHEMBL1502410 & 688623 & 4.6021 & 4.0416 & TST \\
\hline CHEMBL1544557 & 688623 & 4.9723 & 4.6632 & TST \\
\hline CHEMBL1386957 & 688623 & 2.9208 & 2.9488 & TST \\
\hline CHEMBL1480997 & 688623 & 2.9208 & 3.0648 & TST \\
\hline CHEMBL1327056 & 688623 & 4.7347 & 3.9784 & TST \\
\hline CHEMBL1586623 & 688623 & 4.251 & 4.4788 & TST \\
\hline CHEMBL1597748 & 688623 & 2.9208 & 3.7713 & TST \\
\hline CHEMBL3210671 & 688623 & 2.9208 & 4.0154 & TST \\
\hline CHEMBL1556239 & 688623 & 4.7569 & 4.5613 & TST \\
\hline CHEMBL1376166 & 688623 & 8.0 & 6.0121 & TST \\
\hline CHEMBL1540682 & 688623 & 4.9948 & 3.8594 & TST \\
\hline CHEMBL1414112 & 688623 & 8.0 & 5.7458 & TST \\
\hline CHEMBL3039774 & 688623 & 2.9208 & 3.4959 & TST \\
\hline CHEMBL3190770 & 688623 & 2.9208 & 4.1833 & TST \\
\hline CHEMBL1541017 & 688623 & 4.7087 & 6.4173 & TST \\
\hline CHEMBL1342273 & 688623 & 2.9208 & 3.2611 & TST \\
\hline CHEMBL1611223 & 688623 & 4.9913 & 3.4767 & TST \\
\hline CHEMBL1349509 & 688623 & 2.9208 & 3.1579 & TST \\
\hline CHEMBL1603662 & 688623 & 5.0128 & 5.1147 & TST \\
\hline CHEMBL1335978 & 688623 & 2.9208 & 4.0188 & TST \\
\hline CHEMBL1323562 & 688623 & 2.9208 & 3.889 & TST \\
\hline CHEMBL1459746 & 688623 & 6.6556 & 5.1938 & TST \\
\hline CHEMBL259507 & 688623 & 4.6325 & 3.6158 & TST \\
\hline CHEMBL1363839 & 688623 & 4.8284 & 4.5198 & TST \\
\hline CHEMBL267160 & 688623 & 4.836 & 4.584 & TST \\
\hline CHEMBL 3198763 & 688623 & 5.3475 & 5.07100 & $\partial 000000001$ \\
\hline CHEMBL1887153 & 688623 & 6.0092 & 5.7572 & TST \\
\hline CHEMBL1405749 & 688623 & 2.9208 & 6.7667 & TST \\
\hline CHEMBL1459841 & 688623 & 6.6635 & 6.4713 & TST \\
\hline CHEMBL1469224 & 688623 & 4.9112 & 4.6369 & TST \\
\hline CHEMBL1418823 & 688623 & 4.4535 & 3.3326 & TST \\
\hline CHEMBL1390428 & 688623 & 4.9655 & 3.4435 & TST \\
\hline CHEMBL1483913 & 688623 & 4.77 & 4.0964 & TST \\
\hline CHEMBL3193835 & 688623 & 4.9435 & 4.7694 & TST \\
\hline CHEMBL1302164 & 688623 & 5.0297 & 4.4871 & TST \\
\hline CHEMBL1570797 & 688623 & 4.8624 & 4.2705 & TST \\
\hline CHEMBL1536679 & 688623 & 2.9208 & 3.056 & TST \\
\hline CHEMBL1442651 & 688623 & 4.5668 & 4.8003 & TST \\
\hline CHEMBL1339433 & 688623 & 2.9208 & 2.9495 & TST \\
\hline CHEMBL1534592 & 688623 & 4.7904 & 3.1089 & TST \\
\hline CHEMBL3195389 & 688623 & 8.0 & 7.2574 & TST \\
\hline CHEMBL1366573 & 688623 & 2.9208 & 3.5946 & TST \\
\hline CHEMBL1567103 & 688623 & 5.1334 & 4.1615 & TST \\
\hline CHEMBL1348885 & 688623 & 2.9208 & 4.1254 & TST \\
\hline
\end{tabular}


Supplemental Table S2.txt

\begin{tabular}{|c|c|c|c|c|}
\hline CHEMBL1603164 & 688623 & 2.9208 & 3.2895 & TST \\
\hline CHEMBL1488591 & 688623 & 5.0821 & 3.8848 & TST \\
\hline CHEMBL1600977 & 688623 & 2.9208 & 3.5496 & TST \\
\hline CHEMBL1393397 & 688623 & 5.0889 & 4.7447 & TST \\
\hline CHEMBL1594867 & 688623 & 4.9708 & 5.1069 & TST \\
\hline CHEMBL1484169 & 688623 & 2.9208 & 3.6251 & TST \\
\hline CHEMBL1343198 & 688623 & 2.9208 & 3.9918 & TST \\
\hline CHEMBL1351357 & 688623 & 2.9208 & 4.1791 & TST \\
\hline CHEMBL1350021 & 688623 & 2.9208 & 3.4999 & TST \\
\hline CHEMBL1319615 & 688623 & 5.056 & 4.4031 & TST \\
\hline CHEMBL1421255 & 688623 & 4.8288 & 5.0801 & TST \\
\hline CHEMBL1591302 & 688623 & 2.9208 & 3.0676 & TST \\
\hline CHEMBL607309 & 688623 & 4.8626 & 4.5611 & TST \\
\hline CHEMBL1353980 & 688623 & 2.9208 & 4.5798 & TST \\
\hline CHEMBL1608629 & 688623 & 5.1854 & 4.4969 & TST \\
\hline CHEMBL1369106 & 688623 & 6.9281 & 4.3652 & TST \\
\hline CHEMBL1425823 & 688623 & 5.4429 & 5.4786 & TST \\
\hline CHEMBL1304897 & 688623 & 4.743 & 3.1733 & TST \\
\hline CHEMBL1452595 & 688623 & 2.9208 & 3.1194 & TST \\
\hline CHEMBL1978901 & 688623 & 4.8756 & 4.6648 & TST \\
\hline CHEMBL1324569 & 688623 & 4.8367 & 4.402 & TST \\
\hline CHEMBL1979536 & 688623 & 6.3161 & 5.4065 & TST \\
\hline CHEMBL1599438 & 688623 & 4.92399 & 999999995 & 4.2322 \\
\hline CHEMBL1480952 & 688623 & 2.9208 & 3.5275 & TST \\
\hline CHEMBL1335177 & 688623 & 4.766 & 4.4288 & TST \\
\hline CHEMBL1311879 & 688623 & 5.0109 & 4.786006 & 30000000005 \\
\hline CHEMBL1438978 & 688623 & 2.9208 & 4.2986 & TST \\
\hline CHEMBL1458390 & 688623 & 2.9208 & 4.4852 & TST \\
\hline CHEMBL1320808 & 688623 & 4.9257 & 4.1514 & TST \\
\hline CHEMBL1450526 & 688623 & 6.6596 & 4.8362 & TST \\
\hline CHEMBL1563008 & 688623 & 2.9208 & 4.4154 & TST \\
\hline CHEMBL1332395 & 688623 & 2.9208 & 3.5666 & TST \\
\hline CHEMBL1521023 & 688623 & 8.0 & 7.2784 & TST \\
\hline CHEMBL1558287 & 688623 & 4.4769 & 3.9288 & TST \\
\hline CHEMBL1536569 & 688623 & 2.9208 & 3.7374 & TST \\
\hline CHEMBL1438512 & 688623 & 5.5542 & 4.6081 & TST \\
\hline CHEMBL1584183 & 688623 & 2.9208 & 3.8237 & TST \\
\hline CHEMBL1428346 & 688623 & 4.7039 & 3.0401 & TST \\
\hline CHEMBL1573187 & 688623 & 4.9209 & 4.3789 & TST \\
\hline CHEMBL1485010 & 688623 & 5.2373 & 3.2613 & TST \\
\hline CHEMBL1504701 & 688623 & 5.1249 & 5.9821 & TST \\
\hline CHEMBL1305436 & 688623 & 2.9208 & 3.6065 & TST \\
\hline CHEMBL1365398 & 688623 & 4.9989 & 3.9393 & TST \\
\hline CHEMBL1379401 & 688623 & 5.3369 & 3.4965 & TST \\
\hline CHEMBL1394212 & 688623 & 4.803 & 4.2996 & TST \\
\hline CHEMBL1612884 & 688623 & 4.6559 & 3.0206 & TST \\
\hline CHEMBL1525939 & 688623 & 4.7081 & 4.4585 & TST \\
\hline CHEMBL1352257 & 688623 & 2.9208 & 3.9048 & TST \\
\hline
\end{tabular}




\begin{tabular}{|c|c|c|c|c|c|c|}
\hline & & \multicolumn{5}{|c|}{ Supplemental Table S2.txt } \\
\hline CHEMBL 84358 & 358800 & 5.3468 & 5.7398 & TRN & & \\
\hline CHEMBL 80022 & 358800 & 6.8861 & 7.6623 & TRN & & \\
\hline CHEMBL312251 & 358800 & 7.3979 & 7.2244 & TRN & & \\
\hline CHEMBL 84208 & 358800 & 5.6383 & 5.3436 & TRN & & \\
\hline CHEMBL 83783 & 358800 & 5.8539 & 5.8425 & TRN & & \\
\hline CHEMBL180522 & 358800 & 8.1549 & 8.102 & TRN & & \\
\hline CHEMBL314269 & 358800 & 3.8861 & 3.9532 & TRN & & \\
\hline CHEMBL82471 & 358800 & 6.2596 & 6.6254 & TRN & & \\
\hline CHEMBL208799 & 358800 & 7.301 & 7.5738 & TRN & & \\
\hline CHEMBL437117 & 358800 & 2.699 & 2.4917 & TRN & & \\
\hline CHEMBL82691 & 358800 & 2.699 & 2.2801 & TRN & & \\
\hline CHEMBL377202 & 358800 & 7.3665 & 7.7619 & TRN & & \\
\hline CHEMBL313844 & 358800 & 5.7447 & 2.2975 & TST & & \\
\hline CHEMBL 82224 & 358800 & 2.8239 & 2.5453 & TST & & \\
\hline CHEMBL83495 & 358800 & 6.5229 & 6.8511 & TRN & & \\
\hline CHEMBL314331 & 358800 & 2.699 & 3.6335 & TRN & & \\
\hline CHEMBL180330 & 358800 & 7.3979 & 7.6044 & TRN & & \\
\hline CHEMBL 80045 & 358800 & 7.8539 & 7.6589 & TRN & & \\
\hline CHEMBL 206868 & 358800 & 5.0809 & 4.6255 & TST & & \\
\hline CHEMBL 82415 & 358800 & 5.7447 & 4.9383 & TST & & \\
\hline CHEMBL210435 & 358800 & 5.38399 & 99999999 & 995 & 3.4538 & TST \\
\hline CHEMBL207134 & 358800 & 7.5086 & 8.0251 & TRN & & \\
\hline CHEMBL 82052 & 358800 & 5.8239 & 5.6805 & TRN & & \\
\hline CHEMBL 283950 & 358800 & 9.0 & 9.0371 & TRN & & \\
\hline CHEMBL82094 & 358800 & 5.0969 & 5.1593 & TRN & & \\
\hline CHEMBL313624 & 358800 & 5.8539 & 6.0268 & TRN & & \\
\hline CHEMBL381733 & 358800 & 3.5086 & 2.9022 & TST & & \\
\hline CHEMBL310331 & 358800 & 3.4948 & 3.2049 & TST & & \\
\hline CHEMBL 210554 & 358800 & 5.2757 & 3.1675 & TST & & \\
\hline CHEMBL366702 & 358800 & 9.0969 & 8.5069 & TRN & & \\
\hline CHEMBL378250 & 358800 & 2.699 & 3.3325 & TST & & \\
\hline CHEMBL 84002 & 358800 & 7.8239 & 8.0511 & TRN & & \\
\hline CHEMBL 84300 & 358800 & 4.8239 & 3.6923 & TST & & \\
\hline CHEMBL378109 & 358800 & 6.2218 & 6.1432 & TRN & & \\
\hline CHEMBL314618 & 358800 & 5.5086 & 5.7802 & TRN & & \\
\hline CHEMBL425244 & 358800 & 7.0969 & 7.4173 & TRN & & \\
\hline CHEMBL84534 & 358800 & 5.9208 & 6.2392 & TRN & & \\
\hline CHEMBL210310 & 358800 & 4.1765 & 3.8348 & TST & & \\
\hline CHEMBL 207385 & 358800 & 7.301 & 7.0909 & TRN & & \\
\hline CHEMBL366914 & 358800 & 8.0969 & 7.8247 & TRN & & \\
\hline CHEMBL83800 & 358800 & 9.0 & 8.6642 & TRN & & \\
\hline CHEMBL379904 & 358800 & 8.5229 & 8.5327 & TRN & & \\
\hline CHEMBL85059 & 358800 & 8.3979 & 9.0232 & TRN & & \\
\hline CHEMBL 79291 & 358800 & 3.4948 & 2.7639 & TST & & \\
\hline CHEMBL310464 & 358800 & 6.5229 & 6.2444 & TRN & & \\
\hline CHEMBL 79468 & 358800 & 5.0 & 5.2339 & TRN & & \\
\hline CHEMBL286759 & 358800 & 7.699 & 7.7292 & TRN & & \\
\hline CHEMBL209177 & 358800 & 5.2218 & 3.4033 & TST & & \\
\hline
\end{tabular}




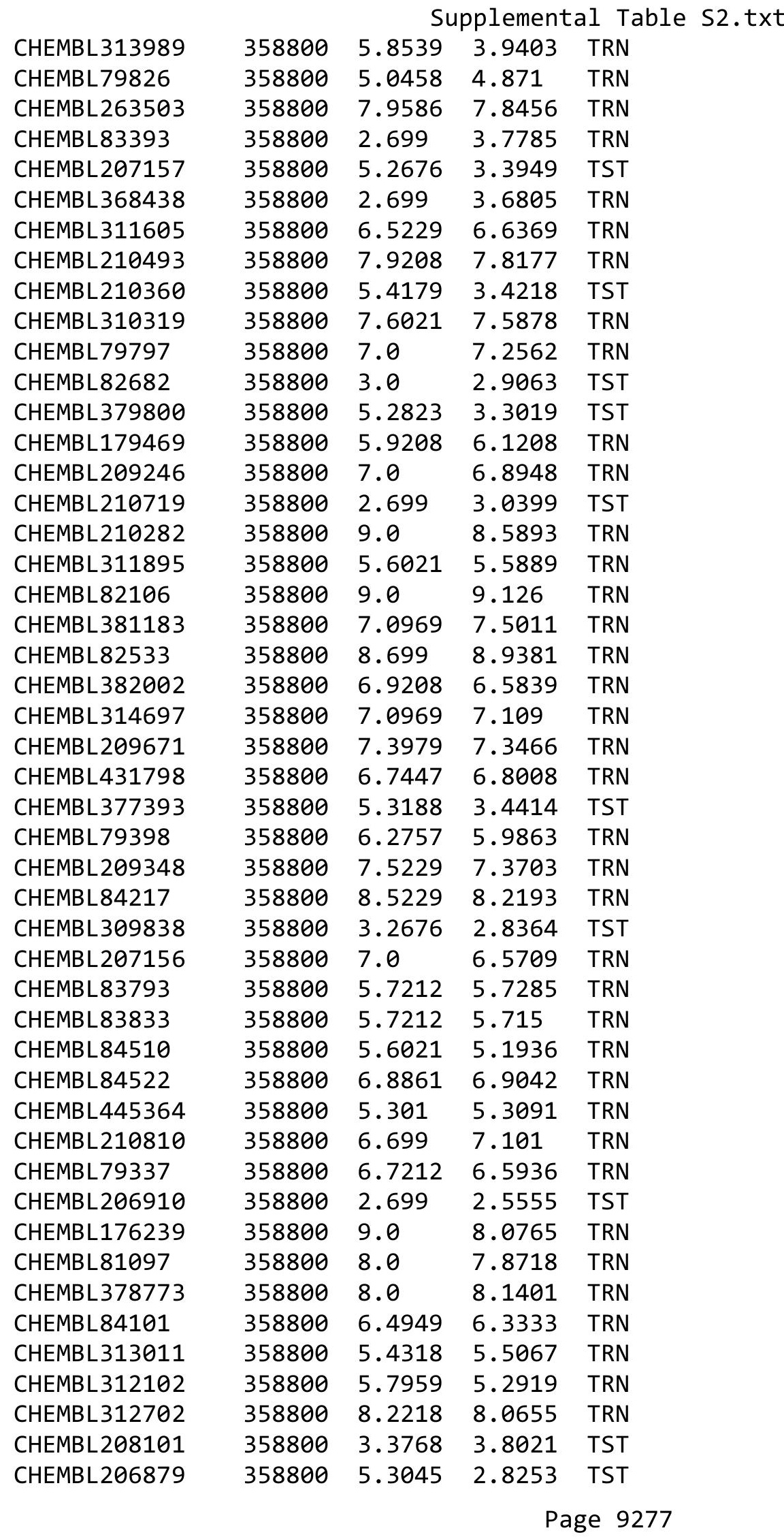




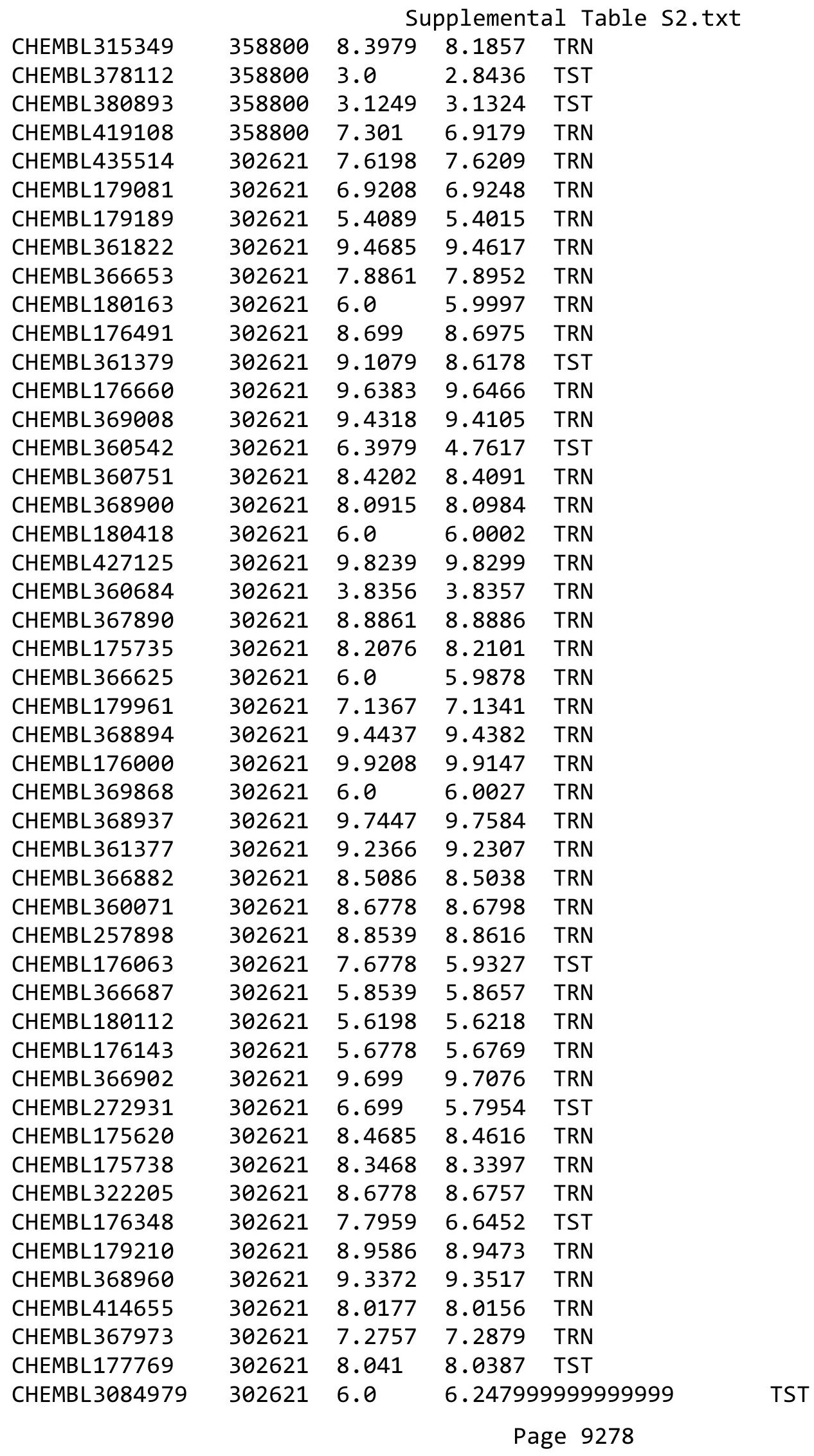


Supplemental Table S2.txt

\begin{tabular}{|c|c|c|c|c|c|}
\hline CHEMBL401737 & 302621 & 8.8239 & 8.0862 & TST & \\
\hline CHEMBL175612 & 302621 & 6.9586 & 6.6642 & TST & \\
\hline CHEMBL367647 & 302621 & 7.8239 & 8.4118 & TST & \\
\hline CHEMBL404728 & 302621 & 7.0706 & 6.499 & TST & \\
\hline CHEMBL176031 & 302621 & 9.8539 & 10.0748 & TST & \\
\hline CHEMBL179004 & 302621 & 5.1487 & 5.5083 & TST & \\
\hline CHEMBL3655046 & 1528274 & 6.9208 & 6.9332 & TRN & \\
\hline CHEMBL3655031 & 1528274 & 7.3468 & 7.2396 & TRN & \\
\hline CHEMBL 3654962 & 1528274 & 6.5884 & 6.8527 & TRN & \\
\hline CHEMBL 3655026 & 1528274 & 7.0088 & 7.0304 & TRN & \\
\hline CHEMBL 3654963 & 1528274 & 6.5436 & 6.4546 & TRN & \\
\hline CHEMBL3605831 & 1528274 & 6.8327 & 7.1115 & TRN & \\
\hline CHEMBL 3655064 & 1528274 & 7.8861 & 7.5837 & TST & \\
\hline CHEMBL 3655034 & 1528274 & 7.1024 & 7.1522 & TRN & \\
\hline CHEMBL 3655025 & 1528274 & 7.1192 & 7.0519 & TRN & \\
\hline CHEMBL 3654980 & 1528274 & 7.3768 & 7.3639 & TRN & \\
\hline CHEMBL3655059 & 1528274 & 7.6383 & 7.6955 & TRN & \\
\hline CHEMBL 3654971 & 1528274 & 6.6421 & 6.6339 & TRN & \\
\hline CHEMBL 3655032 & 1528274 & 7.6198 & 7.4797 & TRN & \\
\hline CHEMBL 3654997 & 1528274 & 7.1549 & 7.0821 & TRN & \\
\hline CHEMBL 3655057 & 1528274 & 7.5528 & 7.5875 & TRN & \\
\hline CHEMBL 3654948 & 1528274 & 6.8268 & 6.5699 & TST & \\
\hline CHEMBL3654999 & 1528274 & 6.8761 & 7.2396 & TRN & \\
\hline CHEMBL 3654967 & 1528274 & 7.3979 & 7.3304 & TRN & \\
\hline CHEMBL 3655050 & 1528274 & 6.7328 & 6.7491 & TRN & \\
\hline CHEMBL 3654968 & 1528274 & 7.2924 & 6.5995 & TST & \\
\hline CHEMBL 3654938 & 1528274 & 6.8125 & 6.4764 & TST & \\
\hline CHEMBL3655047 & 1528274 & 7.0362 & 6.9669 & TRN & \\
\hline CHEMBL 3655022 & 1528274 & 6.9172 & 6.9937 & TRN & \\
\hline CHEMBL 3654998 & 1528274 & \multicolumn{4}{|c|}{6.7620000000000005} \\
\hline CHEMBL3655036 & 1528274 & 8.1549 & 7.5875 & TRN & \\
\hline CHEMBL 3655028 & 1528274 & 6.7496 & 6.7203 & TRN & \\
\hline CHEMBL3654949 & 1528274 & 7.1192 & 7.0665 & TRN & \\
\hline CHEMBL 3654958 & 1528274 & 7.585 & 7.0808 & TRN & \\
\hline CHEMBL 3655048 & 1528274 & 7.2076 & 7.2723 & TRN & \\
\hline CHEMBL3655012 & 1528274 & 6.7852 & 6.912000 & 3000000001 & TRN \\
\hline CHEMBL 3655023 & 1528274 & 6.9355 & 6.8813 & TRN & \\
\hline CHEMBL3654960 & 1528274 & 7.1871 & 7.1094 & TRN & \\
\hline CHEMBL 3655035 & 1528274 & 7.3665 & 7.5875 & TRN & \\
\hline CHEMBL3654986 & 1528274 & 6.6326 & 6.7117 & TRN & \\
\hline CHEMBL 3655053 & 1528274 & 7.2366 & 7.1908 & TRN & \\
\hline CHEMBL 3655041 & 1528274 & 7.2518 & 7.178999 & 9999999999 & I KI \\
\hline CHEMBL 3654979 & 1528274 & 6.8729 & 6.8945 & TRN & \\
\hline CHEMBL3654969 & 1528274 & 6.6925 & 6.8811 & TRN & \\
\hline CHEMBL 3605823 & 1528274 & 6.7747 & 6.6048 & TST & \\
\hline CHEMBL 3654966 & 1528274 & 7.2076 & 7.2186 & TRN & \\
\hline CHEMBL 3654964 & 1528274 & 7.3098 & 7.3499 & TRN & \\
\hline CHEMBL 3654954 & 1528274 & 6.8697 & 7.0808 & TRN & \\
\hline
\end{tabular}




$$
\text { Supplemental Table S2.txt }
$$

\begin{tabular}{|c|c|c|c|c|}
\hline CHEMBL 3655058 & 1528274 & 6.8928 & 6.9416 & TRN \\
\hline CHEMBL 3654978 & 1528274 & 6.71 & 6.8206 & TRN \\
\hline CHEMBL 3655054 & 1528274 & 7.5229 & 7.6013 & TRN \\
\hline CHEMBL 3655042 & 1528274 & 8.0 & 8.0274 & TRN \\
\hline CHEMBL 3655043 & 1528274 & 6.8665 & 6.904 & TRN \\
\hline CHEMBL 3605827 & 1528274 & 6.7852 & 6.7985 & TRN \\
\hline CHEMBL 3654961 & 1528274 & 6.5969 & 6.5111 & TRN \\
\hline CHEMBL 3655038 & 1528274 & 7.5376 & 7.2169 & TST \\
\hline CHEMBL 3654956 & 1528274 & 7.5086 & 7.4113 & TRN \\
\hline CHEMBL 3655027 & 1528274 & 6.7144 & 6.7048 & TST \\
\hline CHEMBL 3654959 & 1528274 & 7.4437 & 7.5259 & TRN \\
\hline CHEMBL 3655017 & 1528274 & 6.0 & 6.0719 & TRN \\
\hline CHEMBL 3655030 & 1528274 & 7.3979 & 7.2396 & TRN \\
\hline CHEMBL 3654982 & 1528274 & 6.7011 & 6.4072 & TST \\
\hline CHEMBL 3655020 & 1528274 & 6.0 & 5.9897 & TRN \\
\hline CHEMBL 3654981 & 1528274 & 6.6576 & 6.8058 & TRN \\
\hline CHEMBL 3654985 & 1528274 & 7.284 & 7.3303 & TRN \\
\hline CHEMBL 3655024 & 1528274 & 6.6289 & 6.5269 & TRN \\
\hline CHEMBL 3654937 & 1528274 & 6.6757 & 6.9981 & TST \\
\hline CHEMBL 3655039 & 1528274 & 7.585 & 7.4564 & TST \\
\hline CHEMBL 3655063 & 1528274 & 6.5918 & 6.5064 & TRN \\
\hline CHEMBL 3655051 & 1528274 & 6.8928 & 7.6416 & TST \\
\hline CHEMBL 3654950 & 1528274 & 7.5528 & 7.3938 & TRN \\
\hline CHEMBL 3654957 & 1528274 & 7.5086 & 7.4736 & TRN \\
\hline CHEMBL 3655019 & 1528274 & 6.0 & 6.3495 & TRN \\
\hline CHEMBL 3655037 & 1528274 & 6.6383 & 7.4135 & TST \\
\hline CHEMBL 3655018 & 1528274 & 6.0 & 5.9586 & TRN \\
\hline CHEMBL 3654955 & 1528274 & 7.2757 & 7.4609 & TRN \\
\hline CHEMBL 3655016 & 1528274 & 6.0 & 6.0141 & TRN \\
\hline CHEMBL 3654983 & 1528274 & 6.5638 & 6.4346 & TST \\
\hline CHEMBL 3654952 & 1528274 & 7.2076 & 7.4184 & TRN \\
\hline CHEMBL 3654984 & 1528274 & 6.7905 & 6.3938 & TST \\
\hline CHEMBL 3655055 & 1528274 & 8.699 & 7.4711 & TST \\
\hline CHEMBL 3655011 & 1528274 & 6.6737 & 6.4537 & TRN \\
\hline CHEMBL 3655029 & 1528274 & 7.1612 & 6.82799 & 9999999999 \\
\hline CHEMBL 3655045 & 1528274 & 7.2291 & 6.8216 & TST \\
\hline CHEMBL 3655021 & 1528274 & 6.0 & 5.8623 & TRN \\
\hline CHEMBL 3655040 & 1528274 & 6.8962 & 7.3714 & TST \\
\hline CHEMBL 3639538 & 1528274 & 6.6696 & 6.6445 & TRN \\
\hline CHEMBL 3655052 & 1528274 & 6.5751 & 7.2275 & TST \\
\hline CHEMBL 3655044 & 1528274 & 6.9031 & 7.0975 & TST \\
\hline CHEMBL 3655033 & 1528274 & 7.4089 & 7.303 & TRN \\
\hline CHEMBL 3655074 & 1528274 & 6.6635 & 6.9615 & TST \\
\hline CHEMBL 3654953 & 1528274 & 6.6615 & 6.657 & TRN \\
\hline CHEMBL 3654951 & 1528274 & 7.4559 & \multicolumn{2}{|c|}{7.417000000000001} \\
\hline CHEMBL 3654970 & 1528274 & 7.6198 & 7.5715 & TRN \\
\hline CHEMBL 3655056 & 1528274 & 7.0044 & 6.8538 & TST \\
\hline CHEMBL3639539 & 1528274 & 8.3979 & 7.4374 & TST \\
\hline
\end{tabular}


Supplemental Table S2.txt

\begin{tabular}{|c|c|c|c|c|}
\hline CHEMBL3655065 & 1528274 & 7.8539 & 7.8213 & TRN \\
\hline CHEMBL3654965 & 1528274 & 6.7447 & 6.7347 & TRN \\
\hline CHEMBL3655049 & 1528274 & 7.4815 & 7.0816 & TST \\
\hline CHEMBL 3195767 & 688597 & 6.8239 & 6.7686 & TRN \\
\hline CHEMBL1469207 & 688597 & 5.2649 & 5.2585 & TRN \\
\hline CHEMBL1496786 & 688597 & 4.9518 & 5.3688 & TRN \\
\hline CHEMBL544584 & 688597 & 6.3788 & 5.7953 & TRN \\
\hline CHEMBL 3145322 & 688597 & 5.4896 & 5.4811 & TRN \\
\hline CHEMBL1459514 & 688597 & 5.3076 & 5.4679 & TRN \\
\hline CHEMBL1322039 & 688597 & 5.0068 & 5.1894 & TRN \\
\hline CHEMBL1714915 & 688597 & 4.9777 & 5.19600 & 0000000001 \\
\hline CHEMBL1501222 & 688597 & 5.2294 & 5.1752 & TRN \\
\hline CHEMBL3193092 & 688597 & 5.5884 & 5.2715 & TRN \\
\hline CHEMBL1476229 & 688597 & 5.37 & 5.1526 & TRN \\
\hline CHEMBL1492565 & 688597 & 5.9226 & 6.2102 & TRN \\
\hline CHEMBL1354041 & 688597 & 5.4204 & 5.3668 & TRN \\
\hline CHEMBL1405968 & 688597 & 6.0097 & 6.1825 & TRN \\
\hline CHEMBL1475524 & 688597 & 4.0128 & 4.5148 & TRN \\
\hline CHEMBL3198659 & 688597 & 5.5078 & 5.4656 & TST \\
\hline CHEMBL1299389 & 688597 & 6.9508 & 6.5423 & TST \\
\hline CHEMBL600778 & 688597 & 5.3768 & 5.4907 & TRN \\
\hline CHEMBL1489865 & 688597 & 5.20200 & 00000000 & 5.4391 \\
\hline CHEMBL3190585 & 688597 & 4.8455 & 5.0694 & TRN \\
\hline CHEMBL1378785 & 688597 & 5.8914 & 5.7642 & TRN \\
\hline CHEMBL580955 & 688597 & 5.2563 & 5.5414 & TRN \\
\hline CHEMBL458094 & 688597 & 5.6696 & 5.7554 & TRN \\
\hline CHEMBL1376174 & 688597 & 5.1346 & 4.6692 & TST \\
\hline CHEMBL1428166 & 688597 & 5.5488 & 5.7398 & TST \\
\hline CHEMBL1426507 & 688597 & 4.7435 & 4.7863 & TRN \\
\hline CHEMBL1457515 & 688597 & 5.5653 & 5.5091 & TST \\
\hline CHEMBL1532783 & 688597 & 4.6737 & 5.4119 & TRN \\
\hline CHEMBL1510680 & 688597 & 4.6031 & 3.6447 & TRN \\
\hline CHEMBL1361033 & 688597 & 5.2134 & 5.1352 & TRN \\
\hline CHEMBL1453572 & 688597 & 5.6902 & 6.057 & TRN \\
\hline CHEMBL1596779 & 688597 & 5.4651 & 5.4019 & TST \\
\hline CHEMBL1381360 & 688597 & 5.2916 & 5.1292 & TST \\
\hline CHEMBL3199104 & 688597 & 5.28 & 5.3672 & TRN \\
\hline CHEMBL1382418 & 688597 & 5.3529 & 5.2523 & TRN \\
\hline CHEMBL3197778 & 688597 & 5.2703 & 5.4725 & TRN \\
\hline CHEMBL1427059 & 688597 & 5.1172 & 5.2635 & TRN \\
\hline CHEMBL1489081 & 688597 & 5.8297 & 5.8043 & TRN \\
\hline CHEMBL3144976 & 688597 & 6.2351 & 6.0419 & TRN \\
\hline CHEMBL1528206 & 688597 & 8.2218 & 8.2359 & TRN \\
\hline CHEMBL1589425 & 688597 & 5.6356 & 5.9241 & TST \\
\hline CHEMBL533226 & 688597 & 5.5302 & 5.3837 & TRN \\
\hline CHEMBL1570738 & 688597 & 6.8928 & 6.6118 & TRN \\
\hline CHEMBL1428451 & 688597 & 4.4526 & 3.4123 & TRN \\
\hline CHEMBL1971532 & 688597 & 5.539 & 5.5434 & TRN \\
\hline
\end{tabular}




\begin{tabular}{|c|c|c|c|c|}
\hline & & & pplement & al $\mathrm{Tc}$ \\
\hline CHEMBL1511580 & 688597 & 5.442 & 5.5348 & TRN \\
\hline CHEMBL355496 & 688597 & 5.5299 & 5.7642 & TRN \\
\hline CHEMBL1345663 & 688597 & 5.2457 & 5.2012 & TRN \\
\hline CHEMBL1421032 & 688597 & 5.9126 & 5.8077 & TRN \\
\hline CHEMBL1540340 & 688597 & 5.357 & 5.2958 & TRN \\
\hline CHEMBL1500481 & 688597 & 5.4264 & 5.0992 & TST \\
\hline CHEMBL1594106 & 688597 & 5.3927 & 5.0437 & TST \\
\hline CHEMBL1536360 & 688597 & 5.4658 & 5.6493 & TRN \\
\hline CHEMBL1487952 & 688597 & 5.0458 & 5.3419 & TRN \\
\hline CHEMBL390559 & 688597 & 5.5168 & 5.3897 & TRN \\
\hline CHEMBL1543052 & 688597 & 5.481 & 5.0884 & TRN \\
\hline CHEMBL1332873 & 688597 & 6.4342 & 6.0069 & TRN \\
\hline CHEMBL1376070 & 688597 & 5.3873 & 5.3133 & TRN \\
\hline CHEMBL1565369 & 688597 & 5.8713 & 5.9569 & TRN \\
\hline CHEMBL 251148 & 688597 & 2.8239 & 3.3679 & TST \\
\hline CHEMBL1576050 & 688597 & 2.8239 & 3.1527 & TRN \\
\hline CHEMBL1303975 & 688597 & 5.1625 & 4.9224 & TRN \\
\hline CHEMBL1558070 & 688597 & 6.5638 & 6.7736 & TRN \\
\hline CHEMBL1303357 & 688597 & 5.6465 & 5.5899 & TRN \\
\hline CHEMBL1336274 & 688597 & 5.0335 & 5.0055 & TRN \\
\hline CHEMBL1567814 & 688597 & 5.4747 & 5.5174 & TRN \\
\hline CHEMBL1477690 & 688597 & 5.2292 & 5.3787 & TRN \\
\hline CHEMBL3194766 & 688597 & 5.2267 & 3.7139 & TRN \\
\hline CHEMBL1479986 & 688597 & 6.0035 & 5.4636 & TRN \\
\hline CHEMBL1588513 & 688597 & 5.5262 & 5.7987 & TRN \\
\hline CHEMBL1498473 & 688597 & 4.9939 & 4.9982 & TST \\
\hline CHEMBL1344082 & 688597 & 5.5989 & 5.5452 & TRN \\
\hline CHEMBL1449124 & 688597 & 5.5561 & 5.3281 & TRN \\
\hline CHEMBL1415587 & 688597 & 4.9185 & 3.6498 & TRN \\
\hline CHEMBL1519807 & 688597 & 5.3779 & 5.3859 & TST \\
\hline CHEMBL1427233 & 688597 & 5.0677 & 5.098 & TRN \\
\hline CHEMBL1406224 & 688597 & 2.8239 & 3.4368 & TRN \\
\hline CHEMBL1466495 & 688597 & 5.1681 & 5.0676 & TRN \\
\hline CHEMBL1302146 & 688597 & 2.8239 & 4.922 & TRN \\
\hline CHEMBL1542654 & 688597 & 5.3782 & 5.1207 & TRN \\
\hline CHEMBL19954 & 688597 & 5.7289 & 5.5723 & TST \\
\hline CHEMBL1490336 & 688597 & 5.7471 & 5.669 & TRN \\
\hline CHEMBL1354909 & 688597 & 5.9255 & 5.9839 & TRN \\
\hline CHEMBL1602883 & 688597 & 5.1297 & 5.1332 & TRN \\
\hline CHEMBL1471099 & 688597 & 4.8335 & 4.6569 & TRN \\
\hline CHEMBL1464656 & 688597 & 5.2305 & 5.2212 & TRN \\
\hline CHEMBL1603637 & 688597 & 6.2857 & 6.1207 & TRN \\
\hline CHEMBL1984190 & 688597 & 5.6162 & 5.6767 & TRN \\
\hline CHEMBL1308615 & 688597 & 5.2931 & 5.4517 & TRN \\
\hline CHEMBL3195662 & 688597 & 5.6554 & 5.7568 & TST \\
\hline CHEMBL1984876 & 688597 & 6.1308 & 6.1844 & TRN \\
\hline CHEMBL1354346 & 688597 & 5.1722 & 5.0321 & TRN \\
\hline CHEMBL1505922 & 688597 & 5.3716 & 5.2552 & TRN \\
\hline
\end{tabular}




\begin{tabular}{|c|c|c|c|c|c|}
\hline \multicolumn{6}{|c|}{ Supplemental Table S2.txt } \\
\hline CHEMBL1321025 & 688597 & 5.7981 & 5.8007 & TRN & \\
\hline CHEMBL1427340 & 688597 & 4.9036 & 5.1231 & TRN & \\
\hline CHEMBL 3196614 & 688597 & 5.0776 & 5.1399 & TRN & \\
\hline CHEMBL1527120 & 688597 & 5.2194 & 5.1507 & TST & \\
\hline CHEMBL1518844 & 688597 & 5.7991 & 5.9191 & TRN & \\
\hline CHEMBL1425861 & 688597 & 5.9263 & 5.8808 & TRN & \\
\hline CHEMBL1431056 & 688597 & 2.8239 & 3.5149 & TST & \\
\hline CHEMBL1502724 & 688597 & 4.7984 & 5.6105 & TRN & \\
\hline CHEMBL1566748 & 688597 & 5.3955 & 5.439 & TRN & \\
\hline CHEMBL1405475 & 688597 & 5.25 & 5.7657 & TRN & \\
\hline CHEMBL1399229 & 688597 & 2.8239 & 3.2238 & TST & \\
\hline CHEMBL1326634 & 688597 & 5.4059 & 5.5082 & TST & \\
\hline CHEMBL1976677 & 688597 & 6.0132 & 5.9473 & TRN & \\
\hline CHEMBL1428827 & 688597 & 6.7055 & 6.5193 & TRN & \\
\hline CHEMBL1481301 & 688597 & 6.466 & 5.8957 & TRN & \\
\hline CHEMBL1563791 & 688597 & 7.0458 & 6.8355 & TRN & \\
\hline CHEMBL1430107 & 688597 & 5.5289 & 5.4163 & TRN & \\
\hline CHEMBL1530995 & 688597 & 5.765 & 5.8057 & TST & \\
\hline CHEMBL1427576 & 688597 & 5.5103 & 5.3227 & TRN & \\
\hline CHEMBL1463856 & 688597 & 2.8239 & 3.9507 & TRN & \\
\hline CHEMBL1402936 & 688597 & 5.4856 & 5.6757 & TRN & \\
\hline CHEMBL1417167 & 688597 & 6.1568 & 5.9985 & TRN & \\
\hline CHEMBL1600314 & 688597 & 5.5844 & 6.0904 & TRN & \\
\hline CHEMBL1302551 & 688597 & 5.4947 & 5.2722 & TRN & \\
\hline CHEMBL 3145192 & 688597 & 5.2344 & 5.5867 & TST & \\
\hline CHEMBL1374595 & 688597 & 5.1349 & 5.0826 & TST & \\
\hline CHEMBL1463163 & 688597 & 5.4796 & 5.1261 & TRN & \\
\hline CHEMBL1427134 & 688597 & 2.8239 & 5.3718 & TST & \\
\hline CHEMBL 3189832 & 688597 & 5.4619 & 5.6752 & TST & \\
\hline CHEMBL1580583 & 688597 & 5.5814 & 5.3668 & TRN & \\
\hline CHEMBL1533981 & 688597 & 5.1605 & 5.61600 & 00000000005 & TRN \\
\hline CHEMBL1558397 & 688597 & 2.8239 & 3.2341 & TRN & \\
\hline CHEMBL1554002 & 688597 & 6.4559 & 6.3098 & TRN & \\
\hline CHEMBL1349905 & 688597 & 5.3009 & 5.7188 & TRN & \\
\hline CHEMBL1559226 & 688597 & 5.0876 & 5.4937 & TRN & \\
\hline CHEMBL1526636 & 688597 & 5.4722 & 5.3751 & TRN & \\
\hline CHEMBL1989426 & 688597 & 5.0993 & 5.6201 & TRN & \\
\hline CHEMBL1324064 & 688597 & 2.8239 & 3.1276 & TST & \\
\hline CHEMBL 3210126 & 688597 & 5.6033 & 5.1955 & TRN & \\
\hline CHEMBL1450648 & 688597 & 5.3499 & 5.3334 & TRN & \\
\hline CHEMBL1436608 & 688597 & 5.7293 & 5.6976 & TRN & \\
\hline CHEMBL1419323 & 688597 & 2.8239 & 3.3356 & TST & \\
\hline CHEMBL1322356 & 688597 & 5.6484 & 5.774 & TRN & \\
\hline CHEMBL532160 & 688597 & 5.5774 & 5.6094 & TST & \\
\hline CHEMBL1463349 & 688597 & 5.5972 & 5.8034 & TRN & \\
\hline CHEMBL1424234 & 688597 & 2.8239 & 3.2008 & TRN & \\
\hline CHEMBL1418812 & 688597 & 6.6289 & 6.4123 & TRN & \\
\hline CHEMBL1580874 & 688597 & 5.2974 & 5.0691 & TRN & \\
\hline
\end{tabular}




\begin{tabular}{|c|c|c|c|c|c|c|}
\hline \multirow[b]{2}{*}{ CHEMBL1450959 } & \multirow[b]{2}{*}{688597} & \multicolumn{5}{|c|}{ Supplemental Table s2.txt } \\
\hline & & 5.5345 & 4.4912 & TRN & & \\
\hline CHEMBL3192725 & 688597 & 5.1308 & 5.3083 & TRN & & \\
\hline CHEMBL1359684 & 688597 & 5.3516 & 5.4268 & TRN & & \\
\hline CHEMBL1322274 & 688597 & 5.1534 & 5.0406 & TRN & & \\
\hline CHEMBL1461142 & 688597 & 5.9586 & 6.0382 & TRN & & \\
\hline CHEMBL1383327 & 688597 & 5.058 & 5.2582 & TRN & & \\
\hline CHEMBL1438389 & 688597 & 5.7897 & 5.6481 & TRN & & \\
\hline CHEMBL1591082 & 688597 & 5.4901 & 5.4837 & TRN & & \\
\hline CHEMBL1457780 & 688597 & 5.2474 & 5.3029 & TRN & & \\
\hline CHEMBL1560577 & 688597 & \multicolumn{3}{|c|}{5.821000000000001} & 6.0007 & TRN \\
\hline CHEMBL1965821 & 688597 & 5.2249 & 5.2925 & TRN & & \\
\hline CHEMBL1604622 & 688597 & 5.9303 & 4.9801 & TST & & \\
\hline CHEMBL1587103 & 688597 & 4.1417 & 4.3543 & TRN & & \\
\hline CHEMBL1350708 & 688597 & 2.8239 & 3.4322 & TRN & & \\
\hline CHEMBL1605733 & 688597 & 6.2848 & 6.0965 & TST & & \\
\hline CHEMBL1387581 & 688597 & 5.4756 & 5.5723 & TRN & & \\
\hline CHEMBL3195997 & 688597 & 5.7773 & 5.8942 & TRN & & \\
\hline CHEMBL1306690 & 688597 & 5.2895 & 5.2262 & TST & & \\
\hline CHEMBL1587636 & 688597 & 5.4123 & 5.0319 & TRN & & \\
\hline CHEMBL1429171 & 688597 & 5.2029 & 4.9887 & TRN & & \\
\hline CHEMBL1338713 & 688597 & 4.6036 & 3.4913 & TRN & & \\
\hline CHEMBL1359345 & 688597 & 2.8239 & 3.1963 & TRN & & \\
\hline CHEMBL1587142 & 688597 & 2.8239 & 3.5025 & TRN & & \\
\hline CHEMBL1534987 & 688597 & 5.3588 & 4.9197 & TRN & & \\
\hline CHEMBL1313861 & 688597 & 4.974 & 5.0925 & TRN & & \\
\hline CHEMBL1301717 & 688597 & 5.2186 & 5.3102 & TRN & & \\
\hline CHEMBL299853 & 688597 & 5.6121 & 5.8686 & TRN & & \\
\hline CHEMBL1985629 & 688597 & 5.5972 & 5.63 & TRN & & \\
\hline CHEMBL1299757 & 688597 & 5.2981 & 5.5271 & TRN & & \\
\hline CHEMBL1430718 & 688597 & \multicolumn{3}{|c|}{5.587999999999999} & 5.9266 & TRN \\
\hline CHEMBL1399221 & 688597 & 6.0 & 5.6174 & TRN & & \\
\hline CHEMBL1476264 & 688597 & 6.5986 & 6.4645 & TRN & & \\
\hline CHEMBL51931 & 688597 & 5.9014 & 5.9734 & TRN & & \\
\hline CHEMBL1444990 & 688597 & 5.1737 & 5.1599 & TRN & & \\
\hline CHEMBL1473268 & 688597 & 5.5745 & 5.5801 & TRN & & \\
\hline CHEMBL 2369228 & 688597 & 5.3147 & 5.3567 & TST & & \\
\hline CHEMBL3211781 & 688597 & 5.6761 & 5.2417 & TRN & & \\
\hline CHEMBL1972915 & 688597 & 5.8901 & 5.6477 & TRN & & \\
\hline CHEMBL3199132 & 688597 & \multicolumn{3}{|c|}{5.752000000000001} & 5.3794 & TRN \\
\hline CHEMBL1343581 & 688597 & 5.1359 & 5.4688 & TRN & & \\
\hline CHEMBL1999630 & 688597 & 5.7219 & 5.9702 & TRN & & \\
\hline CHEMBL1517362 & 688597 & 8.2218 & 7.081 & TRN & & \\
\hline CHEMBL1407260 & 688597 & 5.0533 & 5.1788 & TRN & & \\
\hline CHEMBL193627 & 688597 & 5.4161 & 5.3203 & TST & & \\
\hline CHEMBL1529203 & 688597 & 5.6061 & 5.7944 & TRN & & \\
\hline CHEMBL1461561 & 688597 & 5.2207 & 5.0915 & TRN & & \\
\hline CHEMBL1539510 & 688597 & 4.8081 & 5.0925 & TRN & & \\
\hline CHEMBL1980657 & 688597 & 6.0625 & 5.9074 & TRN & & \\
\hline
\end{tabular}




\begin{tabular}{|c|c|c|c|c|c|}
\hline & & \multicolumn{4}{|c|}{ Supplemental Table S2.txt } \\
\hline CHEMBL1598676 & 688597 & 5.4479 & 5.8028 & TRN & \\
\hline CHEMBL1336675 & 688597 & 6.1215 & 5.9268 & TRN & \\
\hline CHEMBL3211198 & 688597 & 5.581 & 5.4949 & TRN & \\
\hline CHEMBL1312746 & 688597 & 5.3132 & 4.8724 & TRN & \\
\hline CHEMBL1594171 & 688597 & 5.3076 & 5.4276 & TRN & \\
\hline CHEMBL1573813 & 688597 & 5.7378 & 5.8082 & TRN & \\
\hline CHEMBL 3192320 & 688597 & 5.942 & 5.7667 & TRN & \\
\hline CHEMBL1497721 & 688597 & 6.0496 & 5.9198 & TRN & \\
\hline CHEMBL1517752 & 688597 & 5.03 & 5.2818 & TRN & \\
\hline CHEMBL1450597 & 688597 & 5.3763 & 5.5286 & TRN & \\
\hline CHEMBL1559496 & 688597 & 5.3784 & 5.4461 & TST & \\
\hline CHEMBL1461960 & 688597 & 6.2013 & 6.3107 & TRN & \\
\hline CHEMBL1565674 & 688597 & 5.6302 & 5.7818 & TRN & \\
\hline CHEMBL3207294 & 688597 & 2.8239 & 3.5923 & TRN & \\
\hline CHEMBL1240788 & 688597 & 5.0731 & 5.4671 & TRN & \\
\hline CHEMBL1458877 & 688597 & 5.2496 & 5.3763 & TRN & \\
\hline CHEMBL1896972 & 688597 & 5.6934 & 5.01399 & 9999999999 & TRN \\
\hline CHEMBL1335027 & 688597 & 5.8187 & 5.666 & TRN & \\
\hline CHEMBL1402267 & 688597 & 5.1502 & 5.4207 & TRN & \\
\hline CHEMBL1602141 & 688597 & 5.4216 & 5.1384 & TRN & \\
\hline CHEMBL1097074 & 688597 & 4.9344 & 5.0704 & TST & \\
\hline CHEMBL1588975 & 688597 & 5.9274 & 5.4998 & TRN & \\
\hline CHEMBL574189 & 688597 & 5.4259 & 6.3681 & TRN & \\
\hline CHEMBL1584229 & 688597 & 6.0926 & 4.7447 & TRN & \\
\hline CHEMBL1396215 & 688597 & 5.0762 & 4.8131 & TRN & \\
\hline CHEMBL1536558 & 688597 & 5.0834 & 5.215 & TRN & \\
\hline CHEMBL 256042 & 688597 & 6.1993 & 6.1934 & TRN & \\
\hline CHEMBL1462889 & 688597 & 4.9122 & 3.5488 & TRN & \\
\hline CHEMBL1299745 & 688597 & 5.1674 & 5.1618 & TRN & \\
\hline CHEMBL1439990 & 688597 & 4.9635 & 5.0151 & TRN & \\
\hline CHEMBL1520849 & 688597 & 5.6602 & 5.3257 & TRN & \\
\hline CHEMBL1422849 & 688597 & 5.7395 & 5.6507 & TRN & \\
\hline CHEMBL1568827 & 688597 & 5.6021 & 5.5216 & TRN & \\
\hline CHEMBL2006634 & 688597 & 5.7625 & 5.7542 & TRN & \\
\hline CHEMBL3193488 & 688597 & 2.8239 & 3.2324 & TRN & \\
\hline CHEMBL1384748 & 688597 & 5.3182 & 5.1837 & TRN & \\
\hline CHEMBL1403854 & 688597 & 5.5271 & 5.5122 & TRN & \\
\hline CHEMBL1370217 & 688597 & 5.0053 & 5.0127 & TRN & \\
\hline CHEMBL1581000 & 688597 & 5.0175 & 5.0962 & TRN & \\
\hline CHEMBL1471698 & 688597 & 5.9512 & 6.1037 & TRN & \\
\hline CHEMBL1434622 & 688597 & 5.4378 & 5.641 & TRN & \\
\hline CHEMBL1585777 & 688597 & 6.3799 & 5.8758 & TRN & \\
\hline CHEMBL1537542 & 688597 & 8.2218 & 7.6933 & TRN & \\
\hline CHEMBL1542959 & 688597 & 5.5743 & 5.7561 & TRN & \\
\hline CHEMBL1453857 & 688597 & 6.4609 & 6.2136 & TRN & \\
\hline CHEMBL935 & 688597 & 8.2218 & 7.5128 & TST & \\
\hline CHEMBL1971379 & 688597 & 5.8959 & 5.8206 & TRN & \\
\hline CHEMBL600060 & 688597 & 4.8537 & 5.3234 & TRN & \\
\hline
\end{tabular}




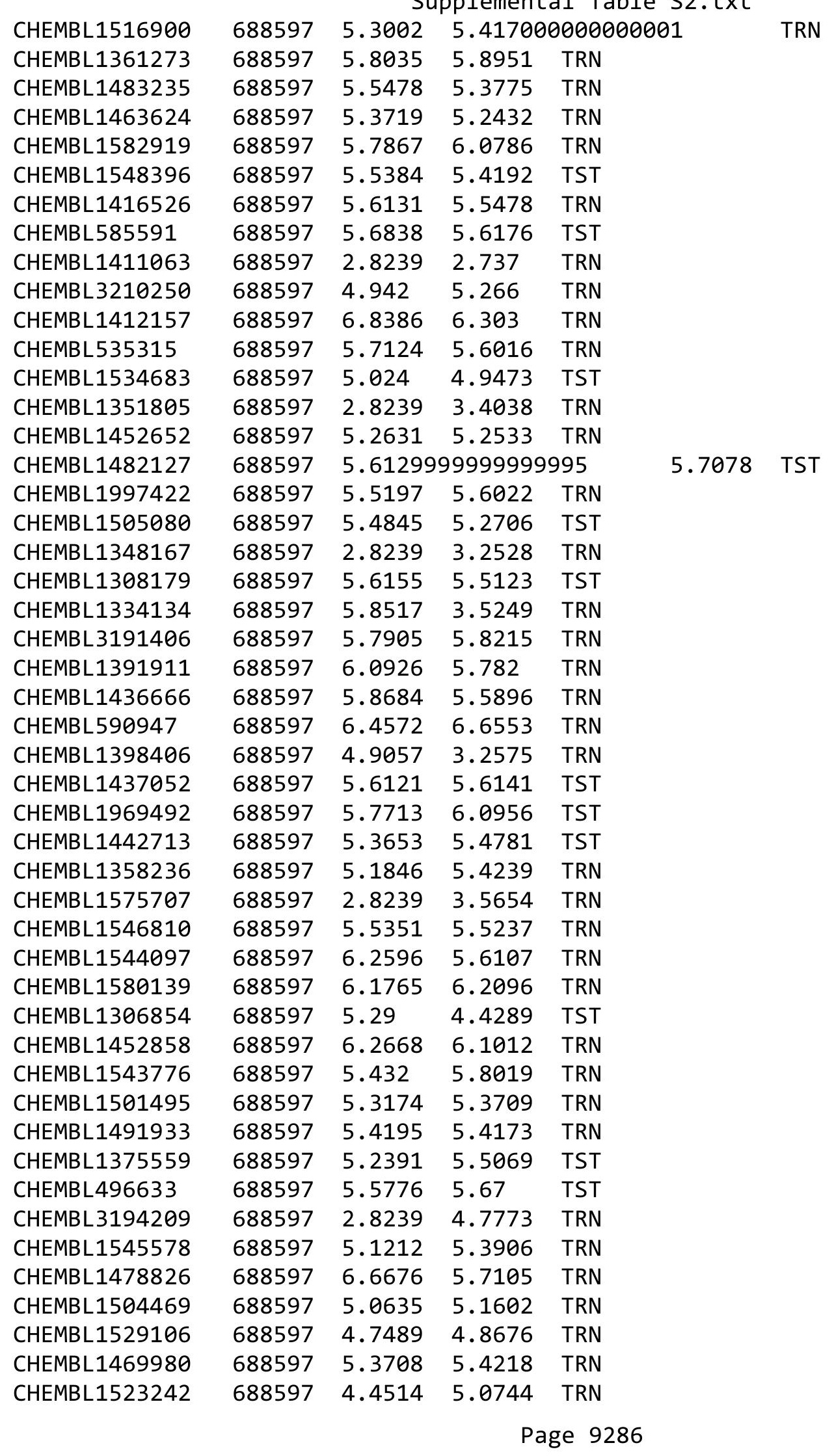




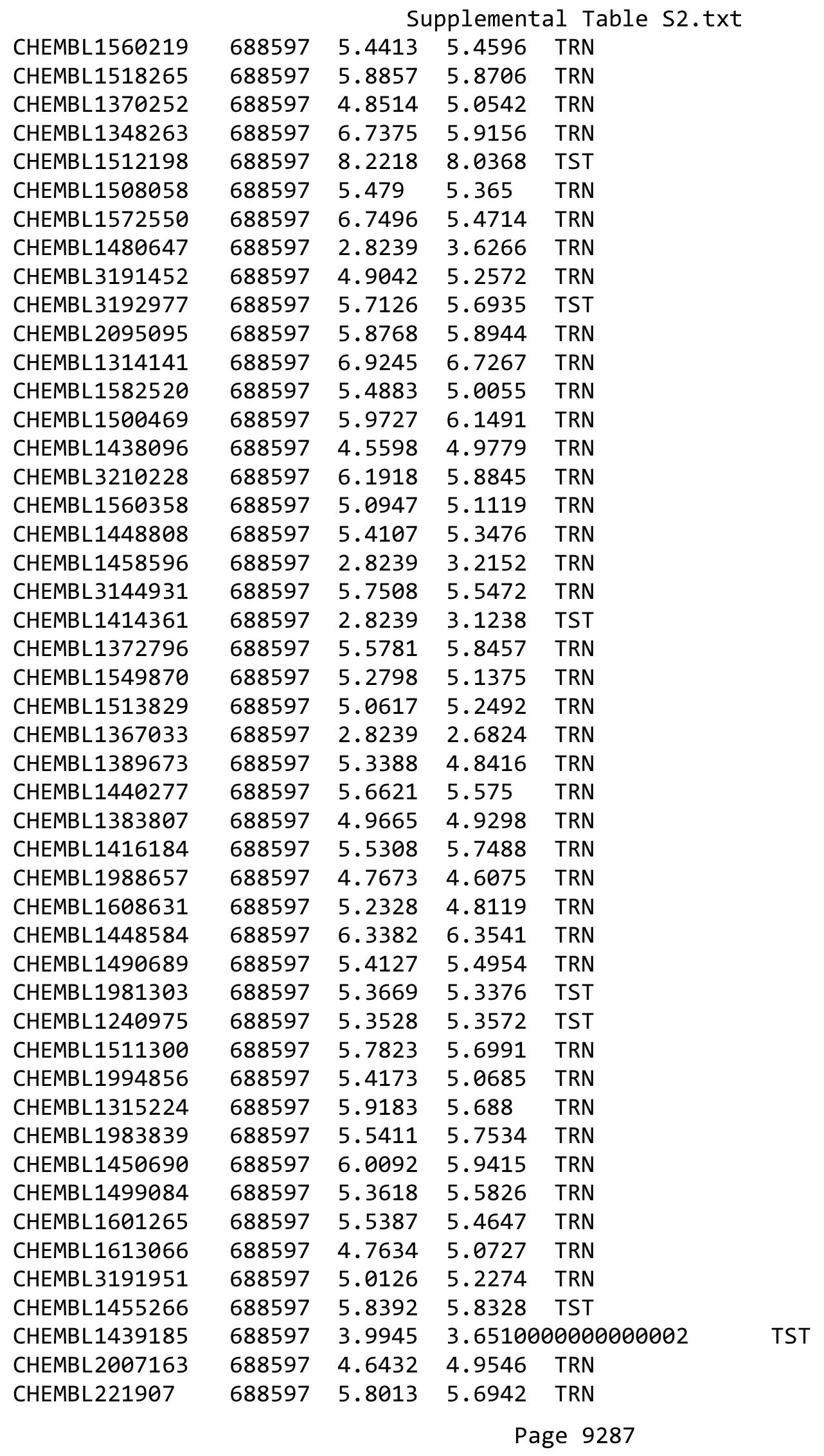




\begin{tabular}{|c|c|c|c|c|c|c|}
\hline & & \multicolumn{5}{|c|}{ Supplemental Table s2.txt } \\
\hline CHEMBL3196681 & 688597 & 4.8134 & 5.1917 & TRN & & \\
\hline CHEMBL1534138 & 688597 & 2.8239 & 3.2084 & TRN & & \\
\hline CHEMBL3190974 & 688597 & 5.5068 & 5.5038 & TRN & & \\
\hline CHEMBL1499220 & 688597 & 5.4689 & 5.4516 & TRN & & \\
\hline CHEMBL1310193 & 688597 & 6.2782 & 5.9342 & TRN & & \\
\hline CHEMBL1376248 & 688597 & 8.2218 & 7.101 & TRN & & \\
\hline CHEMBL1316800 & 688597 & 2.8239 & 3.0089 & TRN & & \\
\hline CHEMBL3209776 & 688597 & 5.6101 & 5.4575 & TRN & & \\
\hline CHEMBL1364119 & 688597 & \multicolumn{3}{|c|}{5.6770000000000005} & 5.7921 & TRN \\
\hline CHEMBL1551048 & 688597 & 4.6557 & 4.6004 & TRN & & \\
\hline CHEMBL1504675 & 688597 & 4.8858 & 5.0094 & TRN & & \\
\hline CHEMBL3190811 & 688597 & 4.6058 & 4.4906 & TRN & & \\
\hline CHEMBL1458809 & 688597 & 5.6221 & 6.1242 & TRN & & \\
\hline CHEMBL1500382 & 688597 & 5.0874 & 4.7166 & TRN & & \\
\hline CHEMBL1327638 & 688597 & 5.1111 & 5.2203 & TRN & & \\
\hline CHEMBL1599708 & 688597 & 8.2218 & 6.6733 & TRN & & \\
\hline CHEMBL1460903 & 688597 & 5.4639 & 5.4983 & TRN & & \\
\hline CHEMBL479765 & 688597 & \multicolumn{3}{|c|}{5.672999999999999} & 5.9483 & TRN \\
\hline CHEMBL1536217 & 688597 & 4.8737 & 5.4032 & TRN & & \\
\hline CHEMBL1553969 & 688597 & 5.7359 & 5.6612 & TRN & & \\
\hline CHEMBL1447541 & 688597 & 4.8673 & 4.7122 & TRN & & \\
\hline CHEMBL1592505 & 688597 & 2.8239 & 3.2557 & TRN & & \\
\hline CHEMBL1455024 & 688597 & 5.2723 & 5.0088 & TRN & & \\
\hline CHEMBL1390437 & 688597 & 2.8239 & 3.0798 & TRN & & \\
\hline CHEMBL1387906 & 688597 & 5.1905 & 5.3267 & TRN & & \\
\hline CHEMBL1416769 & 688597 & 5.7498 & 5.67299 & 9999999999 & & TRN \\
\hline CHEMBL3197740 & 688597 & 5.6866 & 5.9402 & TRN & & \\
\hline CHEMBL1445257 & 688597 & 6.3958 & 6.1215 & TRN & & \\
\hline CHEMBL1520325 & 688597 & 5.4935 & 5.48600 & 0000000001 & & TRN \\
\hline CHEMBL1454039 & 688597 & 6.433 & 6.2333 & TRN & & \\
\hline CHEMBL1990694 & 688597 & 5.2034 & 5.2637 & TST & & \\
\hline CHEMBL3392057 & 688597 & 5.777 & 5.8568 & TRN & & \\
\hline CHEMBL1606412 & 688597 & 5.9978 & 5.7547 & TRN & & \\
\hline CHEMBL1578856 & 688597 & 6.0675 & 6.0917 & TST & & \\
\hline CHEMBL1567518 & 688597 & 6.2248 & 5.9248 & TRN & & \\
\hline CHEMBL1308056 & 688597 & 5.9606 & 5.6191 & TST & & \\
\hline CHEMBL1477844 & 688597 & 2.8239 & 3.2971 & TRN & & \\
\hline CHEMBL1339892 & 688597 & 8.2218 & 8.0464 & TRN & & \\
\hline CHEMBL1602590 & 688597 & 5.2446 & 5.2197 & TRN & & \\
\hline CHEMBL1384341 & 688597 & 5.0047 & 4.8884 & TRN & & \\
\hline CHEMBL1372064 & 688597 & 5.5265 & 5.0043 & TRN & & \\
\hline CHEMBL1596647 & 688597 & 5.0509 & 3.5368 & TRN & & \\
\hline CHEMBL3192555 & 688597 & 5.7802 & 5.9821 & TRN & & \\
\hline CHEMBL1545247 & 688597 & 2.8239 & 3.5157 & TRN & & \\
\hline CHEMBL1495819 & 688597 & 5.7783 & 4.7902 & TST & & \\
\hline CHEMBL1534035 & 688597 & 5.83299 & 99999999 & & 6.0143 & TRN \\
\hline CHEMBL1355233 & 688597 & 5.37200 & 00000000 & & 5.635 & TST \\
\hline CHEMBL1411001 & 688597 & 4.5191 & 4.6743 & TRN & & \\
\hline
\end{tabular}




\begin{tabular}{|c|c|c|c|c|c|c|}
\hline \multicolumn{7}{|c|}{ Supplemental Table S2.txt } \\
\hline CHEMBL3197639 & 688597 & 6.2644 & 6.1412 & TRN & & \\
\hline CHEMBL1353506 & 688597 & 5.9382 & 6.1137 & TRN & & \\
\hline CHEMBL1419303 & 688597 & 5.3502 & 5.25 & TRN & & \\
\hline CHEMBL1471741 & 688597 & 5.647 & 5.7701 & TRN & & \\
\hline CHEMBL1321627 & 688597 & 2.8239 & 3.6145 & TRN & & \\
\hline CHEMBL1551854 & 688597 & 5.62799 & 99999999 & & 5.8055 & TRN \\
\hline CHEMBL1556350 & 688597 & 6.75200 & 00000000 & & 6.6196 & TRN \\
\hline CHEMBL1488460 & 688597 & 5.3644 & 5.4165 & TRN & & \\
\hline CHEMBL3199908 & 688597 & 5.815 & 5.8988 & TST & & \\
\hline CHEMBL1359820 & 688597 & 5.7359 & 5.0614 & TRN & & \\
\hline CHEMBL1537722 & 688597 & 5.3816 & 5.3141 & TST & & \\
\hline CHEMBL1577081 & 688597 & 4.5274 & 4.8021 & TRN & & \\
\hline CHEMBL1564040 & 688597 & 5.1826 & 4.9063 & TRN & & \\
\hline CHEMBL1378331 & 688597 & 5.1872 & 5.0652 & TRN & & \\
\hline CHEMBL1421170 & 688597 & 5.4557 & 5.4382 & TRN & & \\
\hline CHEMBL1334308 & 688597 & 4.6724 & 3.377 & TRN & & \\
\hline CHEMBL3199820 & 688597 & 5.5604 & 5.4075 & TRN & & \\
\hline CHEMBL570400 & 688597 & 5.5027 & 5.70200 & 0000000001 & & TRN \\
\hline CHEMBL1528933 & 688597 & 5.6749 & 5.2794 & TRN & & \\
\hline CHEMBL1990772 & 688597 & 5.8041 & 5.9988 & TRN & & \\
\hline CHEMBL1327628 & 688597 & 5.0607 & 5.1811 & TRN & & \\
\hline CHEMBL1492560 & 688597 & 5.3518 & 4.979 & TRN & & \\
\hline CHEMBL1343073 & 688597 & 5.2155 & 5.6317 & TST & & \\
\hline CHEMBL1451360 & 688597 & 5.3395 & 5.2758 & TRN & & \\
\hline CHEMBL1581194 & 688597 & 5.3344 & 4.7794 & TRN & & \\
\hline CHEMBL3192972 & 688597 & 5.2417 & 5.5008 & TRN & & \\
\hline CHEMBL1510679 & 688597 & 5.8671 & 5.6315 & TRN & & \\
\hline CHEMBL1580555 & 688597 & 5.4449 & 5.2689 & TRN & & \\
\hline CHEMBL1600573 & 688597 & 5.3227 & 5.2101 & TRN & & \\
\hline CHEMBL1606526 & 688597 & 4.8294 & 5.1319 & TRN & & \\
\hline CHEMBL1413672 & 688597 & 5.0832 & 4.9821 & TRN & & \\
\hline CHEMBL1387737 & 688597 & 2.8239 & 3.3622 & TRN & & \\
\hline CHEMBL1601747 & 688597 & 2.8239 & 3.363 & TST & & \\
\hline CHEMBL1477837 & 688597 & 5.4934 & 5.4724 & TRN & & \\
\hline CHEMBL1533320 & 688597 & 6.056 & 5.255 & TRN & & \\
\hline CHEMBL1307382 & 688597 & 4.6307 & 3.4609 & TST & & \\
\hline CHEMBL1563370 & 688597 & 5.5079 & 5.5143 & TST & & \\
\hline CHEMBL1564641 & 688597 & 5.3268 & 5.5962 & TRN & & \\
\hline CHEMBL1336654 & 688597 & 5.2744 & 4.8558 & TST & & \\
\hline CHEMBL1564821 & 688597 & 5.8948 & 5.7089 & TRN & & \\
\hline CHEMBL1354074 & 688597 & 5.0842 & 5.2854 & TRN & & \\
\hline CHEMBL1341100 & 688597 & 4.7879 & 4.8882 & TRN & & \\
\hline CHEMBL1369492 & 688597 & 5.5075 & 5.4656 & TRN & & \\
\hline CHEMBL1428417 & 688597 & 5.6949 & 4.9402 & TRN & & \\
\hline CHEMBL193872 & 688597 & 5.6934 & 5.5029 & TST & & \\
\hline CHEMBL1539224 & 688597 & 5.539 & 5.5393 & TST & & \\
\hline CHEMBL1611573 & 688597 & 5.9296 & 6.3483 & TRN & & \\
\hline CHEMBL3190900 & 688597 & 5.5166 & 5.4038 & TRN & & \\
\hline
\end{tabular}




\begin{tabular}{|c|c|c|c|c|c|}
\hline \multicolumn{6}{|c|}{ Supplemental Table S2.txt } \\
\hline CHEMBL1325303 & 688597 & 5.7662 & 5.2488 & TRN & \\
\hline CHEMBL601757 & 688597 & 5.5581 & 5.3248 & TST & \\
\hline CHEMBL1330429 & 688597 & 4.3331 & 4.8244 & TRN & \\
\hline CHEMBL1531070 & 688597 & 5.4584 & 5.6502 & TST & \\
\hline CHEMBL1604790 & 688597 & 5.5309 & 5.7164 & TRN & \\
\hline CHEMBL1331770 & 688597 & 5.1571 & 5.5092 & TRN & \\
\hline CHEMBL1540328 & 688597 & 5.1465 & 4.8133 & TRN & \\
\hline CHEMBL 3199403 & 688597 & 5.4572 & 5.409 & TRN & \\
\hline CHEMBL1429311 & 688597 & 5.3389 & 5.5827 & TRN & \\
\hline CHEMBL1308201 & 688597 & 5.1686 & 5.013 & TST & \\
\hline CHEMBL 3194024 & 688597 & 4.9705 & 5.5987 & TRN & \\
\hline CHEMBL1321386 & 688597 & 5.166 & 5.4126 & TRN & \\
\hline CHEMBL1547152 & 688597 & 2.8239 & 3.2614 & TRN & \\
\hline CHEMBL1443674 & 688597 & 5.1059 & 5.1517 & TRN & \\
\hline CHEMBL1993993 & 688597 & 5.4522 & 5.50700 & 0000000001 & TRN \\
\hline CHEMBL1494117 & 688597 & 6.4437 & 6.2006 & TRN & \\
\hline CHEMBL 3199742 & 688597 & 5.2859 & 5.3666 & TRN & \\
\hline CHEMBL1462457 & 688597 & 6.295 & 6.1208 & TRN & \\
\hline CHEMBL1539579 & 688597 & 6.2941 & 6.1459 & TRN & \\
\hline CHEMBL1464597 & 688597 & 5.4217 & 5.2267 & TRN & \\
\hline CHEMBL1500712 & 688597 & 5.5134 & 4.723 & TST & \\
\hline CHEMBL1451125 & 688597 & 5.271 & 5.4293 & TRN & \\
\hline CHEMBL1329067 & 688597 & 5.5869 & 5.5997 & TRN & \\
\hline CHEMBL1510905 & 688597 & 5.2262 & 5.5723 & TRN & \\
\hline CHEMBL1533152 & 688597 & 4.8053 & 4.7559 & TRN & \\
\hline CHEMBL3199016 & 688597 & 5.2096 & 5.5938 & TRN & \\
\hline CHEMBL1525098 & 688597 & 6.9393 & 6.9388 & TRN & \\
\hline CHEMBL1374924 & 688597 & 5.065 & 4.9557 & TRN & \\
\hline CHEMBL1332404 & 688597 & 5.2844 & 5.603 & TRN & \\
\hline CHEMBL1510769 & 688597 & 4.4718 & 3.6617 & TST & \\
\hline CHEMBL1314461 & 688597 & 5.4123 & 5.3393 & TRN & \\
\hline CHEMBL1392523 & 688597 & 2.8239 & 3.6693 & TST & \\
\hline CHEMBL 2004918 & 688597 & 5.4927 & 5.2565 & TRN & \\
\hline CHEMBL1371298 & 688597 & 5.0265 & 4.7183 & TRN & \\
\hline CHEMBL1508930 & 688597 & 5.6099 & 5.4687 & TST & \\
\hline CHEMBL1331851 & 688597 & 6.6253 & 6.3656 & TRN & \\
\hline CHEMBL1975652 & 688597 & 5.3506 & 5.1843 & TRN & \\
\hline CHEMBL1384227 & 688597 & 6.4067 & 6.2302 & TRN & \\
\hline CHEMBL1510676 & 688597 & 6.1918 & 5.8939 & TRN & \\
\hline CHEMBL1491019 & 688597 & 6.1273 & 6.2864 & TRN & \\
\hline CHEMBL1369522 & 688597 & 5.234 & 4.4068 & TST & \\
\hline CHEMBL1300497 & 688597 & 6.2798 & 6.3308 & TRN & \\
\hline CHEMBL1302367 & 688597 & 5.5127 & 5.7513 & TRN & \\
\hline CHEMBL1369125 & 688597 & 5.5382 & 5.5144 & TST & \\
\hline CHEMBL1486739 & 688597 & 4.9034 & 5.1419 & TRN & \\
\hline CHEMBL351660 & 688597 & 5.3651 & 5.5389 & TST & \\
\hline CHEMBL 209101 & 688597 & 5.3328 & 5.24 & TRN & \\
\hline CHEMBL1424562 & 688597 & 5.8739 & 5.6329 & TRN & \\
\hline
\end{tabular}




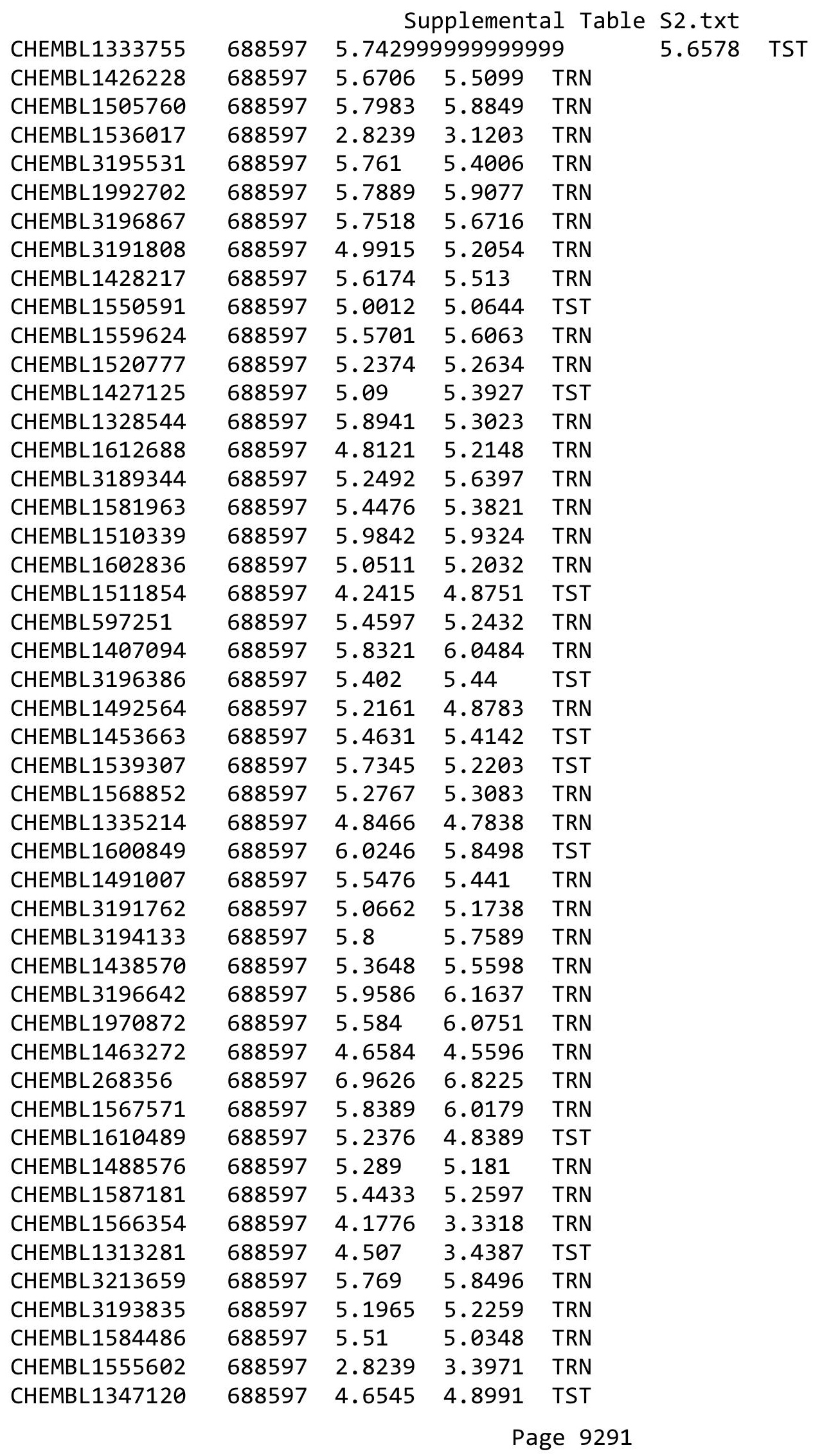


Supplemental Table S2.txt

\begin{tabular}{|c|c|c|c|c|c|}
\hline CHEMBL1555568 & 688597 & 5.9722 & 6.1314 & TRN & \\
\hline CHEMBL1349631 & 688597 & 7.0088 & 7.0582 & TRN & \\
\hline CHEMBL1971127 & 688597 & 5.2874 & 5.3606 & TST & \\
\hline CHEMBL1890591 & 688597 & 6.1296 & 6.0423 & TRN & \\
\hline CHEMBL1359037 & 688597 & 5.1056 & 5.441 & TRN & \\
\hline CHEMBL1338825 & 688597 & 5.053 & 5.3769 & TRN & \\
\hline CHEMBL1989234 & 688597 & 5.8474 & 6.0962 & TRN & \\
\hline CHEMBL1345433 & 688597 & 5.3611 & 5.2861 & TST & \\
\hline CHEMBL1399332 & 688597 & 5.0789 & 5.3606 & TRN & \\
\hline CHEMBL3195142 & 688597 & 5.8294 & 5.7757 & TRN & \\
\hline CHEMBL1358550 & 688597 & 2.8239 & 2.9321 & TRN & \\
\hline CHEMBL1451873 & 688597 & 4.8938 & 3.4945 & TST & \\
\hline CHEMBL1503248 & 688597 & 6.2716 & 6.855 & TRN & \\
\hline CHEMBL1584456 & 688597 & 2.8239 & 3.6021 & TRN & \\
\hline CHEMBL1504993 & 688597 & 5.5795 & 5.6363 & TST & \\
\hline CHEMBL1539624 & 688597 & 6.3778 & 6.4511 & TRN & \\
\hline CHEMBL1605464 & 688597 & 5.1913 & 5.2003 & TRN & \\
\hline CHEMBL1401522 & 688597 & 5.7552 & 5.662000 & 000000001 & TST \\
\hline CHEMBL1330201 & 688597 & 5.7062 & 6.2679 & TRN & \\
\hline CHEMBL1350958 & 688597 & 5.2755 & 5.172000 & 000000001 & TRN \\
\hline CHEMBL3198068 & 688597 & 5.614 & 5.5033 & TRN & \\
\hline CHEMBL1423839 & 688597 & 5.61299 & 999999999 & 5.4437 & \\
\hline CHEMBL1322304 & 688597 & 4.9577 & 5.4204 & TRN & \\
\hline CHEMBL1609420 & 688597 & 2.8239 & 3.3627 & TRN & \\
\hline CHEMBL1330556 & 688597 & 5.6767 & 5.681 & TST & \\
\hline CHEMBL1421905 & 688597 & 5.7447 & 5.9362 & TRN & \\
\hline CHEMBL1519239 & 688597 & 5.1483 & 5.3018 & TRN & \\
\hline CHEMBL1544494 & 688597 & 4.5144 & 4.776 & TST & \\
\hline CHEMBL1339872 & 688597 & 5.0885 & 5.2519 & TST & \\
\hline CHEMBL1378065 & 688597 & 2.8239 & 3.284 & TRN & \\
\hline CHEMBL1545468 & 688597 & 6.6946 & 5.0258 & TRN & \\
\hline CHEMBL1466712 & 688597 & 5.32799 & 999999999 & 5.6631 & I \\
\hline CHEMBL1409001 & 688597 & 5.4807 & 5.6668 & TRN & \\
\hline CHEMBL3199665 & 688597 & 5.6741 & 5.6276 & TRN & \\
\hline CHEMBL1582355 & 688597 & 5.7091 & 5.4408 & TRN & \\
\hline CHEMBL1600566 & 688597 & 5.6782 & 5.6989 & TRN & \\
\hline CHEMBL1389982 & 688597 & 5.0757 & 5.1351 & TRN & \\
\hline CHEMBL1384209 & 688597 & 2.8239 & 3.8568 & TRN & \\
\hline CHEMBL1607568 & 688597 & 5.8492 & 5.9411 & TRN & \\
\hline CHEMBL1578482 & 688597 & 6.4306 & 6.2057 & TRN & \\
\hline CHEMBL1312788 & 688597 & 5.4421 & 5.5887 & TRN & \\
\hline CHEMBL1304605 & 688597 & 5.657 & 5.2056 & TRN & \\
\hline CHEMBL1575766 & 688597 & 5.2129 & 5.3455 & TRN & \\
\hline CHEMBL1606330 & 688597 & 4.723 & 4.7834 & TST & \\
\hline CHEMBL39878 & 688597 & 5.9201 & 5.9119 & TRN & \\
\hline CHEMBL1488364 & 688597 & 5.5328 & 5.6778 & TRN & \\
\hline CHEMBL1299653 & 688597 & 5.2586 & 5.0575 & TST & \\
\hline CHEMBL1437924 & 688597 & 4.8987 & 5.1242 & TST & \\
\hline
\end{tabular}


Supplemental Table S2.txt

\begin{tabular}{|c|c|c|c|c|}
\hline CHEMBL1406895 & 688597 & 5.8877 & 5.7172 & TRN \\
\hline CHEMBL1333387 & 688597 & 5.6596 & 5.5717 & TRN \\
\hline CHEMBL1589444 & 688597 & 2.8239 & 3.5489 & TRN \\
\hline CHEMBL1561569 & 688597 & 2.8239 & 3.3808 & TRN \\
\hline CHEMBL1578411 & 688597 & 5.5586 & 5.5101 & TRN \\
\hline CHEMBL1352564 & 688597 & 5.6465 & 5.7049 & TRN \\
\hline CHEMBL1343705 & 688597 & 5.5589 & 5.66 & TRN \\
\hline CHEMBL1564636 & 688597 & 5.1786 & 5.1124 & TRN \\
\hline CHEMBL1332165 & 688597 & 5.1756 & 5.5761 & TRN \\
\hline CHEMBL1336054 & 688597 & 5.4477 & 5.5701 & TRN \\
\hline CHEMBL199405 & 688597 & 5.9393 & 5.7182 & TRN \\
\hline CHEMBL1504429 & 688597 & 5.6146 & 5.6347 & TRN \\
\hline CHEMBL1532815 & 688597 & 5.5819 & 5.2023 & TRN \\
\hline CHEMBL276139 & 688597 & 5.5792 & 5.5286 & TST \\
\hline CHEMBL1585145 & 688597 & 5.4381 & 5.5002 & TST \\
\hline CHEMBL1429841 & 688597 & 5.8368 & 5.4296 & TRN \\
\hline CHEMBL1491222 & 688597 & 5.9944 & 5.8115 & TRN \\
\hline CHEMBL1440300 & 688597 & 5.7044 & 5.7883 & TST \\
\hline CHEMBL 2002776 & 688597 & 4.7476 & 5.2002 & TRN \\
\hline CHEMBL1492017 & 688597 & 5.6449 & 5.7647 & TRN \\
\hline CHEMBL1431888 & 688597 & 5.2211 & 5.0029 & TRN \\
\hline CHEMBL1463268 & 688597 & 4.8977 & 5.2167 & TRN \\
\hline CHEMBL1343800 & 688597 & 5.78299 & 999999999 & 5.7395 \\
\hline CHEMBL1319643 & 688597 & 7.0088 & 6.9249 & TRN \\
\hline CHEMBL1371202 & 688597 & 5.4227 & 3.6433 & TRN \\
\hline CHEMBL1419536 & 688597 & 6.4413 & 5.0291 & TRN \\
\hline CHEMBL1992943 & 688597 & 5.2529 & 5.3281 & TRN \\
\hline CHEMBL1594907 & 688597 & 2.8239 & 3.3529 & TRN \\
\hline CHEMBL1705092 & 688597 & 5.2642 & 5.6353 & TRN \\
\hline CHEMBL1560329 & 688597 & 5.1926 & 4.8307 & TST \\
\hline CHEMBL1375172 & 688597 & 5.2033 & 5.0134 & TRN \\
\hline CHEMBL1599815 & 688597 & 6.6576 & 6.4872 & TRN \\
\hline CHEMBL1445024 & 688597 & 5.155 & 3.9494 & TRN \\
\hline CHEMBL1585480 & 688597 & 5.3699 & 4.9095 & TRN \\
\hline CHEMBL1532716 & 688597 & 5.8377 & 5.322999 & 99999999995 \\
\hline CHEMBL1346621 & 688597 & 5.3041 & 5.2586 & TRN \\
\hline CHEMBL1558952 & 688597 & 5.6603 & 5.7444 & TRN \\
\hline CHEMBL494083 & 688597 & 5.9918 & 5.9825 & TRN \\
\hline CHEMBL1397158 & 688597 & 5.0331 & 5.1702 & TRN \\
\hline CHEMBL1582111 & 688597 & 5.5289 & 5.4899 & TRN \\
\hline CHEMBL1536034 & 688597 & 5.2161 & 5.2169 & TRN \\
\hline CHEMBL1982010 & 688597 & 5.9263 & 5.9462 & TRN \\
\hline CHEMBL1329129 & 688597 & 5.7796 & 5.6648 & TRN \\
\hline CHEMBL1567899 & 688597 & 5.4364 & 5.9783 & TRN \\
\hline CHEMBL1333978 & 688597 & 5.4791 & 4.6953 & TRN \\
\hline CHEMBL1336205 & 688597 & 5.3035 & 5.6031 & TST \\
\hline CHEMBL 3199044 & 688597 & 5.0824 & 5.2922 & TRN \\
\hline CHEMBL1398664 & 688597 & 5.767 & 5.7236 & TRN \\
\hline
\end{tabular}




\begin{tabular}{|c|c|c|c|c|c|c|}
\hline & & \multicolumn{5}{|c|}{ Supplemental Table S2.txt } \\
\hline CHEMBL1378952 & 688597 & 5.8359 & 5.9251 & TRN & & \\
\hline CHEMBL1532303 & 688597 & 5.0284 & 5.0286 & TRN & & \\
\hline CHEMBL1478314 & 688597 & 5.754 & 5.4655 & TRN & & \\
\hline CHEMBL1583579 & 688597 & 5.0994 & 5.2578 & TRN & & \\
\hline CHEMBL1304168 & 688597 & 5.3439 & 4.752 & TRN & & \\
\hline CHEMBL1361896 & 688597 & \multicolumn{3}{|c|}{5.7860000000000005} & 5.813 & TRN \\
\hline CHEMBL1374950 & 688597 & 5.5474 & 5.6411 & TRN & & \\
\hline CHEMBL1319984 & 688597 & 6.1129 & 6.136 & TRN & & \\
\hline CHEMBL1520545 & 688597 & 5.2018 & 5.3701 & TST & & \\
\hline CHEMBL1510484 & 688597 & 4.3693 & 4.4819 & TRN & & \\
\hline CHEMBL1549777 & 688597 & 4.9584 & 5.4779 & TRN & & \\
\hline CHEMBL1983939 & 688597 & 5.6388 & 5.9597 & TRN & & \\
\hline CHEMBL1602902 & 688597 & 5.0529 & 4.9796 & TRN & & \\
\hline CHEMBL1530220 & 688597 & 5.9686 & 5.7356 & TRN & & \\
\hline CHEMBL1548682 & 688597 & 2.8239 & 3.2306 & TST & & \\
\hline CHEMBL1492045 & 688597 & 5.7997 & 5.6558 & TRN & & \\
\hline CHEMBL1536740 & 688597 & 5.9872 & 5.9981 & TRN & & \\
\hline CHEMBL1495849 & 688597 & 5.3976 & 5.5881 & TRN & & \\
\hline CHEMBL1483287 & 688597 & 2.8239 & 3.9703 & TRN & & \\
\hline CHEMBL1564958 & 688597 & 5.5358 & 5.6441 & TRN & & \\
\hline CHEMBL1324032 & 688597 & 5.1816 & 5.279 & TRN & & \\
\hline CHEMBL1997585 & 688597 & 4.8385 & 4.4953 & TRN & & \\
\hline CHEMBL1606740 & 688597 & 5.0561 & 5.1251 & TRN & & \\
\hline CHEMBL3190592 & 688597 & 5.3287 & 5.6661 & TRN & & \\
\hline CHEMBL1609090 & 688597 & 5.1731 & 5.4755 & TRN & & \\
\hline CHEMBL1344663 & 688597 & 4.3991 & 4.3127 & TRN & & \\
\hline CHEMBL1403620 & 688597 & 2.8239 & 3.2541 & TRN & & \\
\hline CHEMBL1430426 & 688597 & 2.8239 & 3.555 & TST & & \\
\hline CHEMBL1380621 & 688597 & 5.5758 & 5.6151 & TRN & & \\
\hline CHEMBL1529121 & 688597 & 5.1814 & 5.1342 & TRN & & \\
\hline CHEMBL1417731 & 688597 & 6.7423 & 6.5981 & TRN & & \\
\hline CHEMBL1376810 & 688597 & 5.0606 & 5.2265 & TRN & & \\
\hline CHEMBL2001739 & 688597 & 5.9566 & 5.9739 & TRN & & \\
\hline CHEMBL1343101 & 688597 & 5.7151 & 5.67700 & 00000 & 005 & TST \\
\hline CHEMBL1377902 & 688597 & 5.2062 & 5.24799 & 99999 & & TRN \\
\hline CHEMBL1364626 & 688597 & 4.0472 & 3.1726 & TRN & & \\
\hline CHEMBL1310101 & 688597 & 5.3778 & 5.7828 & TRN & & \\
\hline CHEMBL1392438 & 688597 & 5.1114 & 4.5103 & TST & & \\
\hline CHEMBL1578492 & 688597 & 5.2787 & 4.7906 & TRN & & \\
\hline CHEMBL1371792 & 688597 & 4.8749 & 4.9739 & TRN & & \\
\hline CHEMBL1463088 & 688597 & 5.6558 & 5.5713 & TRN & & \\
\hline CHEMBL1478319 & 688597 & 5.51200 & $\partial 0000000$ & 005 & 5.4139 & TST \\
\hline CHEMBL1471932 & 688597 & 5.3054 & 5.2073 & TRN & & \\
\hline CHEMBL1333575 & 688597 & 2.8239 & 3.3375 & TRN & & \\
\hline CHEMBL1466191 & 688597 & 5.7228 & 5.9896 & TRN & & \\
\hline CHEMBL3196175 & 688597 & 5.0615 & 4.8468 & TRN & & \\
\hline CHEMBL1497898 & 688597 & 5.1672 & 4.3453 & TRN & & \\
\hline CHEMBL1390112 & 688597 & 6.1007 & 6.2784 & TRN & & \\
\hline
\end{tabular}




\begin{tabular}{|c|c|c|c|c|c|c|}
\hline \multicolumn{7}{|c|}{ Supplemental Table s2.txt } \\
\hline CHEMBL1574982 & 688597 & 5.2194 & 4.8066 & TRN & & \\
\hline CHEMBL1313731 & 688597 & 2.8239 & 4.9051 & TRN & & \\
\hline CHEMBL1373166 & 688597 & 5.1513 & 5.4297 & TRN & & \\
\hline CHEMBL1473375 & 688597 & 5.5178 & 5.1223 & TRN & & \\
\hline CHEMBL1355207 & 688597 & 2.8239 & 3.4842 & TRN & & \\
\hline CHEMBL1432065 & 688597 & 5.5585 & 5.7117 & TST & & \\
\hline CHEMBL1459241 & 688597 & 2.8239 & 3.1832 & TRN & & \\
\hline CHEMBL1572768 & 688597 & 4.5852 & 3.8991 & TRN & & \\
\hline CHEMBL3191706 & 688597 & 5.0989 & 4.9689 & TRN & & \\
\hline CHEMBL1523597 & 688597 & 4.9697 & 5.1354 & TRN & & \\
\hline CHEMBL1585628 & 688597 & 5.4556 & 5.4645 & TRN & & \\
\hline CHEMBL3191831 & 688597 & 5.6944 & 5.6835 & TRN & & \\
\hline CHEMBL1393796 & 688597 & 3.9155 & 4.53100 & 0000000001 & TRN & \\
\hline CHEMBL 2005246 & 688597 & 6.5901 & 6.3328 & TRN & & \\
\hline CHEMBL1587283 & 688597 & 2.8239 & 3.5206 & TST & & \\
\hline CHEMBL1420051 & 688597 & 5.2784 & 5.5236 & TRN & & \\
\hline CHEMBL1334456 & 688597 & 6.75200 & 00000000 & 01 & 999999995 & TST \\
\hline CHEMBL3197766 & 688597 & 4.9135 & 5.0471 & TRN & & \\
\hline CHEMBL1392351 & 688597 & 5.0036 & 5.4012 & TRN & & \\
\hline CHEMBL3191363 & 688597 & 5.5789 & 5.7411 & TRN & & \\
\hline CHEMBL1588859 & 688597 & 5.228 & 5.4126 & TST & & \\
\hline CHEMBL1543734 & 688597 & 6.1051 & 6.1243 & TRN & & \\
\hline CHEMBL 2003001 & 688597 & 5.3888 & 5.5335 & TRN & & \\
\hline CHEMBL1302617 & 688597 & 4.551 & 4.4991 & TRN & & \\
\hline CHEMBL1470448 & 688597 & 6.6478 & 6.8093 & TRN & & \\
\hline CHEMBL1353426 & 688597 & 5.9901 & 5.2052 & TRN & & \\
\hline CHEMBL3198313 & 688597 & 5.1563 & 5.3467 & TRN & & \\
\hline CHEMBL1347538 & 688597 & 4.7161 & 3.6307 & TST & & \\
\hline CHEMBL1404485 & 688597 & 6.0391 & 6.1692 & TRN & & \\
\hline CHEMBL1991373 & 688597 & 6.3556 & 6.2986 & TRN & & \\
\hline CHEMBL517514 & 688597 & 5.6048 & 6.0066 & TST & & \\
\hline CHEMBL1310411 & 688597 & 2.8239 & 3.4064 & TRN & & \\
\hline CHEMBL1452467 & 688597 & 6.3778 & 6.1932 & TRN & & \\
\hline CHEMBL1975032 & 688597 & 5.7537 & 5.5752 & TRN & & \\
\hline CHEMBL3189802 & 688597 & 2.8239 & 3.4 & TRN & & \\
\hline CHEMBL1413355 & 688597 & 4.6022 & 5.1464 & TRN & & \\
\hline CHEMBL1457175 & 688597 & 5.7289 & 5.6544 & TRN & & \\
\hline CHEMBL1571208 & 688597 & 5.1258 & 4.7456 & TST & & \\
\hline CHEMBL3195778 & 688597 & 5.2952 & 5.5693 & TRN & & \\
\hline CHEMBL1315948 & 688597 & 5.2062 & 5.4646 & TST & & \\
\hline CHEMBL1334100 & 688597 & 5.1529 & 5.2649 & TST & & \\
\hline CHEMBL1470633 & 688597 & 6.295 & 5.84200 & 00000000005 & TRN & \\
\hline CHEMBL1337203 & 688597 & 5.1493 & 3.9149 & TRN & & \\
\hline CHEMBL 1427178 & 688597 & 7.1308 & 6.8234 & TRN & & \\
\hline CHEMBL1309248 & 688597 & 5.3266 & 5.5264 & TRN & & \\
\hline CHEMBL1601133 & 688597 & 5.6133 & 5.5632 & TRN & & \\
\hline CHEMBL1423049 & 688597 & 4.6003 & 4.9833 & TST & & \\
\hline CHEMBL1461547 & 688597 & 5.4735 & 5.5533 & TRN & & \\
\hline
\end{tabular}




\begin{tabular}{|c|c|c|c|c|c|c|}
\hline & & \multicolumn{5}{|c|}{ Supplemental Table S2.txt } \\
\hline CHEMBL 6742 & 688597 & 6.4881 & 6.7369 & TRN & & \\
\hline CHEMBL1323869 & 688597 & 2.8239 & 3.5542 & TST & & \\
\hline CHEMBL1478693 & 688597 & 5.6282 & 5.3949 & TRN & & \\
\hline CHEMBL1577983 & 688597 & 5.5732 & 5.6091 & TRN & & \\
\hline CHEMBL1451491 & 688597 & 5.5311 & 5.8317 & TRN & & \\
\hline CHEMBL1330113 & 688597 & 6.1029 & 5.9868 & TRN & & \\
\hline CHEMBL1407952 & 688597 & 5.8248 & 5.8335 & TRN & & \\
\hline CHEMBL1346860 & 688597 & 5.5075 & 5.8367 & TRN & & \\
\hline CHEMBL1544544 & 688597 & 5.9352 & 6.0216 & TRN & & \\
\hline CHEMBL1360376 & 688597 & 5.4057 & 5.5785 & TRN & & \\
\hline CHEMBL 3195885 & 688597 & 5.6306 & 5.1748 & TRN & & \\
\hline CHEMBL 3190142 & 688597 & 5.1864 & 5.2626 & TRN & & \\
\hline CHEMBL1300170 & 688597 & 6.7328 & 5.4082 & TRN & & \\
\hline CHEMBL1454171 & 688597 & 6.3019 & 5.6283 & TRN & & \\
\hline CHEMBL1544371 & 688597 & 5.7324 & 5.8001 & TRN & & \\
\hline CHEMBL1465946 & 688597 & 6.5171 & 6.3859 & TRN & & \\
\hline CHEMBL1338481 & 688597 & 5.277 & 4.7844 & TRN & & \\
\hline CHEMBL1468058 & 688597 & 4.684 & 4.7525 & TRN & & \\
\hline CHEMBL1409680 & 688597 & 5.7791 & 5.3724 & TRN & & \\
\hline CHEMBL1324005 & 688597 & 6.8827 & 6.9658 & TRN & & \\
\hline CHEMBL1484669 & 688597 & 5.5291 & 5.7182 & TRN & & \\
\hline CHEMBL3197371 & 688597 & 5.7696 & 5.5885 & TRN & & \\
\hline CHEMBL1492943 & 688597 & 6.1457 & 6.1525 & TRN & & \\
\hline CHEMBL1500050 & 688597 & 5.3217 & 5.4297 & TRN & & \\
\hline CHEMBL1993291 & 688597 & 5.4066 & 5.3379 & TRN & & \\
\hline CHEMBL1509051 & 688597 & 6.4078 & 6.5863 & TRN & & \\
\hline CHEMBL1308319 & 688597 & 5.4849 & 5.6114 & TRN & & \\
\hline CHEMBL1332450 & 688597 & 5.7781 & 5.8785 & TRN & & \\
\hline CHEMBL1362528 & 688597 & 2.8239 & 3.2576 & TRN & & \\
\hline CHEMBL1390925 & 688597 & 4.8865 & 5.2207 & TRN & & \\
\hline CHEMBL1355133 & 688597 & 5.2554 & 5.3167 & TRN & & \\
\hline CHEMBL1376974 & 688597 & 6.2147 & 6.0609 & TST & & \\
\hline CHEMBL410525 & 688597 & 5.5485 & 5.9516 & TST & & \\
\hline CHEMBL1450679 & 688597 & 5.144 & 5.2833 & TRN & & \\
\hline CHEMBL1994815 & 688597 & 5.4413 & 5.3456 & TRN & & \\
\hline CHEMBL1385808 & 688597 & 6.0 & 6.1356 & TST & & \\
\hline CHEMBL1588660 & 688597 & 6.0872 & 5.8624 & TRN & & \\
\hline CHEMBL3190621 & 688597 & 5.6778 & 5.79 & TRN & & \\
\hline CHEMBL1486881 & 688597 & 5.7905 & 5.5729 & TRN & & \\
\hline CHEMBL518430 & 688597 & 5.40799 & 99999999 & 995 & 5.4925 & TRN \\
\hline CHEMBL1501874 & 688597 & 4.9115 & 5.1994 & TRN & & \\
\hline CHEMBL1406455 & 688597 & 2.8239 & 3.1218 & TRN & & \\
\hline CHEMBL1466628 & 688597 & 5.8582 & 5.9538 & TRN & & \\
\hline CHEMBL1423858 & 688597 & 5.5481 & 5.5401 & TRN & & \\
\hline CHEMBL1425166 & 688597 & 5.5862 & 5.7006 & TRN & & \\
\hline CHEMBL1487432 & 688597 & 2.8239 & 3.6214 & TST & & \\
\hline CHEMBL1335491 & 688597 & 6.6737 & 6.2568 & TRN & & \\
\hline CHEMBL1559660 & 688597 & 4.9799 & 5.2259 & TST & & \\
\hline
\end{tabular}




\begin{tabular}{|c|c|c|c|c|c|}
\hline & & \multicolumn{4}{|c|}{ Supplemental Table S2.txt } \\
\hline CHEMBL1509762 & 688597 & 5.3251 & 5.3896 & TRN & \\
\hline CHEMBL3199654 & 688597 & 5.1421 & 5.1232 & TRN & \\
\hline CHEMBL1452090 & 688597 & 5.8841 & 5.8186 & TRN & \\
\hline CHEMBL1574283 & 688597 & 6.2132 & 5.9985 & TRN & \\
\hline CHEMBL1568771 & 688597 & 4.7058 & 4.9348 & TRN & \\
\hline CHEMBL1428343 & 688597 & 5.5144 & 5.1764 & TRN & \\
\hline CHEMBL1430574 & 688597 & 6.4711 & 6.6212 & TRN & \\
\hline CHEMBL1379636 & 688597 & 5.5016 & 5.70799 & 9999999999 & TST \\
\hline CHEMBL1494800 & 688597 & 5.2468 & 5.105 & TRN & \\
\hline CHEMBL1579796 & 688597 & 5.3267 & 5.1358 & TRN & \\
\hline CHEMBL1438071 & 688597 & 5.4855 & 5.19799 & 99999999995 & TRN \\
\hline CHEMBL1412412 & 688597 & 5.15 & 4.8094 & TRN & \\
\hline CHEMBL1415442 & 688597 & 5.0714 & 5.2834 & TRN & \\
\hline CHEMBL3190868 & 688597 & 6.2299 & 6.0683 & TRN & \\
\hline CHEMBL1562765 & 688597 & 5.5894 & 5.1407 & TRN & \\
\hline CHEMBL1506216 & 688597 & 5.4903 & 5.6098 & TRN & \\
\hline CHEMBL1609914 & 688597 & 2.8239 & 3.1395 & TRN & \\
\hline CHEMBL1595934 & 688597 & 5.9747 & 6.0329 & TRN & \\
\hline CHEMBL1604272 & 688597 & 4.9097 & 5.1156 & TRN & \\
\hline CHEMBL3207339 & 688597 & 5.1174 & 5.6098 & TRN & \\
\hline CHEMBL1979800 & 688597 & 6.0691 & 5.8423 & TRN & \\
\hline CHEMBL1374335 & 688597 & 5.5435 & 3.6262 & TRN & \\
\hline CHEMBL1361114 & 688597 & 5.7513 & 4.081 & TST & \\
\hline CHEMBL1594585 & 688597 & 2.8239 & 3.3187 & TRN & \\
\hline CHEMBL1470520 & 688597 & $5.3260 e$ & 00000000 & 5.3804 & TRN \\
\hline CHEMBL1346307 & 688597 & 5.1386 & 4.9745 & TRN & \\
\hline CHEMBL1426136 & 688597 & 2.8239 & 2.7547 & TRN & \\
\hline CHEMBL1334568 & 688597 & 6.857 & 6.7494 & TRN & \\
\hline CHEMBL1530542 & 688597 & 2.8239 & 3.7144 & TRN & \\
\hline CHEMBL1524131 & 688597 & 5.6267 & 5.6147 & TRN & \\
\hline CHEMBL3190835 & 688597 & 2.8239 & 3.6296 & TRN & \\
\hline CHEMBL1514790 & 688597 & 5.6117 & 5.4419 & TST & \\
\hline CHEMBL1330522 & 688597 & 8.2218 & 7.5499 & TRN & \\
\hline CHEMBL1301919 & 688597 & 2.8239 & 3.0373 & TRN & \\
\hline CHEMBL1402502 & 688597 & 5.1117 & 5.2551 & TRN & \\
\hline CHEMBL1499490 & 688597 & 5.8722 & 5.8971 & TRN & \\
\hline CHEMBL1558590 & 688597 & 3.9885 & 3.5757 & TST & \\
\hline CHEMBL1547641 & 688597 & 4.9882 & 4.872 & TRN & \\
\hline CHEMBL1541449 & 688597 & 5.3768 & 4.7221 & TRN & \\
\hline CHEMBL1413726 & 688597 & 4.9661 & 5.3359 & TST & \\
\hline CHEMBL1393529 & 688597 & 5.18 & 5.1847 & TRN & \\
\hline CHEMBL1534368 & 688597 & 2.8239 & 3.4541 & TRN & \\
\hline CHEMBL3145304 & 688597 & 5.8642 & 5.8215 & TRN & \\
\hline CHEMBL1328384 & 688597 & 5.2467 & 5.2365 & TST & \\
\hline CHEMBL1589029 & 688597 & 5.7219 & 5.4035 & TRN & \\
\hline CHEMBL1400432 & 688597 & 5.2182 & 5.3602 & TST & \\
\hline CHEMBL1462906 & 688597 & 5.7055 & 5.5814 & TRN & \\
\hline CHEMBL1469579 & 688597 & 5.3939 & 5.5265 & TRN & \\
\hline
\end{tabular}




\begin{tabular}{|c|c|c|c|c|c|}
\hline \multirow[b]{2}{*}{ CHEMBL1604383 } & \multicolumn{5}{|c|}{ Supplemental Table S2.txt } \\
\hline & 688597 & 5.1532 & 5.1294 & TRN & \\
\hline CHEMBL1986418 & 688597 & 5.8085 & 5.8955 & TRN & \\
\hline CHEMBL1534390 & 688597 & 5.647 & 5.7128 & TRN & \\
\hline CHEMBL1321372 & 688597 & 5.1588 & 5.505 & TRN & \\
\hline CHEMBL104270 & 688597 & 6.5287 & 6.4215 & TRN & \\
\hline CHEMBL3214119 & 688597 & 4.5392 & 5.0374 & TST & \\
\hline CHEMBL1541490 & 688597 & 5.2009 & 5.5073 & TRN & \\
\hline CHEMBL1461477 & 688597 & 6.2233 & 6.2438 & TRN & \\
\hline CHEMBL1529276 & 688597 & 5.4254 & 5.4426 & TRN & \\
\hline CHEMBL1335732 & 688597 & 5.3391 & 5.4123 & TRN & \\
\hline CHEMBL1423933 & 688597 & 5.7525 & 5.4777 & TST & \\
\hline CHEMBL1965814 & 688597 & 5.8342 & 5.6625 & TRN & \\
\hline CHEMBL1494274 & 688597 & 2.8239 & 3.3894 & TRN & \\
\hline CHEMBL1353738 & 688597 & 5.3868 & 5.5585 & TRN & \\
\hline CHEMBL1494569 & 688597 & 4.6999 & 3.6047 & TRN & \\
\hline CHEMBL1449956 & 688597 & 2.8239 & 3.3395 & TRN & \\
\hline CHEMBL1532946 & 688597 & 4.6861 & 5.0421 & TRN & \\
\hline CHEMBL1409596 & 688597 & 6.4473 & 3.0562 & TRN & \\
\hline CHEMBL1520696 & 688597 & 5.9024 & 5.7099 & TST & \\
\hline CHEMBL1573692 & 688597 & 5.5591 & 5.5406 & TRN & \\
\hline CHEMBL1977078 & 688597 & 5.6231 & 5.6722 & TST & \\
\hline CHEMBL1411897 & 688597 & 5.2703 & 5.3944 & TST & \\
\hline CHEMBL1601701 & 688597 & 5.5284 & 5.1568 & TST & \\
\hline CHEMBL1463714 & 688597 & 5.7739 & 5.8604 & TRN & \\
\hline CHEMBL1505586 & 688597 & 5.9974 & 5.734 & TST & \\
\hline CHEMBL1311812 & 688597 & 5.5177 & 5.4327 & TRN & \\
\hline CHEMBL1428911 & 688597 & 5.8874 & 6.1164 & TRN & \\
\hline CHEMBL590665 & 688597 & 5.706 & 5.8843 & TRN & \\
\hline CHEMBL1506533 & 688597 & 5.013 & 5.28600 & 00000000005 & TRN \\
\hline CHEMBL 2002465 & 688597 & 6.1818 & 6.2408 & TRN & \\
\hline CHEMBL 3190468 & 688597 & 6.0491 & 6.0976 & TRN & \\
\hline CHEMBL1487959 & 688597 & 5.564 & 5.6061 & TRN & \\
\hline CHEMBL567132 & 688597 & 5.5253 & 5.4485 & TST & \\
\hline CHEMBL1313887 & 688597 & 4.8436 & 5.0835 & TRN & \\
\hline CHEMBL1472447 & 688597 & 5.5003 & 5.3314 & TRN & \\
\hline CHEMBL1362163 & 688597 & 5.4766 & 5.306 & TST & \\
\hline CHEMBL1376019 & 688597 & 5.0967 & 5.4574 & TRN & \\
\hline CHEMBL1351542 & 688597 & 6.1662 & 6.2529 & TRN & \\
\hline CHEMBL1518155 & 688597 & 5.1996 & 5.0854 & TRN & \\
\hline CHEMBL1399543 & 688597 & 6.0173 & 6.1884 & TRN & \\
\hline CHEMBL1341433 & 688597 & 5.9618 & 6.1055 & TRN & \\
\hline CHEMBL1436213 & 688597 & 5.8277 & 6.132006 & 3000000001 & TRN \\
\hline CHEMBL1461513 & 688597 & 5.63899 & 99999999 & 5.4315 & TRN \\
\hline CHEMBL1520896 & 688597 & 6.1713 & 6.1815 & TRN & \\
\hline CHEMBL 2358514 & 688597 & 5.8447 & 5.541 & TST & \\
\hline CHEMBL1545093 & 688597 & 5.7929 & 5.6261 & TRN & \\
\hline CHEMBL1546791 & 688597 & 5.1211 & 5.1719 & TRN & \\
\hline CHEMBL1417054 & 688597 & 4.7779 & 5.29799 & 9999999999 & TRN \\
\hline & & & & 929 & \\
\hline
\end{tabular}




\begin{tabular}{|c|c|c|c|c|c|c|}
\hline & & \multicolumn{4}{|c|}{ Supplemental Table s2.txt } & \\
\hline CHEMBL1977043 & 688597 & \multicolumn{4}{|c|}{5.111000000000001} & TRN \\
\hline CHEMBL1612475 & 688597 & \multicolumn{3}{|c|}{4.821000000000001} & .471 & TRN \\
\hline CHEMBL1338446 & 688597 & 5.4973 & 5.6636 & TRN & & \\
\hline CHEMBL1580917 & 688597 & 5.3814 & 5.3826 & TRN & & \\
\hline CHEMBL1466193 & 688597 & 5.0926 & 5.1453 & TRN & & \\
\hline CHEMBL1439833 & 688597 & 5.9333 & 5.4949 & TRN & & \\
\hline CHEMBL1519764 & 688597 & 5.1223 & 4.9436 & TST & & \\
\hline CHEMBL3195943 & 688597 & 5.0063 & 5.0617 & TRN & & \\
\hline CHEMBL1456639 & 688597 & 2.8239 & 3.4375 & TRN & & \\
\hline CHEMBL3199756 & 688597 & 6.1367 & 6.4189 & TRN & & \\
\hline CHEMBL1416756 & 688597 & 4.9963 & 4.8318 & TRN & & \\
\hline CHEMBL1539860 & 688597 & 5.4731 & 5.6786 & TRN & & \\
\hline CHEMBL1578439 & 688597 & 5.4798 & 5.5014 & TRN & & \\
\hline CHEMBL1390716 & 688597 & 6.3449 & 6.6655 & TRN & & \\
\hline CHEMBL1464544 & 688597 & 5.3277 & 5.4887 & TST & & \\
\hline CHEMBL1503034 & 688597 & 6.0841 & 5.8886 & TRN & & \\
\hline CHEMBL3192817 & 688597 & 5.3572 & 5.5877 & TRN & & \\
\hline CHEMBL1550132 & 688597 & 5.2038 & 5.25899 & 99999999995 & & TRN \\
\hline CHEMBL1585579 & 688597 & 2.8239 & 3.5668 & TRN & & \\
\hline CHEMBL1526490 & 688597 & 6.0762 & 5.2532 & TRN & & \\
\hline CHEMBL1481347 & 688597 & 5.0332 & 5.2957 & TST & & \\
\hline CHEMBL 2004978 & 688597 & 5.644 & 5.5913 & TRN & & \\
\hline CHEMBL1385499 & 688597 & 5.404 & 5.17700 & 00000000005 & & TRN \\
\hline CHEMBL1611858 & 688597 & 5.2025 & 5.2485 & TRN & & \\
\hline CHEMBL1441083 & 688597 & 4.8288 & 4.9737 & TST & & \\
\hline CHEMBL1323512 & 688597 & 5.4786 & 5.3242 & TRN & & \\
\hline CHEMBL1588356 & 688597 & 5.5482 & 5.4503 & TRN & & \\
\hline CHEMBL1522582 & 688597 & 5.6019 & 5.189 & TRN & & \\
\hline CHEMBL1421884 & 688597 & 2.8239 & 4.78 & TRN & & \\
\hline CHEMBL1344358 & 688597 & 2.8239 & 3.5705 & TRN & & \\
\hline CHEMBL1400025 & 688597 & 2.8239 & 3.573 & TRN & & \\
\hline CHEMBL1302894 & 688597 & 5.2756 & 5.3657 & TRN & & \\
\hline CHEMBL1469266 & 688597 & 2.8239 & 2.8966 & TRN & & \\
\hline CHEMBL1395962 & 688597 & 6.0605 & 5.8662 & TST & & \\
\hline CHEMBL1410625 & 688597 & 5.3446 & 5.3246 & TRN & & \\
\hline CHEMBL1431751 & 688597 & 2.8239 & 3.6485 & TRN & & \\
\hline CHEMBL1562033 & 688597 & 6.9393 & 7.6944 & TST & & \\
\hline CHEMBL1513972 & 688597 & 5.3684 & 5.40600 & 0000000001 & & TST \\
\hline CHEMBL1359318 & 688597 & 5.2128 & 5.0489 & TRN & & \\
\hline CHEMBL 3208443 & 688597 & 5.5829 & 5.7699 & TRN & & \\
\hline CHEMBL1370746 & 688597 & 5.4299 & 5.0357 & TRN & & \\
\hline CHEMBL1479408 & 688597 & 5.1399 & 5.0302 & TRN & & \\
\hline CHEMBL1332733 & 688597 & 4.8367 & 5.0331 & TST & & \\
\hline CHEMBL1445145 & 688597 & 5.4479 & 4.8899 & TRN & & \\
\hline CHEMBL1462138 & 688597 & 4.7338 & 4.6068 & TRN & & \\
\hline CHEMBL1305787 & 688597 & $5.4170 €$ & 30000000 & 01 & .4218 & TRN \\
\hline CHEMBL1354631 & 688597 & 4.6471 & 5.1671 & TRN & & \\
\hline CHEMBL1391973 & 688597 & 4.5344 & 5.1589 & TRN & & \\
\hline
\end{tabular}




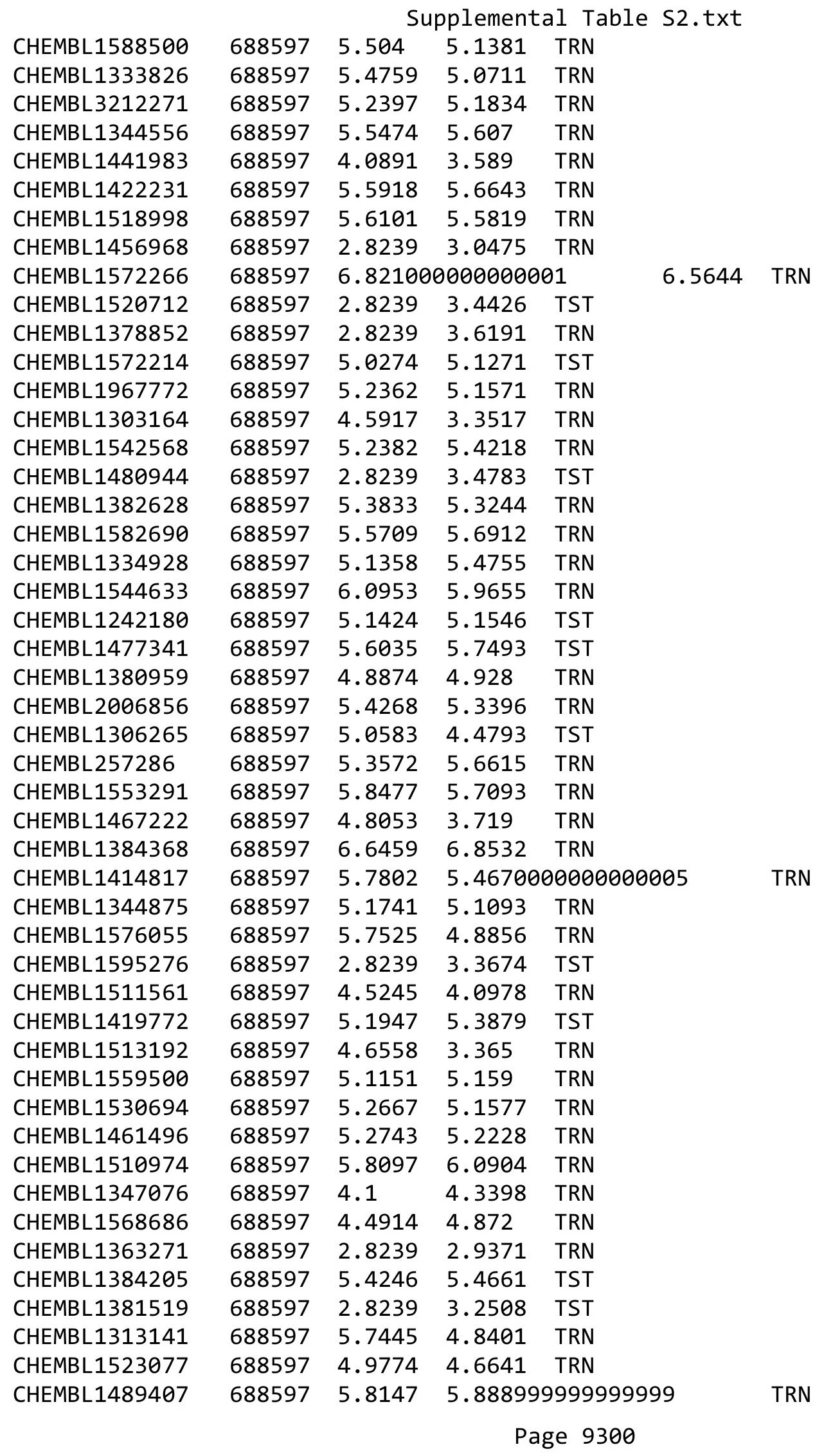




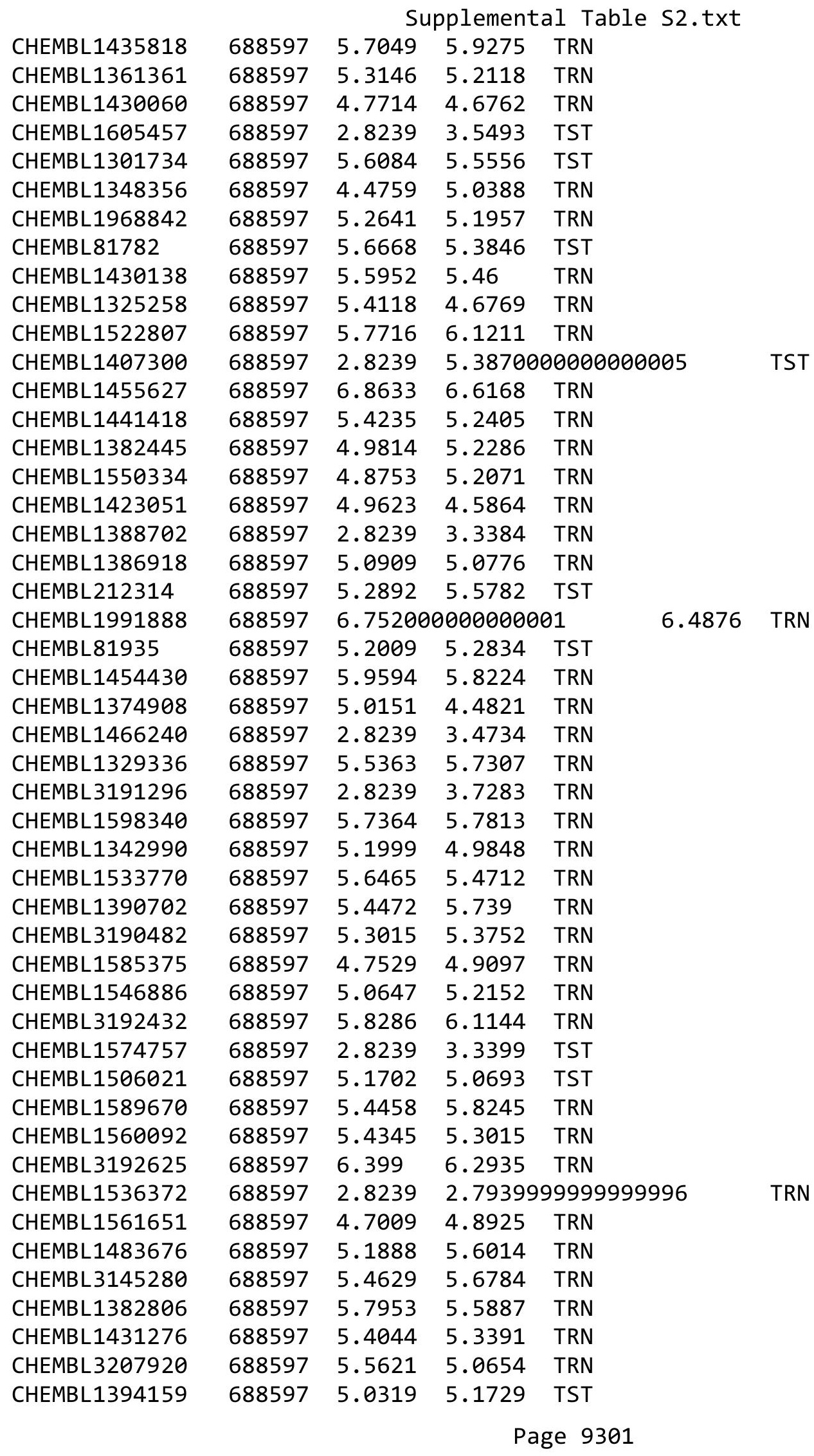




\begin{tabular}{|c|c|c|c|c|}
\hline & & & pplement & \\
\hline CHEMBL1430093 & 688597 & 4.2121 & 3.8864 & TRN \\
\hline CHEMBL1367295 & 688597 & 6.5918 & 5.9963 & TRN \\
\hline CHEMBL3199364 & 688597 & 5.2103 & 5.2015 & TRN \\
\hline CHEMBL1377629 & 688597 & 5.5291 & 5.4865 & TRN \\
\hline CHEMBL1534433 & 688597 & 2.8239 & 3.5106 & TRN \\
\hline CHEMBL577102 & 688597 & 5.5439 & 5.5476 & TRN \\
\hline CHEMBL1480439 & 688597 & 5.3839 & 5.3884 & TST \\
\hline CHEMBL1332013 & 688597 & 5.4765 & 5.3369 & TRN \\
\hline CHEMBL3195410 & 688597 & 6.3526 & 6.3762 & TRN \\
\hline CHEMBL1450872 & 688597 & 5.2093 & 5.4618 & TST \\
\hline CHEMBL1973886 & 688597 & 5.404 & 5.0958 & TRN \\
\hline CHEMBL1600173 & 688597 & 4.886 & 4.875 & TRN \\
\hline CHEMBL1534949 & 688597 & 5.8536 & 5.7109 & TRN \\
\hline CHEMBL1497792 & 688597 & 5.2159 & 5.5622 & TST \\
\hline CHEMBL3192928 & 688597 & 5.6275 & 5.6084 & TRN \\
\hline CHEMBL 3195488 & 688597 & 5.5928 & 5.5608 & TRN \\
\hline CHEMBL1544188 & 688597 & 4.9866 & 5.0671 & TRN \\
\hline CHEMBL1402496 & 688597 & 5.3126 & 5.3909 & TST \\
\hline CHEMBL3190827 & 688597 & 5.4046 & 5.4397 & TRN \\
\hline CHEMBL1443649 & 688597 & 5.4808 & 5.0523 & TST \\
\hline CHEMBL3193769 & 688597 & 4.9254 & 3.5138 & TRN \\
\hline CHEMBL1523130 & 688597 & 5.0297 & 5.2556 & TST \\
\hline CHEMBL1521990 & 688597 & 5.9582 & 5.3205 & TRN \\
\hline CHEMBL1510187 & 688597 & 4.2316 & 3.4644 & TRN \\
\hline CHEMBL3193726 & 688597 & 2.8239 & 3.4772 & TRN \\
\hline CHEMBL1447251 & 688597 & 6.6819 & 5.8491 & TRN \\
\hline CHEMBL1418662 & 688597 & 5.2478 & 5.2959 & TRN \\
\hline CHEMBL1498307 & 688597 & 6.1337 & 6.105 & TRN \\
\hline CHEMBL1588549 & 688597 & 5.9187 & 6.0657 & TRN \\
\hline CHEMBL1597278 & 688597 & 5.5989 & 5.4745 & TRN \\
\hline CHEMBL1568457 & 688597 & 5.0637 & 4.7541 & TRN \\
\hline CHEMBL1508440 & 688597 & 5.4324 & 5.4236 & TST \\
\hline CHEMBL1468612 & 688597 & 4.6097 & 5.2601 & TRN \\
\hline CHEMBL1504848 & 688597 & 2.8239 & 3.0933 & TRN \\
\hline CHEMBL1583127 & 688597 & 5.5147 & 5.6521 & TRN \\
\hline CHEMBL1422105 & 688597 & 5.6133 & 5.7802 & TRN \\
\hline CHEMBL1332598 & 688597 & 5.564 & 3.8098 & TRN \\
\hline CHEMBL1499233 & 688597 & 5.6934 & 5.5709 & TRN \\
\hline CHEMBL3191058 & 688597 & 5.2204 & 5.2416 & TRN \\
\hline CHEMBL3193338 & 688597 & 5.4787 & 5.4085 & TRN \\
\hline CHEMBL1400092 & 688597 & 2.8239 & 3.3625 & TST \\
\hline CHEMBL1533974 & 688597 & 5.3449 & 4.8888 & TRN \\
\hline CHEMBL1333989 & 688597 & 5.033 & 5.001 & TRN \\
\hline CHEMBL1430072 & 688597 & 5.8035 & 5.6794 & TRN \\
\hline CHEMBL45152 & 688597 & 5.9531 & 6.2353 & TRN \\
\hline CHEMBL1354211 & 688597 & 5.341 & 5.2794 & TRN \\
\hline CHEMBL1612250 & 688597 & 5.2672 & 5.3631 & TRN \\
\hline CHEMBL1366055 & 688597 & 6.0264 & 6.4702 & TRN \\
\hline
\end{tabular}




\begin{tabular}{|c|c|c|c|c|}
\hline \multicolumn{5}{|c|}{ Supplemental Table } \\
\hline CHEMBL1603147 & 688597 & 4.7149 & 4.7532 & TST \\
\hline CHEMBL1529601 & 688597 & 4.7341 & 4.9924 & TRN \\
\hline CHEMBL1557651 & 688597 & 5.3458 & 5.1896 & TRN \\
\hline CHEMBL3193701 & 688597 & 5.4284 & 5.6234 & TRN \\
\hline CHEMBL1966025 & 688597 & 5.1182 & 5.2342 & TRN \\
\hline CHEMBL1562446 & 688597 & 2.8239 & 2.7034 & TRN \\
\hline CHEMBL1523372 & 688597 & 5.4578 & 5.4061 & TRN \\
\hline CHEMBL1511380 & 688597 & 2.8239 & 3.5271 & TST \\
\hline CHEMBL1318922 & 688597 & 8.2218 & 8.4261 & TRN \\
\hline CHEMBL1437942 & 688597 & 5.4184 & 5.454 & TRN \\
\hline CHEMBL1391280 & 688597 & 2.8239 & 3.6166 & TRN \\
\hline CHEMBL1571801 & 688597 & 4.814 & 5.1833 & TRN \\
\hline CHEMBL1578141 & 688597 & 5.2071 & 5.3509 & TRN \\
\hline CHEMBL1566076 & 688597 & 5.4554 & 5.4527 & TRN \\
\hline CHEMBL363535 & 688597 & 5.5602 & 5.5562 & TRN \\
\hline CHEMBL1305375 & 688597 & 5.4672 & 5.3284 & TRN \\
\hline CHEMBL1404493 & 688597 & 5.3741 & 5.0756 & TST \\
\hline CHEMBL1969094 & 688597 & 5.109 & 5.2154 & TRN \\
\hline CHEMBL1482053 & 688597 & 5.3029 & 5.3431 & TRN \\
\hline CHEMBL1429682 & 688597 & 5.8722 & 5.9492 & TRN \\
\hline CHEMBL1371231 & 688597 & 2.8239 & 3.5846 & TST \\
\hline CHEMBL1505057 & 688597 & 5.765 & 6.0549 & TRN \\
\hline CHEMBL586135 & 688597 & 8.2218 & 7.2806 & TRN \\
\hline CHEMBL1399370 & 688597 & 5.6196 & 5.7022 & TRN \\
\hline CHEMBL1421347 & 688597 & 5.8972 & 5.9134 & TRN \\
\hline CHEMBL1965679 & 688597 & 5.0492 & 5.1039 & TRN \\
\hline CHEMBL1493953 & 688597 & 5.3197 & 5.3453 & TRN \\
\hline CHEMBL1462041 & 688597 & 4.8686 & 5.0433 & TRN \\
\hline CHEMBL1469901 & 688597 & 2.8239 & 3.2387 & TRN \\
\hline CHEMBL1594517 & 688597 & 5.2038 & 5.0845 & TRN \\
\hline CHEMBL1390139 & 688597 & 5.3876 & 5.2983 & TRN \\
\hline CHEMBL1511893 & 688597 & 5.3053 & 5.4096 & TRN \\
\hline CHEMBL1508334 & 688597 & 5.2465 & 5.4942 & TRN \\
\hline CHEMBL1976312 & 688597 & 5.8133 & 5.8545 & TRN \\
\hline CHEMBL1392637 & 688597 & 6.4413 & 6.1799 & TRN \\
\hline CHEMBL1395907 & 688597 & 5.4356 & 5.5922 & TRN \\
\hline CHEMBL1492510 & 688597 & 4.9545 & 5.0623 & TST \\
\hline CHEMBL1610654 & 688597 & 5.8066 & 6.1737 & TRN \\
\hline CHEMBL1502201 & 688597 & 5.7967 & 5.7833 & TRN \\
\hline CHEMBL1583060 & 688597 & 5.3512 & 5.5354 & TRN \\
\hline CHEMBL1505153 & 688597 & 5.8598 & 5.8515 & TRN \\
\hline CHEMBL1545153 & 688597 & 4.7814 & 4.7571 & TRN \\
\hline CHEMBL1406762 & 688597 & 5.2193 & 5.28 & TRN \\
\hline CHEMBL1480812 & 688597 & 5.6519 & 5.6229 & TRN \\
\hline CHEMBL1384186 & 688597 & 5.2425 & 5.5152 & TRN \\
\hline CHEMBL3192533 & 688597 & 5.2988 & 5.3898 & TRN \\
\hline CHEMBL1337364 & 688597 & 4.5301 & 4.6568 & TRN \\
\hline CHEMBL1553408 & 688597 & 5.2788 & 5.3713 & TRN \\
\hline
\end{tabular}




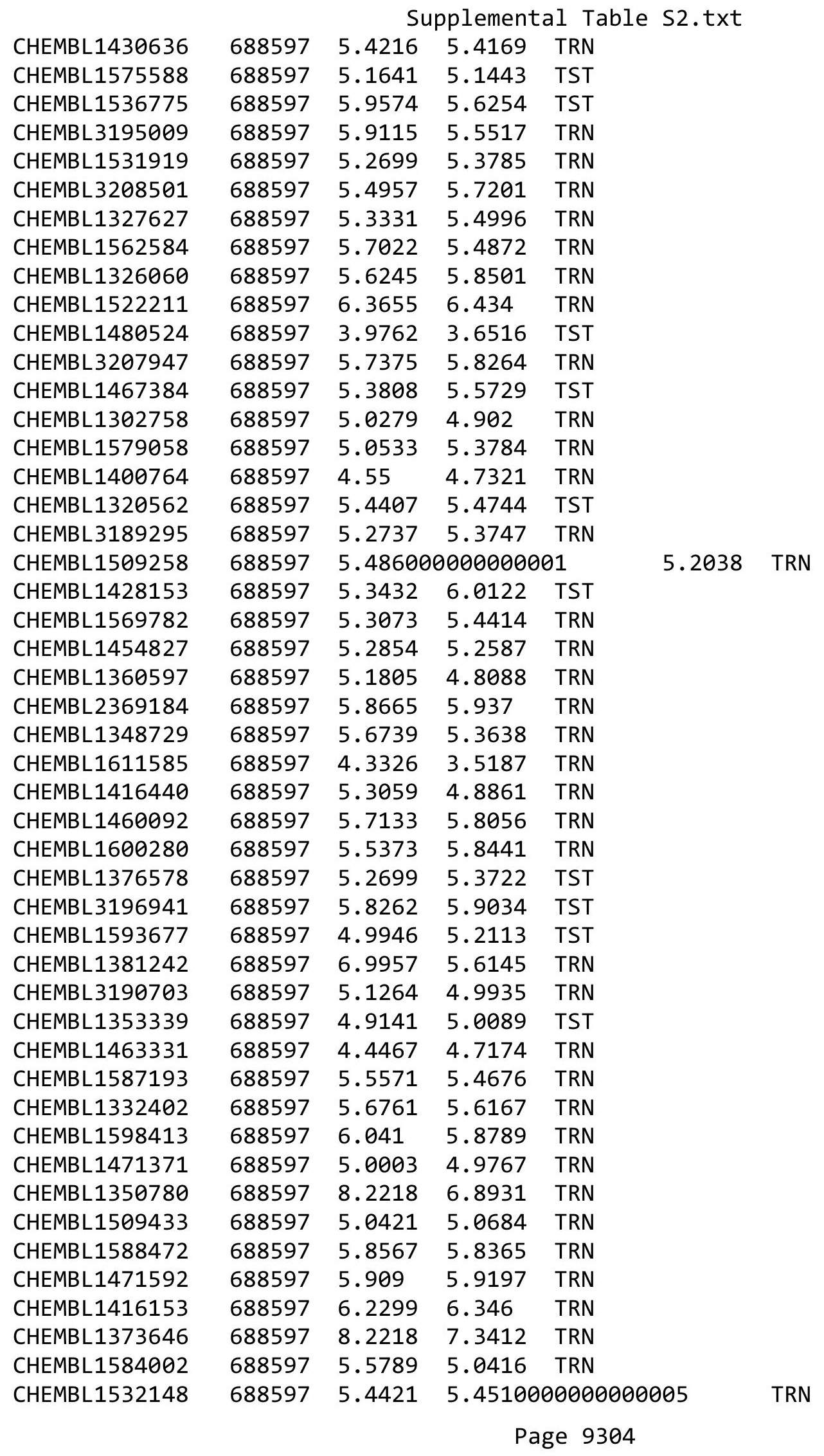




\begin{tabular}{|c|c|c|c|c|c|c|}
\hline & & \multicolumn{5}{|c|}{ Supplemental Table s2.txt } \\
\hline CHEMBL1328229 & 688597 & 5.2842 & 5.1515 & TRN & & \\
\hline CHEMBL3192727 & 688597 & 5.3036 & 5.61 & TRN & & \\
\hline CHEMBL3194847 & 688597 & 5.1449 & 5.1541 & TRN & & \\
\hline CHEMBL1540098 & 688597 & 5.466 & 5.3578 & TRN & & \\
\hline CHEMBL1506394 & 688597 & 4.8399 & 4.7275 & TRN & & \\
\hline CHEMBL1605739 & 688597 & 5.4322 & 4.9633 & TRN & & \\
\hline CHEMBL1525530 & 688597 & 5.6552 & 5.5362 & TRN & & \\
\hline CHEMBL1380365 & 688597 & 5.3239 & 5.1694 & TRN & & \\
\hline CHEMBL1540014 & 688597 & 4.3581 & 4.8366 & TRN & & \\
\hline CHEMBL1392501 & 688597 & 5.7071 & 6.2305 & TRN & & \\
\hline CHEMBL3197446 & 688597 & 5.2052 & 5.4434 & TRN & & \\
\hline CHEMBL169 & 688597 & 5.7471 & 6.229 & TST & & \\
\hline CHEMBL1992164 & 688597 & 5.5272 & 5.534 & TRN & & \\
\hline CHEMBL1360018 & 688597 & 5.4038 & 5.2171 & TRN & & \\
\hline CHEMBL1382035 & 688597 & 5.9069 & 5.3939 & TST & & \\
\hline CHEMBL1502412 & 688597 & 2.8239 & 3.4738 & TRN & & \\
\hline CHEMBL1571348 & 688597 & 5.1014 & 5.2506 & TRN & & \\
\hline CHEMBL1300385 & 688597 & 4.7966 & 4.9657 & TRN & & \\
\hline CHEMBL1510981 & 688597 & 5.182 & 5.2544 & TST & & \\
\hline CHEMBL1479654 & 688597 & 4.9648 & 5.1256 & TST & & \\
\hline CHEMBL1448984 & 688597 & 2.8239 & 4.7106 & TRN & & \\
\hline CHEMBL1313776 & 688597 & 5.1591 & 5.1808 & TRN & & \\
\hline CHEMBL1545839 & 688597 & 2.8239 & 3.471 & TRN & & \\
\hline CHEMBL 2007593 & 688597 & 5.1976 & 5.1265 & TRN & & \\
\hline CHEMBL1557619 & 688597 & 5.3417 & 5.5629 & TRN & & \\
\hline CHEMBL1553636 & 688597 & 4.6549 & 3.3939 & TRN & & \\
\hline CHEMBL1531512 & 688597 & 5.5163 & 5.25200 & 0000000001 & & TST \\
\hline CHEMBL1505674 & 688597 & 5.8693 & 5.5645 & TST & & \\
\hline CHEMBL1991450 & 688597 & 5.6857 & 5.3634 & TRN & & \\
\hline CHEMBL1341590 & 688597 & 5.5538 & 5.6827 & TRN & & \\
\hline CHEMBL 2373661 & 688597 & 8.2218 & 7.5902 & TST & & \\
\hline CHEMBL1570705 & 688597 & 6.767 & 6.1073 & TRN & & \\
\hline CHEMBL 2003808 & 688597 & 6.2197 & 5.95200 & 0000000001 & & TRN \\
\hline CHEMBL1511795 & 688597 & 5.3525 & 5.4717 & TRN & & \\
\hline CHEMBL1369254 & 688597 & 4.9626 & 5.0866 & TRN & & \\
\hline CHEMBL1354009 & 688597 & 4.4631 & 4.5066 & TRN & & \\
\hline CHEMBL3190546 & 688597 & 5.2378 & 5.4577 & TRN & & \\
\hline CHEMBL3209974 & 688597 & 5.7312 & 5.50700 & 0000000001 & & TRN \\
\hline CHEMBL1592582 & 688597 & 4.6031 & 3.4732 & TRN & & \\
\hline CHEMBL180905 & 688597 & 5.50200 & 00000000 & 01 & 5.1999 & TRN \\
\hline CHEMBL1560408 & 688597 & 5.1514 & 5.4841 & TRN & & \\
\hline CHEMBL1538808 & 688597 & 5.20100 & 00000000 & 005 & 5.1364 & TRN \\
\hline CHEMBL1535539 & 688597 & 5.8655 & 6.1344 & TST & & \\
\hline CHEMBL1604283 & 688597 & 8.2218 & 8.1657 & TST & & \\
\hline CHEMBL598883 & 688597 & 6.4976 & 6.6934 & TRN & & \\
\hline CHEMBL1969647 & 688597 & 5.9119 & 5.9441 & TRN & & \\
\hline CHEMBL1410436 & 688597 & 6.4012 & 5.0106 & TRN & & \\
\hline CHEMBL1518085 & 688597 & 6.0535 & 6.1184 & TRN & & \\
\hline
\end{tabular}


Supplemental Table S2.txt

\begin{tabular}{|c|c|c|c|c|c|}
\hline CHEMBL1342842 & 688597 & 5.5129 & 5.5347 & TST & \\
\hline CHEMBL1516396 & 688597 & 8.2218 & 7.3714 & TRN & \\
\hline CHEMBL1417620 & 688597 & 5.7886 & 5.6905 & TRN & \\
\hline CHEMBL1370922 & 688597 & 2.8239 & 3.0975 & TRN & \\
\hline CHEMBL3195381 & 688597 & 5.4816 & 5.1972 & TRN & \\
\hline CHEMBL1440974 & 688597 & 2.8239 & 3.4219 & TRN & \\
\hline CHEMBL1498722 & 688597 & 2.8239 & 3.1155 & TRN & \\
\hline CHEMBL1405964 & 688597 & 5.4643 & 5.4129 & TRN & \\
\hline CHEMBL1471046 & 688597 & 2.8239 & 3.2523 & TRN & \\
\hline CHEMBL1531320 & 688597 & 5.2325 & 4.9434 & TRN & \\
\hline CHEMBL1517346 & 688597 & 2.8239 & 3.60399 & 99999999996 & TST \\
\hline CHEMBL1371877 & 688597 & 5.1284 & 5.4607 & TRN & \\
\hline CHEMBL603031 & 688597 & 5.0831 & 5.1841 & TRN & \\
\hline CHEMBL3191218 & 688597 & 5.2996 & 5.6448 & TRN & \\
\hline CHEMBL1347710 & 688597 & 5.9066 & 5.6414 & TRN & \\
\hline CHEMBL1572031 & 688597 & 6.0022 & 6.1699 & TRN & \\
\hline CHEMBL1535525 & 688597 & 4.7122 & 5.0221 & TRN & \\
\hline CHEMBL1527358 & 688597 & 5.8425 & 5.8304 & TRN & \\
\hline CHEMBL1579335 & 688597 & 2.8239 & 4.8693 & TRN & \\
\hline CHEMBL1471286 & 688597 & 5.9034 & 6.2238 & TRN & \\
\hline CHEMBL1595152 & 688597 & 5.3332 & 5.4007 & TST & \\
\hline CHEMBL1374754 & 688597 & 5.5998 & 5.9165 & TRN & \\
\hline CHEMBL1540901 & 688597 & 2.8239 & 3.1145 & TRN & \\
\hline CHEMBL1536256 & 688597 & 5.7371 & 5.7375 & TRN & \\
\hline CHEMBL1965791 & 688597 & 5.4685 & 5.6206 & TRN & \\
\hline CHEMBL1583194 & 688597 & 2.8239 & 3.4295 & TRN & \\
\hline CHEMBL1441274 & 688597 & 5.4241 & 5.2933 & TRN & \\
\hline CHEMBL1487870 & 688597 & 6.7212 & 6.2666 & TRN & \\
\hline CHEMBL3197489 & 688597 & \multicolumn{2}{|c|}{5.202000000000001} & 5.1347 & TRN \\
\hline CHEMBL1299577 & 688597 & 5.5369 & 4.9038 & TRN & \\
\hline CHEMBL1597967 & 688597 & 4.9324 & 4.7528 & TRN & \\
\hline CHEMBL1558175 & 688597 & 4.7899 & 5.0185 & TRN & \\
\hline CHEMBL1550104 & 688597 & 5.8008 & 5.6932 & TRN & \\
\hline CHEMBL1335546 & 688597 & 5.3106 & 4.8092 & TST & \\
\hline CHEMBL1334272 & 688597 & 5.4245 & \multicolumn{2}{|c|}{5.2410000000000005} & TRN \\
\hline CHEMBL1322496 & 688597 & 5.4226 & 4.9139 & TRN & \\
\hline CHEMBL1971144 & 688597 & 5.8097 & 5.75899 & 99999999995 & TRN \\
\hline CHEMBL3190644 & 688597 & 5.3022 & 5.4247 & TST & \\
\hline CHEMBL1543879 & 688597 & 2.8239 & 3.1309 & TRN & \\
\hline CHEMBL1495998 & 688597 & 5.7484 & 5.6939 & TRN & \\
\hline CHEMBL1472530 & 688597 & 2.8239 & 4.5609 & TRN & \\
\hline CHEMBL3145287 & 688597 & 5.6068 & 5.6157 & TRN & \\
\hline CHEMBL3198213 & 688597 & 8.2218 & 7.6417 & TST & \\
\hline CHEMBL1605015 & 688597 & 6.317 & 6.1749 & TRN & \\
\hline CHEMBL1527478 & 688597 & 2.8239 & 4.4421 & TRN & \\
\hline CHEMBL1497196 & 688597 & 5.66 & 5.5339 & TRN & \\
\hline CHEMBL1451977 & 688597 & 8.2218 & 7.9282 & TRN & \\
\hline CHEMBL1432380 & 688597 & 2.8239 & 3.0611 & TRN & \\
\hline
\end{tabular}




\begin{tabular}{|c|c|c|c|c|c|}
\hline \\
\hline CHEMBL 2005619 & 688597 & 4.7212 & 5.0031 & TST & \\
\hline CHEMBL1320128 & 688597 & 5.3927 & 5.2897 & TRN & \\
\hline CHEMBL 3194900 & 688597 & 4.8888 & 5.3346 & TRN & \\
\hline CHEMBL1450659 & 688597 & 2.8239 & 3.4719 & TST & \\
\hline CHEMBL1599495 & 688597 & 2.8239 & 3.5017 & TRN & \\
\hline CHEMBL1542491 & 688597 & 6.2541 & 5.3003 & TST & \\
\hline CHEMBL1586817 & 688597 & \multicolumn{3}{|c|}{5.8629999999999995} & TRN \\
\hline CHEMBL1333993 & 688597 & 5.4607 & 4.875 & TRN & \\
\hline CHEMBL1370387 & 688597 & 5.0013 & \multicolumn{2}{|c|}{5.361000000000001} & TRIV \\
\hline CHEMBL1531454 & 688597 & 6.251 & 5.7284 & TRN & \\
\hline CHEMBL 3199001 & 688597 & 6.1818 & 6.1411 & TRN & \\
\hline CHEMBL1887153 & 688597 & 5.2472 & 5.7522 & TRN & \\
\hline CHEMBL605185 & 688597 & 6.1871 & 5.9023 & TRN & \\
\hline CHEMBL 1475748 & 688597 & 5.7005 & 5.9854 & TRN & \\
\hline CHEMBL1595820 & 688597 & 6.8268 & 6.6376 & TRN & \\
\hline CHEMBL1446290 & 688597 & 2.8239 & 3.2387 & TRN & \\
\hline CHEMBL1359020 & 688597 & 2.8239 & 3.6488 & TRN & \\
\hline CHEMBL1308687 & 688597 & 5.0989 & 5.1756 & TRN & \\
\hline CHEMBL1613220 & 688597 & 5.9792 & 5.8338 & TRN & \\
\hline CHEMBL1482387 & 688597 & 5.6511 & 5.6033 & TRN & \\
\hline CHEMBL1383333 & 688597 & 6.0888 & 6.3981 & TRN & \\
\hline CHEMBL 1493766 & 688597 & 5.6934 & 5.7527 & TRN & \\
\hline CHEMBL1325551 & 688597 & 2.8239 & 4.6345 & TRN & \\
\hline CHEMBL 1478680 & 688597 & 5.8159 & 5.5954 & TRN & \\
\hline CHEMBL1433263 & 688597 & 4.4449 & 5.005 & TRN & \\
\hline CHEMBL1357862 & 688597 & 4.7116 & 4.6012 & TRN & \\
\hline CHEMBL1361693 & 688597 & 5.3064 & 5.1433 & TRN & \\
\hline CHEMBL 3195273 & 688597 & 4.4335 & 4.9643 & TRN & \\
\hline CHEMBL1483261 & 688597 & 5.1521 & 5.2856 & TRN & \\
\hline CHEMBL1310221 & 688597 & 5.7496 & 5.7971 & TRN & \\
\hline CHEMBL1360492 & 688597 & 2.8239 & \multicolumn{2}{|c|}{ 3. 2569999999999997} & $n$ \\
\hline CHEMBL1506791 & 688597 & 5.6362 & 5.6562 & TRN & \\
\hline CHEMBL 225963 & 688597 & 5.3022 & 5.5546 & TRN & \\
\hline CHEMBL1550274 & 688597 & 5.4919 & 5.7618 & TRN & \\
\hline CHEMBL187460 & 688597 & 5.4031 & 5.438 & TST & \\
\hline CHEMBL1495893 & 688597 & 5.4738 & 5.5051 & TST & \\
\hline CHEMBL 1418885 & 688597 & 5.8771 & 5.8969 & TRN & \\
\hline CHEMBL1546739 & 688597 & 6.8386 & 6.6193 & TRN & \\
\hline CHEMBL1320397 & 688597 & 5.1071 & 5.3269 & TRN & \\
\hline CHEMBL1550672 & 688597 & 5.5885 & 5.4129 & TRN & \\
\hline CHEMBL1585321 & 688597 & 2.8239 & 3.2744 & TST & \\
\hline CHEMBL 1387643 & 688597 & 5.1262 & 5.1195 & TRN & \\
\hline CHEMBL1302815 & 688597 & 5.5586 & 5.8569 & TRN & \\
\hline CHEMBL1328493 & 688597 & 5.5286 & 5.6318 & TRN & \\
\hline CHEMBL1401984 & 688597 & 5.0613 & 4.8424 & TRN & \\
\hline CHEMBL1353166 & 688597 & 2.8239 & 3.1296 & TRN & \\
\hline CHEMBL 1430586 & 688597 & 5.2421 & \multicolumn{2}{|c|}{5.4639999999999995} & K \\
\hline CHEMBL1537118 & 688597 & 5.2197 & 5.1509 & TRN & \\
\hline
\end{tabular}




\begin{tabular}{|c|c|c|c|c|c|}
\hline & & \multicolumn{4}{|c|}{ Supplemental Table s2.txt } \\
\hline CHEMBL1336879 & 688597 & 5.3631 & 5.1392 & TRN & \\
\hline CHEMBL1475279 & 688597 & 4.6652 & 3.6011 & TRN & \\
\hline CHEMBL1459918 & 688597 & 5.5507 & 5.3802 & TRN & \\
\hline CHEMBL3213459 & 688597 & 5.3684 & 5.2925 & TRN & \\
\hline CHEMBL1481616 & 688597 & 6.1343 & 5.9835 & TRN & \\
\hline CHEMBL1609332 & 688597 & 5.4415 & 5.4306 & TRN & \\
\hline CHEMBL1422976 & 688597 & 5.1778 & 5.6839 & TRN & \\
\hline CHEMBL3197459 & 688597 & 6.3316 & 6.2001 & TRN & \\
\hline CHEMBL462721 & 688597 & 5.4399 & 5.3444 & TRN & \\
\hline CHEMBL1327412 & 688597 & 5.6724 & 5.4503 & TRN & \\
\hline CHEMBL1576710 & 688597 & 4.5004 & 4.5324 & TRN & \\
\hline CHEMBL1540469 & 688597 & 5.5538 & 5.1614 & TRN & \\
\hline CHEMBL1549391 & 688597 & 4.3933 & 4.8404 & TRN & \\
\hline CHEMBL1324715 & 688597 & 5.3504 & 4.9143 & TRN & \\
\hline CHEMBL1401989 & 688597 & 5.2275 & 5.711 & TRN & \\
\hline CHEMBL3193419 & 688597 & 5.8821 & 5.8848 & TRN & \\
\hline CHEMBL1382763 & 688597 & 4.6047 & 5.1805 & TRN & \\
\hline CHEMBL1387393 & 688597 & 5.6151 & 4.3192 & TRN & \\
\hline CHEMBL1500128 & 688597 & 5.9658 & 4.8805 & TRN & \\
\hline CHEMBL1596066 & 688597 & 5.7416 & 6.2097 & TRN & \\
\hline CHEMBL1301536 & 688597 & 5.8318 & 5.8356 & TRN & \\
\hline CHEMBL1525619 & 688597 & 5.7749 & 6.0005 & TRN & \\
\hline CHEMBL1472321 & 688597 & 6.1107 & 5.9892 & TRN & \\
\hline CHEMBL1499320 & 688597 & 5.937 & 6.1681 & TRN & \\
\hline CHEMBL1520217 & 688597 & 4.8036 & 4.5295 & TRN & \\
\hline CHEMBL1443198 & 688597 & 5.803 & 5.6695 & TRN & \\
\hline CHEMBL1578728 & 688597 & 5.8219 & 5.5759 & TRN & \\
\hline CHEMBL1345798 & 688597 & 5.6287 & 5.5101 & TRN & \\
\hline CHEMBL1332139 & 688597 & 6.5186 & 6.5267 & TRN & \\
\hline CHEMBL51085 & 688597 & 5.8184 & 6.0542 & TRN & \\
\hline CHEMBL1540122 & 688597 & 4.2397 & 4.95100 & 00000000005 & TRN \\
\hline CHEMBL1338958 & 688597 & 5.0151 & 4.8803 & TRN & \\
\hline CHEMBL3197439 & 688597 & 5.4584 & 4.9521 & TRN & \\
\hline CHEMBL1518285 & 688597 & 5.7373 & 5.5246 & TRN & \\
\hline CHEMBL1408752 & 688597 & 4.8923 & 5.2651 & TRN & \\
\hline CHEMBL1407786 & 688597 & 5.6887 & 5.4277 & TST & \\
\hline CHEMBL1376311 & 688597 & $5.4120 e$ & 00000000 & 5.2122 & TRN \\
\hline CHEMBL1540742 & 688597 & 5.2703 & 5.3046 & TST & \\
\hline CHEMBL223453 & 688597 & 6.2581 & 5.9649 & TRN & \\
\hline CHEMBL1479657 & 688597 & 5.6927 & 5.5874 & TRN & \\
\hline CHEMBL417727 & 688597 & 6.1226 & 6.28100 & 0000000001 & TRN \\
\hline CHEMBL3189714 & 688597 & 5.8431 & 6.3287 & TRN & \\
\hline CHEMBL1520898 & 688597 & 2.8239 & 3.3042 & TST & \\
\hline CHEMBL1353013 & 688597 & 5.0531 & 4.9664 & TRN & \\
\hline CHEMBL1302253 & 688597 & 4.4707 & 4.3032 & TRN & \\
\hline CHEMBL1414923 & 688597 & 6.7595 & 6.58700 & 0000000001 & TRN \\
\hline CHEMBL1604156 & 688597 & 6.0278 & 6.0983 & TRN & \\
\hline CHEMBL1428358 & 688597 & 4.7429 & 4.7374 & TRN & \\
\hline
\end{tabular}


Supplemental Table S2.txt

\begin{tabular}{|c|c|c|c|c|}
\hline CHEMBL1351737 & 688597 & 5.3864 & 5.6375 & TRN \\
\hline CHEMBL1557859 & 688597 & 5.4123 & 5.0784 & TRN \\
\hline CHEMBL1458833 & 688597 & 6.0768 & 6.1015 & TRN \\
\hline CHEMBL1599744 & 688597 & 5.1049 & 5.0166 & TRN \\
\hline CHEMBL1442412 & 688597 & 5.5127 & 5.5559 & TRN \\
\hline CHEMBL1494433 & 688597 & 5.4537 & 5.6972 & TRN \\
\hline CHEMBL3195171 & 688597 & 5.5029 & 5.5676 & TRN \\
\hline CHEMBL1311742 & 688597 & 5.9492 & 5.4028 & TRN \\
\hline CHEMBL 238188 & 688597 & 6.0575 & 5.9643 & TRN \\
\hline CHEMBL1506580 & 688597 & 5.2024 & 5.5907 & TRN \\
\hline CHEMBL1578607 & 688597 & 7.0132 & 6.9927 & TRN \\
\hline CHEMBL1493101 & 688597 & 4.7424 & 4.7054 & TRN \\
\hline CHEMBL1373110 & 688597 & 4.9263 & 5.2504 & TRN \\
\hline CHEMBL1340519 & 688597 & 6.4763 & 6.4441 & TRN \\
\hline CHEMBL1425743 & 688597 & 4.9555 & 4.9479 & TST \\
\hline CHEMBL482116 & 688597 & 4.8524 & 5.5312 & TRN \\
\hline CHEMBL1503381 & 688597 & 4.9046 & 5.1453 & TRN \\
\hline CHEMBL1588234 & 688597 & 5.1846 & 5.3853 & TRN \\
\hline CHEMBL1326381 & 688597 & 5.4844 & 5.2906 & TRN \\
\hline CHEMBL1359792 & 688597 & 5.1305 & 5.2613 & TRN \\
\hline CHEMBL1449811 & 688597 & 5.46899 & 99999995 & 5.3006 \\
\hline CHEMBL1426455 & 688597 & 5.7416 & 5.3905 & TRN \\
\hline CHEMBL1981541 & 688597 & 4.8707 & 5.1554 & TRN \\
\hline CHEMBL1371337 & 688597 & 5.1123 & 5.0662 & TST \\
\hline CHEMBL1552543 & 688597 & 5.8687 & 6.1435 & TRN \\
\hline CHEMBL1599173 & 688597 & 5.8668 & 5.0947 & TRN \\
\hline CHEMBL1557762 & 688597 & 6.5952 & 6.934 & TRN \\
\hline CHEMBL1471170 & 688597 & 5.7765 & 5.9991 & TRN \\
\hline CHEMBL1359609 & 688597 & 5.3568 & 5.4266 & TRN \\
\hline CHEMBL1387110 & 688597 & 5.176 & 5.4408 & TRN \\
\hline CHEMBL3213034 & 688597 & 6.4045 & 6.2119 & TRN \\
\hline CHEMBL1323631 & 688597 & 5.516 & 5.362 & TRN \\
\hline CHEMBL1407169 & 688597 & 6.9393 & 6.422006 & 0000000001 \\
\hline CHEMBL1335383 & 688597 & 5.0552 & 5.4432 & TST \\
\hline CHEMBL1478856 & 688597 & 5.5899 & 5.4044 & TRN \\
\hline CHEMBL1454278 & 688597 & 5.7891 & 5.8061 & TRN \\
\hline CHEMBL1478456 & 688597 & 5.3399 & 5.5544 & TRN \\
\hline CHEMBL1575421 & 688597 & 4.605 & 4.9292 & TRN \\
\hline CHEMBL1611483 & 688597 & 5.2652 & 5.1119 & TST \\
\hline CHEMBL1382674 & 688597 & 8.2218 & 8.5441 & TRN \\
\hline CHEMBL1482215 & 688597 & 5.4594 & 5.645 & TRN \\
\hline CHEMBL1404086 & 688597 & 5.7203 & 5.8847 & TRN \\
\hline CHEMBL1328822 & 688597 & 5.6123 & 5.5811 & TRN \\
\hline CHEMBL1495254 & 688597 & 5.7781 & 5.8409 & TRN \\
\hline CHEMBL1426978 & 688597 & 5.3035 & 5.341 & TRN \\
\hline CHEMBL406652 & 688597 & 5.0703 & 5.3432 & TST \\
\hline CHEMBL1431875 & 688597 & 8.2218 & 7.5224 & TRN \\
\hline CHEMBL1302276 & 688597 & 4.9792 & 5.2728 & TRN \\
\hline
\end{tabular}


Supplemental Table S2.txt

\begin{tabular}{|c|c|c|c|c|}
\hline CHEMBL1464202 & 688597 & 5.1407 & 4.8583 & TRN \\
\hline CHEMBL3211754 & 688597 & 5.0921 & 4.9714 & TRN \\
\hline CHEMBL1965348 & 688597 & 5.6757 & 5.3276 & TRN \\
\hline CHEMBL1573330 & 688597 & 2.8239 & 3.1413 & TRN \\
\hline CHEMBL1975801 & 688597 & 5.3014 & 5.1114 & TRN \\
\hline CHEMBL1975961 & 688597 & 5.3903 & 5.1433 & TRN \\
\hline CHEMBL1432181 & 688597 & 5.6836 & 5.9198 & TRN \\
\hline CHEMBL1610002 & 688597 & 5.2403 & 5.3249 & TST \\
\hline CHEMBL1401629 & 688597 & 5.1313 & 4.7725 & TRN \\
\hline CHEMBL1417429 & 688597 & 5.1912 & 5.1472 & TRN \\
\hline CHEMBL1469659 & 688597 & 5.2142 & 5.1887 & TRN \\
\hline CHEMBL1593888 & 688597 & 7.1308 & 5.9396 & TRN \\
\hline CHEMBL1329980 & 688597 & 5.05 & 4.8458 & TRN \\
\hline CHEMBL3197065 & 688597 & 7.0223 & 6.4857 & TRN \\
\hline CHEMBL1343618 & 688597 & 2.8239 & 4.15600 & $\partial 000000001$ \\
\hline CHEMBL1392311 & 688597 & 2.8239 & 3.39 & TRN \\
\hline CHEMBL1443632 & 688597 & 5.6021 & 5.7667 & TRN \\
\hline CHEMBL1582609 & 688597 & 5.2203 & 5.1316 & TRN \\
\hline CHEMBL3210497 & 688597 & 4.5654 & 4.7592 & TST \\
\hline CHEMBL1349984 & 688597 & 5.4413 & 5.185 & TRN \\
\hline CHEMBL1609756 & 688597 & 5.5204 & 5.6016 & TST \\
\hline CHEMBL3197605 & 688597 & 4.397 & 4.9462 & TRN \\
\hline CHEMBL1978354 & 688597 & 5.1169 & 5.1238 & TRN \\
\hline CHEMBL1994902 & 688597 & 6.2823 & 6.1997 & TRN \\
\hline CHEMBL1442742 & 688597 & 5.7972 & 5.7227 & TRN \\
\hline CHEMBL591834 & 688597 & 5.4773 & 5.5379 & TST \\
\hline CHEMBL1995152 & 688597 & 5.6861 & 5.5374 & TRN \\
\hline CHEMBL1448654 & 688597 & 5.0971 & 4.6426 & TRN \\
\hline CHEMBL1991441 & 688597 & 5.5009 & 5.602 & TST \\
\hline CHEMBL1334290 & 688597 & 2.8239 & 3.042 & TRN \\
\hline CHEMBL1426469 & 688597 & 4.9292 & 5.0143 & TRN \\
\hline CHEMBL1394121 & 688597 & 5.1963 & 5.1987 & TRN \\
\hline CHEMBL1572935 & 688597 & 4.9462 & 5.1874 & TRN \\
\hline CHEMBL1435343 & 688597 & 6.02 & 6.2142 & TRN \\
\hline CHEMBL1486418 & 688597 & 5.3869 & 5.4786 & TRN \\
\hline CHEMBL3212523 & 688597 & 2.8239 & 3.2749 & TRN \\
\hline CHEMBL1372388 & 688597 & 5.1483 & 4.8986 & TRN \\
\hline CHEMBL1992109 & 688597 & 5.9169 & 6.0603 & TRN \\
\hline CHEMBL1337353 & 688597 & 5.3294 & 5.3531 & TRN \\
\hline CHEMBL1366987 & 688597 & 5.1763 & 5.348 & TST \\
\hline CHEMBL1305704 & 688597 & 5.2698 & 4.8496 & TRN \\
\hline CHEMBL1579026 & 688597 & 5.1827 & 5.6117 & TRN \\
\hline CHEMBL607309 & 688597 & 5.6668 & 5.5544 & TST \\
\hline CHEMBL1997052 & 688597 & 5.2908 & 5.4113 & TRN \\
\hline CHEMBL1387503 & 688597 & 2.8239 & 3.2311 & TRN \\
\hline CHEMBL1593697 & 688597 & 7.0223 & 7.3257 & TST \\
\hline CHEMBL1502639 & 688597 & 4.427 & \multicolumn{2}{|c|}{5.122000000000001} \\
\hline CHEMBL1705518 & 688597 & 5.4953 & 5.4852 & TRN \\
\hline
\end{tabular}




\begin{tabular}{|c|c|c|c|c|c|c|}
\hline & & \multicolumn{5}{|c|}{ Supplemental Table S2.txt } \\
\hline CHEMBL1480252 & 688597 & 4.8834 & 4.96899 & 999999 & & TRN \\
\hline CHEMBL1538502 & 688597 & 6.0535 & 5.9013 & TRN & & \\
\hline CHEMBL1300890 & 688597 & 5.6105 & 5.5873 & TRN & & \\
\hline CHEMBL1446187 & 688597 & 5.0187 & 5.1399 & TRN & & \\
\hline CHEMBL1422078 & 688597 & 7.1612 & 7.8317 & TRN & & \\
\hline CHEMBL1584810 & 688597 & 5.2073 & 5.3298 & TRN & & \\
\hline CHEMBL1422750 & 688597 & 2.8239 & 3.4234 & TRN & & \\
\hline CHEMBL601751 & 688597 & 5.2757 & 4.3451 & TRN & & \\
\hline CHEMBL3189613 & 688597 & 5.7151 & 5.5819 & TRN & & \\
\hline CHEMBL1300169 & 688597 & 5.3664 & 5.2158 & TRN & & \\
\hline CHEMBL1613034 & 688597 & 2.8239 & 3.53 & TRN & & \\
\hline CHEMBL1305393 & 688597 & 2.8239 & 3.6244 & TRN & & \\
\hline CHEMBL221137 & 688597 & 5.777 & 5.7599 & TST & & \\
\hline CHEMBL1316798 & 688597 & 5.1729 & 5.3106 & TRN & & \\
\hline CHEMBL1418178 & 688597 & 5.3289 & 4.9109 & TST & & \\
\hline CHEMBL3194892 & 688597 & 5.3739 & 5.2492 & TRN & & \\
\hline CHEMBL1302158 & 688597 & 5.777 & 5.4917 & TRN & & \\
\hline CHEMBL1426440 & 688597 & 5.0106 & 5.365 & TST & & \\
\hline CHEMBL1364216 & 688597 & 5.1698 & 5.2111 & TRN & & \\
\hline CHEMBL1467377 & 688597 & 2.8239 & 3.5613 & TRN & & \\
\hline CHEMBL610463 & 688597 & 4.6906 & 5.0187 & TRN & & \\
\hline CHEMBL1546228 & 688597 & 5.4542 & 5.6865 & TST & & \\
\hline CHEMBL 2005895 & 688597 & 5.5591 & 5.4997 & TRN & & \\
\hline CHEMBL 1454245 & 688597 & 5.8921 & 5.3853 & TRN & & \\
\hline CHEMBL1485275 & 688597 & 8.2218 & 7.9945 & TST & & \\
\hline CHEMBL1388118 & 688597 & 4.7478 & 4.7449 & TST & & \\
\hline CHEMBL1505053 & 688597 & 5.0111 & 5.2547 & TRN & & \\
\hline CHEMBL494252 & 688597 & 5.7298 & 5.8222 & TRN & & \\
\hline CHEMBL1517104 & 688597 & 5.6207 & 5.678 & TRN & & \\
\hline CHEMBL1595700 & 688597 & 4.9941 & 5.1471 & TRN & & \\
\hline CHEMBL1383044 & 688597 & 5.2066 & 5.2077 & TRN & & \\
\hline CHEMBL1414465 & 688597 & 5.2601 & 5.0426 & TRN & & \\
\hline CHEMBL1518871 & 688597 & 5.3175 & 5.593 & TRN & & \\
\hline CHEMBL3190293 & 688597 & 5.8428 & 6.0129 & TRN & & \\
\hline CHEMBL1506301 & 688597 & 5.4807 & 5.5297 & TRN & & \\
\hline CHEMBL1327509 & 688597 & $5.2470 e$ & 00000000 & 01 & 5.0464 & TRN \\
\hline CHEMBL586937 & 688597 & 5.3255 & 5.3544 & TRN & & \\
\hline CHEMBL1488035 & 688597 & 5.8119 & 5.6496 & TST & & \\
\hline CHEMBL587849 & 688597 & 5.7445 & 5.6759 & TRN & & \\
\hline CHEMBL1600644 & 688597 & 5.7319 & 5.5681 & TRN & & \\
\hline CHEMBL1469698 & 688597 & 5.2477 & 5.845 & TRN & & \\
\hline CHEMBL591126 & 688597 & 5.9496 & 5.5818 & TRN & & \\
\hline CHEMBL1333637 & 688597 & 5.3607 & 5.0557 & TST & & \\
\hline CHEMBL1409443 & 688597 & 5.3453 & 5.5884 & TRN & & \\
\hline CHEMBL1429365 & 688597 & 5.176 & 5.3416 & TRN & & \\
\hline CHEMBL 2094567 & 688597 & 7.2007 & 6.909 & TRN & & \\
\hline CHEMBL3197314 & 688597 & 6.056 & 5.7642 & TRN & & \\
\hline CHEMBL1548142 & 688597 & 2.8239 & 3.5333 & TST & & \\
\hline
\end{tabular}




\begin{tabular}{|c|c|c|c|c|c|}
\hline & & & & & \\
\hline CHEMBL3191360 & 688597 & 4.7453 & 4.9572 & TRN & \\
\hline CHEMBL1344918 & 688597 & 5.3984 & 5.329 & TRN & \\
\hline CHEMBL1302439 & 688597 & 5.9974 & 5.699 & TRN & \\
\hline CHEMBL1375468 & 688597 & 5.7607 & 5.7381 & TRN & \\
\hline CHEMBL1465660 & 688597 & 2.8239 & 3.0731 & TRN & \\
\hline CHEMBL1453089 & 688597 & 5.5166 & 5.5108 & TRN & \\
\hline CHEMBL1340792 & 688597 & 5.2806 & 5.0413 & TST & \\
\hline CHEMBL1353643 & 688597 & 5.9062 & 5.7609 & TRN & \\
\hline CHEMBL1603615 & 688597 & 5.3204 & 5.3377 & TRN & \\
\hline CHEMBL1388947 & 688597 & 5.4527 & 5.6683 & TRN & \\
\hline CHEMBL1341913 & 688597 & 5.8523 & 4.783 & TST & \\
\hline CHEMBL1310490 & 688597 & 5.6171 & 4.9879 & TRN & \\
\hline CHEMBL1498273 & 688597 & 4.797 & 5.1794 & TRN & \\
\hline CHEMBL1470030 & 688597 & 2.8239 & 3.2576 & TRN & \\
\hline CHEMBL1988289 & 688597 & 5.9718 & 5.8809 & TRN & \\
\hline CHEMBL1390565 & 688597 & 5.7592 & 5.6501 & TRN & \\
\hline CHEMBL1447853 & 688597 & 5.3219 & 4.6834 & TST & \\
\hline CHEMBL1443591 & 688597 & 5.8094 & 5.94799 & 99999999995 & TST \\
\hline CHEMBL1440838 & 688597 & 2.8239 & 2.7422 & TRN & \\
\hline CHEMBL1455577 & 688597 & 2.8239 & 3.25600 & 00000000002 & TST \\
\hline CHEMBL1987622 & 688597 & 5.5772 & 5.8274 & TRN & \\
\hline CHEMBL1494214 & 688597 & 5.3292 & 4.9274 & TRN & \\
\hline CHEMBL1374864 & 688597 & 5.4305 & 5.1004 & TRN & \\
\hline CHEMBL3196980 & 688597 & 5.3573 & 5.4629 & TRN & \\
\hline CHEMBL1423935 & 688597 & 6.4921 & 6.0168 & TRN & \\
\hline CHEMBL1597289 & 688597 & 5.2336 & 5.3112 & TRN & \\
\hline CHEMBL1414413 & 688597 & 4.199 & $4.35800 t$ & 00000000005 & TRN \\
\hline CHEMBL1569352 & 688597 & 4.7449 & 4.735 & TRN & \\
\hline CHEMBL530682 & 688597 & 5.9408 & 5.0212 & TRN & \\
\hline CHEMBL 2094484 & 688597 & 5.4868 & 5.6473 & TRN & \\
\hline CHEMBL1349757 & 688597 & 4.8413 & 3.4891 & TRN & \\
\hline CHEMBL3192274 & 688597 & 5.5955 & 5.6479 & TRN & \\
\hline CHEMBL1606583 & 688597 & 5.2535 & 5.7151 & TRN & \\
\hline CHEMBL1344296 & 688597 & 4.1012 & 4.4914 & TRN & \\
\hline CHEMBL1365508 & 688597 & 5.7627 & 5.8645 & TRN & \\
\hline CHEMBL3194563 & 688597 & 5.0299 & 5.4006 & TRN & \\
\hline CHEMBL1445659 & 688597 & 5.4847 & 5.6375 & TRN & \\
\hline CHEMBL1333275 & 688597 & 5.23600 & 000000006 & 5.6076 & TRN \\
\hline CHEMBL1348268 & 688597 & 4.1953 & 4.0896 & TRN & \\
\hline CHEMBL1321111 & 688597 & 2.8239 & 3.1364 & TRN & \\
\hline CHEMBL1433095 & 688597 & 5.2765 & 5.2988 & TRN & \\
\hline CHEMBL1392200 & 688597 & 6.0841 & 6.0926 & TRN & \\
\hline CHEMBL1535538 & 688597 & 5.146 & 4.7979 & TRN & \\
\hline CHEMBL1582537 & 688597 & 5.3265 & 5.5628 & TRN & \\
\hline CHEMBL1527660 & 688597 & 2.8239 & 3.5805 & TRN & \\
\hline CHEMBL1419484 & 688597 & 5.9516 & 5.8167 & TRN & \\
\hline CHEMBL1489757 & 688597 & 5.5829 & 5.6959 & TRN & \\
\hline CHEMBL1327034 & 688597 & 4.669 & 4.9887 & TRN & \\
\hline
\end{tabular}




\begin{tabular}{|c|c|c|c|c|c|}
\hline & & & & & \\
\hline CHEMBL1440325 & 688597 & 5.7452 & 5.6003 & TRN & \\
\hline CHEMBL1542263 & 688597 & 7.1079 & 7.2351 & TRN & \\
\hline CHEMBL2369316 & 688597 & 4.5785 & 4.7131 & TRN & \\
\hline CHEMBL1303794 & 688597 & 5.2418 & 5.2835 & TST & \\
\hline CHEMBL1483809 & 688597 & 5.6649 & 5.2964 & TST & \\
\hline CHEMBL1311879 & 688597 & 5.5889 & 5.9171 & TRN & \\
\hline CHEMBL1374801 & 688597 & 2.8239 & 3.3034 & TRN & \\
\hline CHEMBL1713905 & 688597 & 5.0528 & 5.0812 & TST & \\
\hline CHEMBL1549202 & 688597 & 4.9321 & 5.2272 & TRN & \\
\hline CHEMBL3195036 & 688597 & 5.5728 & 4.6943 & TRN & \\
\hline CHEMBL1385676 & 688597 & 5.2207 & 5.7561 & TRN & \\
\hline CHEMBL1463750 & 688597 & 8.2218 & 7.3337 & TRN & \\
\hline CHEMBL1453758 & 688597 & 5.2289 & 5.15799 & 99999999995 & TRN \\
\hline CHEMBL1405220 & 688597 & 5.454 & 5.5042 & TRN & \\
\hline CHEMBL3208362 & 688597 & 5.4194 & 5.4789 & TRN & \\
\hline CHEMBL1988829 & 688597 & 6.767 & 5.7766 & TRN & \\
\hline CHEMBL1508055 & 688597 & 5.4688 & 5.2742 & TRN & \\
\hline CHEMBL1450825 & 688597 & 5.5456 & 5.3851 & TRN & \\
\hline CHEMBL1302620 & 688597 & 2.8239 & 3.3946 & TST & \\
\hline CHEMBL1505044 & 688597 & 4.957 & 5.2913 & TRN & \\
\hline CHEMBL1350749 & 688597 & 5.3647 & 5.3913 & TRN & \\
\hline CHEMBL1433385 & 688597 & 5.2072 & 5.2486 & TRN & \\
\hline CHEMBL3189289 & 688597 & 5.7286 & 5.692 & TRN & \\
\hline CHEMBL1602964 & 688597 & 5.0554 & 5.282 & TRN & \\
\hline CHEMBL1331573 & 688597 & 5.4316 & 5.6565 & TRN & \\
\hline CHEMBL 3193491 & 688597 & 2.8239 & 3.5269 & TST & \\
\hline CHEMBL1395871 & 688597 & 5.319 & 5.0689 & TRN & \\
\hline CHEMBL1599033 & 688597 & 8.2218 & 7.7766 & TST & \\
\hline CHEMBL1303651 & 688597 & 5.8948 & 5.7976 & TRN & \\
\hline CHEMBL1405262 & 688597 & 6.8477 & 5.4713 & TRN & \\
\hline CHEMBL1428886 & 688597 & 4.9323 & 4.8696 & TRN & \\
\hline CHEMBL1426565 & 688597 & 5.3843 & 4.9641 & TRN & \\
\hline CHEMBL1303303 & 688597 & 4.613 & 4.7997 & TRN & \\
\hline CHEMBL1546381 & 688597 & 5.1786 & 5.0623 & TST & \\
\hline CHEMBL1446971 & 688597 & 5.0248 & 5.2711 & TRN & \\
\hline CHEMBL1500199 & 688597 & 5.66799 & 99999999 & 5.4876 & TRN \\
\hline CHEMBL1408463 & 688597 & 5.7249 & 5.6961 & TRN & \\
\hline CHEMBL1429718 & 688597 & 5.0605 & 5.1977 & TST & \\
\hline CHEMBL3191394 & 688597 & 5.3726 & 5.535 & TRN & \\
\hline CHEMBL1428258 & 688597 & 5.4331 & $5.50200 t$ & 0000000001 & TRN \\
\hline CHEMBL1558160 & 688597 & 5.7129 & 5.5878 & TRN & \\
\hline CHEMBL504977 & 688597 & 5.6718 & 6.0576 & TRN & \\
\hline CHEMBL1402670 & 688597 & 5.6421 & 5.4857 & TRN & \\
\hline CHEMBL1403172 & 688597 & 5.1244 & 5.462006 & $\partial 000000001$ & TRN \\
\hline CHEMBL1547867 & 688597 & 5.6712 & 5.5125 & TRN & \\
\hline CHEMBL1477597 & 688597 & 4.7658 & 5.0354 & TRN & \\
\hline CHEMBL1569929 & 688597 & 5.3936 & 5.2616 & TRN & \\
\hline CHEMBL1532819 & 688597 & 5.1554 & 5.3153 & TRN & \\
\hline
\end{tabular}




\begin{tabular}{|c|c|c|c|c|c|c|c|}
\hline \multicolumn{8}{|c|}{ Supplemental Table S2.txt } \\
\hline CHEMBL1492305 & 688597 & 5.3105 & 5.5285 & TRN & & & \\
\hline CHEMBL1471788 & 688597 & 5.7838 & 5.5198 & TRN & & & \\
\hline CHEMBL1418389 & 688597 & 6.82100 & $\partial 0000000$ & & 6.6841 & TRN & \\
\hline CHEMBL1304970 & 688597 & 5.4003 & 5.4106 & TRN & & & \\
\hline CHEMBL1553151 & 688597 & 4.3518 & 4.7936 & TRN & & & \\
\hline CHEMBL1343528 & 688597 & 4.8168 & 4.3304 & TRN & & & \\
\hline CHEMBL1444820 & 688597 & 8.2218 & 8.3143 & TRN & & & \\
\hline CHEMBL1442280 & 688597 & 6.556 & 6.2319 & TRN & & & \\
\hline CHEMBL1566254 & 688597 & 5.04899 & 99999999 & 995 & 5.1827 & TRN & \\
\hline CHEMBL1412704 & 688597 & 5.399 & 5.2921 & TRN & & & \\
\hline CHEMBL1407438 & 688597 & 5.5207 & 4.8742 & TRN & & & \\
\hline CHEMBL1584779 & 688597 & 4.4024 & 4.9687 & TRN & & & \\
\hline CHEMBL1308141 & 688597 & 6.2197 & 6.1636 & TRN & & & \\
\hline CHEMBL1532436 & 688597 & 5.0599 & 5.1366 & TRN & & & \\
\hline CHEMBL1363199 & 688597 & 2.8239 & 3.4085 & TRN & & & \\
\hline CHEMBL1309573 & 688597 & 6.1586 & 5.74100 & 000000000 & 205 & TRN & \\
\hline CHEMBL1384068 & 688597 & 5.4264 & 5.1112 & TRN & & & \\
\hline CHEMBL1427079 & 688597 & 5.1492 & 5.1267 & TST & & & \\
\hline CHEMBL1386957 & 688597 & 5.5327 & 4.9571 & TRN & & & \\
\hline CHEMBL1542640 & 688597 & 2.8239 & 3.5999 & TRN & & & \\
\hline CHEMBL1452379 & 688597 & 5.2466 & 5.4015 & TRN & & & \\
\hline CHEMBL1370838 & 688597 & 4.6465 & 5.2749 & TST & & & \\
\hline CHEMBL1566725 & 688597 & 5.0103 & 5.2894 & TRN & & & \\
\hline CHEMBL1509065 & 688597 & 4.9075 & 5.0402 & TRN & & & \\
\hline CHEMBL1405668 & 688597 & 5.3634 & 5.4512 & TST & & & \\
\hline CHEMBL1533710 & 688597 & 5.6148 & 5.5356 & TRN & & & \\
\hline CHEMBL1378513 & 688597 & 4.8714 & 4.9109 & TRN & & & \\
\hline CHEMBL1445324 & 688597 & 5.9292 & 6.1311 & TRN & & & \\
\hline CHEMBL1377903 & 688597 & 5.1795 & 5.4458 & TST & & & \\
\hline CHEMBL1446293 & 688597 & 5.9215 & 5.6211 & TRN & & & \\
\hline CHEMBL3189984 & 688597 & 6.1308 & 6.0255 & TRN & & & \\
\hline CHEMBL1197556 & 688597 & 5.2157 & 5.1957 & TST & & & \\
\hline CHEMBL1496642 & 688597 & 5.8225 & 5.2652 & TST & & & \\
\hline CHEMBL1420365 & 688597 & 5.5394 & 5.5866 & TRN & & & \\
\hline CHEMBL1451132 & 688597 & 4.5494 & 4.6297 & TRN & & & \\
\hline CHEMBL1541862 & 688597 & 5.0918 & 5.2787 & TRN & & & \\
\hline CHEMBL1459313 & 688597 & 5.739 & 4.8848 & TRN & & & \\
\hline CHEMBL1300408 & 688597 & 5.36600 & $\partial 0000000$ & 005 & 5.28100 & 0000000001 & TRN \\
\hline CHEMBL1586207 & 688597 & 5.2288 & 5.2189 & TST & & & \\
\hline CHEMBL1481849 & 688597 & 5.2675 & 5.5808 & TST & & & \\
\hline CHEMBL1367877 & 688597 & 5.5163 & 5.4274 & TRN & & & \\
\hline CHEMBL1458785 & 688597 & 4.48300 & $\partial 0000000$ & 005 & 4.7033 & TRN & \\
\hline CHEMBL1990786 & 688597 & 5.8931 & 5.9721 & TRN & & & \\
\hline CHEMBL1477713 & 688597 & 5.6291 & 5.1709 & TST & & & \\
\hline CHEMBL1548409 & 688597 & 6.0039 & 5.6484 & TST & & & \\
\hline CHEMBL1352903 & 688597 & 5.0512 & 4.9403 & TRN & & & \\
\hline CHEMBL3197936 & 688597 & 5.6108 & 5.4615 & TRN & & & \\
\hline CHEMBL1510316 & 688597 & 4.7327 & 3.5234 & TST & & & \\
\hline
\end{tabular}


Supplemental Table S2.txt

\begin{tabular}{|c|c|c|c|c|}
\hline CHEMBL568092 & 688597 & 5.3876 & 5.6038 & TST \\
\hline CHEMBL3194477 & 688597 & 5.9329 & 5.7096 & TRN \\
\hline CHEMBL1400237 & 688597 & 5.2354 & 5.4961 & TRN \\
\hline CHEMBL1390021 & 688597 & 5.4377 & 5.1414 & TRN \\
\hline CHEMBL1381704 & 688597 & 2.8239 & 4.6173 & TRN \\
\hline CHEMBL3190753 & 688597 & 5.1833 & 5.21 & TRN \\
\hline CHEMBL1478211 & 688597 & 5.3656 & 5.4813 & TRN \\
\hline CHEMBL1173823 & 688597 & 5.0498 & 4.8763 & TRN \\
\hline CHEMBL3191568 & 688597 & 5.7138 & 5.7201 & TRN \\
\hline CHEMBL1601820 & 688597 & 5.9646 & 5.9495 & TRN \\
\hline CHEMBL1502251 & 688597 & 5.4158 & 5.4147 & TRN \\
\hline CHEMBL1346995 & 688597 & 5.6631 & 6.0464 & TRN \\
\hline CHEMBL1593484 & 688597 & 5.0753 & 5.2099 & TRN \\
\hline CHEMBL1410901 & 688597 & 4.7264 & 4.6579 & TRN \\
\hline CHEMBL 3209772 & 688597 & 5.6623 & 5.3468 & TRN \\
\hline CHEMBL3189161 & 688597 & 5.7804 & 5.6532 & TRN \\
\hline CHEMBL1347479 & 688597 & 5.7918 & 4.9225 & TST \\
\hline CHEMBL1320170 & 688597 & 5.0885 & 5.3137 & TST \\
\hline CHEMBL1509369 & 688597 & 6.8861 & 6.9174 & TRN \\
\hline CHEMBL1547685 & 688597 & 4.9955 & 4.9739 & TRN \\
\hline CHEMBL1575038 & 688597 & 5.9485 & 5.9636 & TRN \\
\hline CHEMBL1468737 & 688597 & 5.7757 & 5.6259 & TRN \\
\hline CHEMBL1301353 & 688597 & 5.4281 & 5.5973 & TRN \\
\hline CHEMBL461820 & 688597 & 5.7251 & 5.8226 & TRN \\
\hline CHEMBL1485168 & 688597 & 5.5427 & 5.9255 & TRN \\
\hline CHEMBL1583236 & 688597 & 6.0106 & 5.5677 & TRN \\
\hline CHEMBL1972864 & 688597 & 5.5342 & 5.61799 & э999999999 \\
\hline CHEMBL1568018 & 688597 & 5.1328 & 5.0181 & TRN \\
\hline CHEMBL1311826 & 688597 & 6.7747 & 6.6741 & TRN \\
\hline CHEMBL1366577 & 688597 & 6.2111 & 6.5584 & TRN \\
\hline CHEMBL1598101 & 688597 & 5.3978 & 5.5387 & TRN \\
\hline CHEMBL1585840 & 688597 & 5.9658 & 5.4139 & TRN \\
\hline CHEMBL1366168 & 688597 & 5.5572 & 5.7001 & TRN \\
\hline CHEMBL3194528 & 688597 & 5.7428 & 6.1348 & TRN \\
\hline CHEMBL1331692 & 688597 & 4.2633 & 4.4441 & TRN \\
\hline CHEMBL3192616 & 688597 & 6.0615 & 6.0137 & TRN \\
\hline CHEMBL1546382 & 688597 & 5.3723 & 5.4639 & TRN \\
\hline CHEMBL539027 & 688597 & 5.2433 & 5.1396 & TST \\
\hline CHEMBL1171857 & 688597 & 4.743 & 3.3957 & TRN \\
\hline CHEMBL1549651 & 688597 & 6.4237 & 6.4109 & TRN \\
\hline CHEMBL1539595 & 688597 & 6.9914 & 6.8316 & TRN \\
\hline CHEMBL1576581 & 688597 & 6.7959 & 6.5594 & TRN \\
\hline CHEMBL1568695 & 688597 & 5.3566 & 5.1943 & TRN \\
\hline CHEMBL1989897 & 688597 & 5.9555 & 5.3504 & TRN \\
\hline CHEMBL1415425 & 688597 & 5.4201 & 5.7048 & TRN \\
\hline CHEMBL1380762 & 688597 & 5.52 & 5.5719 & TRN \\
\hline CHEMBL1988686 & 688597 & 5.1513 & 4.7953 & TST \\
\hline CHEMBL1607698 & 688597 & 5.2561 & 5.1738 & TRN \\
\hline
\end{tabular}


Supplemental Table S2.txt

\begin{tabular}{|c|c|c|c|c|}
\hline CHEMBL1610800 & 688597 & 5.1752 & 4.9372 & TRN \\
\hline CHEMBL1497685 & 688597 & 5.4278 & 4.6535 & TRN \\
\hline CHEMBL1500256 & 688597 & 5.9788 & 6.2164 & TRN \\
\hline CHEMBL 3197243 & 688597 & 5.6444 & 5.6155 & TRN \\
\hline CHEMBL 1487834 & 688597 & 5.0711 & 5.2881 & TRN \\
\hline CHEMBL1483746 & 688597 & 4.9065 & 4.9798 & TRN \\
\hline CHEMBL1518955 & 688597 & 5.2143 & 4.8295 & TRN \\
\hline CHEMBL1564523 & 688597 & 5.2622 & 5.0895 & TRN \\
\hline CHEMBL 3211808 & 688597 & 4.9931 & 4.9783 & TRN \\
\hline CHEMBL1493705 & 688597 & 5.3761 & 5.6626 & TRN \\
\hline CHEMBL1585681 & 688597 & 6.1427 & 5.3645 & TRN \\
\hline CHEMBL1396209 & 688597 & 5.3917 & 5.5191 & TRN \\
\hline CHEMBL1392551 & 688597 & 6.3665 & 6.1257 & TST \\
\hline CHEMBL1600587 & 688597 & 5.5746 & 5.5549 & TRN \\
\hline CHEMBL1515251 & 688597 & 5.4607 & 5.2378 & TRN \\
\hline CHEMBL1450105 & 688597 & 5.7328 & 5.5369 & TRN \\
\hline CHEMBL1384179 & 688597 & 5.5025 & 5.8306 & TRN \\
\hline CHEMBL1972143 & 688597 & 5.2447 & 5.5005 & TRN \\
\hline CHEMBL1314859 & 688597 & 2.8239 & 3.3297 & TRN \\
\hline CHEMBL 3195074 & 688597 & 6.209 & 6.0042 & TRN \\
\hline CHEMBL1388295 & 688597 & 5.6921 & 3.1779 & TRN \\
\hline CHEMBL1582424 & 688597 & 2.8239 & 3.3823 & TRN \\
\hline CHEMBL1365978 & 688597 & 8.2218 & 7.9028 & TRN \\
\hline CHEMBL1992276 & 688597 & 4.9601 & 4.8507 & TRN \\
\hline CHEMBL1971033 & 688597 & 5.4954 & 5.6271 & TRN \\
\hline CHEMBL1422253 & 688597 & 8.2218 & 8.1813 & TRN \\
\hline CHEMBL1387953 & 688597 & 4.7376 & 4.8851 & TRN \\
\hline CHEMBL1428875 & 688597 & 5.1314 & 5.2902 & TST \\
\hline CHEMBL1483252 & 688597 & 5.734 & 5.9003 & TRN \\
\hline CHEMBL 1511042 & 688597 & 5.2884 & 5.4645 & TST \\
\hline CHEMBL459022 & 688597 & 5.2301 & 5.5185 & TST \\
\hline CHEMBL 3194327 & 688597 & 5.5777 & 5.8727 & TRN \\
\hline CHEMBL1603454 & 688597 & 4.5312 & 4.8524 & TRN \\
\hline CHEMBL 3194940 & 688597 & 5.1009 & 4.9547 & TST \\
\hline CHEMBL1461204 & 688597 & 5.6895 & 5.9301 & TRN \\
\hline CHEMBL1604401 & 688597 & 4.8165 & 4.9272 & TRN \\
\hline CHEMBL1369339 & 688597 & 5.4115 & 5.4442 & TRN \\
\hline CHEMBL1463734 & 688597 & 2.8239 & 3.0096 & TRN \\
\hline CHEMBL1482990 & 688597 & 5.4185 & 5.2461 & TRN \\
\hline CHEMBL 1491847 & 688597 & 5.5312 & 5.3856 & TST \\
\hline CHEMBL93109 & 688597 & 2.8239 & 3.6949 & TRN \\
\hline CHEMBL1563623 & 688597 & 5.7445 & 5.6345 & TRN \\
\hline CHEMBL1343674 & 688597 & 5.0798 & 5.2741 & TRN \\
\hline CHEMBL 2000517 & 688597 & 5.7058 & 5.8917 & TRN \\
\hline CHEMBL1466362 & 688597 & 5.4302 & 5.2082 & TRN \\
\hline CHEMBL1489358 & 688597 & 5.4051 & 5.5618 & TST \\
\hline CHEMBL1347270 & 688597 & 5.524 & \multicolumn{2}{|c|}{5.3260000000000005} \\
\hline CHEMBL1384094 & 688597 & 5.0403 & 5.0227 & TST \\
\hline
\end{tabular}


Supplemental Table S2.txt

\begin{tabular}{|c|c|c|c|c|}
\hline CHEMBL1359912 & 688597 & 2.8239 & 3.3951 & TST \\
\hline CHEMBL1401891 & 688597 & 4.4469 & 3.6564 & TST \\
\hline CHEMBL1364011 & 688597 & 8.2218 & 8.6594 & TRN \\
\hline CHEMBL1470321 & 688597 & 5.4114 & 5.1488 & TRN \\
\hline CHEMBL1603581 & 688597 & 5.2958 & 5.4081 & TST \\
\hline CHEMBL1346853 & 688597 & 5.1045 & 5.2977 & TST \\
\hline CHEMBL1425314 & 688597 & 5.1987 & 5.0811 & TRN \\
\hline CHEMBL 240546 & 688597 & 5.5849 & 5.3829 & TRN \\
\hline CHEMBL1572283 & 688597 & 5.7815 & 5.7274 & TRN \\
\hline CHEMBL1402747 & 688597 & 6.0255 & 5.9817 & TRN \\
\hline CHEMBL1495714 & 688597 & 5.8564 & \multicolumn{2}{|c|}{5.872999999999999} \\
\hline CHEMBL1576333 & 688597 & 5.3893 & 5.4573 & TRN \\
\hline CHEMBL1375825 & 688597 & 5.5203 & 5.0442 & TRN \\
\hline CHEMBL1977596 & 688597 & 5.2827 & 5.0309 & TRN \\
\hline CHEMBL1448743 & 688597 & 6.0804 & 5.5971 & TRN \\
\hline CHEMBL 3189460 & 688597 & 5.6211 & 5.7096 & TRN \\
\hline CHEMBL1490222 & 688597 & 5.8486 & 5.9064 & TRN \\
\hline CHEMBL1598311 & 688597 & 5.3946 & 5.312 & TRN \\
\hline CHEMBL1562963 & 688597 & 2.8239 & 5.1853 & TRN \\
\hline CHEMBL1984120 & 688597 & 5.2375 & 5.3398 & TRN \\
\hline CHEMBL1604261 & 688597 & 5.4461 & 5.0631 & TST \\
\hline CHEMBL1503572 & 688597 & 4.2223 & 3.7446 & TRN \\
\hline CHEMBL 2000750 & 688597 & 5.5979 & 5.6758 & TRN \\
\hline CHEMBL1424836 & 688597 & 2.8239 & 3.5914 & TST \\
\hline CHEMBL188423 & 688597 & 5.6985 & 5.7861 & TRN \\
\hline CHEMBL1326349 & 688597 & 5.8225 & 5.6417 & TRN \\
\hline CHEMBL1357870 & 688597 & 4.154 & 3.5496 & TRN \\
\hline CHEMBL1989179 & 688597 & 4.9471 & 4.4418 & TRN \\
\hline CHEMBL1517264 & 688597 & 5.0616 & 4.918 & TRN \\
\hline CHEMBL1506765 & 688597 & 5.1065 & 4.9164 & TRN \\
\hline CHEMBL1977301 & 688597 & 5.7846 & 5.8218 & TRN \\
\hline CHEMBL 3194562 & 688597 & 5.6994 & 5.7453 & TRN \\
\hline CHEMBL1503123 & 688597 & 4.573 & 4.7934 & TRN \\
\hline CHEMBL3199832 & 688597 & 5.2578 & 5.3086 & TRN \\
\hline CHEMBL1256686 & 688597 & 8.2218 & 7.5389 & TST \\
\hline CHEMBL1506230 & 688597 & 5.5349 & 5.3896 & TRN \\
\hline CHEMBL 3191087 & 688597 & 5.9512 & 6.0932 & TRN \\
\hline CHEMBL1320543 & 688597 & 2.8239 & 2.87 & TRN \\
\hline CHEMBL1505552 & 688597 & 5.7913 & 5.8325 & TRN \\
\hline CHEMBL3198912 & 688597 & 5.1463 & 5.2312 & TRN \\
\hline CHEMBL1378290 & 688597 & 5.4551 & 5.3832 & TRN \\
\hline CHEMBL1547542 & 688597 & 2.8239 & 3.5409 & TRN \\
\hline CHEMBL1559190 & 688597 & 5.7203 & 5.1091 & TRN \\
\hline CHEMBL1426435 & 688597 & 6.6038 & 6.5858 & TRN \\
\hline CHEMBL1544901 & 688597 & 5.4293 & 5.3643 & TRN \\
\hline CHEMBL1534781 & 688597 & 5.1677 & 5.3418 & TRN \\
\hline CHEMBL1469460 & 688597 & 5.329 & 5.209 & TST \\
\hline CHEMBL 3191818 & 688597 & 5.7091 & 5.0760 & 00000000005 \\
\hline
\end{tabular}




\begin{tabular}{|c|c|c|c|c|c|c|}
\hline \multirow[b]{2}{*}{ CHEMBL1324944 } & & \multicolumn{5}{|c|}{ Supplemental Table S2.txt } \\
\hline & 688597 & 6.5086 & 6.4159 & TRN & & \\
\hline CHEMBL1328707 & 688597 & 5.16299 & 99999999 & 99 & 5.5696 & TRN \\
\hline CHEMBL1581789 & 688597 & 6.0985 & 6.1696 & TRN & & \\
\hline CHEMBL1422340 & 688597 & 5.5553 & 5.7464 & TST & & \\
\hline CHEMBL1573962 & 688597 & 5.6289 & 5.1751 & TRN & & \\
\hline CHEMBL1344667 & 688597 & 5.2096 & 5.3245 & TRN & & \\
\hline CHEMBL1556925 & 688597 & 5.1459 & 5.1343 & TRN & & \\
\hline CHEMBL1468541 & 688597 & 2.8239 & 2.7871 & TRN & & \\
\hline CHEMBL1470475 & 688597 & 2.8239 & 3.5022 & TST & & \\
\hline CHEMBL3195975 & 688597 & 5.27 & 4.9246 & TRN & & \\
\hline CHEMBL1430104 & 688597 & 5.2929 & 5.4846 & TRN & & \\
\hline CHEMBL1467919 & 688597 & 6.091 & 5.5207 & TRN & & \\
\hline CHEMBL1411744 & 688597 & 2.8239 & 3.3257 & TRN & & \\
\hline CHEMBL1596353 & 688597 & 6.0434 & 6.0147 & TRN & & \\
\hline CHEMBL1300446 & 688597 & 6.1079 & 5.9905 & TRN & & \\
\hline CHEMBL 3196810 & 688597 & 5.3087 & 5.6823 & TRN & & \\
\hline CHEMBL1321754 & 688597 & 4.592 & 5.4563 & TRN & & \\
\hline CHEMBL1587655 & 688597 & 5.3362 & 5.4553 & TRN & & \\
\hline CHEMBL1557782 & 688597 & 5.1334 & 4.6745 & TRN & & \\
\hline CHEMBL1379128 & 688597 & 2.8239 & 3.6093 & TST & & \\
\hline CHEMBL381033 & 688597 & 5.2689 & 5.7551 & TRN & & \\
\hline CHEMBL 3193184 & 688597 & 5.1614 & 5.2068 & TRN & & \\
\hline CHEMBL 3193204 & 688597 & 5.1031 & 5.101 & TRN & & \\
\hline CHEMBL1386564 & 688597 & 5.5864 & 4.8762 & TST & & \\
\hline CHEMBL 3193441 & 688597 & 5.3056 & 5.5137 & TRN & & \\
\hline CHEMBL1470925 & 688597 & 5.3607 & 5.7608 & TRN & & \\
\hline CHEMBL1967185 & 688597 & 5.3929 & 5.5829 & TRN & & \\
\hline CHEMBL 3190608 & 688597 & 5.9355 & 6.0567 & TRN & & \\
\hline CHEMBL581257 & 688597 & 8.2218 & 7.7263 & TRN & & \\
\hline CHEMBL254576 & 688597 & 5.7533 & 5.7707 & TRN & & \\
\hline CHEMBL1449558 & 688597 & 5.6379 & 5.2416 & TRN & & \\
\hline CHEMBL 3192299 & 688597 & 6.015 & 6.0048 & TRN & & \\
\hline CHEMBL1541410 & 688597 & 5.6474 & 5.8906 & TST & & \\
\hline CHEMBL1358081 & 688597 & 2.8239 & 3.1592 & TRN & & \\
\hline CHEMBL1583801 & 688597 & 5.6203 & 5.1896 & TRN & & \\
\hline CHEMBL1402220 & 688597 & 2.8239 & 3.4855 & TRN & & \\
\hline CHEMBL1478231 & 688597 & 5.2195 & 5.4534 & TST & & \\
\hline CHEMBL1591445 & 688597 & 5.3922 & 5.3028 & TRN & & \\
\hline CHEMBL1515506 & 688597 & 5.336 & 5.6442 & TRN & & \\
\hline CHEMBL1335724 & 688597 & 5.4388 & 5.4699 & TRN & & \\
\hline CHEMBL1381257 & 688597 & 5.0336 & 4.6965 & TRN & & \\
\hline CHEMBL1481281 & 688597 & 6.4168 & 5.9035 & TRN & & \\
\hline CHEMBL1306359 & 688597 & 5.9594 & 6.1017 & TRN & & \\
\hline CHEMBL1598569 & 688597 & 6.6055 & 6.53 & TRN & & \\
\hline CHEMBL1428000 & 688597 & 4.0652 & 4.3473 & TST & & \\
\hline CHEMBL 3198791 & 688597 & 5.9559 & 5.8616 & TST & & \\
\hline CHEMBL1376130 & 688597 & 5.1573 & 4.872 & TRN & & \\
\hline CHEMBL1337193 & 688597 & 5.7809 & 5.8254 & TRN & & \\
\hline
\end{tabular}




\begin{tabular}{|c|c|c|c|c|c|c|}
\hline & & \multicolumn{5}{|c|}{ Supplemental Table s2.txt } \\
\hline CHEMBL1522803 & 688597 & 5.0651 & 4.8902 & TST & & \\
\hline CHEMBL454580 & 688597 & 6.08200 & 00000000 & & 6.0456 & TRN \\
\hline CHEMBL1511321 & 688597 & 4.5861 & 4.9012 & TRN & & \\
\hline CHEMBL 1486883 & 688597 & 5.0731 & 5.181 & TRN & & \\
\hline CHEMBL1516527 & 688597 & 5.4671 & 5.2561 & TST & & \\
\hline CHEMBL1421625 & 688597 & 5.7719 & 6.0535 & TRN & & \\
\hline CHEMBL1361740 & 688597 & 5.1862 & 5.3713 & TST & & \\
\hline CHEMBL1307515 & 688597 & 5.5759 & 5.7998 & TST & & \\
\hline CHEMBL498436 & 688597 & 5.5178 & 5.6459 & TST & & \\
\hline CHEMBL1361520 & 688597 & 2.8239 & 3.6638 & TST & & \\
\hline CHEMBL3196139 & 688597 & 5.0526 & 5.2245 & TRN & & \\
\hline CHEMBL1445603 & 688597 & 6.2062 & 6.2888 & TRN & & \\
\hline CHEMBL1537008 & 688597 & 4.6823 & 4.5855 & TRN & & \\
\hline CHEMBL1486536 & 688597 & 5.4911 & 5.5879 & TRN & & \\
\hline CHEMBL1450241 & 688597 & 5.5998 & 5.6428 & TRN & & \\
\hline CHEMBL1577440 & 688597 & 4.9891 & 5.2028 & TRN & & \\
\hline CHEMBL1398268 & 688597 & 4.8964 & 3.3642 & TRN & & \\
\hline CHEMBL1518515 & 688597 & 5.5896 & 5.4848 & TST & & \\
\hline CHEMBL1416018 & 688597 & 5.6782 & 5.7186 & TRN & & \\
\hline CHEMBL1462007 & 688597 & 5.2276 & 4.7745 & TST & & \\
\hline CHEMBL1585843 & 688597 & 5.8765 & 3.4915 & TRN & & \\
\hline CHEMBL1429861 & 688597 & 8.2218 & 5.1157 & TRN & & \\
\hline CHEMBL1511114 & 688597 & 5.2752 & 4.8814 & TRN & & \\
\hline CHEMBL583584 & 688597 & 6.9626 & 7.7279 & TRN & & \\
\hline CHEMBL3192181 & 688597 & 5.4984 & 5.30399 & 9999999999 & & TRN \\
\hline CHEMBL29097 & 688597 & 6.058 & 5.8755 & TST & & \\
\hline CHEMBL1519902 & 688597 & 6.7305 & 6.8474 & TRN & & \\
\hline CHEMBL1345080 & 688597 & 5.2961 & 5.0635 & TRN & & \\
\hline CHEMBL1507262 & 688597 & 4.9349 & 5.0952 & TST & & \\
\hline CHEMBL1503359 & 688597 & 5.0359 & 5.4068 & TRN & & \\
\hline CHEMBL1355961 & 688597 & 5.189 & 5.3463 & TST & & \\
\hline CHEMBL1538099 & 688597 & 5.136 & 5.4184 & TRN & & \\
\hline CHEMBL1596319 & 688597 & 5.8911 & 5.9401 & TRN & & \\
\hline CHEMBL1430631 & 688597 & 5.4765 & 3.4835 & TRN & & \\
\hline CHEMBL1367946 & 688597 & 2.8239 & 3.5645 & TRN & & \\
\hline CHEMBL1370022 & 688597 & 5.2441 & 4.9327 & TRN & & \\
\hline CHEMBL1391069 & 688597 & 2.8239 & 3.3656 & TRN & & \\
\hline CHEMBL1599981 & 688597 & 4.9552 & 5.0346 & TRN & & \\
\hline CHEMBL1996376 & 688597 & 5.5114 & 5.574 & TRN & & \\
\hline CHEMBL3193603 & 688597 & 4.93 & 5.5017 & TRN & & \\
\hline CHEMBL1313236 & 688597 & 5.5177 & 5.3694 & TRN & & \\
\hline CHEMBL1389601 & 688597 & 5.1641 & 4.6803 & TRN & & \\
\hline CHEMBL1468699 & 688597 & 4.9876 & 5.3119 & TRN & & \\
\hline CHEMBL1978315 & 688597 & 4.7919 & 5.2967 & TRN & & \\
\hline CHEMBL31293 & 688597 & 5.9884 & 6.3976 & TRN & & \\
\hline CHEMBL1351595 & 688597 & 5.2699 & 5.2356 & TRN & & \\
\hline CHEMBL1494353 & 688597 & 5.6405 & 5.8009 & TRN & & \\
\hline CHEMBL601768 & 688597 & 5.1424 & 5.6654 & TRN & & \\
\hline
\end{tabular}




\begin{tabular}{|c|c|c|c|c|c|c|}
\hline & & \multicolumn{5}{|c|}{ Supplemental Table s2.txt } \\
\hline CHEMBL1315402 & 688597 & 2.8239 & 3.2961 & TRN & & \\
\hline CHEMBL1597435 & 688597 & 6.1403 & 6.2137 & TRN & & \\
\hline CHEMBL1358861 & 688597 & 2.8239 & 3.7338 & TRN & & \\
\hline CHEMBL1502410 & 688597 & 5.4954 & 5.5252 & TRN & & \\
\hline CHEMBL1464676 & 688597 & 5.2315 & 5.4873 & TRN & & \\
\hline CHEMBL1508616 & 688597 & 5.194 & 5.5061 & TRN & & \\
\hline CHEMBL1387605 & 688597 & 6.5834 & 6.2592 & TRN & & \\
\hline CHEMBL1477640 & 688597 & 5.553 & 5.4998 & TST & & \\
\hline CHEMBL1584796 & 688597 & 5.15 & 5.245 & TRN & & \\
\hline CHEMBL3196731 & 688597 & 4.8745 & 5.1372 & TRN & & \\
\hline CHEMBL1449111 & 688597 & 5.4514 & 5.1064 & TRN & & \\
\hline CHEMBL1999166 & 688597 & 5.5597 & 5.5868 & TST & & \\
\hline CHEMBL1441888 & 688597 & 5.0045 & 5.1252 & TRN & & \\
\hline CHEMBL1375734 & 688597 & 5.2891 & 3.5066 & TRN & & \\
\hline CHEMBL1427928 & 688597 & 6.0367 & 6.0698 & TRN & & \\
\hline CHEMBL3189163 & 688597 & 5.8182 & 5.8685 & TRN & & \\
\hline CHEMBL1434604 & 688597 & 4.8034 & 4.9024 & TST & & \\
\hline CHEMBL579318 & 688597 & 6.0545 & 5.8865 & TRN & & \\
\hline CHEMBL1479888 & 688597 & 5.4342 & 5.5519 & TRN & & \\
\hline CHEMBL 3190775 & 688597 & 5.1245 & 5.5946 & TST & & \\
\hline CHEMBL1349434 & 688597 & 5.9747 & 6.0185 & TRN & & \\
\hline CHEMBL1592387 & 688597 & 4.9274 & 4.854 & TRN & & \\
\hline CHEMBL1407907 & 688597 & 5.3297 & 5.2602 & TRN & & \\
\hline CHEMBL1602599 & 688597 & 4.9672 & 5.1093 & TRN & & \\
\hline CHEMBL1350336 & 688597 & 5.4837 & 5.5809 & TRN & & \\
\hline CHEMBL1497894 & 688597 & 5.6755 & 5.6836 & TRN & & \\
\hline CHEMBL1391179 & 688597 & 5.0641 & 5.3491 & TST & & \\
\hline CHEMBL1964891 & 688597 & 5.694 & 5.6581 & TRN & & \\
\hline CHEMBL1448529 & 688597 & 5.3125 & 5.3002 & TRN & & \\
\hline CHEMBL1350869 & 688597 & 5.78600 & 00000000 & 005 & 5.6439 & TRN \\
\hline CHEMBL1604723 & 688597 & 2.8239 & 3.3378 & TRN & & \\
\hline CHEMBL3196251 & 688597 & 4.9583 & 5.0607 & TRN & & \\
\hline CHEMBL1351081 & 688597 & 4.9387 & 4.9161 & TRN & & \\
\hline CHEMBL1534816 & 688597 & 5.4012 & 4.8238 & TRN & & \\
\hline CHEMBL3199217 & 688597 & 5.4959 & 5.4479 & TRN & & \\
\hline CHEMBL3196117 & 688597 & 5.0585 & 5.0569 & TRN & & \\
\hline CHEMBL1499682 & 688597 & 4.16100 & 00000000 & 005 & 3.5353 & TRN \\
\hline CHEMBL1377978 & 688597 & 5.4307 & 5.4439 & TST & & \\
\hline CHEMBL1595444 & 688597 & 5.8477 & 5.6047 & TST & & \\
\hline CHEMBL1401900 & 688597 & 5.694 & 5.0934 & TRN & & \\
\hline CHEMBL3195760 & 688597 & 8.2218 & 6.3982 & TRN & & \\
\hline CHEMBL1367339 & 688597 & 5.1892 & 5.1432 & TRN & & \\
\hline CHEMBL80799 & 688597 & 5.0558 & 5.0891 & TRN & & \\
\hline CHEMBL1407235 & 688597 & 3.301 & 5.1929 & TRN & & \\
\hline CHEMBL1487657 & 688597 & 5.7385 & 5.7768 & TRN & & \\
\hline CHEMBL1506966 & 688597 & 4.7857 & 5.1052 & TST & & \\
\hline CHEMBL1359321 & 688597 & 5.5618 & 5.5039 & TRN & & \\
\hline CHEMBL 3210343 & 688597 & 5.5379 & 5.4479 & TRN & & \\
\hline
\end{tabular}




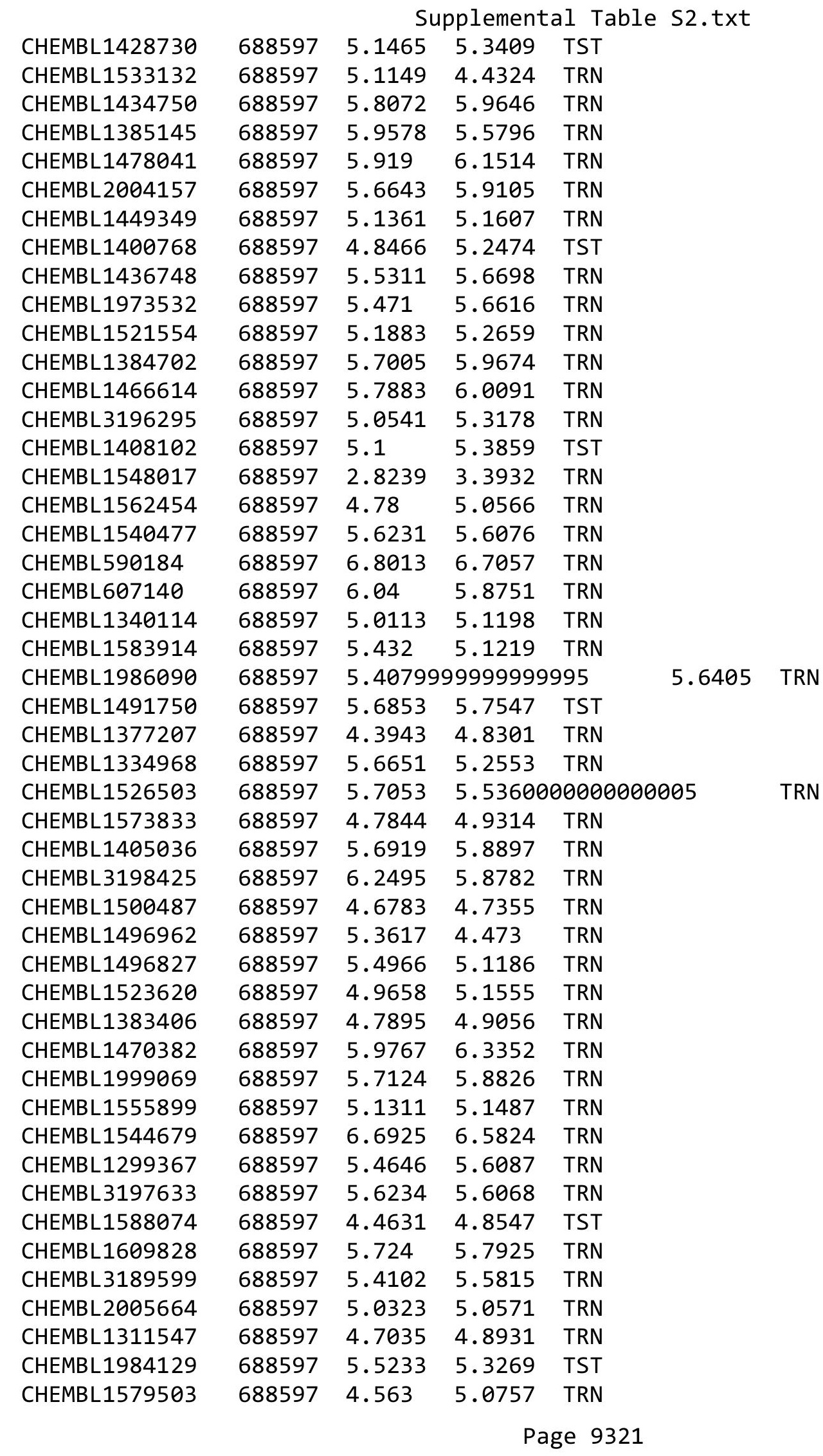


Supplemental Table S2.txt

\begin{tabular}{|c|c|c|c|c|}
\hline CHEMBL1532546 & 688597 & 6.5702 & 6.8382 & TRN \\
\hline CHEMBL1604028 & 688597 & 4.9192 & 4.6639 & TRN \\
\hline CHEMBL3197099 & 688597 & 5.8545 & 6.0515 & TRN \\
\hline CHEMBL1559100 & 688597 & 5.4116 & 5.5199 & TRN \\
\hline CHEMBL1609818 & 688597 & 5.4923 & 5.1963 & TRN \\
\hline CHEMBL197014 & 688597 & 5.0667 & 5.3064 & TRN \\
\hline CHEMBL1361680 & 688597 & 5.4421 & 5.8123 & TRN \\
\hline CHEMBL3208968 & 688597 & 6.0953 & 5.9375 & TRN \\
\hline CHEMBL1466352 & 688597 & 4.9251 & 5.1575 & TST \\
\hline CHEMBL3194214 & 688597 & 5.5119 & 5.5473 & TRN \\
\hline CHEMBL1597758 & 688597 & 5.0517 & 5.192 & TST \\
\hline CHEMBL1492642 & 688597 & 5.5411 & 5.8728 & TRN \\
\hline CHEMBL1561240 & 688597 & 5.1131 & 5.271 & TRN \\
\hline CHEMBL1479271 & 688597 & 2.8239 & 3.2657 & TRN \\
\hline CHEMBL1423338 & 688597 & 4.815 & 4.8942 & TRN \\
\hline CHEMBL1584684 & 688597 & 6.1385 & 5.7665 & TRN \\
\hline CHEMBL1391560 & 688597 & 4.2877 & 5.3562 & TRN \\
\hline CHEMBL1504806 & 688597 & 4.5862 & 4.8828 & TST \\
\hline CHEMBL1361533 & 688597 & 5.4346 & 5.3532 & TST \\
\hline CHEMBL1487309 & 688597 & 5.2216 & 5.2257 & TRN \\
\hline CHEMBL1407961 & 688597 & 5.0262 & 4.5635 & TRN \\
\hline CHEMBL1452303 & 688597 & 8.2218 & 7.6433 & TST \\
\hline CHEMBL1530048 & 688597 & 5.2286 & 5.277 & TRN \\
\hline CHEMBL1546249 & 688597 & 5.5456 & 5.0436 & TRN \\
\hline CHEMBL1310332 & 688597 & 5.019 & 4.9881 & TRN \\
\hline CHEMBL3198554 & 688597 & 5.6702 & 5.7925 & TRN \\
\hline CHEMBL1386200 & 688597 & 5.38200 & 00000000 & 5.5557 \\
\hline CHEMBL1414460 & 688597 & 5.8542 & 5.234 & TRN \\
\hline CHEMBL550826 & 688597 & 5.3311 & 5.38399 & \\
\hline CHEMBL1400889 & 688597 & 5.5148 & 5.3642 & TRN \\
\hline CHEMBL1535622 & 688597 & 5.1821 & 5.2319 & TRN \\
\hline CHEMBL1303126 & 688597 & 4.5221 & 5.1765 & TRN \\
\hline CHEMBL1318350 & 688597 & 5.631 & 5.3554 & TST \\
\hline CHEMBL1588411 & 688597 & 5.109 & 5.4245 & TRN \\
\hline CHEMBL1551880 & 688597 & 5.4038 & 5.2215 & TST \\
\hline CHEMBL1481600 & 688597 & 5.5931 & 5.5444 & TST \\
\hline CHEMBL1546374 & 688597 & 5.4435 & 5.3452 & TST \\
\hline CHEMBL1447061 & 688597 & 2.8239 & 3.1399 & TRN \\
\hline CHEMBL1586416 & 688597 & 5.6119 & 5.4328 & TST \\
\hline CHEMBL1344339 & 688597 & 6.8962 & 6.3536 & TST \\
\hline CHEMBL1346232 & 688597 & 5.1903 & 5.0095 & TRN \\
\hline CHEMBL1393914 & 688597 & 5.5261 & 5.6375 & TRN \\
\hline CHEMBL1605217 & 688597 & 5.0402 & 5.1887 & TRN \\
\hline CHEMBL3207619 & 688597 & 5.3577 & 5.8054 & TRN \\
\hline CHEMBL1484438 & 688597 & 6.9431 & 6.965 & TRN \\
\hline CHEMBL 2006840 & 688597 & 5.7069 & 5.9022 & TRN \\
\hline CHEMBL1304997 & 688597 & 5.3917 & 5.4644 & TRN \\
\hline CHEMBL461579 & 688597 & 5.443 & 5.4522 & TST \\
\hline
\end{tabular}


Supplemental Table S2.txt

\begin{tabular}{|c|c|c|c|c|c|c|}
\hline CHEMBL1588987 & 688597 & 5.5229 & 5.0252 & TRN & & \\
\hline CHEMBL1304666 & 688597 & 6.8601 & 6.5992 & TRN & & \\
\hline CHEMBL3190609 & 688597 & 5.6712 & 5.5458 & TRN & & \\
\hline CHEMBL1415635 & 688597 & 6.1451 & 6.2061 & TRN & & \\
\hline CHEMBL1329634 & 688597 & 5.0448 & 4.8221 & TRN & & \\
\hline CHEMBL1447076 & 688597 & 5.6558 & 5.652 & TRN & & \\
\hline CHEMBL1312122 & 688597 & 5.5547 & 5.6949 & TRN & & \\
\hline CHEMBL1370995 & 688597 & 4.6678 & 4.8762 & TRN & & \\
\hline CHEMBL1529093 & 688597 & 5.7215 & 5.9246 & TST & & \\
\hline CHEMBL1483333 & 688597 & 5.1422 & 5.3799 & TRN & & \\
\hline CHEMBL1594349 & 688597 & 5.2352 & 5.5114 & TRN & & \\
\hline CHEMBL1302569 & 688597 & \multicolumn{3}{|c|}{5.667000000000001} & 5.4948 & TRN \\
\hline CHEMBL1365902 & 688597 & 5.4494 & 5.3591 & TRN & & \\
\hline CHEMBL1518455 & 688597 & 5.0957 & 4.9154 & TRN & & \\
\hline CHEMBL1978479 & 688597 & 6.4473 & 5.9255 & TST & & \\
\hline CHEMBL3211464 & 688597 & 5.1231 & 5.356 & TRN & & \\
\hline CHEMBL1326101 & 688597 & 5.4083 & 5.5394 & TRN & & \\
\hline CHEMBL1499286 & 688597 & 5.6904 & 5.4737 & TRN & & \\
\hline CHEMBL1510761 & 688597 & 5.3256 & 5.5194 & TRN & & \\
\hline CHEMBL 1545384 & 688597 & 5.6668 & 5.7865 & TST & & \\
\hline CHEMBL1433219 & 688597 & 5.0143 & 4.9765 & TRN & & \\
\hline CHEMBL1718568 & 688597 & \multicolumn{3}{|c|}{6.617999999999999} & 6.24 & TRN \\
\hline CHEMBL534353 & 688597 & 5.9485 & 5.8554 & TST & & \\
\hline CHEMBL1401191 & 688597 & 2.8239 & 4.6362 & TST & & \\
\hline CHEMBL1517661 & 688597 & 4.823 & 3.278 & TRN & & \\
\hline CHEMBL1346881 & 688597 & 5.2875 & 5.1695 & TST & & \\
\hline CHEMBL1541834 & 688597 & \multicolumn{3}{|c|}{5.667000000000001} & 5.5821 & TRN \\
\hline CHEMBL1432081 & 688597 & 2.8239 & 3.2365 & TRN & & \\
\hline CHEMBL1530170 & 688597 & 5.2419 & 5.6905 & TRN & & \\
\hline CHEMBL1525775 & 688597 & 5.048 & 3.1182 & TRN & & \\
\hline CHEMBL1327389 & 688597 & 5.5933 & 5.689 & TST & & \\
\hline CHEMBL 2006503 & 688597 & 6.0419 & 6.4506 & TRN & & \\
\hline CHEMBL1994463 & 688597 & 8.2218 & 7.6127 & TRN & & \\
\hline CHEMBL1428894 & 688597 & 6.063 & 5.8432 & TRN & & \\
\hline CHEMBL1359788 & 688597 & 5.3573 & 5.5723 & TRN & & \\
\hline CHEMBL1420623 & 688597 & 5.5972 & 5.5377 & TRN & & \\
\hline CHEMBL3192479 & 688597 & 5.3227 & 5.1911 & TRN & & \\
\hline CHEMBL3191810 & 688597 & 5.3686 & 4.9062 & TRN & & \\
\hline CHEMBL1533459 & 688597 & 6.5272 & 6.3909 & TRN & & \\
\hline CHEMBL1455197 & 688597 & 6.1124 & 6.1606 & TRN & & \\
\hline CHEMBL1237072 & 688597 & 8.2218 & 8.2396 & TST & & \\
\hline CHEMBL1501057 & 688597 & \multicolumn{3}{|c|}{5.962999999999999} & 5.9496 & TRN \\
\hline CHEMBL1379322 & 688597 & 4.6146 & 3.5717 & TRN & & \\
\hline CHEMBL1468577 & 688597 & 5.6223 & 5.3882 & TRN & & \\
\hline CHEMBL1366012 & 688597 & 6.6556 & 5.9845 & TRN & & \\
\hline CHEMBL1305864 & 688597 & 5.0861 & 5.0721 & TST & & \\
\hline CHEMBL3189736 & 688597 & 5.0886 & 5.2135 & TRN & & \\
\hline CHEMBL1383321 & 688597 & 5.4085 & 5.593 & TRN & & \\
\hline
\end{tabular}




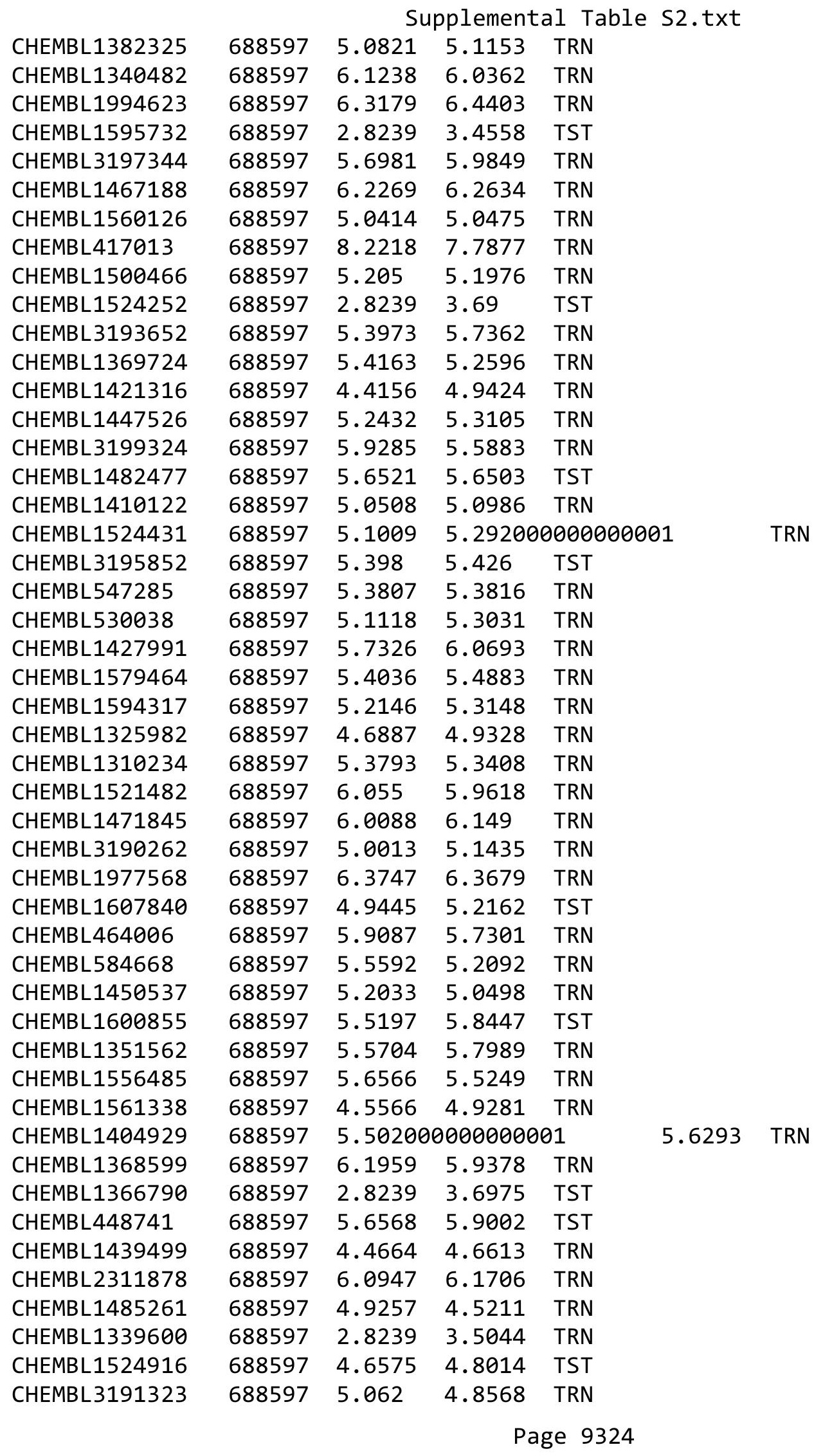




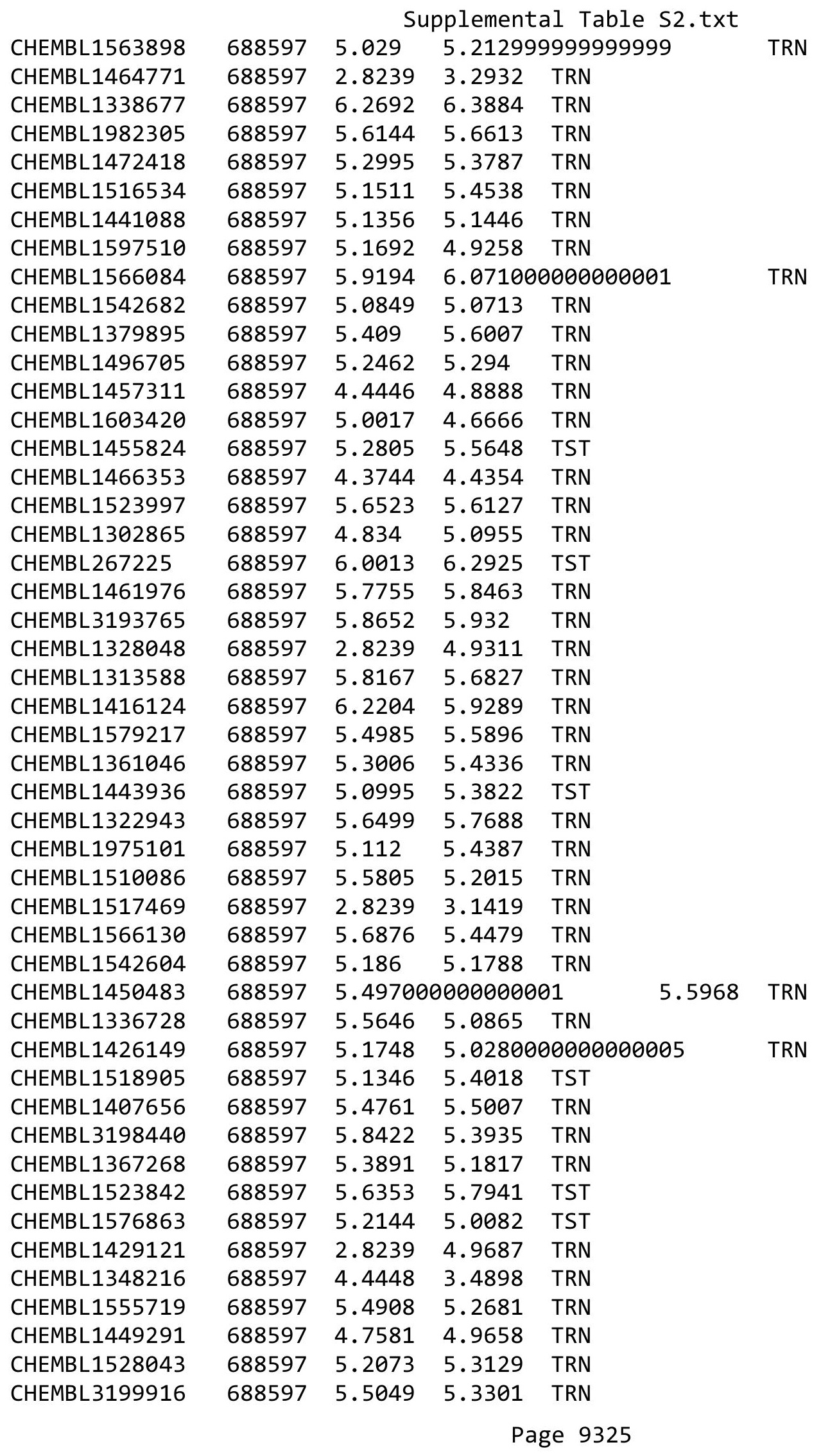




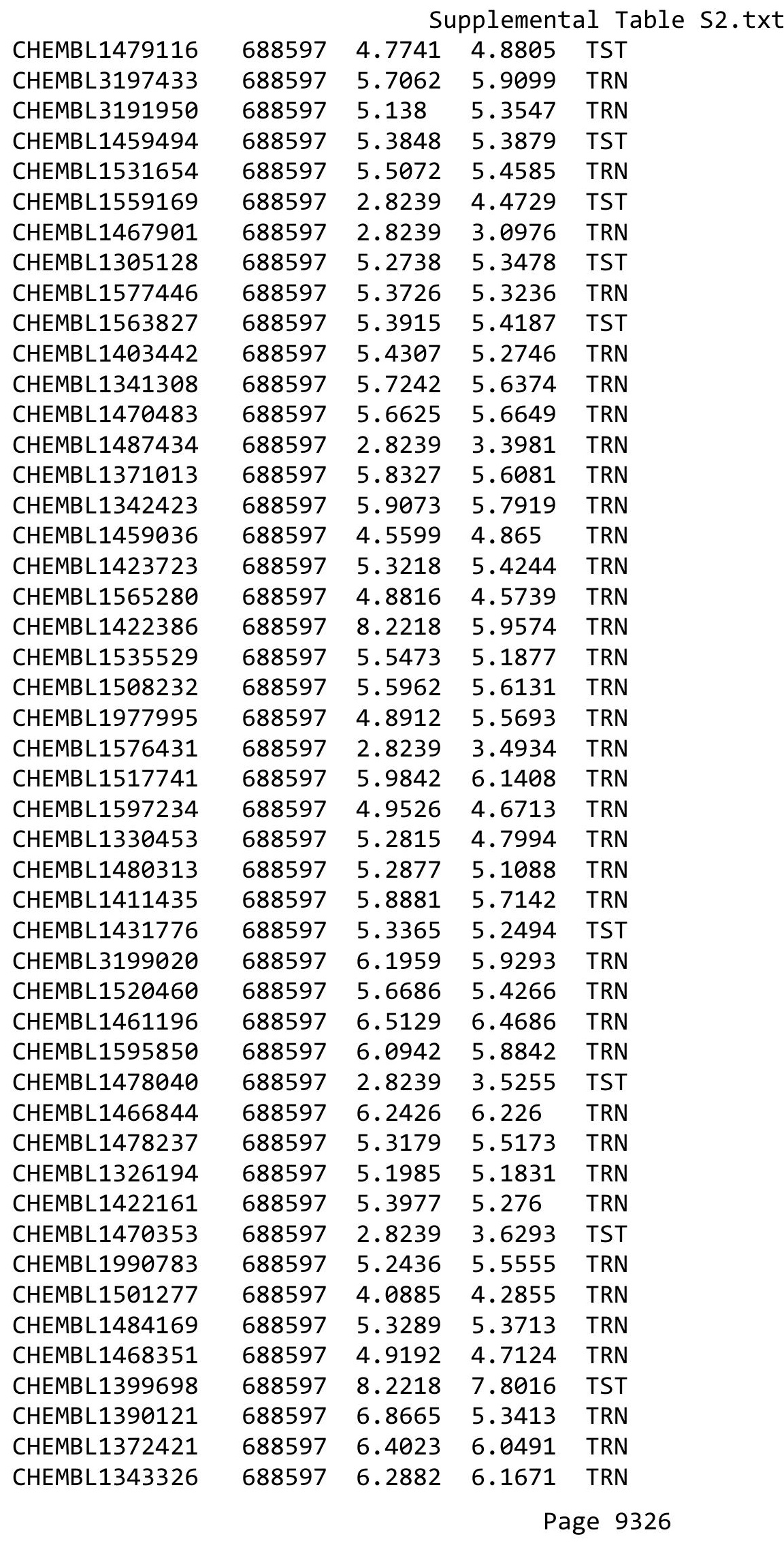




\begin{tabular}{|c|c|c|c|c|c|}
\hline \multirow[b]{2}{*}{ CHEMBL1305498 } & \multicolumn{5}{|c|}{ Supplemental Table S2.txt } \\
\hline & 688597 & 2.8239 & 3.4169 & TST & \\
\hline CHEMBL1548513 & 688597 & 2.8239 & 3.31699 & 99999999997 & TST \\
\hline CHEMBL1410479 & 688597 & 5.7612 & 5.5484 & TRN & \\
\hline CHEMBL1391272 & 688597 & 5.5187 & 5.5816 & TRN & \\
\hline CHEMBL 1300745 & 688597 & 6.1463 & 6.0789 & TRN & \\
\hline CHEMBL1389269 & 688597 & 5.5258 & 5.4754 & TRN & \\
\hline CHEMBL1504588 & 688597 & 2.8239 & 3.1908 & TRN & \\
\hline CHEMBL1541789 & 688597 & 5.3466 & 5.1372 & TRN & \\
\hline CHEMBL314962 & 688597 & 2.8239 & 3.5326 & TRN & \\
\hline CHEMBL1375045 & 688597 & 5.6588 & 5.98799 & 99999999995 & TST \\
\hline CHEMBL1465980 & 688597 & 2.8239 & 3.8695 & TST & \\
\hline CHEMBL1415338 & 688597 & 5.2047 & 4.8686 & TRN & \\
\hline CHEMBL1453924 & 688597 & 3.9884 & 4.7134 & TRN & \\
\hline CHEMBL1407237 & 688597 & 5.7217 & 5.6023 & TRN & \\
\hline CHEMBL1440743 & 688597 & 5.5209 & 5.1874 & TST & \\
\hline CHEMBL598903 & 688597 & 5.4711 & 5.4655 & TST & \\
\hline CHEMBL1372076 & 688597 & 5.1943 & 5.365 & TST & \\
\hline CHEMBL1596326 & 688597 & 5.1004 & 5.0522 & TRN & \\
\hline CHEMBL3197259 & 688597 & 5.8986 & 5.8447 & TRN & \\
\hline CHEMBL1382575 & 688597 & 5.1813 & 5.3176 & TRN & \\
\hline CHEMBL3213413 & 688597 & 5.4027 & 5.3471 & TRN & \\
\hline CHEMBL1481836 & 688597 & 5.5067 & 5.4295 & TRN & \\
\hline CHEMBL1573462 & 688597 & 2.8239 & 3.4596 & TRN & \\
\hline CHEMBL1562524 & 688597 & 5.2289 & 5.2074 & TRN & \\
\hline CHEMBL1539127 & 688597 & 5.2064 & 5.5291 & TRN & \\
\hline CHEMBL1507404 & 688597 & 5.4486 & 5.3944 & TST & \\
\hline CHEMBL1372606 & 688597 & 6.2549 & 6.2528 & TRN & \\
\hline CHEMBL1473916 & 688597 & 5.4548 & 5.1548 & TST & \\
\hline CHEMBL1423286 & 688597 & 6.4112 & 6.3586 & TRN & \\
\hline CHEMBL3191692 & 688597 & 5.2798 & 5.1463 & TRN & \\
\hline CHEMBL283849 & 688597 & 5.3595 & 5.3648 & TRN & \\
\hline CHEMBL1452706 & 688597 & 5.471 & 5.5104 & TRN & \\
\hline CHEMBL1496534 & 688597 & 5.2977 & 5.0934 & TST & \\
\hline CHEMBL1469449 & 688597 & 4.8325 & 4.7741 & TRN & \\
\hline CHEMBL1382853 & 688597 & 4.7434 & 5.104 & TST & \\
\hline CHEMBL1994371 & 688597 & 5.4475 & 5.5692 & TRN & \\
\hline CHEMBL 1453753 & 688597 & 5.3824 & 5.6076 & TRN & \\
\hline CHEMBL1550584 & 688597 & 6.699 & 6.7137 & TRN & \\
\hline CHEMBL1487505 & 688597 & 2.8239 & 3.5905 & TST & \\
\hline CHEMBL1610217 & 688597 & 5.5379 & 5.3204 & TRN & \\
\hline CHEMBL1481198 & 688597 & 6.1002 & 6.2058 & TRN & \\
\hline CHEMBL1549816 & 688597 & 5.4837 & 4.7668 & TRN & \\
\hline CHEMBL1542349 & 688597 & 5.0946 & 5.3879 & TRN & \\
\hline CHEMBL1588702 & 688597 & 5.2902 & 5.3076 & TRN & \\
\hline CHEMBL1503658 & 688597 & 5.6336 & 6.2335 & TRN & \\
\hline CHEMBL1482296 & 688597 & 5.5408 & 5.6441 & TRN & \\
\hline CHEMBL3194106 & 688597 & 5.0717 & 3.4933 & TRN & \\
\hline CHEMBL1603844 & 688597 & 5.9523 & 5.8655 & TST & \\
\hline
\end{tabular}




\begin{tabular}{|c|c|c|c|c|c|c|}
\hline & & \multicolumn{5}{|c|}{ Supplemental Table S2.txt } \\
\hline CHEMBL1463761 & 688597 & 5.3121 & 5.4033 & TST & & \\
\hline CHEMBL1303391 & 688597 & 5.0047 & 5.0815 & TRN & & \\
\hline CHEMBL1453837 & 688597 & 4.913 & 5.14 & TRN & & \\
\hline CHEMBL1504763 & 688597 & 5.6753 & 5.591 & TRN & & \\
\hline CHEMBL1478241 & 688597 & 5.1332 & 5.1861 & TRN & & \\
\hline CHEMBL1423270 & 688597 & 6.6635 & 6.456 & TRN & & \\
\hline CHEMBL1459691 & 688597 & 6.7328 & 6.1164 & TRN & & \\
\hline CHEMBL1559999 & 688597 & 5.2135 & 5.269 & TRN & & \\
\hline CHEMBL 3183210 & 688597 & 5.6214 & 5.4625 & TRN & & \\
\hline CHEMBL1560273 & 688597 & 5.1417 & 5.3308 & TST & & \\
\hline CHEMBL1473799 & 688597 & 4.6399 & 3.3968 & TRN & & \\
\hline CHEMBL1496338 & 688597 & 4.879 & 5.6234 & TRN & & \\
\hline CHEMBL1531676 & 688597 & 5.1379 & 5.2471 & TST & & \\
\hline CHEMBL473107 & 688597 & 5.3995 & 5.4396 & TRN & & \\
\hline CHEMBL1571096 & 688597 & 2.8239 & 3.1389 & TRN & & \\
\hline CHEMBL1564099 & 688597 & 5.1892 & 5.0646 & TRN & & \\
\hline CHEMBL1445327 & 688597 & 4.9957 & 5.379 & TRN & & \\
\hline CHEMBL3195813 & 688597 & 5.6826 & 5.7225 & TRN & & \\
\hline CHEMBL1335220 & 688597 & 5.5728 & 5.6551 & TRN & & \\
\hline CHEMBL1426113 & 688597 & 5.2907 & 5.4044 & TRN & & \\
\hline CHEMBL1527664 & 688597 & 5.4087 & 5.6119 & TST & & \\
\hline CHEMBL1336959 & 688597 & 5.8952 & 6.2152 & TRN & & \\
\hline CHEMBL1558361 & 688597 & 5.3792 & 5.3382 & TRN & & \\
\hline CHEMBL1470099 & 688597 & 6.0218 & 6.1777 & TRN & & \\
\hline CHEMBL1470545 & 688597 & 4.9313 & 5.0789 & TRN & & \\
\hline CHEMBL3189743 & 688597 & 5.4426 & 5.7146 & TRN & & \\
\hline CHEMBL1605854 & 688597 & 5.2172 & 5.0138 & TRN & & \\
\hline CHEMBL1392741 & 688597 & 2.8239 & 3.0766 & TRN & & \\
\hline CHEMBL1535938 & 688597 & 5.0989 & 5.2973 & TRN & & \\
\hline CHEMBL1568310 & 688597 & 5.2552 & 5.5134 & TRN & & \\
\hline CHEMBL1611182 & 688597 & 5.1869 & 5.3187 & TRN & & \\
\hline CHEMBL1515140 & 688597 & 4.9324 & 5.3341 & TRN & & \\
\hline CHEMBL3196688 & 688597 & 5.0068 & 5.0358 & TRN & & \\
\hline CHEMBL3212285 & 688597 & 5.9311 & 5.6783 & TRN & & \\
\hline CHEMBL1315704 & 688597 & 5.7934 & 5.4306 & TRN & & \\
\hline CHEMBL1468672 & 688597 & 5.58799 & 99999999 & 99 & 5.8774 & $1 \mathrm{~K}$ \\
\hline CHEMBL1573586 & 688597 & 5.1996 & 5.5283 & TST & & \\
\hline CHEMBL1449354 & 688597 & 4.6696 & 3.495 & TRN & & \\
\hline CHEMBL1477091 & 688597 & 2.8239 & 3.4951 & TRN & & \\
\hline CHEMBL1379801 & 688597 & 5.4148 & 5.1848 & TST & & \\
\hline CHEMBL1309598 & 688597 & 6.2958 & 6.5045 & TRN & & \\
\hline CHEMBL1504972 & 688597 & 5.3929 & 4.9928 & TRN & & \\
\hline CHEMBL1610738 & 688597 & 2.8239 & 3.2543 & TST & & \\
\hline CHEMBL1363543 & 688597 & 5.3877 & 5.5985 & TRN & & \\
\hline CHEMBL1411838 & 688597 & 2.8239 & 3.3408 & TRN & & \\
\hline CHEMBL1572056 & 688597 & 4.7079 & 4.7318 & TRN & & \\
\hline CHEMBL1382213 & 688597 & 5.2968 & 5.4009 & TRN & & \\
\hline CHEMBL1379894 & 688597 & 5.3424 & 5.4396 & TST & & \\
\hline
\end{tabular}




\begin{tabular}{|c|c|c|c|c|c|c|}
\hline & & \multicolumn{5}{|c|}{ Supplemental Table S2.txt } \\
\hline CHEMBL1527573 & 688597 & 2.8239 & 3.1989 & TRN & & \\
\hline CHEMBL1398075 & 688597 & 2.8239 & 3.556 & TRN & & \\
\hline CHEMBL1578252 & 688597 & 5.5902 & 5.2881 & TRN & & \\
\hline CHEMBL1528835 & 688597 & 5.8011 & 5.7653 & TRN & & \\
\hline CHEMBL1603550 & 688597 & 2.8239 & 3.3963 & TRN & & \\
\hline CHEMBL528694 & 688597 & 6.1518 & 6.0077 & TRN & & \\
\hline CHEMBL1598704 & 688597 & 4.8391 & 4.7992 & TRN & & \\
\hline CHEMBL1482975 & 688597 & 6.8539 & 7.0723 & TRN & & \\
\hline CHEMBL1411777 & 688597 & 5.0594 & 5.5649 & TRN & & \\
\hline CHEMBL1520507 & 688597 & 5.1814 & 5.319 & TRN & & \\
\hline CHEMBL1345800 & 688597 & 5.1552 & 5.5401 & TRN & & \\
\hline CHEMBL1522288 & 688597 & 6.9788 & 6.7878 & TRN & & \\
\hline CHEMBL1414059 & 688597 & 5.3261 & 5.2266 & TRN & & \\
\hline CHEMBL3194816 & 688597 & 4.3835 & 5.0981 & TRN & & \\
\hline CHEMBL1345827 & 688597 & 5.2635 & 5.2168 & TRN & & \\
\hline CHEMBL1467238 & 688597 & 4.76399 & 99999999 & 99 & 3.5019 & TST \\
\hline CHEMBL1445650 & 688597 & 6.1096 & 5.8573 & TRN & & \\
\hline CHEMBL1609988 & 688597 & 5.9404 & 5.733 & TRN & & \\
\hline CHEMBL1471101 & 688597 & 5.2974 & 4.8418 & TRN & & \\
\hline CHEMBL1498998 & 688597 & 5.6988 & 4.4728 & TST & & \\
\hline CHEMBL1306480 & 688597 & 5.4969 & 5.438 & TRN & & \\
\hline CHEMBL591361 & 688597 & 5.9333 & 5.8601 & TRN & & \\
\hline CHEMBL1488172 & 688597 & 6.1518 & 5.7966 & TRN & & \\
\hline CHEMBL1604044 & 688597 & 4.863 & 5.1562 & TRN & & \\
\hline CHEMBL1541350 & 688597 & 5.1876 & 4.8613 & TRN & & \\
\hline CHEMBL171637 & 688597 & 5.1759 & 5.4865 & TST & & \\
\hline CHEMBL1502939 & 688597 & 3.9525 & 3.5865 & TRN & & \\
\hline CHEMBL 2003651 & 688597 & 5.5091 & 5.5785 & TRN & & \\
\hline CHEMBL1365325 & 688597 & 5.7102 & 4.8226 & TRN & & \\
\hline CHEMBL1485259 & 688597 & 6.0334 & 5.987 & TRN & & \\
\hline CHEMBL1299566 & 688597 & 5.272 & 5.6484 & TRN & & \\
\hline CHEMBL1541391 & 688597 & 5.8765 & 5.5483 & TST & & \\
\hline CHEMBL1320506 & 688597 & 5.2085 & 5.4303 & TRN & & \\
\hline CHEMBL 2006511 & 688597 & 6.1403 & 5.8096 & TRN & & \\
\hline CHEMBL1466644 & 688597 & 5.4808 & 5.7047 & TRN & & \\
\hline CHEMBL3197008 & 688597 & 5.4919 & 5.4567 & TRN & & \\
\hline CHEMBL3193666 & 688597 & 5.6668 & 5.5772 & TRN & & \\
\hline CHEMBL1509590 & 688597 & 5.934 & 5.8276 & TRN & & \\
\hline CHEMBL1325644 & 688597 & 5.4637 & 5.5023 & TRN & & \\
\hline CHEMBL1581270 & 688597 & 4.7106 & 4.8476 & TRN & & \\
\hline CHEMBL1458441 & 688597 & 5.5309 & 5.4938 & TRN & & \\
\hline CHEMBL1334670 & 688597 & 5.2203 & 5.2796 & TRN & & \\
\hline CHEMBL1582878 & 688597 & 5.1459 & 5.2271 & TRN & & \\
\hline CHEMBL179611 & 688597 & 5.232 & 5.1669 & TST & & \\
\hline CHEMBL1520702 & 688597 & 5.3146 & 5.2886 & TRN & & \\
\hline CHEMBL1391928 & 688597 & 5.45 & 5.2852 & TRN & & \\
\hline CHEMBL1517683 & 688597 & 5.6189 & 5.187 & TRN & & \\
\hline CHEMBL1964793 & 688597 & 5.706 & 5.7022 & TRN & & \\
\hline
\end{tabular}




\begin{tabular}{|c|c|c|c|c|c|}
\hline \multicolumn{6}{|c|}{ Supplemental Table s2.txt } \\
\hline CHEMBL1580856 & 688597 & 5.3003 & 5.5984 & TRN & \\
\hline CHEMBL1373424 & 688597 & 2.8239 & 3.3593 & TRN & \\
\hline CHEMBL1307746 & 688597 & 2.8239 & 3.5122 & TST & \\
\hline CHEMBL1531834 & 688597 & 6.3382 & 6.0384 & TRN & \\
\hline CHEMBL1487004 & 688597 & 5.4515 & 5.375 & TST & \\
\hline CHEMBL1469052 & 688597 & 2.8239 & 3.4947 & TRN & \\
\hline CHEMBL1349635 & 688597 & 5.011 & 4.5748 & TRN & \\
\hline CHEMBL1484658 & 688597 & 5.3168 & 5.2737 & TRN & \\
\hline CHEMBL1381353 & 688597 & 4.9771 & 4.8599 & TRN & \\
\hline CHEMBL1545225 & 688597 & 6.0947 & 5.8222 & TRN & \\
\hline CHEMBL1537093 & 688597 & 5.2158 & 5.6109 & TRN & \\
\hline CHEMBL1446364 & 688597 & 5.2534 & 5.2988 & TRN & \\
\hline CHEMBL1418598 & 688597 & 5.482 & 5.4568 & TRN & \\
\hline CHEMBL1360461 & 688597 & 5.3485 & 5.6325 & TRN & \\
\hline CHEMBL1542862 & 688597 & 6.0964 & 6.29899 & 99999999995 & TRN \\
\hline CHEMBL531401 & 688597 & 5.2349 & 4.7945 & TRN & \\
\hline CHEMBL1555769 & 688597 & 5.1754 & 5.2771 & TRN & \\
\hline CHEMBL1513407 & 688597 & 6.1618 & 5.9858 & TRN & \\
\hline CHEMBL1360618 & 688597 & 5.1917 & 5.4045 & TRN & \\
\hline CHEMBL1332728 & 688597 & 5.3074 & 5.2895 & TRN & \\
\hline CHEMBL1448732 & 688597 & 5.574 & 5.3795 & TRN & \\
\hline CHEMBL1395220 & 688597 & 4.8807 & 5.1915 & TRN & \\
\hline CHEMBL1436964 & 688597 & 5.9496 & 5.72 & TRN & \\
\hline CHEMBL1385201 & 688597 & 2.8239 & 3.5179 & TRN & \\
\hline CHEMBL1407688 & 688597 & 5.2292 & 3.6164 & TRN & \\
\hline CHEMBL1402051 & 688597 & 5.8425 & 3.6012 & TRN & \\
\hline CHEMBL1380969 & 688597 & 5.165 & 5.272 & TRN & \\
\hline CHEMBL1569639 & 688597 & 2.8239 & 3.1544 & TRN & \\
\hline CHEMBL1585758 & 688597 & 5.0339 & 5.309 & TRN & \\
\hline CHEMBL1368221 & 688597 & 4.8555 & 5.2897 & TRN & \\
\hline CHEMBL1536431 & 688597 & 6.0975 & 5.9716 & TRN & \\
\hline CHEMBL1541683 & 688597 & 5.3421 & 3.7846 & TRN & \\
\hline CHEMBL1400406 & 688597 & 6.2993 & 6.3755 & TRN & \\
\hline CHEMBL478791 & 688597 & 5.7442 & 5.732 & TRN & \\
\hline CHEMBL1562570 & 688597 & 5.0885 & 5.1987 & TRN & \\
\hline CHEMBL1447284 & 688597 & 8.2218 & 6.9478 & TRN & \\
\hline CHEMBL 3145088 & 688597 & 5.9598 & 5.7596 & TRN & \\
\hline CHEMBL3196257 & 688597 & 5.2099 & 5.8244 & TRN & \\
\hline CHEMBL1466621 & 688597 & $5.9670 e$ & 30000000 & 6.059 & TRN \\
\hline CHEMBL1502020 & 688597 & 5.5524 & 5.1755 & TRN & \\
\hline CHEMBL1411449 & 688597 & 5.6002 & 5.7055 & TRN & \\
\hline CHEMBL1505450 & 688597 & 5.1047 & 5.2275 & TRN & \\
\hline CHEMBL1327721 & 688597 & 5.6998 & 5.8192 & TRN & \\
\hline CHEMBL1351309 & 688597 & 5.7093 & 5.54899 & 99999999995 & TST \\
\hline CHEMBL1602088 & 688597 & 6.0894 & 5.8425 & TRN & \\
\hline CHEMBL1304742 & 688597 & 5.3369 & 5.6272 & TST & \\
\hline CHEMBL 3210474 & 688597 & 5.6313 & 5.8559 & TRN & \\
\hline CHEMBL1320542 & 688597 & 6.4841 & 6.356 & TRN & \\
\hline
\end{tabular}


Supplemental Table S2.txt

\begin{tabular}{|c|c|c|c|c|}
\hline CHEMBL1460705 & 688597 & 6.4179 & 6.2352 & TRN \\
\hline CHEMBL1501236 & 688597 & 5.6578 & 4.8645 & TRN \\
\hline CHEMBL1344571 & 688597 & 5.3027 & 5.1708 & TRN \\
\hline CHEMBL1490049 & 688597 & 2.8239 & 3.6758 & TRN \\
\hline CHEMBL1388274 & 688597 & 4.9085 & 5.1945 & TST \\
\hline CHEMBL1375254 & 688597 & 4.0292 & 4.1251 & TRN \\
\hline CHEMBL1519450 & 688597 & 4.4845 & 5.3049 & TRN \\
\hline CHEMBL1546285 & 688597 & 6.0675 & 5.5181 & TRN \\
\hline CHEMBL1307769 & 688597 & 5.2073 & 5.13200 & 0000000001 \\
\hline CHEMBL1301129 & 688597 & 5.3466 & 5.2556 & TRN \\
\hline CHEMBL1413931 & 688597 & 4.9562 & 5.1056 & TRN \\
\hline CHEMBL1498574 & 688597 & 5.3936 & 5.4112 & TRN \\
\hline CHEMBL1453391 & 688597 & 2.8239 & 3.1245 & TRN \\
\hline CHEMBL3211496 & 688597 & 2.8239 & 3.4632 & TRN \\
\hline CHEMBL1598882 & 688597 & 4.9474 & 5.1317 & TRN \\
\hline CHEMBL1609005 & 688597 & 4.2923 & 3.4655 & TRN \\
\hline CHEMBL3208035 & 688597 & 5.1641 & 5.3302 & TRN \\
\hline CHEMBL1613625 & 688597 & 4.7465 & 4.879 & TRN \\
\hline CHEMBL1571174 & 688597 & 2.8239 & 3.4879 & TRN \\
\hline CHEMBL1392828 & 688597 & 4.7306 & 5.0139 & TST \\
\hline CHEMBL1605304 & 688597 & 5.4869 & 5.2145 & TRN \\
\hline CHEMBL1320354 & 688597 & 5.7158 & 5.6812 & TRN \\
\hline CHEMBL1563221 & 688597 & 5.8398 & 5.7388 & TRN \\
\hline CHEMBL1329925 & 688597 & 6.2291 & 6.0803 & TRN \\
\hline CHEMBL1476032 & 688597 & 2.8239 & 2.9542 & TRN \\
\hline CHEMBL1340150 & 688597 & 5.5743 & 5.6348 & TRN \\
\hline CHEMBL1336052 & 688597 & 5.2988 & 5.2742 & TST \\
\hline CHEMBL1333177 & 688597 & 6.0742 & 5.8485 & TST \\
\hline CHEMBL1390963 & 688597 & 6.2628 & 6.6288 & TRN \\
\hline CHEMBL3189407 & 688597 & 5.2323 & 5.3181 & TRN \\
\hline CHEMBL1427661 & 688597 & 5.9215 & 5.7325 & TRN \\
\hline CHEMBL1433404 & 688597 & 2.8239 & 3.0028 & TRN \\
\hline CHEMBL1432888 & 688597 & 5.4179 & 5.5741 & TRN \\
\hline CHEMBL1344388 & 688597 & 6.066 & 6.255 & TRN \\
\hline CHEMBL1477881 & 688597 & 5.7265 & 5.9814 & TRN \\
\hline CHEMBL1535900 & 688597 & 5.0382 & 5.0281 & TST \\
\hline CHEMBL1416165 & 688597 & 5.0474 & 5.0696 & TRN \\
\hline CHEMBL1342028 & 688597 & 5.5305 & 5.3949 & TRN \\
\hline CHEMBL1419518 & 688597 & 5.3899 & 5.7507 & TRN \\
\hline CHEMBL1513240 & 688597 & 5.4098 & 5.6004 & TRN \\
\hline CHEMBL1482637 & 688597 & 5.2949 & 5.5594 & TRN \\
\hline CHEMBL1533835 & 688597 & 5.1363 & 5.1456 & TRN \\
\hline CHEMBL1409851 & 688597 & 5.2818 & 5.2901 & TRN \\
\hline CHEMBL1386178 & 688597 & 5.5277 & 5.7082 & TRN \\
\hline CHEMBL1421570 & 688597 & 2.8239 & 4.4681 & TRN \\
\hline CHEMBL1342436 & 688597 & 8.2218 & 7.5804 & TST \\
\hline CHEMBL1547804 & 688597 & 5.4881 & 5.2656 & TRN \\
\hline CHEMBL1456948 & 688597 & 5.9914 & 6.3444 & TRN \\
\hline
\end{tabular}




\begin{tabular}{|c|c|c|c|c|c|c|}
\hline & & \multicolumn{5}{|c|}{ Supplemental Table S2.txt } \\
\hline CHEMBL1499828 & 688597 & 5.6426 & 5.6696 & TRN & & \\
\hline CHEMBL1982915 & 688597 & 5.4333 & 5.2765 & TRN & & \\
\hline CHEMBL1514534 & 688597 & 5.5261 & 5.4855 & TRN & & \\
\hline CHEMBL 3144984 & 688597 & 5.442 & 5.5432 & TRN & & \\
\hline CHEMBL1388595 & 688597 & 5.3182 & 5.3424 & TRN & & \\
\hline CHEMBL1555362 & 688597 & 5.1489 & 5.1729 & TRN & & \\
\hline CHEMBL1586774 & 688597 & 5.2177 & 3.6943 & TRN & & \\
\hline CHEMBL1523312 & 688597 & 2.8239 & 3.0707 & TRN & & \\
\hline CHEMBL1504407 & 688597 & 5.4765 & 5.6631 & TST & & \\
\hline CHEMBL1594984 & 688597 & 5.9582 & 5.7543 & TRN & & \\
\hline CHEMBL246338 & 688597 & 2.8239 & 3.4552 & TRN & & \\
\hline CHEMBL3191453 & 688597 & 4.7484 & 5.4226 & TRN & & \\
\hline CHEMBL1532755 & 688597 & 5.6772 & 5.7745 & TRN & & \\
\hline CHEMBL431525 & 688597 & 5.7333 & 5.8538 & TST & & \\
\hline CHEMBL1994935 & 688597 & 4.4 & 4.9023 & TRN & & \\
\hline CHEMBL 3213747 & 688597 & 5.3066 & 5.2654 & TST & & \\
\hline CHEMBL1436772 & 688597 & 6.8962 & 6.6585 & TRN & & \\
\hline CHEMBL1970867 & 688597 & 4.919 & 5.6259 & TRN & & \\
\hline CHEMBL1426910 & 688597 & 5.3225 & 5.3391 & TRN & & \\
\hline CHEMBL1589298 & 688597 & 6.6055 & 6.1595 & TRN & & \\
\hline CHEMBL3197091 & 688597 & 5.934 & 6.3109 & TRN & & \\
\hline CHEMBL1521336 & 688597 & 4.9492 & 4.9241 & TRN & & \\
\hline CHEMBL394242 & 688597 & 5.8604 & 6.25200 & 000000000 & & $1 \mathrm{n}$ \\
\hline CHEMBL3197808 & 688597 & 5.3983 & 5.7698 & TRN & & \\
\hline CHEMBL1438684 & 688597 & 4.5683 & 4.9666 & TRN & & \\
\hline CHEMBL1404750 & 688597 & 5.3511 & 5.3254 & TST & & \\
\hline CHEMBL1350169 & 688597 & 5.1989 & 5.1037 & TRN & & \\
\hline CHEMBL1525576 & 688597 & 5.4743 & 5.682 & TRN & & \\
\hline CHEMBL1977376 & 688597 & 2.8239 & 3.4625 & TRN & & \\
\hline CHEMBL1999480 & 688597 & 4.9596 & 5.3307 & TST & & \\
\hline CHEMBL1484547 & 688597 & 5.4368 & 5.8823 & TRN & & \\
\hline CHEMBL1583807 & 688597 & 4.7821 & 5.0704 & TRN & & \\
\hline CHEMBL1548761 & 688597 & 5.5166 & 5.5096 & TRN & & \\
\hline CHEMBL1424933 & 688597 & 5.4812 & 5.1164 & TRN & & \\
\hline CHEMBL411070 & 688597 & 2.8239 & 3.467 & TST & & \\
\hline CHEMBL1503749 & 688597 & 4.3549 & 3.6362 & TRN & & \\
\hline CHEMBL1452449 & 688597 & 6.8416 & 6.6803 & TRN & & \\
\hline CHEMBL1418600 & 688597 & 5.8008 & 5.7146 & TST & & \\
\hline CHEMBL1309059 & 688597 & 5.1392 & 5.3726 & TRN & & \\
\hline CHEMBL1400434 & 688597 & 6.3019 & 6.2668 & TRN & & \\
\hline CHEMBL1612732 & 688597 & 5.0778 & 5.4511 & TRN & & \\
\hline CHEMBL1401144 & 688597 & 4.8823 & 4.9007 & TRN & & \\
\hline CHEMBL1547031 & 688597 & 2.8239 & 4.7714 & TRN & & \\
\hline CHEMBL1430319 & 688597 & 5.6196 & 5.1881 & TRN & & \\
\hline CHEMBL1461180 & 688597 & 5.8377 & 3.1586 & TRN & & \\
\hline CHEMBL1976000 & 688597 & 5.4498 & 5.8544 & TRN & & \\
\hline CHEMBL1483281 & 688597 & 5.96299 & 99999999 & 99 & .7542 & TRN \\
\hline CHEMBL1424907 & 688597 & 5.2353 & 5.6839 & TRN & & \\
\hline
\end{tabular}




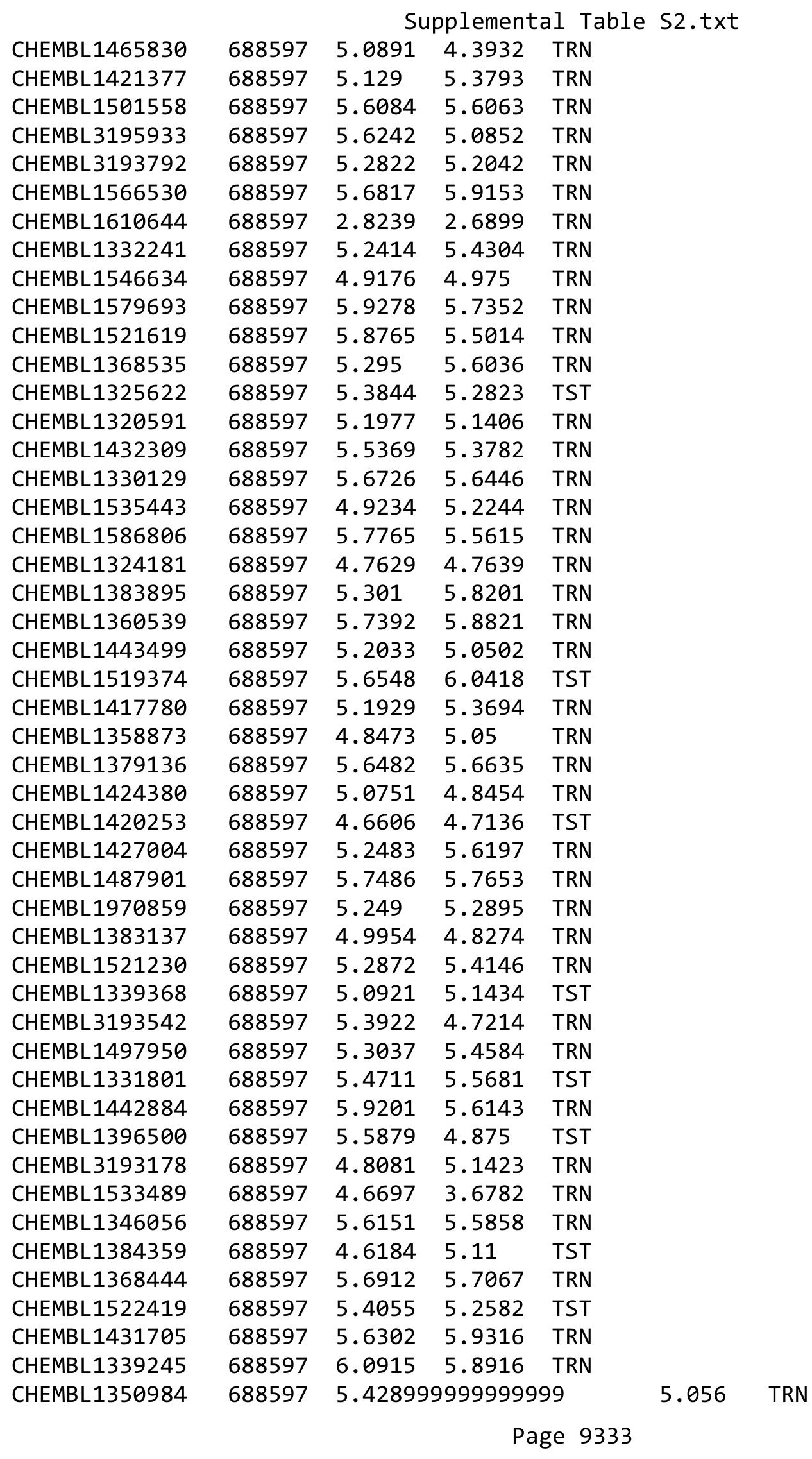




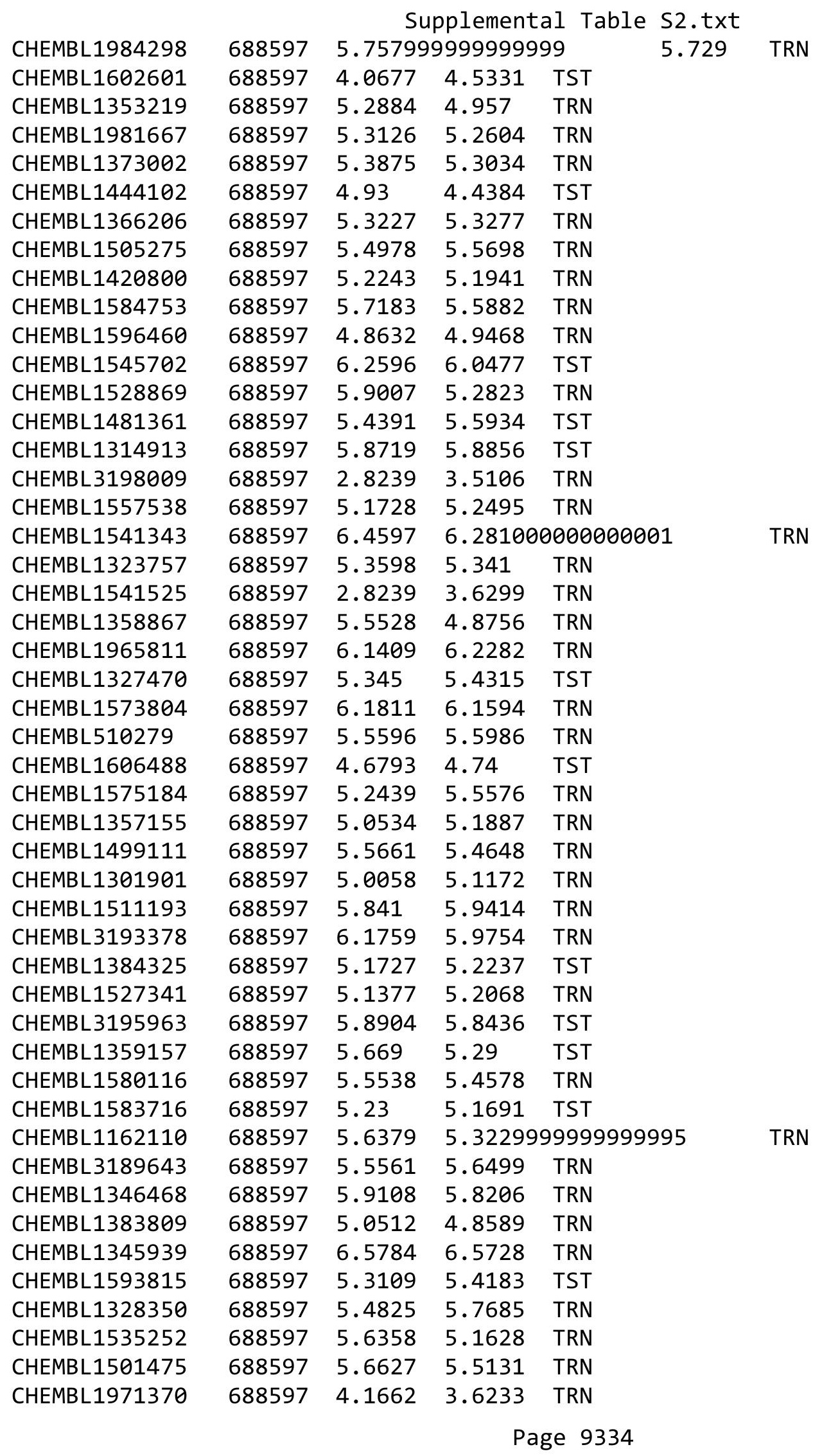




\begin{tabular}{|c|c|c|c|c|c|}
\hline & & \multicolumn{4}{|c|}{ Supplemental Table s2.txt } \\
\hline CHEMBL1312717 & 688597 & 5.0113 & 4.4727 & TRN & \\
\hline CHEMBL532363 & 688597 & 5.2536 & 5.5193 & TRN & \\
\hline CHEMBL1602581 & 688597 & 5.4984 & 5.6959 & TRN & \\
\hline CHEMBL1551022 & 688597 & 5.3653 & 5.2536 & TRN & \\
\hline CHEMBL1511739 & 688597 & 5.3162 & 5.4382 & TRN & \\
\hline CHEMBL1461674 & 688597 & 2.8239 & 3.2996 & TRN & \\
\hline CHEMBL1536606 & 688597 & 5.4325 & \multicolumn{2}{|c|}{5.2379999999999995} & TRN \\
\hline CHEMBL1456926 & 688597 & 6.3768 & 6.51 & TRN & \\
\hline CHEMBL1358093 & 688597 & 5.6584 & 5.5683 & TRN & \\
\hline CHEMBL1341945 & 688597 & 4.7116 & 4.8588 & TRN & \\
\hline CHEMBL1337445 & 688597 & 5.6809 & 5.6094 & TST & \\
\hline CHEMBL1442745 & 688597 & 5.5996 & 5.6282 & TRN & \\
\hline CHEMBL1306986 & 688597 & 7.0915 & 6.4497 & TRN & \\
\hline CHEMBL1351575 & 688597 & 4.7824 & 5.0288 & TRN & \\
\hline CHEMBL3193805 & 688597 & 5.421 & 5.6675 & TRN & \\
\hline CHEMBL1343537 & 688597 & 5.5544 & 5.6121 & TRN & \\
\hline CHEMBL1304169 & 688597 & 5.95 & 5.975 & TRN & \\
\hline CHEMBL1401161 & 688597 & 5.4695 & 5.2852 & TRN & \\
\hline CHEMBL1398910 & 688597 & 5.1813 & \multicolumn{2}{|c|}{4.5489999999999995} & TRN \\
\hline CHEMBL1708832 & 688597 & 4.4461 & 3.6816 & TRN & \\
\hline CHEMBL1520763 & 688597 & 5.2971 & 5.4561 & TRN & \\
\hline CHEMBL1299640 & 688597 & 5.3891 & 5.3522 & TRN & \\
\hline CHEMBL1606685 & 688597 & 5.9666 & 5.8259 & TRN & \\
\hline CHEMBL1308873 & 688597 & 5.8136 & 5.3863 & TRN & \\
\hline CHEMBL1995336 & 688597 & 2.8239 & 3.5247 & TST & \\
\hline CHEMBL1568277 & 688597 & 6.251 & 6.2299 & TRN & \\
\hline CHEMBL1524764 & 688597 & 4.954 & 4.0376 & TRN & \\
\hline CHEMBL1506926 & 688597 & 4.698 & 4.8774 & TRN & \\
\hline CHEMBL1564233 & 688597 & 5.1692 & 5.005 & TRN & \\
\hline CHEMBL1406942 & 688597 & 5.1066 & 5.2579 & TRN & \\
\hline CHEMBL162783 & 688597 & 6.4962 & 6.4503 & TRN & \\
\hline CHEMBL1311479 & 688597 & 2.8239 & 3.2715 & TRN & \\
\hline CHEMBL1303280 & 688597 & 5.8508 & 5.6002 & TRN & \\
\hline CHEMBL1454738 & 688597 & 5.3834 & \multicolumn{2}{|c|}{5.507999999999999} & TRN \\
\hline CHEMBL1313074 & 688597 & 4.9138 & 4.9568 & TST & \\
\hline CHEMBL1422170 & 688597 & 2.8239 & 3.2212 & TRN & \\
\hline CHEMBL1344289 & 688597 & 5.0701 & 4.8639 & TRN & \\
\hline CHEMBL1518264 & 688597 & 5.3606 & 4.8481 & TRN & \\
\hline CHEMBL1557756 & 688597 & 5.6633 & 5.1678 & TST & \\
\hline CHEMBL168 & 688597 & 5.5702 & 5.9486 & TST & \\
\hline CHEMBL1377316 & 688597 & 5.8395 & 5.7927 & TRN & \\
\hline CHEMBL1966798 & 688597 & 5.2292 & 5.3964 & TRN & \\
\hline CHEMBL1575634 & 688597 & 6.7282 & 6.6167 & TRN & \\
\hline CHEMBL1541672 & 688597 & 5.329 & 5.2587 & TRN & \\
\hline CHEMBL1550490 & 688597 & 5.4584 & 5.7445 & TRN & \\
\hline CHEMBL1562776 & 688597 & 2.8239 & 3.5375 & TRN & \\
\hline CHEMBL1339350 & 688597 & 5.1137 & 4.7939 & TRN & \\
\hline CHEMBL1461193 & 688597 & 5.3543 & 5.4272 & TRN & \\
\hline
\end{tabular}




\begin{tabular}{|c|c|c|c|c|c|c|}
\hline & & \multicolumn{5}{|c|}{ Supplemental Table S2.txt } \\
\hline CHEMBL1528965 & 688597 & 5.5926 & 5.9994 & TRN & & \\
\hline CHEMBL1389315 & 688597 & 5.5664 & 5.2801 & TRN & & \\
\hline CHEMBL1454212 & 688597 & 5.5445 & 5.8894 & TRN & & \\
\hline CHEMBL1431676 & 688597 & 5.471 & 5.3784 & TRN & & \\
\hline CHEMBL3210860 & 688597 & 4.8447 & 5.1778 & TRN & & \\
\hline CHEMBL1310223 & 688597 & 2.8239 & 3.3942 & TRN & & \\
\hline CHEMBL1558771 & 688597 & 5.1278 & 4.87 & TRN & & \\
\hline CHEMBL1310449 & 688597 & 6.5258 & 6.6647 & TRN & & \\
\hline CHEMBL1578127 & 688597 & 6.0386 & 5.9504 & TST & & \\
\hline CHEMBL 1470446 & 688597 & 5.9423 & 5.591 & TST & & \\
\hline CHEMBL1478252 & 688597 & 5.5474 & 5.2106 & TST & & \\
\hline CHEMBL1315061 & 688597 & 7.0177 & 6.9989 & TST & & \\
\hline CHEMBL1533269 & 688597 & 5.2506 & 5.3271 & TRN & & \\
\hline CHEMBL1567034 & 688597 & 5.1443 & 5.0372 & TST & & \\
\hline CHEMBL1584720 & 688597 & 5.2267 & 5.0938 & TRN & & \\
\hline CHEMBL1483146 & 688597 & 6.5622 & 7.0135 & TRN & & \\
\hline CHEMBL1611364 & 688597 & 5.2193 & 5.2321 & TRN & & \\
\hline CHEMBL 2006545 & 688597 & 5.8179 & 6.2198 & TRN & & \\
\hline CHEMBL1476225 & 688597 & 5.2253 & 5.2952 & TST & & \\
\hline CHEMBL1608907 & 688597 & 4.7857 & 5.2629 & TRN & & \\
\hline CHEMBL1582575 & 688597 & 2.8239 & 2.8905 & TRN & & \\
\hline CHEMBL1415308 & 688597 & 5.1422 & 4.9461 & TRN & & \\
\hline CHEMBL3194623 & 688597 & 5.5107 & 5.8737 & TRN & & \\
\hline CHEMBL1583292 & 688597 & 6.9666 & 8.0108 & TRN & & \\
\hline CHEMBL1998531 & 688597 & 5.567 & 5.63 & TRN & & \\
\hline CHEMBL1357163 & 688597 & 5.7765 & 5.7007 & TST & & \\
\hline CHEMBL3213728 & 688597 & 4.80399 & 999999999 & 99 & 4.9568 & TRN \\
\hline CHEMBL1533366 & 688597 & 5.9867 & 5.8806 & TRN & & \\
\hline CHEMBL1502019 & 688597 & 5.2135 & 5.1927 & TRN & & \\
\hline CHEMBL1516308 & 688597 & 4.813 & 5.0083 & TRN & & \\
\hline CHEMBL1510940 & 688597 & 5.2624 & 5.0354 & TST & & \\
\hline CHEMBL1444829 & 688597 & 5.0976 & 5.0754 & TRN & & \\
\hline CHEMBL1604302 & 688597 & 5.314 & 5.1147 & TRN & & \\
\hline CHEMBL1309958 & 688597 & 5.5952 & 3.6542 & TST & & \\
\hline CHEMBL1545189 & 688597 & 8.2218 & 7.7052 & TRN & & \\
\hline CHEMBL1437208 & 688597 & 4.704 & 4.907 & TRN & & \\
\hline CHEMBL1339728 & 688597 & 5.4655 & 5.1847 & TRN & & \\
\hline CHEMBL1550760 & 688597 & 4.8384 & 4.8172 & TRN & & \\
\hline CHEMBL1492378 & 688597 & 5.0057 & 4.7527 & TRN & & \\
\hline CHEMBL1305918 & 688597 & $5.9670 e$ & 000000000 & 205 & 5.7868 & TRN \\
\hline CHEMBL1987894 & 688597 & 5.8222 & 5.8904 & TRN & & \\
\hline CHEMBL1534655 & 688597 & 5.1629 & 5.7078 & TRN & & \\
\hline CHEMBL1510346 & 688597 & 2.8239 & 3.1229 & TRN & & \\
\hline CHEMBL1565132 & 688597 & 4.4541 & 3.5388 & TRN & & \\
\hline CHEMBL1587932 & 688597 & 4.8119 & 4.9126 & TRN & & \\
\hline CHEMBL1345195 & 688597 & 5.657 & 5.4932 & TRN & & \\
\hline CHEMBL1353666 & 688597 & 5.3001 & 5.0322 & TRN & & \\
\hline CHEMBL1605668 & 688597 & 5.2591 & 5.2571 & TRN & & \\
\hline
\end{tabular}


Supplemental Table S2.txt

\begin{tabular}{|c|c|c|c|c|}
\hline CHEMBL1346975 & 688597 & 5.2078 & 5.2948 & TRN \\
\hline CHEMBL1366975 & 688597 & 5.817 & 5.6589 & TRN \\
\hline CHEMBL1452235 & 688597 & 5.9367 & 5.91200 & 0000000001 \\
\hline CHEMBL1991388 & 688597 & 5.7602 & 5.7267 & TRN \\
\hline CHEMBL1351184 & 688597 & 5.0037 & 5.0634 & TST \\
\hline CHEMBL1416666 & 688597 & 4.4631 & 4.8304 & TRN \\
\hline CHEMBL1493936 & 688597 & 8.2218 & 7.755 & TRN \\
\hline CHEMBL1415312 & 688597 & 4.6124 & 4.7791 & TRN \\
\hline CHEMBL1505665 & 688597 & 5.3884 & 5.5844 & TRN \\
\hline CHEMBL1507251 & 688597 & 5.6803 & 5.6686 & TRN \\
\hline CHEMBL1457644 & 688597 & 5.4245 & 5.3652 & TRN \\
\hline CHEMBL1455542 & 688597 & 5.7009 & 5.6105 & TRN \\
\hline CHEMBL1435040 & 688597 & 2.8239 & 3.2512 & TRN \\
\hline CHEMBL1327172 & 688597 & 5.9931 & 5.7475 & TRN \\
\hline CHEMBL1356182 & 688597 & 5.4614 & 5.556 & TRN \\
\hline CHEMBL1467058 & 688597 & 8.2218 & 8.1754 & TST \\
\hline CHEMBL1387036 & 688597 & 2.8239 & 3.338 & TST \\
\hline CHEMBL1361866 & 688597 & 5.1202 & 4.78 & TST \\
\hline CHEMBL1327810 & 688597 & 5.3661 & 5.2392 & TRN \\
\hline CHEMBL 3145320 & 688597 & 5.9492 & 5.6818 & TRN \\
\hline CHEMBL1501917 & 688597 & 5.4743 & 5.556 & TRN \\
\hline CHEMBL3213534 & 688597 & 2.8239 & 3.2539 & TRN \\
\hline CHEMBL1445161 & 688597 & 5.5857 & 5.472 & TST \\
\hline CHEMBL1337018 & 688597 & 5.5608 & 5.6417 & TRN \\
\hline CHEMBL1461337 & 688597 & 5.1257 & 5.3591 & TRN \\
\hline CHEMBL1360808 & 688597 & 5.1583 & 5.4828 & TRN \\
\hline CHEMBL3195536 & 688597 & 4.4725 & 4.9569 & TRN \\
\hline CHEMBL1431014 & 688597 & 6.0521 & 5.9637 & TRN \\
\hline CHEMBL1456906 & 688597 & 8.2218 & 8.1651 & TST \\
\hline CHEMBL1579548 & 688597 & 5.8864 & 5.6309 & TRN \\
\hline CHEMBL1449595 & 688597 & 2.8239 & 3.488 & TRN \\
\hline CHEMBL391123 & 688597 & 6.6108 & 6.9596 & TST \\
\hline CHEMBL2002849 & 688597 & 5.3598 & 5.6627 & TRN \\
\hline CHEMBL3193863 & 688597 & 5.3342 & 4.8081 & TRN \\
\hline CHEMBL3198022 & 688597 & 4.2624 & 3.4964 & TRN \\
\hline CHEMBL3190880 & 688597 & 5.766 & 6.0708 & TRN \\
\hline CHEMBL1372434 & 688597 & 5.4577 & 5.3367 & TRN \\
\hline CHEMBL3196513 & 688597 & 4.7525 & 5.0181 & TRN \\
\hline CHEMBL1443205 & 688597 & 5.8462 & 6.0997 & TRN \\
\hline CHEMBL1340487 & 688597 & 5.3702 & 5.2284 & TRN \\
\hline CHEMBL1494267 & 688597 & 2.8239 & 3.6352 & TST \\
\hline CHEMBL588804 & 688597 & 6.2204 & 6.2998 & TRN \\
\hline CHEMBL1468929 & 688597 & 6.1586 & 4.9588 & TST \\
\hline CHEMBL1547350 & 688597 & 6.1818 & 5.9072 & TRN \\
\hline CHEMBL1366997 & 688597 & 6.8729 & 6.8123 & TRN \\
\hline CHEMBL1586809 & 688597 & 5.744 & 5.0282 & TRN \\
\hline CHEMBL1523175 & 688597 & 5.5791 & 5.6104 & TRN \\
\hline CHEMBL1405059 & 688597 & 4.9531 & 4.8802 & TRN \\
\hline
\end{tabular}




\begin{tabular}{|c|c|c|c|c|c|}
\hline & & & & & \\
\hline CHEMBL1526855 & 688597 & 5.0287 & 5.2461 & TST & \\
\hline CHEMBL1374455 & 688597 & 4.3177 & 4.6012 & TRN & \\
\hline CHEMBL1572356 & 688597 & 6.0 & 6.2569 & TRN & \\
\hline CHEMBL1365357 & 688597 & 4.6846 & 4.9485 & TRN & \\
\hline CHEMBL1538317 & 688597 & 2.8239 & 3.653 & TRN & \\
\hline CHEMBL1478587 & 688597 & 5.9439 & 5.70299 & 9999999999 & TRN \\
\hline CHEMBL1350867 & 688597 & 5.0957 & 5.1732 & TRN & \\
\hline CHEMBL1300229 & 688597 & 2.8239 & 3.5365 & TST & \\
\hline CHEMBL1341676 & 688597 & 4.8471 & 5.2552 & TRN & \\
\hline CHEMBL1467749 & 688597 & 5.9144 & 5.8382 & TRN & \\
\hline CHEMBL1574738 & 688597 & 2.8239 & 3.5758 & TRN & \\
\hline CHEMBL3194931 & 688597 & 5.3194 & 5.1594 & TRN & \\
\hline CHEMBL1499597 & 688597 & 5.1862 & 5.1093 & TRN & \\
\hline CHEMBL1609481 & 688597 & 5.8289 & 5.8133 & TRN & \\
\hline CHEMBL166209 & 688597 & 5.2793 & 5.336 & TST & \\
\hline CHEMBL1465097 & 688597 & 5.1879 & 5.1011 & TRN & \\
\hline CHEMBL1371733 & 688597 & 2.8239 & 3.4639 & TRN & \\
\hline CHEMBL1360393 & 688597 & 5.2762 & 4.9814 & TRN & \\
\hline CHEMBL1375199 & 688597 & 5.2351 & 5.44 & TRN & \\
\hline CHEMBL1377813 & 688597 & 5.1336 & 5.1198 & TRN & \\
\hline CHEMBL1312885 & 688597 & 5.6302 & 5.6512 & TST & \\
\hline CHEMBL1602058 & 688597 & 4.8702 & 4.9643 & TRN & \\
\hline CHEMBL1965860 & 688597 & 5.1832 & 5.3398 & TRN & \\
\hline CHEMBL1493438 & 688597 & 5.1856 & 4.9013 & TRN & \\
\hline CHEMBL1462381 & 688597 & 5.0706 & 5.2907 & TRN & \\
\hline CHEMBL1542652 & 688597 & 5.5074 & 5.0758 & TST & \\
\hline CHEMBL590887 & 688597 & 5.4204 & 5.5662 & TRN & \\
\hline CHEMBL1494458 & 688597 & 5.0567 & 5.318 & TST & \\
\hline CHEMBL1576647 & 688597 & 5.1781 & 5.5409 & TRN & \\
\hline CHEMBL1509718 & 688597 & 6.065 & 5.9036 & TST & \\
\hline CHEMBL1536264 & 688597 & 5.755 & 3.5256 & TRN & \\
\hline CHEMBL1588408 & 688597 & 2.8239 & 4.8834 & TRN & \\
\hline CHEMBL1550430 & 688597 & 6.1811 & 5.9714 & TRN & \\
\hline CHEMBL1468147 & 688597 & 5.5476 & 5.59200 & 00000000005 & TRN \\
\hline CHEMBL1524865 & 688597 & 5.1787 & 5.4426 & TRN & \\
\hline CHEMBL1565526 & 688597 & 5.56 & 5.5335 & TRN & \\
\hline CHEMBL1412087 & 688597 & 5.7533 & 5.7711 & TRN & \\
\hline CHEMBL1606646 & 688597 & 5.5909 & 5.696006 & 0000000001 & TRN \\
\hline CHEMBL1984816 & 688597 & 4.796 & 4.8774 & TRN & \\
\hline CHEMBL1555435 & 688597 & 4.0826 & 4.6671 & TRN & \\
\hline CHEMBL1495462 & 688597 & 5.42399 & 79999999 & 5.4876 & TST \\
\hline CHEMBL1589219 & 688597 & 5.3094 & 4.9409 & TST & \\
\hline CHEMBL1386092 & 688597 & 5.4478 & 5.3428 & TST & \\
\hline CHEMBL1447893 & 688597 & 5.4984 & 5.4078 & TRN & \\
\hline CHEMBL1501022 & 688597 & 5.4126 & 5.4492 & TRN & \\
\hline CHEMBL1992174 & 688597 & 5.3118 & 5.4789 & TST & \\
\hline CHEMBL1524393 & 688597 & 4.8799 & 5.0896 & TRN & \\
\hline CHEMBL1580638 & 688597 & 5.8049 & 5.83 & TRN & \\
\hline
\end{tabular}


Supplemental Table S2.txt

\begin{tabular}{|c|c|c|c|c|}
\hline The & & .2723 & & \\
\hline & 88597 & .6904 & 5.5056 & \\
\hline & & & & \\
\hline AEMBL1422 & & 2023 & & \\
\hline AEMBL1496648 & 3597 & 76 & & \\
\hline HEMBL1413629 & 38597 & 1062 & 4352 & \\
\hline HEMBL1604217 & 8597 & 496 & & \\
\hline אבר & & & & \\
\hline HEMBL1525347 & 88597 & 8239 & & \\
\hline HEMBL3196125 & 38597 & 193 & 2591 & \\
\hline HEMBL1368833 & 88597 & 874 & 68 & \\
\hline IEMBL1 & 597 & 35 & 335 & \\
\hline AEMBL & & & & \\
\hline HEMBL1 & 88597 & 284 & & \\
\hline HEMBL1 & 597 & 93 & & \\
\hline AEMBL1 & 88597 & 28 & 95 & \\
\hline AEMBL] & 97 & & & \\
\hline HEMBLI & & & & \\
\hline AEMBL & 88597 & 832 & & \\
\hline AEMBL: & 97 & & & \\
\hline AEIMBL. & 97 & & 17 & ונד \\
\hline AEMBL & 97 & & & \\
\hline AEMBL & 97 & & & \\
\hline AFMI & 88597 & & & \\
\hline IEMBL1 & 97 & & & \\
\hline HEMBL & 97 & 3 & 91 & RIV \\
\hline AEMBL & 97 & & & (1) \\
\hline AFMR & 97 & & 86 & \\
\hline AEMBL & 88597 & & & $T_{2}$ \\
\hline HEMBL15137 & 97 & & & וدד \\
\hline HEMBL1 & 97 & & 863 & ST \\
\hline HEMBL & & 24 & & RN \\
\hline HEMPI & 97 & 36 & & ST \\
\hline HEMBL3194964 & & & & IRN \\
\hline HEMBL1353949 & 88597 & 39 & 978 & TST \\
\hline HEMBL & 88597 & & & RN \\
\hline HCMDI & & & 68 & RN \\
\hline & & 754 & & RN \\
\hline HEMBL1395972 & 88597 & & & TST \\
\hline AEMBL3 & 88597 & & 816 & $\Gamma \mathrm{RN}$ \\
\hline HEMBL2 & 88597 & & 2043 & \\
\hline CHEMBL1343658 & & & & NIV \\
\hline HEMBL3198398 & 88597 & & 2108 & RN \\
\hline AEMBL1611733 & 88597 & 59 & 5375 & TRN \\
\hline HEMBL1 & 88597 & & & RN \\
\hline CHEMBL1 & 88597 & & & \\
\hline CHEMBL 13039 & 88597 & 2.8239 & 3.1853 & \\
\hline CHEMBL1709970 & 688597 & 5.476 & 5.7004 & ГRN \\
\hline
\end{tabular}

Page 9339 


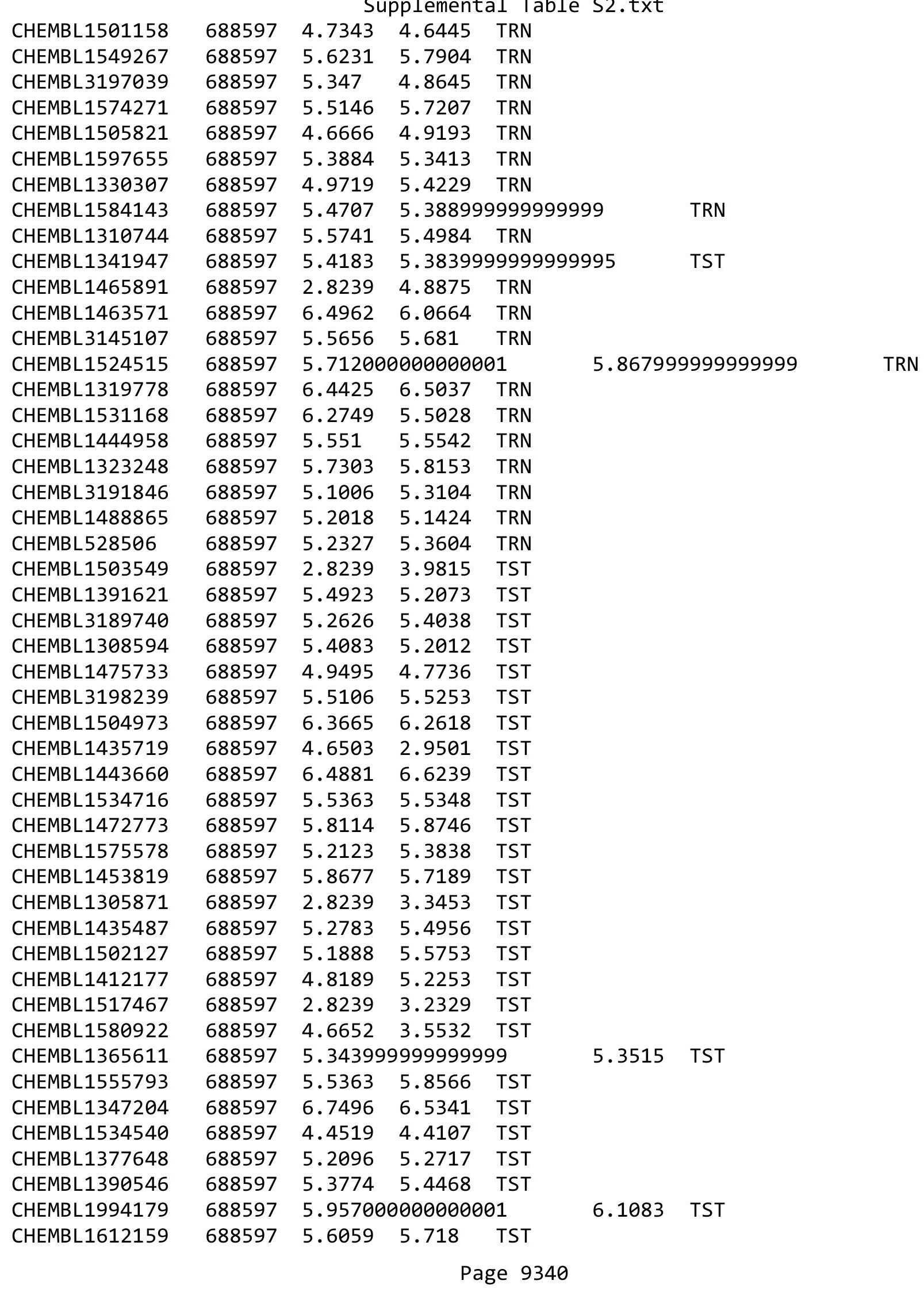




\begin{tabular}{|c|c|c|c|c|c|c|c|}
\hline \multicolumn{8}{|c|}{ Supplemental Table S2.txt } \\
\hline CHEMBL1446095 & 688597 & 5.1933 & 5.5324 & TST & & & \\
\hline CHEMBL1515525 & 688597 & 5.4778 & 5.7342 & TST & & & \\
\hline CHEMBL1360941 & 688597 & 5.7833 & 5.4687 & TST & & & \\
\hline CHEMBL1422471 & 688597 & 5.45299 & 99999999 & & $3.7060 e$ & 00000000004 & TST \\
\hline CHEMBL 3192542 & 688597 & 6.1952 & 6.3702 & TST & & & \\
\hline CHEMBL1427455 & 688597 & 4.8079 & 4.7429 & TST & & & \\
\hline CHEMBL1572510 & 688597 & 8.2218 & 6.2553 & TST & & & \\
\hline CHEMBL1318412 & 688597 & 5.0319 & 4.7943 & TST & & & \\
\hline CHEMBL1492135 & 688597 & 2.8239 & 3.5076 & TST & & & \\
\hline CHEMBL1526472 & 688597 & 5.1172 & 5.2334 & TST & & & \\
\hline CHEMBL1507228 & 688597 & 5.556 & 5.3427 & TST & & & \\
\hline CHEMBL3193989 & 688597 & 5.4747 & 5.3528 & TST & & & \\
\hline CHEMBL1345459 & 688597 & 2.8239 & 3.1155 & TST & & & \\
\hline CHEMBL1320465 & 688597 & 5.2429 & 5.2223 & TST & & & \\
\hline CHEMBL1306856 & 688597 & 4.857 & 4.9867 & TST & & & \\
\hline CHEMBL1481109 & 688597 & 5.2365 & 5.4249 & TST & & & \\
\hline CHEMBL1320940 & 688597 & 5.4647 & 5.5496 & TST & & & \\
\hline CHEMBL1383511 & 688597 & 5.1142 & 5.1112 & TST & & & \\
\hline CHEMBL1580339 & 688597 & 5.3688 & 5.0853 & TST & & & \\
\hline CHEMBL1391055 & 688597 & 5.1996 & 5.42200 & 0000000001 & & TST & \\
\hline CHEMBL1557648 & 688597 & 6.5952 & 6.6742 & TST & & & \\
\hline CHEMBL 3190404 & 688597 & 5.261 & 4.8812 & TST & & & \\
\hline CHEMBL1301179 & 688597 & 5.65600 & 00000000 & & 5.3368 & TST & \\
\hline CHEMBL1305997 & 688597 & 5.6315 & 5.649 & TST & & & \\
\hline CHEMBL1490966 & 688597 & 2.8239 & 3.16899 & 9999999999 & 96 & TST & \\
\hline CHEMBL1450554 & 688597 & 2.8239 & 3.2966 & TST & & & \\
\hline CHEMBL3189712 & 688597 & 5.3886 & 5.7465 & TST & & & \\
\hline CHEMBL1354488 & 688597 & 2.8239 & 3.6022 & TST & & & \\
\hline CHEMBL1325639 & 688597 & 4.8074 & 5.0919 & TST & & & \\
\hline CHEMBL3198886 & 688597 & 6.38299 & 99999999 & 99 & 6.0904 & TST & \\
\hline CHEMBL1519235 & 688597 & 5.3754 & 5.38 & TST & & & \\
\hline CHEMBL1540682 & 688597 & 5.3757 & 5.3134 & TST & & & \\
\hline CHEMBL455284 & 688597 & 5.7537 & 5.7789 & TST & & & \\
\hline CHEMBL3192328 & 688597 & 5.6784 & 5.624 & TST & & & \\
\hline CHEMBL1459931 & 688597 & 2.8239 & 2.7219 & TST & & & \\
\hline CHEMBL1415494 & 688597 & 2.8239 & 3.6277 & TST & & & \\
\hline CHEMBL1367662 & 688597 & 5.3979 & 4.8994 & TST & & & \\
\hline CHEMBL1985479 & 688597 & 5.295 & 5.53600 & 0000000000 & & TST & \\
\hline CHEMBL1497725 & 688597 & 2.8239 & 3.5444 & TST & & & \\
\hline CHEMBL1509694 & 688597 & 4.5166 & 5.0552 & TST & & & \\
\hline CHEMBL1306406 & 688597 & 5.9809 & 6.1493 & TST & & & \\
\hline CHEMBL1519755 & 688597 & 5.636 & 5.7253 & TST & & & \\
\hline CHEMBL1552296 & 688597 & 2.8239 & 5.3359 & TST & & & \\
\hline CHEMBL1539400 & 688597 & 5.3674 & 5.0879 & TST & & & \\
\hline CHEMBL1494782 & 688597 & 2.8239 & 3.2574 & TST & & & \\
\hline CHEMBL1340213 & 688597 & 5.1936 & 5.1549 & TST & & & \\
\hline CHEMBL1416159 & 688597 & 2.8239 & 3.4671 & TST & & & \\
\hline CHEMBL1583802 & 688597 & 6.4202 & 6.7772 & TST & & & \\
\hline
\end{tabular}




\begin{tabular}{|c|c|c|c|c|c|c|}
\hline & & \multicolumn{5}{|c|}{ Supplemental Table S2.txt } \\
\hline CHEMBL 3197982 & 688597 & 4.6742 & 3.5376 & TST & & \\
\hline CHEMBL1428221 & 688597 & 6.011 & 4.9207 & TST & & \\
\hline CHEMBL1327366 & 688597 & 5.4438 & 5.2886 & TST & & \\
\hline CHEMBL1444941 & 688597 & 5.4083 & 5.2116 & TST & & \\
\hline CHEMBL1385362 & 688597 & 2.8239 & 2.79 & TST & & \\
\hline CHEMBL1516792 & 688597 & 4.7749 & 4.6227 & TST & & \\
\hline CHEMBL1409950 & 688597 & 4.9926 & 5.1338 & TST & & \\
\hline CHEMBL1460692 & 688597 & 5.5123 & 5.355 & TST & & \\
\hline CHEMBL1341108 & 688597 & 5.4413 & 5.3947 & TST & & \\
\hline CHEMBL1460352 & 688597 & 5.5297 & 5.2839 & TST & & \\
\hline CHEMBL1613678 & 688597 & 5.1859 & 5.1567 & TST & & \\
\hline CHEMBL1338335 & 688597 & 5.7014 & 5.7733 & TST & & \\
\hline CHEMBL3145296 & 688597 & 6.3686 & 6.3127 & TST & & \\
\hline CHEMBL1427185 & 688597 & 4.9826 & 5.0496 & TST & & \\
\hline CHEMBL1608787 & 688597 & 5.3082 & 5.2986 & TST & & \\
\hline CHEMBL1423138 & 688597 & 6.0044 & 5.8551 & TST & & \\
\hline CHEMBL3189749 & 688597 & 5.2024 & 3.5282 & TST & & \\
\hline CHEMBL1371940 & 688597 & 5.66799 & 99999999 & 99 & 5.4278 & TST \\
\hline CHEMBL1326371 & 688597 & 5.5103 & 5.5165 & TST & & \\
\hline CHEMBL1503729 & 688597 & 5.0517 & 5.4198 & TST & & \\
\hline CHEMBL1528476 & 688597 & 6.2211 & 6.1463 & TST & & \\
\hline CHEMBL1420131 & 688597 & 4.8071 & 4.213 & TST & & \\
\hline CHEMBL3212930 & 688597 & 5.2701 & 5.4299 & TST & & \\
\hline CHEMBL1567674 & 688597 & 4.9882 & 4.9591 & TST & & \\
\hline CHEMBL1417529 & 688597 & 5.6527 & 5.4577 & TST & & \\
\hline CHEMBL1537032 & 688597 & 2.8239 & 4.9062 & TST & & \\
\hline CHEMBL1605393 & 688597 & 5.7886 & 4.9391 & TST & & \\
\hline CHEMBL1974063 & 688597 & 5.5272 & 5.4583 & TST & & \\
\hline CHEMBL1467427 & 688597 & 5.2954 & 5.081 & TST & & \\
\hline CHEMBL1495140 & 688597 & 5.3632 & 5.3808 & TST & & \\
\hline CHEMBL1425091 & 688597 & 5.3135 & 5.4796 & TST & & \\
\hline CHEMBL1537518 & 688597 & 5.2109 & 4.8608 & TST & & \\
\hline CHEMBL1519335 & 688597 & 4.7955 & 4.6148 & TST & & \\
\hline CHEMBL1413243 & 688597 & 5.9212 & 5.7372 & TST & & \\
\hline CHEMBL1333647 & 688597 & 4.1564 & 4.0913 & TST & & \\
\hline CHEMBL1438582 & 688597 & 2.8239 & 3.3009 & TST & & \\
\hline CHEMBL391533 & 688597 & 5.5508 & 5.8625 & TST & & \\
\hline CHEMBL1523859 & 688597 & 5.2615 & 5.3611 & TST & & \\
\hline CHEMBL1383414 & 688597 & 5.7089 & 5.95299 & 9999999999 & & TS \\
\hline CHEMBL1562926 & 688597 & 6.0173 & 6.2012 & TST & & \\
\hline CHEMBL1469791 & 688597 & 6.0048 & 5.9723 & TST & & \\
\hline CHEMBL463175 & 688597 & 6.3002 & 6.4564 & TST & & \\
\hline CHEMBL606167 & 688597 & 5.5232 & 5.4062 & TST & & \\
\hline CHEMBL1410739 & 688597 & 5.5139 & 5.593 & TST & & \\
\hline CHEMBL1565897 & 688597 & 5.394 & 5.6703 & TST & & \\
\hline CHEMBL63354 & 688597 & 5.6386 & 5.7621 & TST & & \\
\hline CHEMBL1441999 & 688597 & 5.9931 & 5.7808 & TST & & \\
\hline CHEMBL1453208 & 688597 & 5.5918 & 5.9682 & TST & & \\
\hline
\end{tabular}


Supplemental Table S2.txt

\begin{tabular}{|c|c|c|c|c|c|c|}
\hline CHEMBL1539864 & 688597 & 5.9978 & \multicolumn{3}{|c|}{6.047000000000001} & TST \\
\hline CHEMBL1310080 & 688597 & 5.7049 & 5.8253 & TST & & \\
\hline CHEMBL1377417 & 688597 & 4.7236 & 4.8262 & TST & & \\
\hline CHEMBL1523566 & 688597 & 5.5707 & 5.4943 & TST & & \\
\hline CHEMBL 3198095 & 688597 & 5.1846 & 4.8707 & TST & & \\
\hline CHEMBL 3192194 & 688597 & 5.7217 & 5.9158 & TST & & \\
\hline CHEMBL1494996 & 688597 & 6.0762 & 6.3443 & TST & & \\
\hline CHEMBL1582557 & 688597 & 4.9242 & 5.1753 & TST & & \\
\hline CHEMBL1561190 & 688597 & 4.6706 & 5.2134 & TST & & \\
\hline CHEMBL1387128 & 688597 & 2.8239 & 3.3891 & TST & & \\
\hline CHEMBL 3194571 & 688597 & 5.9473 & 5.975 & TST & & \\
\hline CHEMBL1452116 & 688597 & 5.8564 & 5.8291 & TST & & \\
\hline CHEMBL1606837 & 688597 & 5.2261 & 5.3076 & TST & & \\
\hline CHEMBL1452612 & 688597 & 5.3303 & 5.4963 & TST & & \\
\hline CHEMBL 2369172 & 688597 & 5.166 & 5.2788 & TST & & \\
\hline CHEMBL1326397 & 688597 & 8.2218 & 8.7265 & TST & & \\
\hline CHEMBL1378131 & 688597 & 6.1085 & 6.4301 & TST & & \\
\hline CHEMBL1522645 & 688597 & 5.3257 & 4.9635 & TST & & \\
\hline CHEMBL1345480 & 688597 & 5.4995 & 5.1204 & TST & & \\
\hline CHEMBL1372805 & 688597 & 5.9458 & 5.5529 & TST & & \\
\hline CHEMBL1582307 & 688597 & 5.7036 & 5.7924 & TST & & \\
\hline CHEMBL1607065 & 688597 & 5.5511 & 5.1036 & TST & & \\
\hline CHEMBL 3196184 & 688597 & 5.9326 & 6.0003 & TST & & \\
\hline CHEMBL1376204 & 688597 & 4.3914 & 4.9728 & TST & & \\
\hline CHEMBL1511495 & 688597 & 5.2219 & 5.3559 & TST & & \\
\hline CHEMBL 2007218 & 688597 & 6.1249 & 6.4697 & TST & & \\
\hline CHEMBL1453497 & 688597 & 5.162999 & 99999999 & 99 & 5.0053 & \\
\hline CHEMBL1411241 & 688597 & 6.7932 & 7.0453 & TST & & \\
\hline CHEMBL1322375 & 688597 & 4.7868 & 4.9709 & TST & & \\
\hline CHEMBL1424051 & 688597 & 2.8239 & 3.1722 & TST & & \\
\hline CHEMBL1520328 & 688597 & 5.5424 & 5.6624 & TST & & \\
\hline CHEMBL1375741 & 688597 & 5.4316 & 5.596 & TST & & \\
\hline CHEMBL1383757 & 688597 & 4.1637 & 3.7222 & TST & & \\
\hline CHEMBL 3199301 & 688597 & 5.548999 & 99999999 & 995 & 5.4723 & \\
\hline CHEMBL1481444 & 688597 & 4.9586 & 5.1101 & TST & & \\
\hline CHEMBL1461661 & 688597 & 5.6017 & 5.9083 & TST & & \\
\hline CHEMBL1344526 & 688597 & 2.8239 & 2.7023 & TST & & \\
\hline CHEMBL1502401 & 688597 & 5.5724 & 5.1237 & TST & & \\
\hline CHEMBL 3190103 & 688597 & 5.5586 & 5.5921 & TST & & \\
\hline CHEMBL1544460 & 688597 & 5.9965 & 6.1227 & TST & & \\
\hline CHEMBL1402915 & 688597 & 2.8239 & 3.8235 & TST & & \\
\hline CHEMBL1383078 & 688597 & 5.5305 & 6.0062 & TST & & \\
\hline CHEMBL1385886 & 688597 & 4.7808 & 4.9174 & TST & & \\
\hline CHEMBL1500450 & 688597 & 5.5613 & 5.8454 & TST & & \\
\hline CHEMBL1338736 & 688597 & 5.4271 & 5.5225 & TST & & \\
\hline CHEMBL1584690 & 688597 & 2.8239 & 3.6092 & TST & & \\
\hline CHEMBL 3211356 & 688597 & 5.3286 & 5.4661 & TST & & \\
\hline CHEMBL1387517 & 688597 & 5.2616 & 4.8926 & TST & & \\
\hline
\end{tabular}


Supplemental Table S2.txt

\begin{tabular}{|c|c|c|c|c|}
\hline CHEMBL1379443 & 688597 & 5.9003 & 5.2879 & TST \\
\hline CHEMBL1404312 & 688597 & 5.5608 & 5.1643 & TST \\
\hline CHEMBL123 & 688597 & 5.5194 & 5.6636 & TST \\
\hline CHEMBL1435933 & 688597 & 5.4318 & 5.5781 & TST \\
\hline CHEMBL3192655 & 688597 & 5.0912 & 5.2967 & TST \\
\hline CHEMBL1564731 & 688597 & 5.7796 & 5.858 & TST \\
\hline CHEMBL589238 & 688597 & 6.6882 & 6.7172 & TST \\
\hline CHEMBL1583785 & 688597 & 4.8598 & 4.7904 & TST \\
\hline CHEMBL1345404 & 688597 & 2.8239 & 3.5695 & TST \\
\hline CHEMBL1418469 & 688597 & 4.8693 & 5.1351 & TST \\
\hline CHEMBL1383799 & 688597 & 5.8125 & 5.7051 & TST \\
\hline CHEMBL3191958 & 688597 & 5.2032 & 5.3466 & TST \\
\hline CHEMBL1610443 & 688597 & 5.9165 & 6.0574 & TST \\
\hline CHEMBL1405742 & 688597 & 4.6676 & 4.8291 & TST \\
\hline CHEMBL1367313 & 688597 & 5.3646 & 5.2557 & TST \\
\hline CHEMBL1530378 & 688597 & 2.8239 & 3.7172 & TST \\
\hline CHEMBL1484097 & 688597 & 5.1705 & 5.1013 & TST \\
\hline CHEMBL1345063 & 688597 & 5.7326 & 5.4201 & TST \\
\hline CHEMBL1326901 & 688597 & 3.301 & 3.4945 & TST \\
\hline CHEMBL1388722 & 688597 & 5.4888 & 5.4554 & TST \\
\hline CHEMBL1504569 & 688597 & 5.5203 & 5.7708 & TST \\
\hline CHEMBL1586706 & 688597 & 5.2463 & 4.8799 & TST \\
\hline CHEMBL1347282 & 688597 & 2.8239 & 3.3715 & TST \\
\hline CHEMBL1408962 & 688597 & 5.6321 & 5.7579 & TST \\
\hline CHEMBL1562608 & 688597 & 5.0851 & 5.4375 & TST \\
\hline CHEMBL1341012 & 688597 & 5.8761 & 5.6761 & TST \\
\hline CHEMBL45281 & 688597 & 5.901 & 5.7563 & TST \\
\hline CHEMBL1425525 & 688597 & 5.7007 & 5.7272 & TST \\
\hline CHEMBL1340458 & 688597 & 5.3811 & 5.3702 & TST \\
\hline CHEMBL1384874 & 688597 & 6.2457 & 6.3136 & TST \\
\hline CHEMBL3191019 & 688597 & 5.027 & 5.2426 & TST \\
\hline CHEMBL1457139 & 688597 & 5.3612 & 5.6685 & TST \\
\hline CHEMBL1327706 & 688597 & 5.9523 & 6.0064 & TST \\
\hline CHEMBL1496635 & 688597 & 5.2859 & 5.4287 & TST \\
\hline CHEMBL1602709 & 688597 & 4.9539 & 5.4717 & TST \\
\hline CHEMBL1355704 & 688597 & 5.7247 & 5.53 & TST \\
\hline CHEMBL1540024 & 688597 & 4.9018 & 5.01699 & 99999999995 \\
\hline CHEMBL1582581 & 688597 & 5.1386 & 4.9442 & TST \\
\hline CHEMBL1533170 & 688597 & 4.2035 & 3.6553 & TST \\
\hline CHEMBL1335030 & 688597 & 6.1772 & 6.425 & TST \\
\hline CHEMBL1538986 & 688597 & 5.2542 & 5.2815 & TST \\
\hline CHEMBL1496647 & 688597 & 5.1029 & 5.0687 & TST \\
\hline CHEMBL1568971 & 688597 & 5.4989 & 5.1953 & TST \\
\hline CHEMBL1569755 & 688597 & 5.2885 & 5.5015 & TST \\
\hline CHEMBL1568696 & 688597 & 2.8239 & 3.49399 & 99999999998 \\
\hline CHEMBL1980844 & 688597 & 8.2218 & 7.8921 & TST \\
\hline CHEMBL1441897 & 688597 & 5.2775 & 5.3282 & TST \\
\hline CHEMBL1301650 & 688597 & 5.7312 & 6.0026 & TST \\
\hline
\end{tabular}




\begin{tabular}{|c|c|c|c|c|c|}
\hline \multicolumn{6}{|c|}{ Supplemental Table s2.txt } \\
\hline CHEMBL1312303 & 688597 & 6.51 & 4.7426 & TST & \\
\hline CHEMBL1315795 & 688597 & 5.3764 & 5.4378 & TST & \\
\hline CHEMBL1557920 & 688597 & 5.1488 & 5.5184 & TST & \\
\hline CHEMBL1494810 & 688597 & 5.3226 & 5.6361 & TST & \\
\hline CHEMBL1323151 & 688597 & 4.7587 & 5.01699 & 99999999995 & TST \\
\hline CHEMBL1460624 & 688597 & 6.4145 & 6.0243 & TST & \\
\hline CHEMBL3197599 & 688597 & 5.4001 & 5.6506 & TST & \\
\hline CHEMBL3189791 & 688597 & 5.6062 & 5.6342 & TST & \\
\hline CHEMBL1399731 & 688597 & 5.2019 & 5.395 & TST & \\
\hline CHEMBL1488021 & 688597 & 5.1161 & 5.2318 & TST & \\
\hline CHEMBL1200847 & 688597 & 5.476 & 5.8254 & TST & \\
\hline CHEMBL3194807 & 688597 & 5.6323 & 5.8718 & TST & \\
\hline CHEMBL504598 & 688597 & 5.7203 & 5.0822 & TST & \\
\hline CHEMBL140425 & 688597 & 6.1068 & 5.9496 & TST & \\
\hline CHEMBL1350930 & 688597 & 5.0989 & 5.0815 & TST & \\
\hline CHEMBL1579808 & 688597 & 5.671 & 5.3367 & TST & \\
\hline CHEMBL1469656 & 688597 & 5.657 & 5.7715 & TST & \\
\hline CHEMBL1521418 & 688597 & 5.3285 & 5.2091 & TST & \\
\hline CHEMBL1424264 & 688597 & 6.1192 & 5.9604 & TST & \\
\hline CHEMBL1508399 & 688597 & 5.5591 & 5.4567 & TST & \\
\hline CHEMBL3191413 & 688597 & 5.7082 & 5.3415 & TST & \\
\hline CHEMBL1428514 & 688597 & 5.5147 & 5.1636 & TST & \\
\hline CHEMBL1431953 & 688597 & 5.5127 & 5.612 & TST & \\
\hline CHEMBL1331239 & 688597 & 5.5311 & 5.1832 & TST & \\
\hline CHEMBL1606687 & 688597 & 2.8239 & 3.6605 & TST & \\
\hline CHEMBL1594567 & 688597 & 5.4752 & 5.2235 & TST & \\
\hline CHEMBL1391743 & 688597 & 6.7258 & 6.1484 & TST & \\
\hline CHEMBL1334663 & 688597 & 2.8239 & 3.1111 & TST & \\
\hline CHEMBL1509878 & 688597 & 6.3507 & 6.4335 & TST & \\
\hline CHEMBL1372492 & 688597 & 5.9682 & 6.2926 & TST & \\
\hline CHEMBL1505192 & 688597 & 5.1508 & 5.3907 & TST & \\
\hline CHEMBL1582831 & 688597 & 5.8145 & 5.9479 & TST & \\
\hline CHEMBL589351 & 688597 & 5.2198 & 5.2439 & TST & \\
\hline CHEMBL1538328 & 688597 & 6.1035 & 5.975 & TST & \\
\hline CHEMBL1525259 & 688597 & 5.5553 & 5.5649 & TST & \\
\hline CHEMBL1599401 & 688597 & 6.7825 & 6.6173 & TST & \\
\hline CHEMBL1486442 & 688597 & 5.0879 & 4.8255 & TST & \\
\hline CHEMBL1483038 & 688597 & 5.1325 & 5.3016 & TST & \\
\hline CHEMBL1315654 & 688597 & 5.3853 & 5.5543 & TST & \\
\hline CHEMBL1361054 & 688597 & 8.2218 & 8.0747 & TST & \\
\hline CHEMBL1306283 & 688597 & 6.5901 & 6.8019 & TST & \\
\hline CHEMBL3192020 & 688597 & 5.7962 & 5.9547 & TST & \\
\hline CHEMBL1606903 & 688597 & 5.3079 & 5.28100 & 0000000001 & TST \\
\hline CHEMBL1466182 & 688597 & 5.4166 & 5.7553 & TST & \\
\hline CHEMBL1586932 & 688597 & 5.2268 & 5.1255 & TST & \\
\hline CHEMBL1587753 & 688597 & 5.4724 & 5.5639 & TST & \\
\hline CHEMBL1377690 & 688597 & 5.4755 & 5.0149 & TST & \\
\hline CHEMBL1420123 & 688597 & 5.3967 & 5.1373 & TST & \\
\hline
\end{tabular}


Supplemental Table S2.txt

\begin{tabular}{|c|c|c|c|c|}
\hline-3 & & & & \\
\hline HEMBL1609946 & 88597 & 7167 & 7.0034 & \\
\hline 39 & & & & \\
\hline CMOI 11 & 597 & 45 & & \\
\hline AEMBL3194704 & 38597 & 834 & & \\
\hline AEMBL1472532 & 88597 & 4683 & 115 & \\
\hline HEMBL1326851 & 88597 & 3957 & 1433 & \\
\hline AFMR 15 & & & & \\
\hline AEMBL1505 & 88597 & 045 & 1919 & \\
\hline AEMBL1453335 & 88597 & 548 & 5955 & \\
\hline HEMBL3213606 & 88597 & .8176 & 6642 & \\
\hline AEMBL1383632 & 88597 & 953 & 7814 & \\
\hline IEMBL13 & & & & \\
\hline AEMBL15 & 97 & 02 & .9241 & \\
\hline AEMBL1544859 & 38597 & 602 & & \\
\hline AEMBL1456111 & 88597 & 68 & 2487 & \\
\hline HEMBL3190533 & 597 & 39 & 39 & \\
\hline HEMBL1598 & & & & \\
\hline HEMBL 153 & 97 & 54 & & \\
\hline AEMBL134 & 97 & & & \\
\hline AEMBL1326559 & 38597 & 39 & 808 & \\
\hline HEMBL1422465 & 597 & 95 & 544 & \\
\hline HEMBL 319 & & & & \\
\hline 52 & & & & \\
\hline IEMBL 208 & 97 & & 18 & ST \\
\hline AEMBL140311 & 597 & & 281 & \\
\hline AEMBL1326819 & 97 & & 102 & \\
\hline 27 & & & 217 & \\
\hline 3L318 & & & & \\
\hline AEMBL15232 & 8597 & & 313 & SI \\
\hline IEMBL19 & 97 & & 66 & \\
\hline 137 & 97 & & 347 & \\
\hline 6 & & & & \\
\hline HEMBL1489078 & & & & \\
\hline HEMBL135987 & 88597 & 74 & 365 & ST \\
\hline AEMBL14669 & 38597 & 224 & 772 & \\
\hline 1 & 97 & 18 & & \\
\hline & & & & \\
\hline HEMBL1570378 & 88597 & 5 & 28 & ST \\
\hline AEMBL1596985 & 88597 & & & ST \\
\hline HEMBL1364447 & 88597 & & & \\
\hline & & & & I \\
\hline HEMBL3209451 & 38597 & 378 & 5.8109 & ST \\
\hline AEMBL1494940 & 88597 & 3564 & 5.8899 & ST \\
\hline EMBL13. & 88597 & & 5.2233 & s \\
\hline HEMBL 3145042 & 588597 & & & \\
\hline 然 & לעם & 5.4089 & 5.4069 & \\
\hline LHEMBL389575e & 1641170 & 7.0269 & 7.1552 & \\
\hline
\end{tabular}


Supplemental Table S2.txt

\begin{tabular}{|c|c|c|c|c|c|}
\hline CHEMBL3928207 & 1641170 & 7.3665 & 6.7443 & TRN & \\
\hline CHEMBL3895425 & 1641170 & 6.0701 & 6.8235 & TST & \\
\hline CHEMBL3964160 & 1641170 & 7.8539 & 7.5887 & TRN & \\
\hline CHEMBL 3895042 & 1641170 & 6.2076 & 6.3831 & TRN & \\
\hline CHEMBL3964759 & 1641170 & 6.0 & 6.9686 & TRN & \\
\hline CHEMBL3925763 & 1641170 & 6.8508 & 6.8592 & TRN & \\
\hline CHEMBL3975880 & 1641170 & 7.4949 & 7.1867 & TRN & \\
\hline CHEMBL3928069 & 1641170 & 7.8539 & 7.9359 & TRN & \\
\hline CHEMBL3938194 & 1641170 & 7.9208 & 7.3792 & TRN & \\
\hline CHEMBL 3912494 & 1641170 & 6.5686 & 6.2712 & TRN & \\
\hline CHEMBL3964751 & 1641170 & 7.0132 & 7.2244 & TRN & \\
\hline CHEMBL3963324 & 1641170 & 5.699 & 6.3123 & TRN & \\
\hline CHEMBL3947884 & 1641170 & 6.7447 & 5.96700 & 00000000005 & TRN \\
\hline CHEMBL3902063 & 1641170 & 6.6968 & 6.9635 & TRN & \\
\hline CHEMBL 3926602 & 1641170 & 7.699 & 8.4548 & TRN & \\
\hline CHEMBL3890196 & 1641170 & 7.4353 & 7.5217 & TRN & \\
\hline CHEMBL3922533 & 1641170 & 6.2596 & 6.2313 & TRN & \\
\hline CHEMBL3960594 & 1641170 & 6.1972 & 6.2826 & TRN & \\
\hline CHEMBL3903594 & 1641170 & 5.4613 & 6.9268 & TRN & \\
\hline CHEMBL3956644 & 1641170 & 8.0555 & 7.6172 & TRN & \\
\hline CHEMBL 3957748 & 1641170 & 6.4622 & 6.6903 & TRN & \\
\hline CHEMBL3934900 & 1641170 & 7.7959 & 6.8752 & TST & \\
\hline CHEMBL3905683 & 1641170 & 6.0 & 7.046 & TST & \\
\hline CHEMBL3954238 & 1641170 & 7.6778 & 7.5717 & TRN & \\
\hline CHEMBL3963703 & 1641170 & 5.4976 & 7.2013 & TST & \\
\hline CHEMBL3955585 & 1641170 & 8.301 & 7.0016 & TRN & \\
\hline CHEMBL3974812 & 1641170 & 6.0 & 7.2796 & TRN & \\
\hline CHEMBL3961723 & 1641170 & 5.2518 & 6.625 & TRN & \\
\hline CHEMBL3972004 & 1641170 & 6.0 & 7.1593 & TRN & \\
\hline CHEMBL3918243 & 1641170 & 6.9245 & 7.6137 & TRN & \\
\hline CHEMBL3981768 & 1641170 & 5.699 & 6.9945 & TRN & \\
\hline CHEMBL3976331 & 1641170 & 7.9586 & 6.8972 & TRN & \\
\hline CHEMBL3974245 & 1641170 & 5.7959 & 6.4349 & TST & \\
\hline CHEMBL3919642 & 1641170 & 6.5086 & 6.3512 & TST & \\
\hline CHEMBL3969827 & 1641170 & 6.0 & 7.05 & TRN & \\
\hline CHEMBL3936790 & 1641170 & 7.6383 & 6.7737 & TRN & \\
\hline CHEMBL 3914524 & 1641170 & 7.0706 & 6.6249 & TST & \\
\hline CHEMBL3622522 & 1641170 & 6.5884 & 6.1119 & TST & \\
\hline CHEMBL3917833 & 1641170 & 6.1079 & 6.5633 & TST & \\
\hline CHEMBL3943874 & 1641170 & 8.2076 & 7.772 & TRN & \\
\hline CHEMBL 3982323 & 1641170 & 6.1427 & 6.4303 & TRN & \\
\hline CHEMBL3900936 & 1641170 & 6.4815 & 7.0086 & TRN & \\
\hline CHEMBL3929443 & 1641170 & 5.8539 & 6.0984 & TRN & \\
\hline CHEMBL3945673 & 1641170 & 6.4855 & 6.3372 & TRN & \\
\hline CHEMBL3953090 & 1641170 & 7.9208 & 6.7502 & TRN & \\
\hline CHEMBL3978430 & 1641170 & 6.1965 & 6.3093 & TRN & \\
\hline CHEMBL3910112 & 1641170 & 5.8315 & 6.2649 & TRN & \\
\hline CHEMBL3970186 & 1641170 & 6.3635 & 6.5589 & TRN & \\
\hline
\end{tabular}


Supplemental Table S2.txt

\begin{tabular}{|c|c|c|}
\hline & & \\
\hline HEMBL3937349 & 1641170 & \\
\hline HEMBL3936520 & 641170 & \\
\hline 053 & 641170 & \\
\hline$A F M B$ & 1170 & 12 \\
\hline HEMBL 397 & 641170 & 769 \\
\hline AEMBL3907540 & 641170 & 8.096 \\
\hline HEMBL3920709 & 1641170 & 5.638 \\
\hline AEMBL3909500 & 170 & 744 \\
\hline IEMBL 3976387 & 170 & 5552 \\
\hline AEMBL3926260 & 1641170 & 7.148 \\
\hline AEMBL3977352 & 641170 & 8.065 \\
\hline AEMBL3892803 & 1170 & 6.73 \\
\hline IEMBL3904670 & 170 & 6.207 \\
\hline HEMBL 394 & & 7.301 \\
\hline AEMBL3906814 & 1170 & 5.657 \\
\hline IEMBL3939188 & 170 & 8.161 \\
\hline HEMBL3940748 & 170 & 5.773 \\
\hline 081 & $1 / 0$ & 19 \\
\hline 206 & & \\
\hline 304 & 170 & 5.273 \\
\hline 101 & & 366 \\
\hline IEMBL 3897619 & 70 & 7.397 \\
\hline 746 & 16 & 6 \\
\hline 447 & 70 & \\
\hline 42 & 170 & 7.1739 \\
\hline L3S & & 7.337 \\
\hline L390 & & 7.795 \\
\hline 554 & & 6.744 \\
\hline 496 & 170 & 6.2366 \\
\hline & & 7.346 \\
\hline L 391 & 70 & 7.028 \\
\hline HEMBL3945947 & 70 & 7.647 \\
\hline 776 & 10 & 7.677 \\
\hline 29 & 16 & 7.886 \\
\hline HEMBL3981826 & 170 & 6.101 \\
\hline AEMBL3961148 & 170 & 5.080 \\
\hline IEMBL3948198 & 16 & 6.468 \\
\hline IFMBI 39 & 16 & 6.183 \\
\hline רבים & 170 & 5.746 \\
\hline HEMBL3985891 & 170 & 5.522 \\
\hline CHEMBL3914561 & 170 & 6.063 \\
\hline (19. & & 5.895 \\
\hline CHEMBL3892038 & 16 & 7.3768 \\
\hline CHEMBL3910439 & 1641170 & 7.3665 \\
\hline HEMBL 3976154 & 1641170 & 6.2565 \\
\hline HEMBL 3896212 & 1641170 & 7.699 \\
\hline HEMPI 20710 & 601170 & 60 \\
\hline
\end{tabular}

6.6381 TRN

5.7129 TRN

6.7861 TST

6.8945 TRN

7.6178 TRN

6.941 TRN

7.5217 TRN

6.334 TST

6.987 TST

6.542999999999999

7.0379 TRN

7.5943 TRN

6.5755 TRN

6.1265 TRN

6.5943 TRN

6.4509 TST

7.9496 TRN

6.4174 TRN

6.8971 TRN

6.3529 TRN

6.1904 TST

7.3744 TRN

7.1253 TRN

7.2238 TRN

6.4573 TRN

7.3304 TRN

7.1401 TRN

7.4504 TRN

6.849 TRN

6.5477 TRN

7.6975 TRN

7.3608 TST

7.6752 TST

7.3059 TRN

7.1012 TRN

6.733 TRN

6.6274 TST

6.2617 TRN

6.3629 TRN

6.3918 TST

6.5428 TRN

6.3709 TRN

6.6631 TRN

7.0324 TRN

7.5511 TRN

6.4013 TRN

6.3427 TRN

6.3868 TRN 
Supplemental Table S2.txt

\begin{tabular}{|c|c|c|c|c|}
\hline CHEMBL3983780 & 1641170 & 7.7447 & 7.2196 & TRN \\
\hline CHEMBL3931339 & 1641170 & 6.8703 & 7.5103 & TRN \\
\hline CHEMBL3912362 & 1641170 & 7.9586 & 7.9556 & TRN \\
\hline CHEMBL3947021 & 1641170 & 6.7212 & 6.3466 & TST \\
\hline CHEMBL3941644 & 1641170 & 6.7696 & 6.3429 & TRN \\
\hline CHEMBL3902247 & 1641170 & 6.3382 & 6.4004 & TST \\
\hline CHEMBL3897984 & 1641170 & 6.4202 & 6.314 & TRN \\
\hline CHEMBL3974386 & 1641170 & 6.7447 & 6.8826 & TRN \\
\hline CHEMBL3948249 & 1641170 & 8.0757 & 7.2248 & TRN \\
\hline CHEMBL3977658 & 1641170 & 5.8277 & 6.2412 & TRN \\
\hline CHEMBL 3983924 & 1641170 & 8.0458 & 7.6112 & TRN \\
\hline CHEMBL3913657 & 1641170 & 6.6778 & 6.4919 & TRN \\
\hline CHEMBL3911711 & 1641170 & 7.3098 & 7.193 & TST \\
\hline CHEMBL3946692 & 1641170 & 5.8861 & 6.9256 & TRN \\
\hline CHEMBL3957950 & 1641170 & 7.2596 & 6.6613 & TST \\
\hline CHEMBL3943914 & 1641170 & 6.699 & \multicolumn{2}{|c|}{6.122000000000001} \\
\hline CHEMBL3931358 & 1641170 & 6.5229 & 6.3144 & TRN \\
\hline CHEMBL3985544 & 1641170 & 7.1308 & 6.02 & TST \\
\hline CHEMBL3962389 & 1641170 & 6.0496 & 6.2487 & TRN \\
\hline CHEMBL3955815 & 1641170 & 5.2502 & 6.8163 & TRN \\
\hline CHEMBL3970853 & 1641170 & 6.0 & 6.4537 & TRN \\
\hline CHEMBL3923813 & 1641170 & 5.7713 & 6.5106 & TST \\
\hline CHEMBL3898096 & 1641170 & 6.0 & 6.4442 & TST \\
\hline CHEMBL3900962 & 1641170 & 7.5686 & 7.6436 & TRN \\
\hline CHEMBL3960645 & 1641170 & 6.8239 & 6.6535 & TST \\
\hline CHEMBL3957741 & 1641170 & 6.284 & 6.8809 & TRN \\
\hline CHEMBL3901837 & 1641170 & 6.7447 & 7.0379 & TRN \\
\hline CHEMBL 3892724 & 1641170 & 6.9586 & 6.5841 & TST \\
\hline CHEMBL3920166 & 1641170 & 7.7696 & 7.9286 & TRN \\
\hline CHEMBL3968337 & 1641170 & 7.6576 & \multicolumn{2}{|c|}{7.0329999999999995} \\
\hline CHEMBL3982211 & 1641170 & 8.301 & 7.8392 & TRN \\
\hline CHEMBL3956973 & 1641170 & 6.4895 & 6.5512 & TRN \\
\hline CHEMBL3951361 & 1641170 & 6.5229 & 6.6367 & TRN \\
\hline CHEMBL3928038 & 1641170 & 5.9348 & 6.2727 & TRN \\
\hline CHEMBL3986463 & 1641170 & 7.1549 & 6.9168 & TRN \\
\hline CHEMBL3353203 & 1641170 & 7.8539 & 6.2823 & TST \\
\hline CHEMBL3900478 & 1641170 & 6.4815 & 6.6203 & TST \\
\hline CHEMBL3909924 & 1641170 & 7.5086 & 7.2985 & TRN \\
\hline CHEMBL3932689 & 1641170 & 7.0 & 7.4028 & TRN \\
\hline CHEMBL3909938 & 1641170 & 8.0 & 7.1778 & TRN \\
\hline CHEMBL3969460 & 1641170 & 6.585 & 6.6258 & TRN \\
\hline CHEMBL3955522 & 1641170 & 7.6021 & 6.9647 & TRN \\
\hline CHEMBL3929081 & 1641170 & 7.9586 & 7.6155 & TRN \\
\hline CHEMBL3951297 & 1641170 & 6.8153 & 7.0838 & TRN \\
\hline CHEMBL3975044 & 1641170 & 6.1844 & 6.5152 & TST \\
\hline CHEMBL3953193 & 1641170 & 7.585 & 6.5686 & TRN \\
\hline CHEMBL3947887 & 1641170 & 5.6146 & \multicolumn{2}{|c|}{6.332000000000001} \\
\hline CHEMBL3932684 & 1641170 & 7.2676 & 7.0652 & TRN \\
\hline
\end{tabular}


Supplemental Table S2.txt

\begin{tabular}{|c|c|c|c|c|}
\hline HEN & 1170 & 5.7959 & & \\
\hline & 641170 & 7.8239 & 7.1961 & \\
\hline 596 & 170 & & & \\
\hline HEMBL398 & & $\partial 915$ & & \\
\hline AEMBL3980721 & 170 & 5021 & & \\
\hline HEMBL3969684 & 170 & 6.8539 & 8903 & \\
\hline HEMBL398 & 170 & 079 & & \\
\hline AEMBL 398 & & & & RN \\
\hline HEMBL 395 & 170 & 6.6021 & 2959 & \\
\hline HEMBL398 & 70 & 7.7212 & 8343 & \\
\hline AEMBL391 & 70 & 7.7471 & 5035 & \\
\hline IEMBL394 & 70 & 518 & 5727 & \\
\hline AEMBL39 & & & 367 & \\
\hline HEMBL397 & 70 & 6.7773 & 5214 & \\
\hline AEMBL39 & 70 & 15 & 316 & \\
\hline AEMBL39 & 70 & 59 & 1417 & \\
\hline AEMBL3S & 80 & & 416 & \\
\hline HEMBL38 & & 6. & 901 & \\
\hline HEMBL39 & & 7.7696 & 811 & \\
\hline AEMBL3S & & & & \\
\hline HEMBLS & $\theta$ & 7 & 34 & KIV \\
\hline HEMBL: & & 36 & 46 & 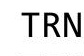 \\
\hline HEMBL & & & 61 & \\
\hline 128 & & & & \\
\hline AEMBL39 & & & & 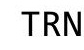 \\
\hline HEMBL3S & $\theta$ & 58 & 559 & r \\
\hline HEMBL & & 33 & 184 & RN \\
\hline HFMBI 36 & & 91 & 941 & \\
\hline HEMBL3S & & & 2677 & TIV \\
\hline HEMBL 397 & & & & 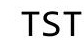 \\
\hline HEMBL3S & 10 & 1 & & RN \\
\hline HEMBL & & & 392 & RN \\
\hline HEMBL. & & 36 & 403 & $\mathrm{RN}$ \\
\hline HEMBL3975 & 70 & & 5153 & IRN \\
\hline HEMBL3965112 & & 7.6021 & 5866 & TRN \\
\hline HEMBL3S & & 6 & 1476 & RN \\
\hline HFMRI & 0 & & 375 & RN \\
\hline HEMBL3 & & 7. & 1945 & RN \\
\hline HEMBL396. & 10 & 5.6192 & 251 & TRN \\
\hline IEMBL39 & & 36 & 577 & TRN \\
\hline HEMBL39 & 70 & 09 & 1679 & \\
\hline HEMBL39 & & & & RN \\
\hline HEMBL396 & & 5.9531 & 6153 & TST \\
\hline HEMBL390 & 70 & 6.1805 & 1899 & TRN \\
\hline MBL & & & 1947 & \\
\hline HEMBL 39 & & & 2755 & \\
\hline HEMBL 39 & & 5.7959 & .3545 & \\
\hline HEMBL3971772 & 1641170 & 6.5229 & 6.5423 & ST \\
\hline
\end{tabular}

Page 9350 
Supplemental Table S2.txt

\begin{tabular}{|c|c|c|c|c|c|}
\hline CHEMBL3976959 & 1641170 & 5.6576 & 6.6683 & TST & \\
\hline CHEMBL3901315 & 1641170 & 8.301 & 6.8273 & TST & \\
\hline CHEMBL3943696 & 1641170 & 6.6576 & 6.6829 & TST & \\
\hline CHEMBL3951641 & 1641170 & 6.4815 & 7.0862 & TRN & \\
\hline CHEMBL3915756 & 1641170 & 6.9469 & 7.4782 & TST & \\
\hline CHEMBL3916847 & 1641170 & 6.0706 & 6.4241 & TST & \\
\hline CHEMBL3945894 & 1641170 & 6.82100 & 000000006 & 6.3792 & TRN \\
\hline CHEMBL3905085 & 1641170 & 7.4685 & 6.9693 & TRN & \\
\hline CHEMBL3905493 & 1641170 & 7.1805 & 7.2269 & TRN & \\
\hline CHEMBL3985171 & 1641170 & 6.3468 & 6.1478 & TRN & \\
\hline CHEMBL3904371 & 1641170 & 7.7212 & 7.1399 & TRN & \\
\hline CHEMBL3912715 & 1641170 & 7.8861 & 7.5291 & TRN & \\
\hline CHEMBL3893933 & 1641170 & 7.8861 & 7.2121 & TRN & \\
\hline CHEMBL3969703 & 1641170 & 7.2441 & 6.9594 & TRN & \\
\hline CHEMBL 3897875 & 1641170 & 6.6459 & 7.8843 & TRN & \\
\hline CHEMBL3893134 & 1641170 & 7.699 & 7.4621 & TRN & \\
\hline CHEMBL3948441 & 1641170 & 6.2403 & 6.035 & TRN & \\
\hline CHEMBL3948010 & 1641170 & 6.27 & 6.4554 & TRN & \\
\hline CHEMBL3958338 & 1641170 & 6.5884 & 6.6837 & TRN & \\
\hline CHEMBL3966430 & 1641170 & 7.4949 & 7.4029 & TRN & \\
\hline CHEMBL3892684 & 1641170 & 6.5281 & 7.1154 & TST & \\
\hline CHEMBL3945726 & 1641170 & 8.699 & 6.4748 & TST & \\
\hline CHEMBL3898493 & 1641170 & 8.2518 & 7.2332 & TST & \\
\hline CHEMBL3973368 & 1641170 & 8.0506 & 7.3217 & TRN & \\
\hline CHEMBL3906964 & 1641170 & 6.1612 & 6.0876 & TRN & \\
\hline CHEMBL3939641 & 1641170 & 8.0458 & 7.1749 & TRN & \\
\hline CHEMBL3929306 & 1641170 & 7.1427 & 6.9529 & TRN & \\
\hline CHEMBL3959157 & 1641170 & 7.7447 & 7.3612 & TRN & \\
\hline CHEMBL3932703 & 1641170 & 5.6457 & 6.0753 & TST & \\
\hline CHEMBL3971606 & 1641170 & 5.0862 & 6.6106 & TST & \\
\hline CHEMBL3899829 & 1641170 & 6.6021 & 6.8628 & TRN & \\
\hline CHEMBL 3892735 & 1641170 & 7.0915 & 6.9866 & TRN & \\
\hline CHEMBL3911654 & 1641170 & 7.0362 & 6.286006 & 20000000005 & TST \\
\hline CHEMBL3960433 & 1641170 & 7.3979 & 7.1667 & TRN & \\
\hline CHEMBL3907116 & 1641170 & 7.2076 & 7.0619 & TRN & \\
\hline CHEMBL3896721 & 1641170 & 6.9431 & 6.4067 & TRN & \\
\hline CHEMBL3929267 & 1641170 & 7.1871 & 6.2491 & TST & \\
\hline CHEMBL3970087 & 1641170 & 7.699 & 7.0984 & TRN & \\
\hline CHEMBL3892549 & 1641170 & 6.1367 & 6.1851 & TRN & \\
\hline CHEMBL3949120 & 1641170 & 6.9586 & 7.289 & TRN & \\
\hline CHEMBL3909098 & 1641170 & 6.0348 & 7.2622 & TST & \\
\hline CHEMBL 3954441 & 1641170 & 7.9208 & 7.5355 & TRN & \\
\hline CHEMBL3940600 & 1641170 & 6.8861 & 6.6901 & TST & \\
\hline CHEMBL3972314 & 1641170 & 7.5686 & 7.4537 & TRN & \\
\hline CHEMBL3964641 & 1641170 & 6.9586 & 6.869 & TRN & \\
\hline CHEMBL3924692 & 1641170 & 5.6021 & 7.3831 & TRN & \\
\hline CHEMBL3985495 & 1641170 & 6.1739 & 6.5312 & TST & \\
\hline CHEMBL3622529 & 1641170 & 6.0721 & 5.9739 & TST & \\
\hline
\end{tabular}


Supplemental Table S2.txt

\begin{tabular}{|c|c|c|c|c|c|c|}
\hline CHEMBL 3966938 & 1641170 & 7.1612 & 6.9118 & TRN & & \\
\hline CHEMBL 3894509 & 1641170 & 7.3768 & 7.6847 & TRN & & \\
\hline CHEMBL 3889677 & 1641170 & 7.9031 & 7.9642 & TRN & & \\
\hline CHEMBL 3977868 & 1641170 & 5.0915 & 6.6424 & TST & & \\
\hline CHEMBL 3976131 & 1641170 & 6.3468 & 6.3503 & TRN & & \\
\hline CHEMBL 3903179 & 1641170 & 8.0969 & 7.4086 & TRN & & \\
\hline CHEMBL 3622527 & 1641170 & 6.9172 & 5.9451 & TST & & \\
\hline CHEMBL 3890088 & 1641170 & 7.0132 & 6.6856 & TRN & & \\
\hline CHEMBL 3984535 & 1641170 & 6.7077 & 7.3605 & TST & & \\
\hline CHEMBL 3900246 & 1641170 & 6.6198 & 7.0252 & TRN & & \\
\hline CHEMBL 3958814 & 1641170 & 7.1367 & 6.6191 & TST & & \\
\hline CHEMBL 3946185 & 1641170 & 7.6383 & 7.6541 & TRN & & \\
\hline CHEMBL 3929220 & 1641170 & 7.6383 & 7.3987 & TST & & \\
\hline CHEMBL3983352 & 1641170 & 7.0044 & 6.9484 & TRN & & \\
\hline CHEMBL 3927213 & 1641170 & 6.3565 & 5.8992 & TRN & & \\
\hline CHEMBL 3978071 & 1641170 & 6.8386 & 6.8757 & TRN & & \\
\hline CHEMBL 3974069 & 1641170 & 8.6021 & 7.1837 & TST & & \\
\hline CHEMBL 3983202 & 1641170 & 5.699 & 6.3658 & TST & & \\
\hline CHEMBL 3919163 & 1641170 & 6.75200 & 000000006 & 1 & 6.4232 & TRN \\
\hline CHEMBL 3892870 & 1641170 & 6.3468 & 6.1001 & TRN & & \\
\hline CHEMBL 3970164 & 1641170 & 5.3098 & 6.5193 & TST & & \\
\hline CHEMBL 3898502 & 1641170 & 7.2441 & 7.9348 & TRN & & \\
\hline CHEMBL 3898529 & 1641170 & 6.0 & 6.5393 & TRN & & \\
\hline CHEMBL 3937263 & 1641170 & 5.7442 & 6.4696 & TST & & \\
\hline CHEMBL 3891375 & 1641170 & 7.3768 & 6.9177 & TRN & & \\
\hline CHEMBL 3967444 & 1641170 & 7.3665 & 6.9612 & TRN & & \\
\hline CHEMBL 3963673 & 1641170 & 5.7696 & 6.6314 & TST & & \\
\hline CHEMBL 3981287 & 1641170 & 7.3279 & 7.599 & TRN & & \\
\hline CHEMBL3910931 & 1641170 & \multicolumn{3}{|c|}{6.718999999999999} & 6.7497 & TRN \\
\hline CHEMBL 3958705 & 1641170 & 7.8761 & 8.1361 & TRN & & \\
\hline CHEMBL 3951532 & 1641170 & 8.0223 & 6.936 & TST & & \\
\hline CHEMBL 3928493 & 1641170 & 7.0458 & 7.2997 & TRN & & \\
\hline CHEMBL 3923741 & 1641170 & 7.6198 & 7.1609 & TRN & & \\
\hline CHEMBL3912755 & 1641170 & 8.1871 & 7.5974 & TRN & & \\
\hline CHEMBL3958595 & 1641170 & 8.0 & 7.7862 & TRN & & \\
\hline CHEMBL3961880 & 1641170 & 6.7447 & 6.6869 & TRN & & \\
\hline CHEMBL3936104 & 1641170 & 7.6778 & 7.6425 & TRN & & \\
\hline CHEMBL 3921218 & 1641170 & 8.2218 & 8.0397 & TRN & & \\
\hline CHEMBL 3928894 & 1641170 & 6.266 & 6.2641 & TRN & & \\
\hline CHEMBL 3967770 & 1641170 & 7.6198 & 7.0511 & TRN & & \\
\hline CHEMBL 3960242 & 1641170 & 7.7212 & 6.3628 & TST & & \\
\hline CHEMBL 3938110 & 1641170 & 7.2218 & 6.8066 & TRN & & \\
\hline CHEMBL 3622519 & 1641170 & 6.0 & 5.9596 & TST & & \\
\hline CHEMBL 3974974 & 1641170 & 7.5784 & 7.9938 & TRN & & \\
\hline CHEMBL 3900410 & 1641170 & 6.857 & 6.8075 & TST & & \\
\hline CHEMBL 3929253 & 1641170 & 8.3979 & 7.4217 & TRN & & \\
\hline CHEMBL 3930165 & 1641170 & 8.0969 & 7.954 & TRN & & \\
\hline CHEMBL 3893118 & 1641170 & 7.7959 & 7.1136 & TRN & & \\
\hline
\end{tabular}

Page 9352 
Supplemental Table S2.txt

\begin{tabular}{|c|c|c|c|c|c|}
\hline CHEMBL3942633 & 1641170 & 6.2441 & 6.8777 & TRN & \\
\hline CHEMBL3936643 & 1641170 & 6.8601 & 7.211 & TRN & \\
\hline CHEMBL3983031 & 1641170 & 6.5467 & 6.9473 & TST & \\
\hline CHEMBL3936017 & 1641170 & 7.0862 & 6.997999 & э999999999 & TRN \\
\hline CHEMBL3923571 & 1641170 & 5.3468 & 6.6317 & TRN & \\
\hline CHEMBL3936678 & 1641170 & 7.3979 & 6.9824 & TRN & \\
\hline CHEMBL3956449 & 1641170 & 7.51 & 7.8009 & TRN & \\
\hline CHEMBL3966466 & 1641170 & 6.0 & 7.5845 & TRN & \\
\hline CHEMBL3897817 & 1641170 & 7.8539 & 7.9926 & TRN & \\
\hline CHEMBL3905646 & 1641170 & 8.0458 & 8.0499 & TRN & \\
\hline CHEMBL3962227 & 1641170 & 6.4685 & 6.4376 & TRN & \\
\hline CHEMBL3980278 & 1641170 & 7.2007 & 7.2231 & TRN & \\
\hline CHEMBL3971525 & 1641170 & 6.0 & 6.4652 & TRN & \\
\hline CHEMBL3944564 & 1641170 & 8.0969 & 7.8733 & TRN & \\
\hline CHEMBL3962182 & 1641170 & 7.6021 & 6.2676 & TST & \\
\hline CHEMBL3974249 & 1641170 & 8.0969 & 7.9736 & TRN & \\
\hline CHEMBL3931046 & 1641170 & 6.6706 & 6.6568 & TST & \\
\hline CHEMBL3974446 & 1641170 & 7.2218 & 6.5731 & TST & \\
\hline CHEMBL3893216 & 1641170 & 8.0 & 7.5482 & TRN & \\
\hline CHEMBL3914153 & 1641170 & 5.6021 & 6.6835 & TST & \\
\hline CHEMBL3902130 & 1641170 & 6.1586 & 6.4246 & TST & \\
\hline CHEMBL3940395 & 1641170 & 6.1938 & 6.4835 & TST & \\
\hline CHEMBL3932012 & 1641170 & 7.6778 & 6.7744 & TRN & \\
\hline CHEMBL3977339 & 1641170 & 7.699 & 7.6528 & TRN & \\
\hline CHEMBL 3962627 & 1641170 & 8.1549 & 6.7069 & TRN & \\
\hline CHEMBL3960186 & 1641170 & 7.9208 & 7.3077 & TRN & \\
\hline CHEMBL3944441 & 1641170 & 7.9281 & 7.772 & TRN & \\
\hline CHEMBL3938633 & 1641170 & 7.3468 & \multicolumn{2}{|c|}{7.2010000000000005} & TRN \\
\hline CHEMBL3969004 & 1641170 & 7.6576 & 7.4091 & TRN & \\
\hline CHEMBL 3917654 & 1641170 & 8.0969 & 7.4205 & TRN & \\
\hline CHEMBL3905027 & 1641170 & 8.0 & 7.2877 & TRN & \\
\hline CHEMBL 3893290 & 1641170 & 6.3316 & 6.66 & TRN & \\
\hline CHEMBL3912441 & 1641170 & 8.4318 & 8.5232 & TRN & \\
\hline CHEMBL3892709 & 1641170 & 6.4089 & 6.3534 & TST & \\
\hline CHEMBL3900669 & 1641170 & 6.0 & 6.5662 & TRN & \\
\hline CHEMBL3900615 & 1641170 & 5.4089 & 6.4402 & TST & \\
\hline CHEMBL3898779 & 1641170 & 7.0506 & 7.358 & TRN & \\
\hline CHEMBL3982129 & 1641170 & 7.2676 & 7.1805 & TRN & \\
\hline CHEMBL3918995 & 1641170 & 6.3468 & 7.166 & TRN & \\
\hline CHEMBL3895742 & 1642434 & 6.1487 & 6.7106 & TRN & \\
\hline CHEMBL3921133 & 1642434 & 7.9586 & 8.495 & TRN & \\
\hline CHEMBL3968840 & 1642434 & 7.699 & 7.0226 & TRN & \\
\hline CHEMBL3918286 & 1642434 & 6.699 & 6.7897 & TRN & \\
\hline CHEMBL3904570 & 1642434 & 5.6861 & 6.7012 & TST & \\
\hline CHEMBL 3984248 & 1642434 & 5.0164 & 6.465 & TRN & \\
\hline CHEMBL3906705 & 1642434 & 7.8539 & 7.812 & TRN & \\
\hline CHEMBL 3895245 & 1642434 & 8.3979 & 7.8981 & TRN & \\
\hline CHEMBL3905588 & 1642434 & 7.9586 & 8.0861 & TRN & \\
\hline
\end{tabular}


Supplemental Table S2.txt

\begin{tabular}{|c|c|c|c|c|c|}
\hline CHEMBL3951492 & 1642434 & 6.5686 & 6.5646 & TRN & \\
\hline CHEMBL3980412 & 1642434 & 6.2147 & 6.8812 & TRN & \\
\hline CHEMBL3944714 & 1642434 & 5.8928 & 5.8192 & TST & \\
\hline CHEMBL3954723 & 1642434 & 8.2218 & 8.0669 & TRN & \\
\hline CHEMBL3942584 & 1642434 & 7.0 & 7.5578 & TST & \\
\hline CHEMBL3976092 & 1642434 & 6.9586 & 6.9599 & TRN & \\
\hline CHEMBL 3923445 & 1642434 & 7.8239 & 7.8583 & TRN & \\
\hline CHEMBL3950300 & 1642434 & 6.4559 & 6.2257 & TST & \\
\hline CHEMBL3906509 & 1642434 & 8.2218 & 8.0508 & TRN & \\
\hline CHEMBL3969347 & 1642434 & 6.8539 & 5.94600 & 2000000001 & TRN \\
\hline CHEMBL3942752 & 1642434 & 7.0969 & 6.9297 & TRN & \\
\hline CHEMBL 3930578 & 1642434 & 8.2218 & 8.3612 & TRN & \\
\hline CHEMBL3892240 & 1642434 & 6.2924 & 7.0663 & TRN & \\
\hline CHEMBL3974161 & 1642434 & 5.4828 & 6.0577 & TST & \\
\hline CHEMBL3890981 & 1642434 & 8.0 & 7.6556 & TRN & \\
\hline CHEMBL3942665 & 1642434 & 7.699 & 8.0922 & TRN & \\
\hline CHEMBL3924031 & 1642434 & 7.301 & 6.7512 & TRN & \\
\hline CHEMBL3889663 & 1642434 & 8.2218 & 7.8838 & TST & \\
\hline CHEMBL3959169 & 1642434 & 6.7212 & 6.4086 & TST & \\
\hline CHEMBL3925732 & 1642434 & 7.0969 & 6.8099 & TRN & \\
\hline CHEMBL3957678 & 1642434 & 8.0458 & 7.831 & TRN & \\
\hline CHEMBL3929015 & 1642434 & 7.2218 & 6.7169 & TRN & \\
\hline CHEMBL3983376 & 1642434 & 6.5086 & 6.6261 & TRN & \\
\hline CHEMBL 3951302 & 1642434 & 7.301 & \multicolumn{2}{|c|}{ 7.218999999999999 } & TRN \\
\hline CHEMBL3899061 & 1642434 & 6.3565 & 6.1883 & TST & \\
\hline CHEMBL3973019 & 1642434 & 7.301 & 6.7422 & TRN & \\
\hline CHEMBL3960098 & 1642434 & 6.1079 & 6.5577 & TRN & \\
\hline CHEMBL3982166 & 1642434 & 5.8416 & 6.5955 & TST & \\
\hline CHEMBL 3960660 & 1642434 & 6.6198 & 6.9216 & TST & \\
\hline CHEMBL3943926 & 1642434 & 8.1549 & 8.0331 & TRN & \\
\hline CHEMBL3965279 & 1642434 & 8.2218 & 7.8026 & TRN & \\
\hline CHEMBL3959494 & 1642434 & 5.9706 & 6.4009 & TST & \\
\hline CHEMBL3920103 & 1642434 & 6.1192 & 6.8112 & TST & \\
\hline CHEMBL 3968232 & 1642434 & 5.3696 & 5.8972 & TRN & \\
\hline CHEMBL3960854 & 1642434 & 6.4685 & 6.3666 & TRN & \\
\hline CHEMBL3891768 & 1642434 & 6.6198 & 6.3421 & TRN & \\
\hline CHEMBL3893311 & 1642434 & 7.2218 & 6.8789 & TRN & \\
\hline CHEMBL3938088 & 1642434 & 5.4123 & 5.8365 & TRN & \\
\hline CHEMBL 3890117 & 1642434 & 7.699 & 7.4119 & TST & \\
\hline CHEMBL3941678 & 1642434 & 6.301 & 6.1707 & TST & \\
\hline CHEMBL3898919 & 1642434 & 7.7696 & 6.9013 & TRN & \\
\hline CHEMBL3984693 & 1642434 & 6.1192 & 6.2445 & TST & \\
\hline CHEMBL3898477 & 1642434 & 5.5376 & 6.1332 & TST & \\
\hline CHEMBL3956739 & 1642434 & 6.2676 & 6.4585 & TRN & \\
\hline CHEMBL3926747 & 1642434 & 6.8539 & 6.394 & TST & \\
\hline CHEMBL3975396 & 1642434 & 7.7959 & 7.29299 & 9999999999 & TST \\
\hline CHEMBL3900129 & 1642434 & 6.585 & 6.4984 & TRN & \\
\hline CHEMBL3958695 & 1642434 & 6.6383 & 6.8816 & TST & \\
\hline
\end{tabular}


Supplemental Table S2.txt

\begin{tabular}{|c|c|c|c|c|}
\hline CHEMBL3978495 & 1642434 & 7.699 & 7.6495 & TST \\
\hline CHEMBL3899962 & 1642434 & 6.6383 & 6.6005 & TRN \\
\hline CHEMBL3928150 & 1642434 & 8.2218 & 8.0465 & TRN \\
\hline CHEMBL 3973437 & 1642434 & 7.5229 & 7.5372 & TRN \\
\hline CHEMBL3952079 & 1642434 & 6.7959 & 6.6908 & TRN \\
\hline CHEMBL3969263 & 1642434 & 5.9914 & 6.9573 & TRN \\
\hline CHEMBL3985907 & 1642434 & 7.5229 & 8.0211 & TRN \\
\hline CHEMBL3908252 & 1642434 & 6.699 & 6.3462 & TST \\
\hline CHEMBL3933482 & 1642434 & 5.983 & \multicolumn{2}{|c|}{6.252000000000001} \\
\hline CHEMBL3967668 & 1642434 & 6.4949 & 6.2369 & TRN \\
\hline CHEMBL 3900170 & 1642434 & 7.0458 & 7.3582 & TRN \\
\hline CHEMBL3952335 & 1642434 & 7.1549 & 6.5713 & TRN \\
\hline CHEMBL 3977171 & 1642434 & 7.3979 & 7.1168 & TRN \\
\hline CHEMBL3967685 & 1642434 & 6.7447 & 6.745 & TRN \\
\hline CHEMBL3909501 & 1642434 & 5.0022 & 5.6548 & TRN \\
\hline CHEMBL 3937443 & 1642434 & 5.2255 & 5.5551 & TRN \\
\hline CHEMBL3909082 & 1642434 & 6.5528 & 7.5886 & TRN \\
\hline CHEMBL 3941522 & 1642434 & 7.1549 & 7.3902 & TRN \\
\hline CHEMBL 3910584 & 1642434 & 8.0 & 7.6946 & TRN \\
\hline CHEMBL 3947352 & 1642434 & 7.8239 & 7.7836 & TRN \\
\hline CHEMBL3910116 & 1642434 & 7.0458 & 6.3682 & TRN \\
\hline CHEMBL3955649 & 1642434 & 7.0 & 6.1604 & TST \\
\hline CHEMBL3906506 & 1642434 & 6.9586 & 6.5562 & TRN \\
\hline CHEMBL 3893127 & 1642434 & 8.0 & 7.8144 & TRN \\
\hline CHEMBL 3952833 & 1642434 & 7.9586 & 7.5897 & TST \\
\hline CHEMBL 3915668 & 1642434 & 8.5229 & 8.508 & TRN \\
\hline CHEMBL3949139 & 1642434 & 6.2924 & 6.2476 & TRN \\
\hline CHEMBL 3942457 & 1642434 & 7.3979 & 6.9557 & TRN \\
\hline CHEMBL 3902589 & 1642434 & 7.0969 & \multicolumn{2}{|c|}{7.132000000000001} \\
\hline CHEMBL3966909 & 1642434 & 4.7836 & 6.3104 & TST \\
\hline CHEMBL3967636 & 1642434 & 6.9586 & 7.2151 & TRN \\
\hline CHEMBL 3891642 & 1642434 & 5.5751 & 6.5677 & TST \\
\hline CHEMBL 3925155 & 1642434 & 7.3979 & 7.6632 & TRN \\
\hline CHEMBL3968088 & 1642434 & 5.1355 & 5.9789 & TRN \\
\hline CHEMBL3971644 & 1642434 & 6.7696 & 6.4457 & TST \\
\hline CHEMBL3933709 & 1642434 & 8.2218 & 8.1831 & TRN \\
\hline CHEMBL3931466 & 1642434 & 6.7447 & 6.4492 & TRN \\
\hline CHEMBL3958830 & 1642434 & 7.0458 & 6.86 & TRN \\
\hline CHEMBL3956046 & 1642434 & 7.0458 & 7.1201 & TRN \\
\hline CHEMBL3981421 & 1642434 & 8.0 & 8.0702 & TRN \\
\hline CHEMBL3953356 & 1642434 & 7.699 & 7.5643 & TRN \\
\hline CHEMBL3934964 & 1642434 & 5.6478 & 6.3065 & TRN \\
\hline CHEMBL 3893620 & 1642434 & 7.3979 & 7.9935 & TRN \\
\hline CHEMBL3979790 & 1642434 & 7.9208 & 8.1265 & TRN \\
\hline CHEMBL3972066 & 1642434 & 6.7212 & 6.3993 & TRN \\
\hline CHEMBL 3972285 & 1642434 & 7.8861 & 7.7784 & TRN \\
\hline CHEMBL3920241 & 1642434 & 7.3979 & 7.2761 & TRN \\
\hline CHEMBL3916139 & 1642434 & 7.5229 & 8.1535 & TRN \\
\hline
\end{tabular}

Page 9355 
Supplemental Table S2.txt

\begin{tabular}{|c|c|c|c|c|}
\hline HEMBL & 642434 & 6.6778 & 6.8279 & TR \\
\hline 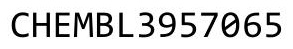 & 642434 & 7.3979 & 6.9253 & \\
\hline $15 \mathrm{M}$ & & & & \\
\hline HEMBL 39280 & & 6.1675 & & $2 \mathrm{~N}$ \\
\hline HEMBL3977328 & $64<434$ & 969 & 593 & \\
\hline HEMBL3902299 & 642434 & 5.9788 & 8122 & \\
\hline HEMBL3905955 & 34 & 9.0 & 538 & \\
\hline AEMBL3976180 & & 33 & & \\
\hline HEMBL3929496 & 64 & 7.699 & 3266 & RN \\
\hline HEMBL3901067 & 64 & 7.1549 & 584 & \\
\hline HEMBL3949745 & 64 & 6.7959 & 66 & \\
\hline AEMBL396 & 4 & 218 & 331 & \\
\hline HEMBL393 & & 208 & & \\
\hline HEMBL3914430 & $62+2>2>$ & 7.1549 & 0462 & \\
\hline AEMBL3938714 & 62 & 6.6576 & 392 & \\
\hline AEMBL3896513 & 64 & 6.3468 & & \\
\hline HEMBL397 & 4 & 229 & & \\
\hline HEMBL 397 & & 969 & & \\
\hline HEMBL391 & & 506 & & \\
\hline HEMBL 397 & 34 & 9 . & & \\
\hline HEMBL39 & 62 & 979 & & RIV \\
\hline HEMBL39 & T & 9 & & Nov \\
\hline HEMBL39 & & & & \\
\hline HEMBL 389 & & 8 . & 7472 & $\omega_{3}+2+3$ \\
\hline HEMBL 369 & & & & iv \\
\hline HEMBL 369 & 1 & & 89 & SN \\
\hline HEMBL9 & & 58 & & RN \\
\hline HEMBL16 & & 5. & & RN \\
\hline HEMBL369 & & 6.2596 & & I KIV \\
\hline HEMBL97632 & & 3 . & & IRIV \\
\hline HEMBL353 & & 5 . & & RN \\
\hline HEMBL36 & & 5. & 43 & ST \\
\hline HEMBL; & & 7. & 57 & RN \\
\hline HEMBL96966 & & 7. & & IRN \\
\hline HEMBL95849 & -8 & 6 . & 5094 & TRN \\
\hline HEMBL557 & & & 39 & 0. \\
\hline HEMRI 3 & & 7 & 26 & RN \\
\hline HEMBL 36 & & & & TST \\
\hline HEMBL36985 & 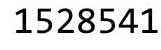 & 6. & 3691 & TST \\
\hline HEMBL 369 & 52 & & 574 & TST \\
\hline HEMBL149 & & 979 & 4395 & TRN \\
\hline CHEMBL317814 & & 6.699 & & TRN \\
\hline HEMBL149172 & 1 & 6.0 & 9473 & $\Gamma \mathrm{RN}$ \\
\hline HEMBL3975\& & 52 & 5.699 & 7166 & $\Gamma R$ \\
\hline MBL166 & $5-2+3>$ & & & \\
\hline HEMBL3175 & & & 8931 & \\
\hline CHEMBL369851e & 152 & .041 & .9903 & \\
\hline CHEMBL369851 & 1528541 & 5.3188 & 5.3191 & ГRN \\
\hline
\end{tabular}

Page 9356 
Supplemental Table S2.txt

\begin{tabular}{|c|c|c|c|c|c|}
\hline CHEMBL148968 & 1528541 & 5.6383 & 5.6642 & TRN & \\
\hline CHEMBL353839 & 1528541 & 7.301 & 7.3034 & TRN & \\
\hline CHEMBL3698523 & 1528541 & 6.0757 & 5.7196 & TST & \\
\hline CHEMBL3698522 & 1528541 & 6.0315 & 5.9611 & TST & \\
\hline CHEMBL95749 & 1528541 & 6.0969 & 6.0817 & TRN & \\
\hline CHEMBL3698506 & 1528541 & 4.6383 & 4.6465 & TRN & \\
\hline CHEMBL3698520 & 1528541 & 6.301 & 5.2683 & TST & \\
\hline CHEMBL97860 & 1528541 & 6.0 & 5.9642 & TRN & \\
\hline CHEMBL148313 & 1528541 & 5.5229 & 5.6876 & TRN & \\
\hline CHEMBL95850 & 1528541 & 6.9208 & 6.9091 & TRN & \\
\hline CHEMBL3639973 & 1528541 & 5.6198 & 5.5997 & TRN & \\
\hline CHEMBL3698499 & 1528541 & 7.5229 & 7.4937 & TRN & \\
\hline CHEMBL552465 & 1528541 & 6.0757 & 6.0786 & TRN & \\
\hline CHEMBL3698497 & 1528541 & 6.1871 & 6.2081 & TRN & \\
\hline CHEMBL3698525 & 1528541 & 6.1549 & 5.4708 & TST & \\
\hline CHEMBL3698515 & 1528541 & 6.1249 & 6.1337 & TST & \\
\hline CHEMBL3698501 & 1528541 & 6.1249 & 6.116000 & 00000000005 & TRN \\
\hline CHEMBL561118 & 1528541 & 5.6198 & 5.346 & TST & \\
\hline CHEMBL359303 & 1528541 & 5.9208 & 5.9473 & TRN & \\
\hline CHEMBL3909651 & 1528541 & 5.301 & 5.2688 & TRN & \\
\hline CHEMBL353658 & 1528541 & 5.6383 & 5.5898 & TRN & \\
\hline CHEMBL145891 & 1528541 & 8.0 & 7.7079 & TRN & \\
\hline CHEMBL95195 & 1528541 & 7.0 & 6.995 & TRN & \\
\hline CHEMBL98346 & 1528541 & 7.0 & 5.5411 & TST & \\
\hline CHEMBL 3698502 & 1528541 & 7.3979 & 7.4107 & TRN & \\
\hline CHEMBL168961 & 1528541 & 7.301 & 7.2632 & TRN & \\
\hline CHEMBL148769 & 1528541 & 6.3188 & 6.3236 & TRN & \\
\hline CHEMBL149534 & 1528541 & 7.301 & 6.8931 & TRN & \\
\hline CHEMBL541426 & 1528541 & 6.0 & 4.968999 & 9999999999 & TST \\
\hline CHEMBL 97108 & 1528541 & 4.7696 & 4.2138 & TST & \\
\hline CHEMBL147506 & 1528541 & 7.2218 & 7.2071 & TRN & \\
\hline CHEMBL98669 & 1528541 & 7.0458 & 6.9853 & TRN & \\
\hline CHEMBL434466 & 1528541 & 7.3979 & 7.7079 & TRN & \\
\hline CHEMBL3698507 & 1528541 & 6.5229 & 6.5081 & TRN & \\
\hline CHEMBL 3698508 & 1528541 & 6.301 & 5.6906 & TST & \\
\hline CHEMBL346414 & 1528541 & 5.8239 & 5.6876 & TRN & \\
\hline CHEMBL3698511 & 1528541 & 7.0 & 5.5981 & TST & \\
\hline CHEMBL 97272 & 1528541 & 6.699 & 6.7402 & TRN & \\
\hline CHEMBL3698496 & 1528541 & 6.0458 & 4.9625 & TST & \\
\hline CHEMBL 3698524 & 1528541 & 6.699 & 5.5315 & TST & \\
\hline CHEMBL95553 & 1528541 & 6.699 & 6.7879 & TRN & \\
\hline CHEMBL3698512 & 1528541 & 5.6383 & 5.6434 & TST & \\
\hline CHEMBL3698505 & 1528541 & 7.0223 & 7.0314 & TRN & \\
\hline CHEMBL169352 & 1528541 & 5.301 & 5.3447 & TRN & \\
\hline CHEMBL 97387 & 1528541 & 6.2441 & 6.2558 & TRN & \\
\hline CHEMBL97384 & 1528541 & 6.2218 & 6.2357 & TRN & \\
\hline CHEMBL166883 & 1528541 & 5.4202 & 5.4395 & TRN & \\
\hline CHEMBL3698495 & 1528541 & 6.5229 & 5.9732 & TST & \\
\hline
\end{tabular}


Supplemental Table S2.txt

\begin{tabular}{|c|c|c|c|c|}
\hline CHEMBL 3698498 & 1528541 & 6.2218 & 6.2067 & TRN \\
\hline CHEMBL165693 & 1528541 & 5.5229 & 5.5208 & TRN \\
\hline CHEMBL1964290 & 809205 & 4.6 & 4.785 & TRN \\
\hline CHEMBL213505 & 809205 & 5.9 & 5.9101 & TRN \\
\hline CHEMBL202721 & 809205 & 4.3 & 4.4367 & TRN \\
\hline CHEMBL1987034 & 809205 & 7.1 & 7.3694 & TRN \\
\hline CHEMBL1993941 & 809205 & 7.0 & 7.3878 & TRN \\
\hline CHEMBL377383 & 809205 & 4.6 & 4.6549 & TRN \\
\hline CHEMBL 2005886 & 809205 & 8.1 & 7.2578 & TRN \\
\hline CHEMBL481491 & 809205 & 4.6 & 4.2626 & TST \\
\hline CHEMBL1682345 & 809205 & 4.6 & 4.6479 & TRN \\
\hline CHEMBL1973142 & 809205 & 4.6 & 4.904 & TST \\
\hline CHEMBL388311 & 809205 & 7.2 & 7.0768 & TRN \\
\hline CHEMBL1973145 & 809205 & 4.6 & 4.7229 & TRN \\
\hline CHEMBL1982924 & 809205 & 5.9 & 5.7632 & TRN \\
\hline CHEMBL2005936 & 809205 & 4.6 & 4.4959 & TRN \\
\hline CHEMBL1807515 & 809205 & 6.4 & 4.9704 & TRN \\
\hline CHEMBL1964948 & 809205 & 4.5 & 4.3486 & TRN \\
\hline CHEMBL1971141 & 809205 & 4.6 & 4.6476 & TRN \\
\hline CHEMBL1995813 & 809205 & 6.2 & 4.9374 & TRN \\
\hline CHEMBL1979718 & 809205 & 4.6 & 4.732 & TRN \\
\hline CHEMBL206236 & 809205 & 4.6 & 4.6198 & TRN \\
\hline CHEMBL1989834 & 809205 & 3.9 & 4.0667 & TRN \\
\hline CHEMBL523823 & 809205 & 4.6 & 4.9133 & TST \\
\hline CHEMBL1987430 & 809205 & 4.5 & 4.4791 & TRN \\
\hline CHEMBL244378 & 809205 & 5.7 & 5.5818 & TRN \\
\hline CHEMBL 2001957 & 809205 & 4.6 & 4.5189 & TRN \\
\hline CHEMBL1969372 & 809205 & 4.6 & 4.3875 & TRN \\
\hline CHEMBL1993413 & 809205 & 4.5 & 4.3933 & TRN \\
\hline CHEMBL1990583 & 809205 & 6.3 & 5.615 & TRN \\
\hline CHEMBL1986943 & 809205 & 6.4 & 5.6958 & TRN \\
\hline CHEMBL2006263 & 809205 & 4.6 & 4.9219 & TST \\
\hline CHEMBL1993584 & 809205 & 4.6 & 4.4161 & TRN \\
\hline CHEMBL1986263 & 809205 & 4.6 & 4.9069 & TRN \\
\hline CHEMBL 2000114 & 809205 & 4.6 & 4.9831 & TRN \\
\hline CHEMBL210618 & 809205 & 4.6 & 4.609 & TRN \\
\hline CHEMBL1986265 & 809205 & 4.5 & 4.3494 & TRN \\
\hline CHEMBL1975647 & 809205 & 4.6 & 4.5429 & TRN \\
\hline CHEMBL1968380 & 809205 & 4.6 & 4.3512 & TRN \\
\hline CHEMBL1964644 & 809205 & 4.6 & 4.6372 & TRN \\
\hline CHEMBL1991734 & 809205 & 6.2 & 5.6866 & TST \\
\hline CHEMBL1981782 & 809205 & 4.6 & 4.5711 & TRN \\
\hline CHEMBL1977681 & 809205 & 4.6 & 4.6578 & TRN \\
\hline CHEMBL1970142 & 809205 & 8.2 & 7.3727 & TRN \\
\hline CHEMBL1990912 & 809205 & 4.6 & 4.5772 & TRN \\
\hline CHEMBL1991782 & 809205 & 3.2 & 3.8477 & TRN \\
\hline CHEMBL1983348 & 809205 & 4.5 & 5.7566 & TRN \\
\hline CHEMBL1988163 & 809205 & 6.0 & 6.1166 & TRN \\
\hline
\end{tabular}




\begin{tabular}{|c|c|c|c|c|c|}
\hline \multirow[b]{2}{*}{ CHEMBL1995592 } & \multirow{2}{*}{809205} & \\
\hline & & 4.6 & 4.801 & TST & \\
\hline CHEMBL1974480 & 809205 & 5.6 & 5.5369 & TST & \\
\hline CHEMBL 2006493 & 809205 & 4.6 & 4.6904 & TST & \\
\hline CHEMBL1986177 & 809205 & 4.5 & 4.6242 & TRN & \\
\hline CHEMBL1983449 & 809205 & 4.6 & 4.4926 & TRN & \\
\hline CHEMBL1992323 & 809205 & 4.6 & 4.6783 & TST & \\
\hline CHEMBL1969735 & 809205 & 4.6 & 4.5962 & TRN & \\
\hline CHEMBL 2003524 & 809205 & 5.8 & 4.494 & TST & \\
\hline CHEMBL 2002649 & 809205 & 6.9 & 5.9676 & TRN & \\
\hline CHEMBL1985367 & 809205 & 4.5 & 5.375 & TST & \\
\hline CHEMBL1996510 & 809205 & 5.6 & 5.0101 & TST & \\
\hline CHEMBL437747 & 809205 & 4.6 & 4.5572 & TRN & \\
\hline CHEMBL1995172 & 809205 & 4.6 & 4.2285 & TST & \\
\hline CHEMBL 2001584 & 809205 & 4.5 & 4.1523 & TRN & \\
\hline CHEMBL507936 & 809205 & 4.6 & 4.4097 & TRN & \\
\hline CHEMBL1971227 & 809205 & 5.7 & 5.0476 & TST & \\
\hline CHEMBL104264 & 809205 & 4.6 & 4.6387 & TST & \\
\hline CHEMBL1967998 & 809205 & 6.6 & \multicolumn{2}{|c|}{6.327999999999999} & TRN \\
\hline CHEMBL1994321 & 809205 & 7.3 & 6.9083 & TRN & \\
\hline CHEMBL1978562 & 809205 & 6.1 & 6.1342 & TST & \\
\hline CHEMBL1997129 & 809205 & 4.6 & 5.1091 & TRN & \\
\hline CHEMBL1984788 & 809205 & 4.6 & 4.657 & TRN & \\
\hline CHEMBL451964 & 809205 & 4.6 & 4.5904 & TRN & \\
\hline CHEMBL1974875 & 809205 & 4.2 & 5.1188 & TST & \\
\hline CHEMBL1964307 & 809205 & 5.8 & 5.2093 & TRN & \\
\hline CHEMBL1989471 & 809205 & 4.5 & 5.4091 & TST & \\
\hline CHEMBL2002099 & 809205 & 4.5 & 4.8846 & TRN & \\
\hline CHEMBL 2000508 & 809205 & 4.6 & 4.6585 & TRN & \\
\hline CHEMBL1971694 & 809205 & 4.6 & 4.6979 & TST & \\
\hline CHEMBL 2001547 & 809205 & 4.6 & 4.6823 & TRN & \\
\hline CHEMBL210928 & 809205 & 4.6 & 4.5473 & TRN & \\
\hline CHEMBL1978195 & 809205 & 4.5 & 4.4336 & TRN & \\
\hline CHEMBL1994361 & 809205 & 4.6 & 4.6358 & TRN & \\
\hline CHEMBL1986603 & 809205 & 4.6 & 4.7703 & TST & \\
\hline CHEMBL1972840 & 809205 & 4.6 & 4.4451 & TRN & \\
\hline CHEMBL1977148 & 809205 & 7.7 & 7.64 & TRN & \\
\hline CHEMBL 2003286 & 809205 & 4.6 & 4.5759 & TRN & \\
\hline CHEMBL1992306 & 809205 & 4.6 & 6.4201 & TRN & \\
\hline CHEMBL 2002165 & 809205 & 7.1 & 7.4465 & TRN & \\
\hline CHEMBL1979318 & 809205 & 4.6 & 4.6429 & TRN & \\
\hline CHEMBL206382 & 809205 & 4.6 & 4.7365 & TRN & \\
\hline CHEMBL1998585 & 809205 & 8.0 & 7.5191 & TRN & \\
\hline CHEMBL127898 & 809205 & 4.6 & 4.718 & TST & \\
\hline CHEMBL519697 & 809205 & 4.6 & 4.3028 & TST & \\
\hline CHEMBL2004934 & 809205 & 4.6 & 4.6303 & TRN & \\
\hline CHEMBL 2000652 & 809205 & 5.9 & 5.4044 & TRN & \\
\hline CHEMBL1973516 & 809205 & 4.5 & 5.7128 & TRN & \\
\hline \multirow[t]{2}{*}{ CHEMBL1996345 } & 809205 & 4.5 & 4.5583 & TST & \\
\hline & & \multicolumn{4}{|c|}{ Page 9359} \\
\hline
\end{tabular}




\begin{tabular}{|c|c|c|c|c|c|}
\hline \multirow{3}{*}{$\begin{array}{l}\text { CHEMBL1975128 } \\
\text { CHEMBL2004025 }\end{array}$} & \multirow{3}{*}{$\begin{array}{l}809205 \\
809205\end{array}$} & \multicolumn{4}{|c|}{ Supplemental Table S2.txt } \\
\hline & & 4.6 & 4.7639 & 9999999999 & TRN \\
\hline & & 6.4 & 5.7395 & TRN & \\
\hline CHEMBL1996048 & 809205 & 4.5 & 4.6894 & TST & \\
\hline CHEMBL461876 & 809205 & 4.5 & 5.0383 & TRN & \\
\hline CHEMBL1965033 & 809205 & 6.4 & 6.2245 & TRN & \\
\hline CHEMBL 2001485 & 809205 & 7.2 & 6.8261 & TRN & \\
\hline CHEMBL1971519 & 809205 & 4.3 & 4.5903 & TRN & \\
\hline CHEMBL504950 & 809205 & 4.6 & 4.6024 & TRN & \\
\hline CHEMBL1997335 & 809205 & 4.5 & 4.6368 & TRN & \\
\hline CHEMBL1966425 & 809205 & 4.6 & 4.8312 & TRN & \\
\hline CHEMBL1984363 & 809205 & 5.3 & 5.4527 & TRN & \\
\hline CHEMBL1978099 & 809205 & 6.4 & 5.8313 & TRN & \\
\hline CHEMBL1977041 & 809205 & 7.0 & 6.5209 & TRN & \\
\hline CHEMBL1968070 & 809205 & 6.1 & 4.7327 & TRN & \\
\hline CHEMBL1988608 & 809205 & 4.6 & 4.413 & TRN & \\
\hline CHEMBL184847 & 809205 & 4.6 & 5.3428 & TRN & \\
\hline CHEMBL1984367 & 809205 & 4.6 & 4.4733 & TRN & \\
\hline CHEMBL226898 & 809205 & 4.6 & 4.6974 & TRN & \\
\hline CHEMBL1982563 & 809205 & 4.6 & 4.5464 & TRN & \\
\hline CHEMBL539474 & 809205 & 6.1 & 4.9717 & TST & \\
\hline CHEMBL575824 & 809205 & 4.6 & 4.7789 & TRN & \\
\hline CHEMBL399530 & 809205 & 3.8 & 4.8075 & TST & \\
\hline CHEMBL1988387 & 809205 & 8.0 & 7.5024 & TRN & \\
\hline CHEMBL1973868 & 809205 & 4.5 & 4.5384 & TRN & \\
\hline CHEMBL1990288 & 809205 & 4.6 & 4.5735 & TRN & \\
\hline CHEMBL1970074 & 809205 & 6.7 & 5.8958 & TRN & \\
\hline CHEMBL1986970 & 809205 & 4.6 & 4.6133 & TRN & \\
\hline CHEMBL1958401 & 809205 & 4.6 & 4.5958 & TRN & \\
\hline CHEMBL 2003456 & 809205 & 4.6 & 4.662 & TRN & \\
\hline CHEMBL1966816 & 809205 & 4.6 & 4.7679 & TRN & \\
\hline CHEMBL1972584 & 809205 & 5.9 & 5.7302 & TRN & \\
\hline CHEMBL 2002992 & 809205 & 4.6 & 4.6477 & TRN & \\
\hline CHEMBL560813 & 809205 & 4.6 & 4.7425 & TRN & \\
\hline CHEMBL1982700 & 809205 & 4.5 & 4.4624 & TST & \\
\hline CHEMBL1968791 & 809205 & 4.6 & 4.7804 & TRN & \\
\hline CHEMBL326282 & 809205 & 4.6 & 4.6645 & TST & \\
\hline CHEMBL1977634 & 809205 & 4.5 & 4.4958 & TRN & \\
\hline CHEMBL1992732 & 809205 & 4.6 & 4.5381 & TST & \\
\hline CHEMBL1971186 & 809205 & 4.6 & 4.5996 & TRN & \\
\hline CHEMBL 2003482 & 809205 & 4.6 & 4.6498 & TRN & \\
\hline CHEMBL 2004887 & 809205 & 4.5 & 4.8177 & TRN & \\
\hline CHEMBL1973211 & 809205 & 4.9 & 6.5464 & TRN & \\
\hline CHEMBL1984700 & 809205 & 4.6 & 4.558 & TRN & \\
\hline CHEMBL 2007151 & 809205 & 4.6 & 4.8752 & TRN & \\
\hline CHEMBL1971606 & 809205 & 4.5 & 4.4716 & TRN & \\
\hline CHEMBL1972125 & 809205 & 4.6 & 4.665 & TRN & \\
\hline CHEMBL1461728 & 809205 & 4.6 & 4.6767 & TRN & \\
\hline CHEMBL1976134 & 809205 & 7.0 & 5.8617 & TRN & \\
\hline
\end{tabular}




\begin{tabular}{|c|c|c|c|c|}
\hline \multicolumn{5}{|c|}{ lemental T } \\
\hline CHEMBL1965131 & 809205 & 4.6 & 4.7631 & TST \\
\hline CHEMBL1972158 & 809205 & 4.6 & 4.8942 & TRN \\
\hline CHEMBL1981215 & 809205 & 4.5 & 4.5542 & TRN \\
\hline CHEMBL1974457 & 809205 & 4.6 & 4.6307 & TRN \\
\hline CHEMBL1999414 & 809205 & 6.6 & 6.6845 & TRN \\
\hline CHEMBL1967336 & 809205 & 4.5 & 4.5685 & TRN \\
\hline CHEMBL 2006581 & 809205 & 4.6 & 4.6127 & TRN \\
\hline CHEMBL1979855 & 809205 & 4.6 & 4.5721 & TRN \\
\hline CHEMBL1970340 & 809205 & 4.6 & 4.0533 & TRN \\
\hline CHEMBL1967992 & 809205 & 4.5 & 4.5434 & TRN \\
\hline CHEMBL 2005186 & 809205 & 4.6 & 4.7993 & TRN \\
\hline CHEMBL 2006450 & 809205 & 4.5 & 4.2354 & TRN \\
\hline CHEMBL1975534 & 809205 & 4.6 & 4.5088 & TRN \\
\hline CHEMBL1993424 & 809205 & 7.0 & 6.7043 & TRN \\
\hline CHEMBL1966703 & 809205 & 4.6 & 4.7476 & TST \\
\hline CHEMBL 2001987 & 809205 & 4.5 & 4.5067 & TRN \\
\hline CHEMBL1969561 & 809205 & 4.6 & 4.5963 & TRN \\
\hline CHEMBL1994555 & 809205 & 4.5 & 4.867 & TST \\
\hline CHEMBL1975121 & 809205 & 4.6 & 4.5393 & TRN \\
\hline CHEMBL1983640 & 809205 & 6.6 & 6.144 & TRN \\
\hline CHEMBL1997023 & 809205 & 4.6 & 4.6716 & TST \\
\hline CHEMBL1964687 & 809205 & 4.9 & 5.9815 & TRN \\
\hline CHEMBL1971943 & 809205 & 4.8 & 4.6334 & TRN \\
\hline CHEMBL1999918 & 809205 & 4.6 & 4.7502 & TRN \\
\hline CHEMBL1974254 & 809205 & 7.2 & 7.5581 & TRN \\
\hline CHEMBL1988537 & 809205 & 4.6 & 4.8048 & TST \\
\hline CHEMBL1969049 & 809205 & 4.6 & 4.651 & TRN \\
\hline CHEMBL 2005828 & 809205 & 5.6 & 4.9167 & TRN \\
\hline CHEMBL1998611 & 809205 & 4.6 & 4.8415 & TST \\
\hline CHEMBL485556 & 809205 & 5.4 & 4.5526 & TST \\
\hline CHEMBL1975900 & 809205 & 4.6 & 4.4667 & TRN \\
\hline CHEMBL 255822 & 809205 & 4.6 & 4.606 & TRN \\
\hline CHEMBL1972221 & 809205 & 4.6 & 4.6077 & TRN \\
\hline CHEMBL 2006778 & 809205 & 6.0 & 6.0562 & TRN \\
\hline CHEMBL378627 & 809205 & 4.6 & 4.5373 & TRN \\
\hline CHEMBL1996979 & 809205 & 6.3 & 5.9245 & TRN \\
\hline CHEMBL1997025 & 809205 & 4.6 & 4.5381 & TRN \\
\hline CHEMBL1968406 & 809205 & 6.3 & 6.0523 & TRN \\
\hline CHEMBL1975921 & 809205 & 4.2 & 4.7257 & TRN \\
\hline CHEMBL 33891 & 809205 & 5.0 & 5.4511 & TRN \\
\hline CHEMBL1982476 & 809205 & 8.1 & 8.1212 & TRN \\
\hline CHEMBL1998545 & 809205 & 4.6 & 4.667 & TRN \\
\hline CHEMBL1986869 & 809205 & 4.6 & 4.7343 & TRN \\
\hline CHEMBL1975923 & 809205 & 4.8 & 4.848 & TST \\
\hline CHEMBL 2005449 & 809205 & 4.5 & 5.5445 & TRN \\
\hline CHEMBL1987998 & 809205 & 4.5 & 4.3695 & TRN \\
\hline CHEMBL1682558 & 809205 & 4.6 & 4.4613 & TRN \\
\hline CHEMBL1990496 & 809205 & 4.6 & 4.4396 & TRN \\
\hline
\end{tabular}




\begin{tabular}{|c|c|c|c|c|c|}
\hline \multicolumn{6}{|c|}{ Supplemental Table S2.txt } \\
\hline CHEMBL242865 & 809205 & 4.5 & 5.046 & TRN & \\
\hline CHEMBL1997623 & 809205 & 7.8 & 6.474 & TRN & \\
\hline CHEMBL1968460 & 809205 & 4.3 & 4.5594 & TRN & \\
\hline CHEMBL2002479 & 809205 & 5.6 & 4.8226 & TRN & \\
\hline CHEMBL1993166 & 809205 & 4.6 & 4.7536 & TRN & \\
\hline CHEMBL1967094 & 809205 & 4.6 & 4.379 & TRN & \\
\hline CHEMBL1966035 & 809205 & 4.6 & 4.5516 & TRN & \\
\hline CHEMBL2003341 & 809205 & 4.6 & 4.688 & TRN & \\
\hline CHEMBL1992645 & 809205 & 4.6 & 4.5316 & TST & \\
\hline CHEMBL1982992 & 809205 & 4.6 & 4.2066 & TRN & \\
\hline CHEMBL1998110 & 809205 & 4.5 & 4.4421 & TRN & \\
\hline CHEMBL1999590 & 809205 & 4.6 & 4.5328 & TST & \\
\hline CHEMBL1981079 & 809205 & 4.6 & 4.6921 & TRN & \\
\hline CHEMBL1978166 & 809205 & 6.2 & 6.0441 & TRN & \\
\hline CHEMBL1972276 & 809205 & 4.6 & 4.58 & TRN & \\
\hline CHEMBL1980489 & 809205 & 4.6 & 4.4245 & TRN & \\
\hline CHEMBL2000832 & 809205 & 4.6 & 4.7443 & TRN & \\
\hline CHEMBL1967116 & 809205 & 8.1 & 8.1787 & TRN & \\
\hline CHEMBL1990590 & 809205 & 4.5 & 4.3468 & TRN & \\
\hline CHEMBL1977814 & 809205 & 4.0 & 5.1037 & TST & \\
\hline CHEMBL1970709 & 809205 & 4.6 & 4.6093 & TRN & \\
\hline CHEMBL1965660 & 809205 & 4.6 & 4.5573 & TRN & \\
\hline CHEMBL1992125 & 809205 & 6.1 & 5.6037 & TRN & \\
\hline CHEMBL1998112 & 809205 & 4.6 & 4.4274 & TRN & \\
\hline CHEMBL1969126 & 809205 & 4.6 & 4.4853 & TRN & \\
\hline CHEMBL1980896 & 809205 & 4.7 & 5.4361 & TRN & \\
\hline CHEMBL1970104 & 809205 & 7.2 & 6.7929 & TRN & \\
\hline CHEMBL1991429 & 809205 & 5.7 & 5.0851 & TRN & \\
\hline CHEMBL1964777 & 809205 & 4.6 & 4.4769 & TRN & \\
\hline CHEMBL1971149 & 809205 & 4.6 & 4.6908 & TRN & \\
\hline CHEMBL1999714 & 809205 & 4.6 & 4.7317 & TRN & \\
\hline CHEMBL1987533 & 809205 & 4.6 & 4.70100 & 00000000005 & TRN \\
\hline CHEMBL1994040 & 809205 & 4.6 & 4.6096 & TRN & \\
\hline CHEMBL388978 & 809205 & 8.2 & 7.4932 & TST & \\
\hline CHEMBL579246 & 809205 & 4.6 & 4.6364 & TRN & \\
\hline CHEMBL398951 & 809205 & 4.6 & 4.0598 & TST & \\
\hline CHEMBL1982506 & 809205 & 4.6 & 4.4533 & TST & \\
\hline CHEMBL 2004716 & 809205 & 7.8 & 7.2513 & TRN & \\
\hline CHEMBL1968127 & 809205 & 4.6 & 4.5902 & TRN & \\
\hline CHEMBL1975233 & 809205 & 4.6 & 4.4902 & TRN & \\
\hline CHEMBL1985406 & 809205 & 4.6 & 4.4632 & TRN & \\
\hline CHEMBL 207400 & 809205 & 4.6 & 5.0718 & TST & \\
\hline CHEMBL 2000894 & 809205 & 4.6 & 4.74100 & 00000000005 & TST \\
\hline CHEMBL1421720 & 809205 & 6.5 & 5.0601 & TRN & \\
\hline CHEMBL1982135 & 809205 & 5.6 & 5.2397 & TRN & \\
\hline CHEMBL1976090 & 809205 & 4.6 & 4.5546 & TRN & \\
\hline CHEMBL1993243 & 809205 & 5.9 & 5.9863 & TRN & \\
\hline CHEMBL2004771 & 809205 & 4.6 & 4.8897 & TRN & \\
\hline
\end{tabular}




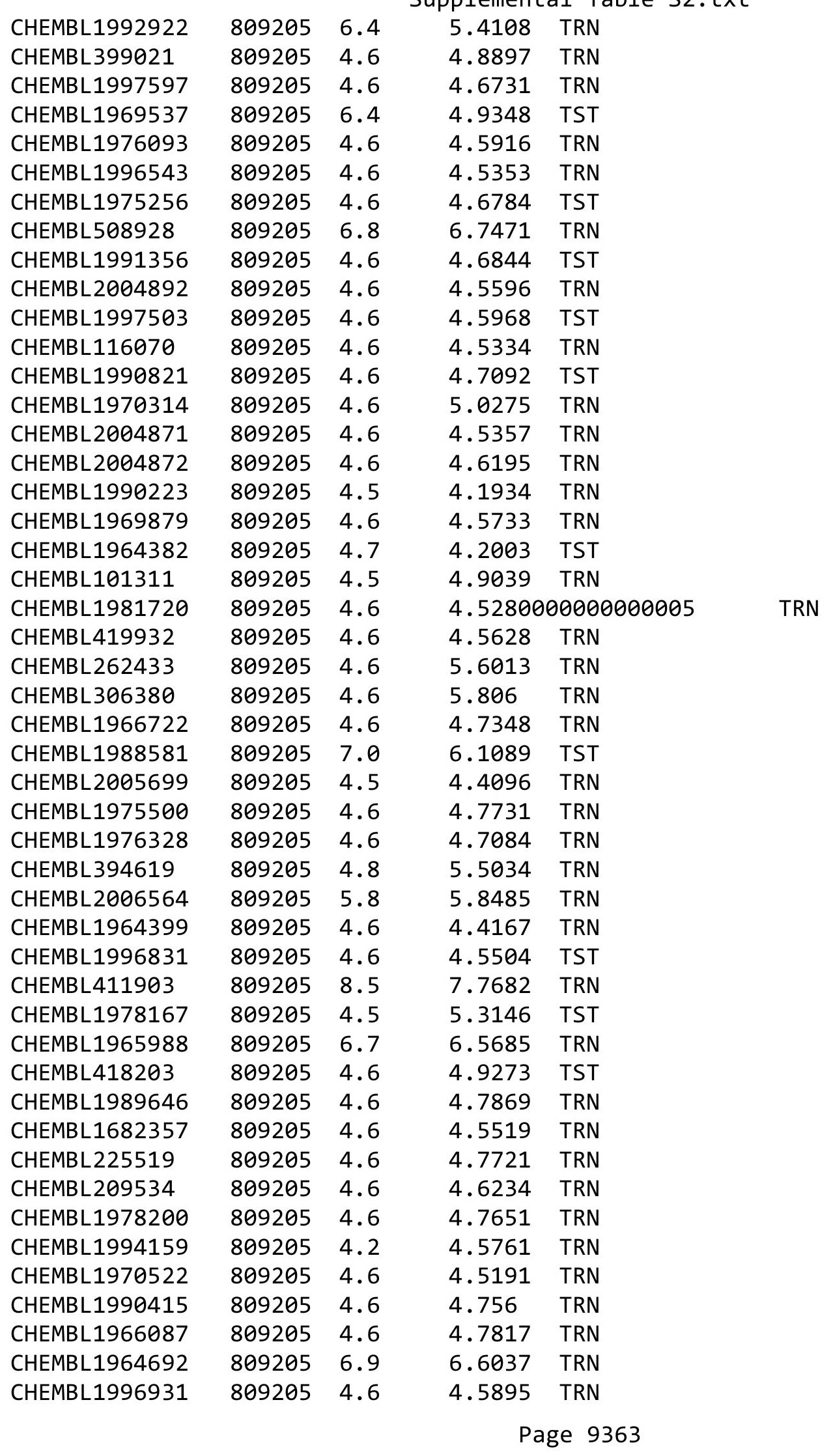




\begin{tabular}{|c|c|c|c|c|}
\hline & & & Supplement & \\
\hline CHEMBL1964413 & 809205 & 4.6 & 4.6634 & TRN \\
\hline CHEMBL1973483 & 809205 & 4.6 & 4.5019 & TRN \\
\hline CHEMBL1998470 & 809205 & 4.5 & 4.2452 & TRN \\
\hline CHEMBL1984432 & 809205 & 4.6 & 4.6101 & TRN \\
\hline CHEMBL219722 & 809205 & 5.9 & 5.9426 & TRN \\
\hline CHEMBL1975903 & 809205 & 4.5 & 5.0741 & TRN \\
\hline CHEMBL1997340 & 809205 & 4.6 & 4.6742 & TRN \\
\hline CHEMBL1522508 & 809205 & 4.6 & 4.3078 & TRN \\
\hline CHEMBL1989474 & 809205 & 4.6 & 4.58 & TRN \\
\hline CHEMBL1090360 & 809205 & 4.6 & 4.5322 & TRN \\
\hline CHEMBL 210887 & 809205 & 4.6 & 4.8153 & TST \\
\hline CHEMBL1988805 & 809205 & 4.5 & 4.4669 & TST \\
\hline CHEMBL458997 & 809205 & 4.8 & 4.9125 & TRN \\
\hline CHEMBL1971021 & 809205 & 7.1 & 6.4331 & TRN \\
\hline CHEMBL 227271 & 809205 & 4.6 & 4.808 & TRN \\
\hline CHEMBL583144 & 809205 & 4.6 & 4.8847 & TST \\
\hline CHEMBL1974310 & 809205 & 4.6 & 4.5752 & TRN \\
\hline CHEMBL1969942 & 809205 & 4.5 & 4.5466 & TRN \\
\hline CHEMBL1978567 & 809205 & 4.5 & 4.4421 & TRN \\
\hline CHEMBL1982660 & 809205 & 4.6 & 4.6028 & TRN \\
\hline CHEMBL1994693 & 809205 & 4.6 & 5.7908 & TRN \\
\hline CHEMBL1982957 & 809205 & 6.7 & 6.1523 & TRN \\
\hline CHEMBL1725279 & 809205 & 5.9 & 6.2958 & TST \\
\hline CHEMBL1975138 & 809205 & 4.6 & 4.628 & TRN \\
\hline CHEMBL424872 & 809205 & 4.6 & 4.5746 & TRN \\
\hline CHEMBL1971947 & 809205 & 7.4 & 6.7919 & TRN \\
\hline CHEMBL412142 & 809205 & 4.6 & 4.6608 & TST \\
\hline CHEMBL1980704 & 809205 & 4.6 & 4.5232 & TST \\
\hline CHEMBL2003271 & 809205 & 4.6 & 4.6896 & TST \\
\hline CHEMBL1966808 & 809205 & 4.6 & 4.6091 & TRN \\
\hline CHEMBL 2004447 & 809205 & 4.6 & 4.7606 & TRN \\
\hline CHEMBL1983111 & 809205 & 7.0 & 6.9889 & TRN \\
\hline CHEMBL1973860 & 809205 & 4.6 & 4.5487 & TRN \\
\hline CHEMBL260135 & 809205 & 4.6 & 4.4345 & TRN \\
\hline CHEMBL 220241 & 809205 & 4.6 & 4.3905 & TRN \\
\hline CHEMBL1988141 & 809205 & 6.9 & 5.8485 & TST \\
\hline CHEMBL1982610 & 809205 & 4.6 & 5.1532 & TST \\
\hline CHEMBL1977134 & 809205 & 7.0 & 6.8302 & TRN \\
\hline CHEMBL1999496 & 809205 & 4.6 & 4.7241 & TRN \\
\hline CHEMBL 2006933 & 809205 & 4.6 & 4.4662 & TST \\
\hline CHEMBL1985206 & 809205 & 4.5 & 4.8933 & TST \\
\hline CHEMBL1988300 & 809205 & 6.8 & 5.4234 & TRN \\
\hline CHEMBL1991078 & 809205 & 5.8 & 5.3334 & TRN \\
\hline CHEMBL1987359 & 809205 & 4.6 & 4.5985 & TST \\
\hline CHEMBL1977749 & 809205 & 4.5 & 4.8105 & TST \\
\hline CHEMBL1975212 & 809205 & 5.3 & 4.6509 & TRN \\
\hline CHEMBL 2000685 & 809205 & 4.6 & 5.0107 & TRN \\
\hline CHEMBL2001613 & 809205 & 4.7 & 4.5407 & TRN \\
\hline
\end{tabular}




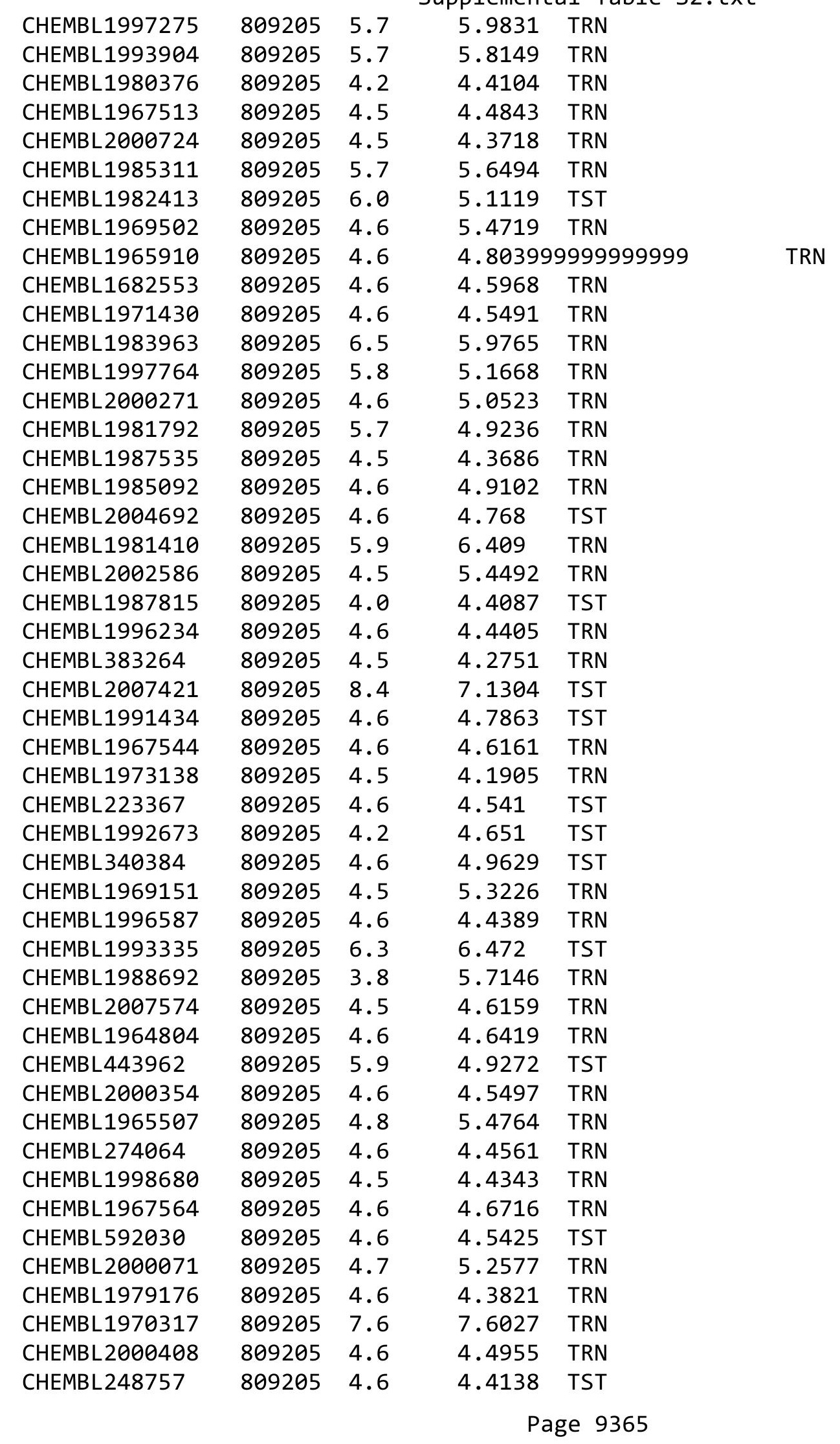




\begin{tabular}{|c|c|c|c|c|}
\hline \multicolumn{5}{|c|}{ Supplemental Table S2.txt } \\
\hline CHEMBL1978014 & 809205 & 4.6 & 4.6511 & TRN \\
\hline CHEMBL 2002736 & 809205 & 3.8 & 4.6931 & TRN \\
\hline CHEMBL1997007 & 809205 & 4.5 & 4.6336 & TRN \\
\hline CHEMBL1994538 & 809205 & 4.6 & 4.7258 & TRN \\
\hline CHEMBL1975490 & 809205 & 4.6 & 4.9418 & TRN \\
\hline CHEMBL1964444 & 809205 & 4.6 & 4.4674 & TRN \\
\hline CHEMBL 2002690 & 809205 & 4.5 & 4.4891 & TRN \\
\hline CHEMBL1984131 & 809205 & 5.3 & 4.7971 & TRN \\
\hline CHEMBL 2006567 & 809205 & 4.6 & 4.4865 & TRN \\
\hline CHEMBL1986139 & 809205 & 4.6 & 4.518 & TRN \\
\hline CHEMBL383527 & 809205 & 4.6 & 4.6841 & TRN \\
\hline CHEMBL1980540 & 809205 & 4.6 & 4.6729 & TRN \\
\hline CHEMBL278041 & 809205 & 4.5 & 5.2225 & TRN \\
\hline CHEMBL1979883 & 809205 & 5.9 & 6.6373 & TRN \\
\hline CHEMBL1984162 & 809205 & 6.5 & 7.1926 & TRN \\
\hline CHEMBL491758 & 809205 & 5.7 & 5.6768 & TRN \\
\hline CHEMBL1986590 & 809205 & 5.9 & 5.954 & TRN \\
\hline CHEMBL549730 & 809205 & 4.6 & 4.5897 & TRN \\
\hline CHEMBL1682360 & 809205 & 4.6 & 4.7242 & TRN \\
\hline CHEMBL1970189 & 809205 & 4.6 & 4.5522 & TRN \\
\hline CHEMBL1870106 & 809205 & 4.5 & 4.592 & TRN \\
\hline CHEMBL1996791 & 809205 & 6.2 & 4.9149 & TRN \\
\hline CHEMBL371206 & 809205 & 6.4 & 6.2037 & TRN \\
\hline CHEMBL1974664 & 809205 & 4.6 & 5.0184 & TST \\
\hline CHEMBL1998477 & 809205 & 5.7 & 5.1776 & TRN \\
\hline CHEMBL406845 & 809205 & 4.5 & 4.7078 & TRN \\
\hline CHEMBL1974288 & 809205 & 4.6 & 4.6927 & TRN \\
\hline CHEMBL1984296 & 809205 & 6.0 & 4.8844 & TST \\
\hline CHEMBL196363 & 809205 & 6.8 & 6.4471 & TRN \\
\hline CHEMBL1190711 & 809205 & 4.6 & 4.9755 & TRN \\
\hline CHEMBL1990346 & 809205 & 4.6 & 4.6231 & TRN \\
\hline CHEMBL1968705 & 809205 & 4.6 & 4.5951 & TRN \\
\hline CHEMBL1964441 & 809205 & 6.2 & 6.4774 & TRN \\
\hline CHEMBL1991410 & 809205 & 4.5 & 4.4352 & TRN \\
\hline CHEMBL546797 & 809205 & 5.7 & 5.2379 & TRN \\
\hline CHEMBL404367 & 809205 & 4.7 & 5.235 & TRN \\
\hline CHEMBL1966343 & 809205 & 5.9 & 4.6331 & TRN \\
\hline CHEMBL1978271 & 809205 & 4.5 & 4.4167 & TRN \\
\hline CHEMBL1967887 & 809205 & 4.6 & 4.8306 & TRN \\
\hline CHEMBL2007266 & 809205 & 4.5 & 4.8291 & TRN \\
\hline CHEMBL 2000568 & 809205 & 4.6 & 4.3051 & TRN \\
\hline CHEMBL1994308 & 809205 & 3.8 & 4.8625 & TST \\
\hline CHEMBL 2000335 & 809205 & 6.3 & 6.3053 & TRN \\
\hline CHEMBL 2007097 & 809205 & 4.4 & 4.5473 & TRN \\
\hline CHEMBL1988717 & 809205 & 7.6 & 7.7351 & TRN \\
\hline CHEMBL1974328 & 809205 & 4.6 & 5.1314 & TRN \\
\hline CHEMBL509032 & 809205 & 4.8 & 5.3259 & TRN \\
\hline CHEMBL1973808 & 809205 & 4.6 & 4.5855 & TRN \\
\hline
\end{tabular}




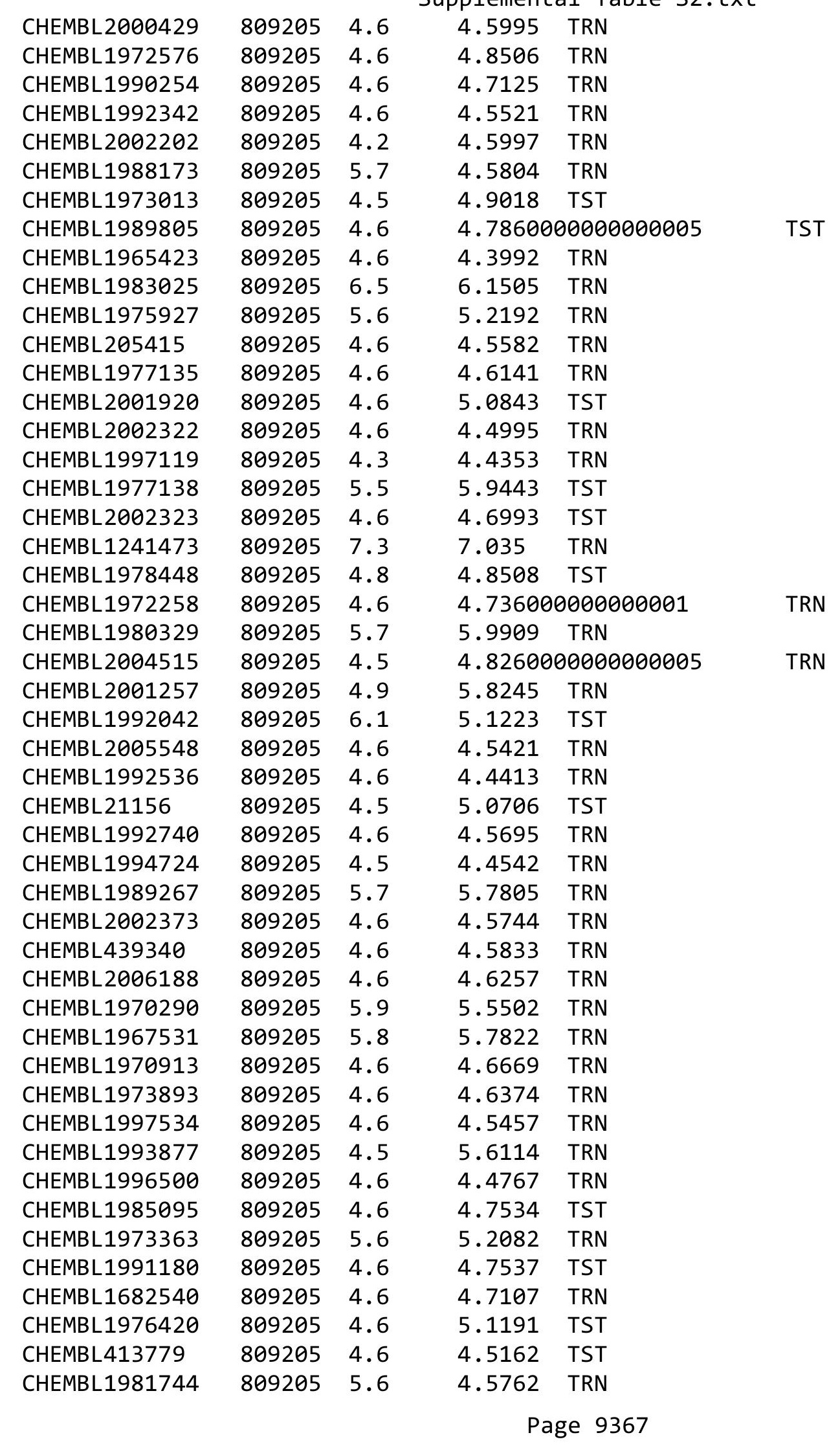




\begin{tabular}{|c|c|c|c|c|}
\hline \multicolumn{5}{|c|}{ Supplemental Table s2.txt } \\
\hline CHEMBL1994864 & 809205 & 4.6 & 4.5383 & TRN \\
\hline CHEMBL 2002446 & 809205 & 6.3 & 5.1747 & TST \\
\hline CHEMBL497151 & 809205 & 4.6 & 4.6092 & TRN \\
\hline CHEMBL 2000029 & 809205 & 4.5 & 4.6474 & TRN \\
\hline CHEMBL1973961 & 809205 & 6.2 & 5.1403 & TRN \\
\hline CHEMBL246970 & 809205 & 4.6 & 4.4122 & TRN \\
\hline CHEMBL340921 & 809205 & 4.6 & 4.7286 & TST \\
\hline CHEMBL1994977 & 809205 & 4.5 & 4.4789 & TRN \\
\hline CHEMBL373598 & 809205 & 4.6 & 4.5144 & TST \\
\hline CHEMBL1999718 & 809205 & 4.6 & 4.6257 & TRN \\
\hline CHEMBL2005478 & 809205 & 6.3 & 6.6516 & TST \\
\hline CHEMBL1276446 & 809205 & 7.7 & 6.4198 & TST \\
\hline CHEMBL1996646 & 809205 & 6.1 & 6.0936 & TRN \\
\hline CHEMBL1979773 & 809205 & 4.5 & 4.2317 & TRN \\
\hline CHEMBL1977346 & 809205 & 4.6 & 5.157 & TRN \\
\hline CHEMBL 2003657 & 809205 & 4.6 & 4.4818 & TRN \\
\hline CHEMBL1971649 & 809205 & 4.6 & 4.5224 & TRN \\
\hline CHEMBL1996702 & 809205 & 4.5 & 4.5739 & TRN \\
\hline CHEMBL 2007124 & 809205 & 5.8 & 5.9935 & TRN \\
\hline CHEMBL 2006439 & 809205 & 5.7 & 5.4531 & TRN \\
\hline CHEMBL1985681 & 809205 & 4.5 & 4.9675 & TST \\
\hline CHEMBL1969190 & 809205 & 5.8 & 5.9539 & TRN \\
\hline CHEMBL1973937 & 809205 & 4.9 & 5.7259 & TRN \\
\hline CHEMBL1991674 & 809205 & 4.6 & 4.7213 & TRN \\
\hline CHEMBL1982711 & 809205 & 4.6 & 4.592 & TRN \\
\hline CHEMBL1984842 & 809205 & 4.6 & 4.4921 & TRN \\
\hline CHEMBL1969102 & 809205 & 7.7 & 7.6796 & TRN \\
\hline CHEMBL 2004118 & 809205 & 4.5 & 5.0245 & TRN \\
\hline CHEMBL1682346 & 809205 & 4.6 & 4.5897 & TRN \\
\hline CHEMBL1996795 & 809205 & 5.7 & 4.7259 & TST \\
\hline CHEMBL 2007044 & 809205 & 4.6 & 4.5825 & TST \\
\hline CHEMBL2001998 & 809205 & 4.6 & 4.2503 & TST \\
\hline CHEMBL1994241 & 809205 & 4.6 & 4.4725 & TRN \\
\hline CHEMBL223460 & 809205 & 4.6 & 4.4859 & TST \\
\hline CHEMBL1998829 & 809205 & 5.7 & 5.1165 & TRN \\
\hline CHEMBL50894 & 809205 & 4.6 & 4.9051 & TRN \\
\hline CHEMBL1995211 & 809205 & 5.6 & 5.7145 & TRN \\
\hline CHEMBL1988838 & 809205 & 6.9 & 6.6174 & TRN \\
\hline CHEMBL1981725 & 809205 & 5.7 & 5.3566 & TRN \\
\hline CHEMBL 375284 & 809205 & 4.6 & 4.7107 & TRN \\
\hline CHEMBL 2006299 & 809205 & 4.5 & 4.4349 & TRN \\
\hline CHEMBL1965169 & 809205 & 4.5 & 4.6362 & TST \\
\hline CHEMBL1081312 & 809205 & 4.5 & 4.7834 & TRN \\
\hline CHEMBL1965170 & 809205 & 7.0 & 7.3335 & TRN \\
\hline CHEMBL1982866 & 809205 & 4.6 & 4.3834 & TRN \\
\hline CHEMBL 2005792 & 809205 & 4.6 & 4.4903 & TRN \\
\hline CHEMBL1968926 & 809205 & 4.6 & 4.6092 & TRN \\
\hline CHEMBL1984206 & 809205 & 4.6 & 4.9783 & TRN \\
\hline
\end{tabular}




\begin{tabular}{|c|c|c|c|c|}
\hline & & & plement & \\
\hline CHEMBL462120 & 809205 & 4.6 & 4.9319 & TST \\
\hline CHEMBL1991577 & 809205 & 4.6 & 4.4543 & TRN \\
\hline CHEMBL1991867 & 809205 & 4.6 & 5.0728 & TST \\
\hline CHEMBL1965570 & 809205 & 6.6 & 6.4315 & TRN \\
\hline CHEMBL 2007592 & 809205 & 4.6 & 4.694 & TRN \\
\hline CHEMBL1972355 & 809205 & 6.4 & 5.7474 & TST \\
\hline CHEMBL1997892 & 809205 & 7.2 & 6.2578 & TRN \\
\hline CHEMBL 2001641 & 809205 & 4.1 & 4.5686 & TRN \\
\hline CHEMBL1997193 & 809205 & 6.2 & 5.2679 & TST \\
\hline CHEMBL210963 & 809205 & 4.6 & 4.5633 & TRN \\
\hline CHEMBL1964902 & 809205 & 4.5 & 4.4333 & TRN \\
\hline CHEMBL1082440 & 809205 & 4.6 & 4.6905 & TST \\
\hline CHEMBL1614705 & 809205 & 4.6 & 4.6631 & TRN \\
\hline CHEMBL1972362 & 809205 & 4.6 & 4.4898 & TRN \\
\hline CHEMBL1984633 & 809205 & 4.6 & 4.5752 & TRN \\
\hline CHEMBL1965845 & 809205 & 4.6 & 4.7401 & TRN \\
\hline CHEMBL 2007372 & 809205 & 4.6 & 4.7139 & TRN \\
\hline CHEMBL1983715 & 809205 & 5.6 & 5.4458 & TRN \\
\hline CHEMBL1971017 & 809205 & 4.6 & 4.7917 & TRN \\
\hline CHEMBL 2006715 & 809205 & 5.6 & 4.8052 & TRN \\
\hline CHEMBL1986597 & 809205 & 4.6 & 4.5266 & TRN \\
\hline CHEMBL1990482 & 809205 & 4.6 & 4.7976 & TRN \\
\hline CHEMBL1990904 & 809205 & 4.6 & 4.3576 & TRN \\
\hline CHEMBL 2000104 & 809205 & 4.6 & 4.3657 & TRN \\
\hline CHEMBL 2005475 & 809205 & 4.6 & 4.715 & TRN \\
\hline CHEMBL402846 & 809205 & 4.8 & 5.4731 & TRN \\
\hline CHEMBL1997349 & 809205 & 6.0 & 4.9927 & TST \\
\hline CHEMBL183844 & 809205 & 4.6 & 4.9595 & TRN \\
\hline CHEMBL220057 & 809205 & 4.9 & 5.8982 & TRN \\
\hline CHEMBL1682545 & 809205 & 4.6 & 4.3514 & TRN \\
\hline CHEMBL1992195 & 809205 & 5.4 & 4.4321 & TST \\
\hline CHEMBL383541 & 809205 & 4.6 & 4.481 & TRN \\
\hline CHEMBL 2001224 & 809205 & 4.6 & 4.6421 & TRN \\
\hline CHEMBL10 & 809205 & 4.6 & 4.3746 & TRN \\
\hline CHEMBL1976732 & 809205 & 4.6 & 4.6013 & TRN \\
\hline CHEMBL1969506 & 809205 & 4.6 & 4.5577 & TRN \\
\hline CHEMBL1980763 & 809205 & 4.5 & 5.1149 & TRN \\
\hline CHEMBL1964937 & 809205 & 4.6 & 4.6794 & TRN \\
\hline CHEMBL1980163 & 809205 & 4.6 & 4.57 & TRN \\
\hline CHEMBL590109 & 809205 & 4.6 & 4.6655 & TST \\
\hline CHEMBL1970879 & 809205 & 5.7 & 5.3459 & TRN \\
\hline CHEMBL1989856 & 809205 & 4.6 & 4.9955 & TST \\
\hline CHEMBL 2005899 & 809205 & 4.6 & 4.5727 & TRN \\
\hline CHEMBL1682552 & 809205 & 4.6 & 4.6766 & TRN \\
\hline CHEMBL259850 & 809205 & 4.6 & 4.5078 & TRN \\
\hline CHEMBL 2007479 & 809205 & 4.5 & 4.4616 & TRN \\
\hline CHEMBL229799 & 809205 & 4.6 & 4.8355 & TRN \\
\hline CHEMBL105739 & 809205 & 6.6 & 6.5564 & TRN \\
\hline
\end{tabular}




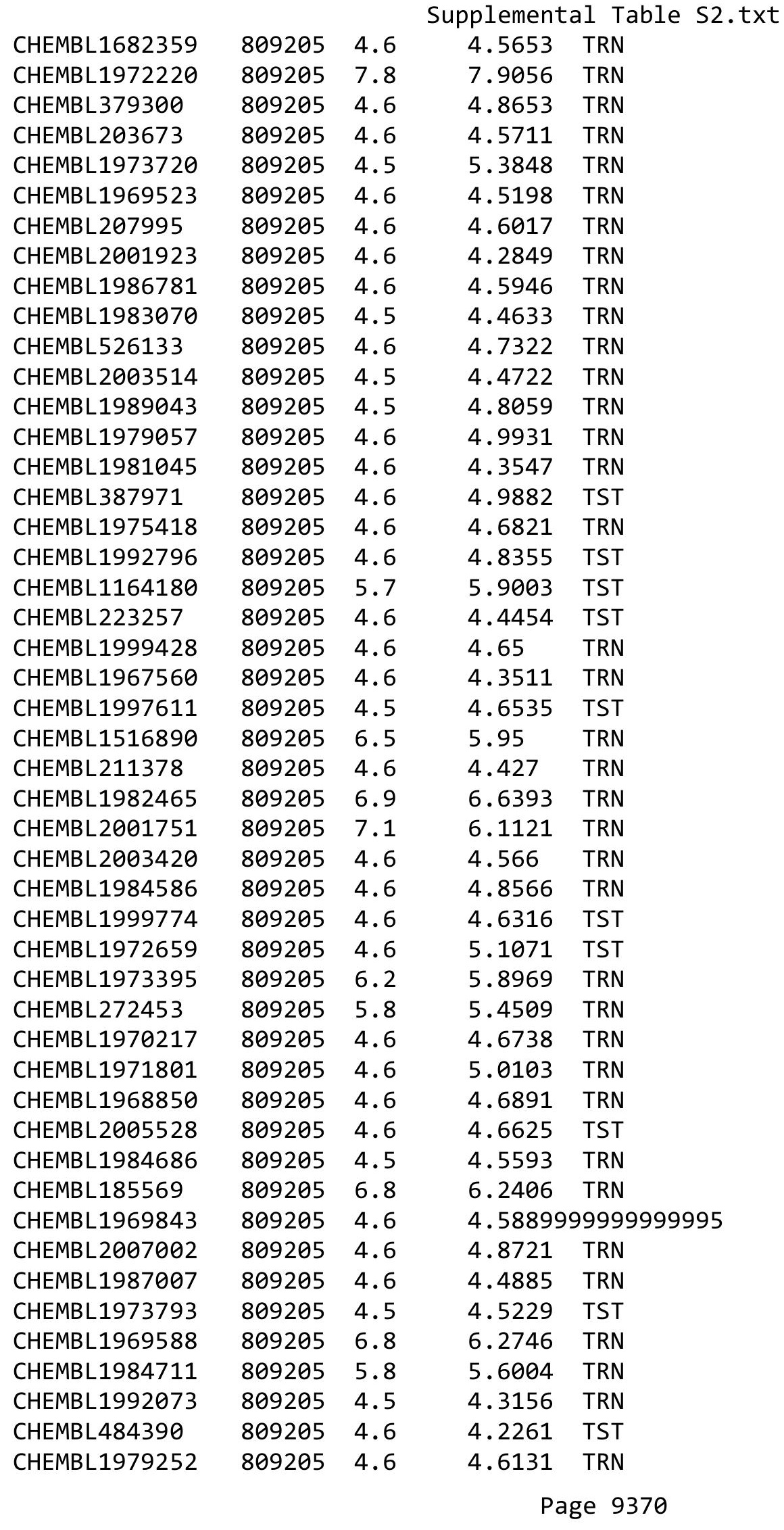




\begin{tabular}{|c|c|c|c|c|}
\hline \multicolumn{5}{|c|}{ olemental I } \\
\hline CHEMBL1986143 & 809205 & 4.5 & 4.5162 & TRN \\
\hline CHEMBL1972934 & 809205 & 4.8 & 4.4183 & TRN \\
\hline CHEMBL2007559 & 809205 & 4.5 & 4.9414 & TRN \\
\hline CHEMBL1992581 & 809205 & 5.0 & 5.5407 & TRN \\
\hline CHEMBL1682341 & 809205 & 4.6 & 4.5626 & TRN \\
\hline CHEMBL 2004290 & 809205 & 7.1 & 7.1983 & TRN \\
\hline CHEMBL1986499 & 809205 & 6.0 & 4.7414 & TRN \\
\hline CHEMBL1972937 & 809205 & 4.6 & 4.6652 & TRN \\
\hline CHEMBL1972250 & 809205 & 4.6 & 4.4144 & TST \\
\hline CHEMBL2000393 & 809205 & 4.6 & 5.7942 & TST \\
\hline CHEMBL1983573 & 809205 & 5.2 & 4.7136 & TRN \\
\hline CHEMBL 2004311 & 809205 & 6.8 & 6.3971 & TRN \\
\hline CHEMBL1992634 & 809205 & 4.6 & 5.7626 & TRN \\
\hline CHEMBL1242373 & 809205 & 5.9 & 6.0599 & TRN \\
\hline CHEMBL1984847 & 809205 & 4.5 & 4.6858 & TST \\
\hline CHEMBL316264 & 809205 & 4.6 & 4.6857 & TRN \\
\hline CHEMBL1988075 & 809205 & 5.6 & 6.0962 & TRN \\
\hline CHEMBL1996576 & 809205 & 4.1 & 4.7927 & TST \\
\hline CHEMBL1991678 & 809205 & 4.5 & 4.5237 & TRN \\
\hline CHEMBL2001239 & 809205 & 4.6 & 4.4183 & TST \\
\hline CHEMBL1988594 & 809205 & 4.6 & 5.1949 & TRN \\
\hline CHEMBL 2001288 & 809205 & 4.6 & 4.6015 & TRN \\
\hline CHEMBL260092 & 809205 & 8.1 & 7.5665 & TRN \\
\hline CHEMBL1999811 & 809205 & 4.6 & 4.7955 & TRN \\
\hline CHEMBL1965495 & 809205 & 4.6 & 4.7234 & TRN \\
\hline CHEMBL235157 & 809205 & 4.5 & 4.5348 & TST \\
\hline CHEMBL1985074 & 809205 & 4.6 & 4.6927 & TST \\
\hline CHEMBL 2000481 & 809205 & 4.6 & 4.5036 & TRN \\
\hline CHEMBL1982874 & 809205 & 4.6 & 4.4321 & TRN \\
\hline CHEMBL1991725 & 809205 & 4.6 & 4.6059 & TRN \\
\hline CHEMBL1992242 & 809205 & 4.6 & 4.7241 & TRN \\
\hline CHEMBL1999860 & 809205 & 5.6 & 5.0767 & TRN \\
\hline CHEMBL 2007296 & 809205 & 4.6 & 4.6522 & TRN \\
\hline CHEMBL208637 & 809205 & 4.6 & 4.6418 & TRN \\
\hline CHEMBL396523 & 809205 & 6.1 & 5.4676 & TRN \\
\hline CHEMBL2004159 & 809205 & 4.5 & 4.4142 & TRN \\
\hline CHEMBL1978371 & 809205 & 6.3 & 5.55399 & 9999999999 \\
\hline CHEMBL1970203 & 809205 & 4.6 & 5.0639 & TRN \\
\hline CHEMBL1986530 & 809205 & 4.6 & 4.3055 & TST \\
\hline CHEMBL440084 & 809205 & 4.5 & 4.604 & TRN \\
\hline CHEMBL1999321 & 809205 & 4.6 & 4.4222 & TRN \\
\hline CHEMBL1968590 & 809205 & 4.6 & 5.0914 & TRN \\
\hline CHEMBL1999749 & 809205 & 4.6 & 4.83 & TRN \\
\hline CHEMBL 2005375 & 809205 & 4.6 & 4.3574 & TRN \\
\hline CHEMBL1984191 & 809205 & 4.6 & 4.5397 & TRN \\
\hline CHEMBL1983006 & 809205 & 4.6 & 4.5514 & TRN \\
\hline CHEMBL1971029 & 809205 & 6.8 & 6.7384 & TRN \\
\hline CHEMBL394790 & 809205 & 4.6 & 5.225 & TRN \\
\hline
\end{tabular}




\begin{tabular}{|c|c|c|c|c|c|}
\hline \multicolumn{6}{|c|}{ Supplemental Table S2.txt } \\
\hline CHEMBL226471 & 809205 & 4.6 & 4.6513 & TRN & \\
\hline CHEMBL1974702 & 809205 & 4.6 & 4.7725 & TST & \\
\hline CHEMBL1996111 & 809205 & 4.6 & 4.4725 & TRN & \\
\hline CHEMBL1966175 & 809205 & 4.5 & 4.337 & TRN & \\
\hline CHEMBL1965589 & 809205 & 4.6 & 4.6689 & TRN & \\
\hline CHEMBL2007375 & 809205 & 4.5 & 4.4616 & TRN & \\
\hline CHEMBL1998193 & 809205 & 4.6 & 4.4513 & TRN & \\
\hline CHEMBL379975 & 809205 & 4.5 & 4.6761 & TST & \\
\hline CHEMBL474432 & 809205 & 4.6 & 5.7789 & TST & \\
\hline CHEMBL1965387 & 809205 & 4.5 & 4.2179 & TRN & \\
\hline CHEMBL1997041 & 809205 & 4.1 & 4.5985 & TRN & \\
\hline CHEMBL1988153 & 809205 & 4.6 & 4.4385 & TRN & \\
\hline CHEMBL550418 & 809205 & 4.5 & 4.689 & TRN & \\
\hline CHEMBL1971289 & 809205 & 4.5 & 4.5313 & TRN & \\
\hline CHEMBL1999556 & 809205 & 4.6 & 4.721 & TRN & \\
\hline CHEMBL1988437 & 809205 & 4.7 & 5.1531 & TST & \\
\hline CHEMBL1968245 & 809205 & 4.6 & 4.5619 & TRN & \\
\hline CHEMBL1979577 & 809205 & 6.7 & 6.4668 & TRN & \\
\hline CHEMBL1998121 & 809205 & 4.6 & 4.6597 & TRN & \\
\hline CHEMBL1233887 & 809205 & 4.5 & 4.9037 & TST & \\
\hline CHEMBL1991800 & 809205 & 4.6 & 4.6037 & TRN & \\
\hline CHEMBL52387 & 809205 & 4.6 & 4.9259 & TST & \\
\hline CHEMBL379835 & 809205 & 4.6 & 4.9222 & TST & \\
\hline CHEMBL1979357 & 809205 & 4.6 & 4.6831 & TRN & \\
\hline CHEMBL1980802 & 809205 & 4.6 & 4.5147 & TST & \\
\hline CHEMBL1996649 & 809205 & 6.1 & 6.1519 & TRN & \\
\hline CHEMBL1996817 & 809205 & 6.0 & 5.5024 & TRN & \\
\hline CHEMBL1979554 & 809205 & 4.6 & 4.4584 & TRN & \\
\hline CHEMBL1986756 & 809205 & 4.5 & 4.5248 & TRN & \\
\hline CHEMBL 2004355 & 809205 & 4.6 & 4.6118 & TRN & \\
\hline CHEMBL468280 & 809205 & 4.6 & 4.73 & TST & \\
\hline CHEMBL1990884 & 809205 & 4.6 & 5.9002 & TRN & \\
\hline CHEMBL 3109278 & 809205 & 6.1 & 5.6471 & TRN & \\
\hline CHEMBL256835 & 809205 & 4.6 & 4.4909 & TRN & \\
\hline CHEMBL1980142 & 809205 & 4.6 & 4.6956 & TRN & \\
\hline CHEMBL41783 & 809205 & 4.6 & 4.5676 & TRN & \\
\hline CHEMBL 2004438 & 809205 & 4.8 & 5.4372 & TRN & \\
\hline CHEMBL2006276 & 809205 & 4.6 & 4.6573 & TRN & \\
\hline CHEMBL191003 & 809205 & 4.5 & 5.7492 & TRN & \\
\hline CHEMBL 271381 & 809205 & 6.0 & 6.3524 & TRN & \\
\hline CHEMBL2006785 & 809205 & 4.6 & 5.0254 & TST & \\
\hline CHEMBL1982466 & 809205 & 7.9 & 7.4464 & TRN & \\
\hline CHEMBL1973359 & 809205 & 6.7 & 5.0507 & TST & \\
\hline CHEMBL1995740 & 809205 & 4.6 & 4.46399 & 99999999995 & TRN \\
\hline CHEMBL1996390 & 809205 & 4.6 & 4.6879 & TRN & \\
\hline CHEMBL1979690 & 809205 & 6.4 & 6.4573 & TRN & \\
\hline CHEMBL 234085 & 809205 & 4.5 & 4.4477 & TRN & \\
\hline CHEMBL1995832 & 809205 & 4.6 & 4.5885 & TRN & \\
\hline
\end{tabular}




\begin{tabular}{|c|c|c|c|c|c|}
\hline \\
\hline CHEMBL1969042 & 809205 & 6.3 & 4.8686 & TRN & \\
\hline CHEMBL 2000345 & 809205 & 4.6 & 4.3674 & TRN & \\
\hline CHEMBL1999931 & 809205 & 4.6 & 5.2749 & TRN & \\
\hline CHEMBL1976376 & 809205 & 4.5 & 4.9686 & TRN & \\
\hline CHEMBL1991640 & 809205 & 4.6 & 4.9279 & TST & \\
\hline CHEMBL1983575 & 809205 & 5.4 & 5.5585 & TRN & \\
\hline CHEMBL1968868 & 809205 & 4.5 & 4.4526 & TRN & \\
\hline CHEMBL1375418 & 809205 & 4.6 & 4.7351 & TRN & \\
\hline CHEMBL 2007064 & 809205 & 6.6 & 6.7017 & TRN & \\
\hline CHEMBL1981047 & 809205 & 6.1 & 6.2576 & TRN & \\
\hline CHEMBL229968 & 809205 & 4.6 & 4.9795 & TRN & \\
\hline CHEMBL1976196 & 809205 & 3.8 & 4.822 & TST & \\
\hline CHEMBL1976240 & 809205 & 4.6 & 4.6395 & TRN & \\
\hline CHEMBL1997197 & 809205 & 4.5 & 4.4622 & TRN & \\
\hline CHEMBL1983630 & 809205 & 4.2 & 4.3232 & TRN & \\
\hline CHEMBL1979093 & 809205 & 6.2 & 5.8571 & TRN & \\
\hline CHEMBL1968151 & 809205 & 4.6 & 4.6563 & TRN & \\
\hline CHEMBL1381197 & 809205 & 4.6 & 4.8055 & TRN & \\
\hline CHEMBL1987009 & 809205 & 4.6 & 4.5169 & TRN & \\
\hline CHEMBL379218 & 809205 & 4.6 & 4.687 & TRN & \\
\hline CHEMBL 2003817 & 809205 & 4.6 & 4.4066 & TRN & \\
\hline CHEMBL336961 & 809205 & 4.6 & 4.8957 & TRN & \\
\hline CHEMBL1994830 & 809205 & 4.6 & 4.5433 & TRN & \\
\hline CHEMBL1987054 & 809205 & 6.7 & 7.08700 & 2000000001 & TRN \\
\hline CHEMBL1970083 & 809205 & 8.6 & 7.7707 & TRN & \\
\hline CHEMBL226403 & 809205 & 4.6 & 4.875 & TRN & \\
\hline CHEMBL 2005631 & 809205 & 7.7 & 7.86799 & 9999999999 & TRN \\
\hline CHEMBL1994938 & 809205 & 6.8 & 6.2613 & TRN & \\
\hline CHEMBL1977223 & 809205 & 4.6 & 4.6015 & TRN & \\
\hline CHEMBL1995765 & 809205 & 4.8 & 4.5792 & TST & \\
\hline CHEMBL1976290 & 809205 & 4.1 & 4.8734 & TRN & \\
\hline CHEMBL1966279 & 809205 & 4.6 & 4.4701 & TRN & \\
\hline CHEMBL1236126 & 809205 & 4.6 & 4.6729 & TST & \\
\hline CHEMBL1997846 & 809205 & 4.6 & 4.8225 & TRN & \\
\hline CHEMBL1984760 & 809205 & 4.5 & 5.047 & TRN & \\
\hline CHEMBL 2004419 & 809205 & 4.6 & 4.74 & TRN & \\
\hline CHEMBL1991728 & 809205 & 4.6 & 4.9008 & TRN & \\
\hline CHEMBL360847 & 809205 & 4.5 & 4.5948 & TST & \\
\hline CHEMBL1995811 & 809205 & 4.5 & 4.6283 & TRN & \\
\hline CHEMBL1975787 & 809205 & 4.6 & 4.5263 & TRN & \\
\hline CHEMBL 2002407 & 809205 & 4.6 & 4.4442 & TRN & \\
\hline CHEMBL1972489 & 809205 & 4.6 & 4.7101 & TRN & \\
\hline CHEMBL1994074 & 809205 & 4.6 & 4.7568 & TRN & \\
\hline CHEMBL1992937 & 809205 & 4.6 & 4.3174 & TST & \\
\hline CHEMBL1985566 & 809205 & 4.6 & 4.3815 & TRN & \\
\hline CHEMBL1972119 & 809205 & 4.6 & 4.8325 & TRN & \\
\hline CHEMBL1986328 & 809205 & 4.6 & 4.6295 & TST & \\
\hline CHEMBL95692 & 809205 & 4.6 & 4.5064 & TRN & \\
\hline & & & & 9373 & \\
\hline
\end{tabular}




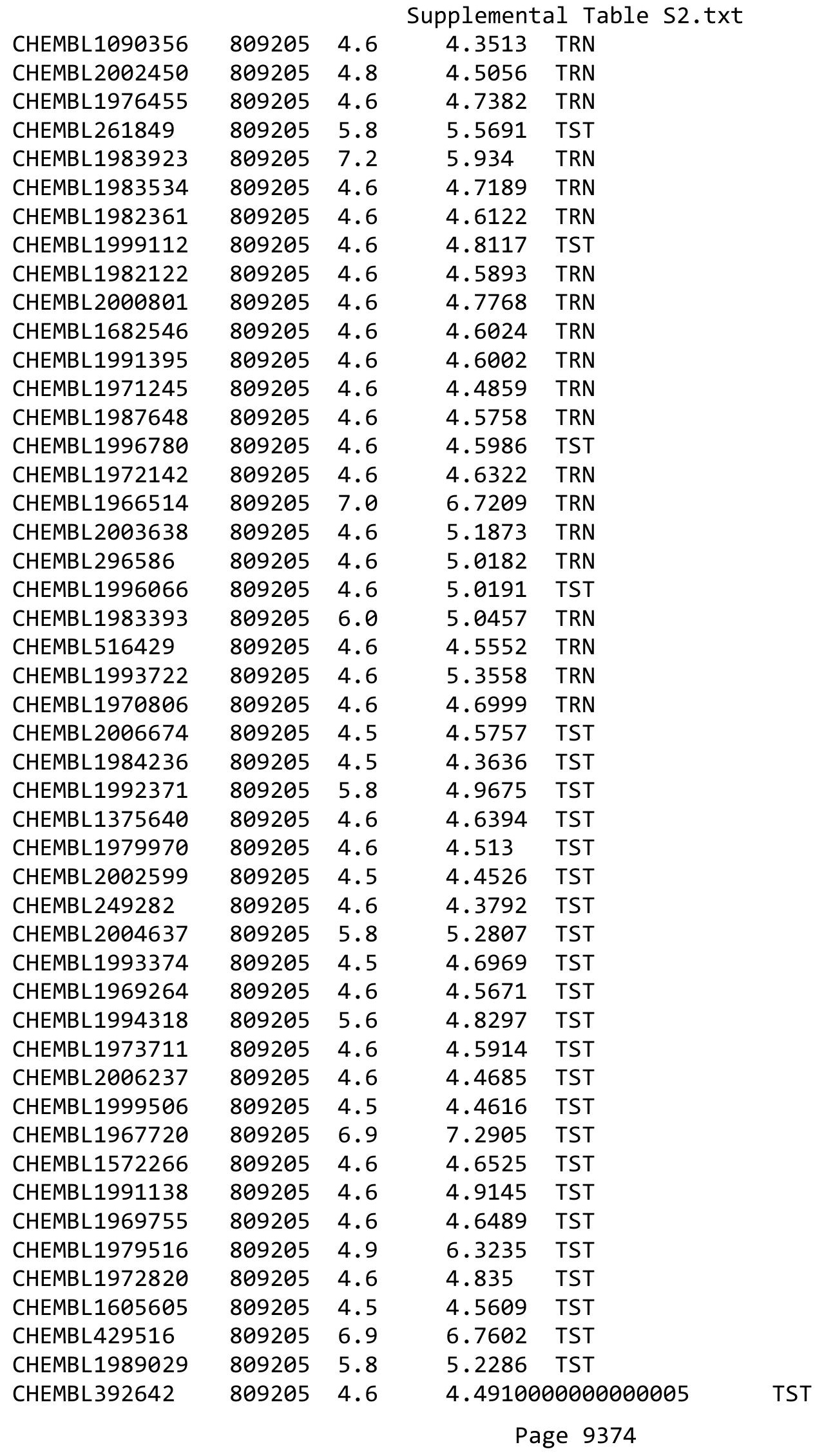




\begin{tabular}{|c|c|c|c|c|c|}
\hline \\
\hline CHEMBL514499 & 809205 & 6.4 & 4.8276 & TST & \\
\hline CHEMBL1970352 & 809205 & 5.8 & 4.6818 & TST & \\
\hline CHEMBL1965631 & 809205 & 4.6 & 4.5643 & TST & \\
\hline CHEMBL1980144 & 809205 & 4.6 & 4.9171 & TST & \\
\hline CHEMBL1991188 & 809205 & 4.6 & 4.5894 & TST & \\
\hline CHEMBL1980167 & 809205 & 6.4 & 5.0788 & TST & \\
\hline CHEMBL1972849 & 809205 & 4.6 & 4.5488 & TST & \\
\hline CHEMBL377408 & 809205 & 4.6 & 4.5789 & TST & \\
\hline CHEMBL215152 & 809205 & 4.6 & 4.083 & TST & \\
\hline CHEMBL231209 & 809205 & 4.6 & 5.0859 & TST & \\
\hline CHEMBL1976220 & 809205 & 5.9 & 5.5708 & TST & \\
\hline CHEMBL 2006765 & 809205 & 6.0 & 6.107 & TST & \\
\hline CHEMBL259922 & 809205 & 4.6 & 4.43 & TST & \\
\hline CHEMBL1997617 & 809205 & 5.9 & 5.6349 & TST & \\
\hline CHEMBL1969301 & 809205 & 4.6 & 4.3483 & TST & \\
\hline CHEMBL1982383 & 809205 & 4.6 & 4.4501 & TST & \\
\hline CHEMBL17370 & 809205 & 4.6 & 4.553 & TST & \\
\hline CHEMBL1980246 & 809205 & 4.5 & 4.4763 & TST & \\
\hline CHEMBL1987910 & 809205 & 4.6 & 4.8716 & TST & \\
\hline CHEMBL1983932 & 809205 & 4.6 & 4.2182 & TST & \\
\hline CHEMBL1983980 & 809205 & 6.0 & 5.4912 & TST & \\
\hline CHEMBL1999484 & 809205 & 4.5 & 5.1051 & TST & \\
\hline CHEMBL1966069 & 809205 & 4.6 & 4.6584 & TST & \\
\hline CHEMBL1986899 & 809205 & 5.6 & 4.6362 & TST & \\
\hline CHEMBL1991285 & 809205 & 4.6 & 4.6951 & TST & \\
\hline CHEMBL1997822 & 809205 & 4.6 & 5.0364 & TST & \\
\hline CHEMBL 243088 & 809205 & 4.6 & 5.5196 & TST & \\
\hline CHEMBL1984038 & 809205 & 4.6 & 4.5015 & TST & \\
\hline CHEMBL1968606 & 809205 & 3.8 & 5.4893 & TST & \\
\hline CHEMBL1993661 & 809205 & 6.9 & 7.6649 & TST & \\
\hline CHEMBL1974416 & 809205 & 5.7 & 5.4015 & TST & \\
\hline CHEMBL1997872 & 809205 & 4.6 & 4.6315 & TST & \\
\hline CHEMBL2180916 & 878514 & 6.7328 & 6.1316 & TRN & \\
\hline CHEMBL2180907 & 878514 & 6.4535 & 4.9517 & TST & \\
\hline CHEMBL2181162 & 878514 & 6.4737 & 6.7052 & TRN & \\
\hline CHEMBL2181155 & 878514 & 6.1543 & 6.307 & TRN & \\
\hline CHEMBL 2180913 & 878514 & 6.6003 & 6.5414 & TRN & \\
\hline CHEMBL2180917 & 878514 & 6.3904 & 6.3444 & TRN & \\
\hline CHEMBL2181148 & 878514 & 6.6819 & 6.6794 & TRN & \\
\hline CHEMBL2180920 & 878514 & 5.8601 & 5.1504 & TST & \\
\hline CHEMBL2180908 & 878514 & 5.1141 & 4.7399 & TST & \\
\hline CHEMBL 2180936 & 878514 & 7.058 & 7.0306 & TRN & \\
\hline CHEMBL2180906 & 878514 & 6.0458 & 6.1271 & TRN & \\
\hline CHEMBL 2181165 & 878514 & 3.5229 & 4.8628 & TST & \\
\hline CHEMBL2181140 & 878514 & 6.8327 & 7.00799 & 9999999999 & TRN \\
\hline CHEMBL2180939 & 878514 & 6.2269 & 6.3623 & TRN & \\
\hline CHEMBL 2181146 & 878514 & 5.2132 & 4.707 & TRN & \\
\hline CHEMBL2180938 & 878514 & 7.1931 & 6.8679 & TRN & \\
\hline
\end{tabular}




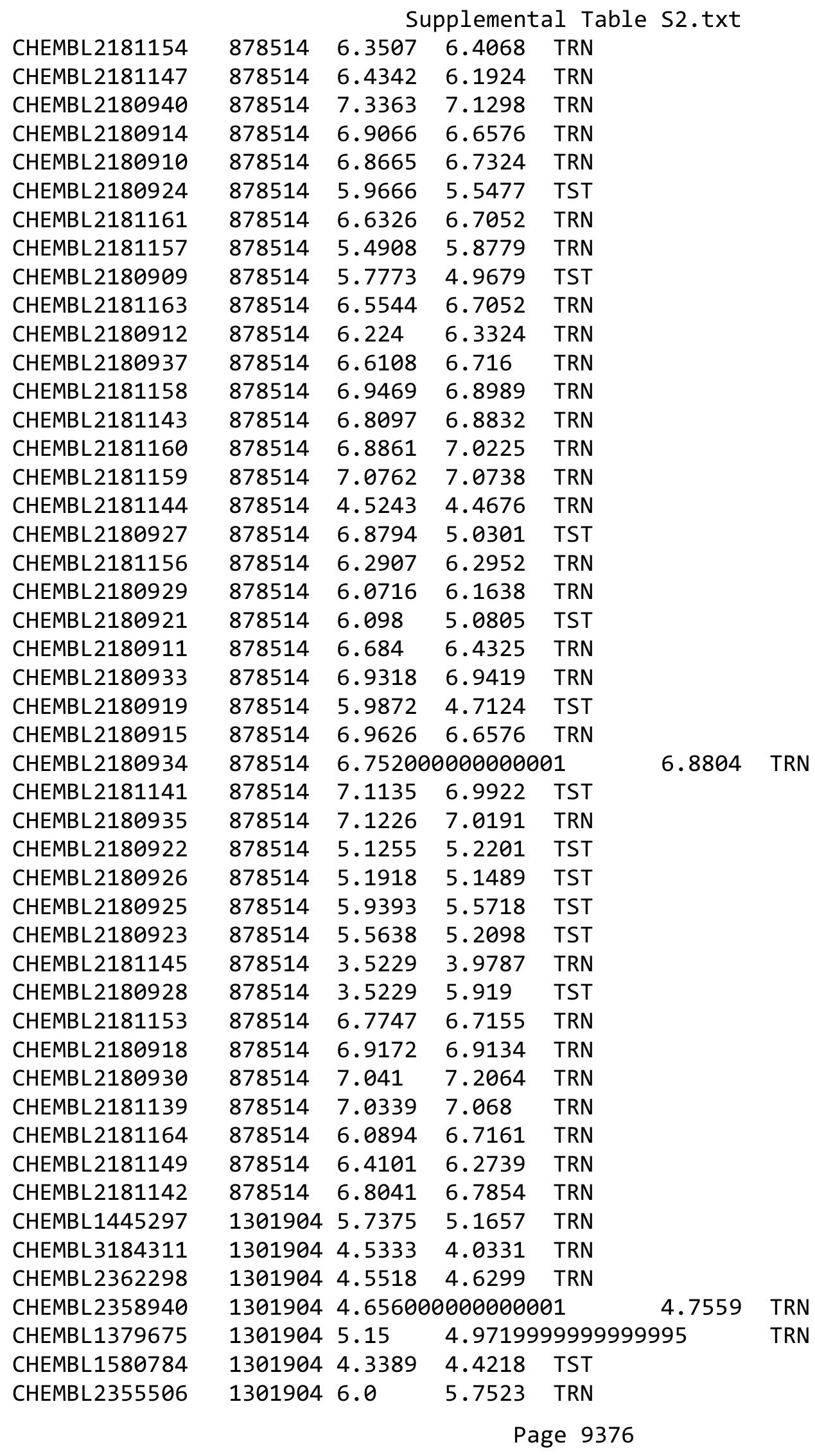


Supplemental Table S2.txt

\begin{tabular}{|c|c|c|c|c|c|}
\hline CHEMBL1544186 & 1301904 & 5.3458 & 5.0966 & TRN & \\
\hline CHEMBL1452421 & 1301904 & 5.4547 & 5.3842 & TRN & \\
\hline CHEMBL2361006 & 1301904 & 4.5795 & 4.812 & TRN & \\
\hline CHEMBL2357026 & 1301904 & 6.0 & 5.9198 & TRN & \\
\hline CHEMBL2354788 & 1301904 & 4.5223 & \multicolumn{2}{|c|}{3.9339999999999997} & TRN \\
\hline CHEMBL 2356271 & 1301904 & 4.4344 & 4.6993 & TRN & \\
\hline CHEMBL3185444 & 1301904 & 5.0747 & 5.2018 & TRN & \\
\hline CHEMBL2359110 & 1301904 & 5.2168 & 4.4531 & TRN & \\
\hline CHEMBL2356872 & 1301904 & 4.6633 & 4.7973 & TRN & \\
\hline CHEMBL1375884 & 1301904 & 4.5032 & 4.7878 & TST & \\
\hline CHEMBL1530866 & 1301904 & 3.0 & 4.1813 & TRN & \\
\hline CHEMBL1375289 & 1301904 & 4.6398 & 3.6495 & TRN & \\
\hline CHEMBL2355890 & 1301904 & 4.3842 & 3.7502 & TRN & \\
\hline CHEMBL1489779 & 1301904 & 4.118 & 4.4803 & TRN & \\
\hline CHEMBL1711200 & 1301904 & 4.2798 & 4.2007 & TRN & \\
\hline CHEMBL1584985 & 1301904 & 5.8297 & 4.5505 & TST & \\
\hline CHEMBL2358863 & 1301904 & 4.582 & \multicolumn{2}{|c|}{4.4510000000000005} & TRN \\
\hline CHEMBL1378851 & 1301904 & 4.4388 & 4.4732 & TST & \\
\hline CHEMBL2355735 & 1301904 & 4.8289 & 4.7831 & TRN & \\
\hline CHEMBL2359040 & 1301904 & 6.0 & 5.972 & TRN & \\
\hline CHEMBL1487099 & 1301904 & 5.5391 & 4.9177 & TST & \\
\hline CHEMBL1622981 & 1301904 & 3.0 & 3.3758 & TRN & \\
\hline CHEMBL1350915 & 1301904 & 3.0 & 4.3212 & TST & \\
\hline CHEMBL1704298 & 1301904 & 4.1358 & 4.2013 & TST & \\
\hline CHEMBL2359612 & 1301904 & 4.7077 & 4.8374 & TRN & \\
\hline CHEMBL2358729 & 1301904 & 3.7959 & 4.6663 & TRN & \\
\hline CHEMBL1602637 & 1301904 & 4.0495 & 4.6547 & TST & \\
\hline CHEMBL3182041 & 1301904 & 4.378 & 4.2868 & TRN & \\
\hline CHEMBL3187821 & 1301904 & 4.7433 & 5.331 & TRN & \\
\hline CHEMBL1451348 & 1301904 & 5.2993 & 4.9922 & TST & \\
\hline CHEMBL1390112 & 1301904 & 5.2358 & 5.1185 & TRN & \\
\hline CHEMBL2356002 & 1301904 & 4.6786 & 4.8874 & TRN & \\
\hline CHEMBL1321622 & 1301904 & 5.1487 & 4.6401 & TST & \\
\hline CHEMBL1405749 & 1301904 & 5.3391 & 4.789 & TRN & \\
\hline CHEMBL2356442 & 1301904 & 4.6409 & 4.4747 & TRN & \\
\hline CHEMBL1299769 & 1301904 & 4.0391 & 4.3583 & TRN & \\
\hline CHEMBL591363 & 1301904 & 5.6364 & 5.5343 & TRN & \\
\hline CHEMBL1551808 & 1301904 & 4.8788 & 4.4747 & TRN & \\
\hline CHEMBL2354497 & 1301904 & 6.0 & 5.5575 & TRN & \\
\hline CHEMBL1536108 & 1301904 & 3.0 & 3.6776 & TRN & \\
\hline CHEMBL1873627 & 1301904 & 3.1549 & 3.8472 & TRN & \\
\hline CHEMBL2355378 & 1301904 & 4.5311 & 4.8844 & TRN & \\
\hline CHEMBL1579170 & 1301904 & 4.3668 & 4.2713 & TRN & \\
\hline CHEMBL1418341 & 1301904 & 4.3657 & 4.2215 & TRN & \\
\hline CHEMBL1559741 & 1301904 & 4.2756 & 4.2857 & TRN & \\
\hline CHEMBL1378232 & 1301904 & 5.6402 & 4.9728 & TST & \\
\hline CHEMBL2357640 & 1301904 & 4.6821 & 4.172 & TRN & \\
\hline CHEMBL2357535 & 1301904 & 5.0292 & 5.3159 & TRN & \\
\hline
\end{tabular}


Supplemental Table S2.txt

\begin{tabular}{|c|c|c|c|c|c|}
\hline CHEMBL2354539 & 1301904 & 3.4948 & 4.2563 & TRN & \\
\hline CHEMBL585827 & 1301904 & 5.6253 & 5.5551 & TRN & \\
\hline CHEMBL1866791 & 1301904 & 4.4814 & 4.2894 & TRN & \\
\hline CHEMBL3183001 & 1301904 & 6.0 & 5.7783 & TRN & \\
\hline CHEMBL1519285 & 1301904 & 4.34399 & э9999999 & 4.4787 & TST \\
\hline CHEMBL1337726 & 1301904 & 4.1217 & 4.3694 & TST & \\
\hline CHEMBL1904071 & 1301904 & 5.4895 & 4.8544 & TST & \\
\hline CHEMBL1483562 & 1301904 & 5.15 & 4.9784 & TST & \\
\hline CHEMBL3188673 & 1301904 & 6.0 & 5.4722 & TRN & \\
\hline CHEMBL1597245 & 1301904 & 5.5735 & $5.07600 t$ & 00000000005 & TST \\
\hline CHEMBL1472681 & 1301904 & 5.8633 & 5.1151 & TST & \\
\hline CHEMBL3188935 & 1301904 & 4.5264 & 4.8303 & TRN & \\
\hline CHEMBL1321427 & 1301904 & 5.4001 & 4.2481 & TST & \\
\hline CHEMBL2354712 & 1301904 & 6.0 & 5.9699 & TRN & \\
\hline CHEMBL1345220 & 1301904 & 4.507 & 3.8529 & TST & \\
\hline CHEMBL1500469 & 1301904 & 5.3143 & 5.2478 & TRN & \\
\hline CHEMBL2361967 & 1301904 & 4.2559 & 4.2584 & TRN & \\
\hline CHEMBL2355635 & 1301904 & 4.6375 & 5.1541 & TRN & \\
\hline CHEMBL3182522 & 1301904 & 6.0 & 5.8437 & TRN & \\
\hline CHEMBL2355724 & 1301904 & 4.5072 & 4.7195 & TRN & \\
\hline CHEMBL 2359406 & 1301904 & 4.8011 & 3.7075 & TRN & \\
\hline CHEMBL2359622 & 1301904 & 5.0857 & 5.0449 & TRN & \\
\hline CHEMBL3182148 & 1301904 & 4.0917 & 3.6907 & TRN & \\
\hline CHEMBL2356549 & 1301904 & 4.2159 & 3.8345 & TRN & \\
\hline CHEMBL1544797 & 1301904 & 4.8447 & 4.6263 & TRN & \\
\hline CHEMBL1564801 & 1301904 & 5.2154 & 5.1189 & TST & \\
\hline CHEMBL1392527 & 1301904 & 4.379 & 4.9212 & TST & \\
\hline CHEMBL1371507 & 1301904 & 5.4248 & 5.0218 & TST & \\
\hline CHEMBL 257286 & 1301904 & 4.479 & 4.8364 & TRN & \\
\hline CHEMBL2137170 & 1301904 & 3.1549 & 3.3344 & TRN & \\
\hline CHEMBL1560774 & 1301904 & 4.2084 & 3.8758 & TRN & \\
\hline CHEMBL3186440 & 1301904 & 3.1549 & 4.2796 & TRN & \\
\hline CHEMBL1543417 & 1301904 & 4.1696 & 4.1687 & TRN & \\
\hline CHEMBL2357173 & 1301904 & 4.6151 & 4.7459 & TRN & \\
\hline CHEMBL1396619 & 1301904 & 4.7565 & 4.6995 & TST & \\
\hline CHEMBL1488060 & 1301904 & 4.6202 & 4.7311 & TST & \\
\hline CHEMBL2361346 & 1301904 & 5.4145 & 4.9119 & TRN & \\
\hline CHEMBL3187483 & 1301904 & 4.112 & 4.2288 & TRN & \\
\hline CHEMBL2359502 & 1301904 & 3.1549 & 4.4747 & TRN & \\
\hline CHEMBL3197634 & 688120 & 7.7212 & 7.4309 & TRN & \\
\hline CHEMBL530291 & 688120 & 8.1549 & 7.5669 & TST & \\
\hline CHEMBL1349490 & 688120 & 7.0915 & 6.7731 & TRN & \\
\hline CHEMBL536166 & 688120 & 8.2218 & 7.5551 & TST & \\
\hline CHEMBL585594 & 688120 & 8.3979 & 7.272 & TRN & \\
\hline CHEMBL1472773 & 688120 & 7.9586 & 7.6624 & TST & \\
\hline CHEMBL1578651 & 688120 & 6.9393 & 7.0618 & TRN & \\
\hline CHEMBL1346837 & 688120 & 6.9469 & 7.2562 & TRN & \\
\hline CHEMBL3199944 & 688120 & 7.5229 & 7.4116 & TRN & \\
\hline
\end{tabular}


Supplemental Table S2.txt

\begin{tabular}{|c|c|c|c|c|}
\hline - & & & & \\
\hline HEMBL1349711 & 88120 & & .2361 & \\
\hline & 120 & & & \\
\hline 491 & 120 & & & \\
\hline AEMBL609438 & 88120 & & 8953 & \\
\hline AEMBL1333600 & 88120 & 5528 & 7322 & \\
\hline HEMBL1596712 & 88120 & & .5095 & \\
\hline AFMB 12 & 120 & & & \\
\hline AEMBL15 & 88120 & & .5825 & \\
\hline AEMBL1468786 & 88120 & & 8438 & \\
\hline HEMBL1527809 & 88120 & & 5355 & \\
\hline JEMBL144 & 88120 & & 582 & \\
\hline AEMBL15 & 120 & & & \\
\hline AEMBL14 & 88120 & & .9902 & \\
\hline IEMBL 14 & 88120 & & 303 & \\
\hline AEMBL139 & 88120 & & 71 & \\
\hline HEMBL14 & 88120 & & 98 & \\
\hline HEMBL 32 & 88120 & & & \\
\hline HEMBL13 & 88120 & & & \\
\hline AEMBL14 & 38120 & & 27 & ST \\
\hline IEMBL1 & 120 & & 77 & \\
\hline HEMBL14 & 88120 & & 63 & \\
\hline HEM & 38120 & & & \\
\hline 80 & 88120 & & & RN \\
\hline IEMBL14 & 20 & & 91 & RN \\
\hline L1 & 20 & & 49 & \\
\hline 53 & 20 & & 22 & RN \\
\hline 54 & & & & \\
\hline IEMBL13 & & & & RN \\
\hline AEMBL15 & 88120 & & 97 & RIN \\
\hline AEMBL13 & 8120 & & $\partial 71$ & RN \\
\hline 2 & 20 & & & \\
\hline & & & & RN \\
\hline HEMBL153 & & & & RN \\
\hline AEMBL1500188 & 88120 & & 016 & RN \\
\hline AEMBL15 & 20 & & 393 & \\
\hline 4 & & & & RN \\
\hline HEMBL1415769 & & & 7.4272 & RN \\
\hline HEMBL1372575 & 88120 & & 397 & RN \\
\hline IEMBL13 & 88120 & & 26 & ST \\
\hline HEMBL150 & 88120 & & 806 & -5 \\
\hline & & & & RN \\
\hline HEMBL15€ & 88120 & & 6.8762 & RN \\
\hline AEMBL1335703 & 88120 & & . 7095 & RN \\
\hline$M P$ & & & & \\
\hline HEMBL 140 & 588120 & & 6.8786 & \\
\hline . & 688120 & 6.5702 & 7.314 & \\
\hline CHEMBL1609301 & 688120 & 7.3768 & 6.9201 & RN \\
\hline
\end{tabular}

Page 9379 


\begin{tabular}{|c|c|c|c|c|c|c|}
\hline & & \multicolumn{5}{|c|}{ Supplemental Table S2.txt } \\
\hline CHEMBL1331384 & 688120 & 7.1549 & 7.322 & TRN & & \\
\hline CHEMBL1583911 & 688120 & 6.6799 & 7.3161 & TST & & \\
\hline CHEMBL1304312 & 688120 & 6.3675 & 7.0192 & TRN & & \\
\hline CHEMBL1437258 & 688120 & 6.4145 & 6.7682 & TRN & & \\
\hline CHEMBL1575081 & 688120 & 7.699 & 7.3622 & TRN & & \\
\hline CHEMBL1327851 & 688120 & 7.8239 & 6.9339 & TST & & \\
\hline CHEMBL1549732 & 688120 & 6.1945 & 6.8729 & TRN & & \\
\hline CHEMBL1729277 & 688120 & 7.2596 & 7.0144 & TRN & & \\
\hline CHEMBL1603578 & 688120 & 7.2076 & 7.0831 & TST & & \\
\hline CHEMBL1596287 & 688120 & 7.2147 & 6.769 & TRN & & \\
\hline CHEMBL1401402 & 688120 & 7.1192 & 6.9231 & TRN & & \\
\hline CHEMBL1504841 & 688120 & 7.6021 & 7.6184 & TRN & & \\
\hline CHEMBL1465112 & 688120 & 6.6556 & 6.6904 & TRN & & \\
\hline CHEMBL1501300 & 688120 & 6.9431 & 7.3615 & TRN & & \\
\hline CHEMBL1429091 & 688120 & 7.0555 & 6.8634 & TRN & & \\
\hline CHEMBL1599468 & 688120 & 7.2147 & 6.919 & TST & & \\
\hline CHEMBL1352337 & 688120 & 7.0506 & 6.6725 & TRN & & \\
\hline CHEMBL1388576 & 688120 & 6.6925 & 6.6162 & TRN & & \\
\hline CHEMBL1529399 & 688120 & 6.9586 & 7.2942 & TST & & \\
\hline CHEMBL586465 & 688120 & 7.5376 & 7.5003 & TRN & & \\
\hline CHEMBL1382191 & 688120 & 7.6383 & 7.9754 & TRN & & \\
\hline CHEMBL1470620 & 688120 & 7.3768 & 6.9042 & TRN & & \\
\hline CHEMBL586135 & 688120 & 7.1308 & 7.9072 & TST & & \\
\hline CHEMBL 1486146 & 688120 & 6.4535 & 7.1841 & TRN & & \\
\hline CHEMBL1480289 & 688120 & 9.3979 & 7.7548 & TRN & & \\
\hline CHEMBL1417099 & 688120 & 9.3979 & 7.8144 & TST & & \\
\hline CHEMBL601547 & 688120 & 6.3536 & 6.6958 & TRN & & \\
\hline CHEMBL1607722 & 688120 & 6.1739 & 7.1266 & TRN & & \\
\hline CHEMBL 1350245 & 688120 & 6.3883 & 7.4587 & TST & & \\
\hline CHEMBL1413835 & 688120 & 7.9208 & 7.5609 & TRN & & \\
\hline CHEMBL1242180 & 688120 & 9.3979 & 8.4867 & TRN & & \\
\hline CHEMBL1571635 & 688120 & 6.7055 & 6.4805 & TRN & & \\
\hline CHEMBL600862 & 688120 & 6.61799 & (9999999 & 99 & 7.4951 & TST \\
\hline CHEMBL1312160 & 688120 & 7.2218 & 7.0584 & TRN & & \\
\hline CHEMBL1462240 & 688120 & 6.5784 & 7.2687 & TST & & \\
\hline CHEMBL3197076 & 688120 & 6.8761 & 7.7381 & TST & & \\
\hline CHEMBL1583585 & 688120 & 8.0458 & 8.0503 & TRN & & \\
\hline CHEMBL1382799 & 688120 & 7.6021 & 7.5547 & TRN & & \\
\hline CHEMBL1404493 & 688120 & 7.3372 & 8.2486 & TRN & & \\
\hline CHEMBL1987108 & 688120 & 6.8153 & 7.2815 & TRN & & \\
\hline CHEMBL1334247 & 688120 & 7.3665 & 7.9439 & TRN & & \\
\hline CHEMBL1399502 & 688120 & 7.4202 & 7.2352 & TRN & & \\
\hline CHEMBL1516689 & 688120 & 8.0969 & 7.3762 & TRN & & \\
\hline CHEMBL1382529 & 688120 & 7.0809 & 7.2518 & TRN & & \\
\hline CHEMBL1610821 & 688120 & 8.2218 & 7.3948 & TST & & \\
\hline CHEMBL1611486 & 688120 & 6.5952 & 7.1691 & TRN & & \\
\hline CHEMBL1612267 & 688120 & 6.4045 & 6.8712 & TRN & & \\
\hline CHEMBL1427739 & 688120 & 6.9208 & 7.1723 & TST & & \\
\hline
\end{tabular}


Supplemental Table S2.txt

\begin{tabular}{|c|c|c|c|c|}
\hline CHEMBL1492965 & 688120 & 7.0757 & 7.2997 & TRN \\
\hline CHEMBL1328537 & 688120 & 7.4559 & 7.4607 & TRN \\
\hline CHEMBL1497167 & 688120 & 7.1367 & 6.7727 & TRN \\
\hline CHEMBL3189272 & 688120 & 6.857 & 7.599 & TST \\
\hline CHEMBL1536905 & 688120 & 7.7212 & 7.2971 & TRN \\
\hline CHEMBL1562159 & 688120 & 6.3893 & 7.1707 & TRN \\
\hline CHEMBL1398621 & 688120 & 7.284 & 6.8232 & TRN \\
\hline CHEMBL1406194 & 688120 & 8.0458 & 7.4622 & TRN \\
\hline CHEMBL1479266 & 688120 & 7.4318 & 7.4305 & TRN \\
\hline CHEMBL3197177 & 688120 & 7.7447 & 6.7782 & TRN \\
\hline CHEMBL3191989 & 688120 & 9.3979 & 7.9904 & TRN \\
\hline CHEMBL1552445 & 688120 & 7.7959 & 7.4514 & TRN \\
\hline CHEMBL1993103 & 688120 & 7.4202 & 6.7928 & TRN \\
\hline CHEMBL1424855 & 688120 & 7.4685 & 7.2239 & TRN \\
\hline CHEMBL3199025 & 688120 & 7.4318 & 6.8883 & TRN \\
\hline CHEMBL1512652 & 688120 & 6.2449 & 7.01 & TRN \\
\hline CHEMBL1531197 & 688120 & 7.0605 & 6.5958 & TRN \\
\hline CHEMBL1572951 & 688120 & 7.4437 & 7.6947 & TRN \\
\hline CHEMBL1402518 & 688120 & 6.4572 & 6.7747 & TRN \\
\hline CHEMBL1380129 & 688120 & 7.3372 & 7.5305 & TRN \\
\hline CHEMBL1600245 & 688120 & 7.4437 & 7.3802 & TRN \\
\hline CHEMBL1503394 & 688120 & 6.8697 & 7.0668 & TST \\
\hline CHEMBL1468457 & 688120 & 8.1549 & 7.7018 & TRN \\
\hline CHEMBL1343003 & 688120 & 7.1024 & 6.8791 & TRN \\
\hline CHEMBL1532608 & 688120 & 7.0223 & 6.9738 & TRN \\
\hline CHEMBL1404792 & 688120 & 7.5086 & 8.0019 & TRN \\
\hline CHEMBL3214537 & 688120 & 7.6576 & 7.1091 & TRN \\
\hline CHEMBL1454557 & 688120 & 7.8239 & 7.351 & TRN \\
\hline CHEMBL1320454 & 688120 & 6.8697 & 7.0511 & TRN \\
\hline CHEMBL1467366 & 688120 & 6.3565 & 6.7512 & TRN \\
\hline CHEMBL1316193 & 688120 & 6.76200 & 000000000 & 7.5386 \\
\hline CHEMBL 2006628 & 688120 & 7.1135 & 7.3118 & TRN \\
\hline CHEMBL1596102 & 688120 & 6.9914 & 6.7985 & TRN \\
\hline CHEMBL1521114 & 688120 & 7.5229 & 6.9713 & TRN \\
\hline CHEMBL578257 & 688120 & 7.2366 & 7.8438 & TRN \\
\hline CHEMBL1534203 & 688120 & 7.3872 & 7.8339 & TRN \\
\hline CHEMBL1601578 & 688120 & 7.0506 & 6.9294 & TRN \\
\hline CHEMBL1341517 & 688120 & 7.7959 & 7.1604 & TRN \\
\hline CHEMBL1425806 & 688120 & 8.0 & 7.0852 & TRN \\
\hline CHEMBL1537043 & 688120 & 6.6655 & 7.3775 & TRN \\
\hline CHEMBL1324755 & 688120 & 7.1367 & 7.3261 & TRN \\
\hline CHEMBL1425518 & 688120 & 6.8125 & 7.177000 & 00000000005 \\
\hline CHEMBL603522 & 688120 & 7.0757 & 7.5159 & TRN \\
\hline CHEMBL1382744 & 688120 & 6.5544 & 7.2901 & TRN \\
\hline CHEMBL584442 & 688120 & 8.2218 & 7.9249 & TRN \\
\hline CHEMBL1525766 & 688120 & 7.4318 & 7.4631 & TRN \\
\hline CHEMBL1302735 & 688120 & 7.2076 & 7.1035 & TRN \\
\hline CHEMBL3213112 & 688120 & 6.9872 & 7.6189 & TST \\
\hline
\end{tabular}




\begin{tabular}{|c|c|c|c|c|c|}
\hline \multirow{3}{*}{$\begin{array}{l}\text { CHEMBL1473119 } \\
\text { CHEMBL1382833 }\end{array}$} & \multirow{3}{*}{$\begin{array}{l}688120 \\
688120\end{array}$} & \multicolumn{4}{|c|}{ Supplemental Table S2.txt } \\
\hline & & 7.0862 & \multicolumn{2}{|c|}{6.672999999999999} & TRN \\
\hline & & 6.684 & 6.6821 & TRN & \\
\hline CHEMBL1429755 & 688120 & 4.0 & 6.2217 & TRN & \\
\hline CHEMBL1602449 & 688120 & 4.0 & 6.8741 & TST & \\
\hline CHEMBL1491724 & 688120 & 7.2218 & 7.2877 & TST & \\
\hline CHEMBL577662 & 688120 & 9.3979 & 7.3627 & TST & \\
\hline CHEMBL1515139 & 688120 & 7.1487 & 7.2172 & TRN & \\
\hline CHEMBL1386133 & 688120 & 6.9172 & 6.7771 & TRN & \\
\hline CHEMBL1485958 & 688120 & 6.6038 & 6.5292 & TRN & \\
\hline CHEMBL1564144 & 688120 & 7.6778 & 7.0668 & TRN & \\
\hline CHEMBL609628 & 688120 & 7.7696 & 7.5067 & TST & \\
\hline CHEMBL1402679 & 688120 & 6.5884 & 6.4708 & TRN & \\
\hline CHEMBL1716494 & 688120 & 8.1549 & \multicolumn{2}{|c|}{7.5120000000000005} & TRN \\
\hline CHEMBL1525538 & 688120 & 6.8962 & 6.8184 & TRN & \\
\hline CHEMBL1351537 & 688120 & 7.7212 & 6.996 & TRN & \\
\hline CHEMBL1385115 & 688120 & 7.7959 & 7.521 & TST & \\
\hline CHEMBL1312953 & 688120 & 6.8356 & 7.8619 & TRN & \\
\hline CHEMBL1329638 & 688120 & 6.6696 & 6.7245 & TRN & \\
\hline CHEMBL1541331 & 688120 & 7.1079 & 6.8118 & TRN & \\
\hline CHEMBL1419470 & 688120 & 6.2314 & 6.6708 & TRN & \\
\hline CHEMBL1596149 & 688120 & 6.5317 & 7.6698 & TRN & \\
\hline CHEMBL584840 & 688120 & 6.3242 & 6.8818 & TST & \\
\hline CHEMBL583558 & 688120 & 7.8239 & 7.9187 & TRN & \\
\hline CHEMBL1588774 & 688120 & 7.9586 & 7.5557 & TRN & \\
\hline CHEMBL3190608 & 688120 & 7.5229 & 7.1337 & TRN & \\
\hline CHEMBL1610820 & 688120 & 6.5719 & 6.8368 & TRN & \\
\hline CHEMBL1360206 & 688120 & 7.3279 & 7.2617 & TRN & \\
\hline CHEMBL1406270 & 688120 & 7.0655 & 6.6069 & TRN & \\
\hline CHEMBL560579 & 688120 & 7.3872 & 7.5321 & TST & \\
\hline CHEMBL1408596 & 688120 & 7.1549 & 7.1913 & TRN & \\
\hline CHEMBL1437823 & 688120 & 6.8894 & 6.9649 & TRN & \\
\hline CHEMBL1322707 & 688120 & 6.5935 & 6.6321 & TRN & \\
\hline CHEMBL1570959 & 688120 & 7.2218 & 7.6033 & TRN & \\
\hline CHEMBL1431641 & 688120 & 6.5638 & 7.1698 & TST & \\
\hline CHEMBL1501557 & 688120 & 7.4815 & 7.3411 & TRN & \\
\hline CHEMBL1399175 & 688120 & 7.1739 & 7.4973 & TST & \\
\hline CHEMBL1469752 & 688120 & 6.6676 & 6.4767 & TST & \\
\hline CHEMBL1402922 & 688120 & 6.6968 & 7.0042 & TRN & \\
\hline CHEMBL1436964 & 688120 & 7.1938 & 7.2327 & TRN & \\
\hline CHEMBL1416618 & 688120 & 6.7773 & 7.9191 & TST & \\
\hline CHEMBL1389078 & 688120 & 7.4815 & 7.20100 & 00000000005 & TRN \\
\hline CHEMBL1404308 & 688120 & 6.7878 & 7.0342 & TRN & \\
\hline CHEMBL1573817 & 688120 & 7.5376 & 7.4231 & TRN & \\
\hline CHEMBL1448592 & 688120 & 6.3565 & 7.7494 & TST & \\
\hline CHEMBL1374222 & 688120 & 6.8153 & 6.9543 & TRN & \\
\hline CHEMBL1424146 & 688120 & 6.9208 & 7.3359 & TRN & \\
\hline CHEMBL1576088 & 688120 & 8.2218 & 7.44 & TRN & \\
\hline CHEMBL1424826 & 688120 & 6.9508 & 6.7541 & TRN & \\
\hline
\end{tabular}




\begin{tabular}{|c|c|c|c|c|}
\hline \multicolumn{5}{|c|}{ Supplemental Table } \\
\hline CHEMBL1595207 & 688120 & 6.7011 & 7.14 & TRN \\
\hline CHEMBL1428354 & 688120 & 7.1612 & 7.0106 & TRN \\
\hline CHEMBL1446762 & 688120 & 6.6799 & 7.2164 & TRN \\
\hline CHEMBL1301226 & 688120 & 7.0555 & 7.1813 & TRN \\
\hline CHEMBL1386599 & 688120 & 7.3979 & 7.3352 & TRN \\
\hline CHEMBL304291 & 688120 & 9.3979 & 6.7082 & TST \\
\hline CHEMBL374107 & 688120 & 6.8153 & 7.7156 & TST \\
\hline CHEMBL1183425 & 688120 & 6.9508 & 7.6029 & TRN \\
\hline CHEMBL1525720 & 688120 & 7.3279 & 6.8914 & TRN \\
\hline CHEMBL1552686 & 688120 & 7.2076 & 6.6883 & TRN \\
\hline CHEMBL3190585 & 688120 & 7.7212 & 7.1069 & TRN \\
\hline CHEMBL1612393 & 688120 & 7.2596 & 7.4967 & TRN \\
\hline CHEMBL1560678 & 688120 & 7.6021 & 7.4441 & TRN \\
\hline CHEMBL1433230 & 688120 & 7.585 & 7.3193 & TRN \\
\hline CHEMBL1369642 & 688120 & 7.2676 & 7.0219 & TRN \\
\hline CHEMBL1518625 & 688120 & 7.8539 & 7.3627 & TST \\
\hline CHEMBL1560237 & 688120 & 7.6576 & 6.7938 & TST \\
\hline CHEMBL3192651 & 688120 & 7.1079 & 7.2306 & TRN \\
\hline CHEMBL1442253 & 688120 & 6.3045 & 6.8242 & TRN \\
\hline CHEMBL1986086 & 688120 & 7.041 & 7.1058 & TRN \\
\hline CHEMBL 3192432 & 688120 & 7.1938 & 7.2644 & TRN \\
\hline CHEMBL1531377 & 688120 & 7.8239 & 7.1664 & TST \\
\hline CHEMBL1593292 & 688120 & 7.2596 & 7.4385 & TRN \\
\hline CHEMBL171289 & 688120 & 7.1024 & 7.2947 & TRN \\
\hline CHEMBL1317288 & 688120 & 6.5784 & 6.6111 & TRN \\
\hline CHEMBL586602 & 688120 & 7.9586 & 7.5551 & TST \\
\hline CHEMBL193627 & 688120 & 9.3979 & 8.1923 & TRN \\
\hline CHEMBL585502 & 688120 & 7.6383 & 8.095 & TRN \\
\hline CHEMBL1353980 & 688120 & 7.3872 & 7.3743 & TRN \\
\hline CHEMBL1612512 & 688120 & 6.9914 & 6.9278 & TRN \\
\hline CHEMBL1557079 & 688120 & 7.8539 & 7.3276 & TST \\
\hline CHEMBL1988686 & 688120 & 6.4737 & 7.1315 & TRN \\
\hline CHEMBL1324481 & 688120 & 6.5751 & 7.0139 & TRN \\
\hline CHEMBL1553717 & 688120 & 6.8297 & 6.803 & TRN \\
\hline CHEMBL1509857 & 688120 & 7.0088 & 7.1837 & TRN \\
\hline CHEMBL1326290 & 688120 & 6.4237 & 6.7679 & TRN \\
\hline CHEMBL1457275 & 688120 & 7.699 & 7.3112 & TRN \\
\hline CHEMBL1600830 & 688120 & 6.6536 & 7.2637 & TRN \\
\hline CHEMBL581346 & 688120 & 7.5686 & 7.7886 & TRN \\
\hline CHEMBL1333006 & 688120 & 6.684 & 6.6776 & TRN \\
\hline CHEMBL1495833 & 688120 & 6.4056 & 6.9427 & TRN \\
\hline CHEMBL1605037 & 688120 & 7.2147 & 7.1444 & TRN \\
\hline CHEMBL1525666 & 688120 & 8.0969 & 7.8155 & TRN \\
\hline CHEMBL1494677 & 688120 & 7.2596 & 7.8365 & TRN \\
\hline CHEMBL1497463 & 688120 & 7.1487 & 6.8346 & TRN \\
\hline CHEMBL1342523 & 688120 & 6.6778 & 7.2181 & TRN \\
\hline CHEMBL1559157 & 688120 & 6.4425 & 6.8698 & TRN \\
\hline CHEMBL1379563 & 688120 & 8.0 & 7.5717 & TRN \\
\hline
\end{tabular}




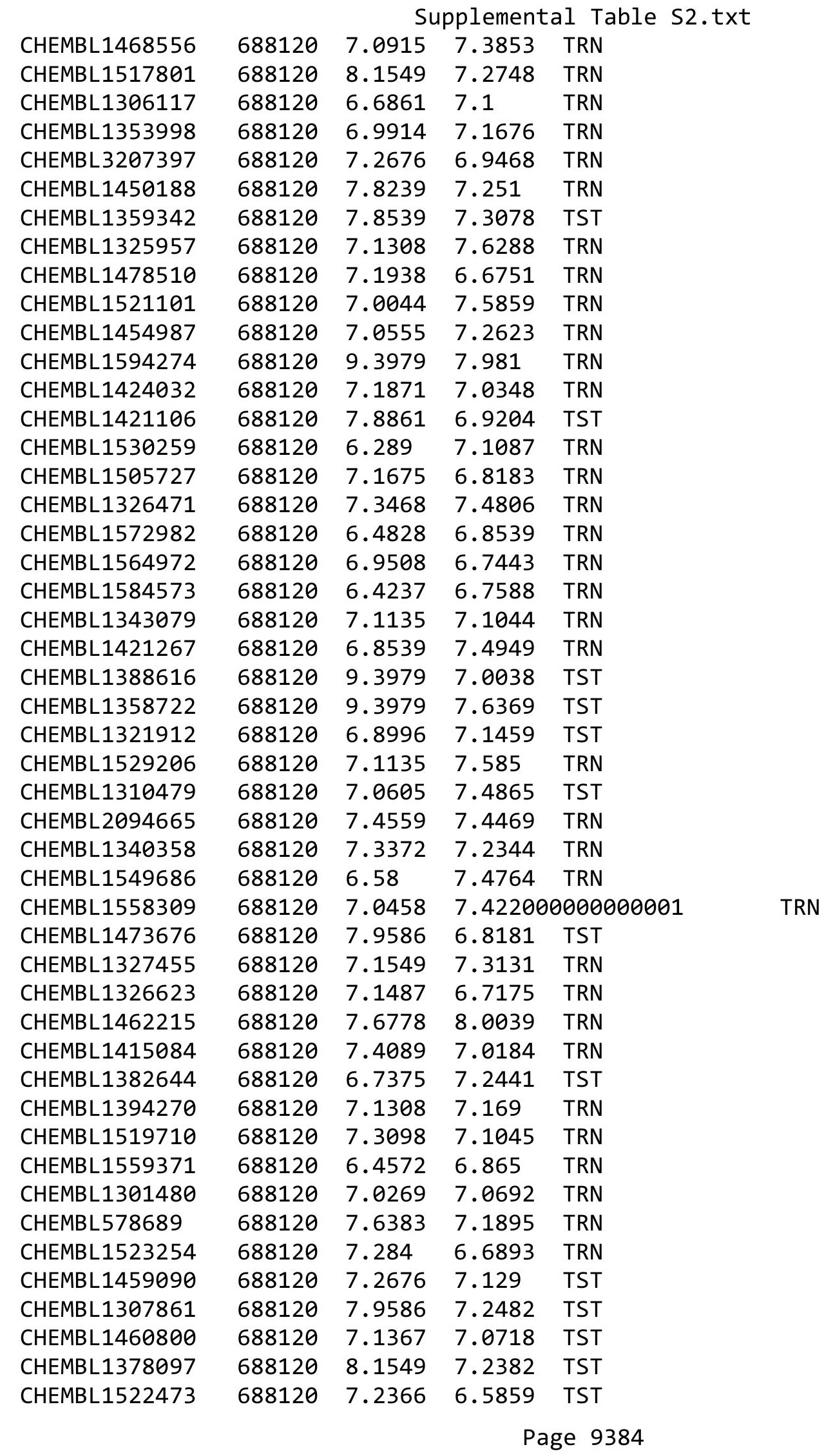




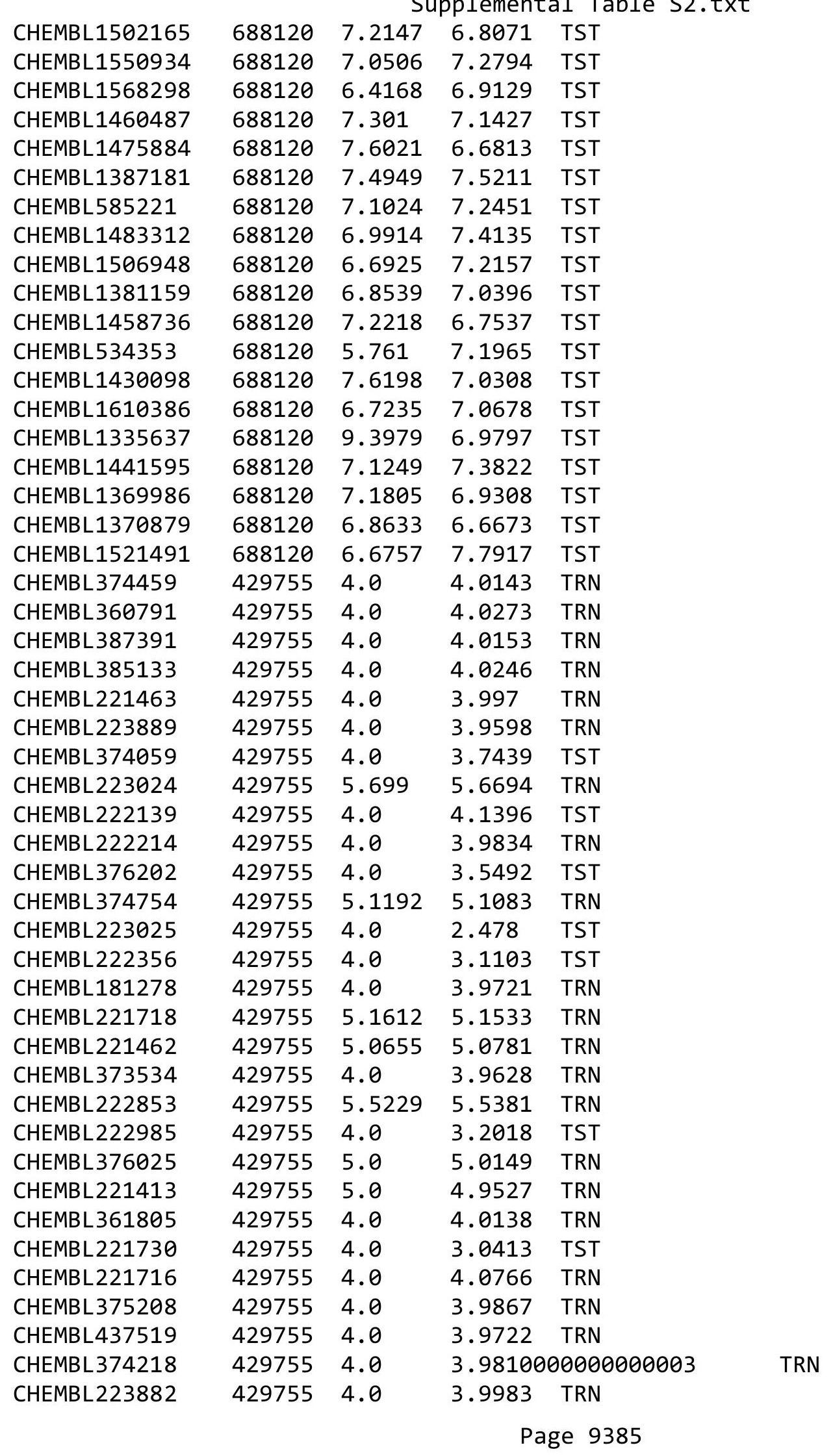




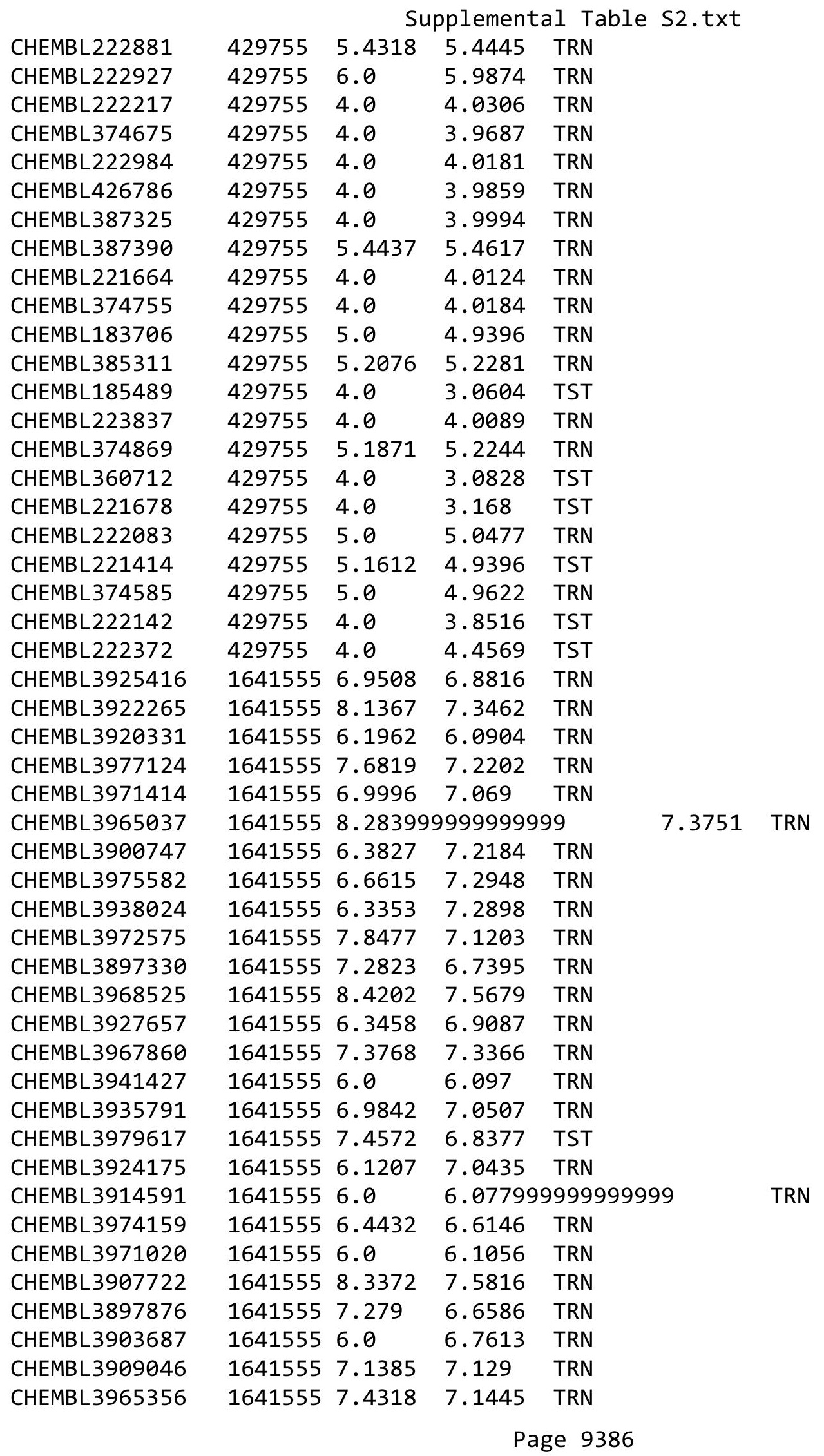


Supplemental Table S2.txt

\begin{tabular}{|c|c|c|c|c|c|}
\hline CHEMBL3923905 & 1641555 & 6.8471 & 7.3699 & TRN & \\
\hline CHEMBL3945765 & 1641555 & 8.0969 & 7.3548 & TST & \\
\hline CHEMBL3965385 & 1641555 & 7.3768 & 6.8579 & TRN & \\
\hline CHEMBL3979953 & 1641555 & 8.1427 & 7.0101 & TST & \\
\hline CHEMBL3915811 & 1641555 & 6.6245 & 7.3756 & TRN & \\
\hline CHEMBL3949988 & 1641555 & 5.9329 & 6.7332 & TRN & \\
\hline CHEMBL3908088 & 1641555 & 6.5274 & 7.362 & TRN & \\
\hline CHEMBL3976344 & 1641555 & 7.8794 & 7.1846 & TRN & \\
\hline CHEMBL3974329 & 1641555 & 7.0565 & 7.0027 & TRN & \\
\hline CHEMBL3929821 & 1641555 & 6.5154 & 7.2073 & TRN & \\
\hline CHEMBL3936626 & 1641555 & 8.0969 & 7.1265 & TRN & \\
\hline CHEMBL3913533 & 1641555 & 7.2565 & 7.224 & TRN & \\
\hline CHEMBL3961521 & 1641555 & 8.7447 & 7.3264 & TRN & \\
\hline CHEMBL3977561 & 1641555 & 6.4076 & 7.2107 & TRN & \\
\hline CHEMBL3910469 & 1641555 & 9.2218 & 7.6056 & TRN & \\
\hline CHEMBL3897012 & 1641555 & 6.9104 & 7.0898 & TRN & \\
\hline CHEMBL3948332 & 1641555 & 8.5122 & 6.7674 & TRN & \\
\hline CHEMBL3898811 & 1641555 & 6.0 & 6.178 & TRN & \\
\hline CHEMBL3954378 & 1641555 & 6.4384 & 7.2453 & TRN & \\
\hline CHEMBL 3908425 & 1641555 & 6.6465 & 7.4061 & TRN & \\
\hline CHEMBL3902118 & 1641555 & 6.4442 & 7.1177 & TRN & \\
\hline CHEMBL3959714 & 1641555 & 6.0 & 6.8063 & TRN & \\
\hline CHEMBL3922428 & 1641555 & 6.0 & 6.6202 & TRN & \\
\hline CHEMBL3975028 & 1641555 & 6.449 & 7.1077 & TRN & \\
\hline CHEMBL3917801 & 1641555 & 6.414 & 6.8793 & TRN & \\
\hline CHEMBL3956862 & 1641555 & 6.7033 & 6.6872 & TRN & \\
\hline CHEMBL3915566 & 1641555 & 6.1795 & 7.24100 & 00000000005 & TRN \\
\hline CHEMBL3941906 & 1641555 & 8.5086 & 7.0026 & TST & \\
\hline CHEMBL3900956 & 1641555 & 8.0706 & 7.1454 & TST & \\
\hline CHEMBL 3976322 & 1641555 & 6.9465 & 7.0153 & TST & \\
\hline CHEMBL3981922 & 1641555 & 6.7433 & 7.1372 & TRN & \\
\hline CHEMBL3906836 & 1641555 & 6.1902 & 6.9302 & TRN & \\
\hline CHEMBL3895889 & 1641555 & 6.6728 & 7.3406 & TRN & \\
\hline CHEMBL3907830 & 1641555 & 6.3531 & 7.0187 & TRN & \\
\hline CHEMBL3922246 & 1641555 & 6.7765 & 7.0805 & TRN & \\
\hline CHEMBL3956445 & 1641555 & 8.1308 & 7.1247 & TRN & \\
\hline CHEMBL3930382 & 1641555 & 8.5686 & 6.50299 & 9999999999 & TRN \\
\hline CHEMBL3966478 & 1641555 & 7.0405 & 7.1977 & TST & \\
\hline CHEMBL3969085 & 1641555 & 6.5819 & 6.9303 & TRN & \\
\hline CHEMBL3982267 & 1641555 & 6.103 & 7.2832 & TRN & \\
\hline CHEMBL3929248 & 1641555 & 7.7905 & 6.6551 & TRN & \\
\hline CHEMBL 3898466 & 1641555 & 6.325 & 6.6724 & TRN & \\
\hline CHEMBL3966532 & 1641555 & 9.699 & 6.5914 & TST & \\
\hline CHEMBL3893410 & 1641555 & 6.4346 & 6.7202 & TRN & \\
\hline CHEMBL3915659 & 1641555 & 6.3832 & 7.1786 & TRN & \\
\hline CHEMBL3906383 & 1641555 & 8.0969 & 7.5695 & TRN & \\
\hline CHEMBL3933319 & 1641555 & 9.2218 & 7.3947 & TRN & \\
\hline CHEMBL3900545 & 1641555 & 7.0872 & 7.416 & TRN & \\
\hline
\end{tabular}


Supplemental Table S2.txt

\begin{tabular}{|c|c|c|c|c|c|}
\hline CHEMBL3950006 & 1641555 & 6.6041 & 7.4965 & TST & \\
\hline CHEMBL3889750 & 1641555 & 6.285 & 6.7066 & TRN & \\
\hline CHEMBL3912335 & 1641555 & 6.8582 & 6.9827 & TST & \\
\hline CHEMBL3962202 & 1641555 & 7.0685 & 7.0294 & TRN & \\
\hline CHEMBL3952240 & 1641555 & 6.9252 & 7.3205 & TST & \\
\hline CHEMBL3923278 & 1641555 & 8.4318 & 7.1941 & TRN & \\
\hline CHEMBL3964993 & 1641555 & 6.2225 & 7.0722 & TRN & \\
\hline CHEMBL3891668 & 1641555 & 7.1024 & 7.2199 & TRN & \\
\hline CHEMBL3921283 & 1641555 & 6.9666 & 7.3152 & TST & \\
\hline CHEMBL3986445 & 1641555 & 6.0 & 6.6314 & TRN & \\
\hline CHEMBL3921429 & 1641555 & 8.2518 & 7.3566 & TRN & \\
\hline CHEMBL3926267 & 1641555 & 7.6021 & 7.164 & TRN & \\
\hline CHEMBL3936687 & 1641555 & 6.7366 & 7.2365 & TRN & \\
\hline CHEMBL3967364 & 1641555 & 8.6383 & 6.8099 & TRN & \\
\hline CHEMBL3925755 & 1641555 & 6.5919 & 7.3549 & TST & \\
\hline CHEMBL3896334 & 1641555 & 8.5528 & 7.609 & TRN & \\
\hline CHEMBL3975859 & 1641555 & 7.52 & 6.3735 & TRN & \\
\hline CHEMBL3913153 & 1641555 & 6.1854 & 7.2799 & TRN & \\
\hline CHEMBL3941824 & 1641555 & 7.3925 & 6.7232 & TRN & \\
\hline CHEMBL3970480 & 1641555 & 7.1367 & 6.9475 & TRN & \\
\hline CHEMBL3982326 & 1641555 & 7.2692 & 7.2082 & TRN & \\
\hline CHEMBL3906905 & 1641555 & 7.58 & 6.8259 & TRN & \\
\hline CHEMBL3939559 & 1641555 & 6.2264 & 7.1345 & TRN & \\
\hline CHEMBL3941576 & 1641555 & 8.2757 & 7.5789 & TRN & \\
\hline CHEMBL3952053 & 1641555 & 9.0969 & 7.1794 & TST & \\
\hline CHEMBL3890211 & 1641555 & 6.6737 & 6.9933 & TST & \\
\hline CHEMBL3899606 & 1641555 & 7.2041 & 6.4596 & TRN & \\
\hline CHEMBL3986371 & 1641555 & 7.4622 & 7.1366 & TST & \\
\hline CHEMBL3964808 & 1641555 & 7.1203 & 6.8135 & TRN & \\
\hline CHEMBL3904141 & 1641555 & 6.1195 & 7.065 & TRN & \\
\hline CHEMBL3923406 & 1641555 & 6.0 & 6.3253 & TRN & \\
\hline CHEMBL3903090 & 1641555 & 7.7235 & 7.1381 & TST & \\
\hline CHEMBL3931137 & 1641555 & 6.515 & 7.2721 & TRN & \\
\hline CHEMBL 3893210 & 1641555 & 7.0783 & \multicolumn{2}{|c|}{7.3870000000000005} & TRN \\
\hline CHEMBL3929961 & 1641555 & 6.9763 & 7.263 & TST & \\
\hline CHEMBL3966159 & 1641555 & 6.0677 & 7.5529 & TRN & \\
\hline CHEMBL3946752 & 1641555 & 6.1146 & 6.6915 & TRN & \\
\hline CHEMBL3906456 & 1641555 & 8.3098 & \multicolumn{2}{|c|}{ 7.32299999999999995 } & TRN \\
\hline CHEMBL 3942450 & 1641555 & 7.8996 & 7.4309 & TRN & \\
\hline CHEMBL3950636 & 1641555 & 8.0458 & 6.8624 & TST & \\
\hline CHEMBL3912397 & 1641555 & 7.4828 & 7.38 & TRN & \\
\hline CHEMBL3892903 & 1641555 & 6.0 & 6.0945 & TRN & \\
\hline CHEMBL3983111 & 1641555 & 6.0 & 6.6612 & TRN & \\
\hline CHEMBL3956804 & 1641555 & 7.9393 & 7.6421 & TRN & \\
\hline CHEMBL3943530 & 1641555 & 6.4385 & 7.1292 & TST & \\
\hline CHEMBL3953077 & 1641555 & 8.2366 & 7.4152 & TST & \\
\hline CHEMBL3971385 & 1641555 & 6.8745 & 7.5176 & TST & \\
\hline CHEMBL3918466 & 1641555 & 6.0151 & 6.9369 & TST & \\
\hline
\end{tabular}


Supplemental Table S2.txt

\begin{tabular}{|c|c|c|c|c|c|}
\hline CHEMBL3967975 & 1641555 & 8.1675 & 7.1946 & TST & \\
\hline CHEMBL3903150 & 1641555 & 6.1115 & 7.5234 & TST & \\
\hline CHEMBL 3901343 & 1641555 & 6.808 & 7.0733 & TST & \\
\hline CHEMBL 3890640 & 1641555 & 7.9914 & 6.5889 & TST & \\
\hline CHEMBL 3932847 & 1641555 & 8.041 & 7.1031 & TST & \\
\hline CHEMBL 3934018 & 1641555 & 7.433 & 7.3745 & TST & \\
\hline CHEMBL 3915420 & 1641555 & 8.3188 & 7.1761 & TST & \\
\hline CHEMBL 3962990 & 1641555 & 6.4689 & 7.2939 & TST & \\
\hline CHEMBL3957653 & 1641555 & 7.0857 & 7.0918 & TST & \\
\hline CHEMBL 3944736 & 1641555 & 6.1778 & 7.2739 & TST & \\
\hline CHEMBL3963021 & 1641555 & 7.2565 & 6.9256 & TST & \\
\hline CHEMBL300389 & 954951 & 6.9841 & 6.7345 & TRN & \\
\hline CHEMBL514499 & 954951 & 8.2129 & 6.9217 & TRN & \\
\hline CHEMBL1190711 & 954951 & 5.7209 & 5.2514 & TRN & \\
\hline CHEMBL180127 & 954951 & 4.5635 & 4.4918 & TRN & \\
\hline CHEMBL1673039 & 954951 & 5.4009 & 5.0192 & TRN & \\
\hline CHEMBL379975 & 954951 & 5.4669 & 5.1989 & TRN & \\
\hline CHEMBL1357247 & 954951 & 3.90199 & 99999999 & 997 & 3.4962 \\
\hline CHEMBL3349342 & 954951 & 5.9431 & 5.2275 & TRN & \\
\hline CHEMBL1970879 & 954951 & 4.0143 & 4.8501 & TRN & \\
\hline CHEMBL191334 & 954951 & 4.3058 & 4.507 & TRN & \\
\hline CHEMBL 258844 & 954951 & 4.6895 & 4.6108 & TRN & \\
\hline CHEMBL1788116 & 954951 & 5.2003 & 4.6142 & TRN & \\
\hline CHEMBL1909414 & 954951 & 5.4062 & 4.3112 & TRN & \\
\hline CHEMBL509032 & 954951 & 6.0744 & 5.7369 & TRN & \\
\hline CHEMBL1230020 & 954951 & 5.6883 & 4.3577 & TRN & \\
\hline CHEMBL92309 & 954951 & 3.3152 & 3.3769 & TST & \\
\hline CHEMBL65 & 954951 & 6.8714 & 7.7526 & TRN & \\
\hline CHEMBL515416 & 954951 & 5.1134 & 4.7421 & TRN & \\
\hline CHEMBL 3186408 & 954951 & 3.9266 & 4.1454 & TST & \\
\hline CHEMBL472940 & 954951 & 4.8932 & 4.0076 & TRN & \\
\hline CHEMBL135561 & 954951 & 3.8875 & 4.6414 & TRN & \\
\hline CHEMBL393929 & 954951 & 3.4133 & 4.2019 & TRN & \\
\hline CHEMBL412142 & 954951 & 3.2089 & 4.2518 & TRN & \\
\hline CHEMBL 2363137 & 954951 & 5.3455 & 4.9402 & TRN & \\
\hline CHEMBL 2144069 & 954951 & 4.69 & 5.0772 & TRN & \\
\hline CHEMBL192566 & 954951 & 8.0937 & 7.8174 & TST & \\
\hline CHEMBL213100 & 954951 & 3.6303 & 5.0532 & TRN & \\
\hline CHEMBL220241 & 954951 & 5.3859 & 4.9644 & TRN & \\
\hline CHEMBL 9470 & 954951 & 5.0005 & 5.8348 & TST & \\
\hline CHEMBL1590308 & 954951 & 4.0721 & 3.7972 & TST & \\
\hline CHEMBL259181 & 954951 & 4.9125 & 4.7551 & TRN & \\
\hline CHEMBL1256459 & 954951 & 6.1066 & 6.9853 & TRN & \\
\hline CHEMBL483847 & 954951 & 3.7681 & 4.477 & TRN & \\
\hline CHEMBL379300 & 954951 & 6.5291 & 6.4683 & TRN & \\
\hline CHEMBL240954 & 954951 & 4.475 & 4.0765 & TST & \\
\hline CHEMBL189584 & 954951 & 5.5674 & 4.8559 & TRN & \\
\hline CHEMBL209148 & 954951 & 4.2073 & 4.7527 & TRN & \\
\hline
\end{tabular}

Page 9389 


\begin{tabular}{|c|c|c|c|c|c|c|}
\hline \multirow[b]{2}{*}{ CHEMBL1643959 } & & \multicolumn{5}{|c|}{ Supplemental Table S2.txt } \\
\hline & 954951 & 4.2837 & 4.0878 & TRN & & \\
\hline CHEMBL585951 & 954951 & 6.0996 & 6.1457 & TRN & & \\
\hline CHEMBL449158 & 954951 & 7.5719 & 6.7044 & TST & & \\
\hline CHEMBL1404918 & 954951 & 3.1545 & 3.3308 & TRN & & \\
\hline CHEMBL558642 & 954951 & 4.6494 & 4.4695 & TRN & & \\
\hline CHEMBL 221137 & 954951 & 4.8064 & 4.8757 & TST & & \\
\hline CHEMBL1242367 & 954951 & \multicolumn{3}{|c|}{5.0089999999999995} & 4.4991 & TRN \\
\hline CHEMBL373751 & 954951 & 3.0135 & 4.0533 & TRN & & \\
\hline CHEMBL 210618 & 954951 & 3.4157 & 3.7524 & TRN & & \\
\hline CHEMBL1516890 & 954951 & 3.7559 & 4.3058 & TRN & & \\
\hline CHEMBL102714 & 954951 & 3.3946 & 3.8943 & TRN & & \\
\hline CHEMBL3392440 & 954951 & 4.2466 & 4.1969 & TRN & & \\
\hline CHEMBL 2005886 & 954951 & 5.3965 & 5.5309 & TRN & & \\
\hline CHEMBL483849 & 954951 & \multicolumn{3}{|c|}{2.8510000000000004} & 2.8379 & TST \\
\hline CHEMBL512504 & 954951 & 6.77 & 5.065 & TST & & \\
\hline CHEMBL3199475 & 954951 & 5.4522 & 4.6575 & TST & & \\
\hline CHEMBL573107 & 954951 & 6.7819 & 5.2627 & TST & & \\
\hline CHEMBL 202721 & 954951 & 6.4188 & 5.1078 & TST & & \\
\hline CHEMBL392695 & 954951 & 5.771 & 5.2689 & TST & & \\
\hline CHEMBL55951 & 545023 & 4.155 & 4.0891 & TRN & & \\
\hline CHEMBL55997 & 545023 & 3.222 & 3.2473 & TRN & & \\
\hline CHEMBL55757 & 545023 & \multicolumn{3}{|c|}{4.2219999999999995} & 4.2066 & TRN \\
\hline CHEMBL 300851 & 545023 & \multicolumn{3}{|c|}{ 4.2219999999999995 } & 4.2678 & TRN \\
\hline CHEMBL57064 & 545023 & 3.367 & 3.293 & TRN & & \\
\hline CHEMBL55186 & 545023 & 4.046 & 3.9801 & TRN & & \\
\hline CHEMBL55187 & 545023 & 4.301 & 4.3442 & TRN & & \\
\hline CHEMBL291983 & 545023 & 4.523 & 4.5829 & TRN & & \\
\hline CHEMBL56135 & 545023 & 4.699 & 4.7756 & TRN & & \\
\hline CHEMBL299001 & 545023 & 5.0 & 5.0371 & TRN & & \\
\hline CHEMBL 301055 & 545023 & 3.523 & 3.6259 & TRN & & \\
\hline CHEMBL432894 & 545023 & 2.456 & 2.3942 & TRN & & \\
\hline CHEMBL292436 & 545023 & 1.097 & 1.3045 & TRN & & \\
\hline CHEMBL299271 & 545023 & 2.62 & 2.7488 & TRN & & \\
\hline CHEMBL 298823 & 545023 & \multicolumn{3}{|c|}{2.2680000000000002} & 2.2192 & TRN \\
\hline CHEMBL58988 & 545023 & 2.523 & 2.6212 & TRN & & \\
\hline CHEMBL53684 & 545023 & 2.523 & 2.6152 & TRN & & \\
\hline CHEMBL57223 & 545023 & 1.699 & 1.65699 & 99999 & 998 & TRN \\
\hline CHEMBL293989 & 545023 & \multicolumn{3}{|c|}{3.2680000000000002} & 3.2835 & TRN \\
\hline CHEMBL 293780 & 545023 & 2.301 & 2.2925 & TRN & & \\
\hline CHEMBL433488 & 545023 & 2.523 & 2.5443 & TRN & & \\
\hline CHEMBL 291532 & 545023 & \multicolumn{3}{|c|}{3.2289999999999996} & 3.0805 & TRN \\
\hline CHEMBL301086 & 545023 & 2.387 & 2.4446 & TRN & & \\
\hline CHEMBL53896 & 545023 & 2.022 & 1.837 & TRN & & \\
\hline CHEMBL54600 & 545023 & 3.398 & 3.2473 & TRN & & \\
\hline CHEMBL54444 & 545023 & 2.638 & 2.6686 & TRN & & \\
\hline CHEMBL55043 & 545023 & \multicolumn{3}{|c|}{1.6019999999999999} & 1.6176 & TRN \\
\hline CHEMBL55199 & 545023 & \multicolumn{3}{|c|}{3.0460000000000003} & 3.0671 & TRN \\
\hline CHEMBL55308 & 545023 & 3.222 & 3.2662 & TRN & & \\
\hline
\end{tabular}




\begin{tabular}{|c|c|c|c|c|c|c|c|}
\hline \multicolumn{7}{|c|}{ Supplemental Table S2.txt } & \\
\hline CHEMBL55271 & 545023 & 2.699 & 2.548 & TRN & & & \\
\hline CHEMBL55387 & 545023 & 2.68399 & 99999999 & 997 & 2.6474 & TRN & \\
\hline CHEMBL55862 & 545023 & 3.495 & 3.2605 & TRN & & & \\
\hline CHEMBL292012 & 545023 & 2.00699 & 99999999 & 997 & 2.7904 & TST & \\
\hline CHEMBL54318 & 545023 & 3.469 & 3.4686 & TRN & & & \\
\hline CHEMBL292644 & 545023 & 1.39800 & 000000006 & 001 & 2.0037 & TST & \\
\hline CHEMBL 293553 & 545023 & 1.848 & 2.3721 & TST & & & \\
\hline CHEMBL294212 & 545023 & 2.40900 & $00000000 t$ & 003 & 1.89800 & 00000000001 & TST \\
\hline CHEMBL56178 & 545023 & 1.694 & 1.5858 & TST & & & \\
\hline CHEMBL55998 & 545023 & 4.09699 & 99999999 & 995 & 2.7197 & TST & \\
\hline CHEMBL299781 & 545023 & 1.40699 & 999999995 & 998 & 1.8008 & TST & \\
\hline CHEMBL 300934 & 545023 & 1.31 & 1.3491 & TST & & & \\
\hline CHEMBL53893 & 545023 & 1.534 & 2.478 & TST & & & \\
\hline CHEMBL 293298 & 545023 & 1.032 & 2.0761 & TST & & & \\
\hline CHEMBL55007 & 545023 & 1.796 & 2.2246 & TST & & & \\
\hline CHEMBL293331 & 545023 & 2.319 & 2.6083 & TST & & & \\
\hline CHEMBL54970 & 545023 & 2.292 & 2.2796 & TRN & & & \\
\hline CHEMBL 292891 & 545023 & 2.699 & 2.7699 & TRN & & & \\
\hline CHEMBL56324 & 545023 & 2.75399 & 99999999 & 996 & 2.8326 & TRN & \\
\hline CHEMBL 294627 & 545023 & 3.367 & 3.1539 & TRN & & & \\
\hline CHEMBL52458 & 545023 & 1.50199 & 999999995 & 998 & 1.5608 & TRN & \\
\hline CHEMBL 293963 & 545023 & 1.893 & 1.9442 & TRN & & & \\
\hline CHEMBL56841 & 545023 & 1.359 & 0.9978 & TRN & & & \\
\hline CHEMBL293806 & 545023 & 2.762 & 2.6858 & TRN & & & \\
\hline CHEMBL56465 & 545023 & 2.292 & 2.2936 & TRN & & & \\
\hline CHEMBL54793 & 545023 & 1.52300 & 00000000 & 001 & 1.7798 & TST & \\
\hline CHEMBL55599 & 545023 & 2.131 & 2.2384 & TRN & & & \\
\hline CHEMBL 300757 & 545023 & 2.387 & 1.9667 & TST & & & \\
\hline CHEMBL51912 & 545023 & 0.93900 & 00000000 & 001 & 1.1487 & TRN & \\
\hline CHEMBL 296376 & 545023 & 2.215 & 2.3334 & TRN & & & \\
\hline CHEMBL 299014 & 545023 & 1.796 & 2.211 & TST & & & \\
\hline CHEMBL51738 & 545023 & 2.222 & 2.2439 & TRN & & & \\
\hline CHEMBL 292464 & 545023 & 2.367 & 2.7884 & TST & & & \\
\hline CHEMBL52068 & 545023 & 1.83599 & 99999999 & 999 & 1.9189 & TRN & \\
\hline CHEMBL449041 & 545023 & 2.009 & 2.0366 & TRN & & & \\
\hline CHEMBL3940076 & 1639954 & 8.0 & 7.6697 & TRN & & & \\
\hline CHEMBL 3899187 & 1639954 & 8.0 & 7.9847 & TRN & & & \\
\hline CHEMBL 3910022 & 1639954 & 8.0 & 7.7798 & TRN & & & \\
\hline CHEMBL 3931348 & 1639954 & 8.0 & 7.8517 & TRN & & & \\
\hline CHEMBL3903125 & 1639954 & 8.0 & 7.6943 & TRN & & & \\
\hline CHEMBL3929057 & 1639954 & 8.0 & 8.2949 & TRN & & & \\
\hline CHEMBL 3906764 & 1639954 & 7.0 & 7.3663 & TRN & & & \\
\hline CHEMBL3971008 & 1639954 & 7.0 & 7.5092 & TRN & & & \\
\hline CHEMBL3894764 & 1639954 & 8.0 & 7.4605 & TST & & & \\
\hline CHEMBL3981990 & 1639954 & 6.0 & 6.5949 & TRN & & & \\
\hline CHEMBL 3891481 & 1639954 & 8.0 & 7.5148 & TRN & & & \\
\hline CHEMBL3910002 & 1639954 & 6.0 & 7.1546 & TRN & & & \\
\hline CHEMBL 3946402 & 1639954 & 8.0 & 7.8095 & TST & & & \\
\hline
\end{tabular}




\begin{tabular}{|c|c|c|c|c|c|}
\hline CHEMBL3916441 & 1639954 & 8.0 & \multicolumn{2}{|c|}{7.497000000000001} & \multirow[t]{2}{*}{ TRN } \\
\hline CHEMBL 3965473 & 1639954 & 7.0 & 7.5965 & TRN & \\
\hline CHEMBL3898393 & 1639954 & 7.0 & 6.9758 & TST & \\
\hline CHEMBL3983242 & 1639954 & 7.0 & 7.7873 & TRN & \\
\hline CHEMBL3922084 & 1639954 & 8.0 & 7.9948 & TRN & \\
\hline CHEMBL3962643 & 1639954 & 8.0 & 8.3884 & TRN & \\
\hline CHEMBL3953389 & 1639954 & 7.0 & 6.9605 & TST & \\
\hline CHEMBL3970317 & 1639954 & 6.0 & 6.7475 & TRN & \\
\hline CHEMBL3905798 & 1639954 & 8.0 & 7.2458 & TRN & \\
\hline CHEMBL3975414 & 1639954 & 8.0 & 8.1629 & TRN & \\
\hline CHEMBL3957159 & 1639954 & 7.0 & 7.1928 & TST & \\
\hline CHEMBL3966631 & 1639954 & 8.0 & 7.7045 & TRN & \\
\hline CHEMBL3903726 & 1639954 & 8.0 & 7.9957 & TST & \\
\hline CHEMBL3889851 & 1639954 & 7.0 & 7.2112 & TST & \\
\hline CHEMBL3942299 & 1639954 & 8.0 & 7.8313 & TRN & \\
\hline CHEMBL3930109 & 1639954 & 8.0 & 8.3508 & TRN & \\
\hline CHEMBL3906243 & 1639954 & 7.0 & 7.024 & TST & \\
\hline CHEMBL3921763 & 1639954 & 8.0 & 7.629 & TRN & \\
\hline CHEMBL3954626 & 1639954 & 8.0 & 7.9267 & TRN & \\
\hline CHEMBL3980924 & 1639954 & 8.0 & 7.7548 & TRN & \\
\hline CHEMBL3911804 & 1639954 & 8.0 & 8.1772 & TRN & \\
\hline CHEMBL3949191 & 1639954 & 7.0 & 7.4698 & TST & \\
\hline CHEMBL3969486 & 1639954 & 8.0 & 8.1005 & TRN & \\
\hline CHEMBL3906492 & 1639954 & 8.0 & 7.9569 & TRN & \\
\hline CHEMBL3920191 & 1639954 & 8.0 & 7.4462 & TRN & \\
\hline CHEMBL3950687 & 1639954 & 8.0 & 7.8206 & TRN & \\
\hline CHEMBL3956883 & 1639954 & 8.0 & 7.8097 & TRN & \\
\hline CHEMBL3889599 & 1639954 & 8.0 & 7.5769 & TRN & \\
\hline CHEMBL3952417 & 1639954 & 8.0 & 7.731 & TRN & \\
\hline CHEMBL3922623 & 1639954 & 8.0 & 7.8549 & TRN & \\
\hline CHEMBL3909078 & 1639954 & 8.0 & 8.2228 & TRN & \\
\hline CHEMBL3892588 & 1639954 & 7.0 & 7.3415 & TST & \\
\hline CHEMBL3927351 & 1639954 & 7.0 & 7.1481 & TRN & \\
\hline CHEMBL3960935 & 1639954 & 6.0 & 6.4221 & TRN & \\
\hline CHEMBL3965793 & 1639954 & 8.0 & 7.0443 & TRN & \\
\hline CHEMBL3927397 & 1639954 & 8.0 & 8.4107 & TRN & \\
\hline CHEMBL3910786 & 1639954 & 8.0 & 8.2155 & TRN & \\
\hline CHEMBL3933708 & 1639954 & 7.0 & 7.4357 & TST & \\
\hline CHEMBL3982279 & 1639954 & 8.0 & 7.5937 & TST & \\
\hline CHEMBL3967114 & 1639954 & 8.0 & 7.352 & TRN & \\
\hline CHEMBL3953985 & 1639954 & 8.0 & 7.6005 & TRN & \\
\hline CHEMBL3975985 & 1639954 & 8.0 & 8.3519 & TRN & \\
\hline CHEMBL3934045 & 1639954 & 8.0 & 7.6559 & TRN & \\
\hline CHEMBL3971495 & 1639954 & 8.0 & 8.3231 & TRN & \\
\hline CHEMBL3927630 & 1639954 & 8.0 & 8.2302 & TRN & \\
\hline CHEMBL3973520 & 1639954 & 8.0 & 8.1712 & TRN & \\
\hline CHEMBL3951798 & 1639954 & 7.0 & 7.0115 & TST & \\
\hline CHEMBL3950710 & 1639954 & 7.0 & 7.25700 & j000000001 & TST \\
\hline & & & & 9392 & \\
\hline
\end{tabular}




\begin{tabular}{|c|c|c|c|c|c|}
\hline CHEMBL 3978301 & 1639954 & 8.0 & 7.1378 & TRN & \\
\hline CHEMBL3966039 & 1639954 & 6.0 & 6.8312 & TRN & \\
\hline CHEMBL3974732 & 1639954 & 8.0 & 7.5445 & TST & \\
\hline CHEMBL3955601 & 1639954 & 6.0 & 7.0357 & TST & \\
\hline CHEMBL3959587 & 1639954 & 8.0 & 7.9069 & TRN & \\
\hline CHEMBL3958236 & 1639954 & 7.0 & \multicolumn{2}{|c|}{ 7. 202999999999999} & TST \\
\hline CHEMBL3986696 & 1639954 & 8.0 & 8.2633 & TRN & \\
\hline CHEMBL3936743 & 1639954 & 8.0 & 8.2759 & TRN & \\
\hline CHEMBL3973612 & 1639954 & 7.0 & 7.5839 & TRN & \\
\hline CHEMBL3969729 & 1639954 & 6.0 & 6.9179 & TRN & \\
\hline CHEMBL3957247 & 1639954 & 8.0 & 7.3993 & TRN & \\
\hline CHEMBL 3902706 & 1639954 & 8.0 & 7.9117 & TRN & \\
\hline CHEMBL3976089 & 1639954 & 8.0 & 8.2274 & TRN & \\
\hline CHEMBL3902667 & 1639954 & 8.0 & 8.3113 & TRN & \\
\hline CHEMBL3909290 & 1639954 & 7.0 & 7.0012 & TRN & \\
\hline CHEMBL3955058 & 1639954 & 8.0 & 7.7032 & TRN & \\
\hline CHEMBL 3942022 & 1639954 & 8.0 & 7.5305 & TRN & \\
\hline CHEMBL3958192 & 1639954 & 8.0 & 8.0905 & TRN & \\
\hline CHEMBL3939157 & 1639954 & 8.0 & 7.8767 & TRN & \\
\hline CHEMBL3927593 & 1639954 & 8.0 & 7.1011 & TRN & \\
\hline CHEMBL3934557 & 1639954 & 8.0 & 7.6455 & TRN & \\
\hline CHEMBL 3944267 & 1639954 & 8.0 & 7.9896 & TRN & \\
\hline CHEMBL 3929514 & 1639954 & 8.0 & 7.5662 & TRN & \\
\hline CHEMBL3983372 & 1639954 & 8.0 & 7.5949 & TST & \\
\hline CHEMBL3941852 & 1639954 & 7.0 & 7.2919 & TRN & \\
\hline CHEMBL3959946 & 1639954 & 8.0 & 8.4065 & TRN & \\
\hline CHEMBL 3942727 & 1639954 & 8.0 & 7.5225 & TRN & \\
\hline CHEMBL 3930063 & 1639954 & 8.0 & 7.45 & TRN & \\
\hline CHEMBL3919359 & 1639954 & 6.0 & 6.5526 & TRN & \\
\hline CHEMBL 3948278 & 1639954 & 8.0 & 8.1134 & TRN & \\
\hline CHEMBL3965479 & 1639954 & 7.0 & 7.2173 & TRN & \\
\hline CHEMBL 3915100 & 1639954 & 8.0 & 7.4763 & TRN & \\
\hline CHEMBL 3903694 & 1639954 & 7.0 & 7.3934 & TRN & \\
\hline CHEMBL3959511 & 1639954 & 7.0 & 6.7652 & TST & \\
\hline CHEMBL3959845 & 1639954 & 7.0 & 7.2137 & TST & \\
\hline CHEMBL3961874 & 1639954 & 8.0 & 7.6632 & TST & \\
\hline CHEMBL 3915663 & 1639954 & 8.0 & 6.9159 & TST & \\
\hline CHEMBL3938334 & 1639954 & 7.0 & 6.981 & TRN & \\
\hline CHEMBL3919707 & 1639954 & 8.0 & 7.631 & TRN & \\
\hline CHEMBL 3897743 & 1639954 & 6.0 & 7.1326 & TRN & \\
\hline CHEMBL3979837 & 1639954 & 8.0 & 7.6184 & TST & \\
\hline CHEMBL3923355 & 1639954 & 7.0 & 7.2232 & TST & \\
\hline CHEMBL3986550 & 1639954 & 8.0 & 7.7621 & TRN & \\
\hline CHEMBL3895940 & 1639954 & 8.0 & 7.1241 & TRN & \\
\hline CHEMBL3953149 & 1639954 & 8.0 & 7.9669 & TRN & \\
\hline CHEMBL 3922446 & 1639954 & 8.0 & 7.73799 & 99999999995 & TRN \\
\hline CHEMBL 3967640 & 1639954 & 6.0 & 6.9899 & TRN & \\
\hline CHEMBL3927084 & 1639954 & 8.0 & 7.8538 & TRN & \\
\hline
\end{tabular}




\begin{tabular}{|c|c|c|c|c|}
\hline \multicolumn{5}{|c|}{ Supplemental Table S2.tx } \\
\hline CHEMBL3893223 & 1639954 & 8.0 & 8.2955 & TRN \\
\hline CHEMBL3986419 & 1639954 & 7.0 & 6.9591 & TRN \\
\hline CHEMBL3967151 & 1639954 & 7.0 & 7.0921 & TST \\
\hline CHEMBL3930632 & 1639954 & 8.0 & 7.9655 & TST \\
\hline CHEMBL3896685 & 1639954 & 8.0 & 8.1802 & TRN \\
\hline CHEMBL3948598 & 1639954 & 8.0 & 7.725 & TST \\
\hline CHEMBL 3899393 & 1639954 & 8.0 & 8.2488 & TRN \\
\hline CHEMBL3939322 & 1639954 & 8.0 & 7.2971 & TRN \\
\hline CHEMBL3891390 & 1639954 & 8.0 & 7.5698 & TRN \\
\hline CHEMBL3937323 & 1639954 & 8.0 & 7.7117 & TRN \\
\hline CHEMBL3977460 & 1639954 & 6.0 & 6.5378 & TRN \\
\hline CHEMBL 3950917 & 1639954 & 8.0 & 8.2865 & TST \\
\hline CHEMBL3955346 & 1639954 & 7.0 & 7.7297 & TST \\
\hline CHEMBL 3912445 & 1639954 & 8.0 & 7.5707 & TRN \\
\hline CHEMBL3967092 & 1639954 & 8.0 & 7.4702 & TRN \\
\hline CHEMBL3986486 & 1639954 & 7.0 & 7.391 & TRN \\
\hline CHEMBL 3978073 & 1639954 & 8.0 & 8.3309 & TRN \\
\hline CHEMBL3983876 & 1639954 & 8.0 & 7.5372 & TRN \\
\hline CHEMBL 3934007 & 1639954 & 7.0 & 7.1088 & TST \\
\hline CHEMBL3926840 & 1639954 & 8.0 & 7.6584 & TRN \\
\hline CHEMBL3919524 & 1639954 & 8.0 & 8.1209 & TRN \\
\hline CHEMBL 3948829 & 1639954 & 7.0 & 7.6485 & TST \\
\hline CHEMBL3958040 & 1639954 & 8.0 & 7.7543 & TST \\
\hline CHEMBL 3925179 & 1639954 & 8.0 & 7.746 & TRN \\
\hline CHEMBL3944996 & 1639954 & 8.0 & 7.8996 & TST \\
\hline CHEMBL3915704 & 1639954 & 6.0 & 7.1301 & TST \\
\hline CHEMBL3912449 & 1639954 & 8.0 & 8.3434 & TRN \\
\hline CHEMBL3938550 & 1639954 & 7.0 & 7.0462 & TRN \\
\hline CHEMBL 3896503 & 1639954 & 7.0 & 6.9103 & TST \\
\hline CHEMBL3973278 & 1639954 & 6.0 & 6.8564 & TRN \\
\hline CHEMBL3972256 & 1639954 & 8.0 & 7.5997 & TRN \\
\hline CHEMBL3905821 & 1639954 & 7.0 & 7.2207 & TST \\
\hline CHEMBL496966 & 496465 & 7.699 & 7.6311 & TRN \\
\hline CHEMBL497998 & 496465 & 7.9208 & 7.9809 & TRN \\
\hline CHEMBL496540 & 496465 & 7.5086 & 6.6957 & TST \\
\hline CHEMBL496532 & 496465 & 7.3468 & 5.9326 & TST \\
\hline CHEMBL498601 & 496465 & 8.0458 & 5.91299 & 9999999999 \\
\hline CHEMBL497999 & 496465 & 7.7959 & 3.8889 & TST \\
\hline CHEMBL455748 & 496465 & 4.4949 & 4.5435 & TRN \\
\hline CHEMBL495915 & 496465 & 7.8239 & 7.8461 & TRN \\
\hline CHEMBL524128 & 496465 & 5.1487 & 5.0924 & TRN \\
\hline CHEMBL523557 & 496465 & 7.6021 & 5.9531 & TST \\
\hline CHEMBL496110 & 496465 & 6.9208 & 6.9284 & TRN \\
\hline CHEMBL498182 & 496465 & 7.4318 & 7.4727 & TRN \\
\hline CHEMBL497790 & 496465 & 7.1612 & 7.3701 & TRN \\
\hline CHEMBL522060 & 496465 & 4.585 & 4.6279 & TRN \\
\hline CHEMBL496318 & 496465 & 7.5229 & 7.5743 & TRN \\
\hline CHEMBL520339 & 496465 & 6.1549 & 6.1001 & TRN \\
\hline
\end{tabular}




\begin{tabular}{|c|c|c|c|c|c|}
\hline & & \multicolumn{4}{|c|}{ Supplemental Table s2.txt } \\
\hline CHEMBL496319 & 496465 & 7.3979 & 7.5282 & TRN & \\
\hline CHEMBL497173 & 496465 & 3.5229 & 3.5983 & TRN & \\
\hline CHEMBL526079 & 496465 & 7.1079 & 7.0937 & TRN & \\
\hline CHEMBL496535 & 496465 & 4.0 & 3.9954 & TRN & \\
\hline CHEMBL492045 & 496465 & 7.7959 & 7.7946 & TRN & \\
\hline CHEMBL526648 & 496465 & 7.1549 & 6.9649 & TRN & \\
\hline CHEMBL521898 & 496465 & 7.4089 & 6.2018 & TST & \\
\hline CHEMBL498384 & 496465 & 8.699 & 8.6844 & TRN & \\
\hline CHEMBL497970 & 496465 & 7.0 & 7.081 & TRN & \\
\hline CHEMBL497784 & 496465 & 8.699 & 8.5819 & TRN & \\
\hline CHEMBL495510 & 496465 & 7.8239 & 3.9226 & TST & \\
\hline CHEMBL496121 & 496465 & 6.301 & 6.3351 & TRN & \\
\hline CHEMBL497380 & 496465 & 3.5229 & 3.4542 & TRN & \\
\hline CHEMBL523397 & 496465 & 7.8239 & 6.4205 & TST & \\
\hline CHEMBL495916 & 496465 & 7.3872 & 7.3395 & TRN & \\
\hline CHEMBL524645 & 496465 & 7.0862 & 5.5054 & TST & \\
\hline CHEMBL523567 & 496465 & 7.284 & 3.427 & TST & \\
\hline CHEMBL521736 & 496465 & 7.3279 & 7.9451 & TST & \\
\hline CHEMBL527085 & 496465 & 3.5229 & 3.4705 & TRN & \\
\hline CHEMBL484681 & 496465 & 5.9586 & 6.0267 & TRN & \\
\hline CHEMBL521899 & 496465 & 7.3979 & 3.29399 & 99999999996 & TST \\
\hline CHEMBL496115 & 496465 & 6.9586 & 6.9672 & TRN & \\
\hline CHEMBL484680 & 496465 & 6.2757 & 6.317 & TRN & \\
\hline CHEMBL526280 & 496465 & 7.8239 & 7.808 & TRN & \\
\hline CHEMBL496533 & 496465 & 7.1249 & 7.2041 & TST & \\
\hline CHEMBL497974 & 496465 & 6.5086 & 6.5341 & TRN & \\
\hline CHEMBL497973 & 496465 & 5.5376 & 5.5065 & TRN & \\
\hline CHEMBL522390 & 496465 & 5.7212 & 5.7577 & TRN & \\
\hline CHEMBL488981 & 496465 & 5.8539 & 5.8241 & TRN & \\
\hline CHEMBL497174 & 496465 & 3.5229 & 3.4778 & TRN & \\
\hline CHEMBL498380 & 496465 & 7.4815 & 7.4417 & TRN & \\
\hline CHEMBL496333 & 496465 & 9.0 & 8.9968 & TRN & \\
\hline CHEMBL496120 & 496465 & 4.0 & 3.9853 & TRN & \\
\hline CHEMBL525726 & 496465 & 7.0 & 7.0716 & TRN & \\
\hline CHEMBL496749 & 496465 & 7.5376 & 7.7263 & TST & \\
\hline CHEMBL524135 & 496465 & 6.3979 & 6.346 & TRN & \\
\hline CHEMBL449784 & 496465 & 3.5229 & 3.6097 & TRN & \\
\hline CHEMBL488980 & 496465 & 4.0 & 4.0024 & TRN & \\
\hline CHEMBL524155 & 496465 & 4.0 & 4.0108 & TRN & \\
\hline CHEMBL495939 & 496465 & 7.2441 & 7.1084 & TRN & \\
\hline CHEMBL496111 & 496465 & 5.7959 & 5.7776 & TRN & \\
\hline CHEMBL497766 & 496465 & 6.7447 & 6.7278 & TRN & \\
\hline CHEMBL522914 & 496465 & 7.3372 & 7.5632 & TST & \\
\hline CHEMBL497770 & 496465 & 5.8861 & 5.8232 & TRN & \\
\hline CHEMBL493079 & 562387 & 7.5 & 6.485 & TRN & \\
\hline CHEMBL494781 & 562387 & 6.3 & 6.5999 & TRN & \\
\hline CHEMBL494996 & 562387 & 5.8 & 5.5819 & TRN & \\
\hline CHEMBL494997 & 562387 & 5.2 & 4.8806 & TRN & \\
\hline
\end{tabular}




\begin{tabular}{|c|c|c|c|c|}
\hline & & & pplement & $\mathrm{a} \perp \mathrm{Ta}$ \\
\hline CHEMBL494998 & 562387 & 4.0 & 3.668 & TRN \\
\hline CHEMBL494836 & 562387 & 6.5 & 6.6461 & TRN \\
\hline CHEMBL492987 & 562387 & 6.2 & 6.6462 & TRN \\
\hline CHEMBL492988 & 562387 & 7.1 & 4.6586 & TST \\
\hline CHEMBL492989 & 562387 & 5.3 & 5.3612 & TRN \\
\hline CHEMBL495357 & 562387 & 4.0 & 4.7098 & TRN \\
\hline CHEMBL523012 & 562387 & 5.4 & 5.2504 & TRN \\
\hline CHEMBL539119 & 562387 & 4.0 & 6.1998 & TST \\
\hline CHEMBL538863 & 562387 & 5.6 & 5.4468 & TRN \\
\hline CHEMBL522992 & 562387 & 5.9 & 6.3322 & TRN \\
\hline CHEMBL492359 & 562387 & 6.7 & 6.7413 & TRN \\
\hline CHEMBL492756 & 562387 & 6.5 & 6.6808 & TST \\
\hline CHEMBL492701 & 562387 & 7.4 & 5.4926 & TST \\
\hline CHEMBL492702 & 562387 & 6.3 & 5.555 & TST \\
\hline CHEMBL521986 & 562387 & 8.2 & 6.3054 & TST \\
\hline CHEMBL522838 & 562387 & 7.5 & 6.3322 & TST \\
\hline CHEMBL493939 & 562387 & 6.6 & 7.1645 & TST \\
\hline CHEMBL494131 & 562387 & 5.5 & 7.3781 & TST \\
\hline CHEMBL524031 & 562387 & 5.6 & 6.2963 & TST \\
\hline CHEMBL524032 & 562387 & 4.0 & 6.6413 & TST \\
\hline CHEMBL494778 & 562387 & 6.6 & 6.8245 & TST \\
\hline CHEMBL494779 & 562387 & 5.2 & 6.5157 & TST \\
\hline CHEMBL494962 & 562387 & 5.1 & 6.3933 & TST \\
\hline CHEMBL495025 & 562387 & 6.5 & 6.1485 & TRN \\
\hline CHEMBL495172 & 562387 & 7.3 & 7.276 & TRN \\
\hline CHEMBL492802 & 562387 & 7.1 & 7.1102 & TRN \\
\hline CHEMBL524168 & 562387 & 6.3 & 5.9233 & TRN \\
\hline CHEMBL 495180 & 562387 & 7.1 & 7.1058 & TRN \\
\hline CHEMBL495360 & 562387 & 6.3 & 6.6682 & TRN \\
\hline CHEMBL495361 & 562387 & 6.0 & 5.7838 & TRN \\
\hline CHEMBL492997 & 562387 & 7.0 & 6.9105 & TRN \\
\hline CHEMBL492998 & 562387 & 6.5 & 6.7655 & TRN \\
\hline CHEMBL494151 & 562387 & 5.4 & 5.477 & TRN \\
\hline CHEMBL494741 & 562387 & 7.3 & 7.1227 & TRN \\
\hline CHEMBL523712 & 562387 & 6.2 & 6.6605 & TRN \\
\hline CHEMBL494742 & 562387 & 6.1 & 6.4219 & TRN \\
\hline CHEMBL492374 & 562387 & 7.7 & 7.2897 & TRN \\
\hline CHEMBL494749 & 562387 & 7.7 & 7.6344 & TRN \\
\hline CHEMBL494950 & 562387 & 6.7 & 6.6679 & TRN \\
\hline CHEMBL494951 & 562387 & 5.7 & 6.0458 & TRN \\
\hline CHEMBL494752 & 562387 & 6.7 & 7.0741 & TRN \\
\hline CHEMBL494953 & 562387 & 6.3 & 6.7983 & TRN \\
\hline CHEMBL492978 & 562387 & 8.0 & 7.5088 & TRN \\
\hline CHEMBL492391 & 562387 & 5.9 & 5.8617 & TRN \\
\hline CHEMBL522020 & 562387 & 8.0 & 6.975 & TRN \\
\hline CHEMBL501486 & 562387 & 5.7 & 5.7104 & TRN \\
\hline CHEMBL494410 & 562387 & 6.6 & 6.9532 & TRN \\
\hline CHEMBL494411 & 562387 & 6.5 & 7.1022 & TRN \\
\hline
\end{tabular}




\begin{tabular}{|c|c|c|c|c|c|c|}
\hline \\
\hline CHEMBL495028 & 562387 & 8.4 & 8.0557 & TRN & & \\
\hline CHEMBL 209148 & 954849 & 5.0669 & 5.0669 & TRN & & \\
\hline CHEMBL2144069 & 954849 & 5.2313 & 5.2313 & TRN & & \\
\hline CHEMBL240954 & 954849 & 4.7372 & 4.7372 & TRN & & \\
\hline CHEMBL483847 & 954849 & 3.745 & 3.745 & TRN & & \\
\hline CHEMBL1404918 & 954849 & 3.0585 & 3.0585 & TRN & & \\
\hline CHEMBL1516890 & 954849 & 3.8044 & 3.8044 & TRN & & \\
\hline CHEMBL3349342 & 954849 & 6.9878 & 6.9878 & TRN & & \\
\hline CHEMBL300389 & 954849 & 6.5836 & 6.5836 & TRN & & \\
\hline CHEMBL1909414 & 954849 & 5.4488 & 5.4488 & TRN & & \\
\hline CHEMBL221137 & 954849 & 4.2517 & 4.8924 & TST & & \\
\hline CHEMBL449158 & 954849 & 5.99299 & 99999999 & 99 & 7.4684 & TST \\
\hline CHEMBL1970879 & 954849 & 3.0453 & 3.0453 & TRN & & \\
\hline CHEMBL210618 & 954849 & 3.5259 & 3.5259 & TRN & & \\
\hline CHEMBL3186408 & 954849 & 4.0725 & 4.2017 & TST & & \\
\hline CHEMBL1242367 & 954849 & 3.2533 & 3.2533 & TRN & & \\
\hline CHEMBL3199475 & 954849 & 4.3336 & 4.3336 & TRN & & \\
\hline CHEMBL515416 & 954849 & 4.6337 & 4.6337 & TRN & & \\
\hline CHEMBL1256459 & 954849 & 6.6632 & 6.6632 & TRN & & \\
\hline CHEMBL573107 & 954849 & 7.4461 & 7.4461 & TRN & & \\
\hline CHEMBL202721 & 954849 & 5.3513 & 5.3513 & TRN & & \\
\hline CHEMBL 9470 & 954849 & 6.1418 & 6.1625 & TST & & \\
\hline CHEMBL 258844 & 954849 & 5.2484 & 5.2484 & TRN & & \\
\hline CHEMBL191334 & 954849 & 4.8488 & 4.8488 & TRN & & \\
\hline CHEMBL2005886 & 954849 & 5.3223 & 5.3223 & TRN & & \\
\hline CHEMBL1190711 & 954849 & 5.3076 & 5.3076 & TRN & & \\
\hline CHEMBL514499 & 954849 & 7.1784 & 7.1784 & TRN & & \\
\hline CHEMBL585951 & 954849 & 5.3733 & 5.3733 & TRN & & \\
\hline CHEMBL393929 & 954849 & 4.2865 & 4.2865 & TRN & & \\
\hline CHEMBL213100 & 954849 & 4.1623 & 4.1623 & TRN & & \\
\hline CHEMBL1673039 & 954849 & 4.4389 & 4.4389 & TRN & & \\
\hline CHEMBL1788116 & 954849 & 4.337 & 4.337 & TRN & & \\
\hline CHEMBL192566 & 954849 & 6.9282 & 8.7595 & TST & & \\
\hline CHEMBL92309 & 954849 & 2.7245 & 3.2499 & TST & & \\
\hline CHEMBL135561 & 954849 & 4.6487 & 4.6487 & TRN & & \\
\hline CHEMBL373751 & 954849 & 3.362 & 3.362 & TRN & & \\
\hline CHEMBL3392440 & 954849 & 3.8455 & 3.8455 & TRN & & \\
\hline CHEMBL1643959 & 954849 & 3.8472 & 3.8472 & TRN & & \\
\hline CHEMBL65 & 954849 & 9.4959 & 9.4959 & TRN & & \\
\hline CHEMBL2363137 & 954849 & 4.3602 & 4.3602 & TRN & & \\
\hline CHEMBL379300 & 954849 & 5.9533 & 5.9533 & TRN & & \\
\hline CHEMBL1357247 & 954849 & 3.3724 & 3.3724 & TRN & & \\
\hline CHEMBL512504 & 954849 & 4.5298 & 4.5298 & TRN & & \\
\hline CHEMBL472940 & 954849 & 4.5295 & 4.5295 & TRN & & \\
\hline CHEMBL509032 & 954849 & 5.3222 & 5.3222 & TRN & & \\
\hline CHEMBL189584 & 954849 & 5.3991 & 5.3991 & TRN & & \\
\hline CHEMBL379975 & 954849 & 6.0237 & 5.5855 & TST & & \\
\hline CHEMBL412142 & 954849 & 3.7531 & 4.0142 & TST & & \\
\hline
\end{tabular}




\begin{tabular}{|c|c|c|c|c|}
\hline & & & pplement & al $\mathrm{T}$ \\
\hline CHEMBL 259181 & 954849 & 4.4091 & 4.833 & TST \\
\hline CHEMBL180127 & 954849 & 2.9 & 3.9934 & TST \\
\hline CHEMBL220241 & 954849 & 3.6704 & 4.6746 & TST \\
\hline CHEMBL392695 & 954849 & 5.3084 & 5.0871 & TST \\
\hline CHEMBL558642 & 954849 & 3.4254 & 4.1336 & TST \\
\hline CHEMBL1590308 & 954849 & 3.2947 & 3.3511 & TST \\
\hline CHEMBL 2418172 & 978478 & 5.3372 & 5.3823 & TRN \\
\hline CHEMBL2418191 & 978478 & 3.6021 & 3.5412 & TRN \\
\hline CHEMBL 2418153 & 978478 & 3.6021 & 3.6157 & TRN \\
\hline CHEMBL2418179 & 978478 & 3.6021 & 4.152 & TRN \\
\hline CHEMBL2418176 & 978478 & 5.3188 & 4.6752 & TRN \\
\hline CHEMBL2418175 & 978478 & 3.6021 & 3.6483 & TRN \\
\hline CHEMBL2418148 & 978478 & 5.0044 & 4.5691 & TST \\
\hline CHEMBL 2418187 & 978478 & 3.6021 & 3.5239 & TRN \\
\hline CHEMBL 2418146 & 978478 & 3.6021 & 3.3749 & TST \\
\hline CHEMBL2418149 & 978478 & 5.0269 & 4.8763 & TST \\
\hline CHEMBL 2418192 & 978478 & 3.6021 & 3.5348 & TRN \\
\hline CHEMBL2418170 & 978478 & 3.6021 & 3.5142 & TRN \\
\hline CHEMBL 2418163 & 978478 & 3.6021 & 3.7091 & TRN \\
\hline CHEMBL 2418139 & 978478 & 4.8729 & 5.0577 & TRN \\
\hline CHEMBL236232 & 978478 & 3.301 & 3.1446 & TRN \\
\hline CHEMBL 2418169 & 978478 & 3.6021 & 3.6054 & TRN \\
\hline CHEMBL2418189 & 978478 & 3.6021 & 3.7408 & TRN \\
\hline CHEMBL 2418154 & 978478 & 3.6021 & 3.5853 & TRN \\
\hline CHEMBL2418166 & 978478 & 3.6021 & 3.755 & TRN \\
\hline CHEMBL 2418168 & 978478 & 3.6021 & 3.3734 & TRN \\
\hline CHEMBL 2418193 & 978478 & 3.6021 & 3.7693 & TRN \\
\hline CHEMBL 2418143 & 978478 & 3.6021 & 3.8656 & TST \\
\hline CHEMBL 2418151 & 978478 & 3.6021 & 3.7509 & TST \\
\hline CHEMBL 2418181 & 978478 & 5.2676 & 4.9766 & TST \\
\hline CHEMBL 2418167 & 978478 & 3.6021 & 3.6051 & TRN \\
\hline CHEMBL2418157 & 978478 & 3.6021 & 3.6599 & TST \\
\hline CHEMBL 2418162 & 978478 & 3.6021 & 3.4739 & TRN \\
\hline CHEMBL 2418171 & 978478 & 3.6021 & 3.5616 & TRN \\
\hline CHEMBL 2418142 & 978478 & 3.6021 & 3.6665 & TRN \\
\hline CHEMBL 2418180 & 978478 & 3.6021 & 4.0004 & TRN \\
\hline CHEMBL2418159 & 978478 & 3.6021 & 3.6082 & TRN \\
\hline CHEMBL2418140 & 978478 & 3.301 & 3.216 & TST \\
\hline CHEMBL 2418174 & 978478 & 3.6021 & 3.8684 & TRN \\
\hline CHEMBL 2418177 & 978478 & 3.6021 & 3.6007 & TRN \\
\hline CHEMBL 2418156 & 978478 & 3.6021 & 3.8439 & TST \\
\hline CHEMBL 2418144 & 978478 & 3.6021 & 3.5102 & TST \\
\hline CHEMBL 2418173 & 978478 & 5.1739 & 5.1268 & TRN \\
\hline CHEMBL 2418141 & 978478 & 3.6021 & 3.3598 & TRN \\
\hline CHEMBL2418164 & 978478 & 3.6021 & 3.5197 & TRN \\
\hline CHEMBL 2418190 & 978478 & 3.6021 & 3.7217 & TRN \\
\hline CHEMBL2418194 & 978478 & 3.6021 & 3.6084 & TRN \\
\hline CHEMBL2418160 & 978478 & 3.6021 & 3.7272 & TRN \\
\hline
\end{tabular}


Supplemental Table S2.txt

\begin{tabular}{|c|c|c|c|c|}
\hline CHEMBL 2418158 & 978478 & 3.6021 & 3.6448 & TRN \\
\hline CHEMBL 2418145 & 978478 & 3.6021 & 3.5627 & TRN \\
\hline CHEMBL 2418152 & 978478 & 3.6021 & 3.5048 & TST \\
\hline CHEMBL 2418178 & 978478 & 5.0223 & 4.4902 & TRN \\
\hline CHEMBL 2418188 & 978478 & 3.6021 & 3.5906 & TRN \\
\hline CHEMBL 2418147 & 978478 & 3.6021 & 3.6912 & TST \\
\hline CHEMBL 2418161 & 978478 & 3.6021 & 3.9702 & TST \\
\hline CHEMBL 2418165 & 978478 & 3.6021 & 3.5614 & TRN \\
\hline CHEMBL 2418183 & 978478 & 3.6021 & 3.8396 & TRN \\
\hline CHEMBL 2418155 & 978478 & 5.2757 & 4.8015 & TST \\
\hline CHEMBL 2418184 & 978478 & 3.6021 & 3.6693 & TRN \\
\hline CHEMBL 2418186 & 978478 & 3.6021 & 3.6083 & TRN \\
\hline CHEMBL 2418185 & 978478 & 3.6021 & 3.4133 & TRN \\
\hline CHEMBL 2418150 & 978478 & 3.6021 & 3.3915 & TST \\
\hline CHEMBL 2418182 & 978478 & 5.301 & 5.2423 & TRN \\
\hline CHEMBL1445297 & 1301777 & 6.6635 & 6.4465 & TRN \\
\hline CHEMBL 2359934 & 1301777 & 4.6326 & 4.7327 & TRN \\
\hline CHEMBL 2362650 & 1301777 & 5.4634 & 5.0431 & TRN \\
\hline CHEMBL 2360483 & 1301777 & 4.4896 & 4.8144 & TRN \\
\hline CHEMBL591363 & 1301777 & 5.3536 & 5.1622 & TRN \\
\hline CHEMBL2355418 & 1301777 & 4.44300 & 000000000 & 4.805 \\
\hline CHEMBL1574530 & 1301777 & 4.4726 & 4.8075 & TST \\
\hline CHEMBL2362669 & 1301777 & 4.8614 & 4.6214 & TRN \\
\hline CHEMBL 3187821 & 1301777 & 4.5688 & 4.6357 & TRN \\
\hline CHEMBL 2360439 & 1301777 & 4.587 & 4.7396 & TRN \\
\hline CHEMBL1345220 & 1301777 & 5.3893 & 5.2873 & TST \\
\hline CHEMBL 2360341 & 1301777 & 4.2585 & 4.6649 & TRN \\
\hline CHEMBL1584985 & 1301777 & 5.9136 & 5.7841 & TST \\
\hline CHEMBL 3182281 & 1301777 & 4.1642 & 4.3394 & TRN \\
\hline CHEMBL 2356019 & 1301777 & 4.4353 & 4.7103 & TRN \\
\hline CHEMBL2357399 & 1301777 & 4.9458 & 4.6617 & TRN \\
\hline CHEMBL1379675 & 1301777 & 5.0353 & 5.0123 & TST \\
\hline CHEMBL 2359895 & 1301777 & 5.16299 & 999999999 & 4.73 \\
\hline CHEMBL1452421 & 1301777 & 5.2388 & \multicolumn{2}{|c|}{5.0889999999999995} \\
\hline CHEMBL 2359406 & 1301777 & 4.6299 & 4.85 & TRN \\
\hline CHEMBL 2355724 & 1301777 & 6.0 & 5.3475 & TRN \\
\hline CHEMBL1321427 & 1301777 & 6.27 & 5.9353 & TST \\
\hline CHEMBL2357924 & 1301777 & 4.9154 & 4.751 & TRN \\
\hline CHEMBL 2138714 & 1301777 & 5.4881 & 5.0559 & TRN \\
\hline CHEMBL 2355402 & 1301777 & 4.6276 & 4.7512 & TRN \\
\hline CHEMBL1378851 & 1301777 & 4.1639 & 4.7773 & TST \\
\hline CHEMBL 2359710 & 1301777 & 4.4652 & 4.7604 & TRN \\
\hline CHEMBL585827 & 1301777 & 4.9606 & 5.2298 & TRN \\
\hline CHEMBL1375884 & 1301777 & 4.978 & 4.8478 & TRN \\
\hline CHEMBL 2356002 & 1301777 & 6.0 & 4.7622 & TRN \\
\hline CHEMBL 2361591 & 1301777 & 6.0 & 5.0345 & TRN \\
\hline CHEMBL 2361979 & 1301777 & 4.2588 & 4.7089 & TRN \\
\hline CHEMBL 2357404 & 1301777 & 4.2882 & 4.7514 & TRN \\
\hline
\end{tabular}


Supplemental Table S2.txt

\begin{tabular}{|c|c|c|c|c|c|}
\hline CHEMBL 2362454 & 1301777 & 4.8972 & 4.6813 & TRN & \\
\hline CHEMBL 2359026 & 1301777 & 4.7701 & 4.6471 & TRN & \\
\hline CHEMBL 2355085 & 1301777 & 4.58 & 4.7488 & TRN & \\
\hline CHEMBL1578386 & 1301777 & 4.5311 & 4.7197 & TST & \\
\hline CHEMBL 2361207 & 1301777 & 6.0 & 4.7501 & TRN & \\
\hline CHEMBL 2359438 & 1301777 & 4.574 & 4.854 & TRN & \\
\hline CHEMBL 2356186 & 1301777 & 4.3931 & 4.7578 & TRN & \\
\hline CHEMBL 2361222 & 1301777 & 4.7151 & 4.726 & TRN & \\
\hline CHEMBL 2359470 & 1301777 & 4.2872 & 5.0796 & TRN & \\
\hline CHEMBL 2358490 & 1301777 & 6.0 & 4.6795 & TRN & \\
\hline CHEMBL1543417 & 1301777 & 4.0978 & 4.4455 & TRN & \\
\hline CHEMBL1559741 & 1301777 & 4.4289 & 5.1842 & TST & \\
\hline CHEMBL 2359952 & 1301777 & 4.3298 & 4.9609 & TRN & \\
\hline CHEMBL3183001 & 1301777 & 4.3714 & 4.6588 & TRN & \\
\hline CHEMBL 2362298 & 1301777 & 4.7029 & 4.8963 & TRN & \\
\hline CHEMBL1428095 & 1301777 & 4.7387 & 4.7755 & TRN & \\
\hline CHEMBL 2358486 & 1301777 & 4.3287 & 4.64 & TRN & \\
\hline CHEMBL 2355758 & 1301777 & 4.3517 & 4.6514 & TRN & \\
\hline CHEMBL 2356655 & 1301777 & 4.6334 & 4.7529 & TRN & \\
\hline CHEMBL 2361274 & 1301777 & 4.9303 & 4.9477 & TRN & \\
\hline CHEMBL 2136180 & 1301777 & 4.1996 & 4.6917 & TRN & \\
\hline CHEMBL1321754 & 1301777 & 4.7622 & 4.9245 & TRN & \\
\hline CHEMBL1344930 & 1301777 & 4.1554 & 4.7158 & TST & \\
\hline CHEMBL 2358729 & 1301777 & 4.587 & 4.9307 & TRN & \\
\hline CHEMBL1530866 & 1301777 & 4.776 & 4.6504 & TRN & \\
\hline CHEMBL 2362415 & 1301777 & 4.3028 & 4.6388 & TRN & \\
\hline CHEMBL1396619 & 1301777 & 4.5854 & 4.8948 & TST & \\
\hline CHEMBL1551808 & 1301777 & 4.6411 & 4.4039 & TRN & \\
\hline CHEMBL 2355407 & 1301777 & 5.4895 & 4.8068 & TRN & \\
\hline CHEMBL 2354969 & 1301777 & 4.7552 & 4.8795 & TRN & \\
\hline CHEMBL1489779 & 1301777 & 6.109 & 6.1728 & TRN & \\
\hline CHEMBL1602637 & 1301777 & 5.5952 & 5.7193 & TRN & \\
\hline CHEMBL1405749 & 1301777 & 6.1864 & 6.419 & TRN & \\
\hline CHEMBL 2362144 & 1301777 & 4.1627 & 4.7441 & TRN & \\
\hline CHEMBL 2357597 & 1301777 & 4.5014 & 4.7811 & TST & \\
\hline CHEMBL 2358424 & 1301777 & 4.3827 & 4.7831 & TRN & \\
\hline CHEMBL 2359466 & 1301777 & 4.4985 & 4.5882 & TRN & \\
\hline CHEMBL1392527 & 1301777 & 6.3947 & 5.7767 & TST & \\
\hline CHEMBL 2360927 & 1301777 & 4.9686 & 4.7607 & TRN & \\
\hline CHEMBL 2361778 & 1301777 & 4.3729 & 4.605 & TRN & \\
\hline CHEMBL 2358924 & 1301777 & 4.6511 & 4.7316 & TRN & \\
\hline CHEMBL 2360811 & 1301777 & 5.055 & 4.9132 & TRN & \\
\hline CHEMBL 2361605 & 1301777 & 4.2894 & 4.7559 & TRN & \\
\hline CHEMBL 2355359 & 1301777 & 4.4812 & 4.9216 & TRN & \\
\hline CHEMBL1544186 & 1301777 & 4.8351 & 4.7621 & TST & \\
\hline CHEMBL 2355076 & 1301777 & 4.5585 & 4.7283 & TRN & \\
\hline CHEMBL1305372 & 1301777 & 4.36100 & 000000006 & $\partial 1$ & 4.3959 \\
\hline CHEMBL 2356480 & 1301777 & 4.4254 & 4.6418 & TRN & \\
\hline
\end{tabular}


Supplemental Table S2.txt

\begin{tabular}{|c|c|c|c|c|c|}
\hline CHEMBL 2355635 & 1301777 & 4.6609 & 4.585 & TRN & \\
\hline CHEMBL2132699 & 1301777 & 6.0 & 4.6002 & TRN & \\
\hline CHEMBL1459394 & 1301777 & 4.6064 & 4.3336 & TRN & \\
\hline CHEMBL2357047 & 1301777 & 4.6308 & 4.5576 & TRN & \\
\hline CHEMBL2357026 & 1301777 & 6.0 & 4.8474 & TRN & \\
\hline CHEMBL2359863 & 1301777 & 4.8821 & 4.735 & TRN & \\
\hline CHEMBL2359989 & 1301777 & 4.435 & 4.6631 & TRN & \\
\hline CHEMBL2359612 & 1301777 & 6.0 & 4.6981 & TRN & \\
\hline CHEMBL2360055 & 1301777 & 4.2941 & 4.7218 & TRN & \\
\hline CHEMBL2361210 & 1301777 & 4.4326 & 4.7096 & TRN & \\
\hline CHEMBL1488060 & 1301777 & 4.0367 & 4.6633 & TST & \\
\hline CHEMBL 2360720 & 1301777 & 4.4833 & \multicolumn{2}{|c|}{4.906000000000001} & TRN \\
\hline CHEMBL2355890 & 1301777 & 6.0 & 4.9094 & TRN & \\
\hline CHEMBL1337726 & 1301777 & 5.0711 & 5.4051 & TRN & \\
\hline CHEMBL2359728 & 1301777 & 4.248 & 4.5857 & TRN & \\
\hline CHEMBL2359131 & 1301777 & 4.249 & 4.6288 & TRN & \\
\hline CHEMBL3182927 & 1301777 & 4.4435 & 4.7814 & TRN & \\
\hline CHEMBL1390112 & 1301777 & 4.7091 & 4.827 & TST & \\
\hline CHEMBL 3182148 & 1301777 & 4.3289 & 4.2742 & TRN & \\
\hline CHEMBL2359541 & 1301777 & 4.4306 & 4.7253 & TRN & \\
\hline CHEMBL1904071 & 1301777 & 4.0906 & 4.9176 & TST & \\
\hline CHEMBL 2358870 & 1301777 & 4.4253 & 4.6404 & TRN & \\
\hline CHEMBL1617452 & 1301777 & 4.8374 & 4.9122 & TST & \\
\hline CHEMBL1378232 & 1301777 & 4.8468 & 4.9051 & TST & \\
\hline CHEMBL1418341 & 1301777 & 4.6609 & 4.8239 & TST & \\
\hline CHEMBL2359013 & 1301777 & 4.6757 & 4.7779 & TST & \\
\hline CHEMBL1544797 & 1301777 & 5.0487 & 5.2767 & TST & \\
\hline CHEMBL 2359372 & 1301777 & 4.311 & 5.0809 & TST & \\
\hline CHEMBL 2357794 & 1301777 & 4.2684 & 4.9316 & TST & \\
\hline CHEMBL1487099 & 1301777 & 5.1824 & 5.5578 & TST & \\
\hline CHEMBL 2360228 & 1301777 & 4.3405 & 4.7247 & TST & \\
\hline CHEMBL1483562 & 1301777 & 4.9378 & 4.8203 & TST & \\
\hline CHEMBL2359515 & 1301777 & 4.1708 & 4.7408 & TST & \\
\hline CHEMBL 2142401 & 1301777 & 4.2497 & 4.6694 & TST & \\
\hline CHEMBL2362547 & 1301777 & 5.0237 & 4.7625 & TST & \\
\hline CHEMBL3103668 & 1285819 & 5.3344 & 5.2262 & TRN & \\
\hline CHEMBL3103667 & 1285819 & 5.5867 & 5.7338 & TRN & \\
\hline CHEMBL3103676 & 1285819 & 4.0 & 3.9771 & TRN & \\
\hline CHEMBL3105492 & 1285819 & 5.3768 & 5.3656 & TRN & \\
\hline CHEMBL3103662 & 1285819 & 5.556 & 5.6385 & TRN & \\
\hline CHEMBL3102989 & 1285819 & 5.8697 & 5.9178 & TRN & \\
\hline CHEMBL3105482 & 1285819 & 6.0 & 5.5944 & TST & \\
\hline CHEMBL3105490 & 1285819 & 5.983 & 5.8193 & TRN & \\
\hline CHEMBL3103669 & 1285819 & 4.0 & 3.965 & TRN & \\
\hline CHEMBL3102990 & 1285819 & 4.0 & 4.0098 & TRN & \\
\hline CHEMBL3105478 & 1285819 & 8.1549 & 5.6343 & TST & \\
\hline CHEMBL3103663 & 1285819 & 5.284 & 5.1146 & TRN & \\
\hline CHEMBL3103659 & 1285819 & 4.0 & 3.9931 & TRN & \\
\hline
\end{tabular}


Supplemental Table S2.txt

\begin{tabular}{|c|c|c|c|c|c|}
\hline CHEMBL3103657 & 1285819 & 5.6576 & 5.6566 & TRN & \\
\hline CHEMBL3103660 & 1285819 & 4.0 & 4.1244 & TRN & \\
\hline CHEMBL3103675 & 1285819 & 4.0 & 3.977 & TRN & \\
\hline CHEMBL3103682 & 1285819 & 4.0 & 3.9854 & TRN & \\
\hline CHEMBL3102987 & 1285819 & 6.056 & 6.0614 & TRN & \\
\hline CHEMBL3102992 & 1285819 & 5.7447 & 5.5839 & TRN & \\
\hline CHEMBL3103661 & 1285819 & 5.7932 & 5.8776 & TRN & \\
\hline CHEMBL3102984 & 1285819 & 5.1267 & 5.1618 & TRN & \\
\hline CHEMBL3105246 & 1285819 & 6.2472 & 6.2269 & TRN & \\
\hline CHEMBL3105493 & 1285819 & 5.2984 & 5.3728 & TRN & \\
\hline CHEMBL3105487 & 1285819 & 6.058 & 6.0844 & TRN & \\
\hline CHEMBL3103658 & 1285819 & 6.3904 & 6.3141 & TRN & \\
\hline CHEMBL3105248 & 1285819 & 7.7011 & 5.0694 & TST & \\
\hline CHEMBL3102991 & 1285819 & 4.0 & 3.9453 & TRN & \\
\hline CHEMBL3105245 & 1285819 & 5.4672 & 5.3864 & TRN & \\
\hline CHEMBL3105479 & 1285819 & 5.5406 & 4.3318 & TST & \\
\hline CHEMBL3102985 & 1285819 & 6.6968 & 6.604 & TRN & \\
\hline CHEMBL3105486 & 1285819 & 5.2832 & 5.7479 & TST & \\
\hline CHEMBL3105252 & 1285819 & 4.0 & 4.0205 & TST & \\
\hline CHEMBL3103666 & 1285819 & 4.0 & 3.9504 & TRN & \\
\hline CHEMBL3105247 & 1285819 & 7.3915 & 5.13 & TST & \\
\hline CHEMBL3105488 & 1285819 & 6.0605 & 6.1447 & TRN & \\
\hline CHEMBL3105483 & 1285819 & 6.2557 & 6.2931 & TRN & \\
\hline CHEMBL3105249 & 1285819 & 7.1851 & 5.5361 & TST & \\
\hline CHEMBL3105484 & 1285819 & 6.3595 & 6.2947 & TRN & \\
\hline CHEMBL3103664 & 1285819 & 4.0 & 3.9117 & TRN & \\
\hline CHEMBL3103665 & 1285819 & 4.0 & 4.0058 & TRN & \\
\hline CHEMBL3103677 & 1285819 & 4.0 & 3.9853 & TRN & \\
\hline CHEMBL3105485 & 1285819 & 4.0 & 4.1583 & TRN & \\
\hline CHEMBL3105480 & 1285819 & 6.4584 & 6.4419 & TRN & \\
\hline CHEMBL3102988 & 1285819 & 5.3716 & 5.507006 & 0000000001 & TRN \\
\hline CHEMBL3102986 & 1285819 & 5.9706 & 5.8468 & TST & \\
\hline CHEMBL3102983 & 1285819 & 5.0747 & 5.2862 & TRN & \\
\hline CHEMBL 3105250 & 1285819 & 6.9586 & 4.8806 & TST & \\
\hline CHEMBL3105489 & 1285819 & 6.1079 & 6.0307 & TRN & \\
\hline CHEMBL3105481 & 1285819 & 6.224 & 6.2815 & TRN & \\
\hline CHEMBL3103679 & 1285819 & 4.0 & 4.0047 & TRN & \\
\hline CHEMBL3103678 & 1285819 & 4.0 & 3.0571 & TST & \\
\hline CHEMBL 3103680 & 1285819 & 4.0 & 2.559 & TST & \\
\hline CHEMBL3105491 & 1285819 & 5.5467 & 5.567 & TRN & \\
\hline CHEMBL3105251 & 1285819 & 4.0 & 4.3009 & TST & \\
\hline CHEMBL3103681 & 1285819 & 4.0 & 3.3094 & TST & \\
\hline CHEMBL1572439 & 688392 & 4.4 & 4.8182 & TRN & \\
\hline CHEMBL1253351 & 688392 & 5.6 & 5.206 & TRN & \\
\hline CHEMBL1340344 & 688392 & 4.9 & 5.1338 & TRN & \\
\hline CHEMBL1526332 & 688392 & 4.35 & 4.9035 & TRN & \\
\hline CHEMBL365327 & 688392 & 4.9 & 4.9707 & TRN & \\
\hline CHEMBL1302533 & 688392 & 4.6 & 5.1144 & TRN & \\
\hline
\end{tabular}




\begin{tabular}{|c|c|c|c|c|c|}
\hline & & \multicolumn{4}{|c|}{ Supplemental Table S2.txt } \\
\hline CHEMBL1465659 & 688392 & 8.6021 & 5.4533 & TRN & \\
\hline CHEMBL1365599 & 688392 & 4.7 & 5.1085 & TRN & \\
\hline CHEMBL3199451 & 688392 & 5.8 & 5.7613 & TRN & \\
\hline CHEMBL1595576 & 688392 & 4.85 & 5.229 & TRN & \\
\hline CHEMBL1572403 & 688392 & 4.9 & 4.9621 & TRN & \\
\hline CHEMBL1981243 & 688392 & 5.15 & 4.9768 & TRN & \\
\hline CHEMBL1493191 & 688392 & 4.8 & 5.12200 & 0000000001 & TRN \\
\hline CHEMBL2000167 & 688392 & 4.85 & 5.0823 & TRN & \\
\hline CHEMBL1412621 & 688392 & 6.0 & 5.1216 & TRN & \\
\hline CHEMBL1470395 & 688392 & 5.05 & 5.2168 & TRN & \\
\hline CHEMBL1331974 & 688392 & 4.95 & 5.1658 & TST & \\
\hline CHEMBL1561713 & 688392 & 4.8 & 4.8096 & TRN & \\
\hline CHEMBL55814 & 688392 & 4.8 & 5.624 & TRN & \\
\hline CHEMBL1434513 & 688392 & 5.4 & 5.6946 & TRN & \\
\hline CHEMBL192566 & 688392 & 4.4 & 5.0224 & TST & \\
\hline CHEMBL1462800 & 688392 & 5.75 & 5.0668 & TRN & \\
\hline CHEMBL1524942 & 688392 & 6.25 & 5.0087 & TRN & \\
\hline CHEMBL1560403 & 688392 & 5.6 & 5.3201 & TST & \\
\hline CHEMBL1417203 & 688392 & 5.0 & 4.8674 & TRN & \\
\hline CHEMBL3191528 & 688392 & 6.3 & 5.2607 & TRN & \\
\hline CHEMBL1441738 & 688392 & 5.15 & 5.334 & TRN & \\
\hline CHEMBL404845 & 688392 & 5.3 & 6.0633 & TRN & \\
\hline CHEMBL1411673 & 688392 & 4.85 & 4.9828 & TRN & \\
\hline CHEMBL1562712 & 688392 & 4.85 & 5.11 & TRN & \\
\hline CHEMBL1329826 & 688392 & 5.15 & 5.8335 & TRN & \\
\hline CHEMBL1375615 & 688392 & 5.55 & 5.2846 & TRN & \\
\hline CHEMBL1310120 & 688392 & 4.4 & 5.1913 & TRN & \\
\hline CHEMBL1358863 & 688392 & 4.95 & 4.9402 & TRN & \\
\hline CHEMBL1448671 & 688392 & 4.9 & 4.9606 & TRN & \\
\hline CHEMBL313737 & 688392 & 4.6 & 5.2287 & TST & \\
\hline CHEMBL1358777 & 688392 & 7.3497 & 5.1661 & TST & \\
\hline CHEMBL1462570 & 688392 & 4.85 & 6.1315 & TRN & \\
\hline CHEMBL1331134 & 688392 & 4.45 & 5.0312 & TRN & \\
\hline CHEMBL1558442 & 688392 & 4.7 & 5.0153 & TRN & \\
\hline CHEMBL1605526 & 688392 & 4.45 & 5.1004 & TRN & \\
\hline CHEMBL1610567 & 688392 & 8.0 & 4.9655 & TST & \\
\hline CHEMBL1401801 & 688392 & 4.35 & 5.1117 & TRN & \\
\hline CHEMBL1597042 & 688392 & 5.3 & 5.0146 & TRN & \\
\hline CHEMBL1091723 & 688392 & 9.1549 & 6.0595 & TRN & \\
\hline CHEMBL1576140 & 688392 & 5.6 & 5.5761 & TRN & \\
\hline CHEMBL3199121 & 688392 & 4.4 & 5.4955 & TRN & \\
\hline CHEMBL 97453 & 688392 & 5.35 & 5.4017 & TRN & \\
\hline CHEMBL1586890 & 688392 & 5.0 & 5.3334 & TRN & \\
\hline CHEMBL1498281 & 688392 & 4.4 & 5.1345 & TRN & \\
\hline CHEMBL1321993 & 688392 & 5.05 & 5.0713 & TRN & \\
\hline CHEMBL1302328 & 688392 & 4.4 & 4.9461 & TRN & \\
\hline CHEMBL1391426 & 688392 & 4.85 & 4.8833 & TRN & \\
\hline CHEMBL1461619 & 688392 & 5.0 & 4.8864 & TRN & \\
\hline
\end{tabular}




\begin{tabular}{|c|c|c|c|c|}
\hline \multicolumn{5}{|c|}{ Supplemental Table S2.txt } \\
\hline CHEMBL1554829 & 688392 & 6.5 & 5.5129 & TRN \\
\hline CHEMBL3235884 & 688392 & 4.75 & 4.8759 & TRN \\
\hline CHEMBL1312996 & 688392 & 4.8 & 5.1408 & TRN \\
\hline CHEMBL1394337 & 688392 & 6.5 & 5.9825 & TRN \\
\hline CHEMBL1566266 & 688392 & 4.8 & 5.0774 & TRN \\
\hline CHEMBL1972037 & 688392 & 5.25 & 6.1679 & TRN \\
\hline CHEMBL1589385 & 688392 & 4.35 & 5.4333 & TST \\
\hline CHEMBL1540272 & 688392 & 4.95 & 5.1376 & TRN \\
\hline CHEMBL1507881 & 688392 & 4.9 & 4.9085 & TRN \\
\hline CHEMBL1555897 & 688392 & 5.05 & 5.5957 & TST \\
\hline CHEMBL1342736 & 688392 & 4.9 & 5.0945 & TRN \\
\hline CHEMBL1467504 & 688392 & 4.4 & 5.107 & TRN \\
\hline CHEMBL1547701 & 688392 & 4.0 & 4.9812 & TRN \\
\hline CHEMBL1360482 & 688392 & 4.0 & 5.1924 & TRN \\
\hline CHEMBL1353221 & 688392 & 4.9 & 5.3342 & TST \\
\hline CHEMBL1365553 & 688392 & 6.15 & 5.3545 & TRN \\
\hline CHEMBL1353644 & 688392 & 6.05 & 5.0177 & TRN \\
\hline CHEMBL1533772 & 688392 & 4.85 & 5.1649 & TST \\
\hline CHEMBL1467236 & 688392 & 4.5 & 4.984 & TRN \\
\hline CHEMBL1421887 & 688392 & 5.5 & 4.8632 & TRN \\
\hline CHEMBL1574206 & 688392 & 4.4 & 4.8802 & TRN \\
\hline CHEMBL1439735 & 688392 & 4.95 & 5.6013 & TRN \\
\hline CHEMBL549640 & 688392 & 4.35 & 5.0873 & TRN \\
\hline CHEMBL1349987 & 688392 & 4.7 & 5.1662 & TRN \\
\hline CHEMBL1390521 & 688392 & 5.4 & 6.2489 & TRN \\
\hline CHEMBL1415426 & 688392 & 4.95 & 5.0339 & TRN \\
\hline CHEMBL1604189 & 688392 & 4.8 & 5.4519 & TRN \\
\hline CHEMBL1536896 & 688392 & 5.65 & 5.3754 & TRN \\
\hline CHEMBL1420111 & 688392 & 4.85 & 5.2021 & TRN \\
\hline CHEMBL 3856144 & 688392 & 5.15 & 5.1487 & TRN \\
\hline CHEMBL1320799 & 688392 & 4.65 & 5.8675 & TRN \\
\hline CHEMBL1496441 & 688392 & 5.05 & 5.023 & TRN \\
\hline CHEMBL1325233 & 688392 & 5.25 & 5.2127 & TRN \\
\hline CHEMBL1349382 & 688392 & 4.55 & 4.874 & TRN \\
\hline CHEMBL1481077 & 688392 & 4.95 & 4.9751 & TRN \\
\hline CHEMBL1377466 & 688392 & 4.85 & 5.0312 & TRN \\
\hline CHEMBL1461843 & 688392 & 4.65 & 4.9842 & TRN \\
\hline CHEMBL1418885 & 688392 & 5.85 & 5.4213 & TRN \\
\hline CHEMBL1424381 & 688392 & 4.4 & 5.1635 & TRN \\
\hline CHEMBL1546656 & 688392 & 4.9 & 4.914 & TRN \\
\hline CHEMBL1331605 & 688392 & 4.8 & 5.7942 & TRN \\
\hline CHEMBL1458130 & 688392 & 4.4 & 5.0126 & TRN \\
\hline CHEMBL1565114 & 688392 & 3.85 & 4.9857 & TRN \\
\hline CHEMBL1311175 & 688392 & 4.9 & 5.2637 & TST \\
\hline CHEMBL1586308 & 688392 & 5.25 & 5.4214 & TRN \\
\hline CHEMBL1560833 & 688392 & 4.4 & 5.0473 & TRN \\
\hline CHEMBL1370873 & 688392 & 5.05 & 5.0612 & TRN \\
\hline CHEMBL1386550 & 688392 & 10.15 & 5.4181 & TST \\
\hline
\end{tabular}




\begin{tabular}{|c|c|c|c|c|}
\hline \multicolumn{5}{|c|}{ Supplemental Table S2.txt } \\
\hline CHEMBL1547238 & 688392 & 5.2 & 5.2271 & TRN \\
\hline CHEMBL1471865 & 688392 & 4.4 & 5.1132 & TRN \\
\hline CHEMBL1346172 & 688392 & 5.05 & 5.4231 & TRN \\
\hline CHEMBL1528814 & 688392 & 4.8 & 5.0926 & TST \\
\hline CHEMBL1547684 & 688392 & 5.65 & 5.2533 & TRN \\
\hline CHEMBL1539325 & 688392 & 5.9 & 5.1979 & TST \\
\hline CHEMBL1509676 & 688392 & 5.3 & 5.1932 & TRN \\
\hline CHEMBL1581251 & 688392 & 5.45 & 5.0099 & TRN \\
\hline CHEMBL1584828 & 688392 & 4.9 & 5.1811 & TRN \\
\hline CHEMBL1597993 & 688392 & 4.7 & 5.24 & TST \\
\hline CHEMBL 3145010 & 688392 & 8.1024 & 5.2743 & TRN \\
\hline CHEMBL408994 & 688392 & 4.85 & 4.8922 & TRN \\
\hline CHEMBL1462701 & 688392 & 4.8 & 4.773 & TRN \\
\hline CHEMBL1308104 & 688392 & 4.05 & 5.0773 & TRN \\
\hline CHEMBL1375018 & 688392 & 5.05 & 5.3219 & TST \\
\hline CHEMBL1373583 & 688392 & 5.6 & 4.9305 & TRN \\
\hline CHEMBL1537012 & 688392 & 5.35 & 5.3993 & TRN \\
\hline CHEMBL1578798 & 688392 & 9.699 & 5.2181 & TRN \\
\hline CHEMBL1447002 & 688392 & 5.05 & 5.1208 & TRN \\
\hline CHEMBL1561759 & 688392 & 5.0 & 5.0904 & TRN \\
\hline CHEMBL1341255 & 688392 & 4.9 & 5.1509 & TST \\
\hline CHEMBL1416177 & 688392 & 6.05 & 5.1485 & TRN \\
\hline CHEMBL163316 & 688392 & 5.0 & 5.5053 & TRN \\
\hline CHEMBL1991573 & 688392 & 5.3 & 4.9799 & TRN \\
\hline CHEMBL164 & 688392 & 5.15 & 6.1165 & TRN \\
\hline CHEMBL1479248 & 688392 & 4.85 & 5.1 & TRN \\
\hline CHEMBL3198983 & 688392 & 4.35 & 5.1502 & TRN \\
\hline CHEMBL1315920 & 688392 & 4.55 & 4.8755 & TRN \\
\hline CHEMBL1305336 & 688392 & 4.95 & 5.2616 & TRN \\
\hline CHEMBL1566165 & 688392 & 5.4 & 5.0186 & TRN \\
\hline CHEMBL1449644 & 688392 & 4.6 & 4.8072 & TRN \\
\hline CHEMBL1403497 & 688392 & 5.25 & 5.0351 & TRN \\
\hline CHEMBL1605033 & 688392 & 4.95 & 5.1548 & TRN \\
\hline CHEMBL3195145 & 688392 & 4.85 & 5.4431 & TRN \\
\hline CHEMBL1390703 & 688392 & 4.4 & 4.9308 & TRN \\
\hline CHEMBL269733 & 688392 & 4.6 & 5.5583 & TRN \\
\hline CHEMBL1362244 & 688392 & 4.85 & 5.0892 & TRN \\
\hline CHEMBL1401747 & 688392 & 5.35 & 5.1262 & TRN \\
\hline CHEMBL3189657 & 688392 & 6.4 & 5.8937 & TRN \\
\hline CHEMBL1985165 & 688392 & 5.95 & 5.1481 & TRN \\
\hline CHEMBL1556215 & 688392 & 5.4 & 4.9335 & TRN \\
\hline CHEMBL1323312 & 688392 & 6.5 & 5.1003 & TRN \\
\hline CHEMBL366861 & 688392 & 4.95 & 5.5265 & TST \\
\hline CHEMBL1344064 & 688392 & 10.6003 & 5.3398 & TRN \\
\hline CHEMBL490355 & 688392 & 4.8 & 5.5618 & TRN \\
\hline CHEMBL1441170 & 688392 & 8.2007 & 5.3713 & TST \\
\hline CHEMBL3351065 & 688392 & 4.65 & 5.3491 & TRN \\
\hline CHEMBL1409844 & 688392 & 8.4559 & 5.3375 & TST \\
\hline
\end{tabular}




\begin{tabular}{|c|c|c|c|c|}
\hline \multicolumn{5}{|c|}{ Supplemental Table s2.txt } \\
\hline CHEMBL1556914 & 688392 & 5.15 & 5.8031 & TRN \\
\hline CHEMBL1323786 & 688392 & 8.9586 & 5.2245 & TRN \\
\hline CHEMBL1353907 & 688392 & 4.95 & 5.2034 & TRN \\
\hline CHEMBL1583598 & 688392 & 4.9 & 4.9185 & TRN \\
\hline CHEMBL1437244 & 688392 & 4.55 & 5.3146 & TRN \\
\hline CHEMBL1548422 & 688392 & 4.4 & 4.988 & TRN \\
\hline CHEMBL1560128 & 688392 & 5.75 & 4.9355 & TRN \\
\hline CHEMBL1484059 & 688392 & 4.8 & 5.1008 & TRN \\
\hline CHEMBL1426947 & 688392 & 5.4 & 4.9444 & TRN \\
\hline CHEMBL1376492 & 688392 & 6.35 & 5.0618 & TRN \\
\hline CHEMBL1453944 & 688392 & 5.5 & 5.3123 & TST \\
\hline CHEMBL1560258 & 688392 & 5.0 & 4.9962 & TRN \\
\hline CHEMBL1407641 & 688392 & 4.4 & 4.9387 & TRN \\
\hline CHEMBL1979383 & 688392 & 4.85 & 5.3943 & TRN \\
\hline CHEMBL1350960 & 688392 & 4.8 & 5.0119 & TRN \\
\hline CHEMBL1348008 & 688392 & 5.5 & 5.0027 & TRN \\
\hline CHEMBL66966 & 688392 & 6.2 & 5.5143 & TRN \\
\hline CHEMBL1554567 & 688392 & 4.8 & 5.056 & TRN \\
\hline CHEMBL1325176 & 688392 & 4.6 & 5.0094 & TRN \\
\hline CHEMBL1305050 & 688392 & 5.35 & 4.8001 & TRN \\
\hline CHEMBL1412968 & 688392 & 4.3 & 5.4161 & TRN \\
\hline CHEMBL1332402 & 688392 & 5.15 & 4.8424 & TRN \\
\hline CHEMBL1492385 & 688392 & 4.5 & 5.1848 & TRN \\
\hline CHEMBL1305391 & 688392 & 4.9 & 5.0938 & TRN \\
\hline CHEMBL1426749 & 688392 & 5.1 & 5.0915 & TRN \\
\hline CHEMBL1540526 & 688392 & 4.4 & 5.1328 & TRN \\
\hline CHEMBL1495997 & 688392 & 6.1 & 5.23600 & 0000000001 \\
\hline CHEMBL1603005 & 688392 & 5.45 & 5.0865 & TRN \\
\hline CHEMBL1469647 & 688392 & 4.85 & 5.1277 & TRN \\
\hline CHEMBL3191780 & 688392 & 4.85 & 5.9187 & TRN \\
\hline CHEMBL1984240 & 688392 & 5.35 & 5.7509 & TRN \\
\hline CHEMBL1544326 & 688392 & 5.0 & 4.8587 & TRN \\
\hline CHEMBL1347789 & 688392 & 5.3 & 5.2441 & TRN \\
\hline CHEMBL 253570 & 688392 & 6.3 & 5.9173 & TRN \\
\hline CHEMBL1486585 & 688392 & 4.8 & 5.0279 & TRN \\
\hline CHEMBL449392 & 688392 & 7.3002 & 6.041 & TRN \\
\hline CHEMBL1391256 & 688392 & 5.4 & 5.1636 & TRN \\
\hline CHEMBL66953 & 688392 & 6.35 & 5.9737 & TRN \\
\hline CHEMBL1561729 & 688392 & 5.4 & 4.8761 & TRN \\
\hline CHEMBL1376870 & 688392 & 4.85 & 5.2382 & TST \\
\hline CHEMBL1380191 & 688392 & 4.4 & 4.9644 & TRN \\
\hline CHEMBL1980844 & 688392 & 4.9 & 5.1508 & TRN \\
\hline CHEMBL1591107 & 688392 & 4.8 & 4.9188 & TRN \\
\hline CHEMBL416657 & 688392 & 4.55 & 5.6623 & TST \\
\hline CHEMBL1975615 & 688392 & 5.1 & 5.8031 & TRN \\
\hline CHEMBL1575701 & 688392 & 4.55 & 5.4468 & TST \\
\hline CHEMBL1303641 & 688392 & 4.85 & 4.9677 & TRN \\
\hline CHEMBL1330039 & 688392 & 4.85 & 5.2559 & TST \\
\hline
\end{tabular}




\begin{tabular}{|c|c|c|c|c|}
\hline \multicolumn{5}{|c|}{ Supplemental Table S2.txt } \\
\hline CHEMBL 3191714 & 688392 & 7.0 & 6.6896 & TRN \\
\hline CHEMBL1532387 & 688392 & 5.25 & 5.0923 & TRN \\
\hline CHEMBL1520373 & 688392 & 5.25 & 5.2009 & TRN \\
\hline CHEMBL1322274 & 688392 & 7.2 & 4.933 & TRN \\
\hline CHEMBL1471220 & 688392 & 5.0 & 5.0704 & TRN \\
\hline CHEMBL 290914 & 688392 & 4.85 & 5.4261 & TRN \\
\hline CHEMBL1345825 & 688392 & 4.9 & 4.8721 & TRN \\
\hline CHEMBL1359806 & 688392 & 5.05 & 5.371 & TST \\
\hline CHEMBL 280563 & 688392 & 5.6 & 5.3164 & TST \\
\hline CHEMBL1993746 & 688392 & 5.3 & 5.7121 & TRN \\
\hline CHEMBL80941 & 688392 & 5.6 & 5.5269 & TRN \\
\hline CHEMBL1462814 & 688392 & 5.4 & 5.0939 & TST \\
\hline CHEMBL3208708 & 688392 & 5.8 & 5.5 & TRN \\
\hline CHEMBL1410367 & 688392 & 8.7447 & 5.0671 & TRN \\
\hline CHEMBL1567670 & 688392 & 4.55 & 5.1635 & TRN \\
\hline CHEMBL43612 & 688392 & 5.0 & 5.3883 & TRN \\
\hline CHEMBL1504887 & 688392 & 4.75 & 4.9487 & TRN \\
\hline CHEMBL1553873 & 688392 & 6.5501 & 5.4623 & TRN \\
\hline CHEMBL1570267 & 688392 & 4.9 & 5.3335 & TST \\
\hline CHEMBL3195717 & 688392 & 5.1 & 5.114 & TRN \\
\hline CHEMBL1586269 & 688392 & 4.8 & 5.1261 & TRN \\
\hline CHEMBL1347598 & 688392 & 4.95 & 5.2165 & TRN \\
\hline CHEMBL1524521 & 688392 & 4.85 & 5.0127 & TRN \\
\hline CHEMBL1501635 & 688392 & 4.45 & 5.2228 & TST \\
\hline CHEMBL1596882 & 688392 & 4.35 & 5.1466 & TRN \\
\hline CHEMBL 216504 & 688392 & 5.45 & 5.1425 & TRN \\
\hline CHEMBL1385660 & 688392 & 4.4 & 5.13200 & 0000000001 \\
\hline CHEMBL1310309 & 688392 & 5.25 & 5.2306 & TRN \\
\hline CHEMBL3196993 & 688392 & 7.4498 & 6.0936 & TRN \\
\hline CHEMBL1368261 & 688392 & 6.0 & 5.6187 & TRN \\
\hline CHEMBL1548834 & 688392 & 4.85 & 4.9925 & TRN \\
\hline CHEMBL165064 & 688392 & 5.55 & 5.4189 & TRN \\
\hline CHEMBL1383473 & 688392 & 5.35 & 5.0796 & TRN \\
\hline CHEMBL1364100 & 688392 & 6.0 & 5.1398 & TRN \\
\hline CHEMBL1492565 & 688392 & 4.4 & 5.0138 & TRN \\
\hline CHEMBL1560136 & 688392 & 6.15 & 4.9649 & TST \\
\hline CHEMBL234338 & 688392 & 6.3 & 5.4548 & TRN \\
\hline CHEMBL1440119 & 688392 & 5.95 & 5.2038 & TRN \\
\hline CHEMBL1325832 & 688392 & 4.6 & 5.2853 & TST \\
\hline CHEMBL1450864 & 688392 & 5.5 & 5.016 & TRN \\
\hline CHEMBL1400620 & 688392 & 5.65 & 4.9535 & TRN \\
\hline CHEMBL1976499 & 688392 & 5.1 & 5.0556 & TRN \\
\hline CHEMBL1366408 & 688392 & 5.5 & 5.5981 & TRN \\
\hline CHEMBL29898 & 688392 & 5.4 & 5.728 & TRN \\
\hline CHEMBL578585 & 688392 & 5.1 & 5.1046 & TRN \\
\hline CHEMBL1368444 & 688392 & 4.8 & 5.2968 & TRN \\
\hline CHEMBL1443822 & 688392 & 4.9 & 5.0189 & TRN \\
\hline CHEMBL1307297 & 688392 & 7.2 & 5.19 & TRN \\
\hline
\end{tabular}




\begin{tabular}{|c|c|c|c|c|c|}
\hline \multicolumn{6}{|c|}{ Supplemental Table S2.txt } \\
\hline CHEMBL1327418 & 688392 & 4.9 & 4.832 & TRN & \\
\hline CHEMBL450948 & 688392 & 4.8 & 5.15799 & 99999999995 & TRN \\
\hline CHEMBL1392921 & 688392 & 4.85 & 5.1133 & TRN & \\
\hline CHEMBL 255881 & 688392 & 6.05 & 5.0219 & TRN & \\
\hline CHEMBL1386676 & 688392 & 6.15 & 4.957 & TRN & \\
\hline CHEMBL1583534 & 688392 & 5.1 & 5.0537 & TST & \\
\hline CHEMBL1452684 & 688392 & 5.55 & 4.8103 & TRN & \\
\hline CHEMBL1430175 & 688392 & 4.9 & 4.9017 & TRN & \\
\hline CHEMBL1310171 & 688392 & 5.5 & 5.0037 & TRN & \\
\hline CHEMBL1517799 & 688392 & 4.4 & 5.0253 & TST & \\
\hline CHEMBL1611199 & 688392 & 4.4 & 4.816 & TRN & \\
\hline CHEMBL1344790 & 688392 & 4.9 & 5.284 & TST & \\
\hline CHEMBL1419637 & 688392 & 6.8499 & 5.4787 & TRN & \\
\hline CHEMBL109037 & 688392 & 6.1 & 5.7155 & TRN & \\
\hline CHEMBL592184 & 688392 & 5.25 & 5.1045 & TRN & \\
\hline CHEMBL1346592 & 688392 & 4.55 & 4.9143 & TRN & \\
\hline CHEMBL1417159 & 688392 & 5.9 & 5.1712 & TST & \\
\hline CHEMBL1512440 & 688392 & 5.6 & 5.9492 & TRN & \\
\hline CHEMBL1323320 & 688392 & 4.85 & 4.9951 & TRN & \\
\hline CHEMBL1413586 & 688392 & 5.0 & 5.4869 & TRN & \\
\hline CHEMBL1431206 & 688392 & 4.4 & 5.0885 & TRN & \\
\hline CHEMBL1500840 & 688392 & 5.25 & 5.1528 & TRN & \\
\hline CHEMBL1310907 & 688392 & 4.95 & 4.9948 & TRN & \\
\hline CHEMBL3198135 & 688392 & 4.4 & 5.4195 & TRN & \\
\hline CHEMBL1522300 & 688392 & 4.55 & 4.9032 & TRN & \\
\hline CHEMBL1398855 & 688392 & 4.55 & 5.2415 & TRN & \\
\hline CHEMBL546257 & 688392 & 4.8 & 5.41799 & 9999999999 & TRN \\
\hline CHEMBL1331939 & 688392 & 7.3002 & 5.0698 & TST & \\
\hline CHEMBL1349475 & 688392 & 5.35 & 5.0696 & TRN & \\
\hline CHEMBL1506123 & 688392 & 5.1 & 5.09699 & 99999999995 & TRN \\
\hline CHEMBL1385364 & 688392 & 6.05 & 5.6155 & TST & \\
\hline CHEMBL1565040 & 688392 & 4.4 & 4.9838 & TRN & \\
\hline CHEMBL1443157 & 688392 & 5.85 & 5.5075 & TST & \\
\hline CHEMBL1547311 & 688392 & 4.55 & 5.6939 & TRN & \\
\hline CHEMBL1549120 & 688392 & 4.55 & 5.0907 & TRN & \\
\hline CHEMBL1530127 & 688392 & 4.4 & 5.0865 & TRN & \\
\hline CHEMBL1594861 & 688392 & 4.9 & 5.0468 & TRN & \\
\hline CHEMBL256097 & 688392 & 5.85 & 4.9233 & TRN & \\
\hline CHEMBL1611306 & 688392 & 8.6021 & 5.1554 & TST & \\
\hline CHEMBL1340216 & 688392 & 4.85 & 5.1846 & TRN & \\
\hline CHEMBL1340565 & 688392 & 4.8 & 4.956 & TRN & \\
\hline CHEMBL1369820 & 688392 & 5.0 & 5.0122 & TRN & \\
\hline CHEMBL1478395 & 688392 & 4.85 & 5.21299 & 9999999999 & TST \\
\hline CHEMBL1426096 & 688392 & 4.35 & 5.0382 & TRN & \\
\hline CHEMBL1305518 & 688392 & 6.4 & 5.1588 & TRN & \\
\hline CHEMBL1304495 & 688392 & 5.3 & 5.2465 & TRN & \\
\hline CHEMBL1987791 & 688392 & 4.75 & 5.4836 & TRN & \\
\hline CHEMBL1413473 & 688392 & 5.85 & 5.078 & TST & \\
\hline
\end{tabular}




\begin{tabular}{|c|c|c|c|c|c|}
\hline & & & & & \\
\hline CHEMBL1560245 & 688392 & 6.4 & 5.0931 & TRN & \\
\hline CHEMBL1730100 & 688392 & 5.85 & 5.61600 & 00000000005 & TST \\
\hline CHEMBL1353227 & 688392 & 4.95 & 5.0215 & TRN & \\
\hline CHEMBL1425998 & 688392 & 4.85 & 5.1247 & TRN & \\
\hline CHEMBL1602644 & 688392 & 4.4 & 5.0809 & TRN & \\
\hline CHEMBL1381306 & 688392 & 5.3 & 5.1146 & TRN & \\
\hline CHEMBL1422657 & 688392 & 5.1 & 4.9829 & TRN & \\
\hline CHEMBL1257080 & 688392 & 4.85 & 5.5289 & TRN & \\
\hline CHEMBL1348074 & 688392 & 4.6 & 5.2211 & TST & \\
\hline CHEMBL1325390 & 688392 & 6.7501 & 5.976 & TRN & \\
\hline CHEMBL1311678 & 688392 & 5.25 & 4.9418 & TRN & \\
\hline CHEMBL1587260 & 688392 & 4.75 & 4.9681 & TRN & \\
\hline CHEMBL1488814 & 688392 & 5.55 & 5.249 & TRN & \\
\hline CHEMBL1404913 & 688392 & 4.4 & 4.8423 & TRN & \\
\hline CHEMBL1427289 & 688392 & 4.6 & 5.2081 & TRN & \\
\hline CHEMBL1525853 & 688392 & 4.4 & 4.9847 & TRN & \\
\hline CHEMBL1374242 & 688392 & 5.5 & 5.2697 & TRN & \\
\hline CHEMBL1474281 & 688392 & 4.8 & 4.9989 & TRN & \\
\hline CHEMBL263972 & 688392 & 5.35 & 5.1333 & TRN & \\
\hline CHEMBL3197141 & 688392 & 8.699 & 6.1656 & TRN & \\
\hline CHEMBL1567471 & 688392 & 3.85 & 5.0838 & TRN & \\
\hline CHEMBL1460721 & 688392 & 5.5 & 4.9348 & TRN & \\
\hline CHEMBL1370610 & 688392 & 5.0 & 5.1784 & TRN & \\
\hline CHEMBL1322068 & 688392 & 4.75 & 5.1612 & TRN & \\
\hline CHEMBL1576814 & 688392 & 7.8013 & 5.24799 & 9999999999 & TRN \\
\hline CHEMBL484640 & 688392 & 5.35 & 5.6017 & TRN & \\
\hline CHEMBL1346055 & 688392 & 4.9 & 4.9448 & TRN & \\
\hline CHEMBL1437075 & 688392 & 5.1 & 5.2785 & TRN & \\
\hline CHEMBL1464373 & 688392 & 5.0 & 4.9493 & TRN & \\
\hline CHEMBL1323674 & 688392 & 5.0 & 5.0499 & TRN & \\
\hline CHEMBL102714 & 688392 & 4.6 & 5.1816 & TST & \\
\hline CHEMBL 212414 & 688392 & 4.85 & 4.8664 & TRN & \\
\hline CHEMBL1517266 & 688392 & 4.85 & 4.7952 & TRN & \\
\hline CHEMBL1491700 & 688392 & 4.9 & 5.0264 & TRN & \\
\hline CHEMBL1492926 & 688392 & 4.9 & 4.9621 & TRN & \\
\hline CHEMBL1548374 & 688392 & 4.95 & 5.046 & TRN & \\
\hline CHEMBL1601846 & 688392 & 6.9 & 6.2896 & TRN & \\
\hline CHEMBL1538023 & 688392 & 8.0 & 5.0682 & TRN & \\
\hline CHEMBL1612018 & 688392 & 4.1 & 5.0532 & TRN & \\
\hline CHEMBL1324556 & 688392 & 4.85 & 5.2756 & TRN & \\
\hline CHEMBL1311273 & 688392 & 4.9 & 4.926 & TRN & \\
\hline CHEMBL1564810 & 688392 & 5.35 & 4.8869 & TRN & \\
\hline CHEMBL1447211 & 688392 & 4.85 & 5.0294 & TRN & \\
\hline CHEMBL23507 & 688392 & 6.8499 & 5.1335 & TST & \\
\hline CHEMBL1530824 & 688392 & 4.85 & 5.0909 & TRN & \\
\hline CHEMBL1334484 & 688392 & 4.4 & 5.3501 & TRN & \\
\hline CHEMBL3199590 & 688392 & 4.9 & 5.0552 & TRN & \\
\hline CHEMBL1578235 & 688392 & 4.55 & 5.4324 & TRN & \\
\hline
\end{tabular}




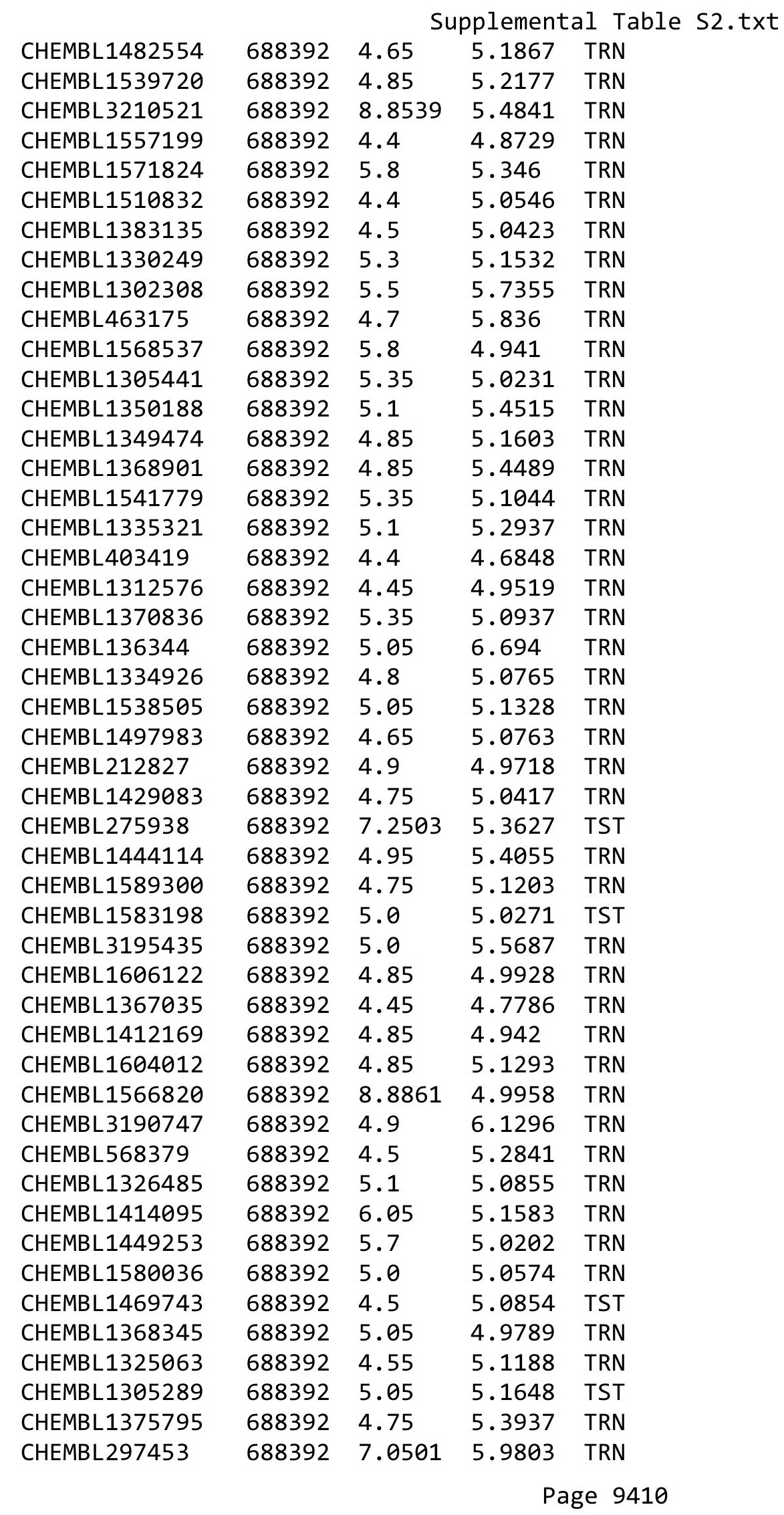




\begin{tabular}{|c|c|c|c|c|c|}
\hline & & \multicolumn{4}{|c|}{ Supplemental Table S2.txt } \\
\hline CHEMBL1348397 & 688392 & 4.95 & 5.3659 & TST & \\
\hline CHEMBL1985664 & 688392 & 5.9 & 5.9331 & TRN & \\
\hline CHEMBL487203 & 688392 & 6.35 & 5.82600 & $\partial 0000000005$ & TRN \\
\hline CHEMBL1535285 & 688392 & 4.65 & 5.2084 & TRN & \\
\hline CHEMBL1606497 & 688392 & 4.75 & 5.183 & TRN & \\
\hline CHEMBL1366048 & 688392 & 5.0 & 5.0214 & TRN & \\
\hline CHEMBL59451 & 688392 & 6.5 & 6.0754 & TRN & \\
\hline CHEMBL1526624 & 688392 & 6.0 & 5.3953 & TRN & \\
\hline CHEMBL1583031 & 688392 & 5.2 & 5.3086 & TST & \\
\hline CHEMBL1552172 & 688392 & 4.5 & 4.9939 & TRN & \\
\hline CHEMBL1459809 & 688392 & 4.9 & 5.14 & TRN & \\
\hline CHEMBL1492995 & 688392 & 5.1 & 4.9281 & TRN & \\
\hline CHEMBL1516565 & 688392 & 5.2 & 5.0623 & TRN & \\
\hline CHEMBL192600 & 688392 & 4.8 & 4.9218 & TRN & \\
\hline CHEMBL1372387 & 688392 & 5.4 & 5.4355 & TRN & \\
\hline CHEMBL1523483 & 688392 & 4.4 & 4.8719 & TRN & \\
\hline CHEMBL1569232 & 688392 & 4.85 & 5.0554 & TRN & \\
\hline CHEMBL123 & 688392 & 5.1 & 5.2418 & TST & \\
\hline CHEMBL1305100 & 688392 & 4.5 & 5.2785 & TRN & \\
\hline CHEMBL 278489 & 688392 & 4.5 & 5.131 & TRN & \\
\hline CHEMBL1336119 & 688392 & 4.9 & 5.0281 & TRN & \\
\hline CHEMBL1490919 & 688392 & 5.95 & 5.6986 & TRN & \\
\hline CHEMBL1404357 & 688392 & 7.5498 & 5.3366 & TST & \\
\hline CHEMBL1256390 & 688392 & 4.55 & 5.1056 & TRN & \\
\hline CHEMBL1414236 & 688392 & 5.65 & 5.334 & TRN & \\
\hline CHEMBL1468796 & 688392 & 4.75 & 5.5917 & TRN & \\
\hline CHEMBL1377441 & 688392 & 4.8 & 5.2431 & TRN & \\
\hline CHEMBL1501526 & 688392 & 5.15 & 5.2062 & TRN & \\
\hline CHEMBL1532515 & 688392 & 5.0 & 5.1428 & TRN & \\
\hline CHEMBL1357894 & 688392 & 4.4 & 5.2922 & TST & \\
\hline CHEMBL1371869 & 688392 & 5.05 & 4.9097 & TRN & \\
\hline CHEMBL1569742 & 688392 & 4.85 & 4.8405 & TRN & \\
\hline CHEMBL1994685 & 688392 & 8.3468 & 5.7758 & TRN & \\
\hline CHEMBL1443059 & 688392 & 4.1 & 5.0325 & TRN & \\
\hline CHEMBL1321148 & 688392 & 8.5528 & 5.0779 & TRN & \\
\hline CHEMBL1257003 & 688392 & 4.55 & 5.9605 & TRN & \\
\hline CHEMBL1403448 & 688392 & 4.4 & 5.2831 & TST & \\
\hline CHEMBL1997422 & 688392 & 4.9 & 5.1891 & TRN & \\
\hline CHEMBL56393 & 688392 & 6.7001 & 6.0136 & TRN & \\
\hline CHEMBL1307301 & 688392 & 4.5 & 4.9215 & TRN & \\
\hline CHEMBL1467089 & 688392 & 4.4 & 5.0633 & TRN & \\
\hline CHEMBL1351173 & 688392 & 5.45 & 4.9047 & TRN & \\
\hline CHEMBL1302595 & 688392 & 4.9 & 4.9847 & TRN & \\
\hline CHEMBL1451483 & 688392 & 5.9 & 5.9816 & TRN & \\
\hline CHEMBL1979849 & 688392 & 5.7 & 5.857 & TRN & \\
\hline CHEMBL1344422 & 688392 & 4.75 & 5.2217 & TRN & \\
\hline CHEMBL1978364 & 688392 & 4.9 & 5.1713 & TRN & \\
\hline CHEMBL1573700 & 688392 & 4.55 & 5.1685 & TRN & \\
\hline
\end{tabular}




\begin{tabular}{|c|c|c|c|c|c|}
\hline \multicolumn{6}{|c|}{ Supplemental Table S2.txt } \\
\hline CHEMBL1352624 & 688392 & 4.9 & 4.937 & TRN & \\
\hline CHEMBL1402286 & 688392 & 4.9 & 4.725 & TRN & \\
\hline CHEMBL1424412 & 688392 & 4.4 & 5.0093 & TRN & \\
\hline CHEMBL1982202 & 688392 & 4.4 & 5.2619 & TST & \\
\hline CHEMBL1417231 & 688392 & 4.3 & 4.9533 & TRN & \\
\hline CHEMBL1500249 & 688392 & 8.2007 & 6.1645 & TRN & \\
\hline CHEMBL1325440 & 688392 & 4.35 & 4.8587 & TRN & \\
\hline CHEMBL1422601 & 688392 & 5.1 & 4.9145 & TRN & \\
\hline CHEMBL1452185 & 688392 & 4.9 & 5.0785 & TRN & \\
\hline CHEMBL1378478 & 688392 & 4.4 & 5.0611 & TRN & \\
\hline CHEMBL533293 & 688392 & 5.05 & 5.1504 & TST & \\
\hline CHEMBL1465935 & 688392 & 5.0 & 5.11600 & 00000000005 & TRN \\
\hline CHEMBL1406708 & 688392 & 5.0 & 5.4675 & TST & \\
\hline CHEMBL1586973 & 688392 & 4.8 & 5.1123 & TRN & \\
\hline CHEMBL 256098 & 688392 & 4.9 & 4.9366 & TRN & \\
\hline CHEMBL1509325 & 688392 & 3.1 & 5.1263 & TST & \\
\hline CHEMBL1991599 & 688392 & 4.8 & 5.7998 & TRN & \\
\hline CHEMBL1389163 & 688392 & 5.4 & 5.061 & TRN & \\
\hline CHEMBL1303939 & 688392 & 4.85 & 4.9453 & TRN & \\
\hline CHEMBL1390780 & 688392 & 4.4 & 5.2879 & TRN & \\
\hline CHEMBL1391235 & 688392 & 4.85 & 5.3972 & TRN & \\
\hline CHEMBL1984703 & 688392 & 5.3 & 5.0306 & TRN & \\
\hline CHEMBL1381676 & 688392 & 4.5 & 4.9521 & TRN & \\
\hline CHEMBL1613634 & 688392 & 4.9 & 5.0683 & TRN & \\
\hline CHEMBL1370375 & 688392 & 4.85 & 5.2617 & TRN & \\
\hline CHEMBL1438439 & 688392 & 6.4 & 6.0669 & TRN & \\
\hline CHEMBL1563612 & 688392 & 4.8 & 4.958 & TRN & \\
\hline CHEMBL1546182 & 688392 & 4.85 & 5.0463 & TRN & \\
\hline CHEMBL1477068 & 688392 & 4.8 & 5.0653 & TRN & \\
\hline CHEMBL1528177 & 688392 & 4.85 & 4.8691 & TRN & \\
\hline CHEMBL1427775 & 688392 & 5.9 & 4.7905 & TRN & \\
\hline CHEMBL1546136 & 688392 & 4.65 & 5.0697 & TRN & \\
\hline CHEMBL1580019 & 688392 & 4.8 & 4.9165 & TST & \\
\hline CHEMBL2005497 & 688392 & 5.45 & 5.1629 & TST & \\
\hline CHEMBL 257359 & 688392 & 5.6 & 5.045 & TST & \\
\hline CHEMBL1464457 & 688392 & 4.8 & 4.9686 & TST & \\
\hline CHEMBL3192160 & 688392 & 4.6 & 5.0878 & TST & \\
\hline CHEMBL515252 & 688392 & 5.7 & 5.4653 & TST & \\
\hline CHEMBL1479272 & 688392 & 4.75 & 5.3032 & TST & \\
\hline CHEMBL1509377 & 688392 & 6.45 & 5.1578 & TST & \\
\hline CHEMBL1323965 & 688392 & 4.85 & 5.00899 & 99999999995 & TST \\
\hline CHEMBL1583805 & 688392 & 4.55 & 5.1712 & TST & \\
\hline CHEMBL3190370 & 688392 & 4.35 & 5.1042 & TST & \\
\hline CHEMBL1391063 & 688392 & 8.6576 & 5.9083 & TST & \\
\hline CHEMBL1387357 & 688392 & 4.3 & 4.9259 & TST & \\
\hline CHEMBL1349942 & 688392 & 4.35 & 5.1602 & TST & \\
\hline CHEMBL1362935 & 688392 & 6.15 & 5.3783 & TST & \\
\hline CHEMBL1601394 & 688392 & 4.9 & 5.5968 & TST & \\
\hline
\end{tabular}




\begin{tabular}{|c|c|c|c|c|}
\hline \multicolumn{5}{|c|}{ Supplemental Table S2.txt } \\
\hline CHEMBL1414240 & 688392 & 4.45 & 5.2033 & TST \\
\hline CHEMBL8260 & 688392 & 6.2 & 5.8578 & TST \\
\hline CHEMBL1350028 & 688392 & 5.1 & 5.0541 & TST \\
\hline CHEMBL402053 & 688392 & 4.85 & 5.0021 & TST \\
\hline CHEMBL1593134 & 688392 & 4.9 & 4.9664 & TST \\
\hline CHEMBL1528722 & 688392 & 4.4 & 5.0479 & TST \\
\hline CHEMBL1500600 & 688392 & 5.4 & 5.0336 & TST \\
\hline CHEMBL1485923 & 688392 & 4.9 & 5.131 & TST \\
\hline CHEMBL578741 & 688392 & 4.8 & 5.30399 & 9999999999 \\
\hline CHEMBL1574857 & 688392 & 5.3 & 5.0383 & TST \\
\hline CHEMBL1713905 & 688392 & 4.8 & 5.3677 & TST \\
\hline CHEMBL1481914 & 688392 & 4.9 & 5.0842 & TST \\
\hline CHEMBL1337575 & 688392 & 4.95 & 5.0671 & TST \\
\hline CHEMBL1609454 & 688392 & 5.05 & 4.9733 & TST \\
\hline CHEMBL1525544 & 688392 & 6.7501 & 5.1198 & TST \\
\hline CHEMBL1445030 & 688392 & 4.4 & 4.9338 & TST \\
\hline CHEMBL1564253 & 688392 & 4.8 & 5.2146 & TST \\
\hline CHEMBL1300008 & 688392 & 5.8 & 4.8394 & TST \\
\hline CHEMBL1460436 & 688392 & 4.8 & 5.2169 & TST \\
\hline CHEMBL1561877 & 688392 & 4.4 & 5.0381 & TST \\
\hline CHEMBL1300593 & 688392 & 4.95 & 4.9714 & TST \\
\hline CHEMBL1367154 & 688392 & 5.75 & 5.3185 & TST \\
\hline CHEMBL1459398 & 688392 & 4.4 & 5.0211 & TST \\
\hline CHEMBL1389034 & 688392 & 4.8 & 4.935 & TST \\
\hline CHEMBL1385027 & 688392 & 4.4 & 4.9661 & TST \\
\hline CHEMBL1398604 & 688392 & 5.0 & 5.1523 & TST \\
\hline CHEMBL8320 & 688392 & 5.15 & 5.4097 & TST \\
\hline CHEMBL1565429 & 688392 & 4.5 & 4.9118 & TST \\
\hline CHEMBL1421172 & 688392 & 4.85 & 5.0105 & TST \\
\hline CHEMBL1451059 & 688392 & 8.4559 & 5.8153 & TST \\
\hline CHEMBL172350 & 688392 & 5.2 & 5.5927 & TST \\
\hline CHEMBL1533166 & 688392 & 4.85 & 5.0308 & TST \\
\hline CHEMBL1300484 & 688392 & 4.9 & 4.9296 & TST \\
\hline CHEMBL399043 & 688392 & 5.7 & 5.3802 & TST \\
\hline CHEMBL3193053 & 688392 & 4.8 & 5.8486 & TST \\
\hline CHEMBL1432717 & 688392 & 8.8539 & 5.3386 & TST \\
\hline CHEMBL1302827 & 688392 & 4.8 & 5.1029 & TST \\
\hline CHEMBL 247378 & 688392 & 4.9 & 5.1922 & TST \\
\hline CHEMBL1578456 & 688392 & 5.3 & 5.0511 & TST \\
\hline CHEMBL1613004 & 688392 & 4.9 & 5.6853 & TST \\
\hline CHEMBL1485442 & 688392 & 5.2 & 5.1828 & TST \\
\hline CHEMBL1549418 & 688392 & 4.95 & 5.2011 & TST \\
\hline CHEMBL1558007 & 688392 & 4.45 & 5.1754 & TST \\
\hline CHEMBL1335170 & 688392 & 4.75 & 5.104 & TST \\
\hline CHEMBL1256623 & 688392 & 6.15 & 5.6368 & TST \\
\hline CHEMBL1419228 & 688392 & 5.5 & 5.3791 & TST \\
\hline CHEMBL3199889 & 688392 & 4.95 & 5.157 & TST \\
\hline CHEMBL1346456 & 688392 & 6.2 & 5.6535 & TST \\
\hline
\end{tabular}




\begin{tabular}{|c|c|c|c|c|}
\hline \multicolumn{5}{|c|}{ Supplemental Table S2.txt } \\
\hline CHEMBL1547446 & 688392 & 4.85 & 4.9683 & TST \\
\hline CHEMBL1340051 & 688392 & 5.0 & 4.9921 & TST \\
\hline CHEMBL1416439 & 688392 & 5.45 & 4.9855 & TST \\
\hline CHEMBL145 & 688392 & 4.45 & 5.5517 & TST \\
\hline CHEMBL1318708 & 688392 & 4.9 & 5.7995 & TST \\
\hline CHEMBL1574133 & 688392 & 5.35 & 4.845 & TST \\
\hline CHEMBL1995948 & 688392 & 4.45 & 5.1554 & TST \\
\hline CHEMBL1594591 & 688392 & 4.8 & 5.0238 & TST \\
\hline CHEMBL1728023 & 688392 & 6.05 & 5.6683 & TST \\
\hline CHEMBL307893 & 688392 & 4.8 & 5.5432 & TST \\
\hline CHEMBL1329848 & 688392 & 4.4 & 4.9616 & TST \\
\hline CHEMBL1305422 & 688392 & 8.8861 & 4.9726 & TST \\
\hline CHEMBL1971760 & 688392 & 8.6576 & 5.4268 & TST \\
\hline CHEMBL23930 & 140228 & 4.9626 & 5.3051 & TRN \\
\hline CHEMBL23611 & 140228 & 3.0 & 2.9815 & TRN \\
\hline CHEMBL23081 & 140228 & 3.5229 & 2.4798 & TST \\
\hline CHEMBL23896 & 140228 & 3.0 & 4.173 & TRN \\
\hline CHEMBL22813 & 140228 & 3.5229 & 2.8607 & TRN \\
\hline CHEMBL23134 & 140228 & 5.0 & 4.2374 & TRN \\
\hline CHEMBL280891 & 140228 & 3.0 & 2.7656 & TRN \\
\hline CHEMBL 25875 & 140228 & 5.4145 & 5.3896 & TRN \\
\hline CHEMBL23637 & 140228 & 4.9431 & 4.7304 & TRN \\
\hline CHEMBL23961 & 140228 & 3.0 & 2.9852 & TRN \\
\hline CHEMBL24490 & 140228 & 3.0 & 2.9622 & TRN \\
\hline CHEMBL23754 & 140228 & 4.6055 & 4.0903 & TRN \\
\hline CHEMBL 278390 & 140228 & 3.0 & 3.0992 & TRN \\
\hline CHEMBL 283379 & 140228 & 4.8508 & 5.3416 & TRN \\
\hline CHEMBL23328 & 140228 & 3.0 & 2.8122 & TRN \\
\hline CHEMBL288092 & 140228 & 3.5229 & 4.1434 & TRN \\
\hline CHEMBL23906 & 140228 & 3.0 & 3.7537 & TRN \\
\hline CHEMBL25599 & 140228 & 3.0 & 3.0263 & TST \\
\hline CHEMBL23399 & 140228 & 3.5229 & 3.9291 & TRN \\
\hline CHEMBL 278800 & 140228 & 5.1675 & 5.4822 & TRN \\
\hline CHEMBL23396 & 140228 & 4.8794 & 5.0092 & TRN \\
\hline CHEMBL286782 & 140228 & 6.0362 & 5.8329 & TRN \\
\hline CHEMBL24207 & 140228 & 5.0835 & 5.0392 & TRN \\
\hline CHEMBL 286530 & 140228 & 4.5287 & 4.0524 & TRN \\
\hline CHEMBL277479 & 140228 & 6.2007 & 5.9601 & TRN \\
\hline CHEMBL22299 & 140228 & 3.0 & 3.0774 & TRN \\
\hline CHEMBL286375 & 140228 & 4.9872 & 5.0912 & TRN \\
\hline CHEMBL415462 & 140228 & 5.8069 & 5.8588 & TRN \\
\hline CHEMBL 24658 & 140228 & 3.0 & 3.4662 & TRN \\
\hline CHEMBL23507 & 140228 & 4.041 & 3.9838 & TRN \\
\hline CHEMBL23255 & 140228 & 5.7932 & 5.5292 & TRN \\
\hline CHEMBL282875 & 140228 & 3.5229 & 3.8971 & TRN \\
\hline CHEMBL 279300 & 140228 & 3.5229 & 3.3359 & TRN \\
\hline CHEMBL24438 & 140228 & 3.0 & 3.0458 & TRN \\
\hline CHEMBL277411 & 140228 & 6.1675 & 5.3159 & TRN \\
\hline
\end{tabular}




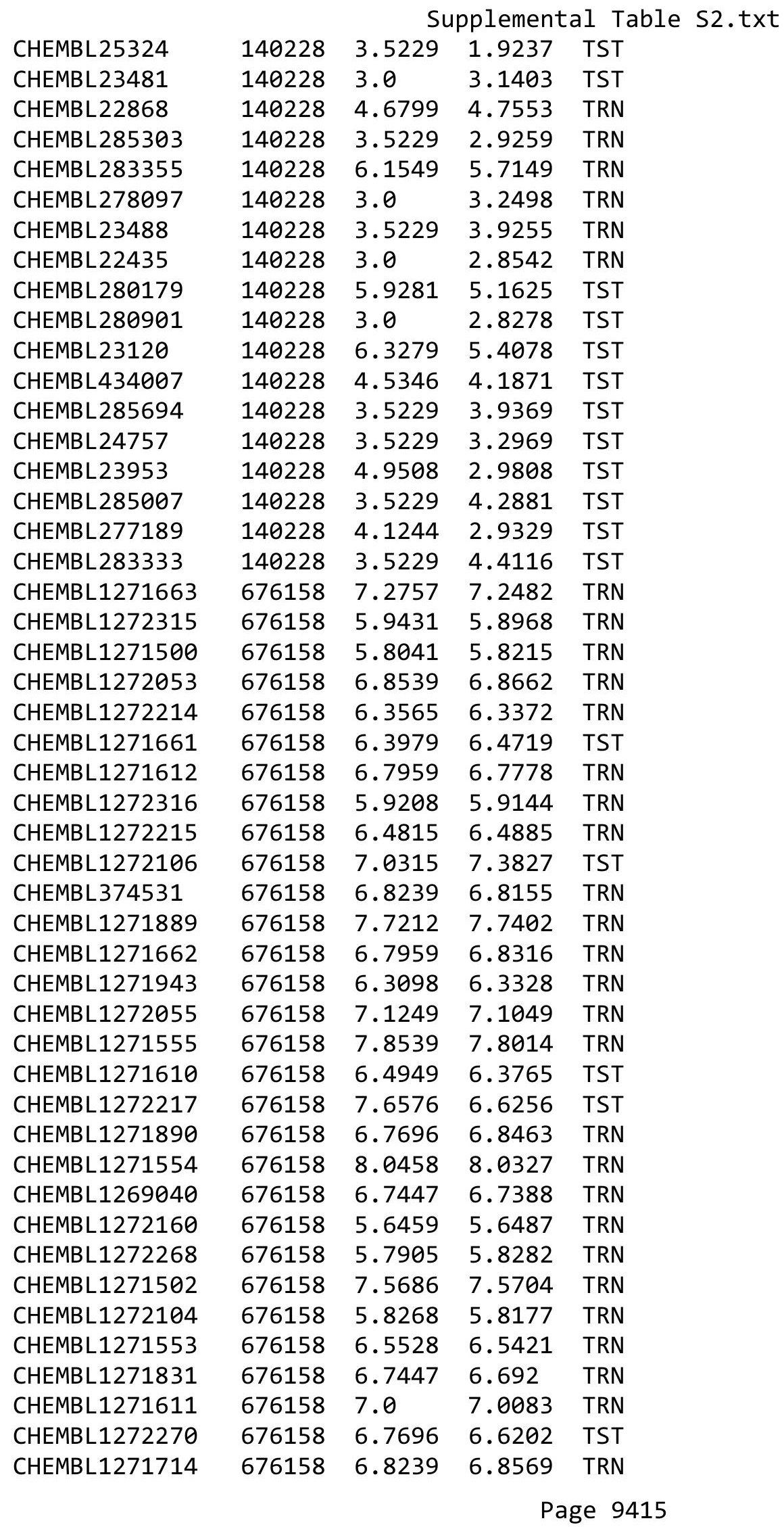




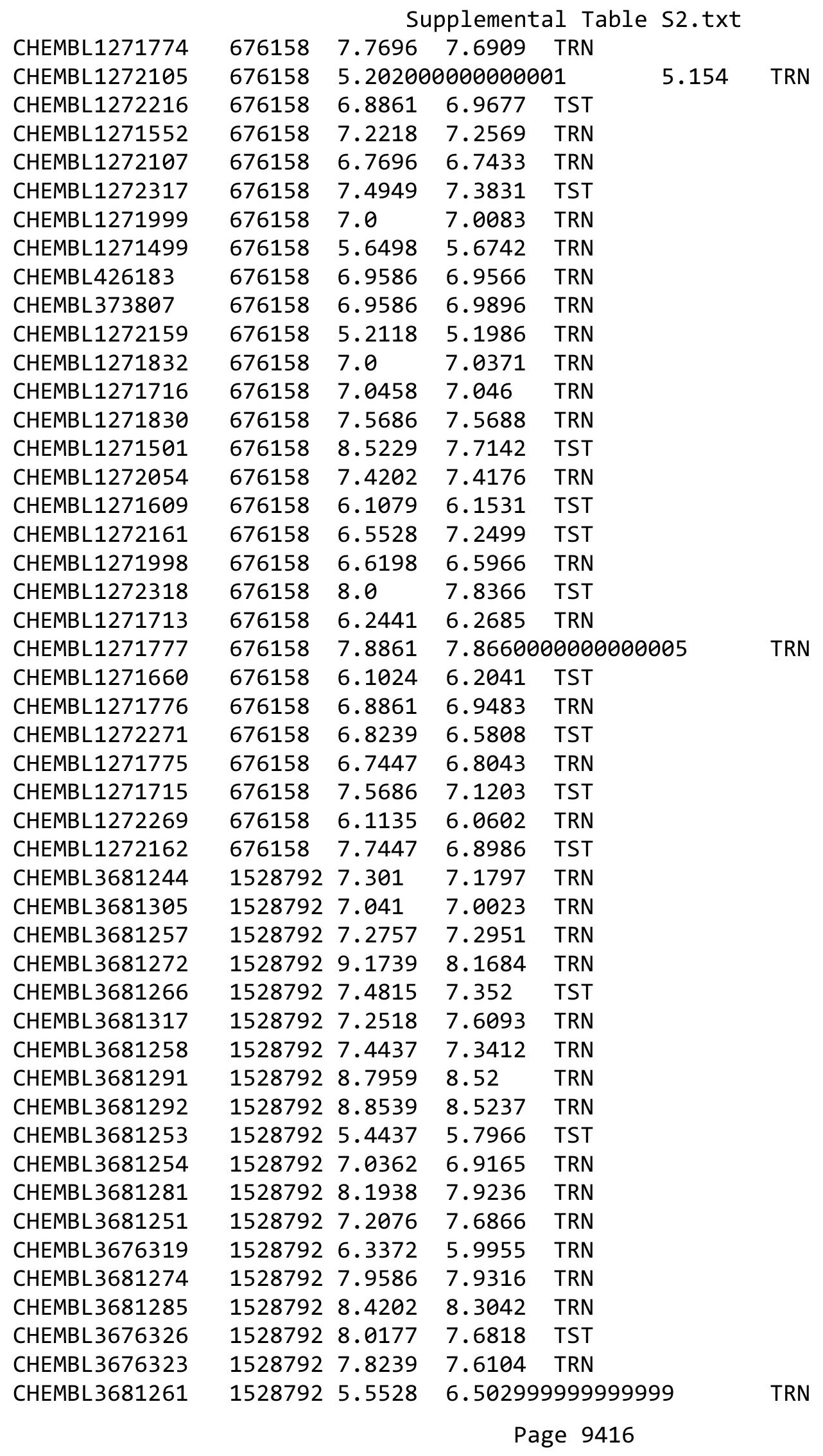


Supplemental Table S2.txt

\begin{tabular}{|c|c|c|c|c|}
\hline IEN & 792 & 6 & 99 & \\
\hline HEMBL3681296 & 528792 & 7.3979 & 7.7117 & \\
\hline$A F M B$ & 28792 & & 0979 & \\
\hline HEMBL3 & 528792 & 4949 & 2845 & \\
\hline HEMBL3676315 & 528792 & 8.5686 & 7481 & \\
\hline AEMBL3681262 & 528792 & 7.1249 & .0671 & \\
\hline AEMBL3681260 & 528792 & 6.6778 & 7975 & \\
\hline AEMBL 36 & 792 & 7.4559 & 1894 & \\
\hline AEMBL3676313 & 792 & 8.2757 & 8.4876 & \\
\hline HEMBL3681246 & 528792 & 7.7447 & .8958 & \\
\hline HEMBL3676324 & 528792 & 8.0 & .0691 & \\
\hline AEMBL3681315 & 528792 & 7.6778 & 8527 & \\
\hline AEMBL36 & & & 6653 & \\
\hline HEMBL3676321 & 792 & 7.0044 & 7.3158 & \\
\hline HEMBL3681286 & 792 & 7.6198 & 7815 & \\
\hline HEMBL3681310 & 92 & 7.4202 & 7.3082 & \\
\hline AEMBL36 & 92 & 915 & 3728 & \\
\hline AEMBL36 & 792 & 99 & 3817 & \\
\hline AEMBL3681306 & 792 & 7.4202 & 7.7681 & \\
\hline HEMBL3681267 & 92 & 586 & 26 & \\
\hline HEMBL3E & 92 & 815 & 56 & \\
\hline HEMBL36 & 92 & 229 & 45 & \\
\hline AEMBL3 & 92 & 229 & 37 & \\
\hline AEMBL3681282 & 792 & 768 & 2022 & \\
\hline HEMBL3681248 & 92 & 98 & 35 & \\
\hline HEMBL 36 & 92 & 685 & 191 & \\
\hline HEMBL3 & 92 & 39 & & \\
\hline HEMBL & 92 & 65 & 91 & \\
\hline HEMBL3676320 & & 7.5229 & 642 & \\
\hline HEMBL3681264 & 92 & 58 & 904 & \\
\hline HEMBL3681316 & 92 & 7.5686 & 5047 & \\
\hline HEMBL3 & 92 & 88 & 51 & \\
\hline HEMBL3 & & 35 & 353 & \\
\hline HEMBL3676314 & 792 & 7.5528 & 67 & \\
\hline HEMBL3676335 & 528792 & 6.585 & 9273 & \\
\hline HEMBL3639801 & 92 & 805 & 809 & \\
\hline HEMBL3 & 2 & 665 & & \\
\hline HEMBL3676331 & & 7.7959 & 7.5622 & \\
\hline HEMBL3676312 & 528792 & 8.301 & 7667 & \\
\hline AEMBL3681276 & 792 & 0088 & 6.0697 & \\
\hline CHEMBL3681242 & 792 & 7.3468 & 7.6803 & \\
\hline CHEMBL3676318 & 1528792 & & 7.1874 & \\
\hline HEMBL3681290 & 1528792 & 8.7447 & 8.9841 & \\
\hline HEMBL3681302 & 528792 & 7.2218 & 7.2022 & \\
\hline HEMBL3681238 & 528792 & 76 & 7.9897 & \\
\hline CHEMBL3681247 & 792 & .7447 & 7.7543 & \\
\hline CHEMBL36 & 792 & .2518 & & \\
\hline CHEMBL3681304 & 1528792 & 7.3372 & 7.4224 & \\
\hline
\end{tabular}


Supplemental Table S2.txt

\begin{tabular}{|c|c|c|c|c|}
\hline 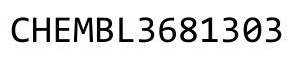 & & & & \\
\hline HEMBL3681239 & 528792 & 6.6383 & 6.8972 & \\
\hline 1319 & 792 & & & \\
\hline 81240 & 792 & 83 & & \\
\hline IEMBL 3676328 & 528792 & 5686 & 748 & \\
\hline HEMBL3681283 & 528792 & 0706 & 9377 & \\
\hline HEMBL3681284 & 528792 & 6021 & 8981 & \\
\hline 81250 & 28792 & 576 & 6289 & \\
\hline 581273 & 528792 & 605 & 3947 & \\
\hline AEMBL3681277 & 528792 & 6.6778 & 0344 & \\
\hline AEMBL3681268 & 528792 & 7.3188 & 2053 & \\
\hline AEMBL3681275 & 528792 & 089 & 2459 & \\
\hline 1311 & & & & \\
\hline 81243 & 92 & 192 & 367 & \\
\hline AEMBL3681263 & 528792 & 89 & 523 & \\
\hline AEMBL3681299 & 528792 & 239 & 263 & \\
\hline HEMBL3681293 & 92 & 49 & 618 & \\
\hline 76317 & & & 16 & \\
\hline 81236 & 92 & 576 & 3563 & \\
\hline AEMBL3681294 & 92 & 47 & 675 & \\
\hline AEMBL3681318 & 92 & & 503 & KIV \\
\hline HEMBL36 & 2 & 768 & 475 & 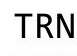 \\
\hline HEMBL36 & & & 28 & \\
\hline 81255 & & 468 & 2912 & \\
\hline AEMBL3676322 & 2 & 15 & 74 & RIN \\
\hline HEMBL36 & 2 & 7 & 697 & RN \\
\hline AEMBL36 & 2 & 706 & 893 & RN \\
\hline 1249 & 92 & 41 & 84 & \\
\hline 1308 & & & 248 & 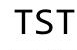 \\
\hline AEMBL3681309 & 92 & 39 & 736 & $\mid$ \\
\hline AEMBL3681300 & 992 & 208 & 57 & ST \\
\hline 6336 & & 35 & 952 & ST \\
\hline 88 & & & 273 & ST \\
\hline HEMBL3681241 & & & & is \\
\hline AEMBL3681269 & 22 & 37 & 183 & TST \\
\hline HEMBL3681314 & 792 & 76 & 812 & ST \\
\hline 270 & 2 & & & ST \\
\hline HEMBL3681287 & & & 399 & ST \\
\hline HEMBL3681256 & 528792 & 7.2757 & 1394 & TST \\
\hline AEMBL3676334 & 22 & 24 & 726 & IST \\
\hline HEMBL3676316 & 528792 & 229 & 471 & ST \\
\hline HEMBL3676332 & & & & ST \\
\hline HEMBL153763 & 13008 & 6.3851 & 1007 & $\mathrm{RN}$ \\
\hline HEMBL178922 & 3008 & 5.585 & 2843 & ST \\
\hline EMBL362611 & ? & 7721 & 7794 & RN \\
\hline HEMBL367792 & & & 9466 & \\
\hline CHEMBL3 & 313008 & 7.1308 & 5.9725 & \\
\hline CHEMBL 367492 & 313008 & 7.8861 & 7.901 & RN \\
\hline
\end{tabular}

Page 9418 


\begin{tabular}{|c|c|c|c|c|c|}
\hline & & & & & \\
\hline CHEMBL179577 & 313008 & 6.9872 & 6.9248 & TRN & \\
\hline CHEMBL179726 & 313008 & 7.4089 & 7.4077 & TRN & \\
\hline CHEMBL179074 & 313008 & 5.9767 & 5.5437 & TST & \\
\hline CHEMBL175557 & 313008 & 7.5376 & 7.524 & TRN & \\
\hline CHEMBL359630 & 313008 & 7.1612 & 7.1627 & TRN & \\
\hline CHEMBL175621 & 313008 & 5.9266 & 5.8953 & TRN & \\
\hline CHEMBL179363 & 313008 & 8.0969 & 8.1053 & TRN & \\
\hline CHEMBL367754 & 313008 & 5.4224 & 5.4074 & TRN & \\
\hline CHEMBL362233 & 313008 & 5.4231 & 5.4132 & TRN & \\
\hline CHEMBL361343 & 313008 & 7.5686 & 7.5516 & TRN & \\
\hline CHEMBL440935 & 313008 & 5.9454 & 5.9541 & TRN & \\
\hline CHEMBL360780 & 313008 & 6.3915 & 6.2635 & TRN & \\
\hline CHEMBL368234 & 313008 & 6.644 & 6.6525 & TRN & \\
\hline CHEMBL178312 & 313008 & 7.2291 & 7.2339 & TRN & \\
\hline CHEMBL359629 & 313008 & 7.699 & 7.731 & TRN & \\
\hline CHEMBL175556 & 313008 & 7.2291 & 7.2442 & TRN & \\
\hline CHEMBL179652 & 313008 & 7.8239 & 6.5583 & TST & \\
\hline CHEMBL175552 & 313008 & 5.6778 & 5.6811 & TRN & \\
\hline CHEMBL179313 & 313008 & 6.5702 & 6.5453 & TRN & \\
\hline CHEMBL179607 & 313008 & 7.0506 & 7.0337 & TRN & \\
\hline CHEMBL180175 & 313008 & 6.8097 & 6.7906 & TRN & \\
\hline CHEMBL180415 & 313008 & 7.6198 & 7.6167 & TRN & \\
\hline CHEMBL175726 & 313008 & 5.8306 & 5.8176 & TRN & \\
\hline CHEMBL175558 & 313008 & $5.9970 e$ & 000000006 & 5.9995 & TRN \\
\hline CHEMBL179310 & 313008 & 6.6383 & 6.2717 & TST & \\
\hline CHEMBL362618 & 313008 & 5.8758 & 5.961 & TRN & \\
\hline CHEMBL175492 & 313008 & 6.6091 & 6.6124 & TRN & \\
\hline CHEMBL424959 & 313008 & 6.4401 & 6.4286 & TRN & \\
\hline CHEMBL 362824 & 313008 & 7.2366 & 7.2484 & TRN & \\
\hline CHEMBL178958 & 313008 & 6.767 & 6.7645 & TRN & \\
\hline CHEMBL179923 & 313008 & 6.1355 & 6.1495 & TRN & \\
\hline CHEMBL 2112990 & 313008 & 6.015 & 6.03299 & 99999999995 & TRN \\
\hline CHEMBL434720 & 313008 & 7.1192 & 7.3013 & TRN & \\
\hline CHEMBL427314 & 313008 & 4.8794 & 4.8936 & TRN & \\
\hline CHEMBL175513 & 313008 & 7.1938 & 7.1903 & TRN & \\
\hline CHEMBL359660 & 313008 & 6.7077 & 6.7124 & TRN & \\
\hline CHEMBL369088 & 313008 & 6.983 & 6.986006 & 2000000001 & TRN \\
\hline CHEMBL178654 & 313008 & 7.4815 & 7.3842 & TRN & \\
\hline CHEMBL179766 & 313008 & 7.0809 & 7.0472 & TRN & \\
\hline CHEMBL175933 & 313008 & 6.4584 & 6.4718 & TRN & \\
\hline CHEMBL178096 & 313008 & 5.9586 & 5.9797 & TRN & \\
\hline CHEMBL360519 & 313008 & 8.0 & 7.9916 & TRN & \\
\hline CHEMBL175840 & 313008 & 6.2041 & 6.2032 & TRN & \\
\hline CHEMBL180516 & 313008 & 7.1079 & 7.1368 & TRN & \\
\hline CHEMBL368702 & 313008 & 7.3979 & 7.4067 & TRN & \\
\hline CHEMBL179527 & 313008 & 6.7932 & 6.7797 & TRN & \\
\hline CHEMBL176199 & 313008 & 7.2076 & 7.222 & TRN & \\
\hline CHEMBL426051 & 313008 & 6.8827 & 6.8886 & TRN & \\
\hline
\end{tabular}




\begin{tabular}{|c|c|c|c|c|c|}
\hline \multirow[b]{2}{*}{ CHEMBL369299 } & \multicolumn{5}{|c|}{ Supplemental Table S2 } \\
\hline & 313008 & 6.3028 & 6.3163 & TRN & \\
\hline CHEMBL179633 & 313008 & 5.4089 & 5.4279 & TRN & \\
\hline CHEMBL359705 & 313008 & 5.8567 & 5.8514 & TRN & \\
\hline CHEMBL178199 & 313008 & 6.5513 & 6.5478 & TRN & \\
\hline CHEMBL179164 & 313008 & 7.6021 & 6.5098 & TST & \\
\hline CHEMBL179052 & 313008 & 7.5528 & 7.5442 & TRN & \\
\hline CHEMBL360958 & 313008 & 7.6021 & 7.5562 & TRN & \\
\hline CHEMBL179123 & 313008 & 7.5528 & 7.5697 & TRN & \\
\hline CHEMBL362232 & 313008 & 7.3565 & 7.3446 & TRN & \\
\hline CHEMBL178573 & 313008 & 7.7447 & 7.5695 & TST & \\
\hline CHEMBL180018 & 313008 & 6.7352 & 6.3426 & TST & \\
\hline CHEMBL179521 & 313008 & 4.8861 & 5.3047 & TST & \\
\hline CHEMBL360028 & 313008 & 7.0915 & 6.8122 & TST & \\
\hline CHEMBL178265 & 313008 & 5.0915 & 5.7799 & TST & \\
\hline CHEMBL179659 & 313008 & 6.8794 & 6.8286 & TST & \\
\hline CHEMBL179572 & 313008 & 7.0809 & 7.5041 & TST & \\
\hline CHEMBL178290 & 313008 & 6.4112 & 7.3253 & TST & \\
\hline CHEMBL360933 & 313008 & 6.2676 & 6.7005 & TST & \\
\hline CHEMBL179458 & 313008 & 6.0969 & 5.5542 & TST & \\
\hline CHEMBL179969 & 313008 & 7.2147 & 6.8656 & TST & \\
\hline CHEMBL178144 & 313008 & 6.7375 & 7.0962 & TST & \\
\hline CHEMBL360211 & 313008 & 6.2197 & 6.7678 & TST & \\
\hline CHEMBL180227 & 313008 & 7.1249 & 6.4352 & TST & \\
\hline CHEMBL1304667 & 688226 & 5.1057 & 5.0495 & TRN & \\
\hline CHEMBL1546834 & 688226 & 5.1439 & 4.84699 & 99999999995 & TRN \\
\hline CHEMBL1355520 & 688226 & 5.3215 & 5.688 & TRN & \\
\hline CHEMBL1516792 & 688226 & 5.983 & 5.4755 & TRN & \\
\hline CHEMBL1477326 & 688226 & 5.118 & 5.2975 & TRN & \\
\hline CHEMBL1557307 & 688226 & 5.2916 & 5.2631 & TRN & \\
\hline CHEMBL1362952 & 688226 & 5.9957 & 5.7824 & TRN & \\
\hline CHEMBL1382216 & 688226 & 5.5317 & 5.5469 & TRN & \\
\hline CHEMBL1519941 & 688226 & 5.3125 & 5.6454 & TRN & \\
\hline CHEMBL1530629 & 688226 & 5.7595 & 5.914 & TRN & \\
\hline CHEMBL1585777 & 688226 & 5.9393 & 5.9052 & TRN & \\
\hline CHEMBL1982010 & 688226 & 6.9208 & 6.54899 & 99999999995 & TRN \\
\hline CHEMBL1495891 & 688226 & 5.8356 & 5.7703 & TRN & \\
\hline CHEMBL1575809 & 688226 & 5.3152 & 5.7043 & TST & \\
\hline CHEMBL1535318 & 688226 & 5.02 & 5.4537 & TRN & \\
\hline CHEMBL1495372 & 688226 & 5.5258 & 5.3742 & TRN & \\
\hline CHEMBL1331064 & 688226 & 6.3372 & 6.1949 & TRN & \\
\hline CHEMBL1304982 & 688226 & 5.1314 & 6.1169 & TRN & \\
\hline CHEMBL1335175 & 688226 & 8.0 & 6.79899 & 99999999995 & TRN \\
\hline CHEMBL1520705 & 688226 & 4.8979 & 5.0582 & TRN & \\
\hline CHEMBL1584810 & 688226 & 4.914 & 5.13299 & 9999999999 & TRN \\
\hline CHEMBL1423318 & 688226 & 5.3261 & 5.8666 & TRN & \\
\hline CHEMBL1520325 & 688226 & 6.0362 & 5.6287 & TRN & \\
\hline CHEMBL1521373 & 688226 & 5.8827 & 5.5647 & TRN & \\
\hline CHEMBL1328261 & 688226 & 6.585 & 5.6761 & TST & \\
\hline & & & & 9420 & \\
\hline
\end{tabular}


Supplemental Table S2.txt

\begin{tabular}{|c|c|c|c|c|}
\hline CHEMBL1991112 & 688226 & 6.5229 & 6.3471 & TST \\
\hline CHEMBL3198632 & 688226 & 5.2125 & 5.2037 & TRN \\
\hline CHEMBL1349631 & 688226 & 5.6946 & 6.0401 & TRN \\
\hline CHEMBL1331485 & 688226 & 6.1805 & 5.5764 & TRN \\
\hline CHEMBL1579305 & 688226 & 5.3915 & 5.8785 & TRN \\
\hline CHEMBL1568747 & 688226 & 5.52 & 5.434 & TRN \\
\hline CHEMBL1408585 & 688226 & 6.5376 & 5.5301 & TRN \\
\hline CHEMBL1421775 & 688226 & 5.0066 & 4.7447 & TRN \\
\hline CHEMBL1455226 & 688226 & 6.1487 & 6.6058 & TRN \\
\hline CHEMBL1323822 & 688226 & 6.699 & 6.3113 & TRN \\
\hline CHEMBL1425875 & 688226 & 6.3565 & 6.1685 & TRN \\
\hline CHEMBL3207466 & 688226 & 6.7447 & 5.8195 & TST \\
\hline CHEMBL1350946 & 688226 & 5.3161 & 5.5954 & TRN \\
\hline CHEMBL1458320 & 688226 & 5.2472 & 5.3263 & TRN \\
\hline CHEMBL1447734 & 688226 & 5.9031 & 6.1712 & TRN \\
\hline CHEMBL1556270 & 688226 & 6.8239 & 5.9578 & TRN \\
\hline CHEMBL1572330 & 688226 & 5.9547 & 6.1056 & TRN \\
\hline CHEMBL1565328 & 688226 & 5.9066 & 6.0122 & TRN \\
\hline CHEMBL1389707 & 688226 & 5.4559 & 5.4206 & TRN \\
\hline CHEMBL1389047 & 688226 & 6.3565 & 6.2554 & TRN \\
\hline CHEMBL1544114 & 688226 & 5.5243 & 6.2574 & TRN \\
\hline CHEMBL1485892 & 688226 & 6.4202 & 6.4922 & TRN \\
\hline CHEMBL1572553 & 688226 & 5.9318 & 5.4718 & TST \\
\hline CHEMBL1540015 & 688226 & 6.0655 & 5.6799 & TRN \\
\hline CHEMBL417727 & 688226 & 5.8601 & 5.9208 & TRN \\
\hline CHEMBL1421168 & 688226 & 5.5214 & 5.9106 & TRN \\
\hline CHEMBL1327627 & 688226 & 5.3872 & 5.5089 & TRN \\
\hline CHEMBL1432154 & 688226 & 6.0862 & 5.7006 & TRN \\
\hline CHEMBL1336298 & 688226 & 6.0555 & 6.3215 & TRN \\
\hline CHEMBL1322689 & 688226 & 5.8508 & 6.0722 & TRN \\
\hline CHEMBL1449916 & 688226 & 6.3372 & 6.2585 & TRN \\
\hline CHEMBL3194842 & 688226 & 5.9318 & 5.6027 & TRN \\
\hline CHEMBL1416899 & 688226 & 5.644 & 5.2305 & TST \\
\hline CHEMBL590947 & 688226 & 5.1798 & 5.24700 & 0000000001 \\
\hline CHEMBL547483 & 688226 & 5.2218 & 5.4673 & TST \\
\hline CHEMBL1989453 & 688226 & 5.7721 & 6.2333 & TRN \\
\hline CHEMBL1541582 & 688226 & 6.301 & 6.527 & TRN \\
\hline CHEMBL1428317 & 688226 & 6.2076 & 5.6715 & TST \\
\hline CHEMBL 1389571 & 688226 & 5.8069 & 5.9911 & TRN \\
\hline CHEMBL1584540 & 688226 & 5.4559 & 6.0901 & TRN \\
\hline CHEMBL1964945 & 688226 & 6.7959 & 6.42200 & 0000000001 \\
\hline CHEMBL1484231 & 688226 & 5.5884 & 5.41700 & 0000000001 \\
\hline CHEMBL579219 & 688226 & 4.9555 & 5.3046 & TRN \\
\hline CHEMBL1313089 & 688226 & 5.0794 & 5.4622 & TRN \\
\hline CHEMBL1414766 & 688226 & 6.0223 & 5.6944 & TST \\
\hline CHEMBL3190811 & 688226 & 6.1549 & 5.8799 & TST \\
\hline CHEMBL1495832 & 688226 & 7.0 & 6.6927 & TRN \\
\hline CHEMBL1600749 & 688226 & 5.5622 & 5.2535 & TRN \\
\hline
\end{tabular}




\begin{tabular}{|c|c|c|c|c|c|}
\hline & & \multicolumn{4}{|c|}{ Supplemental Table S2.txt } \\
\hline CHEMBL1381119 & 688226 & 4.8874 & 5.5795 & TRN & \\
\hline CHEMBL3198701 & 688226 & 5.1192 & 5.9661 & TST & \\
\hline CHEMBL1365535 & 688226 & 4.9602 & 5.331 & TRN & \\
\hline CHEMBL1335336 & 688226 & 5.4342 & 5.3753 & TRN & \\
\hline CHEMBL1499073 & 688226 & 6.6778 & 5.9847 & TRN & \\
\hline CHEMBL1304319 & 688226 & 6.2757 & 6.6611 & TRN & \\
\hline CHEMBL1531791 & 688226 & 6.6198 & 5.9063 & TRN & \\
\hline CHEMBL1520725 & 688226 & 5.5214 & 5.4357 & TRN & \\
\hline CHEMBL1577550 & 688226 & 5.04 & 5.1191 & TRN & \\
\hline CHEMBL1464647 & 688226 & 6.0506 & 6.2158 & TRN & \\
\hline CHEMBL1530057 & 688226 & 5.3915 & 5.6985 & TRN & \\
\hline CHEMBL1393312 & 688226 & 5.6003 & 5.5366 & TRN & \\
\hline CHEMBL1493051 & 688226 & 7.2218 & 6.2022 & TRN & \\
\hline CHEMBL1520671 & 688226 & 4.9516 & 5.5818 & TRN & \\
\hline CHEMBL1377688 & 688226 & 5.7721 & 5.4546 & TRN & \\
\hline CHEMBL1398931 & 688226 & 4.9344 & 5.343 & TRN & \\
\hline CHEMBL1417328 & 688226 & 6.0655 & 5.51399 & 9999999999 & TST \\
\hline CHEMBL1589405 & 688226 & 5.4248 & 5.393 & TRN & \\
\hline CHEMBL1501290 & 688226 & 5.3206 & 5.3875 & TRN & \\
\hline CHEMBL1493137 & 688226 & 5.1798 & 5.0893 & TRN & \\
\hline CHEMBL1406051 & 688226 & 5.4895 & 4.9743 & TRN & \\
\hline CHEMBL1509659 & 688226 & 5.1543 & 5.5059 & TRN & \\
\hline CHEMBL1418045 & 688226 & 6.6198 & 6.2157 & TRN & \\
\hline CHEMBL1440100 & 688226 & 5.3307 & 5.421 & TST & \\
\hline CHEMBL1490750 & 688226 & 5.9626 & 6.2803 & TRN & \\
\hline CHEMBL3211804 & 688226 & 6.6383 & 5.5905 & TST & \\
\hline CHEMBL1600506 & 688226 & 6.0605 & 6.0601 & TST & \\
\hline CHEMBL3192210 & 688226 & 4.9598 & 5.7081 & TST & \\
\hline CHEMBL1458833 & 688226 & 4.0721 & 6.1021 & TST & \\
\hline CHEMBL1356585 & 688226 & 4.9318 & 5.8483 & TST & \\
\hline CHEMBL1525839 & 688226 & 5.056 & 5.1738 & TST & \\
\hline CHEMBL1453439 & 688226 & 5.5735 & 5.6394 & TST & \\
\hline CHEMBL1418441 & 688226 & 6.4202 & 4.4963 & TST & \\
\hline CHEMBL3194024 & 688226 & 6.6576 & 6.4717 & TST & \\
\hline CHEMBL1325818 & 688226 & 6.4559 & 5.5707 & TST & \\
\hline CHEMBL1445436 & 688226 & 6.0757 & 5.3792 & TST & \\
\hline CHEMBL1493936 & 688226 & 6.3768 & 6.1632 & TST & \\
\hline CHEMBL1302442 & 688226 & 6.2596 & 5.4881 & TST & \\
\hline CHEMBL1518265 & 688226 & 5.9066 & 6.3876 & TST & \\
\hline CHEMBL224884 & 429504 & 3.0 & 2.9077 & TRN & \\
\hline CHEMBL222712 & 429504 & 6.2147 & 6.3323 & TRN & \\
\hline CHEMBL224822 & 429504 & 4.2684 & 4.225 & TRN & \\
\hline CHEMBL376435 & 429504 & 4.8827 & 4.728 & TRN & \\
\hline CHEMBL376518 & 429504 & 6.8861 & 6.5974 & TRN & \\
\hline CHEMBL385799 & 429504 & 5.52 & 6.1905 & TST & \\
\hline CHEMBL222795 & 429504 & 3.0 & 3.2504 & TRN & \\
\hline CHEMBL222149 & 429504 & 5.8477 & 5.8476 & TRN & \\
\hline CHEMBL375078 & 429504 & 3.0 & 2.8446 & TRN & \\
\hline
\end{tabular}




\begin{tabular}{|c|c|c|c|c|c|}
\hline \\
\hline CHEMBL117447 & 429504 & 7.6383 & 5.8448 & TST & \\
\hline CHEMBL386000 & 429504 & 4.757 & 4.5561 & TRN & \\
\hline CHEMBL426562 & 429504 & 5.7258 & 5.8213 & TRN & \\
\hline CHEMBL374970 & 429504 & 5.1141 & 5.098 & TRN & \\
\hline CHEMBL326294 & 429504 & 3.0 & 2.8118 & TST & \\
\hline CHEMBL325480 & 429504 & 4.5702 & 4.7052 & TRN & \\
\hline CHEMBL374629 & 429504 & 3.0 & 3.6736 & TST & \\
\hline CHEMBL223001 & 429504 & 4.4437 & 4.3489 & TRN & \\
\hline CHEMBL221669 & 429504 & 4.2573 & 4.6201 & TRN & \\
\hline CHEMBL376290 & 429504 & 4.4672 & 4.3987 & TRN & \\
\hline CHEMBL 327012 & 429504 & 5.9136 & 4.7101 & TST & \\
\hline CHEMBL116040 & 429504 & 3.0 & 2.7991 & TST & \\
\hline CHEMBL221362 & 429504 & 4.71 & 4.4594 & TRN & \\
\hline CHEMBL223254 & 429504 & 3.0 & 2.9838 & TRN & \\
\hline CHEMBL225169 & 429504 & 7.1805 & 5.8156 & TST & \\
\hline CHEMBL375304 & 429504 & 5.3615 & 5.3173 & TRN & \\
\hline CHEMBL442046 & 429504 & 3.0 & 4.026 & TST & \\
\hline CHEMBL374758 & 429504 & 4.4437 & 4.8396 & TRN & \\
\hline CHEMBL222292 & 429504 & 5.0269 & 4.9364 & TRN & \\
\hline CHEMBL373715 & 429504 & 5.2573 & 4.9653 & TRN & \\
\hline CHEMBL223039 & 429504 & 6.2291 & 6.19 & TRN & \\
\hline CHEMBL115897 & 429504 & 4.4989 & 4.5553 & TST & \\
\hline CHEMBL118883 & 429504 & 3.0 & 3.3983 & TST & \\
\hline CHEMBL223000 & 429504 & 6.5376 & 6.6861 & TRN & \\
\hline CHEMBL333636 & 429504 & 3.0 & 3.0695 & TRN & \\
\hline CHEMBL376291 & 429504 & 7.6021 & 7.5703 & TRN & \\
\hline CHEMBL221830 & 429504 & 4.7825 & 4.3241 & TST & \\
\hline CHEMBL374905 & 429504 & 3.0 & $2.89300 t$ & 00000000002 & TRN \\
\hline CHEMBL60569 & 429504 & 5.2692 & 5.2934 & TRN & \\
\hline CHEMBL115581 & 429504 & 5.7696 & 5.8612 & TRN & \\
\hline CHEMBL374331 & 429504 & 5.7905 & 5.3454 & TRN & \\
\hline CHEMBL222190 & 429504 & 4.9431 & 4.903006 & 00000000005 & TRN \\
\hline CHEMBL79466 & 429504 & 3.0 & 2.8308 & TRN & \\
\hline CHEMBL223785 & 429504 & 3.0 & 3.3692 & TRN & \\
\hline CHEMBL221512 & 429504 & 7.7959 & 7.7252 & TRN & \\
\hline CHEMBL374740 & 429504 & 5.4535 & 5.5022 & TRN & \\
\hline CHEMBL225175 & 429504 & 3.0 & 3.4351 & TRN & \\
\hline CHEMBL222851 & 429504 & 5.5768 & 5.331 & TRN & \\
\hline CHEMBL373781 & 429504 & 5.8069 & 6.1377 & TRN & \\
\hline CHEMBL224988 & 429504 & 3.0 & 2.537 & TRN & \\
\hline CHEMBL222644 & 429504 & 8.0 & 7.7252 & TRN & \\
\hline CHEMBL221873 & 429504 & 3.0 & 2.9434 & TRN & \\
\hline CHEMBL375126 & 429504 & 7.5086 & 7.8589 & TRN & \\
\hline CHEMBL222999 & 429504 & 4.6421 & 4.9811 & TRN & \\
\hline CHEMBL222849 & 429504 & 3.0 & 3.1555 & TRN & \\
\hline CHEMBL222988 & 429504 & 4.6778 & 4.8892 & TST & \\
\hline CHEMBL376228 & 429504 & 5.0835 & 5.1226 & TST & \\
\hline CHEMBL222989 & 429504 & 3.0 & 3.1405 & TRN & \\
\hline
\end{tabular}




\begin{tabular}{|c|c|c|c|c|c|}
\hline \multicolumn{6}{|c|}{ plemental } \\
\hline CHEMBL118305 & 429504 & 3.0 & 4.3279 & TST & \\
\hline CHEMBL222711 & 429504 & 3.0 & 2.6313 & TRN & \\
\hline CHEMBL116649 & 429504 & 4.7825 & 4.2143 & TST & \\
\hline CHEMBL222891 & 429504 & 3.0 & 3.5804 & TRN & \\
\hline CHEMBL 385800 & 429504 & 6.0506 & 5.7501 & TST & \\
\hline CHEMBL 385132 & 429504 & 6.2366 & 5.9705 & TRN & \\
\hline CHEMBL 222660 & 429504 & 3.0 & 3.1937 & TST & \\
\hline CHEMBL222752 & 429504 & 8.0969 & 8.0425 & TRN & \\
\hline CHEMBL1964290 & 809212 & 5.9 & 5.5931 & TRN & \\
\hline CHEMBL1230164 & 809212 & 5.7 & 4.8653 & TST & \\
\hline CHEMBL 2003768 & 809212 & 4.1 & 4.162 & TRN & \\
\hline CHEMBL213505 & 809212 & 5.2 & 4.1307 & TRN & \\
\hline CHEMBL1982881 & 809212 & 5.6 & 5.4688 & TRN & \\
\hline CHEMBL1987034 & 809212 & 5.3 & 5.1092 & TRN & \\
\hline CHEMBL1993941 & 809212 & 4.1 & 3.99 & TRN & \\
\hline CHEMBL 377383 & 809212 & 4.1 & 3.978 & TST & \\
\hline CHEMBL2005886 & 809212 & 4.1 & 4.3831 & TRN & \\
\hline CHEMBL481491 & 809212 & 4.1 & 5.0177 & TST & \\
\hline CHEMBL1973142 & 809212 & 5.9 & 5.7367 & TRN & \\
\hline CHEMBL1973145 & 809212 & 4.1 & 4.0552 & TRN & \\
\hline CHEMBL1982924 & 809212 & 4.1 & 4.4722 & TRN & \\
\hline CHEMBL2005936 & 809212 & 5.1 & 4.7589 & TRN & \\
\hline CHEMBL1807515 & 809212 & 6.7 & 6.7586 & TRN & \\
\hline CHEMBL1971141 & 809212 & 4.1 & 4.1316 & TRN & \\
\hline CHEMBL1995813 & 809212 & 6.3 & 6.3857 & TRN & \\
\hline CHEMBL206236 & 809212 & 5.4 & 5.24100 & 00000000005 & TRN \\
\hline CHEMBL1989834 & 809212 & 3.1 & 3.7723 & TRN & \\
\hline CHEMBL1996893 & 809212 & 5.2 & 4.848 & TST & \\
\hline CHEMBL 244378 & 809212 & 7.7 & 7.1966 & TRN & \\
\hline CHEMBL 2001957 & 809212 & 4.1 & 3.8957 & TRN & \\
\hline CHEMBL1969372 & 809212 & 4.1 & 3.8313 & TRN & \\
\hline CHEMBL1990583 & 809212 & 4.1 & 5.8914 & TRN & \\
\hline CHEMBL1986943 & 809212 & 5.5 & 6.5389 & TRN & \\
\hline CHEMBL289959 & 809212 & 4.7 & 4.3188 & TRN & \\
\hline CHEMBL 2006263 & 809212 & 5.3 & 5.2032 & TST & \\
\hline CHEMBL1993584 & 809212 & 4.1 & 5.1117 & TRN & \\
\hline CHEMBL1986263 & 809212 & 5.4 & 5.1848 & TRN & \\
\hline CHEMBL 2000114 & 809212 & 4.1 & 4.1382 & TRN & \\
\hline CHEMBL1975647 & 809212 & 5.6 & 4.6681 & TRN & \\
\hline CHEMBL1968380 & 809212 & 4.1 & 4.1622 & TRN & \\
\hline CHEMBL1964644 & 809212 & 4.1 & 4.0633 & TRN & \\
\hline CHEMBL1981782 & 809212 & 4.1 & 4.2069 & TRN & \\
\hline CHEMBL1977681 & 809212 & 6.5 & 5.8098 & TRN & \\
\hline CHEMBL1970142 & 809212 & 4.1 & 3.95600 & 00000000004 & TRN \\
\hline CHEMBL1990912 & 809212 & 5.3 & 4.7289 & TRN & \\
\hline CHEMBL1988163 & 809212 & 4.1 & 5.6432 & TRN & \\
\hline CHEMBL 2006493 & 809212 & 5.7 & 5.7825 & TST & \\
\hline CHEMBL1996923 & 809212 & 5.4 & 4.81 & TST & \\
\hline
\end{tabular}




\begin{tabular}{|c|c|c|c|c|}
\hline \multicolumn{5}{|c|}{ Supplemental Table S2.txt } \\
\hline CHEMBL1983449 & 809212 & 4.1 & 4.114 & TRN \\
\hline CHEMBL1992323 & 809212 & 6.5 & 5.7803 & TRN \\
\hline CHEMBL1969735 & 809212 & 4.1 & 3.9204 & TRN \\
\hline CHEMBL2002649 & 809212 & 5.3 & 5.1177 & TRN \\
\hline CHEMBL1989423 & 809212 & 4.4 & 4.1366 & TRN \\
\hline CHEMBL1995172 & 809212 & 4.3 & 4.1529 & TST \\
\hline CHEMBL1984788 & 809212 & 6.6 & 5.3469 & TRN \\
\hline CHEMBL1996604 & 809212 & 6.0 & 6.3224 & TRN \\
\hline CHEMBL2000508 & 809212 & 4.1 & 4.0362 & TRN \\
\hline CHEMBL1971694 & 809212 & 5.8 & 5.4647 & TST \\
\hline CHEMBL2001547 & 809212 & 4.1 & 3.9166 & TRN \\
\hline CHEMBL210928 & 809212 & 4.1 & 3.9573 & TST \\
\hline CHEMBL1986603 & 809212 & 4.1 & 4.2896 & TST \\
\hline CHEMBL1977148 & 809212 & 4.1 & 4.1684 & TRN \\
\hline CHEMBL 2003286 & 809212 & 7.4 & 7.2716 & TRN \\
\hline CHEMBL1992306 & 809212 & 4.1 & 4.123 & TRN \\
\hline CHEMBL2002165 & 809212 & 4.1 & 4.0838 & TRN \\
\hline CHEMBL2001668 & 809212 & 4.1 & 4.9037 & TRN \\
\hline CHEMBL1979318 & 809212 & 4.1 & 3.8778 & TST \\
\hline CHEMBL 206382 & 809212 & 4.1 & 5.0216 & TRN \\
\hline CHEMBL1998585 & 809212 & 4.1 & 5.0622 & TRN \\
\hline CHEMBL127898 & 809212 & 4.1 & 4.3877 & TST \\
\hline CHEMBL519697 & 809212 & 4.1 & 3.9199 & TRN \\
\hline CHEMBL2004934 & 809212 & 4.1 & 3.9155 & TRN \\
\hline CHEMBL1981947 & 809212 & 5.2 & 4.827 & TST \\
\hline CHEMBL1977619 & 809212 & 5.9 & 4.7523 & TST \\
\hline CHEMBL1975128 & 809212 & 4.1 & 5.5108 & TRN \\
\hline CHEMBL1970369 & 809212 & 4.1 & 4.0288 & TRN \\
\hline CHEMBL2001485 & 809212 & 4.1 & 3.9852 & TRN \\
\hline CHEMBL1966425 & 809212 & 5.7 & 5.416 & TRN \\
\hline CHEMBL1984363 & 809212 & 4.1 & 4.001 & TRN \\
\hline CHEMBL1978099 & 809212 & 4.1 & 4.6138 & TRN \\
\hline CHEMBL1988608 & 809212 & 5.9 & 5.4447 & TRN \\
\hline CHEMBL184847 & 809212 & 4.1 & 4.9163 & TRN \\
\hline CHEMBL1984367 & 809212 & 4.1 & 4.1424 & TRN \\
\hline CHEMBL178737 & 809212 & 4.1 & 5.3851 & TST \\
\hline CHEMBL1982563 & 809212 & 4.1 & 3.9027 & TRN \\
\hline CHEMBL539474 & 809212 & 4.1 & 4.8313 & TST \\
\hline CHEMBL575824 & 809212 & 6.9 & 6.7717 & TRN \\
\hline CHEMBL1988387 & 809212 & 5.2 & 4.39 & TRN \\
\hline CHEMBL1997759 & 809212 & 4.1 & 4.9422 & TRN \\
\hline CHEMBL1989708 & 809212 & 4.1 & 4.378 & TRN \\
\hline CHEMBL1990288 & 809212 & 4.1 & 4.0051 & TRN \\
\hline CHEMBL1974803 & 809212 & 5.9 & 5.8906 & TRN \\
\hline CHEMBL1968103 & 809212 & 5.3 & 5.0013 & TRN \\
\hline CHEMBL1984500 & 809212 & 3.1 & 4.435 & TRN \\
\hline CHEMBL1986970 & 809212 & 4.1 & 4.9559 & TRN \\
\hline CHEMBL2005112 & 809212 & 6.1 & 6.0552 & TST \\
\hline
\end{tabular}




\begin{tabular}{|c|c|c|c|c|}
\hline \\
\hline CHEMBL1958401 & 809212 & 5.5 & 5.0914 & TRN \\
\hline CHEMBL1984044 & 809212 & 5.6 & 5.1555 & TRN \\
\hline CHEMBL 2003456 & 809212 & 5.2 & 4.7753 & TRN \\
\hline CHEMBL1966816 & 809212 & 5.4 & 5.5793 & TRN \\
\hline CHEMBL1972584 & 809212 & 4.1 & 4.1185 & TRN \\
\hline CHEMBL 2002992 & 809212 & 4.1 & 4.1633 & TST \\
\hline CHEMBL560813 & 809212 & 6.3 & 5.0061 & TRN \\
\hline CHEMBL1968791 & 809212 & 4.1 & 4.2061 & TRN \\
\hline CHEMBL 2002682 & 809212 & 4.1 & 4.3454 & TST \\
\hline CHEMBL1971186 & 809212 & 4.1 & 3.9929 & TRN \\
\hline CHEMBL 2003482 & 809212 & 4.1 & 4.12 & TRN \\
\hline CHEMBL1976872 & 809212 & 3.1 & 3.592 & TST \\
\hline CHEMBL1969156 & 809212 & 3.1 & 3.5525 & TRN \\
\hline CHEMBL1973211 & 809212 & 4.1 & 4.8826 & TRN \\
\hline CHEMBL1984700 & 809212 & 4.1 & 3.9086 & TRN \\
\hline CHEMBL1987899 & 809212 & 5.1 & 4.6214 & TRN \\
\hline CHEMBL1461728 & 809212 & 4.1 & 4.2145 & TRN \\
\hline CHEMBL1976134 & 809212 & 5.9 & 5.3721 & TRN \\
\hline CHEMBL1965131 & 809212 & 6.6 & 5.9574 & TRN \\
\hline CHEMBL1972158 & 809212 & 5.2 & 5.3147 & TRN \\
\hline CHEMBL 2006580 & 809212 & 5.4 & 5.2116 & TRN \\
\hline CHEMBL 2006481 & 809212 & 4.1 & 4.0257 & TRN \\
\hline CHEMBL1979855 & 809212 & 4.1 & 4.0377 & TRN \\
\hline CHEMBL1970340 & 809212 & 4.1 & 4.8123 & TRN \\
\hline CHEMBL 2005186 & 809212 & 4.1 & 4.6689 & TRN \\
\hline CHEMBL1995927 & 809212 & 4.1 & 4.0808 & TST \\
\hline CHEMBL1975534 & 809212 & 4.1 & 4.2044 & TRN \\
\hline CHEMBL1993424 & 809212 & 4.1 & 4.6362 & TRN \\
\hline CHEMBL1966703 & 809212 & 4.1 & 4.2626 & TST \\
\hline CHEMBL1969561 & 809212 & 4.1 & 4.8033 & TRN \\
\hline CHEMBL1975121 & 809212 & 4.1 & 3.8804 & TRN \\
\hline CHEMBL1997023 & 809212 & 5.6 & 5.6683 & TST \\
\hline CHEMBL1964687 & 809212 & 5.2 & 4.691 & TRN \\
\hline CHEMBL1971943 & 809212 & 4.1 & 4.6739 & TST \\
\hline CHEMBL1974254 & 809212 & 4.1 & 4.078 & TRN \\
\hline CHEMBL1988537 & 809212 & 5.4 & 5.4292 & TST \\
\hline CHEMBL1969049 & 809212 & 4.1 & 3.9824 & TRN \\
\hline CHEMBL 2005828 & 809212 & 4.1 & 4.1987 & TRN \\
\hline CHEMBL 2002240 & 809212 & 4.1 & 4.0636 & TST \\
\hline CHEMBL1991143 & 809212 & 4.1 & 4.1276 & TST \\
\hline CHEMBL1998611 & 809212 & 6.3 & 5.6689 & TRN \\
\hline CHEMBL1975900 & 809212 & 4.1 & 4.5487 & TRN \\
\hline CHEMBL 255822 & 809212 & 8.1 & $7.6170 e$ & 0000000001 \\
\hline CHEMBL1972221 & 809212 & 4.1 & 4.212 & TRN \\
\hline CHEMBL378627 & 809212 & 4.1 & 3.9323 & TST \\
\hline CHEMBL1996979 & 809212 & 4.1 & 5.1111 & TRN \\
\hline CHEMBL1968406 & 809212 & 5.2 & 4.1779 & TRN \\
\hline CHEMBL1984274 & 809212 & 4.1 & 4.9719 & TRN \\
\hline
\end{tabular}

TRN 


\begin{tabular}{|c|c|c|c|c|c|}
\hline \multicolumn{6}{|c|}{ Supplemental Table S2.txt } \\
\hline CHEMBL1998545 & 809212 & 4.1 & 3.8779 & TRN & \\
\hline CHEMBL1986869 & 809212 & 4.1 & 4.1172 & TRN & \\
\hline CHEMBL 2006010 & 809212 & 5.1 & 4.1459 & TRN & \\
\hline CHEMBL1682558 & 809212 & 4.1 & 4.1023 & TRN & \\
\hline CHEMBL1990496 & 809212 & 4.1 & 4.1431 & TRN & \\
\hline CHEMBL 2002479 & 809212 & 5.5 & 5.2836 & TRN & \\
\hline CHEMBL1472492 & 809212 & 4.1 & 4.3568 & TST & \\
\hline CHEMBL1967094 & 809212 & 5.4 & 4.1502 & TRN & \\
\hline CHEMBL1966035 & 809212 & 4.1 & 4.2387 & TRN & \\
\hline CHEMBL 2003341 & 809212 & 4.1 & 3.9588 & TRN & \\
\hline CHEMBL1977604 & 809212 & 5.4 & \multicolumn{2}{|c|}{5.492000000000001} & TRN \\
\hline CHEMBL1982992 & 809212 & 4.1 & 5.4319 & TRN & \\
\hline CHEMBL1999590 & 809212 & 4.1 & 4.1014 & TST & \\
\hline CHEMBL1981079 & 809212 & 5.5 & 5.1907 & TRN & \\
\hline CHEMBL1972276 & 809212 & 6.2 & 5.8471 & TRN & \\
\hline CHEMBL1980489 & 809212 & 4.1 & 3.9925 & TRN & \\
\hline CHEMBL 2000832 & 809212 & 5.8 & 5.7093 & TRN & \\
\hline CHEMBL513846 & 809212 & 6.5 & 5.9181 & TRN & \\
\hline CHEMBL1970709 & 809212 & 4.1 & 3.9771 & TRN & \\
\hline CHEMBL1965660 & 809212 & 6.4 & 5.8107 & TRN & \\
\hline CHEMBL1985309 & 809212 & 6.0 & 5.4093 & TRN & \\
\hline CHEMBL1998112 & 809212 & 4.1 & 4.198 & TRN & \\
\hline CHEMBL1969126 & 809212 & 4.1 & 4.0425 & TRN & \\
\hline CHEMBL1980896 & 809212 & 4.1 & 4.1753 & TRN & \\
\hline CHEMBL1970104 & 809212 & 4.1 & 4.5318 & TRN & \\
\hline CHEMBL1991429 & 809212 & 4.1 & 4.0022 & TRN & \\
\hline CHEMBL1964777 & 809212 & 5.2 & 5.6323 & TRN & \\
\hline CHEMBL1971149 & 809212 & 4.1 & 3.937 & TRN & \\
\hline CHEMBL1999714 & 809212 & 4.1 & 3.7641 & TRN & \\
\hline CHEMBL1987533 & 809212 & 4.1 & 4.1416 & TRN & \\
\hline CHEMBL1994040 & 809212 & 4.1 & 3.9585 & TRN & \\
\hline CHEMBL579246 & 809212 & 6.9 & 6.7432 & TRN & \\
\hline CHEMBL1982506 & 809212 & 5.9 & 5.4369 & TST & \\
\hline CHEMBL 2004716 & 809212 & 4.1 & 5.2055 & TRN & \\
\hline CHEMBL1968127 & 809212 & 4.1 & 3.9413 & TRN & \\
\hline CHEMBL1975233 & 809212 & 5.1 & 3.9053 & TRN & \\
\hline CHEMBL1985406 & 809212 & 4.1 & 4.8659 & TRN & \\
\hline CHEMBL 207400 & 809212 & 5.2 & 4.9025 & TST & \\
\hline CHEMBL 2000894 & 809212 & 4.1 & 4.1571 & TST & \\
\hline CHEMBL 2002553 & 809212 & 5.2 & 4.4708 & TRN & \\
\hline CHEMBL1982135 & 809212 & 4.1 & 4.2499 & TRN & \\
\hline CHEMBL1976090 & 809212 & 6.1 & 5.5926 & TRN & \\
\hline CHEMBL1993243 & 809212 & 4.1 & 4.13899 & & TRN \\
\hline CHEMBL 2004771 & 809212 & 4.1 & 5.2951 & TRN & \\
\hline CHEMBL1997597 & 809212 & 4.1 & 4.2084 & TRN & \\
\hline CHEMBL1969537 & 809212 & 8.1 & 6.9791 & TST & \\
\hline CHEMBL1976093 & 809212 & 4.1 & 3.907 & TRN & \\
\hline CHEMBL1975256 & 809212 & 4.1 & 4.1319 & TST & \\
\hline
\end{tabular}




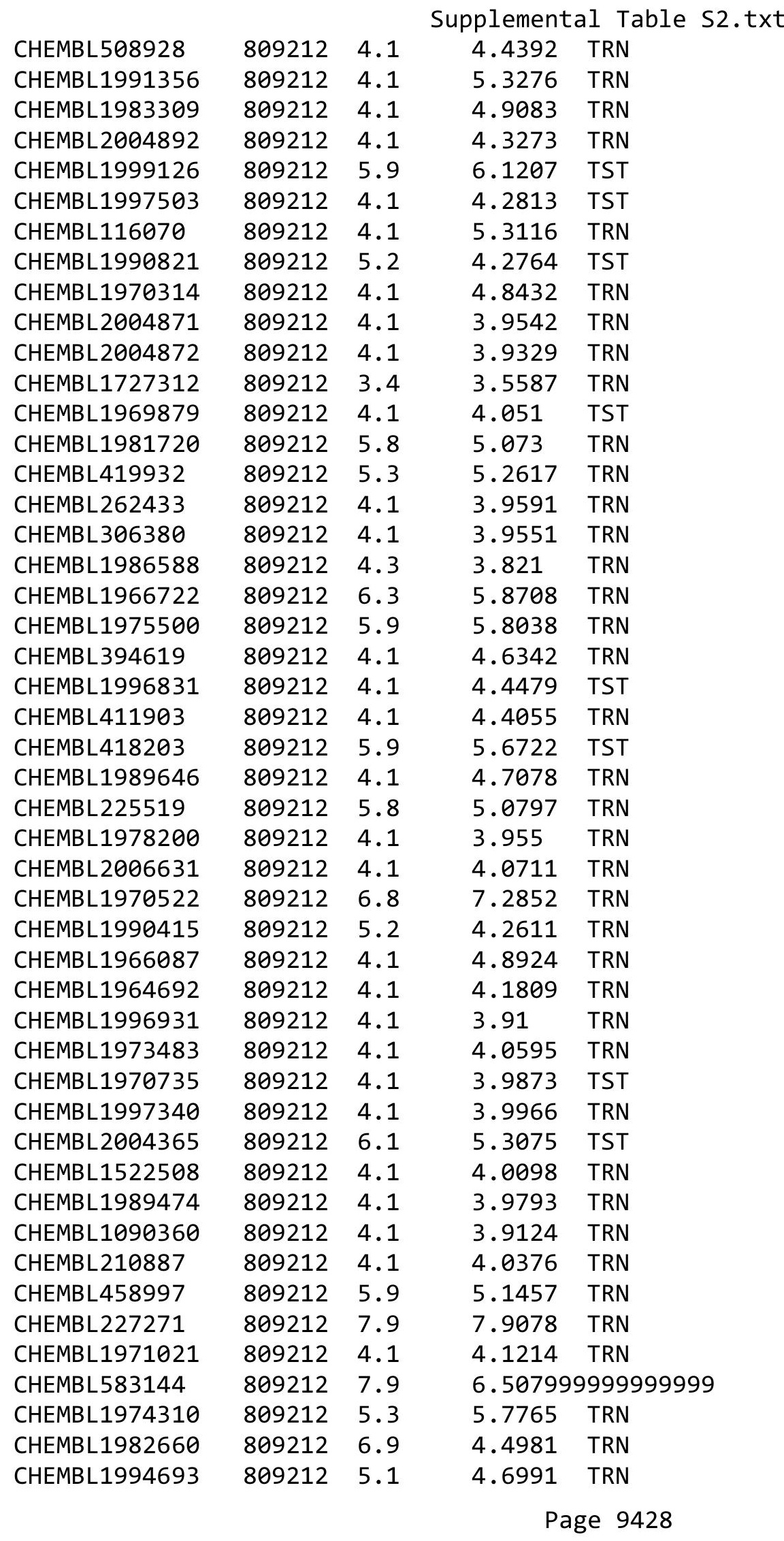

TRN 


\begin{tabular}{|c|c|c|c|c|}
\hline & & & & 11 \\
\hline CHEMBL1982957 & 809212 & 6.4 & 5.5279 & TRN \\
\hline CHEMBL1725279 & 809212 & 6.7 & 6.1217 & TST \\
\hline CHEMBL1975138 & 809212 & 6.2 & 5.6617 & TRN \\
\hline CHEMBL 2002346 & 809212 & 6.6 & 6.6423 & TRN \\
\hline CHEMBL2006836 & 809212 & 5.8 & 5.8466 & TST \\
\hline CHEMBL1980704 & 809212 & 7.1 & 5.61700 & 0000000001 \\
\hline CHEMBL 2003271 & 809212 & 6.0 & 5.7673 & TRN \\
\hline CHEMBL1972365 & 809212 & 4.2 & 4.2605 & TRN \\
\hline CHEMBL1966808 & 809212 & 7.2 & 7.1847 & TST \\
\hline CHEMBL2004447 & 809212 & 4.1 & 4.0029 & TST \\
\hline CHEMBL1983111 & 809212 & 5.1 & 4.8509 & TST \\
\hline CHEMBL1973860 & 809212 & 5.4 & 4.9977 & TRN \\
\hline CHEMBL1977713 & 809212 & 4.1 & 4.1987 & TRN \\
\hline CHEMBL260135 & 809212 & 4.1 & 4.0362 & TRN \\
\hline CHEMBL220241 & 809212 & 5.8 & 5.5624 & TRN \\
\hline CHEMBL 2004544 & 809212 & 4.1 & 4.7305 & TST \\
\hline CHEMBL1982610 & 809212 & 6.4 & 5.6276 & TRN \\
\hline CHEMBL1989569 & 809212 & 5.7 & 5.4522 & TRN \\
\hline CHEMBL1999496 & 809212 & 4.1 & 4.1377 & TRN \\
\hline CHEMBL1970873 & 809212 & 3.4 & 3.5006 & TRN \\
\hline CHEMBL1988300 & 809212 & 4.1 & 4.2984 & TRN \\
\hline CHEMBL1991078 & 809212 & 5.9 & 5.4786 & TRN \\
\hline CHEMBL1987359 & 809212 & 4.1 & 4.4634 & TST \\
\hline CHEMBL1989265 & 809212 & 6.5 & 5.7241 & TRN \\
\hline CHEMBL2004647 & 809212 & 5.8 & 5.4489 & TRN \\
\hline CHEMBL1969502 & 809212 & 6.5 & 5.8822 & TRN \\
\hline CHEMBL1682553 & 809212 & 6.3 & 6.2892 & TRN \\
\hline CHEMBL1971430 & 809212 & 4.1 & 4.0443 & TRN \\
\hline CHEMBL1997764 & 809212 & 4.1 & 4.4143 & TRN \\
\hline CHEMBL1983963 & 809212 & 4.1 & 4.6345 & TRN \\
\hline CHEMBL562488 & 809212 & 5.8 & 5.1014 & TRN \\
\hline CHEMBL354676 & 809212 & 3.1 & 3.5911 & TRN \\
\hline CHEMBL1985092 & 809212 & 5.2 & 4.9181 & TRN \\
\hline CHEMBL 2004692 & 809212 & 4.1 & 3.9638 & TST \\
\hline CHEMBL1981410 & 809212 & 4.1 & 4.1497 & TRN \\
\hline CHEMBL1996234 & 809212 & 4.1 & 4.0456 & TRN \\
\hline CHEMBL1991434 & 809212 & 6.8 & 6.1677 & TRN \\
\hline CHEMBL1967544 & 809212 & 6.6 & 5.9878 & TRN \\
\hline CHEMBL340384 & 809212 & 4.1 & 4.978 & TST \\
\hline CHEMBL1996587 & 809212 & 4.1 & 3.8973 & TRN \\
\hline CHEMBL1964804 & 809212 & 4.1 & 5.1096 & TRN \\
\hline CHEMBL 2000354 & 809212 & 7.3 & 7.2388 & TRN \\
\hline CHEMBL1965507 & 809212 & 4.1 & 5.1791 & TRN \\
\hline CHEMBL1967564 & 809212 & 4.1 & 4.0869 & TRN \\
\hline CHEMBL592030 & 809212 & 7.5 & 5.4117 & TST \\
\hline CHEMBL 2000071 & 809212 & 4.1 & 4.2752 & TRN \\
\hline CHEMBL1979176 & 809212 & 4.1 & 4.136 & TRN \\
\hline CHEMBL 2000408 & 809212 & 4.1 & 3.9429 & TRN \\
\hline
\end{tabular}




\begin{tabular}{|c|c|c|c|c|c|}
\hline \multicolumn{6}{|c|}{ Supplemental Table S2.txt } \\
\hline CHEMBL1978014 & 809212 & 4.1 & 4.4253 & TRN & \\
\hline CHEMBL1994538 & 809212 & 4.1 & 4.5881 & TRN & \\
\hline CHEMBL1983195 & 809212 & 4.1 & 5.1358 & TST & \\
\hline CHEMBL1975490 & 809212 & 6.0 & 5.4653 & TRN & \\
\hline CHEMBL1964444 & 809212 & 6.5 & 4.7499 & TRN & \\
\hline CHEMBL1989957 & 809212 & 4.1 & 4.2369 & TRN & \\
\hline CHEMBL1986139 & 809212 & 5.2 & 4.9981 & TRN & \\
\hline CHEMBL1980540 & 809212 & 4.1 & 4.4064 & TRN & \\
\hline CHEMBL1979883 & 809212 & 4.1 & 5.0221 & TRN & \\
\hline CHEMBL1984162 & 809212 & 5.8 & 6.239 & TRN & \\
\hline CHEMBL491758 & 809212 & 4.1 & 4.2117 & TRN & \\
\hline CHEMBL549730 & 809212 & 4.1 & 4.8845 & TRN & \\
\hline CHEMBL1970189 & 809212 & 4.1 & 3.9465 & TST & \\
\hline CHEMBL1996791 & 809212 & 4.1 & 4.1218 & TRN & \\
\hline CHEMBL371206 & 809212 & 4.1 & 4.3937 & TRN & \\
\hline CHEMBL1974664 & 809212 & 4.1 & 4.189 & TRN & \\
\hline CHEMBL1974288 & 809212 & 4.1 & 3.9132 & TRN & \\
\hline CHEMBL196363 & 809212 & 4.1 & 4.1479 & TRN & \\
\hline CHEMBL1996837 & 809212 & 4.3 & 3.7782 & TRN & \\
\hline CHEMBL1190711 & 809212 & 5.1 & 4.1925 & TRN & \\
\hline CHEMBL1968705 & 809212 & 5.4 & 4.5455 & TRN & \\
\hline CHEMBL1966343 & 809212 & 5.2 & 4.5875 & TRN & \\
\hline CHEMBL404367 & 809212 & 4.1 & 4.0279 & TRN & \\
\hline CHEMBL1967887 & 809212 & 6.9 & 6.1617 & TRN & \\
\hline CHEMBL 2000568 & 809212 & 4.1 & 4.2133 & TRN & \\
\hline CHEMBL 2000335 & 809212 & 4.1 & 4.2735 & TRN & \\
\hline CHEMBL1980161 & 809212 & 3.1 & 3.6679 & TST & \\
\hline CHEMBL1988717 & 809212 & 4.1 & 4.2374 & TRN & \\
\hline CHEMBL1974328 & 809212 & 8.0 & 5.5541 & TRN & \\
\hline CHEMBL509032 & 809212 & 4.1 & 4.5061 & TRN & \\
\hline CHEMBL573339 & 809212 & 5.3 & 5.2371 & TRN & \\
\hline CHEMBL143703 & 809212 & 4.3 & 3.9892 & TRN & \\
\hline CHEMBL1973808 & 809212 & 4.1 & 3.986 & TRN & \\
\hline CHEMBL2000429 & 809212 & 4.1 & 3.8664 & TRN & \\
\hline CHEMBL1972576 & 809212 & 4.1 & 4.2103 & TRN & \\
\hline CHEMBL1990254 & 809212 & 4.1 & 4.11600 & 00000000005 & TRN \\
\hline CHEMBL1992555 & 809212 & 4.1 & 4.3515 & TRN & \\
\hline CHEMBL1992342 & 809212 & 4.1 & 4.2145 & TRN & \\
\hline CHEMBL1988173 & 809212 & 7.1 & 6.0708 & TRN & \\
\hline CHEMBL535331 & 809212 & 4.1 & 4.2862 & TRN & \\
\hline CHEMBL1989805 & 809212 & 5.6 & 4.9102 & TST & \\
\hline CHEMBL1965423 & 809212 & 5.6 & 5.437 & TRN & \\
\hline CHEMBL1982980 & 809212 & 5.3 & 4.3562 & TST & \\
\hline CHEMBL205415 & 809212 & 5.9 & 5.421 & TRN & \\
\hline CHEMBL1977135 & 809212 & 4.1 & 3.9679 & TRN & \\
\hline CHEMBL 2001920 & 809212 & 7.3 & 6.4905 & TRN & \\
\hline CHEMBL1997119 & 809212 & 4.8 & 4.1517 & TRN & \\
\hline CHEMBL1978448 & 809212 & 5.6 & 5.1913 & TST & \\
\hline
\end{tabular}




\begin{tabular}{|c|c|c|c|c|}
\hline \multicolumn{5}{|c|}{ Supplemental Table s2.txt } \\
\hline CHEMBL 2004513 & 809212 & 4.1 & 4.3107 & TRN \\
\hline CHEMBL1972258 & 809212 & 4.1 & 4.8862 & TRN \\
\hline CHEMBL 2001257 & 809212 & 4.1 & 4.3924 & TRN \\
\hline CHEMBL1992536 & 809212 & 4.1 & 4.1394 & TRN \\
\hline CHEMBL1987793 & 809212 & 5.4 & 4.4229 & TST \\
\hline CHEMBL1966354 & 809212 & 5.4 & 5.0872 & TST \\
\hline CHEMBL439340 & 809212 & 7.0 & 6.5378 & TRN \\
\hline CHEMBL 2002373 & 809212 & 4.1 & 3.9507 & TRN \\
\hline CHEMBL 2006188 & 809212 & 4.1 & 4.1171 & TRN \\
\hline CHEMBL1967531 & 809212 & 4.1 & 4.3467 & TRN \\
\hline CHEMBL1973893 & 809212 & 4.1 & 4.124 & TRN \\
\hline CHEMBL1970913 & 809212 & 4.1 & 4.1467 & TRN \\
\hline CHEMBL1995736 & 809212 & 6.0 & 5.3454 & TRN \\
\hline CHEMBL1997534 & 809212 & 4.1 & 4.8659 & TRN \\
\hline CHEMBL1996500 & 809212 & 4.1 & 3.9595 & TRN \\
\hline CHEMBL1985095 & 809212 & 5.5 & 5.3175 & TST \\
\hline CHEMBL1977374 & 809212 & 4.1 & 4.0504 & TRN \\
\hline CHEMBL1998551 & 809212 & 4.1 & 3.9884 & TRN \\
\hline CHEMBL1682540 & 809212 & 5.3 & 5.3936 & TRN \\
\hline CHEMBL1978656 & 809212 & 5.7 & 5.5388 & TRN \\
\hline CHEMBL1976420 & 809212 & 4.1 & 4.03606 & 00000000005 \\
\hline CHEMBL1994864 & 809212 & 4.1 & 3.9631 & TRN \\
\hline CHEMBL497151 & 809212 & 5.9 & 6.5827 & TRN \\
\hline CHEMBL246970 & 809212 & 5.9 & 5.2891 & TST \\
\hline CHEMBL340921 & 809212 & 4.1 & 4.2081 & TST \\
\hline CHEMBL1999718 & 809212 & 4.1 & 4.0919 & TRN \\
\hline CHEMBL1276446 & 809212 & 5.9 & 5.9822 & TST \\
\hline CHEMBL1977346 & 809212 & 4.1 & 4.0544 & TRN \\
\hline CHEMBL1971649 & 809212 & 4.1 & 4.1463 & TRN \\
\hline CHEMBL1998435 & 809212 & 4.1 & 4.1493 & TRN \\
\hline CHEMBL 2006439 & 809212 & 4.1 & 5.6109 & TRN \\
\hline CHEMBL 2006156 & 809212 & 4.1 & 4.474 & TST \\
\hline CHEMBL1969190 & 809212 & 4.1 & 4.1636 & TRN \\
\hline CHEMBL1973937 & 809212 & 4.1 & 4.0553 & TRN \\
\hline CHEMBL1991674 & 809212 & 5.9 & 6.3844 & TRN \\
\hline CHEMBL1982711 & 809212 & 5.9 & 5.6756 & TRN \\
\hline CHEMBL1987982 & 809212 & 4.1 & 4.4323 & TST \\
\hline CHEMBL1998829 & 809212 & 4.1 & 4.1805 & TRN \\
\hline CHEMBL1988838 & 809212 & 4.1 & 4.6831 & TRN \\
\hline CHEMBL1981725 & 809212 & 4.1 & 4.3563 & TRN \\
\hline CHEMBL1982866 & 809212 & 4.1 & 3.9928 & TRN \\
\hline CHEMBL1968926 & 809212 & 4.1 & 4.06 & TRN \\
\hline CHEMBL462120 & 809212 & 4.1 & 5.1015 & TRN \\
\hline CHEMBL1991867 & 809212 & 4.4 & 3.8789 & TST \\
\hline CHEMBL1997839 & 809212 & 5.5 & 5.117 & TST \\
\hline CHEMBL1965570 & 809212 & 4.1 & 4.7527 & TRN \\
\hline CHEMBL 2007592 & 809212 & 5.5 & 6.8359 & TST \\
\hline CHEMBL 210963 & 809212 & 4.1 & 3.9121 & TST \\
\hline
\end{tabular}




\begin{tabular}{|c|c|c|c|c|}
\hline & & & Supplement & \\
\hline CHEMBL1614705 & 809212 & 4.1 & 4.1844 & TRN \\
\hline CHEMBL1984633 & 809212 & 4.1 & 3.9445 & TRN \\
\hline CHEMBL 2007372 & 809212 & 4.1 & 3.873 & TRN \\
\hline CHEMBL1965845 & 809212 & 5.4 & 5.6213 & TRN \\
\hline CHEMBL1982167 & 809212 & 6.4 & 5.035 & TRN \\
\hline CHEMBL 2006715 & 809212 & 4.1 & 4.0965 & TRN \\
\hline CHEMBL1986597 & 809212 & 5.6 & 5.0504 & TRN \\
\hline CHEMBL1990482 & 809212 & 5.5 & 5.2703 & TRN \\
\hline CHEMBL1990904 & 809212 & 4.1 & 3.9934 & TRN \\
\hline CHEMBL 2005475 & 809212 & 5.5 & 5.2289 & TRN \\
\hline CHEMBL402846 & 809212 & 4.1 & 4.0779 & TRN \\
\hline CHEMBL183844 & 809212 & 4.1 & 4.3132 & TRN \\
\hline CHEMBL1997349 & 809212 & 5.9 & 6.1304 & TST \\
\hline CHEMBL220057 & 809212 & 4.1 & 4.0269 & TRN \\
\hline CHEMBL1682545 & 809212 & 5.3 & 5.1077 & TRN \\
\hline CHEMBL383541 & 809212 & 6.0 & 5.8141 & TRN \\
\hline CHEMBL 2001224 & 809212 & 4.1 & 3.9757 & TRN \\
\hline CHEMBL10 & 809212 & 4.1 & 4.0697 & TRN \\
\hline CHEMBL1976732 & 809212 & 4.1 & 4.1123 & TRN \\
\hline CHEMBL1964937 & 809212 & 4.1 & 5.3655 & TRN \\
\hline CHEMBL1969506 & 809212 & 4.1 & 4.0799 & TRN \\
\hline CHEMBL1980163 & 809212 & 4.1 & 4.0426 & TRN \\
\hline CHEMBL 2005899 & 809212 & 4.1 & 4.9143 & TRN \\
\hline CHEMBL1682552 & 809212 & 5.8 & 6.1089 & TRN \\
\hline CHEMBL1972568 & 809212 & 4.1 & 4.3774 & TRN \\
\hline CHEMBL229799 & 809212 & 8.0 & 7.9863 & TRN \\
\hline CHEMBL105739 & 809212 & 4.1 & 4.1245 & TRN \\
\hline CHEMBL 379300 & 809212 & 8.0 & 7.495 & TRN \\
\hline CHEMBL1988995 & 809212 & 4.1 & 4.0429 & TRN \\
\hline CHEMBL1986781 & 809212 & 4.1 & 3.9976 & TRN \\
\hline CHEMBL526133 & 809212 & 6.5 & 5.9879 & TRN \\
\hline CHEMBL387971 & 809212 & 4.1 & 4.2556 & TST \\
\hline CHEMBL1979057 & 809212 & 4.1 & 5.0945 & TRN \\
\hline CHEMBL1967538 & 809212 & 5.6 & 4.8514 & TRN \\
\hline CHEMBL1999428 & 809212 & 4.1 & 3.8844 & TRN \\
\hline CHEMBL1967560 & 809212 & 4.1 & 4.0428 & TRN \\
\hline CHEMBL 211378 & 809212 & 4.1 & 4.0976 & TRN \\
\hline CHEMBL1516890 & 809212 & 5.6 & 5.7301 & TRN \\
\hline CHEMBL 2003420 & 809212 & 4.1 & 3.9748 & TRN \\
\hline CHEMBL1984586 & 809212 & 4.1 & 4.1989 & TRN \\
\hline CHEMBL1972659 & 809212 & 4.1 & 5.4105 & TST \\
\hline CHEMBL 272453 & 809212 & 4.1 & 4.1845 & TRN \\
\hline CHEMBL1970217 & 809212 & 4.1 & 3.9684 & TRN \\
\hline CHEMBL1987143 & 809212 & 4.9 & 4.7216 & TRN \\
\hline CHEMBL 2005528 & 809212 & 6.0 & 5.3521 & TST \\
\hline CHEMBL185569 & 809212 & 4.1 & 5.0711 & TRN \\
\hline CHEMBL1969843 & 809212 & 4.1 & 4.4206 & TRN \\
\hline CHEMBL 2007002 & 809212 & 4.1 & 4.662 & TRN \\
\hline
\end{tabular}




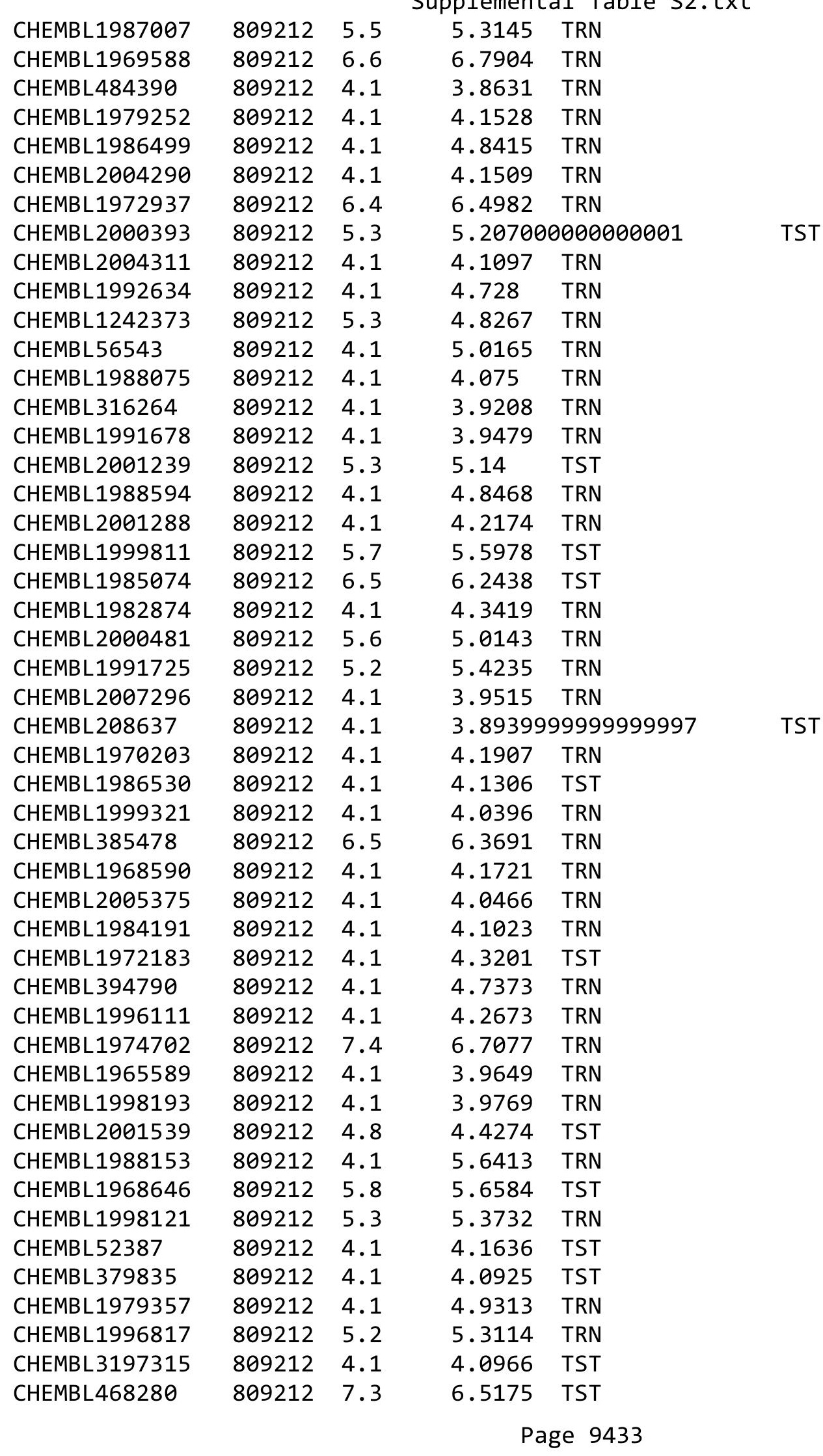




\begin{tabular}{|c|c|c|c|c|c|}
\hline \\
\hline CHEMBL1990884 & 809212 & 4.1 & 4.2596 & TRN & \\
\hline CHEMBL 3109278 & 809212 & 5.8 & 4.8974 & TRN & \\
\hline CHEMBL256835 & 809212 & 4.1 & 3.9755 & TRN & \\
\hline CHEMBL1980142 & 809212 & 4.1 & 4.1644 & TRN & \\
\hline CHEMBL41783 & 809212 & 4.1 & 4.2733 & TRN & \\
\hline CHEMBL 2006276 & 809212 & 4.1 & 4.092 & TRN & \\
\hline CHEMBL271381 & 809212 & 4.1 & 4.5522 & TRN & \\
\hline CHEMBL 2006785 & 809212 & 6.3 & 5.7316 & TRN & \\
\hline CHEMBL1982466 & 809212 & 4.1 & 4.1457 & TRN & \\
\hline CHEMBL1995740 & 809212 & 4.1 & 5.9441 & TRN & \\
\hline CHEMBL 234085 & 809212 & 4.1 & 4.168 & TST & \\
\hline CHEMBL1995832 & 809212 & 4.1 & 3.8749 & TRN & \\
\hline CHEMBL1998414 & 809212 & 4.1 & 4.0979 & TRN & \\
\hline CHEMBL1969042 & 809212 & 4.1 & 4.5276 & TRN & \\
\hline CHEMBL1999931 & 809212 & 6.6 & 6.695 & TRN & \\
\hline CHEMBL1076555 & 809212 & 5.5 & 5.0383 & TRN & \\
\hline CHEMBL1375418 & 809212 & 6.5 & 5.8926 & TRN & \\
\hline CHEMBL 2007064 & 809212 & 4.1 & 4.3364 & TRN & \\
\hline CHEMBL1981047 & 809212 & 4.1 & 4.3362 & TST & \\
\hline CHEMBL 229968 & 809212 & 7.8 & 7.6363 & TRN & \\
\hline CHEMBL1976240 & 809212 & 4.1 & 4.0575 & TRN & \\
\hline CHEMBL1979093 & 809212 & 4.1 & 4.5662 & TRN & \\
\hline CHEMBL1968151 & 809212 & 6.2 & 6.04899 & 99999999995 & TST \\
\hline CHEMBL1987009 & 809212 & 5.9 & 5.3088 & TRN & \\
\hline CHEMBL379218 & 809212 & 7.2 & 7.4272 & TRN & \\
\hline CHEMBL 2003817 & 809212 & 5.3 & 4.2949 & TRN & \\
\hline CHEMBL1994830 & 809212 & 4.1 & 5.8624 & TRN & \\
\hline CHEMBL226403 & 809212 & 7.5 & 6.7119 & TRN & \\
\hline CHEMBL1994938 & 809212 & 4.1 & 4.2983 & TRN & \\
\hline CHEMBL1825138 & 809212 & 4.1 & 4.7055 & TST & \\
\hline CHEMBL1966279 & 809212 & 4.1 & 4.9183 & TRN & \\
\hline CHEMBL1997846 & 809212 & 5.2 & 5.5091 & TRN & \\
\hline CHEMBL 2004419 & 809212 & 5.6 & 5.4374 & TRN & \\
\hline CHEMBL1972489 & 809212 & 4.1 & $3.9610 e$ & 00000000003 & TRN \\
\hline CHEMBL1994074 & 809212 & 4.1 & 4.3408 & TRN & \\
\hline CHEMBL451401 & 809212 & 3.1 & 3.5724 & TRN & \\
\hline CHEMBL1972119 & 809212 & 4.1 & 4.3517 & TRN & \\
\hline CHEMBL1090356 & 809212 & 4.1 & 3.9214 & TRN & \\
\hline CHEMBL95692 & 809212 & 4.1 & 4.0986 & TRN & \\
\hline CHEMBL1986328 & 809212 & 5.1 & 5.0343 & TST & \\
\hline CHEMBL1976455 & 809212 & 6.1 & 5.4276 & TRN & \\
\hline CHEMBL1983923 & 809212 & 4.1 & 4.584 & TST & \\
\hline CHEMBL1982361 & 809212 & 4.1 & 4.9154 & TRN & \\
\hline CHEMBL1983534 & 809212 & 4.1 & 4.2203 & TRN & \\
\hline CHEMBL1982122 & 809212 & 4.1 & 4.921 & TRN & \\
\hline CHEMBL 2000801 & 809212 & 4.1 & 4.1161 & TST & \\
\hline CHEMBL1999112 & 809212 & 5.4 & 4.316 & TST & \\
\hline CHEMBL1682546 & 809212 & 4.1 & 4.2736 & TST & \\
\hline
\end{tabular}




\begin{tabular}{|c|c|c|c|c|c|}
\hline \multicolumn{6}{|c|}{ Supplemental Table S2.txt } \\
\hline CHEMBL1991395 & 809212 & 4.1 & 3.8577 & TST & \\
\hline CHEMBL1971245 & 809212 & 4.1 & 4.1222 & TST & \\
\hline CHEMBL1972142 & 809212 & 4.1 & 4.0678 & TST & \\
\hline CHEMBL 2003638 & 809212 & 6.1 & 5.811 & TST & \\
\hline CHEMBL1996066 & 809212 & 4.1 & 4.5148 & TST & \\
\hline CHEMBL1970806 & 809212 & 6.1 & 6.38899 & 9999999999 & TST \\
\hline CHEMBL1375640 & 809212 & 4.1 & 4.3539 & TST & \\
\hline CHEMBL 2006237 & 809212 & 6.2 & 5.7283 & TST & \\
\hline CHEMBL1967720 & 809212 & 4.1 & 4.0588 & TST & \\
\hline CHEMBL1572266 & 809212 & 4.1 & 4.4504 & TST & \\
\hline CHEMBL1991138 & 809212 & 4.1 & 4.0476 & TST & \\
\hline CHEMBL1969755 & 809212 & 4.1 & 3.9671 & TST & \\
\hline CHEMBL1979516 & 809212 & 4.1 & 3.9992 & TST & \\
\hline CHEMBL1972820 & 809212 & 6.6 & 4.3458 & TST & \\
\hline CHEMBL1996208 & 809212 & 4.1 & 4.3601 & TST & \\
\hline CHEMBL1989029 & 809212 & 5.8 & 5.4881 & TST & \\
\hline CHEMBL392642 & 809212 & 5.6 & 5.4851 & TST & \\
\hline CHEMBL1980144 & 809212 & 5.2 & 4.7632 & TST & \\
\hline CHEMBL1991188 & 809212 & 4.1 & 4.0259 & TST & \\
\hline CHEMBL1972849 & 809212 & 4.1 & 3.9792 & TST & \\
\hline CHEMBL 2003622 & 809212 & 5.4 & 5.0516 & TST & \\
\hline CHEMBL231209 & 809212 & 4.1 & 4.709 & TST & \\
\hline CHEMBL1975357 & 809212 & 5.8 & 5.329 & TST & \\
\hline CHEMBL1976220 & 809212 & 4.1 & 4.1618 & TST & \\
\hline CHEMBL259922 & 809212 & 4.1 & 4.3409 & TST & \\
\hline CHEMBL1997617 & 809212 & 4.1 & 4.7301 & TST & \\
\hline CHEMBL1982383 & 809212 & 4.1 & 3.9054 & TST & \\
\hline CHEMBL1969301 & 809212 & 4.1 & 3.9122 & TST & \\
\hline CHEMBL17370 & 809212 & 4.1 & 3.9772 & TST & \\
\hline CHEMBL1966068 & 809212 & 5.1 & 5.66100 & 00000000005 & TST \\
\hline CHEMBL1987910 & 809212 & 4.1 & 4.1337 & TST & \\
\hline CHEMBL1983932 & 809212 & 4.1 & 5.334 & TST & \\
\hline CHEMBL1973399 & 809212 & 3.1 & 3.9336 & TST & \\
\hline CHEMBL1991285 & 809212 & 4.1 & 3.9642 & TST & \\
\hline CHEMBL1984038 & 809212 & 4.1 & 4.176 & TST & \\
\hline CHEMBL243088 & 809212 & 7.5 & 6.7556 & TST & \\
\hline CHEMBL1993661 & 809212 & 4.1 & 4.9174 & TST & \\
\hline CHEMBL1974416 & 809212 & 4.1 & 4.3604 & TST & \\
\hline CHEMBL2004615 & 809212 & 5.6 & 4.9974 & TST & \\
\hline CHEMBL1984039 & 809212 & 5.1 & 4.3327 & TST & \\
\hline CHEMBL1997872 & 809212 & 4.1 & 4.0413 & TST & \\
\hline CHEMBL3715821 & 1536565 & 8.301 & 7.859 & TRN & \\
\hline CHEMBL3716416 & 1536565 & 7.301 & 5.7272 & TRN & \\
\hline CHEMBL 3717933 & 1536565 & 8.301 & 7.813 & TRN & \\
\hline CHEMBL 3718965 & 1536565 & 6.301 & 6.8326 & TRN & \\
\hline CHEMBL3716575 & 1536565 & 4.301 & 4.3843 & TRN & \\
\hline CHEMBL 3717373 & 1536565 & 4.301 & 5.4547 & TRN & \\
\hline CHEMBL 3718473 & 1536565 & 7.301 & 6.4449 & TRN & \\
\hline
\end{tabular}


Supplemental Table S2.txt

\begin{tabular}{|c|c|c|c|c|c|}
\hline CHEMBL3718453 & 1536565 & 7.301 & 7.1842 & TST & \\
\hline CHEMBL3716567 & 1536565 & 6.301 & 5.7704 & TRN & \\
\hline CHEMBL3716318 & 1536565 & 4.301 & 6.2657 & TRN & \\
\hline CHEMBL3717150 & 1536565 & 4.301 & 4.262 & TRN & \\
\hline CHEMBL3719326 & 1536565 & 7.301 & 6.5753 & TST & \\
\hline CHEMBL3718538 & 1536565 & 4.301 & 4.9011 & TST & \\
\hline CHEMBL3718523 & 1536565 & 7.301 & 7.7099 & TRN & \\
\hline CHEMBL3719165 & 1536565 & 6.301 & 6.4058 & TRN & \\
\hline CHEMBL3719286 & 1536565 & 7.301 & 7.1209 & TRN & \\
\hline CHEMBL3716788 & 1536565 & 7.301 & 6.8073 & TRN & \\
\hline CHEMBL3715872 & 1536565 & 7.301 & 7.859 & TRN & \\
\hline CHEMBL3718891 & 1536565 & 6.301 & 6.7217 & TRN & \\
\hline CHEMBL3719243 & 1536565 & 4.301 & 5.0185 & TRN & \\
\hline CHEMBL3715292 & 1536565 & 8.301 & 7.3095 & TST & \\
\hline CHEMBL3716641 & 1536565 & 4.301 & 3.9547 & TRN & \\
\hline CHEMBL3717236 & 1536565 & 7.301 & 7.357 & TRN & \\
\hline CHEMBL3715380 & 1536565 & 7.301 & 7.1862 & TST & \\
\hline CHEMBL3718459 & 1536565 & 4.301 & 3.9096 & TRN & \\
\hline CHEMBL3717998 & 1536565 & 8.301 & 8.0191 & TRN & \\
\hline CHEMBL3716597 & 1536565 & 7.301 & \multicolumn{2}{|c|}{7.2379999999999995} & TRN \\
\hline CHEMBL3716742 & 1536565 & 6.301 & 6.4685 & TRN & \\
\hline CHEMBL3717759 & 1536565 & 8.301 & 7.899 & TRN & \\
\hline CHEMBL3716753 & 1536565 & 8.301 & \multicolumn{2}{|c|}{6.752000000000001} & TRN \\
\hline CHEMBL3717761 & 1536565 & 4.301 & 5.8129 & TRN & \\
\hline CHEMBL3717022 & 1536565 & 8.301 & 7.7309 & TST & \\
\hline CHEMBL3717335 & 1536565 & 6.301 & 5.8396 & TRN & \\
\hline CHEMBL3715570 & 1536565 & 4.301 & 4.0265 & TRN & \\
\hline CHEMBL3715005 & 1536565 & 6.301 & 6.9937 & TST & \\
\hline CHEMBL3715956 & 1536565 & 7.301 & 6.4846 & TRN & \\
\hline CHEMBL3717111 & 1536565 & 4.301 & 6.9952 & TRN & \\
\hline CHEMBL 3716744 & 1536565 & 7.301 & 6.9073 & TRN & \\
\hline CHEMBL3717452 & 1536565 & 7.301 & 6.9 & TRN & \\
\hline CHEMBL3718499 & 1536565 & 4.301 & 5.6683 & TRN & \\
\hline CHEMBL3715987 & 1536565 & 7.301 & 7.1112 & TST & \\
\hline CHEMBL3715470 & 1536565 & 4.301 & 4.3597 & TRN & \\
\hline CHEMBL3718595 & 1536565 & 4.301 & 3.8749 & TRN & \\
\hline CHEMBL3719083 & 1536565 & 4.301 & \multicolumn{2}{|c|}{5.1610000000000005} & TST \\
\hline CHEMBL3715150 & 1536565 & 4.301 & 4.0795 & TRN & \\
\hline CHEMBL3717391 & 1536565 & 7.301 & 7.2847 & TRN & \\
\hline CHEMBL3715546 & 1536565 & 7.301 & 7.7289 & TST & \\
\hline CHEMBL3717846 & 1536565 & 8.301 & 7.6786 & TST & \\
\hline CHEMBL 3717484 & 1536565 & 7.301 & 6.5425 & TST & \\
\hline CHEMBL3719151 & 1536565 & 4.301 & 3.8935 & TRN & \\
\hline CHEMBL3716666 & 1536565 & 4.301 & 4.3144 & TRN & \\
\hline CHEMBL3717017 & 1536565 & 8.301 & 7.9662 & TRN & \\
\hline CHEMBL3717117 & 1536565 & 4.301 & 4.6852 & TRN & \\
\hline CHEMBL3715041 & 1536565 & 6.301 & 5.5343 & TRN & \\
\hline CHEMBL 3714861 & 1536565 & 8.301 & 7.3315 & TST & \\
\hline
\end{tabular}


Supplemental Table S2.txt

\begin{tabular}{|c|c|c|c|c|c|}
\hline CHEMBL3717424 & 1536565 & 7.301 & 7.2558 & TST & \\
\hline CHEMBL3717193 & 1536565 & 7.301 & 6.4248 & TST & \\
\hline CHEMBL3716968 & 1536565 & 7.301 & 7.0271 & TRN & \\
\hline CHEMBL3716741 & 1536565 & 8.301 & 7.1247 & TRN & \\
\hline CHEMBL3718166 & 1536565 & 7.301 & 6.7437 & TST & \\
\hline CHEMBL3714849 & 1536565 & 6.301 & 5.7226 & TRN & \\
\hline CHEMBL3716849 & 1536565 & 7.301 & 6.8866 & TRN & \\
\hline CHEMBL3718736 & 1536565 & 6.301 & 7.2855 & TRN & \\
\hline CHEMBL3715589 & 1536565 & 7.301 & 5.7829 & TST & \\
\hline CHEMBL3718622 & 1536565 & 4.301 & 4.6672 & TRN & \\
\hline CHEMBL3715050 & 1536565 & 6.301 & 5.9017 & TRN & \\
\hline CHEMBL3718164 & 1536565 & 6.301 & 6.8587 & TRN & \\
\hline CHEMBL3716358 & 1536565 & 4.301 & 4.3293 & TRN & \\
\hline CHEMBL3715969 & 1536565 & 4.301 & 4.3878 & TRN & \\
\hline CHEMBL3715887 & 1536565 & 7.301 & 7.5807 & TRN & \\
\hline CHEMBL3718863 & 1536565 & 4.301 & 4.1889 & TRN & \\
\hline CHEMBL3716888 & 1536565 & 4.301 & 4.5613 & TRN & \\
\hline CHEMBL3715806 & 1536565 & 7.301 & 6.9672 & TRN & \\
\hline CHEMBL3719051 & 1536565 & 6.301 & 6.71 & TRN & \\
\hline CHEMBL3718578 & 1536565 & 4.301 & 4.4644 & TRN & \\
\hline CHEMBL3717584 & 1536565 & 6.301 & 5.9716 & TST & \\
\hline CHEMBL3716774 & 1536565 & 6.301 & 5.5044 & TRN & \\
\hline CHEMBL3716033 & 1536565 & 4.301 & 4.7502 & TST & \\
\hline CHEMBL3715362 & 1536565 & 7.301 & 6.6334 & TST & \\
\hline CHEMBL3717713 & 1536565 & 6.301 & 6.2209 & TRN & \\
\hline CHEMBL3718940 & 1536565 & 6.301 & 6.439 & TRN & \\
\hline CHEMBL3715148 & 1536565 & 7.301 & 7.4262 & TRN & \\
\hline CHEMBL3718066 & 1536565 & 7.301 & 6.8818 & TRN & \\
\hline CHEMBL3715942 & 1536565 & 6.301 & 5.4912 & TRN & \\
\hline CHEMBL3715338 & 1536565 & 4.301 & 4.6029 & TST & \\
\hline CHEMBL3717468 & 1536565 & 7.301 & 7.3256 & TRN & \\
\hline CHEMBL3718397 & 1536565 & 7.301 & 6.9882 & TST & \\
\hline CHEMBL3717552 & 1536565 & 4.301 & 5.4983 & TRN & \\
\hline CHEMBL3718847 & 1536565 & 4.301 & 4.4125 & TST & \\
\hline CHEMBL3717643 & 1536565 & 4.301 & 5.1597 & TRN & \\
\hline CHEMBL3718766 & 1536565 & 4.301 & 4.2921 & TRN & \\
\hline CHEMBL 3717287 & 1536565 & 7.301 & 7.23799 & 99999999995 & TRN \\
\hline CHEMBL3717276 & 1536565 & 4.301 & 4.9145 & TST & \\
\hline CHEMBL3716321 & 1536565 & 4.301 & 4.1913 & TRN & \\
\hline CHEMBL3717227 & 1536565 & 4.301 & 4.3588 & TRN & \\
\hline CHEMBL89873 & 28188 & 6.041 & 6.4015 & TRN & \\
\hline CHEMBL324491 & 28188 & 5.2147 & 5.2811 & TRN & \\
\hline CHEMBL303881 & 28188 & 7.4089 & 6.9594 & TRN & \\
\hline CHEMBL113430 & 28188 & 7.699 & 7.5755 & TRN & \\
\hline CHEMBL444332 & 28188 & 6.0177 & 6.1739 & TRN & \\
\hline CHEMBL418840 & 28188 & 6.0605 & 6.3468 & TRN & \\
\hline CHEMBL 71075 & 28188 & 7.3872 & 7.3732 & TRN & \\
\hline CHEMBL333141 & 28188 & 6.4089 & 6.8491 & TRN & \\
\hline
\end{tabular}




\begin{tabular}{|c|c|c|c|c|c|c|}
\hline & & & & & & \\
\hline CHEMBL306349 & 28188 & 6.0706 & 7.5672 & TST & & \\
\hline CHEMBL113011 & 28188 & 6.7959 & 7.3083 & TRN & & \\
\hline CHEMBL324104 & 28188 & 5.6326 & 7.1348 & TST & & \\
\hline CHEMBL320717 & 28188 & 7.2924 & 6.9888 & TRN & & \\
\hline CHEMBL420119 & 28188 & 7.7447 & 7.6914 & TRN & & \\
\hline CHEMBL324320 & 28188 & 6.7959 & 7.17299 & 9999999999 & & TRN \\
\hline CHEMBL431981 & 28188 & 7.6198 & 7.2062 & TRN & & \\
\hline CHEMBL112525 & 28188 & 6.9586 & 6.9521 & TRN & & \\
\hline CHEMBL113475 & 28188 & 6.4437 & 6.9698 & TRN & & \\
\hline CHEMBL322938 & 28188 & 6.5686 & 6.2932 & TRN & & \\
\hline CHEMBL113549 & 28188 & 7.5528 & 7.3588 & TRN & & \\
\hline CHEMBL113861 & 28188 & 7.5229 & 7.3266 & TST & & \\
\hline CHEMBL113631 & 28188 & 6.71899 & 99999999 & 99 & 7.0591 & TRN \\
\hline CHEMBL73336 & 28188 & 7.3872 & 7.3065 & TST & & \\
\hline CHEMBL430887 & 28188 & 7.9208 & 7.4993 & TRN & & \\
\hline CHEMBL109666 & 28188 & 7.1135 & 7.187 & TRN & & \\
\hline CHEMBL112937 & 28188 & 5.6021 & 5.6306 & TRN & & \\
\hline CHEMBL326882 & 28188 & 5.5686 & 5.7663 & TRN & & \\
\hline CHEMBL113372 & 28188 & 5.2596 & 5.8683 & TRN & & \\
\hline CHEMBL264631 & 28188 & 5.3098 & 5.0902 & TRN & & \\
\hline CHEMBL332944 & 28188 & 7.7447 & 7.2623 & TRN & & \\
\hline CHEMBL326657 & 28188 & 6.699 & 6.7305 & TRN & & \\
\hline CHEMBL326851 & 28188 & 5.3768 & 6.1106 & TRN & & \\
\hline CHEMBL405810 & 28188 & 7.7696 & 7.2318 & TST & & \\
\hline CHEMBL113284 & 28188 & 5.8239 & 5.7563 & TRN & & \\
\hline CHEMBL112177 & 28188 & 6.8539 & 7.0794 & TRN & & \\
\hline CHEMBL113493 & 28188 & 5.3468 & 5.1127 & TRN & & \\
\hline CHEMBL326106 & 28188 & 7.2676 & 7.2069 & TRN & & \\
\hline CHEMBL113910 & 28188 & 7.5229 & 7.4933 & TST & & \\
\hline CHEMBL113252 & 28188 & 7.3468 & 7.1939 & TRN & & \\
\hline CHEMBL113158 & 28188 & 7.6021 & 7.6276 & TRN & & \\
\hline CHEMBL109245 & 28188 & 5.4815 & 6.2763 & TRN & & \\
\hline CHEMBL113398 & 28188 & 6.7447 & 7.4433 & TST & & \\
\hline CHEMBL322937 & 28188 & 5.0 & 6.91799 & 9999999999 & & TST \\
\hline CHEMBL332474 & 28188 & 5.6576 & 4.9985 & TRN & & \\
\hline CHEMBL113079 & 28188 & 6.9208 & 6.7718 & TRN & & \\
\hline CHEMBL113548 & 28188 & 7.6778 & 7.3499 & TRN & & \\
\hline CHEMBL323662 & 28188 & 7.5086 & 7.2091 & TRN & & \\
\hline CHEMBL296055 & 28188 & 7.7696 & 7.4034 & TRN & & \\
\hline CHEMBL111959 & 28188 & 6.6198 & 6.7033 & TRN & & \\
\hline CHEMBL323811 & 28188 & 6.1938 & 6.4326 & TRN & & \\
\hline CHEMBL112361 & 28188 & 7.2366 & 7.3975 & TRN & & \\
\hline CHEMBL325384 & 28188 & 7.2518 & 7.0455 & TRN & & \\
\hline CHEMBL111981 & 28188 & 7.3098 & 6.9931 & TRN & & \\
\hline CHEMBL112519 & 28188 & 7.1871 & 7.3214 & TST & & \\
\hline CHEMBL112738 & 28188 & 6.3279 & 6.106 & TRN & & \\
\hline CHEMBL112429 & 28188 & 7.7959 & 7.4496 & TRN & & \\
\hline CHEMBL304612 & 28188 & 7.5686 & 7.2449 & TST & & \\
\hline
\end{tabular}




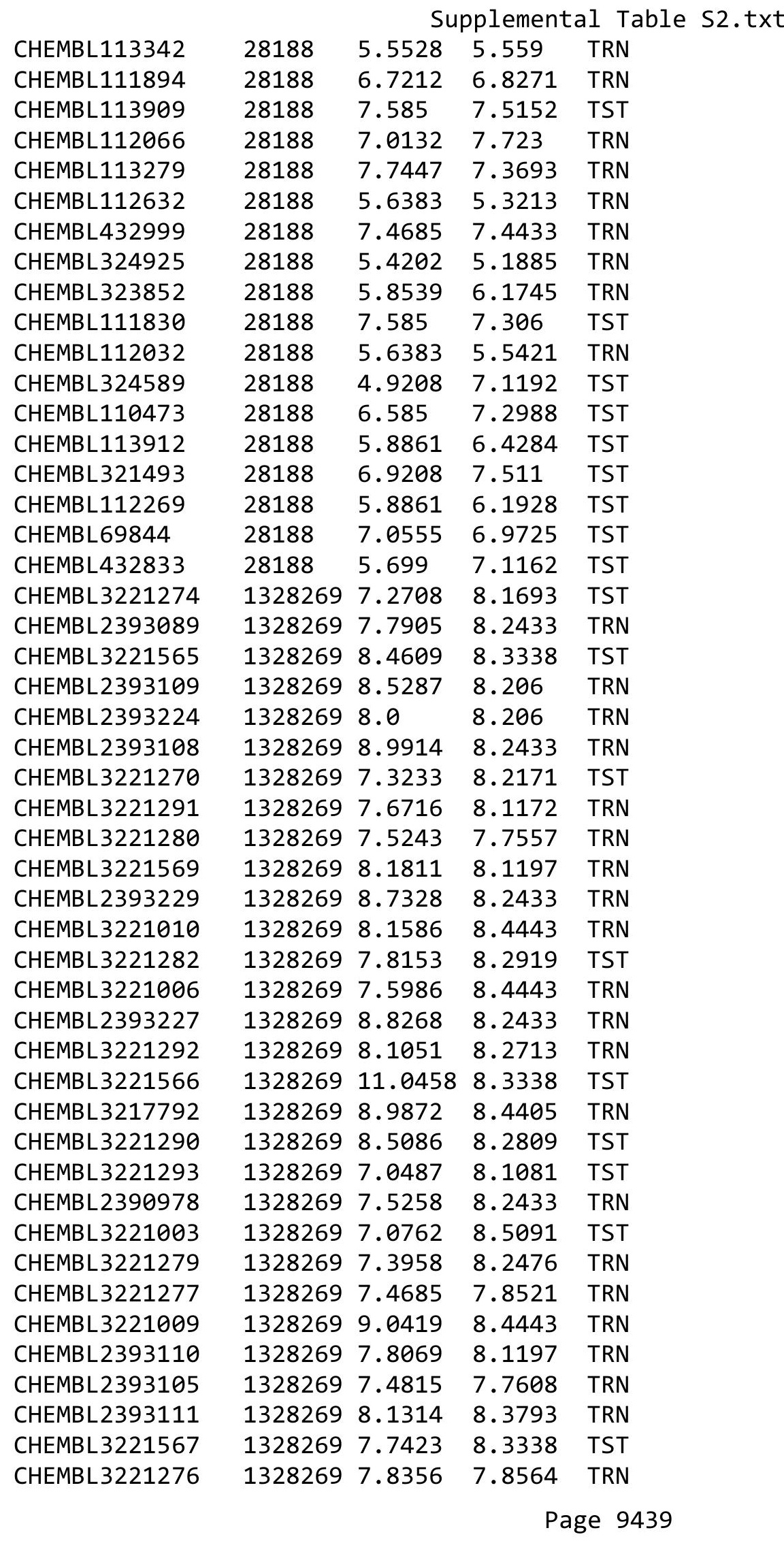


Supplemental Table S2.txt

\begin{tabular}{|c|c|c|c|c|c|c|}
\hline CHEMBL 3221281 & 1328269 & 7.4685 & 7.8521 & TRN & & \\
\hline CHEMBL 3221570 & 1328269 & \multicolumn{3}{|c|}{8.062000000000001} & 8.3793 & TRN \\
\hline CHEMBL 3221275 & 1328269 & 8.6144 & 8.247 & TRN & & \\
\hline CHEMBL 3221273 & 1328269 & 7.6946 & 7.3083 & TRN & & \\
\hline CHEMBL 3221271 & 1328269 & 8.1013 & 8.0312 & TRN & & \\
\hline CHEMBL 3221288 & 1328269 & 7.8356 & 7.7557 & TRN & & \\
\hline CHEMBL 3221278 & 1328269 & 7.2612 & 8.2919 & TST & & \\
\hline CHEMBL 3221287 & 1328269 & 8.3904 & 8.2476 & TRN & & \\
\hline CHEMBL 3221289 & 1328269 & 8.2034 & 7.8521 & TRN & & \\
\hline CHEMBL 3221007 & 1328269 & 10.3468 & 8.4443 & TST & & \\
\hline CHEMBL 3221284 & 1328269 & 7.3507 & 7.7557 & TRN & & \\
\hline CHEMBL 3221283 & 1328269 & 8.9914 & 8.2476 & TRN & & \\
\hline CHEMBL 3221272 & 1328269 & 7.6383 & 7.5603 & TRN & & \\
\hline CHEMBL 3221568 & 1328269 & 8.3036 & 8.206 & TRN & & \\
\hline CHEMBL 3221008 & 1328269 & \multicolumn{3}{|c|}{7.821000000000001} & 8.4443 & \\
\hline CHEMBL 3221285 & 1328269 & 8.4365 & 7.8521 & TRN & & \\
\hline CHEMBL 2393225 & 1328269 & 8.1838 & 8.1197 & TRN & & \\
\hline CHEMBL 3221005 & 1328269 & 9.8894 & 8.4443 & TST & & \\
\hline CHEMBL 2393228 & 1328269 & 8.1726 & 8.2433 & TRN & & \\
\hline CHEMBL 3221286 & 1328269 & 7.7645 & 8.2919 & TST & & \\
\hline CHEMBL 2393107 & 1328269 & 9.5243 & 8.3793 & TRN & & \\
\hline CHEMBL2393226 & 1328269 & 7.8729 & 8.3793 & TRN & & \\
\hline CHEMBL 2393106 & 1328269 & 7.9066 & 8.2363 & TRN & & \\
\hline CHEMBL 3137475 & 1301330 & 4.5226 & 3.5585 & TST & & \\
\hline CHEMBL 3137474 & 1301330 & 4.7525 & 4.7518 & TRN & & \\
\hline CHEMBL 3137465 & 1301330 & 4.2774 & 4.2781 & TRN & & \\
\hline CHEMBL 3137457 & 1301330 & 3.0 & 2.9996 & TRN & & \\
\hline CHEMBL 3104528 & 1301330 & 4.2958 & 4.2954 & TRN & & \\
\hline CHEMBL 3137470 & 1301330 & 3.0 & 3.0002 & TRN & & \\
\hline CHEMBL 3104478 & 1301330 & 3.0 & 2.9988 & TRN & & \\
\hline CHEMBL 3104535 & 1301330 & 4.2159 & 4.2161 & TRN & & \\
\hline CHEMBL 3137461 & 1301330 & 5.0325 & 5.0326 & TRN & & \\
\hline CHEMBL 3137444 & 1301330 & 4.311 & 4.3111 & TRN & & \\
\hline CHEMBL3137466 & 1301330 & 4.2041 & 4.6717 & TST & & \\
\hline CHEMBL 3137445 & 1301330 & \multicolumn{3}{|c|}{ 4. 2410000000000005} & 4.2414 & \\
\hline CHEMBL 3137460 & 1301330 & 4.3089 & 4.3085 & TRN & & \\
\hline CHEMBL 3137462 & 1301330 & 4.9842 & 4.984 & TRN & & \\
\hline CHEMBL 3104532 & 1301330 & 4.195 & 4.1945 & TRN & & \\
\hline CHEMBL 3104529 & 1301330 & 4.2566 & 4.2564 & TRN & & \\
\hline CHEMBL 3104473 & 1301330 & 4.2451 & 4.2456 & TRN & & \\
\hline CHEMBL3137456 & 1301330 & 4.2686 & 4.269 & TRN & & \\
\hline CHEMBL3137450 & 1301330 & 4.7867 & 4.7868 & TRN & & \\
\hline CHEMBL3137459 & 1301330 & 3.0 & 3.0001 & TRN & & \\
\hline CHEMBL 3104530 & 1301330 & 4.2374 & 4.2381 & TRN & & \\
\hline CHEMBL 3137469 & 1301330 & 4.6527 & 4.6521 & TRN & & \\
\hline CHEMBL 3104533 & 1301330 & 4.4883 & 4.4884 & TRN & & \\
\hline CHEMBL 3137442 & 1301330 & 4.1716 & 4.0981 & TST & & \\
\hline CHEMBL 3137451 & 1301330 & 4.3679 & 4.3688 & TRN & & \\
\hline
\end{tabular}


Supplemental Table S2.txt

\begin{tabular}{|c|c|c|c|c|c|c|}
\hline CHEMBL3104477 & 1301330 & 4.5528 & 4.5539 & TRN & & \\
\hline CHEMBL3104476 & 1301330 & 3.0 & 3.0003 & TRN & & \\
\hline CHEMBL3137468 & 1301330 & 4.2796 & 4.2786 & TRN & & \\
\hline CHEMBL3104475 & 1301330 & 4.2951 & 4.2948 & TRN & & \\
\hline CHEMBL3137483 & 1301330 & 3.0 & 4.6379 & TST & & \\
\hline CHEMBL3104534 & 1301330 & 4.26699 & 99999999 & 995 & 4.2673 & TRN \\
\hline CHEMBL3104527 & 1301330 & 4.1921 & 4.1925 & TRN & & \\
\hline CHEMBL3137471 & 1301330 & 4.1613 & 4.1553 & TST & & \\
\hline CHEMBL 3104474 & 1301330 & 4.2598 & 4.2597 & TRN & & \\
\hline CHEMBL3137478 & 1301330 & 3.0 & 3.0005 & TRN & & \\
\hline CHEMBL 3137447 & 1301330 & 4.3411 & 4.3409 & TRN & & \\
\hline CHEMBL3137452 & 1301330 & 4.3824 & 4.3817 & TRN & & \\
\hline CHEMBL3137446 & 1301330 & 4.2829 & 4.2825 & TRN & & \\
\hline CHEMBL3137449 & 1301330 & 4.4346 & 4.4345 & TRN & & \\
\hline CHEMBL3104536 & 1301330 & 3.0 & 3.0002 & TRN & & \\
\hline CHEMBL3137453 & 1301330 & 3.0 & 2.9998 & TRN & & \\
\hline CHEMBL3137479 & 1301330 & 4.1161 & 4.1159 & TRN & & \\
\hline CHEMBL3104538 & 1301330 & 3.0 & 3.0003 & TRN & & \\
\hline CHEMBL 3137473 & 1301330 & 4.6137 & 4.6138 & TRN & & \\
\hline CHEMBL3137458 & 1301330 & 4.2552 & 4.2548 & TRN & & \\
\hline CHEMBL3137472 & 1301330 & 6.0 & 3.7708 & TST & & \\
\hline CHEMBL 3137482 & 1301330 & 4.188 & 4.1879 & TRN & & \\
\hline CHEMBL 3137481 & 1301330 & 4.2882 & 4.1376 & TST & & \\
\hline CHEMBL 3137467 & 1301330 & 4.1068 & 4.1072 & TRN & & \\
\hline CHEMBL3137455 & 1301330 & 4.2749 & 4.1236 & TST & & \\
\hline CHEMBL3137476 & 1301330 & 3.0 & 3.0603 & TST & & \\
\hline CHEMBL 3137464 & 1301330 & 4.6019 & 4.0764 & TST & & \\
\hline CHEMBL3104537 & 1301330 & 4.4013 & 5.4658 & TST & & \\
\hline CHEMBL 3137448 & 1301330 & 4.4059 & 4.7464 & TST & & \\
\hline CHEMBL3104531 & 1301330 & 4.6959 & 4.2628 & TST & & \\
\hline CHEMBL3137477 & 1301330 & 4.3043 & 4.086 & TST & & \\
\hline CHEMBL434209 & 628669 & 7.4 & 7.0717 & TRN & & \\
\hline CHEMBL 70515 & 628669 & 5.35 & 5.6406 & TST & & \\
\hline CHEMBL40321 & 628669 & 6.52 & 6.4459 & TRN & & \\
\hline CHEMBL44037 & 628669 & 6.77 & 6.9327 & TRN & & \\
\hline CHEMBL323539 & 628669 & 6.32 & 6.3607 & TRN & & \\
\hline CHEMBL104759 & 628669 & 6.62 & 6.7752 & TRN & & \\
\hline CHEMBL319624 & 628669 & 5.89 & 5.8999 & TRN & & \\
\hline CHEMBL105260 & 628669 & 5.75 & 5.7815 & TRN & & \\
\hline CHEMBL104025 & 628669 & 6.3 & 6.3934 & TRN & & \\
\hline CHEMBL104748 & 628669 & 6.27 & 6.3497 & TRN & & \\
\hline CHEMBL274495 & 628669 & 4.79 & 4.7383 & TRN & & \\
\hline CHEMBL104694 & 628669 & 4.89 & 4.6359 & TRN & & \\
\hline CHEMBL104104 & 628669 & 4.6 & 4.7485 & TRN & & \\
\hline CHEMBL105370 & 628669 & 6.85 & 6.8538 & TRN & & \\
\hline CHEMBL105426 & 628669 & 4.7 & 5.5109 & TST & & \\
\hline CHEMBL102317 & 628669 & 6.21 & 6.2698 & TRN & & \\
\hline CHEMBL322176 & 628669 & 6.24 & 6.4145 & TRN & & \\
\hline
\end{tabular}




\begin{tabular}{|c|c|c|c|c|c|}
\hline & & \multicolumn{4}{|c|}{ Supplemental Table S2.txt } \\
\hline CHEMBL104638 & 628669 & 5.54 & 5.8018 & TRN & \\
\hline CHEMBL103029 & 628669 & 6.43 & \multicolumn{2}{|c|}{6.297999999999999} & TRN \\
\hline CHEMBL102469 & 628669 & 6.47 & 6.1785 & TRN & \\
\hline CHEMBL319914 & 628669 & 5.24 & \multicolumn{2}{|c|}{5.452999999999999} & TRN \\
\hline CHEMBL321284 & 628669 & 6.19 & 6.1619 & TRN & \\
\hline CHEMBL104483 & 628669 & 6.58 & 6.6907 & TRN & \\
\hline CHEMBL105045 & 628669 & 6.04 & 6.1835 & TRN & \\
\hline CHEMBL104846 & 628669 & 6.66 & 6.5655 & TRN & \\
\hline CHEMBL105519 & 628669 & 6.11 & 6.0317 & TRN & \\
\hline CHEMBL105726 & 628669 & 6.32 & 6.0537 & TRN & \\
\hline CHEMBL317901 & 628669 & 6.62 & 6.7313 & TRN & \\
\hline CHEMBL420279 & 628669 & 6.66 & 6.7215 & TRN & \\
\hline CHEMBL389051 & 628669 & 7.7 & 6.8487 & TST & \\
\hline CHEMBL104230 & 628669 & 8.05 & 7.7557 & TRN & \\
\hline CHEMBL103059 & 628669 & 6.77 & 6.9429 & TST & \\
\hline CHEMBL420280 & 628669 & 7.24 & 7.396 & TST & \\
\hline CHEMBL169981 & 628669 & 7.7 & 7.58 & TRN & \\
\hline CHEMBL321977 & 628669 & 7.01 & 6.8138 & TRN & \\
\hline CHEMBL104410 & 628669 & 7.24 & 7.3752 & TRN & \\
\hline CHEMBL265098 & 628669 & 7.17 & 7.1296 & TRN & \\
\hline CHEMBL105026 & 628669 & 7.44 & 7.6399 & TRN & \\
\hline CHEMBL104533 & 628669 & 5.42 & 5.8556 & TST & \\
\hline CHEMBL307914 & 628669 & 6.92 & 6.8841 & TRN & \\
\hline CHEMBL104856 & 628669 & 7.35 & 7.456 & TRN & \\
\hline CHEMBL320108 & 628669 & 7.12 & 6.91 & TRN & \\
\hline CHEMBL104358 & 628669 & 7.37 & 7.3045 & TRN & \\
\hline CHEMBL105425 & 628669 & 7.11 & 6.8252 & TRN & \\
\hline CHEMBL104851 & 628669 & 6.23 & 6.7421 & TRN & \\
\hline CHEMBL104110 & 628669 & 4.93 & 5.4138 & TRN & \\
\hline CHEMBL321527 & 628669 & 6.77 & 6.5828 & TRN & \\
\hline CHEMBL319629 & 628669 & 5.87 & 5.4488 & TRN & \\
\hline CHEMBL307399 & 628669 & 5.84 & 5.9912 & TRN & \\
\hline CHEMBL104267 & 628669 & 5.03 & 5.2431 & TST & \\
\hline CHEMBL73971 & 628669 & 5.94 & 5.8795 & TRN & \\
\hline CHEMBL105384 & 628669 & 6.17 & 6.1743 & TRN & \\
\hline CHEMBL105208 & 628669 & 5.29 & 5.3513 & TRN & \\
\hline CHEMBL105150 & 628669 & 5.76 & 5.99200 & 0000000001 & TRN \\
\hline CHEMBL104624 & 628669 & 5.45 & 5.5364 & TRN & \\
\hline CHEMBL104670 & 628669 & 6.01 & 5.5219 & TRN & \\
\hline CHEMBL323375 & 628669 & 7.13 & 7.1967 & TRN & \\
\hline CHEMBL105899 & 628669 & 6.92 & 6.9954 & TRN & \\
\hline CHEMBL102938 & 628669 & 6.32 & 6.2996 & TRN & \\
\hline CHEMBL323294 & 628669 & 6.3 & 6.5485 & TRN & \\
\hline CHEMBL320470 & 628669 & 6.03 & 5.9651 & TRN & \\
\hline CHEMBL104871 & 628669 & 6.5 & 6.4269 & TRN & \\
\hline CHEMBL104096 & 628669 & 6.54 & 6.6231 & TRN & \\
\hline CHEMBL105597 & 628669 & 6.07 & 6.03 & TRN & \\
\hline CHEMBL102275 & 628669 & 6.51 & 6.4872 & TRN & \\
\hline
\end{tabular}




\begin{tabular}{|c|c|c|c|c|c|}
\hline \multicolumn{6}{|c|}{ Supplemental Table S2.txt } \\
\hline CHEMBL320621 & 628669 & 7.05 & 7.0424 & TRN & \\
\hline CHEMBL323363 & 628669 & 7.17 & 7.1284 & TRN & \\
\hline CHEMBL105435 & 628669 & 6.72 & 6.9845 & TRN & \\
\hline CHEMBL320464 & 628669 & 6.89 & 6.8513 & TRN & \\
\hline CHEMBL101425 & 628669 & 6.84 & 6.7495 & TRN & \\
\hline CHEMBL1095264 & 628669 & 6.36 & 6.2987 & TRN & \\
\hline CHEMBL68969 & 628669 & 4.61 & 5.3473 & TST & \\
\hline CHEMBL1095266 & 628669 & 6.24 & 6.3309 & TRN & \\
\hline CHEMBL1098901 & 628669 & 5.73 & 5.7308 & TRN & \\
\hline CHEMBL1099239 & 628669 & 5.78 & 5.5286 & TST & \\
\hline CHEMBL1096899 & 628669 & 6.26 & 6.2046 & TST & \\
\hline CHEMBL1095267 & 628669 & 5.92 & 5.7365 & TST & \\
\hline CHEMBL1095593 & 628669 & 5.47 & 5.7215 & TST & \\
\hline CHEMBL1095594 & 628669 & 5.51 & 5.3811 & TST & \\
\hline CHEMBL1095919 & 628669 & 6.64 & 6.4419 & TST & \\
\hline CHEMBL1097231 & 628669 & 5.15 & 5.7047 & TST & \\
\hline CHEMBL1097598 & 628669 & 6.38 & 6.1332 & TST & \\
\hline CHEMBL1097599 & 628669 & 6.64 & 6.4787 & TST & \\
\hline CHEMBL1099256 & 628669 & 5.97 & 5.7174 & TST & \\
\hline CHEMBL1094274 & 628669 & 6.72 & 6.3266 & TST & \\
\hline CHEMBL1094275 & 628669 & 6.38 & 5.9094 & TST & \\
\hline CHEMBL1097201 & 628669 & 5.76 & 5.8652 & TST & \\
\hline CHEMBL1097597 & 628669 & 6.12 & 5.8324 & TST & \\
\hline CHEMBL1097931 & 628669 & 6.03 & 6.9217 & TST & \\
\hline CHEMBL291075 & 628669 & 7.4 & 7.2797 & TRN & \\
\hline CHEMBL295866 & 628669 & 6.46 & 6.3811 & TRN & \\
\hline CHEMBL43454 & 628669 & 6.82 & 6.8297 & TRN & \\
\hline CHEMBL41445 & 628669 & 6.12 & 6.2572 & TRN & \\
\hline CHEMBL41609 & 628669 & 6.8 & 6.7163 & TRN & \\
\hline CHEMBL290930 & 628669 & 5.37 & 6.0288 & TST & \\
\hline CHEMBL40195 & 628669 & 5.63 & 5.5665 & TRN & \\
\hline CHEMBL1406005 & 688422 & 5.35 & 6.016 & TRN & \\
\hline CHEMBL1534785 & 688422 & 7.2503 & 5.1825 & TRN & \\
\hline CHEMBL1367076 & 688422 & 4.95 & 4.8251 & TRN & \\
\hline CHEMBL1479325 & 688422 & 4.45 & 5.1674 & TRN & \\
\hline CHEMBL1463487 & 688422 & 4.5 & 5.28700 & 0000000001 & TRN \\
\hline CHEMBL3214632 & 688422 & 4.85 & 5.3434 & TRN & \\
\hline CHEMBL1539170 & 688422 & 7.8013 & 5.0612 & TRN & \\
\hline CHEMBL3212568 & 688422 & 4.65 & 5.4175 & TST & \\
\hline CHEMBL1546891 & 688422 & 4.45 & 4.784 & TRN & \\
\hline CHEMBL586029 & 688422 & 6.9 & 5.3168 & TST & \\
\hline CHEMBL1509451 & 688422 & 4.7 & 5.29899 & 99999999995 & TST \\
\hline CHEMBL1485116 & 688422 & 5.15 & 5.4087 & TRN & \\
\hline CHEMBL1453942 & 688422 & 4.65 & 4.5434 & TRN & \\
\hline CHEMBL1492296 & 688422 & 6.8499 & 5.2287 & TST & \\
\hline CHEMBL1489843 & 688422 & 5.75 & 5.3993 & TRN & \\
\hline CHEMBL1340747 & 688422 & 4.65 & 5.0513 & TRN & \\
\hline CHEMBL1584910 & 688422 & 4.9 & 5.5309 & TST & \\
\hline
\end{tabular}




\begin{tabular}{|c|c|c|c|c|c|}
\hline \multicolumn{6}{|c|}{ Supplemental Table S2.txt } \\
\hline CHEMBL1494217 & 688422 & 4.45 & 5.4172 & TRN & \\
\hline CHEMBL1418306 & 688422 & 5.45 & 5.5759 & TST & \\
\hline CHEMBL1520051 & 688422 & 5.05 & 5.2145 & TRN & \\
\hline CHEMBL1574590 & 688422 & 4.65 & 4.9843 & TRN & \\
\hline CHEMBL1417823 & 688422 & 4.95 & 4.9868 & TRN & \\
\hline CHEMBL1457712 & 688422 & 6.7501 & 5.6693 & TST & \\
\hline CHEMBL1459063 & 688422 & 4.45 & 5.3107 & TRN & \\
\hline CHEMBL1585138 & 688422 & 5.55 & 5.2361 & TST & \\
\hline CHEMBL1369131 & 688422 & 5.35 & 5.2236 & TST & \\
\hline CHEMBL1432805 & 688422 & 5.8 & 5.5793 & TST & \\
\hline CHEMBL1302589 & 688422 & 5.05 & 5.3526 & TRN & \\
\hline CHEMBL1418531 & 688422 & 8.3468 & 4.7085 & TST & \\
\hline CHEMBL1501626 & 688422 & 4.7 & 5.2273 & TRN & \\
\hline CHEMBL1509790 & 688422 & 4.6 & 5.1594 & TRN & \\
\hline CHEMBL1603374 & 688422 & 4.8 & 4.9929 & TRN & \\
\hline CHEMBL1584552 & 688422 & 8.3468 & 6.0124 & TST & \\
\hline CHEMBL1359412 & 688422 & 4.7 & 5.3169 & TRN & \\
\hline CHEMBL1554515 & 688422 & 7.5498 & 5.0744 & TRN & \\
\hline CHEMBL1422841 & 688422 & 5.2 & 5.0611 & TRN & \\
\hline CHEMBL1495590 & 688422 & 4.8 & 5.4235 & TRN & \\
\hline CHEMBL1591543 & 688422 & 4.7 & 4.8501 & TRN & \\
\hline CHEMBL1457828 & 688422 & 4.95 & 4.9052 & TRN & \\
\hline CHEMBL1518350 & 688422 & 4.95 & 5.2382 & TRN & \\
\hline CHEMBL1334229 & 688422 & 5.4 & 5.49299 & 9999999999 & TRN \\
\hline CHEMBL1374081 & 688422 & 5.75 & 5.4357 & TRN & \\
\hline CHEMBL1607017 & 688422 & 4.85 & 5.4878 & TRN & \\
\hline CHEMBL1595087 & 688422 & 8.4559 & 5.0119 & TST & \\
\hline CHEMBL1322116 & 688422 & 4.8 & 5.1314 & TRN & \\
\hline CHEMBL1406519 & 688422 & 8.3468 & 5.8618 & TRN & \\
\hline CHEMBL1456389 & 688422 & 4.9 & 5.4488 & TST & \\
\hline CHEMBL1348490 & 688422 & 5.0 & 4.9977 & TRN & \\
\hline CHEMBL1365626 & 688422 & 4.95 & 5.3494 & TRN & \\
\hline CHEMBL1564808 & 688422 & 6.1 & 5.5807 & TRN & \\
\hline CHEMBL1318548 & 688422 & 4.55 & 5.4552 & TRN & \\
\hline CHEMBL1331870 & 688422 & 7.4498 & 5.4882 & TST & \\
\hline CHEMBL1605773 & 688422 & 4.95 & 5.2765 & TRN & \\
\hline CHEMBL1494231 & 688422 & 5.15 & 5.5316 & TRN & \\
\hline CHEMBL1496162 & 688422 & 4.5 & 5.431 & TRN & \\
\hline CHEMBL1359162 & 688422 & 4.95 & 5.0706 & TRN & \\
\hline CHEMBL1577291 & 688422 & 4.8 & 5.4482 & TST & \\
\hline CHEMBL1368931 & 688422 & 4.75 & 5.4177 & TRN & \\
\hline CHEMBL1603989 & 688422 & 4.45 & 5.1191 & TRN & \\
\hline CHEMBL3197254 & 688422 & 4.5 & 5.53 & TRN & \\
\hline CHEMBL1389340 & 688422 & 7.5498 & 5.1528 & TRN & \\
\hline CHEMBL1459351 & 688422 & 4.5 & 5.0363 & TRN & \\
\hline CHEMBL600485 & 688422 & 4.7 & 5.2976 & TRN & \\
\hline CHEMBL1613499 & 688422 & 4.8 & 5.0972 & TRN & \\
\hline CHEMBL1563716 & 688422 & 4.55 & 5.2172 & TRN & \\
\hline
\end{tabular}




\begin{tabular}{|c|c|c|c|c|}
\hline \multicolumn{5}{|c|}{ Supplemental Table S2.txt } \\
\hline CHEMBL1596533 & 688422 & 4.9 & 5.0839 & TST \\
\hline CHEMBL1540377 & 688422 & 5.25 & 4.8623 & TRN \\
\hline CHEMBL1347518 & 688422 & 4.85 & 5.2073 & TST \\
\hline CHEMBL1513791 & 688422 & 4.95 & 4.9071 & TRN \\
\hline CHEMBL1390041 & 688422 & 5.6 & 5.7049 & TRN \\
\hline CHEMBL1566742 & 688422 & 4.45 & 4.6448 & TRN \\
\hline CHEMBL1497463 & 688422 & 5.45 & 5.1324 & TRN \\
\hline CHEMBL1550498 & 688422 & 6.5501 & 5.3679 & TRN \\
\hline CHEMBL1439777 & 688422 & 4.45 & 5.4545 & TST \\
\hline CHEMBL3198344 & 688422 & 5.9 & 5.6615 & TRN \\
\hline CHEMBL1362802 & 688422 & 5.45 & 5.6025 & TRN \\
\hline CHEMBL1382569 & 688422 & 6.5501 & 5.2554 & TRN \\
\hline CHEMBL104264 & 688422 & 4.9 & 4.8607 & TRN \\
\hline CHEMBL1599438 & 688422 & 5.7 & 5.1045 & TRN \\
\hline CHEMBL1443602 & 688422 & 5.8 & 5.3616 & TRN \\
\hline CHEMBL1384330 & 688422 & 4.45 & 4.9693 & TRN \\
\hline CHEMBL1413178 & 688422 & 4.95 & 5.4066 & TST \\
\hline CHEMBL1341109 & 688422 & 7.699 & 5.5107 & TST \\
\hline CHEMBL 3190381 & 688422 & 4.65 & 5.334 & TRN \\
\hline CHEMBL1585162 & 688422 & 4.45 & 5.1382 & TST \\
\hline CHEMBL1427563 & 688422 & 4.45 & 4.8683 & TRN \\
\hline CHEMBL1408797 & 688422 & 5.5 & 4.7006 & TRN \\
\hline CHEMBL1543572 & 688422 & 4.45 & 5.2007 & TRN \\
\hline CHEMBL1488969 & 688422 & 4.9 & 5.0963 & TRN \\
\hline CHEMBL1567097 & 688422 & 4.45 & 4.8766 & TRN \\
\hline CHEMBL1965444 & 688422 & 4.45 & 5.5871 & TRN \\
\hline CHEMBL1358754 & 688422 & 4.6 & 5.0611 & TST \\
\hline CHEMBL1605963 & 688422 & 4.7 & 5.3499 & TRN \\
\hline CHEMBL1409727 & 688422 & 7.15 & 6.0506 & TST \\
\hline CHEMBL1366732 & 688422 & 4.9 & 4.8658 & TRN \\
\hline CHEMBL1608159 & 688422 & 5.75 & 6.0592 & TRN \\
\hline CHEMBL1397300 & 688422 & 4.55 & 5.0199 & TRN \\
\hline CHEMBL3190135 & 688422 & 4.45 & 5.5747 & TRN \\
\hline CHEMBL1412324 & 688422 & 4.85 & 5.1991 & TST \\
\hline CHEMBL1386512 & 688422 & 5.15 & 4.9854 & TRN \\
\hline CHEMBL1445323 & 688422 & 5.5 & 5.1513 & TST \\
\hline CHEMBL1410143 & 688422 & 4.85 & 4.9883 & TRN \\
\hline CHEMBL598270 & 688422 & 5.15 & 4.8078 & TST \\
\hline CHEMBL539947 & 688422 & 5.55 & 5.2128 & TRN \\
\hline CHEMBL1447788 & 688422 & 7.3002 & 4.8607 & TRN \\
\hline CHEMBL1400220 & 688422 & 5.35 & 5.504 & TRN \\
\hline CHEMBL1591797 & 688422 & 4.95 & 5.3515 & TRN \\
\hline CHEMBL1479236 & 688422 & 4.65 & 4.7921 & TRN \\
\hline CHEMBL1371282 & 688422 & 7.6003 & 4.9956 & TRN \\
\hline CHEMBL1522820 & 688422 & 4.8 & 5.711 & TST \\
\hline CHEMBL1393639 & 688422 & 8.4949 & 5.2473 & TST \\
\hline CHEMBL1534514 & 688422 & 4.7 & 4.9444 & TST \\
\hline CHEMBL1455331 & 688422 & 4.9 & 4.9408 & TST \\
\hline
\end{tabular}




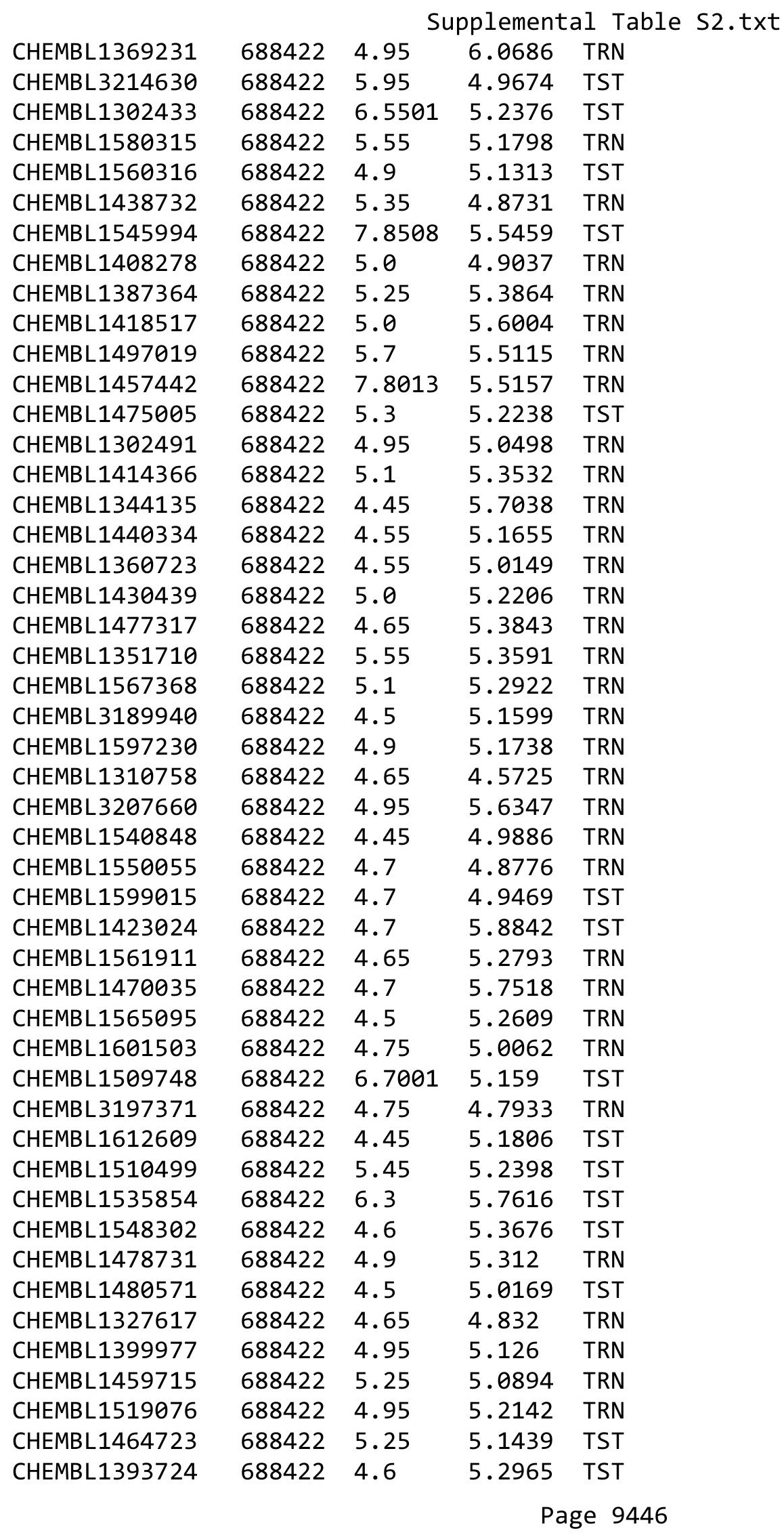




\begin{tabular}{|c|c|c|c|c|c|}
\hline \multicolumn{6}{|c|}{ Supplemental Table S2.txt } \\
\hline CHEMBL1450152 & 688422 & 4.9 & 5.3627 & TRN & \\
\hline CHEMBL1989310 & 688422 & 5.35 & 5.3571 & TST & \\
\hline CHEMBL1496986 & 688422 & 4.45 & 4.793 & TRN & \\
\hline CHEMBL1612924 & 688422 & 4.9 & 5.1649 & TRN & \\
\hline CHEMBL1569625 & 688422 & 4.75 & 4.7591 & TST & \\
\hline CHEMBL1521226 & 688422 & 4.85 & \multicolumn{2}{|c|}{5.513999999999999} & TRN \\
\hline CHEMBL1475211 & 688422 & 5.4 & 5.0554 & TRN & \\
\hline CHEMBL1530631 & 688422 & 4.65 & 5.3073 & TRN & \\
\hline CHEMBL1520679 & 688422 & 4.9 & 4.9617 & TRN & \\
\hline CHEMBL1350830 & 688422 & 4.85 & 5.47 & TRN & \\
\hline CHEMBL1362152 & 688422 & 5.95 & 5.1515 & TRN & \\
\hline CHEMBL1609179 & 688422 & 8.8861 & 5.5184 & TRN & \\
\hline CHEMBL1438381 & 688422 & 4.45 & 5.098 & TRN & \\
\hline CHEMBL1519947 & 688422 & 6.0 & 5.5662 & TST & \\
\hline CHEMBL1613644 & 688422 & 4.8 & 4.6492 & TRN & \\
\hline CHEMBL1304177 & 688422 & 4.5 & 5.0963 & TRN & \\
\hline CHEMBL1607858 & 688422 & 4.45 & 4.9827 & TRN & \\
\hline CHEMBL1382675 & 688422 & 4.45 & 5.5698 & TST & \\
\hline CHEMBL1534222 & 688422 & 4.7 & 5.4466 & TRN & \\
\hline CHEMBL1433291 & 688422 & 4.45 & 5.1842 & TRN & \\
\hline CHEMBL1542797 & 688422 & 4.45 & 4.8876 & TRN & \\
\hline CHEMBL1454677 & 688422 & 4.65 & 4.7271 & TRN & \\
\hline CHEMBL1508709 & 688422 & 4.65 & 5.6969 & TRN & \\
\hline CHEMBL1548101 & 688422 & 4.85 & 5.1344 & TRN & \\
\hline CHEMBL1544919 & 688422 & 4.5 & 4.7553 & TRN & \\
\hline CHEMBL1496183 & 688422 & 5.2 & 5.3377 & TST & \\
\hline CHEMBL1567010 & 688422 & 6.4 & 5.624 & TRN & \\
\hline CHEMBL1466338 & 688422 & 4.75 & 5.0448 & TST & \\
\hline CHEMBL1475908 & 688422 & 4.45 & \multicolumn{2}{|c|}{4.9830000000000005} & TRN \\
\hline CHEMBL1407196 & 688422 & 4.9 & 5.0481 & TRN & \\
\hline CHEMBL1571472 & 688422 & 5.35 & 5.3138 & TST & \\
\hline CHEMBL1495055 & 688422 & 4.7 & 5.121 & TRN & \\
\hline CHEMBL1586237 & 688422 & 4.5 & 5.2611 & TST & \\
\hline CHEMBL3197504 & 688422 & 4.95 & 5.7106 & TRN & \\
\hline CHEMBL1432360 & 688422 & 4.75 & 5.5142 & TRN & \\
\hline CHEMBL1499214 & 688422 & 4.6 & 4.9782 & TRN & \\
\hline CHEMBL1439453 & 688422 & 7.5003 & 5.1341 & TRN & \\
\hline CHEMBL1366860 & 688422 & 4.75 & 4.7542 & TRN & \\
\hline CHEMBL1555387 & 688422 & 5.25 & 5.1423 & TRN & \\
\hline CHEMBL1588827 & 688422 & 4.45 & 5.0296 & TRN & \\
\hline CHEMBL3212933 & 688422 & 4.9 & 5.2183 & TRN & \\
\hline CHEMBL1456994 & 688422 & 4.5 & 5.5568 & TRN & \\
\hline CHEMBL1398729 & 688422 & 7.0 & 5.8051 & TRN & \\
\hline CHEMBL1568562 & 688422 & 4.85 & 5.8489 & TST & \\
\hline CHEMBL1499436 & 688422 & 4.45 & 4.8007 & TST & \\
\hline CHEMBL1416631 & 688422 & 5.45 & 5.8222 & TRN & \\
\hline CHEMBL1480564 & 688422 & 4.45 & \multicolumn{2}{|c|}{5.6370000000000005} & TRN \\
\hline CHEMBL1302851 & 688422 & 4.65 & 5.1096 & TST & \\
\hline
\end{tabular}





\begin{tabular}{|c|c|c|c|c|c|}
\hline \multicolumn{6}{|c|}{ Supplemental Table S2.txt } \\
\hline CHEMBL1337230 & 688422 & 4.8 & 5.3582 & TST & \\
\hline CHEMBL1522020 & 688422 & 4.6 & 5.2775 & TST & \\
\hline CHEMBL1310490 & 688422 & 4.95 & 5.1899 & TST & \\
\hline CHEMBL1321832 & 688422 & 5.1 & 5.0502 & TRN & \\
\hline CHEMBL1573221 & 688422 & 4.45 & 5.5117 & TRN & \\
\hline CHEMBL1330106 & 688422 & 4.85 & 4.916 & TST & \\
\hline CHEMBL1586120 & 688422 & 5.15 & 5.5969 & TST & \\
\hline CHEMBL1304134 & 688422 & 4.45 & 5.3131 & TST & \\
\hline CHEMBL1445887 & 688422 & 4.8 & 4.5738 & TRN & \\
\hline CHEMBL1572703 & 688422 & 4.75 & 5.1431 & TRN & \\
\hline CHEMBL1530611 & 688422 & 4.45 & 5.2055 & TRN & \\
\hline CHEMBL1424253 & 688422 & 4.95 & 5.1032 & TRN & \\
\hline CHEMBL1368836 & 688422 & 5.8 & 5.8355 & TRN & \\
\hline CHEMBL1301094 & 688422 & 4.45 & 5.4371 & TRN & \\
\hline CHEMBL1403551 & 688422 & 5.05 & 5.1906 & TRN & \\
\hline CHEMBL1488286 & 688422 & 4.9 & 5.485 & TST & \\
\hline CHEMBL1540986 & 688422 & 5.9 & 5.7424 & TRN & \\
\hline CHEMBL 3210727 & 688422 & 5.95 & 5.2395 & TRN & \\
\hline CHEMBL1530807 & 688422 & 4.9 & 4.9339 & TRN & \\
\hline CHEMBL1357974 & 688422 & 4.5 & 5.2521 & TRN & \\
\hline CHEMBL1595206 & 688422 & 6.5 & 5.2353 & TRN & \\
\hline CHEMBL1593528 & 688422 & 4.95 & 5.29700 & 0000000001 & TRN \\
\hline CHEMBL1412695 & 688422 & 6.3 & 4.8516 & TRN & \\
\hline CHEMBL1413839 & 688422 & 5.65 & 5.1349 & TRN & \\
\hline CHEMBL1584180 & 688422 & 4.45 & 4.7003 & TRN & \\
\hline CHEMBL1459313 & 688422 & 4.95 & 5.0177 & TRN & \\
\hline CHEMBL1566334 & 688422 & 5.15 & 5.0841 & TRN & \\
\hline CHEMBL1575502 & 688422 & 6.5501 & 5.8079 & TRN & \\
\hline CHEMBL2000619 & 688422 & 5.35 & 5.2979 & TRN & \\
\hline CHEMBL1386915 & 688422 & 6.95 & 4.7486 & TRN & \\
\hline CHEMBL1565286 & 688422 & 5.05 & 4.8003 & TRN & \\
\hline CHEMBL1309692 & 688422 & 4.7 & 5.2536 & TST & \\
\hline CHEMBL1462894 & 688422 & 5.6 & 4.9971 & TRN & \\
\hline CHEMBL1401376 & 688422 & 4.95 & 5.6265 & TRN & \\
\hline CHEMBL1600782 & 688422 & 4.45 & 4.825 & TRN & \\
\hline CHEMBL1483688 & 688422 & 4.9 & 5.1727 & TRN & \\
\hline CHEMBL 244743 & 688422 & 4.95 & 5.5171 & TST & \\
\hline CHEMBL1463118 & 688422 & 4.7 & 5.1122 & TRN & \\
\hline CHEMBL1323891 & 688422 & 4.45 & 5.3373 & TRN & \\
\hline CHEMBL1565523 & 688422 & 4.55 & 5.1841 & TRN & \\
\hline CHEMBL1496959 & 688422 & 5.5 & 4.9901 & TST & \\
\hline CHEMBL1515038 & 688422 & 4.85 & 4.9411 & TRN & \\
\hline CHEMBL1487250 & 688422 & 5.35 & 5.3737 & TST & \\
\hline CHEMBL1453321 & 688422 & 4.65 & 5.0199 & TRN & \\
\hline CHEMBL1547328 & 688422 & 5.05 & 5.1201 & TRN & \\
\hline CHEMBL1446525 & 688422 & 5.05 & 5.5218 & TST & \\
\hline CHEMBL1579354 & 688422 & 4.65 & 5.3523 & TST & \\
\hline CHEMBL1547259 & 688422 & 5.0 & 5.0759 & TRN & \\
\hline
\end{tabular}




\begin{tabular}{|c|c|c|c|c|c|}
\hline \multicolumn{6}{|c|}{ Supplemental Table S2.txt } \\
\hline CHEMBL1354126 & 688422 & 4.75 & 4.7513 & TRN & \\
\hline CHEMBL1542772 & 688422 & 4.45 & 5.3893 & TST & \\
\hline CHEMBL1428730 & 688422 & 4.45 & 4.8913 & TST & \\
\hline CHEMBL1520688 & 688422 & 8.301 & 4.9778 & TRN & \\
\hline CHEMBL1465876 & 688422 & 8.2518 & 5.3664 & TST & \\
\hline CHEMBL1495662 & 688422 & 4.45 & 5.1703 & TRN & \\
\hline CHEMBL1518197 & 688422 & 5.6 & 5.2602 & TRN & \\
\hline CHEMBL1345380 & 688422 & 6.3 & 5.5758 & TRN & \\
\hline CHEMBL130213 & 688422 & 4.6 & 5.6661 & TST & \\
\hline CHEMBL1484051 & 688422 & 5.1 & 5.082 & TRN & \\
\hline CHEMBL1598760 & 688422 & 5.15 & 5.2724 & TRN & \\
\hline CHEMBL1595842 & 688422 & 4.8 & 5.5287 & TRN & \\
\hline CHEMBL3199037 & 688422 & 4.85 & 5.322 & TRN & \\
\hline CHEMBL1496635 & 688422 & 4.65 & 5.0238 & TST & \\
\hline CHEMBL1322915 & 688422 & 4.65 & 5.6795 & TRN & \\
\hline CHEMBL1503124 & 688422 & 4.75 & 5.4194 & TRN & \\
\hline CHEMBL1313417 & 688422 & 4.75 & 4.9783 & TST & \\
\hline CHEMBL1488905 & 688422 & 5.15 & 5.2489 & TST & \\
\hline CHEMBL1469511 & 688422 & 4.7 & 5.4477 & TRN & \\
\hline CHEMBL1371184 & 688422 & 4.65 & 5.0167 & TRN & \\
\hline CHEMBL1342221 & 688422 & 4.9 & 4.6962 & TRN & \\
\hline CHEMBL1364190 & 688422 & 4.45 & 4.6693 & TST & \\
\hline CHEMBL1542701 & 688422 & 4.45 & 5.0674 & TRN & \\
\hline CHEMBL1507757 & 688422 & 5.55 & 5.41100 & 00000000005 & TRN \\
\hline CHEMBL1575339 & 688422 & 4.5 & 5.2505 & TRN & \\
\hline CHEMBL1445372 & 688422 & 5.15 & 5.0283 & TRN & \\
\hline CHEMBL1529960 & 688422 & 5.25 & 5.53600 & 00000000005 & TRN \\
\hline CHEMBL475754 & 688422 & 4.45 & 5.1307 & TRN & \\
\hline CHEMBL1333542 & 688422 & 8.4949 & 5.3391 & TRN & \\
\hline CHEMBL1330390 & 688422 & 4.5 & 5.0291 & TRN & \\
\hline CHEMBL1550616 & 688422 & 4.75 & 5.2565 & TST & \\
\hline CHEMBL1583096 & 688422 & 5.0 & 5.3266 & TST & \\
\hline CHEMBL1459060 & 688422 & 7.6498 & 5.36799 & 9999999999 & TRN \\
\hline CHEMBL1553780 & 688422 & 4.45 & 4.853 & TRN & \\
\hline CHEMBL3189513 & 688422 & 5.0 & 5.3513 & TRN & \\
\hline CHEMBL1546851 & 688422 & 5.2 & 5.8012 & TRN & \\
\hline CHEMBL1309871 & 688422 & 4.8 & 5.4746 & TRN & \\
\hline CHEMBL1320769 & 688422 & 7.699 & 5.7394 & TRN & \\
\hline CHEMBL2005296 & 688422 & 5.25 & 5.1447 & TRN & \\
\hline CHEMBL1612556 & 688422 & 4.75 & 5.6186 & TRN & \\
\hline CHEMBL1549746 & 688422 & 6.35 & 5.9212 & TRN & \\
\hline CHEMBL1451327 & 688422 & 5.05 & 5.6572 & TST & \\
\hline CHEMBL1526023 & 688422 & 4.5 & 5.7529 & TRN & \\
\hline CHEMBL1426972 & 688422 & 4.45 & 5.2762 & TRN & \\
\hline CHEMBL1441450 & 688422 & 6.8 & 5.3603 & TST & \\
\hline CHEMBL1363241 & 688422 & 5.5 & 5.6017 & TRN & \\
\hline CHEMBL1320521 & 688422 & 4.7 & 5.1651 & TRN & \\
\hline CHEMBL1352658 & 688422 & 7.3497 & 6.0368 & TST & \\
\hline
\end{tabular}




\begin{tabular}{|c|c|c|c|c|c|}
\hline \multicolumn{6}{|c|}{ Supplemental Table S2.txt } \\
\hline CHEMBL1371988 & 688422 & 4.8 & 5.1975 & TRN & \\
\hline CHEMBL1469038 & 688422 & 4.45 & 4.8288 & TRN & \\
\hline CHEMBL1498227 & 688422 & 4.85 & 5.3613 & TRN & \\
\hline CHEMBL1309295 & 688422 & 4.6 & 4.8449 & TRN & \\
\hline CHEMBL1548442 & 688422 & 6.4 & 5.5406 & TST & \\
\hline CHEMBL1481013 & 688422 & 5.5 & 5.4533 & TRN & \\
\hline CHEMBL1553803 & 688422 & 4.45 & 4.7562 & TRN & \\
\hline CHEMBL1412412 & 688422 & 4.45 & 4.8303 & TST & \\
\hline CHEMBL1507138 & 688422 & 4.7 & 5.1464 & TRN & \\
\hline CHEMBL1999756 & 688422 & 4.75 & 5.2225 & TRN & \\
\hline CHEMBL1510643 & 688422 & 4.7 & 5.0282 & TRN & \\
\hline CHEMBL1544830 & 688422 & 4.8 & 5.1358 & TRN & \\
\hline CHEMBL1349499 & 688422 & 4.4 & 4.7742 & TST & \\
\hline CHEMBL 279335 & 688422 & 4.45 & 5.3932 & TRN & \\
\hline CHEMBL1341874 & 688422 & 8.0 & 5.67399 & 99999999995 & TST \\
\hline CHEMBL1498891 & 688422 & 4.95 & 5.4357 & TRN & \\
\hline CHEMBL1548109 & 688422 & 4.95 & 5.3811 & TST & \\
\hline CHEMBL1355784 & 688422 & 6.05 & 5.5928 & TRN & \\
\hline CHEMBL1325752 & 688422 & 4.5 & 5.4536 & TRN & \\
\hline CHEMBL1523329 & 688422 & 6.2 & 5.5384 & TRN & \\
\hline CHEMBL1316587 & 688422 & 6.45 & 4.8022 & TRN & \\
\hline CHEMBL1545571 & 688422 & 4.45 & 5.4534 & TST & \\
\hline CHEMBL1320963 & 688422 & 5.95 & 5.3771 & TRN & \\
\hline CHEMBL1450651 & 688422 & 5.0 & 5.0934 & TRN & \\
\hline CHEMBL1467384 & 688422 & 4.65 & 4.7447 & TRN & \\
\hline CHEMBL1410403 & 688422 & 4.45 & 4.8374 & TRN & \\
\hline CHEMBL3198468 & 688422 & 4.65 & 5.4356 & TRN & \\
\hline CHEMBL1560848 & 688422 & 4.65 & 4.8779 & TRN & \\
\hline CHEMBL1517197 & 688422 & 4.85 & 5.0621 & TRN & \\
\hline CHEMBL1561646 & 688422 & 4.45 & 5.0085 & TRN & \\
\hline CHEMBL1370732 & 688422 & 7.699 & 5.7406 & TRN & \\
\hline CHEMBL1996757 & 688422 & 4.7 & 4.7102 & TRN & \\
\hline CHEMBL1439732 & 688422 & 4.6 & 4.8946 & TRN & \\
\hline CHEMBL1346870 & 688422 & 4.8 & 5.1409 & TRN & \\
\hline CHEMBL1558022 & 688422 & 4.45 & 4.9039 & TRN & \\
\hline CHEMBL 2062344 & 688422 & 4.85 & 5.21899 & 9999999999 & TST \\
\hline CHEMBL3196628 & 688422 & 4.75 & 5.056 & TRN & \\
\hline CHEMBL1580543 & 688422 & 5.15 & 5.2529 & TRN & \\
\hline CHEMBL1421612 & 688422 & 6.0 & 5.1459 & TRN & \\
\hline CHEMBL1368030 & 688422 & 6.15 & 5.7037 & TRN & \\
\hline CHEMBL1543008 & 688422 & 4.7 & 5.1536 & TST & \\
\hline CHEMBL601311 & 688422 & 4.45 & 5.2564 & TRN & \\
\hline CHEMBL1396034 & 688422 & 5.4 & 5.1833 & TRN & \\
\hline CHEMBL1531925 & 688422 & 5.05 & 5.0834 & TRN & \\
\hline CHEMBL1496688 & 688422 & 4.8 & 5.0629 & TRN & \\
\hline CHEMBL1409902 & 688422 & 6.5 & 5.0148 & TRN & \\
\hline CHEMBL1517662 & 688422 & 4.8 & 5.2438 & TST & \\
\hline CHEMBL1610696 & 688422 & 7.4001 & 5.4036 & TRN & \\
\hline
\end{tabular}




\begin{tabular}{|c|c|c|c|c|c|}
\hline \multicolumn{6}{|c|}{ Supplemental Table S2.txt } \\
\hline CHEMBL1440409 & 688422 & 4.9 & 5.2975 & TRN & \\
\hline CHEMBL1532745 & 688422 & 5.05 & 4.5307 & TRN & \\
\hline CHEMBL189438 & 688422 & 6.0 & 5.5734 & TST & \\
\hline CHEMBL1368654 & 688422 & 5.55 & 4.9309 & TST & \\
\hline CHEMBL1433843 & 688422 & 8.0 & 5.5455 & TRN & \\
\hline CHEMBL1313846 & 688422 & 5.5 & 5.50700 & 0000000001 & TRN \\
\hline CHEMBL3196901 & 688422 & 4.5 & 5.2523 & TRN & \\
\hline CHEMBL1549900 & 688422 & 4.95 & 4.9325 & TST & \\
\hline CHEMBL1456309 & 688422 & 4.85 & 5.2665 & TRN & \\
\hline CHEMBL1586660 & 688422 & 4.55 & 4.9109 & TRN & \\
\hline CHEMBL1438832 & 688422 & 5.4 & 5.4483 & TST & \\
\hline CHEMBL1329316 & 688422 & 5.35 & 5.4289 & TRN & \\
\hline CHEMBL1299633 & 688422 & 4.45 & 5.5709 & TST & \\
\hline CHEMBL3213982 & 688422 & 4.75 & 5.3736 & TRN & \\
\hline CHEMBL1509967 & 688422 & 4.6 & 5.3905 & TRN & \\
\hline CHEMBL1582710 & 688422 & 4.95 & 5.4085 & TRN & \\
\hline CHEMBL1587608 & 688422 & 4.95 & 5.23600 & 0000000001 & TRN \\
\hline CHEMBL1310710 & 688422 & 4.9 & 4.6402 & TRN & \\
\hline CHEMBL1512701 & 688422 & 4.85 & 4.6755 & TRN & \\
\hline CHEMBL1360854 & 688422 & 8.3468 & 5.2582 & TST & \\
\hline CHEMBL1421576 & 688422 & 4.9 & 5.226 & TST & \\
\hline CHEMBL1325555 & 688422 & 7.699 & 5.3985 & TRN & \\
\hline CHEMBL1524454 & 688422 & 4.55 & 4.4889 & TRN & \\
\hline CHEMBL1516247 & 688422 & 6.15 & 5.1366 & TRN & \\
\hline CHEMBL1457068 & 688422 & 5.5 & 5.0544 & TRN & \\
\hline CHEMBL1341221 & 688422 & 4.6 & 5.061 & TST & \\
\hline CHEMBL3190983 & 688422 & 4.85 & 5.4183 & TRN & \\
\hline CHEMBL1462778 & 688422 & 5.05 & 5.1073 & TRN & \\
\hline CHEMBL1336316 & 688422 & 6.3 & 5.8753 & TST & \\
\hline CHEMBL1582382 & 688422 & 4.75 & 4.9651 & TRN & \\
\hline CHEMBL1545278 & 688422 & 5.25 & 5.4708 & TRN & \\
\hline CHEMBL1572776 & 688422 & 4.55 & 5.4546 & TRN & \\
\hline CHEMBL1381063 & 688422 & 4.9 & 4.7025 & TRN & \\
\hline CHEMBL1500910 & 688422 & 5.55 & 5.169 & TRN & \\
\hline CHEMBL3196267 & 688422 & 4.85 & 5.0001 & TRN & \\
\hline CHEMBL1413121 & 688422 & 4.45 & 5.4128 & TRN & \\
\hline CHEMBL1368702 & 688422 & 4.85 & 5.2421 & TRN & \\
\hline CHEMBL1313860 & 688422 & 4.85 & 5.1386 & TRN & \\
\hline CHEMBL1518742 & 688422 & 4.8 & 5.4252 & TST & \\
\hline CHEMBL1423197 & 688422 & 7.5003 & 5.3792 & TRN & \\
\hline CHEMBL1402491 & 688422 & 6.95 & 5.6464 & TRN & \\
\hline CHEMBL1335947 & 688422 & 6.9 & 5.3972 & TRN & \\
\hline CHEMBL1431384 & 688422 & 4.5 & 5.3358 & TRN & \\
\hline CHEMBL1392810 & 688422 & 4.5 & 5.2687 & TRN & \\
\hline CHEMBL1346164 & 688422 & 4.9 & 5.3103 & TST & \\
\hline CHEMBL1499948 & 688422 & 4.9 & 5.0434 & TRN & \\
\hline CHEMBL1331549 & 688422 & 5.6 & 5.1782 & TRN & \\
\hline CHEMBL1586840 & 688422 & 4.9 & 4.9982 & TST & \\
\hline
\end{tabular}




\begin{tabular}{|c|c|c|c|c|c|}
\hline \multicolumn{6}{|c|}{ Supplemental Table S2.txt } \\
\hline CHEMBL1533346 & 688422 & 5.2 & 5.1462 & TST & \\
\hline CHEMBL1439910 & 688422 & 4.45 & 5.1303 & TST & \\
\hline CHEMBL1510716 & 688422 & 4.95 & 5.2523 & TST & \\
\hline CHEMBL1973729 & 688422 & 4.7 & 4.7384 & TRN & \\
\hline CHEMBL1484195 & 688422 & 7.8996 & 5.2252 & TRN & \\
\hline CHEMBL1513839 & 688422 & 5.45 & 4.9763 & TRN & \\
\hline CHEMBL1356446 & 688422 & 5.3 & 5.1243 & TRN & \\
\hline CHEMBL1400751 & 688422 & 5.4 & 4.7878 & TST & \\
\hline CHEMBL1478668 & 688422 & 4.5 & 4.6505 & TRN & \\
\hline CHEMBL1611137 & 688422 & 5.7 & 4.5697 & TRN & \\
\hline CHEMBL1434233 & 688422 & 5.0 & 5.444 & TST & \\
\hline CHEMBL1506643 & 688422 & 6.45 & 5.7792 & TST & \\
\hline CHEMBL549325 & 688422 & 5.0 & 5.0525 & TRN & \\
\hline CHEMBL539313 & 688422 & 7.3002 & 5.1603 & TST & \\
\hline CHEMBL3213462 & 688422 & 7.5003 & 5.1735 & TRN & \\
\hline CHEMBL1303693 & 688422 & 6.05 & 5.4459 & TRN & \\
\hline CHEMBL1445219 & 688422 & 4.65 & 5.0372 & TST & \\
\hline CHEMBL1507685 & 688422 & 4.8 & 4.9188 & TRN & \\
\hline CHEMBL1303524 & 688422 & 4.85 & 5.17299 & 9999999999 & TRN \\
\hline CHEMBL1483647 & 688422 & 4.85 & 5.0386 & TST & \\
\hline CHEMBL1401691 & 688422 & 4.95 & 5.8953 & TRN & \\
\hline CHEMBL1435533 & 688422 & 4.75 & 5.7301 & TRN & \\
\hline CHEMBL1494038 & 688422 & 4.9 & 4.7056 & TRN & \\
\hline CHEMBL1593090 & 688422 & 7.15 & 5.5401 & TRN & \\
\hline CHEMBL1333540 & 688422 & 6.05 & 6.0694 & TRN & \\
\hline CHEMBL1318228 & 688422 & 4.6 & 5.4372 & TRN & \\
\hline CHEMBL1380080 & 688422 & 6.3 & 5.478 & TRN & \\
\hline CHEMBL1092602 & 688422 & 4.9 & 5.3395 & TST & \\
\hline CHEMBL1518186 & 688422 & 5.2 & 5.1581 & TRN & \\
\hline CHEMBL1306310 & 688422 & 4.85 & 5.1322 & TRN & \\
\hline CHEMBL1524863 & 688422 & 6.1 & 4.8742 & TST & \\
\hline CHEMBL3210161 & 688422 & 5.4 & 5.6152 & TRN & \\
\hline CHEMBL1326949 & 688422 & 4.45 & 5.2046 & TRN & \\
\hline CHEMBL1557747 & 688422 & 4.45 & 5.5183 & TRN & \\
\hline CHEMBL1387282 & 688422 & 4.45 & 5.1742 & TRN & \\
\hline CHEMBL1545848 & 688422 & 5.75 & 4.657 & TRN & \\
\hline CHEMBL3190429 & 688422 & 4.85 & 5.2722 & TRN & \\
\hline CHEMBL1340058 & 688422 & 4.45 & 5.4652 & TRN & \\
\hline CHEMBL1577512 & 688422 & 4.7 & 5.5795 & TRN & \\
\hline CHEMBL1483444 & 688422 & 6.95 & 5.749 & TRN & \\
\hline CHEMBL1384843 & 688422 & 5.4 & 4.8052 & TRN & \\
\hline CHEMBL1404945 & 688422 & 4.45 & 4.9103 & TRN & \\
\hline CHEMBL1364345 & 688422 & 4.65 & 5.4844 & TST & \\
\hline CHEMBL1578739 & 688422 & 4.95 & 4.9802 & TRN & \\
\hline CHEMBL1493418 & 688422 & 4.45 & 5.148 & TRN & \\
\hline CHEMBL1494893 & 688422 & 4.7 & 4.926 & TST & \\
\hline CHEMBL1440296 & 688422 & 5.25 & 5.4595 & TRN & \\
\hline CHEMBL484928 & 688422 & 9.0969 & 5.1997 & TST & \\
\hline
\end{tabular}




\begin{tabular}{|c|c|c|c|c|c|}
\hline \multicolumn{6}{|c|}{ Supplemental Table S2.txt } \\
\hline CHEMBL1341731 & 688422 & 4.5 & 5.4667 & TRN & \\
\hline CHEMBL1498834 & 688422 & 4.85 & 5.5882 & TST & \\
\hline CHEMBL1570367 & 688422 & 8.4949 & 5.5516 & TRN & \\
\hline CHEMBL1490008 & 688422 & 5.95 & 5.1859 & TRN & \\
\hline CHEMBL1446631 & 688422 & 6.35 & 5.4661 & TRN & \\
\hline CHEMBL1463761 & 688422 & 4.95 & 5.1358 & TRN & \\
\hline CHEMBL1318770 & 688422 & 8.4559 & 5.5125 & TRN & \\
\hline CHEMBL1572326 & 688422 & 6.05 & 5.404 & TST & \\
\hline CHEMBL1486121 & 688422 & 5.55 & 5.0798 & TRN & \\
\hline CHEMBL579088 & 688422 & 5.0 & 5.2185 & TRN & \\
\hline CHEMBL3192939 & 688422 & 4.65 & 4.9157 & TRN & \\
\hline CHEMBL1442531 & 688422 & 5.2 & 5.364 & TRN & \\
\hline CHEMBL1402276 & 688422 & 4.45 & 5.7523 & TRN & \\
\hline CHEMBL1546834 & 688422 & 4.75 & 4.6928 & TRN & \\
\hline CHEMBL1591255 & 688422 & 5.45 & 5.5633 & TRN & \\
\hline CHEMBL1387072 & 688422 & 4.65 & 5.3994 & TRN & \\
\hline CHEMBL1437441 & 688422 & 7.2503 & 5.2344 & TRN & \\
\hline CHEMBL1378447 & 688422 & 4.7 & 4.9928 & TRN & \\
\hline CHEMBL1579823 & 688422 & 4.85 & 5.0364 & TRN & \\
\hline CHEMBL1564067 & 688422 & 4.7 & 5.1249 & TRN & \\
\hline CHEMBL1542695 & 688422 & 5.4 & 5.6297 & TRN & \\
\hline CHEMBL1486033 & 688422 & 4.95 & 4.9483 & TRN & \\
\hline CHEMBL1332010 & 688422 & 4.8 & 5.5234 & TRN & \\
\hline CHEMBL1312088 & 688422 & 5.35 & 5.25799 & 9999999999 & TST \\
\hline CHEMBL1409441 & 688422 & 6.7501 & 5.1246 & TRN & \\
\hline CHEMBL1473511 & 688422 & 6.5 & 5.3334 & TRN & \\
\hline CHEMBL428496 & 688422 & 4.95 & 5.7462 & TST & \\
\hline CHEMBL1335705 & 688422 & 6.1 & 5.5664 & TRN & \\
\hline CHEMBL587714 & 688422 & 5.05 & 5.6469 & TST & \\
\hline CHEMBL1582340 & 688422 & 4.85 & 5.477 & TRN & \\
\hline CHEMBL1590255 & 688422 & 8.4949 & 5.8301 & TST & \\
\hline CHEMBL1411404 & 688422 & 5.45 & 5.7476 & TRN & \\
\hline CHEMBL 2004809 & 688422 & 4.85 & 5.2332 & TST & \\
\hline CHEMBL1599427 & 688422 & 4.9 & 5.2915 & TRN & \\
\hline CHEMBL1422695 & 688422 & 4.7 & 4.9565 & TRN & \\
\hline CHEMBL3195771 & 688422 & 4.75 & 5.6395 & TST & \\
\hline CHEMBL1389593 & 688422 & 7.5003 & 5.9352 & TRN & \\
\hline CHEMBL1382815 & 688422 & 5.45 & 5.2935 & TST & \\
\hline CHEMBL1433075 & 688422 & 4.8 & 4.9908 & TRN & \\
\hline CHEMBL1490507 & 688422 & 4.9 & 5.4489 & TRN & \\
\hline CHEMBL1373761 & 688422 & 6.5501 & 5.2477 & TRN & \\
\hline CHEMBL1503329 & 688422 & 5.1 & 5.4675 & TRN & \\
\hline CHEMBL1314793 & 688422 & 8.0 & 5.5967 & TRN & \\
\hline CHEMBL1364519 & 688422 & 4.65 & 5.1595 & TRN & \\
\hline CHEMBL1411641 & 688422 & 8.4559 & 5.1818 & TRN & \\
\hline CHEMBL1304856 & 688422 & 4.45 & 4.8725 & TRN & \\
\hline CHEMBL1600657 & 688422 & 4.7 & 4.992 & TRN & \\
\hline CHEMBL1312975 & 688422 & 4.85 & 4.6214 & TRN & \\
\hline
\end{tabular}




\begin{tabular}{|c|c|c|c|c|}
\hline \multicolumn{5}{|c|}{ Supplemental Table S2.txt } \\
\hline CHEMBL1594821 & 688422 & 6.8 & 5.1459 & TRN \\
\hline CHEMBL1540220 & 688422 & 4.45 & 5.3237 & TRN \\
\hline CHEMBL522121 & 688422 & 4.7 & 4.5262 & TRN \\
\hline CHEMBL1523019 & 688422 & 5.15 & 5.3844 & TST \\
\hline CHEMBL1305322 & 688422 & 4.8 & 5.0093 & TST \\
\hline CHEMBL1310100 & 688422 & 6.9 & 5.4992 & TRN \\
\hline CHEMBL1455646 & 688422 & 4.45 & 5.2098 & TRN \\
\hline CHEMBL1446261 & 688422 & 4.9 & 5.0813 & TRN \\
\hline CHEMBL1527664 & 688422 & 4.85 & 5.1239 & TRN \\
\hline CHEMBL1411111 & 688422 & 4.7 & 4.9719 & TST \\
\hline CHEMBL1413033 & 688422 & 4.75 & 5.0804 & TRN \\
\hline CHEMBL1501701 & 688422 & 4.8 & 5.026 & TRN \\
\hline CHEMBL1313683 & 688422 & 4.95 & 5.2095 & TST \\
\hline CHEMBL1610733 & 688422 & 5.05 & 4.7347 & TRN \\
\hline CHEMBL1568834 & 688422 & 4.9 & 4.8836 & TRN \\
\hline CHEMBL1591063 & 688422 & 5.05 & 5.2344 & TRN \\
\hline CHEMBL1307328 & 688422 & 4.85 & 4.9499 & TRN \\
\hline CHEMBL1388348 & 688422 & 5.3 & 5.7586 & TRN \\
\hline CHEMBL1505937 & 688422 & 7.0501 & 5.1735 & TST \\
\hline CHEMBL1391768 & 688422 & 4.45 & 5.4802 & TRN \\
\hline CHEMBL1486204 & 688422 & 4.7 & 5.4393 & TRN \\
\hline CHEMBL1532716 & 688422 & 4.8 & 5.3634 & TST \\
\hline CHEMBL578502 & 688422 & 4.85 & 5.3316 & TRN \\
\hline CHEMBL3196295 & 688422 & 4.6 & 5.2524 & TRN \\
\hline CHEMBL1308557 & 688422 & 4.8 & 5.1112 & TRN \\
\hline CHEMBL1452417 & 688422 & 4.7 & 5.2451 & TRN \\
\hline CHEMBL1482476 & 688422 & 5.3 & 5.2981 & TRN \\
\hline CHEMBL1435643 & 688422 & 5.25 & 5.8928 & TRN \\
\hline CHEMBL1530214 & 688422 & 7.6498 & 5.9979 & TST \\
\hline CHEMBL1385436 & 688422 & 4.8 & 5.1759 & TST \\
\hline CHEMBL1538027 & 688422 & 5.0 & 5.4549 & TRN \\
\hline CHEMBL1594926 & 688422 & 4.9 & 5.1935 & TRN \\
\hline CHEMBL1548217 & 688422 & 4.5 & 5.0262 & TRN \\
\hline CHEMBL1413597 & 688422 & 4.65 & 5.2009 & TRN \\
\hline CHEMBL1477226 & 688422 & 4.75 & 5.0827 & TRN \\
\hline CHEMBL1536086 & 688422 & 4.7 & 5.1043 & TRN \\
\hline CHEMBL1603387 & 688422 & 5.4 & 5.0227 & TRN \\
\hline CHEMBL1325437 & 688422 & 5.2 & 5.2293 & TST \\
\hline CHEMBL596271 & 688422 & 4.9 & 4.6733 & TRN \\
\hline CHEMBL1361508 & 688422 & 4.7 & 4.6755 & TRN \\
\hline CHEMBL1313408 & 688422 & 4.7 & 5.1123 & TRN \\
\hline CHEMBL1365766 & 688422 & 6.0 & 4.9255 & TRN \\
\hline CHEMBL1484316 & 688422 & 4.9 & 5.3444 & TST \\
\hline CHEMBL1597373 & 688422 & 7.9508 & 5.314 & TRN \\
\hline CHEMBL1460863 & 688422 & 4.85 & 5.3582 & TRN \\
\hline CHEMBL1378594 & 688422 & 4.45 & 4.9767 & TRN \\
\hline CHEMBL1355254 & 688422 & 7.7496 & 5.5983 & TRN \\
\hline CHEMBL1587521 & 688422 & 4.95 & 5.3602 & TRN \\
\hline
\end{tabular}




\begin{tabular}{|c|c|c|c|c|c|}
\hline \multicolumn{6}{|c|}{ Supplemental Table S2.txt } \\
\hline CHEMBL260213 & 688422 & 5.0 & 5.3685 & TRN & \\
\hline CHEMBL578675 & 688422 & 4.45 & 5.3569 & TRN & \\
\hline CHEMBL1362131 & 688422 & 6.45 & 5.3983 & TRN & \\
\hline CHEMBL 3192820 & 688422 & 4.95 & 5.3729 & TRN & \\
\hline CHEMBL1527453 & 688422 & 8.0506 & 5.0851 & TRN & \\
\hline CHEMBL1516377 & 688422 & 8.301 & 5.3783 & TST & \\
\hline CHEMBL1385175 & 688422 & 4.9 & 5.11100 & 0000000001 & TRN \\
\hline CHEMBL1366769 & 688422 & 4.8 & 5.3709 & TRN & \\
\hline CHEMBL1538617 & 688422 & 4.75 & 5.397 & TRN & \\
\hline CHEMBL1419880 & 688422 & 4.75 & 5.1535 & TRN & \\
\hline CHEMBL1321979 & 688422 & 4.6 & 4.9992 & TST & \\
\hline CHEMBL84010 & 688422 & 7.7496 & 5.4758 & TRN & \\
\hline CHEMBL1341676 & 688422 & 4.9 & 4.9151 & TRN & \\
\hline CHEMBL1483171 & 688422 & 4.85 & 5.2899 & TST & \\
\hline CHEMBL1584324 & 688422 & 4.75 & 5.1946 & TRN & \\
\hline CHEMBL1478490 & 688422 & 4.9 & 4.5815 & TRN & \\
\hline CHEMBL1595088 & 688422 & 4.45 & 4.9225 & TRN & \\
\hline CHEMBL1404493 & 688422 & 5.4 & 5.631 & TRN & \\
\hline CHEMBL1449499 & 688422 & 4.65 & 5.0137 & TRN & \\
\hline CHEMBL1613502 & 688422 & 4.75 & 5.0385 & TRN & \\
\hline CHEMBL1326813 & 688422 & 6.05 & 5.12299 & 9999999999 & TST \\
\hline CHEMBL1337255 & 688422 & 4.45 & 5.5746 & TST & \\
\hline CHEMBL1980285 & 688422 & 4.5 & 5.2314 & TRN & \\
\hline CHEMBL1347440 & 688422 & 4.45 & 4.7557 & TRN & \\
\hline CHEMBL1384110 & 688422 & 4.5 & 5.6344 & TRN & \\
\hline CHEMBL1374465 & 688422 & 4.85 & 5.0963 & TRN & \\
\hline CHEMBL1324892 & 688422 & 4.9 & 5.0676 & TRN & \\
\hline CHEMBL1519036 & 688422 & 6.15 & 4.9736 & TRN & \\
\hline CHEMBL1336266 & 688422 & 5.7 & 5.3116 & TRN & \\
\hline CHEMBL1477548 & 688422 & 4.6 & 5.2076 & TST & \\
\hline CHEMBL1461043 & 688422 & 4.65 & 4.8829 & TRN & \\
\hline CHEMBL1596216 & 688422 & 4.75 & 5.431 & TST & \\
\hline CHEMBL1310437 & 688422 & 4.85 & 4.9452 & TRN & \\
\hline CHEMBL1473885 & 688422 & 7.3497 & 5.8262 & TRN & \\
\hline CHEMBL1370891 & 688422 & 6.0 & 5.3329 & TRN & \\
\hline CHEMBL1426183 & 688422 & 4.9 & 5.1461 & TRN & \\
\hline CHEMBL3210018 & 688422 & 5.0 & 5.3532 & TRN & \\
\hline CHEMBL1353983 & 688422 & 5.1 & 5.0309 & TRN & \\
\hline CHEMBL1419590 & 688422 & 6.0 & 5.1109 & TRN & \\
\hline CHEMBL1514267 & 688422 & 5.0 & 5.6533 & TST & \\
\hline CHEMBL1378852 & 688422 & 5.15 & 5.46399 & 99999999995 & TRN \\
\hline CHEMBL1441760 & 688422 & 4.45 & 5.1295 & TRN & \\
\hline CHEMBL1527977 & 688422 & 7.0 & 5.0273 & TRN & \\
\hline CHEMBL1358683 & 688422 & 5.55 & 5.5949 & TRN & \\
\hline CHEMBL1501121 & 688422 & 4.45 & 5.2146 & TST & \\
\hline CHEMBL3214294 & 688422 & 6.0 & 5.1652 & TST & \\
\hline CHEMBL1335944 & 688422 & 4.45 & 5.4457 & TRN & \\
\hline CHEMBL1510490 & 688422 & 5.25 & 4.645 & TRN & \\
\hline
\end{tabular}




\begin{tabular}{|c|c|c|c|c|c|}
\hline \multicolumn{6}{|c|}{ Supplemental Table S2.txt } \\
\hline CHEMBL1577104 & 688422 & 7.15 & 5.4935 & TST & \\
\hline CHEMBL1610262 & 688422 & 8.2518 & 5.8029 & TRN & \\
\hline CHEMBL531401 & 688422 & 4.95 & 5.2684 & TRN & \\
\hline CHEMBL1426549 & 688422 & 5.05 & 5.7525 & TRN & \\
\hline CHEMBL1374895 & 688422 & 4.5 & 5.4063 & TRN & \\
\hline CHEMBL1519290 & 688422 & 5.2 & 5.2488 & TRN & \\
\hline CHEMBL1594085 & 688422 & 5.25 & 5.5354 & TRN & \\
\hline CHEMBL1451924 & 688422 & 5.25 & 5.0652 & TRN & \\
\hline CHEMBL1584784 & 688422 & 5.6 & 5.5825 & TST & \\
\hline CHEMBL1533980 & 688422 & 4.5 & 5.1428 & TRN & \\
\hline CHEMBL1339417 & 688422 & 4.45 & 5.0959 & TST & \\
\hline CHEMBL1305225 & 688422 & 4.45 & 5.2232 & TRN & \\
\hline CHEMBL1472258 & 688422 & 4.85 & 4.9779 & TRN & \\
\hline CHEMBL1438995 & 688422 & 4.45 & 5.2277 & TRN & \\
\hline CHEMBL1346676 & 688422 & 4.65 & 5.33200 & 0000000001 & TRN \\
\hline CHEMBL1370117 & 688422 & 6.5 & 5.2525 & TRN & \\
\hline CHEMBL346516 & 688422 & 5.45 & 5.1216 & TST & \\
\hline CHEMBL1571408 & 688422 & 7.5498 & 5.2719 & TRN & \\
\hline CHEMBL1455396 & 688422 & 4.9 & 5.3202 & TST & \\
\hline CHEMBL126077 & 688422 & 5.1 & 5.2625 & TRN & \\
\hline CHEMBL1359126 & 688422 & 4.85 & 5.1536 & TRN & \\
\hline CHEMBL1350567 & 688422 & 4.9 & 5.4463 & TRN & \\
\hline CHEMBL1388231 & 688422 & 4.8 & 5.1562 & TRN & \\
\hline CHEMBL1309982 & 688422 & 7.6003 & 5.3718 & TRN & \\
\hline CHEMBL1454072 & 688422 & 4.45 & 4.9789 & TRN & \\
\hline CHEMBL1562800 & 688422 & 4.7 & 4.9764 & TRN & \\
\hline CHEMBL1465128 & 688422 & 4.7 & 5.2356 & TRN & \\
\hline CHEMBL1495092 & 688422 & 6.95 & 5.4158 & TST & \\
\hline CHEMBL1381982 & 688422 & 5.7 & 5.4505 & TST & \\
\hline CHEMBL1567438 & 688422 & 4.45 & 4.8683 & TRN & \\
\hline CHEMBL1338060 & 688422 & 6.6 & 5.7719 & TRN & \\
\hline CHEMBL1383461 & 688422 & 5.15 & 5.7545 & TST & \\
\hline CHEMBL1613643 & 688422 & 4.75 & 4.9131 & TRN & \\
\hline CHEMBL1434884 & 688422 & 8.2518 & 5.5252 & TRN & \\
\hline CHEMBL1319668 & 688422 & 7.699 & 5.5579 & TST & \\
\hline CHEMBL1472210 & 688422 & 4.85 & 5.3473 & TRN & \\
\hline CHEMBL1608237 & 688422 & 4.9 & 5.1428 & TRN & \\
\hline CHEMBL1343337 & 688422 & 4.5 & 4.6595 & TRN & \\
\hline CHEMBL1414508 & 688422 & 4.45 & 4.8304 & TRN & \\
\hline CHEMBL1607210 & 688422 & 4.95 & 5.4768 & TRN & \\
\hline CHEMBL1576321 & 688422 & 4.7 & 5.564 & TRN & \\
\hline CHEMBL1432564 & 688422 & 4.65 & 4.5544 & TRN & \\
\hline CHEMBL3199093 & 688422 & 4.5 & 5.12700 & 0000000001 & TST \\
\hline CHEMBL1413806 & 688422 & 4.5 & 5.13 & TST & \\
\hline CHEMBL1327034 & 688422 & 4.95 & 5.1769 & TRN & \\
\hline CHEMBL1562381 & 688422 & 5.55 & 4.72199 & 99999999995 & TRN \\
\hline CHEMBL1471694 & 688422 & 5.05 & 5.3456 & TRN & \\
\hline CHEMBL1311504 & 688422 & 5.35 & 5.2102 & TRN & \\
\hline
\end{tabular}




\begin{tabular}{|c|c|c|c|c|c|}
\hline \multicolumn{6}{|c|}{ Supplemental Table S2.txt } \\
\hline CHEMBL1449787 & 688422 & 4.75 & 5.1317 & TST & \\
\hline CHEMBL1589276 & 688422 & 4.8 & 5.4331 & TRN & \\
\hline CHEMBL1424664 & 688422 & 5.45 & 5.6125 & TST & \\
\hline CHEMBL1546624 & 688422 & 4.65 & 5.1236 & TRN & \\
\hline CHEMBL1459332 & 688422 & 4.45 & 4.9036 & TRN & \\
\hline CHEMBL1312574 & 688422 & 5.35 & 5.3072 & TRN & \\
\hline CHEMBL1416246 & 688422 & 4.45 & 5.2264 & TRN & \\
\hline CHEMBL1505875 & 688422 & 4.5 & 4.945 & TRN & \\
\hline CHEMBL1313660 & 688422 & 4.7 & 5.1946 & TRN & \\
\hline CHEMBL1459330 & 688422 & 4.5 & 4.7214 & TRN & \\
\hline CHEMBL1500262 & 688422 & 4.45 & 5.3672 & TRN & \\
\hline CHEMBL1460877 & 688422 & 4.45 & 5.1972 & TST & \\
\hline CHEMBL1417261 & 688422 & 6.95 & 5.7435 & TRN & \\
\hline CHEMBL1484075 & 688422 & 4.95 & 5.6452 & TRN & \\
\hline CHEMBL1256697 & 688422 & 4.45 & 4.9665 & TRN & \\
\hline CHEMBL1484967 & 688422 & 4.95 & 5.2128 & TRN & \\
\hline CHEMBL1405705 & 688422 & 4.5 & 5.2337 & TRN & \\
\hline CHEMBL1468833 & 688422 & 7.3497 & 5.4471 & TST & \\
\hline CHEMBL1484944 & 688422 & 4.95 & 5.1203 & TRN & \\
\hline CHEMBL1458940 & 688422 & 5.0 & 5.2292 & TRN & \\
\hline CHEMBL1472293 & 688422 & 4.8 & 4.7675 & TRN & \\
\hline CHEMBL1410673 & 688422 & 4.95 & 5.0425 & TST & \\
\hline CHEMBL1568660 & 688422 & 4.65 & 5.3236 & TRN & \\
\hline CHEMBL3189885 & 688422 & 6.2 & 5.1392 & TRN & \\
\hline CHEMBL1341586 & 688422 & 5.55 & 5.1038 & TRN & \\
\hline CHEMBL1543919 & 688422 & 4.95 & 5.2791 & TST & \\
\hline CHEMBL1390521 & 688422 & 7.699 & 5.7487 & TST & \\
\hline CHEMBL1386392 & 688422 & 4.5 & 5.1066 & TST & \\
\hline CHEMBL1483646 & 688422 & 4.45 & 5.2583 & TRN & \\
\hline CHEMBL1312922 & 688422 & 4.45 & 5.1423 & TRN & \\
\hline CHEMBL1354256 & 688422 & 6.5501 & 5.9267 & TRN & \\
\hline CHEMBL1435275 & 688422 & 7.5498 & 5.2707 & TRN & \\
\hline CHEMBL1568820 & 688422 & 6.8 & 5.6394 & TRN & \\
\hline CHEMBL1510213 & 688422 & 5.45 & 4.9722 & TRN & \\
\hline CHEMBL1365843 & 688422 & 5.1 & 4.9598 & TRN & \\
\hline CHEMBL1313899 & 688422 & 4.55 & 5.1648 & TRN & \\
\hline CHEMBL1489733 & 688422 & 4.9 & 5.13399 & 99999999995 & TRN \\
\hline CHEMBL1334169 & 688422 & 5.65 & 5.0294 & TRN & \\
\hline CHEMBL1507377 & 688422 & 4.9 & 5.2172 & TRN & \\
\hline CHEMBL1549030 & 688422 & 4.7 & 4.9655 & TRN & \\
\hline CHEMBL1438530 & 688422 & 4.75 & 5.2616 & TST & \\
\hline CHEMBL1408861 & 688422 & 4.65 & 5.4208 & TRN & \\
\hline CHEMBL3211792 & 688422 & 7.6498 & 5.74799 & 9999999999 & TST \\
\hline CHEMBL1415640 & 688422 & 4.9 & 5.12700 & $\partial 000000001$ & TRN \\
\hline CHEMBL3191865 & 688422 & 6.5501 & 5.1486 & TRN & \\
\hline CHEMBL1545697 & 688422 & 4.65 & 5.3846 & TST & \\
\hline CHEMBL1540227 & 688422 & 4.7 & 5.0379 & TST & \\
\hline CHEMBL1453693 & 688422 & 7.5003 & 5.5108 & TRN & \\
\hline
\end{tabular}




\begin{tabular}{|c|c|c|c|c|}
\hline \multicolumn{5}{|c|}{ Supplemental Table S2.txt } \\
\hline CHEMBL1322969 & 688422 & 4.95 & 5.2176 & TRN \\
\hline CHEMBL1375199 & 688422 & 4.8 & 4.7267 & TRN \\
\hline CHEMBL1587677 & 688422 & 5.5 & 5.5205 & TRN \\
\hline CHEMBL1597320 & 688422 & 4.6 & 5.1565 & TRN \\
\hline CHEMBL1568953 & 688422 & 4.9 & 5.7534 & TST \\
\hline CHEMBL1325907 & 688422 & 4.45 & 5.2038 & TRN \\
\hline CHEMBL1507745 & 688422 & 4.65 & 5.2257 & TRN \\
\hline CHEMBL535331 & 688422 & 5.45 & 5.1234 & TRN \\
\hline CHEMBL1328248 & 688422 & 4.95 & 5.3902 & TRN \\
\hline CHEMBL1436809 & 688422 & 4.95 & 5.1584 & TRN \\
\hline CHEMBL1509829 & 688422 & 5.2 & 5.2422 & TRN \\
\hline CHEMBL1344561 & 688422 & 4.45 & 5.2093 & TRN \\
\hline CHEMBL3213219 & 688422 & 5.9 & 5.4958 & TRN \\
\hline CHEMBL1450860 & 688422 & 4.65 & 5.2831 & TRN \\
\hline CHEMBL3213879 & 688422 & 4.45 & 4.5989 & TRN \\
\hline CHEMBL1449037 & 688422 & 7.4498 & 5.0417 & TRN \\
\hline CHEMBL1456465 & 688422 & 4.8 & 5.2347 & TST \\
\hline CHEMBL1583172 & 688422 & 5.55 & 5.7435 & TRN \\
\hline CHEMBL1497369 & 688422 & 4.5 & 4.975 & TST \\
\hline CHEMBL1532452 & 688422 & 4.55 & 5.0453 & TRN \\
\hline CHEMBL1402153 & 688422 & 5.1 & 5.1334 & TRN \\
\hline CHEMBL1364358 & 688422 & 4.8 & 5.1937 & TST \\
\hline CHEMBL1414028 & 688422 & 6.1 & 5.2484 & TRN \\
\hline CHEMBL1611693 & 688422 & 4.45 & 5.0409 & TRN \\
\hline CHEMBL1353646 & 688422 & 4.45 & 4.874 & TRN \\
\hline CHEMBL1397347 & 688422 & 4.85 & 5.2731 & TRN \\
\hline CHEMBL1446258 & 688422 & 4.95 & 4.9397 & TRN \\
\hline CHEMBL1373087 & 688422 & 4.9 & 5.204 & TST \\
\hline CHEMBL1447578 & 688422 & 4.45 & 5.2902 & TRN \\
\hline CHEMBL1528869 & 688422 & 4.95 & 4.933 & TRN \\
\hline CHEMBL1342722 & 688422 & 4.95 & 4.6458 & TRN \\
\hline CHEMBL1440506 & 688422 & 4.65 & 5.3861 & TRN \\
\hline CHEMBL1349318 & 688422 & 4.7 & 5.6225 & TST \\
\hline CHEMBL1443196 & 688422 & 4.65 & 5.0279 & TRN \\
\hline CHEMBL1525896 & 688422 & 7.2 & 5.2777 & TRN \\
\hline CHEMBL1373678 & 688422 & 6.8499 & 5.2412 & TST \\
\hline CHEMBL1528353 & 688422 & 4.45 & 4.9061 & TRN \\
\hline CHEMBL1395271 & 688422 & 4.95 & 5.2946 & TRN \\
\hline CHEMBL3194263 & 688422 & 4.5 & 5.6069 & TRN \\
\hline CHEMBL3189958 & 688422 & 4.45 & 5.5897 & TRN \\
\hline CHEMBL1566874 & 688422 & 5.25 & 5.1264 & TRN \\
\hline CHEMBL1324074 & 688422 & 5.35 & 5.2296 & TRN \\
\hline CHEMBL1585133 & 688422 & 8.0 & 5.2071 & TRN \\
\hline CHEMBL1347782 & 688422 & 4.8 & 4.7428 & TRN \\
\hline CHEMBL1342523 & 688422 & 5.55 & 5.4968 & TRN \\
\hline CHEMBL1573363 & 688422 & 4.75 & 5.3779 & TST \\
\hline CHEMBL1380855 & 688422 & 4.45 & 5.0589 & TST \\
\hline CHEMBL1576556 & 688422 & 4.7 & 5.7759 & TRN \\
\hline
\end{tabular}




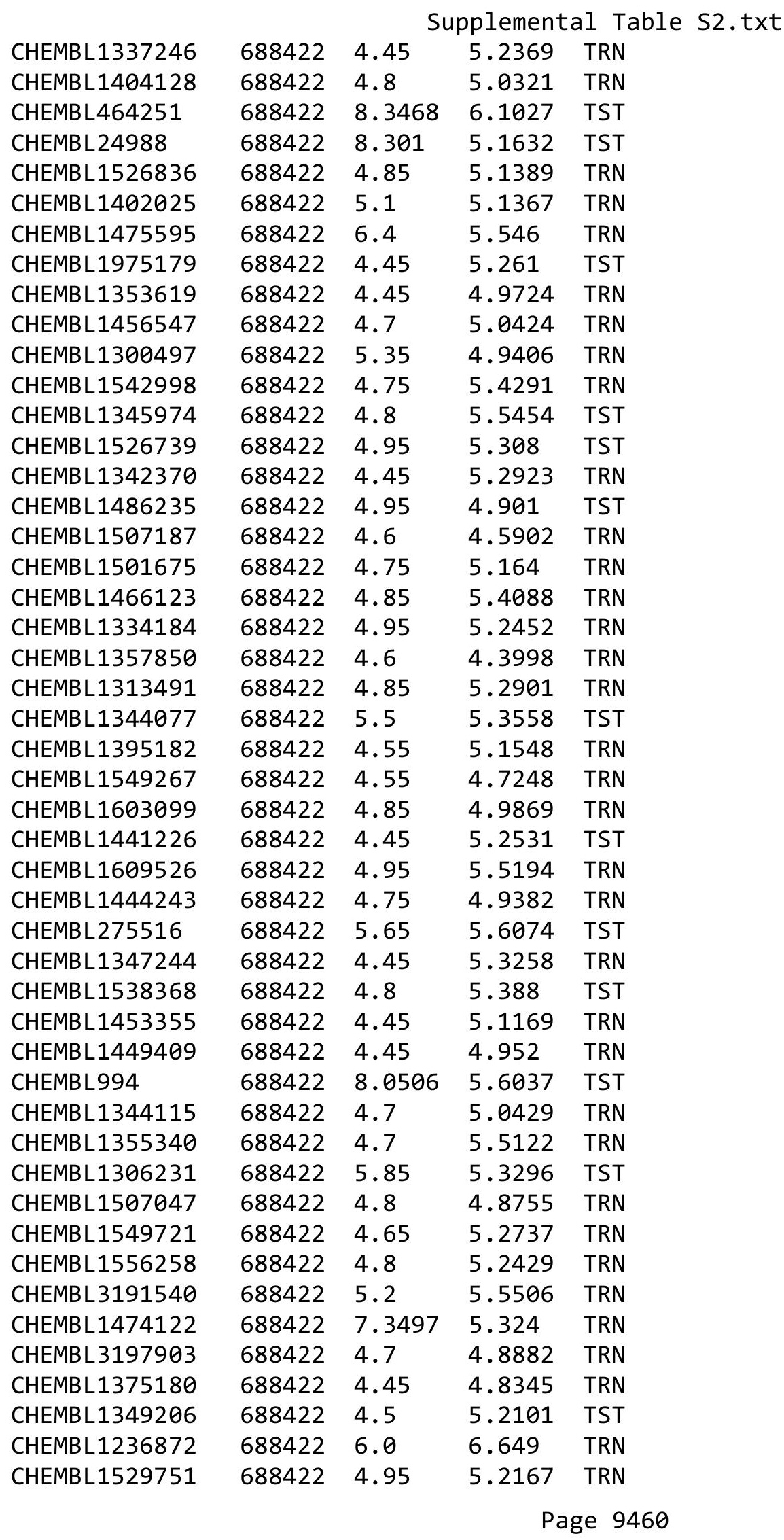




\begin{tabular}{|c|c|c|c|c|c|}
\hline \multicolumn{6}{|c|}{ Supplemental Table S2.txt } \\
\hline CHEMBL1330082 & 688422 & 5.4 & 5.4586 & TST & \\
\hline CHEMBL1416016 & 688422 & 5.55 & 5.2251 & TST & \\
\hline CHEMBL1336286 & 688422 & 4.45 & 5.2412 & TRN & \\
\hline CHEMBL1327784 & 688422 & 4.45 & \multicolumn{2}{|c|}{5.2860000000000005} & TRN \\
\hline CHEMBL1546088 & 688422 & 5.0 & 5.5413 & TST & \\
\hline CHEMBL1557324 & 688422 & 5.15 & 5.3144 & TRN & \\
\hline CHEMBL1449717 & 688422 & 5.85 & 5.5907 & TST & \\
\hline CHEMBL1518739 & 688422 & 4.45 & \multicolumn{2}{|c|}{5.3420000000000005} & TRN \\
\hline CHEMBL1503397 & 688422 & 4.75 & 4.9617 & TRN & \\
\hline CHEMBL1431516 & 688422 & 4.7 & 5.0702 & TRN & \\
\hline CHEMBL1478081 & 688422 & 4.5 & 5.0222 & TRN & \\
\hline CHEMBL1495860 & 688422 & 6.35 & 5.46 & TRN & \\
\hline CHEMBL1380725 & 688422 & 4.45 & 5.0342 & TRN & \\
\hline CHEMBL1478085 & 688422 & 5.3 & 5.4971 & TRN & \\
\hline CHEMBL1421959 & 688422 & 4.6 & 4.82 & TRN & \\
\hline CHEMBL1586442 & 688422 & 5.25 & 5.2363 & TST & \\
\hline CHEMBL1527490 & 688422 & 8.0 & \multicolumn{2}{|c|}{5.162999999999999} & TRN \\
\hline CHEMBL1475286 & 688422 & 6.05 & 5.0601 & TRN & \\
\hline CHEMBL1449637 & 688422 & 5.0 & 4.8154 & TRN & \\
\hline CHEMBL1300177 & 688422 & 5.2 & 4.7664 & TRN & \\
\hline CHEMBL1343392 & 688422 & 5.45 & 5.3309 & TRN & \\
\hline CHEMBL1368165 & 688422 & 4.9 & 5.1841 & TST & \\
\hline CHEMBL1607067 & 688422 & 4.9 & 5.3608 & TRN & \\
\hline CHEMBL1490371 & 688422 & 4.9 & 5.3576 & TRN & \\
\hline CHEMBL1329385 & 688422 & 6.05 & 5.3001 & TRN & \\
\hline CHEMBL1381940 & 688422 & 5.85 & 5.6908 & TRN & \\
\hline CHEMBL1389418 & 688422 & 4.8 & 5.1473 & TRN & \\
\hline CHEMBL1411192 & 688422 & 4.45 & 5.2262 & TST & \\
\hline CHEMBL1418316 & 688422 & 4.95 & 5.6763 & TRN & \\
\hline CHEMBL1599462 & 688422 & 5.85 & 5.2994 & TRN & \\
\hline CHEMBL1405051 & 688422 & 7.5498 & 4.9124 & TRN & \\
\hline CHEMBL1453302 & 688422 & 4.9 & 5.2368 & TST & \\
\hline CHEMBL1418906 & 688422 & 4.45 & 4.731 & TRN & \\
\hline CHEMBL1305315 & 688422 & 4.85 & 5.5733 & TRN & \\
\hline CHEMBL1353829 & 688422 & 4.65 & 4.9571 & TRN & \\
\hline CHEMBL1171204 & 688422 & 5.3 & 5.4049 & TST & \\
\hline CHEMBL1325228 & 688422 & 4.45 & 5.4388 & TST & \\
\hline CHEMBL1613614 & 688422 & 4.8 & 4.7735 & TRN & \\
\hline CHEMBL1984166 & 688422 & 4.95 & 5.2429 & TRN & \\
\hline CHEMBL1581024 & 688422 & 4.95 & 5.6143 & TST & \\
\hline CHEMBL1342231 & 688422 & 5.3 & 5.4012 & TRN & \\
\hline CHEMBL1555417 & 688422 & 4.85 & 5.0852 & TRN & \\
\hline CHEMBL1309175 & 688422 & 4.75 & 4.8935 & TRN & \\
\hline CHEMBL1301994 & 688422 & 5.0 & 4.9269 & TRN & \\
\hline CHEMBL1589574 & 688422 & 4.45 & 5.2848 & TST & \\
\hline CHEMBL1391129 & 688422 & 4.9 & 5.4552 & TRN & \\
\hline CHEMBL1307048 & 688422 & 4.65 & 5.2294 & TRN & \\
\hline CHEMBL1302503 & 688422 & 5.0 & 5.6337 & TST & \\
\hline
\end{tabular}




\begin{tabular}{|c|c|c|c|c|c|}
\hline \\
\hline CHEMBL1457398 & 688422 & 4.5 & 5.6474 & TST & \\
\hline CHEMBL1470537 & 688422 & 6.3 & 5.7871 & TRN & \\
\hline CHEMBL3193315 & 688422 & 5.2 & 5.1611 & TRN & \\
\hline CHEMBL3199685 & 688422 & 4.45 & 5.2839 & TRN & \\
\hline CHEMBL1347663 & 688422 & 4.5 & 4.8346 & TRN & \\
\hline CHEMBL1362225 & 688422 & 4.45 & 5.2944 & TRN & \\
\hline CHEMBL1301093 & 688422 & 4.65 & 5.1739 & TRN & \\
\hline CHEMBL1359567 & 688422 & 4.9 & 5.1671 & TST & \\
\hline CHEMBL1458338 & 688422 & 4.45 & 5.0761 & TST & \\
\hline CHEMBL1430258 & 688422 & 4.6 & 5.0401 & TRN & \\
\hline CHEMBL1341853 & 688422 & 4.45 & 5.612 & TST & \\
\hline CHEMBL1417731 & 688422 & 5.25 & 5.2912 & TRN & \\
\hline CHEMBL1460315 & 688422 & 5.55 & 4.6295 & TRN & \\
\hline CHEMBL 238188 & 688422 & 4.45 & 4.982 & TST & \\
\hline CHEMBL1422690 & 688422 & 4.65 & 4.9982 & TRN & \\
\hline CHEMBL1415654 & 688422 & 4.65 & 5.1392 & TRN & \\
\hline CHEMBL1559736 & 688422 & 4.6 & 4.9295 & TST & \\
\hline CHEMBL1391677 & 688422 & 5.0 & 5.0217 & TST & \\
\hline CHEMBL1570947 & 688422 & 4.6 & 5.19799 & 99999999995 & TRN \\
\hline CHEMBL1501541 & 688422 & 4.45 & 5.0284 & TRN & \\
\hline CHEMBL1486715 & 688422 & 4.7 & 4.7956 & TRN & \\
\hline CHEMBL1347980 & 688422 & 5.55 & 5.7565 & TRN & \\
\hline CHEMBL1316097 & 688422 & 4.45 & 5.0453 & TRN & \\
\hline CHEMBL1534646 & 688422 & 4.8 & 5.3767 & TRN & \\
\hline CHEMBL1402791 & 688422 & 4.65 & 5.3678 & TST & \\
\hline CHEMBL1559782 & 688422 & 4.75 & 5.1941 & TST & \\
\hline CHEMBL1331905 & 688422 & 4.7 & 5.1327 & TST & \\
\hline CHEMBL1399121 & 688422 & 4.6 & 5.0916 & TRN & \\
\hline CHEMBL328834 & 688422 & 4.95 & 6.6232 & TRN & \\
\hline CHEMBL 1380514 & 688422 & 4.55 & 5.1669 & TRN & \\
\hline CHEMBL1559292 & 688422 & 4.6 & 4.681 & TRN & \\
\hline CHEMBL1498621 & 688422 & 4.45 & 5.1841 & TRN & \\
\hline CHEMBL1464132 & 688422 & 5.95 & 5.4594 & TST & \\
\hline CHEMBL1887153 & 688422 & 4.8 & 5.0174 & TRN & \\
\hline CHEMBL1580267 & 688422 & 4.55 & 4.965 & TRN & \\
\hline CHEMBL1561887 & 688422 & 4.8 & 5.3019 & TRN & \\
\hline CHEMBL1345994 & 688422 & 5.7 & 4.9114 & TRN & \\
\hline CHEMBL1553401 & 688422 & 4.9 & 5.3126 & TRN & \\
\hline CHEMBL595331 & 688422 & 4.95 & 5.2796 & TRN & \\
\hline CHEMBL1344089 & 688422 & 4.95 & 4.6952 & TRN & \\
\hline CHEMBL1300881 & 688422 & 4.65 & 4.6215 & TRN & \\
\hline CHEMBL3193982 & 688422 & 5.85 & 5.2989 & TRN & \\
\hline CHEMBL1430872 & 688422 & 4.75 & 4.6856 & TRN & \\
\hline CHEMBL1487485 & 688422 & 8.4949 & 5.5073 & TRN & \\
\hline CHEMBL1573957 & 688422 & 6.5 & 5.29 & TST & \\
\hline CHEMBL1350516 & 688422 & 4.95 & 5.3454 & TRN & \\
\hline CHEMBL1382211 & 688422 & 4.75 & 5.3645 & TRN & \\
\hline CHEMBL1602836 & 688422 & 4.65 & 5.2103 & TRN & \\
\hline
\end{tabular}




\begin{tabular}{|c|c|c|c|c|}
\hline \multicolumn{5}{|c|}{ Supplemental Table S2.txt } \\
\hline CHEMBL1444985 & 688422 & 5.4 & 5.5988 & TST \\
\hline CHEMBL1416924 & 688422 & 6.7001 & 5.0742 & TRN \\
\hline CHEMBL1322174 & 688422 & 8.301 & 5.4607 & TST \\
\hline CHEMBL1343290 & 688422 & 4.45 & 5.1171 & TST \\
\hline CHEMBL1306457 & 688422 & 8.4949 & 5.4123 & TRN \\
\hline CHEMBL1483047 & 688422 & 4.7 & 4.9221 & TRN \\
\hline CHEMBL119841 & 688422 & 4.75 & 4.6799 & TRN \\
\hline CHEMBL1331419 & 688422 & 4.9 & 4.776 & TST \\
\hline CHEMBL1304736 & 688422 & 4.7 & 5.5832 & TST \\
\hline CHEMBL1585221 & 688422 & 4.65 & 5.4647 & TST \\
\hline CHEMBL 3190462 & 688422 & 5.6 & 5.5301 & TRN \\
\hline CHEMBL1303348 & 688422 & 4.45 & 5.1335 & TST \\
\hline CHEMBL1556870 & 688422 & 4.45 & 5.2238 & TRN \\
\hline CHEMBL1509842 & 688422 & 6.6499 & 5.2424 & TRN \\
\hline CHEMBL1456421 & 688422 & 4.95 & 5.3301 & TRN \\
\hline CHEMBL1580960 & 688422 & 4.45 & 4.7952 & TRN \\
\hline CHEMBL1449011 & 688422 & 5.0 & 5.1436 & TRN \\
\hline CHEMBL1305958 & 688422 & 4.9 & 5.2218 & TRN \\
\hline CHEMBL 1410576 & 688422 & 5.3 & 5.2914 & TRN \\
\hline CHEMBL1324067 & 688422 & 4.65 & 4.9101 & TRN \\
\hline CHEMBL1534173 & 688422 & 6.6 & 5.3863 & TRN \\
\hline CHEMBL1510569 & 688422 & 5.25 & 5.4121 & TRN \\
\hline CHEMBL1592982 & 688422 & 4.75 & 4.6898 & TRN \\
\hline CHEMBL1607078 & 688422 & 4.9 & 5.2288 & TRN \\
\hline CHEMBL1381003 & 688422 & 4.95 & 5.4987 & TRN \\
\hline CHEMBL1578858 & 688422 & 5.4 & 5.6598 & TRN \\
\hline CHEMBL1460666 & 688422 & 6.1 & 5.3054 & TRN \\
\hline CHEMBL1550591 & 688422 & 4.75 & 5.0769 & TST \\
\hline CHEMBL1610792 & 688422 & 4.9 & 4.8218 & TST \\
\hline CHEMBL 1459772 & 688422 & 5.5 & 5.4592 & TST \\
\hline CHEMBL1438983 & 688422 & 5.55 & 4.8914 & TST \\
\hline CHEMBL 3213115 & 688422 & 4.65 & 5.4298 & TST \\
\hline CHEMBL1547501 & 688422 & 4.7 & 5.5083 & TRN \\
\hline CHEMBL1586826 & 688422 & 5.1 & 5.6409 & TRN \\
\hline CHEMBL1359200 & 688422 & 5.95 & 5.3758 & TRN \\
\hline CHEMBL3197058 & 688422 & 4.7 & 5.3983 & TRN \\
\hline CHEMBL1492045 & 688422 & 4.45 & 5.1828 & TRN \\
\hline CHEMBL1450323 & 688422 & 5.5 & 5.2826 & TRN \\
\hline CHEMBL1465791 & 688422 & 4.65 & 5.1497 & TRN \\
\hline CHEMBL1380629 & 688422 & 4.9 & 5.0817 & TRN \\
\hline CHEMBL1474739 & 688422 & 7.8013 & 5.3712 & TRN \\
\hline CHEMBL1466059 & 688422 & 6.25 & 5.4541 & TST \\
\hline CHEMBL1498166 & 688422 & 4.7 & 5.2403 & TRN \\
\hline CHEMBL1453418 & 688422 & 6.8499 & 5.3027 & TST \\
\hline CHEMBL468481 & 688422 & 4.45 & 5.0005 & TST \\
\hline CHEMBL1183292 & 688422 & 6.25 & 5.1336 & TRN \\
\hline CHEMBL1582628 & 688422 & 5.4 & 5.3989 & TRN \\
\hline CHEMBL1542519 & 688422 & 5.25 & 5.8305 & TRN \\
\hline
\end{tabular}




\begin{tabular}{|c|c|c|c|c|}
\hline \multicolumn{5}{|c|}{ Supplemental Table S2.txt } \\
\hline CHEMBL1421965 & 688422 & 4.45 & 4.9825 & TST \\
\hline CHEMBL1535632 & 688422 & 5.35 & 5.3106 & TRN \\
\hline CHEMBL1481187 & 688422 & 8.4949 & 5.2622 & TRN \\
\hline CHEMBL1506575 & 688422 & 5.5 & 4.9646 & TRN \\
\hline CHEMBL1503131 & 688422 & 4.75 & 5.0656 & TST \\
\hline CHEMBL1385327 & 688422 & 4.65 & 5.0825 & TST \\
\hline CHEMBL1346781 & 688422 & 4.45 & 5.1158 & TRN \\
\hline CHEMBL3193761 & 688422 & 4.5 & 5.0559 & TST \\
\hline CHEMBL1467506 & 688422 & 8.0 & 5.7103 & TRN \\
\hline CHEMBL1501891 & 688422 & 4.65 & 4.7586 & TST \\
\hline CHEMBL1326349 & 688422 & 5.45 & 5.0222 & TRN \\
\hline CHEMBL1423607 & 688422 & 4.8 & 4.9952 & TRN \\
\hline CHEMBL1578448 & 688422 & 5.0 & 5.6434 & TRN \\
\hline CHEMBL1519041 & 688422 & 5.2 & 5.1567 & TRN \\
\hline CHEMBL1577250 & 688422 & 4.5 & 5.4258 & TRN \\
\hline CHEMBL1526535 & 688422 & 4.85 & 5.2769 & TST \\
\hline CHEMBL1378469 & 688422 & 4.65 & 5.3992 & TST \\
\hline CHEMBL1612151 & 688422 & 5.25 & 5.1798 & TST \\
\hline CHEMBL1413718 & 688422 & 5.1 & 5.5171 & TST \\
\hline CHEMBL1442342 & 688422 & 4.85 & 4.7979 & TRN \\
\hline CHEMBL1363637 & 688422 & 4.9 & 5.3021 & TRN \\
\hline CHEMBL1386801 & 688422 & 5.15 & 5.6361 & TRN \\
\hline CHEMBL1395596 & 688422 & 5.0 & 5.1935 & TRN \\
\hline CHEMBL1545902 & 688422 & 5.0 & 4.9907 & TRN \\
\hline CHEMBL1508937 & 688422 & 4.45 & 5.1653 & TRN \\
\hline CHEMBL1409747 & 688422 & 4.9 & 5.3239 & TRN \\
\hline CHEMBL62 & 688422 & 4.8 & 5.2305 & TRN \\
\hline CHEMBL1304413 & 688422 & 4.45 & 5.2748 & TRN \\
\hline CHEMBL1532506 & 688422 & 4.9 & 5.013 & TRN \\
\hline CHEMBL1373884 & 688422 & 8.4949 & 5.7418 & TST \\
\hline CHEMBL1585618 & 688422 & 4.45 & 5.316 & TRN \\
\hline CHEMBL1484525 & 688422 & 5.15 & 5.4735 & TRN \\
\hline CHEMBL1335988 & 688422 & 5.0 & 5.0489 & TST \\
\hline CHEMBL1426247 & 688422 & 4.85 & 5.2392 & TRN \\
\hline CHEMBL1370285 & 688422 & 5.05 & 5.0657 & TRN \\
\hline CHEMBL1345520 & 688422 & 4.95 & 5.3429 & TST \\
\hline CHEMBL1448795 & 688422 & 4.45 & 4.743 & TRN \\
\hline CHEMBL1464128 & 688422 & 4.75 & 5.2692 & TRN \\
\hline CHEMBL1451580 & 688422 & 4.95 & 4.9324 & TRN \\
\hline CHEMBL1520981 & 688422 & 4.7 & 5.1851 & TRN \\
\hline CHEMBL1387517 & 688422 & 5.05 & 5.4051 & TST \\
\hline CHEMBL1427398 & 688422 & 4.8 & 5.0918 & TRN \\
\hline CHEMBL1342574 & 688422 & 4.9 & 5.3522 & TRN \\
\hline CHEMBL1489624 & 688422 & 4.95 & 5.1523 & TRN \\
\hline CHEMBL1324902 & 688422 & 5.05 & 5.7308 & TRN \\
\hline CHEMBL1402089 & 688422 & 4.95 & 5.2213 & TRN \\
\hline CHEMBL1369606 & 688422 & 4.9 & 5.7303 & TRN \\
\hline CHEMBL1580060 & 688422 & 4.8 & 5.0785 & TST \\
\hline
\end{tabular}




\begin{tabular}{|c|c|c|c|c|}
\hline \multicolumn{5}{|c|}{ Supplemental Table S2.txt } \\
\hline CHEMBL1607675 & 688422 & 4.8 & 4.9612 & TST \\
\hline CHEMBL1348666 & 688422 & 5.6 & 5.1712 & TRN \\
\hline CHEMBL1602983 & 688422 & 4.75 & 5.2378 & TRN \\
\hline CHEMBL547269 & 688422 & 4.7 & 5.2471 & TRN \\
\hline CHEMBL1606826 & 688422 & 4.95 & 5.3673 & TST \\
\hline CHEMBL1357861 & 688422 & 5.55 & 5.4783 & TRN \\
\hline CHEMBL1384263 & 688422 & 4.5 & 4.9446 & TRN \\
\hline CHEMBL1988042 & 688422 & 4.95 & 4.8382 & TRN \\
\hline CHEMBL1308346 & 688422 & 5.2 & 4.7443 & TRN \\
\hline CHEMBL1541120 & 688422 & 4.55 & 4.7991 & TRN \\
\hline CHEMBL1445280 & 688422 & 4.65 & 5.5843 & TRN \\
\hline CHEMBL1316663 & 688422 & 6.9 & 5.1321 & TRN \\
\hline CHEMBL1450384 & 688422 & 5.6 & 4.8448 & TRN \\
\hline CHEMBL1522290 & 688422 & 7.6498 & 5.2261 & TRN \\
\hline CHEMBL1595977 & 688422 & 7.5498 & 5.356 & TST \\
\hline CHEMBL1374418 & 688422 & 7.9508 & 5.2851 & TRN \\
\hline CHEMBL1483676 & 688422 & 5.0 & 5.3668 & TRN \\
\hline CHEMBL1405946 & 688422 & 5.2 & 4.8186 & TRN \\
\hline CHEMBL1599453 & 688422 & 4.45 & 4.7458 & TRN \\
\hline CHEMBL1338773 & 688422 & 7.0501 & 5.5735 & TRN \\
\hline CHEMBL1424917 & 688422 & 4.95 & 4.9848 & TRN \\
\hline CHEMBL1345232 & 688422 & 4.8 & 5.4302 & TRN \\
\hline CHEMBL1566600 & 688422 & 4.5 & 5.1814 & TRN \\
\hline CHEMBL1520913 & 688422 & 7.6498 & 5.38 & TST \\
\hline CHEMBL1470346 & 688422 & 4.7 & 4.846 & TRN \\
\hline CHEMBL1545553 & 688422 & 4.85 & 5.4241 & TRN \\
\hline CHEMBL1340448 & 688422 & 5.8 & 5.5269 & TRN \\
\hline CHEMBL1525712 & 688422 & 6.6499 & 4.9698 & TRN \\
\hline CHEMBL1995296 & 688422 & 8.3468 & 4.6497 & TST \\
\hline CHEMBL1363514 & 688422 & 4.85 & 4.8204 & TST \\
\hline CHEMBL3213305 & 688422 & 4.45 & 5.188 & TRN \\
\hline CHEMBL1446181 & 688422 & 4.45 & 4.8878 & TRN \\
\hline CHEMBL1355593 & 688422 & 7.3002 & 5.465 & TRN \\
\hline CHEMBL1540208 & 688422 & 4.75 & 4.6696 & TST \\
\hline CHEMBL1305305 & 688422 & 5.65 & 5.2327 & TST \\
\hline CHEMBL3190010 & 688422 & 4.65 & 5.5592 & TST \\
\hline CHEMBL1386436 & 688422 & 4.45 & 5.2181 & TST \\
\hline CHEMBL1487433 & 688422 & 5.25 & 5.3933 & TRN \\
\hline CHEMBL3194671 & 688422 & 4.65 & 5.2958 & TST \\
\hline CHEMBL1540541 & 688422 & 4.65 & 5.2165 & TRN \\
\hline CHEMBL1356862 & 688422 & 4.45 & 5.4314 & TRN \\
\hline CHEMBL1347666 & 688422 & 4.85 & 4.8305 & TRN \\
\hline CHEMBL1571481 & 688422 & 5.9 & 5.595 & TRN \\
\hline CHEMBL1438901 & 688422 & 4.45 & 5.621 & TST \\
\hline CHEMBL1588002 & 688422 & 5.25 & 5.0461 & TRN \\
\hline CHEMBL1472989 & 688422 & 7.3002 & 5.5051 & TRN \\
\hline CHEMBL1534831 & 688422 & 5.95 & 5.4316 & TRN \\
\hline CHEMBL1438696 & 688422 & 4.45 & 5.2008 & TRN \\
\hline
\end{tabular}




\begin{tabular}{|c|c|c|c|c|c|}
\hline \multicolumn{6}{|c|}{ Supplemental Table S2.txt } \\
\hline CHEMBL313478 & 688422 & 5.25 & 5.855 & TST & \\
\hline CHEMBL1309969 & 688422 & 4.5 & 5.4191 & TST & \\
\hline CHEMBL1499141 & 688422 & 5.4 & 5.2502 & TRN & \\
\hline CHEMBL1576555 & 688422 & 4.75 & 4.5941 & TRN & \\
\hline CHEMBL1419355 & 688422 & 5.25 & 5.4026 & TST & \\
\hline CHEMBL1468346 & 688422 & 5.0 & 5.1875 & TRN & \\
\hline CHEMBL1448947 & 688422 & 8.3468 & 5.8268 & TRN & \\
\hline CHEMBL1526899 & 688422 & 4.65 & 5.1762 & TRN & \\
\hline CHEMBL1591859 & 688422 & 6.1 & 5.3123 & TRN & \\
\hline CHEMBL1539075 & 688422 & 4.45 & 4.9836 & TRN & \\
\hline CHEMBL1541014 & 688422 & 4.45 & 5.4569 & TST & \\
\hline CHEMBL1487887 & 688422 & 5.0 & 4.9014 & TRN & \\
\hline CHEMBL1309410 & 688422 & 8.3979 & 5.4776 & TRN & \\
\hline CHEMBL1382128 & 688422 & 5.35 & 4.9852 & TRN & \\
\hline CHEMBL1333810 & 688422 & 4.9 & 5.3722 & TRN & \\
\hline CHEMBL1363455 & 688422 & 4.45 & 4.8776 & TRN & \\
\hline CHEMBL1365617 & 688422 & 5.7 & 5.5189 & TST & \\
\hline CHEMBL1346547 & 688422 & 4.45 & 5.2478 & TST & \\
\hline CHEMBL1589053 & 688422 & 4.65 & 5.0041 & TST & \\
\hline CHEMBL3195767 & 688422 & 6.2 & 5.1996 & TST & \\
\hline CHEMBL1329736 & 688422 & 8.1024 & 5.5897 & TST & \\
\hline CHEMBL1593543 & 688422 & 5.55 & 5.2366 & TRN & \\
\hline CHEMBL1311134 & 688422 & 5.45 & 5.9742 & TRN & \\
\hline CHEMBL1550529 & 688422 & 6.45 & 5.2425 & TRN & \\
\hline CHEMBL578515 & 688422 & 4.8 & 4.5884 & TRN & \\
\hline CHEMBL3192753 & 688422 & 4.45 & 5.597 & TRN & \\
\hline CHEMBL1306998 & 688422 & 4.6 & 5.6039 & TRN & \\
\hline CHEMBL1327964 & 688422 & 4.9 & 5.1486 & TRN & \\
\hline CHEMBL1399781 & 688422 & 4.45 & 5.1335 & TRN & \\
\hline CHEMBL1589388 & 688422 & 4.8 & 5.3227 & TRN & \\
\hline CHEMBL1540287 & 688422 & 5.8 & 5.4237 & TST & \\
\hline CHEMBL 2359467 & 688422 & 5.25 & 5.1018 & TRN & \\
\hline CHEMBL 2003806 & 688422 & 5.35 & 5.0276 & TRN & \\
\hline CHEMBL1370746 & 688422 & 5.15 & 4.7303 & TRN & \\
\hline CHEMBL1362466 & 688422 & 7.9508 & 5.4322 & TRN & \\
\hline CHEMBL1429129 & 688422 & 4.45 & 5.4191 & TST & \\
\hline CHEMBL3192666 & 688422 & 4.75 & 4.9759 & TRN & \\
\hline CHEMBL1508158 & 688422 & 4.8 & 4.6871 & TST & \\
\hline CHEMBL1477637 & 688422 & 5.15 & 5.25299 & 7999999999 & TRN \\
\hline CHEMBL1994034 & 688422 & 5.0 & 5.1657 & TRN & \\
\hline CHEMBL1347274 & 688422 & 5.45 & 5.0714 & TRN & \\
\hline CHEMBL1406119 & 688422 & 4.45 & 5.1971 & TRN & \\
\hline CHEMBL1566200 & 688422 & 7.15 & 5.5179 & TRN & \\
\hline CHEMBL1540810 & 688422 & 4.9 & 5.1324 & TRN & \\
\hline CHEMBL1606122 & 688422 & 4.85 & 5.2083 & TRN & \\
\hline CHEMBL3199380 & 688422 & 4.75 & 5.1108 & TRN & \\
\hline CHEMBL1582553 & 688422 & 5.0 & 5.0638 & TRN & \\
\hline CHEMBL1405626 & 688422 & 4.5 & 5.5318 & TST & \\
\hline
\end{tabular}




\begin{tabular}{|c|c|c|c|c|c|}
\hline \multicolumn{6}{|c|}{ Supplemental Table S2.txt } \\
\hline CHEMBL1387575 & 688422 & 5.25 & 5.1466 & TRN & \\
\hline CHEMBL1418494 & 688422 & 4.9 & 4.7529 & TRN & \\
\hline CHEMBL1543048 & 688422 & 4.75 & 5.3082 & TRN & \\
\hline CHEMBL1433725 & 688422 & 4.7 & 4.9854 & TRN & \\
\hline CHEMBL1599484 & 688422 & 4.6 & 5.2153 & TRN & \\
\hline CHEMBL1320665 & 688422 & 5.05 & 4.8533 & TST & \\
\hline CHEMBL1503376 & 688422 & 5.4 & 5.2628 & TRN & \\
\hline CHEMBL1606995 & 688422 & 4.45 & 5.4178 & TRN & \\
\hline CHEMBL1383033 & 688422 & 4.65 & 4.96399 & 99999999995 & TRN \\
\hline CHEMBL507237 & 688422 & 6.7001 & 5.3748 & TST & \\
\hline CHEMBL1319713 & 688422 & 4.75 & 5.4293 & TST & \\
\hline CHEMBL1561756 & 688422 & 4.65 & 4.9101 & TRN & \\
\hline CHEMBL1447059 & 688422 & 4.7 & 5.4084 & TRN & \\
\hline CHEMBL1548820 & 688422 & 5.2 & 5.3152 & TST & \\
\hline CHEMBL1519735 & 688422 & 5.0 & 5.0891 & TST & \\
\hline CHEMBL3189405 & 688422 & 4.9 & 5.50700 & 0000000001 & TRN \\
\hline CHEMBL1354734 & 688422 & 5.2 & 5.6316 & TST & \\
\hline CHEMBL1365490 & 688422 & 4.8 & 5.0672 & TST & \\
\hline CHEMBL1541541 & 688422 & 5.6 & 5.2784 & TRN & \\
\hline CHEMBL 2001226 & 688422 & 4.95 & 4.9613 & TST & \\
\hline CHEMBL1562886 & 688422 & 5.15 & 5.3566 & TRN & \\
\hline CHEMBL1380545 & 688422 & 4.85 & 5.0942 & TRN & \\
\hline CHEMBL1540383 & 688422 & 7.2 & 5.317 & TST & \\
\hline CHEMBL1393241 & 688422 & 4.45 & 5.1508 & TRN & \\
\hline CHEMBL1425421 & 688422 & 5.4 & 5.2988 & TRN & \\
\hline CHEMBL1309003 & 688422 & 4.65 & 5.1735 & TRN & \\
\hline CHEMBL3199091 & 688422 & 5.5 & 4.904 & TRN & \\
\hline CHEMBL1428292 & 688422 & 4.45 & 5.3832 & TST & \\
\hline CHEMBL1416574 & 688422 & 4.8 & 4.9098 & TRN & \\
\hline CHEMBL1549112 & 688422 & 4.6 & 5.6554 & TRN & \\
\hline CHEMBL1329123 & 688422 & 4.75 & 5.1949 & TRN & \\
\hline CHEMBL1465794 & 688422 & 4.9 & 4.8279 & TRN & \\
\hline CHEMBL1478721 & 688422 & 8.4949 & 5.2572 & TST & \\
\hline CHEMBL1434130 & 688422 & 6.8499 & 5.1734 & TRN & \\
\hline CHEMBL1445645 & 688422 & 4.9 & 5.5028 & TRN & \\
\hline CHEMBL1502014 & 688422 & 4.95 & 4.8438 & TST & \\
\hline CHEMBL1445193 & 688422 & 4.5 & 5.152 & TRN & \\
\hline CHEMBL1437633 & 688422 & 4.95 & 4.9367 & TRN & \\
\hline CHEMBL1775009 & 688422 & 5.15 & 6.08700 & 0000000001 & TRN \\
\hline CHEMBL1305747 & 688422 & 4.95 & 5.272 & TRN & \\
\hline CHEMBL1545234 & 688422 & 5.0 & 4.9455 & TRN & \\
\hline CHEMBL1358838 & 688422 & 4.45 & 5.5103 & TRN & \\
\hline CHEMBL1497547 & 688422 & 4.45 & 5.2961 & TST & \\
\hline CHEMBL1467983 & 688422 & 5.65 & 5.345 & TRN & \\
\hline CHEMBL195506 & 688422 & 5.3 & 4.984 & TRN & \\
\hline CHEMBL1389300 & 688422 & 4.65 & 5.2521 & TRN & \\
\hline CHEMBL1462656 & 688422 & 4.95 & 5.1504 & TRN & \\
\hline CHEMBL1255653 & 688422 & 5.2 & 6.0024 & TST & \\
\hline
\end{tabular}




\begin{tabular}{|c|c|c|c|c|c|}
\hline \multicolumn{6}{|c|}{ Supplemental Table S2.txt } \\
\hline CHEMBL1569455 & 688422 & 4.5 & 5.557 & TRN & \\
\hline CHEMBL1407431 & 688422 & 4.8 & 5.1274 & TRN & \\
\hline CHEMBL1444560 & 688422 & 5.5 & 5.3439 & TST & \\
\hline CHEMBL1303453 & 688422 & 7.8996 & 5.2254 & TST & \\
\hline CHEMBL1554401 & 688422 & 5.6 & 5.0957 & TRN & \\
\hline CHEMBL1354944 & 688422 & 6.15 & 5.45799 & 9999999999 & TRN \\
\hline CHEMBL 3144999 & 688422 & 5.15 & 5.1064 & TRN & \\
\hline CHEMBL1345722 & 688422 & 4.45 & 4.8276 & TRN & \\
\hline CHEMBL1389623 & 688422 & 5.0 & 4.9825 & TRN & \\
\hline CHEMBL1524717 & 688422 & 4.65 & 5.4426 & TRN & \\
\hline CHEMBL1319158 & 688422 & 4.45 & 5.2824 & TRN & \\
\hline CHEMBL589920 & 688422 & 4.45 & 5.0259 & TRN & \\
\hline CHEMBL1528337 & 688422 & 4.85 & 5.2698 & TRN & \\
\hline CHEMBL1466959 & 688422 & 4.45 & 5.063 & TRN & \\
\hline CHEMBL1309498 & 688422 & 4.45 & 4.8898 & TRN & \\
\hline CHEMBL1364302 & 688422 & 4.65 & 5.1437 & TRN & \\
\hline CHEMBL1613238 & 688422 & 5.4 & 5.3632 & TRN & \\
\hline CHEMBL1312709 & 688422 & 4.95 & 5.1009 & TRN & \\
\hline CHEMBL1578023 & 688422 & 7.699 & 5.6895 & TST & \\
\hline CHEMBL1468524 & 688422 & 4.85 & 6.1246 & TRN & \\
\hline CHEMBL416657 & 688422 & 4.75 & 4.0068 & TST & \\
\hline CHEMBL593019 & 688422 & 6.35 & 5.8235 & TRN & \\
\hline CHEMBL1561032 & 688422 & 4.8 & 5.4095 & TRN & \\
\hline CHEMBL1339380 & 688422 & 4.6 & 4.9414 & TRN & \\
\hline CHEMBL1466844 & 688422 & 4.45 & 4.8006 & TRN & \\
\hline CHEMBL1334567 & 688422 & 4.65 & 5.2415 & TRN & \\
\hline CHEMBL1523100 & 688422 & 7.5003 & 5.1111 & TRN & \\
\hline CHEMBL1367665 & 688422 & 4.95 & 5.4161 & TST & \\
\hline CHEMBL1554967 & 688422 & 8.4949 & 5.8811 & TST & \\
\hline CHEMBL1385881 & 688422 & 4.9 & 5.4086 & TST & \\
\hline CHEMBL1464727 & 688422 & 5.6 & 5.55399 & 9999999999 & TRN \\
\hline CHEMBL1383333 & 688422 & 4.55 & 4.8944 & TRN & \\
\hline CHEMBL1391839 & 688422 & 4.95 & 5.2994 & TRN & \\
\hline CHEMBL1573076 & 688422 & 8.3468 & 5.5551 & TST & \\
\hline CHEMBL 2359911 & 688422 & 5.0 & 5.2328 & TST & \\
\hline CHEMBL1585233 & 688422 & 4.45 & 4.8444 & TRN & \\
\hline CHEMBL1427713 & 688422 & 4.9 & 5.3885 & TRN & \\
\hline CHEMBL1466855 & 688422 & 4.55 & 5.3946 & TRN & \\
\hline CHEMBL1465779 & 688422 & 5.45 & 4.9153 & TRN & \\
\hline CHEMBL1411165 & 688422 & 4.95 & 5.3466 & TRN & \\
\hline CHEMBL1321725 & 688422 & 4.45 & 5.1485 & TRN & \\
\hline CHEMBL1548548 & 688422 & 5.0 & 5.0194 & TST & \\
\hline CHEMBL3198677 & 688422 & 4.45 & 5.5118 & TRN & \\
\hline CHEMBL1401932 & 688422 & 8.4949 & 5.6114 & TRN & \\
\hline CHEMBL1487690 & 688422 & 4.45 & 5.235 & TRN & \\
\hline CHEMBL1457356 & 688422 & 4.6 & 5.4248 & TRN & \\
\hline CHEMBL1388482 & 688422 & 5.25 & 5.2818 & TRN & \\
\hline CHEMBL1519005 & 688422 & 4.45 & 5.2005 & TRN & \\
\hline
\end{tabular}




\begin{tabular}{|c|c|c|c|c|c|}
\hline \multicolumn{6}{|c|}{ Supplemental Table S2.txt } \\
\hline CHEMBL1429877 & 688422 & 4.45 & 5.4492 & TST & \\
\hline CHEMBL449329 & 688422 & 6.3 & 6.075 & TRN & \\
\hline CHEMBL590186 & 688422 & 5.2 & 5.1902 & TST & \\
\hline CHEMBL 3213876 & 688422 & 4.5 & 5.1448 & TRN & \\
\hline CHEMBL552134 & 688422 & 4.65 & 5.1915 & TST & \\
\hline CHEMBL1567532 & 688422 & 4.75 & 4.9305 & TST & \\
\hline CHEMBL1470255 & 688422 & 4.5 & 5.3416 & TRN & \\
\hline CHEMBL1442501 & 688422 & 4.75 & 5.0735 & TRN & \\
\hline CHEMBL1464906 & 688422 & 6.6499 & 4.8124 & TRN & \\
\hline CHEMBL1537368 & 688422 & 6.8499 & 5.3829 & TRN & \\
\hline CHEMBL1596211 & 688422 & 4.85 & 5.05399 & 9999999999 & TRN \\
\hline CHEMBL1320808 & 688422 & 5.05 & 5.3927 & TRN & \\
\hline CHEMBL1391518 & 688422 & 5.55 & 4.8723 & TRN & \\
\hline CHEMBL1513007 & 688422 & 6.5501 & 5.9465 & TRN & \\
\hline CHEMBL1445589 & 688422 & 4.45 & 5.3548 & TRN & \\
\hline CHEMBL1508896 & 688422 & 4.75 & 5.3802 & TRN & \\
\hline CHEMBL1301930 & 688422 & 7.6003 & 5.5974 & TST & \\
\hline CHEMBL1714386 & 688422 & 4.45 & 5.7036 & TRN & \\
\hline CHEMBL1306528 & 688422 & 4.85 & 4.8721 & TRN & \\
\hline CHEMBL1355387 & 688422 & 4.7 & 5.0695 & TRN & \\
\hline CHEMBL1384913 & 688422 & 4.45 & 5.5141 & TRN & \\
\hline CHEMBL1366216 & 688422 & 4.55 & 5.2123 & TRN & \\
\hline CHEMBL1375004 & 688422 & 7.2503 & 5.6835 & TRN & \\
\hline CHEMBL1468577 & 688422 & 4.85 & 4.8841 & TRN & \\
\hline CHEMBL1350125 & 688422 & 5.2 & 5.2548 & TRN & \\
\hline CHEMBL1413584 & 688422 & 4.8 & 4.9987 & TRN & \\
\hline CHEMBL1560655 & 688422 & 4.95 & 5.3502 & TST & \\
\hline CHEMBL1586062 & 688422 & 5.0 & 4.8371 & TRN & \\
\hline CHEMBL1379008 & 688422 & 4.95 & 5.1041 & TRN & \\
\hline CHEMBL1570006 & 688422 & 4.75 & 5.16799 & 9999999999 & TST \\
\hline CHEMBL1446827 & 688422 & 5.1 & 5.2898 & TRN & \\
\hline CHEMBL1372596 & 688422 & 5.55 & 5.6969 & TRN & \\
\hline CHEMBL 260283 & 688422 & 4.9 & 5.5523 & TRN & \\
\hline CHEMBL1534959 & 688422 & 4.55 & 5.3041 & TRN & \\
\hline CHEMBL1447719 & 688422 & 4.8 & 4.9251 & TRN & \\
\hline CHEMBL1548937 & 688422 & 5.3 & 5.607 & TRN & \\
\hline CHEMBL1375708 & 688422 & 4.45 & 4.8596 & TRN & \\
\hline CHEMBL1452042 & 688422 & 4.75 & 5.1499 & TRN & \\
\hline CHEMBL1444482 & 688422 & 4.8 & 5.0454 & TRN & \\
\hline CHEMBL1488118 & 688422 & 4.9 & 5.5004 & TRN & \\
\hline CHEMBL3195373 & 688422 & 4.7 & 5.1144 & TRN & \\
\hline CHEMBL1513633 & 688422 & 4.7 & 5.0974 & TRN & \\
\hline CHEMBL1542126 & 688422 & 4.85 & 5.0547 & TRN & \\
\hline CHEMBL1561506 & 688422 & 4.45 & 5.1947 & TRN & \\
\hline CHEMBL1445273 & 688422 & 5.55 & 4.8011 & TST & \\
\hline CHEMBL1557680 & 688422 & 6.0 & 5.4741 & TRN & \\
\hline CHEMBL1489599 & 688422 & 4.9 & 5.3393 & TST & \\
\hline CHEMBL1333483 & 688422 & 4.65 & 4.8701 & TRN & \\
\hline
\end{tabular}




\begin{tabular}{|c|c|c|c|c|}
\hline \multicolumn{5}{|c|}{ Supplemental Table S2.txt } \\
\hline CHEMBL1584067 & 688422 & 4.45 & 5.1345 & TRN \\
\hline CHEMBL1463825 & 688422 & 6.25 & 5.1622 & TRN \\
\hline CHEMBL1574861 & 688422 & 5.0 & 5.4761 & TST \\
\hline CHEMBL1393033 & 688422 & 4.6 & 5.6657 & TRN \\
\hline CHEMBL1600991 & 688422 & 5.45 & 5.4401 & TRN \\
\hline CHEMBL1479338 & 688422 & 5.0 & 5.5933 & TST \\
\hline CHEMBL1603469 & 688422 & 4.85 & 5.5233 & TRN \\
\hline CHEMBL3209934 & 688422 & 4.8 & 5.1606 & TRN \\
\hline CHEMBL1549018 & 688422 & 4.45 & 5.012 & TST \\
\hline CHEMBL1464813 & 688422 & 8.301 & 5.3862 & TST \\
\hline CHEMBL1322711 & 688422 & 5.0 & 5.279 & TRN \\
\hline CHEMBL1464661 & 688422 & 7.0501 & 5.8524 & TST \\
\hline CHEMBL1462190 & 688422 & 4.65 & 5.2731 & TRN \\
\hline CHEMBL398969 & 688422 & 4.45 & 5.1814 & TRN \\
\hline CHEMBL1312545 & 688422 & 8.3468 & 5.6258 & TRN \\
\hline CHEMBL1323330 & 688422 & 4.9 & 4.9635 & TRN \\
\hline CHEMBL1421745 & 688422 & 5.65 & 5.3148 & TST \\
\hline CHEMBL1495037 & 688422 & 5.5 & 4.9388 & TRN \\
\hline CHEMBL1504319 & 688422 & 5.55 & 5.4054 & TST \\
\hline CHEMBL1407326 & 688422 & 8.301 & 5.7028 & TRN \\
\hline CHEMBL1544829 & 688422 & 4.45 & 5.0598 & TRN \\
\hline CHEMBL1561005 & 688422 & 4.5 & 4.8537 & TST \\
\hline CHEMBL1574624 & 688422 & 4.6 & 5.7447 & TRN \\
\hline CHEMBL1509981 & 688422 & 4.45 & 5.6273 & TST \\
\hline CHEMBL1534172 & 688422 & 4.8 & 5.2539 & TST \\
\hline CHEMBL1598440 & 688422 & 4.45 & 5.0335 & TST \\
\hline CHEMBL1367973 & 688422 & 8.4559 & 5.2965 & TST \\
\hline CHEMBL1320542 & 688422 & 4.65 & 5.3722 & TRN \\
\hline CHEMBL1548815 & 688422 & 4.95 & 4.6898 & TST \\
\hline CHEMBL1466073 & 688422 & 4.95 & 5.45 & TRN \\
\hline CHEMBL1341707 & 688422 & 5.2 & 5.0424 & TRN \\
\hline CHEMBL1307836 & 688422 & 4.9 & 5.3377 & TRN \\
\hline CHEMBL1425521 & 688422 & 4.95 & 5.012 & TRN \\
\hline CHEMBL344127 & 688422 & 5.2 & 5.4652 & TST \\
\hline CHEMBL1497453 & 688422 & 4.65 & 4.8376 & TRN \\
\hline CHEMBL1402457 & 688422 & 5.15 & 5.3905 & TRN \\
\hline CHEMBL1346648 & 688422 & 4.6 & 5.1722 & TST \\
\hline CHEMBL1512651 & 688422 & 4.5 & 5.6318 & TRN \\
\hline CHEMBL1335162 & 688422 & 4.85 & 4.9939 & TRN \\
\hline CHEMBL1533694 & 688422 & 4.75 & 4.9488 & TRN \\
\hline CHEMBL1341849 & 688422 & 4.65 & 4.8454 & TRN \\
\hline CHEMBL1458098 & 688422 & 8.301 & 5.2427 & TST \\
\hline CHEMBL1577011 & 688422 & 6.2 & 5.9729 & TST \\
\hline CHEMBL1469937 & 688422 & 4.85 & 4.9072 & TRN \\
\hline CHEMBL1301650 & 688422 & 4.9 & 5.0498 & TRN \\
\hline CHEMBL1573242 & 688422 & 4.95 & 5.1042 & TRN \\
\hline CHEMBL1310690 & 688422 & 5.4 & 5.0913 & TRN \\
\hline CHEMBL489 & 688422 & 4.5 & 5.1491 & TST \\
\hline
\end{tabular}




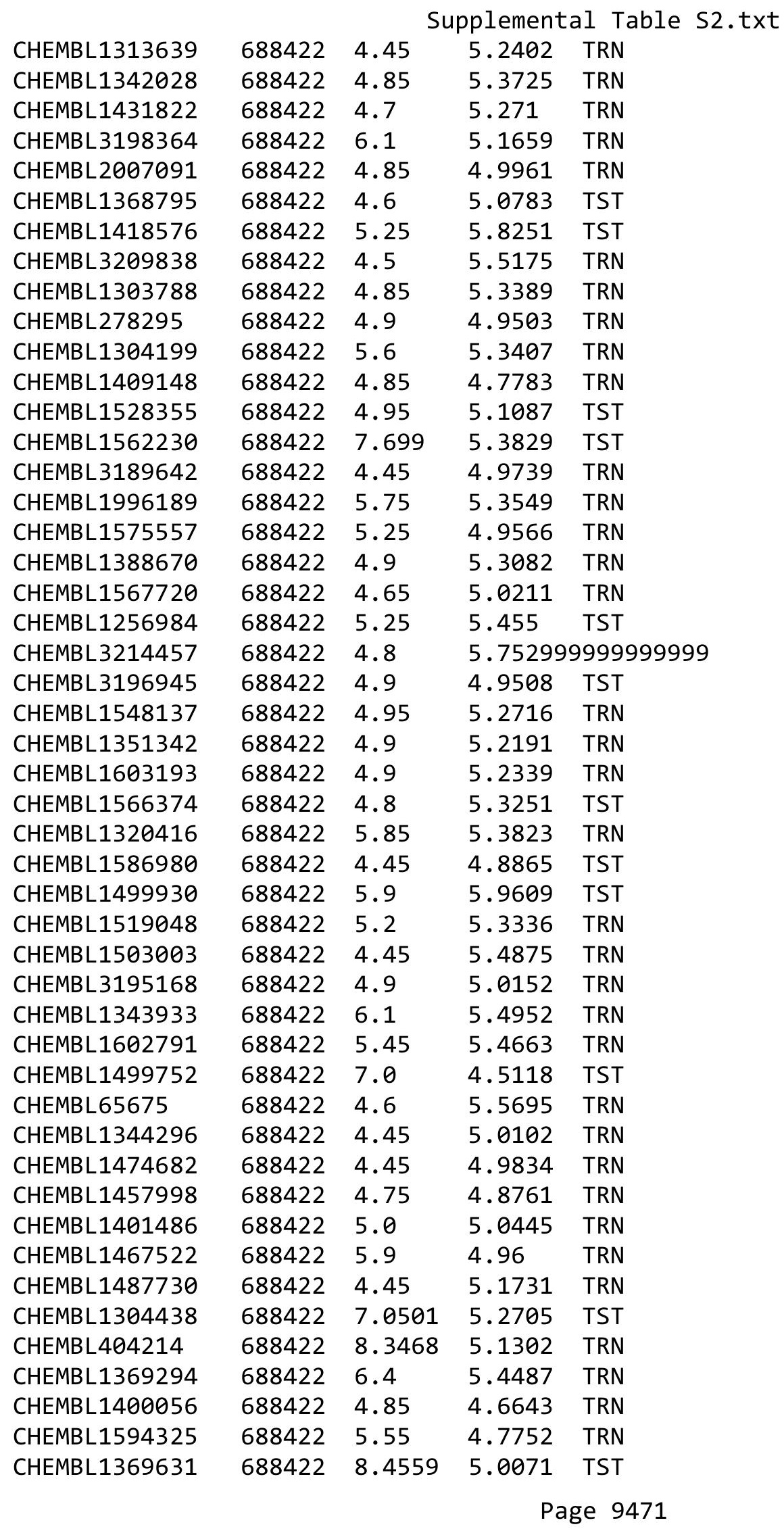




\begin{tabular}{|c|c|c|c|c|}
\hline \multicolumn{5}{|c|}{ Supplemental Table S2.txt } \\
\hline CHEMBL1593784 & 688422 & 4.65 & 5.3754 & TRN \\
\hline CHEMBL1534923 & 688422 & 4.45 & 5.2871 & TRN \\
\hline CHEMBL1548043 & 688422 & 5.15 & 5.1046 & TST \\
\hline CHEMBL1598665 & 688422 & 4.6 & 4.9503 & TRN \\
\hline CHEMBL1507484 & 688422 & 6.1 & 5.7125 & TST \\
\hline CHEMBL1405339 & 688422 & 4.5 & 5.2266 & TST \\
\hline CHEMBL1570293 & 688422 & 6.3 & 5.6909 & TRN \\
\hline CHEMBL1463093 & 688422 & 4.75 & 4.9914 & TRN \\
\hline CHEMBL1366768 & 688422 & 5.2 & 5.5533 & TST \\
\hline CHEMBL 1489429 & 688422 & 4.85 & 4.9729 & TRN \\
\hline CHEMBL1448741 & 688422 & 5.2 & 5.0853 & TRN \\
\hline CHEMBL1326786 & 688422 & 4.6 & 5.1698 & TRN \\
\hline CHEMBL1511589 & 688422 & 4.95 & 4.6126 & TRN \\
\hline CHEMBL1459757 & 688422 & 4.45 & 5.3234 & TRN \\
\hline CHEMBL1447197 & 688422 & 5.4 & 5.7733 & TRN \\
\hline CHEMBL3212998 & 688422 & 4.45 & 4.6551 & TRN \\
\hline CHEMBL1495896 & 688422 & 8.301 & 5.3735 & TRN \\
\hline CHEMBL1456075 & 688422 & 5.0 & 5.0873 & TRN \\
\hline CHEMBL1492181 & 688422 & 8.4949 & 5.7627 & TST \\
\hline CHEMBL1539557 & 688422 & 5.0 & 5.1122 & TRN \\
\hline CHEMBL1414270 & 688422 & 8.4559 & 5.7483 & TRN \\
\hline CHEMBL1607993 & 688422 & 5.4 & 4.7277 & TST \\
\hline CHEMBL1304058 & 688422 & 4.65 & 5.3453 & TRN \\
\hline CHEMBL1532925 & 688422 & 4.5 & 5.2214 & TRN \\
\hline CHEMBL1463699 & 688422 & 4.95 & 5.0069 & TRN \\
\hline CHEMBL1575030 & 688422 & 4.9 & 5.301 & TRN \\
\hline CHEMBL3214333 & 688422 & 4.45 & 5.5498 & TRN \\
\hline CHEMBL1351421 & 688422 & 5.25 & 5.2261 & TRN \\
\hline CHEMBL3212809 & 688422 & 4.45 & 5.5826 & TST \\
\hline CHEMBL1592543 & 688422 & 8.2007 & 5.4061 & TRN \\
\hline CHEMBL1576068 & 688422 & 4.85 & 5.1905 & TRN \\
\hline CHEMBL1256995 & 688422 & 4.7 & 5.2738 & TRN \\
\hline CHEMBL1378097 & 688422 & 4.6 & 5.0451 & TRN \\
\hline CHEMBL1383455 & 688422 & 4.85 & 4.9526 & TRN \\
\hline CHEMBL1593569 & 688422 & 4.65 & 5.3429 & TRN \\
\hline CHEMBL1603896 & 688422 & 4.9 & 4.8532 & TRN \\
\hline CHEMBL1371954 & 688422 & 4.85 & 5.3344 & TST \\
\hline CHEMBL1612390 & 688422 & 4.75 & 5.3879 & TRN \\
\hline CHEMBL1404392 & 688422 & 7.15 & 5.279 & TRN \\
\hline CHEMBL1441181 & 688422 & 4.45 & 5.3386 & TRN \\
\hline CHEMBL1334834 & 688422 & 5.15 & 5.1818 & TRN \\
\hline CHEMBL1561128 & 688422 & 5.1 & 5.3453 & TRN \\
\hline CHEMBL 3208645 & 688422 & 4.95 & 5.3043 & TRN \\
\hline CHEMBL1343366 & 688422 & 4.85 & 4.7123 & TRN \\
\hline CHEMBL1429668 & 688422 & 5.0 & 5.6438 & TRN \\
\hline CHEMBL3199111 & 688422 & 4.45 & 5.5047 & TST \\
\hline CHEMBL1391810 & 688422 & 4.5 & 4.9819 & TRN \\
\hline CHEMBL1382331 & 688422 & 5.6 & 5.3608 & TRN \\
\hline
\end{tabular}




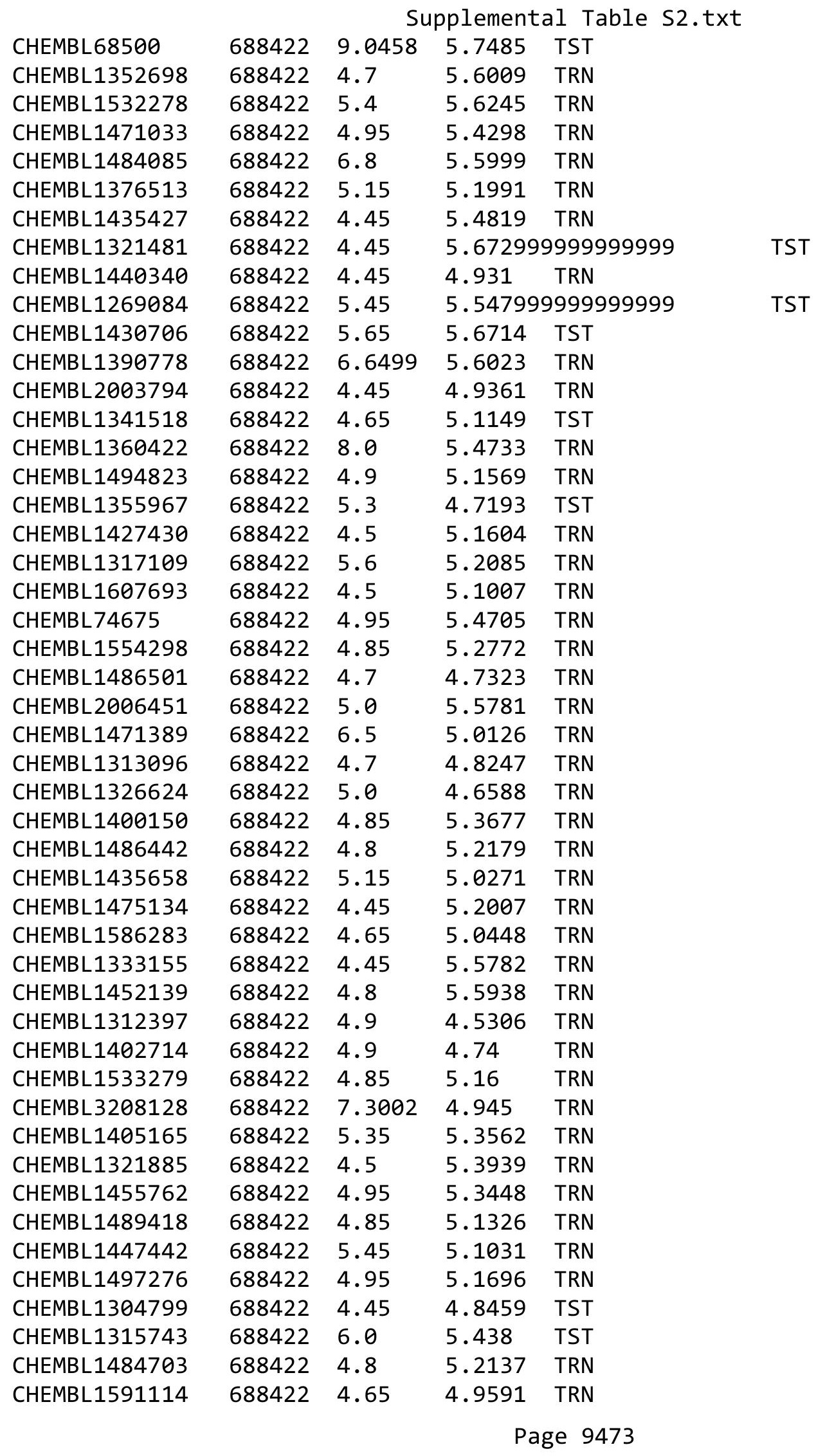




\begin{tabular}{|c|c|c|c|c|c|}
\hline \multicolumn{6}{|c|}{ Supplemental Table S2.txt } \\
\hline CHEMBL1480957 & 688422 & 4.65 & 5.1612 & TST & \\
\hline CHEMBL1429887 & 688422 & 5.25 & 5.0131 & TRN & \\
\hline CHEMBL3196163 & 688422 & 4.85 & 5.2883 & TRN & \\
\hline CHEMBL1332573 & 688422 & 4.5 & 5.2694 & TRN & \\
\hline CHEMBL1368008 & 688422 & 5.25 & 5.5034 & TRN & \\
\hline CHEMBL1571679 & 688422 & 4.65 & 5.1098 & TRN & \\
\hline CHEMBL1363412 & 688422 & 4.45 & 5.0917 & TST & \\
\hline CHEMBL138297 & 688422 & 7.0501 & 6.1618 & TRN & \\
\hline CHEMBL1578085 & 688422 & 4.65 & 5.3548 & TRN & \\
\hline CHEMBL3210083 & 688422 & 4.85 & 4.973 & TST & \\
\hline CHEMBL1480494 & 688422 & 4.75 & 4.7029 & TRN & \\
\hline CHEMBL1373955 & 688422 & 6.8 & 5.7232 & TRN & \\
\hline CHEMBL1420265 & 688422 & 5.25 & 5.3493 & TRN & \\
\hline CHEMBL1525658 & 688422 & 4.6 & 5.1179 & TRN & \\
\hline CHEMBL1480045 & 688422 & 5.2 & 5.3957 & TRN & \\
\hline CHEMBL1484875 & 688422 & 7.6003 & 6.0229 & TRN & \\
\hline CHEMBL1564148 & 688422 & 4.8 & 5.6521 & TST & \\
\hline CHEMBL1504505 & 688422 & 4.75 & 4.8588 & TRN & \\
\hline CHEMBL1380888 & 688422 & 7.699 & 5.76 & TRN & \\
\hline CHEMBL1609898 & 688422 & 4.85 & 4.9342 & TRN & \\
\hline CHEMBL1350669 & 688422 & 4.75 & 6.0172 & TRN & \\
\hline CHEMBL1423147 & 688422 & 4.85 & 5.0774 & TRN & \\
\hline CHEMBL1381918 & 688422 & 4.5 & 4.7819 & TRN & \\
\hline CHEMBL1574403 & 688422 & 4.9 & 4.9331 & TRN & \\
\hline CHEMBL1539484 & 688422 & 5.1 & 5.1697 & TST & \\
\hline CHEMBL1543371 & 688422 & 4.65 & 4.94600 & 0000000001 & TRN \\
\hline CHEMBL1327840 & 688422 & 4.6 & 5.003 & TST & \\
\hline CHEMBL1570936 & 688422 & 5.05 & 5.1626 & TRN & \\
\hline CHEMBL1971324 & 688422 & 6.5501 & 5.2502 & TRN & \\
\hline CHEMBL1574764 & 688422 & 5.05 & 5.526 & TST & \\
\hline CHEMBL1394857 & 688422 & 7.0 & 5.36700 & 0000000001 & TRN \\
\hline CHEMBL418068 & 688422 & 4.9 & 5.6956 & TST & \\
\hline CHEMBL1490623 & 688422 & 4.55 & 5.2651 & TRN & \\
\hline CHEMBL1432893 & 688422 & 4.65 & 5.1579 & TST & \\
\hline CHEMBL1335050 & 688422 & 4.95 & 5.3646 & TRN & \\
\hline CHEMBL1364536 & 688422 & 4.75 & 5.5138 & TRN & \\
\hline CHEMBL1606613 & 688422 & 4.65 & 5.0339 & TRN & \\
\hline CHEMBL1391259 & 688422 & 4.45 & 5.1793 & TRN & \\
\hline CHEMBL1317914 & 688422 & 4.95 & 5.3396 & TRN & \\
\hline CHEMBL1387731 & 688422 & 4.9 & 5.4839 & TRN & \\
\hline CHEMBL1480014 & 688422 & 4.45 & 5.1851 & TRN & \\
\hline CHEMBL1490718 & 688422 & 4.9 & 5.5245 & TRN & \\
\hline CHEMBL1302902 & 688422 & 4.9 & 5.2243 & TST & \\
\hline CHEMBL1256290 & 688422 & 8.2007 & 5.9551 & TST & \\
\hline CHEMBL1460593 & 688422 & 4.45 & 4.8363 & TRN & \\
\hline CHEMBL1337115 & 688422 & 4.45 & 5.2526 & TRN & \\
\hline CHEMBL1608061 & 688422 & 4.9 & 5.3041 & TST & \\
\hline CHEMBL1457924 & 688422 & 4.9 & 5.2768 & TRN & \\
\hline
\end{tabular}




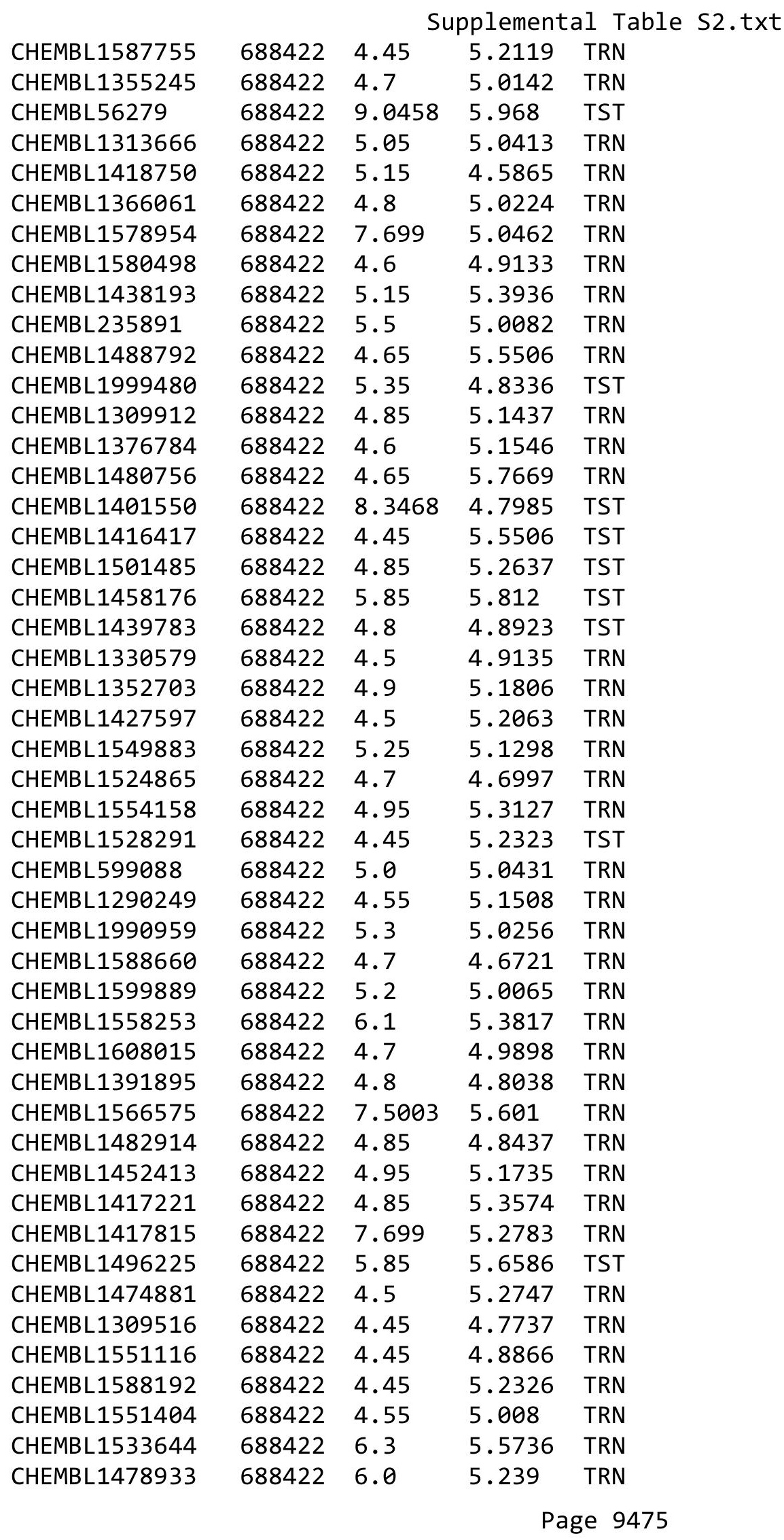




\begin{tabular}{|c|c|c|c|c|c|}
\hline \multicolumn{6}{|c|}{ Supplemental Table S2.txt } \\
\hline CHEMBL1335830 & 688422 & 5.2 & 4.9079 & TRN & \\
\hline CHEMBL1340111 & 688422 & 5.2 & 5.1474 & TST & \\
\hline CHEMBL1372863 & 688422 & 4.85 & 5.1522 & TRN & \\
\hline CHEMBL1385244 & 688422 & 4.85 & 5.1448 & TRN & \\
\hline CHEMBL1571383 & 688422 & 4.95 & 5.2195 & TRN & \\
\hline CHEMBL1380763 & 688422 & 4.9 & 5.1948 & TRN & \\
\hline CHEMBL1361710 & 688422 & 4.85 & 5.37 & TST & \\
\hline CHEMBL1473097 & 688422 & 4.45 & 5.4543 & TRN & \\
\hline CHEMBL1367866 & 688422 & 4.5 & 4.9251 & TRN & \\
\hline CHEMBL1424363 & 688422 & 4.45 & 5.2734 & TST & \\
\hline CHEMBL1523385 & 688422 & 4.45 & 5.1472 & TST & \\
\hline CHEMBL1343187 & 688422 & 4.45 & 5.064 & TST & \\
\hline CHEMBL1427962 & 688422 & 4.8 & 5.0051 & TRN & \\
\hline CHEMBL1429658 & 688422 & 4.45 & 5.7313 & TST & \\
\hline CHEMBL1535226 & 688422 & 5.6 & 5.2729 & TST & \\
\hline CHEMBL1512720 & 688422 & 4.95 & 5.1247 & TRN & \\
\hline CHEMBL1518864 & 688422 & 4.6 & 5.136 & TRN & \\
\hline CHEMBL1440879 & 688422 & 5.35 & 5.4681 & TRN & \\
\hline CHEMBL1463423 & 688422 & 5.4 & 5.1875 & TRN & \\
\hline CHEMBL1429077 & 688422 & 5.3 & 5.2068 & TRN & \\
\hline CHEMBL1518886 & 688422 & 6.35 & 5.4803 & TRN & \\
\hline CHEMBL536375 & 688422 & 4.45 & 5.1096 & TRN & \\
\hline CHEMBL1439899 & 688422 & 4.45 & 5.0638 & TRN & \\
\hline CHEMBL1510563 & 688422 & 4.8 & 5.2312 & TRN & \\
\hline CHEMBL1422639 & 688422 & 5.2 & 6.0712 & TST & \\
\hline CHEMBL1306433 & 688422 & 4.75 & 4.8778 & TRN & \\
\hline CHEMBL1409731 & 688422 & 5.15 & 5.1829 & TRN & \\
\hline CHEMBL1566345 & 688422 & 4.65 & 4.7631 & TRN & \\
\hline CHEMBL1578120 & 688422 & 4.85 & 4.95100 & 00000000005 & TRN \\
\hline CHEMBL1538406 & 688422 & 4.9 & 5.5851 & TRN & \\
\hline CHEMBL3191940 & 688422 & 4.6 & 5.1324 & TST & \\
\hline CHEMBL1584595 & 688422 & 7.699 & 5.131 & TST & \\
\hline CHEMBL1302096 & 688422 & 5.5 & 5.1552 & TRN & \\
\hline CHEMBL1324754 & 688422 & 4.55 & 5.107 & TRN & \\
\hline CHEMBL1299699 & 688422 & 4.65 & 5.1771 & TRN & \\
\hline CHEMBL1321298 & 688422 & 4.5 & 5.2899 & TRN & \\
\hline CHEMBL1578824 & 688422 & 4.65 & 4.9559 & TRN & \\
\hline CHEMBL3191908 & 688422 & 4.65 & 5.602 & TRN & \\
\hline CHEMBL1404572 & 688422 & 5.25 & 5.7766 & TRN & \\
\hline CHEMBL427449 & 688422 & 4.45 & 5.06800 & 00000000005 & TRN \\
\hline CHEMBL1393947 & 688422 & 8.8539 & 5.2815 & TRN & \\
\hline CHEMBL1582826 & 688422 & 4.7 & 5.3809 & TRN & \\
\hline CHEMBL1973525 & 688422 & 4.7 & 5.2838 & TST & \\
\hline CHEMBL1367114 & 688422 & 4.95 & 4.856 & TRN & \\
\hline CHEMBL1572788 & 688422 & 4.8 & 5.2251 & TRN & \\
\hline CHEMBL1386166 & 688422 & 4.7 & 5.0835 & TRN & \\
\hline CHEMBL1565235 & 688422 & 5.0 & 5.4442 & TST & \\
\hline CHEMBL1509979 & 688422 & 4.5 & 5.1599 & TRN & \\
\hline
\end{tabular}




\begin{tabular}{|c|c|c|c|c|c|}
\hline \multicolumn{6}{|c|}{ Supplemental Table S2.txt } \\
\hline CHEMBL1342304 & 688422 & 4.7 & 5.2319 & TRN & \\
\hline CHEMBL1425351 & 688422 & 6.5 & 5.6886 & TRN & \\
\hline CHEMBL1344623 & 688422 & 4.9 & 4.9945 & TRN & \\
\hline CHEMBL1581848 & 688422 & 4.65 & 4.6711 & TRN & \\
\hline CHEMBL1595173 & 688422 & 5.4 & 5.1837 & TRN & \\
\hline CHEMBL1557023 & 688422 & 5.45 & 5.5118 & TRN & \\
\hline CHEMBL1579522 & 688422 & 5.65 & 5.6146 & TRN & \\
\hline CHEMBL1501063 & 688422 & 4.7 & 5.0715 & TRN & \\
\hline CHEMBL1545280 & 688422 & 5.0 & 5.1722 & TRN & \\
\hline CHEMBL1444343 & 688422 & 5.9 & 5.0901 & TRN & \\
\hline CHEMBL1569344 & 688422 & 5.45 & 5.0423 & TRN & \\
\hline CHEMBL1529393 & 688422 & 7.5003 & 5.6484 & TST & \\
\hline CHEMBL3194936 & 688422 & 5.1 & 5.2053 & TRN & \\
\hline CHEMBL1345140 & 688422 & 4.6 & 5.1124 & TRN & \\
\hline CHEMBL1548255 & 688422 & 5.95 & 5.5315 & TST & \\
\hline CHEMBL1604928 & 688422 & 4.45 & 5.1558 & TRN & \\
\hline CHEMBL1521615 & 688422 & 4.45 & 5.5999 & TRN & \\
\hline CHEMBL1486533 & 688422 & 4.75 & 4.835 & TRN & \\
\hline CHEMBL1588406 & 688422 & 4.45 & 4.9912 & TRN & \\
\hline CHEMBL1427180 & 688422 & 4.85 & 5.5378 & TRN & \\
\hline CHEMBL1521090 & 688422 & 4.65 & 5.0691 & TRN & \\
\hline CHEMBL3212728 & 688422 & 4.8 & 5.2843 & TST & \\
\hline CHEMBL1468104 & 688422 & 4.65 & 5.414 & TST & \\
\hline CHEMBL1576836 & 688422 & 4.9 & 4.7782 & TST & \\
\hline CHEMBL1489751 & 688422 & 4.45 & 6.04200 & 0000000001 & TST \\
\hline CHEMBL1448603 & 688422 & 4.45 & 5.1615 & TRN & \\
\hline CHEMBL1973454 & 688422 & 4.7 & 5.4621 & TST & \\
\hline CHEMBL1430769 & 688422 & 4.75 & 4.9526 & TRN & \\
\hline CHEMBL1549157 & 688422 & 5.45 & 5.3089 & TRN & \\
\hline CHEMBL1999019 & 688422 & 4.65 & 4.9841 & TST & \\
\hline CHEMBL1483685 & 688422 & 6.1 & 5.3749 & TRN & \\
\hline CHEMBL1570939 & 688422 & 4.85 & 5.643 & TRN & \\
\hline CHEMBL1299448 & 688422 & 4.75 & 4.9847 & TRN & \\
\hline CHEMBL1315461 & 688422 & 4.7 & 5.0461 & TRN & \\
\hline CHEMBL1440515 & 688422 & 4.65 & 4.8379 & TRN & \\
\hline CHEMBL33171 & 688422 & 5.25 & 5.4879 & TRN & \\
\hline CHEMBL3191747 & 688422 & 4.45 & 5.2294 & TRN & \\
\hline CHEMBL3193924 & 688422 & 4.9 & 5.1718 & TRN & \\
\hline CHEMBL1375499 & 688422 & 4.85 & 5.1803 & TST & \\
\hline CHEMBL 2001024 & 688422 & 5.3 & 5.2907 & TRN & \\
\hline CHEMBL1344718 & 688422 & 4.5 & 5.4125 & TRN & \\
\hline CHEMBL1364780 & 688422 & 6.3 & 5.1678 & TRN & \\
\hline CHEMBL1575540 & 688422 & 8.4949 & 5.5394 & TRN & \\
\hline CHEMBL538595 & 688422 & 5.35 & 5.7606 & TST & \\
\hline CHEMBL1400298 & 688422 & 4.75 & 5.341 & TRN & \\
\hline CHEMBL1390527 & 688422 & 4.65 & 5.3567 & TST & \\
\hline CHEMBL1532664 & 688422 & 7.0 & 5.20100 & 00000000005 & TRN \\
\hline CHEMBL1321317 & 688422 & 5.0 & 5.7846 & TST & \\
\hline
\end{tabular}




\begin{tabular}{|c|c|c|c|c|c|}
\hline & & \multicolumn{4}{|c|}{ Supplemental Table S2.txt } \\
\hline CHEMBL 293749 & 688422 & 9.0969 & 5.2915 & TRN & \\
\hline CHEMBL1604906 & 688422 & 5.85 & 5.1012 & TST & \\
\hline CHEMBL1364739 & 688422 & 5.5 & 5.2815 & TRN & \\
\hline CHEMBL1470919 & 688422 & 4.95 & 5.3748 & TRN & \\
\hline CHEMBL1457317 & 688422 & 4.55 & 5.041 & TRN & \\
\hline CHEMBL1531556 & 688422 & 5.05 & 5.0533 & TST & \\
\hline CHEMBL1602568 & 688422 & 4.7 & 4.833 & TRN & \\
\hline CHEMBL1302367 & 688422 & 4.65 & 5.3075 & TRN & \\
\hline CHEMBL1467679 & 688422 & 5.45 & 5.0583 & TRN & \\
\hline CHEMBL1338768 & 688422 & 4.5 & 5.4675 & TRN & \\
\hline CHEMBL1576078 & 688422 & 4.75 & 5.4834 & TST & \\
\hline CHEMBL1352655 & 688422 & 4.75 & 4.8462 & TRN & \\
\hline CHEMBL1355982 & 688422 & 5.75 & 5.309 & TST & \\
\hline CHEMBL1484020 & 688422 & 7.4001 & 5.1951 & TRN & \\
\hline CHEMBL1480424 & 688422 & 6.45 & 5.0509 & TRN & \\
\hline CHEMBL1342018 & 688422 & 5.35 & 5.1202 & TRN & \\
\hline CHEMBL1435409 & 688422 & 5.7 & 5.03600 & 00000000005 & TRN \\
\hline CHEMBL1440918 & 688422 & 4.8 & 5.1783 & TRN & \\
\hline CHEMBL160053 & 688422 & 5.05 & 5.7612 & TST & \\
\hline CHEMBL1388696 & 688422 & 5.25 & 5.2305 & TST & \\
\hline CHEMBL1324804 & 688422 & 5.5 & 5.1732 & TRN & \\
\hline CHEMBL1442495 & 688422 & 6.35 & 5.3881 & TRN & \\
\hline CHEMBL1505604 & 688422 & 4.9 & 5.3236 & TRN & \\
\hline CHEMBL 2062336 & 688422 & 7.4498 & 5.2373 & TRN & \\
\hline CHEMBL1588387 & 688422 & 4.5 & 5.1512 & TRN & \\
\hline CHEMBL1405922 & 688422 & 5.5 & 5.3819 & TST & \\
\hline CHEMBL1355724 & 688422 & 6.45 & 5.4315 & TRN & \\
\hline CHEMBL1432403 & 688422 & 5.4 & 5.92899 & 9999999999 & TST \\
\hline CHEMBL1468352 & 688422 & 4.45 & 5.2406 & TRN & \\
\hline CHEMBL1464588 & 688422 & 4.75 & 5.4315 & TST & \\
\hline CHEMBL1465913 & 688422 & 4.6 & 5.0226 & TST & \\
\hline CHEMBL1449972 & 688422 & 4.9 & 5.2994 & TRN & \\
\hline CHEMBL1605075 & 688422 & 4.85 & 5.4934 & TST & \\
\hline CHEMBL1414707 & 688422 & 6.9 & 5.8219 & TST & \\
\hline CHEMBL1469815 & 688422 & 5.55 & 5.7139 & TST & \\
\hline CHEMBL1564175 & 688422 & 4.9 & 4.8562 & TST & \\
\hline CHEMBL3189194 & 688422 & 4.65 & 5.5755 & TRN & \\
\hline CHEMBL1488110 & 688422 & 4.9 & 5.0567 & TRN & \\
\hline CHEMBL1398308 & 688422 & 4.45 & 5.4307 & TST & \\
\hline CHEMBL1426818 & 688422 & 4.8 & 5.2621 & TRN & \\
\hline CHEMBL1561417 & 688422 & 6.15 & 5.3557 & TRN & \\
\hline CHEMBL1381731 & 688422 & 4.6 & 5.0405 & TRN & \\
\hline CHEMBL1566928 & 688422 & 4.45 & 5.206 & TST & \\
\hline CHEMBL1563611 & 688422 & 4.5 & 5.1986 & TRN & \\
\hline CHEMBL1492933 & 688422 & 4.6 & 4.9514 & TRN & \\
\hline CHEMBL 2110371 & 688422 & 9.0458 & 5.3829 & TST & \\
\hline CHEMBL1381466 & 688422 & 4.45 & 4.7773 & TRN & \\
\hline CHEMBL1478959 & 688422 & 6.8499 & 5.7324 & TRN & \\
\hline
\end{tabular}




\begin{tabular}{|c|c|c|c|c|c|}
\hline \multicolumn{6}{|c|}{ Supplemental Table s2.txt } \\
\hline CHEMBL599890 & 688422 & 6.05 & 5.3917 & TRN & \\
\hline CHEMBL1594995 & 688422 & 4.75 & 5.0362 & TST & \\
\hline CHEMBL1338012 & 688422 & 4.9 & 5.1608 & TRN & \\
\hline CHEMBL1423296 & 688422 & 5.3 & 5.7 & TRN & \\
\hline CHEMBL1323799 & 688422 & 4.9 & 5.1348 & TRN & \\
\hline CHEMBL1367205 & 688422 & 5.9 & 5.221 & TRN & \\
\hline CHEMBL1480977 & 688422 & 4.45 & 5.3891 & TRN & \\
\hline CHEMBL1343454 & 688422 & 5.2 & 5.2877 & TST & \\
\hline CHEMBL1359238 & 688422 & 4.85 & 5.1684 & TRN & \\
\hline CHEMBL1514683 & 688422 & 6.9 & 5.3691 & TRN & \\
\hline CHEMBL1521827 & 688422 & 4.45 & 4.8547 & TST & \\
\hline CHEMBL1321109 & 688422 & 4.9 & 5.2733 & TRN & \\
\hline CHEMBL1449506 & 688422 & 5.95 & 5.0922 & TRN & \\
\hline CHEMBL1552177 & 688422 & 4.85 & 5.1247 & TRN & \\
\hline CHEMBL1317040 & 688422 & 4.6 & 5.4397 & TST & \\
\hline CHEMBL1468085 & 688422 & 4.7 & 4.922 & TRN & \\
\hline CHEMBL1485463 & 688422 & 5.65 & 4.948 & TST & \\
\hline CHEMBL1459398 & 688422 & 7.6498 & 5.2122 & TST & \\
\hline CHEMBL1573586 & 688422 & 5.0 & 5.6467 & TST & \\
\hline CHEMBL1545905 & 688422 & 7.3002 & 5.757006 & 0000000001 & TST \\
\hline CHEMBL1458757 & 688422 & 4.85 & 4.6391 & TRN & \\
\hline CHEMBL1548273 & 688422 & 5.0 & 5.1359 & TRN & \\
\hline CHEMBL1333616 & 688422 & 4.95 & 4.7535 & TRN & \\
\hline CHEMBL1306870 & 688422 & 4.8 & 5.17200 & 0000000001 & TRN \\
\hline CHEMBL1419232 & 688422 & 4.75 & 5.6575 & TRN & \\
\hline CHEMBL1611170 & 688422 & 4.5 & 5.0925 & TRN & \\
\hline CHEMBL3189663 & 688422 & 4.65 & 4.8922 & TRN & \\
\hline CHEMBL1459259 & 688422 & 4.55 & 4.9014 & TST & \\
\hline CHEMBL1326360 & 688422 & 4.8 & 4.6647 & TRN & \\
\hline CHEMBL1412489 & 688422 & 5.05 & 5.2329 & TRN & \\
\hline CHEMBL1540269 & 688422 & 4.5 & 5.7594 & TST & \\
\hline CHEMBL1481145 & 688422 & 4.8 & 5.5687 & TRN & \\
\hline CHEMBL1606991 & 688422 & 5.25 & 5.6664 & TST & \\
\hline CHEMBL1486485 & 688422 & 4.8 & 5.0672 & TRN & \\
\hline CHEMBL1348181 & 688422 & 4.75 & 5.0911 & TRN & \\
\hline CHEMBL1486028 & 688422 & 4.8 & 4.8943 & TRN & \\
\hline CHEMBL1371410 & 688422 & 5.45 & 4.9118 & TRN & \\
\hline CHEMBL451477 & 688422 & 4.7 & 5.7981 & TST & \\
\hline CHEMBL1543714 & 688422 & 4.5 & 5.2746 & TRN & \\
\hline CHEMBL1561280 & 688422 & 5.35 & 4.8153 & TRN & \\
\hline CHEMBL1494989 & 688422 & 5.5 & 5.49799 & 9999999999 & TRN \\
\hline CHEMBL1302050 & 688422 & 4.45 & 5.9421 & TRN & \\
\hline CHEMBL 2001481 & 688422 & 4.9 & 5.3175 & TST & \\
\hline CHEMBL1516827 & 688422 & 4.75 & 5.0202 & TRN & \\
\hline CHEMBL1588763 & 688422 & 4.45 & 5.1715 & TRN & \\
\hline CHEMBL1532060 & 688422 & 8.4949 & 5.3622 & TRN & \\
\hline CHEMBL1472444 & 688422 & 4.65 & 5.0643 & TRN & \\
\hline CHEMBL1527283 & 688422 & 8.0 & 6.0527 & TST & \\
\hline
\end{tabular}




\begin{tabular}{|c|c|c|c|c|c|}
\hline \multicolumn{6}{|c|}{ Supplemental Table S2.txt } \\
\hline CHEMBL1375889 & 688422 & 5.0 & 5.0009 & TST & \\
\hline CHEMBL1334930 & 688422 & 4.9 & 4.7944 & TRN & \\
\hline CHEMBL1466912 & 688422 & 7.5003 & 5.3423 & TRN & \\
\hline CHEMBL1374800 & 688422 & 5.6 & 5.4634 & TST & \\
\hline CHEMBL1352429 & 688422 & 5.55 & 5.0368 & TRN & \\
\hline CHEMBL1440416 & 688422 & 5.05 & 5.1129 & TRN & \\
\hline CHEMBL1548974 & 688422 & 4.7 & 4.7221 & TRN & \\
\hline CHEMBL1463215 & 688422 & 7.0501 & 5.7659 & TRN & \\
\hline CHEMBL1529957 & 688422 & 4.9 & 5.3408 & TRN & \\
\hline CHEMBL1491623 & 688422 & 4.95 & 4.5789 & TRN & \\
\hline CHEMBL1562441 & 688422 & 7.699 & 5.2925 & TST & \\
\hline CHEMBL1441270 & 688422 & 4.95 & 4.8914 & TRN & \\
\hline CHEMBL1606511 & 688422 & 4.5 & 5.1171 & TRN & \\
\hline CHEMBL1315083 & 688422 & 4.8 & 5.1836 & TRN & \\
\hline CHEMBL3195856 & 688422 & 6.35 & 5.2392 & TST & \\
\hline CHEMBL1569090 & 688422 & 4.75 & 5.2678 & TST & \\
\hline CHEMBL1351815 & 688422 & 4.45 & 5.8118 & TST & \\
\hline CHEMBL1414452 & 688422 & 6.5501 & 6.0154 & TRN & \\
\hline CHEMBL585478 & 688422 & 4.45 & 5.072 & TRN & \\
\hline CHEMBL1533362 & 688422 & 5.25 & 5.1973 & TRN & \\
\hline CHEMBL1490431 & 688422 & 4.75 & 5.3718 & TRN & \\
\hline CHEMBL567332 & 688422 & 5.2 & 4.8584 & TRN & \\
\hline CHEMBL3189322 & 688422 & 5.5 & 5.2825 & TRN & \\
\hline CHEMBL1313232 & 688422 & 4.8 & 5.4299 & TRN & \\
\hline CHEMBL1428120 & 688422 & 4.6 & 5.4611 & TRN & \\
\hline CHEMBL1559898 & 688422 & 4.8 & 5.05 & TST & \\
\hline CHEMBL1487852 & 688422 & 4.95 & 5.2668 & TRN & \\
\hline CHEMBL545050 & 688422 & 5.25 & 6.0243 & TST & \\
\hline CHEMBL1521861 & 688422 & 7.4001 & 5.20200 & 0000000001 & TRN \\
\hline CHEMBL3192894 & 688422 & 4.45 & 5.5491 & TRN & \\
\hline CHEMBL1472230 & 688422 & 4.45 & 5.2168 & TRN & \\
\hline CHEMBL1608927 & 688422 & 5.0 & 5.2829 & TRN & \\
\hline CHEMBL1522937 & 688422 & 4.95 & 4.7063 & TRN & \\
\hline CHEMBL1303034 & 688422 & 5.0 & 5.1591 & TRN & \\
\hline CHEMBL1404086 & 688422 & 4.7 & 5.1155 & TST & \\
\hline CHEMBL1698037 & 688422 & 4.8 & 4.9486 & TRN & \\
\hline CHEMBL1990210 & 688422 & 5.15 & 5.2429 & TRN & \\
\hline CHEMBL1531734 & 688422 & 6.35 & 5.5019 & TRN & \\
\hline CHEMBL1576788 & 688422 & 4.8 & 5.0589 & TRN & \\
\hline CHEMBL1585843 & 688422 & 4.85 & 5.095 & TRN & \\
\hline CHEMBL1580352 & 688422 & 4.9 & 5.4197 & TRN & \\
\hline CHEMBL1337566 & 688422 & 4.45 & 5.2096 & TRN & \\
\hline CHEMBL1465281 & 688422 & 5.35 & 5.1316 & TST & \\
\hline CHEMBL1461661 & 688422 & 4.9 & 4.9926 & TRN & \\
\hline CHEMBL1572629 & 688422 & 4.9 & 5.4651 & TRN & \\
\hline CHEMBL1332860 & 688422 & 5.05 & 5.3141 & TST & \\
\hline CHEMBL1477885 & 688422 & 5.65 & 5.3936 & TST & \\
\hline CHEMBL1305452 & 688422 & 5.4 & 5.2775 & TRN & \\
\hline
\end{tabular}




\begin{tabular}{|c|c|c|c|c|}
\hline \multicolumn{5}{|c|}{ Supplemental Table S2.txt } \\
\hline CHEMBL1571340 & 688422 & 4.8 & 5.1566 & TRN \\
\hline CHEMBL1301308 & 688422 & 4.5 & 4.9008 & TRN \\
\hline CHEMBL1379277 & 688422 & 7.8508 & 5.4695 & TRN \\
\hline CHEMBL1577357 & 688422 & 4.85 & 5.7859 & TRN \\
\hline CHEMBL1545737 & 688422 & 4.45 & 5.2832 & TRN \\
\hline CHEMBL1572758 & 688422 & 4.45 & 5.1407 & TRN \\
\hline CHEMBL1422976 & 688422 & 5.2 & 5.2965 & TRN \\
\hline CHEMBL1407895 & 688422 & 4.55 & 5.4689 & TRN \\
\hline CHEMBL1409349 & 688422 & 4.85 & 4.9639 & TRN \\
\hline CHEMBL1511525 & 688422 & 5.8 & 5.2596 & TRN \\
\hline CHEMBL1515329 & 688422 & 5.0 & 5.516 & TRN \\
\hline CHEMBL1463296 & 688422 & 4.4 & 5.0529 & TRN \\
\hline CHEMBL1541666 & 688422 & 5.0 & 5.5329 & TST \\
\hline CHEMBL1613613 & 688422 & 5.5 & 5.2605 & TRN \\
\hline CHEMBL584759 & 688422 & 5.95 & 5.7533 & TST \\
\hline CHEMBL1504623 & 688422 & 5.5 & 5.2395 & TRN \\
\hline CHEMBL1578018 & 688422 & 8.4949 & 5.3639 & TRN \\
\hline CHEMBL1525759 & 688422 & 5.0 & 5.3338 & TRN \\
\hline CHEMBL1612895 & 688422 & 7.8508 & 5.3406 & TST \\
\hline CHEMBL1533687 & 688422 & 5.2 & 4.7718 & TRN \\
\hline CHEMBL3196186 & 688422 & 4.95 & 4.9831 & TRN \\
\hline CHEMBL3198230 & 688422 & 4.5 & 5.0123 & TST \\
\hline CHEMBL1269255 & 688422 & 5.0 & 5.2369 & TST \\
\hline CHEMBL1566285 & 688422 & 4.7 & 5.1323 & TST \\
\hline CHEMBL1569910 & 688422 & 5.25 & 5.3261 & TRN \\
\hline CHEMBL1374525 & 688422 & 5.1 & 5.1361 & TRN \\
\hline CHEMBL1333897 & 688422 & 5.55 & 5.415 & TRN \\
\hline CHEMBL1508419 & 688422 & 4.85 & 5.489 & TRN \\
\hline CHEMBL1416597 & 688422 & 4.5 & 5.2434 & TST \\
\hline CHEMBL1606431 & 688422 & 4.85 & 4.9708 & TRN \\
\hline CHEMBL3190250 & 688422 & 4.95 & 5.3646 & TRN \\
\hline CHEMBL1489243 & 688422 & 4.45 & 5.5936 & TST \\
\hline CHEMBL1380212 & 688422 & 5.0 & 4.6786 & TRN \\
\hline CHEMBL1442040 & 688422 & 6.8 & 5.8201 & TRN \\
\hline CHEMBL1306884 & 688422 & 5.0 & 5.3722 & TRN \\
\hline CHEMBL1343738 & 688422 & 6.2 & 5.5807 & TRN \\
\hline CHEMBL1517167 & 688422 & 4.75 & 5.2315 & TRN \\
\hline CHEMBL541585 & 688422 & 4.95 & 5.4997 & TST \\
\hline CHEMBL15594 & 688422 & 4.8 & 5.3039 & TRN \\
\hline CHEMBL1387300 & 688422 & 8.0 & 5.6505 & TRN \\
\hline CHEMBL3211754 & 688422 & 5.0 & 5.0655 & TST \\
\hline CHEMBL1601510 & 688422 & 4.45 & 4.9748 & TRN \\
\hline CHEMBL1306296 & 688422 & 4.65 & 4.9154 & TRN \\
\hline CHEMBL1412291 & 688422 & 4.85 & 4.8088 & TRN \\
\hline CHEMBL1505997 & 688422 & 5.1 & 4.8742 & TRN \\
\hline CHEMBL1459942 & 688422 & 4.45 & 5.2 & TRN \\
\hline CHEMBL1475054 & 688422 & 7.3002 & 5.2644 & TRN \\
\hline CHEMBL1607437 & 688422 & 4.6 & 5.0732 & TRN \\
\hline
\end{tabular}




\begin{tabular}{|c|c|c|c|c|}
\hline \multicolumn{5}{|c|}{ Supplemental Table S2.txt } \\
\hline CHEMBL1446092 & 688422 & 4.85 & 5.1731 & TRN \\
\hline CHEMBL581868 & 688422 & 6.8 & 4.9849 & TST \\
\hline CHEMBL1454419 & 688422 & 4.85 & 4.6906 & TRN \\
\hline CHEMBL1300912 & 688422 & 5.25 & 5.2785 & TRN \\
\hline CHEMBL 334378 & 688422 & 9.0458 & 4.9857 & TST \\
\hline CHEMBL1484850 & 688422 & 4.75 & 5.5155 & TRN \\
\hline CHEMBL1598344 & 688422 & 5.0 & 5.3146 & TRN \\
\hline CHEMBL1392326 & 688422 & 4.5 & 5.3673 & TRN \\
\hline CHEMBL1572407 & 688422 & 8.0506 & 5.3171 & TRN \\
\hline CHEMBL1392812 & 688422 & 4.95 & 5.265 & TRN \\
\hline CHEMBL 3198248 & 688422 & 4.65 & 5.0354 & TRN \\
\hline CHEMBL1309193 & 688422 & 4.45 & 5.1028 & TST \\
\hline CHEMBL1341506 & 688422 & 4.95 & 4.9949 & TRN \\
\hline CHEMBL1358224 & 688422 & 5.4 & 5.1296 & TRN \\
\hline CHEMBL1561293 & 688422 & 4.8 & 4.7896 & TRN \\
\hline CHEMBL1517571 & 688422 & 5.95 & 5.3117 & TRN \\
\hline CHEMBL1408320 & 688422 & 4.6 & 5.0776 & TST \\
\hline CHEMBL1491139 & 688422 & 6.95 & 5.3324 & TRN \\
\hline CHEMBL1348263 & 688422 & 5.0 & 5.0568 & TRN \\
\hline CHEMBL1585257 & 688422 & 4.95 & 5.5651 & TST \\
\hline CHEMBL1600997 & 688422 & 4.9 & 5.7829 & TRN \\
\hline CHEMBL1552880 & 688422 & 4.7 & 4.9917 & TRN \\
\hline CHEMBL 258767 & 688422 & 4.95 & 5.3481 & TRN \\
\hline CHEMBL1605965 & 688422 & 4.65 & 4.887 & TRN \\
\hline CHEMBL1557063 & 688422 & 4.45 & 5.2894 & TRN \\
\hline CHEMBL1564527 & 688422 & 4.95 & 5.2625 & TRN \\
\hline CHEMBL1333882 & 688422 & 4.45 & 5.1438 & TRN \\
\hline CHEMBL1478605 & 688422 & 5.95 & 5.5941 & TST \\
\hline CHEMBL1413675 & 688422 & 4.85 & 5.136 & TRN \\
\hline CHEMBL1427506 & 688422 & 4.9 & 5.2991 & TRN \\
\hline CHEMBL1424481 & 688422 & 4.45 & 4.8853 & TST \\
\hline CHEMBL1561831 & 688422 & 4.75 & 5.1956 & TRN \\
\hline CHEMBL1579956 & 688422 & 4.8 & 5.4742 & TRN \\
\hline CHEMBL586602 & 688422 & 4.45 & 5.1664 & TRN \\
\hline CHEMBL1515682 & 688422 & 4.45 & 5.5309 & TST \\
\hline CHEMBL 3209966 & 688422 & 6.9 & 5.8241 & TRN \\
\hline CHEMBL1413963 & 688422 & 4.55 & 4.8408 & TRN \\
\hline CHEMBL1391825 & 688422 & 5.15 & 5.1885 & TST \\
\hline CHEMBL1337869 & 688422 & 7.3497 & 5.1858 & TST \\
\hline CHEMBL388931 & 688422 & 6.9 & 6.1635 & TRN \\
\hline CHEMBL1605952 & 688422 & 6.25 & 5.7448 & TRN \\
\hline CHEMBL1537831 & 688422 & 4.45 & 4.8377 & TRN \\
\hline CHEMBL1474951 & 688422 & 8.3468 & 5.9491 & TRN \\
\hline CHEMBL1469748 & 688422 & 4.75 & 4.7923 & TRN \\
\hline CHEMBL1586520 & 688422 & 8.3468 & 5.6383 & TST \\
\hline CHEMBL1365627 & 688422 & 4.65 & 5.5493 & TST \\
\hline CHEMBL 1571928 & 688422 & 4.8 & 5.4719 & TRN \\
\hline CHEMBL1409923 & 688422 & 4.85 & 5.2092 & TRN \\
\hline
\end{tabular}




\begin{tabular}{|c|c|c|c|c|c|}
\hline \multicolumn{6}{|c|}{ Supplemental Table S2.txt } \\
\hline CHEMBL1518468 & 688422 & 4.45 & 5.0078 & TRN & \\
\hline CHEMBL1509327 & 688422 & 4.7 & 4.9579 & TRN & \\
\hline CHEMBL1477399 & 688422 & 4.45 & 5.0301 & TRN & \\
\hline CHEMBL1551222 & 688422 & 6.1 & 5.229 & TST & \\
\hline CHEMBL1557920 & 688422 & 4.8 & 5.3845 & TRN & \\
\hline CHEMBL1458833 & 688422 & 5.55 & 5.5609 & TRN & \\
\hline CHEMBL1385808 & 688422 & 4.8 & 5.9955 & TRN & \\
\hline CHEMBL1514518 & 688422 & 4.95 & 4.9839 & TST & \\
\hline CHEMBL1598118 & 688422 & 8.0506 & 5.1419 & TRN & \\
\hline CHEMBL1367690 & 688422 & 5.8 & 5.4225 & TST & \\
\hline CHEMBL1595655 & 688422 & 4.65 & 5.0984 & TRN & \\
\hline CHEMBL1553768 & 688422 & 4.85 & 5.1709 & TST & \\
\hline CHEMBL1526256 & 688422 & 4.5 & 5.5149 & TRN & \\
\hline CHEMBL1601905 & 688422 & 5.5 & 6.1274 & TRN & \\
\hline CHEMBL1480712 & 688422 & 5.2 & 5.1428 & TRN & \\
\hline CHEMBL1563621 & 688422 & 4.85 & 5.1984 & TST & \\
\hline CHEMBL1358713 & 688422 & 4.7 & 5.51200 & 00000000005 & TRN \\
\hline CHEMBL546170 & 688422 & 5.4 & 5.1405 & TRN & \\
\hline CHEMBL1325976 & 688422 & 4.55 & 4.9707 & TRN & \\
\hline CHEMBL1519858 & 688422 & 5.45 & 5.3086 & TRN & \\
\hline CHEMBL1357581 & 688422 & 4.9 & 5.1915 & TRN & \\
\hline CHEMBL1413640 & 688422 & 4.5 & 4.9001 & TRN & \\
\hline CHEMBL1302238 & 688422 & 4.95 & 5.2799 & TRN & \\
\hline CHEMBL1334438 & 688422 & 5.15 & 5.175 & TRN & \\
\hline CHEMBL1603476 & 688422 & 4.65 & 5.18 & TST & \\
\hline CHEMBL1418795 & 688422 & 6.2 & 5.3004 & TRN & \\
\hline CHEMBL1362424 & 688422 & 7.6003 & 5.3244 & TRN & \\
\hline CHEMBL277525 & 688422 & 4.65 & 5.435 & TRN & \\
\hline CHEMBL1550074 & 688422 & 4.75 & 5.2881 & TRN & \\
\hline CHEMBL1986380 & 688422 & 5.25 & 5.0502 & TRN & \\
\hline CHEMBL1573684 & 688422 & 4.85 & 5.2648 & TRN & \\
\hline CHEMBL1486993 & 688422 & 5.0 & 4.7712 & TRN & \\
\hline CHEMBL 2007422 & 688422 & 5.5 & 5.1194 & TRN & \\
\hline CHEMBL1477182 & 688422 & 7.699 & 6.472 & TRN & \\
\hline CHEMBL1534650 & 688422 & 4.7 & 5.1536 & TST & \\
\hline CHEMBL1305875 & 688422 & 4.45 & 4.9194 & TRN & \\
\hline CHEMBL1463651 & 688422 & 7.0501 & 5.4413 & TRN & \\
\hline CHEMBL1495094 & 688422 & 4.9 & 4.8535 & TRN & \\
\hline CHEMBL1386757 & 688422 & 4.45 & 5.2527 & TRN & \\
\hline CHEMBL1510148 & 688422 & 4.5 & 5.2059 & TRN & \\
\hline CHEMBL1446960 & 688422 & 4.95 & 5.4594 & TRN & \\
\hline CHEMBL1378561 & 688422 & 4.8 & 4.9068 & TRN & \\
\hline CHEMBL557419 & 688422 & 4.9 & 5.3228 & TRN & \\
\hline CHEMBL1363897 & 688422 & 7.1002 & 5.5805 & TRN & \\
\hline CHEMBL1608750 & 688422 & 7.0501 & 5.5254 & TST & \\
\hline CHEMBL1301426 & 688422 & 4.5 & 5.125 & TRN & \\
\hline CHEMBL1427205 & 688422 & 8.2518 & 5.513 & TRN & \\
\hline CHEMBL1572585 & 688422 & 4.8 & 5.3675 & TRN & \\
\hline
\end{tabular}




\begin{tabular}{|c|c|c|c|c|c|}
\hline & & \multicolumn{4}{|c|}{ Supplemental Table S2.txt } \\
\hline CHEMBL1393582 & 688422 & 4.6 & 4.8854 & TRN & \\
\hline CHEMBL1415361 & 688422 & 4.65 & 5.5733 & TRN & \\
\hline CHEMBL1560397 & 688422 & 7.7496 & 5.1435 & TRN & \\
\hline CHEMBL1354866 & 688422 & 8.4949 & 5.5243 & TRN & \\
\hline CHEMBL1369659 & 688422 & 5.0 & 5.40799 & 99999999995 & TRN \\
\hline CHEMBL1319006 & 688422 & 7.8013 & 6.0657 & TRN & \\
\hline CHEMBL1427171 & 688422 & 5.0 & 5.5656 & TRN & \\
\hline CHEMBL152778 & 688422 & 7.699 & 5.4514 & TRN & \\
\hline CHEMBL1472201 & 688422 & 4.65 & 4.8685 & TST & \\
\hline CHEMBL1313115 & 688422 & 5.6 & 5.1236 & TRN & \\
\hline CHEMBL1446951 & 688422 & 4.75 & 5.4032 & TRN & \\
\hline CHEMBL1422759 & 688422 & 5.65 & 5.0999 & TRN & \\
\hline CHEMBL1382501 & 688422 & 8.3468 & 5.0841 & TRN & \\
\hline CHEMBL1348134 & 688422 & 4.65 & 5.3331 & TST & \\
\hline CHEMBL1320357 & 688422 & 4.85 & 4.9934 & TRN & \\
\hline CHEMBL1550425 & 688422 & 6.3 & 5.4269 & TRN & \\
\hline CHEMBL1549250 & 688422 & 4.9 & 5.0306 & TRN & \\
\hline CHEMBL1480183 & 688422 & 5.1 & 5.3179 & TRN & \\
\hline CHEMBL1536733 & 688422 & 4.55 & 5.2956 & TRN & \\
\hline CHEMBL1363347 & 688422 & 6.0 & 5.5774 & TRN & \\
\hline CHEMBL1493055 & 688422 & 4.65 & 5.3941 & TST & \\
\hline CHEMBL1391747 & 688422 & 5.95 & 5.3005 & TRN & \\
\hline CHEMBL1375753 & 688422 & 5.0 & 5.0919 & TRN & \\
\hline CHEMBL1410843 & 688422 & 5.5 & 5.5487 & TRN & \\
\hline CHEMBL1588738 & 688422 & 4.45 & 5.2814 & TRN & \\
\hline CHEMBL1514756 & 688422 & 7.4498 & 5.7247 & TST & \\
\hline CHEMBL1412560 & 688422 & 4.95 & 5.1302 & TRN & \\
\hline CHEMBL1567726 & 688422 & 4.45 & 4.8891 & TRN & \\
\hline CHEMBL3211905 & 688422 & 4.85 & 5.3472 & TRN & \\
\hline CHEMBL1383706 & 688422 & 7.3497 & 5.4184 & TST & \\
\hline CHEMBL1418359 & 688422 & 5.15 & 5.1812 & TST & \\
\hline CHEMBL1312213 & 688422 & 6.7001 & 6.1308 & TST & \\
\hline CHEMBL1506016 & 688422 & 4.9 & 4.7703 & TRN & \\
\hline CHEMBL1469935 & 688422 & 6.35 & 5.316 & TST & \\
\hline CHEMBL3195213 & 688422 & 4.65 & 5.46399 & 99999999995 & TRN \\
\hline CHEMBL1535693 & 688422 & 4.65 & 4.9728 & TRN & \\
\hline CHEMBL1508384 & 688422 & 4.6 & 4.7324 & TST & \\
\hline CHEMBL578890 & 688422 & 4.95 & 5.0158 & TRN & \\
\hline CHEMBL1555816 & 688422 & 4.6 & 4.9022 & TST & \\
\hline CHEMBL1519490 & 688422 & 4.9 & 5.3152 & TST & \\
\hline CHEMBL1525476 & 688422 & 7.9508 & 5.432 & TST & \\
\hline CHEMBL1333432 & 688422 & 6.0 & 5.2098 & TRN & \\
\hline CHEMBL1588985 & 688422 & 4.8 & 5.399 & TRN & \\
\hline CHEMBL3195397 & 688422 & 5.2 & 5.4425 & TST & \\
\hline CHEMBL1506510 & 688422 & 4.5 & 5.0749 & TRN & \\
\hline CHEMBL1320608 & 688422 & 5.25 & 5.3212 & TRN & \\
\hline CHEMBL1526167 & 688422 & 4.75 & 5.4827 & TST & \\
\hline CHEMBL1385122 & 688422 & 6.15 & 5.0577 & TRN & \\
\hline
\end{tabular}




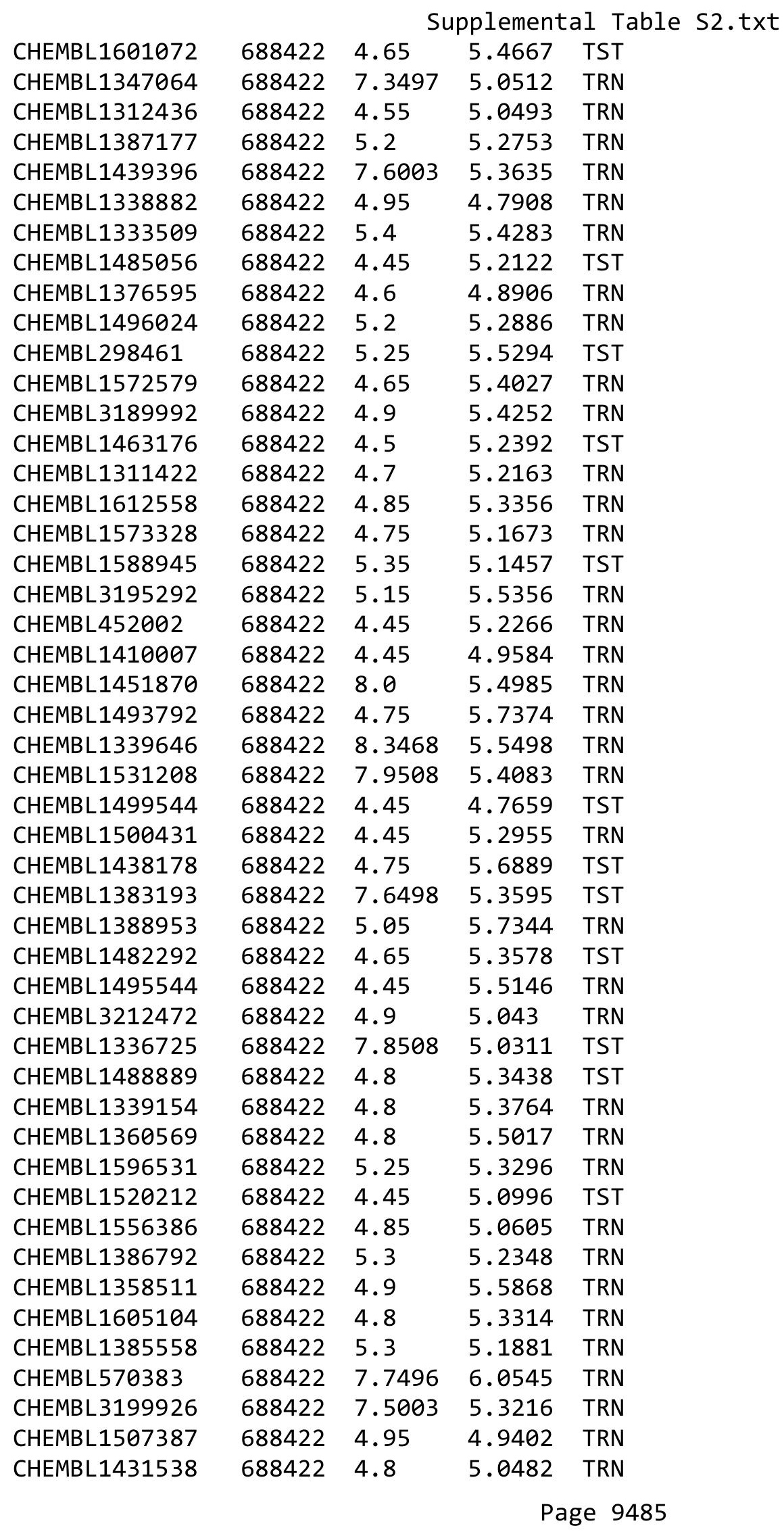




\begin{tabular}{|c|c|c|c|c|}
\hline \multicolumn{5}{|c|}{ Supplemental Table S2.txt } \\
\hline CHEMBL1571448 & 688422 & 4.65 & 4.5734 & TRN \\
\hline CHEMBL1575611 & 688422 & 5.2 & 5.6141 & TST \\
\hline CHEMBL1337018 & 688422 & 4.9 & 5.1962 & TRN \\
\hline CHEMBL1562522 & 688422 & 4.5 & 4.916 & TRN \\
\hline CHEMBL1596125 & 688422 & 5.05 & 5.4058 & TRN \\
\hline CHEMBL1333511 & 688422 & 5.15 & 5.2668 & TRN \\
\hline CHEMBL1318166 & 688422 & 5.1 & 5.5854 & TST \\
\hline CHEMBL1384658 & 688422 & 4.75 & 5.1852 & TRN \\
\hline CHEMBL1467813 & 688422 & 4.45 & 5.4839 & TRN \\
\hline CHEMBL1304154 & 688422 & 5.35 & 5.2076 & TRN \\
\hline CHEMBL1306661 & 688422 & 4.45 & 5.4276 & TST \\
\hline CHEMBL1556888 & 688422 & 4.9 & 5.0699 & TRN \\
\hline CHEMBL1485312 & 688422 & 6.15 & 5.0787 & TRN \\
\hline CHEMBL1504441 & 688422 & 4.85 & 5.2662 & TST \\
\hline CHEMBL1450784 & 688422 & 4.95 & 5.0525 & TST \\
\hline CHEMBL1336563 & 688422 & 6.45 & 4.9706 & TST \\
\hline CHEMBL533602 & 688422 & 5.05 & 5.4656 & TRN \\
\hline CHEMBL1452942 & 688422 & 5.5 & 5.6261 & TRN \\
\hline CHEMBL1384253 & 688422 & 5.5 & 5.2415 & TRN \\
\hline CHEMBL1571328 & 688422 & 4.9 & 5.465 & TST \\
\hline CHEMBL1601147 & 688422 & 4.45 & 4.997 & TRN \\
\hline CHEMBL1352001 & 688422 & 6.25 & 5.7547 & TRN \\
\hline CHEMBL1472594 & 688422 & 5.1 & 5.295 & TRN \\
\hline CHEMBL1385323 & 688422 & 6.1 & 5.1108 & TST \\
\hline CHEMBL1349263 & 688422 & 4.95 & 5.14 & TRN \\
\hline CHEMBL1592367 & 688422 & 4.45 & 5.3257 & TRN \\
\hline CHEMBL3212722 & 688422 & 4.5 & 5.5305 & TST \\
\hline CHEMBL1393078 & 688422 & 6.6499 & 5.4911 & TRN \\
\hline CHEMBL1469638 & 688422 & 4.6 & 4.9068 & TRN \\
\hline CHEMBL1378134 & 688422 & 4.85 & 5.6335 & TST \\
\hline CHEMBL1339821 & 688422 & 4.45 & 4.8533 & TRN \\
\hline CHEMBL1511047 & 688422 & 4.85 & 5.0572 & TRN \\
\hline CHEMBL1467672 & 688422 & 8.1487 & 5.3974 & TST \\
\hline CHEMBL1453616 & 688422 & 4.65 & 5.6991 & TRN \\
\hline CHEMBL1533572 & 688422 & 4.65 & 5.0797 & TRN \\
\hline CHEMBL1415925 & 688422 & 4.65 & 4.9869 & TST \\
\hline CHEMBL1443660 & 688422 & 6.0 & 4.8754 & TRN \\
\hline CHEMBL1362858 & 688422 & 4.9 & 5.5504 & TRN \\
\hline CHEMBL1613571 & 688422 & 4.95 & 5.0586 & TRN \\
\hline CHEMBL1525011 & 688422 & 5.25 & 5.1206 & TRN \\
\hline CHEMBL1573661 & 688422 & 4.9 & 4.7775 & TRN \\
\hline CHEMBL1374840 & 688422 & 4.45 & 5.6407 & TST \\
\hline CHEMBL1495341 & 688422 & 6.95 & 5.3424 & TRN \\
\hline CHEMBL1562891 & 688422 & 5.65 & 5.227 & TRN \\
\hline CHEMBL1326520 & 688422 & 4.45 & 5.6592 & TRN \\
\hline CHEMBL1497314 & 688422 & 4.45 & 5.1608 & TRN \\
\hline CHEMBL1338832 & 688422 & 6.2 & 5.0653 & TST \\
\hline CHEMBL1420181 & 688422 & 5.0 & 5.319 & TRN \\
\hline
\end{tabular}




\begin{tabular}{|c|c|c|c|c|}
\hline \multicolumn{5}{|c|}{ Supplemental Table S2.txt } \\
\hline CHEMBL1357362 & 688422 & 5.4 & 5.0205 & TRN \\
\hline CHEMBL1329472 & 688422 & 4.6 & 5.2542 & TST \\
\hline CHEMBL1428546 & 688422 & 4.75 & 5.3521 & TRN \\
\hline CHEMBL 3210876 & 688422 & 5.2 & 4.9854 & TRN \\
\hline CHEMBL1334281 & 688422 & 4.45 & 5.4101 & TRN \\
\hline CHEMBL1315329 & 688422 & 5.8 & 5.4017 & TRN \\
\hline CHEMBL1450577 & 688422 & 6.1 & 5.3184 & TRN \\
\hline CHEMBL1361916 & 688422 & 4.9 & 5.2687 & TRN \\
\hline CHEMBL1301670 & 688422 & 4.6 & 5.5853 & TRN \\
\hline CHEMBL1314716 & 688422 & 4.9 & 5.0797 & TRN \\
\hline CHEMBL1705518 & 688422 & 4.45 & 5.0088 & TRN \\
\hline CHEMBL1362949 & 688422 & 4.95 & 5.496 & TST \\
\hline CHEMBL3198535 & 688422 & 4.8 & 5.3732 & TRN \\
\hline CHEMBL1353047 & 688422 & 6.95 & 5.3226 & TRN \\
\hline CHEMBL1476373 & 688422 & 4.65 & 5.0889 & TRN \\
\hline CHEMBL1450207 & 688422 & 5.0 & 5.4848 & TRN \\
\hline CHEMBL1453582 & 688422 & 4.45 & 4.9328 & TST \\
\hline CHEMBL1409025 & 688422 & 4.75 & 5.4553 & TRN \\
\hline CHEMBL1346935 & 688422 & 4.85 & 5.2145 & TRN \\
\hline CHEMBL1602145 & 688422 & 4.45 & 4.7822 & TRN \\
\hline CHEMBL1425752 & 688422 & 7.6498 & 5.6891 & TST \\
\hline CHEMBL1349912 & 688422 & 4.45 & 5.2852 & TST \\
\hline CHEMBL1440908 & 688422 & 4.7 & 5.1061 & TRN \\
\hline CHEMBL1311505 & 688422 & 4.75 & 4.9407 & TST \\
\hline CHEMBL1612459 & 688422 & 4.95 & 5.3509 & TRN \\
\hline CHEMBL1305247 & 688422 & 4.45 & 5.2854 & TRN \\
\hline CHEMBL1419188 & 688422 & 4.9 & 5.1566 & TRN \\
\hline CHEMBL1397532 & 688422 & 4.8 & 4.809 & TRN \\
\hline CHEMBL1606390 & 688422 & 5.05 & 4.8686 & TRN \\
\hline CHEMBL1577926 & 688422 & 5.3 & 5.2936 & TST \\
\hline CHEMBL1527299 & 688422 & 4.8 & 5.206 & TRN \\
\hline CHEMBL1400752 & 688422 & 6.2 & 5.0703 & TST \\
\hline CHEMBL1506281 & 688422 & 4.55 & 5.4979 & TRN \\
\hline CHEMBL1969707 & 688422 & 5.0 & 4.8848 & TRN \\
\hline CHEMBL1511607 & 688422 & 5.2 & 5.0671 & TRN \\
\hline CHEMBL1301255 & 688422 & 5.85 & 5.3327 & TST \\
\hline CHEMBL1520915 & 688422 & 5.15 & 5.6827 & TRN \\
\hline CHEMBL1344632 & 688422 & 4.45 & 4.8198 & TRN \\
\hline CHEMBL1592483 & 688422 & 4.75 & 4.7614 & TRN \\
\hline CHEMBL1392266 & 688422 & 5.3 & 5.3208 & TRN \\
\hline CHEMBL1549880 & 688422 & 4.9 & 4.6578 & TRN \\
\hline CHEMBL1432952 & 688422 & 4.8 & 5.0835 & TST \\
\hline CHEMBL1367629 & 688422 & 5.4 & 5.4648 & TRN \\
\hline CHEMBL1509267 & 688422 & 4.85 & 4.7641 & TRN \\
\hline CHEMBL1545155 & 688422 & 5.4 & 4.8509 & TRN \\
\hline CHEMBL3190534 & 688422 & 4.95 & 5.4217 & TRN \\
\hline CHEMBL45068 & 688422 & 8.301 & 5.3822 & TRN \\
\hline CHEMBL1441901 & 688422 & 4.45 & 5.3405 & TRN \\
\hline
\end{tabular}




\begin{tabular}{|c|c|c|c|c|}
\hline \multicolumn{5}{|c|}{ Supplemental Table S2.txt } \\
\hline CHEMBL1576110 & 688422 & 4.95 & 4.9052 & TRN \\
\hline CHEMBL1495269 & 688422 & 4.45 & 5.1207 & TST \\
\hline CHEMBL1467298 & 688422 & 5.0 & 5.1213 & TST \\
\hline CHEMBL1365379 & 688422 & 8.0 & 5.3819 & TST \\
\hline CHEMBL3190362 & 688422 & 5.75 & 5.314 & TRN \\
\hline CHEMBL1405895 & 688422 & 5.0 & 5.5003 & TRN \\
\hline CHEMBL1457003 & 688422 & 7.3497 & 5.2521 & TRN \\
\hline CHEMBL1498430 & 688422 & 4.75 & 5.2907 & TST \\
\hline CHEMBL1538736 & 688422 & 6.4 & 5.6575 & TRN \\
\hline CHEMBL1324265 & 688422 & 5.35 & 5.1498 & TST \\
\hline CHEMBL1312502 & 688422 & 5.45 & 4.7736 & TRN \\
\hline CHEMBL1533043 & 688422 & 6.8 & 5.3414 & TRN \\
\hline CHEMBL1431036 & 688422 & 5.3 & 5.314 & TRN \\
\hline CHEMBL1432535 & 688422 & 4.5 & 4.9391 & TRN \\
\hline CHEMBL1351212 & 688422 & 4.45 & 5.1991 & TRN \\
\hline CHEMBL1455584 & 688422 & 4.7 & 4.9955 & TRN \\
\hline CHEMBL515248 & 688422 & 4.85 & 5.2133 & TST \\
\hline CHEMBL1546005 & 688422 & 6.0 & 5.1032 & TRN \\
\hline CHEMBL1357081 & 688422 & 4.45 & 5.1413 & TRN \\
\hline CHEMBL3198286 & 688422 & 4.95 & 5.0061 & TRN \\
\hline CHEMBL1398816 & 688422 & 4.85 & 5.2507 & TRN \\
\hline CHEMBL1408307 & 688422 & 4.45 & 4.9684 & TST \\
\hline CHEMBL1349082 & 688422 & 5.0 & 5.1472 & TRN \\
\hline CHEMBL1307740 & 688422 & 4.75 & 5.5484 & TRN \\
\hline CHEMBL1595978 & 688422 & 4.45 & 5.4956 & TRN \\
\hline CHEMBL1590225 & 688422 & 5.5 & 5.6056 & TRN \\
\hline CHEMBL1606676 & 688422 & 7.6498 & 5.8749 & TRN \\
\hline CHEMBL1536123 & 688422 & 7.699 & 5.8961 & TRN \\
\hline CHEMBL1606778 & 688422 & 5.9 & 5.1814 & TST \\
\hline CHEMBL1554493 & 688422 & 4.45 & 5.0598 & TRN \\
\hline CHEMBL1514862 & 688422 & 4.95 & 5.0634 & TRN \\
\hline CHEMBL405358 & 688422 & 5.15 & 5.2266 & TST \\
\hline CHEMBL1593031 & 688422 & 4.55 & 4.8482 & TRN \\
\hline CHEMBL1349293 & 688422 & 4.85 & 4.7687 & TRN \\
\hline CHEMBL1388385 & 688422 & 7.3497 & 5.3087 & TRN \\
\hline CHEMBL1412553 & 688422 & 4.45 & 4.9237 & TRN \\
\hline CHEMBL3199036 & 688422 & 4.9 & 4.6618 & TST \\
\hline CHEMBL1575717 & 688422 & 5.25 & 5.0806 & TRN \\
\hline CHEMBL1605919 & 688422 & 5.85 & 5.4544 & TRN \\
\hline CHEMBL1600963 & 688422 & 8.1024 & 5.1372 & TRN \\
\hline CHEMBL1487345 & 688422 & 4.95 & 4.7995 & TRN \\
\hline CHEMBL1501605 & 688422 & 4.45 & 5.313 & TST \\
\hline CHEMBL1372952 & 688422 & 4.45 & 4.9568 & TRN \\
\hline CHEMBL1570958 & 688422 & 5.15 & 5.4497 & TRN \\
\hline CHEMBL3189504 & 688422 & 4.85 & 5.5574 & TST \\
\hline CHEMBL1513295 & 688422 & 5.5 & 5.9198 & TST \\
\hline CHEMBL3193902 & 688422 & 4.7 & 5.5204 & TST \\
\hline CHEMBL1401288 & 688422 & 4.95 & 5.16299 & 9999999999 \\
\hline & & & & 9488 \\
\hline
\end{tabular}




\begin{tabular}{|c|c|c|c|c|c|}
\hline \multicolumn{6}{|c|}{ Supplemental Table S2.txt } \\
\hline CHEMBL1422417 & 688422 & 4.45 & 5.2369 & TRN & \\
\hline CHEMBL1489805 & 688422 & 4.8 & 5.3697 & TST & \\
\hline CHEMBL1572966 & 688422 & 6.25 & 5.3167 & TRN & \\
\hline CHEMBL1505634 & 688422 & 7.0 & 5.3759 & TRN & \\
\hline CHEMBL3213069 & 688422 & 4.9 & 5.1529 & TRN & \\
\hline CHEMBL1471499 & 688422 & 4.65 & 4.6985 & TRN & \\
\hline CHEMBL1392431 & 688422 & 4.65 & 5.0964 & TRN & \\
\hline CHEMBL1511224 & 688422 & 4.45 & 5.21299 & 9999999999 & TRN \\
\hline CHEMBL1487344 & 688422 & 4.65 & 5.1697 & TRN & \\
\hline CHEMBL1362566 & 688422 & 4.65 & 4.7377 & TRN & \\
\hline CHEMBL1469200 & 688422 & 8.0 & 5.0207 & TRN & \\
\hline CHEMBL1361294 & 688422 & 4.65 & 4.9416 & TRN & \\
\hline CHEMBL1563869 & 688422 & 6.05 & 5.6401 & TST & \\
\hline CHEMBL1430227 & 688422 & 5.45 & 5.1832 & TRN & \\
\hline CHEMBL1538396 & 688422 & 4.85 & 4.9841 & TRN & \\
\hline CHEMBL1333503 & 688422 & 5.05 & 5.3086 & TST & \\
\hline CHEMBL1598613 & 688422 & 5.7 & 5.306 & TST & \\
\hline CHEMBL1561439 & 688422 & 5.05 & 4.8479 & TRN & \\
\hline CHEMBL1573809 & 688422 & 5.0 & 5.1966 & TRN & \\
\hline CHEMBL1457427 & 688422 & 5.4 & 4.9153 & TRN & \\
\hline CHEMBL1488836 & 688422 & 6.45 & 5.8921 & TRN & \\
\hline CHEMBL1570712 & 688422 & 4.5 & 5.4389 & TRN & \\
\hline CHEMBL1383077 & 688422 & 4.45 & 4.8408 & TST & \\
\hline CHEMBL 3198852 & 688422 & 4.7 & 5.3952 & TST & \\
\hline CHEMBL1307322 & 688422 & 4.45 & 5.1506 & TRN & \\
\hline CHEMBL1586539 & 688422 & 5.95 & 5.5973 & TRN & \\
\hline CHEMBL1525881 & 688422 & 4.85 & 5.0933 & TRN & \\
\hline CHEMBL1420618 & 688422 & 4.45 & 4.883 & TRN & \\
\hline CHEMBL1549556 & 688422 & 4.5 & 4.8336 & TRN & \\
\hline CHEMBL3198440 & 688422 & 4.65 & 4.8653 & TRN & \\
\hline CHEMBL1310196 & 688422 & 4.65 & 5.1077 & TRN & \\
\hline CHEMBL1461694 & 688422 & 4.75 & 5.5067 & TRN & \\
\hline CHEMBL1419054 & 688422 & 6.7001 & 5.5793 & TRN & \\
\hline CHEMBL1423795 & 688422 & 4.6 & 5.0722 & TRN & \\
\hline CHEMBL3213643 & 688422 & 4.5 & 5.1413 & TRN & \\
\hline CHEMBL1462058 & 688422 & 4.45 & 5.0461 & TRN & \\
\hline CHEMBL1600532 & 688422 & 6.4 & 5.3137 & TRN & \\
\hline CHEMBL1301658 & 688422 & 7.0 & 5.3294 & TRN & \\
\hline CHEMBL1507990 & 688422 & 4.7 & 4.4358 & TRN & \\
\hline CHEMBL1594200 & 688422 & 4.95 & 5.49 & TRN & \\
\hline CHEMBL1485168 & 688422 & 4.9 & 5.3386 & TRN & \\
\hline CHEMBL1411143 & 688422 & 4.6 & 5.5573 & TST & \\
\hline CHEMBL1505097 & 688422 & 4.85 & 5.2116 & TRN & \\
\hline CHEMBL1426235 & 688422 & 5.0 & 4.6615 & TRN & \\
\hline CHEMBL1449614 & 688422 & 7.4498 & 5.3622 & TST & \\
\hline CHEMBL1534042 & 688422 & 5.85 & 5.4777 & TRN & \\
\hline CHEMBL1560459 & 688422 & 4.95 & 4.6739 & TST & \\
\hline CHEMBL1504303 & 688422 & 5.35 & 5.2291 & TRN & \\
\hline
\end{tabular}




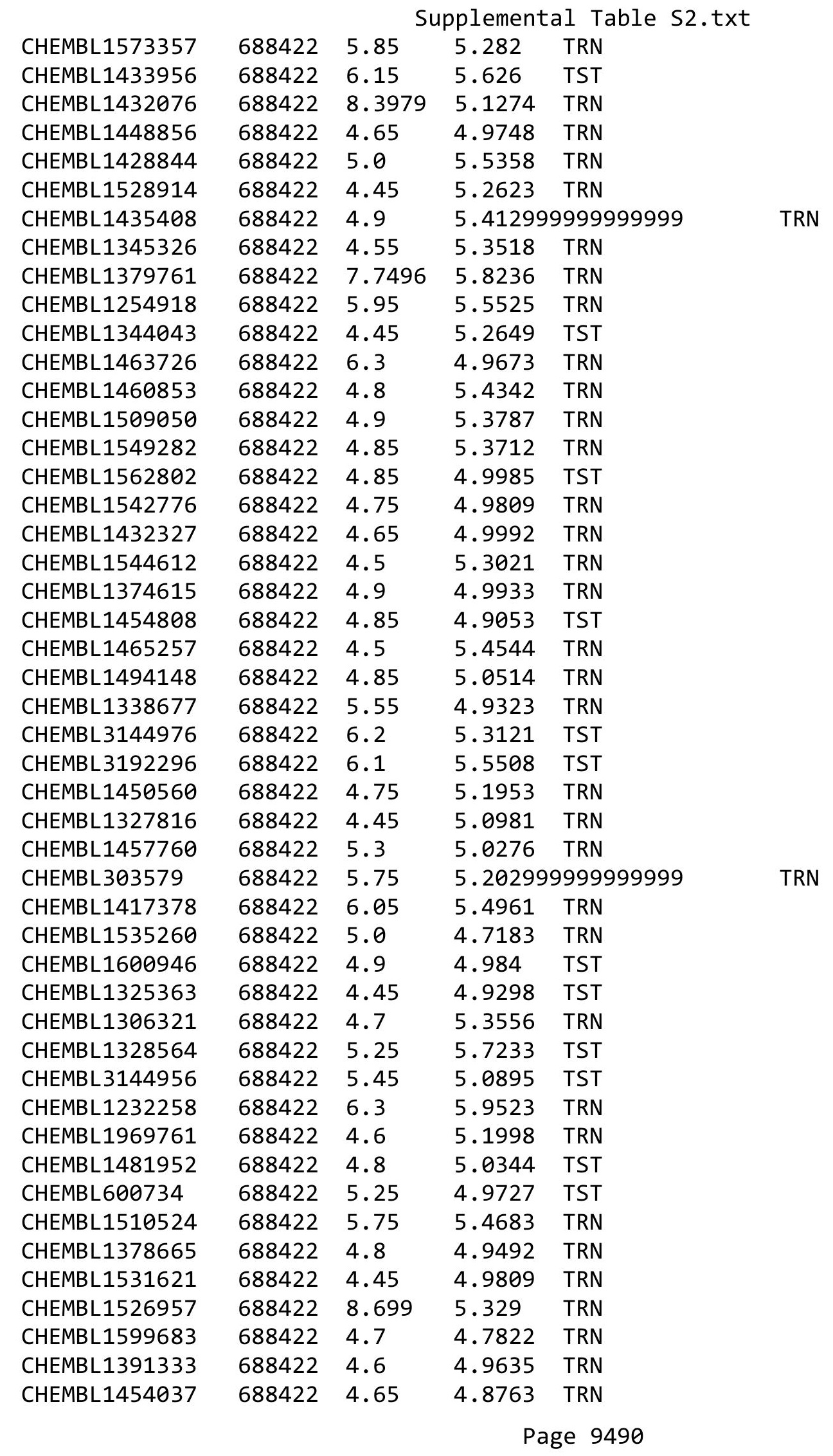




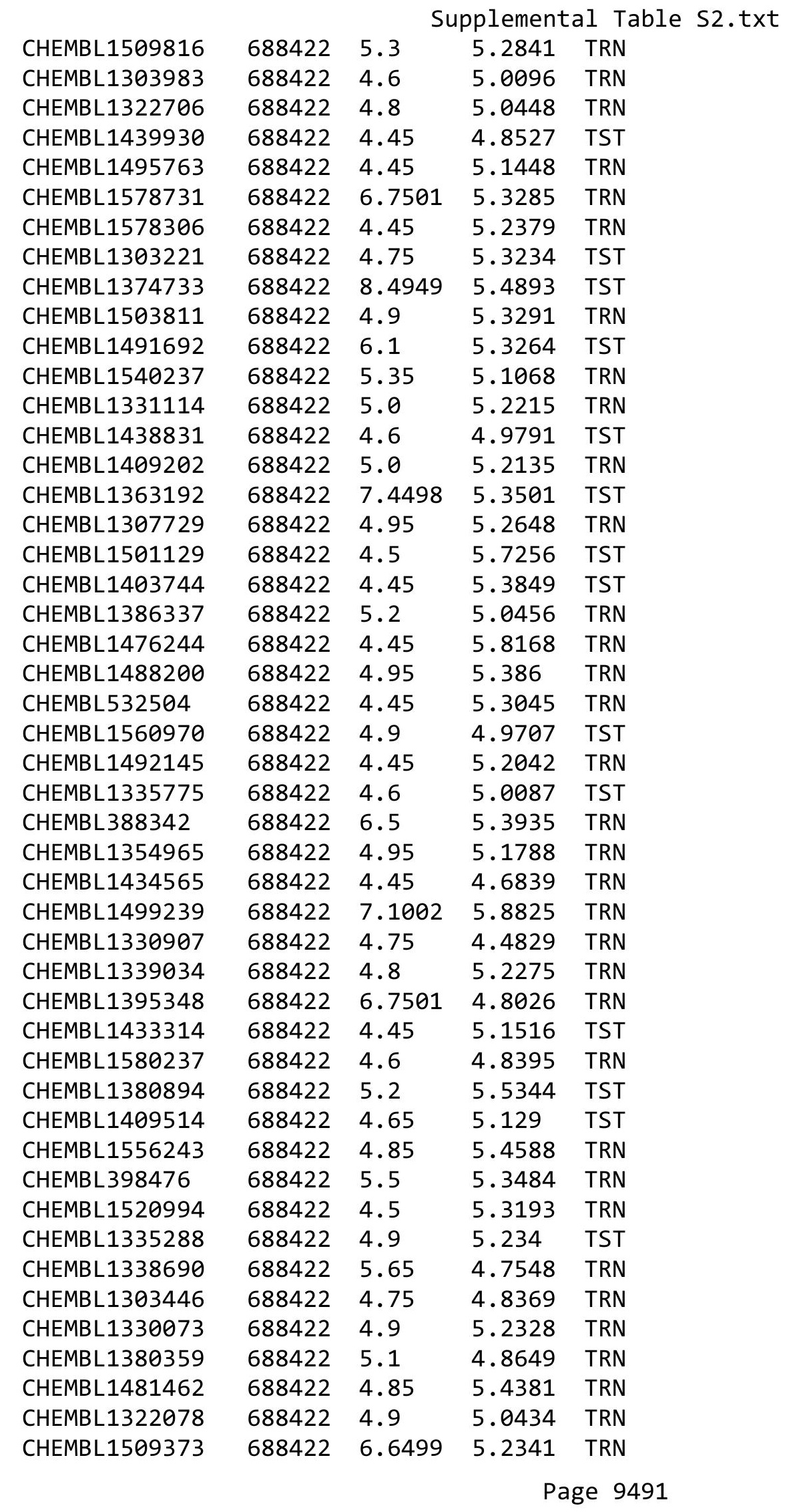




\begin{tabular}{|c|c|c|c|c|c|}
\hline \multirow[b]{2}{*}{ CHEMBL1394658 } & \multicolumn{5}{|c|}{ Supplemental Table S2.txt } \\
\hline & 688422 & 7.5003 & 5.4124 & TST & \\
\hline CHEMBL286722 & 688422 & 4.9 & 5.5795 & TRN & \\
\hline CHEMBL1324678 & 688422 & 7.699 & 5.2479 & TST & \\
\hline CHEMBL52 & 688422 & 5.1 & 5.185 & TRN & \\
\hline CHEMBL1361847 & 688422 & 4.8 & 4.5515 & TRN & \\
\hline CHEMBL1979455 & 688422 & 5.0 & 5.1953 & TRN & \\
\hline CHEMBL1598517 & 688422 & 5.65 & 4.9798 & TRN & \\
\hline CHEMBL1483966 & 688422 & 4.95 & 5.2373 & TRN & \\
\hline CHEMBL1560243 & 688422 & 5.35 & 5.5843 & TRN & \\
\hline CHEMBL1974389 & 688422 & 4.45 & 5.2603 & TRN & \\
\hline CHEMBL1454913 & 688422 & 4.9 & 5.2938 & TST & \\
\hline CHEMBL1566868 & 688422 & 4.45 & 5.4309 & TRN & \\
\hline CHEMBL1349295 & 688422 & 7.699 & 5.5858 & TRN & \\
\hline CHEMBL3208129 & 688422 & 5.15 & 5.5103 & TST & \\
\hline CHEMBL1402041 & 688422 & 4.65 & 5.3439 & TRN & \\
\hline CHEMBL1562623 & 688422 & 4.45 & 4.8634 & TRN & \\
\hline CHEMBL1385466 & 688422 & 4.8 & 5.2658 & TRN & \\
\hline CHEMBL1416021 & 688422 & 7.6498 & 5.4148 & TRN & \\
\hline CHEMBL1601957 & 688422 & 6.1 & 5.4865 & TST & \\
\hline CHEMBL1454262 & 688422 & 7.3497 & 5.3052 & TRN & \\
\hline CHEMBL1422274 & 688422 & 4.45 & 5.3958 & TST & \\
\hline CHEMBL1499914 & 688422 & 4.7 & 5.1872 & TRN & \\
\hline CHEMBL1466303 & 688422 & 4.7 & 4.9772 & TRN & \\
\hline CHEMBL1495849 & 688422 & 5.35 & 5.2436 & TRN & \\
\hline CHEMBL1332508 & 688422 & 4.9 & 5.2707 & TRN & \\
\hline CHEMBL1508364 & 688422 & 4.7 & 5.0914 & TRN & \\
\hline CHEMBL3199198 & 688422 & 5.25 & 5.3935 & TRN & \\
\hline CHEMBL1515197 & 688422 & 4.75 & 4.8906 & TRN & \\
\hline CHEMBL1350660 & 688422 & 4.7 & 5.0705 & TST & \\
\hline CHEMBL1385727 & 688422 & 4.75 & 5.3056 & TST & \\
\hline CHEMBL 1503446 & 688422 & 4.45 & 5.1501 & TST & \\
\hline CHEMBL1362420 & 688422 & 4.95 & 5.0161 & TRN & \\
\hline CHEMBL3145329 & 688422 & 5.55 & 5.1978 & TST & \\
\hline CHEMBL1319441 & 688422 & 4.45 & 5.2511 & TRN & \\
\hline CHEMBL1503253 & 688422 & 4.45 & 5.5109 & TRN & \\
\hline CHEMBL3195684 & 688422 & 4.45 & 5.3101 & TRN & \\
\hline CHEMBL1299519 & 688422 & 4.45 & 4.7242 & TRN & \\
\hline CHEMBL1555160 & 688422 & 7.4001 & 5.3951 & TRN & \\
\hline CHEMBL1316750 & 688422 & 6.7501 & 5.2836 & TRN & \\
\hline CHEMBL1547537 & 688422 & 4.8 & 5.3549 & TRN & \\
\hline CHEMBL1589643 & 688422 & 7.5498 & 4.9158 & TRN & \\
\hline CHEMBL1391824 & 688422 & 4.65 & 5.0068 & TRN & \\
\hline CHEMBL1305879 & 688422 & 4.75 & 5.13299 & 9999999999 & TRN \\
\hline CHEMBL1481390 & 688422 & 4.8 & 5.0657 & TRN & \\
\hline CHEMBL1414310 & 688422 & 5.45 & 5.5571 & TRN & \\
\hline CHEMBL 1573090 & 688422 & 4.5 & 4.78100 & 0000000001 & TRN \\
\hline CHEMBL507122 & 688422 & 9.0458 & 5.5175 & TST & \\
\hline CHEMBL1379149 & 688422 & 4.55 & 4.9004 & TRN & \\
\hline
\end{tabular}




\begin{tabular}{|c|c|c|c|c|}
\hline \multicolumn{5}{|c|}{ Supplemental Table s2.txt } \\
\hline CHEMBL1524612 & 688422 & 4.95 & 5.2985 & TST \\
\hline CHEMBL1554131 & 688422 & 6.0 & 6.3518 & TRN \\
\hline CHEMBL1256132 & 688422 & 5.2 & 6.1358 & TRN \\
\hline CHEMBL 2000847 & 688422 & 4.85 & 5.1975 & TRN \\
\hline CHEMBL1592253 & 688422 & 5.0 & 5.1462 & TRN \\
\hline CHEMBL1427745 & 688422 & 6.45 & 5.4052 & TRN \\
\hline CHEMBL1341140 & 688422 & 5.4 & 5.1716 & TRN \\
\hline CHEMBL311542 & 688422 & 4.45 & 5.3322 & TRN \\
\hline CHEMBL1404236 & 688422 & 6.05 & 5.3232 & TRN \\
\hline CHEMBL1507814 & 688422 & 6.7501 & 5.3711 & TRN \\
\hline CHEMBL1405935 & 688422 & 4.7 & 5.1789 & TRN \\
\hline CHEMBL1575138 & 688422 & 4.9 & 5.3725 & TST \\
\hline CHEMBL1445297 & 688422 & 6.8499 & 5.4664 & TRN \\
\hline CHEMBL1582272 & 688422 & 4.45 & 5.1214 & TST \\
\hline CHEMBL1370450 & 688422 & 4.75 & 5.3242 & TST \\
\hline CHEMBL1393677 & 688422 & 5.25 & 5.2701 & TST \\
\hline CHEMBL1437403 & 688422 & 4.55 & 5.2929 & TRN \\
\hline CHEMBL1344103 & 688422 & 4.8 & 5.0192 & TRN \\
\hline CHEMBL182653 & 688422 & 4.45 & 5.0451 & TRN \\
\hline CHEMBL1527530 & 688422 & 4.85 & 4.743 & TRN \\
\hline CHEMBL1513973 & 688422 & 5.5 & 5.3794 & TRN \\
\hline CHEMBL1349726 & 688422 & 4.65 & 5.1509 & TRN \\
\hline CHEMBL1367461 & 688422 & 5.6 & 5.5378 & TRN \\
\hline CHEMBL1359417 & 688422 & 4.95 & 5.0203 & TRN \\
\hline CHEMBL1357593 & 688422 & 5.4 & 5.6971 & TRN \\
\hline CHEMBL1459511 & 688422 & 4.7 & 4.9083 & TST \\
\hline CHEMBL1444283 & 688422 & 6.8499 & 5.1517 & TRN \\
\hline CHEMBL1447501 & 688422 & 4.9 & 5.1793 & TRN \\
\hline CHEMBL1373969 & 688422 & 5.5 & 4.7352 & TRN \\
\hline CHEMBL1431034 & 688422 & 5.15 & 5.2185 & TRN \\
\hline CHEMBL2369206 & 688422 & 4.5 & 5.3298 & TRN \\
\hline CHEMBL1418360 & 688422 & 4.45 & 5.561 & TRN \\
\hline CHEMBL3198769 & 688422 & 4.9 & 5.2188 & TRN \\
\hline CHEMBL1351210 & 688422 & 4.95 & 5.0977 & TST \\
\hline CHEMBL504977 & 688422 & 4.8 & 5.4343 & TRN \\
\hline CHEMBL1475076 & 688422 & 6.2 & 5.3728 & TRN \\
\hline CHEMBL1582872 & 688422 & 4.8 & 5.0494 & TRN \\
\hline CHEMBL3212901 & 688422 & 4.9 & 5.1065 & TRN \\
\hline CHEMBL1565927 & 688422 & 4.9 & 4.7932 & TRN \\
\hline CHEMBL1501735 & 688422 & 4.45 & 5.3008 & TRN \\
\hline CHEMBL1360838 & 688422 & 4.75 & 5.4847 & TST \\
\hline CHEMBL1572545 & 688422 & 5.0 & 5.3273 & TRN \\
\hline CHEMBL1308255 & 688422 & 4.6 & 5.0529 & TRN \\
\hline CHEMBL1974319 & 688422 & 4.85 & 4.6403 & TRN \\
\hline CHEMBL1613509 & 688422 & 4.65 & 5.0586 & TST \\
\hline CHEMBL3189357 & 688422 & 4.8 & 5.2217 & TRN \\
\hline CHEMBL1508453 & 688422 & 4.9 & 5.3058 & TST \\
\hline CHEMBL1360965 & 688422 & 4.75 & 5.0117 & TST \\
\hline
\end{tabular}




\begin{tabular}{|c|c|c|c|c|c|}
\hline \multicolumn{6}{|c|}{ Supplemental Table S2.txt } \\
\hline CHEMBL1601838 & 688422 & 5.0 & 5.4951 & TST & \\
\hline CHEMBL3199444 & 688422 & 5.7 & 5.4476 & TRN & \\
\hline CHEMBL1409043 & 688422 & 4.45 & 4.9262 & TRN & \\
\hline CHEMBL1393480 & 688422 & 6.3 & 5.2391 & TRN & \\
\hline CHEMBL1415027 & 688422 & 4.95 & 5.0887 & TRN & \\
\hline CHEMBL1571711 & 688422 & 5.45 & 5.1832 & TST & \\
\hline CHEMBL1578289 & 688422 & 4.6 & 4.9685 & TRN & \\
\hline CHEMBL1580046 & 688422 & 4.45 & 5.1009 & TRN & \\
\hline CHEMBL1390905 & 688422 & 5.15 & 4.9235 & TRN & \\
\hline CHEMBL1347637 & 688422 & 4.85 & 5.2881 & TRN & \\
\hline CHEMBL1302345 & 688422 & 4.9 & 5.7322 & TRN & \\
\hline CHEMBL1437075 & 688422 & 4.65 & 4.8663 & TRN & \\
\hline CHEMBL1551427 & 688422 & 7.8013 & 5.246 & TST & \\
\hline CHEMBL373784 & 688422 & 5.65 & 5.3357 & TRN & \\
\hline CHEMBL1538578 & 688422 & 6.4 & 5.5239 & TST & \\
\hline CHEMBL1562324 & 688422 & 4.45 & 5.4387 & TRN & \\
\hline CHEMBL1306291 & 688422 & 8.3468 & 5.80200 & 00000000005 & TRN \\
\hline CHEMBL1417097 & 688422 & 4.7 & 5.2296 & TRN & \\
\hline CHEMBL1604761 & 688422 & 4.45 & 4.8778 & TRN & \\
\hline CHEMBL1345907 & 688422 & 7.0 & 5.6323 & TRN & \\
\hline CHEMBL1595588 & 688422 & 4.8 & 5.5716 & TST & \\
\hline CHEMBL1597427 & 688422 & 4.5 & 4.8814 & TRN & \\
\hline CHEMBL3189217 & 688422 & 4.75 & 5.3038 & TRN & \\
\hline CHEMBL1352697 & 688422 & 5.5 & 5.0518 & TST & \\
\hline CHEMBL1604074 & 688422 & 6.0 & 5.6899 & TRN & \\
\hline CHEMBL1305355 & 688422 & 4.6 & 5.925 & TST & \\
\hline CHEMBL1472532 & 688422 & 4.65 & 5.2043 & TST & \\
\hline CHEMBL1532786 & 688422 & 6.45 & 5.2869 & TST & \\
\hline CHEMBL1316864 & 688422 & 4.45 & 5.1372 & TRN & \\
\hline CHEMBL1332192 & 688422 & 7.15 & 5.0341 & TRN & \\
\hline CHEMBL1305988 & 688422 & 4.7 & 5.4396 & TRN & \\
\hline CHEMBL1374560 & 688422 & 4.45 & 5.2845 & TRN & \\
\hline CHEMBL1450657 & 688422 & 4.45 & 5.3769 & TRN & \\
\hline CHEMBL1301168 & 688422 & 4.9 & 4.984 & TRN & \\
\hline CHEMBL1450527 & 688422 & 6.15 & 5.6246 & TRN & \\
\hline CHEMBL1501476 & 688422 & 8.3468 & 5.8596 & TRN & \\
\hline CHEMBL1497465 & 688422 & 8.4949 & 5.1424 & TRN & \\
\hline CHEMBL1433464 & 688422 & 4.5 & 4.7026 & TRN & \\
\hline CHEMBL1303819 & 688422 & 5.45 & 5.2969 & TRN & \\
\hline CHEMBL1332084 & 688422 & 4.75 & 5.7813 & TRN & \\
\hline CHEMBL1583261 & 688422 & 5.25 & 5.0894 & TRN & \\
\hline CHEMBL1514145 & 688422 & 4.55 & 5.1982 & TRN & \\
\hline CHEMBL1445824 & 688422 & 4.5 & 5.251 & TRN & \\
\hline CHEMBL1491916 & 688422 & 4.95 & 5.3124 & TRN & \\
\hline CHEMBL1399886 & 688422 & 4.75 & 5.1477 & TRN & \\
\hline CHEMBL496729 & 688422 & 4.7 & 5.1282 & TST & \\
\hline CHEMBL1358062 & 688422 & 5.0 & 5.1673 & TRN & \\
\hline CHEMBL1589652 & 688422 & 4.45 & 5.3945 & TST & \\
\hline
\end{tabular}




\begin{tabular}{|c|c|c|c|c|c|}
\hline \multicolumn{6}{|c|}{ Supplemental Table S2.txt } \\
\hline CHEMBL1577649 & 688422 & 4.45 & 4.9982 & TRN & \\
\hline CHEMBL 3208300 & 688422 & 5.5 & 4.8 & TRN & \\
\hline CHEMBL602969 & 688422 & 5.15 & 5.3125 & TST & \\
\hline CHEMBL1550005 & 688422 & 4.45 & 5.8248 & TRN & \\
\hline CHEMBL1432407 & 688422 & 4.8 & 4.8089 & TST & \\
\hline CHEMBL1388387 & 688422 & 4.45 & 5.4436 & TRN & \\
\hline CHEMBL1393465 & 688422 & 4.45 & 5.0794 & TRN & \\
\hline CHEMBL1497900 & 688422 & 4.45 & 5.3084 & TRN & \\
\hline CHEMBL1306679 & 688422 & 4.8 & 5.36100 & 0000000001 & TST \\
\hline CHEMBL1562706 & 688422 & 4.85 & 5.20299 & 9999999999 & TST \\
\hline CHEMBL1481195 & 688422 & 8.4559 & 5.6749 & TRN & \\
\hline CHEMBL1329566 & 688422 & 4.5 & 5.1024 & TRN & \\
\hline CHEMBL1549728 & 688422 & 5.0 & 5.0156 & TST & \\
\hline CHEMBL 3214054 & 688422 & 6.5501 & 5.5613 & TRN & \\
\hline CHEMBL1308003 & 688422 & 5.9 & 5.3556 & TRN & \\
\hline CHEMBL3209624 & 688422 & 5.0 & 5.0875 & TRN & \\
\hline CHEMBL1993522 & 688422 & 4.7 & 5.1395 & TRN & \\
\hline CHEMBL1556824 & 688422 & 4.9 & 5.5317 & TRN & \\
\hline CHEMBL1369492 & 688422 & 7.5003 & 4.8364 & TRN & \\
\hline CHEMBL1492624 & 688422 & 4.6 & 5.6989 & TRN & \\
\hline CHEMBL1470570 & 688422 & 7.5003 & 5.4871 & TRN & \\
\hline CHEMBL1592769 & 688422 & 4.95 & 5.0823 & TRN & \\
\hline CHEMBL1589405 & 688422 & 4.9 & 5.2867 & TRN & \\
\hline CHEMBL1302414 & 688422 & 4.85 & 5.3046 & TRN & \\
\hline CHEMBL1454216 & 688422 & 4.7 & 5.7044 & TRN & \\
\hline CHEMBL1509783 & 688422 & 7.6498 & 4.9991 & TRN & \\
\hline CHEMBL1604297 & 688422 & 6.3 & 5.685 & TRN & \\
\hline CHEMBL1352573 & 688422 & 4.8 & 4.9627 & TRN & \\
\hline CHEMBL 3209737 & 688422 & 4.75 & 5.0569 & TRN & \\
\hline CHEMBL1485522 & 688422 & 4.75 & 4.8331 & TRN & \\
\hline CHEMBL1331766 & 688422 & 5.25 & 5.3273 & TRN & \\
\hline CHEMBL1330616 & 688422 & 4.75 & 5.6762 & TRN & \\
\hline CHEMBL1332111 & 688422 & 5.35 & 5.41200 & 0000000001 & TRN \\
\hline CHEMBL1576412 & 688422 & 4.95 & 5.6986 & TRN & \\
\hline CHEMBL1605621 & 688422 & 6.25 & 5.2386 & TRN & \\
\hline CHEMBL1514532 & 688422 & 4.45 & 5.3145 & TRN & \\
\hline CHEMBL182461 & 688422 & 5.2 & 6.1132 & TST & \\
\hline CHEMBL1466793 & 688422 & 4.9 & 5.4685 & TRN & \\
\hline CHEMBL1610227 & 688422 & 5.65 & 5.1519 & TRN & \\
\hline CHEMBL1302424 & 688422 & 4.95 & 4.8661 & TRN & \\
\hline CHEMBL1545687 & 688422 & 5.4 & 5.5988 & TST & \\
\hline CHEMBL1481927 & 688422 & 8.0 & 5.2703 & TST & \\
\hline CHEMBL1379542 & 688422 & 4.45 & 4.9897 & TST & \\
\hline CHEMBL3196394 & 688422 & 6.7501 & 5.3149 & TST & \\
\hline CHEMBL3195829 & 688422 & 7.0501 & 5.2703 & TST & \\
\hline CHEMBL267476 & 688422 & 6.7501 & 5.3302 & TRN & \\
\hline CHEMBL1361027 & 688422 & 4.55 & 5.0361 & TRN & \\
\hline CHEMBL3193404 & 688422 & 5.9 & 5.1321 & TST & \\
\hline
\end{tabular}




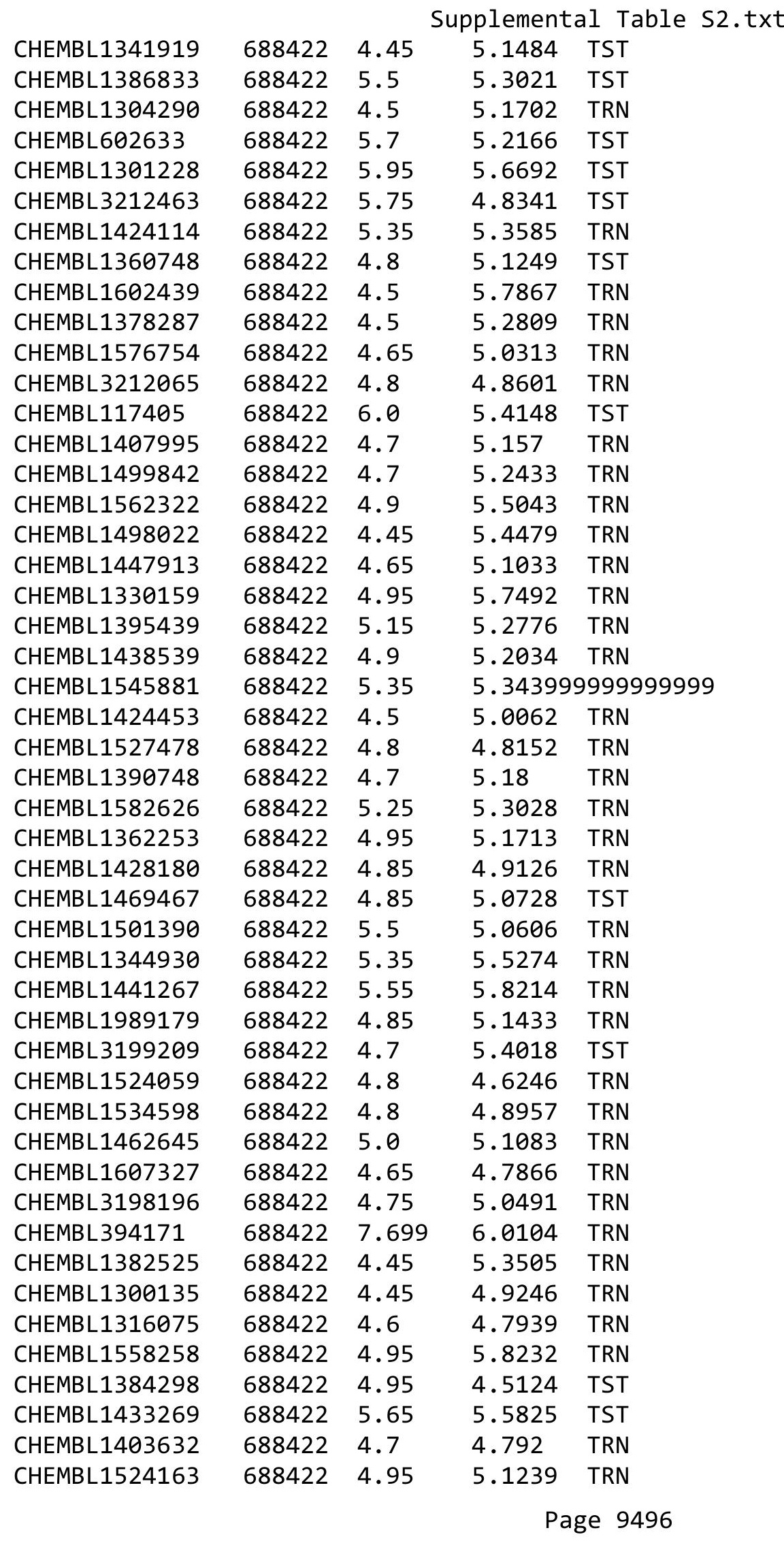

TRN 


\begin{tabular}{|c|c|c|c|c|c|}
\hline \multicolumn{6}{|c|}{ Supplemental Table S2.txt } \\
\hline CHEMBL1566632 & 688422 & 4.45 & 5.2355 & TST & \\
\hline CHEMBL1353568 & 688422 & 4.65 & 5.0915 & TST & \\
\hline CHEMBL1546822 & 688422 & 4.45 & 5.41200 & 0000000001 & TRN \\
\hline CHEMBL1302132 & 688422 & 4.45 & 5.30399 & 9999999999 & TRN \\
\hline CHEMBL1313592 & 688422 & 4.6 & 4.9634 & TRN & \\
\hline CHEMBL1324165 & 688422 & 4.6 & 4.9971 & TRN & \\
\hline CHEMBL1494182 & 688422 & 5.55 & 6.222 & TRN & \\
\hline CHEMBL 3211198 & 688422 & 4.8 & 4.9721 & TRN & \\
\hline CHEMBL1725279 & 688422 & 8.301 & 5.1975 & TST & \\
\hline CHEMBL1569682 & 688422 & 4.95 & 4.9787 & TRN & \\
\hline CHEMBL1336358 & 688422 & 5.45 & 5.5058 & TRN & \\
\hline CHEMBL1533703 & 688422 & 7.5498 & 5.8061 & TRN & \\
\hline CHEMBL1555495 & 688422 & 4.5 & 4.5227 & TRN & \\
\hline CHEMBL1515740 & 688422 & 5.1 & 5.1194 & TRN & \\
\hline CHEMBL1610054 & 688422 & 4.45 & 5.2728 & TRN & \\
\hline CHEMBL1484422 & 688422 & 5.0 & 4.9788 & TRN & \\
\hline CHEMBL1597238 & 688422 & 4.5 & 4.81 & TST & \\
\hline CHEMBL1988457 & 688422 & 4.65 & 4.9672 & TRN & \\
\hline CHEMBL1597458 & 688422 & 4.45 & 5.1825 & TRN & \\
\hline CHEMBL1384060 & 688422 & 5.7 & 5.2822 & TST & \\
\hline CHEMBL1359154 & 688422 & 4.45 & 5.0657 & TRN & \\
\hline CHEMBL1493052 & 688422 & 4.65 & 4.8418 & TRN & \\
\hline CHEMBL1432794 & 688422 & 5.75 & 4.838 & TRN & \\
\hline CHEMBL1377316 & 688422 & 4.55 & 5.3455 & TRN & \\
\hline CHEMBL1389950 & 688422 & 4.8 & 5.2154 & TRN & \\
\hline CHEMBL1344814 & 688422 & 4.5 & 4.8307 & TRN & \\
\hline CHEMBL1359581 & 688422 & 4.85 & 5.5535 & TST & \\
\hline CHEMBL1382590 & 688422 & 4.9 & 4.8156 & TRN & \\
\hline CHEMBL1572836 & 688422 & 4.75 & 5.0177 & TRN & \\
\hline CHEMBL1503995 & 688422 & 4.45 & 4.768 & TRN & \\
\hline CHEMBL1334820 & 688422 & 4.7 & 5.522 & TST & \\
\hline CHEMBL1348026 & 688422 & 4.6 & 5.32100 & 0000000001 & TRN \\
\hline CHEMBL1348852 & 688422 & 4.5 & 4.9546 & TST & \\
\hline CHEMBL1480965 & 688422 & 8.301 & 5.7218 & TRN & \\
\hline CHEMBL1598520 & 688422 & 4.45 & 4.9332 & TRN & \\
\hline CHEMBL1330917 & 688422 & 4.8 & 5.2195 & TRN & \\
\hline CHEMBL1543876 & 688422 & 4.45 & 5.1435 & TST & \\
\hline CHEMBL1495850 & 688422 & 8.301 & 5.4848 & TRN & \\
\hline CHEMBL1428403 & 688422 & 4.75 & 5.4561 & TST & \\
\hline CHEMBL1578920 & 688422 & 5.05 & 5.0295 & TRN & \\
\hline CHEMBL3190467 & 688422 & 4.45 & 4.8504 & TST & \\
\hline CHEMBL1565487 & 688422 & 4.7 & 4.8221 & TST & \\
\hline CHEMBL1526621 & 688422 & 4.9 & 4.9657 & TST & \\
\hline CHEMBL1560379 & 688422 & 4.7 & 4.83 & TRN & \\
\hline CHEMBL1331851 & 688422 & 4.95 & 5.1953 & TRN & \\
\hline CHEMBL1443533 & 688422 & 4.8 & 5.1013 & TRN & \\
\hline CHEMBL1324526 & 688422 & 6.0 & 5.185 & TRN & \\
\hline CHEMBL1570555 & 688422 & 4.6 & 5.2363 & TST & \\
\hline
\end{tabular}




\begin{tabular}{|c|c|c|c|c|}
\hline \multicolumn{5}{|c|}{ Supplemental Table S2.txt } \\
\hline CHEMBL1401158 & 688422 & 6.15 & 5.4494 & TRN \\
\hline CHEMBL1322707 & 688422 & 4.45 & 5.3316 & TRN \\
\hline CHEMBL1580288 & 688422 & 4.65 & 5.1286 & TRN \\
\hline CHEMBL1531231 & 688422 & 5.45 & 5.0542 & TRN \\
\hline CHEMBL1333295 & 688422 & 4.45 & 5.721 & TRN \\
\hline CHEMBL1388853 & 688422 & 7.6003 & 5.1783 & TRN \\
\hline CHEMBL1583806 & 688422 & 4.85 & 4.9147 & TRN \\
\hline CHEMBL1369664 & 688422 & 4.45 & 5.4184 & TST \\
\hline CHEMBL3195982 & 688422 & 4.9 & 5.1814 & TRN \\
\hline CHEMBL1362843 & 688422 & 4.75 & 5.0266 & TRN \\
\hline CHEMBL1462185 & 688422 & 4.65 & 4.9532 & TRN \\
\hline CHEMBL1335464 & 688422 & 4.45 & 4.9783 & TRN \\
\hline CHEMBL3213263 & 688422 & 5.0 & 5.1929 & TRN \\
\hline CHEMBL1403616 & 688422 & 4.85 & 4.9299 & TRN \\
\hline CHEMBL1579771 & 688422 & 4.5 & 5.4436 & TRN \\
\hline CHEMBL1403908 & 688422 & 8.4949 & 4.8229 & TST \\
\hline CHEMBL1523757 & 688422 & 4.5 & 5.2195 & TRN \\
\hline CHEMBL3198347 & 688422 & 6.1 & 5.4605 & TRN \\
\hline CHEMBL1393186 & 688422 & 4.8 & 5.3404 & TST \\
\hline CHEMBL3210261 & 688422 & 7.9508 & 5.8952 & TRN \\
\hline CHEMBL1546569 & 688422 & 6.3 & 5.5209 & TST \\
\hline CHEMBL1449129 & 688422 & 4.85 & 5.376 & TRN \\
\hline CHEMBL1523058 & 688422 & 6.8 & 5.3689 & TRN \\
\hline CHEMBL1602875 & 688422 & 5.0 & 5.2273 & TRN \\
\hline CHEMBL1549333 & 688422 & 5.3 & 4.7298 & TRN \\
\hline CHEMBL1591294 & 688422 & 8.2007 & 5.9863 & TST \\
\hline CHEMBL1327971 & 688422 & 4.5 & 4.6459 & TRN \\
\hline CHEMBL1411511 & 688422 & 5.2 & 4.9697 & TRN \\
\hline CHEMBL1305532 & 688422 & 5.35 & 5.2752 & TRN \\
\hline CHEMBL1455403 & 688422 & 5.5 & 5.1154 & TRN \\
\hline CHEMBL1488070 & 688422 & 6.95 & 5.1038 & TRN \\
\hline CHEMBL1595361 & 688422 & 4.85 & 5.6116 & TRN \\
\hline CHEMBL1515929 & 688422 & 4.7 & 5.5243 & TRN \\
\hline CHEMBL1426446 & 688422 & 4.95 & 4.9754 & TRN \\
\hline CHEMBL1444221 & 688422 & 4.45 & 4.712 & TRN \\
\hline CHEMBL1567345 & 688422 & 4.9 & 4.8891 & TRN \\
\hline CHEMBL1456947 & 688422 & 6.5 & 5.1909 & TRN \\
\hline CHEMBL1299262 & 688422 & 4.85 & 5.1448 & TRN \\
\hline CHEMBL2369277 & 688422 & 5.0 & 5.098 & TST \\
\hline CHEMBL1495621 & 688422 & 4.8 & 5.1884 & TRN \\
\hline CHEMBL 202273 & 688422 & 6.8 & 5.1383 & TRN \\
\hline CHEMBL1364219 & 688422 & 4.9 & 5.1406 & TRN \\
\hline CHEMBL1608011 & 688422 & 4.95 & 5.149 & TRN \\
\hline CHEMBL3195399 & 688422 & 4.5 & 5.187 & TRN \\
\hline CHEMBL1608318 & 688422 & 5.0 & 4.8044 & TRN \\
\hline CHEMBL3213563 & 688422 & 4.6 & 5.5469 & TRN \\
\hline CHEMBL1559109 & 688422 & 4.45 & 5.2884 & TRN \\
\hline CHEMBL3189832 & 688422 & 4.55 & 4.934 & TRN \\
\hline
\end{tabular}





\begin{tabular}{|c|c|c|c|c|c|}
\hline \multicolumn{6}{|c|}{ Supplemental Table S2.txt } \\
\hline CHEMBL1335305 & 688422 & 4.9 & 5.1076 & TST & \\
\hline CHEMBL1453756 & 688422 & 4.45 & 5.3118 & TRN & \\
\hline CHEMBL1964439 & 688422 & 5.05 & 5.1537 & TRN & \\
\hline CHEMBL1309307 & 688422 & 4.85 & 5.2513 & TRN & \\
\hline CHEMBL1485110 & 688422 & 4.55 & 5.0773 & TRN & \\
\hline CHEMBL1577619 & 688422 & 8.0506 & 5.4414 & TRN & \\
\hline CHEMBL1573585 & 688422 & 6.95 & 5.6164 & TRN & \\
\hline CHEMBL1447267 & 688422 & 5.4 & 4.9198 & TRN & \\
\hline CHEMBL1563199 & 688422 & 4.45 & 5.3955 & TRN & \\
\hline CHEMBL1504439 & 688422 & 4.45 & 5.0404 & TRN & \\
\hline CHEMBL1366986 & 688422 & 5.25 & 4.6704 & TST & \\
\hline CHEMBL1972143 & 688422 & 4.7 & 5.2247 & TRN & \\
\hline CHEMBL1516418 & 688422 & 4.95 & 5.1506 & TRN & \\
\hline CHEMBL3209173 & 688422 & 4.95 & 5.0911 & TRN & \\
\hline CHEMBL1497918 & 688422 & 5.2 & 4.8661 & TRN & \\
\hline CHEMBL1307154 & 688422 & 4.85 & 4.7759 & TRN & \\
\hline CHEMBL1397278 & 688422 & 5.45 & 5.164 & TRN & \\
\hline CHEMBL1528771 & 688422 & 6.6499 & 5.3508 & TRN & \\
\hline CHEMBL1453968 & 688422 & 6.05 & 5.4846 & TST & \\
\hline CHEMBL1439874 & 688422 & 4.65 & 5.3696 & TRN & \\
\hline CHEMBL1451162 & 688422 & 7.8996 & 4.7796 & TRN & \\
\hline CHEMBL1421039 & 688422 & 4.85 & 5.398 & TRN & \\
\hline CHEMBL1531670 & 688422 & 5.0 & 4.96399 & 99999999995 & TRN \\
\hline CHEMBL1486368 & 688422 & 4.9 & 5.3328 & TRN & \\
\hline CHEMBL1497075 & 688422 & 4.6 & 5.2121 & TRN & \\
\hline CHEMBL1568518 & 688422 & 8.3468 & 4.8973 & TRN & \\
\hline CHEMBL1589677 & 688422 & 6.15 & 4.9842 & TRN & \\
\hline CHEMBL1595098 & 688422 & 4.85 & 5.1842 & TRN & \\
\hline CHEMBL1432492 & 688422 & 4.45 & 5.4723 & TRN & \\
\hline CHEMBL3189874 & 688422 & 6.7001 & 5.3845 & TST & \\
\hline CHEMBL1397243 & 688422 & 4.45 & 5.3315 & TRN & \\
\hline CHEMBL1592801 & 688422 & 5.1 & 5.9213 & TRN & \\
\hline CHEMBL1572700 & 688422 & 4.45 & 5.7297 & TST & \\
\hline CHEMBL1432173 & 688422 & 5.85 & 5.1608 & TRN & \\
\hline CHEMBL1528611 & 688422 & 7.6498 & 5.2619 & TRN & \\
\hline CHEMBL1336727 & 688422 & 6.4 & 5.0046 & TRN & \\
\hline CHEMBL1491454 & 688422 & 4.75 & 5.3211 & TRN & \\
\hline CHEMBL1473293 & 688422 & 4.65 & 5.4197 & TRN & \\
\hline CHEMBL1387131 & 688422 & 4.45 & 5.3867 & TRN & \\
\hline CHEMBL1550743 & 688422 & 4.45 & 5.0632 & TRN & \\
\hline CHEMBL1570008 & 688422 & 4.95 & 4.8827 & TRN & \\
\hline CHEMBL1371504 & 688422 & 7.8508 & 5.5098 & TRN & \\
\hline CHEMBL1345135 & 688422 & 4.5 & 5.0761 & TRN & \\
\hline CHEMBL1495059 & 688422 & 4.65 & 5.4833 & TRN & \\
\hline CHEMBL1399311 & 688422 & 4.8 & 5.0888 & TRN & \\
\hline CHEMBL1299457 & 688422 & 4.45 & 4.8328 & TRN & \\
\hline CHEMBL1437353 & 688422 & 6.1 & 5.6682 & TRN & \\
\hline CHEMBL1429432 & 688422 & 4.45 & 5.1145 & TRN & \\
\hline
\end{tabular}




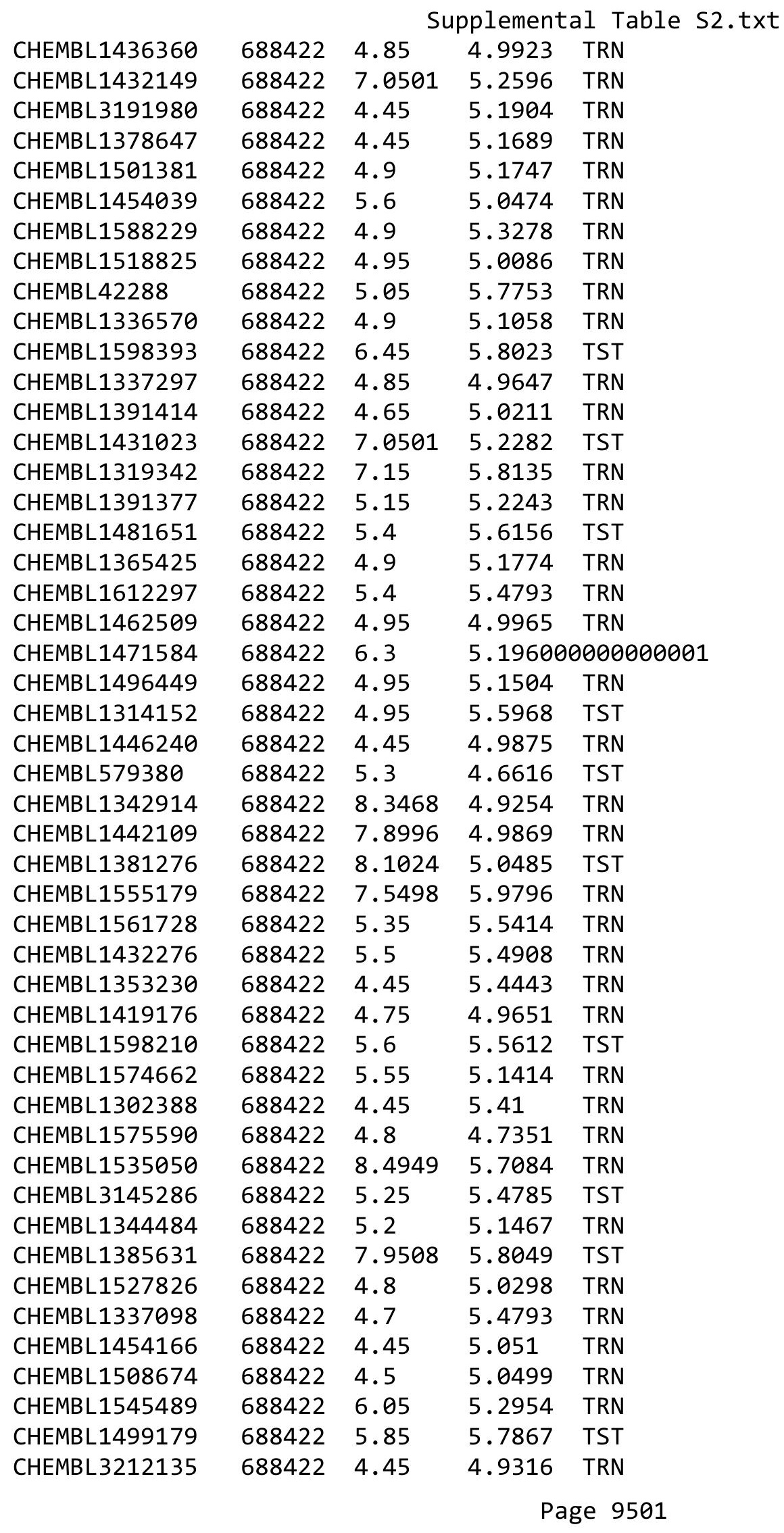




\begin{tabular}{|c|c|c|c|c|}
\hline \multicolumn{5}{|c|}{ Supplemental Table S2.txt } \\
\hline CHEMBL1570857 & 688422 & 4.45 & 4.9681 & TRN \\
\hline CHEMBL1311477 & 688422 & 4.55 & 5.6833 & TRN \\
\hline CHEMBL1571984 & 688422 & 4.85 & 5.1291 & TRN \\
\hline CHEMBL1546655 & 688422 & 4.45 & 5.1042 & TRN \\
\hline CHEMBL597874 & 688422 & 4.95 & 4.859 & TRN \\
\hline CHEMBL1520375 & 688422 & 8.3468 & 5.2563 & TST \\
\hline CHEMBL1598414 & 688422 & 4.6 & 4.8419 & TRN \\
\hline CHEMBL1485026 & 688422 & 4.6 & 4.9828 & TRN \\
\hline CHEMBL1564452 & 688422 & 4.95 & 4.6449 & TRN \\
\hline CHEMBL1310729 & 688422 & 4.5 & 5.4048 & TST \\
\hline CHEMBL1421056 & 688422 & 4.45 & 5.2313 & TRN \\
\hline CHEMBL1598132 & 688422 & 7.2503 & 5.1429 & TRN \\
\hline CHEMBL1342553 & 688422 & 4.45 & 5.3541 & TST \\
\hline CHEMBL1465903 & 688422 & 4.85 & 5.06 & TRN \\
\hline CHEMBL1325462 & 688422 & 5.35 & 5.0945 & TRN \\
\hline CHEMBL1503307 & 688422 & 4.55 & 5.0641 & TRN \\
\hline CHEMBL1456496 & 688422 & 4.45 & 5.0216 & TRN \\
\hline CHEMBL 3210154 & 688422 & 4.95 & 4.7278 & TRN \\
\hline CHEMBL1388809 & 688422 & 4.85 & 4.9856 & TRN \\
\hline CHEMBL1358879 & 688422 & 5.0 & 5.194 & TRN \\
\hline CHEMBL 3207534 & 688422 & 5.0 & 5.2466 & TRN \\
\hline CHEMBL1510393 & 688422 & 4.45 & 5.2962 & TST \\
\hline CHEMBL1596099 & 688422 & 4.45 & 5.7737 & TST \\
\hline CHEMBL1440827 & 688422 & 4.5 & 5.2369 & TRN \\
\hline CHEMBL1513201 & 688422 & 5.0 & 4.8995 & TRN \\
\hline CHEMBL1582033 & 688422 & 4.7 & 5.432 & TST \\
\hline CHEMBL1538053 & 688422 & 6.95 & 5.1083 & TRN \\
\hline CHEMBL 3207721 & 688422 & 5.0 & 5.0376 & TRN \\
\hline CHEMBL1463877 & 688422 & 7.15 & 5.5843 & TRN \\
\hline CHEMBL1350842 & 688422 & 5.0 & 5.4271 & TST \\
\hline CHEMBL1327627 & 688422 & 5.15 & 5.1789 & TRN \\
\hline CHEMBL 3195883 & 688422 & 4.95 & 5.1187 & TST \\
\hline CHEMBL1466482 & 688422 & 5.55 & 5.1457 & TST \\
\hline CHEMBL1460643 & 688422 & 4.65 & 5.4577 & TST \\
\hline CHEMBL1503082 & 688422 & 6.5 & 5.0169 & TRN \\
\hline CHEMBL3190949 & 688422 & 4.85 & 5.6742 & TST \\
\hline CHEMBL1567452 & 688422 & 8.4949 & 6.0635 & TRN \\
\hline CHEMBL1579168 & 688422 & 6.8 & 5.5076 & TST \\
\hline CHEMBL1557494 & 688422 & 4.8 & 5.1512 & TRN \\
\hline CHEMBL1568965 & 688422 & 4.45 & 5.2633 & TRN \\
\hline CHEMBL1353947 & 688422 & 4.45 & 4.9903 & TRN \\
\hline CHEMBL1458205 & 688422 & 4.8 & 5.0229 & TRN \\
\hline CHEMBL1330684 & 688422 & 4.95 & 5.3235 & TST \\
\hline CHEMBL1602503 & 688422 & 8.3468 & 5.0746 & TRN \\
\hline CHEMBL1339745 & 688422 & 4.75 & 5.4198 & TRN \\
\hline CHEMBL1449328 & 688422 & 5.45 & 5.17299 & 9999999999 \\
\hline CHEMBL1357170 & 688422 & 4.45 & 5.2008 & TRN \\
\hline CHEMBL1453854 & 688422 & 4.8 & 5.21 & TST \\
\hline
\end{tabular}

TRN 


\begin{tabular}{|c|c|c|c|c|}
\hline \multicolumn{5}{|c|}{ Supplemental Table S2.txt } \\
\hline CHEMBL1310221 & 688422 & 4.45 & 5.1195 & TRN \\
\hline CHEMBL 3194085 & 688422 & 4.7 & 5.1909 & TRN \\
\hline CHEMBL1406145 & 688422 & 4.7 & 4.84 & TRN \\
\hline CHEMBL 30953 & 688422 & 4.95 & 4.8733 & TRN \\
\hline CHEMBL1392759 & 688422 & 4.45 & 5.7488 & TRN \\
\hline CHEMBL1344973 & 688422 & 4.5 & 5.2887 & TRN \\
\hline CHEMBL1591581 & 688422 & 5.05 & 6.0157 & TRN \\
\hline CHEMBL1972519 & 688422 & 5.85 & 5.9105 & TST \\
\hline CHEMBL1303785 & 688422 & 4.65 & 5.3583 & TRN \\
\hline CHEMBL1499326 & 688422 & 4.45 & 4.8463 & TRN \\
\hline CHEMBL1555719 & 688422 & 4.45 & 5.2499 & TST \\
\hline CHEMBL1463815 & 688422 & 5.35 & 5.1924 & TRN \\
\hline CHEMBL1328217 & 688422 & 8.0 & 5.6916 & TRN \\
\hline CHEMBL1464742 & 688422 & 5.1 & 4.8805 & TST \\
\hline CHEMBL1534644 & 688422 & 5.5 & 5.3862 & TRN \\
\hline CHEMBL1329965 & 688422 & 4.45 & 5.1289 & TRN \\
\hline CHEMBL1377280 & 688422 & 5.5 & 5.3851 & TRN \\
\hline CHEMBL1558545 & 688422 & 7.2503 & 5.0462 & TRN \\
\hline CHEMBL1341865 & 688422 & 4.95 & 5.0527 & TST \\
\hline CHEMBL1546378 & 688422 & 4.65 & 5.4207 & TRN \\
\hline CHEMBL1612633 & 688422 & 4.9 & 4.9751 & TRN \\
\hline CHEMBL1507589 & 688422 & 4.45 & 5.0495 & TRN \\
\hline CHEMBL460601 & 688422 & 7.0 & 5.3825 & TRN \\
\hline CHEMBL1504281 & 688422 & 5.95 & 4.9613 & TRN \\
\hline CHEMBL1594354 & 688422 & 6.8 & 5.2409 & TST \\
\hline CHEMBL1990481 & 688422 & 5.05 & 5.1918 & TRN \\
\hline CHEMBL1562489 & 688422 & 4.5 & 4.9366 & TRN \\
\hline CHEMBL1494221 & 688422 & 4.85 & 5.3344 & TST \\
\hline CHEMBL1347710 & 688422 & 4.55 & 5.1192 & TRN \\
\hline CHEMBL1382925 & 688422 & 5.35 & 5.431 & TRN \\
\hline CHEMBL1526859 & 688422 & 4.55 & 4.9004 & TST \\
\hline CHEMBL1331821 & 688422 & 4.5 & 5.0844 & TST \\
\hline CHEMBL1599120 & 688422 & 4.45 & 5.4892 & TST \\
\hline CHEMBL1382120 & 688422 & 4.45 & 4.8064 & TRN \\
\hline CHEMBL1302170 & 688422 & 4.9 & 4.7256 & TST \\
\hline CHEMBL1365119 & 688422 & 4.95 & 5.7894 & TST \\
\hline CHEMBL1424036 & 688422 & 5.15 & 5.1337 & TRN \\
\hline CHEMBL1407998 & 688422 & 4.6 & 5.1831 & TRN \\
\hline CHEMBL1373642 & 688422 & 4.75 & 5.2587 & TRN \\
\hline CHEMBL1501030 & 688422 & 5.25 & 5.6297 & TRN \\
\hline CHEMBL1507178 & 688422 & 4.65 & 5.1447 & TRN \\
\hline CHEMBL1507702 & 688422 & 4.95 & 4.9589 & TST \\
\hline CHEMBL139935 & 688422 & 5.2 & 5.5608 & TRN \\
\hline CHEMBL1369453 & 688422 & 5.75 & 5.4423 & TRN \\
\hline CHEMBL1340393 & 688422 & 4.85 & 5.1563 & TRN \\
\hline CHEMBL1301510 & 688422 & 7.1002 & 6.0316 & TST \\
\hline CHEMBL1561851 & 688422 & 4.6 & 5.3066 & TRN \\
\hline CHEMBL1368039 & 688422 & 4.95 & 5.0115 & TRN \\
\hline
\end{tabular}




\begin{tabular}{|c|c|c|c|c|c|}
\hline \multicolumn{6}{|c|}{ Supplemental Table S2.txt } \\
\hline CHEMBL1439634 & 688422 & 4.85 & 5.3883 & TST & \\
\hline CHEMBL1566420 & 688422 & 4.45 & 5.4066 & TST & \\
\hline CHEMBL3190241 & 688422 & 4.6 & 5.3603 & TRN & \\
\hline CHEMBL1474399 & 688422 & 4.45 & 4.8854 & TRN & \\
\hline CHEMBL1383575 & 688422 & 5.0 & 5.4297 & TRN & \\
\hline CHEMBL1307495 & 688422 & 4.45 & 4.5952 & TRN & \\
\hline CHEMBL1471351 & 688422 & 4.45 & 4.6933 & TRN & \\
\hline CHEMBL1494225 & 688422 & 5.85 & 5.2807 & TRN & \\
\hline CHEMBL1528172 & 688422 & 4.6 & 4.9292 & TRN & \\
\hline CHEMBL1402447 & 688422 & 6.25 & 5.3549 & TRN & \\
\hline CHEMBL1354925 & 688422 & 6.8 & 5.2486 & TRN & \\
\hline CHEMBL1390812 & 688422 & 5.9 & 5.6141 & TRN & \\
\hline CHEMBL1510581 & 688422 & 4.65 & 5.4096 & TRN & \\
\hline CHEMBL1417610 & 688422 & 4.45 & 5.1496 & TRN & \\
\hline CHEMBL1478000 & 688422 & 4.65 & 5.28600 & 00000000005 & TST \\
\hline CHEMBL1455747 & 688422 & 4.9 & 4.8802 & TRN & \\
\hline CHEMBL1547047 & 688422 & 5.0 & 5.2543 & TRN & \\
\hline CHEMBL1583658 & 688422 & 4.45 & 5.32700 & 0000000001 & TRN \\
\hline CHEMBL1304548 & 688422 & 5.45 & 5.5761 & TRN & \\
\hline CHEMBL1611041 & 688422 & 4.6 & 4.6724 & TRN & \\
\hline CHEMBL1346821 & 688422 & 6.8499 & 5.3663 & TST & \\
\hline CHEMBL1558102 & 688422 & 4.85 & 5.1253 & TRN & \\
\hline CHEMBL1465767 & 688422 & 4.45 & 5.348 & TST & \\
\hline CHEMBL1538600 & 688422 & 4.9 & 4.9981 & TRN & \\
\hline CHEMBL1425788 & 688422 & 4.9 & 5.1453 & TRN & \\
\hline CHEMBL3194764 & 688422 & 4.7 & 5.0414 & TRN & \\
\hline CHEMBL1582877 & 688422 & 4.9 & 4.945 & TRN & \\
\hline CHEMBL1493661 & 688422 & 4.75 & 5.2151 & TRN & \\
\hline CHEMBL1532181 & 688422 & 4.9 & 4.9869 & TRN & \\
\hline CHEMBL1503652 & 688422 & 4.55 & 5.62700 & 3000000001 & TRN \\
\hline CHEMBL1449051 & 688422 & 8.4949 & 5.5847 & TRN & \\
\hline CHEMBL1375193 & 688422 & 4.65 & 5.1181 & TRN & \\
\hline CHEMBL3192856 & 688422 & 4.95 & 4.8618 & TRN & \\
\hline CHEMBL1443976 & 688422 & 4.85 & 5.113 & TRN & \\
\hline CHEMBL1525869 & 688422 & 7.0 & 5.3825 & TRN & \\
\hline CHEMBL3192857 & 688422 & 4.95 & 4.9135 & TRN & \\
\hline CHEMBL1486113 & 688422 & 5.35 & 5.2399 & TST & \\
\hline CHEMBL1375690 & 688422 & 4.45 & 4.8059 & TRN & \\
\hline CHEMBL1457257 & 688422 & 4.65 & 4.8891 & TRN & \\
\hline CHEMBL1371826 & 688422 & 6.3 & 5.4586 & TST & \\
\hline CHEMBL1505115 & 688422 & 4.45 & 5.2295 & TRN & \\
\hline CHEMBL1545271 & 688422 & 4.7 & 4.9666 & TRN & \\
\hline CHEMBL1486517 & 688422 & 5.05 & 5.2634 & TRN & \\
\hline CHEMBL1596549 & 688422 & 4.65 & 5.3345 & TRN & \\
\hline CHEMBL 3145244 & 688422 & 4.75 & 5.1734 & TST & \\
\hline CHEMBL1451269 & 688422 & 4.8 & 5.0493 & TRN & \\
\hline CHEMBL1472906 & 688422 & 6.25 & 5.4533 & TRN & \\
\hline CHEMBL1484995 & 688422 & 6.5 & 6.1106 & TRN & \\
\hline
\end{tabular}




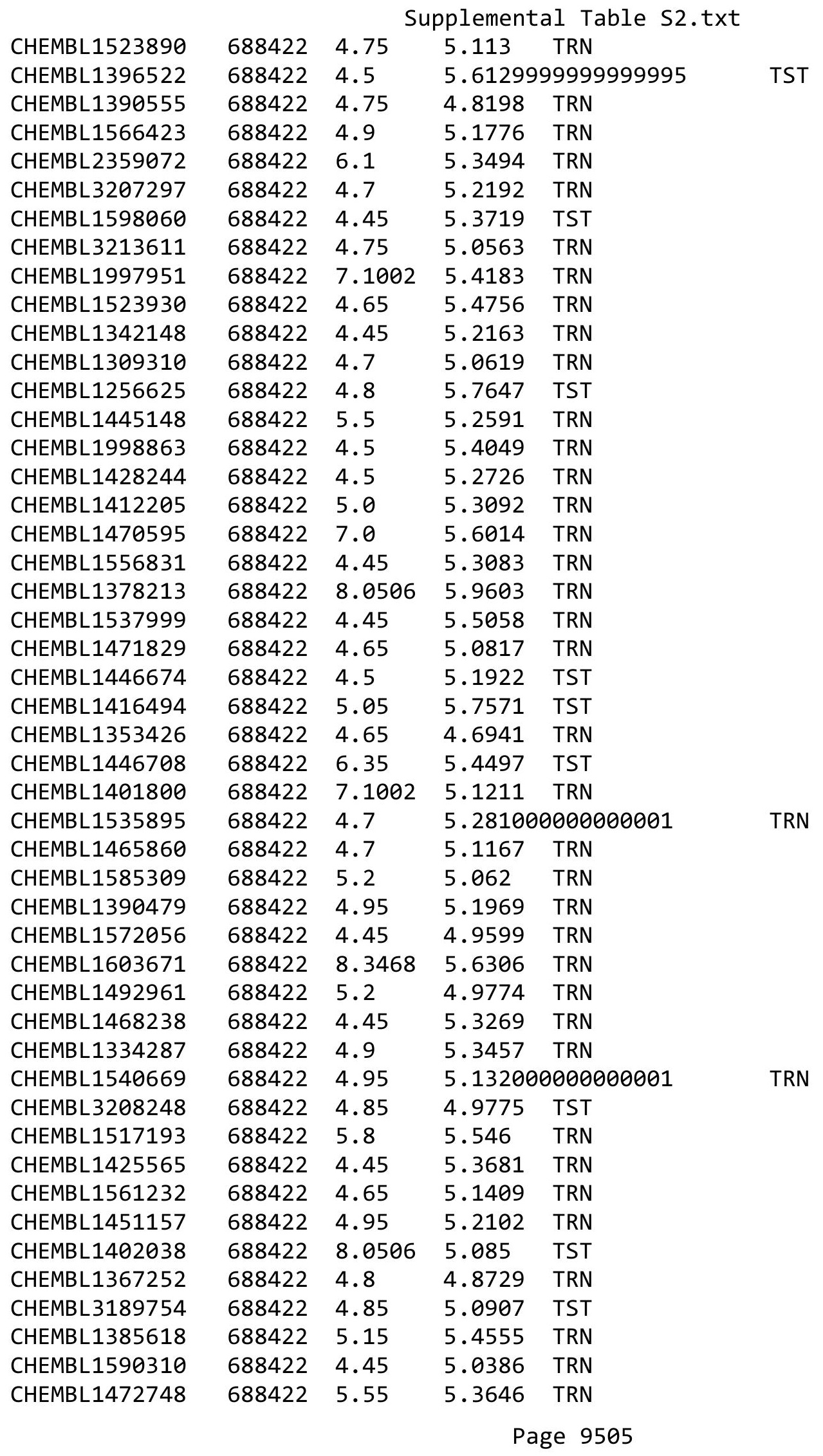




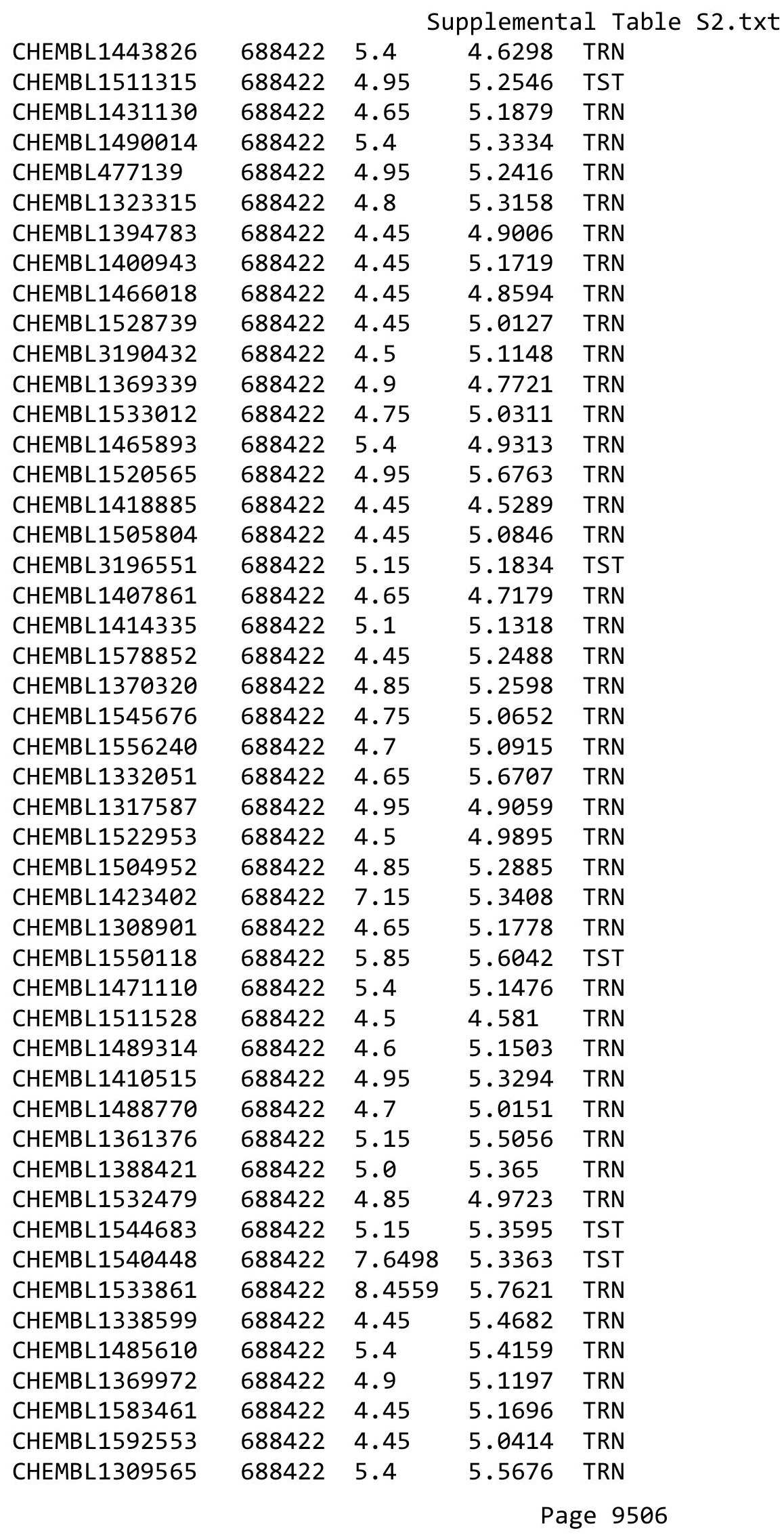




\begin{tabular}{|c|c|c|c|c|}
\hline \multicolumn{5}{|c|}{ Supplemental Table S2.txt } \\
\hline CHEMBL1355582 & 688422 & 6.7001 & 5.4508 & TRN \\
\hline CHEMBL1547674 & 688422 & 4.65 & 5.5729 & TRN \\
\hline CHEMBL1342150 & 688422 & 4.45 & 5.2069 & TRN \\
\hline CHEMBL1586468 & 688422 & 4.5 & 5.0577 & TRN \\
\hline CHEMBL1567225 & 688422 & 4.65 & 4.8656 & TRN \\
\hline CHEMBL1345486 & 688422 & 4.95 & 5.0026 & TRN \\
\hline CHEMBL1989294 & 688422 & 4.9 & 5.3068 & TRN \\
\hline CHEMBL1483321 & 688422 & 5.2 & 4.8484 & TRN \\
\hline CHEMBL1365154 & 688422 & 5.5 & 5.1108 & TRN \\
\hline CHEMBL1341815 & 688422 & 4.9 & 5.0113 & TRN \\
\hline CHEMBL1550008 & 688422 & 4.45 & 4.9358 & TRN \\
\hline CHEMBL1307413 & 688422 & 4.45 & 5.6425 & TST \\
\hline CHEMBL1417715 & 688422 & 8.3468 & 5.4764 & TST \\
\hline CHEMBL1486491 & 688422 & 4.95 & 4.8745 & TRN \\
\hline CHEMBL1448812 & 688422 & 4.95 & 5.426 & TRN \\
\hline CHEMBL1565631 & 688422 & 5.45 & 5.7567 & TST \\
\hline CHEMBL1494340 & 688422 & 4.45 & 4.8615 & TRN \\
\hline CHEMBL1493516 & 688422 & 4.65 & 5.1636 & TRN \\
\hline CHEMBL1498873 & 688422 & 7.5003 & 4.8865 & TRN \\
\hline CHEMBL1369625 & 688422 & 4.75 & 5.3965 & TST \\
\hline CHEMBL1528297 & 688422 & 6.05 & 5.5193 & TST \\
\hline CHEMBL1575086 & 688422 & 5.6 & 5.0216 & TST \\
\hline CHEMBL1325980 & 688422 & 6.8 & 5.2504 & TRN \\
\hline CHEMBL1544860 & 688422 & 4.5 & 5.397 & TST \\
\hline CHEMBL1358914 & 688422 & 5.95 & 5.4754 & TRN \\
\hline CHEMBL1341047 & 688422 & 4.95 & 5.271 & TRN \\
\hline CHEMBL1568293 & 688422 & 4.95 & 5.5575 & TST \\
\hline CHEMBL1385219 & 688422 & 4.8 & 5.1692 & TST \\
\hline CHEMBL3198095 & 688422 & 4.8 & 5.0915 & TRN \\
\hline CHEMBL1492249 & 688422 & 4.9 & 5.0403 & TRN \\
\hline CHEMBL1306044 & 688422 & 5.25 & 5.2447 & TRN \\
\hline CHEMBL1445335 & 688422 & 4.55 & 5.1084 & TRN \\
\hline CHEMBL1478135 & 688422 & 5.05 & 4.9512 & TST \\
\hline CHEMBL1594464 & 688422 & 4.9 & 4.8769 & TST \\
\hline CHEMBL1524608 & 688422 & 5.35 & 4.8701 & TRN \\
\hline CHEMBL1461209 & 688422 & 5.7 & 5.4915 & TRN \\
\hline CHEMBL1471279 & 688422 & 4.45 & 5.2022 & TRN \\
\hline CHEMBL1491033 & 688422 & 4.45 & 5.4263 & TRN \\
\hline CHEMBL1536226 & 688422 & 4.6 & 5.3886 & TRN \\
\hline CHEMBL1398376 & 688422 & 4.95 & 5.3879 & TRN \\
\hline CHEMBL1431373 & 688422 & 4.5 & 5.1391 & TRN \\
\hline CHEMBL1393401 & 688422 & 4.45 & 5.4015 & TST \\
\hline CHEMBL1510469 & 688422 & 4.7 & 5.0563 & TRN \\
\hline CHEMBL1518315 & 688422 & 4.45 & 5.3593 & TRN \\
\hline CHEMBL1506004 & 688422 & 4.85 & 5.0659 & TRN \\
\hline CHEMBL 1607660 & 688422 & 4.85 & 5.3427 & TRN \\
\hline CHEMBL1336187 & 688422 & 4.65 & 4.8612 & TRN \\
\hline CHEMBL1411781 & 688422 & 4.45 & 5.4663 & TRN \\
\hline
\end{tabular}




\begin{tabular}{|c|c|c|c|c|c|}
\hline \multicolumn{6}{|c|}{ Supplemental Table S2.txt } \\
\hline CHEMBL1309802 & 688422 & 6.2 & 4.841 & TRN & \\
\hline CHEMBL1301200 & 688422 & 5.15 & 5.4769 & TST & \\
\hline CHEMBL1339591 & 688422 & 4.85 & 4.8159 & TST & \\
\hline CHEMBL1607463 & 688422 & 5.15 & 4.9806 & TST & \\
\hline CHEMBL1303341 & 688422 & 4.9 & 5.0548 & TRN & \\
\hline CHEMBL 3211390 & 688422 & 4.7 & 5.3014 & TRN & \\
\hline CHEMBL1530687 & 688422 & 4.7 & 5.1217 & TRN & \\
\hline CHEMBL1392426 & 688422 & 5.5 & 5.0605 & TST & \\
\hline CHEMBL1321817 & 688422 & 4.5 & 4.922 & TRN & \\
\hline CHEMBL1997098 & 688422 & 4.45 & 5.0457 & TRN & \\
\hline CHEMBL1424554 & 688422 & 4.65 & 5.4943 & TRN & \\
\hline CHEMBL3199793 & 688422 & 5.0 & 5.0639 & TRN & \\
\hline CHEMBL229907 & 688422 & 4.9 & 5.0985 & TRN & \\
\hline CHEMBL3191221 & 688422 & 4.45 & 4.9871 & TRN & \\
\hline CHEMBL1321349 & 688422 & 4.6 & 5.2506 & TRN & \\
\hline CHEMBL1547840 & 688422 & 6.5 & 5.4043 & TRN & \\
\hline CHEMBL602561 & 688422 & 4.65 & 4.8306 & TRN & \\
\hline CHEMBL1439978 & 688422 & 4.45 & 5.4736 & TRN & \\
\hline CHEMBL1517410 & 688422 & 4.9 & 5.0388 & TRN & \\
\hline CHEMBL1425217 & 688422 & 4.65 & 5.4092 & TRN & \\
\hline CHEMBL1494760 & 688422 & 4.9 & 5.12200 & 0000000001 & TRN \\
\hline CHEMBL1463626 & 688422 & 5.2 & 5.5726 & TRN & \\
\hline CHEMBL1555529 & 688422 & 4.85 & 5.5697 & TST & \\
\hline CHEMBL510533 & 688422 & 4.75 & 5.7491 & TST & \\
\hline CHEMBL1970453 & 688422 & 4.5 & 5.1679 & TRN & \\
\hline CHEMBL1448577 & 688422 & 4.75 & 5.1711 & TRN & \\
\hline CHEMBL1570210 & 688422 & 5.25 & 5.2822 & TRN & \\
\hline CHEMBL1429711 & 688422 & 4.75 & 5.1879 & TST & \\
\hline CHEMBL1530984 & 688422 & 4.95 & 4.82600 & 00000000005 & TRN \\
\hline CHEMBL1516972 & 688422 & 4.85 & 4.9357 & TRN & \\
\hline CHEMBL 3207667 & 688422 & 4.7 & 5.1196 & TRN & \\
\hline CHEMBL1525766 & 688422 & 4.75 & 4.9165 & TST & \\
\hline CHEMBL1429941 & 688422 & 4.7 & 4.9119 & TRN & \\
\hline CHEMBL1330494 & 688422 & 4.8 & 4.9507 & TRN & \\
\hline CHEMBL1304490 & 688422 & 4.9 & 5.5916 & TRN & \\
\hline CHEMBL1493226 & 688422 & 4.6 & 5.4159 & TST & \\
\hline CHEMBL1398384 & 688422 & 4.7 & 5.6981 & TST & \\
\hline CHEMBL1546524 & 688422 & 4.65 & 4.9528 & TRN & \\
\hline CHEMBL1494590 & 688422 & 5.5 & 5.1821 & TRN & \\
\hline CHEMBL1366440 & 688422 & 5.1 & 5.0399 & TRN & \\
\hline CHEMBL1385923 & 688422 & 8.4559 & 5.1724 & TRN & \\
\hline CHEMBL1607509 & 688422 & 5.7 & 5.1648 & TST & \\
\hline CHEMBL1456487 & 688422 & 4.65 & 5.3535 & TRN & \\
\hline CHEMBL1465443 & 688422 & 5.1 & 5.065 & TRN & \\
\hline CHEMBL1369413 & 688422 & 4.75 & 5.23 & TRN & \\
\hline CHEMBL1305797 & 688422 & 4.6 & 5.8114 & TRN & \\
\hline CHEMBL1518794 & 688422 & 4.65 & 5.2288 & TRN & \\
\hline CHEMBL1388831 & 688422 & 4.7 & 5.0567 & TRN & \\
\hline
\end{tabular}




\begin{tabular}{|c|c|c|c|c|}
\hline \multicolumn{5}{|c|}{ Supplemental Table S2.txt } \\
\hline CHEMBL1562458 & 688422 & 4.75 & 5.8961 & TRN \\
\hline CHEMBL1322440 & 688422 & 4.65 & 4.6711 & TRN \\
\hline CHEMBL1548847 & 688422 & 7.0 & 4.9082 & TRN \\
\hline CHEMBL1369323 & 688422 & 4.45 & 5.1199 & TRN \\
\hline CHEMBL1334195 & 688422 & 4.45 & 5.0722 & TRN \\
\hline CHEMBL1571244 & 688422 & 5.75 & 5.8398 & TST \\
\hline CHEMBL1495700 & 688422 & 7.699 & 5.9939 & TRN \\
\hline CHEMBL1487688 & 688422 & 4.85 & 5.1271 & TRN \\
\hline CHEMBL1365652 & 688422 & 5.0 & 5.1928 & TRN \\
\hline CHEMBL1606106 & 688422 & 4.45 & 5.2014 & TRN \\
\hline CHEMBL1363389 & 688422 & 6.6499 & 5.8413 & TST \\
\hline CHEMBL1510550 & 688422 & 4.9 & 5.1537 & TST \\
\hline CHEMBL1312180 & 688422 & 4.8 & 5.0893 & TST \\
\hline CHEMBL1519987 & 688422 & 4.6 & 5.2465 & TST \\
\hline CHEMBL1345246 & 688422 & 7.6003 & 5.32 & TRN \\
\hline CHEMBL1376923 & 688422 & 5.5 & 5.3274 & TRN \\
\hline CHEMBL1598765 & 688422 & 5.5 & 5.772 & TRN \\
\hline CHEMBL1507781 & 688422 & 4.95 & 5.2517 & TST \\
\hline CHEMBL1593365 & 688422 & 4.9 & 5.3375 & TRN \\
\hline CHEMBL1315818 & 688422 & 5.5 & 5.1537 & TRN \\
\hline CHEMBL1484494 & 688422 & 5.2 & 5.3062 & TRN \\
\hline CHEMBL1442652 & 688422 & 5.6 & 5.355 & TRN \\
\hline CHEMBL1393069 & 688422 & 4.9 & 5.0712 & TRN \\
\hline CHEMBL1430356 & 688422 & 4.95 & 4.6957 & TRN \\
\hline CHEMBL1308819 & 688422 & 6.45 & 5.4096 & TRN \\
\hline CHEMBL1435472 & 688422 & 6.3 & 5.0033 & TRN \\
\hline CHEMBL192566 & 688422 & 7.3002 & 5.8755 & TST \\
\hline CHEMBL1455993 & 688422 & 5.45 & 5.2716 & TRN \\
\hline CHEMBL1303092 & 688422 & 4.8 & 5.388 & TST \\
\hline CHEMBL 227744 & 688422 & 9.0458 & 6.0643 & TST \\
\hline CHEMBL1353551 & 688422 & 5.2 & 4.6716 & TRN \\
\hline CHEMBL1342867 & 688422 & 4.7 & 5.5638 & TRN \\
\hline CHEMBL1418209 & 688422 & 4.9 & 4.7274 & TRN \\
\hline CHEMBL1301589 & 688422 & 4.75 & 5.147 & TRN \\
\hline CHEMBL1322066 & 688422 & 4.95 & 5.665 & TST \\
\hline CHEMBL1419240 & 688422 & 6.8 & 5.5658 & TRN \\
\hline CHEMBL1531574 & 688422 & 4.5 & 4.9928 & TRN \\
\hline CHEMBL1329528 & 688422 & 5.3 & 4.9534 & TRN \\
\hline CHEMBL1440815 & 688422 & 4.85 & 5.2339 & TRN \\
\hline CHEMBL1456066 & 688422 & 4.45 & 5.4182 & TRN \\
\hline CHEMBL1354782 & 688422 & 4.9 & 5.3388 & TRN \\
\hline CHEMBL1346472 & 688422 & 7.4001 & 5.2297 & TRN \\
\hline CHEMBL1452020 & 688422 & 4.45 & 5.2826 & TRN \\
\hline CHEMBL1428739 & 688422 & 4.45 & 5.2609 & TRN \\
\hline CHEMBL1395643 & 688422 & 8.1024 & 5.6989 & TRN \\
\hline CHEMBL1538550 & 688422 & 4.65 & 5.2541 & TST \\
\hline CHEMBL1480193 & 688422 & 5.15 & 5.24 & TST \\
\hline CHEMBL1586606 & 688422 & 6.5 & 5.6191 & TRN \\
\hline
\end{tabular}




\begin{tabular}{|c|c|c|c|c|c|}
\hline \multicolumn{6}{|c|}{ Supplemental Table S2.txt } \\
\hline CHEMBL1335684 & 688422 & 5.0 & 5.2348 & TRN & \\
\hline CHEMBL1436151 & 688422 & 8.3468 & 5.7363 & TST & \\
\hline CHEMBL1348483 & 688422 & 4.85 & 4.8065 & TRN & \\
\hline CHEMBL536166 & 688422 & 5.85 & 5.1664 & TRN & \\
\hline CHEMBL1419887 & 688422 & 4.45 & 4.8425 & TRN & \\
\hline CHEMBL1526659 & 688422 & 4.5 & 5.1099 & TRN & \\
\hline CHEMBL1323698 & 688422 & 7.6498 & 5.0119 & TST & \\
\hline CHEMBL1494713 & 688422 & 4.85 & 4.7209 & TRN & \\
\hline CHEMBL1474989 & 688422 & 4.45 & 4.7325 & TRN & \\
\hline CHEMBL1355501 & 688422 & 6.4 & 6.3053 & TST & \\
\hline CHEMBL1386065 & 688422 & 5.6 & 5.1486 & TRN & \\
\hline CHEMBL1525234 & 688422 & 4.95 & 5.4567 & TRN & \\
\hline CHEMBL1364056 & 688422 & 5.0 & 4.8504 & TRN & \\
\hline CHEMBL1305304 & 688422 & 4.95 & 5.2698 & TRN & \\
\hline CHEMBL1313250 & 688422 & 4.5 & 4.7132 & TRN & \\
\hline CHEMBL1461732 & 688422 & 4.95 & 5.072 & TRN & \\
\hline CHEMBL1543260 & 688422 & 4.45 & 5.2486 & TRN & \\
\hline CHEMBL16098 & 688422 & 4.85 & 5.4549 & TRN & \\
\hline CHEMBL1460138 & 688422 & 5.85 & 5.5062 & TRN & \\
\hline CHEMBL1358363 & 688422 & 5.25 & 5.2705 & TRN & \\
\hline CHEMBL1553068 & 688422 & 4.95 & 5.0675 & TRN & \\
\hline CHEMBL1609329 & 688422 & 5.75 & 5.312 & TRN & \\
\hline CHEMBL1386843 & 688422 & 5.1 & 5.0902 & TRN & \\
\hline CHEMBL1601556 & 688422 & 4.95 & 4.9095 & TST & \\
\hline CHEMBL1501760 & 688422 & 4.45 & 5.4208 & TST & \\
\hline CHEMBL1472211 & 688422 & 4.5 & 5.7063 & TRN & \\
\hline CHEMBL1436714 & 688422 & 5.2 & 5.3877 & TRN & \\
\hline CHEMBL1987516 & 688422 & 4.5 & 5.1333 & TST & \\
\hline CHEMBL1408515 & 688422 & 7.3497 & 5.2905 & TRN & \\
\hline CHEMBL1453388 & 688422 & 4.55 & 5.2831 & TRN & \\
\hline CHEMBL1432585 & 688422 & 5.05 & 4.98600 & 0000000001 & TRN \\
\hline CHEMBL1485171 & 688422 & 7.6498 & 5.5932 & TRN & \\
\hline CHEMBL1471602 & 688422 & 4.45 & 5.0566 & TST & \\
\hline CHEMBL3191884 & 688422 & 4.45 & 4.7448 & TRN & \\
\hline CHEMBL1411229 & 688422 & 5.5 & 4.878 & TST & \\
\hline CHEMBL1300069 & 688422 & 5.2 & 4.875 & TRN & \\
\hline CHEMBL1543852 & 688422 & 4.85 & 5.2803 & TRN & \\
\hline CHEMBL1568124 & 688422 & 4.45 & 4.864 & TRN & \\
\hline CHEMBL3195009 & 688422 & 4.8 & 4.8497 & TRN & \\
\hline CHEMBL1477327 & 688422 & 4.45 & 5.6583 & TST & \\
\hline CHEMBL1405224 & 688422 & 7.699 & 5.528 & TRN & \\
\hline CHEMBL567422 & 688422 & 5.05 & 5.8248 & TST & \\
\hline CHEMBL1310115 & 688422 & 4.65 & 5.4651 & TST & \\
\hline CHEMBL1401145 & 688422 & 4.45 & 5.2975 & TRN & \\
\hline CHEMBL1513239 & 688422 & 5.8 & 5.1371 & TRN & \\
\hline CHEMBL1363043 & 688422 & 5.85 & 5.6815 & TRN & \\
\hline CHEMBL1567246 & 688422 & 4.95 & 5.2282 & TST & \\
\hline CHEMBL1447309 & 688422 & 4.6 & 4.7565 & TST & \\
\hline
\end{tabular}




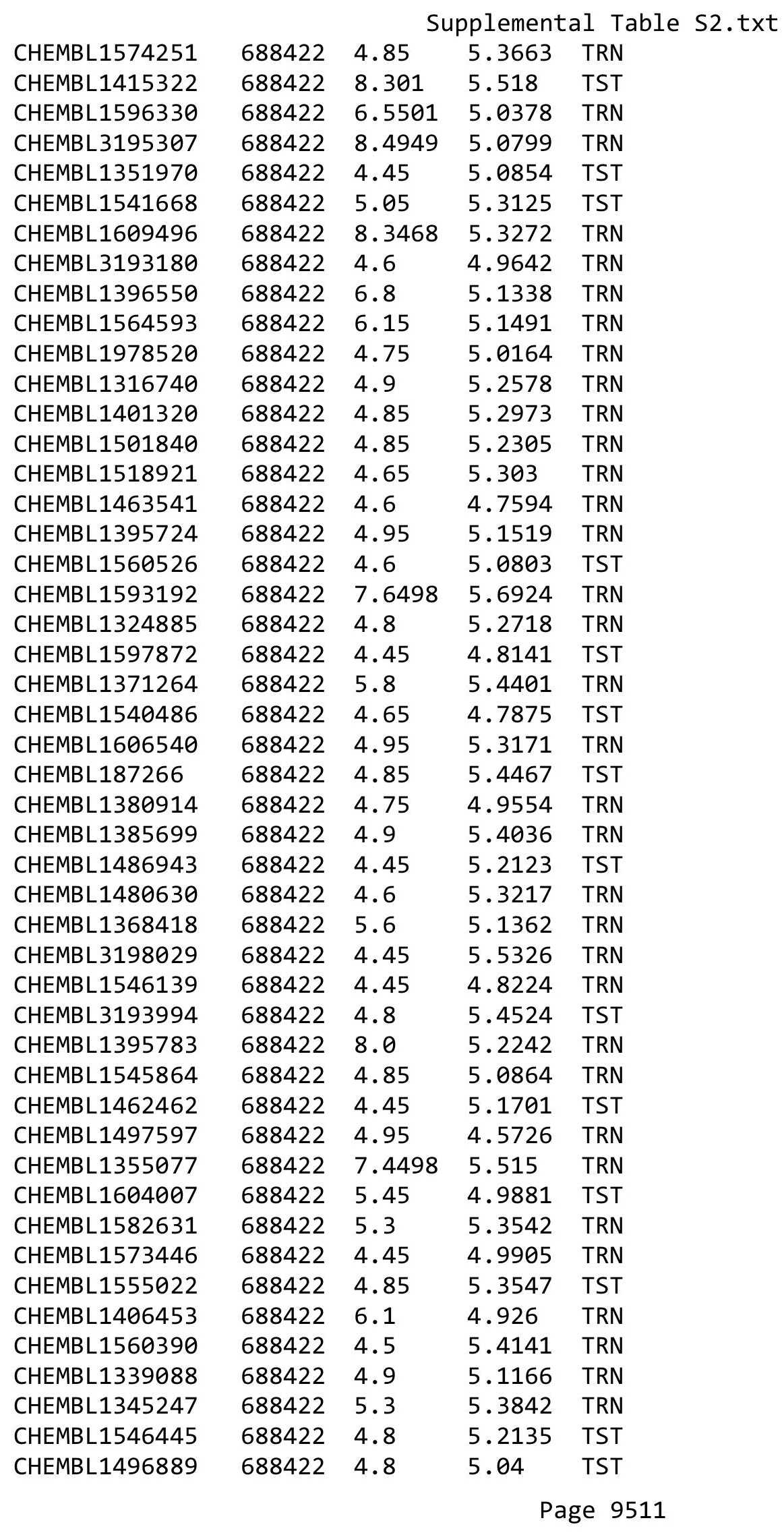




\begin{tabular}{|c|c|c|c|c|}
\hline \multicolumn{5}{|c|}{ Supplemental Table S2.txt } \\
\hline CHEMBL1577143 & 688422 & 4.9 & 5.3712 & TRN \\
\hline CHEMBL1435351 & 688422 & 5.65 & 5.2322 & TRN \\
\hline CHEMBL1470412 & 688422 & 4.85 & 5.1933 & TRN \\
\hline CHEMBL1389331 & 688422 & 7.9508 & 5.4403 & TST \\
\hline CHEMBL1372294 & 688422 & 4.45 & 5.1305 & TRN \\
\hline CHEMBL1538540 & 688422 & 5.1 & 5.1939 & TRN \\
\hline CHEMBL1441227 & 688422 & 4.85 & 5.4525 & TRN \\
\hline CHEMBL1444982 & 688422 & 5.2 & 5.0416 & TRN \\
\hline CHEMBL1403510 & 688422 & 7.0 & 5.8143 & TRN \\
\hline CHEMBL1348716 & 688422 & 5.65 & 5.1956 & TRN \\
\hline CHEMBL1517838 & 688422 & 4.7 & 5.0102 & TRN \\
\hline CHEMBL1353886 & 688422 & 4.7 & 4.8815 & TRN \\
\hline CHEMBL1501728 & 688422 & 5.15 & 5.0456 & TRN \\
\hline CHEMBL1500500 & 688422 & 4.5 & 5.0236 & TRN \\
\hline CHEMBL1561175 & 688422 & 7.2503 & 5.2178 & TRN \\
\hline CHEMBL1380911 & 688422 & 4.85 & 5.0569 & TRN \\
\hline CHEMBL1456289 & 688422 & 8.3468 & 5.0941 & TST \\
\hline CHEMBL1563381 & 688422 & 4.85 & 5.1826 & TRN \\
\hline CHEMBL1475174 & 688422 & 4.6 & 5.0334 & TRN \\
\hline CHEMBL1461283 & 688422 & 5.1 & 4.9735 & TRN \\
\hline CHEMBL1317460 & 688422 & 5.35 & 4.9858 & TRN \\
\hline CHEMBL1405283 & 688422 & 4.9 & 5.2876 & TRN \\
\hline CHEMBL1361715 & 688422 & 5.3 & 5.4383 & TRN \\
\hline CHEMBL1517559 & 688422 & 5.05 & 5.169 & TRN \\
\hline CHEMBL1535396 & 688422 & 5.25 & 5.5825 & TRN \\
\hline CHEMBL1399196 & 688422 & 5.3 & 5.2903 & TRN \\
\hline CHEMBL1442046 & 688422 & 5.9 & 5.2043 & TRN \\
\hline CHEMBL1406619 & 688422 & 4.8 & 5.5072 & TRN \\
\hline CHEMBL3193959 & 688422 & 6.15 & 4.8807 & TRN \\
\hline CHEMBL1338334 & 688422 & 4.45 & 5.3506 & TRN \\
\hline CHEMBL1425242 & 688422 & 7.3497 & 5.3803 & TRN \\
\hline CHEMBL1579152 & 688422 & 4.7 & 4.7146 & TRN \\
\hline CHEMBL1560183 & 688422 & 8.1487 & 4.9245 & TRN \\
\hline CHEMBL1546401 & 688422 & 6.3 & 5.6738 & TRN \\
\hline CHEMBL1549493 & 688422 & 4.7 & 5.2438 & TRN \\
\hline CHEMBL1358597 & 688422 & 5.0 & 4.8607 & TST \\
\hline CHEMBL3191757 & 688422 & 5.0 & 4.9644 & TRN \\
\hline CHEMBL3211926 & 688422 & 4.9 & 5.2146 & TST \\
\hline CHEMBL1389142 & 688422 & 4.95 & 5.13899 & 9999999999 \\
\hline CHEMBL1532679 & 688422 & 4.45 & 4.4943 & TRN \\
\hline CHEMBL1613207 & 688422 & 4.9 & 5.2762 & TRN \\
\hline CHEMBL1467750 & 688422 & 4.45 & 5.3288 & TST \\
\hline CHEMBL1507539 & 688422 & 4.95 & 5.2848 & TST \\
\hline CHEMBL1390565 & 688422 & 4.45 & 5.3174 & TRN \\
\hline CHEMBL1523075 & 688422 & 4.9 & 5.5481 & TST \\
\hline CHEMBL1973265 & 688422 & 4.45 & 5.4329 & TST \\
\hline CHEMBL1498407 & 688422 & 4.9 & 5.149 & TRN \\
\hline CHEMBL1596463 & 688422 & 5.0 & 5.3075 & TRN \\
\hline
\end{tabular}




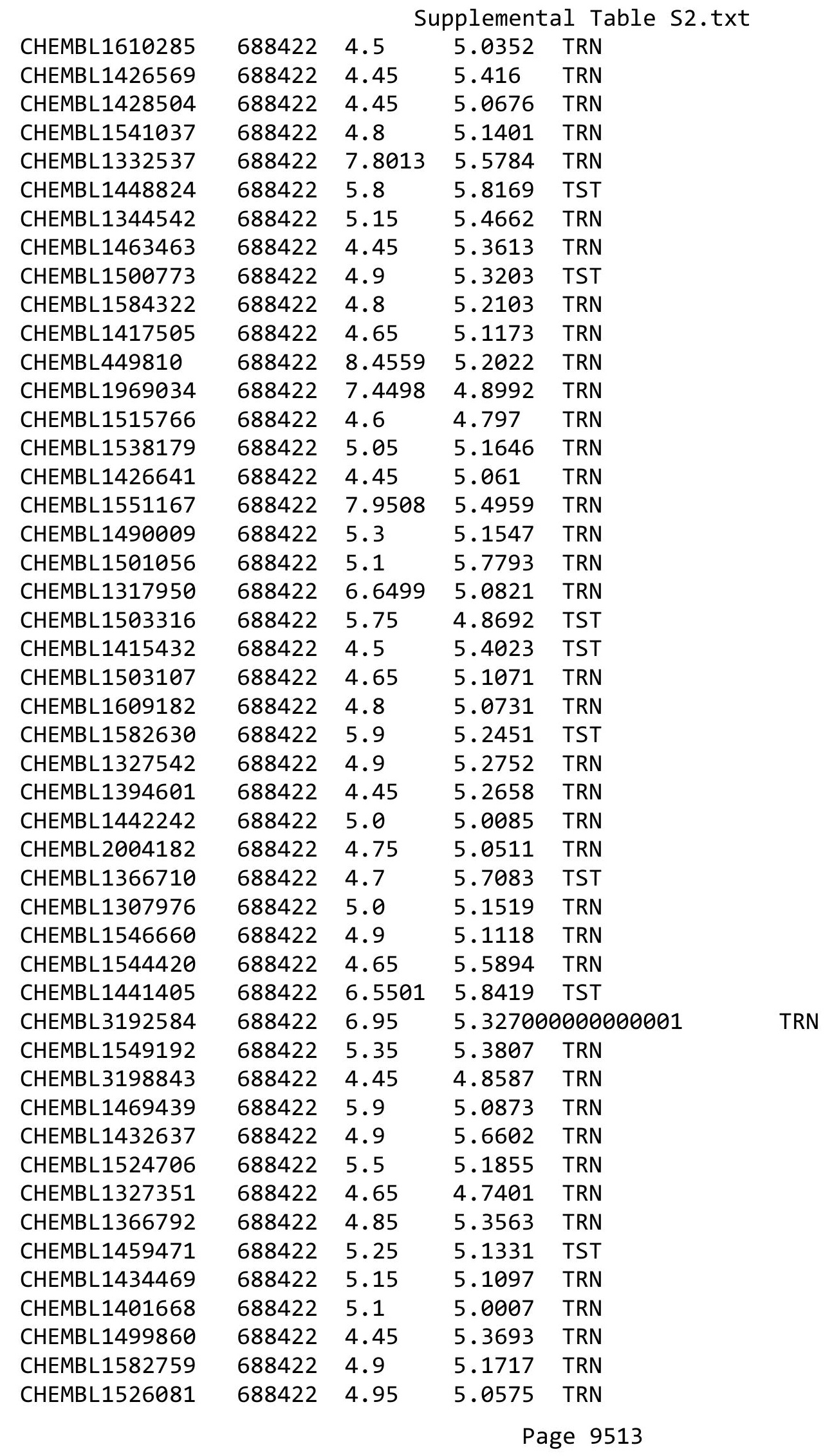




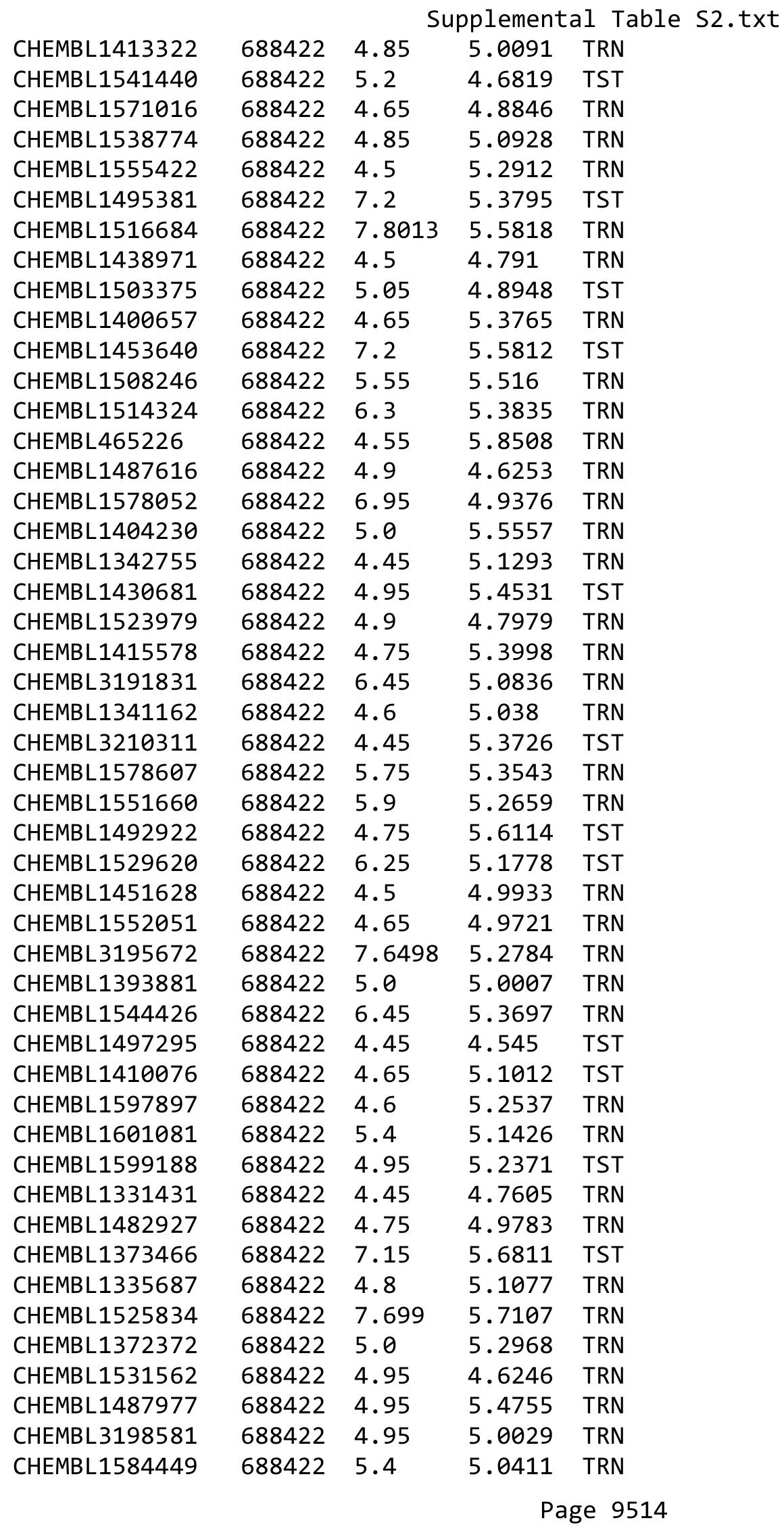




\begin{tabular}{|c|c|c|c|c|c|}
\hline \multicolumn{6}{|c|}{ Supplemental Table s2.txt } \\
\hline CHEMBL350343 & 688422 & 6.5 & 5.6273 & TST & \\
\hline CHEMBL1598764 & 688422 & 4.8 & 5.0241 & TST & \\
\hline CHEMBL1595851 & 688422 & 5.25 & 5.1699 & TRN & \\
\hline CHEMBL1500265 & 688422 & 4.8 & 5.0969 & TRN & \\
\hline CHEMBL1401086 & 688422 & 4.65 & 5.5509 & TRN & \\
\hline CHEMBL1562316 & 688422 & 5.65 & \multicolumn{2}{|c|}{5.462999999999999} & TST \\
\hline CHEMBL1412538 & 688422 & 5.15 & 4.7857 & TRN & \\
\hline CHEMBL1364458 & 688422 & 7.699 & 5.1529 & TST & \\
\hline CHEMBL1162436 & 688422 & 5.1 & 5.0663 & TRN & \\
\hline CHEMBL1447350 & 688422 & 6.05 & 5.3717 & TRN & \\
\hline CHEMBL1511004 & 688422 & 4.85 & 4.8731 & TRN & \\
\hline CHEMBL1567444 & 688422 & 4.45 & 4.6005 & TRN & \\
\hline CHEMBL1591193 & 688422 & 7.6498 & 5.0436 & TRN & \\
\hline CHEMBL1606513 & 688422 & 5.1 & 5.2784 & TRN & \\
\hline CHEMBL1541000 & 688422 & 4.45 & 5.2639 & TRN & \\
\hline CHEMBL 2001631 & 688422 & 4.45 & 5.2534 & TRN & \\
\hline CHEMBL1457994 & 688422 & 4.95 & 5.0777 & TRN & \\
\hline CHEMBL1546737 & 688422 & 4.9 & 4.9607 & TRN & \\
\hline CHEMBL3191235 & 688422 & 5.35 & 5.255 & TRN & \\
\hline CHEMBL1394406 & 688422 & 5.05 & 5.8548 & TRN & \\
\hline CHEMBL1438270 & 688422 & 4.7 & 5.2215 & TRN & \\
\hline CHEMBL1603921 & 688422 & 4.95 & 4.9723 & TRN & \\
\hline CHEMBL1539489 & 688422 & 4.45 & 5.2088 & TRN & \\
\hline CHEMBL1517222 & 688422 & 7.5003 & 5.7838 & TST & \\
\hline CHEMBL1511100 & 688422 & 5.25 & 4.7738 & TST & \\
\hline CHEMBL1434347 & 688422 & 4.95 & 5.471 & TRN & \\
\hline CHEMBL1539981 & 688422 & 4.95 & 5.2737 & TST & \\
\hline CHEMBL1515218 & 688422 & 4.95 & 5.1256 & TRN & \\
\hline CHEMBL1313141 & 688422 & 4.6 & 4.7791 & TST & \\
\hline CHEMBL1348780 & 688422 & 5.3 & 4.8838 & TRN & \\
\hline CHEMBL1509338 & 688422 & 4.95 & 5.3454 & TRN & \\
\hline CHEMBL1456775 & 688422 & 4.85 & 5.2998 & TRN & \\
\hline CHEMBL1340835 & 688422 & 5.35 & 5.4197 & TRN & \\
\hline CHEMBL1356335 & 688422 & 8.4949 & 5.16100 & 00000000005 & TRN \\
\hline CHEMBL1527501 & 688422 & 4.45 & 5.1278 & TRN & \\
\hline CHEMBL3194819 & 688422 & 4.65 & 5.0889 & TRN & \\
\hline CHEMBL1425237 & 688422 & 4.45 & 5.1069 & TRN & \\
\hline CHEMBL1533245 & 688422 & 4.6 & 5.3459 & TRN & \\
\hline CHEMBL1581596 & 688422 & 4.75 & 4.9231 & TRN & \\
\hline CHEMBL1571186 & 688422 & 4.85 & 5.0918 & TRN & \\
\hline CHEMBL1372147 & 688422 & 5.75 & 5.3075 & TST & \\
\hline CHEMBL1466016 & 688422 & 4.45 & 4.9585 & TRN & \\
\hline CHEMBL1594076 & 688422 & 4.85 & 4.6572 & TRN & \\
\hline CHEMBL 2002776 & 688422 & 5.95 & 5.4818 & TRN & \\
\hline CHEMBL1530523 & 688422 & 6.4 & 5.2203 & TRN & \\
\hline CHEMBL1440892 & 688422 & 5.6 & 5.1745 & TRN & \\
\hline CHEMBL1461335 & 688422 & 5.05 & 5.0588 & TRN & \\
\hline \multirow[t]{2}{*}{ CHEMBL1350541 } & 688422 & 4.6 & 5.21299 & 9999999999 & TRN \\
\hline & & \multicolumn{4}{|c|}{ Page 9515} \\
\hline
\end{tabular}




\begin{tabular}{|c|c|c|c|c|c|}
\hline & & \multicolumn{4}{|c|}{ Supplemental Table S2.txt } \\
\hline CHEMBL1384046 & 688422 & 7.3497 & 5.6561 & TRN & \\
\hline CHEMBL1338462 & 688422 & 4.9 & 5.2766 & TST & \\
\hline CHEMBL1398064 & 688422 & 5.5 & 5.1862 & TRN & \\
\hline CHEMBL1344824 & 688422 & 7.3497 & 5.3635 & TRN & \\
\hline CHEMBL 3197280 & 688422 & 5.9 & 5.0877 & TRN & \\
\hline CHEMBL1346809 & 688422 & 8.0506 & 5.2607 & TRN & \\
\hline CHEMBL3196696 & 688422 & 4.45 & 5.0424 & TRN & \\
\hline CHEMBL1603276 & 688422 & 4.7 & 5.3668 & TRN & \\
\hline CHEMBL1408643 & 688422 & 4.8 & 4.9682 & TRN & \\
\hline CHEMBL1368940 & 688422 & 4.65 & 4.8676 & TRN & \\
\hline CHEMBL1463659 & 688422 & 5.35 & 5.5511 & TRN & \\
\hline CHEMBL1598968 & 688422 & 4.9 & 4.8185 & TST & \\
\hline CHEMBL1469523 & 688422 & 5.35 & 5.6959 & TRN & \\
\hline CHEMBL1507749 & 688422 & 4.95 & 5.2905 & TRN & \\
\hline CHEMBL1522516 & 688422 & 4.75 & 4.9155 & TRN & \\
\hline CHEMBL1564867 & 688422 & 4.5 & 5.01699 & 99999999995 & TST \\
\hline CHEMBL1498979 & 688422 & 4.9 & 4.8281 & TRN & \\
\hline CHEMBL1970160 & 688422 & 4.85 & 5.2432 & TRN & \\
\hline CHEMBL1531070 & 688422 & 4.55 & 4.7422 & TST & \\
\hline CHEMBL1446365 & 688422 & 4.7 & 5.4833 & TRN & \\
\hline CHEMBL1494985 & 688422 & 4.6 & 5.3952 & TRN & \\
\hline CHEMBL1546814 & 688422 & 4.9 & 5.1971 & TRN & \\
\hline CHEMBL1337676 & 688422 & 7.3497 & 5.1861 & TRN & \\
\hline CHEMBL1387664 & 688422 & 4.45 & 5.1703 & TRN & \\
\hline CHEMBL1362935 & 688422 & 4.85 & 5.8846 & TST & \\
\hline CHEMBL1611005 & 688422 & 4.45 & 5.1031 & TRN & \\
\hline CHEMBL1404792 & 688422 & 5.0 & 5.4627 & TRN & \\
\hline CHEMBL1526954 & 688422 & 4.45 & 5.8309 & TRN & \\
\hline CHEMBL1403112 & 688422 & 4.6 & 5.4963 & TRN & \\
\hline CHEMBL1993708 & 688422 & 4.85 & 5.3292 & TRN & \\
\hline CHEMBL1550685 & 688422 & 4.95 & 5.0582 & TRN & \\
\hline CHEMBL1498956 & 688422 & 4.9 & 5.1887 & TRN & \\
\hline CHEMBL1308842 & 688422 & 4.75 & 5.385 & TRN & \\
\hline CHEMBL1348210 & 688422 & 6.5 & 5.3988 & TST & \\
\hline CHEMBL1542314 & 688422 & 4.8 & 5.68 & TST & \\
\hline CHEMBL1343555 & 688422 & 4.9 & 5.4009 & TRN & \\
\hline CHEMBL1335645 & 688422 & 4.9 & 5.4302 & TST & \\
\hline CHEMBL1445818 & 688422 & 8.4949 & 5.8438 & TRN & \\
\hline CHEMBL1533645 & 688422 & 4.85 & 5.1507 & TRN & \\
\hline CHEMBL3197735 & 688422 & 4.95 & 5.5883 & TRN & \\
\hline CHEMBL1373054 & 688422 & 4.95 & 5.4373 & TRN & \\
\hline CHEMBL1413484 & 688422 & 4.95 & 5.2622 & TST & \\
\hline CHEMBL1563440 & 688422 & 4.45 & 5.1659 & TRN & \\
\hline CHEMBL1398092 & 688422 & 5.25 & 5.5335 & TRN & \\
\hline CHEMBL1511893 & 688422 & 4.45 & 4.7934 & TRN & \\
\hline CHEMBL1386978 & 688422 & 4.65 & 5.4134 & TRN & \\
\hline CHEMBL1557248 & 688422 & 6.7001 & 5.341 & TRN & \\
\hline CHEMBL1369604 & 688422 & 6.45 & 5.1535 & TRN & \\
\hline
\end{tabular}




\begin{tabular}{|c|c|c|c|c|}
\hline \multicolumn{5}{|c|}{ Supplemental Table S2.txt } \\
\hline CHEMBL1348189 & 688422 & 6.3 & 5.8289 & TST \\
\hline CHEMBL1348277 & 688422 & 4.85 & 5.4602 & TRN \\
\hline CHEMBL489737 & 688422 & 4.75 & 5.082 & TRN \\
\hline CHEMBL2003521 & 688422 & 5.3 & 5.0125 & TRN \\
\hline CHEMBL1338747 & 688422 & 5.05 & 5.4921 & TST \\
\hline CHEMBL1366676 & 688422 & 6.2 & 5.5163 & TRN \\
\hline CHEMBL1480535 & 688422 & 7.9508 & 5.4187 & TRN \\
\hline CHEMBL1439395 & 688422 & 4.7 & 5.233 & TST \\
\hline CHEMBL1321756 & 688422 & 4.5 & 5.0948 & TRN \\
\hline CHEMBL1532898 & 688422 & 4.5 & 4.7908 & TRN \\
\hline CHEMBL1306024 & 688422 & 4.95 & 5.0772 & TRN \\
\hline CHEMBL1526042 & 688422 & 4.65 & 5.2563 & TRN \\
\hline CHEMBL1302820 & 688422 & 4.45 & 5.7304 & TST \\
\hline CHEMBL1605776 & 688422 & 4.5 & 5.1706 & TRN \\
\hline CHEMBL1500974 & 688422 & 4.9 & 5.0939 & TRN \\
\hline CHEMBL1482155 & 688422 & 4.65 & 4.8742 & TRN \\
\hline CHEMBL1457939 & 688422 & 4.45 & 5.1863 & TRN \\
\hline CHEMBL1355955 & 688422 & 6.7001 & 5.2196 & TST \\
\hline CHEMBL1327932 & 688422 & 4.75 & 5.3777 & TRN \\
\hline CHEMBL1442605 & 688422 & 4.8 & 5.2894 & TST \\
\hline CHEMBL1560373 & 688422 & 5.4 & 5.0916 & TRN \\
\hline CHEMBL1429005 & 688422 & 6.2 & 5.4431 & TRN \\
\hline CHEMBL1594182 & 688422 & 4.9 & 5.0255 & TRN \\
\hline CHEMBL1327628 & 688422 & 4.45 & 4.981 & TRN \\
\hline CHEMBL1346187 & 688422 & 4.6 & 4.823 & TRN \\
\hline CHEMBL3190504 & 688422 & 5.7 & 5.3472 & TRN \\
\hline CHEMBL1544579 & 688422 & 5.35 & 5.1809 & TRN \\
\hline CHEMBL1550254 & 688422 & 4.45 & 5.45 & TRN \\
\hline CHEMBL1444128 & 688422 & 4.45 & 4.8658 & TRN \\
\hline CHEMBL1405953 & 688422 & 4.85 & 5.4697 & TST \\
\hline CHEMBL1429587 & 688422 & 8.3468 & 5.7363 & TST \\
\hline CHEMBL1410969 & 688422 & 4.65 & 5.1785 & TRN \\
\hline CHEMBL1327721 & 688422 & 4.95 & 5.1379 & TRN \\
\hline CHEMBL1334202 & 688422 & 6.8 & 5.5044 & TRN \\
\hline CHEMBL1322167 & 688422 & 4.45 & 5.2999 & TST \\
\hline CHEMBL1570707 & 688422 & 6.6 & 5.2923 & TRN \\
\hline CHEMBL1482054 & 688422 & 4.85 & 5.0614 & TRN \\
\hline CHEMBL1411025 & 688422 & 4.45 & 5.5092 & TST \\
\hline CHEMBL1519066 & 688422 & 5.1 & 5.0313 & TRN \\
\hline CHEMBL1404187 & 688422 & 5.8 & 5.3739 & TRN \\
\hline CHEMBL1536942 & 688422 & 4.95 & 4.8684 & TRN \\
\hline CHEMBL1577126 & 688422 & 5.9 & 5.5316 & TRN \\
\hline CHEMBL1476319 & 688422 & 4.85 & 5.4529 & TRN \\
\hline CHEMBL1495248 & 688422 & 5.1 & 5.3278 & TRN \\
\hline CHEMBL1993788 & 688422 & 4.45 & 4.8847 & TRN \\
\hline CHEMBL1365641 & 688422 & 4.7 & 5.078 & TRN \\
\hline CHEMBL1472609 & 688422 & 4.65 & 5.0843 & TRN \\
\hline CHEMBL1597245 & 688422 & 5.75 & 5.23 & TRN \\
\hline
\end{tabular}




\begin{tabular}{|c|c|c|c|c|}
\hline \multicolumn{5}{|c|}{ Supplemental Table s2.txt } \\
\hline CHEMBL1320317 & 688422 & 4.8 & 4.9541 & TRN \\
\hline CHEMBL1396288 & 688422 & 4.95 & 5.233 & TRN \\
\hline CHEMBL1502487 & 688422 & 4.85 & 4.9264 & TRN \\
\hline CHEMBL1454457 & 688422 & 4.45 & 5.2453 & TST \\
\hline CHEMBL 3189905 & 688422 & 4.85 & 4.7208 & TST \\
\hline CHEMBL 3210306 & 688422 & 6.1 & 5.4868 & TST \\
\hline CHEMBL 3191151 & 688422 & 5.2 & 5.6507 & TRN \\
\hline CHEMBL1545727 & 688422 & 4.7 & 5.1278 & TRN \\
\hline CHEMBL1454192 & 688422 & 5.25 & 5.2966 & TRN \\
\hline CHEMBL1375643 & 688422 & 5.95 & 5.1528 & TRN \\
\hline CHEMBL1509148 & 688422 & 4.55 & 5.4467 & TRN \\
\hline CHEMBL 3198499 & 688422 & 4.95 & 4.8805 & TRN \\
\hline CHEMBL1410780 & 688422 & 8.4949 & 5.6795 & TRN \\
\hline CHEMBL1610633 & 688422 & 4.9 & 5.1156 & TRN \\
\hline CHEMBL1531975 & 688422 & 6.3 & 5.7529 & TRN \\
\hline CHEMBL1571207 & 688422 & 4.45 & 5.3835 & TRN \\
\hline CHEMBL1367223 & 688422 & 5.6 & 5.5801 & TRN \\
\hline CHEMBL1376378 & 688422 & 5.0 & 5.5108 & TST \\
\hline CHEMBL1520438 & 688422 & 4.7 & 5.1481 & TST \\
\hline CHEMBL1379739 & 688422 & 7.0 & 5.1963 & TST \\
\hline CHEMBL1583830 & 688422 & 4.85 & 5.0206 & TRN \\
\hline CHEMBL1580363 & 688422 & 8.4949 & 5.2646 & TRN \\
\hline CHEMBL1447768 & 688422 & 4.85 & 4.9121 & TRN \\
\hline CHEMBL1399283 & 688422 & 5.2 & 5.9123 & TRN \\
\hline CHEMBL 1453042 & 688422 & 4.75 & 5.1697 & TRN \\
\hline CHEMBL1420007 & 688422 & 5.2 & 4.9309 & TRN \\
\hline CHEMBL1462280 & 688422 & 4.45 & 5.0233 & TRN \\
\hline CHEMBL1599196 & 688422 & 4.45 & 5.4311 & TST \\
\hline CHEMBL1429521 & 688422 & 4.5 & 5.1345 & TRN \\
\hline CHEMBL1313480 & 688422 & 4.85 & 5.2165 & TST \\
\hline CHEMBL1533836 & 688422 & 4.95 & 4.7927 & TRN \\
\hline CHEMBL1474478 & 688422 & 4.45 & 4.7695 & TRN \\
\hline CHEMBL1319848 & 688422 & 4.5 & 4.9407 & TRN \\
\hline CHEMBL1386430 & 688422 & 5.6 & 5.1189 & TRN \\
\hline CHEMBL1401134 & 688422 & 6.45 & 5.4659 & TST \\
\hline CHEMBL1560579 & 688422 & 4.7 & 5.186 & TRN \\
\hline CHEMBL1300819 & 688422 & 5.25 & 5.3243 & TST \\
\hline CHEMBL1353767 & 688422 & 4.95 & 5.0024 & TST \\
\hline CHEMBL1351942 & 688422 & 4.5 & 5.0332 & TRN \\
\hline CHEMBL1408559 & 688422 & 4.45 & 5.2522 & TST \\
\hline CHEMBL1476110 & 688422 & 7.6003 & 5.5956 & TRN \\
\hline CHEMBL1339527 & 688422 & 5.0 & 5.8173 & TST \\
\hline CHEMBL1449326 & 688422 & 5.05 & 4.862 & TRN \\
\hline CHEMBL1305436 & 688422 & 6.05 & 4.8134 & TRN \\
\hline CHEMBL1436018 & 688422 & 4.45 & 5.5801 & TRN \\
\hline CHEMBL1319071 & 688422 & 4.45 & 5.11 & TRN \\
\hline CHEMBL1330968 & 688422 & 5.9 & 5.1587 & TST \\
\hline CHEMBL1428562 & 688422 & 4.45 & 5.0173 & TRN \\
\hline
\end{tabular}




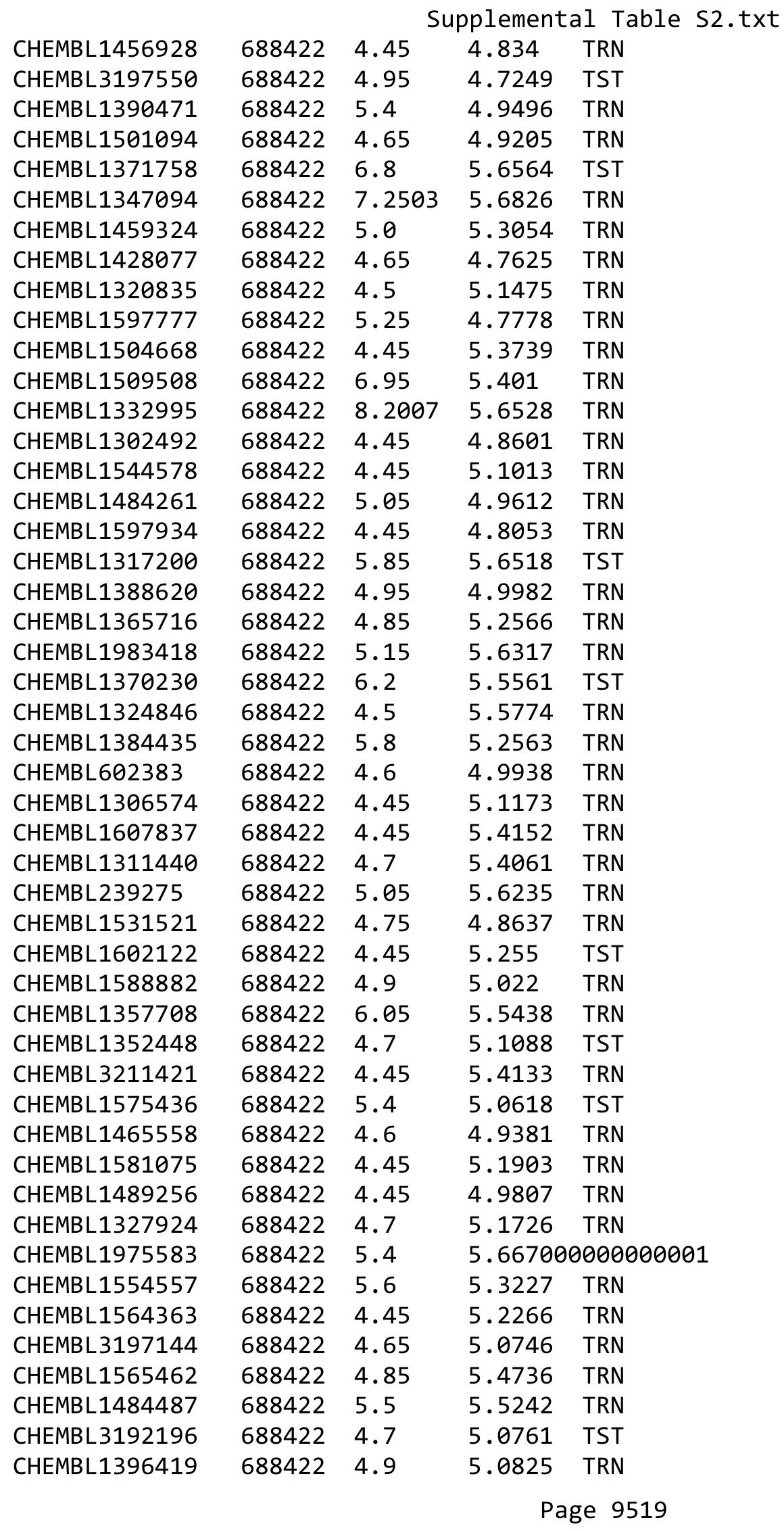




\begin{tabular}{|c|c|c|c|c|c|}
\hline \multicolumn{6}{|c|}{ Supplemental Table s2.txt } \\
\hline CHEMBL1528135 & 688422 & 4.95 & 5.4295 & TST & \\
\hline CHEMBL1471670 & 688422 & 8.3468 & 5.2144 & TST & \\
\hline CHEMBL273103 & 688422 & 4.45 & 5.1603 & TRN & \\
\hline CHEMBL1586421 & 688422 & 4.45 & 5.4123 & TRN & \\
\hline CHEMBL1405937 & 688422 & 6.05 & 5.2934 & TST & \\
\hline CHEMBL1575750 & 688422 & 4.85 & 5.1445 & TRN & \\
\hline CHEMBL1510770 & 688422 & 5.45 & 5.818 & TST & \\
\hline CHEMBL1336098 & 688422 & 4.75 & 5.2058 & TRN & \\
\hline CHEMBL1511703 & 688422 & 4.9 & 5.3491 & TRN & \\
\hline CHEMBL1479873 & 688422 & 4.45 & 4.7397 & TRN & \\
\hline CHEMBL1354675 & 688422 & 8.5528 & 5.6769 & TRN & \\
\hline CHEMBL1437355 & 688422 & 8.301 & 5.723 & TRN & \\
\hline CHEMBL3210985 & 688422 & 5.7 & 4.9623 & TRN & \\
\hline CHEMBL1399887 & 688422 & 5.05 & 5.5756 & TRN & \\
\hline CHEMBL1527364 & 688422 & 4.75 & 5.1442 & TRN & \\
\hline CHEMBL1336245 & 688422 & 4.95 & 5.0367 & TRN & \\
\hline CHEMBL3191100 & 688422 & 7.1002 & 5.4593 & TRN & \\
\hline CHEMBL1372443 & 688422 & 4.8 & 5.0935 & TRN & \\
\hline CHEMBL1362645 & 688422 & 5.5 & 5.6804 & TRN & \\
\hline CHEMBL1395417 & 688422 & 5.0 & 5.0323 & TRN & \\
\hline CHEMBL1305089 & 688422 & 5.5 & 5.4265 & TRN & \\
\hline CHEMBL1593261 & 688422 & 4.75 & 5.32799 & 9999999999 & TRN \\
\hline CHEMBL1396746 & 688422 & 6.0 & 5.2821 & TRN & \\
\hline CHEMBL1562620 & 688422 & 4.9 & 5.2397 & TST & \\
\hline CHEMBL1455013 & 688422 & 5.45 & 5.3724 & TST & \\
\hline CHEMBL1576259 & 688422 & 5.55 & 5.4355 & TRN & \\
\hline CHEMBL1489356 & 688422 & 6.05 & 4.8685 & TRN & \\
\hline CHEMBL1456911 & 688422 & 4.85 & 5.399 & TRN & \\
\hline CHEMBL1543771 & 688422 & 4.85 & 5.3343 & TRN & \\
\hline CHEMBL1542239 & 688422 & 4.95 & 5.2176 & TRN & \\
\hline CHEMBL1300808 & 688422 & 4.65 & 5.4579 & TRN & \\
\hline CHEMBL1595557 & 688422 & 5.65 & 5.6885 & TST & \\
\hline CHEMBL1241371 & 688422 & 5.25 & 5.5158 & TRN & \\
\hline CHEMBL1348462 & 688422 & 5.25 & 4.8996 & TST & \\
\hline CHEMBL1305257 & 688422 & 8.2007 & 5.3432 & TST & \\
\hline CHEMBL1606585 & 688422 & 7.7496 & 4.9557 & TRN & \\
\hline CHEMBL1561991 & 688422 & 4.6 & 4.9829 & TST & \\
\hline CHEMBL1388590 & 688422 & 5.05 & 5.4104 & TST & \\
\hline CHEMBL3197105 & 688422 & 4.9 & 5.3257 & TRN & \\
\hline CHEMBL1367863 & 688422 & 4.95 & 5.0515 & TST & \\
\hline CHEMBL3214354 & 688422 & 4.9 & 5.4799 & TRN & \\
\hline CHEMBL1380013 & 688422 & 6.8499 & 5.41799 & 9999999999 & TST \\
\hline CHEMBL3211392 & 688422 & 5.5 & 5.1805 & TST & \\
\hline CHEMBL1465338 & 688422 & 4.6 & 5.0074 & TRN & \\
\hline CHEMBL1607807 & 688422 & 5.45 & 5.5188 & TRN & \\
\hline CHEMBL1417305 & 688422 & 4.75 & 4.7107 & TRN & \\
\hline CHEMBL1568758 & 688422 & 4.75 & 5.1914 & TRN & \\
\hline CHEMBL1343219 & 688422 & 5.45 & 4.8657 & TST & \\
\hline
\end{tabular}




\begin{tabular}{|c|c|c|c|c|c|}
\hline \multicolumn{6}{|c|}{ Supplemental Table S2.txt } \\
\hline CHEMBL1496395 & 688422 & 4.8 & 4.8743 & TST & \\
\hline CHEMBL1568390 & 688422 & 4.75 & 5.3258 & TRN & \\
\hline CHEMBL1491255 & 688422 & 4.45 & 5.5811 & TST & \\
\hline CHEMBL1404118 & 688422 & 4.45 & 5.2611 & TRN & \\
\hline CHEMBL1548533 & 688422 & 4.9 & 4.7706 & TRN & \\
\hline CHEMBL1499550 & 688422 & 4.85 & 5.6561 & TRN & \\
\hline CHEMBL3197690 & 688422 & 5.7 & 5.3153 & TRN & \\
\hline CHEMBL1331760 & 688422 & 4.5 & 5.0242 & TRN & \\
\hline CHEMBL1475214 & 688422 & 4.55 & 4.7812 & TRN & \\
\hline CHEMBL3210214 & 688422 & 7.4498 & 4.9846 & TRN & \\
\hline CHEMBL1973050 & 688422 & 4.8 & 5.1426 & TRN & \\
\hline CHEMBL1421518 & 688422 & 4.45 & 5.1826 & TRN & \\
\hline CHEMBL1486527 & 688422 & 5.25 & 5.0097 & TRN & \\
\hline CHEMBL1435350 & 688422 & 4.45 & 5.6726 & TRN & \\
\hline CHEMBL1303625 & 688422 & 6.05 & 5.9673 & TRN & \\
\hline CHEMBL1392626 & 688422 & 4.75 & 5.2413 & TRN & \\
\hline CHEMBL1377648 & 688422 & 4.5 & 4.9506 & TRN & \\
\hline CHEMBL1452904 & 688422 & 7.0501 & 5.2699 & TST & \\
\hline CHEMBL1322723 & 688422 & 4.85 & 5.0098 & TRN & \\
\hline CHEMBL3213618 & 688422 & 4.9 & 5.6243 & TST & \\
\hline CHEMBL1447614 & 688422 & 4.65 & 5.1202 & TST & \\
\hline CHEMBL1423137 & 688422 & 6.0 & 5.42299 & 9999999999 & TST \\
\hline CHEMBL1440345 & 688422 & 5.15 & 5.3117 & TST & \\
\hline CHEMBL1307032 & 688422 & 4.9 & 5.3089 & TST & \\
\hline CHEMBL1413600 & 688422 & 4.45 & 5.5028 & TRN & \\
\hline CHEMBL1583950 & 688422 & 4.45 & 5.1104 & TRN & \\
\hline CHEMBL1610622 & 688422 & 4.75 & 5.5518 & TST & \\
\hline CHEMBL1446013 & 688422 & 6.1 & 5.0015 & TRN & \\
\hline CHEMBL1347385 & 688422 & 4.6 & 4.6773 & TST & \\
\hline CHEMBL1475170 & 688422 & 4.45 & 5.0178 & TRN & \\
\hline CHEMBL1578064 & 688422 & 4.9 & 4.7078 & TRN & \\
\hline CHEMBL1527432 & 688422 & 8.4949 & 5.5613 & TRN & \\
\hline CHEMBL1472635 & 688422 & 5.6 & 5.5596 & TRN & \\
\hline CHEMBL1333168 & 688422 & 5.5 & 5.3784 & TST & \\
\hline CHEMBL3211697 & 688422 & 5.5 & 5.5085 & TST & \\
\hline CHEMBL1333679 & 688422 & 4.6 & 4.93199 & 99999999995 & TRN \\
\hline CHEMBL1577139 & 688422 & 5.05 & 4.9217 & TST & \\
\hline CHEMBL1512629 & 688422 & 5.15 & 4.863 & TRN & \\
\hline CHEMBL1452499 & 688422 & 5.0 & 5.2439 & TRN & \\
\hline CHEMBL1531755 & 688422 & 4.95 & 5.4457 & TRN & \\
\hline CHEMBL1417243 & 688422 & 4.5 & 4.9264 & TRN & \\
\hline CHEMBL1334739 & 688422 & 4.7 & 5.2922 & TRN & \\
\hline CHEMBL1493222 & 688422 & 4.45 & 5.1174 & TRN & \\
\hline CHEMBL1427923 & 688422 & 6.6 & 5.5827 & TRN & \\
\hline CHEMBL1557383 & 688422 & 6.0 & 5.8051 & TRN & \\
\hline CHEMBL1442833 & 688422 & 4.65 & 5.2661 & TST & \\
\hline CHEMBL1483590 & 688422 & 8.4949 & 5.3013 & TRN & \\
\hline CHEMBL1344691 & 688422 & 7.5498 & 5.154 & TST & \\
\hline
\end{tabular}




\begin{tabular}{|c|c|c|c|c|}
\hline \multicolumn{5}{|c|}{ Supplemental Table S2.txt } \\
\hline CHEMBL1436640 & 688422 & 4.45 & 5.4891 & TRN \\
\hline CHEMBL1500380 & 688422 & 4.45 & 5.4751 & TRN \\
\hline CHEMBL1562195 & 688422 & 5.35 & 5.1253 & TRN \\
\hline CHEMBL1509364 & 688422 & 4.65 & 5.0682 & TRN \\
\hline CHEMBL1466665 & 688422 & 4.45 & 5.3945 & TST \\
\hline CHEMBL 276679 & 688422 & 6.6499 & 5.3758 & TST \\
\hline CHEMBL3192775 & 688422 & 4.45 & 5.2108 & TST \\
\hline CHEMBL1323841 & 688422 & 5.9 & 5.121 & TRN \\
\hline CHEMBL 3192558 & 688422 & 4.7 & 5.0598 & TRN \\
\hline CHEMBL1972750 & 688422 & 4.65 & 5.1471 & TRN \\
\hline CHEMBL3191069 & 688422 & 5.5 & 4.9661 & TRN \\
\hline CHEMBL1597166 & 688422 & 4.45 & 5.0205 & TST \\
\hline CHEMBL1420640 & 688422 & 7.5003 & 5.3087 & TRN \\
\hline CHEMBL1376215 & 688422 & 4.9 & 5.2885 & TRN \\
\hline CHEMBL1469680 & 688422 & 7.4498 & 4.8794 & TRN \\
\hline CHEMBL1580806 & 688422 & 7.8508 & 5.4571 & TRN \\
\hline CHEMBL1319889 & 688422 & 4.75 & 4.952 & TRN \\
\hline CHEMBL1319309 & 688422 & 4.6 & 5.305 & TST \\
\hline CHEMBL1318254 & 688422 & 6.0 & 5.7868 & TRN \\
\hline CHEMBL1511583 & 688422 & 4.5 & 5.3948 & TST \\
\hline CHEMBL1524969 & 688422 & 5.3 & 5.1085 & TST \\
\hline CHEMBL1477131 & 688422 & 4.6 & 4.8149 & TRN \\
\hline CHEMBL1463229 & 688422 & 4.5 & 5.0606 & TRN \\
\hline CHEMBL1540205 & 688422 & 4.85 & 4.7074 & TRN \\
\hline CHEMBL1583264 & 688422 & 8.4949 & 4.84 & TST \\
\hline CHEMBL1542864 & 688422 & 4.5 & 5.3866 & TRN \\
\hline CHEMBL1506857 & 688422 & 4.45 & 5.5073 & TRN \\
\hline CHEMBL1456242 & 688422 & 4.85 & 5.5435 & TRN \\
\hline CHEMBL1394359 & 688422 & 4.95 & 5.8888 & TRN \\
\hline CHEMBL1430913 & 688422 & 5.4 & 5.8259 & TST \\
\hline CHEMBL1327393 & 688422 & 4.9 & 5.3778 & TRN \\
\hline CHEMBL1443447 & 688422 & 5.0 & 5.5809 & TST \\
\hline CHEMBL1478707 & 688422 & 4.9 & 5.3591 & TRN \\
\hline CHEMBL1591337 & 688422 & 5.4 & 5.1888 & TST \\
\hline CHEMBL1587690 & 688422 & 4.75 & 5.754 & TST \\
\hline CHEMBL3194542 & 688422 & 4.5 & 5.1183 & TRN \\
\hline CHEMBL1389008 & 688422 & 5.85 & 5.3932 & TRN \\
\hline CHEMBL1544499 & 688422 & 4.5 & 4.9216 & TRN \\
\hline CHEMBL1372997 & 688422 & 8.699 & 5.8244 & TST \\
\hline CHEMBL1481249 & 688422 & 4.45 & 5.551 & TRN \\
\hline CHEMBL1549882 & 688422 & 4.55 & 4.8385 & TRN \\
\hline CHEMBL1390253 & 688422 & 4.65 & 5.1591 & TRN \\
\hline CHEMBL1558317 & 688422 & 5.55 & 5.691 & TST \\
\hline CHEMBL1363262 & 688422 & 4.45 & 5.4869 & TRN \\
\hline CHEMBL1539409 & 688422 & 5.15 & 5.1121 & TST \\
\hline CHEMBL566064 & 688422 & 5.5 & 4.9634 & TRN \\
\hline CHEMBL1602130 & 688422 & 4.45 & 4.926 & TRN \\
\hline CHEMBL3190720 & 688422 & 5.05 & 5.2031 & TRN \\
\hline
\end{tabular}




\begin{tabular}{|c|c|c|c|c|c|}
\hline \multicolumn{6}{|c|}{ Supplemental Table S2.txt } \\
\hline CHEMBL2007163 & 688422 & 4.5 & 4.9202 & TRN & \\
\hline CHEMBL1344263 & 688422 & 6.35 & 5.4367 & TST & \\
\hline CHEMBL1338887 & 688422 & 5.4 & 5.305 & TRN & \\
\hline CHEMBL1499175 & 688422 & 4.65 & 4.8699 & TST & \\
\hline CHEMBL1608077 & 688422 & 5.55 & 4.6746 & TRN & \\
\hline CHEMBL1485453 & 688422 & 7.0501 & 5.2987 & TRN & \\
\hline CHEMBL1978623 & 688422 & 4.55 & 4.8557 & TRN & \\
\hline CHEMBL1375531 & 688422 & 5.3 & 5.5517 & TRN & \\
\hline CHEMBL1597763 & 688422 & 4.8 & 5.2151 & TST & \\
\hline CHEMBL1319370 & 688422 & 5.85 & 5.5971 & TRN & \\
\hline CHEMBL1600209 & 688422 & 4.6 & 5.2403 & TRN & \\
\hline CHEMBL1382621 & 688422 & 4.9 & 5.0011 & TRN & \\
\hline CHEMBL1363103 & 688422 & 6.9 & 4.8748 & TST & \\
\hline CHEMBL1355720 & 688422 & 5.35 & 5.0554 & TRN & \\
\hline CHEMBL1301404 & 688422 & 4.85 & 5.8995 & TST & \\
\hline CHEMBL1472004 & 688422 & 4.45 & 4.8094 & TRN & \\
\hline CHEMBL1466117 & 688422 & 5.55 & 5.3886 & TST & \\
\hline CHEMBL1425067 & 688422 & 4.65 & 5.2701 & TST & \\
\hline CHEMBL1410981 & 688422 & 4.45 & 6.04700 & 2000000001 & TRN \\
\hline CHEMBL1553136 & 688422 & 5.05 & 5.1125 & TRN & \\
\hline CHEMBL1462968 & 688422 & 4.6 & 4.6914 & TRN & \\
\hline CHEMBL1523956 & 688422 & 4.45 & 5.1287 & TRN & \\
\hline CHEMBL1557696 & 688422 & 4.8 & 5.3867 & TRN & \\
\hline CHEMBL1547207 & 688422 & 4.95 & 4.8221 & TRN & \\
\hline CHEMBL1303592 & 688422 & 4.45 & 5.63299 & 9999999999 & TRN \\
\hline CHEMBL1453366 & 688422 & 8.301 & 5.5977 & TST & \\
\hline CHEMBL1596764 & 688422 & 4.85 & 4.8619 & TRN & \\
\hline CHEMBL3211007 & 688422 & 5.25 & 5.5967 & TRN & \\
\hline CHEMBL1305122 & 688422 & 4.8 & 4.8158 & TRN & \\
\hline CHEMBL3213168 & 688422 & 4.6 & 4.9245 & TRN & \\
\hline CHEMBL3199432 & 688422 & 5.3 & 5.2706 & TST & \\
\hline CHEMBL1497660 & 688422 & 6.9 & 5.4185 & TST & \\
\hline CHEMBL3194354 & 688422 & 4.7 & 4.9307 & TST & \\
\hline CHEMBL1367422 & 688422 & 4.9 & 4.8263 & TST & \\
\hline CHEMBL1578417 & 688422 & 8.0506 & 5.4566 & TRN & \\
\hline CHEMBL1428965 & 688422 & 4.6 & 5.0586 & TRN & \\
\hline CHEMBL3195803 & 688422 & 4.85 & 4.9661 & TRN & \\
\hline CHEMBL436589 & 688422 & 4.5 & 5.5436 & TST & \\
\hline CHEMBL1482585 & 688422 & 5.6 & 4.9398 & TST & \\
\hline CHEMBL1611154 & 688422 & 4.45 & 5.8254 & TRN & \\
\hline CHEMBL1429448 & 688422 & 4.8 & 4.7788 & TRN & \\
\hline CHEMBL488803 & 688422 & 5.35 & 5.061 & TST & \\
\hline CHEMBL1548266 & 688422 & 4.85 & 5.4469 & TRN & \\
\hline CHEMBL1392343 & 688422 & 5.45 & 5.3697 & TST & \\
\hline CHEMBL3194469 & 688422 & 4.75 & 5.2407 & TRN & \\
\hline CHEMBL1471775 & 688422 & 7.6498 & 5.3749 & TST & \\
\hline CHEMBL1393086 & 688422 & 5.5 & 5.66299 & 9999999999 & TRN \\
\hline CHEMBL1423361 & 688422 & 4.9 & 5.2596 & TRN & \\
\hline
\end{tabular}




\begin{tabular}{|c|c|c|c|c|c|}
\hline \multicolumn{6}{|c|}{ Supplemental Table s2.txt } \\
\hline CHEMBL1359631 & 688422 & 4.95 & 5.4757 & TRN & \\
\hline CHEMBL3209135 & 688422 & 4.45 & 5.1811 & TRN & \\
\hline CHEMBL3209282 & 688422 & 6.2 & 5.51399 & 9999999999 & TRN \\
\hline CHEMBL1359143 & 688422 & 4.9 & 4.8541 & TRN & \\
\hline CHEMBL1340934 & 688422 & 4.5 & 5.316 & TRN & \\
\hline CHEMBL1459486 & 688422 & 7.1002 & 5.5232 & TST & \\
\hline CHEMBL1443757 & 688422 & 4.9 & 5.0178 & TRN & \\
\hline CHEMBL1306280 & 688422 & 4.45 & 5.2665 & TRN & \\
\hline CHEMBL1518020 & 688422 & 4.5 & 5.1704 & TRN & \\
\hline CHEMBL1477488 & 688422 & 4.7 & 4.8324 & TRN & \\
\hline CHEMBL2374031 & 688422 & 4.9 & 5.7418 & TRN & \\
\hline CHEMBL1352063 & 688422 & 4.5 & 5.3025 & TRN & \\
\hline CHEMBL1408191 & 688422 & 4.95 & 4.9673 & TRN & \\
\hline CHEMBL1565059 & 688422 & 4.9 & 5.1198 & TST & \\
\hline CHEMBL1506419 & 688422 & 4.7 & 5.4127 & TRN & \\
\hline CHEMBL1481377 & 688422 & 4.45 & 4.7943 & TRN & \\
\hline CHEMBL1561598 & 688422 & 4.95 & 5.1968 & TST & \\
\hline CHEMBL3197486 & 688422 & 4.45 & 5.5653 & TST & \\
\hline CHEMBL1373461 & 688422 & 4.45 & 4.7653 & TRN & \\
\hline CHEMBL1565519 & 688422 & 4.6 & 5.03100 & 0000000001 & TRN \\
\hline CHEMBL1313610 & 688422 & 5.4 & 5.5343 & TRN & \\
\hline CHEMBL280065 & 688422 & 4.9 & 5.4878 & TRN & \\
\hline CHEMBL1435384 & 688422 & 4.45 & 5.2528 & TRN & \\
\hline CHEMBL1417633 & 688422 & 4.45 & 5.4284 & TST & \\
\hline CHEMBL1336887 & 688422 & 5.6 & 4.7189 & TRN & \\
\hline CHEMBL1408139 & 688422 & 6.95 & 5.2053 & TST & \\
\hline CHEMBL1422539 & 688422 & 4.5 & 5.1716 & TRN & \\
\hline CHEMBL1422255 & 688422 & 5.4 & 5.4071 & TRN & \\
\hline CHEMBL3189375 & 688422 & 8.3468 & 5.3985 & TRN & \\
\hline CHEMBL1383726 & 688422 & 6.45 & 5.1262 & TRN & \\
\hline CHEMBL1549160 & 688422 & 6.0 & 5.0247 & TRN & \\
\hline CHEMBL1552347 & 688422 & 6.5501 & 5.1376 & TRN & \\
\hline CHEMBL1606251 & 688422 & 4.45 & 5.4925 & TRN & \\
\hline CHEMBL1301584 & 688422 & 4.9 & 5.154 & TST & \\
\hline CHEMBL1352829 & 688422 & 4.7 & 5.1636 & TST & \\
\hline CHEMBL1302263 & 688422 & 4.8 & 5.3417 & TRN & \\
\hline CHEMBL68534 & 688422 & 4.65 & 5.3178 & TST & \\
\hline CHEMBL1360495 & 688422 & 6.9 & 5.0882 & TRN & \\
\hline CHEMBL1452561 & 688422 & 6.0 & 5.0598 & TRN & \\
\hline CHEMBL1469453 & 688422 & 4.45 & 5.1728 & TRN & \\
\hline CHEMBL1375240 & 688422 & 5.2 & 5.3502 & TRN & \\
\hline CHEMBL3192297 & 688422 & 4.95 & 5.5626 & TRN & \\
\hline CHEMBL1452645 & 688422 & 4.75 & 5.4753 & TST & \\
\hline CHEMBL1534101 & 688422 & 5.4 & 5.40600 & 0000000001 & TRN \\
\hline CHEMBL1589617 & 688422 & 7.0501 & 5.3184 & TRN & \\
\hline CHEMBL1422691 & 688422 & 4.5 & 4.6829 & TRN & \\
\hline CHEMBL1423702 & 688422 & 4.45 & 5.0057 & TST & \\
\hline CHEMBL1588461 & 688422 & 4.75 & 5.3939 & TRN & \\
\hline
\end{tabular}




\begin{tabular}{|c|c|c|c|c|}
\hline \multicolumn{5}{|c|}{ Supplemental Table s2.txt } \\
\hline CHEMBL1471783 & 688422 & 4.8 & 4.8409 & TRN \\
\hline CHEMBL1553114 & 688422 & 4.95 & 5.09399 & 9999999999 \\
\hline CHEMBL1542638 & 688422 & 6.7501 & 5.2537 & TST \\
\hline CHEMBL1576363 & 688422 & 5.05 & 5.1362 & TRN \\
\hline CHEMBL1590429 & 688422 & 4.8 & 4.9008 & TRN \\
\hline CHEMBL1427605 & 688422 & 4.45 & 5.0593 & TRN \\
\hline CHEMBL1460208 & 688422 & 5.4 & 5.9211 & TRN \\
\hline CHEMBL1423110 & 688422 & 7.0 & 5.3246 & TRN \\
\hline CHEMBL1389421 & 688422 & 4.5 & 4.8661 & TRN \\
\hline CHEMBL1396854 & 688422 & 6.0 & 6.273 & TST \\
\hline CHEMBL1506230 & 688422 & 4.85 & 4.9058 & TST \\
\hline CHEMBL1084301 & 688422 & 5.0 & 5.0611 & TRN \\
\hline CHEMBL1357928 & 688422 & 6.3 & 5.0396 & TRN \\
\hline CHEMBL1422337 & 688422 & 4.7 & 5.3561 & TRN \\
\hline CHEMBL1531643 & 688422 & 4.8 & 5.1361 & TRN \\
\hline CHEMBL1401101 & 688422 & 4.6 & 5.2575 & TRN \\
\hline CHEMBL1342712 & 688422 & 4.8 & 5.2601 & TRN \\
\hline CHEMBL1542091 & 688422 & 4.55 & 5.5229 & TRN \\
\hline CHEMBL1400177 & 688422 & 4.7 & 5.1002 & TRN \\
\hline CHEMBL1518828 & 688422 & 4.8 & 5.6217 & TST \\
\hline CHEMBL1428063 & 688422 & 4.95 & 4.9714 & TRN \\
\hline CHEMBL1980399 & 688422 & 5.5 & 5.4671 & TRN \\
\hline CHEMBL1465143 & 688422 & 4.8 & 5.4194 & TRN \\
\hline CHEMBL1439172 & 688422 & 4.8 & 5.7777 & TST \\
\hline CHEMBL1484059 & 688422 & 6.25 & 5.7999 & TRN \\
\hline CHEMBL1465850 & 688422 & 4.45 & 5.1275 & TST \\
\hline CHEMBL1377035 & 688422 & 4.6 & 5.0197 & TRN \\
\hline CHEMBL1425774 & 688422 & 7.5003 & 5.8151 & TRN \\
\hline CHEMBL1486369 & 688422 & 4.45 & 4.8157 & TRN \\
\hline CHEMBL1508791 & 688422 & 4.45 & 5.0653 & TRN \\
\hline CHEMBL1457264 & 688422 & 4.85 & 5.1359 & TST \\
\hline CHEMBL1864040 & 688422 & 5.55 & 4.9772 & TRN \\
\hline CHEMBL1304623 & 688422 & 6.7001 & 5.0435 & TRN \\
\hline CHEMBL472256 & 688422 & 4.45 & 5.1002 & TRN \\
\hline CHEMBL1427136 & 688422 & 4.9 & 5.2623 & TRN \\
\hline CHEMBL1454956 & 688422 & 4.45 & 4.7338 & TRN \\
\hline CHEMBL1497911 & 688422 & 4.95 & 5.0976 & TRN \\
\hline CHEMBL1586806 & 688422 & 4.6 & 4.7601 & TRN \\
\hline CHEMBL1471631 & 688422 & 4.5 & 5.3476 & TST \\
\hline CHEMBL1597335 & 688422 & 4.85 & 5.3114 & TRN \\
\hline CHEMBL1528047 & 688422 & 5.9 & 5.7496 & TRN \\
\hline CHEMBL1610885 & 688422 & 4.45 & 5.3958 & TRN \\
\hline CHEMBL1456997 & 688422 & 7.4001 & 5.0616 & TRN \\
\hline CHEMBL1457435 & 688422 & 5.15 & 5.1541 & TRN \\
\hline CHEMBL1367739 & 688422 & 7.6498 & 5.2783 & TST \\
\hline CHEMBL1452736 & 688422 & 5.2 & 5.2005 & TST \\
\hline CHEMBL1364417 & 688422 & 4.9 & 5.0693 & TRN \\
\hline CHEMBL1393312 & 688422 & 4.5 & 5.2791 & TRN \\
\hline
\end{tabular}

TRN 


\begin{tabular}{|c|c|c|c|c|c|}
\hline \multicolumn{6}{|c|}{ Supplemental Table S2.txt } \\
\hline CHEMBL1313044 & 688422 & 6.45 & 5.3848 & TRN & \\
\hline CHEMBL3192217 & 688422 & 4.45 & 4.8226 & TRN & \\
\hline CHEMBL1375894 & 688422 & 4.45 & 5.2937 & TRN & \\
\hline CHEMBL1419764 & 688422 & 5.05 & 5.0485 & TST & \\
\hline CHEMBL1490029 & 688422 & 7.6498 & 5.2149 & TRN & \\
\hline CHEMBL1322820 & 688422 & 4.8 & 4.6884 & TRN & \\
\hline CHEMBL1392982 & 688422 & 4.95 & 4.9917 & TRN & \\
\hline CHEMBL1574645 & 688422 & 6.5501 & 5.2965 & TRN & \\
\hline CHEMBL1450665 & 688422 & 4.5 & 4.9197 & TRN & \\
\hline CHEMBL1393859 & 688422 & 4.5 & 5.2088 & TRN & \\
\hline CHEMBL1479406 & 688422 & 5.1 & 5.3119 & TRN & \\
\hline CHEMBL1455963 & 688422 & 4.95 & 5.2838 & TST & \\
\hline CHEMBL1486131 & 688422 & 4.45 & 4.8941 & TRN & \\
\hline CHEMBL1508906 & 688422 & 5.9 & 5.3169 & TRN & \\
\hline CHEMBL3196716 & 688422 & 5.65 & 5.402 & TST & \\
\hline CHEMBL1478257 & 688422 & 4.45 & 4.942 & TRN & \\
\hline CHEMBL1502549 & 688422 & 6.15 & 5.1666 & TRN & \\
\hline CHEMBL1522067 & 688422 & 4.45 & 4.9206 & TRN & \\
\hline CHEMBL1580169 & 688422 & 5.5 & 5.4404 & TRN & \\
\hline CHEMBL1489380 & 688422 & 4.7 & 4.9303 & TRN & \\
\hline CHEMBL1326449 & 688422 & 4.95 & 4.7794 & TRN & \\
\hline CHEMBL1387773 & 688422 & 4.8 & 5.38200 & 0000000001 & TRN \\
\hline CHEMBL1359204 & 688422 & 4.75 & 5.3998 & TRN & \\
\hline CHEMBL3195514 & 688422 & 4.5 & 5.2094 & TRN & \\
\hline CHEMBL1544671 & 688422 & 4.85 & 5.5038 & TRN & \\
\hline CHEMBL3196697 & 688422 & 4.8 & 5.6738 & TST & \\
\hline CHEMBL3207615 & 688422 & 4.5 & 5.3474 & TST & \\
\hline CHEMBL1472880 & 688422 & 4.85 & 5.1953 & TRN & \\
\hline CHEMBL1520477 & 688422 & 4.75 & 5.3383 & TRN & \\
\hline CHEMBL1540870 & 688422 & 6.7001 & 5.525 & TRN & \\
\hline CHEMBL1543401 & 688422 & 4.85 & 5.1351 & TRN & \\
\hline CHEMBL1975809 & 688422 & 4.45 & 5.4137 & TRN & \\
\hline CHEMBL1389509 & 688422 & 5.0 & 4.9162 & TRN & \\
\hline CHEMBL1409879 & 688422 & 5.05 & 5.4303 & TST & \\
\hline CHEMBL1570616 & 688422 & 4.95 & 5.0086 & TRN & \\
\hline CHEMBL1319940 & 688422 & 6.8 & 5.3931 & TST & \\
\hline CHEMBL1524981 & 688422 & 4.85 & 4.8496 & TRN & \\
\hline CHEMBL1412669 & 688422 & 4.45 & 5.2185 & TRN & \\
\hline CHEMBL3193882 & 688422 & 5.25 & 5.2459 & TRN & \\
\hline CHEMBL1512222 & 688422 & 4.9 & 5.0578 & TRN & \\
\hline CHEMBL1553504 & 688422 & 4.9 & 4.8391 & TRN & \\
\hline CHEMBL1528655 & 688422 & 5.0 & 4.6117 & TRN & \\
\hline CHEMBL3191320 & 688422 & 4.65 & 4.7464 & TRN & \\
\hline CHEMBL1469709 & 688422 & 4.5 & 5.1564 & TRN & \\
\hline CHEMBL1492505 & 688422 & 4.95 & 4.9869 & TRN & \\
\hline CHEMBL274189 & 688422 & 6.3 & 5.3197 & TRN & \\
\hline CHEMBL1395543 & 688422 & 6.15 & 5.3542 & TRN & \\
\hline CHEMBL3190662 & 688422 & 4.45 & 5.2552 & TST & \\
\hline
\end{tabular}




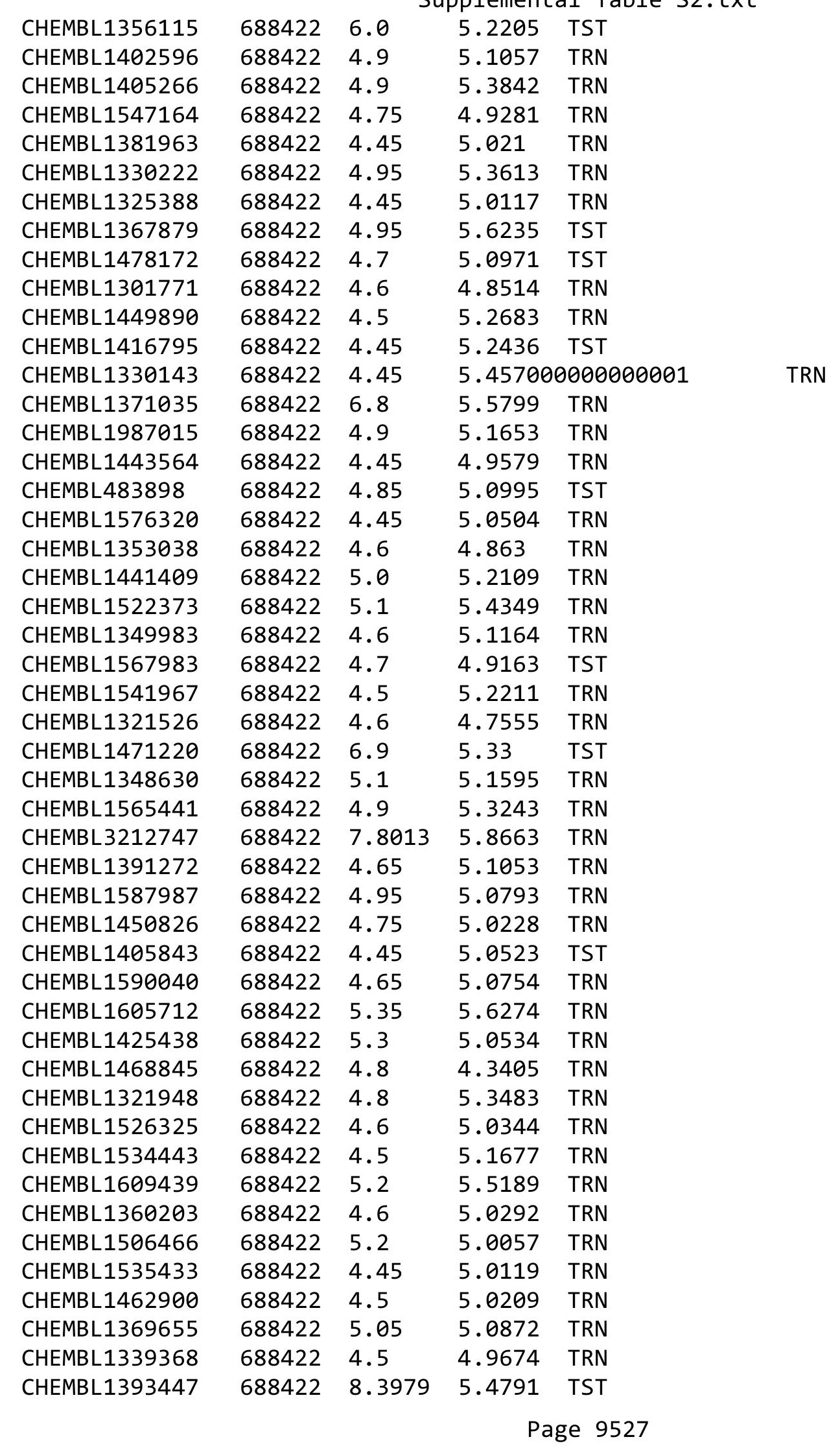




\begin{tabular}{|c|c|c|c|c|c|}
\hline \multicolumn{6}{|c|}{ Supplemental Table S2.txt } \\
\hline CHEMBL1379620 & 688422 & 4.65 & 5.1027 & TRN & \\
\hline CHEMBL468155 & 688422 & 4.45 & 5.2906 & TRN & \\
\hline CHEMBL1341688 & 688422 & 4.8 & 5.3286 & TST & \\
\hline CHEMBL3213482 & 688422 & 4.85 & 5.16100 & 00000000005 & TRN \\
\hline CHEMBL1363842 & 688422 & 6.15 & 5.5589 & TRN & \\
\hline CHEMBL1395117 & 688422 & 5.15 & 5.5075 & TRN & \\
\hline CHEMBL1463519 & 688422 & 4.85 & 5.0864 & TRN & \\
\hline CHEMBL3195336 & 688422 & 5.45 & 4.9301 & TST & \\
\hline CHEMBL1572530 & 688422 & 4.45 & 5.055 & TST & \\
\hline CHEMBL1605660 & 688422 & 5.9 & 5.3318 & TRN & \\
\hline CHEMBL1383901 & 688422 & 4.8 & 5.3769 & TST & \\
\hline CHEMBL3190303 & 688422 & 4.7 & 5.1446 & TST & \\
\hline CHEMBL1321933 & 688422 & 4.75 & 5.0466 & TST & \\
\hline CHEMBL1409901 & 688422 & 8.1024 & 5.1066 & TRN & \\
\hline CHEMBL1470712 & 688422 & 7.5003 & 5.3087 & TRN & \\
\hline CHEMBL3197578 & 688422 & 4.7 & 5.2005 & TRN & \\
\hline CHEMBL1327878 & 688422 & 4.45 & 5.2416 & TST & \\
\hline CHEMBL1520528 & 688422 & 4.45 & 4.8324 & TRN & \\
\hline CHEMBL3191602 & 688422 & 4.9 & 5.2529 & TRN & \\
\hline CHEMBL1337570 & 688422 & 4.6 & 5.3453 & TRN & \\
\hline CHEMBL1425736 & 688422 & 4.95 & 4.7173 & TRN & \\
\hline CHEMBL392680 & 688422 & 4.45 & 4.6973 & TRN & \\
\hline CHEMBL1323681 & 688422 & 7.8508 & 5.1778 & TRN & \\
\hline CHEMBL1543416 & 688422 & 4.5 & 4.8675 & TRN & \\
\hline CHEMBL1384233 & 688422 & 5.0 & 4.8569 & TRN & \\
\hline CHEMBL1337040 & 688422 & 4.45 & 5.9215 & TST & \\
\hline CHEMBL1423564 & 688422 & 5.45 & 5.5605 & TRN & \\
\hline CHEMBL1306216 & 688422 & 8.4559 & 5.7695 & TST & \\
\hline CHEMBL1532318 & 688422 & 4.45 & 5.1976 & TRN & \\
\hline CHEMBL1315771 & 688422 & 7.0 & 5.541 & TRN & \\
\hline CHEMBL1377133 & 688422 & 6.0 & 5.2969 & TRN & \\
\hline CHEMBL1390720 & 688422 & 5.05 & 5.4859 & TRN & \\
\hline CHEMBL1501853 & 688422 & 4.45 & 5.5516 & TRN & \\
\hline CHEMBL1440799 & 688422 & 4.9 & 4.8313 & TRN & \\
\hline CHEMBL1547866 & 688422 & 4.8 & 5.3312 & TRN & \\
\hline CHEMBL1607405 & 688422 & 5.2 & 5.1855 & TRN & \\
\hline CHEMBL1513722 & 688422 & 7.6003 & 5.4509 & TRN & \\
\hline CHEMBL1518878 & 688422 & 4.95 & 5.2727 & TRN & \\
\hline CHEMBL1451566 & 688422 & 4.45 & 5.3573 & TST & \\
\hline CHEMBL516952 & 688422 & 4.75 & 5.2524 & TRN & \\
\hline CHEMBL1363627 & 688422 & 6.8499 & 5.1697 & TRN & \\
\hline CHEMBL1432322 & 688422 & 4.8 & 5.5507 & TST & \\
\hline CHEMBL1321067 & 688422 & 5.0 & 5.0087 & TRN & \\
\hline CHEMBL1507750 & 688422 & 4.85 & 5.3999 & TRN & \\
\hline CHEMBL1391672 & 688422 & 4.7 & 4.8888 & TRN & \\
\hline CHEMBL3194267 & 688422 & 4.65 & 5.1143 & TRN & \\
\hline CHEMBL1537694 & 688422 & 4.8 & 5.1125 & TRN & \\
\hline CHEMBL1440781 & 688422 & 4.95 & 5.4701 & TRN & \\
\hline
\end{tabular}




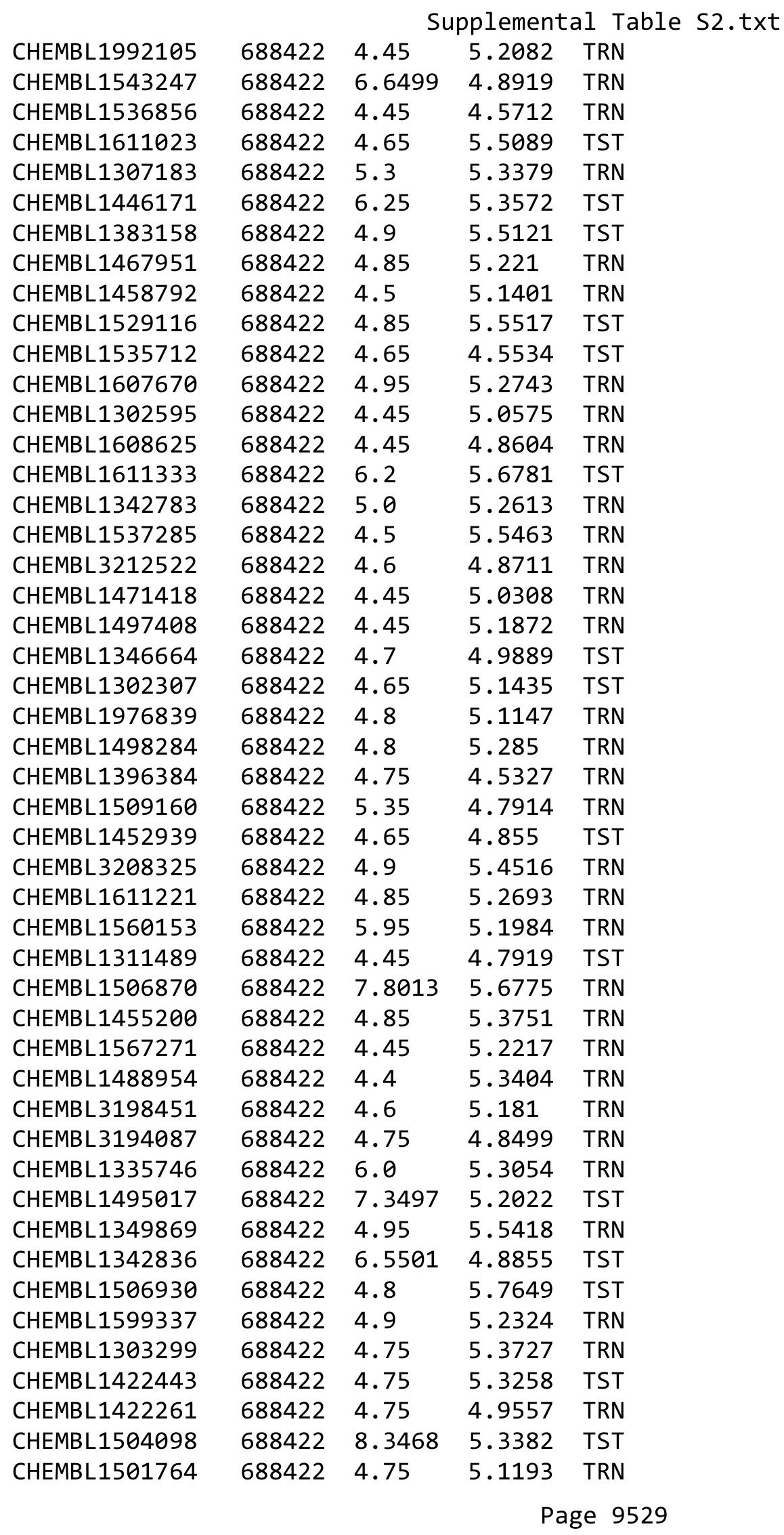




\begin{tabular}{|c|c|c|c|c|c|}
\hline \multirow[b]{2}{*}{ CHEMBL1564813 } & \multicolumn{5}{|c|}{ Supplemental Table S2.txt } \\
\hline & 688422 & 8.3468 & 4.8839 & TRN & \\
\hline CHEMBL1474432 & 688422 & 4.65 & 5.3519 & TRN & \\
\hline CHEMBL1578516 & 688422 & 6.05 & 5.8763 & TRN & \\
\hline CHEMBL1545066 & 688422 & 4.65 & 5.6597 & TRN & \\
\hline CHEMBL1381869 & 688422 & 4.5 & 5.29700 & 0000000001 & TST \\
\hline CHEMBL1333745 & 688422 & 4.9 & 5.2268 & TST & \\
\hline CHEMBL1573451 & 688422 & 4.7 & 4.8145 & TRN & \\
\hline CHEMBL1404867 & 688422 & 5.75 & 5.3031 & TRN & \\
\hline CHEMBL1497781 & 688422 & 4.65 & 4.9553 & TRN & \\
\hline CHEMBL1541520 & 688422 & 4.8 & 4.8547 & TRN & \\
\hline CHEMBL1513125 & 688422 & 4.6 & 5.3964 & TRN & \\
\hline CHEMBL1322853 & 688422 & 4.9 & 5.5733 & TRN & \\
\hline CHEMBL1545639 & 688422 & 4.95 & 5.0329 & TRN & \\
\hline CHEMBL1370002 & 688422 & 4.45 & 5.5121 & TRN & \\
\hline CHEMBL1509185 & 688422 & 4.45 & 5.5684 & TRN & \\
\hline CHEMBL3198692 & 688422 & 4.95 & 5.3026 & TRN & \\
\hline CHEMBL1589925 & 688422 & 4.95 & 4.8058 & TRN & \\
\hline CHEMBL1256813 & 688422 & 5.55 & 5.95100 & 00000000005 & TRN \\
\hline CHEMBL1418591 & 688422 & 7.15 & 5.527 & TST & \\
\hline CHEMBL1421591 & 688422 & 4.95 & 5.0767 & TRN & \\
\hline CHEMBL1403180 & 688422 & 4.75 & 4.9327 & TRN & \\
\hline CHEMBL1607736 & 688422 & 4.8 & 5.0432 & TRN & \\
\hline CHEMBL1547524 & 688422 & 8.1024 & 5.6046 & TRN & \\
\hline CHEMBL1339814 & 688422 & 4.85 & 5.4037 & TRN & \\
\hline CHEMBL1526221 & 688422 & 4.9 & 5.1721 & TRN & \\
\hline CHEMBL1563788 & 688422 & 5.25 & 5.3014 & TRN & \\
\hline CHEMBL1496879 & 688422 & 7.4001 & 5.0186 & TRN & \\
\hline CHEMBL1497129 & 688422 & 4.9 & 5.1255 & TRN & \\
\hline CHEMBL1307148 & 688422 & 5.05 & 5.2421 & TRN & \\
\hline CHEMBL1524828 & 688422 & 4.9 & 5.522 & TRN & \\
\hline CHEMBL595648 & 688422 & 6.25 & 4.8621 & TST & \\
\hline CHEMBL1502592 & 688422 & 4.5 & 4.9725 & TRN & \\
\hline CHEMBL1450858 & 688422 & 4.5 & 5.2902 & TRN & \\
\hline CHEMBL1446786 & 688422 & 5.25 & 4.965 & TRN & \\
\hline CHEMBL1508567 & 688422 & 5.1 & 5.0913 & TRN & \\
\hline CHEMBL1593661 & 688422 & 4.75 & 4.867 & TRN & \\
\hline CHEMBL1360631 & 688422 & 4.8 & 5.1152 & TRN & \\
\hline CHEMBL1334474 & 688422 & 4.5 & 4.9306 & TRN & \\
\hline CHEMBL1322656 & 688422 & 4.45 & 4.7369 & TRN & \\
\hline CHEMBL1409173 & 688422 & 5.3 & 5.4963 & TRN & \\
\hline CHEMBL1350967 & 688422 & 4.55 & 5.38899 & 9999999999 & TRN \\
\hline CHEMBL1517763 & 688422 & 4.45 & 5.2691 & TRN & \\
\hline CHEMBL1471212 & 688422 & 4.5 & 5.194 & TRN & \\
\hline CHEMBL1361626 & 688422 & 6.8 & 5.7633 & TRN & \\
\hline CHEMBL1970221 & 688422 & 4.45 & 5.1654 & TRN & \\
\hline CHEMBL1542592 & 688422 & 7.5003 & 5.0625 & TST & \\
\hline CHEMBL1880070 & 688422 & 4.9 & 5.324 & TST & \\
\hline CHEMBL1412724 & 688422 & 4.9 & 4.9492 & TRN & \\
\hline
\end{tabular}




\begin{tabular}{|c|c|c|c|c|c|}
\hline & & \multicolumn{4}{|c|}{ Supplemental Table S2.txt } \\
\hline CHEMBL1493447 & 688422 & 7.5003 & 5.513 & TRN & \\
\hline CHEMBL1482552 & 688422 & 5.0 & 5.5087 & TST & \\
\hline CHEMBL1489440 & 688422 & 4.85 & 5.0564 & TRN & \\
\hline CHEMBL1561130 & 688422 & 7.2 & 5.6826 & TST & \\
\hline CHEMBL1314706 & 688422 & 5.2 & 5.5978 & TRN & \\
\hline CHEMBL3190064 & 688422 & 4.45 & 4.9107 & TST & \\
\hline CHEMBL1373089 & 688422 & 5.9 & 5.8437 & TST & \\
\hline CHEMBL1468835 & 688422 & 4.85 & 5.4888 & TRN & \\
\hline CHEMBL1304367 & 688422 & 6.45 & 5.8026 & TRN & \\
\hline CHEMBL1493649 & 688422 & 4.8 & 4.9599 & TST & \\
\hline CHEMBL1429739 & 688422 & 4.45 & 5.0125 & TRN & \\
\hline CHEMBL1530112 & 688422 & 4.5 & 4.9596 & TRN & \\
\hline CHEMBL1440525 & 688422 & 4.85 & 5.1629 & TRN & \\
\hline CHEMBL1454148 & 688422 & 4.9 & 5.0796 & TRN & \\
\hline CHEMBL1467490 & 688422 & 4.45 & 5.0795 & TRN & \\
\hline CHEMBL1348555 & 688422 & 4.85 & 4.763999 & 9999999999 & TRN \\
\hline CHEMBL1605837 & 688422 & 8.6576 & 5.3474 & TST & \\
\hline CHEMBL3193156 & 688422 & 4.85 & 5.3763 & TST & \\
\hline CHEMBL1324670 & 688422 & 7.7496 & 5.4887 & TRN & \\
\hline CHEMBL1472108 & 688422 & 4.9 & 4.6878 & TRN & \\
\hline CHEMBL1575204 & 688422 & 4.85 & 4.9629 & TRN & \\
\hline CHEMBL1557521 & 688422 & 4.9 & 5.3415 & TRN & \\
\hline CHEMBL13791 & 688422 & 5.25 & 5.4888 & TRN & \\
\hline CHEMBL3211579 & 688422 & 5.05 & 5.193 & TRN & \\
\hline CHEMBL1595715 & 688422 & 4.95 & 5.5909 & TRN & \\
\hline CHEMBL1302392 & 688422 & 4.9 & 4.8465 & TRN & \\
\hline CHEMBL1577923 & 688422 & 4.45 & 4.8663 & TRN & \\
\hline CHEMBL1560702 & 688422 & 4.85 & 5.3464 & TST & \\
\hline CHEMBL1379240 & 688422 & 5.8 & 5.3616 & TRN & \\
\hline CHEMBL1519585 & 688422 & 4.45 & 5.3657 & TST & \\
\hline CHEMBL1313134 & 688422 & 5.2 & 5.5906 & TRN & \\
\hline CHEMBL1597376 & 688422 & 4.95 & 5.0752 & TRN & \\
\hline CHEMBL1419779 & 688422 & 5.2 & 5.447 & TRN & \\
\hline CHEMBL592363 & 688422 & 5.25 & 5.129 & TRN & \\
\hline CHEMBL1547179 & 688422 & 5.2 & 4.5774 & TRN & \\
\hline CHEMBL1569634 & 688422 & 4.55 & 5.3194 & TST & \\
\hline CHEMBL578872 & 688422 & 4.75 & 5.1009 & TST & \\
\hline CHEMBL1457419 & 688422 & 5.5 & 5.0986 & TST & \\
\hline CHEMBL3209873 & 688422 & 4.45 & 5.1532 & TST & \\
\hline CHEMBL1401771 & 688422 & 5.55 & 5.3217 & TRN & \\
\hline CHEMBL1317876 & 688422 & 4.4 & 5.5763 & TRN & \\
\hline CHEMBL1309269 & 688422 & 4.95 & 4.7432 & TRN & \\
\hline CHEMBL1562851 & 688422 & 4.45 & 4.78100 & 0000000001 & TRN \\
\hline CHEMBL1497109 & 688422 & 5.05 & 4.968 & TRN & \\
\hline CHEMBL1421290 & 688422 & 6.5501 & 5.527 & TRN & \\
\hline CHEMBL1972844 & 688422 & 5.0 & 5.1498 & TRN & \\
\hline CHEMBL1520407 & 688422 & 4.95 & 4.9337 & TRN & \\
\hline CHEMBL1395219 & 688422 & 4.6 & 4.8722 & TRN & \\
\hline
\end{tabular}




\begin{tabular}{|c|c|c|c|c|}
\hline \multicolumn{5}{|c|}{ Supplemental Table S2.txt } \\
\hline CHEMBL1541998 & 688422 & 4.45 & 5.1304 & TRN \\
\hline CHEMBL1506563 & 688422 & 4.95 & 5.6356 & TRN \\
\hline CHEMBL1508671 & 688422 & 4.45 & 4.8767 & TRN \\
\hline CHEMBL1587732 & 688422 & 4.85 & 5.2765 & TRN \\
\hline CHEMBL1968954 & 688422 & 4.75 & 5.4437 & TST \\
\hline CHEMBL1301480 & 688422 & 4.45 & 4.4844 & TRN \\
\hline CHEMBL1586274 & 688422 & 4.85 & 4.9767 & TRN \\
\hline CHEMBL1408266 & 688422 & 4.5 & 4.9814 & TST \\
\hline CHEMBL1353321 & 688422 & 6.0 & 5.6097 & TST \\
\hline CHEMBL 1578640 & 688422 & 4.85 & 5.1527 & TRN \\
\hline CHEMBL1343800 & 688422 & 4.6 & 4.8728 & TST \\
\hline CHEMBL1524034 & 688422 & 7.0501 & 5.0351 & TRN \\
\hline CHEMBL1463899 & 688422 & 6.0 & 5.6972 & TST \\
\hline CHEMBL1399901 & 688422 & 4.75 & 5.4518 & TST \\
\hline CHEMBL1350532 & 688422 & 8.3468 & 5.3778 & TST \\
\hline CHEMBL1607487 & 688422 & 7.2 & 5.2134 & TST \\
\hline CHEMBL1339496 & 688422 & 4.5 & 5.1586 & TRN \\
\hline CHEMBL 3193700 & 688422 & 4.65 & 4.6704 & TRN \\
\hline CHEMBL1378301 & 688422 & 5.15 & 5.597 & TRN \\
\hline CHEMBL1500477 & 688422 & 7.0501 & 5.7741 & TST \\
\hline CHEMBL604156 & 688422 & 4.5 & 5.3818 & TRN \\
\hline CHEMBL1382596 & 688422 & 6.15 & 5.7719 & TRN \\
\hline CHEMBL1303854 & 688422 & 5.75 & 5.7586 & TST \\
\hline CHEMBL1431332 & 688422 & 4.85 & 4.9995 & TRN \\
\hline CHEMBL1440696 & 688422 & 7.2503 & 5.7777 & TRN \\
\hline CHEMBL1476286 & 688422 & 7.8996 & 5.4229 & TRN \\
\hline CHEMBL1384452 & 688422 & 5.95 & 5.3282 & TRN \\
\hline CHEMBL1477472 & 688422 & 7.699 & 5.2878 & TRN \\
\hline CHEMBL1364602 & 688422 & 7.6003 & 5.1857 & TRN \\
\hline CHEMBL 1363248 & 688422 & 5.5 & 5.3563 & TST \\
\hline CHEMBL1253351 & 688422 & 4.9 & 5.4628 & TST \\
\hline CHEMBL1513544 & 688422 & 6.05 & 5.2932 & TRN \\
\hline CHEMBL1403675 & 688422 & 6.3 & 5.3642 & TRN \\
\hline CHEMBL1547771 & 688422 & 4.65 & 5.5463 & TRN \\
\hline CHEMBL1433947 & 688422 & 8.0506 & 5.0326 & TRN \\
\hline CHEMBL1302635 & 688422 & 4.8 & 5.1342 & TST \\
\hline CHEMBL1357210 & 688422 & 4.45 & 5.5831 & TRN \\
\hline CHEMBL1378331 & 688422 & 4.75 & 5.0218 & TRN \\
\hline CHEMBL1606791 & 688422 & 4.9 & 5.2623 & TRN \\
\hline CHEMBL1496055 & 688422 & 4.9 & 5.0975 & TRN \\
\hline CHEMBL1474538 & 688422 & 4.95 & 5.2528 & TRN \\
\hline CHEMBL1560789 & 688422 & 8.0506 & 5.5064 & TRN \\
\hline CHEMBL1546017 & 688422 & 5.3 & 5.3551 & TRN \\
\hline CHEMBL1566094 & 688422 & 4.45 & 5.012 & TST \\
\hline CHEMBL 1460712 & 688422 & 4.8 & 5.37 & TRN \\
\hline CHEMBL1339455 & 688422 & 4.8 & 5.12700 & 0000000001 \\
\hline CHEMBL1408259 & 688422 & 5.0 & 5.3745 & TRN \\
\hline CHEMBL1589780 & 688422 & 4.7 & 5.4519 & TST \\
\hline
\end{tabular}

TRN 


\begin{tabular}{|c|c|c|c|c|c|}
\hline \multicolumn{6}{|c|}{ Supplemental Table S2.txt } \\
\hline CHEMBL1526703 & 688422 & 4.7 & 5.3178 & TRN & \\
\hline CHEMBL1534900 & 688422 & 8.301 & 4.9574 & TRN & \\
\hline CHEMBL1323840 & 688422 & 4.65 & 5.0183 & TRN & \\
\hline CHEMBL1494068 & 688422 & 4.45 & 5.1096 & TRN & \\
\hline CHEMBL1407586 & 688422 & 4.95 & 5.5301 & TRN & \\
\hline CHEMBL1595950 & 688422 & 6.1 & 4.9744 & TRN & \\
\hline CHEMBL1471239 & 688422 & 4.6 & 5.1462 & TRN & \\
\hline CHEMBL1539395 & 688422 & 5.25 & 5.1274 & TRN & \\
\hline CHEMBL1447969 & 688422 & 4.45 & 6.1817 & TRN & \\
\hline CHEMBL1454322 & 688422 & 4.6 & 5.0824 & TRN & \\
\hline CHEMBL 305469 & 688422 & 4.9 & 5.3747 & TRN & \\
\hline CHEMBL587836 & 688422 & 4.45 & 5.1564 & TRN & \\
\hline CHEMBL1434962 & 688422 & 4.45 & 5.5424 & TRN & \\
\hline CHEMBL1490684 & 688422 & 4.9 & 5.1025 & TRN & \\
\hline CHEMBL1547143 & 688422 & 4.45 & 5.1879 & TRN & \\
\hline CHEMBL 22062 & 688422 & 5.55 & 5.1622 & TRN & \\
\hline CHEMBL1491603 & 688422 & 4.9 & 4.9974 & TRN & \\
\hline CHEMBL262627 & 688422 & 5.45 & 4.8607 & TRN & \\
\hline CHEMBL1431343 & 688422 & 4.5 & 4.9494 & TRN & \\
\hline CHEMBL1304048 & 688422 & 5.25 & 5.6812 & TRN & \\
\hline CHEMBL1339614 & 688422 & 4.45 & 5.1935 & TRN & \\
\hline CHEMBL1474485 & 688422 & 7.7496 & 5.57 & TST & \\
\hline CHEMBL1548447 & 688422 & 7.5003 & 5.4733 & TRN & \\
\hline CHEMBL1411060 & 688422 & 4.65 & 5.7131 & TRN & \\
\hline CHEMBL1550266 & 688422 & 5.8 & 5.465 & TRN & \\
\hline CHEMBL1598108 & 688422 & 4.45 & 5.0377 & TRN & \\
\hline CHEMBL1346409 & 688422 & 4.95 & 4.8607 & TST & \\
\hline CHEMBL3191874 & 688422 & 6.0 & 5.5198 & TRN & \\
\hline CHEMBL601567 & 688422 & 8.4949 & 5.5041 & TRN & \\
\hline CHEMBL1569872 & 688422 & 4.9 & 5.1337 & TRN & \\
\hline CHEMBL1519932 & 688422 & 8.1024 & 5.8402 & TRN & \\
\hline CHEMBL1515628 & 688422 & 5.25 & 5.816 & TST & \\
\hline CHEMBL1519817 & 688422 & 5.0 & 5.301 & TRN & \\
\hline CHEMBL1394045 & 688422 & 4.95 & 5.2549 & TRN & \\
\hline CHEMBL1543331 & 688422 & 4.45 & 5.376 & TST & \\
\hline CHEMBL1402837 & 688422 & 4.8 & 4.8699 & TST & \\
\hline CHEMBL1608279 & 688422 & 4.45 & 4.8562 & TRN & \\
\hline CHEMBL1451869 & 688422 & 4.85 & 5.37799 & 9999999999 & TRN \\
\hline CHEMBL1483237 & 688422 & 5.45 & 6.2225 & TST & \\
\hline CHEMBL1543731 & 688422 & 5.35 & 5.6232 & TRN & \\
\hline CHEMBL1517748 & 688422 & 6.35 & 5.0856 & TST & \\
\hline CHEMBL1541600 & 688422 & 4.7 & 5.2171 & TRN & \\
\hline CHEMBL1469579 & 688422 & 4.55 & 4.9319 & TRN & \\
\hline CHEMBL1398873 & 688422 & 4.45 & 5.3674 & TRN & \\
\hline CHEMBL1540933 & 688422 & 5.55 & 5.2577 & TRN & \\
\hline CHEMBL1425253 & 688422 & 5.55 & 5.5405 & TRN & \\
\hline CHEMBL1469931 & 688422 & 7.1002 & 5.1242 & TRN & \\
\hline CHEMBL1418247 & 688422 & 5.55 & 5.2857 & TRN & \\
\hline
\end{tabular}




\begin{tabular}{|c|c|c|c|c|}
\hline \multicolumn{5}{|c|}{ Supplemental Table } \\
\hline CHEMBL1485984 & 688422 & 8.7447 & 6.2858 & TRN \\
\hline CHEMBL1414943 & 688422 & 6.35 & 6.7699 & TRN \\
\hline CHEMBL1316085 & 688422 & 8.0506 & 5.5524 & TRN \\
\hline CHEMBL1464976 & 688422 & 4.95 & 4.7863 & TRN \\
\hline CHEMBL1310832 & 688422 & 4.6 & 4.9657 & TRN \\
\hline CHEMBL1527600 & 688422 & 5.85 & 5.3659 & TRN \\
\hline CHEMBL1554960 & 688422 & 4.9 & 5.1408 & TRN \\
\hline CHEMBL1427523 & 688422 & 5.0 & 5.157 & TRN \\
\hline CHEMBL1462852 & 688422 & 4.9 & 5.0185 & TRN \\
\hline CHEMBL1558846 & 688422 & 5.25 & 4.6688 & TRN \\
\hline CHEMBL1409997 & 688422 & 4.6 & 4.9262 & TRN \\
\hline CHEMBL1602267 & 688422 & 5.75 & 5.2619 & TST \\
\hline CHEMBL1329484 & 688422 & 5.05 & 5.3017 & TRN \\
\hline CHEMBL1413808 & 688422 & 8.3468 & 5.4681 & TRN \\
\hline CHEMBL3190491 & 688422 & 6.4 & 5.3145 & TST \\
\hline CHEMBL3191208 & 688422 & 4.9 & 5.2916 & TST \\
\hline CHEMBL1427882 & 688422 & 4.65 & 5.2882 & TRN \\
\hline CHEMBL1377456 & 688422 & 5.25 & 5.5991 & TRN \\
\hline CHEMBL1508177 & 688422 & 4.85 & 5.3279 & TRN \\
\hline CHEMBL1507334 & 688422 & 4.45 & 5.0266 & TRN \\
\hline CHEMBL1371511 & 688422 & 7.4498 & 5.3617 & TRN \\
\hline CHEMBL1435808 & 688422 & 4.7 & 5.0064 & TRN \\
\hline CHEMBL1569368 & 688422 & 4.6 & 5.271 & TST \\
\hline CHEMBL1491869 & 688422 & 6.6499 & 4.9419 & TRN \\
\hline CHEMBL1511429 & 688422 & 4.45 & 4.9518 & TRN \\
\hline CHEMBL1391887 & 688422 & 5.45 & 5.0637 & TST \\
\hline CHEMBL1397447 & 688422 & 4.65 & 5.0905 & TRN \\
\hline CHEMBL1405378 & 688422 & 4.85 & 5.2135 & TRN \\
\hline CHEMBL1486827 & 688422 & 4.5 & 4.9538 & TST \\
\hline CHEMBL1509928 & 688422 & 5.15 & 5.4845 & TST \\
\hline CHEMBL1543433 & 688422 & 4.8 & 5.3097 & TST \\
\hline CHEMBL1473878 & 688422 & 4.85 & 5.4543 & TRN \\
\hline CHEMBL1539582 & 688422 & 4.85 & 4.9868 & TRN \\
\hline CHEMBL1526850 & 688422 & 5.25 & 5.6578 & TRN \\
\hline CHEMBL1491822 & 688422 & 5.45 & 5.4524 & TRN \\
\hline CHEMBL1547954 & 688422 & 4.45 & 5.5424 & TRN \\
\hline CHEMBL1303946 & 688422 & 6.8499 & 5.0758 & TST \\
\hline CHEMBL1313817 & 688422 & 4.75 & 5.4468 & TRN \\
\hline CHEMBL1586072 & 688422 & 4.95 & 4.7437 & TRN \\
\hline CHEMBL1456428 & 688422 & 4.45 & 4.8241 & TRN \\
\hline CHEMBL1341600 & 688422 & 4.65 & 5.4043 & TST \\
\hline CHEMBL1471422 & 688422 & 4.45 & 5.2531 & TRN \\
\hline CHEMBL1400057 & 688422 & 4.85 & 5.4032 & TST \\
\hline CHEMBL1305275 & 688422 & 4.9 & 5.4054 & TRN \\
\hline CHEMBL1605397 & 688422 & 4.5 & 5.1683 & TST \\
\hline CHEMBL1539536 & 688422 & 4.8 & 4.9059 & TRN \\
\hline CHEMBL1385413 & 688422 & 5.35 & 5.1802 & TRN \\
\hline CHEMBL1548760 & 688422 & 4.95 & 4.7495 & TRN \\
\hline
\end{tabular}




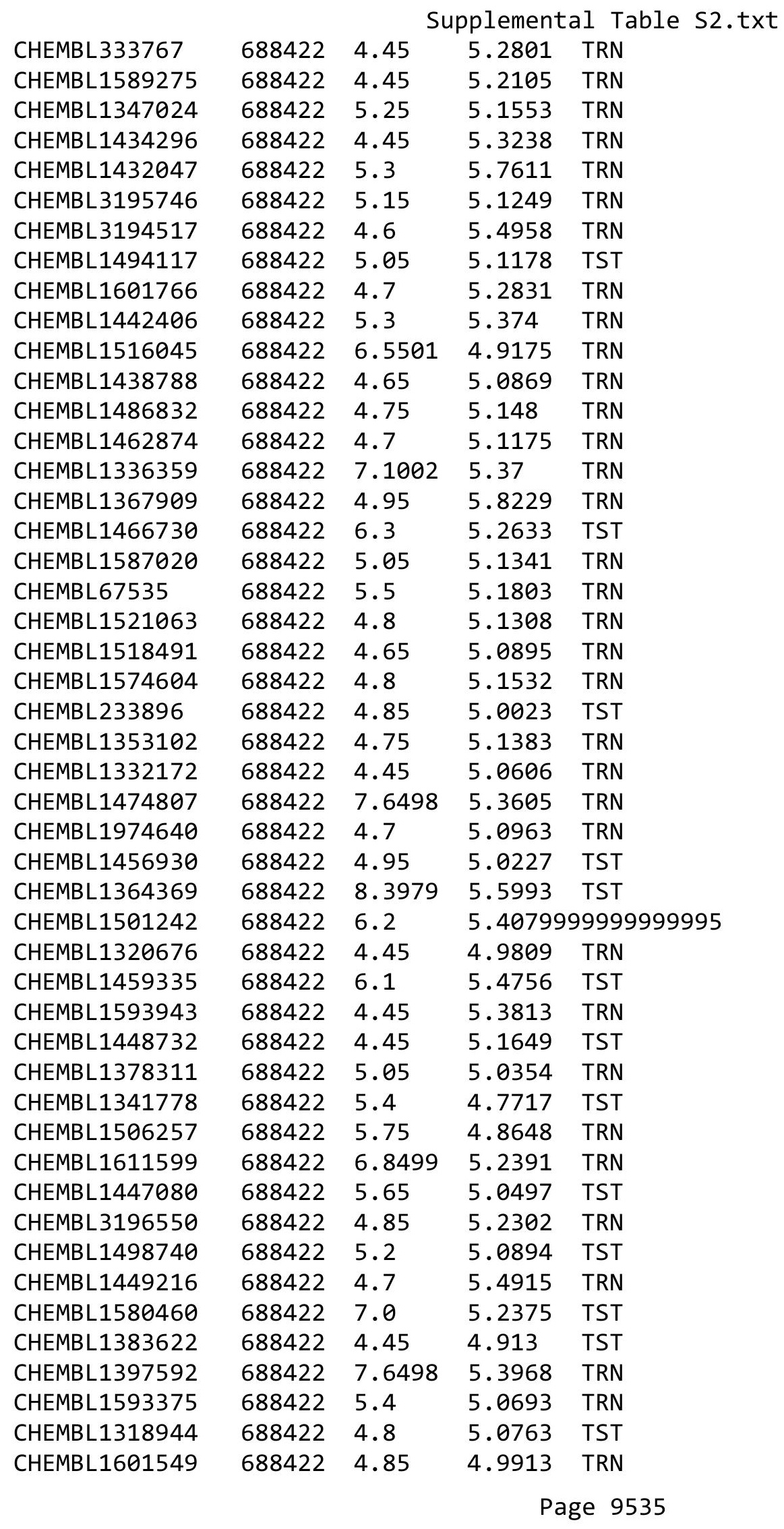




\begin{tabular}{|c|c|c|c|c|}
\hline \multicolumn{5}{|c|}{ Supplemental Table S2.txt } \\
\hline CHEMBL1409928 & 688422 & 4.45 & 5.19 & TST \\
\hline CHEMBL1460496 & 688422 & 5.2 & 5.5868 & TST \\
\hline CHEMBL1330093 & 688422 & 5.7 & 4.7964 & TRN \\
\hline CHEMBL 3196124 & 688422 & 5.1 & 4.9263 & TRN \\
\hline CHEMBL1533944 & 688422 & 4.45 & 5.3731 & TST \\
\hline CHEMBL1326305 & 688422 & 4.9 & 5.3179 & TRN \\
\hline CHEMBL1460543 & 688422 & 4.45 & 4.9766 & TRN \\
\hline CHEMBL1343481 & 688422 & 4.45 & 5.1907 & TRN \\
\hline CHEMBL1309332 & 688422 & 7.1002 & 5.1989 & TST \\
\hline CHEMBL1352461 & 688422 & 4.5 & 5.2086 & TRN \\
\hline CHEMBL1470322 & 688422 & 5.0 & 5.6264 & TRN \\
\hline CHEMBL1576571 & 688422 & 4.45 & 5.0681 & TST \\
\hline CHEMBL1389409 & 688422 & 4.65 & 5.2272 & TRN \\
\hline CHEMBL1517121 & 688422 & 4.95 & 5.1854 & TRN \\
\hline CHEMBL1529295 & 688422 & 4.5 & 4.4917 & TRN \\
\hline CHEMBL1327750 & 688422 & 4.45 & 5.1051 & TRN \\
\hline CHEMBL1442424 & 688422 & 6.3 & 5.5042 & TRN \\
\hline CHEMBL1399727 & 688422 & 5.25 & 5.0287 & TRN \\
\hline CHEMBL1325603 & 688422 & 4.9 & 5.1997 & TRN \\
\hline CHEMBL1387256 & 688422 & 5.25 & 5.1096 & TRN \\
\hline CHEMBL1986741 & 688422 & 4.7 & 5.0111 & TRN \\
\hline CHEMBL1389292 & 688422 & 4.45 & 5.0289 & TRN \\
\hline CHEMBL1327059 & 688422 & 4.8 & 4.8962 & TRN \\
\hline CHEMBL1351103 & 688422 & 4.85 & 5.0794 & TST \\
\hline CHEMBL1366948 & 688422 & 4.95 & 5.1102 & TRN \\
\hline CHEMBL1601153 & 688422 & 4.75 & 5.0302 & TRN \\
\hline CHEMBL1520368 & 688422 & 4.95 & 5.3423 & TST \\
\hline CHEMBL1386022 & 688422 & 4.6 & 5.2052 & TRN \\
\hline CHEMBL1303213 & 688422 & 5.3 & 5.2193 & TRN \\
\hline CHEMBL1970711 & 688422 & 4.75 & 5.2178 & TRN \\
\hline CHEMBL1536791 & 688422 & 4.75 & 5.4279 & TRN \\
\hline CHEMBL1359368 & 688422 & 4.85 & 5.083 & TRN \\
\hline CHEMBL1426821 & 688422 & 5.25 & 5.3297 & TST \\
\hline CHEMBL1300774 & 688422 & 4.95 & 5.284 & TST \\
\hline CHEMBL1303222 & 688422 & 4.9 & 5.1704 & TRN \\
\hline CHEMBL1412804 & 688422 & 4.9 & 4.6441 & TRN \\
\hline CHEMBL1484742 & 688422 & 5.05 & 5.5879 & TRN \\
\hline CHEMBL1557861 & 688422 & 4.5 & 5.0154 & TRN \\
\hline CHEMBL1303610 & 688422 & 7.5498 & 5.1229 & TST \\
\hline CHEMBL1300024 & 688422 & 4.5 & 5.7306 & TST \\
\hline CHEMBL1384512 & 688422 & 4.45 & 5.2418 & TRN \\
\hline CHEMBL1350449 & 688422 & 4.9 & 4.7764 & TRN \\
\hline CHEMBL1385743 & 688422 & 5.55 & 4.8254 & TRN \\
\hline CHEMBL1300162 & 688422 & 6.35 & 5.5269 & TST \\
\hline CHEMBL1458356 & 688422 & 4.5 & 5.5813 & TST \\
\hline CHEMBL1541720 & 688422 & 5.25 & 5.0771 & TST \\
\hline CHEMBL 1345220 & 688422 & 5.6 & 5.2101 & TRN \\
\hline CHEMBL1524292 & 688422 & 4.65 & 4.8606 & TST \\
\hline
\end{tabular}




\begin{tabular}{|c|c|c|c|c|c|}
\hline \multicolumn{6}{|c|}{ Supplemental Table S2.txt } \\
\hline CHEMBL1365128 & 688422 & 4.95 & 5.1271 & TRN & \\
\hline CHEMBL1566835 & 688422 & 5.25 & 5.2403 & TST & \\
\hline CHEMBL1597270 & 688422 & 4.9 & 5.0098 & TST & \\
\hline CHEMBL1345454 & 688422 & 5.9 & 5.3909 & TST & \\
\hline CHEMBL1538089 & 688422 & 5.55 & 5.2941 & TRN & \\
\hline CHEMBL1587380 & 688422 & 7.3002 & 5.4786 & TST & \\
\hline CHEMBL1530520 & 688422 & 4.65 & 5.3682 & TRN & \\
\hline CHEMBL1329378 & 688422 & 6.1 & 5.6236 & TRN & \\
\hline CHEMBL1589197 & 688422 & 4.85 & 5.1221 & TRN & \\
\hline CHEMBL1491981 & 688422 & 5.05 & 5.2264 & TRN & \\
\hline CHEMBL1305344 & 688422 & 4.85 & 5.397 & TRN & \\
\hline CHEMBL 21260 & 688422 & 6.0 & 6.1779 & TRN & \\
\hline CHEMBL1547125 & 688422 & 4.8 & 5.5439 & TRN & \\
\hline CHEMBL 3191473 & 688422 & 5.25 & 5.3904 & TST & \\
\hline CHEMBL1443327 & 688422 & 4.45 & 5.4166 & TST & \\
\hline CHEMBL1600492 & 688422 & 4.9 & 5.6406 & TST & \\
\hline CHEMBL1332033 & 688422 & 4.85 & 5.0808 & TRN & \\
\hline CHEMBL1497343 & 688422 & 4.55 & 5.0389 & TRN & \\
\hline CHEMBL1452459 & 688422 & 4.45 & 5.4955 & TST & \\
\hline CHEMBL1431003 & 688422 & 4.45 & 5.2139 & TRN & \\
\hline CHEMBL1589329 & 688422 & 5.05 & 5.0182 & TRN & \\
\hline CHEMBL1610737 & 688422 & 4.45 & 5.5563 & TRN & \\
\hline CHEMBL1489758 & 688422 & 5.2 & 5.3976 & TRN & \\
\hline CHEMBL1311264 & 688422 & 4.8 & 5.6623 & TRN & \\
\hline CHEMBL1964464 & 688422 & 4.75 & 5.3985 & TRN & \\
\hline CHEMBL1349572 & 688422 & 4.95 & 5.0708 & TRN & \\
\hline CHEMBL1392329 & 688422 & 4.85 & 5.2698 & TRN & \\
\hline CHEMBL1381299 & 688422 & 4.95 & 5.25799 & 9999999999 & TRN \\
\hline CHEMBL1466310 & 688422 & 4.85 & 4.7512 & TRN & \\
\hline CHEMBL1372885 & 688422 & 7.1002 & 5.6266 & TRN & \\
\hline CHEMBL1300215 & 688422 & 8.3468 & 5.3403 & TST & \\
\hline CHEMBL1313246 & 688422 & 4.45 & 5.6125 & TST & \\
\hline CHEMBL1344006 & 688422 & 4.8 & 5.2142 & TST & \\
\hline CHEMBL1608933 & 688422 & 4.95 & 5.0999 & TRN & \\
\hline CHEMBL1451232 & 688422 & 7.3002 & 4.9676 & TST & \\
\hline CHEMBL1444762 & 688422 & 5.3 & 5.1806 & TRN & \\
\hline CHEMBL1414571 & 688422 & 5.2 & 4.8891 & TST & \\
\hline CHEMBL1599728 & 688422 & 4.9 & 5.4929 & TRN & \\
\hline CHEMBL1302376 & 688422 & 4.75 & 4.9194 & TRN & \\
\hline CHEMBL1537297 & 688422 & 4.95 & 5.1543 & TRN & \\
\hline CHEMBL1589879 & 688422 & 4.7 & 5.3614 & TRN & \\
\hline CHEMBL 1454268 & 688422 & 7.699 & 5.5167 & TRN & \\
\hline CHEMBL1458591 & 688422 & 4.5 & 4.6695 & TRN & \\
\hline CHEMBL1406457 & 688422 & 4.45 & 5.077 & TRN & \\
\hline CHEMBL1587602 & 688422 & 4.8 & 4.9793 & TRN & \\
\hline CHEMBL1433873 & 688422 & 4.65 & 4.8729 & TRN & \\
\hline CHEMBL1452606 & 688422 & 5.05 & 5.1854 & TRN & \\
\hline CHEMBL1348839 & 688422 & 4.65 & 5.2578 & TST & \\
\hline
\end{tabular}




\begin{tabular}{|c|c|c|c|c|}
\hline \multicolumn{5}{|c|}{ Supplemental Table S2.txt } \\
\hline CHEMBL1569263 & 688422 & 4.9 & 5.2874 & TRN \\
\hline CHEMBL1365417 & 688422 & 5.1 & 4.6599 & TRN \\
\hline CHEMBL1443499 & 688422 & 5.4 & 5.3747 & TRN \\
\hline CHEMBL1428284 & 688422 & 5.55 & 4.8903 & TRN \\
\hline CHEMBL1581059 & 688422 & 4.75 & 5.3748 & TST \\
\hline CHEMBL1609296 & 688422 & 5.05 & 5.1079 & TRN \\
\hline CHEMBL1356090 & 688422 & 8.5528 & 5.7148 & TRN \\
\hline CHEMBL1302785 & 688422 & 5.25 & 4.8524 & TRN \\
\hline CHEMBL1427516 & 688422 & 4.95 & 5.222 & TST \\
\hline CHEMBL1576791 & 688422 & 5.7 & 4.8729 & TST \\
\hline CHEMBL3209115 & 688422 & 5.5 & 5.3828 & TRN \\
\hline CHEMBL1584502 & 688422 & 5.45 & 5.07 & TRN \\
\hline CHEMBL1567791 & 688422 & 4.5 & 5.4725 & TRN \\
\hline CHEMBL1526864 & 688422 & 4.85 & 5.0985 & TST \\
\hline CHEMBL122270 & 688422 & 6.2 & 5.3435 & TST \\
\hline CHEMBL1397296 & 688422 & 4.9 & 4.7156 & TRN \\
\hline CHEMBL1610397 & 688422 & 4.75 & 5.0317 & TRN \\
\hline CHEMBL3211130 & 688422 & 4.45 & 4.9859 & TRN \\
\hline CHEMBL1165197 & 688422 & 4.45 & 4.8178 & TST \\
\hline CHEMBL1479292 & 688422 & 4.45 & 4.6346 & TST \\
\hline CHEMBL1340478 & 688422 & 4.45 & 5.095 & TRN \\
\hline CHEMBL1359293 & 688422 & 5.95 & 4.9126 & TRN \\
\hline CHEMBL1387673 & 688422 & 4.6 & 5.2605 & TRN \\
\hline CHEMBL1415743 & 688422 & 7.6498 & 5.1484 & TRN \\
\hline CHEMBL410533 & 688422 & 4.8 & 4.9432 & TRN \\
\hline CHEMBL1544433 & 688422 & 4.85 & 5.3329 & TRN \\
\hline CHEMBL3189378 & 688422 & 5.25 & 5.3412 & TRN \\
\hline CHEMBL1357872 & 688422 & 4.45 & 5.2555 & TRN \\
\hline CHEMBL1420973 & 688422 & 8.4559 & 5.6551 & TRN \\
\hline CHEMBL1438501 & 688422 & 4.75 & 5.0202 & TRN \\
\hline CHEMBL1369467 & 688422 & 4.5 & 5.1023 & TRN \\
\hline CHEMBL1599671 & 688422 & 5.5 & 5.3017 & TST \\
\hline CHEMBL1407723 & 688422 & 4.8 & 4.8787 & TST \\
\hline CHEMBL1326921 & 688422 & 6.05 & 5.517 & TRN \\
\hline CHEMBL1359792 & 688422 & 4.45 & 5.4563 & TRN \\
\hline CHEMBL1387202 & 688422 & 4.85 & 5.1102 & TRN \\
\hline CHEMBL1563276 & 688422 & 5.5 & 5.2451 & TRN \\
\hline CHEMBL1403869 & 688422 & 4.85 & 5.4061 & TST \\
\hline CHEMBL1366888 & 688422 & 4.45 & 5.0914 & TRN \\
\hline CHEMBL1381708 & 688422 & 4.85 & 6.0787 & TRN \\
\hline CHEMBL485683 & 688422 & 6.4 & 5.7872 & TRN \\
\hline CHEMBL1473549 & 688422 & 4.45 & 4.8591 & TRN \\
\hline CHEMBL1414053 & 688422 & 5.55 & 5.1443 & TRN \\
\hline CHEMBL1585079 & 688422 & 4.45 & 4.952 & TRN \\
\hline CHEMBL3195258 & 688422 & 4.5 & 4.8306 & TRN \\
\hline CHEMBL1501720 & 688422 & 5.05 & 5.1864 & TRN \\
\hline CHEMBL1523966 & 688422 & 4.9 & 5.6239 & TRN \\
\hline CHEMBL1538235 & 688422 & 4.95 & 5.3496 & TRN \\
\hline
\end{tabular}




\begin{tabular}{|c|c|c|c|c|c|}
\hline \multicolumn{6}{|c|}{ Supplemental Table s2.txt } \\
\hline CHEMBL1503282 & 688422 & 4.45 & 5.532 & TRN & \\
\hline CHEMBL1331483 & 688422 & 4.75 & 5.3135 & TRN & \\
\hline CHEMBL1347208 & 688422 & 4.9 & 5.3844 & TRN & \\
\hline CHEMBL1357303 & 688422 & 4.8 & 5.4029 & TRN & \\
\hline CHEMBL1489306 & 688422 & 5.1 & 4.9039 & TRN & \\
\hline CHEMBL1453602 & 688422 & 7.6003 & 5.3582 & TRN & \\
\hline CHEMBL1553786 & 688422 & 5.55 & 5.3126 & TRN & \\
\hline CHEMBL1475196 & 688422 & 4.95 & 5.0373 & TRN & \\
\hline CHEMBL1337678 & 688422 & 4.75 & 4.873 & TRN & \\
\hline CHEMBL1412448 & 688422 & 4.6 & 4.7356 & TRN & \\
\hline CHEMBL1488578 & 688422 & 4.6 & 5.7803 & TST & \\
\hline CHEMBL1369817 & 688422 & 4.8 & 4.9758 & TRN & \\
\hline CHEMBL1559327 & 688422 & 5.1 & 4.7964 & TRN & \\
\hline CHEMBL1529859 & 688422 & 4.9 & 5.2045 & TRN & \\
\hline CHEMBL1553852 & 688422 & 4.45 & 5.1598 & TRN & \\
\hline CHEMBL1538542 & 688422 & 5.3 & 5.3815 & TST & \\
\hline CHEMBL1432673 & 688422 & 4.45 & 5.0797 & TST & \\
\hline CHEMBL1363763 & 688422 & 4.95 & 5.704 & TRN & \\
\hline CHEMBL1418702 & 688422 & 5.05 & 5.6646 & TRN & \\
\hline CHEMBL1366287 & 688422 & 6.0 & 5.5121 & TST & \\
\hline CHEMBL1512431 & 688422 & 6.7501 & 5.1698 & TRN & \\
\hline CHEMBL1582116 & 688422 & 4.65 & 5.192 & TRN & \\
\hline CHEMBL1974521 & 688422 & 5.8 & 5.3013 & TRN & \\
\hline CHEMBL1462791 & 688422 & 4.85 & 4.8777 & TST & \\
\hline CHEMBL1327166 & 688422 & 5.05 & 5.4458 & TRN & \\
\hline CHEMBL1423073 & 688422 & 4.5 & 5.2023 & TRN & \\
\hline CHEMBL1462387 & 688422 & 4.8 & 5.0907 & TRN & \\
\hline CHEMBL1407408 & 688422 & 4.45 & 5.1454 & TRN & \\
\hline CHEMBL1485353 & 688422 & 4.7 & 5.1093 & TRN & \\
\hline CHEMBL1610649 & 688422 & 4.65 & 5.2825 & TRN & \\
\hline CHEMBL1365746 & 688422 & 4.65 & 5.2081 & TRN & \\
\hline CHEMBL1370479 & 688422 & 5.45 & 4.8848 & TRN & \\
\hline CHEMBL1488685 & 688422 & 5.95 & 5.2545 & TRN & \\
\hline CHEMBL1545766 & 688422 & 4.65 & 5.6423 & TRN & \\
\hline CHEMBL1318773 & 688422 & 4.65 & 5.3855 & TST & \\
\hline CHEMBL1308324 & 688422 & 5.6 & 5.4908 & TST & \\
\hline CHEMBL1312972 & 688422 & 4.9 & 5.0412 & TRN & \\
\hline CHEMBL1389875 & 688422 & 6.2 & 5.57600 & 00000000005 & TRN \\
\hline CHEMBL1559640 & 688422 & 4.75 & 5.3436 & TST & \\
\hline CHEMBL1519539 & 688422 & 4.7 & 5.1045 & TRN & \\
\hline CHEMBL1510165 & 688422 & 6.1 & 5.2879 & TRN & \\
\hline CHEMBL1504385 & 688422 & 4.95 & 4.8069 & TRN & \\
\hline CHEMBL1570675 & 688422 & 5.35 & 5.17700 & 00000000005 & TST \\
\hline CHEMBL1408864 & 688422 & 4.8 & 5.0445 & TRN & \\
\hline CHEMBL1571684 & 688422 & 4.5 & 5.4922 & TRN & \\
\hline CHEMBL1392252 & 688422 & 4.95 & 5.1035 & TRN & \\
\hline CHEMBL1586895 & 688422 & 5.25 & 5.2182 & TRN & \\
\hline CHEMBL1320009 & 688422 & 5.0 & 5.0248 & TRN & \\
\hline
\end{tabular}




\begin{tabular}{|c|c|c|c|c|c|}
\hline \multicolumn{6}{|c|}{ Supplemental Table S2.txt } \\
\hline CHEMBL1303719 & 688422 & 5.0 & 5.15 & TST & \\
\hline CHEMBL1521658 & 688422 & 4.45 & 4.8949 & TRN & \\
\hline CHEMBL1454135 & 688422 & 4.9 & 5.003 & TRN & \\
\hline CHEMBL1491085 & 688422 & 4.8 & 5.2534 & TST & \\
\hline CHEMBL1367097 & 688422 & 4.45 & 5.02 & TRN & \\
\hline CHEMBL1326792 & 688422 & 4.45 & 5.1548 & TRN & \\
\hline CHEMBL1427617 & 688422 & 4.65 & 5.4977 & TRN & \\
\hline CHEMBL1472363 & 688422 & 4.85 & 5.01699 & 99999999995 & TRN \\
\hline CHEMBL1382313 & 688422 & 4.85 & 5.0797 & TRN & \\
\hline CHEMBL1328792 & 688422 & 4.95 & 4.9477 & TRN & \\
\hline CHEMBL1579056 & 688422 & 4.65 & 5.36600 & 20000000005 & TRN \\
\hline CHEMBL1373560 & 688422 & 4.45 & 5.1218 & TRN & \\
\hline CHEMBL1478464 & 688422 & 4.85 & 5.0771 & TST & \\
\hline CHEMBL1364533 & 688422 & 4.45 & 5.1907 & TRN & \\
\hline CHEMBL1572907 & 688422 & 4.65 & 5.36100 & 0000000001 & TRN \\
\hline CHEMBL1519379 & 688422 & 4.8 & 5.0022 & TRN & \\
\hline CHEMBL1588704 & 688422 & 6.05 & 4.8574 & TRN & \\
\hline CHEMBL1522401 & 688422 & 4.55 & 5.4179 & TST & \\
\hline CHEMBL1317709 & 688422 & 4.45 & 5.1023 & TRN & \\
\hline CHEMBL1568575 & 688422 & 4.8 & 4.8384 & TRN & \\
\hline CHEMBL1457056 & 688422 & 4.7 & 4.8897 & TRN & \\
\hline CHEMBL1533049 & 688422 & 4.8 & 4.9121 & TRN & \\
\hline CHEMBL1339551 & 688422 & 5.55 & 4.9057 & TST & \\
\hline CHEMBL1342404 & 688422 & 4.75 & 5.4501 & TRN & \\
\hline CHEMBL1336119 & 688422 & 4.45 & 5.2114 & TST & \\
\hline CHEMBL1563519 & 688422 & 6.5 & 5.3877 & TRN & \\
\hline CHEMBL1305334 & 688422 & 4.95 & 5.5104 & TRN & \\
\hline CHEMBL1467520 & 688422 & 4.85 & 4.9609 & TRN & \\
\hline CHEMBL1373328 & 688422 & 7.8508 & 5.8023 & TRN & \\
\hline CHEMBL1383772 & 688422 & 6.4 & 5.1178 & TRN & \\
\hline CHEMBL1429353 & 688422 & 5.1 & 5.6789 & TRN & \\
\hline CHEMBL1509388 & 688422 & 5.2 & 5.6053 & TRN & \\
\hline CHEMBL1509321 & 688422 & 4.65 & 5.4257 & TRN & \\
\hline CHEMBL1466783 & 688422 & 8.0 & 5.8509 & TST & \\
\hline CHEMBL1565252 & 688422 & 4.85 & 5.1976 & TRN & \\
\hline CHEMBL1580044 & 688422 & 6.3 & 5.4144 & TRN & \\
\hline CHEMBL1419248 & 688422 & 5.2 & 5.8442 & TST & \\
\hline CHEMBL1356806 & 688422 & 5.45 & 5.6153 & TRN & \\
\hline CHEMBL1582290 & 688422 & 5.1 & 5.5058 & TST & \\
\hline CHEMBL1452574 & 688422 & 4.55 & 5.1415 & TST & \\
\hline CHEMBL1366185 & 688422 & 4.95 & 4.6865 & TRN & \\
\hline CHEMBL1362054 & 688422 & 5.8 & 4.9396 & TRN & \\
\hline CHEMBL1378826 & 688422 & 4.5 & 5.4419 & TRN & \\
\hline CHEMBL1403576 & 688422 & 4.5 & 5.043 & TRN & \\
\hline CHEMBL1328962 & 688422 & 4.65 & 5.1332 & TRN & \\
\hline CHEMBL1577137 & 688422 & 5.8 & 5.7707 & TRN & \\
\hline CHEMBL1577642 & 688422 & 7.15 & 4.9968 & TST & \\
\hline CHEMBL1313297 & 688422 & 4.45 & 5.5353 & TRN & \\
\hline
\end{tabular}




\begin{tabular}{|c|c|c|c|c|}
\hline \multicolumn{5}{|c|}{ Supplemental Table S2.txt } \\
\hline CHEMBL1519786 & 688422 & 4.5 & 5.3502 & TST \\
\hline CHEMBL 3195924 & 688422 & 4.95 & 4.9673 & TST \\
\hline CHEMBL1458016 & 688422 & 5.1 & 5.2561 & TRN \\
\hline CHEMBL1257109 & 688422 & 4.85 & 5.4754 & TST \\
\hline CHEMBL1368420 & 688422 & 4.7 & 4.8429 & TRN \\
\hline CHEMBL1373004 & 688422 & 4.9 & 4.8228 & TRN \\
\hline CHEMBL 3211327 & 688422 & 4.5 & 4.8914 & TST \\
\hline CHEMBL1580923 & 688422 & 4.65 & 5.1204 & TST \\
\hline CHEMBL1412013 & 688422 & 4.5 & 5.0198 & TRN \\
\hline CHEMBL1371062 & 688422 & 4.7 & 5.0659 & TRN \\
\hline CHEMBL1466569 & 688422 & 4.9 & 5.0959 & TRN \\
\hline CHEMBL1315305 & 688422 & 5.2 & 5.2488 & TRN \\
\hline CHEMBL1538209 & 688422 & 5.5 & 5.309 & TRN \\
\hline CHEMBL 3211998 & 688422 & 5.2 & 5.2448 & TRN \\
\hline CHEMBL1521086 & 688422 & 4.45 & 5.5096 & TST \\
\hline CHEMBL1991442 & 688422 & 6.05 & 5.1924 & TRN \\
\hline CHEMBL1376504 & 688422 & 4.45 & 4.7088 & TRN \\
\hline CHEMBL1529733 & 688422 & 5.85 & 5.1673 & TRN \\
\hline CHEMBL1505518 & 688422 & 5.05 & 5.2386 & TST \\
\hline CHEMBL1609271 & 688422 & 4.65 & 4.9559 & TRN \\
\hline CHEMBL1491682 & 688422 & 5.0 & 5.7723 & TRN \\
\hline CHEMBL607309 & 688422 & 5.7 & 5.3352 & TST \\
\hline CHEMBL1389449 & 688422 & 4.95 & 4.8814 & TRN \\
\hline CHEMBL1318329 & 688422 & 5.75 & 5.2104 & TRN \\
\hline CHEMBL1583458 & 688422 & 4.65 & 5.532 & TRN \\
\hline CHEMBL1300355 & 688422 & 5.0 & 5.2775 & TRN \\
\hline CHEMBL1256709 & 688422 & 8.4559 & 5.5365 & TRN \\
\hline CHEMBL1517141 & 688422 & 5.25 & 5.3196 & TRN \\
\hline CHEMBL1466837 & 688422 & 7.2503 & 5.2824 & TRN \\
\hline CHEMBL1519590 & 688422 & 4.6 & 5.1253 & TRN \\
\hline CHEMBL1366214 & 688422 & 4.9 & 5.4302 & TST \\
\hline CHEMBL1340219 & 688422 & 6.5501 & 5.2665 & TST \\
\hline CHEMBL1502520 & 688422 & 6.05 & 5.5232 & TST \\
\hline CHEMBL1427253 & 688422 & 5.2 & 5.1702 & TRN \\
\hline CHEMBL1359573 & 688422 & 4.7 & 4.8087 & TRN \\
\hline CHEMBL1547612 & 688422 & 4.45 & 5.0669 & TRN \\
\hline CHEMBL1600455 & 688422 & 6.6 & 5.5014 & TRN \\
\hline CHEMBL1316550 & 688422 & 4.9 & 5.2826 & TRN \\
\hline CHEMBL1412106 & 688422 & 4.65 & 5.0336 & TST \\
\hline CHEMBL1513898 & 688422 & 7.699 & 5.0181 & TRN \\
\hline CHEMBL1414212 & 688422 & 8.3468 & 5.4611 & TST \\
\hline CHEMBL1517989 & 688422 & 7.6498 & 5.3574 & TST \\
\hline CHEMBL1413761 & 688422 & 4.45 & 5.5766 & TRN \\
\hline CHEMBL1505665 & 688422 & 5.15 & 5.465 & TRN \\
\hline CHEMBL 1605450 & 688422 & 4.6 & 5.2411 & TRN \\
\hline CHEMBL1599598 & 688422 & 4.85 & 5.1737 & TST \\
\hline CHEMBL1437818 & 688422 & 5.3 & 5.1614 & TRN \\
\hline CHEMBL1601672 & 688422 & 4.65 & 4.8119 & TRN \\
\hline
\end{tabular}




\begin{tabular}{|c|c|c|c|c|c|}
\hline \multicolumn{6}{|c|}{ Supplemental Table s2.txt } \\
\hline CHEMBL1479197 & 688422 & 4.45 & 5.2153 & TRN & \\
\hline CHEMBL1392298 & 688422 & 5.4 & 5.1965 & TRN & \\
\hline CHEMBL1466936 & 688422 & 5.35 & 5.4505 & TST & \\
\hline CHEMBL1468089 & 688422 & 6.5501 & 5.1828 & TRN & \\
\hline CHEMBL3198010 & 688422 & 6.9 & 5.246 & TRN & \\
\hline CHEMBL1606716 & 688422 & 4.45 & 4.8472 & TRN & \\
\hline CHEMBL 3211338 & 688422 & 4.85 & 5.5138 & TRN & \\
\hline CHEMBL1353881 & 688422 & 4.45 & 5.3002 & TST & \\
\hline CHEMBL1559039 & 688422 & 4.7 & 5.0946 & TRN & \\
\hline CHEMBL3856092 & 688422 & 6.0 & 5.4537 & TST & \\
\hline CHEMBL1395072 & 688422 & 4.45 & \multicolumn{2}{|c|}{5.667000000000001} & TRN \\
\hline CHEMBL254255 & 688422 & 4.45 & 4.8455 & TRN & \\
\hline CHEMBL1610485 & 688422 & 4.9 & 5.6198 & TRN & \\
\hline CHEMBL1301942 & 688422 & 6.05 & 5.9479 & TRN & \\
\hline CHEMBL1542621 & 688422 & 5.95 & 5.6369 & TRN & \\
\hline CHEMBL1611732 & 688422 & 6.25 & 4.9655 & TRN & \\
\hline CHEMBL3211131 & 688422 & 5.0 & 5.3031 & TRN & \\
\hline CHEMBL1372481 & 688422 & 4.7 & \multicolumn{2}{|c|}{4.9430000000000005} & TRN \\
\hline CHEMBL1363044 & 688422 & 6.7501 & 5.3399 & TST & \\
\hline CHEMBL1528052 & 688422 & 5.3 & 5.1143 & TST & \\
\hline CHEMBL1420027 & 688422 & 4.45 & 5.3824 & TRN & \\
\hline CHEMBL1257075 & 688422 & 7.0 & 5.4349 & TST & \\
\hline CHEMBL1381808 & 688422 & 4.9 & \multicolumn{2}{|c|}{5.156000000000001} & TRN \\
\hline CHEMBL1313601 & 688422 & 4.95 & 5.1584 & TRN & \\
\hline CHEMBL1327266 & 688422 & 4.45 & 5.2323 & TST & \\
\hline CHEMBL1388857 & 688422 & 6.9 & 5.7477 & TRN & \\
\hline CHEMBL1427167 & 688422 & 4.85 & 5.0954 & TRN & \\
\hline CHEMBL1326915 & 688422 & 4.45 & 5.2366 & TRN & \\
\hline CHEMBL1535520 & 688422 & 5.55 & 5.073 & TRN & \\
\hline CHEMBL1449766 & 688422 & 6.6 & 5.5131 & TRN & \\
\hline CHEMBL1439625 & 688422 & 4.95 & 5.9369 & TRN & \\
\hline CHEMBL1589560 & 688422 & 4.95 & 5.4562 & TST & \\
\hline CHEMBL1380559 & 688422 & 4.75 & 4.6445 & TRN & \\
\hline CHEMBL1449577 & 688422 & 4.9 & 5.4254 & TRN & \\
\hline CHEMBL1544998 & 688422 & 5.2 & 4.8998 & TRN & \\
\hline CHEMBL1363615 & 688422 & 4.75 & 5.052 & TRN & \\
\hline CHEMBL1606108 & 688422 & 4.45 & 4.9921 & TST & \\
\hline CHEMBL1457682 & 688422 & 4.5 & 5.0373 & TRN & \\
\hline CHEMBL1575258 & 688422 & 4.45 & 4.8755 & TRN & \\
\hline CHEMBL1560049 & 688422 & 4.8 & 5.2251 & TRN & \\
\hline CHEMBL1464030 & 688422 & 5.65 & 5.2564 & TST & \\
\hline CHEMBL1355537 & 688422 & 6.0 & 5.6338 & TST & \\
\hline CHEMBL1399442 & 688422 & 6.8499 & \multicolumn{2}{|c|}{5.707000000000001} & TST \\
\hline CHEMBL1559945 & 688422 & 5.0 & 4.9323 & TRN & \\
\hline CHEMBL1591685 & 688422 & 4.45 & 5.5025 & TRN & \\
\hline CHEMBL1578890 & 688422 & 4.65 & 5.0635 & TRN & \\
\hline CHEMBL1549166 & 688422 & 5.0 & 5.0922 & TST & \\
\hline CHEMBL1536060 & 688422 & 4.9 & 5.0769 & TST & \\
\hline
\end{tabular}




\begin{tabular}{|c|c|c|c|c|}
\hline \multicolumn{5}{|c|}{ Supplemental Table S2.txt } \\
\hline CHEMBL1603817 & 688422 & 4.65 & 5.3879 & TRN \\
\hline CHEMBL1562591 & 688422 & 4.8 & 5.1534 & TST \\
\hline CHEMBL1396292 & 688422 & 5.15 & 5.7244 & TRN \\
\hline CHEMBL1596067 & 688422 & 4.85 & 5.2067 & TST \\
\hline CHEMBL1541964 & 688422 & 7.2503 & 5.0966 & TST \\
\hline CHEMBL1305986 & 688422 & 5.25 & 5.4004 & TRN \\
\hline CHEMBL1311323 & 688422 & 5.3 & 5.4124 & TRN \\
\hline CHEMBL1431310 & 688422 & 4.95 & 5.1564 & TST \\
\hline CHEMBL1340385 & 688422 & 4.65 & 5.5127 & TST \\
\hline CHEMBL1333617 & 688422 & 4.45 & 5.1206 & TST \\
\hline CHEMBL1493606 & 688422 & 4.95 & 5.4847 & TST \\
\hline CHEMBL1367276 & 688422 & 4.75 & 5.4338 & TST \\
\hline CHEMBL1516829 & 688422 & 4.85 & 5.3727 & TST \\
\hline CHEMBL1329658 & 688422 & 5.1 & 4.9476 & TRN \\
\hline CHEMBL1488187 & 688422 & 6.15 & 5.4277 & TRN \\
\hline CHEMBL1327311 & 688422 & 5.45 & 5.2976 & TST \\
\hline CHEMBL1323124 & 688422 & 4.7 & 5.1228 & TRN \\
\hline CHEMBL1391277 & 688422 & 4.65 & 5.0607 & TRN \\
\hline CHEMBL1335678 & 688422 & 4.85 & 4.7917 & TRN \\
\hline CHEMBL1532984 & 688422 & 4.85 & 5.4988 & TST \\
\hline CHEMBL1596554 & 688422 & 4.45 & 4.7607 & TRN \\
\hline CHEMBL1511384 & 688422 & 6.1 & 5.2461 & TRN \\
\hline CHEMBL1408617 & 688422 & 6.6 & 5.2773 & TRN \\
\hline CHEMBL1497747 & 688422 & 4.45 & 5.2141 & TRN \\
\hline CHEMBL1317834 & 688422 & 7.8996 & 4.8929 & TRN \\
\hline CHEMBL1338865 & 688422 & 4.8 & 5.0409 & TRN \\
\hline CHEMBL1598729 & 688422 & 6.1 & 5.1922 & TRN \\
\hline CHEMBL1439952 & 688422 & 5.15 & 4.9619 & TRN \\
\hline CHEMBL1348336 & 688422 & 4.45 & 4.8573 & TRN \\
\hline CHEMBL1379967 & 688422 & 5.5 & 5.1689 & TRN \\
\hline CHEMBL1603704 & 688422 & 4.45 & 5.319 & TRN \\
\hline CHEMBL1373334 & 688422 & 4.7 & 5.4853 & TRN \\
\hline CHEMBL1569833 & 688422 & 4.7 & 4.9633 & TRN \\
\hline CHEMBL1346278 & 688422 & 5.45 & 5.155 & TST \\
\hline CHEMBL1403012 & 688422 & 5.25 & 5.25 & TRN \\
\hline CHEMBL1344854 & 688422 & 7.5003 & 5.7214 & TRN \\
\hline CHEMBL1573864 & 688422 & 5.0 & 5.0669 & TRN \\
\hline CHEMBL1431276 & 688422 & 4.85 & 5.2671 & TST \\
\hline CHEMBL1441265 & 688422 & 4.6 & 5.0106 & TRN \\
\hline CHEMBL1732967 & 688422 & 4.9 & 4.6768 & TRN \\
\hline CHEMBL1396865 & 688422 & 4.45 & 5.5718 & TRN \\
\hline CHEMBL1470359 & 688422 & 4.7 & 5.062 & TST \\
\hline CHEMBL1986418 & 688422 & 5.1 & 5.2575 & TST \\
\hline CHEMBL1477453 & 688422 & 5.05 & 4.9724 & TRN \\
\hline CHEMBL1329625 & 688422 & 6.3 & 5.5468 & TRN \\
\hline CHEMBL1378256 & 688422 & 5.5 & 5.5731 & TRN \\
\hline CHEMBL1564542 & 688422 & 4.45 & 5.003 & TRN \\
\hline CHEMBL1580655 & 688422 & 4.8 & 5.0888 & TRN \\
\hline
\end{tabular}




\begin{tabular}{|c|c|c|c|c|c|}
\hline \multicolumn{6}{|c|}{ Supplemental Table S2.txt } \\
\hline CHEMBL1454456 & 688422 & 5.55 & 5.4032 & TRN & \\
\hline CHEMBL1496585 & 688422 & 4.45 & 4.876 & TRN & \\
\hline CHEMBL1481394 & 688422 & 5.95 & 5.0469 & TRN & \\
\hline CHEMBL1563536 & 688422 & 4.75 & 4.9749 & TST & \\
\hline CHEMBL1447459 & 688422 & 5.5 & 5.0795 & TRN & \\
\hline CHEMBL1351231 & 688422 & 4.9 & 5.2726 & TST & \\
\hline CHEMBL1305755 & 688422 & 4.8 & 5.6468 & TRN & \\
\hline CHEMBL1524805 & 688422 & 4.65 & 5.1451 & TRN & \\
\hline CHEMBL1310861 & 688422 & 4.7 & 5.4894 & TRN & \\
\hline CHEMBL1582108 & 688422 & 5.35 & 5.2443 & TRN & \\
\hline CHEMBL1594437 & 688422 & 4.95 & 5.13399 & 99999999995 & TRN \\
\hline CHEMBL1377441 & 688422 & 5.55 & 5.324 & TST & \\
\hline CHEMBL1455481 & 688422 & 8.2007 & 5.4793 & TST & \\
\hline CHEMBL1494058 & 688422 & 4.45 & 5.6217 & TRN & \\
\hline CHEMBL1448066 & 688422 & 4.6 & 5.1197 & TRN & \\
\hline CHEMBL1441585 & 688422 & 5.0 & 5.6716 & TRN & \\
\hline CHEMBL1494732 & 688422 & 5.05 & 5.3411 & TST & \\
\hline CHEMBL1606583 & 688422 & 4.9 & 5.3148 & TRN & \\
\hline CHEMBL1503834 & 688422 & 4.75 & 4.9505 & TST & \\
\hline CHEMBL1523326 & 688422 & 7.0 & 5.1885 & TRN & \\
\hline CHEMBL1450856 & 688422 & 4.65 & 5.4116 & TRN & \\
\hline CHEMBL1597731 & 688422 & 4.45 & 5.0917 & TRN & \\
\hline CHEMBL1348815 & 688422 & 5.9 & 5.9172 & TRN & \\
\hline CHEMBL1592694 & 688422 & 4.5 & 4.941 & TRN & \\
\hline CHEMBL1327075 & 688422 & 4.8 & 4.8383 & TRN & \\
\hline CHEMBL1590239 & 688422 & 7.2503 & 5.4106 & TRN & \\
\hline CHEMBL1303594 & 688422 & 4.8 & 5.0063 & TRN & \\
\hline CHEMBL1440468 & 688422 & 5.95 & 5.8523 & TST & \\
\hline CHEMBL1545999 & 688422 & 4.95 & 4.7339 & TRN & \\
\hline CHEMBL1471870 & 688422 & 4.85 & 5.6818 & TRN & \\
\hline CHEMBL1574344 & 688422 & 4.85 & 5.1716 & TRN & \\
\hline CHEMBL 1447842 & 688422 & 4.75 & 5.2572 & TRN & \\
\hline CHEMBL1450041 & 688422 & 4.7 & 5.6086 & TST & \\
\hline CHEMBL1457791 & 688422 & 5.4 & 4.9947 & TRN & \\
\hline CHEMBL1526304 & 688422 & 4.45 & 4.6494 & TST & \\
\hline CHEMBL1606112 & 688422 & 4.65 & 5.2354 & TRN & \\
\hline CHEMBL 1328028 & 688422 & 7.6498 & 5.3265 & TRN & \\
\hline CHEMBL1444097 & 688422 & 4.7 & 5.2493 & TRN & \\
\hline CHEMBL1504692 & 688422 & 5.0 & 5.1393 & TRN & \\
\hline CHEMBL1341995 & 688422 & 5.1 & 5.3618 & TRN & \\
\hline CHEMBL1377803 & 688422 & 8.4559 & 5.4204 & TRN & \\
\hline CHEMBL1896042 & 688422 & 4.65 & 4.8126 & TRN & \\
\hline CHEMBL1463737 & 688422 & 5.0 & 5.0933 & TRN & \\
\hline CHEMBL1597920 & 688422 & 4.95 & 5.3157 & TST & \\
\hline CHEMBL1545025 & 688422 & 6.3 & 5.7141 & TRN & \\
\hline CHEMBL1324472 & 688422 & 6.5 & 5.4367 & TST & \\
\hline CHEMBL1515645 & 688422 & 4.7 & 5.0109 & TRN & \\
\hline CHEMBL1299899 & 688422 & 4.95 & 4.908 & TRN & \\
\hline
\end{tabular}




\begin{tabular}{|c|c|c|c|c|}
\hline \multicolumn{5}{|c|}{ Supplemental Table S2.txt } \\
\hline CHEMBL1469904 & 688422 & 4.5 & 4.8625 & TRN \\
\hline CHEMBL39879 & 688422 & 6.0 & 5.9134 & TRN \\
\hline CHEMBL1511131 & 688422 & 4.8 & 5.5479 & TRN \\
\hline CHEMBL1608614 & 688422 & 5.15 & 5.145 & TRN \\
\hline CHEMBL1587904 & 688422 & 8.301 & 5.4416 & TRN \\
\hline CHEMBL1410102 & 688422 & 6.4 & 5.1213 & TRN \\
\hline CHEMBL1993204 & 688422 & 5.25 & 5.0506 & TRN \\
\hline CHEMBL1416346 & 688422 & 4.45 & 4.6205 & TRN \\
\hline CHEMBL1569228 & 688422 & 4.95 & 4.9398 & TRN \\
\hline CHEMBL1353695 & 688422 & 4.45 & 5.9146 & TST \\
\hline CHEMBL3194711 & 688422 & 4.7 & 5.2485 & TST \\
\hline CHEMBL458094 & 688422 & 4.85 & 4.8278 & TRN \\
\hline CHEMBL1481966 & 688422 & 6.45 & 5.7052 & TRN \\
\hline CHEMBL1431305 & 688422 & 4.45 & 5.2389 & TRN \\
\hline CHEMBL1572910 & 688422 & 8.301 & 5.684 & TRN \\
\hline CHEMBL1504131 & 688422 & 4.45 & 5.1074 & TRN \\
\hline CHEMBL1571360 & 688422 & 5.7 & 5.4175 & TRN \\
\hline CHEMBL1399109 & 688422 & 5.0 & 4.9599 & TRN \\
\hline CHEMBL1325888 & 688422 & 4.55 & 5.2036 & TRN \\
\hline CHEMBL1539572 & 688422 & 5.15 & 4.9791 & TRN \\
\hline CHEMBL1409263 & 688422 & 4.8 & 5.3635 & TRN \\
\hline CHEMBL1350930 & 688422 & 4.45 & 5.3869 & TST \\
\hline CHEMBL1558127 & 688422 & 4.9 & 5.3004 & TST \\
\hline CHEMBL1393434 & 688422 & 4.5 & 5.0514 & TRN \\
\hline CHEMBL1603779 & 688422 & 4.45 & 5.1961 & TRN \\
\hline CHEMBL1365742 & 688422 & 7.4498 & 6.15799 & 99999999995 \\
\hline CHEMBL1439445 & 688422 & 5.55 & 5.4899 & TRN \\
\hline CHEMBL1416221 & 688422 & 4.6 & 4.8376 & TRN \\
\hline CHEMBL431525 & 688422 & 6.1 & 5.1003 & TRN \\
\hline CHEMBL1256914 & 688422 & 4.5 & 4.9279 & TST \\
\hline CHEMBL1597789 & 688422 & 4.45 & 5.612 & TRN \\
\hline CHEMBL1589539 & 688422 & 6.3 & 5.4855 & TRN \\
\hline CHEMBL1343643 & 688422 & 5.3 & 5.5928 & TST \\
\hline CHEMBL1369688 & 688422 & 4.5 & 4.742 & TRN \\
\hline CHEMBL104732 & 688422 & 5.35 & 4.9258 & TRN \\
\hline CHEMBL1478046 & 688422 & 4.85 & 5.4468 & TRN \\
\hline CHEMBL1404628 & 688422 & 5.3 & 5.3951 & TST \\
\hline CHEMBL1423516 & 688422 & 4.45 & 5.0563 & TST \\
\hline CHEMBL1525668 & 688422 & 4.5 & 5.2214 & TRN \\
\hline CHEMBL1451931 & 688422 & 4.9 & 5.2364 & TST \\
\hline CHEMBL1328771 & 688422 & 5.2 & 5.58899 & 99999999995 \\
\hline CHEMBL1510798 & 688422 & 6.05 & 5.4511 & TRN \\
\hline CHEMBL1486565 & 688422 & 4.7 & 4.9446 & TRN \\
\hline CHEMBL1497300 & 688422 & 6.2 & 5.2887 & TRN \\
\hline CHEMBL1369576 & 688422 & 4.45 & 5.4959 & TRN \\
\hline CHEMBL1380885 & 688422 & 4.45 & 5.032 & TRN \\
\hline CHEMBL1451664 & 688422 & 4.95 & 4.9454 & TST \\
\hline CHEMBL1352168 & 688422 & 4.65 & 5.4596 & TRN \\
\hline
\end{tabular}




\begin{tabular}{|c|c|c|c|c|c|}
\hline \multicolumn{6}{|c|}{ Supplemental Table S2.txt } \\
\hline CHEMBL1391353 & 688422 & 4.65 & 4.9681 & TRN & \\
\hline CHEMBL1577178 & 688422 & 5.5 & 5.4216 & TRN & \\
\hline CHEMBL1601689 & 688422 & 4.9 & 5.1237 & TRN & \\
\hline CHEMBL1493083 & 688422 & 4.45 & 5.7142 & TST & \\
\hline CHEMBL1580219 & 688422 & 5.0 & 4.9397 & TRN & \\
\hline CHEMBL1528677 & 688422 & 4.55 & 5.0775 & TRN & \\
\hline CHEMBL1503387 & 688422 & 4.45 & 4.7238 & TRN & \\
\hline CHEMBL1467505 & 688422 & 4.45 & 5.2152 & TRN & \\
\hline CHEMBL1468664 & 688422 & 4.45 & \multicolumn{2}{|c|}{5.537000000000001} & TST \\
\hline CHEMBL1344294 & 688422 & 4.95 & 4.8942 & TRN & \\
\hline CHEMBL1370551 & 688422 & 4.65 & 5.9116 & TST & \\
\hline CHEMBL1313274 & 688422 & 5.95 & 5.3033 & TST & \\
\hline CHEMBL1414543 & 688422 & 4.6 & 5.1922 & TST & \\
\hline CHEMBL 3208028 & 688422 & 4.8 & 5.2836 & TST & \\
\hline CHEMBL1302475 & 688422 & 4.75 & 5.6963 & TST & \\
\hline CHEMBL1424630 & 688422 & 5.0 & 5.145 & TRN & \\
\hline CHEMBL1300251 & 688422 & 4.75 & 5.3663 & TST & \\
\hline CHEMBL1427834 & 688422 & 4.45 & 4.917 & TST & \\
\hline CHEMBL1299885 & 688422 & 4.45 & 5.2523 & TRN & \\
\hline CHEMBL1469684 & 688422 & 4.9 & 4.8661 & TRN & \\
\hline CHEMBL1512192 & 688422 & 5.5 & 5.2706 & TST & \\
\hline CHEMBL1352894 & 688422 & 4.9 & 5.0278 & TRN & \\
\hline CHEMBL1407341 & 688422 & 7.2503 & 5.6384 & TRN & \\
\hline CHEMBL1350518 & 688422 & 4.95 & \multicolumn{2}{|c|}{5.3229999999999995} & TRN \\
\hline CHEMBL1348091 & 688422 & 4.8 & 4.8605 & TRN & \\
\hline CHEMBL1556638 & 688422 & 4.95 & 5.0404 & TRN & \\
\hline CHEMBL1545429 & 688422 & 5.2 & 5.0218 & TRN & \\
\hline CHEMBL1458159 & 688422 & 4.85 & 5.2503 & TRN & \\
\hline CHEMBL1589231 & 688422 & 4.65 & 5.3399 & TRN & \\
\hline CHEMBL1507959 & 688422 & 4.45 & 5.0848 & TRN & \\
\hline CHEMBL1374838 & 688422 & 4.5 & 5.4826 & TRN & \\
\hline CHEMBL1355307 & 688422 & 5.4 & 4.8717 & TRN & \\
\hline CHEMBL1485329 & 688422 & 4.5 & 4.956 & TRN & \\
\hline CHEMBL1559455 & 688422 & 4.45 & 4.8369 & TRN & \\
\hline CHEMBL1426308 & 688422 & 4.45 & 5.2338 & TRN & \\
\hline CHEMBL1437139 & 688422 & 5.6 & 6.2523 & TRN & \\
\hline CHEMBL1402637 & 688422 & 4.7 & 4.9507 & TST & \\
\hline CHEMBL1567841 & 688422 & 5.9 & 4.9734 & TST & \\
\hline CHEMBL1309868 & 688422 & 5.0 & 5.2083 & TRN & \\
\hline CHEMBL1607562 & 688422 & 8.3979 & 5.3207 & TRN & \\
\hline CHEMBL1344380 & 688422 & 4.85 & 5.309 & TST & \\
\hline CHEMBL1404427 & 688422 & 7.5003 & 5.4216 & TRN & \\
\hline CHEMBL1421779 & 688422 & 4.95 & 5.1535 & TST & \\
\hline CHEMBL1588565 & 688422 & 5.15 & \multicolumn{2}{|c|}{5.207999999999999} & TRN \\
\hline CHEMBL1408894 & 688422 & 5.5 & 5.3294 & TRN & \\
\hline CHEMBL1392918 & 688422 & 4.45 & 5.1446 & TRN & \\
\hline CHEMBL1491104 & 688422 & 4.45 & 4.7273 & TST & \\
\hline CHEMBL1586741 & 688422 & 4.55 & 4.9133 & TST & \\
\hline
\end{tabular}




\begin{tabular}{|c|c|c|c|c|c|}
\hline \multicolumn{6}{|c|}{ Supplemental Table S2.txt } \\
\hline CHEMBL1605943 & 688422 & 5.35 & 5.5873 & TRN & \\
\hline CHEMBL1360232 & 688422 & 4.65 & 5.4369 & TST & \\
\hline CHEMBL3191259 & 688422 & 4.95 & 5.4193 & TRN & \\
\hline CHEMBL1503736 & 688422 & 4.65 & 4.9765 & TRN & \\
\hline CHEMBL 3212095 & 688422 & 7.2503 & 5.7365 & TST & \\
\hline CHEMBL1579404 & 688422 & 4.8 & 5.3248 & TST & \\
\hline CHEMBL1474151 & 688422 & 4.45 & 4.9852 & TRN & \\
\hline CHEMBL1483623 & 688422 & 4.8 & 5.0495 & TRN & \\
\hline CHEMBL1358416 & 688422 & 9.0458 & 5.6122 & TRN & \\
\hline CHEMBL1522480 & 688422 & 4.45 & 4.9751 & TRN & \\
\hline CHEMBL1484184 & 688422 & 4.65 & 5.0244 & TRN & \\
\hline CHEMBL606167 & 688422 & 4.85 & 5.2175 & TST & \\
\hline CHEMBL1354245 & 688422 & 5.25 & 5.3062 & TRN & \\
\hline CHEMBL1511060 & 688422 & 6.05 & 5.32299 & 99999999995 & TRN \\
\hline CHEMBL1332512 & 688422 & 4.65 & 5.0333 & TRN & \\
\hline CHEMBL1506142 & 688422 & 4.9 & 5.4336 & TRN & \\
\hline CHEMBL1612280 & 688422 & 7.2503 & 5.2007 & TST & \\
\hline CHEMBL1308441 & 688422 & 4.45 & 4.9756 & TRN & \\
\hline CHEMBL3190059 & 688422 & 4.9 & 5.0886 & TRN & \\
\hline CHEMBL1582900 & 688422 & 5.35 & 5.4125 & TRN & \\
\hline CHEMBL1414873 & 688422 & 4.7 & 4.88 & TRN & \\
\hline CHEMBL1558686 & 688422 & 6.8 & 5.4565 & TRN & \\
\hline CHEMBL1337452 & 688422 & 6.5 & 5.0255 & TRN & \\
\hline CHEMBL 3190685 & 688422 & 4.8 & 5.2309 & TST & \\
\hline CHEMBL334707 & 688422 & 5.0 & 5.3801 & TRN & \\
\hline CHEMBL1530554 & 688422 & 4.45 & 5.183 & TST & \\
\hline CHEMBL1605677 & 688422 & 4.7 & 5.4827 & TST & \\
\hline CHEMBL1506744 & 688422 & 4.6 & 5.4883 & TRN & \\
\hline CHEMBL3199138 & 688422 & 4.45 & 5.0973 & TRN & \\
\hline CHEMBL1500177 & 688422 & 7.1002 & 5.4171 & TST & \\
\hline CHEMBL1585275 & 688422 & 4.85 & 4.6097 & TRN & \\
\hline CHEMBL1559053 & 688422 & 5.35 & 5.3034 & TST & \\
\hline CHEMBL1516665 & 688422 & 4.45 & 5.098 & TRN & \\
\hline CHEMBL1435374 & 688422 & 4.9 & 4.9165 & TRN & \\
\hline CHEMBL1422079 & 688422 & 7.6498 & 4.6343 & TST & \\
\hline CHEMBL1510634 & 688422 & 4.95 & 4.8786 & TST & \\
\hline CHEMBL1516567 & 688422 & 5.15 & 5.5267 & TRN & \\
\hline CHEMBL1344489 & 688422 & 4.9 & 5.313 & TRN & \\
\hline CHEMBL1325258 & 688422 & 4.9 & 5.0394 & TRN & \\
\hline CHEMBL1605224 & 688422 & 5.5 & 5.347 & TRN & \\
\hline CHEMBL1422572 & 688422 & 6.2 & 5.1788 & TRN & \\
\hline CHEMBL1565772 & 688422 & 4.45 & 4.9755 & TRN & \\
\hline CHEMBL1523651 & 688422 & 4.5 & 5.0537 & TRN & \\
\hline CHEMBL1585078 & 688422 & 4.45 & 5.2896 & TST & \\
\hline CHEMBL1300393 & 688422 & 4.7 & 4.9091 & TST & \\
\hline CHEMBL3195239 & 688422 & 5.85 & 5.0337 & TRN & \\
\hline CHEMBL1383371 & 688422 & 4.7 & 5.2515 & TRN & \\
\hline CHEMBL1610291 & 688422 & 6.05 & 5.4332 & TRN & \\
\hline
\end{tabular}




\begin{tabular}{|c|c|c|c|c|c|}
\hline \multicolumn{6}{|c|}{ Supplemental Table S2.txt } \\
\hline CHEMBL1493547 & 688422 & 5.3 & 5.0557 & TRN & \\
\hline CHEMBL1519925 & 688422 & 4.95 & 4.9416 & TST & \\
\hline CHEMBL1432309 & 688422 & 4.9 & 5.0632 & TRN & \\
\hline CHEMBL1467832 & 688422 & 4.9 & 5.6016 & TRN & \\
\hline CHEMBL1331816 & 688422 & 4.7 & 5.3143 & TRN & \\
\hline CHEMBL515998 & 688422 & 6.8 & 5.2125 & TRN & \\
\hline CHEMBL1605404 & 688422 & 4.5 & 5.2927 & TRN & \\
\hline CHEMBL1345451 & 688422 & 5.6 & 5.4264 & TRN & \\
\hline CHEMBL1566475 & 688422 & 4.8 & 5.3415 & TRN & \\
\hline CHEMBL1530348 & 688422 & 4.7 & 5.1974 & TST & \\
\hline CHEMBL1378689 & 688422 & 4.95 & 5.7648 & TRN & \\
\hline CHEMBL336467 & 688422 & 4.9 & 5.0194 & TST & \\
\hline CHEMBL1534245 & 688422 & 5.35 & 5.268 & TRN & \\
\hline CHEMBL1482994 & 688422 & 5.65 & 5.256 & TRN & \\
\hline CHEMBL1382246 & 688422 & 4.45 & 5.3212 & TRN & \\
\hline CHEMBL1537383 & 688422 & 4.75 & 5.441 & TRN & \\
\hline CHEMBL1464674 & 688422 & 4.65 & 5.6431 & TST & \\
\hline CHEMBL1388782 & 688422 & 7.2503 & 5.24799 & 9999999999 & TST \\
\hline CHEMBL1339245 & 688422 & 4.8 & 4.9767 & TRN & \\
\hline CHEMBL1517909 & 688422 & 4.65 & 5.3072 & TRN & \\
\hline CHEMBL1354848 & 688422 & 4.9 & 5.2982 & TRN & \\
\hline CHEMBL1411527 & 688422 & 4.9 & 5.0679 & TRN & \\
\hline CHEMBL579859 & 688422 & 4.45 & 4.8489 & TST & \\
\hline CHEMBL3197014 & 688422 & 4.7 & 4.7731 & TST & \\
\hline CHEMBL3197638 & 688422 & 5.2 & 5.1702 & TRN & \\
\hline CHEMBL34704 & 688422 & 6.4 & 5.569 & TST & \\
\hline CHEMBL1371231 & 688422 & 4.9 & 5.4317 & TRN & \\
\hline CHEMBL1535893 & 688422 & 4.65 & 5.1387 & TRN & \\
\hline CHEMBL1373943 & 688422 & 4.45 & 5.2697 & TRN & \\
\hline CHEMBL1320804 & 688422 & 4.45 & 5.1136 & TST & \\
\hline CHEMBL1319537 & 688422 & 4.95 & 5.3567 & TRN & \\
\hline CHEMBL3198905 & 688422 & 4.65 & 5.1532 & TST & \\
\hline CHEMBL1559358 & 688422 & 7.4498 & 5.305 & TRN & \\
\hline CHEMBL1460359 & 688422 & 4.5 & 5.2785 & TRN & \\
\hline CHEMBL1306564 & 688422 & 4.45 & 5.3043 & TRN & \\
\hline CHEMBL1356801 & 688422 & 5.2 & 5.3346 & TRN & \\
\hline CHEMBL1401610 & 688422 & 4.95 & 5.2648 & TRN & \\
\hline CHEMBL3196786 & 688422 & 5.05 & 5.4907 & TST & \\
\hline CHEMBL1407604 & 688422 & 4.95 & 5.0776 & TST & \\
\hline CHEMBL1348574 & 688422 & 4.5 & 5.0406 & TRN & \\
\hline CHEMBL1364769 & 688422 & 4.95 & 5.0641 & TRN & \\
\hline CHEMBL1533244 & 688422 & 8.0 & 5.0301 & TRN & \\
\hline CHEMBL1417862 & 688422 & 6.7501 & 5.4435 & TRN & \\
\hline CHEMBL3145111 & 688422 & 4.45 & 5.1341 & TRN & \\
\hline CHEMBL1593066 & 688422 & 8.2007 & 5.3799 & TRN & \\
\hline CHEMBL1412824 & 688422 & 8.3979 & 6.044 & TST & \\
\hline CHEMBL1557003 & 688422 & 4.9 & 5.856 & TST & \\
\hline CHEMBL125812 & 688422 & 6.4 & 5.6160 & 00000000005 & TRN \\
\hline & & & & e 9548 & \\
\hline
\end{tabular}




\begin{tabular}{|c|c|c|c|c|c|}
\hline \multicolumn{6}{|c|}{ Supplemental Table S2.txt } \\
\hline CHEMBL1387022 & 688422 & 4.9 & 5.0152 & TRN & \\
\hline CHEMBL1566428 & 688422 & 4.9 & 4.9791 & TRN & \\
\hline CHEMBL1568808 & 688422 & 4.45 & 5.0207 & TRN & \\
\hline CHEMBL1303703 & 688422 & 4.75 & 4.9021 & TRN & \\
\hline CHEMBL1481630 & 688422 & 4.75 & 5.2723 & TRN & \\
\hline CHEMBL1501851 & 688422 & 4.85 & 5.5392 & TRN & \\
\hline CHEMBL1995449 & 688422 & 5.05 & 5.404 & TRN & \\
\hline CHEMBL1366547 & 688422 & 4.45 & 5.4348 & TRN & \\
\hline CHEMBL1438970 & 688422 & 4.85 & 5.1016 & TRN & \\
\hline CHEMBL1473158 & 688422 & 5.95 & 4.9919 & TRN & \\
\hline CHEMBL1576395 & 688422 & 4.85 & 5.1471 & TST & \\
\hline CHEMBL1324780 & 688422 & 4.45 & 4.8745 & TRN & \\
\hline CHEMBL1492247 & 688422 & 5.4 & 5.2544 & TRN & \\
\hline CHEMBL1450626 & 688422 & 5.35 & 5.1602 & TST & \\
\hline CHEMBL1490660 & 688422 & 4.55 & 5.2315 & TRN & \\
\hline CHEMBL1302290 & 688422 & 4.95 & 5.0198 & TRN & \\
\hline CHEMBL1514798 & 688422 & 4.7 & 5.2325 & TRN & \\
\hline CHEMBL1544132 & 688422 & 4.85 & 4.9655 & TRN & \\
\hline CHEMBL190982 & 688422 & 4.45 & 5.3689 & TRN & \\
\hline CHEMBL1978186 & 688422 & 4.85 & 5.3051 & TRN & \\
\hline CHEMBL1587434 & 688422 & 5.35 & 5.3208 & TST & \\
\hline CHEMBL1346883 & 688422 & 4.45 & 4.702 & TRN & \\
\hline CHEMBL3198383 & 688422 & 5.45 & 5.1186 & TST & \\
\hline CHEMBL1582639 & 688422 & 5.1 & 5.4242 & TRN & \\
\hline CHEMBL1328707 & 688422 & 4.45 & 4.8376 & TRN & \\
\hline CHEMBL1448901 & 688422 & 4.7 & 4.8912 & TRN & \\
\hline CHEMBL1527470 & 688422 & 5.25 & 5.4558 & TRN & \\
\hline CHEMBL1301227 & 688422 & 4.75 & 5.3539 & TST & \\
\hline CHEMBL1498453 & 688422 & 5.15 & 5.0703 & TRN & \\
\hline CHEMBL1454233 & 688422 & 4.85 & 5.3033 & TRN & \\
\hline CHEMBL1455302 & 688422 & 6.6 & 5.3521 & TRN & \\
\hline CHEMBL1374500 & 688422 & 5.85 & 5.2696 & TRN & \\
\hline CHEMBL1564982 & 688422 & 4.9 & 5.1285 & TRN & \\
\hline CHEMBL1551563 & 688422 & 4.8 & 5.3143 & TRN & \\
\hline CHEMBL494326 & 688422 & 4.75 & 4.7766 & TRN & \\
\hline CHEMBL1533085 & 688422 & 5.55 & 5.1358 & TRN & \\
\hline CHEMBL1548482 & 688422 & 4.85 & 5.117 & TST & \\
\hline CHEMBL1402946 & 688422 & 7.6003 & 4.875 & TRN & \\
\hline CHEMBL1535157 & 688422 & 4.9 & 4.8331 & TRN & \\
\hline CHEMBL1400638 & 688422 & 4.45 & 5.1133 & TRN & \\
\hline CHEMBL1363430 & 688422 & 4.65 & 5.5044 & TRN & \\
\hline CHEMBL1487795 & 688422 & 4.6 & $5.2360 e$ & 0000000001 & TRN \\
\hline CHEMBL1459891 & 688422 & 4.75 & $5.1080 e$ & 00000000005 & TRN \\
\hline CHEMBL1573018 & 688422 & 4.75 & 5.2462 & TRN & \\
\hline CHEMBL1508148 & 688422 & 4.5 & 5.1774 & TRN & \\
\hline CHEMBL3199626 & 688422 & 4.95 & 5.3643 & TRN & \\
\hline CHEMBL1414518 & 688422 & 4.9 & 4.9586 & TRN & \\
\hline CHEMBL1506450 & 688422 & 4.9 & 5.4458 & TRN & \\
\hline
\end{tabular}




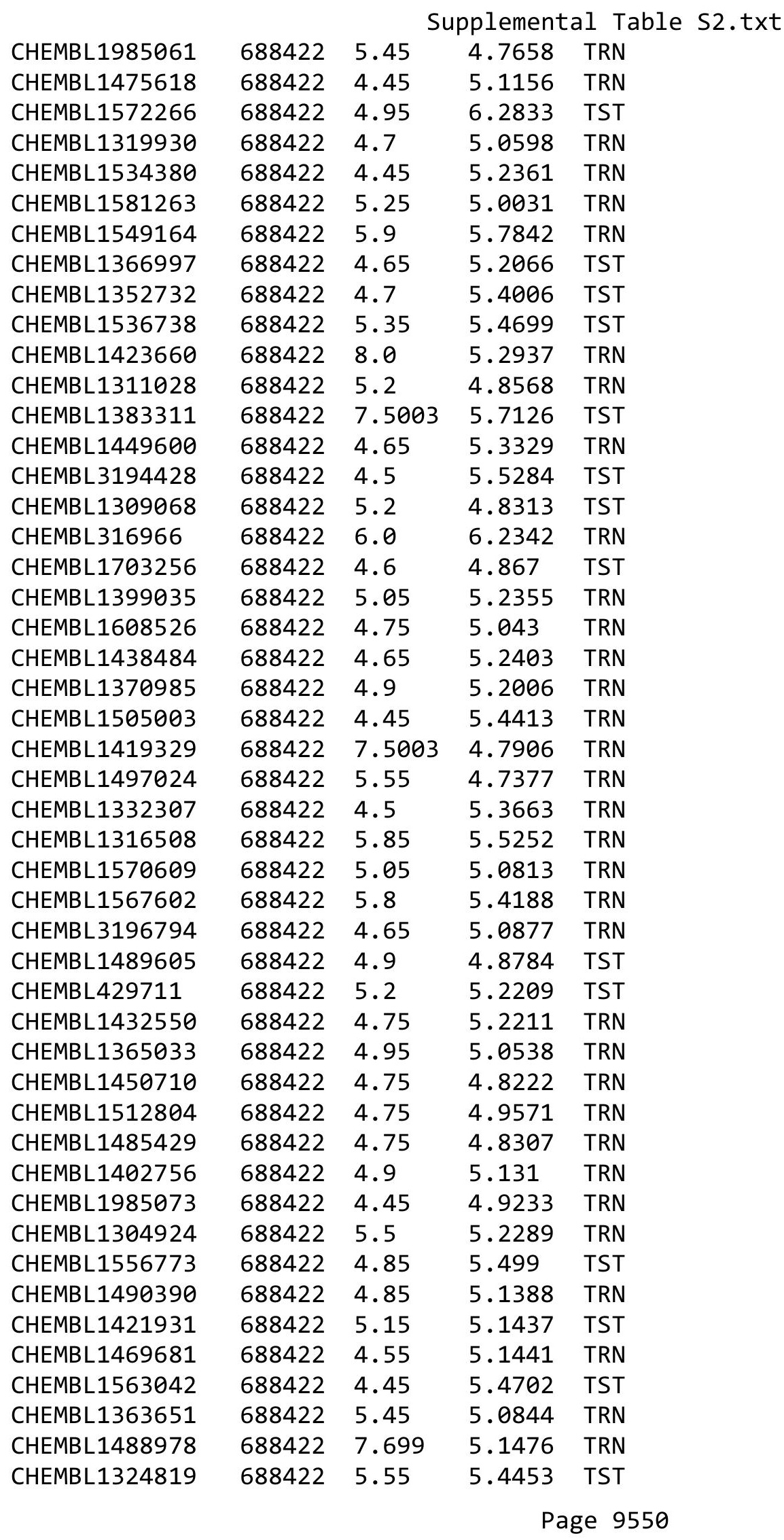




\begin{tabular}{|c|c|c|c|c|c|}
\hline \multicolumn{6}{|c|}{ Supplemental Table S2.txt } \\
\hline CHEMBL1557018 & 688422 & 5.0 & 4.9613 & TRN & \\
\hline CHEMBL1607472 & 688422 & 4.45 & 5.6079 & TST & \\
\hline CHEMBL3210291 & 688422 & 5.25 & 4.9771 & TST & \\
\hline CHEMBL1309215 & 688422 & 4.85 & 5.4153 & TRN & \\
\hline CHEMBL1309006 & 688422 & 4.9 & 5.1458 & TRN & \\
\hline CHEMBL1484565 & 688422 & 4.95 & 4.89199 & 99999999995 & TRN \\
\hline CHEMBL1578386 & 688422 & 5.4 & 4.94600 & 0000000001 & TRN \\
\hline CHEMBL1468023 & 688422 & 4.9 & 4.8142 & TRN & \\
\hline CHEMBL1395125 & 688422 & 5.15 & 5.4315 & TRN & \\
\hline CHEMBL1965911 & 688422 & 5.0 & 4.9823 & TRN & \\
\hline CHEMBL3191625 & 688422 & 4.9 & 5.1385 & TST & \\
\hline CHEMBL 3213241 & 688422 & 4.6 & 5.0514 & TRN & \\
\hline CHEMBL1413146 & 688422 & 5.1 & 4.9496 & TRN & \\
\hline CHEMBL1408074 & 688422 & 4.7 & 5.2492 & TST & \\
\hline CHEMBL1578321 & 688422 & 7.8996 & 5.67299 & 9999999999 & TRN \\
\hline CHEMBL1451483 & 688422 & 4.45 & 5.6233 & TST & \\
\hline CHEMBL1533486 & 688422 & 8.4949 & 5.4294 & TST & \\
\hline CHEMBL1431328 & 688422 & 5.05 & 5.0306 & TST & \\
\hline CHEMBL1515598 & 688422 & 5.0 & 5.0778 & TRN & \\
\hline CHEMBL1420015 & 688422 & 4.6 & 5.6087 & TRN & \\
\hline CHEMBL1542104 & 688422 & 6.5501 & 5.07100 & 0000000001 & TRN \\
\hline CHEMBL1609679 & 688422 & 4.9 & 5.846 & TRN & \\
\hline CHEMBL1404983 & 688422 & 4.5 & 5.2942 & TRN & \\
\hline CHEMBL1604822 & 688422 & 4.9 & 5.2558 & TRN & \\
\hline CHEMBL1364597 & 688422 & 4.7 & 5.3676 & TRN & \\
\hline CHEMBL1531863 & 688422 & 6.0 & 5.6188 & TRN & \\
\hline CHEMBL1587517 & 688422 & 6.1 & 5.3658 & TST & \\
\hline CHEMBL1335974 & 688422 & 5.75 & 5.4775 & TRN & \\
\hline CHEMBL1489694 & 688422 & 4.4 & 4.9338 & TRN & \\
\hline CHEMBL1459048 & 688422 & 7.0501 & 5.5304 & TRN & \\
\hline CHEMBL1452301 & 688422 & 5.95 & 5.4179 & TRN & \\
\hline CHEMBL1320365 & 688422 & 5.55 & 5.49799 & 9999999999 & TRN \\
\hline CHEMBL1607054 & 688422 & 4.8 & 5.2355 & TRN & \\
\hline CHEMBL1452804 & 688422 & 4.75 & 5.4368 & TST & \\
\hline CHEMBL1513262 & 688422 & 5.5 & 5.3486 & TRN & \\
\hline CHEMBL1389661 & 688422 & 4.7 & 5.6199 & TRN & \\
\hline CHEMBL1323220 & 688422 & 5.05 & 5.5973 & TRN & \\
\hline CHEMBL1457400 & 688422 & 5.0 & 5.6069 & TRN & \\
\hline CHEMBL1318627 & 688422 & 6.7501 & 5.3103 & TRN & \\
\hline CHEMBL1391022 & 688422 & 4.9 & 5.042 & TRN & \\
\hline CHEMBL1410312 & 688422 & 6.8 & 5.5065 & TRN & \\
\hline CHEMBL1440005 & 688422 & 4.9 & 5.41299 & 9999999999 & TRN \\
\hline CHEMBL1587572 & 688422 & 5.15 & 4.8659 & TRN & \\
\hline CHEMBL3209904 & 688422 & 5.05 & 5.2553 & TST & \\
\hline CHEMBL1370783 & 688422 & 4.95 & 5.5211 & TRN & \\
\hline CHEMBL1450277 & 688422 & 4.8 & 4.7115 & TRN & \\
\hline CHEMBL1434511 & 688422 & 5.3 & 5.0921 & TRN & \\
\hline CHEMBL1446230 & 688422 & 4.9 & 5.4534 & TRN & \\
\hline
\end{tabular}




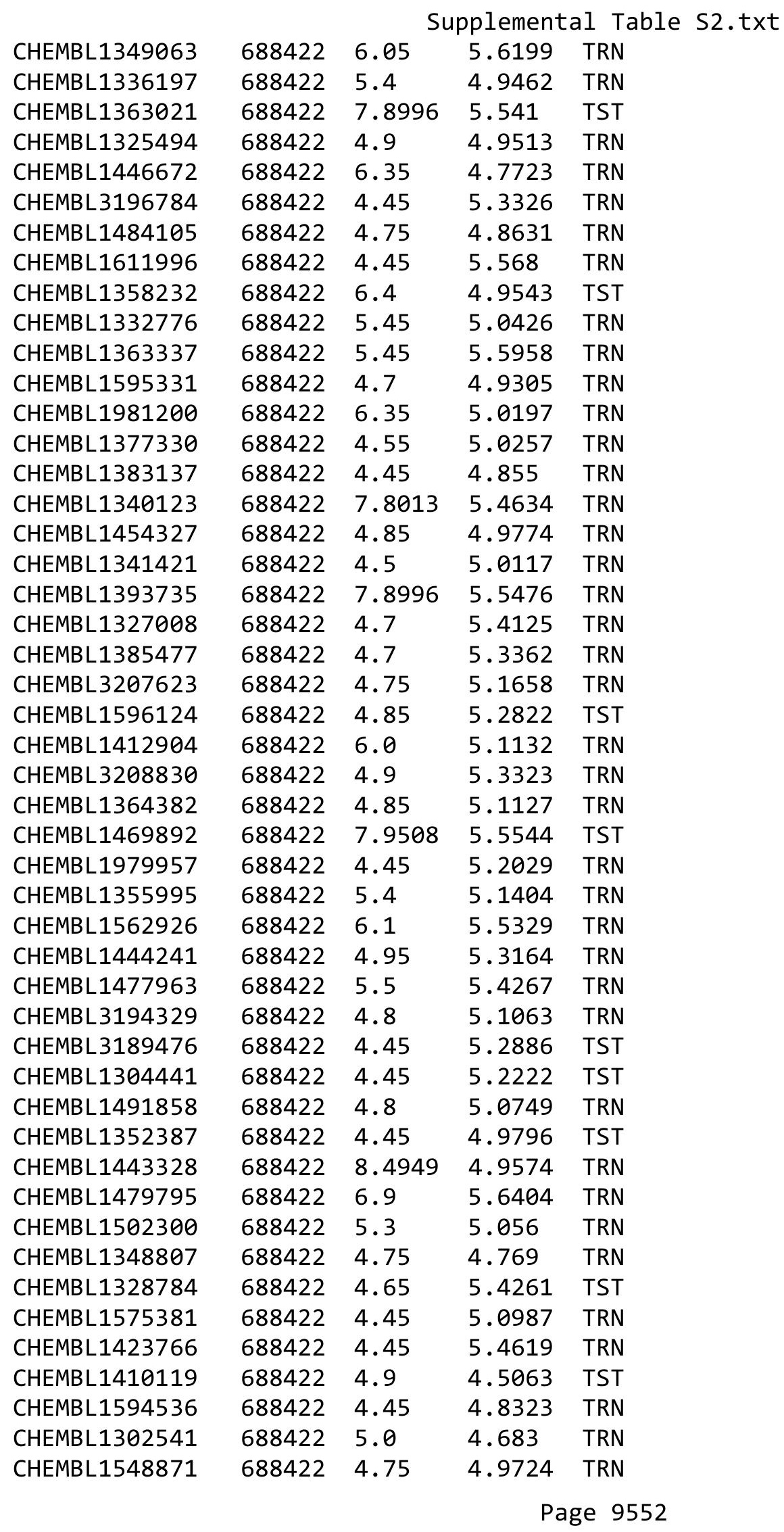




\begin{tabular}{|c|c|c|c|c|c|}
\hline \multicolumn{6}{|c|}{ Supplemental Table S2.txt } \\
\hline CHEMBL1358651 & 688422 & 4.9 & 5.3659 & TRN & \\
\hline CHEMBL1471188 & 688422 & 4.75 & 4.9721 & TRN & \\
\hline CHEMBL1309085 & 688422 & 4.7 & 5.1833 & TRN & \\
\hline CHEMBL1577708 & 688422 & 4.55 & 4.8361 & TRN & \\
\hline CHEMBL1988883 & 688422 & 5.05 & 5.666 & TST & \\
\hline CHEMBL1493936 & 688422 & 5.6 & \multicolumn{2}{|c|}{5.167999999999999} & TRN \\
\hline CHEMBL1499393 & 688422 & 4.45 & 5.4366 & TRN & \\
\hline CHEMBL1568857 & 688422 & 5.95 & 5.2597 & TRN & \\
\hline CHEMBL1370706 & 688422 & 4.45 & 5.0409 & TRN & \\
\hline CHEMBL1554087 & 688422 & 6.0 & 5.3888 & TRN & \\
\hline CHEMBL1439593 & 688422 & 6.45 & 4.7009 & TRN & \\
\hline CHEMBL1374284 & 688422 & 4.45 & 5.5727 & TST & \\
\hline CHEMBL1562060 & 688422 & 4.8 & 4.8962 & TRN & \\
\hline CHEMBL1997970 & 688422 & 4.9 & 5.0914 & TRN & \\
\hline CHEMBL1411449 & 688422 & 4.65 & 5.3708 & TST & \\
\hline CHEMBL1507645 & 688422 & 4.5 & 5.3404 & TRN & \\
\hline CHEMBL1465450 & 688422 & 4.45 & 4.947 & TST & \\
\hline CHEMBL1437755 & 688422 & 4.8 & 5.2422 & TRN & \\
\hline CHEMBL1567859 & 688422 & 4.45 & 4.95 & TRN & \\
\hline CHEMBL1493561 & 688422 & 5.15 & 5.1234 & TRN & \\
\hline CHEMBL1580116 & 688422 & 4.45 & 4.7466 & TST & \\
\hline CHEMBL1447344 & 688422 & 5.15 & 5.2712 & TRN & \\
\hline CHEMBL1536532 & 688422 & 4.45 & 5.5662 & TRN & \\
\hline CHEMBL3199194 & 688422 & 7.1002 & 5.3317 & TST & \\
\hline CHEMBL1398323 & 688422 & 5.7 & 5.1762 & TST & \\
\hline CHEMBL1497808 & 688422 & 6.45 & 5.2604 & TRN & \\
\hline CHEMBL1579239 & 688422 & 5.9 & 5.7928 & TRN & \\
\hline CHEMBL1577874 & 688422 & 4.55 & 5.2777 & TST & \\
\hline CHEMBL1423597 & 688422 & 5.0 & 5.1345 & TST & \\
\hline CHEMBL1397976 & 688422 & 4.55 & 5.3564 & TRN & \\
\hline CHEMBL1510245 & 688422 & 5.4 & 5.3058 & TST & \\
\hline CHEMBL1493428 & 688422 & 4.5 & 4.9162 & TRN & \\
\hline CHEMBL3196086 & 688422 & 4.45 & 5.0458 & TST & \\
\hline CHEMBL1417273 & 688422 & 4.95 & 5.2216 & TRN & \\
\hline CHEMBL1465490 & 688422 & 4.9 & 4.5931 & TRN & \\
\hline CHEMBL1385991 & 688422 & 8.0506 & 5.2079 & TRN & \\
\hline CHEMBL1399810 & 688422 & 5.9 & 5.0444 & TST & \\
\hline CHEMBL165 & 688422 & 6.0 & 5.8079 & TRN & \\
\hline CHEMBL1555435 & 688422 & 4.85 & 4.9389 & TST & \\
\hline CHEMBL1466367 & 688422 & 4.95 & 5.4385 & TRN & \\
\hline CHEMBL1507904 & 688422 & 4.8 & 5.0791 & TRN & \\
\hline CHEMBL1386320 & 688422 & 4.95 & 5.1212 & TRN & \\
\hline CHEMBL1464503 & 688422 & 4.95 & 5.2664 & TRN & \\
\hline CHEMBL1559672 & 688422 & 4.8 & 5.2642 & TST & \\
\hline CHEMBL1547481 & 688422 & 4.85 & 5.2127 & TRN & \\
\hline CHEMBL1450744 & 688422 & 4.65 & 5.1719 & TRN & \\
\hline CHEMBL1355189 & 688422 & 8.5528 & 5.7685 & TRN & \\
\hline CHEMBL1444434 & 688422 & 5.05 & 5.91799 & 999999 & TRN \\
\hline & & & & 955 & \\
\hline
\end{tabular}




\begin{tabular}{|c|c|c|c|c|c|}
\hline \multicolumn{6}{|c|}{ Supplemental Table S2.txt } \\
\hline CHEMBL1464123 & 688422 & 4.65 & 5.4056 & TRN & \\
\hline CHEMBL1450108 & 688422 & 4.65 & 5.2829 & TRN & \\
\hline CHEMBL1453319 & 688422 & 7.5498 & 5.4471 & TRN & \\
\hline CHEMBL1360262 & 688422 & 5.2 & 5.2491 & TST & \\
\hline CHEMBL1973042 & 688422 & 6.05 & 5.1535 & TRN & \\
\hline CHEMBL1559741 & 688422 & 4.5 & 5.1072 & TRN & \\
\hline CHEMBL361197 & 688422 & 7.4498 & 5.07600 & 00000000005 & TRN \\
\hline CHEMBL1305918 & 688422 & 7.4498 & 5.25899 & 99999999995 & TRN \\
\hline CHEMBL1341049 & 688422 & 6.8499 & 5.3501 & TRN & \\
\hline CHEMBL1553661 & 688422 & 4.5 & 5.1288 & TRN & \\
\hline CHEMBL1474860 & 688422 & 6.5 & 5.4719 & TRN & \\
\hline CHEMBL1444045 & 688422 & 4.45 & 5.4235 & TST & \\
\hline CHEMBL1530275 & 688422 & 4.85 & 5.4909 & TRN & \\
\hline CHEMBL1390076 & 688422 & 8.4949 & 5.2659 & TST & \\
\hline CHEMBL1971154 & 688422 & 4.45 & 4.8708 & TRN & \\
\hline CHEMBL1331383 & 688422 & 8.2518 & 6.0338 & TRN & \\
\hline CHEMBL1402027 & 688422 & 6.6 & 5.0239 & TST & \\
\hline CHEMBL1537711 & 688422 & 7.9508 & 5.2518 & TRN & \\
\hline CHEMBL3191916 & 688422 & 4.6 & 5.2251 & TRN & \\
\hline CHEMBL1569012 & 688422 & 4.9 & 4.6842 & TRN & \\
\hline CHEMBL1369265 & 688422 & 7.3497 & 5.301 & TST & \\
\hline CHEMBL1489180 & 688422 & 8.3468 & 5.5466 & TRN & \\
\hline CHEMBL1502848 & 688422 & 4.75 & 5.5149 & TRN & \\
\hline CHEMBL1420855 & 688422 & 5.0 & 5.2121 & TRN & \\
\hline CHEMBL1419359 & 688422 & 5.15 & 5.3328 & TRN & \\
\hline CHEMBL1431720 & 688422 & 6.6499 & 5.4212 & TRN & \\
\hline CHEMBL1559062 & 688422 & 4.45 & 5.2843 & TRN & \\
\hline CHEMBL525816 & 688422 & 4.45 & 5.5222 & TRN & \\
\hline CHEMBL1399048 & 688422 & 4.8 & 5.3657 & TRN & \\
\hline CHEMBL1534436 & 688422 & 4.55 & 5.0752 & TRN & \\
\hline CHEMBL1580057 & 688422 & 4.8 & 5.4705 & TRN & \\
\hline CHEMBL1395347 & 688422 & 4.45 & 4.9815 & TRN & \\
\hline CHEMBL1255966 & 688422 & 6.0 & 5.2421 & TRN & \\
\hline CHEMBL1325395 & 688422 & 6.15 & 5.3484 & TRN & \\
\hline CHEMBL1436423 & 688422 & 4.75 & 5.3107 & TRN & \\
\hline CHEMBL1511377 & 688422 & 5.35 & 5.5808 & TRN & \\
\hline CHEMBL1546100 & 688422 & 4.9 & 5.4097 & TST & \\
\hline CHEMBL1595494 & 688422 & 4.8 & 5.7498 & TRN & \\
\hline CHEMBL1504842 & 688422 & 4.45 & 5.3163 & TST & \\
\hline CHEMBL1451525 & 688422 & 4.45 & 5.2005 & TRN & \\
\hline CHEMBL3196157 & 688422 & 4.45 & 5.5591 & TRN & \\
\hline CHEMBL1525914 & 688422 & 6.3 & 6.0079 & TRN & \\
\hline CHEMBL1350733 & 688422 & 5.4 & 4.9769 & TST & \\
\hline CHEMBL3212912 & 688422 & 4.45 & 5.3368 & TRN & \\
\hline CHEMBL1319474 & 688422 & 6.3 & 5.6152 & TST & \\
\hline CHEMBL1349544 & 688422 & 5.4 & 5.5117 & TRN & \\
\hline CHEMBL3193510 & 688422 & 4.65 & 5.3894 & TST & \\
\hline CHEMBL1393493 & 688422 & 4.5 & 5.1992 & TRN & \\
\hline
\end{tabular}




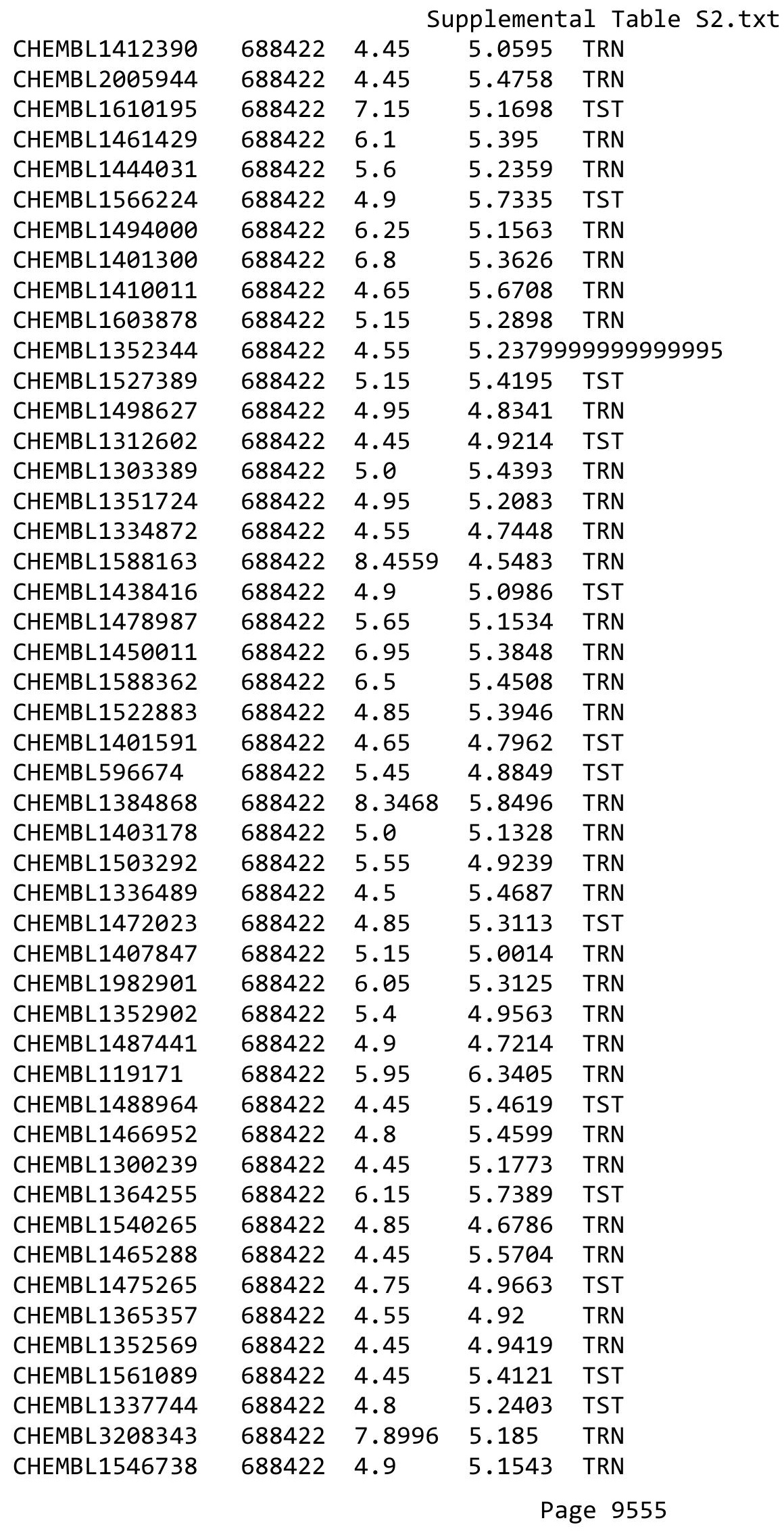




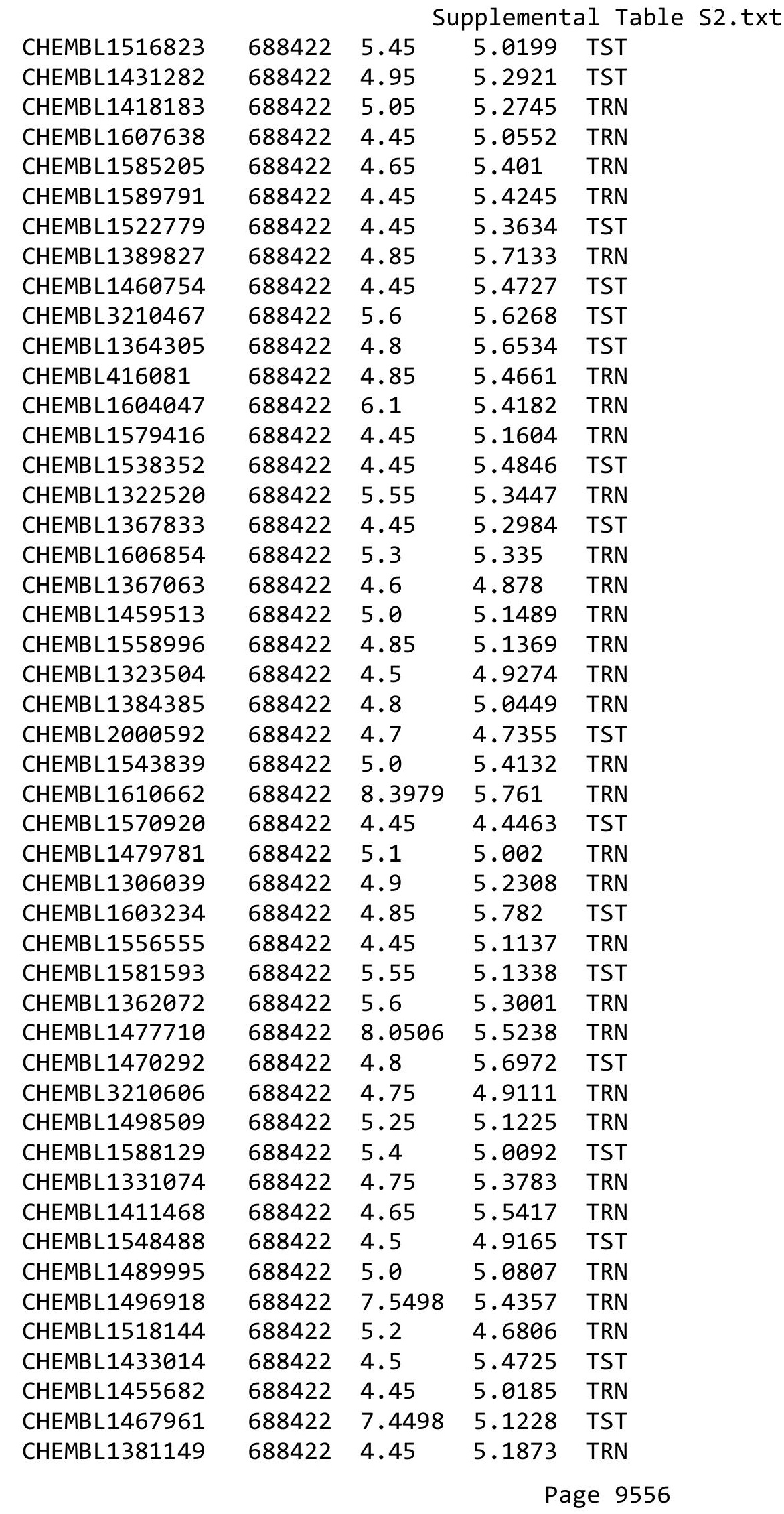




\begin{tabular}{|c|c|c|c|c|}
\hline \multicolumn{5}{|c|}{ Supplemental Table S2.txt } \\
\hline CHEMBL1494527 & 688422 & 4.7 & 5.2828 & TST \\
\hline CHEMBL1555912 & 688422 & 4.9 & 5.9644 & TRN \\
\hline CHEMBL1340873 & 688422 & 4.8 & 5.0801 & TST \\
\hline CHEMBL1448245 & 688422 & 7.4498 & 5.1367 & TRN \\
\hline CHEMBL1498265 & 688422 & 4.45 & 4.9559 & TRN \\
\hline CHEMBL1606022 & 688422 & 4.75 & 5.2369 & TRN \\
\hline CHEMBL1398171 & 688422 & 4.75 & 5.322 & TRN \\
\hline CHEMBL1354232 & 688422 & 4.45 & 5.1756 & TRN \\
\hline CHEMBL1515334 & 688422 & 5.4 & 5.343 & TRN \\
\hline CHEMBL1475564 & 688422 & 5.2 & 5.4907 & TST \\
\hline CHEMBL1429983 & 688422 & 4.65 & 5.6997 & TRN \\
\hline CHEMBL1587570 & 688422 & 4.45 & 5.3836 & TRN \\
\hline CHEMBL1503700 & 688422 & 4.75 & 5.0557 & TRN \\
\hline CHEMBL602632 & 688422 & 7.3497 & 5.329 & TST \\
\hline CHEMBL1422376 & 688422 & 4.95 & 5.2219 & TST \\
\hline CHEMBL 2006072 & 688422 & 4.65 & 5.3899 & TRN \\
\hline CHEMBL1353408 & 688422 & 6.0 & 5.0745 & TRN \\
\hline CHEMBL1441756 & 688422 & 4.8 & 5.0318 & TRN \\
\hline CHEMBL1376306 & 688422 & 4.95 & 5.3133 & TRN \\
\hline CHEMBL1393615 & 688422 & 5.45 & 4.8021 & TRN \\
\hline CHEMBL1322719 & 688422 & 5.75 & 5.6731 & TRN \\
\hline CHEMBL1477277 & 688422 & 4.5 & 5.1616 & TRN \\
\hline CHEMBL582073 & 688422 & 5.15 & 5.55 & TRN \\
\hline CHEMBL1521880 & 688422 & 5.2 & 5.2156 & TST \\
\hline CHEMBL1476941 & 688422 & 4.55 & 4.9933 & TRN \\
\hline CHEMBL1571838 & 688422 & 4.75 & 5.3255 & TRN \\
\hline CHEMBL1597323 & 688422 & 7.3497 & 5.4559 & TRN \\
\hline CHEMBL1425792 & 688422 & 4.7 & 5.3453 & TRN \\
\hline CHEMBL1553593 & 688422 & 5.5 & 5.2783 & TRN \\
\hline CHEMBL1549947 & 688422 & 5.55 & 5.2192 & TST \\
\hline CHEMBL1374172 & 688422 & 4.8 & 5.2237 & TRN \\
\hline CHEMBL1384706 & 688422 & 5.4 & 4.9805 & TST \\
\hline CHEMBL1456847 & 688422 & 4.8 & 4.9691 & TRN \\
\hline CHEMBL1531410 & 688422 & 4.45 & 4.91 & TRN \\
\hline CHEMBL 8145 & 688422 & 8.301 & 5.8258 & TRN \\
\hline CHEMBL1510724 & 688422 & 5.45 & 5.4202 & TST \\
\hline CHEMBL1345939 & 688422 & 4.85 & 5.2855 & TRN \\
\hline CHEMBL1507079 & 688422 & 7.5498 & 5.4753 & TRN \\
\hline CHEMBL328710 & 688422 & 4.55 & 5.2253 & TRN \\
\hline CHEMBL1307240 & 688422 & 4.65 & 4.9078 & TST \\
\hline CHEMBL1337921 & 688422 & 6.1 & 5.0647 & TRN \\
\hline CHEMBL1399837 & 688422 & 4.75 & 5.2896 & TRN \\
\hline CHEMBL1424299 & 688422 & 5.0 & 4.8459 & TRN \\
\hline CHEMBL1525877 & 688422 & 5.4 & 5.33 & TRN \\
\hline CHEMBL1384108 & 688422 & 4.65 & 5.2714 & TST \\
\hline CHEMBL1319490 & 688422 & 4.45 & 5.1821 & TST \\
\hline CHEMBL1555898 & 688422 & 4.9 & 4.9559 & TRN \\
\hline CHEMBL1563013 & 688422 & 5.0 & 5.3181 & TRN \\
\hline
\end{tabular}




\begin{tabular}{|c|c|c|c|c|}
\hline & & & pplement & al \\
\hline CHEMBL1584939 & 688422 & 4.65 & 4.7704 & TRN \\
\hline CHEMBL1420677 & 688422 & 4.95 & 5.0469 & TRN \\
\hline CHEMBL1343806 & 688422 & 4.5 & 4.8246 & TRN \\
\hline CHEMBL1348012 & 688422 & 4.45 & 5.6321 & TST \\
\hline CHEMBL1537470 & 688422 & 5.0 & 5.3474 & TRN \\
\hline CHEMBL1528533 & 688422 & 4.45 & 5.4613 & TRN \\
\hline CHEMBL1533024 & 688422 & 4.85 & 5.0871 & TRN \\
\hline CHEMBL1452944 & 688422 & 4.45 & 5.1542 & TRN \\
\hline CHEMBL1518282 & 688422 & 4.45 & 5.1338 & TRN \\
\hline CHEMBL1312447 & 688422 & 4.9 & 5.3927 & TRN \\
\hline CHEMBL1532867 & 688422 & 4.75 & 4.7059 & TRN \\
\hline CHEMBL1534822 & 688422 & 8.1487 & 5.8113 & TRN \\
\hline CHEMBL1470229 & 688422 & 4.95 & 5.1082 & TRN \\
\hline CHEMBL3197826 & 688422 & 5.0 & 5.1674 & TRN \\
\hline CHEMBL1353480 & 688422 & 5.5 & 5.3712 & TRN \\
\hline CHEMBL1432721 & 688422 & 5.5 & 5.1682 & TRN \\
\hline CHEMBL1528087 & 688422 & 4.45 & 5.1942 & TST \\
\hline CHEMBL1520133 & 688422 & 4.9 & 5.2396 & TST \\
\hline CHEMBL1569446 & 688422 & 5.25 & 5.1985 & TST \\
\hline CHEMBL474589 & 688422 & 6.6 & 5.0078 & TST \\
\hline CHEMBL1540919 & 688422 & 4.95 & 4.8174 & TRN \\
\hline CHEMBL549216 & 688422 & 4.85 & 5.0501 & TRN \\
\hline CHEMBL1582510 & 688422 & 4.9 & 5.3528 & TST \\
\hline CHEMBL1498308 & 688422 & 4.65 & 5.0254 & TRN \\
\hline CHEMBL1328635 & 688422 & 4.5 & 5.1938 & TRN \\
\hline CHEMBL1600495 & 688422 & 4.95 & 5.2885 & TRN \\
\hline CHEMBL1444133 & 688422 & 4.7 & 5.1896 & TRN \\
\hline CHEMBL1457993 & 688422 & 4.85 & 5.2312 & TRN \\
\hline CHEMBL1965461 & 688422 & 5.1 & 5.3187 & TST \\
\hline CHEMBL472760 & 688422 & 4.8 & 5.0768 & TRN \\
\hline CHEMBL1371908 & 688422 & 4.45 & 5.8776 & TST \\
\hline CHEMBL1588859 & 688422 & 4.45 & 4.6428 & TRN \\
\hline CHEMBL1329033 & 688422 & 4.95 & 5.0571 & TST \\
\hline CHEMBL1492073 & 688422 & 4.85 & 5.166 & TRN \\
\hline CHEMBL1513432 & 688422 & 6.8 & 5.19 & TRN \\
\hline CHEMBL1394404 & 688422 & 5.85 & 5.0326 & TST \\
\hline CHEMBL1448982 & 688422 & 5.25 & 5.0818 & TRN \\
\hline CHEMBL1364394 & 688422 & 4.45 & 5.2887 & TST \\
\hline CHEMBL1480759 & 688422 & 5.05 & 5.3506 & TRN \\
\hline CHEMBL1506446 & 688422 & 5.15 & 5.3943 & TRN \\
\hline CHEMBL1983229 & 688422 & 5.2 & 5.2548 & TRN \\
\hline CHEMBL1427602 & 688422 & 4.95 & 4.8566 & TRN \\
\hline CHEMBL1540305 & 688422 & 4.9 & 4.7424 & TRN \\
\hline CHEMBL1384700 & 688422 & 5.0 & 5.3247 & TRN \\
\hline CHEMBL1338292 & 688422 & 6.5 & 4.9704 & TRN \\
\hline CHEMBL1466860 & 688422 & 4.65 & 5.33 & TRN \\
\hline CHEMBL149272 & 688422 & 6.4 & 5.4602 & TST \\
\hline CHEMBL1552630 & 688422 & 6.05 & 6.1104 & TRN \\
\hline
\end{tabular}




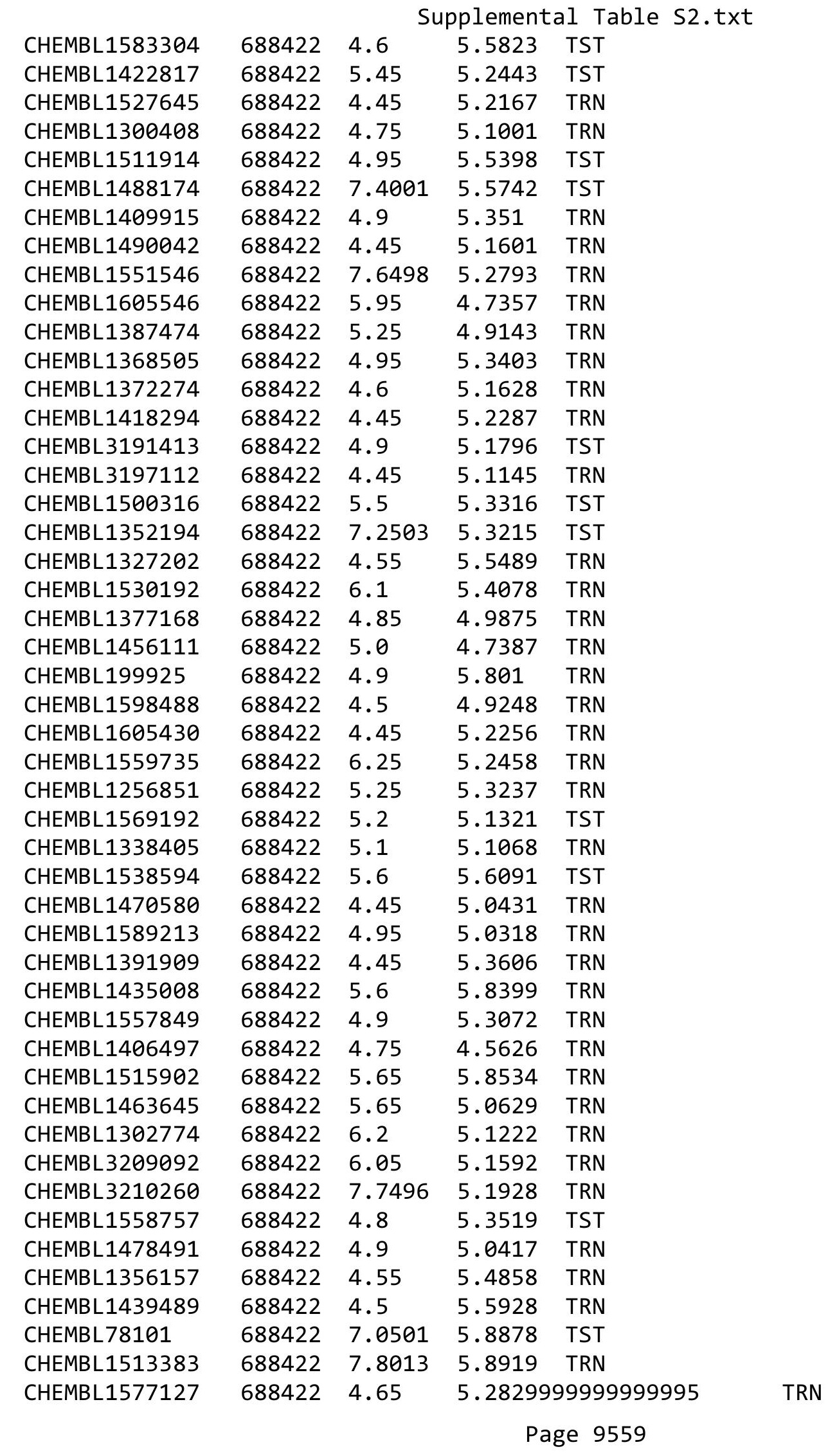




\begin{tabular}{|c|c|c|c|c|c|}
\hline \multicolumn{6}{|c|}{ Supplemental Table s2.txt } \\
\hline CHEMBL1583682 & 688422 & 4.45 & 5.5823 & TST & \\
\hline CHEMBL1370668 & 688422 & 5.25 & 5.3852 & TRN & \\
\hline CHEMBL1416518 & 688422 & 8.4949 & 5.4795 & TRN & \\
\hline CHEMBL1516233 & 688422 & 4.8 & 5.6409 & TRN & \\
\hline CHEMBL1327861 & 688422 & 5.3 & 5.1845 & TRN & \\
\hline CHEMBL1312130 & 688422 & 4.45 & 4.7459 & TRN & \\
\hline CHEMBL1328895 & 688422 & 4.8 & 5.2309 & TRN & \\
\hline CHEMBL1406350 & 688422 & 4.45 & 4.9902 & TRN & \\
\hline CHEMBL1419235 & 688422 & 4.65 & 5.1393 & TRN & \\
\hline CHEMBL1419137 & 688422 & 5.0 & 4.9899 & TRN & \\
\hline CHEMBL1460225 & 688422 & 5.9 & 5.1681 & TRN & \\
\hline CHEMBL1502707 & 688422 & 5.1 & 5.2285 & TRN & \\
\hline CHEMBL1483161 & 688422 & 4.6 & 4.9673 & TRN & \\
\hline CHEMBL1996867 & 688422 & 4.45 & 4.8887 & TST & \\
\hline CHEMBL3189916 & 688422 & 4.75 & 5.3284 & TRN & \\
\hline CHEMBL1523439 & 688422 & 5.2 & 5.7057 & TST & \\
\hline CHEMBL1586445 & 688422 & 5.65 & 5.2216 & TRN & \\
\hline CHEMBL1312285 & 688422 & 7.6003 & 5.1709 & TST & \\
\hline CHEMBL1333157 & 688422 & 4.7 & 5.1952 & TRN & \\
\hline CHEMBL1571045 & 688422 & 4.75 & 5.3281 & TRN & \\
\hline CHEMBL1362371 & 688422 & 5.5 & 5.3412 & TRN & \\
\hline CHEMBL1545873 & 688422 & 4.85 & 5.1829 & TRN & \\
\hline CHEMBL1536585 & 688422 & 4.45 & 5.0354 & TST & \\
\hline CHEMBL1543386 & 688422 & 5.0 & 5.1401 & TRN & \\
\hline CHEMBL1363461 & 688422 & 5.35 & 5.2231 & TRN & \\
\hline CHEMBL1593849 & 688422 & 5.35 & 5.4169 & TRN & \\
\hline CHEMBL1587804 & 688422 & 4.7 & 5.2613 & TRN & \\
\hline CHEMBL1342657 & 688422 & 4.8 & 5.2312 & TST & \\
\hline CHEMBL1317333 & 688422 & 6.25 & 5.3342 & TRN & \\
\hline CHEMBL1460283 & 688422 & 4.45 & 5.3478 & TRN & \\
\hline CHEMBL1489876 & 688422 & 4.45 & 5.5816 & TST & \\
\hline CHEMBL3192010 & 688422 & 4.6 & 5.2373 & TRN & \\
\hline CHEMBL1379812 & 688422 & 4.95 & 5.0907 & TRN & \\
\hline CHEMBL1594254 & 688422 & 4.75 & 4.827 & TRN & \\
\hline CHEMBL1602465 & 688422 & 5.0 & 5.6486 & TRN & \\
\hline CHEMBL1567248 & 688422 & 6.5501 & 4.7575 & TRN & \\
\hline CHEMBL1493811 & 688422 & 4.6 & 4.8475 & TRN & \\
\hline CHEMBL1532623 & 688422 & 4.45 & 5.1303 & TRN & \\
\hline CHEMBL1330247 & 688422 & 4.45 & 5.2765 & TRN & \\
\hline CHEMBL1403333 & 688422 & 4.45 & 4.9885 & TRN & \\
\hline CHEMBL3196472 & 688422 & 6.05 & 5.2742 & TST & \\
\hline CHEMBL1461118 & 688422 & 4.7 & 4.8222 & TRN & \\
\hline CHEMBL1453689 & 688422 & 4.6 & 4.6123 & TRN & \\
\hline CHEMBL3213064 & 688422 & 5.4 & 5.5396 & TRN & \\
\hline CHEMBL1458430 & 688422 & 4.75 & 5.20700 & 3000000001 & TRN \\
\hline CHEMBL1369297 & 688422 & 4.9 & 5.2311 & TRN & \\
\hline CHEMBL1454256 & 688422 & 4.95 & 5.05699 & 99999999995 & TST \\
\hline CHEMBL1424294 & 688422 & 4.45 & 5.0895 & TRN & \\
\hline
\end{tabular}




\begin{tabular}{|c|c|c|c|c|}
\hline \multicolumn{5}{|c|}{ Supplemental Table S2.txt } \\
\hline CHEMBL1552651 & 688422 & 4.85 & 5.2008 & TRN \\
\hline CHEMBL1451445 & 688422 & 4.9 & 5.24200 & 0000000001 \\
\hline CHEMBL1386933 & 688422 & 6.95 & 5.2316 & TRN \\
\hline CHEMBL1463401 & 688422 & 4.45 & 4.6982 & TRN \\
\hline CHEMBL1460289 & 688422 & 4.95 & 5.2955 & TRN \\
\hline CHEMBL1323697 & 688422 & 4.8 & 5.4548 & TRN \\
\hline CHEMBL1558389 & 688422 & 4.7 & 5.0469 & TST \\
\hline CHEMBL1531550 & 688422 & 5.0 & 5.0251 & TRN \\
\hline CHEMBL1520691 & 688422 & 8.0 & 5.5943 & TRN \\
\hline CHEMBL1454532 & 688422 & 4.45 & 5.0933 & TRN \\
\hline CHEMBL1529299 & 688422 & 4.8 & 4.9506 & TRN \\
\hline CHEMBL1316885 & 688422 & 4.5 & 5.4616 & TRN \\
\hline CHEMBL1448705 & 688422 & 4.9 & 5.1218 & TRN \\
\hline CHEMBL1446037 & 688422 & 5.55 & 5.1779 & TRN \\
\hline CHEMBL1538493 & 688422 & 4.8 & 5.5024 & TRN \\
\hline CHEMBL1409089 & 688422 & 4.85 & 5.4521 & TRN \\
\hline CHEMBL3198406 & 688422 & 7.8508 & 5.303 & TRN \\
\hline CHEMBL1496971 & 688422 & 4.6 & 5.2743 & TST \\
\hline CHEMBL1328699 & 688422 & 4.8 & 5.1262 & TST \\
\hline CHEMBL448602 & 688422 & 4.85 & 5.6087 & TRN \\
\hline CHEMBL1345273 & 688422 & 4.45 & 5.4254 & TRN \\
\hline CHEMBL1473845 & 688422 & 5.2 & 5.3053 & TRN \\
\hline CHEMBL1360375 & 688422 & 4.85 & 5.0241 & TRN \\
\hline CHEMBL1994257 & 688422 & 5.4 & 5.313 & TRN \\
\hline CHEMBL1584364 & 688422 & 4.95 & 5.3585 & TRN \\
\hline CHEMBL1420800 & 688422 & 4.9 & 4.8898 & TRN \\
\hline CHEMBL1412744 & 688422 & 5.3 & 5.311 & TST \\
\hline CHEMBL3213825 & 688422 & 6.0 & 5.1819 & TRN \\
\hline CHEMBL1542748 & 688422 & 5.55 & 5.4957 & TRN \\
\hline CHEMBL1301796 & 688422 & 4.65 & 4.9288 & TRN \\
\hline CHEMBL1571224 & 688422 & 4.95 & 5.0306 & TRN \\
\hline CHEMBL1556657 & 688422 & 4.7 & 4.8088 & TRN \\
\hline CHEMBL1557479 & 688422 & 4.75 & 5.4734 & TRN \\
\hline CHEMBL1301176 & 688422 & 5.1 & 5.2936 & TST \\
\hline CHEMBL1303653 & 688422 & 5.25 & 5.0375 & TRN \\
\hline CHEMBL1454802 & 688422 & 4.9 & 5.2518 & TRN \\
\hline CHEMBL1610768 & 688422 & 4.65 & 5.4685 & TRN \\
\hline CHEMBL1385823 & 688422 & 6.15 & 5.4476 & TRN \\
\hline CHEMBL1303077 & 688422 & 4.75 & 5.3039 & TRN \\
\hline CHEMBL1339706 & 688422 & 4.9 & 5.2212 & TRN \\
\hline CHEMBL1342907 & 688422 & 4.9 & 4.8359 & TRN \\
\hline CHEMBL1526008 & 688422 & 5.0 & 5.037 & TRN \\
\hline CHEMBL1501167 & 688422 & 5.8 & 5.186 & TRN \\
\hline CHEMBL1536598 & 688422 & 4.65 & 5.0886 & TRN \\
\hline CHEMBL1388489 & 688422 & 4.45 & 4.8799 & TRN \\
\hline CHEMBL1381656 & 688422 & 7.6498 & 5.4003 & TRN \\
\hline CHEMBL1385329 & 688422 & 4.7 & 4.8885 & TRN \\
\hline CHEMBL1398955 & 688422 & 4.9 & 5.2282 & TRN \\
\hline
\end{tabular}




\begin{tabular}{|c|c|c|c|c|}
\hline \multicolumn{5}{|c|}{ Supplemental Table S2.txt } \\
\hline CHEMBL1490707 & 688422 & 5.05 & 5.0052 & TRN \\
\hline CHEMBL1321515 & 688422 & 4.85 & 4.9513 & TRN \\
\hline CHEMBL1399097 & 688422 & 4.5 & 4.9934 & TRN \\
\hline CHEMBL1546598 & 688422 & 4.85 & 5.4422 & TST \\
\hline CHEMBL 3856088 & 688422 & 4.45 & 5.3216 & TRN \\
\hline CHEMBL1313081 & 688422 & 4.45 & 5.1219 & TST \\
\hline CHEMBL1584396 & 688422 & 4.45 & 5.2517 & TST \\
\hline CHEMBL1582111 & 688422 & 4.45 & 5.1297 & TST \\
\hline CHEMBL1334111 & 688422 & 7.2 & 5.7679 & TRN \\
\hline CHEMBL1383713 & 688422 & 4.75 & 4.9225 & TRN \\
\hline CHEMBL1367120 & 688422 & 4.8 & 5.1887 & TRN \\
\hline CHEMBL1612286 & 688422 & 5.6 & 5.3847 & TRN \\
\hline CHEMBL1572191 & 688422 & 4.65 & 4.8624 & TRN \\
\hline CHEMBL1498882 & 688422 & 4.45 & 5.0365 & TRN \\
\hline CHEMBL1365889 & 688422 & 4.75 & 5.2796 & TRN \\
\hline CHEMBL1327647 & 688422 & 4.45 & 5.3449 & TST \\
\hline CHEMBL3208625 & 688422 & 5.4 & 6.0226 & TST \\
\hline CHEMBL3210917 & 688422 & 4.8 & 5.1416 & TRN \\
\hline CHEMBL1350749 & 688422 & 4.9 & 4.8958 & TRN \\
\hline CHEMBL3199896 & 688422 & 5.3 & 5.1174 & TRN \\
\hline CHEMBL3198822 & 688422 & 4.5 & 5.1195 & TRN \\
\hline CHEMBL1446722 & 688422 & 4.45 & 5.2238 & TRN \\
\hline CHEMBL1410497 & 688422 & 5.1 & 4.9782 & TRN \\
\hline CHEMBL1483785 & 688422 & 6.5 & 5.5609 & TRN \\
\hline CHEMBL1443686 & 688422 & 4.45 & 4.7881 & TRN \\
\hline CHEMBL1612681 & 688422 & 5.0 & 5.3306 & TRN \\
\hline CHEMBL1508591 & 688422 & 4.45 & 4.8037 & TRN \\
\hline CHEMBL3211881 & 688422 & 5.2 & 5.3377 & TRN \\
\hline CHEMBL1506414 & 688422 & 4.65 & 5.6359 & TST \\
\hline CHEMBL1417340 & 688422 & 5.5 & 5.0605 & TRN \\
\hline CHEMBL1346474 & 688422 & 5.05 & 5.0087 & TRN \\
\hline CHEMBL1471671 & 688422 & 4.45 & 4.9199 & TRN \\
\hline CHEMBL1415204 & 688422 & 4.9 & 5.7149 & TST \\
\hline CHEMBL1978773 & 688422 & 5.45 & 4.9443 & TRN \\
\hline CHEMBL1468415 & 688422 & 4.9 & 5.1282 & TRN \\
\hline CHEMBL1389720 & 688422 & 5.05 & 5.5595 & TRN \\
\hline CHEMBL 1408712 & 688422 & 5.0 & 5.1805 & TRN \\
\hline CHEMBL1528795 & 688422 & 4.9 & 5.1047 & TRN \\
\hline CHEMBL1446277 & 688422 & 4.45 & 4.8436 & TRN \\
\hline CHEMBL1466423 & 688422 & 4.5 & 5.3087 & TST \\
\hline CHEMBL1425512 & 688422 & 4.5 & 5.2736 & TRN \\
\hline CHEMBL 1384350 & 688422 & 4.75 & 5.1106 & TRN \\
\hline CHEMBL1362966 & 688422 & 4.8 & 5.019 & TST \\
\hline CHEMBL1521260 & 688422 & 4.85 & 5.0792 & TRN \\
\hline CHEMBL1305951 & 688422 & 4.65 & 5.3887 & TST \\
\hline CHEMBL1404527 & 688422 & 4.85 & 5.0935 & TRN \\
\hline CHEMBL1559733 & 688422 & 6.35 & 5.6776 & TRN \\
\hline CHEMBL1608535 & 688422 & 5.55 & 5.3402 & TRN \\
\hline
\end{tabular}





\begin{tabular}{|c|c|c|c|c|c|}
\hline \multicolumn{6}{|c|}{ Supplemental Table S2.txt } \\
\hline CHEMBL1441601 & 688422 & 5.4 & 5.6642 & TST & \\
\hline CHEMBL1363629 & 688422 & 4.6 & 5.2481 & TRN & \\
\hline CHEMBL1362724 & 688422 & 4.7 & 4.9421 & TRN & \\
\hline CHEMBL1400463 & 688422 & 4.85 & 5.1815 & TRN & \\
\hline CHEMBL3208929 & 688422 & 6.4 & 5.6666 & TST & \\
\hline CHEMBL1490071 & 688422 & 4.45 & 5.6885 & TRN & \\
\hline CHEMBL1587018 & 688422 & 4.7 & 5.3913 & TST & \\
\hline CHEMBL1344500 & 688422 & 4.45 & 5.184 & TRN & \\
\hline CHEMBL1504940 & 688422 & 6.7501 & 5.5161 & TRN & \\
\hline CHEMBL1424068 & 688422 & 4.45 & 5.1168 & TRN & \\
\hline CHEMBL1579173 & 688422 & 4.75 & 4.9985 & TST & \\
\hline CHEMBL1558377 & 688422 & 5.0 & 5.1342 & TRN & \\
\hline CHEMBL1323437 & 688422 & 5.7 & 5.4066 & TRN & \\
\hline CHEMBL595700 & 688422 & 4.95 & 4.7623 & TRN & \\
\hline CHEMBL3195203 & 688422 & 4.45 & 5.5003 & TRN & \\
\hline CHEMBL1527599 & 688422 & 4.5 & 5.3 & TRN & \\
\hline CHEMBL1523589 & 688422 & 4.85 & 6.4214 & TRN & \\
\hline CHEMBL1972346 & 688422 & 7.2503 & 5.5434 & TRN & \\
\hline CHEMBL1432001 & 688422 & 6.6 & 4.994 & TRN & \\
\hline CHEMBL1352472 & 688422 & 4.95 & 5.2515 & TST & \\
\hline CHEMBL1320504 & 688422 & 4.9 & 5.296 & TRN & \\
\hline CHEMBL1523513 & 688422 & 4.7 & 4.9453 & TRN & \\
\hline CHEMBL1341196 & 688422 & 4.5 & 5.0246 & TRN & \\
\hline CHEMBL1529332 & 688422 & 4.9 & 5.1987 & TRN & \\
\hline CHEMBL1401935 & 688422 & 4.45 & 5.6257 & TST & \\
\hline CHEMBL 2369200 & 688422 & 4.5 & 4.85800 & 00000000005 & TRN \\
\hline CHEMBL1353704 & 688422 & 5.0 & 5.3179 & TRN & \\
\hline CHEMBL1538990 & 688422 & 8.0506 & 5.5572 & TST & \\
\hline CHEMBL1313942 & 688422 & 4.95 & 5.5731 & TRN & \\
\hline CHEMBL3193771 & 688422 & 8.301 & 5.4033 & TRN & \\
\hline CHEMBL1517045 & 688422 & 4.8 & 5.1434 & TRN & \\
\hline CHEMBL1393830 & 688422 & 4.55 & 4.8126 & TRN & \\
\hline CHEMBL1458827 & 688422 & 6.9 & 5.4374 & TRN & \\
\hline CHEMBL1304831 & 688422 & 4.45 & 5.0759 & TRN & \\
\hline CHEMBL1404206 & 688422 & 5.35 & 4.863 & TRN & \\
\hline CHEMBL1577293 & 688422 & 5.15 & 5.16799 & 9999999999 & TRN \\
\hline CHEMBL1308088 & 688422 & 4.9 & 5.42899 & 9999999999 & TRN \\
\hline CHEMBL1500719 & 688422 & 4.85 & 4.6987 & TRN & \\
\hline CHEMBL1363782 & 688422 & 6.45 & 5.6057 & TST & \\
\hline CHEMBL1383278 & 688422 & 5.1 & 5.9869 & TST & \\
\hline CHEMBL1310886 & 688422 & 5.0 & 5.2329 & TRN & \\
\hline CHEMBL1547831 & 688422 & 4.95 & 5.4545 & TRN & \\
\hline CHEMBL1390100 & 688422 & 5.35 & 5.2226 & TST & \\
\hline CHEMBL3194454 & 688422 & 4.6 & 5.294 & TRN & \\
\hline CHEMBL1577981 & 688422 & 4.45 & 4.9196 & TRN & \\
\hline CHEMBL1307081 & 688422 & 4.65 & 4.9612 & TRN & \\
\hline CHEMBL1526511 & 688422 & 7.699 & 4.9599 & TST & \\
\hline CHEMBL1557585 & 688422 & 4.9 & 5.1757 & TST & \\
\hline
\end{tabular}




\begin{tabular}{|c|c|c|c|c|}
\hline \multicolumn{5}{|c|}{ Supplemental Table S2.txt } \\
\hline CHEMBL1442849 & 688422 & 4.7 & 5.3928 & TRN \\
\hline CHEMBL1489473 & 688422 & 4.5 & 5.0244 & TRN \\
\hline CHEMBL1200450 & 688422 & 6.0 & 5.6686 & TST \\
\hline CHEMBL1493942 & 688422 & 5.25 & 5.4839 & TST \\
\hline CHEMBL1583185 & 688422 & 7.699 & 5.5333 & TRN \\
\hline CHEMBL1431983 & 688422 & 5.0 & 4.9557 & TRN \\
\hline CHEMBL1585710 & 688422 & 7.6498 & 5.5517 & TST \\
\hline CHEMBL1468340 & 688422 & 4.65 & 5.2664 & TRN \\
\hline CHEMBL1561248 & 688422 & 4.8 & 5.443 & TRN \\
\hline CHEMBL1427976 & 688422 & 4.85 & 4.9931 & TRN \\
\hline CHEMBL1484545 & 688422 & 6.6499 & 5.2414 & TRN \\
\hline CHEMBL1989760 & 688422 & 4.85 & 5.636 & TRN \\
\hline CHEMBL3199023 & 688422 & 6.5501 & 5.2072 & TST \\
\hline CHEMBL1465416 & 688422 & 4.85 & 4.9343 & TRN \\
\hline CHEMBL1592227 & 688422 & 4.85 & 4.7017 & TRN \\
\hline CHEMBL1591263 & 688422 & 5.25 & 5.2905 & TRN \\
\hline CHEMBL1570716 & 688422 & 4.95 & 5.0809 & TRN \\
\hline CHEMBL3196973 & 688422 & 6.05 & 5.3847 & TRN \\
\hline CHEMBL1406073 & 688422 & 4.8 & 5.5713 & TRN \\
\hline CHEMBL1417004 & 688422 & 5.45 & 4.8495 & TRN \\
\hline CHEMBL1388874 & 688422 & 4.45 & 5.0679 & TRN \\
\hline CHEMBL1332427 & 688422 & 4.45 & 5.893 & TST \\
\hline CHEMBL1974937 & 688422 & 4.5 & 5.2767 & TRN \\
\hline CHEMBL1445800 & 688422 & 4.45 & 4.8286 & TRN \\
\hline CHEMBL1452795 & 688422 & 5.55 & 5.9597 & TST \\
\hline CHEMBL1395063 & 688422 & 7.4001 & 5.4647 & TRN \\
\hline CHEMBL1485218 & 688422 & 5.1 & 5.0968 & TRN \\
\hline CHEMBL3214476 & 688422 & 5.55 & 5.1457 & TRN \\
\hline CHEMBL1381388 & 688422 & 7.5003 & 5.4324 & TST \\
\hline CHEMBL1497826 & 688422 & 6.7001 & 5.5186 & TRN \\
\hline CHEMBL3208046 & 688422 & 5.3 & 5.1197 & TST \\
\hline CHEMBL597744 & 688422 & 4.45 & 5.1927 & TRN \\
\hline CHEMBL1303823 & 688422 & 6.5 & 5.5116 & TST \\
\hline CHEMBL1300724 & 688422 & 5.0 & 5.0774 & TST \\
\hline CHEMBL1509220 & 688422 & 6.3 & 5.3105 & TST \\
\hline CHEMBL1556650 & 688422 & 4.45 & 5.1852 & TRN \\
\hline CHEMBL1468271 & 688422 & 5.1 & 5.1306 & TRN \\
\hline CHEMBL1314220 & 688422 & 4.45 & 5.3667 & TST \\
\hline CHEMBL1523358 & 688422 & 7.8508 & 5.2282 & TRN \\
\hline CHEMBL1334541 & 688422 & 4.8 & 5.4165 & TRN \\
\hline CHEMBL3214273 & 688422 & 4.5 & 5.3036 & TRN \\
\hline CHEMBL1591727 & 688422 & 5.0 & 4.8836 & TRN \\
\hline CHEMBL3197065 & 688422 & 5.05 & 4.9761 & TRN \\
\hline CHEMBL1418101 & 688422 & 4.55 & 5.1229 & TRN \\
\hline CHEMBL 3214580 & 688422 & 4.8 & 5.4083 & TRN \\
\hline CHEMBL1597293 & 688422 & 4.95 & 5.2207 & TRN \\
\hline CHEMBL1537318 & 688422 & 5.25 & 5.0133 & TST \\
\hline CHEMBL1592539 & 688422 & 7.4498 & 5.4224 & TRN \\
\hline
\end{tabular}




\begin{tabular}{|c|c|c|c|c|c|}
\hline \multicolumn{6}{|c|}{ Supplemental Table S2.txt } \\
\hline CHEMBL1316171 & 688422 & 5.4 & 5.2168 & TRN & \\
\hline CHEMBL1448533 & 688422 & 5.05 & 5.2803 & TST & \\
\hline CHEMBL3197489 & 688422 & 4.45 & 4.795 & TRN & \\
\hline CHEMBL1530389 & 688422 & 4.65 & 5.3368 & TRN & \\
\hline CHEMBL1368371 & 688422 & 4.45 & 4.8855 & TRN & \\
\hline CHEMBL1338236 & 688422 & 4.45 & 4.974 & TRN & \\
\hline CHEMBL1494196 & 688422 & 4.85 & 5.1417 & TRN & \\
\hline CHEMBL1432927 & 688422 & 4.6 & 4.9488 & TRN & \\
\hline CHEMBL1611575 & 688422 & 4.45 & 5.222 & TST & \\
\hline CHEMBL1531820 & 688422 & 4.95 & 5.1392 & TRN & \\
\hline CHEMBL1483558 & 688422 & 8.5528 & 5.4983 & TRN & \\
\hline CHEMBL1313460 & 688422 & 5.4 & 5.2663 & TRN & \\
\hline CHEMBL1364651 & 688422 & 7.4498 & 5.2501 & TRN & \\
\hline CHEMBL1583155 & 688422 & 4.7 & 5.55399 & 9999999999 & TST \\
\hline CHEMBL1431587 & 688422 & 4.85 & 5.6077 & TRN & \\
\hline CHEMBL1519636 & 688422 & 4.75 & 5.3375 & TST & \\
\hline CHEMBL1427716 & 688422 & 5.0 & 5.142 & TRN & \\
\hline CHEMBL1605286 & 688422 & 8.7447 & 5.7478 & TST & \\
\hline CHEMBL1465159 & 688422 & 5.35 & 4.6787 & TRN & \\
\hline CHEMBL1561928 & 688422 & 4.85 & 5.1088 & TST & \\
\hline CHEMBL1538274 & 688422 & 8.301 & 5.4937 & TRN & \\
\hline CHEMBL1548023 & 688422 & 6.5 & 5.625 & TRN & \\
\hline CHEMBL1516674 & 688422 & 4.4 & 5.1857 & TRN & \\
\hline CHEMBL1384651 & 688422 & 4.45 & 5.1468 & TRN & \\
\hline CHEMBL1434822 & 688422 & 8.4949 & 5.921 & TRN & \\
\hline CHEMBL1531073 & 688422 & 5.25 & 5.0961 & TRN & \\
\hline CHEMBL3198356 & 688422 & 4.9 & 4.9154 & TRN & \\
\hline CHEMBL1600752 & 688422 & 4.45 & 5.1839 & TRN & \\
\hline CHEMBL1366879 & 688422 & 5.3 & 4.9429 & TRN & \\
\hline CHEMBL1608026 & 688422 & 5.6 & 5.5554 & TRN & \\
\hline CHEMBL1383066 & 688422 & 4.9 & 4.8855 & TRN & \\
\hline CHEMBL1496007 & 688422 & 5.25 & 5.0339 & TRN & \\
\hline CHEMBL1446866 & 688422 & 5.05 & 5.073 & TRN & \\
\hline CHEMBL1361125 & 688422 & 4.65 & 4.8644 & TRN & \\
\hline CHEMBL1608078 & 688422 & 4.75 & 5.1724 & TRN & \\
\hline CHEMBL45244 & 688422 & 5.1 & 5.5085 & TRN & \\
\hline CHEMBL1360086 & 688422 & 4.8 & 5.1375 & TRN & \\
\hline CHEMBL1466757 & 688422 & 7.6498 & 5.7198 & TRN & \\
\hline CHEMBL1389622 & 688422 & 5.6 & 5.4637 & TRN & \\
\hline CHEMBL1452045 & 688422 & 5.05 & 4.8824 & TRN & \\
\hline CHEMBL1414036 & 688422 & 4.5 & 5.1599 & TST & \\
\hline CHEMBL1534621 & 688422 & 8.4559 & 5.4445 & TRN & \\
\hline CHEMBL3196459 & 688422 & 4.65 & 4.9995 & TRN & \\
\hline CHEMBL1406933 & 688422 & 4.95 & 5.5158 & TST & \\
\hline CHEMBL1533679 & 688422 & 5.25 & 5.3666 & TST & \\
\hline CHEMBL1516857 & 688422 & 5.4 & 5.015 & TRN & \\
\hline CHEMBL1454616 & 688422 & 5.05 & 5.1054 & TRN & \\
\hline CHEMBL1385661 & 688422 & 4.8 & 5.0185 & TRN & \\
\hline
\end{tabular}




\begin{tabular}{|c|c|c|c|c|c|}
\hline \multicolumn{6}{|c|}{ Supplemental Table S2.txt } \\
\hline CHEMBL1995769 & 688422 & 5.3 & 5.3057 & TRN & \\
\hline CHEMBL1402629 & 688422 & 5.25 & 4.7917 & TRN & \\
\hline CHEMBL1569631 & 688422 & 4.45 & 5.50899 & 99999999995 & TST \\
\hline CHEMBL1502980 & 688422 & 4.9 & 5.0278 & TRN & \\
\hline CHEMBL1505283 & 688422 & 4.85 & 5.114 & TRN & \\
\hline CHEMBL3196248 & 688422 & 4.45 & 5.3265 & TRN & \\
\hline CHEMBL1454110 & 688422 & 6.8499 & 5.4017 & TRN & \\
\hline CHEMBL1416684 & 688422 & 4.45 & 5.1398 & TRN & \\
\hline CHEMBL1329599 & 688422 & 4.75 & 5.1967 & TRN & \\
\hline CHEMBL1391599 & 688422 & 5.15 & 5.5087 & TRN & \\
\hline CHEMBL1335100 & 688422 & 6.5 & 5.3264 & TRN & \\
\hline CHEMBL1385834 & 688422 & 4.85 & 5.1185 & TRN & \\
\hline CHEMBL1469660 & 688422 & 4.95 & 5.3859 & TRN & \\
\hline CHEMBL1558866 & 688422 & 5.0 & 5.2373 & TST & \\
\hline CHEMBL1362191 & 688422 & 6.95 & 5.3854 & TST & \\
\hline CHEMBL1373827 & 688422 & 4.95 & 5.0907 & TRN & \\
\hline CHEMBL1301448 & 688422 & 4.5 & 5.2025 & TRN & \\
\hline CHEMBL1609711 & 688422 & 4.9 & 5.38299 & 9999999999 & TRN \\
\hline CHEMBL1442136 & 688422 & 5.5 & 4.6861 & TST & \\
\hline CHEMBL1497117 & 688422 & 4.65 & 5.3432 & TST & \\
\hline CHEMBL1329428 & 688422 & 4.65 & 5.0216 & TRN & \\
\hline CHEMBL584074 & 688422 & 4.85 & 4.9524 & TRN & \\
\hline CHEMBL1439497 & 688422 & 7.0501 & 5.697 & TST & \\
\hline CHEMBL1483593 & 688422 & 6.95 & 5.1762 & TRN & \\
\hline CHEMBL3189814 & 688422 & 4.5 & 5.0251 & TRN & \\
\hline CHEMBL1523016 & 688422 & 4.45 & 5.3056 & TRN & \\
\hline CHEMBL1342709 & 688422 & 5.0 & 5.4521 & TRN & \\
\hline CHEMBL1406689 & 688422 & 5.4 & 5.1242 & TRN & \\
\hline CHEMBL1303699 & 688422 & 5.0 & 5.3611 & TRN & \\
\hline CHEMBL1397643 & 688422 & 4.5 & 5.831 & TST & \\
\hline CHEMBL1333893 & 688422 & 5.45 & 5.1256 & TRN & \\
\hline CHEMBL 2028085 & 688422 & 5.2 & 5.4688 & TST & \\
\hline CHEMBL1401136 & 688422 & 5.1 & 5.2964 & TRN & \\
\hline CHEMBL1456386 & 688422 & 4.4 & 5.7459 & TST & \\
\hline CHEMBL1365985 & 688422 & 4.85 & 5.0568 & TRN & \\
\hline CHEMBL1470497 & 688422 & 4.6 & 5.3445 & TRN & \\
\hline CHEMBL1514854 & 688422 & 6.95 & 5.3204 & TRN & \\
\hline CHEMBL1525807 & 688422 & 4.8 & 5.2956 & TRN & \\
\hline CHEMBL1498555 & 688422 & 4.65 & 5.0957 & TRN & \\
\hline CHEMBL1472712 & 688422 & 4.45 & 5.0237 & TRN & \\
\hline CHEMBL1453956 & 688422 & 4.6 & 5.16200 & 0000000001 & TRN \\
\hline CHEMBL1458819 & 688422 & 4.45 & 5.3257 & TRN & \\
\hline CHEMBL1404811 & 688422 & 7.5498 & 5.5211 & TRN & \\
\hline CHEMBL1390484 & 688422 & 4.45 & 5.0047 & TST & \\
\hline CHEMBL1445010 & 688422 & 4.85 & 5.1738 & TRN & \\
\hline CHEMBL1359720 & 688422 & 4.9 & 5.3325 & TRN & \\
\hline CHEMBL1567927 & 688422 & 4.9 & 4.9716 & TRN & \\
\hline CHEMBL3194097 & 688422 & 5.05 & 5.0176 & TRN & \\
\hline
\end{tabular}




\begin{tabular}{|c|c|c|c|c|c|}
\hline \multicolumn{6}{|c|}{ Supplemental Table S2.txt } \\
\hline CHEMBL1400924 & 688422 & 4.65 & 5.0275 & TRN & \\
\hline CHEMBL1439401 & 688422 & 4.85 & 4.5839 & TRN & \\
\hline CHEMBL1568148 & 688422 & 5.6 & 5.0438 & TRN & \\
\hline CHEMBL1548716 & 688422 & 5.85 & 5.1311 & TRN & \\
\hline CHEMBL3194961 & 688422 & 7.1002 & 5.5181 & TST & \\
\hline CHEMBL1457058 & 688422 & 4.7 & 5.2212 & TST & \\
\hline CHEMBL1377095 & 688422 & 4.7 & 5.0775 & TRN & \\
\hline CHEMBL1414291 & 688422 & 4.5 & 5.2236 & TRN & \\
\hline CHEMBL1545652 & 688422 & 5.35 & 5.2899 & TRN & \\
\hline CHEMBL1378428 & 688422 & 5.5 & 5.2626 & TRN & \\
\hline CHEMBL1603490 & 688422 & 4.9 & 5.2307 & TRN & \\
\hline CHEMBL1584562 & 688422 & 4.55 & 5.1933 & TRN & \\
\hline CHEMBL1455232 & 688422 & 4.45 & 5.1629 & TRN & \\
\hline CHEMBL1479782 & 688422 & 4.7 & 5.4905 & TRN & \\
\hline CHEMBL1523575 & 688422 & 5.4 & 5.3431 & TRN & \\
\hline CHEMBL1390676 & 688422 & 4.95 & 4.7686 & TRN & \\
\hline CHEMBL1536044 & 688422 & 4.9 & 5.0274 & TRN & \\
\hline CHEMBL567959 & 688422 & 4.95 & 5.0316 & TRN & \\
\hline CHEMBL1366433 & 688422 & 4.6 & 4.8896 & TRN & \\
\hline CHEMBL1526650 & 688422 & 4.8 & 5.0765 & TRN & \\
\hline CHEMBL1548316 & 688422 & 4.85 & 5.1418 & TRN & \\
\hline CHEMBL1346386 & 688422 & 8.0506 & 5.7273 & TRN & \\
\hline CHEMBL1470525 & 688422 & 4.45 & 5.3296 & TST & \\
\hline CHEMBL1412273 & 688422 & 4.45 & 4.894 & TRN & \\
\hline CHEMBL1414606 & 688422 & 7.0501 & 5.53600 & 00000000005 & TRN \\
\hline CHEMBL1481584 & 688422 & 4.85 & 5.6385 & TST & \\
\hline CHEMBL1461349 & 688422 & 4.9 & 5.2158 & TST & \\
\hline CHEMBL1301374 & 688422 & 5.45 & 4.6899 & TST & \\
\hline CHEMBL1441827 & 688422 & 4.9 & 5.1336 & TRN & \\
\hline CHEMBL1415638 & 688422 & 5.45 & 5.0754 & TRN & \\
\hline CHEMBL1554089 & 688422 & 4.45 & 5.1624 & TRN & \\
\hline CHEMBL1569529 & 688422 & 4.45 & 4.9948 & TRN & \\
\hline CHEMBL1444960 & 688422 & 4.45 & 5.24100 & 00000000005 & TST \\
\hline CHEMBL1361104 & 688422 & 4.75 & 5.0386 & TST & \\
\hline CHEMBL1444852 & 688422 & 6.0 & 4.9531 & TST & \\
\hline CHEMBL1345564 & 688422 & 5.35 & 5.0828 & TRN & \\
\hline CHEMBL1467243 & 688422 & 4.95 & 4.6389 & TRN & \\
\hline CHEMBL1608182 & 688422 & 8.0 & 5.2925 & TRN & \\
\hline CHEMBL1544202 & 688422 & 5.5 & 5.2033 & TRN & \\
\hline CHEMBL1442595 & 688422 & 4.45 & 5.0661 & TRN & \\
\hline CHEMBL1430006 & 688422 & 4.65 & 5.3111 & TRN & \\
\hline CHEMBL1483850 & 688422 & 6.95 & 5.3639 & TRN & \\
\hline CHEMBL1496120 & 688422 & 4.45 & 4.7399 & TRN & \\
\hline CHEMBL1604826 & 688422 & 4.45 & 5.0942 & TRN & \\
\hline CHEMBL1585988 & 688422 & 4.45 & 5.2058 & TST & \\
\hline CHEMBL1506256 & 688422 & 4.5 & 5.4841 & TRN & \\
\hline CHEMBL3193647 & 688422 & 4.5 & 5.0794 & TST & \\
\hline CHEMBL1377200 & 688422 & 5.25 & 5.118 & TST & \\
\hline
\end{tabular}




\begin{tabular}{|c|c|c|c|c|}
\hline \multicolumn{5}{|c|}{ Supplemental Table S2.txt } \\
\hline CHEMBL3196831 & 688422 & 5.35 & 5.0955 & TRN \\
\hline CHEMBL1440645 & 688422 & 4.8 & 5.7643 & TRN \\
\hline CHEMBL1376955 & 688422 & 5.9 & 5.3206 & TRN \\
\hline CHEMBL1399543 & 688422 & 5.25 & 5.3511 & TRN \\
\hline CHEMBL1449735 & 688422 & 6.15 & 5.0797 & TRN \\
\hline CHEMBL1609975 & 688422 & 7.3002 & 4.9918 & TRN \\
\hline CHEMBL1456758 & 688422 & 5.4 & 5.4851 & TRN \\
\hline CHEMBL1413758 & 688422 & 4.95 & 5.1763 & TRN \\
\hline CHEMBL1601068 & 688422 & 6.3 & 5.1893 & TRN \\
\hline CHEMBL1442682 & 688422 & 5.0 & 4.7971 & TRN \\
\hline CHEMBL1402278 & 688422 & 5.3 & 5.2707 & TRN \\
\hline CHEMBL1569847 & 688422 & 4.95 & 5.2191 & TRN \\
\hline CHEMBL1584930 & 688422 & 4.75 & 5.1246 & TRN \\
\hline CHEMBL1357130 & 688422 & 4.85 & 5.4021 & TST \\
\hline CHEMBL1460007 & 688422 & 5.45 & 5.1512 & TST \\
\hline CHEMBL1550894 & 688422 & 7.9508 & 5.9101 & TRN \\
\hline CHEMBL1326771 & 688422 & 4.85 & 4.9486 & TST \\
\hline CHEMBL1524754 & 688422 & 4.95 & 5.4679 & TRN \\
\hline CHEMBL1536499 & 688422 & 4.8 & 5.1241 & TRN \\
\hline CHEMBL1366831 & 688422 & 6.8 & 5.2109 & TST \\
\hline CHEMBL1515126 & 688422 & 4.45 & 5.4513 & TST \\
\hline CHEMBL1360208 & 688422 & 5.55 & 4.6123 & TRN \\
\hline CHEMBL1376556 & 688422 & 4.45 & 5.2968 & TRN \\
\hline CHEMBL1409996 & 688422 & 4.8 & 5.1536 & TRN \\
\hline CHEMBL1306172 & 688422 & 8.0506 & 5.6328 & TST \\
\hline CHEMBL1461381 & 688422 & 5.65 & 5.709 & TRN \\
\hline CHEMBL1458509 & 688422 & 5.65 & 5.2268 & TRN \\
\hline CHEMBL1465989 & 688422 & 5.2 & 4.902 & TRN \\
\hline CHEMBL1408129 & 688422 & 5.4 & 5.4248 & TST \\
\hline CHEMBL1579256 & 688422 & 4.7 & 5.1641 & TRN \\
\hline CHEMBL 3190637 & 688422 & 4.65 & 4.8254 & TRN \\
\hline CHEMBL1500623 & 688422 & 4.65 & 4.9944 & TRN \\
\hline CHEMBL 3209170 & 688422 & 4.45 & 5.1826 & TRN \\
\hline CHEMBL1395734 & 688422 & 4.65 & 4.9739 & TRN \\
\hline CHEMBL1370277 & 688422 & 4.55 & 5.1399 & TRN \\
\hline CHEMBL3207343 & 688422 & 4.85 & 5.1483 & TRN \\
\hline CHEMBL1415195 & 688422 & 4.45 & 5.3403 & TRN \\
\hline CHEMBL1583444 & 688422 & 5.15 & 5.5112 & TRN \\
\hline CHEMBL1530290 & 688422 & 8.0 & 5.8224 & TRN \\
\hline CHEMBL1323778 & 688422 & 4.9 & 5.4532 & TRN \\
\hline CHEMBL1559566 & 688422 & 4.5 & 4.9736 & TST \\
\hline CHEMBL1468006 & 688422 & 6.7001 & 4.8148 & TRN \\
\hline CHEMBL1553070 & 688422 & 4.95 & 5.3824 & TRN \\
\hline CHEMBL1585609 & 688422 & 6.05 & 5.3494 & TST \\
\hline CHEMBL1319541 & 688422 & 4.45 & 5.32600 & 00000000005 \\
\hline CHEMBL1477332 & 688422 & 4.45 & 5.0592 & TRN \\
\hline CHEMBL1477241 & 688422 & 6.0 & 4.9854 & TRN \\
\hline CHEMBL1465958 & 688422 & 4.85 & 5.2255 & TST \\
\hline
\end{tabular}




\begin{tabular}{|c|c|c|c|c|}
\hline \multicolumn{5}{|c|}{ Supplemental Table S2.txt } \\
\hline CHEMBL1468378 & 688422 & 4.75 & 5.1932 & TRN \\
\hline CHEMBL 1450621 & 688422 & 4.45 & 5.1616 & TRN \\
\hline CHEMBL460515 & 688422 & 7.0 & 5.0412 & TST \\
\hline CHEMBL 3199779 & 688422 & 6.5 & 5.17299 & 9999999999 \\
\hline CHEMBL3192112 & 688422 & 4.75 & 5.02 & TRN \\
\hline CHEMBL1439301 & 688422 & 4.85 & 5.1257 & TRN \\
\hline CHEMBL1438934 & 688422 & 4.85 & 4.368 & TRN \\
\hline CHEMBL1438605 & 688422 & 8.0 & 5.4783 & TRN \\
\hline CHEMBL1371673 & 688422 & 7.0 & 5.3166 & TST \\
\hline CHEMBL1408736 & 688422 & 6.15 & 4.909 & TRN \\
\hline CHEMBL576349 & 688422 & 5.4 & 5.4403 & TRN \\
\hline CHEMBL1574063 & 688422 & 4.85 & 5.0847 & TRN \\
\hline CHEMBL1519106 & 688422 & 4.8 & 5.8676 & TRN \\
\hline CHEMBL1501295 & 688422 & 4.7 & 5.4579 & TRN \\
\hline CHEMBL1310089 & 688422 & 5.55 & 5.4048 & TST \\
\hline CHEMBL1488655 & 688422 & 4.45 & 5.2212 & TST \\
\hline CHEMBL1589893 & 688422 & 4.9 & 4.9458 & TRN \\
\hline CHEMBL2003595 & 688422 & 4.8 & 5.1767 & TST \\
\hline CHEMBL1548233 & 688422 & 5.4 & 5.0572 & TST \\
\hline CHEMBL1536896 & 688422 & 5.55 & 5.4119 & TRN \\
\hline CHEMBL1532247 & 688422 & 5.0 & 4.8579 & TST \\
\hline CHEMBL1347673 & 688422 & 4.95 & 4.94 & TRN \\
\hline CHEMBL1477794 & 688422 & 5.05 & 5.2686 & TRN \\
\hline CHEMBL1492159 & 688422 & 4.6 & 5.0765 & TRN \\
\hline CHEMBL1578982 & 688422 & 4.6 & 5.1912 & TRN \\
\hline CHEMBL1412854 & 688422 & 6.5 & 5.5739 & TRN \\
\hline CHEMBL1395868 & 688422 & 6.8499 & 5.056 & TRN \\
\hline CHEMBL1461181 & 688422 & 4.45 & 5.0573 & TRN \\
\hline CHEMBL1385428 & 688422 & 5.9 & 4.8597 & TRN \\
\hline CHEMBL1355135 & 688422 & 5.45 & 4.7969 & TRN \\
\hline CHEMBL1302486 & 688422 & 8.301 & 5.6199 & TST \\
\hline CHEMBL77675 & 688422 & 6.2 & 5.2615 & TRN \\
\hline CHEMBL1336537 & 688422 & 4.95 & 5.2402 & TRN \\
\hline CHEMBL1501477 & 688422 & 4.75 & 5.7068 & TRN \\
\hline CHEMBL1516552 & 688422 & 5.5 & 5.2669 & TRN \\
\hline CHEMBL1467839 & 688422 & 4.7 & 5.1804 & TRN \\
\hline CHEMBL67378 & 688422 & 5.2 & 5.2209 & TST \\
\hline CHEMBL1398876 & 688422 & 5.5 & 5.0438 & TRN \\
\hline CHEMBL3197827 & 688422 & 4.5 & 5.2232 & TRN \\
\hline CHEMBL 3210930 & 688422 & 4.45 & 5.155 & TRN \\
\hline CHEMBL1597676 & 688422 & 5.15 & 4.7986 & TRN \\
\hline CHEMBL3199067 & 688422 & 5.55 & 5.3199 & TRN \\
\hline CHEMBL1583327 & 688422 & 5.55 & 4.9556 & TRN \\
\hline CHEMBL1517860 & 688422 & 4.45 & 5.077 & TRN \\
\hline CHEMBL1371232 & 688422 & 4.85 & 5.0867 & TRN \\
\hline CHEMBL1596998 & 688422 & 4.45 & 5.3296 & TRN \\
\hline CHEMBL1457533 & 688422 & 4.45 & 5.0741 & TST \\
\hline CHEMBL1441132 & 688422 & 4.5 & 5.3811 & TRN \\
\hline
\end{tabular}

TRN 


\begin{tabular}{|c|c|c|c|c|}
\hline \multirow[b]{2}{*}{ CHEMBL1605650 } & \multicolumn{4}{|c|}{ Supplemental Table S2.tx } \\
\hline & 688422 & 6.5 & 5.1853 & TST \\
\hline CHEMBL1317923 & 688422 & 4.95 & 5.3387 & TRN \\
\hline CHEMBL1567914 & 688422 & 5.15 & 5.2052 & TRN \\
\hline CHEMBL1521248 & 688422 & 4.45 & 5.0334 & TRN \\
\hline CHEMBL1430047 & 688422 & 4.45 & 5.2995 & TRN \\
\hline CHEMBL1478711 & 688422 & 4.65 & 5.0259 & TRN \\
\hline CHEMBL1557846 & 688422 & 4.75 & 4.9241 & TRN \\
\hline CHEMBL1592735 & 688422 & 4.95 & 5.3045 & TRN \\
\hline CHEMBL1587333 & 688422 & 5.1 & 5.2124 & TRN \\
\hline CHEMBL1488927 & 688422 & 4.8 & 5.2667 & TRN \\
\hline CHEMBL1368879 & 688422 & 4.65 & 5.3735 & TST \\
\hline CHEMBL 3144874 & 688422 & 4.9 & 5.2046 & TRN \\
\hline CHEMBL1449023 & 688422 & 4.7 & 5.0209 & TRN \\
\hline CHEMBL1553442 & 688422 & 4.85 & 5.2092 & TRN \\
\hline CHEMBL1575576 & 688422 & 5.0 & 5.1074 & TRN \\
\hline CHEMBL1418082 & 688422 & 4.4 & 5.1252 & TRN \\
\hline CHEMBL1468994 & 688422 & 5.75 & 5.1787 & TRN \\
\hline CHEMBL1376724 & 688422 & 5.15 & 4.7315 & TRN \\
\hline CHEMBL1609144 & 688422 & 5.0 & 5.2202 & TRN \\
\hline CHEMBL1365585 & 688422 & 6.1 & 5.0158 & TRN \\
\hline CHEMBL1301571 & 688422 & 4.75 & 5.3916 & TRN \\
\hline CHEMBL1563705 & 688422 & 7.699 & 5.2828 & TST \\
\hline CHEMBL1349856 & 688422 & 4.85 & 5.6044 & TRN \\
\hline CHEMBL1575466 & 688422 & 4.95 & 5.1781 & TRN \\
\hline CHEMBL1395177 & 688422 & 5.45 & 5.0375 & TRN \\
\hline CHEMBL1585541 & 688422 & 4.8 & 5.1075 & TRN \\
\hline CHEMBL1381797 & 688422 & 4.9 & 5.0569 & TRN \\
\hline CHEMBL1967821 & 688422 & 7.6498 & 5.1779 & TST \\
\hline CHEMBL533965 & 688422 & 4.95 & 5.3038 & TST \\
\hline CHEMBL1517861 & 688422 & 5.4 & 5.1058 & TST \\
\hline CHEMBL1334982 & 688422 & 4.8 & 5.6937 & TRN \\
\hline CHEMBL1445964 & 688422 & 4.5 & 5.2166 & TST \\
\hline CHEMBL1472122 & 688422 & 4.85 & 4.9089 & TRN \\
\hline CHEMBL1536665 & 688422 & 4.85 & 5.3765 & TRN \\
\hline CHEMBL1332140 & 688422 & 5.35 & 5.1233 & TRN \\
\hline CHEMBL1608170 & 688422 & 7.9508 & 5.2022 & TRN \\
\hline CHEMBL1486423 & 688422 & 4.6 & 5.2604 & TST \\
\hline CHEMBL1497703 & 688422 & 4.85 & 5.1699 & TST \\
\hline CHEMBL1549128 & 688422 & 4.65 & 5.2047 & TST \\
\hline CHEMBL1497370 & 688422 & 4.75 & 5.19 & TST \\
\hline CHEMBL1601752 & 688422 & 4.5 & 5.0062 & TST \\
\hline CHEMBL1525603 & 688422 & 4.45 & 5.3707 & TRN \\
\hline CHEMBL1439925 & 688422 & 4.9 & 4.9992 & TRN \\
\hline CHEMBL1379426 & 688422 & 4.45 & 5.2323 & TST \\
\hline CHEMBL1535104 & 688422 & 4.6 & 4.9754 & TRN \\
\hline CHEMBL1502500 & 688422 & 8.4559 & 5.2863 & TRN \\
\hline CHEMBL1340458 & 688422 & 4.45 & 4.7214 & TRN \\
\hline CHEMBL1498192 & 688422 & 4.45 & 5.4904 & TRN \\
\hline
\end{tabular}




\begin{tabular}{|c|c|c|c|c|c|}
\hline & & \multicolumn{4}{|c|}{ Supplemental Table S2.txt } \\
\hline CHEMBL1479396 & 688422 & 7.6498 & 5.2353 & TRN & \\
\hline CHEMBL1573017 & 688422 & 5.0 & 5.124 & TRN & \\
\hline CHEMBL1430151 & 688422 & 5.25 & 4.8911 & TRN & \\
\hline CHEMBL1316626 & 688422 & 5.65 & 5.4908 & TRN & \\
\hline CHEMBL1357864 & 688422 & 5.35 & 5.2193 & TRN & \\
\hline CHEMBL1582479 & 688422 & 4.45 & 5.1862 & TRN & \\
\hline CHEMBL1432364 & 688422 & 4.95 & 5.13399 & 99999999995 & TRN \\
\hline CHEMBL1500906 & 688422 & 5.9 & 5.4777 & TST & \\
\hline CHEMBL151946 & 688422 & 5.5 & 5.06 & TST & \\
\hline CHEMBL1435771 & 688422 & 7.0501 & 4.9516 & TRN & \\
\hline CHEMBL1314426 & 688422 & 8.301 & 5.3998 & TRN & \\
\hline CHEMBL1380881 & 688422 & 4.65 & 4.9452 & TRN & \\
\hline CHEMBL3194797 & 688422 & 4.85 & 5.4104 & TST & \\
\hline CHEMBL1584578 & 688422 & 4.45 & 4.9858 & TRN & \\
\hline CHEMBL1377690 & 688422 & 5.15 & 4.8028 & TRN & \\
\hline CHEMBL1369093 & 688422 & 4.8 & 5.1221 & TRN & \\
\hline CHEMBL1564473 & 688422 & 4.55 & 4.8316 & TRN & \\
\hline CHEMBL1467467 & 688422 & 4.65 & 5.2248 & TRN & \\
\hline CHEMBL1333110 & 688422 & 4.85 & 5.0315 & TRN & \\
\hline CHEMBL1415343 & 688422 & 5.0 & 5.3916 & TRN & \\
\hline CHEMBL1363237 & 688422 & 4.9 & 5.3039 & TRN & \\
\hline CHEMBL1462498 & 688422 & 5.0 & 5.4044 & TRN & \\
\hline CHEMBL1589536 & 688422 & 4.95 & 5.5439 & TST & \\
\hline CHEMBL1392769 & 688422 & 4.95 & 4.8104 & TRN & \\
\hline CHEMBL1576722 & 688422 & 4.6 & 5.2583 & TRN & \\
\hline CHEMBL1602585 & 688422 & 5.55 & 5.4247 & TRN & \\
\hline CHEMBL1548429 & 688422 & 4.45 & 5.0827 & TRN & \\
\hline CHEMBL1605451 & 688422 & 5.5 & 5.2422 & TRN & \\
\hline CHEMBL1611097 & 688422 & 5.7 & 5.3627 & TRN & \\
\hline CHEMBL1523756 & 688422 & 4.9 & 5.59399 & 9999999999 & TRN \\
\hline CHEMBL1484272 & 688422 & 4.95 & 5.0392 & TRN & \\
\hline CHEMBL1317531 & 688422 & 4.9 & 5.1676 & TRN & \\
\hline CHEMBL1539180 & 688422 & 5.25 & 4.6816 & TRN & \\
\hline CHEMBL1304398 & 688422 & 4.8 & 5.4366 & TRN & \\
\hline CHEMBL1568460 & 688422 & 4.95 & 5.0032 & TRN & \\
\hline CHEMBL1516070 & 688422 & 5.4 & 5.3187 & TRN & \\
\hline CHEMBL1302406 & 688422 & 4.85 & 4.8991 & TRN & \\
\hline CHEMBL1310651 & 688422 & 7.15 & 5.7393 & TST & \\
\hline CHEMBL1455775 & 688422 & 5.75 & 5.6963 & TRN & \\
\hline CHEMBL1465904 & 688422 & 4.65 & 4.9662 & TRN & \\
\hline CHEMBL1432376 & 688422 & 5.45 & 5.0786 & TRN & \\
\hline CHEMBL1435434 & 688422 & 4.75 & 5.5378 & TRN & \\
\hline CHEMBL1563875 & 688422 & 4.45 & 5.2522 & TRN & \\
\hline CHEMBL1410059 & 688422 & 8.4949 & 5.0118 & TST & \\
\hline CHEMBL1597729 & 688422 & 4.85 & 5.169 & TRN & \\
\hline CHEMBL1596460 & 688422 & 4.5 & 5.1789 & TRN & \\
\hline CHEMBL1331865 & 688422 & 4.7 & 4.7211 & TRN & \\
\hline CHEMBL1443740 & 688422 & 7.2503 & 4.8371 & TRN & \\
\hline
\end{tabular}




\begin{tabular}{|c|c|c|c|c|}
\hline \multicolumn{5}{|c|}{ Supplemental Table S2.txt } \\
\hline CHEMBL1362497 & 688422 & 4.65 & 5.4825 & TRN \\
\hline CHEMBL1569195 & 688422 & 5.95 & 5.4881 & TRN \\
\hline CHEMBL1461351 & 688422 & 4.9 & 4.9037 & TRN \\
\hline CHEMBL1361658 & 688422 & 5.25 & 5.8718 & TST \\
\hline CHEMBL1611719 & 688422 & 7.15 & 5.2877 & TRN \\
\hline CHEMBL1348949 & 688422 & 4.95 & 5.1746 & TRN \\
\hline CHEMBL1408056 & 688422 & 5.35 & 5.0435 & TST \\
\hline CHEMBL1441363 & 688422 & 6.1 & 5.4567 & TST \\
\hline CHEMBL 3191730 & 688422 & 5.2 & 5.6045 & TRN \\
\hline CHEMBL1442251 & 688422 & 4.5 & 5.8176 & TST \\
\hline CHEMBL1361777 & 688422 & 4.5 & 4.797 & TRN \\
\hline CHEMBL1577232 & 688422 & 4.45 & 5.1323 & TRN \\
\hline CHEMBL 28862 & 688422 & 9.0969 & 6.359 & TST \\
\hline CHEMBL1302028 & 688422 & 5.25 & 5.1639 & TRN \\
\hline CHEMBL 3208740 & 688422 & 4.8 & 5.2298 & TST \\
\hline CHEMBL1593080 & 688422 & 4.65 & 5.3501 & TRN \\
\hline CHEMBL1411047 & 688422 & 4.5 & 5.1567 & TRN \\
\hline CHEMBL1322196 & 688422 & 4.5 & 4.9864 & TRN \\
\hline CHEMBL1558850 & 688422 & 4.7 & 5.3818 & TRN \\
\hline CHEMBL1583712 & 688422 & 4.7 & 5.1635 & TRN \\
\hline CHEMBL1443088 & 688422 & 4.75 & 4.8786 & TRN \\
\hline CHEMBL1313663 & 688422 & 4.7 & 5.019 & TRN \\
\hline CHEMBL1448344 & 688422 & 4.65 & 4.8676 & TRN \\
\hline CHEMBL1548372 & 688422 & 4.7 & 5.2491 & TST \\
\hline CHEMBL1605044 & 688422 & 4.65 & 4.8841 & TRN \\
\hline CHEMBL1422602 & 688422 & 4.9 & 4.6805 & TRN \\
\hline CHEMBL1591655 & 688422 & 7.9508 & 5.2087 & TRN \\
\hline CHEMBL1416645 & 688422 & 4.95 & 5.2394 & TST \\
\hline CHEMBL1576283 & 688422 & 4.7 & 4.908 & TRN \\
\hline CHEMBL1588628 & 688422 & 4.45 & 4.9702 & TRN \\
\hline CHEMBL1369296 & 688422 & 4.45 & 5.038 & TST \\
\hline CHEMBL1383447 & 688422 & 5.4 & 5.2573 & TST \\
\hline CHEMBL1609375 & 688422 & 5.1 & 5.4733 & TRN \\
\hline CHEMBL1439314 & 688422 & 4.75 & 5.4841 & TRN \\
\hline CHEMBL1480971 & 688422 & 4.75 & 5.2406 & TRN \\
\hline CHEMBL1575317 & 688422 & 5.15 & 5.1738 & TRN \\
\hline CHEMBL 1424326 & 688422 & 4.95 & 5.1318 & TRN \\
\hline CHEMBL578928 & 688422 & 4.85 & 4.649 & TRN \\
\hline CHEMBL1347137 & 688422 & 4.75 & 5.1306 & TST \\
\hline CHEMBL 3213558 & 688422 & 5.3 & 5.3946 & TRN \\
\hline CHEMBL1315180 & 688422 & 8.4949 & 5.255 & TRN \\
\hline CHEMBL1380772 & 688422 & 4.75 & 5.3028 & TST \\
\hline CHEMBL1520484 & 688422 & 7.5498 & 5.6448 & TST \\
\hline CHEMBL1457697 & 688422 & 4.45 & 5.1078 & TRN \\
\hline CHEMBL1387223 & 688422 & 4.45 & 4.9445 & TRN \\
\hline CHEMBL1373981 & 688422 & 8.3468 & 5.8618 & TRN \\
\hline CHEMBL1375179 & 688422 & 6.1 & 5.2915 & TRN \\
\hline CHEMBL3189295 & 688422 & 4.45 & 5.4718 & TST \\
\hline
\end{tabular}




\begin{tabular}{|c|c|c|c|c|c|}
\hline \multicolumn{6}{|c|}{ Supplemental Table s2.txt } \\
\hline CHEMBL1536876 & 688422 & 4.95 & 5.2049 & TRN & \\
\hline CHEMBL1542823 & 688422 & 4.55 & 4.8813 & TST & \\
\hline CHEMBL1451119 & 688422 & 4.65 & 5.2758 & TST & \\
\hline CHEMBL1320806 & 688422 & 4.9 & 5.4392 & TRN & \\
\hline CHEMBL1421675 & 688422 & 4.6 & 4.7244 & TRN & \\
\hline CHEMBL1603829 & 688422 & 4.5 & 5.2482 & TST & \\
\hline CHEMBL3213292 & 688422 & 5.05 & 5.0759 & TRN & \\
\hline CHEMBL1595396 & 688422 & 8.2518 & 5.4314 & TRN & \\
\hline CHEMBL1502550 & 688422 & 4.95 & 4.9409 & TRN & \\
\hline CHEMBL1377958 & 688422 & 4.45 & 5.1366 & TST & \\
\hline CHEMBL1603635 & 688422 & 6.2 & 5.1707 & TRN & \\
\hline CHEMBL1572265 & 688422 & 4.95 & 5.2535 & TRN & \\
\hline CHEMBL1598791 & 688422 & 4.65 & 5.2413 & TST & \\
\hline CHEMBL1399452 & 688422 & 5.6 & 5.2575 & TRN & \\
\hline CHEMBL1464448 & 688422 & 4.85 & 5.5537 & TRN & \\
\hline CHEMBL1447529 & 688422 & 5.5 & 5.2829 & TRN & \\
\hline CHEMBL580340 & 688422 & 5.45 & 4.448 & TRN & \\
\hline CHEMBL1439255 & 688422 & 4.9 & 4.7782 & TRN & \\
\hline CHEMBL1417605 & 688422 & 4.85 & 5.0614 & TRN & \\
\hline CHEMBL1338458 & 688422 & 7.9508 & 5.2507 & TRN & \\
\hline CHEMBL1468344 & 688422 & 5.85 & 5.2044 & TRN & \\
\hline CHEMBL460602 & 688422 & 5.75 & 5.3721 & TRN & \\
\hline CHEMBL1555938 & 688422 & 4.5 & 4.7758 & TRN & \\
\hline CHEMBL1495604 & 688422 & 5.0 & 4.4214 & TRN & \\
\hline CHEMBL3190671 & 688422 & 4.9 & 5.3662 & TRN & \\
\hline CHEMBL1448617 & 688422 & 4.95 & 5.1929 & TRN & \\
\hline CHEMBL1613540 & 688422 & 5.05 & 4.8177 & TRN & \\
\hline CHEMBL1349690 & 688422 & 5.3 & 5.0705 & TRN & \\
\hline CHEMBL1335386 & 688422 & 4.5 & 5.364 & TST & \\
\hline CHEMBL1380414 & 688422 & 6.05 & 5.2724 & TST & \\
\hline CHEMBL1537009 & 688422 & 4.5 & 5.1598 & TRN & \\
\hline CHEMBL1350057 & 688422 & 6.6 & 5.1178 & TST & \\
\hline CHEMBL1495602 & 688422 & 4.5 & 5.016 & TST & \\
\hline CHEMBL607805 & 688422 & 7.3002 & 5.2845 & TRN & \\
\hline CHEMBL1596366 & 688422 & 4.75 & 5.0053 & TRN & \\
\hline CHEMBL3192917 & 688422 & 4.65 & 5.0208 & TRN & \\
\hline CHEMBL1444885 & 688422 & 4.45 & 5.0755 & TRN & \\
\hline CHEMBL1543426 & 688422 & 4.9 & 5.0006 & TST & \\
\hline CHEMBL1537867 & 688422 & 4.95 & 5.2624 & TRN & \\
\hline CHEMBL1454528 & 688422 & 4.45 & 5.54299 & 9999999999 & TRN \\
\hline CHEMBL 2006254 & 688422 & 7.2503 & 5.4864 & TRN & \\
\hline CHEMBL1409619 & 688422 & 4.75 & 4.8631 & TRN & \\
\hline CHEMBL1415585 & 688422 & 4.5 & 4.8841 & TST & \\
\hline CHEMBL1425020 & 688422 & 4.75 & 4.8562 & TST & \\
\hline CHEMBL491771 & 688422 & 4.75 & 4.7131 & TRN & \\
\hline CHEMBL1538365 & 688422 & 4.9 & 4.9108 & TRN & \\
\hline CHEMBL1302377 & 688422 & 7.6003 & 5.67200 & 0000000001 & TRN \\
\hline CHEMBL1303714 & 688422 & 5.35 & 5.7122 & TRN & \\
\hline
\end{tabular}




\begin{tabular}{|c|c|c|c|c|}
\hline \multicolumn{5}{|c|}{ Supplemental Table S2.txt } \\
\hline CHEMBL1428288 & 688422 & 5.25 & 5.2507 & TRN \\
\hline CHEMBL1445786 & 688422 & 4.65 & 5.0375 & TRN \\
\hline CHEMBL1304071 & 688422 & 4.45 & 5.4545 & TST \\
\hline CHEMBL1526851 & 688422 & 5.1 & 5.0192 & TRN \\
\hline CHEMBL1522755 & 688422 & 4.95 & 4.7604 & TST \\
\hline CHEMBL1528966 & 688422 & 5.25 & 5.6202 & TRN \\
\hline CHEMBL1461139 & 688422 & 5.2 & 4.9512 & TST \\
\hline CHEMBL1402538 & 688422 & 4.8 & 5.4396 & TRN \\
\hline CHEMBL1436104 & 688422 & 8.1487 & 5.3959 & TRN \\
\hline CHEMBL1350704 & 688422 & 7.3497 & 5.7599 & TRN \\
\hline CHEMBL1564978 & 688422 & 4.65 & 5.1349 & TST \\
\hline CHEMBL1401630 & 688422 & 5.4 & 5.3622 & TRN \\
\hline CHEMBL1472955 & 688422 & 4.75 & 4.7794 & TRN \\
\hline CHEMBL1534893 & 688422 & 5.15 & 4.9106 & TRN \\
\hline CHEMBL1545718 & 688422 & 4.45 & 4.7998 & TRN \\
\hline CHEMBL1525857 & 688422 & 4.45 & 5.8408 & TST \\
\hline CHEMBL1568988 & 688422 & 4.5 & 5.038 & TST \\
\hline CHEMBL1409364 & 688422 & 4.9 & 5.0573 & TRN \\
\hline CHEMBL1342336 & 688422 & 7.2503 & 5.2819 & TRN \\
\hline CHEMBL1353798 & 688422 & 5.3 & 5.3505 & TST \\
\hline CHEMBL1393569 & 688422 & 4.85 & 4.9564 & TRN \\
\hline CHEMBL1608073 & 688422 & 4.45 & 4.8147 & TRN \\
\hline CHEMBL1462873 & 688422 & 4.45 & 4.9934 & TRN \\
\hline CHEMBL1336345 & 688422 & 5.0 & 5.3282 & TST \\
\hline CHEMBL 2000230 & 688422 & 4.95 & 5.4187 & TRN \\
\hline CHEMBL1465721 & 688422 & 4.9 & 4.8778 & TRN \\
\hline CHEMBL1573894 & 688422 & 6.25 & 5.8723 & TRN \\
\hline CHEMBL1402215 & 688422 & 8.0506 & 5.1279 & TRN \\
\hline CHEMBL1410594 & 688422 & 4.95 & 5.314 & TRN \\
\hline CHEMBL1551778 & 688422 & 4.6 & 4.5584 & TRN \\
\hline CHEMBL1560937 & 688422 & 5.4 & 5.4013 & TRN \\
\hline CHEMBL1595508 & 688422 & 4.9 & 5.635 & TRN \\
\hline CHEMBL1392913 & 688422 & 4.75 & 5.1477 & TRN \\
\hline CHEMBL1396555 & 688422 & 4.45 & 5.175 & TRN \\
\hline CHEMBL1363819 & 688422 & 5.15 & 5.2181 & TRN \\
\hline CHEMBL1403575 & 688422 & 4.7 & 5.269 & TRN \\
\hline CHEMBL1536659 & 688422 & 4.45 & 5.9773 & TRN \\
\hline CHEMBL1339865 & 688422 & 6.8499 & 5.3245 & TRN \\
\hline CHEMBL1388490 & 688422 & 4.45 & 4.6407 & TRN \\
\hline CHEMBL606532 & 688422 & 4.9 & 5.4949 & TRN \\
\hline CHEMBL1517829 & 688422 & 4.8 & 5.0944 & TRN \\
\hline CHEMBL1331475 & 688422 & 5.4 & 4.7822 & TRN \\
\hline CHEMBL1302343 & 688422 & 5.0 & 5.0671 & TRN \\
\hline CHEMBL45281 & 688422 & 4.45 & 5.1768 & TST \\
\hline CHEMBL3190684 & 688422 & 4.95 & 5.043 & TRN \\
\hline CHEMBL1578330 & 688422 & 6.3 & 4.9498 & TRN \\
\hline CHEMBL1450774 & 688422 & 5.35 & 5.6921 & TRN \\
\hline CHEMBL1528305 & 688422 & 4.45 & 4.9486 & TRN \\
\hline
\end{tabular}




\begin{tabular}{|c|c|c|c|c|}
\hline \multicolumn{5}{|c|}{ Supplemental Table S2.txt } \\
\hline CHEMBL1611360 & 688422 & 4.7 & 4.9736 & TRN \\
\hline CHEMBL1425990 & 688422 & 4.9 & 5.2281 & TST \\
\hline CHEMBL3192679 & 688422 & 4.45 & 4.9288 & TRN \\
\hline CHEMBL 3210904 & 688422 & 4.7 & 5.2129 & TST \\
\hline CHEMBL1366518 & 688422 & 4.8 & 5.3619 & TRN \\
\hline CHEMBL1351847 & 688422 & 4.85 & 5.0523 & TRN \\
\hline CHEMBL1512294 & 688422 & 5.15 & 5.2072 & TRN \\
\hline CHEMBL 3196058 & 688422 & 6.2 & 5.609 & TST \\
\hline CHEMBL1366299 & 688422 & 6.25 & 5.2917 & TRN \\
\hline CHEMBL1444410 & 688422 & 5.0 & 5.8638 & TRN \\
\hline CHEMBL1588010 & 688422 & 6.5 & 5.2404 & TST \\
\hline CHEMBL1577587 & 688422 & 6.1 & 5.7264 & TRN \\
\hline CHEMBL1574257 & 688422 & 8.2007 & 5.3089 & TRN \\
\hline CHEMBL1461601 & 688422 & 4.6 & 4.8999 & TRN \\
\hline CHEMBL1319704 & 688422 & 4.8 & 5.0013 & TRN \\
\hline CHEMBL1311636 & 688422 & 4.95 & 4.8601 & TRN \\
\hline CHEMBL1368005 & 688422 & 4.9 & 5.1007 & TRN \\
\hline CHEMBL1384349 & 688422 & 4.45 & 4.8218 & TRN \\
\hline CHEMBL1608680 & 688422 & 5.2 & 5.4292 & TRN \\
\hline CHEMBL1441471 & 688422 & 4.8 & 5.4536 & TRN \\
\hline CHEMBL1608033 & 688422 & 4.5 & 4.8405 & TRN \\
\hline CHEMBL3196980 & 688422 & 5.2 & 5.4804 & TST \\
\hline CHEMBL1493068 & 688422 & 4.65 & 4.8221 & TRN \\
\hline CHEMBL1567653 & 688422 & 5.9 & 5.2053 & TRN \\
\hline CHEMBL1460669 & 688422 & 4.45 & 5.0164 & TRN \\
\hline CHEMBL1325375 & 688422 & 5.1 & 4.8742 & TRN \\
\hline CHEMBL1432083 & 688422 & 4.8 & 4.887 & TRN \\
\hline CHEMBL1444223 & 688422 & 5.35 & 5.2703 & TRN \\
\hline CHEMBL1477791 & 688422 & 4.9 & 5.3452 & TRN \\
\hline CHEMBL1609070 & 688422 & 4.95 & 4.9447 & TST \\
\hline CHEMBL1425919 & 688422 & 4.65 & 5.2357 & TRN \\
\hline CHEMBL1429963 & 688422 & 4.5 & 5.5894 & TST \\
\hline CHEMBL1546768 & 688422 & 5.15 & 5.2525 & TRN \\
\hline CHEMBL1367256 & 688422 & 4.7 & 5.171 & TRN \\
\hline CHEMBL1561026 & 688422 & 5.5 & 5.5295 & TRN \\
\hline CHEMBL1307776 & 688422 & 4.75 & 4.7648 & TRN \\
\hline CHEMBL1483562 & 688422 & 5.45 & 4.6282 & TRN \\
\hline CHEMBL1338680 & 688422 & 7.3497 & 5.7003 & TRN \\
\hline CHEMBL1303533 & 688422 & 6.5501 & 5.4238 & TST \\
\hline CHEMBL1454640 & 688422 & 5.05 & 5.2547 & TST \\
\hline CHEMBL1500450 & 688422 & 4.8 & 5.0893 & TRN \\
\hline CHEMBL1523701 & 688422 & 8.3468 & 5.5608 & TST \\
\hline CHEMBL1501207 & 688422 & 4.45 & 5.2883 & TRN \\
\hline CHEMBL1489353 & 688422 & 5.0 & 5.1461 & TRN \\
\hline CHEMBL1506733 & 688422 & 4.9 & 4.875 & TRN \\
\hline CHEMBL1602767 & 688422 & 4.7 & 5.2732 & TRN \\
\hline CHEMBL1487098 & 688422 & 4.65 & 5.2468 & TRN \\
\hline CHEMBL1348741 & 688422 & 4.75 & 5.3697 & TRN \\
\hline
\end{tabular}




\begin{tabular}{|c|c|c|c|c|}
\hline \multicolumn{5}{|c|}{ Supplemental Table S2.txt } \\
\hline CHEMBL1369218 & 688422 & 7.5003 & 5.3331 & TST \\
\hline CHEMBL1568298 & 688422 & 4.65 & 5.1253 & TRN \\
\hline CHEMBL1589930 & 688422 & 5.8 & 6.0002 & TRN \\
\hline CHEMBL1446335 & 688422 & 4.9 & 4.9729 & TRN \\
\hline CHEMBL1969593 & 688422 & 4.5 & 5.0354 & TRN \\
\hline CHEMBL1395525 & 688422 & 6.3 & 5.9053 & TRN \\
\hline CHEMBL1451012 & 688422 & 8.4559 & 5.5498 & TST \\
\hline CHEMBL1383956 & 688422 & 7.0501 & 5.4161 & TRN \\
\hline CHEMBL1552931 & 688422 & 4.45 & 5.2811 & TST \\
\hline CHEMBL1577077 & 688422 & 4.95 & 5.2 & TRN \\
\hline CHEMBL1374444 & 688422 & 4.7 & 5.2322 & TRN \\
\hline CHEMBL1456591 & 688422 & 7.4498 & 5.4113 & TRN \\
\hline CHEMBL1350636 & 688422 & 4.85 & 5.1887 & TRN \\
\hline CHEMBL1408414 & 688422 & 5.3 & 5.374 & TRN \\
\hline CHEMBL1454964 & 688422 & 4.95 & 5.5622 & TRN \\
\hline CHEMBL1359940 & 688422 & 4.7 & 4.7185 & TRN \\
\hline CHEMBL1331842 & 688422 & 4.45 & 5.2728 & TRN \\
\hline CHEMBL1256996 & 688422 & 6.0 & 5.145 & TRN \\
\hline CHEMBL1526767 & 688422 & 5.4 & 5.4686 & TRN \\
\hline CHEMBL1435958 & 688422 & 4.45 & 5.1852 & TST \\
\hline CHEMBL1527640 & 688422 & 4.45 & 5.4143 & TRN \\
\hline CHEMBL1355322 & 688422 & 4.4 & 5.2227 & TRN \\
\hline CHEMBL1526572 & 688422 & 4.9 & 5.2858 & TRN \\
\hline CHEMBL1386609 & 688422 & 4.85 & 4.9516 & TRN \\
\hline CHEMBL1363334 & 688422 & 4.75 & 5.325 & TRN \\
\hline CHEMBL1360997 & 688422 & 5.6 & 5.2181 & TRN \\
\hline CHEMBL1462724 & 688422 & 4.85 & 5.954 & TRN \\
\hline CHEMBL3189519 & 688422 & 5.25 & 5.1623 & TRN \\
\hline CHEMBL1511490 & 688422 & 4.85 & 5.5826 & TRN \\
\hline CHEMBL1391103 & 688422 & 4.75 & 4.8931 & TRN \\
\hline CHEMBL1529785 & 688422 & 4.7 & 5.6217 & TRN \\
\hline CHEMBL1990571 & 688422 & 7.0 & 5.1785 & TRN \\
\hline CHEMBL1564477 & 688422 & 4.75 & 5.2671 & TRN \\
\hline CHEMBL1415015 & 688422 & 4.9 & 4.8502 & TRN \\
\hline CHEMBL1331474 & 688422 & 6.8 & 5.557 & TST \\
\hline CHEMBL1528130 & 688422 & 4.95 & 4.7678 & TRN \\
\hline CHEMBL1420268 & 688422 & 4.45 & 4.9706 & TRN \\
\hline CHEMBL1366154 & 688422 & 5.0 & 4.9961 & TRN \\
\hline CHEMBL1521005 & 688422 & 4.6 & 4.8675 & TRN \\
\hline CHEMBL1379600 & 688422 & 4.45 & 4.6333 & TST \\
\hline CHEMBL3197815 & 688422 & 4.85 & 4.69 & TRN \\
\hline CHEMBL1479802 & 688422 & 4.45 & 5.4228 & TRN \\
\hline CHEMBL1509017 & 688422 & 4.45 & 5.3399 & TRN \\
\hline CHEMBL1501794 & 688422 & 5.35 & 5.414 & TRN \\
\hline CHEMBL1500320 & 688422 & 5.3 & 5.2237 & TRN \\
\hline CHEMBL1499053 & 688422 & 6.25 & 5.1218 & TRN \\
\hline CHEMBL3195425 & 688422 & 4.85 & 5.0995 & TRN \\
\hline CHEMBL1542479 & 688422 & 4.85 & 5.0671 & TRN \\
\hline
\end{tabular}




\begin{tabular}{|c|c|c|c|c|}
\hline \multicolumn{5}{|c|}{ Supplemental Table S2.txt } \\
\hline CHEMBL1550026 & 688422 & 4.45 & 5.0977 & TRN \\
\hline CHEMBL3192621 & 688422 & 4.5 & 5.484 & TRN \\
\hline CHEMBL1338540 & 688422 & 6.3 & 5.5461 & TRN \\
\hline CHEMBL1483803 & 688422 & 4.45 & 5.0659 & TST \\
\hline CHEMBL1380138 & 688422 & 4.8 & 5.0002 & TRN \\
\hline CHEMBL1468740 & 688422 & 4.9 & 4.823 & TRN \\
\hline CHEMBL1299201 & 688422 & 5.0 & 5.1458 & TRN \\
\hline CHEMBL1333181 & 688422 & 5.2 & 5.2494 & TRN \\
\hline CHEMBL1436311 & 688422 & 6.5501 & 5.1688 & TRN \\
\hline CHEMBL1518305 & 688422 & 4.65 & 4.8564 & TRN \\
\hline CHEMBL1352116 & 688422 & 4.45 & 5.2008 & TRN \\
\hline CHEMBL1331422 & 688422 & 7.7496 & 4.9514 & TST \\
\hline CHEMBL1580534 & 688422 & 4.7 & 5.1469 & TRN \\
\hline CHEMBL1588206 & 688422 & 7.15 & 5.2699 & TRN \\
\hline CHEMBL1304227 & 688422 & 4.85 & 4.7282 & TRN \\
\hline CHEMBL1453160 & 688422 & 4.65 & 5.2249 & TST \\
\hline CHEMBL1570050 & 688422 & 4.7 & 5.3873 & TRN \\
\hline CHEMBL3194415 & 688422 & 4.95 & 4.9678 & TRN \\
\hline CHEMBL1573549 & 688422 & 4.45 & 5.9208 & TST \\
\hline CHEMBL1370622 & 688422 & 4.45 & 4.9078 & TRN \\
\hline CHEMBL1370018 & 688422 & 4.45 & 5.1499 & TRN \\
\hline CHEMBL1455084 & 688422 & 4.45 & 5.0755 & TRN \\
\hline CHEMBL1488938 & 688422 & 4.9 & 5.2954 & TST \\
\hline CHEMBL1428318 & 688422 & 4.85 & 5.2371 & TRN \\
\hline CHEMBL1495433 & 688422 & 4.45 & 5.0781 & TST \\
\hline CHEMBL1485482 & 688422 & 4.6 & 5.1285 & TRN \\
\hline CHEMBL1387120 & 688422 & 4.8 & 5.5051 & TRN \\
\hline CHEMBL1588004 & 688422 & 4.8 & 5.3955 & TRN \\
\hline CHEMBL1458638 & 688422 & 4.8 & 5.44 & TRN \\
\hline CHEMBL1363065 & 688422 & 4.95 & 5.9374 & TST \\
\hline CHEMBL3193793 & 688422 & 7.2503 & 5.3528 & TRN \\
\hline CHEMBL1180496 & 688422 & 5.05 & 5.3846 & TRN \\
\hline CHEMBL1347063 & 688422 & 4.75 & 5.0046 & TRN \\
\hline CHEMBL1405174 & 688422 & 4.6 & 5.182 & TST \\
\hline CHEMBL611494 & 688422 & 6.5501 & 5.6944 & TST \\
\hline CHEMBL1539498 & 688422 & 4.5 & 4.7743 & TRN \\
\hline CHEMBL3209657 & 688422 & 5.35 & 5.4361 & TRN \\
\hline CHEMBL1603631 & 688422 & 4.65 & 5.1317 & TRN \\
\hline CHEMBL1455126 & 688422 & 4.8 & 5.4561 & TRN \\
\hline CHEMBL1302954 & 688422 & 4.95 & 5.2909 & TRN \\
\hline CHEMBL1389903 & 688422 & 4.45 & 5.3389 & TRN \\
\hline CHEMBL1410079 & 688422 & 5.65 & 5.0942 & TRN \\
\hline CHEMBL1394043 & 688422 & 4.9 & 5.3599 & TST \\
\hline CHEMBL1458379 & 688422 & 4.95 & 5.1945 & TST \\
\hline CHEMBL1535842 & 688422 & 5.4 & 5.0725 & TRN \\
\hline CHEMBL1990357 & 688422 & 5.45 & 5.3588 & TRN \\
\hline CHEMBL3191168 & 688422 & 7.1002 & 5.4807 & TRN \\
\hline CHEMBL1564632 & 688422 & 4.6 & 4.7557 & TRN \\
\hline
\end{tabular}




\begin{tabular}{|c|c|c|c|c|c|}
\hline \multicolumn{6}{|c|}{ Supplemental Table S2.txt } \\
\hline CHEMBL1459497 & 688422 & 4.45 & 5.2619 & TRN & \\
\hline CHEMBL1576937 & 688422 & 4.9 & 5.1717 & TRN & \\
\hline CHEMBL1557931 & 688422 & 8.301 & 5.5574 & TST & \\
\hline CHEMBL3190909 & 688422 & 5.0 & 4.9659 & TRN & \\
\hline CHEMBL1595277 & 688422 & 4.45 & 4.7485 & TRN & \\
\hline CHEMBL1494440 & 688422 & 4.9 & 5.1034 & TRN & \\
\hline CHEMBL1317505 & 688422 & 4.95 & 5.16100 & 00000000005 & TRN \\
\hline CHEMBL1438570 & 688422 & 4.65 & 5.82 & TST & \\
\hline CHEMBL1454183 & 688422 & 4.5 & 5.2082 & TST & \\
\hline CHEMBL1399306 & 688422 & 5.15 & 5.3123 & TST & \\
\hline CHEMBL1319380 & 688422 & 6.0 & 5.8201 & TRN & \\
\hline CHEMBL1321017 & 688422 & 5.2 & 5.1864 & TRN & \\
\hline CHEMBL1372439 & 688422 & 4.65 & 4.59699 & 99999999995 & TRN \\
\hline CHEMBL1349172 & 688422 & 4.95 & 4.9526 & TRN & \\
\hline CHEMBL1470993 & 688422 & 4.9 & 5.1814 & TRN & \\
\hline CHEMBL1364104 & 688422 & 4.45 & 5.6865 & TST & \\
\hline CHEMBL1473201 & 688422 & 8.4559 & 5.3995 & TRN & \\
\hline CHEMBL1547403 & 688422 & 6.1 & 5.7968 & TST & \\
\hline CHEMBL1452515 & 688422 & 4.45 & 5.2035 & TRN & \\
\hline CHEMBL1392033 & 688422 & 4.85 & 5.3731 & TRN & \\
\hline CHEMBL1534281 & 688422 & 4.45 & 5.2539 & TRN & \\
\hline CHEMBL1571279 & 688422 & 5.95 & 5.3169 & TRN & \\
\hline CHEMBL1486375 & 688422 & 6.45 & 5.6547 & TRN & \\
\hline CHEMBL1349191 & 688422 & 6.2 & 5.6318 & TRN & \\
\hline CHEMBL1550269 & 688422 & 4.75 & 4.75899 & 99999999995 & TRN \\
\hline CHEMBL1399716 & 688422 & 6.8 & 5.4043 & TRN & \\
\hline CHEMBL1585992 & 688422 & 6.35 & 5.6931 & TRN & \\
\hline CHEMBL3210975 & 688422 & 7.2503 & 5.3772 & TRN & \\
\hline CHEMBL1309816 & 688422 & 4.45 & 5.857 & TST & \\
\hline CHEMBL1449794 & 688422 & 4.95 & 5.0665 & TRN & \\
\hline CHEMBL3198437 & 688422 & 7.2503 & 5.0702 & TST & \\
\hline CHEMBL1357810 & 688422 & 4.8 & 5.3375 & TRN & \\
\hline CHEMBL1426462 & 688422 & 4.85 & 5.1006 & TRN & \\
\hline CHEMBL1511784 & 688422 & 4.7 & 5.1377 & TST & \\
\hline CHEMBL3213956 & 688422 & 4.8 & 5.2603 & TRN & \\
\hline CHEMBL1420074 & 688422 & 4.8 & 5.1215 & TRN & \\
\hline CHEMBL1504160 & 688422 & 4.45 & 5.3065 & TRN & \\
\hline CHEMBL1454540 & 688422 & 4.6 & 5.032 & TST & \\
\hline CHEMBL3144984 & 688422 & 4.75 & 5.0443 & TST & \\
\hline CHEMBL1562153 & 688422 & 5.0 & 5.2175 & TRN & \\
\hline CHEMBL1408788 & 688422 & 5.2 & 5.1563 & TRN & \\
\hline CHEMBL1341396 & 688422 & 4.9 & 5.1159 & TRN & \\
\hline CHEMBL1518814 & 688422 & 7.6003 & 5.3025 & TST & \\
\hline CHEMBL1476239 & 688422 & 4.95 & 5.4716 & TRN & \\
\hline CHEMBL3190827 & 688422 & 4.8 & 5.1268 & TRN & \\
\hline CHEMBL1404494 & 688422 & 5.9 & 4.9242 & TRN & \\
\hline CHEMBL1350169 & 688422 & 4.9 & 4.7173 & TRN & \\
\hline CHEMBL1256775 & 688422 & 7.699 & 5.4439 & TRN & \\
\hline
\end{tabular}




\begin{tabular}{|c|c|c|c|c|c|}
\hline \multicolumn{6}{|c|}{ Supplemental Table S2.txt } \\
\hline CHEMBL1316834 & 688422 & 5.3 & 4.8892 & TST & \\
\hline CHEMBL1445590 & 688422 & 4.9 & 5.085 & TRN & \\
\hline CHEMBL3190314 & 688422 & 4.8 & 4.909 & TRN & \\
\hline CHEMBL1555652 & 688422 & 4.45 & 4.53 & TRN & \\
\hline CHEMBL1397394 & 688422 & 4.6 & 4.9509 & TRN & \\
\hline CHEMBL3191486 & 688422 & 5.2 & 5.3076 & TST & \\
\hline CHEMBL1490923 & 688422 & 5.05 & 5.4539 & TRN & \\
\hline CHEMBL1601122 & 688422 & 8.0 & 5.3526 & TRN & \\
\hline CHEMBL1354017 & 688422 & 4.5 & 4.8688 & TRN & \\
\hline CHEMBL1308297 & 688422 & 6.7001 & 5.2132 & TRN & \\
\hline CHEMBL56731 & 688422 & 5.1 & 4.9447 & TRN & \\
\hline CHEMBL1509754 & 688422 & 4.65 & 4.6031 & TRN & \\
\hline CHEMBL1382827 & 688422 & 5.4 & 5.1877 & TRN & \\
\hline CHEMBL1556656 & 688422 & 4.45 & 5.155 & TRN & \\
\hline CHEMBL1573631 & 688422 & 4.45 & 5.6523 & TST & \\
\hline CHEMBL3196990 & 688422 & 4.9 & 4.7539 & TRN & \\
\hline CHEMBL1585752 & 688422 & 4.45 & 5.1069 & TST & \\
\hline CHEMBL1334530 & 688422 & 4.55 & 4.8516 & TRN & \\
\hline CHEMBL1340253 & 688422 & 6.7001 & 5.3608 & TRN & \\
\hline CHEMBL1308313 & 688422 & 4.45 & 5.5666 & TRN & \\
\hline CHEMBL1561939 & 688422 & 5.25 & 5.7342 & TRN & \\
\hline CHEMBL589235 & 688422 & 4.85 & 4.9115 & TST & \\
\hline CHEMBL1499843 & 688422 & 5.0 & 5.155 & TRN & \\
\hline CHEMBL 3145137 & 688422 & 5.3 & 5.2404 & TST & \\
\hline CHEMBL1416125 & 688422 & 4.5 & 5.0291 & TST & \\
\hline CHEMBL1400617 & 688422 & 4.45 & 5.3976 & TRN & \\
\hline CHEMBL3195852 & 688422 & 4.95 & 5.0018 & TRN & \\
\hline CHEMBL1561474 & 688422 & 5.3 & 6.0339 & TRN & \\
\hline CHEMBL1560233 & 688422 & 8.4949 & 5.8012 & TRN & \\
\hline CHEMBL1579301 & 688422 & 4.95 & 5.3374 & TRN & \\
\hline CHEMBL1591556 & 688422 & 6.0 & 6.5252 & TRN & \\
\hline CHEMBL1331813 & 688422 & 4.5 & 5.1981 & TST & \\
\hline CHEMBL1320368 & 688422 & 4.45 & 5.4867 & TRN & \\
\hline CHEMBL1334732 & 688422 & 6.95 & 4.8042 & TRN & \\
\hline CHEMBL1522707 & 688422 & 5.0 & 5.4206 & TRN & \\
\hline CHEMBL1532357 & 688422 & 4.45 & 5.4147 & TST & \\
\hline CHEMBL1505921 & 688422 & 4.95 & 4.8302 & TRN & \\
\hline CHEMBL1544675 & 688422 & 4.45 & 5.6794 & TRN & \\
\hline CHEMBL1472126 & 688422 & 4.45 & 4.8735 & TRN & \\
\hline CHEMBL1388639 & 688422 & 4.85 & 4.8773 & TRN & \\
\hline CHEMBL1339547 & 688422 & 4.65 & 5.3015 & TST & \\
\hline CHEMBL1571478 & 688422 & 6.25 & 5.5913 & TRN & \\
\hline CHEMBL1544460 & 688422 & 4.45 & 4.9308 & TRN & \\
\hline CHEMBL1507339 & 688422 & 5.45 & 5.2716 & TRN & \\
\hline CHEMBL1302158 & 688422 & 4.95 & 4.85800 & 00000000005 & TRN \\
\hline CHEMBL1522758 & 688422 & 4.45 & 5.21700 & 00000000005 & TRN \\
\hline CHEMBL1597239 & 688422 & 8.6576 & 6.0927 & TRN & \\
\hline CHEMBL1453080 & 688422 & 5.5 & 4.9749 & TRN & \\
\hline
\end{tabular}




\begin{tabular}{|c|c|c|c|c|c|}
\hline \multirow{3}{*}{$\begin{array}{l}\text { CHEMBL1460307 } \\
\text { CHEMBL } 1380270\end{array}$} & & \multicolumn{4}{|c|}{ Supplemental Table S2.txt } \\
\hline & 688422 & 4.6 & \multicolumn{2}{|c|}{5.367000000000001} & TRN \\
\hline & 688422 & 5.05 & 4.9795 & TRN & \\
\hline CHEMBL1332873 & 688422 & 5.6 & 4.8733 & TRN & \\
\hline CHEMBL1428197 & 688422 & 4.85 & 4.6024 & TRN & \\
\hline CHEMBL3207634 & 688422 & 4.7 & 5.2776 & TRN & \\
\hline CHEMBL1988500 & 688422 & 5.25 & 4.9996 & TST & \\
\hline CHEMBL1487065 & 688422 & 4.45 & 5.2248 & TST & \\
\hline CHEMBL1428124 & 688422 & 5.2 & \multicolumn{2}{|c|}{5.0089999999999995} & TST \\
\hline CHEMBL1401170 & 688422 & 4.55 & \multicolumn{2}{|c|}{5.327000000000001} & TRN \\
\hline CHEMBL1388700 & 688422 & 4.7 & 5.5039 & TRN & \\
\hline CHEMBL1605395 & 688422 & 4.5 & 5.0985 & TRN & \\
\hline CHEMBL1429935 & 688422 & 4.45 & 5.063 & TRN & \\
\hline CHEMBL1328775 & 688422 & 6.7001 & 5.6287 & TRN & \\
\hline CHEMBL1390206 & 688422 & 7.2 & 5.2471 & TST & \\
\hline CHEMBL1513600 & 688422 & 7.1002 & 5.9361 & TRN & \\
\hline CHEMBL3189567 & 688422 & 5.55 & 4.9284 & TRN & \\
\hline CHEMBL1305940 & 688422 & 5.75 & 4.9478 & TRN & \\
\hline CHEMBL3195681 & 688422 & 6.4 & \multicolumn{2}{|c|}{5.122000000000001} & TST \\
\hline CHEMBL1431631 & 688422 & 4.7 & 5.1501 & TRN & \\
\hline CHEMBL1964748 & 688422 & 5.3 & 4.9721 & TRN & \\
\hline CHEMBL1362902 & 688422 & 4.65 & 5.1581 & TRN & \\
\hline CHEMBL1351062 & 688422 & 6.1 & 5.5215 & TRN & \\
\hline CHEMBL1311892 & 688422 & 8.1024 & 5.0603 & TST & \\
\hline CHEMBL1556864 & 688422 & 4.55 & 5.318 & TST & \\
\hline CHEMBL1556795 & 688422 & 5.45 & 5.4827 & TRN & \\
\hline CHEMBL1431854 & 688422 & 4.5 & 5.3541 & TST & \\
\hline CHEMBL1999046 & 688422 & 4.5 & 4.8583 & TST & \\
\hline CHEMBL1449336 & 688422 & 5.2 & 5.2673 & TST & \\
\hline CHEMBL1580719 & 688422 & 4.45 & 5.6937 & TRN & \\
\hline CHEMBL1352654 & 688422 & 8.301 & 5.2119 & TRN & \\
\hline CHEMBL1467735 & 688422 & 4.75 & 5.0069 & TRN & \\
\hline CHEMBL1575565 & 688422 & 4.85 & 4.7333 & TRN & \\
\hline CHEMBL1462550 & 688422 & 4.95 & 5.5046 & TRN & \\
\hline CHEMBL1580553 & 688422 & 4.9 & 4.5294 & TST & \\
\hline CHEMBL3213742 & 688422 & 4.85 & 5.273 & TST & \\
\hline CHEMBL1524678 & 688422 & 4.5 & 5.0187 & TST & \\
\hline CHEMBL1526111 & 688422 & 4.45 & 5.3252 & TST & \\
\hline CHEMBL 3190255 & 688422 & 5.2 & 5.0046 & TRN & \\
\hline CHEMBL1337767 & 688422 & 5.4 & 5.3593 & TRN & \\
\hline CHEMBL1323375 & 688422 & 4.85 & 5.221 & TRN & \\
\hline CHEMBL1314100 & 688422 & 6.5501 & 4.7302 & TRN & \\
\hline CHEMBL1447602 & 688422 & 4.45 & 4.772 & TST & \\
\hline CHEMBL1608789 & 688422 & 4.9 & 5.1455 & TRN & \\
\hline CHEMBL1301125 & 688422 & 5.35 & 5.2101 & TRN & \\
\hline CHEMBL1500404 & 688422 & 5.5 & 5.0266 & TRN & \\
\hline CHEMBL1404256 & 688422 & 4.45 & 5.3921 & TRN & \\
\hline CHEMBL1408745 & 688422 & 5.0 & 5.4036 & TRN & \\
\hline CHEMBL1588778 & 688422 & 4.95 & 4.9168 & TRN & \\
\hline
\end{tabular}




\begin{tabular}{|c|c|c|c|c|}
\hline \multicolumn{5}{|c|}{ Supplemental Table S2.txt } \\
\hline CHEMBL1363058 & 688422 & 4.5 & 5.2442 & TRN \\
\hline CHEMBL1376427 & 688422 & 6.35 & 5.2546 & TRN \\
\hline CHEMBL1587416 & 688422 & 4.65 & 5.2069 & TRN \\
\hline CHEMBL 3193104 & 688422 & 4.45 & 5.3923 & TST \\
\hline CHEMBL3197643 & 688422 & 4.95 & 5.0705 & TRN \\
\hline CHEMBL1499271 & 688422 & 4.45 & 5.0871 & TRN \\
\hline CHEMBL1576113 & 688422 & 5.1 & 4.9012 & TRN \\
\hline CHEMBL1469493 & 688422 & 5.55 & 5.1563 & TST \\
\hline CHEMBL1488394 & 688422 & 6.35 & 5.2599 & TRN \\
\hline CHEMBL1596637 & 688422 & 5.5 & 5.2938 & TRN \\
\hline CHEMBL1314082 & 688422 & 7.6498 & 5.6838 & TST \\
\hline CHEMBL1495950 & 688422 & 4.45 & 5.2578 & TST \\
\hline CHEMBL1387762 & 688422 & 4.95 & 4.82 & TRN \\
\hline CHEMBL1487582 & 688422 & 4.45 & 4.8987 & TRN \\
\hline CHEMBL1329997 & 688422 & 4.85 & 4.9667 & TRN \\
\hline CHEMBL1580571 & 688422 & 4.95 & 4.813 & TRN \\
\hline CHEMBL1591471 & 688422 & 7.9508 & 5.7512 & TRN \\
\hline CHEMBL1534748 & 688422 & 4.6 & 5.2233 & TRN \\
\hline CHEMBL1516599 & 688422 & 5.45 & 5.2728 & TST \\
\hline CHEMBL1375326 & 688422 & 5.15 & 4.6318 & TRN \\
\hline CHEMBL1307430 & 688422 & 4.9 & 5.2895 & TRN \\
\hline CHEMBL1419872 & 688422 & 4.5 & 5.176 & TRN \\
\hline CHEMBL1394430 & 688422 & 4.45 & 5.126 & TRN \\
\hline CHEMBL1331168 & 688422 & 4.9 & 5.3743 & TRN \\
\hline CHEMBL1542670 & 688422 & 4.45 & 5.4983 & TST \\
\hline CHEMBL1305665 & 688422 & 5.0 & 5.0253 & TRN \\
\hline CHEMBL1498260 & 688422 & 4.85 & 5.6131 & TST \\
\hline CHEMBL1572896 & 688422 & 4.7 & 4.7328 & TRN \\
\hline CHEMBL1322055 & 688422 & 5.45 & 5.6015 & TST \\
\hline CHEMBL1391031 & 688422 & 4.65 & 4.8211 & TRN \\
\hline CHEMBL1398663 & 688422 & 4.5 & 4.5942 & TRN \\
\hline CHEMBL1304146 & 688422 & 5.25 & 5.7078 & TRN \\
\hline CHEMBL1476193 & 688422 & 6.35 & 5.0932 & TRN \\
\hline CHEMBL1340387 & 688422 & 5.5 & 5.489 & TRN \\
\hline CHEMBL1606030 & 688422 & 4.6 & 5.1979 & TRN \\
\hline CHEMBL1348651 & 688422 & 4.75 & 5.3893 & TRN \\
\hline CHEMBL1335768 & 688422 & 5.35 & 5.2615 & TRN \\
\hline CHEMBL1340766 & 688422 & 5.0 & 4.9915 & TRN \\
\hline CHEMBL1994221 & 688422 & 6.3 & 5.2397 & TRN \\
\hline CHEMBL1532531 & 688422 & 4.75 & 4.7715 & TRN \\
\hline CHEMBL1578503 & 688422 & 4.9 & 4.7146 & TRN \\
\hline CHEMBL3209184 & 688422 & 4.9 & 5.2241 & TST \\
\hline CHEMBL1584454 & 688422 & 4.95 & 5.2374 & TRN \\
\hline CHEMBL1385349 & 688422 & 4.7 & 5.0632 & TRN \\
\hline CHEMBL3190024 & 688422 & 5.5 & 5.2355 & TRN \\
\hline CHEMBL1389322 & 688422 & 4.45 & 5.2742 & TRN \\
\hline CHEMBL1531870 & 688422 & 4.8 & 5.1051 & TRN \\
\hline CHEMBL1457421 & 688422 & 5.65 & 5.7222 & TST \\
\hline
\end{tabular}




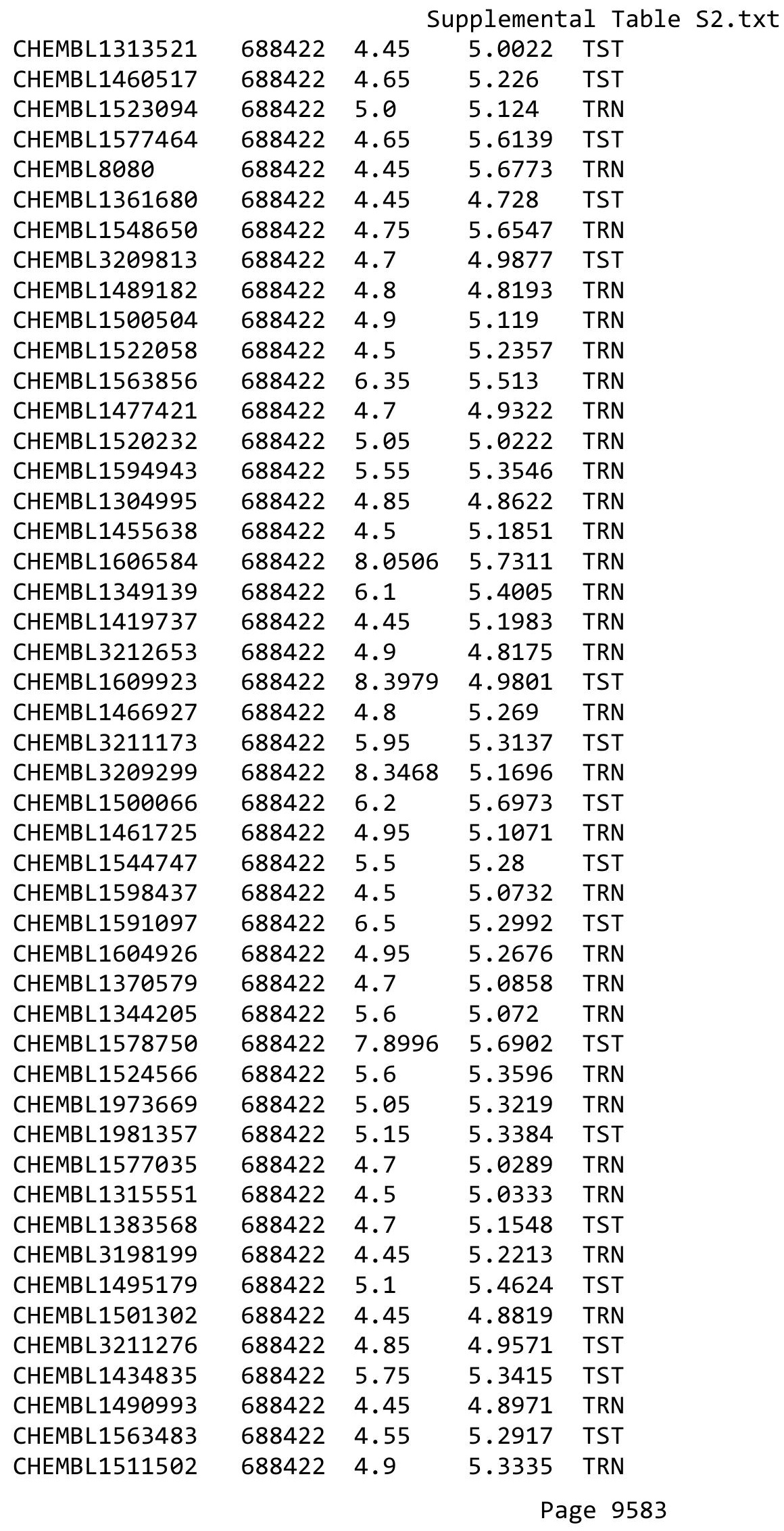




\begin{tabular}{|c|c|c|c|c|}
\hline \multicolumn{5}{|c|}{ Supplemental Table S2.txt } \\
\hline CHEMBL1475366 & 688422 & 4.75 & 4.783 & TRN \\
\hline CHEMBL1345796 & 688422 & 4.65 & 5.3639 & TRN \\
\hline CHEMBL3193886 & 688422 & 4.9 & 4.9914 & TRN \\
\hline CHEMBL1406577 & 688422 & 4.45 & 4.9789 & TRN \\
\hline CHEMBL 291057 & 688422 & 4.45 & 5.4111 & TST \\
\hline CHEMBL1507370 & 688422 & 6.6 & 5.2268 & TST \\
\hline CHEMBL1311910 & 688422 & 4.8 & 5.1793 & TST \\
\hline CHEMBL1364553 & 688422 & 5.05 & 4.8735 & TST \\
\hline CHEMBL1544534 & 688422 & 6.95 & 5.4982 & TST \\
\hline CHEMBL1349114 & 688422 & 4.85 & 5.1122 & TRN \\
\hline CHEMBL1451203 & 688422 & 8.1487 & 5.3951 & TRN \\
\hline CHEMBL1558616 & 688422 & 4.45 & 5.4855 & TRN \\
\hline CHEMBL1586301 & 688422 & 4.9 & 5.3575 & TRN \\
\hline CHEMBL1411378 & 688422 & 5.35 & 5.5535 & TST \\
\hline CHEMBL1578666 & 688422 & 5.3 & 5.6343 & TST \\
\hline CHEMBL1499646 & 688422 & 4.75 & 5.4708 & TRN \\
\hline CHEMBL1390496 & 688422 & 6.45 & 5.4499 & TRN \\
\hline CHEMBL1493797 & 688422 & 5.2 & 4.9461 & TRN \\
\hline CHEMBL1368276 & 688422 & 4.55 & 4.93 & TST \\
\hline CHEMBL1519982 & 688422 & 4.45 & 5.4101 & TRN \\
\hline CHEMBL345083 & 688422 & 6.45 & 5.6545 & TST \\
\hline CHEMBL1429147 & 688422 & 6.3 & 4.6834 & TRN \\
\hline CHEMBL1488028 & 688422 & 6.1 & 5.7975 & TRN \\
\hline CHEMBL1566826 & 688422 & 7.8996 & 5.8453 & TST \\
\hline CHEMBL1312614 & 688422 & 4.65 & 4.6532 & TRN \\
\hline CHEMBL1586326 & 688422 & 4.95 & 5.0947 & TST \\
\hline CHEMBL3208699 & 688422 & 4.85 & 5.6607 & TST \\
\hline CHEMBL1512190 & 688422 & 4.45 & 4.6849 & TRN \\
\hline CHEMBL1303068 & 688422 & 4.8 & 4.3645 & TRN \\
\hline CHEMBL1579795 & 688422 & 4.45 & 5.1047 & TST \\
\hline CHEMBL1413742 & 688422 & 7.7496 & 5.4051 & TST \\
\hline CHEMBL1307559 & 688422 & 4.8 & 4.7933 & TRN \\
\hline CHEMBL1407002 & 688422 & 4.45 & 4.98 & TST \\
\hline CHEMBL465227 & 688422 & 5.0 & 4.9516 & TRN \\
\hline CHEMBL1386458 & 688422 & 5.25 & 5.0647 & TRN \\
\hline CHEMBL1501009 & 688422 & 4.9 & 5.6997 & TRN \\
\hline CHEMBL1478675 & 688422 & 4.45 & 4.9935 & TRN \\
\hline CHEMBL1301470 & 688422 & 4.7 & 5.4819 & TRN \\
\hline CHEMBL1503584 & 688422 & 5.15 & 5.1337 & TST \\
\hline CHEMBL1508232 & 688422 & 4.45 & 5.4179 & TST \\
\hline CHEMBL1440108 & 688422 & 4.6 & 5.0563 & TRN \\
\hline CHEMBL1401198 & 688422 & 6.8499 & 5.1511 & TST \\
\hline CHEMBL1497785 & 688422 & 6.15 & 5.746 & TST \\
\hline CHEMBL1507652 & 688422 & 7.0 & 5.1193 & TRN \\
\hline CHEMBL3208179 & 688422 & 4.75 & 5.0936 & TRN \\
\hline CHEMBL1538515 & 688422 & 5.4 & 5.6242 & TRN \\
\hline CHEMBL1511197 & 688422 & 5.25 & 4.8906 & TRN \\
\hline CHEMBL574583 & 688422 & 5.15 & 5.0769 & TST \\
\hline
\end{tabular}




\begin{tabular}{|c|c|c|c|c|c|}
\hline \multirow[b]{2}{*}{ CHEMBL1488527 } & \multicolumn{5}{|c|}{ Supplemental Table S2.txt } \\
\hline & 688422 & 7.6498 & 5.7657 & TRN & \\
\hline CHEMBL1508182 & 688422 & 4.6 & 5.1674 & TRN & \\
\hline CHEMBL1404337 & 688422 & 4.45 & 5.5074 & TRN & \\
\hline CHEMBL1612094 & 688422 & 7.7496 & 4.967 & TRN & \\
\hline CHEMBL1309645 & 688422 & 5.15 & 4.9607 & TRN & \\
\hline CHEMBL1332198 & 688422 & 4.95 & 4.9981 & TST & \\
\hline CHEMBL1545684 & 688422 & 4.85 & 5.2788 & TRN & \\
\hline CHEMBL1533007 & 688422 & 7.15 & 5.6158 & TRN & \\
\hline CHEMBL1445066 & 688422 & 4.7 & 5.4761 & TRN & \\
\hline CHEMBL1338855 & 688422 & 8.1487 & 5.481 & TST & \\
\hline CHEMBL1302550 & 688422 & 4.65 & 5.5449 & TRN & \\
\hline CHEMBL3197310 & 688422 & 5.4 & 5.3163 & TST & \\
\hline CHEMBL1395098 & 688422 & 4.7 & 4.8875 & TRN & \\
\hline CHEMBL1453432 & 688422 & 5.0 & 5.15799 & 99999999995 & TRN \\
\hline CHEMBL1311611 & 688422 & 4.6 & 5.0798 & TRN & \\
\hline CHEMBL1966848 & 688422 & 4.6 & 5.3595 & TRN & \\
\hline CHEMBL3192536 & 688422 & 4.95 & 5.265 & TST & \\
\hline CHEMBL1504659 & 688422 & 5.15 & 5.3063 & TRN & \\
\hline CHEMBL1465926 & 688422 & 5.85 & 5.2199 & TST & \\
\hline CHEMBL1471956 & 688422 & 4.65 & 5.2528 & TRN & \\
\hline CHEMBL1489124 & 688422 & 6.8 & 5.5095 & TRN & \\
\hline CHEMBL1302535 & 688422 & 5.25 & 5.2475 & TST & \\
\hline CHEMBL1317931 & 688422 & 5.85 & 5.7906 & TST & \\
\hline CHEMBL3196499 & 688422 & 4.9 & 5.1729 & TRN & \\
\hline CHEMBL1314121 & 688422 & 5.05 & 5.6776 & TRN & \\
\hline CHEMBL1462265 & 688422 & 4.6 & 5.3613 & TST & \\
\hline CHEMBL1510726 & 688422 & 4.75 & 5.6735 & TRN & \\
\hline CHEMBL1491941 & 688422 & 5.8 & 6.1279 & TST & \\
\hline CHEMBL1306509 & 688422 & 7.3002 & 5.1977 & TRN & \\
\hline CHEMBL1478271 & 688422 & 4.45 & 5.1773 & TRN & \\
\hline CHEMBL1469898 & 688422 & 4.45 & 5.084 & TRN & \\
\hline CHEMBL1604786 & 688422 & 4.55 & 5.0961 & TRN & \\
\hline CHEMBL1345024 & 688422 & 6.7501 & 5.221 & TST & \\
\hline CHEMBL1986151 & 688422 & 5.05 & 5.2177 & TRN & \\
\hline CHEMBL1417786 & 688422 & 5.3 & 5.3435 & TRN & \\
\hline CHEMBL1558210 & 688422 & 4.45 & 5.2851 & TRN & \\
\hline CHEMBL1323411 & 688422 & 4.75 & 5.6705 & TST & \\
\hline CHEMBL1531933 & 688422 & 4.45 & 5.0541 & TRN & \\
\hline CHEMBL1348874 & 688422 & 4.9 & 4.9043 & TRN & \\
\hline CHEMBL1405695 & 688422 & 4.7 & 5.03100 & 0000000001 & TRN \\
\hline CHEMBL1348505 & 688422 & 6.8 & 5.2665 & TRN & \\
\hline CHEMBL1323412 & 688422 & 5.65 & 4.8939 & TST & \\
\hline CHEMBL1585814 & 688422 & 4.9 & 5.2279 & TRN & \\
\hline CHEMBL1335654 & 688422 & 4.45 & 4.9016 & TRN & \\
\hline CHEMBL1377064 & 688422 & 4.45 & 4.9784 & TST & \\
\hline CHEMBL1450562 & 688422 & 7.15 & 5.5009 & TST & \\
\hline CHEMBL1392939 & 688422 & 7.9508 & 5.7498 & TST & \\
\hline CHEMBL475375 & 688422 & 5.1 & 4.7683 & TRN & \\
\hline
\end{tabular}




\begin{tabular}{|c|c|c|c|c|c|}
\hline \multicolumn{6}{|c|}{ Supplemental Table S2.txt } \\
\hline CHEMBL1423818 & 688422 & 4.5 & 5.4977 & TRN & \\
\hline CHEMBL1322468 & 688422 & 4.85 & 5.126 & TRN & \\
\hline CHEMBL1566786 & 688422 & 5.3 & 5.0972 & TST & \\
\hline CHEMBL1365084 & 688422 & 4.5 & 5.2771 & TRN & \\
\hline CHEMBL1500275 & 688422 & 4.95 & 5.1245 & TRN & \\
\hline CHEMBL1388940 & 688422 & 4.95 & 4.5698 & TRN & \\
\hline CHEMBL1398775 & 688422 & 5.95 & 5.1432 & TST & \\
\hline CHEMBL1437011 & 688422 & 4.85 & 5.2709 & TST & \\
\hline CHEMBL1583529 & 688422 & 7.5498 & 5.2211 & TRN & \\
\hline CHEMBL1967436 & 688422 & 5.5 & 4.8477 & TRN & \\
\hline CHEMBL2006154 & 688422 & 5.1 & 4.8153 & TRN & \\
\hline CHEMBL447861 & 688422 & 4.85 & 5.3921 & TRN & \\
\hline CHEMBL1335028 & 688422 & 4.5 & 4.9948 & TRN & \\
\hline CHEMBL1504393 & 688422 & 4.7 & 5.1594 & TST & \\
\hline CHEMBL1344662 & 688422 & 8.0506 & 5.6888 & TRN & \\
\hline CHEMBL1458825 & 688422 & 4.45 & 5.5439 & TRN & \\
\hline CHEMBL1420879 & 688422 & 4.65 & 5.70700 & 0000000001 & TRN \\
\hline CHEMBL1596514 & 688422 & 4.65 & 5.1867 & TST & \\
\hline CHEMBL3190849 & 688422 & 5.3 & 4.8889 & TRN & \\
\hline CHEMBL1504253 & 688422 & 5.0 & 5.0427 & TRN & \\
\hline CHEMBL1510982 & 688422 & 5.15 & 5.0956 & TRN & \\
\hline CHEMBL1423242 & 688422 & 5.15 & 5.1248 & TRN & \\
\hline CHEMBL1393184 & 688422 & 5.4 & 5.7892 & TRN & \\
\hline CHEMBL1424221 & 688422 & 6.05 & 5.6196 & TRN & \\
\hline CHEMBL1430259 & 688422 & 4.5 & 5.1612 & TRN & \\
\hline CHEMBL1546699 & 688422 & 4.7 & 5.7441 & TST & \\
\hline CHEMBL1346051 & 688422 & 6.1 & 5.6521 & TRN & \\
\hline CHEMBL1578236 & 688422 & 5.6 & 5.439 & TST & \\
\hline CHEMBL1413275 & 688422 & 4.45 & 5.3026 & TST & \\
\hline CHEMBL1328983 & 688422 & 4.95 & 4.9124 & TST & \\
\hline CHEMBL1385062 & 688422 & 4.7 & 5.5426 & TST & \\
\hline CHEMBL1341933 & 688422 & 5.25 & 5.1113 & TST & \\
\hline CHEMBL1555313 & 688422 & 4.8 & 5.5382 & TRN & \\
\hline CHEMBL1325195 & 688422 & 5.4 & 5.5256 & TRN & \\
\hline CHEMBL1413641 & 688422 & 4.8 & 5.2584 & TRN & \\
\hline CHEMBL1516739 & 688422 & 4.75 & 5.2677 & TRN & \\
\hline CHEMBL1541655 & 688422 & 4.9 & 5.3567 & TRN & \\
\hline CHEMBL1421879 & 688422 & 4.45 & 5.3418 & TRN & \\
\hline CHEMBL1488561 & 688422 & 6.4 & 6.21 & TST & \\
\hline CHEMBL1462760 & 688422 & 4.9 & 5.3368 & TRN & \\
\hline CHEMBL1395646 & 688422 & 4.45 & 4.9111 & TRN & \\
\hline CHEMBL1599592 & 688422 & 4.45 & 5.5778 & TRN & \\
\hline CHEMBL1466340 & 688422 & 4.45 & 5.075 & TRN & \\
\hline CHEMBL1402501 & 688422 & 4.45 & 5.2425 & TRN & \\
\hline CHEMBL1534588 & 688422 & 4.75 & 4.6452 & TRN & \\
\hline CHEMBL1437928 & 688422 & 5.25 & 5.6233 & TST & \\
\hline CHEMBL1385745 & 688422 & 4.75 & 5.1855 & TRN & \\
\hline CHEMBL1414513 & 688422 & 4.45 & 5.3431 & TRN & \\
\hline
\end{tabular}




\begin{tabular}{|c|c|c|c|c|c|}
\hline \multicolumn{6}{|c|}{ Supplemental Table S2.txt } \\
\hline CHEMBL1579857 & 688422 & 6.15 & 5.585 & TRN & \\
\hline CHEMBL577635 & 688422 & 5.45 & 5.8962 & TST & \\
\hline CHEMBL1512689 & 688422 & 4.65 & 5.3965 & TRN & \\
\hline CHEMBL1376704 & 688422 & 4.9 & 5.1146 & TRN & \\
\hline CHEMBL1539917 & 688422 & 7.1002 & 4.7622 & TRN & \\
\hline CHEMBL1341925 & 688422 & 4.5 & 5.4632 & TRN & \\
\hline CHEMBL1400925 & 688422 & 4.45 & 4.9763 & TST & \\
\hline CHEMBL1383712 & 688422 & 4.65 & 5.2888 & TRN & \\
\hline CHEMBL1426742 & 688422 & 4.85 & 5.2493 & TRN & \\
\hline CHEMBL1307523 & 688422 & 5.95 & 5.1817 & TST & \\
\hline CHEMBL1442885 & 688422 & 4.8 & 5.0065 & TRN & \\
\hline CHEMBL1411719 & 688422 & 5.45 & 5.3265 & TRN & \\
\hline CHEMBL1322482 & 688422 & 4.9 & 5.0748 & TRN & \\
\hline CHEMBL1366507 & 688422 & 5.2 & 5.0616 & TST & \\
\hline CHEMBL1572469 & 688422 & 5.6 & 4.7882 & TRN & \\
\hline CHEMBL1968540 & 688422 & 4.85 & 5.3659 & TRN & \\
\hline CHEMBL1440664 & 688422 & 5.4 & 5.2884 & TST & \\
\hline CHEMBL1412647 & 688422 & 5.25 & 4.8679 & TRN & \\
\hline CHEMBL1510625 & 688422 & 5.55 & 5.1185 & TRN & \\
\hline CHEMBL3196240 & 688422 & 5.05 & 5.2695 & TRN & \\
\hline CHEMBL1540178 & 688422 & 4.45 & 5.3202 & TRN & \\
\hline CHEMBL1475642 & 688422 & 4.9 & 4.9436 & TRN & \\
\hline CHEMBL1453263 & 688422 & 4.55 & 5.0434 & TRN & \\
\hline CHEMBL1450363 & 688422 & 4.5 & 5.24 & TST & \\
\hline CHEMBL1402898 & 688422 & 4.65 & 5.2595 & TRN & \\
\hline CHEMBL1382915 & 688422 & 4.9 & 5.3995 & TRN & \\
\hline CHEMBL1571980 & 688422 & 5.25 & 5.7092 & TST & \\
\hline CHEMBL1557691 & 688422 & 4.85 & 4.748 & TRN & \\
\hline CHEMBL 3196289 & 688422 & 5.45 & 5.1348 & TRN & \\
\hline CHEMBL1535276 & 688422 & 4.45 & 4.7022 & TRN & \\
\hline CHEMBL1579673 & 688422 & 4.8 & 5.4908 & TRN & \\
\hline CHEMBL 3191030 & 688422 & 4.45 & 5.112 & TRN & \\
\hline CHEMBL 222334 & 688422 & 5.2 & 4.9845 & TST & \\
\hline CHEMBL579498 & 688422 & 5.25 & 5.4669 & TRN & \\
\hline CHEMBL1432029 & 688422 & 4.45 & 4.9696 & TRN & \\
\hline CHEMBL1370618 & 688422 & 8.1487 & 5.3168 & TRN & \\
\hline CHEMBL1605556 & 688422 & 5.35 & 5.0519 & TRN & \\
\hline CHEMBL1340701 & 688422 & 4.8 & 5.2788 & TRN & \\
\hline CHEMBL580155 & 688422 & 7.8996 & 5.05399 & 7999999999 & TRN \\
\hline CHEMBL3207327 & 688422 & 4.45 & 5.1296 & TRN & \\
\hline CHEMBL1523967 & 688422 & 4.9 & 5.4189 & TRN & \\
\hline CHEMBL1392428 & 688422 & 4.45 & 5.6558 & TRN & \\
\hline CHEMBL1527533 & 688422 & 7.699 & 5.545 & TRN & \\
\hline CHEMBL1483061 & 688422 & 4.85 & 5.5699 & TRN & \\
\hline CHEMBL1554989 & 688422 & 5.15 & 5.6453 & TST & \\
\hline CHEMBL1611053 & 688422 & 4.8 & 4.8893 & TRN & \\
\hline CHEMBL1524101 & 688422 & 4.75 & 5.0622 & TRN & \\
\hline CHEMBL1516812 & 688422 & 4.75 & 5.152 & TRN & \\
\hline
\end{tabular}




\begin{tabular}{|c|c|c|c|c|c|}
\hline \multicolumn{6}{|c|}{ Supplemental Table S2.txt } \\
\hline CHEMBL1604508 & 688422 & 8.0 & 5.0612 & TRN & \\
\hline CHEMBL1513202 & 688422 & 4.8 & 5.4769 & TRN & \\
\hline CHEMBL1498043 & 688422 & 4.45 & 5.0298 & TRN & \\
\hline CHEMBL1399881 & 688422 & 4.7 & 5.5548 & TRN & \\
\hline CHEMBL1576058 & 688422 & 6.15 & 5.0837 & TRN & \\
\hline CHEMBL1593214 & 688422 & 4.8 & 5.7541 & TRN & \\
\hline CHEMBL1534049 & 688422 & 8.4949 & 5.3851 & TST & \\
\hline CHEMBL1585833 & 688422 & 4.8 & 5.3289 & TST & \\
\hline CHEMBL1499 & 688422 & 6.25 & 5.7876 & TRN & \\
\hline CHEMBL1604884 & 688422 & 5.45 & 5.1291 & TRN & \\
\hline CHEMBL1520768 & 688422 & 4.85 & 5.14 & TRN & \\
\hline CHEMBL1322181 & 688422 & 4.85 & 5.4756 & TRN & \\
\hline CHEMBL1590388 & 688422 & 4.45 & 5.2849 & TRN & \\
\hline CHEMBL1525510 & 688422 & 4.75 & 4.7103 & TRN & \\
\hline CHEMBL1517787 & 688422 & 5.75 & 5.0039 & TRN & \\
\hline CHEMBL1404622 & 688422 & 5.4 & 5.7311 & TST & \\
\hline CHEMBL1555541 & 688422 & 4.45 & 5.6683 & TST & \\
\hline CHEMBL3189877 & 688422 & 6.1 & 5.1706 & TRN & \\
\hline CHEMBL1575392 & 688422 & 4.95 & 5.2346 & TST & \\
\hline CHEMBL1431251 & 688422 & 4.55 & 5.2129 & TRN & \\
\hline CHEMBL1303183 & 688422 & 4.9 & 4.9846 & TRN & \\
\hline CHEMBL1553187 & 688422 & 4.7 & 5.5514 & TRN & \\
\hline CHEMBL1402951 & 688422 & 4.45 & 4.9423 & TRN & \\
\hline CHEMBL1414225 & 688422 & 4.8 & 5.3362 & TRN & \\
\hline CHEMBL 3208000 & 688422 & 4.45 & 4.9512 & TRN & \\
\hline CHEMBL1588656 & 688422 & 5.3 & 5.1702 & TRN & \\
\hline CHEMBL1582151 & 688422 & 4.8 & 5.2022 & TRN & \\
\hline CHEMBL1400764 & 688422 & 6.0 & 4.8631 & TRN & \\
\hline CHEMBL1300058 & 688422 & 4.5 & 5.45100 & 00000000005 & TRN \\
\hline CHEMBL18686 & 688422 & 5.3 & 5.5712 & TST & \\
\hline CHEMBL1546582 & 688422 & 8.4949 & 5.2124 & TST & \\
\hline CHEMBL1344610 & 688422 & 4.45 & 6.0238 & TRN & \\
\hline CHEMBL1492308 & 688422 & 4.45 & 5.42299 & 9999999999 & TST \\
\hline CHEMBL1502709 & 688422 & 4.8 & 5.2222 & TRN & \\
\hline CHEMBL1569221 & 688422 & 8.4559 & 5.2382 & TRN & \\
\hline CHEMBL1507140 & 688422 & 6.7001 & 5.8437 & TRN & \\
\hline CHEMBL1517012 & 688422 & 7.0 & 5.3439 & TRN & \\
\hline CHEMBL1343975 & 688422 & 5.6 & 5.5313 & TST & \\
\hline CHEMBL1380758 & 688422 & 4.9 & 4.9584 & TRN & \\
\hline CHEMBL1438517 & 688422 & 4.65 & 5.1169 & TRN & \\
\hline CHEMBL1515519 & 688422 & 6.5 & 5.2379 & TRN & \\
\hline CHEMBL1546670 & 688422 & 4.95 & 4.9779 & TRN & \\
\hline CHEMBL603129 & 688422 & 4.9 & 5.1423 & TRN & \\
\hline CHEMBL1445253 & 688422 & 5.25 & 5.44 & TST & \\
\hline CHEMBL1339412 & 688422 & 5.0 & 5.6135 & TRN & \\
\hline CHEMBL1335420 & 688422 & 4.9 & 5.4244 & TRN & \\
\hline CHEMBL1346760 & 688422 & 8.3979 & 5.456 & TST & \\
\hline CHEMBL1358950 & 688422 & 4.9 & 5.2963 & TRN & \\
\hline
\end{tabular}




\begin{tabular}{|c|c|c|c|c|c|}
\hline \multirow{3}{*}{$\begin{array}{l}\text { CHEMBL1435558 } \\
\text { CHEMBL1501509 }\end{array}$} & \multirow{3}{*}{$\begin{array}{l}688422 \\
688422\end{array}$} & \multicolumn{4}{|c|}{ Supplemental Table S2.txt } \\
\hline & & 9.0458 & 5.12700 & 0000000001 & TST \\
\hline & & 4.45 & 5.3135 & TRN & \\
\hline CHEMBL1556088 & 688422 & 4.55 & 5.4833 & TRN & \\
\hline CHEMBL1431874 & 688422 & 4.6 & 5.0873 & TRN & \\
\hline CHEMBL1463663 & 688422 & 4.45 & 4.9501 & TRN & \\
\hline CHEMBL1564006 & 688422 & 6.6 & 5.314 & TRN & \\
\hline CHEMBL1434315 & 688422 & 4.4 & 5.4148 & TRN & \\
\hline CHEMBL1583666 & 688422 & 5.1 & 5.4228 & TRN & \\
\hline CHEMBL1512169 & 688422 & 8.3468 & 5.9137 & TRN & \\
\hline CHEMBL1613209 & 688422 & 4.65 & 5.4364 & TRN & \\
\hline CHEMBL1405217 & 688422 & 6.6499 & 5.3443 & TRN & \\
\hline CHEMBL1404834 & 688422 & 5.0 & 5.2934 & TRN & \\
\hline CHEMBL1378798 & 688422 & 4.45 & 5.0058 & TRN & \\
\hline CHEMBL3209792 & 688422 & 5.2 & 4.888 & TRN & \\
\hline CHEMBL1467297 & 688422 & 5.1 & 4.9893 & TRN & \\
\hline CHEMBL1507657 & 688422 & 4.45 & 4.8781 & TRN & \\
\hline CHEMBL1571644 & 688422 & 5.95 & 5.3384 & TRN & \\
\hline CHEMBL1513421 & 688422 & 7.8996 & 5.1202 & TRN & \\
\hline CHEMBL1585924 & 688422 & 4.85 & 5.5963 & TRN & \\
\hline CHEMBL1406754 & 688422 & 4.65 & 5.1132 & TST & \\
\hline CHEMBL1427189 & 688422 & 4.85 & 5.3353 & TRN & \\
\hline CHEMBL1387387 & 688422 & 4.95 & 5.0537 & TRN & \\
\hline CHEMBL1412053 & 688422 & 4.45 & 5.6088 & TRN & \\
\hline CHEMBL3193056 & 688422 & 5.25 & 5.3638 & TRN & \\
\hline CHEMBL1523450 & 688422 & 4.85 & 5.0463 & TRN & \\
\hline CHEMBL1579464 & 688422 & 4.8 & 4.9898 & TRN & \\
\hline CHEMBL1378357 & 688422 & 4.45 & 5.0118 & TRN & \\
\hline CHEMBL1487311 & 688422 & 4.8 & 4.9237 & TRN & \\
\hline CHEMBL1367702 & 688422 & 4.45 & 4.529 & TRN & \\
\hline CHEMBL1548198 & 688422 & 5.65 & 5.3936 & TRN & \\
\hline CHEMBL1504284 & 688422 & 4.5 & 5.0779 & TST & \\
\hline CHEMBL1418676 & 688422 & 5.2 & 5.5913 & TRN & \\
\hline CHEMBL1404368 & 688422 & 4.85 & 4.9293 & TRN & \\
\hline CHEMBL1371991 & 688422 & 4.85 & 4.888 & TRN & \\
\hline CHEMBL1442738 & 688422 & 7.9508 & 5.5303 & TRN & \\
\hline CHEMBL3196520 & 688422 & 4.95 & 5.7531 & TST & \\
\hline CHEMBL1341100 & 688422 & 5.4 & 5.1946 & TST & \\
\hline CHEMBL1414417 & 688422 & 4.5 & 5.3841 & TRN & \\
\hline CHEMBL1396303 & 688422 & 6.6 & 5.4196 & TRN & \\
\hline CHEMBL1441316 & 688422 & 4.6 & 5.1362 & TST & \\
\hline CHEMBL1487251 & 688422 & 4.95 & 5.0202 & TRN & \\
\hline CHEMBL1594964 & 688422 & 4.45 & 5.0235 & TRN & \\
\hline CHEMBL1582659 & 688422 & 4.45 & 5.1118 & TST & \\
\hline CHEMBL1592767 & 688422 & 5.5 & 5.734 & TRN & \\
\hline CHEMBL1520011 & 688422 & 7.8508 & 5.4574 & TRN & \\
\hline CHEMBL1520266 & 688422 & 4.85 & 5.1077 & TRN & \\
\hline CHEMBL1430445 & 688422 & 4.45 & 5.3953 & TRN & \\
\hline CHEMBL1369691 & 688422 & 4.8 & 5.3903 & TRN & \\
\hline
\end{tabular}




\begin{tabular}{|c|c|c|c|c|c|}
\hline \multicolumn{6}{|c|}{ Supplemental Table S2.txt } \\
\hline CHEMBL1479432 & 688422 & 4.85 & 4.5378 & TRN & \\
\hline CHEMBL585222 & 688422 & 4.9 & 5.4684 & TRN & \\
\hline CHEMBL1525017 & 688422 & 4.45 & 4.7531 & TRN & \\
\hline CHEMBL1539841 & 688422 & 6.15 & 5.1993 & TRN & \\
\hline CHEMBL1388178 & 688422 & 4.7 & 5.5229 & TST & \\
\hline CHEMBL456586 & 688422 & 4.95 & 5.2357 & TST & \\
\hline CHEMBL1201074 & 688422 & 7.1002 & 4.8754 & TRN & \\
\hline CHEMBL1528882 & 688422 & 4.6 & 4.8441 & TRN & \\
\hline CHEMBL1568030 & 688422 & 5.35 & 5.5442 & TRN & \\
\hline CHEMBL1402807 & 688422 & 4.5 & 5.3725 & TRN & \\
\hline CHEMBL1564737 & 688422 & 5.55 & 4.8892 & TRN & \\
\hline CHEMBL1331218 & 688422 & 4.45 & 4.7946 & TRN & \\
\hline CHEMBL1527083 & 688422 & 8.0 & 6.2422 & TST & \\
\hline CHEMBL 1455503 & 688422 & 5.0 & 5.3603 & TRN & \\
\hline CHEMBL1303626 & 688422 & 4.65 & 4.8472 & TST & \\
\hline CHEMBL1605686 & 688422 & 6.6 & 5.4048 & TRN & \\
\hline CHEMBL3208777 & 688422 & 4.8 & 5.016 & TRN & \\
\hline CHEMBL1403766 & 688422 & 4.45 & 5.3565 & TST & \\
\hline CHEMBL1531979 & 688422 & 6.8 & 5.6549 & TRN & \\
\hline CHEMBL1379625 & 688422 & 4.45 & 5.0094 & TRN & \\
\hline CHEMBL1557299 & 688422 & 5.15 & 5.1281 & TRN & \\
\hline CHEMBL1391809 & 688422 & 4.45 & 4.7475 & TRN & \\
\hline CHEMBL1559772 & 688422 & 4.85 & 5.2392 & TRN & \\
\hline CHEMBL 1386820 & 688422 & 5.0 & 5.3573 & TST & \\
\hline CHEMBL1340713 & 688422 & 5.05 & 5.5676 & TST & \\
\hline CHEMBL1417295 & 688422 & 8.4559 & 5.739 & TST & \\
\hline CHEMBL1311360 & 688422 & 7.2 & 5.551 & TRN & \\
\hline CHEMBL1309340 & 688422 & 8.1024 & 5.4628 & TRN & \\
\hline CHEMBL1362157 & 688422 & 5.05 & 4.8014 & TST & \\
\hline CHEMBL1439171 & 688422 & 4.5 & 5.2841 & TRN & \\
\hline CHEMBL1380121 & 688422 & 6.0 & 5.29899 & 99999999995 & TRN \\
\hline CHEMBL1411907 & 688422 & 4.5 & 4.6888 & TRN & \\
\hline CHEMBL1301273 & 688422 & 4.9 & 5.0518 & TRN & \\
\hline CHEMBL1587534 & 688422 & 4.95 & 5.1 & TRN & \\
\hline CHEMBL1464548 & 688422 & 5.2 & 5.2988 & TRN & \\
\hline CHEMBL1605369 & 688422 & 4.9 & 5.2773 & TST & \\
\hline CHEMBL1241420 & 688422 & 4.9 & 5.143 & TRN & \\
\hline CHEMBL1609234 & 688422 & 4.45 & 5.2358 & TRN & \\
\hline CHEMBL1586587 & 688422 & 4.8 & 5.8037 & TRN & \\
\hline CHEMBL1514180 & 688422 & 4.45 & 5.1834 & TRN & \\
\hline CHEMBL1324110 & 688422 & 7.0 & 5.3867 & TST & \\
\hline CHEMBL1474797 & 688422 & 6.5501 & 5.4694 & TRN & \\
\hline CHEMBL1395226 & 688422 & 4.65 & 4.9673 & TRN & \\
\hline CHEMBL1431054 & 688422 & 6.05 & 5.5505 & TRN & \\
\hline CHEMBL1440501 & 688422 & 6.1 & 5.197 & TRN & \\
\hline CHEMBL567132 & 688422 & 4.95 & 4.7104 & TRN & \\
\hline CHEMBL1493396 & 688422 & 4.45 & 4.9396 & TST & \\
\hline CHEMBL1479255 & 688422 & 5.55 & 5.2352 & TST & \\
\hline
\end{tabular}




\begin{tabular}{|c|c|c|c|c|c|}
\hline \multicolumn{6}{|c|}{ Supplemental Table s2.txt } \\
\hline CHEMBL1448836 & 688422 & 5.85 & 5.1444 & TRN & \\
\hline CHEMBL1389856 & 688422 & 4.85 & 4.8559 & TRN & \\
\hline CHEMBL1601599 & 688422 & 4.8 & 4.9043 & TST & \\
\hline CHEMBL 3198672 & 688422 & 4.6 & 5.1455 & TRN & \\
\hline CHEMBL1590761 & 688422 & 5.6 & 5.4727 & TRN & \\
\hline CHEMBL1501590 & 688422 & 4.45 & 4.6858 & TRN & \\
\hline CHEMBL1464603 & 688422 & 4.65 & 5.5381 & TRN & \\
\hline CHEMBL1314549 & 688422 & 4.45 & 5.2632 & TRN & \\
\hline CHEMBL1574041 & 688422 & 4.7 & 5.1843 & TRN & \\
\hline CHEMBL1486213 & 688422 & 6.35 & 5.37 & TRN & \\
\hline CHEMBL1319964 & 688422 & 4.85 & 5.3415 & TRN & \\
\hline CHEMBL1530619 & 688422 & 8.2518 & 5.0603 & TRN & \\
\hline CHEMBL3198089 & 688422 & 5.95 & 5.1131 & TRN & \\
\hline CHEMBL1536785 & 688422 & 4.6 & 5.0441 & TST & \\
\hline CHEMBL1409256 & 688422 & 5.2 & 5.0697 & TST & \\
\hline CHEMBL1396289 & 688422 & 6.05 & 5.0988 & TRN & \\
\hline CHEMBL567850 & 688422 & 5.2 & 5.0907 & TRN & \\
\hline CHEMBL1420368 & 688422 & 4.6 & 5.2685 & TST & \\
\hline CHEMBL1479951 & 688422 & 5.45 & 4.9872 & TRN & \\
\hline CHEMBL1575127 & 688422 & 7.0501 & 5.1886 & TST & \\
\hline CHEMBL1572423 & 688422 & 8.1487 & 4.7683 & TRN & \\
\hline CHEMBL1980667 & 688422 & 5.05 & 5.1108 & TST & \\
\hline CHEMBL1469133 & 688422 & 4.45 & 5.1477 & TRN & \\
\hline CHEMBL1343390 & 688422 & 5.1 & 5.1706 & TRN & \\
\hline CHEMBL1484977 & 688422 & 4.85 & 5.2128 & TRN & \\
\hline CHEMBL503938 & 688422 & 4.85 & 5.6051 & TST & \\
\hline CHEMBL1413400 & 688422 & 4.95 & 5.5144 & TRN & \\
\hline CHEMBL1299463 & 688422 & 5.0 & 4.8054 & TRN & \\
\hline CHEMBL1435978 & 688422 & 5.75 & 5.3455 & TRN & \\
\hline CHEMBL1597172 & 688422 & 5.2 & 5.5137 & TRN & \\
\hline CHEMBL1352025 & 688422 & 4.75 & 5.1552 & TRN & \\
\hline CHEMBL1508455 & 688422 & 4.45 & 4.8123 & TRN & \\
\hline CHEMBL1443625 & 688422 & 4.8 & 5.1814 & TST & \\
\hline CHEMBL1414528 & 688422 & 5.7 & 5.0613 & TRN & \\
\hline CHEMBL1381613 & 688422 & 5.0 & 5.13899 & 9999999999 & TRN \\
\hline CHEMBL1494709 & 688422 & 4.75 & 5.1183 & TRN & \\
\hline CHEMBL1373947 & 688422 & 4.8 & 5.3673 & TRN & \\
\hline CHEMBL1577941 & 688422 & 4.45 & 5.0931 & TRN & \\
\hline CHEMBL1321590 & 688422 & 5.2 & 5.801 & TRN & \\
\hline CHEMBL3192890 & 688422 & 4.8 & 4.8742 & TRN & \\
\hline CHEMBL1607011 & 688422 & 4.8 & 4.8842 & TRN & \\
\hline CHEMBL1453813 & 688422 & 4.75 & 4.8062 & TRN & \\
\hline CHEMBL1427956 & 688422 & 4.45 & 5.15600 & 0000000001 & TRN \\
\hline CHEMBL1307022 & 688422 & 4.8 & 4.7944 & TST & \\
\hline CHEMBL1478005 & 688422 & 4.9 & 5.36299 & 99999999995 & TRN \\
\hline CHEMBL3207415 & 688422 & 4.7 & 5.3574 & TRN & \\
\hline CHEMBL1490954 & 688422 & 4.75 & 5.1935 & TST & \\
\hline CHEMBL1572467 & 688422 & 8.0506 & 5.524 & TST & \\
\hline
\end{tabular}




\begin{tabular}{|c|c|c|c|c|c|}
\hline \multicolumn{6}{|c|}{ Supplemental Table S2.txt } \\
\hline CHEMBL1483882 & 688422 & 4.5 & 4.6733 & TRN & \\
\hline CHEMBL1430358 & 688422 & 4.8 & 5.2841 & TRN & \\
\hline CHEMBL1300051 & 688422 & 4.85 & 5.1135 & TRN & \\
\hline CHEMBL1553220 & 688422 & 5.0 & 5.3887 & TRN & \\
\hline CHEMBL3192582 & 688422 & 4.7 & 5.2327 & TRN & \\
\hline CHEMBL1560032 & 688422 & 8.4949 & 5.4444 & TRN & \\
\hline CHEMBL1423408 & 688422 & 4.7 & 5.4028 & TST & \\
\hline CHEMBL1508443 & 688422 & 4.45 & 5.155 & TRN & \\
\hline CHEMBL1301885 & 688422 & 5.45 & 5.2372 & TRN & \\
\hline CHEMBL224146 & 688422 & 8.1487 & 5.5626 & TST & \\
\hline CHEMBL1415865 & 688422 & 4.65 & 5.0848 & TRN & \\
\hline CHEMBL1432065 & 688422 & 4.7 & 5.6193 & TST & \\
\hline CHEMBL1450716 & 688422 & 4.95 & 4.7702 & TRN & \\
\hline CHEMBL1351716 & 688422 & 4.95 & 5.3451 & TST & \\
\hline CHEMBL1313495 & 688422 & 5.15 & 5.0535 & TRN & \\
\hline CHEMBL1578505 & 688422 & 4.45 & 4.6822 & TRN & \\
\hline CHEMBL1403375 & 688422 & 6.0 & 4.8246 & TRN & \\
\hline CHEMBL1307371 & 688422 & 6.15 & 4.7509 & TRN & \\
\hline CHEMBL1304655 & 688422 & 4.6 & 5.1874 & TST & \\
\hline CHEMBL1531728 & 688422 & 4.65 & 5.204 & TRN & \\
\hline CHEMBL34241 & 688422 & 5.3 & 4.8753 & TST & \\
\hline CHEMBL1321943 & 688422 & 4.6 & 5.3569 & TRN & \\
\hline CHEMBL1387367 & 688422 & 4.9 & 5.0833 & TRN & \\
\hline CHEMBL1508691 & 688422 & 4.45 & 4.9988 & TRN & \\
\hline CHEMBL3211675 & 688422 & 5.85 & 5.1455 & TST & \\
\hline CHEMBL1364122 & 688422 & 4.5 & 5.9605 & TRN & \\
\hline CHEMBL1331319 & 688422 & 7.3002 & 5.20200 & 0000000001 & TST \\
\hline CHEMBL1335002 & 688422 & 4.45 & 4.89199 & 99999999995 & TRN \\
\hline CHEMBL544115 & 688422 & 4.45 & 5.0246 & TRN & \\
\hline CHEMBL1594172 & 688422 & 6.9 & 5.7923 & TST & \\
\hline CHEMBL1329396 & 688422 & 4.6 & 4.8408 & TRN & \\
\hline CHEMBL1429693 & 688422 & 4.45 & 4.9787 & TRN & \\
\hline CHEMBL1356437 & 688422 & 4.45 & 5.0747 & TST & \\
\hline CHEMBL1591600 & 688422 & 4.9 & 4.7152 & TRN & \\
\hline CHEMBL1413489 & 688422 & 5.65 & 5.4362 & TRN & \\
\hline CHEMBL1534925 & 688422 & 4.8 & 5.3028 & TRN & \\
\hline CHEMBL1605284 & 688422 & 4.65 & 4.7741 & TST & \\
\hline CHEMBL1416195 & 688422 & 4.9 & 5.3039 & TST & \\
\hline CHEMBL1378884 & 688422 & 6.6499 & 5.307 & TRN & \\
\hline CHEMBL1515130 & 688422 & 6.3 & 5.4741 & TRN & \\
\hline CHEMBL1523656 & 688422 & 4.65 & 5.2167 & TST & \\
\hline CHEMBL1380337 & 688422 & 4.65 & 4.8485 & TRN & \\
\hline CHEMBL1517255 & 688422 & 5.4 & 5.8208 & TRN & \\
\hline CHEMBL1332077 & 688422 & 4.85 & 4.8202 & TST & \\
\hline CHEMBL1409801 & 688422 & 6.1 & 5.6172 & TST & \\
\hline CHEMBL1522619 & 688422 & 4.95 & 5.4696 & TRN & \\
\hline CHEMBL1371629 & 688422 & 6.1 & 5.3373 & TST & \\
\hline CHEMBL1502255 & 688422 & 8.6576 & 5.8725 & TRN & \\
\hline
\end{tabular}




\begin{tabular}{|c|c|c|c|c|c|}
\hline \multicolumn{6}{|c|}{ Supplemental Table S2.txt } \\
\hline CHEMBL3190986 & 688422 & 5.0 & 4.9808 & TRN & \\
\hline CHEMBL1317156 & 688422 & 6.05 & 5.341 & TRN & \\
\hline CHEMBL1540956 & 688422 & 4.7 & 4.9511 & TRN & \\
\hline CHEMBL1478317 & 688422 & 4.45 & 4.8538 & TRN & \\
\hline CHEMBL1398476 & 688422 & 6.4 & 5.4134 & TRN & \\
\hline CHEMBL1561796 & 688422 & 5.25 & 5.05699 & 99999999995 & TRN \\
\hline CHEMBL1373082 & 688422 & 4.65 & 4.9517 & TRN & \\
\hline CHEMBL1510042 & 688422 & 4.9 & 5.1815 & TST & \\
\hline CHEMBL1341157 & 688422 & 4.75 & 4.9258 & TRN & \\
\hline CHEMBL1547568 & 688422 & 4.8 & 5.3265 & TST & \\
\hline CHEMBL1303896 & 688422 & 5.2 & 5.3935 & TST & \\
\hline CHEMBL1582491 & 688422 & 5.3 & 5.989 & TST & \\
\hline CHEMBL1578626 & 688422 & 4.85 & 5.0462 & TRN & \\
\hline CHEMBL1424009 & 688422 & 4.9 & 5.1782 & TRN & \\
\hline CHEMBL1327272 & 688422 & 5.0 & 5.3066 & TST & \\
\hline CHEMBL1589343 & 688422 & 4.85 & 4.8901 & TRN & \\
\hline CHEMBL1508446 & 688422 & 5.05 & 5.3025 & TST & \\
\hline CHEMBL 267014 & 688422 & 8.301 & 5.16299 & 7999999999 & TRN \\
\hline CHEMBL 1437086 & 688422 & 8.301 & 5.1383 & TRN & \\
\hline CHEMBL1305698 & 688422 & 4.85 & 5.3009 & TST & \\
\hline CHEMBL1402530 & 688422 & 5.25 & 5.4534 & TRN & \\
\hline CHEMBL3193949 & 688422 & 4.7 & 5.0994 & TST & \\
\hline CHEMBL1506201 & 688422 & 6.15 & 5.6446 & TRN & \\
\hline CHEMBL1331125 & 688422 & 4.6 & 5.1509 & TRN & \\
\hline CHEMBL1529509 & 688422 & 7.9508 & 5.1501 & TST & \\
\hline CHEMBL1463388 & 688422 & 4.45 & 5.2694 & TRN & \\
\hline CHEMBL1447896 & 688422 & 5.0 & 5.3617 & TRN & \\
\hline CHEMBL1457081 & 688422 & 8.0506 & 5.2462 & TST & \\
\hline CHEMBL1541199 & 688422 & 4.65 & 4.9948 & TRN & \\
\hline CHEMBL1339208 & 688422 & 5.9 & 5.1056 & TRN & \\
\hline CHEMBL3209648 & 688422 & 5.2 & 5.296 & TRN & \\
\hline CHEMBL3194821 & 688422 & 4.45 & 5.2145 & TRN & \\
\hline CHEMBL1380431 & 688422 & 4.45 & 5.2642 & TST & \\
\hline CHEMBL1333390 & 688422 & 4.75 & 4.6447 & TRN & \\
\hline CHEMBL1563553 & 688422 & 5.85 & 5.2818 & TRN & \\
\hline CHEMBL1509592 & 688422 & 7.6003 & 5.3523 & TRN & \\
\hline CHEMBL1449954 & 688422 & 6.7501 & 5.0447 & TRN & \\
\hline CHEMBL1476690 & 688422 & 4.45 & 5.6964 & TRN & \\
\hline CHEMBL3193011 & 688422 & 4.7 & 5.6459 & TST & \\
\hline CHEMBL3196976 & 688422 & 4.85 & 5.3608 & TRN & \\
\hline CHEMBL1402883 & 688422 & 5.3 & 4.8329 & TRN & \\
\hline CHEMBL1442924 & 688422 & 6.8 & 5.2601 & TRN & \\
\hline CHEMBL1597851 & 688422 & 4.45 & 5.3433 & TRN & \\
\hline CHEMBL1605698 & 688422 & 4.65 & 4.8196 & TRN & \\
\hline CHEMBL3212414 & 688422 & 4.95 & 5.4287 & TRN & \\
\hline CHEMBL265686 & 688422 & 5.6 & 5.6123 & TST & \\
\hline CHEMBL1323027 & 688422 & 4.5 & 4.9698 & TRN & \\
\hline CHEMBL1540947 & 688422 & 4.45 & 5.4578 & TST & \\
\hline
\end{tabular}




\begin{tabular}{|c|c|c|c|c|c|}
\hline \multicolumn{6}{|c|}{ Supplemental Table S2.txt } \\
\hline CHEMBL1496197 & 688422 & 4.65 & 5.393 & TRN & \\
\hline CHEMBL1455631 & 688422 & 4.5 & 5.419 & TRN & \\
\hline CHEMBL1526929 & 688422 & 4.65 & 4.7964 & TRN & \\
\hline CHEMBL486706 & 688422 & 5.5 & 5.2024 & TST & \\
\hline CHEMBL 1475856 & 688422 & 4.45 & 5.4421 & TRN & \\
\hline CHEMBL1305185 & 688422 & 4.85 & 5.4581 & TRN & \\
\hline CHEMBL1482210 & 688422 & 4.9 & 4.9788 & TST & \\
\hline CHEMBL52030 & 688422 & 8.4949 & 5.6139 & TST & \\
\hline CHEMBL1571860 & 688422 & 5.75 & 5.1886 & TRN & \\
\hline CHEMBL1360308 & 688422 & 4.9 & 4.7462 & TST & \\
\hline CHEMBL1601349 & 688422 & 6.8 & 5.5806 & TRN & \\
\hline CHEMBL1410295 & 688422 & 7.3497 & 5.489 & TST & \\
\hline CHEMBL3198571 & 688422 & 4.7 & 5.0081 & TRN & \\
\hline CHEMBL1507332 & 688422 & 7.3002 & 5.371 & TRN & \\
\hline CHEMBL1367758 & 688422 & 7.2 & 5.1245 & TRN & \\
\hline CHEMBL1317983 & 688422 & 7.4498 & 5.7228 & TST & \\
\hline CHEMBL3197396 & 688422 & 5.65 & 5.1156 & TRN & \\
\hline CHEMBL1432787 & 688422 & 4.45 & 4.95100 & 00000000005 & TRN \\
\hline CHEMBL1351200 & 688422 & 4.9 & 5.3992 & TST & \\
\hline CHEMBL1382664 & 688422 & 4.95 & 5.2626 & TST & \\
\hline CHEMBL1477515 & 688422 & 4.45 & 5.2338 & TRN & \\
\hline CHEMBL1485045 & 688422 & 4.5 & 5.2872 & TRN & \\
\hline CHEMBL1425432 & 688422 & 4.9 & 5.0456 & TRN & \\
\hline CHEMBL3212199 & 688422 & 6.8 & 5.7925 & TRN & \\
\hline CHEMBL1569241 & 688422 & 4.45 & 4.8124 & TST & \\
\hline CHEMBL1428944 & 688422 & 5.0 & 5.0973 & TRN & \\
\hline CHEMBL1482943 & 688422 & 4.45 & 4.8682 & TRN & \\
\hline CHEMBL1568881 & 688422 & 4.6 & 5.0379 & TRN & \\
\hline CHEMBL1376057 & 688422 & 4.45 & 5.7981 & TST & \\
\hline CHEMBL1499584 & 688422 & 4.45 & 5.3397 & TST & \\
\hline CHEMBL1442647 & 688422 & 5.25 & 5.4788 & TST & \\
\hline CHEMBL3212696 & 688422 & 5.0 & 5.3688 & TRN & \\
\hline CHEMBL1372998 & 688422 & 6.1 & 5.5632 & TST & \\
\hline CHEMBL1529669 & 688422 & 4.5 & 4.7162 & TRN & \\
\hline CHEMBL1302884 & 688422 & 6.2 & 5.1672 & TRN & \\
\hline CHEMBL445153 & 688422 & 4.5 & 4.8686 & TRN & \\
\hline CHEMBL 1480958 & 688422 & 4.9 & 4.8303 & TRN & \\
\hline CHEMBL1536952 & 688422 & 4.65 & 5.716 & TRN & \\
\hline CHEMBL1414448 & 688422 & 4.8 & 5.5589 & TST & \\
\hline CHEMBL3199768 & 688422 & 6.5 & 5.481 & TRN & \\
\hline CHEMBL1329673 & 688422 & 5.05 & 5.654 & TST & \\
\hline CHEMBL1433171 & 688422 & 4.8 & 5.4564 & TRN & \\
\hline CHEMBL1583283 & 688422 & 4.45 & 5.0341 & TRN & \\
\hline CHEMBL1608523 & 688422 & 5.5 & 5.1762 & TST & \\
\hline CHEMBL1376357 & 688422 & 4.45 & 5.1188 & TRN & \\
\hline CHEMBL1980018 & 688422 & 5.05 & 5.0444 & TRN & \\
\hline CHEMBL1442369 & 688422 & 4.75 & 5.1822 & TRN & \\
\hline CHEMBL1526690 & 688422 & 4.75 & 4.717 & TRN & \\
\hline
\end{tabular}




\begin{tabular}{|c|c|c|c|c|c|}
\hline \multicolumn{6}{|c|}{ Supplemental Table S2.txt } \\
\hline CHEMBL1361904 & 688422 & 4.85 & 5.2932 & TRN & \\
\hline CHEMBL3195637 & 688422 & 4.45 & 5.5578 & TST & \\
\hline CHEMBL1484606 & 688422 & 5.15 & 5.3508 & TST & \\
\hline CHEMBL1461302 & 688422 & 4.45 & 5.4229 & TRN & \\
\hline CHEMBL1405446 & 688422 & 4.85 & 5.0662 & TRN & \\
\hline CHEMBL1431649 & 688422 & 5.75 & 5.8117 & TRN & \\
\hline CHEMBL1537535 & 688422 & 5.35 & 5.2017 & TST & \\
\hline CHEMBL1358207 & 688422 & 5.1 & 5.2511 & TRN & \\
\hline CHEMBL1553311 & 688422 & 5.5 & 5.3759 & TRN & \\
\hline CHEMBL1597709 & 688422 & 7.0501 & 5.5061 & TRN & \\
\hline CHEMBL1314947 & 688422 & 6.8 & 5.312 & TRN & \\
\hline CHEMBL1529767 & 688422 & 6.8 & 5.1116 & TST & \\
\hline CHEMBL1454896 & 688422 & 5.6 & 5.1163 & TRN & \\
\hline CHEMBL3192970 & 688422 & 4.9 & 4.7815 & TRN & \\
\hline CHEMBL1320085 & 688422 & 5.0 & 5.3954 & TRN & \\
\hline CHEMBL1425847 & 688422 & 4.85 & 5.7388 & TST & \\
\hline CHEMBL1323054 & 688422 & 5.45 & 5.13899 & 9999999999 & TRN \\
\hline CHEMBL1335269 & 688422 & 5.05 & 5.5401 & TRN & \\
\hline CHEMBL1428309 & 688422 & 4.45 & 4.9581 & TRN & \\
\hline CHEMBL1430200 & 688422 & 4.8 & 5.2818 & TRN & \\
\hline CHEMBL1487705 & 688422 & 5.1 & 5.1769 & TRN & \\
\hline CHEMBL1485052 & 688422 & 8.301 & 5.2701 & TRN & \\
\hline CHEMBL1422216 & 688422 & 4.95 & 5.2239 & TRN & \\
\hline CHEMBL1447826 & 688422 & 6.5 & 5.5834 & TST & \\
\hline CHEMBL1595606 & 688422 & 4.9 & 5.6263 & TRN & \\
\hline CHEMBL1497147 & 688422 & 6.9 & 5.5974 & TST & \\
\hline CHEMBL1393005 & 688422 & 5.65 & 5.265 & TST & \\
\hline CHEMBL1580232 & 688422 & 5.3 & 5.2441 & TRN & \\
\hline CHEMBL1604235 & 688422 & 4.85 & 5.2362 & TRN & \\
\hline CHEMBL1738986 & 688422 & 4.7 & 4.8205 & TRN & \\
\hline CHEMBL1398815 & 688422 & 4.9 & 4.881 & TRN & \\
\hline CHEMBL1433232 & 688422 & 4.75 & 4.8679 & TRN & \\
\hline CHEMBL1560467 & 688422 & 5.75 & 5.4575 & TRN & \\
\hline CHEMBL1367476 & 688422 & 4.75 & 5.1965 & TST & \\
\hline CHEMBL1331857 & 688422 & 4.65 & 5.3727 & TST & \\
\hline CHEMBL1355964 & 688422 & 7.2 & 4.9534 & TRN & \\
\hline CHEMBL3214154 & 688422 & 5.05 & 5.0055 & TRN & \\
\hline CHEMBL1458441 & 688422 & 4.75 & 4.8908 & TST & \\
\hline CHEMBL1455175 & 688422 & 7.2503 & 5.3271 & TRN & \\
\hline CHEMBL1388947 & 688422 & 5.6 & 5.1811 & TST & \\
\hline CHEMBL1449440 & 688422 & 7.3002 & 5.2491 & TRN & \\
\hline CHEMBL1513494 & 688422 & 4.45 & 5.3595 & TRN & \\
\hline CHEMBL1315347 & 688422 & 7.4498 & 5.3876 & TRN & \\
\hline CHEMBL1324690 & 688422 & 4.85 & 5.4581 & TRN & \\
\hline CHEMBL1331812 & 688422 & 6.9 & 6.2063 & TST & \\
\hline CHEMBL1372333 & 688422 & 4.85 & 5.0471 & TRN & \\
\hline CHEMBL1593084 & 688422 & 5.8 & 5.6209 & TST & \\
\hline CHEMBL1367531 & 688422 & 4.7 & 4.9473 & TRN & \\
\hline
\end{tabular}




\begin{tabular}{|c|c|c|c|c|c|}
\hline \multicolumn{6}{|c|}{ Supplemental Table S2.txt } \\
\hline CHEMBL1340618 & 688422 & 4.45 & 5.12 & TRN & \\
\hline CHEMBL1525599 & 688422 & 4.45 & 5.5232 & TST & \\
\hline CHEMBL1384589 & 688422 & 5.95 & 5.1874 & TRN & \\
\hline CHEMBL1343178 & 688422 & 4.65 & 5.2091 & TRN & \\
\hline CHEMBL1571810 & 688422 & 4.45 & 5.3676 & TRN & \\
\hline CHEMBL1429074 & 688422 & 4.95 & 5.3906 & TRN & \\
\hline CHEMBL1356721 & 688422 & 4.95 & 5.2159 & TRN & \\
\hline CHEMBL3194250 & 688422 & 5.45 & 4.8917 & TRN & \\
\hline CHEMBL1336011 & 688422 & 4.45 & 5.1622 & TRN & \\
\hline CHEMBL1345630 & 688422 & 4.85 & 5.0149 & TST & \\
\hline CHEMBL1550104 & 688422 & 5.05 & 5.0689 & TRN & \\
\hline CHEMBL3145321 & 688422 & 4.65 & 4.9855 & TST & \\
\hline CHEMBL1446402 & 688422 & 5.0 & 5.0544 & TST & \\
\hline CHEMBL1586018 & 688422 & 5.05 & 4.96899 & 9999999999 & TRN \\
\hline CHEMBL1363509 & 688422 & 4.75 & 4.9056 & TRN & \\
\hline CHEMBL1511546 & 688422 & 4.7 & 5.5814 & TRN & \\
\hline CHEMBL1437002 & 688422 & 5.45 & 6.0517 & TST & \\
\hline CHEMBL1427568 & 688422 & 5.55 & 5.0352 & TRN & \\
\hline CHEMBL1534306 & 688422 & 5.0 & 5.1726 & TST & \\
\hline CHEMBL1568198 & 688422 & 4.55 & 4.8093 & TRN & \\
\hline CHEMBL1330311 & 688422 & 4.7 & 5.5255 & TST & \\
\hline CHEMBL1489456 & 688422 & 4.75 & 5.2162 & TRN & \\
\hline CHEMBL1607953 & 688422 & 4.9 & 5.002 & TRN & \\
\hline CHEMBL1440186 & 688422 & 4.85 & 5.2255 & TRN & \\
\hline CHEMBL3197497 & 688422 & 6.45 & 5.0782 & TST & \\
\hline CHEMBL1438050 & 688422 & 4.45 & 5.2116 & TRN & \\
\hline CHEMBL1368252 & 688422 & 4.85 & 4.9521 & TRN & \\
\hline CHEMBL1583826 & 688422 & 4.85 & 4.8017 & TRN & \\
\hline CHEMBL1563006 & 688422 & 5.75 & 5.5386 & TST & \\
\hline CHEMBL1376120 & 688422 & 4.8 & 4.9208 & TRN & \\
\hline CHEMBL1421505 & 688422 & 5.85 & 5.5094 & TRN & \\
\hline CHEMBL1554523 & 688422 & 7.699 & 5.5229 & TST & \\
\hline CHEMBL1361262 & 688422 & 4.45 & 5.3763 & TRN & \\
\hline CHEMBL1532722 & 688422 & 4.9 & 5.0306 & TRN & \\
\hline CHEMBL1476181 & 688422 & 4.75 & 5.0993 & TRN & \\
\hline CHEMBL1502723 & 688422 & 4.45 & 4.9545 & TST & \\
\hline CHEMBL1481912 & 688422 & 5.5 & 4.7654 & TRN & \\
\hline CHEMBL1534058 & 688422 & 4.75 & 5.0024 & TRN & \\
\hline CHEMBL1465135 & 688422 & 5.0 & 5.2586 & TRN & \\
\hline CHEMBL1966224 & 688422 & 4.45 & 5.193 & TST & \\
\hline CHEMBL1442939 & 688422 & 4.45 & 4.893 & TRN & \\
\hline CHEMBL1345309 & 688422 & 4.95 & 5.0506 & TRN & \\
\hline CHEMBL1468216 & 688422 & 4.75 & 5.5171 & TST & \\
\hline CHEMBL1368907 & 688422 & 5.55 & 5.5231 & TRN & \\
\hline CHEMBL1399702 & 688422 & 6.0 & 6.13 & TRN & \\
\hline CHEMBL1548062 & 688422 & 4.45 & 5.1369 & TRN & \\
\hline CHEMBL1461504 & 688422 & 4.5 & 5.0858 & TRN & \\
\hline CHEMBL1578252 & 688422 & 7.1002 & 5.0715 & TST & \\
\hline
\end{tabular}




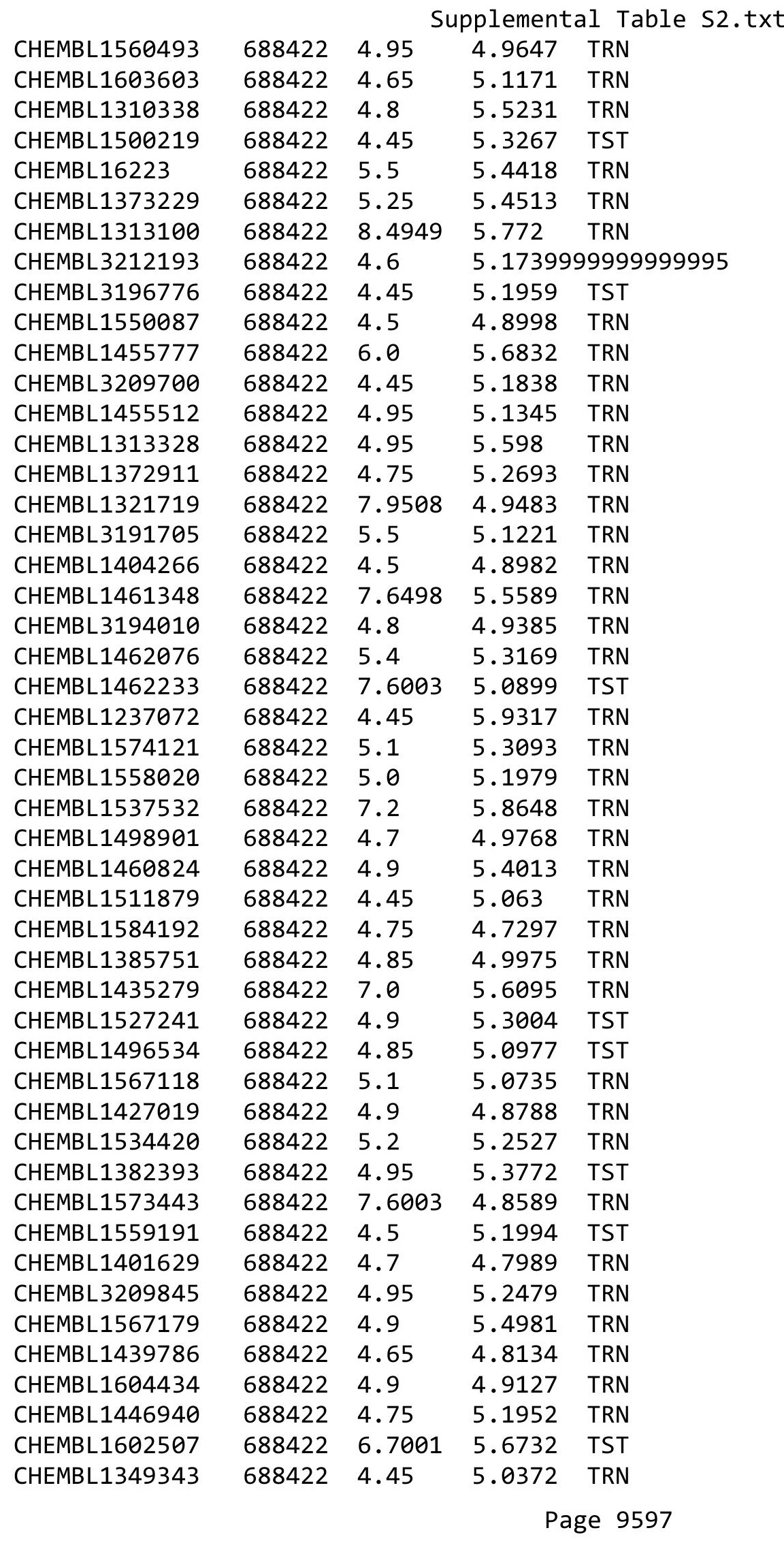




\begin{tabular}{|c|c|c|c|c|c|}
\hline \multicolumn{6}{|c|}{ Supplemental Table S2.txt } \\
\hline CHEMBL1303708 & 688422 & 5.0 & 5.0552 & TST & \\
\hline CHEMBL1600432 & 688422 & 7.8508 & 5.4762 & TRN & \\
\hline CHEMBL1484332 & 688422 & 5.55 & 5.225 & TRN & \\
\hline CHEMBL1584733 & 688422 & 4.45 & 5.3045 & TRN & \\
\hline CHEMBL1527554 & 688422 & 4.45 & 5.38700 & 00000000005 & TRN \\
\hline CHEMBL1348604 & 688422 & 4.45 & 5.0801 & TRN & \\
\hline CHEMBL1544119 & 688422 & 5.2 & 4.6906 & TRN & \\
\hline CHEMBL1451406 & 688422 & 4.8 & 5.4526 & TST & \\
\hline CHEMBL1423194 & 688422 & 4.45 & 5.4463 & TRN & \\
\hline CHEMBL1382917 & 688422 & 5.0 & 5.5893 & TRN & \\
\hline CHEMBL3211710 & 688422 & 6.9 & 5.7658 & TRN & \\
\hline CHEMBL3190801 & 688422 & 4.85 & 4.7663 & TRN & \\
\hline CHEMBL1301465 & 688422 & 4.45 & 5.5764 & TRN & \\
\hline CHEMBL1428760 & 688422 & 4.5 & 4.8655 & TRN & \\
\hline CHEMBL3191981 & 688422 & 4.45 & 5.0777 & TST & \\
\hline CHEMBL3208852 & 688422 & 4.75 & 5.6025 & TST & \\
\hline CHEMBL1334486 & 688422 & 5.55 & 4.8517 & TRN & \\
\hline CHEMBL1457476 & 688422 & 4.65 & 5.0828 & TST & \\
\hline CHEMBL1504567 & 688422 & 4.55 & 4.8522 & TRN & \\
\hline CHEMBL1610209 & 688422 & 4.45 & 5.1489 & TRN & \\
\hline CHEMBL1561960 & 688422 & 4.8 & 4.8087 & TRN & \\
\hline CHEMBL1424957 & 688422 & 4.9 & 5.5293 & TRN & \\
\hline CHEMBL1602090 & 688422 & 4.7 & 5.3406 & TRN & \\
\hline CHEMBL1305359 & 688422 & 5.55 & 5.6203 & TST & \\
\hline CHEMBL1365915 & 688422 & 8.4949 & 5.6773 & TRN & \\
\hline CHEMBL1429786 & 688422 & 4.85 & 5.1251 & TRN & \\
\hline CHEMBL1490902 & 688422 & 6.5501 & 5.0608 & TRN & \\
\hline CHEMBL1533864 & 688422 & 4.95 & 5.4889 & TRN & \\
\hline CHEMBL1335865 & 688422 & 4.9 & 5.2983 & TRN & \\
\hline CHEMBL1366884 & 688422 & 4.8 & 5.2947 & TRN & \\
\hline CHEMBL1323628 & 688422 & 4.45 & 5.3135 & TRN & \\
\hline CHEMBL1324445 & 688422 & 7.7496 & 5.5304 & TRN & \\
\hline CHEMBL1586070 & 688422 & 6.05 & 5.1911 & TRN & \\
\hline CHEMBL1384199 & 688422 & 4.85 & 5.4924 & TRN & \\
\hline CHEMBL1460139 & 688422 & 8.2518 & 5.7225 & TRN & \\
\hline CHEMBL1344444 & 688422 & 5.7 & 5.3339 & TRN & \\
\hline CHEMBL3212019 & 688422 & 6.8 & 5.2608 & TRN & \\
\hline CHEMBL1504171 & 688422 & 4.9 & 5.2522 & TRN & \\
\hline CHEMBL1372654 & 688422 & 4.95 & 5.0953 & TRN & \\
\hline CHEMBL1476430 & 688422 & 4.45 & 4.5066 & TRN & \\
\hline CHEMBL1395468 & 688422 & 7.0 & 5.2497 & TRN & \\
\hline CHEMBL1512422 & 688422 & 4.5 & 5.2687 & TRN & \\
\hline CHEMBL1462858 & 688422 & 8.3468 & 5.5074 & TST & \\
\hline CHEMBL1561670 & 688422 & 5.4 & 4.8668 & TRN & \\
\hline CHEMBL1486031 & 688422 & 4.5 & 5.2084 & TST & \\
\hline CHEMBL1418072 & 688422 & 4.55 & 4.8985 & TRN & \\
\hline CHEMBL1355883 & 688422 & 4.7 & 5.1265 & TRN & \\
\hline CHEMBL1359966 & 688422 & 4.75 & 5.4215 & TRN & \\
\hline
\end{tabular}




\begin{tabular}{|c|c|c|c|c|c|}
\hline \multicolumn{6}{|c|}{ Supplemental Table S2.txt } \\
\hline CHEMBL1320959 & 688422 & 5.0 & 5.1658 & TRN & \\
\hline CHEMBL1410351 & 688422 & 4.45 & 5.0147 & TRN & \\
\hline CHEMBL1550083 & 688422 & 6.5501 & 5.3262 & TRN & \\
\hline CHEMBL1595381 & 688422 & 4.75 & 5.011 & TRN & \\
\hline CHEMBL1371339 & 688422 & 4.95 & 5.2913 & TRN & \\
\hline CHEMBL1392608 & 688422 & 8.0 & 5.1719 & TST & \\
\hline CHEMBL1571053 & 688422 & 4.6 & 5.5223 & TRN & \\
\hline CHEMBL3196080 & 688422 & 4.45 & 5.3415 & TRN & \\
\hline CHEMBL1596996 & 688422 & 4.45 & 4.8544 & TRN & \\
\hline CHEMBL1351612 & 688422 & 4.45 & 5.289 & TST & \\
\hline CHEMBL1515825 & 688422 & 5.95 & 4.9265 & TRN & \\
\hline CHEMBL1402000 & 688422 & 4.5 & 5.6582 & TRN & \\
\hline CHEMBL1508856 & 688422 & 4.8 & 5.454 & TRN & \\
\hline CHEMBL3197196 & 688422 & 4.7 & 5.1478 & TRN & \\
\hline CHEMBL1480529 & 688422 & 4.45 & 5.2559 & TRN & \\
\hline CHEMBL1592975 & 688422 & 5.15 & $5.79200 t$ & 0000000001 & TST \\
\hline CHEMBL1320595 & 688422 & 5.45 & 5.4082 & TRN & \\
\hline CHEMBL1581245 & 688422 & 4.45 & 4.8911 & TRN & \\
\hline CHEMBL1590980 & 688422 & 5.15 & 5.365 & TST & \\
\hline CHEMBL1981449 & 688422 & 5.35 & 5.1577 & TRN & \\
\hline CHEMBL1480852 & 688422 & 6.1 & 5.5206 & TRN & \\
\hline CHEMBL1257234 & 688422 & 4.5 & 5.3641 & TRN & \\
\hline CHEMBL1520021 & 688422 & 5.95 & 5.3835 & TRN & \\
\hline CHEMBL1345854 & 688422 & 4.7 & 5.3148 & TRN & \\
\hline CHEMBL1538364 & 688422 & 4.75 & 4.8493 & TRN & \\
\hline CHEMBL1505774 & 688422 & 4.45 & 4.9013 & TRN & \\
\hline CHEMBL 2006569 & 688422 & 4.95 & 5.4558 & TRN & \\
\hline CHEMBL1325078 & 688422 & 4.8 & 5.772 & TRN & \\
\hline CHEMBL1383025 & 688422 & 5.2 & 5.8733 & TST & \\
\hline CHEMBL1317822 & 688422 & 5.15 & 5.3045 & TRN & \\
\hline CHEMBL1586119 & 688422 & 4.9 & 5.0889 & TRN & \\
\hline CHEMBL1397791 & 688422 & 7.6498 & 4.8775 & TRN & \\
\hline CHEMBL1501540 & 688422 & 4.7 & 5.1343 & TRN & \\
\hline CHEMBL3213149 & 688422 & 5.35 & 4.7886 & TRN & \\
\hline CHEMBL1369618 & 688422 & 4.45 & 5.13899 & 9999999999 & TST \\
\hline CHEMBL1385388 & 688422 & 4.8 & 5.0932 & TRN & \\
\hline CHEMBL89445 & 688422 & 5.25 & 5.9077 & TRN & \\
\hline CHEMBL1380895 & 688422 & 4.45 & 5.1943 & TST & \\
\hline CHEMBL1232398 & 688422 & 4.7 & 6.0705 & TST & \\
\hline CHEMBL1469202 & 688422 & 8.4559 & 5.3491 & TST & \\
\hline CHEMBL1470406 & 688422 & 4.75 & 4.9803 & TRN & \\
\hline CHEMBL278041 & 688422 & 5.3 & 5.3348 & TRN & \\
\hline CHEMBL1586199 & 688422 & 5.5 & 5.2054 & TST & \\
\hline CHEMBL1483347 & 688422 & 4.45 & $4.56800 t$ & 00000000005 & TRN \\
\hline CHEMBL1568633 & 688422 & 4.5 & 5.0309 & TRN & \\
\hline CHEMBL3194518 & 688422 & 4.65 & 5.1373 & TRN & \\
\hline CHEMBL1535888 & 688422 & 7.0501 & 5.6839 & TST & \\
\hline CHEMBL1406858 & 688422 & 4.95 & 5.0352 & TRN & \\
\hline
\end{tabular}




\begin{tabular}{|c|c|c|c|c|}
\hline \multicolumn{5}{|c|}{ Supplemental Table S2.txt } \\
\hline CHEMBL1558526 & 688422 & 4.75 & 4.9338 & TRN \\
\hline CHEMBL1458545 & 688422 & 5.2 & 4.9199 & TRN \\
\hline CHEMBL1584002 & 688422 & 4.9 & 5.3696 & TST \\
\hline CHEMBL1609784 & 688422 & 4.85 & 4.8732 & TRN \\
\hline CHEMBL3195362 & 688422 & 5.55 & 5.4436 & TST \\
\hline CHEMBL3194566 & 688422 & 4.65 & 4.9134 & TST \\
\hline CHEMBL3191217 & 688422 & 4.85 & 5.3935 & TRN \\
\hline CHEMBL1532625 & 688422 & 4.65 & 5.2869 & TST \\
\hline CHEMBL1528465 & 688422 & 5.5 & 5.1696 & TST \\
\hline CHEMBL1319791 & 688422 & 6.3 & 5.3115 & TRN \\
\hline CHEMBL1449793 & 688422 & 4.8 & 5.2604 & TRN \\
\hline CHEMBL1335725 & 688422 & 4.85 & 5.2559 & TRN \\
\hline CHEMBL1345344 & 688422 & 4.45 & 5.3154 & TST \\
\hline CHEMBL251055 & 688422 & 4.95 & 5.3207 & TRN \\
\hline CHEMBL1987417 & 688422 & 4.45 & 4.8121 & TRN \\
\hline CHEMBL313833 & 688422 & 4.85 & 5.647 & TST \\
\hline CHEMBL1507448 & 688422 & 4.45 & 4.9126 & TRN \\
\hline CHEMBL1600313 & 688422 & 4.65 & 5.0154 & TST \\
\hline CHEMBL1581745 & 688422 & 4.8 & 4.9109 & TST \\
\hline CHEMBL1610096 & 688422 & 4.9 & 5.21 & TRN \\
\hline CHEMBL1999060 & 688422 & 7.4001 & 5.9197 & TST \\
\hline CHEMBL1440142 & 688422 & 4.7 & 5.8228 & TST \\
\hline CHEMBL1492835 & 688422 & 4.75 & 5.1404 & TRN \\
\hline CHEMBL1374453 & 688422 & 4.95 & 5.5917 & TRN \\
\hline CHEMBL1370901 & 688422 & 4.45 & 5.5397 & TRN \\
\hline CHEMBL1443948 & 688422 & 4.85 & 5.1476 & TRN \\
\hline CHEMBL1464802 & 688422 & 4.5 & 6.0364 & TRN \\
\hline CHEMBL1409031 & 688422 & 4.9 & 5.0486 & TRN \\
\hline CHEMBL1553532 & 688422 & 6.95 & 5.5706 & TRN \\
\hline CHEMBL1579204 & 688422 & 6.5 & 5.947 & TRN \\
\hline CHEMBL1304569 & 688422 & 6.2 & 5.468 & TRN \\
\hline CHEMBL1482861 & 688422 & 4.9 & 5.1476 & TRN \\
\hline CHEMBL1319000 & 688422 & 4.8 & 5.0021 & TRN \\
\hline CHEMBL1376783 & 688422 & 4.8 & 5.1881 & TRN \\
\hline CHEMBL1505989 & 688422 & 4.45 & 5.2646 & TRN \\
\hline CHEMBL1553445 & 688422 & 6.3 & 5.239 & TRN \\
\hline CHEMBL1592198 & 688422 & 6.3 & 5.7803 & TRN \\
\hline CHEMBL1475778 & 688422 & 5.25 & 4.8596 & TRN \\
\hline CHEMBL1573722 & 688422 & 6.6499 & 5.5088 & TRN \\
\hline CHEMBL1300612 & 688422 & 4.45 & 4.8759 & TST \\
\hline CHEMBL1464978 & 688422 & 4.8 & 4.7555 & TRN \\
\hline CHEMBL1549361 & 688422 & 5.2 & 5.2426 & TRN \\
\hline CHEMBL1556793 & 688422 & 5.45 & 5.4345 & TRN \\
\hline CHEMBL1342093 & 688422 & 4.75 & 5.0744 & TRN \\
\hline CHEMBL1434444 & 688422 & 4.55 & 5.2782 & TRN \\
\hline CHEMBL1316939 & 688422 & 6.3 & 5.4208 & TRN \\
\hline CHEMBL1352924 & 688422 & 4.9 & 5.0085 & TRN \\
\hline CHEMBL1535704 & 688422 & 5.85 & 5.0289 & TRN \\
\hline
\end{tabular}




\begin{tabular}{|c|c|c|c|c|c|}
\hline \\
\hline CHEMBL1543548 & 688422 & 4.8 & 5.2278 & TRN & \\
\hline CHEMBL1570054 & 688422 & 6.3 & 6.1119 & TRN & \\
\hline CHEMBL1429347 & 688422 & 7.6498 & 5.5006 & TST & \\
\hline CHEMBL1416368 & 688422 & 5.5 & 5.2333 & TRN & \\
\hline CHEMBL1520596 & 688422 & 4.7 & 5.4789 & TRN & \\
\hline CHEMBL1527800 & 688422 & 4.95 & 4.8962 & TRN & \\
\hline CHEMBL1368363 & 688422 & 5.25 & 4.8582 & TRN & \\
\hline CHEMBL1523083 & 688422 & 4.45 & 5.4065 & TRN & \\
\hline CHEMBL3195679 & 688422 & 6.3 & 5.6242 & TST & \\
\hline CHEMBL1453291 & 688422 & 4.65 & 5.9728 & TRN & \\
\hline CHEMBL1479937 & 688422 & 6.4 & 5.4318 & TST & \\
\hline CHEMBL1383774 & 688422 & 5.5 & 5.4799 & TRN & \\
\hline CHEMBL1550488 & 688422 & 4.65 & 5.1197 & TRN & \\
\hline CHEMBL1562094 & 688422 & 4.45 & 4.7441 & TRN & \\
\hline CHEMBL1516472 & 688422 & 4.5 & 5.2116 & TRN & \\
\hline CHEMBL1532740 & 688422 & 7.8508 & 5.1024 & TRN & \\
\hline CHEMBL1365619 & 688422 & 5.05 & 5.1229 & TST & \\
\hline CHEMBL1429624 & 688422 & 4.95 & 5.0134 & TRN & \\
\hline CHEMBL1465603 & 688422 & 5.25 & 5.1763 & TRN & \\
\hline CHEMBL1460416 & 688422 & 5.4 & 5.3751 & TST & \\
\hline CHEMBL 974 & 688422 & 4.45 & 5.4502 & TST & \\
\hline CHEMBL1255659 & 688422 & 4.65 & 5.5782 & TST & \\
\hline CHEMBL1301987 & 688422 & 4.45 & 4.8383 & TST & \\
\hline CHEMBL1440674 & 688422 & 4.6 & 4.9218 & TRN & \\
\hline CHEMBL1429402 & 688422 & 6.8 & 5.7098 & TST & \\
\hline CHEMBL 3212074 & 688422 & 4.45 & 5.5336 & TRN & \\
\hline CHEMBL1346658 & 688422 & 4.85 & 5.4432 & TST & \\
\hline CHEMBL1536850 & 688422 & 5.65 & 5.2909 & TRN & \\
\hline CHEMBL1581456 & 688422 & 4.45 & 5.3696 & TRN & \\
\hline CHEMBL1336541 & 688422 & 4.85 & 5.0417 & TST & \\
\hline CHEMBL1586130 & 688422 & 5.3 & 5.41799 & 9999999999 & TST \\
\hline CHEMBL1530382 & 688422 & 6.3 & 5.1535 & TRN & \\
\hline CHEMBL1499020 & 688422 & 4.45 & 4.88399 & 99999999995 & TRN \\
\hline CHEMBL1478289 & 688422 & 4.7 & 5.0688 & TRN & \\
\hline CHEMBL1257024 & 688422 & 4.75 & 5.7476 & TST & \\
\hline CHEMBL1461860 & 688422 & 5.1 & 5.0495 & TRN & \\
\hline CHEMBL1448351 & 688422 & 4.65 & 5.21 & TRN & \\
\hline CHEMBL1602970 & 688422 & 4.45 & 5.2785 & TRN & \\
\hline CHEMBL3191023 & 688422 & 5.7 & 5.21899 & 9999999999 & TRN \\
\hline CHEMBL1546633 & 688422 & 4.85 & 5.0884 & TRN & \\
\hline CHEMBL1557566 & 688422 & 4.6 & 5.4998 & TRN & \\
\hline CHEMBL1319130 & 688422 & 6.45 & 5.086 & TST & \\
\hline CHEMBL1534041 & 688422 & 5.5 & 5.6523 & TST & \\
\hline CHEMBL1543268 & 688422 & 5.65 & 5.0998 & TST & \\
\hline CHEMBL1308291 & 688422 & 4.65 & 5.0543 & TRN & \\
\hline CHEMBL 1256020 & 688422 & 9.0458 & 5.7197 & TRN & \\
\hline CHEMBL376103 & 688422 & 7.3497 & 5.5706 & TST & \\
\hline CHEMBL3189340 & 688422 & 7.699 & 5.7476 & TRN & \\
\hline
\end{tabular}




\begin{tabular}{|c|c|c|c|c|c|}
\hline & & \multicolumn{4}{|c|}{ Supplemental Table S2.txt } \\
\hline CHEMBL1365497 & 688422 & 7.5003 & 5.5084 & TST & \\
\hline CHEMBL1445798 & 688422 & 4.9 & 5.3915 & TST & \\
\hline CHEMBL1455143 & 688422 & 6.5501 & 5.4026 & TRN & \\
\hline CHEMBL1373836 & 688422 & 4.5 & 4.9386 & TRN & \\
\hline CHEMBL1592714 & 688422 & 8.0 & 5.4133 & TRN & \\
\hline CHEMBL87285 & 688422 & 6.0 & 5.8886 & TRN & \\
\hline CHEMBL1358905 & 688422 & 7.6498 & 5.1773 & TRN & \\
\hline CHEMBL1344428 & 688422 & 4.45 & 4.8389 & TRN & \\
\hline CHEMBL1310318 & 688422 & 4.45 & 5.3139 & TST & \\
\hline CHEMBL1418279 & 688422 & 4.45 & 4.9231 & TRN & \\
\hline CHEMBL1981570 & 688422 & 4.85 & 5.3921 & TRN & \\
\hline CHEMBL1492403 & 688422 & 4.8 & 5.1487 & TST & \\
\hline CHEMBL1526286 & 688422 & 4.45 & 5.1507 & TRN & \\
\hline CHEMBL1586500 & 688422 & 4.95 & 5.4991 & TRN & \\
\hline CHEMBL1327537 & 688422 & 7.0501 & 5.3445 & TRN & \\
\hline CHEMBL602718 & 688422 & 4.45 & 5.3921 & TRN & \\
\hline CHEMBL1376269 & 688422 & 4.5 & 5.0788 & TST & \\
\hline CHEMBL1611841 & 688422 & 4.6 & 5.1824 & TRN & \\
\hline CHEMBL1368699 & 688422 & 5.25 & 4.8414 & TRN & \\
\hline CHEMBL1448632 & 688422 & 4.9 & 5.2895 & TRN & \\
\hline CHEMBL3144830 & 688422 & 4.8 & 5.1779 & TRN & \\
\hline CHEMBL1435901 & 688422 & 5.45 & 5.32700 & 0000000001 & TRN \\
\hline CHEMBL1602723 & 688422 & 5.5 & 5.5856 & TST & \\
\hline CHEMBL1419741 & 688422 & 6.15 & 5.4441 & TRN & \\
\hline CHEMBL1483689 & 688422 & 4.8 & 4.8252 & TRN & \\
\hline CHEMBL1316262 & 688422 & 5.15 & 5.4382 & TRN & \\
\hline CHEMBL1536795 & 688422 & 4.65 & 5.2667 & TRN & \\
\hline CHEMBL1301543 & 688422 & 7.3497 & 5.9992 & TRN & \\
\hline CHEMBL1417299 & 688422 & 4.8 & 5.4138 & TST & \\
\hline CHEMBL1480135 & 688422 & 5.15 & 4.7993 & TRN & \\
\hline CHEMBL1578096 & 688422 & 4.45 & 5.4887 & TST & \\
\hline CHEMBL1360480 & 688422 & 5.45 & 5.4609 & TRN & \\
\hline CHEMBL1349225 & 688422 & 4.9 & 4.8743 & TRN & \\
\hline CHEMBL1393172 & 688422 & 4.45 & 4.9018 & TST & \\
\hline CHEMBL1605795 & 688422 & 4.95 & 5.4277 & TRN & \\
\hline CHEMBL1604558 & 688422 & 5.05 & 5.3303 & TRN & \\
\hline CHEMBL1602538 & 688422 & 5.25 & 5.3838 & TRN & \\
\hline CHEMBL1501422 & 688422 & 4.65 & 5.2456 & TST & \\
\hline CHEMBL1365906 & 688422 & 4.65 & 4.7927 & TRN & \\
\hline CHEMBL1428401 & 688422 & 4.5 & 4.7948 & TST & \\
\hline CHEMBL1969893 & 688422 & 4.85 & 5.0594 & TST & \\
\hline CHEMBL1573889 & 688422 & 4.75 & 5.3038 & TST & \\
\hline CHEMBL1379493 & 688422 & 5.15 & 5.2541 & TRN & \\
\hline CHEMBL1488261 & 688422 & 5.5 & 5.5458 & TRN & \\
\hline CHEMBL1452154 & 688422 & 4.95 & 4.9346 & TRN & \\
\hline CHEMBL1301325 & 688422 & 5.3 & 5.4913 & TRN & \\
\hline CHEMBL1577769 & 688422 & 6.1 & 5.683 & TST & \\
\hline CHEMBL1548028 & 688422 & 4.65 & 5.1604 & TRN & \\
\hline
\end{tabular}




\begin{tabular}{|c|c|c|c|c|c|}
\hline \multicolumn{6}{|c|}{ Supplemental Table S2.txt } \\
\hline CHEMBL1305848 & 688422 & 4.8 & 5.1176 & TST & \\
\hline CHEMBL1324947 & 688422 & 4.75 & 5.2304 & TRN & \\
\hline CHEMBL1470245 & 688422 & 4.45 & 5.082 & TRN & \\
\hline CHEMBL1412001 & 688422 & 4.9 & 5.3989 & TST & \\
\hline CHEMBL1374415 & 688422 & 4.8 & 5.2818 & TRN & \\
\hline CHEMBL1420863 & 688422 & 4.45 & 5.1012 & TRN & \\
\hline CHEMBL1532197 & 688422 & 4.45 & 5.6898 & TRN & \\
\hline CHEMBL1510814 & 688422 & 4.55 & 5.6741 & TST & \\
\hline CHEMBL1320698 & 688422 & 5.0 & 5.3951 & TST & \\
\hline CHEMBL1455098 & 688422 & 5.25 & 5.4501 & TST & \\
\hline CHEMBL1583714 & 688422 & 4.85 & 5.1746 & TRN & \\
\hline CHEMBL1339270 & 688422 & 4.85 & 5.5077 & TST & \\
\hline CHEMBL1450098 & 688422 & 5.45 & 5.2337 & TRN & \\
\hline CHEMBL1413952 & 688422 & 8.0506 & 5.7044 & TRN & \\
\hline CHEMBL1535321 & 688422 & 7.699 & 5.1576 & TRN & \\
\hline CHEMBL239276 & 688422 & 4.45 & 5.3369 & TRN & \\
\hline CHEMBL1475747 & 688422 & 4.45 & 5.1094 & TRN & \\
\hline CHEMBL1408872 & 688422 & 4.5 & 5.1466 & TST & \\
\hline CHEMBL1498933 & 688422 & 7.9508 & 5.0192 & TST & \\
\hline CHEMBL1514033 & 688422 & 4.7 & 5.0261 & TRN & \\
\hline CHEMBL1605597 & 688422 & 4.8 & 5.109 & TRN & \\
\hline CHEMBL1348952 & 688422 & 4.65 & 5.1563 & TST & \\
\hline CHEMBL1502929 & 688422 & 4.6 & 5.1059 & TRN & \\
\hline CHEMBL1587836 & 688422 & 5.2 & 5.2798 & TRN & \\
\hline CHEMBL1503764 & 688422 & 5.2 & 4.98600 & 0000000001 & TRN \\
\hline CHEMBL1397681 & 688422 & 5.5 & 5.6011 & TRN & \\
\hline CHEMBL1452771 & 688422 & 6.5 & 5.3376 & TST & \\
\hline CHEMBL 254576 & 688422 & 4.7 & 5.1057 & TST & \\
\hline CHEMBL1607362 & 688422 & 4.9 & 5.0609 & TRN & \\
\hline CHEMBL1303382 & 688422 & 6.6499 & 5.3475 & TRN & \\
\hline CHEMBL1483112 & 688422 & 4.45 & 4.7551 & TRN & \\
\hline CHEMBL1437006 & 688422 & 5.05 & 5.3809 & TST & \\
\hline CHEMBL1505512 & 688422 & 5.5 & 5.3904 & TRN & \\
\hline CHEMBL3197508 & 688422 & 5.0 & 5.2086 & TRN & \\
\hline CHEMBL3192900 & 688422 & 4.5 & 5.3491 & TRN & \\
\hline CHEMBL1543106 & 688422 & 5.75 & 5.6534 & TST & \\
\hline CHEMBL1547873 & 688422 & 5.15 & 5.5627 & TST & \\
\hline CHEMBL1328742 & 688422 & 6.9 & 5.4132 & TRN & \\
\hline CHEMBL1516456 & 688422 & 4.45 & 4.4309 & TRN & \\
\hline CHEMBL1365328 & 688422 & 5.1 & 5.0643 & TRN & \\
\hline CHEMBL1485525 & 688422 & 4.9 & 5.255 & TRN & \\
\hline CHEMBL1563375 & 688422 & 7.0 & 5.3747 & TRN & \\
\hline CHEMBL1306802 & 688422 & 5.35 & 4.9594 & TRN & \\
\hline CHEMBL145558 & 688422 & 4.6 & 5.1848 & TST & \\
\hline CHEMBL1308225 & 688422 & 4.75 & 5.1234 & TRN & \\
\hline CHEMBL1546435 & 688422 & 6.5 & 5.6409 & TRN & \\
\hline CHEMBL1596491 & 688422 & 4.55 & 5.3758 & TRN & \\
\hline CHEMBL1587511 & 688422 & 6.2 & 5.2019 & TRN & \\
\hline
\end{tabular}




\begin{tabular}{|c|c|c|c|c|}
\hline \multicolumn{5}{|c|}{ Supplementa } \\
\hline CHEMBL1459352 & 688422 & 7.15 & 5.5324 & TST \\
\hline CHEMBL1533923 & 688422 & 4.6 & 5.1098 & TST \\
\hline CHEMBL1545105 & 688422 & 5.0 & 5.4459 & TRN \\
\hline CHEMBL1505543 & 688422 & 5.4 & 5.7325 & TST \\
\hline CHEMBL1399557 & 688422 & 4.95 & 5.0747 & TRN \\
\hline CHEMBL1472800 & 688422 & 4.85 & 4.9871 & TST \\
\hline CHEMBL1413021 & 688422 & 8.1024 & 5.0897 & TST \\
\hline CHEMBL1463694 & 688422 & 4.8 & 5.5627 & TRN \\
\hline CHEMBL 3207462 & 688422 & 5.15 & 4.9681 & TST \\
\hline CHEMBL1316904 & 688422 & 6.1 & 5.7027 & TST \\
\hline CHEMBL1589856 & 688422 & 4.6 & 4.9568 & TST \\
\hline CHEMBL1340480 & 688422 & 5.25 & 4.8033 & TRN \\
\hline CHEMBL1577692 & 688422 & 4.85 & 5.1666 & TRN \\
\hline CHEMBL1540006 & 688422 & 4.85 & 5.0397 & TST \\
\hline CHEMBL1459368 & 688422 & 4.75 & 5.2593 & TRN \\
\hline CHEMBL592124 & 688422 & 5.35 & 5.0423 & TRN \\
\hline CHEMBL1539959 & 688422 & 5.35 & 5.3903 & TRN \\
\hline CHEMBL1344732 & 688422 & 5.7 & 4.8194 & TST \\
\hline CHEMBL1421141 & 688422 & 4.75 & 4.9367 & TRN \\
\hline CHEMBL1452644 & 688422 & 4.75 & 5.2629 & TRN \\
\hline CHEMBL1582866 & 688422 & 4.9 & 5.1277 & TRN \\
\hline CHEMBL1350245 & 688422 & 4.45 & 5.3696 & TRN \\
\hline CHEMBL1579102 & 688422 & 5.65 & 5.3874 & TRN \\
\hline CHEMBL1409633 & 688422 & 7.6498 & 5.1981 & TRN \\
\hline CHEMBL1590803 & 688422 & 5.8 & 5.4263 & TRN \\
\hline CHEMBL1348102 & 688422 & 4.45 & 4.9627 & TRN \\
\hline CHEMBL1421914 & 688422 & 4.9 & 5.0722 & TST \\
\hline CHEMBL1361727 & 688422 & 4.8 & 5.1249 & TST \\
\hline CHEMBL1603890 & 688422 & 4.95 & 4.7818 & TRN \\
\hline CHEMBL1356480 & 688422 & 4.45 & 5.3356 & TRN \\
\hline CHEMBL1548000 & 688422 & 6.35 & 5.2689 & TRN \\
\hline CHEMBL1376247 & 688422 & 4.95 & 5.0878 & TRN \\
\hline CHEMBL1492244 & 688422 & 4.6 & 5.2934 & TST \\
\hline CHEMBL1524010 & 688422 & 4.5 & 5.2145 & TRN \\
\hline CHEMBL1534118 & 688422 & 4.9 & 5.2375 & TRN \\
\hline CHEMBL1604453 & 688422 & 5.2 & 5.2851 & TRN \\
\hline CHEMBL1482909 & 688422 & 4.5 & 5.4967 & TRN \\
\hline CHEMBL1312230 & 688422 & 4.7 & 5.5587 & TST \\
\hline CHEMBL1363560 & 688422 & 6.15 & 5.3743 & TRN \\
\hline CHEMBL1412547 & 688422 & 4.5 & 5.1563 & TRN \\
\hline CHEMBL1423021 & 688422 & 4.45 & 5.0951 & TRN \\
\hline CHEMBL1487229 & 688422 & 4.45 & 5.3068 & TRN \\
\hline CHEMBL1583898 & 688422 & 5.5 & 5.1263 & TRN \\
\hline CHEMBL1500184 & 688422 & 8.0 & 5.1738 & TST \\
\hline CHEMBL3197119 & 688422 & 4.8 & 5.0222 & TST \\
\hline CHEMBL1401679 & 688422 & 5.2 & 5.2008 & TRN \\
\hline CHEMBL3193414 & 688422 & 4.85 & 5.0328 & TRN \\
\hline CHEMBL1571646 & 688422 & 7.699 & 5.14 & TRN \\
\hline
\end{tabular}




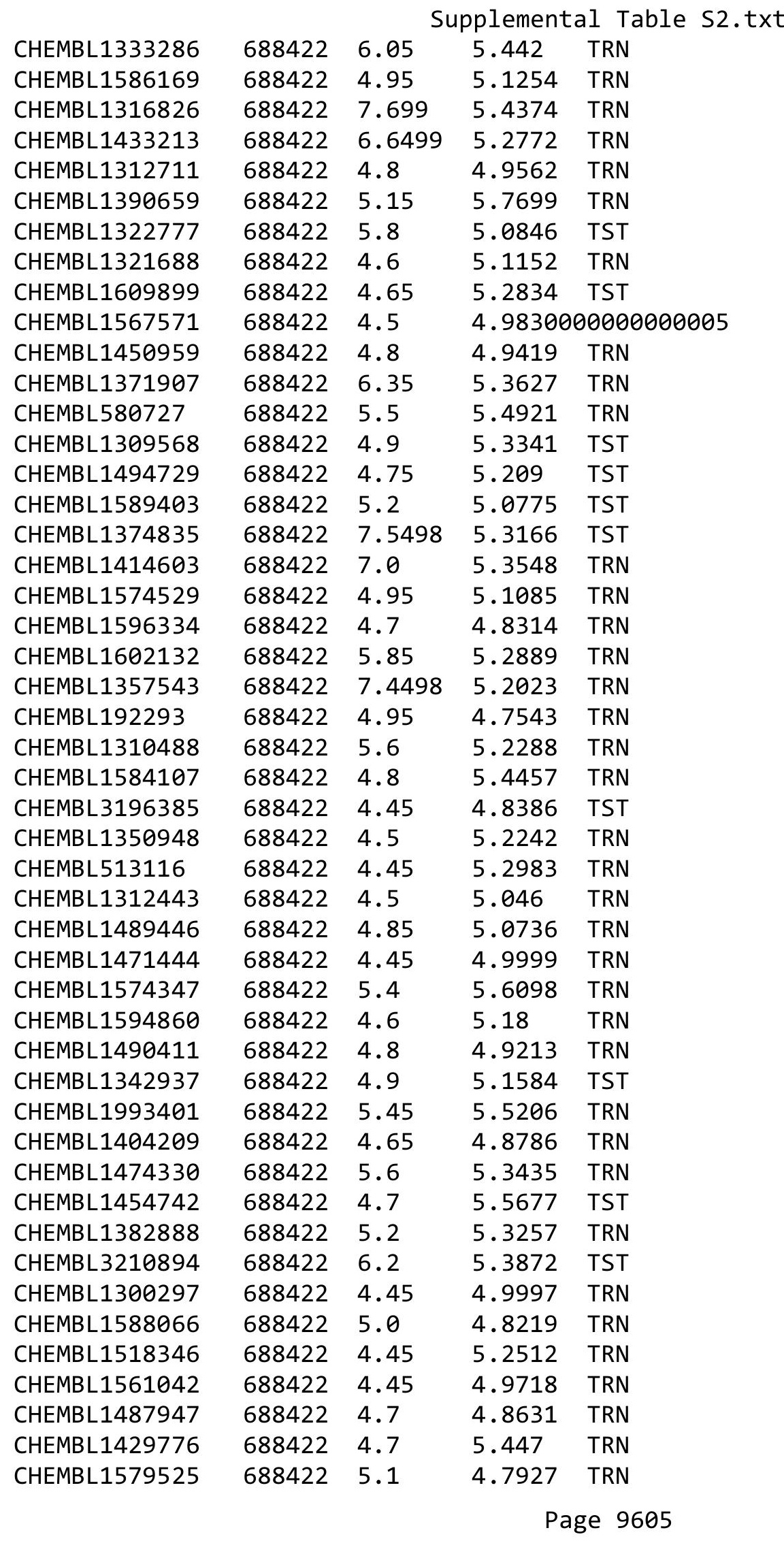




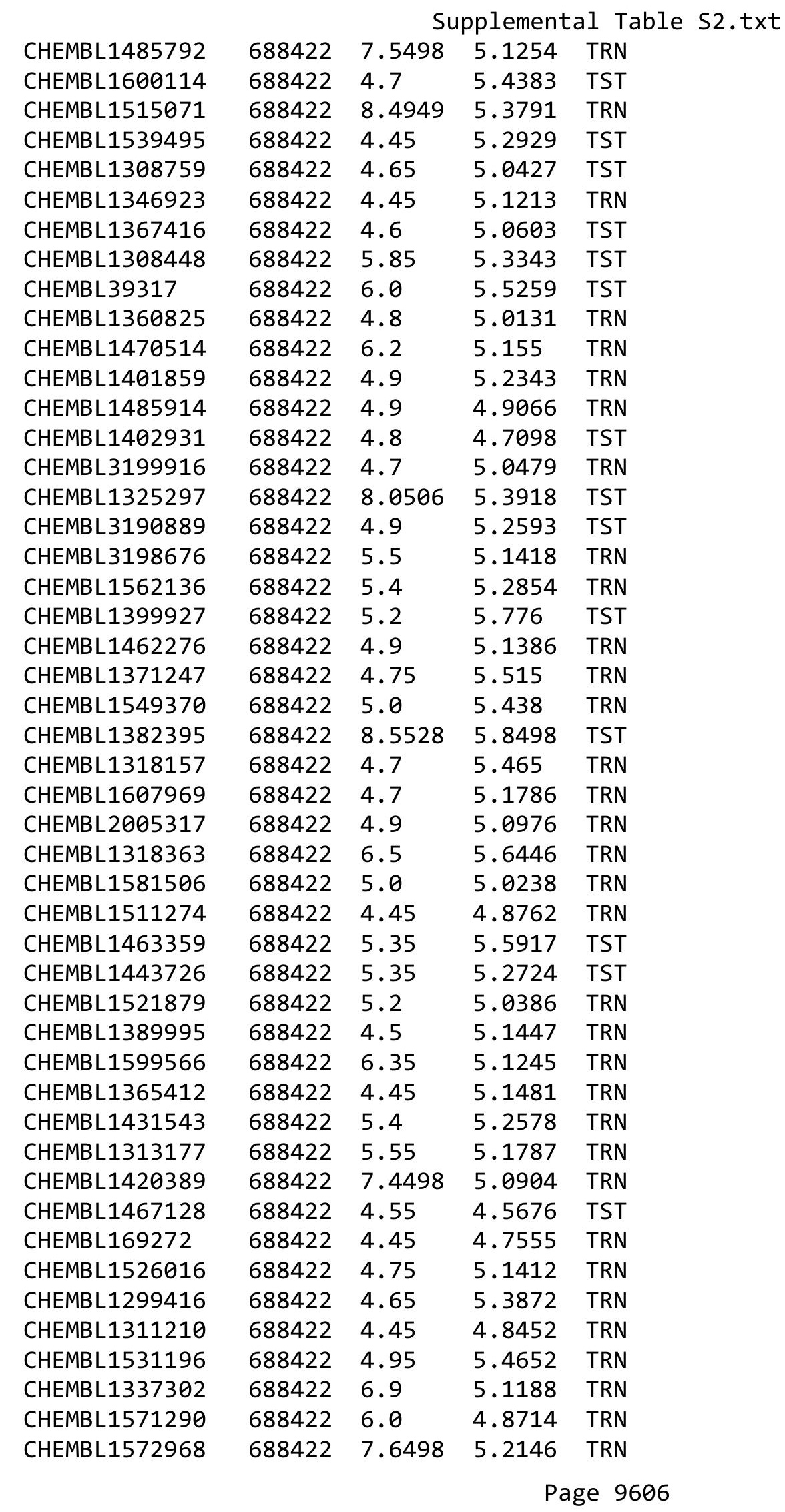




\begin{tabular}{|c|c|c|c|c|}
\hline \multicolumn{5}{|c|}{ Supplemental Table } \\
\hline CHEMBL1333056 & 688422 & 6.5501 & 5.4356 & TST \\
\hline CHEMBL1482357 & 688422 & 5.45 & 5.1544 & TRN \\
\hline CHEMBL1464962 & 688422 & 4.75 & 5.2557 & TRN \\
\hline CHEMBL1307675 & 688422 & 4.9 & 4.7714 & TRN \\
\hline CHEMBL1472296 & 688422 & 5.25 & 5.2204 & TRN \\
\hline CHEMBL1532602 & 688422 & 4.6 & 5.3879 & TRN \\
\hline CHEMBL1599629 & 688422 & 4.75 & 5.1862 & TRN \\
\hline CHEMBL1996281 & 688422 & 4.55 & 4.7842 & TRN \\
\hline CHEMBL1420885 & 688422 & 5.2 & 5.2864 & TRN \\
\hline CHEMBL1485834 & 688422 & 4.95 & 5.3725 & TRN \\
\hline CHEMBL1497215 & 688422 & 6.05 & 5.3127 & TST \\
\hline CHEMBL3194605 & 688422 & 5.7 & 5.0937 & TRN \\
\hline CHEMBL1361596 & 688422 & 4.9 & 5.6486 & TRN \\
\hline CHEMBL340807 & 688422 & 5.15 & 5.2199 & TST \\
\hline CHEMBL1359528 & 688422 & 4.9 & 5.4392 & TRN \\
\hline CHEMBL1548882 & 688422 & 4.55 & 5.4733 & TRN \\
\hline CHEMBL1381618 & 688422 & 7.0501 & 5.4694 & TRN \\
\hline CHEMBL1398084 & 688422 & 6.05 & 5.4089 & TRN \\
\hline CHEMBL1511798 & 688422 & 5.3 & 5.1474 & TST \\
\hline CHEMBL1428677 & 688422 & 5.0 & 5.0213 & TRN \\
\hline CHEMBL1427693 & 688422 & 5.35 & 5.3699 & TRN \\
\hline CHEMBL1391894 & 688422 & 7.9508 & 5.3382 & TST \\
\hline CHEMBL1574954 & 688422 & 4.95 & 5.0217 & TRN \\
\hline CHEMBL1430852 & 688422 & 4.95 & 5.0088 & TST \\
\hline CHEMBL1567703 & 688422 & 4.7 & 5.2091 & TRN \\
\hline CHEMBL1348607 & 688422 & 4.8 & 5.0833 & TRN \\
\hline CHEMBL1406564 & 688422 & 4.7 & 5.3136 & TST \\
\hline CHEMBL1595934 & 688422 & 5.0 & 4.9371 & TRN \\
\hline CHEMBL1409750 & 688422 & 4.9 & 4.9718 & TRN \\
\hline CHEMBL1490910 & 688422 & 5.6 & 4.9257 & TST \\
\hline CHEMBL1563087 & 688422 & 4.5 & 5.215 & TRN \\
\hline CHEMBL1309672 & 688422 & 4.7 & 5.5613 & TRN \\
\hline CHEMBL1566031 & 688422 & 7.3497 & 5.1691 & TST \\
\hline CHEMBL3191956 & 688422 & 4.8 & 5.0993 & TRN \\
\hline CHEMBL1350673 & 688422 & 5.45 & 5.4741 & TRN \\
\hline CHEMBL1479201 & 688422 & 4.9 & 5.0859 & TRN \\
\hline CHEMBL1511133 & 688422 & 4.75 & 5.3604 & TRN \\
\hline CHEMBL1487259 & 688422 & 4.5 & 5.1592 & TRN \\
\hline CHEMBL1438821 & 688422 & 8.3468 & 4.9322 & TRN \\
\hline CHEMBL1344473 & 688422 & 4.55 & 5.399 & TRN \\
\hline CHEMBL1530229 & 688422 & 5.05 & 4.8089 & TRN \\
\hline CHEMBL1372878 & 688422 & 4.9 & 5.3595 & TST \\
\hline CHEMBL1342307 & 688422 & 6.35 & 5.1418 & TRN \\
\hline CHEMBL1344806 & 688422 & 4.45 & 5.4153 & TST \\
\hline CHEMBL1504859 & 688422 & 4.8 & 5.1593 & TRN \\
\hline CHEMBL1338179 & 688422 & 5.7 & 5.3485 & TST \\
\hline CHEMBL1530018 & 688422 & 4.45 & 4.7514 & TRN \\
\hline CHEMBL571700 & 688422 & 5.4 & 5.8037 & TST \\
\hline
\end{tabular}




\begin{tabular}{|c|c|c|c|c|c|}
\hline \multicolumn{6}{|c|}{ Supplemental Table S2.txt } \\
\hline CHEMBL3197042 & 688422 & 4.5 & 5.2395 & TRN & \\
\hline CHEMBL1345849 & 688422 & 4.95 & 4.8184 & TST & \\
\hline CHEMBL1452485 & 688422 & 4.5 & 5.0767 & TRN & \\
\hline CHEMBL1581374 & 688422 & 4.5 & 4.9172 & TRN & \\
\hline CHEMBL1542272 & 688422 & 5.9 & 4.9604 & TRN & \\
\hline CHEMBL1579267 & 688422 & 4.45 & 5.2356 & TST & \\
\hline CHEMBL1524063 & 688422 & 4.45 & 5.1367 & TRN & \\
\hline CHEMBL3189946 & 688422 & 4.45 & 5.3675 & TRN & \\
\hline CHEMBL1553103 & 688422 & 8.0506 & 5.6698 & TST & \\
\hline CHEMBL3191846 & 688422 & 4.45 & 5.4234 & TRN & \\
\hline CHEMBL1343711 & 688422 & 6.25 & 5.1259 & TRN & \\
\hline CHEMBL1311901 & 688422 & 4.45 & 5.4685 & TRN & \\
\hline CHEMBL1590573 & 688422 & 4.75 & 5.1972 & TRN & \\
\hline CHEMBL1383332 & 688422 & 4.5 & 4.8934 & TST & \\
\hline CHEMBL1336514 & 688422 & 5.0 & 5.3663 & TST & \\
\hline CHEMBL1577509 & 688422 & 7.3002 & 5.3175 & TST & \\
\hline CHEMBL1505340 & 688422 & 4.95 & 5.4324 & TRN & \\
\hline CHEMBL1466196 & 688422 & 4.75 & 5.7324 & TRN & \\
\hline CHEMBL1496768 & 688422 & 4.45 & 5.2586 & TRN & \\
\hline CHEMBL1304748 & 688422 & 4.85 & 5.4122 & TST & \\
\hline CHEMBL1384689 & 688422 & 5.2 & 4.9198 & TST & \\
\hline CHEMBL1430382 & 688422 & 5.35 & 5.3695 & TRN & \\
\hline CHEMBL1173823 & 688422 & 4.85 & 4.938 & TST & \\
\hline CHEMBL1588531 & 688422 & 4.45 & 5.0261 & TST & \\
\hline CHEMBL1464549 & 688422 & 4.95 & 5.0961 & TRN & \\
\hline CHEMBL1545664 & 688422 & 5.35 & 5.1743 & TRN & \\
\hline CHEMBL1566940 & 688422 & 5.5 & 4.7796 & TRN & \\
\hline CHEMBL1424801 & 688422 & 4.95 & 5.1738 & TST & \\
\hline CHEMBL1361361 & 688422 & 4.5 & 4.9882 & TRN & \\
\hline CHEMBL1586734 & 688422 & 4.45 & 5.0977 & TST & \\
\hline CHEMBL1532802 & 688422 & 5.25 & 5.6973 & TRN & \\
\hline CHEMBL277362 & 688422 & 8.4559 & 5.4997 & TRN & \\
\hline CHEMBL1386162 & 688422 & 5.4 & 5.2059 & TRN & \\
\hline CHEMBL1537758 & 688422 & 4.45 & 5.17200 & 2000000001 & TRN \\
\hline CHEMBL1970812 & 688422 & 4.8 & 5.5502 & TRN & \\
\hline CHEMBL1594164 & 688422 & 4.9 & 5.3658 & TRN & \\
\hline CHEMBL1321457 & 688422 & 5.75 & 5.5223 & TST & \\
\hline CHEMBL1407442 & 688422 & 4.45 & 5.2646 & TST & \\
\hline CHEMBL1318619 & 688422 & 5.05 & 5.61700 & 2000000001 & TRN \\
\hline CHEMBL1437138 & 688422 & 4.85 & 5.0526 & TRN & \\
\hline CHEMBL1436465 & 688422 & 7.15 & 5.2461 & TRN & \\
\hline CHEMBL1609841 & 688422 & 4.65 & 4.9904 & TRN & \\
\hline CHEMBL1379797 & 688422 & 4.95 & 5.2272 & TRN & \\
\hline CHEMBL1271764 & 688422 & 4.5 & 5.4813 & TST & \\
\hline CHEMBL1492661 & 688422 & 4.45 & 5.2058 & TST & \\
\hline CHEMBL1599154 & 688422 & 5.4 & 5.4168 & TRN & \\
\hline CHEMBL1361686 & 688422 & 5.6 & 4.9493 & TRN & \\
\hline CHEMBL3210677 & 688422 & 5.5 & 5.6518 & TST & \\
\hline
\end{tabular}




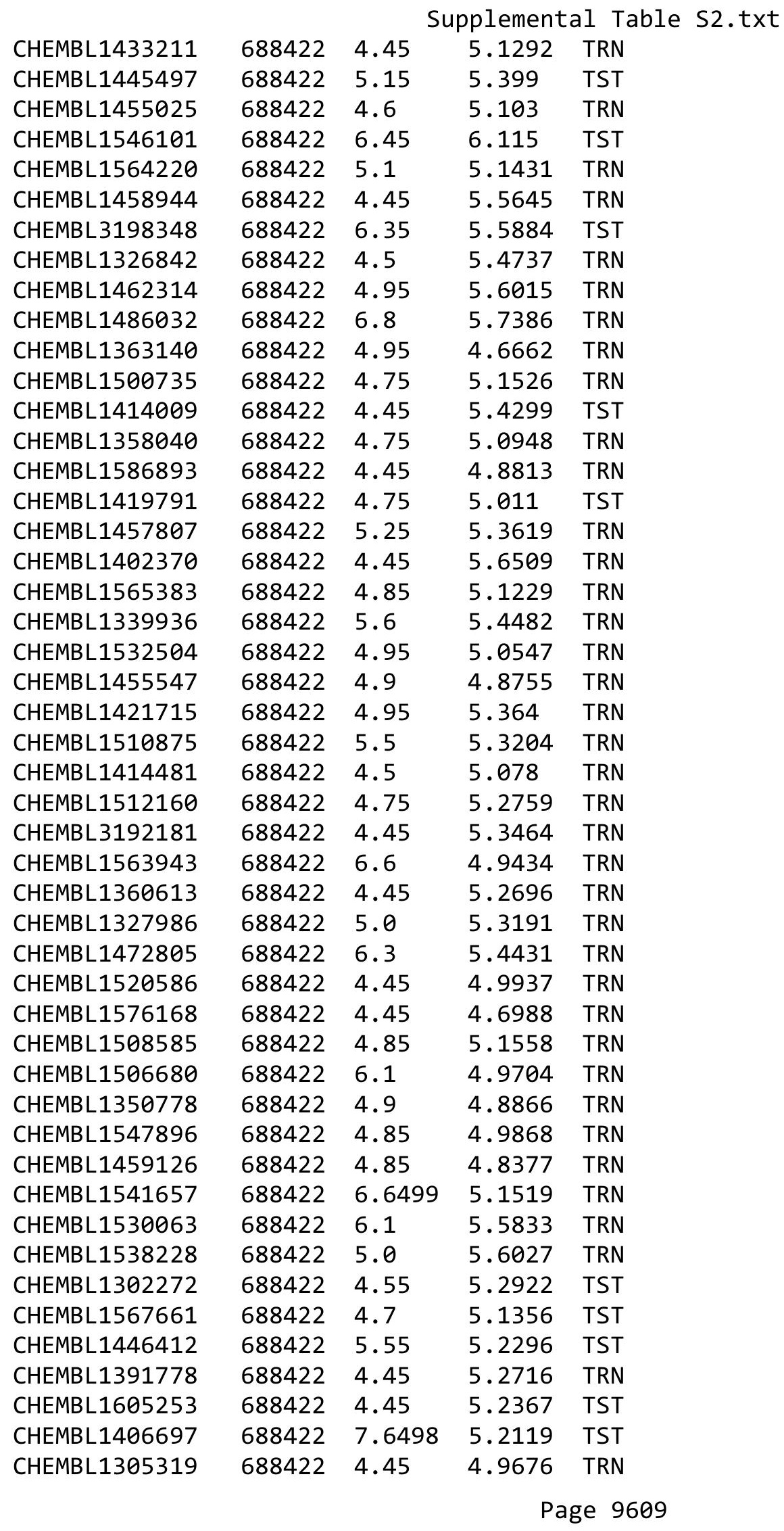




\begin{tabular}{|c|c|c|c|c|c|}
\hline \multicolumn{6}{|c|}{ Supplemental Table S2.txt } \\
\hline CHEMBL1326959 & 688422 & 4.75 & 5.1329 & TRN & \\
\hline CHEMBL323668 & 688422 & 6.05 & 6.0685 & TRN & \\
\hline CHEMBL1601261 & 688422 & 4.9 & 5.2542 & TRN & \\
\hline CHEMBL1572721 & 688422 & 4.8 & 5.1413 & TRN & \\
\hline CHEMBL1405949 & 688422 & 4.95 & 5.4292 & TRN & \\
\hline CHEMBL1364294 & 688422 & 4.45 & 4.5573 & TRN & \\
\hline CHEMBL1562005 & 688422 & 4.95 & 4.8729 & TST & \\
\hline CHEMBL1610845 & 688422 & 4.9 & 5.2056 & TRN & \\
\hline CHEMBL3196120 & 688422 & 5.0 & 5.1514 & TST & \\
\hline CHEMBL1085765 & 688422 & 4.9 & 4.7026 & TRN & \\
\hline CHEMBL1545530 & 688422 & 4.45 & 5.1073 & TRN & \\
\hline CHEMBL1305444 & 688422 & 4.5 & 5.6182 & TRN & \\
\hline CHEMBL1523204 & 688422 & 7.15 & 5.4617 & TST & \\
\hline CHEMBL1471486 & 688422 & 4.45 & 4.71899 & 9999999999 & TRN \\
\hline CHEMBL1405974 & 688422 & 7.8996 & 5.6436 & TRN & \\
\hline CHEMBL1458753 & 688422 & 6.3 & 5.0791 & TRN & \\
\hline CHEMBL1472083 & 688422 & 4.7 & 4.9561 & TRN & \\
\hline CHEMBL1392998 & 688422 & 4.45 & 5.0362 & TRN & \\
\hline CHEMBL1430703 & 688422 & 4.95 & 5.0095 & TRN & \\
\hline CHEMBL3212640 & 688422 & 4.75 & 5.3032 & TRN & \\
\hline CHEMBL1325864 & 688422 & 5.55 & 5.1327 & TRN & \\
\hline CHEMBL1586556 & 688422 & 4.9 & 5.325 & TST & \\
\hline CHEMBL1318836 & 688422 & 4.5 & 5.4395 & TRN & \\
\hline CHEMBL44 & 688422 & 4.8 & 5.8982 & TRN & \\
\hline CHEMBL1522288 & 688422 & 4.85 & 5.3472 & TRN & \\
\hline CHEMBL1569039 & 688422 & 4.45 & 5.3676 & TRN & \\
\hline CHEMBL1369249 & 688422 & 4.9 & 5.0283 & TRN & \\
\hline CHEMBL1462761 & 688422 & 4.45 & 4.9021 & TRN & \\
\hline CHEMBL1432857 & 688422 & 4.65 & 5.0459 & TRN & \\
\hline CHEMBL1566737 & 688422 & 5.5 & 4.9472 & TRN & \\
\hline CHEMBL1516388 & 688422 & 6.0 & 5.6478 & TST & \\
\hline CHEMBL1428517 & 688422 & 4.5 & 5.3029 & TRN & \\
\hline CHEMBL1482188 & 688422 & 5.3 & 5.6492 & TRN & \\
\hline CHEMBL1557666 & 688422 & 4.75 & 5.2184 & TRN & \\
\hline CHEMBL1337423 & 688422 & 4.7 & 5.20200 & 0000000001 & TST \\
\hline CHEMBL1423452 & 688422 & 4.9 & 5.1131 & TRN & \\
\hline CHEMBL1533607 & 688422 & 5.85 & 4.8189 & TRN & \\
\hline CHEMBL1508179 & 688422 & 4.5 & 5.5831 & TRN & \\
\hline CHEMBL1389704 & 688422 & 4.9 & 5.0059 & TRN & \\
\hline CHEMBL556001 & 688422 & 5.25 & 5.5397 & TST & \\
\hline CHEMBL1405894 & 688422 & 7.2 & 5.5165 & TST & \\
\hline CHEMBL1539793 & 688422 & 4.45 & 4.9742 & TST & \\
\hline CHEMBL1561163 & 688422 & 4.45 & 5.4006 & TST & \\
\hline CHEMBL1549469 & 688422 & 4.5 & 4.8496 & TRN & \\
\hline CHEMBL1500603 & 688422 & 5.85 & 5.5832 & TRN & \\
\hline CHEMBL1511203 & 688422 & 4.85 & 5.0058 & TRN & \\
\hline CHEMBL1569973 & 688422 & 6.45 & 5.6547 & TRN & \\
\hline CHEMBL1528027 & 688422 & 4.45 & 5.3406 & TRN & \\
\hline
\end{tabular}




\begin{tabular}{|c|c|c|c|c|c|}
\hline \multicolumn{6}{|c|}{ Supplemental Table s2.txt } \\
\hline CHEMBL1555416 & 688422 & 4.85 & 4.9757 & TRN & \\
\hline CHEMBL3192475 & 688422 & 4.45 & 5.3227 & TST & \\
\hline CHEMBL1538322 & 688422 & 5.45 & 5.1322 & TST & \\
\hline CHEMBL1593582 & 688422 & 5.25 & 4.8532 & TRN & \\
\hline CHEMBL1492095 & 688422 & 4.45 & 4.9652 & TRN & \\
\hline CHEMBL1403854 & 688422 & 4.45 & 5.0314 & TRN & \\
\hline CHEMBL1312782 & 688422 & 4.45 & 5.3865 & TST & \\
\hline CHEMBL1411658 & 688422 & 5.0 & 4.9557 & TRN & \\
\hline CHEMBL1548275 & 688422 & 6.45 & 5.5872 & TRN & \\
\hline CHEMBL1545212 & 688422 & 4.65 & 5.0872 & TRN & \\
\hline CHEMBL1412417 & 688422 & 5.05 & 5.0124 & TRN & \\
\hline CHEMBL1588269 & 688422 & 4.65 & 5.3308 & TRN & \\
\hline CHEMBL1495481 & 688422 & 4.6 & 5.45799 & 9999999999 & TST \\
\hline CHEMBL3196107 & 688422 & 4.45 & 5.0429 & TST & \\
\hline CHEMBL1451808 & 688422 & 4.85 & 5.0572 & TRN & \\
\hline CHEMBL1341030 & 688422 & 4.65 & 4.7 & TRN & \\
\hline CHEMBL1427894 & 688422 & 5.2 & 5.0182 & TRN & \\
\hline CHEMBL1576132 & 688422 & 6.0 & 5.7569 & TRN & \\
\hline CHEMBL1510347 & 688422 & 4.65 & 5.3892 & TST & \\
\hline CHEMBL1495725 & 688422 & 5.1 & 5.2603 & TRN & \\
\hline CHEMBL1374944 & 688422 & 4.45 & 5.1967 & TRN & \\
\hline CHEMBL1320778 & 688422 & 7.699 & 5.3681 & TST & \\
\hline CHEMBL1348797 & 688422 & 6.35 & 4.6307 & TST & \\
\hline CHEMBL1477070 & 688422 & 5.6 & 5.2686 & TRN & \\
\hline CHEMBL1453979 & 688422 & 4.9 & 5.1734 & TRN & \\
\hline CHEMBL41016 & 688422 & 5.05 & 5.3047 & TRN & \\
\hline CHEMBL3208404 & 688422 & 7.0501 & 5.1373 & TRN & \\
\hline CHEMBL1591138 & 688422 & 4.6 & 5.6287 & TRN & \\
\hline CHEMBL1569293 & 688422 & 4.5 & 5.0975 & TRN & \\
\hline CHEMBL221612 & 688422 & 5.0 & 5.2115 & TRN & \\
\hline CHEMBL3213386 & 688422 & 4.5 & 5.294 & TST & \\
\hline CHEMBL1484187 & 688422 & 5.2 & 5.4761 & TST & \\
\hline CHEMBL1437352 & 688422 & 4.45 & 4.9938 & TRN & \\
\hline CHEMBL1502297 & 688422 & 4.45 & 4.8929 & TRN & \\
\hline CHEMBL1413583 & 688422 & 4.45 & 5.2829 & TRN & \\
\hline CHEMBL1319259 & 688422 & 8.3468 & 5.5076 & TRN & \\
\hline CHEMBL1491079 & 688422 & 5.6 & 4.7275 & TRN & \\
\hline CHEMBL1584891 & 688422 & 4.8 & 4.8212 & TRN & \\
\hline CHEMBL1524226 & 688422 & 4.95 & 5.4983 & TRN & \\
\hline CHEMBL1318386 & 688422 & 7.0501 & 5.2425 & TRN & \\
\hline CHEMBL1395787 & 688422 & 6.3 & 5.6723 & TST & \\
\hline CHEMBL1487380 & 688422 & 5.7 & 4.9487 & TRN & \\
\hline CHEMBL1359235 & 688422 & 8.4949 & 5.5048 & TST & \\
\hline CHEMBL1578648 & 688422 & 6.35 & 5.1415 & TRN & \\
\hline CHEMBL1491792 & 688422 & 4.85 & 5.1355 & TRN & \\
\hline CHEMBL1986319 & 688422 & 4.45 & 5.5114 & TRN & \\
\hline CHEMBL1465720 & 688422 & 5.2 & 5.1295 & TST & \\
\hline CHEMBL1313335 & 688422 & 4.45 & 4.8127 & TRN & \\
\hline
\end{tabular}




\begin{tabular}{|c|c|c|c|c|c|}
\hline & & \multicolumn{4}{|c|}{ Supplemental Table S2.txt } \\
\hline CHEMBL1364661 & 688422 & 5.55 & 5.3783 & TRN & \\
\hline CHEMBL1569276 & 688422 & 4.9 & 5.25299 & 9999999999 & TRN \\
\hline CHEMBL1470511 & 688422 & 5.95 & 5.3217 & TRN & \\
\hline CHEMBL1372447 & 688422 & 4.45 & 5.466 & TRN & \\
\hline CHEMBL1538608 & 688422 & 4.45 & 5.1231 & TST & \\
\hline CHEMBL1424960 & 688422 & 6.5 & 5.42299 & 9999999999 & TST \\
\hline CHEMBL1326589 & 688422 & 5.35 & 5.585 & TST & \\
\hline CHEMBL1303580 & 688422 & 5.5 & 4.9889 & TRN & \\
\hline CHEMBL1375547 & 688422 & 4.95 & 5.3751 & TRN & \\
\hline CHEMBL1328282 & 688422 & 4.45 & 5.4014 & TST & \\
\hline CHEMBL1528675 & 688422 & 4.95 & 5.6316 & TST & \\
\hline CHEMBL1396053 & 688422 & 6.8 & 5.5491 & TRN & \\
\hline CHEMBL1370371 & 688422 & 4.7 & 5.0259 & TRN & \\
\hline CHEMBL1343480 & 688422 & 4.95 & 4.8277 & TRN & \\
\hline CHEMBL1584564 & 688422 & 5.35 & 5.6177 & TRN & \\
\hline CHEMBL1369097 & 688422 & 4.5 & 5.0696 & TRN & \\
\hline CHEMBL1414475 & 688422 & 4.95 & 5.5592 & TST & \\
\hline CHEMBL1552011 & 688422 & 4.7 & 5.2865 & TRN & \\
\hline CHEMBL1537507 & 688422 & 4.45 & 5.0526 & TRN & \\
\hline CHEMBL1452312 & 688422 & 4.9 & 5.4482 & TRN & \\
\hline CHEMBL1492680 & 688422 & 7.1002 & 5.5979 & TRN & \\
\hline CHEMBL1464202 & 688422 & 5.35 & 4.9297 & TRN & \\
\hline CHEMBL1383739 & 688422 & 4.8 & 5.3077 & TRN & \\
\hline CHEMBL1510141 & 688422 & 5.9 & 5.2994 & TRN & \\
\hline CHEMBL1424877 & 688422 & 4.5 & 5.3659 & TST & \\
\hline CHEMBL1396389 & 688422 & 4.75 & 5.3138 & TRN & \\
\hline CHEMBL1572744 & 688422 & 4.45 & 4.97 & TRN & \\
\hline CHEMBL1477452 & 688422 & 5.15 & 5.4093 & TST & \\
\hline CHEMBL 3210276 & 688422 & 5.9 & 5.3629 & TRN & \\
\hline CHEMBL1547603 & 688422 & 5.25 & 5.3304 & TRN & \\
\hline CHEMBL1518564 & 688422 & 6.5501 & 5.8542 & TRN & \\
\hline CHEMBL1581098 & 688422 & 4.95 & 5.2502 & TRN & \\
\hline CHEMBL1462875 & 688422 & 4.45 & 5.3824 & TST & \\
\hline CHEMBL1454476 & 688422 & 4.9 & 5.325 & TRN & \\
\hline CHEMBL1456751 & 688422 & 5.5 & 5.3314 & TRN & \\
\hline CHEMBL1322678 & 688422 & 5.45 & 5.5889 & TRN & \\
\hline CHEMBL1365384 & 688422 & 4.95 & 5.3113 & TRN & \\
\hline CHEMBL1313852 & 688422 & 4.9 & 5.1544 & TRN & \\
\hline CHEMBL1484948 & 688422 & 4.45 & 5.1652 & TRN & \\
\hline CHEMBL1335570 & 688422 & 5.1 & 5.3889 & TRN & \\
\hline CHEMBL1522201 & 688422 & 7.0501 & 5.70299 & 9999999999 & TST \\
\hline CHEMBL3213943 & 688422 & 5.4 & 5.0418 & TST & \\
\hline CHEMBL1586983 & 688422 & 4.85 & 5.2283 & TRN & \\
\hline CHEMBL1321347 & 688422 & 8.301 & 5.3657 & TST & \\
\hline CHEMBL1566719 & 688422 & 6.15 & 5.5335 & TRN & \\
\hline CHEMBL1471600 & 688422 & 7.5498 & 5.335 & TRN & \\
\hline CHEMBL1350166 & 688422 & 4.45 & 5.5023 & TRN & \\
\hline CHEMBL1329402 & 688422 & 5.55 & 5.6456 & TRN & \\
\hline
\end{tabular}




\begin{tabular}{|c|c|c|c|c|c|}
\hline \multirow[b]{2}{*}{ CHEMBL1544400 } & & \multicolumn{4}{|c|}{ Supplemental Table S2.txt } \\
\hline & 688422 & 7.4498 & \multicolumn{2}{|c|}{5.6339999999999995} & TRN \\
\hline CHEMBL3209202 & 688422 & 5.4 & 5.3385 & TST & \\
\hline CHEMBL164747 & 688422 & 9.0969 & 5.3439 & TST & \\
\hline CHEMBL1526136 & 688422 & 6.3 & 4.7397 & TST & \\
\hline CHEMBL1420993 & 688422 & 4.75 & 5.13 & TRN & \\
\hline CHEMBL1385606 & 688422 & 4.9 & 5.3199 & TRN & \\
\hline CHEMBL1510271 & 688422 & 5.45 & 5.1974 & TRN & \\
\hline CHEMBL1470549 & 688422 & 4.65 & 5.3387 & TRN & \\
\hline CHEMBL1349520 & 688422 & 4.85 & 5.4503 & TST & \\
\hline CHEMBL1300267 & 688422 & 4.85 & 5.2169 & TRN & \\
\hline CHEMBL1378654 & 688422 & 4.7 & 4.524 & TRN & \\
\hline CHEMBL1472302 & 688422 & 4.85 & 5.3662 & TRN & \\
\hline CHEMBL1472033 & 688422 & 4.6 & 5.3085 & TRN & \\
\hline CHEMBL1387421 & 688422 & 4.45 & 5.2176 & TRN & \\
\hline CHEMBL 2369166 & 688422 & 4.95 & 4.8642 & TST & \\
\hline CHEMBL3198903 & 688422 & 5.8 & 5.6351 & TRN & \\
\hline CHEMBL1527439 & 688422 & 4.95 & \multicolumn{2}{|c|}{5.8389999999999995} & TRN \\
\hline CHEMBL1447374 & 688422 & 4.65 & 5.7846 & TST & \\
\hline CHEMBL1348393 & 688422 & 4.75 & 5.2362 & TRN & \\
\hline CHEMBL1355477 & 688422 & 5.5 & 5.5414 & TRN & \\
\hline CHEMBL3196580 & 688422 & 5.6 & 5.5704 & TST & \\
\hline CHEMBL1371489 & 688422 & 4.9 & 5.2244 & TST & \\
\hline CHEMBL1552542 & 688422 & 4.8 & 4.8507 & TRN & \\
\hline CHEMBL3192463 & 688422 & 4.9 & 5.0786 & TRN & \\
\hline CHEMBL1367704 & 688422 & 5.9 & 5.5795 & TST & \\
\hline CHEMBL1528775 & 688422 & 5.1 & \multicolumn{2}{|c|}{5.4239999999999995} & TST \\
\hline CHEMBL1575924 & 688422 & 4.45 & 5.1026 & TRN & \\
\hline CHEMBL1422078 & 688422 & 5.4 & 5.4155 & TRN & \\
\hline CHEMBL1541601 & 688422 & 4.45 & 5.4062 & TRN & \\
\hline CHEMBL1566710 & 688422 & 4.45 & 5.2859 & TST & \\
\hline CHEMBL1323388 & 688422 & 5.65 & 5.5128 & TRN & \\
\hline CHEMBL1517513 & 688422 & 4.55 & 5.1985 & TST & \\
\hline CHEMBL1339657 & 688422 & 4.5 & 5.0888 & TRN & \\
\hline CHEMBL1465298 & 688422 & 4.55 & 5.6755 & TRN & \\
\hline CHEMBL1576939 & 688422 & 4.8 & 5.3092 & TRN & \\
\hline CHEMBL3199825 & 688422 & 4.9 & 5.078 & TST & \\
\hline CHEMBL1458849 & 688422 & 4.75 & 5.0482 & TRN & \\
\hline CHEMBL1313265 & 688422 & 4.85 & 5.3844 & TRN & \\
\hline CHEMBL1605568 & 688422 & 4.6 & 4.8996 & TRN & \\
\hline CHEMBL 1605780 & 688422 & 4.95 & 5.0339 & TRN & \\
\hline CHEMBL1431776 & 688422 & 4.75 & 5.1159 & TST & \\
\hline CHEMBL1381321 & 688422 & 5.7 & 5.4191 & TRN & \\
\hline CHEMBL3198083 & 688422 & 5.45 & 5.0355 & TST & \\
\hline CHEMBL1561596 & 688422 & 5.3 & 5.841 & TRN & \\
\hline CHEMBL1454030 & 688422 & 7.9508 & \multicolumn{2}{|c|}{5.422999999999999} & TRN \\
\hline CHEMBL579104 & 688422 & 5.0 & 5.3449 & TRN & \\
\hline CHEMBL1420139 & 688422 & 4.95 & \multicolumn{2}{|c|}{5.053999999999999} & TRN \\
\hline CHEMBL1314051 & 688422 & 8.301 & 5.6779 & TRN & \\
\hline
\end{tabular}




\begin{tabular}{|c|c|c|c|c|c|}
\hline \multicolumn{6}{|c|}{ Supplemental Table s2.txt } \\
\hline CHEMBL1402587 & 688422 & 5.85 & 5.4306 & TRN & \\
\hline CHEMBL1340614 & 688422 & 4.8 & 4.9404 & TRN & \\
\hline CHEMBL1585332 & 688422 & 4.7 & 4.7744 & TRN & \\
\hline CHEMBL1327048 & 688422 & 4.6 & 5.0312 & TRN & \\
\hline CHEMBL1503705 & 688422 & 4.95 & 5.4579 & TRN & \\
\hline CHEMBL1438566 & 688422 & 4.95 & 5.5433 & TRN & \\
\hline CHEMBL1473703 & 688422 & 5.2 & 5.0137 & TRN & \\
\hline CHEMBL1603331 & 688422 & 7.3497 & 5.0476 & TRN & \\
\hline CHEMBL1471223 & 688422 & 7.3002 & 5.607 & TRN & \\
\hline CHEMBL1426711 & 688422 & 4.55 & 5.0262 & TRN & \\
\hline CHEMBL1309547 & 688422 & 4.8 & 5.0201 & TRN & \\
\hline CHEMBL1496624 & 688422 & 6.35 & 5.3646 & TRN & \\
\hline CHEMBL1337747 & 688422 & 4.95 & 5.2486 & TRN & \\
\hline CHEMBL1299698 & 688422 & 4.45 & 5.0476 & TRN & \\
\hline CHEMBL1424903 & 688422 & 5.0 & 5.46399 & 99999999995 & TRN \\
\hline CHEMBL3212670 & 688422 & 4.8 & 5.2615 & TST & \\
\hline CHEMBL1458822 & 688422 & 4.45 & 5.3469 & TRN & \\
\hline CHEMBL1482983 & 688422 & 4.45 & 5.3004 & TST & \\
\hline CHEMBL131921 & 688422 & 4.55 & 5.4671 & TRN & \\
\hline CHEMBL1466549 & 688422 & 4.45 & 5.0 & TST & \\
\hline CHEMBL1564710 & 688422 & 4.45 & 4.6892 & TRN & \\
\hline CHEMBL1456772 & 688422 & 5.0 & 5.2813 & TRN & \\
\hline CHEMBL1340715 & 688422 & 6.2 & 5.6795 & TRN & \\
\hline CHEMBL1369433 & 688422 & 5.3 & 4.9707 & TRN & \\
\hline CHEMBL1456001 & 688422 & 4.45 & 4.6991 & TRN & \\
\hline CHEMBL1332076 & 688422 & 4.9 & 4.8736 & TRN & \\
\hline CHEMBL3194884 & 688422 & 4.65 & 5.925 & TST & \\
\hline CHEMBL1383376 & 688422 & 4.8 & 5.4038 & TRN & \\
\hline CHEMBL1366258 & 688422 & 4.8 & 5.1449 & TRN & \\
\hline CHEMBL1413715 & 688422 & 4.85 & 5.4305 & TST & \\
\hline CHEMBL1576871 & 688422 & 4.45 & 5.4551 & TST & \\
\hline CHEMBL1464526 & 688422 & 4.6 & 4.9995 & TST & \\
\hline CHEMBL1419702 & 688422 & 4.7 & 5.38399 & 99999999995 & TRN \\
\hline CHEMBL1347797 & 688422 & 4.45 & 5.4568 & TRN & \\
\hline CHEMBL1528565 & 688422 & 4.95 & 5.2525 & TST & \\
\hline CHEMBL1366032 & 688422 & 5.0 & 5.1116 & TST & \\
\hline CHEMBL1475060 & 688422 & 5.45 & 5.05 & TRN & \\
\hline CHEMBL1575870 & 688422 & 5.7 & 5.9055 & TST & \\
\hline CHEMBL1510985 & 688422 & 4.5 & 5.2141 & TRN & \\
\hline CHEMBL1427633 & 688422 & 4.9 & 5.2493 & TRN & \\
\hline CHEMBL1336872 & 688422 & 5.2 & 5.9287 & TRN & \\
\hline CHEMBL1369193 & 688422 & 4.5 & 5.3836 & TRN & \\
\hline CHEMBL1546003 & 688422 & 4.95 & 5.5967 & TRN & \\
\hline CHEMBL1461585 & 688422 & 4.45 & 4.919 & TRN & \\
\hline CHEMBL1498794 & 688422 & 4.45 & 5.0996 & TRN & \\
\hline CHEMBL1300093 & 688422 & 4.45 & 5.3773 & TST & \\
\hline CHEMBL1443541 & 688422 & 7.6498 & 5.6647 & TST & \\
\hline CHEMBL1315119 & 688422 & 8.0 & 5.6544 & TRN & \\
\hline
\end{tabular}




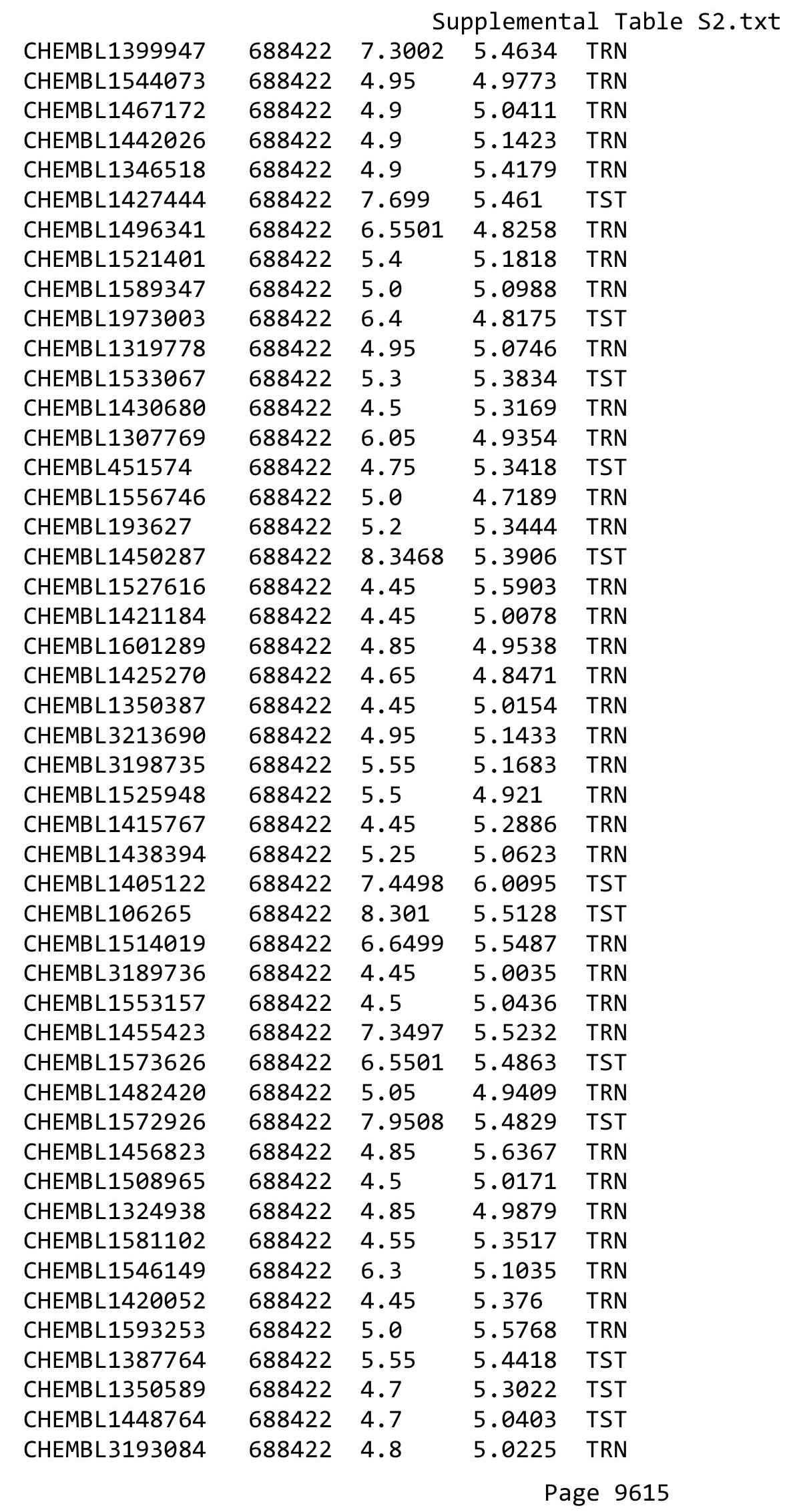




\begin{tabular}{|c|c|c|c|c|c|}
\hline \multicolumn{6}{|c|}{ Supplemental Table S2.txt } \\
\hline CHEMBL1506629 & 688422 & 6.05 & 5.3833 & TRN & \\
\hline CHEMBL1314281 & 688422 & 7.3002 & 5.4034 & TRN & \\
\hline CHEMBL1560370 & 688422 & 5.7 & 5.7395 & TST & \\
\hline CHEMBL1336568 & 688422 & 4.85 & 5.2354 & TRN & \\
\hline CHEMBL1511982 & 688422 & 4.75 & 5.2478 & TRN & \\
\hline CHEMBL1553825 & 688422 & 4.85 & 5.1153 & TRN & \\
\hline CHEMBL1420415 & 688422 & 4.45 & 4.9644 & TST & \\
\hline CHEMBL1390546 & 688422 & 4.45 & 4.8091 & TRN & \\
\hline CHEMBL600968 & 688422 & 5.1 & 5.0532 & TRN & \\
\hline CHEMBL1586438 & 688422 & 4.45 & 4.8144 & TST & \\
\hline CHEMBL1568736 & 688422 & 5.75 & 5.2399 & TST & \\
\hline CHEMBL1366190 & 688422 & 6.6499 & 5.8176 & TRN & \\
\hline CHEMBL1449150 & 688422 & 4.5 & 4.5601 & TRN & \\
\hline CHEMBL1318717 & 688422 & 4.8 & 5.1477 & TST & \\
\hline CHEMBL3190648 & 688422 & 5.25 & 5.2306 & TRN & \\
\hline CHEMBL1341794 & 688422 & 4.7 & 4.6217 & TRN & \\
\hline CHEMBL1416709 & 688422 & 4.95 & 5.3375 & TRN & \\
\hline CHEMBL1571874 & 688422 & 4.45 & 4.9479 & TST & \\
\hline CHEMBL 1451086 & 688422 & 5.1 & 5.4358 & TRN & \\
\hline CHEMBL1330678 & 688422 & 4.45 & 5.3406 & TST & \\
\hline CHEMBL1405919 & 688422 & 5.0 & 4.652 & TST & \\
\hline CHEMBL1453006 & 688422 & 4.65 & 4.9906 & TRN & \\
\hline CHEMBL1439151 & 688422 & 4.7 & 5.5274 & TRN & \\
\hline CHEMBL3192035 & 688422 & 4.85 & 4.9272 & TRN & \\
\hline CHEMBL585820 & 688422 & 4.5 & 5.3981 & TRN & \\
\hline CHEMBL1518259 & 688422 & 4.45 & 5.2152 & TRN & \\
\hline CHEMBL1541906 & 688422 & 4.8 & 5.3822 & TRN & \\
\hline CHEMBL1485113 & 688422 & 7.4498 & 5.8504 & TRN & \\
\hline CHEMBL1408846 & 688422 & 4.6 & 4.7572 & TRN & \\
\hline CHEMBL3189201 & 688422 & 5.0 & 5.61299 & 99999999995 & TRN \\
\hline CHEMBL292500 & 688422 & 4.85 & 6.0565 & TST & \\
\hline CHEMBL3209065 & 688422 & 4.6 & 4.881 & TRN & \\
\hline CHEMBL1613371 & 688422 & 5.05 & 5.4055 & TRN & \\
\hline CHEMBL1554005 & 688422 & 5.35 & 5.0877 & TRN & \\
\hline CHEMBL1536117 & 688422 & 5.35 & 5.185 & TRN & \\
\hline CHEMBL1541530 & 688422 & 4.5 & 4.7457 & TRN & \\
\hline CHEMBL1432126 & 688422 & 7.699 & 5.7076 & TST & \\
\hline CHEMBL3191978 & 688422 & 5.45 & 5.5122 & TRN & \\
\hline CHEMBL1570999 & 688422 & 4.45 & 5.6565 & TRN & \\
\hline CHEMBL1543123 & 688422 & 4.45 & 5.1594 & TST & \\
\hline CHEMBL 3214440 & 688422 & 5.45 & 5.5474 & TRN & \\
\hline CHEMBL1608819 & 688422 & 4.65 & 5.4709 & TRN & \\
\hline CHEMBL3212453 & 688422 & 5.2 & 4.9006 & TRN & \\
\hline CHEMBL1520808 & 688422 & 4.9 & 5.1931 & TRN & \\
\hline CHEMBL1408827 & 688422 & 4.75 & 5.6414 & TRN & \\
\hline CHEMBL1552495 & 688422 & 4.65 & 5.1022 & TST & \\
\hline CHEMBL1567561 & 688422 & 4.55 & 5.4924 & TRN & \\
\hline CHEMBL3196326 & 688422 & 4.5 & 5.4345 & TRN & \\
\hline
\end{tabular}




\begin{tabular}{|c|c|c|c|c|c|}
\hline \multicolumn{6}{|c|}{ Supplemental Table s2.txt } \\
\hline CHEMBL1311633 & 688422 & 5.2 & 5.0006 & TRN & \\
\hline CHEMBL1595858 & 688422 & 4.95 & 5.0232 & TRN & \\
\hline CHEMBL1335920 & 688422 & 5.0 & 5.2801 & TRN & \\
\hline CHEMBL1389185 & 688422 & 4.65 & 4.6297 & TRN & \\
\hline CHEMBL3214013 & 688422 & 6.8499 & 5.2121 & TST & \\
\hline CHEMBL1308648 & 688422 & 5.45 & 5.3745 & TRN & \\
\hline CHEMBL1474050 & 688422 & 6.35 & 5.0459 & TRN & \\
\hline CHEMBL1453014 & 688422 & 8.0506 & 5.7995 & TST & \\
\hline CHEMBL1541617 & 688422 & 4.5 & 5.1422 & TRN & \\
\hline CHEMBL1361232 & 688422 & 4.65 & 5.5177 & TST & \\
\hline CHEMBL1446779 & 688422 & 4.75 & 4.8784 & TRN & \\
\hline CHEMBL1398980 & 688422 & 4.45 & 4.8576 & TRN & \\
\hline CHEMBL1391479 & 688422 & 4.85 & 5.3678 & TRN & \\
\hline CHEMBL1522183 & 688422 & 4.7 & 5.2876 & TRN & \\
\hline CHEMBL1371368 & 688422 & 7.2503 & 5.7993 & TRN & \\
\hline CHEMBL1533541 & 688422 & 4.45 & 5.3416 & TRN & \\
\hline CHEMBL585861 & 688422 & 5.4 & 4.8017 & TRN & \\
\hline CHEMBL1309654 & 688422 & 4.55 & 5.2275 & TST & \\
\hline CHEMBL1594885 & 688422 & 4.8 & 5.0589 & TRN & \\
\hline CHEMBL1336722 & 688422 & 4.85 & 5.1547 & TRN & \\
\hline CHEMBL1321036 & 688422 & 5.0 & 5.3952 & TRN & \\
\hline CHEMBL1351628 & 688422 & 4.65 & 4.9715 & TRN & \\
\hline CHEMBL1483207 & 688422 & 4.45 & 5.6404 & TRN & \\
\hline CHEMBL1330166 & 688422 & 4.9 & 4.8763 & TRN & \\
\hline CHEMBL1308436 & 688422 & 6.05 & 5.1983 & TRN & \\
\hline CHEMBL1344060 & 688422 & 4.5 & 5.3767 & TRN & \\
\hline CHEMBL583900 & 688422 & 7.4001 & 5.9243 & TRN & \\
\hline CHEMBL1575665 & 688422 & 6.05 & 5.12200 & 0000000001 & TRN \\
\hline CHEMBL1503815 & 688422 & 4.65 & 5.1081 & TST & \\
\hline CHEMBL 1417210 & 688422 & 7.6498 & 5.5797 & TST & \\
\hline CHEMBL1349574 & 688422 & 4.65 & 5.4522 & TRN & \\
\hline CHEMBL1499741 & 688422 & 5.4 & 5.121 & TRN & \\
\hline CHEMBL1311673 & 688422 & 5.15 & 4.54 & TRN & \\
\hline CHEMBL1444278 & 688422 & 5.7 & 5.1874 & TRN & \\
\hline CHEMBL1446671 & 688422 & 4.65 & 5.4322 & TRN & \\
\hline CHEMBL1516103 & 688422 & 4.65 & 4.732 & TRN & \\
\hline CHEMBL1420116 & 688422 & 4.45 & 5.1151 & TST & \\
\hline CHEMBL1371101 & 688422 & 4.45 & 4.8426 & TRN & \\
\hline CHEMBL1344184 & 688422 & 4.5 & 4.853 & TRN & \\
\hline CHEMBL1408820 & 688422 & 5.55 & 5.3714 & TRN & \\
\hline CHEMBL1543704 & 688422 & 5.15 & 5.1131 & TST & \\
\hline CHEMBL1611658 & 688422 & 4.45 & 4.9862 & TRN & \\
\hline CHEMBL1547928 & 688422 & 4.45 & 5.0055 & TRN & \\
\hline CHEMBL1441481 & 688422 & 4.65 & 5.0459 & TST & \\
\hline CHEMBL1533538 & 688422 & 4.85 & 5.3844 & TRN & \\
\hline CHEMBL1393793 & 688422 & 4.65 & 5.0632 & TRN & \\
\hline CHEMBL1380577 & 688422 & 5.0 & 5.239 & TRN & \\
\hline CHEMBL1361475 & 688422 & 4.75 & 5.4231 & TRN & \\
\hline
\end{tabular}




\begin{tabular}{|c|c|c|c|c|c|}
\hline \multicolumn{6}{|c|}{ Supplemental Table S2.txt } \\
\hline CHEMBL1332770 & 688422 & 4.9 & 5.3243 & TRN & \\
\hline CHEMBL1477186 & 688422 & 4.45 & 5.2551 & TST & \\
\hline CHEMBL1511795 & 688422 & 4.95 & 5.0296 & TRN & \\
\hline CHEMBL1384172 & 688422 & 5.15 & 5.4419 & TRN & \\
\hline CHEMBL1339050 & 688422 & 5.2 & 4.8402 & TRN & \\
\hline CHEMBL1373809 & 688422 & 5.95 & 5.2839 & TRN & \\
\hline CHEMBL1382293 & 688422 & 4.5 & 5.012 & TRN & \\
\hline CHEMBL 3199734 & 688422 & 4.9 & 5.3041 & TRN & \\
\hline CHEMBL559797 & 688422 & 4.45 & 5.5554 & TST & \\
\hline CHEMBL1451409 & 688422 & 5.9 & 5.0056 & TRN & \\
\hline CHEMBL1557076 & 688422 & 4.7 & 4.9573 & TRN & \\
\hline CHEMBL1436272 & 688422 & 4.8 & 4.7363 & TRN & \\
\hline CHEMBL1613200 & 688422 & 4.7 & 5.40600 & 0000000001 & TST \\
\hline CHEMBL 3189287 & 688422 & 5.05 & 5.2456 & TST & \\
\hline CHEMBL1462997 & 688422 & 5.2 & 5.1333 & TST & \\
\hline CHEMBL1419721 & 688422 & 4.75 & 5.2146 & TRN & \\
\hline CHEMBL1303949 & 688422 & 4.55 & 5.5449 & TST & \\
\hline CHEMBL1491591 & 688422 & 4.6 & 5.6458 & TRN & \\
\hline CHEMBL1304837 & 688422 & 5.05 & 4.8079 & TRN & \\
\hline CHEMBL1419903 & 688422 & 4.75 & 5.3532 & TST & \\
\hline CHEMBL1500751 & 688422 & 4.85 & 5.1866 & TST & \\
\hline CHEMBL1419335 & 688422 & 5.55 & 4.7206 & TRN & \\
\hline CHEMBL546257 & 688422 & 6.0 & 5.4199 & TST & \\
\hline CHEMBL3214195 & 688422 & 4.85 & 5.0641 & TRN & \\
\hline CHEMBL1487477 & 688422 & 4.9 & 4.8514 & TRN & \\
\hline CHEMBL1501454 & 688422 & 4.85 & 4.9274 & TST & \\
\hline CHEMBL1312934 & 688422 & 4.8 & 5.6255 & TST & \\
\hline CHEMBL1528114 & 688422 & 5.3 & 4.9751 & TRN & \\
\hline CHEMBL1346432 & 688422 & 5.55 & 5.58899 & 99999999995 & TRN \\
\hline CHEMBL1611171 & 688422 & 5.35 & 5.3356 & TST & \\
\hline CHEMBL1362247 & 688422 & 4.45 & 5.308 & TRN & \\
\hline CHEMBL3194725 & 688422 & 4.6 & 4.9579 & TRN & \\
\hline CHEMBL1606562 & 688422 & 8.3468 & 5.075 & TST & \\
\hline CHEMBL1330980 & 688422 & 4.5 & 5.2858 & TRN & \\
\hline CHEMBL1377922 & 688422 & 6.9 & 5.6878 & TST & \\
\hline CHEMBL1586093 & 688422 & 4.7 & 5.6099 & TRN & \\
\hline CHEMBL1435394 & 688422 & 4.45 & 5.0351 & TRN & \\
\hline CHEMBL1412869 & 688422 & 5.25 & 5.9372 & TRN & \\
\hline CHEMBL1547028 & 688422 & 5.25 & 5.2058 & TST & \\
\hline CHEMBL1478344 & 688422 & 4.5 & 5.0539 & TRN & \\
\hline CHEMBL1586038 & 688422 & 4.75 & 5.3412 & TRN & \\
\hline CHEMBL1344000 & 688422 & 4.65 & 4.7874 & TRN & \\
\hline CHEMBL1561050 & 688422 & 4.7 & 5.2015 & TRN & \\
\hline CHEMBL1433559 & 688422 & 5.15 & 4.876 & TRN & \\
\hline CHEMBL1369254 & 688422 & 5.25 & 4.8534 & TRN & \\
\hline CHEMBL1341771 & 688422 & 4.65 & 5.1405 & TRN & \\
\hline CHEMBL1494863 & 688422 & 5.35 & 5.3033 & TRN & \\
\hline CHEMBL1306236 & 688422 & 6.0 & 5.4703 & TRN & \\
\hline
\end{tabular}




\begin{tabular}{|c|c|c|c|c|}
\hline \multicolumn{5}{|c|}{ Supplemental Table S2.txt } \\
\hline CHEMBL1372762 & 688422 & 4.9 & 5.2862 & TST \\
\hline CHEMBL1545777 & 688422 & 4.5 & 5.0897 & TRN \\
\hline CHEMBL1564515 & 688422 & 6.3 & 4.9709 & TRN \\
\hline CHEMBL1436912 & 688422 & 4.9 & 5.6358 & TRN \\
\hline CHEMBL1364723 & 688422 & 4.45 & 5.0376 & TST \\
\hline CHEMBL1453789 & 688422 & 4.65 & 5.5347 & TRN \\
\hline CHEMBL1596508 & 688422 & 4.65 & 5.0708 & TRN \\
\hline CHEMBL1409333 & 688422 & 4.45 & 5.3191 & TRN \\
\hline CHEMBL1490169 & 688422 & 4.9 & 5.0195 & TRN \\
\hline CHEMBL1356362 & 688422 & 5.4 & 5.3185 & TRN \\
\hline CHEMBL1300943 & 688422 & 4.65 & 5.5 & TRN \\
\hline CHEMBL1468974 & 688422 & 4.45 & 5.1934 & TRN \\
\hline CHEMBL1380156 & 688422 & 4.9 & 4.8494 & TRN \\
\hline CHEMBL1469808 & 688422 & 4.45 & 4.8794 & TST \\
\hline CHEMBL99203 & 688422 & 5.55 & 6.4901 & TRN \\
\hline CHEMBL1320092 & 688422 & 4.45 & 4.9009 & TRN \\
\hline CHEMBL3199153 & 688422 & 4.6 & 5.7356 & TST \\
\hline CHEMBL1480691 & 688422 & 4.5 & 4.8315 & TRN \\
\hline CHEMBL1463037 & 688422 & 6.8499 & 5.7944 & TRN \\
\hline CHEMBL1398933 & 688422 & 4.85 & 4.9845 & TRN \\
\hline CHEMBL1498893 & 688422 & 5.35 & 5.0869 & TRN \\
\hline CHEMBL1429842 & 688422 & 4.75 & 5.2952 & TRN \\
\hline CHEMBL1590950 & 688422 & 4.55 & 5.3641 & TRN \\
\hline CHEMBL3210051 & 688422 & 4.65 & 4.6726 & TRN \\
\hline CHEMBL1308140 & 688422 & 4.5 & 5.2813 & TRN \\
\hline CHEMBL3196822 & 688422 & 4.95 & 4.9929 & TRN \\
\hline CHEMBL1600959 & 688422 & 4.9 & 5.6042 & TRN \\
\hline CHEMBL1411106 & 688422 & 4.8 & 4.8263 & TRN \\
\hline CHEMBL1549539 & 688422 & 5.25 & 5.6381 & TST \\
\hline CHEMBL1401586 & 688422 & 6.5 & 5.1947 & TRN \\
\hline CHEMBL1397427 & 688422 & 4.7 & 5.3055 & TRN \\
\hline CHEMBL1483913 & 688422 & 5.95 & 5.2706 & TRN \\
\hline CHEMBL1609372 & 688422 & 4.8 & 5.0776 & TRN \\
\hline CHEMBL1306124 & 688422 & 4.75 & 5.1978 & TRN \\
\hline CHEMBL1565338 & 688422 & 5.1 & 5.4281 & TRN \\
\hline CHEMBL1452932 & 688422 & 4.85 & 5.3956 & TST \\
\hline CHEMBL 1587186 & 688422 & 5.0 & 5.4534 & TRN \\
\hline CHEMBL1548538 & 688422 & 6.7501 & 4.937 & TRN \\
\hline CHEMBL1449598 & 688422 & 4.85 & 5.2572 & TST \\
\hline CHEMBL1377920 & 688422 & 5.35 & 5.1846 & TST \\
\hline CHEMBL 2001983 & 688422 & 4.45 & 5.1636 & TST \\
\hline CHEMBL1332862 & 688422 & 5.2 & 5.2346 & TRN \\
\hline CHEMBL1560341 & 688422 & 4.9 & 5.0283 & TST \\
\hline CHEMBL1320243 & 688422 & 4.6 & 4.6812 & TRN \\
\hline CHEMBL1460025 & 688422 & 5.4 & 5.4549 & TRN \\
\hline CHEMBL1600772 & 688422 & 4.75 & 4.8608 & TRN \\
\hline CHEMBL1504816 & 688422 & 4.45 & 4.8473 & TRN \\
\hline CHEMBL 2005580 & 688422 & 5.15 & 5.2618 & TRN \\
\hline
\end{tabular}




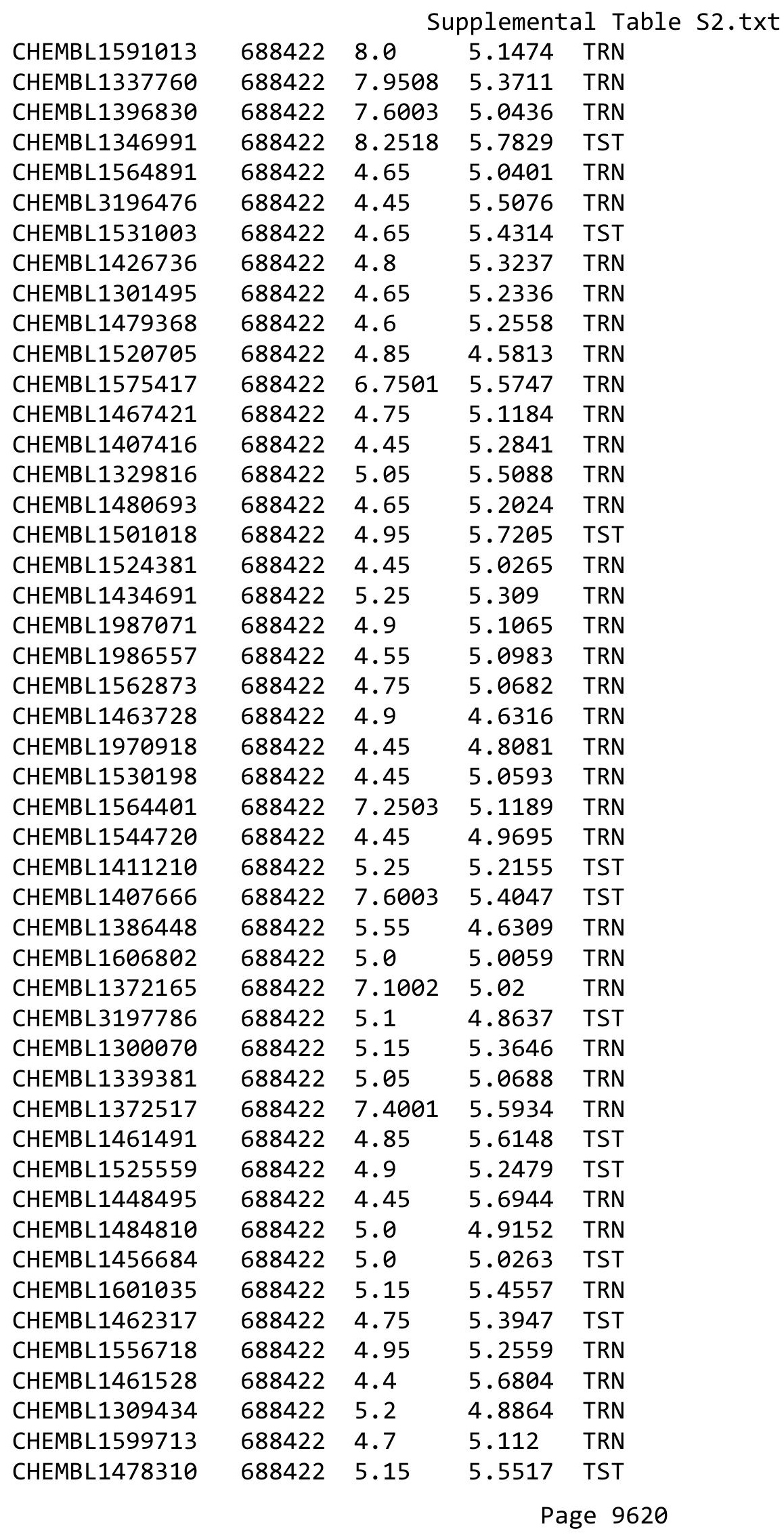




\begin{tabular}{|c|c|c|c|c|}
\hline \multicolumn{5}{|c|}{ Supplemental Table S2.txt } \\
\hline CHEMBL1475318 & 688422 & 6.5 & 5.1825 & TRN \\
\hline CHEMBL1557619 & 688422 & 5.4 & 4.9959 & TRN \\
\hline CHEMBL1527355 & 688422 & 5.7 & 5.6107 & TST \\
\hline CHEMBL1565266 & 688422 & 7.699 & 5.4174 & TRN \\
\hline CHEMBL1350934 & 688422 & 5.65 & 5.0091 & TRN \\
\hline CHEMBL1348826 & 688422 & 4.7 & 5.294 & TRN \\
\hline CHEMBL1530460 & 688422 & 6.1 & 5.3251 & TST \\
\hline CHEMBL1557111 & 688422 & 4.7 & 5.4644 & TST \\
\hline CHEMBL1971634 & 688422 & 5.0 & 5.1538 & TRN \\
\hline CHEMBL1374163 & 688422 & 4.8 & 5.2415 & TRN \\
\hline CHEMBL1440114 & 688422 & 6.1 & 5.4382 & TST \\
\hline CHEMBL1565478 & 688422 & 4.75 & 5.308 & TRN \\
\hline CHEMBL1402850 & 688422 & 5.45 & 5.4661 & TRN \\
\hline CHEMBL1569410 & 688422 & 4.45 & 5.0233 & TRN \\
\hline CHEMBL1585327 & 688422 & 4.45 & 5.0865 & TST \\
\hline CHEMBL1344174 & 688422 & 5.55 & 5.2673 & TST \\
\hline CHEMBL1534509 & 688422 & 6.9 & 5.1269 & TRN \\
\hline CHEMBL1415483 & 688422 & 6.5 & 4.9563 & TRN \\
\hline CHEMBL1380609 & 688422 & 4.45 & 5.1022 & TST \\
\hline CHEMBL1575711 & 688422 & 5.55 & 5.3831 & TST \\
\hline CHEMBL1338448 & 688422 & 4.65 & 5.1735 & TST \\
\hline CHEMBL1496712 & 688422 & 4.45 & 5.1024 & TRN \\
\hline CHEMBL1414465 & 688422 & 5.55 & 4.8185 & TST \\
\hline CHEMBL1410412 & 688422 & 4.45 & 4.879 & TRN \\
\hline CHEMBL 2138014 & 688422 & 4.75 & 4.8919 & TRN \\
\hline CHEMBL1453394 & 688422 & 5.55 & 5.0513 & TST \\
\hline CHEMBL1530238 & 688422 & 4.95 & 5.0689 & TRN \\
\hline CHEMBL1323922 & 688422 & 6.05 & 5.6735 & TST \\
\hline CHEMBL1466263 & 688422 & 6.05 & 5.539 & TRN \\
\hline CHEMBL1391055 & 688422 & 4.9 & 5.1091 & TRN \\
\hline CHEMBL1585051 & 688422 & 4.95 & 5.2398 & TRN \\
\hline CHEMBL1553403 & 688422 & 5.25 & 4.8331 & TRN \\
\hline CHEMBL1440311 & 688422 & 4.75 & 5.1312 & TST \\
\hline CHEMBL1495978 & 688422 & 4.9 & 5.4047 & TRN \\
\hline CHEMBL1399494 & 688422 & 5.3 & 5.784 & TRN \\
\hline CHEMBL1320061 & 688422 & 5.0 & 4.9056 & TRN \\
\hline CHEMBL1466246 & 688422 & 4.95 & 5.2961 & TRN \\
\hline CHEMBL 27403 & 688422 & 4.85 & 5.0497 & TST \\
\hline CHEMBL1492359 & 688422 & 4.45 & 4.9403 & TST \\
\hline CHEMBL1374257 & 688422 & 4.5 & 5.0219 & TRN \\
\hline CHEMBL1373351 & 688422 & 5.2 & 5.4585 & TRN \\
\hline CHEMBL1530571 & 688422 & 6.2 & 5.3603 & TST \\
\hline CHEMBL47940 & 688422 & 4.9 & 4.8842 & TST \\
\hline CHEMBL1348403 & 688422 & 4.45 & 5.2915 & TST \\
\hline CHEMBL1497433 & 688422 & 4.95 & 4.9312 & TRN \\
\hline CHEMBL1371720 & 688422 & 4.7 & 4.8541 & TRN \\
\hline CHEMBL1367980 & 688422 & 4.6 & 5.6959 & TRN \\
\hline CHEMBL1330031 & 688422 & 4.45 & 5.515 & TRN \\
\hline
\end{tabular}




\begin{tabular}{|c|c|c|c|c|c|}
\hline \multicolumn{6}{|c|}{ Supplemental Table S2.txt } \\
\hline CHEMBL1380985 & 688422 & 4.85 & 5.1749 & TRN & \\
\hline CHEMBL1529847 & 688422 & 4.9 & 4.9483 & TRN & \\
\hline CHEMBL1389572 & 688422 & 5.2 & 5.3685 & TRN & \\
\hline CHEMBL 2373666 & 688422 & 4.8 & 5.9751 & TRN & \\
\hline CHEMBL 3208638 & 688422 & 4.85 & 5.2654 & TRN & \\
\hline CHEMBL1449587 & 688422 & 4.95 & 5.6385 & TST & \\
\hline CHEMBL1300843 & 688422 & 5.55 & 4.855 & TRN & \\
\hline CHEMBL1463974 & 688422 & 4.75 & 5.1639 & TST & \\
\hline CHEMBL1362986 & 688422 & 4.45 & 5.4254 & TST & \\
\hline CHEMBL1481889 & 688422 & 8.0 & 5.2826 & TRN & \\
\hline CHEMBL1576071 & 688422 & 5.35 & 5.7953 & TRN & \\
\hline CHEMBL1449155 & 688422 & 4.8 & 5.6788 & TRN & \\
\hline CHEMBL1337235 & 688422 & 4.95 & 4.8844 & TRN & \\
\hline CHEMBL1579046 & 688422 & 4.45 & 5.2266 & TRN & \\
\hline CHEMBL1479341 & 688422 & 4.45 & 5.6503 & TST & \\
\hline CHEMBL1569719 & 688422 & 6.25 & 5.4573 & TRN & \\
\hline CHEMBL1343729 & 688422 & 5.35 & 5.2775 & TRN & \\
\hline CHEMBL1523801 & 688422 & 4.7 & 5.4021 & TRN & \\
\hline CHEMBL1608297 & 688422 & 5.9 & 5.3529 & TRN & \\
\hline CHEMBL1585432 & 688422 & 5.0 & 5.1445 & TST & \\
\hline CHEMBL1373652 & 688422 & 4.65 & 5.1215 & TRN & \\
\hline CHEMBL491499 & 688422 & 4.55 & 5.4616 & TRN & \\
\hline CHEMBL1458403 & 688422 & 4.95 & 5.4296 & TRN & \\
\hline CHEMBL1568578 & 688422 & 5.1 & 4.7742 & TRN & \\
\hline CHEMBL 201325 & 688422 & 4.95 & 5.0109 & TRN & \\
\hline CHEMBL1543949 & 688422 & 4.65 & 5.2327 & TST & \\
\hline CHEMBL1442786 & 688422 & 4.8 & 5.2354 & TRN & \\
\hline CHEMBL1374968 & 688422 & 5.35 & 5.0383 & TRN & \\
\hline CHEMBL1484425 & 688422 & 4.95 & 5.2465 & TST & \\
\hline CHEMBL1589751 & 688422 & 4.8 & 5.2608 & TST & \\
\hline CHEMBL1422271 & 688422 & 5.1 & 5.4291 & TRN & \\
\hline CHEMBL1393849 & 688422 & 4.9 & 5.2833 & TRN & \\
\hline CHEMBL1347829 & 688422 & 4.45 & 5.2852 & TST & \\
\hline CHEMBL1374457 & 688422 & 4.45 & 4.928 & TRN & \\
\hline CHEMBL1465186 & 688422 & 5.5 & 5.20700 & 0000000001 & TRN \\
\hline CHEMBL528373 & 688422 & 4.9 & 5.003 & TST & \\
\hline CHEMBL 2002830 & 688422 & 5.45 & 5.2088 & TRN & \\
\hline CHEMBL1553462 & 688422 & 4.5 & 5.1173 & TRN & \\
\hline CHEMBL1527131 & 688422 & 4.75 & 5.2112 & TRN & \\
\hline CHEMBL1360018 & 688422 & 4.8 & 5.1078 & TRN & \\
\hline CHEMBL1504346 & 688422 & 5.05 & 5.2303 & TRN & \\
\hline CHEMBL1573466 & 688422 & 4.6 & 4.976 & TRN & \\
\hline CHEMBL1328556 & 688422 & 4.9 & 5.6472 & TRN & \\
\hline CHEMBL1335714 & 688422 & 5.65 & 5.005 & TRN & \\
\hline CHEMBL 2006441 & 688422 & 4.45 & 5.0223 & TRN & \\
\hline CHEMBL1974348 & 688422 & 4.8 & 4.899 & TST & \\
\hline CHEMBL1429497 & 688422 & 8.4559 & 5.1186 & TRN & \\
\hline CHEMBL1548743 & 688422 & 4.45 & 4.6491 & TRN & \\
\hline
\end{tabular}




\begin{tabular}{|c|c|c|c|c|}
\hline \multicolumn{5}{|c|}{ Supplemental Table S2.txt } \\
\hline CHEMBL1352666 & 688422 & 4.6 & 4.8864 & TRN \\
\hline CHEMBL1721226 & 688422 & 4.8 & 5.9215 & TRN \\
\hline CHEMBL1338886 & 688422 & 4.45 & 5.0045 & TST \\
\hline CHEMBL1527372 & 688422 & 4.9 & 4.9468 & TRN \\
\hline CHEMBL1347831 & 688422 & 4.55 & 5.0911 & TRN \\
\hline CHEMBL1400353 & 688422 & 5.0 & 5.558 & TRN \\
\hline CHEMBL1574730 & 688422 & 4.7 & 5.2271 & TST \\
\hline CHEMBL1531156 & 688422 & 4.45 & 5.1422 & TRN \\
\hline CHEMBL1486326 & 688422 & 7.2503 & 5.0698 & TRN \\
\hline CHEMBL1559663 & 688422 & 6.6499 & 6.091 & TST \\
\hline CHEMBL1528951 & 688422 & 4.45 & 5.0776 & TRN \\
\hline CHEMBL1336122 & 688422 & 8.7447 & 5.5711 & TST \\
\hline CHEMBL1427102 & 688422 & 5.25 & 5.3799 & TRN \\
\hline CHEMBL 3194640 & 688422 & 4.45 & 5.2189 & TRN \\
\hline CHEMBL1302196 & 688422 & 5.9 & 5.6494 & TRN \\
\hline CHEMBL1458345 & 688422 & 4.5 & 5.1565 & TRN \\
\hline CHEMBL1374555 & 688422 & 4.85 & 5.1545 & TRN \\
\hline CHEMBL1591893 & 688422 & 4.65 & 4.6937 & TRN \\
\hline CHEMBL1539485 & 688422 & 6.6 & 5.029 & TRN \\
\hline CHEMBL1333919 & 688422 & 4.75 & 5.1717 & TRN \\
\hline CHEMBL1586152 & 688422 & 5.25 & 5.1935 & TST \\
\hline CHEMBL1524496 & 688422 & 4.8 & 5.704 & TRN \\
\hline CHEMBL1410438 & 688422 & 8.4949 & 5.066 & TRN \\
\hline CHEMBL1416710 & 688422 & 4.75 & 4.8824 & TRN \\
\hline CHEMBL1569108 & 688422 & 6.45 & 5.2527 & TRN \\
\hline CHEMBL586830 & 688422 & 4.9 & 5.0759 & TRN \\
\hline CHEMBL1523393 & 688422 & 6.4 & 5.989 & TST \\
\hline CHEMBL1392138 & 688422 & 5.05 & 5.0479 & TST \\
\hline CHEMBL3197807 & 688422 & 4.45 & 5.1876 & TST \\
\hline CHEMBL1544109 & 688422 & 6.15 & 5.4114 & TRN \\
\hline CHEMBL1330838 & 688422 & 4.95 & 5.2014 & TRN \\
\hline CHEMBL1442969 & 688422 & 5.3 & 5.3254 & TST \\
\hline CHEMBL1372412 & 688422 & 4.8 & 5.3183 & TRN \\
\hline CHEMBL1313972 & 688422 & 4.5 & 5.2189 & TRN \\
\hline CHEMBL155563 & 688422 & 4.95 & 4.8849 & TRN \\
\hline CHEMBL1601176 & 688422 & 4.9 & 5.1035 & TRN \\
\hline CHEMBL1553010 & 688422 & 5.65 & 5.8751 & TRN \\
\hline CHEMBL1353797 & 688422 & 4.65 & 5.3361 & TST \\
\hline CHEMBL1361496 & 688422 & 7.6498 & 5.3573 & TRN \\
\hline CHEMBL1406049 & 688422 & 5.7 & 4.8666 & TRN \\
\hline CHEMBL1355348 & 688422 & 4.65 & 4.9798 & TRN \\
\hline CHEMBL 286077 & 688422 & 8.301 & 6.2841 & TST \\
\hline CHEMBL1418687 & 688422 & 5.15 & 5.0276 & TRN \\
\hline CHEMBL1549479 & 688422 & 5.2 & 4.8036 & TRN \\
\hline CHEMBL1434207 & 688422 & 5.25 & 5.3484 & TRN \\
\hline CHEMBL1309913 & 688422 & 4.75 & 5.3463 & TRN \\
\hline CHEMBL1208858 & 688422 & 4.9 & 4.8288 & TRN \\
\hline CHEMBL1350537 & 688422 & 4.8 & 5.1009 & TRN \\
\hline
\end{tabular}




\begin{tabular}{|c|c|c|c|c|c|}
\hline \multicolumn{6}{|c|}{ Supplemental Table s2.txt } \\
\hline CHEMBL1423004 & 688422 & 6.95 & 5.5567 & TRN & \\
\hline CHEMBL1441404 & 688422 & 4.65 & 4.8972 & TST & \\
\hline CHEMBL1533263 & 688422 & 5.2 & 5.1391 & TST & \\
\hline CHEMBL150 & 688422 & 5.45 & 5.6171 & TRN & \\
\hline CHEMBL1351395 & 688422 & 4.45 & 5.3863 & TRN & \\
\hline CHEMBL1418892 & 688422 & 4.95 & 5.4325 & TST & \\
\hline CHEMBL1594191 & 688422 & 5.7 & 4.6293 & TRN & \\
\hline CHEMBL1970286 & 688422 & 6.1 & 5.1238 & TRN & \\
\hline CHEMBL1572028 & 688422 & 4.45 & 4.9239 & TRN & \\
\hline CHEMBL1299985 & 688422 & 4.95 & 4.7649 & TRN & \\
\hline CHEMBL1429949 & 688422 & 4.45 & 5.3753 & TRN & \\
\hline CHEMBL1508659 & 688422 & 5.0 & 5.0872 & TRN & \\
\hline CHEMBL3391701 & 688422 & 6.4 & 5.6107 & TRN & \\
\hline CHEMBL1311346 & 688422 & 7.699 & 5.7312 & TRN & \\
\hline CHEMBL1591340 & 688422 & 4.65 & 5.05699 & 99999999995 & TRN \\
\hline CHEMBL1489835 & 688422 & 4.55 & 4.8846 & TRN & \\
\hline CHEMBL1347577 & 688422 & 4.45 & 4.8567 & TRN & \\
\hline CHEMBL1613656 & 688422 & 4.65 & 5.3665 & TST & \\
\hline CHEMBL1426514 & 688422 & 4.45 & 4.9065 & TRN & \\
\hline CHEMBL1425202 & 688422 & 6.2 & 5.414 & TST & \\
\hline CHEMBL1575715 & 688422 & 4.9 & 5.0278 & TRN & \\
\hline CHEMBL1502446 & 688422 & 4.5 & 4.8349 & TRN & \\
\hline CHEMBL1508134 & 688422 & 5.2 & 5.4216 & TRN & \\
\hline CHEMBL1383874 & 688422 & 4.65 & 5.2968 & TST & \\
\hline CHEMBL1536033 & 688422 & 6.8 & 5.2404 & TST & \\
\hline CHEMBL1348430 & 688422 & 4.45 & 5.0823 & TRN & \\
\hline CHEMBL3194214 & 688422 & 5.1 & 5.2223 & TST & \\
\hline CHEMBL1967273 & 688422 & 4.75 & 5.3349 & TRN & \\
\hline CHEMBL1442353 & 688422 & 5.3 & 5.5858 & TRN & \\
\hline CHEMBL1998188 & 688422 & 4.8 & 5.1959 & TRN & \\
\hline CHEMBL3197050 & 688422 & 6.6499 & 5.3016 & TRN & \\
\hline CHEMBL1343971 & 688422 & 4.85 & 5.3224 & TRN & \\
\hline CHEMBL 3144890 & 688422 & 4.5 & 4.9734 & TST & \\
\hline CHEMBL3197567 & 688422 & 5.0 & 5.1181 & TRN & \\
\hline CHEMBL1331210 & 688422 & 5.15 & 5.0293 & TRN & \\
\hline CHEMBL1416644 & 688422 & 5.2 & 5.1043 & TST & \\
\hline CHEMBL1423064 & 688422 & 5.6 & 5.1977 & TRN & \\
\hline CHEMBL1530312 & 688422 & 7.4001 & 5.2544 & TST & \\
\hline CHEMBL1371568 & 688422 & 4.9 & 5.0138 & TRN & \\
\hline CHEMBL1417647 & 688422 & 7.0 & 5.5957 & TST & \\
\hline CHEMBL1369206 & 688422 & 6.45 & 5.223 & TRN & \\
\hline CHEMBL1562264 & 688422 & 5.85 & 5.7155 & TST & \\
\hline CHEMBL1381397 & 688422 & 4.9 & 4.8229 & TRN & \\
\hline CHEMBL1350075 & 688422 & 4.65 & 4.8366 & TRN & \\
\hline CHEMBL1964398 & 688422 & 4.9 & 5.1202 & TRN & \\
\hline CHEMBL1377543 & 688422 & 4.65 & 5.5742 & TRN & \\
\hline CHEMBL1358814 & 688422 & 5.0 & 4.6031 & TST & \\
\hline CHEMBL1502301 & 688422 & 4.95 & 5.6698 & TRN & \\
\hline
\end{tabular}




\begin{tabular}{|c|c|c|c|c|}
\hline \multicolumn{5}{|c|}{ Supplemental Table S2.txt } \\
\hline CHEMBL 3199125 & 688422 & 4.85 & 5.3047 & TRN \\
\hline CHEMBL1524783 & 688422 & 4.9 & 4.8478 & TRN \\
\hline CHEMBL1338889 & 688422 & 4.8 & 5.01 & TRN \\
\hline CHEMBL1459106 & 688422 & 5.2 & 5.3031 & TRN \\
\hline CHEMBL1563231 & 688422 & 8.0 & 5.8252 & TRN \\
\hline CHEMBL1422787 & 688422 & 5.4 & 5.1624 & TRN \\
\hline CHEMBL1422892 & 688422 & 5.35 & 5.3014 & TRN \\
\hline CHEMBL1430469 & 688422 & 4.9 & 4.6424 & TRN \\
\hline CHEMBL1437101 & 688422 & 6.8 & 5.2286 & TRN \\
\hline CHEMBL1306160 & 688422 & 6.8499 & 5.3498 & TRN \\
\hline CHEMBL1566199 & 688422 & 7.5003 & 5.2865 & TRN \\
\hline CHEMBL1324988 & 688422 & 5.05 & 5.1556 & TRN \\
\hline CHEMBL1343759 & 688422 & 4.95 & 5.01 & TST \\
\hline CHEMBL1341274 & 688422 & 4.85 & 5.5444 & TST \\
\hline CHEMBL1459087 & 688422 & 5.35 & 5.1746 & TRN \\
\hline CHEMBL1411726 & 688422 & 4.45 & 4.9624 & TRN \\
\hline CHEMBL432527 & 688422 & 5.05 & 5.2484 & TST \\
\hline CHEMBL1531354 & 688422 & 5.25 & 5.1781 & TST \\
\hline CHEMBL1329957 & 688422 & 5.75 & 5.5405 & TST \\
\hline CHEMBL1561044 & 688422 & 4.45 & 5.0773 & TRN \\
\hline CHEMBL59461 & 688422 & 4.45 & 5.3885 & TST \\
\hline CHEMBL1351019 & 688422 & 5.85 & 5.2362 & TRN \\
\hline CHEMBL1478158 & 688422 & 5.2 & 5.1655 & TST \\
\hline CHEMBL1430240 & 688422 & 5.5 & 5.1355 & TST \\
\hline CHEMBL1339659 & 688422 & 4.65 & 4.8774 & TRN \\
\hline CHEMBL1377807 & 688422 & 5.3 & 5.5068 & TRN \\
\hline CHEMBL1506791 & 688422 & 4.65 & 5.3841 & TST \\
\hline CHEMBL1424144 & 688422 & 5.45 & 5.3353 & TST \\
\hline CHEMBL1569349 & 688422 & 4.8 & 5.3189 & TRN \\
\hline CHEMBL 1432727 & 688422 & 4.5 & 4.9271 & TRN \\
\hline CHEMBL1609409 & 688422 & 4.75 & 5.2559 & TST \\
\hline CHEMBL1401818 & 688422 & 4.65 & 4.7618 & TRN \\
\hline CHEMBL1532309 & 688422 & 4.45 & 5.2908 & TST \\
\hline CHEMBL1520135 & 688422 & 4.65 & 5.0686 & TRN \\
\hline CHEMBL1397262 & 688422 & 5.2 & 5.5353 & TST \\
\hline CHEMBL1459288 & 688422 & 4.45 & 4.8929 & TRN \\
\hline CHEMBL1974180 & 688422 & 5.0 & 5.21200 & 0000000001 \\
\hline CHEMBL1303424 & 688422 & 4.45 & 5.3168 & TST \\
\hline CHEMBL1605917 & 688422 & 4.6 & 4.8007 & TRN \\
\hline CHEMBL1384217 & 688422 & 5.2 & 5.1966 & TRN \\
\hline CHEMBL1393523 & 688422 & 4.45 & 5.1989 & TRN \\
\hline CHEMBL339561 & 688422 & 4.45 & 5.5687 & TST \\
\hline CHEMBL1391494 & 688422 & 5.8 & 5.2235 & TRN \\
\hline CHEMBL1553352 & 688422 & 4.45 & 4.7999 & TRN \\
\hline CHEMBL1373172 & 688422 & 4.75 & 5.1426 & TRN \\
\hline CHEMBL1477856 & 688422 & 5.2 & 5.1211 & TRN \\
\hline CHEMBL1509308 & 688422 & 4.95 & 4.9919 & TRN \\
\hline CHEMBL1411739 & 688422 & 4.85 & 5.0302 & TRN \\
\hline
\end{tabular}




\begin{tabular}{|c|c|c|c|c|c|}
\hline & & & & & \\
\hline CHEMBL1565379 & 688422 & 4.8 & 5.0691 & TRN & \\
\hline CHEMBL1510628 & 688422 & 4.45 & 5.3675 & TST & \\
\hline CHEMBL1402855 & 688422 & 4.85 & 4.9721 & TRN & \\
\hline CHEMBL1466380 & 688422 & 4.45 & 5.1099 & TRN & \\
\hline CHEMBL1411321 & 688422 & 5.85 & 5.4014 & TRN & \\
\hline CHEMBL1367635 & 688422 & 8.0506 & 5.7831 & TRN & \\
\hline CHEMBL1544298 & 688422 & 5.0 & 5.2593 & TRN & \\
\hline CHEMBL1528529 & 688422 & 4.45 & 5.3381 & TST & \\
\hline CHEMBL1339505 & 688422 & 4.85 & 5.07100 & 0000000001 & TST \\
\hline CHEMBL1405782 & 688422 & 4.6 & 4.7958 & TRN & \\
\hline CHEMBL1513624 & 688422 & 4.45 & 5.3671 & TST & \\
\hline CHEMBL1379185 & 688422 & 4.7 & 5.1317 & TRN & \\
\hline CHEMBL1357454 & 688422 & 4.8 & 5.1155 & TRN & \\
\hline CHEMBL1376043 & 688422 & 4.65 & 5.2183 & TST & \\
\hline CHEMBL1611557 & 688422 & 4.45 & 5.2434 & TRN & \\
\hline CHEMBL1612273 & 688422 & 4.95 & 5.3661 & TST & \\
\hline CHEMBL1481347 & 688422 & 4.7 & 5.2622 & TRN & \\
\hline CHEMBL 3195793 & 688422 & 4.65 & 5.17899 & 9999999999 & TRN \\
\hline CHEMBL1320771 & 688422 & 4.45 & 5.0928 & TRN & \\
\hline CHEMBL1531383 & 688422 & 4.65 & 4.5245 & TRN & \\
\hline CHEMBL1557437 & 688422 & 5.05 & 5.2968 & TST & \\
\hline CHEMBL1535205 & 688422 & 7.6003 & 5.5114 & TRN & \\
\hline CHEMBL1429837 & 688422 & 5.5 & 5.4423 & TRN & \\
\hline CHEMBL1472375 & 688422 & 4.45 & 4.9619 & TRN & \\
\hline CHEMBL1369050 & 688422 & 4.9 & 5.0252 & TRN & \\
\hline CHEMBL1405930 & 688422 & 4.7 & 5.0564 & TRN & \\
\hline CHEMBL1584637 & 688422 & 5.45 & 5.169 & TRN & \\
\hline CHEMBL1322714 & 688422 & 4.45 & 4.9758 & TRN & \\
\hline CHEMBL1467785 & 688422 & 4.5 & 4.888 & TRN & \\
\hline CHEMBL1986504 & 688422 & 4.8 & 5.3748 & TRN & \\
\hline CHEMBL1307103 & 688422 & 4.5 & 5.3781 & TRN & \\
\hline CHEMBL1313578 & 688422 & 4.6 & 5.6261 & TST & \\
\hline CHEMBL1464951 & 688422 & 4.6 & 4.5781 & TRN & \\
\hline CHEMBL2001936 & 688422 & 4.75 & 5.2819 & TRN & \\
\hline CHEMBL1343705 & 688422 & 4.9 & 5.4228 & TRN & \\
\hline CHEMBL1556273 & 688422 & 4.65 & 5.004 & TST & \\
\hline CHEMBL1474007 & 688422 & 8.1024 & 6.01200 & 00000000005 & TRN \\
\hline CHEMBL1541860 & 688422 & 5.4 & 5.5258 & TRN & \\
\hline CHEMBL536932 & 688422 & 4.65 & 5.25700 & 0000000001 & TRN \\
\hline CHEMBL1418145 & 688422 & 4.45 & 5.4174 & TST & \\
\hline CHEMBL1474557 & 688422 & 4.75 & 5.6068 & TRN & \\
\hline CHEMBL1603422 & 688422 & 4.45 & 5.4922 & TRN & \\
\hline CHEMBL1984604 & 688422 & 4.45 & 4.7949 & TRN & \\
\hline CHEMBL1521433 & 688422 & 4.85 & 5.1667 & TRN & \\
\hline CHEMBL259516 & 688422 & 7.5498 & 5.6515 & TST & \\
\hline CHEMBL1386928 & 688422 & 4.45 & 4.9414 & TRN & \\
\hline CHEMBL3192902 & 688422 & 5.95 & 5.2394 & TRN & \\
\hline CHEMBL1349115 & 688422 & 4.9 & 5.2672 & TRN & \\
\hline
\end{tabular}




\begin{tabular}{|c|c|c|c|c|c|}
\hline \multicolumn{6}{|c|}{ Supplemental Table S2.txt } \\
\hline CHEMBL1522419 & 688422 & 4.8 & 5.3146 & TST & \\
\hline CHEMBL1454186 & 688422 & 8.3468 & 5.191 & TRN & \\
\hline CHEMBL1530397 & 688422 & 4.8 & 5.4182 & TRN & \\
\hline CHEMBL1607253 & 688422 & 5.2 & 4.7375 & TRN & \\
\hline CHEMBL1299744 & 688422 & 4.8 & 5.6309 & TRN & \\
\hline CHEMBL1313600 & 688422 & 4.45 & 4.9875 & TRN & \\
\hline CHEMBL1581378 & 688422 & 5.3 & 5.0783 & TRN & \\
\hline CHEMBL1323805 & 688422 & 5.35 & 5.3266 & TRN & \\
\hline CHEMBL3195749 & 688422 & 4.45 & 5.2819 & TRN & \\
\hline CHEMBL1486253 & 688422 & 5.6 & 5.0182 & TST & \\
\hline CHEMBL304621 & 688422 & 4.85 & 5.1204 & TRN & \\
\hline CHEMBL1302147 & 688422 & 4.75 & 5.1142 & TRN & \\
\hline CHEMBL1502724 & 688422 & 4.45 & 4.9446 & TRN & \\
\hline CHEMBL1605006 & 688422 & 4.8 & 4.8631 & TRN & \\
\hline CHEMBL1586489 & 688422 & 5.55 & 5.0969 & TRN & \\
\hline CHEMBL1392517 & 688422 & 4.85 & 5.5536 & TRN & \\
\hline CHEMBL1309225 & 688422 & 4.7 & 4.8663 & TST & \\
\hline CHEMBL1309529 & 688422 & 4.5 & 5.20200 & 0000000001 & TRN \\
\hline CHEMBL418509 & 688422 & 9.0458 & 5.7313 & TRN & \\
\hline CHEMBL1404519 & 688422 & 6.8499 & 5.4077 & TST & \\
\hline CHEMBL1600915 & 688422 & 4.8 & 5.2487 & TRN & \\
\hline CHEMBL1397996 & 688422 & 6.5501 & 5.483 & TRN & \\
\hline CHEMBL1447724 & 688422 & 4.85 & 4.9548 & TRN & \\
\hline CHEMBL1984772 & 688422 & 4.45 & 5.2816 & TRN & \\
\hline CHEMBL1598265 & 688422 & 4.85 & 5.0989 & TRN & \\
\hline CHEMBL1511037 & 688422 & 4.8 & 4.7058 & TRN & \\
\hline CHEMBL1356667 & 688422 & 4.45 & 4.8827 & TRN & \\
\hline CHEMBL1367848 & 688422 & 4.8 & 5.5111 & TST & \\
\hline CHEMBL1581663 & 688422 & 4.45 & 5.224 & TRN & \\
\hline CHEMBL1553113 & 688422 & 4.95 & 5.3032 & TRN & \\
\hline CHEMBL1505571 & 688422 & 4.5 & 5.0526 & TRN & \\
\hline CHEMBL1416554 & 688422 & 8.4949 & 5.2518 & TRN & \\
\hline CHEMBL1365697 & 688422 & 4.6 & 5.1158 & TRN & \\
\hline CHEMBL1552280 & 688422 & 6.95 & 5.3134 & TRN & \\
\hline CHEMBL1376345 & 688422 & 4.5 & 5.4499 & TRN & \\
\hline CHEMBL1475689 & 688422 & 4.9 & 5.2697 & TRN & \\
\hline CHEMBL1339828 & 688422 & 6.5501 & 5.4118 & TRN & \\
\hline CHEMBL1359749 & 688422 & 6.0 & 5.2699 & TST & \\
\hline CHEMBL1452618 & 688422 & 7.9508 & 5.4878 & TRN & \\
\hline CHEMBL1572877 & 688422 & 4.45 & 4.8104 & TST & \\
\hline CHEMBL1589351 & 688422 & 5.55 & 5.593 & TST & \\
\hline CHEMBL3211865 & 688422 & 4.75 & 5.42399 & 99999999995 & TST \\
\hline CHEMBL1452258 & 688422 & 4.9 & 5.4628 & TRN & \\
\hline CHEMBL1426264 & 688422 & 4.7 & 5.6706 & TST & \\
\hline CHEMBL1417496 & 688422 & 4.45 & 4.8446 & TRN & \\
\hline CHEMBL1410749 & 688422 & 4.8 & 5.2208 & TRN & \\
\hline CHEMBL1387555 & 688422 & 5.0 & 5.4116 & TRN & \\
\hline CHEMBL1417134 & 688422 & 5.5 & 5.5414 & TRN & \\
\hline
\end{tabular}




\begin{tabular}{|c|c|c|c|c|c|}
\hline \multicolumn{6}{|c|}{ Supplemental Table s2.txt } \\
\hline CHEMBL1371305 & 688422 & 4.75 & 5.3748 & TRN & \\
\hline CHEMBL1532466 & 688422 & 4.45 & 5.1242 & TRN & \\
\hline CHEMBL1442928 & 688422 & 4.75 & 5.1604 & TRN & \\
\hline CHEMBL1360351 & 688422 & 6.5501 & 5.4347 & TRN & \\
\hline CHEMBL1373689 & 688422 & 4.7 & 4.9923 & TRN & \\
\hline CHEMBL1444621 & 688422 & 4.9 & 5.5647 & TRN & \\
\hline CHEMBL1563323 & 688422 & 4.5 & 5.2626 & TRN & \\
\hline CHEMBL1450869 & 688422 & 4.65 & 5.0759 & TRN & \\
\hline CHEMBL1539097 & 688422 & 4.7 & 5.0355 & TRN & \\
\hline CHEMBL1500160 & 688422 & 7.5003 & 5.6628 & TST & \\
\hline CHEMBL1540517 & 688422 & 5.95 & 5.23799 & 99999999995 & TRN \\
\hline CHEMBL1988798 & 688422 & 5.25 & 5.0808 & TRN & \\
\hline CHEMBL1565710 & 688422 & 4.5 & 5.4342 & TRN & \\
\hline CHEMBL1502528 & 688422 & 4.9 & 4.7312 & TRN & \\
\hline CHEMBL1339064 & 688422 & 7.6498 & 5.4135 & TRN & \\
\hline CHEMBL1383635 & 688422 & 4.6 & 4.8261 & TRN & \\
\hline CHEMBL1522027 & 688422 & 4.95 & 5.0332 & TRN & \\
\hline CHEMBL3191420 & 688422 & 6.9 & 4.936 & TRN & \\
\hline CHEMBL565856 & 688422 & 5.05 & 4.5547 & TRN & \\
\hline CHEMBL1410520 & 688422 & 4.7 & 5.1429 & TRN & \\
\hline CHEMBL1299717 & 688422 & 4.9 & 5.0869 & TST & \\
\hline CHEMBL1535508 & 688422 & 5.5 & 5.5259 & TST & \\
\hline CHEMBL1570163 & 688422 & 6.1 & 5.3878 & TST & \\
\hline CHEMBL1351058 & 688422 & 4.9 & 4.8937 & TRN & \\
\hline CHEMBL1381463 & 688422 & 5.95 & 5.0977 & TRN & \\
\hline CHEMBL1388501 & 688422 & 4.6 & 5.1182 & TRN & \\
\hline CHEMBL1403181 & 688422 & 4.45 & 5.3744 & TST & \\
\hline CHEMBL3189613 & 688422 & 4.9 & 4.9695 & TRN & \\
\hline CHEMBL1334650 & 688422 & 4.95 & 5.0817 & TRN & \\
\hline CHEMBL1517493 & 688422 & 4.55 & 4.8668 & TRN & \\
\hline CHEMBL1340479 & 688422 & 4.8 & 5.2504 & TST & \\
\hline CHEMBL1541260 & 688422 & 4.8 & 4.7153 & TRN & \\
\hline CHEMBL1403206 & 688422 & 5.75 & 5.5752 & TST & \\
\hline CHEMBL1572542 & 688422 & 4.45 & 6.1388 & TST & \\
\hline CHEMBL1607403 & 688422 & 4.9 & 4.9351 & TRN & \\
\hline CHEMBL1389654 & 688422 & 4.5 & 5.4562 & TRN & \\
\hline CHEMBL1595093 & 688422 & 4.5 & 5.1615 & TRN & \\
\hline CHEMBL1518364 & 688422 & 5.9 & 5.4044 & TST & \\
\hline CHEMBL1338463 & 688422 & 6.45 & 5.4364 & TRN & \\
\hline CHEMBL1415308 & 688422 & 4.9 & 4.8851 & TRN & \\
\hline CHEMBL1597191 & 688422 & 4.95 & 5.0697 & TRN & \\
\hline CHEMBL1391453 & 688422 & 4.95 & 5.1945 & TRN & \\
\hline CHEMBL1386133 & 688422 & 4.9 & 5.5032 & TRN & \\
\hline CHEMBL1979937 & 688422 & 4.9 & 4.9633 & TRN & \\
\hline CHEMBL1329048 & 688422 & 5.25 & 4.5244 & TRN & \\
\hline CHEMBL1330342 & 688422 & 4.85 & 5.1379 & TRN & \\
\hline CHEMBL1299274 & 688422 & 4.75 & 4.96399 & 99999999995 & TRN \\
\hline CHEMBL1564300 & 688422 & 7.4498 & 5.1761 & TRN & \\
\hline
\end{tabular}




\begin{tabular}{|c|c|c|c|c|c|}
\hline \multicolumn{6}{|c|}{ Supplemental Table S2.txt } \\
\hline CHEMBL3195616 & 688422 & 4.95 & 4.9078 & TRN & \\
\hline CHEMBL1608407 & 688422 & 4.8 & 5.3492 & TRN & \\
\hline CHEMBL1332164 & 688422 & 8.0 & 5.586 & TRN & \\
\hline CHEMBL1320170 & 688422 & 4.95 & 4.9665 & TRN & \\
\hline CHEMBL1472945 & 688422 & 8.0506 & 5.0181 & TRN & \\
\hline CHEMBL1605237 & 688422 & 4.7 & 4.9584 & TRN & \\
\hline CHEMBL1979536 & 688422 & 5.4 & 5.2492 & TRN & \\
\hline CHEMBL1496126 & 688422 & 4.95 & 5.1091 & TRN & \\
\hline CHEMBL1496215 & 688422 & 4.45 & 5.2423 & TRN & \\
\hline CHEMBL1343883 & 688422 & 5.55 & 4.8503 & TRN & \\
\hline CHEMBL 3212713 & 688422 & 4.45 & 5.3116 & TRN & \\
\hline CHEMBL1435347 & 688422 & 7.6498 & 5.24200 & 0000000001 & TRN \\
\hline CHEMBL3209174 & 688422 & 8.5528 & 5.1475 & TST & \\
\hline CHEMBL1569370 & 688422 & 4.5 & 5.0525 & TRN & \\
\hline CHEMBL1426457 & 688422 & 5.25 & 5.7134 & TRN & \\
\hline CHEMBL1603225 & 688422 & 4.8 & 5.3222 & TST & \\
\hline CHEMBL1446716 & 688422 & 9.3979 & 4.9885 & TRN & \\
\hline CHEMBL1563157 & 688422 & 4.5 & 5.3433 & TRN & \\
\hline CHEMBL1417934 & 688422 & 8.1024 & 5.444 & TRN & \\
\hline CHEMBL1391470 & 688422 & 8.3468 & 5.3669 & TRN & \\
\hline CHEMBL1415579 & 688422 & 4.7 & 5.3141 & TRN & \\
\hline CHEMBL1589457 & 688422 & 4.8 & 4.7965 & TRN & \\
\hline CHEMBL1368134 & 688422 & 6.4 & 5.6027 & TRN & \\
\hline CHEMBL1446267 & 688422 & 4.45 & 4.9354 & TRN & \\
\hline CHEMBL1506740 & 688422 & 5.0 & 5.1113 & TRN & \\
\hline CHEMBL1308183 & 688422 & 4.9 & 5.2475 & TST & \\
\hline CHEMBL1351020 & 688422 & 4.85 & 4.9338 & TRN & \\
\hline CHEMBL1610143 & 688422 & 5.2 & 5.3362 & TST & \\
\hline CHEMBL1612613 & 688422 & 6.3 & 5.6551 & TRN & \\
\hline CHEMBL1465966 & 688422 & 4.7 & 5.7915 & TST & \\
\hline CHEMBL1583665 & 688422 & 4.8 & 4.9518 & TRN & \\
\hline CHEMBL1412127 & 688422 & 6.6499 & 5.2223 & TRN & \\
\hline CHEMBL1548234 & 688422 & 5.5 & 4.7518 & TRN & \\
\hline CHEMBL1380091 & 688422 & 4.5 & 4.8743 & TRN & \\
\hline CHEMBL1580969 & 688422 & 4.5 & 4.9007 & TST & \\
\hline CHEMBL1334697 & 688422 & 4.45 & 5.3741 & TRN & \\
\hline CHEMBL1342583 & 688422 & 4.45 & 5.3993 & TST & \\
\hline CHEMBL1453488 & 688422 & 8.3979 & 5.4496 & TRN & \\
\hline CHEMBL1607840 & 688422 & 4.45 & 5.1525 & TRN & \\
\hline CHEMBL1558488 & 688422 & 4.9 & 5.3332 & TRN & \\
\hline CHEMBL1426825 & 688422 & 4.45 & 5.4576 & TRN & \\
\hline CHEMBL1587496 & 688422 & 4.9 & 4.7783 & TRN & \\
\hline CHEMBL1368515 & 688422 & 4.8 & 5.4125 & TST & \\
\hline CHEMBL1233274 & 688422 & 5.45 & 5.5977 & TRN & \\
\hline CHEMBL1401938 & 688422 & 4.5 & 5.2472 & TRN & \\
\hline CHEMBL 2005721 & 688422 & 5.5 & 4.868 & TST & \\
\hline CHEMBL1598561 & 688422 & 4.9 & 4.6 & TST & \\
\hline CHEMBL1556566 & 688422 & 4.45 & 5.6952 & TRN & \\
\hline
\end{tabular}




\begin{tabular}{|c|c|c|c|c|}
\hline \multicolumn{5}{|c|}{ Supplemental Table S2.txt } \\
\hline CHEMBL1306363 & 688422 & 8.0 & 5.5657 & TRN \\
\hline CHEMBL1377757 & 688422 & 4.85 & 5.2115 & TRN \\
\hline CHEMBL1319984 & 688422 & 4.45 & 5.0249 & TRN \\
\hline CHEMBL1442864 & 688422 & 4.95 & 5.432 & TRN \\
\hline CHEMBL1563587 & 688422 & 4.85 & 5.3574 & TRN \\
\hline CHEMBL 3190974 & 688422 & 4.5 & 4.8468 & TST \\
\hline CHEMBL1306384 & 688422 & 5.3 & 5.1006 & TRN \\
\hline CHEMBL1462379 & 688422 & 4.5 & 5.0855 & TRN \\
\hline CHEMBL1319958 & 688422 & 4.85 & 5.2786 & TRN \\
\hline CHEMBL3207353 & 688422 & 4.7 & 5.4576 & TRN \\
\hline CHEMBL1397566 & 688422 & 4.65 & 5.5019 & TST \\
\hline CHEMBL1510432 & 688422 & 5.65 & 5.3521 & TRN \\
\hline CHEMBL1390881 & 688422 & 4.75 & 5.5902 & TST \\
\hline CHEMBL1577186 & 688422 & 4.65 & 5.1759 & TRN \\
\hline CHEMBL1537242 & 688422 & 5.25 & 5.6221 & TST \\
\hline CHEMBL1380530 & 688422 & 4.75 & 5.0131 & TRN \\
\hline CHEMBL1502448 & 688422 & 4.55 & 4.9518 & TRN \\
\hline CHEMBL1607521 & 688422 & 4.5 & 5.1375 & TST \\
\hline CHEMBL1550963 & 688422 & 4.8 & 5.3232 & TRN \\
\hline CHEMBL 2007390 & 688422 & 4.85 & 4.9739 & TST \\
\hline CHEMBL1425129 & 688422 & 4.85 & 5.2214 & TST \\
\hline CHEMBL1608465 & 688422 & 4.45 & 4.7588 & TRN \\
\hline CHEMBL1424797 & 688422 & 4.65 & 5.3555 & TST \\
\hline CHEMBL1483508 & 688422 & 4.7 & 5.2272 & TRN \\
\hline CHEMBL1413078 & 688422 & 4.8 & 5.5732 & TRN \\
\hline CHEMBL1554717 & 688422 & 4.95 & 4.9138 & TRN \\
\hline CHEMBL1535617 & 688422 & 4.45 & 5.3429 & TST \\
\hline CHEMBL1407685 & 688422 & 4.9 & 5.2198 & TRN \\
\hline CHEMBL1404997 & 688422 & 6.35 & 5.2509 & TRN \\
\hline CHEMBL1569676 & 688422 & 5.9 & 5.7781 & TST \\
\hline CHEMBL1424479 & 688422 & 5.5 & 4.5962 & TRN \\
\hline CHEMBL 3191137 & 688422 & 4.8 & 4.8767 & TRN \\
\hline CHEMBL1361962 & 688422 & 4.5 & 5.2048 & TRN \\
\hline CHEMBL1435777 & 688422 & 4.9 & 4.5842 & TRN \\
\hline CHEMBL1463892 & 688422 & 7.0501 & 5.1254 & TST \\
\hline CHEMBL1332242 & 688422 & 5.25 & 5.0001 & TRN \\
\hline CHEMBL1405586 & 688422 & 5.9 & 5.6141 & TRN \\
\hline CHEMBL1415039 & 688422 & 5.2 & 5.5117 & TRN \\
\hline CHEMBL1377486 & 688422 & 5.55 & 5.2444 & TST \\
\hline CHEMBL1423533 & 688422 & 4.85 & 5.5633 & TST \\
\hline CHEMBL1604018 & 688422 & 5.8 & 5.9149 & TRN \\
\hline CHEMBL1467250 & 688422 & 4.45 & 5.3167 & TRN \\
\hline CHEMBL1426706 & 688422 & 6.4 & 5.3286 & TRN \\
\hline CHEMBL1406961 & 688422 & 4.9 & 4.8526 & TRN \\
\hline CHEMBL1335518 & 688422 & 4.5 & 5.0769 & TRN \\
\hline CHEMBL1542305 & 688422 & 5.45 & 5.32600 & 00000000005 \\
\hline CHEMBL1348535 & 688422 & 6.8499 & 5.3159 & TRN \\
\hline CHEMBL1455262 & 688422 & 6.1 & 5.3828 & TRN \\
\hline
\end{tabular}




\begin{tabular}{|c|c|c|c|c|c|}
\hline \multicolumn{6}{|c|}{ Supplemental Table S2.txt } \\
\hline CHEMBL1417124 & 688422 & 4.95 & 5.6704 & TRN & \\
\hline CHEMBL1375549 & 688422 & 4.45 & 5.5354 & TST & \\
\hline CHEMBL1399287 & 688422 & 4.95 & 4.795 & TRN & \\
\hline CHEMBL1342840 & 688422 & 4.9 & 5.0622 & TRN & \\
\hline CHEMBL1336991 & 688422 & 4.45 & 5.2403 & TST & \\
\hline CHEMBL1598769 & 688422 & 4.5 & 5.6623 & TRN & \\
\hline CHEMBL1349000 & 688422 & 4.45 & 4.91 & TST & \\
\hline CHEMBL1488379 & 688422 & 5.8 & 5.7479 & TST & \\
\hline CHEMBL1999900 & 688422 & 4.95 & 5.3903 & TST & \\
\hline CHEMBL1521049 & 688422 & 8.4949 & 4.9695 & TST & \\
\hline CHEMBL1545395 & 688422 & 4.9 & 5.0038 & TRN & \\
\hline CHEMBL410484 & 688422 & 4.9 & 5.3027 & TRN & \\
\hline CHEMBL1611811 & 688422 & 4.45 & 5.0888 & TRN & \\
\hline CHEMBL1545690 & 688422 & 4.45 & 5.0158 & TRN & \\
\hline CHEMBL1459129 & 688422 & 4.9 & 4.8793 & TRN & \\
\hline CHEMBL1581176 & 688422 & 4.75 & 5.3026 & TRN & \\
\hline CHEMBL1423773 & 688422 & 4.9 & 5.0076 & TRN & \\
\hline CHEMBL1610358 & 688422 & 6.4 & 5.76 & TRN & \\
\hline CHEMBL1536262 & 688422 & 5.65 & 4.9139 & TRN & \\
\hline CHEMBL88621 & 688422 & 8.2007 & 6.3174 & TRN & \\
\hline CHEMBL1462469 & 688422 & 5.0 & 5.0244 & TRN & \\
\hline CHEMBL1411614 & 688422 & 5.0 & 5.1513 & TRN & \\
\hline CHEMBL1351669 & 688422 & 5.0 & 5.1422 & TRN & \\
\hline CHEMBL1547971 & 688422 & 4.45 & 4.8768 & TRN & \\
\hline CHEMBL1479953 & 688422 & 4.9 & 5.1986 & TRN & \\
\hline CHEMBL1422445 & 688422 & 5.55 & 5.3492 & TRN & \\
\hline CHEMBL1307764 & 688422 & 5.0 & 5.0904 & TRN & \\
\hline CHEMBL1339411 & 688422 & 4.9 & 5.5622 & TRN & \\
\hline CHEMBL1343268 & 688422 & 5.35 & 5.2758 & TRN & \\
\hline CHEMBL1329513 & 688422 & 5.1 & 5.1117 & TRN & \\
\hline CHEMBL1332731 & 688422 & 4.6 & 5.3543 & TRN & \\
\hline CHEMBL1577275 & 688422 & 4.9 & 4.8087 & TRN & \\
\hline CHEMBL1388186 & 688422 & 5.25 & 5.3841 & TRN & \\
\hline CHEMBL1535951 & 688422 & 4.65 & 5.3651 & TRN & \\
\hline CHEMBL1483333 & 688422 & 4.95 & 4.8284 & TRN & \\
\hline CHEMBL1602636 & 688422 & 5.7 & 5.5064 & TRN & \\
\hline CHEMBL1547736 & 688422 & 4.6 & 5.11100 & 0000000001 & TRN \\
\hline CHEMBL1370234 & 688422 & 5.25 & 5.3561 & TRN & \\
\hline CHEMBL1533840 & 688422 & 4.5 & 5.1325 & TRN & \\
\hline CHEMBL1523624 & 688422 & 5.65 & 5.4355 & TST & \\
\hline CHEMBL 3195004 & 688422 & 7.0 & 5.2564 & TRN & \\
\hline CHEMBL1365834 & 688422 & 6.4 & 5.4562 & TRN & \\
\hline CHEMBL1436762 & 688422 & 4.5 & 5.5057 & TRN & \\
\hline CHEMBL1330095 & 688422 & 4.75 & 4.9545 & TRN & \\
\hline CHEMBL1407260 & 688422 & 4.45 & 5.0251 & TST & \\
\hline CHEMBL1440237 & 688422 & 4.95 & 4.8684 & TRN & \\
\hline CHEMBL1530098 & 688422 & 7.8013 & 4.9928 & TRN & \\
\hline CHEMBL1407387 & 688422 & 5.55 & 5.325 & TST & \\
\hline
\end{tabular}




\begin{tabular}{|c|c|c|c|c|c|}
\hline \multicolumn{6}{|c|}{ Supplemental Table S2.txt } \\
\hline CHEMBL1343906 & 688422 & 4.45 & 5.2039 & TST & \\
\hline CHEMBL1367247 & 688422 & 4.45 & 5.126 & TRN & \\
\hline CHEMBL1457638 & 688422 & 5.05 & 5.3668 & TST & \\
\hline CHEMBL1484878 & 688422 & 4.9 & 5.6362 & TST & \\
\hline CHEMBL1418430 & 688422 & 4.45 & 5.1211 & TRN & \\
\hline CHEMBL1561747 & 688422 & 5.0 & 5.0262 & TRN & \\
\hline CHEMBL1394450 & 688422 & 6.45 & 5.0829 & TRN & \\
\hline CHEMBL1418056 & 688422 & 4.45 & 5.3221 & TRN & \\
\hline CHEMBL1582080 & 688422 & 4.45 & 5.2408 & TST & \\
\hline CHEMBL1352586 & 688422 & 4.45 & 5.0133 & TRN & \\
\hline CHEMBL1606839 & 688422 & 5.0 & 5.0226 & TRN & \\
\hline CHEMBL1599760 & 688422 & 8.1024 & 5.859 & TRN & \\
\hline CHEMBL1384611 & 688422 & 7.6003 & 5.4863 & TRN & \\
\hline CHEMBL1302420 & 688422 & 4.65 & 5.1668 & TRN & \\
\hline CHEMBL1311768 & 688422 & 4.7 & 5.2231 & TRN & \\
\hline CHEMBL1399623 & 688422 & 4.45 & 5.1531 & TST & \\
\hline CHEMBL1564471 & 688422 & 4.9 & 5.2182 & TRN & \\
\hline CHEMBL 2007414 & 688422 & 4.75 & 4.9782 & TST & \\
\hline CHEMBL 374632 & 688422 & 5.95 & 5.9183 & TRN & \\
\hline CHEMBL1300979 & 688422 & 5.75 & 6.0916 & TST & \\
\hline CHEMBL3199258 & 688422 & 4.65 & 5.4182 & TRN & \\
\hline CHEMBL1497874 & 688422 & 4.85 & 5.0274 & TRN & \\
\hline CHEMBL1573907 & 688422 & 5.25 & 5.5102 & TST & \\
\hline CHEMBL1486366 & 688422 & 4.85 & 4.9891 & TRN & \\
\hline CHEMBL1428278 & 688422 & 4.65 & 5.1871 & TRN & \\
\hline CHEMBL1556148 & 688422 & 5.0 & 4.8203 & TRN & \\
\hline CHEMBL1583236 & 688422 & 5.05 & 4.8882 & TRN & \\
\hline CHEMBL1389443 & 688422 & 4.95 & 5.0462 & TRN & \\
\hline CHEMBL1345350 & 688422 & 5.25 & 4.9051 & TRN & \\
\hline CHEMBL1574680 & 688422 & 4.6 & 5.2335 & TRN & \\
\hline CHEMBL1498052 & 688422 & 4.85 & 4.9863 & TRN & \\
\hline CHEMBL1576081 & 688422 & 8.301 & 6.0253 & TST & \\
\hline CHEMBL1326401 & 688422 & 4.95 & 5.4122 & TRN & \\
\hline CHEMBL1543669 & 688422 & 4.9 & 5.10800 & 00000000005 & TRN \\
\hline CHEMBL1458697 & 688422 & 4.5 & 4.9929 & TST & \\
\hline CHEMBL1426285 & 688422 & 4.45 & 5.3036 & TRN & \\
\hline CHEMBL1603325 & 688422 & 4.75 & 5.4929 & TRN & \\
\hline CHEMBL1419696 & 688422 & 4.45 & 5.1813 & TST & \\
\hline CHEMBL1320353 & 688422 & 5.55 & 5.3909 & TRN & \\
\hline CHEMBL1564066 & 688422 & 4.6 & 4.5208 & TRN & \\
\hline CHEMBL1586656 & 688422 & 4.5 & 5.3539 & TRN & \\
\hline CHEMBL1309557 & 688422 & 4.45 & 5.0616 & TST & \\
\hline CHEMBL1489828 & 688422 & 6.35 & 5.7462 & TRN & \\
\hline CHEMBL586061 & 688422 & 5.0 & 5.0353 & TRN & \\
\hline CHEMBL1445617 & 688422 & 4.5 & 4.8444 & TST & \\
\hline CHEMBL1459532 & 688422 & 4.9 & 5.1348 & TRN & \\
\hline CHEMBL1609564 & 688422 & 4.6 & 5.4953 & TST & \\
\hline CHEMBL1477538 & 688422 & 4.45 & 5.1806 & TST & \\
\hline
\end{tabular}




\begin{tabular}{|c|c|c|c|c|}
\hline \multicolumn{5}{|c|}{ Supplemental Table S2.txt } \\
\hline CHEMBL1455440 & 688422 & 4.9 & 5.938 & TST \\
\hline CHEMBL1438082 & 688422 & 4.45 & 5.3392 & TST \\
\hline CHEMBL1535149 & 688422 & 5.95 & 5.78 & TRN \\
\hline CHEMBL1371982 & 688422 & 4.45 & 5.8679 & TRN \\
\hline CHEMBL1338368 & 688422 & 6.1 & 5.5457 & TRN \\
\hline CHEMBL1575315 & 688422 & 4.85 & 4.9627 & TRN \\
\hline CHEMBL1575447 & 688422 & 4.5 & 4.993 & TRN \\
\hline CHEMBL1601908 & 688422 & 4.7 & 5.0913 & TRN \\
\hline CHEMBL1447963 & 688422 & 5.15 & 4.8904 & TRN \\
\hline CHEMBL1349340 & 688422 & 5.0 & 5.0825 & TRN \\
\hline CHEMBL1557364 & 688422 & 4.5 & 5.008 & TRN \\
\hline CHEMBL1444735 & 688422 & 4.8 & 4.7832 & TRN \\
\hline CHEMBL3198840 & 688422 & 6.25 & 5.2095 & TRN \\
\hline CHEMBL 2002849 & 688422 & 5.25 & 4.9813 & TST \\
\hline CHEMBL1500138 & 688422 & 5.4 & 5.0121 & TRN \\
\hline CHEMBL1462721 & 688422 & 4.5 & 5.4334 & TRN \\
\hline CHEMBL1601077 & 688422 & 4.7 & 5.0681 & TRN \\
\hline CHEMBL1305716 & 688422 & 4.75 & 5.2948 & TRN \\
\hline CHEMBL1466995 & 688422 & 5.7 & 5.6839 & TRN \\
\hline CHEMBL1365493 & 688422 & 8.4949 & 5.0407 & TRN \\
\hline CHEMBL1302093 & 688422 & 4.5 & 5.1838 & TRN \\
\hline CHEMBL1336028 & 688422 & 5.45 & 5.4777 & TRN \\
\hline CHEMBL1409739 & 688422 & 4.45 & 5.3284 & TRN \\
\hline CHEMBL1557459 & 688422 & 6.45 & 5.1977 & TRN \\
\hline CHEMBL1425952 & 688422 & 4.9 & 4.8537 & TST \\
\hline CHEMBL1431025 & 688422 & 6.5 & 5.5776 & TST \\
\hline CHEMBL1446306 & 688422 & 6.05 & 5.3815 & TRN \\
\hline CHEMBL1374664 & 688422 & 4.45 & 5.1379 & TRN \\
\hline CHEMBL1508956 & 688422 & 4.9 & 5.4119 & TRN \\
\hline CHEMBL1400090 & 688422 & 5.45 & 5.631 & TRN \\
\hline CHEMBL1515918 & 688422 & 4.9 & 4.9451 & TRN \\
\hline CHEMBL1588042 & 688422 & 4.7 & 4.9556 & TRN \\
\hline CHEMBL1337033 & 688422 & 4.65 & 5.0789 & TST \\
\hline CHEMBL1532790 & 688422 & 5.55 & 5.79 & TRN \\
\hline CHEMBL1566050 & 688422 & 6.3 & 5.0722 & TRN \\
\hline CHEMBL1599944 & 688422 & 5.6 & 5.6282 & TST \\
\hline CHEMBL1602963 & 688422 & 4.8 & 5.0212 & TRN \\
\hline CHEMBL3193851 & 688422 & 4.45 & 5.2771 & TRN \\
\hline CHEMBL1596118 & 688422 & 4.75 & 5.2198 & TRN \\
\hline CHEMBL1321086 & 688422 & 4.45 & 4.7469 & TRN \\
\hline CHEMBL1379213 & 688422 & 5.75 & 5.2245 & TRN \\
\hline CHEMBL1320151 & 688422 & 7.6498 & 4.79 & TST \\
\hline CHEMBL1388175 & 688422 & 5.25 & 4.8642 & TRN \\
\hline CHEMBL1309312 & 688422 & 4.6 & 4.8524 & TRN \\
\hline CHEMBL1255941 & 688422 & 8.6576 & 5.5459 & TST \\
\hline CHEMBL1424856 & 688422 & 4.45 & 4.9761 & TRN \\
\hline CHEMBL1311406 & 688422 & 4.45 & 5.5625 & TST \\
\hline CHEMBL1572707 & 688422 & 4.45 & 5.1453 & TRN \\
\hline
\end{tabular}




\begin{tabular}{|c|c|c|c|c|}
\hline \multicolumn{5}{|c|}{ Supplemental Tab. } \\
\hline CHEMBL1339398 & 688422 & 5.7 & 5.3357 & TST \\
\hline CHEMBL1521691 & 688422 & 4.45 & 4.9074 & TRN \\
\hline CHEMBL1461938 & 688422 & 5.7 & 5.3601 & TRN \\
\hline CHEMBL1482407 & 688422 & 7.15 & 5.6287 & TRN \\
\hline CHEMBL1578194 & 688422 & 5.35 & 5.6561 & TRN \\
\hline CHEMBL1363760 & 688422 & 7.4001 & 5.5148 & TRN \\
\hline CHEMBL1446991 & 688422 & 4.95 & 5.1707 & TRN \\
\hline CHEMBL1587335 & 688422 & 6.8 & 5.4217 & TST \\
\hline CHEMBL1343882 & 688422 & 4.65 & 5.2855 & TRN \\
\hline CHEMBL1974713 & 688422 & 5.55 & 5.1077 & TRN \\
\hline CHEMBL1327547 & 688422 & 4.45 & 5.0419 & TST \\
\hline CHEMBL1393129 & 688422 & 4.8 & 5.5365 & TST \\
\hline CHEMBL1591510 & 688422 & 8.301 & 5.0003 & TRN \\
\hline CHEMBL1514545 & 688422 & 4.45 & 5.1825 & TRN \\
\hline CHEMBL1472667 & 688422 & 4.45 & 5.3884 & TRN \\
\hline CHEMBL3192127 & 688422 & 6.9 & 5.4761 & TST \\
\hline CHEMBL3207367 & 688422 & 4.6 & 5.1009 & TST \\
\hline CHEMBL1378875 & 688422 & 4.45 & 5.4878 & TST \\
\hline CHEMBL1576625 & 688422 & 5.15 & 5.4179 & TST \\
\hline CHEMBL1541684 & 688422 & 4.8 & 5.0839 & TRN \\
\hline CHEMBL1359978 & 688422 & 5.0 & 5.3356 & TRN \\
\hline CHEMBL1585725 & 688422 & 4.95 & 5.4134 & TST \\
\hline CHEMBL1603307 & 688422 & 6.95 & 5.3199 & TRN \\
\hline CHEMBL1608031 & 688422 & 6.45 & 5.849 & TRN \\
\hline CHEMBL1386564 & 688422 & 4.5 & 4.7159 & TRN \\
\hline CHEMBL3190961 & 688422 & 5.05 & 5.4516 & TRN \\
\hline CHEMBL1446499 & 688422 & 4.45 & 5.479 & TST \\
\hline CHEMBL1510974 & 688422 & 4.7 & 4.9111 & TST \\
\hline CHEMBL1546853 & 688422 & 4.5 & 4.2856 & TRN \\
\hline CHEMBL1474488 & 688422 & 8.4949 & 5.4262 & TRN \\
\hline CHEMBL3209208 & 688422 & 4.5 & 5.5644 & TRN \\
\hline CHEMBL1555574 & 688422 & 4.9 & 4.8987 & TRN \\
\hline CHEMBL 3208141 & 688422 & 4.95 & 5.0584 & TRN \\
\hline CHEMBL1613041 & 688422 & 5.1 & 5.2845 & TRN \\
\hline CHEMBL1613661 & 688422 & 5.35 & 4.5987 & TRN \\
\hline CHEMBL1363803 & 688422 & 5.25 & 5.2251 & TRN \\
\hline CHEMBL1473933 & 688422 & 5.5 & 5.974 & TST \\
\hline CHEMBL1562169 & 688422 & 4.75 & 5.3041 & TRN \\
\hline CHEMBL1598286 & 688422 & 4.9 & 5.2223 & TST \\
\hline CHEMBL1299619 & 688422 & 8.4559 & 5.118 & TRN \\
\hline CHEMBL1337337 & 688422 & 4.45 & 4.8947 & TRN \\
\hline CHEMBL1526107 & 688422 & 6.3 & 5.232 & TRN \\
\hline CHEMBL1508833 & 688422 & 5.55 & 5.3353 & TST \\
\hline CHEMBL542493 & 688422 & 4.8 & 5.0935 & TRN \\
\hline CHEMBL1532089 & 688422 & 6.6499 & 4.8981 & TRN \\
\hline CHEMBL1585839 & 688422 & 4.8 & 4.99 & TRN \\
\hline CHEMBL1431641 & 688422 & 4.45 & 5.5082 & TST \\
\hline CHEMBL1408629 & 688422 & 5.95 & 5.077 & TRN \\
\hline
\end{tabular}




\begin{tabular}{|c|c|c|c|c|c|}
\hline \multicolumn{6}{|c|}{ Supplemental Table s2.txt } \\
\hline CHEMBL 3197388 & 688422 & 4.95 & 5.7503 & TRN & \\
\hline CHEMBL1487004 & 688422 & 4.7 & 5.0177 & TRN & \\
\hline CHEMBL1310261 & 688422 & 4.8 & 5.3281 & TRN & \\
\hline CHEMBL1468908 & 688422 & 4.45 & 5.2506 & TST & \\
\hline CHEMBL1479574 & 688422 & 4.85 & 4.6898 & TRN & \\
\hline CHEMBL1565158 & 688422 & 5.05 & 4.9504 & TRN & \\
\hline CHEMBL1347962 & 688422 & 4.8 & 4.7458 & TRN & \\
\hline CHEMBL1392953 & 688422 & 4.6 & 5.2641 & TRN & \\
\hline CHEMBL1396790 & 688422 & 4.45 & 5.6818 & TRN & \\
\hline CHEMBL1427666 & 688422 & 6.5 & 5.3193 & TRN & \\
\hline CHEMBL1439696 & 688422 & 5.1 & 5.5232 & TRN & \\
\hline CHEMBL1452037 & 688422 & 4.85 & 5.6013 & TRN & \\
\hline CHEMBL1351197 & 688422 & 4.5 & 5.4787 & TST & \\
\hline CHEMBL1329265 & 688422 & 5.95 & 5.0157 & TRN & \\
\hline CHEMBL1467959 & 688422 & 4.95 & 5.8537 & TRN & \\
\hline CHEMBL1327088 & 688422 & 4.45 & 4.9377 & TRN & \\
\hline CHEMBL1386901 & 688422 & 4.85 & 5.1354 & TRN & \\
\hline CHEMBL1329175 & 688422 & 4.9 & 5.805 & TST & \\
\hline CHEMBL1580672 & 688422 & 4.8 & 5.1562 & TRN & \\
\hline CHEMBL1377785 & 688422 & 4.9 & 5.2625 & TRN & \\
\hline CHEMBL1410492 & 688422 & 4.85 & 5.3683 & TRN & \\
\hline CHEMBL1391191 & 688422 & 4.45 & 5.0306 & TST & \\
\hline CHEMBL1535435 & 688422 & 4.9 & 6.0151 & TRN & \\
\hline CHEMBL1510649 & 688422 & 4.95 & 4.7973 & TRN & \\
\hline CHEMBL1452157 & 688422 & 5.5 & 5.0828 & TRN & \\
\hline CHEMBL1403690 & 688422 & 4.95 & 5.007 & TST & \\
\hline CHEMBL1522522 & 688422 & 4.45 & 5.1262 & TRN & \\
\hline CHEMBL1578687 & 688422 & 7.8508 & 5.254 & TRN & \\
\hline CHEMBL3197921 & 688422 & 4.45 & 4.707 & TRN & \\
\hline CHEMBL3194100 & 688422 & 4.8 & 4.9082 & TST & \\
\hline CHEMBL1433063 & 688422 & 4.95 & 5.1396 & TST & \\
\hline CHEMBL3210873 & 688422 & 4.95 & 4.9152 & TRN & \\
\hline CHEMBL1337473 & 688422 & 4.75 & 5.0619 & TRN & \\
\hline CHEMBL1553440 & 688422 & 4.45 & 5.3666 & TRN & \\
\hline CHEMBL1511791 & 688422 & 5.55 & 5.4417 & TRN & \\
\hline CHEMBL1371443 & 688422 & 4.5 & 5.9665 & TST & \\
\hline CHEMBL1450318 & 688422 & 4.8 & 4.7814 & TRN & \\
\hline CHEMBL1610831 & 688422 & 4.45 & 5.0982 & TST & \\
\hline CHEMBL1312419 & 688422 & 8.3468 & 5.3098 & TST & \\
\hline CHEMBL1480489 & 688422 & 7.6003 & 5.6142 & TRN & \\
\hline CHEMBL1543541 & 688422 & 4.85 & 5.0933 & TRN & \\
\hline CHEMBL3212555 & 688422 & 6.9 & 5.3118 & TRN & \\
\hline CHEMBL1407220 & 688422 & 4.45 & 4.8909 & TST & \\
\hline CHEMBL1314042 & 688422 & 4.9 & 4.8722 & TRN & \\
\hline CHEMBL1548032 & 688422 & 5.25 & 5.16299 & 9999999999 & TST \\
\hline CHEMBL164405 & 688422 & 6.45 & 5.6972 & TRN & \\
\hline CHEMBL1382624 & 688422 & 4.9 & 5.1894 & TRN & \\
\hline CHEMBL1371222 & 688422 & 4.65 & 5.26200 & 00000000005 & TRN \\
\hline & & & & 9635 & \\
\hline
\end{tabular}




\begin{tabular}{|c|c|c|c|c|c|}
\hline \multicolumn{6}{|c|}{ Supplemental Table S2.txt } \\
\hline CHEMBL3198589 & 688422 & 5.05 & 5.3041 & TST & \\
\hline CHEMBL1459114 & 688422 & 6.35 & 5.3579 & TRN & \\
\hline CHEMBL1571875 & 688422 & 4.8 & 4.9985 & TRN & \\
\hline CHEMBL 3197474 & 688422 & 5.7 & 5.2652 & TST & \\
\hline CHEMBL1379716 & 688422 & 5.2 & 5.8662 & TST & \\
\hline CHEMBL1554664 & 688422 & 4.45 & 4.5565 & TRN & \\
\hline CHEMBL1335734 & 688422 & 4.6 & 4.905 & TST & \\
\hline CHEMBL1486096 & 688422 & 4.85 & 5.5217 & TRN & \\
\hline CHEMBL1494809 & 688422 & 4.45 & 5.9825 & TST & \\
\hline CHEMBL1403640 & 688422 & 8.0 & 5.9888 & TRN & \\
\hline CHEMBL1493258 & 688422 & 4.45 & 5.2374 & TST & \\
\hline CHEMBL 2006628 & 688422 & 4.45 & 5.5262 & TRN & \\
\hline CHEMBL 3189165 & 688422 & 4.85 & 5.22 & TST & \\
\hline CHEMBL507264 & 688422 & 4.8 & 5.1141 & TRN & \\
\hline CHEMBL1428824 & 688422 & 6.95 & 5.4384 & TRN & \\
\hline CHEMBL1572901 & 688422 & 5.1 & 5.3069 & TRN & \\
\hline CHEMBL1359276 & 688422 & 4.65 & 5.1709 & TRN & \\
\hline CHEMBL1345333 & 688422 & 5.25 & 5.0977 & TST & \\
\hline CHEMBL1322690 & 688422 & 4.45 & 4.9089 & TRN & \\
\hline CHEMBL1516163 & 688422 & 4.9 & 4.8458 & TRN & \\
\hline CHEMBL3199452 & 688422 & 4.55 & 5.3026 & TRN & \\
\hline CHEMBL1309127 & 688422 & 4.85 & 5.2853 & TRN & \\
\hline CHEMBL1310797 & 688422 & 4.65 & 5.1765 & TST & \\
\hline CHEMBL1563947 & 688422 & 4.85 & 4.9677 & TRN & \\
\hline CHEMBL1599946 & 688422 & 5.95 & 5.2091 & TRN & \\
\hline CHEMBL1340168 & 688422 & 5.35 & 5.5202 & TST & \\
\hline CHEMBL1492230 & 688422 & 7.8508 & 5.8016 & TRN & \\
\hline CHEMBL1362838 & 688422 & 5.35 & 5.21299 & & TRN \\
\hline CHEMBL1485097 & 688422 & 6.7501 & 5.2028 & TRN & \\
\hline CHEMBL1466542 & 688422 & 5.2 & 5.6082 & TRN & \\
\hline CHEMBL1582561 & 688422 & 4.65 & 5.2246 & TRN & \\
\hline CHEMBL1605327 & 688422 & 8.2007 & 5.2848 & TRN & \\
\hline CHEMBL3198441 & 688422 & 6.8 & 5.2055 & TRN & \\
\hline CHEMBL1456699 & 688422 & 5.55 & 5.1844 & TRN & \\
\hline CHEMBL1459023 & 688422 & 4.95 & 5.2294 & TRN & \\
\hline CHEMBL3194157 & 688422 & 5.45 & 5.3853 & TST & \\
\hline CHEMBL1592175 & 688422 & 7.2503 & 5.4476 & TRN & \\
\hline CHEMBL1488010 & 688422 & 4.45 & 5.7037 & TST & \\
\hline CHEMBL1521875 & 688422 & 7.6003 & 5.1132 & TRN & \\
\hline CHEMBL3199539 & 688422 & 4.6 & 5.079 & TRN & \\
\hline CHEMBL1355201 & 688422 & 4.95 & 4.8472 & TRN & \\
\hline CHEMBL1549742 & 688422 & 4.6 & 5.2256 & TRN & \\
\hline CHEMBL1331587 & 688422 & 4.6 & 5.5576 & TST & \\
\hline CHEMBL1380378 & 688422 & 5.95 & 5.6634 & TRN & \\
\hline CHEMBL1511503 & 688422 & 7.8013 & 5.5112 & TST & \\
\hline CHEMBL1607239 & 688422 & 6.7501 & 6.0119 & TST & \\
\hline CHEMBL1462044 & 688422 & 4.95 & 5.0554 & TRN & \\
\hline CHEMBL1364655 & 688422 & 4.9 & 5.0354 & TRN & \\
\hline
\end{tabular}




\begin{tabular}{|c|c|c|c|c|c|}
\hline \multicolumn{6}{|c|}{ Supplemental Table S2.txt } \\
\hline CHEMBL429023 & 688422 & 6.0 & 5.9282 & TRN & \\
\hline CHEMBL1494586 & 688422 & 4.7 & 4.9417 & TRN & \\
\hline CHEMBL1409726 & 688422 & 4.8 & 5.4464 & TST & \\
\hline CHEMBL1377629 & 688422 & 4.65 & 5.0206 & TRN & \\
\hline CHEMBL3194413 & 688422 & 5.0 & 5.1073 & TRN & \\
\hline CHEMBL1475705 & 688422 & 5.15 & 5.3201 & TRN & \\
\hline CHEMBL1447700 & 688422 & 4.95 & 4.8852 & TRN & \\
\hline CHEMBL1353735 & 688422 & 7.15 & 5.0442 & TRN & \\
\hline CHEMBL1497684 & 688422 & 4.45 & 5.2048 & TRN & \\
\hline CHEMBL1342007 & 688422 & 5.25 & 5.2022 & TRN & \\
\hline CHEMBL1556597 & 688422 & 4.9 & 5.159 & TRN & \\
\hline CHEMBL1597546 & 688422 & 8.301 & 6.011 & TRN & \\
\hline CHEMBL1427492 & 688422 & 4.45 & 5.1455 & TRN & \\
\hline CHEMBL1597600 & 688422 & 4.45 & 5.2558 & TRN & \\
\hline CHEMBL1463185 & 688422 & 5.0 & 5.05699 & 99999999995 & TRN \\
\hline CHEMBL1303722 & 688422 & 4.95 & 5.0791 & TRN & \\
\hline CHEMBL1403955 & 688422 & 5.25 & 4.7911 & TRN & \\
\hline CHEMBL1416184 & 688422 & 4.8 & 5.061 & TRN & \\
\hline CHEMBL1355196 & 688422 & 6.4 & 5.8121 & TST & \\
\hline CHEMBL1335109 & 688422 & 4.8 & 5.4122 & TST & \\
\hline CHEMBL1335274 & 688422 & 10.35 & 5.4194 & TRN & \\
\hline CHEMBL1605981 & 688422 & 6.15 & 5.5683 & TST & \\
\hline CHEMBL3199492 & 688422 & 4.95 & 5.3102 & TRN & \\
\hline CHEMBL1393259 & 688422 & 4.65 & 5.3265 & TRN & \\
\hline CHEMBL1322071 & 688422 & 5.25 & 5.4997 & TRN & \\
\hline CHEMBL1479547 & 688422 & 4.45 & 5.2049 & TRN & \\
\hline CHEMBL1338555 & 688422 & 5.35 & 5.4626 & TST & \\
\hline CHEMBL543763 & 688422 & 8.4559 & 5.3031 & TST & \\
\hline CHEMBL1486462 & 688422 & 4.95 & 5.4262 & TRN & \\
\hline CHEMBL1339135 & 688422 & 4.8 & 5.437 & TRN & \\
\hline CHEMBL1373288 & 688422 & 7.9508 & 5.3343 & TST & \\
\hline CHEMBL1529766 & 688422 & 5.6 & 5.2272 & TST & \\
\hline CHEMBL601353 & 688422 & 5.3 & 4.8639 & TST & \\
\hline CHEMBL1515710 & 688422 & 7.7496 & 5.5057 & TRN & \\
\hline CHEMBL1480952 & 688422 & 4.65 & 4.9562 & TRN & \\
\hline CHEMBL1312355 & 688422 & 4.6 & 4.9573 & TRN & \\
\hline CHEMBL1464834 & 688422 & 4.45 & 4.6921 & TRN & \\
\hline CHEMBL1549990 & 688422 & 4.5 & 5.2674 & TRN & \\
\hline CHEMBL1458022 & 688422 & 6.2 & 5.7524 & TST & \\
\hline CHEMBL1471489 & 688422 & 5.9 & 5.4122 & TRN & \\
\hline CHEMBL1328227 & 688422 & 5.0 & 5.5188 & TRN & \\
\hline CHEMBL1414631 & 688422 & 4.5 & 4.8951 & TRN & \\
\hline CHEMBL1487453 & 688422 & 4.7 & 4.8947 & TRN & \\
\hline CHEMBL1462836 & 688422 & 4.5 & 5.0464 & TRN & \\
\hline CHEMBL1585734 & 688422 & 6.35 & 5.6696 & TST & \\
\hline CHEMBL1603373 & 688422 & 4.95 & 4.6806 & TRN & \\
\hline CHEMBL1378033 & 688422 & 4.45 & 4.8717 & TRN & \\
\hline CHEMBL1479844 & 688422 & 8.5528 & 5.4802 & TRN & \\
\hline
\end{tabular}




\begin{tabular}{|c|c|c|c|c|c|}
\hline \multicolumn{6}{|c|}{ Supplemental Table S2.txt } \\
\hline CHEMBL1443238 & 688422 & 4.95 & 5.8926 & TST & \\
\hline CHEMBL1309489 & 688422 & 4.8 & \multicolumn{2}{|c|}{5.361000000000001} & TRN \\
\hline CHEMBL1319962 & 688422 & 4.45 & 5.1958 & TRN & \\
\hline CHEMBL1441897 & 688422 & 4.45 & 5.0592 & TRN & \\
\hline CHEMBL3212851 & 688422 & 4.7 & 5.4466 & TRN & \\
\hline CHEMBL1438613 & 688422 & 4.9 & 5.2737 & TRN & \\
\hline CHEMBL1580773 & 688422 & 4.75 & 5.0418 & TRN & \\
\hline CHEMBL1542491 & 688422 & 4.45 & 4.9745 & TST & \\
\hline CHEMBL1990694 & 688422 & 4.8 & 4.9009 & TRN & \\
\hline CHEMBL1301232 & 688422 & 5.3 & 5.0687 & TRN & \\
\hline CHEMBL 3212456 & 688422 & 4.5 & 5.0057 & TST & \\
\hline CHEMBL1330767 & 688422 & 4.85 & 5.0521 & TRN & \\
\hline CHEMBL1596653 & 688422 & 4.7 & 5.3552 & TRN & \\
\hline CHEMBL1559388 & 688422 & 4.65 & 5.0136 & TRN & \\
\hline CHEMBL1381805 & 688422 & 4.9 & 5.2147 & TST & \\
\hline CHEMBL1423275 & 688422 & 4.85 & 5.4778 & TRN & \\
\hline CHEMBL1414356 & 688422 & 4.8 & 5.4544 & TST & \\
\hline CHEMBL1556079 & 688422 & 6.05 & 4.9408 & TRN & \\
\hline CHEMBL3194989 & 688422 & 4.45 & 5.1072 & TST & \\
\hline CHEMBL1545195 & 688422 & 5.05 & 5.2791 & TST & \\
\hline CHEMBL1452001 & 688422 & 4.5 & 5.1423 & TRN & \\
\hline CHEMBL1390699 & 688422 & 4.5 & 4.7045 & TRN & \\
\hline CHEMBL1602184 & 688422 & 6.8499 & 5.5045 & TRN & \\
\hline CHEMBL1580679 & 688422 & 4.9 & 5.1754 & TST & \\
\hline CHEMBL1453214 & 688422 & 4.5 & 5.1386 & TRN & \\
\hline CHEMBL1581361 & 688422 & 4.45 & 5.0515 & TRN & \\
\hline CHEMBL1362483 & 688422 & 5.25 & 5.3237 & TST & \\
\hline CHEMBL1308004 & 688422 & 4.95 & 4.9493 & TRN & \\
\hline CHEMBL1527353 & 688422 & 7.8996 & 4.973 & TRN & \\
\hline CHEMBL1421263 & 688422 & 5.4 & 5.8784 & TRN & \\
\hline CHEMBL1480843 & 688422 & 4.7 & 5.2563 & TRN & \\
\hline CHEMBL1542191 & 688422 & 4.9 & 5.2298 & TRN & \\
\hline CHEMBL1506066 & 688422 & 5.25 & 4.6309 & TRN & \\
\hline CHEMBL1542509 & 688422 & 6.8 & 5.1915 & TRN & \\
\hline CHEMBL1586148 & 688422 & 4.95 & 5.185 & TST & \\
\hline CHEMBL1318203 & 688422 & 7.6003 & 4.9027 & TRN & \\
\hline CHEMBL1354252 & 688422 & 6.35 & 5.1229 & TRN & \\
\hline CHEMBL1523086 & 688422 & 6.1 & 5.4891 & TST & \\
\hline CHEMBL1541715 & 688422 & 4.45 & 5.1929 & TRN & \\
\hline CHEMBL1457735 & 688422 & 4.65 & 5.0881 & TRN & \\
\hline CHEMBL1452334 & 688422 & 5.5 & 5.1761 & TRN & \\
\hline CHEMBL1606215 & 688422 & 5.9 & 5.3429 & TRN & \\
\hline CHEMBL1360457 & 688422 & 4.6 & 4.8573 & TST & \\
\hline CHEMBL3189325 & 688422 & 5.5 & 5.4563 & TRN & \\
\hline CHEMBL1337947 & 688422 & 4.5 & 5.2891 & TRN & \\
\hline CHEMBL1445650 & 688422 & 4.8 & 5.2989 & TRN & \\
\hline CHEMBL1499384 & 688422 & 5.65 & 5.58899 & 99999999995 & TRN \\
\hline CHEMBL1574069 & 688422 & 4.95 & 5.6713 & TRN & \\
\hline
\end{tabular}




\begin{tabular}{|c|c|c|c|c|}
\hline \multicolumn{5}{|c|}{ Supplemental Table } \\
\hline CHEMBL1575117 & 688422 & 6.7501 & 5.895 & TRN \\
\hline CHEMBL1333433 & 688422 & 4.85 & 4.8246 & TRN \\
\hline CHEMBL1603418 & 688422 & 4.75 & 5.0295 & TRN \\
\hline CHEMBL1540043 & 688422 & 4.9 & 5.1269 & TRN \\
\hline CHEMBL1567154 & 688422 & 5.05 & 4.9858 & TRN \\
\hline CHEMBL 3198588 & 688422 & 4.55 & 5.227 & TRN \\
\hline CHEMBL1344674 & 688422 & 6.9 & 5.1903 & TST \\
\hline CHEMBL599304 & 688422 & 5.15 & 5.2976 & TRN \\
\hline CHEMBL1483427 & 688422 & 4.45 & 4.9026 & TRN \\
\hline CHEMBL3198418 & 688422 & 4.8 & 5.2008 & TRN \\
\hline CHEMBL1517382 & 688422 & 5.0 & 5.4021 & TST \\
\hline CHEMBL1585192 & 688422 & 4.9 & 5.3334 & TST \\
\hline CHEMBL1601116 & 688422 & 5.3 & 5.1061 & TRN \\
\hline CHEMBL1476353 & 688422 & 4.75 & 4.7043 & TRN \\
\hline CHEMBL1544137 & 688422 & 4.9 & 5.1741 & TRN \\
\hline CHEMBL1453920 & 688422 & 5.5 & 5.2844 & TRN \\
\hline CHEMBL1490877 & 688422 & 5.85 & 5.7408 & TST \\
\hline CHEMBL1513126 & 688422 & 8.3468 & 5.8654 & TRN \\
\hline CHEMBL1449467 & 688422 & 5.25 & 5.4653 & TRN \\
\hline CHEMBL1513381 & 688422 & 5.15 & 5.1759 & TRN \\
\hline CHEMBL1403722 & 688422 & 4.45 & 5.4726 & TRN \\
\hline CHEMBL1344800 & 688422 & 4.6 & 4.7452 & TRN \\
\hline CHEMBL1326489 & 688422 & 4.95 & 5.0232 & TRN \\
\hline CHEMBL1319728 & 688422 & 5.05 & 5.398 & TRN \\
\hline CHEMBL1579510 & 688422 & 5.9 & 5.8014 & TST \\
\hline CHEMBL1483555 & 688422 & 5.1 & 4.5992 & TRN \\
\hline CHEMBL1478678 & 688422 & 4.7 & 5.3025 & TRN \\
\hline CHEMBL1604068 & 688422 & 4.45 & 5.2037 & TRN \\
\hline CHEMBL1508080 & 688422 & 4.8 & 5.1723 & TST \\
\hline CHEMBL1500249 & 688422 & 4.9 & 5.4235 & TST \\
\hline CHEMBL1524592 & 688422 & 4.9 & 5.0579 & TRN \\
\hline CHEMBL1336686 & 688422 & 4.9 & 4.6528 & TRN \\
\hline CHEMBL1345902 & 688422 & 4.7 & 5.3462 & TST \\
\hline CHEMBL1510941 & 688422 & 4.8 & 5.2809 & TST \\
\hline CHEMBL1506243 & 688422 & 4.45 & 5.086 & TRN \\
\hline CHEMBL1368995 & 688422 & 4.9 & 5.1335 & TRN \\
\hline CHEMBL1415478 & 688422 & 4.7 & 5.0428 & TRN \\
\hline CHEMBL1455301 & 688422 & 8.2518 & 5.734 & TST \\
\hline CHEMBL1374594 & 688422 & 5.1 & 4.6777 & TRN \\
\hline CHEMBL1377936 & 688422 & 4.95 & 5.1131 & TRN \\
\hline CHEMBL1576971 & 688422 & 4.85 & 5.0838 & TST \\
\hline CHEMBL1399554 & 688422 & 4.5 & 5.4754 & TRN \\
\hline CHEMBL1300008 & 688422 & 4.55 & 5.2202 & TRN \\
\hline CHEMBL1369488 & 688422 & 4.95 & 5.1329 & TRN \\
\hline CHEMBL1562941 & 688422 & 5.25 & 5.3436 & TST \\
\hline CHEMBL1545332 & 688422 & 5.9 & 5.4993 & TRN \\
\hline CHEMBL1324263 & 688422 & 4.45 & 5.0481 & TRN \\
\hline CHEMBL1526753 & 688422 & 8.0 & 5.2628 & TRN \\
\hline
\end{tabular}




\begin{tabular}{|c|c|c|c|c|}
\hline \multicolumn{5}{|c|}{ Supplemental Table S2.txt } \\
\hline CHEMBL1519766 & 688422 & 4.9 & 5.4157 & TRN \\
\hline CHEMBL1586823 & 688422 & 5.0 & 5.3636 & TST \\
\hline CHEMBL1568891 & 688422 & 5.95 & 5.1008 & TST \\
\hline CHEMBL1300873 & 688422 & 4.7 & 5.6726 & TST \\
\hline CHEMBL1411765 & 688422 & 4.95 & 5.2666 & TST \\
\hline CHEMBL1515246 & 688422 & 5.0 & 5.0772 & TRN \\
\hline CHEMBL1310209 & 688422 & 4.65 & 5.3143 & TRN \\
\hline CHEMBL 3189856 & 688422 & 4.45 & 5.0936 & TRN \\
\hline CHEMBL1560938 & 688422 & 4.45 & 5.0304 & TRN \\
\hline CHEMBL1579592 & 688422 & 4.95 & 5.3106 & TRN \\
\hline CHEMBL1589042 & 688422 & 4.9 & 5.1354 & TRN \\
\hline CHEMBL1440162 & 688422 & 4.65 & 4.9724 & TST \\
\hline CHEMBL1327892 & 688422 & 4.45 & 5.2198 & TST \\
\hline CHEMBL3191958 & 688422 & 4.45 & 5.2627 & TRN \\
\hline CHEMBL1531928 & 688422 & 4.45 & 5.296 & TRN \\
\hline CHEMBL1519726 & 688422 & 6.05 & 5.6571 & TRN \\
\hline CHEMBL1420596 & 688422 & 5.3 & 5.1497 & TST \\
\hline CHEMBL1397219 & 688422 & 7.7496 & 5.0929 & TRN \\
\hline CHEMBL1577703 & 688422 & 5.85 & 5.7883 & TST \\
\hline CHEMBL3195237 & 688422 & 4.6 & 5.3177 & TRN \\
\hline CHEMBL485957 & 688422 & 4.9 & 5.2084 & TRN \\
\hline CHEMBL1376376 & 688422 & 4.45 & 5.3553 & TST \\
\hline CHEMBL1349282 & 688422 & 5.25 & 5.1655 & TRN \\
\hline CHEMBL1464848 & 688422 & 7.0501 & 5.2586 & TRN \\
\hline CHEMBL1307127 & 688422 & 4.65 & 5.3874 & TRN \\
\hline CHEMBL1347461 & 688422 & 5.05 & 5.4639 & TRN \\
\hline CHEMBL1585968 & 688422 & 4.75 & 4.9254 & TRN \\
\hline CHEMBL1557200 & 688422 & 4.9 & 4.8484 & TRN \\
\hline CHEMBL1501307 & 688422 & 5.55 & 5.229 & TST \\
\hline CHEMBL1330201 & 688422 & 4.95 & 4.662 & TRN \\
\hline CHEMBL1554181 & 688422 & 5.1 & 5.4092 & TRN \\
\hline CHEMBL1443325 & 688422 & 4.8 & 5.4114 & TRN \\
\hline CHEMBL1312783 & 688422 & 4.45 & 4.9838 & TRN \\
\hline CHEMBL443343 & 688422 & 4.95 & 5.1186 & TRN \\
\hline CHEMBL1342930 & 688422 & 4.85 & 5.1278 & TRN \\
\hline CHEMBL3210015 & 688422 & 4.95 & 5.2722 & TRN \\
\hline CHEMBL 3667549 & 688422 & 4.95 & 5.0283 & TST \\
\hline CHEMBL1330794 & 688422 & 4.9 & 5.0543 & TST \\
\hline CHEMBL1302120 & 688422 & 4.7 & 5.504 & TRN \\
\hline CHEMBL1510234 & 688422 & 5.15 & 4.9624 & TRN \\
\hline CHEMBL1488928 & 688422 & 4.45 & 5.3781 & TST \\
\hline CHEMBL1601133 & 688422 & 5.05 & 5.3174 & TRN \\
\hline CHEMBL1433008 & 688422 & 5.7 & 5.2234 & TRN \\
\hline CHEMBL1330739 & 688422 & 4.65 & 5.1837 & TST \\
\hline CHEMBL1301993 & 688422 & 7.0501 & 4.881 & TST \\
\hline CHEMBL1434809 & 688422 & 5.65 & 5.3013 & TRN \\
\hline CHEMBL1499606 & 688422 & 4.65 & 5.1596 & TRN \\
\hline CHEMBL523663 & 688422 & 4.45 & 4.8653 & TRN \\
\hline
\end{tabular}




\begin{tabular}{|c|c|c|c|c|c|}
\hline \multicolumn{6}{|c|}{ Supplemental Table S2.txt } \\
\hline CHEMBL1571018 & 688422 & 4.85 & 5.3433 & TRN & \\
\hline CHEMBL3208594 & 688422 & 4.9 & 5.472 & TRN & \\
\hline CHEMBL1390973 & 688422 & 4.45 & 5.0339 & TRN & \\
\hline CHEMBL1350349 & 688422 & 5.55 & 5.2359 & TRN & \\
\hline CHEMBL1363513 & 688422 & 5.0 & 4.9482 & TRN & \\
\hline CHEMBL1535742 & 688422 & 5.55 & 4.9678 & TRN & \\
\hline CHEMBL1427408 & 688422 & 4.85 & 4.9044 & TRN & \\
\hline CHEMBL1497999 & 688422 & 4.9 & 5.3065 & TRN & \\
\hline CHEMBL1995550 & 688422 & 4.45 & 5.2064 & TST & \\
\hline CHEMBL1420246 & 688422 & 4.5 & 5.1884 & TRN & \\
\hline CHEMBL1446565 & 688422 & 4.6 & 5.6093 & TRN & \\
\hline CHEMBL 3194400 & 688422 & 4.65 & 4.7979 & TRN & \\
\hline CHEMBL1485304 & 688422 & 5.3 & 5.2453 & TRN & \\
\hline CHEMBL1256772 & 688422 & 7.8013 & 5.5911 & TST & \\
\hline CHEMBL3194168 & 688422 & 4.75 & 5.1373 & TRN & \\
\hline CHEMBL1543242 & 688422 & 4.65 & 5.5061 & TRN & \\
\hline CHEMBL1578009 & 688422 & 4.6 & 5.4667 & TST & \\
\hline CHEMBL1448271 & 688422 & 7.5498 & 5.6342 & TRN & \\
\hline CHEMBL1518628 & 688422 & 6.2 & 5.3945 & TST & \\
\hline CHEMBL1558021 & 688422 & 4.9 & 5.1886 & TRN & \\
\hline CHEMBL1549094 & 688422 & 5.3 & 5.07100 & 0000000001 & TRN \\
\hline CHEMBL1401350 & 688422 & 7.2 & 5.3416 & TRN & \\
\hline CHEMBL1494059 & 688422 & 4.65 & 5.1097 & TRN & \\
\hline CHEMBL1379632 & 688422 & 4.9 & 4.93199 & 99999999995 & TRN \\
\hline CHEMBL1328466 & 688422 & 5.6 & 5.2356 & TRN & \\
\hline CHEMBL1583883 & 688422 & 5.25 & 4.9397 & TRN & \\
\hline CHEMBL1530963 & 688422 & 6.15 & 4.7237 & TRN & \\
\hline CHEMBL1409216 & 688422 & 4.7 & 4.9772 & TRN & \\
\hline CHEMBL1333117 & 688422 & 5.5 & 4.7221 & TST & \\
\hline CHEMBL 2003567 & 688422 & 5.1 & 5.1026 & TST & \\
\hline CHEMBL1560080 & 688422 & 5.9 & 5.7463 & TRN & \\
\hline CHEMBL310396 & 688422 & 5.1 & 5.5963 & TST & \\
\hline CHEMBL1576547 & 688422 & 8.4559 & 5.2419 & TRN & \\
\hline CHEMBL1327830 & 688422 & 4.45 & 4.9613 & TRN & \\
\hline CHEMBL1562404 & 688422 & 7.7496 & 5.2589 & TRN & \\
\hline CHEMBL1601097 & 688422 & 4.9 & 5.1199 & TRN & \\
\hline CHEMBL 1547746 & 688422 & 4.45 & 4.9268 & TRN & \\
\hline CHEMBL1338738 & 688422 & 5.15 & 5.2624 & TRN & \\
\hline CHEMBL598263 & 688422 & 7.2 & 5.6025 & TST & \\
\hline CHEMBL284895 & 688422 & 5.2 & 6.0183 & TST & \\
\hline CHEMBL1560816 & 688422 & 4.7 & 5.1912 & TST & \\
\hline CHEMBL1980959 & 688422 & 5.2 & 4.8838 & TRN & \\
\hline CHEMBL3196542 & 688422 & 4.6 & 5.6094 & TRN & \\
\hline CHEMBL 1600276 & 688422 & 4.45 & 4.9789 & TST & \\
\hline CHEMBL1442155 & 688422 & 4.9 & 5.4361 & TRN & \\
\hline CHEMBL1396337 & 688422 & 5.95 & 5.5743 & TRN & \\
\hline CHEMBL1574043 & 688422 & 4.95 & 5.3997 & TST & \\
\hline CHEMBL1339994 & 688422 & 4.8 & 5.0697 & TRN & \\
\hline
\end{tabular}




\begin{tabular}{|c|c|c|c|c|c|}
\hline \multicolumn{6}{|c|}{ Supplemental Table S2.txt } \\
\hline CHEMBL1368150 & 688422 & 4.5 & 5.2563 & TST & \\
\hline CHEMBL1480540 & 688422 & 6.5501 & 5.46 & TRN & \\
\hline CHEMBL1438785 & 688422 & 4.7 & 4.8579 & TRN & \\
\hline CHEMBL1231847 & 688422 & 4.7 & 5.2034 & TRN & \\
\hline CHEMBL1324650 & 688422 & 4.45 & 5.2569 & TRN & \\
\hline CHEMBL1448892 & 688422 & 4.45 & 4.9756 & TRN & \\
\hline CHEMBL1445549 & 688422 & 6.15 & 5.3866 & TRN & \\
\hline CHEMBL1323637 & 688422 & 4.55 & 4.6299 & TRN & \\
\hline CHEMBL3190807 & 688422 & 4.45 & 5.2278 & TRN & \\
\hline CHEMBL1390781 & 688422 & 4.9 & 4.8317 & TRN & \\
\hline CHEMBL 3197314 & 688422 & 4.7 & 4.9535 & TRN & \\
\hline CHEMBL3197711 & 688422 & 4.6 & 5.1195 & TST & \\
\hline CHEMBL1390452 & 688422 & 5.25 & 5.403 & TRN & \\
\hline CHEMBL1463551 & 688422 & 5.5 & 5.1025 & TRN & \\
\hline CHEMBL129795 & 688422 & 6.0 & 5.07100 & 0000000001 & TRN \\
\hline CHEMBL1450492 & 688422 & 7.5498 & 5.1467 & TRN & \\
\hline CHEMBL1577055 & 688422 & 4.45 & 5.3868 & TRN & \\
\hline CHEMBL1469300 & 688422 & 4.45 & 5.5148 & TRN & \\
\hline CHEMBL1501447 & 688422 & 5.5 & 5.3924 & TST & \\
\hline CHEMBL1345139 & 688422 & 4.45 & 4.6665 & TRN & \\
\hline CHEMBL1390636 & 688422 & 8.0 & 5.1748 & TRN & \\
\hline CHEMBL1560093 & 688422 & 4.95 & 5.2986 & TRN & \\
\hline CHEMBL3208898 & 688422 & 5.85 & 5.5203 & TRN & \\
\hline CHEMBL1359800 & 688422 & 5.3 & 5.4012 & TRN & \\
\hline CHEMBL1479020 & 688422 & 4.9 & 5.1163 & TST & \\
\hline CHEMBL1472179 & 688422 & 4.45 & 5.6101 & TRN & \\
\hline CHEMBL1393860 & 688422 & 4.6 & 4.6868 & TST & \\
\hline CHEMBL1590197 & 688422 & 4.55 & 4.9829 & TRN & \\
\hline CHEMBL1427364 & 688422 & 8.699 & 5.5841 & TST & \\
\hline CHEMBL1512744 & 688422 & 5.0 & 5.1287 & TRN & \\
\hline CHEMBL1468206 & 688422 & 6.05 & 4.874 & TRN & \\
\hline CHEMBL3193531 & 688422 & 4.45 & 5.2915 & TRN & \\
\hline CHEMBL1567159 & 688422 & 4.6 & 5.1389 & TST & \\
\hline CHEMBL1992081 & 688422 & 7.0501 & 4.9895 & TRN & \\
\hline CHEMBL1496766 & 688422 & 7.4498 & 5.3447 & TST & \\
\hline CHEMBL1521937 & 688422 & 4.6 & 5.0234 & TRN & \\
\hline CHEMBL1492269 & 688422 & 5.55 & 5.5217 & TRN & \\
\hline CHEMBL571295 & 688422 & 4.95 & 5.7025 & TST & \\
\hline CHEMBL1306343 & 688422 & 5.45 & 5.5894 & TRN & \\
\hline CHEMBL1490503 & 688422 & 6.25 & 5.5599 & TRN & \\
\hline CHEMBL1370130 & 688422 & 4.6 & 5.5232 & TRN & \\
\hline CHEMBL1551255 & 688422 & 4.45 & 5.1139 & TRN & \\
\hline CHEMBL1446901 & 688422 & 4.45 & 5.2968 & TRN & \\
\hline CHEMBL1611118 & 688422 & 4.6 & 5.1341 & TST & \\
\hline CHEMBL565654 & 688422 & 4.65 & 4.6559 & TRN & \\
\hline CHEMBL1495198 & 688422 & 4.45 & 5.2944 & TST & \\
\hline CHEMBL1357199 & 688422 & 4.6 & 4.9685 & TRN & \\
\hline CHEMBL1340407 & 688422 & 4.95 & 4.9889 & TRN & \\
\hline
\end{tabular}




\begin{tabular}{|c|c|c|c|c|}
\hline \multicolumn{5}{|c|}{ Supplemental Table S2.txt } \\
\hline CHEMBL1510208 & 688422 & 4.65 & 4.8959 & TRN \\
\hline CHEMBL1537129 & 688422 & 4.65 & 5.3473 & TRN \\
\hline CHEMBL1610067 & 688422 & 4.45 & 4.9357 & TRN \\
\hline CHEMBL591412 & 688422 & 5.35 & 5.4488 & TRN \\
\hline CHEMBL 1337434 & 688422 & 5.0 & 5.6436 & TRN \\
\hline CHEMBL1586346 & 688422 & 4.95 & 5.2692 & TRN \\
\hline CHEMBL1600987 & 688422 & 4.5 & 5.1538 & TRN \\
\hline CHEMBL1308857 & 688422 & 4.5 & 5.3583 & TRN \\
\hline CHEMBL1594435 & 688422 & 4.65 & 5.2595 & TRN \\
\hline CHEMBL1597704 & 688422 & 4.9 & 4.9304 & TRN \\
\hline CHEMBL1344292 & 688422 & 5.3 & 5.1038 & TRN \\
\hline CHEMBL1980530 & 688422 & 4.5 & 5.2172 & TRN \\
\hline CHEMBL1501376 & 688422 & 4.55 & 4.8341 & TRN \\
\hline CHEMBL1320505 & 688422 & 4.45 & 5.4701 & TRN \\
\hline CHEMBL1603246 & 688422 & 4.85 & 5.3528 & TST \\
\hline CHEMBL1474573 & 688422 & 6.2 & 5.3857 & TRN \\
\hline CHEMBL3145373 & 688422 & 6.35 & 5.5885 & TRN \\
\hline CHEMBL1346285 & 688422 & 5.35 & 5.4322 & TST \\
\hline CHEMBL1437176 & 688422 & 4.6 & 5.0901 & TRN \\
\hline CHEMBL1431082 & 688422 & 4.5 & 5.2342 & TRN \\
\hline CHEMBL1987848 & 688422 & 5.0 & 4.9404 & TST \\
\hline CHEMBL1424697 & 688422 & 4.6 & 5.0787 & TRN \\
\hline CHEMBL3193383 & 688422 & 4.45 & 5.1902 & TRN \\
\hline CHEMBL1491446 & 688422 & 4.85 & 4.9305 & TST \\
\hline CHEMBL1477258 & 688422 & 4.95 & 5.5508 & TRN \\
\hline CHEMBL1595678 & 688422 & 7.8013 & 5.2693 & TRN \\
\hline CHEMBL1448977 & 688422 & 7.4498 & 5.7061 & TST \\
\hline CHEMBL1550080 & 688422 & 4.45 & 4.9498 & TRN \\
\hline CHEMBL1397472 & 688422 & 5.85 & 5.4341 & TRN \\
\hline CHEMBL1358721 & 688422 & 4.45 & 5.2993 & TRN \\
\hline CHEMBL1444392 & 688422 & 4.45 & 4.6607 & TRN \\
\hline CHEMBL 1413518 & 688422 & 4.5 & 5.565 & TRN \\
\hline CHEMBL1339696 & 688422 & 5.25 & 5.0835 & TRN \\
\hline CHEMBL1406072 & 688422 & 4.55 & 5.43 & TRN \\
\hline CHEMBL1311206 & 688422 & 6.0 & 5.4148 & TRN \\
\hline CHEMBL1353993 & 688422 & 5.05 & 4.8754 & TRN \\
\hline CHEMBL 1413371 & 688422 & 5.2 & 5.5167 & TST \\
\hline CHEMBL1495856 & 688422 & 6.0 & 5.4319 & TST \\
\hline CHEMBL1358033 & 688422 & 5.75 & 5.1871 & TRN \\
\hline CHEMBL1460216 & 688422 & 4.45 & 5.3726 & TST \\
\hline CHEMBL1978424 & 688422 & 6.9 & 5.1482 & TRN \\
\hline CHEMBL1462788 & 688422 & 4.75 & 5.375 & TRN \\
\hline CHEMBL1543499 & 688422 & 4.85 & 5.2674 & TRN \\
\hline CHEMBL1557706 & 688422 & 4.5 & 5.8349 & TST \\
\hline CHEMBL1306893 & 688422 & 6.7001 & 5.3986 & TRN \\
\hline CHEMBL1529236 & 688422 & 4.6 & 4.6504 & TRN \\
\hline CHEMBL1544634 & 688422 & 5.55 & 5.6065 & TST \\
\hline CHEMBL1367736 & 688422 & 4.75 & 5.3922 & TRN \\
\hline
\end{tabular}




\begin{tabular}{|c|c|c|c|c|c|}
\hline \multicolumn{6}{|c|}{ Supplemental Table S2.txt } \\
\hline CHEMBL1469035 & 688422 & 5.2 & 5.029 & TRN & \\
\hline CHEMBL1557445 & 688422 & 4.85 & 4.9364 & TRN & \\
\hline CHEMBL1350899 & 688422 & 5.85 & 5.24700 & 0000000001 & TRN \\
\hline CHEMBL1584260 & 688422 & 4.5 & 5.0225 & TRN & \\
\hline CHEMBL1587619 & 688422 & 4.5 & 5.3866 & TRN & \\
\hline CHEMBL3208264 & 688422 & 5.0 & 5.5727 & TRN & \\
\hline CHEMBL1582706 & 688422 & 4.45 & 5.1158 & TRN & \\
\hline CHEMBL1606504 & 688422 & 4.6 & 4.8792 & TRN & \\
\hline CHEMBL1466294 & 688422 & 5.2 & 5.4719 & TRN & \\
\hline CHEMBL1411583 & 688422 & 8.1487 & 5.5027 & TST & \\
\hline CHEMBL1353571 & 688422 & 4.85 & 5.0853 & TRN & \\
\hline CHEMBL1493415 & 688422 & 4.85 & 5.4953 & TST & \\
\hline CHEMBL1469032 & 688422 & 5.0 & 5.4078 & TRN & \\
\hline CHEMBL254833 & 688422 & 5.3 & 5.171 & TRN & \\
\hline CHEMBL1556975 & 688422 & 4.65 & 5.3432 & TST & \\
\hline CHEMBL1556592 & 688422 & 4.45 & 5.6625 & TRN & \\
\hline CHEMBL1320940 & 688422 & 4.45 & 5.136 & TRN & \\
\hline CHEMBL1480651 & 688422 & 4.45 & 5.2075 & TRN & \\
\hline CHEMBL1393655 & 688422 & 4.7 & 4.9389 & TRN & \\
\hline CHEMBL1376514 & 688422 & 4.8 & 5.216 & TRN & \\
\hline CHEMBL1482408 & 688422 & 4.75 & 4.7257 & TRN & \\
\hline CHEMBL1325883 & 688422 & 4.55 & 5.00899 & 99999999995 & TRN \\
\hline CHEMBL1455053 & 688422 & 4.7 & 5.2923 & TST & \\
\hline CHEMBL1458506 & 688422 & 4.9 & 5.2929 & TRN & \\
\hline CHEMBL1570650 & 688422 & 5.45 & 4.9379 & TST & \\
\hline CHEMBL1348232 & 688422 & 4.45 & 5.5238 & TRN & \\
\hline CHEMBL1320049 & 688422 & 5.75 & 5.3759 & TST & \\
\hline CHEMBL1354768 & 688422 & 6.95 & 4.745 & TRN & \\
\hline CHEMBL1528800 & 688422 & 7.4498 & 5.8522 & TRN & \\
\hline CHEMBL1461027 & 688422 & 6.1 & 5.53 & TRN & \\
\hline CHEMBL1519429 & 688422 & 4.85 & 5.2532 & TST & \\
\hline CHEMBL1351329 & 688422 & 4.7 & 5.2773 & TRN & \\
\hline CHEMBL1587285 & 688422 & 5.55 & 5.41100 & 00000000005 & TRN \\
\hline CHEMBL1569307 & 688422 & 5.15 & 5.2279 & TRN & \\
\hline CHEMBL1333629 & 688422 & 4.9 & 5.4494 & TST & \\
\hline CHEMBL1599876 & 688422 & 5.4 & 5.3051 & TST & \\
\hline CHEMBL3207844 & 688422 & 5.4 & 5.8013 & TRN & \\
\hline CHEMBL1305664 & 688422 & 4.45 & 5.2984 & TRN & \\
\hline CHEMBL1410893 & 688422 & 5.5 & 5.3703 & TRN & \\
\hline CHEMBL1433113 & 688422 & 5.7 & 5.7664 & TRN & \\
\hline CHEMBL1317788 & 688422 & 5.4 & 5.227 & TRN & \\
\hline CHEMBL1572276 & 688422 & 7.5003 & 5.6424 & TST & \\
\hline CHEMBL1330509 & 688422 & 4.55 & 5.3408 & TRN & \\
\hline CHEMBL1585962 & 688422 & 5.55 & 5.477 & TRN & \\
\hline CHEMBL1383476 & 688422 & 4.45 & 5.388 & TRN & \\
\hline CHEMBL1437586 & 688422 & 4.45 & 4.849 & TRN & \\
\hline CHEMBL1352637 & 688422 & 4.85 & 5.3969 & TRN & \\
\hline CHEMBL1546314 & 688422 & 5.5 & 5.0543 & TRN & \\
\hline
\end{tabular}




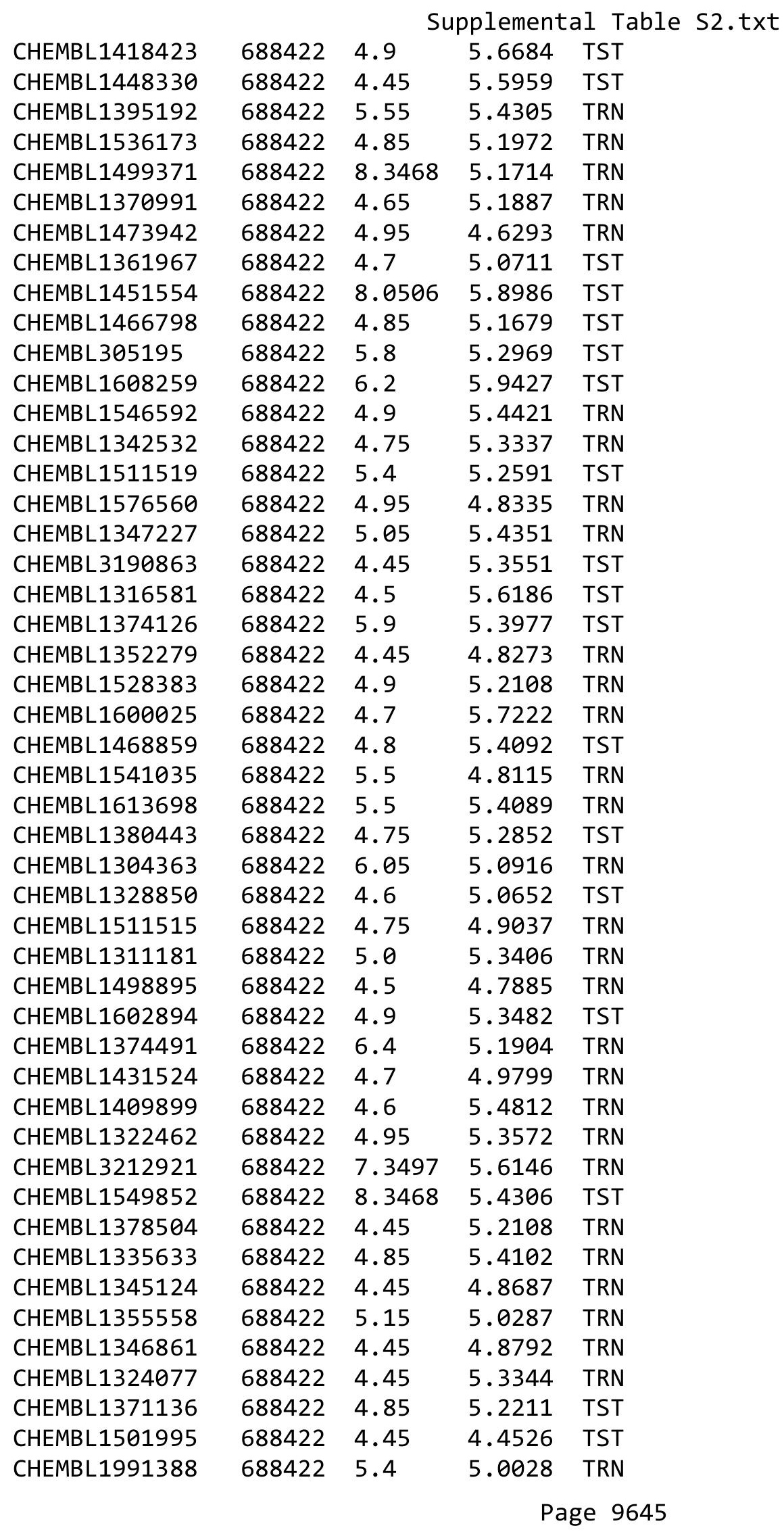




\begin{tabular}{|c|c|c|c|c|c|}
\hline \multicolumn{6}{|c|}{ Supplemental Table S2.txt } \\
\hline CHEMBL1607586 & 688422 & 4.45 & 5.1084 & TRN & \\
\hline CHEMBL1586899 & 688422 & 4.75 & 5.4192 & TRN & \\
\hline CHEMBL1309553 & 688422 & 4.9 & 4.9592 & TRN & \\
\hline CHEMBL1464525 & 688422 & 4.85 & 4.9698 & TST & \\
\hline CHEMBL1456442 & 688422 & 4.5 & 5.1201 & TRN & \\
\hline CHEMBL1568078 & 688422 & 4.95 & 5.0252 & TRN & \\
\hline CHEMBL1493117 & 688422 & 5.45 & 5.1781 & TST & \\
\hline CHEMBL1361474 & 688422 & 4.45 & 5.1916 & TST & \\
\hline CHEMBL1559993 & 688422 & 4.55 & 5.0427 & TRN & \\
\hline CHEMBL1316964 & 688422 & 7.0 & 5.8459 & TRN & \\
\hline CHEMBL1409434 & 688422 & 5.5 & 5.5919 & TRN & \\
\hline CHEMBL1406316 & 688422 & 4.9 & 5.584 & TRN & \\
\hline CHEMBL266084 & 688422 & 8.2518 & 5.5159 & TST & \\
\hline CHEMBL1467265 & 688422 & 5.25 & 5.3838 & TRN & \\
\hline CHEMBL1370744 & 688422 & 7.15 & 4.9435 & TRN & \\
\hline CHEMBL1299526 & 688422 & 4.45 & 5.4439 & TRN & \\
\hline CHEMBL1417990 & 688422 & 4.45 & 5.5173 & TST & \\
\hline CHEMBL1468302 & 688422 & 4.95 & 5.1188 & TRN & \\
\hline CHEMBL1457026 & 688422 & 5.4 & 5.42899 & 7999999999 & TRN \\
\hline CHEMBL8739 & 688422 & 4.65 & 5.5682 & TRN & \\
\hline CHEMBL1515882 & 688422 & 5.2 & 4.9948 & TRN & \\
\hline CHEMBL3197035 & 688422 & 6.3 & 5.1967 & TRN & \\
\hline CHEMBL1316715 & 688422 & 4.45 & 5.644 & TRN & \\
\hline CHEMBL1319939 & 688422 & 4.9 & 4.6353 & TRN & \\
\hline CHEMBL1326759 & 688422 & 4.45 & 5.2895 & TRN & \\
\hline CHEMBL3210384 & 688422 & 5.9 & 4.9938 & TRN & \\
\hline CHEMBL1573480 & 688422 & 4.85 & 5.1314 & TST & \\
\hline CHEMBL1558305 & 688422 & 4.5 & 5.0316 & TRN & \\
\hline CHEMBL1598471 & 688422 & 5.5 & 5.5849 & TRN & \\
\hline CHEMBL1312358 & 688422 & 5.65 & 5.407 & TRN & \\
\hline CHEMBL1381978 & 688422 & 4.85 & 5.5429 & TST & \\
\hline CHEMBL3212142 & 688422 & 6.8 & 5.3517 & TST & \\
\hline CHEMBL1531133 & 688422 & 4.8 & 4.8864 & TRN & \\
\hline CHEMBL1599743 & 688422 & 4.9 & 5.2538 & TRN & \\
\hline CHEMBL1424504 & 688422 & 5.0 & 5.2112 & TST & \\
\hline CHEMBL1600146 & 688422 & 4.5 & 5.1384 & TRN & \\
\hline CHEMBL1554808 & 688422 & 5.5 & 5.2414 & TRN & \\
\hline CHEMBL1497693 & 688422 & 4.95 & 5.221 & TRN & \\
\hline CHEMBL1504310 & 688422 & 4.85 & 4.9795 & TST & \\
\hline CHEMBL1418707 & 688422 & 4.45 & 5.2581 & TRN & \\
\hline CHEMBL1410105 & 688422 & 4.8 & 4.9056 & TRN & \\
\hline CHEMBL1333532 & 688422 & 8.0506 & 5.3045 & TRN & \\
\hline CHEMBL1499833 & 688422 & 8.2007 & 5.4659 & TST & \\
\hline CHEMBL1506282 & 688422 & 6.15 & 4.9827 & TRN & \\
\hline CHEMBL1378883 & 688422 & 4.75 & 4.6997 & TRN & \\
\hline CHEMBL1522846 & 688422 & 5.2 & 5.3824 & TST & \\
\hline CHEMBL1536588 & 688422 & 4.95 & 4.9021 & TRN & \\
\hline CHEMBL1393357 & 688422 & 5.3 & 4.8487 & TRN & \\
\hline
\end{tabular}




\begin{tabular}{|c|c|c|c|c|c|}
\hline \multicolumn{6}{|c|}{ Supplemental Table s2.txt } \\
\hline CHEMBL1327583 & 688422 & 4.45 & 5.415 & TST & \\
\hline CHEMBL1405811 & 688422 & 5.35 & 5.4182 & TST & \\
\hline CHEMBL1568641 & 688422 & 5.2 & 5.4831 & TRN & \\
\hline CHEMBL1312830 & 688422 & 6.95 & 5.3517 & TRN & \\
\hline CHEMBL1586332 & 688422 & 4.45 & 4.8423 & TRN & \\
\hline CHEMBL1485233 & 688422 & 5.85 & 5.3343 & TRN & \\
\hline CHEMBL1573598 & 688422 & 7.3497 & 5.6129 & TST & \\
\hline CHEMBL1487487 & 688422 & 5.05 & 5.2113 & TRN & \\
\hline CHEMBL1476443 & 688422 & 7.6498 & 5.3745 & TRN & \\
\hline CHEMBL1547145 & 688422 & 4.8 & 5.047 & TRN & \\
\hline CHEMBL1527965 & 688422 & 5.25 & 4.8894 & TRN & \\
\hline CHEMBL3191598 & 688422 & 5.0 & 5.271 & TRN & \\
\hline CHEMBL1992394 & 688422 & 5.3 & 4.927 & TRN & \\
\hline CHEMBL1536362 & 688422 & 5.2 & 5.4118 & TRN & \\
\hline CHEMBL1519906 & 688422 & 6.95 & 5.5194 & TRN & \\
\hline CHEMBL1501300 & 688422 & 4.5 & 5.4701 & TRN & \\
\hline CHEMBL1606329 & 688422 & 5.95 & 5.24100 & 00000000005 & TRN \\
\hline CHEMBL1439300 & 688422 & 5.45 & 4.9854 & TRN & \\
\hline CHEMBL1490980 & 688422 & 4.7 & 5.5877 & TRN & \\
\hline CHEMBL1987884 & 688422 & 4.7 & 5.1268 & TRN & \\
\hline CHEMBL1507744 & 688422 & 6.8 & 5.2984 & TRN & \\
\hline CHEMBL1305462 & 688422 & 5.4 & 5.2853 & TRN & \\
\hline CHEMBL1523623 & 688422 & 4.45 & 5.1274 & TRN & \\
\hline CHEMBL1563531 & 688422 & 4.7 & 4.6523 & TRN & \\
\hline CHEMBL1475047 & 688422 & 5.75 & 5.3692 & TRN & \\
\hline CHEMBL3190364 & 688422 & 4.45 & 5.0407 & TRN & \\
\hline CHEMBL1403568 & 688422 & 4.45 & 4.9061 & TRN & \\
\hline CHEMBL1505644 & 688422 & 4.75 & 5.2009 & TRN & \\
\hline CHEMBL1332926 & 688422 & 4.95 & 5.8742 & TRN & \\
\hline CHEMBL1342527 & 688422 & 4.95 & 4.9576 & TST & \\
\hline CHEMBL1568570 & 688422 & 5.25 & 5.5672 & TST & \\
\hline CHEMBL1528876 & 688422 & 4.45 & 5.4262 & TST & \\
\hline CHEMBL1330687 & 688422 & 7.8013 & 5.2285 & TST & \\
\hline CHEMBL1428652 & 688422 & 4.45 & 5.3523 & TRN & \\
\hline CHEMBL1391545 & 688422 & 4.95 & 5.146 & TRN & \\
\hline CHEMBL1448027 & 688422 & 5.95 & 5.4466 & TST & \\
\hline CHEMBL3190423 & 688422 & 5.2 & 5.4204 & TST & \\
\hline CHEMBL1599021 & 688422 & 4.8 & 5.2439 & TRN & \\
\hline CHEMBL1441549 & 688422 & 6.05 & 5.4375 & TRN & \\
\hline CHEMBL1523172 & 688422 & 5.45 & 4.9662 & TST & \\
\hline CHEMBL1602715 & 688422 & 7.1002 & 5.0323 & TST & \\
\hline CHEMBL1604962 & 688422 & 6.05 & 5.4158 & TRN & \\
\hline CHEMBL1386588 & 688422 & 5.4 & 4.9687 & TRN & \\
\hline CHEMBL3208158 & 688422 & 5.1 & 5.33799 & 9999999999 & TRN \\
\hline CHEMBL1531097 & 688422 & 8.3468 & 5.2672 & TST & \\
\hline CHEMBL3209909 & 688422 & 4.7 & 5.2462 & TRN & \\
\hline CHEMBL1336445 & 688422 & 7.2 & 5.37299 & 9999999999 & TRN \\
\hline CHEMBL1419058 & 688422 & 4.95 & 5.2214 & TRN & \\
\hline
\end{tabular}




\begin{tabular}{|c|c|c|c|c|c|}
\hline \multicolumn{6}{|c|}{ Supplemental Table S2.txt } \\
\hline CHEMBL1467209 & 688422 & 4.6 & 5.3581 & TRN & \\
\hline CHEMBL1392136 & 688422 & 4.5 & 4.9511 & TRN & \\
\hline CHEMBL1342546 & 688422 & 4.65 & 5.0013 & TRN & \\
\hline CHEMBL3198435 & 688422 & 4.9 & 5.0488 & TST & \\
\hline CHEMBL1590744 & 688422 & 5.0 & 4.989 & TRN & \\
\hline CHEMBL1456254 & 688422 & 4.8 & 5.0554 & TRN & \\
\hline CHEMBL1347306 & 688422 & 4.7 & 5.5807 & TST & \\
\hline CHEMBL1542862 & 688422 & 4.7 & 4.7048 & TRN & \\
\hline CHEMBL1541855 & 688422 & 6.25 & 5.175 & TRN & \\
\hline CHEMBL1330506 & 688422 & 4.65 & 5.4211 & TST & \\
\hline CHEMBL89697 & 688422 & 5.0 & 5.1242 & TRN & \\
\hline CHEMBL1521263 & 688422 & 4.9 & 5.2135 & TRN & \\
\hline CHEMBL1601852 & 688422 & 8.0 & 5.3611 & TRN & \\
\hline CHEMBL1470589 & 688422 & 4.45 & 5.4895 & TRN & \\
\hline CHEMBL1549489 & 688422 & 8.4559 & 5.4076 & TST & \\
\hline CHEMBL1501814 & 688422 & 4.95 & 5.5555 & TST & \\
\hline CHEMBL1349892 & 688422 & 4.5 & 5.2469 & TRN & \\
\hline CHEMBL3211664 & 688422 & 5.8 & 5.4295 & TRN & \\
\hline CHEMBL1562515 & 688422 & 7.699 & 5.2068 & TRN & \\
\hline CHEMBL1345294 & 688422 & 4.9 & 4.7091 & TRN & \\
\hline CHEMBL1331229 & 688422 & 4.8 & 5.0349 & TRN & \\
\hline CHEMBL1600698 & 688422 & 4.75 & 5.062 & TRN & \\
\hline CHEMBL1387069 & 688422 & 4.7 & 5.0101 & TRN & \\
\hline CHEMBL 290077 & 688422 & 4.45 & 6.4445 & TRN & \\
\hline CHEMBL1498302 & 688422 & 6.4 & 5.2895 & TRN & \\
\hline CHEMBL1332955 & 688422 & 4.85 & 5.3508 & TST & \\
\hline CHEMBL1434003 & 688422 & 6.35 & 5.6007 & TRN & \\
\hline CHEMBL1529946 & 688422 & 4.5 & 5.0134 & TST & \\
\hline CHEMBL1564801 & 688422 & 4.9 & 4.9094 & TST & \\
\hline CHEMBL1469846 & 688422 & 5.7 & 5.485 & TRN & \\
\hline CHEMBL1516852 & 688422 & 4.55 & 5.555 & TST & \\
\hline CHEMBL1471204 & 688422 & 5.55 & 5.5042 & TRN & \\
\hline CHEMBL1522226 & 688422 & 4.9 & 5.403 & TRN & \\
\hline CHEMBL1422047 & 688422 & 4.85 & 5.2105 & TRN & \\
\hline CHEMBL1579676 & 688422 & 6.45 & 5.4155 & TST & \\
\hline CHEMBL1502097 & 688422 & 5.8 & 5.6218 & TST & \\
\hline CHEMBL1308224 & 688422 & 4.45 & 4.6686 & TRN & \\
\hline CHEMBL1555869 & 688422 & 7.4001 & 5.6945 & TRN & \\
\hline CHEMBL580918 & 688422 & 4.6 & 5.1664 & TRN & \\
\hline CHEMBL1481439 & 688422 & 4.7 & 5.0285 & TRN & \\
\hline CHEMBL1355814 & 688422 & 4.85 & 5.2158 & TRN & \\
\hline CHEMBL1416418 & 688422 & 4.85 & 5.2361 & TRN & \\
\hline CHEMBL1340733 & 688422 & 4.5 & 5.5281 & TST & \\
\hline CHEMBL1366635 & 688422 & 4.7 & 5.05399 & 9999999999 & TST \\
\hline CHEMBL1530935 & 688422 & 4.45 & 4.8746 & TRN & \\
\hline CHEMBL1324710 & 688422 & 4.9 & 5.1725 & TRN & \\
\hline CHEMBL1576155 & 688422 & 4.85 & 5.38299 & 9999999999 & TRN \\
\hline CHEMBL1463177 & 688422 & 5.55 & 5.3566 & TRN & \\
\hline
\end{tabular}




\begin{tabular}{|c|c|c|c|c|}
\hline \multicolumn{5}{|c|}{ Supplemental Table S2.txt } \\
\hline CHEMBL1533567 & 688422 & 4.65 & 5.2507 & TRN \\
\hline CHEMBL1425415 & 688422 & 4.45 & 5.324 & TRN \\
\hline CHEMBL1538300 & 688422 & 4.5 & 5.7715 & TST \\
\hline CHEMBL1535385 & 688422 & 4.75 & 5.2739 & TRN \\
\hline CHEMBL1401647 & 688422 & 6.1 & 5.9071 & TRN \\
\hline CHEMBL1586054 & 688422 & 4.75 & 5.5376 & TST \\
\hline CHEMBL1427152 & 688422 & 4.5 & 4.8903 & TRN \\
\hline CHEMBL1511869 & 688422 & 5.6 & 5.3305 & TST \\
\hline CHEMBL1434827 & 688422 & 8.3979 & 5.1978 & TRN \\
\hline CHEMBL1457842 & 688422 & 6.5501 & 5.3964 & TST \\
\hline CHEMBL1583248 & 688422 & 4.45 & 5.0018 & TRN \\
\hline CHEMBL1538446 & 688422 & 4.85 & 5.4253 & TRN \\
\hline CHEMBL1423288 & 688422 & 4.45 & 4.976 & TST \\
\hline CHEMBL1344918 & 688422 & 5.25 & 5.1538 & TRN \\
\hline CHEMBL3198947 & 688422 & 4.65 & 5.0183 & TRN \\
\hline CHEMBL1509879 & 688422 & 5.5 & 5.7582 & TST \\
\hline CHEMBL1553660 & 688422 & 4.45 & 5.1942 & TRN \\
\hline CHEMBL1389161 & 688422 & 4.95 & 5.0471 & TRN \\
\hline CHEMBL1305486 & 688422 & 5.35 & 4.8883 & TRN \\
\hline CHEMBL1345839 & 688422 & 4.75 & 5.5807 & TRN \\
\hline CHEMBL1501953 & 688422 & 4.65 & 5.1949 & TST \\
\hline CHEMBL1511816 & 688422 & 4.9 & 4.9343 & TRN \\
\hline CHEMBL1451362 & 688422 & 5.35 & 5.3354 & TRN \\
\hline CHEMBL1325873 & 688422 & 4.8 & 5.0742 & TRN \\
\hline CHEMBL1475255 & 688422 & 5.35 & 4.9536 & TRN \\
\hline CHEMBL1367222 & 688422 & 4.9 & 5.0594 & TRN \\
\hline CHEMBL1571245 & 688422 & 4.9 & 5.3419 & TRN \\
\hline CHEMBL1339296 & 688422 & 4.65 & 5.901 & TST \\
\hline CHEMBL1521643 & 688422 & 5.6 & 5.5472 & TRN \\
\hline CHEMBL1377869 & 688422 & 6.8499 & 5.2775 & TST \\
\hline CHEMBL1367711 & 688422 & 4.45 & 4.8322 & TRN \\
\hline CHEMBL1588584 & 688422 & 4.65 & 5.6375 & TST \\
\hline CHEMBL1303513 & 688422 & 5.65 & 5.1663 & TST \\
\hline CHEMBL1473523 & 688422 & 6.4 & 5.3599 & TST \\
\hline CHEMBL1530090 & 688422 & 4.95 & 5.2499 & TRN \\
\hline CHEMBL1357646 & 688422 & 7.699 & 5.2651 & TST \\
\hline CHEMBL1527843 & 688422 & 4.85 & 5.2547 & TST \\
\hline CHEMBL1577210 & 688422 & 4.45 & 4.9658 & TRN \\
\hline CHEMBL1510455 & 688422 & 5.0 & 5.3174 & TST \\
\hline CHEMBL1348000 & 688422 & 7.3002 & 5.2785 & TRN \\
\hline CHEMBL1508560 & 688422 & 4.65 & 5.2315 & TRN \\
\hline CHEMBL 1570557 & 688422 & 4.6 & 5.2684 & TRN \\
\hline CHEMBL1559586 & 688422 & 4.8 & 5.1454 & TRN \\
\hline CHEMBL1522212 & 688422 & 4.85 & 5.4486 & TRN \\
\hline CHEMBL1536728 & 688422 & 4.65 & 4.7437 & TRN \\
\hline CHEMBL1327781 & 688422 & 5.7 & 4.8667 & TRN \\
\hline CHEMBL1590309 & 688422 & 4.45 & 5.6354 & TRN \\
\hline CHEMBL1472585 & 688422 & 5.05 & 6.0658 & TST \\
\hline
\end{tabular}




\begin{tabular}{|c|c|c|c|c|c|}
\hline \multicolumn{6}{|c|}{ Supplemental Table S2.txt } \\
\hline CHEMBL1380630 & 688422 & 4.45 & 5.6554 & TRN & \\
\hline CHEMBL487958 & 688422 & 6.5 & 5.1661 & TRN & \\
\hline CHEMBL1402543 & 688422 & 4.95 & 5.3061 & TRN & \\
\hline CHEMBL1976099 & 688422 & 5.2 & 4.9462 & TRN & \\
\hline CHEMBL3207581 & 688422 & 4.9 & 5.2410 & 00000000005 & TRN \\
\hline CHEMBL1422205 & 688422 & 4.65 & 5.2360 & 0000000001 & TST \\
\hline CHEMBL1516211 & 688422 & 4.45 & 5.0663 & TRN & \\
\hline CHEMBL1396897 & 688422 & 4.45 & 5.6028 & TRN & \\
\hline CHEMBL1991055 & 688422 & 4.45 & 5.3211 & TST & \\
\hline CHEMBL1345685 & 688422 & 4.6 & 5.0099 & TRN & \\
\hline CHEMBL1301271 & 688422 & 5.0 & 5.0129 & TRN & \\
\hline CHEMBL1496452 & 688422 & 4.55 & 5.2231 & TRN & \\
\hline CHEMBL1451428 & 688422 & 6.3 & 5.1751 & TRN & \\
\hline CHEMBL1470176 & 688422 & 4.8 & 4.9862 & TRN & \\
\hline CHEMBL1515852 & 688422 & 5.65 & 5.4747 & TRN & \\
\hline CHEMBL1334556 & 688422 & 5.25 & 5.1752 & TST & \\
\hline CHEMBL1363949 & 688422 & 4.45 & 4.9424 & TRN & \\
\hline CHEMBL1475180 & 688422 & 4.45 & 5.3199 & TRN & \\
\hline CHEMBL1374177 & 688422 & 6.1 & 5.0939 & TST & \\
\hline CHEMBL1469750 & 688422 & 4.6 & 5.0382 & TST & \\
\hline CHEMBL1583869 & 688422 & 5.5 & 5.2233 & TST & \\
\hline CHEMBL1213137 & 688422 & 5.05 & 5.3058 & TST & \\
\hline CHEMBL1523567 & 688422 & 4.85 & 4.9055 & TRN & \\
\hline CHEMBL1474267 & 688422 & 5.45 & 5.5035 & TRN & \\
\hline CHEMBL1481098 & 688422 & 4.9 & 5.1103 & TRN & \\
\hline CHEMBL1538833 & 688422 & 4.65 & 5.0182 & TRN & \\
\hline CHEMBL1519884 & 688422 & 5.35 & 5.4143 & TST & \\
\hline CHEMBL1865649 & 688422 & 5.3 & 5.5906 & TRN & \\
\hline CHEMBL1311806 & 688422 & 4.45 & 5.1610 & 00000000005 & TST \\
\hline CHEMBL1400533 & 688422 & 5.25 & 5.3355 & TST & \\
\hline CHEMBL1376468 & 688422 & 4.45 & 5.1983 & TRN & \\
\hline CHEMBL1313133 & 688422 & 4.85 & 5.6599 & TST & \\
\hline CHEMBL548062 & 688422 & 4.95 & 5.0871 & TST & \\
\hline CHEMBL1388958 & 688422 & 4.95 & 5.0792 & TRN & \\
\hline CHEMBL3213757 & 688422 & 4.45 & 5.4108 & TRN & \\
\hline CHEMBL1563044 & 688422 & 5.05 & 5.1211 & TRN & \\
\hline CHEMBL1443408 & 688422 & 4.9 & 5.0289 & TRN & \\
\hline CHEMBL1324496 & 688422 & 4.6 & 5.0444 & TRN & \\
\hline CHEMBL1354748 & 688422 & 4.5 & 5.4778 & TRN & \\
\hline CHEMBL1559126 & 688422 & 4.45 & 5.1193 & TRN & \\
\hline CHEMBL1407472 & 688422 & 4.95 & 5.5120 & 00000000005 & TRN \\
\hline CHEMBL1433566 & 688422 & 5.95 & 5.0086 & TRN & \\
\hline CHEMBL1504127 & 688422 & 4.6 & 4.7684 & TRN & \\
\hline CHEMBL1361574 & 688422 & 4.8 & 5.1263 & TRN & \\
\hline CHEMBL1522484 & 688422 & 4.5 & 5.2535 & TRN & \\
\hline CHEMBL1381047 & 688422 & 4.45 & 5.2345 & TRN & \\
\hline CHEMBL1424769 & 688422 & 5.55 & 5.1537 & TST & \\
\hline CHEMBL1466376 & 688422 & 5.55 & 5.6986 & TST & \\
\hline
\end{tabular}




\begin{tabular}{|c|c|c|c|c|c|}
\hline \multicolumn{6}{|c|}{ Supplemental Table s2.txt } \\
\hline CHEMBL1562618 & 688422 & 5.3 & 5.2714 & TRN & \\
\hline CHEMBL3210767 & 688422 & 6.35 & 5.3983 & TRN & \\
\hline CHEMBL1448336 & 688422 & 4.8 & 5.3015 & TRN & \\
\hline CHEMBL1311570 & 688422 & 4.45 & 4.7749 & TRN & \\
\hline CHEMBL1586681 & 688422 & 5.0 & 5.1197 & TRN & \\
\hline CHEMBL1348030 & 688422 & 4.6 & 5.2993 & TRN & \\
\hline CHEMBL1387205 & 688422 & 4.9 & 4.8046 & TST & \\
\hline CHEMBL1312445 & 688422 & 5.6 & 5.1133 & TRN & \\
\hline CHEMBL1302894 & 688422 & 4.45 & 5.0549 & TST & \\
\hline CHEMBL1364048 & 688422 & 4.7 & 5.526 & TRN & \\
\hline CHEMBL1520239 & 688422 & 4.9 & 5.3482 & TRN & \\
\hline CHEMBL1362066 & 688422 & 4.45 & 5.2856 & TST & \\
\hline CHEMBL1510038 & 688422 & 6.1 & 4.9046 & TRN & \\
\hline CHEMBL15799 & 688422 & 6.1 & 5.4496 & TRN & \\
\hline CHEMBL1498523 & 688422 & 4.9 & 4.8928 & TST & \\
\hline CHEMBL1524831 & 688422 & 4.45 & 5.2598 & TRN & \\
\hline CHEMBL1445124 & 688422 & 4.45 & 4.8924 & TST & \\
\hline CHEMBL1479905 & 688422 & 4.45 & 5.2793 & TRN & \\
\hline CHEMBL1997747 & 688422 & 4.95 & 5.4053 & TRN & \\
\hline CHEMBL1586022 & 688422 & 4.6 & 5.3458 & TRN & \\
\hline CHEMBL1374814 & 688422 & 4.45 & 4.9172 & TRN & \\
\hline CHEMBL1506459 & 688422 & 4.9 & 4.6029 & TRN & \\
\hline CHEMBL1311871 & 688422 & 4.8 & 5.0097 & TRN & \\
\hline CHEMBL1422674 & 688422 & 8.4949 & 5.2416 & TRN & \\
\hline CHEMBL1404408 & 688422 & 4.45 & 4.8978 & TRN & \\
\hline CHEMBL1399528 & 688422 & 5.0 & 4.9645 & TRN & \\
\hline CHEMBL1445456 & 688422 & 4.5 & 5.0186 & TRN & \\
\hline CHEMBL3189712 & 688422 & 5.1 & 5.1654 & TRN & \\
\hline CHEMBL1470611 & 688422 & 4.45 & 4.74100 & 00000000005 & TRN \\
\hline CHEMBL1416781 & 688422 & 4.7 & 4.8669 & TRN & \\
\hline CHEMBL1533353 & 688422 & 4.45 & 5.0822 & TRN & \\
\hline CHEMBL1415358 & 688422 & 4.7 & 5.3053 & TST & \\
\hline CHEMBL1480909 & 688422 & 4.95 & 5.2069 & TRN & \\
\hline CHEMBL1573667 & 688422 & 6.1 & 4.993 & TRN & \\
\hline CHEMBL1308037 & 688422 & 4.5 & 4.7302 & TRN & \\
\hline CHEMBL1376451 & 688422 & 4.7 & 4.9075 & TST & \\
\hline CHEMBL1447716 & 688422 & 5.2 & 5.1943 & TRN & \\
\hline CHEMBL1379659 & 688422 & 4.6 & 5.1288 & TRN & \\
\hline CHEMBL1492214 & 688422 & 4.9 & 4.9159 & TST & \\
\hline CHEMBL3198860 & 688422 & 6.5501 & 5.1373 & TRN & \\
\hline CHEMBL1602799 & 688422 & 4.45 & 4.9201 & TRN & \\
\hline CHEMBL 72365 & 688422 & 4.95 & 5.2337 & TST & \\
\hline CHEMBL3189770 & 688422 & 4.95 & 5.1645 & TST & \\
\hline CHEMBL1325819 & 688422 & 4.9 & 5.3545 & TST & \\
\hline CHEMBL1334825 & 688422 & 4.45 & 5.0662 & TST & \\
\hline CHEMBL1543939 & 688422 & 5.2 & 4.9992 & TST & \\
\hline CHEMBL1320716 & 688422 & 4.65 & 5.3056 & TRN & \\
\hline CHEMBL1486652 & 688422 & 4.65 & 4.935 & TRN & \\
\hline
\end{tabular}




\begin{tabular}{|c|c|c|c|c|}
\hline \multicolumn{5}{|c|}{ Supplemental Table S2.txt } \\
\hline CHEMBL1573546 & 688422 & 4.95 & 5.3829 & TRN \\
\hline CHEMBL1593345 & 688422 & 5.0 & 5.0289 & TST \\
\hline CHEMBL1415508 & 688422 & 4.45 & 5.046 & TRN \\
\hline CHEMBL1496972 & 688422 & 5.0 & 4.8248 & TRN \\
\hline CHEMBL1325724 & 688422 & 4.95 & 5.1163 & TST \\
\hline CHEMBL3194320 & 688422 & 5.45 & 5.9703 & TRN \\
\hline CHEMBL1452951 & 688422 & 7.2503 & 5.0839 & TST \\
\hline CHEMBL1499195 & 688422 & 5.5 & 4.9818 & TRN \\
\hline CHEMBL1374653 & 688422 & 4.95 & 5.1158 & TRN \\
\hline CHEMBL1470121 & 688422 & 4.45 & 4.7106 & TRN \\
\hline CHEMBL1357617 & 688422 & 8.0 & 4.6205 & TRN \\
\hline CHEMBL1301555 & 688422 & 4.8 & 5.1933 & TRN \\
\hline CHEMBL1399299 & 688422 & 4.95 & 5.4304 & TST \\
\hline CHEMBL1389264 & 688422 & 4.9 & 5.3353 & TRN \\
\hline CHEMBL1413480 & 688422 & 4.8 & 5.5829 & TRN \\
\hline CHEMBL1606110 & 688422 & 4.5 & 4.8035 & TRN \\
\hline CHEMBL1309011 & 688422 & 8.0 & 5.2129 & TST \\
\hline CHEMBL1495584 & 688422 & 5.55 & 5.3981 & TRN \\
\hline CHEMBL1453959 & 688422 & 4.85 & 5.1312 & TRN \\
\hline CHEMBL1543625 & 688422 & 4.8 & 5.3833 & TRN \\
\hline CHEMBL1342825 & 688422 & 4.8 & 5.2269 & TRN \\
\hline CHEMBL1488697 & 688422 & 8.4949 & 5.5768 & TRN \\
\hline CHEMBL1425746 & 688422 & 4.75 & 5.4924 & TRN \\
\hline CHEMBL1387988 & 688422 & 4.45 & 4.9705 & TRN \\
\hline CHEMBL1422173 & 688422 & 4.9 & 5.5774 & TRN \\
\hline CHEMBL1506218 & 688422 & 4.95 & 5.3968 & TRN \\
\hline CHEMBL484901 & 688422 & 7.0501 & 5.5948 & TRN \\
\hline CHEMBL1581491 & 688422 & 4.65 & 4.8335 & TRN \\
\hline CHEMBL586024 & 688422 & 4.65 & 5.1969 & TRN \\
\hline CHEMBL3190337 & 688422 & 4.45 & 5.2398 & TST \\
\hline CHEMBL1531444 & 688422 & 5.95 & 5.4526 & TRN \\
\hline CHEMBL582737 & 688422 & 5.1 & 5.601 & TRN \\
\hline CHEMBL1491292 & 688422 & 6.6 & 5.5437 & TRN \\
\hline CHEMBL1363882 & 688422 & 5.9 & 5.5417 & TRN \\
\hline CHEMBL1346610 & 688422 & 4.95 & 5.0248 & TRN \\
\hline CHEMBL1504243 & 688422 & 4.85 & 5.3143 & TRN \\
\hline CHEMBL1541518 & 688422 & 4.65 & 5.2548 & TRN \\
\hline CHEMBL1505089 & 688422 & 4.85 & 4.8077 & TRN \\
\hline CHEMBL1531880 & 688422 & 4.6 & 4.9074 & TRN \\
\hline CHEMBL1447664 & 688422 & 6.8499 & 5.5479 & TST \\
\hline CHEMBL1582279 & 688422 & 4.85 & 5.6434 & TRN \\
\hline CHEMBL3210711 & 688422 & 4.5 & 4.9971 & TRN \\
\hline CHEMBL1435278 & 688422 & 5.85 & 5.3452 & TRN \\
\hline CHEMBL1424246 & 688422 & 8.1024 & 5.4415 & TRN \\
\hline CHEMBL1596702 & 688422 & 4.6 & 5.0849 & TST \\
\hline CHEMBL 258485 & 688422 & 4.85 & 5.1277 & TRN \\
\hline CHEMBL1568310 & 688422 & 4.5 & 5.4755 & TRN \\
\hline CHEMBL1486041 & 688422 & 4.75 & 5.2256 & TRN \\
\hline
\end{tabular}




\begin{tabular}{|c|c|c|c|c|c|}
\hline \multirow[b]{2}{*}{ CHEMBL1315542 } & \multicolumn{5}{|c|}{ Supplemental Table S2.txt } \\
\hline & 688422 & 6.5501 & 5.2393 & TRN & \\
\hline CHEMBL1443276 & 688422 & 4.9 & 5.4031 & TST & \\
\hline CHEMBL1389604 & 688422 & 8.3468 & 5.5779 & TRN & \\
\hline CHEMBL1319534 & 688422 & 5.1 & 5.0099 & TRN & \\
\hline CHEMBL1362939 & 688422 & 6.8499 & 5.5912 & TST & \\
\hline CHEMBL1421211 & 688422 & 4.8 & 5.0931 & TRN & \\
\hline CHEMBL1508388 & 688422 & 5.85 & 5.3853 & TRN & \\
\hline CHEMBL539027 & 688422 & 4.65 & 4.8516 & TRN & \\
\hline CHEMBL1541834 & 688422 & 5.05 & 5.29700 & 0000000001 & TRN \\
\hline CHEMBL1369144 & 688422 & 5.05 & 4.8844 & TST & \\
\hline CHEMBL1200921 & 688422 & 6.35 & 6.0088 & TST & \\
\hline CHEMBL525888 & 688422 & 4.95 & 5.7463 & TRN & \\
\hline CHEMBL1362746 & 688422 & 6.35 & 5.517 & TRN & \\
\hline CHEMBL1437081 & 688422 & 4.85 & 5.5001 & TRN & \\
\hline CHEMBL3195935 & 688422 & 5.6 & 5.1416 & TRN & \\
\hline CHEMBL1412996 & 688422 & 4.85 & 5.3409 & TRN & \\
\hline CHEMBL1409488 & 688422 & 6.9 & 5.3158 & TRN & \\
\hline CHEMBL1568026 & 688422 & 4.85 & 5.2304 & TST & \\
\hline CHEMBL1350095 & 688422 & 4.8 & 5.3573 & TRN & \\
\hline CHEMBL3211833 & 688422 & 4.6 & 5.2924 & TRN & \\
\hline CHEMBL1308931 & 688422 & 4.6 & 5.6873 & TRN & \\
\hline CHEMBL1465508 & 688422 & 4.45 & 4.9894 & TST & \\
\hline CHEMBL1503946 & 688422 & 4.7 & 4.9656 & TRN & \\
\hline CHEMBL1403148 & 688422 & 5.55 & 4.7488 & TRN & \\
\hline CHEMBL1438379 & 688422 & 4.95 & 5.5722 & TRN & \\
\hline CHEMBL3195202 & 688422 & 5.0 & 5.3124 & TRN & \\
\hline CHEMBL1523465 & 688422 & 4.9 & 5.3771 & TRN & \\
\hline CHEMBL1401091 & 688422 & 4.95 & 4.8948 & TRN & \\
\hline CHEMBL1394137 & 688422 & 5.0 & 5.1202 & TRN & \\
\hline CHEMBL1426700 & 688422 & 5.85 & 5.282 & TRN & \\
\hline CHEMBL1586773 & 688422 & 4.8 & 6.1354 & TRN & \\
\hline CHEMBL1607859 & 688422 & 5.2 & 5.0653 & TST & \\
\hline CHEMBL1568371 & 688422 & 5.0 & 5.0213 & TST & \\
\hline CHEMBL1504424 & 688422 & 4.95 & 5.0083 & TRN & \\
\hline CHEMBL1450040 & 688422 & 5.5 & 5.1807 & TRN & \\
\hline CHEMBL1437577 & 688422 & 4.8 & 5.3072 & TRN & \\
\hline CHEMBL1487155 & 688422 & 5.0 & 4.9478 & TRN & \\
\hline CHEMBL1512164 & 688422 & 7.8508 & 4.8726 & TRN & \\
\hline CHEMBL1390931 & 688422 & 4.45 & 5.5601 & TRN & \\
\hline CHEMBL1431139 & 688422 & 4.75 & 4.9323 & TRN & \\
\hline CHEMBL1506082 & 688422 & 6.2 & 5.186 & TRN & \\
\hline CHEMBL3210216 & 688422 & 5.95 & 5.3284 & TRN & \\
\hline CHEMBL1382264 & 688422 & 4.95 & 4.9447 & TRN & \\
\hline CHEMBL1367899 & 688422 & 4.65 & 4.8091 & TRN & \\
\hline CHEMBL1541819 & 688422 & 4.95 & 5.13 & TRN & \\
\hline CHEMBL1735961 & 688422 & 5.45 & 5.6835 & TRN & \\
\hline CHEMBL3196553 & 688422 & 4.45 & 5.7334 & TST & \\
\hline CHEMBL1526778 & 688422 & 4.9 & 4.9821 & TST & \\
\hline
\end{tabular}




\begin{tabular}{|c|c|c|c|c|}
\hline \multicolumn{5}{|c|}{ Supplemental Table S2.txt } \\
\hline CHEMBL1571498 & 688422 & 5.75 & 5.3626 & TRN \\
\hline CHEMBL1481714 & 688422 & 8.3468 & 5.3345 & TRN \\
\hline CHEMBL1594507 & 688422 & 8.1487 & 5.4271 & TST \\
\hline CHEMBL1544847 & 688422 & 5.25 & 4.9915 & TRN \\
\hline CHEMBL1256737 & 688422 & 6.0 & 5.2019 & TRN \\
\hline CHEMBL1307725 & 688422 & 4.45 & 4.8574 & TRN \\
\hline CHEMBL1398241 & 688422 & 4.75 & 5.2727 & TRN \\
\hline CHEMBL1587218 & 688422 & 5.55 & 5.3013 & TRN \\
\hline CHEMBL1302320 & 688422 & 4.45 & 5.0245 & TRN \\
\hline CHEMBL1301072 & 688422 & 5.55 & 5.3608 & TST \\
\hline CHEMBL1429272 & 688422 & 4.6 & 5.4606 & TRN \\
\hline CHEMBL1523918 & 688422 & 4.85 & 4.9781 & TRN \\
\hline CHEMBL1552711 & 688422 & 4.95 & 5.5375 & TRN \\
\hline CHEMBL1522374 & 688422 & 5.55 & 5.4606 & TRN \\
\hline CHEMBL1541391 & 688422 & 4.6 & 4.6774 & TST \\
\hline CHEMBL1371385 & 688422 & 5.45 & 5.6746 & TST \\
\hline CHEMBL1496157 & 688422 & 6.95 & 6.0021 & TST \\
\hline CHEMBL1325882 & 688422 & 5.9 & 5.0397 & TST \\
\hline CHEMBL1390441 & 688422 & 4.45 & 5.4171 & TRN \\
\hline CHEMBL1324626 & 688422 & 6.5 & 5.3276 & TRN \\
\hline CHEMBL1605234 & 688422 & 6.4 & 5.5488 & TRN \\
\hline CHEMBL1481295 & 688422 & 4.75 & 5.0932 & TRN \\
\hline CHEMBL1579580 & 688422 & 5.25 & 5.2588 & TRN \\
\hline CHEMBL3189172 & 688422 & 4.85 & 5.3749 & TST \\
\hline CHEMBL1348074 & 688422 & 4.85 & 5.1945 & TRN \\
\hline CHEMBL1327373 & 688422 & 4.8 & 5.1712 & TRN \\
\hline CHEMBL112060 & 688422 & 4.95 & 4.8798 & TRN \\
\hline CHEMBL1483542 & 688422 & 5.5 & 4.9947 & TRN \\
\hline CHEMBL1315208 & 688422 & 5.25 & 5.7037 & TRN \\
\hline CHEMBL1509258 & 688422 & 4.45 & 4.7517 & TST \\
\hline CHEMBL1332792 & 688422 & 5.45 & 5.9349 & TST \\
\hline CHEMBL1368074 & 688422 & 4.6 & 5.2358 & TST \\
\hline CHEMBL1482056 & 688422 & 5.55 & 5.4635 & TST \\
\hline CHEMBL1484249 & 688422 & 8.4559 & 5.447 & TRN \\
\hline CHEMBL530291 & 688422 & 4.95 & 5.2622 & TRN \\
\hline CHEMBL3210628 & 688422 & 4.45 & 5.1274 & TST \\
\hline CHEMBL 266997 & 688422 & 4.65 & 5.2978 & TRN \\
\hline CHEMBL1338820 & 688422 & 4.55 & 5.2042 & TST \\
\hline CHEMBL1367735 & 688422 & 4.9 & 5.226 & TRN \\
\hline CHEMBL1610717 & 688422 & 4.75 & 5.4184 & TRN \\
\hline CHEMBL1426372 & 688422 & 6.25 & 5.7417 & TST \\
\hline CHEMBL1317423 & 688422 & 4.7 & 4.8423 & TRN \\
\hline CHEMBL3198616 & 688422 & 6.0 & 5.1685 & TRN \\
\hline CHEMBL1597351 & 688422 & 5.35 & 4.9998 & TST \\
\hline CHEMBL1524757 & 688422 & 4.95 & 5.0734 & TRN \\
\hline CHEMBL1581807 & 688422 & 4.8 & 5.2455 & TST \\
\hline CHEMBL1425409 & 688422 & 4.85 & 5.2058 & TST \\
\hline CHEMBL1600868 & 688422 & 4.9 & 5.1645 & TRN \\
\hline
\end{tabular}




\begin{tabular}{|c|c|c|c|c|c|}
\hline \multicolumn{6}{|c|}{ Supplemental Table s2.txt } \\
\hline CHEMBL1568950 & 688422 & 4.65 & 4.6521 & TST & \\
\hline CHEMBL 3196548 & 688422 & 4.9 & 5.1502 & TRN & \\
\hline CHEMBL1444006 & 688422 & 4.85 & 5.2638 & TRN & \\
\hline CHEMBL1515185 & 688422 & 5.2 & 5.4282 & TRN & \\
\hline CHEMBL1316953 & 688422 & 9.0969 & 5.6223 & TRN & \\
\hline CHEMBL1449569 & 688422 & 4.65 & 4.6789 & TRN & \\
\hline CHEMBL1369824 & 688422 & 5.2 & 4.9024 & TRN & \\
\hline CHEMBL1577737 & 688422 & 6.45 & 5.2268 & TRN & \\
\hline CHEMBL3195398 & 688422 & 5.3 & 5.1962 & TST & \\
\hline CHEMBL1353661 & 688422 & 4.95 & 5.1249 & TRN & \\
\hline CHEMBL3198512 & 688422 & 4.85 & 5.8924 & TST & \\
\hline CHEMBL1490529 & 688422 & 4.65 & 5.0058 & TRN & \\
\hline CHEMBL1471980 & 688422 & 5.5 & 5.142 & TRN & \\
\hline CHEMBL1500226 & 688422 & 4.55 & 4.9009 & TST & \\
\hline CHEMBL1399747 & 688422 & 4.75 & 4.8402 & TST & \\
\hline CHEMBL1581656 & 688422 & 5.0 & 5.5419 & TRN & \\
\hline CHEMBL1546134 & 688422 & 4.7 & 4.8701 & TST & \\
\hline CHEMBL1433562 & 688422 & 7.4001 & 5.2154 & TRN & \\
\hline CHEMBL1334563 & 688422 & 5.0 & 4.7565 & TRN & \\
\hline CHEMBL3209769 & 688422 & 4.95 & 4.7529 & TRN & \\
\hline CHEMBL1427906 & 688422 & 4.75 & 4.7749 & TRN & \\
\hline CHEMBL1532635 & 688422 & 4.95 & 5.3815 & TRN & \\
\hline CHEMBL1573045 & 688422 & 4.45 & 5.0391 & TRN & \\
\hline CHEMBL1454945 & 688422 & 4.8 & 5.3995 & TRN & \\
\hline CHEMBL1411456 & 688422 & 5.15 & 5.0904 & TRN & \\
\hline CHEMBL3193389 & 688422 & 4.6 & 4.9364 & TRN & \\
\hline CHEMBL1505833 & 688422 & 5.25 & 5.5234 & TRN & \\
\hline CHEMBL1507903 & 688422 & 8.1024 & 5.5258 & TRN & \\
\hline CHEMBL1352160 & 688422 & 4.95 & 4.9631 & TRN & \\
\hline CHEMBL1305333 & 688422 & 5.85 & 5.2104 & TRN & \\
\hline CHEMBL1379232 & 688422 & 6.1 & 4.9076 & TRN & \\
\hline CHEMBL1535921 & 688422 & 4.95 & 5.5269 & TRN & \\
\hline CHEMBL1418200 & 688422 & 4.95 & 5.3753 & TST & \\
\hline CHEMBL1468766 & 688422 & 4.8 & 5.2875 & TST & \\
\hline CHEMBL1305214 & 688422 & 4.55 & 5.0923 & TRN & \\
\hline CHEMBL1478128 & 688422 & 4.85 & 5.605 & TST & \\
\hline CHEMBL1402563 & 688422 & 4.9 & 5.5106 & TRN & \\
\hline CHEMBL1602927 & 688422 & 5.0 & 5.2356 & TST & \\
\hline CHEMBL1524203 & 688422 & 4.5 & 5.1909 & TST & \\
\hline CHEMBL1419963 & 688422 & 5.4 & 6.1126 & TRN & \\
\hline CHEMBL1474761 & 688422 & 4.85 & 5.88700 & 00000000005 & TRN \\
\hline CHEMBL1500101 & 688422 & 4.65 & 5.4427 & TRN & \\
\hline CHEMBL1609794 & 688422 & 4.7 & 5.5607 & TST & \\
\hline CHEMBL1473242 & 688422 & 6.0 & 5.0357 & TRN & \\
\hline CHEMBL1320640 & 688422 & 4.5 & 5.0916 & TRN & \\
\hline CHEMBL1525659 & 688422 & 5.4 & 5.3657 & TRN & \\
\hline CHEMBL1335890 & 688422 & 4.7 & 4.9184 & TRN & \\
\hline CHEMBL1360794 & 688422 & 4.95 & 5.36700 & $\partial 000000001$ & TRN \\
\hline & & & & 9655 & \\
\hline
\end{tabular}




\begin{tabular}{|c|c|c|c|c|}
\hline \multicolumn{5}{|c|}{ Supplemental Table S2.txt } \\
\hline CHEMBL1584669 & 688422 & 4.8 & 5.1511 & TRN \\
\hline CHEMBL1362712 & 688422 & 4.65 & 4.9579 & TRN \\
\hline CHEMBL1473205 & 688422 & 7.2503 & 5.2982 & TST \\
\hline CHEMBL1314638 & 688422 & 5.0 & 5.5717 & TRN \\
\hline CHEMBL1319486 & 688422 & 5.25 & 5.4289 & TRN \\
\hline CHEMBL1391423 & 688422 & 7.0 & 5.9351 & TRN \\
\hline CHEMBL1561033 & 688422 & 6.5 & 5.7291 & TRN \\
\hline CHEMBL1476962 & 688422 & 5.0 & 5.2834 & TRN \\
\hline CHEMBL1443584 & 688422 & 4.5 & 5.0936 & TRN \\
\hline CHEMBL117966 & 688422 & 4.45 & 5.2339 & TRN \\
\hline CHEMBL1538507 & 688422 & 5.2 & 5.4676 & TRN \\
\hline CHEMBL1364826 & 688422 & 4.85 & 5.685 & TST \\
\hline CHEMBL1360012 & 688422 & 4.6 & 5.4667 & TRN \\
\hline CHEMBL1585677 & 688422 & 4.95 & 5.0501 & TRN \\
\hline CHEMBL1604886 & 688422 & 5.25 & 5.2753 & TRN \\
\hline CHEMBL1340310 & 688422 & 5.45 & 5.0159 & TST \\
\hline CHEMBL1400792 & 688422 & 4.75 & 5.2054 & TRN \\
\hline CHEMBL1592989 & 688422 & 4.45 & 5.3349 & TRN \\
\hline CHEMBL1495497 & 688422 & 4.8 & 4.9997 & TRN \\
\hline CHEMBL1488534 & 688422 & 5.5 & 5.1927 & TRN \\
\hline CHEMBL3196688 & 688422 & 4.45 & 4.7642 & TRN \\
\hline CHEMBL3194116 & 688422 & 5.2 & 5.2144 & TRN \\
\hline CHEMBL1350894 & 688422 & 4.85 & 5.2817 & TRN \\
\hline CHEMBL1502862 & 688422 & 4.45 & 5.1484 & TRN \\
\hline CHEMBL1356109 & 688422 & 4.45 & 5.1365 & TST \\
\hline CHEMBL1424565 & 688422 & 5.45 & 5.6666 & TRN \\
\hline CHEMBL1503155 & 688422 & 5.15 & 4.8572 & TRN \\
\hline CHEMBL1551503 & 688422 & 4.75 & 5.2708 & TRN \\
\hline CHEMBL63976 & 688422 & 4.5 & 5.0951 & TRN \\
\hline CHEMBL1428886 & 688422 & 6.05 & 5.0474 & TRN \\
\hline CHEMBL1429713 & 688422 & 4.75 & 5.3333 & TRN \\
\hline CHEMBL1353483 & 688422 & 8.4949 & 5.6337 & TRN \\
\hline CHEMBL 3198821 & 688422 & 5.15 & 5.7919 & TST \\
\hline CHEMBL1374685 & 688422 & 4.45 & 4.905 & TRN \\
\hline CHEMBL1334932 & 688422 & 5.15 & 5.5493 & TRN \\
\hline CHEMBL1573243 & 688422 & 5.6 & 4.961 & TRN \\
\hline CHEMBL1573999 & 688422 & 8.0 & 5.1968 & TRN \\
\hline CHEMBL1342213 & 688422 & 4.6 & 5.0191 & TST \\
\hline CHEMBL1347644 & 688422 & 4.6 & 4.7985 & TST \\
\hline CHEMBL1345338 & 688422 & 4.9 & 4.798 & TRN \\
\hline CHEMBL1419372 & 688422 & 5.2 & 5.159 & TRN \\
\hline CHEMBL1330029 & 688422 & 5.5 & 5.2159 & TRN \\
\hline CHEMBL1500635 & 688422 & 5.0 & 5.0775 & TRN \\
\hline CHEMBL3191212 & 688422 & 4.45 & 5.1364 & TRN \\
\hline CHEMBL1500070 & 688422 & 4.45 & 4.8903 & TRN \\
\hline CHEMBL1585551 & 688422 & 8.3468 & 5.343 & TRN \\
\hline CHEMBL1593236 & 688422 & 4.45 & 4.9865 & TRN \\
\hline CHEMBL1558675 & 688422 & 7.7496 & 5.6525 & TRN \\
\hline
\end{tabular}




\begin{tabular}{|c|c|c|c|c|c|}
\hline \multicolumn{6}{|c|}{ Supplemental Table s2.txt } \\
\hline CHEMBL1400067 & 688422 & 5.3 & 5.2334 & TRN & \\
\hline CHEMBL 3194747 & 688422 & 4.65 & 5.4418 & TRN & \\
\hline CHEMBL1385281 & 688422 & 8.301 & 5.3431 & TST & \\
\hline CHEMBL1576221 & 688422 & 4.75 & 5.0687 & TRN & \\
\hline CHEMBL1421720 & 688422 & 4.8 & 5.2146 & TRN & \\
\hline CHEMBL1451929 & 688422 & 4.6 & 5.1103 & TRN & \\
\hline CHEMBL1518017 & 688422 & 6.25 & 6.0231 & TST & \\
\hline CHEMBL1370967 & 688422 & 5.55 & 5.5921 & TRN & \\
\hline CHEMBL513436 & 688422 & 4.85 & 5.2029 & TRN & \\
\hline CHEMBL1415509 & 688422 & 4.45 & 5.3237 & TST & \\
\hline CHEMBL1543719 & 688422 & 4.7 & 5.3693 & TRN & \\
\hline CHEMBL1604162 & 688422 & 4.45 & 5.0751 & TRN & \\
\hline CHEMBL1590311 & 688422 & 5.0 & 5.1733 & TRN & \\
\hline CHEMBL1495550 & 688422 & 5.35 & 5.2563 & TST & \\
\hline CHEMBL1595690 & 688422 & 4.95 & 5.1359 & TRN & \\
\hline CHEMBL1342883 & 688422 & 8.4949 & 5.2489 & TRN & \\
\hline CHEMBL1452729 & 688422 & 4.8 & 5.2867 & TST & \\
\hline CHEMBL1372231 & 688422 & 4.65 & 5.1534 & TRN & \\
\hline CHEMBL1377183 & 688422 & 4.7 & 5.2446 & TRN & \\
\hline CHEMBL1461147 & 688422 & 5.0 & 4.7443 & TST & \\
\hline CHEMBL1598285 & 688422 & 5.95 & 4.9546 & TRN & \\
\hline CHEMBL1494168 & 688422 & 6.45 & 5.4185 & TRN & \\
\hline CHEMBL1559100 & 688422 & 4.45 & 4.96899 & 9999999999 & TRN \\
\hline CHEMBL1611801 & 688422 & 8.3468 & 5.2645 & TRN & \\
\hline CHEMBL1350028 & 688422 & 5.3 & 5.7417 & TRN & \\
\hline CHEMBL1328085 & 688422 & 5.0 & 5.5899 & TRN & \\
\hline CHEMBL1518570 & 688422 & 6.0 & 5.3261 & TST & \\
\hline CHEMBL1580805 & 688422 & 4.85 & 5.1671 & TST & \\
\hline CHEMBL1558204 & 688422 & 8.4559 & 5.6597 & TRN & \\
\hline CHEMBL1423633 & 688422 & 5.55 & 5.6916 & TRN & \\
\hline CHEMBL1432427 & 688422 & 4.65 & 5.3183 & TRN & \\
\hline CHEMBL1377287 & 688422 & 4.9 & 4.9925 & TRN & \\
\hline CHEMBL408982 & 688422 & 6.1 & 5.2804 & TRN & \\
\hline CHEMBL1549744 & 688422 & 4.7 & 4.908 & TRN & \\
\hline CHEMBL 271139 & 688422 & 8.1024 & 5.7316 & TST & \\
\hline CHEMBL1607828 & 688422 & 4.95 & 5.0355 & TRN & \\
\hline CHEMBL1313043 & 688422 & 4.95 & 5.2425 & TST & \\
\hline CHEMBL1524477 & 688422 & 6.5501 & 5.1467 & TRN & \\
\hline CHEMBL1328128 & 688422 & 4.85 & 5.3239 & TRN & \\
\hline CHEMBL1492519 & 688422 & 4.95 & 5.0525 & TRN & \\
\hline CHEMBL1318174 & 688422 & 5.55 & 4.9754 & TRN & \\
\hline CHEMBL1384802 & 688422 & 7.699 & 5.771 & TST & \\
\hline CHEMBL3199526 & 688422 & 4.9 & 5.0963 & TRN & \\
\hline CHEMBL1559514 & 688422 & 5.05 & 5.3893 & TST & \\
\hline CHEMBL1545245 & 688422 & 5.5 & 5.1835 & TRN & \\
\hline CHEMBL1356146 & 688422 & 4.75 & 4.8742 & TRN & \\
\hline CHEMBL1420829 & 688422 & 4.95 & 5.50299 & 9999999999 & TRN \\
\hline CHEMBL1397050 & 688422 & 5.05 & 5.4398 & TST & \\
\hline
\end{tabular}




\begin{tabular}{|c|c|c|c|c|c|}
\hline \multirow{3}{*}{$\begin{array}{l}\text { CHEMBL1346479 } \\
\text { CHFMBI } 1611353\end{array}$} & \multirow{3}{*}{$\begin{array}{l}688422 \\
688422\end{array}$} & \multicolumn{4}{|c|}{ Supplemental Table S2.txt } \\
\hline & & 7.5003 & 5.37200 & 0000000001 & TRN \\
\hline & & 6.7001 & 5.6958 & TRN & \\
\hline CHEMBL1455957 & 688422 & 4.45 & 5.3992 & TST & \\
\hline CHEMBL 1496820 & 688422 & 7.0501 & 5.4411 & TST & \\
\hline CHEMBL1363996 & 688422 & 5.45 & 5.1827 & TRN & \\
\hline CHEMBL1392405 & 688422 & 4.8 & 5.0027 & TRN & \\
\hline CHEMBL1352919 & 688422 & 8.3468 & 5.5081 & TRN & \\
\hline CHEMBL1991327 & 688422 & 4.9 & 5.0579 & TRN & \\
\hline CHEMBL1330357 & 688422 & 6.0 & 5.3057 & TRN & \\
\hline CHEMBL1364316 & 688422 & 5.8 & 5.3047 & TRN & \\
\hline CHEMBL1332376 & 688422 & 4.65 & 5.45299 & 9999999999 & TRN \\
\hline CHEMBL1367341 & 688422 & 4.55 & 4.8524 & TRN & \\
\hline CHEMBL1351722 & 688422 & 5.15 & 5.042 & TRN & \\
\hline CHEMBL1364068 & 688422 & 4.75 & 5.2862 & TRN & \\
\hline CHEMBL1537658 & 688422 & 4.5 & 5.1639 & TRN & \\
\hline CHEMBL1373084 & 688422 & 4.45 & 4.8674 & TRN & \\
\hline CHEMBL1322532 & 688422 & 4.8 & 5.5985 & TRN & \\
\hline CHEMBL1550942 & 688422 & 5.25 & 5.5233 & TRN & \\
\hline CHEMBL3214364 & 688422 & 4.8 & 5.2567 & TRN & \\
\hline CHEMBL1429270 & 688422 & 4.7 & 5.6576 & TRN & \\
\hline CHEMBL1562304 & 688422 & 5.0 & 5.1319 & TRN & \\
\hline CHEMBL1577165 & 688422 & 5.95 & 5.3939 & TRN & \\
\hline CHEMBL1550755 & 688422 & 4.8 & 5.1667 & TRN & \\
\hline CHEMBL 1422576 & 688422 & 5.25 & 5.3489 & TST & \\
\hline CHEMBL1372378 & 688422 & 6.8499 & 5.4175 & TRN & \\
\hline CHEMBL1569530 & 688422 & 7.6498 & 5.3426 & TRN & \\
\hline CHEMBL1516918 & 688422 & 4.85 & 5.5219 & TRN & \\
\hline CHEMBL1500885 & 688422 & 4.45 & 5.25899 & 99999999995 & TRN \\
\hline CHEMBL1583129 & 688422 & 5.1 & 5.1354 & TST & \\
\hline CHEMBL1451375 & 688422 & 7.1002 & 5.1771 & TST & \\
\hline CHEMBL1436271 & 688422 & 5.4 & 5.1858 & TRN & \\
\hline CHEMBL368700 & 688422 & 4.95 & 5.4911 & TST & \\
\hline CHEMBL1446523 & 688422 & 4.7 & 5.2142 & TRN & \\
\hline CHEMBL1509805 & 688422 & 4.45 & 5.4106 & TRN & \\
\hline CHEMBL1505038 & 688422 & 4.45 & 5.3403 & TRN & \\
\hline CHEMBL1401424 & 688422 & 5.05 & 5.1471 & TRN & \\
\hline CHEMBL1303553 & 688422 & 5.0 & 5.4572 & TST & \\
\hline CHEMBL3189902 & 688422 & 7.4001 & 5.3081 & TRN & \\
\hline CHEMBL1592682 & 688422 & 4.95 & 5.1457 & TRN & \\
\hline CHEMBL1591494 & 688422 & 5.55 & 5.2492 & TRN & \\
\hline CHEMBL1506954 & 688422 & 4.65 & 5.0581 & TST & \\
\hline CHEMBL1555380 & 688422 & 4.45 & 4.8873 & TST & \\
\hline CHEMBL3197992 & 688422 & 4.9 & 5.0079 & TRN & \\
\hline CHEMBL1398442 & 688422 & 8.2518 & 5.3329 & TRN & \\
\hline CHEMBL1546347 & 688422 & 6.6 & 5.4997 & TST & \\
\hline CHEMBL1347752 & 688422 & 8.3468 & 5.1545 & TRN & \\
\hline CHEMBL1542429 & 688422 & 4.65 & 5.4005 & TRN & \\
\hline CHEMBL1392256 & 688422 & 5.95 & 4.7627 & TRN & \\
\hline
\end{tabular}




\begin{tabular}{|c|c|c|c|c|c|}
\hline & & \multicolumn{4}{|c|}{ Supplemental Table S2.txt } \\
\hline CHEMBL1432372 & 688422 & 7.0501 & 5.2141 & TRN & \\
\hline CHEMBL1413145 & 688422 & 8.4949 & 5.6025 & TRN & \\
\hline CHEMBL1331100 & 688422 & 4.85 & 5.1825 & TRN & \\
\hline CHEMBL1310468 & 688422 & 7.15 & 5.4583 & TST & \\
\hline CHEMBL1341142 & 688422 & 4.9 & 5.3021 & TRN & \\
\hline CHEMBL1451640 & 688422 & 5.35 & 5.71299 & 9999999999 & TST \\
\hline CHEMBL1601768 & 688422 & 4.95 & 5.7638 & TRN & \\
\hline CHEMBL1542958 & 688422 & 4.85 & 5.2279 & TST & \\
\hline CHEMBL1540918 & 688422 & 7.9508 & 5.308 & TRN & \\
\hline CHEMBL1611105 & 688422 & 4.45 & 5.1931 & TRN & \\
\hline CHEMBL1463984 & 688422 & 5.45 & 4.9073 & TRN & \\
\hline CHEMBL1377863 & 688422 & 5.0 & 4.7789 & TRN & \\
\hline CHEMBL3189154 & 688422 & 4.5 & 4.8132 & TRN & \\
\hline CHEMBL1610627 & 688422 & 5.25 & 5.2751 & TRN & \\
\hline CHEMBL1462049 & 688422 & 4.9 & 5.1213 & TRN & \\
\hline CHEMBL1380401 & 688422 & 4.8 & 5.2071 & TRN & \\
\hline CHEMBL1561091 & 688422 & 5.6 & 5.55399 & 9999999999 & TRN \\
\hline CHEMBL1410332 & 688422 & 4.45 & 5.7242 & TST & \\
\hline CHEMBL1437747 & 688422 & 4.9 & 4.9086 & TRN & \\
\hline CHEMBL1566099 & 688422 & 4.45 & 5.197 & TRN & \\
\hline CHEMBL1565076 & 688422 & 8.3468 & 5.2524 & TST & \\
\hline CHEMBL1488636 & 688422 & 5.15 & 5.0483 & TRN & \\
\hline CHEMBL1499582 & 688422 & 4.65 & 4.9751 & TRN & \\
\hline CHEMBL1464307 & 688422 & 4.45 & 5.0557 & TRN & \\
\hline CHEMBL1383599 & 688422 & 4.85 & 4.8359 & TRN & \\
\hline CHEMBL1429843 & 688422 & 4.95 & 4.8547 & TRN & \\
\hline CHEMBL1476020 & 688422 & 4.6 & 5.1628 & TRN & \\
\hline CHEMBL1527704 & 688422 & 5.75 & 5.5703 & TST & \\
\hline CHEMBL1385088 & 688422 & 4.45 & 5.3336 & TRN & \\
\hline CHEMBL1416344 & 688422 & 5.0 & 4.7153 & TRN & \\
\hline CHEMBL1485154 & 688422 & 5.5 & 5.5081 & TST & \\
\hline CHEMBL1592596 & 688422 & 5.6 & 5.4839 & TRN & \\
\hline CHEMBL1507498 & 688422 & 7.7496 & 5.2223 & TST & \\
\hline CHEMBL3145192 & 688422 & 4.7 & 5.1213 & TRN & \\
\hline CHEMBL1466523 & 688422 & 5.6 & 5.4909 & TRN & \\
\hline CHEMBL1344274 & 688422 & 4.8 & 4.9201 & TRN & \\
\hline CHEMBL1358824 & 688422 & 5.65 & 5.3197 & TST & \\
\hline CHEMBL1429835 & 688422 & 4.55 & 4.63 & TRN & \\
\hline CHEMBL1491488 & 688422 & 5.55 & 5.3359 & TRN & \\
\hline CHEMBL1385093 & 688422 & 5.55 & 5.4509 & TST & \\
\hline CHEMBL1526676 & 688422 & 4.45 & 4.9319 & TST & \\
\hline CHEMBL1310473 & 688422 & 4.85 & 5.2992 & TRN & \\
\hline CHEMBL1477552 & 688422 & 5.55 & 5.1379 & TRN & \\
\hline CHEMBL77098 & 688422 & 4.75 & 5.2814 & TRN & \\
\hline CHEMBL1483341 & 688422 & 4.85 & 5.7112 & TST & \\
\hline CHEMBL1556308 & 688422 & 4.85 & 4.8693 & TST & \\
\hline CHEMBL1573909 & 688422 & 4.45 & 5.3308 & TRN & \\
\hline CHEMBL1521747 & 688422 & 4.8 & 5.0934 & TRN & \\
\hline
\end{tabular}




\begin{tabular}{|c|c|c|c|c|c|}
\hline \multicolumn{6}{|c|}{ Supplemental Table S2.txt } \\
\hline CHEMBL1566651 & 688422 & 4.45 & 5.06 & TRN & \\
\hline CHEMBL1505625 & 688422 & 7.0 & 4.7675 & TRN & \\
\hline CHEMBL1302599 & 688422 & 6.05 & 4.9737 & TST & \\
\hline CHEMBL1428913 & 688422 & 4.45 & 5.4194 & TRN & \\
\hline CHEMBL1447252 & 688422 & 5.3 & 5.4875 & TRN & \\
\hline CHEMBL1474353 & 688422 & 5.5 & 5.7663 & TST & \\
\hline CHEMBL1492022 & 688422 & 6.6 & 5.3155 & TST & \\
\hline CHEMBL1408147 & 688422 & 4.45 & 4.8264 & TST & \\
\hline CHEMBL1399053 & 688422 & 4.45 & 5.4055 & TST & \\
\hline CHEMBL1561339 & 688422 & 4.85 & 5.3207 & TRN & \\
\hline CHEMBL1476987 & 688422 & 5.0 & 5.0693 & TRN & \\
\hline CHEMBL1538796 & 688422 & 4.45 & 4.7448 & TST & \\
\hline CHEMBL1425940 & 688422 & 4.85 & 5.2495 & TRN & \\
\hline CHEMBL1562042 & 688422 & 4.45 & \multicolumn{2}{|c|}{5.542000000000001} & TRN \\
\hline CHEMBL1469885 & 688422 & 5.2 & 5.1788 & TRN & \\
\hline CHEMBL1467756 & 688422 & 4.45 & 5.4448 & TST & \\
\hline CHEMBL1971872 & 688422 & 5.05 & 5.0886 & TRN & \\
\hline CHEMBL3199716 & 688422 & 4.9 & 4.8902 & TRN & \\
\hline CHEMBL1377941 & 688422 & 10.35 & \multicolumn{2}{|c|}{5.207999999999999} & TST \\
\hline CHEMBL1408442 & 688422 & 4.45 & 4.7943 & TRN & \\
\hline CHEMBL1382748 & 688422 & 4.65 & 5.6323 & TRN & \\
\hline CHEMBL1406920 & 688422 & 4.7 & 5.0286 & TRN & \\
\hline CHEMBL1515626 & 688422 & 6.05 & 5.3446 & TRN & \\
\hline CHEMBL1432529 & 688422 & 7.2503 & 5.4894 & TRN & \\
\hline CHEMBL1335536 & 688422 & 7.2 & 5.4392 & TRN & \\
\hline CHEMBL1345576 & 688422 & 4.7 & 5.0526 & TRN & \\
\hline CHEMBL1597005 & 688422 & 4.7 & 5.3492 & TRN & \\
\hline CHEMBL1445515 & 688422 & 4.75 & 5.4031 & TRN & \\
\hline CHEMBL1323309 & 688422 & 4.75 & 5.3271 & TRN & \\
\hline CHEMBL1460150 & 688422 & 5.0 & 5.6601 & TST & \\
\hline CHEMBL3189208 & 688422 & 4.75 & 4.9763 & TRN & \\
\hline CHEMBL1566656 & 688422 & 4.45 & 5.0649 & TRN & \\
\hline CHEMBL 1447750 & 688422 & 4.9 & 4.8173 & TRN & \\
\hline CHEMBL1365738 & 688422 & 4.45 & 5.2187 & TST & \\
\hline CHEMBL1447623 & 688422 & 7.8508 & 5.3499 & TRN & \\
\hline CHEMBL1305811 & 688422 & 4.8 & 5.1996 & TRN & \\
\hline CHEMBL1595480 & 688422 & 5.05 & 5.8847 & TST & \\
\hline CHEMBL1584360 & 688422 & 4.5 & 5.3178 & TST & \\
\hline CHEMBL1451423 & 688422 & 5.55 & 5.131 & TRN & \\
\hline CHEMBL1361017 & 688422 & 4.9 & 5.1078 & TRN & \\
\hline CHEMBL1512967 & 688422 & 4.45 & 5.1943 & TRN & \\
\hline CHEMBL1366193 & 688422 & 4.95 & 5.2847 & TST & \\
\hline CHEMBL1565367 & 688422 & 8.1487 & 5.6239 & TRN & \\
\hline CHEMBL1321513 & 688422 & 5.1 & 4.9725 & TRN & \\
\hline CHEMBL1352438 & 688422 & 5.0 & 5.1837 & TRN & \\
\hline CHEMBL1489002 & 688422 & 4.65 & 5.6579 & TRN & \\
\hline CHEMBL1976374 & 688422 & 6.5 & 5.1998 & TST & \\
\hline CHEMBL1380917 & 688422 & 5.45 & 5.5556 & TST & \\
\hline
\end{tabular}




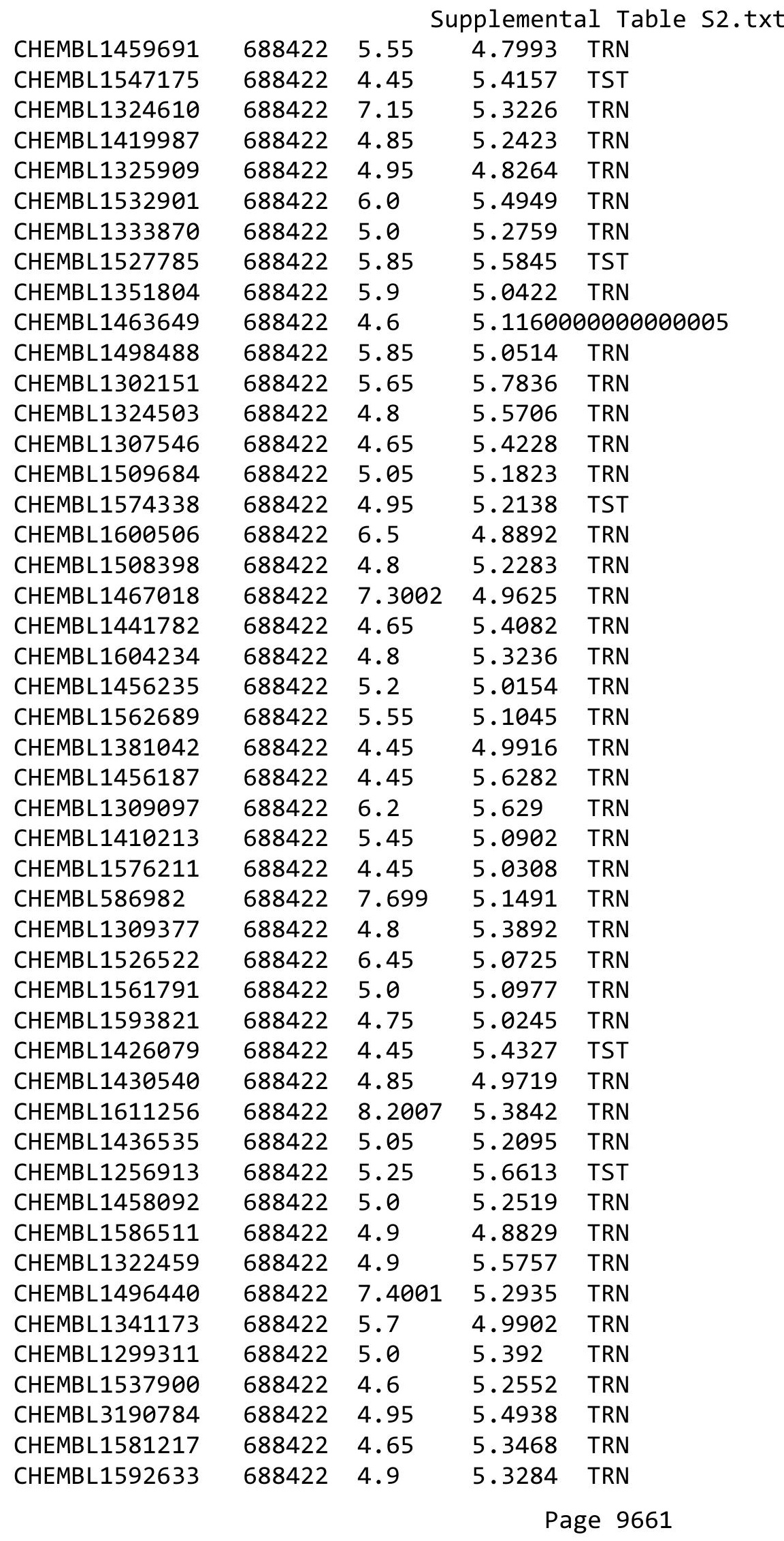




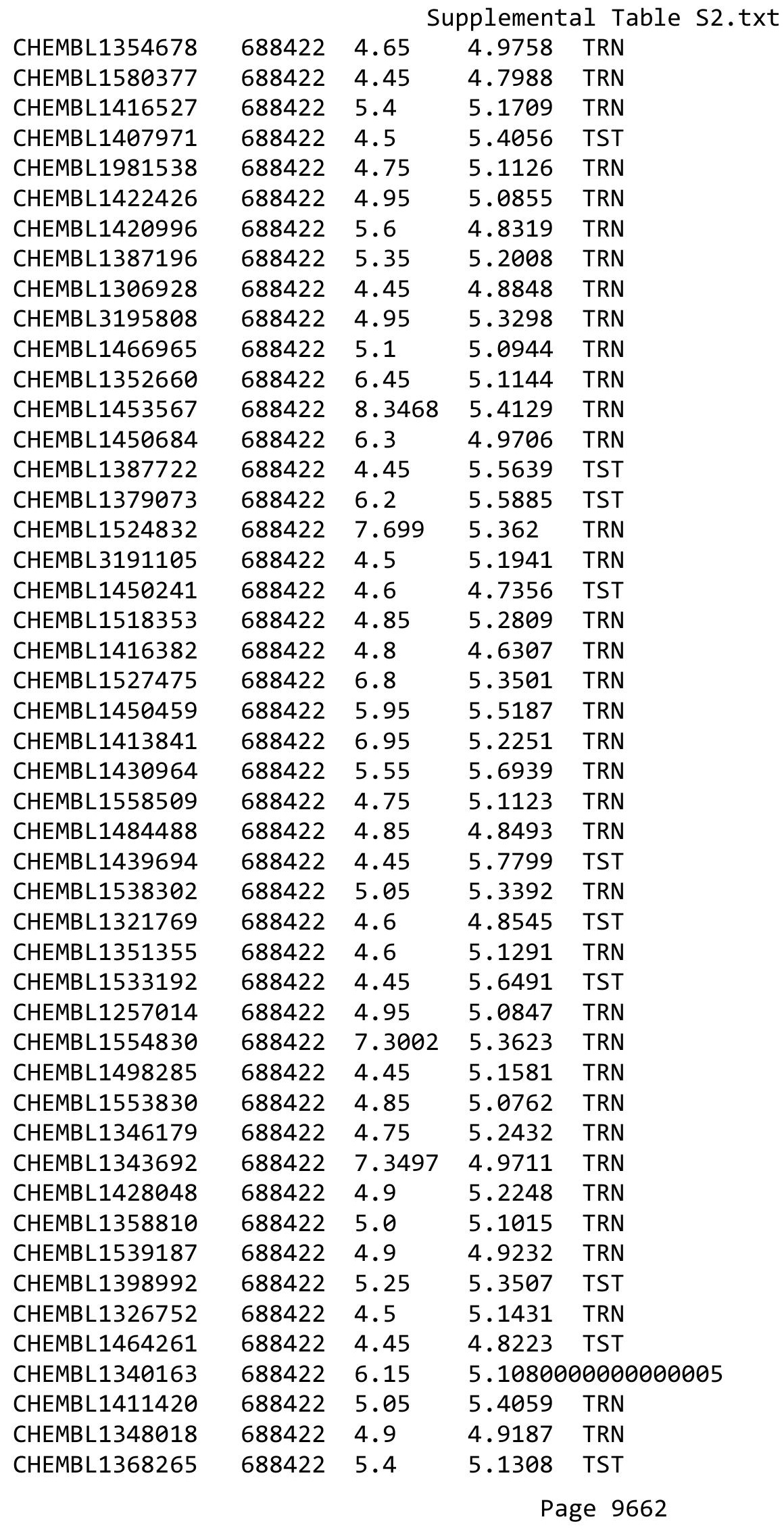

TRN 


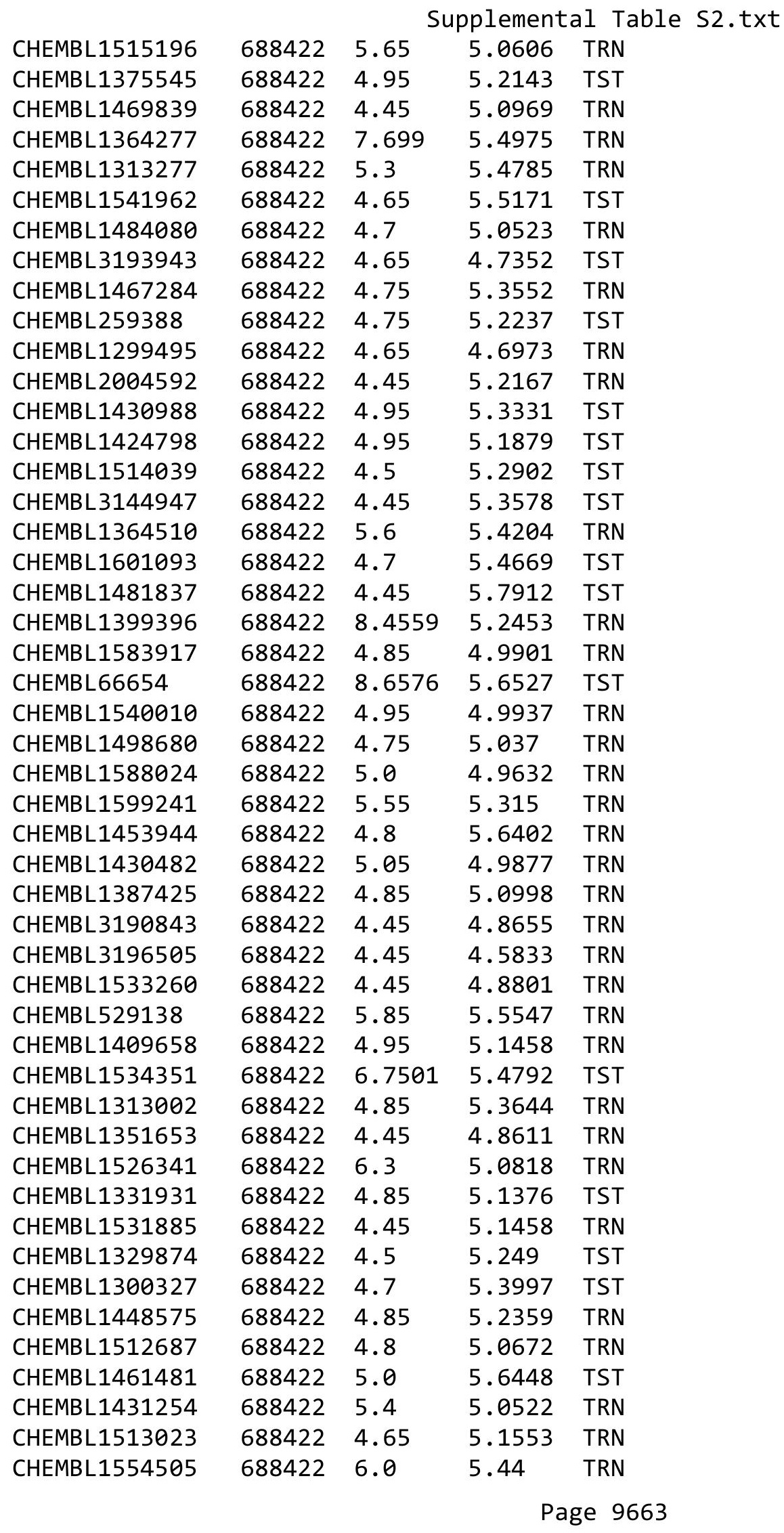




\begin{tabular}{|c|c|c|c|c|c|}
\hline \multicolumn{6}{|c|}{ Supplemental Table S2.txt } \\
\hline CHEMBL1330308 & 688422 & 4.9 & 5.1553 & TRN & \\
\hline CHEMBL1399992 & 688422 & 5.3 & 5.4243 & TST & \\
\hline CHEMBL1456606 & 688422 & 4.95 & 5.0289 & TST & \\
\hline CHEMBL1324543 & 688422 & 4.4 & 5.3397 & TRN & \\
\hline CHEMBL1520466 & 688422 & 7.5498 & 5.7634 & TST & \\
\hline CHEMBL1425161 & 688422 & 4.95 & 5.78600 & 00000000005 & TRN \\
\hline CHEMBL3192164 & 688422 & 4.95 & 5.1028 & TRN & \\
\hline CHEMBL1525742 & 688422 & 4.55 & 5.0121 & TRN & \\
\hline CHEMBL1561904 & 688422 & 6.8 & 5.0874 & TRN & \\
\hline CHEMBL1413278 & 688422 & 5.4 & 5.3091 & TST & \\
\hline CHEMBL1442585 & 688422 & 4.85 & 4.8617 & TRN & \\
\hline CHEMBL1495435 & 688422 & 5.0 & 5.6951 & TRN & \\
\hline CHEMBL1505838 & 688422 & 4.5 & 5.3642 & TRN & \\
\hline CHEMBL1578800 & 688422 & 4.45 & 5.0372 & TRN & \\
\hline CHEMBL149322 & 688422 & 4.8 & 5.07600 & 00000000005 & TRN \\
\hline CHEMBL 240332 & 688422 & 4.6 & 4.9554 & TRN & \\
\hline CHEMBL1583069 & 688422 & 4.9 & 5.3796 & TRN & \\
\hline CHEMBL1983533 & 688422 & 4.7 & 5.3438 & TRN & \\
\hline CHEMBL1519338 & 688422 & 4.45 & 5.4095 & TRN & \\
\hline CHEMBL1328362 & 688422 & 4.75 & 4.9581 & TRN & \\
\hline CHEMBL1541502 & 688422 & 4.95 & 5.033 & TST & \\
\hline CHEMBL1367043 & 688422 & 4.95 & 4.6941 & TRN & \\
\hline CHEMBL1549595 & 688422 & 4.55 & 5.197 & TRN & \\
\hline CHEMBL1348534 & 688422 & 4.85 & 5.3036 & TRN & \\
\hline CHEMBL1456415 & 688422 & 4.85 & 5.3108 & TST & \\
\hline CHEMBL1314367 & 688422 & 5.15 & 5.1548 & TRN & \\
\hline CHEMBL1485561 & 688422 & 4.95 & 4.8179 & TRN & \\
\hline CHEMBL1540850 & 688422 & 4.45 & 5.0912 & TRN & \\
\hline CHEMBL1547180 & 688422 & 7.1002 & 5.2405 & TRN & \\
\hline CHEMBL1575354 & 688422 & 4.65 & 5.3025 & TRN & \\
\hline CHEMBL1341736 & 688422 & 4.9 & 4.823 & TRN & \\
\hline CHEMBL1562727 & 688422 & 5.0 & 5.1819 & TST & \\
\hline CHEMBL1351321 & 688422 & 4.9 & 5.0023 & TRN & \\
\hline CHEMBL1582973 & 688422 & 4.45 & 4.9541 & TRN & \\
\hline CHEMBL1312558 & 688422 & 5.45 & 5.2271 & TRN & \\
\hline CHEMBL1464998 & 688422 & 4.5 & 4.9546 & TRN & \\
\hline CHEMBL1334506 & 688422 & 4.6 & 5.1045 & TRN & \\
\hline CHEMBL1334615 & 688422 & 4.5 & 4.8963 & TST & \\
\hline CHEMBL1503997 & 688422 & 4.9 & 4.923 & TRN & \\
\hline CHEMBL1506966 & 688422 & 4.55 & 4.9959 & TST & \\
\hline CHEMBL1412968 & 688422 & 4.8 & 4.9347 & TRN & \\
\hline CHEMBL1599657 & 688422 & 5.5 & 5.5783 & TST & \\
\hline CHEMBL3213148 & 688422 & 5.0 & 5.0126 & TRN & \\
\hline CHEMBL1413445 & 688422 & 4.45 & 4.8324 & TRN & \\
\hline CHEMBL1501378 & 688422 & 4.95 & 4.6316 & TRN & \\
\hline CHEMBL1537619 & 688422 & 6.95 & 4.9377 & TST & \\
\hline CHEMBL1504875 & 688422 & 4.8 & 4.9242 & TRN & \\
\hline CHEMBL1452948 & 688422 & 4.5 & 5.1105 & TRN & \\
\hline
\end{tabular}




\begin{tabular}{|c|c|c|c|c|c|}
\hline \multicolumn{6}{|c|}{ Supplemental Table S2.txt } \\
\hline CHEMBL1381206 & 688422 & 4.85 & 5.0952 & TST & \\
\hline CHEMBL1376164 & 688422 & 4.6 & 4.8248 & TRN & \\
\hline CHEMBL1314301 & 688422 & 7.0 & 5.5978 & TRN & \\
\hline CHEMBL1984764 & 688422 & 4.95 & 4.9813 & TRN & \\
\hline CHEMBL1303089 & 688422 & 4.45 & 4.8133 & TRN & \\
\hline CHEMBL1511029 & 688422 & 5.5 & 5.3136 & TRN & \\
\hline CHEMBL1488280 & 688422 & 4.45 & 4.9732 & TRN & \\
\hline CHEMBL1344250 & 688422 & 5.0 & 4.8652 & TRN & \\
\hline CHEMBL1357994 & 688422 & 4.45 & 4.8664 & TRN & \\
\hline CHEMBL1335367 & 688422 & 4.8 & 4.7492 & TRN & \\
\hline CHEMBL3144955 & 688422 & 5.2 & 5.4231 & TST & \\
\hline CHEMBL1464573 & 688422 & 5.0 & 4.989 & TRN & \\
\hline CHEMBL1448251 & 688422 & 5.65 & 4.9803 & TRN & \\
\hline CHEMBL1484784 & 688422 & 7.0 & 5.2441 & TST & \\
\hline CHEMBL1333906 & 688422 & 4.9 & 5.1808 & TRN & \\
\hline CHEMBL1391028 & 688422 & 4.8 & 5.3272 & TRN & \\
\hline CHEMBL1492648 & 688422 & 5.4 & 5.0086 & TRN & \\
\hline CHEMBL1521003 & 688422 & 5.25 & 5.0954 & TST & \\
\hline CHEMBL87385 & 688422 & 5.95 & 5.17700 & 00000000005 & TRN \\
\hline CHEMBL1349839 & 688422 & 5.6 & 4.7436 & TRN & \\
\hline CHEMBL1546503 & 688422 & 5.1 & 5.0443 & TRN & \\
\hline CHEMBL1324301 & 688422 & 5.05 & 4.9347 & TRN & \\
\hline CHEMBL1451381 & 688422 & 4.9 & 4.8667 & TRN & \\
\hline CHEMBL1519684 & 688422 & 7.6498 & 5.6066 & TRN & \\
\hline CHEMBL1345115 & 688422 & 4.75 & 5.0433 & TRN & \\
\hline CHEMBL1442325 & 688422 & 4.7 & 5.5331 & TRN & \\
\hline CHEMBL317364 & 688422 & 5.15 & 5.4612 & TST & \\
\hline CHEMBL1366499 & 688422 & 8.0 & 5.2486 & TRN & \\
\hline CHEMBL1453502 & 688422 & 4.65 & 5.0764 & TRN & \\
\hline CHEMBL1550164 & 688422 & 4.7 & 4.7945 & TRN & \\
\hline CHEMBL1487135 & 688422 & 4.45 & 5.0514 & TRN & \\
\hline CHEMBL1316048 & 688422 & 7.2 & 5.4385 & TRN & \\
\hline CHEMBL1509077 & 688422 & 4.5 & 5.4808 & TRN & \\
\hline CHEMBL1502307 & 688422 & 5.6 & 5.1376 & TRN & \\
\hline CHEMBL1510200 & 688422 & 7.2 & 5.6227 & TST & \\
\hline CHEMBL1367085 & 688422 & 6.8499 & 5.4839 & TST & \\
\hline CHEMBL1323631 & 688422 & 4.85 & 4.7803 & TST & \\
\hline CHEMBL1411492 & 688422 & 4.95 & 5.2813 & TRN & \\
\hline CHEMBL1454966 & 688422 & 5.45 & 5.3632 & TST & \\
\hline CHEMBL1349488 & 688422 & 5.75 & 5.4539 & TRN & \\
\hline CHEMBL1555856 & 688422 & 8.4949 & 5.5137 & TRN & \\
\hline CHEMBL1594369 & 688422 & 4.95 & 5.3118 & TST & \\
\hline CHEMBL1373252 & 688422 & 5.5 & 4.7314 & TRN & \\
\hline CHEMBL1303194 & 688422 & 4.5 & 5.8585 & TRN & \\
\hline CHEMBL1427567 & 688422 & 5.05 & 5.1102 & TRN & \\
\hline CHEMBL1461389 & 688422 & 4.8 & 4.9909 & TRN & \\
\hline CHEMBL1335077 & 688422 & 4.65 & 4.8972 & TRN & \\
\hline CHEMBL1315110 & 688422 & 5.35 & 5.1382 & TRN & \\
\hline
\end{tabular}




\begin{tabular}{|c|c|c|c|c|c|}
\hline \multicolumn{6}{|c|}{ Supplemental Table S2.txt } \\
\hline CHEMBL1420488 & 688422 & 4.45 & 5.1821 & TRN & \\
\hline CHEMBL1588513 & 688422 & 5.25 & 5.2792 & TRN & \\
\hline CHEMBL1469075 & 688422 & 4.45 & 4.912 & TST & \\
\hline CHEMBL1522723 & 688422 & 4.6 & 5.432 & TRN & \\
\hline CHEMBL1313749 & 688422 & 5.0 & 5.4216 & TRN & \\
\hline CHEMBL1344478 & 688422 & 5.2 & 5.1019 & TRN & \\
\hline CHEMBL1362799 & 688422 & 4.85 & 5.0666 & TRN & \\
\hline CHEMBL1517259 & 688422 & 4.6 & 4.7563 & TRN & \\
\hline CHEMBL1364872 & 688422 & 4.85 & 5.1994 & TRN & \\
\hline CHEMBL1325390 & 688422 & 4.85 & 5.475 & TST & \\
\hline CHEMBL1459477 & 688422 & 5.45 & 5.8961 & TST & \\
\hline CHEMBL1368075 & 688422 & 8.1024 & 5.2499 & TRN & \\
\hline CHEMBL1362903 & 688422 & 5.45 & 5.7455 & TRN & \\
\hline CHEMBL1520546 & 688422 & 4.95 & 5.2781 & TRN & \\
\hline CHEMBL1512853 & 688422 & 4.7 & 5.1901 & TRN & \\
\hline CHEMBL1353928 & 688422 & 5.15 & 5.29700 & 0000000001 & TRN \\
\hline CHEMBL1383533 & 688422 & 6.25 & 5.2499 & TRN & \\
\hline CHEMBL3213058 & 688422 & 4.9 & 4.9588 & TST & \\
\hline CHEMBL1375279 & 688422 & 6.6 & 5.2278 & TRN & \\
\hline CHEMBL1563710 & 688422 & 4.45 & 4.9671 & TRN & \\
\hline CHEMBL 2005364 & 688422 & 5.25 & 5.2078 & TRN & \\
\hline CHEMBL1353969 & 688422 & 5.0 & 5.1615 & TRN & \\
\hline CHEMBL1506731 & 688422 & 5.3 & 5.5369 & TST & \\
\hline CHEMBL1516870 & 688422 & 4.6 & 5.126 & TRN & \\
\hline CHEMBL1604091 & 688422 & 4.85 & 5.3482 & TRN & \\
\hline CHEMBL1585064 & 688422 & 4.95 & 5.3694 & TRN & \\
\hline CHEMBL1976304 & 688422 & 5.6 & 4.9289 & TST & \\
\hline CHEMBL1590871 & 688422 & 6.7001 & 5.6314 & TRN & \\
\hline CHEMBL1376288 & 688422 & 7.4498 & 5.2589 & TST & \\
\hline CHEMBL1452706 & 688422 & 5.95 & 5.0379 & TRN & \\
\hline CHEMBL1613015 & 688422 & 5.5 & 5.4987 & TST & \\
\hline CHEMBL1418241 & 688422 & 6.15 & 5.9817 & TRN & \\
\hline CHEMBL1471806 & 688422 & 6.7001 & 6.0493 & TRN & \\
\hline CHEMBL1547617 & 688422 & 4.45 & 5.06 & TRN & \\
\hline CHEMBL1390014 & 688422 & 4.75 & 5.1836 & TRN & \\
\hline CHEMBL1556113 & 688422 & 4.45 & 5.1528 & TRN & \\
\hline CHEMBL1600873 & 688422 & 4.9 & 5.1696 & TRN & \\
\hline CHEMBL3212549 & 688422 & 4.45 & 5.2698 & TST & \\
\hline CHEMBL1349774 & 688422 & 4.7 & 5.067 & TRN & \\
\hline CHEMBL1396484 & 688422 & 5.1 & 5.4633 & TRN & \\
\hline CHEMBL1414473 & 688422 & 7.5003 & 5.6081 & TST & \\
\hline CHEMBL1333228 & 688422 & 5.45 & 5.3265 & TRN & \\
\hline CHEMBL1308578 & 688422 & 4.45 & 4.9792 & TRN & \\
\hline CHEMBL 1477846 & 688422 & 4.6 & 5.2522 & TST & \\
\hline CHEMBL1330749 & 688422 & 6.7001 & 5.4291 & TST & \\
\hline CHEMBL1995097 & 688422 & 5.0 & 5.106 & TRN & \\
\hline CHEMBL1567660 & 688422 & 5.25 & 5.5046 & TST & \\
\hline CHEMBL1359606 & 688422 & 5.5 & 5.2743 & TST & \\
\hline
\end{tabular}




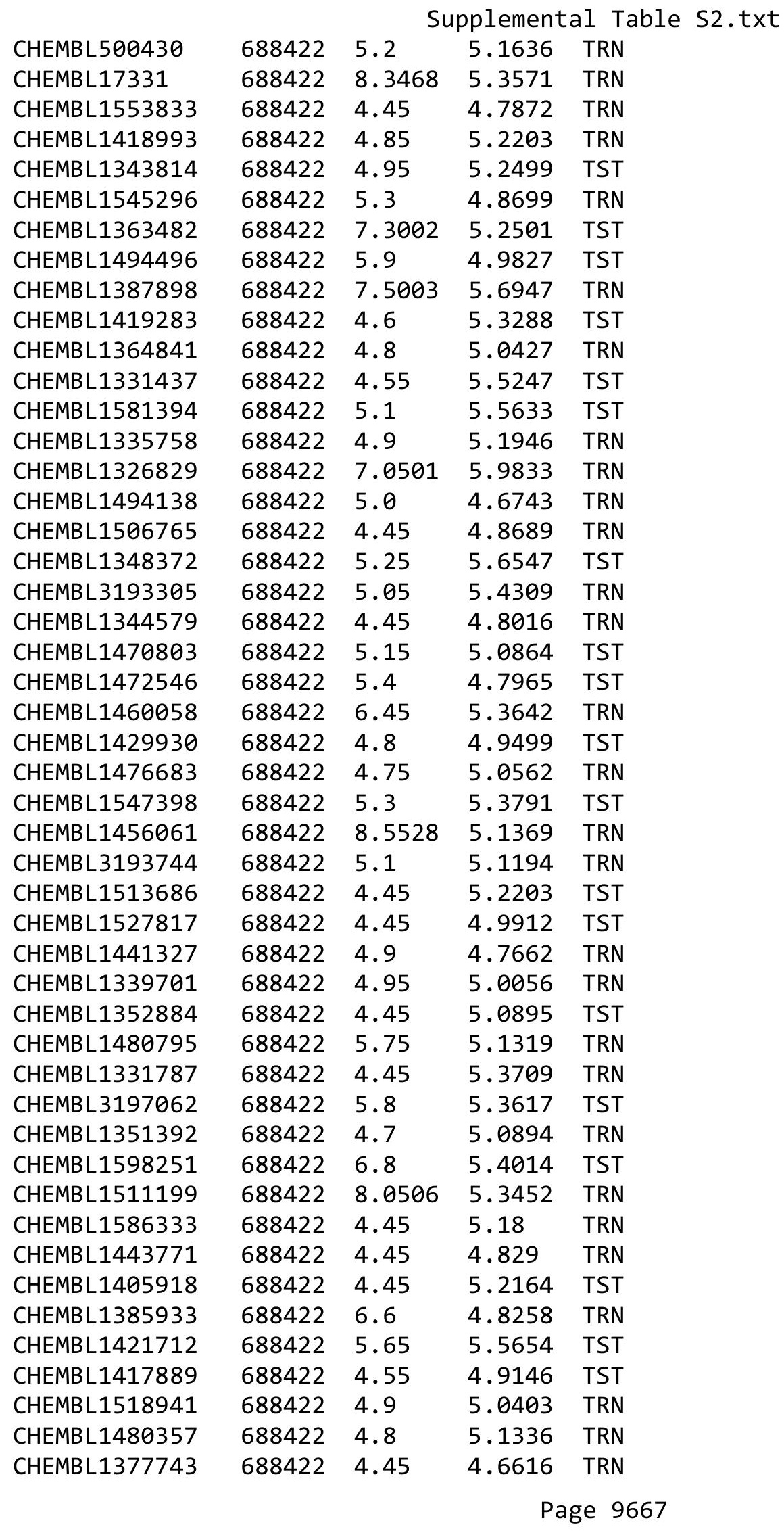




\begin{tabular}{|c|c|c|c|c|}
\hline \multicolumn{5}{|c|}{ Supplemental Table S2.txt } \\
\hline CHEMBL1509079 & 688422 & 4.45 & 5.3313 & TRN \\
\hline CHEMBL1595611 & 688422 & 4.5 & 4.9301 & TRN \\
\hline CHEMBL1309785 & 688422 & 4.8 & 5.5959 & TRN \\
\hline CHEMBL1594922 & 688422 & 4.85 & 5.3904 & TRN \\
\hline CHEMBL1584506 & 688422 & 5.7 & 5.4011 & TRN \\
\hline CHEMBL1326720 & 688422 & 4.95 & 4.8285 & TRN \\
\hline CHEMBL1325840 & 688422 & 5.85 & 5.5496 & TRN \\
\hline CHEMBL1480894 & 688422 & 4.45 & 4.8734 & TRN \\
\hline CHEMBL1338297 & 688422 & 4.45 & 5.2615 & TRN \\
\hline CHEMBL 1480031 & 688422 & 5.25 & 4.666 & TRN \\
\hline CHEMBL1573729 & 688422 & 4.5 & 5.5957 & TRN \\
\hline CHEMBL1601532 & 688422 & 4.9 & 4.9027 & TRN \\
\hline CHEMBL1373385 & 688422 & 4.45 & 4.8764 & TRN \\
\hline CHEMBL1503923 & 688422 & 4.75 & 4.9131 & TRN \\
\hline CHEMBL1334925 & 688422 & 4.45 & 5.1921 & TST \\
\hline CHEMBL77387 & 688422 & 4.45 & 5.4104 & TRN \\
\hline CHEMBL1587882 & 688422 & 4.45 & 4.9902 & TRN \\
\hline CHEMBL1545412 & 688422 & 8.4949 & 5.2911 & TRN \\
\hline CHEMBL1613574 & 688422 & 4.45 & 4.7441 & TRN \\
\hline CHEMBL1533081 & 688422 & 4.95 & 5.2522 & TRN \\
\hline CHEMBL1302630 & 688422 & 4.8 & 5.1535 & TRN \\
\hline CHEMBL1526214 & 688422 & 5.3 & 5.2501 & TRN \\
\hline CHEMBL1491342 & 688422 & 4.6 & 5.1535 & TRN \\
\hline CHEMBL1347109 & 688422 & 4.75 & 4.9823 & TRN \\
\hline CHEMBL1386061 & 688422 & 4.65 & 5.1835 & TRN \\
\hline CHEMBL1390573 & 688422 & 4.45 & 5.1242 & TST \\
\hline CHEMBL3211314 & 688422 & 4.8 & 4.9896 & TST \\
\hline CHEMBL601757 & 688422 & 5.7 & 5.7356 & TRN \\
\hline CHEMBL1556830 & 688422 & 5.0 & 4.7909 & TRN \\
\hline CHEMBL1303162 & 688422 & 4.65 & 5.6729 & TRN \\
\hline CHEMBL1304361 & 688422 & 7.2503 & 5.4875 & TST \\
\hline CHEMBL1330864 & 688422 & 4.95 & 5.0812 & TRN \\
\hline CHEMBL1314837 & 688422 & 4.65 & 4.941 & TRN \\
\hline CHEMBL1394962 & 688422 & 7.0501 & 5.5472 & TRN \\
\hline CHEMBL1411022 & 688422 & 5.4 & 5.3952 & TRN \\
\hline CHEMBL1384489 & 688422 & 5.25 & 4.463 & TRN \\
\hline CHEMBL1506677 & 688422 & 4.9 & 4.8226 & TRN \\
\hline CHEMBL1408204 & 688422 & 4.65 & 4.8846 & TRN \\
\hline CHEMBL1418203 & 688422 & 4.45 & 5.1219 & TRN \\
\hline CHEMBL1492459 & 688422 & 8.0 & 5.4431 & TRN \\
\hline CHEMBL1606905 & 688422 & 5.65 & 5.7605 & TRN \\
\hline CHEMBL1384654 & 688422 & 4.85 & 5.021 & TRN \\
\hline CHEMBL1586979 & 688422 & 6.2 & 5.2915 & TRN \\
\hline CHEMBL1506166 & 688422 & 4.85 & 5.0904 & TRN \\
\hline CHEMBL1610002 & 688422 & 5.3 & 4.8917 & TRN \\
\hline CHEMBL1379686 & 688422 & 4.45 & 5.051 & TRN \\
\hline CHEMBL1492521 & 688422 & 4.45 & 5.3298 & TST \\
\hline CHEMBL1325479 & 688422 & 4.9 & 4.7778 & TRN \\
\hline
\end{tabular}




\begin{tabular}{|c|c|c|c|c|c|}
\hline \multicolumn{6}{|c|}{ Supplemental Table S2.txt } \\
\hline CHEMBL1533390 & 688422 & 4.8 & 5.1529 & TRN & \\
\hline CHEMBL1600768 & 688422 & 5.05 & 4.8344 & TRN & \\
\hline CHEMBL1319004 & 688422 & 5.25 & 5.0368 & TRN & \\
\hline CHEMBL3194360 & 688422 & 5.1 & 5.1061 & TST & \\
\hline CHEMBL1562003 & 688422 & 5.05 & 5.2567 & TRN & \\
\hline CHEMBL1388901 & 688422 & 5.15 & 5.2175 & TRN & \\
\hline CHEMBL1426390 & 688422 & 4.9 & 5.4479 & TST & \\
\hline CHEMBL1494575 & 688422 & 5.5 & 5.66200 & 0000000001 & TRN \\
\hline CHEMBL1451268 & 688422 & 4.45 & 5.2339 & TRN & \\
\hline CHEMBL1603182 & 688422 & 5.1 & 5.32799 & 9999999999 & TRN \\
\hline CHEMBL1382847 & 688422 & 4.6 & 5.62 & TRN & \\
\hline CHEMBL1549654 & 688422 & 4.9 & 4.9244 & TRN & \\
\hline CHEMBL1978791 & 688422 & 4.65 & 4.9876 & TRN & \\
\hline CHEMBL1530481 & 688422 & 7.6003 & 5.3047 & TRN & \\
\hline CHEMBL1597580 & 688422 & 5.35 & 5.4144 & TRN & \\
\hline CHEMBL1314513 & 688422 & 7.5498 & 5.6814 & TST & \\
\hline CHEMBL1459474 & 688422 & 4.55 & 5.4926 & TRN & \\
\hline CHEMBL1381646 & 688422 & 4.7 & 5.8035 & TRN & \\
\hline CHEMBL1579223 & 688422 & 5.15 & 4.7084 & TST & \\
\hline CHEMBL1508932 & 688422 & 6.8499 & 4.9528 & TST & \\
\hline CHEMBL1324080 & 688422 & 4.55 & 5.0461 & TRN & \\
\hline CHEMBL1308127 & 688422 & 5.15 & 4.9943 & TRN & \\
\hline CHEMBL1610679 & 688422 & 4.75 & 5.3795 & TRN & \\
\hline CHEMBL1596771 & 688422 & 6.9 & 5.5341 & TST & \\
\hline CHEMBL1387510 & 688422 & 5.55 & 4.8543 & TST & \\
\hline CHEMBL1549334 & 688422 & 4.65 & 4.9778 & TRN & \\
\hline CHEMBL1444770 & 688422 & 4.85 & 5.1102 & TRN & \\
\hline CHEMBL1552644 & 688422 & 7.5003 & 5.9994 & TRN & \\
\hline CHEMBL1563911 & 688422 & 4.9 & 5.0423 & TRN & \\
\hline CHEMBL1502867 & 688422 & 4.45 & 5.3854 & TRN & \\
\hline CHEMBL1547795 & 688422 & 4.45 & 5.4004 & TRN & \\
\hline CHEMBL1534464 & 688422 & 6.95 & 5.3894 & TRN & \\
\hline CHEMBL1301881 & 688422 & 5.6 & 4.4426 & TRN & \\
\hline CHEMBL1490173 & 688422 & 4.45 & 5.3491 & TRN & \\
\hline CHEMBL1317938 & 688422 & 4.45 & 5.5091 & TRN & \\
\hline CHEMBL1351133 & 688422 & 4.45 & 5.2392 & TRN & \\
\hline CHEMBL1347552 & 688422 & 4.6 & 4.8165 & TRN & \\
\hline CHEMBL1387767 & 688422 & 4.45 & 4.9804 & TST & \\
\hline CHEMBL1308665 & 688422 & 4.75 & 5.0182 & TRN & \\
\hline CHEMBL1330679 & 688422 & 4.45 & 4.9778 & TST & \\
\hline CHEMBL1613092 & 688422 & 5.15 & 5.228 & TRN & \\
\hline CHEMBL1518446 & 688422 & 4.95 & 5.4323 & TST & \\
\hline CHEMBL1329772 & 688422 & 5.25 & 5.4216 & TST & \\
\hline CHEMBL1363849 & 688422 & 5.7 & 5.6203 & TRN & \\
\hline CHEMBL1580092 & 688422 & 5.35 & 5.4927 & TRN & \\
\hline CHEMBL1422749 & 688422 & 4.45 & 5.8127 & TST & \\
\hline CHEMBL1491222 & 688422 & 4.8 & 5.2175 & TRN & \\
\hline CHEMBL3213566 & 688422 & 5.0 & 5.2738 & TRN & \\
\hline
\end{tabular}




\begin{tabular}{|c|c|c|c|c|}
\hline \multicolumn{5}{|c|}{ Supplemental Table S2.txt } \\
\hline CHEMBL1610009 & 688422 & 5.1 & 5.3303 & TRN \\
\hline CHEMBL1551619 & 688422 & 6.0 & 5.6521 & TRN \\
\hline CHEMBL1527581 & 688422 & 4.9 & 4.9133 & TST \\
\hline CHEMBL1389547 & 688422 & 4.8 & 5.0064 & TRN \\
\hline CHEMBL1521842 & 688422 & 4.45 & 5.3324 & TST \\
\hline CHEMBL1574497 & 688422 & 5.0 & 5.218 & TRN \\
\hline CHEMBL1518851 & 688422 & 4.5 & 5.1682 & TRN \\
\hline CHEMBL1568908 & 688422 & 6.4 & 5.3397 & TST \\
\hline CHEMBL1486546 & 688422 & 4.45 & 5.2196 & TRN \\
\hline CHEMBL1444844 & 688422 & 9.699 & 5.6313 & TST \\
\hline CHEMBL1509590 & 688422 & 4.45 & 5.0435 & TST \\
\hline CHEMBL1541531 & 688422 & 4.7 & 4.6151 & TRN \\
\hline CHEMBL1599495 & 688422 & 4.9 & 4.9198 & TRN \\
\hline CHEMBL1443084 & 688422 & 5.25 & 5.584 & TRN \\
\hline CHEMBL1580735 & 688422 & 5.15 & 5.3475 & TST \\
\hline CHEMBL1593300 & 688422 & 6.2 & 5.4698 & TST \\
\hline CHEMBL3198142 & 688422 & 4.45 & 5.0394 & TRN \\
\hline CHEMBL1538250 & 688422 & 4.6 & 5.0704 & TST \\
\hline CHEMBL1470800 & 688422 & 4.75 & 4.9315 & TRN \\
\hline CHEMBL1602870 & 688422 & 4.4 & 5.7279 & TRN \\
\hline CHEMBL1370159 & 688422 & 5.9 & 5.4147 & TRN \\
\hline CHEMBL1983243 & 688422 & 5.0 & 5.371 & TRN \\
\hline CHEMBL1517207 & 688422 & 4.7 & 5.4982 & TST \\
\hline CHEMBL1378432 & 688422 & 8.4949 & 5.5399 & TRN \\
\hline CHEMBL1468451 & 688422 & 7.5498 & 5.6385 & TRN \\
\hline CHEMBL1461171 & 688422 & 4.7 & 4.7337 & TRN \\
\hline CHEMBL1600473 & 688422 & 5.0 & 5.1381 & TRN \\
\hline CHEMBL589694 & 688422 & 4.45 & 4.7204 & TRN \\
\hline CHEMBL1580344 & 688422 & 7.7496 & 5.3392 & TST \\
\hline CHEMBL1458537 & 688422 & 6.45 & 4.829 & TST \\
\hline CHEMBL1302371 & 688422 & 6.25 & 5.1699 & TRN \\
\hline CHEMBL1526751 & 688422 & 5.5 & 5.2219 & TRN \\
\hline CHEMBL1554289 & 688422 & 5.8 & 5.3302 & TRN \\
\hline CHEMBL1575493 & 688422 & 4.55 & 4.9643 & TRN \\
\hline CHEMBL1567087 & 688422 & 5.15 & 4.9566 & TST \\
\hline CHEMBL1325661 & 688422 & 7.9508 & 5.1527 & TRN \\
\hline CHEMBL1565306 & 688422 & 4.7 & 4.9805 & TRN \\
\hline CHEMBL1338425 & 688422 & 4.45 & 5.0906 & TRN \\
\hline CHEMBL1536689 & 688422 & 5.05 & 5.1538 & TRN \\
\hline CHEMBL3196135 & 688422 & 4.95 & 5.3076 & TST \\
\hline CHEMBL1331971 & 688422 & 8.4949 & 5.3338 & TRN \\
\hline CHEMBL1413032 & 688422 & 4.5 & 5.3224 & TRN \\
\hline CHEMBL128427 & 688422 & 4.45 & 5.5049 & TRN \\
\hline CHEMBL1442280 & 688422 & 5.45 & 5.3543 & TRN \\
\hline CHEMBL1563592 & 688422 & 4.45 & 4.7476 & TRN \\
\hline CHEMBL1595642 & 688422 & 4.45 & 5.1456 & TST \\
\hline CHEMBL1508642 & 688422 & 5.9 & 5.2273 & TRN \\
\hline CHEMBL550826 & 688422 & 4.45 & 5.1979 & TST \\
\hline
\end{tabular}




\begin{tabular}{|c|c|c|c|c|c|}
\hline \multicolumn{6}{|c|}{ Supplemental Table S2.txt } \\
\hline CHEMBL1337580 & 688422 & 5.05 & 5.4973 & TRN & \\
\hline CHEMBL1386621 & 688422 & 4.65 & 5.4222 & TRN & \\
\hline CHEMBL1734063 & 688422 & 4.75 & 5.0233 & TRN & \\
\hline CHEMBL1507073 & 688422 & 5.25 & 5.2194 & TRN & \\
\hline CHEMBL1347161 & 688422 & 5.1 & 5.2684 & TRN & \\
\hline CHEMBL1528776 & 688422 & 4.8 & 5.3713 & TRN & \\
\hline CHEMBL1562144 & 688422 & 4.6 & 5.0267 & TRN & \\
\hline CHEMBL1333304 & 688422 & 4.75 & 5.4678 & TRN & \\
\hline CHEMBL1413136 & 688422 & 5.5 & 5.0743 & TRN & \\
\hline CHEMBL1439657 & 688422 & 4.45 & 5.3011 & TRN & \\
\hline CHEMBL1581146 & 688422 & 4.65 & 5.1309 & TRN & \\
\hline CHEMBL1312556 & 688422 & 4.75 & 5.3006 & TST & \\
\hline CHEMBL1378436 & 688422 & 4.45 & 5.1846 & TRN & \\
\hline CHEMBL1440221 & 688422 & 5.0 & 5.0213 & TRN & \\
\hline CHEMBL1536693 & 688422 & 4.45 & 4.937 & TRN & \\
\hline CHEMBL1528625 & 688422 & 5.25 & 5.7332 & TRN & \\
\hline CHEMBL1436049 & 688422 & 5.45 & 4.9096 & TRN & \\
\hline CHEMBL1534178 & 688422 & 6.8 & 5.4883 & TST & \\
\hline CHEMBL1401871 & 688422 & 5.35 & 5.9294 & TRN & \\
\hline CHEMBL1534330 & 688422 & 4.6 & 5.2112 & TST & \\
\hline CHEMBL1428570 & 688422 & 7.4001 & 5.6183 & TST & \\
\hline CHEMBL1490596 & 688422 & 4.6 & 5.2138 & TRN & \\
\hline CHEMBL1559583 & 688422 & 4.45 & 5.5258 & TRN & \\
\hline CHEMBL1345082 & 688422 & 4.8 & 5.0815 & TST & \\
\hline CHEMBL1349435 & 688422 & 4.8 & 5.2533 & TST & \\
\hline CHEMBL1398505 & 688422 & 5.65 & 4.8786 & TRN & \\
\hline CHEMBL1452346 & 688422 & 8.4949 & 5.5837 & TRN & \\
\hline CHEMBL1395131 & 688422 & 5.2 & 4.8813 & TRN & \\
\hline CHEMBL1393104 & 688422 & 4.45 & 5.5458 & TRN & \\
\hline CHEMBL1336378 & 688422 & 5.15 & 4.9449 & TRN & \\
\hline CHEMBL1353391 & 688422 & 4.85 & 5.26399 & 9999999999 & TRN \\
\hline CHEMBL1564115 & 688422 & 4.5 & 4.9049 & TRN & \\
\hline CHEMBL3194401 & 688422 & 4.95 & 5.0119 & TST & \\
\hline CHEMBL1466740 & 688422 & 6.1 & 5.1724 & TST & \\
\hline CHEMBL1382979 & 688422 & 5.65 & 4.7598 & TRN & \\
\hline CHEMBL1476383 & 688422 & 6.35 & 6.0637 & TRN & \\
\hline CHEMBL1516281 & 688422 & 6.15 & 5.7735 & TST & \\
\hline CHEMBL3190152 & 688422 & 4.5 & 5.5854 & TST & \\
\hline CHEMBL1449719 & 688422 & 4.45 & 5.1031 & TRN & \\
\hline CHEMBL1578927 & 688422 & 4.7 & 5.4941 & TRN & \\
\hline CHEMBL1584969 & 688422 & 4.8 & 5.2588 & TST & \\
\hline CHEMBL1469759 & 688422 & 4.95 & 5.3969 & TST & \\
\hline CHEMBL1323451 & 688422 & 4.6 & 5.3175 & TRN & \\
\hline CHEMBL1390302 & 688422 & 4.85 & 5.0202 & TRN & \\
\hline CHEMBL1517818 & 688422 & 5.0 & 5.2417 & TRN & \\
\hline CHEMBL1374924 & 688422 & 5.5 & 4.7521 & TRN & \\
\hline CHEMBL1303283 & 688422 & 6.3 & 5.5171 & TST & \\
\hline CHEMBL1416868 & 688422 & 4.7 & 5.135 & TRN & \\
\hline
\end{tabular}




\begin{tabular}{|c|c|c|c|c|c|}
\hline \multicolumn{6}{|c|}{ Supplemental Table S2.txt } \\
\hline CHEMBL1505058 & 688422 & 4.75 & 5.2362 & TRN & \\
\hline CHEMBL1418735 & 688422 & 5.0 & 5.2185 & TRN & \\
\hline CHEMBL1302862 & 688422 & 5.9 & 5.5673 & TRN & \\
\hline CHEMBL1464249 & 688422 & 4.45 & 5.0724 & TRN & \\
\hline CHEMBL1332783 & 688422 & 4.9 & 5.3663 & TRN & \\
\hline CHEMBL 3207715 & 688422 & 4.9 & 4.8643 & TST & \\
\hline CHEMBL1600778 & 688422 & 5.7 & 5.4593 & TRN & \\
\hline CHEMBL3193726 & 688422 & 6.7001 & 5.2108 & TRN & \\
\hline CHEMBL241657 & 688422 & 4.85 & 5.1695 & TRN & \\
\hline CHEMBL1486960 & 688422 & 4.9 & 4.813 & TRN & \\
\hline CHEMBL1559624 & 688422 & 4.45 & 5.3031 & TRN & \\
\hline CHEMBL1965415 & 688422 & 4.6 & 5.015 & TRN & \\
\hline CHEMBL1398983 & 688422 & 4.85 & 5.0551 & TST & \\
\hline CHEMBL1355543 & 688422 & 4.55 & 4.6408 & TRN & \\
\hline CHEMBL1442458 & 688422 & 6.05 & 5.1206 & TRN & \\
\hline CHEMBL1608398 & 688422 & 7.0501 & 5.7569 & TRN & \\
\hline CHEMBL1315657 & 688422 & 4.6 & 5.0275 & TRN & \\
\hline CHEMBL1479393 & 688422 & 4.75 & 4.6815 & TST & \\
\hline CHEMBL1447391 & 688422 & 5.5 & 5.2406 & TST & \\
\hline CHEMBL1310893 & 688422 & 4.45 & 4.9251 & TRN & \\
\hline CHEMBL1446491 & 688422 & 4.95 & 4.9822 & TRN & \\
\hline CHEMBL1417089 & 688422 & 4.9 & 5.1085 & TRN & \\
\hline CHEMBL1601254 & 688422 & 7.4498 & 5.6834 & TRN & \\
\hline CHEMBL1421019 & 688422 & 5.0 & 5.4431 & TRN & \\
\hline CHEMBL1428809 & 688422 & 6.25 & 5.2122 & TST & \\
\hline CHEMBL1425287 & 688422 & 7.8508 & 5.5076 & TST & \\
\hline CHEMBL1576810 & 688422 & 4.6 & 4.9676 & TRN & \\
\hline CHEMBL1344136 & 688422 & 4.45 & 5.4987 & TRN & \\
\hline CHEMBL1530033 & 688422 & 5.5 & 5.1627 & TRN & \\
\hline CHEMBL1332984 & 688422 & 4.45 & 4.9932 & TRN & \\
\hline CHEMBL1418371 & 688422 & 5.25 & 5.1106 & TRN & \\
\hline CHEMBL1426583 & 688422 & 4.45 & 5.5194 & TST & \\
\hline CHEMBL1428147 & 688422 & 4.45 & 4.99100 & 00000000005 & TRN \\
\hline CHEMBL1521925 & 688422 & 4.45 & 4.9068 & TRN & \\
\hline CHEMBL1454933 & 688422 & 7.699 & 5.8222 & TRN & \\
\hline CHEMBL1378378 & 688422 & 4.95 & 5.5019 & TRN & \\
\hline CHEMBL1449174 & 688422 & 5.85 & 4.936 & TRN & \\
\hline CHEMBL1973411 & 688422 & 5.6 & 5.1164 & TST & \\
\hline CHEMBL1445838 & 688422 & 5.0 & 5.5184 & TRN & \\
\hline CHEMBL1513456 & 688422 & 5.15 & 5.2902 & TRN & \\
\hline CHEMBL1546668 & 688422 & 4.9 & 5.2283 & TST & \\
\hline CHEMBL1530928 & 688422 & 6.1 & 5.0352 & TRN & \\
\hline CHEMBL1331161 & 688422 & 4.65 & 5.2003 & TST & \\
\hline CHEMBL1334062 & 688422 & 5.45 & 4.9324 & TRN & \\
\hline CHEMBL1471626 & 688422 & 4.75 & 4.9883 & TRN & \\
\hline CHEMBL1309191 & 688422 & 5.4 & 5.4609 & TST & \\
\hline CHEMBL1540544 & 688422 & 5.0 & 5.5618 & TRN & \\
\hline CHEMBL1593001 & 688422 & 6.45 & 4.9189 & TRN & \\
\hline
\end{tabular}




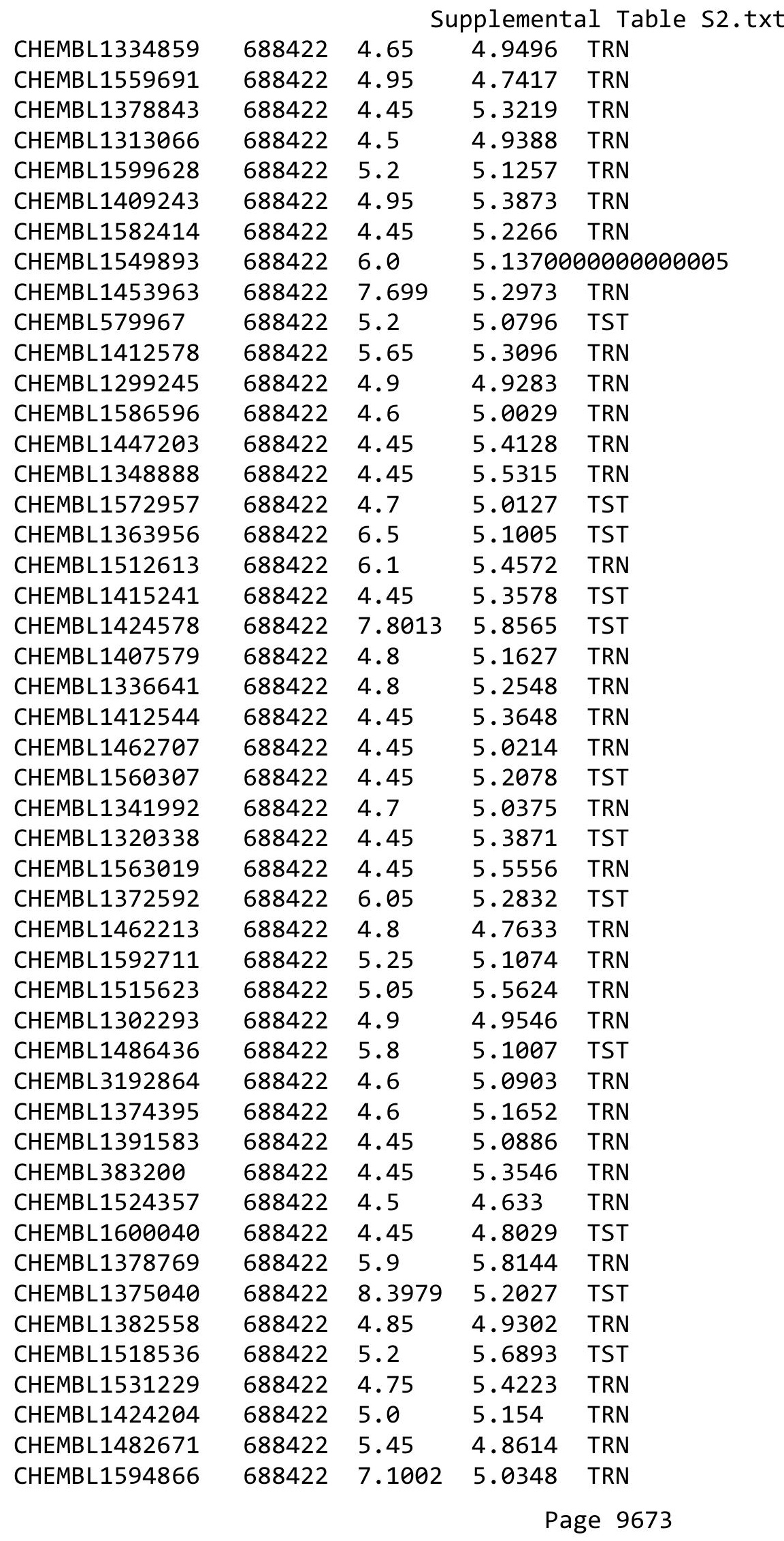




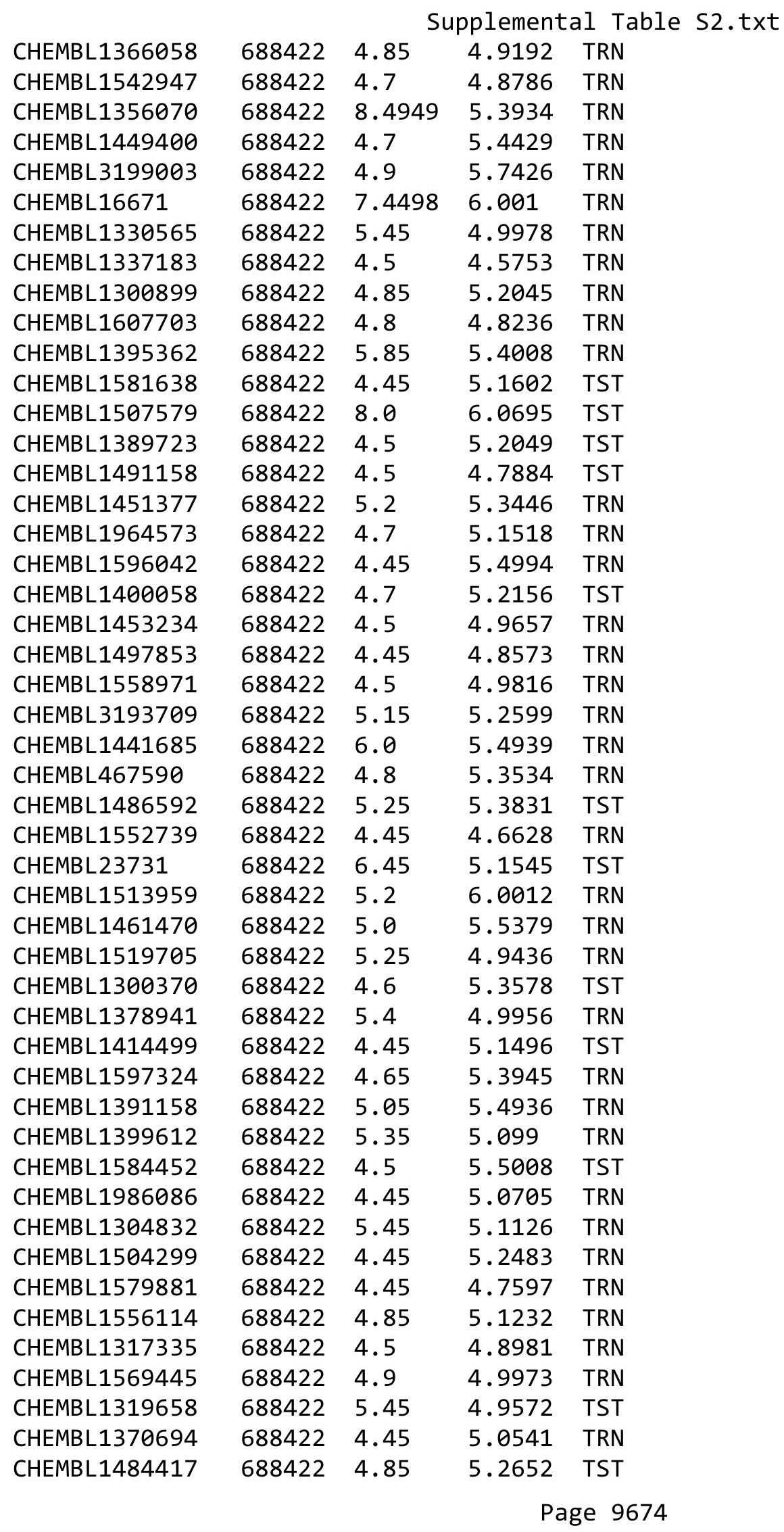




\begin{tabular}{|c|c|c|c|c|c|}
\hline \multicolumn{6}{|c|}{ Supplemental Table S2.txt } \\
\hline CHEMBL1353089 & 688422 & 4.8 & 4.7265 & TRN & \\
\hline CHEMBL1373007 & 688422 & 5.4 & 5.1591 & TST & \\
\hline CHEMBL1528127 & 688422 & 4.85 & 5.221 & TRN & \\
\hline CHEMBL1389688 & 688422 & 4.75 & 5.4334 & TRN & \\
\hline CHEMBL1461586 & 688422 & 8.0 & 5.6084 & TRN & \\
\hline CHEMBL1536593 & 688422 & 6.1 & 5.5681 & TRN & \\
\hline CHEMBL1555813 & 688422 & 7.8996 & 5.8757 & TST & \\
\hline CHEMBL1542257 & 688422 & 5.2 & 5.1476 & TRN & \\
\hline CHEMBL1589016 & 688422 & 7.4001 & 5.5534 & TRN & \\
\hline CHEMBL1334259 & 688422 & 4.9 & 5.1601 & TST & \\
\hline CHEMBL1546386 & 688422 & 4.5 & 5.5919 & TST & \\
\hline CHEMBL1435838 & 688422 & 5.55 & 5.1332 & TST & \\
\hline CHEMBL1371066 & 688422 & 4.95 & 5.3302 & TRN & \\
\hline CHEMBL1485192 & 688422 & 4.7 & 5.7415 & TST & \\
\hline CHEMBL1256776 & 688422 & 8.6576 & 5.5108 & TRN & \\
\hline CHEMBL1363965 & 688422 & 5.55 & 4.9675 & TST & \\
\hline CHEMBL1528359 & 688422 & 4.75 & 5.3642 & TST & \\
\hline CHEMBL1440272 & 688422 & 8.1487 & 5.2408 & TRN & \\
\hline CHEMBL1597692 & 688422 & 5.2 & 5.4411 & TRN & \\
\hline CHEMBL3199466 & 688422 & 5.8 & 5.62299 & 9999999999 & TRN \\
\hline CHEMBL1471323 & 688422 & 4.6 & 5.0885 & TRN & \\
\hline CHEMBL1374189 & 688422 & 4.9 & 5.379 & TRN & \\
\hline CHEMBL3213649 & 688422 & 4.9 & 5.4379 & TST & \\
\hline CHEMBL3192961 & 688422 & 4.65 & 5.388 & TST & \\
\hline CHEMBL1531580 & 688422 & 6.35 & 5.4939 & TST & \\
\hline CHEMBL1331193 & 688422 & 4.65 & 5.1193 & TRN & \\
\hline CHEMBL1417200 & 688422 & 4.75 & 5.2591 & TRN & \\
\hline CHEMBL1455727 & 688422 & 5.25 & 6.2956 & TRN & \\
\hline CHEMBL1443205 & 688422 & 5.0 & 5.2256 & TRN & \\
\hline CHEMBL1401979 & 688422 & 5.25 & 5.0339 & TRN & \\
\hline CHEMBL1368388 & 688422 & 7.6003 & 5.2284 & TRN & \\
\hline CHEMBL147514 & 688422 & 5.25 & 5.2655 & TRN & \\
\hline CHEMBL1361588 & 688422 & 4.8 & 5.1026 & TRN & \\
\hline CHEMBL1478563 & 688422 & 4.75 & 4.7802 & TRN & \\
\hline CHEMBL1396782 & 688422 & 8.301 & 6.0074 & TRN & \\
\hline CHEMBL1339896 & 688422 & 4.7 & 5.6228 & TRN & \\
\hline CHEMBL1418567 & 688422 & 4.75 & 4.9538 & TRN & \\
\hline CHEMBL1568504 & 688422 & 5.25 & 5.1712 & TRN & \\
\hline CHEMBL1309943 & 688422 & 8.8539 & 5.2442 & TST & \\
\hline CHEMBL1444661 & 688422 & 4.9 & 5.2985 & TST & \\
\hline CHEMBL1318751 & 688422 & 4.45 & 5.5081 & TRN & \\
\hline CHEMBL1555884 & 688422 & 5.25 & 5.9967 & TST & \\
\hline CHEMBL1435676 & 688422 & 5.9 & 5.4546 & TRN & \\
\hline CHEMBL1442620 & 688422 & 5.65 & 4.6746 & TST & \\
\hline CHEMBL1485126 & 688422 & 5.45 & 5.3201 & TRN & \\
\hline CHEMBL1369282 & 688422 & 5.85 & 5.0688 & TST & \\
\hline CHEMBL1497731 & 688422 & 4.45 & 5.3481 & TRN & \\
\hline CHEMBL1428515 & 688422 & 5.9 & 5.3757 & TST & \\
\hline
\end{tabular}




\begin{tabular}{|c|c|c|c|c|c|}
\hline \multicolumn{6}{|c|}{ Supplemental Table S2.txt } \\
\hline CHEMBL1401686 & 688422 & 5.0 & 5.1174 & TRN & \\
\hline CHEMBL1466979 & 688422 & 4.7 & 5.37299 & 9999999999 & TRN \\
\hline CHEMBL1360839 & 688422 & 7.6498 & 4.7897 & TRN & \\
\hline CHEMBL1344254 & 688422 & 4.7 & 5.4319 & TRN & \\
\hline CHEMBL1501723 & 688422 & 5.45 & 5.2335 & TST & \\
\hline CHEMBL1573015 & 688422 & 4.85 & 5.4426 & TRN & \\
\hline CHEMBL1594714 & 688422 & 5.4 & 5.5169 & TRN & \\
\hline CHEMBL1548067 & 688422 & 4.45 & 5.204 & TST & \\
\hline CHEMBL1486931 & 688422 & 5.75 & 5.4258 & TRN & \\
\hline CHEMBL1442437 & 688422 & 5.6 & 5.1785 & TRN & \\
\hline CHEMBL1595603 & 688422 & 4.85 & 5.5842 & TRN & \\
\hline CHEMBL1604834 & 688422 & 4.85 & 5.46700 & 00000000005 & TRN \\
\hline CHEMBL1530353 & 688422 & 5.15 & 5.7704 & TRN & \\
\hline CHEMBL1462456 & 688422 & 4.8 & 5.2513 & TRN & \\
\hline CHEMBL1343088 & 688422 & 4.95 & 5.3093 & TRN & \\
\hline CHEMBL1433093 & 688422 & 4.45 & 5.4105 & TRN & \\
\hline CHEMBL1406734 & 688422 & 6.05 & 5.439 & TRN & \\
\hline CHEMBL1563851 & 688422 & 4.6 & 4.8574 & TRN & \\
\hline CHEMBL1580999 & 688422 & 4.65 & 5.7584 & TRN & \\
\hline CHEMBL1987344 & 688422 & 5.85 & 5.5537 & TRN & \\
\hline CHEMBL1489709 & 688422 & 4.9 & 4.9941 & TRN & \\
\hline CHEMBL1537039 & 688422 & 4.45 & 5.6452 & TRN & \\
\hline CHEMBL1440589 & 688422 & 4.95 & 5.3184 & TRN & \\
\hline CHEMBL601320 & 688422 & 5.25 & 5.2638 & TRN & \\
\hline CHEMBL1338380 & 688422 & 5.1 & 5.5286 & TST & \\
\hline CHEMBL1457624 & 688422 & 4.95 & 5.2648 & TRN & \\
\hline CHEMBL585444 & 688422 & 4.5 & 5.3843 & TST & \\
\hline CHEMBL1350820 & 688422 & 4.6 & 5.1686 & TRN & \\
\hline CHEMBL1466458 & 688422 & 4.6 & 4.9986 & TRN & \\
\hline CHEMBL1461527 & 688422 & 5.85 & 5.5157 & TST & \\
\hline CHEMBL1592863 & 688422 & 7.0501 & 5.3671 & TRN & \\
\hline CHEMBL3190389 & 688422 & 4.6 & 4.9594 & TST & \\
\hline CHEMBL1482258 & 688422 & 5.25 & 5.1442 & TRN & \\
\hline CHEMBL1473732 & 688422 & 4.6 & 5.0946 & TRN & \\
\hline CHEMBL1300265 & 688422 & 7.2503 & 5.0892 & TRN & \\
\hline CHEMBL1536923 & 688422 & 4.95 & 5.2941 & TRN & \\
\hline CHEMBL1506640 & 688422 & 4.9 & 5.5709 & TRN & \\
\hline CHEMBL1472213 & 688422 & 5.0 & 5.2188 & TRN & \\
\hline CHEMBL1539742 & 688422 & 4.6 & 5.4884 & TRN & \\
\hline CHEMBL1330068 & 688422 & 4.6 & 4.9748 & TST & \\
\hline CHEMBL1489024 & 688422 & 5.2 & 4.9975 & TRN & \\
\hline CHEMBL1469435 & 688422 & 5.0 & 4.9497 & TRN & \\
\hline CHEMBL1505398 & 688422 & 4.45 & 5.0154 & TRN & \\
\hline CHEMBL1574150 & 688422 & 4.95 & 4.982 & TRN & \\
\hline CHEMBL1481281 & 688422 & 5.15 & 5.1786 & TRN & \\
\hline CHEMBL1583112 & 688422 & 4.5 & 5.65799 & 99999999995 & TST \\
\hline CHEMBL1568020 & 688422 & 4.7 & 5.2841 & TST & \\
\hline CHEMBL1160544 & 688422 & 5.1 & 6.0018 & TRN & \\
\hline
\end{tabular}




\begin{tabular}{|c|c|c|c|c|c|}
\hline \multirow[b]{2}{*}{ CHEMBL1310872 } & \multicolumn{5}{|c|}{ Supplemental Table S2.txt } \\
\hline & 688422 & 7.5003 & 5.5658 & TRN & \\
\hline CHEMBL1428219 & 688422 & 5.05 & 5.0252 & TST & \\
\hline CHEMBL1544271 & 688422 & 4.85 & 5.0353 & TRN & \\
\hline CHEMBL1309248 & 688422 & 4.9 & 5.15 & TRN & \\
\hline CHEMBL1578783 & 688422 & 5.0 & 5.2444 & TRN & \\
\hline CHEMBL1410297 & 688422 & 4.45 & 5.1511 & TRN & \\
\hline CHEMBL1378085 & 688422 & 8.301 & 4.9801 & TRN & \\
\hline CHEMBL1364682 & 688422 & 4.75 & 4.7036 & TRN & \\
\hline CHEMBL601737 & 688422 & 4.95 & 5.2085 & TRN & \\
\hline CHEMBL1340222 & 688422 & 8.301 & 5.4221 & TRN & \\
\hline CHEMBL3198808 & 688422 & 6.7001 & 5.6911 & TRN & \\
\hline CHEMBL1438981 & 688422 & 4.35 & 5.2284 & TST & \\
\hline CHEMBL1483692 & 688422 & 4.9 & 5.1082 & TST & \\
\hline CHEMBL1412662 & 688422 & 4.45 & 5.2206 & TRN & \\
\hline CHEMBL1327233 & 688422 & 5.1 & 5.2104 & TRN & \\
\hline CHEMBL1427629 & 688422 & 5.5 & 4.9734 & TRN & \\
\hline CHEMBL1381653 & 688422 & 4.45 & 5.4346 & TRN & \\
\hline CHEMBL1526639 & 688422 & 4.6 & 5.2866 & TRN & \\
\hline CHEMBL1418027 & 688422 & 4.75 & 5.0752 & TRN & \\
\hline CHEMBL1399655 & 688422 & 4.9 & 5.4814 & TRN & \\
\hline CHEMBL1498903 & 688422 & 6.45 & 5.09699 & 99999999995 & TRN \\
\hline CHEMBL3208181 & 688422 & 4.95 & 5.1117 & TRN & \\
\hline CHEMBL1598406 & 688422 & 4.5 & 5.5249 & TST & \\
\hline CHEMBL1373626 & 688422 & 4.45 & 5.0129 & TRN & \\
\hline CHEMBL1542600 & 688422 & 4.6 & 5.2176 & TRN & \\
\hline CHEMBL1577674 & 688422 & 4.65 & 4.7523 & TRN & \\
\hline CHEMBL1357278 & 688422 & 4.65 & 5.2989 & TRN & \\
\hline CHEMBL1970368 & 688422 & 4.7 & 5.2986 & TRN & \\
\hline CHEMBL1365696 & 688422 & 4.85 & 4.9841 & TRN & \\
\hline CHEMBL1392893 & 688422 & 4.85 & 5.0738 & TRN & \\
\hline CHEMBL1498473 & 688422 & 4.5 & 5.1696 & TRN & \\
\hline CHEMBL1425291 & 688422 & 5.0 & 4.8799 & TRN & \\
\hline CHEMBL1431783 & 688422 & 4.7 & 5.2018 & TRN & \\
\hline CHEMBL1325890 & 688422 & 4.8 & 4.9483 & TRN & \\
\hline CHEMBL1504059 & 688422 & 4.45 & 5.5386 & TRN & \\
\hline CHEMBL1311781 & 688422 & 5.55 & 5.2828 & TRN & \\
\hline CHEMBL1973647 & 688422 & 5.55 & 4.6818 & TRN & \\
\hline CHEMBL1601570 & 688422 & 4.45 & 5.1687 & TRN & \\
\hline CHEMBL1565510 & 688422 & 5.45 & 5.1433 & TST & \\
\hline CHEMBL1392026 & 688422 & 5.05 & 5.36100 & 0000000001 & TRN \\
\hline CHEMBL1547522 & 688422 & 4.9 & 5.3558 & TRN & \\
\hline CHEMBL1586676 & 688422 & 6.2 & 5.5714 & TST & \\
\hline CHEMBL1380900 & 688422 & 4.45 & 4.9525 & TRN & \\
\hline CHEMBL1572867 & 688422 & 4.9 & 5.1189 & TRN & \\
\hline CHEMBL1585566 & 688422 & 7.6003 & 5.5003 & TRN & \\
\hline CHEMBL1387487 & 688422 & 4.45 & 4.7777 & TRN & \\
\hline CHEMBL1421780 & 688422 & 4.9 & 5.1926 & TRN & \\
\hline CHEMBL1421709 & 688422 & 6.4 & 5.5576 & TST & \\
\hline
\end{tabular}




\begin{tabular}{|c|c|c|c|c|c|}
\hline \multicolumn{6}{|c|}{ Supplemental Table S2.txt } \\
\hline CHEMBL1350682 & 688422 & 5.15 & 5.0623 & TRN & \\
\hline CHEMBL1373171 & 688422 & 5.05 & 5.1823 & TST & \\
\hline CHEMBL3213242 & 688422 & 6.5 & 5.2561 & TST & \\
\hline CHEMBL1303957 & 688422 & 4.8 & 5.4664 & TRN & \\
\hline CHEMBL1335146 & 688422 & 4.9 & 4.7857 & TRN & \\
\hline CHEMBL1553592 & 688422 & 6.8 & 5.2498 & TST & \\
\hline CHEMBL1315714 & 688422 & 8.2518 & 5.8258 & TST & \\
\hline CHEMBL1341920 & 688422 & 4.85 & 5.4525 & TRN & \\
\hline CHEMBL1308145 & 688422 & 6.5501 & 5.7616 & TST & \\
\hline CHEMBL1408416 & 688422 & 5.05 & 5.2724 & TRN & \\
\hline CHEMBL1474462 & 688422 & 4.65 & 4.84699 & 99999999995 & TRN \\
\hline CHEMBL1495409 & 688422 & 5.35 & 5.3173 & TRN & \\
\hline CHEMBL1353533 & 688422 & 5.35 & 5.3267 & TRN & \\
\hline CHEMBL1503452 & 688422 & 4.75 & 4.9227 & TST & \\
\hline CHEMBL1313845 & 688422 & 5.15 & 5.4558 & TRN & \\
\hline CHEMBL1421972 & 688422 & 4.45 & 5.1636 & TST & \\
\hline CHEMBL1540412 & 688422 & 5.0 & 5.3141 & TST & \\
\hline CHEMBL1392937 & 688422 & 4.9 & 5.41299 & 9999999999 & TRN \\
\hline CHEMBL1514210 & 688422 & 4.6 & 5.1807 & TRN & \\
\hline CHEMBL1992689 & 688422 & 6.45 & 5.1556 & TRN & \\
\hline CHEMBL1597928 & 688422 & 7.2 & 5.5242 & TRN & \\
\hline CHEMBL1389609 & 688422 & 5.35 & 5.0378 & TRN & \\
\hline CHEMBL1323406 & 688422 & 4.45 & 5.4092 & TRN & \\
\hline CHEMBL1473958 & 688422 & 4.75 & 4.8829 & TRN & \\
\hline CHEMBL 3207378 & 688422 & 5.35 & 5.2521 & TST & \\
\hline CHEMBL1331494 & 688422 & 4.45 & 4.8785 & TRN & \\
\hline CHEMBL1444643 & 688422 & 4.45 & 5.2283 & TRN & \\
\hline CHEMBL1531042 & 688422 & 4.75 & 4.8834 & TRN & \\
\hline CHEMBL1310839 & 688422 & 4.65 & 5.1429 & TRN & \\
\hline CHEMBL1438513 & 688422 & 6.5501 & 5.6125 & TST & \\
\hline CHEMBL1332095 & 688422 & 4.95 & 5.2505 & TRN & \\
\hline CHEMBL1570491 & 688422 & 5.4 & 5.4668 & TRN & \\
\hline CHEMBL1368689 & 688422 & 8.1024 & 5.1917 & TST & \\
\hline CHEMBL1564976 & 688422 & 7.3497 & 5.106 & TST & \\
\hline CHEMBL1478815 & 688422 & 4.75 & 5.0535 & TRN & \\
\hline CHEMBL1524669 & 688422 & 4.85 & 5.1742 & TRN & \\
\hline CHEMBL449392 & 688422 & 5.25 & 5.6881 & TST & \\
\hline CHEMBL1332656 & 688422 & 6.0 & 5.1679 & TRN & \\
\hline CHEMBL1436427 & 688422 & 4.65 & 5.5371 & TRN & \\
\hline CHEMBL1533963 & 688422 & 4.95 & 4.9955 & TST & \\
\hline CHEMBL1415217 & 688422 & 4.8 & 4.9658 & TRN & \\
\hline CHEMBL1516817 & 688422 & 4.95 & 5.2238 & TRN & \\
\hline CHEMBL1389627 & 688422 & 4.7 & 5.1579 & TST & \\
\hline CHEMBL1995177 & 688422 & 4.85 & 5.2351 & TST & \\
\hline CHEMBL1377603 & 688422 & 5.4 & 5.6902 & TRN & \\
\hline CHEMBL1508982 & 688422 & 4.7 & 5.2012 & TRN & \\
\hline CHEMBL1599874 & 688422 & 4.85 & 5.146 & TRN & \\
\hline CHEMBL1375563 & 688422 & 4.95 & 4.7924 & TRN & \\
\hline
\end{tabular}




\begin{tabular}{|c|c|c|c|c|}
\hline \multicolumn{5}{|c|}{ Supplemental Table S2.txt } \\
\hline CHEMBL1309247 & 688422 & 4.55 & 5.1738 & TRN \\
\hline CHEMBL1606742 & 688422 & 5.1 & 5.5889 & TRN \\
\hline CHEMBL1376653 & 688422 & 6.1 & 5.29 & TRN \\
\hline CHEMBL1500771 & 688422 & 5.0 & 5.369 & TST \\
\hline CHEMBL1507680 & 688422 & 6.1 & 5.1201 & TRN \\
\hline CHEMBL1479450 & 688422 & 6.0 & 5.454 & TRN \\
\hline CHEMBL1471106 & 688422 & 4.9 & 5.1777 & TRN \\
\hline CHEMBL1478751 & 688422 & 4.95 & 4.879 & TRN \\
\hline CHEMBL1603192 & 688422 & 4.75 & 4.5777 & TRN \\
\hline CHEMBL1327789 & 688422 & 5.25 & 4.996 & TRN \\
\hline CHEMBL1432305 & 688422 & 4.45 & 5.5673 & TRN \\
\hline CHEMBL1610549 & 688422 & 4.9 & 5.4738 & TRN \\
\hline CHEMBL1432151 & 688422 & 5.05 & 5.0506 & TRN \\
\hline CHEMBL1454812 & 688422 & 4.8 & 5.0809 & TRN \\
\hline CHEMBL1586518 & 688422 & 5.3 & 5.2697 & TRN \\
\hline CHEMBL1469584 & 688422 & 5.05 & 5.1626 & TRN \\
\hline CHEMBL1522653 & 688422 & 5.2 & 5.9517 & TRN \\
\hline CHEMBL1331634 & 688422 & 6.0 & 5.2652 & TRN \\
\hline CHEMBL1551050 & 688422 & 4.5 & 5.1906 & TRN \\
\hline CHEMBL1607279 & 688422 & 4.8 & 5.2309 & TST \\
\hline CHEMBL1475497 & 688422 & 4.85 & 4.8049 & TRN \\
\hline CHEMBL1980120 & 688422 & 7.699 & 5.0254 & TRN \\
\hline CHEMBL3197285 & 688422 & 4.6 & 5.0786 & TRN \\
\hline CHEMBL1367599 & 688422 & 7.699 & 5.4484 & TRN \\
\hline CHEMBL1431403 & 688422 & 5.25 & 5.3795 & TRN \\
\hline CHEMBL1485048 & 688422 & 9.0458 & 5.4148 & TRN \\
\hline CHEMBL1584752 & 688422 & 4.45 & 5.0916 & TRN \\
\hline CHEMBL1595933 & 688422 & 7.5498 & 5.3295 & TRN \\
\hline CHEMBL1571269 & 688422 & 5.1 & 5.6647 & TRN \\
\hline CHEMBL1545888 & 688422 & 5.2 & 4.9047 & TRN \\
\hline CHEMBL1321886 & 688422 & 5.0 & 5.5899 & TRN \\
\hline CHEMBL1458119 & 688422 & 4.8 & 5.4068 & TRN \\
\hline CHEMBL1459774 & 688422 & 4.45 & 5.3998 & TRN \\
\hline CHEMBL1382453 & 688422 & 4.8 & 5.0841 & TRN \\
\hline CHEMBL1427972 & 688422 & 4.95 & 5.3699 & TRN \\
\hline CHEMBL1326791 & 688422 & 4.95 & 5.1643 & TST \\
\hline CHEMBL1414327 & 688422 & 4.95 & 4.7026 & TRN \\
\hline CHEMBL3196262 & 688422 & 4.6 & 5.1574 & TRN \\
\hline CHEMBL1347660 & 688422 & 4.7 & 4.9655 & TRN \\
\hline CHEMBL1511162 & 688422 & 4.8 & 5.1727 & TST \\
\hline CHEMBL1550264 & 688422 & 4.75 & 5.6447 & TRN \\
\hline CHEMBL1322646 & 688422 & 4.9 & 4.9221 & TRN \\
\hline CHEMBL1449871 & 688422 & 4.45 & 4.6921 & TRN \\
\hline CHEMBL1430041 & 688422 & 4.8 & 4.9775 & TST \\
\hline CHEMBL1528970 & 688422 & 4.9 & 5.2135 & TRN \\
\hline CHEMBL3195232 & 688422 & 4.9 & 5.0034 & TRN \\
\hline CHEMBL1575693 & 688422 & 7.8013 & 6.0906 & TRN \\
\hline CHEMBL1535559 & 688422 & 4.9 & 5.1465 & TRN \\
\hline
\end{tabular}




\begin{tabular}{|c|c|c|c|c|c|}
\hline \multicolumn{6}{|c|}{ Supplemental Table S2.txt } \\
\hline CHEMBL3196611 & 688422 & 4.5 & 5.1172 & TRN & \\
\hline CHEMBL3194654 & 688422 & 4.9 & 5.0449 & TRN & \\
\hline CHEMBL1548769 & 688422 & 4.7 & 4.7342 & TRN & \\
\hline CHEMBL1385437 & 688422 & 4.65 & 5.0477 & TRN & \\
\hline CHEMBL1351304 & 688422 & 4.95 & 5.3769 & TRN & \\
\hline CHEMBL1965174 & 688422 & 4.5 & 5.4508 & TST & \\
\hline CHEMBL1449760 & 688422 & 8.3468 & 5.1308 & TRN & \\
\hline CHEMBL1495231 & 688422 & 5.3 & 5.5823 & TRN & \\
\hline CHEMBL1507674 & 688422 & 5.7 & 5.1873 & TRN & \\
\hline CHEMBL1610155 & 688422 & 6.6 & 5.3937 & TRN & \\
\hline CHEMBL1328200 & 688422 & 5.25 & 5.1055 & TRN & \\
\hline CHEMBL1307319 & 688422 & 6.15 & 5.0641 & TST & \\
\hline CHEMBL1405939 & 688422 & 4.95 & 4.7177 & TRN & \\
\hline CHEMBL1474856 & 688422 & 4.9 & 5.38700 & 00000000005 & TST \\
\hline CHEMBL1574799 & 688422 & 4.6 & 5.1073 & TRN & \\
\hline CHEMBL1360296 & 688422 & 4.9 & 4.859 & TRN & \\
\hline CHEMBL1302439 & 688422 & 5.05 & 5.0509 & TST & \\
\hline CHEMBL1353522 & 688422 & 4.85 & 5.3474 & TRN & \\
\hline CHEMBL3193102 & 688422 & 4.45 & 5.2465 & TRN & \\
\hline CHEMBL1542833 & 688422 & 5.9 & 5.3098 & TRN & \\
\hline CHEMBL1420895 & 688422 & 4.75 & 5.3976 & TST & \\
\hline CHEMBL1359347 & 688422 & 6.35 & 5.4721 & TST & \\
\hline CHEMBL1464442 & 688422 & 4.45 & 5.4025 & TRN & \\
\hline CHEMBL1492369 & 688422 & 4.6 & 5.7417 & TST & \\
\hline CHEMBL3195443 & 688422 & 5.05 & 5.29299 & 9999999999 & TRN \\
\hline CHEMBL1334437 & 688422 & 4.8 & 5.4126 & TST & \\
\hline CHEMBL1334221 & 688422 & 4.5 & 5.4132 & TRN & \\
\hline CHEMBL1465373 & 688422 & 5.0 & 5.5963 & TRN & \\
\hline CHEMBL1552882 & 688422 & 4.45 & 4.7074 & TRN & \\
\hline CHEMBL1312643 & 688422 & 4.5 & 5.3175 & TRN & \\
\hline CHEMBL1347759 & 688422 & 7.6003 & 5.4645 & TRN & \\
\hline CHEMBL1353285 & 688422 & 4.85 & 5.6059 & TST & \\
\hline CHEMBL1420649 & 688422 & 5.8 & 5.1697 & TRN & \\
\hline CHEMBL1405862 & 688422 & 8.3468 & 5.8222 & TRN & \\
\hline CHEMBL1562786 & 688422 & 5.0 & 4.7752 & TRN & \\
\hline CHEMBL1556623 & 688422 & 4.5 & 5.1174 & TRN & \\
\hline CHEMBL1572975 & 688422 & 4.5 & 4.9609 & TRN & \\
\hline CHEMBL1532734 & 688422 & 4.95 & 6.01200 & 00000000005 & TST \\
\hline CHEMBL1351105 & 688422 & 4.85 & 5.0812 & TST & \\
\hline CHEMBL1540534 & 688422 & 4.95 & 5.2002 & TST & \\
\hline CHEMBL1321337 & 688422 & 4.45 & 5.3212 & TRN & \\
\hline CHEMBL1511259 & 688422 & 4.95 & 5.7211 & TRN & \\
\hline CHEMBL1431920 & 688422 & 5.2 & 4.989 & TRN & \\
\hline CHEMBL1404580 & 688422 & 6.35 & 5.5423 & TRN & \\
\hline CHEMBL1486842 & 688422 & 4.9 & 4.734 & TST & \\
\hline CHEMBL1410324 & 688422 & 5.05 & 5.0485 & TRN & \\
\hline CHEMBL1499711 & 688422 & 4.85 & 5.045 & TRN & \\
\hline CHEMBL1513727 & 688422 & 5.35 & 5.1812 & TRN & \\
\hline
\end{tabular}




\begin{tabular}{|c|c|c|c|c|}
\hline \multicolumn{5}{|c|}{ Supplemental Table S2.txt } \\
\hline CHEMBL3212347 & 688422 & 5.05 & 5.2995 & TST \\
\hline CHEMBL1595266 & 688422 & 4.75 & 5.6865 & TST \\
\hline CHEMBL1580179 & 688422 & 4.85 & 5.0397 & TRN \\
\hline CHEMBL1393659 & 688422 & 4.65 & 5.4768 & TRN \\
\hline CHEMBL 3208546 & 688422 & 9.0 & 5.2273 & TST \\
\hline CHEMBL1379228 & 688422 & 4.45 & 5.4517 & TRN \\
\hline CHEMBL1422520 & 688422 & 5.0 & 4.9504 & TST \\
\hline CHEMBL1540910 & 688422 & 4.8 & 5.0271 & TRN \\
\hline CHEMBL3198912 & 688422 & 6.15 & 5.3739 & TST \\
\hline CHEMBL1500767 & 688422 & 4.6 & 5.2969 & TRN \\
\hline CHEMBL1411217 & 688422 & 4.85 & 5.2574 & TRN \\
\hline CHEMBL1310726 & 688422 & 5.5 & 4.9191 & TRN \\
\hline CHEMBL3195483 & 688422 & 4.5 & 5.1844 & TST \\
\hline CHEMBL1496289 & 688422 & 4.75 & 5.5905 & TRN \\
\hline CHEMBL3208970 & 688422 & 4.9 & 5.0895 & TRN \\
\hline CHEMBL1306923 & 688422 & 4.45 & 5.0541 & TST \\
\hline CHEMBL1313982 & 688422 & 4.45 & 5.0347 & TRN \\
\hline CHEMBL1509537 & 688422 & 4.6 & 5.2692 & TST \\
\hline CHEMBL1597146 & 688422 & 4.85 & 5.0365 & TRN \\
\hline CHEMBL1522710 & 688422 & 4.8 & 5.7336 & TST \\
\hline CHEMBL1400407 & 688422 & 6.8499 & 5.4156 & TRN \\
\hline CHEMBL1346584 & 688422 & 4.75 & 5.0252 & TRN \\
\hline CHEMBL1421912 & 688422 & 5.0 & 5.0199 & TRN \\
\hline CHEMBL1374973 & 688422 & 6.45 & 5.7073 & TRN \\
\hline CHEMBL3212106 & 688422 & 7.1002 & 5.3184 & TRN \\
\hline CHEMBL1407252 & 688422 & 7.2503 & 5.2356 & TRN \\
\hline CHEMBL3195153 & 688422 & 7.4001 & 5.3696 & TRN \\
\hline CHEMBL1325250 & 688422 & 4.95 & 4.7339 & TRN \\
\hline CHEMBL1353641 & 688422 & 4.7 & 4.9064 & TRN \\
\hline CHEMBL1445196 & 688422 & 4.45 & 5.2317 & TST \\
\hline CHEMBL1603194 & 688422 & 4.5 & 5.6416 & TST \\
\hline CHEMBL554041 & 688422 & 5.0 & 5.6094 & TST \\
\hline CHEMBL1547580 & 688422 & 4.45 & 5.1679 & TRN \\
\hline CHEMBL1403555 & 688422 & 5.35 & 5.2348 & TST \\
\hline CHEMBL1484206 & 688422 & 4.85 & 5.1528 & TRN \\
\hline CHEMBL1469247 & 688422 & 5.15 & 5.4497 & TST \\
\hline CHEMBL1330034 & 688422 & 4.75 & 4.8699 & TST \\
\hline CHEMBL1370006 & 688422 & 5.25 & 5.3553 & TRN \\
\hline CHEMBL1341038 & 688422 & 5.5 & 4.7701 & TRN \\
\hline CHEMBL1593429 & 688422 & 8.3979 & 5.1969 & TRN \\
\hline CHEMBL1555871 & 688422 & 4.45 & 5.0938 & TRN \\
\hline CHEMBL491555 & 688422 & 4.85 & 5.0089 & TRN \\
\hline CHEMBL1302979 & 688422 & 4.85 & 5.0232 & TRN \\
\hline CHEMBL1594875 & 688422 & 4.95 & 4.8326 & TRN \\
\hline CHEMBL1443082 & 688422 & 5.2 & 5.2064 & TST \\
\hline CHEMBL3210769 & 688422 & 4.7 & 5.1485 & TST \\
\hline CHEMBL1579681 & 688422 & 4.65 & 4.6987 & TRN \\
\hline CHEMBL1464522 & 688422 & 4.75 & 5.1749 & TRN \\
\hline
\end{tabular}




\begin{tabular}{|c|c|c|c|c|}
\hline \multicolumn{5}{|c|}{ Supplemental Table S2.txt } \\
\hline CHEMBL1545860 & 688422 & 8.0 & 5.4567 & TST \\
\hline CHEMBL1587861 & 688422 & 5.2 & 5.1078 & TRN \\
\hline CHEMBL1313646 & 688422 & 4.45 & 5.1354 & TST \\
\hline CHEMBL1471516 & 688422 & 4.9 & 5.2731 & TRN \\
\hline CHEMBL1581299 & 688422 & 4.95 & 5.2319 & TST \\
\hline CHEMBL1341036 & 688422 & 5.5 & 5.1659 & TRN \\
\hline CHEMBL1369174 & 688422 & 4.9 & 5.3853 & TST \\
\hline CHEMBL1363267 & 688422 & 5.25 & 5.5511 & TRN \\
\hline CHEMBL1303754 & 688422 & 5.15 & 4.9684 & TRN \\
\hline CHEMBL1311470 & 688422 & 4.55 & 5.3377 & TRN \\
\hline CHEMBL1331136 & 688422 & 4.7 & 5.5425 & TRN \\
\hline CHEMBL1491829 & 688422 & 7.6003 & 5.3914 & TRN \\
\hline CHEMBL1487867 & 688422 & 5.25 & 5.6438 & TST \\
\hline CHEMBL1395307 & 688422 & 4.55 & 5.1974 & TRN \\
\hline CHEMBL1592444 & 688422 & 6.2 & 5.5928 & TST \\
\hline CHEMBL1426853 & 688422 & 4.45 & 4.7944 & TST \\
\hline CHEMBL1421231 & 688422 & 6.45 & 5.0989 & TRN \\
\hline CHEMBL1493372 & 688422 & 4.9 & 5.477 & TRN \\
\hline CHEMBL1360449 & 688422 & 4.85 & 5.131 & TRN \\
\hline CHEMBL1495234 & 688422 & 5.0 & 5.3599 & TST \\
\hline CHEMBL1334208 & 688422 & 5.3 & 5.1657 & TRN \\
\hline CHEMBL1335323 & 688422 & 4.95 & 4.9538 & TRN \\
\hline CHEMBL1308455 & 688422 & 4.45 & 4.8402 & TST \\
\hline CHEMBL3210296 & 688422 & 5.25 & 5.2476 & TST \\
\hline CHEMBL1326071 & 688422 & 6.7501 & 5.1092 & TRN \\
\hline CHEMBL1507941 & 688422 & 4.65 & 5.1344 & TRN \\
\hline CHEMBL1476725 & 688422 & 5.05 & 5.5086 & TRN \\
\hline CHEMBL1581879 & 688422 & 4.8 & 4.6862 & TRN \\
\hline CHEMBL1308043 & 688422 & 4.7 & 5.3124 & TRN \\
\hline CHEMBL3210049 & 688422 & 4.75 & 5.1226 & TRN \\
\hline CHEMBL1613066 & 688422 & 4.55 & 4.9489 & TRN \\
\hline CHEMBL1557179 & 688422 & 5.2 & 5.0913 & TRN \\
\hline CHEMBL1374247 & 688422 & 5.15 & 5.1411 & TRN \\
\hline CHEMBL1310601 & 688422 & 5.1 & 5.0464 & TST \\
\hline CHEMBL3192884 & 688422 & 6.95 & 5.0418 & TRN \\
\hline CHEMBL1385416 & 688422 & 4.8 & 5.1667 & TRN \\
\hline CHEMBL1421146 & 688422 & 4.65 & 5.5153 & TST \\
\hline CHEMBL1594251 & 688422 & 4.5 & 4.7958 & TRN \\
\hline CHEMBL1516231 & 688422 & 5.3 & 5.1471 & TRN \\
\hline CHEMBL1594668 & 688422 & 5.0 & 5.4057 & TRN \\
\hline CHEMBL1347724 & 688422 & 5.45 & 5.1449 & TST \\
\hline CHEMBL1516928 & 688422 & 4.45 & 5.2564 & TRN \\
\hline CHEMBL1415642 & 688422 & 4.45 & 4.7097 & TST \\
\hline CHEMBL1338064 & 688422 & 4.45 & 4.8489 & TRN \\
\hline CHEMBL1521374 & 688422 & 4.6 & 5.0281 & TRN \\
\hline CHEMBL1361049 & 688422 & 6.2 & 5.6903 & TRN \\
\hline CHEMBL1460984 & 688422 & 4.45 & 4.9446 & TRN \\
\hline CHEMBL1323855 & 688422 & 4.75 & 5.0106 & TRN \\
\hline
\end{tabular}




\begin{tabular}{|c|c|c|c|c|}
\hline \multicolumn{5}{|c|}{ Supplemental Table S2.txt } \\
\hline CHEMBL1511363 & 688422 & 6.1 & 5.771 & TST \\
\hline CHEMBL1518842 & 688422 & 4.9 & 4.8619 & TRN \\
\hline CHEMBL1438062 & 688422 & 5.25 & 5.3653 & TST \\
\hline CHEMBL1402707 & 688422 & 4.7 & 5.2392 & TRN \\
\hline CHEMBL1505801 & 688422 & 4.85 & 5.4577 & TRN \\
\hline CHEMBL1556431 & 688422 & 4.85 & 4.7667 & TRN \\
\hline CHEMBL1586531 & 688422 & 5.05 & 5.1886 & TST \\
\hline CHEMBL1372466 & 688422 & 4.45 & 5.2239 & TRN \\
\hline CHEMBL1532997 & 688422 & 4.65 & 5.6653 & TST \\
\hline CHEMBL297304 & 688422 & 4.95 & 5.5268 & TST \\
\hline CHEMBL1510371 & 688422 & 5.35 & 5.2398 & TRN \\
\hline CHEMBL1594634 & 688422 & 7.15 & 5.2088 & TST \\
\hline CHEMBL1567802 & 688422 & 4.75 & 4.7561 & TRN \\
\hline CHEMBL1585248 & 688422 & 4.45 & 5.345 & TRN \\
\hline CHEMBL1313360 & 688422 & 6.6499 & 5.6129 & TRN \\
\hline CHEMBL1584501 & 688422 & 4.45 & 5.1332 & TRN \\
\hline CHEMBL1523151 & 688422 & 4.95 & 5.313 & TRN \\
\hline CHEMBL1401485 & 688422 & 4.7 & 5.864 & TRN \\
\hline CHEMBL1487723 & 688422 & 4.5 & 4.7341 & TRN \\
\hline CHEMBL1415972 & 688422 & 4.9 & 5.1811 & TST \\
\hline CHEMBL1391066 & 688422 & 4.7 & 5.2347 & TST \\
\hline CHEMBL1434203 & 688422 & 5.15 & 4.997 & TRN \\
\hline CHEMBL1343525 & 688422 & 5.15 & 5.3536 & TRN \\
\hline CHEMBL3212579 & 688422 & 4.6 & 5.2719 & TRN \\
\hline CHEMBL1419526 & 688422 & 4.8 & 5.0151 & TRN \\
\hline CHEMBL1362503 & 688422 & 5.45 & 5.0951 & TRN \\
\hline CHEMBL1425390 & 688422 & 4.8 & 5.2804 & TRN \\
\hline CHEMBL3197023 & 688422 & 4.9 & 5.2206 & TRN \\
\hline CHEMBL1320088 & 688422 & 4.65 & 5.3869 & TST \\
\hline CHEMBL1605378 & 688422 & 8.3979 & 4.8914 & TST \\
\hline CHEMBL1505715 & 688422 & 4.45 & 4.8988 & TRN \\
\hline CHEMBL1387269 & 688422 & 4.9 & 4.9283 & TST \\
\hline CHEMBL1424514 & 688422 & 7.3497 & 5.5849 & TST \\
\hline CHEMBL1326833 & 688422 & 4.8 & 5.3492 & TST \\
\hline CHEMBL1401188 & 688422 & 4.9 & 5.5581 & TRN \\
\hline CHEMBL1404056 & 688422 & 5.35 & 4.9475 & TRN \\
\hline CHEMBL1420638 & 688422 & 4.45 & 5.0077 & TRN \\
\hline CHEMBL1510582 & 688422 & 5.4 & 4.8832 & TRN \\
\hline CHEMBL1312792 & 688422 & 5.0 & 4.9577 & TRN \\
\hline CHEMBL1575169 & 688422 & 4.45 & 5.2632 & TRN \\
\hline CHEMBL1313927 & 688422 & 4.9 & 5.4636 & TST \\
\hline CHEMBL1411585 & 688422 & 4.65 & 5.0893 & TRN \\
\hline CHEMBL1509914 & 688422 & 4.7 & 4.7698 & TST \\
\hline CHEMBL1606872 & 688422 & 6.25 & 5.301 & TRN \\
\hline CHEMBL1373750 & 688422 & 5.55 & 5.6341 & TRN \\
\hline CHEMBL1567897 & 688422 & 4.9 & 5.3093 & TRN \\
\hline CHEMBL1305190 & 688422 & 5.0 & 5.1055 & TRN \\
\hline CHEMBL1461646 & 688422 & 5.45 & 5.1831 & TRN \\
\hline
\end{tabular}




\begin{tabular}{|c|c|c|c|c|c|}
\hline \multicolumn{6}{|c|}{ Supplemental Table s2.txt } \\
\hline CHEMBL1591003 & 688422 & 6.45 & 5.3467 & TST & \\
\hline CHEMBL1605189 & 688422 & 4.95 & 5.1737 & TST & \\
\hline CHEMBL1468734 & 688422 & 4.7 & 5.1782 & TRN & \\
\hline CHEMBL1416676 & 688422 & 6.7501 & 5.5198 & TRN & \\
\hline CHEMBL1439697 & 688422 & 7.15 & 4.9542 & TST & \\
\hline CHEMBL1318220 & 688422 & 5.25 & 5.3175 & TRN & \\
\hline CHEMBL 3197290 & 688422 & 4.9 & 5.2784 & TRN & \\
\hline CHEMBL1518812 & 688422 & 4.6 & 5.1204 & TRN & \\
\hline CHEMBL1318273 & 688422 & 5.0 & 5.4772 & TRN & \\
\hline CHEMBL1306841 & 688422 & 7.0501 & 5.7113 & TRN & \\
\hline CHEMBL1407512 & 688422 & 4.75 & 4.8348 & TRN & \\
\hline CHEMBL1310857 & 688422 & 4.75 & 4.8101 & TRN & \\
\hline CHEMBL1499743 & 688422 & 4.5 & 4.9303 & TRN & \\
\hline CHEMBL1303945 & 688422 & 5.05 & 4.862 & TRN & \\
\hline CHEMBL1417592 & 688422 & 4.65 & 5.047 & TRN & \\
\hline CHEMBL1386139 & 688422 & 6.6 & 5.7056 & TRN & \\
\hline CHEMBL392515 & 688422 & 4.95 & 5.1916 & TRN & \\
\hline CHEMBL1537171 & 688422 & 4.5 & 5.313 & TRN & \\
\hline CHEMBL1366987 & 688422 & 5.1 & 4.8072 & TST & \\
\hline CHEMBL1454070 & 688422 & 5.4 & 5.3746 & TRN & \\
\hline CHEMBL3193498 & 688422 & 8.3468 & 5.3487 & TST & \\
\hline CHEMBL1402159 & 688422 & 4.9 & 5.063 & TRN & \\
\hline CHEMBL1495555 & 688422 & 4.75 & 4.8336 & TRN & \\
\hline CHEMBL3190274 & 688422 & 6.15 & 4.9454 & TRN & \\
\hline CHEMBL1362484 & 688422 & 4.45 & 5.3533 & TRN & \\
\hline CHEMBL1321903 & 688422 & 5.4 & 5.1644 & TRN & \\
\hline CHEMBL1450769 & 688422 & 5.75 & 5.496 & TRN & \\
\hline CHEMBL1413244 & 688422 & 4.85 & 5.09399 & 9999999999 & TRN \\
\hline CHEMBL1412263 & 688422 & 4.45 & 5.1027 & TRN & \\
\hline CHEMBL1585745 & 688422 & 5.7 & 5.2736 & TRN & \\
\hline CHEMBL1555323 & 688422 & 6.5501 & 4.9401 & TRN & \\
\hline CHEMBL1593754 & 688422 & 8.6576 & 5.8222 & TST & \\
\hline CHEMBL1388094 & 688422 & 6.3 & 5.3722 & TST & \\
\hline CHEMBL1967837 & 688422 & 4.45 & 5.5946 & TRN & \\
\hline CHEMBL1417942 & 688422 & 4.85 & 5.0586 & TRN & \\
\hline CHEMBL1447781 & 688422 & 4.5 & 5.1662 & TRN & \\
\hline CHEMBL1502020 & 688422 & 4.6 & 5.2191 & TRN & \\
\hline CHEMBL3211449 & 688422 & 4.85 & 5.2113 & TRN & \\
\hline CHEMBL1092115 & 688422 & 7.6498 & 5.4975 & TST & \\
\hline CHEMBL1422314 & 688422 & 4.45 & 5.2168 & TRN & \\
\hline CHEMBL1482365 & 688422 & 5.0 & 5.102 & TRN & \\
\hline CHEMBL1347301 & 688422 & 4.85 & 4.8457 & TRN & \\
\hline CHEMBL3193570 & 688422 & 4.45 & 5.2396 & TRN & \\
\hline CHEMBL1352759 & 688422 & 6.7501 & 5.24799 & 9999999999 & TRN \\
\hline CHEMBL1449221 & 688422 & 8.0 & 5.4028 & TST & \\
\hline CHEMBL1538118 & 688422 & 4.9 & 5.001 & TRN & \\
\hline CHEMBL1299801 & 688422 & 4.55 & 5.49 & TST & \\
\hline CHEMBL1379922 & 688422 & 5.35 & 5.38299 & 9999999999 & TRN \\
\hline & & & & 968 & \\
\hline
\end{tabular}




\begin{tabular}{|c|c|c|c|c|c|}
\hline \multicolumn{6}{|c|}{ Supplemental Table S2.txt } \\
\hline CHEMBL1371340 & 688422 & 4.85 & 5.3861 & TST & \\
\hline CHEMBL1544185 & 688422 & 5.9 & 5.4842 & TST & \\
\hline CHEMBL1387272 & 688422 & 7.15 & 5.0067 & TST & \\
\hline CHEMBL3209342 & 688422 & 4.8 & 5.2006 & TRN & \\
\hline CHEMBL1577367 & 688422 & 4.8 & 5.29299 & 9999999999 & TRN \\
\hline CHEMBL339304 & 688422 & 4.9 & 5.2183 & TRN & \\
\hline CHEMBL1501105 & 688422 & 5.0 & 4.723 & TRN & \\
\hline CHEMBL1552915 & 688422 & 4.95 & 5.5972 & TRN & \\
\hline CHEMBL1595940 & 688422 & 4.55 & 5.0097 & TRN & \\
\hline CHEMBL1463167 & 688422 & 4.8 & 5.3054 & TRN & \\
\hline CHEMBL1587758 & 688422 & 7.1002 & 5.1011 & TRN & \\
\hline CHEMBL1521696 & 688422 & 4.5 & 5.0813 & TST & \\
\hline CHEMBL 2001433 & 688422 & 4.45 & 4.9048 & TRN & \\
\hline CHEMBL1987685 & 688422 & 4.95 & 5.0374 & TRN & \\
\hline CHEMBL1411222 & 688422 & 4.95 & 5.92899 & 9999999999 & TRN \\
\hline CHEMBL1608209 & 688422 & 4.5 & 5.09699 & 99999999995 & TRN \\
\hline CHEMBL1982868 & 688422 & 5.05 & 5.0095 & TRN & \\
\hline CHEMBL1329829 & 688422 & 5.25 & 5.5572 & TRN & \\
\hline CHEMBL1513163 & 688422 & 5.85 & 5.218 & TRN & \\
\hline CHEMBL1595663 & 688422 & 4.85 & 5.1531 & TRN & \\
\hline CHEMBL1592757 & 688422 & 5.4 & 5.5648 & TRN & \\
\hline CHEMBL1597267 & 688422 & 8.3468 & 5.23799 & 99999999995 & TRN \\
\hline CHEMBL1608119 & 688422 & 5.3 & 5.227 & TRN & \\
\hline CHEMBL1361128 & 688422 & 5.3 & 5.0582 & TRN & \\
\hline CHEMBL1398821 & 688422 & 5.55 & 5.7046 & TRN & \\
\hline CHEMBL1547546 & 688422 & 5.5 & 5.9546 & TRN & \\
\hline CHEMBL1591601 & 688422 & 5.5 & 5.5087 & TRN & \\
\hline CHEMBL1395058 & 688422 & 8.3468 & 5.0655 & TRN & \\
\hline CHEMBL1432837 & 688422 & 4.6 & 5.1788 & TRN & \\
\hline CHEMBL1567543 & 688422 & 4.45 & 5.2969 & TRN & \\
\hline CHEMBL1502752 & 688422 & 4.45 & 5.1796 & TST & \\
\hline CHEMBL1328517 & 688422 & 5.6 & 5.0034 & TRN & \\
\hline CHEMBL1301721 & 688422 & 4.95 & 5.1849 & TRN & \\
\hline CHEMBL1613582 & 688422 & 6.35 & 5.0316 & TRN & \\
\hline CHEMBL1342326 & 688422 & 6.5501 & 5.6222 & TST & \\
\hline CHEMBL3191274 & 688422 & 4.95 & 5.651 & TRN & \\
\hline CHEMBL1576166 & 688422 & 4.7 & 5.472 & TRN & \\
\hline CHEMBL1592761 & 688422 & 6.1 & 5.4761 & TST & \\
\hline CHEMBL1359037 & 688422 & 5.15 & 5.2024 & TRN & \\
\hline CHEMBL1573275 & 688422 & 4.8 & 5.106 & TRN & \\
\hline CHEMBL1455388 & 688422 & 8.301 & 5.7608 & TST & \\
\hline CHEMBL1596232 & 688422 & 5.5 & 5.0853 & TRN & \\
\hline CHEMBL1424404 & 688422 & 4.95 & 5.499 & TRN & \\
\hline CHEMBL1532472 & 688422 & 5.0 & 5.4203 & TRN & \\
\hline CHEMBL3193999 & 688422 & 8.4949 & 5.4514 & TST & \\
\hline CHEMBL1598442 & 688422 & 5.55 & 5.075 & TRN & \\
\hline CHEMBL1543577 & 688422 & 4.85 & 5.3498 & TRN & \\
\hline CHEMBL1491545 & 688422 & 6.15 & 5.3965 & TRN & \\
\hline
\end{tabular}




\begin{tabular}{|c|c|c|c|c|}
\hline \multicolumn{5}{|c|}{ Supplemental Table S2.txt } \\
\hline CHEMBL1331560 & 688422 & 4.5 & 5.3481 & TRN \\
\hline CHEMBL1526771 & 688422 & 5.4 & 5.5878 & TRN \\
\hline CHEMBL1320902 & 688422 & 5.65 & 5.3828 & TRN \\
\hline CHEMBL1575125 & 688422 & 4.45 & 4.5472 & TRN \\
\hline CHEMBL3197633 & 688422 & 4.5 & 5.2767 & TRN \\
\hline CHEMBL1567692 & 688422 & 5.2 & 5.0051 & TRN \\
\hline CHEMBL1598598 & 688422 & 4.45 & 5.0406 & TRN \\
\hline CHEMBL1422757 & 688422 & 5.4 & 5.4974 & TST \\
\hline CHEMBL1319767 & 688422 & 5.5 & 5.4347 & TRN \\
\hline CHEMBL1392690 & 688422 & 7.699 & 5.3686 & TST \\
\hline CHEMBL1376065 & 688422 & 5.0 & 5.2121 & TST \\
\hline CHEMBL1351813 & 688422 & 4.65 & 5.3795 & TST \\
\hline CHEMBL1475294 & 688422 & 4.45 & 5.7182 & TRN \\
\hline CHEMBL1508467 & 688422 & 5.05 & 5.2546 & TRN \\
\hline CHEMBL1446098 & 688422 & 4.85 & 5.0948 & TRN \\
\hline CHEMBL1521753 & 688422 & 4.45 & 5.7354 & TRN \\
\hline CHEMBL1585048 & 688422 & 6.4 & 5.7428 & TRN \\
\hline CHEMBL1355144 & 688422 & 7.8508 & 5.2824 & TRN \\
\hline CHEMBL1409613 & 688422 & 4.95 & 4.8018 & TRN \\
\hline CHEMBL1480234 & 688422 & 8.301 & 5.4536 & TRN \\
\hline CHEMBL1430757 & 688422 & 4.95 & 5.1575 & TRN \\
\hline CHEMBL1508108 & 688422 & 4.8 & 5.4061 & TRN \\
\hline CHEMBL1504989 & 688422 & 5.05 & 5.1544 & TRN \\
\hline CHEMBL1369590 & 688422 & 4.8 & 4.9649 & TRN \\
\hline CHEMBL1351731 & 688422 & 4.45 & 4.9161 & TST \\
\hline CHEMBL1450289 & 688422 & 4.7 & 5.3591 & TRN \\
\hline CHEMBL1494214 & 688422 & 4.65 & 5.3414 & TRN \\
\hline CHEMBL1555687 & 688422 & 4.45 & 5.4567 & TRN \\
\hline CHEMBL1369328 & 688422 & 6.4 & 5.5082 & TST \\
\hline CHEMBL1391533 & 688422 & 4.85 & 4.849 & TRN \\
\hline CHEMBL1406845 & 688422 & 5.3 & 4.8728 & TRN \\
\hline CHEMBL1516189 & 688422 & 4.5 & 4.9625 & TRN \\
\hline CHEMBL605499 & 688422 & 8.4949 & 5.38 & TRN \\
\hline CHEMBL1966890 & 688422 & 5.15 & 5.2258 & TRN \\
\hline CHEMBL1431012 & 688422 & 4.85 & 5.5318 & TRN \\
\hline CHEMBL1587849 & 688422 & 4.9 & 5.1631 & TRN \\
\hline CHEMBL1560779 & 688422 & 5.2 & 5.5142 & TST \\
\hline CHEMBL1606158 & 688422 & 4.9 & 4.7566 & TRN \\
\hline CHEMBL1368140 & 688422 & 4.8 & 4.9574 & TRN \\
\hline CHEMBL1343969 & 688422 & 5.1 & 5.2981 & TRN \\
\hline CHEMBL1609827 & 688422 & 6.05 & 5.3211 & TRN \\
\hline CHEMBL 260148 & 688422 & 4.85 & 5.0997 & TRN \\
\hline CHEMBL1413181 & 688422 & 6.5501 & 5.9539 & TRN \\
\hline CHEMBL1367487 & 688422 & 5.25 & 5.3497 & TRN \\
\hline CHEMBL1519220 & 688422 & 4.6 & 4.7536 & TRN \\
\hline CHEMBL1978150 & 688422 & 4.6 & 5.3962 & TRN \\
\hline CHEMBL1563206 & 688422 & 4.75 & 5.4403 & TRN \\
\hline CHEMBL1332967 & 688422 & 4.45 & 5.2251 & TRN \\
\hline
\end{tabular}




\begin{tabular}{|c|c|c|c|c|}
\hline \multicolumn{5}{|c|}{ Supplemental Table S2.txt } \\
\hline CHEMBL1592051 & 688422 & 7.9508 & 5.5178 & TRN \\
\hline CHEMBL1317572 & 688422 & 5.75 & 5.9144 & TRN \\
\hline CHEMBL1384723 & 688422 & 8.1487 & 5.3062 & TRN \\
\hline CHEMBL1604090 & 688422 & 4.45 & 4.6027 & TRN \\
\hline CHEMBL1421513 & 688422 & 4.45 & 5.7695 & TRN \\
\hline CHEMBL1364400 & 688422 & 8.1487 & 5.1229 & TRN \\
\hline CHEMBL1546736 & 688422 & 4.8 & 5.2579 & TRN \\
\hline CHEMBL1367108 & 688422 & 4.75 & 5.2028 & TRN \\
\hline CHEMBL1451245 & 688422 & 7.0501 & 5.3089 & TRN \\
\hline CHEMBL1500291 & 688422 & 4.85 & 5.5061 & TST \\
\hline CHEMBL1409318 & 688422 & 4.95 & 5.4716 & TST \\
\hline CHEMBL1457776 & 688422 & 5.6 & 5.0449 & TRN \\
\hline CHEMBL1498396 & 688422 & 5.45 & 5.1994 & TRN \\
\hline CHEMBL1394351 & 688422 & 8.4949 & 5.6046 & TRN \\
\hline CHEMBL1418115 & 688422 & 5.25 & 5.5008 & TRN \\
\hline CHEMBL1610781 & 688422 & 7.9508 & 5.2921 & TRN \\
\hline CHEMBL1426468 & 688422 & 4.95 & 5.2927 & TRN \\
\hline CHEMBL1483586 & 688422 & 5.45 & 5.4118 & TRN \\
\hline CHEMBL1428004 & 688422 & 4.9 & 5.1279 & TRN \\
\hline CHEMBL1380884 & 688422 & 4.45 & 5.1449 & TRN \\
\hline CHEMBL 1385342 & 688422 & 4.85 & 4.9187 & TRN \\
\hline CHEMBL1537853 & 688422 & 4.45 & 5.3465 & TRN \\
\hline CHEMBL1475208 & 688422 & 4.45 & 5.3049 & TST \\
\hline CHEMBL1533731 & 688422 & 4.85 & 4.7124 & TRN \\
\hline CHEMBL1511404 & 688422 & 4.9 & 5.2339 & TRN \\
\hline CHEMBL 1317537 & 688422 & 4.95 & 4.9254 & TRN \\
\hline CHEMBL1583258 & 688422 & 5.75 & 5.7063 & TST \\
\hline CHEMBL1610551 & 688422 & 6.2 & 5.4983 & TRN \\
\hline CHEMBL1593308 & 688422 & 5.45 & 5.0067 & TRN \\
\hline CHEMBL1467314 & 688422 & 7.6498 & 5.6651 & TST \\
\hline CHEMBL 3195640 & 688422 & 5.4 & 5.1847 & TRN \\
\hline CHEMBL1531932 & 688422 & 4.75 & 4.8329 & TST \\
\hline CHEMBL1399663 & 688422 & 4.6 & 5.0865 & TRN \\
\hline CHEMBL1994668 & 688422 & 5.4 & 5.3467 & TRN \\
\hline CHEMBL1362615 & 688422 & 5.25 & 5.1715 & TST \\
\hline CHEMBL1460363 & 688422 & 4.45 & 5.4571 & TRN \\
\hline CHEMBL1564091 & 688422 & 5.05 & 5.0849 & TRN \\
\hline CHEMBL1440201 & 688422 & 6.3 & 5.37299 & 9999999999 \\
\hline CHEMBL1334133 & 688422 & 4.45 & 5.2225 & TRN \\
\hline CHEMBL1585024 & 688422 & 4.85 & 4.8094 & TRN \\
\hline CHEMBL1477112 & 688422 & 4.45 & 5.5518 & TRN \\
\hline CHEMBL1554976 & 688422 & 5.05 & 4.8613 & TRN \\
\hline CHEMBL1431705 & 688422 & 4.8 & 4.8641 & TRN \\
\hline CHEMBL1464134 & 688422 & 4.85 & 5.4667 & TST \\
\hline CHEMBL1429273 & 688422 & 4.9 & 5.1528 & TRN \\
\hline CHEMBL1562333 & 688422 & 4.65 & 5.0635 & TRN \\
\hline CHEMBL1579553 & 688422 & 4.85 & 5.2161 & TRN \\
\hline CHEMBL1411203 & 688422 & 4.5 & 4.5463 & TST \\
\hline
\end{tabular}




\begin{tabular}{|c|c|c|c|c|c|}
\hline \multirow{3}{*}{$\begin{array}{l}\text { CHEMBL1576169 } \\
\text { CHEMBL } 1405352\end{array}$} & \multirow{3}{*}{$\begin{array}{l}688422 \\
688422\end{array}$} & \multicolumn{4}{|c|}{ Supplemental Table s2.txt } \\
\hline & & 5.7 & 5.41200 & 0000000001 & TRN \\
\hline & & 4.65 & 5.1264 & TRN & \\
\hline CHEMBL1434739 & 688422 & 7.5003 & 6.3382 & TRN & \\
\hline CHEMBL588384 & 688422 & 5.5 & 4.7605 & TRN & \\
\hline CHEMBL1417692 & 688422 & 5.3 & 5.2435 & TRN & \\
\hline CHEMBL1550090 & 688422 & 4.45 & 5.2155 & TRN & \\
\hline CHEMBL1455416 & 688422 & 4.45 & 5.1693 & TRN & \\
\hline CHEMBL1466219 & 688422 & 4.85 & 5.57 & TRN & \\
\hline CHEMBL1596875 & 688422 & 4.9 & 4.9566 & TRN & \\
\hline CHEMBL1584001 & 688422 & 4.95 & 5.6641 & TRN & \\
\hline CHEMBL1538120 & 688422 & 4.45 & 4.8995 & TRN & \\
\hline CHEMBL1333244 & 688422 & 7.4001 & 5.8906 & TRN & \\
\hline CHEMBL1303916 & 688422 & 4.45 & 4.9853 & TRN & \\
\hline CHEMBL1346567 & 688422 & 4.45 & 4.9559 & TRN & \\
\hline CHEMBL1607849 & 688422 & 4.95 & 5.2308 & TRN & \\
\hline CHEMBL1421480 & 688422 & 5.0 & 5.0514 & TRN & \\
\hline CHEMBL1376643 & 688422 & 4.45 & 5.37799 & 9999999999 & TRN \\
\hline CHEMBL1343080 & 688422 & 5.0 & 5.1824 & TRN & \\
\hline CHEMBL1529660 & 688422 & 6.05 & 5.0934 & TST & \\
\hline CHEMBL1309632 & 688422 & 4.85 & 5.254 & TRN & \\
\hline CHEMBL1384167 & 688422 & 4.7 & 5.4359 & TRN & \\
\hline CHEMBL1493336 & 688422 & 5.2 & 5.182 & TRN & \\
\hline CHEMBL1599740 & 688422 & 5.7 & 4.9467 & TRN & \\
\hline CHEMBL3195308 & 688422 & 4.45 & 5.0213 & TRN & \\
\hline CHEMBL1498606 & 688422 & 4.45 & 5.553 & TST & \\
\hline CHEMBL1440204 & 688422 & 7.0501 & 5.9012 & TRN & \\
\hline CHEMBL1996730 & 688422 & 5.85 & 5.6331 & TRN & \\
\hline CHEMBL1374943 & 688422 & 4.45 & 5.4404 & TRN & \\
\hline CHEMBL1306320 & 688422 & 8.4949 & 5.6828 & TRN & \\
\hline CHEMBL1313786 & 688422 & 6.7501 & 5.3921 & TRN & \\
\hline CHEMBL1471205 & 688422 & 4.95 & 5.0815 & TRN & \\
\hline CHEMBL1335024 & 688422 & 4.5 & 5.7974 & TST & \\
\hline CHEMBL1404211 & 688422 & 4.45 & 5.0279 & TRN & \\
\hline CHEMBL1567558 & 688422 & 7.4001 & 5.7376 & TRN & \\
\hline CHEMBL1543947 & 688422 & 4.7 & 5.075 & TRN & \\
\hline CHEMBL1455255 & 688422 & 5.2 & 5.1083 & TRN & \\
\hline CHEMBL1381384 & 688422 & 5.55 & 5.3419 & TRN & \\
\hline CHEMBL221190 & 688422 & 5.05 & 5.1853 & TST & \\
\hline CHEMBL1562244 & 688422 & 5.4 & 5.6678 & TRN & \\
\hline CHEMBL1390532 & 688422 & 6.5501 & 5.5688 & TST & \\
\hline CHEMBL1420002 & 688422 & 5.25 & 5.8039 & TST & \\
\hline CHEMBL1403638 & 688422 & 5.05 & 5.2389 & TRN & \\
\hline CHEMBL1235551 & 688422 & 6.7001 & 5.6442 & TST & \\
\hline CHEMBL177820 & 688422 & 4.9 & 5.9264 & TST & \\
\hline CHEMBL1391504 & 688422 & 4.5 & 5.4359 & TRN & \\
\hline CHEMBL1312250 & 688422 & 4.45 & 5.2377 & TRN & \\
\hline CHEMBL1371520 & 688422 & 4.45 & 4.8721 & TRN & \\
\hline CHEMBL1608827 & 688422 & 5.2 & 5.6148 & TRN & \\
\hline
\end{tabular}




\begin{tabular}{|c|c|c|c|c|c|}
\hline \multicolumn{6}{|c|}{ Supplemental Table s2.txt } \\
\hline CHEMBL 3212117 & 688422 & 6.0 & 5.0831 & TST & \\
\hline CHEMBL1447759 & 688422 & 4.45 & 5.8065 & TST & \\
\hline CHEMBL1518696 & 688422 & 4.5 & 4.7977 & TST & \\
\hline CHEMBL1401914 & 688422 & 7.7496 & 5.4743 & TRN & \\
\hline CHEMBL1507053 & 688422 & 5.05 & 5.5607 & TRN & \\
\hline CHEMBL1521919 & 688422 & 4.7 & 5.3299 & TRN & \\
\hline CHEMBL1417339 & 688422 & 4.45 & 5.0086 & TRN & \\
\hline CHEMBL1372286 & 688422 & 4.45 & 5.0823 & TRN & \\
\hline CHEMBL1463676 & 688422 & 7.2 & 5.6518 & TRN & \\
\hline CHEMBL1491130 & 688422 & 4.65 & 5.3166 & TRN & \\
\hline CHEMBL1525619 & 688422 & 5.0 & 5.1798 & TRN & \\
\hline CHEMBL1340146 & 688422 & 4.45 & 5.1135 & TST & \\
\hline CHEMBL1433012 & 688422 & 4.45 & 4.9007 & TRN & \\
\hline CHEMBL1402016 & 688422 & 4.45 & 5.1901 & TST & \\
\hline CHEMBL1498391 & 688422 & 4.45 & 5.1894 & TST & \\
\hline CHEMBL1356546 & 688422 & 4.65 & 5.2904 & TRN & \\
\hline CHEMBL1327359 & 688422 & 7.1002 & 5.2474 & TRN & \\
\hline CHEMBL1443920 & 688422 & 4.5 & 5.4763 & TRN & \\
\hline CHEMBL1302809 & 688422 & 4.65 & 5.2233 & TST & \\
\hline CHEMBL1486168 & 688422 & 4.8 & 5.2616 & TRN & \\
\hline CHEMBL1416333 & 688422 & 5.0 & 5.1764 & TRN & \\
\hline CHEMBL1511312 & 688422 & 4.9 & 5.0999 & TRN & \\
\hline CHEMBL1506468 & 688422 & 7.699 & 6.0066 & TRN & \\
\hline CHEMBL3191726 & 688422 & 4.45 & 5.2595 & TRN & \\
\hline CHEMBL1551515 & 688422 & 6.35 & 5.3905 & TRN & \\
\hline CHEMBL1467133 & 688422 & 5.1 & 4.8606 & TST & \\
\hline CHEMBL1437230 & 688422 & 4.65 & 4.7644 & TRN & \\
\hline CHEMBL1308948 & 688422 & 4.9 & 5.2254 & TST & \\
\hline CHEMBL1488030 & 688422 & 4.7 & 5.2811 & TRN & \\
\hline CHEMBL1334024 & 688422 & 5.05 & 5.7562 & TRN & \\
\hline CHEMBL1508646 & 688422 & 4.45 & 4.7317 & TRN & \\
\hline CHEMBL1398473 & 688422 & 7.15 & 5.2226 & TRN & \\
\hline CHEMBL 2006258 & 688422 & 5.15 & 5.4273 & TST & \\
\hline CHEMBL1605841 & 688422 & 4.9 & 5.6352 & TST & \\
\hline CHEMBL 3207394 & 688422 & 4.5 & 5.50899 & 99999999995 & TRN \\
\hline CHEMBL1564250 & 688422 & 4.45 & 5.1868 & TST & \\
\hline CHEMBL1509744 & 688422 & 4.45 & 4.7259 & TRN & \\
\hline CHEMBL1496457 & 688422 & 4.45 & 4.9057 & TST & \\
\hline CHEMBL1587878 & 688422 & 4.95 & 5.2202 & TRN & \\
\hline CHEMBL1514346 & 688422 & 7.5498 & 5.5913 & TRN & \\
\hline CHEMBL1554822 & 688422 & 8.0 & 5.8509 & TRN & \\
\hline CHEMBL3190468 & 688422 & 4.5 & 4.8611 & TRN & \\
\hline CHEMBL1382807 & 688422 & 4.8 & 5.4247 & TRN & \\
\hline CHEMBL1323923 & 688422 & 5.25 & 5.2324 & TRN & \\
\hline CHEMBL1446294 & 688422 & 6.4 & 5.4279 & TST & \\
\hline CHEMBL1472866 & 688422 & 4.95 & 5.2264 & TST & \\
\hline CHEMBL1428821 & 688422 & 7.5498 & 5.5208 & TRN & \\
\hline CHEMBL1534838 & 688422 & 5.0 & 5.1991 & TRN & \\
\hline
\end{tabular}




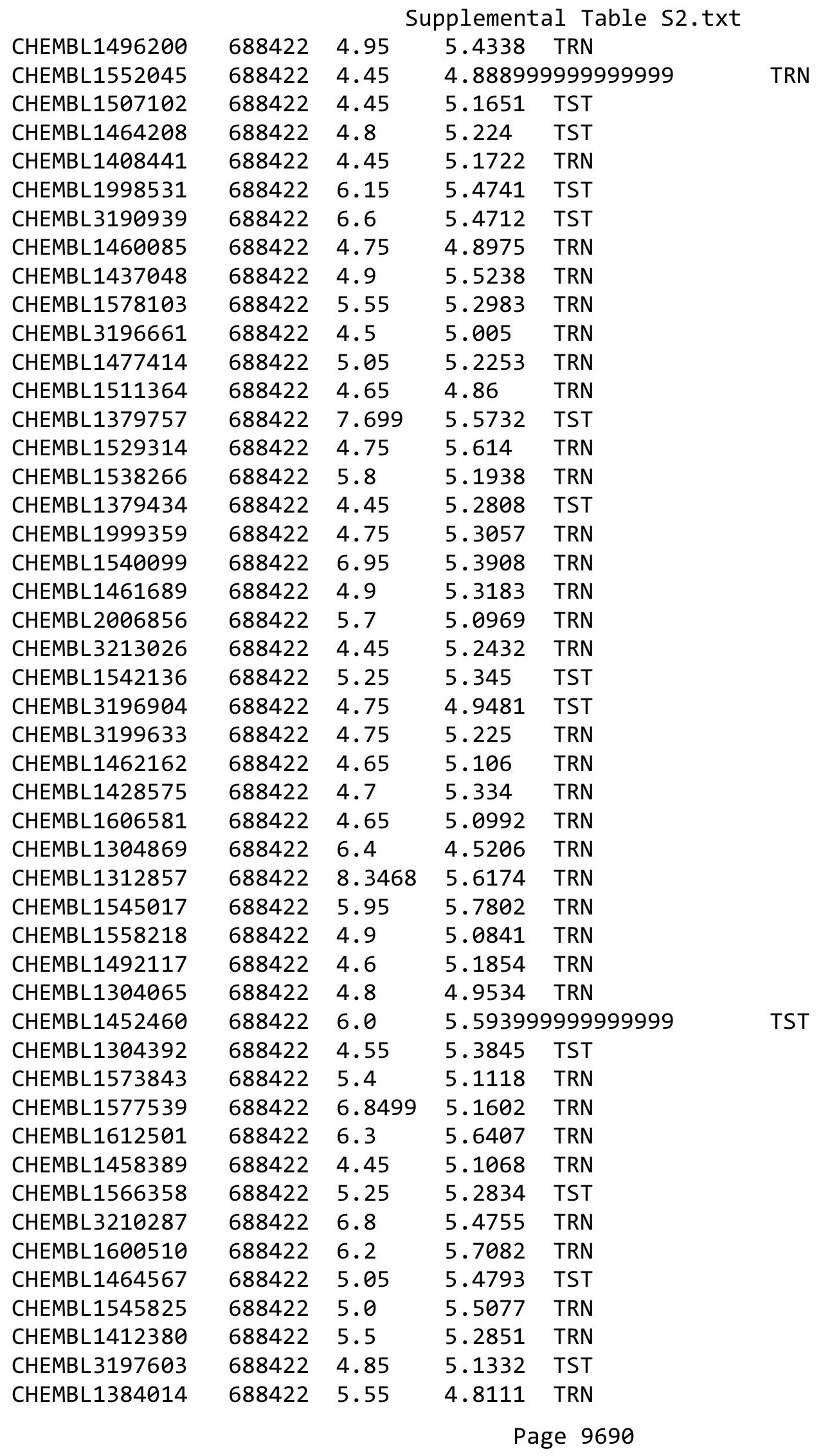




\begin{tabular}{|c|c|c|c|c|}
\hline \multicolumn{5}{|c|}{ Supplemental Table } \\
\hline CHEMBL1411133 & 688422 & 5.15 & 5.3114 & TRN \\
\hline CHEMBL1359102 & 688422 & 4.85 & 4.9448 & TRN \\
\hline CHEMBL1603364 & 688422 & 4.95 & 5.2614 & TRN \\
\hline CHEMBL1527256 & 688422 & 8.301 & 5.1371 & TRN \\
\hline CHEMBL1409925 & 688422 & 5.6 & 5.63 & TRN \\
\hline CHEMBL1460692 & 688422 & 4.95 & 4.5913 & TST \\
\hline CHEMBL1576875 & 688422 & 4.65 & 4.9416 & TRN \\
\hline CHEMBL1299997 & 688422 & 5.0 & 5.3905 & TRN \\
\hline CHEMBL1329577 & 688422 & 4.55 & 4.9511 & TRN \\
\hline CHEMBL1421218 & 688422 & 4.95 & 5.2075 & TRN \\
\hline CHEMBL1403914 & 688422 & 4.7 & 4.84 & TRN \\
\hline CHEMBL1375244 & 688422 & 6.9 & 5.5267 & TRN \\
\hline CHEMBL1608090 & 688422 & 4.5 & 5.0005 & TRN \\
\hline CHEMBL1579618 & 688422 & 4.6 & 5.2404 & TRN \\
\hline CHEMBL1372832 & 688422 & 4.65 & 4.9917 & TRN \\
\hline CHEMBL1559303 & 688422 & 6.25 & 5.8995 & TST \\
\hline CHEMBL3213310 & 688422 & 6.1 & 5.5436 & TRN \\
\hline CHEMBL1421750 & 688422 & 4.7 & 5.3368 & TRN \\
\hline CHEMBL1418866 & 688422 & 4.9 & 5.3197 & TST \\
\hline CHEMBL1334286 & 688422 & 6.05 & 5.1917 & TRN \\
\hline CHEMBL1590863 & 688422 & 6.4 & 5.6429 & TRN \\
\hline CHEMBL1491237 & 688422 & 7.2 & 5.1298 & TRN \\
\hline CHEMBL1470470 & 688422 & 4.45 & 5.2239 & TRN \\
\hline CHEMBL1488472 & 688422 & 5.9 & 5.2739 & TRN \\
\hline CHEMBL1500186 & 688422 & 4.95 & 5.1293 & TRN \\
\hline CHEMBL1564312 & 688422 & 4.7 & 5.3416 & TRN \\
\hline CHEMBL605077 & 688422 & 5.95 & 5.1927 & TRN \\
\hline CHEMBL1994683 & 688422 & 4.95 & 5.1068 & TRN \\
\hline CHEMBL1590294 & 688422 & 4.45 & 5.1846 & TRN \\
\hline CHEMBL1563285 & 688422 & 6.1 & 5.6916 & TRN \\
\hline CHEMBL1464266 & 688422 & 5.55 & 5.0299 & TRN \\
\hline CHEMBL1460164 & 688422 & 6.4 & 5.5528 & TST \\
\hline CHEMBL1300999 & 688422 & 5.0 & 4.9914 & TRN \\
\hline CHEMBL1376689 & 688422 & 5.4 & 5.5392 & TRN \\
\hline CHEMBL1342435 & 688422 & 6.0 & 5.4387 & TST \\
\hline CHEMBL1602303 & 688422 & 4.45 & 5.1688 & TRN \\
\hline CHEMBL1602058 & 688422 & 4.45 & 5.0651 & TRN \\
\hline CHEMBL1397548 & 688422 & 4.95 & 4.7668 & TRN \\
\hline CHEMBL1309874 & 688422 & 4.45 & 5.0301 & TRN \\
\hline CHEMBL3211459 & 688422 & 4.45 & 5.2369 & TRN \\
\hline CHEMBL1370062 & 688422 & 4.65 & 4.9107 & TRN \\
\hline CHEMBL1421544 & 688422 & 4.45 & 4.9284 & TST \\
\hline CHEMBL1491000 & 688422 & 5.55 & 5.3594 & TRN \\
\hline CHEMBL456678 & 688422 & 4.85 & 4.7421 & TRN \\
\hline CHEMBL1430875 & 688422 & 4.5 & 5.2516 & TST \\
\hline CHEMBL1440562 & 688422 & 4.85 & 5.2251 & TRN \\
\hline CHEMBL1348930 & 688422 & 4.9 & 5.4619 & TRN \\
\hline CHEMBL1429615 & 688422 & 6.25 & 5.1186 & TST \\
\hline
\end{tabular}




\begin{tabular}{|c|c|c|c|c|}
\hline \multicolumn{5}{|c|}{ Supplemental Table S2.txt } \\
\hline CHEMBL1333061 & 688422 & 8.4559 & 4.8949 & TRN \\
\hline CHEMBL1386418 & 688422 & 4.65 & 4.8811 & TRN \\
\hline CHEMBL1995825 & 688422 & 4.85 & 5.1013 & TRN \\
\hline CHEMBL1437953 & 688422 & 5.15 & 5.2539 & TST \\
\hline CHEMBL1455438 & 688422 & 4.8 & 5.2216 & TRN \\
\hline CHEMBL1399332 & 688422 & 4.9 & 4.7491 & TRN \\
\hline CHEMBL1510287 & 688422 & 5.0 & 5.3886 & TRN \\
\hline CHEMBL1384062 & 688422 & 5.35 & 5.4534 & TST \\
\hline CHEMBL1420333 & 688422 & 5.15 & 4.9832 & TST \\
\hline CHEMBL1388795 & 688422 & 4.65 & 4.9168 & TRN \\
\hline CHEMBL1405102 & 688422 & 4.45 & 4.6778 & TRN \\
\hline CHEMBL1484139 & 688422 & 4.75 & 5.4676 & TST \\
\hline CHEMBL1531295 & 688422 & 5.15 & 4.9958 & TRN \\
\hline CHEMBL 3194477 & 688422 & 4.8 & 4.9283 & TRN \\
\hline CHEMBL1329595 & 688422 & 4.9 & 5.5137 & TST \\
\hline CHEMBL1312266 & 688422 & 4.85 & 5.6113 & TRN \\
\hline CHEMBL1479882 & 688422 & 4.65 & 5.5902 & TRN \\
\hline CHEMBL1415885 & 688422 & 4.95 & 4.8268 & TRN \\
\hline CHEMBL3144970 & 688422 & 5.0 & 5.0073 & TRN \\
\hline CHEMBL1332396 & 688422 & 8.301 & 5.4635 & TRN \\
\hline CHEMBL1375046 & 688422 & 4.75 & 4.9577 & TRN \\
\hline CHEMBL1541021 & 688422 & 4.8 & 5.1192 & TRN \\
\hline CHEMBL1604355 & 688422 & 7.6498 & 5.8101 & TST \\
\hline CHEMBL1461441 & 688422 & 4.9 & 5.3644 & TST \\
\hline CHEMBL1340053 & 688422 & 4.9 & 5.4285 & TRN \\
\hline CHEMBL1391140 & 688422 & 4.5 & 5.358 & TRN \\
\hline CHEMBL1342281 & 688422 & 4.45 & 4.9062 & TRN \\
\hline CHEMBL1567331 & 688422 & 5.65 & 5.2379 & TRN \\
\hline CHEMBL1503206 & 688422 & 5.0 & 5.1251 & TRN \\
\hline CHEMBL1593481 & 688422 & 4.5 & 5.4419 & TRN \\
\hline CHEMBL1482761 & 688422 & 6.35 & 5.3068 & TST \\
\hline CHEMBL1368297 & 688422 & 5.25 & 5.3085 & TST \\
\hline CHEMBL1255657 & 688422 & 5.2 & 6.0423 & TST \\
\hline CHEMBL1363934 & 688422 & 6.1 & 5.0809 & TST \\
\hline CHEMBL 1343878 & 688422 & 5.95 & 5.1705 & TST \\
\hline CHEMBL1550382 & 688422 & 5.35 & 5.2683 & TRN \\
\hline CHEMBL1990275 & 688422 & 5.2 & 5.3199 & TRN \\
\hline CHEMBL1471054 & 688422 & 5.2 & 5.1765 & TRN \\
\hline CHEMBL1510488 & 688422 & 4.45 & 4.9304 & TRN \\
\hline CHEMBL1302064 & 688422 & 5.0 & 5.1475 & TRN \\
\hline CHEMBL1389768 & 688422 & 5.0 & 5.1407 & TRN \\
\hline CHEMBL1393625 & 688422 & 4.9 & 4.8677 & TRN \\
\hline CHEMBL1480222 & 688422 & 5.25 & 5.0564 & TRN \\
\hline CHEMBL1405114 & 688422 & 5.15 & 5.3274 & TRN \\
\hline CHEMBL1348984 & 688422 & 4.5 & 5.8063 & TST \\
\hline CHEMBL1576385 & 688422 & 4.7 & 5.3163 & TRN \\
\hline CHEMBL1610565 & 688422 & 5.0 & 4.6468 & TRN \\
\hline CHEMBL1478961 & 688422 & 4.95 & 5.1323 & TRN \\
\hline
\end{tabular}




\begin{tabular}{|c|c|c|c|c|c|}
\hline \multirow{2}{*}{ CHEMBL1382018 } & \multirow{2}{*}{688422} & \\
\hline & & 4.8 & 5.0078 & TRN & \\
\hline CHEMBL1382774 & 688422 & 6.9 & 5.374 & TST & \\
\hline CHEMBL1413070 & 688422 & 4.7 & 5.2897 & TRN & \\
\hline CHEMBL1439796 & 688422 & 4.7 & 5.1013 & TRN & \\
\hline CHEMBL1482980 & 688422 & 4.85 & 4.8458 & TRN & \\
\hline CHEMBL1478524 & 688422 & 4.95 & 5.0314 & TRN & \\
\hline CHEMBL1512179 & 688422 & 4.55 & 4.9561 & TRN & \\
\hline CHEMBL1427471 & 688422 & 4.8 & 5.4782 & TRN & \\
\hline CHEMBL1546566 & 688422 & 4.5 & \multicolumn{2}{|c|}{5.617999999999999} & TRN \\
\hline CHEMBL1586104 & 688422 & 4.6 & 4.942 & TST & \\
\hline CHEMBL1594614 & 688422 & 8.4559 & 5.1396 & TRN & \\
\hline CHEMBL1312690 & 688422 & 5.55 & 4.9325 & TRN & \\
\hline CHEMBL1378294 & 688422 & 5.5 & 5.096 & TST & \\
\hline CHEMBL1346545 & 688422 & 7.6003 & 5.1126 & TRN & \\
\hline CHEMBL1608247 & 688422 & 5.5 & 5.6374 & TRN & \\
\hline CHEMBL1482169 & 688422 & 6.15 & 5.6154 & TRN & \\
\hline CHEMBL1504805 & 688422 & 4.5 & 5.62 & TRN & \\
\hline CHEMBL1411875 & 688422 & 5.5 & 5.3525 & TRN & \\
\hline CHEMBL1381853 & 688422 & 4.5 & 5.2662 & TRN & \\
\hline CHEMBL1311209 & 688422 & 5.4 & 5.3339 & TRN & \\
\hline CHEMBL1353882 & 688422 & 4.95 & 5.2114 & TRN & \\
\hline CHEMBL1310792 & 688422 & 4.95 & 5.3165 & TRN & \\
\hline CHEMBL1477591 & 688422 & 6.95 & 5.6419 & TST & \\
\hline CHEMBL1329416 & 688422 & 8.5528 & 5.1506 & TST & \\
\hline CHEMBL1382260 & 688422 & 5.4 & 5.3566 & TRN & \\
\hline CHEMBL1443886 & 688422 & 4.45 & 5.2234 & TRN & \\
\hline CHEMBL1567857 & 688422 & 5.15 & 5.5617 & TST & \\
\hline CHEMBL1439184 & 688422 & 4.9 & 5.0971 & TRN & \\
\hline CHEMBL1491576 & 688422 & 6.0 & 5.6576 & TRN & \\
\hline CHEMBL1464293 & 688422 & 4.7 & 5.1835 & TRN & \\
\hline CHEMBL1520648 & 688422 & 6.35 & 5.2389 & TRN & \\
\hline CHEMBL1482020 & 688422 & 4.95 & 5.0809 & TRN & \\
\hline CHEMBL1606318 & 688422 & 5.15 & 5.4898 & TRN & \\
\hline CHEMBL1400375 & 688422 & 5.4 & 5.5684 & TST & \\
\hline CHEMBL1606918 & 688422 & 4.45 & 4.8988 & TST & \\
\hline CHEMBL1595225 & 688422 & 4.45 & 5.7322 & TST & \\
\hline CHEMBL1542836 & 688422 & 7.4498 & 5.0502 & TST & \\
\hline CHEMBL1388671 & 688422 & 5.3 & 5.7546 & TST & \\
\hline CHEMBL1385055 & 688422 & 5.45 & 5.1767 & TRN & \\
\hline CHEMBL1426772 & 688422 & 8.4949 & 5.579 & TST & \\
\hline CHEMBL1608180 & 688422 & 4.7 & 4.9122 & TRN & \\
\hline CHEMBL 3208465 & 688422 & 4.45 & 4.9286 & TRN & \\
\hline CHEMBL1479405 & 688422 & 4.65 & 5.1907 & TRN & \\
\hline CHEMBL1429636 & 688422 & 4.45 & 5.0537 & TRN & \\
\hline CHEMBL1612634 & 688422 & 5.3 & 5.2089 & TST & \\
\hline CHEMBL1422733 & 688422 & 4.65 & 5.3447 & TRN & \\
\hline CHEMBL1308147 & 688422 & 4.45 & 5.1083 & TRN & \\
\hline CHEMBL1406051 & 688422 & 4.65 & 5.90799 & 99999999995 & TRN \\
\hline & & & & e 9693 & \\
\hline
\end{tabular}




\begin{tabular}{|c|c|c|c|c|}
\hline \multicolumn{5}{|c|}{ Supplemental Table S2.txt } \\
\hline CHEMBL1303612 & 688422 & 4.6 & 5.6081 & TST \\
\hline CHEMBL1310093 & 688422 & 4.45 & 5.5494 & TRN \\
\hline CHEMBL1411684 & 688422 & 4.55 & 5.3151 & TST \\
\hline CHEMBL1969088 & 688422 & 4.75 & 5.0844 & TST \\
\hline CHEMBL1530932 & 688422 & 4.65 & 5.2002 & TRN \\
\hline CHEMBL1500946 & 688422 & 4.45 & 5.1317 & TRN \\
\hline CHEMBL1613033 & 688422 & 4.6 & 5.565 & TST \\
\hline CHEMBL 587728 & 688422 & 4.9 & 5.0388 & TRN \\
\hline CHEMBL1612597 & 688422 & 4.45 & 5.5053 & TST \\
\hline CHEMBL1541046 & 688422 & 4.75 & 5.6771 & TRN \\
\hline CHEMBL1560305 & 688422 & 4.75 & 4.7747 & TRN \\
\hline CHEMBL1411089 & 688422 & 4.45 & 5.1319 & TST \\
\hline CHEMBL 253765 & 688422 & 6.45 & 5.4389 & TST \\
\hline CHEMBL1366017 & 688422 & 5.3 & 5.0242 & TRN \\
\hline CHEMBL1374718 & 688422 & 5.3 & 5.5078 & TRN \\
\hline CHEMBL 1438044 & 688422 & 4.45 & 5.0133 & TRN \\
\hline CHEMBL1501649 & 688422 & 4.85 & 4.8939 & TRN \\
\hline CHEMBL1392891 & 688422 & 4.45 & 5.5511 & TRN \\
\hline CHEMBL1414202 & 688422 & 4.5 & 5.3508 & TRN \\
\hline CHEMBL1591205 & 688422 & 7.7496 & 6.3284 & TRN \\
\hline CHEMBL1489092 & 688422 & 6.7501 & 5.3874 & TRN \\
\hline CHEMBL1594367 & 688422 & 5.3 & 4.8371 & TRN \\
\hline CHEMBL1385269 & 688422 & 6.95 & 5.4709 & TRN \\
\hline CHEMBL1418095 & 688422 & 5.8 & 5.3708 & TRN \\
\hline CHEMBL1611484 & 688422 & 4.75 & 4.9839 & TRN \\
\hline CHEMBL1606491 & 688422 & 6.0 & 5.5455 & TRN \\
\hline CHEMBL1521233 & 688422 & 4.9 & 5.0052 & TRN \\
\hline CHEMBL1512946 & 688422 & 4.85 & 5.9261 & TRN \\
\hline CHEMBL1321523 & 688422 & 4.9 & 5.5426 & TRN \\
\hline CHEMBL1376777 & 688422 & 4.7 & 5.0429 & TRN \\
\hline CHEMBL1324393 & 688422 & 4.65 & 4.965 & TRN \\
\hline CHEMBL1487884 & 688422 & 4.8 & 5.1995 & TRN \\
\hline CHEMBL1408742 & 688422 & 4.45 & 5.2622 & TRN \\
\hline CHEMBL1452329 & 688422 & 6.15 & 5.6521 & TRN \\
\hline CHEMBL1299843 & 688422 & 5.6 & 5.4557 & TST \\
\hline CHEMBL1417328 & 688422 & 5.2 & 5.5684 & TRN \\
\hline CHEMBL1564953 & 688422 & 6.8499 & 5.2702 & TST \\
\hline CHEMBL1499275 & 688422 & 5.45 & 4.8439 & TRN \\
\hline CHEMBL1418802 & 688422 & 4.9 & 5.4445 & TRN \\
\hline CHEMBL1548856 & 688422 & 4.7 & 5.3959 & TST \\
\hline CHEMBL1589594 & 688422 & 4.45 & 5.1863 & TRN \\
\hline CHEMBL1329397 & 688422 & 6.9 & 5.6141 & TRN \\
\hline CHEMBL1528426 & 688422 & 4.95 & 5.566 & TRN \\
\hline CHEMBL1387780 & 688422 & 5.1 & 5.1507 & TRN \\
\hline CHEMBL1386505 & 688422 & 5.55 & 5.6495 & TRN \\
\hline CHEMBL 2002248 & 688422 & 4.45 & 4.9829 & TRN \\
\hline CHEMBL1492253 & 688422 & 6.45 & 5.1884 & TRN \\
\hline CHEMBL1531836 & 688422 & 4.95 & 5.1967 & TRN \\
\hline
\end{tabular}




\begin{tabular}{|c|c|c|c|c|}
\hline \multicolumn{5}{|c|}{ Supplemental Table S2.txt } \\
\hline CHEMBL1417120 & 688422 & 4.45 & 4.7826 & TRN \\
\hline CHEMBL1613195 & 688422 & 4.65 & 5.0769 & TRN \\
\hline CHEMBL1451065 & 688422 & 4.75 & 5.4657 & TST \\
\hline CHEMBL1450096 & 688422 & 4.45 & 5.3373 & TST \\
\hline CHEMBL1343329 & 688422 & 4.45 & 5.2064 & TRN \\
\hline CHEMBL3193076 & 688422 & 4.45 & 5.2167 & TRN \\
\hline CHEMBL1363759 & 688422 & 6.35 & 5.1941 & TST \\
\hline CHEMBL171137 & 688422 & 5.5 & 5.2096 & TST \\
\hline CHEMBL1417724 & 688422 & 4.55 & 4.665 & TST \\
\hline CHEMBL1368468 & 688422 & 5.45 & 4.5386 & TRN \\
\hline CHEMBL1509244 & 688422 & 5.05 & 5.2673 & TRN \\
\hline CHEMBL3199580 & 688422 & 4.65 & 4.8995 & TST \\
\hline CHEMBL1499211 & 688422 & 5.0 & 5.2594 & TST \\
\hline CHEMBL1337718 & 688422 & 4.85 & 5.2199 & TRN \\
\hline CHEMBL1517327 & 688422 & 4.45 & 4.973 & TRN \\
\hline CHEMBL1425183 & 688422 & 5.2 & 4.9142 & TST \\
\hline CHEMBL1534731 & 688422 & 4.6 & 5.0249 & TRN \\
\hline CHEMBL1454997 & 688422 & 4.75 & 5.3686 & TRN \\
\hline CHEMBL1310294 & 688422 & 4.75 & 4.8459 & TRN \\
\hline CHEMBL1387923 & 688422 & 5.35 & 4.9347 & TRN \\
\hline CHEMBL1602557 & 688422 & 5.0 & 4.95 & TRN \\
\hline CHEMBL1571551 & 688422 & 4.45 & 5.6067 & TRN \\
\hline CHEMBL1326723 & 688422 & 4.5 & 5.2219 & TRN \\
\hline CHEMBL1592095 & 688422 & 8.3468 & 5.9593 & TRN \\
\hline CHEMBL1577422 & 688422 & 5.3 & 5.2754 & TST \\
\hline CHEMBL1606993 & 688422 & 5.0 & 4.9817 & TRN \\
\hline CHEMBL1441690 & 688422 & 4.75 & 4.9854 & TRN \\
\hline CHEMBL1351267 & 688422 & 4.9 & 6.3696 & TRN \\
\hline CHEMBL 3198579 & 688422 & 4.95 & 4.8713 & TRN \\
\hline CHEMBL1585446 & 688422 & 4.9 & 5.4805 & TRN \\
\hline CHEMBL1311491 & 688422 & 4.45 & 5.038 & TRN \\
\hline CHEMBL1463769 & 688422 & 4.9 & 5.016 & TRN \\
\hline CHEMBL1613323 & 688422 & 4.85 & 4.8517 & TRN \\
\hline CHEMBL1534297 & 688422 & 6.4 & 5.3791 & TRN \\
\hline CHEMBL1455510 & 688422 & 4.85 & 5.6851 & TRN \\
\hline CHEMBL1319087 & 688422 & 4.65 & 5.1151 & TRN \\
\hline CHEMBL2001195 & 688422 & 5.1 & 5.5103 & TRN \\
\hline CHEMBL1303885 & 688422 & 4.9 & 5.6813 & TST \\
\hline CHEMBL1402065 & 688422 & 4.65 & 5.124 & TRN \\
\hline CHEMBL1358548 & 688422 & 5.4 & 5.1621 & TRN \\
\hline CHEMBL1526578 & 688422 & 4.8 & 5.4943 & TST \\
\hline CHEMBL1596406 & 688422 & 4.9 & 5.154 & TRN \\
\hline CHEMBL1533428 & 688422 & 4.45 & 5.1712 & TRN \\
\hline CHEMBL1531851 & 688422 & 6.1 & 5.3447 & TRN \\
\hline CHEMBL1414264 & 688422 & 8.0 & 5.8041 & TRN \\
\hline CHEMBL1547847 & 688422 & 6.05 & 4.6236 & TRN \\
\hline CHEMBL1525314 & 688422 & 4.95 & 4.6148 & TRN \\
\hline CHEMBL1971015 & 688422 & 4.45 & 5.2183 & TRN \\
\hline
\end{tabular}




\begin{tabular}{|c|c|c|c|c|}
\hline \multicolumn{5}{|c|}{ Supplemental Table S2.txt } \\
\hline CHEMBL1405658 & 688422 & 4.85 & 5.7111 & TST \\
\hline CHEMBL1501806 & 688422 & 4.4 & 5.3937 & TST \\
\hline CHEMBL1374306 & 688422 & 4.9 & 4.9512 & TRN \\
\hline CHEMBL1435633 & 688422 & 4.45 & 5.0732 & TRN \\
\hline CHEMBL1385523 & 688422 & 4.45 & 5.4281 & TRN \\
\hline CHEMBL1595143 & 688422 & 4.7 & 5.2092 & TRN \\
\hline CHEMBL1414265 & 688422 & 4.45 & 5.1797 & TRN \\
\hline CHEMBL1598592 & 688422 & 4.9 & 5.4418 & TST \\
\hline CHEMBL1386350 & 688422 & 5.15 & 5.1594 & TRN \\
\hline CHEMBL1601701 & 688422 & 4.75 & 5.2782 & TRN \\
\hline CHEMBL1514268 & 688422 & 8.3468 & 5.2642 & TRN \\
\hline CHEMBL1575817 & 688422 & 4.45 & 5.2938 & TST \\
\hline CHEMBL1526979 & 688422 & 4.7 & 4.9266 & TRN \\
\hline CHEMBL1441688 & 688422 & 4.9 & 4.9028 & TRN \\
\hline CHEMBL1504472 & 688422 & 5.5 & 5.2406 & TST \\
\hline CHEMBL1461180 & 688422 & 5.05 & 5.2344 & TRN \\
\hline CHEMBL1429836 & 688422 & 4.8 & 4.6041 & TRN \\
\hline CHEMBL1429535 & 688422 & 5.0 & 5.1928 & TRN \\
\hline CHEMBL333889 & 688422 & 7.4498 & 5.5659 & TRN \\
\hline CHEMBL1447353 & 688422 & 5.55 & 5.8455 & TRN \\
\hline CHEMBL1612097 & 688422 & 4.5 & 5.3922 & TRN \\
\hline CHEMBL1402462 & 688422 & 7.8013 & 5.2914 & TRN \\
\hline CHEMBL1343489 & 688422 & 4.55 & 4.8094 & TRN \\
\hline CHEMBL1466540 & 688422 & 4.45 & 5.1221 & TRN \\
\hline CHEMBL1577745 & 688422 & 4.6 & 5.155 & TRN \\
\hline CHEMBL1430255 & 688422 & 4.95 & 5.0736 & TST \\
\hline CHEMBL1330635 & 688422 & 5.9 & 5.2751 & TRN \\
\hline CHEMBL1519067 & 688422 & 8.0506 & 5.5976 & TRN \\
\hline CHEMBL1306338 & 688422 & 4.65 & 5.3207 & TST \\
\hline CHEMBL1439989 & 688422 & 4.65 & 5.2409 & TRN \\
\hline CHEMBL1567707 & 688422 & 4.45 & 5.3001 & TST \\
\hline CHEMBL1424902 & 688422 & 4.75 & 5.1148 & TST \\
\hline CHEMBL1517847 & 688422 & 4.9 & 5.3301 & TRN \\
\hline CHEMBL1375394 & 688422 & 4.45 & 4.9282 & TRN \\
\hline CHEMBL2069121 & 688422 & 6.5 & 6.2116 & TRN \\
\hline CHEMBL 28140 & 688422 & 6.5501 & 5.7187 & TST \\
\hline CHEMBL1438960 & 688422 & 7.699 & 5.5824 & TST \\
\hline CHEMBL1601384 & 688422 & 5.55 & 5.2543 & TRN \\
\hline CHEMBL1311693 & 688422 & 6.5501 & 5.1797 & TRN \\
\hline CHEMBL3199808 & 688422 & 4.95 & 5.294 & TRN \\
\hline CHEMBL1346168 & 688422 & 4.9 & 5.0019 & TRN \\
\hline CHEMBL3195046 & 688422 & 5.0 & 5.3825 & TRN \\
\hline CHEMBL1597082 & 688422 & 4.5 & 5.0226 & TRN \\
\hline CHEMBL1359073 & 688422 & 4.95 & 5.9546 & TST \\
\hline CHEMBL1384620 & 688422 & 4.85 & 5.4138 & TRN \\
\hline CHEMBL1513435 & 688422 & 4.65 & 5.4056 & TRN \\
\hline CHEMBL1974901 & 688422 & 5.2 & 5.7455 & TRN \\
\hline CHEMBL1522538 & 688422 & 4.45 & 4.8063 & TST \\
\hline
\end{tabular}




\begin{tabular}{|c|c|c|c|c|c|}
\hline \multicolumn{6}{|c|}{ Supplemental Table s2.txt } \\
\hline CHEMBL1444986 & 688422 & 4.95 & 5.2698 & TRN & \\
\hline CHEMBL1433722 & 688422 & 5.3 & 5.1685 & TRN & \\
\hline CHEMBL1604921 & 688422 & 7.0501 & 5.4977 & TRN & \\
\hline CHEMBL1574599 & 688422 & 7.9508 & 5.2545 & TRN & \\
\hline CHEMBL3198639 & 688422 & 4.5 & 5.0711 & TST & \\
\hline CHEMBL1571396 & 688422 & 6.1 & 5.3731 & TRN & \\
\hline CHEMBL1377745 & 688422 & 4.8 & 5.4807 & TRN & \\
\hline CHEMBL1508222 & 688422 & 4.55 & 5.6189 & TRN & \\
\hline CHEMBL1452547 & 688422 & 7.5498 & 5.6508 & TST & \\
\hline CHEMBL1580082 & 688422 & 4.8 & 5.0512 & TRN & \\
\hline CHEMBL1526063 & 688422 & 4.95 & 5.8337 & TRN & \\
\hline CHEMBL1359087 & 688422 & 4.95 & 5.1775 & TST & \\
\hline CHEMBL1426804 & 688422 & 4.95 & 5.0893 & TRN & \\
\hline CHEMBL1511305 & 688422 & 4.9 & 4.9758 & TRN & \\
\hline CHEMBL1364354 & 688422 & 4.45 & 5.0316 & TRN & \\
\hline CHEMBL1537036 & 688422 & 4.45 & 5.7316 & TRN & \\
\hline CHEMBL1502775 & 688422 & 4.65 & 4.8535 & TRN & \\
\hline CHEMBL3196007 & 688422 & 5.3 & 5.5583 & TRN & \\
\hline CHEMBL1369778 & 688422 & 5.3 & 5.2259 & TRN & \\
\hline CHEMBL1448195 & 688422 & 7.699 & 5.1959 & TRN & \\
\hline CHEMBL1372723 & 688422 & 4.95 & 5.5888 & TRN & \\
\hline CHEMBL3195538 & 688422 & 6.0 & 5.2861 & TST & \\
\hline CHEMBL1577931 & 688422 & 4.9 & 5.6856 & TRN & \\
\hline CHEMBL1509137 & 688422 & 4.85 & 4.8228 & TRN & \\
\hline CHEMBL1316544 & 688422 & 4.65 & 5.4044 & TRN & \\
\hline CHEMBL250574 & 688422 & 4.45 & 5.1358 & TST & \\
\hline CHEMBL1463840 & 688422 & 4.8 & 5.30200 & 20000000005 & TRN \\
\hline CHEMBL1449625 & 688422 & 4.45 & 5.5167 & TST & \\
\hline CHEMBL1427949 & 688422 & 4.6 & 5.1475 & TRN & \\
\hline CHEMBL1376794 & 688422 & 4.8 & 4.9703 & TRN & \\
\hline CHEMBL1534418 & 688422 & 6.5501 & 5.3732 & TST & \\
\hline CHEMBL1330383 & 688422 & 5.2 & 5.21299 & 9999999999 & TST \\
\hline CHEMBL1559841 & 688422 & 5.95 & 5.3992 & TRN & \\
\hline CHEMBL1438675 & 688422 & 7.699 & 5.3485 & TRN & \\
\hline CHEMBL1319613 & 688422 & 5.3 & 5.1467 & TRN & \\
\hline CHEMBL1346768 & 688422 & 4.45 & 5.2511 & TRN & \\
\hline CHEMBL1506728 & 688422 & 4.6 & 5.1004 & TRN & \\
\hline CHEMBL1453534 & 688422 & 4.5 & 4.8906 & TRN & \\
\hline CHEMBL1325826 & 688422 & 4.85 & 4.9783 & TST & \\
\hline CHEMBL1434083 & 688422 & 7.6498 & 5.6769 & TRN & \\
\hline CHEMBL1307866 & 688422 & 7.6498 & 4.8884 & TRN & \\
\hline CHEMBL1538947 & 688422 & 8.0506 & 5.7445 & TST & \\
\hline CHEMBL1388753 & 688422 & 4.45 & 5.0455 & TRN & \\
\hline CHEMBL1299956 & 688422 & 4.5 & 5.3119 & TST & \\
\hline CHEMBL1433249 & 688422 & 4.45 & 5.0548 & TST & \\
\hline CHEMBL1341735 & 688422 & 4.45 & 5.0716 & TRN & \\
\hline CHEMBL1431564 & 688422 & 4.8 & 4.8251 & TST & \\
\hline CHEMBL1362773 & 688422 & 8.1487 & 5.3257 & TST & \\
\hline
\end{tabular}




\begin{tabular}{|c|c|c|c|c|}
\hline \multicolumn{5}{|c|}{ Supplemental Table S2.txt } \\
\hline CHEMBL1547853 & 688422 & 5.4 & 5.1406 & TST \\
\hline CHEMBL1553694 & 688422 & 4.7 & 4.6754 & TRN \\
\hline CHEMBL1425184 & 688422 & 4.6 & 5.1999 & TRN \\
\hline CHEMBL1461748 & 688422 & 4.9 & 4.7677 & TRN \\
\hline CHEMBL1454194 & 688422 & 4.6 & 5.1588 & TRN \\
\hline CHEMBL 3198054 & 688422 & 4.45 & 5.2612 & TRN \\
\hline CHEMBL1529928 & 688422 & 5.5 & 4.7792 & TRN \\
\hline CHEMBL1575531 & 688422 & 4.6 & 5.2064 & TST \\
\hline CHEMBL1587355 & 688422 & 6.15 & 5.1611 & TRN \\
\hline CHEMBL1340341 & 688422 & 4.6 & 5.0941 & TRN \\
\hline CHEMBL1415258 & 688422 & 4.85 & 5.329 & TRN \\
\hline CHEMBL1329237 & 688422 & 7.0 & 5.1616 & TST \\
\hline CHEMBL1461818 & 688422 & 4.8 & 4.9011 & TST \\
\hline CHEMBL3216928 & 688422 & 4.45 & 5.2283 & TST \\
\hline CHEMBL1578082 & 688422 & 4.6 & 5.2458 & TST \\
\hline CHEMBL1982010 & 688422 & 4.45 & 5.2731 & TRN \\
\hline CHEMBL3191202 & 688422 & 6.9 & 5.1398 & TRN \\
\hline CHEMBL1503797 & 688422 & 4.5 & 5.4659 & TST \\
\hline CHEMBL1341601 & 688422 & 4.8 & 5.0776 & TST \\
\hline CHEMBL1519713 & 688422 & 4.45 & 4.8582 & TRN \\
\hline CHEMBL1603638 & 688422 & 4.85 & 5.8018 & TRN \\
\hline CHEMBL1593600 & 688422 & 4.85 & 5.5009 & TRN \\
\hline CHEMBL1465694 & 688422 & 4.45 & 4.7503 & TST \\
\hline CHEMBL1567644 & 688422 & 8.2007 & 5.3939 & TRN \\
\hline CHEMBL1592784 & 688422 & 4.5 & 5.5641 & TRN \\
\hline CHEMBL1411002 & 688422 & 5.2 & 5.1805 & TRN \\
\hline CHEMBL1312115 & 688422 & 5.2 & 5.4306 & TST \\
\hline CHEMBL1516826 & 688422 & 5.05 & 4.9187 & TRN \\
\hline CHEMBL1318128 & 688422 & 8.3468 & 5.0733 & TRN \\
\hline CHEMBL1374953 & 688422 & 4.9 & 5.3447 & TRN \\
\hline CHEMBL1346823 & 688422 & 7.6003 & 5.2372 & TRN \\
\hline CHEMBL1319487 & 688422 & 5.3 & 5.2223 & TRN \\
\hline CHEMBL1594252 & 688422 & 7.4001 & 5.6402 & TRN \\
\hline CHEMBL1459701 & 688422 & 4.55 & 4.9026 & TRN \\
\hline CHEMBL1401044 & 688422 & 5.9 & 5.1223 & TRN \\
\hline CHEMBL1579227 & 688422 & 4.85 & 5.3955 & TRN \\
\hline CHEMBL1372089 & 688422 & 8.0506 & 5.0407 & TRN \\
\hline CHEMBL1529760 & 688422 & 8.301 & 4.8589 & TRN \\
\hline CHEMBL1437965 & 688422 & 4.65 & 5.1041 & TRN \\
\hline CHEMBL1565768 & 688422 & 5.2 & 5.2706 & TRN \\
\hline CHEMBL1362734 & 688422 & 4.45 & 5.026 & TRN \\
\hline CHEMBL1372805 & 688422 & 4.45 & 4.8717 & TRN \\
\hline CHEMBL1322708 & 688422 & 4.6 & 5.5432 & TST \\
\hline CHEMBL570400 & 688422 & 4.5 & 5.1396 & TRN \\
\hline CHEMBL1517357 & 688422 & 5.25 & 5.5326 & TST \\
\hline CHEMBL1528950 & 688422 & 4.45 & 5.4377 & TRN \\
\hline CHEMBL1482136 & 688422 & 8.3468 & 5.2748 & TRN \\
\hline CHEMBL1476302 & 688422 & 5.45 & 4.9163 & TRN \\
\hline
\end{tabular}




\begin{tabular}{|c|c|c|c|c|c|}
\hline \multicolumn{6}{|c|}{ Supplemental Table s2.txt } \\
\hline CHEMBL1426886 & 688422 & 4.45 & 4.9277 & TRN & \\
\hline CHEMBL1485127 & 688422 & 4.6 & 4.8022 & TRN & \\
\hline CHEMBL1576076 & 688422 & 4.6 & 5.3758 & TST & \\
\hline CHEMBL1459804 & 688422 & 4.45 & 5.8803 & TST & \\
\hline CHEMBL1427061 & 688422 & 4.9 & 5.317 & TRN & \\
\hline CHEMBL1423612 & 688422 & 4.45 & 5.3834 & TRN & \\
\hline CHEMBL1596226 & 688422 & 4.95 & 4.9974 & TRN & \\
\hline CHEMBL1559509 & 688422 & 7.5498 & 5.4579 & TRN & \\
\hline CHEMBL1371379 & 688422 & 4.45 & 4.9934 & TRN & \\
\hline CHEMBL1566912 & 688422 & 5.45 & 5.6441 & TRN & \\
\hline CHEMBL1300067 & 688422 & 4.45 & 5.529 & TRN & \\
\hline CHEMBL1329612 & 688422 & 4.45 & 4.8183 & TST & \\
\hline CHEMBL3196863 & 688422 & 4.65 & 5.1249 & TRN & \\
\hline CHEMBL 3197259 & 688422 & 4.9 & 5.0932 & TRN & \\
\hline CHEMBL1495904 & 688422 & 4.75 & 5.4435 & TST & \\
\hline CHEMBL1456594 & 688422 & 5.25 & 5.7133 & TRN & \\
\hline CHEMBL3198544 & 688422 & 5.75 & 5.5338 & TRN & \\
\hline CHEMBL1378404 & 688422 & 6.2 & 5.0998 & TST & \\
\hline CHEMBL1384919 & 688422 & 4.55 & 5.2102 & TST & \\
\hline CHEMBL1420817 & 688422 & 4.45 & 5.3067 & TRN & \\
\hline CHEMBL1568367 & 688422 & 4.95 & 5.0941 & TRN & \\
\hline CHEMBL1302712 & 688422 & 5.15 & 5.6805 & TRN & \\
\hline CHEMBL1467020 & 688422 & 5.2 & 5.5943 & TRN & \\
\hline CHEMBL3197326 & 688422 & 4.9 & 4.8532 & TRN & \\
\hline CHEMBL1392799 & 688422 & 5.8 & 5.0607 & TST & \\
\hline CHEMBL1514036 & 688422 & 4.7 & 5.21700 & 00000000005 & TRN \\
\hline CHEMBL1718568 & 688422 & 5.25 & 4.8098 & TST & \\
\hline CHEMBL1387894 & 688422 & 4.95 & 5.4694 & TRN & \\
\hline CHEMBL1588806 & 688422 & 5.3 & 5.118 & TRN & \\
\hline CHEMBL1521481 & 688422 & 5.3 & 5.0871 & TRN & \\
\hline CHEMBL1301379 & 688422 & 6.6 & 5.2007 & TRN & \\
\hline CHEMBL1555032 & 688422 & 4.65 & 5.1573 & TRN & \\
\hline CHEMBL1404951 & 688422 & 7.6003 & 5.4887 & TRN & \\
\hline CHEMBL1502817 & 688422 & 5.45 & 5.2938 & TST & \\
\hline CHEMBL1340843 & 688422 & 4.45 & 4.829 & TRN & \\
\hline CHEMBL1611564 & 688422 & 5.0 & 5.3957 & TRN & \\
\hline CHEMBL1487624 & 688422 & 5.0 & 5.2256 & TRN & \\
\hline CHEMBL1554263 & 688422 & 4.8 & 5.74 & TRN & \\
\hline CHEMBL1345191 & 688422 & 5.0 & 5.3942 & TRN & \\
\hline CHEMBL1601960 & 688422 & 5.55 & 5.2507 & TRN & \\
\hline CHEMBL1333727 & 688422 & 5.4 & 5.5316 & TRN & \\
\hline CHEMBL1499919 & 688422 & 4.65 & 5.4265 & TST & \\
\hline CHEMBL1490080 & 688422 & 4.75 & 4.9063 & TRN & \\
\hline CHEMBL1588880 & 688422 & 4.95 & 5.35 & TRN & \\
\hline CHEMBL1454866 & 688422 & 7.5498 & 5.54200 & 0000000001 & TRN \\
\hline CHEMBL1312198 & 688422 & 4.85 & 4.9439 & TRN & \\
\hline CHEMBL1542477 & 688422 & 5.2 & 5.362 & TRN & \\
\hline CHEMBL1450612 & 688422 & 5.05 & 5.1355 & TRN & \\
\hline
\end{tabular}




\begin{tabular}{|c|c|c|c|c|c|}
\hline \\
\hline CHEMBL1351497 & 688422 & 6.5 & 5.3546 & TRN & \\
\hline CHEMBL1309216 & 688422 & 4.95 & 5.0043 & TST & \\
\hline CHEMBL1587630 & 688422 & 6.25 & 4.7306 & TRN & \\
\hline CHEMBL1523096 & 688422 & 5.1 & 4.9305 & TRN & \\
\hline CHEMBL1607372 & 688422 & 5.45 & 5.3449 & TRN & \\
\hline CHEMBL1538876 & 688422 & 6.8 & 5.1654 & TRN & \\
\hline CHEMBL1593538 & 688422 & 4.55 & 5.4571 & TRN & \\
\hline CHEMBL1599981 & 688422 & 4.85 & 5.3899 & TST & \\
\hline CHEMBL1506200 & 688422 & 5.6 & 4.9941 & TRN & \\
\hline CHEMBL1458774 & 688422 & 6.4 & 5.0545 & TRN & \\
\hline CHEMBL1327237 & 688422 & 5.15 & 5.1148 & TRN & \\
\hline CHEMBL1425870 & 688422 & 4.4 & 5.553 & TST & \\
\hline CHEMBL1389747 & 688422 & 4.9 & 5.2193 & TRN & \\
\hline CHEMBL1515873 & 688422 & 6.0 & 5.0454 & TRN & \\
\hline CHEMBL1979574 & 688422 & 4.85 & 4.9383 & TST & \\
\hline CHEMBL1316877 & 688422 & 4.9 & 5.0814 & TRN & \\
\hline CHEMBL 8211 & 688422 & 5.2 & 5.7557 & TST & \\
\hline CHEMBL1378283 & 688422 & 5.4 & 5.41100 & 00000000005 & TRN \\
\hline CHEMBL1380142 & 688422 & 4.5 & 4.9259 & TRN & \\
\hline CHEMBL1519983 & 688422 & 4.75 & 4.8407 & TRN & \\
\hline CHEMBL1545863 & 688422 & 5.45 & 5.511 & TRN & \\
\hline CHEMBL1499079 & 688422 & 4.95 & 4.9257 & TRN & \\
\hline CHEMBL1439805 & 688422 & 6.3 & 5.5724 & TRN & \\
\hline CHEMBL598680 & 688422 & 4.7 & 5.2181 & TRN & \\
\hline CHEMBL1567962 & 688422 & 4.5 & 4.9835 & TRN & \\
\hline CHEMBL1525291 & 688422 & 4.45 & 5.274 & TST & \\
\hline CHEMBL1353179 & 688422 & 4.7 & 5.4505 & TST & \\
\hline CHEMBL1347600 & 688422 & 4.75 & 5.2099 & TST & \\
\hline CHEMBL1610890 & 688422 & 6.45 & 5.4346 & TRN & \\
\hline CHEMBL1439591 & 688422 & 4.5 & 5.2462 & TRN & \\
\hline CHEMBL1335773 & 688422 & 5.3 & 5.3486 & TST & \\
\hline CHEMBL1344158 & 688422 & 5.9 & 4.9036 & TRN & \\
\hline CHEMBL1536036 & 688422 & 5.05 & 5.1434 & TRN & \\
\hline CHEMBL1606798 & 688422 & 4.5 & 5.0996 & TRN & \\
\hline CHEMBL1465040 & 688422 & 5.5 & 5.396 & TRN & \\
\hline CHEMBL1396817 & 688422 & 5.0 & 4.7787 & TRN & \\
\hline CHEMBL1610037 & 688422 & 4.8 & 4.5316 & TRN & \\
\hline CHEMBL1545194 & 688422 & 4.45 & 5.6195 & TRN & \\
\hline CHEMBL1495293 & 688422 & 4.45 & 4.7194 & TRN & \\
\hline CHEMBL1431882 & 688422 & 4.85 & 5.2714 & TRN & \\
\hline CHEMBL1373534 & 688422 & 4.5 & 4.8976 & TRN & \\
\hline CHEMBL1456112 & 688422 & 4.5 & 5.7984 & TRN & \\
\hline CHEMBL3212833 & 688422 & 4.55 & 5.0061 & TRN & \\
\hline CHEMBL1590384 & 688422 & 6.35 & 5.4262 & TRN & \\
\hline CHEMBL1585652 & 688422 & 4.8 & 5.0871 & TRN & \\
\hline CHEMBL3211984 & 688422 & 4.95 & 5.6906 & TST & \\
\hline CHEMBL 2373620 & 688422 & 7.1002 & 5.4313 & TRN & \\
\hline CHEMBL1584235 & 688422 & 6.95 & 5.3875 & TRN & \\
\hline
\end{tabular}




\begin{tabular}{|c|c|c|c|c|c|}
\hline & & \multicolumn{4}{|c|}{ Supplemental Table S2.txt } \\
\hline CHEMBL1370292 & 688422 & 4.45 & 5.1578 & TRN & \\
\hline CHEMBL262083 & 688422 & 6.0 & 5.9104 & TRN & \\
\hline CHEMBL1598679 & 688422 & 4.75 & 4.9492 & TRN & \\
\hline CHEMBL1464140 & 688422 & 4.5 & 5.3199 & TRN & \\
\hline CHEMBL1574845 & 688422 & 5.55 & 5.20100 & 00000000005 & TRN \\
\hline CHEMBL1336951 & 688422 & 4.45 & 5.3129 & TRN & \\
\hline CHEMBL1322689 & 688422 & 5.55 & 4.9322 & TRN & \\
\hline CHEMBL1300749 & 688422 & 4.45 & 5.331 & TRN & \\
\hline CHEMBL1604707 & 688422 & 4.95 & 5.0304 & TST & \\
\hline CHEMBL1588515 & 688422 & 4.75 & 5.4429 & TRN & \\
\hline CHEMBL1369352 & 688422 & 4.7 & 5.4736 & TRN & \\
\hline CHEMBL1467438 & 688422 & 4.85 & 5.2501 & TRN & \\
\hline CHEMBL1444853 & 688422 & 4.8 & 5.026 & TRN & \\
\hline CHEMBL1525680 & 688422 & 7.0 & 5.5196 & TRN & \\
\hline CHEMBL1602523 & 688422 & 4.7 & 5.3643 & TRN & \\
\hline CHEMBL1488494 & 688422 & 4.65 & 5.1133 & TRN & \\
\hline CHEMBL1344875 & 688422 & 4.95 & 4.8629 & TRN & \\
\hline CHEMBL153072 & 688422 & 4.45 & 5.3368 & TRN & \\
\hline CHEMBL1560542 & 688422 & 7.3002 & 5.0662 & TRN & \\
\hline CHEMBL1533498 & 688422 & 4.45 & 5.1613 & TRN & \\
\hline CHEMBL1571034 & 688422 & 4.6 & 5.6215 & TST & \\
\hline CHEMBL1425544 & 688422 & 4.45 & 5.215 & TRN & \\
\hline CHEMBL1331200 & 688422 & 4.45 & 5.4124 & TST & \\
\hline CHEMBL1471465 & 688422 & 4.75 & 4.855 & TRN & \\
\hline CHEMBL1344347 & 688422 & 6.3 & 5.439 & TRN & \\
\hline CHEMBL1564474 & 688422 & 5.45 & 5.5887 & TST & \\
\hline CHEMBL258405 & 688422 & 5.2 & 5.5194 & TST & \\
\hline CHEMBL1256656 & 688422 & 4.95 & 5.3448 & TST & \\
\hline CHEMBL1400259 & 688422 & 4.45 & 5.3061 & TRN & \\
\hline CHEMBL1355863 & 688422 & 5.85 & 5.3787 & TRN & \\
\hline CHEMBL1608832 & 688422 & 4.5 & 4.8806 & TRN & \\
\hline CHEMBL1602531 & 688422 & 4.45 & 5.3472 & TRN & \\
\hline CHEMBL1525328 & 688422 & 5.2 & 5.1096 & TST & \\
\hline CHEMBL1456282 & 688422 & 6.7001 & 5.6575 & TRN & \\
\hline CHEMBL1307251 & 688422 & 4.8 & 5.1292 & TRN & \\
\hline CHEMBL3194943 & 688422 & 4.55 & 5.3229 & TST & \\
\hline CHEMBL1470532 & 688422 & 7.5498 & 5.6518 & TRN & \\
\hline CHEMBL3194054 & 688422 & 4.75 & 5.5589 & TRN & \\
\hline CHEMBL1611372 & 688422 & 4.95 & 4.8756 & TRN & \\
\hline CHEMBL1349075 & 688422 & 4.95 & 5.3037 & TRN & \\
\hline CHEMBL1544402 & 688422 & 5.85 & 5.2556 & TST & \\
\hline CHEMBL1541809 & 688422 & 5.15 & 5.3466 & TST & \\
\hline CHEMBL1498256 & 688422 & 4.45 & 5.2217 & TST & \\
\hline CHEMBL1540343 & 688422 & 4.6 & 5.1654 & TRN & \\
\hline CHEMBL1467499 & 688422 & 4.75 & 5.0543 & TRN & \\
\hline CHEMBL1519938 & 688422 & 6.1 & 5.4867 & TST & \\
\hline CHEMBL1458723 & 688422 & 4.6 & 4.9731 & TRN & \\
\hline CHEMBL1357176 & 688422 & 5.5 & 5.8389 & TRN & \\
\hline
\end{tabular}




\begin{tabular}{|c|c|c|c|c|c|}
\hline \multicolumn{6}{|c|}{ Supplemental Table S2.txt } \\
\hline CHEMBL1335610 & 688422 & 5.55 & 5.0605 & TRN & \\
\hline CHEMBL1346898 & 688422 & 4.75 & 5.1098 & TRN & \\
\hline CHEMBL1596724 & 688422 & 4.7 & 4.8111 & TRN & \\
\hline CHEMBL 3197607 & 688422 & 4.45 & 5.49 & TRN & \\
\hline CHEMBL1419847 & 688422 & 6.05 & 4.9642 & TST & \\
\hline CHEMBL 3190146 & 688422 & 5.85 & 5.3962 & TRN & \\
\hline CHEMBL1513304 & 688422 & 5.2 & 5.6233 & TST & \\
\hline CHEMBL1408268 & 688422 & 6.05 & 5.0959 & TRN & \\
\hline CHEMBL1321947 & 688422 & 4.95 & 5.3557 & TST & \\
\hline CHEMBL1514802 & 688422 & 4.45 & 5.2183 & TRN & \\
\hline CHEMBL540303 & 688422 & 5.2 & 5.9391 & TST & \\
\hline CHEMBL1366312 & 688422 & 4.95 & 5.6963 & TRN & \\
\hline CHEMBL1570076 & 688422 & 4.45 & 5.4615 & TRN & \\
\hline CHEMBL1386092 & 688422 & 4.95 & 5.4062 & TST & \\
\hline CHEMBL1353359 & 688422 & 5.4 & 5.3393 & TST & \\
\hline CHEMBL1348419 & 688422 & 5.6 & 5.4231 & TRN & \\
\hline CHEMBL1523232 & 688422 & 5.55 & 4.9545 & TST & \\
\hline CHEMBL1471090 & 688422 & 4.45 & 5.2444 & TRN & \\
\hline CHEMBL1554897 & 688422 & 6.95 & 5.2596 & TST & \\
\hline CHEMBL1537569 & 688422 & 4.7 & 4.8351 & TRN & \\
\hline CHEMBL1399240 & 688422 & 4.55 & 5.1865 & TRN & \\
\hline CHEMBL1600123 & 688422 & 4.85 & 5.4515 & TRN & \\
\hline CHEMBL1517833 & 688422 & 4.45 & 5.0914 & TRN & \\
\hline CHEMBL1588083 & 688422 & 4.45 & 5.3729 & TST & \\
\hline CHEMBL1434829 & 688422 & 4.45 & 5.1745 & TRN & \\
\hline CHEMBL1545268 & 688422 & 4.9 & 5.3228 & TRN & \\
\hline CHEMBL1523637 & 688422 & 4.9 & 5.0477 & TRN & \\
\hline CHEMBL1339951 & 688422 & 5.0 & 5.3083 & TRN & \\
\hline CHEMBL1492769 & 688422 & 4.65 & 5.1133 & TRN & \\
\hline CHEMBL1480011 & 688422 & 4.6 & 5.3394 & TRN & \\
\hline CHEMBL1301129 & 688422 & 4.65 & 5.1129 & TRN & \\
\hline CHEMBL1504108 & 688422 & 4.85 & 4.9849 & TRN & \\
\hline CHEMBL1409912 & 688422 & 5.1 & 4.87 & TRN & \\
\hline CHEMBL1459075 & 688422 & 4.65 & 5.1961 & TRN & \\
\hline CHEMBL1391128 & 688422 & 6.1 & 5.0476 & TRN & \\
\hline CHEMBL1408308 & 688422 & 7.3002 & 4.8241 & TRN & \\
\hline CHEMBL1437933 & 688422 & 4.85 & 5.19799 & 99999999995 & TRN \\
\hline CHEMBL1605478 & 688422 & 4.75 & 4.9491 & TRN & \\
\hline CHEMBL1310930 & 688422 & 5.15 & 4.8244 & TRN & \\
\hline CHEMBL1529170 & 688422 & 4.65 & 5.3563 & TRN & \\
\hline CHEMBL1430557 & 688422 & 4.45 & 5.2438 & TST & \\
\hline CHEMBL388978 & 688422 & 6.0 & 5.95 & TST & \\
\hline CHEMBL1531385 & 688422 & 4.55 & 5.3434 & TST & \\
\hline CHEMBL1500161 & 688422 & 4.65 & 5.0232 & TST & \\
\hline CHEMBL1560694 & 688422 & 5.2 & 5.0895 & TRN & \\
\hline CHEMBL1544239 & 688422 & 4.45 & 5.2771 & TRN & \\
\hline CHEMBL1306287 & 688422 & 4.85 & 5.0089 & TRN & \\
\hline CHEMBL1400498 & 688422 & 4.65 & 5.2447 & TRN & \\
\hline
\end{tabular}





\begin{tabular}{|c|c|c|c|c|c|}
\hline \multicolumn{6}{|c|}{ Supplemental Table S2.txt } \\
\hline CHEMBL1513695 & 688422 & 4.5 & 5.1281 & TRN & \\
\hline CHEMBL1517911 & 688422 & 4.65 & 5.364 & TRN & \\
\hline CHEMBL1430362 & 688422 & 5.0 & 5.3453 & TRN & \\
\hline CHEMBL 236615 & 688422 & 4.95 & 5.45 & TRN & \\
\hline CHEMBL1366357 & 688422 & 5.45 & 4.8811 & TRN & \\
\hline CHEMBL1593522 & 688422 & 4.45 & 5.0153 & TRN & \\
\hline CHEMBL1547464 & 688422 & 4.9 & 5.1976 & TRN & \\
\hline CHEMBL1537885 & 688422 & 5.1 & 5.5443 & TRN & \\
\hline CHEMBL1582213 & 688422 & 4.85 & 5.1917 & TRN & \\
\hline CHEMBL1565231 & 688422 & 4.5 & 5.091 & TRN & \\
\hline CHEMBL1549689 & 688422 & 4.7 & 4.8872 & TST & \\
\hline CHEMBL1388183 & 688422 & 4.65 & 5.5013 & TRN & \\
\hline CHEMBL1500536 & 688422 & 4.95 & 5.3832 & TST & \\
\hline CHEMBL 3199221 & 688422 & 4.45 & 5.0631 & TRN & \\
\hline CHEMBL1380289 & 688422 & 4.95 & 5.1795 & TRN & \\
\hline CHEMBL1440281 & 688422 & 5.8 & 5.3348 & TST & \\
\hline CHEMBL1350976 & 688422 & 4.65 & 5.6135 & TST & \\
\hline CHEMBL1389021 & 688422 & 4.7 & 4.9744 & TST & \\
\hline CHEMBL3191171 & 688422 & 5.45 & 5.4366 & TRN & \\
\hline CHEMBL1429409 & 688422 & 4.5 & 5.0028 & TRN & \\
\hline CHEMBL1330374 & 688422 & 5.0 & 5.107 & TRN & \\
\hline CHEMBL1991303 & 688422 & 7.4001 & 5.17899 & 9999999999 & TRN \\
\hline CHEMBL1589790 & 688422 & 5.35 & 5.2622 & TRN & \\
\hline CHEMBL1353026 & 688422 & 5.3 & 5.1159 & TRN & \\
\hline CHEMBL1322990 & 688422 & 4.95 & 5.9664 & TST & \\
\hline CHEMBL1590220 & 688422 & 4.45 & 5.1349 & TRN & \\
\hline CHEMBL1303080 & 688422 & 6.3 & 5.4439 & TST & \\
\hline CHEMBL1316888 & 688422 & 7.0501 & 5.1692 & TST & \\
\hline CHEMBL1486691 & 688422 & 6.9 & 5.1443 & TST & \\
\hline CHEMBL1569018 & 688422 & 4.45 & 4.8567 & TST & \\
\hline CHEMBL1330662 & 688422 & 5.1 & 5.004 & TRN & \\
\hline CHEMBL1502227 & 688422 & 5.6 & 4.9955 & TST & \\
\hline CHEMBL1308574 & 688422 & 5.0 & 5.4331 & TRN & \\
\hline CHEMBL414890 & 688422 & 4.5 & 5.7038 & TRN & \\
\hline CHEMBL1489194 & 688422 & 4.45 & 5.3448 & TRN & \\
\hline CHEMBL1348738 & 688422 & 4.7 & 5.3552 & TST & \\
\hline CHEMBL1482107 & 688422 & 5.15 & 5.2903 & TST & \\
\hline CHEMBL1514737 & 688422 & 5.25 & 5.5559 & TRN & \\
\hline CHEMBL1359872 & 688422 & 6.3 & 5.4919 & TRN & \\
\hline CHEMBL1345548 & 688422 & 5.45 & 5.2762 & TRN & \\
\hline CHEMBL1445889 & 688422 & 7.5003 & 5.3493 & TRN & \\
\hline CHEMBL1422039 & 688422 & 4.7 & 5.088 & TRN & \\
\hline CHEMBL1450288 & 688422 & 5.45 & 4.9175 & TRN & \\
\hline CHEMBL1340619 & 688422 & 4.95 & 5.1211 & TRN & \\
\hline CHEMBL1387006 & 688422 & 6.95 & 5.8703 & TST & \\
\hline CHEMBL1440099 & 688422 & 6.3 & 5.0316 & TST & \\
\hline CHEMBL1367445 & 688422 & 4.95 & 5.1439 & TRN & \\
\hline CHEMBL1365784 & 688422 & 4.95 & 5.2015 & TRN & \\
\hline
\end{tabular}




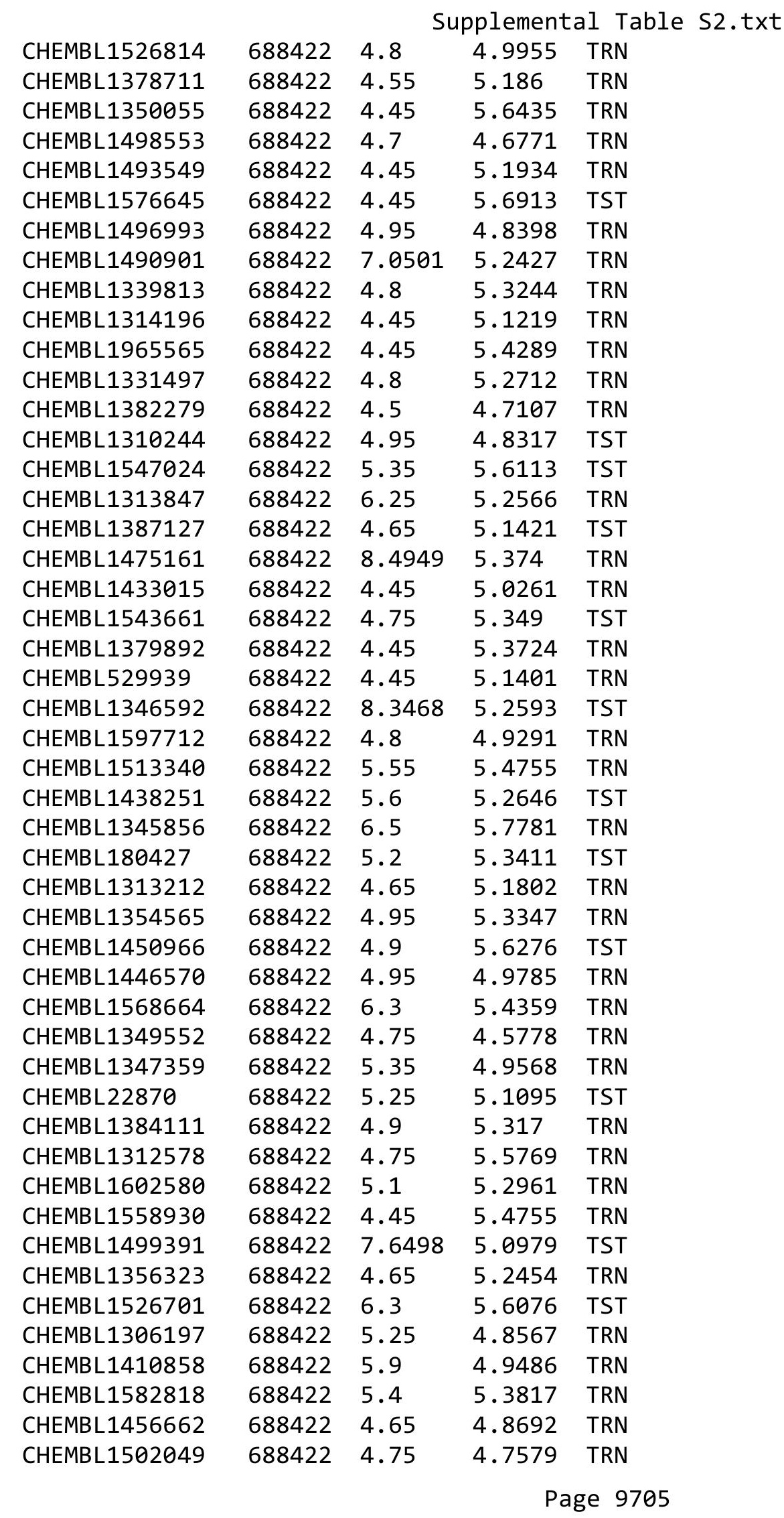





\begin{tabular}{|c|c|c|c|c|c|}
\hline \multirow[b]{2}{*}{ CHEMBL1347490 } & \\
\hline & 688422 & 4.9 & 5.0291 & TRN & \\
\hline CHEMBL1467363 & 688422 & 4.45 & 5.32700 & 0000000001 & TRN \\
\hline CHEMBL1966108 & 688422 & 4.95 & 5.0246 & TRN & \\
\hline CHEMBL1399989 & 688422 & 4.95 & 4.9751 & TRN & \\
\hline CHEMBL1498640 & 688422 & 8.301 & 5.5191 & TRN & \\
\hline CHEMBL1318943 & 688422 & 4.95 & 5.1414 & TST & \\
\hline CHEMBL1351349 & 688422 & 4.8 & 5.0215 & TRN & \\
\hline CHEMBL1379191 & 688422 & 4.95 & 5.1083 & TST & \\
\hline CHEMBL1343788 & 688422 & 4.65 & 5.1365 & TRN & \\
\hline CHEMBL1545432 & 688422 & 4.7 & 5.0273 & TRN & \\
\hline CHEMBL1528766 & 688422 & 4.45 & 5.5719 & TST & \\
\hline CHEMBL1508578 & 688422 & 4.85 & 5.3814 & TRN & \\
\hline CHEMBL1576399 & 688422 & 4.85 & 4.8674 & TRN & \\
\hline CHEMBL3189161 & 688422 & 4.85 & 5.3605 & TRN & \\
\hline CHEMBL1444255 & 688422 & 4.45 & 5.189 & TRN & \\
\hline CHEMBL1339358 & 688422 & 5.0 & 5.2416 & TST & \\
\hline CHEMBL1364299 & 688422 & 4.8 & 4.9985 & TST & \\
\hline CHEMBL1466435 & 688422 & 5.3 & 5.4234 & TRN & \\
\hline CHEMBL1464838 & 688422 & 5.7 & 5.5324 & TRN & \\
\hline CHEMBL1493175 & 688422 & 6.15 & 5.6349 & TRN & \\
\hline CHEMBL1332654 & 688422 & 5.05 & 5.4696 & TRN & \\
\hline CHEMBL1315385 & 688422 & 5.5 & 5.0187 & TRN & \\
\hline CHEMBL1433302 & 688422 & 6.15 & 5.7658 & TRN & \\
\hline CHEMBL1316669 & 688422 & 4.45 & 5.5534 & TRN & \\
\hline CHEMBL1423760 & 688422 & 5.45 & 5.2868 & TRN & \\
\hline CHEMBL1408705 & 688422 & 4.5 & 4.9247 & TST & \\
\hline CHEMBL1421873 & 688422 & 7.8996 & 5.3498 & TST & \\
\hline CHEMBL1313479 & 688422 & 4.75 & 4.8308 & TRN & \\
\hline CHEMBL1462332 & 688422 & 4.45 & 4.7348 & TRN & \\
\hline CHEMBL1324628 & 688422 & 4.95 & 5.5661 & TST & \\
\hline CHEMBL1486477 & 688422 & 4.65 & 5.2077 & TST & \\
\hline CHEMBL1527693 & 688422 & 4.65 & 5.4807 & TRN & \\
\hline CHEMBL1492534 & 688422 & 5.8 & 4.8954 & TRN & \\
\hline CHEMBL1607237 & 688422 & 4.45 & 5.4555 & TRN & \\
\hline CHEMBL 3213750 & 688422 & 5.0 & 5.29200 & 3000000001 & TRN \\
\hline CHEMBL1385003 & 688422 & 5.45 & 5.3484 & TRN & \\
\hline CHEMBL1351116 & 688422 & 5.25 & 4.8222 & TRN & \\
\hline CHEMBL1542470 & 688422 & 4.9 & 5.0726 & TST & \\
\hline CHEMBL3208197 & 688422 & 5.0 & 5.4443 & TST & \\
\hline CHEMBL1491791 & 688422 & 8.0 & 5.6565 & TRN & \\
\hline CHEMBL1307169 & 688422 & 4.75 & 5.2484 & TST & \\
\hline CHEMBL1349842 & 688422 & 8.4949 & 5.6829 & TRN & \\
\hline CHEMBL3198219 & 688422 & 4.45 & 5.4839 & TRN & \\
\hline CHEMBL1402418 & 688422 & 4.65 & 5.5254 & TRN & \\
\hline CHEMBL 1447432 & 688422 & 5.35 & 5.3801 & TRN & \\
\hline CHEMBL1407637 & 688422 & 4.5 & 5.1566 & TRN & \\
\hline CHEMBL1519347 & 688422 & 4.85 & 5.4516 & TST & \\
\hline CHEMBL1319458 & 688422 & 4.45 & 5.1571 & TRN & \\
\hline & & & & 9707 & \\
\hline
\end{tabular}




\begin{tabular}{|c|c|c|c|c|c|}
\hline \multicolumn{6}{|c|}{ Supplemental Table S2.txt } \\
\hline CHEMBL1568767 & 688422 & 4.6 & 4.6851 & TRN & \\
\hline CHEMBL1383097 & 688422 & 5.0 & 5.6711 & TRN & \\
\hline CHEMBL1304033 & 688422 & 4.5 & 5.0268 & TST & \\
\hline CHEMBL1458759 & 688422 & 6.7001 & 5.5526 & TRN & \\
\hline CHEMBL1481147 & 688422 & 5.35 & 5.0638 & TRN & \\
\hline CHEMBL1519818 & 688422 & 5.1 & 5.2925 & TST & \\
\hline CHEMBL86997 & 688422 & 4.45 & 5.2594 & TRN & \\
\hline CHEMBL1390716 & 688422 & 4.45 & 5.095 & TRN & \\
\hline CHEMBL1307056 & 688422 & 4.85 & 5.0286 & TRN & \\
\hline CHEMBL1502908 & 688422 & 8.3468 & 5.7575 & TRN & \\
\hline CHEMBL1387835 & 688422 & 4.85 & 5.58700 & 0000000001 & TST \\
\hline CHEMBL1305455 & 688422 & 5.15 & 5.1575 & TST & \\
\hline CHEMBL1469102 & 688422 & 5.6 & 4.9734 & TRN & \\
\hline CHEMBL1452264 & 688422 & 5.35 & 5.3471 & TRN & \\
\hline CHEMBL1494858 & 688422 & 4.85 & 5.3518 & TRN & \\
\hline CHEMBL1452726 & 688422 & 4.9 & 5.3294 & TST & \\
\hline CHEMBL1493953 & 688422 & 4.75 & 5.0531 & TRN & \\
\hline CHEMBL1581396 & 688422 & 4.45 & 4.7778 & TRN & \\
\hline CHEMBL1524953 & 688422 & 6.6 & 5.5769 & TRN & \\
\hline CHEMBL1432886 & 688422 & 4.7 & 5.4734 & TRN & \\
\hline CHEMBL79192 & 688422 & 4.45 & 5.052 & TRN & \\
\hline CHEMBL1385622 & 688422 & 5.0 & 5.3841 & TRN & \\
\hline CHEMBL1507254 & 688422 & 5.15 & 5.1802 & TRN & \\
\hline CHEMBL1590105 & 688422 & 5.0 & 4.9494 & TRN & \\
\hline CHEMBL1397372 & 688422 & 4.9 & 5.2636 & TRN & \\
\hline CHEMBL1303288 & 688422 & 6.6 & 5.3016 & TST & \\
\hline CHEMBL1317148 & 688422 & 6.0 & 5.79299 & 9999999999 & TRN \\
\hline CHEMBL1404954 & 688422 & 5.55 & 5.0172 & TRN & \\
\hline CHEMBL1312549 & 688422 & 4.9 & 5.1506 & TST & \\
\hline CHEMBL1357293 & 688422 & 4.45 & 4.8665 & TRN & \\
\hline CHEMBL1583242 & 688422 & 4.9 & 5.0304 & TRN & \\
\hline CHEMBL1369442 & 688422 & 4.85 & 5.3641 & TRN & \\
\hline CHEMBL1534659 & 688422 & 4.8 & 5.4351 & TRN & \\
\hline CHEMBL1586359 & 688422 & 4.45 & 5.3567 & TST & \\
\hline CHEMBL1479425 & 688422 & 4.65 & 5.5623 & TST & \\
\hline CHEMBL1427702 & 688422 & 4.75 & 4.8738 & TRN & \\
\hline CHEMBL1356085 & 688422 & 4.9 & 5.1163 & TRN & \\
\hline CHEMBL1412080 & 688422 & 4.85 & 5.3584 & TRN & \\
\hline CHEMBL1485057 & 688422 & 4.45 & 5.3043 & TST & \\
\hline CHEMBL1539540 & 688422 & 4.5 & 5.5793 & TRN & \\
\hline CHEMBL1516574 & 688422 & 6.4 & 5.6475 & TRN & \\
\hline CHEMBL1329177 & 688422 & 4.45 & 5.0612 & TRN & \\
\hline CHEMBL1306541 & 688422 & 4.9 & 4.9651 & TRN & \\
\hline CHEMBL1476264 & 688422 & 6.5 & 5.7765 & TRN & \\
\hline CHEMBL1966751 & 688422 & 5.6 & 4.9471 & TRN & \\
\hline CHEMBL1373314 & 688422 & 5.25 & 5.3397 & TST & \\
\hline CHEMBL1578237 & 688422 & 4.45 & 4.825 & TRN & \\
\hline CHEMBL1419251 & 688422 & 5.05 & 4.8506 & TRN & \\
\hline
\end{tabular}




\begin{tabular}{|c|c|c|c|c|c|}
\hline \multicolumn{6}{|c|}{ Supplemental Table S2.txt } \\
\hline CHEMBL1435874 & 688422 & 6.05 & 5.4442 & TRN & \\
\hline CHEMBL1421533 & 688422 & 4.9 & 5.2302 & TST & \\
\hline CHEMBL1568069 & 688422 & 5.95 & 5.2548 & TST & \\
\hline CHEMBL1308129 & 688422 & 4.95 & 5.2634 & TST & \\
\hline CHEMBL1518540 & 688422 & 4.8 & 5.3734 & TRN & \\
\hline CHEMBL1576109 & 688422 & 4.6 & 5.2216 & TST & \\
\hline CHEMBL1337810 & 688422 & 4.6 & 5.0215 & TRN & \\
\hline CHEMBL1343998 & 688422 & 5.35 & 5.2878 & TRN & \\
\hline CHEMBL1363913 & 688422 & 5.25 & 5.2442 & TRN & \\
\hline CHEMBL3193723 & 688422 & 4.85 & 5.0158 & TRN & \\
\hline CHEMBL1462513 & 688422 & 4.65 & 5.1418 & TRN & \\
\hline CHEMBL3193660 & 688422 & 4.7 & 5.2415 & TST & \\
\hline CHEMBL1496450 & 688422 & 5.2 & 4.8258 & TRN & \\
\hline CHEMBL1478509 & 688422 & 5.2 & 5.4667 & TRN & \\
\hline CHEMBL3198659 & 688422 & 4.6 & 4.9618 & TRN & \\
\hline CHEMBL1322789 & 688422 & 6.35 & 5.142 & TST & \\
\hline CHEMBL1444357 & 688422 & 6.15 & 5.66700 & 0000000001 & TST \\
\hline CHEMBL1602598 & 688422 & 6.8499 & 5.2256 & TRN & \\
\hline CHEMBL1538959 & 688422 & 4.45 & 5.437 & TRN & \\
\hline CHEMBL1446548 & 688422 & 4.6 & 4.805 & TRN & \\
\hline CHEMBL1360149 & 688422 & 4.7 & 5.2503 & TRN & \\
\hline CHEMBL1434429 & 688422 & 7.0501 & 5.2696 & TRN & \\
\hline CHEMBL1256360 & 688422 & 6.0 & 5.6397 & TRN & \\
\hline CHEMBL1348275 & 688422 & 4.7 & 5.2185 & TRN & \\
\hline CHEMBL1434623 & 688422 & 7.1002 & 5.4552 & TRN & \\
\hline CHEMBL1386080 & 688422 & 4.45 & 5.2772 & TST & \\
\hline CHEMBL1590123 & 688422 & 4.8 & 4.5155 & TRN & \\
\hline CHEMBL1504939 & 688422 & 5.85 & 5.3797 & TRN & \\
\hline CHEMBL1483226 & 688422 & 7.15 & 5.2478 & TRN & \\
\hline CHEMBL1966948 & 688422 & 4.45 & 5.3929 & TRN & \\
\hline CHEMBL1582446 & 688422 & 4.45 & 5.2748 & TRN & \\
\hline CHEMBL1480454 & 688422 & 8.4559 & 5.5551 & TST & \\
\hline CHEMBL1342874 & 688422 & 4.8 & 4.872 & TRN & \\
\hline CHEMBL1320890 & 688422 & 4.6 & 4.9823 & TST & \\
\hline CHEMBL1435045 & 688422 & 4.8 & 4.8306 & TRN & \\
\hline CHEMBL1523052 & 688422 & 4.85 & 5.1724 & TST & \\
\hline CHEMBL1461436 & 688422 & 4.65 & 5.5992 & TRN & \\
\hline CHEMBL1393128 & 688422 & 7.2503 & 5.6077 & TRN & \\
\hline CHEMBL1534709 & 688422 & 4.7 & 4.7089 & TRN & \\
\hline CHEMBL1989662 & 688422 & 5.25 & 5.4006 & TRN & \\
\hline CHEMBL1584306 & 688422 & 4.95 & 5.2557 & TST & \\
\hline CHEMBL1374958 & 688422 & 5.55 & 4.9342 & TRN & \\
\hline CHEMBL1519559 & 688422 & 4.9 & 5.2185 & TST & \\
\hline CHEMBL3198328 & 688422 & 8.301 & 5.671 & TST & \\
\hline CHEMBL1428502 & 688422 & 4.75 & 5.1981 & TRN & \\
\hline CHEMBL1572766 & 688422 & 4.95 & 5.1883 & TRN & \\
\hline CHEMBL1464904 & 688422 & 4.65 & 4.879 & TRN & \\
\hline CHEMBL3190310 & 688422 & 4.7 & 5.4211 & TRN & \\
\hline
\end{tabular}




\begin{tabular}{|c|c|c|c|c|}
\hline \multicolumn{5}{|c|}{ Supplemental Table S2.txt } \\
\hline CHEMBL1415669 & 688422 & 4.45 & 5.101 & TST \\
\hline CHEMBL1541924 & 688422 & 4.8 & 5.1218 & TRN \\
\hline CHEMBL1590363 & 688422 & 5.9 & 5.0975 & TRN \\
\hline CHEMBL1532011 & 688422 & 4.45 & 5.5045 & TRN \\
\hline CHEMBL1539405 & 688422 & 4.75 & 5.0596 & TRN \\
\hline CHEMBL1330784 & 688422 & 6.7001 & 5.6313 & TST \\
\hline CHEMBL1322054 & 688422 & 4.6 & 5.0273 & TRN \\
\hline CHEMBL1602732 & 688422 & 4.95 & 5.6198 & TST \\
\hline CHEMBL1501911 & 688422 & 7.4498 & 5.3746 & TRN \\
\hline CHEMBL1421776 & 688422 & 4.9 & 5.5732 & TRN \\
\hline CHEMBL1606626 & 688422 & 4.75 & 5.2436 & TRN \\
\hline CHEMBL1582415 & 688422 & 6.25 & 5.1155 & TRN \\
\hline CHEMBL1539893 & 688422 & 4.9 & 5.0568 & TRN \\
\hline CHEMBL1970152 & 688422 & 4.75 & 5.2046 & TRN \\
\hline CHEMBL1582063 & 688422 & 4.95 & 5.3704 & TST \\
\hline CHEMBL1612505 & 688422 & 5.05 & 5.0984 & TRN \\
\hline CHEMBL1373783 & 688422 & 4.45 & 4.8427 & TRN \\
\hline CHEMBL1368300 & 688422 & 4.7 & 5.1717 & TRN \\
\hline CHEMBL1411036 & 688422 & 4.95 & 4.9847 & TRN \\
\hline CHEMBL582699 & 688422 & 4.6 & 4.8119 & TRN \\
\hline CHEMBL1505319 & 688422 & 7.4001 & 5.6454 & TRN \\
\hline CHEMBL1522149 & 688422 & 5.9 & 5.2272 & TRN \\
\hline CHEMBL1347707 & 688422 & 7.4498 & 5.4415 & TRN \\
\hline CHEMBL1535351 & 688422 & 5.45 & 5.1858 & TRN \\
\hline CHEMBL1605179 & 688422 & 4.9 & 5.3291 & TRN \\
\hline CHEMBL1399210 & 688422 & 4.5 & 4.7408 & TRN \\
\hline CHEMBL1582161 & 688422 & 4.95 & 5.0497 & TRN \\
\hline CHEMBL1556640 & 688422 & 4.45 & 5.1346 & TST \\
\hline CHEMBL1395290 & 688422 & 4.8 & 4.9886 & TST \\
\hline CHEMBL1479414 & 688422 & 4.85 & 5.0752 & TRN \\
\hline CHEMBL1602037 & 688422 & 6.1 & 5.4832 & TRN \\
\hline CHEMBL1438308 & 688422 & 4.65 & 4.965 & TRN \\
\hline CHEMBL1382135 & 688422 & 4.65 & 5.3471 & TRN \\
\hline CHEMBL1355305 & 688422 & 7.15 & 4.8553 & TRN \\
\hline CHEMBL1374165 & 688422 & 4.5 & 5.3152 & TST \\
\hline CHEMBL1451617 & 688422 & 4.95 & 5.1157 & TRN \\
\hline CHEMBL1561254 & 688422 & 4.5 & 5.0031 & TRN \\
\hline CHEMBL1526804 & 688422 & 6.0 & 5.4574 & TRN \\
\hline CHEMBL1591073 & 688422 & 5.65 & 5.1745 & TRN \\
\hline CHEMBL1612026 & 688422 & 5.45 & 4.8661 & TRN \\
\hline CHEMBL1474890 & 688422 & 5.05 & 4.7523 & TRN \\
\hline CHEMBL1369595 & 688422 & 4.45 & 5.4284 & TRN \\
\hline CHEMBL1430467 & 688422 & 4.55 & 5.3983 & TST \\
\hline CHEMBL1535241 & 688422 & 4.45 & 4.8583 & TST \\
\hline CHEMBL1364729 & 688422 & 4.45 & 5.8071 & TST \\
\hline CHEMBL1992044 & 688422 & 6.1 & 5.403 & TST \\
\hline CHEMBL1326188 & 688422 & 4.95 & 5.1891 & TRN \\
\hline CHEMBL1492352 & 688422 & 4.65 & 4.7965 & TRN \\
\hline
\end{tabular}




\begin{tabular}{|c|c|c|c|c|c|}
\hline \multicolumn{6}{|c|}{ Supplemental Table S2.txt } \\
\hline CHEMBL3213856 & 688422 & 4.5 & 5.6877 & TST & \\
\hline CHEMBL1531076 & 688422 & 4.75 & 5.3121 & TRN & \\
\hline CHEMBL1480350 & 688422 & 4.95 & 5.1316 & TRN & \\
\hline CHEMBL3194000 & 688422 & 4.45 & 5.2227 & TST & \\
\hline CHEMBL3195603 & 688422 & 4.8 & 5.1677 & TRN & \\
\hline CHEMBL1332377 & 688422 & 4.8 & \multicolumn{2}{|c|}{5.292000000000001} & TRN \\
\hline CHEMBL1390797 & 688422 & 5.35 & 5.1917 & TRN & \\
\hline CHEMBL1582519 & 688422 & 5.45 & 4.8179 & TRN & \\
\hline CHEMBL1453673 & 688422 & 4.45 & 4.9077 & TRN & \\
\hline CHEMBL1417530 & 688422 & 7.8508 & 5.3023 & TRN & \\
\hline CHEMBL1520140 & 688422 & 4.85 & 5.1103 & TRN & \\
\hline CHEMBL1305901 & 688422 & 5.2 & 5.4178 & TST & \\
\hline CHEMBL1449135 & 688422 & 4.45 & 4.8201 & TST & \\
\hline CHEMBL 276618 & 688422 & 5.5 & 5.2579 & TRN & \\
\hline CHEMBL1486808 & 688422 & 5.15 & 5.2662 & TRN & \\
\hline CHEMBL1401588 & 688422 & 4.45 & 4.7016 & TRN & \\
\hline CHEMBL1330303 & 688422 & 5.0 & 5.2488 & TRN & \\
\hline CHEMBL1509374 & 688422 & 5.0 & 5.0555 & TST & \\
\hline CHEMBL1613717 & 688422 & 4.8 & 5.0664 & TRN & \\
\hline CHEMBL1450822 & 688422 & 4.5 & 4.6616 & TST & \\
\hline CHEMBL1585335 & 688422 & 5.1 & 5.152 & TRN & \\
\hline CHEMBL1399130 & 688422 & 4.5 & 5.2579 & TRN & \\
\hline CHEMBL1389939 & 688422 & 4.65 & 5.2005 & TRN & \\
\hline CHEMBL1317949 & 688422 & 4.45 & 5.3862 & TRN & \\
\hline CHEMBL589101 & 688422 & 4.95 & 4.7257 & TRN & \\
\hline CHEMBL1416112 & 688422 & 7.7496 & 5.0428 & TRN & \\
\hline CHEMBL1443087 & 688422 & 7.0501 & 5.3182 & TRN & \\
\hline CHEMBL1412987 & 688422 & 4.8 & 5.2637 & TRN & \\
\hline CHEMBL1388984 & 688422 & 4.45 & 5.1505 & TRN & \\
\hline CHEMBL1364847 & 688422 & 5.4 & 5.191 & TRN & \\
\hline CHEMBL1509433 & 688422 & 4.85 & 5.1711 & TRN & \\
\hline CHEMBL1358374 & 688422 & 6.25 & 5.2119 & TRN & \\
\hline CHEMBL1595681 & 688422 & 4.85 & 5.0051 & TRN & \\
\hline CHEMBL1459274 & 688422 & 4.9 & 5.6613 & TRN & \\
\hline CHEMBL1327005 & 688422 & 4.75 & 5.3598 & TRN & \\
\hline CHEMBL1370879 & 688422 & 4.7 & 5.3265 & TRN & \\
\hline CHEMBL1575072 & 688422 & 4.95 & 5.1859 & TST & \\
\hline CHEMBL1305943 & 688422 & 7.6498 & \multicolumn{2}{|c|}{5.882000000000001} & TST \\
\hline CHEMBL1356568 & 688422 & 4.85 & 5.3563 & TRN & \\
\hline CHEMBL1384412 & 688422 & 4.8 & 5.4378 & TST & \\
\hline CHEMBL1318971 & 688422 & 5.15 & 4.6675 & TST & \\
\hline CHEMBL1563327 & 688422 & 4.45 & 5.3525 & TST & \\
\hline CHEMBL1471088 & 688422 & 4.95 & 5.0435 & TRN & \\
\hline CHEMBL1499755 & 688422 & 4.85 & 5.2604 & TST & \\
\hline CHEMBL1359419 & 688422 & 4.7 & \multicolumn{2}{|c|}{5.3870000000000005} & TRN \\
\hline CHEMBL1392263 & 688422 & 4.5 & 5.2347 & TST & \\
\hline CHEMBL1411125 & 688422 & 5.55 & 5.474 & TRN & \\
\hline CHEMBL1412318 & 688422 & 5.15 & 5.2794 & TRN & \\
\hline
\end{tabular}




\begin{tabular}{|c|c|c|c|c|c|}
\hline \multirow{3}{*}{$\begin{array}{l}\text { CHEMBL1516054 } \\
\text { CHEMBL1527762 }\end{array}$} & \multirow{3}{*}{$\begin{array}{l}688422 \\
688422\end{array}$} & \multicolumn{4}{|c|}{ Supplemental Table S2.txt } \\
\hline & & 4.65 & 4.53100 & 0000000001 & TRN \\
\hline & & 5.55 & 5.7933 & TST & \\
\hline CHEMBL1585043 & 688422 & 4.85 & 5.1198 & TRN & \\
\hline CHEMBL1482398 & 688422 & 4.55 & 5.032 & TRN & \\
\hline CHEMBL1447553 & 688422 & 5.9 & 5.0163 & TRN & \\
\hline CHEMBL1493421 & 688422 & 5.75 & 5.3534 & TST & \\
\hline CHEMBL1595632 & 688422 & 4.95 & 5.7596 & TRN & \\
\hline CHEMBL1305471 & 688422 & 4.45 & 5.0945 & TRN & \\
\hline CHEMBL1397552 & 688422 & 4.95 & 5.1585 & TRN & \\
\hline CHEMBL3192270 & 688422 & 5.4 & 4.9749 & TRN & \\
\hline CHEMBL1601244 & 688422 & 4.95 & 5.0463 & TST & \\
\hline CHEMBL1505855 & 688422 & 6.1 & 5.7033 & TRN & \\
\hline CHEMBL1384153 & 688422 & 5.0 & 5.1367 & TRN & \\
\hline CHEMBL3208695 & 688422 & 6.8 & 4.9794 & TRN & \\
\hline CHEMBL1561176 & 688422 & 4.7 & 5.4648 & TRN & \\
\hline CHEMBL1424928 & 688422 & 4.45 & 5.4315 & TST & \\
\hline CHEMBL589421 & 688422 & 5.35 & 5.7079 & TST & \\
\hline CHEMBL1577238 & 688422 & 6.45 & 5.4299 & TRN & \\
\hline CHEMBL1570150 & 688422 & 4.7 & 5.0722 & TRN & \\
\hline CHEMBL492193 & 688422 & 5.8 & 5.5567 & TST & \\
\hline CHEMBL3194375 & 688422 & 4.8 & 5.5246 & TRN & \\
\hline CHEMBL1405516 & 688422 & 4.45 & 5.4195 & TRN & \\
\hline CHEMBL1307705 & 688422 & 4.9 & 5.4199 & TRN & \\
\hline CHEMBL1466305 & 688422 & 5.9 & 5.6628 & TRN & \\
\hline CHEMBL1379442 & 688422 & 4.85 & 5.4177 & TRN & \\
\hline CHEMBL1306347 & 688422 & 4.8 & 5.6719 & TRN & \\
\hline CHEMBL1329046 & 688422 & 4.45 & 5.2878 & TST & \\
\hline CHEMBL1517784 & 688422 & 5.1 & 5.4783 & TRN & \\
\hline CHEMBL1477847 & 688422 & 4.95 & 5.1076 & TRN & \\
\hline CHEMBL1353108 & 688422 & 4.8 & 4.9396 & TST & \\
\hline CHEMBL1576568 & 688422 & 5.75 & 5.2656 & TRN & \\
\hline CHEMBL1573523 & 688422 & 5.2 & 4.9594 & TRN & \\
\hline CHEMBL1570468 & 688422 & 8.3468 & 5.3707 & TRN & \\
\hline CHEMBL1443218 & 688422 & 4.7 & 4.8876 & TRN & \\
\hline CHEMBL533226 & 688422 & 5.2 & 5.1501 & TRN & \\
\hline CHEMBL1367897 & 688422 & 4.45 & 5.0775 & TRN & \\
\hline CHEMBL1487208 & 688422 & 4.85 & 5.4823 & TST & \\
\hline CHEMBL1570762 & 688422 & 7.15 & 5.711 & TRN & \\
\hline CHEMBL1475829 & 688422 & 5.3 & 5.5548 & TRN & \\
\hline CHEMBL1363951 & 688422 & 4.95 & 5.1799 & TRN & \\
\hline CHEMBL1577181 & 688422 & 4.9 & 5.2366 & TRN & \\
\hline CHEMBL3192799 & 688422 & 4.65 & 4.8348 & TRN & \\
\hline CHEMBL1326106 & 688422 & 5.9 & 5.3809 & TRN & \\
\hline CHEMBL1308550 & 688422 & 4.5 & 5.2614 & TRN & \\
\hline CHEMBL1403853 & 688422 & 5.05 & 5.0947 & TRN & \\
\hline CHEMBL1613522 & 688422 & 4.9 & 5.1928 & TST & \\
\hline CHEMBL1472991 & 688422 & 4.8 & 5.5914 & TRN & \\
\hline CHEMBL1257125 & 688422 & 4.9 & 5.4504 & TRN & \\
\hline
\end{tabular}




\begin{tabular}{|c|c|c|c|c|}
\hline \multicolumn{5}{|c|}{ Supplemental Table S2.txt } \\
\hline CHEMBL1506358 & 688422 & 4.45 & 5.2944 & TRN \\
\hline CHEMBL1388769 & 688422 & 4.9 & 4.927 & TRN \\
\hline CHEMBL1597540 & 688422 & 4.45 & 5.1812 & TRN \\
\hline CHEMBL1519226 & 688422 & 8.4949 & 5.6647 & TRN \\
\hline CHEMBL1612117 & 688422 & 4.45 & 4.9837 & TRN \\
\hline CHEMBL1512597 & 688422 & 4.9 & 4.992 & TRN \\
\hline CHEMBL1330913 & 688422 & 4.45 & 5.0869 & TRN \\
\hline CHEMBL2001712 & 688422 & 5.4 & 4.9989 & TRN \\
\hline CHEMBL1411540 & 688422 & 5.2 & 5.3524 & TRN \\
\hline CHEMBL1307225 & 688422 & 8.4949 & 5.6013 & TRN \\
\hline CHEMBL1496577 & 688422 & 4.45 & 4.998 & TRN \\
\hline CHEMBL1363912 & 688422 & 5.45 & 5.4505 & TRN \\
\hline CHEMBL1563889 & 688422 & 4.45 & 5.4304 & TRN \\
\hline CHEMBL1539413 & 688422 & 4.65 & 5.0843 & TRN \\
\hline CHEMBL1464060 & 688422 & 4.65 & 5.3648 & TRN \\
\hline CHEMBL1459851 & 688422 & 5.35 & 5.1784 & TRN \\
\hline CHEMBL1392854 & 688422 & 4.85 & 5.3153 & TST \\
\hline CHEMBL1429637 & 688422 & 4.65 & 5.2885 & TRN \\
\hline CHEMBL1533351 & 688422 & 4.55 & 4.8445 & TRN \\
\hline CHEMBL1514877 & 688422 & 7.15 & 5.0849 & TST \\
\hline CHEMBL1371240 & 688422 & 4.9 & 5.2291 & TST \\
\hline CHEMBL1436678 & 688422 & 4.9 & 5.0004 & TRN \\
\hline CHEMBL1503922 & 688422 & 4.45 & 4.7526 & TRN \\
\hline CHEMBL1502505 & 688422 & 4.65 & 5.1048 & TST \\
\hline CHEMBL1468909 & 688422 & 4.45 & 4.8296 & TRN \\
\hline CHEMBL1531392 & 688422 & 5.5 & 5.3654 & TRN \\
\hline CHEMBL1383944 & 688422 & 4.5 & 5.6175 & TRN \\
\hline CHEMBL1590054 & 688422 & 6.0 & 5.1229 & TRN \\
\hline CHEMBL1989262 & 688422 & 4.85 & 5.1461 & TST \\
\hline CHEMBL1457553 & 688422 & 4.45 & 5.5053 & TRN \\
\hline CHEMBL1499099 & 688422 & 4.75 & 5.5548 & TST \\
\hline CHEMBL1392793 & 688422 & 4.45 & 4.8574 & TST \\
\hline CHEMBL1443213 & 688422 & 5.4 & 5.4274 & TRN \\
\hline CHEMBL1548291 & 688422 & 5.2 & 5.1352 & TST \\
\hline CHEMBL1502678 & 688422 & 4.45 & 5.3522 & TRN \\
\hline CHEMBL1581250 & 688422 & 4.9 & 5.0646 & TRN \\
\hline CHEMBL1411680 & 688422 & 4.65 & 4.86 & TRN \\
\hline CHEMBL1309450 & 688422 & 5.1 & 5.80399 & 9999999999 \\
\hline CHEMBL1550640 & 688422 & 5.4 & 5.0386 & TRN \\
\hline CHEMBL1550335 & 688422 & 4.85 & 5.0085 & TST \\
\hline CHEMBL1545156 & 688422 & 5.55 & 5.3261 & TST \\
\hline CHEMBL1361793 & 688422 & 4.45 & 4.8259 & TRN \\
\hline CHEMBL1518591 & 688422 & 5.4 & 5.1229 & TRN \\
\hline CHEMBL1314122 & 688422 & 4.85 & 5.3406 & TRN \\
\hline CHEMBL1971267 & 688422 & 5.25 & 5.6054 & TRN \\
\hline CHEMBL1331104 & 688422 & 7.699 & 5.1391 & TRN \\
\hline CHEMBL1408955 & 688422 & 5.0 & 5.7336 & TRN \\
\hline CHEMBL1458286 & 688422 & 4.45 & 4.6448 & TST \\
\hline
\end{tabular}




\begin{tabular}{|c|c|c|c|c|c|}
\hline \multicolumn{6}{|c|}{ Supplemental Table S2.txt } \\
\hline CHEMBL1493293 & 688422 & 4.5 & 5.1051 & TRN & \\
\hline CHEMBL3195704 & 688422 & 5.45 & 5.4363 & TRN & \\
\hline CHEMBL1977867 & 688422 & 4.65 & 5.4174 & TST & \\
\hline CHEMBL1513275 & 688422 & 7.9508 & 5.3784 & TRN & \\
\hline CHEMBL1498364 & 688422 & 6.05 & 4.8824 & TRN & \\
\hline CHEMBL1455279 & 688422 & 5.15 & 5.2741 & TST & \\
\hline CHEMBL1307473 & 688422 & 4.5 & 5.0957 & TRN & \\
\hline CHEMBL1256974 & 688422 & 7.5003 & 5.42899 & 9999999999 & TRN \\
\hline CHEMBL1405142 & 688422 & 4.7 & 4.7155 & TRN & \\
\hline CHEMBL1353565 & 688422 & 4.45 & 5.0194 & TRN & \\
\hline CHEMBL1482468 & 688422 & 5.4 & 5.2188 & TRN & \\
\hline CHEMBL1453443 & 688422 & 4.65 & 4.9109 & TST & \\
\hline CHEMBL1372897 & 688422 & 5.85 & 5.5527 & TRN & \\
\hline CHEMBL1597389 & 688422 & 5.9 & 5.1411 & TST & \\
\hline CHEMBL1547516 & 688422 & 4.95 & 4.8446 & TRN & \\
\hline CHEMBL1459175 & 688422 & 4.8 & 5.5687 & TRN & \\
\hline CHEMBL1333826 & 688422 & 6.0 & 4.6711 & TRN & \\
\hline CHEMBL1518620 & 688422 & 4.45 & 5.3531 & TRN & \\
\hline CHEMBL1608569 & 688422 & 4.45 & 4.8384 & TRN & \\
\hline CHEMBL1556022 & 688422 & 4.5 & 5.3709 & TST & \\
\hline CHEMBL1393809 & 688422 & 6.0 & 5.376 & TRN & \\
\hline CHEMBL1317655 & 688422 & 4.95 & 5.0817 & TRN & \\
\hline CHEMBL1390091 & 688422 & 7.699 & 5.5007 & TST & \\
\hline CHEMBL1378502 & 688422 & 4.9 & 5.1617 & TRN & \\
\hline CHEMBL1602501 & 688422 & 6.1 & 5.9065 & TRN & \\
\hline CHEMBL1612721 & 688422 & 8.1024 & 4.9401 & TST & \\
\hline CHEMBL1602203 & 688422 & 4.65 & 5.21200 & 3000000001 & TST \\
\hline CHEMBL1333966 & 688422 & 4.5 & 4.8942 & TRN & \\
\hline CHEMBL1309856 & 688422 & 4.75 & 5.2042 & TRN & \\
\hline CHEMBL 1575735 & 688422 & 5.1 & 5.006 & TRN & \\
\hline CHEMBL1580761 & 688422 & 4.85 & 5.0031 & TRN & \\
\hline CHEMBL1442919 & 688422 & 4.95 & 4.734 & TRN & \\
\hline CHEMBL1564234 & 688422 & 4.35 & 5.5394 & TRN & \\
\hline CHEMBL1552409 & 688422 & 5.1 & 5.9965 & TST & \\
\hline CHEMBL1480653 & 688422 & 7.699 & 6.0373 & TRN & \\
\hline CHEMBL1325513 & 688422 & 4.7 & 5.0734 & TRN & \\
\hline CHEMBL1518248 & 688422 & 4.8 & 5.2179 & TRN & \\
\hline CHEMBL1324486 & 688422 & 4.45 & 5.0773 & TRN & \\
\hline CHEMBL1385704 & 688422 & 5.05 & 5.3601 & TRN & \\
\hline CHEMBL1317482 & 688422 & 5.25 & 5.0984 & TRN & \\
\hline CHEMBL1461951 & 688422 & 4.65 & 5.3186 & TRN & \\
\hline CHEMBL1428645 & 688422 & 4.8 & 5.0871 & TST & \\
\hline CHEMBL1370374 & 688422 & 7.6498 & 5.2425 & TST & \\
\hline CHEMBL1578679 & 688422 & 4.95 & 5.1302 & TRN & \\
\hline CHEMBL1420427 & 688422 & 8.3468 & 5.6897 & TRN & \\
\hline CHEMBL1356596 & 688422 & 5.25 & 5.7454 & TRN & \\
\hline CHEMBL1494593 & 688422 & 4.95 & 4.9879 & TRN & \\
\hline CHEMBL3193273 & 688422 & 4.45 & 5.43 & TRN & \\
\hline
\end{tabular}




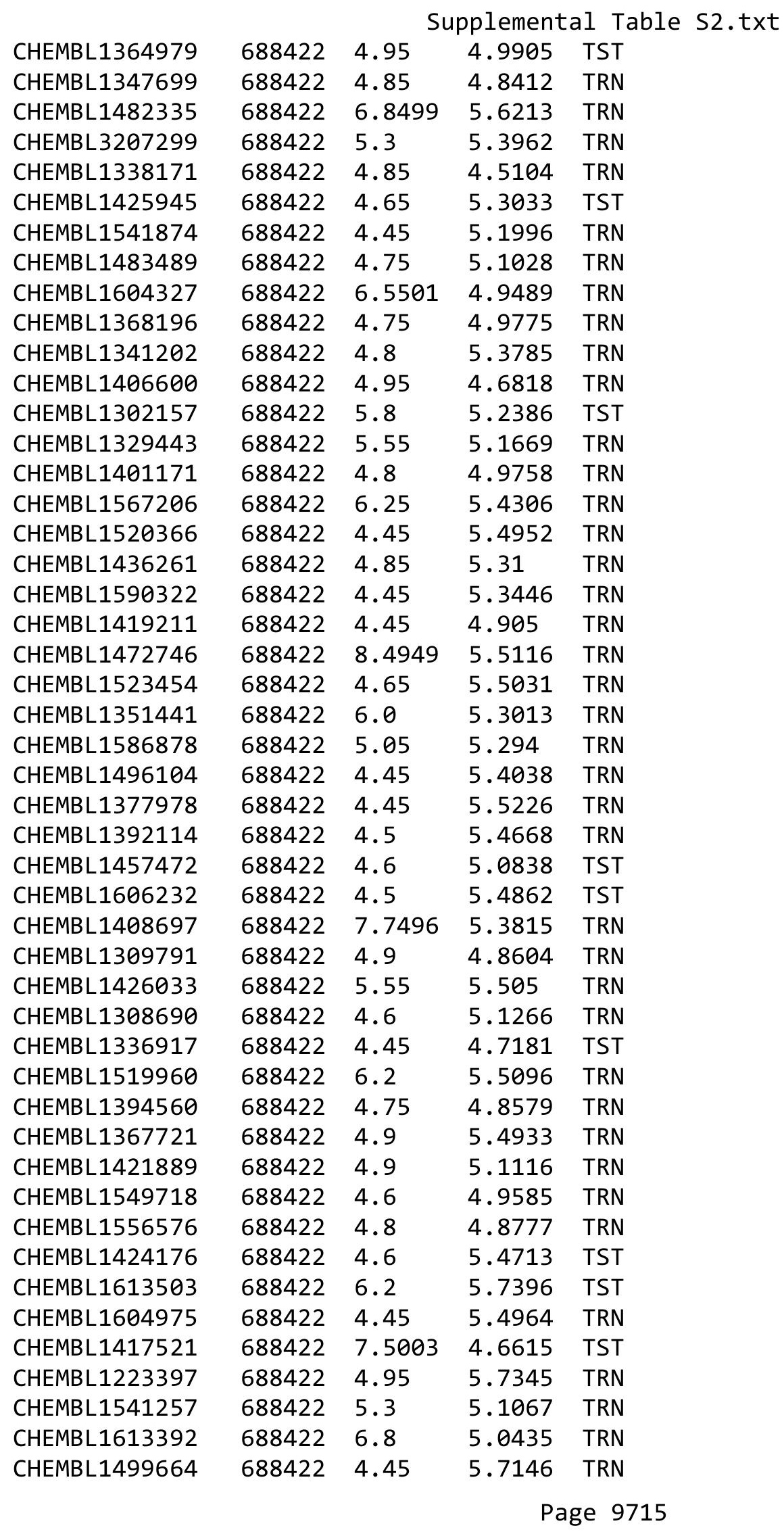




\begin{tabular}{|c|c|c|c|c|c|}
\hline \multicolumn{6}{|c|}{ Supplemental Table S2.txt } \\
\hline CHEMBL1397214 & 688422 & 5.0 & 5.0094 & TRN & \\
\hline CHEMBL1521164 & 688422 & 4.65 & 5.443 & TST & \\
\hline CHEMBL1574102 & 688422 & 5.45 & 5.7248 & TST & \\
\hline CHEMBL 3198170 & 688422 & 4.9 & 5.6275 & TST & \\
\hline CHEMBL1475212 & 688422 & 7.699 & 5.2434 & TRN & \\
\hline CHEMBL1407672 & 688422 & 5.7 & 5.6776 & TST & \\
\hline CHEMBL1505293 & 688422 & 4.7 & 4.9068 & TRN & \\
\hline CHEMBL1578150 & 688422 & 6.0 & 4.9712 & TST & \\
\hline CHEMBL1412414 & 688422 & 4.75 & 4.9337 & TRN & \\
\hline CHEMBL1340886 & 688422 & 4.75 & 5.4372 & TST & \\
\hline CHEMBL1507286 & 688422 & 4.5 & $5.36100 t$ & 0000000001 & TRN \\
\hline CHEMBL1966853 & 688422 & 5.0 & 5.1505 & TRN & \\
\hline CHEMBL1445602 & 688422 & 4.95 & 4.8612 & TRN & \\
\hline CHEMBL3189192 & 688422 & 8.4559 & 5.1413 & TRN & \\
\hline CHEMBL1569271 & 688422 & 4.9 & 4.6721 & TRN & \\
\hline CHEMBL1447563 & 688422 & 5.5 & 4.9776 & TRN & \\
\hline CHEMBL1407903 & 688422 & 4.6 & 5.1382 & TRN & \\
\hline CHEMBL1355524 & 688422 & 5.6 & 5.1195 & TRN & \\
\hline CHEMBL1412040 & 688422 & 5.0 & 5.2616 & TRN & \\
\hline CHEMBL1585887 & 688422 & 4.85 & 4.9998 & TRN & \\
\hline CHEMBL1584152 & 688422 & 5.65 & 5.5087 & TRN & \\
\hline CHEMBL1440087 & 688422 & 4.95 & 5.6283 & TRN & \\
\hline CHEMBL1391655 & 688422 & 5.5 & 5.5028 & TRN & \\
\hline CHEMBL1429672 & 688422 & 6.8 & 5.4235 & TST & \\
\hline CHEMBL1307409 & 688422 & 5.0 & 5.0942 & TRN & \\
\hline CHEMBL1328350 & 688422 & 4.65 & 5.1534 & TRN & \\
\hline CHEMBL1432030 & 688422 & 4.85 & 5.4085 & TST & \\
\hline CHEMBL1358260 & 688422 & 8.301 & 5.5564 & TST & \\
\hline CHEMBL1524731 & 688422 & 4.9 & 4.6594 & TRN & \\
\hline CHEMBL1416562 & 688422 & 4.95 & $4.98600 t$ & 0000000001 & TRN \\
\hline CHEMBL1461683 & 688422 & 4.45 & 5.2516 & TST & \\
\hline CHEMBL3194012 & 688422 & 5.45 & 5.4248 & TRN & \\
\hline CHEMBL1517484 & 688422 & 4.65 & 5.0713 & TRN & \\
\hline CHEMBL1579927 & 688422 & 5.55 & 5.5201 & TRN & \\
\hline CHEMBL3197349 & 688422 & 4.7 & 5.7424 & TRN & \\
\hline CHEMBL1454428 & 688422 & 4.85 & 4.8992 & TRN & \\
\hline CHEMBL1509145 & 688422 & 4.55 & 4.9567 & TRN & \\
\hline CHEMBL1347846 & 688422 & 4.9 & 5.0979 & TRN & \\
\hline CHEMBL1312504 & 688422 & 4.6 & 4.8838 & TRN & \\
\hline CHEMBL 203108 & 688422 & 4.9 & 5.1402 & TST & \\
\hline CHEMBL1564150 & 688422 & 5.25 & 5.25299 & 9999999999 & TST \\
\hline CHEMBL1489200 & 688422 & 5.85 & 5.1244 & TST & \\
\hline CHEMBL1353804 & 688422 & 4.85 & 5.3239 & TST & \\
\hline CHEMBL3193816 & 688422 & 4.8 & 5.0479 & TRN & \\
\hline CHEMBL3191200 & 688422 & 4.45 & 4.8023 & TRN & \\
\hline CHEMBL1367316 & 688422 & 4.9 & 5.2187 & TRN & \\
\hline CHEMBL1311564 & 688422 & 5.0 & 5.4251 & TRN & \\
\hline CHEMBL1387750 & 688422 & 5.45 & 5.0863 & TRN & \\
\hline
\end{tabular}




\begin{tabular}{|c|c|c|c|c|c|}
\hline \multicolumn{6}{|c|}{ Supplemental Table S2.txt } \\
\hline CHEMBL1413047 & 688422 & 4.8 & 4.8252 & TRN & \\
\hline CHEMBL1517120 & 688422 & 4.5 & 5.118 & TST & \\
\hline CHEMBL1510616 & 688422 & 6.45 & 5.4934 & TST & \\
\hline CHEMBL1345169 & 688422 & 4.75 & 5.5888 & TRN & \\
\hline CHEMBL1550245 & 688422 & 4.75 & 5.2638 & TST & \\
\hline CHEMBL1537683 & 688422 & 4.6 & 5.1615 & TRN & \\
\hline CHEMBL1430473 & 688422 & 7.0 & 5.2797 & TST & \\
\hline CHEMBL1517231 & 688422 & 4.5 & 5.1305 & TRN & \\
\hline CHEMBL1452432 & 688422 & 5.65 & 5.1606 & TRN & \\
\hline CHEMBL1366093 & 688422 & 4.5 & 5.3832 & TRN & \\
\hline CHEMBL1572019 & 688422 & 4.75 & 5.2884 & TRN & \\
\hline CHEMBL1606291 & 688422 & 5.1 & 5.3584 & TST & \\
\hline CHEMBL1451570 & 688422 & 5.2 & 5.6286 & TRN & \\
\hline CHEMBL1485881 & 688422 & 4.45 & 5.5698 & TRN & \\
\hline CHEMBL1333449 & 688422 & 6.05 & 5.5795 & TRN & \\
\hline CHEMBL1344676 & 688422 & 4.7 & 4.90300 & 30000000005 & TRN \\
\hline CHEMBL1336728 & 688422 & 4.45 & 4.5242 & TRN & \\
\hline CHEMBL1332936 & 688422 & 8.0 & 5.4517 & TST & \\
\hline CHEMBL1552980 & 688422 & 7.8013 & 4.9401 & TRN & \\
\hline CHEMBL3199156 & 688422 & 4.55 & 5.092 & TRN & \\
\hline CHEMBL1448642 & 688422 & 5.85 & 5.225 & TRN & \\
\hline CHEMBL1452568 & 688422 & 4.6 & 5.0395 & TRN & \\
\hline CHEMBL1481528 & 688422 & 4.95 & 4.8985 & TRN & \\
\hline CHEMBL1346498 & 688422 & 4.5 & 4.9915 & TRN & \\
\hline CHEMBL3213330 & 688422 & 5.15 & 5.0692 & TRN & \\
\hline CHEMBL1999513 & 688422 & 4.65 & 4.9809 & TRN & \\
\hline CHEMBL1511762 & 688422 & 4.45 & 5.1066 & TST & \\
\hline CHEMBL1410714 & 688422 & 4.75 & 5.3765 & TRN & \\
\hline CHEMBL1317153 & 688422 & 4.5 & 5.6021 & TRN & \\
\hline CHEMBL1530444 & 688422 & 4.8 & 5.5961 & TRN & \\
\hline CHEMBL1380392 & 688422 & 5.9 & 5.1802 & TRN & \\
\hline CHEMBL1437351 & 688422 & 7.6003 & 5.9108 & TRN & \\
\hline CHEMBL1256686 & 688422 & 5.5 & 5.7424 & TST & \\
\hline CHEMBL1496489 & 688422 & 8.1024 & 5.2261 & TRN & \\
\hline CHEMBL1303332 & 688422 & 4.45 & 4.9838 & TST & \\
\hline CHEMBL1321137 & 688422 & 4.45 & 4.5071 & TRN & \\
\hline CHEMBL1607916 & 688422 & 8.3468 & 5.4085 & TRN & \\
\hline CHEMBL543467 & 688422 & 6.0 & 5.5612 & TST & \\
\hline CHEMBL1387015 & 688422 & 5.05 & 5.3154 & TRN & \\
\hline CHEMBL1434172 & 688422 & 7.6498 & 5.0792 & TRN & \\
\hline CHEMBL1316891 & 688422 & 4.45 & 4.6359 & TRN & \\
\hline CHEMBL1329206 & 688422 & 4.55 & 4.9423 & TRN & \\
\hline CHEMBL1481313 & 688422 & 4.55 & 4.8755 & TST & \\
\hline CHEMBL1347220 & 688422 & 4.5 & 5.3183 & TRN & \\
\hline CHEMBL1594335 & 688422 & 6.45 & 5.1718 & TST & \\
\hline CHEMBL387108 & 688422 & 5.8 & 5.5286 & TST & \\
\hline CHEMBL1329725 & 688422 & 4.6 & 5.4052 & TRN & \\
\hline CHEMBL3190293 & 688422 & 5.2 & 4.9189 & TRN & \\
\hline
\end{tabular}




\begin{tabular}{|c|c|c|c|c|}
\hline & & \multicolumn{3}{|c|}{ Supplemental Table S2.txt } \\
\hline CHEMBL1356161 & 688422 & 8.3979 & 5.1506 & TRN \\
\hline CHEMBL1542386 & 688422 & 6.8499 & 4.928 & TST \\
\hline CHEMBL1306658 & 688422 & 4.5 & 4.9962 & TRN \\
\hline CHEMBL1327534 & 688422 & 5.0 & 4.7789 & TRN \\
\hline CHEMBL1472737 & 688422 & 6.5 & 5.4499 & TRN \\
\hline CHEMBL1552331 & 688422 & 8.4949 & 5.1479 & TST \\
\hline CHEMBL1509877 & 688422 & 4.45 & 4.8515 & TRN \\
\hline CHEMBL1536493 & 688422 & 5.25 & 5.3068 & TRN \\
\hline CHEMBL1568175 & 688422 & 8.4949 & 5.0782 & TRN \\
\hline CHEMBL1303305 & 688422 & 4.95 & 5.1202 & TRN \\
\hline CHEMBL1405262 & 688422 & 4.7 & 5.0737 & TRN \\
\hline CHEMBL1372681 & 688422 & 4.75 & 5.0146 & TRN \\
\hline CHEMBL1457095 & 688422 & 4.45 & 5.79899 & 99999999995 \\
\hline CHEMBL1391347 & 688422 & 4.45 & 5.2019 & TRN \\
\hline CHEMBL1506496 & 688422 & 4.65 & 4.702 & TRN \\
\hline CHEMBL1310914 & 688422 & 4.85 & 5.145 & TRN \\
\hline CHEMBL1511328 & 688422 & 4.45 & 5.5023 & TST \\
\hline CHEMBL1426226 & 688422 & 4.7 & 5.1783 & TST \\
\hline CHEMBL1466840 & 688422 & 4.5 & 5.3399 & TRN \\
\hline CHEMBL1574884 & 688422 & 6.5501 & 5.2151 & TRN \\
\hline CHEMBL1309644 & 688422 & 5.25 & 5.3948 & TRN \\
\hline CHEMBL1989750 & 688422 & 4.95 & 5.6412 & TST \\
\hline CHEMBL1451912 & 688422 & 4.85 & 4.7069 & TRN \\
\hline CHEMBL1563530 & 688422 & 4.45 & 5.3195 & TRN \\
\hline CHEMBL1413504 & 688422 & 4.6 & 4.9638 & TRN \\
\hline CHEMBL1592342 & 688422 & 4.9 & 5.3685 & TRN \\
\hline CHEMBL1394752 & 688422 & 4.7 & 5.0273 & TRN \\
\hline CHEMBL1509515 & 688422 & 4.95 & 4.9981 & TRN \\
\hline CHEMBL1374788 & 688422 & 5.95 & 5.3578 & TST \\
\hline CHEMBL1605836 & 688422 & 5.45 & 5.6939 & TRN \\
\hline CHEMBL 3214520 & 688422 & 6.9 & 5.374 & TST \\
\hline CHEMBL1601134 & 688422 & 4.5 & 5.291 & TRN \\
\hline CHEMBL412603 & 688422 & 4.45 & 4.8242 & TRN \\
\hline CHEMBL1356980 & 688422 & 4.45 & 4.8639 & TRN \\
\hline CHEMBL1389742 & 688422 & 5.0 & 4.9613 & TST \\
\hline CHEMBL1608578 & 688422 & 4.45 & 5.1072 & TST \\
\hline CHEMBL1373474 & 688422 & 4.8 & 5.0474 & TRN \\
\hline CHEMBL1535440 & 688422 & 4.95 & 5.0189 & TRN \\
\hline CHEMBL 3197445 & 688422 & 4.75 & 5.7445 & TRN \\
\hline CHEMBL1562267 & 688422 & 5.25 & 5.09699 & 99999999995 \\
\hline CHEMBL1537502 & 688422 & 4.9 & 5.2315 & TRN \\
\hline CHEMBL1352321 & 688422 & 6.1 & 5.3835 & TST \\
\hline CHEMBL1567952 & 688422 & 5.2 & 4.9299 & TRN \\
\hline CHEMBL1547454 & 688422 & 6.5 & 5.8004 & TST \\
\hline CHEMBL1407622 & 688422 & 4.45 & 5.0293 & TRN \\
\hline CHEMBL1477415 & 688422 & 5.9 & 5.7509 & TRN \\
\hline CHEMBL600572 & 688422 & 4.45 & 5.0263 & TRN \\
\hline CHEMBL1411788 & 688422 & 4.45 & 5.0995 & TRN \\
\hline
\end{tabular}




\begin{tabular}{|c|c|c|c|c|c|}
\hline \multicolumn{6}{|c|}{ Supplemental Table S2.txt } \\
\hline CHEMBL1520381 & 688422 & 4.9 & 5.1056 & TST & \\
\hline CHEMBL1538035 & 688422 & 4.5 & 4.5023 & TRN & \\
\hline CHEMBL1545920 & 688422 & 4.9 & 5.0335 & TRN & \\
\hline CHEMBL585594 & 688422 & 4.95 & 4.9656 & TRN & \\
\hline CHEMBL1416992 & 688422 & 4.9 & 5.2218 & TST & \\
\hline CHEMBL1420433 & 688422 & 7.5498 & 5.4595 & TRN & \\
\hline CHEMBL1455625 & 688422 & 5.0 & 5.1375 & TRN & \\
\hline CHEMBL1329712 & 688422 & 5.25 & 5.1387 & TRN & \\
\hline CHEMBL1575512 & 688422 & 7.7496 & 5.6312 & TST & \\
\hline CHEMBL3190941 & 688422 & 5.5 & 4.8677 & TRN & \\
\hline CHEMBL1426942 & 688422 & 4.45 & 5.4093 & TRN & \\
\hline CHEMBL1417143 & 688422 & 7.5003 & 5.33799 & 9999999999 & TRN \\
\hline CHEMBL1589094 & 688422 & 5.8 & 5.765 & TRN & \\
\hline CHEMBL1473430 & 688422 & 4.75 & 5.0991 & TST & \\
\hline CHEMBL1322566 & 688422 & 6.4 & 5.0975 & TRN & \\
\hline CHEMBL1382562 & 688422 & 4.9 & 5.221 & TST & \\
\hline CHEMBL1475423 & 688422 & 6.05 & 5.4788 & TST & \\
\hline CHEMBL1608585 & 688422 & 4.45 & 5.1129 & TRN & \\
\hline CHEMBL289277 & 688422 & 8.2518 & 5.4697 & TST & \\
\hline CHEMBL1412822 & 688422 & 5.0 & 4.9425 & TRN & \\
\hline CHEMBL1479680 & 688422 & 5.8 & 5.8576 & TST & \\
\hline CHEMBL1411453 & 688422 & 5.6 & 5.6754 & TST & \\
\hline CHEMBL1414038 & 688422 & 4.85 & 5.2892 & TRN & \\
\hline CHEMBL1511564 & 688422 & 5.15 & 5.0261 & TRN & \\
\hline CHEMBL1486238 & 688422 & 4.95 & 5.3525 & TRN & \\
\hline CHEMBL1410299 & 688422 & 5.05 & 5.0893 & TST & \\
\hline CHEMBL1438869 & 688422 & 4.7 & 5.5324 & TST & \\
\hline CHEMBL1480730 & 688422 & 4.75 & 5.42399 & 99999999995 & TST \\
\hline CHEMBL1302488 & 688422 & 4.9 & 4.9642 & TRN & \\
\hline CHEMBL1489925 & 688422 & 4.45 & 5.2606 & TRN & \\
\hline CHEMBL1399495 & 688422 & 4.85 & 4.9646 & TRN & \\
\hline CHEMBL1428262 & 688422 & 4.5 & 4.8269 & TRN & \\
\hline CHEMBL1518244 & 688422 & 4.75 & 5.085 & TRN & \\
\hline CHEMBL1589110 & 688422 & 4.8 & 5.0522 & TST & \\
\hline CHEMBL1479279 & 688422 & 4.95 & 4.9118 & TRN & \\
\hline CHEMBL1331599 & 688422 & 5.9 & 5.3542 & TST & \\
\hline CHEMBL1986765 & 688422 & 5.75 & 5.6419 & TST & \\
\hline CHEMBL1463277 & 688422 & 4.8 & 5.5375 & TRN & \\
\hline CHEMBL1365764 & 688422 & 4.95 & 5.3786 & TST & \\
\hline CHEMBL1427789 & 688422 & 4.45 & 5.2738 & TST & \\
\hline CHEMBL1600169 & 688422 & 4.9 & 5.077 & TRN & \\
\hline CHEMBL2373579 & 688422 & 7.699 & 5.9997 & TRN & \\
\hline CHEMBL1539004 & 688422 & 4.9 & 5.185 & TRN & \\
\hline CHEMBL1367801 & 688422 & 4.45 & 4.9144 & TRN & \\
\hline CHEMBL1330555 & 688422 & 5.45 & 5.2284 & TRN & \\
\hline CHEMBL1437488 & 688422 & 6.5501 & 5.8107 & TRN & \\
\hline CHEMBL1986232 & 688422 & 5.15 & 5.1578 & TRN & \\
\hline CHEMBL1440575 & 688422 & 7.4498 & 5.171 & TRN & \\
\hline
\end{tabular}




\begin{tabular}{|c|c|c|c|c|c|}
\hline \multicolumn{6}{|c|}{ Supplemental Table s2.txt } \\
\hline CHEMBL1588366 & 688422 & 5.95 & 5.6136 & TRN & \\
\hline CHEMBL1338266 & 688422 & 4.8 & 5.4661 & TST & \\
\hline CHEMBL1401114 & 688422 & 4.45 & 5.1123 & TST & \\
\hline CHEMBL1369387 & 688422 & 4.7 & 5.4595 & TST & \\
\hline CHEMBL1393799 & 688422 & 6.25 & 5.8088 & TST & \\
\hline CHEMBL1423761 & 688422 & 4.6 & 4.8796 & TRN & \\
\hline CHEMBL1388950 & 688422 & 4.8 & 4.7116 & TRN & \\
\hline CHEMBL1372094 & 688422 & 4.55 & 5.4088 & TRN & \\
\hline CHEMBL1382832 & 688422 & 4.9 & 5.0912 & TRN & \\
\hline CHEMBL1337702 & 688422 & 4.45 & 5.2134 & TRN & \\
\hline CHEMBL1590182 & 688422 & 7.2503 & 5.0206 & TST & \\
\hline CHEMBL1441465 & 688422 & 4.85 & 5.1514 & TRN & \\
\hline CHEMBL1504350 & 688422 & 4.75 & 4.9579 & TRN & \\
\hline CHEMBL1512762 & 688422 & 5.45 & 5.0825 & TRN & \\
\hline CHEMBL1457196 & 688422 & 4.8 & 4.8666 & TRN & \\
\hline CHEMBL1437690 & 688422 & 4.9 & 4.7867 & TRN & \\
\hline CHEMBL1446209 & 688422 & 4.85 & 4.8915 & TRN & \\
\hline CHEMBL1507821 & 688422 & 5.0 & 5.2733 & TRN & \\
\hline CHEMBL1480341 & 688422 & 4.5 & 5.0344 & TRN & \\
\hline CHEMBL1409758 & 688422 & 4.45 & 4.7495 & TRN & \\
\hline CHEMBL1465462 & 688422 & 4.8 & 5.6556 & TRN & \\
\hline CHEMBL1563472 & 688422 & 5.5 & 5.5897 & TRN & \\
\hline CHEMBL1437258 & 688422 & 6.35 & 4.8926 & TRN & \\
\hline CHEMBL 3197092 & 688422 & 4.7 & 4.9677 & TRN & \\
\hline CHEMBL244948 & 688422 & 4.6 & 5.2967 & TST & \\
\hline CHEMBL1419423 & 688422 & 5.4 & 5.0448 & TRN & \\
\hline CHEMBL1375630 & 688422 & 4.45 & 4.8717 & TST & \\
\hline CHEMBL1410006 & 688422 & 5.55 & 5.5969 & TRN & \\
\hline CHEMBL1570348 & 688422 & 5.1 & 5.0751 & TST & \\
\hline CHEMBL 3212927 & 688422 & 4.75 & 5.2898 & TRN & \\
\hline CHEMBL 3209048 & 688422 & 7.5003 & 5.41200 & 0000000001 & TRN \\
\hline CHEMBL1609252 & 688422 & 5.25 & 4.9411 & TRN & \\
\hline CHEMBL1594346 & 688422 & 5.0 & 5.1782 & TRN & \\
\hline CHEMBL1200471 & 688422 & 7.0 & 5.9126 & TST & \\
\hline CHEMBL1391960 & 688422 & 6.0 & 5.2221 & TST & \\
\hline CHEMBL1599131 & 688422 & 8.0 & 5.3623 & TRN & \\
\hline CHEMBL1501458 & 688422 & 4.6 & 5.2121 & TRN & \\
\hline CHEMBL1577189 & 688422 & 5.65 & 5.574 & TST & \\
\hline CHEMBL1600751 & 688422 & 4.85 & 5.209 & TRN & \\
\hline CHEMBL1231193 & 688422 & 6.35 & 5.4287 & TRN & \\
\hline CHEMBL1544311 & 688422 & 5.15 & 4.9602 & TST & \\
\hline CHEMBL1544453 & 688422 & 4.5 & 5.4934 & TRN & \\
\hline CHEMBL1580210 & 688422 & 8.3468 & 5.3757 & TST & \\
\hline CHEMBL1525939 & 688422 & 4.85 & 5.1356 & TST & \\
\hline CHEMBL589703 & 688422 & 5.7 & 4.9397 & TRN & \\
\hline CHEMBL1306683 & 688422 & 5.55 & 5.1264 & TRN & \\
\hline CHEMBL1338422 & 688422 & 5.0 & 5.1229 & TRN & \\
\hline CHEMBL1507623 & 688422 & 4.55 & 5.4351 & TST & \\
\hline
\end{tabular}




\begin{tabular}{|c|c|c|c|c|}
\hline \multicolumn{5}{|c|}{ Supplemental Table S2.txt } \\
\hline CHEMBL1443237 & 688422 & 4.45 & 5.1382 & TRN \\
\hline CHEMBL3209560 & 688422 & 6.0 & 5.4754 & TRN \\
\hline CHEMBL1416010 & 688422 & 4.9 & 5.0075 & TRN \\
\hline CHEMBL1340675 & 688422 & 4.95 & 5.0874 & TRN \\
\hline CHEMBL1351516 & 688422 & 4.65 & 4.8587 & TRN \\
\hline CHEMBL1586226 & 688422 & 4.85 & 5.2382 & TRN \\
\hline CHEMBL1411226 & 688422 & 4.9 & 4.9932 & TRN \\
\hline CHEMBL1400430 & 688422 & 6.15 & 5.1064 & TRN \\
\hline CHEMBL1474343 & 688422 & 6.45 & 4.9959 & TRN \\
\hline CHEMBL1502443 & 688422 & 4.9 & 5.2359 & TST \\
\hline CHEMBL1517655 & 688422 & 7.6498 & 5.2144 & TRN \\
\hline CHEMBL1386797 & 688422 & 4.9 & 4.8889 & TRN \\
\hline CHEMBL1722566 & 688422 & 4.9 & 5.0024 & TST \\
\hline CHEMBL1462257 & 688422 & 5.85 & 5.2784 & TST \\
\hline CHEMBL1367455 & 688422 & 4.75 & 4.9649 & TRN \\
\hline CHEMBL1372314 & 688422 & 4.5 & 5.0138 & TRN \\
\hline CHEMBL1602956 & 688422 & 4.85 & 5.0321 & TRN \\
\hline CHEMBL1449018 & 688422 & 5.85 & 5.2603 & TST \\
\hline CHEMBL1603559 & 688422 & 5.8 & 5.0285 & TRN \\
\hline CHEMBL1504014 & 688422 & 4.85 & 5.1835 & TRN \\
\hline CHEMBL1499939 & 688422 & 4.7 & 5.0545 & TRN \\
\hline CHEMBL8747 & 688422 & 6.0 & 4.8288 & TST \\
\hline CHEMBL1455399 & 688422 & 4.6 & 4.7096 & TRN \\
\hline CHEMBL1464730 & 688422 & 5.4 & 5.0609 & TRN \\
\hline CHEMBL1364610 & 688422 & 7.0 & 5.2284 & TRN \\
\hline CHEMBL1401781 & 688422 & 5.3 & 5.2687 & TRN \\
\hline CHEMBL1491264 & 688422 & 7.2503 & 5.3591 & TRN \\
\hline CHEMBL1549641 & 688422 & 4.65 & 5.3837 & TST \\
\hline CHEMBL1538582 & 688422 & 5.2 & 4.8285 & TRN \\
\hline CHEMBL3189993 & 688422 & 5.7 & 5.0975 & TRN \\
\hline CHEMBL1605604 & 688422 & 7.3497 & 5.4616 & TRN \\
\hline CHEMBL1326623 & 688422 & 4.5 & 5.3497 & TRN \\
\hline CHEMBL1304206 & 688422 & 4.6 & 5.4469 & TRN \\
\hline CHEMBL1433587 & 688422 & 6.5 & 5.3853 & TST \\
\hline CHEMBL1420675 & 688422 & 7.4001 & 5.3215 & TRN \\
\hline CHEMBL1314648 & 688422 & 5.0 & 5.3191 & TRN \\
\hline CHEMBL1987427 & 688422 & 4.95 & 4.978 & TRN \\
\hline CHEMBL1341513 & 688422 & 4.45 & 4.9247 & TRN \\
\hline CHEMBL1394547 & 688422 & 5.4 & 5.4948 & TRN \\
\hline CHEMBL1595218 & 688422 & 4.5 & 4.8145 & TRN \\
\hline CHEMBL3191517 & 688422 & 7.699 & 5.3619 & TRN \\
\hline CHEMBL3197895 & 688422 & 4.5 & 5.3452 & TST \\
\hline CHEMBL1559159 & 688422 & 4.9 & 5.2272 & TRN \\
\hline CHEMBL1608784 & 688422 & 6.4 & 5.1694 & TST \\
\hline CHEMBL1348304 & 688422 & 5.85 & 5.4714 & TRN \\
\hline CHEMBL1308274 & 688422 & 4.45 & 5.0593 & TST \\
\hline CHEMBL1989706 & 688422 & 8.1487 & 5.3576 & TRN \\
\hline CHEMBL1313890 & 688422 & 4.8 & 5.0181 & TRN \\
\hline
\end{tabular}




\begin{tabular}{|c|c|c|c|c|}
\hline \multicolumn{5}{|c|}{ Supplemental Table S2.txt } \\
\hline CHEMBL1577664 & 688422 & 4.75 & 5.4571 & TRN \\
\hline CHEMBL3195832 & 688422 & 4.65 & 5.1097 & TRN \\
\hline CHEMBL1336669 & 688422 & 4.7 & 5.0262 & TRN \\
\hline CHEMBL1586716 & 688422 & 4.45 & 4.9975 & TRN \\
\hline CHEMBL1420032 & 688422 & 6.05 & 5.1652 & TRN \\
\hline CHEMBL1613298 & 688422 & 5.45 & 5.1884 & TRN \\
\hline CHEMBL1433108 & 688422 & 4.95 & 5.3621 & TRN \\
\hline CHEMBL1452003 & 688422 & 4.85 & 5.3261 & TRN \\
\hline CHEMBL1521560 & 688422 & 7.6498 & 5.7509 & TST \\
\hline CHEMBL1435331 & 688422 & 4.7 & 5.2832 & TRN \\
\hline CHEMBL1577613 & 688422 & 8.0 & 5.5012 & TRN \\
\hline CHEMBL1337261 & 688422 & 4.45 & 4.7697 & TRN \\
\hline CHEMBL1454493 & 688422 & 6.4 & 5.5135 & TST \\
\hline CHEMBL3210961 & 688422 & 6.5501 & 5.1756 & TST \\
\hline CHEMBL1359788 & 688422 & 4.7 & 5.1134 & TRN \\
\hline CHEMBL16312 & 688422 & 4.95 & 5.1578 & TRN \\
\hline CHEMBL1515916 & 688422 & 6.6 & 5.4797 & TRN \\
\hline CHEMBL1388282 & 688422 & 4.45 & 4.8654 & TRN \\
\hline CHEMBL1563426 & 688422 & 5.5 & 5.2987 & TRN \\
\hline CHEMBL1329652 & 688422 & 4.95 & 5.2795 & TST \\
\hline CHEMBL1318045 & 688422 & 4.65 & 4.9719 & TRN \\
\hline CHEMBL1546594 & 688422 & 4.45 & 5.3142 & TRN \\
\hline CHEMBL1332493 & 688422 & 4.8 & 5.1641 & TST \\
\hline CHEMBL1336526 & 688422 & 5.65 & 5.0526 & TRN \\
\hline CHEMBL1527442 & 688422 & 5.25 & 5.4036 & TST \\
\hline CHEMBL1342926 & 688422 & 4.45 & 5.4535 & TST \\
\hline CHEMBL1534792 & 688422 & 8.4949 & 5.399 & TST \\
\hline CHEMBL1540384 & 688422 & 4.9 & 4.8714 & TRN \\
\hline CHEMBL1544103 & 688422 & 5.9 & 5.8355 & TRN \\
\hline CHEMBL1517925 & 688422 & 4.9 & 5.0894 & TRN \\
\hline CHEMBL1565121 & 688422 & 6.95 & 5.2601 & TRN \\
\hline CHEMBL1566062 & 688422 & 4.8 & 5.3038 & TRN \\
\hline CHEMBL1414705 & 688422 & 5.55 & 5.5234 & TRN \\
\hline CHEMBL467706 & 688422 & 5.25 & 5.4662 & TST \\
\hline CHEMBL1487087 & 688422 & 4.45 & 5.0904 & TRN \\
\hline CHEMBL1424604 & 688422 & 4.95 & 5.4414 & TRN \\
\hline CHEMBL1611218 & 688422 & 5.9 & 5.5994 & TST \\
\hline CHEMBL1334432 & 688422 & 5.9 & 5.2321 & TST \\
\hline CHEMBL1595094 & 688422 & 4.9 & 5.3447 & TRN \\
\hline CHEMBL1367809 & 688422 & 4.45 & 5.5104 & TRN \\
\hline CHEMBL1583521 & 688422 & 7.699 & 5.4117 & TST \\
\hline CHEMBL1302286 & 688422 & 5.45 & 5.2432 & TRN \\
\hline CHEMBL3427333 & 688422 & 7.6498 & 4.9273 & TRN \\
\hline CHEMBL 3195872 & 688422 & 6.4 & 5.6225 & TST \\
\hline CHEMBL1534689 & 688422 & 6.5501 & 5.2803 & TST \\
\hline CHEMBL1571343 & 688422 & 4.45 & 5.165 & TST \\
\hline CHEMBL1561388 & 688422 & 4.95 & 5.0419 & TRN \\
\hline CHEMBL1409287 & 688422 & 5.0 & 5.2926 & TRN \\
\hline
\end{tabular}




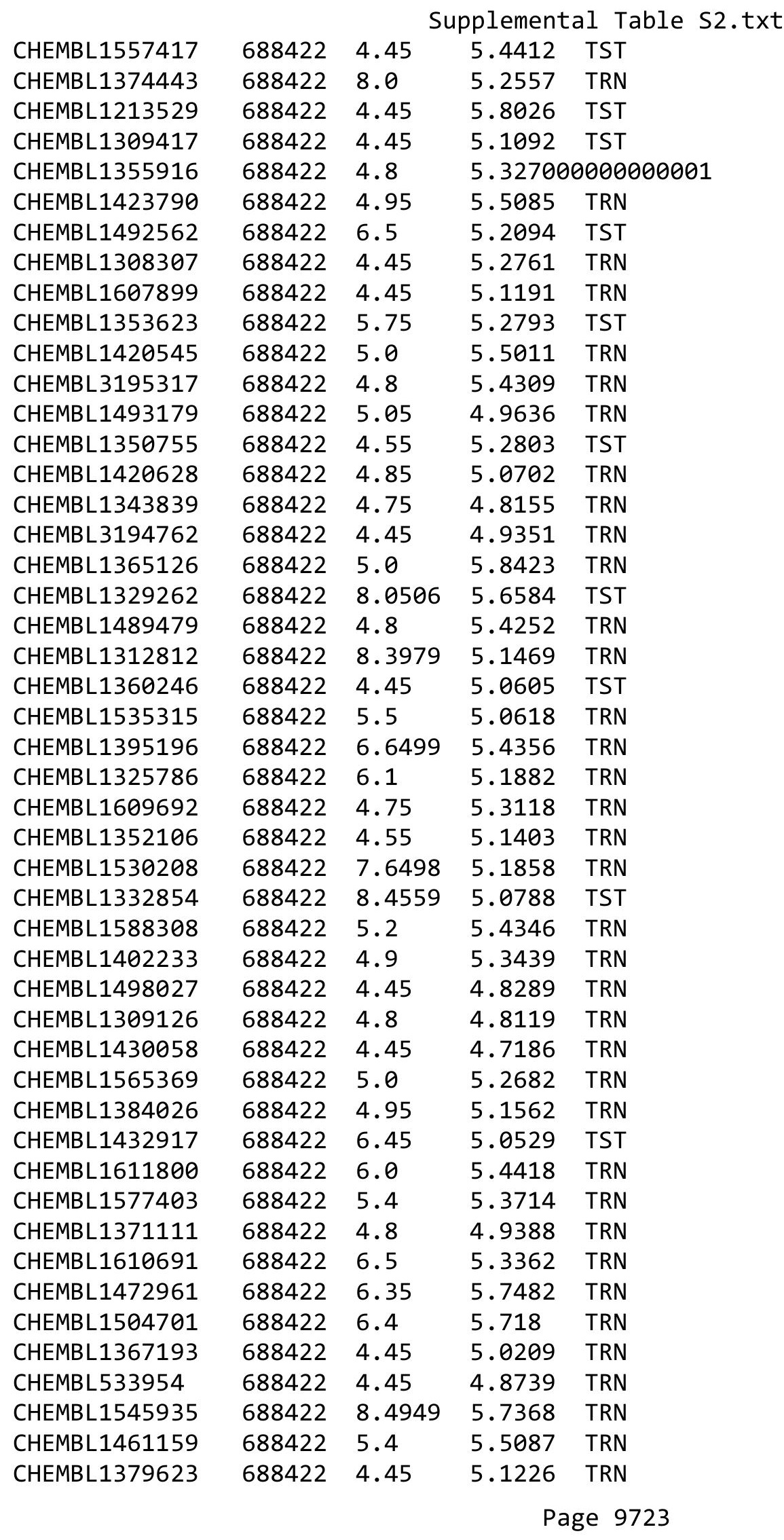

TRN 


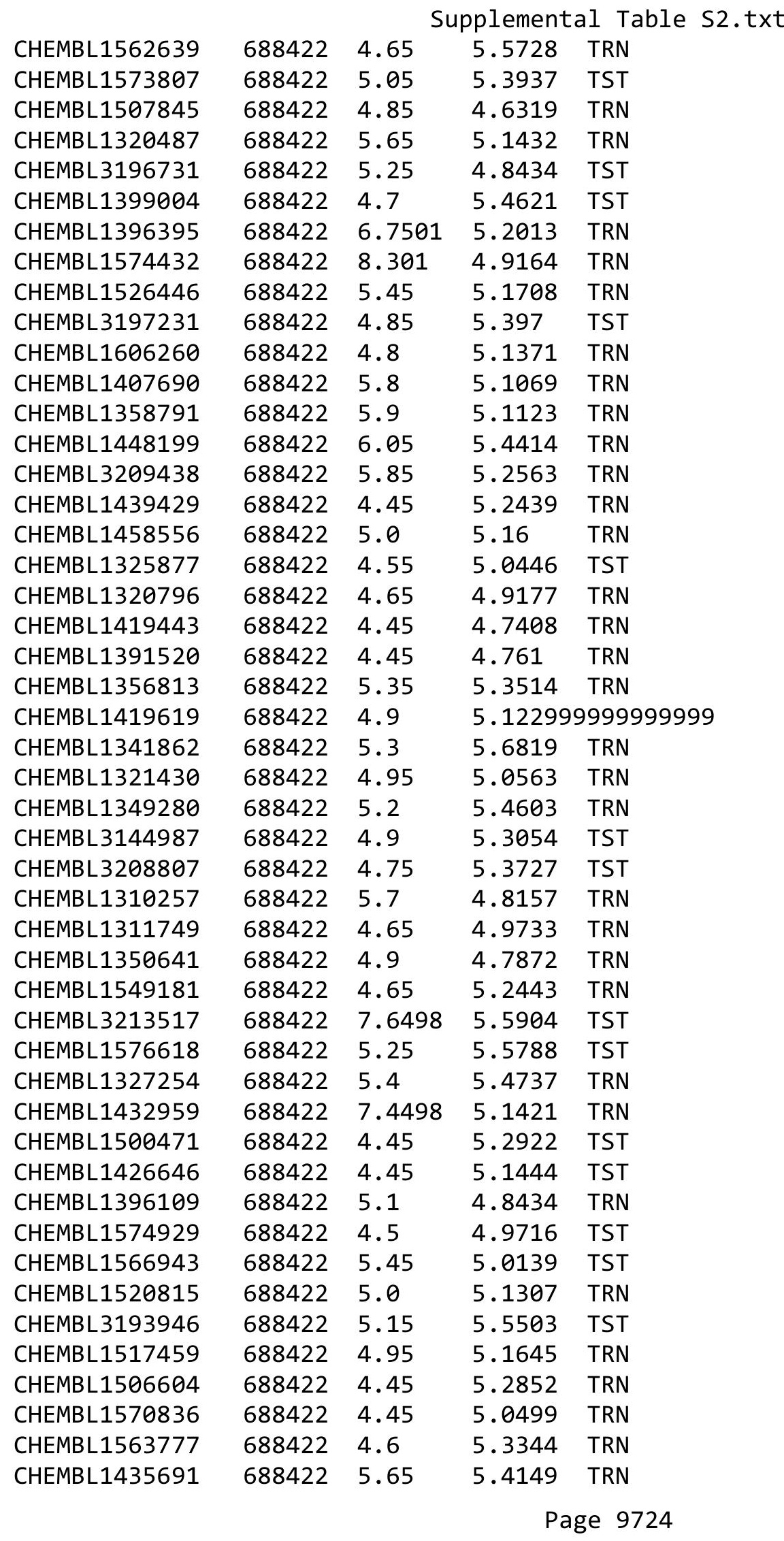

TRN 


\begin{tabular}{|c|c|c|c|c|c|}
\hline \multicolumn{6}{|c|}{ Supplemental Table S2.txt } \\
\hline CHEMBL1458055 & 688422 & 4.95 & 5.4127 & TST & \\
\hline CHEMBL579105 & 688422 & 4.85 & 4.8019 & TRN & \\
\hline CHEMBL1346897 & 688422 & 8.4559 & 5.7935 & TST & \\
\hline CHEMBL1467391 & 688422 & 4.45 & 5.3102 & TST & \\
\hline CHEMBL1345642 & 688422 & 4.7 & 4.6839 & TRN & \\
\hline CHEMBL1488106 & 688422 & 8.0 & 5.3291 & TRN & \\
\hline CHEMBL1513701 & 688422 & 6.8 & 5.6539 & TRN & \\
\hline CHEMBL1334225 & 688422 & 4.45 & 5.414 & TST & \\
\hline CHEMBL1605435 & 688422 & 5.1 & 5.419 & TST & \\
\hline CHEMBL3189393 & 688422 & 4.9 & 5.2092 & TST & \\
\hline CHEMBL1390428 & 688422 & 4.95 & 5.1264 & TST & \\
\hline CHEMBL1500821 & 688422 & 4.85 & 4.7335 & TST & \\
\hline CHEMBL1511649 & 688422 & 4.55 & 5.5854 & TST & \\
\hline CHEMBL1345433 & 688422 & 4.65 & 4.984 & TST & \\
\hline CHEMBL1333869 & 688422 & 7.15 & 5.57100 & 0000000001 & TST \\
\hline CHEMBL3199411 & 688422 & 5.15 & 5.3531 & TRN & \\
\hline CHEMBL1443902 & 688422 & 5.0 & 5.5064 & TRN & \\
\hline CHEMBL1494558 & 688422 & 4.45 & 5.1737 & TRN & \\
\hline CHEMBL1365522 & 688422 & 5.05 & 4.7115 & TRN & \\
\hline CHEMBL1352004 & 688422 & 4.9 & 5.7038 & TRN & \\
\hline CHEMBL1402453 & 688422 & 6.5501 & 5.3655 & TST & \\
\hline CHEMBL1411571 & 688422 & 4.65 & 5.2662 & TST & \\
\hline CHEMBL1360849 & 688422 & 4.45 & 5.4807 & TRN & \\
\hline CHEMBL1364736 & 688422 & 4.95 & 5.3668 & TRN & \\
\hline CHEMBL1367862 & 688422 & 5.0 & 5.3452 & TST & \\
\hline CHEMBL1983234 & 688422 & 5.25 & 5.0956 & TST & \\
\hline CHEMBL1341829 & 688422 & 8.3468 & 5.3272 & TRN & \\
\hline CHEMBL1471358 & 688422 & 4.7 & 5.086 & TRN & \\
\hline CHEMBL 2369230 & 688422 & 5.8 & 5.3056 & TST & \\
\hline CHEMBL1229712 & 688422 & 4.85 & 5.0507 & TRN & \\
\hline CHEMBL1539414 & 688422 & 6.35 & 5.169 & TRN & \\
\hline CHEMBL1515643 & 688422 & 5.3 & 5.4135 & TRN & \\
\hline CHEMBL1590963 & 688422 & 5.15 & 5.2375 & TRN & \\
\hline CHEMBL1503477 & 688422 & 4.85 & 5.0227 & TRN & \\
\hline CHEMBL1390645 & 688422 & 4.8 & 4.8061 & TRN & \\
\hline CHEMBL1448648 & 688422 & 4.65 & 5.3886 & TRN & \\
\hline CHEMBL1505030 & 688422 & 4.65 & 5.0381 & TRN & \\
\hline CHEMBL1548265 & 688422 & 4.65 & 5.2119 & TRN & \\
\hline CHEMBL1520721 & 688422 & 4.85 & 5.1593 & TRN & \\
\hline CHEMBL1386050 & 688422 & 4.85 & 5.1616 & TRN & \\
\hline CHEMBL1597062 & 688422 & 4.65 & 4.8885 & TRN & \\
\hline CHEMBL1333358 & 688422 & 4.45 & 5.46399 & 99999999995 & TST \\
\hline CHEMBL1347817 & 688422 & 4.8 & 5.2141 & TST & \\
\hline CHEMBL1423574 & 688422 & 5.55 & 5.3087 & TRN & \\
\hline CHEMBL602828 & 688422 & 5.45 & 5.0947 & TRN & \\
\hline CHEMBL1521697 & 688422 & 4.45 & 5.404 & TRN & \\
\hline CHEMBL1538646 & 688422 & 7.3497 & 5.3473 & TRN & \\
\hline CHEMBL1503468 & 688422 & 4.45 & 5.0356 & TRN & \\
\hline
\end{tabular}




\begin{tabular}{|c|c|c|c|c|c|}
\hline \multicolumn{6}{|c|}{ Supplemental Table S2.txt } \\
\hline CHEMBL1310085 & 688422 & 5.2 & 5.3605 & TRN & \\
\hline CHEMBL1575547 & 688422 & 4.6 & 5.4399 & TRN & \\
\hline CHEMBL1612219 & 688422 & 4.9 & 5.0778 & TRN & \\
\hline CHEMBL1401458 & 688422 & 4.7 & 4.9817 & TST & \\
\hline CHEMBL1469857 & 688422 & 4.45 & 5.2027 & TRN & \\
\hline CHEMBL1419992 & 688422 & 4.7 & 5.5014 & TRN & \\
\hline CHEMBL1521482 & 688422 & 4.6 & 5.2914 & TRN & \\
\hline CHEMBL1431190 & 688422 & 7.7496 & 5.3094 & TRN & \\
\hline CHEMBL1375226 & 688422 & 4.5 & 4.7372 & TRN & \\
\hline CHEMBL1544604 & 688422 & 4.45 & 5.5028 & TST & \\
\hline CHEMBL1319339 & 688422 & 5.3 & 5.1182 & TRN & \\
\hline CHEMBL501246 & 688422 & 4.9 & 5.2143 & TRN & \\
\hline CHEMBL1399145 & 688422 & 4.75 & 5.1301 & TRN & \\
\hline CHEMBL1479084 & 688422 & 4.45 & 4.9339 & TRN & \\
\hline CHEMBL1379724 & 688422 & 4.65 & 5.4896 & TRN & \\
\hline CHEMBL1581723 & 688422 & 4.9 & 5.1533 & TRN & \\
\hline CHEMBL3199095 & 688422 & 8.3468 & 5.0061 & TST & \\
\hline CHEMBL1563862 & 688422 & 4.45 & 4.9663 & TST & \\
\hline CHEMBL1329843 & 688422 & 4.75 & 5.176 & TRN & \\
\hline CHEMBL1495780 & 688422 & 8.3468 & 5.3956 & TRN & \\
\hline CHEMBL3189207 & 688422 & 4.45 & 4.8752 & TRN & \\
\hline CHEMBL1461394 & 688422 & 5.7 & 5.1322 & TST & \\
\hline CHEMBL1580789 & 688422 & 4.75 & 5.6061 & TST & \\
\hline CHEMBL1583676 & 688422 & 8.3468 & 5.2407 & TST & \\
\hline CHEMBL1476289 & 688422 & 5.35 & 5.3016 & TRN & \\
\hline CHEMBL1519513 & 688422 & 4.85 & $5.1220 e$ & 0000000001 & TRN \\
\hline CHEMBL1484306 & 688422 & 5.3 & 4.8402 & TRN & \\
\hline CHEMBL1542237 & 688422 & 4.75 & 4.8135 & TRN & \\
\hline CHEMBL1432936 & 688422 & 4.85 & 5.7371 & TST & \\
\hline CHEMBL1471485 & 688422 & 5.4 & 5.351 & TST & \\
\hline CHEMBL1499296 & 688422 & 4.65 & 4.8273 & TRN & \\
\hline CHEMBL1562576 & 688422 & 6.45 & 5.4963 & TRN & \\
\hline CHEMBL1332567 & 688422 & 4.8 & 5.2961 & TRN & \\
\hline CHEMBL1368244 & 688422 & 4.95 & 5.0464 & TST & \\
\hline CHEMBL1448706 & 688422 & 8.4949 & 5.7447 & TRN & \\
\hline CHEMBL1426875 & 688422 & 7.0501 & 6.0891 & TRN & \\
\hline CHEMBL1312636 & 688422 & 4.95 & 5.0473 & TST & \\
\hline CHEMBL1353757 & 688422 & 4.65 & 4.9302 & TRN & \\
\hline CHEMBL1344832 & 688422 & 4.7 & 5.4358 & TRN & \\
\hline CHEMBL1308177 & 688422 & 6.6 & 5.5588 & TRN & \\
\hline CHEMBL1559221 & 688422 & 4.6 & 5.5888 & TST & \\
\hline CHEMBL1529428 & 688422 & 4.65 & 4.7159 & TST & \\
\hline CHEMBL1374383 & 688422 & 4.8 & 5.7 & TRN & \\
\hline CHEMBL1352335 & 688422 & 5.0 & 5.0136 & TRN & \\
\hline CHEMBL1540581 & 688422 & 4.6 & 5.0515 & TRN & \\
\hline CHEMBL1351533 & 688422 & 4.45 & 4.9489 & TRN & \\
\hline CHEMBL1325972 & 688422 & 5.95 & 5.074 & TRN & \\
\hline CHEMBL1415988 & 688422 & 5.45 & 5.6276 & TRN & \\
\hline
\end{tabular}




\begin{tabular}{|c|c|c|c|c|c|}
\hline \multicolumn{6}{|c|}{ Supplemental Table S2.txt } \\
\hline CHEMBL1533479 & 688422 & 6.15 & 5.4687 & TRN & \\
\hline CHEMBL1461188 & 688422 & 4.45 & 5.2167 & TRN & \\
\hline CHEMBL1535720 & 688422 & 5.05 & 5.2293 & TRN & \\
\hline CHEMBL1375364 & 688422 & 4.45 & 5.2882 & TRN & \\
\hline CHEMBL1489716 & 688422 & 4.45 & 4.9138 & TRN & \\
\hline CHEMBL1611267 & 688422 & 4.65 & 5.2176 & TRN & \\
\hline CHEMBL1522784 & 688422 & 4.9 & 5.1084 & TRN & \\
\hline CHEMBL1348461 & 688422 & 4.45 & 5.3751 & TST & \\
\hline CHEMBL1462207 & 688422 & 4.8 & 4.4602 & TRN & \\
\hline CHEMBL1453649 & 688422 & 4.45 & 5.1024 & TRN & \\
\hline CHEMBL1490365 & 688422 & 4.85 & 5.2599 & TRN & \\
\hline CHEMBL1503895 & 688422 & 7.699 & 5.6342 & TST & \\
\hline CHEMBL1584481 & 688422 & 6.5 & 5.0135 & TRN & \\
\hline CHEMBL1419977 & 688422 & 4.45 & 5.0297 & TRN & \\
\hline CHEMBL1438166 & 688422 & 4.55 & 5.1064 & TRN & \\
\hline CHEMBL1312836 & 688422 & 4.75 & 4.9704 & TST & \\
\hline CHEMBL1605847 & 688422 & 5.25 & 5.62200 & 0000000001 & TRN \\
\hline CHEMBL1429975 & 688422 & 5.2 & 5.0466 & TRN & \\
\hline CHEMBL1540523 & 688422 & 4.45 & 5.6795 & TRN & \\
\hline CHEMBL1498207 & 688422 & 4.6 & 5.36299 & 99999999995 & TRN \\
\hline CHEMBL1502386 & 688422 & 7.5498 & 5.0942 & TRN & \\
\hline CHEMBL1600887 & 688422 & 5.55 & 5.4881 & TRN & \\
\hline CHEMBL1442371 & 688422 & 5.2 & 5.2132 & TRN & \\
\hline CHEMBL1566022 & 688422 & 5.95 & 5.351 & TRN & \\
\hline CHEMBL1554405 & 688422 & 8.4949 & 5.393 & TST & \\
\hline CHEMBL1401120 & 688422 & 4.8 & 5.1698 & TRN & \\
\hline CHEMBL1504295 & 688422 & 5.15 & 5.2748 & TRN & \\
\hline CHEMBL1303658 & 688422 & 4.85 & 5.2436 & TST & \\
\hline CHEMBL1432128 & 688422 & 5.9 & 5.4595 & TST & \\
\hline CHEMBL1980561 & 688422 & 5.0 & 5.1325 & TRN & \\
\hline CHEMBL1974112 & 688422 & 4.9 & 5.0527 & TST & \\
\hline CHEMBL1573815 & 688422 & 4.8 & 5.3618 & TRN & \\
\hline CHEMBL1546463 & 688422 & 4.9 & 4.7087 & TST & \\
\hline CHEMBL1556968 & 688422 & 4.5 & 5.0464 & TRN & \\
\hline CHEMBL1976317 & 688422 & 4.45 & 5.4022 & TST & \\
\hline CHEMBL1331124 & 688422 & 4.45 & 5.4891 & TRN & \\
\hline CHEMBL1367073 & 688422 & 5.05 & 5.3108 & TRN & \\
\hline CHEMBL1585661 & 688422 & 4.45 & 5.0021 & TRN & \\
\hline CHEMBL1366423 & 688422 & 4.6 & 5.0212 & TRN & \\
\hline CHEMBL1993431 & 688422 & 5.25 & 5.0467 & TST & \\
\hline CHEMBL1311428 & 688422 & 5.9 & 5.3181 & TRN & \\
\hline CHEMBL1388415 & 688422 & 4.9 & 5.2185 & TRN & \\
\hline CHEMBL1434950 & 688422 & 6.0 & 5.7695 & TRN & \\
\hline CHEMBL1604854 & 688422 & 8.6576 & 5.1468 & TST & \\
\hline CHEMBL1441508 & 688422 & 4.45 & 5.1971 & TRN & \\
\hline CHEMBL1448051 & 688422 & 5.45 & 5.7984 & TRN & \\
\hline CHEMBL1331155 & 688422 & 4.8 & 5.143 & TRN & \\
\hline CHEMBL1464916 & 688422 & 4.9 & 5.1732 & TRN & \\
\hline
\end{tabular}




\begin{tabular}{|c|c|c|c|c|c|}
\hline \multirow[b]{2}{*}{ CHEMBL1224685 } & \multicolumn{5}{|c|}{ Supplemental Table S2.txt } \\
\hline & 688422 & 7.4498 & 5.2446 & TRN & \\
\hline CHEMBL1299540 & 688422 & 5.0 & 5.3312 & TRN & \\
\hline CHEMBL1345812 & 688422 & 5.0 & 4.8167 & TST & \\
\hline CHEMBL1478720 & 688422 & 4.8 & 5.5242 & TST & \\
\hline CHEMBL1467668 & 688422 & 4.45 & 5.0744 & TST & \\
\hline CHEMBL1413277 & 688422 & 4.45 & 4.8694 & TRN & \\
\hline CHEMBL1529094 & 688422 & 4.75 & 4.912 & TRN & \\
\hline CHEMBL1607939 & 688422 & 4.6 & 4.9116 & TRN & \\
\hline CHEMBL1256663 & 688422 & 4.85 & 5.8608 & TRN & \\
\hline CHEMBL1378489 & 688422 & 4.45 & 4.9249 & TST & \\
\hline CHEMBL1557310 & 688422 & 8.301 & 5.4853 & TRN & \\
\hline CHEMBL3199204 & 688422 & 4.95 & 4.7662 & TRN & \\
\hline CHEMBL1381936 & 688422 & 4.45 & 5.1832 & TRN & \\
\hline CHEMBL1315457 & 688422 & 5.55 & 5.5666 & TST & \\
\hline CHEMBL1455412 & 688422 & 6.5 & 5.6416 & TST & \\
\hline CHEMBL1508135 & 688422 & 5.05 & 5.23600 & 0000000001 & TRN \\
\hline CHEMBL1393485 & 688422 & 5.0 & 4.7461 & TST & \\
\hline CHEMBL1452225 & 688422 & 5.55 & 5.4117 & TRN & \\
\hline CHEMBL1322114 & 688422 & 4.75 & 5.4997 & TRN & \\
\hline CHEMBL1355323 & 688422 & 6.35 & 5.5352 & TST & \\
\hline CHEMBL1341000 & 688422 & 4.5 & 5.0974 & TRN & \\
\hline CHEMBL355496 & 688422 & 5.55 & 4.9981 & TRN & \\
\hline CHEMBL1597510 & 688422 & 4.45 & 5.0983 & TST & \\
\hline CHEMBL1366731 & 688422 & 5.05 & 5.1669 & TRN & \\
\hline CHEMBL1546010 & 688422 & 4.45 & 5.3429 & TST & \\
\hline CHEMBL1438359 & 688422 & 4.8 & 5.0356 & TST & \\
\hline CHEMBL1413287 & 688422 & 4.7 & 5.6266 & TRN & \\
\hline CHEMBL1415134 & 688422 & 4.45 & 5.0946 & TRN & \\
\hline CHEMBL1517192 & 688422 & 4.45 & 5.374 & TST & \\
\hline CHEMBL3190347 & 688422 & 4.5 & 5.2525 & TRN & \\
\hline CHEMBL1364944 & 688422 & 4.45 & 5.144 & TRN & \\
\hline CHEMBL1399013 & 688422 & 4.45 & 5.0708 & TRN & \\
\hline CHEMBL1450647 & 688422 & 4.45 & 5.1771 & TRN & \\
\hline CHEMBL1469612 & 688422 & 5.25 & 5.2647 & TRN & \\
\hline CHEMBL3199050 & 688422 & 4.45 & 5.4772 & TRN & \\
\hline CHEMBL489534 & 688422 & 4.5 & 4.8793 & TRN & \\
\hline CHEMBL1403808 & 688422 & 4.45 & 4.7376 & TRN & \\
\hline CHEMBL1547916 & 688422 & 4.45 & 5.5788 & TRN & \\
\hline CHEMBL1572127 & 688422 & 4.85 & 5.4837 & TRN & \\
\hline CHEMBL1390168 & 688422 & 8.4949 & 5.5347 & TRN & \\
\hline CHEMBL1439371 & 688422 & 4.95 & 5.026 & TRN & \\
\hline CHEMBL1304187 & 688422 & 4.75 & 5.12299 & 9999999999 & TRN \\
\hline CHEMBL1534666 & 688422 & 5.35 & 5.3696 & TRN & \\
\hline CHEMBL3145094 & 688422 & 4.9 & 5.0247 & TRN & \\
\hline CHEMBL1537717 & 688422 & 6.0 & 5.0505 & TRN & \\
\hline CHEMBL1365700 & 688422 & 4.75 & 5.1754 & TST & \\
\hline CHEMBL1384145 & 688422 & 4.8 & 5.2611 & TRN & \\
\hline CHEMBL1595489 & 688422 & 8.0506 & 5.6813 & TRN & \\
\hline
\end{tabular}




\begin{tabular}{|c|c|c|c|c|c|}
\hline \multicolumn{6}{|c|}{ Supplemental Table s2.txt } \\
\hline CHEMBL1483175 & 688422 & 4.45 & 5.1279 & TRN & \\
\hline CHEMBL 3192360 & 688422 & 5.05 & 5.2703 & TST & \\
\hline CHEMBL1445172 & 688422 & 5.8 & 5.9339 & TST & \\
\hline CHEMBL1389550 & 688422 & 4.55 & 5.0632 & TRN & \\
\hline CHEMBL1436103 & 688422 & 5.45 & 5.0465 & TRN & \\
\hline CHEMBL1429823 & 688422 & 5.15 & 4.9684 & TRN & \\
\hline CHEMBL1303733 & 688422 & 4.45 & 4.8345 & TRN & \\
\hline CHEMBL591834 & 688422 & 4.75 & 5.7099 & TST & \\
\hline CHEMBL1428072 & 688422 & 6.5 & 5.1801 & TRN & \\
\hline CHEMBL1329024 & 688422 & 5.6 & 5.8992 & TRN & \\
\hline CHEMBL1481987 & 688422 & 4.95 & 5.2848 & TRN & \\
\hline CHEMBL1520216 & 688422 & 5.0 & 5.0975 & TRN & \\
\hline CHEMBL1479864 & 688422 & 4.85 & 4.8811 & TRN & \\
\hline CHEMBL1340363 & 688422 & 4.9 & 5.138 & TRN & \\
\hline CHEMBL1363324 & 688422 & 4.85 & 4.8883 & TRN & \\
\hline CHEMBL1393695 & 688422 & 4.65 & 5.2122 & TRN & \\
\hline CHEMBL1424951 & 688422 & 4.55 & 5.0612 & TRN & \\
\hline CHEMBL1580845 & 688422 & 4.7 & 5.2348 & TRN & \\
\hline CHEMBL1585583 & 688422 & 6.1 & 5.649 & TST & \\
\hline CHEMBL1488473 & 688422 & 4.7 & 5.1162 & TRN & \\
\hline CHEMBL1346792 & 688422 & 6.3 & 5.2139 & TST & \\
\hline CHEMBL1452766 & 688422 & 4.75 & 5.12200 & 0000000001 & TST \\
\hline CHEMBL1406615 & 688422 & 4.85 & 5.1012 & TRN & \\
\hline CHEMBL1393415 & 688422 & 7.9508 & 5.4866 & TRN & \\
\hline CHEMBL1576508 & 688422 & 4.7 & 5.4333 & TST & \\
\hline CHEMBL17468 & 688422 & 8.3979 & 5.4605 & TST & \\
\hline CHEMBL1401143 & 688422 & 5.5 & 5.2377 & TRN & \\
\hline CHEMBL1346859 & 688422 & 4.45 & 4.8698 & TST & \\
\hline CHEMBL1554669 & 688422 & 5.05 & 5.7573 & TRN & \\
\hline CHEMBL1447393 & 688422 & 7.699 & 5.0047 & TRN & \\
\hline CHEMBL1510542 & 688422 & 4.45 & 5.2337 & TRN & \\
\hline CHEMBL1299350 & 688422 & 4.65 & 4.96899 & 9999999999 & TRN \\
\hline CHEMBL1381644 & 688422 & 4.7 & 5.9131 & TST & \\
\hline CHEMBL3193093 & 688422 & 4.7 & 5.3364 & TRN & \\
\hline CHEMBL1542077 & 688422 & 4.45 & 5.6327 & TRN & \\
\hline CHEMBL1582962 & 688422 & 7.0 & 5.3529 & TST & \\
\hline CHEMBL1399490 & 688422 & 4.8 & 5.0318 & TRN & \\
\hline CHEMBL1323873 & 688422 & 5.4 & 5.8324 & TST & \\
\hline CHEMBL1979047 & 688422 & 5.5 & 5.5327 & TRN & \\
\hline CHEMBL1517107 & 688422 & 4.45 & 4.7785 & TRN & \\
\hline CHEMBL1546188 & 688422 & 4.45 & 5.31 & TRN & \\
\hline CHEMBL1526266 & 688422 & 4.9 & 5.088 & TRN & \\
\hline CHEMBL1575634 & 688422 & 5.2 & 5.0326 & TRN & \\
\hline CHEMBL1991736 & 688422 & 4.7 & 4.8541 & TRN & \\
\hline CHEMBL1409460 & 688422 & 7.3002 & 5.45100 & 00000000005 & TST \\
\hline CHEMBL1352968 & 688422 & 5.15 & 4.6037 & TRN & \\
\hline CHEMBL1464734 & 688422 & 4.95 & 5.1606 & TRN & \\
\hline CHEMBL1565019 & 688422 & 4.45 & 4.8588 & TRN & \\
\hline
\end{tabular}




\begin{tabular}{|c|c|c|c|c|c|}
\hline \multicolumn{6}{|c|}{ Supplemental Table S2.txt } \\
\hline CHEMBL1344133 & 688422 & 6.8 & 5.474 & TRN & \\
\hline CHEMBL3196517 & 688422 & 4.45 & 5.0314 & TRN & \\
\hline CHEMBL1413909 & 688422 & 4.85 & 5.0319 & TRN & \\
\hline CHEMBL 3197754 & 688422 & 4.45 & 4.8561 & TRN & \\
\hline CHEMBL1385756 & 688422 & 5.8 & 5.7626 & TST & \\
\hline CHEMBL490107 & 688422 & 8.1024 & 5.3259 & TRN & \\
\hline CHEMBL1607984 & 688422 & 4.85 & 5.5614 & TST & \\
\hline CHEMBL1431614 & 688422 & 4.65 & 5.5501 & TRN & \\
\hline CHEMBL1305368 & 688422 & 6.5501 & 5.5306 & TST & \\
\hline CHEMBL1600638 & 688422 & 4.95 & 5.3503 & TRN & \\
\hline CHEMBL1525429 & 688422 & 4.45 & 4.8809 & TRN & \\
\hline CHEMBL1569816 & 688422 & 4.8 & 5.159 & TST & \\
\hline CHEMBL1577908 & 688422 & 4.45 & 4.993 & TST & \\
\hline CHEMBL1452794 & 688422 & 4.9 & 5.0785 & TRN & \\
\hline CHEMBL1509609 & 688422 & 7.5498 & 5.3339 & TST & \\
\hline CHEMBL3195077 & 688422 & 4.45 & 5.4209 & TRN & \\
\hline CHEMBL1309467 & 688422 & 4.45 & 5.1515 & TST & \\
\hline CHEMBL1406910 & 688422 & 4.9 & 5.0103 & TRN & \\
\hline CHEMBL1346894 & 688422 & 4.45 & 4.9737 & TRN & \\
\hline CHEMBL1093246 & 688422 & 4.55 & 5.0969 & TST & \\
\hline CHEMBL1340298 & 688422 & 4.6 & 4.9846 & TRN & \\
\hline CHEMBL1467876 & 688422 & 4.45 & 4.96899 & 9999999999 & TRN \\
\hline CHEMBL3196177 & 688422 & 6.3 & 5.2369 & TST & \\
\hline CHEMBL3207329 & 688422 & 4.8 & 5.1025 & TRN & \\
\hline CHEMBL3189766 & 688422 & 4.9 & 5.5625 & TRN & \\
\hline CHEMBL1564407 & 688422 & 4.45 & 5.2786 & TRN & \\
\hline CHEMBL1493746 & 688422 & 4.45 & 4.5699 & TST & \\
\hline CHEMBL1375355 & 688422 & 4.8 & 5.4673 & TRN & \\
\hline CHEMBL601970 & 688422 & 4.95 & 5.1788 & TRN & \\
\hline CHEMBL1400901 & 688422 & 4.8 & 5.2493 & TRN & \\
\hline CHEMBL1555890 & 688422 & 4.95 & 4.8494 & TRN & \\
\hline CHEMBL1603790 & 688422 & 4.65 & 5.4567 & TRN & \\
\hline CHEMBL1353306 & 688422 & 5.0 & 5.5401 & TRN & \\
\hline CHEMBL1422756 & 688422 & 5.05 & 5.2539 & TST & \\
\hline CHEMBL1522495 & 688422 & 5.45 & 5.7468 & TRN & \\
\hline CHEMBL1607116 & 688422 & 4.45 & 5.209 & TRN & \\
\hline CHEMBL1336294 & 688422 & 4.75 & 5.5478 & TRN & \\
\hline CHEMBL1319623 & 688422 & 4.45 & 4.7696 & TRN & \\
\hline CHEMBL1313923 & 688422 & 5.35 & 4.9348 & TST & \\
\hline CHEMBL1439790 & 688422 & 4.95 & 5.1604 & TRN & \\
\hline CHEMBL1401378 & 688422 & 4.75 & 5.061 & TRN & \\
\hline CHEMBL1485988 & 688422 & 5.95 & 4.8141 & TRN & \\
\hline CHEMBL1337025 & 688422 & 4.9 & 4.8779 & TRN & \\
\hline CHEMBL1309358 & 688422 & 4.85 & 5.5564 & TST & \\
\hline CHEMBL1371270 & 688422 & 4.45 & 5.347 & TRN & \\
\hline CHEMBL1585390 & 688422 & 5.0 & 5.5279 & TST & \\
\hline CHEMBL602375 & 688422 & 5.15 & 5.2797 & TST & \\
\hline CHEMBL1431692 & 688422 & 7.8996 & 5.215 & TRN & \\
\hline
\end{tabular}




\begin{tabular}{|c|c|c|c|c|c|}
\hline \multicolumn{6}{|c|}{ Supplemental Table S2.txt } \\
\hline CHEMBL 3190246 & 688422 & 5.0 & 5.3976 & TRN & \\
\hline CHEMBL30432 & 688422 & 8.3468 & 4.9254 & TST & \\
\hline CHEMBL1333468 & 688422 & 4.45 & 5.4039 & TRN & \\
\hline CHEMBL1547627 & 688422 & 4.95 & 5.68 & TST & \\
\hline CHEMBL1561350 & 688422 & 4.7 & 5.1635 & TRN & \\
\hline CHEMBL1417046 & 688422 & 5.25 & 5.4612 & TRN & \\
\hline CHEMBL1358432 & 688422 & 7.4001 & 5.3178 & TRN & \\
\hline CHEMBL1322772 & 688422 & 4.85 & 5.4338 & TRN & \\
\hline CHEMBL1403538 & 688422 & 4.45 & 4.8681 & TST & \\
\hline CHEMBL1576053 & 688422 & 5.55 & 5.8123 & TST & \\
\hline CHEMBL1388126 & 688422 & 4.45 & 5.008 & TRN & \\
\hline CHEMBL1463786 & 688422 & 4.9 & 5.4884 & TRN & \\
\hline CHEMBL1505768 & 688422 & 6.7501 & 5.2388 & TRN & \\
\hline CHEMBL1373977 & 688422 & 4.65 & 5.4806 & TRN & \\
\hline CHEMBL1577044 & 688422 & 4.8 & 4.8096 & TRN & \\
\hline CHEMBL1442903 & 688422 & 4.45 & 5.1983 & TST & \\
\hline CHEMBL1461698 & 688422 & 4.45 & 4.9122 & TRN & \\
\hline CHEMBL1304967 & 688422 & 7.2 & 5.1878 & TST & \\
\hline CHEMBL1310208 & 688422 & 4.85 & 5.3079 & TST & \\
\hline CHEMBL1336871 & 688422 & 5.25 & 5.1505 & TRN & \\
\hline CHEMBL1535527 & 688422 & 5.25 & 5.147 & TRN & \\
\hline CHEMBL1466304 & 688422 & 6.3 & 5.3301 & TRN & \\
\hline CHEMBL1607995 & 688422 & 4.45 & 4.9793 & TRN & \\
\hline CHEMBL1390995 & 688422 & 4.45 & 5.072 & TRN & \\
\hline CHEMBL1382158 & 688422 & 4.6 & 5.0426 & TRN & \\
\hline CHEMBL1309445 & 688422 & 4.7 & 5.6011 & TST & \\
\hline CHEMBL1378292 & 688422 & 4.45 & 5.2763 & TRN & \\
\hline CHEMBL1511010 & 688422 & 4.45 & 5.3299 & TRN & \\
\hline CHEMBL1518379 & 688422 & 5.45 & 5.3577 & TRN & \\
\hline CHEMBL1365068 & 688422 & 4.8 & 5.4006 & TRN & \\
\hline CHEMBL1415762 & 688422 & 5.95 & 5.5095 & TRN & \\
\hline CHEMBL1322609 & 688422 & 6.45 & 5.7444 & TRN & \\
\hline CHEMBL1345332 & 688422 & 4.95 & 4.9539 & TRN & \\
\hline CHEMBL1321046 & 688422 & 5.4 & 5.4073 & TRN & \\
\hline CHEMBL1523302 & 688422 & 5.05 & 5.6165 & TST & \\
\hline CHEMBL 1385840 & 688422 & 5.25 & 5.7613 & TRN & \\
\hline CHEMBL1572726 & 688422 & 4.45 & 5.3504 & TST & \\
\hline CHEMBL1424340 & 688422 & 4.85 & 5.4647 & TRN & \\
\hline CHEMBL1502367 & 688422 & 4.9 & 5.3612 & TST & \\
\hline CHEMBL1342974 & 688422 & 4.95 & 4.9878 & TRN & \\
\hline CHEMBL1365755 & 688422 & 4.85 & 5.37200 & 0000000001 & TST \\
\hline CHEMBL1509200 & 688422 & 7.6498 & 5.3209 & TRN & \\
\hline CHEMBL1425648 & 688422 & 4.45 & 4.9344 & TRN & \\
\hline CHEMBL1386146 & 688422 & 4.95 & 5.3286 & TRN & \\
\hline CHEMBL1583513 & 688422 & 5.45 & 4.7597 & TRN & \\
\hline CHEMBL1486262 & 688422 & 4.8 & 5.0268 & TRN & \\
\hline CHEMBL1323722 & 688422 & 5.15 & 4.7949 & TRN & \\
\hline CHEMBL1368966 & 688422 & 5.45 & 5.4022 & TRN & \\
\hline
\end{tabular}




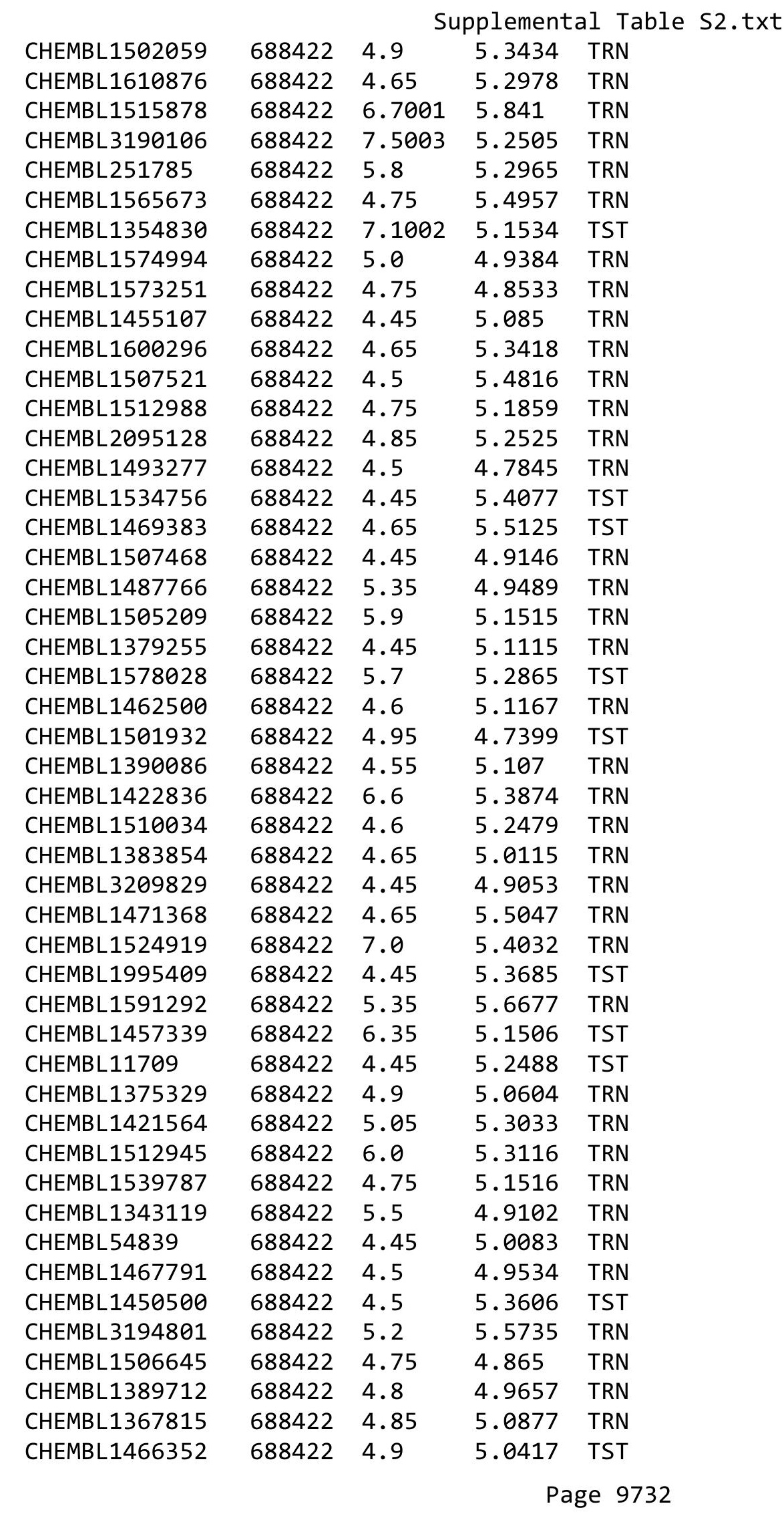




\begin{tabular}{|c|c|c|c|c|}
\hline \multicolumn{5}{|c|}{ Supplemental Table s2.txt } \\
\hline CHEMBL1447359 & 688422 & 4.9 & 5.5079 & TRN \\
\hline CHEMBL 3195247 & 688422 & 4.5 & 5.1548 & TRN \\
\hline CHEMBL1559383 & 688422 & 4.45 & 5.0885 & TRN \\
\hline CHEMBL1521190 & 688422 & 4.6 & 5.1573 & TRN \\
\hline CHEMBL1498431 & 688422 & 5.25 & 5.3092 & TRN \\
\hline CHEMBL1558563 & 688422 & 4.45 & 5.4986 & TST \\
\hline CHEMBL1572798 & 688422 & 6.2 & 5.0072 & TST \\
\hline CHEMBL1377465 & 688422 & 4.6 & 5.61299 & 99999999995 \\
\hline CHEMBL1385317 & 688422 & 4.9 & 5.3177 & TRN \\
\hline CHEMBL1306979 & 688422 & 3.6 & 5.1789 & TST \\
\hline CHEMBL1426529 & 688422 & 6.4 & 5.8438 & TRN \\
\hline CHEMBL1559321 & 688422 & 8.3468 & 5.3777 & TST \\
\hline CHEMBL1604920 & 688422 & 4.45 & 5.0424 & TST \\
\hline CHEMBL1391213 & 688422 & 5.05 & 5.6615 & TST \\
\hline CHEMBL1525757 & 688422 & 4.95 & 5.3961 & TRN \\
\hline CHEMBL1319643 & 688422 & 5.35 & 5.4701 & TRN \\
\hline CHEMBL1507441 & 688422 & 4.7 & 4.9073 & TRN \\
\hline CHEMBL1576777 & 688422 & 4.75 & 4.7436 & TRN \\
\hline CHEMBL1965376 & 688422 & 4.45 & 5.5171 & TRN \\
\hline CHEMBL1446783 & 688422 & 5.9 & 5.6113 & TRN \\
\hline CHEMBL1393927 & 688422 & 8.3979 & 4.7858 & TST \\
\hline CHEMBL1458080 & 688422 & 4.85 & 4.7877 & TRN \\
\hline CHEMBL1590680 & 688422 & 6.5 & 5.0651 & TRN \\
\hline CHEMBL1369096 & 688422 & 4.9 & 5.1047 & TRN \\
\hline CHEMBL1523867 & 688422 & 4.65 & 5.1257 & TRN \\
\hline CHEMBL3192707 & 688422 & 5.35 & 5.2559 & TRN \\
\hline CHEMBL1333235 & 688422 & 4.9 & 5.1466 & TRN \\
\hline CHEMBL1484623 & 688422 & 6.1 & 5.4722 & TRN \\
\hline CHEMBL1327658 & 688422 & 5.0 & 4.9952 & TRN \\
\hline CHEMBL1496245 & 688422 & 4.5 & 5.5794 & TRN \\
\hline CHEMBL1439525 & 688422 & 4.9 & 5.0019 & TRN \\
\hline CHEMBL1308075 & 688422 & 4.8 & 4.8058 & TRN \\
\hline CHEMBL3196064 & 688422 & 4.75 & 5.1104 & TRN \\
\hline CHEMBL1503604 & 688422 & 4.9 & 4.8498 & TST \\
\hline CHEMBL1585278 & 688422 & 6.25 & 5.4025 & TST \\
\hline CHEMBL1346226 & 688422 & 4.45 & 5.1057 & TRN \\
\hline CHEMBL1486330 & 688422 & 4.7 & 5.0531 & TRN \\
\hline CHEMBL1488386 & 688422 & 7.3497 & 5.3192 & TRN \\
\hline CHEMBL1466620 & 688422 & 4.45 & 5.1481 & TRN \\
\hline CHEMBL1512657 & 688422 & 4.9 & 5.4036 & TRN \\
\hline CHEMBL1606326 & 688422 & 5.25 & 5.4922 & TST \\
\hline CHEMBL3212181 & 688422 & 4.9 & 5.1702 & TST \\
\hline CHEMBL1405545 & 688422 & 4.5 & 4.966 & TST \\
\hline CHEMBL1502453 & 688422 & 4.45 & 5.388 & TRN \\
\hline CHEMBL1494878 & 688422 & 4.9 & 5.2992 & TST \\
\hline CHEMBL1350867 & 688422 & 4.45 & 5.1973 & TRN \\
\hline CHEMBL1467114 & 688422 & 4.6 & 5.3537 & TRN \\
\hline CHEMBL1406799 & 688422 & 6.8 & 5.4244 & TST \\
\hline
\end{tabular}




\begin{tabular}{|c|c|c|c|c|c|}
\hline \multicolumn{6}{|c|}{ Supplemental Table S2.txt } \\
\hline CHEMBL1566271 & 688422 & 4.75 & 5.0629 & TRN & \\
\hline CHEMBL1322409 & 688422 & 7.8996 & 5.5111 & TST & \\
\hline CHEMBL1449508 & 688422 & 7.5003 & 5.3345 & TRN & \\
\hline CHEMBL1582834 & 688422 & 4.7 & 4.7708 & TRN & \\
\hline CHEMBL1431893 & 688422 & 4.65 & 5.2571 & TRN & \\
\hline CHEMBL1546590 & 688422 & 4.45 & 5.2676 & TRN & \\
\hline CHEMBL1349338 & 688422 & 5.15 & 5.2146 & TRN & \\
\hline CHEMBL1368578 & 688422 & 4.5 & 4.9317 & TRN & \\
\hline CHEMBL1421615 & 688422 & 4.9 & 5.5076 & TRN & \\
\hline CHEMBL1386806 & 688422 & 6.35 & 5.0934 & TRN & \\
\hline CHEMBL1485054 & 688422 & 4.75 & 5.1538 & TRN & \\
\hline CHEMBL 3192375 & 688422 & 4.95 & 5.0142 & TRN & \\
\hline CHEMBL1405159 & 688422 & 7.7496 & 5.7697 & TRN & \\
\hline CHEMBL1529293 & 688422 & 7.7496 & 5.0084 & TRN & \\
\hline CHEMBL1462110 & 688422 & 4.85 & 5.0539 & TRN & \\
\hline CHEMBL1354955 & 688422 & 4.75 & 5.8626 & TRN & \\
\hline CHEMBL1507662 & 688422 & 8.4949 & 5.38700 & 00000000005 & TST \\
\hline CHEMBL1353218 & 688422 & 5.4 & 5.1997 & TRN & \\
\hline CHEMBL1510977 & 688422 & 4.45 & 5.4936 & TRN & \\
\hline CHEMBL1424392 & 688422 & 4.8 & 4.8983 & TST & \\
\hline CHEMBL1331263 & 688422 & 5.2 & 5.1989 & TRN & \\
\hline CHEMBL1431439 & 688422 & 6.7001 & 5.3904 & TRN & \\
\hline CHEMBL1314255 & 688422 & 4.7 & 4.86100 & 3000000001 & TRN \\
\hline CHEMBL1571934 & 688422 & 5.45 & 5.2206 & TRN & \\
\hline CHEMBL1535755 & 688422 & 5.5 & 5.043 & TST & \\
\hline CHEMBL 3214241 & 688422 & 4.45 & 5.1523 & TRN & \\
\hline CHEMBL1571866 & 688422 & 8.3468 & 5.3022 & TST & \\
\hline CHEMBL1477373 & 688422 & 4.9 & 4.981 & TRN & \\
\hline CHEMBL1554373 & 688422 & 4.9 & 5.2183 & TRN & \\
\hline CHEMBL1550588 & 688422 & 7.15 & 4.9773 & TRN & \\
\hline CHEMBL1369461 & 688422 & 8.0 & 6.1148 & TRN & \\
\hline CHEMBL1468693 & 688422 & 7.5003 & 4.9205 & TRN & \\
\hline CHEMBL1542514 & 688422 & 5.8 & 5.3541 & TRN & \\
\hline CHEMBL1407741 & 688422 & 4.65 & 5.305 & TRN & \\
\hline CHEMBL1479505 & 688422 & 6.1 & 5.9448 & TRN & \\
\hline CHEMBL1490111 & 688422 & 4.65 & 5.0128 & TRN & \\
\hline CHEMBL1531101 & 688422 & 4.95 & 5.4933 & TST & \\
\hline CHEMBL3199860 & 688422 & 5.5 & 5.0467 & TRN & \\
\hline CHEMBL1439744 & 688422 & 4.7 & 5.5736 & TST & \\
\hline CHEMBL1529873 & 688422 & 4.75 & 4.8137 & TRN & \\
\hline CHEMBL1574093 & 688422 & 4.45 & 5.4154 & TRN & \\
\hline CHEMBL1451234 & 688422 & 5.25 & 5.2535 & TST & \\
\hline CHEMBL1565446 & 688422 & 4.7 & 4.9327 & TRN & \\
\hline CHEMBL1454951 & 688422 & 4.65 & 4.9622 & TST & \\
\hline CHEMBL578905 & 688422 & 6.8499 & 5.067 & TRN & \\
\hline CHEMBL1585719 & 688422 & 4.95 & 4.9824 & TST & \\
\hline CHEMBL1390369 & 688422 & 6.35 & 5.2173 & TRN & \\
\hline CHEMBL1341764 & 688422 & 4.45 & 5.185 & TST & \\
\hline
\end{tabular}




\begin{tabular}{|c|c|c|c|c|c|}
\hline \multicolumn{6}{|c|}{ Supplemental Table s2.txt } \\
\hline CHEMBL1502092 & 688422 & 4.65 & 5.0056 & TRN & \\
\hline CHEMBL1430800 & 688422 & 4.6 & 4.9719 & TRN & \\
\hline CHEMBL1964556 & 688422 & 4.9 & 5.1879 & TRN & \\
\hline CHEMBL1484709 & 688422 & 4.7 & 5.4477 & TRN & \\
\hline CHEMBL1462041 & 688422 & 4.8 & 5.1557 & TST & \\
\hline CHEMBL1303995 & 688422 & 4.65 & 5.4317 & TRN & \\
\hline CHEMBL1469488 & 688422 & 4.8 & 4.8522 & TRN & \\
\hline CHEMBL1385123 & 688422 & 4.45 & 4.9935 & TRN & \\
\hline CHEMBL1522724 & 688422 & 6.3 & 4.8834 & TRN & \\
\hline CHEMBL1536786 & 688422 & 7.1002 & 5.025 & TRN & \\
\hline CHEMBL1522598 & 688422 & 4.95 & 5.5834 & TST & \\
\hline CHEMBL1463658 & 688422 & 4.6 & 5.0499 & TRN & \\
\hline CHEMBL3189575 & 688422 & 5.4 & 5.3381 & TST & \\
\hline CHEMBL1542274 & 688422 & 6.8 & 5.479 & TRN & \\
\hline CHEMBL1373490 & 688422 & 4.45 & 5.1 & TRN & \\
\hline CHEMBL1609470 & 688422 & 4.45 & 5.5245 & TRN & \\
\hline CHEMBL1964978 & 688422 & 5.25 & 5.2828 & TST & \\
\hline CHEMBL1394084 & 688422 & 5.35 & 5.0699 & TRN & \\
\hline CHEMBL1351615 & 688422 & 4.9 & 5.4313 & TST & \\
\hline CHEMBL1321181 & 688422 & 4.45 & 4.8354 & TRN & \\
\hline CHEMBL1515717 & 688422 & 4.9 & 4.5269 & TRN & \\
\hline CHEMBL1526735 & 688422 & 5.2 & 5.4265 & TRN & \\
\hline CHEMBL1468335 & 688422 & 4.5 & 4.681 & TRN & \\
\hline CHEMBL1570227 & 688422 & 4.8 & 5.25899 & 99999999995 & TRN \\
\hline CHEMBL1391047 & 688422 & 4.65 & 5.56 & TRN & \\
\hline CHEMBL1548598 & 688422 & 4.9 & 4.9955 & TRN & \\
\hline CHEMBL1458059 & 688422 & 5.35 & 5.3939 & TRN & \\
\hline CHEMBL1996830 & 688422 & 5.2 & 4.4615 & TRN & \\
\hline CHEMBL1550315 & 688422 & 4.8 & 5.5499 & TST & \\
\hline CHEMBL1561957 & 688422 & 4.45 & 5.5395 & TRN & \\
\hline CHEMBL1301943 & 688422 & 7.0501 & 5.0929 & TRN & \\
\hline CHEMBL1351269 & 688422 & 6.3 & 4.9818 & TRN & \\
\hline CHEMBL1966865 & 688422 & 5.35 & 5.3215 & TRN & \\
\hline CHEMBL1433079 & 688422 & 6.25 & 5.0203 & TRN & \\
\hline CHEMBL1607288 & 688422 & 4.9 & 5.4341 & TRN & \\
\hline CHEMBL1562712 & 688422 & 4.5 & 5.4379 & TST & \\
\hline CHEMBL1492110 & 688422 & 4.85 & 5.4298 & TST & \\
\hline CHEMBL1583075 & 688422 & 4.7 & 5.6483 & TRN & \\
\hline CHEMBL1419712 & 688422 & 4.95 & 4.9264 & TRN & \\
\hline CHEMBL1383950 & 688422 & 7.3497 & 5.34200 & 00000000005 & TRN \\
\hline CHEMBL1397164 & 688422 & 4.45 & 5.0815 & TRN & \\
\hline CHEMBL1506750 & 688422 & 4.6 & 5.3053 & TRN & \\
\hline CHEMBL3199084 & 688422 & 4.7 & 5.0196 & TST & \\
\hline CHEMBL1388691 & 688422 & 4.95 & 5.1428 & TRN & \\
\hline CHEMBL1442339 & 688422 & 6.2 & 5.3839 & TRN & \\
\hline CHEMBL1417053 & 688422 & 4.45 & 5.4098 & TRN & \\
\hline CHEMBL1388911 & 688422 & 4.9 & 5.5121 & TRN & \\
\hline CHEMBL1575408 & 688422 & 5.6 & 5.1238 & TRN & \\
\hline
\end{tabular}




\begin{tabular}{|c|c|c|c|c|c|}
\hline \multicolumn{6}{|c|}{ Supplemental Table S2.txt } \\
\hline CHEMBL1511040 & 688422 & 6.05 & 5.3816 & TRN & \\
\hline CHEMBL1592368 & 688422 & 4.5 & 5.2195 & TST & \\
\hline CHEMBL1465114 & 688422 & 4.8 & 4.763 & TRN & \\
\hline CHEMBL1477411 & 688422 & 4.75 & 5.0974 & TST & \\
\hline CHEMBL1398599 & 688422 & 5.25 & 5.5515 & TRN & \\
\hline CHEMBL1319784 & 688422 & 4.65 & 5.16299 & 9999999999 & TST \\
\hline CHEMBL3198273 & 688422 & 4.75 & 5.4978 & TRN & \\
\hline CHEMBL1513659 & 688422 & 4.75 & 4.8132 & TRN & \\
\hline CHEMBL1384470 & 688422 & 4.5 & 5.0719 & TST & \\
\hline CHEMBL1603906 & 688422 & 4.6 & 4.7426 & TRN & \\
\hline CHEMBL1545991 & 688422 & 4.5 & 5.3935 & TRN & \\
\hline CHEMBL1536993 & 688422 & 4.45 & 5.2782 & TRN & \\
\hline CHEMBL1498050 & 688422 & 6.1 & 5.5725 & TST & \\
\hline CHEMBL1455214 & 688422 & 5.25 & 4.96 & TRN & \\
\hline CHEMBL1366231 & 688422 & 4.45 & 4.7461 & TRN & \\
\hline CHEMBL1343617 & 688422 & 4.95 & 4.8891 & TST & \\
\hline CHEMBL1329544 & 688422 & 4.85 & 5.1456 & TRN & \\
\hline CHEMBL1311515 & 688422 & 4.85 & 4.8707 & TRN & \\
\hline CHEMBL1468773 & 688422 & 4.5 & 5.26399 & 7999999999 & TRN \\
\hline CHEMBL1600373 & 688422 & 4.5 & 4.784 & TRN & \\
\hline CHEMBL1323165 & 688422 & 4.9 & 5.2151 & TRN & \\
\hline CHEMBL1412300 & 688422 & 4.9 & 4.9596 & TRN & \\
\hline CHEMBL1603618 & 688422 & 4.95 & 5.2963 & TRN & \\
\hline CHEMBL1441052 & 688422 & 4.85 & 4.918 & TST & \\
\hline CHEMBL1563874 & 688422 & 4.45 & 4.7903 & TRN & \\
\hline CHEMBL1426979 & 688422 & 4.85 & 4.7228 & TST & \\
\hline CHEMBL1419909 & 688422 & 4.45 & 5.5852 & TRN & \\
\hline CHEMBL1490323 & 688422 & 4.45 & 5.3934 & TRN & \\
\hline CHEMBL1256814 & 688422 & 8.3468 & 4.9161 & TRN & \\
\hline CHEMBL1508313 & 688422 & 5.25 & 5.2345 & TST & \\
\hline CHEMBL1317342 & 688422 & 6.3 & 5.8337 & TRN & \\
\hline CHEMBL1992641 & 688422 & 4.45 & 5.4735 & TRN & \\
\hline CHEMBL1372590 & 688422 & 4.7 & 5.2477 & TRN & \\
\hline CHEMBL1431827 & 688422 & 4.85 & 5.6196 & TRN & \\
\hline CHEMBL1603556 & 688422 & 8.3979 & 5.3959 & TRN & \\
\hline CHEMBL1424463 & 688422 & 4.5 & 5.3965 & TST & \\
\hline CHEMBL1372884 & 688422 & 4.8 & 5.4151 & TST & \\
\hline CHEMBL1488746 & 688422 & 6.3 & 5.5062 & TRN & \\
\hline CHEMBL1502077 & 688422 & 6.7501 & 5.6995 & TRN & \\
\hline CHEMBL1528764 & 688422 & 5.15 & 5.2916 & TRN & \\
\hline CHEMBL1583515 & 688422 & 4.85 & 5.0868 & TST & \\
\hline CHEMBL447507 & 688422 & 4.7 & 4.8448 & TRN & \\
\hline CHEMBL 70880 & 688422 & 5.5 & 4.9839 & TRN & \\
\hline CHEMBL601184 & 688422 & 4.65 & 4.9114 & TRN & \\
\hline CHEMBL1418079 & 688422 & 5.45 & 4.9289 & TST & \\
\hline CHEMBL1569433 & 688422 & 4.7 & 5.2939 & TST & \\
\hline CHEMBL1319154 & 688422 & 4.5 & 4.9407 & TRN & \\
\hline CHEMBL1396976 & 688422 & 5.0 & 5.4919 & TST & \\
\hline
\end{tabular}




\begin{tabular}{|c|c|c|c|c|c|}
\hline \multicolumn{6}{|c|}{ Supplemental Table S2.txt } \\
\hline CHEMBL1504815 & 688422 & 5.1 & 4.8568 & TRN & \\
\hline CHEMBL1388972 & 688422 & 6.8 & 5.1224 & TST & \\
\hline CHEMBL3195530 & 688422 & 8.301 & 5.4323 & TRN & \\
\hline CHEMBL1387853 & 688422 & 8.0506 & 5.8012 & TST & \\
\hline CHEMBL1312337 & 688422 & 4.8 & 4.6303 & TRN & \\
\hline CHEMBL1488076 & 688422 & 5.25 & 5.0554 & TRN & \\
\hline CHEMBL1580704 & 688422 & 4.9 & 5.3207 & TRN & \\
\hline CHEMBL1414843 & 688422 & 4.45 & 4.9805 & TST & \\
\hline CHEMBL1460731 & 688422 & 4.8 & 5.4664 & TRN & \\
\hline CHEMBL1580359 & 688422 & 4.9 & 5.2961 & TRN & \\
\hline CHEMBL1490804 & 688422 & 4.45 & 5.2739 & TRN & \\
\hline CHEMBL1328270 & 688422 & 5.4 & 5.6805 & TST & \\
\hline CHEMBL1488337 & 688422 & 4.5 & 4.9353 & TRN & \\
\hline CHEMBL1462523 & 688422 & 6.35 & 5.6889 & TRN & \\
\hline CHEMBL1343352 & 688422 & 4.45 & 5.5482 & TRN & \\
\hline CHEMBL1534146 & 688422 & 4.45 & 5.3539 & TRN & \\
\hline CHEMBL1429703 & 688422 & 4.7 & 5.2988 & TST & \\
\hline CHEMBL1340514 & 688422 & 4.45 & 4.6189 & TRN & \\
\hline CHEMBL1466627 & 688422 & 5.2 & 5.3661 & TRN & \\
\hline CHEMBL1535025 & 688422 & 4.8 & 5.263 & TRN & \\
\hline CHEMBL1411587 & 688422 & 5.55 & 5.3801 & TRN & \\
\hline CHEMBL1425335 & 688422 & 5.05 & 5.7075 & TST & \\
\hline CHEMBL1478396 & 688422 & 7.699 & 5.30200 & 00000000005 & TRN \\
\hline CHEMBL1409840 & 688422 & 5.35 & 5.4944 & TST & \\
\hline CHEMBL1412573 & 688422 & 4.8 & 5.2753 & TST & \\
\hline CHEMBL1419536 & 688422 & 4.55 & 4.96399 & 99999999995 & TRN \\
\hline CHEMBL1500647 & 688422 & 4.7 & 5.2143 & TRN & \\
\hline CHEMBL1559243 & 688422 & 4.65 & 5.197 & TRN & \\
\hline CHEMBL1368621 & 688422 & 4.7 & 4.8107 & TRN & \\
\hline CHEMBL1408013 & 688422 & 5.0 & 4.8506 & TRN & \\
\hline CHEMBL1559575 & 688422 & 4.9 & 5.1837 & TRN & \\
\hline CHEMBL1380052 & 688422 & 4.45 & 5.4585 & TST & \\
\hline CHEMBL1477416 & 688422 & 5.25 & 5.3149 & TRN & \\
\hline CHEMBL1602391 & 688422 & 4.9 & 5.1753 & TRN & \\
\hline CHEMBL1428015 & 688422 & 5.4 & 4.9781 & TRN & \\
\hline CHEMBL1320418 & 688422 & 5.75 & 5.0667 & TRN & \\
\hline CHEMBL1585487 & 688422 & 4.6 & 4.9601 & TST & \\
\hline CHEMBL3214524 & 688422 & 7.8996 & 5.6733 & TST & \\
\hline CHEMBL1393234 & 688422 & 5.05 & 5.0074 & TRN & \\
\hline CHEMBL1404200 & 688422 & 4.5 & 5.5688 & TRN & \\
\hline CHEMBL3199844 & 688422 & 5.25 & 5.4863 & TRN & \\
\hline CHEMBL1485778 & 688422 & 4.45 & 5.3191 & TST & \\
\hline CHEMBL3209623 & 688422 & 5.05 & 5.0695 & TRN & \\
\hline CHEMBL1528442 & 688422 & 8.0 & 5.4199 & TRN & \\
\hline CHEMBL1512828 & 688422 & 5.2 & 5.0053 & TRN & \\
\hline CHEMBL1337831 & 688422 & 4.75 & 4.9842 & TRN & \\
\hline CHEMBL1435485 & 688422 & 8.4949 & 5.4022 & TST & \\
\hline CHEMBL1540736 & 688422 & 4.85 & 4.97199 & 99999999995 & TRN \\
\hline & & & & 973 & \\
\hline
\end{tabular}




\begin{tabular}{|c|c|c|c|c|c|}
\hline \multicolumn{6}{|c|}{ Supplemental Table s2.txt } \\
\hline CHEMBL1606325 & 688422 & 5.4 & 4.9081 & TRN & \\
\hline CHEMBL 2001739 & 688422 & 5.5 & 5.3715 & TST & \\
\hline CHEMBL1411250 & 688422 & 5.05 & 4.873 & TRN & \\
\hline CHEMBL1399601 & 688422 & 4.5 & 4.9011 & TRN & \\
\hline CHEMBL1592574 & 688422 & 4.45 & 5.6869 & TRN & \\
\hline CHEMBL1604939 & 688422 & 4.85 & 5.181 & TRN & \\
\hline CHEMBL1474309 & 688422 & 4.8 & 5.2937 & TRN & \\
\hline CHEMBL1300769 & 688422 & 4.9 & 4.9867 & TST & \\
\hline CHEMBL1470264 & 688422 & 5.8 & 5.2616 & TST & \\
\hline CHEMBL1503884 & 688422 & 4.95 & 5.575 & TRN & \\
\hline CHEMBL1306267 & 688422 & 4.95 & 5.3482 & TRN & \\
\hline CHEMBL1328760 & 688422 & 4.95 & 5.474 & TRN & \\
\hline CHEMBL1423046 & 688422 & 4.45 & 5.3024 & TRN & \\
\hline CHEMBL1486920 & 688422 & 7.3497 & 5.4292 & TST & \\
\hline CHEMBL1376751 & 688422 & 5.6 & 5.1244 & TRN & \\
\hline CHEMBL1382518 & 688422 & 4.5 & 4.8433 & TRN & \\
\hline CHEMBL1324524 & 688422 & 4.75 & 5.1899 & TRN & \\
\hline CHEMBL1503948 & 688422 & 5.55 & 5.3277 & TRN & \\
\hline CHEMBL570345 & 688422 & 7.8013 & 5.3956 & TST & \\
\hline CHEMBL1512639 & 688422 & 6.35 & 5.4545 & TRN & \\
\hline CHEMBL1516180 & 688422 & 4.45 & 5.2742 & TRN & \\
\hline CHEMBL1550274 & 688422 & 4.8 & 5.0913 & TRN & \\
\hline CHEMBL3189891 & 688422 & 4.45 & 5.4358 & TRN & \\
\hline CHEMBL3144917 & 688422 & 4.9 & 4.9626 & TRN & \\
\hline CHEMBL1334275 & 688422 & 5.0 & 5.0786 & TRN & \\
\hline CHEMBL1360097 & 688422 & 4.7 & 4.9784 & TRN & \\
\hline CHEMBL1463787 & 688422 & 5.4 & 5.4614 & TST & \\
\hline CHEMBL1572159 & 688422 & 7.15 & 5.6249 & TST & \\
\hline CHEMBL1582592 & 688422 & 7.699 & 5.7489 & TST & \\
\hline CHEMBL1546530 & 688422 & 5.45 & 4.7458 & TRN & \\
\hline CHEMBL1605367 & 688422 & 5.25 & 5.722 & TRN & \\
\hline CHEMBL1460394 & 688422 & 7.9508 & 5.78299 & 99999999995 & TRN \\
\hline CHEMBL1468767 & 688422 & 4.8 & 4.9048 & TRN & \\
\hline CHEMBL1414001 & 688422 & 5.5 & 5.7945 & TRN & \\
\hline CHEMBL1398991 & 688422 & 5.25 & 5.2511 & TRN & \\
\hline CHEMBL1333095 & 688422 & 4.85 & 5.0882 & TRN & \\
\hline CHEMBL1507626 & 688422 & 4.85 & 5.2633 & TRN & \\
\hline CHEMBL1418451 & 688422 & 4.75 & 5.1328 & TRN & \\
\hline CHEMBL1533511 & 688422 & 4.85 & 5.3028 & TRN & \\
\hline CHEMBL1510661 & 688422 & 4.95 & 5.1439 & TRN & \\
\hline CHEMBL1482593 & 688422 & 5.25 & 5.0755 & TRN & \\
\hline CHEMBL1579968 & 688422 & 4.45 & 4.9667 & TRN & \\
\hline CHEMBL1321434 & 688422 & 7.5003 & 5.0477 & TRN & \\
\hline CHEMBL1443348 & 688422 & 5.6 & 5.335 & TRN & \\
\hline CHEMBL1542758 & 688422 & 4.8 & 4.7978 & TRN & \\
\hline CHEMBL1308331 & 688422 & 4.45 & 5.1252 & TRN & \\
\hline CHEMBL1344260 & 688422 & 4.85 & 5.3829 & TRN & \\
\hline CHEMBL1519664 & 688422 & 4.45 & 5.2522 & TRN & \\
\hline
\end{tabular}




\begin{tabular}{|c|c|c|c|c|c|}
\hline \multicolumn{6}{|c|}{ Supplemental Table S2.txt } \\
\hline CHEMBL1299946 & 688422 & 5.9 & 5.3943 & TRN & \\
\hline CHEMBL1574609 & 688422 & 8.1487 & 5.0623 & TRN & \\
\hline CHEMBL1977877 & 688422 & 5.3 & 5.6092 & TRN & \\
\hline CHEMBL1381518 & 688422 & 4.5 & 5.2258 & TRN & \\
\hline CHEMBL1464371 & 688422 & 4.45 & 4.9891 & TRN & \\
\hline CHEMBL1485551 & 688422 & 5.9 & 4.9496 & TRN & \\
\hline CHEMBL1537117 & 688422 & 4.85 & 5.144 & TRN & \\
\hline CHEMBL1601695 & 688422 & 4.85 & 5.1685 & TRN & \\
\hline CHEMBL1599400 & 688422 & 4.6 & 5.2533 & TRN & \\
\hline CHEMBL1570845 & 688422 & 4.5 & 5.5093 & TST & \\
\hline CHEMBL1561897 & 688422 & 5.7 & 5.0629 & TRN & \\
\hline CHEMBL1525357 & 688422 & 4.45 & 5.3713 & TRN & \\
\hline CHEMBL1407295 & 688422 & 4.45 & 5.0761 & TRN & \\
\hline CHEMBL3193665 & 688422 & 5.05 & 5.5565 & TRN & \\
\hline CHEMBL1606906 & 688422 & 5.35 & 5.0049 & TST & \\
\hline CHEMBL1422155 & 688422 & 5.8 & 5.41100 & 00000000005 & TRN \\
\hline CHEMBL1391573 & 688422 & 4.8 & 5.0229 & TRN & \\
\hline CHEMBL1595110 & 688422 & 7.6003 & 5.6333 & TRN & \\
\hline CHEMBL1465706 & 688422 & 6.25 & 5.3308 & TRN & \\
\hline CHEMBL1307792 & 688422 & 4.65 & 5.284 & TRN & \\
\hline CHEMBL1378268 & 688422 & 4.65 & 5.2826 & TRN & \\
\hline CHEMBL1447827 & 688422 & 6.5501 & 5.5268 & TRN & \\
\hline CHEMBL1520176 & 688422 & 5.2 & 4.7939 & TRN & \\
\hline CHEMBL1505338 & 688422 & 4.6 & 5.0901 & TST & \\
\hline CHEMBL1581094 & 688422 & 8.0506 & 5.4632 & TRN & \\
\hline CHEMBL491548 & 688422 & 6.35 & 4.9365 & TRN & \\
\hline CHEMBL1547110 & 688422 & 5.4 & 5.8301 & TST & \\
\hline CHEMBL1470284 & 688422 & 8.1024 & 5.4677 & TRN & \\
\hline CHEMBL1563212 & 688422 & 4.95 & 5.5442 & TRN & \\
\hline CHEMBL1546858 & 688422 & 4.85 & 5.3346 & TRN & \\
\hline CHEMBL1608282 & 688422 & 7.5498 & 5.8072 & TST & \\
\hline CHEMBL1416887 & 688422 & 4.45 & 4.9744 & TRN & \\
\hline CHEMBL1532433 & 688422 & 4.45 & 5.0438 & TST & \\
\hline CHEMBL1613337 & 688422 & 4.45 & 5.157 & TRN & \\
\hline CHEMBL1606360 & 688422 & 4.45 & 5.1812 & TRN & \\
\hline CHEMBL1580897 & 688422 & 4.45 & 4.9116 & TRN & \\
\hline CHEMBL463588 & 688422 & 4.45 & 5.0759 & TRN & \\
\hline CHEMBL1501745 & 688422 & 4.45 & 5.24 & TST & \\
\hline CHEMBL1330096 & 688422 & 4.85 & 5.2725 & TST & \\
\hline CHEMBL1607302 & 688422 & 4.45 & 5.1446 & TRN & \\
\hline CHEMBL1366636 & 688422 & 5.6 & 5.3879 & TRN & \\
\hline CHEMBL1465003 & 688422 & 4.8 & 5.2364 & TRN & \\
\hline CHEMBL1398583 & 688422 & 5.0 & 5.0819 & TRN & \\
\hline CHEMBL1590527 & 688422 & 5.2 & 5.0044 & TRN & \\
\hline CHEMBL1306051 & 688422 & 5.0 & 5.4245 & TRN & \\
\hline CHEMBL1613467 & 688422 & 6.25 & 5.4505 & TST & \\
\hline CHEMBL1603691 & 688422 & 4.5 & 5.2499 & TST & \\
\hline CHEMBL1491965 & 688422 & 4.65 & 4.7735 & TRN & \\
\hline
\end{tabular}




\begin{tabular}{|c|c|c|c|c|c|}
\hline & & \multicolumn{4}{|c|}{ Supplemental Table S2.txt } \\
\hline CHEMBL1521669 & 688422 & 4.85 & 5.2758 & TST & \\
\hline CHEMBL1597114 & 688422 & 8.4949 & 5.1318 & TRN & \\
\hline CHEMBL1395044 & 688422 & 5.1 & 5.7213 & TRN & \\
\hline CHEMBL1392258 & 688422 & 4.9 & 5.28600 & 00000000005 & TRN \\
\hline CHEMBL1365462 & 688422 & 5.2 & 5.5318 & TRN & \\
\hline CHEMBL1415944 & 688422 & 4.65 & 4.8328 & TST & \\
\hline CHEMBL1576867 & 688422 & 5.0 & 5.3326 & TRN & \\
\hline CHEMBL1555047 & 688422 & 4.8 & 5.1402 & TRN & \\
\hline CHEMBL1339346 & 688422 & 5.05 & 5.0764 & TRN & \\
\hline CHEMBL1374357 & 688422 & 4.7 & 5.1145 & TRN & \\
\hline CHEMBL1890899 & 688422 & 5.7 & 4.8088 & TRN & \\
\hline CHEMBL491547 & 688422 & 5.2 & 4.8494 & TRN & \\
\hline CHEMBL1593599 & 688422 & 4.7 & 5.277 & TRN & \\
\hline CHEMBL1535116 & 688422 & 4.45 & 5.1722 & TRN & \\
\hline CHEMBL1495193 & 688422 & 5.4 & 5.2762 & TRN & \\
\hline CHEMBL1406588 & 688422 & 5.85 & 5.1434 & TRN & \\
\hline CHEMBL1357030 & 688422 & 6.8 & 5.6069 & TRN & \\
\hline CHEMBL1300242 & 688422 & 6.5501 & 5.1751 & TRN & \\
\hline CHEMBL1500035 & 688422 & 4.45 & 5.0782 & TST & \\
\hline CHEMBL1494464 & 688422 & 4.9 & 5.4418 & TRN & \\
\hline CHEMBL1369318 & 688422 & 5.05 & 5.1733 & TRN & \\
\hline CHEMBL 255027 & 688422 & 5.5 & 6.1245 & TST & \\
\hline CHEMBL1544150 & 688422 & 4.7 & 5.2878 & TRN & \\
\hline CHEMBL1564425 & 688422 & 4.95 & 4.7845 & TRN & \\
\hline CHEMBL1437328 & 688422 & 4.85 & 5.0703 & TRN & \\
\hline CHEMBL1557077 & 688422 & 6.3 & 5.4254 & TST & \\
\hline CHEMBL1494844 & 688422 & 5.4 & 5.1591 & TST & \\
\hline CHEMBL1389677 & 688422 & 4.7 & 5.3695 & TRN & \\
\hline CHEMBL1491438 & 688422 & 4.65 & 4.9666 & TRN & \\
\hline CHEMBL1501623 & 688422 & 4.9 & 4.8996 & TRN & \\
\hline CHEMBL1474227 & 688422 & 4.95 & 5.7641 & TRN & \\
\hline CHEMBL1500335 & 688422 & 4.45 & 5.3855 & TRN & \\
\hline CHEMBL1362875 & 688422 & 4.45 & 5.1839 & TRN & \\
\hline CHEMBL1448277 & 688422 & 4.65 & 5.0793 & TRN & \\
\hline CHEMBL1510259 & 688422 & 5.35 & 5.309 & TRN & \\
\hline CHEMBL1564438 & 688422 & 4.85 & 5.3131 & TRN & \\
\hline CHEMBL1546767 & 688422 & 5.4 & 5.3826 & TRN & \\
\hline CHEMBL1405347 & 688422 & 4.7 & 4.6902 & TRN & \\
\hline CHEMBL1437084 & 688422 & 5.65 & 5.1155 & TRN & \\
\hline CHEMBL1344650 & 688422 & 4.45 & 5.3297 & TRN & \\
\hline CHEMBL1301937 & 688422 & 8.3468 & 5.0407 & TRN & \\
\hline CHEMBL1373464 & 688422 & 4.5 & 5.8458 & TST & \\
\hline CHEMBL1448262 & 688422 & 6.5 & 5.4379 & TRN & \\
\hline CHEMBL1593018 & 688422 & 4.45 & 5.013 & TRN & \\
\hline CHEMBL1604382 & 688422 & 7.15 & 5.6122 & TST & \\
\hline CHEMBL1514384 & 688422 & 4.45 & 5.8542 & TRN & \\
\hline CHEMBL1373733 & 688422 & 5.55 & 5.6802 & TRN & \\
\hline CHEMBL1334899 & 688422 & 5.05 & 5.0314 & TRN & \\
\hline
\end{tabular}




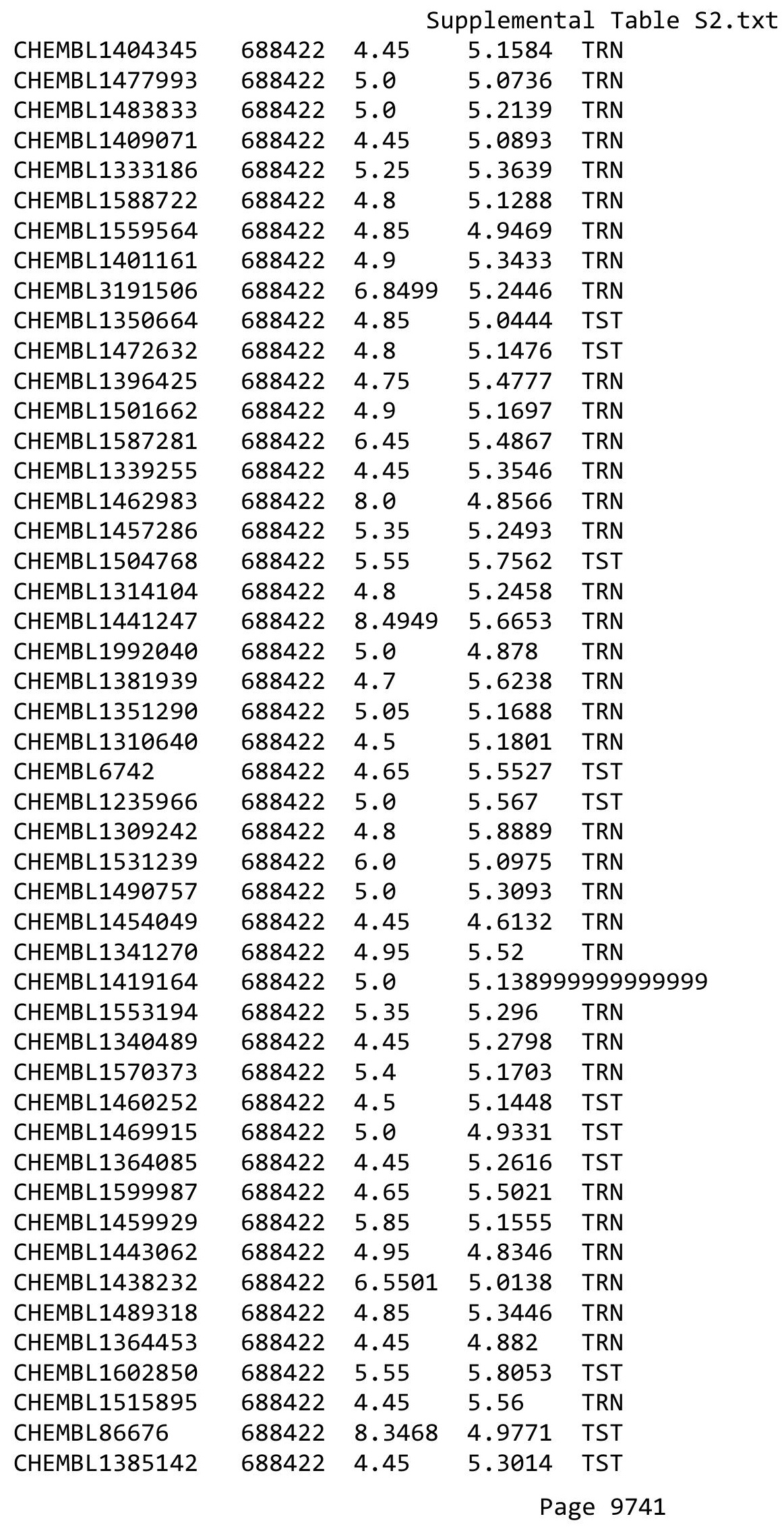




\begin{tabular}{|c|c|c|c|c|c|}
\hline & & \multicolumn{4}{|c|}{ Supplemental Table S2.txt } \\
\hline CHEMBL1507345 & 688422 & 4.5 & 4.9923 & TST & \\
\hline CHEMBL1330602 & 688422 & 7.3002 & 5.5524 & TRN & \\
\hline CHEMBL1471170 & 688422 & 5.05 & 4.9897 & TRN & \\
\hline CHEMBL1492021 & 688422 & 4.85 & 4.7305 & TRN & \\
\hline CHEMBL1326118 & 688422 & 4.6 & 4.8101 & TRN & \\
\hline CHEMBL1536911 & 688422 & 7.3002 & 5.4027 & TST & \\
\hline CHEMBL1368060 & 688422 & 4.45 & 5.4552 & TRN & \\
\hline CHEMBL1601148 & 688422 & 4.8 & 4.71899 & 9999999999 & TRN \\
\hline CHEMBL1316928 & 688422 & 4.45 & 4.7477 & TRN & \\
\hline CHEMBL1338190 & 688422 & 4.75 & 5.2955 & TST & \\
\hline CHEMBL1329154 & 688422 & 5.0 & 5.3125 & TST & \\
\hline CHEMBL1394264 & 688422 & 4.8 & 5.1072 & TRN & \\
\hline CHEMBL1306668 & 688422 & 4.7 & 5.4159 & TRN & \\
\hline CHEMBL1448265 & 688422 & 4.45 & 5.0278 & TRN & \\
\hline CHEMBL1421668 & 688422 & 4.9 & 5.1022 & TRN & \\
\hline CHEMBL1477360 & 688422 & 4.45 & 4.9686 & TST & \\
\hline CHEMBL2003942 & 688422 & 5.5 & 5.4935 & TRN & \\
\hline CHEMBL183 & 688422 & 4.45 & 5.4674 & TST & \\
\hline CHEMBL1499780 & 688422 & 4.95 & 5.5517 & TRN & \\
\hline CHEMBL1561231 & 688422 & 5.45 & 5.2266 & TRN & \\
\hline CHEMBL1497440 & 688422 & 4.45 & 5.2987 & TRN & \\
\hline CHEMBL1595510 & 688422 & 4.75 & 4.8347 & TRN & \\
\hline CHEMBL1335441 & 688422 & 4.7 & 5.2072 & TST & \\
\hline CHEMBL1515843 & 688422 & 5.2 & 4.8521 & TRN & \\
\hline CHEMBL1518885 & 688422 & 4.5 & 5.5306 & TRN & \\
\hline CHEMBL1506621 & 688422 & 8.4949 & 5.3976 & TRN & \\
\hline CHEMBL3213501 & 688422 & 7.5003 & 5.0761 & TRN & \\
\hline CHEMBL3196082 & 688422 & 4.45 & 5.4372 & TRN & \\
\hline CHEMBL1576942 & 688422 & 4.45 & 5.0019 & TRN & \\
\hline CHEMBL1379304 & 688422 & 4.45 & 5.256 & TST & \\
\hline CHEMBL1994068 & 688422 & 4.9 & 5.2125 & TRN & \\
\hline CHEMBL3192393 & 688422 & 4.8 & 4.6392 & TRN & \\
\hline CHEMBL 3210738 & 688422 & 4.85 & 5.4345 & TST & \\
\hline CHEMBL1312716 & 688422 & 4.7 & 5.2709 & TRN & \\
\hline CHEMBL1498420 & 688422 & 4.45 & 4.8439 & TST & \\
\hline CHEMBL1591973 & 688422 & 5.9 & 5.7762 & TST & \\
\hline CHEMBL1457529 & 688422 & 4.95 & 5.2131 & TRN & \\
\hline CHEMBL1367217 & 688422 & 5.4 & 5.4486 & TRN & \\
\hline CHEMBL1545554 & 688422 & 4.75 & 5.2488 & TST & \\
\hline CHEMBL1351558 & 688422 & 5.1 & 5.5943 & TRN & \\
\hline CHEMBL1457110 & 688422 & 5.25 & 5.4123 & TRN & \\
\hline CHEMBL1541876 & 688422 & 4.45 & 5.084 & TRN & \\
\hline CHEMBL1319771 & 688422 & 8.1487 & 5.2396 & TST & \\
\hline CHEMBL1346856 & 688422 & 4.85 & 5.0058 & TRN & \\
\hline CHEMBL1578738 & 688422 & 4.85 & 5.2778 & TRN & \\
\hline CHEMBL1564561 & 688422 & 4.9 & 5.1766 & TRN & \\
\hline CHEMBL3210071 & 688422 & 4.8 & 5.1827 & TST & \\
\hline CHEMBL1440504 & 688422 & 4.5 & 4.8121 & TRN & \\
\hline
\end{tabular}




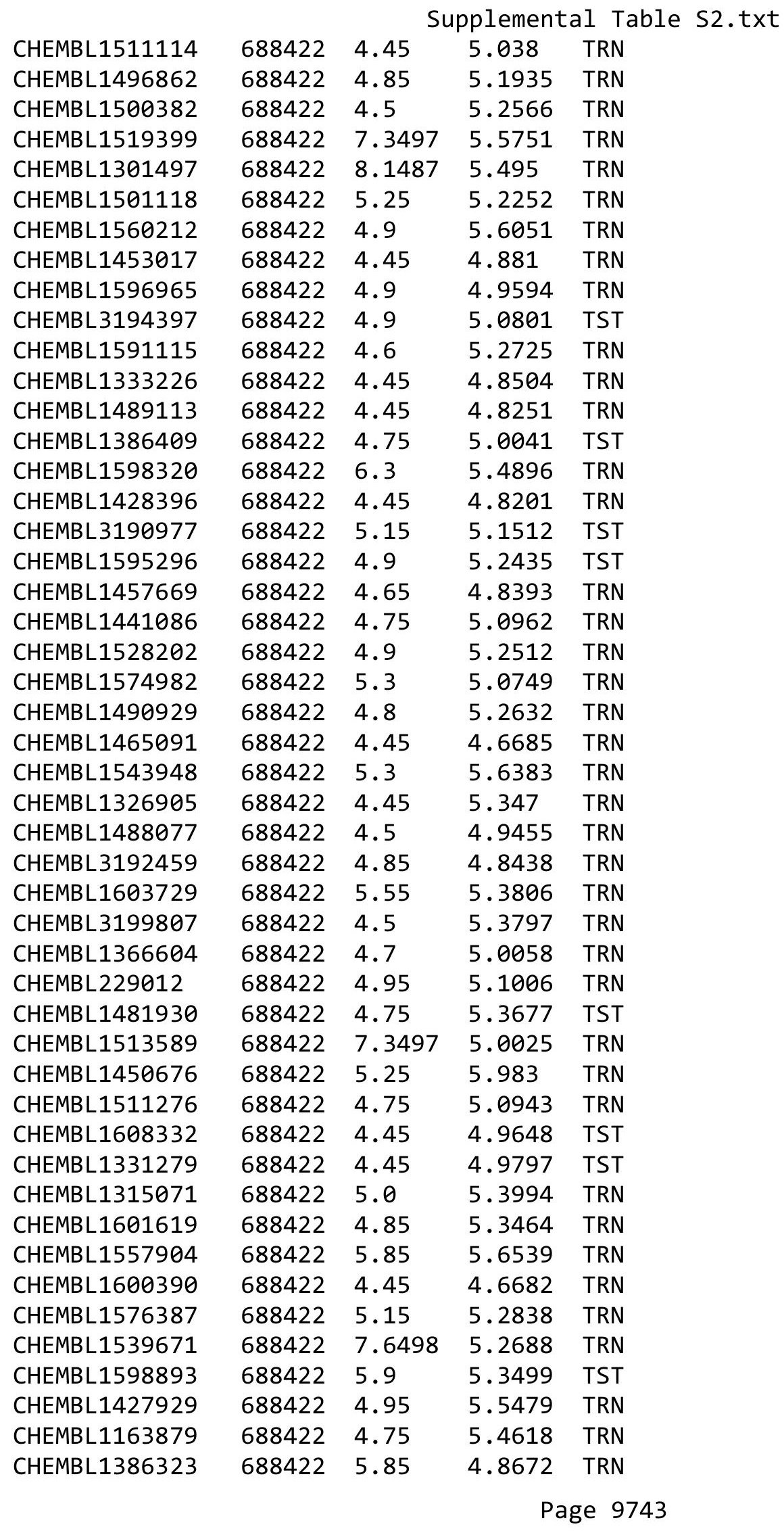




\begin{tabular}{|c|c|c|c|c|c|}
\hline \multicolumn{6}{|c|}{ Supplemental Table S2.txt } \\
\hline CHEMBL1420462 & 688422 & 4.45 & 5.0225 & TRN & \\
\hline CHEMBL1505755 & 688422 & 4.9 & 5.2616 & TRN & \\
\hline CHEMBL1483813 & 688422 & 6.7001 & 5.3913 & TRN & \\
\hline CHEMBL1497304 & 688422 & 5.5 & 5.316 & TRN & \\
\hline CHEMBL323542 & 688422 & 7.699 & 5.0611 & TST & \\
\hline CHEMBL1173475 & 688422 & 4.85 & 5.5209 & TRN & \\
\hline CHEMBL1562725 & 688422 & 4.75 & 4.8161 & TRN & \\
\hline CHEMBL1387156 & 688422 & 4.45 & 4.9518 & TST & \\
\hline CHEMBL1505065 & 688422 & 4.95 & 5.37 & TRN & \\
\hline CHEMBL84472 & 688422 & 6.7001 & 5.49100 & 00000000005 & TRN \\
\hline CHEMBL1503518 & 688422 & 4.95 & 5.0394 & TST & \\
\hline CHEMBL1335165 & 688422 & 5.5 & 5.0586 & TST & \\
\hline CHEMBL1316367 & 688422 & 4.5 & 5.2893 & TRN & \\
\hline CHEMBL1505186 & 688422 & 6.7001 & 5.4081 & TRN & \\
\hline CHEMBL1347211 & 688422 & 5.5 & 5.0345 & TRN & \\
\hline CHEMBL1570002 & 688422 & 4.45 & 4.8287 & TST & \\
\hline CHEMBL1347695 & 688422 & 4.55 & 5.3947 & TRN & \\
\hline CHEMBL1409334 & 688422 & 4.75 & 4.97199 & 99999999995 & TRN \\
\hline CHEMBL1354594 & 688422 & 7.4001 & 5.3021 & TRN & \\
\hline CHEMBL1328405 & 688422 & 4.9 & 5.1334 & TRN & \\
\hline CHEMBL1462566 & 688422 & 4.85 & 5.0093 & TRN & \\
\hline CHEMBL1541511 & 688422 & 4.65 & 5.2876 & TST & \\
\hline CHEMBL1477451 & 688422 & 4.7 & 5.0826 & TRN & \\
\hline CHEMBL1536613 & 688422 & 4.5 & 5.1504 & TRN & \\
\hline CHEMBL1322608 & 688422 & 9.0 & 5.8437 & TRN & \\
\hline CHEMBL1433609 & 688422 & 6.25 & 5.7463 & TRN & \\
\hline CHEMBL1340792 & 688422 & 4.95 & 4.4993 & TRN & \\
\hline CHEMBL1537276 & 688422 & 4.6 & 4.9106 & TRN & \\
\hline CHEMBL1300822 & 688422 & 4.8 & 5.0402 & TST & \\
\hline CHEMBL1363024 & 688422 & 4.7 & 5.6128 & TST & \\
\hline CHEMBL1307235 & 688422 & 7.6498 & 5.5302 & TRN & \\
\hline CHEMBL1498649 & 688422 & 4.8 & 4.9434 & TRN & \\
\hline CHEMBL1491038 & 688422 & 5.2 & 5.5128 & TRN & \\
\hline CHEMBL1300140 & 688422 & 5.95 & 4.8898 & TRN & \\
\hline CHEMBL3190507 & 688422 & 5.65 & 4.8287 & TRN & \\
\hline CHEMBL1312654 & 688422 & 5.25 & 4.7735 & TST & \\
\hline CHEMBL1507474 & 688422 & 4.45 & 5.2001 & TRN & \\
\hline CHEMBL1519678 & 688422 & 5.85 & 5.0515 & TRN & \\
\hline CHEMBL261777 & 688422 & 7.7496 & 5.1996 & TRN & \\
\hline CHEMBL1365333 & 688422 & 4.75 & 5.5607 & TRN & \\
\hline CHEMBL1351268 & 688422 & 4.9 & 5.37 & TST & \\
\hline CHEMBL1318984 & 688422 & 5.65 & 5.3176 & TRN & \\
\hline CHEMBL1495977 & 688422 & 6.3 & 5.6124 & TRN & \\
\hline CHEMBL1345775 & 688422 & 4.5 & 5.1993 & TRN & \\
\hline CHEMBL1600111 & 688422 & 6.15 & 5.1607 & TRN & \\
\hline CHEMBL1408821 & 688422 & 4.45 & 5.9937 & TRN & \\
\hline CHEMBL3210922 & 688422 & 4.8 & 5.6452 & TRN & \\
\hline CHEMBL1347023 & 688422 & 4.85 & 5.2031 & TRN & \\
\hline
\end{tabular}




\begin{tabular}{|c|c|c|c|c|}
\hline \multicolumn{5}{|c|}{ Supplemental Table S2.txt } \\
\hline CHEMBL1529489 & 688422 & 4.5 & 5.4473 & TRN \\
\hline CHEMBL1612250 & 688422 & 4.45 & 5.1185 & TRN \\
\hline CHEMBL1309795 & 688422 & 4.5 & 5.3075 & TRN \\
\hline CHEMBL1593180 & 688422 & 4.95 & 5.0611 & TRN \\
\hline CHEMBL1559229 & 688422 & 5.3 & 5.8368 & TST \\
\hline CHEMBL1605412 & 688422 & 4.45 & 5.3948 & TST \\
\hline CHEMBL1406200 & 688422 & 7.8013 & 5.4039 & TRN \\
\hline CHEMBL1457783 & 688422 & 4.5 & 5.3031 & TRN \\
\hline CHEMBL1313760 & 688422 & 4.75 & 4.7238 & TRN \\
\hline CHEMBL1364630 & 688422 & 5.25 & 5.4232 & TST \\
\hline CHEMBL1609875 & 688422 & 4.45 & 5.4892 & TST \\
\hline CHEMBL1484169 & 688422 & 4.9 & 5.3137 & TRN \\
\hline CHEMBL1305548 & 688422 & 6.0 & 5.2494 & TRN \\
\hline CHEMBL 3189537 & 688422 & 4.45 & 5.1693 & TRN \\
\hline CHEMBL1409561 & 688422 & 4.45 & 4.9433 & TRN \\
\hline CHEMBL1606638 & 688422 & 4.45 & 5.0159 & TRN \\
\hline CHEMBL1468522 & 688422 & 4.6 & 5.0238 & TRN \\
\hline CHEMBL1389482 & 688422 & 5.45 & 5.4811 & TRN \\
\hline CHEMBL1307843 & 688422 & 4.75 & 5.0807 & TST \\
\hline CHEMBL1508524 & 688422 & 5.45 & 5.1262 & TST \\
\hline CHEMBL1331363 & 688422 & 4.45 & 5.4326 & TRN \\
\hline CHEMBL1581182 & 688422 & 4.75 & 5.3112 & TRN \\
\hline CHEMBL1533767 & 688422 & 4.5 & 5.3565 & TRN \\
\hline CHEMBL1429583 & 688422 & 5.55 & 5.433 & TST \\
\hline CHEMBL1590821 & 688422 & 4.9 & 5.2596 & TST \\
\hline CHEMBL1305121 & 688422 & 6.5 & 5.7216 & TST \\
\hline CHEMBL1324386 & 688422 & 4.6 & 5.0645 & TRN \\
\hline CHEMBL1331165 & 688422 & 5.15 & 5.3627 & TRN \\
\hline CHEMBL1443215 & 688422 & 4.75 & 5.2216 & TRN \\
\hline CHEMBL1443620 & 688422 & 5.55 & 5.6089 & TRN \\
\hline CHEMBL1613521 & 688422 & 7.0501 & 5.3993 & TRN \\
\hline CHEMBL1487837 & 688422 & 9.3979 & 5.5987 & TST \\
\hline CHEMBL1414714 & 688422 & 4.85 & 5.1071 & TST \\
\hline CHEMBL1470411 & 688422 & 4.75 & 5.1417 & TRN \\
\hline CHEMBL1395655 & 688422 & 4.55 & 5.2672 & TRN \\
\hline CHEMBL1520976 & 688422 & 6.0 & 5.9518 & TST \\
\hline CHEMBL1975216 & 688422 & 4.9 & 5.4053 & TRN \\
\hline CHEMBL432608 & 688422 & 5.2 & 5.0093 & TST \\
\hline CHEMBL1496307 & 688422 & 5.05 & 5.2331 & TST \\
\hline CHEMBL1508337 & 688422 & 5.2 & 5.6914 & TRN \\
\hline CHEMBL1551128 & 688422 & 4.45 & 5.4964 & TRN \\
\hline CHEMBL1307428 & 688422 & 5.7 & 5.0864 & TRN \\
\hline CHEMBL1331921 & 688422 & 6.25 & 5.1783 & TRN \\
\hline CHEMBL 3195343 & 688422 & 4.85 & 5.088 & TST \\
\hline CHEMBL1517217 & 688422 & 4.8 & 4.9555 & TRN \\
\hline CHEMBL1459284 & 688422 & 7.0501 & 5.3182 & TRN \\
\hline CHEMBL1570004 & 688422 & 4.45 & 4.5859 & TST \\
\hline CHEMBL1512458 & 688422 & 6.8499 & 5.3448 & TRN \\
\hline
\end{tabular}




\begin{tabular}{|c|c|c|c|c|c|}
\hline \multicolumn{6}{|c|}{ Supplemental Table S2.txt } \\
\hline CHEMBL1990527 & 688422 & 6.0 & 5.2307 & TRN & \\
\hline CHEMBL1419542 & 688422 & 7.0 & 4.9081 & TRN & \\
\hline CHEMBL1542276 & 688422 & 4.95 & 5.2748 & TRN & \\
\hline CHEMBL1443977 & 688422 & 4.7 & 5.0458 & TST & \\
\hline CHEMBL1558819 & 688422 & 4.45 & 5.065 & TRN & \\
\hline CHEMBL1547170 & 688422 & 8.3468 & 5.1374 & TRN & \\
\hline CHEMBL1347323 & 688422 & 4.9 & 4.8063 & TRN & \\
\hline CHEMBL1373634 & 688422 & 4.45 & 5.0509 & TST & \\
\hline CHEMBL1549345 & 688422 & 4.6 & 4.6896 & TRN & \\
\hline CHEMBL1388752 & 688422 & 4.45 & 4.9805 & TRN & \\
\hline CHEMBL1433701 & 688422 & 4.5 & 5.053 & TRN & \\
\hline CHEMBL1556277 & 688422 & 4.5 & 4.9516 & TRN & \\
\hline CHEMBL1470953 & 688422 & 4.9 & 4.7284 & TRN & \\
\hline CHEMBL1390882 & 688422 & 5.25 & 4.9414 & TRN & \\
\hline CHEMBL1483755 & 688422 & 5.15 & 5.1715 & TRN & \\
\hline CHEMBL1450148 & 688422 & 4.6 & 5.3946 & TRN & \\
\hline CHEMBL1512959 & 688422 & 7.4001 & 5.3076 & TRN & \\
\hline CHEMBL1557256 & 688422 & 4.95 & 5.2927 & TRN & \\
\hline CHEMBL1556634 & 688422 & 4.65 & 5.0975 & TRN & \\
\hline CHEMBL1599636 & 688422 & 4.45 & 4.7297 & TRN & \\
\hline CHEMBL1496663 & 688422 & 4.45 & 5.1385 & TST & \\
\hline CHEMBL3145030 & 688422 & 5.65 & 5.29299 & 9999999999 & TST \\
\hline CHEMBL1471607 & 688422 & 4.65 & 4.9594 & TRN & \\
\hline CHEMBL1602290 & 688422 & 4.6 & 5.0593 & TST & \\
\hline CHEMBL1376835 & 688422 & 4.45 & 5.1914 & TST & \\
\hline CHEMBL1361244 & 688422 & 5.0 & 5.3134 & TRN & \\
\hline CHEMBL1299671 & 688422 & 7.0501 & 5.0195 & TST & \\
\hline CHEMBL1576750 & 688422 & 4.9 & 5.1005 & TRN & \\
\hline CHEMBL1403003 & 688422 & 5.0 & 5.1044 & TRN & \\
\hline CHEMBL1579693 & 688422 & 4.5 & 5.2392 & TRN & \\
\hline CHEMBL1469691 & 688422 & 5.1 & 5.0088 & TRN & \\
\hline CHEMBL1512697 & 688422 & 4.75 & 5.8242 & TRN & \\
\hline CHEMBL1602686 & 688422 & 4.45 & 5.3003 & TRN & \\
\hline CHEMBL600332 & 688422 & 5.25 & 5.2975 & TRN & \\
\hline CHEMBL1582448 & 688422 & 4.45 & 5.4266 & TRN & \\
\hline CHEMBL1361176 & 688422 & 4.65 & 5.2027 & TRN & \\
\hline CHEMBL1437573 & 688422 & 4.55 & 5.0756 & TRN & \\
\hline CHEMBL1537146 & 688422 & 5.45 & 5.2578 & TRN & \\
\hline CHEMBL1469057 & 688422 & 4.45 & 5.1061 & TRN & \\
\hline CHEMBL1465765 & 688422 & 5.0 & 4.7367 & TRN & \\
\hline CHEMBL1302217 & 688422 & 4.85 & 5.0365 & TRN & \\
\hline CHEMBL1363253 & 688422 & 4.8 & 5.0608 & TRN & \\
\hline CHEMBL1611011 & 688422 & 4.9 & 5.1417 & TRN & \\
\hline CHEMBL1375671 & 688422 & 6.1 & 5.4739 & TRN & \\
\hline CHEMBL1556612 & 688422 & 4.7 & 5.0018 & TRN & \\
\hline CHEMBL1991885 & 688422 & 4.7 & 5.1426 & TRN & \\
\hline CHEMBL1587286 & 688422 & 4.75 & 5.1646 & TRN & \\
\hline CHEMBL1610665 & 688422 & 4.7 & 4.6959 & TRN & \\
\hline
\end{tabular}




\begin{tabular}{|c|c|c|c|c|c|}
\hline \multicolumn{6}{|c|}{ Supplemental Table S2.txt } \\
\hline CHEMBL1323261 & 688422 & 6.25 & 5.6548 & TRN & \\
\hline CHEMBL1561998 & 688422 & 7.0501 & 5.3233 & TST & \\
\hline CHEMBL3661373 & 688422 & 4.7 & 4.9938 & TRN & \\
\hline CHEMBL1534220 & 688422 & 4.5 & 4.9668 & TST & \\
\hline CHEMBL262636 & 688422 & 4.85 & 5.3798 & TRN & \\
\hline CHEMBL1484443 & 688422 & 5.35 & 5.7167 & TRN & \\
\hline CHEMBL1507815 & 688422 & 5.0 & 5.2773 & TRN & \\
\hline CHEMBL1323798 & 688422 & 6.5501 & 5.2481 & TRN & \\
\hline CHEMBL1564102 & 688422 & 4.65 & 5.1042 & TST & \\
\hline CHEMBL1423733 & 688422 & 4.85 & 5.6792 & TRN & \\
\hline CHEMBL 3196123 & 688422 & 5.65 & 5.5601 & TST & \\
\hline CHEMBL602722 & 688422 & 5.9 & 4.9777 & TRN & \\
\hline CHEMBL3210742 & 688422 & 4.75 & 5.5154 & TRN & \\
\hline CHEMBL1486857 & 688422 & 4.8 & 5.0068 & TRN & \\
\hline CHEMBL1336683 & 688422 & 4.6 & 5.3262 & TRN & \\
\hline CHEMBL1478876 & 688422 & 5.15 & 4.7818 & TRN & \\
\hline CHEMBL1418387 & 688422 & 5.35 & 5.2101 & TRN & \\
\hline CHEMBL1476445 & 688422 & 4.4 & 5.0545 & TRN & \\
\hline CHEMBL1600767 & 688422 & 4.85 & 5.2977 & TST & \\
\hline CHEMBL1443441 & 688422 & 4.45 & 4.9153 & TRN & \\
\hline CHEMBL1405432 & 688422 & 4.75 & 4.9183 & TST & \\
\hline CHEMBL1596452 & 688422 & 6.4 & 5.585 & TRN & \\
\hline CHEMBL1612413 & 688422 & 4.45 & 5.1974 & TRN & \\
\hline CHEMBL3195037 & 688422 & 4.65 & 5.7614 & TRN & \\
\hline CHEMBL1368868 & 688422 & 4.45 & 5.4496 & TRN & \\
\hline CHEMBL1429429 & 688422 & 4.8 & 4.9262 & TST & \\
\hline CHEMBL1480656 & 688422 & 5.15 & 6.2492 & TST & \\
\hline CHEMBL1525015 & 688422 & 4.85 & 5.1683 & TST & \\
\hline CHEMBL1387931 & 688422 & 5.1 & 5.2009 & TRN & \\
\hline CHEMBL1598921 & 688422 & 4.9 & 4.7751 & TRN & \\
\hline CHEMBL1535018 & 688422 & 5.2 & 4.9114 & TRN & \\
\hline CHEMBL1370884 & 688422 & 5.2 & 5.3186 & TRN & \\
\hline CHEMBL1531955 & 688422 & 4.75 & 5.1042 & TRN & \\
\hline CHEMBL1470903 & 688422 & 4.45 & 4.73 & TRN & \\
\hline CHEMBL1568626 & 688422 & 5.55 & 4.8413 & TRN & \\
\hline CHEMBL1459316 & 688422 & 4.45 & 5.3653 & TRN & \\
\hline CHEMBL1581950 & 688422 & 4.75 & 4.7427 & TRN & \\
\hline CHEMBL1471679 & 688422 & 7.3002 & 5.6679 & TRN & \\
\hline CHEMBL1607804 & 688422 & 5.15 & 5.0062 & TRN & \\
\hline CHEMBL1499366 & 688422 & 4.75 & 5.0462 & TRN & \\
\hline CHEMBL1331252 & 688422 & 5.1 & 5.1714 & TST & \\
\hline CHEMBL1466333 & 688422 & 5.4 & 5.3374 & TST & \\
\hline CHEMBL1552878 & 688422 & 7.5003 & 5.8153 & TRN & \\
\hline CHEMBL1401828 & 688422 & 4.9 & 5.29899 & 99999999995 & TRN \\
\hline CHEMBL1321217 & 688422 & 6.0 & 4.9403 & TST & \\
\hline CHEMBL1507002 & 688422 & 4.5 & 5.1694 & TST & \\
\hline CHEMBL1366489 & 688422 & 4.75 & 5.1717 & TST & \\
\hline CHEMBL1524881 & 688422 & 4.7 & 4.9142 & TRN & \\
\hline
\end{tabular}




\begin{tabular}{|c|c|c|c|c|}
\hline \multicolumn{5}{|c|}{ Supplemental Table S2.txt } \\
\hline CHEMBL1473660 & 688422 & 4.7 & 5.2448 & TRN \\
\hline CHEMBL1602937 & 688422 & 5.25 & 5.7795 & TRN \\
\hline CHEMBL1585164 & 688422 & 5.05 & 4.9553 & TRN \\
\hline CHEMBL1589671 & 688422 & 4.8 & 5.1187 & TST \\
\hline CHEMBL 1558756 & 688422 & 4.8 & 5.2488 & TRN \\
\hline CHEMBL1526635 & 688422 & 4.95 & 4.945 & TRN \\
\hline CHEMBL1452111 & 688422 & 4.45 & 5.4902 & TRN \\
\hline CHEMBL1540836 & 688422 & 5.6 & 5.3561 & TRN \\
\hline CHEMBL1976198 & 688422 & 4.95 & 5.0973 & TRN \\
\hline CHEMBL1473755 & 688422 & 4.7 & 4.7258 & TRN \\
\hline CHEMBL1480340 & 688422 & 4.6 & 5.42 & TRN \\
\hline CHEMBL1444690 & 688422 & 5.0 & 4.8901 & TST \\
\hline CHEMBL1523598 & 688422 & 8.3468 & 5.4147 & TRN \\
\hline CHEMBL1524972 & 688422 & 4.95 & 5.3281 & TRN \\
\hline CHEMBL1320080 & 688422 & 4.95 & 5.0033 & TRN \\
\hline CHEMBL1526413 & 688422 & 4.95 & 5.136 & TRN \\
\hline CHEMBL1577254 & 688422 & 4.5 & 5.2095 & TRN \\
\hline CHEMBL1440006 & 688422 & 4.85 & 5.4571 & TRN \\
\hline CHEMBL1343095 & 688422 & 4.45 & 4.872 & TRN \\
\hline CHEMBL1468680 & 688422 & 4.75 & 4.9717 & TRN \\
\hline CHEMBL1561148 & 688422 & 5.6 & 5.6515 & TST \\
\hline CHEMBL1359770 & 688422 & 4.45 & 5.2646 & TRN \\
\hline CHEMBL1483076 & 688422 & 4.45 & 5.1978 & TST \\
\hline CHEMBL1585984 & 688422 & 4.6 & 5.2807 & TST \\
\hline CHEMBL1447085 & 688422 & 5.55 & 5.0414 & TRN \\
\hline CHEMBL1594822 & 688422 & 6.05 & 5.6222 & TRN \\
\hline CHEMBL1550876 & 688422 & 7.6498 & 5.5938 & TRN \\
\hline CHEMBL1396972 & 688422 & 8.4949 & 5.4936 & TRN \\
\hline CHEMBL1613324 & 688422 & 8.0 & 5.1129 & TST \\
\hline CHEMBL1604396 & 688422 & 4.7 & 5.2884 & TST \\
\hline CHEMBL1535361 & 688422 & 5.5 & 5.121 & TRN \\
\hline CHEMBL3192616 & 688422 & 4.45 & 5.0095 & TRN \\
\hline CHEMBL1417893 & 688422 & 4.65 & 5.1229 & TST \\
\hline CHEMBL1419184 & 688422 & 4.95 & 5.3421 & TRN \\
\hline CHEMBL1359396 & 688422 & 5.0 & 4.9125 & TRN \\
\hline CHEMBL1471740 & 688422 & 7.6003 & 5.0694 & TRN \\
\hline CHEMBL1503020 & 688422 & 6.1 & 5.3085 & TRN \\
\hline CHEMBL1421880 & 688422 & 5.4 & 5.2456 & TRN \\
\hline CHEMBL1480848 & 688422 & 7.5498 & 5.5117 & TRN \\
\hline CHEMBL1373006 & 688422 & 4.45 & 5.273 & TRN \\
\hline CHEMBL1474255 & 688422 & 5.05 & 5.2298 & TRN \\
\hline CHEMBL1509242 & 688422 & 4.75 & 5.5759 & TST \\
\hline CHEMBL1457675 & 688422 & 4.85 & 5.0159 & TRN \\
\hline CHEMBL1385267 & 688422 & 4.5 & 5.1387 & TRN \\
\hline CHEMBL1362715 & 688422 & 5.0 & 5.0161 & TRN \\
\hline CHEMBL3195879 & 688422 & 4.45 & 4.8946 & TRN \\
\hline CHEMBL1536681 & 688422 & 5.3 & 5.3185 & TST \\
\hline CHEMBL1582535 & 688422 & 6.95 & 5.0075 & TRN \\
\hline
\end{tabular}




\begin{tabular}{|c|c|c|c|c|}
\hline \multicolumn{5}{|c|}{ Supplemental Table S2.txt } \\
\hline CHEMBL1417390 & 688422 & 4.9 & 5.1018 & TRN \\
\hline CHEMBL1545613 & 688422 & 4.65 & 5.0763 & TST \\
\hline CHEMBL3197306 & 688422 & 4.6 & 5.3949 & TRN \\
\hline CHEMBL1523266 & 688422 & 4.65 & 5.6239 & TST \\
\hline CHEMBL1352314 & 688422 & 4.5 & 5.4962 & TRN \\
\hline CHEMBL1303701 & 688422 & 4.45 & 5.3671 & TRN \\
\hline CHEMBL1256364 & 688422 & 5.45 & 5.3632 & TRN \\
\hline CHEMBL1524712 & 688422 & 4.9 & 5.1966 & TRN \\
\hline CHEMBL1571714 & 688422 & 7.6498 & 5.2672 & TRN \\
\hline CHEMBL1325062 & 688422 & 4.45 & 4.5033 & TST \\
\hline CHEMBL1540915 & 688422 & 5.15 & 5.4022 & TST \\
\hline CHEMBL1580868 & 688422 & 6.0 & 4.9733 & TRN \\
\hline CHEMBL1408577 & 688422 & 4.9 & 5.0902 & TST \\
\hline CHEMBL1466260 & 688422 & 5.0 & 4.8275 & TRN \\
\hline CHEMBL1507995 & 688422 & 4.85 & 5.4968 & TRN \\
\hline CHEMBL3207694 & 688422 & 5.55 & 5.1961 & TRN \\
\hline CHEMBL1609192 & 688422 & 4.65 & 5.4379 & TST \\
\hline CHEMBL1490905 & 688422 & 4.9 & 4.9784 & TRN \\
\hline CHEMBL1508043 & 688422 & 4.55 & 5.4491 & TRN \\
\hline CHEMBL1496101 & 688422 & 4.45 & 4.655 & TRN \\
\hline CHEMBL1362505 & 688422 & 4.45 & 5.38 & TST \\
\hline CHEMBL1349431 & 688422 & 8.301 & 5.7348 & TST \\
\hline CHEMBL1303809 & 688422 & 4.85 & 5.2424 & TRN \\
\hline CHEMBL1451846 & 688422 & 4.5 & 4.7742 & TRN \\
\hline CHEMBL1594812 & 688422 & 5.0 & 5.0679 & TRN \\
\hline CHEMBL1348582 & 688422 & 4.95 & 5.393 & TRN \\
\hline CHEMBL1463661 & 688422 & 5.9 & 5.5935 & TST \\
\hline CHEMBL3212859 & 688422 & 4.9 & 5.1353 & TST \\
\hline CHEMBL1314985 & 688422 & 4.45 & 5.0362 & TRN \\
\hline CHEMBL1527722 & 688422 & 5.25 & 6.3977 & TRN \\
\hline CHEMBL1583812 & 688422 & 4.45 & 5.2296 & TRN \\
\hline CHEMBL1392235 & 688422 & 4.5 & 4.7199 & TRN \\
\hline CHEMBL1370357 & 688422 & 5.3 & 5.4197 & TST \\
\hline CHEMBL1489565 & 688422 & 5.05 & 4.9777 & TRN \\
\hline CHEMBL3209859 & 688422 & 4.95 & 5.0139 & TRN \\
\hline CHEMBL1349796 & 688422 & 4.45 & 5.3025 & TRN \\
\hline CHEMBL1299901 & 688422 & 5.0 & 5.1223 & TRN \\
\hline CHEMBL1480780 & 688422 & 7.15 & 5.0812 & TST \\
\hline CHEMBL1582067 & 688422 & 5.9 & 4.8584 & TRN \\
\hline CHEMBL1354100 & 688422 & 5.25 & 4.9877 & TST \\
\hline CHEMBL1472578 & 688422 & 6.5 & 4.9961 & TST \\
\hline CHEMBL1381875 & 688422 & 6.3 & 5.5899 & TRN \\
\hline CHEMBL1512038 & 688422 & 4.45 & 5.2685 & TRN \\
\hline CHEMBL1347203 & 688422 & 7.5498 & 5.2793 & TRN \\
\hline CHEMBL1435500 & 688422 & 4.45 & 5.3899 & TRN \\
\hline CHEMBL1520025 & 688422 & 5.15 & 5.92 & TRN \\
\hline CHEMBL1417896 & 688422 & 4.7 & 4.997 & TRN \\
\hline CHEMBL1346240 & 688422 & 5.45 & 5.2839 & TRN \\
\hline
\end{tabular}




\begin{tabular}{|c|c|c|c|c|c|}
\hline \multirow[b]{2}{*}{ CHEMBL1546204 } & \multicolumn{5}{|c|}{ Supplemental Table S2.txt } \\
\hline & 688422 & 7.4498 & 5.3106 & TRN & \\
\hline CHEMBL1599023 & 688422 & 5.4 & 5.3823 & TST & \\
\hline CHEMBL1602484 & 688422 & 4.45 & 5.0646 & TRN & \\
\hline CHEMBL3191783 & 688422 & 4.95 & 5.0123 & TRN & \\
\hline CHEMBL3191446 & 688422 & 4.45 & 5.3604 & TRN & \\
\hline CHEMBL1583717 & 688422 & 5.0 & 5.5266 & TRN & \\
\hline CHEMBL1557771 & 688422 & 5.45 & 5.3272 & TRN & \\
\hline CHEMBL1449041 & 688422 & 4.7 & 5.8389 & TRN & \\
\hline CHEMBL1314722 & 688422 & 7.15 & 5.7565 & TRN & \\
\hline CHEMBL1609104 & 688422 & 5.3 & 5.1321 & TRN & \\
\hline CHEMBL1504881 & 688422 & 7.2503 & 5.2651 & TRN & \\
\hline CHEMBL1507490 & 688422 & 5.5 & 4.957 & TRN & \\
\hline CHEMBL1328877 & 688422 & 5.35 & 5.6326 & TRN & \\
\hline CHEMBL1443783 & 688422 & 4.55 & 4.8629 & TRN & \\
\hline CHEMBL1419069 & 688422 & 4.8 & 4.8912 & TRN & \\
\hline CHEMBL1302953 & 688422 & 4.8 & 4.8481 & TRN & \\
\hline CHEMBL1601941 & 688422 & 5.0 & 4.7871 & TST & \\
\hline CHEMBL1437013 & 688422 & 4.7 & 5.2116 & TRN & \\
\hline CHEMBL1472138 & 688422 & 4.85 & 5.4982 & TRN & \\
\hline CHEMBL1403023 & 688422 & 8.3979 & 5.7083 & TRN & \\
\hline CHEMBL 1386372 & 688422 & 4.5 & 5.4348 & TRN & \\
\hline CHEMBL1461040 & 688422 & 4.7 & 5.1308 & TRN & \\
\hline CHEMBL1363812 & 688422 & 4.5 & 4.8352 & TRN & \\
\hline CHEMBL1368770 & 688422 & 5.75 & 5.6291 & TRN & \\
\hline CHEMBL1464599 & 688422 & 4.7 & 4.6934 & TRN & \\
\hline CHEMBL1393326 & 688422 & 4.85 & 5.6532 & TRN & \\
\hline CHEMBL1590878 & 688422 & 8.4949 & 5.3552 & TRN & \\
\hline CHEMBL1301811 & 688422 & 4.9 & 5.1943 & TST & \\
\hline CHEMBL1363598 & 688422 & 5.9 & 5.2981 & TST & \\
\hline CHEMBL1543051 & 688422 & 4.45 & 5.0655 & TRN & \\
\hline CHEMBL1356873 & 688422 & 4.95 & 5.4193 & TRN & \\
\hline CHEMBL1391513 & 688422 & 4.7 & 4.8817 & TRN & \\
\hline CHEMBL1549450 & 688422 & 6.45 & 5.0938 & TRN & \\
\hline CHEMBL1324807 & 688422 & 7.4001 & 5.6078 & TST & \\
\hline CHEMBL1585697 & 688422 & 4.6 & 5.3785 & TRN & \\
\hline CHEMBL1379958 & 688422 & 7.8508 & 5.5495 & TRN & \\
\hline CHEMBL1454382 & 688422 & 4.95 & 4.757 & TST & \\
\hline CHEMBL1313791 & 688422 & 5.9 & 5.41200 & 2000000001 & TRN \\
\hline CHEMBL1433588 & 688422 & 5.25 & 4.9829 & TST & \\
\hline CHEMBL1594777 & 688422 & 4.45 & 5.495 & TST & \\
\hline CHEMBL1533447 & 688422 & 4.95 & 5.1632 & TST & \\
\hline CHEMBL1319235 & 688422 & 4.95 & 5.1836 & TRN & \\
\hline CHEMBL1411528 & 688422 & 4.8 & 4.8477 & TRN & \\
\hline CHEMBL1330065 & 688422 & 4.95 & 5.4802 & TRN & \\
\hline CHEMBL1337461 & 688422 & 6.6499 & 5.6452 & TRN & \\
\hline CHEMBL 3194959 & 688422 & 5.65 & 5.6017 & TRN & \\
\hline CHEMBL1322783 & 688422 & 4.45 & 4.8304 & TST & \\
\hline CHEMBL1600921 & 688422 & 4.95 & 4.8086 & TST & \\
\hline
\end{tabular}




\begin{tabular}{|c|c|c|c|c|}
\hline \multicolumn{5}{|r|}{ al Table } \\
\hline CHEMBL1569478 & 688422 & 6.6 & 5.8744 & TRN \\
\hline CHEMBL1384368 & 688422 & 5.1 & 5.1645 & TRN \\
\hline CHEMBL1589512 & 688422 & 5.3 & 4.9805 & TRN \\
\hline CHEMBL1478978 & 688422 & 5.65 & 5.4127 & TST \\
\hline CHEMBL1430492 & 688422 & 5.45 & 5.1333 & TRN \\
\hline CHEMBL1329661 & 688422 & 5.05 & \multicolumn{2}{|c|}{5.132999999999999} \\
\hline CHEMBL1545802 & 688422 & 4.5 & 5.303 & TRN \\
\hline CHEMBL1422940 & 688422 & 4.95 & 5.4632 & TST \\
\hline CHEMBL1407292 & 688422 & 4.6 & 5.5687 & TRN \\
\hline CHEMBL1437671 & 688422 & 4.9 & 5.3006 & TRN \\
\hline CHEMBL 1405220 & 688422 & 4.9 & 5.1606 & TRN \\
\hline CHEMBL1991234 & 688422 & 4.6 & 5.2488 & TRN \\
\hline CHEMBL1344352 & 688422 & 7.9508 & 5.5658 & TRN \\
\hline CHEMBL1416927 & 688422 & 6.7501 & 5.5311 & TRN \\
\hline CHEMBL1506997 & 688422 & 4.65 & 5.3721 & TST \\
\hline CHEMBL 1544867 & 688422 & 5.4 & 5.3237 & TRN \\
\hline CHEMBL1454976 & 688422 & 4.45 & 4.8949 & TRN \\
\hline CHEMBL1357654 & 688422 & 6.2 & 6.0473 & TST \\
\hline CHEMBL1490764 & 688422 & 4.6 & 4.8839 & TST \\
\hline CHEMBL1408368 & 688422 & 4.95 & 5.2009 & TRN \\
\hline CHEMBL1326129 & 688422 & 4.6 & 4.8414 & TRN \\
\hline CHEMBL590427 & 688422 & 6.45 & 4.6373 & TST \\
\hline CHEMBL1311154 & 688422 & 5.45 & 5.7195 & TST \\
\hline CHEMBL1411502 & 688422 & 4.85 & 5.3674 & TRN \\
\hline CHEMBL1554356 & 688422 & 7.8508 & 5.0667 & TRN \\
\hline CHEMBL1308614 & 688422 & 4.5 & 4.7463 & TST \\
\hline CHEMBL1370870 & 688422 & 5.45 & 4.9289 & TRN \\
\hline CHEMBL1405734 & 688422 & 5.3 & 4.9006 & TRN \\
\hline CHEMBL1403650 & 688422 & 4.9 & 5.0939 & TRN \\
\hline CHEMBL1371124 & 688422 & 4.6 & 5.3568 & TRN \\
\hline CHEMBL536950 & 688422 & 4.8 & 5.42 & TST \\
\hline CHEMBL1573428 & 688422 & 4.95 & 4.9886 & TRN \\
\hline CHEMBL1375133 & 688422 & 4.8 & 4.4772 & TRN \\
\hline CHEMBL1553901 & 688422 & 8.4949 & 5.7996 & TRN \\
\hline CHEMBL1497502 & 688422 & 4.5 & 5.4468 & TST \\
\hline CHEMBL1432114 & 688422 & 7.9508 & 5.851 & TRN \\
\hline CHEMBL1542809 & 688422 & 5.2 & 5.2822 & TRN \\
\hline CHEMBL1334968 & 688422 & 4.45 & 5.4921 & TRN \\
\hline CHEMBL1582586 & 688422 & 7.3497 & 5.1557 & TST \\
\hline CHEMBL3190112 & 688422 & 8.3979 & 5.4573 & TRN \\
\hline CHEMBL1487676 & 688422 & 4.5 & 5.0147 & TRN \\
\hline CHEMBL1473481 & 688422 & 4.45 & 5.0741 & TRN \\
\hline CHEMBL 1988536 & 688422 & 5.0 & 4.8443 & TRN \\
\hline CHEMBL1543764 & 688422 & 5.4 & 5.4744 & TST \\
\hline CHEMBL1380552 & 688422 & 4.6 & 5.0099 & TRN \\
\hline CHEMBL1458025 & 688422 & 4.45 & 5.1098 & TRN \\
\hline CHEMBL1578981 & 688422 & 7.2503 & 5.2407 & TST \\
\hline CHEMBL1606065 & 688422 & 4.85 & 5.4476 & TST \\
\hline
\end{tabular}




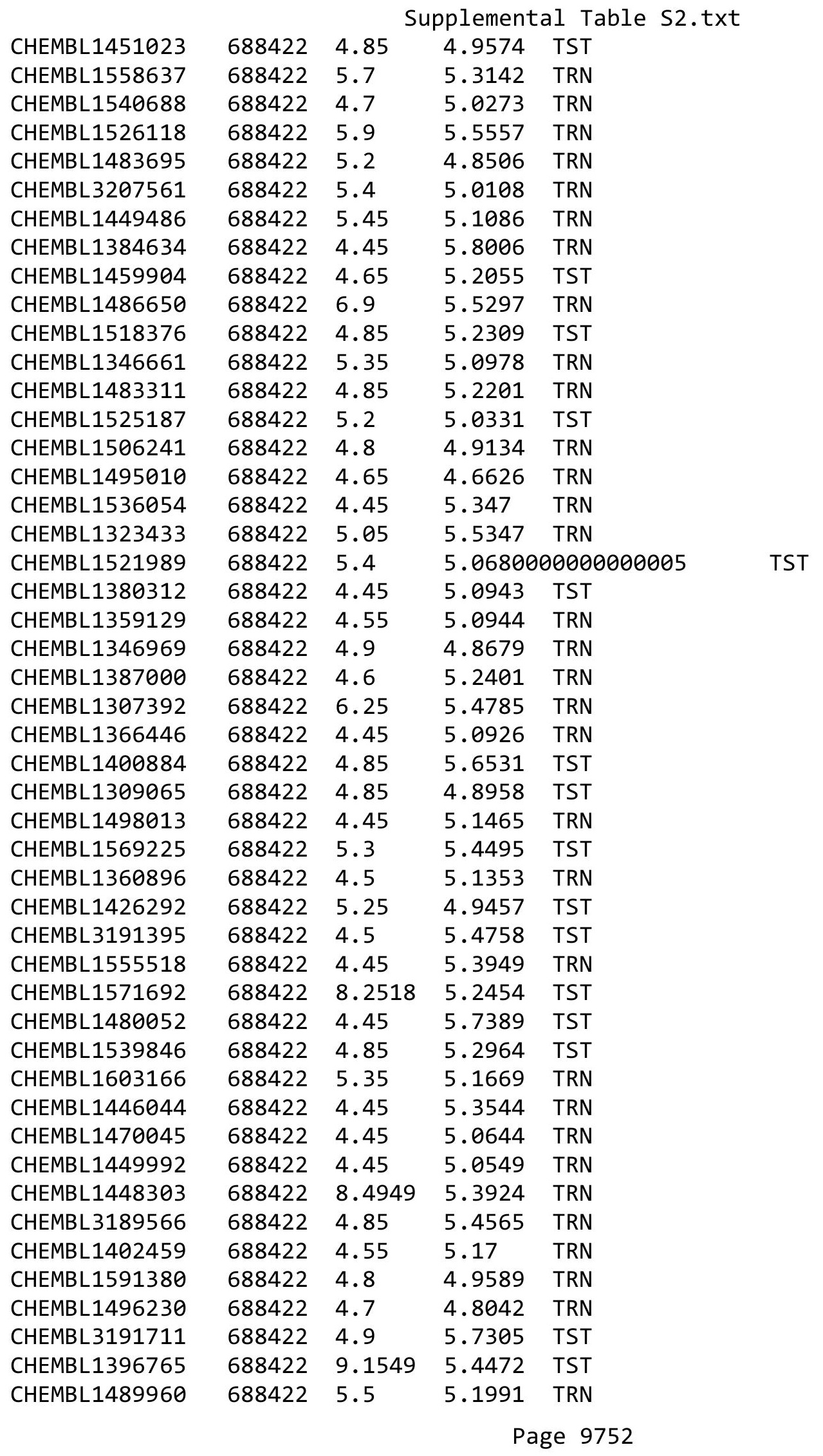




\begin{tabular}{|c|c|c|c|c|c|}
\hline & & & & & \\
\hline CHEMBL1323587 & 688422 & 4.9 & 5.1417 & TRN & \\
\hline CHEMBL1377592 & 688422 & 4.7 & 4.8442 & TRN & \\
\hline CHEMBL1500851 & 688422 & 4.8 & 5.2807 & TRN & \\
\hline CHEMBL1568015 & 688422 & 4.45 & 5.4866 & TST & \\
\hline CHEMBL1543953 & 688422 & 4.9 & 5.3782 & TRN & \\
\hline CHEMBL1975975 & 688422 & 6.25 & 5.2178 & TRN & \\
\hline CHEMBL1424982 & 688422 & 4.75 & 4.9901 & TRN & \\
\hline CHEMBL1563791 & 688422 & 4.75 & 4.9532 & TRN & \\
\hline CHEMBL1367103 & 688422 & 8.2518 & 5.0938 & TRN & \\
\hline CHEMBL1525793 & 688422 & 4.65 & 5.5639 & TRN & \\
\hline CHEMBL588038 & 688422 & 5.5 & 5.2698 & TRN & \\
\hline CHEMBL1994803 & 688422 & 4.8 & 5.1812 & TRN & \\
\hline CHEMBL1386383 & 688422 & 4.45 & 4.803 & TRN & \\
\hline CHEMBL1378991 & 688422 & 4.5 & 4.7147 & TRN & \\
\hline CHEMBL1462274 & 688422 & 5.0 & 5.0756 & TRN & \\
\hline CHEMBL1400599 & 688422 & 4.45 & 4.997 & TST & \\
\hline CHEMBL1513130 & 688422 & 4.65 & 5.3801 & TST & \\
\hline CHEMBL1378237 & 688422 & 4.75 & 5.0702 & TRN & \\
\hline CHEMBL1367102 & 688422 & 7.5003 & 5.1212 & TRN & \\
\hline CHEMBL1406468 & 688422 & 7.6498 & 5.6474 & TRN & \\
\hline CHEMBL1300736 & 688422 & 4.45 & 4.75899 & 99999999995 & TRN \\
\hline CHEMBL1529149 & 688422 & 4.45 & 5.27 & TRN & \\
\hline CHEMBL3193269 & 688422 & 4.45 & 5.3508 & TRN & \\
\hline CHEMBL1577231 & 688422 & 5.75 & 5.2055 & TRN & \\
\hline CHEMBL1587340 & 688422 & 4.95 & 5.0863 & TRN & \\
\hline CHEMBL1346326 & 688422 & 6.7501 & 5.09399 & 9999999999 & TRN \\
\hline CHEMBL1547135 & 688422 & 8.0 & 5.57799 & 9999999999 & TRN \\
\hline CHEMBL23507 & 688422 & 5.85 & 5.8085 & TST & \\
\hline CHEMBL1466281 & 688422 & 4.85 & 5.1699 & TRN & \\
\hline CHEMBL1569786 & 688422 & 4.95 & 5.1581 & TRN & \\
\hline CHEMBL317469 & 688422 & 4.45 & 4.8534 & TRN & \\
\hline CHEMBL116569 & 688422 & 6.0 & 5.4751 & TRN & \\
\hline CHEMBL1460718 & 688422 & 5.75 & 5.0165 & TRN & \\
\hline CHEMBL1580548 & 688422 & 4.75 & 5.1647 & TRN & \\
\hline CHEMBL1459636 & 688422 & 7.3497 & 5.899 & TST & \\
\hline CHEMBL1476709 & 688422 & 6.6499 & 5.3094 & TST & \\
\hline CHEMBL1545760 & 688422 & 5.75 & 4.9424 & TRN & \\
\hline CHEMBL1388898 & 688422 & 6.95 & 5.5146 & TRN & \\
\hline CHEMBL1566153 & 688422 & 5.15 & 4.439 & TRN & \\
\hline CHEMBL1333901 & 688422 & 4.85 & 5.5466 & TRN & \\
\hline CHEMBL1352557 & 688422 & 4.9 & 4.7721 & TRN & \\
\hline CHEMBL1445131 & 688422 & 6.4 & 5.1047 & TRN & \\
\hline CHEMBL1572924 & 688422 & 4.8 & 4.8078 & TRN & \\
\hline CHEMBL1371168 & 688422 & 5.15 & 5.1136 & TRN & \\
\hline CHEMBL1501432 & 688422 & 4.7 & 5.8102 & TRN & \\
\hline CHEMBL1403898 & 688422 & 4.5 & 5.0213 & TRN & \\
\hline CHEMBL1401305 & 688422 & 4.8 & 5.3188 & TRN & \\
\hline CHEMBL1346550 & 688422 & 4.95 & 5.3735 & TST & \\
\hline & & & & 9753 & \\
\hline
\end{tabular}




\begin{tabular}{|c|c|c|c|c|}
\hline \multicolumn{5}{|c|}{ Supplemental Table S2.txt } \\
\hline CHEMBL1399594 & 688422 & 5.5 & 5.4029 & TRN \\
\hline CHEMBL1534616 & 688422 & 4.95 & 5.5418 & TST \\
\hline CHEMBL1574583 & 688422 & 4.8 & 5.4605 & TRN \\
\hline CHEMBL1484562 & 688422 & 5.0 & 5.1205 & TST \\
\hline CHEMBL1531366 & 688422 & 4.45 & 5.6292 & TRN \\
\hline CHEMBL1485372 & 688422 & 5.0 & 5.1222 & TRN \\
\hline CHEMBL1299783 & 688422 & 4.45 & 5.0086 & TRN \\
\hline CHEMBL1369692 & 688422 & 5.2 & 5.5369 & TRN \\
\hline CHEMBL1504204 & 688422 & 4.5 & 5.1815 & TRN \\
\hline CHEMBL1579317 & 688422 & 4.5 & 4.9518 & TRN \\
\hline CHEMBL1320877 & 688422 & 4.8 & 5.2875 & TRN \\
\hline CHEMBL1986187 & 688422 & 4.9 & 5.4869 & TRN \\
\hline CHEMBL1595081 & 688422 & 4.6 & 4.859 & TRN \\
\hline CHEMBL3190979 & 688422 & 6.1 & 5.2049 & TRN \\
\hline CHEMBL1454845 & 688422 & 4.45 & 5.0909 & TRN \\
\hline CHEMBL1494525 & 688422 & 4.9 & 5.3403 & TRN \\
\hline CHEMBL1572651 & 688422 & 5.75 & 5.3793 & TST \\
\hline CHEMBL1611187 & 688422 & 4.45 & 4.8792 & TRN \\
\hline CHEMBL1382535 & 688422 & 4.85 & 4.9305 & TRN \\
\hline CHEMBL1322780 & 688422 & 4.65 & 5.4662 & TRN \\
\hline CHEMBL1456147 & 688422 & 5.1 & 5.3951 & TRN \\
\hline CHEMBL1300258 & 688422 & 4.75 & 5.3207 & TRN \\
\hline CHEMBL1543857 & 688422 & 4.45 & 4.5676 & TRN \\
\hline CHEMBL1466774 & 688422 & 4.45 & 4.887 & TRN \\
\hline CHEMBL1525358 & 688422 & 6.0 & 5.3138 & TST \\
\hline CHEMBL1600085 & 688422 & 5.1 & 5.269 & TST \\
\hline CHEMBL1580631 & 688422 & 4.45 & 5.3912 & TST \\
\hline CHEMBL1500199 & 688422 & 4.45 & 4.8869 & TRN \\
\hline CHEMBL1399191 & 688422 & 4.65 & 5.2476 & TST \\
\hline CHEMBL1598716 & 688422 & 4.65 & 4.8831 & TRN \\
\hline CHEMBL1412501 & 688422 & 4.75 & 5.0901 & TRN \\
\hline CHEMBL1579234 & 688422 & 4.9 & 4.9209 & TRN \\
\hline CHEMBL 2000440 & 688422 & 5.75 & 5.5622 & TRN \\
\hline CHEMBL1382309 & 688422 & 4.85 & 5.1298 & TRN \\
\hline CHEMBL1330929 & 688422 & 4.45 & 5.0423 & TRN \\
\hline CHEMBL1566818 & 688422 & 4.8 & 5.3034 & TST \\
\hline CHEMBL1314502 & 688422 & 5.2 & 5.1381 & TRN \\
\hline CHEMBL1329300 & 688422 & 5.4 & 4.7467 & TRN \\
\hline CHEMBL1502518 & 688422 & 4.45 & 5.3248 & TRN \\
\hline CHEMBL1442952 & 688422 & 4.7 & 5.095 & TRN \\
\hline CHEMBL1524762 & 688422 & 4.5 & 5.2461 & TRN \\
\hline CHEMBL1400549 & 688422 & 4.45 & 5.1262 & TRN \\
\hline CHEMBL1415013 & 688422 & 4.75 & 5.5531 & TRN \\
\hline CHEMBL1504704 & 688422 & 5.7 & 5.1245 & TRN \\
\hline CHEMBL1529874 & 688422 & 4.95 & 5.2979 & TRN \\
\hline CHEMBL1382611 & 688422 & 6.5 & 4.9213 & TRN \\
\hline CHEMBL 1224310 & 688422 & 4.45 & 5.2995 & TST \\
\hline CHEMBL1310004 & 688422 & 4.65 & 5.1213 & TST \\
\hline
\end{tabular}




\begin{tabular}{|c|c|c|c|c|}
\hline \multicolumn{5}{|c|}{ Supplemental Table S2.txt } \\
\hline CHEMBL1321951 & 688422 & 4.95 & 5.2285 & TRN \\
\hline CHEMBL1589056 & 688422 & 4.95 & 5.3422 & TRN \\
\hline CHEMBL1384056 & 688422 & 5.05 & 5.0623 & TST \\
\hline CHEMBL1975191 & 688422 & 5.4 & 5.289 & TRN \\
\hline CHEMBL1536282 & 688422 & 4.7 & 5.3799 & TRN \\
\hline CHEMBL 1577850 & 688422 & 4.6 & 5.1301 & TST \\
\hline CHEMBL311389 & 688422 & 8.7447 & 5.7265 & TRN \\
\hline CHEMBL1415660 & 688422 & 4.45 & 5.1619 & TST \\
\hline CHEMBL1523022 & 688422 & 6.6 & 5.1748 & TRN \\
\hline CHEMBL1603582 & 688422 & 4.85 & 6.1337 & TRN \\
\hline CHEMBL333985 & 688422 & 4.95 & 5.0001 & TST \\
\hline CHEMBL500996 & 688422 & 9.0969 & 5.3682 & TST \\
\hline CHEMBL1304634 & 688422 & 4.65 & 4.8139 & TRN \\
\hline CHEMBL1563373 & 688422 & 8.3468 & 5.4266 & TRN \\
\hline CHEMBL1493903 & 688422 & 4.75 & 4.9673 & TRN \\
\hline CHEMBL1308005 & 688422 & 4.95 & 5.1257 & TRN \\
\hline CHEMBL1533946 & 688422 & 4.9 & 5.6314 & TRN \\
\hline CHEMBL1421602 & 688422 & 5.25 & 5.1483 & TRN \\
\hline CHEMBL1334823 & 688422 & 4.8 & 5.0419 & TRN \\
\hline CHEMBL366390 & 688422 & 5.9 & 5.5851 & TRN \\
\hline CHEMBL1427399 & 688422 & 4.45 & 4.8936 & TRN \\
\hline CHEMBL1466789 & 688422 & 4.55 & 4.9521 & TRN \\
\hline CHEMBL1468879 & 688422 & 4.45 & 4.973 & TRN \\
\hline CHEMBL1542406 & 688422 & 4.45 & 5.5077 & TRN \\
\hline CHEMBL1565033 & 688422 & 4.7 & 5.1338 & TRN \\
\hline CHEMBL1520000 & 688422 & 4.85 & 5.3941 & TRN \\
\hline CHEMBL1483554 & 688422 & 5.5 & 5.5272 & TRN \\
\hline CHEMBL1603602 & 688422 & 4.45 & 5.0025 & TRN \\
\hline CHEMBL1519435 & 688422 & 4.6 & 4.6283 & TRN \\
\hline CHEMBL1589428 & 688422 & 4.9 & 5.1495 & TST \\
\hline CHEMBL501174 & 688422 & 4.95 & 5.6658 & TST \\
\hline CHEMBL1355936 & 688422 & 4.95 & 5.3463 & TRN \\
\hline CHEMBL1432870 & 688422 & 4.45 & 4.7945 & TRN \\
\hline CHEMBL1546025 & 688422 & 6.5501 & 5.7344 & TRN \\
\hline CHEMBL1463381 & 688422 & 4.75 & 5.3337 & TRN \\
\hline CHEMBL1307370 & 688422 & 4.7 & 5.5939 & TRN \\
\hline CHEMBL1516589 & 688422 & 4.75 & 5.2609 & TRN \\
\hline CHEMBL1340593 & 688422 & 4.45 & 4.8738 & TST \\
\hline CHEMBL1463808 & 688422 & 4.75 & 5.3286 & TRN \\
\hline CHEMBL1510946 & 688422 & 5.2 & 5.3519 & TRN \\
\hline CHEMBL1308940 & 688422 & 5.3 & 5.3996 & TRN \\
\hline CHEMBL1421645 & 688422 & 7.5003 & 5.937 & TRN \\
\hline CHEMBL1378223 & 688422 & 4.85 & 6.2163 & TST \\
\hline CHEMBL1592722 & 688422 & 4.8 & 5.0886 & TRN \\
\hline CHEMBL41794 & 688422 & 4.45 & 5.37700 & 0000000001 \\
\hline CHEMBL1416512 & 688422 & 4.45 & 5.2388 & TST \\
\hline CHEMBL1399698 & 688422 & 5.3 & 5.1924 & TRN \\
\hline CHEMBL1516584 & 688422 & 4.4 & 5.4453 & TRN \\
\hline
\end{tabular}

TRN 


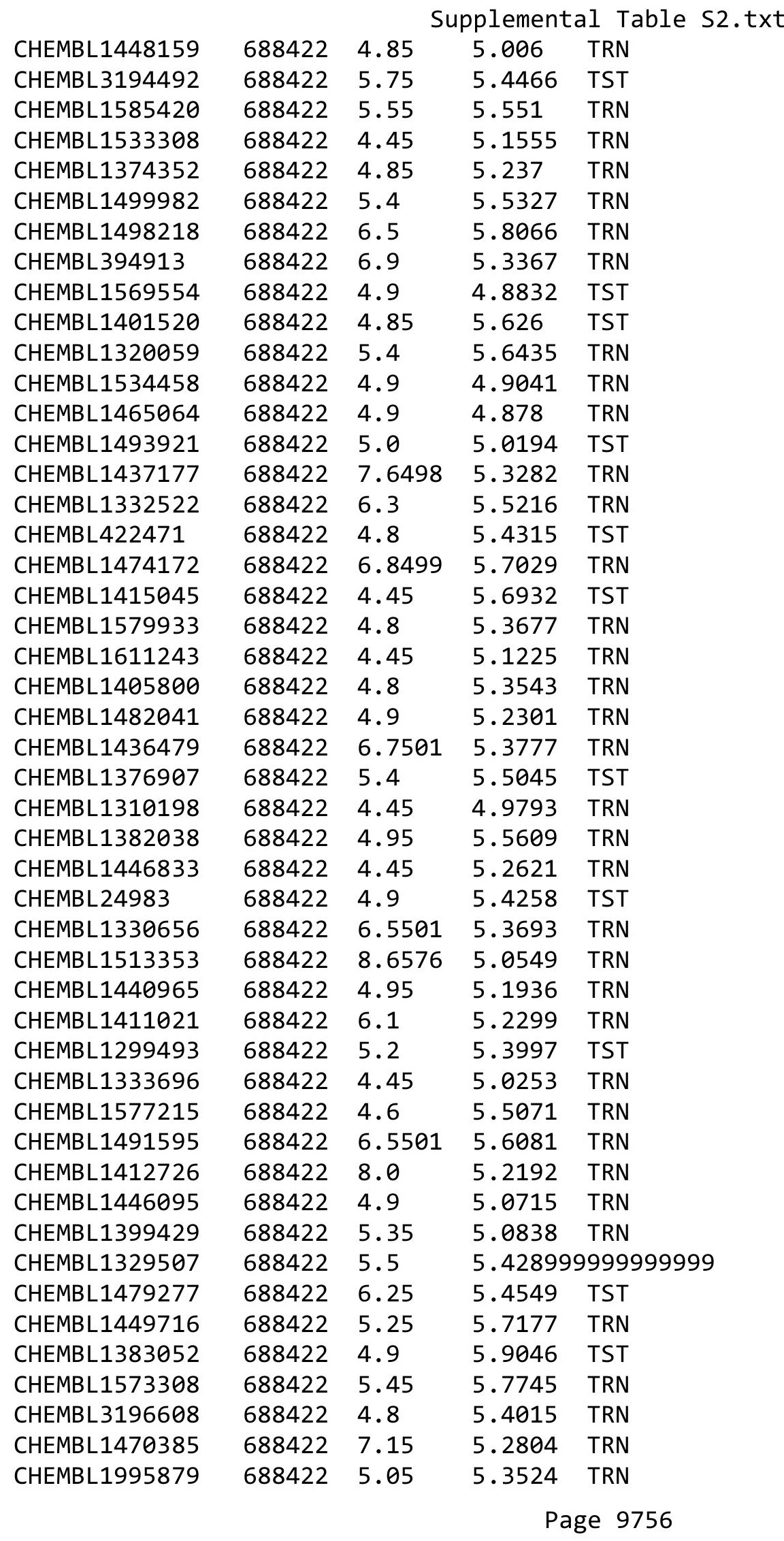




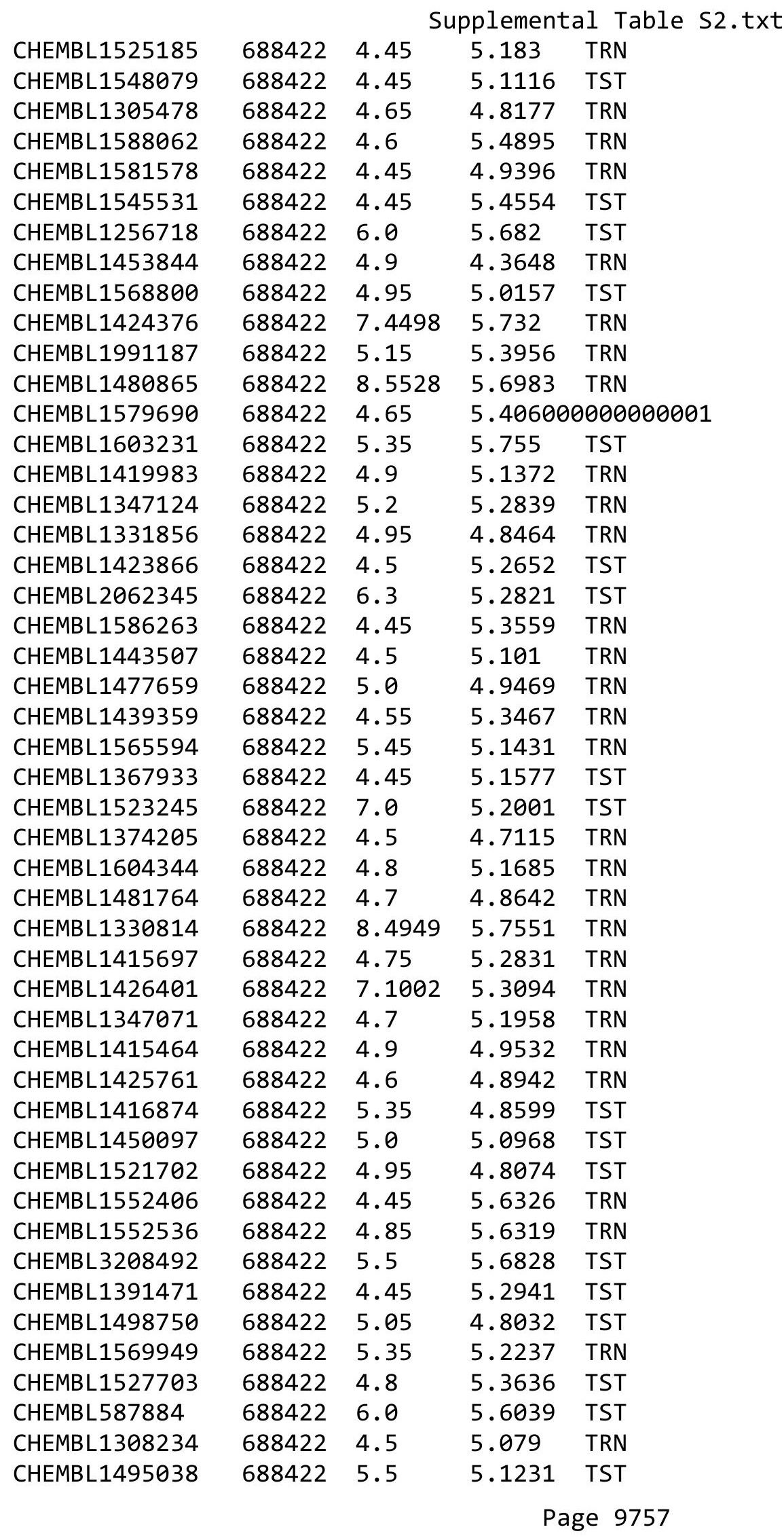




\begin{tabular}{|c|c|c|c|c|}
\hline \multicolumn{5}{|c|}{ Supplemental Table s2.txt } \\
\hline CHEMBL1512799 & 688422 & 7.699 & 5.3176 & TRN \\
\hline CHEMBL1540434 & 688422 & 4.75 & 5.4836 & TST \\
\hline CHEMBL1521258 & 688422 & 5.15 & 5.3116 & TRN \\
\hline CHEMBL1379097 & 688422 & 5.6 & 5.1651 & TRN \\
\hline CHEMBL1208903 & 688422 & 4.7 & 5.0609 & TRN \\
\hline CHEMBL 267548 & 688422 & 5.0 & 5.7576 & TST \\
\hline CHEMBL1491460 & 688422 & 4.45 & 5.414 & TST \\
\hline CHEMBL1350398 & 688422 & 4.95 & 5.6726 & TST \\
\hline CHEMBL1596241 & 688422 & 4.95 & 4.7191 & TRN \\
\hline CHEMBL1580565 & 688422 & 6.35 & 5.5619 & TRN \\
\hline CHEMBL1312658 & 688422 & 5.0 & 5.0112 & TST \\
\hline CHEMBL1463642 & 688422 & 7.7496 & 5.5631 & TRN \\
\hline CHEMBL1613253 & 688422 & 4.55 & 4.9358 & TRN \\
\hline CHEMBL 3189218 & 688422 & 4.45 & 5.2888 & TRN \\
\hline CHEMBL1585966 & 688422 & 5.55 & 5.4119 & TRN \\
\hline CHEMBL1467985 & 688422 & 4.5 & 5.0754 & TST \\
\hline CHEMBL1423599 & 688422 & 4.75 & 4.9136 & TRN \\
\hline CHEMBL1509511 & 688422 & 4.8 & 4.8367 & TRN \\
\hline CHEMBL1574078 & 688422 & 4.45 & 5.2691 & TST \\
\hline CHEMBL1532024 & 688422 & 7.8996 & 5.6358 & TST \\
\hline CHEMBL1530060 & 688422 & 4.45 & 5.1789 & TRN \\
\hline CHEMBL1544192 & 688422 & 4.9 & 5.0711 & TRN \\
\hline CHEMBL1200889 & 688422 & 8.3979 & 6.0203 & TRN \\
\hline CHEMBL1980967 & 688422 & 4.45 & 4.9798 & TRN \\
\hline CHEMBL1599473 & 688422 & 4.9 & 5.3169 & TST \\
\hline CHEMBL1493092 & 688422 & 5.3 & 5.5605 & TRN \\
\hline CHEMBL1363424 & 688422 & 7.4498 & 5.3294 & TRN \\
\hline CHEMBL1534788 & 688422 & 4.45 & 4.9977 & TRN \\
\hline CHEMBL1600303 & 688422 & 4.45 & 5.5506 & TST \\
\hline CHEMBL1398919 & 688422 & 5.0 & 5.1643 & TRN \\
\hline CHEMBL1361457 & 688422 & 6.2 & 5.0746 & TRN \\
\hline CHEMBL1317223 & 688422 & 5.95 & 5.1297 & TRN \\
\hline CHEMBL 1457094 & 688422 & 4.5 & 5.3083 & TRN \\
\hline CHEMBL1501969 & 688422 & 6.7501 & 4.9634 & TST \\
\hline CHEMBL1589998 & 688422 & 6.3 & 5.6985 & TST \\
\hline CHEMBL1606614 & 688422 & 4.45 & 4.8614 & TRN \\
\hline CHEMBL1486502 & 688422 & 7.2 & 5.3822 & TRN \\
\hline CHEMBL1508874 & 688422 & 5.9 & 5.1171 & TRN \\
\hline CHEMBL1524956 & 688422 & 4.45 & 5.524 & TST \\
\hline CHEMBL1392950 & 688422 & 7.699 & 5.3956 & TST \\
\hline CHEMBL1327268 & 688422 & 6.2 & 5.4372 & TRN \\
\hline CHEMBL1612896 & 688422 & 5.85 & 5.3268 & TRN \\
\hline CHEMBL1447849 & 688422 & 4.95 & 5.0603 & TRN \\
\hline CHEMBL1451746 & 688422 & 4.45 & 5.2975 & TRN \\
\hline CHEMBL1478282 & 688422 & 5.15 & 5.5438 & TRN \\
\hline CHEMBL1543216 & 688422 & 5.0 & 5.1556 & TRN \\
\hline CHEMBL1328664 & 688422 & 4.45 & 5.3602 & TST \\
\hline CHEMBL1359125 & 688422 & 6.8499 & 5.5044 & TRN \\
\hline
\end{tabular}




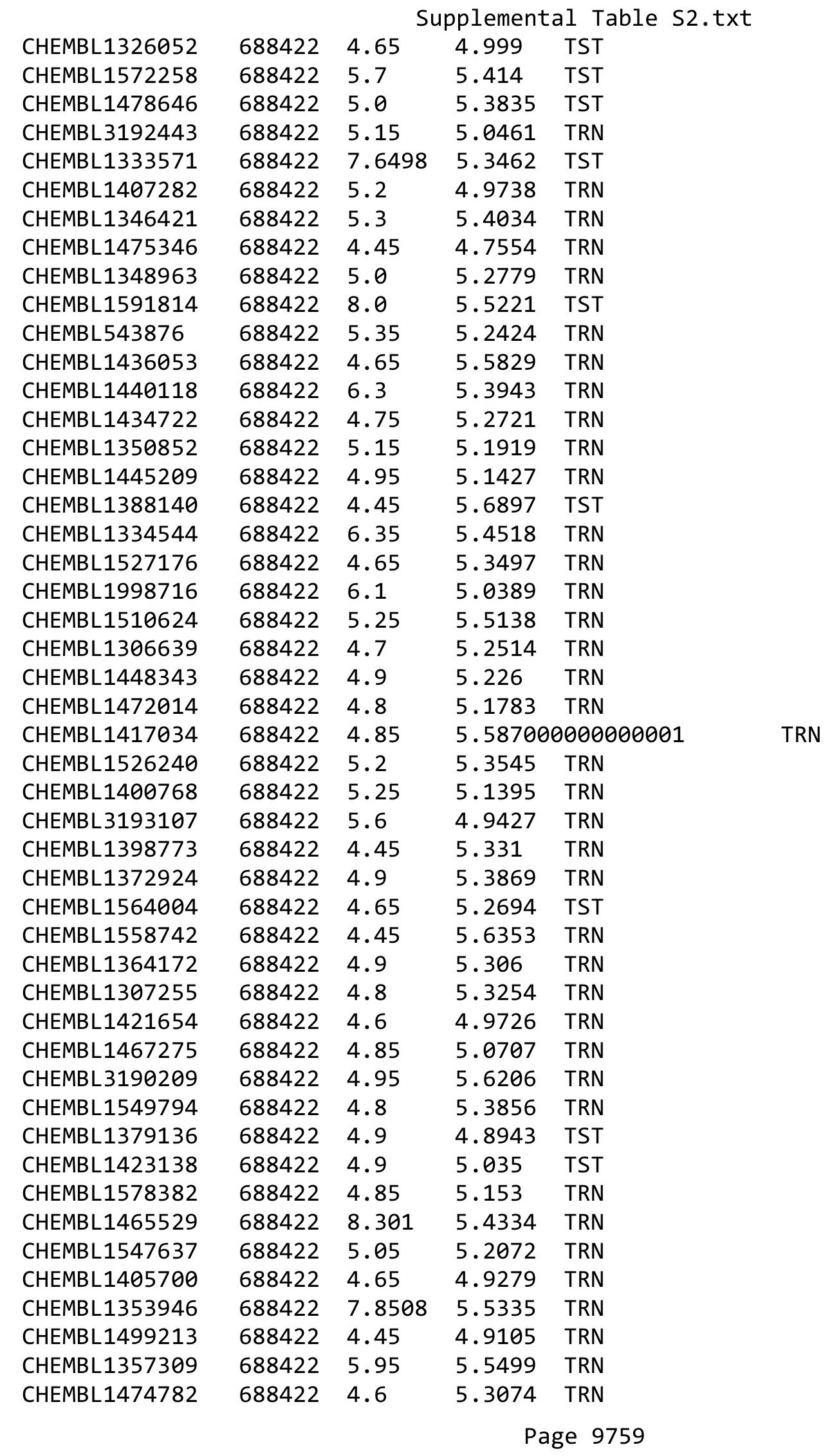




\begin{tabular}{|c|c|c|c|c|c|}
\hline \multicolumn{6}{|c|}{ Supplemental Table S2.txt } \\
\hline CHEMBL1405301 & 688422 & 4.9 & 4.7898 & TRN & \\
\hline CHEMBL1312531 & 688422 & 4.45 & 4.9676 & TRN & \\
\hline CHEMBL3196756 & 688422 & 4.95 & 5.51399 & 9999999999 & TRN \\
\hline CHEMBL1565189 & 688422 & 5.2 & 5.1521 & TST & \\
\hline CHEMBL1607495 & 688422 & 4.9 & 5.1278 & TRN & \\
\hline CHEMBL1486503 & 688422 & 4.65 & 5.086 & TRN & \\
\hline CHEMBL1457265 & 688422 & 4.45 & 5.4007 & TST & \\
\hline CHEMBL1345214 & 688422 & 5.65 & 5.6876 & TST & \\
\hline CHEMBL 1606586 & 688422 & 4.45 & 4.7591 & TRN & \\
\hline CHEMBL1256362 & 688422 & 9.0969 & 5.9513 & TST & \\
\hline CHEMBL1335120 & 688422 & 6.7501 & 5.1679 & TRN & \\
\hline CHEMBL1465154 & 688422 & 4.45 & 5.0889 & TRN & \\
\hline CHEMBL1409291 & 688422 & 4.85 & 4.9565 & TRN & \\
\hline CHEMBL1419950 & 688422 & 5.3 & 5.09699 & 99999999995 & TRN \\
\hline CHEMBL1256754 & 688422 & 8.4559 & 4.9848 & TRN & \\
\hline CHEMBL1390868 & 688422 & 5.8 & 5.3597 & TST & \\
\hline CHEMBL1508617 & 688422 & 4.45 & 5.5091 & TRN & \\
\hline CHEMBL1388647 & 688422 & 7.6003 & 6.0145 & TRN & \\
\hline CHEMBL1323484 & 688422 & 5.05 & 4.887 & TRN & \\
\hline CHEMBL1341691 & 688422 & 4.45 & 5.2655 & TRN & \\
\hline CHEMBL1433142 & 688422 & 4.85 & 5.6315 & TST & \\
\hline CHEMBL1417771 & 688422 & 5.6 & 4.8343 & TRN & \\
\hline CHEMBL1417234 & 688422 & 4.5 & 4.9872 & TRN & \\
\hline CHEMBL1459266 & 688422 & 4.8 & 5.2767 & TRN & \\
\hline CHEMBL1480142 & 688422 & 4.95 & 5.6367 & TRN & \\
\hline CHEMBL1506396 & 688422 & 4.45 & 5.2729 & TST & \\
\hline CHEMBL1368136 & 688422 & 5.55 & 5.2831 & TRN & \\
\hline CHEMBL1391124 & 688422 & 4.45 & 5.0992 & TST & \\
\hline CHEMBL 1557815 & 688422 & 4.7 & 5.2457 & TRN & \\
\hline CHEMBL1588183 & 688422 & 4.5 & 5.1692 & TRN & \\
\hline CHEMBL3213612 & 688422 & 4.95 & 5.4335 & TST & \\
\hline CHEMBL1534229 & 688422 & 4.5 & 4.9827 & TRN & \\
\hline CHEMBL1436826 & 688422 & 4.8 & 5.5725 & TRN & \\
\hline CHEMBL1379786 & 688422 & 4.45 & 5.0923 & TRN & \\
\hline CHEMBL1301206 & 688422 & 4.65 & 5.266 & TRN & \\
\hline CHEMBL1476791 & 688422 & 4.6 & 5.0356 & TRN & \\
\hline CHEMBL1463954 & 688422 & 4.45 & 4.9366 & TRN & \\
\hline CHEMBL1433935 & 688422 & 7.699 & 5.6491 & TRN & \\
\hline CHEMBL1430266 & 688422 & 4.55 & 4.9359 & TRN & \\
\hline CHEMBL1505204 & 688422 & 5.0 & 5.3269 & TRN & \\
\hline CHEMBL1371080 & 688422 & 4.45 & 5.1497 & TRN & \\
\hline CHEMBL1391205 & 688422 & 7.2 & 5.1493 & TRN & \\
\hline CHEMBL1396595 & 688422 & 5.55 & 5.2919 & TRN & \\
\hline CHEMBL1448041 & 688422 & 4.75 & 5.3743 & TST & \\
\hline CHEMBL1416970 & 688422 & 4.6 & 5.0257 & TST & \\
\hline CHEMBL1505151 & 688422 & 4.9 & 5.2421 & TST & \\
\hline CHEMBL1428529 & 688422 & 8.3468 & 5.3181 & TRN & \\
\hline CHEMBL3191901 & 688422 & 4.45 & 5.249 & TRN & \\
\hline
\end{tabular}




\begin{tabular}{|c|c|c|c|c|}
\hline \multicolumn{5}{|c|}{ Supplemental Table S2.txt } \\
\hline CHEMBL261642 & 688422 & 4.75 & 5.7909 & TST \\
\hline CHEMBL1550515 & 688422 & 4.8 & 5.3031 & TRN \\
\hline CHEMBL1408184 & 688422 & 4.85 & 5.324 & TST \\
\hline CHEMBL1483479 & 688422 & 5.4 & 4.7268 & TRN \\
\hline CHEMBL1352741 & 688422 & 4.45 & 5.5214 & TRN \\
\hline CHEMBL1400603 & 688422 & 4.8 & 5.3407 & TRN \\
\hline CHEMBL3190601 & 688422 & 4.85 & 5.0734 & TRN \\
\hline CHEMBL1567229 & 688422 & 4.95 & 5.3522 & TST \\
\hline CHEMBL1504575 & 688422 & 5.5 & 5.15 & TRN \\
\hline CHEMBL1415016 & 688422 & 4.9 & 5.2376 & TRN \\
\hline CHEMBL1608935 & 688422 & 4.5 & 5.2781 & TST \\
\hline CHEMBL1410584 & 688422 & 5.55 & 5.3937 & TRN \\
\hline CHEMBL1405841 & 688422 & 5.25 & 5.2379 & TRN \\
\hline CHEMBL1376277 & 688422 & 4.6 & 5.1394 & TRN \\
\hline CHEMBL3195641 & 688422 & 5.0 & 5.0894 & TRN \\
\hline CHEMBL1459444 & 688422 & 4.95 & 5.1233 & TRN \\
\hline CHEMBL1516287 & 688422 & 4.45 & 5.107 & TRN \\
\hline CHEMBL1560086 & 688422 & 4.95 & 5.3541 & TRN \\
\hline CHEMBL1566136 & 688422 & 4.45 & 4.9429 & TST \\
\hline CHEMBL1383439 & 688422 & 4.65 & 4.9554 & TRN \\
\hline CHEMBL1535000 & 688422 & 4.45 & 5.3961 & TRN \\
\hline CHEMBL1390939 & 688422 & 5.95 & 5.6243 & TST \\
\hline CHEMBL1370296 & 688422 & 4.95 & 4.8692 & TRN \\
\hline CHEMBL1420325 & 688422 & 5.1 & 4.9768 & TST \\
\hline CHEMBL1592103 & 688422 & 5.5 & 4.7598 & TRN \\
\hline CHEMBL1433119 & 688422 & 4.45 & 5.1039 & TST \\
\hline CHEMBL1439271 & 688422 & 4.75 & 5.1946 & TRN \\
\hline CHEMBL1335139 & 688422 & 6.5 & 5.4378 & TRN \\
\hline CHEMBL3195155 & 688422 & 6.5501 & 5.3964 & TST \\
\hline CHEMBL1606350 & 688422 & 6.8 & 5.3974 & TRN \\
\hline CHEMBL1341432 & 688422 & 4.8 & 4.9031 & TRN \\
\hline CHEMBL3192073 & 688422 & 7.9508 & 5.4343 & TRN \\
\hline CHEMBL1517714 & 688422 & 7.0501 & 5.2924 & TST \\
\hline CHEMBL3189449 & 688422 & 4.5 & 5.2029 & TST \\
\hline CHEMBL1375741 & 688422 & 4.45 & 4.9519 & TRN \\
\hline CHEMBL1403319 & 688422 & 5.0 & 5.6854 & TRN \\
\hline CHEMBL1432897 & 688422 & 4.6 & 5.3062 & TRN \\
\hline CHEMBL1440661 & 688422 & 4.75 & 4.9916 & TRN \\
\hline CHEMBL1966366 & 688422 & 4.9 & 5.3059 & TST \\
\hline CHEMBL1416734 & 688422 & 4.85 & 5.5631 & TST \\
\hline CHEMBL1514440 & 688422 & 7.0 & 5.4733 & TRN \\
\hline CHEMBL1462667 & 688422 & 4.45 & 5.4521 & TRN \\
\hline CHEMBL1452298 & 688422 & 4.8 & 5.1923 & TRN \\
\hline CHEMBL1386907 & 688422 & 5.6 & 5.0733 & TST \\
\hline CHEMBL1371244 & 688422 & 4.85 & 5.1756 & TRN \\
\hline CHEMBL1357069 & 688422 & 5.6 & 5.4173 & TRN \\
\hline CHEMBL1527216 & 688422 & 4.9 & 5.564 & TRN \\
\hline CHEMBL1559813 & 688422 & 4.45 & 5.1681 & TRN \\
\hline
\end{tabular}




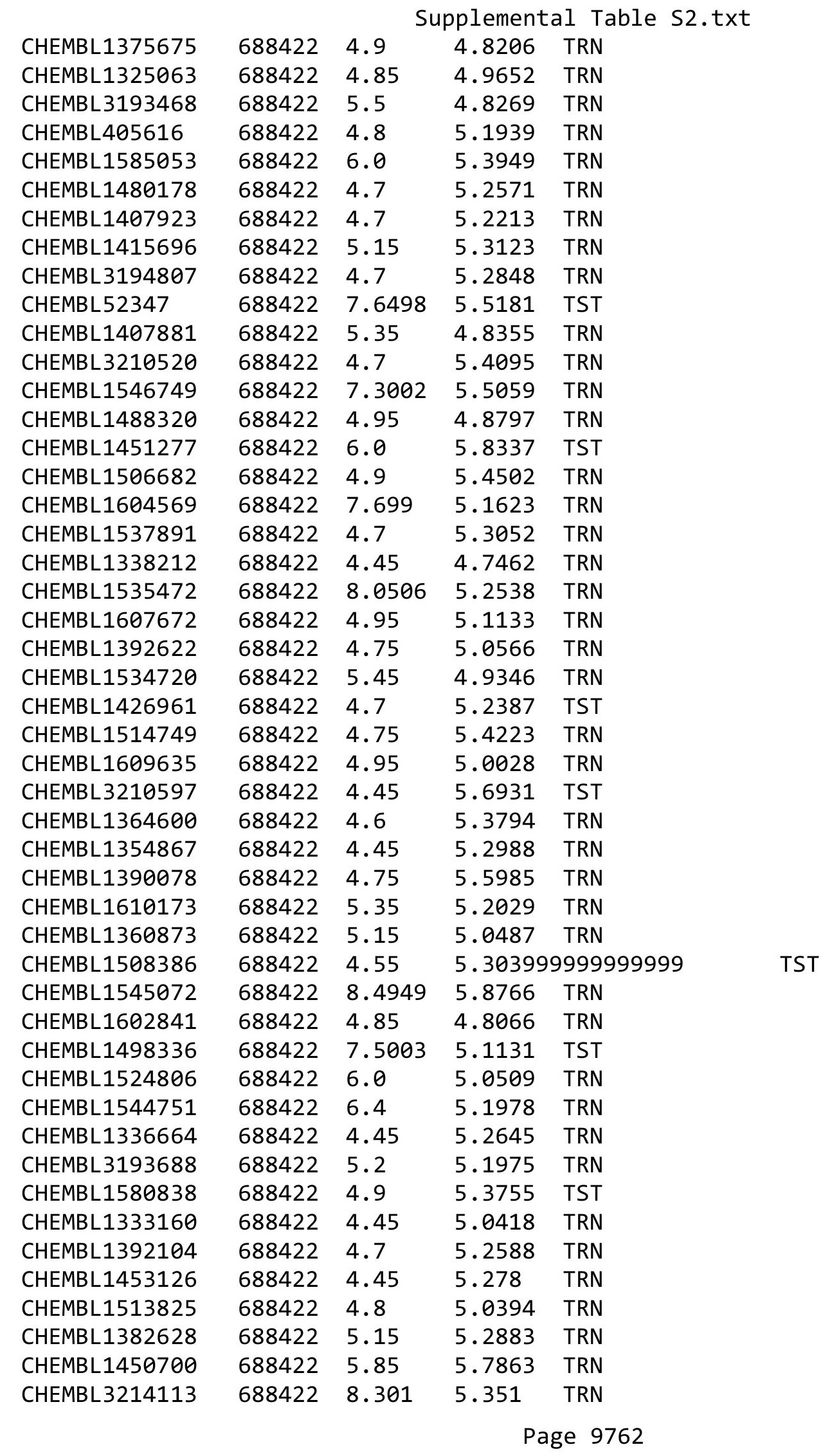




\begin{tabular}{|c|c|c|c|c|}
\hline \multicolumn{5}{|c|}{ Supplemental Table S2.txt } \\
\hline CHEMBL3191039 & 688422 & 5.05 & 4.8429 & TRN \\
\hline CHEMBL 3184468 & 688422 & 4.45 & 5.7574 & TST \\
\hline CHEMBL1526540 & 688422 & 4.9 & 5.2997 & TRN \\
\hline CHEMBL13790 & 688422 & 5.2 & 5.3877 & TRN \\
\hline CHEMBL1525175 & 688422 & 5.8 & 4.8186 & TRN \\
\hline CHEMBL3210164 & 688422 & 6.1 & 5.5308 & TRN \\
\hline CHEMBL1425381 & 688422 & 5.6 & 4.8851 & TRN \\
\hline CHEMBL 3210032 & 688422 & 5.35 & 5.1402 & TRN \\
\hline CHEMBL1545750 & 688422 & 5.25 & 5.3394 & TRN \\
\hline CHEMBL3197613 & 688422 & 6.5 & 5.4196 & TRN \\
\hline CHEMBL1408928 & 688422 & 4.45 & 4.7997 & TRN \\
\hline CHEMBL1323354 & 688422 & 6.5501 & 4.8974 & TST \\
\hline CHEMBL3192236 & 688422 & 7.6498 & 5.1997 & TST \\
\hline CHEMBL1457777 & 688422 & 4.5 & 5.4232 & TST \\
\hline CHEMBL1314236 & 688422 & 5.0 & 5.3932 & TRN \\
\hline CHEMBL1436148 & 688422 & 4.5 & 5.0745 & TRN \\
\hline CHEMBL1376074 & 688422 & 8.301 & 5.7602 & TRN \\
\hline CHEMBL1327035 & 688422 & 7.0501 & 5.6316 & TRN \\
\hline CHEMBL1548411 & 688422 & 5.1 & 5.2801 & TST \\
\hline CHEMBL1471919 & 688422 & 4.6 & 5.1238 & TST \\
\hline CHEMBL1563686 & 688422 & 4.95 & 5.2574 & TRN \\
\hline CHEMBL1449438 & 688422 & 4.8 & 5.1825 & TST \\
\hline CHEMBL1351823 & 688422 & 4.7 & 4.8545 & TRN \\
\hline CHEMBL3196832 & 688422 & 5.5 & 5.3972 & TRN \\
\hline CHEMBL1360343 & 688422 & 4.6 & 5.1607 & TST \\
\hline CHEMBL1431810 & 688422 & 5.0 & 5.2727 & TST \\
\hline CHEMBL1456213 & 688422 & 4.9 & 5.2682 & TST \\
\hline CHEMBL1516323 & 688422 & 8.5528 & 5.3563 & TRN \\
\hline CHEMBL1429415 & 688422 & 4.8 & 4.8777 & TST \\
\hline CHEMBL1432712 & 688422 & 4.95 & 5.455 & TRN \\
\hline CHEMBL1542448 & 688422 & 5.0 & 4.9113 & TRN \\
\hline CHEMBL1581155 & 688422 & 5.0 & 5.3233 & TST \\
\hline CHEMBL1608522 & 688422 & 6.25 & 4.8277 & TRN \\
\hline CHEMBL1602947 & 688422 & 4.45 & 5.0449 & TRN \\
\hline CHEMBL1567146 & 688422 & 5.0 & 5.269 & TRN \\
\hline CHEMBL3196450 & 688422 & 4.5 & 5.4388 & TRN \\
\hline CHEMBL1502712 & 688422 & 4.45 & 4.809 & TRN \\
\hline CHEMBL1308343 & 688422 & 5.2 & 5.4622 & TRN \\
\hline CHEMBL1320825 & 688422 & 4.95 & 4.9601 & TRN \\
\hline CHEMBL1410049 & 688422 & 4.45 & 5.41 & TST \\
\hline CHEMBL1513936 & 688422 & 4.85 & 4.8215 & TRN \\
\hline CHEMBL1560460 & 688422 & 4.75 & 4.6881 & TST \\
\hline CHEMBL1500847 & 688422 & 4.85 & 5.6382 & TRN \\
\hline CHEMBL1450841 & 688422 & 4.5 & 5.3702 & TRN \\
\hline CHEMBL1389745 & 688422 & 4.75 & 5.0936 & TRN \\
\hline CHEMBL1453730 & 688422 & 5.85 & 4.9979 & TRN \\
\hline CHEMBL1342586 & 688422 & 4.85 & 5.3267 & TRN \\
\hline CHEMBL2005961 & 688422 & 4.45 & 5.4537 & TRN \\
\hline
\end{tabular}




\begin{tabular}{|c|c|c|c|c|c|}
\hline \multicolumn{6}{|c|}{ Supplemental Table S2.txt } \\
\hline CHEMBL1571564 & 688422 & 5.2 & 5.5817 & TRN & \\
\hline CHEMBL1331553 & 688422 & 5.85 & 5.3827 & TRN & \\
\hline CHEMBL1364914 & 688422 & 8.3468 & 5.9108 & TRN & \\
\hline CHEMBL1348155 & 688422 & 5.55 & 5.2758 & TST & \\
\hline CHEMBL1563305 & 688422 & 4.9 & 5.2825 & TRN & \\
\hline CHEMBL1360609 & 688422 & 4.9 & 5.2356 & TRN & \\
\hline CHEMBL1521269 & 688422 & 5.2 & 5.0876 & TRN & \\
\hline CHEMBL1474266 & 688422 & 5.45 & 5.5109 & TRN & \\
\hline CHEMBL1484049 & 688422 & 4.45 & 4.9466 & TRN & \\
\hline CHEMBL1337614 & 688422 & 5.3 & 5.3246 & TRN & \\
\hline CHEMBL1505492 & 688422 & 4.8 & 5.0979 & TST & \\
\hline CHEMBL1366606 & 688422 & 5.2 & 5.522 & TRN & \\
\hline CHEMBL1580426 & 688422 & 4.45 & 4.9639 & TRN & \\
\hline CHEMBL1450765 & 688422 & 4.9 & 5.0265 & TRN & \\
\hline CHEMBL1414761 & 688422 & 4.5 & 5.0514 & TRN & \\
\hline CHEMBL1371143 & 688422 & 4.95 & 5.3173 & TRN & \\
\hline CHEMBL1540483 & 688422 & 4.9 & 5.1872 & TST & \\
\hline CHEMBL1355504 & 688422 & 5.25 & 5.4793 & TST & \\
\hline CHEMBL1406801 & 688422 & 4.5 & 5.4785 & TRN & \\
\hline CHEMBL1500686 & 688422 & 4.9 & 4.638 & TST & \\
\hline CHEMBL3190500 & 688422 & 4.95 & 5.58299 & 9999999999 & TRN \\
\hline CHEMBL1365959 & 688422 & 4.45 & 4.7987 & TRN & \\
\hline CHEMBL1540861 & 688422 & 4.7 & 5.23799 & 99999999995 & TRN \\
\hline CHEMBL1542224 & 688422 & 4.45 & 5.2662 & TRN & \\
\hline CHEMBL1515270 & 688422 & 6.5501 & 5.4715 & TST & \\
\hline CHEMBL1605089 & 688422 & 4.75 & 5.5034 & TRN & \\
\hline CHEMBL1324413 & 688422 & 7.3497 & 5.2192 & TST & \\
\hline CHEMBL1330348 & 688422 & 4.95 & 5.0862 & TRN & \\
\hline CHEMBL1523467 & 688422 & 4.9 & 4.8588 & TST & \\
\hline CHEMBL1376437 & 688422 & 4.9 & 5.3523 & TRN & \\
\hline CHEMBL1552601 & 688422 & 8.0 & 4.9956 & TRN & \\
\hline CHEMBL3191599 & 688422 & 5.55 & 5.3939 & TRN & \\
\hline CHEMBL1409737 & 688422 & 4.75 & 5.0127 & TRN & \\
\hline CHEMBL1480255 & 688422 & 7.8013 & 5.4848 & TRN & \\
\hline CHEMBL1598925 & 688422 & 4.85 & 5.2642 & TRN & \\
\hline CHEMBL1398753 & 688422 & 8.4559 & 5.5864 & TRN & \\
\hline CHEMBL1604027 & 688422 & 4.9 & 5.3839 & TRN & \\
\hline CHEMBL1303257 & 688422 & 4.45 & 4.664 & TRN & \\
\hline CHEMBL3199928 & 688422 & 8.3979 & 5.2763 & TRN & \\
\hline CHEMBL1578481 & 688422 & 5.2 & 5.46700 & 00000000005 & TRN \\
\hline CHEMBL1492868 & 688422 & 4.55 & 4.931 & TRN & \\
\hline CHEMBL1493546 & 688422 & 5.3 & 5.2528 & TST & \\
\hline CHEMBL1457496 & 688422 & 4.45 & 5.0189 & TRN & \\
\hline CHEMBL1408012 & 688422 & 4.55 & 5.4764 & TRN & \\
\hline CHEMBL1256759 & 688422 & 4.85 & 5.6858 & TRN & \\
\hline CHEMBL1434397 & 688422 & 4.75 & 5.2427 & TRN & \\
\hline CHEMBL1520616 & 688422 & 4.8 & 5.2732 & TRN & \\
\hline CHEMBL1377459 & 688422 & 4.9 & 5.4087 & TRN & \\
\hline
\end{tabular}




\begin{tabular}{|c|c|c|c|c|c|}
\hline \multicolumn{6}{|c|}{ Supplemental Table S2.txt } \\
\hline CHEMBL1432437 & 688422 & 5.7 & 5.4148 & TRN & \\
\hline CHEMBL1555913 & 688422 & 4.5 & 5.4204 & TRN & \\
\hline CHEMBL1389724 & 688422 & 4.65 & 5.4953 & TST & \\
\hline CHEMBL1502376 & 688422 & 5.15 & 5.2933 & TST & \\
\hline CHEMBL1581856 & 688422 & 5.1 & 5.46 & TRN & \\
\hline CHEMBL1457007 & 688422 & 4.9 & 5.0219 & TRN & \\
\hline CHEMBL1597190 & 688422 & 4.5 & 5.0684 & TRN & \\
\hline CHEMBL1571464 & 688422 & 5.0 & 5.3665 & TRN & \\
\hline CHEMBL1305077 & 688422 & 5.4 & 4.7967 & TRN & \\
\hline CHEMBL1600341 & 688422 & 4.45 & 5.2834 & TRN & \\
\hline CHEMBL1530756 & 688422 & 5.15 & 5.2571 & TRN & \\
\hline CHEMBL272465 & 688422 & 4.45 & 5.5631 & TST & \\
\hline CHEMBL1308779 & 688422 & 5.0 & 4.9905 & TRN & \\
\hline CHEMBL1531500 & 688422 & 7.3497 & 4.922 & TRN & \\
\hline CHEMBL1566169 & 688422 & 7.5003 & \multicolumn{2}{|c|}{5.537999999999999} & TRN \\
\hline CHEMBL1528633 & 688422 & 4.45 & 4.8369 & TRN & \\
\hline CHEMBL1256147 & 688422 & 6.8499 & 6.1573 & TST & \\
\hline CHEMBL1522674 & 688422 & 7.5003 & 5.2355 & TST & \\
\hline CHEMBL1333498 & 688422 & 4.65 & 4.8054 & TRN & \\
\hline CHEMBL1454438 & 688422 & 4.7 & 5.1925 & TRN & \\
\hline CHEMBL1422236 & 688422 & 4.45 & 5.5099 & TRN & \\
\hline CHEMBL1383258 & 688422 & 4.65 & 5.5088 & TRN & \\
\hline CHEMBL1314388 & 688422 & 4.45 & 4.3648 & TRN & \\
\hline CHEMBL1368544 & 688422 & 4.65 & 5.1239 & TRN & \\
\hline CHEMBL1523636 & 688422 & 5.65 & 5.0275 & TRN & \\
\hline CHEMBL592184 & 688422 & 4.45 & 4.9629 & TST & \\
\hline CHEMBL1461432 & 688422 & 6.4 & 5.0812 & TST & \\
\hline CHEMBL1516923 & 688422 & 7.8996 & 5.7615 & TST & \\
\hline CHEMBL1311042 & 688422 & 4.95 & 5.2614 & TST & \\
\hline CHEMBL1478761 & 688422 & 5.35 & 4.9919 & TRN & \\
\hline CHEMBL1409684 & 688422 & 4.45 & 5.5644 & TST & \\
\hline CHEMBL1470540 & 688422 & 4.95 & 4.9566 & TST & \\
\hline CHEMBL1595786 & 688422 & 4.45 & 5.1609 & TRN & \\
\hline CHEMBL1413456 & 688422 & 4.45 & 5.6627 & TST & \\
\hline CHEMBL3193204 & 688422 & 4.9 & 4.9467 & TRN & \\
\hline CHEMBL1362248 & 688422 & 4.8 & 5.1777 & TRN & \\
\hline CHEMBL1345584 & 688422 & 4.95 & 5.1116 & TRN & \\
\hline CHEMBL606474 & 688422 & 5.0 & 5.2619 & TRN & \\
\hline CHEMBL1538799 & 688422 & 4.95 & 5.0367 & TRN & \\
\hline CHEMBL 3212844 & 688422 & 4.9 & 5.2652 & TRN & \\
\hline CHEMBL1556207 & 688422 & 4.7 & 5.943 & TRN & \\
\hline CHEMBL1571900 & 688422 & 8.4559 & 5.3418 & TRN & \\
\hline CHEMBL1589064 & 688422 & 4.75 & 5.0173 & TST & \\
\hline CHEMBL1358724 & 688422 & 4.65 & 5.3081 & TST & \\
\hline CHEMBL1588432 & 688422 & 4.65 & 4.9823 & TRN & \\
\hline CHEMBL1548377 & 688422 & 5.2 & 4.6754 & TRN & \\
\hline CHEMBL1315045 & 688422 & 8.4949 & 5.51200 & 00000000005 & TRN \\
\hline CHEMBL1352555 & 688422 & 5.6 & 5.0403 & TRN & \\
\hline
\end{tabular}




\begin{tabular}{|c|c|c|c|c|}
\hline \multicolumn{5}{|c|}{ Supplemental Table S2.txt } \\
\hline CHEMBL1461574 & 688422 & 6.2 & 5.1903 & TRN \\
\hline CHEMBL1528790 & 688422 & 5.1 & 5.189 & TRN \\
\hline CHEMBL1602985 & 688422 & 5.35 & 5.5322 & TRN \\
\hline CHEMBL1328708 & 688422 & 6.5 & 5.8468 & TST \\
\hline CHEMBL1598397 & 688422 & 6.2 & 5.4884 & TST \\
\hline CHEMBL1464126 & 688422 & 4.75 & 5.1618 & TST \\
\hline CHEMBL1302927 & 688422 & 5.3 & 5.0993 & TRN \\
\hline CHEMBL1606105 & 688422 & 4.9 & 5.4 & TRN \\
\hline CHEMBL1453940 & 688422 & 5.85 & 5.5311 & TRN \\
\hline CHEMBL3210575 & 688422 & 4.55 & 5.0505 & TST \\
\hline CHEMBL3192026 & 688422 & 6.95 & 5.3291 & TRN \\
\hline CHEMBL1502919 & 688422 & 4.5 & 5.2763 & TRN \\
\hline CHEMBL1560884 & 688422 & 8.4949 & 6.104 & TRN \\
\hline CHEMBL1403076 & 688422 & 8.301 & 5.3525 & TRN \\
\hline CHEMBL1500960 & 688422 & 4.75 & 5.722 & TST \\
\hline CHEMBL1431615 & 688422 & 4.9 & 5.3059 & TRN \\
\hline CHEMBL1395128 & 688422 & 5.7 & 5.7524 & TST \\
\hline CHEMBL1508068 & 688422 & 5.0 & 5.2339 & TRN \\
\hline CHEMBL1352743 & 688422 & 4.85 & 5.0609 & TRN \\
\hline CHEMBL1452610 & 688422 & 4.85 & 4.7997 & TRN \\
\hline CHEMBL1606602 & 688422 & 7.2503 & 5.2712 & TST \\
\hline CHEMBL1495714 & 688422 & 4.45 & 5.319 & TRN \\
\hline CHEMBL1444476 & 688422 & 6.5 & 5.485 & TRN \\
\hline CHEMBL1563600 & 688422 & 5.4 & 5.1877 & TRN \\
\hline CHEMBL1337385 & 688422 & 6.8499 & 5.4791 & TST \\
\hline CHEMBL1380373 & 688422 & 6.4 & 5.4603 & TRN \\
\hline CHEMBL1494785 & 688422 & 4.85 & 5.1846 & TRN \\
\hline CHEMBL1507976 & 688422 & 4.7 & 5.4536 & TST \\
\hline CHEMBL1611083 & 688422 & 4.6 & 5.0983 & TRN \\
\hline CHEMBL1390578 & 688422 & 5.0 & 5.3702 & TRN \\
\hline CHEMBL1433333 & 688422 & 4.45 & 5.3318 & TRN \\
\hline CHEMBL1300015 & 688422 & 4.65 & 4.8522 & TRN \\
\hline CHEMBL1488640 & 688422 & 5.35 & 5.2174 & TST \\
\hline CHEMBL1597675 & 688422 & 8.3979 & 5.565 & TRN \\
\hline CHEMBL1484180 & 688422 & 4.45 & 5.5031 & TRN \\
\hline CHEMBL1560473 & 688422 & 5.4 & 5.249 & TRN \\
\hline CHEMBL1307407 & 688422 & 4.5 & 4.8609 & TRN \\
\hline CHEMBL1554423 & 688422 & 4.45 & 5.1043 & TRN \\
\hline CHEMBL1560599 & 688422 & 4.85 & 5.1209 & TST \\
\hline CHEMBL1590109 & 688422 & 4.45 & 5.3998 & TRN \\
\hline CHEMBL1475562 & 688422 & 4.9 & 5.0859 & TRN \\
\hline CHEMBL1360490 & 688422 & 4.45 & 5.3927 & TRN \\
\hline CHEMBL1416959 & 688422 & 4.5 & 5.7939 & TST \\
\hline CHEMBL1369666 & 688422 & 4.55 & 5.114 & TRN \\
\hline CHEMBL1319772 & 688422 & 4.9 & 5.6688 & TST \\
\hline CHEMBL1536722 & 688422 & 5.05 & 5.0736 & TST \\
\hline CHEMBL1488898 & 688422 & 4.45 & 4.3922 & TRN \\
\hline CHEMBL3199290 & 688422 & 5.2 & 5.1748 & TRN \\
\hline
\end{tabular}




\begin{tabular}{|c|c|c|c|c|}
\hline \multicolumn{5}{|c|}{ Supplemental Table S2.txt } \\
\hline CHEMBL1416863 & 688422 & 5.4 & 5.1469 & TRN \\
\hline CHEMBL1608893 & 688422 & 4.85 & 4.8343 & TRN \\
\hline CHEMBL1408856 & 688422 & 5.4 & 5.0041 & TRN \\
\hline CHEMBL1965069 & 688422 & 6.0 & 5.5445 & TRN \\
\hline CHEMBL1366311 & 688422 & 5.25 & 5.2026 & TRN \\
\hline CHEMBL3199726 & 688422 & 4.9 & 4.8384 & TRN \\
\hline CHEMBL1378736 & 688422 & 5.25 & 5.0387 & TRN \\
\hline CHEMBL1514367 & 688422 & 7.5003 & 5.25 & TRN \\
\hline CHEMBL1438033 & 688422 & 5.8 & 5.0283 & TRN \\
\hline CHEMBL1996013 & 688422 & 4.85 & 4.8467 & TRN \\
\hline CHEMBL1548848 & 688422 & 4.45 & 5.1478 & TRN \\
\hline CHEMBL1300434 & 688422 & 5.3 & 5.7341 & TST \\
\hline CHEMBL1396390 & 688422 & 4.85 & 5.8157 & TST \\
\hline CHEMBL1573136 & 688422 & 4.8 & 5.022 & TRN \\
\hline CHEMBL1575814 & 688422 & 4.55 & 5.3331 & TRN \\
\hline CHEMBL1457228 & 688422 & 5.5 & 5.2512 & TRN \\
\hline CHEMBL1471977 & 688422 & 6.0 & 5.7676 & TST \\
\hline CHEMBL1494526 & 688422 & 4.95 & 5.1089 & TST \\
\hline CHEMBL 3196447 & 688422 & 5.1 & 5.2124 & TRN \\
\hline CHEMBL1556269 & 688422 & 4.65 & 5.0456 & TST \\
\hline CHEMBL1610188 & 688422 & 5.8 & 5.6378 & TST \\
\hline CHEMBL1337140 & 688422 & 4.9 & 5.4171 & TST \\
\hline CHEMBL1589682 & 688422 & 4.45 & 5.0617 & TRN \\
\hline CHEMBL1448094 & 688422 & 5.0 & 4.9766 & TRN \\
\hline CHEMBL1531437 & 688422 & 4.45 & 5.7123 & TST \\
\hline CHEMBL1582092 & 688422 & 6.3 & 5.9105 & TRN \\
\hline CHEMBL1525945 & 688422 & 4.8 & 4.9988 & TST \\
\hline CHEMBL1518096 & 688422 & 5.1 & 4.9044 & TRN \\
\hline CHEMBL1347311 & 688422 & 5.65 & 5.192 & TRN \\
\hline CHEMBL1398249 & 688422 & 5.15 & 4.7628 & TRN \\
\hline CHEMBL1581163 & 688422 & 5.45 & 5.3278 & TST \\
\hline CHEMBL1414789 & 688422 & 6.2 & 5.2075 & TRN \\
\hline CHEMBL1434996 & 688422 & 4.45 & 5.465 & TRN \\
\hline CHEMBL1554330 & 688422 & 4.9 & 5.5362 & TRN \\
\hline CHEMBL1571275 & 688422 & 4.9 & 5.5678 & TRN \\
\hline CHEMBL1505565 & 688422 & 7.5498 & 5.0915 & TRN \\
\hline CHEMBL1387800 & 688422 & 4.95 & 5.1045 & TRN \\
\hline CHEMBL1432523 & 688422 & 4.7 & 4.7913 & TRN \\
\hline CHEMBL1498779 & 688422 & 5.4 & 5.0932 & TRN \\
\hline CHEMBL1431563 & 688422 & 4.45 & 5.0382 & TST \\
\hline CHEMBL1510486 & 688422 & 4.45 & 5.4308 & TRN \\
\hline CHEMBL1453704 & 688422 & 5.5 & 5.3261 & TRN \\
\hline CHEMBL1387037 & 688422 & 4.65 & 5.081 & TRN \\
\hline CHEMBL1360808 & 688422 & 4.45 & 5.0853 & TRN \\
\hline CHEMBL1429245 & 688422 & 5.3 & 5.805 & TST \\
\hline CHEMBL1427120 & 688422 & 4.45 & 4.9551 & TRN \\
\hline CHEMBL1452063 & 688422 & 5.05 & 5.064 & TRN \\
\hline CHEMBL1344598 & 688422 & 4.85 & 5.1618 & TRN \\
\hline
\end{tabular}




\begin{tabular}{|c|c|c|c|c|c|}
\hline \multicolumn{6}{|c|}{ Supplemental Table S2.txt } \\
\hline CHEMBL1499414 & 688422 & 5.5 & 5.5547 & TRN & \\
\hline CHEMBL1566778 & 688422 & 4.7 & 5.3272 & TST & \\
\hline CHEMBL1603767 & 688422 & 5.25 & 5.6111 & TRN & \\
\hline CHEMBL1416966 & 688422 & 4.75 & 5.1212 & TRN & \\
\hline CHEMBL1313973 & 688422 & 4.95 & 4.5217 & TST & \\
\hline CHEMBL1528944 & 688422 & 4.7 & 5.4178 & TST & \\
\hline CHEMBL1414635 & 688422 & 4.9 & 5.3651 & TST & \\
\hline CHEMBL1438451 & 688422 & 4.85 & 5.3719 & TRN & \\
\hline CHEMBL1418483 & 688422 & 4.95 & 4.9725 & TRN & \\
\hline CHEMBL1351810 & 688422 & 5.0 & 5.4704 & TST & \\
\hline CHEMBL1592262 & 688422 & 7.0 & 5.2641 & TRN & \\
\hline CHEMBL1335583 & 688422 & 5.2 & 4.90600 & 0000000001 & TRN \\
\hline CHEMBL1439577 & 688422 & 4.65 & 5.5662 & TRN & \\
\hline CHEMBL1497467 & 688422 & 4.85 & 5.1305 & TRN & \\
\hline CHEMBL1535681 & 688422 & 4.45 & 5.5588 & TST & \\
\hline CHEMBL1554925 & 688422 & 7.6003 & 6.1115 & TRN & \\
\hline CHEMBL1563045 & 688422 & 5.0 & 5.2733 & TRN & \\
\hline CHEMBL1362031 & 688422 & 4.45 & 4.9775 & TRN & \\
\hline CHEMBL1598927 & 688422 & 4.65 & 5.4143 & TRN & \\
\hline CHEMBL1472953 & 688422 & 4.55 & 5.3284 & TRN & \\
\hline CHEMBL1600862 & 688422 & 4.75 & 4.9691 & TRN & \\
\hline CHEMBL1310624 & 688422 & 8.4949 & 4.9682 & TRN & \\
\hline CHEMBL1357243 & 688422 & 4.9 & 5.4453 & TRN & \\
\hline CHEMBL1421182 & 688422 & 5.0 & 4.9532 & TRN & \\
\hline CHEMBL1556568 & 688422 & 7.7496 & 5.5557 & TRN & \\
\hline CHEMBL1481365 & 688422 & 5.95 & 5.5949 & TRN & \\
\hline CHEMBL1484976 & 688422 & 4.9 & 4.9875 & TRN & \\
\hline CHEMBL1578499 & 688422 & 4.5 & 5.1344 & TST & \\
\hline CHEMBL1400295 & 688422 & 4.45 & 5.2841 & TRN & \\
\hline CHEMBL1574451 & 688422 & 4.7 & 5.3611 & TRN & \\
\hline CHEMBL1515160 & 688422 & 4.95 & 4.8969 & TRN & \\
\hline CHEMBL1508457 & 688422 & 4.8 & 5.3524 & TRN & \\
\hline CHEMBL1572752 & 688422 & 4.7 & 4.8515 & TRN & \\
\hline CHEMBL1411023 & 688422 & 5.7 & 5.3822 & TST & \\
\hline CHEMBL1353841 & 688422 & 4.75 & 5.2824 & TRN & \\
\hline CHEMBL1600311 & 688422 & 4.45 & 5.1624 & TRN & \\
\hline CHEMBL1597655 & 688422 & 5.0 & 5.2509 & TRN & \\
\hline CHEMBL1430605 & 688422 & 4.75 & 5.346 & TRN & \\
\hline CHEMBL1303200 & 688422 & 4.45 & 5.1521 & TRN & \\
\hline CHEMBL1572800 & 688422 & 4.8 & 5.1213 & TST & \\
\hline CHEMBL1520261 & 688422 & 4.45 & 5.2819 & TRN & \\
\hline CHEMBL3209534 & 688422 & 5.0 & 5.2785 & TRN & \\
\hline CHEMBL3196591 & 688422 & 4.45 & 5.2991 & TRN & \\
\hline CHEMBL3208314 & 688422 & 6.7001 & 5.7725 & TRN & \\
\hline CHEMBL1421619 & 688422 & 4.45 & 5.2886 & TRN & \\
\hline CHEMBL1404976 & 688422 & 6.0 & 5.1279 & TST & \\
\hline CHEMBL1437159 & 688422 & 4.45 & 4.9509 & TRN & \\
\hline CHEMBL1542726 & 688422 & 5.15 & 5.0493 & TST & \\
\hline
\end{tabular}




\begin{tabular}{|c|c|c|c|c|c|}
\hline \multicolumn{6}{|c|}{ Supplemental Table S2.txt } \\
\hline CHEMBL1392067 & 688422 & 4.6 & 5.4846 & TRN & \\
\hline CHEMBL1523719 & 688422 & 4.75 & 5.6313 & TRN & \\
\hline CHEMBL1500317 & 688422 & 4.95 & 5.6867 & TRN & \\
\hline CHEMBL1546996 & 688422 & 4.45 & 5.1876 & TRN & \\
\hline CHEMBL1385616 & 688422 & 4.45 & 5.7786 & TST & \\
\hline CHEMBL1541939 & 688422 & 7.699 & 5.2392 & TST & \\
\hline CHEMBL1567956 & 688422 & 4.9 & 5.2198 & TRN & \\
\hline CHEMBL1512442 & 688422 & 7.0501 & 5.141 & TRN & \\
\hline CHEMBL1379900 & 688422 & 4.9 & 5.3553 & TRN & \\
\hline CHEMBL1403380 & 688422 & 4.55 & 5.23600 & 0000000001 & TRN \\
\hline CHEMBL269733 & 688422 & 8.3468 & 5.5246 & TST & \\
\hline CHEMBL1425517 & 688422 & 4.45 & 5.5223 & TST & \\
\hline CHEMBL1512679 & 688422 & 5.2 & 5.3194 & TST & \\
\hline CHEMBL1371941 & 688422 & 7.0501 & 5.4037 & TRN & \\
\hline CHEMBL3213692 & 688422 & 4.95 & 5.3312 & TRN & \\
\hline CHEMBL1351896 & 688422 & 4.45 & 5.4858 & TRN & \\
\hline CHEMBL1440857 & 688422 & 4.65 & 5.8712 & TRN & \\
\hline CHEMBL597035 & 688422 & 5.0 & 5.1189 & TST & \\
\hline CHEMBL1444002 & 688422 & 6.95 & 5.3862 & TRN & \\
\hline CHEMBL1418559 & 688422 & 4.8 & 5.0739 & TRN & \\
\hline CHEMBL1408111 & 688422 & 5.75 & 5.2708 & TRN & \\
\hline CHEMBL1331694 & 688422 & 4.8 & 5.2081 & TRN & \\
\hline CHEMBL1580757 & 688422 & 4.65 & 4.7925 & TRN & \\
\hline CHEMBL 3208425 & 688422 & 4.75 & 5.1713 & TST & \\
\hline CHEMBL1324561 & 688422 & 4.45 & 5.0597 & TRN & \\
\hline CHEMBL1530205 & 688422 & 8.4559 & 5.6214 & TST & \\
\hline CHEMBL1589463 & 688422 & 4.85 & 4.5242 & TST & \\
\hline CHEMBL1432227 & 688422 & 5.4 & 5.5558 & TRN & \\
\hline CHEMBL1609103 & 688422 & 4.6 & 5.5165 & TRN & \\
\hline CHEMBL1494696 & 688422 & 4.9 & 5.2825 & TRN & \\
\hline CHEMBL3198967 & 688422 & 4.45 & 5.0684 & TRN & \\
\hline CHEMBL1550776 & 688422 & 6.5 & 5.2298 & TRN & \\
\hline CHEMBL1497481 & 688422 & 4.65 & 5.0088 & TRN & \\
\hline CHEMBL1434848 & 688422 & 4.95 & 5.2375 & TRN & \\
\hline CHEMBL1420683 & 688422 & 4.85 & 5.0478 & TST & \\
\hline CHEMBL495778 & 688422 & 5.05 & 5.8574 & TST & \\
\hline CHEMBL1418849 & 688422 & 4.7 & 5.5247 & TRN & \\
\hline CHEMBL1502254 & 688422 & 4.95 & 4.9597 & TRN & \\
\hline CHEMBL1319186 & 688422 & 4.9 & 5.1684 & TST & \\
\hline CHEMBL1311776 & 688422 & 7.5003 & 5.2412 & TRN & \\
\hline CHEMBL1420432 & 688422 & 5.0 & 5.2284 & TRN & \\
\hline CHEMBL1455629 & 688422 & 4.95 & 5.3828 & TST & \\
\hline CHEMBL1579368 & 688422 & 4.45 & 5.53 & TST & \\
\hline CHEMBL1345634 & 688422 & 4.7 & 4.7652 & TRN & \\
\hline CHEMBL1564028 & 688422 & 4.8 & 4.9689 & TST & \\
\hline CHEMBL1316314 & 688422 & 4.8 & 4.8385 & TST & \\
\hline CHEMBL1328473 & 688422 & 5.15 & 4.5863 & TRN & \\
\hline CHEMBL1556937 & 688422 & 5.1 & 5.2797 & TRN & \\
\hline
\end{tabular}




\begin{tabular}{|c|c|c|c|c|c|}
\hline \multicolumn{6}{|c|}{ Supplemental Table S2.txt } \\
\hline CHEMBL1506022 & 688422 & 4.45 & 5.0615 & TST & \\
\hline CHEMBL1978236 & 688422 & 6.15 & 5.3397 & TST & \\
\hline CHEMBL1469620 & 688422 & 4.85 & 4.8762 & TRN & \\
\hline CHEMBL1478846 & 688422 & 6.3 & 5.1269 & TRN & \\
\hline CHEMBL1425231 & 688422 & 4.5 & 5.3526 & TRN & \\
\hline CHEMBL1600127 & 688422 & 4.75 & 5.5412 & TST & \\
\hline CHEMBL1343895 & 688422 & 4.8 & 4.7312 & TRN & \\
\hline CHEMBL1605721 & 688422 & 4.4 & 5.32799 & 9999999999 & TRN \\
\hline CHEMBL1564617 & 688422 & 4.75 & 4.7601 & TRN & \\
\hline CHEMBL1553433 & 688422 & 8.4949 & 5.4918 & TRN & \\
\hline CHEMBL1585468 & 688422 & 4.45 & 5.0611 & TRN & \\
\hline CHEMBL1568248 & 688422 & 4.95 & 5.1535 & TST & \\
\hline CHEMBL1607527 & 688422 & 4.9 & 5.1736 & TRN & \\
\hline CHEMBL1425004 & 688422 & 5.1 & 5.1016 & TST & \\
\hline CHEMBL1498693 & 688422 & 4.9 & 4.8878 & TRN & \\
\hline CHEMBL1314953 & 688422 & 8.0 & 5.2775 & TRN & \\
\hline CHEMBL1308397 & 688422 & 7.4001 & 5.4172 & TST & \\
\hline CHEMBL1589633 & 688422 & 4.85 & 5.3357 & TRN & \\
\hline CHEMBL3197291 & 688422 & 4.9 & 4.5577 & TRN & \\
\hline CHEMBL1551620 & 688422 & 7.2503 & 5.3079 & TRN & \\
\hline CHEMBL1404222 & 688422 & 4.95 & 5.7238 & TRN & \\
\hline CHEMBL511207 & 688422 & 4.9 & 4.9231 & TRN & \\
\hline CHEMBL1588162 & 688422 & 4.9 & 4.8503 & TRN & \\
\hline CHEMBL600715 & 688422 & 5.0 & 5.4476 & TST & \\
\hline CHEMBL3195101 & 688422 & 5.15 & 5.3682 & TRN & \\
\hline CHEMBL1410679 & 688422 & 5.2 & 5.6245 & TST & \\
\hline CHEMBL1531474 & 688422 & 7.3002 & 5.3057 & TRN & \\
\hline CHEMBL1543555 & 688422 & 7.4001 & 5.2974 & TST & \\
\hline CHEMBL3192415 & 688422 & 5.95 & 5.1343 & TRN & \\
\hline CHEMBL1353110 & 688422 & 4.65 & 5.314 & TRN & \\
\hline CHEMBL1978315 & 688422 & 5.65 & 4.9486 & TRN & \\
\hline CHEMBL1977226 & 688422 & 4.7 & 5.1412 & TST & \\
\hline CHEMBL1555396 & 688422 & 6.8 & 5.4759 & TRN & \\
\hline CHEMBL1473769 & 688422 & 4.8 & 5.1504 & TRN & \\
\hline CHEMBL3191353 & 688422 & 4.45 & 5.3854 & TST & \\
\hline CHEMBL1327873 & 688422 & 7.1002 & 5.9095 & TRN & \\
\hline CHEMBL1497637 & 688422 & 5.2 & 5.0752 & TST & \\
\hline CHEMBL1485602 & 688422 & 8.301 & 5.2816 & TRN & \\
\hline CHEMBL1380402 & 688422 & 4.85 & 5.3983 & TRN & \\
\hline CHEMBL1551535 & 688422 & 4.45 & 4.9741 & TRN & \\
\hline CHEMBL1538419 & 688422 & 5.45 & 4.9702 & TRN & \\
\hline CHEMBL1566602 & 688422 & 4.6 & 5.1857 & TST & \\
\hline CHEMBL1588633 & 688422 & 4.85 & 5.1244 & TRN & \\
\hline CHEMBL1300959 & 688422 & 5.45 & 4.8935 & TRN & \\
\hline CHEMBL1544440 & 688422 & 4.95 & 5.5364 & TRN & \\
\hline CHEMBL1256647 & 688422 & 4.7 & 5.7745 & TST & \\
\hline CHEMBL1528936 & 688422 & 6.1 & 5.5415 & TRN & \\
\hline CHEMBL1602931 & 688422 & 4.45 & 4.7867 & TRN & \\
\hline
\end{tabular}




\begin{tabular}{|c|c|c|c|c|c|}
\hline \multicolumn{6}{|c|}{ Supplemental Table S2.txt } \\
\hline CHEMBL1311622 & 688422 & 6.9 & 5.3316 & TRN & \\
\hline CHEMBL1412395 & 688422 & 4.85 & 5.1691 & TST & \\
\hline CHEMBL1453108 & 688422 & 6.0 & 5.1416 & TRN & \\
\hline CHEMBL1390649 & 688422 & 6.6499 & 5.4003 & TRN & \\
\hline CHEMBL3189528 & 688422 & 4.95 & 5.1251 & TRN & \\
\hline CHEMBL1458567 & 688422 & 4.85 & 5.0781 & TRN & \\
\hline CHEMBL1538630 & 688422 & 5.0 & 5.4295 & TRN & \\
\hline CHEMBL1613463 & 688422 & 7.0 & 4.9437 & TST & \\
\hline CHEMBL1503484 & 688422 & 4.85 & 5.0417 & TRN & \\
\hline CHEMBL1469874 & 688422 & 4.45 & 5.1018 & TST & \\
\hline CHEMBL1497265 & 688422 & 4.65 & 5.2953 & TRN & \\
\hline CHEMBL1430117 & 688422 & 8.4949 & 4.9678 & TST & \\
\hline CHEMBL1574895 & 688422 & 7.5003 & 5.505 & TST & \\
\hline CHEMBL1344604 & 688422 & 4.75 & \multicolumn{2}{|c|}{5.013999999999999} & TRN \\
\hline CHEMBL1438267 & 688422 & 6.3 & \multicolumn{2}{|c|}{5.372999999999999} & TST \\
\hline CHEMBL1455708 & 688422 & 5.4 & 5.5173 & TRN & \\
\hline CHEMBL1386280 & 688422 & 4.95 & 4.8242 & TRN & \\
\hline CHEMBL1470074 & 688422 & 4.65 & 5.4754 & TRN & \\
\hline CHEMBL97760 & 688422 & 5.55 & 5.6326 & TRN & \\
\hline CHEMBL1407035 & 688422 & 4.85 & 5.0236 & TRN & \\
\hline CHEMBL1580532 & 688422 & 4.5 & 4.8125 & TRN & \\
\hline CHEMBL1525244 & 688422 & 4.9 & 5.5119 & TRN & \\
\hline CHEMBL1470676 & 688422 & 4.45 & 5.1921 & TRN & \\
\hline CHEMBL1591375 & 688422 & 4.85 & 5.4495 & TRN & \\
\hline CHEMBL1501775 & 688422 & 5.95 & 5.4056 & TST & \\
\hline CHEMBL3192295 & 688422 & 6.8 & 5.3598 & TST & \\
\hline CHEMBL1462792 & 688422 & 5.4 & 5.3979 & TRN & \\
\hline CHEMBL414400 & 688422 & 5.1 & 5.7112 & TRN & \\
\hline CHEMBL1380085 & 688422 & 5.5 & 5.2208 & TRN & \\
\hline CHEMBL1355963 & 688422 & 6.4 & 5.5659 & TST & \\
\hline CHEMBL1544432 & 688422 & 4.55 & 5.0078 & TRN & \\
\hline CHEMBL1329093 & 688422 & 4.5 & 5.2512 & TRN & \\
\hline CHEMBL1344476 & 688422 & 4.45 & 4.9798 & TRN & \\
\hline CHEMBL1370555 & 688422 & 4.45 & 4.7779 & TRN & \\
\hline CHEMBL1304540 & 688422 & 7.3002 & 5.2835 & TRN & \\
\hline CHEMBL1545322 & 688422 & 4.5 & 5.3815 & TRN & \\
\hline CHEMBL3196712 & 688422 & 4.75 & 5.5888 & TRN & \\
\hline CHEMBL1328216 & 688422 & 4.45 & 5.6381 & TRN & \\
\hline CHEMBL1495974 & 688422 & 4.55 & \multicolumn{2}{|c|}{5.303999999999999} & TRN \\
\hline CHEMBL1458784 & 688422 & 6.8499 & 5.4242 & TRN & \\
\hline CHEMBL1520010 & 688422 & 7.3002 & 6.1967 & TST & \\
\hline CHEMBL1467291 & 688422 & 4.95 & 5.1703 & TRN & \\
\hline CHEMBL1428679 & 688422 & 5.3 & 5.4249 & TRN & \\
\hline CHEMBL1390307 & 688422 & 4.45 & 5.4859 & TRN & \\
\hline CHEMBL1516732 & 688422 & 5.15 & 5.1371 & TRN & \\
\hline CHEMBL1501249 & 688422 & 4.75 & 5.0363 & TRN & \\
\hline CHEMBL1487823 & 688422 & 4.45 & 5.0007 & TRN & \\
\hline \multirow[t]{2}{*}{ CHEMBL1321995 } & 688422 & 5.15 & \multicolumn{2}{|c|}{5.297000000000001} & TRN \\
\hline & & & & 9771 & \\
\hline
\end{tabular}




\begin{tabular}{|c|c|c|c|c|c|}
\hline \multicolumn{6}{|c|}{ Supplemental Table s2.txt } \\
\hline CHEMBL1304505 & 688422 & 7.0 & 5.6188 & TST & \\
\hline CHEMBL1540371 & 688422 & 4.5 & 5.307 & TST & \\
\hline CHEMBL3212514 & 688422 & 5.6 & 5.175 & TRN & \\
\hline CHEMBL1344374 & 688422 & 5.05 & 4.9647 & TRN & \\
\hline CHEMBL1409072 & 688422 & 7.2503 & 5.4056 & TRN & \\
\hline CHEMBL1450296 & 688422 & 4.95 & 5.2613 & TST & \\
\hline CHEMBL1818878 & 688422 & 5.3 & 5.5828 & TRN & \\
\hline CHEMBL1569525 & 688422 & 4.45 & 5.0596 & TRN & \\
\hline CHEMBL1371069 & 688422 & 4.95 & 5.3537 & TST & \\
\hline CHEMBL1472999 & 688422 & 7.3497 & 5.5166 & TRN & \\
\hline CHEMBL1514589 & 688422 & 6.7001 & 5.2104 & TRN & \\
\hline CHEMBL1456817 & 688422 & 4.8 & 4.9696 & TST & \\
\hline CHEMBL1555960 & 688422 & 4.85 & 5.2069 & TRN & \\
\hline CHEMBL1412921 & 688422 & 4.5 & 5.0551 & TRN & \\
\hline CHEMBL1528745 & 688422 & 4.9 & 5.0275 & TRN & \\
\hline CHEMBL1484145 & 688422 & 4.5 & 5.358 & TST & \\
\hline CHEMBL1420358 & 688422 & 4.45 & 5.0108 & TRN & \\
\hline CHEMBL1468579 & 688422 & 4.9 & 4.9629 & TRN & \\
\hline CHEMBL1570272 & 688422 & 4.7 & 4.8467 & TRN & \\
\hline CHEMBL1350141 & 688422 & 4.9 & 5.4309 & TRN & \\
\hline CHEMBL1428862 & 688422 & 4.5 & 4.8962 & TRN & \\
\hline CHEMBL1408631 & 688422 & 4.45 & 5.0685 & TRN & \\
\hline CHEMBL1487735 & 688422 & 4.45 & 4.8078 & TRN & \\
\hline CHEMBL1592088 & 688422 & 4.9 & 5.2442 & TRN & \\
\hline CHEMBL1378146 & 688422 & 4.5 & 5.2825 & TRN & \\
\hline CHEMBL1471622 & 688422 & 4.8 & 5.2158 & TRN & \\
\hline CHEMBL1565010 & 688422 & 4.45 & 5.6533 & TRN & \\
\hline CHEMBL1457201 & 688422 & 5.3 & 4.5921 & TRN & \\
\hline CHEMBL1391121 & 688422 & 4.95 & 5.2215 & TST & \\
\hline CHEMBL1598455 & 688422 & 4.45 & 5.0372 & TRN & \\
\hline CHEMBL1408866 & 688422 & 5.55 & 5.28700 & 0000000001 & TRN \\
\hline CHEMBL1458668 & 688422 & 4.65 & 5.2181 & TRN & \\
\hline CHEMBL1381091 & 688422 & 4.65 & 5.0989 & TST & \\
\hline CHEMBL1586450 & 688422 & 4.8 & 5.454 & TRN & \\
\hline CHEMBL576208 & 688422 & 5.25 & 5.1086 & TRN & \\
\hline CHEMBL1439957 & 688422 & 4.45 & 5.2659 & TRN & \\
\hline CHEMBL1432809 & 688422 & 5.2 & 5.0718 & TRN & \\
\hline CHEMBL1596944 & 688422 & 5.45 & 4.8195 & TRN & \\
\hline CHEMBL1345360 & 688422 & 5.75 & 5.1138 & TST & \\
\hline CHEMBL1390224 & 688422 & 7.8013 & 5.275 & TRN & \\
\hline CHEMBL1488649 & 688422 & 5.45 & 5.5626 & TRN & \\
\hline CHEMBL1464553 & 688422 & 4.45 & 4.4931 & TRN & \\
\hline CHEMBL1582747 & 688422 & 6.0 & 5.3145 & TRN & \\
\hline CHEMBL1451396 & 688422 & 5.6 & 5.5372 & TST & \\
\hline CHEMBL1487995 & 688422 & 5.25 & 5.7148 & TRN & \\
\hline CHEMBL1477330 & 688422 & 4.85 & 5.2852 & TRN & \\
\hline CHEMBL1374355 & 688422 & 4.9 & 5.4002 & TRN & \\
\hline CHEMBL1350412 & 688422 & 4.9 & 5.0996 & TST & \\
\hline
\end{tabular}




\begin{tabular}{|c|c|c|c|c|c|}
\hline \multicolumn{6}{|c|}{ Supplemental Table S2.txt } \\
\hline CHEMBL1518705 & 688422 & 4.5 & 5.21 & TRN & \\
\hline CHEMBL1532644 & 688422 & 4.45 & 5.7397 & TRN & \\
\hline CHEMBL1445101 & 688422 & 4.7 & 5.45299 & 9999999999 & TST \\
\hline CHEMBL1423405 & 688422 & 6.8499 & 5.2889 & TRN & \\
\hline CHEMBL1517527 & 688422 & 5.4 & 5.3233 & TRN & \\
\hline CHEMBL1539380 & 688422 & 8.3468 & 5.4938 & TST & \\
\hline CHEMBL3196065 & 688422 & 4.75 & 5.0719 & TRN & \\
\hline CHEMBL1324890 & 688422 & 4.95 & 5.2743 & TRN & \\
\hline CHEMBL1512269 & 688422 & 4.9 & 5.1719 & TRN & \\
\hline CHEMBL1519367 & 688422 & 5.3 & 5.4123 & TRN & \\
\hline CHEMBL1372967 & 688422 & 6.5 & 5.07600 & 00000000005 & TRN \\
\hline CHEMBL1606737 & 688422 & 4.45 & 5.7919 & TST & \\
\hline CHEMBL1553905 & 688422 & 6.2 & 5.5806 & TRN & \\
\hline CHEMBL1595474 & 688422 & 4.9 & 5.3279 & TRN & \\
\hline CHEMBL1609270 & 688422 & 6.8499 & 4.8815 & TRN & \\
\hline CHEMBL1455448 & 688422 & 4.5 & 5.3529 & TST & \\
\hline CHEMBL2369306 & 688422 & 4.85 & 5.1817 & TST & \\
\hline CHEMBL1448997 & 688422 & 4.8 & 5.48799 & 99999999995 & TRN \\
\hline CHEMBL1526371 & 688422 & 5.1 & 5.805 & TST & \\
\hline CHEMBL1412529 & 688422 & 4.7 & 5.0176 & TRN & \\
\hline CHEMBL1429531 & 688422 & 5.25 & 5.3054 & TST & \\
\hline CHEMBL1478233 & 688422 & 5.0 & 5.1193 & TRN & \\
\hline CHEMBL1574616 & 688422 & 4.45 & 5.0049 & TRN & \\
\hline CHEMBL1504265 & 688422 & 5.45 & 5.1106 & TST & \\
\hline CHEMBL1327040 & 688422 & 4.4 & 5.1499 & TST & \\
\hline CHEMBL1364832 & 688422 & 5.2 & 5.4447 & TRN & \\
\hline CHEMBL1558065 & 688422 & 5.55 & 5.0419 & TRN & \\
\hline CHEMBL1527649 & 688422 & 4.65 & 5.0512 & TRN & \\
\hline CHEMBL1313676 & 688422 & 5.8 & 5.7993 & TRN & \\
\hline CHEMBL1426321 & 688422 & 4.5 & 4.9258 & TRN & \\
\hline CHEMBL1409280 & 688422 & 5.0 & 5.24200 & 0000000001 & TRN \\
\hline CHEMBL598663 & 688422 & 4.45 & 4.8903 & TRN & \\
\hline CHEMBL3191829 & 688422 & 4.55 & 5.1943 & TRN & \\
\hline CHEMBL1489273 & 688422 & 5.5 & 5.0254 & TRN & \\
\hline CHEMBL1509107 & 688422 & 4.45 & 4.9793 & TST & \\
\hline CHEMBL1363275 & 688422 & 4.6 & 4.8953 & TRN & \\
\hline CHEMBL3191234 & 688422 & 4.75 & 5.1363 & TST & \\
\hline CHEMBL1495939 & 688422 & 4.85 & 4.7864 & TRN & \\
\hline CHEMBL1337113 & 688422 & 5.25 & 5.5111 & TRN & \\
\hline CHEMBL1381777 & 688422 & 6.1 & 5.1849 & TST & \\
\hline CHEMBL1563691 & 688422 & 4.9 & 4.8819 & TRN & \\
\hline CHEMBL1566351 & 688422 & 4.75 & 5.4561 & TST & \\
\hline CHEMBL1360282 & 688422 & 4.7 & 5.0114 & TRN & \\
\hline CHEMBL1458646 & 688422 & 4.45 & 5.254 & TRN & \\
\hline CHEMBL1587518 & 688422 & 4.45 & 5.0077 & TST & \\
\hline CHEMBL1583184 & 688422 & 4.5 & 4.6997 & TST & \\
\hline CHEMBL1584767 & 688422 & 4.65 & 5.3863 & TST & \\
\hline CHEMBL1573850 & 688422 & 4.45 & 4.8546 & TRN & \\
\hline
\end{tabular}




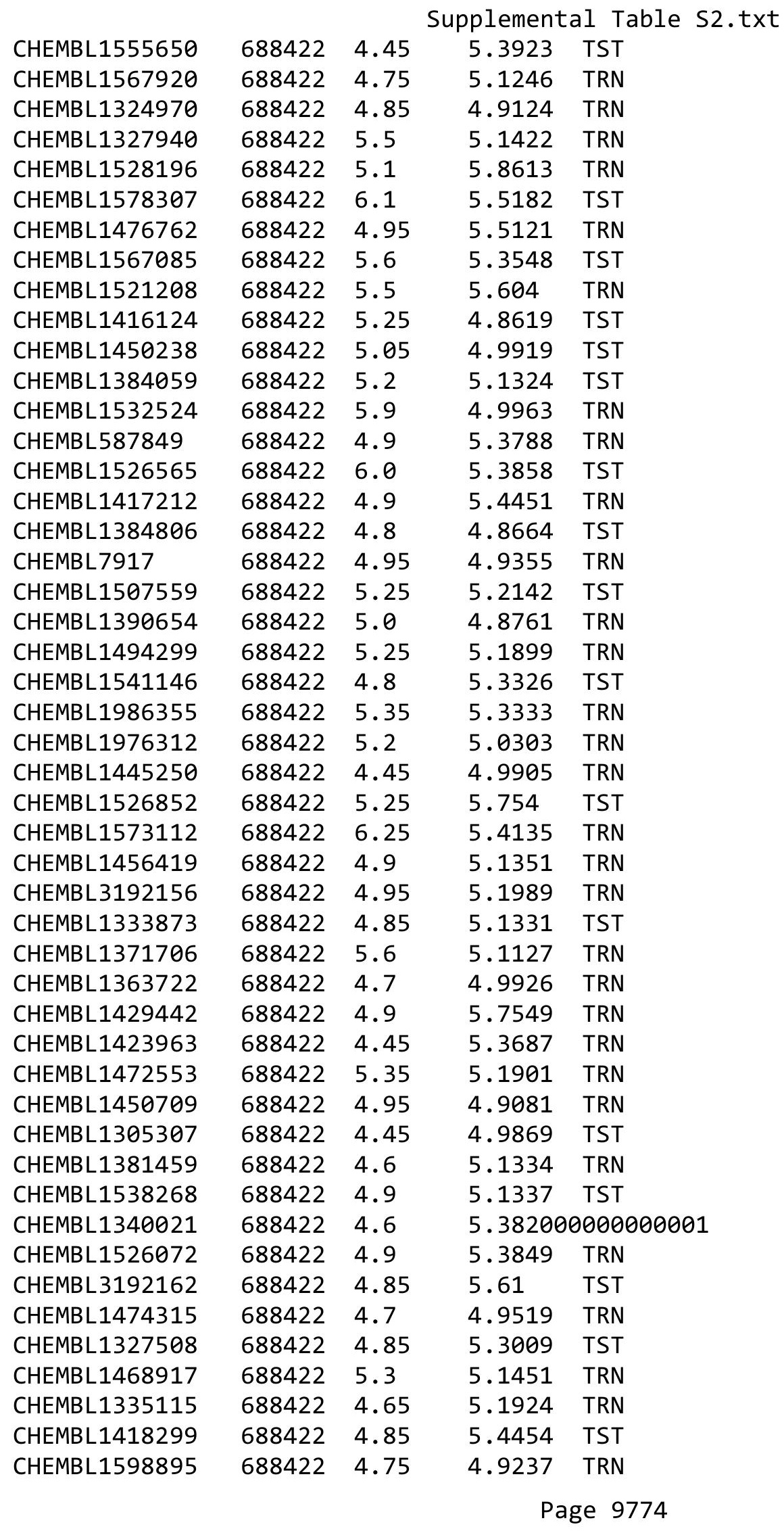




\begin{tabular}{|c|c|c|c|c|c|}
\hline \multicolumn{6}{|c|}{ Supplemental Table s2.txt } \\
\hline CHEMBL1483738 & 688422 & 5.4 & 5.421 & TRN & \\
\hline CHEMBL1379592 & 688422 & 6.05 & 5.6132 & TST & \\
\hline CHEMBL1079460 & 688422 & 5.35 & 5.4431 & TST & \\
\hline CHEMBL1442466 & 688422 & 4.5 & 5.7738 & TST & \\
\hline CHEMBL1523846 & 688422 & 4.9 & 4.9338 & TRN & \\
\hline CHEMBL1526130 & 688422 & 4.95 & 5.13299 & 9999999999 & TRN \\
\hline CHEMBL1334200 & 688422 & 5.0 & 5.4709 & TRN & \\
\hline CHEMBL1980684 & 688422 & 4.5 & 5.2264 & TRN & \\
\hline CHEMBL1503682 & 688422 & 5.2 & 5.3814 & TRN & \\
\hline CHEMBL1366992 & 688422 & 5.0 & 4.9341 & TRN & \\
\hline CHEMBL1401270 & 688422 & 5.1 & 5.0337 & TRN & \\
\hline CHEMBL1422200 & 688422 & 4.45 & 4.9001 & TST & \\
\hline CHEMBL1349632 & 688422 & 4.45 & 5.2516 & TRN & \\
\hline CHEMBL1485326 & 688422 & 4.95 & 5.0912 & TRN & \\
\hline CHEMBL1965126 & 688422 & 4.65 & 5.1547 & TRN & \\
\hline CHEMBL1433445 & 688422 & 8.4949 & 5.0292 & TRN & \\
\hline CHEMBL1588137 & 688422 & 5.5 & 5.2368 & TST & \\
\hline CHEMBL3197369 & 688422 & 4.45 & 5.1106 & TRN & \\
\hline CHEMBL1555038 & 688422 & 4.9 & 5.0554 & TRN & \\
\hline CHEMBL1414268 & 688422 & 5.65 & 4.9607 & TRN & \\
\hline CHEMBL1507828 & 688422 & 4.95 & 4.7559 & TRN & \\
\hline CHEMBL1385807 & 688422 & 5.3 & 4.958 & TRN & \\
\hline CHEMBL1380198 & 688422 & 4.45 & 4.9501 & TRN & \\
\hline CHEMBL1578092 & 688422 & 8.3468 & 5.4314 & TRN & \\
\hline CHEMBL1576888 & 688422 & 4.5 & 5.3276 & TRN & \\
\hline CHEMBL1326689 & 688422 & 4.5 & 5.4702 & TRN & \\
\hline CHEMBL1317784 & 688422 & 4.85 & 4.874 & TST & \\
\hline CHEMBL1406221 & 688422 & 6.5501 & 5.1741 & TST & \\
\hline CHEMBL3190739 & 688422 & 4.5 & 4.9613 & TRN & \\
\hline CHEMBL3190894 & 688422 & 4.6 & 4.9599 & TRN & \\
\hline CHEMBL1584078 & 688422 & 4.65 & 5.835 & TRN & \\
\hline CHEMBL1605471 & 688422 & 4.8 & 5.0874 & TRN & \\
\hline CHEMBL1544679 & 688422 & 4.5 & 5.1728 & TRN & \\
\hline CHEMBL1407656 & 688422 & 5.55 & 5.4688 & TRN & \\
\hline CHEMBL1437007 & 688422 & 4.85 & 4.9901 & TRN & \\
\hline CHEMBL1586241 & 688422 & 4.75 & 5.21700 & 00000000005 & TRN \\
\hline CHEMBL1384195 & 688422 & 4.45 & 5.1488 & TRN & \\
\hline CHEMBL1520645 & 688422 & 5.0 & 5.0532 & TRN & \\
\hline CHEMBL1503229 & 688422 & 4.6 & 5.1411 & TST & \\
\hline CHEMBL1445623 & 688422 & 4.85 & 5.5887 & TST & \\
\hline CHEMBL1494400 & 688422 & 4.95 & 5.0217 & TRN & \\
\hline CHEMBL1403096 & 688422 & 6.5501 & 5.4253 & TRN & \\
\hline CHEMBL1384194 & 688422 & 5.15 & 4.7362 & TRN & \\
\hline CHEMBL1362499 & 688422 & 4.9 & 4.891 & TRN & \\
\hline CHEMBL1385986 & 688422 & 4.5 & 5.018 & TRN & \\
\hline CHEMBL1492800 & 688422 & 4.9 & 5.2301 & TRN & \\
\hline CHEMBL1556416 & 688422 & 4.6 & 5.439 & TRN & \\
\hline CHEMBL1312031 & 688422 & 4.45 & 5.3912 & TRN & \\
\hline
\end{tabular}




\begin{tabular}{|c|c|c|c|c|c|}
\hline \multicolumn{6}{|c|}{ Supplemental Table s2.txt } \\
\hline CHEMBL3191964 & 688422 & 5.15 & 5.5593 & TRN & \\
\hline CHEMBL1593872 & 688422 & 4.6 & 5.2602 & TRN & \\
\hline CHEMBL1524482 & 688422 & 4.9 & 5.1452 & TRN & \\
\hline CHEMBL1443546 & 688422 & 4.45 & 5.4449 & TRN & \\
\hline CHEMBL3198529 & 688422 & 5.65 & 4.9931 & TRN & \\
\hline CHEMBL1438255 & 688422 & 4.75 & 5.4809 & TST & \\
\hline CHEMBL1397500 & 688422 & 6.2 & 5.0466 & TRN & \\
\hline CHEMBL1467286 & 688422 & 4.65 & 5.5603 & TRN & \\
\hline CHEMBL1434150 & 688422 & 6.95 & 5.2917 & TRN & \\
\hline CHEMBL1415208 & 688422 & 4.45 & 5.4567 & TRN & \\
\hline CHEMBL1609146 & 688422 & 5.35 & 5.4498 & TST & \\
\hline CHEMBL1471276 & 688422 & 4.65 & 4.7467 & TRN & \\
\hline CHEMBL1529889 & 688422 & 4.9 & 5.0359 & TRN & \\
\hline CHEMBL1339443 & 688422 & 4.85 & 4.9489 & TRN & \\
\hline CHEMBL1334419 & 688422 & 4.5 & 4.9603 & TRN & \\
\hline CHEMBL1412298 & 688422 & 5.15 & 5.4006 & TST & \\
\hline CHEMBL1511925 & 688422 & 4.95 & 5.36600 & 00000000005 & TRN \\
\hline CHEMBL1423995 & 688422 & 6.0 & 5.129 & TRN & \\
\hline CHEMBL1303671 & 688422 & 4.45 & 5.2665 & TRN & \\
\hline CHEMBL3211345 & 688422 & 7.1002 & 5.3594 & TRN & \\
\hline CHEMBL1409445 & 688422 & 5.5 & 5.1395 & TRN & \\
\hline CHEMBL1544989 & 688422 & 4.9 & 4.938 & TRN & \\
\hline CHEMBL1370383 & 688422 & 5.95 & 5.1705 & TRN & \\
\hline CHEMBL581910 & 688422 & 4.45 & 4.8058 & TST & \\
\hline CHEMBL1484006 & 688422 & 4.75 & 5.2115 & TRN & \\
\hline CHEMBL1592238 & 688422 & 4.45 & 5.5882 & TST & \\
\hline CHEMBL3196457 & 688422 & 4.9 & 5.0845 & TRN & \\
\hline CHEMBL1309398 & 688422 & 5.55 & 4.9547 & TRN & \\
\hline CHEMBL1495685 & 688422 & 4.45 & 4.9821 & TST & \\
\hline CHEMBL1539055 & 688422 & 5.4 & 5.4198 & TRN & \\
\hline CHEMBL1523206 & 688422 & 4.45 & 4.8093 & TRN & \\
\hline CHEMBL1350332 & 688422 & 5.3 & 5.3669 & TRN & \\
\hline CHEMBL1459381 & 688422 & 4.65 & 5.0504 & TRN & \\
\hline CHEMBL1392427 & 688422 & 5.6 & 5.1559 & TRN & \\
\hline CHEMBL1486729 & 688422 & 4.65 & 5.3174 & TST & \\
\hline CHEMBL1462582 & 688422 & 5.1 & 4.9779 & TST & \\
\hline CHEMBL1363083 & 688422 & 4.65 & 5.1288 & TRN & \\
\hline CHEMBL1372347 & 688422 & 4.9 & 5.2298 & TRN & \\
\hline CHEMBL1576946 & 688422 & 7.8013 & 5.1404 & TRN & \\
\hline CHEMBL1528742 & 688422 & 4.95 & 5.3737 & TRN & \\
\hline CHEMBL1415851 & 688422 & 5.0 & 5.0086 & TRN & \\
\hline CHEMBL1319883 & 688422 & 7.2 & 5.4112 & TRN & \\
\hline CHEMBL1391380 & 688422 & 4.9 & 5.2419 & TST & \\
\hline CHEMBL1303418 & 688422 & 4.45 & 5.32100 & 3000000001 & TRN \\
\hline CHEMBL1451522 & 688422 & 4.5 & 4.9681 & TRN & \\
\hline CHEMBL1607656 & 688422 & 5.35 & 5.0658 & TST & \\
\hline CHEMBL1429705 & 688422 & 5.0 & 5.0782 & TRN & \\
\hline CHEMBL1579248 & 688422 & 4.5 & 4.9383 & TRN & \\
\hline
\end{tabular}




\begin{tabular}{|c|c|c|c|c|c|}
\hline & & \multicolumn{4}{|c|}{ Supplemental Table S2.txt } \\
\hline CHEMBL547977 & 688422 & 8.3468 & 4.9234 & TRN & \\
\hline CHEMBL1513338 & 688422 & 5.6 & 5.5773 & TRN & \\
\hline CHEMBL1585499 & 688422 & 4.5 & 4.7522 & TRN & \\
\hline CHEMBL73310 & 688422 & 5.1 & 5.45299 & 9999999999 & TST \\
\hline CHEMBL1487131 & 688422 & 4.5 & 4.8629 & TRN & \\
\hline CHEMBL1365553 & 688422 & 5.45 & 5.1554 & TST & \\
\hline CHEMBL1476096 & 688422 & 4.85 & 5.80200 & 00000000005 & TST \\
\hline CHEMBL1968356 & 688422 & 5.35 & 5.1826 & TST & \\
\hline CHEMBL1503726 & 688422 & 4.45 & 5.0376 & TRN & \\
\hline CHEMBL1479345 & 688422 & 5.25 & 5.8153 & TRN & \\
\hline CHEMBL1383570 & 688422 & 4.7 & 5.1995 & TRN & \\
\hline CHEMBL1395811 & 688422 & 5.5 & 5.4645 & TRN & \\
\hline CHEMBL1498315 & 688422 & 4.45 & 5.1825 & TST & \\
\hline CHEMBL1555409 & 688422 & 4.85 & 5.0147 & TRN & \\
\hline CHEMBL1609522 & 688422 & 6.7001 & 5.4325 & TRN & \\
\hline CHEMBL1462610 & 688422 & 4.7 & 5.1679 & TRN & \\
\hline CHEMBL1352253 & 688422 & 4.95 & 4.9451 & TRN & \\
\hline CHEMBL1364457 & 688422 & 5.8 & 6.334 & TRN & \\
\hline CHEMBL1539645 & 688422 & 5.35 & 5.4032 & TRN & \\
\hline CHEMBL1388359 & 688422 & 4.45 & 5.4671 & TRN & \\
\hline CHEMBL1588013 & 688422 & 4.45 & 5.1568 & TRN & \\
\hline CHEMBL1478213 & 688422 & 4.55 & 4.6894 & TRN & \\
\hline CHEMBL1526321 & 688422 & 5.05 & 5.2592 & TRN & \\
\hline CHEMBL1522856 & 688422 & 4.75 & 5.1817 & TRN & \\
\hline CHEMBL1538109 & 688422 & 5.4 & 4.9435 & TRN & \\
\hline CHEMBL1349446 & 688422 & 4.45 & 5.6091 & TRN & \\
\hline CHEMBL1344191 & 688422 & 4.45 & 5.4036 & TRN & \\
\hline CHEMBL1355762 & 688422 & 4.85 & 4.7264 & TST & \\
\hline CHEMBL1342943 & 688422 & 4.95 & 5.6364 & TRN & \\
\hline CHEMBL516194 & 688422 & 7.3002 & 5.4207 & TRN & \\
\hline CHEMBL1577583 & 688422 & 4.8 & 5.0587 & TRN & \\
\hline CHEMBL1600820 & 688422 & 6.3 & 5.6289 & TRN & \\
\hline CHEMBL1443784 & 688422 & 4.65 & 4.8771 & TST & \\
\hline CHEMBL1357962 & 688422 & 7.5498 & 5.0086 & TRN & \\
\hline CHEMBL1550456 & 688422 & 6.15 & 5.1424 & TRN & \\
\hline CHEMBL1419178 & 688422 & 6.1 & 5.1078 & TRN & \\
\hline CHEMBL1315793 & 688422 & 5.3 & 5.2486 & TRN & \\
\hline CHEMBL1580478 & 688422 & 4.95 & 5.143 & TRN & \\
\hline CHEMBL1434112 & 688422 & 8.0506 & 5.1985 & TST & \\
\hline CHEMBL1597921 & 688422 & 5.2 & 5.1789 & TRN & \\
\hline CHEMBL3194398 & 688422 & 4.45 & 5.5265 & TRN & \\
\hline CHEMBL1320389 & 688422 & 4.45 & 4.9991 & TRN & \\
\hline CHEMBL1576941 & 688422 & 4.9 & 4.4864 & TRN & \\
\hline CHEMBL1350889 & 688422 & 4.9 & 4.8601 & TRN & \\
\hline CHEMBL1600269 & 688422 & 4.9 & 4.7574 & TRN & \\
\hline CHEMBL1603978 & 688422 & 4.45 & 5.1202 & TRN & \\
\hline CHEMBL1450964 & 688422 & 4.7 & 5.2748 & TRN & \\
\hline CHEMBL1543636 & 688422 & 4.45 & 4.8944 & TRN & \\
\hline
\end{tabular}




\begin{tabular}{|c|c|c|c|c|c|}
\hline \multicolumn{6}{|c|}{ Supplemental Table s2.txt } \\
\hline CHEMBL8867 & 688422 & 6.8 & 5.7932 & TRN & \\
\hline CHEMBL1456956 & 688422 & 6.5 & 5.2733 & TRN & \\
\hline CHEMBL1592413 & 688422 & 5.0 & 5.078 & TRN & \\
\hline CHEMBL1415153 & 688422 & 4.9 & 5.0916 & TRN & \\
\hline CHEMBL1580627 & 688422 & 7.2503 & 5.9307 & TRN & \\
\hline CHEMBL1612483 & 688422 & 4.95 & 4.8141 & TRN & \\
\hline CHEMBL1475542 & 688422 & 4.95 & 5.1964 & TRN & \\
\hline CHEMBL391123 & 688422 & 4.9 & 5.0284 & TRN & \\
\hline CHEMBL1574029 & 688422 & 4.45 & 4.9247 & TRN & \\
\hline CHEMBL1468275 & 688422 & 4.65 & 5.1584 & TRN & \\
\hline CHEMBL1337963 & 688422 & 4.95 & 5.0515 & TRN & \\
\hline CHEMBL1533474 & 688422 & 6.15 & 4.9014 & TST & \\
\hline CHEMBL1506626 & 688422 & 5.0 & 4.9676 & TST & \\
\hline CHEMBL1611765 & 688422 & 4.45 & 4.8879 & TRN & \\
\hline CHEMBL1375331 & 688422 & 4.8 & 4.9441 & TRN & \\
\hline CHEMBL1533639 & 688422 & 4.8 & 4.9776 & TRN & \\
\hline CHEMBL1393471 & 688422 & 5.3 & 5.32700 & $\partial 000000001$ & TST \\
\hline CHEMBL 25236 & 688422 & 5.05 & 5.1728 & TRN & \\
\hline CHEMBL1553120 & 688422 & 5.25 & 5.171 & TRN & \\
\hline CHEMBL3195064 & 688422 & 4.85 & 5.0987 & TRN & \\
\hline CHEMBL1408931 & 688422 & 6.95 & 6.1456 & TRN & \\
\hline CHEMBL1449320 & 688422 & 4.55 & 5.2413 & TRN & \\
\hline CHEMBL1414021 & 688422 & 4.45 & 5.5976 & TRN & \\
\hline CHEMBL1482982 & 688422 & 4.45 & 5.1438 & TRN & \\
\hline CHEMBL1601814 & 688422 & 5.05 & 5.1632 & TRN & \\
\hline CHEMBL1354451 & 688422 & 4.95 & 4.9433 & TRN & \\
\hline CHEMBL1515515 & 688422 & 5.5 & 5.0552 & TRN & \\
\hline CHEMBL1540576 & 688422 & 4.85 & 4.9699 & TRN & \\
\hline CHEMBL1338487 & 688422 & 4.95 & 4.9637 & TRN & \\
\hline CHEMBL1516861 & 688422 & 7.3497 & 5.0617 & TST & \\
\hline CHEMBL1481205 & 688422 & 4.5 & 5.2279 & TRN & \\
\hline CHEMBL1569927 & 688422 & 4.65 & 4.6149 & TST & \\
\hline CHEMBL1567966 & 688422 & 4.8 & 5.0562 & TRN & \\
\hline CHEMBL1570594 & 688422 & 5.0 & 5.0361 & TRN & \\
\hline CHEMBL585443 & 688422 & 4.7 & 5.0938 & TRN & \\
\hline CHEMBL1343144 & 688422 & 4.5 & 5.3251 & TRN & \\
\hline CHEMBL1479154 & 688422 & 5.6 & 5.5087 & TRN & \\
\hline CHEMBL1314994 & 688422 & 6.7501 & 5.1604 & TRN & \\
\hline CHEMBL1493202 & 688422 & 4.95 & 4.9166 & TRN & \\
\hline CHEMBL1571624 & 688422 & 5.0 & 5.4525 & TRN & \\
\hline CHEMBL1522276 & 688422 & 4.85 & 5.2864 & TRN & \\
\hline CHEMBL1578521 & 688422 & 4.75 & 5.0848 & TST & \\
\hline CHEMBL1521214 & 688422 & 4.95 & 5.291 & TRN & \\
\hline CHEMBL1597186 & 688422 & 4.95 & 5.2204 & TRN & \\
\hline CHEMBL1469095 & 688422 & 4.55 & 5.1807 & TRN & \\
\hline CHEMBL1551422 & 688422 & 5.25 & 5.1349 & TRN & \\
\hline CHEMBL1347369 & 688422 & 5.15 & 5.1153 & TRN & \\
\hline CHEMBL1411009 & 688422 & 5.35 & 5.1541 & TRN & \\
\hline
\end{tabular}




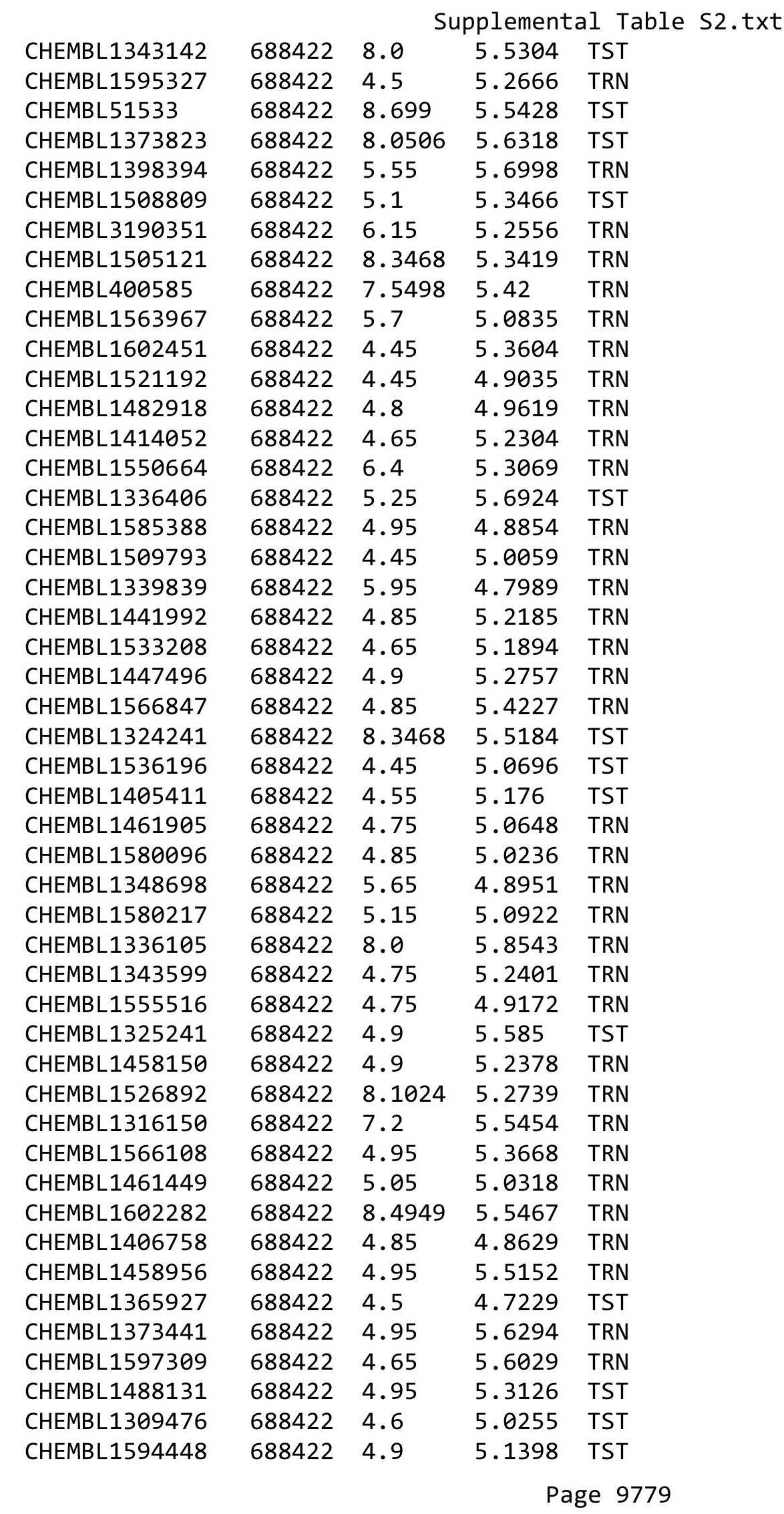




\begin{tabular}{|c|c|c|c|c|}
\hline \multicolumn{5}{|c|}{ Supplemental Table S2.txt } \\
\hline CHEMBL1331050 & 688422 & 4.9 & 5.6941 & TST \\
\hline CHEMBL1522208 & 688422 & 7.2503 & 5.5542 & TST \\
\hline CHEMBL1332844 & 688422 & 5.1 & 5.1585 & TRN \\
\hline CHEMBL 2068728 & 688422 & 4.9 & 4.9279 & TST \\
\hline CHEMBL1303657 & 688422 & 5.45 & 4.774 & TRN \\
\hline CHEMBL3199358 & 688422 & 5.65 & 5.8389 & TRN \\
\hline CHEMBL1514165 & 688422 & 4.45 & 4.9879 & TRN \\
\hline CHEMBL1471115 & 688422 & 4.65 & 5.30399 & 9999999999 \\
\hline CHEMBL1475695 & 688422 & 4.7 & 5.1292 & TRN \\
\hline CHEMBL411236 & 688422 & 4.6 & 5.3356 & TRN \\
\hline CHEMBL1605548 & 688422 & 4.95 & 5.1222 & TST \\
\hline CHEMBL1468486 & 688422 & 4.85 & 5.2139 & TRN \\
\hline CHEMBL1585003 & 688422 & 4.45 & 5.1667 & TST \\
\hline CHEMBL1606886 & 688422 & 4.75 & 5.1098 & TRN \\
\hline CHEMBL1434044 & 688422 & 7.1002 & 6.1838 & TRN \\
\hline CHEMBL1967081 & 688422 & 4.95 & 5.1304 & TRN \\
\hline CHEMBL1598530 & 688422 & 4.45 & 5.0958 & TRN \\
\hline CHEMBL1374411 & 688422 & 4.85 & 5.3274 & TST \\
\hline CHEMBL1534449 & 688422 & 4.7 & 5.1205 & TRN \\
\hline CHEMBL1324040 & 688422 & 6.6 & 5.6852 & TRN \\
\hline CHEMBL1343910 & 688422 & 4.9 & 5.1886 & TRN \\
\hline CHEMBL1419158 & 688422 & 4.65 & 5.1101 & TST \\
\hline CHEMBL1361752 & 688422 & 4.65 & 4.9429 & TRN \\
\hline CHEMBL1372271 & 688422 & 4.8 & 5.0352 & TRN \\
\hline CHEMBL1508934 & 688422 & 5.05 & 5.2973 & TRN \\
\hline CHEMBL1300625 & 688422 & 5.0 & 4.9075 & TRN \\
\hline CHEMBL1345400 & 688422 & 5.3 & 4.9189 & TRN \\
\hline CHEMBL 3208257 & 688422 & 8.3468 & 5.1752 & TST \\
\hline CHEMBL1388935 & 688422 & 4.85 & 5.3051 & TRN \\
\hline CHEMBL1565001 & 688422 & 4.75 & 4.8446 & TRN \\
\hline CHEMBL3191738 & 688422 & 8.4949 & 5.3079 & TRN \\
\hline CHEMBL3208130 & 688422 & 4.45 & 5.0296 & TRN \\
\hline CHEMBL1567239 & 688422 & 4.45 & 5.483 & TRN \\
\hline CHEMBL1346970 & 688422 & 4.7 & 5.2562 & TRN \\
\hline CHEMBL1321026 & 688422 & 4.85 & 5.2464 & TRN \\
\hline CHEMBL1566861 & 688422 & 5.2 & 5.6622 & TRN \\
\hline CHEMBL1329925 & 688422 & 5.15 & 5.0295 & TST \\
\hline CHEMBL1232474 & 688422 & 5.1 & 5.0973 & TRN \\
\hline CHEMBL1454195 & 688422 & 4.7 & 5.018 & TRN \\
\hline CHEMBL1304582 & 688422 & 5.25 & 5.3343 & TRN \\
\hline CHEMBL1581047 & 688422 & 7.8013 & 5.2744 & TST \\
\hline CHEMBL1525979 & 688422 & 4.8 & 4.9953 & TRN \\
\hline CHEMBL1399604 & 688422 & 4.95 & 4.9599 & TRN \\
\hline CHEMBL1446843 & 688422 & 4.8 & 5.4532 & TST \\
\hline CHEMBL497939 & 688422 & 7.2 & 5.8768 & TRN \\
\hline CHEMBL1500629 & 688422 & 5.0 & 5.2457 & TRN \\
\hline CHEMBL1445490 & 688422 & 4.8 & 5.046 & TRN \\
\hline CHEMBL1573367 & 688422 & 4.95 & 5.4873 & TRN \\
\hline
\end{tabular}




\begin{tabular}{|c|c|c|c|c|c|}
\hline & & \multicolumn{4}{|c|}{ Supplemental Table S2.txt } \\
\hline CHEMBL1569826 & 688422 & 7.8996 & 5.4984 & TST & \\
\hline CHEMBL1410536 & 688422 & 4.45 & 4.8261 & TRN & \\
\hline CHEMBL1581200 & 688422 & 6.8 & 5.7974 & TRN & \\
\hline CHEMBL1490989 & 688422 & 5.0 & 4.9637 & TRN & \\
\hline CHEMBL1425166 & 688422 & 4.95 & 4.8328 & TST & \\
\hline CHEMBL1359968 & 688422 & 4.95 & 5.1306 & TRN & \\
\hline CHEMBL1453558 & 688422 & 5.9 & 5.5066 & TRN & \\
\hline CHEMBL1604958 & 688422 & 6.05 & 5.5376 & TRN & \\
\hline CHEMBL580071 & 688422 & 7.9508 & 5.2258 & TRN & \\
\hline CHEMBL1604244 & 688422 & 4.9 & 5.2261 & TST & \\
\hline CHEMBL 2000814 & 688422 & 5.5 & 5.3709 & TST & \\
\hline CHEMBL1312682 & 688422 & 8.4949 & 5.5739 & TRN & \\
\hline CHEMBL1581810 & 688422 & 5.05 & 5.3283 & TRN & \\
\hline CHEMBL1389083 & 688422 & 5.55 & 5.434 & TRN & \\
\hline CHEMBL1476066 & 688422 & 6.5 & 5.6217 & TRN & \\
\hline CHEMBL1563812 & 688422 & 4.65 & 5.265 & TST & \\
\hline CHEMBL1603778 & 688422 & 4.65 & 5.6039 & TRN & \\
\hline CHEMBL1438818 & 688422 & 4.85 & 4.8499 & TRN & \\
\hline CHEMBL1324079 & 688422 & 4.85 & 5.2317 & TRN & \\
\hline CHEMBL1576828 & 688422 & 7.0501 & 5.4294 & TRN & \\
\hline CHEMBL1320929 & 688422 & 4.45 & 5.3748 & TRN & \\
\hline CHEMBL1591135 & 688422 & 4.8 & 4.9302 & TRN & \\
\hline CHEMBL1435615 & 688422 & 6.0 & 5.7216 & TRN & \\
\hline CHEMBL56543 & 688422 & 4.8 & 5.1809 & TRN & \\
\hline CHEMBL1541433 & 688422 & 4.85 & 5.8183 & TST & \\
\hline CHEMBL1408169 & 688422 & 5.75 & 5.3342 & TRN & \\
\hline CHEMBL1444103 & 688422 & 5.2 & 5.0269 & TRN & \\
\hline CHEMBL1427033 & 688422 & 4.6 & 5.1826 & TRN & \\
\hline CHEMBL1363446 & 688422 & 5.15 & 5.3989 & TST & \\
\hline CHEMBL1441038 & 688422 & 4.65 & 5.3217 & TRN & \\
\hline CHEMBL1538081 & 688422 & 8.3979 & 5.1896 & TST & \\
\hline CHEMBL1319631 & 688422 & 6.2 & 5.5219 & TST & \\
\hline CHEMBL1557094 & 688422 & 4.95 & 5.0704 & TST & \\
\hline CHEMBL1308081 & 688422 & 5.4 & 4.9272 & TST & \\
\hline CHEMBL3194892 & 688422 & 5.5 & 5.2621 & TRN & \\
\hline CHEMBL1509755 & 688422 & 4.75 & 4.7945 & TRN & \\
\hline CHEMBL1420219 & 688422 & 4.5 & 5.0774 & TRN & \\
\hline CHEMBL3191622 & 688422 & 4.95 & 5.4495 & TST & \\
\hline CHEMBL1450083 & 688422 & 6.7501 & 4.8745 & TRN & \\
\hline CHEMBL1391097 & 688422 & 4.45 & 5.3008 & TRN & \\
\hline CHEMBL3194929 & 688422 & 4.95 & 5.3142 & TRN & \\
\hline CHEMBL1417751 & 688422 & 4.6 & 5.602 & TRN & \\
\hline CHEMBL1490423 & 688422 & 4.45 & 4.957 & TRN & \\
\hline CHEMBL1276874 & 688422 & 4.7 & 5.2427 & TST & \\
\hline CHEMBL1310336 & 688422 & 4.9 & 5.06800 & 00000000005 & TRN \\
\hline CHEMBL 1493490 & 688422 & 5.5 & 5.3866 & TST & \\
\hline CHEMBL1374834 & 688422 & 4.5 & 5.4146 & TRN & \\
\hline CHEMBL3197466 & 688422 & 4.95 & 5.3804 & TRN & \\
\hline
\end{tabular}




\begin{tabular}{|c|c|c|c|c|}
\hline \multicolumn{5}{|c|}{ Supplemental Table S2.txt } \\
\hline CHEMBL1534844 & 688422 & 4.85 & 5.4496 & TRN \\
\hline CHEMBL1489602 & 688422 & 4.45 & 5.26399 & 9999999999 \\
\hline CHEMBL1407054 & 688422 & 5.25 & 4.8679 & TRN \\
\hline CHEMBL1581916 & 688422 & 4.45 & 5.4289 & TRN \\
\hline CHEMBL1508015 & 688422 & 5.3 & 5.5799 & TST \\
\hline CHEMBL1438348 & 688422 & 4.75 & 5.0234 & TRN \\
\hline CHEMBL1465564 & 688422 & 4.6 & 4.875 & TRN \\
\hline CHEMBL 365423 & 688422 & 4.7 & 5.8562 & TST \\
\hline CHEMBL 2001216 & 688422 & 4.5 & 5.153 & TRN \\
\hline CHEMBL1374965 & 688422 & 4.75 & 5.3052 & TRN \\
\hline CHEMBL 3197879 & 688422 & 5.3 & 5.311 & TRN \\
\hline CHEMBL1602441 & 688422 & 4.45 & 5.4001 & TST \\
\hline CHEMBL1610203 & 688422 & 4.45 & 5.4681 & TRN \\
\hline CHEMBL1444288 & 688422 & 4.5 & 5.0404 & TST \\
\hline CHEMBL1422479 & 688422 & 5.85 & 5.4066 & TST \\
\hline CHEMBL1541554 & 688422 & 5.3 & 5.4101 & TRN \\
\hline CHEMBL1503702 & 688422 & 5.35 & 5.6155 & TRN \\
\hline CHEMBL1456763 & 688422 & 5.3 & 5.5822 & TRN \\
\hline CHEMBL1534106 & 688422 & 4.9 & 5.3606 & TRN \\
\hline CHEMBL1356744 & 688422 & 4.9 & 5.3441 & TRN \\
\hline CHEMBL1533947 & 688422 & 8.3979 & 5.3289 & TRN \\
\hline CHEMBL1453328 & 688422 & 4.8 & 5.1161 & TRN \\
\hline CHEMBL1517241 & 688422 & 5.4 & 5.1288 & TRN \\
\hline CHEMBL1351100 & 688422 & 4.95 & 5.1644 & TRN \\
\hline CHEMBL1564753 & 688422 & 4.85 & 4.8932 & TRN \\
\hline CHEMBL1505295 & 688422 & 4.45 & 5.4282 & TRN \\
\hline CHEMBL1605262 & 688422 & 4.65 & 5.2286 & TST \\
\hline CHEMBL3194631 & 688422 & 7.9508 & 5.0498 & TRN \\
\hline CHEMBL1543271 & 688422 & 4.75 & 5.4348 & TRN \\
\hline CHEMBL1542535 & 688422 & 7.699 & 5.2713 & TRN \\
\hline CHEMBL1344508 & 688422 & 4.45 & 5.1349 & TRN \\
\hline CHEMBL3211386 & 688422 & 5.05 & 5.4709 & TST \\
\hline CHEMBL3199803 & 688422 & 4.9 & 4.9587 & TRN \\
\hline CHEMBL1548803 & 688422 & 4.75 & 5.5015 & TRN \\
\hline CHEMBL1428076 & 688422 & 6.15 & 5.4806 & TRN \\
\hline CHEMBL1487418 & 688422 & 5.45 & 4.9606 & TRN \\
\hline CHEMBL1318585 & 688422 & 5.8 & 5.7393 & TRN \\
\hline CHEMBL1544371 & 688422 & 6.25 & 5.3485 & TRN \\
\hline CHEMBL1379293 & 688422 & 8.3468 & 5.4403 & TRN \\
\hline CHEMBL1519655 & 688422 & 4.45 & 5.1004 & TRN \\
\hline CHEMBL1363769 & 688422 & 4.65 & 5.4 & TST \\
\hline CHEMBL1535377 & 688422 & 4.7 & 5.1198 & TST \\
\hline CHEMBL1427808 & 688422 & 4.45 & 5.0741 & TRN \\
\hline CHEMBL1571945 & 688422 & 7.5498 & 5.7812 & TST \\
\hline CHEMBL1388040 & 688422 & 4.45 & 5.2774 & TRN \\
\hline CHEMBL1572312 & 688422 & 4.45 & 5.2154 & TRN \\
\hline CHEMBL1460029 & 688422 & 6.15 & 5.4933 & TRN \\
\hline CHEMBL1439212 & 688422 & 4.45 & 5.4737 & TRN \\
\hline
\end{tabular}




\begin{tabular}{|c|c|c|c|c|c|}
\hline \multirow[b]{2}{*}{ CHEMBL1565498 } & \multicolumn{5}{|c|}{ Supplemental Table S2.txt } \\
\hline & 688422 & 4.85 & 4.7918 & TRN & \\
\hline CHEMBL1594144 & 688422 & 4.9 & 5.3947 & TRN & \\
\hline CHEMBL107201 & 688422 & 4.95 & 5.61100 & 2000000001 & TST \\
\hline CHEMBL1446691 & 688422 & 6.45 & 5.285 & TST & \\
\hline CHEMBL3196898 & 688422 & 4.45 & 5.0849 & TRN & \\
\hline CHEMBL1399183 & 688422 & 7.4001 & 5.2254 & TST & \\
\hline CHEMBL1375338 & 688422 & 5.3 & 4.9772 & TRN & \\
\hline CHEMBL1605977 & 688422 & 4.7 & 5.4097 & TRN & \\
\hline CHEMBL1432328 & 688422 & 7.3002 & 5.3872 & TRN & \\
\hline CHEMBL1990675 & 688422 & 5.15 & 4.9867 & TRN & \\
\hline CHEMBL1987441 & 688422 & 4.9 & 5.4793 & TRN & \\
\hline CHEMBL1334572 & 688422 & 4.5 & 5.4281 & TST & \\
\hline CHEMBL1328356 & 688422 & 4.75 & 5.2231 & TRN & \\
\hline CHEMBL1321262 & 688422 & 5.55 & 5.2243 & TRN & \\
\hline CHEMBL1517047 & 688422 & 4.5 & 5.2745 & TST & \\
\hline CHEMBL1505867 & 688422 & 4.65 & 5.4261 & TST & \\
\hline CHEMBL1338673 & 688422 & 4.45 & 4.6431 & TRN & \\
\hline CHEMBL1419967 & 688422 & 4.85 & 5.2943 & TRN & \\
\hline CHEMBL1380651 & 688422 & 4.85 & 5.0749 & TRN & \\
\hline CHEMBL1414768 & 688422 & 8.3468 & 5.3243 & TRN & \\
\hline CHEMBL1439215 & 688422 & 5.4 & 5.8856 & TST & \\
\hline CHEMBL1517806 & 688422 & 4.65 & 5.3649 & TRN & \\
\hline CHEMBL602424 & 688422 & 5.0 & 5.428 & TRN & \\
\hline CHEMBL1478595 & 688422 & 4.8 & 5.1737 & TRN & \\
\hline CHEMBL1381426 & 688422 & 4.5 & 5.1697 & TRN & \\
\hline CHEMBL1468751 & 688422 & 5.25 & 5.4729 & TST & \\
\hline CHEMBL1368581 & 688422 & 7.2503 & 5.1749 & TRN & \\
\hline CHEMBL1365118 & 688422 & 4.7 & 5.2128 & TRN & \\
\hline CHEMBL1502940 & 688422 & 4.6 & 4.9103 & TRN & \\
\hline CHEMBL1553316 & 688422 & 4.45 & 5.0095 & TRN & \\
\hline CHEMBL1386201 & 688422 & 4.5 & 5.225 & TRN & \\
\hline CHEMBL1432356 & 688422 & 4.95 & 5.1342 & TRN & \\
\hline CHEMBL1440157 & 688422 & 4.75 & 4.7351 & TRN & \\
\hline CHEMBL1343033 & 688422 & 5.95 & 5.4308 & TRN & \\
\hline CHEMBL1377299 & 688422 & 4.45 & 5.0628 & TST & \\
\hline CHEMBL1517623 & 688422 & 4.95 & 4.6003 & TRN & \\
\hline CHEMBL1426932 & 688422 & 4.7 & 4.8738 & TRN & \\
\hline CHEMBL1403565 & 688422 & 6.7001 & 5.4914 & TRN & \\
\hline CHEMBL1464836 & 688422 & 4.45 & 5.1674 & TRN & \\
\hline CHEMBL1340079 & 688422 & 4.5 & 5.2608 & TST & \\
\hline CHEMBL1469941 & 688422 & 5.25 & 5.195 & TRN & \\
\hline CHEMBL1416876 & 688422 & 4.45 & 5.0461 & TRN & \\
\hline CHEMBL1555526 & 688422 & 4.55 & 5.5188 & TRN & \\
\hline CHEMBL1350768 & 688422 & 4.95 & 5.1839 & TRN & \\
\hline CHEMBL1526471 & 688422 & 4.45 & 4.9412 & TRN & \\
\hline CHEMBL1307191 & 688422 & 4.85 & 5.0711 & TRN & \\
\hline CHEMBL1313171 & 688422 & 5.0 & 5.4198 & TST & \\
\hline CHEMBL1367917 & 688422 & 4.45 & 4.91100 & 00000000005 & TRN \\
\hline & & & & 9783 & \\
\hline
\end{tabular}




\begin{tabular}{|c|c|c|c|c|c|}
\hline \multicolumn{6}{|c|}{ Supplemental Table s2.txt } \\
\hline CHEMBL1358050 & 688422 & 5.2 & 4.6952 & TRN & \\
\hline CHEMBL1413517 & 688422 & 4.7 & 5.1822 & TST & \\
\hline CHEMBL1374464 & 688422 & 4.9 & 4.8641 & TRN & \\
\hline CHEMBL1339310 & 688422 & 4.65 & 5.0749 & TRN & \\
\hline CHEMBL1605094 & 688422 & 4.45 & 5.3402 & TRN & \\
\hline CHEMBL1560571 & 688422 & 4.9 & 5.3169 & TRN & \\
\hline CHEMBL1592811 & 688422 & 8.3979 & 5.4596 & TRN & \\
\hline CHEMBL1438448 & 688422 & 4.85 & 5.755 & TRN & \\
\hline CHEMBL1563047 & 688422 & 4.95 & 5.5905 & TRN & \\
\hline CHEMBL1493484 & 688422 & 4.45 & 5.46299 & 9999999999 & TRN \\
\hline CHEMBL1328484 & 688422 & 4.85 & 6.0532 & TST & \\
\hline CHEMBL1586987 & 688422 & 4.9 & 5.5644 & TST & \\
\hline CHEMBL1415632 & 688422 & 4.4 & 5.3597 & TRN & \\
\hline CHEMBL1613089 & 688422 & 4.85 & 5.2063 & TRN & \\
\hline CHEMBL1489149 & 688422 & 6.05 & 5.3515 & TRN & \\
\hline CHEMBL1346931 & 688422 & 4.5 & 5.1806 & TRN & \\
\hline CHEMBL1526624 & 688422 & 4.8 & 4.7702 & TRN & \\
\hline CHEMBL1423366 & 688422 & 4.95 & 5.145 & TRN & \\
\hline CHEMBL1595052 & 688422 & 4.45 & 5.308 & TRN & \\
\hline CHEMBL1325264 & 688422 & 5.05 & 5.3518 & TRN & \\
\hline CHEMBL1432933 & 688422 & 4.65 & 5.0722 & TRN & \\
\hline CHEMBL 3213321 & 688422 & 6.4 & 5.4334 & TRN & \\
\hline CHEMBL1366832 & 688422 & 4.45 & 4.9017 & TRN & \\
\hline CHEMBL1343972 & 688422 & 4.45 & 5.1811 & TRN & \\
\hline CHEMBL1486415 & 688422 & 4.9 & 5.1926 & TRN & \\
\hline CHEMBL1580606 & 688422 & 4.85 & 5.3726 & TRN & \\
\hline CHEMBL1307271 & 688422 & 4.45 & 5.5814 & TRN & \\
\hline CHEMBL1547092 & 688422 & 5.3 & 4.995 & TST & \\
\hline CHEMBL1582687 & 688422 & 5.3 & 5.17700 & 00000000005 & TRN \\
\hline CHEMBL1586019 & 688422 & 5.15 & 5.28100 & 0000000001 & TST \\
\hline CHEMBL3197332 & 688422 & 4.45 & 5.104 & TST & \\
\hline CHEMBL1376213 & 688422 & 5.5 & 5.1799 & TRN & \\
\hline CHEMBL1408592 & 688422 & 4.45 & 5.5181 & TRN & \\
\hline CHEMBL1398784 & 688422 & 6.25 & 5.157 & TRN & \\
\hline CHEMBL1486095 & 688422 & 5.65 & 4.6494 & TRN & \\
\hline CHEMBL1476745 & 688422 & 8.3468 & 5.7066 & TRN & \\
\hline CHEMBL568379 & 688422 & 4.9 & 4.7006 & TRN & \\
\hline CHEMBL1454982 & 688422 & 4.95 & 5.3547 & TRN & \\
\hline CHEMBL1456795 & 688422 & 7.1002 & 5.6087 & TRN & \\
\hline CHEMBL3193575 & 688422 & 4.65 & 5.4426 & TST & \\
\hline CHEMBL1353199 & 688422 & 4.9 & 4.9324 & TST & \\
\hline CHEMBL1381180 & 688422 & 4.45 & 5.5235 & TST & \\
\hline CHEMBL1299599 & 688422 & 4.55 & 5.6402 & TRN & \\
\hline CHEMBL1483245 & 688422 & 6.5 & 5.2907 & TRN & \\
\hline CHEMBL1503221 & 688422 & 7.5003 & 5.5141 & TRN & \\
\hline CHEMBL1485779 & 688422 & 5.2 & 5.46700 & 00000000005 & TST \\
\hline CHEMBL1514144 & 688422 & 4.45 & 4.8658 & TRN & \\
\hline CHEMBL1551069 & 688422 & 5.4 & 5.2339 & TRN & \\
\hline
\end{tabular}




\begin{tabular}{|c|c|c|c|c|}
\hline \multicolumn{5}{|c|}{ Supplemental Table S2.txt } \\
\hline CHEMBL1528903 & 688422 & 4.45 & 4.8077 & TRN \\
\hline CHEMBL1356771 & 688422 & 4.8 & 5.0422 & TRN \\
\hline CHEMBL1347484 & 688422 & 4.6 & 5.9402 & TRN \\
\hline CHEMBL1392406 & 688422 & 4.6 & 5.4135 & TRN \\
\hline CHEMBL1398114 & 688422 & 6.6 & 5.5663 & TRN \\
\hline CHEMBL1315920 & 688422 & 4.8 & 4.7226 & TRN \\
\hline CHEMBL1569739 & 688422 & 4.7 & 4.8944 & TRN \\
\hline CHEMBL1518615 & 688422 & 5.25 & 5.0097 & TRN \\
\hline CHEMBL1435488 & 688422 & 4.95 & 5.3462 & TRN \\
\hline CHEMBL1528262 & 688422 & 4.45 & 4.7698 & TRN \\
\hline CHEMBL1404038 & 688422 & 4.95 & 4.8875 & TRN \\
\hline CHEMBL1485774 & 688422 & 4.85 & 5.2503 & TRN \\
\hline CHEMBL1591498 & 688422 & 5.0 & 5.4149 & TRN \\
\hline CHEMBL1370044 & 688422 & 5.4 & 5.1008 & TRN \\
\hline CHEMBL1996697 & 688422 & 5.4 & 5.1107 & TRN \\
\hline CHEMBL1510144 & 688422 & 4.45 & 5.3357 & TRN \\
\hline CHEMBL1430669 & 688422 & 5.15 & 5.4481 & TRN \\
\hline CHEMBL1577986 & 688422 & 4.5 & 4.9773 & TRN \\
\hline CHEMBL1390617 & 688422 & 5.1 & 5.0432 & TRN \\
\hline CHEMBL1606070 & 688422 & 4.45 & 4.9794 & TRN \\
\hline CHEMBL1403085 & 688422 & 4.8 & 5.0573 & TRN \\
\hline CHEMBL1290699 & 688422 & 4.8 & 5.3135 & TRN \\
\hline CHEMBL1473238 & 688422 & 5.05 & 5.1455 & TRN \\
\hline CHEMBL1391406 & 688422 & 5.55 & 5.3833 & TST \\
\hline CHEMBL1990093 & 688422 & 5.05 & 5.3587 & TRN \\
\hline CHEMBL3209990 & 688422 & 4.95 & 5.3659 & TRN \\
\hline CHEMBL1332714 & 688422 & 4.45 & 5.5069 & TRN \\
\hline CHEMBL1409367 & 688422 & 5.1 & 5.1784 & TRN \\
\hline CHEMBL1414454 & 688422 & 6.15 & 5.5632 & TRN \\
\hline CHEMBL1311399 & 688422 & 4.85 & 4.5098 & TRN \\
\hline CHEMBL1416649 & 688422 & 5.4 & 5.3664 & TST \\
\hline CHEMBL1461433 & 688422 & 6.15 & 5.2691 & TST \\
\hline CHEMBL1398721 & 688422 & 4.6 & 4.6273 & TRN \\
\hline CHEMBL1441493 & 688422 & 4.75 & 5.3473 & TRN \\
\hline CHEMBL1457964 & 688422 & 4.65 & 5.4083 & TRN \\
\hline CHEMBL338314 & 688422 & 4.5 & 5.6326 & TST \\
\hline CHEMBL1599784 & 688422 & 5.35 & 4.7024 & TRN \\
\hline CHEMBL1513327 & 688422 & 4.95 & 5.5684 & TRN \\
\hline CHEMBL1449350 & 688422 & 5.15 & 4.9387 & TRN \\
\hline CHEMBL1403942 & 688422 & 7.5003 & 5.7903 & TRN \\
\hline CHEMBL1442576 & 688422 & 5.25 & 4.9807 & TRN \\
\hline CHEMBL1421778 & 688422 & 5.9 & 5.7461 & TST \\
\hline CHEMBL1467369 & 688422 & 4.85 & 5.3006 & TRN \\
\hline CHEMBL1385163 & 688422 & 6.7001 & 5.6768 & TRN \\
\hline CHEMBL1387002 & 688422 & 4.65 & 5.4462 & TST \\
\hline CHEMBL1467579 & 688422 & 4.9 & 5.0348 & TST \\
\hline CHEMBL1308677 & 688422 & 4.75 & 4.9866 & TRN \\
\hline CHEMBL1332251 & 688422 & 5.45 & 5.8663 & TRN \\
\hline
\end{tabular}




\begin{tabular}{|c|c|c|c|c|}
\hline \multicolumn{5}{|c|}{ Supplemental Table S2.txt } \\
\hline CHEMBL1612176 & 688422 & 4.45 & 5.3095 & TRN \\
\hline CHEMBL3199486 & 688422 & 4.7 & 4.9717 & TRN \\
\hline CHEMBL1509094 & 688422 & 4.65 & 5.1272 & TRN \\
\hline CHEMBL1305812 & 688422 & 5.15 & 5.1859 & TRN \\
\hline CHEMBL1484409 & 688422 & 5.15 & 5.5598 & TST \\
\hline CHEMBL3198430 & 688422 & 4.9 & 4.8651 & TRN \\
\hline CHEMBL1360064 & 688422 & 4.75 & 5.3336 & TRN \\
\hline CHEMBL1560931 & 688422 & 7.5003 & 5.5409 & TRN \\
\hline CHEMBL1424916 & 688422 & 4.9 & 5.015 & TRN \\
\hline CHEMBL1379506 & 688422 & 5.25 & 5.2372 & TRN \\
\hline CHEMBL473106 & 688422 & 4.85 & 5.04899 & 99999999995 \\
\hline CHEMBL1579153 & 688422 & 5.5 & 5.3203 & TRN \\
\hline CHEMBL1519381 & 688422 & 5.5 & 5.0798 & TRN \\
\hline CHEMBL1459111 & 688422 & 5.45 & 4.8267 & TRN \\
\hline CHEMBL1362256 & 688422 & 4.7 & 4.9714 & TRN \\
\hline CHEMBL1536403 & 688422 & 6.45 & 5.6377 & TST \\
\hline CHEMBL1504786 & 688422 & 4.85 & 5.0828 & TST \\
\hline CHEMBL1306488 & 688422 & 4.9 & 5.0201 & TRN \\
\hline CHEMBL1529961 & 688422 & 8.0 & 5.0222 & TRN \\
\hline CHEMBL1592008 & 688422 & 5.1 & 5.1767 & TRN \\
\hline CHEMBL1471498 & 688422 & 5.4 & 5.5792 & TST \\
\hline CHEMBL1310868 & 688422 & 4.75 & 5.2574 & TRN \\
\hline CHEMBL3196451 & 688422 & 5.5 & 5.126 & TRN \\
\hline CHEMBL1476894 & 688422 & 4.7 & 5.4216 & TRN \\
\hline CHEMBL1507658 & 688422 & 4.45 & 5.1162 & TST \\
\hline CHEMBL1517360 & 688422 & 4.85 & 5.1673 & TRN \\
\hline CHEMBL1337177 & 688422 & 4.45 & 4.6725 & TRN \\
\hline CHEMBL1411645 & 688422 & 7.0 & 5.2077 & TRN \\
\hline CHEMBL1318296 & 688422 & 7.9508 & 5.24 & TST \\
\hline CHEMBL1435261 & 688422 & 5.35 & 5.8089 & TRN \\
\hline CHEMBL1367396 & 688422 & 4.95 & 5.2376 & TRN \\
\hline CHEMBL1595709 & 688422 & 8.3979 & 5.7024 & TRN \\
\hline CHEMBL1530797 & 688422 & 4.45 & 5.0411 & TST \\
\hline CHEMBL1590902 & 688422 & 6.4 & 6.0508 & TRN \\
\hline CHEMBL1556330 & 688422 & 7.2 & 5.0664 & TRN \\
\hline CHEMBL1510965 & 688422 & 6.6 & 5.2646 & TRN \\
\hline CHEMBL1420252 & 688422 & 4.8 & 5.4119 & TRN \\
\hline CHEMBL1416543 & 688422 & 4.6 & 5.2409 & TST \\
\hline CHEMBL3197854 & 688422 & 4.85 & 5.2872 & TRN \\
\hline CHEMBL1462262 & 688422 & 4.9 & 5.1459 & TRN \\
\hline CHEMBL1530001 & 688422 & 5.55 & 5.1216 & TRN \\
\hline CHEMBL1383344 & 688422 & 5.95 & 5.5227 & TRN \\
\hline CHEMBL1520741 & 688422 & 4.45 & 5.2213 & TRN \\
\hline CHEMBL1481243 & 688422 & 7.699 & 5.6355 & TRN \\
\hline CHEMBL1485976 & 688422 & 5.15 & 5.4435 & TST \\
\hline CHEMBL1486282 & 688422 & 5.6 & 5.7254 & TRN \\
\hline CHEMBL1551736 & 688422 & 8.0 & 5.3406 & TRN \\
\hline CHEMBL1607093 & 688422 & 4.45 & 5.6632 & TRN \\
\hline
\end{tabular}




\begin{tabular}{|c|c|c|c|c|}
\hline \multicolumn{5}{|c|}{ Supplemental Table S2.txt } \\
\hline CHEMBL1497000 & 688422 & 4.5 & 5.2531 & TRN \\
\hline CHEMBL1509493 & 688422 & 5.85 & 5.6329 & TRN \\
\hline CHEMBL1350524 & 688422 & 7.4498 & 5.7656 & TRN \\
\hline CHEMBL1332330 & 688422 & 6.8 & 5.1792 & TRN \\
\hline CHEMBL1459290 & 688422 & 4.9 & 5.0295 & TRN \\
\hline CHEMBL1516188 & 688422 & 4.6 & 5.0755 & TRN \\
\hline CHEMBL1607298 & 688422 & 5.7 & 5.4816 & TRN \\
\hline CHEMBL1540815 & 688422 & 4.65 & 4.862 & TRN \\
\hline CHEMBL1542099 & 688422 & 4.7 & 5.4283 & TRN \\
\hline CHEMBL1369574 & 688422 & 6.15 & 5.2038 & TST \\
\hline CHEMBL1404507 & 688422 & 4.45 & 4.8461 & TRN \\
\hline CHEMBL3208938 & 688422 & 5.5 & 5.1089 & TST \\
\hline CHEMBL459939 & 688422 & 7.3002 & 5.1742 & TRN \\
\hline CHEMBL1377815 & 688422 & 4.7 & 5.2404 & TRN \\
\hline CHEMBL1522582 & 688422 & 4.6 & 4.8384 & TRN \\
\hline CHEMBL1413240 & 688422 & 4.95 & 4.8821 & TST \\
\hline CHEMBL1309799 & 688422 & 4.85 & 4.9957 & TRN \\
\hline CHEMBL1428071 & 688422 & 4.75 & 4.6436 & TRN \\
\hline CHEMBL1342459 & 688422 & 4.45 & 4.9326 & TRN \\
\hline CHEMBL1441823 & 688422 & 4.45 & 4.9911 & TRN \\
\hline CHEMBL1583965 & 688422 & 5.5 & 5.8172 & TST \\
\hline CHEMBL1470135 & 688422 & 4.95 & 4.7352 & TRN \\
\hline CHEMBL1562501 & 688422 & 4.95 & 5.1799 & TRN \\
\hline CHEMBL1336549 & 688422 & 5.1 & 5.0619 & TRN \\
\hline CHEMBL1452226 & 688422 & 6.5501 & 5.0507 & TST \\
\hline CHEMBL1376001 & 688422 & 5.55 & 5.1867 & TRN \\
\hline CHEMBL1545544 & 688422 & 5.9 & 5.7017 & TRN \\
\hline CHEMBL1399987 & 688422 & 4.8 & 4.9471 & TRN \\
\hline CHEMBL1421574 & 688422 & 4.45 & 4.9926 & TRN \\
\hline CHEMBL1445710 & 688422 & 4.55 & 4.9682 & TRN \\
\hline CHEMBL1544478 & 688422 & 5.1 & 5.3676 & TRN \\
\hline CHEMBL1495024 & 688422 & 4.75 & 4.9167 & TRN \\
\hline CHEMBL1538370 & 688422 & 5.15 & 4.9622 & TRN \\
\hline CHEMBL1437916 & 688422 & 5.6 & 5.8332 & TST \\
\hline CHEMBL1361568 & 688422 & 4.9 & 5.1172 & TRN \\
\hline CHEMBL1575894 & 688422 & 4.75 & 4.7931 & TRN \\
\hline CHEMBL1606484 & 688422 & 4.45 & 5.2544 & TRN \\
\hline CHEMBL1610217 & 688422 & 7.1002 & 5.4855 & TRN \\
\hline CHEMBL1541763 & 688422 & 4.45 & 5.2707 & TST \\
\hline CHEMBL1322584 & 688422 & 5.15 & 5.041 & TRN \\
\hline CHEMBL1345104 & 688422 & 4.45 & 5.1221 & TRN \\
\hline CHEMBL1529722 & 688422 & 5.1 & 5.1597 & TRN \\
\hline CHEMBL1314646 & 688422 & 6.6 & 5.6413 & TRN \\
\hline CHEMBL1337175 & 688422 & 4.8 & 5.0953 & TRN \\
\hline CHEMBL1432204 & 688422 & 4.45 & 5.0367 & TRN \\
\hline CHEMBL1532737 & 688422 & 4.65 & 4.8585 & TRN \\
\hline CHEMBL1341947 & 688422 & 5.4 & 4.9141 & TRN \\
\hline CHEMBL1478820 & 688422 & 4.5 & 4.6163 & TRN \\
\hline
\end{tabular}




\begin{tabular}{|c|c|c|c|c|c|}
\hline \multicolumn{6}{|c|}{ Supplemental Table S2.txt } \\
\hline CHEMBL607253 & 688422 & 4.7 & 5.1974 & TST & \\
\hline CHEMBL1464257 & 688422 & 4.95 & 4.9664 & TRN & \\
\hline CHEMBL1399023 & 688422 & 5.0 & 5.5837 & TRN & \\
\hline CHEMBL1546724 & 688422 & 4.45 & 5.0966 & TRN & \\
\hline CHEMBL1419258 & 688422 & 4.65 & 5.1053 & TRN & \\
\hline CHEMBL1552275 & 688422 & 5.3 & 5.6824 & TRN & \\
\hline CHEMBL1453916 & 688422 & 4.85 & 5.3351 & TRN & \\
\hline CHEMBL1587448 & 688422 & 4.8 & 5.1979 & TRN & \\
\hline CHEMBL3193239 & 688422 & 8.4949 & 5.113 & TRN & \\
\hline CHEMBL1464426 & 688422 & 4.5 & 5.3885 & TRN & \\
\hline CHEMBL1361527 & 688422 & 6.25 & 5.2055 & TRN & \\
\hline CHEMBL473314 & 688422 & 5.5 & 5.6367 & TRN & \\
\hline CHEMBL1491879 & 688422 & 4.95 & 5.0292 & TRN & \\
\hline CHEMBL1343462 & 688422 & 8.301 & 5.1732 & TRN & \\
\hline CHEMBL1495033 & 688422 & 5.0 & 5.0117 & TRN & \\
\hline CHEMBL1337504 & 688422 & 4.7 & 4.8915 & TRN & \\
\hline CHEMBL1585276 & 688422 & 4.45 & 5.0389 & TRN & \\
\hline CHEMBL1540556 & 688422 & 6.3 & 4.8813 & TST & \\
\hline CHEMBL1402982 & 688422 & 4.95 & 5.4701 & TST & \\
\hline CHEMBL1506501 & 688422 & 4.5 & 5.818 & TST & \\
\hline CHEMBL1376657 & 688422 & 5.1 & 5.3113 & TRN & \\
\hline CHEMBL1353723 & 688422 & 4.9 & 5.0976 & TRN & \\
\hline CHEMBL1387872 & 688422 & 8.5528 & 5.0962 & TRN & \\
\hline CHEMBL1528896 & 688422 & 6.5501 & 5.4407 & TRN & \\
\hline CHEMBL1465797 & 688422 & 4.9 & 5.3504 & TRN & \\
\hline CHEMBL1602853 & 688422 & 4.45 & 5.20799 & 9999999999 & TRN \\
\hline CHEMBL1361190 & 688422 & 5.4 & 5.5048 & TRN & \\
\hline CHEMBL1477629 & 688422 & 4.85 & 5.3346 & TRN & \\
\hline CHEMBL1313319 & 688422 & 4.45 & 5.0104 & TST & \\
\hline CHEMBL1600804 & 688422 & 6.3 & 5.2889 & TRN & \\
\hline CHEMBL1528726 & 688422 & 4.65 & 5.026 & TRN & \\
\hline CHEMBL1516818 & 688422 & 4.9 & 5.3256 & TRN & \\
\hline CHEMBL1537002 & 688422 & 4.45 & 4.9076 & TRN & \\
\hline CHEMBL1475168 & 688422 & 6.2 & 5.4815 & TRN & \\
\hline CHEMBL1585448 & 688422 & 4.7 & 5.0225 & TRN & \\
\hline CHEMBL1323586 & 688422 & 5.55 & 5.2836 & TST & \\
\hline CHEMBL1417197 & 688422 & 4.65 & 4.9959 & TRN & \\
\hline CHEMBL1431789 & 688422 & 4.8 & 5.1363 & TRN & \\
\hline CHEMBL1459149 & 688422 & 4.65 & 5.1821 & TRN & \\
\hline CHEMBL1336151 & 688422 & 4.55 & 4.7245 & TRN & \\
\hline CHEMBL1564618 & 688422 & 4.9 & 5.4147 & TST & \\
\hline CHEMBL1527929 & 688422 & 4.45 & 5.6219 & TRN & \\
\hline CHEMBL1457582 & 688422 & 4.95 & 5.0994 & TST & \\
\hline CHEMBL1404113 & 688422 & 5.25 & 4.9912 & TRN & \\
\hline CHEMBL1482007 & 688422 & 5.2 & 4.5262 & TRN & \\
\hline CHEMBL1557622 & 688422 & 4.45 & 5.2482 & TRN & \\
\hline CHEMBL1350661 & 688422 & 8.4949 & 5.3517 & TRN & \\
\hline CHEMBL1306274 & 688422 & 4.5 & 5.3994 & TST & \\
\hline
\end{tabular}




\begin{tabular}{|c|c|c|c|c|c|}
\hline \multicolumn{6}{|c|}{ Supplemental Table S2.txt } \\
\hline CHEMBL1338548 & 688422 & 4.45 & 5.5899 & TRN & \\
\hline CHEMBL1588670 & 688422 & 7.5498 & 5.3014 & TRN & \\
\hline CHEMBL1413265 & 688422 & 4.8 & 4.8591 & TRN & \\
\hline CHEMBL1361528 & 688422 & 4.6 & 5.0392 & TRN & \\
\hline CHEMBL1379997 & 688422 & 5.05 & 5.2701 & TRN & \\
\hline CHEMBL1306329 & 688422 & 4.65 & 5.124 & TRN & \\
\hline CHEMBL1584187 & 688422 & 5.15 & 5.2392 & TST & \\
\hline CHEMBL1582149 & 688422 & 8.2518 & 5.3058 & TST & \\
\hline CHEMBL1305396 & 688422 & 4.5 & 4.8408 & TRN & \\
\hline CHEMBL1584264 & 688422 & 4.65 & 5.1961 & TST & \\
\hline CHEMBL47 & 688422 & 6.0 & 5.3153 & TST & \\
\hline CHEMBL1313307 & 688422 & 5.55 & 5.1616 & TRN & \\
\hline CHEMBL1369623 & 688422 & 4.85 & 5.3228 & TST & \\
\hline CHEMBL1451340 & 688422 & 6.4 & 5.2319 & TRN & \\
\hline CHEMBL1535257 & 688422 & 4.8 & 4.7796 & TRN & \\
\hline CHEMBL1569654 & 688422 & 4.6 & 4.9334 & TRN & \\
\hline CHEMBL1443016 & 688422 & 4.95 & 4.9655 & TRN & \\
\hline CHEMBL1592871 & 688422 & 7.2 & 5.1718 & TST & \\
\hline CHEMBL1476350 & 688422 & 5.0 & 5.393 & TRN & \\
\hline CHEMBL1473027 & 688422 & 7.6003 & 5.8167 & TRN & \\
\hline CHEMBL1504758 & 688422 & 4.6 & 5.1985 & TRN & \\
\hline CHEMBL1376292 & 688422 & 4.85 & 5.2402 & TST & \\
\hline CHEMBL1558336 & 688422 & 4.8 & 5.2957 & TRN & \\
\hline CHEMBL1466926 & 688422 & 4.7 & 4.9834 & TRN & \\
\hline CHEMBL1543549 & 688422 & 4.95 & 5.2365 & TST & \\
\hline CHEMBL1364395 & 688422 & 4.65 & 5.6238 & TST & \\
\hline CHEMBL3192796 & 688422 & 4.45 & 5.21700 & 00000000005 & TST \\
\hline CHEMBL1536234 & 688422 & 8.0 & 5.3924 & TST & \\
\hline CHEMBL1373432 & 688422 & 4.45 & 5.0351 & TRN & \\
\hline CHEMBL3193152 & 688422 & 4.95 & 5.2534 & TRN & \\
\hline CHEMBL1422766 & 688422 & 4.5 & 5.5362 & TST & \\
\hline CHEMBL3199218 & 688422 & 4.95 & 5.1291 & TST & \\
\hline CHEMBL1479382 & 688422 & 4.45 & 5.087 & TRN & \\
\hline CHEMBL1536491 & 688422 & 4.45 & 5.0591 & TRN & \\
\hline CHEMBL1315222 & 688422 & 5.8 & 5.3976 & TRN & \\
\hline CHEMBL1430569 & 688422 & 5.9 & 5.4359 & TRN & \\
\hline CHEMBL1321159 & 688422 & 4.5 & 5.0744 & TRN & \\
\hline CHEMBL1445160 & 688422 & 4.6 & 4.9958 & TRN & \\
\hline CHEMBL1392294 & 688422 & 4.7 & 5.1182 & TRN & \\
\hline CHEMBL1497078 & 688422 & 4.85 & 5.05699 & 99999999995 & TRN \\
\hline CHEMBL1429573 & 688422 & 5.0 & 5.7794 & TST & \\
\hline CHEMBL1578967 & 688422 & 4.95 & 5.3281 & TST & \\
\hline CHEMBL1561757 & 688422 & 4.95 & 5.4037 & TRN & \\
\hline CHEMBL1419442 & 688422 & 4.8 & 5.2096 & TRN & \\
\hline CHEMBL576932 & 688422 & 4.45 & 5.5403 & TRN & \\
\hline CHEMBL1440037 & 688422 & 5.7 & 4.91100 & 00000000005 & TRN \\
\hline CHEMBL1465870 & 688422 & 4.45 & 5.4329 & TRN & \\
\hline CHEMBL1408803 & 688422 & 4.75 & 5.2404 & TRN & \\
\hline
\end{tabular}




\begin{tabular}{|c|c|c|c|c|c|}
\hline \multirow[b]{2}{*}{ CHEMBL1549221 } & \multicolumn{5}{|c|}{ Supplemental Table S2.txt } \\
\hline & 688422 & 7.8508 & 5.4377 & TRN & \\
\hline CHEMBL1362590 & 688422 & 7.6498 & 5.5648 & TST & \\
\hline CHEMBL1482199 & 688422 & 4.45 & 4.716 & TRN & \\
\hline CHEMBL1448849 & 688422 & 4.9 & 4.9943 & TRN & \\
\hline CHEMBL1541807 & 688422 & 4.8 & 4.7652 & TRN & \\
\hline CHEMBL 1256480 & 688422 & 5.2 & 6.237 & TST & \\
\hline CHEMBL1391827 & 688422 & 4.45 & 5.7774 & TRN & \\
\hline CHEMBL1415878 & 688422 & 4.45 & 5.0828 & TRN & \\
\hline CHEMBL1594864 & 688422 & 5.05 & 5.1287 & TST & \\
\hline CHEMBL1390836 & 688422 & 4.8 & 5.2635 & TRN & \\
\hline CHEMBL1302833 & 688422 & 8.301 & 5.4965 & TRN & \\
\hline CHEMBL1468540 & 688422 & 4.45 & 5.2474 & TST & \\
\hline CHEMBL1465659 & 688422 & 5.05 & 5.1046 & TST & \\
\hline CHEMBL1391148 & 688422 & 5.9 & 5.1314 & TRN & \\
\hline CHEMBL1341491 & 688422 & 4.65 & 5.3822 & TRN & \\
\hline CHEMBL1530791 & 688422 & 5.55 & 5.0905 & TRN & \\
\hline CHEMBL1466239 & 688422 & 4.45 & 5.2169 & TRN & \\
\hline CHEMBL1323927 & 688422 & 4.8 & 5.2059 & TRN & \\
\hline CHEMBL1444897 & 688422 & 4.45 & 5.1111 & TST & \\
\hline CHEMBL1450588 & 688422 & 8.4949 & 5.5709 & TRN & \\
\hline CHEMBL1977653 & 688422 & 4.5 & 5.3375 & TRN & \\
\hline CHEMBL1414382 & 688422 & 5.1 & 4.9181 & TRN & \\
\hline CHEMBL1467136 & 688422 & 4.85 & 4.7854 & TRN & \\
\hline CHEMBL1432735 & 688422 & 4.5 & 5.5791 & TRN & \\
\hline CHEMBL3191302 & 688422 & 4.45 & 5.3946 & TRN & \\
\hline CHEMBL1556505 & 688422 & 4.5 & 5.1979 & TRN & \\
\hline CHEMBL1605525 & 688422 & 4.85 & 5.3405 & TRN & \\
\hline CHEMBL1321228 & 688422 & 4.9 & 5.0305 & TRN & \\
\hline CHEMBL1491089 & 688422 & 7.8013 & 5.6123 & TST & \\
\hline CHEMBL1461879 & 688422 & 4.5 & 5.0179 & TRN & \\
\hline CHEMBL1036 & 688422 & 4.8 & 5.3737 & TST & \\
\hline CHEMBL1306684 & 688422 & 4.5 & 5.04899 & 99999999995 & TRN \\
\hline CHEMBL1409903 & 688422 & 4.95 & 5.1639 & TRN & \\
\hline CHEMBL1538326 & 688422 & 7.699 & 5.1476 & TRN & \\
\hline CHEMBL1503027 & 688422 & 4.5 & 5.29200 & 0000000001 & TRN \\
\hline CHEMBL1524395 & 688422 & 4.75 & 4.5464 & TST & \\
\hline CHEMBL1585026 & 688422 & 5.0 & 5.1853 & TRN & \\
\hline CHEMBL 3190181 & 688422 & 5.25 & 5.1527 & TRN & \\
\hline CHEMBL435392 & 688422 & 4.9 & 4.9287 & TRN & \\
\hline CHEMBL1331944 & 688422 & 4.45 & 4.9991 & TRN & \\
\hline CHEMBL1439768 & 688422 & 4.65 & 5.4203 & TRN & \\
\hline CHEMBL1971142 & 688422 & 6.0 & 5.809 & TRN & \\
\hline CHEMBL1580053 & 688422 & 4.95 & 4.9394 & TST & \\
\hline CHEMBL1423231 & 688422 & 5.6 & 5.5516 & TST & \\
\hline CHEMBL1972129 & 688422 & 4.95 & 5.4306 & TST & \\
\hline CHEMBL1476440 & 688422 & 4.45 & 5.2805 & TRN & \\
\hline CHEMBL1421299 & 688422 & 5.8 & 5.466 & TRN & \\
\hline CHEMBL1435259 & 688422 & 4.9 & 4.8636 & TRN & \\
\hline
\end{tabular}




\begin{tabular}{|c|c|c|c|c|c|}
\hline & & \multicolumn{4}{|c|}{ Supplemental Table S2.txt } \\
\hline CHEMBL1420642 & 688422 & 7.8996 & 5.0636 & TST & \\
\hline CHEMBL1472406 & 688422 & 5.55 & 5.1679 & TRN & \\
\hline CHEMBL1321122 & 688422 & 5.0 & 4.8163 & TRN & \\
\hline CHEMBL1343994 & 688422 & 4.7 & 5.2833 & TRN & \\
\hline CHEMBL1340220 & 688422 & 4.85 & 5.3049 & TRN & \\
\hline CHEMBL1537279 & 688422 & 4.85 & 5.4662 & TST & \\
\hline CHEMBL1382479 & 688422 & 4.45 & 4.6215 & TRN & \\
\hline CHEMBL1588930 & 688422 & 4.75 & 4.8701 & TRN & \\
\hline CHEMBL1529675 & 688422 & 4.45 & 5.7385 & TRN & \\
\hline CHEMBL279539 & 688422 & 5.3 & 5.4888 & TRN & \\
\hline CHEMBL1610812 & 688422 & 4.45 & 5.2342 & TST & \\
\hline CHEMBL1443775 & 688422 & 4.45 & \multicolumn{2}{|c|}{5.281000000000001} & TRN \\
\hline CHEMBL1444074 & 688422 & 4.45 & 5.4353 & TRN & \\
\hline CHEMBL264931 & 688422 & 6.9 & 5.5025 & TST & \\
\hline CHEMBL1562407 & 688422 & 5.45 & 5.2788 & TRN & \\
\hline CHEMBL1301819 & 688422 & 4.65 & 5.3398 & TST & \\
\hline CHEMBL1497706 & 688422 & 4.75 & \multicolumn{2}{|c|}{5.122000000000001} & TST \\
\hline CHEMBL1300305 & 688422 & 5.4 & 5.069 & TRN & \\
\hline CHEMBL1402218 & 688422 & 4.65 & 4.9465 & TRN & \\
\hline CHEMBL1490872 & 688422 & 4.9 & 5.1276 & TRN & \\
\hline CHEMBL1450686 & 688422 & 4.45 & 4.7772 & TRN & \\
\hline CHEMBL1303489 & 688422 & 4.9 & \multicolumn{2}{|c|}{5.167000000000001} & TRN \\
\hline CHEMBL400374 & 688422 & 5.2 & 5.4064 & TRN & \\
\hline CHEMBL 1452585 & 688422 & 4.5 & 5.0012 & TST & \\
\hline CHEMBL1356312 & 688422 & 4.65 & 4.8943 & TRN & \\
\hline CHEMBL1518042 & 688422 & 4.45 & 5.2727 & TRN & \\
\hline CHEMBL1574203 & 688422 & 4.7 & 4.9124 & TRN & \\
\hline CHEMBL1432896 & 688422 & 5.2 & 5.4472 & TRN & \\
\hline CHEMBL1320281 & 688422 & 4.8 & 5.171 & TRN & \\
\hline CHEMBL1331773 & 688422 & 8.4559 & 5.1829 & TST & \\
\hline CHEMBL 3145205 & 688422 & 5.6 & 5.4208 & TRN & \\
\hline CHEMBL1560954 & 688422 & 4.6 & 5.227 & TRN & \\
\hline CHEMBL1357492 & 688422 & 4.45 & 5.3763 & TRN & \\
\hline CHEMBL1459977 & 688422 & 4.9 & 4.8533 & TRN & \\
\hline CHEMBL1490942 & 688422 & 4.45 & 4.8611 & TRN & \\
\hline CHEMBL1312888 & 688422 & 4.75 & 4.9591 & TRN & \\
\hline CHEMBL1445358 & 688422 & 5.3 & 5.216 & TRN & \\
\hline CHEMBL1440814 & 688422 & 4.45 & 5.365 & TRN & \\
\hline CHEMBL1481025 & 688422 & 4.8 & 4.9943 & TRN & \\
\hline CHEMBL1592274 & 688422 & 4.55 & 5.0212 & TRN & \\
\hline CHEMBL1404060 & 688422 & 4.95 & 4.8134 & TRN & \\
\hline CHEMBL3196253 & 688422 & 4.95 & 5.4466 & TRN & \\
\hline CHEMBL1502372 & 688422 & 7.3002 & 4.9797 & TST & \\
\hline CHEMBL 295212 & 688422 & 4.7 & 5.5674 & TST & \\
\hline CHEMBL1980322 & 688422 & 5.45 & 5.1222 & TRN & \\
\hline CHEMBL1968732 & 688422 & 5.35 & 5.1866 & TRN & \\
\hline CHEMBL1315281 & 688422 & 4.65 & 5.4252 & TST & \\
\hline CHEMBL1462803 & 688422 & 4.65 & 5.1507 & TRN & \\
\hline
\end{tabular}




\begin{tabular}{|c|c|c|c|c|c|}
\hline \multicolumn{6}{|c|}{ Supplemental Table s2.txt } \\
\hline CHEMBL472437 & 688422 & 4.45 & 5.6983 & TST & \\
\hline CHEMBL1427851 & 688422 & 4.85 & 5.0552 & TRN & \\
\hline CHEMBL1345739 & 688422 & 4.7 & 5.24299 & 9999999999 & TRN \\
\hline CHEMBL1518617 & 688422 & 7.1002 & 5.6092 & TRN & \\
\hline CHEMBL1549946 & 688422 & 5.25 & 5.6365 & TST & \\
\hline CHEMBL1581142 & 688422 & 4.95 & 5.3392 & TST & \\
\hline CHEMBL56225 & 688422 & 4.5 & 5.724 & TST & \\
\hline CHEMBL1471591 & 688422 & 4.45 & 5.1524 & TRN & \\
\hline CHEMBL1349937 & 688422 & 4.8 & 5.0765 & TRN & \\
\hline CHEMBL3199861 & 688422 & 6.15 & 5.3569 & TRN & \\
\hline CHEMBL1496338 & 688422 & 4.85 & 5.178 & TRN & \\
\hline CHEMBL1591669 & 688422 & 6.8499 & 5.4495 & TRN & \\
\hline CHEMBL1400354 & 688422 & 4.45 & 5.0645 & TRN & \\
\hline CHEMBL1423114 & 688422 & 5.95 & 5.4079 & TST & \\
\hline CHEMBL1446584 & 688422 & 5.15 & 5.233 & TST & \\
\hline CHEMBL1495740 & 688422 & 4.95 & 4.8657 & TRN & \\
\hline CHEMBL1472947 & 688422 & 4.7 & 5.637006 & 00000000005 & TRN \\
\hline CHEMBL1321643 & 688422 & 4.7 & 5.1825 & TRN & \\
\hline CHEMBL1556769 & 688422 & 4.45 & 5.1831 & TST & \\
\hline CHEMBL1448555 & 688422 & 5.45 & 5.5514 & TRN & \\
\hline CHEMBL1519434 & 688422 & 4.45 & 5.1938 & TST & \\
\hline CHEMBL1478480 & 688422 & 4.75 & 4.777 & TRN & \\
\hline CHEMBL1331009 & 688422 & 7.4001 & 5.374 & TRN & \\
\hline CHEMBL1446422 & 688422 & 5.35 & 5.0729 & TST & \\
\hline CHEMBL1427026 & 688422 & 4.6 & 5.4088 & TST & \\
\hline CHEMBL1331170 & 688422 & 4.85 & 4.9915 & TRN & \\
\hline CHEMBL1542834 & 688422 & 4.75 & 5.1719 & TRN & \\
\hline CHEMBL1311272 & 688422 & 6.1 & 5.2397 & TRN & \\
\hline CHEMBL1468928 & 688422 & 4.8 & 4.7757 & TRN & \\
\hline CHEMBL261113 & 688422 & 5.8 & 5.7008 & TRN & \\
\hline CHEMBL1458219 & 688422 & 7.2503 & 5.8582 & TRN & \\
\hline CHEMBL1535444 & 688422 & 4.65 & 5.17299 & 9999999999 & TRN \\
\hline CHEMBL1572487 & 688422 & 6.8499 & 5.8536 & TST & \\
\hline CHEMBL1343922 & 688422 & 4.65 & 5.2758 & TST & \\
\hline CHEMBL1575130 & 688422 & 5.25 & 5.606 & TST & \\
\hline CHEMBL1435108 & 688422 & 5.45 & 5.5649 & TRN & \\
\hline CHEMBL3210460 & 688422 & 4.95 & 5.3197 & TRN & \\
\hline CHEMBL1406831 & 688422 & 4.75 & 5.7357 & TRN & \\
\hline CHEMBL1508584 & 688422 & 4.9 & 5.2527 & TST & \\
\hline CHEMBL1612954 & 688422 & 4.45 & 5.0221 & TST & \\
\hline CHEMBL1489528 & 688422 & 4.6 & 5.1534 & TRN & \\
\hline CHEMBL1558777 & 688422 & 4.45 & 5.0329 & TRN & \\
\hline CHEMBL1467195 & 688422 & 4.9 & 5.4708 & TRN & \\
\hline CHEMBL1317745 & 688422 & 6.05 & 5.444 & TRN & \\
\hline CHEMBL1309587 & 688422 & 6.15 & $5.41200 t$ & 0000000001 & TRN \\
\hline CHEMBL3199665 & 688422 & 5.5 & 5.5186 & TRN & \\
\hline CHEMBL1452409 & 688422 & 4.7 & 5.2275 & TRN & \\
\hline CHEMBL1572048 & 688422 & 4.45 & 5.9134 & TST & \\
\hline
\end{tabular}




\begin{tabular}{|c|c|c|c|c|c|}
\hline \multicolumn{6}{|c|}{ Supplemental Table s2.txt } \\
\hline CHEMBL1413932 & 688422 & 4.6 & 5.6163 & TRN & \\
\hline CHEMBL1463346 & 688422 & 6.2 & 5.4421 & TRN & \\
\hline CHEMBL1404355 & 688422 & 7.15 & 5.54 & TST & \\
\hline CHEMBL3208904 & 688422 & 5.2 & 5.1241 & TRN & \\
\hline CHEMBL1595576 & 688422 & 4.8 & 4.5146 & TRN & \\
\hline CHEMBL1542714 & 688422 & 4.6 & 5.5056 & TRN & \\
\hline CHEMBL1546437 & 688422 & 4.45 & 5.3341 & TST & \\
\hline CHEMBL1527170 & 688422 & 4.5 & 5.2939 & TRN & \\
\hline CHEMBL1413470 & 688422 & 5.4 & 5.0005 & TRN & \\
\hline CHEMBL1345669 & 688422 & 7.8996 & 5.403 & TRN & \\
\hline CHEMBL1386536 & 688422 & 4.95 & 5.0211 & TRN & \\
\hline CHEMBL1429291 & 688422 & 7.2503 & 4.9499 & TRN & \\
\hline CHEMBL1560004 & 688422 & 4.45 & 4.9039 & TRN & \\
\hline CHEMBL1381537 & 688422 & 4.6 & 4.6923 & TRN & \\
\hline CHEMBL3192625 & 688422 & 5.95 & 4.9045 & TRN & \\
\hline CHEMBL1597400 & 688422 & 7.7496 & 5.8558 & TST & \\
\hline CHEMBL1458643 & 688422 & 4.5 & 4.6762 & TRN & \\
\hline CHEMBL1586702 & 688422 & 4.8 & 5.3491 & TRN & \\
\hline CHEMBL1357987 & 688422 & 7.6003 & 5.3656 & TRN & \\
\hline CHEMBL1311094 & 688422 & 4.5 & 5.6252 & TRN & \\
\hline CHEMBL1347425 & 688422 & 5.15 & 5.32600 & 00000000005 & TRN \\
\hline CHEMBL1583628 & 688422 & 5.2 & 5.1592 & TST & \\
\hline CHEMBL1613651 & 688422 & 6.95 & 5.6384 & TRN & \\
\hline CHEMBL1372444 & 688422 & 5.85 & 5.0822 & TRN & \\
\hline CHEMBL1360349 & 688422 & 6.35 & 5.4143 & TST & \\
\hline CHEMBL3207643 & 688422 & 4.85 & 4.8213 & TRN & \\
\hline CHEMBL1471972 & 688422 & 5.35 & 5.2523 & TST & \\
\hline CHEMBL1387670 & 688422 & 4.45 & 5.379 & TRN & \\
\hline CHEMBL1456318 & 688422 & 4.45 & 5.4067 & TRN & \\
\hline CHEMBL1411990 & 688422 & 4.95 & 5.4988 & TST & \\
\hline CHEMBL1173694 & 688422 & 4.9 & 5.567 & TRN & \\
\hline CHEMBL1572576 & 688422 & 4.6 & 5.1675 & TRN & \\
\hline CHEMBL1528441 & 688422 & 4.9 & 5.3749 & TRN & \\
\hline CHEMBL1538376 & 688422 & 7.8996 & 5.8897 & TRN & \\
\hline CHEMBL1540981 & 688422 & 5.2 & 5.3894 & TRN & \\
\hline CHEMBL531709 & 688422 & 4.9 & 4.9881 & TRN & \\
\hline CHEMBL1561024 & 688422 & 4.75 & 4.6418 & TST & \\
\hline CHEMBL1413897 & 688422 & 4.45 & 5.3976 & TST & \\
\hline CHEMBL1327744 & 688422 & 5.55 & 5.2374 & TRN & \\
\hline CHEMBL1339229 & 688422 & 4.6 & 5.2764 & TST & \\
\hline CHEMBL1388983 & 688422 & 4.45 & 5.1057 & TRN & \\
\hline CHEMBL1505749 & 688422 & 4.45 & 5.1219 & TST & \\
\hline CHEMBL1600004 & 688422 & 5.35 & 5.53600 & 00000000005 & TRN \\
\hline CHEMBL1543779 & 688422 & 5.3 & 4.79899 & 99999999995 & TRN \\
\hline CHEMBL1474154 & 688422 & 4.5 & 5.1224 & TRN & \\
\hline CHEMBL1480317 & 688422 & 5.45 & 5.4022 & TST & \\
\hline CHEMBL1331491 & 688422 & 4.85 & 4.92399 & 99999999995 & TRN \\
\hline CHEMBL1597953 & 688422 & 4.75 & 5.15 & TRN & \\
\hline
\end{tabular}




\begin{tabular}{|c|c|c|c|c|c|}
\hline \multicolumn{6}{|c|}{ Supplemental Table S2.txt } \\
\hline CHEMBL1587919 & 688422 & 4.6 & 5.2994 & TRN & \\
\hline CHEMBL1581068 & 688422 & 4.95 & 5.4772 & TRN & \\
\hline CHEMBL1555840 & 688422 & 4.5 & 5.4236 & TRN & \\
\hline CHEMBL1609297 & 688422 & 5.3 & 5.2166 & TST & \\
\hline CHEMBL1345505 & 688422 & 4.45 & 5.2112 & TRN & \\
\hline CHEMBL 3194592 & 688422 & 4.45 & 5.476 & TRN & \\
\hline CHEMBL 275938 & 688422 & 4.65 & 6.0688 & TST & \\
\hline CHEMBL1387717 & 688422 & 4.85 & 4.8319 & TRN & \\
\hline CHEMBL3193392 & 688422 & 4.6 & 5.4423 & TRN & \\
\hline CHEMBL3212823 & 688422 & 4.6 & 5.518 & TST & \\
\hline CHEMBL1327355 & 688422 & 4.45 & 4.766 & TRN & \\
\hline CHEMBL1449669 & 688422 & 5.1 & 5.3612 & TRN & \\
\hline CHEMBL1390932 & 688422 & 4.9 & 5.5753 & TRN & \\
\hline CHEMBL1328050 & 688422 & 5.15 & 5.5733 & TRN & \\
\hline CHEMBL1525164 & 688422 & 4.45 & 5.3858 & TST & \\
\hline CHEMBL1523126 & 688422 & 4.75 & 5.1684 & TRN & \\
\hline CHEMBL1434090 & 688422 & 5.35 & 4.9296 & TRN & \\
\hline CHEMBL1468507 & 688422 & 4.85 & 5.1598 & TST & \\
\hline CHEMBL1388443 & 688422 & 4.45 & 5.4015 & TST & \\
\hline CHEMBL1581201 & 688422 & 4.8 & 4.9611 & TRN & \\
\hline CHEMBL1448854 & 688422 & 4.45 & 5.5936 & TRN & \\
\hline CHEMBL1346130 & 688422 & 5.5 & 5.3256 & TRN & \\
\hline CHEMBL1469219 & 688422 & 4.75 & 5.3763 & TRN & \\
\hline CHEMBL1354517 & 688422 & 4.75 & 5.2067 & TRN & \\
\hline CHEMBL567337 & 688422 & 5.1 & 5.07600 & 00000000005 & TRN \\
\hline CHEMBL1379987 & 688422 & 4.85 & 5.0668 & TRN & \\
\hline CHEMBL1461680 & 688422 & 4.55 & 4.9815 & TRN & \\
\hline CHEMBL1330185 & 688422 & 4.95 & 5.186 & TRN & \\
\hline CHEMBL1393376 & 688422 & 4.5 & 5.3975 & TRN & \\
\hline CHEMBL1549985 & 688422 & 4.45 & 5.3579 & TRN & \\
\hline CHEMBL1463014 & 688422 & 4.45 & 5.2762 & TRN & \\
\hline CHEMBL1499879 & 688422 & 4.45 & 5.4286 & TST & \\
\hline CHEMBL1597112 & 688422 & 4.5 & 5.0821 & TRN & \\
\hline CHEMBL1362588 & 688422 & 5.6 & 5.211 & TRN & \\
\hline CHEMBL1555145 & 688422 & 8.1487 & 5.7619 & TRN & \\
\hline CHEMBL3190563 & 688422 & 4.85 & 4.9718 & TRN & \\
\hline CHEMBL1446060 & 688422 & 4.9 & 5.2444 & TRN & \\
\hline CHEMBL1596443 & 688422 & 4.7 & 5.4694 & TST & \\
\hline CHEMBL51931 & 688422 & 5.5 & 5.3832 & TRN & \\
\hline CHEMBL1356505 & 688422 & 4.65 & 4.9899 & TRN & \\
\hline CHEMBL1376562 & 688422 & 5.25 & 5.3746 & TST & \\
\hline CHEMBL1493020 & 688422 & 5.25 & 5.0224 & TRN & \\
\hline CHEMBL1300918 & 688422 & 8.4559 & 5.1674 & TST & \\
\hline CHEMBL1347494 & 688422 & 4.8 & 4.5058 & TRN & \\
\hline CHEMBL1478812 & 688422 & 5.2 & 5.5563 & TRN & \\
\hline CHEMBL1325763 & 688422 & 4.65 & 5.955 & TRN & \\
\hline CHEMBL1540863 & 688422 & 4.85 & 5.534 & TRN & \\
\hline CHEMBL1434838 & 688422 & 4.45 & 4.8971 & TRN & \\
\hline
\end{tabular}




\begin{tabular}{|c|c|c|c|c|}
\hline \multicolumn{5}{|c|}{ Supplemental Table S2.txt } \\
\hline CHEMBL467987 & 688422 & 4.75 & 5.5695 & TRN \\
\hline CHEMBL1359956 & 688422 & 5.5 & 5.2583 & TRN \\
\hline CHEMBL3212049 & 688422 & 4.45 & 5.105 & TRN \\
\hline CHEMBL1594764 & 688422 & 5.65 & 5.4611 & TRN \\
\hline CHEMBL1503615 & 688422 & 6.05 & 5.4995 & TRN \\
\hline CHEMBL1383820 & 688422 & 4.95 & 5.0872 & TRN \\
\hline CHEMBL1350047 & 688422 & 4.45 & 4.9965 & TRN \\
\hline CHEMBL1503110 & 688422 & 4.7 & 4.8434 & TRN \\
\hline CHEMBL1430269 & 688422 & 4.75 & 5.1161 & TRN \\
\hline CHEMBL1453773 & 688422 & 5.75 & 5.0325 & TRN \\
\hline CHEMBL3211689 & 688422 & 4.65 & 5.4025 & TRN \\
\hline CHEMBL1256660 & 688422 & 4.45 & 4.9446 & TRN \\
\hline CHEMBL1525133 & 688422 & 4.6 & 5.037 & TRN \\
\hline CHEMBL1502346 & 688422 & 4.45 & 5.0409 & TRN \\
\hline CHEMBL1534905 & 688422 & 4.9 & 5.29 & TRN \\
\hline CHEMBL1571222 & 688422 & 4.5 & 5.3919 & TST \\
\hline CHEMBL1537795 & 688422 & 4.45 & 4.9885 & TRN \\
\hline CHEMBL1470871 & 688422 & 4.45 & 5.3961 & TRN \\
\hline CHEMBL1328367 & 688422 & 4.45 & 4.8723 & TRN \\
\hline CHEMBL1447010 & 688422 & 4.45 & 4.8217 & TST \\
\hline CHEMBL 2001111 & 688422 & 4.6 & 5.3654 & TRN \\
\hline CHEMBL563294 & 688422 & 5.1 & 5.0692 & TRN \\
\hline CHEMBL 3189341 & 688422 & 4.75 & 5.2326 & TRN \\
\hline CHEMBL1326477 & 688422 & 4.7 & 5.4571 & TST \\
\hline CHEMBL1521888 & 688422 & 4.65 & 5.2943 & TRN \\
\hline CHEMBL1312969 & 688422 & 5.25 & 5.1692 & TRN \\
\hline CHEMBL1415555 & 688422 & 4.45 & 5.1438 & TRN \\
\hline CHEMBL140 & 688422 & 6.0 & 5.3599 & TRN \\
\hline CHEMBL1503784 & 688422 & 5.1 & 5.0597 & TRN \\
\hline CHEMBL1552180 & 688422 & 5.3 & 5.2208 & TRN \\
\hline CHEMBL1584551 & 688422 & 6.0 & 5.3382 & TRN \\
\hline CHEMBL1367384 & 688422 & 4.9 & 5.1438 & TRN \\
\hline CHEMBL1475815 & 688422 & 4.45 & 5.1857 & TRN \\
\hline CHEMBL1535182 & 688422 & 4.95 & 5.3983 & TST \\
\hline CHEMBL1542752 & 688422 & 5.0 & 5.3543 & TRN \\
\hline CHEMBL302213 & 688422 & 5.6 & 5.6587 & TST \\
\hline CHEMBL1531329 & 688422 & 4.7 & 4.9958 & TRN \\
\hline CHEMBL1345223 & 688422 & 4.45 & 5.0887 & TRN \\
\hline CHEMBL448741 & 688422 & 4.9 & 5.5266 & TST \\
\hline CHEMBL1569274 & 688422 & 4.95 & 5.0217 & TRN \\
\hline CHEMBL1314011 & 688422 & 4.8 & 4.7874 & TST \\
\hline CHEMBL3209947 & 688422 & 5.35 & 5.9111 & TST \\
\hline CHEMBL1514230 & 688422 & 5.9 & 5.5986 & TRN \\
\hline CHEMBL1450777 & 688422 & 5.2 & 4.9933 & TRN \\
\hline CHEMBL1317208 & 688422 & 8.7447 & 5.5621 & TST \\
\hline CHEMBL1367426 & 688422 & 4.9 & 5.1663 & TRN \\
\hline CHEMBL1329232 & 688422 & 4.75 & 4.8339 & TRN \\
\hline CHEMBL1302442 & 688422 & 4.7 & 5.2072 & TRN \\
\hline
\end{tabular}




\begin{tabular}{|c|c|c|c|c|c|}
\hline & & \multicolumn{4}{|c|}{ Supplemental Table S2.txt } \\
\hline CHEMBL1308523 & 688422 & 5.4 & 5.1075 & TST & \\
\hline CHEMBL1307781 & 688422 & 5.9 & 5.0125 & TRN & \\
\hline CHEMBL1331001 & 688422 & 8.2007 & 5.0733 & TRN & \\
\hline CHEMBL1300586 & 688422 & 4.7 & 4.857 & TRN & \\
\hline CHEMBL1370057 & 688422 & 4.6 & 5.4253 & TRN & \\
\hline CHEMBL1448573 & 688422 & 4.5 & 4.9399 & TST & \\
\hline CHEMBL1327693 & 688422 & 5.55 & 5.38200 & 2000000001 & TRN \\
\hline CHEMBL1589532 & 688422 & 5.35 & 5.1732 & TRN & \\
\hline CHEMBL1530373 & 688422 & 5.3 & 5.1404 & TRN & \\
\hline CHEMBL1423338 & 688422 & 4.75 & 5.4171 & TRN & \\
\hline CHEMBL1504348 & 688422 & 4.8 & 4.7253 & TRN & \\
\hline CHEMBL1535886 & 688422 & 5.45 & 5.4581 & TST & \\
\hline CHEMBL1449686 & 688422 & 5.5 & 5.2523 & TRN & \\
\hline CHEMBL1376528 & 688422 & 4.9 & 5.1851 & TRN & \\
\hline CHEMBL1385375 & 688422 & 5.1 & 5.5616 & TST & \\
\hline CHEMBL1356761 & 688422 & 4.9 & 5.2502 & TRN & \\
\hline CHEMBL1512797 & 688422 & 4.45 & 5.9311 & TRN & \\
\hline CHEMBL1544742 & 688422 & 6.5 & 5.0512 & TRN & \\
\hline CHEMBL1312320 & 688422 & 4.45 & 5.1034 & TRN & \\
\hline CHEMBL1302822 & 688422 & 5.3 & 5.2407 & TRN & \\
\hline CHEMBL1452205 & 688422 & 4.95 & 5.4468 & TRN & \\
\hline CHEMBL1380197 & 688422 & 5.85 & 5.5685 & TST & \\
\hline CHEMBL1420667 & 688422 & 4.9 & 5.1194 & TRN & \\
\hline CHEMBL1432929 & 688422 & 5.35 & 5.4593 & TST & \\
\hline CHEMBL1360433 & 688422 & 7.0501 & 5.2748 & TRN & \\
\hline CHEMBL1524895 & 688422 & 6.95 & 5.3092 & TRN & \\
\hline CHEMBL1524884 & 688422 & 4.6 & 5.0948 & TRN & \\
\hline CHEMBL1440669 & 688422 & 4.8 & 5.3591 & TRN & \\
\hline CHEMBL1424882 & 688422 & 4.75 & 5.7451 & TRN & \\
\hline CHEMBL1394308 & 688422 & 7.0501 & 5.8132 & TRN & \\
\hline CHEMBL1527778 & 688422 & 6.1 & 6.0752 & TST & \\
\hline CHEMBL3197530 & 688422 & 4.95 & 5.1645 & TRN & \\
\hline CHEMBL1379329 & 688422 & 4.45 & 5.153 & TRN & \\
\hline CHEMBL1544345 & 688422 & 5.9 & 5.4235 & TST & \\
\hline CHEMBL1414983 & 688422 & 5.55 & 5.394 & TST & \\
\hline CHEMBL1501964 & 688422 & 4.9 & 4.8166 & TRN & \\
\hline CHEMBL1510509 & 688422 & 5.25 & 5.3966 & TRN & \\
\hline CHEMBL1550635 & 688422 & 4.95 & 5.4496 & TRN & \\
\hline CHEMBL1551101 & 688422 & 4.95 & 5.3893 & TRN & \\
\hline CHEMBL1430295 & 688422 & 4.6 & 5.5101 & TRN & \\
\hline CHEMBL1349609 & 688422 & 4.95 & 5.0585 & TRN & \\
\hline CHEMBL1503374 & 688422 & 4.9 & 5.3553 & TRN & \\
\hline CHEMBL1475551 & 688422 & 9.0969 & 5.3162 & TRN & \\
\hline CHEMBL1607610 & 688422 & 5.25 & 5.3868 & TRN & \\
\hline CHEMBL1311219 & 688422 & 4.95 & 4.9094 & TST & \\
\hline CHEMBL3197922 & 688422 & 8.301 & 5.4957 & TRN & \\
\hline CHEMBL1506847 & 688422 & 4.9 & 5.1575 & TRN & \\
\hline CHEMBL2003869 & 688422 & 5.25 & 5.1996 & TRN & \\
\hline
\end{tabular}




\begin{tabular}{|c|c|c|c|c|c|}
\hline \multicolumn{6}{|c|}{ Supplemental Table S2.txt } \\
\hline CHEMBL1506706 & 688422 & 4.9 & 5.1597 & TRN & \\
\hline CHEMBL1456501 & 688422 & 5.0 & 5.0269 & TRN & \\
\hline CHEMBL1532234 & 688422 & 4.9 & 4.9479 & TST & \\
\hline CHEMBL1583946 & 688422 & 4.8 & 5.0583 & TRN & \\
\hline CHEMBL1503138 & 688422 & 4.75 & 5.3412 & TRN & \\
\hline CHEMBL3213728 & 688422 & 4.5 & 5.2419 & TRN & \\
\hline CHEMBL1379139 & 688422 & 4.85 & 5.1878 & TRN & \\
\hline CHEMBL1417763 & 688422 & 4.7 & 4.9017 & TRN & \\
\hline CHEMBL1325101 & 688422 & 4.8 & 4.9173 & TST & \\
\hline CHEMBL1415829 & 688422 & 5.6 & 5.2055 & TRN & \\
\hline CHEMBL1392500 & 688422 & 5.0 & 4.4699 & TRN & \\
\hline CHEMBL 3194760 & 688422 & 5.2 & 5.2144 & TRN & \\
\hline CHEMBL1327595 & 688422 & 4.5 & 5.9527 & TST & \\
\hline CHEMBL3193507 & 688422 & 4.45 & 4.7755 & TST & \\
\hline CHEMBL1365291 & 688422 & 4.85 & 5.2337 & TRN & \\
\hline CHEMBL1572754 & 688422 & 7.7496 & 5.8886 & TRN & \\
\hline CHEMBL1323624 & 688422 & 4.45 & 5.3139 & TRN & \\
\hline CHEMBL1382067 & 688422 & 4.7 & 4.9498 & TRN & \\
\hline CHEMBL1469860 & 688422 & 4.45 & 5.0266 & TRN & \\
\hline CHEMBL1465527 & 688422 & 5.0 & 4.9682 & TST & \\
\hline CHEMBL1361191 & 688422 & 4.85 & 5.016 & TRN & \\
\hline CHEMBL1422311 & 688422 & 4.7 & 5.1384 & TRN & \\
\hline CHEMBL1326765 & 688422 & 4.9 & 5.2789 & TRN & \\
\hline CHEMBL1445139 & 688422 & 5.55 & 5.1971 & TRN & \\
\hline CHEMBL1364376 & 688422 & 5.95 & 5.6733 & TRN & \\
\hline CHEMBL1336603 & 688422 & 6.8499 & 5.2019 & TRN & \\
\hline CHEMBL1506778 & 688422 & 4.55 & 4.9152 & TRN & \\
\hline CHEMBL1404234 & 688422 & 4.45 & 5.1507 & TRN & \\
\hline CHEMBL3191720 & 688422 & 4.5 & 5.1448 & TRN & \\
\hline CHEMBL1361506 & 688422 & 5.45 & 5.1244 & TRN & \\
\hline CHEMBL1544762 & 688422 & 4.9 & 4.9966 & TRN & \\
\hline CHEMBL419815 & 688422 & 4.85 & 5.20799 & 9999999999 & TRN \\
\hline CHEMBL1496627 & 688422 & 6.25 & 5.3717 & TST & \\
\hline CHEMBL1561023 & 688422 & 6.25 & 5.294 & TRN & \\
\hline CHEMBL1504891 & 688422 & 4.8 & 5.24299 & 9999999999 & TRN \\
\hline CHEMBL1499973 & 688422 & 7.0501 & 5.9557 & TRN & \\
\hline CHEMBL1565402 & 688422 & 5.3 & 5.08899 & 99999999995 & TST \\
\hline CHEMBL1424064 & 688422 & 6.0 & 4.8766 & TST & \\
\hline CHEMBL1545717 & 688422 & 6.0 & 5.2252 & TRN & \\
\hline CHEMBL1516200 & 688422 & 6.1 & 5.4857 & TRN & \\
\hline CHEMBL1449117 & 688422 & 4.85 & 5.2102 & TRN & \\
\hline CHEMBL1350915 & 688422 & 4.95 & 5.2199 & TRN & \\
\hline CHEMBL1563204 & 688422 & 4.9 & 5.1043 & TRN & \\
\hline CHEMBL1427066 & 688422 & 5.55 & 5.2968 & TRN & \\
\hline CHEMBL1598020 & 688422 & 5.0 & 5.561 & TRN & \\
\hline CHEMBL1326621 & 688422 & 4.9 & 5.0068 & TRN & \\
\hline CHEMBL1392693 & 688422 & 7.0501 & 5.2532 & TRN & \\
\hline CHEMBL1572873 & 688422 & 4.75 & 5.0696 & TRN & \\
\hline
\end{tabular}




\begin{tabular}{|c|c|c|c|c|c|}
\hline \multicolumn{6}{|c|}{ Supplemental Table S2.txt } \\
\hline CHEMBL1358252 & 688422 & 4.95 & 4.8701 & TRN & \\
\hline CHEMBL1386562 & 688422 & 4.7 & 4.9551 & TRN & \\
\hline CHEMBL1565285 & 688422 & 4.5 & 5.2891 & TRN & \\
\hline CHEMBL1358977 & 688422 & 4.45 & 5.2132 & TST & \\
\hline CHEMBL1448442 & 688422 & 4.75 & 4.8446 & TRN & \\
\hline CHEMBL1585727 & 688422 & 8.301 & 5.5199 & TST & \\
\hline CHEMBL1369733 & 688422 & 4.45 & 4.8733 & TRN & \\
\hline CHEMBL1546439 & 688422 & 4.65 & 5.31 & TRN & \\
\hline CHEMBL1446296 & 688422 & 6.05 & 5.0601 & TST & \\
\hline CHEMBL1363475 & 688422 & 4.55 & 5.5174 & TRN & \\
\hline CHEMBL1506865 & 688422 & 7.6003 & 5.1032 & TRN & \\
\hline CHEMBL1524833 & 688422 & 4.8 & 4.9536 & TRN & \\
\hline CHEMBL1482251 & 688422 & 4.95 & 5.3465 & TRN & \\
\hline CHEMBL1515493 & 688422 & 6.15 & 5.2164 & TRN & \\
\hline CHEMBL1383654 & 688422 & 4.45 & 4.6782 & TRN & \\
\hline CHEMBL1601853 & 688422 & 5.0 & 5.19799 & 99999999995 & TST \\
\hline CHEMBL1305303 & 688422 & 4.5 & 5.1467 & TRN & \\
\hline CHEMBL1458937 & 688422 & 7.8996 & 5.6547 & TRN & \\
\hline CHEMBL1365570 & 688422 & 4.45 & 4.9007 & TRN & \\
\hline CHEMBL1548692 & 688422 & 4.85 & 5.2004 & TST & \\
\hline CHEMBL1410025 & 688422 & 4.85 & 5.6882 & TRN & \\
\hline CHEMBL1388622 & 688422 & 5.5 & 5.3856 & TRN & \\
\hline CHEMBL1372678 & 688422 & 4.5 & 5.15 & TRN & \\
\hline CHEMBL1467629 & 688422 & 4.85 & 5.5135 & TRN & \\
\hline CHEMBL1429513 & 688422 & 4.7 & 5.4237 & TRN & \\
\hline CHEMBL1507018 & 688422 & 5.5 & 4.9665 & TRN & \\
\hline CHEMBL581452 & 688422 & 4.55 & 5.034 & TRN & \\
\hline CHEMBL3190357 & 688422 & 5.55 & 5.6996 & TST & \\
\hline CHEMBL1490542 & 688422 & 4.5 & 4.7924 & TRN & \\
\hline CHEMBL1537898 & 688422 & 5.25 & 5.7686 & TST & \\
\hline CHEMBL1561722 & 688422 & 4.7 & 4.8751 & TRN & \\
\hline CHEMBL1308929 & 688422 & 5.8 & 5.5178 & TST & \\
\hline CHEMBL1607032 & 688422 & 4.75 & 5.2211 & TRN & \\
\hline CHEMBL3191765 & 688422 & 4.55 & 5.2847 & TST & \\
\hline CHEMBL1571479 & 688422 & 4.7 & 4.7975 & TRN & \\
\hline CHEMBL1300746 & 688422 & 4.85 & 5.1079 & TST & \\
\hline CHEMBL1304991 & 688422 & 6.6499 & 5.42 & TRN & \\
\hline CHEMBL1549188 & 688422 & 4.75 & 5.4046 & TRN & \\
\hline CHEMBL1422301 & 688422 & 8.2518 & 5.0163 & TRN & \\
\hline CHEMBL1442909 & 688422 & 4.9 & 4.712 & TRN & \\
\hline CHEMBL1332129 & 688422 & 4.55 & 5.4209 & TRN & \\
\hline CHEMBL1328077 & 688422 & 4.45 & 5.1915 & TRN & \\
\hline CHEMBL1380252 & 688422 & 5.25 & 5.1882 & TRN & \\
\hline CHEMBL1421999 & 688422 & 5.15 & 5.7849 & TST & \\
\hline CHEMBL1463582 & 688422 & 4.9 & 4.9003 & TRN & \\
\hline CHEMBL1400688 & 688422 & 5.2 & 5.6175 & TST & \\
\hline CHEMBL42219 & 688422 & 4.65 & 5.3051 & TRN & \\
\hline CHEMBL1364573 & 688422 & 5.1 & 5.195 & TST & \\
\hline
\end{tabular}




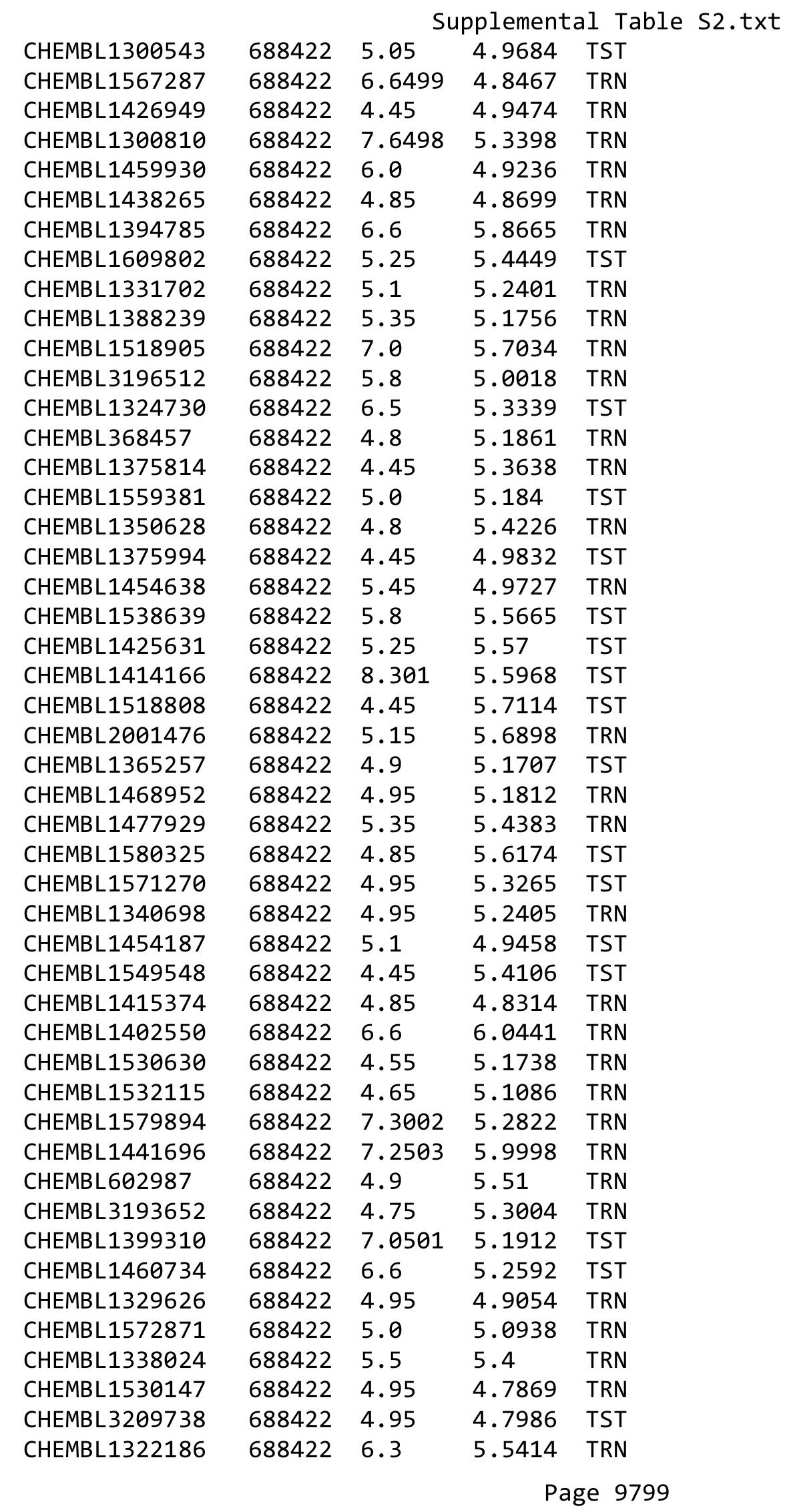




\begin{tabular}{|c|c|c|c|c|c|}
\hline \multicolumn{6}{|c|}{ Supplemental Table S2.txt } \\
\hline CHEMBL1558327 & 688422 & 4.9 & 5.1824 & TRN & \\
\hline CHEMBL1601587 & 688422 & 4.6 & 4.7882 & TRN & \\
\hline CHEMBL3194824 & 688422 & 4.85 & 5.4689 & TRN & \\
\hline CHEMBL1370250 & 688422 & 4.85 & 5.1502 & TRN & \\
\hline CHEMBL528181 & 688422 & 4.75 & 4.5332 & TRN & \\
\hline CHEMBL1463973 & 688422 & 4.9 & 5.0625 & TRN & \\
\hline CHEMBL1486975 & 688422 & 6.9 & 4.8693 & TRN & \\
\hline CHEMBL1568178 & 688422 & 5.45 & 5.3937 & TRN & \\
\hline CHEMBL1309750 & 688422 & 4.8 & 5.8025 & TRN & \\
\hline CHEMBL1512932 & 688422 & 4.9 & 5.5775 & TRN & \\
\hline CHEMBL1312786 & 688422 & 6.4 & 5.6266 & TST & \\
\hline CHEMBL1567395 & 688422 & 4.45 & 5.1819 & TRN & \\
\hline CHEMBL1370428 & 688422 & 5.25 & 5.1812 & TRN & \\
\hline CHEMBL1332282 & 688422 & 4.45 & 4.7925 & TST & \\
\hline CHEMBL1305030 & 688422 & 4.85 & 5.2123 & TRN & \\
\hline CHEMBL1449476 & 688422 & 7.4498 & 5.42299 & 9999999999 & TRN \\
\hline CHEMBL1346422 & 688422 & 5.0 & 5.4467 & TST & \\
\hline CHEMBL1464192 & 688422 & 4.7 & 5.2571 & TRN & \\
\hline CHEMBL581865 & 688422 & 4.45 & 5.0542 & TST & \\
\hline CHEMBL1499456 & 688422 & 5.55 & 5.01399 & 9999999999 & TRN \\
\hline CHEMBL1336793 & 688422 & 5.05 & 5.0584 & TRN & \\
\hline CHEMBL1468482 & 688422 & 6.25 & 5.0802 & TRN & \\
\hline CHEMBL1459394 & 688422 & 5.1 & 5.2108 & TRN & \\
\hline CHEMBL3145187 & 688422 & 4.9 & 5.5736 & TST & \\
\hline CHEMBL1524785 & 688422 & 5.95 & 5.5553 & TST & \\
\hline CHEMBL1321713 & 688422 & 4.5 & 5.0938 & TRN & \\
\hline CHEMBL1376813 & 688422 & 4.95 & 5.2849 & TRN & \\
\hline CHEMBL1497317 & 688422 & 4.8 & 4.9462 & TST & \\
\hline CHEMBL1468855 & 688422 & 4.9 & 5.4002 & TRN & \\
\hline CHEMBL1419589 & 688422 & 5.75 & 5.3135 & TRN & \\
\hline CHEMBL1987892 & 688422 & 4.85 & 5.30200 & 00000000005 & TRN \\
\hline CHEMBL1599666 & 688422 & 4.7 & 5.2826 & TST & \\
\hline CHEMBL1421803 & 688422 & 4.45 & 5.5125 & TRN & \\
\hline CHEMBL1299757 & 688422 & 4.9 & 5.1477 & TST & \\
\hline CHEMBL1535507 & 688422 & 5.4 & 5.4777 & TRN & \\
\hline CHEMBL 284028 & 688422 & 4.95 & 5.4556 & TRN & \\
\hline CHEMBL1312991 & 688422 & 4.8 & 4.9998 & TRN & \\
\hline CHEMBL1426192 & 688422 & 4.75 & 5.0876 & TRN & \\
\hline CHEMBL3192533 & 688422 & 4.95 & 5.5195 & TRN & \\
\hline CHEMBL1306985 & 688422 & 4.45 & 5.0307 & TRN & \\
\hline CHEMBL1401683 & 688422 & 4.45 & 5.0462 & TRN & \\
\hline CHEMBL1397876 & 688422 & 7.9508 & 5.4018 & TST & \\
\hline CHEMBL1553017 & 688422 & 6.5501 & 5.1166 & TRN & \\
\hline CHEMBL3189179 & 688422 & 4.95 & 5.2 & TRN & \\
\hline CHEMBL1559248 & 688422 & 4.95 & 5.1506 & TRN & \\
\hline CHEMBL1418714 & 688422 & 4.85 & 4.8704 & TST & \\
\hline CHEMBL1469119 & 688422 & 8.3468 & 5.1351 & TRN & \\
\hline CHEMBL3199085 & 688422 & 4.45 & 5.4053 & TRN & \\
\hline
\end{tabular}




\begin{tabular}{|c|c|c|c|c|}
\hline \multicolumn{5}{|c|}{ Supplemental Table S2.txt } \\
\hline CHEMBL1728023 & 688422 & 4.65 & 5.4555 & TRN \\
\hline CHEMBL1584218 & 688422 & 6.25 & 5.3481 & TST \\
\hline CHEMBL1493620 & 688422 & 4.45 & 5.0076 & TRN \\
\hline CHEMBL1394472 & 688422 & 6.45 & 5.2766 & TST \\
\hline CHEMBL 3191251 & 688422 & 4.45 & 5.2646 & TST \\
\hline CHEMBL1609203 & 688422 & 4.45 & 5.2632 & TRN \\
\hline CHEMBL 1400280 & 688422 & 5.0 & 5.1407 & TST \\
\hline CHEMBL1483733 & 688422 & 4.9 & 5.6303 & TST \\
\hline CHEMBL1510950 & 688422 & 5.05 & 5.2288 & TRN \\
\hline CHEMBL1321983 & 688422 & 8.0506 & 5.5868 & TRN \\
\hline CHEMBL1363854 & 688422 & 5.1 & 4.7955 & TRN \\
\hline CHEMBL1601897 & 688422 & 5.1 & 5.2211 & TST \\
\hline CHEMBL1418817 & 688422 & 5.0 & 5.4905 & TRN \\
\hline CHEMBL1464684 & 688422 & 4.95 & 5.3286 & TRN \\
\hline CHEMBL1519620 & 688422 & 4.6 & 4.865 & TRN \\
\hline CHEMBL1441881 & 688422 & 4.45 & 5.1571 & TRN \\
\hline CHEMBL1425400 & 688422 & 4.45 & 5.6034 & TRN \\
\hline CHEMBL1545040 & 688422 & 5.65 & 4.9185 & TRN \\
\hline CHEMBL1539364 & 688422 & 4.6 & 4.9008 & TST \\
\hline CHEMBL 3191164 & 688422 & 4.7 & 5.1189 & TST \\
\hline CHEMBL1604132 & 688422 & 4.9 & 5.2183 & TRN \\
\hline CHEMBL3190600 & 688422 & 4.75 & 5.2466 & TRN \\
\hline CHEMBL1324917 & 688422 & 4.95 & 4.9442 & TRN \\
\hline CHEMBL1415201 & 688422 & 4.7 & 5.1843 & TRN \\
\hline CHEMBL1603830 & 688422 & 5.0 & 5.1835 & TRN \\
\hline CHEMBL1372732 & 688422 & 4.45 & 5.522 & TST \\
\hline CHEMBL1367779 & 688422 & 5.35 & 4.9759 & TRN \\
\hline CHEMBL1604552 & 688422 & 5.35 & 4.8348 & TRN \\
\hline CHEMBL1555166 & 688422 & 5.05 & 4.7784 & TRN \\
\hline CHEMBL3196607 & 688422 & 6.6499 & 5.1575 & TRN \\
\hline CHEMBL1520615 & 688422 & 4.45 & 5.1652 & TST \\
\hline CHEMBL1302112 & 688422 & 4.85 & 5.2012 & TST \\
\hline CHEMBL1474404 & 688422 & 6.0 & 5.0286 & TRN \\
\hline CHEMBL1551557 & 688422 & 5.15 & 5.3153 & TRN \\
\hline CHEMBL1324739 & 688422 & 4.8 & 5.1283 & TRN \\
\hline CHEMBL 2007056 & 688422 & 4.65 & 5.1119 & TST \\
\hline CHEMBL1432768 & 688422 & 4.6 & 5.4099 & TRN \\
\hline CHEMBL1588557 & 688422 & 6.05 & 4.8591 & TRN \\
\hline CHEMBL1357438 & 688422 & 7.6003 & 5.9384 & TRN \\
\hline CHEMBL1552998 & 688422 & 4.95 & 5.3024 & TST \\
\hline CHEMBL1390613 & 688422 & 5.65 & 5.1648 & TRN \\
\hline CHEMBL1591321 & 688422 & 5.65 & 5.0994 & TRN \\
\hline CHEMBL1562581 & 688422 & 4.85 & 5.1597 & TRN \\
\hline CHEMBL1523661 & 688422 & 7.0501 & 5.1472 & TST \\
\hline CHEMBL1509424 & 688422 & 4.7 & 5.6022 & TRN \\
\hline CHEMBL1339421 & 688422 & 4.45 & 5.6091 & TRN \\
\hline CHEMBL1556955 & 688422 & 4.85 & 4.8056 & TRN \\
\hline CHEMBL1310347 & 688422 & 5.1 & 5.6482 & TRN \\
\hline
\end{tabular}




\begin{tabular}{|c|c|c|c|c|c|}
\hline \multicolumn{6}{|c|}{ Supplemental Table S2.txt } \\
\hline CHEMBL1460227 & 688422 & 4.65 & 5.5627 & TST & \\
\hline CHEMBL1471435 & 688422 & 4.7 & 5.0365 & TRN & \\
\hline CHEMBL1415277 & 688422 & 5.7 & 4.72 & TRN & \\
\hline CHEMBL1557729 & 688422 & 5.2 & 5.8971 & TST & \\
\hline CHEMBL2006988 & 688422 & 4.65 & 5.1931 & TRN & \\
\hline CHEMBL1499929 & 688422 & 4.9 & 5.3823 & TRN & \\
\hline CHEMBL1530139 & 688422 & 4.85 & 4.7365 & TRN & \\
\hline CHEMBL1535031 & 688422 & 4.85 & 5.3933 & TRN & \\
\hline CHEMBL1504806 & 688422 & 4.65 & 5.1243 & TST & \\
\hline CHEMBL1453411 & 688422 & 4.9 & 5.2751 & TRN & \\
\hline CHEMBL1432556 & 688422 & 5.05 & 4.9248 & TST & \\
\hline CHEMBL1568877 & 688422 & 5.4 & 5.0002 & TRN & \\
\hline CHEMBL1383553 & 688422 & 5.0 & 5.4407 & TRN & \\
\hline CHEMBL 2005424 & 688422 & 6.5501 & 5.1484 & TRN & \\
\hline CHEMBL450516 & 688422 & 8.301 & 5.4541 & TRN & \\
\hline CHEMBL1400132 & 688422 & 4.6 & 4.8226 & TRN & \\
\hline CHEMBL3209243 & 688422 & 5.1 & 5.0849 & TRN & \\
\hline CHEMBL1433866 & 688422 & 5.75 & 5.8831 & TRN & \\
\hline CHEMBL1334984 & 688422 & 4.45 & 5.5217 & TST & \\
\hline CHEMBL1541904 & 688422 & 4.65 & 5.0642 & TST & \\
\hline CHEMBL 2004449 & 688422 & 4.9 & 5.0776 & TRN & \\
\hline CHEMBL1519210 & 688422 & 4.95 & 5.0811 & TRN & \\
\hline CHEMBL3210117 & 688422 & 4.85 & 5.1582 & TRN & \\
\hline CHEMBL1440227 & 688422 & 5.9 & 5.21899 & 9999999999 & TRN \\
\hline CHEMBL1350548 & 688422 & 6.05 & 5.516 & TST & \\
\hline CHEMBL1569574 & 688422 & 5.1 & 5.2094 & TRN & \\
\hline CHEMBL1348795 & 688422 & 5.05 & 5.1609 & TRN & \\
\hline CHEMBL1386633 & 688422 & 6.7001 & 5.4903 & TRN & \\
\hline CHEMBL1535530 & 688422 & 4.45 & 5.0923 & TRN & \\
\hline CHEMBL1419705 & 688422 & 4.8 & 5.3375 & TRN & \\
\hline CHEMBL1398806 & 688422 & 4.85 & 5.175 & TRN & \\
\hline CHEMBL1605959 & 688422 & 4.45 & 5.2063 & TRN & \\
\hline CHEMBL1570860 & 688422 & 4.9 & 5.3004 & TRN & \\
\hline CHEMBL1439499 & 688422 & 4.8 & 4.9424 & TRN & \\
\hline CHEMBL1427757 & 688422 & 4.95 & 4.9817 & TST & \\
\hline CHEMBL1256910 & 688422 & 4.8 & 5.61100 & 0000000001 & TRN \\
\hline CHEMBL1536167 & 688422 & 4.45 & 4.999 & TRN & \\
\hline CHEMBL1362075 & 688422 & 4.45 & 5.0609 & TRN & \\
\hline CHEMBL1540649 & 688422 & 5.85 & 5.1567 & TRN & \\
\hline CHEMBL1445489 & 688422 & 5.25 & 5.2858 & TRN & \\
\hline CHEMBL1312611 & 688422 & 4.65 & 5.0676 & TRN & \\
\hline CHEMBL1612979 & 688422 & 5.45 & 5.0816 & TST & \\
\hline CHEMBL1519375 & 688422 & 4.45 & 5.2527 & TRN & \\
\hline CHEMBL1469044 & 688422 & 4.5 & 5.041 & TRN & \\
\hline CHEMBL1529561 & 688422 & 5.5 & 5.9894 & TST & \\
\hline CHEMBL1467257 & 688422 & 8.3468 & 5.6377 & TST & \\
\hline CHEMBL1431216 & 688422 & 8.3468 & 5.8846 & TRN & \\
\hline CHEMBL3182281 & 688422 & 5.1 & 5.0389 & TRN & \\
\hline
\end{tabular}




\begin{tabular}{|c|c|c|c|c|c|}
\hline \multicolumn{6}{|c|}{ Supplemental Table S2.txt } \\
\hline CHEMBL1458090 & 688422 & 4.45 & 5.2992 & TST & \\
\hline CHEMBL1308680 & 688422 & 5.9 & 5.4223 & TST & \\
\hline CHEMBL1461691 & 688422 & 8.3468 & 5.5231 & TRN & \\
\hline CHEMBL1519507 & 688422 & 4.8 & 5.0494 & TRN & \\
\hline CHEMBL1331381 & 688422 & 6.25 & 5.7061 & TRN & \\
\hline CHEMBL1483678 & 688422 & 7.6003 & 5.1852 & TRN & \\
\hline CHEMBL1555558 & 688422 & 5.55 & 5.1775 & TRN & \\
\hline CHEMBL1452881 & 688422 & 9.3979 & 5.37299 & 9999999999 & TRN \\
\hline CHEMBL274619 & 688422 & 7.8996 & 6.5402 & TST & \\
\hline CHEMBL1325947 & 688422 & 4.85 & 5.1081 & TRN & \\
\hline CHEMBL1371916 & 688422 & 4.85 & 5.2091 & TRN & \\
\hline CHEMBL3199448 & 688422 & 4.95 & 5.3422 & TRN & \\
\hline CHEMBL1473135 & 688422 & 6.5 & 4.9806 & TRN & \\
\hline CHEMBL1518645 & 688422 & 4.5 & 4.7307 & TRN & \\
\hline CHEMBL3208797 & 688422 & 4.75 & 5.104 & TRN & \\
\hline CHEMBL1543843 & 688422 & 4.75 & 5.0471 & TRN & \\
\hline CHEMBL1349322 & 688422 & 4.45 & 5.2988 & TRN & \\
\hline CHEMBL1312486 & 688422 & 4.45 & 4.5634 & TRN & \\
\hline CHEMBL1595058 & 688422 & 5.6 & 5.4556 & TST & \\
\hline CHEMBL1388556 & 688422 & 4.7 & 5.0261 & TRN & \\
\hline CHEMBL1378513 & 688422 & 5.55 & 5.0103 & TST & \\
\hline CHEMBL1413574 & 688422 & 4.45 & 5.5675 & TRN & \\
\hline CHEMBL1561002 & 688422 & 5.55 & 5.336 & TRN & \\
\hline CHEMBL1455418 & 688422 & 6.8499 & 5.4279 & TRN & \\
\hline CHEMBL1572328 & 688422 & 4.45 & 5.2118 & TRN & \\
\hline CHEMBL1604685 & 688422 & 4.95 & 5.0636 & TRN & \\
\hline CHEMBL1334012 & 688422 & 4.8 & 5.09699 & 99999999995 & TRN \\
\hline CHEMBL1535296 & 688422 & 5.55 & 5.784 & TRN & \\
\hline CHEMBL1381070 & 688422 & 4.45 & 5.2601 & TRN & \\
\hline CHEMBL1474713 & 688422 & 8.3468 & 4.9844 & TRN & \\
\hline CHEMBL1583165 & 688422 & 4.45 & 5.4113 & TRN & \\
\hline CHEMBL3196770 & 688422 & 4.8 & 5.3936 & TRN & \\
\hline CHEMBL1351715 & 688422 & 5.5 & 5.17899 & 9999999999 & TRN \\
\hline CHEMBL1473089 & 688422 & 4.9 & 4.9689 & TRN & \\
\hline CHEMBL1552258 & 688422 & 4.45 & 4.8861 & TRN & \\
\hline CHEMBL1465362 & 688422 & 4.5 & 5.3507 & TRN & \\
\hline CHEMBL1339845 & 688422 & 4.3 & 5.7921 & TST & \\
\hline CHEMBL1303105 & 688422 & 5.35 & 5.755 & TRN & \\
\hline CHEMBL1359135 & 688422 & 5.6 & 5.3906 & TST & \\
\hline CHEMBL1331809 & 688422 & 4.6 & 4.8512 & TST & \\
\hline CHEMBL1460719 & 688422 & 4.45 & 4.9902 & TRN & \\
\hline CHEMBL1523662 & 688422 & 4.65 & 4.7805 & TRN & \\
\hline CHEMBL1516772 & 688422 & 4.45 & 4.8482 & TRN & \\
\hline CHEMBL1455281 & 688422 & 4.75 & 4.9602 & TST & \\
\hline CHEMBL1499165 & 688422 & 4.75 & 5.2804 & TRN & \\
\hline CHEMBL1421014 & 688422 & 4.5 & 5.0678 & TRN & \\
\hline CHEMBL1453802 & 688422 & 5.1 & 4.9273 & TRN & \\
\hline CHEMBL1392734 & 688422 & 4.7 & 5.1485 & TRN & \\
\hline
\end{tabular}




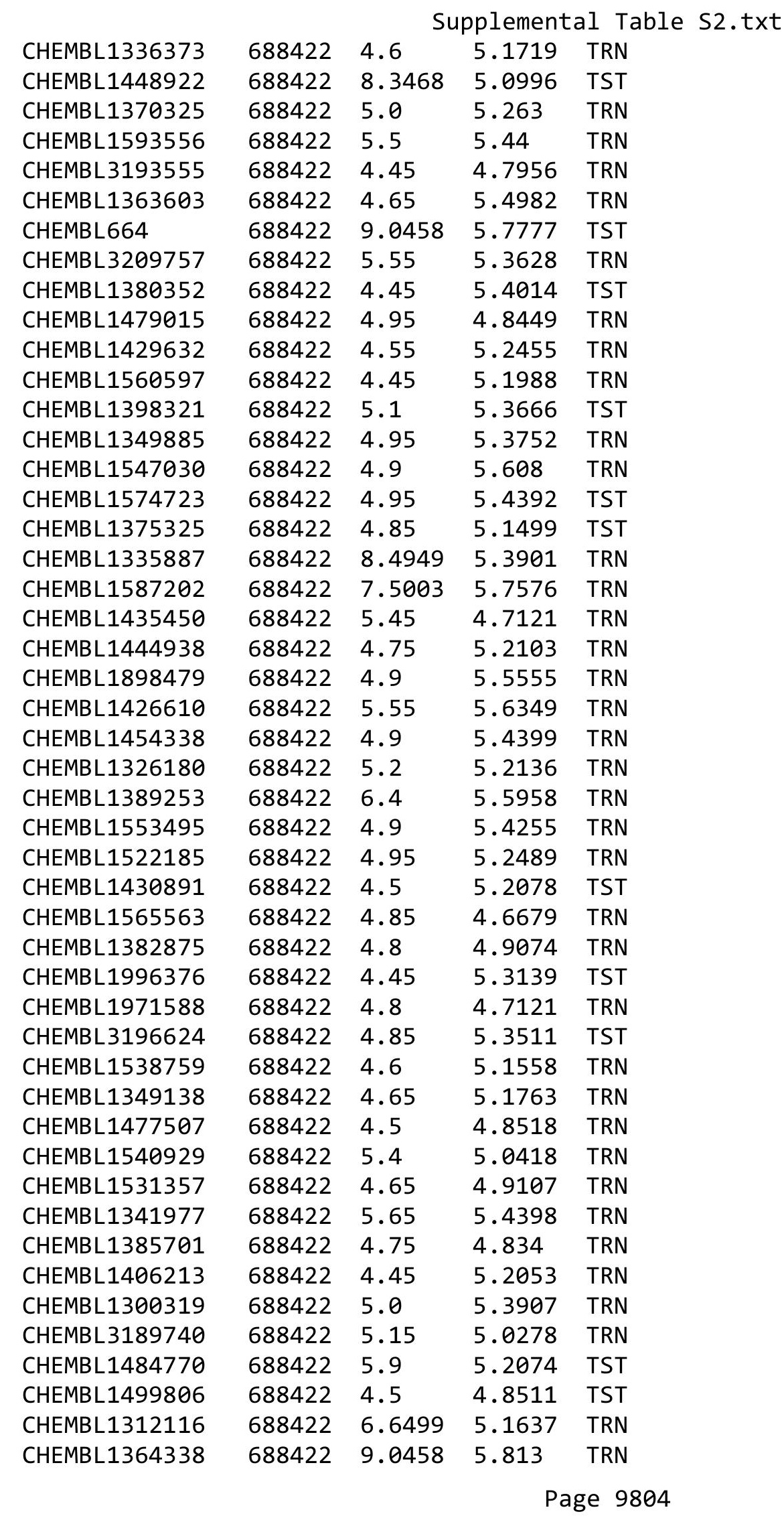




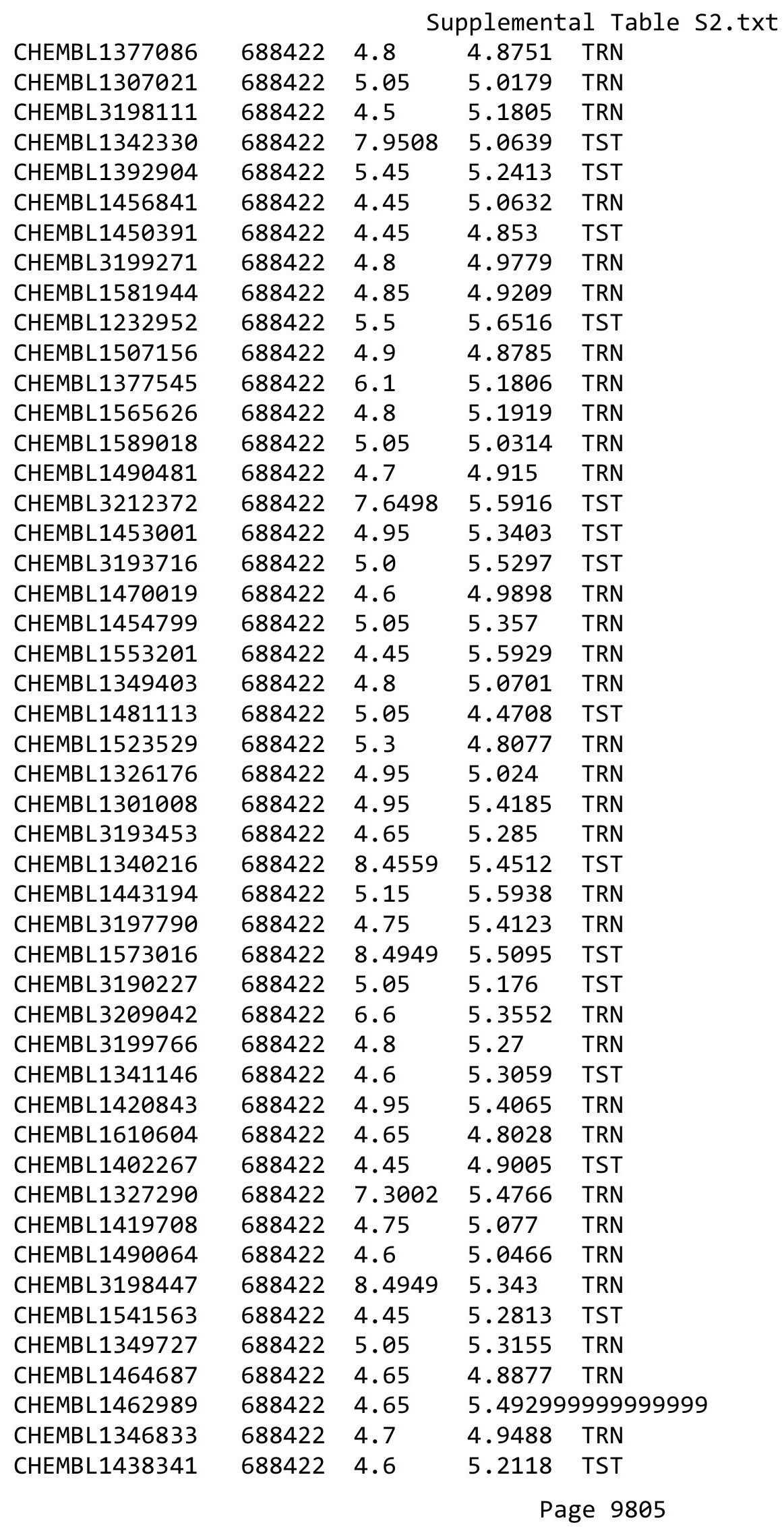

TRN 


\begin{tabular}{|c|c|c|c|c|c|}
\hline \multicolumn{6}{|c|}{ Supplemental Table S2.txt } \\
\hline CHEMBL1605577 & 688422 & 5.8 & 5.5259 & TST & \\
\hline CHEMBL1359982 & 688422 & 5.75 & 5.5306 & TRN & \\
\hline CHEMBL1441780 & 688422 & 4.95 & 4.8293 & TRN & \\
\hline CHEMBL1433027 & 688422 & 4.8 & 5.4125 & TRN & \\
\hline CHEMBL1414977 & 688422 & 5.9 & 5.6384 & TRN & \\
\hline CHEMBL1502851 & 688422 & 5.0 & 4.8917 & TST & \\
\hline CHEMBL1455567 & 688422 & 4.45 & 5.1347 & TST & \\
\hline CHEMBL1383721 & 688422 & 4.45 & 5.1687 & TRN & \\
\hline CHEMBL1499663 & 688422 & 5.3 & 5.1983 & TST & \\
\hline CHEMBL1409212 & 688422 & 7.5003 & 5.3369 & TRN & \\
\hline CHEMBL1334777 & 688422 & 4.9 & 4.9709 & TST & \\
\hline CHEMBL1596893 & 688422 & 4.9 & 5.7059 & TRN & \\
\hline CHEMBL1450983 & 688422 & 4.95 & 5.0589 & TRN & \\
\hline CHEMBL3212963 & 688422 & 4.45 & 5.2862 & TRN & \\
\hline CHEMBL1416321 & 688422 & 5.4 & 5.0605 & TRN & \\
\hline CHEMBL1322081 & 688422 & 6.3 & 5.1481 & TRN & \\
\hline CHEMBL1482667 & 688422 & 4.45 & 5.3435 & TRN & \\
\hline CHEMBL1346433 & 688422 & 5.1 & 5.25899 & 99999999995 & TRN \\
\hline CHEMBL 3207648 & 688422 & 7.1002 & 5.2385 & TST & \\
\hline CHEMBL1494889 & 688422 & 7.3002 & 6.072 & TRN & \\
\hline CHEMBL1569375 & 688422 & 4.5 & 4.9351 & TRN & \\
\hline CHEMBL1488317 & 688422 & 4.8 & 4.9616 & TRN & \\
\hline CHEMBL1338593 & 688422 & 4.75 & 4.9225 & TRN & \\
\hline CHEMBL1543757 & 688422 & 4.95 & 5.4155 & TRN & \\
\hline CHEMBL1342410 & 688422 & 4.6 & 4.8331 & TST & \\
\hline CHEMBL1597619 & 688422 & 7.2 & 5.3732 & TRN & \\
\hline CHEMBL1496527 & 688422 & 5.0 & 5.5977 & TST & \\
\hline CHEMBL1499431 & 688422 & 4.45 & 5.05 & TRN & \\
\hline CHEMBL1964614 & 688422 & 5.4 & 4.9885 & TRN & \\
\hline CHEMBL277120 & 688422 & 8.2518 & 5.2069 & TRN & \\
\hline CHEMBL1466363 & 688422 & 5.7 & 5.9413 & TRN & \\
\hline CHEMBL1485548 & 688422 & 4.45 & 5.5893 & TRN & \\
\hline CHEMBL3211661 & 688422 & 5.2 & 5.3789 & TST & \\
\hline CHEMBL1366506 & 688422 & 4.45 & 4.8238 & TRN & \\
\hline CHEMBL1328633 & 688422 & 6.6499 & 5.5492 & TRN & \\
\hline CHEMBL1313128 & 688422 & 4.45 & 4.7876 & TRN & \\
\hline CHEMBL1332403 & 688422 & 4.95 & 4.9739 & TST & \\
\hline CHEMBL1526044 & 688422 & 6.1 & 4.9558 & TRN & \\
\hline CHEMBL1542501 & 688422 & 4.45 & 5.3283 & TRN & \\
\hline CHEMBL1467053 & 688422 & 4.6 & 5.0973 & TRN & \\
\hline CHEMBL1456917 & 688422 & 4.45 & 5.4957 & TRN & \\
\hline CHEMBL1353151 & 688422 & 5.4 & 5.4875 & TST & \\
\hline CHEMBL1337567 & 688422 & 5.0 & 5.1851 & TRN & \\
\hline CHEMBL1460316 & 688422 & 4.95 & 5.3432 & TRN & \\
\hline CHEMBL1582965 & 688422 & 4.75 & 5.5252 & TRN & \\
\hline CHEMBL1369911 & 688422 & 4.45 & 4.9856 & TRN & \\
\hline CHEMBL 1447792 & 688422 & 4.6 & 5.2103 & TRN & \\
\hline CHEMBL1369877 & 688422 & 5.0 & 5.1742 & TST & \\
\hline
\end{tabular}





\begin{tabular}{|c|c|c|c|c|}
\hline \multicolumn{5}{|c|}{ Supplemental Table S2.txt } \\
\hline CHEMBL1571604 & 688422 & 5.3 & 5.3624 & TST \\
\hline CHEMBL1413494 & 688422 & 5.05 & 4.9637 & TRN \\
\hline CHEMBL1475496 & 688422 & 4.45 & 5.2081 & TRN \\
\hline CHEMBL1335967 & 688422 & 4.75 & 4.9694 & TRN \\
\hline CHEMBL1383954 & 688422 & 4.9 & 5.1444 & TRN \\
\hline CHEMBL1429929 & 688422 & 4.85 & 5.0597 & TRN \\
\hline CHEMBL3209660 & 688422 & 7.1002 & 5.4937 & TRN \\
\hline CHEMBL1321224 & 688422 & 5.0 & 5.6819 & TRN \\
\hline CHEMBL1372016 & 688422 & 5.8 & 5.4326 & TRN \\
\hline CHEMBL1507915 & 688422 & 5.2 & 5.2542 & TRN \\
\hline CHEMBL1349050 & 688422 & 5.4 & 5.1556 & TRN \\
\hline CHEMBL 245954 & 688422 & 4.45 & 5.0734 & TRN \\
\hline CHEMBL1548227 & 688422 & 4.45 & 5.8128 & TST \\
\hline CHEMBL1596927 & 688422 & 4.45 & 5.0912 & TRN \\
\hline CHEMBL1381106 & 688422 & 7.15 & 5.2217 & TRN \\
\hline CHEMBL1571909 & 688422 & 4.5 & 5.138 & TRN \\
\hline CHEMBL1300351 & 688422 & 4.45 & 4.871 & TRN \\
\hline CHEMBL3197571 & 688422 & 4.45 & 4.901 & TST \\
\hline CHEMBL1416353 & 688422 & 6.6 & 5.6686 & TRN \\
\hline CHEMBL1308838 & 688422 & 4.45 & 5.279 & TRN \\
\hline CHEMBL3195075 & 688422 & 5.4 & 5.5889 & TST \\
\hline CHEMBL1522508 & 688422 & 4.45 & 4.8342 & TRN \\
\hline CHEMBL1386151 & 688422 & 6.35 & 5.6344 & TST \\
\hline CHEMBL1543718 & 688422 & 5.0 & 5.2224 & TRN \\
\hline CHEMBL1462637 & 688422 & 4.95 & 5.0052 & TRN \\
\hline CHEMBL1308549 & 688422 & 4.95 & 5.1493 & TRN \\
\hline CHEMBL1366942 & 688422 & 5.3 & 5.4185 & TRN \\
\hline CHEMBL1350147 & 688422 & 7.699 & 5.0927 & TRN \\
\hline CHEMBL 1477680 & 688422 & 4.45 & 4.8679 & TRN \\
\hline CHEMBL1575753 & 688422 & 4.45 & 5.2508 & TRN \\
\hline CHEMBL1607885 & 688422 & 4.8 & 4.4223 & TRN \\
\hline CHEMBL1611035 & 688422 & 4.45 & 5.0869 & TRN \\
\hline CHEMBL1412064 & 688422 & 5.15 & 5.4285 & TRN \\
\hline CHEMBL3207686 & 688422 & 4.45 & 5.0222 & TST \\
\hline CHEMBL1450113 & 688422 & 5.65 & 5.3751 & TST \\
\hline CHEMBL526952 & 688422 & 5.15 & 5.0502 & TRN \\
\hline CHEMBL1441671 & 688422 & 5.1 & 5.3014 & TRN \\
\hline CHEMBL1386472 & 688422 & 5.6 & 5.5286 & TST \\
\hline CHEMBL1587137 & 688422 & 5.5 & 5.307 & TRN \\
\hline CHEMBL1374956 & 688422 & 4.65 & 5.6297 & TST \\
\hline CHEMBL1372993 & 688422 & 7.4498 & 5.23 & TRN \\
\hline CHEMBL1547262 & 688422 & 6.25 & 5.6189 & TST \\
\hline CHEMBL 23957 & 688422 & 4.7 & 5.7268 & TST \\
\hline CHEMBL1597535 & 688422 & 5.2 & 5.1835 & TRN \\
\hline CHEMBL1364596 & 688422 & 5.0 & 5.0162 & TRN \\
\hline CHEMBL1566965 & 688422 & 4.7 & 5.5982 & TRN \\
\hline CHEMBL1328960 & 688422 & 4.9 & 5.1665 & TST \\
\hline CHEMBL1445776 & 688422 & 4.45 & 5.1533 & TRN \\
\hline
\end{tabular}




\begin{tabular}{|c|c|c|c|c|c|}
\hline & & & & & \\
\hline CHEMBL1507020 & 688422 & 4.5 & 5.2354 & TRN & \\
\hline CHEMBL1588640 & 688422 & 5.65 & 5.4965 & TRN & \\
\hline CHEMBL1363310 & 688422 & 5.85 & 5.6848 & TST & \\
\hline CHEMBL1386271 & 688422 & 4.45 & 5.0708 & TRN & \\
\hline CHEMBL1545516 & 688422 & 4.75 & 4.9759 & TRN & \\
\hline CHEMBL1342702 & 688422 & 4.85 & 4.9414 & TRN & \\
\hline CHEMBL1456774 & 688422 & 4.45 & 5.2488 & TST & \\
\hline CHEMBL473107 & 688422 & 4.95 & 5.3004 & TST & \\
\hline CHEMBL1578814 & 688422 & 4.85 & 5.0044 & TRN & \\
\hline CHEMBL1343740 & 688422 & 4.45 & 5.0244 & TRN & \\
\hline CHEMBL1347919 & 688422 & 4.8 & 5.50799 & 9999999999 & TRN \\
\hline CHEMBL1410731 & 688422 & 5.0 & 5.4198 & TRN & \\
\hline CHEMBL1499736 & 688422 & 4.5 & 5.2959 & TRN & \\
\hline CHEMBL1534160 & 688422 & 5.2 & 5.147 & TST & \\
\hline CHEMBL3196606 & 688422 & 4.6 & 5.0019 & TRN & \\
\hline CHEMBL3198242 & 688422 & 4.95 & 5.1528 & TRN & \\
\hline CHEMBL1517930 & 688422 & 4.9 & 5.3545 & TRN & \\
\hline CHEMBL1334877 & 688422 & 4.75 & 4.9976 & TST & \\
\hline CHEMBL1542693 & 688422 & 4.45 & 4.9942 & TRN & \\
\hline CHEMBL1401661 & 688422 & 4.45 & 4.6222 & TRN & \\
\hline CHEMBL1380230 & 688422 & 4.5 & 5.8328 & TST & \\
\hline CHEMBL1563134 & 688422 & 4.9 & 5.039 & TRN & \\
\hline CHEMBL1482643 & 688422 & 4.5 & 5.2236 & TRN & \\
\hline CHEMBL1587840 & 688422 & 4.8 & 5.4273 & TRN & \\
\hline CHEMBL1521278 & 688422 & 4.95 & 5.112 & TST & \\
\hline CHEMBL1440254 & 688422 & 4.45 & 5.4047 & TRN & \\
\hline CHEMBL1524703 & 688422 & 4.7 & 5.1121 & TST & \\
\hline CHEMBL1566487 & 688422 & 6.15 & 4.7017 & TRN & \\
\hline CHEMBL1508166 & 688422 & 4.85 & 5.4813 & TRN & \\
\hline CHEMBL1539556 & 688422 & 4.7 & 5.1873 & TRN & \\
\hline CHEMBL1547161 & 688422 & 4.9 & 5.4044 & TRN & \\
\hline CHEMBL394143 & 688422 & 4.8 & 5.0445 & TRN & \\
\hline CHEMBL3196722 & 688422 & 4.45 & 5.6555 & TST & \\
\hline CHEMBL1530317 & 688422 & 5.0 & 4.8564 & TRN & \\
\hline CHEMBL1557947 & 688422 & 4.9 & 4.9265 & TRN & \\
\hline CHEMBL1566808 & 688422 & 7.5003 & 5.0999 & TRN & \\
\hline CHEMBL1529352 & 688422 & 4.6 & 4.711 & TRN & \\
\hline CHEMBL1490935 & 688422 & 4.45 & 5.2075 & TRN & \\
\hline CHEMBL1341301 & 688422 & 4.95 & 4.9077 & TRN & \\
\hline CHEMBL1353976 & 688422 & 4.45 & 5.1032 & TRN & \\
\hline CHEMBL1562310 & 688422 & 4.45 & 5.4681 & TRN & \\
\hline CHEMBL1511188 & 688422 & 4.5 & 5.4561 & TST & \\
\hline CHEMBL1543163 & 688422 & 4.45 & 5.12799 & 9999999999 & TST \\
\hline CHEMBL1493465 & 688422 & 4.6 & 4.9837 & TRN & \\
\hline CHEMBL1539372 & 688422 & 4.7 & 5.3021 & TRN & \\
\hline CHEMBL75967 & 688422 & 4.7 & 5.7704 & TST & \\
\hline CHEMBL1379448 & 688422 & 7.5498 & 5.7749 & TST & \\
\hline CHEMBL1393579 & 688422 & 5.4 & 4.76399 & 9999999999 & TRN \\
\hline & & & & 9809 & \\
\hline
\end{tabular}




\begin{tabular}{|c|c|c|c|c|}
\hline \multicolumn{5}{|c|}{ Supplemental Table S2.txt } \\
\hline CHEMBL1349383 & 688422 & 5.95 & 5.3237 & TRN \\
\hline CHEMBL1569555 & 688422 & 4.95 & 5.6987 & TST \\
\hline CHEMBL1487856 & 688422 & 5.2 & 5.7325 & TRN \\
\hline CHEMBL1596499 & 688422 & 4.85 & 5.1599 & TRN \\
\hline CHEMBL1485674 & 688422 & 4.45 & 5.2805 & TRN \\
\hline CHEMBL1353950 & 688422 & 4.8 & 5.2447 & TRN \\
\hline CHEMBL1451015 & 688422 & 5.05 & 5.3758 & TRN \\
\hline CHEMBL1397002 & 688422 & 4.45 & 5.0283 & TRN \\
\hline CHEMBL579621 & 688422 & 5.35 & 5.0823 & TRN \\
\hline CHEMBL1543196 & 688422 & 4.8 & 5.0106 & TRN \\
\hline CHEMBL3207920 & 688422 & 4.5 & 5.2671 & TST \\
\hline CHEMBL1329003 & 688422 & 5.55 & 5.4998 & TRN \\
\hline CHEMBL1550133 & 688422 & 4.9 & 4.8869 & TRN \\
\hline CHEMBL1429428 & 688422 & 5.0 & 5.4398 & TRN \\
\hline CHEMBL1570193 & 688422 & 4.65 & 5.1271 & TST \\
\hline CHEMBL1583997 & 688422 & 4.5 & 5.033 & TST \\
\hline CHEMBL1514209 & 688422 & 4.45 & 5.3571 & TRN \\
\hline CHEMBL1344091 & 688422 & 8.4949 & 5.4412 & TRN \\
\hline CHEMBL1310962 & 688422 & 7.15 & 5.4401 & TRN \\
\hline CHEMBL1593330 & 688422 & 6.7001 & 4.8706 & TST \\
\hline CHEMBL1437950 & 688422 & 4.45 & 4.888 & TST \\
\hline CHEMBL9225 & 688422 & 6.5 & 5.2449 & TRN \\
\hline CHEMBL1558306 & 688422 & 4.65 & 4.8426 & TRN \\
\hline CHEMBL1401777 & 688422 & 4.9 & 5.4591 & TRN \\
\hline CHEMBL1509051 & 688422 & 4.85 & 5.0269 & TRN \\
\hline CHEMBL393287 & 688422 & 4.45 & 5.016 & TRN \\
\hline CHEMBL1477845 & 688422 & 4.45 & 5.2344 & TRN \\
\hline CHEMBL1495787 & 688422 & 4.75 & 5.5362 & TRN \\
\hline CHEMBL1564840 & 688422 & 5.2 & 5.4196 & TRN \\
\hline CHEMBL1411371 & 688422 & 5.3 & 5.4901 & TRN \\
\hline CHEMBL1340399 & 688422 & 4.65 & 4.9715 & TST \\
\hline CHEMBL1333942 & 688422 & 4.45 & 4.8148 & TRN \\
\hline CHEMBL1483085 & 688422 & 4.45 & 6.0572 & TST \\
\hline CHEMBL1353015 & 688422 & 4.85 & 5.3187 & TST \\
\hline CHEMBL1568899 & 688422 & 4.7 & 5.1175 & TRN \\
\hline CHEMBL1392042 & 688422 & 4.45 & 4.6669 & TRN \\
\hline CHEMBL1464863 & 688422 & 4.5 & 4.9653 & TRN \\
\hline CHEMBL1588476 & 688422 & 4.75 & 4.9066 & TRN \\
\hline CHEMBL1409604 & 688422 & 4.65 & 4.7736 & TRN \\
\hline CHEMBL1535067 & 688422 & 4.45 & 5.6418 & TST \\
\hline CHEMBL1456937 & 688422 & 4.65 & 4.9356 & TRN \\
\hline CHEMBL1483975 & 688422 & 5.0 & 4.4703 & TRN \\
\hline CHEMBL1423460 & 688422 & 7.2503 & 5.4494 & TST \\
\hline CHEMBL1457523 & 688422 & 5.4 & 5.7012 & TST \\
\hline CHEMBL1364963 & 688422 & 4.85 & 5.4802 & TRN \\
\hline CHEMBL1568046 & 688422 & 6.2 & 5.7813 & TST \\
\hline CHEMBL1312083 & 688422 & 4.8 & 5.0024 & TRN \\
\hline CHEMBL1404608 & 688422 & 4.45 & 5.3764 & TRN \\
\hline
\end{tabular}




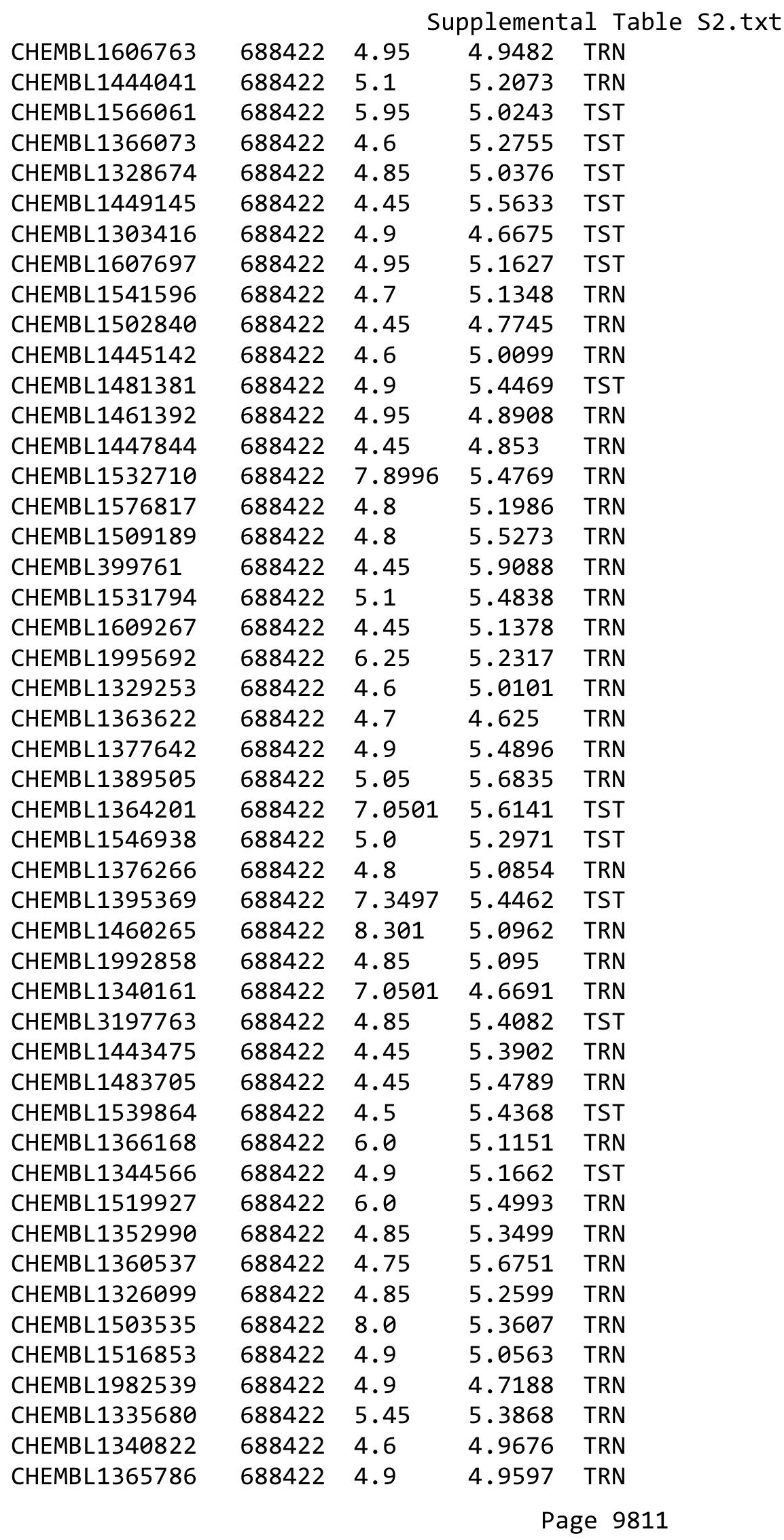




\begin{tabular}{|c|c|c|c|c|c|}
\hline \multicolumn{6}{|c|}{ Supplemental Table S2.txt } \\
\hline CHEMBL1565328 & 688422 & 4.8 & 5.32 & TRN & \\
\hline CHEMBL1593470 & 688422 & 4.85 & 4.9469 & TST & \\
\hline CHEMBL1496720 & 688422 & 5.05 & 5.1995 & TST & \\
\hline CHEMBL1506144 & 688422 & 4.65 & 5.3649 & TST & \\
\hline CHEMBL1512284 & 688422 & 4.75 & 5.2142 & TRN & \\
\hline CHEMBL1531805 & 688422 & 4.6 & 5.058 & TRN & \\
\hline CHEMBL1409562 & 688422 & 4.45 & 5.3273 & TST & \\
\hline CHEMBL1329879 & 688422 & 5.7 & 5.3967 & TRN & \\
\hline CHEMBL1377056 & 688422 & 6.05 & 5.4024 & TRN & \\
\hline CHEMBL1494714 & 688422 & 6.3 & 5.4384 & TRN & \\
\hline CHEMBL1453262 & 688422 & 4.85 & 5.0746 & TRN & \\
\hline CHEMBL1521618 & 688422 & 4.45 & 4.8953 & TRN & \\
\hline CHEMBL1473914 & 688422 & 5.6 & 5.0749 & TRN & \\
\hline CHEMBL1555801 & 688422 & 5.8 & 4.9865 & TRN & \\
\hline CHEMBL1419618 & 688422 & 5.0 & 5.4786 & TRN & \\
\hline CHEMBL1446087 & 688422 & 4.95 & 5.4988 & TRN & \\
\hline CHEMBL1305805 & 688422 & 4.75 & 5.05699 & 99999999995 & TRN \\
\hline CHEMBL1480238 & 688422 & 6.9 & 5.5784 & TRN & \\
\hline CHEMBL1554245 & 688422 & 4.5 & 5.2205 & TRN & \\
\hline CHEMBL1539941 & 688422 & 5.0 & 5.147 & TRN & \\
\hline CHEMBL1402134 & 688422 & 4.5 & 5.2572 & TRN & \\
\hline CHEMBL1543834 & 688422 & 4.45 & 5.0846 & TRN & \\
\hline CHEMBL76904 & 688422 & 4.6 & 5.3392 & TRN & \\
\hline CHEMBL1596784 & 688422 & 4.5 & 5.1516 & TRN & \\
\hline CHEMBL1489769 & 688422 & 6.0 & 5.3398 & TST & \\
\hline CHEMBL1444568 & 688422 & 5.55 & 4.8216 & TRN & \\
\hline CHEMBL1447453 & 688422 & 4.6 & 4.8982 & TRN & \\
\hline CHEMBL1504394 & 688422 & 5.0 & 5.4833 & TST & \\
\hline CHEMBL3190868 & 688422 & 5.5 & 5.5057 & TRN & \\
\hline CHEMBL1493900 & 688422 & 7.0501 & 5.8257 & TRN & \\
\hline CHEMBL1429549 & 688422 & 4.5 & 5.0211 & TST & \\
\hline CHEMBL1326980 & 688422 & 5.15 & 5.3973 & TST & \\
\hline CHEMBL1447433 & 688422 & 4.8 & 5.2919 & TST & \\
\hline CHEMBL1356968 & 688422 & 6.95 & 5.5148 & TST & \\
\hline CHEMBL1532976 & 688422 & 4.6 & 4.9212 & TRN & \\
\hline CHEMBL1480224 & 688422 & 4.8 & 5.2633 & TRN & \\
\hline CHEMBL1486188 & 688422 & 4.45 & 5.8905 & TRN & \\
\hline CHEMBL1325593 & 688422 & 4.7 & 5.2221 & TRN & \\
\hline CHEMBL1401369 & 688422 & 5.2 & 4.8303 & TRN & \\
\hline CHEMBL1423596 & 688422 & 4.45 & 5.07 & TRN & \\
\hline CHEMBL1349938 & 688422 & 4.45 & 4.9667 & TRN & \\
\hline CHEMBL3190770 & 688422 & 5.05 & 5.2927 & TRN & \\
\hline CHEMBL1402455 & 688422 & 4.45 & 5.2952 & TRN & \\
\hline CHEMBL1556017 & 688422 & 4.45 & 5.2309 & TRN & \\
\hline CHEMBL1487506 & 688422 & 5.15 & 5.2709 & TRN & \\
\hline CHEMBL1545588 & 688422 & 4.45 & 5.3154 & TST & \\
\hline CHEMBL1984338 & 688422 & 5.35 & 5.4099 & TRN & \\
\hline CHEMBL1304237 & 688422 & 4.45 & 5.4919 & TRN & \\
\hline
\end{tabular}




\begin{tabular}{|c|c|c|c|c|c|}
\hline & & \multicolumn{4}{|c|}{ Supplemental Table s2.txt } \\
\hline CHEMBL1439575 & 688422 & 5.35 & 5.0282 & TRN & \\
\hline CHEMBL1437582 & 688422 & 5.2 & 5.3781 & TRN & \\
\hline CHEMBL1600781 & 688422 & 4.45 & 5.2165 & TRN & \\
\hline CHEMBL1459754 & 688422 & 4.45 & 5.3531 & TRN & \\
\hline CHEMBL1403468 & 688422 & 4.65 & 5.2683 & TST & \\
\hline CHEMBL1475331 & 688422 & 5.55 & 5.2777 & TRN & \\
\hline CHEMBL1358199 & 688422 & 6.2 & 5.2634 & TRN & \\
\hline CHEMBL3191541 & 688422 & 5.7 & 5.1821 & TRN & \\
\hline CHEMBL1561676 & 688422 & 4.45 & 4.8927 & TRN & \\
\hline CHEMBL1587299 & 688422 & 4.9 & 5.0921 & TRN & \\
\hline CHEMBL1563352 & 688422 & 4.75 & 5.5434 & TST & \\
\hline CHEMBL1607418 & 688422 & 4.6 & 4.8426 & TRN & \\
\hline CHEMBL1351702 & 688422 & 4.75 & 5.0779 & TRN & \\
\hline CHEMBL1493200 & 688422 & 4.45 & 5.4013 & TRN & \\
\hline CHEMBL1607871 & 688422 & 4.65 & 5.8518 & TRN & \\
\hline CHEMBL1597506 & 688422 & 6.0 & 4.8434 & TRN & \\
\hline CHEMBL1459278 & 688422 & 4.75 & 5.2015 & TRN & \\
\hline CHEMBL1455588 & 688422 & 4.6 & 5.267 & TRN & \\
\hline CHEMBL1328497 & 688422 & 4.8 & 5.2392 & TRN & \\
\hline CHEMBL1411209 & 688422 & 5.1 & 4.8673 & TRN & \\
\hline CHEMBL1474468 & 688422 & 4.45 & 4.7167 & TRN & \\
\hline CHEMBL1613652 & 688422 & 4.9 & 5.2661 & TRN & \\
\hline CHEMBL1569508 & 688422 & 7.2 & 5.6733 & TRN & \\
\hline CHEMBL1512347 & 688422 & 8.4949 & 5.3395 & TRN & \\
\hline CHEMBL1490138 & 688422 & 4.45 & 5.319 & TST & \\
\hline CHEMBL1500027 & 688422 & 4.45 & 4.7814 & TST & \\
\hline CHEMBL1611866 & 688422 & 4.45 & 5.3079 & TRN & \\
\hline CHEMBL1521619 & 688422 & 4.45 & 5.284 & TST & \\
\hline CHEMBL1484163 & 688422 & 4.95 & 5.0638 & TRN & \\
\hline CHEMBL1387710 & 688422 & 4.7 & 4.7984 & TST & \\
\hline CHEMBL1991936 & 688422 & 7.8508 & 5.5734 & TST & \\
\hline CHEMBL1573786 & 688422 & 4.9 & 5.3224 & TRN & \\
\hline CHEMBL1558607 & 688422 & 5.4 & 4.9758 & TRN & \\
\hline CHEMBL1333847 & 688422 & 6.0 & 5.6093 & TST & \\
\hline CHEMBL1544171 & 688422 & 4.75 & 5.15600 & 0000000001 & TRN \\
\hline CHEMBL1311714 & 688422 & 5.0 & 5.1758 & TRN & \\
\hline CHEMBL1394647 & 688422 & 4.4 & 5.5585 & TRN & \\
\hline CHEMBL1491519 & 688422 & 4.8 & 5.2665 & TST & \\
\hline CHEMBL1566174 & 688422 & 4.8 & 4.9419 & TRN & \\
\hline CHEMBL1547647 & 688422 & 4.55 & 5.2305 & TST & \\
\hline CHEMBL1590735 & 688422 & 8.1487 & 5.3241 & TRN & \\
\hline CHEMBL1573422 & 688422 & 6.0 & 5.17700 & 00000000005 & TRN \\
\hline CHEMBL1447922 & 688422 & 4.9 & 5.2889 & TRN & \\
\hline CHEMBL1495219 & 688422 & 4.65 & 5.2026 & TRN & \\
\hline CHEMBL1463070 & 688422 & 6.7001 & 5.3771 & TRN & \\
\hline CHEMBL1538014 & 688422 & 4.6 & 4.599 & TRN & \\
\hline CHEMBL1304059 & 688422 & 5.45 & 5.5847 & TRN & \\
\hline CHEMBL1303315 & 688422 & 5.0 & 5.0025 & TRN & \\
\hline
\end{tabular}





\begin{tabular}{|c|c|c|c|c|c|}
\hline \multicolumn{6}{|c|}{ Supplemental Table s2.txt } \\
\hline CHEMBL1490084 & 688422 & 4.45 & 5.1404 & TRN & \\
\hline CHEMBL1512021 & 688422 & 5.9 & 5.8891 & TRN & \\
\hline CHEMBL1439841 & 688422 & 4.45 & 5.1349 & TRN & \\
\hline CHEMBL1363583 & 688422 & 4.8 & 5.0222 & TST & \\
\hline CHEMBL1558184 & 688422 & 5.15 & 5.1134 & TRN & \\
\hline CHEMBL1479908 & 688422 & 4.6 & 5.6835 & TRN & \\
\hline CHEMBL1542584 & 688422 & 4.45 & 5.1178 & TST & \\
\hline CHEMBL1612425 & 688422 & 5.0 & 5.3032 & TRN & \\
\hline CHEMBL1300259 & 688422 & 4.65 & 5.1244 & TST & \\
\hline CHEMBL1256654 & 688422 & 6.6 & 5.26399 & 9999999999 & TST \\
\hline CHEMBL1609314 & 688422 & 4.45 & 6.0062 & TRN & \\
\hline CHEMBL1382977 & 688422 & 4.8 & 4.8789 & TRN & \\
\hline CHEMBL1613639 & 688422 & 5.85 & 5.9342 & TRN & \\
\hline CHEMBL1338019 & 688422 & 4.9 & 5.1697 & TRN & \\
\hline CHEMBL1487371 & 688422 & 5.15 & 5.6409 & TST & \\
\hline CHEMBL1530120 & 688422 & 7.3002 & 5.0729 & TRN & \\
\hline CHEMBL1507299 & 688422 & 4.85 & 5.3961 & TRN & \\
\hline CHEMBL1499887 & 688422 & 4.45 & 5.0813 & TST & \\
\hline CHEMBL1327925 & 688422 & 7.0 & 5.4862 & TRN & \\
\hline CHEMBL1353453 & 688422 & 4.45 & 5.1118 & TST & \\
\hline CHEMBL1466828 & 688422 & 7.9508 & 5.227 & TRN & \\
\hline CHEMBL1416904 & 688422 & 4.5 & 5.3959 & TRN & \\
\hline CHEMBL1541546 & 688422 & 4.5 & 5.4501 & TRN & \\
\hline CHEMBL1331016 & 688422 & 4.8 & 5.346 & TRN & \\
\hline CHEMBL1368253 & 688422 & 4.65 & 5.4623 & TRN & \\
\hline CHEMBL593120 & 688422 & 4.9 & 4.9827 & TST & \\
\hline CHEMBL72628 & 688422 & 4.45 & 5.7 & TRN & \\
\hline CHEMBL1303589 & 688422 & 4.9 & 5.3395 & TRN & \\
\hline CHEMBL1378168 & 688422 & 8.0506 & 5.394 & TRN & \\
\hline CHEMBL1562010 & 688422 & 6.15 & 5.0111 & TST & \\
\hline CHEMBL1443355 & 688422 & 4.75 & 5.1434 & TRN & \\
\hline CHEMBL1414449 & 688422 & 4.5 & 5.2538 & TRN & \\
\hline CHEMBL1439275 & 688422 & 4.8 & 5.4841 & TRN & \\
\hline CHEMBL3214141 & 688422 & 4.45 & 5.2123 & TRN & \\
\hline CHEMBL1439833 & 688422 & 5.55 & 5.4411 & TRN & \\
\hline CHEMBL3198008 & 688422 & 4.45 & 4.8893 & TRN & \\
\hline CHEMBL1511887 & 688422 & 4.8 & 4.994 & TRN & \\
\hline CHEMBL1344381 & 688422 & 4.85 & 4.7721 & TRN & \\
\hline CHEMBL1608471 & 688422 & 4.7 & 5.0564 & TRN & \\
\hline CHEMBL1432038 & 688422 & 4.75 & 5.2398 & TRN & \\
\hline CHEMBL1413442 & 688422 & 5.7 & 5.3111 & TRN & \\
\hline CHEMBL1301322 & 688422 & 4.95 & 5.2448 & TRN & \\
\hline CHEMBL1312653 & 688422 & 5.0 & 5.6613 & TRN & \\
\hline CHEMBL 3207830 & 688422 & 5.4 & 5.3477 & TRN & \\
\hline CHEMBL1430931 & 688422 & 4.7 & 4.8244 & TRN & \\
\hline CHEMBL 3198503 & 688422 & 4.75 & 5.0819 & TRN & \\
\hline CHEMBL3190455 & 688422 & 5.5 & 5.48600 & 0000000001 & TRN \\
\hline CHEMBL1422048 & 688422 & 4.75 & 4.9215 & TRN & \\
\hline
\end{tabular}




\begin{tabular}{|c|c|c|c|c|c|}
\hline \multicolumn{6}{|c|}{ Supplemental Table S2.txt } \\
\hline CHEMBL1591164 & 688422 & 4.5 & 4.9167 & TRN & \\
\hline CHEMBL1339350 & 688422 & 4.7 & 5.5967 & TRN & \\
\hline CHEMBL1537897 & 688422 & 5.35 & 5.4188 & TST & \\
\hline CHEMBL1966497 & 688422 & 4.95 & 5.0271 & TRN & \\
\hline CHEMBL1555492 & 688422 & 4.95 & 5.2588 & TST & \\
\hline CHEMBL1544156 & 688422 & 4.7 & 4.8517 & TRN & \\
\hline CHEMBL1449542 & 688422 & 5.55 & 5.5915 & TRN & \\
\hline CHEMBL1428979 & 688422 & 4.8 & 5.2556 & TRN & \\
\hline CHEMBL1370392 & 688422 & 4.65 & 5.3558 & TRN & \\
\hline CHEMBL1584300 & 688422 & 4.5 & 5.3871 & TST & \\
\hline CHEMBL1525148 & 688422 & 5.65 & 5.2318 & TRN & \\
\hline CHEMBL1563012 & 688422 & 5.65 & 4.7738 & TRN & \\
\hline CHEMBL1477994 & 688422 & 5.1 & 5.1867 & TRN & \\
\hline CHEMBL1393564 & 688422 & 4.75 & 4.9477 & TST & \\
\hline CHEMBL1448561 & 688422 & 5.0 & 5.631 & TST & \\
\hline CHEMBL1497445 & 688422 & 4.45 & 5.4578 & TST & \\
\hline CHEMBL1449718 & 688422 & 4.6 & 5.2345 & TST & \\
\hline CHEMBL1458724 & 688422 & 4.45 & 5.0912 & TST & \\
\hline CHEMBL1464153 & 688422 & 4.45 & 5.38299 & 9999999999 & TRN \\
\hline CHEMBL1573337 & 688422 & 5.2 & 5.1707 & TST & \\
\hline CHEMBL1439060 & 688422 & 4.45 & 5.2826 & TRN & \\
\hline CHEMBL1527318 & 688422 & 4.65 & 5.0669 & TST & \\
\hline CHEMBL1392878 & 688422 & 4.7 & 5.1665 & TST & \\
\hline CHEMBL1504949 & 688422 & 4.7 & 4.7944 & TRN & \\
\hline CHEMBL3211557 & 688422 & 7.5003 & 5.0061 & TRN & \\
\hline CHEMBL1455033 & 688422 & 5.5 & 5.523 & TRN & \\
\hline CHEMBL1611296 & 688422 & 5.55 & 5.4705 & TST & \\
\hline CHEMBL1424867 & 688422 & 4.45 & 5.0804 & TRN & \\
\hline CHEMBL1369448 & 688422 & 4.45 & 5.0369 & TRN & \\
\hline CHEMBL1355360 & 688422 & 7.3497 & 5.2686 & TRN & \\
\hline CHEMBL1420441 & 688422 & 5.5 & 5.5275 & TST & \\
\hline CHEMBL1377261 & 688422 & 5.0 & 4.9272 & TRN & \\
\hline CHEMBL580819 & 688422 & 4.45 & 5.0192 & TRN & \\
\hline CHEMBL3214429 & 688422 & 4.8 & 5.5275 & TRN & \\
\hline CHEMBL1470132 & 688422 & 4.45 & 5.1318 & TST & \\
\hline CHEMBL3194473 & 688422 & 4.6 & 5.1789 & TRN & \\
\hline CHEMBL1430991 & 688422 & 4.45 & 4.8931 & TST & \\
\hline CHEMBL1348305 & 688422 & 4.95 & 4.6607 & TRN & \\
\hline CHEMBL1391740 & 688422 & 4.65 & 5.2705 & TRN & \\
\hline CHEMBL1518444 & 688422 & 8.3468 & 5.5657 & TRN & \\
\hline CHEMBL1340513 & 688422 & 4.45 & 4.8961 & TRN & \\
\hline CHEMBL1577665 & 688422 & 4.95 & 5.3 & TRN & \\
\hline CHEMBL1588871 & 688422 & 4.6 & 4.9334 & TRN & \\
\hline CHEMBL1369904 & 688422 & 4.5 & 5.1647 & TRN & \\
\hline CHEMBL1417577 & 688422 & 4.5 & 5.3372 & TRN & \\
\hline CHEMBL1438596 & 688422 & 4.45 & 4.6391 & TST & \\
\hline CHEMBL1405493 & 688422 & 4.85 & 5.0009 & TRN & \\
\hline CHEMBL1580002 & 688422 & 4.6 & 5.2534 & TRN & \\
\hline
\end{tabular}




\begin{tabular}{|c|c|c|c|c|c|}
\hline \multicolumn{6}{|c|}{ Supplemental Table s2.txt } \\
\hline CHEMBL1533810 & 688422 & 4.45 & 5.064 & TRN & \\
\hline CHEMBL1566314 & 688422 & 4.65 & 5.1831 & TST & \\
\hline CHEMBL1345978 & 688422 & 7.9508 & 5.4932 & TRN & \\
\hline CHEMBL1307184 & 688422 & 5.55 & 5.1909 & TRN & \\
\hline CHEMBL1353167 & 688422 & 8.5528 & 5.1324 & TRN & \\
\hline CHEMBL3214439 & 688422 & 4.9 & 5.2312 & TST & \\
\hline CHEMBL1448142 & 688422 & 4.6 & 5.1752 & TRN & \\
\hline CHEMBL1327079 & 688422 & 4.45 & 5.0389 & TST & \\
\hline CHEMBL1467924 & 688422 & 6.8499 & 5.6262 & TRN & \\
\hline CHEMBL1545631 & 688422 & 4.95 & 5.1444 & TRN & \\
\hline CHEMBL1530174 & 688422 & 4.9 & 5.0446 & TRN & \\
\hline CHEMBL1588709 & 688422 & 4.95 & 5.1222 & TRN & \\
\hline CHEMBL1411594 & 688422 & 4.75 & 5.1578 & TRN & \\
\hline CHEMBL1465841 & 688422 & 4.45 & 4.9625 & TRN & \\
\hline CHEMBL1446404 & 688422 & 4.95 & 5.3262 & TRN & \\
\hline CHEMBL1373150 & 688422 & 8.1487 & 5.7128 & TRN & \\
\hline CHEMBL1502036 & 688422 & 4.95 & 5.1854 & TST & \\
\hline CHEMBL1453981 & 688422 & 4.9 & 5.5303 & TRN & \\
\hline CHEMBL1385920 & 688422 & 4.45 & 5.3942 & TRN & \\
\hline CHEMBL1438136 & 688422 & 8.699 & 5.3496 & TST & \\
\hline CHEMBL1501400 & 688422 & 4.65 & 4.8455 & TRN & \\
\hline CHEMBL1345798 & 688422 & 4.75 & 5.0819 & TRN & \\
\hline CHEMBL1500793 & 688422 & 5.3 & 5.191 & TRN & \\
\hline CHEMBL1447822 & 688422 & 4.65 & 4.9668 & TRN & \\
\hline CHEMBL1534536 & 688422 & 6.25 & 5.1764 & TRN & \\
\hline CHEMBL1401905 & 688422 & 6.35 & 5.3283 & TRN & \\
\hline CHEMBL1406469 & 688422 & 5.2 & 5.5355 & TRN & \\
\hline CHEMBL1493633 & 688422 & 4.65 & 4.6777 & TRN & \\
\hline CHEMBL1518276 & 688422 & 4.9 & 5.4353 & TRN & \\
\hline CHEMBL1391422 & 688422 & 4.8 & 4.7702 & TRN & \\
\hline CHEMBL1382181 & 688422 & 4.6 & 5.3304 & TST & \\
\hline CHEMBL1464344 & 688422 & 4.6 & 5.0127 & TST & \\
\hline CHEMBL1338612 & 688422 & 7.3002 & 5.0118 & TRN & \\
\hline CHEMBL1346628 & 688422 & 4.45 & 5.06800 & 00000000005 & TST \\
\hline CHEMBL473326 & 688422 & 4.85 & 4.9454 & TRN & \\
\hline CHEMBL1361455 & 688422 & 8.3468 & 5.2826 & TRN & \\
\hline CHEMBL1514509 & 688422 & 6.8 & 5.5688 & TRN & \\
\hline CHEMBL1360980 & 688422 & 4.9 & 5.2173 & TRN & \\
\hline CHEMBL1551079 & 688422 & 7.4498 & 5.0708 & TRN & \\
\hline CHEMBL1374907 & 688422 & 4.45 & 5.1168 & TRN & \\
\hline CHEMBL1359008 & 688422 & 4.9 & 5.45799 & 9999999999 & TRN \\
\hline CHEMBL1303890 & 688422 & 4.6 & 5.7404 & TRN & \\
\hline CHEMBL1998302 & 688422 & 4.95 & 5.5031 & TRN & \\
\hline CHEMBL1340481 & 688422 & 4.65 & 5.2709 & TST & \\
\hline CHEMBL1504737 & 688422 & 7.6498 & 5.1915 & TST & \\
\hline CHEMBL1599605 & 688422 & 5.45 & 5.2844 & TST & \\
\hline CHEMBL1378397 & 688422 & 4.95 & 5.2955 & TRN & \\
\hline CHEMBL1372072 & 688422 & 6.5501 & 4.9955 & TST & \\
\hline
\end{tabular}




\begin{tabular}{|c|c|c|c|c|c|}
\hline \multicolumn{6}{|c|}{ Supplemental Table s2.txt } \\
\hline CHEMBL 3191858 & 688422 & 4.45 & 5.1804 & TRN & \\
\hline CHEMBL1311809 & 688422 & 4.5 & 5.0814 & TST & \\
\hline CHEMBL1330487 & 688422 & 4.45 & 5.3424 & TRN & \\
\hline CHEMBL1525287 & 688422 & 6.45 & 5.2886 & TRN & \\
\hline CHEMBL1393450 & 688422 & 4.85 & 5.3051 & TST & \\
\hline CHEMBL1416269 & 688422 & 4.9 & 5.0576 & TRN & \\
\hline CHEMBL1373361 & 688422 & 4.45 & 4.7508 & TST & \\
\hline CHEMBL1405021 & 688422 & 5.0 & 5.6115 & TST & \\
\hline CHEMBL 3145293 & 688422 & 4.75 & 4.9766 & TST & \\
\hline CHEMBL1485191 & 688422 & 7.8996 & 5.2661 & TRN & \\
\hline CHEMBL1501776 & 688422 & 4.95 & 5.2728 & TRN & \\
\hline CHEMBL1566903 & 688422 & 4.6 & 5.386 & TST & \\
\hline CHEMBL1570339 & 688422 & 5.2 & 5.5042 & TRN & \\
\hline CHEMBL1540282 & 688422 & 5.25 & 4.9619 & TRN & \\
\hline CHEMBL1423453 & 688422 & 4.95 & 5.0801 & TRN & \\
\hline CHEMBL1399221 & 688422 & 6.0 & 5.0274 & TRN & \\
\hline CHEMBL1450336 & 688422 & 5.25 & 5.1548 & TST & \\
\hline CHEMBL1384501 & 688422 & 4.7 & 5.1846 & TRN & \\
\hline CHEMBL1527426 & 688422 & 4.9 & 4.8015 & TRN & \\
\hline CHEMBL1197556 & 688422 & 5.25 & 5.4763 & TRN & \\
\hline CHEMBL1586753 & 688422 & 7.0501 & 5.7819 & TRN & \\
\hline CHEMBL1582385 & 688422 & 6.6499 & 5.8815 & TST & \\
\hline CHEMBL1476191 & 688422 & 4.7 & 5.0434 & TST & \\
\hline CHEMBL227925 & 688422 & 4.5 & 5.3903 & TRN & \\
\hline CHEMBL1440715 & 688422 & 4.7 & 5.3079 & TRN & \\
\hline CHEMBL1591673 & 688422 & 5.05 & 5.1712 & TRN & \\
\hline CHEMBL1395936 & 688422 & 5.35 & 5.2007 & TRN & \\
\hline CHEMBL3191322 & 688422 & 6.0 & 5.261 & TRN & \\
\hline CHEMBL1487178 & 688422 & 7.3497 & 4.7435 & TST & \\
\hline CHEMBL603945 & 688422 & 4.7 & 5.1501 & TRN & \\
\hline CHEMBL1438395 & 688422 & 7.6498 & 5.3459 & TRN & \\
\hline CHEMBL3189272 & 688422 & 4.95 & 5.7597 & TST & \\
\hline CHEMBL1528094 & 688422 & 4.7 & 5.0672 & TRN & \\
\hline CHEMBL1407352 & 688422 & 4.85 & 5.5089 & TST & \\
\hline CHEMBL1346572 & 688422 & 5.15 & 5.1144 & TST & \\
\hline CHEMBL1361970 & 688422 & 4.95 & 5.4548 & TRN & \\
\hline CHEMBL1418287 & 688422 & 7.8996 & 5.4455 & TRN & \\
\hline CHEMBL1578789 & 688422 & 6.05 & 5.3535 & TRN & \\
\hline CHEMBL540851 & 688422 & 6.0 & 5.8931 & TRN & \\
\hline CHEMBL1511194 & 688422 & 4.45 & 5.3401 & TRN & \\
\hline CHEMBL1455027 & 688422 & 6.95 & 5.2213 & TRN & \\
\hline CHEMBL1578826 & 688422 & 4.45 & 4.7978 & TRN & \\
\hline CHEMBL1326553 & 688422 & 4.7 & 5.3596 & TRN & \\
\hline CHEMBL1448069 & 688422 & 4.95 & 4.9512 & TRN & \\
\hline CHEMBL1532755 & 688422 & 4.85 & 5.2271 & TRN & \\
\hline CHEMBL1571795 & 688422 & 4.45 & 5.2688 & TRN & \\
\hline CHEMBL1497726 & 688422 & 6.95 & 5.6199 & TRN & \\
\hline CHEMBL1532729 & 688422 & 4.65 & 5.16700 & 0000000001 & TRN \\
\hline & & & & 9818 & \\
\hline
\end{tabular}




\begin{tabular}{|c|c|c|c|c|c|}
\hline \multicolumn{6}{|c|}{ Supplemental Table S2.txt } \\
\hline CHEMBL1511500 & 688422 & 5.65 & 5.0654 & TRN & \\
\hline CHEMBL1352622 & 688422 & 4.8 & 4.989 & TRN & \\
\hline CHEMBL1596145 & 688422 & 6.6499 & 5.2436 & TRN & \\
\hline CHEMBL1442090 & 688422 & 8.3468 & 5.3148 & TRN & \\
\hline CHEMBL1551465 & 688422 & 5.0 & 5.1652 & TRN & \\
\hline CHEMBL1338437 & 688422 & 4.75 & 5.2823 & TRN & \\
\hline CHEMBL1455877 & 688422 & 5.25 & 5.0427 & TRN & \\
\hline CHEMBL1524792 & 688422 & 4.5 & 4.9911 & TRN & \\
\hline CHEMBL1344911 & 688422 & 4.95 & 5.0125 & TRN & \\
\hline CHEMBL1578580 & 688422 & 4.45 & 5.534 & TRN & \\
\hline CHEMBL1538896 & 688422 & 5.05 & 5.3648 & TRN & \\
\hline CHEMBL1352272 & 688422 & 4.75 & 5.3404 & TRN & \\
\hline CHEMBL3189321 & 688422 & 4.45 & 5.0142 & TRN & \\
\hline CHEMBL1334212 & 688422 & 7.3497 & 5.3084 & TRN & \\
\hline CHEMBL1479964 & 688422 & 7.6498 & 5.3734 & TST & \\
\hline CHEMBL1349542 & 688422 & 4.75 & 5.2515 & TST & \\
\hline CHEMBL1363498 & 688422 & 5.95 & 4.7206 & TRN & \\
\hline CHEMBL1543167 & 688422 & 4.45 & 4.6995 & TRN & \\
\hline CHEMBL1558648 & 688422 & 4.85 & 5.2061 & TRN & \\
\hline CHEMBL1401211 & 688422 & 4.45 & 5.3544 & TST & \\
\hline CHEMBL1360005 & 688422 & 4.8 & 5.6718 & TRN & \\
\hline CHEMBL1350971 & 688422 & 5.0 & 5.0941 & TST & \\
\hline CHEMBL3209181 & 688422 & 4.85 & 5.6749 & TST & \\
\hline CHEMBL1407425 & 688422 & 5.35 & 6.046 & TST & \\
\hline CHEMBL1592481 & 688422 & 4.95 & 5.4647 & TST & \\
\hline CHEMBL1375592 & 688422 & 6.05 & 5.194 & TRN & \\
\hline CHEMBL1312843 & 688422 & 4.45 & 5.225 & TRN & \\
\hline CHEMBL1411156 & 688422 & 5.7 & 5.2304 & TST & \\
\hline CHEMBL1543760 & 688422 & 4.6 & 4.9881 & TRN & \\
\hline CHEMBL1420229 & 688422 & 4.45 & 4.9886 & TRN & \\
\hline CHEMBL1382239 & 688422 & 4.6 & 5.29700 & 0000000001 & TRN \\
\hline CHEMBL1600757 & 688422 & 6.7501 & 4.9337 & TRN & \\
\hline CHEMBL1432388 & 688422 & 4.9 & 5.401 & TRN & \\
\hline CHEMBL1988657 & 688422 & 4.7 & 4.8616 & TRN & \\
\hline CHEMBL1486923 & 688422 & 4.45 & 5.4156 & TST & \\
\hline CHEMBL1505118 & 688422 & 4.95 & 5.2155 & TST & \\
\hline CHEMBL1401099 & 688422 & 4.45 & 5.083 & TRN & \\
\hline CHEMBL1362059 & 688422 & 5.65 & 4.992 & TRN & \\
\hline CHEMBL1548428 & 688422 & 5.35 & 5.2556 & TRN & \\
\hline CHEMBL1447262 & 688422 & 4.65 & 4.9558 & TRN & \\
\hline CHEMBL1397344 & 688422 & 7.2503 & 6.1862 & TRN & \\
\hline CHEMBL1303491 & 688422 & 4.65 & 5.039 & TRN & \\
\hline CHEMBL1559928 & 688422 & 4.85 & 4.6972 & TRN & \\
\hline CHEMBL1581420 & 688422 & 4.8 & 4.7052 & TRN & \\
\hline CHEMBL1471728 & 688422 & 4.55 & 5.2553 & TRN & \\
\hline CHEMBL1405153 & 688422 & 4.8 & 4.9765 & TRN & \\
\hline CHEMBL1489054 & 688422 & 5.9 & 5.5837 & TRN & \\
\hline CHEMBL1483004 & 688422 & 4.85 & 5.2024 & TRN & \\
\hline
\end{tabular}




\begin{tabular}{|c|c|c|c|c|c|}
\hline \multicolumn{6}{|c|}{ Supplemental Table s2.txt } \\
\hline CHEMBL1492744 & 688422 & 4.45 & 5.5333 & TRN & \\
\hline CHEMBL1333378 & 688422 & 6.05 & 5.6828 & TRN & \\
\hline CHEMBL1484314 & 688422 & 4.9 & 5.3622 & TST & \\
\hline CHEMBL1461750 & 688422 & 4.8 & 4.7942 & TRN & \\
\hline CHEMBL1418466 & 688422 & 6.3 & 5.2368 & TST & \\
\hline CHEMBL1510797 & 688422 & 5.35 & 4.9606 & TRN & \\
\hline CHEMBL1354182 & 688422 & 4.9 & 5.3221 & TRN & \\
\hline CHEMBL3197475 & 688422 & 4.65 & 5.0453 & TRN & \\
\hline CHEMBL1553249 & 688422 & 9.5229 & 5.5381 & TST & \\
\hline CHEMBL1540698 & 688422 & 4.85 & 5.1895 & TRN & \\
\hline CHEMBL1561085 & 688422 & 6.25 & 5.1343 & TRN & \\
\hline CHEMBL1405704 & 688422 & 4.95 & 5.0112 & TRN & \\
\hline CHEMBL1374997 & 688422 & 7.3497 & 5.3522 & TRN & \\
\hline CHEMBL3199237 & 688422 & 4.95 & 5.1461 & TRN & \\
\hline CHEMBL1606705 & 688422 & 4.45 & 5.0234 & TRN & \\
\hline CHEMBL1350459 & 688422 & 8.3468 & 5.5642 & TST & \\
\hline CHEMBL1419940 & 688422 & 4.6 & 5.285 & TRN & \\
\hline CHEMBL3196140 & 688422 & 6.1 & 5.0105 & TRN & \\
\hline CHEMBL1534003 & 688422 & 8.4949 & 5.3867 & TRN & \\
\hline CHEMBL1319583 & 688422 & 5.7 & 5.5244 & TRN & \\
\hline CHEMBL1331684 & 688422 & 7.5498 & 5.3166 & TRN & \\
\hline CHEMBL1408020 & 688422 & 4.45 & 5.4003 & TRN & \\
\hline CHEMBL1388611 & 688422 & 6.35 & 5.3346 & TRN & \\
\hline CHEMBL1520078 & 688422 & 4.8 & 4.8826 & TRN & \\
\hline CHEMBL1356106 & 688422 & 5.55 & 5.6672 & TRN & \\
\hline CHEMBL1325917 & 688422 & 7.699 & 5.6219 & TRN & \\
\hline CHEMBL1542599 & 688422 & 5.85 & 4.9457 & TST & \\
\hline CHEMBL1579321 & 688422 & 4.95 & 5.4591 & TRN & \\
\hline CHEMBL1310793 & 688422 & 5.0 & 5.3902 & TRN & \\
\hline CHEMBL1552080 & 688422 & 6.0 & 5.2426 & TRN & \\
\hline CHEMBL3193818 & 688422 & 4.9 & 5.03100 & 0000000001 & TST \\
\hline CHEMBL1327470 & 688422 & 4.85 & 5.4208 & TRN & \\
\hline CHEMBL1358175 & 688422 & 6.35 & 5.2478 & TRN & \\
\hline CHEMBL1492859 & 688422 & 4.9 & 5.1028 & TRN & \\
\hline CHEMBL1421066 & 688422 & 5.2 & 5.6904 & TRN & \\
\hline CHEMBL1320386 & 688422 & 5.1 & 5.2729 & TRN & \\
\hline CHEMBL1507975 & 688422 & 4.95 & 4.8447 & TRN & \\
\hline CHEMBL1392564 & 688422 & 4.6 & 5.0975 & TST & \\
\hline CHEMBL1407698 & 688422 & 4.85 & 5.0835 & TRN & \\
\hline CHEMBL1554745 & 688422 & 4.95 & 4.9486 & TRN & \\
\hline CHEMBL1490682 & 688422 & 4.45 & 5.4141 & TRN & \\
\hline CHEMBL1328363 & 688422 & 4.45 & 5.1979 & TRN & \\
\hline CHEMBL1542543 & 688422 & 5.25 & 5.6487 & TRN & \\
\hline CHEMBL1382714 & 688422 & 4.45 & 5.3706 & TRN & \\
\hline CHEMBL3192862 & 688422 & 4.45 & 4.7918 & TRN & \\
\hline CHEMBL1497150 & 688422 & 5.0 & 5.5198 & TRN & \\
\hline CHEMBL1338475 & 688422 & 4.45 & 5.3558 & TRN & \\
\hline CHEMBL1404576 & 688422 & 4.45 & 5.4641 & TST & \\
\hline
\end{tabular}




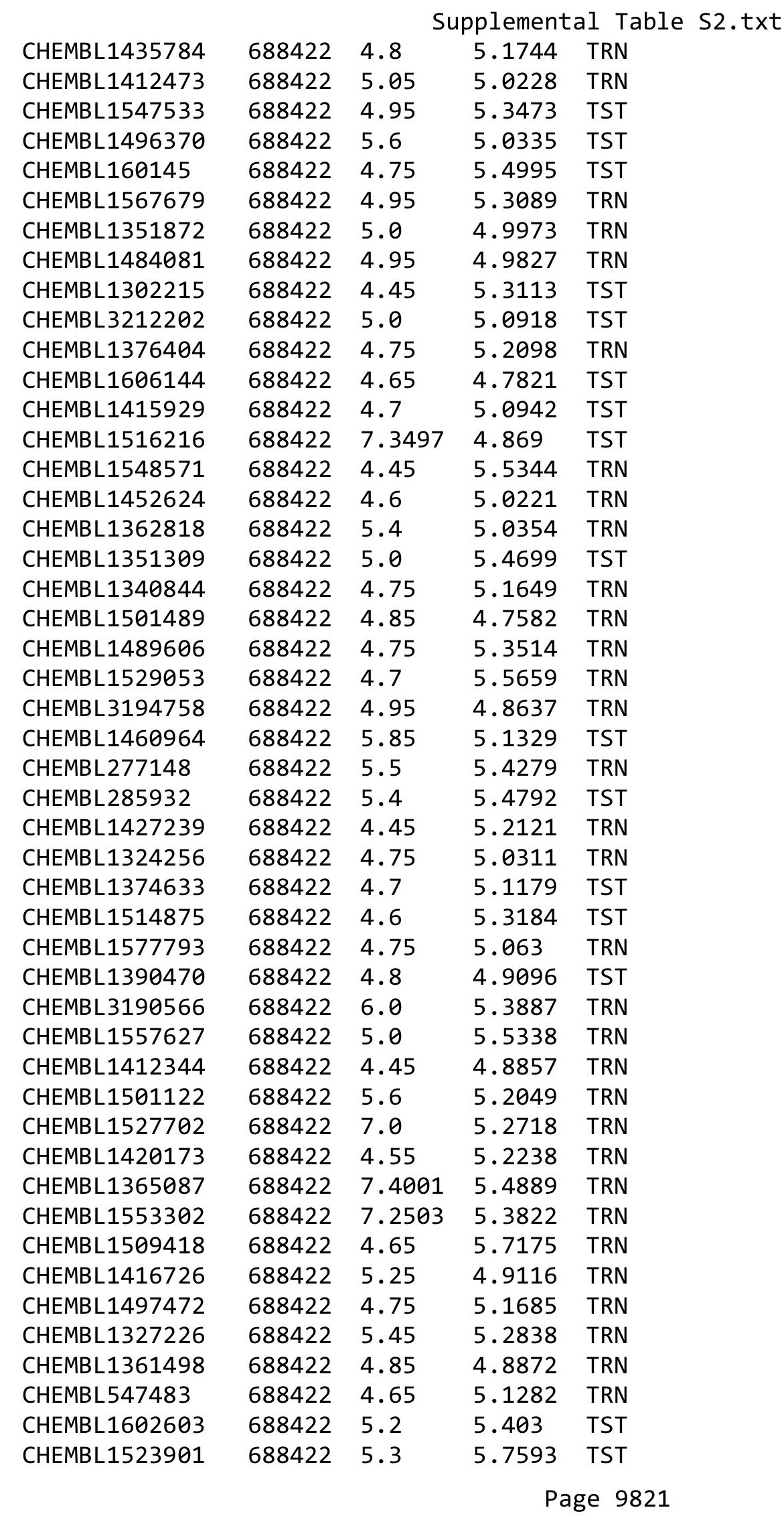




\begin{tabular}{|c|c|c|c|c|}
\hline \multicolumn{5}{|c|}{ Supplemental Table S2.txt } \\
\hline CHEMBL1550642 & 688422 & 4.45 & 5.4224 & TST \\
\hline CHEMBL1569513 & 688422 & 5.0 & 5.4469 & TRN \\
\hline CHEMBL1578621 & 688422 & 4.55 & 5.1714 & TRN \\
\hline CHEMBL1608840 & 688422 & 5.8 & 5.3902 & TRN \\
\hline CHEMBL1082515 & 688422 & 7.0501 & 5.7038 & TST \\
\hline CHEMBL1345090 & 688422 & 4.5 & 5.149 & TRN \\
\hline CHEMBL1399349 & 688422 & 5.25 & 5.6102 & TST \\
\hline CHEMBL1399436 & 688422 & 4.95 & 5.5724 & TST \\
\hline CHEMBL1364639 & 688422 & 4.45 & 5.1039 & TST \\
\hline CHEMBL1567315 & 688422 & 4.9 & 5.2689 & TRN \\
\hline CHEMBL1342745 & 688422 & 4.65 & 4.7314 & TRN \\
\hline CHEMBL1416928 & 688422 & 4.45 & 5.2108 & TST \\
\hline CHEMBL1505452 & 688422 & 4.45 & 4.8972 & TRN \\
\hline CHEMBL1380760 & 688422 & 4.8 & 4.9772 & TST \\
\hline CHEMBL3199302 & 688422 & 4.45 & 5.0266 & TRN \\
\hline CHEMBL1470898 & 688422 & 4.6 & 5.8904 & TRN \\
\hline CHEMBL18701 & 688422 & 4.65 & 5.2943 & TST \\
\hline CHEMBL1490495 & 688422 & 9.0458 & 6.1262 & TRN \\
\hline CHEMBL1400275 & 688422 & 4.65 & 5.1696 & TST \\
\hline CHEMBL1319067 & 688422 & 5.2 & 5.1849 & TST \\
\hline CHEMBL1431048 & 688422 & 6.8499 & 5.6964 & TRN \\
\hline CHEMBL1326861 & 688422 & 4.45 & 5.1852 & TRN \\
\hline CHEMBL1448378 & 688422 & 4.5 & 4.9199 & TRN \\
\hline CHEMBL1591370 & 688422 & 7.8508 & 5.6596 & TRN \\
\hline CHEMBL1345961 & 688422 & 5.0 & 5.3791 & TRN \\
\hline CHEMBL1479683 & 688422 & 4.45 & 4.8594 & TST \\
\hline CHEMBL3193168 & 688422 & 4.45 & 4.8755 & TRN \\
\hline CHEMBL1484284 & 688422 & 7.3497 & 5.3319 & TST \\
\hline CHEMBL1391071 & 688422 & 4.6 & 5.0975 & TRN \\
\hline CHEMBL1388436 & 688422 & 4.65 & 5.1335 & TRN \\
\hline CHEMBL1371239 & 688422 & 4.95 & 4.9014 & TRN \\
\hline CHEMBL1311158 & 688422 & 4.9 & 4.902 & TRN \\
\hline CHEMBL1477767 & 688422 & 8.4949 & 5.5806 & TRN \\
\hline CHEMBL1360715 & 688422 & 4.8 & 5.0099 & TRN \\
\hline CHEMBL1384704 & 688422 & 6.95 & 5.3236 & TRN \\
\hline CHEMBL1414849 & 688422 & 4.85 & 5.5075 & TST \\
\hline CHEMBL1316226 & 688422 & 4.65 & 5.5984 & TRN \\
\hline CHEMBL1347084 & 688422 & 4.45 & 5.1507 & TRN \\
\hline CHEMBL1982450 & 688422 & 4.9 & 5.2288 & TRN \\
\hline CHEMBL1402494 & 688422 & 5.55 & 5.1512 & TRN \\
\hline CHEMBL1427423 & 688422 & 4.45 & 5.2172 & TST \\
\hline CHEMBL 1444488 & 688422 & 4.65 & 5.2038 & TST \\
\hline CHEMBL1420871 & 688422 & 4.45 & 5.0415 & TRN \\
\hline CHEMBL1500804 & 688422 & 4.85 & 4.9231 & TRN \\
\hline CHEMBL1422678 & 688422 & 6.0 & 5.4613 & TST \\
\hline CHEMBL1371774 & 688422 & 5.3 & 5.0561 & TRN \\
\hline CHEMBL1584620 & 688422 & 4.95 & 5.0228 & TRN \\
\hline CHEMBL1539183 & 688422 & 8.3468 & 5.4676 & TRN \\
\hline
\end{tabular}




\begin{tabular}{|c|c|c|c|c|c|}
\hline \multicolumn{6}{|c|}{ Supplemental Table S2.txt } \\
\hline CHEMBL1558201 & 688422 & 4.65 & 4.961 & TST & \\
\hline CHEMBL1371004 & 688422 & 4.5 & 4.8928 & TST & \\
\hline CHEMBL1351064 & 688422 & 8.301 & 5.6399 & TST & \\
\hline CHEMBL1499782 & 688422 & 6.15 & 5.0337 & TRN & \\
\hline CHEMBL1449393 & 688422 & 4.5 & 5.2213 & TRN & \\
\hline CHEMBL1439534 & 688422 & 7.3002 & 5.2603 & TRN & \\
\hline CHEMBL1399167 & 688422 & 5.9 & 5.45200 & 0000000001 & TRN \\
\hline CHEMBL1349049 & 688422 & 7.3002 & 5.92 & TST & \\
\hline CHEMBL1413105 & 688422 & 5.45 & 5.1859 & TRN & \\
\hline CHEMBL1426831 & 688422 & 5.15 & 5.5134 & TRN & \\
\hline CHEMBL1344847 & 688422 & 4.85 & 5.2796 & TST & \\
\hline CHEMBL1336297 & 688422 & 6.5 & 5.5122 & TRN & \\
\hline CHEMBL1539148 & 688422 & 4.8 & 5.2754 & TRN & \\
\hline CHEMBL1590879 & 688422 & 4.45 & 5.2929 & TRN & \\
\hline CHEMBL1471303 & 688422 & 4.9 & 5.0544 & TRN & \\
\hline CHEMBL1336997 & 688422 & 4.5 & 5.2115 & TST & \\
\hline CHEMBL1510937 & 688422 & 4.95 & 5.3197 & TST & \\
\hline CHEMBL1553983 & 688422 & 6.1 & 5.716 & TRN & \\
\hline CHEMBL3199262 & 688422 & 4.45 & 5.1107 & TST & \\
\hline CHEMBL1527588 & 688422 & 5.0 & 5.6455 & TST & \\
\hline CHEMBL1496724 & 688422 & 4.8 & 5.296 & TRN & \\
\hline CHEMBL1363313 & 688422 & 4.9 & 4.516 & TRN & \\
\hline CHEMBL1407413 & 688422 & 4.9 & 5.0478 & TST & \\
\hline CHEMBL1391796 & 688422 & 5.85 & 5.5804 & TST & \\
\hline CHEMBL1544282 & 688422 & 4.45 & 5.0528 & TRN & \\
\hline CHEMBL1507423 & 688422 & 4.45 & 4.8602 & TRN & \\
\hline CHEMBL1321578 & 688422 & 5.55 & 5.2664 & TRN & \\
\hline CHEMBL1530499 & 688422 & 6.7501 & 4.9032 & TRN & \\
\hline CHEMBL1572247 & 688422 & 4.45 & 5.5767 & TRN & \\
\hline CHEMBL1536653 & 688422 & 4.7 & 5.2901 & TRN & \\
\hline CHEMBL1492186 & 688422 & 5.05 & 4.9216 & TRN & \\
\hline CHEMBL1558535 & 688422 & 5.55 & 5.3451 & TRN & \\
\hline CHEMBL1445566 & 688422 & 4.65 & 5.2273 & TRN & \\
\hline CHEMBL1312009 & 688422 & 4.45 & 5.4895 & TRN & \\
\hline CHEMBL1343689 & 688422 & 4.95 & 5.6984 & TRN & \\
\hline CHEMBL1358455 & 688422 & 8.301 & 5.9035 & TRN & \\
\hline CHEMBL1318915 & 688422 & 4.95 & 5.1284 & TRN & \\
\hline CHEMBL1256283 & 688422 & 5.8 & 6.4858 & TST & \\
\hline CHEMBL1384119 & 688422 & 4.75 & 5.182 & TRN & \\
\hline CHEMBL1411305 & 688422 & 5.45 & 5.3391 & TRN & \\
\hline CHEMBL 2002634 & 688422 & 5.05 & 5.391 & TST & \\
\hline CHEMBL1414261 & 688422 & 4.5 & 4.9439 & TRN & \\
\hline CHEMBL1536304 & 688422 & 4.8 & 5.2003 & TST & \\
\hline CHEMBL1362916 & 688422 & 4.9 & 5.1204 & TRN & \\
\hline CHEMBL1508910 & 688422 & 4.45 & 5.4451 & TST & \\
\hline CHEMBL1338833 & 688422 & 4.45 & 5.2895 & TST & \\
\hline CHEMBL1595446 & 688422 & 4.9 & 4.7814 & TRN & \\
\hline CHEMBL1241452 & 688422 & 4.9 & 5.4106 & TRN & \\
\hline
\end{tabular}




\begin{tabular}{|c|c|c|c|c|c|}
\hline \multirow{3}{*}{$\begin{array}{l}\text { CHEMBL1576374 } \\
\text { CHEMBL1483219 }\end{array}$} & \multirow{3}{*}{$\begin{array}{l}688422 \\
688422\end{array}$} & \multicolumn{4}{|c|}{ Supplemental Table S2.txt } \\
\hline & & 4.5 & \multicolumn{2}{|c|}{5.202999999999999} & TST \\
\hline & & 4.8 & 5.2112 & TRN & \\
\hline CHEMBL1473141 & 688422 & 5.45 & 5.5906 & TRN & \\
\hline CHEMBL1457420 & 688422 & 5.1 & 5.2639 & TRN & \\
\hline CHEMBL1521215 & 688422 & 4.85 & 4.9749 & TRN & \\
\hline CHEMBL1371925 & 688422 & 4.45 & 4.7741 & TRN & \\
\hline CHEMBL1451106 & 688422 & 6.6 & 5.1968 & TRN & \\
\hline CHEMBL1477113 & 688422 & 5.0 & 5.3701 & TRN & \\
\hline CHEMBL1462555 & 688422 & 4.45 & 5.7146 & TRN & \\
\hline CHEMBL1422042 & 688422 & 4.9 & 5.2652 & TRN & \\
\hline CHEMBL3189348 & 688422 & 4.95 & 5.5324 & TRN & \\
\hline CHEMBL1301846 & 688422 & 5.85 & 5.193 & TRN & \\
\hline CHEMBL1509605 & 688422 & 4.65 & 5.15 & TRN & \\
\hline CHEMBL1509174 & 688422 & 4.75 & 5.2023 & TRN & \\
\hline CHEMBL 3145107 & 688422 & 4.5 & 5.3058 & TRN & \\
\hline CHEMBL1968859 & 688422 & 5.5 & 5.4997 & TRN & \\
\hline CHEMBL1577933 & 688422 & 5.05 & 4.9856 & TRN & \\
\hline CHEMBL1498955 & 688422 & 4.6 & 4.7093 & TRN & \\
\hline CHEMBL1613163 & 688422 & 4.8 & 5.1828 & TST & \\
\hline CHEMBL1331889 & 688422 & 6.0 & 5.6116 & TST & \\
\hline CHEMBL 3214378 & 688422 & 4.7 & 5.2377 & TST & \\
\hline CHEMBL1373110 & 688422 & 4.45 & 5.4449 & TRN & \\
\hline CHEMBL1480326 & 688422 & 5.05 & 5.2896 & TRN & \\
\hline CHEMBL1429800 & 688422 & 4.95 & 5.5821 & TRN & \\
\hline CHEMBL1592126 & 688422 & 5.85 & 5.5904 & TST & \\
\hline CHEMBL1445993 & 688422 & 7.5498 & 5.6596 & TST & \\
\hline CHEMBL1564705 & 688422 & 6.35 & 5.0931 & TST & \\
\hline CHEMBL1468530 & 688422 & 6.1 & 5.6807 & TRN & \\
\hline CHEMBL1307310 & 688422 & 5.5 & 5.6187 & TRN & \\
\hline CHEMBL1535539 & 688422 & 7.5003 & 5.0373 & TST & \\
\hline CHEMBL3196514 & 688422 & 4.85 & 5.4867 & TST & \\
\hline CHEMBL1428877 & 688422 & 5.0 & 4.7308 & TRN & \\
\hline CHEMBL1568007 & 688422 & 4.7 & 5.2131 & TRN & \\
\hline CHEMBL1394101 & 688422 & 8.1024 & 5.4233 & TRN & \\
\hline CHEMBL1567374 & 688422 & 4.6 & 5.3128 & TST & \\
\hline CHEMBL2140526 & 688422 & 4.65 & 5.1504 & TST & \\
\hline CHEMBL1561655 & 688422 & 4.5 & 5.2583 & TRN & \\
\hline CHEMBL1303545 & 688422 & 4.5 & 4.7088 & TRN & \\
\hline CHEMBL1579347 & 688422 & 4.75 & 5.6958 & TRN & \\
\hline CHEMBL1457930 & 688422 & 5.4 & 5.8519 & TRN & \\
\hline CHEMBL1431655 & 688422 & 8.0 & 4.9319 & TST & \\
\hline CHEMBL1497732 & 688422 & 4.65 & 4.9779 & TST & \\
\hline CHEMBL1506080 & 688422 & 5.15 & 5.069 & TRN & \\
\hline CHEMBL1522922 & 688422 & 4.85 & 4.9485 & TRN & \\
\hline CHEMBL1565245 & 688422 & 4.95 & 5.0989 & TRN & \\
\hline CHEMBL1373974 & 688422 & 4.75 & 4.80699 & 99999999995 & TRN \\
\hline CHEMBL582030 & 688422 & 4.9 & 4.5816 & TRN & \\
\hline CHEMBL1380279 & 688422 & 4.6 & 5.1157 & TRN & \\
\hline
\end{tabular}





\begin{tabular}{|c|c|c|c|c|}
\hline \multicolumn{5}{|c|}{ Supplemental Table S2.txt } \\
\hline CHEMBL1391062 & 688422 & 4.85 & 4.9718 & TRN \\
\hline CHEMBL1465705 & 688422 & 4.45 & 5.3158 & TST \\
\hline CHEMBL1585050 & 688422 & 6.9 & 5.3927 & TRN \\
\hline CHEMBL1547823 & 688422 & 4.45 & 5.4885 & TRN \\
\hline CHEMBL1375489 & 688422 & 4.45 & 5.0397 & TST \\
\hline CHEMBL1314510 & 688422 & 5.0 & 5.2189 & TRN \\
\hline CHEMBL1529940 & 688422 & 4.45 & 5.4494 & TRN \\
\hline CHEMBL 3189465 & 688422 & 5.05 & 4.7972 & TRN \\
\hline CHEMBL1371038 & 688422 & 7.6498 & 5.0824 & TST \\
\hline CHEMBL1408738 & 688422 & 4.75 & 5.2861 & TRN \\
\hline CHEMBL1278035 & 688422 & 4.45 & 4.8433 & TRN \\
\hline CHEMBL1340565 & 688422 & 5.2 & 5.0929 & TRN \\
\hline CHEMBL1417593 & 688422 & 4.45 & 4.9214 & TRN \\
\hline CHEMBL1542886 & 688422 & 5.35 & 5.3142 & TRN \\
\hline CHEMBL1393657 & 688422 & 4.6 & 4.9972 & TRN \\
\hline CHEMBL1304103 & 688422 & 4.95 & 5.5234 & TRN \\
\hline CHEMBL1327283 & 688422 & 4.45 & 4.7579 & TRN \\
\hline CHEMBL1600057 & 688422 & 4.45 & 4.9043 & TRN \\
\hline CHEMBL1612201 & 688422 & 6.1 & 5.4752 & TRN \\
\hline CHEMBL1328388 & 688422 & 4.95 & 5.2377 & TRN \\
\hline CHEMBL1331593 & 688422 & 5.35 & 4.7521 & TRN \\
\hline CHEMBL1496607 & 688422 & 5.7 & 5.1933 & TRN \\
\hline CHEMBL1330075 & 688422 & 4.75 & 5.0598 & TRN \\
\hline CHEMBL1255866 & 688422 & 4.9 & 5.2833 & TST \\
\hline CHEMBL1379814 & 688422 & 5.9 & 5.2115 & TRN \\
\hline CHEMBL1467803 & 688422 & 4.8 & 5.0049 & TRN \\
\hline CHEMBL1571935 & 688422 & 5.2 & 5.4538 & TRN \\
\hline CHEMBL1396459 & 688422 & 5.4 & 5.2716 & TRN \\
\hline CHEMBL1538689 & 688422 & 5.1 & 5.3607 & TRN \\
\hline CHEMBL1355252 & 688422 & 4.45 & 5.6287 & TRN \\
\hline CHEMBL3193460 & 688422 & 4.65 & 5.0683 & TRN \\
\hline CHEMBL1519134 & 688422 & 4.65 & 5.1909 & TRN \\
\hline CHEMBL1527249 & 688422 & 6.05 & 5.1681 & TRN \\
\hline CHEMBL1532629 & 688422 & 6.8 & 5.5461 & TRN \\
\hline CHEMBL1328395 & 688422 & 4.85 & 5.0505 & TRN \\
\hline CHEMBL1526508 & 688422 & 4.95 & 4.7928 & TRN \\
\hline CHEMBL1388666 & 688422 & 4.85 & 5.1622 & TRN \\
\hline CHEMBL1611300 & 688422 & 4.95 & 5.1434 & TRN \\
\hline CHEMBL1547187 & 688422 & 4.65 & 5.2735 & TRN \\
\hline CHEMBL1428236 & 688422 & 4.9 & 5.1601 & TRN \\
\hline CHEMBL1580434 & 688422 & 5.65 & 4.9198 & TRN \\
\hline CHEMBL1475865 & 688422 & 4.7 & 4.9862 & TRN \\
\hline CHEMBL1983104 & 688422 & 4.55 & 4.9055 & TRN \\
\hline CHEMBL1605239 & 688422 & 5.55 & 5.3552 & TRN \\
\hline CHEMBL1574151 & 688422 & 4.65 & 5.3582 & TRN \\
\hline CHEMBL 2007057 & 688422 & 4.9 & 5.2689 & TRN \\
\hline CHEMBL1447975 & 688422 & 4.8 & 5.1195 & TRN \\
\hline CHEMBL1583928 & 688422 & 4.9 & 5.1961 & TRN \\
\hline
\end{tabular}




\begin{tabular}{|c|c|c|c|c|c|}
\hline \multicolumn{6}{|c|}{ Supplemental Table S2.txt } \\
\hline CHEMBL1965786 & 688422 & 4.65 & 5.1547 & TRN & \\
\hline CHEMBL1568751 & 688422 & 4.9 & 4.916 & TST & \\
\hline CHEMBL1341895 & 688422 & 4.45 & 4.8634 & TRN & \\
\hline CHEMBL1310614 & 688422 & 4.6 & 5.1735 & TRN & \\
\hline CHEMBL1544548 & 688422 & 4.8 & 5.3564 & TRN & \\
\hline CHEMBL1336259 & 688422 & 4.5 & 5.4819 & TST & \\
\hline CHEMBL1436586 & 688422 & 6.95 & 5.4084 & TRN & \\
\hline CHEMBL1439424 & 688422 & 4.85 & 5.0556 & TRN & \\
\hline CHEMBL1495098 & 688422 & 4.9 & 5.3921 & TST & \\
\hline CHEMBL530361 & 688422 & 4.95 & 4.7156 & TRN & \\
\hline CHEMBL1479278 & 688422 & 4.45 & 4.775 & TRN & \\
\hline CHEMBL236554 & 688422 & 4.6 & 5.2799 & TRN & \\
\hline CHEMBL1389542 & 688422 & 4.75 & 5.1003 & TRN & \\
\hline CHEMBL1383856 & 688422 & 4.5 & 5.0435 & TRN & \\
\hline CHEMBL1609161 & 688422 & 8.3468 & 6.3134 & TRN & \\
\hline CHEMBL1480516 & 688422 & 6.0 & 5.67200 & 0000000001 & TST \\
\hline CHEMBL3196672 & 688422 & 4.65 & 5.0851 & TST & \\
\hline CHEMBL1377650 & 688422 & 4.45 & 5.3669 & TRN & \\
\hline CHEMBL1456473 & 688422 & 4.95 & 5.3866 & TRN & \\
\hline CHEMBL1407799 & 688422 & 4.7 & 5.1145 & TRN & \\
\hline CHEMBL 2095095 & 688422 & 5.3 & 5.0932 & TRN & \\
\hline CHEMBL1442384 & 688422 & 6.05 & 5.4526 & TRN & \\
\hline CHEMBL1520845 & 688422 & 5.0 & 5.4236 & TST & \\
\hline CHEMBL1582675 & 688422 & 4.7 & 4.8255 & TRN & \\
\hline CHEMBL1377784 & 688422 & 4.45 & 5.2589 & TRN & \\
\hline CHEMBL1609437 & 688422 & 4.9 & 4.613 & TRN & \\
\hline CHEMBL1337126 & 688422 & 7.2 & 5.9936 & TRN & \\
\hline CHEMBL1414575 & 688422 & 4.9 & 5.0485 & TST & \\
\hline CHEMBL1991516 & 688422 & 5.1 & 5.1241 & TST & \\
\hline CHEMBL1440703 & 688422 & 5.05 & 5.7584 & TST & \\
\hline CHEMBL1475272 & 688422 & 4.95 & 5.4682 & TRN & \\
\hline CHEMBL1597352 & 688422 & 4.75 & 5.2496 & TRN & \\
\hline CHEMBL1371864 & 688422 & 4.9 & 4.8245 & TRN & \\
\hline CHEMBL41680 & 688422 & 6.0 & 5.9593 & TST & \\
\hline CHEMBL1333754 & 688422 & 7.0501 & 5.6763 & TRN & \\
\hline CHEMBL1381020 & 688422 & 4.45 & 5.0721 & TRN & \\
\hline CHEMBL1376822 & 688422 & 4.5 & 5.6566 & TST & \\
\hline CHEMBL3213273 & 688422 & 5.45 & 5.7261 & TST & \\
\hline CHEMBL1586545 & 688422 & 5.25 & 5.4535 & TRN & \\
\hline CHEMBL1407659 & 688422 & 5.45 & 5.2296 & TRN & \\
\hline CHEMBL1575353 & 688422 & 6.0 & 5.5088 & TST & \\
\hline CHEMBL1357162 & 688422 & 6.8 & 5.6328 & TRN & \\
\hline CHEMBL1502348 & 688422 & 4.9 & 4.5627 & TST & \\
\hline CHEMBL1334310 & 688422 & 4.6 & 4.7984 & TRN & \\
\hline CHEMBL576809 & 688422 & 5.15 & 5.3142 & TRN & \\
\hline CHEMBL1335042 & 688422 & 5.3 & 5.3185 & TRN & \\
\hline CHEMBL1626274 & 688422 & 5.2 & 5.4601 & TST & \\
\hline CHEMBL1427010 & 688422 & 4.75 & 5.2873 & TRN & \\
\hline
\end{tabular}




\begin{tabular}{|c|c|c|c|c|c|}
\hline \multirow[b]{2}{*}{ CHEMBL1355139 } & \multicolumn{5}{|c|}{ Supplemental Table S2.txt } \\
\hline & 688422 & 4.45 & 4.7379 & TRN & \\
\hline CHEMBL1441988 & 688422 & 7.3497 & 5.2652 & TRN & \\
\hline CHEMBL1441178 & 688422 & 5.45 & 5.0164 & TST & \\
\hline CHEMBL1387563 & 688422 & 4.85 & 5.2046 & TRN & \\
\hline CHEMBL1428932 & 688422 & 4.9 & 5.2511 & TRN & \\
\hline CHEMBL1612783 & 688422 & 5.85 & 5.0564 & TRN & \\
\hline CHEMBL1341120 & 688422 & 4.45 & 4.9399 & TRN & \\
\hline CHEMBL1519056 & 688422 & 4.9 & 4.9956 & TRN & \\
\hline CHEMBL 1383758 & 688422 & 4.7 & 4.5298 & TRN & \\
\hline CHEMBL1356060 & 688422 & 6.05 & 5.0074 & TRN & \\
\hline CHEMBL1575914 & 688422 & 4.55 & 5.0622 & TRN & \\
\hline CHEMBL1556254 & 688422 & 4.45 & 5.2846 & TRN & \\
\hline CHEMBL3391713 & 688422 & 4.9 & 5.2916 & TRN & \\
\hline CHEMBL1544945 & 688422 & 5.4 & 4.9652 & TST & \\
\hline CHEMBL1516028 & 688422 & 4.8 & 5.0991 & TRN & \\
\hline CHEMBL1366153 & 688422 & 4.75 & 4.9215 & TRN & \\
\hline CHEMBL1447416 & 688422 & 5.55 & 5.438 & TRN & \\
\hline CHEMBL1569732 & 688422 & 4.85 & 5.0451 & TST & \\
\hline CHEMBL1317925 & 688422 & 4.9 & 5.7859 & TRN & \\
\hline CHEMBL1478 & 688422 & 5.85 & 5.99299 & 9999999999 & TRN \\
\hline CHEMBL3208167 & 688422 & 4.45 & 5.4926 & TST & \\
\hline CHEMBL1526421 & 688422 & 4.75 & 4.9126 & TRN & \\
\hline CHEMBL582081 & 688422 & 4.9 & 5.1682 & TST & \\
\hline CHEMBL1402962 & 688422 & 4.7 & 5.0418 & TRN & \\
\hline CHEMBL1481956 & 688422 & 4.45 & 5.2334 & TRN & \\
\hline CHEMBL1467237 & 688422 & 8.4949 & 5.6294 & TST & \\
\hline CHEMBL1384912 & 688422 & 6.35 & 5.8183 & TRN & \\
\hline CHEMBL1450176 & 688422 & 5.55 & 5.2057 & TRN & \\
\hline CHEMBL1316947 & 688422 & 6.9 & 5.2541 & TRN & \\
\hline CHEMBL1467724 & 688422 & 4.65 & 5.13700 & 30000000005 & TRN \\
\hline CHEMBL1586139 & 688422 & 4.65 & 5.2487 & TRN & \\
\hline CHEMBL1382105 & 688422 & 5.4 & 5.5339 & TRN & \\
\hline CHEMBL1354563 & 688422 & 4.75 & 4.7982 & TRN & \\
\hline CHEMBL1506711 & 688422 & 6.8499 & 5.3556 & TRN & \\
\hline CHEMBL1559113 & 688422 & 4.95 & 5.6385 & TST & \\
\hline CHEMBL1607948 & 688422 & 4.45 & 4.7445 & TRN & \\
\hline CHEMBL1418338 & 688422 & 8.4949 & 5.3748 & TST & \\
\hline CHEMBL1428899 & 688422 & 8.3979 & 5.8453 & TRN & \\
\hline CHEMBL3193435 & 688422 & 4.55 & 5.2632 & TRN & \\
\hline CHEMBL1363753 & 688422 & 5.5 & 4.7952 & TRN & \\
\hline CHEMBL1516530 & 688422 & 5.0 & 4.9553 & TRN & \\
\hline CHEMBL1383072 & 688422 & 4.85 & 5.6404 & TST & \\
\hline CHEMBL1510511 & 688422 & 5.3 & 5.7052 & TRN & \\
\hline CHEMBL1974269 & 688422 & 5.5 & 4.9142 & TRN & \\
\hline CHEMBL1462375 & 688422 & 5.0 & 4.855 & TRN & \\
\hline CHEMBL1303810 & 688422 & 4.45 & 5.2941 & TRN & \\
\hline CHEMBL1598910 & 688422 & 4.85 & 5.5492 & TRN & \\
\hline CHEMBL1598230 & 688422 & 5.85 & 5.1721 & TRN & \\
\hline
\end{tabular}




\begin{tabular}{|c|c|c|c|c|c|}
\hline \multicolumn{6}{|c|}{ Supplemental Table S2.txt } \\
\hline CHEMBL1541975 & 688422 & 5.3 & 4.8607 & TRN & \\
\hline CHEMBL1590438 & 688422 & 5.55 & 5.6 & TRN & \\
\hline CHEMBL1477996 & 688422 & 4.45 & 5.5547 & TRN & \\
\hline CHEMBL1490276 & 688422 & 5.15 & 5.3357 & TST & \\
\hline CHEMBL223453 & 688422 & 5.4 & 4.7034 & TRN & \\
\hline CHEMBL1517435 & 688422 & 7.6498 & 5.3657 & TRN & \\
\hline CHEMBL1509718 & 688422 & 4.45 & 5.0153 & TST & \\
\hline CHEMBL1569581 & 688422 & 5.2 & 5.6493 & TRN & \\
\hline CHEMBL1539133 & 688422 & 4.65 & 5.4046 & TRN & \\
\hline CHEMBL1471554 & 688422 & 5.4 & 5.44799 & 99999999995 & TRN \\
\hline CHEMBL1388357 & 688422 & 4.45 & 5.28700 & 0000000001 & TRN \\
\hline CHEMBL1528089 & 688422 & 4.5 & 5.7575 & TST & \\
\hline CHEMBL1460540 & 688422 & 4.65 & 5.5407 & TRN & \\
\hline CHEMBL1324005 & 688422 & 4.8 & 5.409 & TRN & \\
\hline CHEMBL1577621 & 688422 & 5.2 & 5.9862 & TST & \\
\hline CHEMBL1392789 & 688422 & 4.85 & 4.9731 & TRN & \\
\hline CHEMBL1520612 & 688422 & 5.2 & 4.894 & TRN & \\
\hline CHEMBL1471592 & 688422 & 5.9 & 4.9117 & TRN & \\
\hline CHEMBL1520417 & 688422 & 4.8 & 4.8651 & TRN & \\
\hline CHEMBL1403345 & 688422 & 4.7 & 4.9428 & TST & \\
\hline CHEMBL1342652 & 688422 & 4.45 & 4.9188 & TRN & \\
\hline CHEMBL1573365 & 688422 & 4.65 & 5.3298 & TST & \\
\hline CHEMBL1550534 & 688422 & 4.85 & 5.5965 & TRN & \\
\hline CHEMBL1565355 & 688422 & 4.85 & 5.6446 & TRN & \\
\hline CHEMBL1606962 & 688422 & 4.45 & 5.2821 & TRN & \\
\hline CHEMBL1332598 & 688422 & 4.45 & 5.2711 & TRN & \\
\hline CHEMBL341886 & 688422 & 4.95 & 5.2912 & TRN & \\
\hline CHEMBL1326629 & 688422 & 4.45 & 4.9271 & TRN & \\
\hline CHEMBL1304751 & 688422 & 8.6576 & 5.3911 & TRN & \\
\hline CHEMBL1573752 & 688422 & 4.45 & 5.2964 & TRN & \\
\hline CHEMBL1535946 & 688422 & 5.4 & 4.5875 & TRN & \\
\hline CHEMBL1399521 & 688422 & 5.4 & 5.2504 & TRN & \\
\hline CHEMBL1524990 & 688422 & 5.0 & 5.2953 & TRN & \\
\hline CHEMBL1502932 & 688422 & 5.25 & 4.6158 & TRN & \\
\hline CHEMBL3199064 & 688422 & 4.65 & 4.6248 & TRN & \\
\hline CHEMBL1345216 & 688422 & 4.45 & 5.1559 & TRN & \\
\hline CHEMBL1598091 & 688422 & 4.45 & 4.6958 & TRN & \\
\hline CHEMBL1509365 & 688422 & 5.45 & 5.1382 & TRN & \\
\hline CHEMBL1556449 & 688422 & 5.7 & 5.152 & TRN & \\
\hline CHEMBL1458850 & 688422 & 5.15 & 5.6041 & TST & \\
\hline CHEMBL1465235 & 688422 & 6.95 & 5.2091 & TST & \\
\hline CHEMBL1510131 & 688422 & 4.55 & 5.9378 & TST & \\
\hline CHEMBL1400753 & 688422 & 4.45 & 6.1607 & TST & \\
\hline CHEMBL1342916 & 688422 & 4.5 & 4.9501 & TRN & \\
\hline CHEMBL1566523 & 688422 & 5.0 & 5.4943 & TST & \\
\hline CHEMBL1370083 & 688422 & 4.8 & 4.8034 & TRN & \\
\hline CHEMBL3189634 & 688422 & 4.9 & 5.1501 & TRN & \\
\hline CHEMBL1441883 & 688422 & 4.95 & 5.3157 & TRN & \\
\hline
\end{tabular}




\begin{tabular}{|c|c|c|c|c|c|}
\hline \multicolumn{6}{|c|}{ Supplemental Table s2.txt } \\
\hline CHEMBL1520341 & 688422 & 4.45 & 4.6314 & TRN & \\
\hline CHEMBL1314204 & 688422 & 5.25 & 5.1776 & TRN & \\
\hline CHEMBL3193338 & 688422 & 4.45 & 4.8902 & TRN & \\
\hline CHEMBL1994709 & 688422 & 4.7 & 4.9725 & TRN & \\
\hline CHEMBL1488036 & 688422 & 4.85 & 4.9501 & TRN & \\
\hline CHEMBL1379828 & 688422 & 5.0 & 5.1219 & TRN & \\
\hline CHEMBL 3213748 & 688422 & 4.9 & 5.3469 & TRN & \\
\hline CHEMBL1342486 & 688422 & 4.85 & 4.9154 & TRN & \\
\hline CHEMBL1447810 & 688422 & 5.85 & 5.4375 & TRN & \\
\hline CHEMBL1466247 & 688422 & 6.25 & 5.3078 & TRN & \\
\hline CHEMBL1587075 & 688422 & 6.45 & 5.1646 & TST & \\
\hline CHEMBL1327684 & 688422 & 5.85 & 5.3927 & TST & \\
\hline CHEMBL1365081 & 688422 & 4.75 & 5.0923 & TRN & \\
\hline CHEMBL1312232 & 688422 & 4.45 & 4.845 & TRN & \\
\hline CHEMBL1364803 & 688422 & 4.45 & 4.7831 & TRN & \\
\hline CHEMBL1325951 & 688422 & 4.55 & 5.5657 & TRN & \\
\hline CHEMBL1427161 & 688422 & 6.4 & 5.47 & TRN & \\
\hline CHEMBL1565280 & 688422 & 4.45 & 5.0676 & TST & \\
\hline CHEMBL1417663 & 688422 & 7.0 & 5.1472 & TRN & \\
\hline CHEMBL3191648 & 688422 & 4.5 & 5.2183 & TRN & \\
\hline CHEMBL1581843 & 688422 & 5.0 & 5.1386 & TRN & \\
\hline CHEMBL1420114 & 688422 & 4.75 & 4.9193 & TRN & \\
\hline CHEMBL1566289 & 688422 & 5.1 & 5.6188 & TST & \\
\hline CHEMBL1565508 & 688422 & 4.7 & 4.982 & TRN & \\
\hline CHEMBL1319026 & 688422 & 4.45 & 5.193 & TRN & \\
\hline CHEMBL1450885 & 688422 & 4.55 & 5.0537 & TRN & \\
\hline CHEMBL1530136 & 688422 & 4.5 & 5.4371 & TRN & \\
\hline CHEMBL1509666 & 688422 & 4.6 & 5.2203 & TST & \\
\hline CHEMBL1454102 & 688422 & 4.45 & 4.9163 & TRN & \\
\hline CHEMBL1421500 & 688422 & 5.1 & 5.1545 & TRN & \\
\hline CHEMBL1529707 & 688422 & 7.2503 & 5.6947 & TRN & \\
\hline CHEMBL1576067 & 688422 & 4.55 & 5.0063 & TRN & \\
\hline CHEMBL1492400 & 688422 & 5.45 & 5.32600 & 00000000005 & TRN \\
\hline CHEMBL1414557 & 688422 & 4.7 & 5.1296 & TRN & \\
\hline CHEMBL1397078 & 688422 & 4.75 & 5.2386 & TRN & \\
\hline CHEMBL1384613 & 688422 & 6.15 & 5.6447 & TRN & \\
\hline CHEMBL1460914 & 688422 & 4.45 & 5.1111 & TRN & \\
\hline CHEMBL1319337 & 688422 & 6.3 & 5.5295 & TRN & \\
\hline CHEMBL1314222 & 688422 & 4.7 & 4.7 & TRN & \\
\hline CHEMBL1506814 & 688422 & 4.65 & 4.9312 & TST & \\
\hline CHEMBL1447457 & 688422 & 4.85 & 5.0686 & TST & \\
\hline CHEMBL1403097 & 688422 & 5.15 & 5.2421 & TRN & \\
\hline CHEMBL1326950 & 688422 & 5.05 & 4.9749 & TST & \\
\hline CHEMBL 3199744 & 688422 & 4.95 & 5.2999 & TRN & \\
\hline CHEMBL1364581 & 688422 & 4.9 & 5.1328 & TRN & \\
\hline CHEMBL1306944 & 688422 & 4.6 & 5.0408 & TRN & \\
\hline CHEMBL1546932 & 688422 & 4.9 & 5.1551 & TRN & \\
\hline CHEMBL1494014 & 688422 & 6.3 & 5.481 & TST & \\
\hline
\end{tabular}




\begin{tabular}{|c|c|c|c|c|c|}
\hline \multicolumn{6}{|c|}{ Supplemental Table S2.txt } \\
\hline CHEMBL1397833 & 688422 & 5.7 & 5.8283 & TST & \\
\hline CHEMBL1319715 & 688422 & 4.9 & 5.0556 & TRN & \\
\hline CHEMBL1517889 & 688422 & 4.75 & 4.9093 & TRN & \\
\hline CHEMBL56 & 688422 & 8.2518 & 5.2926 & TRN & \\
\hline CHEMBL1544325 & 688422 & 4.95 & 5.4343 & TRN & \\
\hline CHEMBL1374224 & 688422 & 5.1 & 4.7558 & TRN & \\
\hline CHEMBL1442334 & 688422 & 7.4001 & 5.3702 & TST & \\
\hline CHEMBL3194934 & 688422 & 5.1 & 4.9804 & TST & \\
\hline CHEMBL3193275 & 688422 & 5.0 & 5.3356 & TRN & \\
\hline CHEMBL1459447 & 688422 & 5.25 & 5.2905 & TST & \\
\hline CHEMBL1566873 & 688422 & 4.55 & 5.1862 & TRN & \\
\hline CHEMBL1541969 & 688422 & 4.9 & 5.2298 & TRN & \\
\hline CHEMBL1380582 & 688422 & 4.5 & 4.8647 & TST & \\
\hline CHEMBL1424355 & 688422 & 4.8 & 5.0465 & TRN & \\
\hline CHEMBL1322983 & 688422 & 5.3 & 5.0983 & TRN & \\
\hline CHEMBL1322784 & 688422 & 4.95 & 5.4688 & TRN & \\
\hline CHEMBL1334445 & 688422 & 5.85 & 4.7449 & TRN & \\
\hline CHEMBL1417381 & 688422 & 5.6 & 4.9766 & TRN & \\
\hline CHEMBL1319136 & 688422 & 6.25 & 5.1688 & TRN & \\
\hline CHEMBL1789998 & 688422 & 4.85 & 5.1511 & TRN & \\
\hline CHEMBL1308898 & 688422 & 4.6 & 5.1095 & TRN & \\
\hline CHEMBL1359905 & 688422 & 5.25 & 5.3684 & TRN & \\
\hline CHEMBL1326728 & 688422 & 4.45 & 5.1392 & TRN & \\
\hline CHEMBL1493896 & 688422 & 4.8 & 5.1303 & TRN & \\
\hline CHEMBL1365799 & 688422 & 4.7 & 5.6611 & TST & \\
\hline CHEMBL1327532 & 688422 & 6.5 & 5.3578 & TST & \\
\hline CHEMBL1319635 & 688422 & 4.55 & 5.2088 & TRN & \\
\hline CHEMBL1592244 & 688422 & 4.95 & 4.9454 & TRN & \\
\hline CHEMBL1349832 & 688422 & 4.5 & 5.2632 & TRN & \\
\hline CHEMBL1413849 & 688422 & 4.75 & 5.371 & TRN & \\
\hline CHEMBL1566193 & 688422 & 5.0 & 5.3716 & TRN & \\
\hline CHEMBL1475873 & 688422 & 4.9 & 5.5117 & TRN & \\
\hline CHEMBL1608219 & 688422 & 7.1002 & 5.2205 & TRN & \\
\hline CHEMBL1496707 & 688422 & 4.95 & 5.2471 & TST & \\
\hline CHEMBL3209242 & 688422 & 5.0 & 5.1623 & TRN & \\
\hline CHEMBL1452462 & 688422 & 5.4 & 5.2133 & TRN & \\
\hline CHEMBL1450250 & 688422 & 4.45 & 5.2317 & TRN & \\
\hline CHEMBL1330005 & 688422 & 6.2 & 5.5511 & TRN & \\
\hline CHEMBL1479032 & 688422 & 5.4 & 5.0642 & TST & \\
\hline CHEMBL1493600 & 688422 & 6.7001 & 5.4655 & TRN & \\
\hline CHEMBL1601788 & 688422 & 4.9 & 4.8621 & TRN & \\
\hline CHEMBL1540090 & 688422 & 4.45 & 4.9739 & TST & \\
\hline CHEMBL1414201 & 688422 & 9.0 & 5.6022 & TRN & \\
\hline CHEMBL1356072 & 688422 & 8.4949 & 5.5252 & TRN & \\
\hline CHEMBL1489226 & 688422 & 4.45 & 4.8789 & TRN & \\
\hline CHEMBL1583406 & 688422 & 4.5 & 5.24799 & 9999999999 & TRN \\
\hline CHEMBL1508883 & 688422 & 5.05 & 5.0089 & TRN & \\
\hline CHEMBL1556578 & 688422 & 6.8499 & 4.9665 & TRN & \\
\hline
\end{tabular}

Page 9831 


\begin{tabular}{|c|c|c|c|c|}
\hline \multicolumn{5}{|c|}{ Supplemental Table S2.txt } \\
\hline CHEMBL1312885 & 688422 & 4.95 & 5.1136 & TST \\
\hline CHEMBL1304946 & 688422 & 4.45 & 4.8784 & TRN \\
\hline CHEMBL3195813 & 688422 & 4.6 & 5.1045 & TRN \\
\hline CHEMBL1507162 & 688422 & 4.55 & 4.8163 & TRN \\
\hline CHEMBL1381056 & 688422 & 4.75 & 5.3225 & TRN \\
\hline CHEMBL1353385 & 688422 & 4.85 & 5.0806 & TST \\
\hline CHEMBL1480652 & 688422 & 5.2 & 5.7276 & TST \\
\hline CHEMBL1396646 & 688422 & 5.9 & 5.484 & TRN \\
\hline CHEMBL1991311 & 688422 & 4.85 & 4.8137 & TRN \\
\hline CHEMBL1456852 & 688422 & 4.9 & 5.2985 & TRN \\
\hline CHEMBL1327719 & 688422 & 4.9 & 5.0475 & TRN \\
\hline CHEMBL1485175 & 688422 & 6.7001 & 5.6953 & TRN \\
\hline CHEMBL1597824 & 688422 & 8.4949 & 5.4626 & TRN \\
\hline CHEMBL 3214510 & 688422 & 4.9 & 4.8138 & TRN \\
\hline CHEMBL1424190 & 688422 & 5.0 & 5.2057 & TST \\
\hline CHEMBL1601354 & 688422 & 4.45 & 4.8541 & TRN \\
\hline CHEMBL1587258 & 688422 & 6.8499 & 5.324 & TRN \\
\hline CHEMBL1311185 & 688422 & 5.6 & 5.4715 & TST \\
\hline CHEMBL1526662 & 688422 & 4.5 & 5.1798 & TRN \\
\hline CHEMBL3209521 & 688422 & 6.9 & 4.7813 & TRN \\
\hline CHEMBL1431024 & 688422 & 4.9 & 4.8447 & TST \\
\hline CHEMBL1361225 & 688422 & 6.7501 & 5.4567 & TST \\
\hline CHEMBL1410951 & 688422 & 7.3002 & 5.4953 & TRN \\
\hline CHEMBL1561738 & 688422 & 4.95 & 4.9201 & TST \\
\hline CHEMBL3209412 & 688422 & 4.8 & 5.0871 & TRN \\
\hline CHEMBL1433928 & 688422 & 4.45 & 5.1702 & TRN \\
\hline CHEMBL1438750 & 688422 & 4.6 & 5.1676 & TST \\
\hline CHEMBL3197766 & 688422 & 4.9 & 5.2214 & TRN \\
\hline CHEMBL1518947 & 688422 & 4.7 & 5.2347 & TRN \\
\hline CHEMBL1461203 & 688422 & 4.95 & 5.0203 & TRN \\
\hline CHEMBL1423690 & 688422 & 4.5 & 4.9561 & TRN \\
\hline CHEMBL1514153 & 688422 & 4.45 & 5.2871 & TST \\
\hline CHEMBL1530658 & 688422 & 4.85 & 4.9624 & TRN \\
\hline CHEMBL1548142 & 688422 & 4.85 & 5.2553 & TST \\
\hline CHEMBL1481252 & 688422 & 5.35 & 5.4621 & TRN \\
\hline CHEMBL1470374 & 688422 & 4.7 & 5.3191 & TRN \\
\hline CHEMBL1583598 & 688422 & 8.4949 & 5.3261 & TRN \\
\hline CHEMBL3199425 & 688422 & 4.45 & 4.8917 & TST \\
\hline CHEMBL1400385 & 688422 & 4.45 & 5.3311 & TRN \\
\hline CHEMBL1300447 & 688422 & 7.6498 & 5.614 & TRN \\
\hline CHEMBL1428539 & 688422 & 4.95 & 5.4882 & TST \\
\hline CHEMBL3194373 & 688422 & 5.0 & 5.2688 & TRN \\
\hline CHEMBL1399366 & 688422 & 4.9 & 4.8403 & TRN \\
\hline CHEMBL1993301 & 688422 & 5.05 & 5.0128 & TRN \\
\hline CHEMBL1399744 & 688422 & 4.45 & 4.9943 & TRN \\
\hline CHEMBL1524069 & 688422 & 7.5003 & 5.1088 & TRN \\
\hline CHEMBL1600340 & 688422 & 4.85 & 5.5761 & TRN \\
\hline CHEMBL1448934 & 688422 & 8.301 & 5.1257 & TRN \\
\hline
\end{tabular}




\begin{tabular}{|c|c|c|c|c|}
\hline \multicolumn{5}{|c|}{ Supplemental Table S2.txt } \\
\hline CHEMBL1398258 & 688422 & 4.9 & 5.0522 & TRN \\
\hline CHEMBL1486934 & 688422 & 5.15 & 5.0359 & TRN \\
\hline CHEMBL1553923 & 688422 & 4.5 & 5.1511 & TRN \\
\hline CHEMBL1504139 & 688422 & 5.9 & 4.319 & TRN \\
\hline CHEMBL1451438 & 688422 & 4.65 & 5.6798 & TST \\
\hline CHEMBL1539087 & 688422 & 4.75 & 4.6565 & TST \\
\hline CHEMBL1330701 & 688422 & 4.45 & 5.5309 & TRN \\
\hline CHEMBL1591598 & 688422 & 7.0 & 5.0572 & TRN \\
\hline CHEMBL1441653 & 688422 & 8.4949 & 5.0893 & TRN \\
\hline CHEMBL1467570 & 688422 & 4.5 & 5.2796 & TRN \\
\hline CHEMBL1583300 & 688422 & 5.05 & 5.1149 & TRN \\
\hline CHEMBL1609025 & 688422 & 4.65 & 5.194 & TST \\
\hline CHEMBL1461745 & 688422 & 5.7 & 4.8709 & TST \\
\hline CHEMBL1358878 & 688422 & 8.4949 & 5.4318 & TRN \\
\hline CHEMBL1427796 & 688422 & 5.35 & 5.5452 & TST \\
\hline CHEMBL1426523 & 688422 & 4.45 & 5.1536 & TRN \\
\hline CHEMBL1560757 & 688422 & 5.25 & 5.7737 & TRN \\
\hline CHEMBL1569585 & 688422 & 5.45 & 5.5981 & TRN \\
\hline CHEMBL1998940 & 688422 & 5.4 & 4.9794 & TRN \\
\hline CHEMBL1612009 & 688422 & 4.45 & 5.2359 & TST \\
\hline CHEMBL3189397 & 688422 & 6.35 & 4.9036 & TRN \\
\hline CHEMBL1489587 & 688422 & 4.7 & 5.7208 & TST \\
\hline CHEMBL1343062 & 688422 & 6.5 & 5.9728 & TRN \\
\hline CHEMBL1383321 & 688422 & 4.5 & 5.0548 & TRN \\
\hline CHEMBL1417206 & 688422 & 4.85 & 5.0445 & TRN \\
\hline CHEMBL1447831 & 688422 & 5.5 & 4.6991 & TRN \\
\hline CHEMBL1544996 & 688422 & 4.9 & 4.8751 & TRN \\
\hline CHEMBL1498773 & 688422 & 4.9 & 5.1969 & TST \\
\hline CHEMBL 3212312 & 688422 & 4.7 & 5.0779 & TRN \\
\hline CHEMBL1365941 & 688422 & 4.75 & 5.1539 & TRN \\
\hline CHEMBL434063 & 688422 & 5.25 & 5.567 & TST \\
\hline CHEMBL1458023 & 688422 & 4.65 & 5.3852 & TST \\
\hline CHEMBL1311769 & 688422 & 5.25 & 4.9409 & TST \\
\hline CHEMBL1449930 & 688422 & 4.65 & 5.2391 & TST \\
\hline CHEMBL 3214346 & 688422 & 4.45 & 5.0059 & TRN \\
\hline CHEMBL1420247 & 688422 & 4.75 & 4.9637 & TRN \\
\hline CHEMBL1522713 & 688422 & 4.9 & 5.3171 & TRN \\
\hline CHEMBL1549993 & 688422 & 4.9 & 4.9416 & TST \\
\hline CHEMBL1349329 & 688422 & 4.95 & 5.3724 & TRN \\
\hline CHEMBL 3189753 & 688422 & 5.15 & 5.3312 & TRN \\
\hline CHEMBL1309210 & 688422 & 5.5 & 5.2432 & TRN \\
\hline CHEMBL1529368 & 688422 & 5.25 & 4.76 & TRN \\
\hline CHEMBL1335738 & 688422 & 4.75 & 5.0291 & TRN \\
\hline CHEMBL1596240 & 688422 & 6.3 & 4.966 & TRN \\
\hline CHEMBL1575588 & 688422 & 5.0 & 5.2457 & TRN \\
\hline CHEMBL250450 & 688422 & 4.55 & 5.7727 & TRN \\
\hline CHEMBL1335149 & 688422 & 4.9 & 4.997 & TST \\
\hline CHEMBL1554797 & 688422 & 6.95 & 5.8053 & TRN \\
\hline
\end{tabular}




\begin{tabular}{|c|c|c|c|c|c|}
\hline \multicolumn{6}{|c|}{ Supplemental Table S2.txt } \\
\hline CHEMBL1304788 & 688422 & 5.25 & 5.0844 & TST & \\
\hline CHEMBL1469864 & 688422 & 4.65 & 4.8825 & TRN & \\
\hline CHEMBL3189246 & 688422 & 4.85 & 5.2882 & TST & \\
\hline CHEMBL1437827 & 688422 & 5.05 & 5.9417 & TRN & \\
\hline CHEMBL1386015 & 688422 & 4.9 & 5.1433 & TRN & \\
\hline CHEMBL1488689 & 688422 & 4.45 & 5.2207 & TRN & \\
\hline CHEMBL1590473 & 688422 & 4.7 & 5.1839 & TRN & \\
\hline CHEMBL1515435 & 688422 & 6.45 & 4.9128 & TRN & \\
\hline CHEMBL1469474 & 688422 & 6.8499 & 5.5291 & TRN & \\
\hline CHEMBL296586 & 688422 & 5.25 & 5.595 & TST & \\
\hline CHEMBL1509260 & 688422 & 5.0 & 5.1097 & TRN & \\
\hline CHEMBL1454088 & 688422 & 4.8 & 5.1418 & TRN & \\
\hline CHEMBL1311247 & 688422 & 6.6 & 5.9024 & TST & \\
\hline CHEMBL1336392 & 688422 & 5.2 & 5.2071 & TRN & \\
\hline CHEMBL3190095 & 688422 & 5.95 & 5.3189 & TRN & \\
\hline CHEMBL1365954 & 688422 & 6.15 & 5.5002 & TRN & \\
\hline CHEMBL1498602 & 688422 & 4.8 & 5.3705 & TST & \\
\hline CHEMBL1996679 & 688422 & 4.75 & 5.3971 & TRN & \\
\hline CHEMBL1417620 & 688422 & 4.75 & 4.6114 & TRN & \\
\hline CHEMBL1314781 & 688422 & 8.2007 & 5.1714 & TRN & \\
\hline CHEMBL1446488 & 688422 & 5.45 & 4.9681 & TRN & \\
\hline CHEMBL1580071 & 688422 & 4.9 & 4.8959 & TRN & \\
\hline CHEMBL1359432 & 688422 & 4.95 & 5.4909 & TRN & \\
\hline CHEMBL1471128 & 688422 & 4.45 & 5.0783 & TRN & \\
\hline CHEMBL1583393 & 688422 & 6.8 & 5.6559 & TRN & \\
\hline CHEMBL1517304 & 688422 & 4.75 & 5.2379 & TRN & \\
\hline CHEMBL1461196 & 688422 & 5.15 & 5.8292 & TRN & \\
\hline CHEMBL602158 & 688422 & 4.9 & 5.17399 & 99999999995 & TRN \\
\hline CHEMBL1468652 & 688422 & 4.65 & 5.6602 & TRN & \\
\hline CHEMBL1997171 & 688422 & 7.0 & 5.0867 & TRN & \\
\hline CHEMBL1399534 & 688422 & 4.65 & 5.3341 & TRN & \\
\hline CHEMBL1350586 & 688422 & 5.65 & 5.1612 & TRN & \\
\hline CHEMBL1384323 & 688422 & 4.6 & 5.3582 & TST & \\
\hline CHEMBL1397828 & 688422 & 7.3002 & 5.7564 & TRN & \\
\hline CHEMBL1378972 & 688422 & 4.7 & 5.2464 & TRN & \\
\hline CHEMBL1444747 & 688422 & 6.5501 & 5.1626 & TRN & \\
\hline CHEMBL1403248 & 688422 & 4.9 & 4.9089 & TRN & \\
\hline CHEMBL3209249 & 688422 & 7.1002 & 5.5993 & TST & \\
\hline CHEMBL1550519 & 688422 & 5.25 & 5.2109 & TRN & \\
\hline CHEMBL1213905 & 688422 & 4.65 & 5.441 & TRN & \\
\hline CHEMBL1299319 & 688422 & 5.3 & 5.2215 & TRN & \\
\hline CHEMBL1328182 & 688422 & 4.6 & 5.2952 & TRN & \\
\hline CHEMBL1367755 & 688422 & 5.4 & 5.4137 & TRN & \\
\hline CHEMBL1528375 & 688422 & 4.9 & 5.1682 & TRN & \\
\hline CHEMBL1444681 & 688422 & 4.55 & 5.4434 & TST & \\
\hline CHEMBL1430864 & 688422 & 7.5003 & 5.6444 & TRN & \\
\hline CHEMBL3190226 & 688422 & 5.15 & 5.3325 & TRN & \\
\hline CHEMBL1478758 & 688422 & 4.95 & 5.2536 & TRN & \\
\hline
\end{tabular}




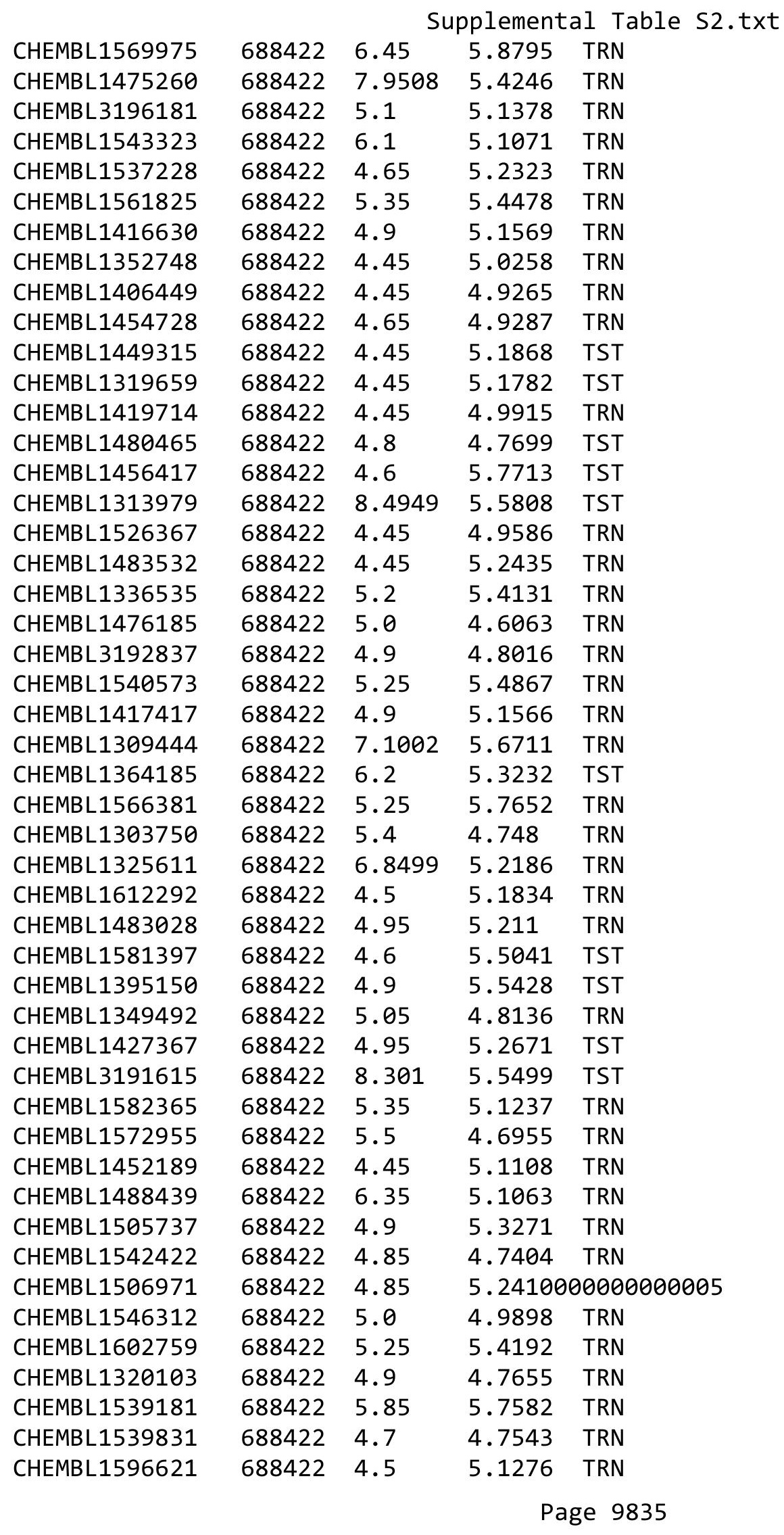




\begin{tabular}{|c|c|c|c|c|c|}
\hline \multicolumn{6}{|c|}{ Supplemental Table S2.txt } \\
\hline CHEMBL1579089 & 688422 & 4.9 & 5.495 & TRN & \\
\hline CHEMBL1554615 & 688422 & 4.55 & 5.2343 & TRN & \\
\hline CHEMBL1345393 & 688422 & 6.4 & 5.6009 & TST & \\
\hline CHEMBL1502139 & 688422 & 4.75 & 4.8687 & TRN & \\
\hline CHEMBL3210166 & 688422 & 4.95 & 5.0642 & TRN & \\
\hline CHEMBL1450076 & 688422 & 4.95 & 4.9088 & TRN & \\
\hline CHEMBL1425337 & 688422 & 4.9 & 5.3062 & TST & \\
\hline CHEMBL1311222 & 688422 & 4.45 & 5.05699 & 79999999995 & TRN \\
\hline CHEMBL1481780 & 688422 & 4.45 & 4.9086 & TST & \\
\hline CHEMBL1540480 & 688422 & 6.1 & 5.2575 & TRN & \\
\hline CHEMBL1420271 & 688422 & 4.85 & 5.1918 & TRN & \\
\hline CHEMBL1605312 & 688422 & 4.9 & 5.7021 & TRN & \\
\hline CHEMBL1504720 & 688422 & 4.9 & 4.5354 & TRN & \\
\hline CHEMBL1477243 & 688422 & 4.9 & 4.8566 & TRN & \\
\hline CHEMBL1419513 & 688422 & 6.15 & 5.7358 & TST & \\
\hline CHEMBL1404727 & 688422 & 4.45 & 5.1809 & TRN & \\
\hline CHEMBL1518480 & 688422 & 4.95 & 5.3288 & TRN & \\
\hline CHEMBL1474753 & 688422 & 4.45 & 4.8809 & TRN & \\
\hline CHEMBL1574951 & 688422 & 7.15 & 5.0407 & TRN & \\
\hline CHEMBL1339772 & 688422 & 5.35 & 5.2655 & TRN & \\
\hline CHEMBL1423575 & 688422 & 4.75 & 5.0247 & TRN & \\
\hline CHEMBL1314926 & 688422 & 6.15 & 5.4442 & TRN & \\
\hline CHEMBL1530940 & 688422 & 4.45 & 5.0186 & TRN & \\
\hline CHEMBL1404173 & 688422 & 4.6 & 4.7425 & TST & \\
\hline CHEMBL1537369 & 688422 & 4.65 & 5.5919 & TRN & \\
\hline CHEMBL1547222 & 688422 & 5.6 & 5.099 & TST & \\
\hline CHEMBL1429422 & 688422 & 7.0 & 4.966 & TRN & \\
\hline CHEMBL1590930 & 688422 & 7.2 & 5.3148 & TST & \\
\hline CHEMBL3189212 & 688422 & 4.9 & 5.0264 & TST & \\
\hline CHEMBL1566443 & 688422 & 6.6499 & 5.0626 & TRN & \\
\hline CHEMBL1593110 & 688422 & 5.2 & 5.409 & TRN & \\
\hline CHEMBL1495589 & 688422 & 4.45 & 4.7834 & TRN & \\
\hline CHEMBL3190958 & 688422 & 8.301 & 5.4525 & TRN & \\
\hline CHEMBL1556857 & 688422 & 7.4001 & 5.0611 & TST & \\
\hline CHEMBL1589626 & 688422 & 6.3 & 5.2498 & TST & \\
\hline CHEMBL1612761 & 688422 & 7.8996 & 4.7558 & TRN & \\
\hline CHEMBL1447458 & 688422 & 7.6498 & 5.4117 & TRN & \\
\hline CHEMBL1533814 & 688422 & 5.35 & 5.4384 & TRN & \\
\hline CHEMBL1401832 & 688422 & 5.25 & 5.4035 & TRN & \\
\hline CHEMBL1602357 & 688422 & 4.85 & 5.138 & TST & \\
\hline CHEMBL1306108 & 688422 & 4.7 & 5.4284 & TRN & \\
\hline CHEMBL1555358 & 688422 & 4.95 & 5.271 & TRN & \\
\hline CHEMBL1594506 & 688422 & 5.95 & 5.4463 & TRN & \\
\hline CHEMBL1455127 & 688422 & 4.85 & 5.1649 & TRN & \\
\hline CHEMBL1374371 & 688422 & 4.55 & 5.1189 & TRN & \\
\hline CHEMBL1299777 & 688422 & 4.45 & 4.8452 & TRN & \\
\hline CHEMBL1165723 & 688422 & 4.65 & 4.8843 & TST & \\
\hline CHEMBL 1407 & 688422 & 6.0 & 5.4206 & TRN & \\
\hline
\end{tabular}




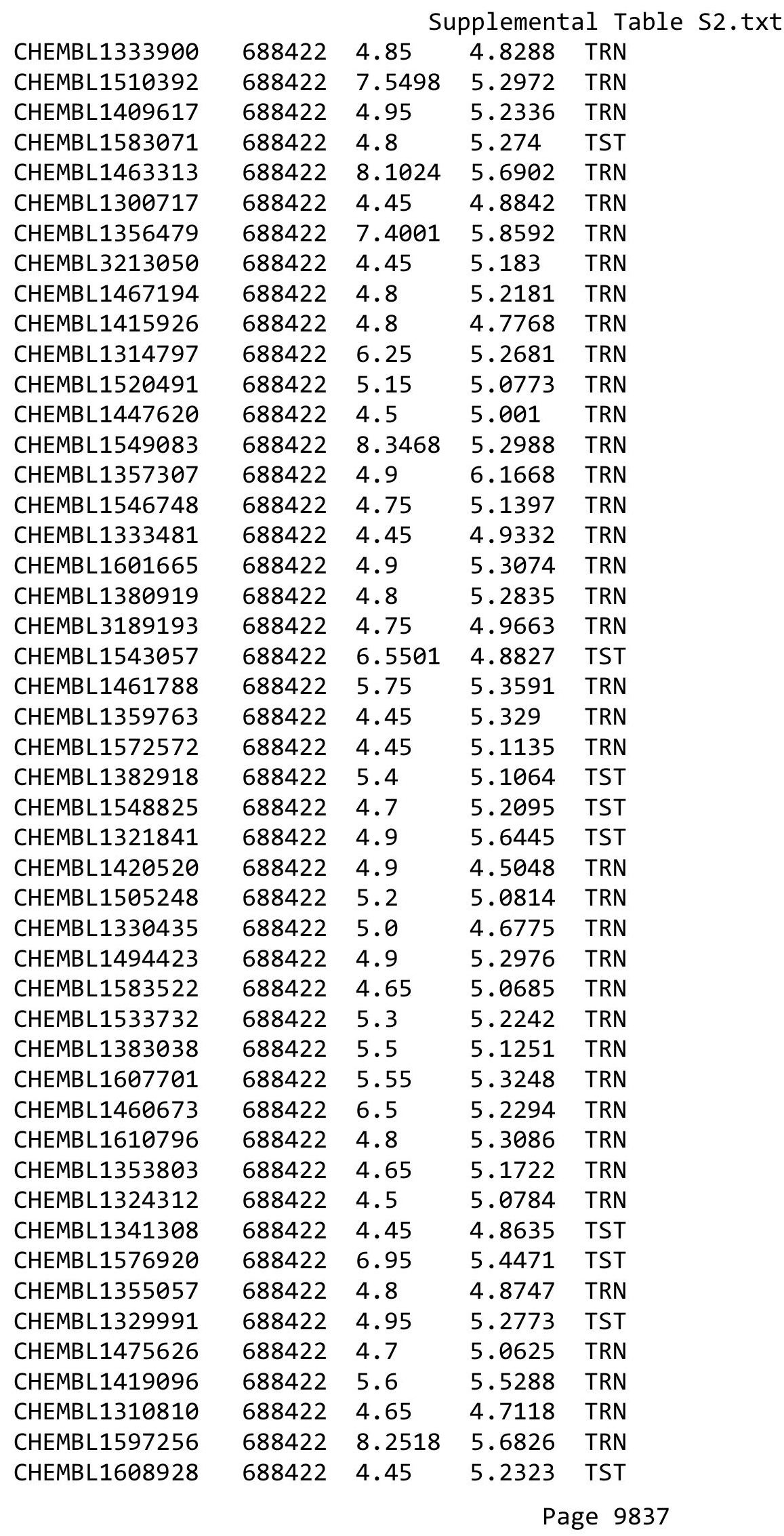




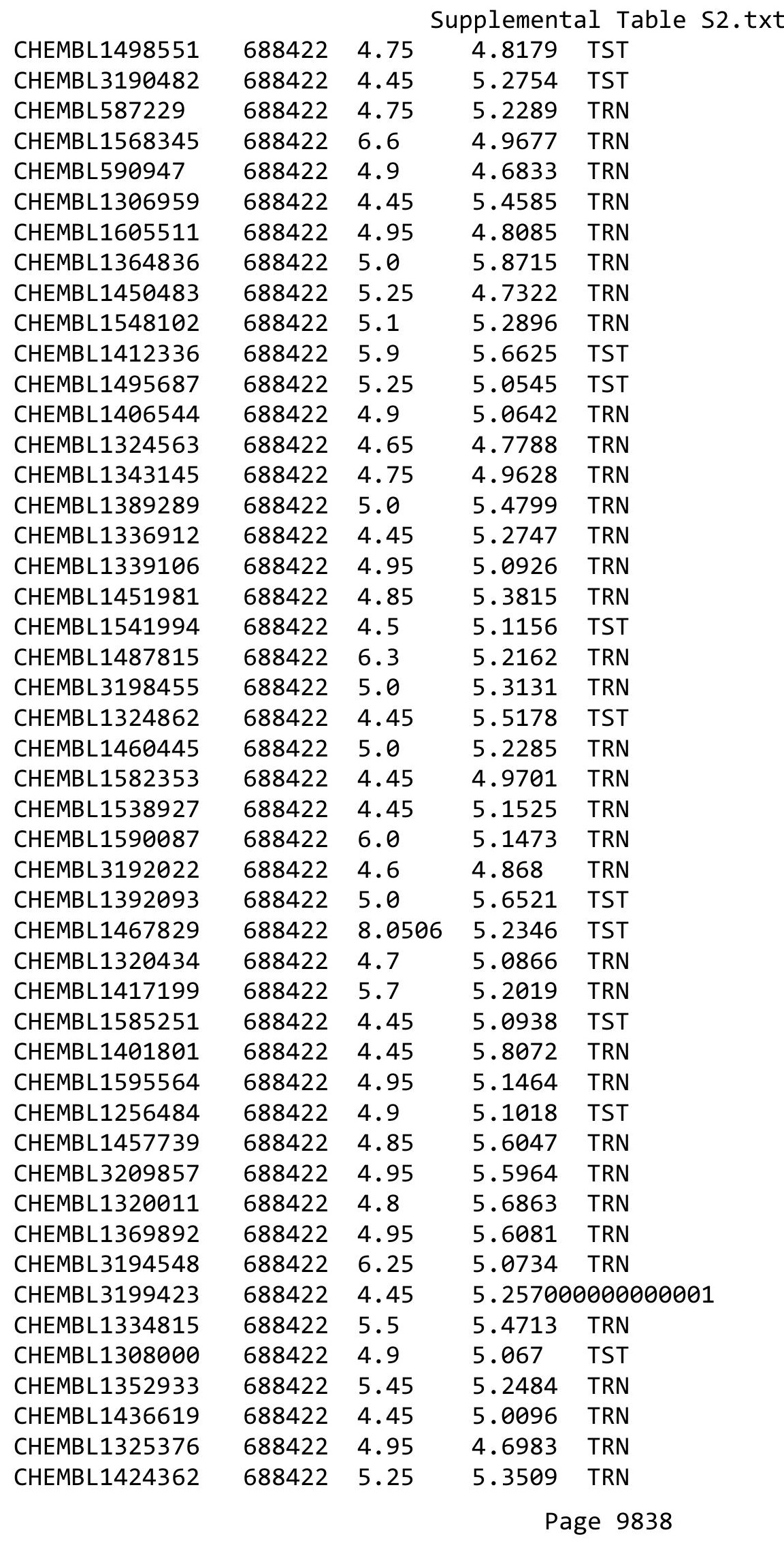




\begin{tabular}{|c|c|c|c|c|}
\hline \multicolumn{5}{|c|}{ Supplemental Table S2.txt } \\
\hline CHEMBL1970621 & 688422 & 4.45 & 4.955 & TRN \\
\hline CHEMBL1431645 & 688422 & 4.9 & 4.6466 & TRN \\
\hline CHEMBL1566565 & 688422 & 4.45 & 5.3079 & TST \\
\hline CHEMBL1362368 & 688422 & 4.45 & 5.2637 & TRN \\
\hline CHEMBL1461972 & 688422 & 5.25 & 5.2174 & TRN \\
\hline CHEMBL1508699 & 688422 & 5.5 & 5.4897 & TRN \\
\hline CHEMBL1461103 & 688422 & 4.85 & 5.0872 & TST \\
\hline CHEMBL1468900 & 688422 & 4.85 & 5.3246 & TRN \\
\hline CHEMBL1299795 & 688422 & 4.8 & 5.5871 & TST \\
\hline CHEMBL1562113 & 688422 & 6.5501 & 5.3918 & TRN \\
\hline CHEMBL1400017 & 688422 & 5.3 & 5.8618 & TRN \\
\hline CHEMBL1310838 & 688422 & 6.45 & 5.5038 & TST \\
\hline CHEMBL1397271 & 688422 & 5.4 & 5.6186 & TRN \\
\hline CHEMBL1438419 & 688422 & 6.25 & 5.8723 & TST \\
\hline CHEMBL1587274 & 688422 & 5.4 & 5.4117 & TRN \\
\hline CHEMBL 273807 & 688422 & 5.65 & 5.5318 & TST \\
\hline CHEMBL1415588 & 688422 & 5.05 & 4.687 & TRN \\
\hline CHEMBL1601046 & 688422 & 4.65 & 5.3138 & TRN \\
\hline CHEMBL1379675 & 688422 & 4.45 & 4.9448 & TRN \\
\hline CHEMBL1349062 & 688422 & 4.95 & 5.3372 & TRN \\
\hline CHEMBL602776 & 688422 & 4.75 & 5.0248 & TRN \\
\hline CHEMBL1363762 & 688422 & 4.75 & 4.5774 & TRN \\
\hline CHEMBL1448822 & 688422 & 4.5 & 4.8119 & TRN \\
\hline CHEMBL1327942 & 688422 & 7.3497 & 5.1279 & TST \\
\hline CHEMBL1548642 & 688422 & 4.45 & 5.6461 & TST \\
\hline CHEMBL1335502 & 688422 & 4.75 & 5.2693 & TST \\
\hline CHEMBL1612846 & 688422 & 4.85 & 5.3745 & TRN \\
\hline CHEMBL1481338 & 688422 & 4.9 & 4.9762 & TST \\
\hline CHEMBL1477631 & 688422 & 8.1024 & 5.9916 & TST \\
\hline CHEMBL1512199 & 688422 & 4.85 & 5.4211 & TRN \\
\hline CHEMBL1442029 & 688422 & 6.1 & 5.8879 & TRN \\
\hline CHEMBL 3144931 & 688422 & 4.55 & 5.2777 & TRN \\
\hline CHEMBL1540050 & 688422 & 5.25 & 5.3761 & TRN \\
\hline CHEMBL1603472 & 688422 & 5.0 & 5.4809 & TRN \\
\hline CHEMBL1532738 & 688422 & 4.45 & 5.7536 & TST \\
\hline CHEMBL1504677 & 688422 & 4.55 & 5.3261 & TRN \\
\hline CHEMBL1608285 & 688422 & 5.15 & 5.4159 & TST \\
\hline CHEMBL1399642 & 688422 & 6.35 & 5.0206 & TRN \\
\hline CHEMBL1367380 & 688422 & 4.95 & 5.4404 & TRN \\
\hline CHEMBL1447210 & 688422 & 5.55 & 5.2609 & TRN \\
\hline CHEMBL1341088 & 688422 & 5.65 & 5.2038 & TRN \\
\hline CHEMBL1357167 & 688422 & 4.8 & 4.6773 & TRN \\
\hline CHEMBL1342337 & 688422 & 4.45 & 4.8035 & TST \\
\hline CHEMBL1479234 & 688422 & 4.75 & 5.4301 & TRN \\
\hline CHEMBL1462172 & 688422 & 5.55 & 5.0002 & TRN \\
\hline CHEMBL1323139 & 688422 & 5.45 & 5.466 & TRN \\
\hline CHEMBL1440293 & 688422 & 5.7 & 5.131 & TRN \\
\hline CHEMBL1491897 & 688422 & 4.45 & 5.414 & TRN \\
\hline
\end{tabular}




\begin{tabular}{|c|c|c|c|c|c|}
\hline \multicolumn{6}{|c|}{ Supplemental Table S2.txt } \\
\hline CHEMBL1380158 & 688422 & 5.1 & 5.3559 & TRN & \\
\hline CHEMBL1299807 & 688422 & 4.95 & 5.1934 & TRN & \\
\hline CHEMBL1363915 & 688422 & 4.7 & 5.2404 & TRN & \\
\hline CHEMBL1378013 & 688422 & 4.45 & 5.3822 & TRN & \\
\hline CHEMBL1575312 & 688422 & 8.301 & 5.1521 & TRN & \\
\hline CHEMBL 3145108 & 688422 & 4.6 & 5.1086 & TST & \\
\hline CHEMBL1466068 & 688422 & 4.95 & 5.0028 & TRN & \\
\hline CHEMBL1462365 & 688422 & 8.3468 & 5.3219 & TRN & \\
\hline CHEMBL1449740 & 688422 & 5.2 & 5.1783 & TRN & \\
\hline CHEMBL1377469 & 688422 & 4.45 & 5.8543 & TRN & \\
\hline CHEMBL1378644 & 688422 & 4.65 & 4.6014 & TRN & \\
\hline CHEMBL1450889 & 688422 & 4.85 & 5.02800 & 00000000005 & TST \\
\hline CHEMBL1344538 & 688422 & 4.75 & 5.3638 & TRN & \\
\hline CHEMBL1578346 & 688422 & 4.45 & 4.9132 & TST & \\
\hline CHEMBL3189912 & 688422 & 4.5 & 4.9545 & TST & \\
\hline CHEMBL1594517 & 688422 & 4.95 & 5.0118 & TRN & \\
\hline CHEMBL1302175 & 688422 & 4.8 & 5.0771 & TST & \\
\hline CHEMBL1464297 & 688422 & 5.05 & 5.4406 & TRN & \\
\hline CHEMBL1597158 & 688422 & 5.55 & 5.0491 & TRN & \\
\hline CHEMBL1410240 & 688422 & 5.65 & 5.38 & TST & \\
\hline CHEMBL1479583 & 688422 & 4.9 & 5.2905 & TRN & \\
\hline CHEMBL1362190 & 688422 & 6.4 & 5.5343 & TRN & \\
\hline CHEMBL1421187 & 688422 & 4.7 & 4.9614 & TST & \\
\hline CHEMBL1582655 & 688422 & 4.45 & 5.4262 & TST & \\
\hline CHEMBL1477338 & 688422 & 4.9 & 5.1645 & TRN & \\
\hline CHEMBL1432100 & 688422 & 5.2 & 5.2569 & TST & \\
\hline CHEMBL1302699 & 688422 & 6.45 & 5.7444 & TRN & \\
\hline CHEMBL1318340 & 688422 & 4.85 & 5.1062 & TRN & \\
\hline CHEMBL1307167 & 688422 & 5.25 & 4.8216 & TRN & \\
\hline CHEMBL1475558 & 688422 & 8.3979 & 5.5694 & TST & \\
\hline CHEMBL1509080 & 688422 & 4.65 & 4.7072 & TRN & \\
\hline CHEMBL1360601 & 688422 & 4.45 & 5.3405 & TRN & \\
\hline CHEMBL1391829 & 688422 & 4.45 & 5.0997 & TRN & \\
\hline CHEMBL1586367 & 688422 & 4.45 & 5.25299 & 9999999999 & TRN \\
\hline CHEMBL1530735 & 688422 & 5.6 & 5.1374 & TRN & \\
\hline CHEMBL1546650 & 688422 & 6.8499 & 5.2108 & TRN & \\
\hline CHEMBL1329678 & 688422 & 4.95 & 5.3551 & TRN & \\
\hline CHEMBL 2005737 & 688422 & 5.0 & 5.525 & TST & \\
\hline CHEMBL1346316 & 688422 & 5.0 & 4.4439 & TRN & \\
\hline CHEMBL1601397 & 688422 & 4.65 & 4.8611 & TRN & \\
\hline CHEMBL1497880 & 688422 & 4.9 & 5.0175 & TRN & \\
\hline CHEMBL1503103 & 688422 & 5.35 & 5.3833 & TRN & \\
\hline CHEMBL1370953 & 688422 & 4.5 & 5.2737 & TST & \\
\hline CHEMBL1430079 & 688422 & 4.95 & 5.3423 & TST & \\
\hline CHEMBL1413756 & 688422 & 4.45 & 5.4411 & TRN & \\
\hline CHEMBL1613336 & 688422 & 4.85 & 5.3796 & TRN & \\
\hline CHEMBL1469666 & 688422 & 7.699 & 5.7363 & TRN & \\
\hline CHEMBL601176 & 688422 & 4.85 & 4.9985 & TRN & \\
\hline
\end{tabular}




\begin{tabular}{|c|c|c|c|c|c|}
\hline \\
\hline CHEMBL1397970 & 688422 & 4.9 & 5.7541 & TRN & \\
\hline CHEMBL1374298 & 688422 & 4.45 & 5.0576 & TST & \\
\hline CHEMBL1565304 & 688422 & 5.5 & 4.8841 & TRN & \\
\hline CHEMBL1536353 & 688422 & 5.45 & 5.5559 & TRN & \\
\hline CHEMBL1493423 & 688422 & 4.95 & 4.9806 & TRN & \\
\hline CHEMBL1336113 & 688422 & 4.95 & 4.9969 & TST & \\
\hline CHEMBL1592133 & 688422 & 5.65 & 5.1566 & TRN & \\
\hline CHEMBL1384085 & 688422 & 4.85 & 5.3173 & TRN & \\
\hline CHEMBL582259 & 688422 & 4.85 & 5.3882 & TRN & \\
\hline CHEMBL1401860 & 688422 & 4.8 & 5.2264 & TRN & \\
\hline CHEMBL1518107 & 688422 & 5.0 & 4.6064 & TRN & \\
\hline CHEMBL1525007 & 688422 & 5.4 & 5.32100 & 3000000001 & TRN \\
\hline CHEMBL1480186 & 688422 & 4.8 & 5.7945 & TRN & \\
\hline CHEMBL1520427 & 688422 & 4.75 & 4.8806 & TRN & \\
\hline CHEMBL1511924 & 688422 & 5.25 & 4.6857 & TRN & \\
\hline CHEMBL1523139 & 688422 & 4.9 & 5.2327 & TRN & \\
\hline CHEMBL1499139 & 688422 & 8.301 & 5.7003 & TST & \\
\hline CHEMBL3190419 & 688422 & 5.2 & 5.3366 & TRN & \\
\hline CHEMBL1611056 & 688422 & 5.4 & 5.483 & TRN & \\
\hline CHEMBL1571888 & 688422 & 4.85 & 5.1068 & TRN & \\
\hline CHEMBL1391297 & 688422 & 8.0 & 5.3171 & TST & \\
\hline CHEMBL1418227 & 688422 & 5.5 & 5.6958 & TST & \\
\hline CHEMBL1549821 & 688422 & 4.7 & 5.1487 & TRN & \\
\hline CHEMBL1359384 & 688422 & 4.9 & 5.17700 & 00000000005 & TRN \\
\hline CHEMBL1592580 & 688422 & 4.9 & 5.0683 & TRN & \\
\hline CHEMBL1479863 & 688422 & 4.55 & 5.1907 & TRN & \\
\hline CHEMBL1493725 & 688422 & 4.45 & 4.9827 & TRN & \\
\hline CHEMBL1566542 & 688422 & 4.6 & 5.2971 & TRN & \\
\hline CHEMBL1499216 & 688422 & 4.75 & 4.949 & TRN & \\
\hline CHEMBL1562991 & 688422 & 5.55 & 4.9436 & TRN & \\
\hline CHEMBL1564445 & 688422 & 5.15 & 4.9457 & TRN & \\
\hline CHEMBL1374970 & 688422 & 4.9 & 5.06800 & 00000000005 & TRN \\
\hline CHEMBL1430686 & 688422 & 4.75 & 5.0294 & TRN & \\
\hline CHEMBL1529264 & 688422 & 4.5 & 5.3118 & TRN & \\
\hline CHEMBL3213147 & 688422 & 4.75 & 4.9507 & TRN & \\
\hline CHEMBL1458630 & 688422 & 4.65 & 5.4515 & TRN & \\
\hline CHEMBL1453581 & 688422 & 4.45 & 5.1567 & TRN & \\
\hline CHEMBL1586044 & 688422 & 5.25 & 5.4251 & TRN & \\
\hline CHEMBL1567814 & 688422 & 5.55 & 4.8642 & TRN & \\
\hline CHEMBL1513311 & 688422 & 4.45 & 5.5627 & TRN & \\
\hline CHEMBL1584016 & 688422 & 4.6 & 5.1317 & TRN & \\
\hline CHEMBL1503743 & 688422 & 4.85 & 5.2082 & TRN & \\
\hline CHEMBL3195428 & 688422 & 4.65 & 5.1725 & TST & \\
\hline CHEMBL1583491 & 688422 & 5.25 & 5.4977 & TRN & \\
\hline CHEMBL1517736 & 688422 & 4.85 & 5.9373 & TRN & \\
\hline CHEMBL1359105 & 688422 & 4.55 & 5.1079 & TRN & \\
\hline CHEMBL1397966 & 688422 & 4.45 & 4.6963 & TRN & \\
\hline CHEMBL1440205 & 688422 & 7.5003 & 5.2176 & TRN & \\
\hline
\end{tabular}




\begin{tabular}{|c|c|c|c|c|}
\hline \multicolumn{5}{|c|}{ Supplemental Table S2.txt } \\
\hline CHEMBL3190913 & 688422 & 4.9 & 5.084 & TRN \\
\hline CHEMBL3210362 & 688422 & 5.25 & 5.3086 & TRN \\
\hline CHEMBL1555934 & 688422 & 5.45 & 5.5322 & TST \\
\hline CHEMBL1396894 & 688422 & 4.75 & 5.1158 & TRN \\
\hline CHEMBL1330713 & 688422 & 4.9 & 5.211 & TRN \\
\hline CHEMBL3208968 & 688422 & 4.5 & 4.8418 & TST \\
\hline CHEMBL1568295 & 688422 & 5.25 & 5.8689 & TRN \\
\hline CHEMBL1608168 & 688422 & 4.75 & 4.738 & TRN \\
\hline CHEMBL1336817 & 688422 & 5.0 & 5.5724 & TRN \\
\hline CHEMBL1564821 & 688422 & 4.85 & 5.1218 & TRN \\
\hline CHEMBL1557474 & 688422 & 4.95 & 4.65 & TRN \\
\hline CHEMBL1505031 & 688422 & 4.95 & 5.0106 & TRN \\
\hline CHEMBL1387189 & 688422 & 5.9 & 5.0911 & TRN \\
\hline CHEMBL1455120 & 688422 & 4.45 & 5.65 & TRN \\
\hline CHEMBL1460114 & 688422 & 4.45 & 5.0888 & TRN \\
\hline CHEMBL1460388 & 688422 & 4.9 & 5.5342 & TRN \\
\hline CHEMBL1351330 & 688422 & 5.05 & 4.9409 & TRN \\
\hline CHEMBL1405104 & 688422 & 4.95 & 4.955 & TRN \\
\hline CHEMBL1498857 & 688422 & 4.5 & 5.2487 & TRN \\
\hline CHEMBL1990783 & 688422 & 4.55 & 5.5991 & TRN \\
\hline CHEMBL1479829 & 688422 & 4.45 & 4.8789 & TRN \\
\hline CHEMBL1550449 & 688422 & 4.7 & 4.8007 & TST \\
\hline CHEMBL1440330 & 688422 & 4.7 & 5.0138 & TRN \\
\hline CHEMBL1378285 & 688422 & 4.6 & 5.2512 & TRN \\
\hline CHEMBL1563816 & 688422 & 8.1024 & 5.4 & TRN \\
\hline CHEMBL1332499 & 688422 & 4.55 & 5.1956 & TRN \\
\hline CHEMBL1610907 & 688422 & 4.9 & 5.3527 & TRN \\
\hline CHEMBL1552808 & 688422 & 6.5 & 5.7573 & TST \\
\hline CHEMBL1575823 & 688422 & 4.45 & 5.3931 & TST \\
\hline CHEMBL1451844 & 688422 & 4.95 & 5.4009 & TST \\
\hline CHEMBL1381632 & 688422 & 5.6 & 5.2912 & TRN \\
\hline CHEMBL1540677 & 688422 & 4.45 & 5.2559 & TST \\
\hline CHEMBL1314215 & 688422 & 7.5003 & 5.2415 & TRN \\
\hline CHEMBL1310545 & 688422 & 7.7496 & 5.1847 & TRN \\
\hline CHEMBL1320794 & 688422 & 4.8 & 4.8125 & TRN \\
\hline CHEMBL3198573 & 688422 & 4.95 & 5.2133 & TRN \\
\hline CHEMBL 1557186 & 688422 & 4.65 & 5.0811 & TST \\
\hline CHEMBL1521722 & 688422 & 4.95 & 5.1237 & TRN \\
\hline CHEMBL1363436 & 688422 & 7.3002 & 5.2083 & TRN \\
\hline CHEMBL243652 & 688422 & 4.45 & 5.4521 & TST \\
\hline CHEMBL1388977 & 688422 & 4.65 & 5.3742 & TRN \\
\hline CHEMBL1390774 & 688422 & 4.85 & 4.9809 & TRN \\
\hline CHEMBL1446667 & 688422 & 4.9 & 4.7229 & TST \\
\hline CHEMBL1344605 & 688422 & 4.9 & 5.3316 & TRN \\
\hline CHEMBL1479493 & 688422 & 8.0506 & 5.676 & TRN \\
\hline CHEMBL1420404 & 688422 & 4.45 & 5.0192 & TST \\
\hline CHEMBL1479489 & 688422 & 4.75 & 5.1052 & TRN \\
\hline CHEMBL1448882 & 688422 & 4.5 & 4.7643 & TRN \\
\hline
\end{tabular}




\begin{tabular}{|c|c|c|c|c|c|}
\hline & & \multicolumn{4}{|c|}{ Supplemental Table S2.txt } \\
\hline CHEMBL1308243 & 688422 & 4.7 & 5.3536 & TST & \\
\hline CHEMBL1413172 & 688422 & 5.0 & 5.02 & TRN & \\
\hline CHEMBL1386967 & 688422 & 7.4498 & 5.0611 & TRN & \\
\hline CHEMBL1420314 & 688422 & 4.95 & 5.2609 & TRN & \\
\hline CHEMBL1554153 & 688422 & 4.85 & 5.2534 & TRN & \\
\hline CHEMBL1325932 & 688422 & 4.9 & 5.5953 & TRN & \\
\hline CHEMBL1448015 & 688422 & 4.7 & 5.3274 & TST & \\
\hline CHEMBL1421534 & 688422 & 4.65 & 5.62200 & 0000000001 & TRN \\
\hline CHEMBL3191781 & 688422 & 5.2 & 5.1375 & TRN & \\
\hline CHEMBL2003798 & 688422 & 5.25 & 5.096 & TRN & \\
\hline CHEMBL1345908 & 688422 & 4.8 & 5.2791 & TST & \\
\hline CHEMBL1599701 & 688422 & 5.0 & 5.7468 & TRN & \\
\hline CHEMBL1417430 & 688422 & 4.55 & 5.5511 & TRN & \\
\hline CHEMBL1318495 & 688422 & 5.55 & 5.2076 & TRN & \\
\hline CHEMBL1368455 & 688422 & 7.0 & 5.3741 & TST & \\
\hline CHEMBL1545191 & 688422 & 6.2 & 5.204 & TRN & \\
\hline CHEMBL1333653 & 688422 & 5.45 & 5.4507 & TST & \\
\hline CHEMBL1390825 & 688422 & 5.25 & 5.1391 & TST & \\
\hline CHEMBL1422180 & 688422 & 4.8 & 4.9444 & TST & \\
\hline CHEMBL1555815 & 688422 & 4.85 & 5.0115 & TST & \\
\hline CHEMBL1315190 & 688422 & 6.9 & 5.5046 & TRN & \\
\hline CHEMBL1374726 & 688422 & 5.0 & 5.4331 & TRN & \\
\hline CHEMBL1518163 & 688422 & 5.05 & 5.5467 & TRN & \\
\hline CHEMBL1360170 & 688422 & 4.9 & 4.753 & TRN & \\
\hline CHEMBL1307824 & 688422 & 4.7 & 5.4023 & TRN & \\
\hline CHEMBL1358708 & 688422 & 6.0 & 5.9036 & TST & \\
\hline CHEMBL1481943 & 688422 & 4.45 & 5.2344 & TST & \\
\hline CHEMBL1599767 & 688422 & 4.45 & 5.3219 & TST & \\
\hline CHEMBL1559678 & 688422 & 4.95 & 5.3333 & TST & \\
\hline CHEMBL1528043 & 688422 & 5.0 & 5.0505 & TST & \\
\hline CHEMBL1994599 & 688422 & 4.95 & 4.9406 & TRN & \\
\hline CHEMBL1356133 & 688422 & 7.9508 & 5.0538 & TRN & \\
\hline CHEMBL3192897 & 688422 & 4.85 & 5.1269 & TST & \\
\hline CHEMBL1533328 & 688422 & 7.1002 & 5.4 & TRN & \\
\hline CHEMBL1350732 & 688422 & 4.45 & 5.1188 & TST & \\
\hline CHEMBL1480377 & 688422 & 4.9 & 5.3288 & TRN & \\
\hline CHEMBL1604844 & 688422 & 4.45 & 5.1557 & TRN & \\
\hline CHEMBL1578294 & 688422 & 4.45 & 4.6908 & TRN & \\
\hline CHEMBL1373105 & 688422 & 6.15 & 5.2428 & TRN & \\
\hline CHEMBL1452255 & 688422 & 7.6498 & 5.6113 & TRN & \\
\hline CHEMBL1357618 & 688422 & 5.15 & 5.2861 & TST & \\
\hline CHEMBL1303834 & 688422 & 4.65 & 5.0559 & TRN & \\
\hline CHEMBL1403488 & 688422 & 4.8 & 5.1356 & TRN & \\
\hline CHEMBL1480416 & 688422 & 5.0 & 5.3252 & TRN & \\
\hline CHEMBL1343816 & 688422 & 5.45 & 5.6804 & TST & \\
\hline CHEMBL1605534 & 688422 & 4.65 & 5.2269 & TRN & \\
\hline CHEMBL1584333 & 688422 & 5.6 & 5.6814 & TRN & \\
\hline CHEMBL1522486 & 688422 & 6.0 & 5.8841 & TRN & \\
\hline
\end{tabular}




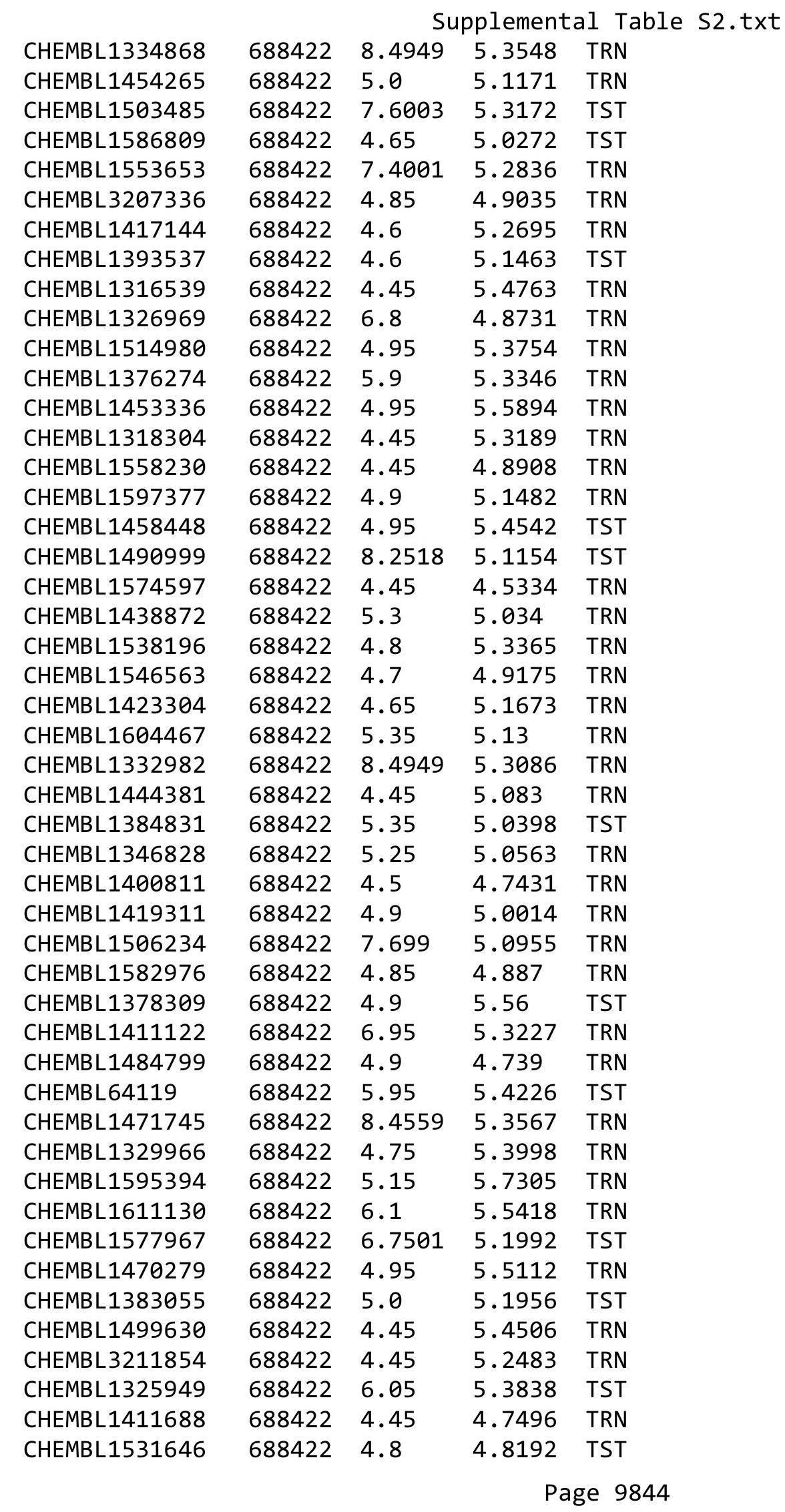




\begin{tabular}{|c|c|c|c|c|c|}
\hline \multirow[b]{2}{*}{ CHEMBL1471419 } & \multicolumn{5}{|c|}{ Supplemental Table S2.txt } \\
\hline & 688422 & 7.3497 & 5.6296 & TRN & \\
\hline CHEMBL1321022 & 688422 & 4.75 & 5.3125 & TRN & \\
\hline CHEMBL1487276 & 688422 & 5.2 & 5.6145 & TRN & \\
\hline CHEMBL1355071 & 688422 & 5.85 & 4.7682 & TRN & \\
\hline CHEMBL1464614 & 688422 & 5.05 & 4.8461 & TRN & \\
\hline CHEMBL1535379 & 688422 & 8.301 & 5.2542 & TRN & \\
\hline CHEMBL1503731 & 688422 & 4.45 & 5.0875 & TRN & \\
\hline CHEMBL1350656 & 688422 & 4.95 & 4.8166 & TRN & \\
\hline CHEMBL1469991 & 688422 & 4.75 & 5.6347 & TST & \\
\hline CHEMBL3196587 & 688422 & 5.6 & 5.4685 & TST & \\
\hline CHEMBL1364822 & 688422 & 5.4 & 5.1881 & TRN & \\
\hline CHEMBL1441326 & 688422 & 6.15 & 5.524 & TST & \\
\hline CHEMBL1502687 & 688422 & 5.0 & 5.3 & TST & \\
\hline CHEMBL1429498 & 688422 & 4.8 & 5.1826 & TRN & \\
\hline CHEMBL1420768 & 688422 & 4.5 & 5.05699 & 99999999995 & TST \\
\hline CHEMBL1497951 & 688422 & 4.45 & 5.1057 & TST & \\
\hline CHEMBL1611271 & 688422 & 5.5 & 5.4086 & TST & \\
\hline CHEMBL1545160 & 688422 & 4.45 & 5.0619 & TRN & \\
\hline CHEMBL1303336 & 688422 & 4.9 & 4.9091 & TRN & \\
\hline CHEMBL1510635 & 688422 & 4.9 & 5.1718 & TRN & \\
\hline CHEMBL 3144884 & 688422 & 4.75 & 4.9215 & TST & \\
\hline CHEMBL1611338 & 688422 & 4.5 & 4.7803 & TRN & \\
\hline CHEMBL1599875 & 688422 & 5.3 & 5.2352 & TRN & \\
\hline CHEMBL1452090 & 688422 & 5.2 & 5.3809 & TRN & \\
\hline CHEMBL1512880 & 688422 & 4.45 & 5.6529 & TRN & \\
\hline CHEMBL1596990 & 688422 & 7.0 & 5.4569 & TST & \\
\hline CHEMBL1401360 & 688422 & 4.9 & 4.96399 & 99999999995 & TRN \\
\hline CHEMBL 2005764 & 688422 & 4.7 & 5.3015 & TST & \\
\hline CHEMBL1342040 & 688422 & 5.25 & 5.3144 & TST & \\
\hline CHEMBL1583241 & 688422 & 8.4949 & 5.3837 & TST & \\
\hline CHEMBL1584840 & 688422 & 5.0 & 5.1335 & TRN & \\
\hline CHEMBL1336469 & 688422 & 5.3 & 5.2145 & TST & \\
\hline CHEMBL1363376 & 688422 & 4.6 & 5.32299 & 99999999995 & TRN \\
\hline CHEMBL1467141 & 688422 & 5.35 & 5.2974 & TRN & \\
\hline CHEMBL1462985 & 688422 & 4.65 & 4.971 & TST & \\
\hline CHEMBL1309376 & 688422 & 4.6 & 5.4763 & TRN & \\
\hline CHEMBL3189917 & 688422 & 4.95 & 5.3229 & TRN & \\
\hline CHEMBL1351922 & 688422 & 4.55 & 5.3592 & TRN & \\
\hline CHEMBL1321760 & 688422 & 4.85 & 5.2278 & TST & \\
\hline CHEMBL1518901 & 688422 & 4.8 & 5.3862 & TRN & \\
\hline CHEMBL1465103 & 688422 & 5.15 & 5.5239 & TRN & \\
\hline CHEMBL1342293 & 688422 & 4.5 & 5.0831 & TRN & \\
\hline CHEMBL1570687 & 688422 & 5.1 & 5.0408 & TRN & \\
\hline CHEMBL1438112 & 688422 & 8.0 & 4.8858 & TRN & \\
\hline CHEMBL1393701 & 688422 & 4.85 & 5.1061 & TRN & \\
\hline CHEMBL1575111 & 688422 & 7.1002 & 5.3391 & TST & \\
\hline CHEMBL1461123 & 688422 & 5.0 & 5.0683 & TRN & \\
\hline CHEMBL1431941 & 688422 & 4.65 & 5.306 & TRN & \\
\hline
\end{tabular}




\begin{tabular}{|c|c|c|c|c|c|}
\hline \multicolumn{6}{|c|}{ Supplemental Table S2.txt } \\
\hline CHEMBL1534947 & 688422 & 4.9 & 5.2179 & TRN & \\
\hline CHEMBL1562498 & 688422 & 5.85 & 5.3007 & TRN & \\
\hline CHEMBL1540446 & 688422 & 4.45 & 5.2065 & TRN & \\
\hline CHEMBL1454177 & 688422 & 4.45 & 5.08899 & 99999999995 & TRN \\
\hline CHEMBL1328202 & 688422 & 4.8 & 4.6778 & TRN & \\
\hline CHEMBL1579559 & 688422 & 7.6498 & 5.0023 & TRN & \\
\hline CHEMBL1366285 & 688422 & 5.15 & 5.5401 & TRN & \\
\hline CHEMBL1382922 & 688422 & 4.85 & 5.0317 & TST & \\
\hline CHEMBL1346885 & 688422 & 4.5 & 5.0321 & TRN & \\
\hline CHEMBL49247 & 688422 & 8.3468 & 5.1864 & TST & \\
\hline CHEMBL1469016 & 688422 & 6.25 & 5.4903 & TRN & \\
\hline CHEMBL1556186 & 688422 & 4.9 & 5.3183 & TST & \\
\hline CHEMBL1582635 & 688422 & 5.25 & 5.3237 & TRN & \\
\hline CHEMBL 389704 & 688422 & 5.0 & 5.5662 & TRN & \\
\hline CHEMBL1346762 & 688422 & 4.9 & 5.2818 & TST & \\
\hline CHEMBL1507948 & 688422 & 4.45 & 5.2281 & TRN & \\
\hline CHEMBL3192905 & 688422 & 4.8 & 5.2762 & TRN & \\
\hline CHEMBL1310133 & 688422 & 4.6 & 4.8039 & TRN & \\
\hline CHEMBL1589242 & 688422 & 8.0506 & 5.3134 & TRN & \\
\hline CHEMBL1471121 & 688422 & 5.15 & 5.4408 & TRN & \\
\hline CHEMBL1491815 & 688422 & 5.25 & 5.0265 & TRN & \\
\hline CHEMBL1323994 & 688422 & 4.9 & 5.1462 & TRN & \\
\hline CHEMBL1480806 & 688422 & 4.6 & 4.6387 & TRN & \\
\hline CHEMBL1308971 & 688422 & 4.75 & 5.3637 & TRN & \\
\hline CHEMBL1524403 & 688422 & 4.45 & 4.8843 & TRN & \\
\hline CHEMBL1556323 & 688422 & 4.5 & 4.7734 & TST & \\
\hline CHEMBL1461074 & 688422 & 8.301 & 5.3871 & TRN & \\
\hline CHEMBL1374158 & 688422 & 4.45 & 5.2113 & TRN & \\
\hline CHEMBL1341453 & 688422 & 4.8 & 5.0352 & TRN & \\
\hline CHEMBL1562202 & 688422 & 4.5 & 5.0402 & TRN & \\
\hline CHEMBL1562340 & 688422 & 4.95 & 4.8857 & TRN & \\
\hline CHEMBL1337055 & 688422 & 4.5 & 5.3112 & TRN & \\
\hline CHEMBL1312308 & 688422 & 4.85 & 5.3167 & TST & \\
\hline CHEMBL1467305 & 688422 & 4.65 & 5.37700 & 0000000001 & TST \\
\hline CHEMBL580609 & 688422 & 5.6 & 4.7228 & TRN & \\
\hline CHEMBL1583011 & 688422 & 5.55 & 4.9358 & TRN & \\
\hline CHEMBL1388722 & 688422 & 5.75 & 5.1405 & TRN & \\
\hline CHEMBL1419309 & 688422 & 7.3497 & 4.8544 & TRN & \\
\hline CHEMBL1299363 & 688422 & 4.45 & 5.0697 & TST & \\
\hline CHEMBL1482759 & 688422 & 4.45 & 5.011 & TRN & \\
\hline CHEMBL1400579 & 688422 & 4.95 & 5.2747 & TRN & \\
\hline CHEMBL1606948 & 688422 & 4.45 & 5.2333 & TRN & \\
\hline CHEMBL1336714 & 688422 & 4.95 & 5.235 & TRN & \\
\hline CHEMBL1504829 & 688422 & 4.75 & 5.2527 & TRN & \\
\hline CHEMBL1593056 & 688422 & 5.0 & 4.7289 & TRN & \\
\hline CHEMBL1502655 & 688422 & 7.8996 & 5.4821 & TRN & \\
\hline CHEMBL3197425 & 688422 & 4.65 & 5.0618 & TRN & \\
\hline CHEMBL1528474 & 688422 & 4.85 & 5.3842 & TRN & \\
\hline
\end{tabular}




\begin{tabular}{|c|c|c|c|c|c|}
\hline \multicolumn{6}{|c|}{ Supplemental Table S2.txt } \\
\hline CHEMBL1367949 & 688422 & 4.75 & 5.359 & TRN & \\
\hline CHEMBL1333077 & 688422 & 4.45 & 5.5128 & TST & \\
\hline CHEMBL1607877 & 688422 & 4.45 & 4.8025 & TRN & \\
\hline CHEMBL1402864 & 688422 & 5.0 & 5.9272 & TRN & \\
\hline CHEMBL1346385 & 688422 & 4.7 & 5.19799 & 99999999995 & TRN \\
\hline CHEMBL1473513 & 688422 & 6.8 & 5.3792 & TST & \\
\hline CHEMBL1470194 & 688422 & 6.45 & 5.5258 & TRN & \\
\hline CHEMBL1331349 & 688422 & 4.65 & 4.7964 & TRN & \\
\hline CHEMBL1448518 & 688422 & 4.9 & 4.9823 & TRN & \\
\hline CHEMBL1306176 & 688422 & 4.65 & 5.0593 & TRN & \\
\hline CHEMBL1556239 & 688422 & 5.05 & 5.5363 & TST & \\
\hline CHEMBL1501896 & 688422 & 5.45 & 5.402 & TRN & \\
\hline CHEMBL3189370 & 688422 & 6.05 & 5.5076 & TRN & \\
\hline CHEMBL3193064 & 688422 & 4.45 & 5.4187 & TRN & \\
\hline CHEMBL1579869 & 688422 & 4.45 & 5.1061 & TRN & \\
\hline CHEMBL1561409 & 688422 & 5.2 & 5.2557 & TST & \\
\hline CHEMBL1378063 & 688422 & 5.9 & 5.7019 & TRN & \\
\hline CHEMBL1405279 & 688422 & 4.85 & 5.4561 & TST & \\
\hline CHEMBL1342741 & 688422 & 4.45 & 4.9413 & TRN & \\
\hline CHEMBL1454333 & 688422 & 8.3468 & 5.2749 & TRN & \\
\hline CHEMBL1531333 & 688422 & 8.0 & 5.2774 & TST & \\
\hline CHEMBL3212279 & 688422 & 4.45 & 5.3941 & TST & \\
\hline CHEMBL1537163 & 688422 & 4.75 & 5.5381 & TRN & \\
\hline CHEMBL 292368 & 688422 & 4.8 & 5.4106 & TST & \\
\hline CHEMBL1526311 & 688422 & 5.4 & 5.9525 & TRN & \\
\hline CHEMBL1313614 & 688422 & 4.45 & 5.25899 & 99999999995 & TRN \\
\hline CHEMBL1407835 & 688422 & 5.45 & 5.3144 & TRN & \\
\hline CHEMBL1412709 & 688422 & 4.85 & 4.8435 & TST & \\
\hline CHEMBL1561890 & 688422 & 5.6 & 5.2902 & TRN & \\
\hline CHEMBL564201 & 688422 & 6.6499 & 6.44600 & 0000000001 & TRN \\
\hline CHEMBL1485240 & 688422 & 4.8 & 5.564 & TST & \\
\hline CHEMBL1586686 & 688422 & 4.8 & 5.3378 & TST & \\
\hline CHEMBL1589248 & 688422 & 4.95 & 4.5311 & TRN & \\
\hline CHEMBL1579907 & 688422 & 8.4559 & 5.5305 & TRN & \\
\hline CHEMBL1385427 & 688422 & 5.1 & 5.3196 & TRN & \\
\hline CHEMBL1508014 & 688422 & 5.9 & 5.3857 & TRN & \\
\hline CHEMBL1499432 & 688422 & 4.5 & 5.0537 & TST & \\
\hline CHEMBL3209224 & 688422 & 4.45 & 5.2521 & TRN & \\
\hline CHEMBL1485101 & 688422 & 4.45 & 5.2233 & TST & \\
\hline CHEMBL1339987 & 688422 & 5.0 & 5.085 & TRN & \\
\hline CHEMBL3192208 & 688422 & 4.45 & 4.8621 & TRN & \\
\hline CHEMBL1313691 & 688422 & 5.0 & 5.28600 & 00000000005 & TRN \\
\hline CHEMBL1609693 & 688422 & 7.699 & 5.6706 & TRN & \\
\hline CHEMBL3198152 & 688422 & 4.45 & 5.5989 & TRN & \\
\hline CHEMBL1501505 & 688422 & 4.45 & 4.9644 & TRN & \\
\hline CHEMBL1528593 & 688422 & 4.9 & 5.2264 & TRN & \\
\hline CHEMBL1304918 & 688422 & 4.45 & 4.9897 & TRN & \\
\hline CHEMBL3195164 & 688422 & 5.4 & 5.3119 & TRN & \\
\hline
\end{tabular}




\begin{tabular}{|c|c|c|c|c|}
\hline \multicolumn{5}{|c|}{ Supplemental Table S2.txt } \\
\hline CHEMBL1375377 & 688422 & 4.65 & 5.2173 & TRN \\
\hline CHEMBL1977763 & 688422 & 5.15 & 5.1358 & TRN \\
\hline CHEMBL 3856090 & 688422 & 4.9 & 5.4273 & TRN \\
\hline CHEMBL1489974 & 688422 & 4.6 & 4.8934 & TRN \\
\hline CHEMBL3195599 & 688422 & 4.5 & 5.3845 & TRN \\
\hline CHEMBL1547874 & 688422 & 8.3468 & 5.3883 & TST \\
\hline CHEMBL1418713 & 688422 & 8.0 & 5.1005 & TST \\
\hline CHEMBL1471693 & 688422 & 4.45 & 5.21 & TRN \\
\hline CHEMBL1457779 & 688422 & 5.25 & 5.0462 & TST \\
\hline CHEMBL1597790 & 688422 & 4.45 & 6.0592 & TRN \\
\hline CHEMBL1525736 & 688422 & 4.8 & 5.475 & TRN \\
\hline CHEMBL1412742 & 688422 & 4.95 & 5.3961 & TST \\
\hline CHEMBL1414634 & 688422 & 6.5501 & 5.0076 & TRN \\
\hline CHEMBL1496487 & 688422 & 4.45 & 5.0178 & TRN \\
\hline CHEMBL1501793 & 688422 & 5.0 & 5.3564 & TST \\
\hline CHEMBL1338554 & 688422 & 4.45 & 5.1413 & TRN \\
\hline CHEMBL1449552 & 688422 & 4.5 & 5.3591 & TRN \\
\hline CHEMBL1580342 & 688422 & 4.45 & 5.026 & TRN \\
\hline CHEMBL1520214 & 688422 & 4.6 & 4.9635 & TRN \\
\hline CHEMBL1574207 & 688422 & 4.5 & 5.3139 & TRN \\
\hline CHEMBL1565290 & 688422 & 4.45 & 4.8782 & TRN \\
\hline CHEMBL1585030 & 688422 & 4.65 & 5.2242 & TRN \\
\hline CHEMBL1522468 & 688422 & 4.85 & 4.9732 & TRN \\
\hline CHEMBL1442446 & 688422 & 6.05 & 5.4494 & TST \\
\hline CHEMBL1329436 & 688422 & 4.9 & 5.0771 & TRN \\
\hline CHEMBL1509029 & 688422 & 5.55 & 5.2666 & TRN \\
\hline CHEMBL1429184 & 688422 & 5.45 & 5.8812 & TST \\
\hline CHEMBL1414585 & 688422 & 5.05 & 5.7323 & TRN \\
\hline CHEMBL1374562 & 688422 & 5.2 & 5.4238 & TRN \\
\hline CHEMBL1400152 & 688422 & 4.45 & 5.0753 & TRN \\
\hline CHEMBL1479340 & 688422 & 4.55 & 4.8673 & TST \\
\hline CHEMBL1364018 & 688422 & 5.6 & 4.977 & TRN \\
\hline CHEMBL1450974 & 688422 & 4.85 & 4.925 & TRN \\
\hline CHEMBL1549791 & 688422 & 4.8 & 5.1416 & TRN \\
\hline CHEMBL589232 & 688422 & 5.15 & 5.5367 & TRN \\
\hline CHEMBL240836 & 688422 & 4.45 & 4.9948 & TST \\
\hline CHEMBL1544164 & 688422 & 4.75 & 4.9912 & TRN \\
\hline CHEMBL1483547 & 688422 & 5.75 & 5.2868 & TRN \\
\hline CHEMBL1523685 & 688422 & 5.0 & 4.9593 & TRN \\
\hline CHEMBL1503883 & 688422 & 4.65 & 4.7893 & TRN \\
\hline CHEMBL1450414 & 688422 & 5.3 & 5.442 & TRN \\
\hline CHEMBL1481932 & 688422 & 5.85 & 5.2475 & TRN \\
\hline CHEMBL1365741 & 688422 & 5.55 & 5.2205 & TRN \\
\hline CHEMBL1324514 & 688422 & 6.0 & 5.186 & TRN \\
\hline CHEMBL3194416 & 688422 & 8.3468 & 5.3733 & TST \\
\hline CHEMBL1524383 & 688422 & 4.6 & 5.0209 & TRN \\
\hline CHEMBL1587730 & 688422 & 4.45 & 5.0311 & TRN \\
\hline CHEMBL1451622 & 688422 & 5.0 & 4.7706 & TRN \\
\hline
\end{tabular}




\begin{tabular}{|c|c|c|c|c|c|}
\hline \multicolumn{6}{|c|}{ Supplemental Table S2.txt } \\
\hline CHEMBL1458758 & 688422 & 4.9 & 5.471 & TST & \\
\hline CHEMBL1359848 & 688422 & 4.45 & 4.8377 & TRN & \\
\hline CHEMBL1388599 & 688422 & 4.7 & 5.1485 & TRN & \\
\hline CHEMBL1310772 & 688422 & 5.15 & 5.0937 & TRN & \\
\hline CHEMBL1390539 & 688422 & 4.45 & 4.8438 & TRN & \\
\hline CHEMBL1311587 & 688422 & 4.45 & 5.1154 & TRN & \\
\hline CHEMBL1377883 & 688422 & 5.6 & 5.1531 & TRN & \\
\hline CHEMBL1325610 & 688422 & 5.3 & 5.183 & TRN & \\
\hline CHEMBL1571598 & 688422 & 5.05 & 5.5123 & TRN & \\
\hline CHEMBL1307019 & 688422 & 4.7 & 4.8236 & TRN & \\
\hline CHEMBL1410434 & 688422 & 4.5 & 5.1623 & TST & \\
\hline CHEMBL1329952 & 688422 & 4.45 & 5.0289 & TRN & \\
\hline CHEMBL1421818 & 688422 & 4.45 & 5.195 & TST & \\
\hline CHEMBL1980844 & 688422 & 7.0 & 5.7007 & TST & \\
\hline CHEMBL1439454 & 688422 & 6.4 & 5.6461 & TRN & \\
\hline CHEMBL 3214250 & 688422 & 4.45 & 5.5044 & TRN & \\
\hline CHEMBL1606986 & 688422 & 4.45 & 5.1343 & TRN & \\
\hline CHEMBL1606174 & 688422 & 4.9 & 5.2379 & TRN & \\
\hline CHEMBL1593774 & 688422 & 4.9 & 4.8573 & TRN & \\
\hline CHEMBL1478942 & 688422 & 4.85 & 5.5713 & TST & \\
\hline CHEMBL1437712 & 688422 & 4.95 & 5.63899 & 9999999999 & TRN \\
\hline CHEMBL1539450 & 688422 & 4.6 & 5.3989 & TST & \\
\hline CHEMBL1407479 & 688422 & 4.45 & 4.5622 & TRN & \\
\hline CHEMBL1410645 & 688422 & 8.3979 & 5.91799 & 9999999999 & TST \\
\hline CHEMBL1533494 & 688422 & 4.9 & 4.7589 & TRN & \\
\hline CHEMBL1385527 & 688422 & 4.8 & 4.968 & TRN & \\
\hline CHEMBL1472037 & 688422 & 4.95 & 5.1793 & TST & \\
\hline CHEMBL1582864 & 688422 & 5.5 & 5.675 & TRN & \\
\hline CHEMBL1335226 & 688422 & 4.95 & 4.9821 & TRN & \\
\hline CHEMBL1333702 & 688422 & 4.75 & 5.0996 & TRN & \\
\hline CHEMBL1536801 & 688422 & 4.65 & 4.9694 & TRN & \\
\hline CHEMBL1344810 & 688422 & 4.5 & 4.6971 & TRN & \\
\hline CHEMBL3191974 & 688422 & 6.7501 & 5.415 & TST & \\
\hline CHEMBL1475364 & 688422 & 5.15 & 5.3427 & TRN & \\
\hline CHEMBL3194435 & 688422 & 4.9 & 5.0888 & TST & \\
\hline CHEMBL3144873 & 688422 & 4.95 & 5.2548 & TRN & \\
\hline CHEMBL1537164 & 688422 & 4.85 & 5.3178 & TST & \\
\hline CHEMBL1509538 & 688422 & 4.45 & 5.1719 & TRN & \\
\hline CHEMBL1300080 & 688422 & 5.4 & 5.0251 & TRN & \\
\hline CHEMBL1580658 & 688422 & 4.9 & 5.0465 & TRN & \\
\hline CHEMBL1447636 & 688422 & 5.1 & 5.4705 & TRN & \\
\hline CHEMBL1328576 & 688422 & 8.2518 & 5.897 & TRN & \\
\hline CHEMBL1495157 & 688422 & 5.8 & 5.3723 & TST & \\
\hline CHEMBL1531663 & 688422 & 7.3497 & 5.4642 & TRN & \\
\hline CHEMBL1547601 & 688422 & 5.75 & 5.3268 & TRN & \\
\hline CHEMBL3211103 & 688422 & 4.45 & 5.0759 & TST & \\
\hline CHEMBL1383683 & 688422 & 4.65 & 5.5151 & TRN & \\
\hline CHEMBL1473697 & 688422 & 5.75 & 5.3658 & TRN & \\
\hline
\end{tabular}




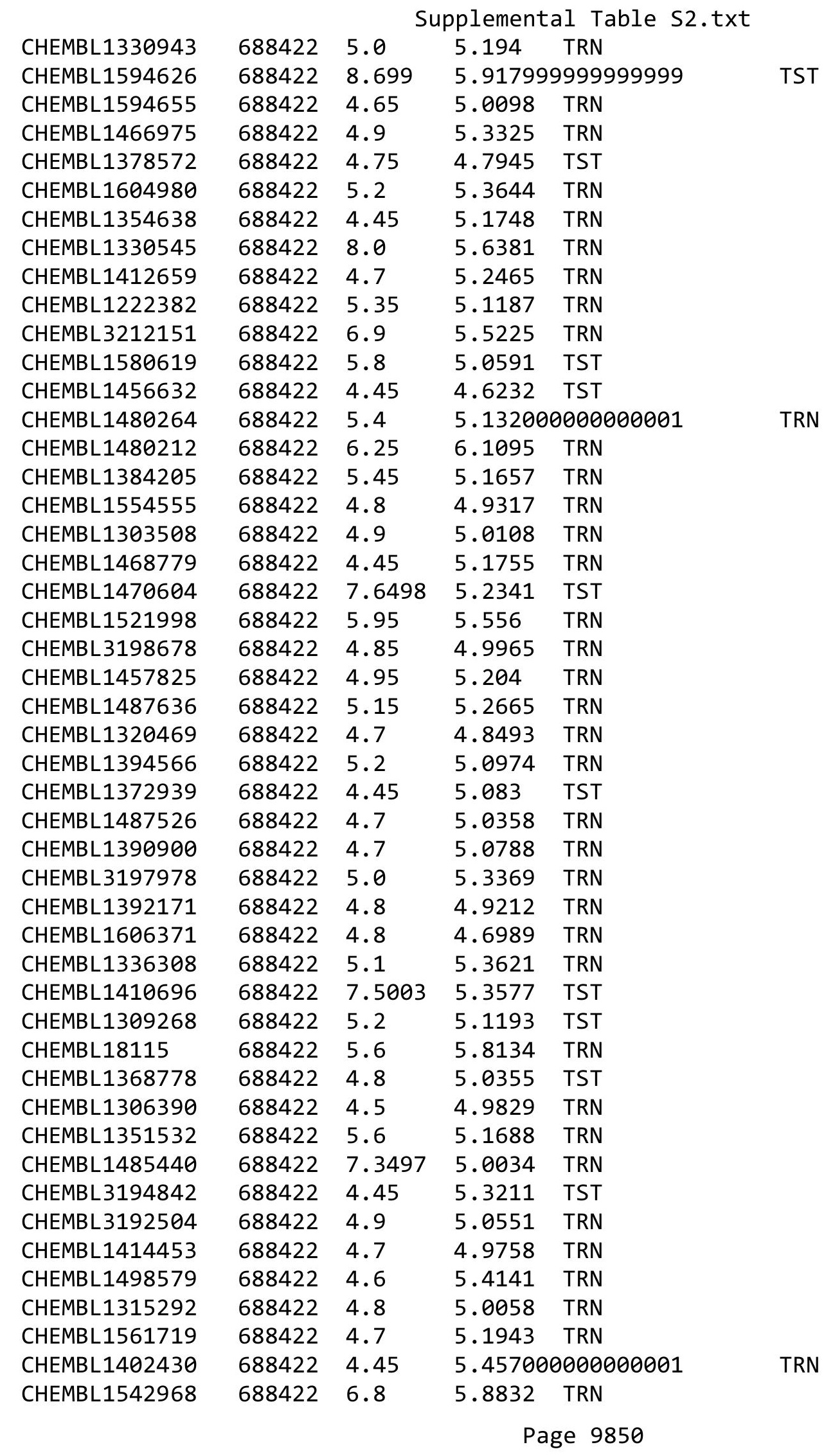




\begin{tabular}{|c|c|c|c|c|c|}
\hline \multicolumn{6}{|c|}{ Supplemental Table S2.txt } \\
\hline CHEMBL1339565 & 688422 & 4.95 & 4.7614 & TST & \\
\hline CHEMBL1459539 & 688422 & 4.45 & 5.0996 & TRN & \\
\hline CHEMBL1383681 & 688422 & 5.7 & 5.1073 & TRN & \\
\hline CHEMBL1435143 & 688422 & 4.45 & 5.0577 & TRN & \\
\hline CHEMBL1387334 & 688422 & 4.45 & 4.6906 & TRN & \\
\hline CHEMBL1452132 & 688422 & 4.45 & 4.6743 & TRN & \\
\hline CHEMBL1445914 & 688422 & 6.8 & 5.4038 & TRN & \\
\hline CHEMBL1393805 & 688422 & 4.9 & 4.8502 & TRN & \\
\hline CHEMBL1441934 & 688422 & 4.45 & 5.1393 & TST & \\
\hline CHEMBL1611902 & 688422 & 4.75 & 4.7654 & TST & \\
\hline CHEMBL1345251 & 688422 & 7.699 & 5.2612 & TRN & \\
\hline CHEMBL1980677 & 688422 & 7.6003 & 5.5755 & TST & \\
\hline CHEMBL1375998 & 688422 & 4.65 & 4.6403 & TRN & \\
\hline CHEMBL1361165 & 688422 & 5.85 & 5.1846 & TRN & \\
\hline CHEMBL1383567 & 688422 & 4.9 & 4.9519 & TRN & \\
\hline CHEMBL1410701 & 688422 & 4.55 & 5.5756 & TRN & \\
\hline CHEMBL1340578 & 688422 & 4.7 & 4.912 & TRN & \\
\hline CHEMBL1387577 & 688422 & 4.45 & 5.2664 & TRN & \\
\hline CHEMBL1415331 & 688422 & 4.85 & 5.5953 & TRN & \\
\hline CHEMBL1366005 & 688422 & 8.4949 & 5.3205 & TRN & \\
\hline CHEMBL1584397 & 688422 & 5.5 & 4.8916 & TRN & \\
\hline CHEMBL1338384 & 688422 & 4.45 & 5.0861 & TRN & \\
\hline CHEMBL1477915 & 688422 & 4.8 & 5.1561 & TRN & \\
\hline CHEMBL1434782 & 688422 & 7.5498 & 5.289 & TRN & \\
\hline CHEMBL494474 & 688422 & 4.95 & 5.234 & TRN & \\
\hline CHEMBL1544508 & 688422 & 4.65 & 5.2815 & TRN & \\
\hline CHEMBL1308607 & 688422 & 4.95 & 5.0024 & TRN & \\
\hline CHEMBL1542539 & 688422 & 4.75 & 5.4775 & TST & \\
\hline CHEMBL1544486 & 688422 & 8.0 & 5.4662 & TRN & \\
\hline CHEMBL1607444 & 688422 & 5.3 & 5.0554 & TST & \\
\hline CHEMBL1610741 & 688422 & 5.8 & 5.3291 & TST & \\
\hline CHEMBL1463054 & 688422 & 4.9 & 5.2023 & TRN & \\
\hline CHEMBL1385657 & 688422 & 4.45 & 5.13 & TRN & \\
\hline CHEMBL1458726 & 688422 & 4.45 & 5.0482 & TRN & \\
\hline CHEMBL1304356 & 688422 & 5.0 & 4.82600 & 00000000005 & TST \\
\hline CHEMBL3195824 & 688422 & 4.5 & 5.1506 & TST & \\
\hline CHEMBL3210284 & 688422 & 7.8996 & 5.641 & TRN & \\
\hline CHEMBL3196987 & 688422 & 5.1 & 5.1923 & TST & \\
\hline CHEMBL3194186 & 688422 & 4.5 & 5.3572 & TRN & \\
\hline CHEMBL1488994 & 688422 & 4.45 & 5.3665 & TST & \\
\hline CHEMBL1398960 & 688422 & 4.8 & 5.4728 & TST & \\
\hline CHEMBL1596068 & 688422 & 5.15 & 5.5901 & TRN & \\
\hline CHEMBL1421073 & 688422 & 7.1002 & 5.3246 & TRN & \\
\hline CHEMBL1611622 & 688422 & 5.0 & 5.2244 & TST & \\
\hline CHEMBL1414188 & 688422 & 4.85 & 4.4712 & TRN & \\
\hline CHEMBL585999 & 688422 & 4.85 & 5.2949 & TRN & \\
\hline CHEMBL1584567 & 688422 & 4.85 & 5.2045 & TRN & \\
\hline CHEMBL1611434 & 688422 & 4.85 & 4.738 & TRN & \\
\hline
\end{tabular}




\begin{tabular}{|c|c|c|c|c|}
\hline \multicolumn{5}{|c|}{ Supplemental Table S2.txt } \\
\hline CHEMBL1588063 & 688422 & 4.45 & 5.4216 & TRN \\
\hline CHEMBL1500466 & 688422 & 5.55 & 5.2129 & TRN \\
\hline CHEMBL1530915 & 688422 & 5.95 & 5.5282 & TRN \\
\hline CHEMBL1322976 & 688422 & 4.7 & 5.6785 & TRN \\
\hline CHEMBL1401636 & 688422 & 7.4001 & 5.5692 & TRN \\
\hline CHEMBL1612858 & 688422 & 4.5 & 5.3214 & TRN \\
\hline CHEMBL1611210 & 688422 & 4.5 & 4.5674 & TRN \\
\hline CHEMBL1542802 & 688422 & 5.25 & 5.2298 & TST \\
\hline CHEMBL1493957 & 688422 & 4.45 & 5.2266 & TRN \\
\hline CHEMBL3191074 & 688422 & 5.75 & 5.6902 & TRN \\
\hline CHEMBL1487853 & 688422 & 4.95 & 5.1914 & TRN \\
\hline CHEMBL1589622 & 688422 & 7.3002 & 5.269 & TST \\
\hline CHEMBL1339218 & 688422 & 4.7 & 5.3564 & TRN \\
\hline CHEMBL1347610 & 688422 & 6.45 & 5.2538 & TRN \\
\hline CHEMBL1353530 & 688422 & 4.9 & 4.9826 & TST \\
\hline CHEMBL1564598 & 688422 & 4.75 & 5.23 & TRN \\
\hline CHEMBL1369761 & 688422 & 6.15 & 5.7501 & TRN \\
\hline CHEMBL1565861 & 688422 & 6.0 & 5.551 & TRN \\
\hline CHEMBL1354691 & 688422 & 4.45 & 5.9425 & TST \\
\hline CHEMBL1321097 & 688422 & 4.65 & 4.6763 & TRN \\
\hline CHEMBL1362564 & 688422 & 4.7 & 5.1025 & TRN \\
\hline CHEMBL1581555 & 688422 & 4.8 & 4.7769 & TRN \\
\hline CHEMBL1372556 & 688422 & 4.8 & 4.9667 & TRN \\
\hline CHEMBL1604735 & 688422 & 4.45 & 4.9743 & TST \\
\hline CHEMBL24223 & 688422 & 5.85 & 5.2426 & TST \\
\hline CHEMBL1392200 & 688422 & 5.15 & 5.449 & TRN \\
\hline CHEMBL1464161 & 688422 & 5.85 & 5.6012 & TRN \\
\hline CHEMBL3197697 & 688422 & 7.6498 & 5.4634 & TRN \\
\hline CHEMBL1400543 & 688422 & 7.2 & 5.3628 & TST \\
\hline CHEMBL1526273 & 688422 & 4.85 & 5.0193 & TRN \\
\hline CHEMBL1505224 & 688422 & 5.1 & 5.3064 & TRN \\
\hline CHEMBL1531037 & 688422 & 8.0 & 5.1006 & TRN \\
\hline CHEMBL3196605 & 688422 & 4.95 & 5.0231 & TRN \\
\hline CHEMBL 3196585 & 688422 & 4.45 & 5.2025 & TST \\
\hline CHEMBL1477423 & 688422 & 5.15 & 5.2451 & TRN \\
\hline CHEMBL1497680 & 688422 & 4.85 & 5.2293 & TST \\
\hline CHEMBL1561715 & 688422 & 4.8 & 5.1828 & TST \\
\hline CHEMBL1301534 & 688422 & 4.8 & 5.2726 & TRN \\
\hline CHEMBL1595723 & 688422 & 4.9 & 5.2174 & TRN \\
\hline CHEMBL 3197263 & 688422 & 4.95 & 5.0329 & TRN \\
\hline CHEMBL1580472 & 688422 & 5.35 & 4.9841 & TRN \\
\hline CHEMBL1320633 & 688422 & 4.8 & 5.4763 & TST \\
\hline CHEMBL1440565 & 688422 & 4.45 & 5.1676 & TRN \\
\hline CHEMBL1357369 & 688422 & 7.2503 & 6.6043 & TRN \\
\hline CHEMBL1419571 & 688422 & 4.45 & 5.4789 & TRN \\
\hline CHEMBL1405669 & 688422 & 4.7 & 5.0708 & TRN \\
\hline CHEMBL1592910 & 688422 & 4.7 & 4.8462 & TRN \\
\hline CHEMBL1430105 & 688422 & 4.95 & 5.1346 & TST \\
\hline
\end{tabular}




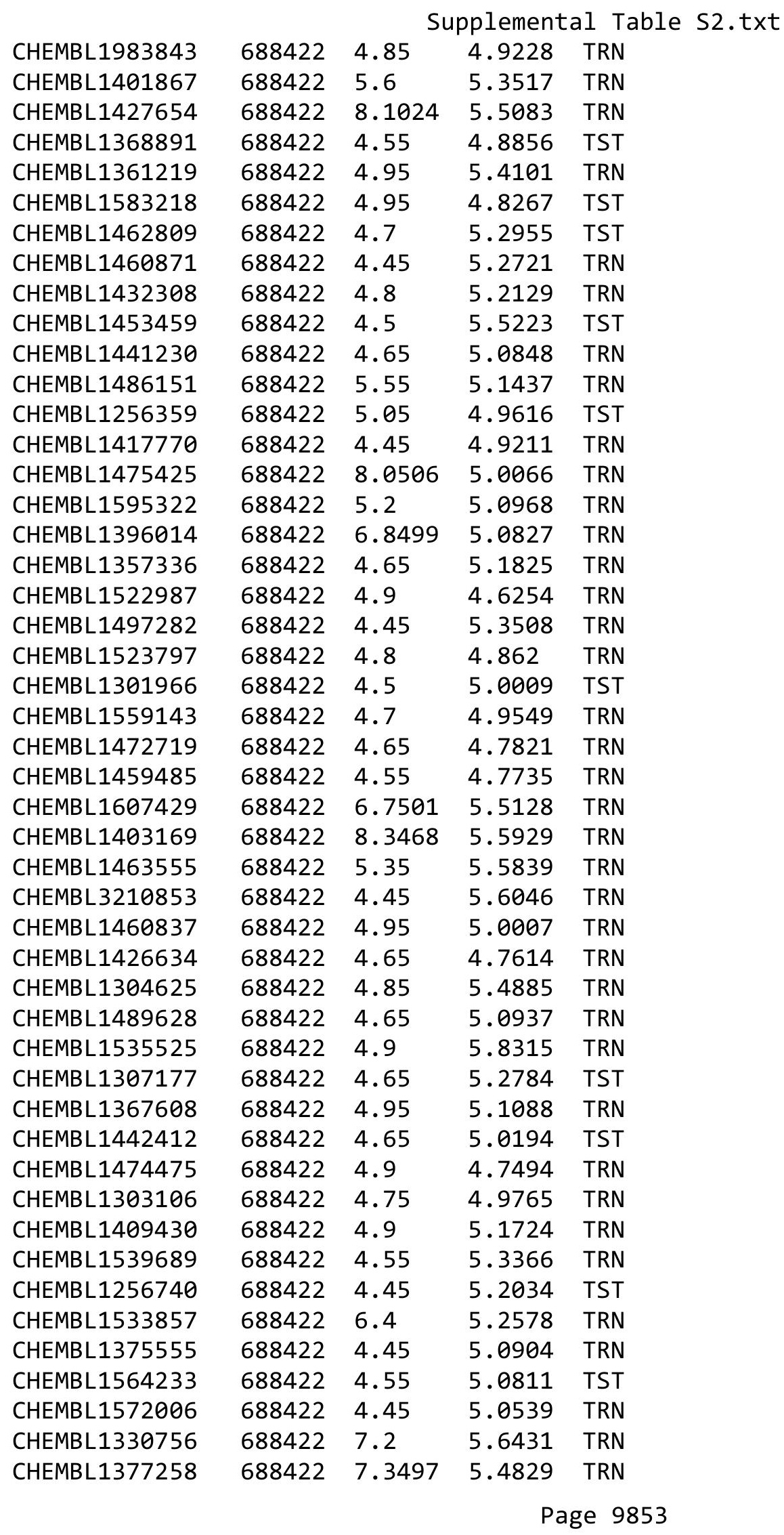




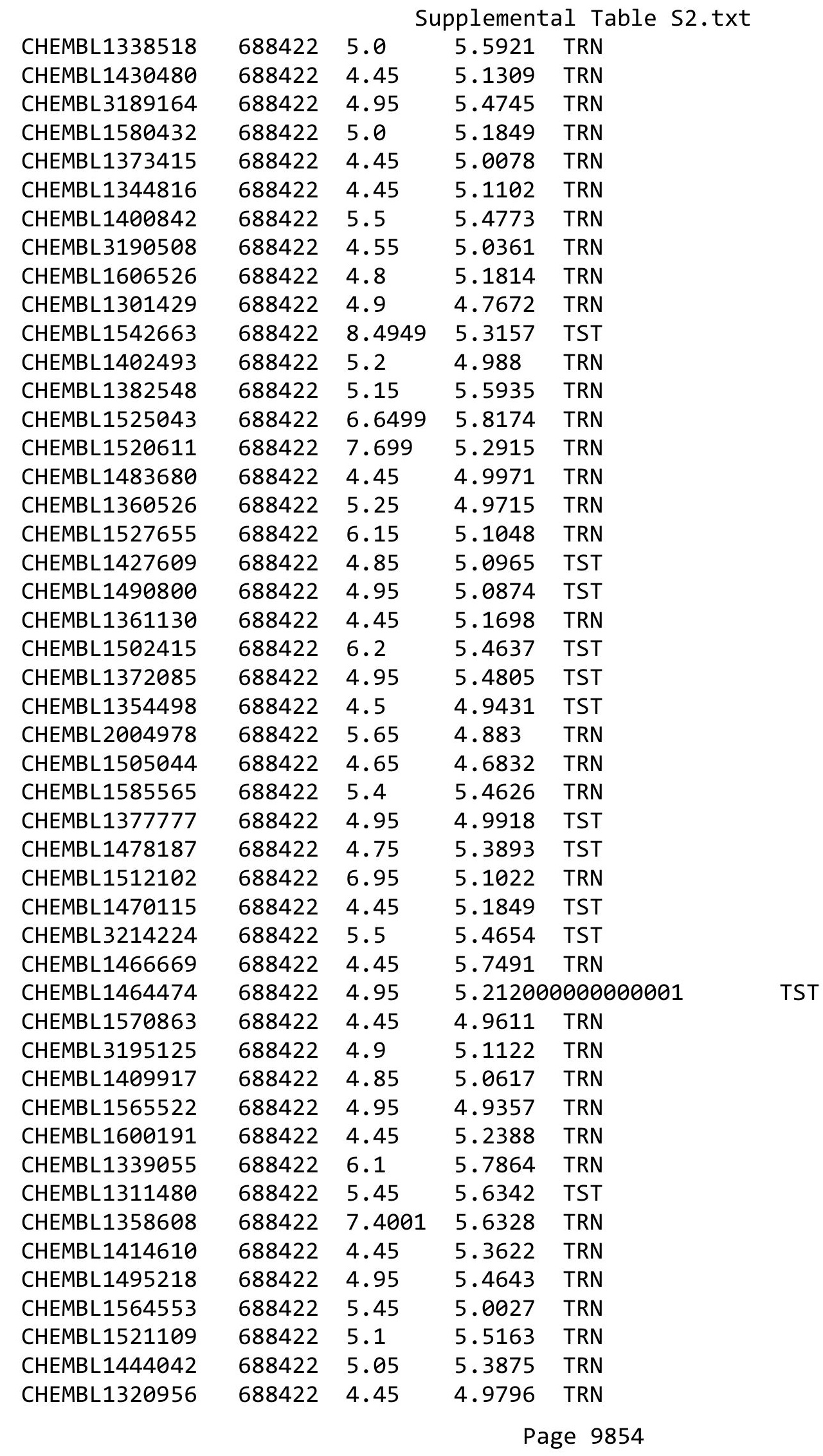




\begin{tabular}{|c|c|c|c|c|c|}
\hline \multirow[b]{2}{*}{ CHEMBL1464174 } & \multicolumn{5}{|c|}{ Supplemental Table S2.txt } \\
\hline & 688422 & 4.95 & 4.9784 & TRN & \\
\hline CHEMBL1313486 & 688422 & 6.4 & 5.74100 & 00000000005 & TRN \\
\hline CHEMBL1333395 & 688422 & 4.85 & 5.3262 & TST & \\
\hline CHEMBL1338168 & 688422 & 4.45 & 5.2236 & TST & \\
\hline CHEMBL1389918 & 688422 & 4.8 & 5.5184 & TST & \\
\hline CHEMBL1310478 & 688422 & 4.75 & 4.9669 & TRN & \\
\hline CHEMBL1550078 & 688422 & 8.0 & 5.1125 & TST & \\
\hline CHEMBL1522841 & 688422 & 4.8 & 5.4922 & TST & \\
\hline CHEMBL1428207 & 688422 & 4.45 & 5.1799 & TRN & \\
\hline CHEMBL1373605 & 688422 & 4.95 & 5.4762 & TST & \\
\hline CHEMBL1397069 & 688422 & 8.3979 & 6.0161 & TST & \\
\hline CHEMBL3191597 & 688422 & 7.6498 & 4.9737 & TRN & \\
\hline CHEMBL1485866 & 688422 & 4.45 & 4.8076 & TST & \\
\hline CHEMBL1446541 & 688422 & 4.85 & 5.1879 & TRN & \\
\hline CHEMBL1458510 & 688422 & 4.9 & 5.1488 & TST & \\
\hline CHEMBL1509514 & 688422 & 4.5 & 5.2326 & TRN & \\
\hline CHEMBL1388951 & 688422 & 5.2 & 5.3072 & TRN & \\
\hline CHEMBL1602064 & 688422 & 4.9 & 5.2073 & TST & \\
\hline CHEMBL1301528 & 688422 & 4.5 & 5.3389 & TRN & \\
\hline CHEMBL1444260 & 688422 & 4.75 & 5.5121 & TST & \\
\hline CHEMBL1499260 & 688422 & 5.05 & 5.3688 & TRN & \\
\hline CHEMBL1605078 & 688422 & 5.15 & 5.2952 & TRN & \\
\hline CHEMBL1599378 & 688422 & 5.05 & 5.2123 & TRN & \\
\hline CHEMBL1531853 & 688422 & 5.7 & 5.1889 & TRN & \\
\hline CHEMBL1301139 & 688422 & 5.4 & 5.2559 & TRN & \\
\hline CHEMBL1413473 & 688422 & 5.55 & 5.4597 & TRN & \\
\hline CHEMBL1330256 & 688422 & 4.6 & 4.8989 & TRN & \\
\hline CHEMBL1523610 & 688422 & 4.55 & 4.756 & TRN & \\
\hline CHEMBL3197015 & 688422 & 4.45 & 4.9003 & TRN & \\
\hline CHEMBL1396958 & 688422 & 5.4 & 5.1223 & TRN & \\
\hline CHEMBL1405788 & 688422 & 4.95 & 5.0324 & TST & \\
\hline CHEMBL1305463 & 688422 & 5.15 & 5.1698 & TRN & \\
\hline CHEMBL3191801 & 688422 & 4.7 & 5.1086 & TRN & \\
\hline CHEMBL1499985 & 688422 & 4.75 & 4.7761 & TRN & \\
\hline CHEMBL1455386 & 688422 & 6.2 & 5.5344 & TRN & \\
\hline CHEMBL1566409 & 688422 & 4.5 & 5.2876 & TRN & \\
\hline CHEMBL3213183 & 688422 & 5.05 & 5.2157 & TST & \\
\hline CHEMBL1598016 & 688422 & 6.7501 & 5.615 & TRN & \\
\hline CHEMBL1557656 & 688422 & 7.0 & 5.2134 & TST & \\
\hline CHEMBL1373262 & 688422 & 5.2 & 5.2288 & TRN & \\
\hline CHEMBL1609952 & 688422 & 4.8 & 5.1156 & TRN & \\
\hline CHEMBL1545031 & 688422 & 4.9 & 6.0016 & TST & \\
\hline CHEMBL1496012 & 688422 & 5.9 & 5.3852 & TRN & \\
\hline CHEMBL1536981 & 688422 & 6.8499 & 5.142 & TRN & \\
\hline CHEMBL1497661 & 688422 & 4.7 & 5.3177 & TRN & \\
\hline CHEMBL1427146 & 688422 & 4.65 & 5.5103 & TST & \\
\hline CHEMBL1485343 & 688422 & 6.5501 & 5.4077 & TRN & \\
\hline CHEMBL1471217 & 688422 & 4.85 & 5.2721 & TRN & \\
\hline
\end{tabular}




\begin{tabular}{|c|c|c|c|c|c|}
\hline \multicolumn{6}{|c|}{ Supplemental Table S2.txt } \\
\hline CHEMBL1360151 & 688422 & 4.8 & 5.2403 & TRN & \\
\hline CHEMBL470881 & 688422 & 5.45 & 5.7163 & TST & \\
\hline CHEMBL 3194865 & 688422 & 5.15 & 5.3984 & TST & \\
\hline CHEMBL1425143 & 688422 & 4.45 & 4.8586 & TRN & \\
\hline CHEMBL1346672 & 688422 & 4.45 & 4.7068 & TRN & \\
\hline CHEMBL1404473 & 688422 & 4.45 & 5.055 & TST & \\
\hline CHEMBL 1457515 & 688422 & 4.95 & 5.0754 & TST & \\
\hline CHEMBL1349735 & 688422 & 7.3002 & 5.1327 & TRN & \\
\hline CHEMBL1401052 & 688422 & 4.45 & 5.1553 & TRN & \\
\hline CHEMBL3199324 & 688422 & 5.2 & 5.2798 & TRN & \\
\hline CHEMBL598885 & 688422 & 7.6498 & 5.1452 & TRN & \\
\hline CHEMBL 1557625 & 688422 & 4.8 & 4.9285 & TST & \\
\hline CHEMBL601550 & 688422 & 4.8 & 4.9267 & TST & \\
\hline CHEMBL1604846 & 688422 & 4.6 & 5.5348 & TRN & \\
\hline CHEMBL1487599 & 688422 & 4.9 & 5.13399 & 99999999995 & TRN \\
\hline CHEMBL1382551 & 688422 & 5.6 & 5.3396 & TRN & \\
\hline CHEMBL1309276 & 688422 & 5.25 & 5.0248 & TST & \\
\hline CHEMBL1440008 & 688422 & 4.8 & 5.1321 & TST & \\
\hline CHEMBL1433543 & 688422 & 6.7501 & 5.4333 & TRN & \\
\hline CHEMBL1589662 & 688422 & 4.8 & 5.3346 & TRN & \\
\hline CHEMBL1575331 & 688422 & 4.75 & 5.4692 & TRN & \\
\hline CHEMBL1327738 & 688422 & 5.3 & 5.2731 & TST & \\
\hline CHEMBL1513895 & 688422 & 6.45 & 5.5504 & TST & \\
\hline CHEMBL1612649 & 688422 & 4.7 & 5.0201 & TRN & \\
\hline CHEMBL1475306 & 688422 & 6.45 & 5.4232 & TRN & \\
\hline CHEMBL1472135 & 688422 & 4.85 & 5.007 & TRN & \\
\hline CHEMBL1373194 & 688422 & 4.5 & 5.4434 & TRN & \\
\hline CHEMBL1362660 & 688422 & 4.8 & 5.7658 & TRN & \\
\hline CHEMBL1562012 & 688422 & 4.45 & 4.9892 & TRN & \\
\hline CHEMBL 1572842 & 688422 & 7.1002 & 5.1195 & TRN & \\
\hline CHEMBL1455681 & 688422 & 4.8 & 5.2748 & TRN & \\
\hline CHEMBL1326691 & 688422 & 4.45 & 5.2778 & TRN & \\
\hline CHEMBL1581497 & 688422 & 4.75 & 4.7011 & TRN & \\
\hline CHEMBL1399408 & 688422 & 5.0 & 5.0664 & TST & \\
\hline CHEMBL1418008 & 688422 & 7.699 & 5.4215 & TRN & \\
\hline CHEMBL1609505 & 688422 & 6.1 & 5.7034 & TRN & \\
\hline CHEMBL1323000 & 688422 & 4.45 & 4.9812 & TST & \\
\hline CHEMBL1392545 & 688422 & 4.8 & 5.5563 & TRN & \\
\hline CHEMBL1595759 & 688422 & 4.7 & 5.1908 & TRN & \\
\hline CHEMBL1581923 & 688422 & 4.8 & 5.2184 & TRN & \\
\hline CHEMBL1372095 & 688422 & 4.55 & 5.1185 & TRN & \\
\hline CHEMBL1438466 & 688422 & 5.6 & 5.3023 & TRN & \\
\hline CHEMBL1405679 & 688422 & 6.2 & 5.0602 & TST & \\
\hline CHEMBL 3190774 & 688422 & 4.5 & 5.1442 & TRN & \\
\hline CHEMBL1570319 & 688422 & 4.9 & 5.2285 & TRN & \\
\hline CHEMBL1308223 & 688422 & 5.9 & 5.4781 & TRN & \\
\hline CHEMBL1558155 & 688422 & 4.5 & 5.6904 & TST & \\
\hline CHEMBL34730 & 688422 & 9.0 & 5.6045 & TRN & \\
\hline
\end{tabular}




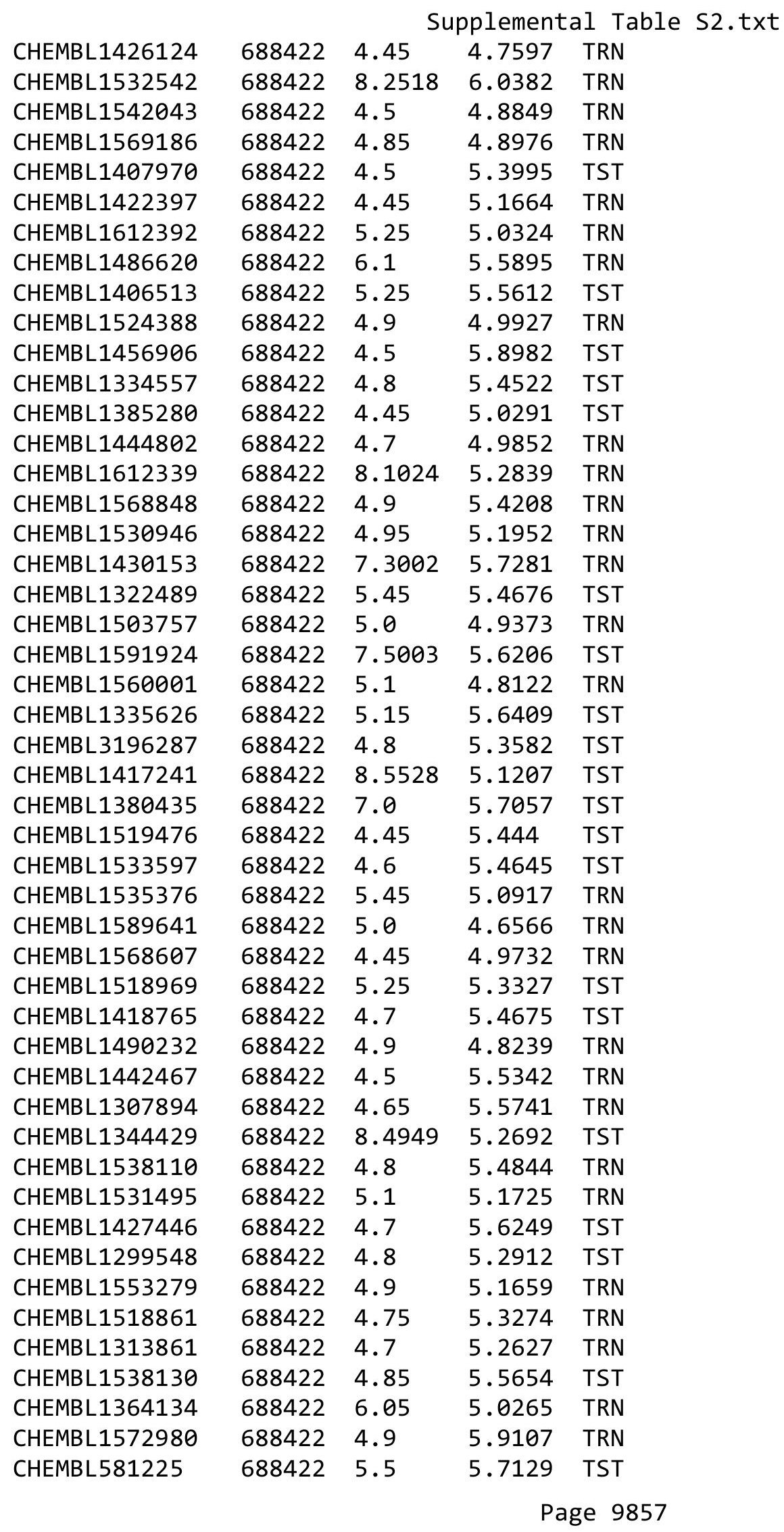




\begin{tabular}{|c|c|c|c|c|c|}
\hline \multicolumn{6}{|c|}{ Supplemental Table S2.txt } \\
\hline CHEMBL1972722 & 688422 & 4.7 & 5.216 & TRN & \\
\hline CHEMBL1388048 & 688422 & 7.1002 & 5.3034 & TRN & \\
\hline CHEMBL1509917 & 688422 & 4.75 & 5.8976 & TST & \\
\hline CHEMBL1306803 & 688422 & 4.9 & 5.1679 & TST & \\
\hline CHEMBL1504762 & 688422 & 5.8 & 5.1827 & TRN & \\
\hline CHEMBL1438942 & 688422 & 4.9 & 4.8451 & TRN & \\
\hline CHEMBL1322935 & 688422 & 7.5003 & 5.9905 & TRN & \\
\hline CHEMBL1530189 & 688422 & 4.45 & 5.0428 & TST & \\
\hline CHEMBL1422336 & 688422 & 6.5 & 5.6948 & TRN & \\
\hline CHEMBL1327930 & 688422 & 6.25 & 5.36299 & 99999999995 & TST \\
\hline CHEMBL1409748 & 688422 & 4.45 & 5.356 & TRN & \\
\hline CHEMBL1501859 & 688422 & 4.45 & 5.3282 & TRN & \\
\hline CHEMBL1476851 & 688422 & 5.9 & 5.3159 & TRN & \\
\hline CHEMBL1551218 & 688422 & 6.5501 & 5.6395 & TRN & \\
\hline CHEMBL1314799 & 688422 & 5.05 & 5.1325 & TRN & \\
\hline CHEMBL1585938 & 688422 & 4.5 & 4.9085 & TRN & \\
\hline CHEMBL1332631 & 688422 & 7.2503 & 6.0304 & TRN & \\
\hline CHEMBL1531215 & 688422 & 7.6498 & 5.5235 & TST & \\
\hline CHEMBL1574873 & 688422 & 8.3468 & 5.789 & TRN & \\
\hline CHEMBL1596628 & 688422 & 4.6 & 5.0627 & TRN & \\
\hline CHEMBL1335853 & 688422 & 4.8 & 5.3019 & TRN & \\
\hline CHEMBL1567428 & 688422 & 4.65 & 5.3017 & TRN & \\
\hline CHEMBL1324974 & 688422 & 8.0506 & 5.2308 & TRN & \\
\hline CHEMBL1543026 & 688422 & 6.05 & 5.5763 & TST & \\
\hline CHEMBL1597215 & 688422 & 6.95 & 5.5433 & TRN & \\
\hline CHEMBL1306911 & 688422 & 4.6 & 5.2254 & TRN & \\
\hline CHEMBL1345262 & 688422 & 4.8 & 4.8877 & TRN & \\
\hline CHEMBL1471350 & 688422 & 4.45 & 4.977 & TRN & \\
\hline CHEMBL1436843 & 688422 & 6.15 & 5.0948 & TRN & \\
\hline CHEMBL1448956 & 688422 & 4.8 & 5.0577 & TRN & \\
\hline CHEMBL1452840 & 688422 & 5.9 & 5.3335 & TST & \\
\hline CHEMBL3194195 & 688422 & 5.3 & 5.0714 & TST & \\
\hline CHEMBL1303320 & 688422 & 5.35 & 4.9558 & TRN & \\
\hline CHEMBL1299880 & 688422 & 4.5 & 5.2064 & TRN & \\
\hline CHEMBL1457690 & 688422 & 4.55 & 4.9849 & TRN & \\
\hline CHEMBL1312683 & 688422 & 4.8 & 5.2854 & TRN & \\
\hline CHEMBL1377544 & 688422 & 4.7 & 4.9035 & TRN & \\
\hline CHEMBL1436319 & 688422 & 8.4949 & 5.1787 & TRN & \\
\hline CHEMBL1469417 & 688422 & 4.7 & 5.0678 & TRN & \\
\hline CHEMBL3199883 & 688422 & 4.45 & 5.0743 & TST & \\
\hline CHEMBL1533591 & 688422 & 4.45 & 5.6035 & TRN & \\
\hline CHEMBL3196383 & 688422 & 5.2 & 5.1713 & TRN & \\
\hline CHEMBL1467247 & 688422 & 4.7 & 5.4892 & TST & \\
\hline CHEMBL1343508 & 688422 & 4.6 & 4.6609 & TRN & \\
\hline CHEMBL1478506 & 688422 & 7.8996 & 5.3406 & TRN & \\
\hline CHEMBL1401265 & 688422 & 4.9 & 5.3997 & TST & \\
\hline CHEMBL1520068 & 688422 & 4.95 & 5.6391 & TRN & \\
\hline CHEMBL1406041 & 688422 & 4.45 & 5.1267 & TRN & \\
\hline
\end{tabular}




\begin{tabular}{|c|c|c|c|c|c|}
\hline & & \multicolumn{4}{|c|}{ Supplemental Table S2.txt } \\
\hline CHEMBL1375437 & 688422 & 4.55 & 5.2263 & TRN & \\
\hline CHEMBL1336937 & 688422 & 4.7 & 5.3062 & TRN & \\
\hline CHEMBL1584610 & 688422 & 4.85 & 5.0062 & TRN & \\
\hline CHEMBL1455421 & 688422 & 4.75 & 5.1363 & TRN & \\
\hline CHEMBL1512127 & 688422 & 5.0 & 5.394 & TRN & \\
\hline CHEMBL1526561 & 688422 & 4.9 & 4.9923 & TRN & \\
\hline CHEMBL1384904 & 688422 & 4.65 & 5.0565 & TST & \\
\hline CHEMBL1483764 & 688422 & 5.15 & 5.3034 & TRN & \\
\hline CHEMBL1345969 & 688422 & 5.3 & 5.0549 & TRN & \\
\hline CHEMBL1578440 & 688422 & 4.45 & 4.9599 & TRN & \\
\hline CHEMBL1430692 & 688422 & 4.8 & 5.1316 & TRN & \\
\hline CHEMBL1390559 & 688422 & 5.95 & 5.1989 & TST & \\
\hline CHEMBL1483713 & 688422 & 5.0 & 5.1301 & TRN & \\
\hline CHEMBL1347614 & 688422 & 4.45 & 5.3273 & TST & \\
\hline CHEMBL1388036 & 688422 & 4.65 & 4.8845 & TST & \\
\hline CHEMBL1325231 & 688422 & 4.95 & 5.4439 & TRN & \\
\hline CHEMBL1362336 & 688422 & 4.75 & 5.4523 & TST & \\
\hline CHEMBL291746 & 688422 & 4.45 & 5.1171 & TRN & \\
\hline CHEMBL 309016 & 688422 & 4.45 & 5.0453 & TRN & \\
\hline CHEMBL1577352 & 688422 & 4.65 & 5.4142 & TRN & \\
\hline CHEMBL1591094 & 688422 & 4.45 & 5.025 & TRN & \\
\hline CHEMBL1526714 & 688422 & 7.8013 & 5.3297 & TRN & \\
\hline CHEMBL1454580 & 688422 & 6.3 & 5.1683 & TST & \\
\hline CHEMBL1367761 & 688422 & 5.0 & 5.0746 & TRN & \\
\hline CHEMBL1510574 & 688422 & 8.0 & 5.149 & TST & \\
\hline CHEMBL1407795 & 688422 & 4.8 & 4.7526 & TRN & \\
\hline CHEMBL1583625 & 688422 & 4.6 & 5.2776 & TRN & \\
\hline CHEMBL1543422 & 688422 & 4.45 & 5.2658 & TRN & \\
\hline CHEMBL1537481 & 688422 & 4.45 & 4.68 & TRN & \\
\hline CHEMBL1404747 & 688422 & 5.0 & 5.678 & TRN & \\
\hline CHEMBL1598694 & 688422 & 4.45 & 4.9897 & TST & \\
\hline CHEMBL1349863 & 688422 & 4.6 & 5.4749 & TRN & \\
\hline CHEMBL1364349 & 688422 & 6.4 & 5.48600 & $\partial 000000001$ & TRN \\
\hline CHEMBL1376861 & 688422 & 4.45 & 4.984 & TRN & \\
\hline CHEMBL1301210 & 688422 & 5.25 & 5.0958 & TST & \\
\hline CHEMBL1556924 & 688422 & 4.65 & 5.5325 & TRN & \\
\hline CHEMBL1495638 & 688422 & 4.7 & 5.7162 & TST & \\
\hline CHEMBL1450487 & 688422 & 4.5 & 5.4098 & TST & \\
\hline CHEMBL1560290 & 688422 & 5.55 & 4.8757 & TRN & \\
\hline CHEMBL3189696 & 688422 & 4.45 & 5.1846 & TRN & \\
\hline CHEMBL1460761 & 688422 & 4.85 & 5.4531 & TRN & \\
\hline CHEMBL1467999 & 688422 & 5.45 & 5.0977 & TRN & \\
\hline CHEMBL1522857 & 688422 & 4.95 & 5.1327 & TRN & \\
\hline CHEMBL1545112 & 688422 & 4.45 & 5.3975 & TST & \\
\hline CHEMBL1479847 & 688422 & 4.3 & 5.1466 & TRN & \\
\hline CHEMBL1380507 & 688422 & 6.35 & 5.0018 & TRN & \\
\hline CHEMBL1366573 & 688422 & 4.7 & 5.1241 & TRN & \\
\hline CHEMBL1256148 & 688422 & 8.8539 & 5.8617 & TST & \\
\hline
\end{tabular}




\begin{tabular}{|c|c|c|c|c|c|}
\hline \\
\hline CHEMBL1457001 & 688422 & 6.8 & 5.2191 & TRN & \\
\hline CHEMBL1582497 & 688422 & 6.7501 & 5.4366 & TST & \\
\hline CHEMBL1524095 & 688422 & 5.1 & 5.0624 & TRN & \\
\hline CHEMBL1569376 & 688422 & 5.0 & 5.1589 & TRN & \\
\hline CHEMBL518292 & 688422 & 4.45 & 5.6683 & TST & \\
\hline CHEMBL310310 & 688422 & 5.25 & 5.21700 & 20000000005 & TRN \\
\hline CHEMBL1484449 & 688422 & 4.45 & 5.0676 & TST & \\
\hline CHEMBL1329089 & 688422 & 4.85 & 5.3742 & TRN & \\
\hline CHEMBL1545657 & 688422 & 5.0 & 5.0666 & TRN & \\
\hline CHEMBL3196071 & 688422 & 4.45 & 4.9735 & TST & \\
\hline CHEMBL3207947 & 688422 & 5.3 & 5.3412 & TST & \\
\hline CHEMBL1609102 & 688422 & 4.45 & 5.3268 & TRN & \\
\hline CHEMBL1573989 & 688422 & 5.05 & 5.4766 & TRN & \\
\hline CHEMBL1338048 & 688422 & 4.8 & 5.4035 & TST & \\
\hline CHEMBL1338570 & 688422 & 5.6 & 5.1095 & TRN & \\
\hline CHEMBL1501495 & 688422 & 5.4 & 4.894 & TRN & \\
\hline CHEMBL1474183 & 688422 & 4.9 & 5.2197 & TRN & \\
\hline CHEMBL1461955 & 688422 & 4.45 & 5.2448 & TRN & \\
\hline CHEMBL1613266 & 688422 & 4.45 & 5.085 & TRN & \\
\hline CHEMBL1456194 & 688422 & 5.0 & 5.0754 & TRN & \\
\hline CHEMBL1498628 & 688422 & 5.2 & 5.1707 & TRN & \\
\hline CHEMBL1371756 & 688422 & 5.5 & 5.0481 & TST & \\
\hline CHEMBL1524319 & 688422 & 6.5 & 5.3323 & TST & \\
\hline CHEMBL1472867 & 688422 & 4.5 & 5.7643 & TRN & \\
\hline CHEMBL1323714 & 688422 & 5.2 & 5.2362 & TST & \\
\hline CHEMBL1348231 & 688422 & 4.95 & 5.6465 & TRN & \\
\hline CHEMBL3214217 & 688422 & 4.95 & 5.3493 & TRN & \\
\hline CHEMBL1459796 & 688422 & 4.95 & 5.2138 & TRN & \\
\hline CHEMBL1430317 & 688422 & 5.85 & 5.1482 & TRN & \\
\hline CHEMBL1606099 & 688422 & 4.9 & 5.4299 & TRN & \\
\hline CHEMBL1391087 & 688422 & 4.75 & 4.5582 & TRN & \\
\hline CHEMBL1518664 & 688422 & 4.45 & 5.0003 & TRN & \\
\hline CHEMBL1578492 & 688422 & 4.95 & 4.9408 & TRN & \\
\hline CHEMBL1522002 & 688422 & 4.45 & 5.1492 & TRN & \\
\hline CHEMBL1474019 & 688422 & 4.75 & 5.6209 & TRN & \\
\hline CHEMBL1551011 & 688422 & 4.45 & 5.1579 & TRN & \\
\hline CHEMBL1593331 & 688422 & 5.2 & 5.9537 & TRN & \\
\hline CHEMBL1505789 & 688422 & 6.95 & 6.1019 & TST & \\
\hline CHEMBL1491010 & 688422 & 5.1 & 5.0262 & TST & \\
\hline CHEMBL1876078 & 688422 & 5.2 & 5.3579 & TRN & \\
\hline CHEMBL1530423 & 688422 & 4.45 & 4.6455 & TRN & \\
\hline CHEMBL1412556 & 688422 & 4.8 & 5.3399 & TRN & \\
\hline CHEMBL1306053 & 688422 & 4.5 & 5.2703 & TRN & \\
\hline CHEMBL1504635 & 688422 & 4.75 & 5.2087 & TRN & \\
\hline CHEMBL1357224 & 688422 & 7.8508 & 5.374 & TRN & \\
\hline CHEMBL1393096 & 688422 & 4.45 & 4.6835 & TRN & \\
\hline CHEMBL3210236 & 688422 & 4.45 & 5.102 & TST & \\
\hline CHEMBL1320214 & 688422 & 4.45 & 5.3784 & TRN & \\
\hline
\end{tabular}




\begin{tabular}{|c|c|c|c|c|c|}
\hline & & \multicolumn{4}{|c|}{ Supplemental Table S2.txt } \\
\hline CHEMBL1490425 & 688422 & 7.5498 & 5.4919 & TST & \\
\hline CHEMBL1304158 & 688422 & 5.05 & 5.2817 & TST & \\
\hline CHEMBL1362476 & 688422 & 4.9 & 5.228 & TST & \\
\hline CHEMBL3190149 & 688422 & 4.8 & 4.9466 & TST & \\
\hline CHEMBL1353413 & 688422 & 4.45 & 4.7953 & TST & \\
\hline CHEMBL1529590 & 688422 & 6.5 & 5.4247 & TST & \\
\hline CHEMBL1414580 & 688422 & 4.8 & 5.1768 & TRN & \\
\hline CHEMBL1486265 & 688422 & 8.0506 & 5.3344 & TRN & \\
\hline CHEMBL1491728 & 688422 & 4.65 & 5.0324 & TRN & \\
\hline CHEMBL1425620 & 688422 & 4.8 & 5.1708 & TST & \\
\hline CHEMBL1391346 & 688422 & 4.8 & 4.8348 & TRN & \\
\hline CHEMBL1299238 & 688422 & 4.95 & 4.9005 & TRN & \\
\hline CHEMBL1607364 & 688422 & 4.55 & 5.2788 & TRN & \\
\hline CHEMBL1314955 & 688422 & 6.8 & 5.2345 & TST & \\
\hline CHEMBL1558955 & 688422 & 4.85 & 5.38899 & 9999999999 & TRN \\
\hline CHEMBL3212469 & 688422 & 4.75 & 5.3459 & TRN & \\
\hline CHEMBL1429412 & 688422 & 4.95 & 5.5815 & TRN & \\
\hline CHEMBL1501898 & 688422 & 4.95 & 5.4605 & TST & \\
\hline CHEMBL1988541 & 688422 & 4.8 & 5.4117 & TRN & \\
\hline CHEMBL1344070 & 688422 & 7.3497 & 5.2394 & TRN & \\
\hline CHEMBL1420390 & 688422 & 5.35 & 5.2251 & TST & \\
\hline CHEMBL1544342 & 688422 & 4.85 & 5.0265 & TRN & \\
\hline CHEMBL1391535 & 688422 & 4.45 & 5.366006 & 00000000005 & TRN \\
\hline CHEMBL1548881 & 688422 & 4.95 & 5.0924 & TRN & \\
\hline CHEMBL1392832 & 688422 & 4.9 & 5.4503 & TRN & \\
\hline CHEMBL1493890 & 688422 & 5.2 & 5.4287 & TRN & \\
\hline CHEMBL1353422 & 688422 & 5.0 & 5.2354 & TST & \\
\hline CHEMBL1434082 & 688422 & 5.0 & 5.0988 & TRN & \\
\hline CHEMBL1608316 & 688422 & 7.2 & 5.3145 & TRN & \\
\hline CHEMBL18840 & 688422 & 4.55 & 5.8372 & TST & \\
\hline CHEMBL1566900 & 688422 & 4.85 & 5.8054 & TST & \\
\hline CHEMBL3195436 & 688422 & 5.4 & 5.5421 & TRN & \\
\hline CHEMBL1462746 & 688422 & 4.9 & 5.2248 & TRN & \\
\hline CHEMBL1415818 & 688422 & 6.7501 & 5.3565 & TRN & \\
\hline CHEMBL 3194388 & 688422 & 5.8 & 5.7006 & TRN & \\
\hline CHEMBL1370262 & 688422 & 4.45 & 5.1246 & TST & \\
\hline CHEMBL1548451 & 688422 & 5.45 & 5.0926 & TRN & \\
\hline CHEMBL1557460 & 688422 & 4.85 & 4.9856 & TRN & \\
\hline CHEMBL1308622 & 688422 & 8.3468 & 5.0945 & TRN & \\
\hline CHEMBL1524943 & 688422 & 4.55 & 5.3545 & TRN & \\
\hline CHEMBL1996233 & 688422 & 5.25 & 5.1775 & TST & \\
\hline CHEMBL1539731 & 688422 & 7.5003 & 5.4294 & TRN & \\
\hline CHEMBL1468051 & 688422 & 4.45 & 4.9437 & TST & \\
\hline CHEMBL1509861 & 688422 & 4.6 & 5.2623 & TRN & \\
\hline CHEMBL1592642 & 688422 & 4.65 & 5.4398 & TRN & \\
\hline CHEMBL1578932 & 688422 & 4.65 & 5.5148 & TRN & \\
\hline CHEMBL1349777 & 688422 & 6.25 & 5.4893 & TST & \\
\hline CHEMBL1325031 & 688422 & 4.65 & 5.4798 & TRN & \\
\hline
\end{tabular}




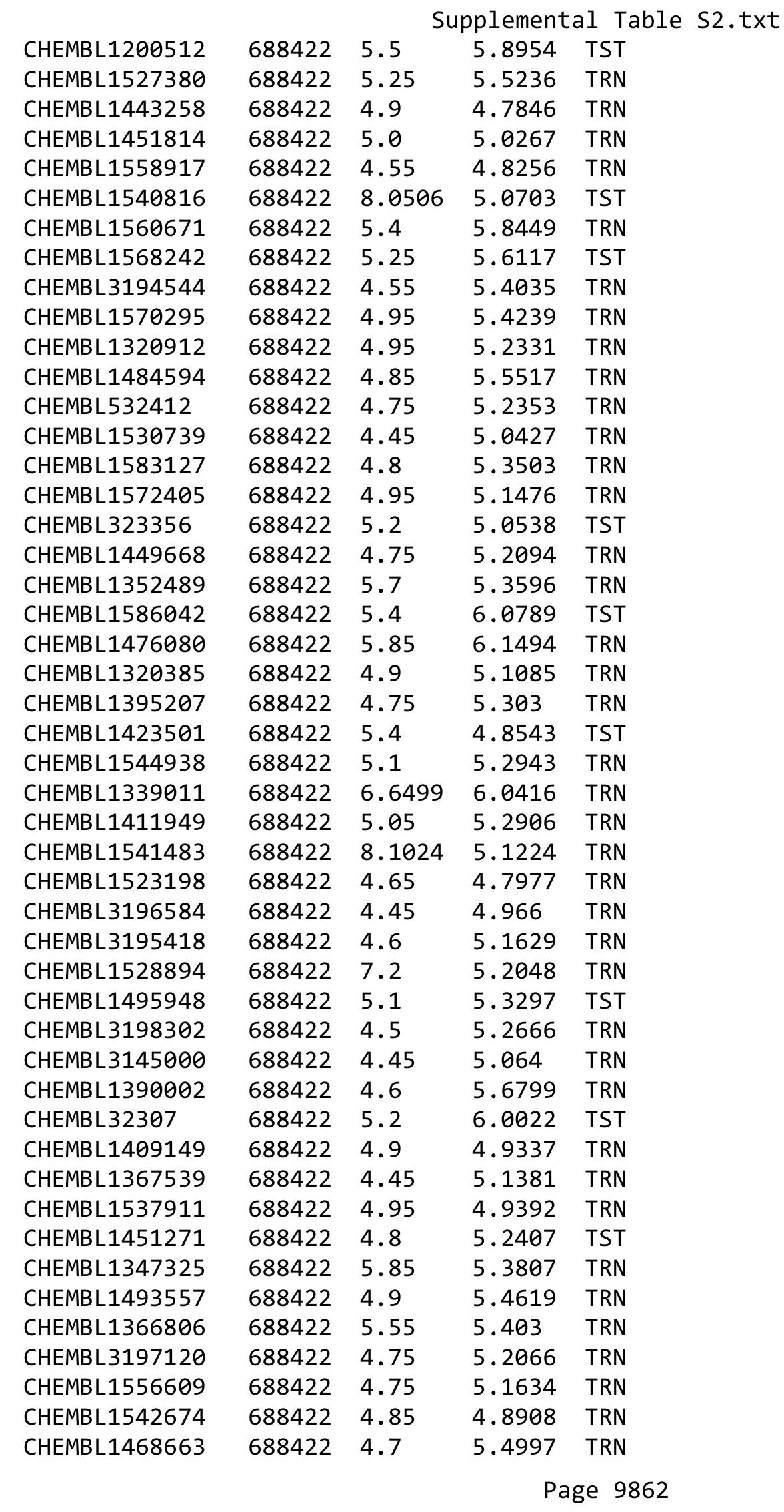




\begin{tabular}{|c|c|c|c|c|c|}
\hline \multicolumn{6}{|c|}{ Supplemental Table S2.txt } \\
\hline CHEMBL1560955 & 688422 & 5.0 & 5.2057 & TRN & \\
\hline CHEMBL1374108 & 688422 & 4.9 & 5.4008 & TRN & \\
\hline CHEMBL1468492 & 688422 & 5.75 & 5.5079 & TRN & \\
\hline CHEMBL1566675 & 688422 & 5.55 & 5.3449 & TST & \\
\hline CHEMBL1419303 & 688422 & 4.45 & 4.8472 & TST & \\
\hline CHEMBL1364002 & 688422 & 5.1 & 5.447 & TRN & \\
\hline CHEMBL1575858 & 688422 & 6.8 & 5.4564 & TRN & \\
\hline CHEMBL1325587 & 688422 & 4.45 & 5.13899 & 9999999999 & TRN \\
\hline CHEMBL1470270 & 688422 & 4.45 & 5.2757 & TRN & \\
\hline CHEMBL1300201 & 688422 & 4.45 & 5.3511 & TRN & \\
\hline CHEMBL1531259 & 688422 & 6.1 & 5.6752 & TRN & \\
\hline CHEMBL1476879 & 688422 & 4.45 & 4.8612 & TRN & \\
\hline CHEMBL1467538 & 688422 & 4.5 & 4.4818 & TST & \\
\hline CHEMBL1383279 & 688422 & 4.45 & 5.2709 & TST & \\
\hline CHEMBL1466045 & 688422 & 4.85 & 5.8497 & TRN & \\
\hline CHEMBL1507968 & 688422 & 4.9 & 5.1285 & TRN & \\
\hline CHEMBL1485945 & 688422 & 4.45 & 5.1841 & TRN & \\
\hline CHEMBL1346609 & 688422 & 4.8 & 5.2753 & TRN & \\
\hline CHEMBL1407944 & 688422 & 5.85 & 5.3666 & TRN & \\
\hline CHEMBL1578344 & 688422 & 8.4949 & 5.6054 & TRN & \\
\hline CHEMBL1603795 & 688422 & 7.7496 & 4.998 & TRN & \\
\hline CHEMBL1421286 & 688422 & 4.45 & 4.5724 & TRN & \\
\hline CHEMBL1448091 & 688422 & 6.4 & 4.9047 & TRN & \\
\hline CHEMBL1437142 & 688422 & 6.6499 & 5.6815 & TRN & \\
\hline CHEMBL1372789 & 688422 & 7.699 & 5.7676 & TST & \\
\hline CHEMBL1526308 & 688422 & 4.9 & 4.5591 & TRN & \\
\hline CHEMBL1328252 & 688422 & 4.6 & 5.305 & TRN & \\
\hline CHEMBL1457407 & 688422 & 4.6 & 5.2492 & TRN & \\
\hline CHEMBL1528871 & 688422 & 4.95 & 5.0542 & TRN & \\
\hline CHEMBL1520414 & 688422 & 5.0 & 4.6234 & TRN & \\
\hline CHEMBL1606450 & 688422 & 5.0 & 4.7459 & TRN & \\
\hline CHEMBL1537919 & 688422 & 4.8 & 5.5681 & TRN & \\
\hline CHEMBL1483396 & 688422 & 7.5003 & 5.2471 & TRN & \\
\hline CHEMBL1347790 & 688422 & 4.95 & 4.9875 & TST & \\
\hline CHEMBL1541320 & 688422 & 4.95 & 5.0568 & TST & \\
\hline CHEMBL1520405 & 688422 & 4.5 & 5.2916 & TRN & \\
\hline CHEMBL1414720 & 688422 & 4.6 & 4.7627 & TRN & \\
\hline CHEMBL3191569 & 688422 & 7.5498 & 5.3221 & TRN & \\
\hline CHEMBL1491703 & 688422 & 4.9 & 5.2808 & TST & \\
\hline CHEMBL1598843 & 688422 & 4.9 & 5.0071 & TST & \\
\hline CHEMBL1572789 & 688422 & 4.45 & 5.0663 & TRN & \\
\hline CHEMBL1312122 & 688422 & 8.1487 & 4.8944 & TST & \\
\hline CHEMBL1328838 & 688422 & 4.45 & 5.8869 & TRN & \\
\hline CHEMBL1572547 & 688422 & 4.5 & 5.5357 & TRN & \\
\hline CHEMBL1371882 & 688422 & 4.65 & 4.8993 & TRN & \\
\hline CHEMBL1314286 & 688422 & 7.3497 & 5.6975 & TST & \\
\hline CHEMBL1424063 & 688422 & 4.85 & 4.9256 & TRN & \\
\hline CHEMBL1353412 & 688422 & 4.45 & 4.9229 & TRN & \\
\hline
\end{tabular}




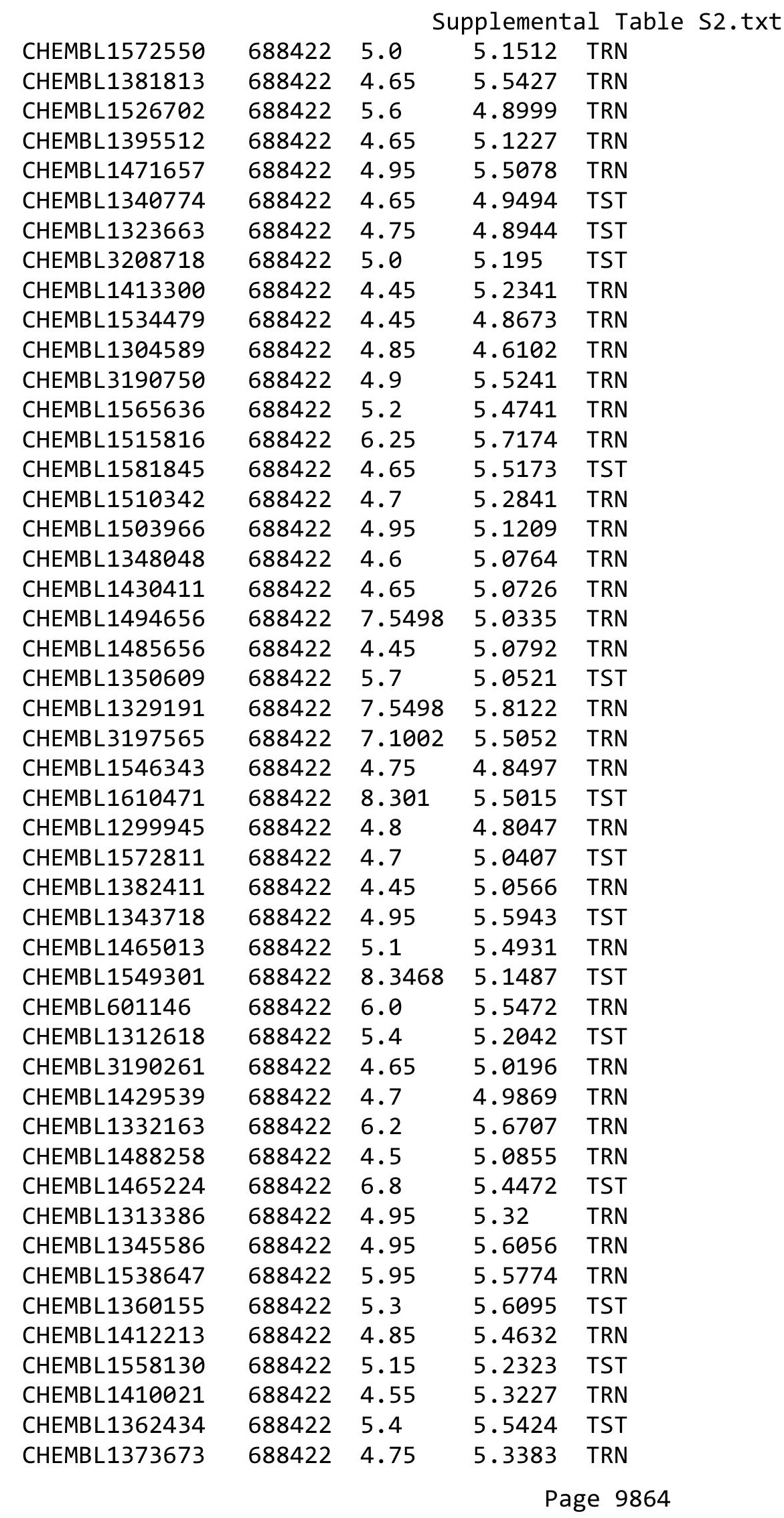




\begin{tabular}{|c|c|c|c|c|}
\hline \multicolumn{5}{|c|}{ Supplemental Table s2.txt } \\
\hline CHEMBL1310098 & 688422 & 4.8 & 5.0294 & TST \\
\hline CHEMBL1542508 & 688422 & 6.7501 & 5.5137 & TST \\
\hline CHEMBL1528118 & 688422 & 6.1 & 5.1827 & TRN \\
\hline CHEMBL1570495 & 688422 & 6.5501 & 5.3976 & TRN \\
\hline CHEMBL1508037 & 688422 & 4.75 & 5.1094 & TRN \\
\hline CHEMBL1468603 & 688422 & 5.75 & 5.6073 & TST \\
\hline CHEMBL1497501 & 688422 & 4.95 & 4.7902 & TST \\
\hline CHEMBL1375570 & 688422 & 5.55 & 5.1817 & TST \\
\hline CHEMBL1306573 & 688422 & 4.85 & 5.4177 & TRN \\
\hline CHEMBL1523434 & 688422 & 5.0 & 5.121 & TST \\
\hline CHEMBL1585767 & 688422 & 4.75 & 5.0911 & TRN \\
\hline CHEMBL1566378 & 688422 & 4.45 & 4.6988 & TRN \\
\hline CHEMBL1455873 & 688422 & 4.65 & 4.716 & TRN \\
\hline CHEMBL1357428 & 688422 & 4.6 & 4.8965 & TRN \\
\hline CHEMBL1441969 & 688422 & 7.0501 & 4.9841 & TRN \\
\hline CHEMBL1319776 & 688422 & 4.55 & 5.0294 & TST \\
\hline CHEMBL1542361 & 688422 & 4.45 & 5.3366 & TRN \\
\hline CHEMBL1374250 & 688422 & 4.45 & 5.3451 & TRN \\
\hline CHEMBL1528102 & 688422 & 5.45 & 4.7743 & TRN \\
\hline CHEMBL3198630 & 688422 & 4.6 & 4.9347 & TRN \\
\hline CHEMBL1472988 & 688422 & 7.0 & 5.5107 & TRN \\
\hline CHEMBL1555562 & 688422 & 4.75 & 5.1436 & TRN \\
\hline CHEMBL3199659 & 688422 & 8.0 & 5.1694 & TRN \\
\hline CHEMBL1318697 & 688422 & 5.55 & 5.5093 & TRN \\
\hline CHEMBL1580790 & 688422 & 4.7 & 4.7452 & TST \\
\hline CHEMBL1979539 & 688422 & 4.9 & 5.4408 & TRN \\
\hline CHEMBL1601200 & 688422 & 4.45 & 5.1185 & TRN \\
\hline CHEMBL1396956 & 688422 & 5.75 & 5.1981 & TRN \\
\hline CHEMBL3197031 & 688422 & 5.25 & 5.1363 & TRN \\
\hline CHEMBL1303361 & 688422 & 4.45 & 5.0789 & TRN \\
\hline CHEMBL1467342 & 688422 & 7.9508 & 5.2405 & TRN \\
\hline CHEMBL3193221 & 688422 & 4.65 & 5.4821 & TST \\
\hline CHEMBL3214112 & 688422 & 4.45 & 5.6157 & TRN \\
\hline CHEMBL1523410 & 688422 & 4.45 & 4.9679 & TRN \\
\hline CHEMBL1509417 & 688422 & 5.2 & 5.2085 & TRN \\
\hline CHEMBL1576694 & 688422 & 5.45 & 5.1549 & TRN \\
\hline CHEMBL327708 & 688422 & 7.7496 & 5.3157 & TST \\
\hline CHEMBL1448707 & 688422 & 4.45 & 5.57799 & 9999999999 \\
\hline CHEMBL1572214 & 688422 & 6.35 & 5.2329 & TST \\
\hline CHEMBL1504063 & 688422 & 4.8 & 4.8076 & TRN \\
\hline CHEMBL3211305 & 688422 & 4.9 & 5.724 & TST \\
\hline CHEMBL1604587 & 688422 & 4.55 & 5.2271 & TRN \\
\hline CHEMBL1370347 & 688422 & 6.3 & 4.9517 & TRN \\
\hline CHEMBL1355837 & 688422 & 4.45 & 5.7853 & TST \\
\hline CHEMBL1406276 & 688422 & 4.75 & 5.7961 & TST \\
\hline CHEMBL1564460 & 688422 & 4.55 & 5.3535 & TRN \\
\hline CHEMBL1336419 & 688422 & 4.45 & 5.2429 & TRN \\
\hline CHEMBL1430454 & 688422 & 4.6 & 5.0376 & TRN \\
\hline
\end{tabular}




\begin{tabular}{|c|c|c|c|c|c|}
\hline \multicolumn{6}{|c|}{ Supplemental Table s2.txt } \\
\hline CHEMBL1467935 & 688422 & 6.7001 & 5.8703 & TST & \\
\hline CHEMBL1478105 & 688422 & 7.6003 & 5.6026 & TRN & \\
\hline CHEMBL1492339 & 688422 & 4.9 & 5.0577 & TRN & \\
\hline CHEMBL1308151 & 688422 & 4.85 & 5.4115 & TRN & \\
\hline CHEMBL1346468 & 688422 & 4.5 & 5.1519 & TST & \\
\hline CHEMBL1394945 & 688422 & 5.2 & 6.1033 & TRN & \\
\hline CHEMBL1565349 & 688422 & 4.9 & 4.7967 & TRN & \\
\hline CHEMBL1542307 & 688422 & 4.6 & 5.3409 & TRN & \\
\hline CHEMBL1387048 & 688422 & 4.85 & 5.6536 & TST & \\
\hline CHEMBL2000259 & 688422 & 4.9 & 5.329 & TST & \\
\hline CHEMBL1428228 & 688422 & 5.25 & 4.8607 & TRN & \\
\hline CHEMBL1447757 & 688422 & 8.4949 & 4.8766 & TRN & \\
\hline CHEMBL3190832 & 688422 & 4.5 & 4.9272 & TRN & \\
\hline CHEMBL 2003195 & 688422 & 4.45 & 5.2229 & TRN & \\
\hline CHEMBL1545361 & 688422 & 4.85 & 4.744 & TRN & \\
\hline CHEMBL1391665 & 688422 & 4.65 & 5.3444 & TRN & \\
\hline CHEMBL1325886 & 688422 & 5.85 & 5.1045 & TRN & \\
\hline CHEMBL1591582 & 688422 & 8.4949 & 5.1852 & TRN & \\
\hline CHEMBL1349792 & 688422 & 4.8 & 4.7239 & TRN & \\
\hline CHEMBL1561947 & 688422 & 4.85 & 5.004 & TRN & \\
\hline CHEMBL1311174 & 688422 & 4.45 & 5.3272 & TST & \\
\hline CHEMBL1505585 & 688422 & 4.95 & 4.8994 & TRN & \\
\hline CHEMBL1347607 & 688422 & 4.7 & 5.5406 & TRN & \\
\hline CHEMBL1494834 & 688422 & 4.45 & 5.5318 & TRN & \\
\hline CHEMBL 23832 & 688422 & 5.25 & 5.78299 & 99999999995 & TRN \\
\hline CHEMBL1565932 & 688422 & 4.45 & 5.1855 & TRN & \\
\hline CHEMBL1524538 & 688422 & 5.25 & 5.3321 & TST & \\
\hline CHEMBL1416602 & 688422 & 5.5 & 4.7776 & TRN & \\
\hline CHEMBL1544226 & 688422 & 6.35 & 5.1634 & TRN & \\
\hline CHEMBL1611789 & 688422 & 4.45 & 5.1083 & TRN & \\
\hline CHEMBL1599037 & 688422 & 5.0 & 4.8699 & TRN & \\
\hline CHEMBL1377237 & 688422 & 8.3468 & 5.3598 & TRN & \\
\hline CHEMBL1439142 & 688422 & 5.0 & 5.2372 & TST & \\
\hline CHEMBL1502893 & 688422 & 5.4 & 5.6973 & TST & \\
\hline CHEMBL1607498 & 688422 & 7.3497 & 5.3479 & TRN & \\
\hline CHEMBL1608000 & 688422 & 4.45 & 5.2484 & TRN & \\
\hline CHEMBL1367353 & 688422 & 6.4 & 5.2685 & TST & \\
\hline CHEMBL1490709 & 688422 & 5.35 & 4.9605 & TRN & \\
\hline CHEMBL1605817 & 688422 & 4.45 & 4.9269 & TRN & \\
\hline CHEMBL1323537 & 688422 & 7.0501 & 4.802 & TST & \\
\hline CHEMBL1386055 & 688422 & 4.45 & 5.5291 & TST & \\
\hline CHEMBL1601409 & 688422 & 7.699 & 5.428 & TRN & \\
\hline CHEMBL1593743 & 688422 & 6.6 & 5.3637 & TST & \\
\hline CHEMBL1559937 & 688422 & 4.9 & 5.1312 & TRN & \\
\hline CHEMBL1562165 & 688422 & 4.45 & 5.3173 & TST & \\
\hline CHEMBL1557465 & 688422 & 4.95 & 5.0195 & TST & \\
\hline CHEMBL1386510 & 688422 & 4.45 & 5.2292 & TST & \\
\hline CHEMBL1566076 & 688422 & 4.5 & 5.39 & TRN & \\
\hline
\end{tabular}




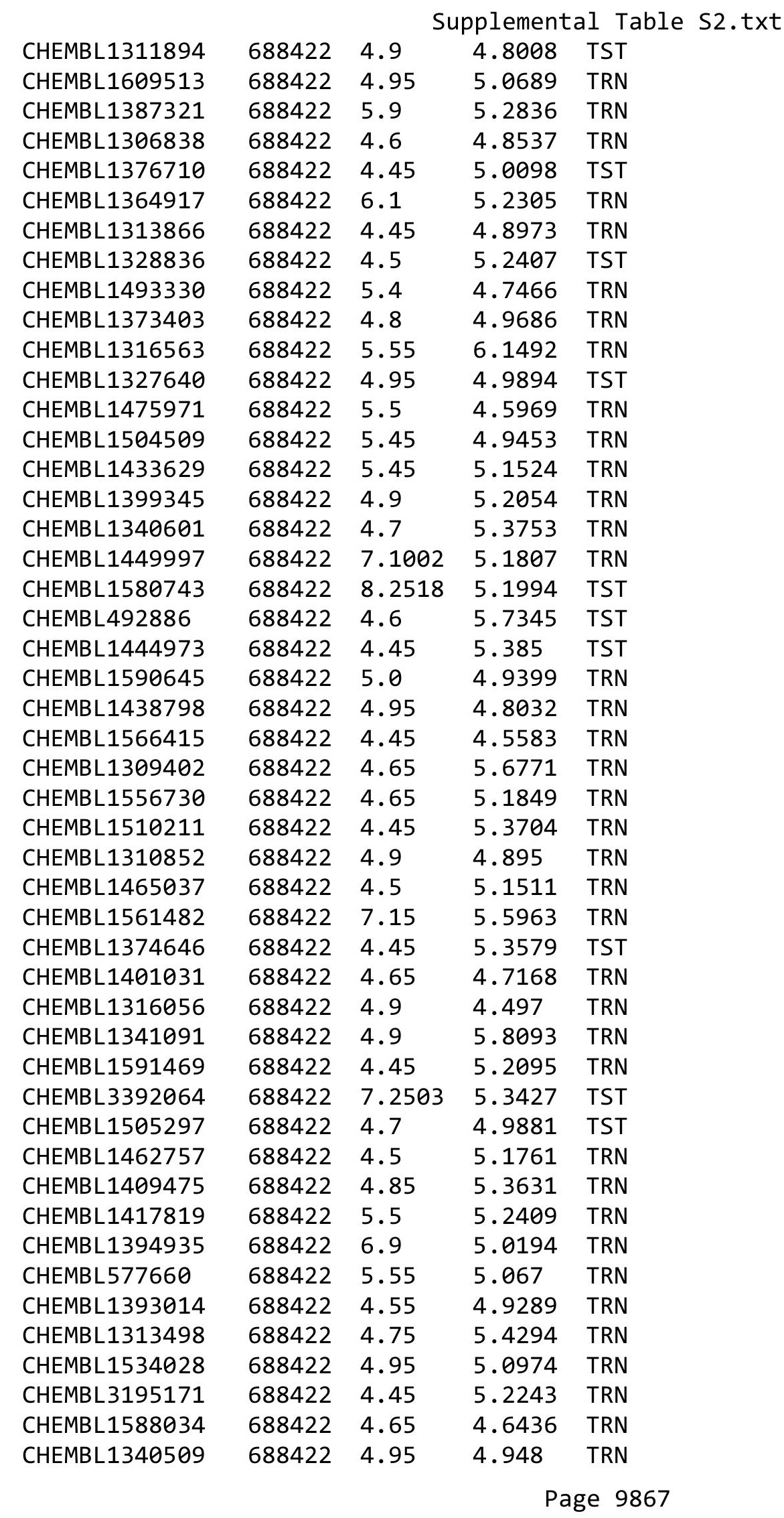




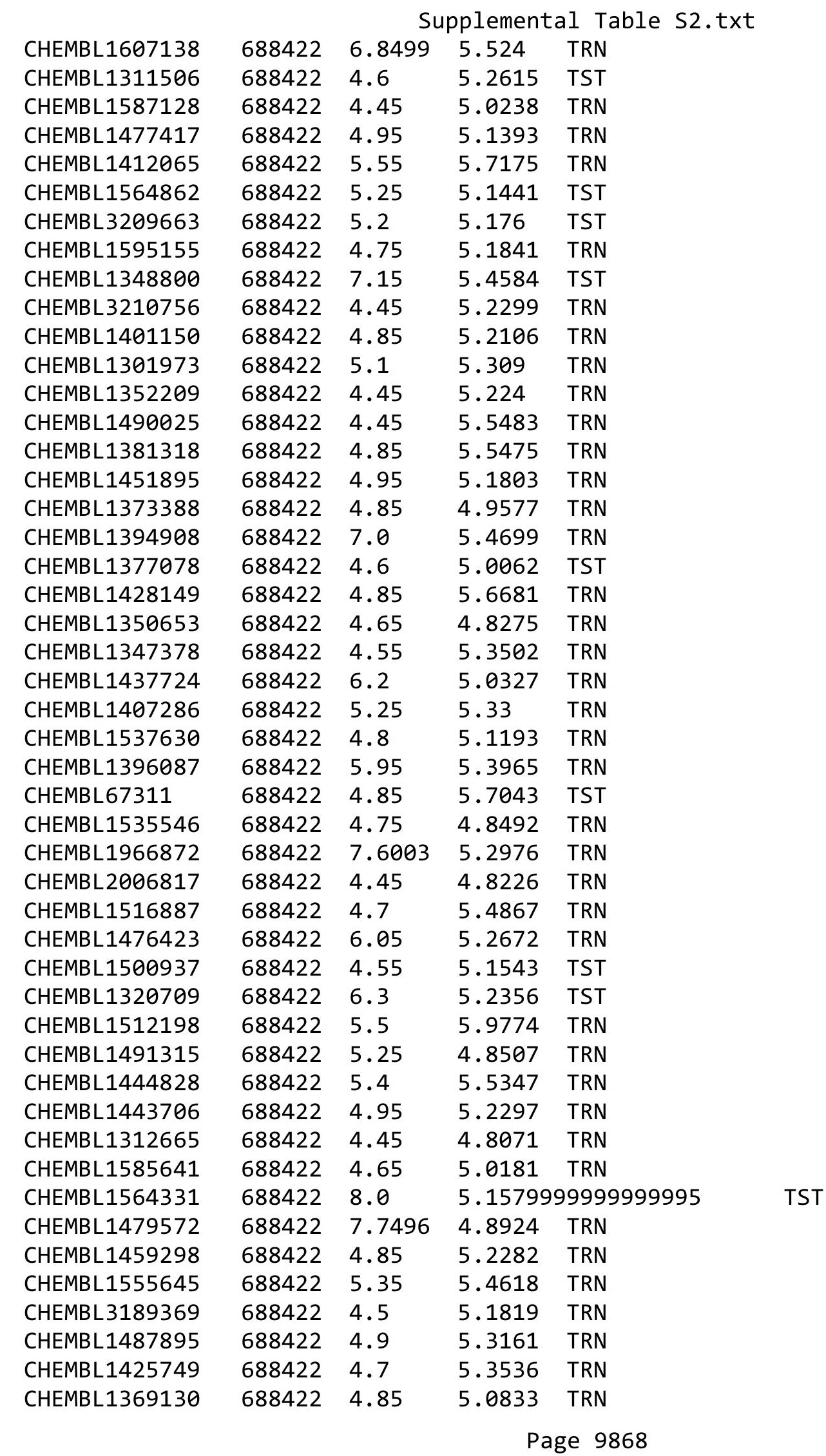




\begin{tabular}{|c|c|c|c|c|c|}
\hline & & \multicolumn{4}{|c|}{ Supplemental Table S2.txt } \\
\hline CHEMBL3193359 & 688422 & 5.15 & 5.0748 & TST & \\
\hline CHEMBL3191182 & 688422 & 5.0 & 4.9394 & TRN & \\
\hline CHEMBL1576355 & 688422 & 4.65 & 4.7936 & TRN & \\
\hline CHEMBL1451599 & 688422 & 4.95 & 5.4724 & TRN & \\
\hline CHEMBL1433384 & 688422 & 5.05 & 4.8587 & TRN & \\
\hline CHEMBL1317752 & 688422 & 4.85 & 5.1182 & TRN & \\
\hline CHEMBL1587591 & 688422 & 4.9 & 5.7695 & TRN & \\
\hline CHEMBL1469446 & 688422 & 4.45 & 4.9499 & TST & \\
\hline CHEMBL1458108 & 688422 & 6.5 & 5.4928 & TRN & \\
\hline CHEMBL3196582 & 688422 & 4.9 & 4.8593 & TRN & \\
\hline CHEMBL1525418 & 688422 & 4.85 & 5.2094 & TRN & \\
\hline CHEMBL1610654 & 688422 & 4.6 & 5.4201 & TST & \\
\hline CHEMBL1530732 & 688422 & 6.8 & 5.5218 & TRN & \\
\hline CHEMBL1598623 & 688422 & 4.85 & 5.4014 & TRN & \\
\hline CHEMBL1598827 & 688422 & 5.25 & 5.4241 & TRN & \\
\hline CHEMBL1526946 & 688422 & 4.45 & 5.3904 & TRN & \\
\hline CHEMBL1321546 & 688422 & 4.45 & 5.1999 & TRN & \\
\hline CHEMBL1593164 & 688422 & 4.45 & 4.9406 & TRN & \\
\hline CHEMBL1350491 & 688422 & 5.9 & 4.7584 & TRN & \\
\hline CHEMBL1302867 & 688422 & 4.95 & 5.5683 & TRN & \\
\hline CHEMBL1314267 & 688422 & 5.45 & 5.2265 & TRN & \\
\hline CHEMBL1328087 & 688422 & 4.45 & 5.2447 & TRN & \\
\hline CHEMBL 30095 & 688422 & 4.5 & 5.0022 & TRN & \\
\hline CHEMBL1611371 & 688422 & 4.45 & 5.0995 & TRN & \\
\hline CHEMBL1416769 & 688422 & 4.75 & 4.7819 & TRN & \\
\hline CHEMBL1352597 & 688422 & 4.45 & 5.3709 & TRN & \\
\hline CHEMBL 242080 & 688422 & 5.9 & 5.0712 & TST & \\
\hline CHEMBL1359664 & 688422 & 6.5 & 5.1347 & TRN & \\
\hline CHEMBL1415670 & 688422 & 4.95 & 5.0251 & TRN & \\
\hline CHEMBL1462157 & 688422 & 5.0 & 5.204 & TRN & \\
\hline CHEMBL1381305 & 688422 & 4.5 & 5.1593 & TRN & \\
\hline CHEMBL 3195720 & 688422 & 4.45 & 5.0799 & TRN & \\
\hline CHEMBL1521034 & 688422 & 5.4 & 5.4815 & TST & \\
\hline CHEMBL1339240 & 688422 & 4.7 & 5.2005 & TRN & \\
\hline CHEMBL1322455 & 688422 & 7.0501 & 5.00899 & 99999999995 & TRN \\
\hline CHEMBL 275311 & 688422 & 4.45 & 5.66799 & 9999999999 & TST \\
\hline CHEMBL1433231 & 688422 & 4.45 & 5.2402 & TRN & \\
\hline CHEMBL1467797 & 688422 & 4.45 & 4.9939 & TRN & \\
\hline CHEMBL1396235 & 688422 & 5.15 & 5.6371 & TRN & \\
\hline CHEMBL1372483 & 688422 & 6.6 & 5.9453 & TST & \\
\hline CHEMBL1535861 & 688422 & 5.0 & 5.1243 & TRN & \\
\hline CHEMBL1484667 & 688422 & 4.85 & 5.3168 & TRN & \\
\hline CHEMBL3190421 & 688422 & 4.75 & 5.2989 & TRN & \\
\hline CHEMBL 2311878 & 688422 & 4.9 & 5.1888 & TRN & \\
\hline CHEMBL1510092 & 688422 & 4.45 & 5.331 & TRN & \\
\hline CHEMBL1311177 & 688422 & 4.5 & 5.1864 & TRN & \\
\hline CHEMBL3194822 & 688422 & 4.55 & 5.6895 & TRN & \\
\hline CHEMBL1503513 & 688422 & 5.4 & 5.2895 & TST & \\
\hline
\end{tabular}




\begin{tabular}{|c|c|c|c|c|}
\hline \multicolumn{5}{|c|}{ Supplemental Table S2.txt } \\
\hline CHEMBL1520600 & 688422 & 4.75 & 5.2645 & TRN \\
\hline CHEMBL1360734 & 688422 & 4.6 & 4.8831 & TRN \\
\hline CHEMBL1326835 & 688422 & 5.4 & 5.9685 & TST \\
\hline CHEMBL1410768 & 688422 & 4.9 & 5.0394 & TRN \\
\hline CHEMBL1448872 & 688422 & 4.8 & 5.2173 & TRN \\
\hline CHEMBL3208338 & 688422 & 4.55 & 5.1476 & TRN \\
\hline CHEMBL 1486780 & 688422 & 6.45 & 5.069 & TRN \\
\hline CHEMBL1593427 & 688422 & 5.9 & 5.2875 & TRN \\
\hline CHEMBL 1586860 & 688422 & 5.5 & 5.6498 & TST \\
\hline CHEMBL1337500 & 688422 & 4.45 & 5.5294 & TST \\
\hline CHEMBL306380 & 688422 & 4.95 & 5.2697 & TRN \\
\hline CHEMBL1583180 & 688422 & 4.95 & 4.6892 & TRN \\
\hline CHEMBL 3189338 & 688422 & 4.45 & 5.4595 & TRN \\
\hline CHEMBL1405313 & 688422 & 4.45 & 4.8964 & TST \\
\hline CHEMBL1558682 & 688422 & 4.65 & 5.3954 & TRN \\
\hline CHEMBL1360140 & 688422 & 6.8 & 5.2782 & TRN \\
\hline CHEMBL3193230 & 688422 & 8.3468 & 5.8867 & TRN \\
\hline CHEMBL1581713 & 688422 & 4.6 & 5.1813 & TRN \\
\hline CHEMBL 3194575 & 688422 & 4.45 & 5.2158 & TRN \\
\hline CHEMBL1493905 & 688422 & 5.2 & 5.0766 & TRN \\
\hline CHEMBL3208296 & 688422 & 4.85 & 5.0125 & TRN \\
\hline CHEMBL1602407 & 688422 & 4.5 & 4.9339 & TRN \\
\hline CHEMBL1462865 & 688422 & 4.9 & 5.2486 & TRN \\
\hline CHEMBL1369724 & 688422 & 4.45 & 4.7685 & TRN \\
\hline CHEMBL1456595 & 688422 & 4.9 & 5.0794 & TRN \\
\hline CHEMBL1403348 & 688422 & 4.9 & 5.3509 & TRN \\
\hline CHEMBL1457518 & 688422 & 5.15 & 5.1851 & TRN \\
\hline CHEMBL1540257 & 688422 & 5.2 & 4.8939 & TRN \\
\hline CHEMBL1312373 & 688422 & 8.301 & 5.4614 & TRN \\
\hline CHEMBL 1494407 & 688422 & 7.6498 & 5.4296 & TST \\
\hline CHEMBL1475448 & 688422 & 4.65 & 5.1994 & TRN \\
\hline CHEMBL1464786 & 688422 & 4.95 & 5.1759 & TRN \\
\hline CHEMBL1320236 & 688422 & 4.6 & 5.1035 & TRN \\
\hline CHEMBL1528630 & 688422 & 7.3497 & 5.7866 & TST \\
\hline CHEMBL1416441 & 688422 & 4.75 & 5.3938 & TST \\
\hline CHEMBL1376069 & 688422 & 4.45 & 5.2655 & TRN \\
\hline CHEMBL1414621 & 688422 & 5.6 & 5.4376 & TRN \\
\hline CHEMBL1397616 & 688422 & 8.3468 & 5.1262 & TRN \\
\hline CHEMBL1491819 & 688422 & 4.45 & 5.2875 & TST \\
\hline CHEMBL569020 & 688422 & 4.7 & 5.1241 & TST \\
\hline CHEMBL3191848 & 688422 & 8.5528 & 5.4226 & TST \\
\hline CHEMBL1597211 & 688422 & 4.95 & 5.16200 & 0000000001 \\
\hline CHEMBL1452364 & 688422 & 4.45 & 5.1779 & TRN \\
\hline CHEMBL1459724 & 688422 & 6.6 & 5.6159 & TRN \\
\hline CHEMBL1406173 & 688422 & 7.4001 & 5.1633 & TRN \\
\hline CHEMBL1336068 & 688422 & 4.95 & 4.9439 & TRN \\
\hline CHEMBL 29726 & 688422 & 5.2 & 5.9665 & TST \\
\hline CHEMBL1372909 & 688422 & 4.65 & 5.3481 & TST \\
\hline
\end{tabular}

TRN 


\begin{tabular}{|c|c|c|c|c|}
\hline \multicolumn{5}{|c|}{ Supplemental Table S2.txt } \\
\hline CHEMBL1459305 & 688422 & 4.7 & 5.2991 & TST \\
\hline CHEMBL148124 & 688422 & 4.7 & 5.4004 & TRN \\
\hline CHEMBL1596465 & 688422 & 5.1 & 5.7375 & TST \\
\hline CHEMBL1431218 & 688422 & 7.15 & 5.6222 & TST \\
\hline CHEMBL1334036 & 688422 & 4.5 & 5.2462 & TRN \\
\hline CHEMBL1429437 & 688422 & 4.85 & 5.2447 & TST \\
\hline CHEMBL1555210 & 688422 & 5.45 & 5.2682 & TRN \\
\hline CHEMBL1454238 & 688422 & 8.301 & 5.5329 & TRN \\
\hline CHEMBL1480541 & 688422 & 7.4498 & 4.7995 & TRN \\
\hline CHEMBL3189686 & 688422 & 4.45 & 5.1905 & TRN \\
\hline CHEMBL1367744 & 688422 & 4.45 & 5.6295 & TRN \\
\hline CHEMBL1398232 & 688422 & 8.5528 & 5.2888 & TRN \\
\hline CHEMBL1472666 & 688422 & 5.15 & 5.0107 & TRN \\
\hline CHEMBL1421407 & 688422 & 5.2 & 5.5026 & TST \\
\hline CHEMBL1378830 & 688422 & 4.85 & 5.3471 & TRN \\
\hline CHEMBL541521 & 688422 & 6.0 & 5.4556 & TRN \\
\hline CHEMBL1544647 & 688422 & 4.45 & 4.7037 & TRN \\
\hline CHEMBL1364640 & 688422 & 5.0 & 4.7941 & TRN \\
\hline CHEMBL1483013 & 688422 & 4.95 & 4.8392 & TRN \\
\hline CHEMBL1320586 & 688422 & 4.95 & 5.2983 & TRN \\
\hline CHEMBL1405868 & 688422 & 4.85 & 5.0004 & TRN \\
\hline CHEMBL1423461 & 688422 & 5.2 & 5.0086 & TRN \\
\hline CHEMBL1474473 & 688422 & 5.85 & 5.263 & TST \\
\hline CHEMBL1505859 & 688422 & 4.75 & 5.2683 & TRN \\
\hline CHEMBL1401241 & 688422 & 5.0 & 5.3768 & TRN \\
\hline CHEMBL1605099 & 688422 & 5.0 & 4.6683 & TRN \\
\hline CHEMBL1371959 & 688422 & 4.45 & 5.0428 & TRN \\
\hline CHEMBL3199569 & 688422 & 4.95 & 5.6335 & TST \\
\hline CHEMBL1393838 & 688422 & 7.7496 & 5.2089 & TST \\
\hline CHEMBL1559999 & 688422 & 4.9 & 5.1151 & TRN \\
\hline CHEMBL1348501 & 688422 & 4.65 & 4.9708 & TST \\
\hline CHEMBL1504087 & 688422 & 4.8 & 5.266 & TRN \\
\hline CHEMBL1387580 & 688422 & 5.25 & 5.1724 & TRN \\
\hline CHEMBL1579186 & 688422 & 7.2503 & 4.9306 & TST \\
\hline CHEMBL1340623 & 688422 & 7.9508 & 5.3851 & TST \\
\hline CHEMBL1520311 & 688422 & 4.9 & 5.1631 & TRN \\
\hline CHEMBL3191604 & 688422 & 4.8 & 5.6113 & TRN \\
\hline CHEMBL1516331 & 688422 & 5.0 & 4.9857 & TRN \\
\hline CHEMBL1344902 & 688422 & 5.5 & 5.1082 & TRN \\
\hline CHEMBL1442695 & 688422 & 5.55 & 5.0313 & TRN \\
\hline CHEMBL1319950 & 688422 & 4.7 & 5.5255 & TRN \\
\hline CHEMBL1463007 & 688422 & 4.95 & 4.6467 & TRN \\
\hline CHEMBL44876 & 688422 & 4.9 & 5.3223 & TRN \\
\hline CHEMBL1420801 & 688422 & 7.8508 & 6.0303 & TST \\
\hline CHEMBL1596397 & 688422 & 6.5 & 5.375 & TRN \\
\hline CHEMBL1441777 & 688422 & 4.7 & 4.8842 & TRN \\
\hline CHEMBL1371065 & 688422 & 4.55 & 5.2337 & TRN \\
\hline CHEMBL1566464 & 688422 & 4.45 & 5.0668 & TRN \\
\hline
\end{tabular}




\begin{tabular}{|c|c|c|c|c|}
\hline \multicolumn{5}{|c|}{ Supplemental Table s2.txt } \\
\hline CHEMBL1362127 & 688422 & 4.9 & 5.5905 & TRN \\
\hline CHEMBL1579331 & 688422 & 4.9 & 5.0829 & TST \\
\hline CHEMBL1465321 & 688422 & 4.9 & 5.1351 & TRN \\
\hline CHEMBL3194089 & 688422 & 6.15 & 5.46 & TRN \\
\hline CHEMBL3193835 & 688422 & 5.0 & 5.0088 & TST \\
\hline CHEMBL1344822 & 688422 & 4.85 & 5.0356 & TRN \\
\hline CHEMBL1543916 & 688422 & 5.0 & 5.3733 & TRN \\
\hline CHEMBL1358946 & 688422 & 4.65 & 5.0011 & TRN \\
\hline CHEMBL1611939 & 688422 & 4.7 & 4.9921 & TRN \\
\hline CHEMBL1496600 & 688422 & 4.5 & 5.0033 & TST \\
\hline CHEMBL1398567 & 688422 & 5.45 & 4.8013 & TRN \\
\hline CHEMBL3191141 & 688422 & 4.6 & 5.1714 & TRN \\
\hline CHEMBL1562959 & 688422 & 4.8 & 5.4917 & TRN \\
\hline CHEMBL1416948 & 688422 & 4.9 & 5.3502 & TRN \\
\hline CHEMBL1549736 & 688422 & 4.65 & 5.3448 & TRN \\
\hline CHEMBL1326132 & 688422 & 4.9 & 4.942 & TRN \\
\hline CHEMBL1505299 & 688422 & 4.45 & 5.0084 & TST \\
\hline CHEMBL495068 & 688422 & 4.75 & 4.7128 & TRN \\
\hline CHEMBL3145028 & 688422 & 5.0 & 5.5656 & TRN \\
\hline CHEMBL1610194 & 688422 & 5.25 & 5.3613 & TST \\
\hline CHEMBL1500190 & 688422 & 6.25 & 5.0497 & TRN \\
\hline CHEMBL1383589 & 688422 & 4.95 & 5.2372 & TRN \\
\hline CHEMBL1603434 & 688422 & 5.05 & 5.117 & TRN \\
\hline CHEMBL1493135 & 688422 & 5.75 & 5.5647 & TRN \\
\hline CHEMBL1536994 & 688422 & 4.45 & 5.3237 & TRN \\
\hline CHEMBL1484597 & 688422 & 4.55 & 5.1115 & TST \\
\hline CHEMBL1519696 & 688422 & 4.8 & 5.0303 & TRN \\
\hline CHEMBL1420409 & 688422 & 4.45 & 5.8553 & TRN \\
\hline CHEMBL1415449 & 688422 & 5.0 & 5.0489 & TRN \\
\hline CHEMBL1427052 & 688422 & 4.6 & 4.8892 & TRN \\
\hline CHEMBL1544147 & 688422 & 5.15 & 5.1821 & TRN \\
\hline CHEMBL1335212 & 688422 & 4.85 & 5.0866 & TRN \\
\hline CHEMBL1462451 & 688422 & 5.05 & 5.0326 & TRN \\
\hline CHEMBL1301414 & 688422 & 7.3002 & 5.763 & TRN \\
\hline CHEMBL1404781 & 688422 & 4.45 & 5.1316 & TRN \\
\hline CHEMBL1595144 & 688422 & 4.75 & 5.3678 & TRN \\
\hline CHEMBL1345388 & 688422 & 5.35 & 5.0478 & TRN \\
\hline CHEMBL1600618 & 688422 & 5.65 & 5.6372 & TRN \\
\hline CHEMBL1576064 & 688422 & 6.25 & 5.345 & TST \\
\hline CHEMBL1423687 & 688422 & 5.1 & 5.5099 & TRN \\
\hline CHEMBL1384436 & 688422 & 5.95 & 5.3075 & TST \\
\hline CHEMBL1350019 & 688422 & 4.75 & 5.0736 & TRN \\
\hline CHEMBL1390246 & 688422 & 6.5 & 4.9741 & TRN \\
\hline CHEMBL1438038 & 688422 & 6.15 & 5.3087 & TRN \\
\hline CHEMBL3194528 & 688422 & 4.55 & 5.0179 & TRN \\
\hline CHEMBL3192881 & 688422 & 4.5 & 5.043 & TST \\
\hline CHEMBL1422341 & 688422 & 4.85 & 5.82299 & 99999999995 \\
\hline CHEMBL3213630 & 688422 & 4.85 & 5.0958 & TRN \\
\hline
\end{tabular}




\begin{tabular}{|c|c|c|c|c|c|}
\hline \multicolumn{6}{|c|}{ Supplemental Table S2.txt } \\
\hline CHEMBL1361273 & 688422 & 5.5 & 5.1633 & TST & \\
\hline CHEMBL1329805 & 688422 & 5.05 & 5.9241 & TRN & \\
\hline CHEMBL1606172 & 688422 & 4.45 & 5.2321 & TRN & \\
\hline CHEMBL1492046 & 688422 & 4.9 & 5.4817 & TRN & \\
\hline CHEMBL1390109 & 688422 & 7.9508 & 5.3082 & TRN & \\
\hline CHEMBL1359861 & 688422 & 8.4949 & 5.0873 & TST & \\
\hline CHEMBL1536110 & 688422 & 8.3468 & 5.2103 & TRN & \\
\hline CHEMBL1509613 & 688422 & 7.3497 & 5.4006 & TST & \\
\hline CHEMBL1460259 & 688422 & 4.9 & 5.6618 & TRN & \\
\hline CHEMBL1484467 & 688422 & 4.6 & 5.5248 & TST & \\
\hline CHEMBL1575549 & 688422 & 4.55 & 5.1852 & TST & \\
\hline CHEMBL1380796 & 688422 & 4.55 & 5.0093 & TRN & \\
\hline CHEMBL1327115 & 688422 & 7.3497 & 5.6597 & TRN & \\
\hline CHEMBL1350777 & 688422 & 5.55 & 4.8861 & TRN & \\
\hline CHEMBL1409689 & 688422 & 5.0 & 4.9282 & TRN & \\
\hline CHEMBL1313456 & 688422 & 4.9 & 5.5774 & TRN & \\
\hline CHEMBL1499272 & 688422 & 4.65 & 5.0414 & TRN & \\
\hline CHEMBL1387948 & 688422 & 4.9 & 5.0263 & TRN & \\
\hline CHEMBL1476712 & 688422 & 5.25 & 4.9858 & TRN & \\
\hline CHEMBL1323979 & 688422 & 6.7001 & 5.6607 & TRN & \\
\hline CHEMBL1399006 & 688422 & 4.5 & 5.2502 & TRN & \\
\hline CHEMBL1380958 & 688422 & 4.7 & 5.2959 & TRN & \\
\hline CHEMBL1346796 & 688422 & 4.95 & 5.2795 & TST & \\
\hline CHEMBL1448095 & 688422 & 4.95 & 5.1699 & TRN & \\
\hline CHEMBL1519477 & 688422 & 4.9 & 4.9667 & TRN & \\
\hline CHEMBL1192187 & 688422 & 7.5498 & 5.5642 & TST & \\
\hline CHEMBL1253382 & 688422 & 4.95 & 4.7257 & TST & \\
\hline CHEMBL1567951 & 688422 & 5.0 & 4.976 & TRN & \\
\hline CHEMBL1429775 & 688422 & 4.9 & 4.9901 & TRN & \\
\hline CHEMBL1396324 & 688422 & 6.05 & 5.3497 & TRN & \\
\hline CHEMBL1335079 & 688422 & 4.7 & 5.2813 & TRN & \\
\hline CHEMBL1407563 & 688422 & 4.8 & 4.862 & TRN & \\
\hline CHEMBL1438789 & 688422 & 7.4498 & 5.4196 & TST & \\
\hline CHEMBL1544917 & 688422 & 5.35 & 5.2687 & TRN & \\
\hline CHEMBL1523926 & 688422 & 4.95 & 5.5477 & TRN & \\
\hline CHEMBL1372163 & 688422 & 6.6 & 5.59 & TRN & \\
\hline CHEMBL1341810 & 688422 & 5.25 & 5.29700 & 0000000001 & TRN \\
\hline CHEMBL1572923 & 688422 & 4.5 & 4.9414 & TRN & \\
\hline CHEMBL1366718 & 688422 & 4.45 & 5.1583 & TRN & \\
\hline CHEMBL1608898 & 688422 & 4.85 & 5.2806 & TRN & \\
\hline CHEMBL1421981 & 688422 & 6.4 & 5.3294 & TRN & \\
\hline CHEMBL1435885 & 688422 & 5.85 & 5.4566 & TRN & \\
\hline CHEMBL1430038 & 688422 & 4.45 & 4.9504 & TRN & \\
\hline CHEMBL1376054 & 688422 & 4.45 & 5.0683 & TRN & \\
\hline CHEMBL1582039 & 688422 & 4.85 & 5.24799 & 9999999999 & TRN \\
\hline CHEMBL1305806 & 688422 & 5.15 & 5.103 & TRN & \\
\hline CHEMBL1374974 & 688422 & 7.7496 & 5.9191 & TRN & \\
\hline CHEMBL1378668 & 688422 & 5.0 & 4.8291 & TRN & \\
\hline
\end{tabular}




\begin{tabular}{|c|c|c|c|c|c|}
\hline \multicolumn{6}{|c|}{ Supplemental Table s2.txt } \\
\hline CHEMBL1493788 & 688422 & 8.0 & 5.2708 & TRN & \\
\hline CHEMBL1337783 & 688422 & 7.2 & 5.1779 & TRN & \\
\hline CHEMBL1333720 & 688422 & 5.85 & 4.8249 & TRN & \\
\hline CHEMBL1464019 & 688422 & 4.8 & 5.0073 & TRN & \\
\hline CHEMBL1549798 & 688422 & 4.45 & 5.0507 & TRN & \\
\hline CHEMBL1453383 & 688422 & 4.95 & 5.0257 & TRN & \\
\hline CHEMBL1466166 & 688422 & 4.85 & 5.1156 & TST & \\
\hline CHEMBL1467977 & 688422 & 5.1 & 4.8891 & TRN & \\
\hline CHEMBL1604860 & 688422 & 4.7 & 5.3441 & TRN & \\
\hline CHEMBL1977773 & 688422 & 4.95 & 5.2041 & TRN & \\
\hline CHEMBL1510852 & 688422 & 5.2 & 5.0599 & TRN & \\
\hline CHEMBL1401960 & 688422 & 4.95 & 4.9058 & TRN & \\
\hline CHEMBL1539140 & 688422 & 7.0 & 5.0074 & TRN & \\
\hline CHEMBL1438655 & 688422 & 4.55 & 5.3296 & TST & \\
\hline CHEMBL1610559 & 688422 & 5.1 & 5.3116 & TRN & \\
\hline CHEMBL1499893 & 688422 & 5.25 & 5.2512 & TRN & \\
\hline CHEMBL1491716 & 688422 & 4.5 & 5.3015 & TRN & \\
\hline CHEMBL169 & 688422 & 4.8 & 5.5051 & TRN & \\
\hline CHEMBL 265943 & 688422 & 4.6 & 5.2758 & TRN & \\
\hline CHEMBL1584535 & 688422 & 5.7 & 4.8546 & TRN & \\
\hline CHEMBL1978355 & 688422 & 5.15 & 5.1833 & TST & \\
\hline CHEMBL1525033 & 688422 & 5.0 & 4.9955 & TRN & \\
\hline CHEMBL1346786 & 688422 & 4.45 & 5.1177 & TRN & \\
\hline CHEMBL1490674 & 688422 & 4.65 & 5.4226 & TRN & \\
\hline CHEMBL1584226 & 688422 & 4.65 & 5.1824 & TRN & \\
\hline CHEMBL1324944 & 688422 & 4.7 & 5.0761 & TRN & \\
\hline CHEMBL1493137 & 688422 & 4.5 & 5.2939 & TRN & \\
\hline CHEMBL1989234 & 688422 & 4.45 & 5.1723 & TRN & \\
\hline CHEMBL3199412 & 688422 & 6.05 & 4.6981 & TRN & \\
\hline CHEMBL1503392 & 688422 & 4.45 & 5.1672 & TRN & \\
\hline CHEMBL1471369 & 688422 & 5.3 & 5.153 & TRN & \\
\hline CHEMBL1369200 & 688422 & 5.45 & 4.8664 & TRN & \\
\hline CHEMBL1386363 & 688422 & 7.0 & 5.3289 & TRN & \\
\hline CHEMBL1576762 & 688422 & 4.9 & 5.4253 & TRN & \\
\hline CHEMBL1342859 & 688422 & 4.8 & 5.28 & TST & \\
\hline CHEMBL1506351 & 688422 & 5.0 & 5.2108 & TRN & \\
\hline CHEMBL1364496 & 688422 & 4.45 & 5.12299 & 9999999999 & TRN \\
\hline CHEMBL1525329 & 688422 & 4.95 & 5.52 & TRN & \\
\hline CHEMBL1491398 & 688422 & 5.2 & 4.9667 & TRN & \\
\hline CHEMBL1388542 & 688422 & 4.65 & 5.1041 & TST & \\
\hline CHEMBL117804 & 688422 & 7.5003 & 5.0328 & TRN & \\
\hline CHEMBL1493997 & 688422 & 4.9 & 5.1237 & TRN & \\
\hline CHEMBL1369011 & 688422 & 7.6003 & 5.6508 & TRN & \\
\hline CHEMBL1534140 & 688422 & 4.45 & 4.7195 & TRN & \\
\hline CHEMBL1354079 & 688422 & 5.2 & 5.1137 & TRN & \\
\hline CHEMBL1345717 & 688422 & 4.7 & 5.0114 & TRN & \\
\hline CHEMBL3209603 & 688422 & 4.9 & 5.5257 & TST & \\
\hline CHEMBL1509978 & 688422 & 6.35 & 4.8407 & TRN & \\
\hline
\end{tabular}




\begin{tabular}{|c|c|c|c|c|c|}
\hline \multicolumn{6}{|c|}{ Supplemental Table S2.txt } \\
\hline CHEMBL3209543 & 688422 & 4.65 & 5.1688 & TRN & \\
\hline CHEMBL1448075 & 688422 & 8.4559 & 5.5588 & TST & \\
\hline CHEMBL1493146 & 688422 & 7.3497 & 5.3574 & TRN & \\
\hline CHEMBL1553043 & 688422 & 4.4 & 5.5423 & TRN & \\
\hline CHEMBL1316961 & 688422 & 4.45 & 5.2917 & TRN & \\
\hline CHEMBL1447872 & 688422 & 4.45 & 5.038 & TRN & \\
\hline CHEMBL1545491 & 688422 & 5.85 & 5.4151 & TST & \\
\hline CHEMBL1404559 & 688422 & 4.75 & 5.0566 & TRN & \\
\hline CHEMBL1369524 & 688422 & 4.45 & 5.8194 & TST & \\
\hline CHEMBL1516185 & 688422 & 4.9 & 5.2439 & TRN & \\
\hline CHEMBL1332139 & 688422 & 4.45 & 5.5133 & TRN & \\
\hline CHEMBL1567307 & 688422 & 5.45 & 5.2999 & TST & \\
\hline CHEMBL1574649 & 688422 & 4.6 & 4.8056 & TRN & \\
\hline CHEMBL1303889 & 688422 & 4.75 & 5.3304 & TST & \\
\hline CHEMBL3196136 & 688422 & 6.25 & 5.9139 & TST & \\
\hline CHEMBL1483624 & 688422 & 4.6 & 5.3218 & TRN & \\
\hline CHEMBL1432185 & 688422 & 4.65 & 4.7983 & TRN & \\
\hline CHEMBL1309690 & 688422 & 4.45 & 5.0588 & TST & \\
\hline CHEMBL 1444400 & 688422 & 4.45 & 5.3701 & TRN & \\
\hline CHEMBL1256761 & 688422 & 4.9 & 5.5121 & TRN & \\
\hline CHEMBL1452266 & 688422 & 4.9 & 5.2107 & TRN & \\
\hline CHEMBL3193123 & 688422 & 4.45 & 5.6871 & TRN & \\
\hline CHEMBL1556111 & 688422 & 4.7 & 5.1425 & TRN & \\
\hline CHEMBL3197243 & 688422 & 4.45 & 4.8975 & TRN & \\
\hline CHEMBL1386983 & 688422 & 4.6 & 5.0424 & TRN & \\
\hline CHEMBL1382959 & 688422 & 4.8 & 5.6967 & TRN & \\
\hline CHEMBL1448730 & 688422 & 5.5 & 5.371 & TRN & \\
\hline CHEMBL1577360 & 688422 & 4.5 & 4.9979 & TST & \\
\hline CHEMBL1333589 & 688422 & 7.15 & 5.1769 & TRN & \\
\hline CHEMBL1441999 & 688422 & 7.6003 & 5.3936 & TRN & \\
\hline CHEMBL1402324 & 688422 & 4.6 & 4.9366 & TST & \\
\hline CHEMBL1453212 & 688422 & 4.45 & 4.9753 & TST & \\
\hline CHEMBL1383873 & 688422 & 6.7501 & 4.9145 & TRN & \\
\hline CHEMBL1505039 & 688422 & 4.5 & 5.0249 & TRN & \\
\hline CHEMBL1554101 & 688422 & 4.45 & 5.6293 & TRN & \\
\hline CHEMBL1388267 & 688422 & 4.75 & 5.155 & TRN & \\
\hline CHEMBL1477125 & 688422 & 4.85 & 5.0421 & TRN & \\
\hline CHEMBL1600986 & 688422 & 6.0 & 5.0925 & TRN & \\
\hline CHEMBL1584691 & 688422 & 5.25 & 5.8617 & TRN & \\
\hline CHEMBL1440833 & 688422 & 4.45 & 4.9278 & TST & \\
\hline CHEMBL1611356 & 688422 & 4.45 & 4.7982 & TST & \\
\hline CHEMBL1574557 & 688422 & 4.45 & 5.4537 & TST & \\
\hline CHEMBL1569841 & 688422 & 4.95 & 4.9062 & TRN & \\
\hline CHEMBL1382882 & 688422 & 7.6003 & 5.34200 & 00000000005 & TRN \\
\hline CHEMBL1355824 & 688422 & 7.699 & 5.4925 & TRN & \\
\hline CHEMBL1575373 & 688422 & 4.85 & 5.1221 & TRN & \\
\hline CHEMBL1316979 & 688422 & 4.8 & 4.4228 & TRN & \\
\hline CHEMBL1348389 & 688422 & 4.6 & 5.3643 & TRN & \\
\hline
\end{tabular}




\begin{tabular}{|c|c|c|c|c|c|}
\hline \multicolumn{6}{|c|}{ Supplemental Table S2.txt } \\
\hline CHEMBL1516125 & 688422 & 4.95 & 5.1394 & TRN & \\
\hline CHEMBL1600523 & 688422 & 4.95 & 5.1041 & TRN & \\
\hline CHEMBL3212396 & 688422 & 4.9 & 4.8996 & TRN & \\
\hline CHEMBL1483138 & 688422 & 4.6 & 5.0785 & TST & \\
\hline CHEMBL1329058 & 688422 & 4.45 & 5.4645 & TST & \\
\hline CHEMBL1437050 & 688422 & 5.85 & 5.3656 & TRN & \\
\hline CHEMBL1417982 & 688422 & 7.8996 & 5.6394 & TRN & \\
\hline CHEMBL1479774 & 688422 & 5.45 & 5.2582 & TST & \\
\hline CHEMBL1607650 & 688422 & 4.8 & 4.7047 & TRN & \\
\hline CHEMBL1397854 & 688422 & 6.45 & 5.0317 & TRN & \\
\hline CHEMBL1402400 & 688422 & 6.15 & 5.1633 & TRN & \\
\hline CHEMBL1352853 & 688422 & 4.65 & 4.8792 & TRN & \\
\hline CHEMBL1863606 & 688422 & 4.45 & 5.1845 & TRN & \\
\hline CHEMBL1303322 & 688422 & 4.45 & 5.1821 & TRN & \\
\hline CHEMBL1559368 & 688422 & 4.45 & 5.0074 & TRN & \\
\hline CHEMBL1501771 & 688422 & 4.75 & 5.15799 & 99999999995 & TRN \\
\hline CHEMBL1610522 & 688422 & 4.45 & 5.1496 & TRN & \\
\hline CHEMBL1342283 & 688422 & 4.9 & 5.4493 & TRN & \\
\hline CHEMBL1383593 & 688422 & 4.8 & 5.0662 & TRN & \\
\hline CHEMBL1578552 & 688422 & 8.3468 & 5.5753 & TRN & \\
\hline CHEMBL194400 & 688422 & 4.6 & 5.6238 & TST & \\
\hline CHEMBL3199748 & 688422 & 4.7 & 5.2004 & TRN & \\
\hline CHEMBL1519672 & 688422 & 4.45 & 5.1423 & TRN & \\
\hline CHEMBL1322778 & 688422 & 4.45 & 5.58 & TRN & \\
\hline CHEMBL1428967 & 688422 & 4.85 & 5.1012 & TRN & \\
\hline CHEMBL1594107 & 688422 & 7.15 & 5.3295 & TRN & \\
\hline CHEMBL1565659 & 688422 & 7.1002 & 5.5894 & TST & \\
\hline CHEMBL1411193 & 688422 & 4.5 & 5.194 & TRN & \\
\hline CHEMBL1475920 & 688422 & 5.5 & 5.6752 & TRN & \\
\hline CHEMBL1512704 & 688422 & 7.5003 & 5.2735 & TRN & \\
\hline CHEMBL1373982 & 688422 & 5.0 & 5.5581 & TST & \\
\hline CHEMBL1542436 & 688422 & 4.45 & 4.6761 & TRN & \\
\hline CHEMBL1612980 & 688422 & 5.9 & 5.5565 & TST & \\
\hline CHEMBL1465704 & 688422 & 4.65 & 5.0501 & TRN & \\
\hline CHEMBL1360879 & 688422 & 5.0 & 5.0645 & TRN & \\
\hline CHEMBL1558234 & 688422 & 4.45 & 5.2926 & TST & \\
\hline CHEMBL1333574 & 688422 & 6.7501 & 5.6656 & TRN & \\
\hline CHEMBL1366367 & 688422 & 4.7 & 4.7606 & TRN & \\
\hline CHEMBL1517393 & 688422 & 4.8 & 5.1802 & TST & \\
\hline CHEMBL1343237 & 688422 & 4.6 & 5.3369 & TST & \\
\hline CHEMBL1237212 & 688422 & 6.0 & 5.8899 & TST & \\
\hline CHEMBL1483698 & 688422 & 5.55 & 5.222 & TST & \\
\hline CHEMBL1300171 & 688422 & 5.2 & 5.2229 & TRN & \\
\hline CHEMBL1575666 & 688422 & 4.55 & 5.6394 & TRN & \\
\hline CHEMBL1501596 & 688422 & 4.45 & 5.3012 & TRN & \\
\hline CHEMBL1492468 & 688422 & 6.6 & 5.729 & TRN & \\
\hline CHEMBL1596348 & 688422 & 4.45 & 5.6145 & TST & \\
\hline CHEMBL1300494 & 688422 & 4.8 & 5.0341 & TST & \\
\hline
\end{tabular}




\begin{tabular}{|c|c|c|c|c|}
\hline \multicolumn{5}{|c|}{ Supplemental Table S2.txt } \\
\hline CHEMBL1348808 & 688422 & 4.5 & 5.3641 & TST \\
\hline CHEMBL1432334 & 688422 & 4.45 & 5.0002 & TRN \\
\hline CHEMBL1439644 & 688422 & 4.9 & 5.6488 & TRN \\
\hline CHEMBL1970836 & 688422 & 4.85 & 5.4258 & TST \\
\hline CHEMBL1530569 & 688422 & 5.05 & 5.1794 & TST \\
\hline CHEMBL1604790 & 688422 & 6.35 & 5.3931 & TST \\
\hline CHEMBL1590549 & 688422 & 7.0 & 5.4394 & TRN \\
\hline CHEMBL1374058 & 688422 & 4.7 & 5.0196 & TRN \\
\hline CHEMBL1442566 & 688422 & 5.2 & 5.4083 & TRN \\
\hline CHEMBL1341124 & 688422 & 4.95 & 5.2117 & TRN \\
\hline CHEMBL500351 & 688422 & 5.15 & 4.9425 & TRN \\
\hline CHEMBL1411748 & 688422 & 8.4949 & 5.4309 & TRN \\
\hline CHEMBL1373331 & 688422 & 4.9 & 4.7736 & TRN \\
\hline CHEMBL 2136498 & 688422 & 4.95 & 4.9415 & TRN \\
\hline CHEMBL1423207 & 688422 & 5.3 & 5.1658 & TRN \\
\hline CHEMBL1478236 & 688422 & 4.9 & 5.0835 & TRN \\
\hline CHEMBL1581158 & 688422 & 4.45 & 5.3515 & TST \\
\hline CHEMBL1418624 & 688422 & 8.0 & 5.3272 & TST \\
\hline CHEMBL1392003 & 688422 & 4.6 & 5.0743 & TRN \\
\hline CHEMBL1458719 & 688422 & 4.45 & 4.9161 & TST \\
\hline CHEMBL1516676 & 688422 & 5.35 & 5.6325 & TRN \\
\hline CHEMBL1505982 & 688422 & 5.25 & 5.0423 & TST \\
\hline CHEMBL1537312 & 688422 & 4.45 & 5.7884 & TST \\
\hline CHEMBL1448184 & 688422 & 6.1 & 5.5031 & TRN \\
\hline CHEMBL1510215 & 688422 & 8.0 & 5.6449 & TRN \\
\hline CHEMBL1559948 & 688422 & 4.9 & 4.6365 & TRN \\
\hline CHEMBL417727 & 688422 & 5.45 & 5.5729 & TRN \\
\hline CHEMBL1511138 & 688422 & 5.25 & 5.319 & TRN \\
\hline CHEMBL1574541 & 688422 & 4.45 & 5.2617 & TRN \\
\hline CHEMBL1351617 & 688422 & 4.8 & 4.8457 & TRN \\
\hline CHEMBL1311514 & 688422 & 4.9 & 5.0709 & TRN \\
\hline CHEMBL 262347 & 688422 & 4.95 & 5.1654 & TRN \\
\hline CHEMBL1610808 & 688422 & 4.45 & 5.1788 & TRN \\
\hline CHEMBL1348057 & 688422 & 5.5 & 4.5205 & TRN \\
\hline CHEMBL1470848 & 688422 & 4.65 & 5.0271 & TST \\
\hline CHEMBL1486174 & 688422 & 4.45 & 5.2463 & TST \\
\hline CHEMBL1575757 & 688422 & 5.25 & 5.5789 & TRN \\
\hline CHEMBL1453863 & 688422 & 4.45 & 5.2255 & TRN \\
\hline CHEMBL1309049 & 688422 & 5.1 & 5.4678 & TRN \\
\hline CHEMBL1336848 & 688422 & 4.65 & 5.0147 & TST \\
\hline CHEMBL1967540 & 688422 & 4.8 & 5.2319 & TRN \\
\hline CHEMBL1357268 & 688422 & 8.2518 & 5.3724 & TRN \\
\hline CHEMBL1546953 & 688422 & 4.9 & 5.5065 & TRN \\
\hline CHEMBL1554392 & 688422 & 4.95 & 5.1606 & TRN \\
\hline CHEMBL1420811 & 688422 & 4.85 & $5.3670 e$ & 0000000001 \\
\hline CHEMBL1461711 & 688422 & 7.2 & 5.8872 & TRN \\
\hline CHEMBL1499932 & 688422 & 4.85 & 5.0087 & TST \\
\hline CHEMBL1589436 & 688422 & 4.45 & 4.9224 & TST \\
\hline
\end{tabular}




\begin{tabular}{|c|c|c|c|c|}
\hline \multicolumn{5}{|c|}{ Supplemental Table S2.txt } \\
\hline CHEMBL1425808 & 688422 & 4.45 & 5.5842 & TST \\
\hline CHEMBL1421478 & 688422 & 4.95 & 5.1862 & TRN \\
\hline CHEMBL1526937 & 688422 & 4.5 & 5.4935 & TRN \\
\hline CHEMBL 259840 & 688422 & 4.45 & 5.4442 & TST \\
\hline CHEMBL1527885 & 688422 & 4.65 & 5.1591 & TST \\
\hline CHEMBL1434709 & 688422 & 5.7 & 5.5219 & TRN \\
\hline CHEMBL1377917 & 688422 & 4.45 & 5.2128 & TRN \\
\hline CHEMBL1305049 & 688422 & 7.9508 & 5.3784 & TST \\
\hline CHEMBL1527739 & 688422 & 5.0 & 4.9444 & TRN \\
\hline CHEMBL600713 & 688422 & 5.25 & 5.2696 & TRN \\
\hline CHEMBL1389653 & 688422 & 4.9 & 5.1848 & TRN \\
\hline CHEMBL1581566 & 688422 & 4.55 & 4.7535 & TRN \\
\hline CHEMBL1364928 & 688422 & 4.9 & 5.0212 & TRN \\
\hline CHEMBL1255733 & 688422 & 6.0 & 6.2273 & TST \\
\hline CHEMBL1507051 & 688422 & 4.45 & 5.0551 & TST \\
\hline CHEMBL1350258 & 688422 & 5.15 & 5.4518 & TST \\
\hline CHEMBL1403383 & 688422 & 4.8 & 5.2032 & TST \\
\hline CHEMBL1456312 & 688422 & 5.25 & 5.6497 & TST \\
\hline CHEMBL1501835 & 688422 & 4.8 & 5.263 & TRN \\
\hline CHEMBL1307116 & 688422 & 5.15 & 5.2281 & TRN \\
\hline CHEMBL1580953 & 688422 & 7.5003 & 5.4739 & TRN \\
\hline CHEMBL1375161 & 688422 & 4.95 & 5.4413 & TRN \\
\hline CHEMBL1304886 & 688422 & 8.3468 & 5.4919 & TRN \\
\hline CHEMBL1385134 & 688422 & 5.0 & 5.192 & TRN \\
\hline CHEMBL1573053 & 688422 & 5.7 & 5.6883 & TST \\
\hline CHEMBL1486190 & 688422 & 4.45 & 5.2037 & TRN \\
\hline CHEMBL1465422 & 688422 & 4.9 & 4.7922 & TRN \\
\hline CHEMBL1444294 & 688422 & 5.0 & 4.6639 & TST \\
\hline CHEMBL1341534 & 688422 & 5.7 & 5.3633 & TRN \\
\hline CHEMBL1323876 & 688422 & 4.45 & 5.2311 & TRN \\
\hline CHEMBL1593178 & 688422 & 5.75 & 5.4134 & TRN \\
\hline CHEMBL1461881 & 688422 & 5.15 & 5.0121 & TRN \\
\hline CHEMBL1537469 & 688422 & 5.6 & 5.4629 & TRN \\
\hline CHEMBL1607568 & 688422 & 5.1 & 5.4793 & TRN \\
\hline CHEMBL 3193765 & 688422 & 4.8 & 5.0865 & TRN \\
\hline CHEMBL146855 & 688422 & 5.5 & 5.5859 & TST \\
\hline CHEMBL1418016 & 688422 & 6.2 & 5.6027 & TST \\
\hline CHEMBL1532035 & 688422 & 4.6 & 5.0301 & TRN \\
\hline CHEMBL1371624 & 688422 & 4.65 & 5.1195 & TRN \\
\hline CHEMBL1557167 & 688422 & 5.2 & 5.3068 & TRN \\
\hline CHEMBL1418598 & 688422 & 4.65 & 4.814 & TRN \\
\hline CHEMBL1428331 & 688422 & 7.1002 & 5.2368 & TRN \\
\hline CHEMBL1366939 & 688422 & 4.75 & 5.3803 & TRN \\
\hline CHEMBL1406129 & 688422 & 4.45 & 5.5059 & TRN \\
\hline CHEMBL1542167 & 688422 & 5.0 & 4.9667 & TRN \\
\hline CHEMBL1995904 & 688422 & 5.4 & 5.4813 & TRN \\
\hline CHEMBL1490409 & 688422 & 4.5 & 4.6516 & TRN \\
\hline CHEMBL1425914 & 688422 & 4.9 & 5.1231 & TST \\
\hline
\end{tabular}




\begin{tabular}{|c|c|c|c|c|c|}
\hline & & \multicolumn{4}{|c|}{ Supplemental Table S2.txt } \\
\hline CHEMBL3207361 & 688422 & 8.301 & 5.2924 & TRN & \\
\hline CHEMBL1474645 & 688422 & 6.6 & 5.2292 & TRN & \\
\hline CHEMBL1447341 & 688422 & 4.65 & 5.2149 & TRN & \\
\hline CHEMBL1549827 & 688422 & 4.75 & 4.9667 & TRN & \\
\hline CHEMBL1413331 & 688422 & 7.5003 & 5.7139 & TRN & \\
\hline CHEMBL1586107 & 688422 & 4.9 & 5.15799 & 99999999995 & TRN \\
\hline CHEMBL1371637 & 688422 & 4.6 & 5.2091 & TRN & \\
\hline CHEMBL1330780 & 688422 & 4.9 & 5.1101 & TRN & \\
\hline CHEMBL1363019 & 688422 & 5.35 & 5.5701 & TRN & \\
\hline CHEMBL1468750 & 688422 & 5.3 & 5.1338 & TRN & \\
\hline CHEMBL1357024 & 688422 & 7.2503 & 5.7842 & TRN & \\
\hline CHEMBL1606787 & 688422 & 4.95 & 4.9456 & TRN & \\
\hline CHEMBL1465620 & 688422 & 4.9 & 5.5008 & TST & \\
\hline CHEMBL1359108 & 688422 & 4.85 & 5.2192 & TRN & \\
\hline CHEMBL1499383 & 688422 & 4.45 & 5.4753 & TRN & \\
\hline CHEMBL1389728 & 688422 & 4.5 & 4.8438 & TRN & \\
\hline CHEMBL1411306 & 688422 & 4.85 & 5.2283 & TRN & \\
\hline CHEMBL1376669 & 688422 & 7.4498 & 5.3143 & TRN & \\
\hline CHEMBL1384845 & 688422 & 5.45 & 4.975 & TRN & \\
\hline CHEMBL1328373 & 688422 & 4.85 & 5.1776 & TRN & \\
\hline CHEMBL1374439 & 688422 & 8.4559 & 5.2191 & TRN & \\
\hline CHEMBL1597128 & 688422 & 4.95 & 5.2943 & TRN & \\
\hline CHEMBL222409 & 688422 & 5.7 & 5.4124 & TRN & \\
\hline CHEMBL1523379 & 688422 & 4.5 & 4.9286 & TRN & \\
\hline CHEMBL1304919 & 688422 & 4.45 & 5.2381 & TRN & \\
\hline CHEMBL1437095 & 688422 & 5.0 & 5.0524 & TRN & \\
\hline CHEMBL1446743 & 688422 & 8.4949 & 5.3524 & TST & \\
\hline CHEMBL1360135 & 688422 & 4.45 & 5.4679 & TST & \\
\hline CHEMBL1603820 & 688422 & 8.7959 & 5.7063 & TST & \\
\hline CHEMBL1509880 & 688422 & 6.6499 & 5.292006 & 0000000001 & TST \\
\hline CHEMBL 3198094 & 688422 & 5.0 & 5.2308 & TRN & \\
\hline CHEMBL1498753 & 688422 & 4.8 & 5.5583 & TRN & \\
\hline CHEMBL1494428 & 688422 & 4.45 & 5.0409 & TRN & \\
\hline CHEMBL1382494 & 688422 & 4.45 & 5.0395 & TRN & \\
\hline CHEMBL1462019 & 688422 & 4.45 & 5.1766 & TRN & \\
\hline CHEMBL1300817 & 688422 & 4.85 & 5.6524 & TRN & \\
\hline CHEMBL1456015 & 688422 & 4.75 & 4.6991 & TRN & \\
\hline CHEMBL1419587 & 688422 & 4.9 & 5.5656 & TRN & \\
\hline CHEMBL1532162 & 688422 & 6.05 & 5.2226 & TRN & \\
\hline CHEMBL1407793 & 688422 & 5.9 & 5.1541 & TRN & \\
\hline CHEMBL1582061 & 688422 & 4.45 & 5.0638 & TRN & \\
\hline CHEMBL1391094 & 688422 & 5.0 & 5.5779 & TST & \\
\hline CHEMBL1382461 & 688422 & 5.3 & 4.8408 & TRN & \\
\hline CHEMBL1510153 & 688422 & 4.45 & 5.1597 & TST & \\
\hline CHEMBL1425684 & 688422 & 4.5 & 4.6669 & TRN & \\
\hline CHEMBL 3208787 & 688422 & 4.7 & 5.18 & TRN & \\
\hline CHEMBL1567829 & 688422 & 4.45 & 4.7677 & TRN & \\
\hline CHEMBL1562871 & 688422 & 4.75 & 4.9494 & TRN & \\
\hline
\end{tabular}




\begin{tabular}{|c|c|c|c|c|c|}
\hline \multicolumn{6}{|c|}{ Supplemental Table S2.txt } \\
\hline CHEMBL1396534 & 688422 & 4.5 & 5.3431 & TRN & \\
\hline CHEMBL1484030 & 688422 & 4.95 & 5.5674 & TRN & \\
\hline CHEMBL3193628 & 688422 & 5.15 & 5.2067 & TRN & \\
\hline CHEMBL1460776 & 688422 & 6.5501 & 5.7128 & TRN & \\
\hline CHEMBL 26320 & 688422 & 4.75 & 5.4244 & TRN & \\
\hline CHEMBL1406782 & 688422 & 4.95 & 5.0957 & TRN & \\
\hline CHEMBL3193865 & 688422 & 4.8 & 4.9267 & TRN & \\
\hline CHEMBL1492839 & 688422 & 5.3 & 5.4926 & TRN & \\
\hline CHEMBL1299418 & 688422 & 4.45 & 5.1063 & TRN & \\
\hline CHEMBL1332895 & 688422 & 6.3 & 5.169 & TRN & \\
\hline CHEMBL1450935 & 688422 & 4.75 & 5.3655 & TRN & \\
\hline CHEMBL1306076 & 688422 & 4.75 & 4.9714 & TRN & \\
\hline CHEMBL1357622 & 688422 & 8.4559 & 5.2412 & TRN & \\
\hline CHEMBL1589370 & 688422 & 4.45 & 5.0249 & TRN & \\
\hline CHEMBL1500830 & 688422 & 4.45 & 4.83899 & 99999999995 & TRN \\
\hline CHEMBL1504057 & 688422 & 4.5 & 5.1156 & TRN & \\
\hline CHEMBL1586425 & 688422 & 5.9 & 5.4968 & TRN & \\
\hline CHEMBL1305770 & 688422 & 5.05 & 4.9693 & TRN & \\
\hline CHEMBL1299943 & 688422 & 5.0 & 5.4442 & TRN & \\
\hline CHEMBL1454278 & 688422 & 4.45 & 5.1485 & TST & \\
\hline CHEMBL1574275 & 688422 & 4.85 & 5.2527 & TRN & \\
\hline CHEMBL1366616 & 688422 & 5.35 & 5.5649 & TST & \\
\hline CHEMBL1517849 & 688422 & 4.7 & 5.2653 & TRN & \\
\hline CHEMBL1465851 & 688422 & 4.5 & 5.5398 & TRN & \\
\hline CHEMBL1420253 & 688422 & 4.65 & 5.0114 & TST & \\
\hline CHEMBL1323790 & 688422 & 4.65 & 5.3536 & TRN & \\
\hline CHEMBL3195553 & 688422 & 4.45 & 5.4106 & TRN & \\
\hline CHEMBL1405708 & 688422 & 4.75 & 4.9989 & TRN & \\
\hline CHEMBL 3214509 & 688422 & 5.1 & 5.2544 & TRN & \\
\hline CHEMBL1566268 & 688422 & 4.45 & 5.5096 & TRN & \\
\hline CHEMBL1547399 & 688422 & 4.5 & 5.1947 & TST & \\
\hline CHEMBL1459784 & 688422 & 4.9 & 5.5539 & TRN & \\
\hline CHEMBL1404745 & 688422 & 4.85 & 5.2281 & TRN & \\
\hline CHEMBL1583576 & 688422 & 6.6499 & 5.5914 & TRN & \\
\hline CHEMBL1586315 & 688422 & 4.5 & 4.7996 & TST & \\
\hline CHEMBL1506417 & 688422 & 5.4 & 5.3529 & TST & \\
\hline CHEMBL 1600360 & 688422 & 4.95 & 5.0486 & TRN & \\
\hline CHEMBL1532681 & 688422 & 5.0 & 5.1204 & TRN & \\
\hline CHEMBL1588172 & 688422 & 4.9 & 5.393 & TRN & \\
\hline CHEMBL1613478 & 688422 & 4.9 & 4.9508 & TST & \\
\hline CHEMBL1422256 & 688422 & 4.45 & 5.2133 & TRN & \\
\hline CHEMBL1331219 & 688422 & 8.1487 & 5.5649 & TRN & \\
\hline CHEMBL1341008 & 688422 & 5.0 & 5.1672 & TST & \\
\hline CHEMBL1978383 & 688422 & 4.8 & 5.3912 & TRN & \\
\hline CHEMBL1452608 & 688422 & 4.45 & 4.9182 & TRN & \\
\hline CHEMBL1535038 & 688422 & 6.9 & 5.2849 & TRN & \\
\hline CHEMBL1463807 & 688422 & 7.1002 & 4.7235 & TRN & \\
\hline CHEMBL1424319 & 688422 & 4.9 & 5.1521 & TRN & \\
\hline
\end{tabular}




\begin{tabular}{|c|c|c|c|c|c|}
\hline \multicolumn{6}{|c|}{ Supplemental Table S2.txt } \\
\hline CHEMBL1565435 & 688422 & 4.5 & 4.8375 & TST & \\
\hline CHEMBL1382447 & 688422 & 4.45 & 5.2144 & TRN & \\
\hline CHEMBL1305240 & 688422 & 5.0 & 5.3908 & TST & \\
\hline CHEMBL3193111 & 688422 & 4.9 & 5.2363 & TRN & \\
\hline CHEMBL1339736 & 688422 & 5.3 & 5.261 & TRN & \\
\hline CHEMBL1551689 & 688422 & 7.699 & 5.2071 & TRN & \\
\hline CHEMBL1490864 & 688422 & 4.9 & 5.1664 & TRN & \\
\hline CHEMBL1508555 & 688422 & 4.45 & 5.3146 & TRN & \\
\hline CHEMBL1996426 & 688422 & 4.7 & 5.4313 & TST & \\
\hline CHEMBL1363042 & 688422 & 4.75 & 5.1773 & TRN & \\
\hline CHEMBL1313919 & 688422 & 4.45 & 5.2093 & TRN & \\
\hline CHEMBL1343065 & 688422 & 4.65 & 5.2348 & TST & \\
\hline CHEMBL1479350 & 688422 & 6.35 & 5.1132 & TRN & \\
\hline CHEMBL 3212762 & 688422 & 5.05 & 5.1564 & TRN & \\
\hline CHEMBL1347232 & 688422 & 4.95 & 5.2313 & TST & \\
\hline CHEMBL109037 & 688422 & 4.6 & 6.0142 & TST & \\
\hline CHEMBL3207325 & 688422 & 7.3497 & 5.5205 & TRN & \\
\hline CHEMBL1604769 & 688422 & 8.3979 & 4.966 & TST & \\
\hline CHEMBL1534672 & 688422 & 6.05 & 5.0637 & TRN & \\
\hline CHEMBL1532439 & 688422 & 7.6498 & 5.3277 & TST & \\
\hline CHEMBL1319142 & 688422 & 4.45 & 5.2645 & TRN & \\
\hline CHEMBL1599968 & 688422 & 4.65 & 4.8742 & TRN & \\
\hline CHEMBL1453700 & 688422 & 5.6 & 5.6319 & TRN & \\
\hline CHEMBL1610480 & 688422 & 4.6 & 5.2196 & TST & \\
\hline CHEMBL1610180 & 688422 & 4.5 & 5.4795 & TRN & \\
\hline CHEMBL1328117 & 688422 & 4.9 & 5.1462 & TRN & \\
\hline CHEMBL1434882 & 688422 & 4.65 & 4.5241 & TRN & \\
\hline CHEMBL1430306 & 688422 & 4.7 & 5.6203 & TRN & \\
\hline CHEMBL1607408 & 688422 & 5.7 & 5.0367 & TST & \\
\hline CHEMBL 1447974 & 688422 & 4.65 & 4.6709 & TRN & \\
\hline CHEMBL1433322 & 688422 & 6.35 & 5.0678 & TRN & \\
\hline CHEMBL1312953 & 688422 & 5.15 & 5.1708 & TRN & \\
\hline CHEMBL1415853 & 688422 & 5.15 & 5.476 & TRN & \\
\hline CHEMBL1309542 & 688422 & 5.2 & 5.2296 & TRN & \\
\hline CHEMBL1601438 & 688422 & 6.7501 & 5.2956 & TRN & \\
\hline CHEMBL3195608 & 688422 & 5.5 & 5.614 & TRN & \\
\hline CHEMBL24510 & 688422 & 5.15 & 5.6535 & TST & \\
\hline CHEMBL270635 & 688422 & 6.05 & 5.1632 & TRN & \\
\hline CHEMBL3196747 & 688422 & 5.95 & 4.8702 & TRN & \\
\hline CHEMBL576317 & 688422 & 4.5 & 5.3643 & TRN & \\
\hline CHEMBL1507512 & 688422 & 4.95 & 5.5812 & TRN & \\
\hline CHEMBL1605585 & 688422 & 4.5 & 5.3225 & TRN & \\
\hline CHEMBL3211215 & 688422 & 4.85 & 4.9409 & TRN & \\
\hline CHEMBL1556484 & 688422 & 4.9 & 5.4731 & TRN & \\
\hline CHEMBL1394991 & 688422 & 4.95 & 5.84399 & 9999999999 & TRN \\
\hline CHEMBL1379801 & 688422 & 4.8 & 5.0119 & TRN & \\
\hline CHEMBL1454662 & 688422 & 4.9 & 5.2782 & TRN & \\
\hline CHEMBL1307394 & 688422 & 4.95 & 5.0812 & TRN & \\
\hline
\end{tabular}




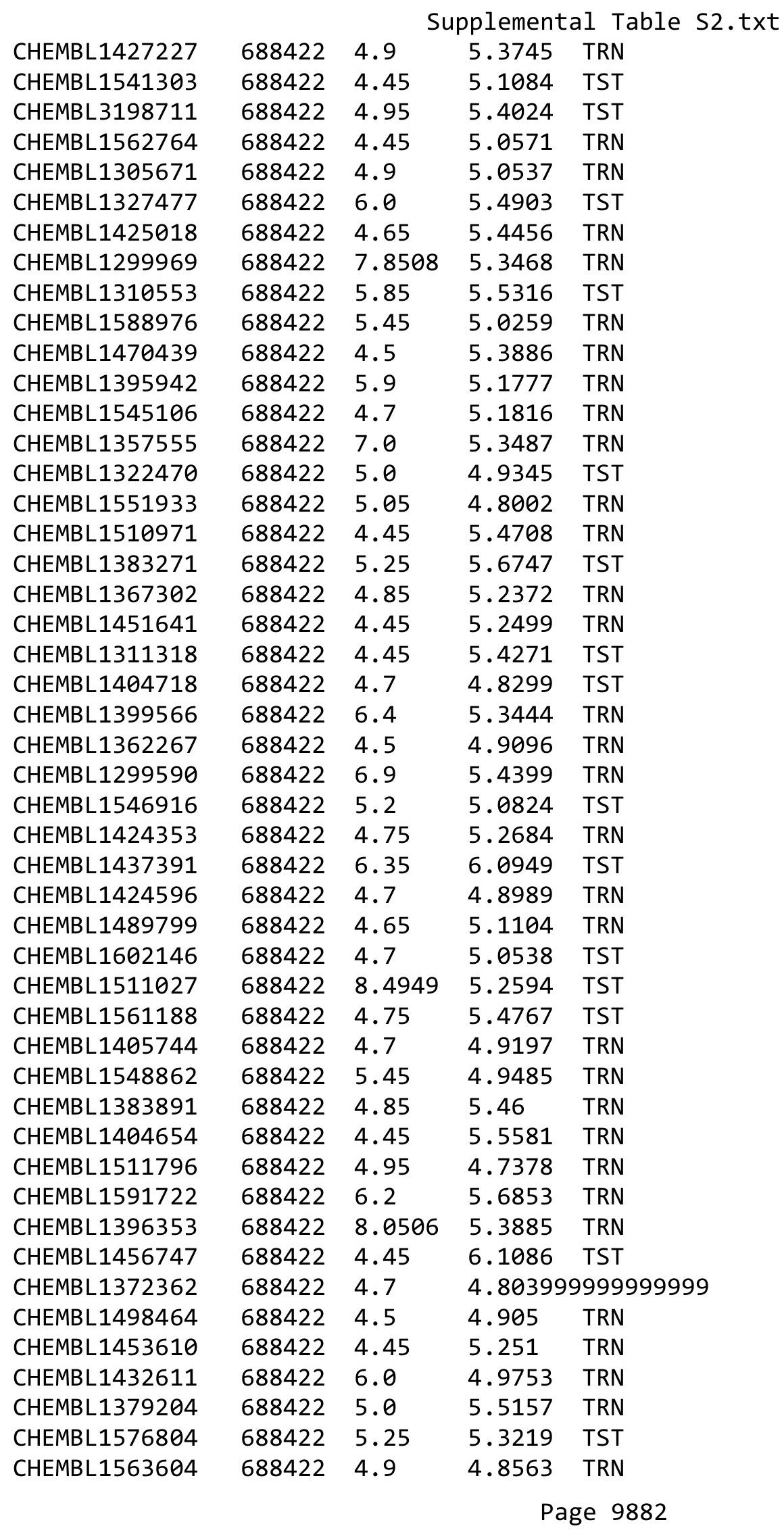




\begin{tabular}{|c|c|c|c|c|c|}
\hline \multicolumn{6}{|c|}{ Supplemental Table S2.txt } \\
\hline CHEMBL1597656 & 688422 & 4.85 & 5.0439 & TRN & \\
\hline CHEMBL1603493 & 688422 & 4.7 & 4.8682 & TST & \\
\hline CHEMBL1494373 & 688422 & 5.25 & 5.0908 & TRN & \\
\hline CHEMBL1382339 & 688422 & 4.45 & 4.9359 & TRN & \\
\hline CHEMBL1399131 & 688422 & 4.95 & 4.8843 & TRN & \\
\hline CHEMBL1577406 & 688422 & 4.45 & 5.3591 & TRN & \\
\hline CHEMBL1582408 & 688422 & 4.65 & 5.3499 & TRN & \\
\hline CHEMBL3198287 & 688422 & 4.95 & 5.135 & TRN & \\
\hline CHEMBL1602838 & 688422 & 5.05 & 4.8661 & TRN & \\
\hline CHEMBL1465656 & 688422 & 5.3 & 5.2389 & TRN & \\
\hline CHEMBL1497589 & 688422 & 4.85 & 5.3393 & TRN & \\
\hline CHEMBL1590073 & 688422 & 7.2503 & 5.1932 & TRN & \\
\hline CHEMBL1337802 & 688422 & 5.2 & 5.3027 & TRN & \\
\hline CHEMBL1312571 & 688422 & 4.8 & 5.1347 & TRN & \\
\hline CHEMBL1479600 & 688422 & 8.3979 & 5.3734 & TRN & \\
\hline CHEMBL1484335 & 688422 & 5.3 & 5.1775 & TRN & \\
\hline CHEMBL1482724 & 688422 & 7.5003 & 5.1025 & TST & \\
\hline CHEMBL1494238 & 688422 & 5.05 & 5.2016 & TST & \\
\hline CHEMBL1602461 & 688422 & 4.45 & 4.7097 & TRN & \\
\hline CHEMBL1527348 & 688422 & 4.7 & 5.1752 & TRN & \\
\hline CHEMBL 2369290 & 688422 & 4.9 & 5.2389 & TST & \\
\hline CHEMBL1551073 & 688422 & 4.45 & 4.9149 & TRN & \\
\hline CHEMBL1325377 & 688422 & 5.45 & 5.3026 & TRN & \\
\hline CHEMBL1594483 & 688422 & 4.45 & 5.5939 & TST & \\
\hline CHEMBL1319573 & 688422 & 5.55 & 5.2046 & TST & \\
\hline CHEMBL3210576 & 688422 & 4.85 & 5.0877 & TRN & \\
\hline CHEMBL1466004 & 688422 & 4.8 & 5.2528 & TRN & \\
\hline CHEMBL1547600 & 688422 & 4.45 & 5.43 & TRN & \\
\hline CHEMBL1411067 & 688422 & 4.75 & 5.0975 & TRN & \\
\hline CHEMBL1376841 & 688422 & 5.35 & 5.8022 & TST & \\
\hline CHEMBL1583745 & 688422 & 4.95 & 5.6044 & TST & \\
\hline CHEMBL1475993 & 688422 & 4.85 & 5.1624 & TRN & \\
\hline CHEMBL1452508 & 688422 & 4.75 & 5.0191 & TRN & \\
\hline CHEMBL1445771 & 688422 & 5.25 & 5.12700 & 0000000001 & TRN \\
\hline CHEMBL1400292 & 688422 & 6.25 & 5.1235 & TRN & \\
\hline CHEMBL1515683 & 688422 & 5.0 & 5.1146 & TRN & \\
\hline CHEMBL1381126 & 688422 & 6.8 & 4.9442 & TST & \\
\hline CHEMBL1409046 & 688422 & 6.5 & 6.02 & TST & \\
\hline CHEMBL1539084 & 688422 & 4.9 & 5.0872 & TST & \\
\hline CHEMBL1412086 & 688422 & 4.45 & 5.3813 & TRN & \\
\hline CHEMBL1457787 & 688422 & 4.9 & 5.0128 & TST & \\
\hline CHEMBL1311767 & 688422 & 5.0 & 5.6307 & TST & \\
\hline CHEMBL1326509 & 688422 & 5.2 & 5.4883 & TRN & \\
\hline CHEMBL3197282 & 688422 & 4.9 & 5.8384 & TRN & \\
\hline CHEMBL1478786 & 688422 & 4.5 & 5.5074 & TRN & \\
\hline CHEMBL1407308 & 688422 & 4.85 & 4.947 & TRN & \\
\hline CHEMBL1450343 & 688422 & 4.45 & 4.7734 & TRN & \\
\hline CHEMBL1443298 & 688422 & 4.75 & 5.3513 & TST & \\
\hline
\end{tabular}




\begin{tabular}{|c|c|c|c|c|}
\hline \multicolumn{5}{|c|}{ Supplemental Table S2.txt } \\
\hline CHEMBL1536324 & 688422 & 6.25 & 5.1309 & TRN \\
\hline CHEMBL1362975 & 688422 & 4.8 & 5.1986 & TRN \\
\hline CHEMBL1541852 & 688422 & 4.6 & 4.9484 & TRN \\
\hline CHEMBL1374388 & 688422 & 4.9 & 4.6252 & TST \\
\hline CHEMBL1502305 & 688422 & 5.4 & 5.5238 & TST \\
\hline CHEMBL1536808 & 688422 & 4.95 & 5.0822 & TST \\
\hline CHEMBL1526742 & 688422 & 5.4 & 5.5745 & TRN \\
\hline CHEMBL 222838 & 688422 & 6.0 & 5.6244 & TST \\
\hline CHEMBL1477863 & 688422 & 4.6 & 4.8151 & TRN \\
\hline CHEMBL1494658 & 688422 & 4.45 & 5.1461 & TRN \\
\hline CHEMBL1380805 & 688422 & 5.2 & 5.4164 & TST \\
\hline CHEMBL1410683 & 688422 & 4.55 & 5.3705 & TRN \\
\hline CHEMBL1523566 & 688422 & 4.75 & 4.6637 & TST \\
\hline CHEMBL1516649 & 688422 & 4.45 & 5.1493 & TST \\
\hline CHEMBL1605785 & 688422 & 8.0 & 6.3654 & TST \\
\hline CHEMBL1303401 & 688422 & 4.45 & 5.0566 & TRN \\
\hline CHEMBL1454770 & 688422 & 4.9 & 5.0406 & TRN \\
\hline CHEMBL1434308 & 688422 & 4.65 & 4.7907 & TRN \\
\hline CHEMBL1536966 & 688422 & 5.5 & 5.5042 & TRN \\
\hline CHEMBL3212028 & 688422 & 6.15 & 5.1066 & TRN \\
\hline CHEMBL1311030 & 688422 & 7.6003 & 5.8124 & TRN \\
\hline CHEMBL1610452 & 688422 & 5.0 & 5.8391 & TST \\
\hline CHEMBL1442275 & 688422 & 5.9 & 5.5674 & TRN \\
\hline CHEMBL1375115 & 688422 & 4.45 & 4.9645 & TST \\
\hline CHEMBL1445388 & 688422 & 4.7 & 5.019 & TRN \\
\hline CHEMBL1410733 & 688422 & 6.15 & 5.0 & TST \\
\hline CHEMBL1489900 & 688422 & 5.45 & 5.1574 & TST \\
\hline CHEMBL1417527 & 688422 & 5.05 & 5.0337 & TRN \\
\hline CHEMBL1542364 & 688422 & 4.45 & 5.2618 & TRN \\
\hline CHEMBL1369671 & 688422 & 5.45 & 4.9412 & TRN \\
\hline CHEMBL1537568 & 688422 & 6.6499 & 5.5266 & TRN \\
\hline CHEMBL1561214 & 688422 & 4.8 & 5.0289 & TRN \\
\hline CHEMBL1320785 & 688422 & 4.5 & 5.0561 & TRN \\
\hline CHEMBL421215 & 688422 & 5.3 & 5.4032 & TST \\
\hline CHEMBL1573134 & 688422 & 4.45 & 4.9619 & TST \\
\hline CHEMBL1418442 & 688422 & 5.55 & 4.6869 & TRN \\
\hline CHEMBL3189703 & 688422 & 4.9 & 4.6612 & TRN \\
\hline CHEMBL3193965 & 688422 & 4.45 & 5.1114 & TRN \\
\hline CHEMBL1414637 & 688422 & 4.45 & 5.4962 & TRN \\
\hline CHEMBL1407248 & 688422 & 8.1024 & 5.7004 & TRN \\
\hline CHEMBL1352235 & 688422 & 4.5 & 5.0086 & TRN \\
\hline CHEMBL1484955 & 688422 & 4.85 & 5.2045 & TRN \\
\hline CHEMBL1534490 & 688422 & 4.7 & 5.3715 & TST \\
\hline CHEMBL1556134 & 688422 & 4.9 & 5.1256 & TRN \\
\hline CHEMBL1612603 & 688422 & 4.7 & 5.5678 & TST \\
\hline CHEMBL1471345 & 688422 & 4.85 & 5.4148 & TRN \\
\hline CHEMBL1318242 & 688422 & 8.4949 & 5.6809 & TRN \\
\hline CHEMBL1416035 & 688422 & 4.85 & 4.7649 & TRN \\
\hline
\end{tabular}




\begin{tabular}{|c|c|c|c|c|}
\hline \multicolumn{5}{|c|}{ Supplemental Table S2.txt } \\
\hline CHEMBL1502628 & 688422 & 5.05 & 5.3243 & TRN \\
\hline CHEMBL1459155 & 688422 & 5.55 & 4.9411 & TST \\
\hline CHEMBL1429629 & 688422 & 4.95 & 5.3611 & TST \\
\hline CHEMBL1586772 & 688422 & 4.9 & 5.3959 & TST \\
\hline CHEMBL1372851 & 688422 & 4.6 & 4.9145 & TRN \\
\hline CHEMBL1373788 & 688422 & 5.05 & 5.3123 & TRN \\
\hline CHEMBL 3195024 & 688422 & 5.2 & 5.2668 & TST \\
\hline CHEMBL1481931 & 688422 & 6.1 & 5.1301 & TST \\
\hline CHEMBL1551083 & 688422 & 6.7501 & 5.7046 & TRN \\
\hline CHEMBL1508918 & 688422 & 4.85 & 5.1015 & TRN \\
\hline CHEMBL 2006762 & 688422 & 5.05 & 5.5294 & TRN \\
\hline CHEMBL1386126 & 688422 & 4.8 & 4.8288 & TRN \\
\hline CHEMBL1482092 & 688422 & 5.25 & 5.3082 & TST \\
\hline CHEMBL1542792 & 688422 & 4.65 & 5.0529 & TRN \\
\hline CHEMBL1365287 & 688422 & 4.55 & 4.9106 & TRN \\
\hline CHEMBL1470398 & 688422 & 4.7 & 5.0187 & TRN \\
\hline CHEMBL1554150 & 688422 & 5.55 & 5.7491 & TRN \\
\hline CHEMBL1449819 & 688422 & 5.35 & 5.8391 & TRN \\
\hline CHEMBL1607546 & 688422 & 4.8 & 4.8641 & TRN \\
\hline CHEMBL1359007 & 688422 & 4.45 & 5.2702 & TST \\
\hline CHEMBL1310875 & 688422 & 4.95 & 5.2647 & TRN \\
\hline CHEMBL1593327 & 688422 & 4.45 & 5.4501 & TRN \\
\hline CHEMBL1554580 & 688422 & 4.45 & 5.0156 & TRN \\
\hline CHEMBL19980 & 688422 & 6.0 & 6.2408 & TST \\
\hline CHEMBL1509447 & 688422 & 5.15 & 5.40600 & 0000000001 \\
\hline CHEMBL1966025 & 688422 & 5.1 & 5.2743 & TRN \\
\hline CHEMBL3198969 & 688422 & 4.85 & 5.1636 & TRN \\
\hline CHEMBL1554396 & 688422 & 4.45 & 5.3623 & TRN \\
\hline CHEMBL1459968 & 688422 & 5.05 & 5.0526 & TRN \\
\hline CHEMBL 1605446 & 688422 & 5.15 & 5.4683 & TRN \\
\hline CHEMBL1310744 & 688422 & 4.45 & 5.2769 & TRN \\
\hline CHEMBL1308266 & 688422 & 4.9 & 5.0882 & TRN \\
\hline CHEMBL1392851 & 688422 & 5.4 & 4.8826 & TRN \\
\hline CHEMBL1494829 & 688422 & 4.9 & 4.9729 & TST \\
\hline CHEMBL1307737 & 688422 & 4.45 & 5.3076 & TRN \\
\hline CHEMBL1407752 & 688422 & 4.95 & 5.6508 & TRN \\
\hline CHEMBL1555444 & 688422 & 4.7 & 5.3386 & TRN \\
\hline CHEMBL1351755 & 688422 & 4.45 & 4.5588 & TRN \\
\hline CHEMBL1360516 & 688422 & 4.45 & 5.0849 & TRN \\
\hline CHEMBL1502229 & 688422 & 4.9 & 5.1303 & TST \\
\hline CHEMBL1550961 & 688422 & 6.5 & 5.3625 & TST \\
\hline CHEMBL1430957 & 688422 & 4.6 & 5.3486 & TRN \\
\hline CHEMBL1526472 & 688422 & 4.45 & 5.0019 & TRN \\
\hline CHEMBL 3211722 & 688422 & 6.6 & 5.2916 & TST \\
\hline CHEMBL1485259 & 688422 & 4.45 & 5.1197 & TRN \\
\hline CHEMBL1436580 & 688422 & 5.7 & 5.3166 & TST \\
\hline CHEMBL1436367 & 688422 & 7.8996 & 5.178 & TRN \\
\hline CHEMBL1464385 & 688422 & 4.5 & 4.9277 & TRN \\
\hline
\end{tabular}




\begin{tabular}{|c|c|c|c|c|c|}
\hline \multicolumn{6}{|c|}{ Supplemental Table S2.txt } \\
\hline CHEMBL1425639 & 688422 & 4.9 & 5.8342 & TST & \\
\hline CHEMBL1408240 & 688422 & 4.45 & 5.0728 & TRN & \\
\hline CHEMBL1533408 & 688422 & 4.6 & 5.2164 & TRN & \\
\hline CHEMBL548540 & 688422 & 5.45 & 5.2762 & TRN & \\
\hline CHEMBL3208900 & 688422 & 4.6 & 5.2926 & TRN & \\
\hline CHEMBL1438779 & 688422 & 5.65 & 5.2634 & TRN & \\
\hline CHEMBL3392075 & 688422 & 4.85 & 5.5606 & TRN & \\
\hline CHEMBL1508513 & 688422 & 4.45 & 5.3385 & TRN & \\
\hline CHEMBL584015 & 688422 & 4.75 & 5.3436 & TRN & \\
\hline CHEMBL3208498 & 688422 & 5.5 & 5.3083 & TST & \\
\hline CHEMBL1578365 & 688422 & 4.95 & 5.3038 & TRN & \\
\hline CHEMBL1382498 & 688422 & 4.5 & 5.2137 & TRN & \\
\hline CHEMBL1401743 & 688422 & 4.45 & 5.3151 & TRN & \\
\hline CHEMBL1480197 & 688422 & 4.5 & 5.197 & TST & \\
\hline CHEMBL1471699 & 688422 & 4.7 & 5.1192 & TRN & \\
\hline CHEMBL1519279 & 688422 & 4.95 & 5.2737 & TRN & \\
\hline CHEMBL1504449 & 688422 & 5.2 & 5.6678 & TRN & \\
\hline CHEMBL1380757 & 688422 & 4.85 & 4.9334 & TRN & \\
\hline CHEMBL3211835 & 688422 & 7.4001 & 5.7231 & TRN & \\
\hline CHEMBL1493663 & 688422 & 4.85 & 5.4098 & TRN & \\
\hline CHEMBL1359815 & 688422 & 4.95 & 5.3415 & TRN & \\
\hline CHEMBL1321580 & 688422 & 4.45 & 4.9699 & TST & \\
\hline CHEMBL1524165 & 688422 & 7.4001 & 5.1074 & TRN & \\
\hline CHEMBL1301634 & 688422 & 4.8 & 4.6801 & TRN & \\
\hline CHEMBL1450118 & 688422 & 5.9 & 5.4996 & TRN & \\
\hline CHEMBL1995910 & 688422 & 6.6 & 5.2473 & TRN & \\
\hline CHEMBL3189935 & 688422 & 5.0 & 5.2418 & TST & \\
\hline CHEMBL1573690 & 688422 & 4.95 & 5.01399 & 9999999999 & TRN \\
\hline CHEMBL1328403 & 688422 & 4.45 & 4.9753 & TRN & \\
\hline CHEMBL1537935 & 688422 & 4.65 & 5.0743 & TRN & \\
\hline CHEMBL1384981 & 688422 & 4.45 & 5.5226 & TST & \\
\hline CHEMBL1302330 & 688422 & 6.1 & 5.1596 & TRN & \\
\hline CHEMBL1412190 & 688422 & 4.45 & 5.1171 & TRN & \\
\hline CHEMBL1448382 & 688422 & 4.65 & 5.0169 & TRN & \\
\hline CHEMBL1429984 & 688422 & 4.75 & 5.1617 & TRN & \\
\hline CHEMBL1568625 & 688422 & 5.15 & 5.3663 & TRN & \\
\hline CHEMBL1539672 & 688422 & 5.0 & 5.3434 & TRN & \\
\hline CHEMBL1599901 & 688422 & 4.75 & 5.1916 & TRN & \\
\hline CHEMBL1569342 & 688422 & 4.9 & 5.3053 & TRN & \\
\hline CHEMBL1497632 & 688422 & 5.4 & 5.1176 & TRN & \\
\hline CHEMBL1526028 & 688422 & 4.5 & 5.2434 & TRN & \\
\hline CHEMBL1578175 & 688422 & 4.75 & 5.2873 & TST & \\
\hline CHEMBL1546667 & 688422 & 4.75 & 5.3423 & TRN & \\
\hline CHEMBL1527445 & 688422 & 4.8 & 5.0256 & TST & \\
\hline CHEMBL1484401 & 688422 & 4.45 & 5.1885 & TRN & \\
\hline CHEMBL1323704 & 688422 & 4.7 & 5.6134 & TRN & \\
\hline CHEMBL1313058 & 688422 & 4.45 & 5.9315 & TRN & \\
\hline CHEMBL1393687 & 688422 & 4.95 & 5.5331 & TRN & \\
\hline
\end{tabular}




\begin{tabular}{|c|c|c|c|c|c|}
\hline \multicolumn{6}{|c|}{ Supplemental Table S2.txt } \\
\hline CHEMBL453388 & 688422 & 6.0 & 5.7389 & TRN & \\
\hline CHEMBL1431091 & 688422 & 4.8 & 4.9958 & TRN & \\
\hline CHEMBL1510473 & 688422 & 4.45 & 5.1036 & TRN & \\
\hline CHEMBL1426451 & 688422 & 4.9 & 4.9961 & TRN & \\
\hline CHEMBL1380495 & 688422 & 5.25 & 5.496 & TRN & \\
\hline CHEMBL3198554 & 688422 & 5.2 & 4.9586 & TST & \\
\hline CHEMBL1563269 & 688422 & 4.95 & 5.20100 & 00000000005 & TRN \\
\hline CHEMBL1736171 & 688422 & 4.9 & 5.4435 & TST & \\
\hline CHEMBL1571208 & 688422 & 4.5 & 4.6915 & TRN & \\
\hline CHEMBL1543774 & 688422 & 7.9508 & 5.3708 & TRN & \\
\hline CHEMBL1384525 & 688422 & 4.45 & 5.2782 & TST & \\
\hline CHEMBL1612359 & 688422 & 5.0 & 5.2375 & TRN & \\
\hline CHEMBL1325852 & 688422 & 4.55 & 5.0635 & TRN & \\
\hline CHEMBL1451020 & 688422 & 5.65 & 5.5518 & TRN & \\
\hline CHEMBL1484727 & 688422 & 4.95 & 5.2212 & TRN & \\
\hline CHEMBL1305330 & 688422 & 5.3 & 5.7872 & TRN & \\
\hline CHEMBL1498063 & 688422 & 4.75 & 5.3145 & TRN & \\
\hline CHEMBL1363413 & 688422 & 4.65 & 5.5118 & TRN & \\
\hline CHEMBL1538648 & 688422 & 4.45 & 5.5137 & TRN & \\
\hline CHEMBL1486550 & 688422 & 4.9 & 4.9483 & TRN & \\
\hline CHEMBL1543936 & 688422 & 4.9 & 4.7579 & TRN & \\
\hline CHEMBL1332916 & 688422 & 6.15 & 5.0737 & TRN & \\
\hline CHEMBL1544726 & 688422 & 4.9 & 5.1435 & TRN & \\
\hline CHEMBL1527613 & 688422 & 4.75 & 5.2848 & TRN & \\
\hline CHEMBL1586972 & 688422 & 4.8 & 5.4069 & TRN & \\
\hline CHEMBL1402717 & 688422 & 4.8 & 5.1652 & TST & \\
\hline CHEMBL1455824 & 688422 & 5.35 & 5.266 & TRN & \\
\hline CHEMBL1351680 & 688422 & 5.5 & 5.1485 & TRN & \\
\hline CHEMBL1347184 & 688422 & 6.5501 & 5.487 & TST & \\
\hline CHEMBL1355350 & 688422 & 6.5 & 5.37200 & 0000000001 & TRN \\
\hline CHEMBL1527563 & 688422 & 4.65 & 5.0519 & TRN & \\
\hline CHEMBL1436555 & 688422 & 5.25 & 6.2623 & TRN & \\
\hline CHEMBL1307156 & 688422 & 4.5 & 4.3651 & TRN & \\
\hline CHEMBL1320694 & 688422 & 5.0 & 4.8815 & TRN & \\
\hline CHEMBL1410495 & 688422 & 5.45 & 5.312 & TST & \\
\hline CHEMBL1547940 & 688422 & 4.65 & 5.506 & TRN & \\
\hline CHEMBL1596871 & 688422 & 5.75 & 5.0192 & TRN & \\
\hline CHEMBL1305581 & 688422 & 6.7001 & 5.4381 & TRN & \\
\hline CHEMBL1528784 & 688422 & 4.75 & 5.092 & TRN & \\
\hline CHEMBL1326896 & 688422 & 4.65 & 5.4499 & TRN & \\
\hline CHEMBL1478367 & 688422 & 6.7001 & 5.5866 & TRN & \\
\hline CHEMBL1463088 & 688422 & 4.45 & 5.7486 & TST & \\
\hline CHEMBL1457396 & 688422 & 4.95 & 5.6683 & TRN & \\
\hline CHEMBL1530045 & 688422 & 4.8 & 5.2374 & TST & \\
\hline CHEMBL1338903 & 688422 & 5.2 & 5.3823 & TRN & \\
\hline CHEMBL1539584 & 688422 & 4.65 & 5.5328 & TRN & \\
\hline CHEMBL1595926 & 688422 & 5.35 & 5.2447 & TRN & \\
\hline CHEMBL1473299 & 688422 & 5.3 & 5.6058 & TRN & \\
\hline
\end{tabular}




\begin{tabular}{|c|c|c|c|c|c|}
\hline \multicolumn{6}{|c|}{ Supplemental Table S2.txt } \\
\hline CHEMBL1302988 & 688422 & 4.95 & 4.8753 & TST & \\
\hline CHEMBL 1463570 & 688422 & 5.6 & 5.4702 & TRN & \\
\hline CHEMBL1508157 & 688422 & 4.95 & 4.7953 & TST & \\
\hline CHEMBL1372459 & 688422 & 4.45 & 5.1231 & TRN & \\
\hline CHEMBL1387937 & 688422 & 4.95 & 5.1091 & TRN & \\
\hline CHEMBL1447370 & 688422 & 5.2 & 5.2456 & TRN & \\
\hline CHEMBL1489172 & 688422 & 4.7 & 5.3633 & TST & \\
\hline CHEMBL1599971 & 688422 & 4.85 & 5.1969 & TST & \\
\hline CHEMBL1426948 & 688422 & 4.45 & 5.3858 & TRN & \\
\hline CHEMBL1612381 & 688422 & 4.75 & 4.685 & TRN & \\
\hline CHEMBL1560030 & 688422 & 6.4 & 5.75299 & 9999999999 & TRN \\
\hline CHEMBL1086026 & 688422 & 4.7 & 5.231 & TST & \\
\hline CHEMBL1360007 & 688422 & 5.2 & 5.5241 & TRN & \\
\hline CHEMBL1603982 & 688422 & 4.8 & 5.0217 & TRN & \\
\hline CHEMBL1596718 & 688422 & 4.5 & 5.2182 & TRN & \\
\hline CHEMBL1433633 & 688422 & 4.95 & 5.2549 & TRN & \\
\hline CHEMBL1326757 & 688422 & 5.45 & 5.7502 & TRN & \\
\hline CHEMBL1367596 & 688422 & 4.45 & 5.2289 & TRN & \\
\hline CHEMBL1377517 & 688422 & 4.85 & 4.9644 & TST & \\
\hline CHEMBL1477311 & 688422 & 4.7 & 5.0089 & TRN & \\
\hline CHEMBL1336704 & 688422 & 5.25 & 4.5922 & TRN & \\
\hline CHEMBL 2002008 & 688422 & 4.7 & 5.0465 & TRN & \\
\hline CHEMBL1256749 & 688422 & 4.95 & 5.2409 & TST & \\
\hline CHEMBL1360434 & 688422 & 4.65 & 5.3954 & TRN & \\
\hline CHEMBL1507604 & 688422 & 6.8499 & 5.2307 & TST & \\
\hline CHEMBL1499337 & 688422 & 4.45 & 5.7812 & TST & \\
\hline CHEMBL1501421 & 688422 & 4.45 & 5.294 & TST & \\
\hline CHEMBL1342437 & 688422 & 4.85 & 4.9576 & TRN & \\
\hline CHEMBL1506757 & 688422 & 5.95 & 4.89199 & 99999999995 & TST \\
\hline CHEMBL1537686 & 688422 & 5.55 & 5.001 & TRN & \\
\hline CHEMBL1395669 & 688422 & 4.45 & 4.9729 & TRN & \\
\hline CHEMBL1563002 & 688422 & 4.5 & 5.4323 & TST & \\
\hline CHEMBL1484350 & 688422 & 4.45 & 5.0758 & TRN & \\
\hline CHEMBL3213965 & 688422 & 5.5 & 5.3175 & TRN & \\
\hline CHEMBL1606041 & 688422 & 4.45 & 4.9705 & TRN & \\
\hline CHEMBL1596138 & 688422 & 7.7496 & 5.3766 & TST & \\
\hline CHEMBL1349831 & 688422 & 4.45 & 4.9602 & TRN & \\
\hline CHEMBL1432134 & 688422 & 4.5 & 4.9046 & TRN & \\
\hline CHEMBL1373848 & 688422 & 4.65 & 4.8167 & TRN & \\
\hline CHEMBL1335406 & 688422 & 8.2518 & 5.3267 & TST & \\
\hline CHEMBL1557254 & 688422 & 5.0 & 5.0987 & TST & \\
\hline CHEMBL1479337 & 688422 & 7.699 & 5.3416 & TRN & \\
\hline CHEMBL3199228 & 688422 & 4.9 & 5.0734 & TRN & \\
\hline CHEMBL1442663 & 688422 & 5.5 & 5.1057 & TRN & \\
\hline CHEMBL1472397 & 688422 & 5.75 & 6.0487 & TST & \\
\hline CHEMBL534084 & 688422 & 8.301 & 4.984 & TRN & \\
\hline CHEMBL1302736 & 688422 & 4.8 & 5.244 & TST & \\
\hline CHEMBL1311279 & 688422 & 4.8 & 5.0498 & TRN & \\
\hline
\end{tabular}




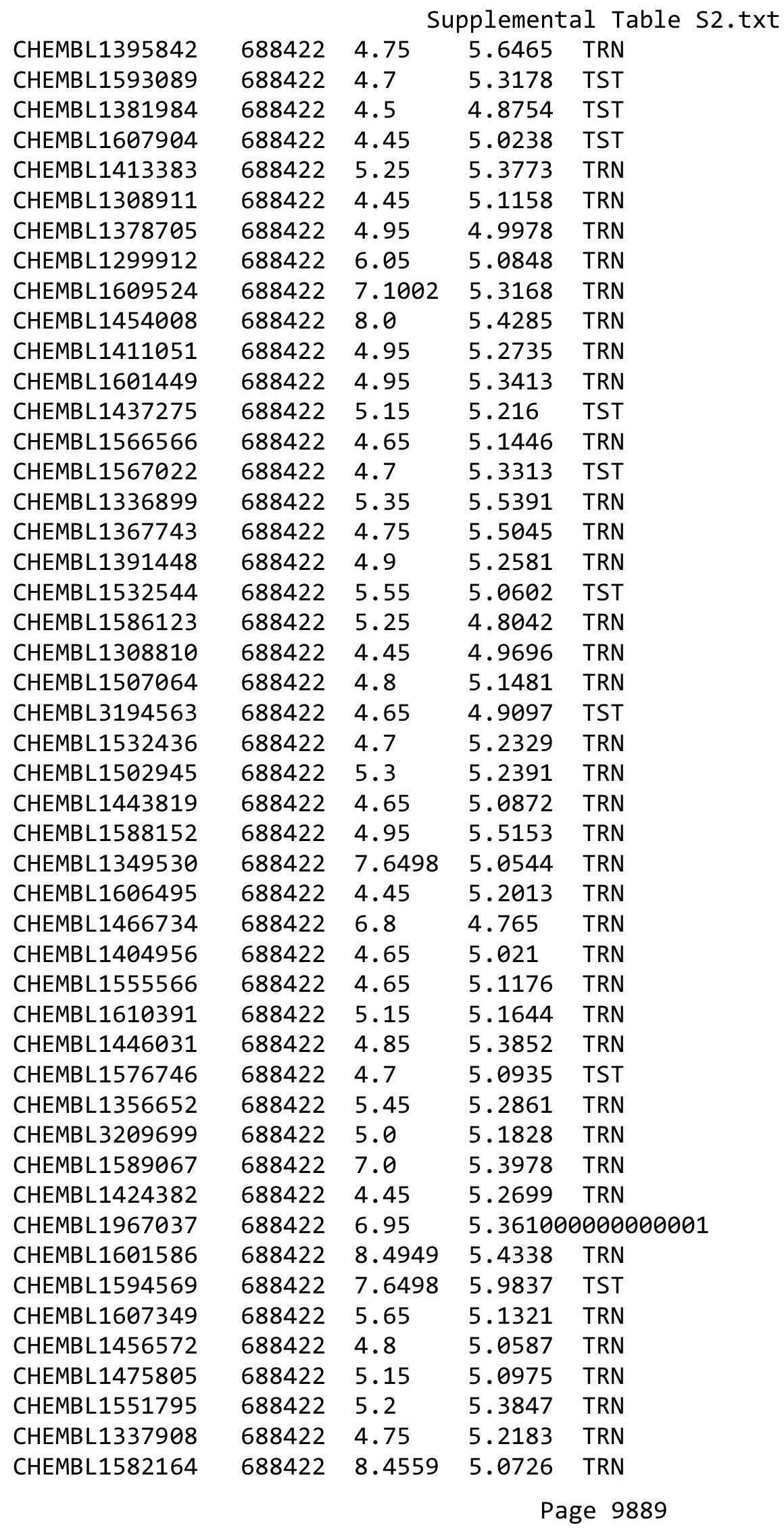




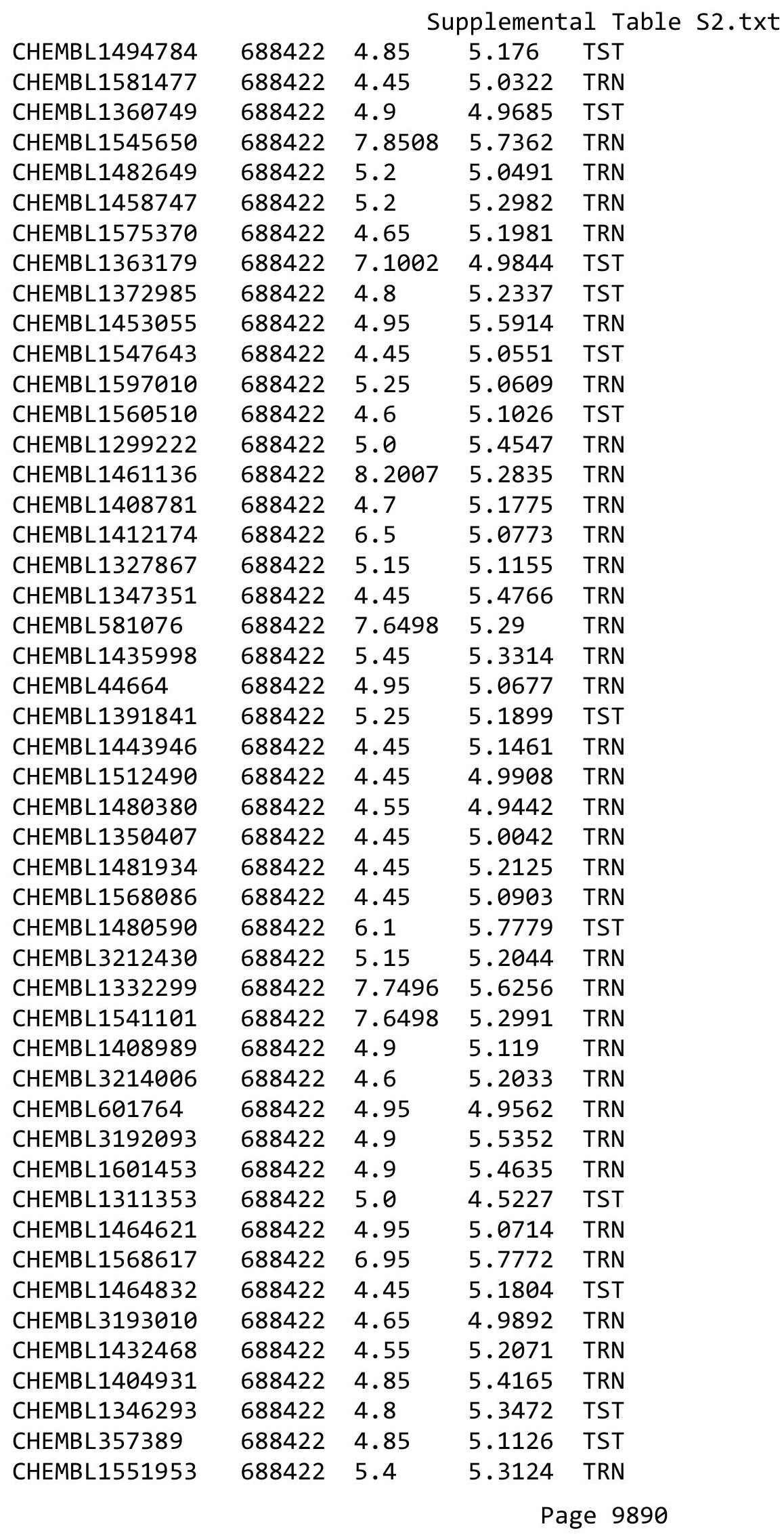




\begin{tabular}{|c|c|c|c|c|c|}
\hline \multicolumn{6}{|c|}{ Supplemental Table S2.txt } \\
\hline CHEMBL1492014 & 688422 & 4.85 & 5.1939 & TRN & \\
\hline CHEMBL1406061 & 688422 & 5.6 & 4.939 & TRN & \\
\hline CHEMBL1410042 & 688422 & 4.8 & 5.0623 & TST & \\
\hline CHEMBL1363121 & 688422 & 4.9 & 4.8316 & TRN & \\
\hline CHEMBL1465226 & 688422 & 5.3 & 5.3955 & TST & \\
\hline CHEMBL 3145245 & 688422 & 5.1 & 5.3199 & TRN & \\
\hline CHEMBL1497967 & 688422 & 4.9 & 5.2921 & TST & \\
\hline CHEMBL1464618 & 688422 & 4.95 & 4.8051 & TRN & \\
\hline CHEMBL1436153 & 688422 & 6.05 & 5.8425 & TRN & \\
\hline CHEMBL1587940 & 688422 & 5.95 & 5.0194 & TRN & \\
\hline CHEMBL1477912 & 688422 & 5.0 & 5.0814 & TRN & \\
\hline CHEMBL1516844 & 688422 & 4.7 & 5.3008 & TRN & \\
\hline CHEMBL1514468 & 688422 & 8.4949 & 5.3319 & TRN & \\
\hline CHEMBL1587549 & 688422 & 4.55 & 4.9845 & TRN & \\
\hline CHEMBL1392751 & 688422 & 6.8499 & 5.0992 & TRN & \\
\hline CHEMBL 2004361 & 688422 & 4.6 & 5.5393 & TST & \\
\hline CHEMBL1402227 & 688422 & 4.45 & 4.485 & TRN & \\
\hline CHEMBL1316037 & 688422 & 5.5 & 5.315 & TST & \\
\hline CHEMBL1462458 & 688422 & 4.6 & 5.037 & TRN & \\
\hline CHEMBL1353936 & 688422 & 4.8 & 5.3683 & TST & \\
\hline CHEMBL1326658 & 688422 & 6.8 & 5.3131 & TRN & \\
\hline CHEMBL1602150 & 688422 & 5.5 & 4.8167 & TRN & \\
\hline CHEMBL1334320 & 688422 & 4.85 & 5.2442 & TRN & \\
\hline CHEMBL1338140 & 688422 & 4.7 & 5.0268 & TRN & \\
\hline CHEMBL1407886 & 688422 & 4.85 & 5.6963 & TST & \\
\hline CHEMBL1407954 & 688422 & 8.3468 & 5.6434 & TRN & \\
\hline CHEMBL1485472 & 688422 & 4.7 & 5.4128 & TRN & \\
\hline CHEMBL1517835 & 688422 & 6.1 & 5.2345 & TRN & \\
\hline CHEMBL1561018 & 688422 & 4.9 & 5.3102 & TRN & \\
\hline CHEMBL1333052 & 688422 & 5.2 & 4.894 & TRN & \\
\hline CHEMBL1492018 & 688422 & 5.45 & 5.2616 & TST & \\
\hline CHEMBL1415088 & 688422 & 4.8 & 4.8911 & TRN & \\
\hline CHEMBL1448407 & 688422 & 4.45 & 5.3355 & TRN & \\
\hline CHEMBL1484063 & 688422 & 4.85 & 5.42700 & 00000000005 & TRN \\
\hline CHEMBL1522649 & 688422 & 5.1 & 5.5678 & TRN & \\
\hline CHEMBL1411337 & 688422 & 4.85 & 5.9597 & TST & \\
\hline CHEMBL1520542 & 688422 & 4.7 & 5.5277 & TST & \\
\hline CHEMBL1596755 & 688422 & 4.8 & 5.1657 & TRN & \\
\hline CHEMBL1556256 & 688422 & 4.7 & 5.3432 & TRN & \\
\hline CHEMBL1317114 & 688422 & 5.5 & 5.5272 & TST & \\
\hline CHEMBL1335366 & 688422 & 8.301 & 5.7082 & TRN & \\
\hline CHEMBL1447755 & 688422 & 4.45 & 5.3043 & TRN & \\
\hline CHEMBL3191970 & 688422 & 4.45 & 4.9308 & TRN & \\
\hline CHEMBL1362130 & 688422 & 7.5003 & 5.6329 & TRN & \\
\hline CHEMBL1323262 & 688422 & 5.9 & 5.7286 & TRN & \\
\hline CHEMBL1410448 & 688422 & 7.6498 & 5.4308 & TRN & \\
\hline CHEMBL1500987 & 688422 & 4.7 & 5.1611 & TRN & \\
\hline CHEMBL1595686 & 688422 & 5.25 & 5.6705 & TRN & \\
\hline
\end{tabular}




\begin{tabular}{|c|c|c|c|c|}
\hline \multicolumn{5}{|c|}{ Supplemental Table S2.txt } \\
\hline CHEMBL1461508 & 688422 & 4.45 & 5.075 & TST \\
\hline CHEMBL1516561 & 688422 & 4.7 & 5.63899 & 9999999999 \\
\hline CHEMBL1448206 & 688422 & 4.45 & 5.305 & TRN \\
\hline CHEMBL1548890 & 688422 & 4.45 & 5.0178 & TRN \\
\hline CHEMBL1301696 & 688422 & 5.15 & 5.1771 & TRN \\
\hline CHEMBL1454879 & 688422 & 5.1 & 5.2987 & TRN \\
\hline CHEMBL1532059 & 688422 & 5.3 & 5.0153 & TRN \\
\hline CHEMBL1569461 & 688422 & 8.3468 & 5.6323 & TRN \\
\hline CHEMBL1971120 & 688422 & 5.7 & 5.0606 & TST \\
\hline CHEMBL1435397 & 688422 & 6.8 & 5.5446 & TRN \\
\hline CHEMBL1470517 & 688422 & 4.5 & 5.4115 & TST \\
\hline CHEMBL1412835 & 688422 & 4.9 & 5.1992 & TRN \\
\hline CHEMBL1371245 & 688422 & 7.7496 & 5.3649 & TST \\
\hline CHEMBL1592554 & 688422 & 5.15 & 5.4276 & TST \\
\hline CHEMBL1405578 & 688422 & 4.95 & 4.7063 & TRN \\
\hline CHEMBL1420184 & 688422 & 4.45 & 4.6671 & TRN \\
\hline CHEMBL1311877 & 688422 & 6.4 & 5.5834 & TRN \\
\hline CHEMBL1336783 & 688422 & 5.5 & 5.2403 & TRN \\
\hline CHEMBL1423797 & 688422 & 5.4 & 5.3605 & TST \\
\hline CHEMBL1417480 & 688422 & 5.35 & 4.8865 & TRN \\
\hline CHEMBL1379721 & 688422 & 5.0 & 4.8099 & TST \\
\hline CHEMBL1550962 & 688422 & 4.75 & 5.0523 & TRN \\
\hline CHEMBL1593733 & 688422 & 5.1 & 4.9499 & TRN \\
\hline CHEMBL1446199 & 688422 & 5.6 & 5.2777 & TRN \\
\hline CHEMBL1530216 & 688422 & 4.65 & 4.8213 & TRN \\
\hline CHEMBL1373462 & 688422 & 4.75 & 5.847 & TRN \\
\hline CHEMBL1318114 & 688422 & 4.95 & 5.0338 & TRN \\
\hline CHEMBL1356206 & 688422 & 4.45 & 5.0619 & TRN \\
\hline CHEMBL1588774 & 688422 & 7.7496 & 5.8452 & TST \\
\hline CHEMBL 373481 & 688422 & 4.85 & 5.6299 & TRN \\
\hline CHEMBL1514035 & 688422 & 5.3 & 5.4108 & TRN \\
\hline CHEMBL1334350 & 688422 & 7.5498 & 5.5816 & TRN \\
\hline CHEMBL1508868 & 688422 & 5.4 & 5.5652 & TRN \\
\hline CHEMBL1999437 & 688422 & 4.45 & 5.3731 & TST \\
\hline CHEMBL1589768 & 688422 & 4.45 & 4.8535 & TRN \\
\hline CHEMBL1407732 & 688422 & 4.8 & 4.9261 & TRN \\
\hline CHEMBL1497460 & 688422 & 4.45 & 5.2331 & TST \\
\hline CHEMBL1577851 & 688422 & 6.6 & 5.7475 & TRN \\
\hline CHEMBL1352085 & 688422 & 5.2 & 5.6534 & TST \\
\hline CHEMBL1590154 & 688422 & 5.3 & 5.3808 & TRN \\
\hline CHEMBL1600003 & 688422 & 4.85 & 4.846 & TRN \\
\hline CHEMBL1320372 & 688422 & 4.75 & 4.8237 & TRN \\
\hline CHEMBL1498977 & 688422 & 4.95 & 5.0463 & TST \\
\hline CHEMBL1497266 & 688422 & 4.75 & 5.3659 & TRN \\
\hline CHEMBL1541405 & 688422 & 4.8 & 4.8547 & TRN \\
\hline CHEMBL1564386 & 688422 & 4.85 & 4.812 & TRN \\
\hline CHEMBL1377970 & 688422 & 4.7 & 5.3371 & TRN \\
\hline CHEMBL1990505 & 688422 & 4.45 & 5.535 & TRN \\
\hline
\end{tabular}




\begin{tabular}{|c|c|c|c|c|}
\hline \multicolumn{5}{|c|}{ Supplemental Table S2.txt } \\
\hline CHEMBL1523306 & 688422 & 5.95 & 5.5292 & TRN \\
\hline CHEMBL1968316 & 688422 & 5.4 & 5.0514 & TRN \\
\hline CHEMBL1495310 & 688422 & 5.45 & 5.1238 & TRN \\
\hline CHEMBL1590876 & 688422 & 5.05 & 5.4647 & TST \\
\hline CHEMBL1531919 & 688422 & 4.6 & 5.0324 & TRN \\
\hline CHEMBL1303021 & 688422 & 4.75 & 4.8868 & TRN \\
\hline CHEMBL1478216 & 688422 & 4.45 & 5.1333 & TRN \\
\hline CHEMBL1565237 & 688422 & 4.65 & 5.114 & TST \\
\hline CHEMBL400875 & 688422 & 9.3979 & 5.5997 & TST \\
\hline CHEMBL1580035 & 688422 & 5.2 & 5.3542 & TRN \\
\hline CHEMBL2374063 & 688422 & 5.2 & 5.8619 & TRN \\
\hline CHEMBL1437027 & 688422 & 4.65 & 5.3103 & TRN \\
\hline CHEMBL1583426 & 688422 & 6.0 & 5.002 & TST \\
\hline CHEMBL1366464 & 688422 & 6.5501 & 5.5615 & TRN \\
\hline CHEMBL1381941 & 688422 & 8.4559 & 4.9131 & TST \\
\hline CHEMBL1567148 & 688422 & 4.6 & 5.0366 & TRN \\
\hline CHEMBL1550778 & 688422 & 4.45 & 5.2058 & TRN \\
\hline CHEMBL1969713 & 688422 & 4.6 & 5.1021 & TST \\
\hline CHEMBL1451481 & 688422 & 4.95 & 5.4547 & TRN \\
\hline CHEMBL1446445 & 688422 & 4.75 & 4.7199 & TST \\
\hline CHEMBL1394538 & 688422 & 4.75 & 5.2969 & TRN \\
\hline CHEMBL1610701 & 688422 & 6.0 & 5.1702 & TRN \\
\hline CHEMBL1390026 & 688422 & 4.85 & 5.2142 & TRN \\
\hline CHEMBL 2001100 & 688422 & 4.85 & 5.5041 & TRN \\
\hline CHEMBL1608847 & 688422 & 5.3 & 5.216 & TST \\
\hline CHEMBL1478067 & 688422 & 6.1 & 5.1045 & TRN \\
\hline CHEMBL1301377 & 688422 & 4.85 & 4.7075 & TRN \\
\hline CHEMBL1457525 & 688422 & 4.45 & 5.1383 & TRN \\
\hline CHEMBL1455653 & 688422 & 4.7 & 5.2312 & TRN \\
\hline CHEMBL3194172 & 688422 & 6.25 & 5.5013 & TST \\
\hline CHEMBL1575410 & 688422 & 5.75 & 5.5957 & TST \\
\hline CHEMBL1969300 & 688422 & 4.8 & 5.0252 & TRN \\
\hline CHEMBL1602372 & 688422 & 4.5 & 4.9427 & TRN \\
\hline CHEMBL1358756 & 688422 & 4.85 & 5.0219 & TRN \\
\hline CHEMBL1417895 & 688422 & 4.75 & 4.7873 & TRN \\
\hline CHEMBL1592436 & 688422 & 4.75 & 5.5959 & TRN \\
\hline CHEMBL1542847 & 688422 & 5.5 & 5.4561 & TRN \\
\hline CHEMBL1580903 & 688422 & 4.9 & 5.1242 & TRN \\
\hline CHEMBL1373063 & 688422 & 4.5 & 5.1116 & TST \\
\hline CHEMBL1480321 & 688422 & 5.0 & 5.0441 & TRN \\
\hline CHEMBL1424460 & 688422 & 4.75 & 5.206 & TRN \\
\hline CHEMBL1581672 & 688422 & 4.95 & 5.1909 & TRN \\
\hline CHEMBL1341897 & 688422 & 5.15 & 5.6437 & TRN \\
\hline CHEMBL1477881 & 688422 & 4.85 & 5.3759 & TRN \\
\hline CHEMBL1444270 & 688422 & 5.6 & 5.3123 & TRN \\
\hline CHEMBL1490564 & 688422 & 4.9 & 4.8393 & TRN \\
\hline CHEMBL1404632 & 688422 & 5.25 & 5.1504 & TRN \\
\hline CHEMBL1510800 & 688422 & 4.7 & 5.1527 & TRN \\
\hline
\end{tabular}




\begin{tabular}{|c|c|c|c|c|c|}
\hline \multicolumn{6}{|c|}{ Supplemental Table S2.txt } \\
\hline CHEMBL1457010 & 688422 & 4.85 & 5.2001 & TRN & \\
\hline CHEMBL1367285 & 688422 & 4.9 & 5.7152 & TRN & \\
\hline CHEMBL1412743 & 688422 & 7.0501 & 5.4211 & TRN & \\
\hline CHEMBL1544831 & 688422 & 4.45 & 5.1481 & TRN & \\
\hline CHEMBL1378547 & 688422 & 5.05 & 5.2211 & TRN & \\
\hline CHEMBL1460157 & 688422 & 4.6 & 5.3286 & TRN & \\
\hline CHEMBL1406326 & 688422 & 4.45 & 5.555 & TST & \\
\hline CHEMBL1600937 & 688422 & 4.45 & 5.0038 & TRN & \\
\hline CHEMBL1450368 & 688422 & 7.3497 & 5.1746 & TRN & \\
\hline CHEMBL1364681 & 688422 & 5.1 & 5.5109 & TRN & \\
\hline CHEMBL 3194615 & 688422 & 4.95 & 5.0286 & TRN & \\
\hline CHEMBL1573862 & 688422 & 4.7 & 4.7415 & TRN & \\
\hline CHEMBL 3198191 & 688422 & 6.3 & 5.4899 & TRN & \\
\hline CHEMBL1366338 & 688422 & 4.9 & 5.1737 & TRN & \\
\hline CHEMBL1375090 & 688422 & 7.2 & 5.608 & TST & \\
\hline CHEMBL1568851 & 688422 & 4.95 & 5.1344 & TRN & \\
\hline CHEMBL1438063 & 688422 & 4.85 & 5.6299 & TST & \\
\hline CHEMBL 3189949 & 688422 & 7.3002 & 5.1418 & TRN & \\
\hline CHEMBL1332059 & 688422 & 5.1 & 5.3483 & TST & \\
\hline CHEMBL1442529 & 688422 & 4.85 & 5.1002 & TRN & \\
\hline CHEMBL1417459 & 688422 & 4.45 & 4.865 & TST & \\
\hline CHEMBL1321253 & 688422 & 4.75 & 5.0611 & TRN & \\
\hline CHEMBL1584914 & 688422 & 4.75 & 5.2391 & TRN & \\
\hline CHEMBL1522671 & 688422 & 5.25 & 5.4202 & TST & \\
\hline CHEMBL1573481 & 688422 & 5.0 & 5.3998 & TRN & \\
\hline CHEMBL1426274 & 688422 & 5.0 & 4.9275 & TRN & \\
\hline CHEMBL3197082 & 688422 & 4.65 & 5.3242 & TRN & \\
\hline CHEMBL 3194891 & 688422 & 4.9 & 5.0743 & TRN & \\
\hline CHEMBL1468968 & 688422 & 7.8996 & 5.3685 & TST & \\
\hline CHEMBL1356686 & 688422 & 4.7 & 5.4477 & TRN & \\
\hline CHEMBL1301599 & 688422 & 4.45 & 4.8925 & TRN & \\
\hline CHEMBL1410187 & 688422 & 4.85 & 4.8089 & TRN & \\
\hline CHEMBL1462952 & 688422 & 4.65 & 5.2403 & TRN & \\
\hline CHEMBL 260775 & 688422 & 5.5 & 4.8389 & TRN & \\
\hline CHEMBL1560549 & 688422 & 4.45 & 5.3338 & TRN & \\
\hline CHEMBL1299759 & 688422 & 4.9 & 5.358 & TRN & \\
\hline CHEMBL1405968 & 688422 & 5.55 & 4.8554 & TRN & \\
\hline CHEMBL1529288 & 688422 & 4.75 & 4.7701 & TRN & \\
\hline CHEMBL1309001 & 688422 & 4.75 & 5.3423 & TRN & \\
\hline CHEMBL1357140 & 688422 & 5.55 & 5.2373 & TRN & \\
\hline CHEMBL1565830 & 688422 & 4.75 & 5.2856 & TRN & \\
\hline CHEMBL1598373 & 688422 & 4.5 & 5.0877 & TRN & \\
\hline CHEMBL1483869 & 688422 & 8.3468 & 5.7051 & TST & \\
\hline CHEMBL1485231 & 688422 & 4.45 & 5.5799 & TST & \\
\hline CHEMBL1504403 & 688422 & 4.45 & 5.13700 & 00000000005 & TRN \\
\hline CHEMBL1345447 & 688422 & 4.65 & 4.9283 & TST & \\
\hline CHEMBL1712384 & 688422 & 4.9 & 5.1493 & TRN & \\
\hline CHEMBL1508418 & 688422 & 4.45 & 5.0453 & TRN & \\
\hline
\end{tabular}




\begin{tabular}{|c|c|c|c|c|c|}
\hline & & \multicolumn{4}{|c|}{ Supplemental Table S2.txt } \\
\hline CHEMBL1606772 & 688422 & 4.45 & 5.3276 & TRN & \\
\hline CHEMBL 3189714 & 688422 & 5.5 & 5.274 & TRN & \\
\hline CHEMBL1484616 & 688422 & 4.65 & 5.2933 & TRN & \\
\hline CHEMBL 3199083 & 688422 & 4.45 & 4.9931 & TRN & \\
\hline CHEMBL1544552 & 688422 & 4.65 & 5.3745 & TST & \\
\hline CHEMBL1982913 & 688422 & 4.45 & 5.5659 & TST & \\
\hline CHEMBL1608364 & 688422 & 4.45 & 5.13200 & 3000000001 & TRN \\
\hline CHEMBL1511156 & 688422 & 4.45 & 5.0338 & TRN & \\
\hline CHEMBL1510681 & 688422 & 4.85 & 5.3825 & TRN & \\
\hline CHEMBL1464097 & 688422 & 4.7 & 5.4414 & TRN & \\
\hline CHEMBL1327568 & 688422 & 4.5 & 5.3572 & TST & \\
\hline CHEMBL1539910 & 688422 & 4.7 & 5.2552 & TRN & \\
\hline CHEMBL1445807 & 688422 & 6.9 & 5.4531 & TST & \\
\hline CHEMBL1406571 & 688422 & 7.1002 & 5.3073 & TRN & \\
\hline CHEMBL1556573 & 688422 & 6.2 & 5.2203 & TRN & \\
\hline CHEMBL1348007 & 688422 & 5.05 & 5.3967 & TRN & \\
\hline CHEMBL1390646 & 688422 & 6.05 & 5.6145 & TST & \\
\hline CHEMBL1429361 & 688422 & 4.95 & 5.1184 & TRN & \\
\hline CHEMBL1325760 & 688422 & 5.45 & 5.324 & TRN & \\
\hline CHEMBL1480803 & 688422 & 4.85 & 5.3312 & TRN & \\
\hline CHEMBL1584664 & 688422 & 7.0 & 5.6834 & TST & \\
\hline CHEMBL1519953 & 688422 & 5.05 & 5.3135 & TRN & \\
\hline CHEMBL1399949 & 688422 & 4.8 & 5.4682 & TST & \\
\hline CHEMBL 2007377 & 688422 & 5.4 & 5.0059 & TRN & \\
\hline CHEMBL1503043 & 688422 & 5.45 & 5.7767 & TST & \\
\hline CHEMBL1604009 & 688422 & 4.6 & 5.2856 & TST & \\
\hline CHEMBL1432769 & 688422 & 8.4949 & 5.3975 & TST & \\
\hline CHEMBL1516931 & 688422 & 5.2 & 5.1403 & TRN & \\
\hline CHEMBL1459907 & 688422 & 4.8 & 5.1116 & TRN & \\
\hline CHEMBL1391774 & 688422 & 4.9 & 5.2714 & TRN & \\
\hline CHEMBL1498143 & 688422 & 4.45 & 4.9517 & TRN & \\
\hline CHEMBL1405805 & 688422 & 5.3 & 4.9032 & TRN & \\
\hline CHEMBL1406794 & 688422 & 6.15 & 5.4354 & TST & \\
\hline CHEMBL1603413 & 688422 & 4.45 & 4.9946 & TST & \\
\hline CHEMBL3207982 & 688422 & 5.1 & 4.956 & TRN & \\
\hline CHEMBL1575174 & 688422 & 5.2 & 5.6281 & TRN & \\
\hline CHEMBL1595177 & 688422 & 4.75 & 5.2156 & TST & \\
\hline CHEMBL1603252 & 688422 & 5.4 & 5.1307 & TRN & \\
\hline CHEMBL1529147 & 688422 & 6.0 & 6.0883 & TST & \\
\hline CHEMBL1428972 & 688422 & 5.05 & 5.3062 & TRN & \\
\hline CHEMBL3208917 & 688422 & 4.45 & 4.7776 & TRN & \\
\hline CHEMBL1381757 & 688422 & 4.45 & 5.1493 & TST & \\
\hline CHEMBL1352867 & 688422 & 4.45 & 4.7373 & TRN & \\
\hline CHEMBL1970542 & 688422 & 5.25 & 5.461 & TRN & \\
\hline CHEMBL1564143 & 688422 & 4.45 & 4.9137 & TRN & \\
\hline CHEMBL1370661 & 688422 & 4.45 & 5.449 & TRN & \\
\hline CHEMBL1401197 & 688422 & 4.7 & 5.2405 & TRN & \\
\hline CHEMBL1337547 & 688422 & 4.65 & 4.9802 & TST & \\
\hline
\end{tabular}




\begin{tabular}{|c|c|c|c|c|c|}
\hline \multicolumn{6}{|c|}{ Supplemental Table S2.txt } \\
\hline CHEMBL1373163 & 688422 & 4.45 & 5.8947 & TST & \\
\hline CHEMBL1537815 & 688422 & 4.95 & 5.1732 & TRN & \\
\hline CHEMBL1581725 & 688422 & 5.05 & 5.1914 & TRN & \\
\hline CHEMBL1479689 & 688422 & 7.699 & 5.2894 & TRN & \\
\hline CHEMBL188 & 688422 & 4.95 & 5.4611 & TST & \\
\hline CHEMBL1385853 & 688422 & 5.45 & 4.9991 & TRN & \\
\hline CHEMBL1590418 & 688422 & 4.75 & 5.1645 & TRN & \\
\hline CHEMBL1384998 & 688422 & 4.8 & 4.6263 & TRN & \\
\hline CHEMBL1384457 & 688422 & 4.85 & 5.2389 & TST & \\
\hline CHEMBL1535356 & 688422 & 4.45 & 4.8637 & TRN & \\
\hline CHEMBL1387247 & 688422 & 4.45 & 5.38200 & 2000000001 & TRN \\
\hline CHEMBL1484408 & 688422 & 4.5 & 5.5094 & TRN & \\
\hline CHEMBL1378564 & 688422 & 4.8 & 5.0189 & TRN & \\
\hline CHEMBL1362163 & 688422 & 5.5 & 5.3892 & TRN & \\
\hline CHEMBL1548720 & 688422 & 4.95 & 4.7644 & TRN & \\
\hline CHEMBL1581154 & 688422 & 4.8 & 5.1644 & TRN & \\
\hline CHEMBL1360638 & 688422 & 8.3468 & 5.2769 & TST & \\
\hline CHEMBL1396591 & 688422 & 4.5 & 5.5058 & TRN & \\
\hline CHEMBL1332759 & 688422 & 4.85 & 5.0532 & TRN & \\
\hline CHEMBL1580028 & 688422 & 4.45 & 5.0266 & TRN & \\
\hline CHEMBL1366163 & 688422 & 6.3 & 5.5626 & TRN & \\
\hline CHEMBL1556631 & 688422 & 4.9 & 5.2516 & TRN & \\
\hline CHEMBL1502259 & 688422 & 4.85 & 4.9921 & TST & \\
\hline CHEMBL1535069 & 688422 & 6.8499 & 5.8688 & TST & \\
\hline CHEMBL1304775 & 688422 & 4.95 & 4.9617 & TRN & \\
\hline CHEMBL1421118 & 688422 & 4.45 & 4.7369 & TRN & \\
\hline CHEMBL1370419 & 688422 & 6.4 & 5.1856 & TRN & \\
\hline CHEMBL1451565 & 688422 & 5.35 & 5.7274 & TRN & \\
\hline CHEMBL1355043 & 688422 & 8.0 & 5.4193 & TRN & \\
\hline CHEMBL1363144 & 688422 & 7.7496 & 5.6852 & TRN & \\
\hline CHEMBL1547141 & 688422 & 4.65 & 4.9498 & TRN & \\
\hline CHEMBL1463828 & 688422 & 5.2 & 5.2752 & TST & \\
\hline CHEMBL1447984 & 688422 & 4.45 & 4.9681 & TST & \\
\hline CHEMBL1481162 & 688422 & 5.95 & 5.1747 & TRN & \\
\hline CHEMBL1414045 & 688422 & 4.65 & 5.0314 & TRN & \\
\hline CHEMBL1524368 & 688422 & 5.6 & 5.5625 & TST & \\
\hline CHEMBL1577993 & 688422 & 5.05 & 5.1453 & TST & \\
\hline CHEMBL1609713 & 688422 & 4.5 & 5.3043 & TRN & \\
\hline CHEMBL1494827 & 688422 & 5.9 & 5.478 & TST & \\
\hline CHEMBL1485276 & 688422 & 4.5 & 5.2068 & TST & \\
\hline CHEMBL1559014 & 688422 & 4.65 & 5.1357 & TRN & \\
\hline CHEMBL1611737 & 688422 & 5.8 & 5.6809 & TRN & \\
\hline CHEMBL1589726 & 688422 & 4.7 & 4.7333 & TRN & \\
\hline CHEMBL1365336 & 688422 & 4.65 & 5.2728 & TRN & \\
\hline CHEMBL1603604 & 688422 & 4.95 & 5.1536 & TST & \\
\hline CHEMBL1403964 & 688422 & 5.0 & 5.225 & TRN & \\
\hline CHEMBL 1423708 & 688422 & 4.85 & 5.7526 & TST & \\
\hline CHEMBL1345510 & 688422 & 4.65 & 5.3119 & TRN & \\
\hline
\end{tabular}




\begin{tabular}{|c|c|c|c|c|c|}
\hline \multicolumn{6}{|c|}{ Supplemental Table S2.txt } \\
\hline CHEMBL1326475 & 688422 & 4.9 & 4.9643 & TST & \\
\hline CHEMBL1323060 & 688422 & 6.7501 & 5.2384 & TRN & \\
\hline CHEMBL1335196 & 688422 & 7.699 & 5.1556 & TRN & \\
\hline CHEMBL1438808 & 688422 & 7.5003 & 5.159 & TRN & \\
\hline CHEMBL1365721 & 688422 & 6.7501 & 5.0547 & TST & \\
\hline CHEMBL1384825 & 688422 & 4.85 & 5.1144 & TRN & \\
\hline CHEMBL1361987 & 688422 & 4.9 & 4.9594 & TRN & \\
\hline CHEMBL1255655 & 688422 & 7.0501 & 5.4089 & TST & \\
\hline CHEMBL1506899 & 688422 & 4.5 & 4.9754 & TRN & \\
\hline CHEMBL1326851 & 688422 & 4.8 & 5.1546 & TST & \\
\hline CHEMBL1480370 & 688422 & 4.45 & 5.6727 & TRN & \\
\hline CHEMBL1558725 & 688422 & 4.9 & 5.0647 & TRN & \\
\hline CHEMBL1534300 & 688422 & 4.75 & 5.2779 & TRN & \\
\hline CHEMBL1366094 & 688422 & 4.95 & 5.5331 & TRN & \\
\hline CHEMBL1519065 & 688422 & 5.5 & 4.862 & TST & \\
\hline CHEMBL1383900 & 688422 & 4.9 & 5.25200 & 0000000001 & TRN \\
\hline CHEMBL1569232 & 688422 & 4.9 & 5.237 & TRN & \\
\hline CHEMBL 3192782 & 688422 & 4.5 & 5.0522 & TST & \\
\hline CHEMBL1504894 & 688422 & 4.85 & 5.0918 & TST & \\
\hline CHEMBL1360597 & 688422 & 5.0 & 5.6509 & TRN & \\
\hline CHEMBL600495 & 688422 & 4.45 & 5.343 & TST & \\
\hline CHEMBL1517204 & 688422 & 5.3 & 5.4505 & TRN & \\
\hline CHEMBL3192555 & 688422 & 5.4 & 5.3301 & TRN & \\
\hline CHEMBL1486672 & 688422 & 4.95 & 5.2194 & TRN & \\
\hline CHEMBL 3207645 & 688422 & 4.45 & 5.2522 & TRN & \\
\hline CHEMBL1358558 & 688422 & 7.699 & 5.2276 & TRN & \\
\hline CHEMBL1393901 & 688422 & 5.75 & 4.9521 & TST & \\
\hline CHEMBL1502616 & 688422 & 8.4949 & 5.4348 & TRN & \\
\hline CHEMBL1575807 & 688422 & 6.4 & 5.8493 & TST & \\
\hline CHEMBL1579906 & 688422 & 4.7 & 5.165 & TRN & \\
\hline CHEMBL1544947 & 688422 & 4.9 & 5.3317 & TRN & \\
\hline CHEMBL1498707 & 688422 & 4.45 & 5.0729 & TRN & \\
\hline CHEMBL1495653 & 688422 & 6.15 & 5.4068 & TRN & \\
\hline CHEMBL1401532 & 688422 & 5.3 & 5.3667 & TRN & \\
\hline CHEMBL3208473 & 688422 & 5.45 & 5.6402 & TST & \\
\hline CHEMBL1580272 & 688422 & 4.95 & 5.2701 & TRN & \\
\hline CHEMBL1341239 & 688422 & 4.65 & 5.564 & TRN & \\
\hline CHEMBL1391965 & 688422 & 5.1 & 4.4292 & TRN & \\
\hline CHEMBL1390755 & 688422 & 5.3 & 4.8711 & TST & \\
\hline CHEMBL1336146 & 688422 & 4.45 & 5.2661 & TRN & \\
\hline CHEMBL1433759 & 688422 & 6.1 & 5.3634 & TRN & \\
\hline CHEMBL1472016 & 688422 & 4.75 & 5.1629 & TRN & \\
\hline CHEMBL1421632 & 688422 & 4.45 & 5.5659 & TRN & \\
\hline CHEMBL1443575 & 688422 & 4.65 & 5.481 & TRN & \\
\hline CHEMBL1445681 & 688422 & 5.35 & 5.2755 & TST & \\
\hline CHEMBL1343568 & 688422 & 5.15 & 4.9935 & TRN & \\
\hline CHEMBL1534336 & 688422 & 4.45 & 4.8082 & TRN & \\
\hline CHEMBL1377868 & 688422 & 4.7 & 5.0202 & TRN & \\
\hline
\end{tabular}




\begin{tabular}{|c|c|c|c|c|}
\hline \multicolumn{5}{|c|}{ Supplemental Table S2.txt } \\
\hline CHEMBL1477584 & 688422 & 4.6 & 5.2066 & TST \\
\hline CHEMBL1490020 & 688422 & 4.45 & 4.8541 & TST \\
\hline CHEMBL3192325 & 688422 & 4.65 & 5.1634 & TRN \\
\hline CHEMBL1307360 & 688422 & 6.7501 & 5.1851 & TRN \\
\hline CHEMBL 2236406 & 688422 & 5.55 & 4.9643 & TST \\
\hline CHEMBL1341072 & 688422 & 4.45 & 4.9814 & TRN \\
\hline CHEMBL1546621 & 688422 & 5.15 & 5.1794 & TRN \\
\hline CHEMBL1525930 & 688422 & 4.85 & 4.907 & TRN \\
\hline CHEMBL1488218 & 688422 & 4.45 & 5.3601 & TRN \\
\hline CHEMBL1342367 & 688422 & 4.45 & 5.2828 & TRN \\
\hline CHEMBL1454843 & 688422 & 5.1 & 5.2959 & TRN \\
\hline CHEMBL1501737 & 688422 & 5.2 & 5.2294 & TRN \\
\hline CHEMBL1593815 & 688422 & 6.0 & 6.2448 & TST \\
\hline CHEMBL1332979 & 688422 & 4.8 & 4.8123 & TRN \\
\hline CHEMBL1406074 & 688422 & 4.45 & 4.9746 & TST \\
\hline CHEMBL1349482 & 688422 & 5.75 & 4.7827 & TST \\
\hline CHEMBL1324053 & 688422 & 4.45 & 5.8636 & TRN \\
\hline CHEMBL1389514 & 688422 & 5.3 & 5.271 & TRN \\
\hline CHEMBL3198313 & 688422 & 4.9 & 5.4201 & TRN \\
\hline CHEMBL1299973 & 688422 & 4.6 & 5.2356 & TRN \\
\hline CHEMBL1974538 & 688422 & 4.85 & 5.4018 & TRN \\
\hline CHEMBL1604779 & 688422 & 4.8 & 4.8619 & TRN \\
\hline CHEMBL1440335 & 688422 & 5.2 & 5.7522 & TST \\
\hline CHEMBL1430714 & 688422 & 4.85 & 5.0593 & TST \\
\hline CHEMBL1333355 & 688422 & 5.6 & 5.4757 & TST \\
\hline CHEMBL1327137 & 688422 & 4.5 & 4.7955 & TRN \\
\hline CHEMBL1992817 & 688422 & 4.65 & 4.9588 & TST \\
\hline CHEMBL1316534 & 688422 & 4.45 & 5.0629 & TRN \\
\hline CHEMBL1514662 & 688422 & 7.4498 & 5.0452 & TST \\
\hline CHEMBL1330317 & 688422 & 4.45 & 4.7974 & TRN \\
\hline CHEMBL1596906 & 688422 & 4.5 & 5.2185 & TRN \\
\hline CHEMBL 3213787 & 688422 & 5.0 & 5.088 & TRN \\
\hline CHEMBL1998200 & 688422 & 5.35 & 5.064 & TRN \\
\hline CHEMBL1343087 & 688422 & 5.8 & 5.935 & TRN \\
\hline CHEMBL1497877 & 688422 & 4.9 & 5.0694 & TRN \\
\hline CHEMBL1368051 & 688422 & 5.25 & 5.9842 & TRN \\
\hline CHEMBL1594974 & 688422 & 4.9 & 4.8998 & TRN \\
\hline CHEMBL1520124 & 688422 & 4.45 & 5.3754 & TRN \\
\hline CHEMBL1362279 & 688422 & 4.45 & 5.2486 & TRN \\
\hline CHEMBL1335252 & 688422 & 4.45 & 5.1387 & TRN \\
\hline CHEMBL1451893 & 688422 & 5.45 & 5.3583 & TST \\
\hline CHEMBL1516990 & 688422 & 4.65 & 5.3179 & TRN \\
\hline CHEMBL1580283 & 688422 & 6.05 & 5.3744 & TRN \\
\hline CHEMBL1414303 & 688422 & 5.25 & 4.9877 & TRN \\
\hline CHEMBL1507748 & 688422 & 4.8 & 5.4379 & TST \\
\hline CHEMBL1482777 & 688422 & 4.65 & 4.9726 & TRN \\
\hline CHEMBL1341192 & 688422 & 4.6 & 5.7 & TRN \\
\hline CHEMBL1359739 & 688422 & 4.9 & 4.8936 & TRN \\
\hline
\end{tabular}




\begin{tabular}{|c|c|c|c|c|c|}
\hline \multicolumn{6}{|c|}{ Supplemental Table S2.txt } \\
\hline CHEMBL567323 & 688422 & 4.95 & 5.3607 & TRN & \\
\hline CHEMBL1424462 & 688422 & 5.6 & 5.5092 & TRN & \\
\hline CHEMBL1422385 & 688422 & 4.8 & 5.356 & TRN & \\
\hline CHEMBL1535737 & 688422 & 4.6 & 4.8947 & TRN & \\
\hline CHEMBL1609555 & 688422 & 4.45 & 5.5055 & TST & \\
\hline CHEMBL1460095 & 688422 & 4.85 & 5.1441 & TRN & \\
\hline CHEMBL1537622 & 688422 & 4.8 & 5.2345 & TST & \\
\hline CHEMBL3197678 & 688422 & 4.95 & 4.9633 & TRN & \\
\hline CHEMBL1519195 & 688422 & 4.5 & 5.0051 & TRN & \\
\hline CHEMBL1444164 & 688422 & 4.85 & 4.834 & TST & \\
\hline CHEMBL1313251 & 688422 & 4.95 & 4.6802 & TRN & \\
\hline CHEMBL 3193878 & 688422 & 4.9 & 5.0712 & TRN & \\
\hline CHEMBL1498892 & 688422 & 8.4559 & 5.4538 & TRN & \\
\hline CHEMBL3209961 & 688422 & 5.9 & 5.517 & TST & \\
\hline CHEMBL1412292 & 688422 & 4.9 & 5.3173 & TRN & \\
\hline CHEMBL1597234 & 688422 & 4.95 & 5.1467 & TRN & \\
\hline CHEMBL1486176 & 688422 & 5.25 & 4.979 & TRN & \\
\hline CHEMBL1439149 & 688422 & 4.85 & 5.1283 & TRN & \\
\hline CHEMBL1587009 & 688422 & 4.45 & 5.2123 & TRN & \\
\hline CHEMBL1519422 & 688422 & 5.4 & 5.0827 & TRN & \\
\hline CHEMBL1987622 & 688422 & 5.85 & 5.3003 & TST & \\
\hline CHEMBL1340882 & 688422 & 5.85 & 4.8641 & TRN & \\
\hline CHEMBL1393048 & 688422 & 5.2 & 5.1209 & TRN & \\
\hline CHEMBL1342760 & 688422 & 5.1 & 5.0808 & TRN & \\
\hline CHEMBL1318615 & 688422 & 4.8 & 5.4683 & TST & \\
\hline CHEMBL1539146 & 688422 & 4.85 & 5.5938 & TRN & \\
\hline CHEMBL1527746 & 688422 & 5.0 & 5.3464 & TRN & \\
\hline CHEMBL1467430 & 688422 & 5.45 & 5.3425 & TRN & \\
\hline CHEMBL1370542 & 688422 & 4.75 & 5.0243 & TST & \\
\hline CHEMBL1384351 & 688422 & 4.95 & 5.4503 & TRN & \\
\hline CHEMBL1300712 & 688422 & 4.95 & 4.993 & TRN & \\
\hline CHEMBL1597671 & 688422 & 4.9 & 5.2835 & TRN & \\
\hline CHEMBL1586371 & 688422 & 6.2 & 5.3169 & TRN & \\
\hline CHEMBL1518057 & 688422 & 4.45 & 4.6234 & TRN & \\
\hline CHEMBL1511663 & 688422 & 4.9 & 4.8621 & TRN & \\
\hline CHEMBL1600996 & 688422 & 4.85 & 5.5895 & TRN & \\
\hline CHEMBL1530211 & 688422 & 4.6 & 4.9677 & TRN & \\
\hline CHEMBL1411663 & 688422 & 4.85 & 4.7572 & TRN & \\
\hline CHEMBL1302437 & 688422 & 4.85 & 5.3636 & TRN & \\
\hline CHEMBL1529080 & 688422 & 4.95 & 5.4148 & TST & \\
\hline CHEMBL1324200 & 688422 & 5.35 & 5.0041 & TRN & \\
\hline CHEMBL1387687 & 688422 & 8.4949 & 5.9134 & TST & \\
\hline CHEMBL1429564 & 688422 & 4.85 & 5.20200 & 3000000001 & TRN \\
\hline CHEMBL1488383 & 688422 & 4.9 & 4.8733 & TRN & \\
\hline CHEMBL 2375170 & 688422 & 6.0 & 5.4333 & TST & \\
\hline CHEMBL1583872 & 688422 & 6.0 & 5.4803 & TRN & \\
\hline CHEMBL1389179 & 688422 & 4.5 & 5.0951 & TRN & \\
\hline CHEMBL1536990 & 688422 & 4.8 & 4.9455 & TRN & \\
\hline
\end{tabular}




\begin{tabular}{|c|c|c|c|c|c|}
\hline \multicolumn{6}{|c|}{ Supplemental Table S2.txt } \\
\hline CHEMBL1865547 & 688422 & 4.8 & 5.3045 & TRN & \\
\hline CHEMBL1454473 & 688422 & 4.95 & 5.3422 & TRN & \\
\hline CHEMBL3210881 & 688422 & 5.6 & 5.3184 & TRN & \\
\hline CHEMBL1599355 & 688422 & 7.4001 & 5.1405 & TRN & \\
\hline CHEMBL1306558 & 688422 & 4.9 & 4.6774 & TRN & \\
\hline CHEMBL3196396 & 688422 & 4.5 & 5.0343 & TST & \\
\hline CHEMBL3211133 & 688422 & 4.6 & 4.7746 & TST & \\
\hline CHEMBL1570647 & 688422 & 4.85 & 4.9435 & TRN & \\
\hline CHEMBL1373577 & 688422 & 4.45 & 5.052 & TRN & \\
\hline CHEMBL1516710 & 688422 & 6.6 & 4.9801 & TST & \\
\hline CHEMBL1458934 & 688422 & 7.699 & 6.0341 & TRN & \\
\hline CHEMBL1613262 & 688422 & 6.1 & 5.3868 & TST & \\
\hline CHEMBL1507620 & 688422 & 4.85 & 5.4084 & TST & \\
\hline CHEMBL1411269 & 688422 & 6.95 & 5.1796 & TRN & \\
\hline CHEMBL1520634 & 688422 & 4.8 & 5.37799 & 9999999999 & TST \\
\hline CHEMBL1479883 & 688422 & 4.9 & 5.1994 & TRN & \\
\hline CHEMBL1311085 & 688422 & 4.45 & 5.4841 & TRN & \\
\hline CHEMBL1484990 & 688422 & 4.8 & 5.3019 & TRN & \\
\hline CHEMBL1585072 & 688422 & 4.45 & 5.0688 & TRN & \\
\hline CHEMBL1501446 & 688422 & 4.65 & 5.50299 & 9999999999 & TRN \\
\hline CHEMBL1342609 & 688422 & 4.45 & 5.0457 & TRN & \\
\hline CHEMBL1308335 & 688422 & 4.8 & 5.2178 & TRN & \\
\hline CHEMBL1467783 & 688422 & 5.1 & 5.6384 & TST & \\
\hline CHEMBL1582933 & 688422 & 4.45 & 4.7226 & TST & \\
\hline CHEMBL1602582 & 688422 & 5.25 & 5.2836 & TRN & \\
\hline CHEMBL1978331 & 688422 & 5.4 & 5.59 & TRN & \\
\hline CHEMBL1486325 & 688422 & 4.7 & 5.3873 & TRN & \\
\hline CHEMBL1442296 & 688422 & 4.75 & 5.4335 & TRN & \\
\hline CHEMBL1414138 & 688422 & 4.6 & 4.9454 & TRN & \\
\hline CHEMBL 3208121 & 688422 & 6.8499 & 5.6282 & TRN & \\
\hline CHEMBL1404663 & 688422 & 6.3 & 5.725 & TST & \\
\hline CHEMBL3194916 & 688422 & 4.9 & 5.1838 & TRN & \\
\hline CHEMBL1441292 & 688422 & 4.95 & 5.3722 & TRN & \\
\hline CHEMBL1346707 & 688422 & 4.9 & 5.0279 & TST & \\
\hline CHEMBL 2003214 & 688422 & 4.45 & 5.5892 & TRN & \\
\hline CHEMBL1320669 & 688422 & 6.9 & 5.563 & TRN & \\
\hline CHEMBL1481079 & 688422 & 4.95 & 4.9807 & TRN & \\
\hline CHEMBL456807 & 688422 & 7.5003 & 5.6103 & TST & \\
\hline CHEMBL1384092 & 688422 & 5.5 & 5.6438 & TRN & \\
\hline CHEMBL1502656 & 688422 & 5.45 & 5.4337 & TRN & \\
\hline CHEMBL1525381 & 688422 & 5.45 & 5.4318 & TRN & \\
\hline CHEMBL1574840 & 688422 & 6.1 & 5.7614 & TST & \\
\hline CHEMBL1387122 & 688422 & 6.3 & 5.4012 & TRN & \\
\hline CHEMBL1336953 & 688422 & 4.5 & 5.2118 & TRN & \\
\hline CHEMBL1380082 & 688422 & 4.75 & 5.209 & TRN & \\
\hline CHEMBL1519805 & 688422 & 4.85 & 4.9707 & TRN & \\
\hline CHEMBL1476486 & 688422 & 5.2 & 5.4333 & TST & \\
\hline CHEMBL1369837 & 688422 & 4.95 & 5.0462 & TRN & \\
\hline
\end{tabular}




\begin{tabular}{|c|c|c|c|c|c|}
\hline \multicolumn{6}{|c|}{ Supplemental Table s2.txt } \\
\hline CHEMBL1415205 & 688422 & 5.4 & 5.3089 & TST & \\
\hline CHEMBL1441656 & 688422 & 4.45 & 5.1819 & TRN & \\
\hline CHEMBL1346984 & 688422 & 4.9 & 5.0362 & TRN & \\
\hline CHEMBL1548193 & 688422 & 4.7 & 5.3113 & TRN & \\
\hline CHEMBL3196282 & 688422 & 4.8 & 5.1537 & TRN & \\
\hline CHEMBL1578072 & 688422 & 4.45 & 5.862 & TRN & \\
\hline CHEMBL1608986 & 688422 & 5.05 & 5.3054 & TRN & \\
\hline CHEMBL1603131 & 688422 & 4.7 & 5.0788 & TRN & \\
\hline CHEMBL1543822 & 688422 & 4.9 & 4.9607 & TST & \\
\hline CHEMBL525106 & 688422 & 4.5 & 5.0167 & TRN & \\
\hline CHEMBL1377705 & 688422 & 4.45 & 4.8706 & TRN & \\
\hline CHEMBL1307560 & 688422 & 5.5 & 5.5512 & TRN & \\
\hline CHEMBL1394018 & 688422 & 4.6 & 4.9216 & TRN & \\
\hline CHEMBL1447402 & 688422 & 5.4 & 4.8889 & TRN & \\
\hline CHEMBL1431536 & 688422 & 4.65 & 5.018 & TST & \\
\hline CHEMBL1581547 & 688422 & 5.4 & 5.5756 & TRN & \\
\hline CHEMBL1441738 & 688422 & 6.3 & 5.42399 & 99999999995 & TRN \\
\hline CHEMBL1450430 & 688422 & 4.45 & 4.6901 & TRN & \\
\hline CHEMBL 3207786 & 688422 & 5.5 & 5.1508 & TST & \\
\hline CHEMBL1380063 & 688422 & 5.45 & 5.1352 & TRN & \\
\hline CHEMBL1344330 & 688422 & 5.6 & 5.4156 & TST & \\
\hline CHEMBL1455984 & 688422 & 6.95 & 5.6235 & TRN & \\
\hline CHEMBL1442722 & 688422 & 4.75 & 5.2307 & TST & \\
\hline CHEMBL1429996 & 688422 & 7.6498 & 5.8285 & TST & \\
\hline CHEMBL191015 & 688422 & 4.5 & 5.2599 & TST & \\
\hline CHEMBL1537458 & 688422 & 4.45 & 5.103 & TST & \\
\hline CHEMBL1437930 & 688422 & 5.85 & 5.0708 & TRN & \\
\hline CHEMBL1497927 & 688422 & 5.0 & 5.2521 & TRN & \\
\hline CHEMBL1414486 & 688422 & 4.7 & 5.204 & TRN & \\
\hline CHEMBL1382031 & 688422 & 5.15 & 5.1131 & TST & \\
\hline CHEMBL1536625 & 688422 & 4.85 & 4.7082 & TRN & \\
\hline CHEMBL1311509 & 688422 & 4.95 & 5.0154 & TRN & \\
\hline CHEMBL1400986 & 688422 & 5.05 & 5.0439 & TRN & \\
\hline CHEMBL1351826 & 688422 & 4.65 & 4.8048 & TRN & \\
\hline CHEMBL1319263 & 688422 & 4.45 & 4.8442 & TRN & \\
\hline CHEMBL1603527 & 688422 & 7.5498 & 5.4252 & TRN & \\
\hline CHEMBL1528898 & 688422 & 6.45 & 5.0931 & TRN & \\
\hline CHEMBL1342993 & 688422 & 4.9 & 5.1215 & TST & \\
\hline CHEMBL1521526 & 688422 & 6.15 & 5.7159 & TRN & \\
\hline CHEMBL1535055 & 688422 & 4.45 & 5.2206 & TRN & \\
\hline CHEMBL1525294 & 688422 & 6.35 & 5.5624 & TRN & \\
\hline CHEMBL1367246 & 688422 & 4.45 & 5.24200 & 0000000001 & TST \\
\hline CHEMBL1460229 & 688422 & 4.8 & 5.2565 & TST & \\
\hline CHEMBL1430435 & 688422 & 7.3497 & 5.2617 & TRN & \\
\hline CHEMBL1598401 & 688422 & 6.2 & 5.0257 & TRN & \\
\hline CHEMBL1500058 & 688422 & 8.0 & 5.5532 & TST & \\
\hline CHEMBL1354889 & 688422 & 4.9 & 5.4959 & TRN & \\
\hline CHEMBL1546211 & 688422 & 5.2 & 4.5353 & TRN & \\
\hline
\end{tabular}




\begin{tabular}{|c|c|c|c|c|c|}
\hline \multicolumn{6}{|c|}{ Supplemental Table S2.txt } \\
\hline CHEMBL1509727 & 688422 & 5.1 & 5.09 & TST & \\
\hline CHEMBL1526330 & 688422 & 4.45 & 5.2793 & TRN & \\
\hline CHEMBL3196193 & 688422 & 5.0 & 5.1426 & TRN & \\
\hline CHEMBL1503303 & 688422 & 4.5 & 5.245 & TRN & \\
\hline CHEMBL1613636 & 688422 & 4.45 & 5.3686 & TRN & \\
\hline CHEMBL1555513 & 688422 & 8.0506 & 5.3414 & TST & \\
\hline CHEMBL1460313 & 688422 & 4.6 & 5.4197 & TST & \\
\hline CHEMBL1505313 & 688422 & 4.85 & 5.3874 & TST & \\
\hline CHEMBL1383992 & 688422 & 4.85 & 5.3946 & TRN & \\
\hline CHEMBL1529098 & 688422 & 7.5498 & 5.6086 & TST & \\
\hline CHEMBL1535926 & 688422 & 4.45 & 4.9442 & TRN & \\
\hline CHEMBL1379677 & 688422 & 4.6 & 5.17299 & 9999999999 & TRN \\
\hline CHEMBL1547995 & 688422 & 4.8 & 5.2743 & TRN & \\
\hline CHEMBL1423465 & 688422 & 6.7001 & 5.853 & TRN & \\
\hline CHEMBL3208381 & 688422 & 4.8 & 5.1701 & TRN & \\
\hline CHEMBL1417153 & 688422 & 7.8508 & 5.6219 & TRN & \\
\hline CHEMBL1562014 & 688422 & 4.8 & 5.732 & TST & \\
\hline CHEMBL1544327 & 688422 & 4.85 & 5.4488 & TST & \\
\hline CHEMBL1560530 & 688422 & 5.0 & 5.1051 & TRN & \\
\hline CHEMBL1551014 & 688422 & 5.45 & 5.8623 & TRN & \\
\hline CHEMBL1423832 & 688422 & 4.9 & 4.8829 & TRN & \\
\hline CHEMBL1362322 & 688422 & 4.7 & 5.5237 & TST & \\
\hline CHEMBL3193897 & 688422 & 5.0 & 5.355 & TRN & \\
\hline CHEMBL1374591 & 688422 & 5.6 & 5.5367 & TRN & \\
\hline CHEMBL3197771 & 688422 & 4.8 & 5.1125 & TRN & \\
\hline CHEMBL1368311 & 688422 & 4.45 & 4.8219 & TRN & \\
\hline CHEMBL583578 & 688422 & 4.9 & 5.3492 & TRN & \\
\hline CHEMBL1487890 & 688422 & 4.45 & 5.4838 & TRN & \\
\hline CHEMBL1342604 & 688422 & 5.0 & 5.4068 & TRN & \\
\hline CHEMBL1438746 & 688422 & 4.65 & 5.1399 & TRN & \\
\hline CHEMBL1464963 & 688422 & 4.6 & 5.2431 & TRN & \\
\hline CHEMBL1551471 & 688422 & 4.95 & 4.9613 & TRN & \\
\hline CHEMBL1403052 & 688422 & 4.85 & 5.6307 & TRN & \\
\hline CHEMBL1361267 & 688422 & 4.5 & 4.8981 & TRN & \\
\hline CHEMBL1547444 & 688422 & 4.45 & 5.1691 & TRN & \\
\hline CHEMBL1469228 & 688422 & 4.55 & 5.3918 & TST & \\
\hline CHEMBL1479746 & 688422 & 4.95 & 5.019 & TRN & \\
\hline CHEMBL1600351 & 688422 & 4.85 & 4.8709 & TRN & \\
\hline CHEMBL1576578 & 688422 & 4.45 & 5.3016 & TST & \\
\hline CHEMBL1581273 & 688422 & 5.45 & 5.1719 & TST & \\
\hline CHEMBL1486386 & 688422 & 7.4498 & 5.4639 & TST & \\
\hline CHEMBL1519968 & 688422 & 7.6498 & 5.553 & TRN & \\
\hline CHEMBL1600381 & 688422 & 4.95 & 5.1728 & TRN & \\
\hline CHEMBL1612313 & 688422 & 4.55 & 5.4647 & TRN & \\
\hline CHEMBL1338107 & 688422 & 4.65 & 4.8494 & TRN & \\
\hline CHEMBL1336202 & 688422 & 5.1 & 5.559 & TRN & \\
\hline CHEMBL1514072 & 688422 & 5.05 & 5.4726 & TRN & \\
\hline CHEMBL1469022 & 688422 & 4.45 & 4.7481 & TST & \\
\hline
\end{tabular}




\begin{tabular}{|c|c|c|c|c|c|}
\hline & & \multicolumn{4}{|c|}{ Supplemental Table S2.txt } \\
\hline CHEMBL1393775 & 688422 & 7.0501 & 5.5439 & TRN & \\
\hline CHEMBL1345545 & 688422 & 7.1002 & 5.3968 & TRN & \\
\hline CHEMBL1593000 & 688422 & 5.2 & 5.4042 & TRN & \\
\hline CHEMBL1360881 & 688422 & 4.7 & 5.4459 & TST & \\
\hline CHEMBL1532563 & 688422 & 5.25 & 4.9132 & TRN & \\
\hline CHEMBL1398698 & 688422 & 4.95 & 5.279 & TRN & \\
\hline CHEMBL1378771 & 688422 & 4.9 & 4.8355 & TRN & \\
\hline CHEMBL3192398 & 688422 & 4.5 & 5.3515 & TRN & \\
\hline CHEMBL1348324 & 688422 & 8.0506 & 5.143 & TST & \\
\hline CHEMBL3196936 & 688422 & 5.2 & 5.4724 & TRN & \\
\hline CHEMBL1374485 & 688422 & 4.7 & 5.6117 & TST & \\
\hline CHEMBL1363773 & 688422 & 4.95 & 5.2242 & TRN & \\
\hline CHEMBL1491019 & 688422 & 5.35 & 5.3377 & TST & \\
\hline CHEMBL1345227 & 688422 & 4.55 & 5.6673 & TRN & \\
\hline CHEMBL1303054 & 688422 & 4.75 & 5.2262 & TRN & \\
\hline CHEMBL1526543 & 688422 & 6.0 & 5.6822 & TRN & \\
\hline CHEMBL1384475 & 688422 & 4.95 & 5.0982 & TST & \\
\hline CHEMBL1538271 & 688422 & 4.95 & 5.2517 & TRN & \\
\hline CHEMBL1353629 & 688422 & 4.9 & 5.2293 & TRN & \\
\hline CHEMBL1532072 & 688422 & 4.45 & 4.9393 & TRN & \\
\hline CHEMBL1589371 & 688422 & 4.8 & 4.8784 & TRN & \\
\hline CHEMBL1497933 & 688422 & 7.0501 & 5.3589 & TST & \\
\hline CHEMBL1359623 & 688422 & 5.1 & 4.9283 & TRN & \\
\hline CHEMBL1585274 & 688422 & 4.55 & 5.1812 & TRN & \\
\hline CHEMBL1570795 & 688422 & 8.0 & 5.2241 & TST & \\
\hline CHEMBL1510648 & 688422 & 4.9 & 5.0962 & TST & \\
\hline CHEMBL1588020 & 688422 & 5.4 & 5.0951 & TRN & \\
\hline CHEMBL1413351 & 688422 & 4.5 & 5.7026 & TST & \\
\hline CHEMBL1407632 & 688422 & 4.6 & 5.2127 & TRN & \\
\hline CHEMBL1589570 & 688422 & 7.699 & 5.597 & TST & \\
\hline CHEMBL 3197287 & 688422 & 5.2 & 5.1949 & TST & \\
\hline CHEMBL1308010 & 688422 & 4.95 & 4.396 & TRN & \\
\hline CHEMBL1305179 & 688422 & 4.45 & 5.33299 & 9999999999 & TRN \\
\hline CHEMBL1425821 & 688422 & 4.5 & 5.3854 & TRN & \\
\hline CHEMBL1571264 & 688422 & 4.9 & 4.8032 & TRN & \\
\hline CHEMBL3198417 & 688422 & 4.45 & 5.4441 & TRN & \\
\hline CHEMBL1392903 & 688422 & 4.45 & 5.16 & TRN & \\
\hline CHEMBL1447879 & 688422 & 4.9 & 5.1538 & TST & \\
\hline CHEMBL1337750 & 688422 & 6.05 & 5.5369 & TRN & \\
\hline CHEMBL1318320 & 688422 & 5.75 & 5.1727 & TST & \\
\hline CHEMBL1431962 & 688422 & 4.45 & 5.1369 & TST & \\
\hline CHEMBL1484095 & 688422 & 6.0 & 4.9634 & TRN & \\
\hline CHEMBL1414867 & 688422 & 4.6 & 4.7813 & TRN & \\
\hline CHEMBL1364636 & 688422 & 5.25 & 5.5686 & TRN & \\
\hline CHEMBL1453020 & 688422 & 4.75 & 5.4981 & TRN & \\
\hline CHEMBL1601114 & 688422 & 5.5 & 5.2932 & TRN & \\
\hline CHEMBL1970864 & 688422 & 5.2 & 5.1993 & TRN & \\
\hline CHEMBL1612763 & 688422 & 4.95 & 5.4215 & TST & \\
\hline
\end{tabular}




\begin{tabular}{|c|c|c|c|c|c|}
\hline \multicolumn{6}{|c|}{ Supplemental Table S2.txt } \\
\hline CHEMBL1500185 & 688422 & 5.25 & 5.2764 & TST & \\
\hline CHEMBL1388766 & 688422 & 5.0 & 5.2922 & TRN & \\
\hline CHEMBL1407819 & 688422 & 5.45 & 5.4238 & TST & \\
\hline CHEMBL1558823 & 688422 & 4.65 & 5.4836 & TST & \\
\hline CHEMBL 1327086 & 688422 & 4.45 & 5.5096 & TRN & \\
\hline CHEMBL1529586 & 688422 & 4.9 & 5.54299 & 9999999999 & TRN \\
\hline CHEMBL1438515 & 688422 & 4.6 & 4.9577 & TRN & \\
\hline CHEMBL1527332 & 688422 & 4.9 & 4.7457 & TRN & \\
\hline CHEMBL1409882 & 688422 & 4.5 & 5.0929 & TRN & \\
\hline CHEMBL1466901 & 688422 & 4.5 & 4.9212 & TST & \\
\hline CHEMBL1382022 & 688422 & 4.45 & 4.8051 & TRN & \\
\hline CHEMBL1516638 & 688422 & 4.8 & 5.4249 & TST & \\
\hline CHEMBL1389441 & 688422 & 4.6 & 5.2488 & TST & \\
\hline CHEMBL3198297 & 688422 & 4.45 & 5.2491 & TRN & \\
\hline CHEMBL1537206 & 688422 & 4.65 & 5.4698 & TST & \\
\hline CHEMBL1438663 & 688422 & 4.95 & 5.1778 & TRN & \\
\hline CHEMBL1608757 & 688422 & 4.5 & 4.9775 & TST & \\
\hline CHEMBL1373079 & 688422 & 6.0 & 5.3192 & TRN & \\
\hline CHEMBL1338634 & 688422 & 5.45 & 5.8626 & TRN & \\
\hline CHEMBL1549839 & 688422 & 4.85 & 5.5174 & TST & \\
\hline CHEMBL1409876 & 688422 & 7.2 & 5.2111 & TST & \\
\hline CHEMBL1430906 & 688422 & 4.7 & 5.0232 & TRN & \\
\hline CHEMBL1560628 & 688422 & 4.7 & 4.7024 & TRN & \\
\hline CHEMBL1475830 & 688422 & 4.95 & 5.0648 & TRN & \\
\hline CHEMBL1523468 & 688422 & 4.95 & 5.2335 & TRN & \\
\hline CHEMBL3198663 & 688422 & 4.7 & 5.1568 & TRN & \\
\hline CHEMBL1341497 & 688422 & 4.45 & 5.3084 & TRN & \\
\hline CHEMBL1386455 & 688422 & 5.25 & 5.694 & TRN & \\
\hline CHEMBL1698464 & 688422 & 5.25 & 4.7583 & TRN & \\
\hline CHEMBL1599292 & 688422 & 4.7 & 5.3135 & TRN & \\
\hline CHEMBL1302084 & 688422 & 4.5 & 5.0563 & TRN & \\
\hline CHEMBL1371848 & 688422 & 4.45 & 5.1514 & TRN & \\
\hline CHEMBL1358735 & 688422 & 4.95 & 5.7081 & TST & \\
\hline CHEMBL1483859 & 688422 & 4.9 & 5.3449 & TRN & \\
\hline CHEMBL1543483 & 688422 & 4.8 & 4.872 & TRN & \\
\hline CHEMBL1574258 & 688422 & 4.45 & 5.1295 & TRN & \\
\hline CHEMBL1528716 & 688422 & 5.0 & 5.1746 & TRN & \\
\hline CHEMBL1458737 & 688422 & 4.95 & 4.7087 & TRN & \\
\hline CHEMBL3194053 & 688422 & 4.9 & 5.0569 & TST & \\
\hline CHEMBL1577570 & 688422 & 4.45 & 4.9112 & TRN & \\
\hline CHEMBL1377069 & 688422 & 4.9 & 5.5675 & TRN & \\
\hline CHEMBL1493455 & 688422 & 5.2 & 5.1752 & TRN & \\
\hline CHEMBL1406349 & 688422 & 7.6498 & 5.5198 & TRN & \\
\hline CHEMBL1300294 & 688422 & 4.45 & 5.5557 & TRN & \\
\hline CHEMBL1529490 & 688422 & 6.0 & 5.5297 & TST & \\
\hline CHEMBL1499041 & 688422 & 4.45 & 4.8893 & TRN & \\
\hline CHEMBL 1317358 & 688422 & 4.7 & 5.2653 & TRN & \\
\hline CHEMBL1606412 & 688422 & 4.45 & 5.2085 & TRN & \\
\hline
\end{tabular}




\begin{tabular}{|c|c|c|c|c|c|}
\hline \\
\hline CHEMBL1574911 & 688422 & 4.9 & 5.0454 & TRN & \\
\hline CHEMBL1395137 & 688422 & 4.9 & 4.863 & TRN & \\
\hline CHEMBL1450981 & 688422 & 4.45 & 5.1083 & TRN & \\
\hline CHEMBL1403937 & 688422 & 5.4 & 5.5636 & TRN & \\
\hline CHEMBL1585099 & 688422 & 4.85 & 4.9409 & TRN & \\
\hline CHEMBL1439385 & 688422 & 4.45 & 5.178 & TRN & \\
\hline CHEMBL1425943 & 688422 & 4.65 & 4.7194 & TRN & \\
\hline CHEMBL1432607 & 688422 & 4.65 & 5.5468 & TRN & \\
\hline CHEMBL1565905 & 688422 & 4.5 & 5.7886 & TRN & \\
\hline CHEMBL1607689 & 688422 & 5.8 & 5.7139 & TST & \\
\hline CHEMBL1610775 & 688422 & 5.7 & 5.3896 & TRN & \\
\hline CHEMBL1416711 & 688422 & 4.45 & 5.2522 & TRN & \\
\hline CHEMBL1576704 & 688422 & 5.45 & 5.2099 & TST & \\
\hline CHEMBL1599152 & 688422 & 4.6 & 5.19799 & 99999999995 & TRN \\
\hline CHEMBL1473834 & 688422 & 4.75 & 5.0416 & TRN & \\
\hline CHEMBL1501865 & 688422 & 4.45 & 5.2842 & TRN & \\
\hline CHEMBL1536121 & 688422 & 4.45 & 4.8663 & TRN & \\
\hline CHEMBL1308269 & 688422 & 5.9 & 5.7785 & TST & \\
\hline CHEMBL1517542 & 688422 & 4.65 & 5.3581 & TRN & \\
\hline CHEMBL1579624 & 688422 & 7.7496 & 5.5449 & TST & \\
\hline CHEMBL1326451 & 688422 & 4.45 & 5.1946 & TRN & \\
\hline CHEMBL1404076 & 688422 & 4.75 & 4.9249 & TRN & \\
\hline CHEMBL3208934 & 688422 & 7.8508 & 5.0707 & TRN & \\
\hline CHEMBL1600323 & 688422 & 7.3002 & 5.2093 & TRN & \\
\hline CHEMBL1361279 & 688422 & 5.5 & 4.9601 & TRN & \\
\hline CHEMBL1500422 & 688422 & 4.95 & 4.8461 & TRN & \\
\hline CHEMBL1484318 & 688422 & 6.6499 & 4.9258 & TST & \\
\hline CHEMBL1329044 & 688422 & 4.85 & 6.0977 & TST & \\
\hline CHEMBL1567134 & 688422 & 4.55 & 5.2762 & TRN & \\
\hline CHEMBL1436262 & 688422 & 5.45 & 4.8971 & TRN & \\
\hline CHEMBL1567815 & 688422 & 5.5 & 5.0181 & TRN & \\
\hline CHEMBL1599179 & 688422 & 4.9 & 5.1371 & TRN & \\
\hline CHEMBL1334680 & 688422 & 4.9 & 4.9388 & TRN & \\
\hline CHEMBL1370572 & 688422 & 4.5 & 5.0926 & TRN & \\
\hline CHEMBL1543943 & 688422 & 4.75 & 5.1938 & TST & \\
\hline CHEMBL1421216 & 688422 & 4.95 & 5.1123 & TRN & \\
\hline CHEMBL1552116 & 688422 & 7.15 & 5.4538 & TST & \\
\hline CHEMBL1330627 & 688422 & 5.85 & 5.473 & TRN & \\
\hline CHEMBL1322203 & 688422 & 4.45 & 5.4025 & TRN & \\
\hline CHEMBL1458900 & 688422 & 7.15 & 4.9577 & TRN & \\
\hline CHEMBL1401057 & 688422 & 6.35 & 5.0554 & TRN & \\
\hline CHEMBL583555 & 688422 & 4.95 & 5.3762 & TST & \\
\hline CHEMBL1559749 & 688422 & 4.65 & 4.8698 & TRN & \\
\hline CHEMBL1592325 & 688422 & 5.65 & 5.126 & TRN & \\
\hline CHEMBL1334328 & 688422 & 6.05 & 5.3728 & TRN & \\
\hline CHEMBL1529178 & 688422 & 4.8 & 5.2028 & TRN & \\
\hline CHEMBL 7976 & 688422 & 4.65 & 4.8089 & TRN & \\
\hline CHEMBL1475616 & 688422 & 6.0 & 5.2896 & TRN & \\
\hline
\end{tabular}




\begin{tabular}{|c|c|c|c|c|}
\hline \multicolumn{5}{|c|}{ Supplemental Table S2.txt } \\
\hline CHEMBL1478514 & 688422 & 4.45 & 5.2288 & TRN \\
\hline CHEMBL1571857 & 688422 & 6.4 & 5.3364 & TST \\
\hline CHEMBL1598365 & 688422 & 4.85 & 4.9222 & TRN \\
\hline CHEMBL1407081 & 688422 & 5.45 & 5.2024 & TST \\
\hline CHEMBL601351 & 688422 & 4.7 & 5.1248 & TST \\
\hline CHEMBL1429717 & 688422 & 4.8 & 5.1459 & TRN \\
\hline CHEMBL1611966 & 688422 & 5.55 & 4.9845 & TRN \\
\hline CHEMBL1522383 & 688422 & 4.7 & 4.8739 & TRN \\
\hline CHEMBL1483225 & 688422 & 4.5 & 5.3403 & TST \\
\hline CHEMBL1423096 & 688422 & 5.25 & 5.2265 & TST \\
\hline CHEMBL1306383 & 688422 & 4.8 & 5.1312 & TRN \\
\hline CHEMBL1300017 & 688422 & 4.45 & 4.9854 & TRN \\
\hline CHEMBL1321273 & 688422 & 4.95 & 5.1729 & TRN \\
\hline CHEMBL1467492 & 688422 & 4.45 & 5.1018 & TRN \\
\hline CHEMBL1607381 & 688422 & 5.2 & 5.6436 & TRN \\
\hline CHEMBL1542760 & 688422 & 4.8 & 5.2985 & TRN \\
\hline CHEMBL1544036 & 688422 & 4.45 & 4.8128 & TRN \\
\hline CHEMBL1612623 & 688422 & 4.85 & 5.6071 & TRN \\
\hline CHEMBL1543654 & 688422 & 4.65 & 4.8627 & TRN \\
\hline CHEMBL1332636 & 688422 & 4.65 & 5.4334 & TRN \\
\hline CHEMBL1439043 & 688422 & 6.95 & 5.5914 & TRN \\
\hline CHEMBL451226 & 688422 & 5.2 & 5.8206 & TST \\
\hline CHEMBL1082192 & 688422 & 7.699 & 5.0129 & TST \\
\hline CHEMBL1546534 & 688422 & 4.45 & 4.6352 & TRN \\
\hline CHEMBL1440516 & 688422 & 5.0 & 5.1761 & TRN \\
\hline CHEMBL1483492 & 688422 & 4.45 & 5.1916 & TRN \\
\hline CHEMBL1603351 & 688422 & 4.7 & 5.0166 & TRN \\
\hline CHEMBL1490234 & 688422 & 4.45 & 5.4815 & TRN \\
\hline CHEMBL1552807 & 688422 & 6.15 & 5.2066 & TRN \\
\hline CHEMBL1384465 & 688422 & 4.8 & 5.2855 & TRN \\
\hline CHEMBL1484622 & 688422 & 4.5 & 5.4465 & TRN \\
\hline CHEMBL1466050 & 688422 & 7.5498 & 5.166 & TST \\
\hline CHEMBL1498545 & 688422 & 4.5 & 5.0568 & TRN \\
\hline CHEMBL1384179 & 688422 & 5.1 & 5.4325 & TST \\
\hline CHEMBL1991487 & 688422 & 6.0 & 5.2908 & TRN \\
\hline CHEMBL1493044 & 688422 & 4.95 & 5.186 & TRN \\
\hline CHEMBL1443807 & 688422 & 4.95 & 5.1092 & TRN \\
\hline CHEMBL1367330 & 688422 & 4.75 & 5.5 & TRN \\
\hline CHEMBL1339366 & 688422 & 5.2 & 5.5919 & TRN \\
\hline CHEMBL1425527 & 688422 & 4.75 & 4.7803 & TRN \\
\hline CHEMBL1353163 & 688422 & 4.95 & 4.9993 & TRN \\
\hline CHEMBL1416888 & 688422 & 4.95 & 5.2892 & TST \\
\hline CHEMBL1307104 & 688422 & 4.8 & 5.1335 & TRN \\
\hline CHEMBL1351781 & 688422 & 4.85 & 5.4134 & TRN \\
\hline CHEMBL1326311 & 688422 & 6.4 & 5.218 & TST \\
\hline CHEMBL1401425 & 688422 & 4.5 & 5.2598 & TRN \\
\hline CHEMBL1538195 & 688422 & 5.7 & 6.0485 & TRN \\
\hline CHEMBL1587508 & 688422 & 6.7001 & 5.4426 & TRN \\
\hline
\end{tabular}




\begin{tabular}{|c|c|c|c|c|}
\hline \multicolumn{5}{|c|}{ Supplemental Table S2.txt } \\
\hline CHEMBL1534035 & 688422 & 5.35 & 5.2892 & TST \\
\hline CHEMBL1446942 & 688422 & 7.5498 & 5.048 & TRN \\
\hline CHEMBL1426911 & 688422 & 4.8 & 5.438 & TST \\
\hline CHEMBL1572875 & 688422 & 5.05 & 5.1784 & TRN \\
\hline CHEMBL148072 & 688422 & 4.5 & 5.7478 & TST \\
\hline CHEMBL 3191258 & 688422 & 5.0 & 5.1678 & TST \\
\hline CHEMBL1341020 & 688422 & 5.2 & 5.2567 & TRN \\
\hline CHEMBL1300765 & 688422 & 5.25 & 5.5136 & TRN \\
\hline CHEMBL1562876 & 688422 & 4.5 & 5.1186 & TRN \\
\hline CHEMBL935 & 688422 & 6.0 & 5.6474 & TRN \\
\hline CHEMBL1474279 & 688422 & 6.5501 & 5.3757 & TST \\
\hline CHEMBL1532219 & 688422 & 5.0 & 5.4683 & TRN \\
\hline CHEMBL1300363 & 688422 & 4.45 & 5.1304 & TRN \\
\hline CHEMBL1342957 & 688422 & 5.25 & 5.1669 & TRN \\
\hline CHEMBL1558434 & 688422 & 4.45 & 5.518 & TRN \\
\hline CHEMBL1376126 & 688422 & 4.9 & 5.104 & TRN \\
\hline CHEMBL1361473 & 688422 & 4.75 & 5.5435 & TST \\
\hline CHEMBL597251 & 688422 & 4.45 & 4.7146 & TRN \\
\hline CHEMBL1527950 & 688422 & 4.95 & 5.4344 & TRN \\
\hline CHEMBL1510317 & 688422 & 5.25 & 5.6291 & TST \\
\hline CHEMBL1531186 & 688422 & 4.9 & 5.0165 & TRN \\
\hline CHEMBL1307942 & 688422 & 4.95 & 4.9939 & TRN \\
\hline CHEMBL1508508 & 688422 & 4.65 & 5.4542 & TRN \\
\hline CHEMBL1604880 & 688422 & 4.95 & 5.229 & TRN \\
\hline CHEMBL1401918 & 688422 & 4.5 & 5.2711 & TRN \\
\hline CHEMBL1608392 & 688422 & 5.35 & 4.9693 & TRN \\
\hline CHEMBL1454150 & 688422 & 4.45 & 5.5572 & TRN \\
\hline CHEMBL1465573 & 688422 & 4.5 & 5.4174 & TST \\
\hline CHEMBL1524921 & 688422 & 6.45 & 4.7671 & TRN \\
\hline CHEMBL1308986 & 688422 & 4.9 & 5.0005 & TST \\
\hline CHEMBL1452074 & 688422 & 4.9 & 5.6003 & TST \\
\hline CHEMBL1988907 & 688422 & 5.3 & 5.1714 & TRN \\
\hline CHEMBL1313264 & 688422 & 4.45 & 5.2143 & TRN \\
\hline CHEMBL1550423 & 688422 & 4.8 & 4.9753 & TST \\
\hline CHEMBL3196483 & 688422 & 5.4 & 5.1201 & TRN \\
\hline CHEMBL1387154 & 688422 & 4.9 & 5.2225 & TRN \\
\hline CHEMBL1564365 & 688422 & 4.9 & 4.9545 & TRN \\
\hline CHEMBL1575060 & 688422 & 5.65 & 5.7382 & TST \\
\hline CHEMBL1455446 & 688422 & 4.75 & 5.0245 & TRN \\
\hline CHEMBL1468397 & 688422 & 5.3 & 4.9727 & TRN \\
\hline CHEMBL1574349 & 688422 & 4.85 & 4.9754 & TRN \\
\hline CHEMBL1398552 & 688422 & 7.5498 & 5.197 & TRN \\
\hline CHEMBL1439893 & 688422 & 4.95 & 4.6486 & TRN \\
\hline CHEMBL1327850 & 688422 & 4.85 & 5.0712 & TST \\
\hline CHEMBL1732228 & 688422 & 4.45 & 4.8938 & TST \\
\hline CHEMBL1307565 & 688422 & 6.25 & 5.6371 & TST \\
\hline CHEMBL1994963 & 688422 & 4.45 & 4.845 & TRN \\
\hline CHEMBL1339991 & 688422 & 4.95 & 5.1608 & TRN \\
\hline
\end{tabular}




\begin{tabular}{|c|c|c|c|c|}
\hline \multicolumn{5}{|c|}{ Supplemental Table S2.txt } \\
\hline CHEMBL1584200 & 688422 & 4.45 & 5.2843 & TRN \\
\hline CHEMBL1335987 & 688422 & 5.0 & 5.3585 & TRN \\
\hline CHEMBL1393267 & 688422 & 4.8 & 5.233 & TRN \\
\hline CHEMBL1326812 & 688422 & 4.9 & 5.3325 & TST \\
\hline CHEMBL1519630 & 688422 & 4.8 & 4.8793 & TRN \\
\hline CHEMBL1505071 & 688422 & 5.1 & 4.9459 & TRN \\
\hline CHEMBL1429469 & 688422 & 6.4 & 5.0792 & TRN \\
\hline CHEMBL1589265 & 688422 & 8.1024 & 5.2164 & TRN \\
\hline CHEMBL1458735 & 688422 & 6.2 & 4.9787 & TRN \\
\hline CHEMBL1557356 & 688422 & 4.85 & 5.2552 & TRN \\
\hline CHEMBL1473957 & 688422 & 5.9 & 5.3078 & TRN \\
\hline CHEMBL1421550 & 688422 & 4.6 & 4.8103 & TRN \\
\hline CHEMBL1477056 & 688422 & 4.45 & 5.3753 & TRN \\
\hline CHEMBL1327227 & 688422 & 4.5 & 5.3197 & TRN \\
\hline CHEMBL1475338 & 688422 & 4.5 & 4.6416 & TRN \\
\hline CHEMBL1585905 & 688422 & 4.8 & 5.3603 & TRN \\
\hline CHEMBL1561115 & 688422 & 4.45 & 4.8099 & TRN \\
\hline CHEMBL1313679 & 688422 & 4.45 & 5.1922 & TRN \\
\hline CHEMBL1568646 & 688422 & 5.15 & 5.1506 & TST \\
\hline CHEMBL1433963 & 688422 & 6.8 & 5.4831 & TRN \\
\hline CHEMBL1611227 & 688422 & 5.05 & 4.997 & TRN \\
\hline CHEMBL3187596 & 688422 & 4.95 & 4.8275 & TRN \\
\hline CHEMBL1374260 & 688422 & 4.6 & 4.9426 & TST \\
\hline CHEMBL1370548 & 688422 & 5.05 & 4.6878 & TRN \\
\hline CHEMBL1235001 & 688422 & 5.3 & 5.1643 & TRN \\
\hline CHEMBL1354363 & 688422 & 5.8 & 5.8671 & TRN \\
\hline CHEMBL1329195 & 688422 & 5.3 & 5.0056 & TRN \\
\hline CHEMBL1318859 & 688422 & 4.45 & 5.1235 & TRN \\
\hline CHEMBL1466609 & 688422 & 5.95 & 5.439 & TRN \\
\hline CHEMBL1474126 & 688422 & 4.95 & 5.1156 & TRN \\
\hline CHEMBL1423698 & 688422 & 4.9 & 4.8395 & TRN \\
\hline CHEMBL1493103 & 688422 & 4.45 & 5.6434 & TST \\
\hline CHEMBL1568250 & 688422 & 4.95 & 5.2115 & TRN \\
\hline CHEMBL1536366 & 688422 & 7.1002 & 5.435 & TRN \\
\hline CHEMBL1492271 & 688422 & 8.2518 & 5.5887 & TST \\
\hline CHEMBL3193642 & 688422 & 6.2 & 5.4809 & TRN \\
\hline CHEMBL1442742 & 688422 & 4.6 & 4.8868 & TRN \\
\hline CHEMBL1560590 & 688422 & 5.55 & 5.2225 & TRN \\
\hline CHEMBL1318998 & 688422 & 4.5 & 4.7558 & TRN \\
\hline CHEMBL1450799 & 688422 & 4.5 & 4.999 & TRN \\
\hline CHEMBL1613713 & 688422 & 4.65 & 5.4305 & TST \\
\hline CHEMBL1342062 & 688422 & 5.5 & 4.8156 & TRN \\
\hline CHEMBL1350098 & 688422 & 8.3468 & 5.178 & TRN \\
\hline CHEMBL1605073 & 688422 & 4.85 & 4.9051 & TRN \\
\hline CHEMBL1550155 & 688422 & 4.6 & 5.2159 & TRN \\
\hline CHEMBL1414483 & 688422 & 4.5 & 4.9924 & TRN \\
\hline CHEMBL1503237 & 688422 & 8.4949 & 5.1661 & TST \\
\hline CHEMBL1357645 & 688422 & 6.15 & 5.6006 & TRN \\
\hline
\end{tabular}




\begin{tabular}{|c|c|c|c|c|c|}
\hline \multicolumn{6}{|c|}{ Supplemental Table s2.txt } \\
\hline CHEMBL1536118 & 688422 & 6.95 & 5.2363 & TRN & \\
\hline CHEMBL1307108 & 688422 & 7.15 & 5.1805 & TST & \\
\hline CHEMBL1314777 & 688422 & 4.75 & 5.1445 & TRN & \\
\hline CHEMBL 3191537 & 688422 & 4.45 & 4.6815 & TRN & \\
\hline CHEMBL1453153 & 688422 & 4.45 & 5.3294 & TRN & \\
\hline CHEMBL1494070 & 688422 & 7.0 & 5.5814 & TRN & \\
\hline CHEMBL1401649 & 688422 & 4.65 & 5.2254 & TRN & \\
\hline CHEMBL1473236 & 688422 & 7.15 & 5.5148 & TST & \\
\hline CHEMBL1560876 & 688422 & 4.45 & 4.9941 & TRN & \\
\hline CHEMBL1589250 & 688422 & 5.1 & 4.9311 & TRN & \\
\hline CHEMBL 2000517 & 688422 & 5.25 & 5.20100 & 00000000005 & TRN \\
\hline CHEMBL1367691 & 688422 & 4.45 & 4.7739 & TRN & \\
\hline CHEMBL1610866 & 688422 & 4.9 & 4.8211 & TRN & \\
\hline CHEMBL1385529 & 688422 & 5.35 & 5.5371 & TRN & \\
\hline CHEMBL1467701 & 688422 & 4.85 & 5.336 & TRN & \\
\hline CHEMBL1432062 & 688422 & 4.9 & 5.0494 & TRN & \\
\hline CHEMBL1309549 & 688422 & 7.8996 & 5.0325 & TRN & \\
\hline CHEMBL3198489 & 688422 & 4.8 & 5.0192 & TRN & \\
\hline CHEMBL1374686 & 688422 & 4.95 & 4.7491 & TRN & \\
\hline CHEMBL1448326 & 688422 & 8.301 & 5.6312 & TST & \\
\hline CHEMBL1565022 & 688422 & 5.15 & 6.0107 & TST & \\
\hline CHEMBL1480001 & 688422 & 4.9 & 5.2288 & TST & \\
\hline CHEMBL1443824 & 688422 & 4.6 & 4.8267 & TRN & \\
\hline CHEMBL1325512 & 688422 & 4.65 & 5.2951 & TRN & \\
\hline CHEMBL1307304 & 688422 & 4.5 & 4.9333 & TRN & \\
\hline CHEMBL411307 & 688422 & 4.65 & 4.8523 & TRN & \\
\hline CHEMBL1501331 & 688422 & 5.3 & 5.5038 & TRN & \\
\hline CHEMBL1505823 & 688422 & 4.45 & 5.2909 & TST & \\
\hline CHEMBL1430575 & 688422 & 8.0506 & 5.1276 & TST & \\
\hline CHEMBL1570631 & 688422 & 4.9 & 5.1309 & TRN & \\
\hline CHEMBL1580203 & 688422 & 7.15 & 5.6261 & TRN & \\
\hline CHEMBL1574484 & 688422 & 5.5 & 5.70200 & 0000000001 & TRN \\
\hline CHEMBL1598803 & 688422 & 4.9 & 5.3388 & TRN & \\
\hline CHEMBL1602904 & 688422 & 4.75 & 4.9722 & TST & \\
\hline CHEMBL1605087 & 688422 & 7.8013 & 5.2358 & TRN & \\
\hline CHEMBL1399696 & 688422 & 6.45 & 5.8054 & TRN & \\
\hline CHEMBL1488610 & 688422 & 4.45 & 5.1771 & TRN & \\
\hline CHEMBL1382595 & 688422 & 4.8 & 5.5456 & TRN & \\
\hline CHEMBL1428552 & 688422 & 4.8 & 5.4622 & TRN & \\
\hline CHEMBL1328029 & 688422 & 4.95 & 5.2189 & TRN & \\
\hline CHEMBL1518543 & 688422 & 4.85 & 5.2793 & TRN & \\
\hline CHEMBL1419455 & 688422 & 4.7 & 5.3179 & TRN & \\
\hline CHEMBL3207449 & 688422 & 4.45 & 5.1791 & TST & \\
\hline CHEMBL1402521 & 688422 & 4.6 & 5.2165 & TRN & \\
\hline CHEMBL1440902 & 688422 & 4.65 & 4.4809 & TRN & \\
\hline CHEMBL1427125 & 688422 & 4.9 & 5.2233 & TST & \\
\hline CHEMBL1301368 & 688422 & 4.5 & 5.1919 & TRN & \\
\hline CHEMBL1483325 & 688422 & 4.5 & 5.4819 & TST & \\
\hline
\end{tabular}




\begin{tabular}{|c|c|c|c|c|}
\hline \multicolumn{5}{|c|}{ Supplemental Table S2.txt } \\
\hline CHEMBL1530285 & 688422 & 5.75 & 5.8566 & TRN \\
\hline CHEMBL1356708 & 688422 & 5.0 & 4.9747 & TRN \\
\hline CHEMBL1361562 & 688422 & 4.65 & 5.4372 & TRN \\
\hline CHEMBL1547977 & 688422 & 6.3 & 5.8379 & TRN \\
\hline CHEMBL3196637 & 688422 & 5.85 & 5.2808 & TRN \\
\hline CHEMBL1316992 & 688422 & 5.7 & 5.2113 & TRN \\
\hline CHEMBL1989904 & 688422 & 5.8 & 5.2751 & TRN \\
\hline CHEMBL1312656 & 688422 & 6.0 & 4.9069 & TRN \\
\hline CHEMBL1446032 & 688422 & 4.5 & 5.5789 & TRN \\
\hline CHEMBL1522566 & 688422 & 4.9 & 4.8156 & TRN \\
\hline CHEMBL1580626 & 688422 & 4.9 & 5.4453 & TRN \\
\hline CHEMBL1453570 & 688422 & 4.7 & 5.0349 & TRN \\
\hline CHEMBL1383826 & 688422 & 4.95 & 5.0372 & TRN \\
\hline CHEMBL1570003 & 688422 & 4.9 & 5.1734 & TRN \\
\hline CHEMBL1586551 & 688422 & 4.45 & 5.4748 & TRN \\
\hline CHEMBL1377048 & 688422 & 4.45 & 5.3401 & TST \\
\hline CHEMBL1480458 & 688422 & 5.2 & 5.4783 & TRN \\
\hline CHEMBL1392514 & 688422 & 6.8499 & 5.7782 & TST \\
\hline CHEMBL1482697 & 688422 & 4.45 & 5.744 & TRN \\
\hline CHEMBL1431672 & 688422 & 8.0 & 4.8888 & TST \\
\hline CHEMBL1444202 & 688422 & 4.85 & 4.877 & TRN \\
\hline CHEMBL1462785 & 688422 & 4.85 & 5.3505 & TRN \\
\hline CHEMBL1403577 & 688422 & 5.55 & 5.1905 & TST \\
\hline CHEMBL1594348 & 688422 & 4.65 & 5.6072 & TST \\
\hline CHEMBL1331828 & 688422 & 5.35 & 5.6249 & TRN \\
\hline CHEMBL1425076 & 688422 & 4.9 & 4.9508 & TRN \\
\hline CHEMBL3194333 & 688422 & 4.75 & 5.3961 & TRN \\
\hline CHEMBL1379052 & 688422 & 4.45 & 5.8824 & TST \\
\hline CHEMBL453066 & 688422 & 9.0 & 5.3966 & TST \\
\hline CHEMBL1489324 & 688422 & 4.9 & 5.7588 & TST \\
\hline CHEMBL1350596 & 688422 & 4.5 & 4.7335 & TRN \\
\hline CHEMBL1379553 & 688422 & 5.45 & 5.1791 & TRN \\
\hline CHEMBL1352967 & 688422 & 5.05 & 5.0747 & TRN \\
\hline CHEMBL1409082 & 688422 & 4.9 & 5.0473 & TST \\
\hline CHEMBL1427814 & 688422 & 4.75 & 5.4821 & TRN \\
\hline CHEMBL1342983 & 688422 & 4.6 & 4.9358 & TRN \\
\hline CHEMBL1482256 & 688422 & 6.8 & 5.0363 & TRN \\
\hline CHEMBL1596806 & 688422 & 8.4559 & 5.2527 & TRN \\
\hline CHEMBL286346 & 688422 & 5.1 & 5.5781 & TST \\
\hline CHEMBL1436711 & 688422 & 8.0 & 5.4563 & TRN \\
\hline CHEMBL1451002 & 688422 & 5.1 & 5.3143 & TRN \\
\hline CHEMBL1529220 & 688422 & 4.55 & 5.0305 & TRN \\
\hline CHEMBL1563025 & 688422 & 7.5003 & 5.5184 & TRN \\
\hline CHEMBL1604480 & 688422 & 4.9 & 5.3651 & TRN \\
\hline CHEMBL1608317 & 688422 & 6.1 & 4.7473 & TRN \\
\hline CHEMBL1505922 & 688422 & 5.6 & 5.0584 & TRN \\
\hline CHEMBL1384345 & 688422 & 4.95 & 5.5878 & TRN \\
\hline CHEMBL1410522 & 688422 & 6.95 & 5.3811 & TRN \\
\hline
\end{tabular}




\begin{tabular}{|c|c|c|c|c|}
\hline \multicolumn{5}{|c|}{ Supplemental Table S2.txt } \\
\hline CHEMBL1489793 & 688422 & 4.9 & 5.1455 & TRN \\
\hline CHEMBL1599558 & 688422 & 4.8 & 4.9936 & TRN \\
\hline CHEMBL1519870 & 688422 & 4.6 & 4.9856 & TRN \\
\hline CHEMBL1986678 & 688422 & 4.85 & 4.9261 & TRN \\
\hline CHEMBL1549801 & 688422 & 6.45 & 5.5657 & TST \\
\hline CHEMBL1415385 & 688422 & 4.55 & 4.9591 & TRN \\
\hline CHEMBL1326215 & 688422 & 4.95 & 5.0544 & TST \\
\hline CHEMBL 1406427 & 688422 & 5.25 & 5.4076 & TST \\
\hline CHEMBL1545734 & 688422 & 5.5 & 5.1375 & TRN \\
\hline CHEMBL1530200 & 688422 & 4.45 & 5.642 & TST \\
\hline CHEMBL1607549 & 688422 & 4.95 & 4.9661 & TRN \\
\hline CHEMBL1525103 & 688422 & 4.7 & 5.3892 & TST \\
\hline CHEMBL1392384 & 688422 & 8.301 & 5.1243 & TRN \\
\hline CHEMBL1300397 & 688422 & 5.35 & 4.6925 & TRN \\
\hline CHEMBL1509711 & 688422 & 5.2 & 5.0364 & TRN \\
\hline CHEMBL1358427 & 688422 & 4.35 & 5.1429 & TRN \\
\hline CHEMBL1367282 & 688422 & 4.8 & 5.5129 & TRN \\
\hline CHEMBL1421336 & 688422 & 5.0 & 5.5068 & TRN \\
\hline CHEMBL1500341 & 688422 & 4.9 & 5.2577 & TST \\
\hline CHEMBL1549165 & 688422 & 4.55 & 4.9851 & TRN \\
\hline CHEMBL1471461 & 688422 & 4.9 & 5.6935 & TRN \\
\hline CHEMBL1573257 & 688422 & 7.0501 & 5.7887 & TST \\
\hline CHEMBL1581410 & 688422 & 4.85 & 5.375 & TRN \\
\hline CHEMBL1385251 & 688422 & 4.7 & 4.9493 & TRN \\
\hline CHEMBL1576773 & 688422 & 5.0 & 5.2158 & TRN \\
\hline CHEMBL1305220 & 688422 & 4.45 & 4.81 & TST \\
\hline CHEMBL1604895 & 688422 & 6.4 & 5.1773 & TRN \\
\hline CHEMBL1515749 & 688422 & 4.6 & 5.2748 & TST \\
\hline CHEMBL1300763 & 688422 & 4.45 & 5.2366 & TRN \\
\hline CHEMBL1452943 & 688422 & 5.35 & 5.0665 & TST \\
\hline CHEMBL1467936 & 688422 & 5.9 & 4.7659 & TST \\
\hline CHEMBL3193490 & 688422 & 5.95 & 5.3865 & TRN \\
\hline CHEMBL64391 & 688422 & 5.35 & 5.393 & TST \\
\hline CHEMBL1468130 & 688422 & 4.65 & 5.2411 & TST \\
\hline CHEMBL 3213422 & 688422 & 4.5 & 4.7515 & TRN \\
\hline CHEMBL1451820 & 688422 & 7.6498 & 5.0827 & TRN \\
\hline CHEMBL1348847 & 688422 & 4.5 & 5.1201 & TST \\
\hline CHEMBL1499016 & 688422 & 4.95 & 5.3564 & TRN \\
\hline CHEMBL494083 & 688422 & 4.85 & 4.856 & TRN \\
\hline CHEMBL1340050 & 688422 & 5.0 & 5.58700 & 0000000001 \\
\hline CHEMBL1589300 & 688422 & 6.3 & 5.0866 & TST \\
\hline CHEMBL1544922 & 688422 & 4.45 & 5.0629 & TRN \\
\hline CHEMBL1424900 & 688422 & 4.95 & 5.3566 & TST \\
\hline CHEMBL1445361 & 688422 & 4.9 & 5.1098 & TST \\
\hline CHEMBL1408599 & 688422 & 8.0 & 5.5966 & TRN \\
\hline CHEMBL1481525 & 688422 & 4.45 & 4.7145 & TST \\
\hline CHEMBL1555296 & 688422 & 4.75 & 5.043 & TST \\
\hline CHEMBL1583749 & 688422 & 7.7496 & 5.5082 & TRN \\
\hline
\end{tabular}




\begin{tabular}{|c|c|c|c|c|c|}
\hline & & \multicolumn{4}{|c|}{ Supplemental Table s2.txt } \\
\hline CHEMBL1558367 & 688422 & 6.25 & 5.4113 & TST & \\
\hline CHEMBL1343541 & 688422 & 5.7 & 5.164 & TST & \\
\hline CHEMBL1366537 & 688422 & 4.85 & 5.2821 & TRN & \\
\hline CHEMBL1460105 & 688422 & 4.45 & 5.1514 & TRN & \\
\hline CHEMBL1329301 & 688422 & 4.45 & 5.0991 & TRN & \\
\hline CHEMBL1375740 & 688422 & 4.45 & 5.9451 & TRN & \\
\hline CHEMBL1320102 & 688422 & 4.5 & 4.6375 & TRN & \\
\hline CHEMBL1596856 & 688422 & 7.0 & 5.4551 & TRN & \\
\hline CHEMBL1463211 & 688422 & 5.1 & 4.8626 & TRN & \\
\hline CHEMBL1300344 & 688422 & 5.35 & 5.2324 & TST & \\
\hline CHEMBL1303876 & 688422 & 5.1 & 4.729 & TRN & \\
\hline CHEMBL3207916 & 688422 & 5.8 & 5.5574 & TRN & \\
\hline CHEMBL1405786 & 688422 & 7.5498 & 5.58899 & 99999999995 & TRN \\
\hline CHEMBL1341978 & 688422 & 4.65 & 5.0966 & TRN & \\
\hline CHEMBL3196291 & 688422 & 5.6 & 5.0179 & TST & \\
\hline CHEMBL1586046 & 688422 & 6.1 & 5.0623 & TRN & \\
\hline CHEMBL1351837 & 688422 & 4.6 & 5.3779 & TRN & \\
\hline CHEMBL3194782 & 688422 & 4.45 & 4.7856 & TRN & \\
\hline CHEMBL1353463 & 688422 & 6.4 & 5.4037 & TRN & \\
\hline CHEMBL1333660 & 688422 & 4.8 & 4.8946 & TST & \\
\hline CHEMBL461 & 688422 & 6.5 & 6.0835 & TRN & \\
\hline CHEMBL1309219 & 688422 & 4.75 & 4.9746 & TRN & \\
\hline CHEMBL1473246 & 688422 & 4.6 & 5.3179 & TRN & \\
\hline CHEMBL1343832 & 688422 & 7.8508 & 5.7411 & TST & \\
\hline CHEMBL1509691 & 688422 & 4.45 & 5.402 & TRN & \\
\hline CHEMBL1359883 & 688422 & 4.5 & 5.6815 & TST & \\
\hline CHEMBL1518202 & 688422 & 4.75 & 5.308 & TRN & \\
\hline CHEMBL1536407 & 688422 & 4.9 & 5.1707 & TRN & \\
\hline CHEMBL1496878 & 688422 & 4.55 & 5.5223 & TST & \\
\hline CHEMBL1402920 & 688422 & 4.65 & 4.9027 & TRN & \\
\hline CHEMBL1540926 & 688422 & 4.45 & 4.9511 & TRN & \\
\hline CHEMBL1555606 & 688422 & 5.6 & 5.3657 & TST & \\
\hline CHEMBL1358292 & 688422 & 8.6021 & 5.3375 & TST & \\
\hline CHEMBL1482449 & 688422 & 4.9 & 5.2885 & TST & \\
\hline CHEMBL1419245 & 688422 & 5.55 & 5.419 & TST & \\
\hline CHEMBL1460574 & 688422 & 4.5 & 5.1195 & TRN & \\
\hline CHEMBL1322637 & 688422 & 4.8 & 5.0112 & TRN & \\
\hline CHEMBL1305144 & 688422 & 7.699 & 5.6334 & TST & \\
\hline CHEMBL1427435 & 688422 & 4.7 & 5.6254 & TRN & \\
\hline CHEMBL1331364 & 688422 & 5.0 & 5.2741 & TRN & \\
\hline CHEMBL1466460 & 688422 & 4.55 & 4.8344 & TRN & \\
\hline CHEMBL1310523 & 688422 & 4.45 & 4.7281 & TRN & \\
\hline CHEMBL1357920 & 688422 & 5.45 & 5.3083 & TRN & \\
\hline CHEMBL1598527 & 688422 & 6.4 & 5.5044 & TRN & \\
\hline CHEMBL1361930 & 688422 & 7.4001 & 5.0191 & TST & \\
\hline CHEMBL1519612 & 688422 & 4.9 & 5.9289 & TST & \\
\hline CHEMBL1323670 & 688422 & 4.45 & 5.4438 & TRN & \\
\hline CHEMBL1578419 & 688422 & 5.25 & 5.7628 & TRN & \\
\hline
\end{tabular}





\begin{tabular}{|c|c|c|c|c|}
\hline \multicolumn{5}{|c|}{ Supplemental Table S2.txt } \\
\hline CHEMBL1309756 & 688422 & 4.7 & 4.9036 & TST \\
\hline CHEMBL1608868 & 688422 & 5.4 & 4.8011 & TRN \\
\hline CHEMBL1558083 & 688422 & 4.8 & 4.9957 & TRN \\
\hline CHEMBL1350868 & 688422 & 4.55 & 4.8988 & TRN \\
\hline CHEMBL1402442 & 688422 & 4.95 & 4.7448 & TRN \\
\hline CHEMBL1569408 & 688422 & 5.0 & 5.7261 & TST \\
\hline CHEMBL 2373640 & 688422 & 5.75 & 5.9153 & TRN \\
\hline CHEMBL1484942 & 688422 & 4.5 & 5.2093 & TST \\
\hline CHEMBL1463683 & 688422 & 4.45 & 5.0456 & TRN \\
\hline CHEMBL1506830 & 688422 & 4.8 & 5.2026 & TST \\
\hline CHEMBL1412878 & 688422 & 4.45 & 5.0076 & TRN \\
\hline CHEMBL1609300 & 688422 & 5.0 & 5.0348 & TRN \\
\hline CHEMBL1363107 & 688422 & 4.65 & 5.2283 & TRN \\
\hline CHEMBL1367902 & 688422 & 7.15 & 5.4699 & TST \\
\hline CHEMBL1412818 & 688422 & 4.85 & 4.9826 & TRN \\
\hline CHEMBL1594911 & 688422 & 7.9508 & 5.0011 & TRN \\
\hline CHEMBL1447884 & 688422 & 4.45 & 5.1466 & TST \\
\hline CHEMBL1575872 & 688422 & 5.0 & 5.5013 & TST \\
\hline CHEMBL1356286 & 688422 & 5.6 & 5.4302 & TRN \\
\hline CHEMBL146525 & 688422 & 4.95 & 5.2855 & TST \\
\hline CHEMBL588749 & 688422 & 4.9 & 5.3131 & TRN \\
\hline CHEMBL1441813 & 688422 & 5.2 & 5.1799 & TRN \\
\hline CHEMBL1443449 & 688422 & 4.45 & 4.9732 & TST \\
\hline CHEMBL1326758 & 688422 & 4.85 & 4.9286 & TRN \\
\hline CHEMBL1381576 & 688422 & 4.5 & 4.7904 & TRN \\
\hline CHEMBL1557885 & 688422 & 4.8 & 5.0848 & TRN \\
\hline CHEMBL1582259 & 688422 & 4.75 & 5.2798 & TST \\
\hline CHEMBL1548173 & 688422 & 4.55 & 5.4528 & TST \\
\hline CHEMBL1349715 & 688422 & 6.05 & 5.4095 & TRN \\
\hline CHEMBL1580588 & 688422 & 4.75 & 5.1497 & TRN \\
\hline CHEMBL1537106 & 688422 & 4.9 & 5.2109 & TRN \\
\hline CHEMBL1372292 & 688422 & 6.4 & 5.675 & TRN \\
\hline CHEMBL1447028 & 688422 & 5.0 & 5.2768 & TRN \\
\hline CHEMBL1513343 & 688422 & 9.1549 & 5.4553 & TST \\
\hline CHEMBL1338674 & 688422 & 4.45 & 4.9551 & TRN \\
\hline CHEMBL1481666 & 688422 & 7.0501 & 5.5407 & TRN \\
\hline CHEMBL1498844 & 688422 & 5.2 & 5.0714 & TST \\
\hline CHEMBL3198751 & 688422 & 5.05 & 5.4112 & TRN \\
\hline CHEMBL1567908 & 688422 & 7.6498 & 5.5292 & TRN \\
\hline CHEMBL1356858 & 688422 & 5.85 & 5.1258 & TRN \\
\hline CHEMBL1540682 & 688422 & 5.15 & 5.2215 & TRN \\
\hline CHEMBL3190474 & 688422 & 8.4949 & 5.0655 & TRN \\
\hline CHEMBL1501091 & 688422 & 5.4 & 4.9599 & TRN \\
\hline CHEMBL3209868 & 688422 & 4.5 & 5.2845 & TRN \\
\hline CHEMBL1500327 & 688422 & 4.45 & 4.8481 & TRN \\
\hline CHEMBL1565585 & 688422 & 4.75 & 5.629 & TST \\
\hline CHEMBL3195636 & 688422 & 5.15 & 5.0776 & TRN \\
\hline CHEMBL1404221 & 688422 & 4.4 & 5.2987 & TRN \\
\hline
\end{tabular}




\begin{tabular}{|c|c|c|c|c|c|}
\hline \multicolumn{6}{|c|}{ Supplemental Table S2.txt } \\
\hline CHEMBL1598101 & 688422 & 4.75 & 4.9488 & TRN & \\
\hline CHEMBL1350178 & 688422 & 4.9 & 4.9377 & TRN & \\
\hline CHEMBL1351713 & 688422 & 4.8 & 5.013 & TRN & \\
\hline CHEMBL1507428 & 688422 & 4.45 & 5.2543 & TST & \\
\hline CHEMBL1584024 & 688422 & 4.5 & 5.2743 & TRN & \\
\hline CHEMBL1455508 & 688422 & 4.45 & 4.9371 & TRN & \\
\hline CHEMBL1539220 & 688422 & 4.5 & 5.24799 & 9999999999 & TRN \\
\hline CHEMBL1341317 & 688422 & 4.8 & 5.0459 & TRN & \\
\hline CHEMBL1382484 & 688422 & 5.7 & 6.0622 & TST & \\
\hline CHEMBL1505158 & 688422 & 4.75 & 5.033 & TRN & \\
\hline CHEMBL1410068 & 688422 & 4.55 & 5.1867 & TST & \\
\hline CHEMBL1418611 & 688422 & 6.0 & 4.9919 & TRN & \\
\hline CHEMBL1419508 & 688422 & 4.75 & 4.962 & TST & \\
\hline CHEMBL1563355 & 688422 & 5.25 & 5.0924 & TRN & \\
\hline CHEMBL1430886 & 688422 & 4.65 & 4.8945 & TRN & \\
\hline CHEMBL1428211 & 688422 & 4.45 & 5.2413 & TRN & \\
\hline CHEMBL1539092 & 688422 & 4.45 & 5.0912 & TRN & \\
\hline CHEMBL1372514 & 688422 & 6.45 & 5.1777 & TRN & \\
\hline CHEMBL1437299 & 688422 & 8.301 & 5.3944 & TRN & \\
\hline CHEMBL1357939 & 688422 & 5.65 & 4.853 & TRN & \\
\hline CHEMBL1452847 & 688422 & 4.65 & 4.905 & TRN & \\
\hline CHEMBL1442271 & 688422 & 4.85 & 5.2828 & TST & \\
\hline CHEMBL3196320 & 688422 & 5.35 & 5.71899 & 7999999999 & TST \\
\hline CHEMBL1538246 & 688422 & 5.55 & 5.1531 & TRN & \\
\hline CHEMBL1384715 & 688422 & 4.85 & 4.7996 & TRN & \\
\hline CHEMBL1563664 & 688422 & 6.3 & 5.2297 & TST & \\
\hline CHEMBL1407830 & 688422 & 5.7 & 5.4716 & TRN & \\
\hline CHEMBL3196678 & 688422 & 5.1 & 5.0356 & TST & \\
\hline CHEMBL1305974 & 688422 & 4.75 & 5.1393 & TRN & \\
\hline CHEMBL1429269 & 688422 & 4.8 & 5.3538 & TRN & \\
\hline CHEMBL1467533 & 688422 & 5.9 & 5.2293 & TRN & \\
\hline CHEMBL3199368 & 688422 & 4.85 & 4.9784 & TST & \\
\hline CHEMBL1353865 & 688422 & 5.6 & 5.0233 & TRN & \\
\hline CHEMBL1347179 & 688422 & 4.8 & 5.2654 & TST & \\
\hline CHEMBL1498877 & 688422 & 4.95 & 4.6874 & TST & \\
\hline CHEMBL1549780 & 688422 & 4.75 & 5.3002 & TRN & \\
\hline CHEMBL1603384 & 688422 & 4.45 & 5.5042 & TRN & \\
\hline CHEMBL1603146 & 688422 & 6.9 & 5.1597 & TST & \\
\hline CHEMBL1604734 & 688422 & 4.45 & 5.1042 & TRN & \\
\hline CHEMBL1544094 & 688422 & 5.2 & 5.0971 & TRN & \\
\hline CHEMBL3209013 & 688422 & 4.7 & 5.2129 & TST & \\
\hline CHEMBL1586460 & 688422 & 4.75 & 4.8244 & TRN & \\
\hline CHEMBL1415517 & 688422 & 6.15 & 5.2178 & TRN & \\
\hline CHEMBL1403318 & 688422 & 6.9 & 5.3738 & TRN & \\
\hline CHEMBL1492280 & 688422 & 5.2 & 5.0313 & TRN & \\
\hline CHEMBL1405573 & 688422 & 4.8 & 5.1875 & TRN & \\
\hline CHEMBL1339336 & 688422 & 4.45 & 5.4639 & TST & \\
\hline CHEMBL1529827 & 688422 & 4.85 & 4.7622 & TRN & \\
\hline
\end{tabular}




\begin{tabular}{|c|c|c|c|c|c|}
\hline \multicolumn{6}{|c|}{ Supplemental Table S2.txt } \\
\hline CHEMBL1384213 & 688422 & 4.8 & 4.9896 & TRN & \\
\hline CHEMBL1345225 & 688422 & 4.85 & 5.3948 & TRN & \\
\hline CHEMBL1402045 & 688422 & 4.5 & 5.2273 & TRN & \\
\hline CHEMBL1320842 & 688422 & 4.95 & 5.0389 & TRN & \\
\hline CHEMBL523200 & 688422 & 4.45 & 4.9573 & TRN & \\
\hline CHEMBL1416398 & 688422 & 4.6 & 5.2762 & TRN & \\
\hline CHEMBL1573351 & 688422 & 5.95 & 5.2129 & TRN & \\
\hline CHEMBL1604813 & 688422 & 4.65 & 5.1717 & TRN & \\
\hline CHEMBL1405934 & 688422 & 4.6 & 5.0746 & TRN & \\
\hline CHEMBL1438126 & 688422 & 6.15 & 5.6138 & TST & \\
\hline CHEMBL 3193170 & 688422 & 4.75 & 4.9535 & TRN & \\
\hline CHEMBL1599863 & 688422 & 6.05 & 5.1621 & TST & \\
\hline CHEMBL1342173 & 688422 & 5.15 & 5.1107 & TRN & \\
\hline CHEMBL1567031 & 688422 & 6.25 & 5.88899 & 9999999999 & TST \\
\hline CHEMBL1463214 & 688422 & 4.85 & 5.1571 & TRN & \\
\hline CHEMBL1300073 & 688422 & 7.6003 & 5.5169 & TST & \\
\hline CHEMBL1504433 & 688422 & 5.35 & 5.5987 & TRN & \\
\hline CHEMBL1529845 & 688422 & 4.85 & 5.1202 & TRN & \\
\hline CHEMBL1459981 & 688422 & 4.9 & 5.2937 & TRN & \\
\hline CHEMBL1537104 & 688422 & 4.95 & 5.3422 & TST & \\
\hline CHEMBL407874 & 688422 & 4.7 & 5.6828 & TST & \\
\hline CHEMBL1486967 & 688422 & 4.8 & 5.2839 & TST & \\
\hline CHEMBL1338660 & 688422 & 4.8 & 4.9505 & TRN & \\
\hline CHEMBL1511409 & 688422 & 4.75 & 5.1691 & TRN & \\
\hline CHEMBL1477555 & 688422 & 4.85 & 5.2989 & TRN & \\
\hline CHEMBL1518916 & 688422 & 5.9 & 5.352 & TRN & \\
\hline CHEMBL1469476 & 688422 & 4.45 & 5.2059 & TRN & \\
\hline CHEMBL1306671 & 688422 & 4.45 & 5.2821 & TRN & \\
\hline CHEMBL 21241 & 688422 & 4.65 & 4.9183 & TST & \\
\hline CHEMBL3211817 & 688422 & 4.5 & 5.4488 & TRN & \\
\hline CHEMBL1988969 & 688422 & 6.1 & 5.4977 & TST & \\
\hline CHEMBL1523563 & 688422 & 4.6 & 4.7301 & TRN & \\
\hline CHEMBL1577428 & 688422 & 4.9 & 5.3172 & TST & \\
\hline CHEMBL1322918 & 688422 & 4.5 & 5.066 & TRN & \\
\hline CHEMBL1427272 & 688422 & 5.0 & 4.8715 & TST & \\
\hline CHEMBL1544818 & 688422 & 4.45 & 5.2917 & TRN & \\
\hline CHEMBL1302137 & 688422 & 5.85 & 4.9575 & TST & \\
\hline CHEMBL1497928 & 688422 & 6.2 & 5.2883 & TRN & \\
\hline CHEMBL1603707 & 688422 & 4.95 & 5.3159 & TRN & \\
\hline CHEMBL1372668 & 688422 & 4.45 & 4.8944 & TST & \\
\hline CHEMBL1389982 & 688422 & 4.85 & 4.7726 & TRN & \\
\hline CHEMBL1384103 & 688422 & 4.45 & 4.7974 & TRN & \\
\hline CHEMBL1507034 & 688422 & 4.85 & 5.2382 & TRN & \\
\hline CHEMBL1404000 & 688422 & 5.55 & 6.1636 & TST & \\
\hline CHEMBL1535008 & 688422 & 7.3002 & 5.4963 & TRN & \\
\hline CHEMBL1557780 & 688422 & 4.6 & 5.5201 & TST & \\
\hline CHEMBL448060 & 688422 & 4.5 & 5.53 & TRN & \\
\hline CHEMBL1453469 & 688422 & 5.5 & 5.1317 & TRN & \\
\hline
\end{tabular}




\begin{tabular}{|c|c|c|c|c|c|}
\hline \multicolumn{6}{|c|}{ Supplemental Table S2.txt } \\
\hline CHEMBL1427162 & 688422 & 4.7 & 5.0061 & TRN & \\
\hline CHEMBL 3198212 & 688422 & 4.45 & 5.3623 & TRN & \\
\hline CHEMBL1447053 & 688422 & 7.0 & 5.4281 & TRN & \\
\hline CHEMBL1583708 & 688422 & 4.65 & 5.0573 & TRN & \\
\hline CHEMBL3211567 & 688422 & 4.8 & 5.0867 & TST & \\
\hline CHEMBL1558540 & 688422 & 8.4949 & 5.1945 & TRN & \\
\hline CHEMBL1472133 & 688422 & 4.7 & 4.9685 & TST & \\
\hline CHEMBL1486682 & 688422 & 4.95 & 5.3134 & TRN & \\
\hline CHEMBL 88034 & 688422 & 9.0458 & 6.0849 & TST & \\
\hline CHEMBL3213197 & 688422 & 4.9 & 5.075 & TST & \\
\hline CHEMBL1389380 & 688422 & 4.85 & 4.9435 & TRN & \\
\hline CHEMBL1450239 & 688422 & 4.9 & 5.5352 & TRN & \\
\hline CHEMBL1524500 & 688422 & 5.5 & 5.1312 & TRN & \\
\hline CHEMBL1453865 & 688422 & 4.5 & 5.5385 & TST & \\
\hline CHEMBL1530970 & 688422 & 6.7501 & 5.9891 & TRN & \\
\hline CHEMBL1428565 & 688422 & 4.65 & 5.3342 & TST & \\
\hline CHEMBL1522377 & 688422 & 4.8 & 5.2383 & TRN & \\
\hline CHEMBL1501402 & 688422 & 4.85 & 5.4735 & TST & \\
\hline CHEMBL1471370 & 688422 & 6.5 & 5.397 & TRN & \\
\hline CHEMBL 3214424 & 688422 & 4.85 & 5.6783 & TRN & \\
\hline CHEMBL1578269 & 688422 & 4.95 & 4.8122 & TRN & \\
\hline CHEMBL1417587 & 688422 & 4.45 & 5.7379 & TST & \\
\hline CHEMBL1571568 & 688422 & 4.45 & 5.1881 & TRN & \\
\hline CHEMBL1415076 & 688422 & 4.45 & 5.1446 & TRN & \\
\hline CHEMBL1321469 & 688422 & 4.65 & 5.2569 & TRN & \\
\hline CHEMBL1450781 & 688422 & 4.45 & 5.4766 & TRN & \\
\hline CHEMBL1479269 & 688422 & 4.6 & 4.98600 & 0000000001 & TRN \\
\hline CHEMBL1604033 & 688422 & 5.5 & 5.6007 & TRN & \\
\hline CHEMBL1470975 & 688422 & 4.45 & 5.4545 & TRN & \\
\hline CHEMBL1573942 & 688422 & 4.45 & 4.976 & TRN & \\
\hline CHEMBL1416266 & 688422 & 4.75 & 5.113 & TRN & \\
\hline CHEMBL1434528 & 688422 & 5.55 & 5.1754 & TRN & \\
\hline CHEMBL1433771 & 688422 & 7.0 & 5.19799 & 99999999995 & TST \\
\hline CHEMBL1305911 & 688422 & 4.85 & 5.0338 & TRN & \\
\hline CHEMBL1480485 & 688422 & 6.9 & 5.2404 & TRN & \\
\hline CHEMBL1374166 & 688422 & 5.3 & 5.1668 & TRN & \\
\hline CHEMBL1388625 & 688422 & 4.9 & 5.12799 & 9999999999 & TRN \\
\hline CHEMBL1577714 & 688422 & 4.95 & 4.7962 & TRN & \\
\hline CHEMBL1552571 & 688422 & 4.9 & 5.7854 & TRN & \\
\hline CHEMBL1489471 & 688422 & 4.8 & 5.1798 & TRN & \\
\hline CHEMBL1569782 & 688422 & 4.65 & 4.8021 & TRN & \\
\hline CHEMBL1590837 & 688422 & 4.45 & 5.0101 & TRN & \\
\hline CHEMBL1531695 & 688422 & 4.85 & 5.0587 & TRN & \\
\hline CHEMBL1482510 & 688422 & 4.45 & 4.9952 & TRN & \\
\hline CHEMBL1522995 & 688422 & 5.1 & 5.2302 & TRN & \\
\hline CHEMBL1537452 & 688422 & 5.9 & 5.2483 & TRN & \\
\hline CHEMBL1255646 & 688422 & 7.2503 & 5.3851 & TST & \\
\hline CHEMBL1424929 & 688422 & 7.8013 & 4.9052 & TST & \\
\hline
\end{tabular}




\begin{tabular}{|c|c|c|c|c|}
\hline \multicolumn{5}{|c|}{ Supplemental Table s2.txt } \\
\hline CHEMBL1500359 & 688422 & 5.55 & 5.1568 & TRN \\
\hline CHEMBL1518405 & 688422 & 4.9 & 5.3387 & TRN \\
\hline CHEMBL1350429 & 688422 & 4.8 & 5.0914 & TRN \\
\hline CHEMBL3190794 & 688422 & 5.6 & 5.0481 & TRN \\
\hline CHEMBL1540664 & 688422 & 4.7 & 5.2116 & TST \\
\hline CHEMBL609027 & 688422 & 5.45 & 5.4618 & TST \\
\hline CHEMBL1461517 & 688422 & 8.1487 & 5.7109 & TRN \\
\hline CHEMBL1299940 & 688422 & 5.15 & 5.0011 & TRN \\
\hline CHEMBL1403306 & 688422 & 4.9 & 5.0946 & TRN \\
\hline CHEMBL1608983 & 688422 & 4.9 & 5.0979 & TST \\
\hline CHEMBL1504547 & 688422 & 4.85 & 5.2509 & TRN \\
\hline CHEMBL1385078 & 688422 & 5.4 & 4.9419 & TRN \\
\hline CHEMBL1383602 & 688422 & 4.8 & 5.1917 & TRN \\
\hline CHEMBL1492208 & 688422 & 5.85 & 4.9633 & TRN \\
\hline CHEMBL1352064 & 688422 & 4.8 & 5.3388 & TRN \\
\hline CHEMBL1340519 & 688422 & 4.95 & 5.0273 & TRN \\
\hline CHEMBL1461366 & 688422 & 8.0 & 5.2521 & TRN \\
\hline CHEMBL1325161 & 688422 & 4.75 & 4.9492 & TRN \\
\hline CHEMBL1362560 & 688422 & 4.7 & 5.0538 & TRN \\
\hline CHEMBL1594782 & 688422 & 5.25 & 5.2017 & TRN \\
\hline CHEMBL1543918 & 688422 & 4.5 & 5.4724 & TRN \\
\hline CHEMBL1577978 & 688422 & 6.5501 & 5.2756 & TRN \\
\hline CHEMBL1343828 & 688422 & 5.4 & 5.2614 & TRN \\
\hline CHEMBL358546 & 688422 & 4.6 & 5.0965 & TRN \\
\hline CHEMBL1376792 & 688422 & 4.9 & 5.0217 & TRN \\
\hline CHEMBL1445491 & 688422 & 4.45 & 5.1772 & TRN \\
\hline CHEMBL1376445 & 688422 & 4.9 & 5.3364 & TST \\
\hline CHEMBL1456771 & 688422 & 4.45 & 4.8431 & TRN \\
\hline CHEMBL1457679 & 688422 & 4.45 & 5.4748 & TRN \\
\hline CHEMBL1306004 & 688422 & 5.0 & 4.6355 & TRN \\
\hline CHEMBL1380386 & 688422 & 4.45 & 4.8723 & TRN \\
\hline CHEMBL1289144 & 688422 & 4.65 & 5.3844 & TRN \\
\hline CHEMBL1521960 & 688422 & 5.6 & 5.2062 & TRN \\
\hline CHEMBL521653 & 688422 & 4.45 & 4.9888 & TRN \\
\hline CHEMBL1452449 & 688422 & 5.5 & 5.2736 & TRN \\
\hline CHEMBL1341803 & 688422 & 4.9 & 5.2859 & TST \\
\hline CHEMBL3211060 & 688422 & 5.7 & 4.9187 & TRN \\
\hline CHEMBL1547352 & 688422 & 4.45 & 5.3323 & TRN \\
\hline CHEMBL1394193 & 688422 & 4.5 & 5.4493 & TRN \\
\hline CHEMBL1388109 & 688422 & 6.05 & 5.2054 & TRN \\
\hline CHEMBL1600468 & 688422 & 4.5 & 4.8892 & TRN \\
\hline CHEMBL1380408 & 688422 & 5.35 & 5.6766 & TRN \\
\hline CHEMBL1399289 & 688422 & 4.45 & 5.0538 & TRN \\
\hline CHEMBL1534806 & 688422 & 7.5003 & 5.2715 & TST \\
\hline CHEMBL438352 & 688422 & 8.4559 & 5.5282 & TST \\
\hline CHEMBL 3192557 & 688422 & 4.45 & 5.0203 & TRN \\
\hline CHEMBL1568246 & 688422 & 4.8 & 5.17899 & 9999999999 \\
\hline CHEMBL1406511 & 688422 & 4.6 & 5.1318 & TRN \\
\hline
\end{tabular}

TRN 


\begin{tabular}{|c|c|c|c|c|}
\hline \multicolumn{5}{|c|}{ Supplemental Table } \\
\hline CHEMBL1602762 & 688422 & 8.3468 & 5.6453 & TRN \\
\hline CHEMBL 2369184 & 688422 & 5.25 & 4.9183 & TST \\
\hline CHEMBL1402665 & 688422 & 4.85 & 5.0388 & TRN \\
\hline CHEMBL1515221 & 688422 & 4.45 & 4.8845 & TRN \\
\hline CHEMBL1400514 & 688422 & 4.85 & 5.0178 & TST \\
\hline CHEMBL1383805 & 688422 & 4.9 & 5.3914 & TRN \\
\hline CHEMBL1313267 & 688422 & 4.75 & 4.9625 & TRN \\
\hline CHEMBL3192785 & 688422 & 4.75 & 5.4353 & TST \\
\hline CHEMBL1396813 & 688422 & 5.6 & 5.0849 & TRN \\
\hline CHEMBL1347838 & 688422 & 7.0501 & 5.3707 & TRN \\
\hline CHEMBL1374399 & 688422 & 4.45 & 4.9142 & TRN \\
\hline CHEMBL1320207 & 688422 & 5.15 & 5.5232 & TRN \\
\hline CHEMBL1438487 & 688422 & 4.7 & 5.3831 & TRN \\
\hline CHEMBL1383666 & 688422 & 4.5 & 5.1482 & TRN \\
\hline CHEMBL1330043 & 688422 & 5.3 & 5.1158 & TRN \\
\hline CHEMBL1512242 & 688422 & 4.75 & 5.2848 & TRN \\
\hline CHEMBL1465410 & 688422 & 5.15 & 5.0983 & TRN \\
\hline CHEMBL 2374023 & 688422 & 4.45 & 5.7295 & TST \\
\hline CHEMBL1364589 & 688422 & 5.25 & 5.7047 & TRN \\
\hline CHEMBL1599693 & 688422 & 6.1 & 5.9207 & TST \\
\hline CHEMBL1539903 & 688422 & 5.05 & 5.5262 & TRN \\
\hline CHEMBL3208554 & 688422 & 4.45 & 5.9622 & TST \\
\hline CHEMBL1599620 & 688422 & 4.75 & 5.1896 & TRN \\
\hline CHEMBL1472890 & 688422 & 7.8996 & 5.4418 & TRN \\
\hline CHEMBL1570841 & 688422 & 6.45 & 5.2717 & TRN \\
\hline CHEMBL1515465 & 688422 & 6.15 & 5.475 & TRN \\
\hline CHEMBL1360539 & 688422 & 5.45 & 5.2555 & TRN \\
\hline CHEMBL1372730 & 688422 & 4.5 & 4.9041 & TRN \\
\hline CHEMBL3192406 & 688422 & 5.35 & 5.1494 & TRN \\
\hline CHEMBL1355525 & 688422 & 4.6 & 5.1089 & TRN \\
\hline CHEMBL1542340 & 688422 & 5.05 & 5.087 & TRN \\
\hline CHEMBL1532092 & 688422 & 4.6 & 5.0407 & TRN \\
\hline CHEMBL1417603 & 688422 & 6.25 & 5.0222 & TRN \\
\hline CHEMBL1388967 & 688422 & 5.95 & 5.5366 & TRN \\
\hline CHEMBL1552766 & 688422 & 5.15 & 5.3393 & TRN \\
\hline CHEMBL1425652 & 688422 & 4.95 & 4.7141 & TRN \\
\hline CHEMBL1453825 & 688422 & 4.6 & 5.1472 & TST \\
\hline CHEMBL1517637 & 688422 & 4.75 & 5.2769 & TRN \\
\hline CHEMBL591126 & 688422 & 8.0 & 5.4952 & TRN \\
\hline CHEMBL1433783 & 688422 & 5.4 & 5.2396 & TST \\
\hline CHEMBL1308061 & 688422 & 4.95 & 5.1934 & TRN \\
\hline CHEMBL3198192 & 688422 & 6.05 & 5.4945 & TST \\
\hline CHEMBL1313821 & 688422 & 4.9 & 4.8913 & TRN \\
\hline CHEMBL1484777 & 688422 & 4.9 & 5.0712 & TRN \\
\hline CHEMBL1375532 & 688422 & 4.85 & 4.9769 & TRN \\
\hline CHEMBL1363964 & 688422 & 5.55 & 5.3401 & TST \\
\hline CHEMBL1315881 & 688422 & 5.4 & 5.2946 & TRN \\
\hline CHEMBL1565943 & 688422 & 6.05 & 5.5039 & TRN \\
\hline
\end{tabular}




\begin{tabular}{|c|c|c|c|c|}
\hline \multicolumn{5}{|c|}{ Supplemental Table S2.txt } \\
\hline CHEMBL1439618 & 688422 & 5.6 & 5.4462 & TST \\
\hline CHEMBL1583471 & 688422 & 5.1 & 5.0827 & TRN \\
\hline CHEMBL1356069 & 688422 & 4.8 & 5.4264 & TST \\
\hline CHEMBL1501305 & 688422 & 4.8 & 5.29299 & 9999999999 \\
\hline CHEMBL1382368 & 688422 & 5.0 & 4.8248 & TST \\
\hline CHEMBL1526789 & 688422 & 5.15 & 5.0518 & TRN \\
\hline CHEMBL1364278 & 688422 & 4.45 & 4.785 & TRN \\
\hline CHEMBL3349009 & 688422 & 7.4001 & 5.8474 & TST \\
\hline CHEMBL3192789 & 688422 & 4.85 & 4.9989 & TST \\
\hline CHEMBL1512006 & 688422 & 5.8 & 5.336 & TRN \\
\hline CHEMBL1527987 & 688422 & 4.85 & 5.5288 & TRN \\
\hline CHEMBL1327775 & 688422 & 6.1 & 5.8239 & TRN \\
\hline CHEMBL1594676 & 688422 & 4.6 & 5.2089 & TRN \\
\hline CHEMBL 3195664 & 688422 & 4.6 & 5.0817 & TRN \\
\hline CHEMBL1439467 & 688422 & 4.45 & 5.4201 & TRN \\
\hline CHEMBL1419131 & 688422 & 4.9 & 5.7149 & TRN \\
\hline CHEMBL 1340040 & 688422 & 7.6003 & 5.1678 & TST \\
\hline CHEMBL1326664 & 688422 & 5.55 & 5.2613 & TRN \\
\hline CHEMBL1462696 & 688422 & 4.45 & 5.0867 & TRN \\
\hline CHEMBL1600744 & 688422 & 4.7 & 5.4165 & TRN \\
\hline CHEMBL1602709 & 688422 & 4.45 & 4.9918 & TRN \\
\hline CHEMBL1402154 & 688422 & 4.75 & 5.4255 & TRN \\
\hline CHEMBL1523735 & 688422 & 4.8 & 4.8392 & TRN \\
\hline CHEMBL1453562 & 688422 & 7.5498 & 5.4822 & TRN \\
\hline CHEMBL1504117 & 688422 & 5.4 & 5.1147 & TRN \\
\hline CHEMBL1448929 & 688422 & 5.1 & 4.9319 & TRN \\
\hline CHEMBL1305831 & 688422 & 5.05 & 5.1899 & TRN \\
\hline CHEMBL1578495 & 688422 & 4.45 & 5.4579 & TRN \\
\hline CHEMBL 3213254 & 688422 & 5.3 & 5.5173 & TRN \\
\hline CHEMBL1391582 & 688422 & 5.25 & 5.2385 & TST \\
\hline CHEMBL1433131 & 688422 & 5.05 & 5.5597 & TST \\
\hline CHEMBL1448602 & 688422 & 6.95 & 5.8124 & TRN \\
\hline CHEMBL1458490 & 688422 & 4.95 & 5.3393 & TRN \\
\hline CHEMBL3214212 & 688422 & 7.5003 & 5.6033 & TST \\
\hline CHEMBL1561888 & 688422 & 5.05 & 5.1293 & TRN \\
\hline CHEMBL1349757 & 688422 & 5.05 & 5.3683 & TRN \\
\hline CHEMBL1587334 & 688422 & 5.95 & 5.3164 & TRN \\
\hline CHEMBL1555628 & 688422 & 5.35 & 4.9734 & TRN \\
\hline CHEMBL1528296 & 688422 & 4.45 & 4.801 & TRN \\
\hline CHEMBL1574420 & 688422 & 5.5 & 5.5784 & TST \\
\hline CHEMBL3213202 & 688422 & 4.85 & 5.3236 & TST \\
\hline CHEMBL1998263 & 688422 & 5.0 & 5.3006 & TST \\
\hline CHEMBL1488834 & 688422 & 4.75 & 5.1493 & TRN \\
\hline CHEMBL1504710 & 688422 & 4.6 & 5.0171 & TRN \\
\hline CHEMBL1410651 & 688422 & 4.75 & 5.5892 & TRN \\
\hline CHEMBL1379250 & 688422 & 5.25 & 5.0272 & TRN \\
\hline CHEMBL1549644 & 688422 & 4.55 & 5.2952 & TRN \\
\hline CHEMBL1561034 & 688422 & 6.8 & 5.1471 & TST \\
\hline
\end{tabular}




\begin{tabular}{|c|c|c|c|c|c|}
\hline \multicolumn{6}{|c|}{ Supplemental Table S2.txt } \\
\hline CHEMBL1390750 & 688422 & 4.7 & 5.1303 & TRN & \\
\hline CHEMBL1501506 & 688422 & 5.6 & 5.2585 & TST & \\
\hline CHEMBL1386396 & 688422 & 6.5501 & 5.2492 & TRN & \\
\hline CHEMBL1512308 & 688422 & 6.1 & 5.88200 & 0000000001 & TRN \\
\hline CHEMBL1479028 & 688422 & 4.95 & 4.9471 & TRN & \\
\hline CHEMBL1414769 & 688422 & 4.9 & 5.221 & TRN & \\
\hline CHEMBL1379581 & 688422 & 5.0 & 5.6269 & TRN & \\
\hline CHEMBL1468795 & 688422 & 4.45 & 4.9999 & TRN & \\
\hline CHEMBL1460066 & 688422 & 8.1487 & 5.3619 & TRN & \\
\hline CHEMBL1356871 & 688422 & 7.1002 & 5.3963 & TRN & \\
\hline CHEMBL1520985 & 688422 & 5.55 & 5.2986 & TST & \\
\hline CHEMBL1393831 & 688422 & 4.5 & 5.4548 & TRN & \\
\hline CHEMBL1410734 & 688422 & 4.9 & 4.9307 & TRN & \\
\hline CHEMBL1459746 & 688422 & 5.55 & 5.4537 & TRN & \\
\hline CHEMBL1303697 & 688422 & 4.45 & 5.1477 & TRN & \\
\hline CHEMBL1440027 & 688422 & 4.7 & 5.4639 & TST & \\
\hline CHEMBL1310309 & 688422 & 4.6 & 4.8433 & TRN & \\
\hline CHEMBL1379634 & 688422 & 4.45 & 5.0842 & TRN & \\
\hline CHEMBL299613 & 688422 & 6.0 & 5.5775 & TRN & \\
\hline CHEMBL 299853 & 688422 & 4.45 & 5.1261 & TRN & \\
\hline CHEMBL1411689 & 688422 & 4.45 & 4.9408 & TRN & \\
\hline CHEMBL1525696 & 688422 & 5.45 & 5.1468 & TRN & \\
\hline CHEMBL1256687 & 688422 & 4.65 & 5.4488 & TST & \\
\hline CHEMBL1375514 & 688422 & 4.45 & 4.9011 & TRN & \\
\hline CHEMBL3195057 & 688422 & 5.55 & 5.2083 & TRN & \\
\hline CHEMBL3199360 & 688422 & 5.3 & 5.2525 & TRN & \\
\hline CHEMBL3211093 & 688422 & 7.0 & 4.9793 & TST & \\
\hline CHEMBL1471738 & 688422 & 5.05 & 5.7785 & TRN & \\
\hline CHEMBL1384895 & 688422 & 4.75 & 5.1329 & TST & \\
\hline CHEMBL1365054 & 688422 & 4.7 & 5.232 & TRN & \\
\hline CHEMBL1256865 & 688422 & 5.25 & 5.5214 & TST & \\
\hline CHEMBL1350513 & 688422 & 4.45 & 5.3015 & TRN & \\
\hline CHEMBL1344207 & 688422 & 4.95 & 5.1252 & TST & \\
\hline CHEMBL1336485 & 688422 & 4.85 & 5.0669 & TRN & \\
\hline CHEMBL1440375 & 688422 & 6.4 & 5.68 & TST & \\
\hline CHEMBL19612 & 688422 & 6.05 & 6.2228 & TRN & \\
\hline CHEMBL1515302 & 688422 & 4.3 & 5.1532 & TRN & \\
\hline CHEMBL1563800 & 688422 & 4.45 & 5.0293 & TRN & \\
\hline CHEMBL3197433 & 688422 & 4.85 & 5.1568 & TRN & \\
\hline CHEMBL1528019 & 688422 & 5.05 & 5.3379 & TRN & \\
\hline CHEMBL1423037 & 688422 & 4.65 & 5.3243 & TRN & \\
\hline CHEMBL1489050 & 688422 & 5.6 & 5.6145 & TST & \\
\hline CHEMBL1399984 & 688422 & 4.95 & 4.8631 & TRN & \\
\hline CHEMBL1353743 & 688422 & 6.95 & 5.1052 & TST & \\
\hline CHEMBL1310532 & 688422 & 4.7 & 5.33700 & 0000000001 & TRN \\
\hline CHEMBL1520507 & 688422 & 4.45 & 4.9475 & TST & \\
\hline CHEMBL1500657 & 688422 & 4.8 & 5.6626 & TRN & \\
\hline CHEMBL3192901 & 688422 & 5.75 & 5.3416 & TRN & \\
\hline
\end{tabular}




\begin{tabular}{|c|c|c|c|c|c|}
\hline \multicolumn{6}{|c|}{ Supplemental Table S2.txt } \\
\hline CHEMBL1349059 & 688422 & 4.45 & 4.895 & TRN & \\
\hline CHEMBL275006 & 688422 & 5.35 & 5.7548 & TST & \\
\hline CHEMBL3210356 & 688422 & 6.35 & 5.3598 & TST & \\
\hline CHEMBL 2094652 & 688422 & 4.85 & 5.3289 & TRN & \\
\hline CHEMBL1573665 & 688422 & 5.45 & 5.0716 & TRN & \\
\hline CHEMBL1414914 & 688422 & 4.9 & 5.148 & TRN & \\
\hline CHEMBL3190479 & 688422 & 4.45 & 5.2477 & TST & \\
\hline CHEMBL1412101 & 688422 & 4.6 & 5.2097 & TRN & \\
\hline CHEMBL1453067 & 688422 & 4.45 & 5.2183 & TRN & \\
\hline CHEMBL1557346 & 688422 & 4.95 & 5.1457 & TRN & \\
\hline CHEMBL1308415 & 688422 & 4.75 & 4.7982 & TST & \\
\hline CHEMBL1565381 & 688422 & 5.0 & 5.1647 & TST & \\
\hline CHEMBL1389343 & 688422 & 4.5 & 4.9487 & TRN & \\
\hline CHEMBL1386668 & 688422 & 4.8 & 5.0511 & TRN & \\
\hline CHEMBL189382 & 688422 & 5.75 & 5.5722 & TST & \\
\hline CHEMBL1530972 & 688422 & 4.9 & 5.6063 & TST & \\
\hline CHEMBL1556337 & 688422 & 4.45 & 5.5465 & TST & \\
\hline CHEMBL1519178 & 688422 & 5.25 & 5.4197 & TST & \\
\hline CHEMBL3191897 & 688422 & 4.8 & 5.4001 & TRN & \\
\hline CHEMBL1386506 & 688422 & 6.35 & 5.71299 & э999999999 & TST \\
\hline CHEMBL1481445 & 688422 & 4.95 & 5.145 & TRN & \\
\hline CHEMBL1301364 & 688422 & 4.9 & 4.6583 & TRN & \\
\hline CHEMBL1346225 & 688422 & 4.65 & 4.8466 & TRN & \\
\hline CHEMBL1356227 & 688422 & 7.9508 & 5.3918 & TRN & \\
\hline CHEMBL1400261 & 688422 & 4.45 & 5.2074 & TRN & \\
\hline CHEMBL1419979 & 688422 & 4.55 & 5.3235 & TRN & \\
\hline CHEMBL1454255 & 688422 & 4.7 & 5.072 & TRN & \\
\hline CHEMBL1322600 & 688422 & 4.95 & 5.2115 & TRN & \\
\hline CHEMBL1355940 & 688422 & 5.5 & 5.1513 & TRN & \\
\hline CHEMBL1405447 & 688422 & 4.95 & 4.9878 & TST & \\
\hline CHEMBL326958 & 688422 & 5.2 & 6.0903 & TRN & \\
\hline CHEMBL1409752 & 688422 & 6.0 & 5.6324 & TST & \\
\hline CHEMBL3211471 & 688422 & 4.5 & 5.5534 & TST & \\
\hline CHEMBL1976719 & 688422 & 4.6 & 5.032 & TRN & \\
\hline CHEMBL1603961 & 688422 & 4.95 & 5.2875 & TRN & \\
\hline CHEMBL1495473 & 688422 & 4.95 & 5.6658 & TRN & \\
\hline CHEMBL1505906 & 688422 & 4.45 & 5.00899 & 99999999995 & TRN \\
\hline CHEMBL1534772 & 688422 & 4.6 & 4.7629 & TRN & \\
\hline CHEMBL1544407 & 688422 & 5.45 & 5.0803 & TRN & \\
\hline CHEMBL1464561 & 688422 & 5.4 & 5.0715 & TRN & \\
\hline CHEMBL1444854 & 688422 & 5.45 & 4.8378 & TRN & \\
\hline CHEMBL1395882 & 688422 & 4.9 & 5.2122 & TST & \\
\hline CHEMBL1346084 & 688422 & 6.1 & 5.399 & TRN & \\
\hline CHEMBL1393486 & 688422 & 4.95 & 5.3648 & TRN & \\
\hline CHEMBL 28 & 688422 & 6.0 & 5.722 & TRN & \\
\hline CHEMBL1353706 & 688422 & 4.5 & 5.225 & TST & \\
\hline CHEMBL1551175 & 688422 & 5.5 & 5.0605 & TRN & \\
\hline CHEMBL1395663 & 688422 & 5.85 & 5.7102 & TST & \\
\hline
\end{tabular}




\begin{tabular}{|c|c|c|c|c|c|}
\hline \multicolumn{6}{|c|}{ Supplemental Table S2.txt } \\
\hline CHEMBL1392873 & 688422 & 5.15 & 5.0411 & TST & \\
\hline CHEMBL1387720 & 688422 & 4.9 & 5.4807 & TRN & \\
\hline CHEMBL1317151 & 688422 & 4.5 & 5.3748 & TRN & \\
\hline CHEMBL1487885 & 688422 & 6.1 & 5.5736 & TRN & \\
\hline CHEMBL1542391 & 688422 & 6.05 & 5.6702 & TRN & \\
\hline CHEMBL1335510 & 688422 & 4.9 & 5.6636 & TRN & \\
\hline CHEMBL1337990 & 688422 & 4.6 & 4.5243 & TRN & \\
\hline CHEMBL3209165 & 688422 & 4.6 & 5.2255 & TRN & \\
\hline CHEMBL1966202 & 688422 & 4.45 & 5.2032 & TST & \\
\hline CHEMBL1348931 & 688422 & 5.65 & 5.2817 & TRN & \\
\hline CHEMBL1395795 & 688422 & 5.25 & 5.1866 & TRN & \\
\hline CHEMBL1502856 & 688422 & 4.7 & 5.7868 & TRN & \\
\hline CHEMBL1523444 & 688422 & 4.75 & 5.7087 & TST & \\
\hline CHEMBL1330885 & 688422 & 4.9 & 5.0959 & TRN & \\
\hline CHEMBL1609850 & 688422 & 8.3468 & 5.2461 & TRN & \\
\hline CHEMBL1356796 & 688422 & 6.5501 & 4.971 & TRN & \\
\hline CHEMBL1467809 & 688422 & 4.6 & 5.1742 & TRN & \\
\hline CHEMBL3189300 & 688422 & 4.5 & 5.4466 & TRN & \\
\hline CHEMBL1536878 & 688422 & 8.3468 & 5.109 & TRN & \\
\hline CHEMBL1352117 & 688422 & 4.95 & 5.04 & TRN & \\
\hline CHEMBL 287193 & 688422 & 4.45 & 5.2206 & TRN & \\
\hline CHEMBL1581727 & 688422 & 4.9 & 5.0497 & TRN & \\
\hline CHEMBL1317806 & 688422 & 7.3497 & 5.8545 & TRN & \\
\hline CHEMBL1546773 & 688422 & 4.9 & 5.474 & TRN & \\
\hline CHEMBL1385161 & 688422 & 5.55 & 5.5849 & TRN & \\
\hline CHEMBL1606808 & 688422 & 6.5501 & 5.3747 & TRN & \\
\hline CHEMBL1435200 & 688422 & 5.0 & 5.6532 & TRN & \\
\hline CHEMBL3193515 & 688422 & 4.55 & 5.2178 & TRN & \\
\hline CHEMBL3189694 & 688422 & 4.45 & 4.538 & TST & \\
\hline CHEMBL1368089 & 688422 & 4.45 & 4.8995 & TRN & \\
\hline CHEMBL610463 & 688422 & 4.95 & 5.16100 & 00000000005 & TRN \\
\hline CHEMBL1525140 & 688422 & 4.6 & 5.296 & TRN & \\
\hline CHEMBL3196281 & 688422 & 4.85 & 5.4363 & TRN & \\
\hline CHEMBL1457531 & 688422 & 4.65 & 5.1016 & TRN & \\
\hline CHEMBL463763 & 688422 & 7.0501 & 5.9612 & TST & \\
\hline CHEMBL1527134 & 688422 & 4.45 & 5.0083 & TRN & \\
\hline CHEMBL1432981 & 688422 & 4.95 & 4.9596 & TST & \\
\hline CHEMBL1344339 & 688422 & 5.55 & 5.0934 & TST & \\
\hline CHEMBL3193195 & 688422 & 4.45 & 5.4791 & TRN & \\
\hline CHEMBL1327105 & 688422 & 8.4949 & 5.8567 & TRN & \\
\hline CHEMBL1478525 & 688422 & 4.45 & 4.8848 & TRN & \\
\hline CHEMBL1346972 & 688422 & 5.2 & 4.9202 & TRN & \\
\hline CHEMBL1337510 & 688422 & 7.2503 & 5.235 & TRN & \\
\hline CHEMBL1545634 & 688422 & 5.25 & 5.4619 & TST & \\
\hline CHEMBL28324 & 688422 & 4.9 & 4.6075 & TST & \\
\hline CHEMBL1343060 & 688422 & 4.45 & 5.2029 & TST & \\
\hline CHEMBL1511327 & 688422 & 4.8 & 5.2054 & TRN & \\
\hline CHEMBL1345334 & 688422 & 4.95 & 4.6062 & TRN & \\
\hline
\end{tabular}




\begin{tabular}{|c|c|c|c|c|c|}
\hline \multicolumn{6}{|c|}{ Supplemental Table S2.txt } \\
\hline CHEMBL3145383 & 688422 & 4.95 & 5.3622 & TRN & \\
\hline CHEMBL1577742 & 688422 & 4.5 & 4.9553 & TRN & \\
\hline CHEMBL1606313 & 688422 & 4.75 & 5.18 & TRN & \\
\hline CHEMBL 3197482 & 688422 & 4.55 & 5.4717 & TRN & \\
\hline CHEMBL1319617 & 688422 & 5.0 & 5.3337 & TRN & \\
\hline CHEMBL1577726 & 688422 & 7.7496 & 4.9939 & TST & \\
\hline CHEMBL1479349 & 688422 & 6.05 & 5.9233 & TRN & \\
\hline CHEMBL1526310 & 688422 & 4.45 & 5.6397 & TRN & \\
\hline CHEMBL1541259 & 688422 & 6.15 & 5.3142 & TST & \\
\hline CHEMBL1467407 & 688422 & 4.45 & 5.2267 & TRN & \\
\hline CHEMBL3195606 & 688422 & 4.9 & 5.0191 & TRN & \\
\hline CHEMBL1359215 & 688422 & 4.8 & 5.3536 & TRN & \\
\hline CHEMBL1725507 & 688422 & 5.0 & 5.4605 & TRN & \\
\hline CHEMBL1511699 & 688422 & 5.0 & 5.0508 & TRN & \\
\hline CHEMBL3198664 & 688422 & 6.15 & 5.3614 & TRN & \\
\hline CHEMBL1407635 & 688422 & 5.05 & 5.0068 & TRN & \\
\hline CHEMBL1326531 & 688422 & 4.45 & 5.2307 & TRN & \\
\hline CHEMBL1369291 & 688422 & 4.75 & 5.63299 & э999999999 & TRN \\
\hline CHEMBL1480827 & 688422 & 4.45 & 5.3094 & TRN & \\
\hline CHEMBL1390683 & 688422 & 4.65 & 5.1844 & TRN & \\
\hline CHEMBL1401415 & 688422 & 8.3979 & 5.5437 & TRN & \\
\hline CHEMBL1505880 & 688422 & 5.0 & 5.1163 & TRN & \\
\hline CHEMBL1588173 & 688422 & 4.45 & 4.7973 & TRN & \\
\hline CHEMBL1516621 & 688422 & 4.5 & 5.1367 & TRN & \\
\hline CHEMBL1309763 & 688422 & 4.45 & 5.0802 & TST & \\
\hline CHEMBL1337288 & 688422 & 4.8 & 4.7025 & TRN & \\
\hline CHEMBL1994838 & 688422 & 7.9508 & 5.3543 & TRN & \\
\hline CHEMBL 145 & 688422 & 5.55 & 5.3395 & TRN & \\
\hline CHEMBL1562359 & 688422 & 4.85 & 5.5499 & TRN & \\
\hline CHEMBL1453071 & 688422 & 4.45 & 5.4541 & TRN & \\
\hline CHEMBL1562605 & 688422 & 6.15 & 4.9945 & TST & \\
\hline CHEMBL1589076 & 688422 & 4.5 & 5.2365 & TRN & \\
\hline CHEMBL3190473 & 688422 & 4.75 & 5.5873 & TRN & \\
\hline CHEMBL3210895 & 688422 & 4.75 & 4.8357 & TRN & \\
\hline CHEMBL3198243 & 688422 & 4.85 & 5.348 & TRN & \\
\hline CHEMBL1391495 & 688422 & 4.75 & 5.3427 & TRN & \\
\hline CHEMBL1339433 & 688422 & 4.45 & 4.7906 & TRN & \\
\hline CHEMBL1411573 & 688422 & 4.9 & 5.055 & TRN & \\
\hline CHEMBL1398645 & 688422 & 5.1 & 5.3951 & TST & \\
\hline CHEMBL1256285 & 688422 & 5.25 & 5.6246 & TST & \\
\hline CHEMBL1373220 & 688422 & 7.2503 & 5.3997 & TRN & \\
\hline CHEMBL1308686 & 688422 & 4.45 & 5.0079 & TRN & \\
\hline CHEMBL1544175 & 688422 & 4.6 & 4.8125 & TST & \\
\hline CHEMBL1415883 & 688422 & 4.45 & 5.228 & TRN & \\
\hline CHEMBL1415553 & 688422 & 5.45 & 5.3632 & TRN & \\
\hline CHEMBL1444713 & 688422 & 5.25 & 5.50200 & 0000000001 & TRN \\
\hline CHEMBL3191969 & 688422 & 5.45 & 4.7723 & TRN & \\
\hline CHEMBL1497240 & 688422 & 4.9 & 5.6185 & TRN & \\
\hline
\end{tabular}




\begin{tabular}{|c|c|c|c|c|}
\hline \multicolumn{5}{|c|}{ Supplemental Table S2.txt } \\
\hline CHEMBL1469460 & 688422 & 4.45 & 4.4934 & TST \\
\hline CHEMBL1518193 & 688422 & 5.35 & 5.3074 & TRN \\
\hline CHEMBL1423839 & 688422 & 7.8013 & 4.8355 & TST \\
\hline CHEMBL 3192833 & 688422 & 4.45 & 4.9778 & TRN \\
\hline CHEMBL 1400435 & 688422 & 5.0 & 4.9664 & TRN \\
\hline CHEMBL1308028 & 688422 & 6.05 & 5.3319 & TRN \\
\hline CHEMBL1560610 & 688422 & 4.45 & 5.2806 & TRN \\
\hline CHEMBL1983451 & 688422 & 4.95 & 5.8682 & TRN \\
\hline CHEMBL1518544 & 688422 & 5.6 & 5.7387 & TRN \\
\hline CHEMBL1523141 & 688422 & 4.8 & 5.1702 & TRN \\
\hline CHEMBL1371347 & 688422 & 6.5501 & 5.8335 & TRN \\
\hline CHEMBL1541930 & 688422 & 4.45 & 5.5246 & TST \\
\hline CHEMBL1495439 & 688422 & 5.05 & 5.1277 & TRN \\
\hline CHEMBL1412303 & 688422 & 5.2 & 5.7304 & TRN \\
\hline CHEMBL1570071 & 688422 & 4.55 & 4.7203 & TRN \\
\hline CHEMBL1542469 & 688422 & 4.45 & 5.314 & TST \\
\hline CHEMBL1530236 & 688422 & 4.5 & 5.166 & TRN \\
\hline CHEMBL1550299 & 688422 & 5.85 & 5.2919 & TRN \\
\hline CHEMBL47875 & 688422 & 7.3497 & 5.1239 & TST \\
\hline CHEMBL1516010 & 688422 & 4.45 & 5.5027 & TST \\
\hline CHEMBL1426792 & 688422 & 5.45 & 4.8765 & TRN \\
\hline CHEMBL1528930 & 688422 & 5.3 & 5.3588 & TRN \\
\hline CHEMBL1589331 & 688422 & 4.45 & 4.9606 & TRN \\
\hline CHEMBL1458524 & 688422 & 5.45 & 5.1772 & TRN \\
\hline CHEMBL1422254 & 688422 & 4.45 & 5.3039 & TRN \\
\hline CHEMBL1483318 & 688422 & 5.65 & 5.0205 & TRN \\
\hline CHEMBL1343502 & 688422 & 4.85 & 5.3921 & TRN \\
\hline CHEMBL1305217 & 688422 & 4.9 & 5.4731 & TRN \\
\hline CHEMBL1993796 & 688422 & 6.25 & 5.5097 & TRN \\
\hline CHEMBL1573389 & 688422 & 4.95 & 4.9789 & TRN \\
\hline CHEMBL1309274 & 688422 & 5.35 & 5.5776 & TST \\
\hline CHEMBL1558496 & 688422 & 4.9 & 5.5234 & TRN \\
\hline CHEMBL1583212 & 688422 & 5.2 & 5.8106 & TST \\
\hline CHEMBL1589415 & 688422 & 4.9 & 4.9918 & TST \\
\hline CHEMBL1380740 & 688422 & 5.7 & 5.02 & TST \\
\hline CHEMBL1406016 & 688422 & 4.95 & 5.2216 & TRN \\
\hline CHEMBL1555949 & 688422 & 4.8 & 5.2675 & TST \\
\hline CHEMBL3195316 & 688422 & 4.9 & 5.3968 & TST \\
\hline CHEMBL1521075 & 688422 & 4.85 & 4.9452 & TST \\
\hline CHEMBL1449732 & 688422 & 6.45 & 6.0496 & TRN \\
\hline CHEMBL1381347 & 688422 & 4.8 & 5.0479 & TST \\
\hline CHEMBL1318509 & 688422 & 4.95 & 5.1532 & TST \\
\hline CHEMBL1322580 & 688422 & 5.0 & 4.9225 & TRN \\
\hline CHEMBL1324878 & 688422 & 4.95 & 5.1223 & TRN \\
\hline CHEMBL1489723 & 688422 & 5.25 & 5.1248 & TRN \\
\hline CHEMBL1365533 & 688422 & 4.5 & 4.4159 & TST \\
\hline CHEMBL1409505 & 688422 & 5.1 & 5.3406 & TRN \\
\hline CHEMBL 3214220 & 688422 & 5.25 & 5.1226 & TST \\
\hline
\end{tabular}




\begin{tabular}{|c|c|c|c|c|c|}
\hline & & \multicolumn{4}{|c|}{ Supplemental Table S2.txt } \\
\hline CHEMBL1346595 & 688422 & 5.0 & 4.9685 & TST & \\
\hline CHEMBL1538843 & 688422 & 5.1 & 4.7491 & TRN & \\
\hline CHEMBL1609751 & 688422 & 4.45 & 5.0993 & TRN & \\
\hline CHEMBL1489552 & 688422 & 4.65 & 5.2565 & TRN & \\
\hline CHEMBL1357612 & 688422 & 4.45 & 5.5934 & TRN & \\
\hline CHEMBL1446115 & 688422 & 5.05 & 4.9381 & TRN & \\
\hline CHEMBL1564201 & 688422 & 5.25 & 4.875 & TST & \\
\hline CHEMBL1472244 & 688422 & 5.5 & 4.9026 & TRN & \\
\hline CHEMBL1403905 & 688422 & 4.45 & 4.6804 & TRN & \\
\hline CHEMBL1538535 & 688422 & 4.7 & 4.8063 & TRN & \\
\hline CHEMBL1369332 & 688422 & 4.5 & 5.0051 & TRN & \\
\hline CHEMBL 3191350 & 688422 & 4.5 & 5.3865 & TST & \\
\hline CHEMBL1517546 & 688422 & 4.95 & 5.4951 & TRN & \\
\hline CHEMBL1331348 & 688422 & 4.45 & 5.2147 & TST & \\
\hline CHEMBL1419451 & 688422 & 5.7 & 5.7809 & TST & \\
\hline CHEMBL1422343 & 688422 & 5.85 & 5.3663 & TRN & \\
\hline CHEMBL1360383 & 688422 & 4.5 & 5.0231 & TST & \\
\hline CHEMBL1322221 & 688422 & 4.45 & 5.2919 & TST & \\
\hline CHEMBL1531332 & 688422 & 5.85 & 5.7612 & TST & \\
\hline CHEMBL1607196 & 688422 & 4.65 & 5.3325 & TRN & \\
\hline CHEMBL1357894 & 688422 & 5.25 & 5.7025 & TST & \\
\hline CHEMBL1432894 & 688422 & 4.5 & 4.9676 & TRN & \\
\hline CHEMBL1392596 & 688422 & 6.5501 & 5.3896 & TST & \\
\hline CHEMBL1359669 & 688422 & 4.45 & 5.2654 & TRN & \\
\hline CHEMBL1342053 & 688422 & 4.85 & 5.0111 & TRN & \\
\hline CHEMBL1334040 & 688422 & 4.5 & 4.9293 & TST & \\
\hline CHEMBL1413987 & 688422 & 6.0 & 5.4264 & TRN & \\
\hline CHEMBL 3199285 & 688422 & 4.85 & 5.101 & TRN & \\
\hline CHEMBL1598625 & 688422 & 4.7 & 5.8913 & TST & \\
\hline CHEMBL1387162 & 688422 & 5.3 & 5.0051 & TRN & \\
\hline CHEMBL1380563 & 688422 & 7.0501 & 5.4898 & TRN & \\
\hline CHEMBL1335197 & 688422 & 4.85 & 5.0916 & TRN & \\
\hline CHEMBL1594247 & 688422 & 5.75 & 5.3235 & TST & \\
\hline CHEMBL1453883 & 688422 & 5.0 & 5.3627 & TST & \\
\hline CHEMBL1352452 & 688422 & 5.05 & 5.0486 & TST & \\
\hline CHEMBL1449731 & 688422 & 4.85 & 5.4553 & TST & \\
\hline CHEMBL1481240 & 688422 & 4.45 & 5.3455 & TRN & \\
\hline CHEMBL1368962 & 688422 & 4.45 & 5.0708 & TRN & \\
\hline CHEMBL1427387 & 688422 & 7.1002 & 5.1507 & TRN & \\
\hline CHEMBL1597037 & 688422 & 4.95 & 4.8111 & TRN & \\
\hline CHEMBL1321662 & 688422 & 4.45 & 4.985 & TRN & \\
\hline CHEMBL 260370 & 688422 & 4.8 & 4.7495 & TRN & \\
\hline CHEMBL1441888 & 688422 & 5.1 & 5.1772 & TRN & \\
\hline CHEMBL1479639 & 688422 & 4.75 & 5.41299 & 9999999999 & TRN \\
\hline CHEMBL1436938 & 688422 & 4.8 & 4.7976 & TRN & \\
\hline CHEMBL1334884 & 688422 & 4.65 & 4.921 & TRN & \\
\hline CHEMBL1545055 & 688422 & 4.9 & 5.124 & TRN & \\
\hline CHEMBL1501864 & 688422 & 4.45 & 5.0686 & TRN & \\
\hline
\end{tabular}




\begin{tabular}{|c|c|c|c|c|c|}
\hline \multirow[b]{2}{*}{ CHEMBL1456760 } & \multicolumn{5}{|c|}{ Supplemental Table S2.txt } \\
\hline & 688422 & 7.5498 & 4.8447 & TRN & \\
\hline CHEMBL1512133 & 688422 & 6.6 & 5.6422 & TRN & \\
\hline CHEMBL1565762 & 688422 & 5.6 & 5.40799 & 99999999995 & TRN \\
\hline CHEMBL1522802 & 688422 & 4.95 & 4.6648 & TRN & \\
\hline CHEMBL1309548 & 688422 & 5.25 & 5.4488 & TRN & \\
\hline CHEMBL1370314 & 688422 & 5.35 & 5.1276 & TRN & \\
\hline CHEMBL1357247 & 688422 & 4.7 & 5.0329 & TST & \\
\hline CHEMBL1428337 & 688422 & 4.8 & 5.3426 & TRN & \\
\hline CHEMBL1588150 & 688422 & 4.9 & 5.2266 & TRN & \\
\hline CHEMBL1311453 & 688422 & 4.55 & 4.6059 & TRN & \\
\hline CHEMBL1356135 & 688422 & 4.8 & 5.1981 & TRN & \\
\hline CHEMBL1536172 & 688422 & 6.5 & 5.2587 & TRN & \\
\hline CHEMBL1535943 & 688422 & 4.65 & 5.2059 & TST & \\
\hline CHEMBL1586405 & 688422 & 4.5 & 5.1899 & TRN & \\
\hline CHEMBL1300535 & 688422 & 4.95 & 4.9539 & TRN & \\
\hline CHEMBL1928491 & 688422 & 5.3 & 5.3272 & TRN & \\
\hline CHEMBL 372840 & 688422 & 5.4 & 5.7206 & TRN & \\
\hline CHEMBL1549682 & 688422 & 4.55 & 5.2755 & TST & \\
\hline CHEMBL1384667 & 688422 & 4.9 & 5.1046 & TRN & \\
\hline CHEMBL1435644 & 688422 & 5.6 & 4.9855 & TRN & \\
\hline CHEMBL1533318 & 688422 & 4.85 & 5.1289 & TRN & \\
\hline CHEMBL1976446 & 688422 & 4.65 & 4.6841 & TRN & \\
\hline CHEMBL1518816 & 688422 & 8.4949 & 5.4642 & TRN & \\
\hline CHEMBL1479630 & 688422 & 4.85 & 5.5256 & TRN & \\
\hline CHEMBL1573482 & 688422 & 5.1 & 5.129 & TRN & \\
\hline CHEMBL1325647 & 688422 & 4.95 & 4.9215 & TRN & \\
\hline CHEMBL1566813 & 688422 & 5.0 & 5.2001 & TRN & \\
\hline CHEMBL1513027 & 688422 & 5.55 & 5.8281 & TRN & \\
\hline CHEMBL1359482 & 688422 & 4.9 & 4.8892 & TRN & \\
\hline CHEMBL1495188 & 688422 & 4.55 & 5.1838 & TRN & \\
\hline CHEMBL1435441 & 688422 & 4.6 & 5.0945 & TST & \\
\hline CHEMBL1328811 & 688422 & 4.45 & 5.1329 & TRN & \\
\hline CHEMBL1579873 & 688422 & 6.1 & 5.0818 & TST & \\
\hline CHEMBL1399651 & 688422 & 4.45 & 5.3362 & TRN & \\
\hline CHEMBL1428196 & 688422 & 4.7 & 5.8276 & TRN & \\
\hline CHEMBL1404332 & 688422 & 5.35 & 5.3221 & TST & \\
\hline CHEMBL1389959 & 688422 & 4.9 & 5.0129 & TRN & \\
\hline CHEMBL1304974 & 688422 & 4.7 & 5.1041 & TST & \\
\hline CHEMBL1548323 & 688422 & 4.6 & 5.2428 & TRN & \\
\hline CHEMBL1552842 & 688422 & 5.65 & 5.4327 & TRN & \\
\hline CHEMBL1543766 & 688422 & 5.45 & 5.776 & TST & \\
\hline CHEMBL1372293 & 688422 & 4.9 & 5.0136 & TRN & \\
\hline CHEMBL1570652 & 688422 & 4.95 & 5.3063 & TST & \\
\hline CHEMBL1587043 & 688422 & 4.9 & 5.3636 & TRN & \\
\hline CHEMBL61189 & 688422 & 7.4498 & 5.4046 & TRN & \\
\hline CHEMBL1582268 & 688422 & 4.45 & 5.0023 & TRN & \\
\hline CHEMBL1469659 & 688422 & 4.85 & 4.9728 & TRN & \\
\hline CHEMBL1544803 & 688422 & 4.95 & 5.1571 & TRN & \\
\hline
\end{tabular}




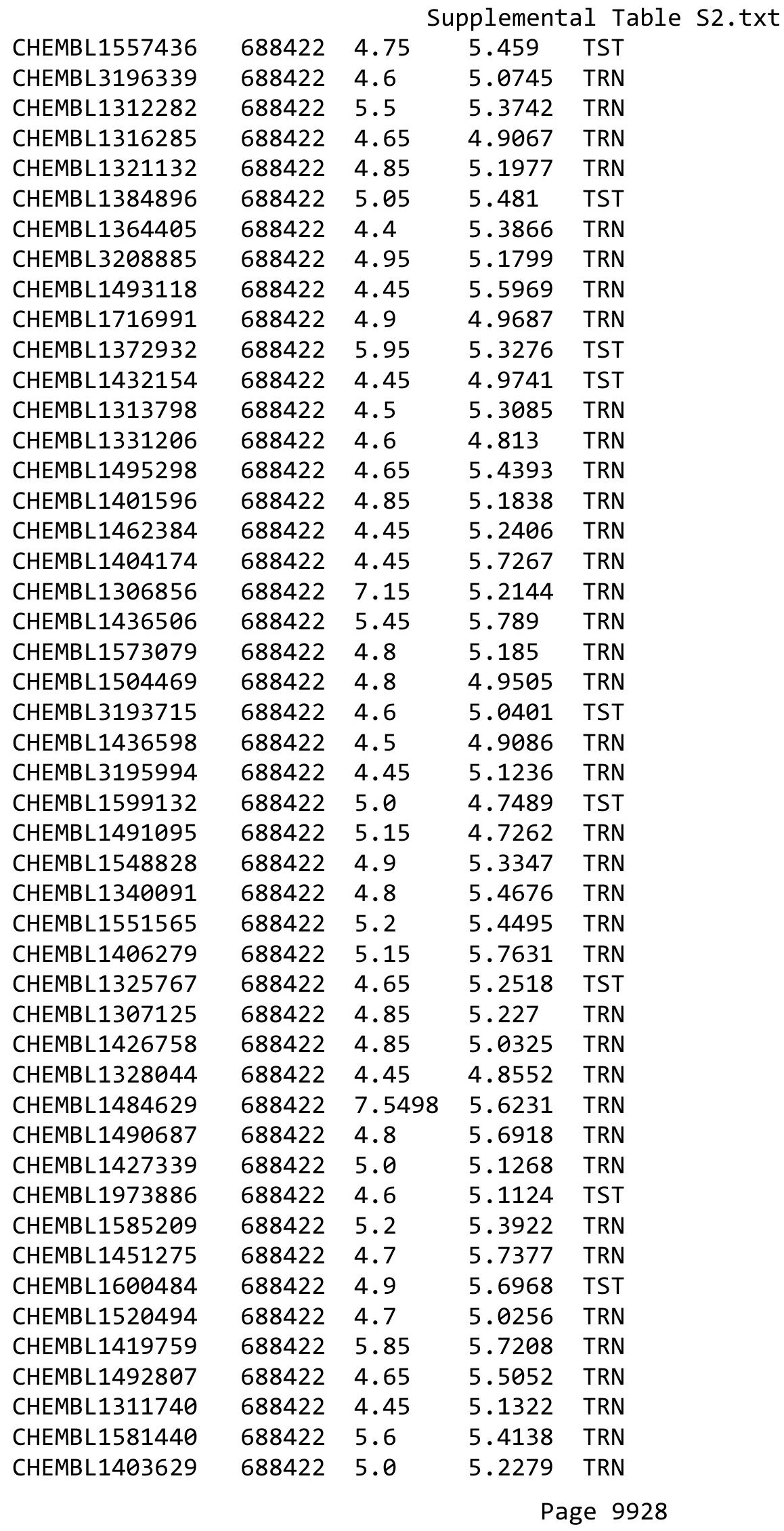




\begin{tabular}{|c|c|c|c|c|c|}
\hline & & \multicolumn{4}{|c|}{ Supplemental Table S2.txt } \\
\hline CHEMBL1441399 & 688422 & 8.3468 & 5.0713 & TRN & \\
\hline CHEMBL1396407 & 688422 & 4.95 & 4.8183 & TRN & \\
\hline CHEMBL1561843 & 688422 & 4.85 & 5.1286 & TRN & \\
\hline CHEMBL1512014 & 688422 & 6.3 & 5.1844 & TRN & \\
\hline CHEMBL1558761 & 688422 & 4.5 & 4.8027 & TRN & \\
\hline CHEMBL1588639 & 688422 & 5.0 & 5.46 & TRN & \\
\hline CHEMBL1530707 & 688422 & 5.05 & 4.999 & TRN & \\
\hline CHEMBL1367976 & 688422 & 5.15 & 5.544 & TST & \\
\hline CHEMBL1420418 & 688422 & 5.1 & 5.0956 & TRN & \\
\hline CHEMBL1550295 & 688422 & 4.65 & 4.9211 & TRN & \\
\hline CHEMBL1582892 & 688422 & 5.05 & 5.3257 & TRN & \\
\hline CHEMBL1468333 & 688422 & 4.85 & 5.32600 & 00000000005 & TRN \\
\hline CHEMBL1443867 & 688422 & 5.6 & 5.1664 & TRN & \\
\hline CHEMBL1579490 & 688422 & 4.9 & 4.9025 & TRN & \\
\hline CHEMBL1315546 & 688422 & 4.45 & 5.6047 & TRN & \\
\hline CHEMBL1401844 & 688422 & 4.85 & 5.6892 & TRN & \\
\hline CHEMBL1464827 & 688422 & 4.45 & 5.1256 & TRN & \\
\hline CHEMBL1313909 & 688422 & 4.95 & 5.455 & TRN & \\
\hline CHEMBL1604715 & 688422 & 4.9 & 5.3491 & TRN & \\
\hline CHEMBL1300608 & 688422 & 4.45 & 4.941 & TRN & \\
\hline CHEMBL3189568 & 688422 & 4.65 & 4.9309 & TRN & \\
\hline CHEMBL1320279 & 688422 & 6.2 & 5.8501 & TST & \\
\hline CHEMBL1433308 & 688422 & 4.85 & 5.3747 & TRN & \\
\hline CHEMBL1355446 & 688422 & 7.5498 & 5.9327 & TRN & \\
\hline CHEMBL1468714 & 688422 & 4.45 & 5.0152 & TRN & \\
\hline CHEMBL1467324 & 688422 & 4.9 & 4.8816 & TRN & \\
\hline CHEMBL1461738 & 688422 & 5.15 & 4.7525 & TRN & \\
\hline CHEMBL1387807 & 688422 & 4.7 & 5.4044 & TRN & \\
\hline CHEMBL1509065 & 688422 & 5.1 & 5.1631 & TRN & \\
\hline CHEMBL1456245 & 688422 & 4.45 & 4.9472 & TRN & \\
\hline CHEMBL1323968 & 688422 & 4.45 & 5.4648 & TRN & \\
\hline CHEMBL1564986 & 688422 & 4.45 & 4.942 & TRN & \\
\hline CHEMBL1556582 & 688422 & 4.85 & 4.9704 & TST & \\
\hline CHEMBL1315839 & 688422 & 5.0 & 5.966 & TRN & \\
\hline CHEMBL3199481 & 688422 & 5.2 & 5.4064 & TRN & \\
\hline CHEMBL1528110 & 688422 & 4.85 & 5.2821 & TRN & \\
\hline CHEMBL1402226 & 688422 & 4.75 & 5.546 & TRN & \\
\hline CHEMBL3192674 & 688422 & 4.95 & 5.1959 & TRN & \\
\hline CHEMBL1981379 & 688422 & 5.45 & 5.4193 & TST & \\
\hline CHEMBL1604237 & 688422 & 4.45 & 5.0382 & TRN & \\
\hline CHEMBL1402715 & 688422 & 4.9 & 4.909 & TRN & \\
\hline CHEMBL1352014 & 688422 & 4.5 & 5.1393 & TRN & \\
\hline CHEMBL1583408 & 688422 & 4.95 & 5.2964 & TRN & \\
\hline CHEMBL1982304 & 688422 & 4.45 & 4.9223 & TRN & \\
\hline CHEMBL1440100 & 688422 & 4.85 & 4.9931 & TRN & \\
\hline CHEMBL484385 & 688422 & 5.3 & 5.4749 & TRN & \\
\hline CHEMBL1455666 & 688422 & 4.75 & 5.1404 & TRN & \\
\hline CHEMBL1569152 & 688422 & 6.7501 & 5.2036 & TRN & \\
\hline
\end{tabular}




\begin{tabular}{|c|c|c|c|c|c|}
\hline \multicolumn{6}{|c|}{ Supplemental Table S2.txt } \\
\hline CHEMBL1492593 & 688422 & 5.2 & 5.6778 & TRN & \\
\hline CHEMBL1439672 & 688422 & 4.95 & 5.1138 & TRN & \\
\hline CHEMBL1336931 & 688422 & 5.0 & 5.4115 & TRN & \\
\hline CHEMBL1608220 & 688422 & 4.85 & 5.0991 & TRN & \\
\hline CHEMBL1510938 & 688422 & 7.0501 & 4.8246 & TST & \\
\hline CHEMBL 274438 & 688422 & 4.9 & 5.38700 & 00000000005 & TST \\
\hline CHEMBL1534086 & 688422 & 8.4949 & 5.335 & TRN & \\
\hline CHEMBL1582017 & 688422 & 4.55 & 5.3655 & TST & \\
\hline CHEMBL1419152 & 688422 & 4.45 & 5.3318 & TRN & \\
\hline CHEMBL1455375 & 688422 & 4.45 & 5.0924 & TRN & \\
\hline CHEMBL1572345 & 688422 & 5.25 & 5.3062 & TRN & \\
\hline CHEMBL1499489 & 688422 & 4.8 & 4.9276 & TST & \\
\hline CHEMBL1584174 & 688422 & 4.45 & 5.0354 & TRN & \\
\hline CHEMBL1507014 & 688422 & 5.8 & 5.1383 & TST & \\
\hline CHEMBL1475442 & 688422 & 4.8 & 5.3099 & TRN & \\
\hline CHEMBL 1353676 & 688422 & 4.5 & 5.125 & TST & \\
\hline CHEMBL1314410 & 688422 & 8.4949 & 5.5425 & TRN & \\
\hline CHEMBL1348549 & 688422 & 4.45 & 5.7305 & TRN & \\
\hline CHEMBL1599947 & 688422 & 4.45 & 5.4717 & TST & \\
\hline CHEMBL1467260 & 688422 & 4.85 & 5.0155 & TRN & \\
\hline CHEMBL1544016 & 688422 & 4.7 & 4.8359 & TRN & \\
\hline CHEMBL1989823 & 688422 & 4.45 & 5.2443 & TRN & \\
\hline CHEMBL1511171 & 688422 & 6.2 & 5.154 & TST & \\
\hline CHEMBL1361552 & 688422 & 4.9 & 4.9298 & TRN & \\
\hline CHEMBL1724937 & 688422 & 5.05 & 5.3014 & TRN & \\
\hline CHEMBL 1463433 & 688422 & 4.45 & 5.4326 & TRN & \\
\hline CHEMBL1497259 & 688422 & 4.6 & 4.8974 & TRN & \\
\hline CHEMBL1539982 & 688422 & 4.7 & 4.8695 & TRN & \\
\hline CHEMBL1368199 & 688422 & 4.85 & 5.1764 & TRN & \\
\hline CHEMBL1444539 & 688422 & 4.5 & 4.985 & TRN & \\
\hline CHEMBL 1567910 & 688422 & 5.75 & 5.1436 & TRN & \\
\hline CHEMBL1379298 & 688422 & 7.9508 & 5.6875 & TST & \\
\hline CHEMBL3199161 & 688422 & 5.1 & 4.7795 & TRN & \\
\hline CHEMBL1321447 & 688422 & 4.6 & 4.9896 & TRN & \\
\hline CHEMBL1486846 & 688422 & 5.4 & 5.4494 & TST & \\
\hline CHEMBL1572196 & 688422 & 5.45 & 5.0087 & TRN & \\
\hline CHEMBL1328827 & 688422 & 4.45 & 4.8853 & TRN & \\
\hline CHEMBL1609264 & 688422 & 5.35 & 5.1612 & TRN & \\
\hline CHEMBL1358671 & 688422 & 4.75 & 4.8184 & TRN & \\
\hline CHEMBL1445937 & 688422 & 8.0506 & 5.5602 & TST & \\
\hline CHEMBL3197885 & 688422 & 4.85 & 4.9562 & TRN & \\
\hline CHEMBL1426594 & 688422 & 4.95 & 5.0469 & TRN & \\
\hline CHEMBL1442998 & 688422 & 4.8 & 5.2425 & TRN & \\
\hline CHEMBL1370928 & 688422 & 4.95 & 5.2688 & TRN & \\
\hline CHEMBL1321360 & 688422 & 8.4559 & 5.8068 & TST & \\
\hline CHEMBL1341775 & 688422 & 5.25 & 5.7843 & TST & \\
\hline CHEMBL1582769 & 688422 & 4.65 & 5.1734 & TST & \\
\hline CHEMBL75978 & 688422 & 4.85 & 5.2882 & TRN & \\
\hline
\end{tabular}




\begin{tabular}{|c|c|c|c|c|c|}
\hline \multicolumn{6}{|c|}{ Supplemental Table s2.txt } \\
\hline CHEMBL1440258 & 688422 & 4.9 & 5.1333 & TRN & \\
\hline CHEMBL1396942 & 688422 & 4.8 & 5.7928 & TRN & \\
\hline CHEMBL468018 & 688422 & 4.9 & 4.649 & TRN & \\
\hline CHEMBL1442383 & 688422 & 4.85 & 5.2321 & TST & \\
\hline CHEMBL1365560 & 688422 & 4.55 & 5.3429 & TRN & \\
\hline CHEMBL3207702 & 688422 & 4.8 & 5.3071 & TRN & \\
\hline CHEMBL1375376 & 688422 & 4.55 & 4.7017 & TRN & \\
\hline CHEMBL1487258 & 688422 & 4.95 & 4.8281 & TRN & \\
\hline CHEMBL1528234 & 688422 & 4.7 & 5.2304 & TST & \\
\hline CHEMBL1496728 & 688422 & 8.4949 & 5.4913 & TRN & \\
\hline CHEMBL1379254 & 688422 & 4.45 & 5.3834 & TRN & \\
\hline CHEMBL1309164 & 688422 & 5.75 & 4.9022 & TRN & \\
\hline CHEMBL1425696 & 688422 & 4.9 & 5.1469 & TRN & \\
\hline CHEMBL1576031 & 688422 & 4.6 & 5.2793 & TST & \\
\hline CHEMBL1495150 & 688422 & 4.9 & 5.0351 & TRN & \\
\hline CHEMBL1503935 & 688422 & 6.0 & 5.2587 & TST & \\
\hline CHEMBL1496095 & 688422 & 4.5 & 5.1778 & TRN & \\
\hline CHEMBL1499306 & 688422 & 4.45 & 5.2307 & TRN & \\
\hline CHEMBL1353778 & 688422 & 4.9 & 5.67700 & 00000000005 & TRN \\
\hline CHEMBL1321212 & 688422 & 7.699 & 5.6956 & TRN & \\
\hline CHEMBL60718 & 688422 & 6.0 & 4.9933 & TRN & \\
\hline CHEMBL1528245 & 688422 & 4.65 & 5.4249 & TRN & \\
\hline CHEMBL3192019 & 688422 & 4.6 & 5.1639 & TRN & \\
\hline CHEMBL1512023 & 688422 & 5.0 & 5.0902 & TRN & \\
\hline CHEMBL1334733 & 688422 & 5.1 & 5.2889 & TST & \\
\hline CHEMBL1387990 & 688422 & 4.95 & 5.1529 & TRN & \\
\hline CHEMBL1498146 & 688422 & 4.75 & 4.8745 & TRN & \\
\hline CHEMBL1402623 & 688422 & 4.5 & 4.978 & TRN & \\
\hline CHEMBL1482228 & 688422 & 7.15 & 5.3602 & TRN & \\
\hline CHEMBL16105 & 688422 & 6.0 & 5.9173 & TST & \\
\hline CHEMBL1594456 & 688422 & 4.9 & 5.2493 & TRN & \\
\hline CHEMBL1546866 & 688422 & 4.6 & 4.9384 & TRN & \\
\hline CHEMBL1457436 & 688422 & 5.65 & 5.4686 & TRN & \\
\hline CHEMBL1428636 & 688422 & 4.45 & 4.7436 & TRN & \\
\hline CHEMBL1521239 & 688422 & 4.45 & 5.3362 & TST & \\
\hline CHEMBL1503254 & 688422 & 6.1 & 4.8552 & TRN & \\
\hline CHEMBL1436784 & 688422 & 4.8 & 4.9952 & TRN & \\
\hline CHEMBL1602802 & 688422 & 4.75 & 4.9364 & TRN & \\
\hline CHEMBL1329564 & 688422 & 6.5501 & 5.1849 & TRN & \\
\hline CHEMBL1557584 & 688422 & 5.25 & 4.8596 & TRN & \\
\hline CHEMBL1478041 & 688422 & 5.55 & 5.5824 & TRN & \\
\hline CHEMBL1609242 & 688422 & 4.7 & 5.0724 & TST & \\
\hline CHEMBL1381761 & 688422 & 6.7501 & 5.1916 & TRN & \\
\hline CHEMBL1571835 & 688422 & 5.15 & 5.5443 & TST & \\
\hline CHEMBL1309483 & 688422 & 4.9 & 4.7663 & TRN & \\
\hline CHEMBL1347688 & 688422 & 7.1002 & 5.3861 & TST & \\
\hline CHEMBL1486101 & 688422 & 4.95 & 5.428 & TRN & \\
\hline CHEMBL1546643 & 688422 & 4.45 & 5.1888 & TRN & \\
\hline
\end{tabular}




\begin{tabular}{|c|c|c|c|c|c|}
\hline \multicolumn{6}{|c|}{ Supplemental Table S2.txt } \\
\hline CHEMBL1368619 & 688422 & 4.5 & 5.5781 & TST & \\
\hline CHEMBL1467655 & 688422 & 4.9 & 4.9206 & TRN & \\
\hline CHEMBL1482490 & 688422 & 5.2 & 5.2251 & TRN & \\
\hline CHEMBL1585100 & 688422 & 5.05 & 4.8328 & TRN & \\
\hline CHEMBL1479467 & 688422 & 5.3 & 5.1205 & TRN & \\
\hline CHEMBL1560445 & 688422 & 5.0 & 5.228 & TRN & \\
\hline CHEMBL1472922 & 688422 & 4.75 & 5.1363 & TRN & \\
\hline CHEMBL1442203 & 688422 & 7.0 & 4.9172 & TRN & \\
\hline CHEMBL1579788 & 688422 & 4.5 & 5.1775 & TRN & \\
\hline CHEMBL1308168 & 688422 & 4.9 & 4.7466 & TRN & \\
\hline CHEMBL1459187 & 688422 & 5.25 & 5.3476 & TRN & \\
\hline CHEMBL1366480 & 688422 & 4.9 & 5.7496 & TRN & \\
\hline CHEMBL3209871 & 688422 & 6.1 & 5.2419 & TST & \\
\hline CHEMBL1301321 & 688422 & 4.45 & 5.5456 & TST & \\
\hline CHEMBL1301558 & 688422 & 4.85 & 5.3193 & TST & \\
\hline CHEMBL3192203 & 688422 & 6.15 & 4.8691 & TRN & \\
\hline CHEMBL1317841 & 688422 & 7.0501 & 5.4301 & TRN & \\
\hline CHEMBL1441761 & 688422 & 4.85 & 5.1747 & TRN & \\
\hline CHEMBL1330405 & 688422 & 7.8013 & 5.1536 & TST & \\
\hline CHEMBL 3210692 & 688422 & 4.85 & 5.2565 & TRN & \\
\hline CHEMBL1533270 & 688422 & 5.6 & 5.3497 & TRN & \\
\hline CHEMBL1555804 & 688422 & 7.4001 & 5.3079 & TRN & \\
\hline CHEMBL1415798 & 688422 & 4.8 & 4.9839 & TRN & \\
\hline CHEMBL1170485 & 688422 & 5.45 & 5.3212 & TST & \\
\hline CHEMBL1569126 & 688422 & 5.15 & 4.8163 & TRN & \\
\hline CHEMBL1338857 & 688422 & 4.5 & 5.1362 & TRN & \\
\hline CHEMBL1324783 & 688422 & 4.75 & 5.3557 & TRN & \\
\hline CHEMBL1347052 & 688422 & 4.8 & 5.046 & TRN & \\
\hline CHEMBL1543235 & 688422 & 4.45 & 5.3874 & TRN & \\
\hline CHEMBL1486836 & 688422 & 5.35 & 5.36299 & 99999999995 & TRN \\
\hline CHEMBL1415790 & 688422 & 4.75 & 4.6998 & TRN & \\
\hline CHEMBL1480367 & 688422 & 4.85 & 5.1562 & TRN & \\
\hline CHEMBL1318070 & 688422 & 8.4949 & 5.6712 & TRN & \\
\hline CHEMBL1587981 & 688422 & 4.9 & 5.1239 & TRN & \\
\hline CHEMBL1377902 & 688422 & 5.4 & 5.1281 & TRN & \\
\hline CHEMBL1453125 & 688422 & 5.0 & 5.2026 & TST & \\
\hline CHEMBL1398779 & 688422 & 4.45 & 5.6731 & TRN & \\
\hline CHEMBL1312328 & 688422 & 4.7 & 5.0826 & TRN & \\
\hline CHEMBL1301069 & 688422 & 4.8 & 5.0946 & TRN & \\
\hline CHEMBL1399166 & 688422 & 5.95 & 5.7641 & TRN & \\
\hline CHEMBL1379100 & 688422 & 5.2 & 5.4323 & TRN & \\
\hline CHEMBL1972651 & 688422 & 4.65 & 5.3795 & TRN & \\
\hline CHEMBL1370361 & 688422 & 5.25 & 5.2816 & TRN & \\
\hline CHEMBL1454464 & 688422 & 4.9 & 5.2719 & TRN & \\
\hline CHEMBL1600144 & 688422 & 4.6 & 5.1067 & TRN & \\
\hline CHEMBL1342146 & 688422 & 8.301 & 5.5196 & TRN & \\
\hline CHEMBL1566405 & 688422 & 4.5 & 4.8199 & TST & \\
\hline CHEMBL1347108 & 688422 & 8.4559 & 4.9481 & TST & \\
\hline
\end{tabular}




\begin{tabular}{|c|c|c|c|c|c|}
\hline \multicolumn{6}{|c|}{ Supplemental Table S2.txt } \\
\hline CHEMBL1522605 & 688422 & 6.5 & 5.5213 & TST & \\
\hline CHEMBL1529058 & 688422 & 4.65 & 5.0729 & TRN & \\
\hline CHEMBL1365047 & 688422 & 4.85 & 5.4231 & TRN & \\
\hline CHEMBL1340706 & 688422 & 4.45 & 5.3187 & TRN & \\
\hline CHEMBL1335273 & 688422 & 5.7 & 4.7926 & TRN & \\
\hline CHEMBL1421004 & 688422 & 4.5 & 4.9702 & TRN & \\
\hline CHEMBL3194167 & 688422 & 4.45 & 5.1025 & TRN & \\
\hline CHEMBL1538504 & 688422 & 4.45 & 5.3785 & TRN & \\
\hline CHEMBL1315145 & 688422 & 4.95 & 4.9534 & TRN & \\
\hline CHEMBL1580507 & 688422 & 7.8996 & 5.141 & TRN & \\
\hline CHEMBL1405957 & 688422 & 4.95 & 5.4088 & TRN & \\
\hline CHEMBL1343165 & 688422 & 4.95 & 5.0625 & TRN & \\
\hline CHEMBL1472513 & 688422 & 4.45 & 5.3567 & TRN & \\
\hline CHEMBL1350313 & 688422 & 5.05 & 5.4058 & TRN & \\
\hline CHEMBL1078384 & 688422 & 6.0 & 5.4686 & TST & \\
\hline CHEMBL1575034 & 688422 & 5.6 & 4.9972 & TRN & \\
\hline CHEMBL1613331 & 688422 & 4.45 & 5.25899 & 99999999995 & TRN \\
\hline CHEMBL1477244 & 688422 & 4.45 & 5.1779 & TRN & \\
\hline CHEMBL1477392 & 688422 & 4.75 & 5.6839 & TST & \\
\hline CHEMBL1424623 & 688422 & 4.45 & 4.6977 & TRN & \\
\hline CHEMBL1381491 & 688422 & 4.65 & 5.2833 & TRN & \\
\hline CHEMBL1486500 & 688422 & 4.45 & 5.3183 & TRN & \\
\hline CHEMBL1501274 & 688422 & 4.55 & 5.6629 & TST & \\
\hline CHEMBL1445211 & 688422 & 5.55 & 4.8434 & TST & \\
\hline CHEMBL1301109 & 688422 & 4.5 & 5.3455 & TST & \\
\hline CHEMBL1317891 & 688422 & 5.55 & 5.1448 & TRN & \\
\hline CHEMBL1485393 & 688422 & 4.45 & 5.6325 & TRN & \\
\hline CHEMBL1405838 & 688422 & 4.75 & 5.0124 & TRN & \\
\hline CHEMBL1510017 & 688422 & 8.301 & 5.4973 & TST & \\
\hline CHEMBL3198595 & 688422 & 4.9 & 4.8482 & TRN & \\
\hline CHEMBL1592452 & 688422 & 5.1 & 4.8106 & TRN & \\
\hline CHEMBL1500939 & 688422 & 4.8 & 5.3468 & TRN & \\
\hline CHEMBL1521846 & 688422 & 4.4 & 5.1766 & TRN & \\
\hline CHEMBL1573605 & 688422 & 4.9 & 4.8745 & TRN & \\
\hline CHEMBL1392754 & 688422 & 4.85 & 4.9475 & TRN & \\
\hline CHEMBL1445230 & 688422 & 4.65 & 5.1213 & TRN & \\
\hline CHEMBL1606130 & 688422 & 4.7 & 4.9786 & TRN & \\
\hline CHEMBL1582640 & 688422 & 4.95 & 5.2477 & TRN & \\
\hline CHEMBL1536469 & 688422 & 4.45 & 5.3187 & TRN & \\
\hline CHEMBL1346860 & 688422 & 4.45 & 4.5377 & TRN & \\
\hline CHEMBL1538225 & 688422 & 6.7501 & 5.7346 & TRN & \\
\hline CHEMBL1481294 & 688422 & 4.85 & 5.1744 & TRN & \\
\hline CHEMBL1452934 & 688422 & 4.9 & 5.1979 & TRN & \\
\hline CHEMBL1462817 & 688422 & 4.95 & 5.5719 & TRN & \\
\hline CHEMBL1437730 & 688422 & 4.45 & 5.3509 & TRN & \\
\hline CHEMBL1516222 & 688422 & 7.4498 & 6.1248 & TRN & \\
\hline CHEMBL1424393 & 688422 & 5.35 & 5.1733 & TRN & \\
\hline CHEMBL1353620 & 688422 & 7.5498 & 5.4844 & TRN & \\
\hline
\end{tabular}




\begin{tabular}{|c|c|c|c|c|c|}
\hline \multicolumn{6}{|c|}{ Supplemental Table S2.txt } \\
\hline CHEMBL1554710 & 688422 & 5.15 & 5.7704 & TST & \\
\hline CHEMBL1571929 & 688422 & 5.1 & 6.0199 & TRN & \\
\hline CHEMBL1573677 & 688422 & 4.8 & 5.7691 & TRN & \\
\hline CHEMBL1502441 & 688422 & 4.45 & 5.1882 & TST & \\
\hline CHEMBL1537459 & 688422 & 6.05 & 5.2487 & TRN & \\
\hline CHEMBL1311676 & 688422 & 4.95 & 5.1244 & TRN & \\
\hline CHEMBL1455867 & 688422 & 5.65 & 5.6352 & TRN & \\
\hline CHEMBL1302339 & 688422 & 4.8 & 4.973 & TRN & \\
\hline CHEMBL1370957 & 688422 & 4.8 & 5.01 & TST & \\
\hline CHEMBL1415303 & 688422 & 4.65 & 5.42899 & 9999999999 & TRN \\
\hline CHEMBL1348410 & 688422 & 5.6 & 5.3326 & TRN & \\
\hline CHEMBL 3195842 & 688422 & 4.45 & 5.1573 & TST & \\
\hline CHEMBL1459341 & 688422 & 4.95 & 5.3695 & TRN & \\
\hline CHEMBL9666 & 688422 & 5.2 & 5.4854 & TRN & \\
\hline CHEMBL1304120 & 688422 & 4.75 & 5.3699 & TRN & \\
\hline CHEMBL1521843 & 688422 & 8.3979 & 5.2622 & TRN & \\
\hline CHEMBL1529031 & 688422 & 4.45 & 5.6537 & TRN & \\
\hline CHEMBL1376308 & 688422 & 4.9 & 5.3183 & TST & \\
\hline CHEMBL1591464 & 688422 & 6.8499 & 5.265 & TRN & \\
\hline CHEMBL1409443 & 688422 & 4.45 & 4.5468 & TRN & \\
\hline CHEMBL1448296 & 688422 & 4.75 & 5.2972 & TST & \\
\hline CHEMBL1570082 & 688422 & 4.95 & 5.2286 & TST & \\
\hline CHEMBL1383583 & 688422 & 5.5 & 5.3841 & TST & \\
\hline CHEMBL1416497 & 688422 & 4.9 & 4.6657 & TRN & \\
\hline CHEMBL1606279 & 688422 & 5.75 & 5.7866 & TST & \\
\hline CHEMBL1378485 & 688422 & 5.55 & 5.1249 & TST & \\
\hline CHEMBL1539430 & 688422 & 4.65 & 5.077 & TRN & \\
\hline CHEMBL1381778 & 688422 & 4.5 & 5.1405 & TRN & \\
\hline CHEMBL1348119 & 688422 & 5.2 & 5.1254 & TRN & \\
\hline CHEMBL1376892 & 688422 & 4.75 & 5.4178 & TRN & \\
\hline CHEMBL1529417 & 688422 & 5.55 & 4.8427 & TRN & \\
\hline CHEMBL1502462 & 688422 & 4.6 & 5.1379 & TST & \\
\hline CHEMBL1438939 & 688422 & 4.5 & 5.4593 & TRN & \\
\hline CHEMBL1547235 & 688422 & 4.45 & 5.402 & TRN & \\
\hline CHEMBL1358026 & 688422 & 6.95 & 5.1477 & TRN & \\
\hline CHEMBL1410281 & 688422 & 4.9 & 5.6035 & TRN & \\
\hline CHEMBL1506819 & 688422 & 4.85 & 5.0498 & TRN & \\
\hline CHEMBL1581425 & 688422 & 4.45 & 5.1122 & TST & \\
\hline CHEMBL1982308 & 688422 & 4.65 & 5.1213 & TRN & \\
\hline CHEMBL1605540 & 688422 & 5.05 & 5.064 & TRN & \\
\hline CHEMBL1598050 & 688422 & 7.6498 & 5.2573 & TRN & \\
\hline CHEMBL1411436 & 688422 & 4.9 & 5.3425 & TRN & \\
\hline CHEMBL1313863 & 688422 & 4.45 & 5.3942 & TST & \\
\hline CHEMBL1467885 & 688422 & 4.95 & 5.2215 & TRN & \\
\hline CHEMBL13647 & 688422 & 5.2 & 5.5925 & TST & \\
\hline CHEMBL1373146 & 688422 & 4.8 & 5.5069 & TRN & \\
\hline CHEMBL1587794 & 688422 & 4.85 & 5.0471 & TRN & \\
\hline CHEMBL1397115 & 688422 & 5.7 & 4.6829 & TRN & \\
\hline
\end{tabular}




\begin{tabular}{|c|c|c|c|c|c|}
\hline \\
\hline CHEMBL1581326 & 688422 & 6.0 & 5.4911 & TST & \\
\hline CHEMBL1585782 & 688422 & 4.45 & 4.9725 & TRN & \\
\hline CHEMBL1538342 & 688422 & 5.1 & 5.1881 & TRN & \\
\hline CHEMBL1431909 & 688422 & 4.95 & 5.6442 & TST & \\
\hline CHEMBL1397572 & 688422 & 7.699 & 5.3273 & TRN & \\
\hline CHEMBL1312569 & 688422 & 5.8 & 5.5619 & TST & \\
\hline CHEMBL1394997 & 688422 & 4.5 & 5.2542 & TRN & \\
\hline CHEMBL1449742 & 688422 & 4.9 & 5.3643 & TRN & \\
\hline CHEMBL1597522 & 688422 & 5.25 & 4.7861 & TST & \\
\hline CHEMBL1332355 & 688422 & 4.9 & 5.3906 & TRN & \\
\hline CHEMBL1349394 & 688422 & 4.45 & 4.8171 & TRN & \\
\hline CHEMBL1339538 & 688422 & 4.95 & 5.149 & TST & \\
\hline CHEMBL1478188 & 688422 & 7.0501 & 5.9816 & TST & \\
\hline CHEMBL1307086 & 688422 & 6.0 & 5.254 & TST & \\
\hline CHEMBL1409104 & 688422 & 4.9 & 5.2206 & TST & \\
\hline CHEMBL1470287 & 688422 & 4.9 & 5.4455 & TST & \\
\hline CHEMBL1442312 & 688422 & 5.25 & 5.04899 & 99999999995 & TRN \\
\hline CHEMBL1354561 & 688422 & 5.2 & 4.7543 & TRN & \\
\hline CHEMBL1552519 & 688422 & 5.25 & 4.8874 & TRN & \\
\hline CHEMBL1613215 & 688422 & 5.5 & 5.0262 & TRN & \\
\hline CHEMBL1479077 & 688422 & 4.85 & 5.0642 & TRN & \\
\hline CHEMBL1399936 & 688422 & 5.25 & 5.5538 & TRN & \\
\hline CHEMBL1411001 & 688422 & 4.8 & 4.8182 & TRN & \\
\hline CHEMBL1436682 & 688422 & 5.75 & 5.0067 & TRN & \\
\hline CHEMBL1464984 & 688422 & 5.4 & 5.5068 & TRN & \\
\hline CHEMBL1309656 & 688422 & 4.65 & 5.2168 & TST & \\
\hline CHEMBL1306259 & 688422 & 4.65 & 5.1452 & TRN & \\
\hline CHEMBL1525725 & 688422 & 4.45 & 5.2061 & TRN & \\
\hline CHEMBL1310866 & 688422 & 4.4 & 5.403 & TST & \\
\hline CHEMBL1095276 & 688422 & 8.0506 & 5.4089 & TRN & \\
\hline CHEMBL1432848 & 688422 & 4.75 & 4.8364 & TRN & \\
\hline CHEMBL1326329 & 688422 & 4.45 & 5.3665 & TRN & \\
\hline CHEMBL1312478 & 688422 & 4.95 & 5.4645 & TRN & \\
\hline CHEMBL1482757 & 688422 & 4.75 & 5.0807 & TRN & \\
\hline CHEMBL1578163 & 688422 & 6.7501 & 5.3537 & TRN & \\
\hline CHEMBL1480313 & 688422 & 4.5 & 5.4134 & TST & \\
\hline CHEMBL1402711 & 688422 & 4.85 & 5.2759 & TRN & \\
\hline CHEMBL3189717 & 688422 & 4.85 & 5.2738 & TST & \\
\hline CHEMBL1299760 & 688422 & 4.7 & 4.8529 & TRN & \\
\hline CHEMBL 2002150 & 688422 & 4.45 & 5.4896 & TRN & \\
\hline CHEMBL1421677 & 688422 & 6.45 & 5.3701 & TST & \\
\hline CHEMBL1439858 & 688422 & 7.9508 & 5.7264 & TRN & \\
\hline CHEMBL1353755 & 688422 & 8.4949 & 5.2502 & TST & \\
\hline CHEMBL1380365 & 688422 & 4.45 & 5.2037 & TRN & \\
\hline CHEMBL1576643 & 688422 & 5.8 & $5.23600 t$ & 0000000001 & TRN \\
\hline CHEMBL1433092 & 688422 & 5.75 & 5.63 & TRN & \\
\hline CHEMBL1352589 & 688422 & 4.9 & 5.1182 & TST & \\
\hline CHEMBL1541186 & 688422 & 5.25 & 4.7986 & TRN & \\
\hline
\end{tabular}




\begin{tabular}{|c|c|c|c|c|}
\hline \multicolumn{5}{|c|}{ Supplemental Table S2.txt } \\
\hline CHEMBL3195229 & 688422 & 4.75 & 4.8837 & TRN \\
\hline CHEMBL1542702 & 688422 & 4.95 & 5.4518 & TRN \\
\hline CHEMBL1545695 & 688422 & 5.2 & 4.9298 & TRN \\
\hline CHEMBL1605753 & 688422 & 4.95 & 5.1417 & TRN \\
\hline CHEMBL1374899 & 688422 & 4.8 & 5.4187 & TRN \\
\hline CHEMBL1994268 & 688422 & 4.85 & 5.4043 & TRN \\
\hline CHEMBL1543896 & 688422 & 5.85 & 5.4918 & TST \\
\hline CHEMBL1505567 & 688422 & 4.95 & 5.1982 & TRN \\
\hline CHEMBL1557345 & 688422 & 5.2 & 5.3924 & TRN \\
\hline CHEMBL3211055 & 688422 & 6.4 & 5.1553 & TRN \\
\hline CHEMBL1429372 & 688422 & 4.85 & 5.519 & TRN \\
\hline CHEMBL1305276 & 688422 & 4.45 & 4.8344 & TRN \\
\hline CHEMBL1542048 & 688422 & 7.2503 & 5.2091 & TRN \\
\hline CHEMBL1445117 & 688422 & 8.301 & 5.2204 & TRN \\
\hline CHEMBL1520485 & 688422 & 4.8 & 5.1646 & TRN \\
\hline CHEMBL3198921 & 688422 & 4.9 & 5.2755 & TST \\
\hline CHEMBL111750 & 688422 & 5.95 & 5.2323 & TRN \\
\hline CHEMBL1992382 & 688422 & 4.45 & 5.6275 & TRN \\
\hline CHEMBL1518722 & 688422 & 5.4 & 5.532 & TST \\
\hline CHEMBL1510060 & 688422 & 5.4 & 5.2482 & TST \\
\hline CHEMBL2136569 & 688422 & 4.75 & 5.0804 & TRN \\
\hline CHEMBL1496379 & 688422 & 5.35 & 5.2627 & TRN \\
\hline CHEMBL1340089 & 688422 & 5.0 & 5.0383 & TRN \\
\hline CHEMBL1470997 & 688422 & 4.5 & 5.1522 & TRN \\
\hline CHEMBL1559236 & 688422 & 4.9 & 4.875 & TST \\
\hline CHEMBL1232207 & 688422 & 4.45 & 6.3774 & TRN \\
\hline CHEMBL1466341 & 688422 & 5.25 & 5.33899 & 99999999995 \\
\hline CHEMBL1458660 & 688422 & 4.45 & 5.0228 & TRN \\
\hline CHEMBL1517587 & 688422 & 6.35 & 5.171 & TRN \\
\hline CHEMBL1520005 & 688422 & 5.55 & 4.9603 & TRN \\
\hline CHEMBL1458840 & 688422 & 5.0 & 4.918 & TST \\
\hline CHEMBL1517752 & 688422 & 5.25 & 5.0483 & TRN \\
\hline CHEMBL1611222 & 688422 & 4.45 & 5.2573 & TRN \\
\hline CHEMBL1504520 & 688422 & 4.85 & 5.1291 & TRN \\
\hline CHEMBL1544002 & 688422 & 4.9 & 5.3086 & TST \\
\hline CHEMBL1498574 & 688422 & 5.25 & 4.8162 & TRN \\
\hline CHEMBL1428181 & 688422 & 4.65 & 4.9431 & TRN \\
\hline CHEMBL1453777 & 688422 & 4.9 & 4.6532 & TRN \\
\hline CHEMBL1443659 & 688422 & 5.5 & 5.4366 & TRN \\
\hline CHEMBL1363584 & 688422 & 8.1024 & 5.3159 & TST \\
\hline CHEMBL1348940 & 688422 & 4.95 & 5.0041 & TRN \\
\hline CHEMBL1452333 & 688422 & 4.8 & 5.0984 & TRN \\
\hline CHEMBL1549606 & 688422 & 4.9 & 5.0554 & TRN \\
\hline CHEMBL1457550 & 688422 & 7.1002 & 5.3143 & TST \\
\hline CHEMBL1578315 & 688422 & 4.8 & 5.7477 & TST \\
\hline CHEMBL1381685 & 688422 & 7.9508 & 5.1821 & TST \\
\hline CHEMBL1421559 & 688422 & 5.35 & 4.5994 & TRN \\
\hline CHEMBL1439001 & 688422 & 8.301 & 5.3125 & TRN \\
\hline
\end{tabular}




\begin{tabular}{|c|c|c|c|c|c|}
\hline \multicolumn{6}{|c|}{ Supplemental Table s2.txt } \\
\hline CHEMBL1450266 & 688422 & 5.1 & 5.5091 & TRN & \\
\hline CHEMBL1321384 & 688422 & 6.3 & 5.5156 & TRN & \\
\hline CHEMBL1411784 & 688422 & 4.95 & 5.523 & TRN & \\
\hline CHEMBL1571335 & 688422 & 5.1 & 5.3418 & TRN & \\
\hline CHEMBL1390139 & 688422 & 4.6 & 4.8434 & TRN & \\
\hline CHEMBL1540987 & 688422 & 4.6 & 5.4514 & TRN & \\
\hline CHEMBL1342887 & 688422 & 5.3 & 5.7612 & TST & \\
\hline CHEMBL1554486 & 688422 & 4.8 & 6.0149 & TRN & \\
\hline CHEMBL1322633 & 688422 & 4.45 & 5.0433 & TRN & \\
\hline CHEMBL1310381 & 688422 & 4.7 & 5.012 & TST & \\
\hline CHEMBL1373122 & 688422 & 5.7 & 5.5018 & TST & \\
\hline CHEMBL1521023 & 688422 & 5.0 & 5.4773 & TRN & \\
\hline CHEMBL1336745 & 688422 & 4.7 & 5.3655 & TRN & \\
\hline CHEMBL1543875 & 688422 & 5.35 & 4.7633 & TRN & \\
\hline CHEMBL1356737 & 688422 & 5.35 & 5.5858 & TST & \\
\hline CHEMBL1459273 & 688422 & 4.9 & 4.9172 & TRN & \\
\hline CHEMBL1467476 & 688422 & 4.75 & 5.6453 & TRN & \\
\hline CHEMBL1466708 & 688422 & 4.8 & 5.033 & TRN & \\
\hline CHEMBL1477101 & 688422 & 5.35 & 5.3984 & TRN & \\
\hline CHEMBL1429370 & 688422 & 6.0 & 5.0474 & TRN & \\
\hline CHEMBL1393390 & 688422 & 4.45 & 5.1562 & TST & \\
\hline CHEMBL1458776 & 688422 & 5.35 & 5.0058 & TST & \\
\hline CHEMBL1524766 & 688422 & 4.65 & 5.0913 & TRN & \\
\hline CHEMBL1507351 & 688422 & 6.15 & 5.7014 & TST & \\
\hline CHEMBL3211296 & 688422 & 4.45 & 5.49700 & 0000000001 & TRN \\
\hline CHEMBL1361675 & 688422 & 4.45 & 5.1447 & TRN & \\
\hline CHEMBL1590617 & 688422 & 6.25 & 5.2401 & TRN & \\
\hline CHEMBL1537584 & 688422 & 4.8 & 5.1049 & TRN & \\
\hline CHEMBL15968 & 688422 & 5.55 & 5.4642 & TRN & \\
\hline CHEMBL1561861 & 688422 & 5.0 & 4.7249 & TRN & \\
\hline CHEMBL1323355 & 688422 & 4.85 & 5.2073 & TRN & \\
\hline CHEMBL1515844 & 688422 & 8.0506 & 5.3356 & TST & \\
\hline CHEMBL1353349 & 688422 & 4.75 & 5.6749 & TRN & \\
\hline CHEMBL1392681 & 688422 & 4.45 & 5.0329 & TRN & \\
\hline CHEMBL1612873 & 688422 & 4.45 & 5.1706 & TRN & \\
\hline CHEMBL1501762 & 688422 & 4.5 & 5.311 & TRN & \\
\hline CHEMBL1491401 & 688422 & 7.699 & 5.2576 & TST & \\
\hline CHEMBL3190016 & 688422 & 4.75 & 5.2401 & TRN & \\
\hline CHEMBL1522947 & 688422 & 4.9 & 5.0324 & TRN & \\
\hline CHEMBL590927 & 688422 & 5.2 & 5.4993 & TRN & \\
\hline CHEMBL1344988 & 688422 & 4.8 & 5.0277 & TRN & \\
\hline CHEMBL1890161 & 688422 & 4.9 & 5.539 & TRN & \\
\hline CHEMBL1373256 & 688422 & 5.4 & 4.9668 & TRN & \\
\hline CHEMBL1965384 & 688422 & 5.25 & 5.3365 & TST & \\
\hline CHEMBL1313087 & 688422 & 4.95 & 5.0449 & TRN & \\
\hline CHEMBL3193378 & 688422 & 4.95 & 5.4959 & TRN & \\
\hline CHEMBL1452542 & 688422 & 5.1 & 5.4357 & TRN & \\
\hline CHEMBL490706 & 688422 & 4.95 & 4.6384 & TRN & \\
\hline
\end{tabular}




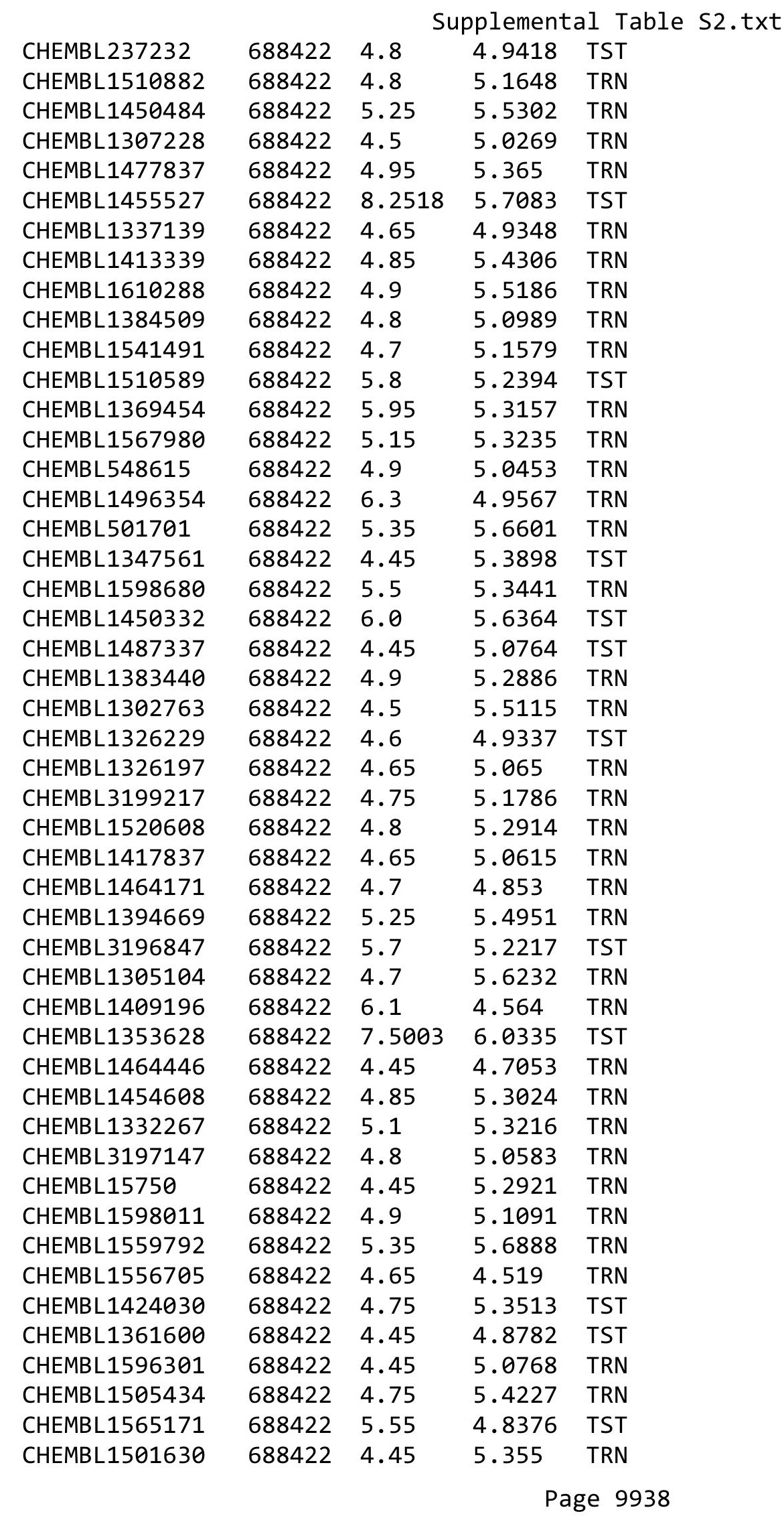




\begin{tabular}{|c|c|c|c|c|c|}
\hline \multicolumn{6}{|c|}{ Supplemental Table S2.txt } \\
\hline CHEMBL1379817 & 688422 & 4.45 & 4.7231 & TRN & \\
\hline CHEMBL3210626 & 688422 & 4.65 & 4.9734 & TRN & \\
\hline CHEMBL1539307 & 688422 & 4.9 & 4.8268 & TST & \\
\hline CHEMBL1525064 & 688422 & 4.75 & 5.2462 & TST & \\
\hline CHEMBL1379991 & 688422 & 4.7 & 4.7144 & TST & \\
\hline CHEMBL1495906 & 688422 & 4.45 & 5.1182 & TRN & \\
\hline CHEMBL3196849 & 688422 & 4.9 & 5.2149 & TST & \\
\hline CHEMBL1447075 & 688422 & 4.75 & 5.7236 & TRN & \\
\hline CHEMBL1500816 & 688422 & 4.8 & 5.0929 & TRN & \\
\hline CHEMBL1349359 & 688422 & 5.25 & 5.5673 & TST & \\
\hline CHEMBL1446389 & 688422 & 4.45 & 5.2209 & TRN & \\
\hline CHEMBL1537449 & 688422 & 6.5 & 5.334 & TRN & \\
\hline CHEMBL1606396 & 688422 & 4.65 & 5.2293 & TST & \\
\hline CHEMBL1342398 & 688422 & 5.1 & 5.1156 & TRN & \\
\hline CHEMBL1538117 & 688422 & 5.35 & 5.57799 & 9999999999 & TRN \\
\hline CHEMBL1580031 & 688422 & 5.0 & 5.3359 & TRN & \\
\hline CHEMBL1602895 & 688422 & 6.6499 & 4.6953 & TST & \\
\hline CHEMBL1381593 & 688422 & 4.65 & 5.4263 & TRN & \\
\hline CHEMBL1497884 & 688422 & 4.85 & 5.3373 & TRN & \\
\hline CHEMBL1599786 & 688422 & 4.95 & 5.0845 & TRN & \\
\hline CHEMBL1450225 & 688422 & 5.0 & 5.0674 & TRN & \\
\hline CHEMBL1998118 & 688422 & 4.95 & 5.1589 & TRN & \\
\hline CHEMBL1364260 & 688422 & 4.5 & 5.4478 & TST & \\
\hline CHEMBL1449366 & 688422 & 4.9 & 5.1824 & TRN & \\
\hline CHEMBL1594941 & 688422 & 6.3 & 5.3356 & TST & \\
\hline CHEMBL1398656 & 688422 & 5.25 & 5.6635 & TST & \\
\hline CHEMBL1488162 & 688422 & 7.6498 & 5.6092 & TRN & \\
\hline CHEMBL1438908 & 688422 & 4.5 & 5.1055 & TRN & \\
\hline CHEMBL1568352 & 688422 & 4.85 & 5.8821 & TRN & \\
\hline CHEMBL 1467740 & 688422 & 4.45 & 5.7012 & TRN & \\
\hline CHEMBL1577618 & 688422 & 6.8499 & 5.5468 & TRN & \\
\hline CHEMBL1353783 & 688422 & 4.5 & 5.53600 & 00000000005 & TRN \\
\hline CHEMBL1452868 & 688422 & 5.6 & 5.522 & TRN & \\
\hline CHEMBL1371618 & 688422 & 4.7 & 5.3358 & TRN & \\
\hline CHEMBL1490452 & 688422 & 5.5 & 5.1474 & TRN & \\
\hline CHEMBL1510273 & 688422 & 4.8 & 5.5919 & TRN & \\
\hline CHEMBL1472561 & 688422 & 5.25 & 6.1979 & TST & \\
\hline CHEMBL1469086 & 688422 & 4.9 & 5.3311 & TST & \\
\hline CHEMBL1469357 & 688422 & 8.3979 & 5.1472 & TRN & \\
\hline CHEMBL1553692 & 688422 & 5.0 & 5.3907 & TRN & \\
\hline CHEMBL1578087 & 688422 & 4.45 & 4.9276 & TRN & \\
\hline CHEMBL3195713 & 688422 & 4.8 & 4.8069 & TRN & \\
\hline CHEMBL1491246 & 688422 & 4.8 & 5.0506 & TRN & \\
\hline CHEMBL1459910 & 688422 & 4.5 & 5.4354 & TRN & \\
\hline CHEMBL 3207590 & 688422 & 4.9 & 5.3517 & TRN & \\
\hline CHEMBL1554879 & 688422 & 6.8499 & 5.4317 & TST & \\
\hline CHEMBL1301968 & 688422 & 5.1 & 5.0907 & TRN & \\
\hline CHEMBL1550950 & 688422 & 6.8499 & 5.275 & TRN & \\
\hline
\end{tabular}




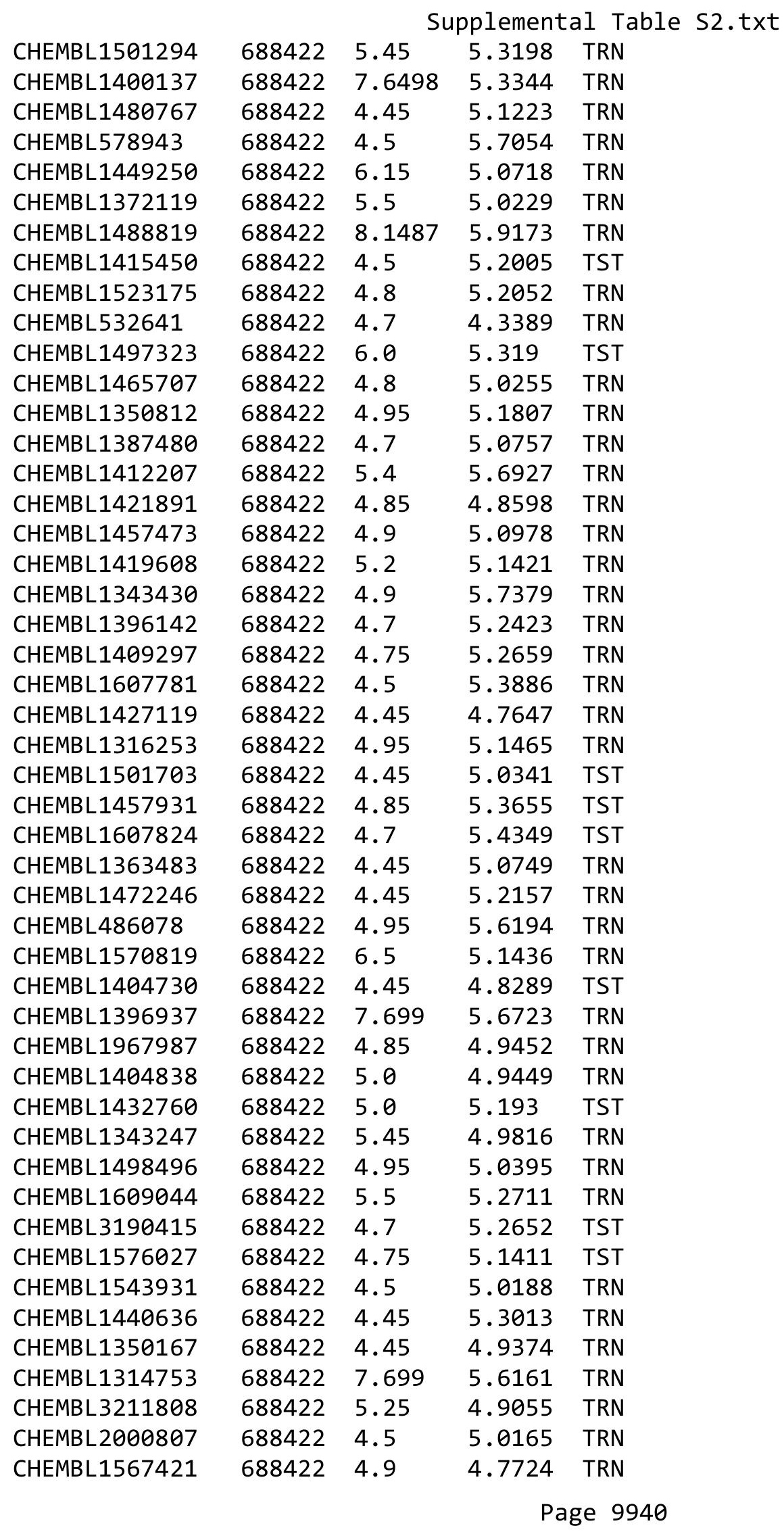




\begin{tabular}{|c|c|c|c|c|c|}
\hline \multicolumn{6}{|c|}{ Supplemental Table S2.txt } \\
\hline CHEMBL1521840 & 688422 & 4.85 & 5.4525 & TRN & \\
\hline CHEMBL1379190 & 688422 & 7.3002 & 5.3069 & TRN & \\
\hline CHEMBL1412091 & 688422 & 4.45 & 5.2647 & TRN & \\
\hline CHEMBL 3207437 & 688422 & 5.6 & 4.7091 & TST & \\
\hline CHEMBL1424944 & 688422 & 5.0 & 4.9695 & TRN & \\
\hline CHEMBL1434359 & 688422 & 5.25 & 5.3329 & TRN & \\
\hline CHEMBL1325495 & 688422 & 5.45 & 5.0468 & TRN & \\
\hline CHEMBL1567613 & 688422 & 4.95 & 5.3239 & TRN & \\
\hline CHEMBL1336107 & 688422 & 5.7 & 5.591 & TRN & \\
\hline CHEMBL1611948 & 688422 & 4.85 & 5.532 & TRN & \\
\hline CHEMBL1501472 & 688422 & 4.45 & 5.4207 & TRN & \\
\hline CHEMBL1457763 & 688422 & 4.95 & 5.2776 & TRN & \\
\hline CHEMBL1375509 & 688422 & 4.5 & 5.1871 & TRN & \\
\hline CHEMBL3198193 & 688422 & 7.5498 & 5.1657 & TST & \\
\hline CHEMBL1532651 & 688422 & 5.2 & 5.4345 & TRN & \\
\hline CHEMBL1510580 & 688422 & 4.45 & 5.1503 & TRN & \\
\hline CHEMBL1543977 & 688422 & 7.2503 & 5.2587 & TRN & \\
\hline CHEMBL1489189 & 688422 & 5.65 & 5.1777 & TST & \\
\hline CHEMBL1506505 & 688422 & 4.45 & 4.9812 & TST & \\
\hline CHEMBL1570382 & 688422 & 4.95 & 5.037 & TRN & \\
\hline CHEMBL1419104 & 688422 & 4.75 & 5.3691 & TST & \\
\hline CHEMBL1350981 & 688422 & 4.8 & 5.0852 & TRN & \\
\hline CHEMBL3190120 & 688422 & 6.0 & 5.70100 & 00000000005 & TRN \\
\hline CHEMBL1462243 & 688422 & 4.45 & 5.2371 & TST & \\
\hline CHEMBL1355145 & 688422 & 4.8 & 5.0278 & TRN & \\
\hline CHEMBL1425768 & 688422 & 6.4 & 5.1586 & TST & \\
\hline CHEMBL1526433 & 688422 & 5.05 & 5.3197 & TRN & \\
\hline CHEMBL602126 & 688422 & 5.65 & 5.3445 & TRN & \\
\hline CHEMBL1386804 & 688422 & 5.0 & 5.2366 & TRN & \\
\hline CHEMBL1460529 & 688422 & 5.55 & 5.0977 & TRN & \\
\hline CHEMBL1365634 & 688422 & 4.9 & 5.0645 & TRN & \\
\hline CHEMBL1378822 & 688422 & 5.1 & 5.1316 & TRN & \\
\hline CHEMBL1436022 & 688422 & 5.2 & 5.5461 & TRN & \\
\hline CHEMBL1560564 & 688422 & 4.95 & 5.1723 & TRN & \\
\hline CHEMBL1404424 & 688422 & 4.9 & 5.0885 & TRN & \\
\hline CHEMBL3197809 & 688422 & 8.3468 & 5.4309 & TRN & \\
\hline CHEMBL1536852 & 688422 & 4.45 & 5.2546 & TST & \\
\hline CHEMBL1372531 & 688422 & 5.25 & 5.4547 & TRN & \\
\hline CHEMBL1561768 & 688422 & 4.75 & 4.7205 & TRN & \\
\hline CHEMBL1402285 & 688422 & 7.5498 & 5.0547 & TST & \\
\hline CHEMBL1427825 & 688422 & 5.0 & 5.1389 & TRN & \\
\hline CHEMBL1591458 & 688422 & 4.95 & 5.3943 & TRN & \\
\hline CHEMBL1525771 & 688422 & 6.7001 & 5.3181 & TST & \\
\hline CHEMBL1348449 & 688422 & 4.45 & 5.4437 & TST & \\
\hline CHEMBL1612403 & 688422 & 4.85 & 5.3566 & TRN & \\
\hline CHEMBL1555258 & 688422 & 5.05 & 5.2029 & TRN & \\
\hline CHEMBL1473767 & 688422 & 6.7001 & 5.151 & TRN & \\
\hline CHEMBL1484158 & 688422 & 7.0501 & 5.5304 & TRN & \\
\hline
\end{tabular}




\begin{tabular}{|c|c|c|c|c|}
\hline & & & oplement & al Ta \\
\hline CHEMBL1494284 & 688422 & 7.699 & 5.5148 & TRN \\
\hline CHEMBL1530347 & 688422 & 6.95 & 4.9204 & TRN \\
\hline CHEMBL3196737 & 688422 & 4.65 & 5.3678 & TRN \\
\hline CHEMBL1355038 & 688422 & 4.8 & 5.1813 & TST \\
\hline CHEMBL1545681 & 688422 & 5.65 & 5.8972 & TST \\
\hline CHEMBL1548423 & 688422 & 4.9 & 5.0833 & TST \\
\hline CHEMBL1376135 & 688422 & 4.7 & 5.2772 & TRN \\
\hline CHEMBL1456416 & 688422 & 4.55 & 5.2115 & TRN \\
\hline CHEMBL1395948 & 688422 & 4.65 & 4.9112 & TRN \\
\hline CHEMBL1586726 & 688422 & 4.95 & 5.5593 & TST \\
\hline CHEMBL1605875 & 688422 & 5.3 & 4.7446 & TRN \\
\hline CHEMBL1447793 & 688422 & 4.65 & 5.0857 & TRN \\
\hline CHEMBL1494360 & 688422 & 4.5 & 5.4442 & TST \\
\hline CHEMBL1551523 & 688422 & 8.4949 & 6.0064 & TRN \\
\hline CHEMBL1446040 & 688422 & 4.85 & 5.682 & TST \\
\hline CHEMBL1587606 & 688422 & 4.85 & 4.8137 & TRN \\
\hline CHEMBL1568587 & 688422 & 4.65 & 4.8322 & TRN \\
\hline CHEMBL1491150 & 688422 & 4.7 & 5.3871 & TRN \\
\hline CHEMBL1585706 & 688422 & 4.6 & 4.841 & TRN \\
\hline CHEMBL1586513 & 688422 & 4.8 & 5.0213 & TRN \\
\hline CHEMBL1599659 & 688422 & 8.3468 & 5.4832 & TRN \\
\hline CHEMBL1347816 & 688422 & 4.8 & 4.9492 & TRN \\
\hline CHEMBL1508019 & 688422 & 4.45 & 5.5808 & TST \\
\hline CHEMBL1560557 & 688422 & 4.65 & 4.6517 & TST \\
\hline CHEMBL1381356 & 688422 & 7.0501 & 5.5085 & TST \\
\hline CHEMBL1365180 & 688422 & 6.8 & 5.8559 & TST \\
\hline CHEMBL1398981 & 688422 & 5.4 & 5.1912 & TRN \\
\hline CHEMBL1326781 & 688422 & 4.45 & 4.9727 & TRN \\
\hline CHEMBL1371842 & 688422 & 4.8 & 5.0415 & TRN \\
\hline CHEMBL1545472 & 688422 & 4.45 & 5.3173 & TST \\
\hline CHEMBL1549478 & 688422 & 8.4949 & 5.3253 & TRN \\
\hline CHEMBL1533442 & 688422 & 4.45 & 4.8214 & TRN \\
\hline CHEMBL1349410 & 688422 & 4.45 & 5.2322 & TRN \\
\hline CHEMBL1443270 & 688422 & 4.45 & 5.4581 & TST \\
\hline CHEMBL1414932 & 688422 & 5.05 & 5.065 & TRN \\
\hline CHEMBL1397974 & 688422 & 4.9 & 5.5335 & TRN \\
\hline CHEMBL1479438 & 688422 & 4.65 & 5.1331 & TRN \\
\hline CHEMBL1540365 & 688422 & 4.95 & 5.4003 & TST \\
\hline CHEMBL1379297 & 688422 & 4.9 & 5.1983 & TRN \\
\hline CHEMBL1407336 & 688422 & 4.75 & 5.2178 & TRN \\
\hline CHEMBL1506820 & 688422 & 5.35 & 4.8792 & TRN \\
\hline CHEMBL1553882 & 688422 & 5.5 & 5.5789 & TST \\
\hline CHEMBL1337343 & 688422 & 4.95 & 5.0506 & TRN \\
\hline CHEMBL1493441 & 688422 & 4.85 & 5.612 & TRN \\
\hline CHEMBL1490424 & 688422 & 4.6 & 5.0749 & TST \\
\hline CHEMBL1376416 & 688422 & 4.7 & 4.8774 & TRN \\
\hline CHEMBL1485228 & 688422 & 4.85 & 4.921 & TRN \\
\hline CHEMBL1488687 & 688422 & 5.35 & 5.0005 & TRN \\
\hline
\end{tabular}




\begin{tabular}{|c|c|c|c|c|c|}
\hline \multicolumn{6}{|c|}{ Supplemental Table S2.txt } \\
\hline CHEMBL1612187 & 688422 & 6.2 & 5.2977 & TRN & \\
\hline CHEMBL1540879 & 688422 & 4.85 & 5.1418 & TRN & \\
\hline CHEMBL1450205 & 688422 & 4.85 & 5.2213 & TRN & \\
\hline CHEMBL1578722 & 688422 & 4.9 & 5.0354 & TST & \\
\hline CHEMBL1326391 & 688422 & 4.65 & 5.9301 & TST & \\
\hline CHEMBL1587293 & 688422 & 4.85 & 5.37700 & 0000000001 & TRN \\
\hline CHEMBL1505305 & 688422 & 6.25 & 5.3606 & TST & \\
\hline CHEMBL3193098 & 688422 & 5.0 & 5.3967 & TRN & \\
\hline CHEMBL1467437 & 688422 & 4.65 & 5.335 & TRN & \\
\hline CHEMBL1302199 & 688422 & 8.4559 & 5.1022 & TRN & \\
\hline CHEMBL598688 & 688422 & 5.0 & 5.215 & TRN & \\
\hline CHEMBL3195422 & 688422 & 4.6 & 5.4437 & TRN & \\
\hline CHEMBL1609117 & 688422 & 4.7 & 4.6113 & TRN & \\
\hline CHEMBL1450435 & 688422 & 8.1024 & 5.3104 & TRN & \\
\hline CHEMBL1464768 & 688422 & 4.7 & 5.5882 & TST & \\
\hline CHEMBL1489597 & 688422 & 4.65 & 5.1161 & TRN & \\
\hline CHEMBL1497077 & 688422 & 6.0 & 5.3353 & TST & \\
\hline CHEMBL1427637 & 688422 & 4.8 & 5.1059 & TST & \\
\hline CHEMBL1353696 & 688422 & 4.8 & 5.193 & TRN & \\
\hline CHEMBL1413672 & 688422 & 4.6 & 4.6625 & TRN & \\
\hline CHEMBL1557714 & 688422 & 7.4498 & 4.88399 & 99999999995 & TRN \\
\hline CHEMBL1551841 & 688422 & 4.9 & 5.1834 & TRN & \\
\hline CHEMBL1986443 & 688422 & 5.1 & 5.2547 & TST & \\
\hline CHEMBL1543372 & 688422 & 4.6 & 5.3049 & TRN & \\
\hline CHEMBL1331786 & 688422 & 6.45 & 5.5464 & TST & \\
\hline CHEMBL1335867 & 688422 & 5.2 & 5.4899 & TST & \\
\hline CHEMBL1573144 & 688422 & 4.45 & 5.1213 & TRN & \\
\hline CHEMBL1510323 & 688422 & 6.1 & 5.2779 & TRN & \\
\hline CHEMBL1463919 & 688422 & 4.65 & 4.9768 & TRN & \\
\hline CHEMBL1421699 & 688422 & 4.5 & 5.3374 & TRN & \\
\hline CHEMBL1447270 & 688422 & 7.6498 & 5.0659 & TST & \\
\hline CHEMBL1307920 & 688422 & 4.45 & 5.2211 & TRN & \\
\hline CHEMBL1322756 & 688422 & 4.9 & 4.8691 & TRN & \\
\hline CHEMBL1589812 & 688422 & 5.25 & 5.2031 & TRN & \\
\hline CHEMBL1588544 & 688422 & 5.1 & 4.9748 & TST & \\
\hline CHEMBL1380468 & 688422 & 6.3 & 5.1126 & TRN & \\
\hline CHEMBL1314398 & 688422 & 6.05 & 5.4154 & TRN & \\
\hline CHEMBL1466636 & 688422 & 4.6 & 4.8975 & TST & \\
\hline CHEMBL1317996 & 688422 & 5.55 & 5.6947 & TST & \\
\hline CHEMBL1306215 & 688422 & 6.5501 & 5.0217 & TRN & \\
\hline CHEMBL1424608 & 688422 & 8.301 & 5.7081 & TRN & \\
\hline CHEMBL1575340 & 688422 & 4.9 & 5.2093 & TST & \\
\hline CHEMBL1368641 & 688422 & 4.45 & 5.7277 & TRN & \\
\hline CHEMBL1313885 & 688422 & 4.45 & 4.5957 & TRN & \\
\hline CHEMBL1543858 & 688422 & 5.55 & 5.2038 & TRN & \\
\hline CHEMBL1492446 & 688422 & 4.75 & 5.3035 & TRN & \\
\hline CHEMBL1336605 & 688422 & 4.5 & 5.2399 & TRN & \\
\hline CHEMBL1513669 & 688422 & 4.75 & 4.6451 & TRN & \\
\hline
\end{tabular}




\begin{tabular}{|c|c|c|c|c|c|}
\hline \multicolumn{6}{|c|}{ Supplemental Table s2.txt } \\
\hline CHEMBL1566876 & 688422 & 4.75 & 5.6572 & TRN & \\
\hline CHEMBL1317052 & 688422 & 6.8 & 5.0599 & TRN & \\
\hline CHEMBL60518 & 688422 & 8.3468 & 5.4169 & TRN & \\
\hline CHEMBL1530282 & 688422 & 4.8 & 5.0864 & TRN & \\
\hline CHEMBL1528656 & 688422 & 4.5 & 4.81 & TST & \\
\hline CHEMBL1508274 & 688422 & 5.65 & 5.11600 & 00000000005 & TRN \\
\hline CHEMBL601119 & 688422 & 4.95 & 5.1797 & TRN & \\
\hline CHEMBL1610509 & 688422 & 4.6 & 5.6916 & TRN & \\
\hline CHEMBL 1415712 & 688422 & 4.45 & 5.3235 & TRN & \\
\hline CHEMBL1465684 & 688422 & 4.45 & 5.8732 & TST & \\
\hline CHEMBL1443667 & 688422 & 6.35 & 5.1828 & TRN & \\
\hline CHEMBL1600976 & 688422 & 6.4 & 5.2148 & TST & \\
\hline CHEMBL1472147 & 688422 & 5.45 & 5.1994 & TRN & \\
\hline CHEMBL1303668 & 688422 & 4.95 & 4.9634 & TRN & \\
\hline CHEMBL1589797 & 688422 & 4.75 & 5.4674 & TST & \\
\hline CHEMBL1729277 & 688422 & 6.5 & 5.1999 & TRN & \\
\hline CHEMBL1386554 & 688422 & 4.85 & 5.5997 & TRN & \\
\hline CHEMBL1468286 & 688422 & 4.45 & 5.5162 & TRN & \\
\hline CHEMBL1332864 & 688422 & 8.0 & 5.4156 & TRN & \\
\hline CHEMBL1427734 & 688422 & 4.75 & 4.96399 & 99999999995 & TRN \\
\hline CHEMBL1609569 & 688422 & 4.7 & 4.6614 & TRN & \\
\hline CHEMBL1431295 & 688422 & 4.8 & 5.1487 & TRN & \\
\hline CHEMBL1563319 & 688422 & 6.8499 & 5.2441 & TRN & \\
\hline CHEMBL1299806 & 688422 & 5.25 & 5.3534 & TRN & \\
\hline CHEMBL1443696 & 688422 & 5.1 & 5.45 & TRN & \\
\hline CHEMBL1592186 & 688422 & 4.85 & 4.8564 & TRN & \\
\hline CHEMBL1368819 & 688422 & 4.75 & 5.1283 & TST & \\
\hline CHEMBL1567944 & 688422 & 6.0 & 6.1716 & TST & \\
\hline CHEMBL1450461 & 688422 & 4.5 & 4.9143 & TRN & \\
\hline CHEMBL1317757 & 688422 & 4.95 & 5.2442 & TRN & \\
\hline CHEMBL1564991 & 688422 & 4.7 & 4.8152 & TST & \\
\hline CHEMBL1336054 & 688422 & 5.0 & 5.146 & TST & \\
\hline CHEMBL1575155 & 688422 & 4.45 & 5.129 & TRN & \\
\hline CHEMBL1311324 & 688422 & 4.45 & 5.087 & TRN & \\
\hline CHEMBL1437554 & 688422 & 4.45 & 5.1863 & TRN & \\
\hline CHEMBL1345852 & 688422 & 6.35 & 5.4599 & TST & \\
\hline CHEMBL1330018 & 688422 & 4.9 & 5.2358 & TRN & \\
\hline CHEMBL1402476 & 688422 & 6.1 & 5.5967 & TRN & \\
\hline CHEMBL1608932 & 688422 & 4.7 & 5.7752 & TRN & \\
\hline CHEMBL1561240 & 688422 & 4.9 & 4.7392 & TRN & \\
\hline CHEMBL1582010 & 688422 & 4.8 & 5.11600 & 00000000005 & TRN \\
\hline CHEMBL1581025 & 688422 & 4.7 & 5.2483 & TRN & \\
\hline CHEMBL1523994 & 688422 & 5.45 & 5.006 & TRN & \\
\hline CHEMBL1465172 & 688422 & 5.0 & 4.7343 & TRN & \\
\hline CHEMBL1307412 & 688422 & 7.0 & 5.3079 & TRN & \\
\hline CHEMBL3191927 & 688422 & 4.5 & 5.1249 & TRN & \\
\hline CHEMBL1396546 & 688422 & 5.65 & 5.8015 & TST & \\
\hline CHEMBL1334291 & 688422 & 5.05 & 5.3484 & TST & \\
\hline
\end{tabular}




\begin{tabular}{|c|c|c|c|c|c|}
\hline \multicolumn{6}{|c|}{ Supplemental Table S2.txt } \\
\hline CHEMBL1509574 & 688422 & 4.85 & 4.9359 & TRN & \\
\hline CHEMBL1522238 & 688422 & 5.25 & 4.8882 & TRN & \\
\hline CHEMBL3198070 & 688422 & 4.45 & 5.2912 & TST & \\
\hline CHEMBL1475709 & 688422 & 5.55 & 5.0988 & TRN & \\
\hline CHEMBL1311916 & 688422 & 5.75 & 5.2511 & TRN & \\
\hline CHEMBL1595580 & 688422 & 5.7 & 5.4711 & TRN & \\
\hline CHEMBL1325446 & 688422 & 4.65 & 5.0533 & TRN & \\
\hline CHEMBL1344061 & 688422 & 8.0506 & 5.3424 & TST & \\
\hline CHEMBL1317615 & 688422 & 5.5 & 5.5336 & TRN & \\
\hline CHEMBL1518995 & 688422 & 4.8 & 4.888 & TRN & \\
\hline CHEMBL1497715 & 688422 & 5.0 & 6.3073 & TRN & \\
\hline CHEMBL1301422 & 688422 & 4.75 & 5.6725 & TRN & \\
\hline CHEMBL1565685 & 688422 & 5.55 & 5.13200 & 0000000001 & TRN \\
\hline CHEMBL1555853 & 688422 & 4.95 & 5.0869 & TRN & \\
\hline CHEMBL1531822 & 688422 & 7.699 & 5.1749 & TRN & \\
\hline CHEMBL1366339 & 688422 & 4.95 & 5.5334 & TST & \\
\hline CHEMBL1348255 & 688422 & 7.15 & 5.5974 & TST & \\
\hline CHEMBL1534465 & 688422 & 4.95 & 5.2316 & TRN & \\
\hline CHEMBL1481086 & 688422 & 4.7 & 5.1105 & TRN & \\
\hline CHEMBL1445531 & 688422 & 4.85 & 4.9085 & TRN & \\
\hline CHEMBL1586875 & 688422 & 4.6 & 5.0201 & TST & \\
\hline CHEMBL1586957 & 688422 & 4.8 & 5.2737 & TRN & \\
\hline CHEMBL1305166 & 688422 & 4.85 & 4.7779 & TRN & \\
\hline CHEMBL3195880 & 688422 & 6.25 & 5.569 & TRN & \\
\hline CHEMBL1307381 & 688422 & 4.7 & 5.2679 & TRN & \\
\hline CHEMBL1330505 & 688422 & 5.0 & 5.0119 & TST & \\
\hline CHEMBL1528505 & 688422 & 4.85 & 5.1162 & TST & \\
\hline CHEMBL1613086 & 688422 & 5.6 & 5.3847 & TRN & \\
\hline CHEMBL3189751 & 688422 & 4.7 & 5.075 & TRN & \\
\hline CHEMBL1601981 & 688422 & 6.8499 & 5.4553 & TRN & \\
\hline CHEMBL1540596 & 688422 & 5.15 & 5.0541 & TRN & \\
\hline CHEMBL1303373 & 688422 & 4.85 & 5.0609 & TRN & \\
\hline CHEMBL1477512 & 688422 & 4.45 & 5.1698 & TRN & \\
\hline CHEMBL1479108 & 688422 & 4.9 & 5.3963 & TST & \\
\hline CHEMBL1312005 & 688422 & 6.4 & 4.9035 & TRN & \\
\hline CHEMBL1523982 & 688422 & 6.45 & 4.7296 & TRN & \\
\hline CHEMBL102970 & 688422 & 4.5 & 5.3879 & TRN & \\
\hline CHEMBL1490649 & 688422 & 4.5 & 4.8894 & TRN & \\
\hline CHEMBL1309160 & 688422 & 5.55 & 5.54299 & 9999999999 & TST \\
\hline CHEMBL3197847 & 688422 & 5.5 & 5.2452 & TST & \\
\hline CHEMBL1548546 & 688422 & 4.5 & 5.2991 & TST & \\
\hline CHEMBL1497459 & 688422 & 4.6 & 5.6786 & TST & \\
\hline CHEMBL1309700 & 688422 & 4.45 & 4.7856 & TRN & \\
\hline CHEMBL1312186 & 688422 & 4.9 & 5.2231 & TRN & \\
\hline CHEMBL1326483 & 688422 & 4.9 & 5.4517 & TRN & \\
\hline CHEMBL1570419 & 688422 & 4.75 & 5.1778 & TRN & \\
\hline CHEMBL1354506 & 688422 & 4.6 & 5.063 & TRN & \\
\hline CHEMBL1575345 & 688422 & 4.45 & 5.0168 & TRN & \\
\hline
\end{tabular}




\begin{tabular}{|c|c|c|c|c|c|}
\hline \multicolumn{6}{|c|}{ Supplemental Table S2.txt } \\
\hline CHEMBL1473602 & 688422 & 5.55 & 5.3441 & TRN & \\
\hline CHEMBL1509306 & 688422 & 4.65 & 4.7979 & TRN & \\
\hline CHEMBL1972977 & 688422 & 4.75 & 5.2684 & TRN & \\
\hline CHEMBL1347119 & 688422 & 4.45 & 5.1924 & TRN & \\
\hline CHEMBL3192613 & 688422 & 4.45 & 5.5441 & TRN & \\
\hline CHEMBL1490692 & 688422 & 5.4 & 4.9595 & TST & \\
\hline CHEMBL1354842 & 688422 & 7.5498 & 5.1748 & TRN & \\
\hline CHEMBL1488624 & 688422 & 7.6498 & 5.2826 & TRN & \\
\hline CHEMBL1502674 & 688422 & 4.85 & 5.0529 & TRN & \\
\hline CHEMBL3191253 & 688422 & 4.8 & 4.9633 & TRN & \\
\hline CHEMBL1416297 & 688422 & 8.4949 & 5.0609 & TST & \\
\hline CHEMBL1507600 & 688422 & 4.5 & 4.8082 & TRN & \\
\hline CHEMBL1447801 & 688422 & 5.0 & 5.5862 & TRN & \\
\hline CHEMBL1469616 & 688422 & 5.55 & 5.4323 & TRN & \\
\hline CHEMBL1460377 & 688422 & 4.4 & 5.1049 & TRN & \\
\hline CHEMBL1390963 & 688422 & 4.8 & 5.3197 & TST & \\
\hline CHEMBL1561654 & 688422 & 4.9 & 5.4116 & TRN & \\
\hline CHEMBL1403774 & 688422 & 4.95 & 4.8419 & TRN & \\
\hline CHEMBL18096 & 688422 & 4.65 & 5.1064 & TRN & \\
\hline CHEMBL1420282 & 688422 & 5.6 & 5.3446 & TRN & \\
\hline CHEMBL1587806 & 688422 & 4.7 & 5.3574 & TST & \\
\hline CHEMBL1714574 & 688422 & 8.1024 & 5.1087 & TST & \\
\hline CHEMBL1357525 & 688422 & 5.75 & 5.2603 & TST & \\
\hline CHEMBL3197688 & 688422 & 4.45 & 4.9368 & TRN & \\
\hline CHEMBL1381546 & 688422 & 4.85 & 5.393 & TST & \\
\hline CHEMBL1508946 & 688422 & 5.55 & 5.0695 & TRN & \\
\hline CHEMBL1613442 & 688422 & 6.5 & 5.2855 & TRN & \\
\hline CHEMBL1526926 & 688422 & 4.95 & 4.875 & TRN & \\
\hline CHEMBL1607537 & 688422 & 4.75 & 4.9525 & TRN & \\
\hline CHEMBL1585946 & 688422 & 8.4559 & 5.6213 & TRN & \\
\hline CHEMBL1590543 & 688422 & 4.8 & 5.7379 & TST & \\
\hline CHEMBL3197200 & 688422 & 6.6 & 5.301 & TRN & \\
\hline CHEMBL1461192 & 688422 & 4.7 & 5.20799 & & TRN \\
\hline CHEMBL1499308 & 688422 & 4.85 & 4.9218 & TRN & \\
\hline CHEMBL1508086 & 688422 & 4.85 & 5.2864 & TRN & \\
\hline CHEMBL1463164 & 688422 & 6.3 & 5.0518 & TRN & \\
\hline CHEMBL1321701 & 688422 & 4.6 & 4.9642 & TRN & \\
\hline CHEMBL1341544 & 688422 & 4.5 & 5.1399 & TRN & \\
\hline CHEMBL429095 & 688422 & 5.3 & 5.5502 & TST & \\
\hline CHEMBL3209974 & 688422 & 4.45 & 5.1675 & TRN & \\
\hline CHEMBL1310005 & 688422 & 4.85 & 4.7898 & TRN & \\
\hline CHEMBL1388811 & 688422 & 7.2503 & 5.3128 & TRN & \\
\hline CHEMBL1995040 & 688422 & 5.1 & 5.4825 & TRN & \\
\hline CHEMBL1607335 & 688422 & 4.45 & 5.4568 & TST & \\
\hline CHEMBL1337251 & 688422 & 6.05 & 5.3038 & TRN & \\
\hline CHEMBL1567706 & 688422 & 4.45 & 5.0529 & TRN & \\
\hline CHEMBL1353219 & 688422 & 5.0 & 4.9457 & TRN & \\
\hline CHEMBL1535568 & 688422 & 5.0 & 5.5126 & TRN & \\
\hline
\end{tabular}




\begin{tabular}{|c|c|c|c|c|c|}
\hline \multicolumn{6}{|c|}{ Supplemental Table S2.txt } \\
\hline CHEMBL1361709 & 688422 & 5.25 & 4.9676 & TRN & \\
\hline CHEMBL1473750 & 688422 & 8.1487 & 5.2076 & TRN & \\
\hline CHEMBL1496854 & 688422 & 4.45 & 5.4534 & TRN & \\
\hline CHEMBL1545641 & 688422 & 4.9 & 5.1327 & TRN & \\
\hline CHEMBL1594423 & 688422 & 7.5498 & 6.0379 & TRN & \\
\hline CHEMBL1575003 & 688422 & 4.4 & 4.7612 & TRN & \\
\hline CHEMBL3209588 & 688422 & 8.0506 & 5.0109 & TRN & \\
\hline CHEMBL1547494 & 688422 & 4.95 & 4.8249 & TRN & \\
\hline CHEMBL1493101 & 688422 & 5.05 & 5.0432 & TRN & \\
\hline CHEMBL1576787 & 688422 & 5.05 & 4.9966 & TST & \\
\hline CHEMBL1241822 & 688422 & 7.7496 & 5.2118 & TRN & \\
\hline CHEMBL1331366 & 688422 & 7.2 & 5.8753 & TST & \\
\hline CHEMBL1612476 & 688422 & 8.301 & 5.1324 & TRN & \\
\hline CHEMBL1551840 & 688422 & 7.5498 & 5.4593 & TRN & \\
\hline CHEMBL1413993 & 688422 & 5.25 & 5.3826 & TRN & \\
\hline CHEMBL1443782 & 688422 & 7.1002 & 6.0223 & TRN & \\
\hline CHEMBL1464765 & 688422 & 5.5 & 5.2057 & TRN & \\
\hline CHEMBL1416764 & 688422 & 4.45 & 5.6782 & TST & \\
\hline CHEMBL1408965 & 688422 & 4.95 & 5.2165 & TRN & \\
\hline CHEMBL1457557 & 688422 & 6.0 & 5.1981 & TRN & \\
\hline CHEMBL1332130 & 688422 & 4.9 & 5.4925 & TRN & \\
\hline CHEMBL1447931 & 688422 & 2.35 & 5.3166 & TST & \\
\hline CHEMBL1346489 & 688422 & 4.6 & 5.2505 & TST & \\
\hline CHEMBL1560995 & 688422 & 4.6 & 5.2568 & TRN & \\
\hline CHEMBL1439681 & 688422 & 4.9 & 5.4761 & TST & \\
\hline CHEMBL1523894 & 688422 & 4.75 & 5.4387 & TST & \\
\hline CHEMBL3199828 & 688422 & 4.5 & 5.00899 & 99999999995 & TST \\
\hline CHEMBL1570017 & 688422 & 4.5 & 5.3739 & TRN & \\
\hline CHEMBL1595884 & 688422 & 5.1 & 5.2324 & TRN & \\
\hline CHEMBL1378051 & 688422 & 4.45 & 5.5277 & TST & \\
\hline CHEMBL1429579 & 688422 & 5.0 & 4.8963 & TRN & \\
\hline CHEMBL1449254 & 688422 & 5.75 & 4.9739 & TST & \\
\hline CHEMBL1339184 & 688422 & 4.5 & 4.7869 & TRN & \\
\hline CHEMBL1386803 & 688422 & 5.5 & 5.2529 & TRN & \\
\hline CHEMBL1311339 & 688422 & 7.2 & 5.7195 & TST & \\
\hline CHEMBL 29837 & 688422 & 4.45 & 5.2188 & TRN & \\
\hline CHEMBL1401481 & 688422 & 4.6 & 5.7419 & TRN & \\
\hline CHEMBL1524042 & 688422 & 5.05 & 5.6982 & TST & \\
\hline CHEMBL1310341 & 688422 & 4.95 & 4.8841 & TRN & \\
\hline CHEMBL1574729 & 688422 & 4.45 & 5.2976 & TST & \\
\hline CHEMBL1307839 & 688422 & 4.6 & 5.3989 & TRN & \\
\hline CHEMBL1507373 & 688422 & 6.1 & 5.4066 & TRN & \\
\hline CHEMBL521970 & 688422 & 5.65 & 4.6706 & TRN & \\
\hline CHEMBL1398824 & 688422 & 5.0 & 4.9482 & TRN & \\
\hline CHEMBL1302527 & 688422 & 4.95 & 5.671 & TRN & \\
\hline CHEMBL1462322 & 688422 & 4.45 & 5.2697 & TST & \\
\hline CHEMBL1319773 & 688422 & 4.9 & 4.9656 & TST & \\
\hline CHEMBL1539718 & 688422 & 4.95 & 5.3079 & TRN & \\
\hline
\end{tabular}




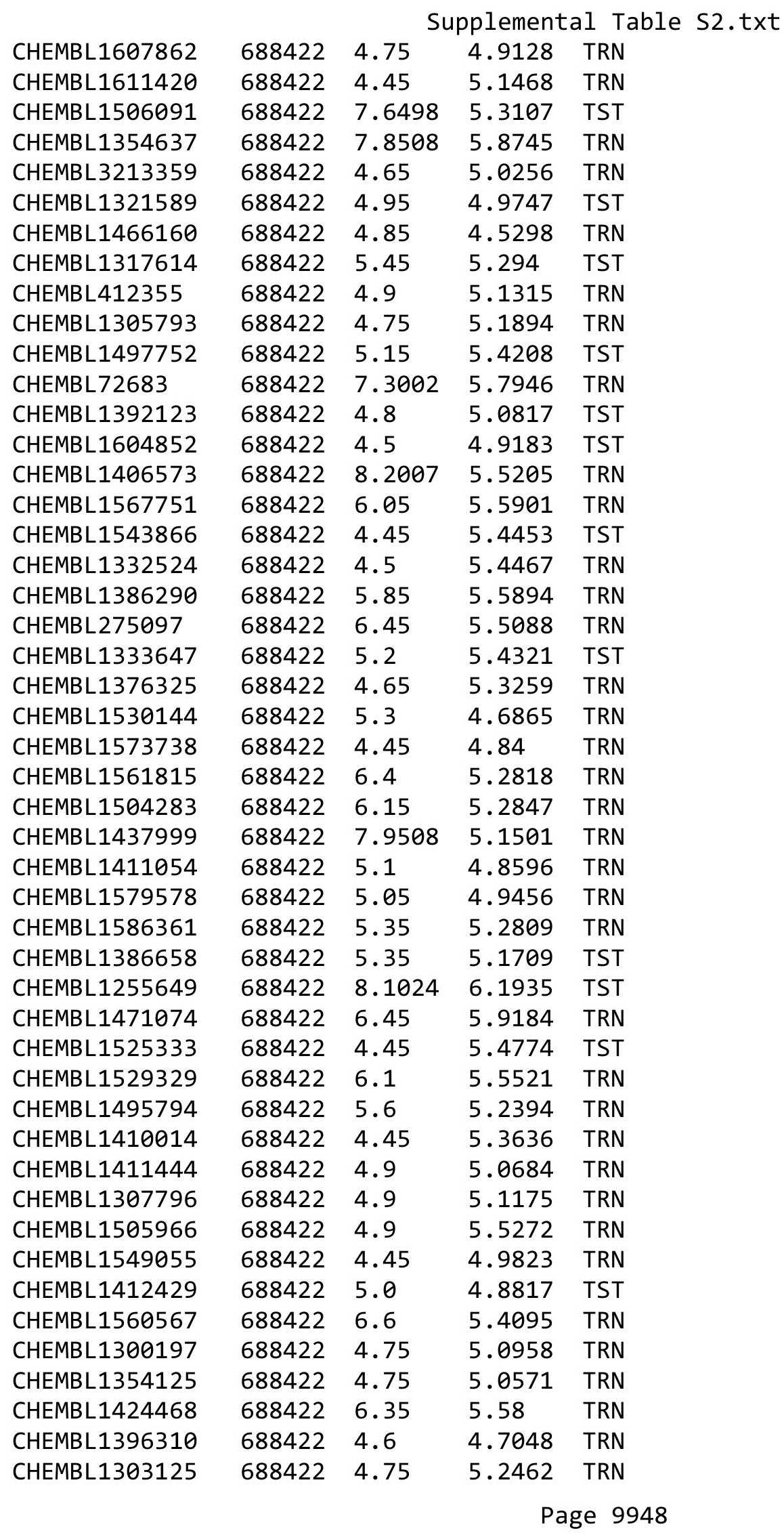




\begin{tabular}{|c|c|c|c|c|c|}
\hline \multicolumn{6}{|c|}{ Supplemental Table S2.txt } \\
\hline CHEMBL1455596 & 688422 & 5.4 & 5.3031 & TST & \\
\hline CHEMBL1418744 & 688422 & 4.6 & 4.7189 & TRN & \\
\hline CHEMBL1534441 & 688422 & 4.9 & 5.3775 & TRN & \\
\hline CHEMBL1499789 & 688422 & 5.0 & 5.5286 & TST & \\
\hline CHEMBL1322790 & 688422 & 4.75 & 5.1879 & TRN & \\
\hline CHEMBL1508190 & 688422 & 5.2 & 5.2877 & TRN & \\
\hline CHEMBL1313101 & 688422 & 5.05 & 4.97199 & 99999999995 & TRN \\
\hline CHEMBL1414426 & 688422 & 4.9 & 5.0998 & TRN & \\
\hline CHEMBL1307996 & 688422 & 4.65 & 5.1507 & TRN & \\
\hline CHEMBL1413140 & 688422 & 4.45 & 6.189 & TST & \\
\hline CHEMBL3196680 & 688422 & 4.45 & 5.187 & TST & \\
\hline CHEMBL1462417 & 688422 & 4.5 & 5.4327 & TRN & \\
\hline CHEMBL1412965 & 688422 & 4.45 & 5.1396 & TRN & \\
\hline CHEMBL1330351 & 688422 & 4.45 & 5.2682 & TRN & \\
\hline CHEMBL3209511 & 688422 & 5.15 & 4.8064 & TRN & \\
\hline CHEMBL1451504 & 688422 & 5.0 & 5.1671 & TRN & \\
\hline CHEMBL1537780 & 688422 & 4.7 & 5.1868 & TRN & \\
\hline CHEMBL1313030 & 688422 & 4.6 & 5.0258 & TRN & \\
\hline CHEMBL1407262 & 688422 & 5.05 & 5.2636 & TRN & \\
\hline CHEMBL1537428 & 688422 & 4.75 & 5.1241 & TRN & \\
\hline CHEMBL1416024 & 688422 & 4.7 & 5.1356 & TRN & \\
\hline CHEMBL1382949 & 688422 & 4.95 & 5.4412 & TRN & \\
\hline CHEMBL1480875 & 688422 & 5.35 & 5.4577 & TRN & \\
\hline CHEMBL1458160 & 688422 & 4.6 & 5.0651 & TRN & \\
\hline CHEMBL1608854 & 688422 & 8.3979 & 5.3284 & TRN & \\
\hline CHEMBL1578861 & 688422 & 4.6 & 5.0289 & TRN & \\
\hline CHEMBL1605778 & 688422 & 4.45 & 4.9434 & TRN & \\
\hline CHEMBL1349783 & 688422 & 4.6 & 5.12200 & 0000000001 & TRN \\
\hline CHEMBL1314834 & 688422 & 4.6 & 5.4278 & TRN & \\
\hline CHEMBL1568783 & 688422 & 4.7 & 4.6533 & TST & \\
\hline CHEMBL1448548 & 688422 & 5.35 & 5.3985 & TRN & \\
\hline CHEMBL1479107 & 688422 & 3.4 & 5.1464 & TST & \\
\hline CHEMBL1602599 & 688422 & 4.65 & 5.3808 & TRN & \\
\hline CHEMBL1555980 & 688422 & 4.9 & 5.1065 & TRN & \\
\hline CHEMBL1528935 & 688422 & 8.0506 & 5.5908 & TST & \\
\hline CHEMBL1482542 & 688422 & 5.4 & 5.2627 & TRN & \\
\hline CHEMBL1610306 & 688422 & 6.95 & 5.6309 & TST & \\
\hline CHEMBL1548093 & 688422 & 5.45 & 5.6201 & TST & \\
\hline CHEMBL1338736 & 688422 & 4.6 & 4.9673 & TST & \\
\hline CHEMBL1364082 & 688422 & 8.0 & 5.3873 & TRN & \\
\hline CHEMBL1533401 & 688422 & 4.45 & 5.1112 & TST & \\
\hline CHEMBL1593714 & 688422 & 7.5498 & 4.9908 & TRN & \\
\hline CHEMBL1332697 & 688422 & 4.85 & 5.4151 & TRN & \\
\hline CHEMBL1336767 & 688422 & 4.45 & 4.9231 & TST & \\
\hline CHEMBL1305075 & 688422 & 4.65 & 5.11 & TRN & \\
\hline CHEMBL1498519 & 688422 & 5.15 & 5.4522 & TRN & \\
\hline CHEMBL1408201 & 688422 & 4.8 & 5.5704 & TRN & \\
\hline CHEMBL1345869 & 688422 & 4.45 & 5.3469 & TRN & \\
\hline
\end{tabular}




\begin{tabular}{|c|c|c|c|c|}
\hline \multicolumn{5}{|c|}{ Supplemental Table S2.txt } \\
\hline CHEMBL1421164 & 688422 & 4.85 & 5.2575 & TRN \\
\hline CHEMBL3191562 & 688422 & 4.9 & 5.3547 & TST \\
\hline CHEMBL1310504 & 688422 & 4.75 & 5.0686 & TRN \\
\hline CHEMBL1457031 & 688422 & 4.5 & 5.5092 & TRN \\
\hline CHEMBL373137 & 688422 & 6.6 & 5.5638 & TRN \\
\hline CHEMBL1314967 & 688422 & 5.3 & 5.2137 & TRN \\
\hline CHEMBL30707 & 688422 & 4.85 & 5.5065 & TST \\
\hline CHEMBL1510904 & 688422 & 4.75 & 5.1623 & TRN \\
\hline CHEMBL1464595 & 688422 & 4.85 & 5.3421 & TST \\
\hline CHEMBL1469251 & 688422 & 4.45 & 5.2166 & TST \\
\hline CHEMBL1569078 & 688422 & 4.6 & 5.0278 & TRN \\
\hline CHEMBL 3193422 & 688422 & 5.2 & 5.4747 & TRN \\
\hline CHEMBL1397281 & 688422 & 4.45 & 4.9537 & TRN \\
\hline CHEMBL1591649 & 688422 & 5.0 & 5.4134 & TRN \\
\hline CHEMBL1444044 & 688422 & 4.9 & 5.0251 & TST \\
\hline CHEMBL1339679 & 688422 & 4.9 & 5.0104 & TRN \\
\hline CHEMBL65699 & 688422 & 8.2518 & 5.3631 & TST \\
\hline CHEMBL1557020 & 688422 & 7.5003 & 5.3743 & TRN \\
\hline CHEMBL1549476 & 688422 & 5.65 & 5.1111 & TRN \\
\hline CHEMBL1507388 & 688422 & 5.2 & 5.3101 & TST \\
\hline CHEMBL1535017 & 688422 & 4.9 & 4.7413 & TRN \\
\hline CHEMBL605003 & 688422 & 5.5 & 5.1678 & TST \\
\hline CHEMBL1520890 & 688422 & 6.1 & 5.2605 & TRN \\
\hline CHEMBL1496473 & 688422 & 4.45 & 5.871 & TST \\
\hline CHEMBL1475037 & 688422 & 4.45 & 4.8718 & TRN \\
\hline CHEMBL1542910 & 688422 & 8.3468 & 5.0763 & TRN \\
\hline CHEMBL1320679 & 688422 & 7.4001 & 5.2503 & TRN \\
\hline CHEMBL1451112 & 688422 & 4.9 & 5.0209 & TRN \\
\hline CHEMBL1530518 & 688422 & 4.45 & 5.5891 & TRN \\
\hline CHEMBL3197516 & 688422 & 4.6 & 4.9807 & TRN \\
\hline CHEMBL1582052 & 688422 & 4.45 & 4.842 & TRN \\
\hline CHEMBL1594063 & 688422 & 4.6 & 4.757 & TRN \\
\hline CHEMBL1327681 & 688422 & 4.65 & 4.6557 & TRN \\
\hline CHEMBL1380824 & 688422 & 4.85 & 5.3572 & TRN \\
\hline CHEMBL1583975 & 688422 & 4.45 & 4.9188 & TST \\
\hline CHEMBL1504479 & 688422 & 4.6 & 5.0456 & TRN \\
\hline CHEMBL1338845 & 688422 & 7.0 & 5.0386 & TRN \\
\hline CHEMBL1425674 & 688422 & 6.8 & 5.6216 & TRN \\
\hline CHEMBL1558556 & 688422 & 5.15 & 5.6542 & TRN \\
\hline CHEMBL1462695 & 688422 & 4.85 & 5.2994 & TST \\
\hline CHEMBL1533348 & 688422 & 6.6 & 5.4188 & TST \\
\hline CHEMBL1338466 & 688422 & 4.9 & 5.2583 & TST \\
\hline CHEMBL42529 & 688422 & 5.0 & 6.2902 & TRN \\
\hline CHEMBL1308522 & 688422 & 4.7 & 5.5315 & TRN \\
\hline CHEMBL1400196 & 688422 & 4.45 & 5.1114 & TST \\
\hline CHEMBL1403902 & 688422 & 4.45 & 5.0598 & TRN \\
\hline CHEMBL1549962 & 688422 & 7.8013 & 5.8992 & TRN \\
\hline CHEMBL3193566 & 688422 & 4.55 & 4.8315 & TRN \\
\hline
\end{tabular}




\begin{tabular}{|c|c|c|c|c|}
\hline \multicolumn{5}{|c|}{ Supplemental Table s2.txt } \\
\hline CHEMBL1500497 & 688422 & 7.9508 & 5.3788 & TST \\
\hline CHEMBL1503377 & 688422 & 4.95 & 5.165 & TST \\
\hline CHEMBL1396501 & 688422 & 4.9 & 5.6445 & TRN \\
\hline CHEMBL1324010 & 688422 & 5.9 & 5.6488 & TRN \\
\hline CHEMBL1463603 & 688422 & 5.15 & 5.5888 & TRN \\
\hline CHEMBL1400270 & 688422 & 4.45 & 5.2412 & TRN \\
\hline CHEMBL 3207400 & 688422 & 4.7 & 4.8715 & TST \\
\hline CHEMBL1572076 & 688422 & 7.0501 & 4.9501 & TST \\
\hline CHEMBL1535222 & 688422 & 4.45 & 4.97 & TRN \\
\hline CHEMBL1505570 & 688422 & 4.45 & 5.3886 & TST \\
\hline CHEMBL1588046 & 688422 & 4.95 & 5.3627 & TRN \\
\hline CHEMBL1523706 & 688422 & 5.0 & 5.0801 & TRN \\
\hline CHEMBL1576976 & 688422 & 7.4001 & 6.1544 & TST \\
\hline CHEMBL1324253 & 688422 & 4.6 & 4.6765 & TRN \\
\hline CHEMBL1569531 & 688422 & 6.3 & 5.4786 & TRN \\
\hline CHEMBL1545324 & 688422 & 5.9 & 5.2837 & TRN \\
\hline CHEMBL1609332 & 688422 & 4.9 & 4.9881 & TRN \\
\hline CHEMBL1516500 & 688422 & 4.9 & 5.2605 & TRN \\
\hline CHEMBL1352974 & 688422 & 4.6 & 4.9809 & TRN \\
\hline CHEMBL1445418 & 688422 & 4.8 & 4.8943 & TRN \\
\hline CHEMBL1539786 & 688422 & 4.85 & 5.2415 & TRN \\
\hline CHEMBL1504109 & 688422 & 5.55 & 5.1592 & TRN \\
\hline CHEMBL1441385 & 688422 & 4.65 & 5.3583 & TRN \\
\hline CHEMBL1358633 & 688422 & 4.4 & 5.3464 & TRN \\
\hline CHEMBL1330090 & 688422 & 4.85 & 5.1614 & TRN \\
\hline CHEMBL1471734 & 688422 & 4.95 & 5.1447 & TRN \\
\hline CHEMBL1477735 & 688422 & 4.45 & 5.0972 & TRN \\
\hline CHEMBL1329718 & 688422 & 4.95 & 5.4467 & TST \\
\hline CHEMBL1374084 & 688422 & 5.25 & 5.4892 & TRN \\
\hline CHEMBL1453286 & 688422 & 6.35 & 5.4814 & TST \\
\hline CHEMBL1607641 & 688422 & 4.65 & 5.4347 & TRN \\
\hline CHEMBL1573118 & 688422 & 5.1 & 5.2149 & TRN \\
\hline CHEMBL1467541 & 688422 & 4.95 & 5.5195 & TRN \\
\hline CHEMBL3196444 & 688422 & 7.699 & 5.0927 & TRN \\
\hline CHEMBL1423477 & 688422 & 5.4 & 5.1889 & TRN \\
\hline CHEMBL3198228 & 688422 & 4.7 & 5.5521 & TST \\
\hline CHEMBL1308006 & 688422 & 4.65 & 4.7017 & TRN \\
\hline CHEMBL1472659 & 688422 & 8.5528 & 5.567 & TRN \\
\hline CHEMBL1500874 & 688422 & 4.9 & 5.0539 & TRN \\
\hline CHEMBL1527073 & 688422 & 5.9 & 5.466 & TST \\
\hline CHEMBL1428765 & 688422 & 4.45 & 4.8895 & TRN \\
\hline CHEMBL1505787 & 688422 & 4.95 & 5.2582 & TST \\
\hline CHEMBL1351569 & 688422 & 5.55 & 6.6138 & TST \\
\hline CHEMBL1360765 & 688422 & 4.45 & 5.5078 & TRN \\
\hline CHEMBL3212654 & 688422 & 8.4559 & 5.5186 & TST \\
\hline CHEMBL1410915 & 688422 & 4.8 & 5.0879 & TRN \\
\hline CHEMBL1567637 & 688422 & 7.699 & 5.5634 & TRN \\
\hline CHEMBL1356429 & 688422 & 5.35 & 5.8788 & TRN \\
\hline
\end{tabular}




\begin{tabular}{|c|c|c|c|c|c|}
\hline \multicolumn{6}{|c|}{ Supplemental Table S2.txt } \\
\hline CHEMBL1411681 & 688422 & 4.75 & 4.7641 & TRN & \\
\hline CHEMBL1478837 & 688422 & 5.25 & 5.1634 & TRN & \\
\hline CHEMBL1411738 & 688422 & 4.45 & 4.8726 & TRN & \\
\hline CHEMBL1318732 & 688422 & 4.8 & 5.6742 & TRN & \\
\hline CHEMBL1404946 & 688422 & 4.7 & 4.7592 & TRN & \\
\hline CHEMBL1579650 & 688422 & 4.5 & 5.5648 & TST & \\
\hline CHEMBL1428272 & 688422 & 4.45 & 5.0776 & TRN & \\
\hline CHEMBL1349539 & 688422 & 4.45 & 5.17899 & 9999999999 & TRN \\
\hline CHEMBL1459152 & 688422 & 4.8 & 5.0637 & TRN & \\
\hline CHEMBL1390492 & 688422 & 4.45 & 5.1551 & TRN & \\
\hline CHEMBL1603721 & 688422 & 6.8 & 5.7972 & TST & \\
\hline CHEMBL1304859 & 688422 & 4.45 & 5.5728 & TST & \\
\hline CHEMBL1310750 & 688422 & 4.8 & 5.0989 & TST & \\
\hline CHEMBL1608563 & 688422 & 4.45 & 4.8675 & TRN & \\
\hline CHEMBL1467956 & 688422 & 4.85 & 5.1362 & TRN & \\
\hline CHEMBL1603826 & 688422 & 4.45 & 5.1402 & TRN & \\
\hline CHEMBL1325267 & 688422 & 4.5 & 4.822 & TRN & \\
\hline CHEMBL1545209 & 688422 & 4.95 & 5.3081 & TRN & \\
\hline CHEMBL1380762 & 688422 & 4.75 & 4.7561 & TRN & \\
\hline CHEMBL1524734 & 688422 & 6.05 & 5.6603 & TRN & \\
\hline CHEMBL1474517 & 688422 & 6.2 & 6.2716 & TST & \\
\hline CHEMBL1440659 & 688422 & 4.45 & 5.2035 & TRN & \\
\hline CHEMBL1456371 & 688422 & 4.75 & 4.93 & TST & \\
\hline CHEMBL1574077 & 688422 & 4.8 & 5.0365 & TRN & \\
\hline CHEMBL 3209077 & 688422 & 8.0 & 5.3589 & TRN & \\
\hline CHEMBL3194210 & 688422 & 5.0 & 5.1249 & TST & \\
\hline CHEMBL1518551 & 688422 & 4.45 & 4.9704 & TRN & \\
\hline CHEMBL3194571 & 688422 & 5.2 & 4.9959 & TRN & \\
\hline CHEMBL 3197762 & 688422 & 5.1 & 4.9788 & TST & \\
\hline CHEMBL1985759 & 688422 & 5.4 & 5.2659 & TRN & \\
\hline CHEMBL1312357 & 688422 & 7.5003 & 5.4751 & TRN & \\
\hline CHEMBL1365795 & 688422 & 5.45 & 5.1317 & TRN & \\
\hline CHEMBL1362878 & 688422 & 4.75 & 5.1113 & TRN & \\
\hline CHEMBL1530220 & 688422 & 4.65 & 5.1127 & TST & \\
\hline CHEMBL1412264 & 688422 & 5.4 & 5.0899 & TST & \\
\hline CHEMBL1598261 & 688422 & 4.85 & 5.05699 & 99999999995 & TRN \\
\hline CHEMBL1396684 & 688422 & 5.65 & 5.8366 & TRN & \\
\hline CHEMBL1300536 & 688422 & 5.2 & 5.0 & TRN & \\
\hline CHEMBL1506924 & 688422 & 7.6498 & 5.9003 & TRN & \\
\hline CHEMBL1511790 & 688422 & 5.9 & 6.14 & TRN & \\
\hline CHEMBL1612793 & 688422 & 5.7 & 5.2506 & TRN & \\
\hline CHEMBL1438084 & 688422 & 5.25 & 5.1983 & TST & \\
\hline CHEMBL1430084 & 688422 & 4.5 & 4.8234 & TRN & \\
\hline CHEMBL1353943 & 688422 & 4.65 & 4.7686 & TRN & \\
\hline CHEMBL1578657 & 688422 & 4.9 & 4.9451 & TST & \\
\hline CHEMBL1412583 & 688422 & 5.2 & 4.8048 & TST & \\
\hline CHEMBL1336423 & 688422 & 5.1 & 5.3966 & TRN & \\
\hline CHEMBL1349765 & 688422 & 4.9 & 5.7493 & TST & \\
\hline
\end{tabular}




\begin{tabular}{|c|c|c|c|c|c|}
\hline \multicolumn{6}{|c|}{ Supplemental Table S2.txt } \\
\hline CHEMBL1598075 & 688422 & 4.45 & 5.0767 & TRN & \\
\hline CHEMBL1559592 & 688422 & 6.25 & 5.6205 & TST & \\
\hline CHEMBL1585378 & 688422 & 4.45 & 5.5221 & TST & \\
\hline CHEMBL1459515 & 688422 & 4.45 & 5.2902 & TST & \\
\hline CHEMBL1488210 & 688422 & 4.65 & 5.3308 & TRN & \\
\hline CHEMBL1417178 & 688422 & 8.3468 & 5.4424 & TRN & \\
\hline CHEMBL1965223 & 688422 & 4.75 & 4.8385 & TRN & \\
\hline CHEMBL1487564 & 688422 & 4.95 & 5.087 & TST & \\
\hline CHEMBL1373576 & 688422 & 5.9 & 5.0091 & TRN & \\
\hline CHEMBL590695 & 688422 & 4.45 & 5.4497 & TRN & \\
\hline CHEMBL1368851 & 688422 & 4.45 & 5.6784 & TRN & \\
\hline CHEMBL1337137 & 688422 & 5.55 & 5.2851 & TST & \\
\hline CHEMBL1506559 & 688422 & 6.8499 & 5.3073 & TST & \\
\hline CHEMBL1469924 & 688422 & 4.95 & 5.2707 & TST & \\
\hline CHEMBL1304874 & 688422 & 4.45 & 5.36700 & 0000000001 & TRN \\
\hline CHEMBL1559375 & 688422 & 4.85 & 4.8213 & TRN & \\
\hline CHEMBL1301398 & 688422 & 6.8 & 5.3108 & TRN & \\
\hline CHEMBL1415333 & 688422 & 4.45 & 5.2759 & TST & \\
\hline CHEMBL1522892 & 688422 & 5.65 & 4.9982 & TRN & \\
\hline CHEMBL1497549 & 688422 & 5.7 & 5.9328 & TRN & \\
\hline CHEMBL1500390 & 688422 & 5.0 & 5.7674 & TST & \\
\hline CHEMBL1597011 & 688422 & 4.95 & 5.1975 & TRN & \\
\hline CHEMBL1610709 & 688422 & 4.45 & 5.7665 & TRN & \\
\hline CHEMBL 3214267 & 688422 & 4.7 & 5.3649 & TST & \\
\hline CHEMBL1441312 & 688422 & 8.301 & 5.6492 & TST & \\
\hline CHEMBL1573910 & 688422 & 5.55 & 5.6602 & TRN & \\
\hline CHEMBL1388896 & 688422 & 7.4001 & 5.2776 & TRN & \\
\hline CHEMBL1376834 & 688422 & 6.25 & 5.7468 & TST & \\
\hline CHEMBL1435232 & 688422 & 6.15 & 5.4091 & TRN & \\
\hline CHEMBL1456615 & 688422 & 4.65 & 4.82100 & 0000000001 & TRN \\
\hline CHEMBL1560087 & 688422 & 4.55 & 4.9346 & TRN & \\
\hline CHEMBL1303920 & 688422 & 8.3468 & 5.4315 & TRN & \\
\hline CHEMBL1611058 & 688422 & 6.7501 & 5.0773 & TRN & \\
\hline CHEMBL1565374 & 688422 & 6.1 & 4.8946 & TRN & \\
\hline CHEMBL1529287 & 688422 & 4.85 & 5.6022 & TRN & \\
\hline CHEMBL1561537 & 688422 & 4.45 & 5.1016 & TRN & \\
\hline CHEMBL1313356 & 688422 & 5.0 & 4.7198 & TRN & \\
\hline CHEMBL119247 & 688422 & 4.45 & 5.093 & TRN & \\
\hline CHEMBL1448939 & 688422 & 4.8 & 5.1467 & TRN & \\
\hline CHEMBL1464651 & 688422 & 4.65 & 5.0352 & TRN & \\
\hline CHEMBL1472395 & 688422 & 4.7 & 4.9614 & TRN & \\
\hline CHEMBL1515449 & 688422 & 6.5 & 5.1333 & TRN & \\
\hline CHEMBL1326527 & 688422 & 4.85 & 5.0611 & TRN & \\
\hline CHEMBL1300592 & 688422 & 4.9 & 4.90300 & 00000000005 & TRN \\
\hline CHEMBL1322957 & 688422 & 4.45 & 5.0727 & TRN & \\
\hline CHEMBL1392648 & 688422 & 5.25 & 5.4601 & TRN & \\
\hline CHEMBL1513333 & 688422 & 5.45 & 5.727 & TRN & \\
\hline CHEMBL1371777 & 688422 & 4.75 & 4.8195 & TST & \\
\hline
\end{tabular}




\begin{tabular}{|c|c|c|c|c|}
\hline \multicolumn{5}{|c|}{ Supplemental Table S2.txt } \\
\hline CHEMBL1523418 & 688422 & 5.05 & 5.5309 & TRN \\
\hline CHEMBL1512977 & 688422 & 7.6498 & 5.484 & TRN \\
\hline CHEMBL1367014 & 688422 & 5.2 & 6.1636 & TRN \\
\hline CHEMBL1593627 & 688422 & 5.8 & 5.3937 & TRN \\
\hline CHEMBL1483957 & 688422 & 7.6498 & 5.4 & TRN \\
\hline CHEMBL1468172 & 688422 & 4.45 & 5.3786 & TRN \\
\hline CHEMBL1474801 & 688422 & 4.95 & 5.325 & TST \\
\hline CHEMBL30037 & 688422 & 4.45 & 6.1448 & TST \\
\hline CHEMBL1466320 & 688422 & 6.05 & 5.3904 & TST \\
\hline CHEMBL1511362 & 688422 & 4.45 & 5.0859 & TST \\
\hline CHEMBL1325713 & 688422 & 4.95 & 5.6004 & TRN \\
\hline CHEMBL1500142 & 688422 & 8.0 & 5.1168 & TST \\
\hline CHEMBL1383082 & 688422 & 4.5 & 5.4187 & TRN \\
\hline CHEMBL1612854 & 688422 & 4.45 & 5.4545 & TRN \\
\hline CHEMBL1523835 & 688422 & 4.45 & 4.7009 & TST \\
\hline CHEMBL1506246 & 688422 & 5.3 & 5.2083 & TST \\
\hline CHEMBL1582442 & 688422 & 4.5 & 5.0968 & TST \\
\hline CHEMBL1315851 & 688422 & 6.05 & 5.2932 & TRN \\
\hline CHEMBL1329082 & 688422 & 4.7 & 5.1142 & TRN \\
\hline CHEMBL1336397 & 688422 & 4.6 & 4.8869 & TRN \\
\hline CHEMBL1352563 & 688422 & 4.8 & 5.0573 & TRN \\
\hline CHEMBL3196949 & 688422 & 5.4 & 5.2694 & TRN \\
\hline CHEMBL1521390 & 688422 & 5.9 & 4.9229 & TST \\
\hline CHEMBL268609 & 688422 & 5.5 & 5.4331 & TRN \\
\hline CHEMBL3209281 & 688422 & 4.45 & 5.2741 & TRN \\
\hline CHEMBL1386502 & 688422 & 4.45 & 5.5471 & TST \\
\hline CHEMBL1330015 & 688422 & 7.6003 & 5.2425 & TST \\
\hline CHEMBL1336442 & 688422 & 4.65 & 5.3623 & TRN \\
\hline CHEMBL1312338 & 688422 & 4.45 & 5.0074 & TRN \\
\hline CHEMBL1389927 & 688422 & 6.6499 & 5.6093 & TST \\
\hline CHEMBL1605605 & 688422 & 5.2 & 5.7466 & TST \\
\hline CHEMBL1560591 & 688422 & 8.1024 & 5.1292 & TST \\
\hline CHEMBL1354802 & 688422 & 4.75 & 5.5502 & TRN \\
\hline CHEMBL1380009 & 688422 & 4.9 & 5.3096 & TRN \\
\hline CHEMBL1347260 & 688422 & 4.45 & 6.0257 & TRN \\
\hline CHEMBL1608635 & 688422 & 6.5501 & 5.4249 & TRN \\
\hline CHEMBL3198134 & 688422 & 5.3 & 5.5437 & TST \\
\hline CHEMBL1308930 & 688422 & 4.95 & 5.6099 & TST \\
\hline CHEMBL1372136 & 688422 & 4.5 & 5.0692 & TRN \\
\hline CHEMBL1585267 & 688422 & 4.45 & 4.707 & TRN \\
\hline CHEMBL1610049 & 688422 & 4.45 & 4.8848 & TRN \\
\hline CHEMBL3210729 & 688422 & 5.0 & 5.1384 & TRN \\
\hline CHEMBL1468661 & 688422 & 4.45 & 4.7272 & TST \\
\hline CHEMBL1346785 & 688422 & 5.25 & 6.1134 & TRN \\
\hline CHEMBL1492608 & 688422 & 4.65 & 5.4073 & TRN \\
\hline CHEMBL3209206 & 688422 & 4.45 & 5.1476 & TST \\
\hline CHEMBL1522241 & 688422 & 7.0501 & 5.6283 & TST \\
\hline CHEMBL3391890 & 688422 & 8.3468 & 5.4126 & TRN \\
\hline
\end{tabular}




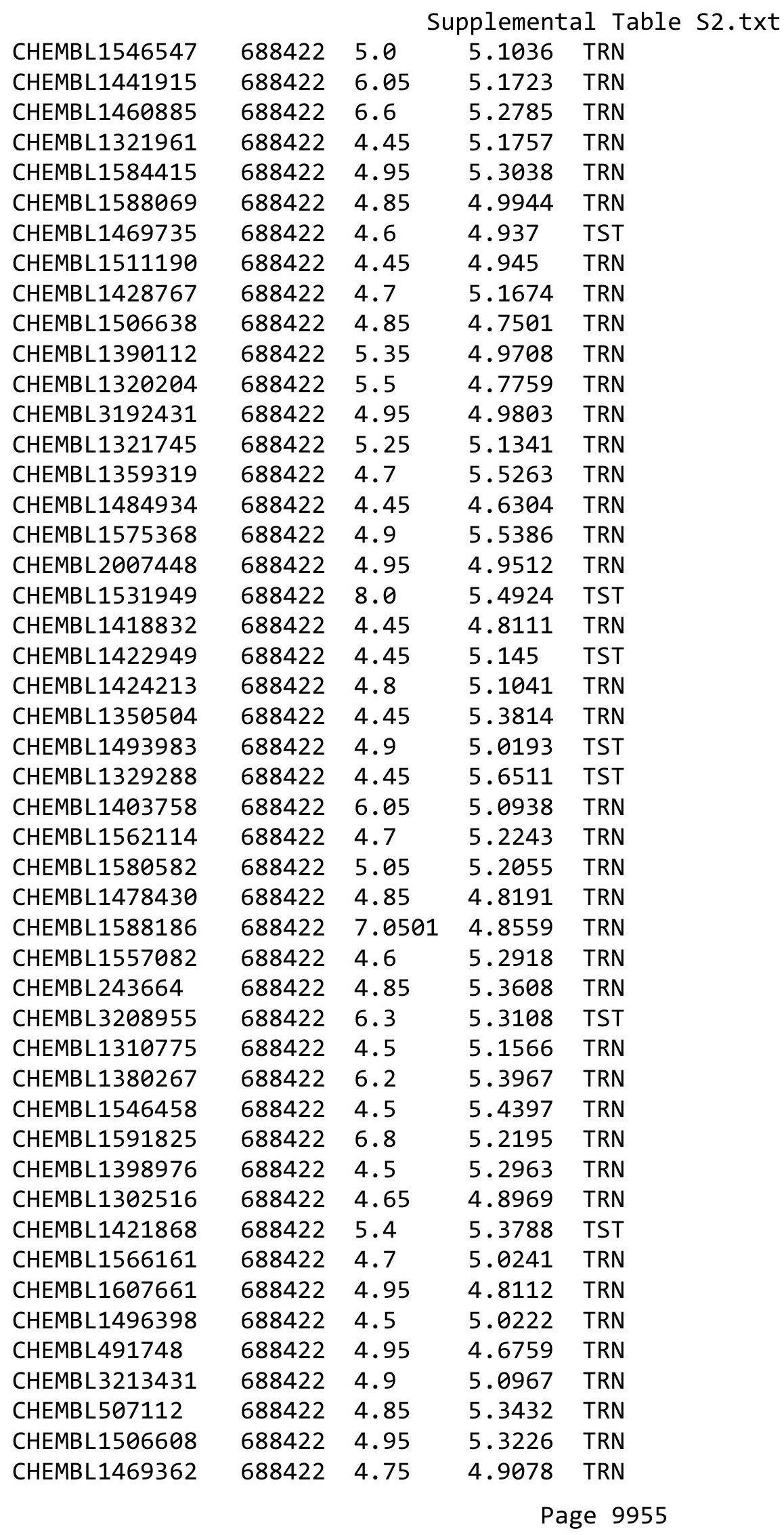




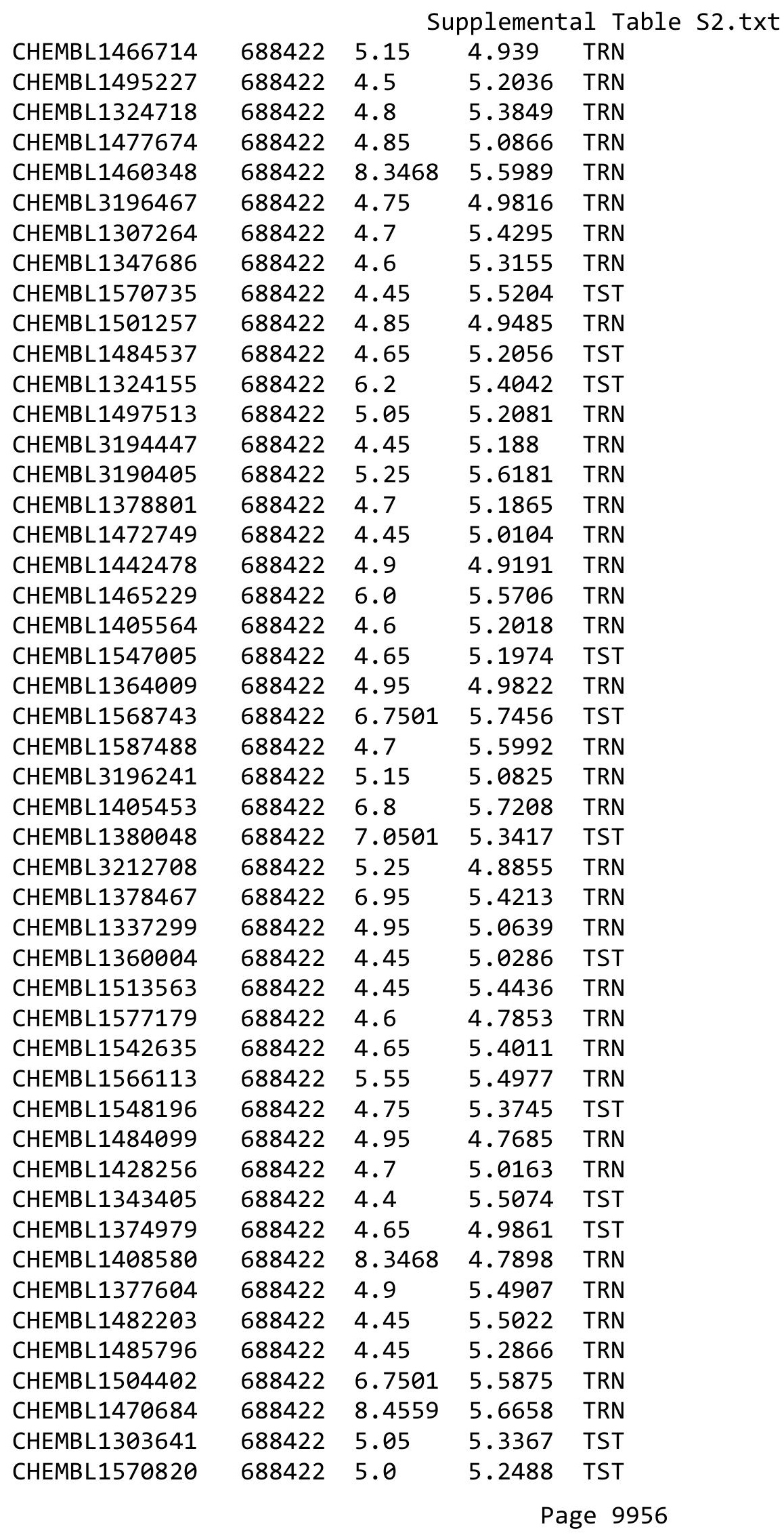




\begin{tabular}{|c|c|c|c|c|c|}
\hline \multicolumn{6}{|c|}{ Supplemental Table S2.txt } \\
\hline CHEMBL3212330 & 688422 & 5.0 & 5.2191 & TST & \\
\hline CHEMBL1499535 & 688422 & 4.85 & 5.2018 & TRN & \\
\hline CHEMBL1348715 & 688422 & 4.75 & 5.8322 & TST & \\
\hline CHEMBL1387904 & 688422 & 7.0501 & 5.2766 & TRN & \\
\hline CHEMBL1577346 & 688422 & 7.5003 & 5.1538 & TST & \\
\hline CHEMBL1330461 & 688422 & 8.3468 & 5.2317 & TST & \\
\hline CHEMBL1567453 & 688422 & 5.5 & 5.5781 & TRN & \\
\hline CHEMBL1379424 & 688422 & 4.45 & 5.1111 & TRN & \\
\hline CHEMBL1571054 & 688422 & 4.6 & 5.1467 & TRN & \\
\hline CHEMBL1597255 & 688422 & 4.8 & 5.9685 & TRN & \\
\hline CHEMBL1583324 & 688422 & 4.45 & 5.1972 & TRN & \\
\hline CHEMBL1608134 & 688422 & 4.7 & 4.9736 & TRN & \\
\hline CHEMBL1580849 & 688422 & 6.1 & 5.479 & TST & \\
\hline CHEMBL1381439 & 688422 & 4.8 & 5.5416 & TST & \\
\hline CHEMBL1335356 & 688422 & 6.7001 & 5.7625 & TST & \\
\hline CHEMBL3191442 & 688422 & 4.95 & 5.2015 & TRN & \\
\hline CHEMBL1525602 & 688422 & 4.9 & 4.6148 & TRN & \\
\hline CHEMBL1610732 & 688422 & 4.6 & 5.4678 & TRN & \\
\hline CHEMBL1418821 & 688422 & 4.95 & 5.2991 & TRN & \\
\hline CHEMBL1330693 & 688422 & 4.95 & 5.6296 & TRN & \\
\hline CHEMBL1467680 & 688422 & 4.45 & 5.2272 & TRN & \\
\hline CHEMBL1493219 & 688422 & 4.45 & 5.5833 & TRN & \\
\hline CHEMBL1377627 & 688422 & 4.8 & 5.3126 & TRN & \\
\hline CHEMBL1368647 & 688422 & 4.5 & 5.0736 & TRN & \\
\hline CHEMBL1494470 & 688422 & 4.8 & 5.1276 & TRN & \\
\hline CHEMBL1528316 & 688422 & 4.5 & 4.7879 & TST & \\
\hline CHEMBL1430559 & 688422 & 4.6 & 5.5565 & TST & \\
\hline CHEMBL1522472 & 688422 & 4.75 & 5.2697 & TST & \\
\hline CHEMBL1419893 & 688422 & 6.25 & 5.5268 & TRN & \\
\hline CHEMBL1338960 & 688422 & 4.45 & 5.1606 & TST & \\
\hline CHEMBL1425634 & 688422 & 5.0 & 5.4592 & TRN & \\
\hline CHEMBL1503605 & 688422 & 4.5 & 5.1253 & TRN & \\
\hline CHEMBL1411860 & 688422 & 4.75 & 5.3227 & TRN & \\
\hline CHEMBL1409775 & 688422 & 5.8 & 4.9262 & TST & \\
\hline CHEMBL1472193 & 688422 & 5.0 & 5.37700 & 0000000001 & TRN \\
\hline CHEMBL288096 & 688422 & 4.95 & 5.2962 & TRN & \\
\hline CHEMBL1383379 & 688422 & 4.7 & 5.5145 & TRN & \\
\hline CHEMBL1347975 & 688422 & 4.45 & 5.2922 & TST & \\
\hline CHEMBL1410906 & 688422 & 4.45 & 5.2804 & TRN & \\
\hline CHEMBL1522603 & 688422 & 4.65 & 5.3566 & TRN & \\
\hline CHEMBL1410479 & 688422 & 4.85 & 4.8155 & TRN & \\
\hline CHEMBL1480845 & 688422 & 6.5 & 5.1468 & TRN & \\
\hline CHEMBL1348761 & 688422 & 4.55 & 4.9589 & TRN & \\
\hline CHEMBL1536754 & 688422 & 6.1 & 5.5015 & TRN & \\
\hline CHEMBL1424672 & 688422 & 4.9 & 5.4899 & TRN & \\
\hline CHEMBL1324757 & 688422 & 8.0 & 5.6892 & TRN & \\
\hline CHEMBL1305642 & 688422 & 5.2 & 4.6228 & TRN & \\
\hline CHEMBL1452126 & 688422 & 4.65 & 5.6109 & TRN & \\
\hline
\end{tabular}




\begin{tabular}{|c|c|c|c|c|}
\hline \multicolumn{5}{|c|}{ Supplemental Table S2.txt } \\
\hline CHEMBL1506488 & 688422 & 6.4 & 5.2163 & TRN \\
\hline CHEMBL1455864 & 688422 & 8.4949 & 5.8637 & TRN \\
\hline CHEMBL1531826 & 688422 & 4.7 & 4.8457 & TRN \\
\hline CHEMBL1356752 & 688422 & 4.45 & 5.2942 & TRN \\
\hline CHEMBL 1406980 & 688422 & 5.55 & 5.2288 & TRN \\
\hline CHEMBL1455042 & 688422 & 4.6 & 4.7611 & TRN \\
\hline CHEMBL1501998 & 688422 & 5.6 & 5.2028 & TRN \\
\hline CHEMBL1391711 & 688422 & 4.9 & 5.1127 & TRN \\
\hline CHEMBL1506339 & 688422 & 4.45 & 5.079 & TRN \\
\hline CHEMBL1313766 & 688422 & 5.5 & 4.8456 & TRN \\
\hline CHEMBL3199312 & 688422 & 4.45 & 5.0884 & TRN \\
\hline CHEMBL1590398 & 688422 & 5.45 & 5.1076 & TRN \\
\hline CHEMBL1339554 & 688422 & 4.75 & 5.2235 & TRN \\
\hline CHEMBL1388256 & 688422 & 5.0 & 5.0727 & TST \\
\hline CHEMBL1334614 & 688422 & 5.0 & 4.9656 & TRN \\
\hline CHEMBL1429230 & 688422 & 4.5 & 4.7712 & TRN \\
\hline CHEMBL1592207 & 688422 & 4.95 & 4.8757 & TST \\
\hline CHEMBL485636 & 688422 & 5.25 & 5.5218 & TRN \\
\hline CHEMBL1601754 & 688422 & 5.0 & 5.2104 & TRN \\
\hline CHEMBL1525949 & 688422 & 4.8 & 5.0111 & TRN \\
\hline CHEMBL1523426 & 688422 & 5.05 & 5.7179 & TRN \\
\hline CHEMBL1355522 & 688422 & 7.15 & 6.6509 & TRN \\
\hline CHEMBL1518985 & 688422 & 5.25 & 5.1139 & TRN \\
\hline CHEMBL1503571 & 688422 & 4.45 & 4.9497 & TRN \\
\hline CHEMBL1473037 & 688422 & 5.15 & 5.2415 & TRN \\
\hline CHEMBL1444370 & 688422 & 4.85 & 4.8877 & TRN \\
\hline CHEMBL1368484 & 688422 & 4.45 & 4.9005 & TRN \\
\hline CHEMBL 2000436 & 688422 & 4.45 & 5.0728 & TRN \\
\hline CHEMBL1400207 & 688422 & 4.45 & 5.2157 & TRN \\
\hline CHEMBL1392341 & 688422 & 5.4 & 4.9139 & TRN \\
\hline CHEMBL1483446 & 688422 & 4.45 & 5.0832 & TRN \\
\hline CHEMBL1445480 & 688422 & 4.9 & 5.3106 & TST \\
\hline CHEMBL1349814 & 688422 & 4.95 & 5.3032 & TRN \\
\hline CHEMBL1520920 & 688422 & 8.4559 & 5.5692 & TST \\
\hline CHEMBL196228 & 688422 & 5.0 & 5.7365 & TRN \\
\hline CHEMBL1585944 & 688422 & 4.45 & 5.5544 & TRN \\
\hline CHEMBL1462585 & 688422 & 4.8 & 4.8759 & TRN \\
\hline CHEMBL1354419 & 688422 & 8.3979 & 5.4094 & TRN \\
\hline CHEMBL1447408 & 688422 & 5.0 & 5.2164 & TST \\
\hline CHEMBL1327979 & 688422 & 5.5 & 5.3671 & TRN \\
\hline CHEMBL1311513 & 688422 & 4.75 & 4.9772 & TRN \\
\hline CHEMBL1521050 & 688422 & 4.8 & 5.1404 & TRN \\
\hline CHEMBL600121 & 688422 & 4.6 & 4.7094 & TRN \\
\hline CHEMBL1411787 & 688422 & 5.1 & 4.8241 & TRN \\
\hline CHEMBL1323290 & 688422 & 5.9 & 5.3304 & TRN \\
\hline CHEMBL1606180 & 688422 & 4.45 & 5.4507 & TRN \\
\hline CHEMBL1606592 & 688422 & 5.15 & 5.3138 & TST \\
\hline CHEMBL1364730 & 688422 & 5.05 & 5.4888 & TRN \\
\hline
\end{tabular}




\begin{tabular}{|c|c|c|c|c|c|}
\hline \multirow{3}{*}{$\begin{array}{l}\text { CHEMBL1418596 } \\
\text { CHEMBL } 1566618\end{array}$} & & \multicolumn{4}{|c|}{ Supplemental Table s2.txt } \\
\hline & 688422 & 4.6 & \multicolumn{2}{|c|}{5.757999999999999} & TST \\
\hline & 688422 & 4.5 & 4.784 & TRN & \\
\hline CHEMBL1307416 & 688422 & 4.5 & 5.1754 & TST & \\
\hline CHEMBL1580782 & 688422 & 7.5498 & 5.7754 & TRN & \\
\hline CHEMBL1478468 & 688422 & 4.9 & 4.9526 & TRN & \\
\hline CHEMBL1488436 & 688422 & 4.45 & 5.3171 & TRN & \\
\hline CHEMBL1552761 & 688422 & 4.45 & 5.2765 & TRN & \\
\hline CHEMBL1303678 & 688422 & 4.85 & 4.9919 & TRN & \\
\hline CHEMBL1558892 & 688422 & 4.85 & 4.885 & TRN & \\
\hline CHEMBL1463564 & 688422 & 4.6 & 4.8159 & TRN & \\
\hline CHEMBL1375824 & 688422 & 4.95 & 4.8713 & TRN & \\
\hline CHEMBL1456562 & 688422 & 7.1002 & 5.9556 & TRN & \\
\hline CHEMBL1510848 & 688422 & 4.65 & 5.2535 & TRN & \\
\hline CHEMBL1375927 & 688422 & 4.8 & 5.1411 & TRN & \\
\hline CHEMBL1965687 & 688422 & 4.65 & 4.7272 & TRN & \\
\hline CHEMBL1544814 & 688422 & 4.95 & 5.1376 & TRN & \\
\hline CHEMBL1533387 & 688422 & 4.45 & 4.9757 & TRN & \\
\hline CHEMBL1403824 & 688422 & 4.65 & 5.1815 & TRN & \\
\hline CHEMBL1390477 & 688422 & 6.6499 & 5.4324 & TRN & \\
\hline CHEMBL1519014 & 688422 & 5.05 & 5.6823 & TRN & \\
\hline CHEMBL1437954 & 688422 & 4.45 & 4.8275 & TST & \\
\hline CHEMBL1310759 & 688422 & 4.95 & 5.426 & TRN & \\
\hline CHEMBL1537023 & 688422 & 4.85 & 5.2277 & TRN & \\
\hline CHEMBL306946 & 688422 & 6.45 & 5.3197 & TRN & \\
\hline CHEMBL1352200 & 688422 & 4.85 & 5.6412 & TRN & \\
\hline CHEMBL1414034 & 688422 & 4.9 & 5.0164 & TRN & \\
\hline CHEMBL1498309 & 688422 & 4.45 & 5.6165 & TST & \\
\hline CHEMBL1374076 & 688422 & 4.9 & 5.0345 & TRN & \\
\hline CHEMBL1516303 & 688422 & 4.45 & 5.2868 & TRN & \\
\hline CHEMBL1505827 & 688422 & 4.9 & 5.2303 & TRN & \\
\hline CHEMBL1583966 & 688422 & 4.85 & 5.1113 & TST & \\
\hline CHEMBL1478366 & 688422 & 4.45 & 5.2228 & TRN & \\
\hline CHEMBL1305960 & 688422 & 4.6 & 5.1162 & TRN & \\
\hline CHEMBL1491068 & 688422 & 4.65 & 4.7439 & TRN & \\
\hline CHEMBL1603191 & 688422 & 5.5 & 5.1466 & TRN & \\
\hline CHEMBL1430195 & 688422 & 4.6 & 5.0676 & TRN & \\
\hline CHEMBL1410266 & 688422 & 4.7 & 5.1 & TST & \\
\hline CHEMBL1501553 & 688422 & 4.8 & 5.2651 & TRN & \\
\hline CHEMBL1452390 & 688422 & 4.45 & 5.1404 & TRN & \\
\hline CHEMBL1320967 & 688422 & 5.5 & 5.3347 & TRN & \\
\hline CHEMBL3197436 & 688422 & 4.4 & 5.6436 & TRN & \\
\hline CHEMBL1507616 & 688422 & 5.0 & 4.9397 & TRN & \\
\hline CHEMBL1565363 & 688422 & 4.6 & 5.2751 & TRN & \\
\hline CHEMBL3198284 & 688422 & 6.7501 & 5.1596 & TRN & \\
\hline CHEMBL1302054 & 688422 & 4.7 & 4.9634 & TRN & \\
\hline CHEMBL1327844 & 688422 & 4.45 & 5.1184 & TRN & \\
\hline CHEMBL1482307 & 688422 & 4.45 & 4.8551 & TRN & \\
\hline CHEMBL1471707 & 688422 & 7.699 & 5.3232 & TRN & \\
\hline
\end{tabular}




\begin{tabular}{|c|c|c|c|c|c|}
\hline \multicolumn{6}{|c|}{ Supplemental Table S2.txt } \\
\hline CHEMBL1562480 & 688422 & 4.45 & 5.0804 & TRN & \\
\hline CHEMBL1583280 & 688422 & 5.0 & 5.4515 & TST & \\
\hline CHEMBL1339746 & 688422 & 4.9 & 5.5262 & TST & \\
\hline CHEMBL1310774 & 688422 & 4.45 & 4.9469 & TRN & \\
\hline CHEMBL1469995 & 688422 & 4.6 & 4.982 & TST & \\
\hline CHEMBL1344212 & 688422 & 4.9 & 5.0846 & TRN & \\
\hline CHEMBL1341259 & 688422 & 4.65 & 5.3167 & TRN & \\
\hline CHEMBL1905194 & 688422 & 5.15 & 5.1377 & TRN & \\
\hline CHEMBL1499115 & 688422 & 4.7 & 5.1095 & TST & \\
\hline CHEMBL1316306 & 688422 & 5.6 & 5.16100 & 00000000005 & TRN \\
\hline CHEMBL1410625 & 688422 & 4.5 & 5.0556 & TRN & \\
\hline CHEMBL1590476 & 688422 & 4.45 & 4.9399 & TRN & \\
\hline CHEMBL1358192 & 688422 & 7.6498 & 5.2672 & TRN & \\
\hline CHEMBL1548942 & 688422 & 5.05 & 5.0518 & TRN & \\
\hline CHEMBL1403917 & 688422 & 4.45 & 5.1276 & TRN & \\
\hline CHEMBL1494384 & 688422 & 5.1 & 5.561 & TST & \\
\hline CHEMBL1502358 & 688422 & 5.55 & 5.3228 & TST & \\
\hline CHEMBL1381753 & 688422 & 4.55 & 5.4032 & TRN & \\
\hline CHEMBL1612206 & 688422 & 5.35 & 5.9628 & TRN & \\
\hline CHEMBL1344249 & 688422 & 4.45 & 4.8378 & TRN & \\
\hline CHEMBL1538778 & 688422 & 6.05 & 5.3282 & TST & \\
\hline CHEMBL1542798 & 688422 & 4.45 & 5.343 & TRN & \\
\hline CHEMBL1598284 & 688422 & 5.6 & 4.6637 & TRN & \\
\hline CHEMBL1604118 & 688422 & 4.9 & 5.1209 & TRN & \\
\hline CHEMBL1480241 & 688422 & 4.5 & 5.0169 & TRN & \\
\hline CHEMBL1341852 & 688422 & 4.9 & 4.9525 & TST & \\
\hline CHEMBL1422196 & 688422 & 8.0 & 5.3229 & TRN & \\
\hline CHEMBL1373259 & 688422 & 4.95 & 4.9152 & TRN & \\
\hline CHEMBL1446401 & 688422 & 4.9 & 5.08899 & 99999999995 & TRN \\
\hline CHEMBL1352013 & 688422 & 4.65 & 5.3869 & TRN & \\
\hline CHEMBL1546299 & 688422 & 4.95 & 5.3036 & TRN & \\
\hline CHEMBL1382784 & 688422 & 5.1 & 5.0014 & TST & \\
\hline CHEMBL1424193 & 688422 & 8.1024 & 5.94 & TST & \\
\hline CHEMBL1445058 & 688422 & 5.05 & 5.5916 & TRN & \\
\hline CHEMBL 3193598 & 688422 & 5.45 & 5.2168 & TRN & \\
\hline CHEMBL1468169 & 688422 & 4.45 & 4.9386 & TRN & \\
\hline CHEMBL1521902 & 688422 & 5.05 & 4.7609 & TRN & \\
\hline CHEMBL1513802 & 688422 & 4.85 & 5.1943 & TRN & \\
\hline CHEMBL1602201 & 688422 & 4.45 & 5.1948 & TST & \\
\hline CHEMBL1535416 & 688422 & 4.45 & 5.0754 & TST & \\
\hline CHEMBL1427766 & 688422 & 4.65 & 5.3679 & TRN & \\
\hline CHEMBL1608355 & 688422 & 4.95 & 5.0527 & TRN & \\
\hline CHEMBL1375733 & 688422 & 5.2 & 5.0737 & TST & \\
\hline CHEMBL1350543 & 688422 & 4.45 & 5.4333 & TRN & \\
\hline CHEMBL1550346 & 688422 & 7.3497 & 5.1791 & TRN & \\
\hline CHEMBL1371880 & 688422 & 4.45 & 5.0474 & TRN & \\
\hline CHEMBL1478073 & 688422 & 4.45 & 5.0587 & TRN & \\
\hline CHEMBL1570753 & 688422 & 4.45 & 4.8736 & TST & \\
\hline
\end{tabular}




\begin{tabular}{|c|c|c|c|c|c|}
\hline \multicolumn{6}{|c|}{ Supplemental Table S2.txt } \\
\hline CHEMBL1315325 & 688422 & 4.8 & 4.8004 & TRN & \\
\hline CHEMBL1310954 & 688422 & 4.45 & 5.1617 & TRN & \\
\hline CHEMBL1358722 & 688422 & 6.0 & 6.6261 & TST & \\
\hline CHEMBL1519959 & 688422 & 4.75 & 5.5933 & TST & \\
\hline CHEMBL 3192293 & 688422 & 4.45 & 4.7316 & TRN & \\
\hline CHEMBL1504085 & 688422 & 5.05 & 5.9339 & TST & \\
\hline CHEMBL540848 & 688422 & 4.6 & 5.19799 & 99999999995 & TST \\
\hline CHEMBL1488681 & 688422 & 4.75 & 5.0358 & TST & \\
\hline CHEMBL1490784 & 688422 & 6.1 & 5.6823 & TST & \\
\hline CHEMBL1565454 & 688422 & 6.45 & 5.1451 & TRN & \\
\hline CHEMBL1511233 & 688422 & 4.95 & 5.3428 & TST & \\
\hline CHEMBL1436076 & 688422 & 6.7501 & 5.51200 & 00000000005 & TRN \\
\hline CHEMBL1543794 & 688422 & 5.2 & 5.2467 & TST & \\
\hline CHEMBL1468234 & 688422 & 4.85 & 5.2078 & TRN & \\
\hline CHEMBL1324686 & 688422 & 4.9 & 5.4498 & TST & \\
\hline CHEMBL1441545 & 688422 & 4.45 & 4.86100 & 0000000001 & TRN \\
\hline CHEMBL1588295 & 688422 & 4.45 & 5.0347 & TST & \\
\hline CHEMBL1382924 & 688422 & 4.5 & 5.3718 & TRN & \\
\hline CHEMBL1410698 & 688422 & 4.9 & 5.2656 & TST & \\
\hline CHEMBL1385397 & 688422 & 4.95 & 4.9146 & TRN & \\
\hline CHEMBL1500691 & 688422 & 4.6 & 4.89 & TST & \\
\hline CHEMBL1341092 & 688422 & 4.85 & 5.2253 & TST & \\
\hline CHEMBL3213935 & 688422 & 5.7 & 5.9151 & TRN & \\
\hline CHEMBL1362639 & 688422 & 8.4949 & 5.7273 & TRN & \\
\hline CHEMBL1511236 & 688422 & 4.7 & 5.2644 & TRN & \\
\hline CHEMBL1611819 & 688422 & 4.7 & 5.4467 & TRN & \\
\hline CHEMBL1429097 & 688422 & 4.85 & 5.0941 & TRN & \\
\hline CHEMBL1504810 & 688422 & 4.9 & 5.0874 & TRN & \\
\hline CHEMBL1547000 & 688422 & 4.8 & 5.2673 & TRN & \\
\hline CHEMBL3196732 & 688422 & 4.85 & 4.994 & TST & \\
\hline CHEMBL1378829 & 688422 & 4.95 & 5.1441 & TST & \\
\hline CHEMBL1404701 & 688422 & 4.9 & 5.2442 & TST & \\
\hline CHEMBL1435049 & 688422 & 5.55 & 5.1692 & TRN & \\
\hline CHEMBL1529007 & 688422 & 4.7 & 5.5166 & TST & \\
\hline CHEMBL1344342 & 688422 & 4.7 & 4.9381 & TST & \\
\hline CHEMBL1556185 & 688422 & 5.1 & 4.9917 & TRN & \\
\hline CHEMBL1507217 & 688422 & 8.301 & 5.4268 & TST & \\
\hline CHEMBL1446329 & 688422 & 4.85 & 5.3938 & TST & \\
\hline CHEMBL1314110 & 688422 & 7.15 & 5.5057 & TST & \\
\hline CHEMBL1563673 & 688422 & 5.55 & 4.9677 & TRN & \\
\hline CHEMBL1510881 & 688422 & 4.95 & 5.4223 & TRN & \\
\hline CHEMBL1313190 & 688422 & 5.05 & 5.4482 & TRN & \\
\hline CHEMBL1368777 & 688422 & 5.25 & 4.8162 & TRN & \\
\hline CHEMBL1370183 & 688422 & 4.9 & 4.9454 & TRN & \\
\hline CHEMBL1502480 & 688422 & 7.7496 & 5.6987 & TRN & \\
\hline CHEMBL1583945 & 688422 & 4.45 & 5.5611 & TRN & \\
\hline CHEMBL1600803 & 688422 & 4.7 & 5.3386 & TST & \\
\hline CHEMBL1354520 & 688422 & 4.75 & 5.1159 & TRN & \\
\hline
\end{tabular}




\begin{tabular}{|c|c|c|c|c|}
\hline \multicolumn{5}{|c|}{ Supplemental Table S2.txt } \\
\hline CHEMBL1593851 & 688422 & 7.1002 & 5.6782 & TRN \\
\hline CHEMBL3196572 & 688422 & 4.45 & 5.0203 & TRN \\
\hline CHEMBL1321334 & 688422 & 6.5 & 5.3875 & TRN \\
\hline CHEMBL1477551 & 688422 & 5.45 & 5.6346 & TST \\
\hline CHEMBL1541023 & 688422 & 5.05 & 5.141 & TRN \\
\hline CHEMBL1346235 & 688422 & 4.5 & 5.4243 & TRN \\
\hline CHEMBL1362376 & 688422 & 4.9 & 5.3812 & TST \\
\hline CHEMBL1475527 & 688422 & 7.6003 & 5.1963 & TRN \\
\hline CHEMBL1385355 & 688422 & 4.45 & 5.0998 & TRN \\
\hline CHEMBL1445425 & 688422 & 4.5 & 5.3186 & TRN \\
\hline CHEMBL 1455720 & 688422 & 4.7 & 5.3686 & TRN \\
\hline CHEMBL3189318 & 688422 & 4.85 & 5.1393 & TRN \\
\hline CHEMBL 2004157 & 688422 & 4.65 & 5.0209 & TRN \\
\hline CHEMBL1559506 & 688422 & 4.45 & 4.9167 & TRN \\
\hline CHEMBL1408843 & 688422 & 6.05 & 5.2453 & TRN \\
\hline CHEMBL1567638 & 688422 & 4.65 & 5.2776 & TRN \\
\hline CHEMBL1599776 & 688422 & 4.95 & 5.6245 & TST \\
\hline CHEMBL1372751 & 688422 & 4.75 & 4.9767 & TRN \\
\hline CHEMBL1303944 & 688422 & 4.65 & 5.7503 & TRN \\
\hline CHEMBL1382773 & 688422 & 5.15 & 4.794 & TRN \\
\hline CHEMBL1559832 & 688422 & 4.9 & 5.2231 & TRN \\
\hline CHEMBL1384466 & 688422 & 4.65 & 5.651 & TRN \\
\hline CHEMBL1386270 & 688422 & 4.6 & 5.0754 & TRN \\
\hline CHEMBL1521360 & 688422 & 4.45 & 4.7742 & TST \\
\hline CHEMBL1573457 & 688422 & 4.45 & 5.2754 & TST \\
\hline CHEMBL1341708 & 688422 & 4.65 & 5.1777 & TRN \\
\hline CHEMBL1404785 & 688422 & 8.4559 & 5.0964 & TST \\
\hline CHEMBL1521021 & 688422 & 4.9 & 5.0305 & TRN \\
\hline CHEMBL1363379 & 688422 & 4.9 & 5.5555 & TST \\
\hline CHEMBL1441088 & 688422 & 4.65 & 4.7719 & TRN \\
\hline CHEMBL1391860 & 688422 & 4.95 & 5.1328 & TRN \\
\hline CHEMBL1390038 & 688422 & 4.85 & 5.2156 & TRN \\
\hline CHEMBL1500805 & 688422 & 4.5 & 5.086 & TRN \\
\hline CHEMBL1522583 & 688422 & 6.3 & 5.0056 & TRN \\
\hline CHEMBL1610148 & 688422 & 4.45 & 5.4928 & TRN \\
\hline CHEMBL1600347 & 688422 & 4.65 & 5.1086 & TST \\
\hline CHEMBL1410279 & 688422 & 4.5 & 5.3313 & TRN \\
\hline CHEMBL1610115 & 688422 & 6.15 & 5.35 & TRN \\
\hline CHEMBL1438389 & 688422 & 4.45 & 5.2221 & TRN \\
\hline CHEMBL455399 & 688422 & 5.45 & 5.1196 & TRN \\
\hline CHEMBL 1475114 & 688422 & 4.45 & 5.3034 & TRN \\
\hline CHEMBL1484171 & 688422 & 7.3497 & 5.7933 & TRN \\
\hline CHEMBL1396374 & 688422 & 5.05 & 4.3061 & TRN \\
\hline CHEMBL1303655 & 688422 & 4.95 & 5.6551 & TRN \\
\hline CHEMBL1581933 & 688422 & 5.5 & 5.5078 & TST \\
\hline CHEMBL 1543932 & 688422 & 4.45 & 5.7219 & TST \\
\hline CHEMBL1518206 & 688422 & 4.9 & 4.9799 & TST \\
\hline CHEMBL1406304 & 688422 & 5.4 & 5.2634 & TST \\
\hline
\end{tabular}




\begin{tabular}{|c|c|c|c|c|c|}
\hline \multicolumn{6}{|c|}{ Supplemental Table S2.txt } \\
\hline CHEMBL1415279 & 688422 & 4.45 & 5.2303 & TRN & \\
\hline CHEMBL1369893 & 688422 & 5.15 & 5.4761 & TRN & \\
\hline CHEMBL1465176 & 688422 & 4.65 & 5.4446 & TST & \\
\hline CHEMBL1359849 & 688422 & 4.8 & 5.1783 & TRN & \\
\hline CHEMBL1256869 & 688422 & 4.75 & 5.3709 & TST & \\
\hline CHEMBL1365690 & 688422 & 8.4949 & 5.0942 & TST & \\
\hline CHEMBL1512416 & 688422 & 4.85 & 5.1394 & TRN & \\
\hline CHEMBL 2002482 & 688422 & 5.45 & 5.155 & TRN & \\
\hline CHEMBL1602867 & 688422 & 4.5 & 5.0591 & TRN & \\
\hline CHEMBL1441390 & 688422 & 6.8 & 5.566 & TST & \\
\hline CHEMBL1408170 & 688422 & 5.35 & 5.4928 & TRN & \\
\hline CHEMBL1303867 & 688422 & 6.15 & 5.6683 & TRN & \\
\hline CHEMBL1315348 & 688422 & 5.4 & 4.9156 & TRN & \\
\hline CHEMBL1588196 & 688422 & 5.45 & 5.2065 & TRN & \\
\hline CHEMBL1492152 & 688422 & 7.699 & 5.1682 & TRN & \\
\hline CHEMBL1305350 & 688422 & 4.45 & 5.6935 & TRN & \\
\hline CHEMBL1380192 & 688422 & 5.3 & 5.1389 & TRN & \\
\hline CHEMBL1608408 & 688422 & 4.7 & 5.4602 & TRN & \\
\hline CHEMBL1390142 & 688422 & 4.95 & 5.4929 & TRN & \\
\hline CHEMBL1369225 & 688422 & 4.5 & 5.5266 & TST & \\
\hline CHEMBL1337819 & 688422 & 5.15 & 5.8493 & TRN & \\
\hline CHEMBL1365740 & 688422 & 4.6 & 5.1012 & TRN & \\
\hline CHEMBL1526022 & 688422 & 4.7 & 5.1276 & TRN & \\
\hline CHEMBL1481814 & 688422 & 4.75 & 5.4028 & TRN & \\
\hline CHEMBL1334377 & 688422 & 7.7496 & 5.5155 & TRN & \\
\hline CHEMBL1347112 & 688422 & 5.7 & 5.1998 & TRN & \\
\hline CHEMBL1570195 & 688422 & 4.65 & 5.45799 & & TRN \\
\hline CHEMBL1604548 & 688422 & 4.45 & 4.8159 & TRN & \\
\hline CHEMBL1534310 & 688422 & 5.85 & 5.2392 & TRN & \\
\hline CHEMBL1335884 & 688422 & 4.6 & 5.9273 & TRN & \\
\hline CHEMBL1344137 & 688422 & 4.45 & 5.1849 & TST & \\
\hline CHEMBL1448529 & 688422 & 4.45 & 5.0397 & TRN & \\
\hline CHEMBL1413056 & 688422 & 6.2 & 4.9607 & TRN & \\
\hline CHEMBL1430124 & 688422 & 4.5 & 4.8999 & TRN & \\
\hline CHEMBL1453849 & 688422 & 5.85 & 5.5508 & TRN & \\
\hline CHEMBL1312749 & 688422 & 4.9 & 5.1642 & TRN & \\
\hline CHEMBL1471752 & 688422 & 4.75 & 5.2136 & TRN & \\
\hline CHEMBL1343700 & 688422 & 6.8 & 5.0747 & TRN & \\
\hline CHEMBL1395678 & 688422 & 4.95 & 5.2493 & TRN & \\
\hline CHEMBL3213382 & 688422 & 4.7 & 5.0847 & TRN & \\
\hline CHEMBL1301926 & 688422 & 4.45 & 5.1959 & TRN & \\
\hline CHEMBL3196266 & 688422 & 5.0 & 4.7697 & TRN & \\
\hline CHEMBL1444187 & 688422 & 4.45 & 5.1007 & TRN & \\
\hline CHEMBL 3195409 & 688422 & 4.75 & 5.0256 & TRN & \\
\hline CHEMBL1554036 & 688422 & 4.85 & 5.4826 & TRN & \\
\hline CHEMBL1377315 & 688422 & 7.699 & 5.3231 & TRN & \\
\hline CHEMBL1378536 & 688422 & 4.5 & 5.4034 & TST & \\
\hline CHEMBL1514325 & 688422 & 5.6 & 5.4125 & TST & \\
\hline
\end{tabular}




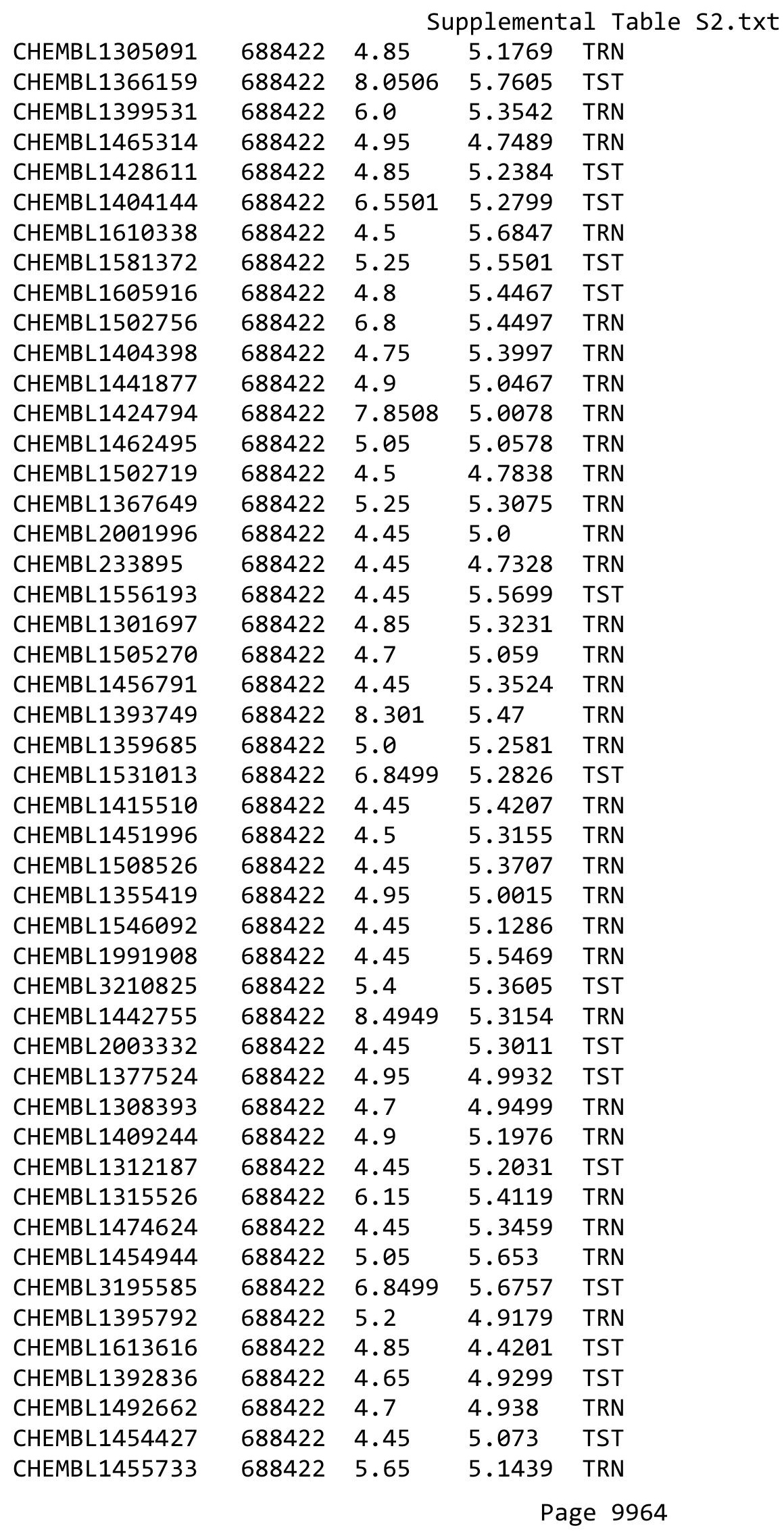




\begin{tabular}{|c|c|c|c|c|}
\hline \multicolumn{5}{|c|}{ Supplemental Table S2.txt } \\
\hline CHEMBL1337917 & 688422 & 4.95 & 5.1292 & TRN \\
\hline CHEMBL 2002465 & 688422 & 5.0 & 5.0625 & TRN \\
\hline CHEMBL1553003 & 688422 & 5.55 & 4.9341 & TRN \\
\hline CHEMBL1428525 & 688422 & 4.85 & 5.4281 & TRN \\
\hline CHEMBL1320148 & 688422 & 4.45 & 4.9088 & TRN \\
\hline CHEMBL1538098 & 688422 & 4.95 & 5.1766 & TRN \\
\hline CHEMBL1401675 & 688422 & 5.65 & 5.9275 & TRN \\
\hline CHEMBL1343964 & 688422 & 4.9 & 5.1595 & TRN \\
\hline CHEMBL1506978 & 688422 & 4.45 & 5.5005 & TRN \\
\hline CHEMBL1383497 & 688422 & 4.65 & 4.9253 & TRN \\
\hline CHEMBL1564834 & 688422 & 4.5 & 5.2668 & TRN \\
\hline CHEMBL3209274 & 688422 & 5.6 & 5.0331 & TST \\
\hline CHEMBL1256695 & 688422 & 9.0969 & 5.3703 & TST \\
\hline CHEMBL1400605 & 688422 & 7.0501 & 4.9624 & TST \\
\hline CHEMBL1338358 & 688422 & 4.85 & 4.4545 & TST \\
\hline CHEMBL1505606 & 688422 & 4.45 & 5.0775 & TRN \\
\hline CHEMBL1318606 & 688422 & 6.35 & 4.824 & TRN \\
\hline CHEMBL 2374058 & 688422 & 4.45 & 6.1241 & TST \\
\hline CHEMBL1482373 & 688422 & 5.25 & 5.1072 & TRN \\
\hline CHEMBL1388529 & 688422 & 4.6 & 4.7804 & TRN \\
\hline CHEMBL1355868 & 688422 & 7.9508 & 5.2952 & TRN \\
\hline CHEMBL1306634 & 688422 & 4.45 & 5.2234 & TRN \\
\hline CHEMBL1365435 & 688422 & 4.9 & 5.6689 & TRN \\
\hline CHEMBL1374931 & 688422 & 8.4559 & 5.11 & TRN \\
\hline CHEMBL1412369 & 688422 & 4.6 & 5.0629 & TRN \\
\hline CHEMBL1384043 & 688422 & 5.1 & 5.2521 & TST \\
\hline CHEMBL1564310 & 688422 & 4.65 & 5.0585 & TRN \\
\hline CHEMBL1420190 & 688422 & 5.05 & 5.4098 & TST \\
\hline CHEMBL1483822 & 688422 & 8.3468 & 5.6186 & TRN \\
\hline CHEMBL1968462 & 688422 & 4.5 & 4.9873 & TRN \\
\hline CHEMBL1598587 & 688422 & 7.15 & 5.566 & TST \\
\hline CHEMBL1398796 & 688422 & 4.45 & 5.1295 & TRN \\
\hline CHEMBL1536048 & 688422 & 4.85 & 4.9539 & TRN \\
\hline CHEMBL1548440 & 688422 & 4.45 & 5.1712 & TRN \\
\hline CHEMBL1557219 & 688422 & 4.8 & 5.0143 & TRN \\
\hline CHEMBL1562117 & 688422 & 4.45 & 4.8358 & TST \\
\hline CHEMBL 2003873 & 688422 & 5.4 & 4.885 & TST \\
\hline CHEMBL1369808 & 688422 & 7.699 & 5.3244 & TRN \\
\hline CHEMBL1484672 & 688422 & 4.45 & 5.1011 & TRN \\
\hline CHEMBL1443804 & 688422 & 4.75 & 5.1457 & TRN \\
\hline CHEMBL1605576 & 688422 & 5.15 & 5.4655 & TRN \\
\hline CHEMBL1361899 & 688422 & 6.05 & 5.3129 & TRN \\
\hline CHEMBL1380498 & 688422 & 4.75 & 5.3021 & TRN \\
\hline CHEMBL1609172 & 688422 & 5.0 & 4.4271 & TST \\
\hline CHEMBL1573750 & 688422 & 5.0 & 5.4836 & TRN \\
\hline CHEMBL1520669 & 688422 & 8.2007 & 5.4879 & TST \\
\hline CHEMBL3190354 & 688422 & 5.4 & 5.2752 & TRN \\
\hline CHEMBL1445279 & 688422 & 4.45 & 5.0842 & TRN \\
\hline
\end{tabular}




\begin{tabular}{|c|c|c|c|c|}
\hline \multicolumn{5}{|c|}{ Supplemental Table S2.txt } \\
\hline CHEMBL1423878 & 688422 & 4.45 & 5.1347 & TRN \\
\hline CHEMBL1472577 & 688422 & 7.0501 & 5.0093 & TST \\
\hline CHEMBL1972029 & 688422 & 4.6 & 5.2497 & TRN \\
\hline CHEMBL1325958 & 688422 & 4.65 & 4.8457 & TRN \\
\hline CHEMBL1451919 & 688422 & 7.4498 & 5.643 & TRN \\
\hline CHEMBL1334763 & 688422 & 4.6 & 5.1085 & TRN \\
\hline CHEMBL1429289 & 688422 & 7.4001 & 5.5007 & TRN \\
\hline CHEMBL1450770 & 688422 & 5.25 & 5.4695 & TST \\
\hline CHEMBL1526323 & 688422 & 4.8 & 5.2522 & TRN \\
\hline CHEMBL1356351 & 688422 & 7.0 & 5.0049 & TRN \\
\hline CHEMBL1391455 & 688422 & 4.85 & 5.2459 & TRN \\
\hline CHEMBL259474 & 688422 & 4.45 & 5.2903 & TRN \\
\hline CHEMBL1527879 & 688422 & 6.35 & 5.4512 & TRN \\
\hline CHEMBL3189225 & 688422 & 4.6 & 5.02 & TST \\
\hline CHEMBL1594282 & 688422 & 5.15 & 5.2192 & TRN \\
\hline CHEMBL1425445 & 688422 & 4.9 & 5.3099 & TRN \\
\hline CHEMBL1563318 & 688422 & 4.65 & 5.0135 & TRN \\
\hline CHEMBL1536621 & 688422 & 5.05 & 5.4492 & TRN \\
\hline CHEMBL1470072 & 688422 & 6.1 & 5.4594 & TST \\
\hline CHEMBL1516672 & 688422 & 5.1 & 5.27 & TRN \\
\hline CHEMBL1496734 & 688422 & 4.9 & 4.9127 & TST \\
\hline CHEMBL1511413 & 688422 & 4.7 & 5.1012 & TST \\
\hline CHEMBL3191114 & 688422 & 8.0 & 5.0028 & TST \\
\hline CHEMBL1536646 & 688422 & 5.45 & 4.4612 & TRN \\
\hline CHEMBL1451470 & 688422 & 5.45 & 4.7229 & TRN \\
\hline CHEMBL1570620 & 688422 & 6.5 & 5.2372 & TST \\
\hline CHEMBL1353130 & 688422 & 4.7 & 5.41200 & 2000000001 \\
\hline CHEMBL1596754 & 688422 & 5.15 & 5.8523 & TST \\
\hline CHEMBL1556676 & 688422 & 6.05 & 5.3236 & TRN \\
\hline CHEMBL1360889 & 688422 & 6.45 & 5.0103 & TST \\
\hline CHEMBL1304680 & 688422 & 6.4 & 5.5192 & TRN \\
\hline CHEMBL1365367 & 688422 & 4.8 & 5.0021 & TRN \\
\hline CHEMBL56393 & 688422 & 4.8 & 5.0539 & TRN \\
\hline CHEMBL1580139 & 688422 & 4.8 & 5.3394 & TRN \\
\hline CHEMBL3196851 & 688422 & 6.5501 & 5.2974 & TRN \\
\hline CHEMBL1528225 & 688422 & 4.95 & 4.87 & TRN \\
\hline CHEMBL1358727 & 688422 & 4.55 & 5.0533 & TRN \\
\hline CHEMBL1341873 & 688422 & 5.2 & 5.2047 & TRN \\
\hline CHEMBL920 & 688422 & 5.25 & 5.9654 & TST \\
\hline CHEMBL1300231 & 688422 & 5.05 & 4.7579 & TRN \\
\hline CHEMBL1463263 & 688422 & 4.45 & 4.8886 & TRN \\
\hline CHEMBL1568279 & 688422 & 4.45 & 5.0771 & TRN \\
\hline CHEMBL1442173 & 688422 & 4.6 & 5.018 & TRN \\
\hline CHEMBL3192758 & 688422 & 4.5 & 5.138 & TRN \\
\hline CHEMBL1534136 & 688422 & 4.95 & 5.1559 & TRN \\
\hline CHEMBL1307196 & 688422 & 4.55 & 5.4152 & TST \\
\hline CHEMBL1335593 & 688422 & 5.1 & 5.9487 & TST \\
\hline CHEMBL1376949 & 688422 & 5.3 & 5.5616 & TRN \\
\hline
\end{tabular}




\begin{tabular}{|c|c|c|c|c|c|}
\hline \multicolumn{6}{|c|}{ Supplemental Table S2.txt } \\
\hline CHEMBL3196046 & 688422 & 4.5 & 5.114 & TRN & \\
\hline CHEMBL1522443 & 688422 & 5.1 & 5.2215 & TRN & \\
\hline CHEMBL3193629 & 688422 & 5.0 & 5.1691 & TRN & \\
\hline CHEMBL1546843 & 688422 & 5.65 & 4.6267 & TRN & \\
\hline CHEMBL1477021 & 688422 & 5.55 & 5.5042 & TRN & \\
\hline CHEMBL590422 & 688422 & 4.65 & 5.1689 & TRN & \\
\hline CHEMBL1365908 & 688422 & 7.3002 & 5.8616 & TST & \\
\hline CHEMBL1402437 & 688422 & 4.8 & 5.3346 & TRN & \\
\hline CHEMBL1346764 & 688422 & 4.45 & 5.4312 & TRN & \\
\hline CHEMBL1541075 & 688422 & 5.3 & 5.2493 & TST & \\
\hline CHEMBL1597810 & 688422 & 4.45 & 5.0792 & TRN & \\
\hline CHEMBL1500981 & 688422 & 4.8 & 5.0535 & TST & \\
\hline CHEMBL1310804 & 688422 & 7.4498 & 5.1479 & TST & \\
\hline CHEMBL1535738 & 688422 & 4.85 & 5.3922 & TST & \\
\hline CHEMBL1462691 & 688422 & 5.2 & 5.4597 & TST & \\
\hline CHEMBL1335688 & 688422 & 4.8 & 5.1398 & TRN & \\
\hline CHEMBL1584303 & 688422 & 7.699 & 5.7366 & TRN & \\
\hline CHEMBL1561213 & 688422 & 7.7496 & 5.5814 & TST & \\
\hline CHEMBL1563011 & 688422 & 5.7 & 5.3788 & TRN & \\
\hline CHEMBL1499797 & 688422 & 4.75 & 5.6714 & TST & \\
\hline CHEMBL1390118 & 688422 & 5.85 & 5.2087 & TRN & \\
\hline CHEMBL1457134 & 688422 & 5.9 & 5.3685 & TRN & \\
\hline CHEMBL3193433 & 688422 & 8.3979 & 5.3515 & TRN & \\
\hline CHEMBL1434956 & 688422 & 5.75 & 5.3077 & TRN & \\
\hline CHEMBL1351315 & 688422 & 4.6 & 5.0982 & TST & \\
\hline CHEMBL1487321 & 688422 & 4.5 & 5.2086 & TRN & \\
\hline CHEMBL1460913 & 688422 & 4.5 & 5.53100 & 0000000001 & TRN \\
\hline CHEMBL1599520 & 688422 & 4.8 & 5.1908 & TRN & \\
\hline CHEMBL1991441 & 688422 & 5.35 & 5.1864 & TST & \\
\hline CHEMBL1350375 & 688422 & 7.2 & 5.4298 & TST & \\
\hline CHEMBL1429574 & 688422 & 5.0 & 5.1223 & TRN & \\
\hline CHEMBL1484039 & 688422 & 4.85 & 5.3292 & TRN & \\
\hline CHEMBL1481353 & 688422 & 5.45 & 5.0066 & TST & \\
\hline CHEMBL1405890 & 688422 & 5.35 & 5.0996 & TRN & \\
\hline CHEMBL1325688 & 688422 & 4.65 & 5.3832 & TRN & \\
\hline CHEMBL1333276 & 688422 & 4.45 & 5.1797 & TRN & \\
\hline CHEMBL1426754 & 688422 & 6.0 & 5.0169 & TST & \\
\hline CHEMBL1336035 & 688422 & 4.9 & 4.893 & TRN & \\
\hline CHEMBL1472704 & 688422 & 6.25 & 5.37200 & $\partial 000000001$ & TRN \\
\hline CHEMBL1478021 & 688422 & 5.15 & 5.0985 & TRN & \\
\hline CHEMBL1471799 & 688422 & 5.9 & 5.32600 & 00000000005 & TRN \\
\hline CHEMBL1311617 & 688422 & 4.7 & 4.9022 & TRN & \\
\hline CHEMBL3194361 & 688422 & 4.9 & 5.449 & TST & \\
\hline CHEMBL428064 & 688422 & 6.1 & 5.5644 & TRN & \\
\hline CHEMBL1385457 & 688422 & 4.45 & 5.0162 & TRN & \\
\hline CHEMBL1382245 & 688422 & 4.55 & 5.7628 & TRN & \\
\hline CHEMBL1608120 & 688422 & 4.55 & 4.8971 & TRN & \\
\hline CHEMBL1544737 & 688422 & 4.55 & 5.0228 & TST & \\
\hline
\end{tabular}




\begin{tabular}{|c|c|c|c|c|c|}
\hline \multicolumn{6}{|c|}{ Supplemental Table s2.txt } \\
\hline CHEMBL1479401 & 688422 & 4.45 & 5.1928 & TRN & \\
\hline CHEMBL1484167 & 688422 & 4.85 & 4.9991 & TST & \\
\hline CHEMBL1503075 & 688422 & 4.45 & 5.3366 & TST & \\
\hline CHEMBL1339694 & 688422 & 7.1002 & 5.1145 & TRN & \\
\hline CHEMBL1458079 & 688422 & 4.7 & 5.1229 & TRN & \\
\hline CHEMBL1533458 & 688422 & 5.3 & 5.4988 & TRN & \\
\hline CHEMBL1509603 & 688422 & 4.75 & 4.9192 & TRN & \\
\hline CHEMBL3208361 & 688422 & 4.9 & 5.0775 & TRN & \\
\hline CHEMBL1360261 & 688422 & 6.1 & 5.4118 & TRN & \\
\hline CHEMBL3211917 & 688422 & 4.45 & 5.1858 & TST & \\
\hline CHEMBL1565342 & 688422 & 6.95 & 5.4839 & TRN & \\
\hline CHEMBL3190052 & 688422 & 4.95 & 5.3546 & TRN & \\
\hline CHEMBL1365810 & 688422 & 5.2 & 5.0544 & TRN & \\
\hline CHEMBL1427448 & 688422 & 4.65 & 4.8903 & TST & \\
\hline CHEMBL1569892 & 688422 & 4.95 & 5.1128 & TRN & \\
\hline CHEMBL1515305 & 688422 & 5.25 & 5.6974 & TST & \\
\hline CHEMBL1365032 & 688422 & 4.45 & 5.3946 & TRN & \\
\hline CHEMBL3214127 & 688422 & 8.3979 & 5.4106 & TST & \\
\hline CHEMBL454487 & 688422 & 4.45 & 5.186 & TRN & \\
\hline CHEMBL1429782 & 688422 & 5.2 & 5.4237 & TRN & \\
\hline CHEMBL1347618 & 688422 & 5.1 & 5.2905 & TRN & \\
\hline CHEMBL1585776 & 688422 & 4.45 & 4.67 & TRN & \\
\hline CHEMBL1527982 & 688422 & 5.4 & 5.2508 & TRN & \\
\hline CHEMBL1442990 & 688422 & 6.8 & 5.1037 & TRN & \\
\hline CHEMBL1522657 & 688422 & 4.65 & 5.3052 & TRN & \\
\hline CHEMBL3199648 & 688422 & 4.65 & 4.8242 & TRN & \\
\hline CHEMBL1606727 & 688422 & 4.8 & 4.8015 & TRN & \\
\hline CHEMBL1310906 & 688422 & 5.15 & 5.175 & TRN & \\
\hline CHEMBL1403691 & 688422 & 5.85 & 5.1756 & TST & \\
\hline CHEMBL1421227 & 688422 & 4.8 & 5.7994 & TRN & \\
\hline CHEMBL1557367 & 688422 & 5.0 & 5.4519 & TRN & \\
\hline CHEMBL1361034 & 688422 & 5.0 & 5.144 & TST & \\
\hline CHEMBL3192332 & 688422 & 5.55 & 5.50799 & & TST \\
\hline CHEMBL1362687 & 688422 & 4.7 & 5.035 & TRN & \\
\hline CHEMBL1396988 & 688422 & 7.8508 & 5.2185 & TRN & \\
\hline CHEMBL1469394 & 688422 & 5.05 & 5.1935 & TRN & \\
\hline CHEMBL1319956 & 688422 & 4.95 & 5.037 & TRN & \\
\hline CHEMBL1388107 & 688422 & 4.75 & 5.4913 & TRN & \\
\hline CHEMBL1461719 & 688422 & 4.45 & 5.5482 & TRN & \\
\hline CHEMBL1482574 & 688422 & 4.9 & 5.2282 & TRN & \\
\hline CHEMBL3191708 & 688422 & 4.95 & 5.3609 & TRN & \\
\hline CHEMBL1478511 & 688422 & 4.8 & 5.0964 & TST & \\
\hline CHEMBL1302113 & 688422 & 4.65 & 5.3479 & TRN & \\
\hline CHEMBL1349356 & 688422 & 4.45 & 5.2892 & TRN & \\
\hline CHEMBL1371474 & 688422 & 5.3 & 5.2175 & TRN & \\
\hline CHEMBL1394732 & 688422 & 4.6 & 5.7465 & TRN & \\
\hline CHEMBL1312291 & 688422 & 4.45 & 4.6374 & TRN & \\
\hline CHEMBL1498953 & 688422 & 4.8 & 5.0856 & TRN & \\
\hline
\end{tabular}




\begin{tabular}{|c|c|c|c|c|}
\hline \multicolumn{5}{|c|}{ Supplemental Table S2.txt } \\
\hline CHEMBL1613113 & 688422 & 4.45 & 5.6683 & TRN \\
\hline CHEMBL1311796 & 688422 & 5.55 & 4.9712 & TRN \\
\hline CHEMBL1344225 & 688422 & 4.9 & 5.1583 & TRN \\
\hline CHEMBL1383241 & 688422 & 4.95 & 5.3636 & TST \\
\hline CHEMBL1403503 & 688422 & 5.0 & 5.4709 & TST \\
\hline CHEMBL1589344 & 688422 & 6.25 & 5.1214 & TRN \\
\hline CHEMBL1419015 & 688422 & 4.7 & 5.4596 & TST \\
\hline CHEMBL1312006 & 688422 & 4.9 & 5.096 & TRN \\
\hline CHEMBL1427710 & 688422 & 4.9 & 5.22 & TRN \\
\hline CHEMBL1481664 & 688422 & 4.95 & 5.3745 & TRN \\
\hline CHEMBL1433819 & 688422 & 4.45 & 4.9838 & TRN \\
\hline CHEMBL1443459 & 688422 & 5.35 & 5.6948 & TST \\
\hline CHEMBL335619 & 688422 & 6.1 & 5.5353 & TST \\
\hline CHEMBL1447889 & 688422 & 4.6 & 5.5476 & TRN \\
\hline CHEMBL1572716 & 688422 & 4.95 & 4.7368 & TST \\
\hline CHEMBL1334257 & 688422 & 4.45 & 5.68 & TRN \\
\hline CHEMBL1381605 & 688422 & 6.8 & 4.996 & TRN \\
\hline CHEMBL1587738 & 688422 & 4.55 & 5.4825 & TRN \\
\hline CHEMBL1500938 & 688422 & 5.95 & 5.3058 & TST \\
\hline CHEMBL1568515 & 688422 & 5.55 & 5.1718 & TRN \\
\hline CHEMBL1500966 & 688422 & 4.45 & 5.2888 & TRN \\
\hline CHEMBL1307909 & 688422 & 4.75 & 4.9841 & TST \\
\hline CHEMBL1423834 & 688422 & 5.25 & 5.5756 & TRN \\
\hline CHEMBL1347950 & 688422 & 4.45 & 5.7195 & TST \\
\hline CHEMBL1995330 & 688422 & 4.45 & 5.3532 & TRN \\
\hline CHEMBL1583447 & 688422 & 5.3 & 5.6303 & TRN \\
\hline CHEMBL1465439 & 688422 & 4.45 & 4.9087 & TRN \\
\hline CHEMBL1546348 & 688422 & 7.1002 & 5.3424 & TRN \\
\hline CHEMBL1327662 & 688422 & 4.9 & 4.9594 & TRN \\
\hline CHEMBL3195975 & 688422 & 4.5 & 5.1148 & TRN \\
\hline CHEMBL1483273 & 688422 & 7.699 & 6.1251 & TRN \\
\hline CHEMBL1551372 & 688422 & 6.5 & 5.9972 & TRN \\
\hline CHEMBL1559853 & 688422 & 5.4 & 5.2596 & TST \\
\hline CHEMBL1426483 & 688422 & 4.5 & 5.325 & TRN \\
\hline CHEMBL1357573 & 688422 & 4.85 & 5.2338 & TRN \\
\hline CHEMBL1553953 & 688422 & 5.75 & 5.4185 & TRN \\
\hline CHEMBL1573699 & 688422 & 6.45 & 5.0879 & TRN \\
\hline CHEMBL1531536 & 688422 & 5.35 & 5.2135 & TRN \\
\hline CHEMBL1519139 & 688422 & 7.5003 & 5.3068 & TRN \\
\hline CHEMBL3211959 & 688422 & 7.9508 & 5.4639 & TRN \\
\hline CHEMBL1455235 & 688422 & 7.3002 & 5.1794 & TRN \\
\hline CHEMBL1588753 & 688422 & 4.45 & 5.1255 & TRN \\
\hline CHEMBL1493497 & 688422 & 4.7 & 5.3522 & TRN \\
\hline CHEMBL1306926 & 688422 & 4.45 & 5.1006 & TRN \\
\hline CHEMBL1342506 & 688422 & 4.7 & 5.1069 & TST \\
\hline CHEMBL1315925 & 688422 & 4.6 & 5.2053 & TRN \\
\hline CHEMBL1561748 & 688422 & 4.85 & 5.4194 & TRN \\
\hline CHEMBL1453809 & 688422 & 4.45 & 5.3953 & TST \\
\hline
\end{tabular}




\begin{tabular}{|c|c|c|c|c|}
\hline \multicolumn{5}{|c|}{ Supplemental Table S2.txt } \\
\hline CHEMBL1435357 & 688422 & 6.25 & 5.9642 & TRN \\
\hline CHEMBL1383762 & 688422 & 4.75 & 4.9677 & TRN \\
\hline CHEMBL1361431 & 688422 & 4.9 & 5.3645 & TRN \\
\hline CHEMBL1301028 & 688422 & 5.0 & 5.0974 & TST \\
\hline CHEMBL1397720 & 688422 & 4.95 & 5.3962 & TRN \\
\hline CHEMBL1561338 & 688422 & 4.95 & 4.9876 & TST \\
\hline CHEMBL1300311 & 688422 & 5.6 & 4.7246 & TRN \\
\hline CHEMBL1429259 & 688422 & 4.6 & 5.4402 & TST \\
\hline CHEMBL1516517 & 688422 & 4.45 & 5.2003 & TRN \\
\hline CHEMBL1455108 & 688422 & 4.5 & 5.2111 & TRN \\
\hline CHEMBL1407872 & 688422 & 4.5 & 5.4551 & TST \\
\hline CHEMBL1495244 & 688422 & 4.9 & 5.1825 & TRN \\
\hline CHEMBL1310709 & 688422 & 7.8996 & 5.5597 & TRN \\
\hline CHEMBL1322183 & 688422 & 4.85 & 5.0749 & TRN \\
\hline CHEMBL1576061 & 688422 & 4.65 & 5.3697 & TST \\
\hline CHEMBL1497605 & 688422 & 4.7 & 5.3746 & TST \\
\hline CHEMBL3192476 & 688422 & 4.45 & 5.4267 & TRN \\
\hline CHEMBL1407258 & 688422 & 4.45 & 5.2974 & TRN \\
\hline CHEMBL1589687 & 688422 & 4.9 & 5.1037 & TRN \\
\hline CHEMBL1402198 & 688422 & 4.7 & 5.055 & TRN \\
\hline CHEMBL3189169 & 688422 & 4.75 & 5.1792 & TRN \\
\hline CHEMBL1467705 & 688422 & 4.8 & 5.3733 & TRN \\
\hline CHEMBL3197368 & 688422 & 4.45 & 4.8663 & TRN \\
\hline CHEMBL1547457 & 688422 & 4.45 & 4.8647 & TRN \\
\hline CHEMBL1976225 & 688422 & 4.85 & 5.1714 & TRN \\
\hline CHEMBL1354765 & 688422 & 4.95 & 5.4361 & TST \\
\hline CHEMBL1408463 & 688422 & 4.45 & 5.2006 & TST \\
\hline CHEMBL1332566 & 688422 & 4.75 & 5.301 & TRN \\
\hline CHEMBL1474411 & 688422 & 4.9 & 4.9081 & TRN \\
\hline CHEMBL 3192542 & 688422 & 6.35 & 5.0777 & TRN \\
\hline CHEMBL1365104 & 688422 & 4.85 & 4.7168 & TRN \\
\hline CHEMBL1534558 & 688422 & 5.6 & 5.1133 & TST \\
\hline CHEMBL1555531 & 688422 & 6.1 & 5.5131 & TRN \\
\hline CHEMBL1311011 & 688422 & 4.7 & 5.2555 & TRN \\
\hline CHEMBL1601646 & 688422 & 4.9 & 5.0322 & TST \\
\hline CHEMBL1441114 & 688422 & 4.9 & 5.1374 & TRN \\
\hline CHEMBL1460215 & 688422 & 4.5 & 4.6426 & TST \\
\hline CHEMBL1420945 & 688422 & 4.65 & 5.0803 & TRN \\
\hline CHEMBL1318706 & 688422 & 5.05 & 4.8819 & TRN \\
\hline CHEMBL1413096 & 688422 & 4.5 & 5.4366 & TRN \\
\hline CHEMBL1303851 & 688422 & 4.85 & 5.2091 & TRN \\
\hline CHEMBL1561472 & 688422 & 4.9 & 5.2527 & TRN \\
\hline CHEMBL1420179 & 688422 & 4.5 & 4.9141 & TST \\
\hline CHEMBL1312118 & 688422 & 4.9 & 5.6034 & TST \\
\hline CHEMBL3213238 & 688422 & 5.55 & 4.9346 & TRN \\
\hline CHEMBL1455125 & 688422 & 4.5 & 5.2126 & TRN \\
\hline CHEMBL1305183 & 688422 & 5.2 & 5.2605 & TRN \\
\hline CHEMBL1523527 & 688422 & 5.3 & 5.3883 & TRN \\
\hline
\end{tabular}




\begin{tabular}{|c|c|c|c|c|c|}
\hline \multicolumn{6}{|c|}{ Supplemental Table S2.txt } \\
\hline CHEMBL1502850 & 688422 & 4.45 & 5.2379 & TST & \\
\hline CHEMBL3191971 & 688422 & 5.45 & 5.2904 & TST & \\
\hline CHEMBL1534090 & 688422 & 4.85 & 5.2781 & TRN & \\
\hline CHEMBL1320193 & 688422 & 5.65 & 5.3693 & TST & \\
\hline CHEMBL 1612236 & 688422 & 4.7 & 5.2469 & TST & \\
\hline CHEMBL1566731 & 688422 & 4.7 & 5.0283 & TRN & \\
\hline CHEMBL1444326 & 688422 & 6.8 & 5.3559 & TST & \\
\hline CHEMBL1571540 & 688422 & 4.9 & 5.0398 & TRN & \\
\hline CHEMBL1348391 & 688422 & 4.45 & 5.6124 & TST & \\
\hline CHEMBL1460383 & 688422 & 4.95 & 5.191 & TRN & \\
\hline CHEMBL1468925 & 688422 & 5.05 & 5.3005 & TST & \\
\hline CHEMBL1594527 & 688422 & 4.45 & 5.125 & TST & \\
\hline CHEMBL1542570 & 688422 & 4.75 & 5.5275 & TRN & \\
\hline CHEMBL1423747 & 688422 & 4.45 & 5.3514 & TST & \\
\hline CHEMBL1407374 & 688422 & 5.5 & 5.2422 & TST & \\
\hline CHEMBL1410221 & 688422 & 4.65 & 5.46200 & 0000000001 & TRN \\
\hline CHEMBL1556428 & 688422 & 4.65 & 4.917 & TRN & \\
\hline CHEMBL1540513 & 688422 & 4.45 & 5.0907 & TRN & \\
\hline CHEMBL1426402 & 688422 & 5.55 & 4.9874 & TRN & \\
\hline CHEMBL1499004 & 688422 & 5.0 & 4.9465 & TRN & \\
\hline CHEMBL1437630 & 688422 & 5.05 & 5.2848 & TRN & \\
\hline CHEMBL1391216 & 688422 & 5.15 & 5.4901 & TRN & \\
\hline CHEMBL1463491 & 688422 & 4.75 & 5.4083 & TRN & \\
\hline CHEMBL1165239 & 688422 & 5.25 & 5.8531 & TST & \\
\hline CHEMBL1595549 & 688422 & 4.7 & 5.2933 & TST & \\
\hline CHEMBL1423933 & 688422 & 4.45 & 5.1918 & TST & \\
\hline CHEMBL1602659 & 688422 & 5.55 & 5.2087 & TST & \\
\hline CHEMBL1589447 & 688422 & 8.4949 & 5.3226 & TRN & \\
\hline CHEMBL1327927 & 688422 & 8.3468 & 5.2541 & TRN & \\
\hline CHEMBL1363877 & 688422 & 6.35 & 5.5905 & TST & \\
\hline CHEMBL1603525 & 688422 & 7.5003 & 5.0905 & TRN & \\
\hline CHEMBL42355 & 688422 & 4.6 & 5.1097 & TST & \\
\hline CHEMBL1322516 & 688422 & 5.4 & 5.0362 & TST & \\
\hline CHEMBL1501186 & 688422 & 5.55 & 5.2672 & TST & \\
\hline CHEMBL1420172 & 688422 & 5.0 & 5.3383 & TRN & \\
\hline CHEMBL1423779 & 688422 & 4.8 & 5.0442 & TST & \\
\hline CHEMBL3189627 & 688422 & 5.9 & 4.9273 & TST & \\
\hline CHEMBL1455225 & 688422 & 5.25 & 5.1249 & TRN & \\
\hline CHEMBL1545666 & 688422 & 4.5 & 5.0976 & TRN & \\
\hline CHEMBL1511268 & 688422 & 4.9 & 5.4719 & TRN & \\
\hline CHEMBL3197595 & 688422 & 4.8 & 4.9365 & TRN & \\
\hline CHEMBL 1475440 & 688422 & 4.95 & 5.4238 & TRN & \\
\hline CHEMBL1459545 & 688422 & 4.85 & 5.1002 & TRN & \\
\hline CHEMBL1299352 & 688422 & 4.85 & 5.4444 & TST & \\
\hline CHEMBL1568425 & 688422 & 4.85 & 4.9927 & TRN & \\
\hline CHEMBL1609818 & 688422 & 5.0 & 4.9194 & TRN & \\
\hline CHEMBL1461248 & 688422 & 7.0501 & 5.334 & TRN & \\
\hline CHEMBL1609197 & 688422 & 4.75 & 4.9293 & TRN & \\
\hline
\end{tabular}




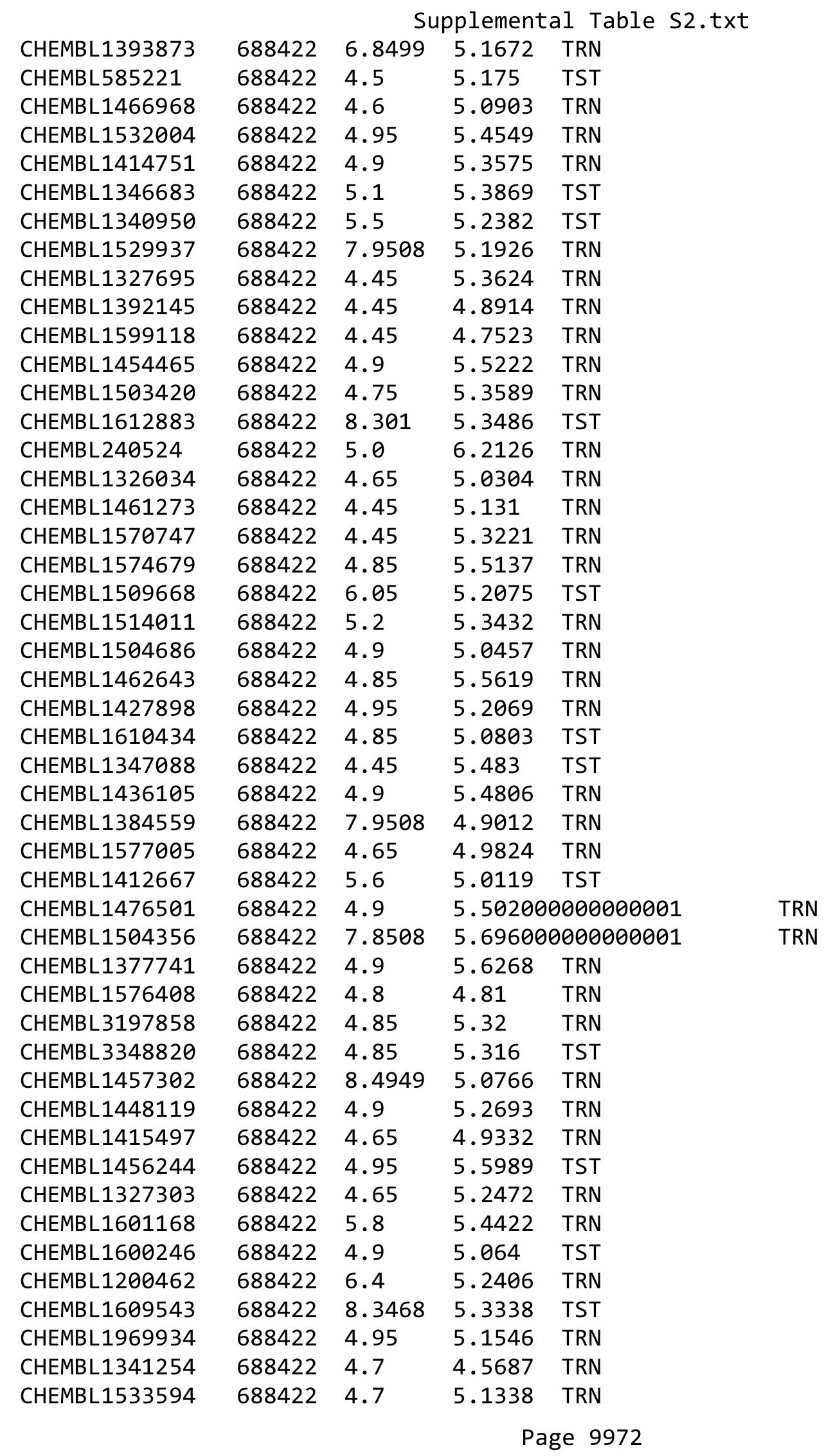




\begin{tabular}{|c|c|c|c|c|c|}
\hline & & & & & \\
\hline CHEMBL1407489 & 688422 & 4.7 & 5.6896 & TST & \\
\hline CHEMBL1359909 & 688422 & 4.85 & 4.8544 & TRN & \\
\hline CHEMBL582722 & 688422 & 4.45 & 5.0588 & TST & \\
\hline CHEMBL1556525 & 688422 & 4.9 & 5.0339 & TST & \\
\hline CHEMBL1385843 & 688422 & 4.7 & 5.8639 & TRN & \\
\hline CHEMBL1346508 & 688422 & 4.6 & 5.4078 & TRN & \\
\hline CHEMBL1530303 & 688422 & 4.45 & 5.3069 & TRN & \\
\hline CHEMBL1466820 & 688422 & 4.45 & 5.1117 & TRN & \\
\hline CHEMBL1454853 & 688422 & 5.05 & 5.0305 & TST & \\
\hline CHEMBL1391932 & 688422 & 6.4 & 5.5267 & TRN & \\
\hline CHEMBL565489 & 688422 & 4.45 & 5.625 & TST & \\
\hline CHEMBL1526606 & 688422 & 7.3002 & 5.3262 & TST & \\
\hline CHEMBL1399812 & 688422 & 5.1 & 5.0147 & TST & \\
\hline CHEMBL1597076 & 688422 & 7.4001 & 5.3446 & TRN & \\
\hline CHEMBL1606984 & 688422 & 4.9 & 5.4432 & TRN & \\
\hline CHEMBL1376872 & 688422 & 4.45 & 4.8449 & TRN & \\
\hline CHEMBL1572931 & 688422 & 4.9 & 5.3964 & TST & \\
\hline CHEMBL1604223 & 688422 & 4.9 & 4.745 & TRN & \\
\hline CHEMBL1349992 & 688422 & 4.7 & 4.7647 & TST & \\
\hline CHEMBL1329311 & 688422 & 4.65 & 4.9601 & TRN & \\
\hline CHEMBL1605555 & 688422 & 4.7 & 5.17 & TRN & \\
\hline CHEMBL1306731 & 688422 & 7.5003 & 4.8606 & TST & \\
\hline CHEMBL1353604 & 688422 & 6.5 & 5.5848 & TRN & \\
\hline CHEMBL1560527 & 688422 & 4.45 & 5.1287 & TRN & \\
\hline CHEMBL1420034 & 688422 & 7.4498 & 5.2694 & TRN & \\
\hline CHEMBL1334416 & 688422 & 4.95 & 5.15 & TRN & \\
\hline CHEMBL1347526 & 688422 & 4.95 & 5.84399 & 9999999999 & TRN \\
\hline CHEMBL1426243 & 688422 & 5.85 & 5.5553 & TRN & \\
\hline CHEMBL1421385 & 688422 & 4.45 & 5.3158 & TRN & \\
\hline CHEMBL1594612 & 688422 & 4.75 & 5.4549 & TRN & \\
\hline CHEMBL1411258 & 688422 & 4.45 & 5.54799 & 9999999999 & TRN \\
\hline CHEMBL1334764 & 688422 & 5.25 & 5.3898 & TST & \\
\hline CHEMBL1530714 & 688422 & 5.9 & 5.0854 & TST & \\
\hline CHEMBL1606534 & 688422 & 4.65 & 5.3881 & TRN & \\
\hline CHEMBL1428986 & 688422 & 4.95 & 4.9126 & TRN & \\
\hline CHEMBL1400018 & 688422 & 4.45 & 5.0377 & TRN & \\
\hline CHEMBL1596380 & 688422 & 6.15 & 4.914 & TRN & \\
\hline CHEMBL1391075 & 688422 & 7.4498 & 4.9625 & TST & \\
\hline CHEMBL3197887 & 688422 & 5.85 & 5.5007 & TRN & \\
\hline CHEMBL1486042 & 688422 & 4.65 & 4.9743 & TRN & \\
\hline CHEMBL1467420 & 688422 & 4.45 & 5.2786 & TRN & \\
\hline CHEMBL1321994 & 688422 & 7.0501 & 5.3038 & TRN & \\
\hline CHEMBL1573946 & 688422 & 4.65 & 4.8962 & TST & \\
\hline CHEMBL1321932 & 688422 & 4.9 & 4.7087 & TRN & \\
\hline CHEMBL1406488 & 688422 & 4.9 & 4.7905 & TRN & \\
\hline CHEMBL1395776 & 688422 & 4.45 & 6.0252 & TRN & \\
\hline CHEMBL1581127 & 688422 & 4.55 & 5.358 & TRN & \\
\hline CHEMBL3214303 & 688422 & 8.0 & 5.83799 & & TRN \\
\hline & & & & 9973 & \\
\hline
\end{tabular}




\begin{tabular}{|c|c|c|c|c|c|}
\hline \multicolumn{6}{|c|}{ Supplemental Table S2.txt } \\
\hline CHEMBL1364051 & 688422 & 4.75 & 5.1727 & TRN & \\
\hline CHEMBL1450035 & 688422 & 4.95 & 5.1666 & TRN & \\
\hline CHEMBL1467698 & 688422 & 4.8 & 5.3303 & TRN & \\
\hline CHEMBL1984130 & 688422 & 5.4 & 4.8863 & TRN & \\
\hline CHEMBL3189189 & 688422 & 4.45 & 5.3806 & TRN & \\
\hline CHEMBL1579319 & 688422 & 4.45 & 5.1759 & TRN & \\
\hline CHEMBL1396237 & 688422 & 7.9508 & 5.3838 & TRN & \\
\hline CHEMBL1437364 & 688422 & 4.45 & 4.9919 & TRN & \\
\hline CHEMBL1373938 & 688422 & 4.6 & 4.727 & TST & \\
\hline CHEMBL1306146 & 688422 & 4.45 & 5.46299 & 9999999999 & TRN \\
\hline CHEMBL1511005 & 688422 & 5.25 & 4.8398 & TRN & \\
\hline CHEMBL1450390 & 688422 & 5.25 & 5.1256 & TRN & \\
\hline CHEMBL1414332 & 688422 & 6.3 & 5.654 & TRN & \\
\hline CHEMBL319931 & 688422 & 6.0 & 5.4227 & TRN & \\
\hline CHEMBL1472228 & 688422 & 4.5 & 5.0499 & TRN & \\
\hline CHEMBL1305285 & 688422 & 4.85 & 5.4214 & TRN & \\
\hline CHEMBL1469281 & 688422 & 4.85 & 4.739 & TRN & \\
\hline CHEMBL1349745 & 688422 & 4.75 & 5.5198 & TRN & \\
\hline CHEMBL 375270 & 688422 & 4.95 & 4.9675 & TRN & \\
\hline CHEMBL1549777 & 688422 & 4.55 & 5.0672 & TRN & \\
\hline CHEMBL1301475 & 688422 & 4.8 & 5.0983 & TST & \\
\hline CHEMBL1414529 & 688422 & 4.7 & 5.0548 & TST & \\
\hline CHEMBL1523900 & 688422 & 4.65 & 5.4882 & TRN & \\
\hline CHEMBL1492303 & 688422 & 4.55 & 5.4038 & TST & \\
\hline CHEMBL1558928 & 688422 & 4.85 & 4.7574 & TRN & \\
\hline CHEMBL1415608 & 688422 & 4.45 & 5.3804 & TST & \\
\hline CHEMBL1609666 & 688422 & 4.85 & 5.209 & TST & \\
\hline CHEMBL1608444 & 688422 & 4.95 & 5.1747 & TRN & \\
\hline CHEMBL1328026 & 688422 & 4.95 & 5.0932 & TRN & \\
\hline CHEMBL1607720 & 688422 & 8.1024 & 5.3205 & TRN & \\
\hline CHEMBL1969617 & 688422 & 4.45 & 5.1981 & TRN & \\
\hline CHEMBL1488172 & 688422 & 4.8 & 4.9576 & TRN & \\
\hline CHEMBL1482698 & 688422 & 4.7 & 5.3888 & TRN & \\
\hline CHEMBL1600201 & 688422 & 6.45 & 5.2761 & TRN & \\
\hline CHEMBL1417398 & 688422 & 6.1 & 5.254 & TST & \\
\hline CHEMBL1453002 & 688422 & 4.65 & 5.2292 & TST & \\
\hline CHEMBL1462108 & 688422 & 4.65 & 5.0097 & TRN & \\
\hline CHEMBL1450202 & 688422 & 4.45 & 5.0057 & TRN & \\
\hline CHEMBL1570294 & 688422 & 6.8499 & 5.4317 & TRN & \\
\hline CHEMBL1511534 & 688422 & 4.5 & 5.2935 & TST & \\
\hline CHEMBL1346306 & 688422 & 4.7 & 4.6575 & TRN & \\
\hline CHEMBL1462482 & 688422 & 4.45 & 4.6102 & TRN & \\
\hline CHEMBL1357553 & 688422 & 4.85 & 4.9422 & TRN & \\
\hline CHEMBL1340571 & 688422 & 4.65 & 5.3825 & TRN & \\
\hline CHEMBL1417311 & 688422 & 8.4949 & 5.0243 & TST & \\
\hline CHEMBL1482215 & 688422 & 4.6 & 5.1545 & TST & \\
\hline CHEMBL1483731 & 688422 & 4.95 & 4.8749 & TRN & \\
\hline CHEMBL1328875 & 688422 & 4.5 & 4.7826 & TRN & \\
\hline
\end{tabular}




\begin{tabular}{|c|c|c|c|c|c|}
\hline \multicolumn{6}{|c|}{ Supplemental Table S2.txt } \\
\hline CHEMBL1378234 & 688422 & 4.65 & 5.4168 & TRN & \\
\hline CHEMBL1455389 & 688422 & 4.45 & 4.9208 & TRN & \\
\hline CHEMBL1402750 & 688422 & 4.85 & 4.944 & TRN & \\
\hline CHEMBL1525003 & 688422 & 4.45 & 5.2776 & TST & \\
\hline CHEMBL1600182 & 688422 & 4.45 & 5.0487 & TRN & \\
\hline CHEMBL1482957 & 688422 & 4.9 & 5.0191 & TRN & \\
\hline CHEMBL1601377 & 688422 & 7.6003 & 4.923 & TRN & \\
\hline CHEMBL1533547 & 688422 & 4.8 & 5.1735 & TST & \\
\hline CHEMBL1501933 & 688422 & 4.6 & 5.0276 & TRN & \\
\hline CHEMBL1449995 & 688422 & 4.55 & 4.9936 & TRN & \\
\hline CHEMBL1372071 & 688422 & 6.0 & 5.2771 & TRN & \\
\hline CHEMBL1447086 & 688422 & 5.25 & 5.4409 & TRN & \\
\hline CHEMBL1502121 & 688422 & 7.6498 & 5.3544 & TRN & \\
\hline CHEMBL1591107 & 688422 & 4.5 & 4.6119 & TRN & \\
\hline CHEMBL1380741 & 688422 & 5.9 & 5.25700 & 0000000001 & TST \\
\hline CHEMBL1459673 & 688422 & 4.75 & 5.4707 & TRN & \\
\hline CHEMBL3197920 & 688422 & 5.1 & 5.5357 & TRN & \\
\hline CHEMBL1367798 & 688422 & 5.05 & 5.0766 & TRN & \\
\hline CHEMBL1513090 & 688422 & 4.45 & 4.6978 & TRN & \\
\hline CHEMBL1418421 & 688422 & 4.95 & 5.1907 & TRN & \\
\hline CHEMBL1347392 & 688422 & 4.9 & 4.7352 & TRN & \\
\hline CHEMBL1470148 & 688422 & 4.75 & 4.8126 & TRN & \\
\hline CHEMBL1393788 & 688422 & 4.45 & 5.1865 & TRN & \\
\hline CHEMBL1422316 & 688422 & 4.45 & 5.2915 & TST & \\
\hline CHEMBL1547148 & 688422 & 8.0506 & 5.6758 & TRN & \\
\hline CHEMBL1336763 & 688422 & 4.6 & 5.4846 & TRN & \\
\hline CHEMBL1507257 & 688422 & 5.75 & 5.2737 & TRN & \\
\hline CHEMBL1545132 & 688422 & 4.45 & 5.3338 & TRN & \\
\hline CHEMBL1497012 & 688422 & 4.85 & 5.4346 & TRN & \\
\hline CHEMBL1565496 & 688422 & 4.85 & 5.1171 & TRN & \\
\hline CHEMBL1414269 & 688422 & 4.45 & 4.9516 & TRN & \\
\hline CHEMBL1499127 & 688422 & 7.6498 & 5.3085 & TRN & \\
\hline CHEMBL1534004 & 688422 & 5.45 & 5.2149 & TRN & \\
\hline CHEMBL1337954 & 688422 & 4.95 & 5.6021 & TRN & \\
\hline CHEMBL1986986 & 688422 & 4.45 & 5.3702 & TRN & \\
\hline CHEMBL1581590 & 688422 & 7.5003 & 5.1197 & TST & \\
\hline CHEMBL1518849 & 688422 & 5.25 & 5.4474 & TRN & \\
\hline CHEMBL1588898 & 688422 & 8.1487 & 5.2319 & TRN & \\
\hline CHEMBL1352932 & 688422 & 4.45 & 5.0822 & TRN & \\
\hline CHEMBL1351634 & 688422 & 4.45 & 4.9961 & TRN & \\
\hline CHEMBL1470038 & 688422 & 4.5 & 5.0217 & TRN & \\
\hline CHEMBL3190343 & 688422 & 4.45 & 5.103 & TST & \\
\hline CHEMBL1378099 & 688422 & 4.45 & 5.4187 & TRN & \\
\hline CHEMBL1483581 & 688422 & 7.9508 & 5.7249 & TRN & \\
\hline CHEMBL1383267 & 688422 & 5.8 & 5.2258 & TRN & \\
\hline CHEMBL1338198 & 688422 & 6.05 & 5.4304 & TRN & \\
\hline CHEMBL1321663 & 688422 & 5.45 & 5.29299 & 9999999999 & TRN \\
\hline CHEMBL1447733 & 688422 & 4.95 & 5.8015 & TST & \\
\hline
\end{tabular}




\begin{tabular}{|c|c|c|c|c|}
\hline & & & oplement & al $\mathrm{T}$ \\
\hline CHEMBL1309143 & 688422 & 7.3002 & 5.0008 & TST \\
\hline CHEMBL1464804 & 688422 & 4.45 & 4.9466 & TRN \\
\hline CHEMBL1550204 & 688422 & 4.75 & 4.9089 & TRN \\
\hline CHEMBL1531819 & 688422 & 4.45 & 4.7906 & TRN \\
\hline CHEMBL1427324 & 688422 & 4.45 & 5.0656 & TRN \\
\hline CHEMBL105608 & 688422 & 8.4559 & 5.8137 & TST \\
\hline CHEMBL1474416 & 688422 & 4.6 & 5.2152 & TST \\
\hline CHEMBL1465049 & 688422 & 4.45 & 4.828 & TRN \\
\hline CHEMBL1517618 & 688422 & 7.5498 & 5.4972 & TRN \\
\hline CHEMBL1575206 & 688422 & 5.1 & 5.599 & TST \\
\hline CHEMBL1496865 & 688422 & 4.85 & 5.3679 & TRN \\
\hline CHEMBL1525056 & 688422 & 4.85 & 5.3743 & TRN \\
\hline CHEMBL1458226 & 688422 & 5.35 & 5.1944 & TRN \\
\hline CHEMBL1395567 & 688422 & 4.75 & 5.0653 & TRN \\
\hline CHEMBL1566164 & 688422 & 8.1487 & 4.895 & TRN \\
\hline CHEMBL1534999 & 688422 & 4.85 & 4.8324 & TRN \\
\hline CHEMBL1393070 & 688422 & 4.9 & 4.8782 & TRN \\
\hline CHEMBL1517836 & 688422 & 5.65 & 5.1861 & TRN \\
\hline CHEMBL1583770 & 688422 & 5.4 & 5.2137 & TRN \\
\hline CHEMBL1379918 & 688422 & 4.7 & 4.9264 & TRN \\
\hline CHEMBL1344363 & 688422 & 5.0 & 5.3549 & TRN \\
\hline CHEMBL1516965 & 688422 & 4.95 & 5.2771 & TRN \\
\hline CHEMBL1559809 & 688422 & 8.9586 & 5.2546 & TRN \\
\hline CHEMBL1304829 & 688422 & 5.0 & 5.0409 & TRN \\
\hline CHEMBL1603615 & 688422 & 4.65 & 5.0981 & TRN \\
\hline CHEMBL3196619 & 688422 & 4.95 & 5.5737 & TRN \\
\hline CHEMBL1558086 & 688422 & 5.9 & 5.0416 & TRN \\
\hline CHEMBL1336649 & 688422 & 4.7 & 5.1835 & TST \\
\hline CHEMBL1407780 & 688422 & 4.5 & 5.0409 & TRN \\
\hline CHEMBL1415126 & 688422 & 4.8 & 4.9131 & TST \\
\hline CHEMBL1375153 & 688422 & 4.45 & 4.7311 & TRN \\
\hline CHEMBL 3195441 & 688422 & 4.45 & 5.112 & TRN \\
\hline CHEMBL1590390 & 688422 & 5.8 & 5.0938 & TRN \\
\hline CHEMBL1082832 & 688422 & 8.3468 & 5.5189 & TRN \\
\hline CHEMBL1488403 & 688422 & 4.6 & 5.0115 & TST \\
\hline CHEMBL1332099 & 688422 & 4.45 & 5.2132 & TRN \\
\hline CHEMBL1480091 & 688422 & 4.85 & 5.0955 & TRN \\
\hline CHEMBL1317458 & 688422 & 8.0506 & 5.0989 & TST \\
\hline CHEMBL1367669 & 688422 & 7.0 & 6.0029 & TST \\
\hline CHEMBL1425604 & 688422 & 6.5 & 5.5825 & TRN \\
\hline CHEMBL1502931 & 688422 & 4.8 & 4.8813 & TST \\
\hline CHEMBL1453484 & 688422 & 8.0 & 5.2717 & TRN \\
\hline CHEMBL1549911 & 688422 & 4.85 & 4.7752 & TRN \\
\hline CHEMBL1341609 & 688422 & 4.5 & 5.5941 & TRN \\
\hline CHEMBL1542804 & 688422 & 6.5 & 4.7993 & TRN \\
\hline CHEMBL1537379 & 688422 & 5.35 & 5.2073 & TRN \\
\hline CHEMBL1341869 & 688422 & 4.9 & 5.3744 & TRN \\
\hline CHEMBL1544711 & 688422 & 5.3 & 4.7677 & TRN \\
\hline
\end{tabular}




\begin{tabular}{|c|c|c|c|c|c|}
\hline \multicolumn{6}{|c|}{ Supplemental Table S2.txt } \\
\hline CHEMBL1481473 & 688422 & 4.9 & 5.0566 & TRN & \\
\hline CHEMBL1402615 & 688422 & 4.85 & 5.1805 & TRN & \\
\hline CHEMBL521784 & 688422 & 4.45 & 5.5201 & TST & \\
\hline CHEMBL117108 & 688422 & 4.7 & 4.6727 & TRN & \\
\hline CHEMBL1447263 & 688422 & 4.9 & 5.1642 & TRN & \\
\hline CHEMBL1460908 & 688422 & 4.9 & 5.1536 & TRN & \\
\hline CHEMBL1344976 & 688422 & 4.9 & 5.119 & TRN & \\
\hline CHEMBL528694 & 688422 & 6.05 & 5.3729 & TRN & \\
\hline CHEMBL1486608 & 688422 & 4.75 & 5.2513 & TRN & \\
\hline CHEMBL1600043 & 688422 & 5.4 & 5.52 & TST & \\
\hline CHEMBL 3191914 & 688422 & 6.15 & 5.4796 & TST & \\
\hline CHEMBL1555810 & 688422 & 8.3979 & 6.0026 & TST & \\
\hline CHEMBL1460372 & 688422 & 6.05 & 5.7719 & TST & \\
\hline CHEMBL1463049 & 688422 & 4.7 & 5.3254 & TRN & \\
\hline CHEMBL1528941 & 688422 & 5.0 & 5.3504 & TRN & \\
\hline CHEMBL1572685 & 688422 & 4.9 & 5.276 & TRN & \\
\hline CHEMBL1363538 & 688422 & 4.45 & 5.2512 & TRN & \\
\hline CHEMBL1541879 & 688422 & 7.0501 & 5.4978 & TRN & \\
\hline CHEMBL1300116 & 688422 & 4.75 & 5.5603 & TST & \\
\hline CHEMBL1414871 & 688422 & 4.65 & 5.1408 & TRN & \\
\hline CHEMBL1415738 & 688422 & 5.45 & 5.2826 & TST & \\
\hline CHEMBL3192133 & 688422 & 7.2 & 5.30200 & 00000000005 & TRN \\
\hline CHEMBL1377730 & 688422 & 4.7 & 4.9519 & TRN & \\
\hline CHEMBL1425953 & 688422 & 6.15 & 5.2486 & TRN & \\
\hline CHEMBL1062 & 688422 & 6.0 & 5.8539 & TRN & \\
\hline CHEMBL1459800 & 688422 & 4.95 & 5.0855 & TST & \\
\hline CHEMBL1571227 & 688422 & 5.5 & 5.8713 & TST & \\
\hline CHEMBL1458593 & 688422 & 4.8 & 5.1208 & TRN & \\
\hline CHEMBL1522198 & 688422 & 4.95 & 5.1281 & TST & \\
\hline CHEMBL1327335 & 688422 & 4.5 & 5.2792 & TST & \\
\hline CHEMBL1424473 & 688422 & 4.95 & 5.12299 & 9999999999 & TST \\
\hline CHEMBL1417733 & 688422 & 4.8 & 4.9729 & TRN & \\
\hline CHEMBL1464189 & 688422 & 4.9 & 5.3944 & TRN & \\
\hline CHEMBL1319029 & 688422 & 4.65 & 5.1167 & TST & \\
\hline CHEMBL1354494 & 688422 & 4.45 & 4.8705 & TRN & \\
\hline CHEMBL1457111 & 688422 & 4.85 & 5.2546 & TRN & \\
\hline CHEMBL1303329 & 688422 & 5.6 & 5.2537 & TST & \\
\hline CHEMBL1589147 & 688422 & 6.6499 & 5.2006 & TRN & \\
\hline CHEMBL1383732 & 688422 & 6.45 & 4.8752 & TRN & \\
\hline CHEMBL1592571 & 688422 & 4.45 & 5.5062 & TRN & \\
\hline CHEMBL1444764 & 688422 & 5.05 & 5.0113 & TRN & \\
\hline CHEMBL1344549 & 688422 & 4.7 & 5.2023 & TRN & \\
\hline CHEMBL1305908 & 688422 & 4.95 & 4.8838 & TRN & \\
\hline CHEMBL1386211 & 688422 & 4.75 & 5.1565 & TRN & \\
\hline CHEMBL1607309 & 688422 & 5.15 & 4.9743 & TRN & \\
\hline CHEMBL3198709 & 688422 & 4.75 & 5.1366 & TRN & \\
\hline CHEMBL1544955 & 688422 & 4.45 & 5.0127 & TRN & \\
\hline CHEMBL 3209754 & 688422 & 7.4498 & 4.9771 & TST & \\
\hline
\end{tabular}




\begin{tabular}{|c|c|c|c|c|}
\hline \multicolumn{5}{|c|}{ Supplemental Table S2.txt } \\
\hline CHEMBL1400874 & 688422 & 4.45 & 5.3243 & TRN \\
\hline CHEMBL1372140 & 688422 & 5.1 & 5.4922 & TRN \\
\hline CHEMBL1559178 & 688422 & 4.95 & 5.6712 & TRN \\
\hline CHEMBL1547891 & 688422 & 4.85 & 4.7713 & TRN \\
\hline CHEMBL1494604 & 688422 & 4.85 & 5.1847 & TRN \\
\hline CHEMBL1418656 & 688422 & 4.45 & 5.0436 & TRN \\
\hline CHEMBL1386184 & 688422 & 4.65 & 5.3851 & TRN \\
\hline CHEMBL1310319 & 688422 & 4.75 & 5.2589 & TST \\
\hline CHEMBL1421045 & 688422 & 4.65 & 4.667 & TRN \\
\hline CHEMBL1490295 & 688422 & 4.8 & 5.086 & TRN \\
\hline CHEMBL1390021 & 688422 & 4.8 & 4.8736 & TST \\
\hline CHEMBL3191093 & 688422 & 4.7 & 5.4368 & TRN \\
\hline CHEMBL1570200 & 688422 & 5.4 & 5.0121 & TRN \\
\hline CHEMBL1464671 & 688422 & 5.05 & 4.9718 & TRN \\
\hline CHEMBL1484227 & 688422 & 5.35 & 5.2795 & TST \\
\hline CHEMBL1516884 & 688422 & 5.2 & 4.8565 & TRN \\
\hline CHEMBL1346640 & 688422 & 4.5 & 4.5884 & TRN \\
\hline CHEMBL1592684 & 688422 & 5.1 & 5.3186 & TST \\
\hline CHEMBL1451447 & 688422 & 4.5 & 5.4726 & TRN \\
\hline CHEMBL1403184 & 688422 & 7.0 & 5.2405 & TRN \\
\hline CHEMBL1334665 & 688422 & 4.9 & 5.0671 & TRN \\
\hline CHEMBL1571794 & 688422 & 7.699 & 5.1568 & TRN \\
\hline CHEMBL1583670 & 688422 & 5.05 & 5.5942 & TRN \\
\hline CHEMBL1493204 & 688422 & 4.7 & 5.0279 & TST \\
\hline CHEMBL1374110 & 688422 & 4.45 & 5.2194 & TRN \\
\hline CHEMBL1558810 & 688422 & 4.6 & 4.7999 & TRN \\
\hline CHEMBL1600649 & 688422 & 4.5 & 5.0729 & TRN \\
\hline CHEMBL3191675 & 688422 & 4.6 & 5.2827 & TST \\
\hline CHEMBL1423508 & 688422 & 4.45 & 5.2675 & TRN \\
\hline CHEMBL3192020 & 688422 & 4.6 & 4.7998 & TRN \\
\hline CHEMBL1380053 & 688422 & 4.45 & 5.2134 & TST \\
\hline CHEMBL1458106 & 688422 & 4.75 & 5.2177 & TRN \\
\hline CHEMBL1579743 & 688422 & 4.45 & 5.1982 & TRN \\
\hline CHEMBL1341669 & 688422 & 5.3 & 5.2645 & TRN \\
\hline CHEMBL1542915 & 688422 & 4.85 & 5.0023 & TRN \\
\hline CHEMBL1484519 & 688422 & 4.95 & 5.1741 & TST \\
\hline CHEMBL 1474046 & 688422 & 4.45 & 5.2673 & TRN \\
\hline CHEMBL1534804 & 688422 & 5.4 & 5.1433 & TRN \\
\hline CHEMBL1314371 & 688422 & 5.4 & 4.8585 & TRN \\
\hline CHEMBL1419641 & 688422 & 4.75 & 4.8798 & TRN \\
\hline CHEMBL1397753 & 688422 & 7.4498 & 5.6316 & TRN \\
\hline CHEMBL1356643 & 688422 & 8.3468 & 5.1664 & TRN \\
\hline CHEMBL1256876 & 688422 & 4.95 & 5.3211 & TST \\
\hline CHEMBL1503046 & 688422 & 4.85 & 5.3173 & TST \\
\hline CHEMBL1500130 & 688422 & 4.85 & 4.975 & TRN \\
\hline CHEMBL3189531 & 688422 & 4.45 & 5.5567 & TST \\
\hline CHEMBL1567403 & 688422 & 5.25 & 4.9314 & TRN \\
\hline CHEMBL1583046 & 688422 & 4.65 & 5.3143 & TRN \\
\hline
\end{tabular}




\begin{tabular}{|c|c|c|c|c|c|}
\hline \multicolumn{6}{|c|}{ Supplemental Table S2.txt } \\
\hline CHEMBL1407627 & 688422 & 4.45 & 4.9563 & TRN & \\
\hline CHEMBL1514402 & 688422 & 7.699 & 5.4565 & TST & \\
\hline CHEMBL3195474 & 688422 & 4.5 & 5.4263 & TRN & \\
\hline CHEMBL 1406820 & 688422 & 4.7 & 5.058 & TST & \\
\hline CHEMBL107514 & 688422 & 4.95 & 5.4134 & TRN & \\
\hline CHEMBL1424095 & 688422 & 4.85 & 5.5091 & TRN & \\
\hline CHEMBL1407857 & 688422 & 4.95 & 5.1137 & TRN & \\
\hline CHEMBL1438748 & 688422 & 4.5 & 5.1059 & TRN & \\
\hline CHEMBL1339961 & 688422 & 4.45 & 5.0627 & TRN & \\
\hline CHEMBL1418457 & 688422 & 6.8 & 5.8202 & TRN & \\
\hline CHEMBL1527766 & 688422 & 4.6 & 5.1332 & TST & \\
\hline CHEMBL1496243 & 688422 & 4.9 & 5.0368 & TRN & \\
\hline CHEMBL1602323 & 688422 & 4.75 & 5.073 & TRN & \\
\hline CHEMBL1503577 & 688422 & 4.9 & 5.5047 & TRN & \\
\hline CHEMBL1419157 & 688422 & 4.45 & 5.1535 & TRN & \\
\hline CHEMBL1452858 & 688422 & 4.45 & 5.2327 & TRN & \\
\hline CHEMBL1509391 & 688422 & 4.45 & 5.33700 & 0000000001 & TST \\
\hline CHEMBL1369061 & 688422 & 4.6 & 5.0997 & TRN & \\
\hline CHEMBL1422909 & 688422 & 4.45 & 5.6344 & TRN & \\
\hline CHEMBL1410374 & 688422 & 4.95 & 4.9793 & TRN & \\
\hline CHEMBL1565391 & 688422 & 4.45 & 5.3699 & TRN & \\
\hline CHEMBL1388653 & 688422 & 7.0501 & 4.7613 & TRN & \\
\hline CHEMBL1577090 & 688422 & 7.0501 & 5.3763 & TRN & \\
\hline CHEMBL1580305 & 688422 & 4.45 & 5.4532 & TST & \\
\hline CHEMBL1372613 & 688422 & 4.45 & 5.3528 & TRN & \\
\hline CHEMBL1410061 & 688422 & 5.15 & 5.1753 & TRN & \\
\hline CHEMBL3196392 & 688422 & 4.45 & 5.082 & TRN & \\
\hline CHEMBL1600538 & 688422 & 6.15 & 5.45299 & 9999999999 & TRN \\
\hline CHEMBL1409679 & 688422 & 6.15 & 5.5856 & TRN & \\
\hline CHEMBL1488090 & 688422 & 6.6 & 5.2715 & TRN & \\
\hline CHEMBL1523592 & 688422 & 4.45 & 5.3124 & TRN & \\
\hline CHEMBL1449260 & 688422 & 4.65 & 4.801 & TRN & \\
\hline CHEMBL1407548 & 688422 & 5.4 & 5.0773 & TRN & \\
\hline CHEMBL1419548 & 688422 & 6.6 & 5.3671 & TRN & \\
\hline CHEMBL266459 & 688422 & 7.0501 & 5.0411 & TST & \\
\hline CHEMBL1518001 & 688422 & 5.0 & 5.4433 & TRN & \\
\hline CHEMBL1443478 & 688422 & 4.5 & 5.0508 & TST & \\
\hline CHEMBL1485790 & 688422 & 5.4 & 5.1358 & TRN & \\
\hline CHEMBL1503502 & 688422 & 4.5 & 5.3928 & TRN & \\
\hline CHEMBL1413497 & 688422 & 4.9 & 5.1931 & TRN & \\
\hline CHEMBL1414391 & 688422 & 5.2 & 5.1019 & TRN & \\
\hline CHEMBL1410484 & 688422 & 4.6 & 5.0571 & TST & \\
\hline CHEMBL3208421 & 688422 & 8.0 & 5.3581 & TRN & \\
\hline CHEMBL1332308 & 688422 & 4.6 & 4.9917 & TRN & \\
\hline CHEMBL1562083 & 688422 & 5.45 & 5.7115 & TRN & \\
\hline CHEMBL3211767 & 688422 & 6.3 & 5.5133 & TRN & \\
\hline CHEMBL1334407 & 688422 & 5.1 & 5.2597 & TRN & \\
\hline CHEMBL1430566 & 688422 & 5.0 & 5.3757 & TRN & \\
\hline
\end{tabular}




\begin{tabular}{|c|c|c|c|c|c|}
\hline & & \multicolumn{4}{|c|}{ Supplemental Table S2.txt } \\
\hline CHEMBL1300376 & 688422 & 7.3002 & 5.6078 & TST & \\
\hline CHEMBL1547169 & 688422 & 6.25 & 4.773 & TRN & \\
\hline CHEMBL1319601 & 688422 & 4.95 & 5.0495 & TST & \\
\hline CHEMBL1435077 & 688422 & 4.85 & 5.0586 & TRN & \\
\hline CHEMBL1468246 & 688422 & 4.65 & 4.9632 & TRN & \\
\hline CHEMBL1596490 & 688422 & 5.2 & 5.2773 & TRN & \\
\hline CHEMBL1580481 & 688422 & 4.45 & 5.006 & TRN & \\
\hline CHEMBL1380826 & 688422 & 5.4 & 4.94600 & 0000000001 & TRN \\
\hline CHEMBL1393581 & 688422 & 4.45 & 5.2262 & TRN & \\
\hline CHEMBL1564658 & 688422 & 5.95 & 5.1539 & TRN & \\
\hline CHEMBL1406045 & 688422 & 5.15 & 5.3136 & TRN & \\
\hline CHEMBL1554447 & 688422 & 5.7 & 5.3439 & TRN & \\
\hline CHEMBL1420529 & 688422 & 4.45 & 5.1459 & TRN & \\
\hline CHEMBL3194481 & 688422 & 7.4001 & 5.209 & TST & \\
\hline CHEMBL1302366 & 688422 & 4.95 & 4.9326 & TRN & \\
\hline CHEMBL1352778 & 688422 & 4.8 & 4.9918 & TST & \\
\hline CHEMBL580183 & 688422 & 4.9 & 5.3277 & TST & \\
\hline CHEMBL1417253 & 688422 & 5.25 & 5.6931 & TST & \\
\hline CHEMBL1497503 & 688422 & 5.4 & 4.9347 & TRN & \\
\hline CHEMBL1609884 & 688422 & 5.5 & 5.0205 & TRN & \\
\hline CHEMBL1575198 & 688422 & 5.5 & 4.7113 & TST & \\
\hline CHEMBL1326110 & 688422 & 5.5 & 5.2957 & TST & \\
\hline CHEMBL1420809 & 688422 & 6.5501 & 5.5966 & TST & \\
\hline CHEMBL1321249 & 688422 & 6.8 & 5.8503 & TRN & \\
\hline CHEMBL389162 & 688422 & 4.75 & 5.2529 & TRN & \\
\hline CHEMBL1575906 & 688422 & 5.0 & 5.2344 & TRN & \\
\hline CHEMBL1361803 & 688422 & 4.8 & 5.2948 & TST & \\
\hline CHEMBL1518073 & 688422 & 5.25 & 5.4457 & TRN & \\
\hline CHEMBL1563661 & 688422 & 4.95 & 5.8655 & TST & \\
\hline CHEMBL 1457848 & 688422 & 7.3002 & 5.8152 & TRN & \\
\hline CHEMBL 2006840 & 688422 & 5.5 & 4.752 & TRN & \\
\hline CHEMBL342995 & 688422 & 4.9 & 5.3478 & TST & \\
\hline CHEMBL1444377 & 688422 & 4.45 & 5.012 & TRN & \\
\hline CHEMBL1515642 & 688422 & 5.95 & 5.5062 & TRN & \\
\hline CHEMBL1517532 & 688422 & 4.85 & 4.9164 & TRN & \\
\hline CHEMBL1580073 & 688422 & 4.95 & 5.0937 & TST & \\
\hline CHEMBL1525960 & 688422 & 4.45 & 5.2452 & TRN & \\
\hline CHEMBL1341968 & 688422 & 5.15 & 5.7731 & TST & \\
\hline CHEMBL1311772 & 688422 & 4.95 & 5.1484 & TRN & \\
\hline CHEMBL1343654 & 688422 & 4.9 & 5.1861 & TST & \\
\hline CHEMBL3212894 & 688422 & 4.5 & 5.3787 & TRN & \\
\hline CHEMBL3209553 & 688422 & 6.8 & 5.5634 & TRN & \\
\hline CHEMBL1470087 & 688422 & 5.35 & 5.5489 & TST & \\
\hline CHEMBL3192160 & 688422 & 4.45 & 5.1606 & TRN & \\
\hline CHEMBL1329086 & 688422 & 8.4949 & 5.0478 & TST & \\
\hline CHEMBL1326747 & 688422 & 4.65 & 4.8776 & TRN & \\
\hline CHEMBL1504973 & 688422 & 4.9 & 4.9684 & TRN & \\
\hline CHEMBL3198239 & 688422 & 4.85 & 4.7524 & TRN & \\
\hline
\end{tabular}




\begin{tabular}{|c|c|c|c|c|}
\hline \multicolumn{5}{|c|}{ Supplemental Table S2.txt } \\
\hline CHEMBL1415635 & 688422 & 4.9 & 5.3072 & TRN \\
\hline CHEMBL1582941 & 688422 & 5.0 & 5.0609 & TRN \\
\hline CHEMBL609036 & 688422 & 5.2 & 4.9846 & TRN \\
\hline CHEMBL1354587 & 688422 & 4.75 & 5.3898 & TRN \\
\hline CHEMBL 285123 & 688422 & 4.9 & 6.3303 & TRN \\
\hline CHEMBL3192070 & 688422 & 4.45 & 5.4379 & TRN \\
\hline CHEMBL1424495 & 688422 & 4.9 & 5.3803 & TRN \\
\hline CHEMBL1405975 & 688422 & 5.1 & 5.2639 & TRN \\
\hline CHEMBL1384537 & 688422 & 4.6 & 5.171 & TRN \\
\hline CHEMBL1555249 & 688422 & 6.5 & 5.5218 & TST \\
\hline CHEMBL1455888 & 688422 & 4.95 & 5.1725 & TRN \\
\hline CHEMBL1355882 & 688422 & 4.8 & 4.9609 & TRN \\
\hline CHEMBL1538765 & 688422 & 4.9 & 4.9867 & TRN \\
\hline CHEMBL1427678 & 688422 & 4.9 & 5.683 & TRN \\
\hline CHEMBL1460179 & 688422 & 4.9 & 4.7506 & TRN \\
\hline CHEMBL1497089 & 688422 & 4.6 & 4.7981 & TRN \\
\hline CHEMBL1547567 & 688422 & 4.45 & 5.193 & TST \\
\hline CHEMBL1604690 & 688422 & 4.85 & 4.8443 & TRN \\
\hline CHEMBL1302074 & 688422 & 5.1 & 5.4658 & TRN \\
\hline CHEMBL1424755 & 688422 & 4.55 & 4.6146 & TRN \\
\hline CHEMBL1493517 & 688422 & 5.4 & 5.0784 & TRN \\
\hline CHEMBL1257078 & 688422 & 6.0 & 5.4644 & TST \\
\hline CHEMBL1584321 & 688422 & 4.85 & 5.5167 & TST \\
\hline CHEMBL1314906 & 688422 & 4.45 & 4.8194 & TRN \\
\hline CHEMBL1605460 & 688422 & 4.9 & 4.7401 & TRN \\
\hline CHEMBL1593469 & 688422 & 4.45 & 4.9365 & TRN \\
\hline CHEMBL1495910 & 688422 & 5.1 & 5.5295 & TRN \\
\hline CHEMBL1423314 & 688422 & 4.8 & 5.2603 & TRN \\
\hline CHEMBL1419564 & 688422 & 7.8996 & 5.5 & TRN \\
\hline CHEMBL1500893 & 688422 & 8.0506 & 4.9593 & TRN \\
\hline CHEMBL1440695 & 688422 & 4.7 & 5.3495 & TRN \\
\hline CHEMBL1590865 & 688422 & 8.301 & 5.7082 & TRN \\
\hline CHEMBL1507906 & 688422 & 5.35 & 5.715 & TRN \\
\hline CHEMBL1481805 & 688422 & 4.45 & 5.2822 & TRN \\
\hline CHEMBL1546315 & 688422 & 5.0 & 4.7559 & TRN \\
\hline CHEMBL1441256 & 688422 & 4.85 & 5.4442 & TRN \\
\hline CHEMBL1462993 & 688422 & 5.0 & 5.4549 & TRN \\
\hline CHEMBL1325470 & 688422 & 4.45 & 5.0912 & TRN \\
\hline CHEMBL1493282 & 688422 & 6.45 & 5.5218 & TST \\
\hline CHEMBL1371027 & 688422 & 4.45 & 5.152 & TRN \\
\hline CHEMBL1488117 & 688422 & 6.0 & 5.0656 & TRN \\
\hline CHEMBL1422092 & 688422 & 4.8 & 5.3637 & TRN \\
\hline CHEMBL1440564 & 688422 & 4.9 & 5.4135 & TRN \\
\hline CHEMBL1970371 & 688422 & 6.1 & 5.0588 & TST \\
\hline CHEMBL3208210 & 688422 & 8.3468 & 5.4902 & TRN \\
\hline CHEMBL1400235 & 688422 & 5.25 & 5.6071 & TRN \\
\hline CHEMBL1583434 & 688422 & 4.45 & 5.2709 & TRN \\
\hline CHEMBL1504037 & 688422 & 4.95 & 5.2953 & TRN \\
\hline
\end{tabular}




\begin{tabular}{|c|c|c|c|c|}
\hline \multicolumn{5}{|c|}{ Supplemental Table S2.txt } \\
\hline CHEMBL1505461 & 688422 & 4.95 & 5.2536 & TST \\
\hline CHEMBL1336567 & 688422 & 5.1 & 4.9086 & TRN \\
\hline CHEMBL1370612 & 688422 & 5.0 & 5.1745 & TRN \\
\hline CHEMBL1310186 & 688422 & 4.7 & 5.3784 & TRN \\
\hline CHEMBL3193020 & 688422 & 5.4 & 5.1147 & TRN \\
\hline CHEMBL1541306 & 688422 & 4.95 & 5.1609 & TRN \\
\hline CHEMBL1472464 & 688422 & 4.9 & 4.8148 & TRN \\
\hline CHEMBL1350698 & 688422 & 4.45 & 5.1688 & TRN \\
\hline CHEMBL 3196840 & 688422 & 4.45 & 5.2433 & TRN \\
\hline CHEMBL1325211 & 688422 & 5.95 & 5.3967 & TST \\
\hline CHEMBL1307956 & 688422 & 4.5 & 4.8481 & TRN \\
\hline CHEMBL1539915 & 688422 & 5.35 & 5.0028 & TRN \\
\hline CHEMBL1299492 & 688422 & 4.9 & 4.9441 & TST \\
\hline CHEMBL1591352 & 688422 & 8.4949 & 5.5182 & TRN \\
\hline CHEMBL7664 & 688422 & 5.4 & 5.8003 & TST \\
\hline CHEMBL1411550 & 688422 & 5.35 & 4.8711 & TRN \\
\hline CHEMBL1495707 & 688422 & 4.6 & 5.4418 & TRN \\
\hline CHEMBL1546313 & 688422 & 5.0 & 5.3681 & TST \\
\hline CHEMBL578512 & 688422 & 5.3 & 5.7043 & TRN \\
\hline CHEMBL1587028 & 688422 & 5.25 & 5.0522 & TRN \\
\hline CHEMBL1321613 & 688422 & 4.95 & 4.785 & TRN \\
\hline CHEMBL1470009 & 688422 & 4.45 & 5.1803 & TST \\
\hline CHEMBL1464882 & 688422 & 4.95 & 5.455 & TST \\
\hline CHEMBL1497659 & 688422 & 4.65 & 4.9577 & TRN \\
\hline CHEMBL1366114 & 688422 & 4.45 & 5.2357 & TST \\
\hline CHEMBL1565602 & 688422 & 5.55 & 5.3965 & TRN \\
\hline CHEMBL1377977 & 688422 & 5.3 & 5.0076 & TRN \\
\hline CHEMBL1494687 & 688422 & 4.45 & 5.3028 & TRN \\
\hline CHEMBL1301752 & 688422 & 4.45 & 5.1794 & TST \\
\hline CHEMBL526034 & 688422 & 5.05 & 5.1519 & TST \\
\hline CHEMBL1439688 & 688422 & 6.05 & 5.4767 & TRN \\
\hline CHEMBL1594522 & 688422 & 5.1 & 4.8398 & TRN \\
\hline CHEMBL1366856 & 688422 & 5.2 & 4.9578 & TRN \\
\hline CHEMBL1342662 & 688422 & 5.3 & 5.0757 & TRN \\
\hline CHEMBL1609419 & 688422 & 4.45 & 5.0759 & TRN \\
\hline CHEMBL1371092 & 688422 & 5.25 & 5.1822 & TRN \\
\hline CHEMBL1467631 & 688422 & 4.65 & 5.0904 & TST \\
\hline CHEMBL1506692 & 688422 & 4.8 & 4.7165 & TRN \\
\hline CHEMBL1336123 & 688422 & 4.45 & 5.0233 & TST \\
\hline CHEMBL1441554 & 688422 & 4.4 & 4.9419 & TRN \\
\hline CHEMBL1585818 & 688422 & 4.65 & 4.7069 & TST \\
\hline CHEMBL1442176 & 688422 & 4.75 & 5.3858 & TRN \\
\hline CHEMBL1606138 & 688422 & 4.65 & 5.0067 & TRN \\
\hline CHEMBL1536957 & 688422 & 4.85 & 5.2818 & TRN \\
\hline CHEMBL1506885 & 688422 & 4.85 & 5.375 & TRN \\
\hline CHEMBL1459771 & 688422 & 4.75 & 5.2483 & TST \\
\hline CHEMBL1352181 & 688422 & 5.4 & 4.9658 & TRN \\
\hline CHEMBL1465201 & 688422 & 4.7 & 4.9102 & TST \\
\hline
\end{tabular}




\begin{tabular}{|c|c|c|c|c|}
\hline \multicolumn{5}{|c|}{ Supplemental Table S2.txt } \\
\hline CHEMBL589479 & 688422 & 5.2 & 5.1435 & TRN \\
\hline CHEMBL1437876 & 688422 & 7.5003 & 5.4416 & TRN \\
\hline CHEMBL1979671 & 688422 & 5.55 & 4.7618 & TRN \\
\hline CHEMBL1482521 & 688422 & 5.45 & 5.1535 & TRN \\
\hline CHEMBL1419326 & 688422 & 4.85 & 4.7204 & TRN \\
\hline CHEMBL1517553 & 688422 & 4.75 & 5.118 & TST \\
\hline CHEMBL1548657 & 688422 & 4.45 & 4.9812 & TRN \\
\hline CHEMBL1464477 & 688422 & 4.85 & 4.9627 & TRN \\
\hline CHEMBL1387718 & 688422 & 5.1 & 5.0224 & TRN \\
\hline CHEMBL1591258 & 688422 & 5.0 & 5.4675 & TST \\
\hline CHEMBL1443699 & 688422 & 4.5 & 5.1622 & TRN \\
\hline CHEMBL1361201 & 688422 & 6.0 & 5.4244 & TRN \\
\hline CHEMBL1423348 & 688422 & 4.45 & 5.3798 & TRN \\
\hline CHEMBL1397107 & 688422 & 4.9 & 5.443 & TRN \\
\hline CHEMBL441282 & 688422 & 5.5 & 4.947 & TST \\
\hline CHEMBL1342441 & 688422 & 4.8 & 5.0941 & TRN \\
\hline CHEMBL1469510 & 688422 & 4.75 & 5.5594 & TST \\
\hline CHEMBL1522577 & 688422 & 4.85 & 5.1723 & TRN \\
\hline CHEMBL1494056 & 688422 & 4.85 & 5.1298 & TRN \\
\hline CHEMBL1556145 & 688422 & 4.45 & 5.3619 & TST \\
\hline CHEMBL1455938 & 688422 & 4.8 & 5.0273 & TRN \\
\hline CHEMBL1590433 & 688422 & 4.6 & 5.6944 & TRN \\
\hline CHEMBL1490473 & 688422 & 7.699 & 5.3745 & TRN \\
\hline CHEMBL1452403 & 688422 & 4.95 & 5.3038 & TRN \\
\hline CHEMBL1519398 & 688422 & 4.5 & 5.4084 & TRN \\
\hline CHEMBL1520209 & 688422 & 5.8 & 5.8982 & TST \\
\hline CHEMBL1438323 & 688422 & 4.6 & 4.8383 & TRN \\
\hline CHEMBL1596779 & 688422 & 4.45 & 5.32 & TST \\
\hline CHEMBL1306666 & 688422 & 4.85 & 5.1754 & TRN \\
\hline CHEMBL1381856 & 688422 & 4.8 & 4.963 & TRN \\
\hline CHEMBL1480968 & 688422 & 4.85 & 5.2042 & TRN \\
\hline CHEMBL1555933 & 688422 & 5.05 & 5.0639 & TST \\
\hline CHEMBL1538240 & 688422 & 4.65 & 5.2966 & TRN \\
\hline CHEMBL1425613 & 688422 & 4.45 & 4.7847 & TRN \\
\hline CHEMBL1353052 & 688422 & 6.25 & 5.4506 & TRN \\
\hline CHEMBL1451466 & 688422 & 4.45 & 5.9199 & TRN \\
\hline CHEMBL1461324 & 688422 & 6.8499 & 5.7943 & TST \\
\hline CHEMBL1460352 & 688422 & 5.5 & 5.0818 & TRN \\
\hline CHEMBL1391790 & 688422 & 4.65 & 5.4522 & TRN \\
\hline CHEMBL3207953 & 688422 & 4.45 & 5.2614 & TRN \\
\hline CHEMBL1394497 & 688422 & 8.4949 & 4.795 & TRN \\
\hline CHEMBL1310132 & 688422 & 6.05 & 4.8887 & TRN \\
\hline CHEMBL1978117 & 688422 & 6.4 & 5.3576 & TRN \\
\hline CHEMBL1383736 & 688422 & 4.85 & 5.0365 & TRN \\
\hline CHEMBL3198693 & 688422 & 5.3 & 5.018 & TRN \\
\hline CHEMBL1602833 & 688422 & 4.9 & 4.9189 & TRN \\
\hline CHEMBL1406827 & 688422 & 7.0501 & 5.5251 & TST \\
\hline CHEMBL1385659 & 688422 & 5.5 & 5.5553 & TST \\
\hline
\end{tabular}




\begin{tabular}{|c|c|c|c|c|c|}
\hline \multicolumn{6}{|c|}{ Supplemental Table S2.txt } \\
\hline CHEMBL1588082 & 688422 & 4.95 & 5.1266 & TST & \\
\hline CHEMBL1414676 & 688422 & 6.95 & 5.1888 & TRN & \\
\hline CHEMBL1612861 & 688422 & 4.45 & 5.2101 & TRN & \\
\hline CHEMBL1401889 & 688422 & 4.85 & 5.4096 & TRN & \\
\hline CHEMBL 3213634 & 688422 & 5.15 & 5.1086 & TRN & \\
\hline CHEMBL1371377 & 688422 & 5.8 & 5.0653 & TRN & \\
\hline CHEMBL1487692 & 688422 & 4.95 & 5.2441 & TST & \\
\hline CHEMBL1393543 & 688422 & 4.85 & 4.9284 & TRN & \\
\hline CHEMBL1515795 & 688422 & 8.5528 & 5.5808 & TRN & \\
\hline CHEMBL1348954 & 688422 & 4.95 & 5.3356 & TRN & \\
\hline CHEMBL 3192408 & 688422 & 4.95 & 5.2782 & TST & \\
\hline CHEMBL1363708 & 688422 & 5.5 & 5.29299 & 9999999999 & TRN \\
\hline CHEMBL1369125 & 688422 & 4.45 & 5.0609 & TRN & \\
\hline CHEMBL1397983 & 688422 & 5.35 & 4.6967 & TRN & \\
\hline CHEMBL1324061 & 688422 & 6.2 & 5.3186 & TRN & \\
\hline CHEMBL1300555 & 688422 & 7.4001 & 4.9997 & TRN & \\
\hline CHEMBL1598231 & 688422 & 4.95 & 5.4516 & TRN & \\
\hline CHEMBL1532674 & 688422 & 7.3002 & 5.3058 & TRN & \\
\hline CHEMBL1481929 & 688422 & 4.7 & 5.2786 & TRN & \\
\hline CHEMBL1469529 & 688422 & 4.45 & 5.4195 & TST & \\
\hline CHEMBL1467636 & 688422 & 4.45 & 4.7633 & TRN & \\
\hline CHEMBL1604286 & 688422 & 4.95 & 4.7079 & TRN & \\
\hline CHEMBL1428588 & 688422 & 4.9 & 4.7687 & TRN & \\
\hline CHEMBL1465964 & 688422 & 4.6 & 4.9594 & TRN & \\
\hline CHEMBL1572198 & 688422 & 4.95 & 5.255 & TRN & \\
\hline CHEMBL1495847 & 688422 & 5.8 & 5.3831 & TRN & \\
\hline CHEMBL1419017 & 688422 & 4.45 & 5.3005 & TRN & \\
\hline CHEMBL1585681 & 688422 & 4.55 & 5.2742 & TRN & \\
\hline CHEMBL1407143 & 688422 & 5.6 & 4.8862 & TRN & \\
\hline CHEMBL1306395 & 688422 & 4.65 & 5.1803 & TRN & \\
\hline CHEMBL1416434 & 688422 & 4.95 & 5.3988 & TST & \\
\hline CHEMBL1473631 & 688422 & 7.5003 & 5.4149 & TRN & \\
\hline CHEMBL585081 & 688422 & 4.45 & 5.181 & TRN & \\
\hline CHEMBL1404678 & 688422 & 6.05 & 5.5618 & TRN & \\
\hline CHEMBL1301613 & 688422 & 6.8 & 5.8406 & TRN & \\
\hline CHEMBL1538259 & 688422 & 5.1 & 5.035 & TST & \\
\hline CHEMBL 3192348 & 688422 & 4.85 & 5.1864 & TRN & \\
\hline CHEMBL1492568 & 688422 & 5.5 & 5.5898 & TRN & \\
\hline CHEMBL1299424 & 688422 & 4.65 & 5.3431 & TRN & \\
\hline CHEMBL1441274 & 688422 & 4.45 & 5.2026 & TRN & \\
\hline CHEMBL1469282 & 688422 & 4.5 & 5.4298 & TRN & \\
\hline CHEMBL1313522 & 688422 & 4.7 & 5.1941 & TRN & \\
\hline CHEMBL1507962 & 688422 & 4.8 & 5.1215 & TRN & \\
\hline CHEMBL1596324 & 688422 & 4.85 & 4.8928 & TRN & \\
\hline CHEMBL1589108 & 688422 & 5.25 & 5.528 & TRN & \\
\hline CHEMBL1299269 & 688422 & 4.85 & 5.1845 & TST & \\
\hline CHEMBL1487611 & 688422 & 7.699 & 5.5837 & TST & \\
\hline CHEMBL1509335 & 688422 & 4.9 & 5.0591 & TRN & \\
\hline
\end{tabular}




\begin{tabular}{|c|c|c|c|c|c|}
\hline \multicolumn{6}{|c|}{ Supplemental Table S2.txt } \\
\hline CHEMBL1404762 & 688422 & 7.0 & 5.3692 & TRN & \\
\hline CHEMBL1524365 & 688422 & 5.0 & 5.2158 & TST & \\
\hline CHEMBL1328629 & 688422 & 4.45 & 4.8515 & TST & \\
\hline CHEMBL1337997 & 688422 & 4.95 & 4.6916 & TRN & \\
\hline CHEMBL1539141 & 688422 & 4.45 & 5.023 & TRN & \\
\hline CHEMBL1482008 & 688422 & 5.5 & 5.3568 & TST & \\
\hline CHEMBL1599835 & 688422 & 7.8996 & 5.4492 & TST & \\
\hline CHEMBL1476593 & 688422 & 7.699 & 5.5505 & TRN & \\
\hline CHEMBL1399087 & 688422 & 4.45 & 5.7632 & TRN & \\
\hline CHEMBL1441840 & 688422 & 4.55 & 4.953 & TRN & \\
\hline CHEMBL1415751 & 688422 & 7.4001 & 5.4153 & TST & \\
\hline CHEMBL1369680 & 688422 & 5.5 & 5.1577 & TRN & \\
\hline CHEMBL1478974 & 688422 & 7.6498 & 4.9692 & TRN & \\
\hline CHEMBL1420320 & 688422 & 4.65 & 4.5912 & TRN & \\
\hline CHEMBL1341752 & 688422 & 4.45 & 5.0407 & TST & \\
\hline CHEMBL3191066 & 688422 & 6.3 & 5.3538 & TRN & \\
\hline CHEMBL1506771 & 688422 & 6.0 & 5.2557 & TRN & \\
\hline CHEMBL1369929 & 688422 & 4.85 & 5.0761 & TRN & \\
\hline CHEMBL1533320 & 688422 & 5.2 & 5.2113 & TRN & \\
\hline CHEMBL1357151 & 688422 & 5.7 & 5.7205 & TST & \\
\hline CHEMBL1608618 & 688422 & 4.45 & 5.2046 & TRN & \\
\hline CHEMBL215684 & 688422 & 5.5 & 5.2977 & TRN & \\
\hline CHEMBL1440471 & 688422 & 4.45 & 4.7802 & TRN & \\
\hline CHEMBL1364239 & 688422 & 4.85 & 5.3976 & TRN & \\
\hline CHEMBL3193997 & 688422 & 4.5 & 5.278 & TRN & \\
\hline CHEMBL1466524 & 688422 & 5.4 & 5.3118 & TRN & \\
\hline CHEMBL3209352 & 688422 & 4.9 & 5.3331 & TRN & \\
\hline CHEMBL581677 & 688422 & 4.85 & 4.9488 & TRN & \\
\hline CHEMBL1572883 & 688422 & 4.9 & 5.0823 & TRN & \\
\hline CHEMBL1412523 & 688422 & 4.45 & 4.9118 & TRN & \\
\hline CHEMBL1412349 & 688422 & 7.0 & 5.6765 & TRN & \\
\hline CHEMBL1357074 & 688422 & 7.699 & 5.0394 & TRN & \\
\hline CHEMBL1507181 & 688422 & 4.45 & 5.1192 & TRN & \\
\hline CHEMBL 2003808 & 688422 & 5.0 & 5.1639 & TRN & \\
\hline CHEMBL1380723 & 688422 & 5.3 & 5.3721 & TRN & \\
\hline CHEMBL1576437 & 688422 & 5.25 & 5.7526 & TST & \\
\hline CHEMBL1491654 & 688422 & 5.2 & 5.1581 & TRN & \\
\hline CHEMBL1333643 & 688422 & 4.9 & 5.4631 & TRN & \\
\hline CHEMBL1311296 & 688422 & 4.75 & 5.31 & TRN & \\
\hline CHEMBL1397815 & 688422 & 4.45 & 5.2146 & TRN & \\
\hline CHEMBL1464931 & 688422 & 4.5 & 4.9314 & TRN & \\
\hline CHEMBL1605421 & 688422 & 4.65 & 5.53100 & 0000000001 & TRN \\
\hline CHEMBL430893 & 688422 & 8.699 & 5.6733 & TST & \\
\hline CHEMBL1399415 & 688422 & 5.7 & 5.7754 & TST & \\
\hline CHEMBL1979806 & 688422 & 5.85 & 4.7861 & TST & \\
\hline CHEMBL1388278 & 688422 & 5.0 & 5.3021 & TRN & \\
\hline CHEMBL1318886 & 688422 & 4.7 & 5.1651 & TRN & \\
\hline CHEMBL1981610 & 688422 & 4.95 & 5.0272 & TRN & \\
\hline
\end{tabular}




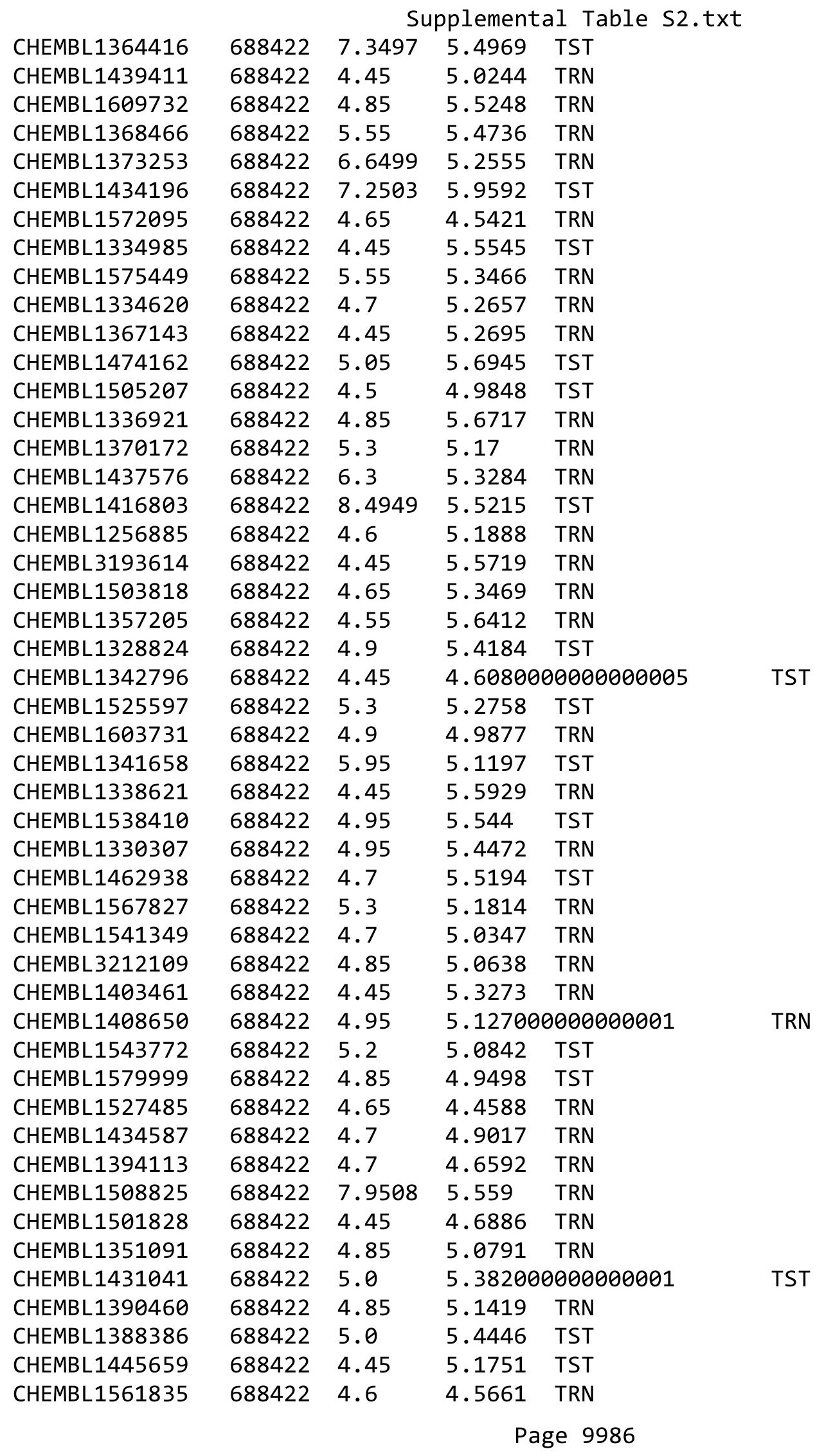




\begin{tabular}{|c|c|c|c|c|}
\hline \multicolumn{5}{|c|}{ Supplemental Table S2.txt } \\
\hline CHEMBL1573700 & 688422 & 4.7 & 5.3554 & TRN \\
\hline CHEMBL1469237 & 688422 & 6.15 & 5.7829 & TRN \\
\hline CHEMBL1451721 & 688422 & 5.05 & 5.0349 & TRN \\
\hline CHEMBL512649 & 688422 & 5.25 & 5.0102 & TST \\
\hline CHEMBL 1454798 & 688422 & 4.45 & 5.1297 & TRN \\
\hline CHEMBL1580575 & 688422 & 4.75 & 5.3703 & TRN \\
\hline CHEMBL1376490 & 688422 & 8.0506 & 5.4712 & TST \\
\hline CHEMBL1320641 & 688422 & 6.2 & 4.9179 & TRN \\
\hline CHEMBL1557922 & 688422 & 5.0 & 5.0082 & TRN \\
\hline CHEMBL 1605048 & 688422 & 4.7 & 4.8246 & TRN \\
\hline CHEMBL1438691 & 688422 & 5.25 & 5.2505 & TRN \\
\hline CHEMBL1325923 & 688422 & 6.5 & 5.4637 & TRN \\
\hline CHEMBL1397130 & 688422 & 4.75 & 4.9839 & TRN \\
\hline CHEMBL1328930 & 688422 & 4.5 & 5.2551 & TRN \\
\hline CHEMBL1340152 & 688422 & 4.65 & 5.1016 & TRN \\
\hline CHEMBL1309997 & 688422 & 5.55 & 5.2204 & TST \\
\hline CHEMBL1528007 & 688422 & 4.45 & 5.0918 & TRN \\
\hline CHEMBL1531693 & 688422 & 4.45 & 4.9406 & TRN \\
\hline CHEMBL1450653 & 688422 & 5.25 & 5.5169 & TRN \\
\hline CHEMBL1384382 & 688422 & 4.5 & 5.19 & TRN \\
\hline CHEMBL1470715 & 688422 & 4.9 & 5.5478 & TST \\
\hline CHEMBL1557752 & 688422 & 7.15 & 5.4425 & TST \\
\hline CHEMBL1411069 & 688422 & 4.45 & 5.1492 & TST \\
\hline CHEMBL1464302 & 688422 & 8.0 & 5.5203 & TST \\
\hline CHEMBL1478479 & 688422 & 4.45 & 5.5463 & TRN \\
\hline CHEMBL1416594 & 688422 & 4.65 & 5.3106 & TRN \\
\hline CHEMBL1468353 & 688422 & 4.65 & 5.1532 & TRN \\
\hline CHEMBL1342656 & 688422 & 7.0 & 5.7768 & TST \\
\hline CHEMBL1491617 & 688422 & 4.6 & 5.0651 & TRN \\
\hline CHEMBL 1407724 & 688422 & 5.65 & 5.7289 & TST \\
\hline CHEMBL1492623 & 688422 & 8.301 & 5.2354 & TST \\
\hline CHEMBL1557537 & 688422 & 5.0 & 4.8181 & TRN \\
\hline CHEMBL1391560 & 688422 & 4.85 & 4.9736 & TRN \\
\hline CHEMBL1541010 & 688422 & 5.3 & 5.102 & TST \\
\hline CHEMBL1586270 & 688422 & 4.9 & 5.1429 & TRN \\
\hline CHEMBL1444549 & 688422 & 7.3497 & 5.1356 & TRN \\
\hline CHEMBL1508744 & 688422 & 5.2 & 5.9326 & TRN \\
\hline CHEMBL1440011 & 688422 & 4.5 & 4.8639 & TRN \\
\hline CHEMBL1357021 & 688422 & 6.3 & 5.1805 & TRN \\
\hline CHEMBL1341426 & 688422 & 4.9 & 5.2457 & TRN \\
\hline CHEMBL1538716 & 688422 & 6.0 & 4.9753 & TRN \\
\hline CHEMBL1435768 & 688422 & 5.85 & 5.2759 & TRN \\
\hline CHEMBL1567790 & 688422 & 4.6 & 4.9786 & TRN \\
\hline CHEMBL1447386 & 688422 & 4.9 & 5.0945 & TRN \\
\hline CHEMBL1401242 & 688422 & 4.65 & 5.2227 & TRN \\
\hline CHEMBL1562206 & 688422 & 4.9 & 5.2075 & TST \\
\hline CHEMBL1426368 & 688422 & 4.9 & 5.532 & TRN \\
\hline CHEMBL1470977 & 688422 & 5.9 & 5.4568 & TST \\
\hline
\end{tabular}




\begin{tabular}{|c|c|c|c|c|c|}
\hline \multicolumn{6}{|c|}{ Supplemental Table S2.txt } \\
\hline CHEMBL1411847 & 688422 & 4.5 & 5.3828 & TRN & \\
\hline CHEMBL1306159 & 688422 & 7.4001 & 5.3886 & TRN & \\
\hline CHEMBL1354044 & 688422 & 4.9 & 5.1204 & TRN & \\
\hline CHEMBL1562611 & 688422 & 4.45 & 5.2452 & TRN & \\
\hline CHEMBL1473654 & 688422 & 4.5 & 5.6818 & TRN & \\
\hline CHEMBL1468183 & 688422 & 4.45 & 5.3006 & TST & \\
\hline CHEMBL1358369 & 688422 & 4.85 & 5.6062 & TRN & \\
\hline CHEMBL3213820 & 688422 & 4.45 & 4.988 & TST & \\
\hline CHEMBL 1606510 & 688422 & 4.45 & 4.9566 & TST & \\
\hline CHEMBL1497119 & 688422 & 5.1 & 5.1985 & TST & \\
\hline CHEMBL1398958 & 688422 & 6.9 & 5.5893 & TST & \\
\hline CHEMBL1348518 & 688422 & 4.45 & 4.9435 & TRN & \\
\hline CHEMBL1593827 & 688422 & 4.9 & 4.9729 & TRN & \\
\hline CHEMBL530038 & 688422 & 5.0 & 5.6788 & TST & \\
\hline CHEMBL1374211 & 688422 & 4.65 & 5.2166 & TST & \\
\hline CHEMBL1543705 & 688422 & 4.45 & 5.1535 & TRN & \\
\hline CHEMBL1443420 & 688422 & 6.15 & 5.1739 & TRN & \\
\hline CHEMBL1965821 & 688422 & 4.6 & 4.9196 & TRN & \\
\hline CHEMBL 1352416 & 688422 & 4.95 & 5.3409 & TRN & \\
\hline CHEMBL1542861 & 688422 & 5.15 & 5.6037 & TRN & \\
\hline CHEMBL1595820 & 688422 & 4.8 & 5.0843 & TRN & \\
\hline CHEMBL1965191 & 688422 & 5.15 & 5.3431 & TRN & \\
\hline CHEMBL3196230 & 688422 & 4.5 & 5.0116 & TST & \\
\hline CHEMBL1579704 & 688422 & 4.45 & 5.2412 & TST & \\
\hline CHEMBL1384058 & 688422 & 4.7 & 5.20799 & 9999999999 & TRN \\
\hline CHEMBL1581772 & 688422 & 6.5501 & 5.6369 & TRN & \\
\hline CHEMBL1482965 & 688422 & 4.8 & 5.4389 & TRN & \\
\hline CHEMBL1574294 & 688422 & 4.45 & 5.0014 & TRN & \\
\hline CHEMBL1521108 & 688422 & 7.6498 & 5.1593 & TRN & \\
\hline CHEMBL1570149 & 688422 & 4.85 & 5.3517 & TRN & \\
\hline CHEMBL1494460 & 688422 & 4.65 & 4.897 & TST & \\
\hline CHEMBL1396981 & 688422 & 4.5 & 5.4937 & TRN & \\
\hline CHEMBL1426332 & 688422 & 4.6 & 5.0158 & TRN & \\
\hline CHEMBL1360745 & 688422 & 7.699 & 5.619 & TRN & \\
\hline CHEMBL3195069 & 688422 & 6.6 & 5.3971 & TST & \\
\hline CHEMBL1385980 & 688422 & 7.9508 & 4.8956 & TST & \\
\hline CHEMBL1592192 & 688422 & 8.3468 & 5.4565 & TST & \\
\hline CHEMBL1609245 & 688422 & 4.75 & 5.2558 & TRN & \\
\hline CHEMBL1500469 & 688422 & 4.9 & 4.7981 & TRN & \\
\hline CHEMBL1971604 & 688422 & 4.8 & 5.1451 & TRN & \\
\hline CHEMBL1334969 & 688422 & 4.45 & 4.8767 & TRN & \\
\hline CHEMBL1352293 & 688422 & 7.0 & 5.8498 & TRN & \\
\hline CHEMBL1385053 & 688422 & 5.55 & 5.5811 & TRN & \\
\hline CHEMBL3209377 & 688422 & 5.25 & 5.3377 & TRN & \\
\hline CHEMBL1448778 & 688422 & 6.95 & 5.4628 & TRN & \\
\hline CHEMBL1481161 & 688422 & 4.5 & 4.9624 & TRN & \\
\hline CHEMBL3214055 & 688422 & 4.65 & 5.5909 & TRN & \\
\hline CHEMBL1355988 & 688422 & 7.0501 & 5.5055 & TST & \\
\hline
\end{tabular}




\begin{tabular}{|c|c|c|c|c|}
\hline \multicolumn{5}{|c|}{ Supplemental Table s2.txt } \\
\hline CHEMBL1577194 & 688422 & 4.7 & 5.4548 & TRN \\
\hline CHEMBL1554466 & 688422 & 6.15 & 5.2723 & TRN \\
\hline CHEMBL3212972 & 688422 & 4.45 & 5.0431 & TRN \\
\hline CHEMBL1438717 & 688422 & 4.45 & 4.8436 & TRN \\
\hline CHEMBL1587587 & 688422 & 4.45 & 4.7562 & TRN \\
\hline CHEMBL1303665 & 688422 & 4.85 & 5.2641 & TST \\
\hline CHEMBL1591438 & 688422 & 7.5003 & 5.2221 & TRN \\
\hline CHEMBL1332047 & 688422 & 4.45 & 5.0354 & TRN \\
\hline CHEMBL1456608 & 688422 & 6.5 & 5.4671 & TRN \\
\hline CHEMBL1377015 & 688422 & 4.45 & 5.0102 & TRN \\
\hline CHEMBL1498370 & 688422 & 4.5 & 5.426 & TST \\
\hline CHEMBL1416318 & 688422 & 4.45 & 5.2351 & TRN \\
\hline CHEMBL1465839 & 688422 & 6.95 & 5.0593 & TRN \\
\hline CHEMBL1388398 & 688422 & 4.95 & 5.3426 & TST \\
\hline CHEMBL1483549 & 688422 & 4.75 & 5.018 & TRN \\
\hline CHEMBL1462507 & 688422 & 5.05 & 5.3246 & TRN \\
\hline CHEMBL1534254 & 688422 & 5.2 & 5.4347 & TRN \\
\hline CHEMBL1556820 & 688422 & 4.5 & 5.0285 & TRN \\
\hline CHEMBL1440278 & 688422 & 4.9 & 5.3179 & TRN \\
\hline CHEMBL1468641 & 688422 & 4.65 & 5.4213 & TRN \\
\hline CHEMBL3192030 & 688422 & 4.75 & 5.0455 & TST \\
\hline CHEMBL1561532 & 688422 & 4.85 & 4.9915 & TRN \\
\hline CHEMBL1326874 & 688422 & 4.85 & 4.7764 & TRN \\
\hline CHEMBL1457085 & 688422 & 4.9 & 5.0132 & TRN \\
\hline CHEMBL1590169 & 688422 & 6.6 & 5.3713 & TRN \\
\hline CHEMBL1563293 & 688422 & 4.9 & 5.165 & TRN \\
\hline CHEMBL1409293 & 688422 & 4.5 & 4.875 & TRN \\
\hline CHEMBL1458877 & 688422 & 4.6 & 5.1583 & TRN \\
\hline CHEMBL 2006503 & 688422 & 5.4 & 5.0869 & TRN \\
\hline CHEMBL1551712 & 688422 & 7.699 & 5.4982 & TST \\
\hline CHEMBL1607035 & 688422 & 5.45 & 5.0169 & TRN \\
\hline CHEMBL1514612 & 688422 & 5.8 & 5.2583 & TRN \\
\hline CHEMBL1338919 & 688422 & 5.25 & 4.9047 & TRN \\
\hline CHEMBL1305374 & 688422 & 4.5 & 5.5143 & TRN \\
\hline CHEMBL1355411 & 688422 & 5.2 & 4.9981 & TRN \\
\hline CHEMBL1579450 & 688422 & 5.25 & 5.7947 & TRN \\
\hline CHEMBL1613725 & 688422 & 4.45 & 4.8155 & TRN \\
\hline CHEMBL1988782 & 688422 & 4.45 & 5.1551 & TST \\
\hline CHEMBL1356777 & 688422 & 5.75 & 5.6202 & TRN \\
\hline CHEMBL1424231 & 688422 & 5.55 & 5.3104 & TRN \\
\hline CHEMBL3199407 & 688422 & 5.15 & 4.8701 & TRN \\
\hline CHEMBL 1474572 & 688422 & 4.7 & 5.3992 & TRN \\
\hline CHEMBL1300396 & 688422 & 4.95 & 4.9918 & TRN \\
\hline CHEMBL 2068684 & 688422 & 4.45 & 5.7494 & TST \\
\hline CHEMBL1493853 & 688422 & 4.45 & 5.4729 & TRN \\
\hline CHEMBL1365262 & 688422 & 4.75 & 4.4485 & TRN \\
\hline CHEMBL3190885 & 688422 & 4.45 & 5.2997 & TST \\
\hline CHEMBL1351492 & 688422 & 4.65 & 5.4717 & TRN \\
\hline
\end{tabular}




\begin{tabular}{|c|c|c|c|c|c|}
\hline \multirow{3}{*}{$\begin{array}{l}\text { CHEMBL1315568 } \\
\text { CHEMBL1372356 }\end{array}$} & \multirow{3}{*}{$\begin{array}{l}688422 \\
688422\end{array}$} & \multicolumn{4}{|c|}{ Supplemental Table S2.txt } \\
\hline & & 7.6498 & \multicolumn{2}{|c|}{5.6739999999999995} & TRN \\
\hline & & 4.65 & 4.8417 & TRN & \\
\hline CHEMBL2003621 & 688422 & 5.25 & 5.6432 & TRN & \\
\hline CHEMBL1487256 & 688422 & 4.45 & 5.4124 & TRN & \\
\hline CHEMBL 3145382 & 688422 & 5.3 & 5.2579 & TRN & \\
\hline CHEMBL3196960 & 688422 & 5.0 & 4.9422 & TRN & \\
\hline CHEMBL1582324 & 688422 & 4.45 & 4.994 & TRN & \\
\hline CHEMBL1492274 & 688422 & 4.5 & 5.7269 & TRN & \\
\hline CHEMBL1458637 & 688422 & 5.75 & 5.2713 & TRN & \\
\hline CHEMBL1559856 & 688422 & 4.45 & 5.6104 & TRN & \\
\hline CHEMBL1361487 & 688422 & 4.85 & 4.9883 & TRN & \\
\hline CHEMBL3198419 & 688422 & 5.25 & 5.1055 & TRN & \\
\hline CHEMBL1470905 & 688422 & 5.25 & 4.7947 & TST & \\
\hline CHEMBL1333288 & 688422 & 7.2503 & 5.5674 & TRN & \\
\hline CHEMBL1613237 & 688422 & 4.95 & 5.0863 & TRN & \\
\hline CHEMBL1556615 & 688422 & 5.15 & 5.007 & TRN & \\
\hline CHEMBL1462603 & 688422 & 5.7 & 5.0677 & TRN & \\
\hline CHEMBL1460624 & 688422 & 5.0 & 5.1499 & TST & \\
\hline CHEMBL1364720 & 688422 & 4.8 & 4.824 & TRN & \\
\hline CHEMBL1452968 & 688422 & 4.45 & 5.13399 & 99999999995 & TST \\
\hline CHEMBL1529505 & 688422 & 4.85 & 5.0586 & TRN & \\
\hline CHEMBL118009 & 688422 & 4.5 & 5.3137 & TRN & \\
\hline CHEMBL1350805 & 688422 & 5.4 & 5.5703 & TRN & \\
\hline CHEMBL1492256 & 688422 & 4.7 & 4.8284 & TRN & \\
\hline CHEMBL1303675 & 688422 & 4.95 & 5.229 & TRN & \\
\hline CHEMBL1578011 & 688422 & 4.8 & 5.0038 & TRN & \\
\hline CHEMBL1510252 & 688422 & 6.25 & 5.6694 & TRN & \\
\hline CHEMBL1608539 & 688422 & 4.5 & 5.5621 & TRN & \\
\hline CHEMBL1516681 & 688422 & 4.45 & 5.1328 & TST & \\
\hline CHEMBL1373871 & 688422 & 4.8 & 5.3377 & TRN & \\
\hline CHEMBL1326191 & 688422 & 8.4949 & 5.5408 & TRN & \\
\hline CHEMBL1488221 & 688422 & 6.3 & 5.4721 & TRN & \\
\hline CHEMBL1369635 & 688422 & 7.15 & 5.256 & TRN & \\
\hline CHEMBL1557782 & 688422 & 4.7 & 5.0646 & TRN & \\
\hline CHEMBL1586243 & 688422 & 5.05 & 4.9972 & TRN & \\
\hline CHEMBL1300770 & 688422 & 4.8 & 5.6533 & TRN & \\
\hline CHEMBL1540977 & 688422 & 4.45 & 5.566 & TRN & \\
\hline CHEMBL1306332 & 688422 & 4.5 & 5.6068 & TRN & \\
\hline CHEMBL1534407 & 688422 & 4.95 & 5.7173 & TRN & \\
\hline CHEMBL3189235 & 688422 & 7.7496 & 5.0551 & TST & \\
\hline CHEMBL3198429 & 688422 & 8.4949 & 5.6366 & TRN & \\
\hline CHEMBL1497224 & 688422 & 5.0 & 5.2367 & TRN & \\
\hline CHEMBL1332345 & 688422 & 5.65 & 5.1326 & TST & \\
\hline CHEMBL1309562 & 688422 & 4.45 & 5.1978 & TST & \\
\hline CHEMBL1335880 & 688422 & 5.4 & 5.0187 & TRN & \\
\hline CHEMBL1369269 & 688422 & 5.0 & 5.191 & TST & \\
\hline CHEMBL1389657 & 688422 & 4.7 & 5.3038 & TRN & \\
\hline CHEMBL1995997 & 688422 & 4.75 & 5.0564 & TST & \\
\hline
\end{tabular}




\begin{tabular}{|c|c|c|c|c|}
\hline \multicolumn{5}{|c|}{ Supplemental Table S2.txt } \\
\hline CHEMBL1540230 & 688422 & 5.3 & 5.1333 & TRN \\
\hline CHEMBL1416086 & 688422 & 5.25 & 5.3478 & TRN \\
\hline CHEMBL1353899 & 688422 & 4.45 & 5.2771 & TRN \\
\hline CHEMBL1993287 & 688422 & 4.85 & 4.985 & TST \\
\hline CHEMBL3195378 & 688422 & 5.15 & 5.4549 & TRN \\
\hline CHEMBL1581991 & 688422 & 4.7 & 5.4374 & TRN \\
\hline CHEMBL1453821 & 688422 & 4.65 & 5.1051 & TRN \\
\hline CHEMBL1557450 & 688422 & 4.45 & 5.4679 & TRN \\
\hline CHEMBL1432203 & 688422 & 5.45 & 5.3811 & TRN \\
\hline CHEMBL1544092 & 688422 & 4.9 & 5.4202 & TRN \\
\hline CHEMBL1445683 & 688422 & 4.8 & 4.806 & TRN \\
\hline CHEMBL1505457 & 688422 & 5.2 & 5.1594 & TRN \\
\hline CHEMBL1611695 & 688422 & 6.45 & 4.8437 & TRN \\
\hline CHEMBL1334187 & 688422 & 7.8508 & 5.1147 & TRN \\
\hline CHEMBL1411650 & 688422 & 6.25 & 5.6976 & TRN \\
\hline CHEMBL1442259 & 688422 & 5.0 & 5.6782 & TRN \\
\hline CHEMBL1426651 & 688422 & 4.75 & 5.2438 & TRN \\
\hline CHEMBL1608527 & 688422 & 4.65 & 5.1061 & TRN \\
\hline CHEMBL1500448 & 688422 & 6.0 & 4.6712 & TRN \\
\hline CHEMBL1477154 & 688422 & 4.45 & 5.0198 & TRN \\
\hline CHEMBL1351458 & 688422 & 4.5 & 4.6059 & TRN \\
\hline CHEMBL1550677 & 688422 & 5.25 & 5.3392 & TST \\
\hline CHEMBL1417586 & 688422 & 4.5 & 5.2088 & TRN \\
\hline CHEMBL1449459 & 688422 & 4.9 & 4.882 & TRN \\
\hline CHEMBL1320934 & 688422 & 4.8 & 5.6782 & TRN \\
\hline CHEMBL1322115 & 688422 & 4.5 & 5.2754 & TRN \\
\hline CHEMBL1431948 & 688422 & 4.45 & 5.1712 & TRN \\
\hline CHEMBL1540291 & 688422 & 4.8 & 5.1383 & TRN \\
\hline CHEMBL1334924 & 688422 & 4.9 & 5.5017 & TRN \\
\hline CHEMBL1514303 & 688422 & 4.45 & 5.1164 & TRN \\
\hline CHEMBL1332327 & 688422 & 4.95 & 5.6605 & TRN \\
\hline CHEMBL1331904 & 688422 & 6.3 & 5.0018 & TRN \\
\hline CHEMBL1567526 & 688422 & 5.15 & 5.1438 & TST \\
\hline CHEMBL1596357 & 688422 & 4.7 & 4.938 & TRN \\
\hline CHEMBL1601047 & 688422 & 4.85 & 5.5003 & TRN \\
\hline CHEMBL1427849 & 688422 & 4.5 & 5.432 & TRN \\
\hline CHEMBL1326316 & 688422 & 4.55 & 5.4032 & TRN \\
\hline CHEMBL1459069 & 688422 & 4.9 & 4.5928 & TRN \\
\hline CHEMBL1587985 & 688422 & 4.9 & 5.4887 & TST \\
\hline CHEMBL1567014 & 688422 & 4.85 & 5.9302 & TRN \\
\hline CHEMBL1380441 & 688422 & 4.65 & 5.3431 & TST \\
\hline CHEMBL1321005 & 688422 & 6.0 & 5.6217 & TRN \\
\hline CHEMBL1439356 & 688422 & 4.95 & 5.234 & TRN \\
\hline CHEMBL1299863 & 688422 & 7.9508 & 4.9246 & TRN \\
\hline CHEMBL1402713 & 688422 & 4.8 & 5.075 & TRN \\
\hline CHEMBL3196407 & 688422 & 5.25 & 4.6728 & TRN \\
\hline CHEMBL1312016 & 688422 & 5.05 & 4.9199 & TRN \\
\hline CHEMBL1583371 & 688422 & 5.0 & 5.0596 & TRN \\
\hline
\end{tabular}




\begin{tabular}{|c|c|c|c|c|c|}
\hline \multicolumn{6}{|c|}{ Supplemental Table S2.txt } \\
\hline CHEMBL1368661 & 688422 & 5.25 & 5.1887 & TST & \\
\hline CHEMBL1303898 & 688422 & 5.35 & 5.3537 & TRN & \\
\hline CHEMBL1371306 & 688422 & 5.3 & 5.4244 & TST & \\
\hline CHEMBL3198682 & 688422 & 4.55 & 5.4296 & TST & \\
\hline CHEMBL 1370770 & 688422 & 4.75 & 5.0777 & TRN & \\
\hline CHEMBL1340107 & 688422 & 4.9 & 5.5112 & TRN & \\
\hline CHEMBL1560646 & 688422 & 4.95 & 5.0877 & TRN & \\
\hline CHEMBL1523446 & 688422 & 5.15 & 5.397 & TRN & \\
\hline CHEMBL1609337 & 688422 & 4.65 & 5.5109 & TST & \\
\hline CHEMBL1512145 & 688422 & 8.301 & 5.6483 & TRN & \\
\hline CHEMBL1507817 & 688422 & 4.5 & 4.9124 & TRN & \\
\hline CHEMBL1413364 & 688422 & 4.75 & 5.5502 & TST & \\
\hline CHEMBL1329878 & 688422 & 4.75 & 4.7374 & TST & \\
\hline CHEMBL1383196 & 688422 & 4.45 & 5.3795 & TRN & \\
\hline CHEMBL1467322 & 688422 & 4.45 & 4.9479 & TRN & \\
\hline CHEMBL1319436 & 688422 & 4.45 & 5.685 & TRN & \\
\hline CHEMBL1546981 & 688422 & 6.95 & 5.2135 & TRN & \\
\hline CHEMBL1346909 & 688422 & 4.45 & 5.3558 & TRN & \\
\hline CHEMBL1399364 & 688422 & 8.4559 & 5.2192 & TRN & \\
\hline CHEMBL1504854 & 688422 & 5.35 & 5.29700 & 0000000001 & TRN \\
\hline CHEMBL1486567 & 688422 & 4.45 & 4.8875 & TST & \\
\hline CHEMBL1545510 & 688422 & 5.1 & 5.58700 & 0000000001 & TRN \\
\hline CHEMBL1448761 & 688422 & 7.5003 & 5.7448 & TRN & \\
\hline CHEMBL1311851 & 688422 & 4.6 & 5.3456 & TRN & \\
\hline CHEMBL1331582 & 688422 & 4.95 & 5.2118 & TRN & \\
\hline CHEMBL3190115 & 688422 & 4.95 & 5.1569 & TRN & \\
\hline CHEMBL1521562 & 688422 & 4.95 & 5.1645 & TRN & \\
\hline CHEMBL1363112 & 688422 & 6.95 & 4.7861 & TRN & \\
\hline CHEMBL1580135 & 688422 & 4.45 & 5.2881 & TRN & \\
\hline CHEMBL1566070 & 688422 & 6.6 & 5.2908 & TRN & \\
\hline CHEMBL1360484 & 688422 & 6.05 & 5.1119 & TRN & \\
\hline CHEMBL1459917 & 688422 & 4.8 & 4.918 & TRN & \\
\hline CHEMBL1602010 & 688422 & 4.9 & 5.2541 & TST & \\
\hline CHEMBL1299659 & 688422 & 5.1 & 5.1451 & TRN & \\
\hline CHEMBL1326769 & 688422 & 4.75 & 5.7156 & TRN & \\
\hline CHEMBL1305014 & 688422 & 4.8 & 4.9508 & TRN & \\
\hline CHEMBL1303649 & 688422 & 4.75 & 5.3412 & TRN & \\
\hline CHEMBL1346651 & 688422 & 4.65 & 5.0578 & TRN & \\
\hline CHEMBL1447176 & 688422 & 4.7 & 5.32 & TRN & \\
\hline CHEMBL1513703 & 688422 & 4.45 & 4.8687 & TST & \\
\hline CHEMBL1505401 & 688422 & 8.3468 & 5.8932 & TRN & \\
\hline CHEMBL1516427 & 688422 & 4.85 & 4.8743 & TST & \\
\hline CHEMBL1597992 & 688422 & 6.95 & 5.5211 & TRN & \\
\hline CHEMBL1538893 & 688422 & 4.45 & 5.2034 & TRN & \\
\hline CHEMBL1577631 & 688422 & 4.45 & 4.949 & TRN & \\
\hline CHEMBL3214426 & 688422 & 4.65 & 5.1927 & TRN & \\
\hline CHEMBL 1558534 & 688422 & 4.5 & 5.1861 & TRN & \\
\hline CHEMBL1399600 & 688422 & 4.55 & 4.9543 & TRN & \\
\hline
\end{tabular}




\begin{tabular}{|c|c|c|c|c|c|}
\hline \multicolumn{6}{|c|}{ Supplemental Table s2.txt } \\
\hline CHEMBL1416310 & 688422 & 5.65 & 5.0151 & TRN & \\
\hline CHEMBL1572441 & 688422 & 5.15 & 5.2187 & TRN & \\
\hline CHEMBL1529174 & 688422 & 4.95 & 5.3792 & TRN & \\
\hline CHEMBL1502607 & 688422 & 4.6 & 5.0187 & TST & \\
\hline CHEMBL1553185 & 688422 & 4.6 & 4.5663 & TRN & \\
\hline CHEMBL1317707 & 688422 & 5.7 & 4.9464 & TST & \\
\hline CHEMBL1459620 & 688422 & 5.35 & 5.3672 & TST & \\
\hline CHEMBL 3212642 & 688422 & 5.25 & 5.1791 & TRN & \\
\hline CHEMBL 3209288 & 688422 & 5.55 & 5.28299 & 99999999995 & TST \\
\hline CHEMBL1361229 & 688422 & 4.5 & 5.1116 & TRN & \\
\hline CHEMBL1378755 & 688422 & 6.9 & 5.2088 & TRN & \\
\hline CHEMBL1459537 & 688422 & 4.9 & 5.5925 & TRN & \\
\hline CHEMBL1299582 & 688422 & 4.55 & 5.1775 & TRN & \\
\hline CHEMBL1416165 & 688422 & 4.45 & 5.2536 & TRN & \\
\hline CHEMBL1386136 & 688422 & 4.5 & 5.0051 & TRN & \\
\hline CHEMBL3214607 & 688422 & 6.5 & 5.2091 & TST & \\
\hline CHEMBL1550580 & 688422 & 4.9 & 4.9794 & TRN & \\
\hline CHEMBL1503312 & 688422 & 4.5 & 5.3908 & TRN & \\
\hline CHEMBL1359561 & 688422 & 4.45 & 5.6643 & TST & \\
\hline CHEMBL1490404 & 688422 & 5.3 & 4.8988 & TRN & \\
\hline CHEMBL1302781 & 688422 & 4.7 & 5.4458 & TST & \\
\hline CHEMBL1531726 & 688422 & 8.0506 & 4.7859 & TST & \\
\hline CHEMBL3145314 & 688422 & 4.9 & 5.1728 & TST & \\
\hline CHEMBL197014 & 688422 & 4.75 & 4.7846 & TRN & \\
\hline CHEMBL1471832 & 688422 & 4.95 & 4.9933 & TRN & \\
\hline CHEMBL1085065 & 688422 & 4.85 & 5.2659 & TST & \\
\hline CHEMBL1579513 & 688422 & 4.65 & 5.144 & TRN & \\
\hline CHEMBL1349633 & 688422 & 4.7 & 4.8743 & TRN & \\
\hline CHEMBL1557648 & 688422 & 5.25 & 5.3537 & TRN & \\
\hline CHEMBL1582192 & 688422 & 6.2 & 5.6436 & TRN & \\
\hline CHEMBL1465144 & 688422 & 4.5 & 5.23600 & 0000000001 & TST \\
\hline CHEMBL1591617 & 688422 & 5.9 & 5.3923 & TRN & \\
\hline CHEMBL1524336 & 688422 & 4.45 & 5.12 & TST & \\
\hline CHEMBL1588027 & 688422 & 4.45 & 5.4087 & TST & \\
\hline CHEMBL1583149 & 688422 & 6.25 & 5.5391 & TRN & \\
\hline CHEMBL1517746 & 688422 & 4.95 & 4.9051 & TRN & \\
\hline CHEMBL1410179 & 688422 & 4.9 & 5.0116 & TRN & \\
\hline CHEMBL1391673 & 688422 & 4.85 & 4.9104 & TRN & \\
\hline CHEMBL1419673 & 688422 & 4.85 & 5.176 & TRN & \\
\hline CHEMBL3195621 & 688422 & 5.0 & 5.2534 & TRN & \\
\hline CHEMBL1378398 & 688422 & 5.55 & 4.891 & TRN & \\
\hline CHEMBL1453868 & 688422 & 4.5 & 4.9909 & TRN & \\
\hline CHEMBL1613097 & 688422 & 4.45 & 5.1202 & TRN & \\
\hline CHEMBL1547087 & 688422 & 5.15 & 5.3216 & TRN & \\
\hline CHEMBL1497571 & 688422 & 6.1 & 5.5567 & TRN & \\
\hline CHEMBL574181 & 688422 & 4.45 & 5.5454 & TST & \\
\hline CHEMBL1381601 & 688422 & 5.2 & 5.4918 & TRN & \\
\hline CHEMBL1480110 & 688422 & 5.25 & 5.1936 & TRN & \\
\hline
\end{tabular}




\begin{tabular}{|c|c|c|c|c|c|}
\hline \multicolumn{6}{|c|}{ Supplemental Table S2.txt } \\
\hline CHEMBL1346011 & 688422 & 4.65 & 5.0262 & TRN & \\
\hline CHEMBL1464268 & 688422 & 6.5501 & 5.6737 & TRN & \\
\hline CHEMBL1458551 & 688422 & 4.75 & 5.3133 & TRN & \\
\hline CHEMBL1441610 & 688422 & 4.9 & 5.2598 & TST & \\
\hline CHEMBL3190572 & 688422 & 4.9 & 5.033 & TRN & \\
\hline CHEMBL1594872 & 688422 & 4.7 & 5.2203 & TRN & \\
\hline CHEMBL1487820 & 688422 & 4.7 & 5.7097 & TRN & \\
\hline CHEMBL1456354 & 688422 & 5.25 & 5.1903 & TST & \\
\hline CHEMBL1433897 & 688422 & 6.6 & 5.6183 & TST & \\
\hline CHEMBL1400336 & 688422 & 4.7 & 4.9997 & TST & \\
\hline CHEMBL1321867 & 688422 & 7.2 & 5.9448 & TST & \\
\hline CHEMBL1551151 & 688422 & 4.85 & 6.3796 & TRN & \\
\hline CHEMBL1603889 & 688422 & 4.65 & 5.32600 & 00000000005 & TRN \\
\hline CHEMBL1464815 & 688422 & 5.05 & 5.1187 & TRN & \\
\hline CHEMBL1470617 & 688422 & 4.45 & 5.4259 & TRN & \\
\hline CHEMBL1333726 & 688422 & 4.95 & 4.4253 & TRN & \\
\hline CHEMBL1571851 & 688422 & 5.5 & 6.4127 & TRN & \\
\hline CHEMBL1516549 & 688422 & 6.3 & 5.1241 & TRN & \\
\hline CHEMBL1517732 & 688422 & 8.0506 & 5.3051 & TRN & \\
\hline CHEMBL3214617 & 688422 & 8.0506 & 5.6309 & TRN & \\
\hline CHEMBL1558733 & 688422 & 5.3 & 5.1297 & TRN & \\
\hline CHEMBL1469736 & 688422 & 4.45 & 4.9158 & TRN & \\
\hline CHEMBL1568695 & 688422 & 4.45 & 4.7418 & TRN & \\
\hline CHEMBL1487463 & 688422 & 4.45 & 5.15600 & 0000000001 & TST \\
\hline CHEMBL1378248 & 688422 & 4.45 & 5.0424 & TRN & \\
\hline CHEMBL1522988 & 688422 & 4.6 & 4.9945 & TRN & \\
\hline CHEMBL1469479 & 688422 & 5.4 & 5.3342 & TRN & \\
\hline CHEMBL1552638 & 688422 & 4.45 & 5.0424 & TRN & \\
\hline CHEMBL1578200 & 688422 & 4.45 & 5.4702 & TST & \\
\hline CHEMBL1363516 & 688422 & 4.9 & 5.1153 & TRN & \\
\hline CHEMBL1376364 & 688422 & 4.45 & 5.0864 & TST & \\
\hline CHEMBL1392476 & 688422 & 7.5498 & 5.6974 & TRN & \\
\hline CHEMBL1382656 & 688422 & 5.2 & 5.3375 & TST & \\
\hline CHEMBL1507568 & 688422 & 4.8 & 5.0035 & TRN & \\
\hline CHEMBL1303170 & 688422 & 4.65 & 5.0563 & TST & \\
\hline CHEMBL1539376 & 688422 & 4.95 & 4.9669 & TST & \\
\hline CHEMBL1529536 & 688422 & 6.15 & 5.2628 & TRN & \\
\hline CHEMBL1374512 & 688422 & 8.1024 & 5.21 & TRN & \\
\hline CHEMBL1427498 & 688422 & 5.65 & 5.4151 & TRN & \\
\hline CHEMBL1523293 & 688422 & 5.35 & 5.2524 & TST & \\
\hline CHEMBL1504697 & 688422 & 4.45 & 5.129 & TRN & \\
\hline CHEMBL1450578 & 688422 & 5.25 & 5.5506 & TRN & \\
\hline CHEMBL1398419 & 688422 & 5.95 & 5.49200 & 0000000001 & TRN \\
\hline CHEMBL3192045 & 688422 & 4.45 & 5.2217 & TRN & \\
\hline CHEMBL1563100 & 688422 & 4.7 & 4.8395 & TRN & \\
\hline CHEMBL1529948 & 688422 & 4.45 & 5.1282 & TRN & \\
\hline CHEMBL1599630 & 688422 & 4.85 & 4.8967 & TRN & \\
\hline CHEMBL1467749 & 688422 & 4.5 & 5.5778 & TST & \\
\hline
\end{tabular}




\begin{tabular}{|c|c|c|c|c|c|}
\hline \multicolumn{6}{|c|}{ emental } \\
\hline CHEMBL1384787 & 688422 & 4.45 & 5.41100 & 20000000005 & TRN \\
\hline CHEMBL1334326 & 688422 & 4.95 & 5.1542 & TRN & \\
\hline CHEMBL1330078 & 688422 & 5.1 & 5.1882 & TRN & \\
\hline CHEMBL1447504 & 688422 & 5.5 & 5.7097 & TRN & \\
\hline CHEMBL1586997 & 688422 & 4.45 & 4.8536 & TRN & \\
\hline CHEMBL3192053 & 688422 & 4.45 & 5.2455 & TRN & \\
\hline CHEMBL1299381 & 688422 & 4.95 & 5.3205 & TRN & \\
\hline CHEMBL1438556 & 688422 & 7.5003 & 6.0506 & TRN & \\
\hline CHEMBL1414534 & 688422 & 5.0 & 4.8368 & TRN & \\
\hline CHEMBL1397369 & 688422 & 4.5 & 5.2627 & TST & \\
\hline CHEMBL3189914 & 688422 & 4.5 & 5.3314 & TRN & \\
\hline CHEMBL1449485 & 688422 & 4.45 & 5.051 & TST & \\
\hline CHEMBL1444197 & 688422 & 7.4001 & 5.6028 & TST & \\
\hline CHEMBL1538806 & 688422 & 4.9 & 5.2606 & TRN & \\
\hline CHEMBL1511091 & 688422 & 4.65 & 5.1507 & TRN & \\
\hline CHEMBL1562037 & 688422 & 4.9 & 5.1326 & TRN & \\
\hline CHEMBL1406381 & 688422 & 5.2 & 5.1173 & TST & \\
\hline CHEMBL1402900 & 688422 & 5.25 & 4.9653 & TRN & \\
\hline CHEMBL1358954 & 688422 & 7.5498 & 5.5328 & TRN & \\
\hline CHEMBL1452681 & 688422 & 4.95 & 5.2126 & TRN & \\
\hline CHEMBL3190592 & 688422 & 4.45 & 5.6995 & TRN & \\
\hline CHEMBL1433966 & 688422 & 5.25 & 5.5407 & TRN & \\
\hline CHEMBL1513511 & 688422 & 4.45 & 4.6757 & TRN & \\
\hline CHEMBL1431569 & 688422 & 4.45 & 4.9062 & TST & \\
\hline CHEMBL1530219 & 688422 & 6.3 & 5.4369 & TST & \\
\hline CHEMBL1496597 & 688422 & 4.95 & 5.5653 & TRN & \\
\hline CHEMBL1430429 & 688422 & 5.4 & 5.2561 & TST & \\
\hline CHEMBL1530048 & 688422 & 4.95 & 5.3579 & TRN & \\
\hline CHEMBL1360725 & 688422 & 8.4559 & 5.3431 & TST & \\
\hline CHEMBL1391330 & 688422 & 4.65 & 5.2333 & TRN & \\
\hline CHEMBL1371704 & 688422 & 4.95 & 5.2337 & TST & \\
\hline CHEMBL1464306 & 688422 & 4.7 & 5.1347 & TRN & \\
\hline CHEMBL63957 & 688422 & 5.95 & 5.7393 & TRN & \\
\hline CHEMBL1721986 & 688422 & 5.4 & 5.1327 & TRN & \\
\hline CHEMBL1508689 & 688422 & 4.85 & 5.2463 & TRN & \\
\hline CHEMBL1588456 & 688422 & 4.45 & 4.9406 & TRN & \\
\hline CHEMBL1392550 & 688422 & 4.9 & 5.0662 & TRN & \\
\hline CHEMBL1587288 & 688422 & 4.6 & 5.4708 & TRN & \\
\hline CHEMBL9113 & 688422 & 5.2 & 5.276 & TST & \\
\hline CHEMBL3192589 & 688422 & 4.5 & 4.6809 & TST & \\
\hline CHEMBL1405089 & 688422 & 5.55 & 5.5868 & TST & \\
\hline CHEMBL1479741 & 688422 & 4.85 & 4.6166 & TRN & \\
\hline CHEMBL1426897 & 688422 & 4.6 & 5.0416 & TRN & \\
\hline CHEMBL1403294 & 688422 & 4.45 & 5.4782 & TRN & \\
\hline CHEMBL1459256 & 688422 & 4.9 & 5.4196 & TRN & \\
\hline CHEMBL1566349 & 688422 & 8.301 & 5.7409 & TRN & \\
\hline CHEMBL1526803 & 688422 & 4.85 & 5.5428 & TRN & \\
\hline CHEMBL1342641 & 688422 & 7.15 & 5.6878 & TST & \\
\hline
\end{tabular}




\begin{tabular}{|c|c|c|c|c|c|}
\hline \multicolumn{6}{|c|}{ Supplemental Table S2.txt } \\
\hline CHEMBL13960 & 688422 & 7.15 & 6.1005 & TST & \\
\hline CHEMBL1423390 & 688422 & 5.35 & 5.3867 & TRN & \\
\hline CHEMBL1374568 & 688422 & 7.2503 & 5.5086 & TST & \\
\hline CHEMBL1548893 & 688422 & 4.45 & 5.0092 & TST & \\
\hline CHEMBL1976375 & 688422 & 4.45 & 5.1934 & TRN & \\
\hline CHEMBL1491849 & 688422 & 5.85 & 5.0553 & TRN & \\
\hline CHEMBL1579936 & 688422 & 4.45 & 6.0078 & TST & \\
\hline CHEMBL1581719 & 688422 & 4.95 & 5.13200 & 0000000001 & TRN \\
\hline CHEMBL1441473 & 688422 & 4.7 & 5.1605 & TRN & \\
\hline CHEMBL1328655 & 688422 & 4.5 & 5.2845 & TST & \\
\hline CHEMBL1545708 & 688422 & 4.45 & 5.178 & TRN & \\
\hline CHEMBL1985091 & 688422 & 4.9 & 5.1726 & TRN & \\
\hline CHEMBL 2369205 & 688422 & 6.1 & 5.153 & TRN & \\
\hline CHEMBL1327938 & 688422 & 4.45 & 4.9599 & TST & \\
\hline CHEMBL1546497 & 688422 & 4.8 & 5.3976 & TRN & \\
\hline CHEMBL1512951 & 688422 & 5.4 & 5.3073 & TRN & \\
\hline CHEMBL1478276 & 688422 & 4.6 & 4.8412 & TRN & \\
\hline CHEMBL1423635 & 688422 & 4.95 & 4.6998 & TRN & \\
\hline CHEMBL1160706 & 688422 & 6.6 & 5.5938 & TST & \\
\hline CHEMBL1523147 & 688422 & 4.9 & 4.9785 & TRN & \\
\hline CHEMBL1340063 & 688422 & 4.95 & 5.2589 & TRN & \\
\hline CHEMBL1387335 & 688422 & 4.65 & 5.0443 & TRN & \\
\hline CHEMBL1403598 & 688422 & 4.45 & 4.942 & TRN & \\
\hline CHEMBL1380500 & 688422 & 4.85 & 5.1187 & TRN & \\
\hline CHEMBL1535532 & 688422 & 4.85 & 4.9544 & TRN & \\
\hline CHEMBL1544346 & 688422 & 7.0 & 5.7774 & TRN & \\
\hline CHEMBL1472200 & 688422 & 4.7 & 5.3026 & TRN & \\
\hline CHEMBL1371946 & 688422 & 4.45 & 5.0882 & TRN & \\
\hline CHEMBL1522550 & 688422 & 4.9 & 5.3237 & TST & \\
\hline CHEMBL1341530 & 688422 & 6.9 & 5.8438 & TRN & \\
\hline CHEMBL1992154 & 688422 & 4.65 & 4.978 & TRN & \\
\hline CHEMBL1484987 & 688422 & 4.65 & 5.0393 & TRN & \\
\hline CHEMBL1589649 & 688422 & 4.9 & 5.2 & TST & \\
\hline CHEMBL1399801 & 688422 & 5.4 & 5.9678 & TST & \\
\hline CHEMBL1602088 & 688422 & 5.3 & 5.0768 & TRN & \\
\hline CHEMBL1365609 & 688422 & 4.5 & 5.085 & TRN & \\
\hline CHEMBL1594890 & 688422 & 5.5 & 5.112 & TRN & \\
\hline CHEMBL491940 & 688422 & 4.75 & 4.6102 & TRN & \\
\hline CHEMBL1588256 & 688422 & 4.95 & 5.1155 & TRN & \\
\hline CHEMBL 2003149 & 688422 & 5.2 & 5.0622 & TRN & \\
\hline CHEMBL1468261 & 688422 & 4.9 & 5.0469 & TST & \\
\hline CHEMBL1410308 & 688422 & 4.95 & 5.1119 & TRN & \\
\hline CHEMBL1444756 & 688422 & 4.45 & 4.9017 & TRN & \\
\hline CHEMBL1574675 & 688422 & 6.1 & 5.6795 & TST & \\
\hline CHEMBL1400332 & 688422 & 4.95 & 5.3303 & TST & \\
\hline CHEMBL3208102 & 688422 & 7.7496 & 5.6496 & TRN & \\
\hline CHEMBL582717 & 688422 & 4.7 & 5.3392 & TRN & \\
\hline CHEMBL1413282 & 688422 & 5.25 & 5.2513 & TRN & \\
\hline
\end{tabular}




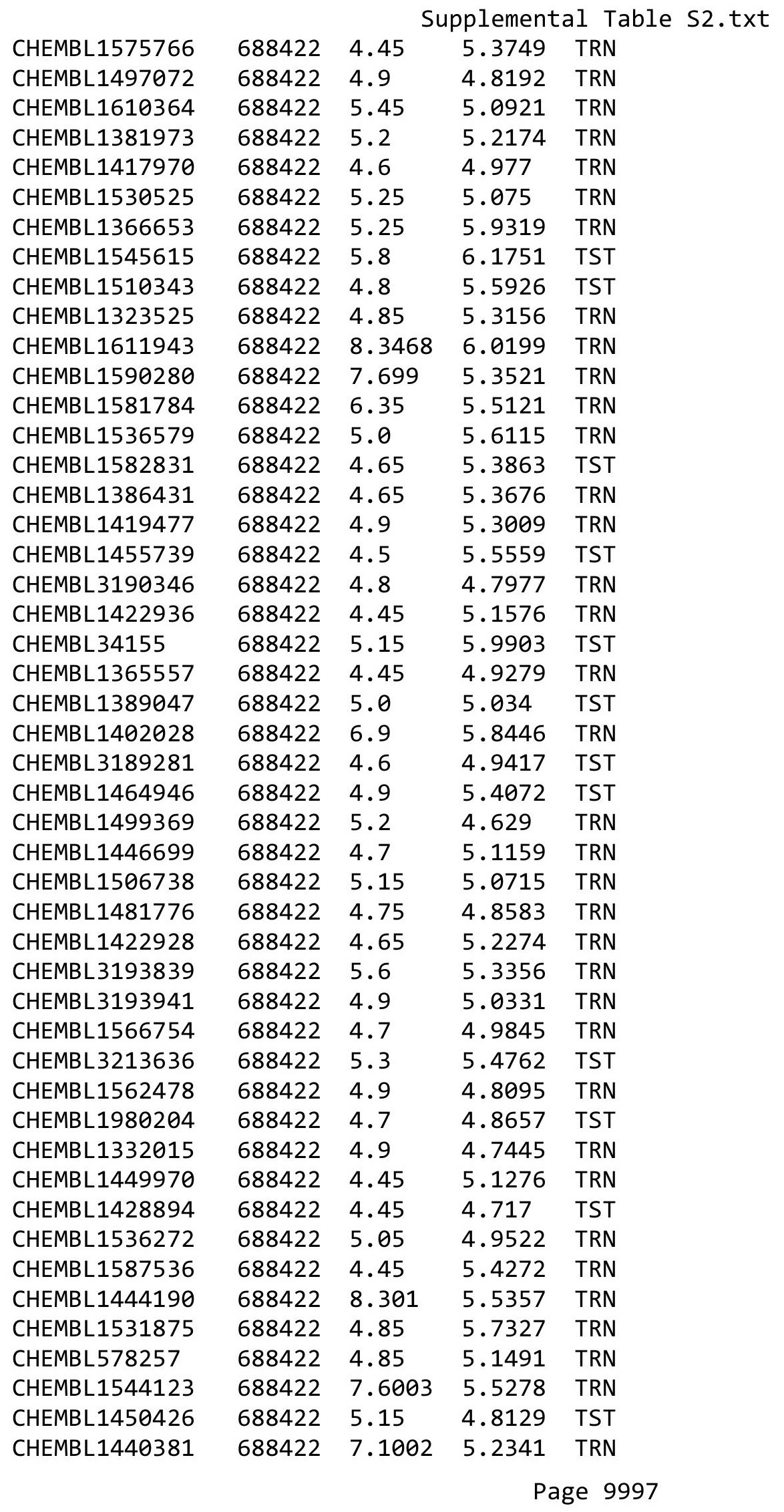




\begin{tabular}{|c|c|c|c|c|}
\hline \multicolumn{5}{|c|}{ Supplemental Table S2.txt } \\
\hline CHEMBL1481418 & 688422 & 6.0 & 5.6174 & TRN \\
\hline CHEMBL1434032 & 688422 & 4.45 & 5.7046 & TRN \\
\hline CHEMBL1484038 & 688422 & 4.95 & 4.9789 & TRN \\
\hline CHEMBL1371304 & 688422 & 4.85 & 5.13200 & 0000000001 \\
\hline CHEMBL1384581 & 688422 & 4.45 & 5.072 & TRN \\
\hline CHEMBL1342832 & 688422 & 5.0 & 5.5575 & TST \\
\hline CHEMBL1967857 & 688422 & 5.25 & 5.5016 & TST \\
\hline CHEMBL1457766 & 688422 & 4.7 & 5.7608 & TRN \\
\hline CHEMBL1526648 & 688422 & 4.6 & 4.8036 & TRN \\
\hline CHEMBL1597297 & 688422 & 7.3497 & 5.7035 & TRN \\
\hline CHEMBL1600854 & 688422 & 6.4 & 5.0216 & TRN \\
\hline CHEMBL1450465 & 688422 & 4.8 & 5.227 & TRN \\
\hline CHEMBL1509464 & 688422 & 5.65 & 5.07 & TRN \\
\hline CHEMBL1324939 & 688422 & 4.45 & 5.6477 & TST \\
\hline CHEMBL1300360 & 688422 & 4.95 & 4.8556 & TRN \\
\hline CHEMBL1538378 & 688422 & 8.0 & 5.3364 & TST \\
\hline CHEMBL1441035 & 688422 & 7.5498 & 5.6628 & TST \\
\hline CHEMBL1560886 & 688422 & 5.85 & 5.4357 & TRN \\
\hline CHEMBL1473203 & 688422 & 8.4949 & 5.7505 & TRN \\
\hline CHEMBL1566562 & 688422 & 5.05 & 5.0624 & TST \\
\hline CHEMBL1526058 & 688422 & 5.1 & 5.7091 & TST \\
\hline CHEMBL1578154 & 688422 & 4.6 & 5.3628 & TST \\
\hline CHEMBL1418980 & 688422 & 5.55 & 5.0823 & TRN \\
\hline CHEMBL1495194 & 688422 & 4.65 & 5.2584 & TRN \\
\hline CHEMBL1429384 & 688422 & 8.301 & 5.6701 & TST \\
\hline CHEMBL1464004 & 688422 & 4.9 & 5.0604 & TST \\
\hline CHEMBL1562280 & 688422 & 5.45 & 5.5853 & TST \\
\hline CHEMBL1403793 & 688422 & 6.6 & 5.0679 & TRN \\
\hline CHEMBL1503262 & 688422 & 4.7 & 5.3899 & TRN \\
\hline CHEMBL1508223 & 688422 & 4.5 & 4.9128 & TST \\
\hline CHEMBL1476942 & 688422 & 5.5 & 5.176 & TRN \\
\hline CHEMBL1414210 & 688422 & 5.9 & 5.2551 & TRN \\
\hline CHEMBL3197216 & 688422 & 4.45 & 5.357 & TRN \\
\hline CHEMBL1392591 & 688422 & 4.45 & 5.2922 & TRN \\
\hline CHEMBL1408211 & 688422 & 4.95 & 5.2694 & TST \\
\hline CHEMBL1390581 & 688422 & 5.3 & 5.6318 & TRN \\
\hline CHEMBL3211785 & 688422 & 4.45 & 5.0632 & TRN \\
\hline CHEMBL1372377 & 688422 & 5.0 & 4.6517 & TRN \\
\hline CHEMBL1992764 & 688422 & 4.85 & 5.1654 & TRN \\
\hline CHEMBL1589773 & 688422 & 5.2 & 5.5675 & TST \\
\hline CHEMBL1386104 & 688422 & 4.55 & 5.3843 & TRN \\
\hline CHEMBL1420460 & 688422 & 4.45 & 5.3379 & TRN \\
\hline CHEMBL1392046 & 688422 & 5.0 & 4.8374 & TRN \\
\hline CHEMBL1499805 & 688422 & 5.4 & 5.1325 & TRN \\
\hline CHEMBL1509254 & 688422 & 5.2 & 4.7797 & TRN \\
\hline CHEMBL1469761 & 688422 & 7.0501 & 4.9476 & TST \\
\hline CHEMBL1494995 & 688422 & 4.8 & 5.6144 & TRN \\
\hline CHEMBL3195634 & 688422 & 4.9 & 4.9735 & TRN \\
\hline
\end{tabular}




\begin{tabular}{|c|c|c|c|c|}
\hline \multicolumn{5}{|c|}{ Supplemental Table S2.txt } \\
\hline CHEMBL1491886 & 688422 & 4.95 & 5.3343 & TRN \\
\hline CHEMBL1362309 & 688422 & 4.9 & 5.3392 & TRN \\
\hline CHEMBL1372315 & 688422 & 5.1 & 5.0582 & TRN \\
\hline CHEMBL1372923 & 688422 & 4.7 & 5.4193 & TRN \\
\hline CHEMBL1347343 & 688422 & 6.05 & 5.5419 & TRN \\
\hline CHEMBL1341031 & 688422 & 5.6 & 5.2239 & TRN \\
\hline CHEMBL1372326 & 688422 & 4.9 & 4.8823 & TRN \\
\hline CHEMBL1332580 & 688422 & 7.2 & 5.7075 & TRN \\
\hline CHEMBL1371343 & 688422 & 5.0 & 5.3563 & TRN \\
\hline CHEMBL1612167 & 688422 & 4.5 & 5.2902 & TST \\
\hline CHEMBL1562043 & 688422 & 6.1 & 5.4212 & TST \\
\hline CHEMBL3192567 & 688422 & 4.45 & 5.5018 & TST \\
\hline CHEMBL3190259 & 688422 & 4.9 & 5.0913 & TST \\
\hline CHEMBL1491144 & 688422 & 7.8508 & 5.3587 & TST \\
\hline CHEMBL1567142 & 688422 & 4.5 & 4.5541 & TRN \\
\hline CHEMBL1480844 & 688422 & 4.45 & 5.5592 & TRN \\
\hline CHEMBL1566938 & 688422 & 4.85 & 4.8224 & TRN \\
\hline CHEMBL1380482 & 688422 & 4.65 & 5.2614 & TST \\
\hline CHEMBL1322905 & 688422 & 5.4 & 5.375 & TRN \\
\hline CHEMBL1552257 & 688422 & 5.75 & 5.4181 & TRN \\
\hline CHEMBL1361603 & 688422 & 4.45 & 5.7131 & TRN \\
\hline CHEMBL1439004 & 688422 & 4.8 & 5.25 & TRN \\
\hline CHEMBL1496413 & 688422 & 4.45 & 4.7622 & TRN \\
\hline CHEMBL1471180 & 688422 & 4.9 & 4.9838 & TST \\
\hline CHEMBL1549492 & 688422 & 5.4 & 5.4109 & TRN \\
\hline CHEMBL1613388 & 688422 & 5.25 & 5.1446 & TRN \\
\hline CHEMBL1422277 & 688422 & 5.05 & 5.0628 & TRN \\
\hline CHEMBL1521407 & 688422 & 4.85 & 5.4331 & TRN \\
\hline CHEMBL1443440 & 688422 & 4.45 & 4.9941 & TST \\
\hline CHEMBL1543954 & 688422 & 4.8 & 4.6579 & TRN \\
\hline CHEMBL1335634 & 688422 & 5.2 & 5.9575 & TRN \\
\hline CHEMBL1519622 & 688422 & 4.8 & 5.2433 & TRN \\
\hline CHEMBL1421405 & 688422 & 5.3 & 4.8144 & TST \\
\hline CHEMBL1555463 & 688422 & 4.9 & 4.9681 & TRN \\
\hline CHEMBL1554019 & 688422 & 5.0 & 5.3163 & TRN \\
\hline CHEMBL1376174 & 688422 & 5.85 & 5.5227 & TST \\
\hline CHEMBL1326559 & 688422 & 5.15 & 5.1291 & TST \\
\hline CHEMBL1313620 & 688422 & 4.7 & 4.6477 & TRN \\
\hline CHEMBL 3144932 & 688422 & 4.75 & 5.0908 & TRN \\
\hline CHEMBL1510139 & 688422 & 4.95 & 5.075 & TST \\
\hline CHEMBL1468537 & 688422 & 4.45 & 4.792 & TRN \\
\hline CHEMBL 233549 & 688422 & 4.65 & 5.4417 & TRN \\
\hline CHEMBL1429108 & 688422 & 5.45 & 4.9676 & TRN \\
\hline CHEMBL1488340 & 688422 & 4.95 & 5.51 & TRN \\
\hline CHEMBL1378930 & 688422 & 8.301 & 5.154 & TST \\
\hline CHEMBL1577350 & 688422 & 4.45 & 5.659 & TRN \\
\hline CHEMBL1563162 & 688422 & 4.7 & 4.9331 & TST \\
\hline CHEMBL1576339 & 688422 & 4.8 & 5.3193 & TST \\
\hline
\end{tabular}




\begin{tabular}{|c|c|c|c|c|c|}
\hline \multicolumn{6}{|c|}{ Supplemental Table S2.txt } \\
\hline CHEMBL1592389 & 688422 & 5.4 & 5.5383 & TRN & \\
\hline CHEMBL1421192 & 688422 & 4.45 & 4.6724 & TRN & \\
\hline CHEMBL1595133 & 688422 & 5.2 & 5.6731 & TRN & \\
\hline CHEMBL1507149 & 688422 & 4.6 & 5.0115 & TRN & \\
\hline CHEMBL584619 & 688422 & 4.8 & 5.1935 & TRN & \\
\hline CHEMBL1597470 & 688422 & 8.3468 & 5.2302 & TST & \\
\hline CHEMBL1399522 & 688422 & 4.65 & 5.3623 & TRN & \\
\hline CHEMBL1471547 & 688422 & 4.7 & 4.9451 & TRN & \\
\hline CHEMBL 3210645 & 688422 & 6.25 & 5.7559 & TST & \\
\hline CHEMBL1440627 & 688422 & 4.7 & 4.9884 & TRN & \\
\hline CHEMBL3191886 & 688422 & 4.45 & 5.2901 & TST & \\
\hline CHEMBL1330729 & 688422 & 6.0 & 5.82799 & 9999999999 & TRN \\
\hline CHEMBL1407766 & 688422 & 4.65 & 5.0577 & TRN & \\
\hline CHEMBL1306525 & 688422 & 5.15 & 5.285 & TRN & \\
\hline CHEMBL1486619 & 688422 & 5.05 & 4.8984 & TRN & \\
\hline CHEMBL3198729 & 688422 & 4.65 & 5.0254 & TRN & \\
\hline CHEMBL3209142 & 688422 & 5.3 & 5.0043 & TRN & \\
\hline CHEMBL1478229 & 688422 & 5.6 & 5.2002 & TST & \\
\hline CHEMBL1567168 & 688422 & 6.5 & 6.1525 & TRN & \\
\hline CHEMBL1506576 & 688422 & 6.6 & 5.5557 & TRN & \\
\hline CHEMBL1380272 & 688422 & 5.5 & 5.5983 & TST & \\
\hline CHEMBL1598726 & 688422 & 4.8 & 5.5058 & TRN & \\
\hline CHEMBL1501031 & 688422 & 5.4 & 5.3697 & TRN & \\
\hline CHEMBL1446441 & 688422 & 5.2 & 5.1754 & TST & \\
\hline CHEMBL3209999 & 688422 & 4.75 & 6.0681 & TST & \\
\hline CHEMBL1299580 & 688422 & 4.45 & 5.2172 & TRN & \\
\hline CHEMBL1481327 & 688422 & 4.9 & 4.8684 & TRN & \\
\hline CHEMBL1491977 & 688422 & 4.75 & 4.958 & TRN & \\
\hline CHEMBL 3145304 & 688422 & 4.45 & 5.118 & TRN & \\
\hline CHEMBL1608249 & 688422 & 4.45 & 5.1478 & TRN & \\
\hline CHEMBL1425624 & 688422 & 4.65 & 4.8443 & TRN & \\
\hline CHEMBL1306778 & 688422 & 5.3 & 5.8378 & TRN & \\
\hline CHEMBL1502000 & 688422 & 4.6 & 4.7846 & TRN & \\
\hline CHEMBL1392245 & 688422 & 4.65 & 5.0445 & TRN & \\
\hline CHEMBL1436063 & 688422 & 4.5 & 5.6056 & TST & \\
\hline CHEMBL1566585 & 688422 & 6.8 & 5.6987 & TST & \\
\hline CHEMBL1524905 & 688422 & 6.9 & 5.7075 & TRN & \\
\hline CHEMBL1467463 & 688422 & 4.7 & 5.1593 & TST & \\
\hline CHEMBL1593763 & 688422 & 5.4 & 5.7139 & TRN & \\
\hline CHEMBL1484120 & 688422 & 5.15 & 4.849 & TRN & \\
\hline CHEMBL1435498 & 688422 & 5.05 & 5.4538 & TRN & \\
\hline CHEMBL1332958 & 688422 & 4.5 & 5.2942 & TST & \\
\hline CHEMBL1428521 & 688422 & 4.65 & 4.9833 & TRN & \\
\hline CHEMBL1587062 & 688422 & 4.8 & 5.5692 & TRN & \\
\hline CHEMBL1331101 & 688422 & 5.15 & 5.2585 & TRN & \\
\hline CHEMBL1504970 & 688422 & 4.45 & 4.824 & TRN & \\
\hline CHEMBL1447166 & 688422 & 4.7 & 5.0687 & TRN & \\
\hline CHEMBL3199277 & 688422 & 4.6 & 5.0503 & TRN & \\
\hline
\end{tabular}




\begin{tabular}{|c|c|c|c|c|c|}
\hline \multicolumn{6}{|c|}{ Supplemental Table s2.txt } \\
\hline CHEMBL1491225 & 688422 & 6.25 & 5.5485 & TRN & \\
\hline CHEMBL3194298 & 688422 & 4.75 & 5.6785 & TRN & \\
\hline CHEMBL1516815 & 688422 & 4.5 & 5.1176 & TRN & \\
\hline CHEMBL1300745 & 688422 & 4.65 & 5.3449 & TRN & \\
\hline CHEMBL1502228 & 688422 & 4.5 & 4.8599 & TST & \\
\hline CHEMBL1488932 & 688422 & 4.75 & 4.7036 & TRN & \\
\hline CHEMBL1407952 & 688422 & 4.95 & 5.4972 & TRN & \\
\hline CHEMBL1999595 & 688422 & 7.5003 & 5.1874 & TRN & \\
\hline CHEMBL1537396 & 688422 & 4.45 & 5.2026 & TRN & \\
\hline CHEMBL1400145 & 688422 & 7.2 & 5.3036 & TRN & \\
\hline CHEMBL1408090 & 688422 & 4.95 & 4.7626 & TRN & \\
\hline CHEMBL1376386 & 688422 & 4.85 & 5.1911 & TST & \\
\hline CHEMBL1595873 & 688422 & 5.0 & 6.0495 & TRN & \\
\hline CHEMBL1347861 & 688422 & 5.2 & 5.1712 & TRN & \\
\hline CHEMBL1504020 & 688422 & 4.45 & 5.6025 & TRN & \\
\hline CHEMBL479368 & 688422 & 5.05 & 4.9181 & TRN & \\
\hline CHEMBL1408003 & 688422 & 4.85 & 5.2291 & TRN & \\
\hline CHEMBL1381607 & 688422 & 4.45 & 5.3976 & TRN & \\
\hline CHEMBL1299421 & 688422 & 4.5 & 5.0595 & TRN & \\
\hline CHEMBL1481967 & 688422 & 4.65 & 5.059 & TST & \\
\hline CHEMBL1376981 & 688422 & 4.9 & 5.1373 & TRN & \\
\hline CHEMBL1327276 & 688422 & 6.0 & 5.4519 & TRN & \\
\hline CHEMBL1448583 & 688422 & 4.6 & 5.4201 & TST & \\
\hline CHEMBL1545832 & 688422 & 5.55 & 4.9683 & TRN & \\
\hline CHEMBL1537547 & 688422 & 7.6498 & 5.4398 & TRN & \\
\hline CHEMBL1341892 & 688422 & 4.85 & 5.1227 & TRN & \\
\hline CHEMBL3189329 & 688422 & 4.45 & 5.2336 & TRN & \\
\hline CHEMBL1581314 & 688422 & 4.5 & 4.7613 & TRN & \\
\hline CHEMBL1515001 & 688422 & 6.4 & 5.33799 & 9999999999 & TST \\
\hline CHEMBL2002522 & 688422 & 4.85 & 5.4017 & TST & \\
\hline CHEMBL1569176 & 688422 & 4.65 & 5.3566 & TRN & \\
\hline CHEMBL1385987 & 688422 & 4.75 & 5.4435 & TRN & \\
\hline CHEMBL1600173 & 688422 & 4.85 & 5.0529 & TRN & \\
\hline CHEMBL1421882 & 688422 & 7.4498 & 5.6982 & TST & \\
\hline CHEMBL1466361 & 688422 & 5.8 & 5.3453 & TRN & \\
\hline CHEMBL3213332 & 688422 & 4.45 & 5.2587 & TRN & \\
\hline CHEMBL1447498 & 688422 & 4.45 & 5.2834 & TRN & \\
\hline CHEMBL1450079 & 688422 & 6.2 & 6.2859 & TRN & \\
\hline CHEMBL3208691 & 688422 & 5.2 & 5.0222 & TST & \\
\hline CHEMBL3197122 & 688422 & 5.95 & 5.49299 & 9999999999 & TRN \\
\hline CHEMBL1324093 & 688422 & 4.9 & 4.9144 & TST & \\
\hline CHEMBL1331037 & 688422 & 4.6 & 4.9871 & TRN & \\
\hline CHEMBL2003973 & 688422 & 4.45 & 5.46299 & 9999999999 & TST \\
\hline CHEMBL1608132 & 688422 & 4.9 & 5.416 & TST & \\
\hline CHEMBL1309401 & 688422 & 4.95 & 5.1193 & TRN & \\
\hline CHEMBL1353538 & 688422 & 4.45 & 5.1613 & TRN & \\
\hline CHEMBL1454494 & 688422 & 4.45 & 4.9404 & TST & \\
\hline CHEMBL1301297 & 688422 & 6.05 & 5.6657 & TRN & \\
\hline
\end{tabular}




\begin{tabular}{|c|c|c|c|c|c|}
\hline \multicolumn{6}{|c|}{ Supplemental Table S2.txt } \\
\hline CHEMBL1546328 & 688422 & 4.6 & 5.1766 & TRN & \\
\hline CHEMBL1600203 & 688422 & 4.95 & 4.9855 & TRN & \\
\hline CHEMBL1411440 & 688422 & 5.15 & 5.6218 & TRN & \\
\hline CHEMBL1335093 & 688422 & 4.85 & 4.7723 & TRN & \\
\hline CHEMBL1311260 & 688422 & 4.9 & 5.2213 & TRN & \\
\hline CHEMBL1485292 & 688422 & 4.5 & 5.3755 & TRN & \\
\hline CHEMBL1346826 & 688422 & 6.1 & 4.9977 & TRN & \\
\hline CHEMBL1329052 & 688422 & 4.7 & 5.5485 & TRN & \\
\hline CHEMBL1308366 & 688422 & 4.65 & 5.079 & TST & \\
\hline CHEMBL1580375 & 688422 & 5.0 & 5.1327 & TRN & \\
\hline CHEMBL1305002 & 688422 & 4.45 & 5.12200 & 0000000001 & TRN \\
\hline CHEMBL1546684 & 688422 & 5.15 & 5.2683 & TST & \\
\hline CHEMBL1340838 & 688422 & 5.55 & 5.3473 & TRN & \\
\hline CHEMBL1342181 & 688422 & 4.45 & 5.7601 & TRN & \\
\hline CHEMBL1428252 & 688422 & 7.8508 & 5.5739 & TST & \\
\hline CHEMBL1422217 & 688422 & 4.7 & 4.5088 & TRN & \\
\hline CHEMBL1501209 & 688422 & 4.5 & 4.9928 & TST & \\
\hline CHEMBL1347520 & 688422 & 4.45 & 5.1432 & TRN & \\
\hline CHEMBL1531362 & 688422 & 4.85 & 5.1228 & TRN & \\
\hline CHEMBL1536873 & 688422 & 4.55 & 4.9696 & TST & \\
\hline CHEMBL1603997 & 688422 & 5.25 & 5.2786 & TST & \\
\hline CHEMBL1309202 & 688422 & 5.4 & 5.1368 & TRN & \\
\hline CHEMBL1346630 & 688422 & 4.65 & 5.251 & TRN & \\
\hline CHEMBL1486625 & 688422 & 6.15 & 5.7282 & TST & \\
\hline CHEMBL1438200 & 688422 & 4.65 & 5.4907 & TRN & \\
\hline CHEMBL1407912 & 688422 & 4.45 & 5.1667 & TRN & \\
\hline CHEMBL1309678 & 688422 & 4.45 & 5.8993 & TST & \\
\hline CHEMBL1520574 & 688422 & 4.45 & 5.3512 & TST & \\
\hline CHEMBL1326411 & 688422 & 4.75 & 5.0911 & TRN & \\
\hline CHEMBL578284 & 688422 & 4.85 & 5.17399 & 99999999995 & TRN \\
\hline CHEMBL1326898 & 688422 & 6.8 & 5.1684 & TRN & \\
\hline CHEMBL1384481 & 688422 & 4.6 & 5.8273 & TRN & \\
\hline CHEMBL1325210 & 688422 & 4.7 & 5.4277 & TRN & \\
\hline CHEMBL1578718 & 688422 & 6.3 & 4.9758 & TRN & \\
\hline CHEMBL1525697 & 688422 & 4.45 & 4.6849 & TRN & \\
\hline CHEMBL65 & 688422 & 6.0 & 6.3214 & TST & \\
\hline CHEMBL1367776 & 688422 & 4.6 & 5.0679 & TST & \\
\hline CHEMBL1567326 & 688422 & 5.9 & 5.5526 & TRN & \\
\hline CHEMBL1352614 & 688422 & 5.4 & 5.3222 & TRN & \\
\hline CHEMBL609606 & 688422 & 5.55 & 5.6911 & TRN & \\
\hline CHEMBL1493378 & 688422 & 4.95 & 5.141 & TRN & \\
\hline CHEMBL1569952 & 688422 & 4.9 & 5.2728 & TRN & \\
\hline CHEMBL1303457 & 688422 & 4.85 & 4.8914 & TRN & \\
\hline CHEMBL1576638 & 688422 & 5.3 & 5.6672 & TST & \\
\hline CHEMBL1559707 & 688422 & 5.0 & 4.6304 & TRN & \\
\hline CHEMBL402468 & 688422 & 4.9 & 5.3896 & TRN & \\
\hline CHEMBL1492485 & 688422 & 5.6 & 5.1819 & TRN & \\
\hline CHEMBL1359668 & 688422 & 4.65 & 5.2693 & TRN & \\
\hline
\end{tabular}




\begin{tabular}{|c|c|c|c|c|c|}
\hline \multicolumn{6}{|c|}{ Supplemental Table S2.txt } \\
\hline CHEMBL1595183 & 688422 & 4.9 & 4.9338 & TRN & \\
\hline CHEMBL1309118 & 688422 & 5.2 & 4.9367 & TRN & \\
\hline CHEMBL1387661 & 688422 & 6.5501 & 5.7377 & TST & \\
\hline CHEMBL1335602 & 688422 & 4.9 & 5.3005 & TRN & \\
\hline CHEMBL1469371 & 688422 & 4.65 & 4.7897 & TST & \\
\hline CHEMBL1588979 & 688422 & 4.5 & 4.8207 & TRN & \\
\hline CHEMBL1464164 & 688422 & 4.45 & 5.1973 & TRN & \\
\hline CHEMBL1480833 & 688422 & 4.45 & 5.6954 & TST & \\
\hline CHEMBL1456853 & 688422 & 5.7 & 5.3867 & TRN & \\
\hline CHEMBL3193197 & 688422 & 4.45 & 4.953 & TRN & \\
\hline CHEMBL1506308 & 688422 & 5.25 & 4.9885 & TRN & \\
\hline CHEMBL1464558 & 688422 & 4.45 & 5.3527 & TRN & \\
\hline CHEMBL1472919 & 688422 & 6.8 & 5.5934 & TRN & \\
\hline CHEMBL1463531 & 688422 & 6.0 & 5.8283 & TST & \\
\hline CHEMBL1431314 & 688422 & 5.45 & 4.9285 & TRN & \\
\hline CHEMBL1256959 & 688422 & 5.25 & 5.4421 & TRN & \\
\hline CHEMBL3193572 & 688422 & 5.05 & 4.9064 & TRN & \\
\hline CHEMBL1379189 & 688422 & 5.0 & 5.3903 & TRN & \\
\hline CHEMBL1503580 & 688422 & 4.45 & 5.0824 & TRN & \\
\hline CHEMBL1492526 & 688422 & 4.45 & 4.9828 & TRN & \\
\hline CHEMBL1470065 & 688422 & 4.85 & 5.1395 & TST & \\
\hline CHEMBL1584754 & 688422 & 5.3 & 5.449 & TST & \\
\hline CHEMBL1394000 & 688422 & 6.3 & 5.83799 & 9999999999 & TST \\
\hline CHEMBL1355530 & 688422 & 6.95 & 5.8008 & TRN & \\
\hline CHEMBL1351983 & 688422 & 4.7 & 5.4492 & TRN & \\
\hline CHEMBL1609691 & 688422 & 5.8 & 5.4585 & TRN & \\
\hline CHEMBL1357186 & 688422 & 4.8 & 4.8787 & TRN & \\
\hline CHEMBL1484317 & 688422 & 4.8 & 5.0088 & TRN & \\
\hline CHEMBL1504293 & 688422 & 4.85 & 5.2955 & TRN & \\
\hline CHEMBL3214200 & 688422 & 4.45 & 4.9815 & TRN & \\
\hline CHEMBL1503507 & 688422 & 5.15 & 5.048 & TRN & \\
\hline CHEMBL1490906 & 688422 & 4.95 & 5.42399 & 99999999995 & TRN \\
\hline CHEMBL1354090 & 688422 & 7.0501 & 5.8214 & TST & \\
\hline CHEMBL1302043 & 688422 & 5.55 & 5.4837 & TRN & \\
\hline CHEMBL1384265 & 688422 & 4.85 & 5.2969 & TRN & \\
\hline CHEMBL1415843 & 688422 & 6.15 & 5.6766 & TRN & \\
\hline CHEMBL1509890 & 688422 & 4.5 & 5.1793 & TRN & \\
\hline CHEMBL1319464 & 688422 & 6.35 & 5.21899 & 9999999999 & TRN \\
\hline CHEMBL1339728 & 688422 & 4.6 & 4.7962 & TRN & \\
\hline CHEMBL1392398 & 688422 & 4.45 & 5.0124 & TST & \\
\hline CHEMBL1475162 & 688422 & 5.25 & 5.4701 & TRN & \\
\hline CHEMBL1518893 & 688422 & 4.7 & 5.2198 & TRN & \\
\hline CHEMBL1389621 & 688422 & 4.45 & 5.1078 & TRN & \\
\hline CHEMBL1596854 & 688422 & 6.7501 & 5.31 & TRN & \\
\hline CHEMBL3192357 & 688422 & 4.75 & 5.2696 & TRN & \\
\hline CHEMBL1425890 & 688422 & 4.45 & 5.0978 & TRN & \\
\hline CHEMBL1504510 & 688422 & 4.7 & 5.2124 & TRN & \\
\hline CHEMBL1390756 & 688422 & 5.25 & 5.1773 & TRN & \\
\hline
\end{tabular}




\begin{tabular}{|c|c|c|c|c|c|}
\hline \multicolumn{6}{|c|}{ Supplemental Table S2.txt } \\
\hline CHEMBL1405855 & 688422 & 5.5 & 5.3397 & TRN & \\
\hline CHEMBL1547470 & 688422 & 4.85 & 4.9557 & TRN & \\
\hline CHEMBL1384708 & 688422 & 5.75 & 5.6068 & TRN & \\
\hline CHEMBL1331927 & 688422 & 4.5 & 5.4185 & TRN & \\
\hline CHEMBL1593819 & 688422 & 6.8499 & 5.6205 & TRN & \\
\hline CHEMBL3199477 & 688422 & 5.0 & 5.3461 & TRN & \\
\hline CHEMBL1458225 & 688422 & 4.45 & 5.2647 & TRN & \\
\hline CHEMBL1503039 & 688422 & 4.55 & 4.92 & TRN & \\
\hline CHEMBL1331281 & 688422 & 4.9 & 5.0351 & TRN & \\
\hline CHEMBL1605009 & 688422 & 4.8 & 5.2155 & TST & \\
\hline CHEMBL1340197 & 688422 & 4.85 & 4.8056 & TRN & \\
\hline CHEMBL1589637 & 688422 & 4.95 & 4.7702 & TST & \\
\hline CHEMBL1400715 & 688422 & 4.45 & 5.455 & TRN & \\
\hline CHEMBL1320486 & 688422 & 4.45 & 5.0326 & TRN & \\
\hline CHEMBL1415362 & 688422 & 5.35 & 5.5566 & TRN & \\
\hline CHEMBL1450185 & 688422 & 5.25 & 5.4298 & TST & \\
\hline CHEMBL1529398 & 688422 & 4.9 & 5.3056 & TRN & \\
\hline CHEMBL1569297 & 688422 & 4.9 & 5.2593 & TST & \\
\hline CHEMBL1578547 & 688422 & 4.65 & 4.713 & TRN & \\
\hline CHEMBL1535919 & 688422 & 4.45 & 5.0435 & TRN & \\
\hline CHEMBL1476385 & 688422 & 5.5 & 5.314 & TRN & \\
\hline CHEMBL1318696 & 688422 & 7.699 & 5.0013 & TRN & \\
\hline CHEMBL1343949 & 688422 & 4.45 & 5.0135 & TRN & \\
\hline CHEMBL1422847 & 688422 & 4.85 & 5.1436 & TRN & \\
\hline CHEMBL1332063 & 688422 & 5.55 & 5.3082 & TST & \\
\hline CHEMBL1556876 & 688422 & 7.1002 & 5.1375 & TRN & \\
\hline CHEMBL1415429 & 688422 & 5.0 & 4.8173 & TRN & \\
\hline CHEMBL1571991 & 688422 & 4.45 & 5.8189 & TRN & \\
\hline CHEMBL1492585 & 688422 & 5.85 & 5.3815 & TRN & \\
\hline CHEMBL1373279 & 688422 & 4.45 & 5.2945 & TRN & \\
\hline CHEMBL1483750 & 688422 & 6.05 & 4.9045 & TRN & \\
\hline CHEMBL1304007 & 688422 & 7.6498 & 5.0425 & TRN & \\
\hline CHEMBL1369255 & 688422 & 4.45 & 5.4396 & TRN & \\
\hline CHEMBL1348824 & 688422 & 4.9 & 4.8011 & TRN & \\
\hline CHEMBL1440191 & 688422 & 4.7 & 5.1872 & TRN & \\
\hline CHEMBL1366820 & 688422 & 4.7 & 4.8685 & TRN & \\
\hline CHEMBL1542347 & 688422 & 4.6 & 5.1019 & TRN & \\
\hline CHEMBL409906 & 688422 & 4.45 & 5.0197 & TRN & \\
\hline CHEMBL1440979 & 688422 & 4.8 & 5.478 & TRN & \\
\hline CHEMBL 3211164 & 688422 & 4.45 & 4.83899 & 99999999995 & TRN \\
\hline CHEMBL1430208 & 688422 & 4.9 & 5.1458 & TST & \\
\hline CHEMBL3199110 & 688422 & 5.25 & 5.2477 & TRN & \\
\hline CHEMBL1478997 & 688422 & 6.5 & 5.1174 & TRN & \\
\hline CHEMBL1308972 & 688422 & 4.9 & 5.194 & TRN & \\
\hline CHEMBL1429388 & 688422 & 4.9 & 4.8269 & TRN & \\
\hline CHEMBL1503006 & 688422 & 4.9 & 5.0743 & TRN & \\
\hline CHEMBL1331601 & 688422 & 4.45 & 5.3738 & TST & \\
\hline CHEMBL1329509 & 688422 & 5.75 & 5.2954 & TRN & \\
\hline
\end{tabular}




\begin{tabular}{|c|c|c|c|c|c|}
\hline \multicolumn{6}{|c|}{ Supplemental Table S2.txt } \\
\hline CHEMBL1495774 & 688422 & 4.45 & 4.9412 & TRN & \\
\hline CHEMBL1429850 & 688422 & 5.95 & 5.4707 & TST & \\
\hline CHEMBL1304530 & 688422 & 4.55 & 5.2432 & TRN & \\
\hline CHEMBL1362022 & 688422 & 5.95 & 5.3427 & TRN & \\
\hline CHEMBL1574263 & 688422 & 4.8 & 4.9906 & TRN & \\
\hline CHEMBL1489209 & 688422 & 4.45 & 5.245 & TRN & \\
\hline CHEMBL1380558 & 688422 & 5.0 & 5.2442 & TRN & \\
\hline CHEMBL1566662 & 688422 & 8.3468 & 5.1415 & TRN & \\
\hline CHEMBL1507180 & 688422 & 4.8 & 4.7214 & TRN & \\
\hline CHEMBL1519261 & 688422 & 4.95 & 4.872 & TRN & \\
\hline CHEMBL1445282 & 688422 & 4.65 & 5.0024 & TRN & \\
\hline CHEMBL1369279 & 688422 & 5.9 & 5.4218 & TST & \\
\hline CHEMBL1362198 & 688422 & 4.85 & 5.5853 & TRN & \\
\hline CHEMBL1339363 & 688422 & 4.65 & 5.01 & TRN & \\
\hline CHEMBL1213045 & 688422 & 4.45 & 5.37700 & 0000000001 & TRN \\
\hline CHEMBL1449289 & 688422 & 4.9 & 4.905 & TRN & \\
\hline CHEMBL1433508 & 688422 & 4.85 & 5.3262 & TRN & \\
\hline CHEMBL1376413 & 688422 & 4.8 & 5.3635 & TRN & \\
\hline CHEMBL1403041 & 688422 & 4.45 & 5.069 & TRN & \\
\hline CHEMBL1578784 & 688422 & 8.2007 & 4.9558 & TST & \\
\hline CHEMBL1606397 & 688422 & 5.05 & 5.2044 & TRN & \\
\hline CHEMBL1559836 & 688422 & 7.5498 & 5.6648 & TRN & \\
\hline CHEMBL1570510 & 688422 & 4.75 & 5.3552 & TRN & \\
\hline CHEMBL1530247 & 688422 & 4.75 & 5.2202 & TRN & \\
\hline CHEMBL1351261 & 688422 & 5.45 & 4.9869 & TRN & \\
\hline CHEMBL310798 & 688422 & 4.95 & 5.2482 & TRN & \\
\hline CHEMBL1343059 & 688422 & 8.0506 & 5.4983 & TST & \\
\hline CHEMBL1560198 & 688422 & 5.15 & 5.0601 & TRN & \\
\hline CHEMBL1419110 & 688422 & 6.25 & 5.3083 & TRN & \\
\hline CHEMBL1583947 & 688422 & 5.25 & 5.654 & TRN & \\
\hline CHEMBL1411458 & 688422 & 7.8996 & 5.2528 & TST & \\
\hline CHEMBL1363654 & 688422 & 4.45 & 5.0722 & TRN & \\
\hline CHEMBL1422794 & 688422 & 4.45 & 5.1339 & TRN & \\
\hline CHEMBL1520694 & 688422 & 5.0 & 4.5466 & TRN & \\
\hline CHEMBL1473678 & 688422 & 4.65 & 5.0701 & TRN & \\
\hline CHEMBL1313174 & 688422 & 4.95 & 5.0296 & TRN & \\
\hline CHEMBL3192395 & 688422 & 7.6498 & 5.3912 & TRN & \\
\hline CHEMBL1505016 & 688422 & 4.45 & 4.9084 & TST & \\
\hline CHEMBL1496296 & 688422 & 4.95 & 4.9751 & TRN & \\
\hline CHEMBL3192858 & 688422 & 6.5 & 5.6696 & TRN & \\
\hline CHEMBL1304034 & 688422 & 4.45 & 5.348 & TRN & \\
\hline CHEMBL1542165 & 688422 & 5.7 & 5.0827 & TRN & \\
\hline CHEMBL1492503 & 688422 & 5.1 & 5.4206 & TRN & \\
\hline CHEMBL1368748 & 688422 & 7.8996 & 5.1306 & TRN & \\
\hline CHEMBL1408486 & 688422 & 5.9 & 5.4516 & TRN & \\
\hline CHEMBL1505474 & 688422 & 4.95 & 5.0313 & TRN & \\
\hline CHEMBL 1488442 & 688422 & 4.45 & 5.2956 & TRN & \\
\hline CHEMBL1382617 & 688422 & 4.95 & 5.1468 & TRN & \\
\hline
\end{tabular}




\begin{tabular}{|c|c|c|c|c|}
\hline \multicolumn{5}{|c|}{ Supplemental Table S2.txt } \\
\hline CHEMBL 3190509 & 688422 & 6.5 & 5.487 & TST \\
\hline CHEMBL1508620 & 688422 & 4.8 & 4.8728 & TRN \\
\hline CHEMBL1524089 & 688422 & 4.7 & 5.2319 & TRN \\
\hline CHEMBL1392387 & 688422 & 4.9 & 5.1458 & TRN \\
\hline CHEMBL1467154 & 688422 & 4.75 & 5.5421 & TRN \\
\hline CHEMBL1314545 & 688422 & 8.2007 & 5.7621 & TRN \\
\hline CHEMBL1432447 & 688422 & 5.45 & 5.206 & TRN \\
\hline CHEMBL1383000 & 688422 & 4.95 & 5.2272 & TRN \\
\hline CHEMBL1374592 & 688422 & 7.9508 & 5.33200 & 0000000001 \\
\hline CHEMBL1595068 & 688422 & 4.5 & 5.0429 & TRN \\
\hline CHEMBL1541315 & 688422 & 4.5 & 5.4047 & TST \\
\hline CHEMBL 1481785 & 688422 & 4.5 & 5.101 & TRN \\
\hline CHEMBL1560948 & 688422 & 6.25 & 5.4889 & TRN \\
\hline CHEMBL1572043 & 688422 & 5.3 & 4.7916 & TRN \\
\hline CHEMBL1459661 & 688422 & 4.6 & 4.9072 & TRN \\
\hline CHEMBL1381676 & 688422 & 4.45 & 5.3452 & TST \\
\hline CHEMBL1507277 & 688422 & 4.6 & 5.515 & TRN \\
\hline CHEMBL1386032 & 688422 & 4.65 & 5.1442 & TRN \\
\hline CHEMBL1326194 & 688422 & 4.7 & 4.7894 & TRN \\
\hline CHEMBL1575912 & 688422 & 4.45 & 5.317 & TST \\
\hline CHEMBL1345820 & 688422 & 4.45 & 5.2706 & TRN \\
\hline CHEMBL1359031 & 688422 & 4.9 & 5.3198 & TRN \\
\hline CHEMBL1538920 & 688422 & 4.75 & 5.2135 & TRN \\
\hline CHEMBL1336732 & 688422 & 4.95 & 5.4869 & TRN \\
\hline CHEMBL1558175 & 688422 & 4.7 & 4.9343 & TRN \\
\hline CHEMBL1432770 & 688422 & 5.5 & 5.7493 & TRN \\
\hline CHEMBL1339533 & 688422 & 7.699 & 5.3929 & TST \\
\hline CHEMBL1595766 & 688422 & 4.65 & 5.17 & TRN \\
\hline CHEMBL1586230 & 688422 & 4.65 & 4.8473 & TST \\
\hline CHEMBL1549979 & 688422 & 6.95 & 5.2874 & TST \\
\hline CHEMBL1543198 & 688422 & 4.9 & 5.3955 & TST \\
\hline CHEMBL1376770 & 688422 & 4.85 & 4.721 & TRN \\
\hline CHEMBL1366816 & 688422 & 4.95 & 5.4674 & TRN \\
\hline CHEMBL 3194785 & 688422 & 4.5 & 5.1393 & TRN \\
\hline CHEMBL1415932 & 688422 & 4.5 & 4.7386 & TRN \\
\hline CHEMBL1427857 & 688422 & 4.45 & 5.352 & TST \\
\hline CHEMBL1563018 & 688422 & 4.8 & 5.8074 & TST \\
\hline CHEMBL1308130 & 688422 & 4.85 & 5.6326 & TST \\
\hline CHEMBL1420524 & 688422 & 4.5 & 4.9818 & TRN \\
\hline CHEMBL1410531 & 688422 & 6.45 & 5.4614 & TST \\
\hline CHEMBL1385634 & 688422 & 5.15 & 5.1489 & TRN \\
\hline CHEMBL1315274 & 688422 & 4.5 & 4.5009 & TRN \\
\hline CHEMBL1544703 & 688422 & 4.45 & 5.0557 & TRN \\
\hline CHEMBL1566497 & 688422 & 5.0 & 5.1291 & TRN \\
\hline CHEMBL1540943 & 688422 & 4.7 & 4.6946 & TRN \\
\hline CHEMBL1567339 & 688422 & 4.45 & 5.5615 & TRN \\
\hline CHEMBL1302007 & 688422 & 5.3 & 5.3505 & TST \\
\hline CHEMBL1580566 & 688422 & 4.65 & 5.5543 & TRN \\
\hline
\end{tabular}




\begin{tabular}{|c|c|c|c|c|c|}
\hline \multicolumn{6}{|c|}{ Supplemental Table S2.txt } \\
\hline CHEMBL1562397 & 688422 & 5.0 & 5.1122 & TRN & \\
\hline CHEMBL1340201 & 688422 & 4.45 & 5.1914 & TRN & \\
\hline CHEMBL1515786 & 688422 & 5.4 & 5.4282 & TRN & \\
\hline CHEMBL1519501 & 688422 & 4.85 & 5.0784 & TRN & \\
\hline CHEMBL1524890 & 688422 & 4.95 & 5.2741 & TRN & \\
\hline CHEMBL1307744 & 688422 & 4.45 & 4.8657 & TRN & \\
\hline CHEMBL3195091 & 688422 & 5.2 & 5.2461 & TRN & \\
\hline CHEMBL3195977 & 688422 & 4.45 & 5.2542 & TRN & \\
\hline CHEMBL1401759 & 688422 & 7.2 & 5.5224 & TST & \\
\hline CHEMBL1552265 & 688422 & 7.8996 & 5.8879 & TRN & \\
\hline CHEMBL1448931 & 688422 & 5.65 & 4.916 & TRN & \\
\hline CHEMBL1462208 & 688422 & 4.95 & 5.0387 & TRN & \\
\hline CHEMBL1393795 & 688422 & 4.9 & 5.4599 & TST & \\
\hline CHEMBL3199869 & 688422 & 4.65 & \multicolumn{2}{|c|}{5.832999999999999} & TRN \\
\hline CHEMBL1613117 & 688422 & 4.85 & 5.2741 & TRN & \\
\hline CHEMBL1386649 & 688422 & 4.5 & 5.4965 & TST & \\
\hline CHEMBL1603051 & 688422 & 5.35 & 5.5176 & TRN & \\
\hline CHEMBL1446463 & 688422 & 4.5 & 5.1915 & TRN & \\
\hline CHEMBL1459983 & 688422 & 4.9 & 5.1317 & TRN & \\
\hline CHEMBL1548253 & 688422 & 4.45 & 5.1451 & TRN & \\
\hline CHEMBL1347598 & 688422 & 5.0 & 5.5373 & TRN & \\
\hline CHEMBL40274 & 688422 & 8.6021 & 5.9432 & TST & \\
\hline CHEMBL1352430 & 688422 & 4.85 & \multicolumn{2}{|c|}{5.1739999999999995} & TRN \\
\hline CHEMBL1603636 & 688422 & 4.95 & 5.4635 & TRN & \\
\hline CHEMBL3197511 & 688422 & 4.95 & 4.9456 & TRN & \\
\hline CHEMBL1568453 & 688422 & 4.65 & \multicolumn{2}{|c|}{5.167000000000001} & TST \\
\hline CHEMBL1534876 & 688422 & 7.0501 & 4.926 & TST & \\
\hline CHEMBL1341395 & 688422 & 4.95 & 4.8923 & TRN & \\
\hline CHEMBL1308354 & 688422 & 5.1 & 5.1456 & TST & \\
\hline CHEMBL1467978 & 688422 & 6.8499 & 5.4917 & TST & \\
\hline CHEMBL498373 & 688422 & 4.95 & 5.4801 & TRN & \\
\hline CHEMBL1383806 & 688422 & 4.9 & 4.9991 & TRN & \\
\hline CHEMBL 3193241 & 688422 & 5.1 & 5.3972 & TRN & \\
\hline CHEMBL1424498 & 688422 & 4.95 & 5.7687 & TST & \\
\hline CHEMBL1464858 & 688422 & 4.7 & 5.4321 & TRN & \\
\hline CHEMBL1497658 & 688422 & 5.1 & 5.0224 & TRN & \\
\hline CHEMBL1335023 & 688422 & 5.2 & 4.6404 & TRN & \\
\hline CHEMBL1358212 & 688422 & 5.45 & 4.8065 & TRN & \\
\hline CHEMBL1480115 & 688422 & 4.45 & 5.2453 & TRN & \\
\hline CHEMBL1424968 & 688422 & 4.85 & 4.8018 & TRN & \\
\hline CHEMBL23236 & 688422 & 6.0 & 5.3424 & TRN & \\
\hline CHEMBL1454840 & 688422 & 4.9 & 5.6095 & TRN & \\
\hline CHEMBL1587373 & 688422 & 4.65 & 4.7354 & TRN & \\
\hline CHEMBL1440791 & 688422 & 4.5 & 4.7372 & TRN & \\
\hline CHEMBL1347498 & 688422 & 7.6003 & 5.7671 & TRN & \\
\hline CHEMBL1359165 & 688422 & 4.75 & 5.1842 & TRN & \\
\hline CHEMBL1600320 & 688422 & 4.7 & 5.268 & TST & \\
\hline CHEMBL1327496 & 688422 & 5.6 & 5.724 & TRN & \\
\hline
\end{tabular}




\begin{tabular}{|c|c|c|c|c|c|}
\hline \multirow{3}{*}{$\begin{array}{l}\text { CHEMBL } 1445875 \\
\text { CHEMBL } 574319\end{array}$} & \multirow{3}{*}{$\begin{array}{l}688422 \\
688422\end{array}$} & \multicolumn{4}{|c|}{ Supplemental Table s2.txt } \\
\hline & & 4.95 & 5.30399 & 9999999999 & TRN \\
\hline & & 4.45 & 5.1709 & TST & \\
\hline CHEMBL1541342 & 688422 & 4.8 & 5.1091 & TRN & \\
\hline CHEMBL1555831 & 688422 & 4.9 & 5.3296 & TRN & \\
\hline CHEMBL 1354156 & 688422 & 5.0 & 4.6856 & TRN & \\
\hline CHEMBL1602141 & 688422 & 4.5 & 5.0872 & TST & \\
\hline CHEMBL1331878 & 688422 & 4.6 & 5.1642 & TRN & \\
\hline CHEMBL1450936 & 688422 & 8.0 & 5.4006 & TST & \\
\hline CHEMBL1418330 & 688422 & 5.05 & 4.5284 & TRN & \\
\hline CHEMBL1383603 & 688422 & 4.5 & 4.9606 & TRN & \\
\hline CHEMBL1492081 & 688422 & 5.85 & 4.9672 & TRN & \\
\hline CHEMBL1310527 & 688422 & 5.25 & 4.9459 & TRN & \\
\hline CHEMBL1363950 & 688422 & 4.45 & 5.3623 & TRN & \\
\hline CHEMBL1518146 & 688422 & 4.45 & 5.0725 & TRN & \\
\hline CHEMBL1402072 & 688422 & 6.8 & 5.199 & TRN & \\
\hline CHEMBL1435446 & 688422 & 4.65 & 5.34 & TRN & \\
\hline CHEMBL1441523 & 688422 & 4.5 & 5.2145 & TRN & \\
\hline CHEMBL1379901 & 688422 & 6.7501 & 5.1744 & TRN & \\
\hline CHEMBL1357390 & 688422 & 4.8 & 5.1101 & TRN & \\
\hline CHEMBL1401577 & 688422 & 4.65 & 4.8512 & TRN & \\
\hline CHEMBL3196351 & 688422 & 4.9 & 5.4159 & TRN & \\
\hline CHEMBL1486889 & 688422 & 4.65 & 4.9418 & TRN & \\
\hline CHEMBL1447382 & 688422 & 5.55 & 5.1617 & TRN & \\
\hline CHEMBL1442707 & 688422 & 4.6 & 5.2431 & TST & \\
\hline CHEMBL1340638 & 688422 & 4.5 & 4.988 & TST & \\
\hline CHEMBL1428725 & 688422 & 4.5 & 5.3991 & TRN & \\
\hline CHEMBL1322429 & 688422 & 4.45 & 5.1837 & TRN & \\
\hline CHEMBL1356026 & 688422 & 4.65 & 5.5748 & TRN & \\
\hline CHEMBL1459902 & 688422 & 4.5 & 4.7721 & TRN & \\
\hline CHEMBL1413141 & 688422 & 5.0 & 4.9604 & TRN & \\
\hline CHEMBL1540103 & 688422 & 5.05 & 5.6894 & TRN & \\
\hline CHEMBL 2356804 & 688422 & 5.35 & 5.1242 & TRN & \\
\hline CHEMBL1361883 & 688422 & 4.75 & 5.3668 & TRN & \\
\hline CHEMBL1370216 & 688422 & 5.75 & 5.0614 & TRN & \\
\hline CHEMBL1563735 & 688422 & 4.9 & 5.4239 & TST & \\
\hline CHEMBL1573421 & 688422 & 4.95 & 5.1153 & TRN & \\
\hline CHEMBL 1343046 & 688422 & 4.95 & 5.5498 & TST & \\
\hline CHEMBL1525862 & 688422 & 6.25 & 5.6783 & TRN & \\
\hline CHEMBL3193655 & 688422 & 7.5003 & 5.521 & TRN & \\
\hline CHEMBL1600688 & 688422 & 4.9 & 5.3606 & TRN & \\
\hline CHEMBL1363959 & 688422 & 4.85 & 5.2873 & TST & \\
\hline CHEMBL 1370218 & 688422 & 4.85 & 5.0635 & TRN & \\
\hline CHEMBL1333538 & 688422 & 4.65 & 5.0252 & TRN & \\
\hline CHEMBL3214129 & 688422 & 4.5 & 5.6491 & TST & \\
\hline CHEMBL1433177 & 688422 & 4.85 & 5.2565 & TRN & \\
\hline CHEMBL1500144 & 688422 & 4.8 & 5.3346 & TRN & \\
\hline CHEMBL1426127 & 688422 & 4.75 & 5.5035 & TST & \\
\hline CHEMBL1574931 & 688422 & 4.5 & 4.9362 & TST & \\
\hline
\end{tabular}




\begin{tabular}{|c|c|c|c|c|}
\hline \multicolumn{5}{|c|}{ Supplemental Table } \\
\hline CHEMBL1974529 & 688422 & 4.75 & 5.0531 & TRN \\
\hline CHEMBL1500581 & 688422 & 6.1 & 5.2921 & TRN \\
\hline CHEMBL1460742 & 688422 & 4.45 & 5.2541 & TST \\
\hline CHEMBL1501604 & 688422 & 7.6498 & 5.5035 & TRN \\
\hline CHEMBL1381833 & 688422 & 5.45 & 5.3443 & TRN \\
\hline CHEMBL2360527 & 688422 & 4.45 & 5.2338 & TRN \\
\hline CHEMBL1603232 & 688422 & 4.75 & 5.065 & TST \\
\hline CHEMBL1999947 & 688422 & 4.75 & 5.0291 & TST \\
\hline CHEMBL1425658 & 688422 & 4.45 & 5.141 & TRN \\
\hline CHEMBL1595329 & 688422 & 4.5 & 5.4036 & TST \\
\hline CHEMBL1519160 & 688422 & 4.95 & 5.1143 & TRN \\
\hline CHEMBL1536742 & 688422 & 7.6498 & 6.0039 & TRN \\
\hline CHEMBL1200958 & 688422 & 6.0 & 5.8646 & TST \\
\hline CHEMBL1544553 & 688422 & 5.25 & 5.4765 & TST \\
\hline CHEMBL1390648 & 688422 & 4.85 & 5.1849 & TST \\
\hline CHEMBL1486187 & 688422 & 7.5003 & 5.3421 & TRN \\
\hline CHEMBL1376547 & 688422 & 4.95 & 5.6763 & TST \\
\hline CHEMBL1441956 & 688422 & 7.3497 & 5.585 & TST \\
\hline CHEMBL1299342 & 688422 & 5.15 & 4.9467 & TRN \\
\hline CHEMBL1578699 & 688422 & 5.45 & 5.23 & TRN \\
\hline CHEMBL1319570 & 688422 & 7.4001 & 5.5282 & TRN \\
\hline CHEMBL1454807 & 688422 & 4.8 & 5.0855 & TRN \\
\hline CHEMBL1417474 & 688422 & 5.8 & 5.5644 & TRN \\
\hline CHEMBL1417029 & 688422 & 7.3002 & 5.1811 & TRN \\
\hline CHEMBL1492541 & 688422 & 5.05 & 5.0756 & TRN \\
\hline CHEMBL1450215 & 688422 & 4.7 & 4.8913 & TRN \\
\hline CHEMBL1336299 & 688422 & 8.301 & 5.4912 & TRN \\
\hline CHEMBL1534620 & 688422 & 4.65 & 4.6834 & TRN \\
\hline CHEMBL1365598 & 688422 & 5.95 & 5.8444 & TST \\
\hline CHEMBL1308511 & 688422 & 4.5 & 5.4531 & TST \\
\hline CHEMBL566899 & 688422 & 5.0 & 4.748 & TRN \\
\hline CHEMBL1300797 & 688422 & 4.7 & 4.9435 & TRN \\
\hline CHEMBL1490591 & 688422 & 6.7501 & 5.4168 & TRN \\
\hline CHEMBL1539469 & 688422 & 5.15 & 5.2956 & TRN \\
\hline CHEMBL567331 & 688422 & 4.85 & 4.5902 & TRN \\
\hline CHEMBL1588769 & 688422 & 4.5 & 4.6837 & TRN \\
\hline CHEMBL1330062 & 688422 & 4.5 & 4.9403 & TRN \\
\hline CHEMBL1256655 & 688422 & 4.45 & 5.2578 & TST \\
\hline CHEMBL1456568 & 688422 & 4.9 & 4.5288 & TRN \\
\hline CHEMBL3198961 & 688422 & 4.8 & 5.106 & TRN \\
\hline CHEMBL1538643 & 688422 & 4.95 & 4.4756 & TRN \\
\hline CHEMBL1409680 & 688422 & 4.85 & 4.7447 & TRN \\
\hline CHEMBL1558612 & 688422 & 4.7 & 5.4165 & TST \\
\hline CHEMBL1362893 & 688422 & 5.15 & 5.4826 & TST \\
\hline CHEMBL3197136 & 688422 & 4.95 & 4.9395 & TST \\
\hline CHEMBL1532301 & 688422 & 6.4 & 5.2887 & TRN \\
\hline CHEMBL1514288 & 688422 & 5.5 & 5.3242 & TRN \\
\hline CHEMBL1608715 & 688422 & 4.95 & 4.7055 & TRN \\
\hline
\end{tabular}




\begin{tabular}{|c|c|c|c|c|c|}
\hline \multicolumn{6}{|c|}{ Supplemental Table S2.txt } \\
\hline CHEMBL1605201 & 688422 & 4.45 & 5.2704 & TST & \\
\hline CHEMBL1346361 & 688422 & 4.45 & 5.5822 & TRN & \\
\hline CHEMBL1380777 & 688422 & 5.0 & 5.1677 & TRN & \\
\hline CHEMBL1378671 & 688422 & 6.4 & 5.8764 & TRN & \\
\hline CHEMBL1316019 & 688422 & 4.45 & 4.9021 & TRN & \\
\hline CHEMBL1538822 & 688422 & 4.75 & 5.6008 & TRN & \\
\hline CHEMBL1536915 & 688422 & 4.5 & 5.1101 & TRN & \\
\hline CHEMBL1578791 & 688422 & 4.45 & 5.2024 & TRN & \\
\hline CHEMBL1467646 & 688422 & 4.8 & 5.1419 & TST & \\
\hline CHEMBL1506622 & 688422 & 4.45 & 4.56800 & 00000000005 & TRN \\
\hline CHEMBL1368229 & 688422 & 4.85 & 5.5683 & TRN & \\
\hline CHEMBL3195233 & 688422 & 4.5 & 5.1296 & TST & \\
\hline CHEMBL1507028 & 688422 & 6.05 & 5.39 & TRN & \\
\hline CHEMBL1502247 & 688422 & 4.95 & 5.2265 & TRN & \\
\hline CHEMBL1490950 & 688422 & 5.3 & 5.6547 & TST & \\
\hline CHEMBL1471421 & 688422 & 4.95 & 5.1298 & TRN & \\
\hline CHEMBL1224512 & 688422 & 8.301 & 5.4626 & TRN & \\
\hline CHEMBL1406027 & 688422 & 4.85 & 5.28799 & 9999999999 & TRN \\
\hline CHEMBL1421179 & 688422 & 4.8 & 4.989 & TRN & \\
\hline CHEMBL1336558 & 688422 & 4.45 & 5.2407 & TRN & \\
\hline CHEMBL1363850 & 688422 & 4.6 & 5.026 & TRN & \\
\hline CHEMBL1548261 & 688422 & 4.95 & 5.186 & TST & \\
\hline CHEMBL1493043 & 688422 & 5.2 & 5.295 & TRN & \\
\hline CHEMBL1312714 & 688422 & 4.9 & 5.0672 & TRN & \\
\hline CHEMBL1605820 & 688422 & 8.3468 & 5.397 & TRN & \\
\hline CHEMBL3189906 & 688422 & 5.05 & 5.4902 & TRN & \\
\hline CHEMBL1521944 & 688422 & 4.7 & 5.3336 & TRN & \\
\hline CHEMBL1378976 & 688422 & 4.65 & 5.7235 & TRN & \\
\hline CHEMBL1311173 & 688422 & 4.45 & 4.9982 & TRN & \\
\hline CHEMBL1982484 & 688422 & 6.5501 & 4.8009 & TRN & \\
\hline CHEMBL1467310 & 688422 & 4.85 & 5.2791 & TRN & \\
\hline CHEMBL1383866 & 688422 & 5.2 & 5.1379 & TRN & \\
\hline CHEMBL3209231 & 688422 & 4.75 & 5.187 & TST & \\
\hline CHEMBL1522456 & 688422 & 5.85 & 5.5023 & TRN & \\
\hline CHEMBL1500510 & 688422 & 4.9 & 4.6564 & TRN & \\
\hline CHEMBL1460075 & 688422 & 4.95 & 5.0278 & TRN & \\
\hline CHEMBL1464070 & 688422 & 4.45 & 5.1695 & TRN & \\
\hline CHEMBL1331882 & 688422 & 8.2518 & 5.1261 & TRN & \\
\hline CHEMBL1302828 & 688422 & 5.45 & 4.7789 & TRN & \\
\hline CHEMBL1372646 & 688422 & 4.85 & 4.7686 & TRN & \\
\hline CHEMBL1336812 & 688422 & 4.85 & 5.0803 & TRN & \\
\hline CHEMBL1318554 & 688422 & 4.45 & 5.3825 & TRN & \\
\hline CHEMBL3193792 & 688422 & 4.45 & 5.1423 & TRN & \\
\hline CHEMBL1566269 & 688422 & 5.55 & 5.5261 & TRN & \\
\hline CHEMBL1461551 & 688422 & 4.45 & 5.402 & TST & \\
\hline CHEMBL1605238 & 688422 & 4.9 & 5.0477 & TRN & \\
\hline CHEMBL 1544775 & 688422 & 6.25 & 5.2843 & TRN & \\
\hline CHEMBL1595402 & 688422 & 7.4498 & 5.4013 & TRN & \\
\hline
\end{tabular}




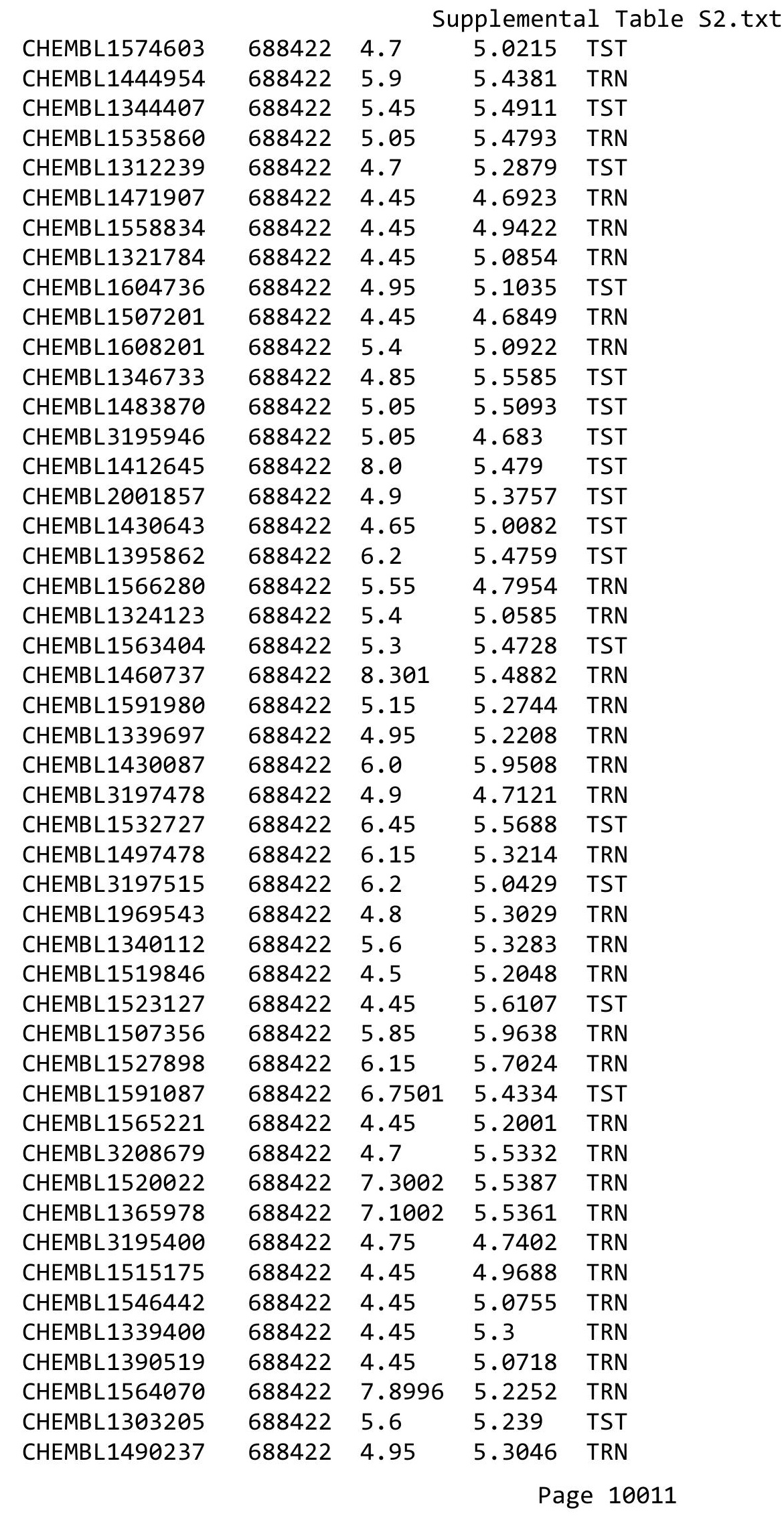




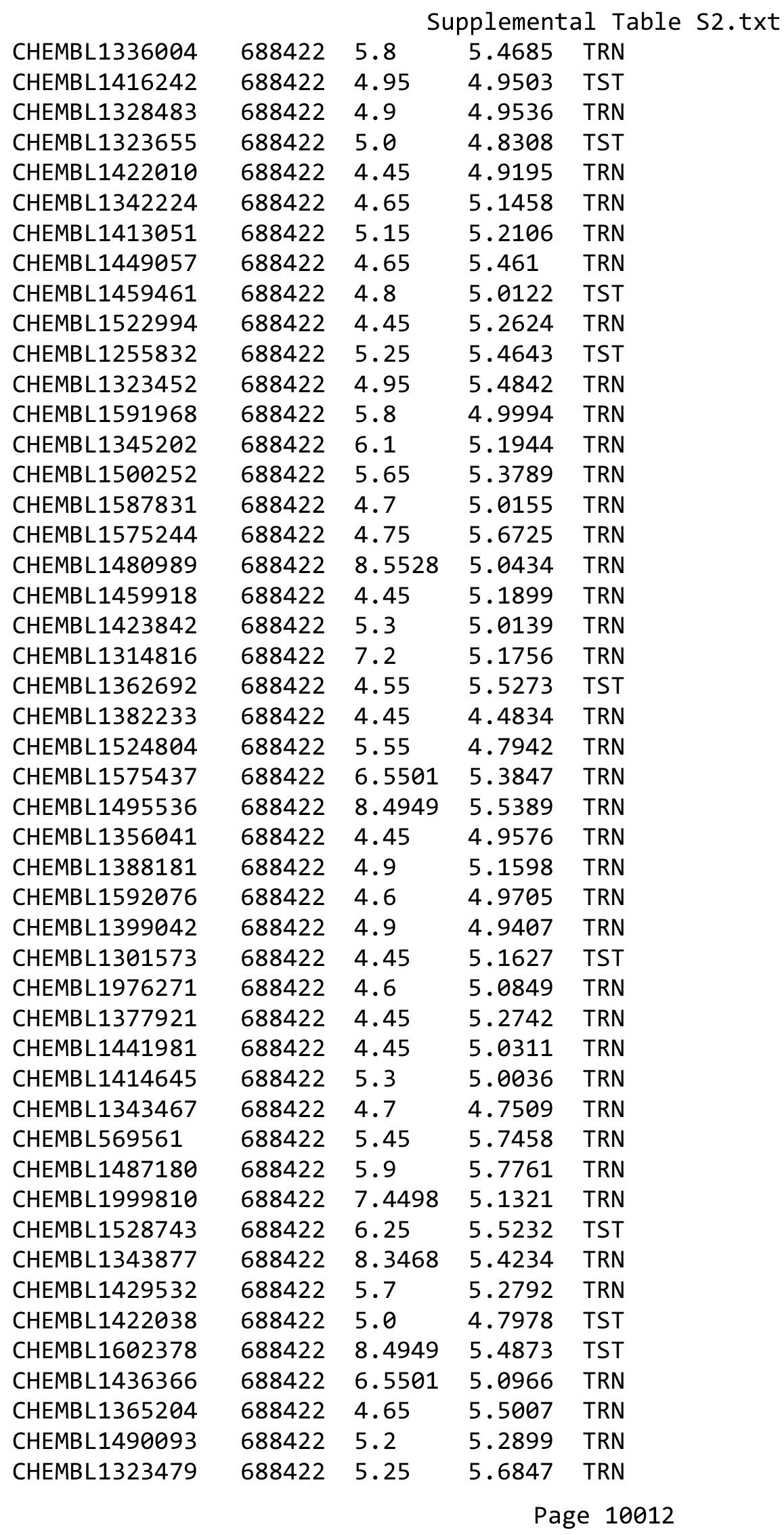




\begin{tabular}{|c|c|c|c|c|}
\hline \multicolumn{5}{|c|}{ Supplemental Table S2.txt } \\
\hline CHEMBL1552937 & 688422 & 4.45 & 5.2812 & TRN \\
\hline CHEMBL1440884 & 688422 & 4.65 & 5.3805 & TRN \\
\hline CHEMBL3193970 & 688422 & 5.0 & 5.3438 & TST \\
\hline CHEMBL1342620 & 688422 & 4.95 & 4.8997 & TRN \\
\hline CHEMBL1399016 & 688422 & 4.45 & 5.2035 & TRN \\
\hline CHEMBL3197471 & 688422 & 4.55 & 4.8152 & TRN \\
\hline CHEMBL1370700 & 688422 & 5.6 & 5.7513 & TRN \\
\hline CHEMBL1603534 & 688422 & 7.0501 & 5.7052 & TRN \\
\hline CHEMBL1425675 & 688422 & 4.8 & 4.8846 & TRN \\
\hline CHEMBL1321451 & 688422 & 4.95 & 5.3742 & TRN \\
\hline CHEMBL1562405 & 688422 & 4.95 & 5.0293 & TRN \\
\hline CHEMBL1439106 & 688422 & 4.95 & 4.9992 & TRN \\
\hline CHEMBL1459566 & 688422 & 4.95 & 5.5041 & TST \\
\hline CHEMBL1428700 & 688422 & 5.6 & 5.9163 & TST \\
\hline CHEMBL1435610 & 688422 & 4.45 & 5.6751 & TRN \\
\hline CHEMBL1450741 & 688422 & 5.05 & 5.3401 & TST \\
\hline CHEMBL3189409 & 688422 & 4.65 & 4.8766 & TRN \\
\hline CHEMBL1419664 & 688422 & 4.9 & 5.6381 & TRN \\
\hline CHEMBL1983530 & 688422 & 4.75 & 5.4681 & TST \\
\hline CHEMBL1376645 & 688422 & 4.9 & 5.3176 & TRN \\
\hline CHEMBL1531172 & 688422 & 4.8 & 4.6684 & TRN \\
\hline CHEMBL1317234 & 688422 & 4.85 & 5.1443 & TST \\
\hline CHEMBL1501890 & 688422 & 4.9 & 4.9052 & TRN \\
\hline CHEMBL1340801 & 688422 & 5.2 & 5.545 & TRN \\
\hline CHEMBL1348914 & 688422 & 7.2 & 5.5092 & TST \\
\hline CHEMBL1415950 & 688422 & 5.5 & 5.1425 & TRN \\
\hline CHEMBL602922 & 688422 & 5.0 & 5.2581 & TRN \\
\hline CHEMBL1378641 & 688422 & 5.45 & 5.5838 & TRN \\
\hline CHEMBL1533157 & 688422 & 7.3002 & 5.8738 & TST \\
\hline CHEMBL1333985 & 688422 & 5.0 & 4.8123 & TST \\
\hline CHEMBL1511867 & 688422 & 4.95 & 5.0657 & TST \\
\hline CHEMBL1608246 & 688422 & 4.95 & 5.1927 & TRN \\
\hline CHEMBL1506585 & 688422 & 4.8 & 5.0735 & TRN \\
\hline CHEMBL1370917 & 688422 & 5.6 & 5.0655 & TRN \\
\hline CHEMBL1556041 & 688422 & 4.85 & 5.4545 & TRN \\
\hline CHEMBL1484844 & 688422 & 4.45 & 5.4978 & TST \\
\hline CHEMBL1330629 & 688422 & 6.5 & 5.3726 & TRN \\
\hline CHEMBL1605476 & 688422 & 4.45 & 5.0431 & TRN \\
\hline CHEMBL1566871 & 688422 & 4.6 & 5.0204 & TRN \\
\hline CHEMBL1567647 & 688422 & 7.3497 & 4.7924 & TRN \\
\hline CHEMBL1426337 & 688422 & 4.95 & 5.3617 & TRN \\
\hline CHEMBL1558159 & 688422 & 4.45 & 5.3251 & TRN \\
\hline CHEMBL1570186 & 688422 & 6.1 & 5.5492 & TST \\
\hline CHEMBL3189239 & 688422 & 7.8013 & 5.2179 & TRN \\
\hline CHEMBL1371725 & 688422 & 6.45 & 4.8111 & TRN \\
\hline CHEMBL1573217 & 688422 & 6.1 & 5.2469 & TRN \\
\hline CHEMBL1611398 & 688422 & 4.85 & 5.2193 & TRN \\
\hline CHEMBL1546068 & 688422 & 4.45 & 5.164 & TRN \\
\hline
\end{tabular}




\begin{tabular}{|c|c|c|c|c|}
\hline \multicolumn{5}{|c|}{ Supplemental Table s2.txt } \\
\hline CHEMBL1432145 & 688422 & 4.8 & 4.9367 & TST \\
\hline CHEMBL1418391 & 688422 & 4.45 & 5.5489 & TRN \\
\hline CHEMBL1996536 & 688422 & 4.7 & 5.0034 & TRN \\
\hline CHEMBL1407925 & 688422 & 4.7 & 5.2742 & TRN \\
\hline CHEMBL258893 & 688422 & 5.5 & 5.5297 & TST \\
\hline CHEMBL1402385 & 688422 & 4.75 & 4.8912 & TRN \\
\hline CHEMBL1521107 & 688422 & 4.6 & 4.7131 & TRN \\
\hline CHEMBL1496293 & 688422 & 4.85 & 4.7202 & TRN \\
\hline CHEMBL1442095 & 688422 & 5.55 & 5.2371 & TRN \\
\hline CHEMBL1311616 & 688422 & 4.85 & 4.9198 & TST \\
\hline CHEMBL1354069 & 688422 & 4.45 & 4.6847 & TST \\
\hline CHEMBL1366972 & 688422 & 5.05 & 5.4272 & TRN \\
\hline CHEMBL1995862 & 688422 & 4.45 & 5.5604 & TRN \\
\hline CHEMBL1383456 & 688422 & 5.65 & 5.5133 & TST \\
\hline CHEMBL1574594 & 688422 & 7.3002 & 5.5189 & TST \\
\hline CHEMBL1594948 & 688422 & 4.9 & 5.4262 & TST \\
\hline CHEMBL1417105 & 688422 & 6.25 & 5.5201 & TRN \\
\hline CHEMBL1316346 & 688422 & 7.3002 & 5.3152 & TST \\
\hline CHEMBL1382463 & 688422 & 4.45 & 5.5361 & TRN \\
\hline CHEMBL1482198 & 688422 & 6.3 & 5.3494 & TRN \\
\hline CHEMBL1313068 & 688422 & 5.05 & 4.9477 & TRN \\
\hline CHEMBL1501558 & 688422 & 4.8 & 5.0304 & TRN \\
\hline CHEMBL1501726 & 688422 & 4.9 & 5.2767 & TRN \\
\hline CHEMBL1503677 & 688422 & 4.85 & 5.5123 & TRN \\
\hline CHEMBL1336305 & 688422 & 5.0 & 5.4096 & TRN \\
\hline CHEMBL1502038 & 688422 & 4.45 & 4.985 & TRN \\
\hline CHEMBL1361564 & 688422 & 4.65 & 5.5052 & TRN \\
\hline CHEMBL1390925 & 688422 & 4.95 & 5.3976 & TRN \\
\hline CHEMBL1561610 & 688422 & 4.7 & 4.9263 & TRN \\
\hline CHEMBL1578645 & 688422 & 4.7 & 5.2399 & TRN \\
\hline CHEMBL1360439 & 688422 & 4.55 & 5.0644 & TRN \\
\hline CHEMBL1310934 & 688422 & 4.45 & 5.4875 & TRN \\
\hline CHEMBL1381892 & 688422 & 4.9 & 5.1324 & TRN \\
\hline CHEMBL1404846 & 688422 & 4.95 & 5.1034 & TRN \\
\hline CHEMBL1896972 & 688422 & 4.5 & 5.0339 & TRN \\
\hline CHEMBL1357126 & 688422 & 4.8 & 5.4776 & TST \\
\hline CHEMBL1537623 & 688422 & 5.05 & 5.1972 & TST \\
\hline CHEMBL1562026 & 688422 & 4.9 & 5.2952 & TRN \\
\hline CHEMBL1456383 & 688422 & 5.75 & 5.4829 & TRN \\
\hline CHEMBL1508914 & 688422 & 5.45 & 4.8563 & TRN \\
\hline CHEMBL1475532 & 688422 & 5.0 & 5.0773 & TRN \\
\hline CHEMBL1488197 & 688422 & 6.0 & 4.9344 & TRN \\
\hline CHEMBL1577147 & 688422 & 5.1 & 5.1154 & TRN \\
\hline CHEMBL1463970 & 688422 & 4.65 & 4.9769 & TRN \\
\hline CHEMBL1446084 & 688422 & 4.95 & 5.32299 & 99999999995 \\
\hline CHEMBL1308999 & 688422 & 6.05 & 5.1502 & TRN \\
\hline CHEMBL1386897 & 688422 & 4.45 & 4.8645 & TRN \\
\hline CHEMBL1599295 & 688422 & 4.8 & 5.1994 & TRN \\
\hline
\end{tabular}




\begin{tabular}{|c|c|c|c|c|}
\hline & & & pplement & al $\mathrm{T}$ \\
\hline CHEMBL1299858 & 688422 & 8.301 & 5.1838 & TRN \\
\hline CHEMBL1311879 & 688422 & 6.9 & 5.4503 & TRN \\
\hline CHEMBL1513009 & 688422 & 4.8 & 5.024 & TRN \\
\hline CHEMBL1588363 & 688422 & 4.6 & 4.8901 & TST \\
\hline CHEMBL1466481 & 688422 & 4.95 & 5.0538 & TST \\
\hline CHEMBL1346981 & 688422 & 4.45 & 5.2246 & TST \\
\hline CHEMBL1371989 & 688422 & 5.65 & 5.2021 & TRN \\
\hline CHEMBL1420781 & 688422 & 5.0 & 5.0074 & TRN \\
\hline CHEMBL1506602 & 688422 & 6.3 & 5.6631 & TRN \\
\hline CHEMBL1518929 & 688422 & 4.65 & 4.9617 & TRN \\
\hline CHEMBL1549305 & 688422 & 4.85 & 5.2046 & TRN \\
\hline CHEMBL1516646 & 688422 & 4.95 & 5.2432 & TRN \\
\hline CHEMBL1536466 & 688422 & 6.95 & 5.4123 & TST \\
\hline CHEMBL1547893 & 688422 & 4.45 & 5.0377 & TST \\
\hline CHEMBL1589778 & 688422 & 5.4 & 5.0853 & TST \\
\hline CHEMBL1459140 & 688422 & 6.0 & 5.3308 & TST \\
\hline CHEMBL1483734 & 688422 & 4.45 & 5.3022 & TRN \\
\hline CHEMBL1334797 & 688422 & 4.65 & 4.9515 & TST \\
\hline CHEMBL3214167 & 688422 & 4.75 & 5.2659 & TST \\
\hline CHEMBL1391443 & 688422 & 4.85 & 5.2565 & TST \\
\hline CHEMBL1589274 & 688422 & 6.95 & 5.4354 & TRN \\
\hline CHEMBL1565923 & 688422 & 5.0 & 5.138 & TRN \\
\hline CHEMBL1412847 & 688422 & 4.85 & 4.9651 & TST \\
\hline CHEMBL1393761 & 688422 & 4.45 & 5.2689 & TST \\
\hline CHEMBL1491431 & 688422 & 4.8 & 5.4476 & TRN \\
\hline CHEMBL1382834 & 688422 & 5.55 & 5.0675 & TRN \\
\hline CHEMBL1361091 & 688422 & 7.9508 & 5.3664 & TRN \\
\hline CHEMBL1399418 & 688422 & 5.2 & 5.9128 & TST \\
\hline CHEMBL1569961 & 688422 & 4.7 & 5.1742 & TRN \\
\hline CHEMBL1495868 & 688422 & 7.8508 & 5.3099 & TRN \\
\hline CHEMBL1574219 & 688422 & 5.0 & 5.2649 & TRN \\
\hline CHEMBL1468636 & 688422 & 4.45 & 5.0707 & TRN \\
\hline CHEMBL1467225 & 688422 & 4.95 & 5.3983 & TRN \\
\hline CHEMBL1603388 & 688422 & 4.6 & 5.3535 & TRN \\
\hline CHEMBL1481711 & 688422 & 4.95 & 5.1825 & TST \\
\hline CHEMBL1406603 & 688422 & 5.0 & 5.7465 & TRN \\
\hline CHEMBL1372307 & 688422 & 5.55 & 5.6834 & TRN \\
\hline CHEMBL1507747 & 688422 & 5.3 & 5.2287 & TRN \\
\hline CHEMBL1360791 & 688422 & 4.8 & 5.7672 & TRN \\
\hline CHEMBL1407753 & 688422 & 5.15 & 4.9903 & TRN \\
\hline CHEMBL3197599 & 688422 & 4.95 & 4.9012 & TRN \\
\hline CHEMBL1561864 & 688422 & 5.15 & 5.2019 & TST \\
\hline CHEMBL1393143 & 688422 & 4.6 & 5.0466 & TRN \\
\hline CHEMBL3189433 & 688422 & 5.4 & 4.9311 & TRN \\
\hline CHEMBL1366115 & 688422 & 4.75 & 4.8265 & TST \\
\hline CHEMBL1429267 & 688422 & 4.85 & 4.9157 & TRN \\
\hline CHEMBL1300975 & 688422 & 8.4949 & 5.1086 & TRN \\
\hline CHEMBL1421098 & 688422 & 5.35 & 5.4172 & TST \\
\hline
\end{tabular}




\begin{tabular}{|c|c|c|c|c|c|}
\hline \multicolumn{6}{|c|}{ Supplemental Table S2.txt } \\
\hline CHEMBL1610842 & 688422 & 4.7 & 5.4457 & TST & \\
\hline CHEMBL1441819 & 688422 & 5.4 & 5.1699 & TST & \\
\hline CHEMBL1311707 & 688422 & 4.75 & 5.0594 & TST & \\
\hline CHEMBL1550507 & 688422 & 4.9 & 5.0332 & TRN & \\
\hline CHEMBL1339492 & 688422 & 5.3 & 5.4759 & TRN & \\
\hline CHEMBL1564900 & 688422 & 5.0 & 5.2116 & TRN & \\
\hline CHEMBL1306655 & 688422 & 7.5003 & 4.8512 & TRN & \\
\hline CHEMBL1377176 & 688422 & 4.45 & 4.9325 & TST & \\
\hline CHEMBL1322191 & 688422 & 7.6003 & 6.0253 & TRN & \\
\hline CHEMBL1485246 & 688422 & 4.95 & 4.8243 & TRN & \\
\hline CHEMBL1480329 & 688422 & 4.65 & 5.1345 & TRN & \\
\hline CHEMBL1580341 & 688422 & 6.6499 & 5.4071 & TRN & \\
\hline CHEMBL1556235 & 688422 & 4.75 & 4.703 & TRN & \\
\hline CHEMBL1301848 & 688422 & 4.45 & 5.4655 & TRN & \\
\hline CHEMBL1300155 & 688422 & 4.8 & 5.1087 & TRN & \\
\hline CHEMBL1604057 & 688422 & 6.4 & 5.3606 & TRN & \\
\hline CHEMBL1368497 & 688422 & 7.6003 & 5.876 & TRN & \\
\hline CHEMBL1447011 & 688422 & 6.0 & 4.8232 & TST & \\
\hline CHEMBL3195401 & 688422 & 4.9 & 5.1314 & TST & \\
\hline CHEMBL1426340 & 688422 & 4.5 & 5.29700 & 0000000001 & TRN \\
\hline CHEMBL1350165 & 688422 & 4.7 & 5.0179 & TST & \\
\hline CHEMBL1332871 & 688422 & 4.4 & 5.3148 & TRN & \\
\hline CHEMBL1529553 & 688422 & 4.85 & 5.1378 & TST & \\
\hline CHEMBL1400100 & 688422 & 7.2503 & 5.8379 & TST & \\
\hline CHEMBL1419533 & 688422 & 5.25 & 5.3716 & TRN & \\
\hline CHEMBL1384510 & 688422 & 7.15 & 5.4127 & TST & \\
\hline CHEMBL1345687 & 688422 & 4.45 & 5.2446 & TRN & \\
\hline CHEMBL1527714 & 688422 & 4.9 & 5.2785 & TRN & \\
\hline CHEMBL1591090 & 688422 & 4.65 & 5.2432 & TRN & \\
\hline CHEMBL1339911 & 688422 & 4.95 & 5.518 & TST & \\
\hline CHEMBL1528531 & 688422 & 4.65 & 5.3505 & TST & \\
\hline CHEMBL1606752 & 688422 & 5.0 & 4.8023 & TRN & \\
\hline CHEMBL1305537 & 688422 & 4.95 & 4.9031 & TST & \\
\hline CHEMBL1599836 & 688422 & 4.85 & 4.9415 & TRN & \\
\hline CHEMBL1321744 & 688422 & 5.25 & 5.2432 & TRN & \\
\hline CHEMBL1302288 & 688422 & 4.9 & 5.2331 & TRN & \\
\hline CHEMBL1380303 & 688422 & 4.75 & 5.4758 & TRN & \\
\hline CHEMBL1997716 & 688422 & 4.5 & 5.4354 & TRN & \\
\hline CHEMBL3211046 & 688422 & 5.0 & 5.6006 & TRN & \\
\hline CHEMBL1610614 & 688422 & 4.65 & 5.416 & TST & \\
\hline CHEMBL1401762 & 688422 & 4.75 & 5.0853 & TRN & \\
\hline CHEMBL1599458 & 688422 & 4.7 & 4.8436 & TRN & \\
\hline CHEMBL1350350 & 688422 & 5.55 & 5.1225 & TRN & \\
\hline CHEMBL1329027 & 688422 & 5.45 & 5.1641 & TRN & \\
\hline CHEMBL1369732 & 688422 & 6.7501 & 5.4024 & TRN & \\
\hline CHEMBL1564133 & 688422 & 4.9 & 5.1894 & TRN & \\
\hline CHEMBL1403057 & 688422 & 5.95 & 5.6691 & TRN & \\
\hline CHEMBL1462982 & 688422 & 6.1 & 4.9819 & TST & \\
\hline
\end{tabular}




\begin{tabular}{|c|c|c|c|c|}
\hline \multicolumn{5}{|c|}{ Supplemental Table S2.txt } \\
\hline CHEMBL 3213088 & 688422 & 5.6 & 5.3652 & TRN \\
\hline CHEMBL1451586 & 688422 & 4.75 & 5.3428 & TRN \\
\hline CHEMBL1602287 & 688422 & 4.7 & 5.1322 & TRN \\
\hline CHEMBL1458161 & 688422 & 7.15 & 5.7969 & TST \\
\hline CHEMBL1558194 & 688422 & 6.3 & 5.4755 & TRN \\
\hline CHEMBL1170612 & 688422 & 6.7001 & 5.4314 & TRN \\
\hline CHEMBL1386541 & 688422 & 5.4 & 5.7364 & TRN \\
\hline CHEMBL1312456 & 688422 & 4.75 & 4.9143 & TRN \\
\hline CHEMBL1536052 & 688422 & 4.75 & 5.0682 & TRN \\
\hline CHEMBL1329570 & 688422 & 4.8 & 5.4138 & TRN \\
\hline CHEMBL1337075 & 688422 & 5.55 & 5.0966 & TRN \\
\hline CHEMBL1530358 & 688422 & 4.5 & 5.3116 & TRN \\
\hline CHEMBL1455149 & 688422 & 4.75 & 5.0944 & TRN \\
\hline CHEMBL1564640 & 688422 & 5.1 & 5.1242 & TRN \\
\hline CHEMBL1348278 & 688422 & 4.85 & 5.1453 & TRN \\
\hline CHEMBL484663 & 688422 & 5.5 & 5.5418 & TRN \\
\hline CHEMBL1537086 & 688422 & 4.45 & 5.4561 & TST \\
\hline CHEMBL1427457 & 688422 & 6.0 & 5.4687 & TRN \\
\hline CHEMBL1463361 & 688422 & 5.15 & 5.3505 & TST \\
\hline CHEMBL1561395 & 688422 & 4.95 & 5.2449 & TRN \\
\hline CHEMBL1384251 & 688422 & 4.85 & 5.178 & TRN \\
\hline CHEMBL1334487 & 688422 & 4.75 & 5.3133 & TRN \\
\hline CHEMBL1468167 & 688422 & 4.45 & 5.0882 & TRN \\
\hline CHEMBL1595001 & 688422 & 5.05 & 5.2797 & TST \\
\hline CHEMBL1373503 & 688422 & 4.75 & 4.7465 & TRN \\
\hline CHEMBL 2000584 & 688422 & 4.45 & 5.4071 & TRN \\
\hline CHEMBL1399628 & 688422 & 4.6 & 5.9343 & TST \\
\hline CHEMBL1468959 & 688422 & 4.95 & 5.0199 & TST \\
\hline CHEMBL445102 & 688422 & 8.0506 & 5.1025 & TRN \\
\hline CHEMBL1607992 & 688422 & 5.05 & 5.7587 & TRN \\
\hline CHEMBL1406002 & 688422 & 4.45 & 5.3374 & TRN \\
\hline CHEMBL1497953 & 688422 & 4.95 & 5.2072 & TRN \\
\hline CHEMBL1496223 & 688422 & 4.8 & 4.9723 & TRN \\
\hline CHEMBL1408812 & 688422 & 4.9 & 5.3444 & TRN \\
\hline CHEMBL1580593 & 688422 & 6.9 & 5.2185 & TRN \\
\hline CHEMBL3207488 & 688422 & 6.9 & 5.6686 & TRN \\
\hline CHEMBL1573333 & 688422 & 5.05 & 5.4082 & TRN \\
\hline CHEMBL1457330 & 688422 & 4.5 & 4.9642 & TRN \\
\hline CHEMBL1489588 & 688422 & 5.25 & 5.1751 & TRN \\
\hline CHEMBL98350 & 688422 & 4.8 & 5.3676 & TST \\
\hline CHEMBL1331917 & 688422 & 4.8 & 5.2444 & TRN \\
\hline CHEMBL1569094 & 688422 & 4.85 & 4.9967 & TRN \\
\hline CHEMBL1475195 & 688422 & 4.45 & 5.2678 & TRN \\
\hline CHEMBL1486102 & 688422 & 4.65 & 5.3079 & TST \\
\hline CHEMBL1986259 & 688422 & 4.45 & 5.4839 & TRN \\
\hline CHEMBL1420969 & 688422 & 4.45 & 4.923 & TRN \\
\hline CHEMBL1444110 & 688422 & 4.85 & 4.6914 & TRN \\
\hline CHEMBL1436828 & 688422 & 5.0 & 5.3577 & TRN \\
\hline
\end{tabular}




\begin{tabular}{|c|c|c|c|c|c|}
\hline \multicolumn{6}{|c|}{ Supplemental Table S2.txt } \\
\hline CHEMBL1549599 & 688422 & 4.45 & 5.6638 & TRN & \\
\hline CHEMBL1409554 & 688422 & 5.3 & 5.0051 & TRN & \\
\hline CHEMBL1364878 & 688422 & 5.1 & 5.0146 & TST & \\
\hline CHEMBL334255 & 688422 & 5.25 & 5.7067 & TST & \\
\hline CHEMBL3193769 & 688422 & 4.9 & 5.0569 & TRN & \\
\hline CHEMBL1538022 & 688422 & 7.4001 & 5.4947 & TRN & \\
\hline CHEMBL3207783 & 688422 & 4.8 & 5.7376 & TRN & \\
\hline CHEMBL1441118 & 688422 & 4.8 & 4.6346 & TRN & \\
\hline CHEMBL1445222 & 688422 & 6.25 & 5.314 & TRN & \\
\hline CHEMBL1465278 & 688422 & 4.85 & 5.0555 & TRN & \\
\hline CHEMBL1309641 & 688422 & 6.5501 & 5.4065 & TST & \\
\hline CHEMBL1541952 & 688422 & 4.55 & 5.0527 & TRN & \\
\hline CHEMBL1534302 & 688422 & 4.7 & 5.3071 & TRN & \\
\hline CHEMBL1387224 & 688422 & 4.85 & 5.4288 & TRN & \\
\hline CHEMBL1586758 & 688422 & 8.4559 & 5.4151 & TRN & \\
\hline CHEMBL1447711 & 688422 & 4.5 & 5.1778 & TRN & \\
\hline CHEMBL1994815 & 688422 & 4.8 & 4.8142 & TRN & \\
\hline CHEMBL1487865 & 688422 & 4.45 & 4.9509 & TRN & \\
\hline CHEMBL1332188 & 688422 & 4.45 & 5.3914 & TRN & \\
\hline CHEMBL3211168 & 688422 & 7.0 & 5.3197 & TRN & \\
\hline CHEMBL1511872 & 688422 & 7.0501 & 5.5517 & TST & \\
\hline CHEMBL1301844 & 688422 & 4.45 & 4.6579 & TRN & \\
\hline CHEMBL1330987 & 688422 & 4.8 & 5.6792 & TST & \\
\hline CHEMBL1339830 & 688422 & 4.45 & 4.9543 & TRN & \\
\hline CHEMBL1404863 & 688422 & 5.45 & 5.5111 & TST & \\
\hline CHEMBL1584923 & 688422 & 5.25 & 5.3188 & TRN & \\
\hline CHEMBL1566389 & 688422 & 5.6 & 5.7549 & TRN & \\
\hline CHEMBL1458451 & 688422 & 4.6 & 4.8202 & TRN & \\
\hline CHEMBL1449950 & 688422 & 5.45 & 5.3237 & TRN & \\
\hline CHEMBL1535161 & 688422 & 5.0 & 4.956 & TST & \\
\hline CHEMBL1517299 & 688422 & 5.2 & 5.1744 & TST & \\
\hline CHEMBL1443526 & 688422 & 6.05 & 5.8086 & TRN & \\
\hline CHEMBL1408752 & 688422 & 4.85 & 5.71299 & & TRN \\
\hline CHEMBL3190845 & 688422 & 5.25 & 5.3442 & TST & \\
\hline CHEMBL1562579 & 688422 & 4.7 & 5.3307 & TST & \\
\hline CHEMBL1496110 & 688422 & 4.45 & 5.2687 & TST & \\
\hline CHEMBL1513905 & 688422 & 4.45 & 5.2311 & TRN & \\
\hline CHEMBL1489362 & 688422 & 4.45 & 5.06 & TRN & \\
\hline CHEMBL3211695 & 688422 & 4.45 & 5.0524 & TRN & \\
\hline CHEMBL1340187 & 688422 & 4.85 & 5.601 & TRN & \\
\hline CHEMBL1517097 & 688422 & 4.45 & 5.3951 & TRN & \\
\hline CHEMBL1470674 & 688422 & 4.9 & 5.083 & TRN & \\
\hline CHEMBL1311348 & 688422 & 4.7 & 5.0098 & TST & \\
\hline CHEMBL1502463 & 688422 & 5.15 & 5.4635 & TST & \\
\hline CHEMBL1522143 & 688422 & 5.0 & 5.1587 & TRN & \\
\hline CHEMBL1318039 & 688422 & 6.45 & 5.6567 & TRN & \\
\hline CHEMBL1577764 & 688422 & 7.15 & 5.3736 & TST & \\
\hline CHEMBL1559527 & 688422 & 4.8 & 6.0163 & TRN & \\
\hline
\end{tabular}




\begin{tabular}{|c|c|c|c|c|}
\hline \multicolumn{5}{|c|}{ Supplemental Table S2.txt } \\
\hline CHEMBL1586459 & 688422 & 4.45 & 5.5554 & TST \\
\hline CHEMBL1539216 & 688422 & 4.95 & 5.3065 & TRN \\
\hline CHEMBL1344720 & 688422 & 4.45 & 5.6608 & TST \\
\hline CHEMBL1332898 & 688422 & 4.8 & 5.2692 & TRN \\
\hline CHEMBL1407736 & 688422 & 4.45 & 4.9435 & TRN \\
\hline CHEMBL3197634 & 688422 & 4.65 & 5.3204 & TRN \\
\hline CHEMBL1993807 & 688422 & 4.95 & 5.3259 & TRN \\
\hline CHEMBL1523887 & 688422 & 4.5 & 5.5203 & TRN \\
\hline CHEMBL1562667 & 688422 & 4.45 & 5.0971 & TRN \\
\hline CHEMBL1591425 & 688422 & 4.7 & 4.9114 & TST \\
\hline CHEMBL1454121 & 688422 & 4.75 & 5.0671 & TRN \\
\hline CHEMBL1407298 & 688422 & 4.5 & 5.1479 & TRN \\
\hline CHEMBL1437711 & 688422 & 8.6576 & 5.9334 & TRN \\
\hline CHEMBL3213210 & 688422 & 4.9 & 5.3272 & TRN \\
\hline CHEMBL1361160 & 688422 & 4.45 & 4.9545 & TRN \\
\hline CHEMBL1577452 & 688422 & 4.45 & 5.0899 & TRN \\
\hline CHEMBL1506673 & 688422 & 4.65 & 4.8644 & TST \\
\hline CHEMBL3190403 & 688422 & 4.95 & 5.2745 & TRN \\
\hline CHEMBL1376741 & 688422 & 5.65 & 4.9639 & TRN \\
\hline CHEMBL1457767 & 688422 & 4.85 & 5.0598 & TST \\
\hline CHEMBL516075 & 688422 & 4.8 & 4.658 & TRN \\
\hline CHEMBL1514619 & 688422 & 4.45 & 5.3728 & TRN \\
\hline CHEMBL1327987 & 688422 & 4.45 & 5.2306 & TRN \\
\hline CHEMBL1481374 & 688422 & 4.8 & 5.0753 & TRN \\
\hline CHEMBL1345853 & 688422 & 6.8 & 5.433 & TRN \\
\hline CHEMBL1311415 & 688422 & 4.6 & 5.2946 & TST \\
\hline CHEMBL1402793 & 688422 & 4.9 & 4.8634 & TRN \\
\hline CHEMBL1321709 & 688422 & 5.4 & 5.4632 & TRN \\
\hline CHEMBL1361076 & 688422 & 4.45 & 5.2844 & TRN \\
\hline CHEMBL1493426 & 688422 & 4.8 & 5.3907 & TST \\
\hline CHEMBL1461558 & 688422 & 5.05 & 5.1112 & TRN \\
\hline CHEMBL1313721 & 688422 & 4.7 & 5.4433 & TRN \\
\hline CHEMBL1303147 & 688422 & 4.75 & 5.035 & TRN \\
\hline CHEMBL3210389 & 688422 & 5.45 & 5.2269 & TRN \\
\hline CHEMBL1338811 & 688422 & 4.45 & 5.3735 & TRN \\
\hline CHEMBL1481475 & 688422 & 4.6 & 5.0434 & TRN \\
\hline CHEMBL3199447 & 688422 & 4.45 & 4.9259 & TRN \\
\hline CHEMBL1415422 & 688422 & 5.0 & 5.8408 & TRN \\
\hline CHEMBL1534547 & 688422 & 5.45 & 5.0108 & TRN \\
\hline CHEMBL1507505 & 688422 & 4.75 & 5.2357 & TRN \\
\hline CHEMBL1330153 & 688422 & 4.8 & 5.0459 & TRN \\
\hline CHEMBL1348191 & 688422 & 4.8 & 5.1448 & TRN \\
\hline CHEMBL3207894 & 688422 & 4.45 & 5.0148 & TRN \\
\hline CHEMBL1554238 & 688422 & 7.6498 & 5.1208 & TRN \\
\hline CHEMBL1492174 & 688422 & 4.45 & 5.0259 & TRN \\
\hline CHEMBL1525131 & 688422 & 6.25 & 5.3482 & TRN \\
\hline CHEMBL1563419 & 688422 & 5.5 & 5.0113 & TST \\
\hline CHEMBL1502600 & 688422 & 4.85 & 4.9778 & TST \\
\hline
\end{tabular}




\begin{tabular}{|c|c|c|c|c|c|}
\hline \multicolumn{6}{|c|}{ Supplemental Table s2.txt } \\
\hline CHEMBL1314211 & 688422 & 4.45 & 4.6667 & TRN & \\
\hline CHEMBL1604766 & 688422 & 4.9 & 5.3624 & TRN & \\
\hline CHEMBL1495289 & 688422 & 8.301 & 5.8568 & TRN & \\
\hline CHEMBL1473710 & 688422 & 6.05 & 5.4414 & TRN & \\
\hline CHEMBL1344348 & 688422 & 5.2 & 5.4791 & TRN & \\
\hline CHEMBL1600009 & 688422 & 5.45 & 4.9561 & TRN & \\
\hline CHEMBL1454734 & 688422 & 4.45 & 5.3852 & TST & \\
\hline CHEMBL3191949 & 688422 & 4.8 & 5.0138 & TST & \\
\hline CHEMBL1363203 & 688422 & 4.45 & 4.7815 & TRN & \\
\hline CHEMBL1359366 & 688422 & 4.45 & 4.7921 & TRN & \\
\hline CHEMBL1543295 & 688422 & 4.45 & 4.8645 & TRN & \\
\hline CHEMBL1375566 & 688422 & 4.7 & 5.21200 & 0000000001 & TRN \\
\hline CHEMBL1538798 & 688422 & 4.65 & 4.9312 & TRN & \\
\hline CHEMBL1344838 & 688422 & 5.7 & 4.8517 & TRN & \\
\hline CHEMBL1442317 & 688422 & 4.85 & 4.7737 & TRN & \\
\hline CHEMBL1487238 & 688422 & 4.45 & 5.2047 & TRN & \\
\hline CHEMBL1574132 & 688422 & 5.4 & 5.2837 & TRN & \\
\hline CHEMBL1362232 & 688422 & 5.15 & 4.8468 & TRN & \\
\hline CHEMBL1548675 & 688422 & 4.85 & 5.1916 & TRN & \\
\hline CHEMBL3193536 & 688422 & 6.15 & 4.9449 & TRN & \\
\hline CHEMBL1502481 & 688422 & 7.1002 & 5.3771 & TRN & \\
\hline CHEMBL1570243 & 688422 & 6.95 & 5.3535 & TRN & \\
\hline CHEMBL 582287 & 688422 & 5.0 & 5.0353 & TRN & \\
\hline CHEMBL1505174 & 688422 & 4.45 & 5.3218 & TST & \\
\hline CHEMBL1598292 & 688422 & 4.5 & 5.3194 & TST & \\
\hline CHEMBL1429114 & 688422 & 4.65 & 5.0674 & TST & \\
\hline CHEMBL1563637 & 688422 & 8.301 & 5.732 & TST & \\
\hline CHEMBL1333064 & 688422 & 4.95 & 4.9979 & TRN & \\
\hline CHEMBL1304647 & 688422 & 5.65 & 5.0802 & TST & \\
\hline CHEMBL1383352 & 688422 & 4.95 & 5.5632 & TRN & \\
\hline CHEMBL1470321 & 688422 & 4.45 & 4.9935 & TRN & \\
\hline CHEMBL1469111 & 688422 & 4.65 & 5.4512 & TRN & \\
\hline CHEMBL1306305 & 688422 & 4.85 & 4.8174 & TRN & \\
\hline CHEMBL1437187 & 688422 & 4.65 & 5.2505 & TRN & \\
\hline CHEMBL1582336 & 688422 & 5.3 & 5.2764 & TRN & \\
\hline CHEMBL1554937 & 688422 & 4.95 & 5.2769 & TRN & \\
\hline CHEMBL562193 & 688422 & 5.4 & 4.9498 & TRN & \\
\hline CHEMBL1486089 & 688422 & 6.6499 & 5.3265 & TRN & \\
\hline CHEMBL1557212 & 688422 & 4.45 & 5.7149 & TST & \\
\hline CHEMBL1347446 & 688422 & 4.9 & 5.0913 & TRN & \\
\hline CHEMBL1437809 & 688422 & 4.95 & 5.4294 & TRN & \\
\hline CHEMBL3192605 & 688422 & 4.45 & 5.2556 & TRN & \\
\hline CHEMBL1504938 & 688422 & 4.45 & 5.5026 & TRN & \\
\hline CHEMBL1479849 & 688422 & 4.95 & 5.4184 & TRN & \\
\hline CHEMBL1561809 & 688422 & 5.2 & 4.6866 & TRN & \\
\hline CHEMBL1428450 & 688422 & 4.6 & 5.4509 & TRN & \\
\hline CHEMBL1509091 & 688422 & 5.4 & 5.442 & TST & \\
\hline CHEMBL1305438 & 688422 & 4.7 & 5.1652 & TRN & \\
\hline
\end{tabular}




\begin{tabular}{|c|c|c|c|c|c|}
\hline & & \multicolumn{4}{|c|}{ Supplemental Table s2.txt } \\
\hline CHEMBL1368924 & 688422 & 4.45 & 5.0704 & TST & \\
\hline CHEMBL1561092 & 688422 & 4.8 & 4.9902 & TRN & \\
\hline CHEMBL1499085 & 688422 & 4.8 & 5.13399 & 99999999995 & TRN \\
\hline CHEMBL1565180 & 688422 & 4.9 & 5.0379 & TRN & \\
\hline CHEMBL1556395 & 688422 & 4.95 & 5.0457 & TRN & \\
\hline CHEMBL1978651 & 688422 & 5.25 & 5.0314 & TRN & \\
\hline CHEMBL1494052 & 688422 & 4.95 & 5.1524 & TRN & \\
\hline CHEMBL1549986 & 688422 & 4.6 & 5.0322 & TRN & \\
\hline CHEMBL1589079 & 688422 & 4.65 & 5.1133 & TRN & \\
\hline CHEMBL1611401 & 688422 & 4.45 & 5.4067 & TRN & \\
\hline CHEMBL1554736 & 688422 & 4.5 & 5.0095 & TRN & \\
\hline CHEMBL1355744 & 688422 & 4.6 & 5.4634 & TRN & \\
\hline CHEMBL3210528 & 688422 & 5.35 & 5.489 & TST & \\
\hline CHEMBL1555346 & 688422 & 4.7 & 5.0802 & TRN & \\
\hline CHEMBL1323821 & 688422 & 4.65 & 5.3146 & TST & \\
\hline CHEMBL1503136 & 688422 & 4.75 & 5.399 & TRN & \\
\hline CHEMBL1417604 & 688422 & 4.7 & 5.1075 & TRN & \\
\hline CHEMBL1368090 & 688422 & 4.45 & 5.121 & TST & \\
\hline CHEMBL1480671 & 688422 & 4.95 & 4.7909 & TRN & \\
\hline CHEMBL1377250 & 688422 & 4.65 & 4.8211 & TRN & \\
\hline CHEMBL1578570 & 688422 & 4.45 & 5.0503 & TRN & \\
\hline CHEMBL1428070 & 688422 & 4.85 & 5.3729 & TRN & \\
\hline CHEMBL1493888 & 688422 & 5.3 & 5.581 & TRN & \\
\hline CHEMBL1495618 & 688422 & 7.0 & 5.4788 & TST & \\
\hline CHEMBL1545592 & 688422 & 4.45 & 4.9268 & TRN & \\
\hline CHEMBL1328860 & 688422 & 4.45 & 5.3659 & TST & \\
\hline CHEMBL1329907 & 688422 & 4.9 & 4.9356 & TST & \\
\hline CHEMBL1545701 & 688422 & 4.45 & 5.3216 & TST & \\
\hline CHEMBL1490264 & 688422 & 4.9 & 5.1357 & TRN & \\
\hline CHEMBL1514873 & 688422 & 4.45 & 4.9368 & TRN & \\
\hline CHEMBL1325308 & 688422 & 5.3 & 5.4233 & TRN & \\
\hline CHEMBL1417347 & 688422 & 4.45 & 5.4254 & TRN & \\
\hline CHEMBL1581231 & 688422 & 4.9 & 5.8022 & TRN & \\
\hline CHEMBL1420536 & 688422 & 4.45 & 5.8168 & TRN & \\
\hline CHEMBL1387562 & 688422 & 4.9 & 4.5562 & TST & \\
\hline CHEMBL1545312 & 688422 & 4.75 & 5.4198 & TRN & \\
\hline CHEMBL1319502 & 688422 & 5.6 & 5.2816 & TRN & \\
\hline CHEMBL1511901 & 688422 & 5.1 & 5.2219 & TRN & \\
\hline CHEMBL1494197 & 688422 & 4.95 & 5.0979 & TRN & \\
\hline CHEMBL1498042 & 688422 & 4.5 & 5.2766 & TRN & \\
\hline CHEMBL1501003 & 688422 & 4.5 & 5.0329 & TRN & \\
\hline CHEMBL1463525 & 688422 & 5.05 & 5.6102 & TRN & \\
\hline CHEMBL1498537 & 688422 & 5.4 & 4.996 & TST & \\
\hline CHEMBL1327810 & 688422 & 6.5 & 5.0874 & TST & \\
\hline CHEMBL1534878 & 688422 & 8.301 & 5.6489 & TST & \\
\hline CHEMBL1478975 & 688422 & 4.45 & 5.0429 & TRN & \\
\hline CHEMBL1407860 & 688422 & 4.45 & 5.434 & TRN & \\
\hline CHEMBL1423638 & 688422 & 4.45 & 5.3349 & TRN & \\
\hline
\end{tabular}




\begin{tabular}{|c|c|c|c|c|}
\hline \multicolumn{5}{|c|}{ Supplemental Table } \\
\hline CHEMBL3207717 & 688422 & 4.45 & 5.3616 & TST \\
\hline CHEMBL1506665 & 688422 & 4.85 & 4.7868 & TRN \\
\hline CHEMBL3193844 & 688422 & 5.55 & 5.2094 & TRN \\
\hline CHEMBL1590479 & 688422 & 4.5 & 5.5284 & TRN \\
\hline CHEMBL1409320 & 688422 & 4.75 & 4.7284 & TRN \\
\hline CHEMBL1383688 & 688422 & 4.45 & 5.2834 & TRN \\
\hline CHEMBL1325149 & 688422 & 5.3 & 5.2956 & TRN \\
\hline CHEMBL1386178 & 688422 & 5.6 & 5.435 & TRN \\
\hline CHEMBL1447668 & 688422 & 5.5 & 4.9839 & TST \\
\hline CHEMBL1307221 & 688422 & 7.5498 & 5.0677 & TST \\
\hline CHEMBL1518386 & 688422 & 4.9 & 5.3094 & TRN \\
\hline CHEMBL1530047 & 688422 & 4.45 & 5.1247 & TST \\
\hline CHEMBL1454495 & 688422 & 4.6 & 4.9778 & TRN \\
\hline CHEMBL1373504 & 688422 & 4.75 & 4.8164 & TRN \\
\hline CHEMBL1368575 & 688422 & 5.75 & 5.3599 & TST \\
\hline CHEMBL1299662 & 688422 & 6.0 & 5.2717 & TRN \\
\hline CHEMBL1323243 & 688422 & 4.45 & 4.9675 & TST \\
\hline CHEMBL487187 & 688422 & 4.45 & 5.3389 & TRN \\
\hline CHEMBL1581724 & 688422 & 8.301 & 5.5446 & TST \\
\hline CHEMBL1523579 & 688422 & 4.6 & 4.9112 & TRN \\
\hline CHEMBL1477120 & 688422 & 4.7 & 4.715 & TRN \\
\hline CHEMBL1517751 & 688422 & 6.05 & 5.4294 & TRN \\
\hline CHEMBL1426985 & 688422 & 4.75 & 5.1079 & TRN \\
\hline CHEMBL1368832 & 688422 & 4.8 & 4.6822 & TRN \\
\hline CHEMBL1454463 & 688422 & 6.5501 & 4.9496 & TRN \\
\hline CHEMBL1504641 & 688422 & 4.45 & 4.7701 & TRN \\
\hline CHEMBL1598289 & 688422 & 4.45 & 5.1591 & TRN \\
\hline CHEMBL1462334 & 688422 & 4.8 & 5.0616 & TRN \\
\hline CHEMBL1454138 & 688422 & 8.0 & 5.4594 & TRN \\
\hline CHEMBL54277 & 688422 & 4.85 & 5.7165 & TST \\
\hline CHEMBL1577784 & 688422 & 4.5 & 5.0813 & TRN \\
\hline CHEMBL1368649 & 688422 & 4.6 & 5.2121 & TRN \\
\hline CHEMBL533082 & 688422 & 4.8 & 5.2633 & TRN \\
\hline CHEMBL1612619 & 688422 & 4.45 & 5.1184 & TRN \\
\hline CHEMBL1350497 & 688422 & 4.65 & 5.3962 & TRN \\
\hline CHEMBL1568377 & 688422 & 6.05 & 5.2545 & TRN \\
\hline CHEMBL1304584 & 688422 & 4.45 & 5.3682 & TRN \\
\hline CHEMBL1480768 & 688422 & 4.95 & 5.5192 & TST \\
\hline CHEMBL1555873 & 688422 & 5.2 & 5.3576 & TRN \\
\hline CHEMBL1409324 & 688422 & 4.85 & 5.4111 & TST \\
\hline CHEMBL3191058 & 688422 & 4.45 & 5.0592 & TST \\
\hline CHEMBL1539816 & 688422 & 7.15 & 5.2732 & TRN \\
\hline CHEMBL1397624 & 688422 & 4.45 & 5.8059 & TRN \\
\hline CHEMBL1459795 & 688422 & 5.6 & 5.2501 & TRN \\
\hline CHEMBL1485220 & 688422 & 5.15 & 5.2684 & TST \\
\hline CHEMBL1609792 & 688422 & 5.2 & 5.2977 & TRN \\
\hline CHEMBL491909 & 688422 & 4.7 & 4.9143 & TST \\
\hline CHEMBL1447973 & 688422 & 4.7 & 5.5387 & TRN \\
\hline
\end{tabular}




\begin{tabular}{|c|c|c|c|c|}
\hline \multicolumn{5}{|c|}{ Supplemental Table } \\
\hline CHEMBL1565736 & 688422 & 6.6499 & 5.31 & TRN \\
\hline CHEMBL1511580 & 688422 & 4.45 & 4.9703 & TRN \\
\hline CHEMBL1596738 & 688422 & 4.85 & 5.2174 & TRN \\
\hline CHEMBL1570541 & 688422 & 4.45 & 5.7 & TRN \\
\hline CHEMBL1313048 & 688422 & 4.45 & 5.3922 & TRN \\
\hline CHEMBL 2007120 & 688422 & 4.45 & 5.1407 & TRN \\
\hline CHEMBL 244023 & 688422 & 6.8499 & 5.5655 & TRN \\
\hline CHEMBL1582229 & 688422 & 6.35 & 5.6324 & TRN \\
\hline CHEMBL1434334 & 688422 & 8.6576 & 5.8289 & TRN \\
\hline CHEMBL1573245 & 688422 & 4.8 & 5.6661 & TRN \\
\hline CHEMBL1330437 & 688422 & 4.45 & 4.7743 & TRN \\
\hline CHEMBL1509483 & 688422 & 4.75 & 4.9404 & TRN \\
\hline CHEMBL3189615 & 688422 & 5.5 & 5.1407 & TRN \\
\hline CHEMBL1534763 & 688422 & 5.15 & 5.4847 & TRN \\
\hline CHEMBL1407401 & 688422 & 4.5 & 4.971 & TST \\
\hline CHEMBL1304819 & 688422 & 6.05 & 5.1422 & TRN \\
\hline CHEMBL1309798 & 688422 & 4.8 & 5.2298 & TRN \\
\hline CHEMBL1546781 & 688422 & 5.0 & 5.1216 & TRN \\
\hline CHEMBL1370220 & 688422 & 4.9 & 5.3206 & TRN \\
\hline CHEMBL 2000736 & 688422 & 4.6 & 5.862 & TST \\
\hline CHEMBL1503663 & 688422 & 4.75 & 4.9866 & TRN \\
\hline CHEMBL1326309 & 688422 & 4.7 & 4.7704 & TRN \\
\hline CHEMBL1517202 & 688422 & 5.0 & 5.5913 & TRN \\
\hline CHEMBL1430019 & 688422 & 4.85 & 5.1671 & TRN \\
\hline CHEMBL1611749 & 688422 & 4.7 & 5.4456 & TRN \\
\hline CHEMBL1582812 & 688422 & 4.85 & 5.0915 & TRN \\
\hline CHEMBL1597080 & 688422 & 5.0 & 4.6114 & TRN \\
\hline CHEMBL1299225 & 688422 & 4.9 & 5.1085 & TRN \\
\hline CHEMBL1302225 & 688422 & 4.95 & 5.0036 & TRN \\
\hline CHEMBL1561173 & 688422 & 6.6499 & 5.0742 & TRN \\
\hline CHEMBL1541132 & 688422 & 7.0501 & 5.5167 & TRN \\
\hline CHEMBL1534276 & 688422 & 5.15 & 5.7261 & TRN \\
\hline CHEMBL405317 & 688422 & 4.55 & 5.8963 & TRN \\
\hline CHEMBL1603420 & 688422 & 4.75 & 5.2816 & TRN \\
\hline CHEMBL1576303 & 688422 & 4.9 & 4.8888 & TRN \\
\hline CHEMBL1483661 & 688422 & 4.5 & 4.7765 & TRN \\
\hline CHEMBL1500923 & 688422 & 6.8 & 5.8276 & TST \\
\hline CHEMBL1548641 & 688422 & 4.65 & 5.114 & TRN \\
\hline CHEMBL1326006 & 688422 & 6.1 & 5.0595 & TRN \\
\hline CHEMBL1461257 & 688422 & 4.75 & 5.8208 & TRN \\
\hline CHEMBL1588352 & 688422 & 4.45 & 4.8449 & TRN \\
\hline CHEMBL1399759 & 688422 & 4.45 & 5.0732 & TRN \\
\hline CHEMBL1517825 & 688422 & 4.85 & 5.385 & TRN \\
\hline CHEMBL1518098 & 688422 & 5.15 & 5.0773 & TST \\
\hline CHEMBL1600876 & 688422 & 4.45 & 4.9461 & TRN \\
\hline CHEMBL1304579 & 688422 & 4.9 & 5.2768 & TRN \\
\hline CHEMBL3193188 & 688422 & 4.45 & 5.4915 & TST \\
\hline CHEMBL1589279 & 688422 & 5.3 & 4.9643 & TRN \\
\hline
\end{tabular}




\begin{tabular}{|c|c|c|c|c|c|}
\hline \multicolumn{6}{|c|}{ Supplemental Table S2.txt } \\
\hline CHEMBL1545699 & 688422 & 4.65 & 5.0805 & TRN & \\
\hline CHEMBL1988660 & 688422 & 5.75 & 5.2375 & TST & \\
\hline CHEMBL1370757 & 688422 & 4.6 & 5.1056 & TRN & \\
\hline CHEMBL1584976 & 688422 & 4.45 & 5.0415 & TRN & \\
\hline CHEMBL1309365 & 688422 & 5.0 & 5.3007 & TRN & \\
\hline CHEMBL1434485 & 688422 & 8.1024 & 5.67200 & 0000000001 & TRN \\
\hline CHEMBL1447638 & 688422 & 4.65 & 5.2329 & TRN & \\
\hline CHEMBL1315733 & 688422 & 6.1 & 5.2151 & TST & \\
\hline CHEMBL1385264 & 688422 & 4.8 & 5.6165 & TST & \\
\hline CHEMBL1392454 & 688422 & 4.75 & 5.1859 & TRN & \\
\hline CHEMBL1538966 & 688422 & 4.45 & 5.4213 & TST & \\
\hline CHEMBL1528822 & 688422 & 4.75 & 4.8433 & TRN & \\
\hline CHEMBL1432752 & 688422 & 4.8 & 5.4023 & TRN & \\
\hline CHEMBL1568226 & 688422 & 4.45 & 5.0219 & TRN & \\
\hline CHEMBL1435551 & 688422 & 4.65 & 5.8692 & TRN & \\
\hline CHEMBL3193578 & 688422 & 4.75 & 4.9699 & TRN & \\
\hline CHEMBL1440078 & 688422 & 4.45 & 5.4233 & TRN & \\
\hline CHEMBL1537715 & 688422 & 5.25 & 5.4145 & TST & \\
\hline CHEMBL1550862 & 688422 & 4.7 & 5.1345 & TRN & \\
\hline CHEMBL1436432 & 688422 & 6.3 & 5.5426 & TRN & \\
\hline CHEMBL1467457 & 688422 & 5.6 & 5.103 & TST & \\
\hline CHEMBL1581259 & 688422 & 5.0 & 4.862 & TRN & \\
\hline CHEMBL1474909 & 688422 & 7.2 & 5.2171 & TRN & \\
\hline CHEMBL1516865 & 688422 & 4.95 & 5.2674 & TRN & \\
\hline CHEMBL1372749 & 688422 & 7.699 & 4.9776 & TST & \\
\hline CHEMBL3210132 & 688422 & 6.8 & 5.2777 & TST & \\
\hline CHEMBL1577776 & 688422 & 4.7 & 4.8177 & TRN & \\
\hline CHEMBL1572320 & 688422 & 5.25 & 5.5293 & TST & \\
\hline CHEMBL1491904 & 688422 & 5.15 & 4.5476 & TRN & \\
\hline CHEMBL1476828 & 688422 & 4.45 & 4.8419 & TRN & \\
\hline CHEMBL1390878 & 688422 & 4.45 & 5.7997 & TST & \\
\hline CHEMBL1965956 & 688422 & 5.1 & 5.3557 & TRN & \\
\hline CHEMBL1591377 & 688422 & 4.85 & 5.4989 & TST & \\
\hline CHEMBL1368192 & 688422 & 4.5 & 5.3726 & TRN & \\
\hline CHEMBL1486969 & 688422 & 4.9 & 5.3074 & TST & \\
\hline CHEMBL1358474 & 688422 & 7.5003 & 4.9411 & TRN & \\
\hline CHEMBL1390181 & 688422 & 7.2503 & 5.3645 & TST & \\
\hline CHEMBL1465096 & 688422 & 4.45 & 5.1008 & TRN & \\
\hline CHEMBL1987078 & 688422 & 4.85 & 5.49 & TRN & \\
\hline CHEMBL1344108 & 688422 & 6.3 & 5.0804 & TST & \\
\hline CHEMBL1482488 & 688422 & 5.0 & 5.1703 & TRN & \\
\hline CHEMBL1549881 & 688422 & 4.95 & 4.9318 & TRN & \\
\hline CHEMBL1576330 & 688422 & 4.9 & 5.0687 & TST & \\
\hline CHEMBL1531761 & 688422 & 5.0 & 5.3976 & TRN & \\
\hline CHEMBL1478054 & 688422 & 4.45 & 5.0759 & TRN & \\
\hline CHEMBL1589262 & 688422 & 6.5 & 5.2334 & TST & \\
\hline CHEMBL1523460 & 688422 & 5.1 & 4.8786 & TRN & \\
\hline CHEMBL1380680 & 688422 & 4.45 & 5.1568 & TRN & \\
\hline
\end{tabular}




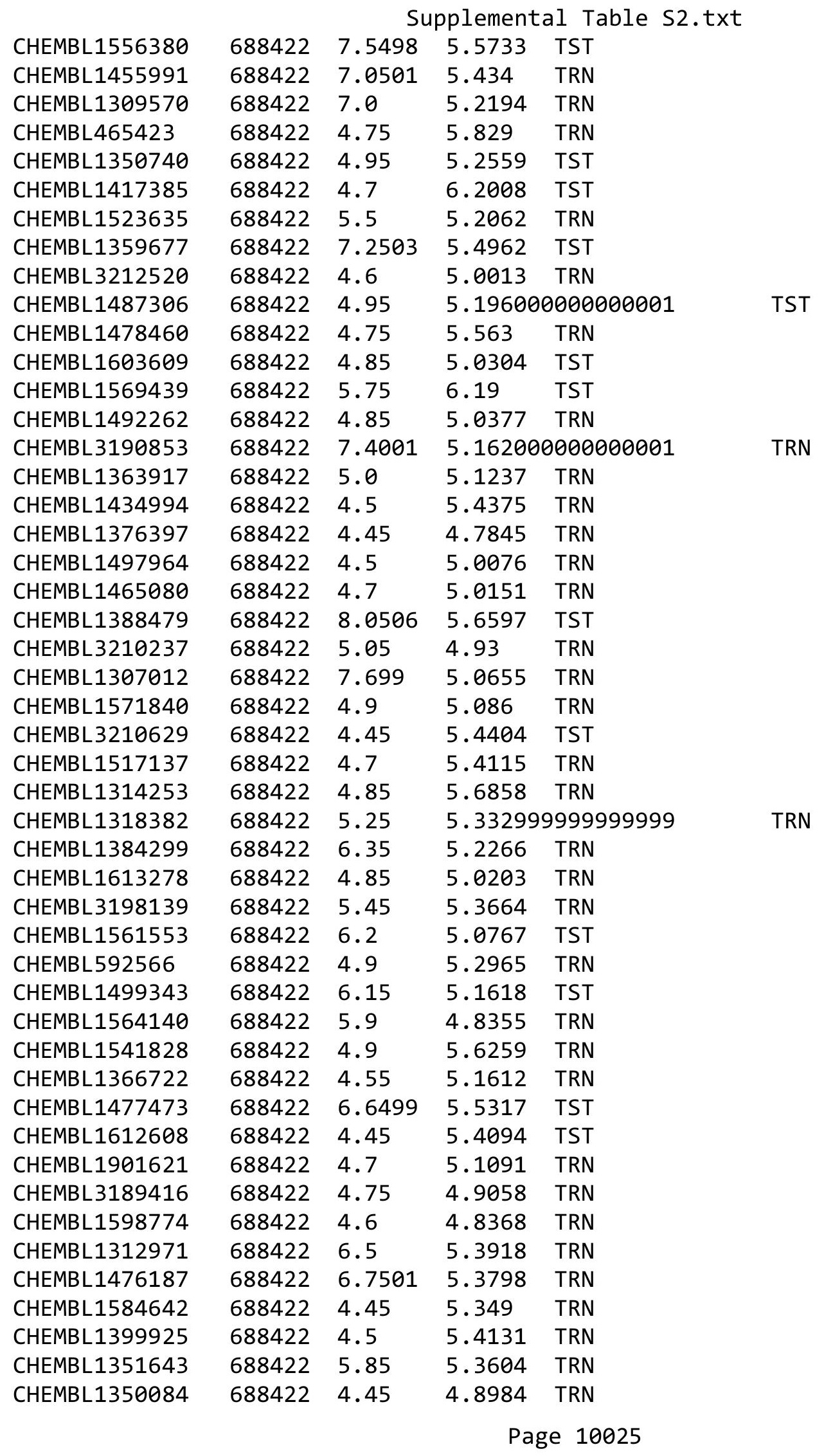




\begin{tabular}{|c|c|c|c|c|c|}
\hline \multicolumn{6}{|c|}{ Supplemental Table S2.txt } \\
\hline CHEMBL1425352 & 688422 & 4.45 & 5.7547 & TRN & \\
\hline CHEMBL1603328 & 688422 & 6.4 & 5.4968 & TRN & \\
\hline CHEMBL1433073 & 688422 & 4.5 & 5.1542 & TST & \\
\hline CHEMBL1380978 & 688422 & 5.0 & 5.4757 & TRN & \\
\hline CHEMBL1404437 & 688422 & 5.3 & 5.6191 & TRN & \\
\hline CHEMBL1435754 & 688422 & 5.9 & 5.7945 & TRN & \\
\hline CHEMBL1384952 & 688422 & 6.45 & 5.4555 & TRN & \\
\hline CHEMBL1452116 & 688422 & 4.45 & 5.4885 & TST & \\
\hline CHEMBL1310080 & 688422 & 4.75 & 5.5117 & TRN & \\
\hline CHEMBL1587432 & 688422 & 4.65 & 5.4178 & TST & \\
\hline CHEMBL3213395 & 688422 & 5.2 & 5.0766 & TRN & \\
\hline CHEMBL1436765 & 688422 & 4.65 & 5.4751 & TRN & \\
\hline CHEMBL1374947 & 688422 & 5.45 & 5.0782 & TRN & \\
\hline CHEMBL1525577 & 688422 & 4.8 & 5.3758 & TRN & \\
\hline CHEMBL1505643 & 688422 & 4.45 & 5.6109 & TRN & \\
\hline CHEMBL1352394 & 688422 & 8.3468 & 5.2504 & TRN & \\
\hline CHEMBL1497309 & 688422 & 5.0 & 5.3646 & TST & \\
\hline CHEMBL1331294 & 688422 & 4.85 & 5.5145 & TRN & \\
\hline CHEMBL1467359 & 688422 & 5.45 & 4.7393 & TRN & \\
\hline CHEMBL1542608 & 688422 & 5.0 & 4.9925 & TRN & \\
\hline CHEMBL1332127 & 688422 & 7.6498 & 5.3898 & TRN & \\
\hline CHEMBL3196288 & 688422 & 7.9508 & 5.1545 & TRN & \\
\hline CHEMBL440464 & 688422 & 8.3468 & 5.6248 & TRN & \\
\hline CHEMBL1469557 & 688422 & 4.75 & 4.9933 & TRN & \\
\hline CHEMBL1583936 & 688422 & 4.5 & 5.518 & TRN & \\
\hline CHEMBL 2135351 & 688422 & 5.8 & 4.823 & TRN & \\
\hline CHEMBL1601847 & 688422 & 5.7 & 5.2644 & TRN & \\
\hline CHEMBL3192664 & 688422 & 5.0 & 5.0996 & TRN & \\
\hline CHEMBL1354492 & 688422 & 9.0458 & 5.8484 & TST & \\
\hline CHEMBL1415785 & 688422 & 4.45 & 4.7615 & TRN & \\
\hline CHEMBL3199919 & 688422 & 6.05 & 5.1949 & TST & \\
\hline CHEMBL1532642 & 688422 & 5.2 & 4.8646 & TRN & \\
\hline CHEMBL1415492 & 688422 & 5.2 & 5.3098 & TRN & \\
\hline CHEMBL1498749 & 688422 & 4.6 & 5.5621 & TRN & \\
\hline CHEMBL1381600 & 688422 & 4.45 & 5.2087 & TRN & \\
\hline CHEMBL1607208 & 688422 & 4.95 & 5.1419 & TST & \\
\hline CHEMBL1477436 & 688422 & 4.45 & 5.3489 & TRN & \\
\hline CHEMBL1531201 & 688422 & 7.6003 & 5.5881 & TST & \\
\hline CHEMBL1330665 & 688422 & 5.5 & 5.0541 & TRN & \\
\hline CHEMBL 74287 & 688422 & 7.9508 & 5.57600 & 00000000005 & TRN \\
\hline CHEMBL1360356 & 688422 & 4.85 & 5.3132 & TRN & \\
\hline CHEMBL1462478 & 688422 & 5.05 & 5.079 & TST & \\
\hline CHEMBL1471808 & 688422 & 4.95 & 5.2138 & TRN & \\
\hline CHEMBL1486234 & 688422 & 6.3 & 5.5268 & TST & \\
\hline CHEMBL1487402 & 688422 & 4.45 & 5.0956 & TRN & \\
\hline CHEMBL1505847 & 688422 & 5.35 & 5.2654 & TRN & \\
\hline CHEMBL1982391 & 688422 & 5.65 & 5.1467 & TRN & \\
\hline CHEMBL1500577 & 688422 & 4.95 & 4.875 & TRN & \\
\hline
\end{tabular}




\begin{tabular}{|c|c|c|c|c|c|}
\hline \multicolumn{6}{|c|}{ Supplemental Table S2.txt } \\
\hline CHEMBL1507532 & 688422 & 6.05 & 5.6865 & TRN & \\
\hline CHEMBL1473047 & 688422 & 4.45 & 5.5687 & TRN & \\
\hline CHEMBL475198 & 688422 & 4.75 & 4.5269 & TRN & \\
\hline CHEMBL1391101 & 688422 & 6.15 & 5.5896 & TRN & \\
\hline CHEMBL1408107 & 688422 & 4.7 & 5.1843 & TRN & \\
\hline CHEMBL1381031 & 688422 & 4.45 & 5.2513 & TRN & \\
\hline CHEMBL1158 & 688422 & 8.3468 & 6.1529 & TST & \\
\hline CHEMBL1368139 & 688422 & 8.4949 & 5.4688 & TRN & \\
\hline CHEMBL1547957 & 688422 & 4.7 & 5.8555 & TRN & \\
\hline CHEMBL1446054 & 688422 & 4.8 & 5.2523 & TST & \\
\hline CHEMBL1560562 & 688422 & 4.7 & 5.2673 & TRN & \\
\hline CHEMBL1596245 & 688422 & 4.85 & 5.209 & TST & \\
\hline CHEMBL1612828 & 688422 & 6.5 & 5.0177 & TRN & \\
\hline CHEMBL3210339 & 688422 & 4.9 & 5.1278 & TRN & \\
\hline CHEMBL1563062 & 688422 & 4.8 & 5.4533 & TST & \\
\hline CHEMBL1521121 & 688422 & 4.8 & 5.0115 & TRN & \\
\hline CHEMBL1314090 & 688422 & 6.95 & 5.1241 & TST & \\
\hline CHEMBL1487540 & 688422 & 8.4559 & 4.9988 & TRN & \\
\hline CHEMBL1424683 & 688422 & 4.65 & 5.3016 & TRN & \\
\hline CHEMBL1428960 & 688422 & 4.75 & 5.1957 & TRN & \\
\hline CHEMBL3196621 & 688422 & 4.45 & 5.0688 & TRN & \\
\hline CHEMBL1609369 & 688422 & 4.5 & 5.0207 & TRN & \\
\hline CHEMBL1554341 & 688422 & 8.4949 & 5.4717 & TRN & \\
\hline CHEMBL1351662 & 688422 & 4.65 & 5.5006 & TST & \\
\hline CHEMBL1416808 & 688422 & 4.6 & 5.0433 & TRN & \\
\hline CHEMBL1369994 & 688422 & 6.0 & 5.4555 & TRN & \\
\hline CHEMBL1358979 & 688422 & 5.5 & 5.6551 & TST & \\
\hline CHEMBL1596723 & 688422 & 4.95 & 5.972 & TST & \\
\hline CHEMBL1360378 & 688422 & 5.1 & 5.29299 & 9999999999 & TRN \\
\hline CHEMBL1581045 & 688422 & 4.85 & 4.9734 & TRN & \\
\hline CHEMBL1518724 & 688422 & 4.5 & 5.4723 & TRN & \\
\hline CHEMBL1603150 & 688422 & 4.6 & 4.7928 & TRN & \\
\hline CHEMBL1431684 & 688422 & 4.45 & 4.7553 & TRN & \\
\hline CHEMBL1545024 & 688422 & 6.1 & 5.5025 & TRN & \\
\hline CHEMBL1364064 & 688422 & 4.45 & 5.1868 & TRN & \\
\hline CHEMBL1347758 & 688422 & 4.45 & 5.0019 & TRN & \\
\hline CHEMBL1499670 & 688422 & 6.6 & 5.7123 & TST & \\
\hline CHEMBL1561542 & 688422 & 4.45 & 5.43 & TRN & \\
\hline CHEMBL1324137 & 688422 & 4.7 & 4.8698 & TRN & \\
\hline CHEMBL1360675 & 688422 & 4.9 & 5.0934 & TRN & \\
\hline CHEMBL1580915 & 688422 & 5.6 & 5.2884 & TRN & \\
\hline CHEMBL1383474 & 688422 & 4.45 & 5.0148 & TST & \\
\hline CHEMBL1379017 & 688422 & 4.9 & 5.4351 & TST & \\
\hline CHEMBL1466096 & 688422 & 4.6 & 5.1712 & TRN & \\
\hline CHEMBL3192493 & 688422 & 4.6 & 4.9616 & TST & \\
\hline CHEMBL1303056 & 688422 & 5.0 & 5.3653 & TST & \\
\hline CHEMBL1557499 & 688422 & 5.25 & 5.1983 & TRN & \\
\hline CHEMBL1552785 & 688422 & 7.7496 & 5.7843 & TRN & \\
\hline
\end{tabular}




\begin{tabular}{|c|c|c|c|c|c|}
\hline \multicolumn{6}{|c|}{ Supplemental Table S2.txt } \\
\hline CHEMBL1516992 & 688422 & 4.9 & 5.0925 & TRN & \\
\hline CHEMBL1610659 & 688422 & 4.7 & 5.2793 & TST & \\
\hline CHEMBL1409016 & 688422 & 4.8 & 5.2967 & TRN & \\
\hline CHEMBL1443320 & 688422 & 5.0 & 5.5619 & TRN & \\
\hline CHEMBL1602115 & 688422 & 4.85 & $5.2870 e$ & 0000000001 & TRN \\
\hline CHEMBL1572823 & 688422 & 4.5 & 5.5233 & TRN & \\
\hline CHEMBL1440044 & 688422 & 8.3468 & 5.6109 & TRN & \\
\hline CHEMBL1612745 & 688422 & 4.9 & 5.1134 & TRN & \\
\hline CHEMBL1307031 & 688422 & 4.75 & 5.6686 & TST & \\
\hline CHEMBL1519057 & 688422 & 4.65 & 5.2109 & TST & \\
\hline CHEMBL3213287 & 688422 & 5.85 & 5.2608 & TRN & \\
\hline CHEMBL1506609 & 688422 & 4.65 & 5.2664 & TRN & \\
\hline CHEMBL1613550 & 688422 & 4.7 & 5.038 & TRN & \\
\hline CHEMBL1596353 & 688422 & 4.95 & 5.0411 & TRN & \\
\hline CHEMBL3193782 & 688422 & 6.5501 & 5.0097 & TST & \\
\hline CHEMBL1548453 & 688422 & 4.5 & 4.9859 & TRN & \\
\hline CHEMBL1498405 & 688422 & 5.0 & 5.7497 & TRN & \\
\hline CHEMBL1431676 & 688422 & 4.6 & 4.7797 & TRN & \\
\hline CHEMBL1405627 & 688422 & 4.95 & 5.0473 & TRN & \\
\hline CHEMBL1300364 & 688422 & 4.7 & 5.0249 & TRN & \\
\hline CHEMBL1536488 & 688422 & 4.95 & 5.1582 & TST & \\
\hline CHEMBL1197835 & 688422 & 4.9 & 5.1002 & TRN & \\
\hline CHEMBL1579327 & 688422 & 5.75 & 4.9961 & TRN & \\
\hline CHEMBL1536550 & 688422 & 4.75 & 4.8609 & TRN & \\
\hline CHEMBL1483884 & 688422 & 5.55 & 5.2268 & TST & \\
\hline CHEMBL1540742 & 688422 & 4.45 & 4.8477 & TST & \\
\hline CHEMBL1389138 & 688422 & 4.45 & 5.044 & TST & \\
\hline CHEMBL1556391 & 688422 & 4.45 & 5.1894 & TRN & \\
\hline CHEMBL1411070 & 688422 & 4.6 & 4.9477 & TST & \\
\hline CHEMBL1486475 & 688422 & 8.4949 & 5.54299 & 9999999999 & TRN \\
\hline CHEMBL1309521 & 688422 & 5.75 & 5.3152 & TRN & \\
\hline CHEMBL1544764 & 688422 & 5.45 & 5.5416 & TRN & \\
\hline CHEMBL1502869 & 688422 & 4.8 & 5.4225 & TRN & \\
\hline CHEMBL1526455 & 688422 & 8.3468 & 5.2443 & TRN & \\
\hline CHEMBL1543585 & 688422 & 5.5 & 5.1288 & TST & \\
\hline CHEMBL3196518 & 688422 & 6.2 & 5.6107 & TRN & \\
\hline CHEMBL1557961 & 688422 & 4.75 & 5.4086 & TST & \\
\hline CHEMBL1327501 & 688422 & 4.8 & 4.7786 & TRN & \\
\hline CHEMBL1336437 & 688422 & 5.3 & 5.291 & TST & \\
\hline CHEMBL3191025 & 688422 & 5.2 & 4.9344 & TST & \\
\hline CHEMBL1487202 & 688422 & 5.1 & 5.2296 & TRN & \\
\hline CHEMBL1501184 & 688422 & 4.7 & 5.0456 & TRN & \\
\hline CHEMBL1538651 & 688422 & 4.7 & 4.9328 & TRN & \\
\hline CHEMBL1613417 & 688422 & 4.45 & 5.5741 & TRN & \\
\hline CHEMBL1452279 & 688422 & 4.8 & 5.3032 & TRN & \\
\hline CHEMBL1353275 & 688422 & 4.6 & 5.2258 & TRN & \\
\hline CHEMBL1608149 & 688422 & 4.8 & 5.1886 & TRN & \\
\hline CHEMBL1439063 & 688422 & 7.1002 & 5.3784 & TRN & \\
\hline
\end{tabular}




\begin{tabular}{|c|c|c|c|c|c|}
\hline \multicolumn{6}{|c|}{ Supplemental Table S2.txt } \\
\hline CHEMBL3197331 & 688422 & 4.95 & 4.8954 & TRN & \\
\hline CHEMBL1568735 & 688422 & 4.9 & 5.041 & TRN & \\
\hline CHEMBL1509593 & 688422 & 6.95 & 5.6866 & TST & \\
\hline CHEMBL1371099 & 688422 & 5.05 & 5.4763 & TRN & \\
\hline CHEMBL1454739 & 688422 & 5.2 & 5.4207 & TRN & \\
\hline CHEMBL1529581 & 688422 & 4.85 & 5.2988 & TRN & \\
\hline CHEMBL3199347 & 688422 & 4.95 & 4.9898 & TST & \\
\hline CHEMBL1545632 & 688422 & 4.45 & 4.8867 & TST & \\
\hline CHEMBL1437883 & 688422 & 4.7 & 4.6292 & TRN & \\
\hline CHEMBL1200344 & 688422 & 5.65 & 5.4006 & TRN & \\
\hline CHEMBL3195220 & 688422 & 4.45 & 5.4565 & TST & \\
\hline CHEMBL1464327 & 688422 & 7.3002 & 6.6207 & TRN & \\
\hline CHEMBL95606 & 688422 & 6.0 & 6.6408 & TRN & \\
\hline CHEMBL1450386 & 688422 & 4.95 & 5.3713 & TRN & \\
\hline CHEMBL1513986 & 688422 & 7.7496 & 5.023 & TRN & \\
\hline CHEMBL1380415 & 688422 & 5.5 & 5.3034 & TST & \\
\hline CHEMBL1315611 & 688422 & 4.85 & 5.4005 & TRN & \\
\hline CHEMBL1463930 & 688422 & 4.6 & 5.4129 & TST & \\
\hline CHEMBL1590211 & 688422 & 5.05 & 5.0336 & TRN & \\
\hline CHEMBL1462264 & 688422 & 4.45 & 5.6541 & TRN & \\
\hline CHEMBL1612232 & 688422 & 5.1 & 5.181 & TRN & \\
\hline CHEMBL1328033 & 688422 & 7.699 & 5.2907 & TRN & \\
\hline CHEMBL1571153 & 688422 & 7.4498 & 5.1236 & TRN & \\
\hline CHEMBL1491340 & 688422 & 4.95 & 5.9682 & TST & \\
\hline CHEMBL1319996 & 688422 & 4.85 & 5.0054 & TRN & \\
\hline CHEMBL1504205 & 688422 & 4.85 & 4.8439 & TRN & \\
\hline CHEMBL1446036 & 688422 & 5.0 & 5.1683 & TRN & \\
\hline CHEMBL1365070 & 688422 & 4.95 & 5.1412 & TST & \\
\hline CHEMBL1503238 & 688422 & 8.3468 & 5.1239 & TST & \\
\hline CHEMBL1968739 & 688422 & 5.25 & 5.2118 & TRN & \\
\hline CHEMBL1342141 & 688422 & 4.9 & 5.5757 & TST & \\
\hline CHEMBL1575603 & 688422 & 4.7 & 5.1516 & TRN & \\
\hline CHEMBL1403075 & 688422 & 4.5 & 4.9434 & TRN & \\
\hline CHEMBL1357195 & 688422 & 8.7959 & 6.0083 & TST & \\
\hline CHEMBL1420862 & 688422 & 4.65 & 5.3038 & TST & \\
\hline CHEMBL1609195 & 688422 & 4.95 & 5.2874 & TRN & \\
\hline CHEMBL1347396 & 688422 & 4.65 & 5.54700 & 0000000001 & TRN \\
\hline CHEMBL1257076 & 688422 & 9.0969 & 5.3139 & TST & \\
\hline CHEMBL1529294 & 688422 & 4.8 & 4.5543 & TRN & \\
\hline CHEMBL1364547 & 688422 & 4.45 & 5.2065 & TRN & \\
\hline CHEMBL1511676 & 688422 & 8.0 & 4.9528 & TST & \\
\hline CHEMBL1512823 & 688422 & 4.65 & 5.5704 & TRN & \\
\hline CHEMBL1405458 & 688422 & 5.0 & 5.1352 & TRN & \\
\hline CHEMBL1586048 & 688422 & 4.45 & 5.0338 & TRN & \\
\hline CHEMBL1426146 & 688422 & 4.95 & 5.1897 & TRN & \\
\hline CHEMBL1527611 & 688422 & 4.45 & 5.2122 & TRN & \\
\hline CHEMBL1589006 & 688422 & 4.55 & 5.1417 & TRN & \\
\hline CHEMBL1607137 & 688422 & 4.65 & 4.8908 & TRN & \\
\hline
\end{tabular}




\begin{tabular}{|c|c|c|c|c|}
\hline \multicolumn{5}{|c|}{ Supplemental Table S2.txt } \\
\hline CHEMBL1601615 & 688422 & 6.1 & 5.2568 & TST \\
\hline CHEMBL1330478 & 688422 & 4.5 & 5.0653 & TRN \\
\hline CHEMBL1518159 & 688422 & 5.5 & 5.3386 & TST \\
\hline CHEMBL509256 & 688422 & 4.8 & 5.3897 & TRN \\
\hline CHEMBL1380903 & 688422 & 4.45 & 5.5089 & TRN \\
\hline CHEMBL1589538 & 688422 & 4.65 & 5.3944 & TRN \\
\hline CHEMBL1520015 & 688422 & 7.4498 & 5.4872 & TRN \\
\hline CHEMBL1411130 & 688422 & 4.45 & 4.9556 & TRN \\
\hline CHEMBL1428389 & 688422 & 4.8 & 5.5302 & TST \\
\hline CHEMBL1548206 & 688422 & 4.85 & 5.3291 & TRN \\
\hline CHEMBL1428307 & 688422 & 5.0 & 5.0237 & TRN \\
\hline CHEMBL1536637 & 688422 & 4.85 & 5.1693 & TRN \\
\hline CHEMBL1401065 & 688422 & 4.45 & 5.2073 & TRN \\
\hline CHEMBL1493171 & 688422 & 5.5 & 4.7904 & TRN \\
\hline CHEMBL1450971 & 688422 & 4.8 & 5.1864 & TRN \\
\hline CHEMBL1467973 & 688422 & 4.8 & 5.2002 & TRN \\
\hline CHEMBL10347 & 688422 & 6.0 & 5.5964 & TRN \\
\hline CHEMBL1522535 & 688422 & 6.2 & 5.5369 & TRN \\
\hline CHEMBL1308152 & 688422 & 4.5 & 5.1342 & TRN \\
\hline CHEMBL1551532 & 688422 & 7.4001 & 5.8658 & TRN \\
\hline CHEMBL1565648 & 688422 & 4.9 & 5.5998 & TRN \\
\hline CHEMBL1501035 & 688422 & 7.2503 & 5.2775 & TRN \\
\hline CHEMBL1607077 & 688422 & 4.85 & 5.3674 & TRN \\
\hline CHEMBL1558760 & 688422 & 4.75 & 4.7481 & TST \\
\hline CHEMBL1346004 & 688422 & 4.45 & 4.882 & TST \\
\hline CHEMBL1478718 & 688422 & 4.8 & 5.088 & TRN \\
\hline CHEMBL1422056 & 688422 & 6.7001 & 5.3787 & TST \\
\hline CHEMBL1563415 & 688422 & 4.75 & 5.3133 & TRN \\
\hline CHEMBL1429794 & 688422 & 5.9 & 4.7669 & TRN \\
\hline CHEMBL1472409 & 688422 & 4.9 & 4.9901 & TRN \\
\hline CHEMBL1462930 & 688422 & 4.45 & 4.9177 & TRN \\
\hline CHEMBL3191505 & 688422 & 6.1 & 5.4108 & TRN \\
\hline CHEMBL1532668 & 688422 & 4.9 & 5.5728 & TST \\
\hline CHEMBL1532048 & 688422 & 5.2 & 5.5459 & TRN \\
\hline CHEMBL1375417 & 688422 & 4.45 & 5.1456 & TST \\
\hline CHEMBL1435377 & 688422 & 7.699 & 5.3426 & TRN \\
\hline CHEMBL1439230 & 688422 & 4.5 & 5.0145 & TST \\
\hline CHEMBL1448471 & 688422 & 8.301 & 5.6792 & TST \\
\hline CHEMBL1342556 & 688422 & 4.75 & 5.3905 & TST \\
\hline CHEMBL1380943 & 688422 & 4.85 & 5.0139 & TST \\
\hline CHEMBL1556838 & 688422 & 4.45 & 5.3208 & TST \\
\hline CHEMBL1419786 & 688422 & 5.3 & 5.1185 & TRN \\
\hline CHEMBL1481939 & 688422 & 5.15 & 5.4393 & TRN \\
\hline CHEMBL1380951 & 688422 & 8.301 & 5.3237 & TRN \\
\hline CHEMBL1377385 & 688422 & 4.6 & 5.7868 & TRN \\
\hline CHEMBL1600406 & 688422 & 4.9 & 5.1364 & TRN \\
\hline CHEMBL1409486 & 688422 & 4.65 & 4.834 & TRN \\
\hline CHEMBL3209126 & 688422 & 7.4001 & 5.5862 & TRN \\
\hline
\end{tabular}




\begin{tabular}{|c|c|c|c|c|c|}
\hline \multicolumn{6}{|c|}{ Supplemental Table S2.txt } \\
\hline CHEMBL1431975 & 688422 & 4.65 & 5.1274 & TRN & \\
\hline CHEMBL1527779 & 688422 & 4.6 & 5.0205 & TRN & \\
\hline CHEMBL1587557 & 688422 & 4.65 & 5.2467 & TST & \\
\hline CHEMBL1457034 & 688422 & 5.0 & 4.9566 & TST & \\
\hline CHEMBL1365158 & 688422 & 8.3468 & 4.9633 & TRN & \\
\hline CHEMBL1513578 & 688422 & 4.85 & 4.8229 & TRN & \\
\hline CHEMBL1355044 & 688422 & 5.0 & 5.1223 & TRN & \\
\hline CHEMBL1604401 & 688422 & 4.55 & 4.7992 & TRN & \\
\hline CHEMBL1480928 & 688422 & 4.8 & 4.9578 & TRN & \\
\hline CHEMBL1598371 & 688422 & 5.0 & 4.8978 & TRN & \\
\hline CHEMBL1435798 & 688422 & 4.85 & 5.5121 & TRN & \\
\hline CHEMBL1413388 & 688422 & 5.75 & 5.4712 & TRN & \\
\hline CHEMBL1365456 & 688422 & 6.1 & 5.37799 & 9999999999 & TRN \\
\hline CHEMBL1476023 & 688422 & 8.3979 & 5.9469 & TRN & \\
\hline CHEMBL1327203 & 688422 & 4.9 & 5.2423 & TRN & \\
\hline CHEMBL1322073 & 688422 & 4.45 & 4.8854 & TRN & \\
\hline CHEMBL1366886 & 688422 & 4.45 & 4.8727 & TRN & \\
\hline CHEMBL1372862 & 688422 & 4.95 & 5.1722 & TRN & \\
\hline CHEMBL1302836 & 688422 & 5.85 & 5.0819 & TST & \\
\hline CHEMBL1579644 & 688422 & 4.7 & 5.0295 & TRN & \\
\hline CHEMBL1495169 & 688422 & 4.9 & 5.0687 & TRN & \\
\hline CHEMBL1370223 & 688422 & 4.75 & 5.4408 & TRN & \\
\hline CHEMBL1487246 & 688422 & 4.5 & 5.1094 & TRN & \\
\hline CHEMBL1547254 & 688422 & 4.7 & 5.1775 & TRN & \\
\hline CHEMBL1536232 & 688422 & 4.7 & 5.6263 & TST & \\
\hline CHEMBL1509554 & 688422 & 5.2 & 5.606 & TST & \\
\hline CHEMBL1446949 & 688422 & 5.55 & 5.5811 & TST & \\
\hline CHEMBL1499908 & 688422 & 5.55 & 5.3934 & TST & \\
\hline CHEMBL1337193 & 688422 & 4.6 & 5.1286 & TRN & \\
\hline CHEMBL1475990 & 688422 & 4.45 & 4.6448 & TRN & \\
\hline CHEMBL1535131 & 688422 & 8.0 & 5.1629 & TRN & \\
\hline CHEMBL1452475 & 688422 & 4.95 & 5.1013 & TRN & \\
\hline CHEMBL1437743 & 688422 & 4.9 & 5.1643 & TRN & \\
\hline CHEMBL1503781 & 688422 & 4.45 & 4.9757 & TRN & \\
\hline CHEMBL1472998 & 688422 & 4.6 & 5.0406 & TST & \\
\hline CHEMBL1496880 & 688422 & 7.5003 & 5.4033 & TRN & \\
\hline CHEMBL1547780 & 688422 & 4.95 & 4.8958 & TRN & \\
\hline CHEMBL1613055 & 688422 & 5.6 & 5.0548 & TRN & \\
\hline CHEMBL1580029 & 688422 & 5.1 & 5.1806 & TST & \\
\hline CHEMBL1425250 & 688422 & 5.1 & 5.2619 & TST & \\
\hline CHEMBL1478677 & 688422 & 5.0 & 5.3699 & TRN & \\
\hline CHEMBL 2358966 & 688422 & 5.2 & 5.2529 & TRN & \\
\hline CHEMBL1454577 & 688422 & 5.0 & 4.885 & TRN & \\
\hline CHEMBL1396003 & 688422 & 4.8 & 5.2961 & TRN & \\
\hline CHEMBL1382232 & 688422 & 4.85 & 5.0626 & TRN & \\
\hline CHEMBL1327085 & 688422 & 4.55 & 5.5912 & TST & \\
\hline CHEMBL 1343282 & 688422 & 4.85 & 5.2813 & TRN & \\
\hline CHEMBL1387781 & 688422 & 4.5 & 5.2691 & TST & \\
\hline
\end{tabular}




\begin{tabular}{|c|c|c|c|c|c|}
\hline \multirow[b]{2}{*}{ CHEMBL1596700 } & \multicolumn{5}{|c|}{ suppsenterlicas to } \\
\hline & 688422 & 4.85 & 4.9397 & TRN & \\
\hline CHEMBL1420729 & 688422 & 4.75 & 5.1893 & TRN & \\
\hline CHEMBL1584954 & 688422 & 4.9 & 4.902 & TRN & \\
\hline CHEMBL1988708 & 688422 & 5.5 & 5.3367 & TRN & \\
\hline CHEMBL1451772 & 688422 & 4.45 & 4.8763 & TRN & \\
\hline CHEMBL1348406 & 688422 & 4.95 & 5.3893 & TRN & \\
\hline CHEMBL1319979 & 688422 & 4.9 & 5.1918 & TRN & \\
\hline CHEMBL1591221 & 688422 & 4.4 & 5.2438 & TRN & \\
\hline CHEMBL1364044 & 688422 & 4.95 & 5.7834 & TRN & \\
\hline CHEMBL1365970 & 688422 & 4.45 & 4.9788 & TST & \\
\hline CHEMBL1415920 & 688422 & 4.6 & 5.067 & TRN & \\
\hline CHEMBL3197217 & 688422 & 4.65 & 4.8603 & TRN & \\
\hline CHEMBL577102 & 688422 & 4.8 & 5.1579 & TRN & \\
\hline CHEMBL1415693 & 688422 & 4.85 & 5.2687 & TRN & \\
\hline CHEMBL1302146 & 688422 & 4.95 & 5.2884 & TRN & \\
\hline CHEMBL1479786 & 688422 & 4.7 & 5.1828 & TRN & \\
\hline CHEMBL1320229 & 688422 & 5.9 & 5.3055 & TRN & \\
\hline CHEMBL1452556 & 688422 & 5.95 & 5.5795 & TRN & \\
\hline CHEMBL1967772 & 688422 & 5.1 & 5.26399 & 9999999999 & TRN \\
\hline CHEMBL1319230 & 688422 & 4.45 & 5.3556 & TRN & \\
\hline CHEMBL1379071 & 688422 & 5.4 & 4.7804 & TRN & \\
\hline CHEMBL1457324 & 688422 & 5.3 & 4.8626 & TRN & \\
\hline CHEMBL1333504 & 688422 & 4.95 & 5.20299 & 9999999999 & TST \\
\hline CHEMBL1568474 & 688422 & 4.45 & 5.2891 & TST & \\
\hline CHEMBL1516882 & 688422 & 4.7 & 5.3293 & TRN & \\
\hline CHEMBL1480978 & 688422 & 4.45 & 5.2835 & TST & \\
\hline CHEMBL1544983 & 688422 & 4.8 & 5.4002 & TRN & \\
\hline CHEMBL1524779 & 688422 & 4.5 & 5.1551 & TRN & \\
\hline CHEMBL3192021 & 688422 & 4.75 & 5.3325 & TRN & \\
\hline CHEMBL576412 & 688422 & 4.9 & 5.0713 & TRN & \\
\hline CHEMBL1381040 & 688422 & 4.85 & 5.2843 & TRN & \\
\hline CHEMBL3190901 & 688422 & 4.9 & 5.2858 & TRN & \\
\hline CHEMBL1540231 & 688422 & 4.7 & 5.2298 & TRN & \\
\hline CHEMBL1597943 & 688422 & 4.45 & 5.2027 & TRN & \\
\hline CHEMBL1594650 & 688422 & 4.6 & 5.1275 & TRN & \\
\hline CHEMBL1505088 & 688422 & 5.4 & 5.1984 & TRN & \\
\hline CHEMBL1471305 & 688422 & 4.95 & 5.3892 & TRN & \\
\hline CHEMBL3197536 & 688422 & 4.85 & 5.5251 & TRN & \\
\hline CHEMBL1353474 & 688422 & 5.65 & 5.5099 & TRN & \\
\hline CHEMBL1598836 & 688422 & 4.55 & 5.3778 & TRN & \\
\hline CHEMBL1607924 & 688422 & 5.05 & 5.3072 & TST & \\
\hline CHEMBL1587150 & 688422 & 4.6 & 5.6174 & TRN & \\
\hline CHEMBL1586234 & 688422 & 5.0 & 5.1017 & TRN & \\
\hline CHEMBL1431620 & 688422 & 4.5 & 5.1092 & TST & \\
\hline CHEMBL1328764 & 688422 & 7.9508 & 5.41700 & 0000000001 & TRN \\
\hline CHEMBL1558905 & 688422 & 7.0501 & 5.4236 & TRN & \\
\hline CHEMBL1323389 & 688422 & 5.95 & 5.5618 & TRN & \\
\hline CHEMBL1608505 & 688422 & 4.7 & 5.6425 & TRN & \\
\hline
\end{tabular}




\begin{tabular}{|c|c|c|c|c|c|}
\hline \multicolumn{6}{|c|}{ Supplemental Table S2.txt } \\
\hline CHEMBL1403779 & 688422 & 4.65 & 5.1104 & TST & \\
\hline CHEMBL1455579 & 688422 & 5.05 & 5.3326 & TRN & \\
\hline CHEMBL1376392 & 688422 & 4.45 & 5.3915 & TRN & \\
\hline CHEMBL1454870 & 688422 & 4.5 & 4.9741 & TRN & \\
\hline CHEMBL1423975 & 688422 & 8.301 & 5.4475 & TRN & \\
\hline CHEMBL1418959 & 688422 & 4.75 & 5.0408 & TRN & \\
\hline CHEMBL1428566 & 688422 & 5.25 & 5.1863 & TRN & \\
\hline CHEMBL1485198 & 688422 & 5.0 & 4.7213 & TRN & \\
\hline CHEMBL1457337 & 688422 & 4.45 & 5.7121 & TST & \\
\hline CHEMBL1589063 & 688422 & 5.0 & 5.2751 & TRN & \\
\hline CHEMBL1604945 & 688422 & 5.5 & 5.6128 & TRN & \\
\hline CHEMBL1299420 & 688422 & 4.6 & 5.1916 & TRN & \\
\hline CHEMBL1320310 & 688422 & 6.0 & 5.819 & TST & \\
\hline CHEMBL 3197284 & 688422 & 4.75 & 5.6073 & TST & \\
\hline CHEMBL 1483000 & 688422 & 4.8 & 5.3568 & TRN & \\
\hline CHEMBL3209257 & 688422 & 4.85 & 5.0038 & TRN & \\
\hline CHEMBL1357564 & 688422 & 4.95 & 5.2734 & TRN & \\
\hline CHEMBL1587208 & 688422 & 5.25 & 5.1921 & TST & \\
\hline CHEMBL1463102 & 688422 & 7.8996 & 5.1907 & TST & \\
\hline CHEMBL 1548070 & 688422 & 4.45 & 5.36700 & 0000000001 & TRN \\
\hline CHEMBL1597855 & 688422 & 4.5 & 5.4232 & TST & \\
\hline CHEMBL1432010 & 688422 & 4.9 & 5.4272 & TRN & \\
\hline CHEMBL1595646 & 688422 & 4.8 & 4.9922 & TRN & \\
\hline CHEMBL1552175 & 688422 & 4.45 & 5.544 & TRN & \\
\hline CHEMBL1520067 & 688422 & 5.55 & 4.8479 & TRN & \\
\hline CHEMBL1372218 & 688422 & 4.85 & 5.08899 & 99999999995 & TRN \\
\hline CHEMBL1340626 & 688422 & 4.65 & 5.4056 & TRN & \\
\hline CHEMBL1401243 & 688422 & 4.9 & 4.7016 & TRN & \\
\hline CHEMBL1463885 & 688422 & 4.45 & 4.9355 & TRN & \\
\hline CHEMBL1457695 & 688422 & 4.7 & 5.0518 & TRN & \\
\hline CHEMBL1312365 & 688422 & 4.65 & 5.1209 & TRN & \\
\hline CHEMBL1359750 & 688422 & 4.8 & 5.0113 & TRN & \\
\hline CHEMBL1544544 & 688422 & 6.95 & 5.3642 & TRN & \\
\hline CHEMBL1480192 & 688422 & 5.25 & 5.1503 & TRN & \\
\hline CHEMBL1572954 & 688422 & 5.05 & 5.1864 & TRN & \\
\hline CHEMBL1337065 & 688422 & 7.8508 & 6.1578 & TRN & \\
\hline CHEMBL1514149 & 688422 & 4.8 & 4.676 & TRN & \\
\hline CHEMBL1540525 & 688422 & 4.75 & 5.0899 & TRN & \\
\hline CHEMBL1397454 & 688422 & 4.95 & 4.9655 & TRN & \\
\hline CHEMBL1355040 & 688422 & 5.6 & 5.9168 & TST & \\
\hline CHEMBL1540509 & 688422 & 6.95 & 5.4651 & TRN & \\
\hline CHEMBL3198993 & 688422 & 7.4498 & 5.5161 & TST & \\
\hline CHEMBL1560645 & 688422 & 5.15 & 5.477 & TST & \\
\hline CHEMBL1571752 & 688422 & 7.8508 & 5.5021 & TRN & \\
\hline CHEMBL1374715 & 688422 & 5.95 & 5.2352 & TST & \\
\hline CHEMBL1381570 & 688422 & 4.95 & 5.3045 & TST & \\
\hline CHEMBL1505902 & 688422 & 5.45 & 5.5305 & TST & \\
\hline CHEMBL1335644 & 688422 & 4.45 & 4.9828 & TRN & \\
\hline
\end{tabular}




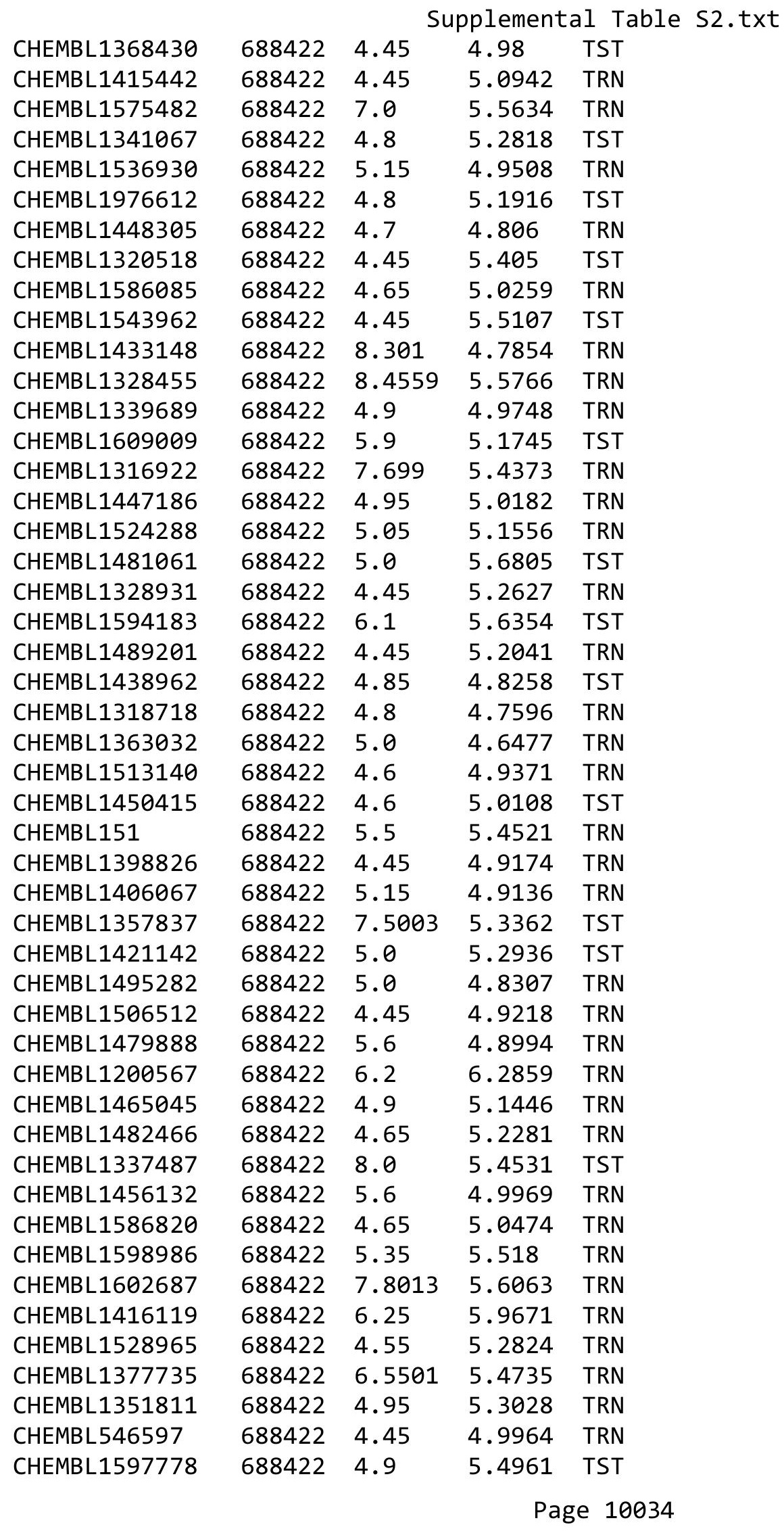




\begin{tabular}{|c|c|c|c|c|c|}
\hline \multicolumn{6}{|c|}{ Supplemental Table S2.txt } \\
\hline CHEMBL556398 & 688422 & 4.9 & 4.6632 & TRN & \\
\hline CHEMBL1513638 & 688422 & 4.45 & 4.792 & TRN & \\
\hline CHEMBL1500630 & 688422 & 4.9 & 5.3524 & TST & \\
\hline CHEMBL1374437 & 688422 & 4.5 & 5.059 & TRN & \\
\hline CHEMBL1430074 & 688422 & 4.95 & 5.0113 & TST & \\
\hline CHEMBL81935 & 688422 & 6.5 & 5.26200 & 00000000005 & TRN \\
\hline CHEMBL1393029 & 688422 & 4.5 & 5.3365 & TRN & \\
\hline CHEMBL1493812 & 688422 & 4.65 & 5.2494 & TST & \\
\hline CHEMBL1462070 & 688422 & 4.6 & 4.6728 & TST & \\
\hline CHEMBL1423758 & 688422 & 5.0 & 5.0925 & TST & \\
\hline CHEMBL1588332 & 688422 & 4.7 & 5.7466 & TRN & \\
\hline CHEMBL1471973 & 688422 & 4.55 & 5.3044 & TST & \\
\hline CHEMBL1334792 & 688422 & 6.5501 & 5.1607 & TRN & \\
\hline CHEMBL1595524 & 688422 & 4.6 & 4.9105 & TRN & \\
\hline CHEMBL1335254 & 688422 & 4.6 & 4.6703 & TRN & \\
\hline CHEMBL1302359 & 688422 & 4.6 & 5.343 & TRN & \\
\hline CHEMBL1423321 & 688422 & 5.35 & 5.388 & TST & \\
\hline CHEMBL1476594 & 688422 & 7.699 & 5.5335 & TRN & \\
\hline CHEMBL1578846 & 688422 & 8.2518 & 5.9357 & TRN & \\
\hline CHEMBL1556350 & 688422 & 4.6 & 5.371 & TRN & \\
\hline CHEMBL3212733 & 688422 & 8.0506 & 5.4638 & TST & \\
\hline CHEMBL3191762 & 688422 & 5.6 & 5.0174 & TRN & \\
\hline CHEMBL1363111 & 688422 & 4.45 & 5.4421 & TRN & \\
\hline CHEMBL1489067 & 688422 & 4.65 & 5.3258 & TRN & \\
\hline CHEMBL1534805 & 688422 & 6.05 & 5.5527 & TRN & \\
\hline CHEMBL1330924 & 688422 & 4.45 & 5.0561 & TRN & \\
\hline CHEMBL1310780 & 688422 & 4.75 & 5.1991 & TST & \\
\hline CHEMBL1498887 & 688422 & 5.45 & 4.7904 & TRN & \\
\hline CHEMBL1569572 & 688422 & 5.5 & 5.3547 & TRN & \\
\hline CHEMBL1969161 & 688422 & 6.4 & 5.3321 & TST & \\
\hline CHEMBL1431604 & 688422 & 4.6 & 4.995 & TST & \\
\hline CHEMBL1533459 & 688422 & 4.85 & 5.0321 & TRN & \\
\hline CHEMBL1563714 & 688422 & 4.75 & 5.6663 & TRN & \\
\hline CHEMBL1536006 & 688422 & 4.95 & 5.0604 & TRN & \\
\hline CHEMBL1304887 & 688422 & 4.8 & 5.25700 & 0000000001 & TRN \\
\hline CHEMBL1571672 & 688422 & 6.5501 & 5.5351 & TRN & \\
\hline CHEMBL1391298 & 688422 & 5.5 & 5.234 & TRN & \\
\hline CHEMBL1495412 & 688422 & 4.85 & 5.7675 & TST & \\
\hline CHEMBL1438963 & 688422 & 7.9508 & 5.9169 & TRN & \\
\hline CHEMBL1587152 & 688422 & 4.9 & 4.7586 & TST & \\
\hline CHEMBL1371940 & 688422 & 4.45 & 5.1048 & TST & \\
\hline CHEMBL1508431 & 688422 & 4.45 & 5.0377 & TST & \\
\hline CHEMBL1319602 & 688422 & 4.45 & 5.4559 & TST & \\
\hline CHEMBL1525651 & 688422 & 4.95 & 5.3173 & TRN & \\
\hline CHEMBL1608954 & 688422 & 4.45 & 4.8858 & TRN & \\
\hline CHEMBL1476954 & 688422 & 5.65 & 5.1341 & TRN & \\
\hline CHEMBL1511191 & 688422 & 4.75 & 5.2463 & TRN & \\
\hline CHEMBL1514593 & 688422 & 4.45 & 5.3141 & TRN & \\
\hline
\end{tabular}




\begin{tabular}{|c|c|c|c|c|}
\hline & & & pplement & al Ta \\
\hline CHEMBL1540488 & 688422 & 4.45 & 5.483 & TST \\
\hline CHEMBL1568303 & 688422 & 5.0 & 5.2847 & TRN \\
\hline CHEMBL1323385 & 688422 & 4.45 & 5.0756 & TRN \\
\hline CHEMBL3211289 & 688422 & 4.45 & 5.5387 & TRN \\
\hline CHEMBL1435438 & 688422 & 6.35 & 5.3982 & TRN \\
\hline CHEMBL1548597 & 688422 & 6.15 & 5.3418 & TRN \\
\hline CHEMBL1491253 & 688422 & 4.95 & 5.0749 & TRN \\
\hline CHEMBL1520591 & 688422 & 4.45 & 4.918 & TRN \\
\hline CHEMBL1325024 & 688422 & 6.8499 & 5.5437 & TRN \\
\hline CHEMBL1320262 & 688422 & 4.6 & 5.1541 & TRN \\
\hline CHEMBL1520142 & 688422 & 5.0 & 5.0959 & TRN \\
\hline CHEMBL1329248 & 688422 & 5.85 & 5.3239 & TRN \\
\hline CHEMBL1342298 & 688422 & 4.45 & 5.4826 & TRN \\
\hline CHEMBL1389145 & 688422 & 4.85 & 5.2457 & TRN \\
\hline CHEMBL1395164 & 688422 & 6.45 & 5.2915 & TRN \\
\hline CHEMBL3191246 & 688422 & 5.35 & 5.4138 & TRN \\
\hline CHEMBL1485898 & 688422 & 4.85 & 5.2834 & TRN \\
\hline CHEMBL1539702 & 688422 & 4.5 & 5.1007 & TST \\
\hline CHEMBL1528393 & 688422 & 4.6 & 5.0673 & TST \\
\hline CHEMBL1311893 & 688422 & 7.7496 & 5.4837 & TRN \\
\hline CHEMBL1569501 & 688422 & 4.85 & 4.7495 & TRN \\
\hline CHEMBL1379082 & 688422 & 5.05 & 5.3046 & TRN \\
\hline CHEMBL1508535 & 688422 & 5.25 & 5.256 & TRN \\
\hline CHEMBL1383269 & 688422 & 4.8 & 4.9958 & TST \\
\hline CHEMBL1467751 & 688422 & 6.05 & 5.4664 & TST \\
\hline CHEMBL1407033 & 688422 & 4.7 & 5.3349 & TRN \\
\hline CHEMBL1587516 & 688422 & 4.9 & 5.4611 & TRN \\
\hline CHEMBL1363056 & 688422 & 4.5 & 4.6853 & TRN \\
\hline CHEMBL 3209157 & 688422 & 5.3 & 5.0439 & TRN \\
\hline CHEMBL1534392 & 688422 & 7.3497 & 5.0186 & TST \\
\hline CHEMBL1410494 & 688422 & 4.8 & 5.0173 & TRN \\
\hline CHEMBL1366622 & 688422 & 4.85 & 5.5043 & TRN \\
\hline CHEMBL1504609 & 688422 & 4.9 & 4.8435 & TRN \\
\hline CHEMBL1375327 & 688422 & 7.5003 & 5.3684 & TRN \\
\hline CHEMBL1384028 & 688422 & 4.45 & 5.2303 & TRN \\
\hline CHEMBL1302920 & 688422 & 4.75 & 5.1472 & TRN \\
\hline CHEMBL1337641 & 688422 & 4.75 & 4.8548 & TRN \\
\hline CHEMBL1351610 & 688422 & 4.85 & 5.0325 & TST \\
\hline CHEMBL1439585 & 688422 & 5.05 & 5.5507 & TRN \\
\hline CHEMBL1472567 & 688422 & 5.25 & 5.6954 & TRN \\
\hline CHEMBL1493339 & 688422 & 5.15 & 5.4133 & TRN \\
\hline CHEMBL1597869 & 688422 & 5.5 & 5.7316 & TST \\
\hline CHEMBL1301760 & 688422 & 4.8 & 4.8122 & TRN \\
\hline CHEMBL1504258 & 688422 & 4.45 & 5.7352 & TRN \\
\hline CHEMBL1572263 & 688422 & 4.75 & 4.9418 & TRN \\
\hline CHEMBL1347966 & 688422 & 5.5 & 5.8288 & TST \\
\hline CHEMBL1544121 & 688422 & 5.0 & 4.9309 & TRN \\
\hline CHEMBL1605353 & 688422 & 4.95 & 5.218 & TRN \\
\hline
\end{tabular}




\begin{tabular}{|c|c|c|c|c|}
\hline \multicolumn{5}{|c|}{ Supplemental Table S2.txt } \\
\hline CHEMBL1398165 & 688422 & 4.45 & 5.1808 & TRN \\
\hline CHEMBL1384458 & 688422 & 4.85 & 5.3992 & TRN \\
\hline CHEMBL1392507 & 688422 & 4.55 & 5.5178 & TRN \\
\hline CHEMBL1470391 & 688422 & 4.75 & 5.1163 & TRN \\
\hline CHEMBL1300610 & 688422 & 4.8 & 5.3265 & TST \\
\hline CHEMBL1488460 & 688422 & 4.5 & 5.1902 & TRN \\
\hline CHEMBL1368107 & 688422 & 4.9 & 5.4541 & TRN \\
\hline CHEMBL1612493 & 688422 & 4.55 & 5.4206 & TRN \\
\hline CHEMBL1322119 & 688422 & 4.85 & 5.4216 & TRN \\
\hline CHEMBL1567419 & 688422 & 8.1024 & 4.9412 & TST \\
\hline CHEMBL1551123 & 688422 & 8.3468 & 5.8352 & TRN \\
\hline CHEMBL1415287 & 688422 & 5.85 & 5.8411 & TRN \\
\hline CHEMBL1551349 & 688422 & 4.65 & 5.0593 & TRN \\
\hline CHEMBL1548570 & 688422 & 4.8 & 5.1479 & TRN \\
\hline CHEMBL1432417 & 688422 & 4.45 & 5.3514 & TRN \\
\hline CHEMBL1523600 & 688422 & 5.1 & 5.3357 & TST \\
\hline CHEMBL1417937 & 688422 & 4.8 & 5.2701 & TRN \\
\hline CHEMBL1354897 & 688422 & 9.0 & 5.2695 & TRN \\
\hline CHEMBL1450237 & 688422 & 5.9 & 5.3697 & TST \\
\hline CHEMBL1447419 & 688422 & 5.0 & 5.351 & TRN \\
\hline CHEMBL363131 & 688422 & 4.75 & 5.2751 & TRN \\
\hline CHEMBL3209689 & 688422 & 6.0 & 5.2328 & TRN \\
\hline CHEMBL1442714 & 688422 & 5.95 & 5.2569 & TRN \\
\hline CHEMBL1455097 & 688422 & 6.25 & 5.5923 & TRN \\
\hline CHEMBL1603947 & 688422 & 7.15 & 5.2546 & TRN \\
\hline CHEMBL1322679 & 688422 & 5.15 & 5.175 & TRN \\
\hline CHEMBL1322834 & 688422 & 4.45 & 5.4045 & TRN \\
\hline CHEMBL1444967 & 688422 & 4.5 & 5.3939 & TRN \\
\hline CHEMBL1424480 & 688422 & 4.55 & 5.1425 & TRN \\
\hline CHEMBL1485325 & 688422 & 7.0 & 5.223 & TRN \\
\hline CHEMBL1881714 & 688422 & 5.1 & 4.613 & TRN \\
\hline CHEMBL1513885 & 688422 & 6.6499 & 5.6192 & TRN \\
\hline CHEMBL1390166 & 688422 & 4.45 & 5.4613 & TRN \\
\hline CHEMBL1320069 & 688422 & 4.5 & 4.8058 & TRN \\
\hline CHEMBL1354700 & 688422 & 4.8 & 5.1517 & TRN \\
\hline CHEMBL1392358 & 688422 & 4.65 & 5.2051 & TST \\
\hline CHEMBL1560982 & 688422 & 4.85 & 5.6034 & TRN \\
\hline CHEMBL1313351 & 688422 & 4.9 & 5.2919 & TRN \\
\hline CHEMBL1578368 & 688422 & 4.8 & 5.0812 & TRN \\
\hline CHEMBL1392922 & 688422 & 4.65 & 5.4666 & TRN \\
\hline CHEMBL1328648 & 688422 & 6.25 & 5.1908 & TST \\
\hline CHEMBL1481486 & 688422 & 4.55 & 5.3958 & TRN \\
\hline CHEMBL1412609 & 688422 & 4.8 & 5.193 & TRN \\
\hline CHEMBL3211789 & 688422 & 4.85 & 5.7035 & TRN \\
\hline CHEMBL1455024 & 688422 & 4.45 & 4.717 & TRN \\
\hline CHEMBL1334574 & 688422 & 4.45 & 5.0981 & TRN \\
\hline CHEMBL1377243 & 688422 & 5.15 & 5.3864 & TRN \\
\hline CHEMBL1466398 & 688422 & 4.75 & 5.58299 & 9999999999 \\
\hline & & & & 10037 \\
\hline
\end{tabular}

TRN 


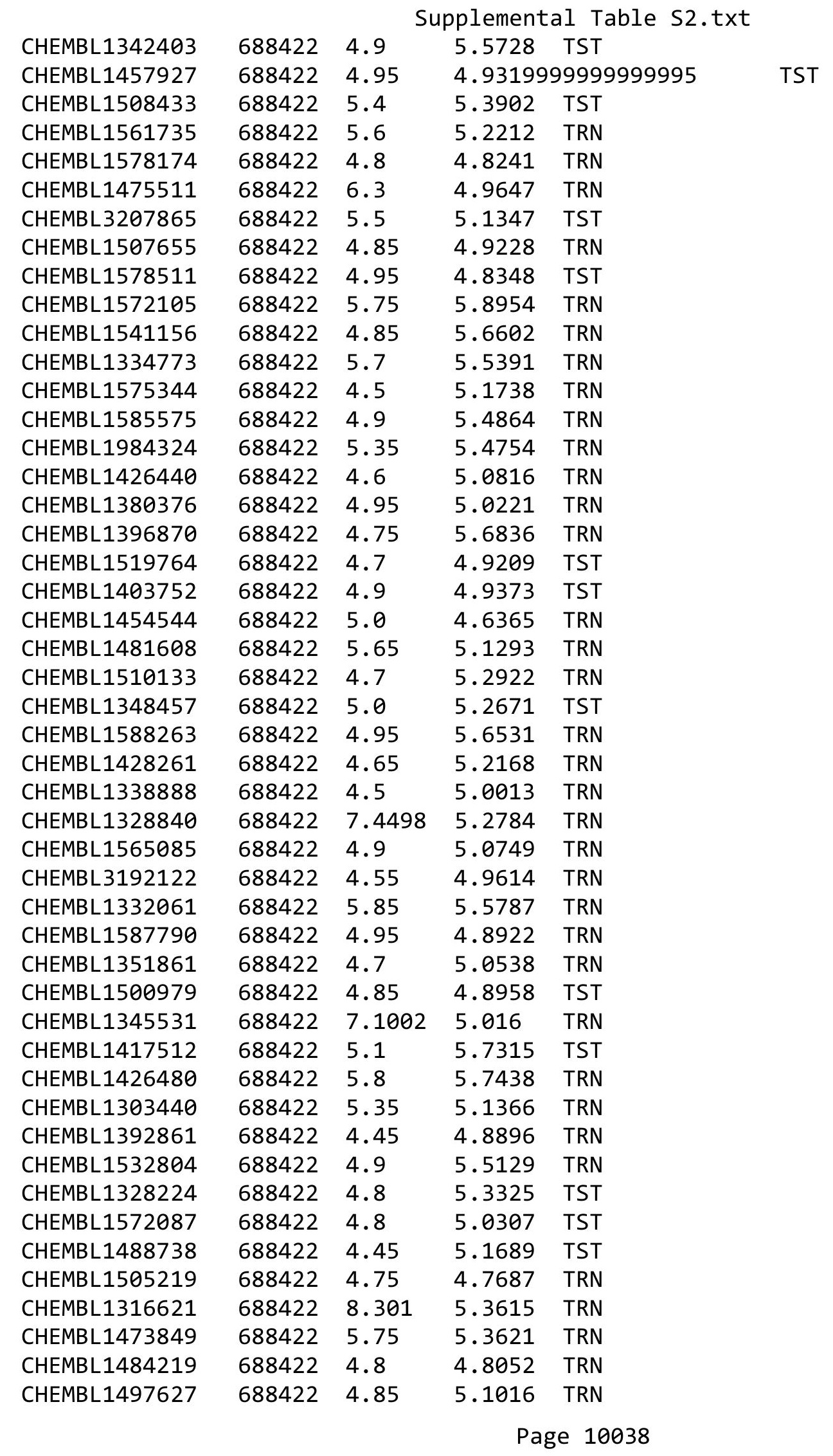




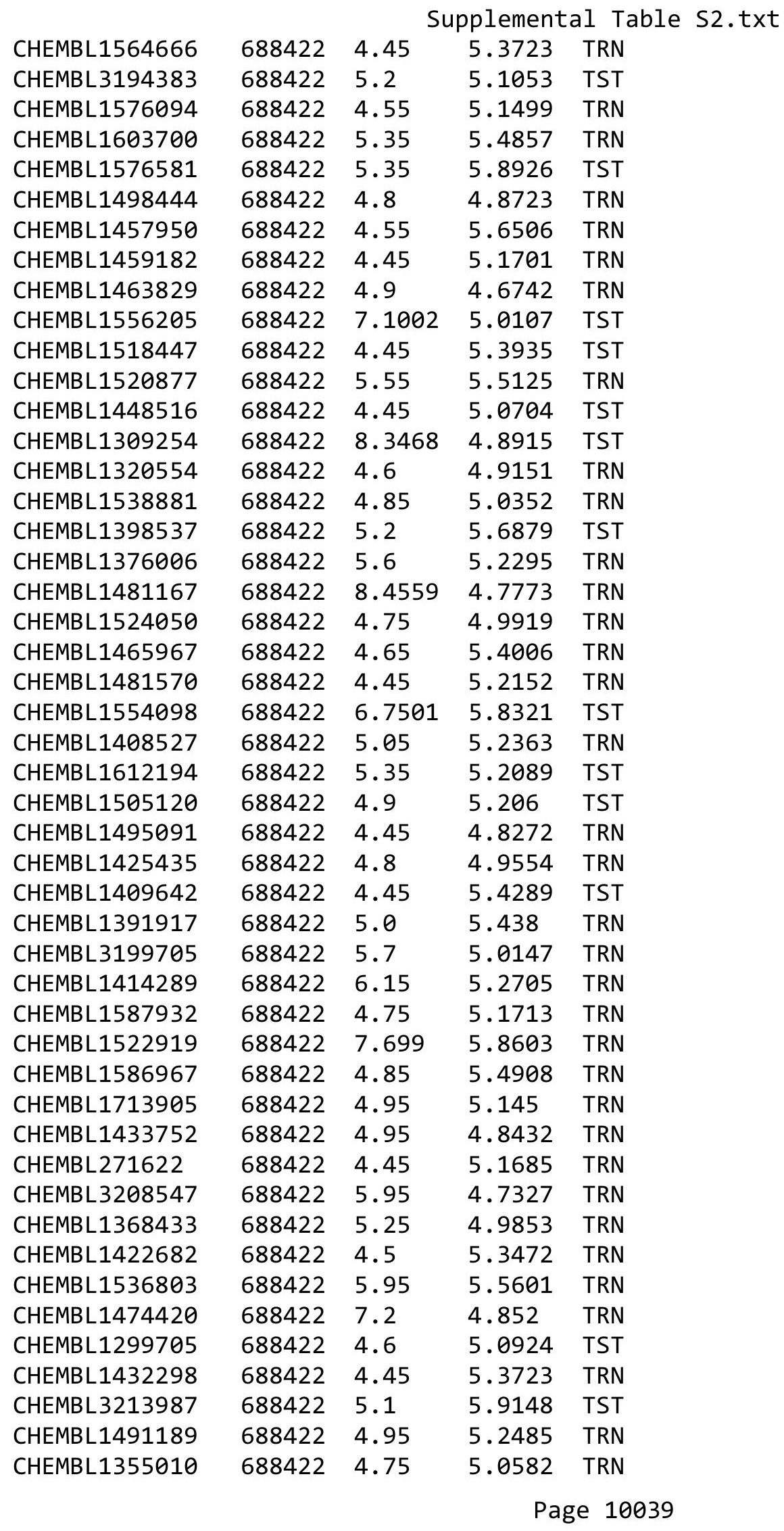




\begin{tabular}{|c|c|c|c|c|c|}
\hline \multicolumn{6}{|c|}{ Supplemental Table S2.txt } \\
\hline CHEMBL1411547 & 688422 & 5.4 & 5.2085 & TRN & \\
\hline CHEMBL8197 & 688422 & 5.95 & 5.5784 & TRN & \\
\hline CHEMBL1474293 & 688422 & 4.45 & 5.1964 & TRN & \\
\hline CHEMBL1348172 & 688422 & 4.95 & 5.5149 & TRN & \\
\hline CHEMBL3192696 & 688422 & 4.5 & 5.4015 & TRN & \\
\hline CHEMBL1398620 & 688422 & 4.5 & 4.8489 & TRN & \\
\hline CHEMBL1316142 & 688422 & 7.3002 & 5.2235 & TRN & \\
\hline CHEMBL1510714 & 688422 & 7.0501 & 5.2176 & TRN & \\
\hline CHEMBL1607143 & 688422 & 5.7 & 5.0203 & TRN & \\
\hline CHEMBL1434900 & 688422 & 4.45 & 5.4699 & TST & \\
\hline CHEMBL1527705 & 688422 & 4.75 & 4.7358 & TRN & \\
\hline CHEMBL1607452 & 688422 & 4.8 & 4.9749 & TRN & \\
\hline CHEMBL1312231 & 688422 & 5.3 & 4.4482 & TRN & \\
\hline CHEMBL1385994 & 688422 & 6.5 & 5.4668 & TST & \\
\hline CHEMBL1505931 & 688422 & 5.2 & 5.0203 & TRN & \\
\hline CHEMBL1351148 & 688422 & 6.5 & 4.7924 & TRN & \\
\hline CHEMBL1997347 & 688422 & 5.2 & 5.4685 & TRN & \\
\hline CHEMBL282489 & 688422 & 4.7 & 5.2075 & TST & \\
\hline CHEMBL1429728 & 688422 & 4.7 & 5.0418 & TST & \\
\hline CHEMBL1446520 & 688422 & 7.3497 & 5.473 & TST & \\
\hline CHEMBL1508728 & 688422 & 4.75 & 5.2069 & TRN & \\
\hline CHEMBL1522651 & 688422 & 4.85 & 5.1075 & TRN & \\
\hline CHEMBL1533100 & 688422 & 8.1024 & 5.26399 & 9999999999 & TRN \\
\hline CHEMBL1567775 & 688422 & 4.45 & 5.4302 & TRN & \\
\hline CHEMBL1574179 & 688422 & 8.2007 & 6.3506 & TST & \\
\hline CHEMBL1577208 & 688422 & 4.5 & 5.5325 & TRN & \\
\hline CHEMBL1607156 & 688422 & 4.9 & 5.2232 & TST & \\
\hline CHEMBL1421459 & 688422 & 4.9 & 5.0186 & TST & \\
\hline CHEMBL1318976 & 688422 & 4.75 & 5.1274 & TRN & \\
\hline CHEMBL1307715 & 688422 & 4.6 & 4.7821 & TRN & \\
\hline CHEMBL 2000945 & 688422 & 6.5 & 5.1982 & TRN & \\
\hline CHEMBL1303121 & 688422 & 7.3497 & 5.2784 & TRN & \\
\hline CHEMBL1594208 & 688422 & 5.0 & 5.8918 & TST & \\
\hline CHEMBL1599138 & 688422 & 4.6 & 5.3767 & TRN & \\
\hline CHEMBL1352521 & 688422 & 5.25 & 5.53700 & 0000000001 & TST \\
\hline CHEMBL1551418 & 688422 & 6.0 & 5.7982 & TRN & \\
\hline CHEMBL1494907 & 688422 & 4.9 & 4.885 & TRN & \\
\hline CHEMBL1471737 & 688422 & 4.7 & 4.8515 & TST & \\
\hline CHEMBL1523475 & 688422 & 4.8 & 4.8801 & TRN & \\
\hline CHEMBL1304442 & 688422 & 4.5 & 5.1076 & TRN & \\
\hline CHEMBL1400531 & 688422 & 4.9 & 5.1406 & TRN & \\
\hline CHEMBL1371920 & 688422 & 7.699 & 5.2998 & TRN & \\
\hline CHEMBL1413660 & 688422 & 5.15 & 5.5411 & TRN & \\
\hline CHEMBL1347626 & 688422 & 5.1 & 4.9276 & TST & \\
\hline CHEMBL1604864 & 688422 & 4.5 & 4.9848 & TRN & \\
\hline CHEMBL1349040 & 688422 & 4.85 & 5.2685 & TRN & \\
\hline CHEMBL1490638 & 688422 & 4.95 & 5.0695 & TRN & \\
\hline CHEMBL1426407 & 688422 & 5.3 & 5.3625 & TRN & \\
\hline
\end{tabular}




\begin{tabular}{|c|c|c|c|c|c|}
\hline \multicolumn{6}{|c|}{ Supplemental Table S2.txt } \\
\hline CHEMBL1370100 & 688422 & 4.45 & 5.1231 & TRN & \\
\hline CHEMBL1416138 & 688422 & 4.8 & 5.3508 & TRN & \\
\hline CHEMBL1464172 & 688422 & 5.0 & 5.3673 & TRN & \\
\hline CHEMBL1565911 & 688422 & 7.0 & 5.9332 & TST & \\
\hline CHEMBL1604389 & 688422 & 4.45 & 5.2985 & TRN & \\
\hline CHEMBL1533867 & 688422 & 4.6 & 4.9109 & TRN & \\
\hline CHEMBL1402832 & 688422 & 4.85 & 4.9269 & TRN & \\
\hline CHEMBL1447566 & 688422 & 4.7 & 5.2853 & TRN & \\
\hline CHEMBL1349461 & 688422 & 5.15 & 4.9675 & TST & \\
\hline CHEMBL1407463 & 688422 & 4.95 & 5.1252 & TST & \\
\hline CHEMBL3214537 & 688422 & 4.45 & 5.53799 & 9999999999 & TRN \\
\hline CHEMBL1348015 & 688422 & 7.0501 & 5.2859 & TST & \\
\hline CHEMBL1317708 & 688422 & 8.4559 & 5.1522 & TRN & \\
\hline CHEMBL1462786 & 688422 & 4.85 & 5.1632 & TST & \\
\hline CHEMBL1306934 & 688422 & 4.9 & 5.1125 & TST & \\
\hline CHEMBL1418084 & 688422 & 5.25 & 5.4807 & TST & \\
\hline CHEMBL1560258 & 688422 & 4.5 & 4.8747 & TRN & \\
\hline CHEMBL1312723 & 688422 & 5.1 & 5.4832 & TRN & \\
\hline CHEMBL1985327 & 688422 & 4.85 & 4.9151 & TRN & \\
\hline CHEMBL1386676 & 688422 & 4.9 & 5.1952 & TRN & \\
\hline CHEMBL1406703 & 688422 & 4.45 & 5.0892 & TST & \\
\hline CHEMBL1478356 & 688422 & 6.7501 & 5.2517 & TRN & \\
\hline CHEMBL1331145 & 688422 & 4.85 & 5.2109 & TRN & \\
\hline CHEMBL1408787 & 688422 & 6.8 & 5.254 & TRN & \\
\hline CHEMBL1566196 & 688422 & 5.65 & 5.4572 & TRN & \\
\hline CHEMBL1547278 & 688422 & 4.85 & 4.6789 & TRN & \\
\hline CHEMBL1341797 & 688422 & 5.4 & 5.1825 & TRN & \\
\hline CHEMBL1542105 & 688422 & 7.3002 & 5.4738 & TRN & \\
\hline CHEMBL1494202 & 688422 & 4.6 & 4.8912 & TST & \\
\hline CHEMBL1200919 & 688422 & 6.7001 & 5.928 & TST & \\
\hline CHEMBL1353544 & 688422 & 5.75 & 4.9027 & TRN & \\
\hline CHEMBL1568923 & 688422 & 5.45 & 5.4306 & TRN & \\
\hline CHEMBL1976197 & 688422 & 5.15 & 5.1938 & TRN & \\
\hline CHEMBL1610197 & 688422 & 4.65 & 5.1627 & TRN & \\
\hline CHEMBL1482009 & 688422 & 4.7 & 5.0445 & TRN & \\
\hline CHEMBL1404877 & 688422 & 5.0 & 4.9389 & TRN & \\
\hline CHEMBL 1473578 & 688422 & 4.75 & 5.5107 & TRN & \\
\hline CHEMBL1455729 & 688422 & 5.0 & 5.6732 & TRN & \\
\hline CHEMBL1415921 & 688422 & 5.55 & 5.0791 & TST & \\
\hline CHEMBL1601033 & 688422 & 7.2503 & 5.7647 & TRN & \\
\hline CHEMBL1423029 & 688422 & 4.45 & 4.9923 & TST & \\
\hline CHEMBL1447682 & 688422 & 4.45 & 4.6195 & TRN & \\
\hline CHEMBL1497648 & 688422 & 8.3468 & 5.6527 & TST & \\
\hline CHEMBL1322376 & 688422 & 5.4 & 5.1796 & TST & \\
\hline CHEMBL1566383 & 688422 & 7.0501 & 5.3245 & TRN & \\
\hline CHEMBL1354269 & 688422 & 4.45 & 5.2321 & TRN & \\
\hline CHEMBL1470481 & 688422 & 4.65 & 5.1245 & TRN & \\
\hline CHEMBL1409540 & 688422 & 4.8 & 5.0306 & TRN & \\
\hline
\end{tabular}




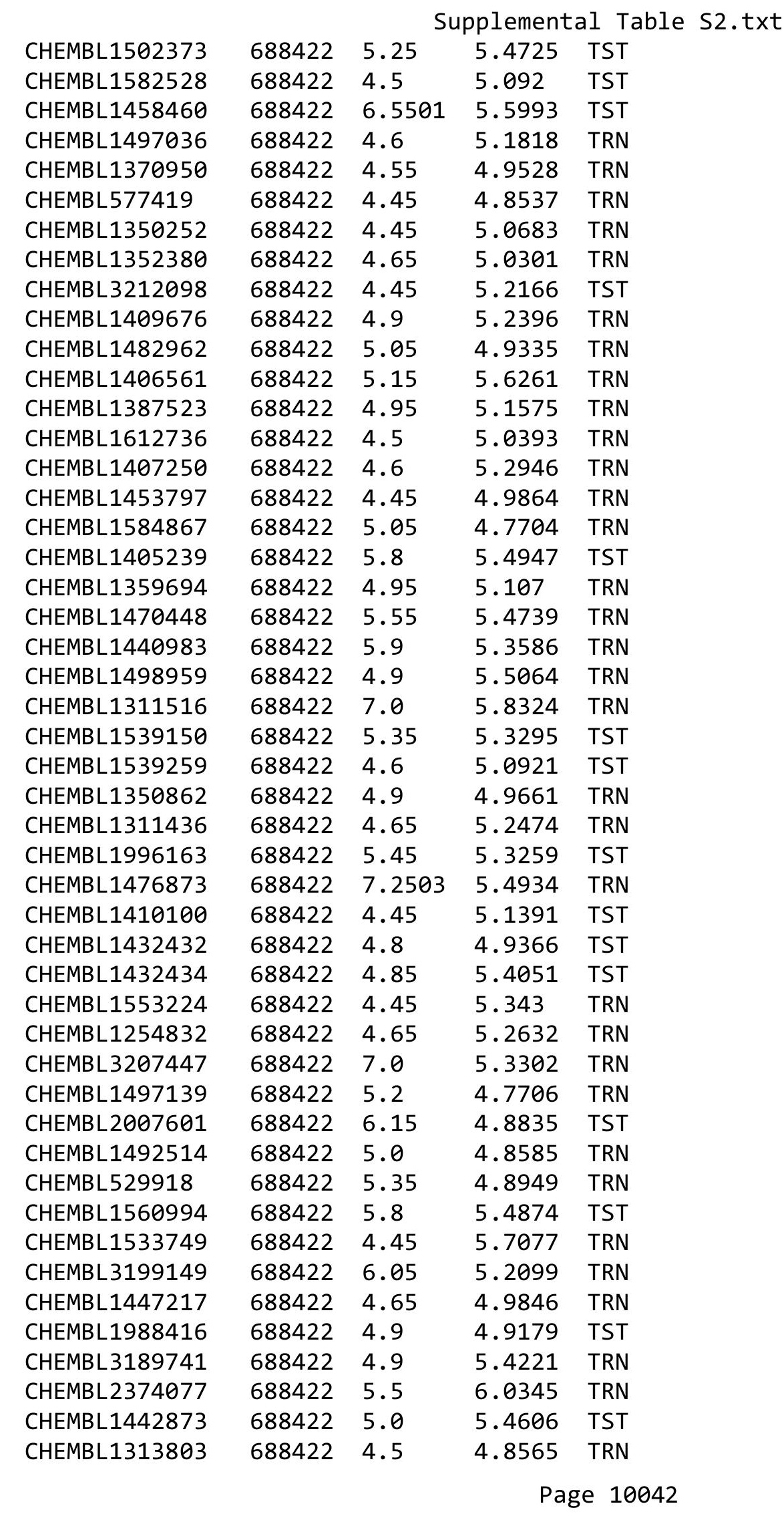




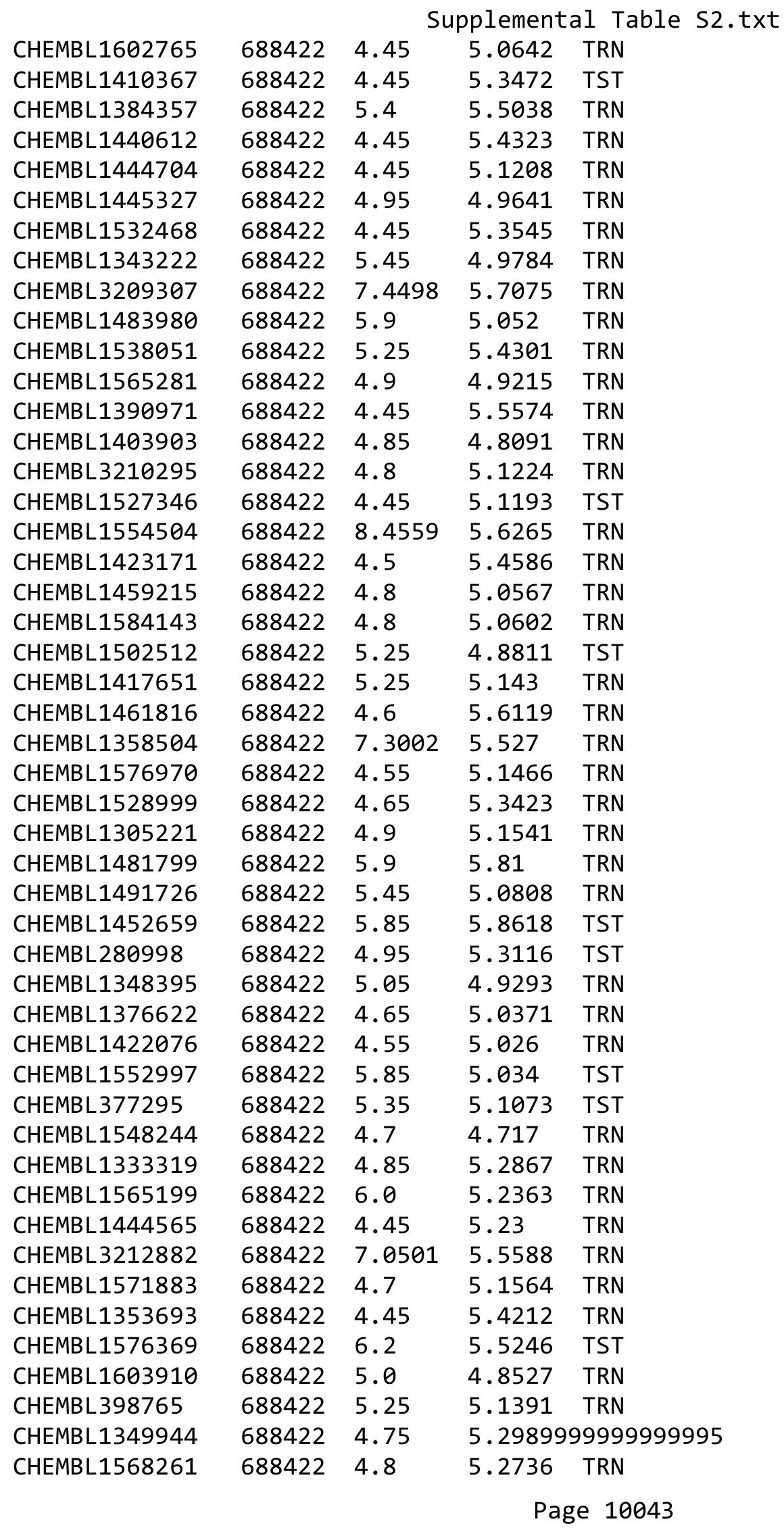

TRN 


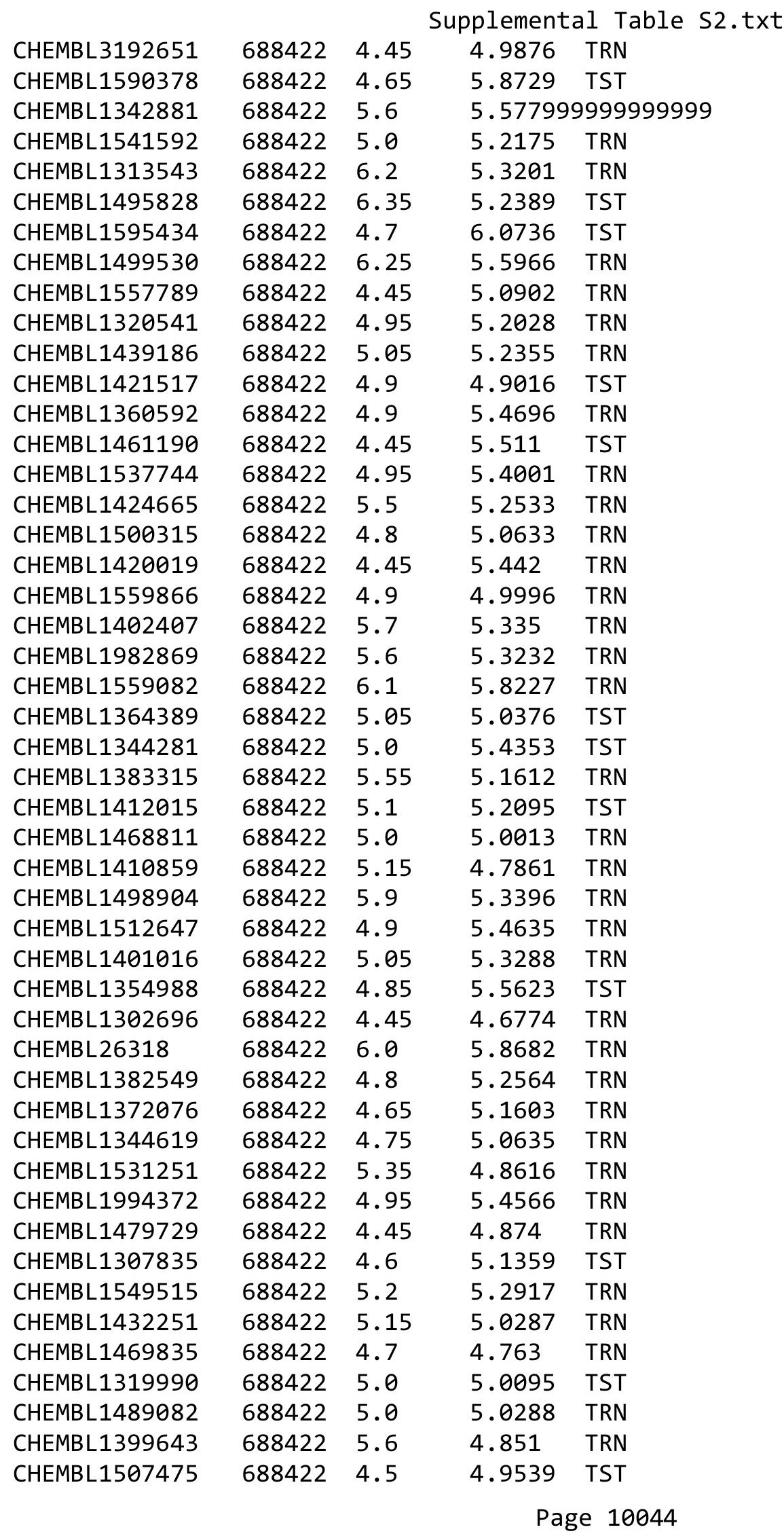

TRN 


\begin{tabular}{|c|c|c|c|c|}
\hline \multicolumn{5}{|c|}{ Supplemental Table S2.txt } \\
\hline CHEMBL1381262 & 688422 & 4.8 & 5.1935 & TRN \\
\hline CHEMBL1373756 & 688422 & 4.9 & 5.3543 & TRN \\
\hline CHEMBL1363312 & 688422 & 4.65 & 5.0916 & TRN \\
\hline CHEMBL1470450 & 688422 & 4.65 & 5.0956 & TRN \\
\hline CHEMBL1443375 & 688422 & 5.05 & 5.5124 & TST \\
\hline CHEMBL1360145 & 688422 & 5.0 & 5.7105 & TRN \\
\hline CHEMBL1309171 & 688422 & 4.9 & 4.9928 & TST \\
\hline CHEMBL1466983 & 688422 & 4.65 & 5.4983 & TRN \\
\hline CHEMBL1353518 & 688422 & 4.45 & 4.9657 & TRN \\
\hline CHEMBL1505497 & 688422 & 7.0501 & 5.4031 & TST \\
\hline CHEMBL1403284 & 688422 & 5.0 & 5.1201 & TRN \\
\hline CHEMBL1560468 & 688422 & 8.4559 & 4.8385 & TRN \\
\hline CHEMBL1413559 & 688422 & 5.2 & 5.2844 & TRN \\
\hline CHEMBL1328175 & 688422 & 5.15 & 4.7932 & TRN \\
\hline CHEMBL 2018847 & 688422 & 4.65 & 5.1202 & TST \\
\hline CHEMBL1457820 & 688422 & 4.45 & 5.2221 & TRN \\
\hline CHEMBL1492919 & 688422 & 4.45 & 5.1536 & TST \\
\hline CHEMBL1429680 & 688422 & 4.5 & 4.9948 & TST \\
\hline CHEMBL1373547 & 688422 & 4.45 & 4.9433 & TRN \\
\hline CHEMBL1457126 & 688422 & 4.6 & 5.1405 & TRN \\
\hline CHEMBL1464634 & 688422 & 5.2 & 5.6886 & TST \\
\hline CHEMBL1602447 & 688422 & 4.55 & 5.2335 & TST \\
\hline CHEMBL1362859 & 688422 & 4.85 & 5.3286 & TRN \\
\hline CHEMBL1419582 & 688422 & 4.45 & 5.3323 & TRN \\
\hline CHEMBL1327026 & 688422 & 4.45 & 4.7926 & TRN \\
\hline CHEMBL1441415 & 688422 & 4.45 & 4.8221 & TRN \\
\hline CHEMBL1450956 & 688422 & 4.5 & 5.1241 & TRN \\
\hline CHEMBL1352841 & 688422 & 8.1487 & 5.5088 & TRN \\
\hline CHEMBL1339415 & 688422 & 4.45 & 5.4922 & TRN \\
\hline CHEMBL1346881 & 688422 & 4.7 & 5.0411 & TST \\
\hline CHEMBL1387338 & 688422 & 6.3 & 5.2941 & TRN \\
\hline CHEMBL1538093 & 688422 & 4.65 & 5.1063 & TRN \\
\hline CHEMBL3191566 & 688422 & 6.2 & 5.2583 & TRN \\
\hline CHEMBL1534430 & 688422 & 4.95 & 5.2846 & TRN \\
\hline CHEMBL325245 & 688422 & 4.65 & 5.0102 & TRN \\
\hline CHEMBL1542319 & 688422 & 4.85 & 5.5325 & TST \\
\hline CHEMBL1375769 & 688422 & 4.65 & 5.0168 & TRN \\
\hline CHEMBL1419527 & 688422 & 5.15 & 5.5649 & TRN \\
\hline CHEMBL1505926 & 688422 & 5.35 & 5.7268 & TST \\
\hline CHEMBL1353371 & 688422 & 4.65 & 5.3795 & TST \\
\hline CHEMBL3190014 & 688422 & 4.8 & 5.0783 & TRN \\
\hline CHEMBL1308487 & 688422 & 5.55 & 4.8125 & TST \\
\hline CHEMBL1548832 & 688422 & 4.6 & 4.8354 & TRN \\
\hline CHEMBL1436860 & 688422 & 6.05 & 5.3149 & TRN \\
\hline CHEMBL1512567 & 688422 & 8.6021 & 5.9302 & TST \\
\hline CHEMBL3191590 & 688422 & 4.45 & 4.9304 & TRN \\
\hline CHEMBL1319093 & 688422 & 4.45 & 5.0587 & TRN \\
\hline CHEMBL1307567 & 688422 & 4.45 & 5.1445 & TRN \\
\hline
\end{tabular}




\begin{tabular}{|c|c|c|c|c|}
\hline \multicolumn{5}{|c|}{ Supplemental Table S2.txt } \\
\hline CHEMBL1572946 & 688422 & 5.35 & 5.657 & TRN \\
\hline CHEMBL1398910 & 688422 & 4.45 & 5.1959 & TRN \\
\hline CHEMBL1473142 & 688422 & 8.301 & 5.3387 & TRN \\
\hline CHEMBL1323186 & 688422 & 4.6 & 5.0476 & TRN \\
\hline CHEMBL1576334 & 688422 & 5.9 & 5.3612 & TRN \\
\hline CHEMBL1515100 & 688422 & 6.2 & 5.2962 & TRN \\
\hline CHEMBL 3198365 & 688422 & 5.2 & 5.1148 & TRN \\
\hline CHEMBL1464274 & 688422 & 7.1002 & 5.8025 & TST \\
\hline CHEMBL1482768 & 688422 & 7.0 & 5.6323 & TRN \\
\hline CHEMBL1376746 & 688422 & 5.95 & 5.3713 & TRN \\
\hline CHEMBL1611107 & 688422 & 4.8 & 5.2876 & TRN \\
\hline CHEMBL1323217 & 688422 & 4.45 & 5.2362 & TST \\
\hline CHEMBL1313329 & 688422 & 5.2 & 5.2125 & TST \\
\hline CHEMBL1431154 & 688422 & 4.45 & 5.1372 & TST \\
\hline CHEMBL1409339 & 688422 & 4.85 & 5.39 & TST \\
\hline CHEMBL1357520 & 688422 & 4.75 & 4.9885 & TRN \\
\hline CHEMBL1460753 & 688422 & 6.8499 & 5.2125 & TRN \\
\hline CHEMBL3192842 & 688422 & 4.8 & 5.0236 & TST \\
\hline CHEMBL1584238 & 688422 & 8.0 & 5.4894 & TRN \\
\hline CHEMBL1322193 & 688422 & 4.75 & 5.2986 & TRN \\
\hline CHEMBL1585000 & 688422 & 6.7501 & 5.1964 & TRN \\
\hline CHEMBL1307756 & 688422 & 6.5501 & 5.3324 & TRN \\
\hline CHEMBL1370467 & 688422 & 4.45 & 5.4297 & TRN \\
\hline CHEMBL1479114 & 688422 & 5.5 & 5.0814 & TRN \\
\hline CHEMBL1609651 & 688422 & 4.45 & 5.4242 & TST \\
\hline CHEMBL1329461 & 688422 & 4.95 & 5.1397 & TRN \\
\hline CHEMBL1369955 & 688422 & 6.35 & 5.9207 & TST \\
\hline CHEMBL1608488 & 688422 & 5.25 & 5.3422 & TRN \\
\hline CHEMBL3197839 & 688422 & 8.4949 & 5.1362 & TST \\
\hline CHEMBL1377799 & 688422 & 4.9 & 5.1244 & TRN \\
\hline CHEMBL3199404 & 688422 & 4.6 & 5.1743 & TRN \\
\hline CHEMBL1316319 & 688422 & 5.95 & 5.1927 & TRN \\
\hline CHEMBL1365648 & 688422 & 6.5 & 5.5952 & TRN \\
\hline CHEMBL1494617 & 688422 & 4.45 & 5.2102 & TRN \\
\hline CHEMBL1431035 & 688422 & 4.95 & 5.1315 & TRN \\
\hline CHEMBL1581798 & 688422 & 4.9 & 4.7735 & TRN \\
\hline CHEMBL1561030 & 688422 & 4.5 & 5.0183 & TRN \\
\hline CHEMBL1572414 & 688422 & 4.8 & 4.9512 & TRN \\
\hline CHEMBL1417470 & 688422 & 4.8 & 4.9813 & TRN \\
\hline CHEMBL1391819 & 688422 & 5.4 & 5.2753 & TST \\
\hline CHEMBL1586752 & 688422 & 4.7 & 5.0276 & TST \\
\hline CHEMBL1543082 & 688422 & 5.2 & 4.85 & TRN \\
\hline CHEMBL1593624 & 688422 & 7.8508 & 5.3828 & TRN \\
\hline CHEMBL1471067 & 688422 & 7.5003 & 5.2481 & TRN \\
\hline CHEMBL3192232 & 688422 & 6.2 & 5.9124 & TRN \\
\hline CHEMBL1456678 & 688422 & 8.301 & 5.3138 & TST \\
\hline CHEMBL3196411 & 688422 & 4.45 & 5.3052 & TST \\
\hline CHEMBL1429124 & 688422 & 4.9 & 5.2324 & TRN \\
\hline
\end{tabular}




\begin{tabular}{|c|c|c|c|c|c|}
\hline \multicolumn{6}{|c|}{ Supplemental Table S2.txt } \\
\hline CHEMBL1558822 & 688422 & 5.0 & 5.0665 & TRN & \\
\hline CHEMBL1403578 & 688422 & 5.0 & 4.7317 & TRN & \\
\hline CHEMBL1522066 & 688422 & 5.05 & 5.0353 & TRN & \\
\hline CHEMBL1485015 & 688422 & 5.05 & 4.9063 & TRN & \\
\hline CHEMBL1591361 & 688422 & 6.4 & 5.0331 & TRN & \\
\hline CHEMBL1495631 & 688422 & 6.05 & 5.6235 & TRN & \\
\hline CHEMBL1319307 & 688422 & 5.25 & 5.1335 & TRN & \\
\hline CHEMBL1431888 & 688422 & 4.85 & 5.2129 & TRN & \\
\hline CHEMBL1545131 & 688422 & 4.8 & 5.2312 & TRN & \\
\hline CHEMBL1505364 & 688422 & 4.7 & 5.3681 & TRN & \\
\hline CHEMBL3194534 & 688422 & 5.0 & 5.4725 & TST & \\
\hline CHEMBL1599626 & 688422 & 4.45 & 5.1607 & TRN & \\
\hline CHEMBL1305165 & 688422 & 4.9 & 5.2921 & TRN & \\
\hline CHEMBL1609148 & 688422 & 4.45 & 5.2058 & TST & \\
\hline CHEMBL1401676 & 688422 & 5.05 & 5.5193 & TRN & \\
\hline CHEMBL1583788 & 688422 & 4.8 & 4.8688 & TRN & \\
\hline CHEMBL1516774 & 688422 & 4.85 & 4.8242 & TRN & \\
\hline CHEMBL1324072 & 688422 & 4.8 & 5.1854 & TRN & \\
\hline CHEMBL1517059 & 688422 & 4.9 & 4.7246 & TRN & \\
\hline CHEMBL1501561 & 688422 & 5.3 & 5.4339 & TRN & \\
\hline CHEMBL1330972 & 688422 & 5.25 & 5.2007 & TRN & \\
\hline CHEMBL1538267 & 688422 & 4.5 & 4.8493 & TRN & \\
\hline CHEMBL1978643 & 688422 & 5.6 & 5.4099 & TRN & \\
\hline CHEMBL1304254 & 688422 & 4.95 & 5.0419 & TRN & \\
\hline CHEMBL1346817 & 688422 & 4.5 & 5.1476 & TRN & \\
\hline CHEMBL1464644 & 688422 & 4.9 & 5.1337 & TST & \\
\hline CHEMBL1393185 & 688422 & 5.35 & 5.5946 & TRN & \\
\hline CHEMBL1378949 & 688422 & 6.8 & 5.1488 & TST & \\
\hline CHEMBL1468100 & 688422 & 4.7 & 4.9151 & TRN & \\
\hline CHEMBL1421902 & 688422 & 7.8508 & 5.3033 & TRN & \\
\hline CHEMBL1389387 & 688422 & 4.45 & 5.4353 & TRN & \\
\hline CHEMBL1415460 & 688422 & 4.45 & 5.5701 & TST & \\
\hline CHEMBL1389414 & 688422 & 5.15 & 5.4235 & TRN & \\
\hline CHEMBL1543492 & 688422 & 4.85 & 5.0523 & TRN & \\
\hline CHEMBL1440428 & 688422 & 4.85 & 5.4691 & TST & \\
\hline CHEMBL1543169 & 688422 & 4.65 & 4.9944 & TRN & \\
\hline CHEMBL1489732 & 688422 & 4.45 & $5.4510 e$ & 00000000005 & TRN \\
\hline CHEMBL1355895 & 688422 & 6.1 & 5.3892 & TST & \\
\hline CHEMBL1328059 & 688422 & 4.45 & 5.2024 & TST & \\
\hline CHEMBL1353226 & 688422 & 4.9 & 5.6175 & TST & \\
\hline CHEMBL1489566 & 688422 & 5.0 & 5.1289 & TRN & \\
\hline CHEMBL1586928 & 688422 & 5.75 & $5.5470 e$ & 2000000001 & TRN \\
\hline CHEMBL1314543 & 688422 & 4.45 & 4.9675 & TST & \\
\hline CHEMBL1358767 & 688422 & 6.9 & 5.1748 & TRN & \\
\hline CHEMBL1555527 & 688422 & 5.1 & 5.8669 & TRN & \\
\hline CHEMBL1427251 & 688422 & 4.5 & 5.3737 & TRN & \\
\hline CHEMBL1362864 & 688422 & 4.45 & 5.0688 & TRN & \\
\hline CHEMBL1408036 & 688422 & 6.1 & 5.4737 & TST & \\
\hline
\end{tabular}




\begin{tabular}{|c|c|c|c|c|c|}
\hline \multicolumn{6}{|c|}{ Supplemental Table s2.txt } \\
\hline CHEMBL1498 & 688422 & 5.4 & 6.0778 & TRN & \\
\hline CHEMBL1396565 & 688422 & 5.3 & 5.2471 & TRN & \\
\hline CHEMBL1589577 & 688422 & 4.5 & 5.7756 & TST & \\
\hline CHEMBL508030 & 688422 & 4.7 & 5.6753 & TST & \\
\hline CHEMBL1300500 & 688422 & 4.7 & 5.28 & TRN & \\
\hline CHEMBL1404130 & 688422 & 4.45 & 5.0274 & TRN & \\
\hline CHEMBL1448772 & 688422 & 7.2 & 5.3934 & TRN & \\
\hline CHEMBL1413726 & 688422 & 4.5 & 4.9152 & TRN & \\
\hline CHEMBL1609398 & 688422 & 5.4 & 5.6164 & TST & \\
\hline CHEMBL1609218 & 688422 & 4.85 & 4.957 & TRN & \\
\hline CHEMBL1433586 & 688422 & 5.2 & 4.9496 & TRN & \\
\hline CHEMBL1309481 & 688422 & 8.4949 & 5.7146 & TST & \\
\hline CHEMBL1576308 & 688422 & 4.65 & 4.7574 & TRN & \\
\hline CHEMBL1530891 & 688422 & 5.5 & 5.4027 & TRN & \\
\hline CHEMBL1389701 & 688422 & 4.45 & 4.9269 & TRN & \\
\hline CHEMBL1397766 & 688422 & 8.0506 & 5.3765 & TST & \\
\hline CHEMBL1389685 & 688422 & 4.5 & 5.1313 & TST & \\
\hline CHEMBL1444205 & 688422 & 4.9 & 5.521 & TST & \\
\hline CHEMBL1588184 & 688422 & 4.45 & 5.2272 & TRN & \\
\hline CHEMBL1404832 & 688422 & 4.65 & 5.7055 & TRN & \\
\hline CHEMBL1454887 & 688422 & 4.95 & 5.2295 & TRN & \\
\hline CHEMBL1499247 & 688422 & 4.65 & 5.1542 & TRN & \\
\hline CHEMBL3195437 & 688422 & 4.95 & 5.3457 & TST & \\
\hline CHEMBL1481148 & 688422 & 8.4949 & 5.3511 & TRN & \\
\hline CHEMBL1493898 & 688422 & 5.5 & 5.2529 & TRN & \\
\hline CHEMBL1426924 & 688422 & 7.8508 & 5.17200 & 0000000001 & TRN \\
\hline CHEMBL1374365 & 688422 & 4.85 & 5.4714 & TST & \\
\hline CHEMBL1406911 & 688422 & 4.6 & 5.1335 & TRN & \\
\hline CHEMBL1413820 & 688422 & 5.0 & 5.0776 & TRN & \\
\hline CHEMBL1455644 & 688422 & 4.6 & 5.1144 & TRN & \\
\hline CHEMBL3197765 & 688422 & 4.9 & 5.3126 & TST & \\
\hline CHEMBL1418843 & 688422 & 4.8 & 5.0838 & TRN & \\
\hline CHEMBL1317277 & 688422 & 4.45 & 5.36100 & 0000000001 & TST \\
\hline CHEMBL312163 & 688422 & 4.95 & 5.2971 & TRN & \\
\hline CHEMBL1452728 & 688422 & 4.9 & 5.0694 & TRN & \\
\hline CHEMBL1524490 & 688422 & 4.95 & 5.2992 & TRN & \\
\hline CHEMBL1451395 & 688422 & 6.05 & 5.3443 & TST & \\
\hline CHEMBL1375187 & 688422 & 5.45 & 5.1967 & TST & \\
\hline CHEMBL1315062 & 688422 & 7.5498 & 4.8787 & TRN & \\
\hline CHEMBL1431309 & 688422 & 4.85 & 5.4005 & TST & \\
\hline CHEMBL1586153 & 688422 & 4.45 & 4.8246 & TRN & \\
\hline CHEMBL1374571 & 688422 & 5.7 & 5.1867 & TRN & \\
\hline CHEMBL1523519 & 688422 & 5.6 & 5.5101 & TRN & \\
\hline CHEMBL1374114 & 688422 & 5.5 & 5.3601 & TST & \\
\hline CHEMBL1348139 & 688422 & 4.85 & 5.1846 & TRN & \\
\hline CHEMBL1527321 & 688422 & 7.0501 & 5.4823 & TRN & \\
\hline CHEMBL3195118 & 688422 & 4.45 & 5.1479 & TST & \\
\hline CHEMBL1492044 & 688422 & 6.95 & 5.6794 & TRN & \\
\hline
\end{tabular}




\begin{tabular}{|c|c|c|c|c|c|}
\hline \multicolumn{6}{|c|}{ Supplemental Table S2.txt } \\
\hline CHEMBL1313608 & 688422 & 4.65 & 4.7328 & TRN & \\
\hline CHEMBL1522305 & 688422 & 5.0 & 5.6406 & TST & \\
\hline CHEMBL1464748 & 688422 & 5.55 & 5.2452 & TRN & \\
\hline CHEMBL1348049 & 688422 & 4.45 & 5.3557 & TRN & \\
\hline CHEMBL1446577 & 688422 & 5.5 & 5.584 & TRN & \\
\hline CHEMBL1602704 & 688422 & 6.5501 & 5.3102 & TST & \\
\hline CHEMBL1448503 & 688422 & 5.0 & 5.3483 & TRN & \\
\hline CHEMBL1478093 & 688422 & 7.7496 & 5.3145 & TST & \\
\hline CHEMBL1454716 & 688422 & 4.8 & 5.2327 & TRN & \\
\hline CHEMBL1357936 & 688422 & 4.45 & 5.0976 & TRN & \\
\hline CHEMBL1385145 & 688422 & 4.45 & 5.1073 & TST & \\
\hline CHEMBL1969332 & 688422 & 4.8 & 5.3973 & TRN & \\
\hline CHEMBL3191902 & 688422 & 4.85 & 5.0693 & TST & \\
\hline CHEMBL1359544 & 688422 & 4.7 & 5.29200 & 0000000001 & TST \\
\hline CHEMBL1459304 & 688422 & 4.65 & 5.4088 & TST & \\
\hline CHEMBL1600058 & 688422 & 5.9 & 5.3637 & TRN & \\
\hline CHEMBL1457866 & 688422 & 5.95 & 5.4797 & TRN & \\
\hline CHEMBL1607426 & 688422 & 4.75 & 5.2072 & TRN & \\
\hline CHEMBL1423622 & 688422 & 4.8 & 4.9542 & TRN & \\
\hline CHEMBL1357552 & 688422 & 4.5 & 5.2203 & TRN & \\
\hline CHEMBL1428342 & 688422 & 7.3002 & 5.99 & TST & \\
\hline CHEMBL1575051 & 688422 & 4.95 & 4.8403 & TRN & \\
\hline CHEMBL1359171 & 688422 & 4.7 & 5.2986 & TST & \\
\hline CHEMBL1564427 & 688422 & 7.8013 & 5.5383 & TRN & \\
\hline CHEMBL1316317 & 688422 & 4.7 & 5.1333 & TRN & \\
\hline CHEMBL1329537 & 688422 & 4.65 & 4.9408 & TST & \\
\hline CHEMBL1418830 & 688422 & 4.95 & 4.8199 & TRN & \\
\hline CHEMBL1426207 & 688422 & 5.05 & 4.9644 & TST & \\
\hline CHEMBL1501061 & 688422 & 4.45 & 5.1142 & TRN & \\
\hline CHEMBL1540629 & 688422 & 4.45 & 5.3587 & TRN & \\
\hline CHEMBL1480464 & 688422 & 4.5 & 5.231 & TRN & \\
\hline CHEMBL1327737 & 688422 & 4.6 & 5.153 & TRN & \\
\hline CHEMBL1557157 & 688422 & 4.95 & 5.3588 & TRN & \\
\hline CHEMBL1428198 & 688422 & 4.45 & 5.4904 & TST & \\
\hline CHEMBL1426530 & 688422 & 4.45 & 5.6309 & TRN & \\
\hline CHEMBL1477240 & 688422 & 6.0 & 6.2099 & TRN & \\
\hline CHEMBL1410641 & 688422 & 4.8 & 5.0771 & TST & \\
\hline CHEMBL1495788 & 688422 & 5.45 & 5.0827 & TRN & \\
\hline CHEMBL1345928 & 688422 & 5.0 & 5.2568 & TRN & \\
\hline CHEMBL1549783 & 688422 & 4.45 & 5.29 & TRN & \\
\hline CHEMBL1488234 & 688422 & 5.25 & 5.4451 & TST & \\
\hline CHEMBL1371903 & 688422 & 4.45 & 5.4312 & TRN & \\
\hline CHEMBL3195877 & 688422 & 4.9 & 5.4015 & TRN & \\
\hline CHEMBL1407769 & 688422 & 5.25 & 5.5874 & TST & \\
\hline CHEMBL1499864 & 688422 & 4.65 & 5.4928 & TST & \\
\hline CHEMBL1502750 & 688422 & 4.7 & 5.1912 & TRN & \\
\hline CHEMBL3198130 & 688422 & 4.75 & 4.9617 & TST & \\
\hline CHEMBL46703 & 688422 & 5.15 & 6.0201 & TRN & \\
\hline
\end{tabular}




\begin{tabular}{|c|c|c|c|c|c|}
\hline \multicolumn{6}{|c|}{ Supplemental Table S2.txt } \\
\hline CHEMBL1566655 & 688422 & 4.45 & 5.3399 & TRN & \\
\hline CHEMBL1319258 & 688422 & 4.5 & 4.7386 & TRN & \\
\hline CHEMBL1343213 & 688422 & 4.85 & 5.1779 & TRN & \\
\hline CHEMBL1418880 & 688422 & 4.85 & 5.612 & TRN & \\
\hline CHEMBL1352375 & 688422 & 4.85 & 4.7117 & TRN & \\
\hline CHEMBL1385962 & 688422 & 4.95 & 5.4123 & TRN & \\
\hline CHEMBL1350119 & 688422 & 6.15 & 5.5036 & TST & \\
\hline CHEMBL1519955 & 688422 & 6.7501 & 5.1952 & TRN & \\
\hline CHEMBL1301557 & 688422 & 4.85 & 5.2173 & TRN & \\
\hline CHEMBL3194789 & 688422 & 4.65 & 5.2843 & TRN & \\
\hline CHEMBL1492122 & 688422 & 4.8 & 4.7333 & TRN & \\
\hline CHEMBL3196986 & 688422 & 4.95 & 5.0499 & TRN & \\
\hline CHEMBL1329282 & 688422 & 5.2 & 5.6373 & TRN & \\
\hline CHEMBL1388163 & 688422 & 4.8 & 5.1456 & TRN & \\
\hline CHEMBL1334462 & 688422 & 6.7001 & 5.33200 & 0000000001 & TRN \\
\hline CHEMBL1342335 & 688422 & 4.65 & 5.3275 & TRN & \\
\hline CHEMBL577862 & 688422 & 4.85 & 5.28799 & 9999999999 & TRN \\
\hline CHEMBL1390350 & 688422 & 6.3 & 5.4973 & TST & \\
\hline CHEMBL1430197 & 688422 & 5.05 & 5.6608 & TRN & \\
\hline CHEMBL1388618 & 688422 & 4.7 & 4.9094 & TST & \\
\hline CHEMBL1365244 & 688422 & 4.85 & 5.3688 & TRN & \\
\hline CHEMBL1456201 & 688422 & 4.6 & 5.0529 & TRN & \\
\hline CHEMBL1459612 & 688422 & 4.75 & 5.4422 & TST & \\
\hline CHEMBL1437231 & 688422 & 5.45 & 5.6307 & TRN & \\
\hline CHEMBL1467382 & 688422 & 4.45 & 5.4374 & TRN & \\
\hline CHEMBL1407257 & 688422 & 4.9 & 5.13200 & 0000000001 & TRN \\
\hline CHEMBL1986541 & 688422 & 4.8 & 5.2648 & TRN & \\
\hline CHEMBL3197849 & 688422 & 4.7 & 5.1058 & TRN & \\
\hline CHEMBL1517642 & 688422 & 4.45 & 5.564 & TRN & \\
\hline CHEMBL1431189 & 688422 & 5.2 & 5.4109 & TRN & \\
\hline CHEMBL1539680 & 688422 & 5.7 & 5.1838 & TRN & \\
\hline CHEMBL1308070 & 688422 & 4.5 & 4.9832 & TST & \\
\hline CHEMBL1438770 & 688422 & 7.5003 & 5.4761 & TRN & \\
\hline CHEMBL1325295 & 688422 & 4.9 & 5.0651 & TRN & \\
\hline CHEMBL1471858 & 688422 & 4.55 & 5.063 & TRN & \\
\hline CHEMBL1609988 & 688422 & 4.7 & 4.9219 & TRN & \\
\hline CHEMBL1413183 & 688422 & 5.3 & 5.4918 & TRN & \\
\hline CHEMBL1537558 & 688422 & 4.6 & 5.3937 & TRN & \\
\hline CHEMBL3199540 & 688422 & 4.45 & 5.0864 & TRN & \\
\hline CHEMBL1338007 & 688422 & 4.45 & 5.011 & TRN & \\
\hline CHEMBL1490118 & 688422 & 6.2 & 5.3115 & TRN & \\
\hline CHEMBL1368342 & 688422 & 4.9 & 4.89 & TRN & \\
\hline CHEMBL1450326 & 688422 & 4.45 & 5.7172 & TRN & \\
\hline CHEMBL1491704 & 688422 & 5.9 & 5.3059 & TST & \\
\hline CHEMBL1600154 & 688422 & 4.5 & 5.2106 & TRN & \\
\hline CHEMBL1423325 & 688422 & 4.65 & 4.9072 & TRN & \\
\hline CHEMBL1373255 & 688422 & 4.45 & 4.9186 & TRN & \\
\hline CHEMBL1538414 & 688422 & 7.3002 & 5.6081 & TST & \\
\hline
\end{tabular}




\begin{tabular}{|c|c|c|c|c|}
\hline \multicolumn{5}{|c|}{ Supplemental Tab } \\
\hline CHEMBL1354200 & 688422 & 4.5 & 5.2669 & TST \\
\hline CHEMBL1382703 & 688422 & 5.0 & 5.3278 & TRN \\
\hline CHEMBL1335096 & 688422 & 4.75 & 5.2754 & TRN \\
\hline CHEMBL1427769 & 688422 & 4.8 & 5.9882 & TRN \\
\hline CHEMBL494325 & 688422 & 4.95 & 5.0317 & TRN \\
\hline CHEMBL1388894 & 688422 & 6.15 & 4.8199 & TRN \\
\hline CHEMBL1474861 & 688422 & 4.45 & 5.4097 & TRN \\
\hline CHEMBL1334119 & 688422 & 6.6 & 6.1734 & TST \\
\hline CHEMBL1333147 & 688422 & 4.65 & 5.0309 & TRN \\
\hline CHEMBL1548195 & 688422 & 5.4 & 5.7318 & TST \\
\hline CHEMBL1473809 & 688422 & 5.6 & 4.7645 & TRN \\
\hline CHEMBL1516298 & 688422 & 4.55 & 4.7411 & TRN \\
\hline CHEMBL 3191811 & 688422 & 5.1 & 5.2828 & TRN \\
\hline CHEMBL1548758 & 688422 & 8.3468 & 5.3119 & TRN \\
\hline CHEMBL1549193 & 688422 & 5.0 & 4.9018 & TRN \\
\hline CHEMBL1582179 & 688422 & 5.15 & 5.0265 & TRN \\
\hline CHEMBL1546512 & 688422 & 6.0 & 5.1151 & TST \\
\hline CHEMBL1402767 & 688422 & 4.9 & 4.8977 & TRN \\
\hline CHEMBL1358777 & 688422 & 5.5 & 5.0679 & TRN \\
\hline CHEMBL1507046 & 688422 & 4.9 & 4.9518 & TRN \\
\hline CHEMBL1502122 & 688422 & 5.2 & 5.3081 & TRN \\
\hline CHEMBL1477599 & 688422 & 4.8 & 5.254 & TRN \\
\hline CHEMBL1563835 & 688422 & 5.35 & 5.218 & TST \\
\hline CHEMBL1611029 & 688422 & 8.301 & 5.4081 & TRN \\
\hline CHEMBL1387783 & 688422 & 7.0 & 5.2232 & TRN \\
\hline CHEMBL1420108 & 688422 & 4.7 & 5.4702 & TST \\
\hline CHEMBL1423458 & 688422 & 6.35 & 5.4277 & TRN \\
\hline CHEMBL1321836 & 688422 & 4.45 & 5.3146 & TRN \\
\hline CHEMBL1353509 & 688422 & 4.7 & 5.2859 & TRN \\
\hline CHEMBL1492196 & 688422 & 5.2 & 5.862 & TST \\
\hline CHEMBL1433444 & 688422 & 4.45 & 5.1993 & TRN \\
\hline CHEMBL1544459 & 688422 & 6.5501 & 4.9765 & TST \\
\hline CHEMBL1563930 & 688422 & 4.65 & 4.7849 & TRN \\
\hline CHEMBL1368029 & 688422 & 4.65 & 5.6056 & TST \\
\hline CHEMBL1384508 & 688422 & 5.1 & 5.2189 & TRN \\
\hline CHEMBL1384158 & 688422 & 4.5 & 5.1207 & TST \\
\hline CHEMBL1340493 & 688422 & 4.45 & 5.2093 & TST \\
\hline CHEMBL1333392 & 688422 & 4.85 & 4.8927 & TRN \\
\hline CHEMBL1537582 & 688422 & 4.45 & 5.1798 & TRN \\
\hline CHEMBL1476170 & 688422 & 6.1 & 5.6854 & TRN \\
\hline CHEMBL1427382 & 688422 & 4.95 & 5.2705 & TRN \\
\hline CHEMBL1433385 & 688422 & 4.45 & 5.1589 & TRN \\
\hline CHEMBL1535716 & 688422 & 8.3468 & 5.6083 & TST \\
\hline CHEMBL1479550 & 688422 & 4.9 & 5.0457 & TST \\
\hline CHEMBL1462974 & 688422 & 4.85 & 5.4198 & TST \\
\hline CHEMBL1488675 & 688422 & 4.45 & 5.5071 & TRN \\
\hline CHEMBL1359157 & 688422 & 4.45 & 5.0922 & TST \\
\hline CHEMBL1425713 & 688422 & 4.45 & 5.3165 & TST \\
\hline
\end{tabular}




\begin{tabular}{|c|c|c|c|c|c|}
\hline \multicolumn{6}{|c|}{ Supplemental Table S2.txt } \\
\hline CHEMBL1334066 & 688422 & 4.85 & 5.5538 & TRN & \\
\hline CHEMBL1525407 & 688422 & 8.3468 & 5.2957 & TRN & \\
\hline CHEMBL1485239 & 688422 & 7.2503 & 4.8259 & TRN & \\
\hline CHEMBL1345561 & 688422 & 4.85 & 5.2758 & TST & \\
\hline CHEMBL1568514 & 688422 & 4.9 & 5.20700 & 0000000001 & TRN \\
\hline CHEMBL1981770 & 688422 & 5.35 & 5.2562 & TRN & \\
\hline CHEMBL1380684 & 688422 & 6.0 & 5.6874 & TRN & \\
\hline CHEMBL1360786 & 688422 & 4.45 & 5.151 & TRN & \\
\hline CHEMBL1464686 & 688422 & 5.3 & 5.4202 & TRN & \\
\hline CHEMBL1983342 & 688422 & 6.35 & 5.4091 & TRN & \\
\hline CHEMBL1488059 & 688422 & 4.55 & 5.0552 & TRN & \\
\hline CHEMBL1588627 & 688422 & 7.5003 & 5.2676 & TRN & \\
\hline CHEMBL1400959 & 688422 & 4.45 & 4.8373 & TST & \\
\hline CHEMBL1989897 & 688422 & 5.25 & 5.2219 & TST & \\
\hline CHEMBL1337986 & 688422 & 4.45 & 5.4467 & TRN & \\
\hline CHEMBL1383320 & 688422 & 4.5 & 4.7514 & TRN & \\
\hline CHEMBL1312977 & 688422 & 4.65 & 5.1179 & TRN & \\
\hline CHEMBL1453856 & 688422 & 5.55 & 5.1212 & TRN & \\
\hline CHEMBL1385926 & 688422 & 6.7501 & 4.9328 & TRN & \\
\hline CHEMBL1469575 & 688422 & 4.95 & 5.3169 & TRN & \\
\hline CHEMBL1539732 & 688422 & 7.0501 & 5.2709 & TST & \\
\hline CHEMBL1373467 & 688422 & 4.45 & 5.5318 & TST & \\
\hline CHEMBL1553261 & 688422 & 5.2 & 5.2847 & TRN & \\
\hline CHEMBL1529890 & 688422 & 7.7496 & 4.9908 & TRN & \\
\hline CHEMBL1333877 & 688422 & 4.45 & 5.3865 & TST & \\
\hline CHEMBL1389082 & 688422 & 6.5 & 5.3792 & TRN & \\
\hline CHEMBL1326819 & 688422 & 4.6 & 4.8115 & TRN & \\
\hline CHEMBL1310969 & 688422 & 4.45 & 5.1289 & TRN & \\
\hline CHEMBL1569013 & 688422 & 5.4 & 5.294 & TRN & \\
\hline CHEMBL1484741 & 688422 & 5.55 & 5.4438 & TRN & \\
\hline CHEMBL1434887 & 688422 & 4.9 & 5.2262 & TRN & \\
\hline CHEMBL1554673 & 688422 & 4.5 & 4.9731 & TRN & \\
\hline CHEMBL1536767 & 688422 & 6.7001 & 4.9713 & TRN & \\
\hline CHEMBL1497267 & 688422 & 4.6 & 5.3208 & TRN & \\
\hline CHEMBL1549202 & 688422 & 4.55 & 5.2047 & TRN & \\
\hline CHEMBL1349840 & 688422 & 5.0 & 5.1224 & TRN & \\
\hline CHEMBL1506271 & 688422 & 5.0 & 5.2751 & TRN & \\
\hline CHEMBL1315609 & 688422 & 4.8 & 5.1451 & TRN & \\
\hline CHEMBL1442709 & 688422 & 5.1 & 5.2124 & TRN & \\
\hline CHEMBL1421466 & 688422 & 4.45 & 5.0127 & TRN & \\
\hline CHEMBL1474937 & 688422 & 5.35 & 5.1478 & TRN & \\
\hline CHEMBL1581893 & 688422 & 4.8 & 5.2804 & TST & \\
\hline CHEMBL1560159 & 688422 & 4.75 & 5.1851 & TRN & \\
\hline CHEMBL3189855 & 688422 & 4.9 & 5.0008 & TRN & \\
\hline CHEMBL1442142 & 688422 & 4.95 & 4.9114 & TRN & \\
\hline CHEMBL1449991 & 688422 & 4.75 & 5.4146 & TRN & \\
\hline CHEMBL1603530 & 688422 & 4.95 & 4.9479 & TRN & \\
\hline CHEMBL1467732 & 688422 & 5.4 & 5.0022 & TST & \\
\hline
\end{tabular}




\begin{tabular}{|c|c|c|c|c|c|}
\hline \multicolumn{6}{|c|}{ Supplemental Table S2.txt } \\
\hline CHEMBL1514919 & 688422 & 4.85 & 6.575 & TRN & \\
\hline CHEMBL1546440 & 688422 & 4.6 & 5.3379 & TRN & \\
\hline CHEMBL1362965 & 688422 & 4.9 & 6.0075 & TST & \\
\hline CHEMBL1331727 & 688422 & 4.45 & 5.1407 & TRN & \\
\hline CHEMBL1503960 & 688422 & 5.2 & 5.0502 & TRN & \\
\hline CHEMBL3209943 & 688422 & 4.5 & 5.2057 & TRN & \\
\hline CHEMBL1327642 & 688422 & 4.45 & 5.3583 & TRN & \\
\hline CHEMBL1599870 & 688422 & 5.6 & 5.5144 & TRN & \\
\hline CHEMBL1567304 & 688422 & 4.4 & 5.2705 & TST & \\
\hline CHEMBL1406922 & 688422 & 4.85 & 4.9703 & TRN & \\
\hline CHEMBL1344349 & 688422 & 6.25 & 5.6932 & TST & \\
\hline CHEMBL1570643 & 688422 & 5.2 & 5.1765 & TRN & \\
\hline CHEMBL1554874 & 688422 & 7.0501 & 5.5429 & TST & \\
\hline CHEMBL1478191 & 688422 & 7.4498 & 5.4611 & TST & \\
\hline CHEMBL1377425 & 688422 & 4.7 & 4.8591 & TRN & \\
\hline CHEMBL1485970 & 688422 & 4.75 & 5.5075 & TRN & \\
\hline CHEMBL1303367 & 688422 & 4.65 & 5.2699 & TRN & \\
\hline CHEMBL1439266 & 688422 & 5.2 & 5.1553 & TRN & \\
\hline CHEMBL1372064 & 688422 & 4.8 & 4.8807 & TRN & \\
\hline CHEMBL3199104 & 688422 & 4.95 & 4.9696 & TRN & \\
\hline CHEMBL1573230 & 688422 & 4.75 & 5.0386 & TST & \\
\hline CHEMBL1398284 & 688422 & 4.6 & 5.1297 & TRN & \\
\hline CHEMBL1547514 & 688422 & 4.95 & 5.0893 & TST & \\
\hline CHEMBL 225230 & 688422 & 4.9 & 5.3981 & TRN & \\
\hline CHEMBL1510894 & 688422 & 5.25 & 5.3156 & TRN & \\
\hline CHEMBL1400876 & 688422 & 4.45 & 5.0634 & TRN & \\
\hline CHEMBL1595263 & 688422 & 5.15 & 5.5018 & TRN & \\
\hline CHEMBL1407215 & 688422 & 5.65 & 4.8453 & TST & \\
\hline CHEMBL3196158 & 688422 & 5.6 & 5.3901 & TRN & \\
\hline CHEMBL1424243 & 688422 & 4.5 & 5.2207 & TST & \\
\hline CHEMBL1592868 & 688422 & 7.3002 & 5.8051 & TRN & \\
\hline CHEMBL1328016 & 688422 & 8.301 & 5.5988 & TRN & \\
\hline CHEMBL1440681 & 688422 & 7.2503 & 4.8144 & TRN & \\
\hline CHEMBL1422001 & 688422 & 6.5 & 4.99100 & 00000000005 & TRN \\
\hline CHEMBL1310499 & 688422 & 4.45 & 5.1451 & TST & \\
\hline CHEMBL1343078 & 688422 & 5.3 & 5.7233 & TRN & \\
\hline CHEMBL1343584 & 688422 & 6.25 & 5.7314 & TST & \\
\hline CHEMBL1470767 & 688422 & 5.85 & 5.652 & TRN & \\
\hline CHEMBL1521275 & 688422 & 5.65 & 5.1502 & TRN & \\
\hline CHEMBL1309288 & 688422 & 4.9 & 5.1949 & TRN & \\
\hline CHEMBL1445091 & 688422 & 5.85 & 5.4192 & TRN & \\
\hline CHEMBL1421784 & 688422 & 5.05 & 5.2297 & TRN & \\
\hline CHEMBL1492108 & 688422 & 4.85 & 5.34 & TST & \\
\hline CHEMBL1306569 & 688422 & 4.9 & 4.8777 & TRN & \\
\hline CHEMBL1577124 & 688422 & 6.6 & 5.4627 & TRN & \\
\hline CHEMBL1449651 & 688422 & 6.2 & 6.0824 & TST & \\
\hline CHEMBL1499631 & 688422 & 6.05 & 5.8602 & TST & \\
\hline CHEMBL1491958 & 688422 & 4.45 & 5.2245 & TRN & \\
\hline
\end{tabular}




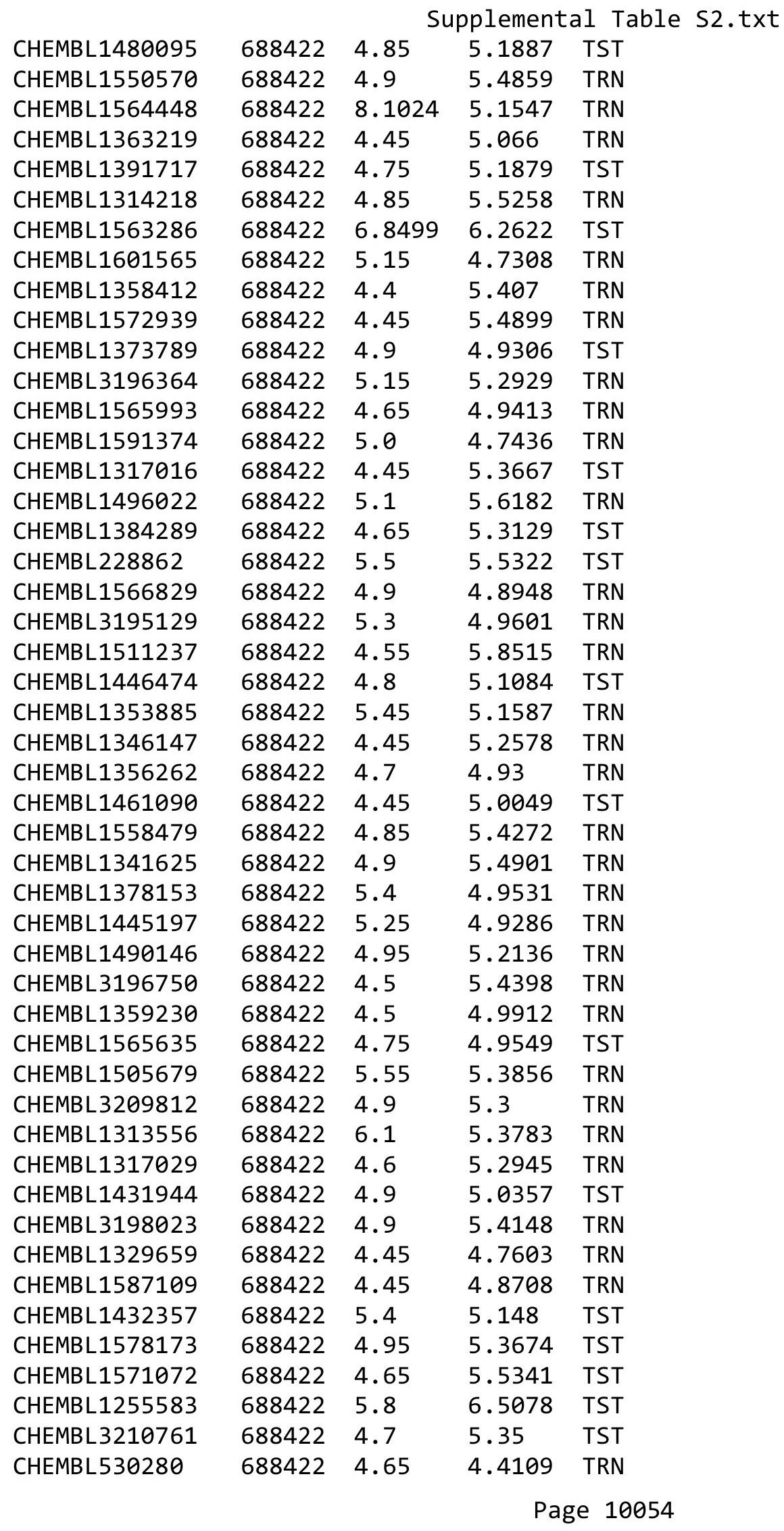




\begin{tabular}{|c|c|c|c|c|}
\hline \multicolumn{5}{|c|}{ Supplemental Table S2.txt } \\
\hline CHEMBL1528059 & 688422 & 5.0 & 5.2283 & TRN \\
\hline CHEMBL1463952 & 688422 & 5.0 & 5.3745 & TST \\
\hline CHEMBL1322545 & 688422 & 4.9 & 5.1493 & TRN \\
\hline CHEMBL1320907 & 688422 & 5.0 & 5.1105 & TST \\
\hline CHEMBL1490629 & 688422 & 5.45 & 4.9867 & TRN \\
\hline CHEMBL1555221 & 688422 & 8.301 & 5.6452 & TRN \\
\hline CHEMBL1573293 & 688422 & 4.5 & 5.4287 & TRN \\
\hline CHEMBL1303098 & 688422 & 6.0 & 5.444 & TRN \\
\hline CHEMBL1518103 & 688422 & 7.699 & 5.9634 & TRN \\
\hline CHEMBL1321276 & 688422 & 5.6 & 5.0005 & TRN \\
\hline CHEMBL1387352 & 688422 & 4.45 & 5.5831 & TST \\
\hline CHEMBL1348900 & 688422 & 5.85 & 5.5895 & TRN \\
\hline CHEMBL1419296 & 688422 & 8.1487 & 5.5897 & TRN \\
\hline CHEMBL1453335 & 688422 & 4.65 & 4.9248 & TRN \\
\hline CHEMBL1390094 & 688422 & 4.95 & 5.0916 & TRN \\
\hline CHEMBL1332669 & 688422 & 4.75 & 4.9613 & TRN \\
\hline CHEMBL1578409 & 688422 & 4.75 & 5.4666 & TRN \\
\hline CHEMBL1362352 & 688422 & 4.95 & 4.7323 & TRN \\
\hline CHEMBL1396489 & 688422 & 6.1 & 5.5211 & TST \\
\hline CHEMBL1555711 & 688422 & 4.5 & 4.9641 & TRN \\
\hline CHEMBL1568995 & 688422 & 5.5 & 5.2997 & TRN \\
\hline CHEMBL1320866 & 688422 & 7.5003 & 5.8103 & TRN \\
\hline CHEMBL1560916 & 688422 & 7.3497 & 4.9937 & TST \\
\hline CHEMBL1300284 & 688422 & 5.0 & 4.7357 & TST \\
\hline CHEMBL1529883 & 688422 & 5.0 & 5.1009 & TRN \\
\hline CHEMBL1354551 & 688422 & 4.55 & 5.1029 & TST \\
\hline CHEMBL1362161 & 688422 & 5.6 & 5.2246 & TRN \\
\hline CHEMBL1365290 & 688422 & 4.6 & 5.1057 & TRN \\
\hline CHEMBL1558529 & 688422 & 5.4 & 5.2636 & TRN \\
\hline CHEMBL1338947 & 688422 & 4.9 & 5.0178 & TRN \\
\hline CHEMBL1300063 & 688422 & 4.45 & 5.2977 & TRN \\
\hline CHEMBL1369052 & 688422 & 4.65 & 5.1909 & TST \\
\hline CHEMBL1346271 & 688422 & 4.75 & 5.1165 & TRN \\
\hline CHEMBL1604551 & 688422 & 4.45 & 5.2797 & TST \\
\hline CHEMBL1597435 & 688422 & 4.65 & 5.1532 & TRN \\
\hline CHEMBL1318617 & 688422 & 5.7 & 5.3067 & TRN \\
\hline CHEMBL1493141 & 688422 & 4.45 & 5.2641 & TRN \\
\hline CHEMBL1456293 & 688422 & 4.5 & 4.9912 & TRN \\
\hline CHEMBL1534154 & 688422 & 4.9 & 5.0222 & TST \\
\hline CHEMBL1428969 & 688422 & 4.55 & 5.5914 & TRN \\
\hline CHEMBL1357770 & 688422 & 5.95 & 5.6504 & TST \\
\hline CHEMBL1582691 & 688422 & 4.45 & 4.9382 & TRN \\
\hline CHEMBL1323264 & 688422 & 4.45 & 5.2605 & TRN \\
\hline CHEMBL1374194 & 688422 & 5.05 & 5.0107 & TRN \\
\hline CHEMBL1557640 & 688422 & 4.45 & 5.227 & TST \\
\hline CHEMBL1597231 & 688422 & 4.95 & 5.0855 & TRN \\
\hline CHEMBL1508845 & 688422 & 4.45 & 5.4258 & TRN \\
\hline CHEMBL1430613 & 688422 & 4.45 & 4.9696 & TRN \\
\hline
\end{tabular}




\begin{tabular}{|c|c|c|c|c|c|}
\hline \multicolumn{6}{|c|}{ Supplemental Table S2.txt } \\
\hline CHEMBL1975487 & 688422 & 4.9 & 4.9631 & TST & \\
\hline CHEMBL1486128 & 688422 & 6.7501 & 4.9308 & TRN & \\
\hline CHEMBL1515235 & 688422 & 4.5 & \multicolumn{2}{|c|}{5.031000000000001} & TRN \\
\hline CHEMBL 3194272 & 688422 & 5.5 & 5.2993 & TST & \\
\hline CHEMBL1372571 & 688422 & 4.6 & 4.9203 & TRN & \\
\hline CHEMBL1610800 & 688422 & 4.65 & 5.3477 & TST & \\
\hline CHEMBL1386745 & 688422 & 4.85 & 5.0965 & TRN & \\
\hline CHEMBL1602622 & 688422 & 4.75 & 4.9594 & TRN & \\
\hline CHEMBL102714 & 688422 & 5.2 & 5.0614 & TST & \\
\hline CHEMBL1321739 & 688422 & 4.9 & 5.0345 & TRN & \\
\hline CHEMBL1512666 & 688422 & 5.65 & 5.5136 & TST & \\
\hline CHEMBL1351241 & 688422 & 4.8 & 4.8952 & TRN & \\
\hline CHEMBL1309183 & 688422 & 4.45 & 4.8571 & TRN & \\
\hline CHEMBL1357270 & 688422 & 4.7 & 5.0359 & TRN & \\
\hline CHEMBL1591187 & 688422 & 4.7 & 5.3555 & TRN & \\
\hline CHEMBL1419004 & 688422 & 4.8 & 5.1933 & TRN & \\
\hline CHEMBL1393284 & 688422 & 5.25 & 5.3346 & TST & \\
\hline CHEMBL1563569 & 688422 & 4.45 & 4.765 & TRN & \\
\hline CHEMBL1352453 & 688422 & 4.45 & 5.6734 & TRN & \\
\hline CHEMBL1432180 & 688422 & 5.0 & 4.9481 & TRN & \\
\hline CHEMBL1478659 & 688422 & 4.85 & 5.5685 & TRN & \\
\hline CHEMBL1578113 & 688422 & 4.45 & 5.1899 & TST & \\
\hline CHEMBL1397857 & 688422 & 6.1 & 5.6316 & TRN & \\
\hline CHEMBL1309883 & 688422 & 4.9 & 5.1819 & TRN & \\
\hline CHEMBL1494313 & 688422 & 4.75 & 5.2053 & TRN & \\
\hline CHEMBL1431514 & 688422 & 5.5 & 5.5115 & TST & \\
\hline CHEMBL1449224 & 688422 & 4.75 & 4.9976 & TRN & \\
\hline CHEMBL1324047 & 688422 & 4.95 & 5.36 & TRN & \\
\hline CHEMBL1471348 & 688422 & 5.45 & 4.8803 & TRN & \\
\hline CHEMBL1580826 & 688422 & 6.6499 & 5.1087 & TRN & \\
\hline CHEMBL1417363 & 688422 & 4.45 & 5.4279 & TRN & \\
\hline CHEMBL1322793 & 688422 & 5.2 & 5.5327 & TRN & \\
\hline CHEMBL1465151 & 688422 & 4.45 & 5.1767 & TRN & \\
\hline CHEMBL1470052 & 688422 & 5.4 & 5.5983 & TST & \\
\hline CHEMBL1461940 & 688422 & 4.5 & 5.6328 & TST & \\
\hline CHEMBL1502788 & 688422 & 4.8 & 5.3574 & TRN & \\
\hline CHEMBL1554073 & 688422 & 6.0 & 5.5833 & TRN & \\
\hline CHEMBL1384297 & 688422 & 4.9 & 5.3573 & TST & \\
\hline CHEMBL1523048 & 688422 & 8.4949 & 5.5042 & TST & \\
\hline CHEMBL1382692 & 688422 & 5.15 & 5.0983 & TRN & \\
\hline CHEMBL1343875 & 688422 & 4.9 & 4.9701 & TRN & \\
\hline CHEMBL3195109 & 688422 & 4.45 & 5.0223 & TRN & \\
\hline CHEMBL1300273 & 688422 & 5.7 & 5.4406 & TRN & \\
\hline CHEMBL1471789 & 688422 & 5.4 & 5.1887 & TST & \\
\hline CHEMBL1406879 & 688422 & 4.65 & 5.0501 & TRN & \\
\hline CHEMBL1452342 & 688422 & 4.8 & 5.4207 & TRN & \\
\hline CHEMBL1387571 & 688422 & 5.0 & 5.16799 & 9999999999 & TRN \\
\hline CHEMBL1596468 & 688422 & 4.6 & 4.7343 & TRN & \\
\hline & & & & 10056 & \\
\hline
\end{tabular}




\begin{tabular}{|c|c|c|c|c|c|}
\hline \multicolumn{6}{|c|}{ Supplemental Table S2.txt } \\
\hline CHEMBL1543701 & 688422 & 4.85 & 5.0144 & TRN & \\
\hline CHEMBL1523115 & 688422 & 6.5 & 4.919 & TRN & \\
\hline CHEMBL 2002898 & 688422 & 5.1 & 5.131 & TRN & \\
\hline CHEMBL1549860 & 688422 & 4.9 & 4.6949 & TRN & \\
\hline CHEMBL1491946 & 688422 & 5.05 & 4.8899 & TRN & \\
\hline CHEMBL1594747 & 688422 & 4.8 & 5.2268 & TRN & \\
\hline CHEMBL1574194 & 688422 & 8.0506 & 5.4861 & TRN & \\
\hline CHEMBL1545407 & 688422 & 4.7 & 5.0816 & TRN & \\
\hline CHEMBL1374583 & 688422 & 4.55 & 4.8647 & TRN & \\
\hline CHEMBL1361785 & 688422 & 4.75 & 5.3703 & TRN & \\
\hline CHEMBL1440238 & 688422 & 4.45 & 4.7625 & TRN & \\
\hline CHEMBL1519621 & 688422 & 4.45 & 5.065 & TRN & \\
\hline CHEMBL1976299 & 688422 & 5.35 & 5.0724 & TST & \\
\hline CHEMBL1361821 & 688422 & 5.35 & 5.0006 & TRN & \\
\hline CHEMBL1465356 & 688422 & 5.45 & 4.7638 & TRN & \\
\hline CHEMBL1301169 & 688422 & 5.2 & 5.2164 & TRN & \\
\hline CHEMBL1414664 & 688422 & 8.4559 & 5.5091 & TRN & \\
\hline CHEMBL1333704 & 688422 & 6.9 & 5.4872 & TRN & \\
\hline CHEMBL1319304 & 688422 & 6.1 & 5.0718 & TRN & \\
\hline CHEMBL1316276 & 688422 & 5.0 & 5.3739 & TRN & \\
\hline CHEMBL3196660 & 688422 & 4.45 & 5.3783 & TST & \\
\hline CHEMBL1427685 & 688422 & 4.95 & 5.0491 & TST & \\
\hline CHEMBL1451585 & 688422 & 4.5 & 5.0989 & TST & \\
\hline CHEMBL1426597 & 688422 & 5.5 & 5.6232 & TRN & \\
\hline CHEMBL1410809 & 688422 & 4.9 & 5.0395 & TRN & \\
\hline CHEMBL1527288 & 688422 & 4.6 & 5.6457 & TRN & \\
\hline CHEMBL1580164 & 688422 & 5.0 & 5.0551 & TRN & \\
\hline CHEMBL1320831 & 688422 & 7.8508 & 5.039 & TRN & \\
\hline CHEMBL1353863 & 688422 & 6.5501 & 5.3986 & TST & \\
\hline CHEMBL1467287 & 688422 & 5.05 & 5.2138 & TST & \\
\hline CHEMBL1541082 & 688422 & 4.45 & 5.3656 & TRN & \\
\hline CHEMBL1341248 & 688422 & 4.65 & 5.2936 & TRN & \\
\hline CHEMBL1366364 & 688422 & 7.0 & 5.17200 & 0000000001 & TRN \\
\hline CHEMBL1609686 & 688422 & 4.9 & 5.2167 & TRN & \\
\hline CHEMBL1422529 & 688422 & 5.4 & 5.3404 & TRN & \\
\hline CHEMBL1463875 & 688422 & 4.65 & 5.6907 & TRN & \\
\hline CHEMBL1461593 & 688422 & 5.55 & 5.1019 & TST & \\
\hline CHEMBL1589416 & 688422 & 4.85 & 5.1527 & TRN & \\
\hline CHEMBL1560333 & 688422 & 4.45 & 5.78100 & 2000000001 & TST \\
\hline CHEMBL1532816 & 688422 & 4.7 & 5.1732 & TRN & \\
\hline CHEMBL1613002 & 688422 & 4.85 & 5.8013 & TST & \\
\hline CHEMBL1330163 & 688422 & 4.85 & 5.246 & TST & \\
\hline CHEMBL1404633 & 688422 & 4.9 & 5.1752 & TRN & \\
\hline CHEMBL1591887 & 688422 & 5.35 & 5.45 & TRN & \\
\hline CHEMBL1347145 & 688422 & 4.95 & 5.0522 & TRN & \\
\hline CHEMBL1535578 & 688422 & 4.45 & 4.9575 & TRN & \\
\hline CHEMBL207714 & 688422 & 4.85 & 4.9105 & TRN & \\
\hline CHEMBL1356321 & 688422 & 4.45 & 5.0786 & TRN & \\
\hline
\end{tabular}




\begin{tabular}{|c|c|c|c|c|}
\hline \multicolumn{5}{|c|}{ Supplemental Table S2.txt } \\
\hline CHEMBL1455036 & 688422 & 5.2 & 5.516 & TRN \\
\hline CHEMBL1379877 & 688422 & 5.35 & 5.2399 & TRN \\
\hline CHEMBL1340087 & 688422 & 4.5 & 5.106 & TRN \\
\hline CHEMBL1343688 & 688422 & 7.2 & 5.1676 & TST \\
\hline CHEMBL1438702 & 688422 & 4.6 & 5.1013 & TRN \\
\hline CHEMBL1365949 & 688422 & 4.85 & 5.1513 & TST \\
\hline CHEMBL1580678 & 688422 & 4.9 & 5.7752 & TRN \\
\hline CHEMBL1464550 & 688422 & 4.8 & 4.9833 & TRN \\
\hline CHEMBL1308167 & 688422 & 6.2 & 5.8898 & TST \\
\hline CHEMBL1588645 & 688422 & 4.9 & 5.6161 & TRN \\
\hline CHEMBL1499527 & 688422 & 5.25 & 5.1719 & TRN \\
\hline CHEMBL1523590 & 688422 & 5.1 & 5.455 & TRN \\
\hline CHEMBL1357947 & 688422 & 4.65 & 4.9154 & TRN \\
\hline CHEMBL1310184 & 688422 & 5.2 & 5.2394 & TRN \\
\hline CHEMBL1577584 & 688422 & 4.8 & 5.3525 & TRN \\
\hline CHEMBL1506077 & 688422 & 8.0 & 5.4436 & TRN \\
\hline CHEMBL1967586 & 688422 & 6.2 & 5.3303 & TRN \\
\hline CHEMBL465843 & 688422 & 5.5 & 5.7859 & TRN \\
\hline CHEMBL1612768 & 688422 & 4.45 & 5.1292 & TRN \\
\hline CHEMBL1558716 & 688422 & 4.45 & 5.1828 & TRN \\
\hline CHEMBL1490721 & 688422 & 4.9 & 5.393 & TST \\
\hline CHEMBL1408021 & 688422 & 5.85 & 5.5982 & TRN \\
\hline CHEMBL1531754 & 688422 & 6.0 & 5.6032 & TRN \\
\hline CHEMBL1437482 & 688422 & 6.0 & 5.3925 & TRN \\
\hline CHEMBL1587226 & 688422 & 4.95 & 5.066 & TST \\
\hline CHEMBL1334179 & 688422 & 4.8 & 4.8652 & TRN \\
\hline CHEMBL1462827 & 688422 & 5.85 & 5.3177 & TRN \\
\hline CHEMBL1457385 & 688422 & 4.6 & 5.1632 & TRN \\
\hline CHEMBL1310302 & 688422 & 4.9 & 4.8984 & TRN \\
\hline CHEMBL1531388 & 688422 & 4.9 & 5.1582 & TRN \\
\hline CHEMBL1336051 & 688422 & 4.9 & 5.074 & TRN \\
\hline CHEMBL1547468 & 688422 & 4.45 & 5.0638 & TST \\
\hline CHEMBL1330923 & 688422 & 4.45 & 5.2631 & TRN \\
\hline CHEMBL1588151 & 688422 & 4.85 & 5.2891 & TRN \\
\hline CHEMBL1480836 & 688422 & 7.5003 & 5.115 & TRN \\
\hline CHEMBL 3193474 & 688422 & 4.9 & 5.144 & TRN \\
\hline CHEMBL581886 & 688422 & 7.4001 & 6.2203 & TST \\
\hline CHEMBL1426306 & 688422 & 4.45 & 4.9487 & TRN \\
\hline CHEMBL1520388 & 688422 & 4.45 & 5.4347 & TRN \\
\hline CHEMBL1593707 & 688422 & 4.85 & 5.0986 & TRN \\
\hline CHEMBL1552320 & 688422 & 4.75 & 5.5403 & TRN \\
\hline CHEMBL1344621 & 688422 & 4.85 & 5.5992 & TRN \\
\hline CHEMBL1602579 & 688422 & 6.1 & 5.5822 & TST \\
\hline CHEMBL1559473 & 688422 & 5.4 & 4.9136 & TRN \\
\hline CHEMBL1483096 & 688422 & 5.4 & 5.2685 & TRN \\
\hline CHEMBL1462683 & 688422 & 4.85 & 4.7182 & TRN \\
\hline CHEMBL1569989 & 688422 & 5.2 & 5.5299 & TRN \\
\hline CHEMBL1323861 & 688422 & 4.8 & 5.5728 & TRN \\
\hline
\end{tabular}




\begin{tabular}{|c|c|c|c|c|c|}
\hline \multicolumn{6}{|c|}{ Supplemental Table s2.txt } \\
\hline CHEMBL1334997 & 688422 & 4.85 & 5.1658 & TRN & \\
\hline CHEMBL1596597 & 688422 & 5.35 & 5.2604 & TRN & \\
\hline CHEMBL1586744 & 688422 & 4.8 & 4.99 & TRN & \\
\hline CHEMBL 3207497 & 688422 & 6.3 & 5.4027 & TRN & \\
\hline CHEMBL1299991 & 688422 & 4.9 & 5.2265 & TST & \\
\hline CHEMBL1600726 & 688422 & 4.95 & 5.3119 & TRN & \\
\hline CHEMBL1425133 & 688422 & 8.699 & 5.0993 & TST & \\
\hline CHEMBL1307761 & 688422 & 4.45 & 5.1263 & TRN & \\
\hline CHEMBL1400896 & 688422 & 4.75 & 5.3111 & TRN & \\
\hline CHEMBL1456361 & 688422 & 4.45 & 4.8813 & TRN & \\
\hline CHEMBL1612323 & 688422 & 5.45 & 5.1974 & TRN & \\
\hline CHEMBL1426729 & 688422 & 5.35 & 4.5055 & TRN & \\
\hline CHEMBL1413986 & 688422 & 4.95 & 5.54 & TST & \\
\hline CHEMBL1346120 & 688422 & 5.25 & 5.4736 & TRN & \\
\hline CHEMBL1359713 & 688422 & 6.0 & 5.1558 & TRN & \\
\hline CHEMBL1408740 & 688422 & 4.85 & 5.3654 & TRN & \\
\hline CHEMBL1559459 & 688422 & 4.5 & 4.6283 & TST & \\
\hline CHEMBL1497305 & 688422 & 4.65 & 4.9748 & TRN & \\
\hline CHEMBL1321297 & 688422 & 4.5 & 4.9665 & TRN & \\
\hline CHEMBL1508295 & 688422 & 4.75 & 5.2545 & TRN & \\
\hline CHEMBL1435578 & 688422 & 5.2 & 5.3607 & TST & \\
\hline CHEMBL3193015 & 688422 & 4.8 & 5.5762 & TST & \\
\hline CHEMBL1514074 & 688422 & 4.85 & 5.2054 & TRN & \\
\hline CHEMBL 3195272 & 688422 & 4.8 & 5.1693 & TRN & \\
\hline CHEMBL1394714 & 688422 & 5.0 & 5.13399 & 99999999995 & TRN \\
\hline CHEMBL1387100 & 688422 & 4.8 & 5.0658 & TRN & \\
\hline CHEMBL1480641 & 688422 & 4.45 & 5.5949 & TRN & \\
\hline CHEMBL1473833 & 688422 & 4.95 & 5.516 & TRN & \\
\hline CHEMBL1395050 & 688422 & 6.95 & 5.3925 & TRN & \\
\hline CHEMBL1426049 & 688422 & 4.65 & 5.4677 & TRN & \\
\hline CHEMBL1370181 & 688422 & 5.7 & 5.0142 & TRN & \\
\hline CHEMBL1442944 & 688422 & 4.45 & 4.8532 & TRN & \\
\hline CHEMBL1464830 & 688422 & 4.9 & 4.8264 & TRN & \\
\hline CHEMBL1370681 & 688422 & 4.9 & 5.1606 & TRN & \\
\hline CHEMBL1300193 & 688422 & 5.5 & 5.1644 & TRN & \\
\hline CHEMBL1354302 & 688422 & 6.15 & 5.26 & TRN & \\
\hline CHEMBL1380511 & 688422 & 4.7 & 4.8102 & TRN & \\
\hline CHEMBL1548458 & 688422 & 5.05 & 5.0524 & TRN & \\
\hline CHEMBL1382983 & 688422 & 7.0 & 5.0829 & TRN & \\
\hline CHEMBL1313879 & 688422 & 4.5 & 5.2279 & TRN & \\
\hline CHEMBL1302563 & 688422 & 4.6 & 4.937 & TST & \\
\hline CHEMBL3190733 & 688422 & 4.7 & 5.1454 & TRN & \\
\hline CHEMBL1605411 & 688422 & 5.1 & 4.9072 & TST & \\
\hline CHEMBL1333482 & 688422 & 4.95 & 5.4174 & TRN & \\
\hline CHEMBL1544491 & 688422 & 5.0 & 4.7915 & TRN & \\
\hline CHEMBL1361551 & 688422 & 4.9 & 5.2369 & TST & \\
\hline CHEMBL1474775 & 688422 & 4.85 & 5.0862 & TRN & \\
\hline CHEMBL1313792 & 688422 & 5.5 & 5.0184 & TST & \\
\hline
\end{tabular}




\begin{tabular}{|c|c|c|c|c|c|}
\hline \multicolumn{6}{|c|}{ Supplemental Table S2.txt } \\
\hline CHEMBL1376603 & 688422 & 4.7 & 5.4161 & TRN & \\
\hline CHEMBL1366393 & 688422 & 4.9 & 4.5695 & TRN & \\
\hline CHEMBL1407682 & 688422 & 4.85 & 5.5258 & TRN & \\
\hline CHEMBL1358873 & 688422 & 4.95 & 4.7238 & TRN & \\
\hline CHEMBL1498652 & 688422 & 4.45 & 5.7613 & TST & \\
\hline CHEMBL1580258 & 688422 & 7.9508 & 5.3955 & TST & \\
\hline CHEMBL1474155 & 688422 & 4.6 & 4.9155 & TRN & \\
\hline CHEMBL1394568 & 688422 & 4.8 & 4.8189 & TRN & \\
\hline CHEMBL1473693 & 688422 & 5.0 & 5.3702 & TRN & \\
\hline CHEMBL1504222 & 688422 & 7.8996 & 5.13700 & 00000000005 & TRN \\
\hline CHEMBL1555503 & 688422 & 4.9 & 4.9864 & TRN & \\
\hline CHEMBL1370550 & 688422 & 4.95 & 4.9505 & TST & \\
\hline CHEMBL1576046 & 688422 & 4.7 & 5.3522 & TST & \\
\hline CHEMBL1494499 & 688422 & 4.65 & 5.1891 & TST & \\
\hline CHEMBL1583494 & 688422 & 4.6 & 4.7086 & TRN & \\
\hline CHEMBL1334855 & 688422 & 7.699 & 5.4915 & TRN & \\
\hline CHEMBL1382157 & 688422 & 4.95 & 5.4493 & TST & \\
\hline CHEMBL1362433 & 688422 & 7.6003 & 5.6381 & TRN & \\
\hline CHEMBL1477294 & 688422 & 5.2 & 5.5224 & TST & \\
\hline CHEMBL1490880 & 688422 & 7.5003 & 5.3189 & TRN & \\
\hline CHEMBL1494418 & 688422 & 5.7 & 5.1738 & TRN & \\
\hline CHEMBL1320019 & 688422 & 4.65 & 5.1943 & TRN & \\
\hline CHEMBL1421261 & 688422 & 4.45 & 4.6696 & TRN & \\
\hline CHEMBL1352632 & 688422 & 4.9 & 5.5101 & TST & \\
\hline CHEMBL1537399 & 688422 & 4.95 & 5.3123 & TRN & \\
\hline CHEMBL1308170 & 688422 & 7.4498 & 5.5153 & TRN & \\
\hline CHEMBL1502546 & 688422 & 4.7 & 5.305 & TRN & \\
\hline CHEMBL1388863 & 688422 & 6.0 & 5.5734 & TST & \\
\hline CHEMBL1300891 & 688422 & 5.6 & 5.3741 & TRN & \\
\hline CHEMBL1533366 & 688422 & 5.35 & 5.1469 & TRN & \\
\hline CHEMBL1395431 & 688422 & 4.9 & 4.7875 & TRN & \\
\hline CHEMBL1367745 & 688422 & 4.5 & 5.2795 & TRN & \\
\hline CHEMBL1330653 & 688422 & 5.25 & 5.3384 & TRN & \\
\hline CHEMBL1366683 & 688422 & 6.05 & 5.1914 & TRN & \\
\hline CHEMBL1541604 & 688422 & 4.75 & 5.5823 & TST & \\
\hline CHEMBL1490131 & 688422 & 7.6498 & 5.3351 & TST & \\
\hline CHEMBL1545945 & 688422 & 4.9 & 5.3646 & TRN & \\
\hline CHEMBL1609727 & 688422 & 6.0 & 5.1427 & TRN & \\
\hline CHEMBL1383401 & 688422 & 8.0506 & 5.4781 & TRN & \\
\hline CHEMBL1341424 & 688422 & 4.5 & 5.0399 & TRN & \\
\hline CHEMBL1599856 & 688422 & 4.8 & 4.7258 & TRN & \\
\hline CHEMBL1380636 & 688422 & 4.45 & 5.8209 & TRN & \\
\hline CHEMBL1611291 & 688422 & 6.45 & 5.037 & TST & \\
\hline CHEMBL3196224 & 688422 & 4.5 & 5.3298 & TRN & \\
\hline CHEMBL1433331 & 688422 & 4.45 & 4.9231 & TRN & \\
\hline CHEMBL1487171 & 688422 & 4.9 & 5.0902 & TRN & \\
\hline CHEMBL1471292 & 688422 & 4.45 & 4.9418 & TRN & \\
\hline CHEMBL1480185 & 688422 & 5.0 & 4.9405 & TRN & \\
\hline
\end{tabular}




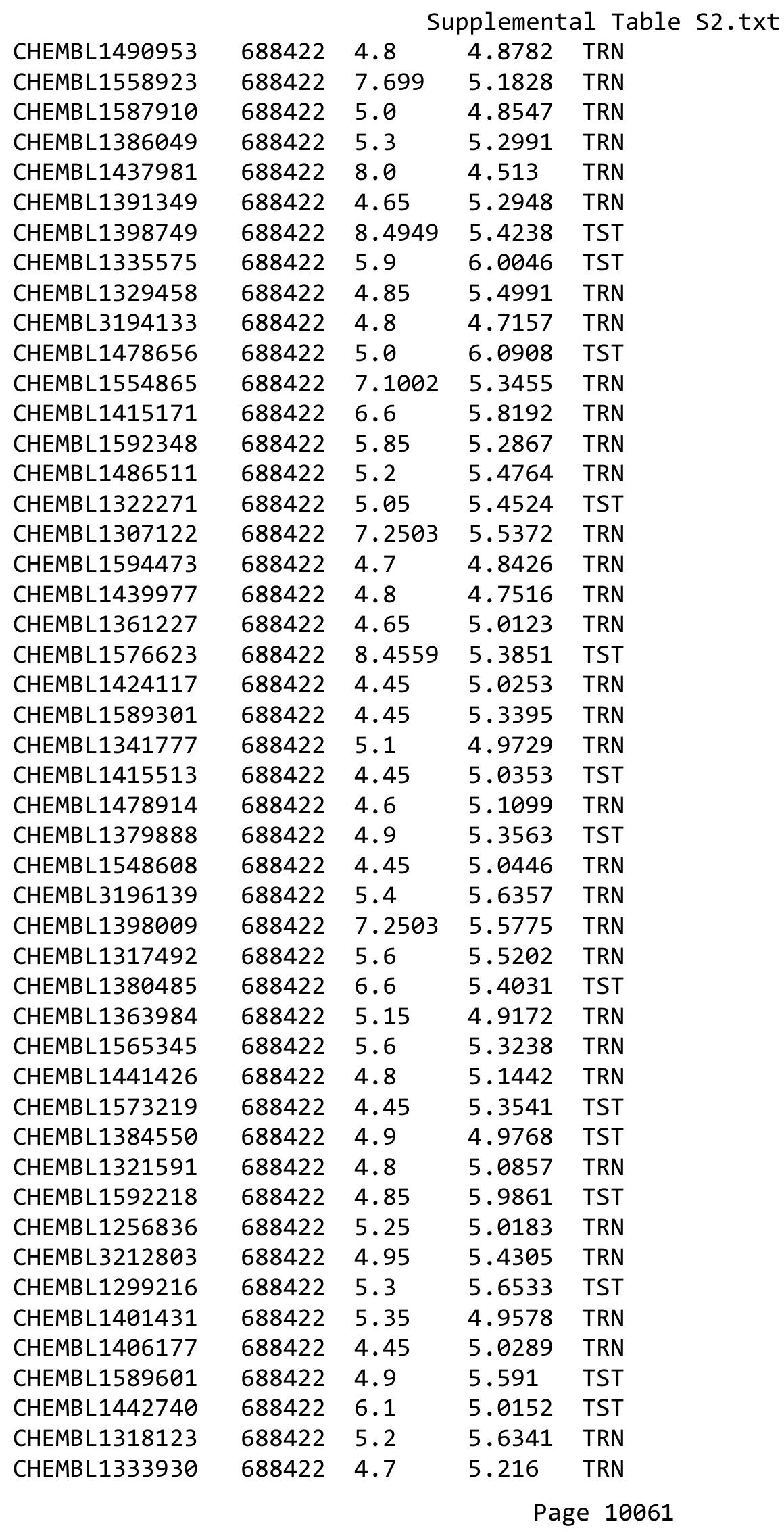




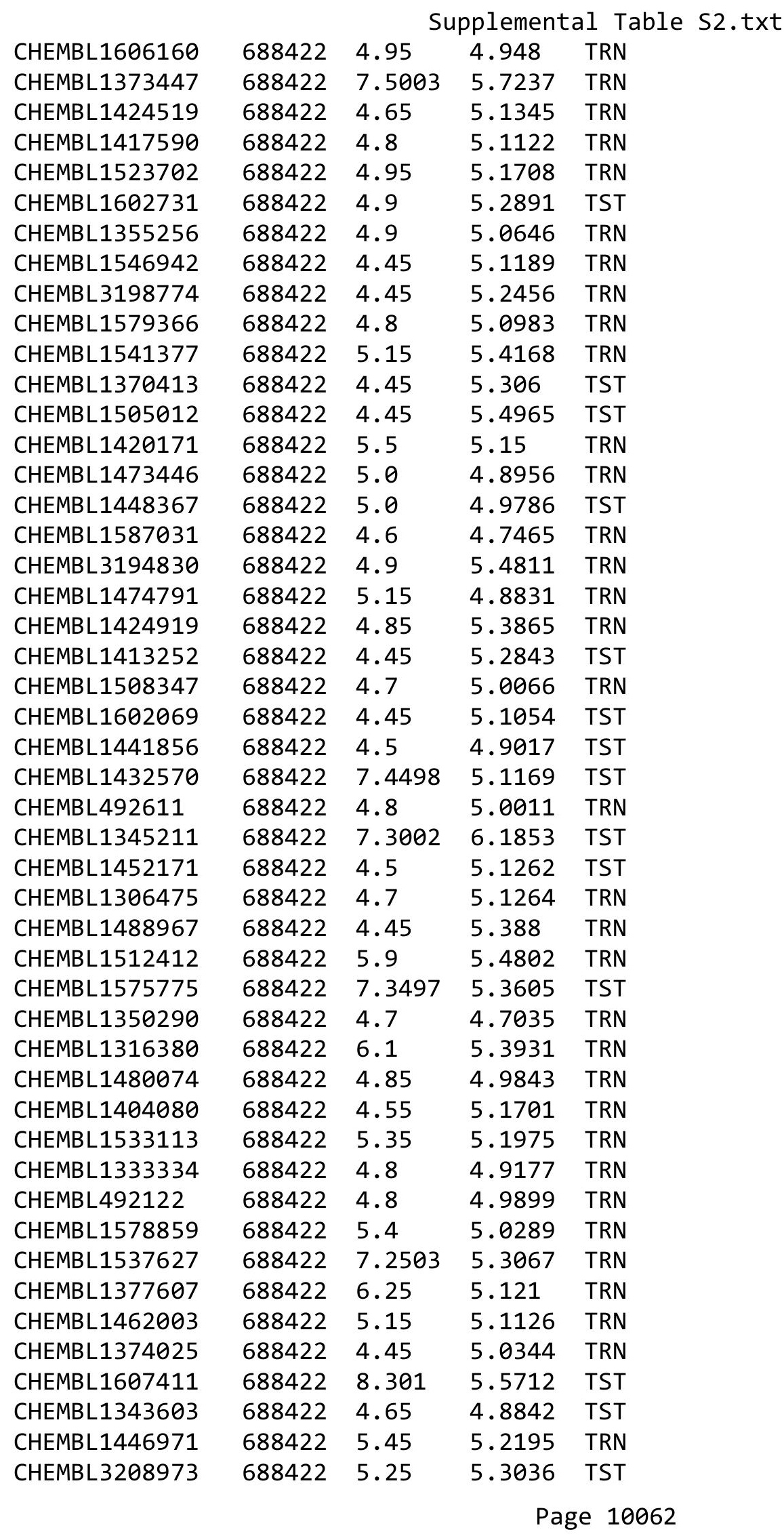




\begin{tabular}{|c|c|c|c|c|c|}
\hline \multicolumn{6}{|c|}{ Supplemental Table S2.txt } \\
\hline CHEMBL1422097 & 688422 & 5.3 & 5.5203 & TST & \\
\hline CHEMBL1611771 & 688422 & 5.55 & 5.0142 & TRN & \\
\hline CHEMBL1601387 & 688422 & 4.65 & 5.1042 & TRN & \\
\hline CHEMBL1332668 & 688422 & 4.45 & 5.2215 & TRN & \\
\hline CHEMBL1501282 & 688422 & 4.9 & 5.0147 & TRN & \\
\hline CHEMBL3197792 & 688422 & 4.65 & 4.8203 & TRN & \\
\hline CHEMBL3189853 & 688422 & 4.7 & 5.0551 & TRN & \\
\hline CHEMBL1347808 & 688422 & 6.25 & 4.9695 & TRN & \\
\hline CHEMBL1529647 & 688422 & 4.7 & 5.1426 & TST & \\
\hline CHEMBL1510653 & 688422 & 4.8 & 5.8167 & TRN & \\
\hline CHEMBL1383669 & 688422 & 4.95 & 5.0317 & TST & \\
\hline CHEMBL1448397 & 688422 & 7.6498 & 5.4694 & TRN & \\
\hline CHEMBL1383529 & 688422 & 4.7 & 5.2827 & TRN & \\
\hline CHEMBL1436478 & 688422 & 5.8 & 5.1074 & TRN & \\
\hline CHEMBL1438216 & 688422 & 5.95 & 5.4358 & TST & \\
\hline CHEMBL1301909 & 688422 & 5.5 & 5.0605 & TRN & \\
\hline CHEMBL1433626 & 688422 & 5.2 & 4.9878 & TRN & \\
\hline CHEMBL1396203 & 688422 & 4.45 & 4.6242 & TRN & \\
\hline CHEMBL1539399 & 688422 & 4.45 & 4.9682 & TRN & \\
\hline CHEMBL1364477 & 688422 & 5.1 & 4.8162 & TRN & \\
\hline CHEMBL1091556 & 688422 & 4.45 & 5.2478 & TRN & \\
\hline CHEMBL1488071 & 688422 & 4.85 & 5.0684 & TRN & \\
\hline CHEMBL1565214 & 688422 & 4.45 & 5.0693 & TST & \\
\hline CHEMBL1424155 & 688422 & 7.5498 & 5.4827 & TRN & \\
\hline CHEMBL3189960 & 688422 & 4.75 & 5.00899 & 99999999995 & TST \\
\hline CHEMBL1465435 & 688422 & 4.6 & 4.8531 & TRN & \\
\hline CHEMBL3195981 & 688422 & 4.45 & 4.9468 & TST & \\
\hline CHEMBL1364799 & 688422 & 4.95 & 5.0249 & TRN & \\
\hline CHEMBL1372199 & 688422 & 5.9 & 5.5131 & TRN & \\
\hline CHEMBL1504216 & 688422 & 4.5 & 5.3989 & TRN & \\
\hline CHEMBL1481572 & 688422 & 4.7 & 5.011 & TRN & \\
\hline CHEMBL1466699 & 688422 & 5.3 & 5.2343 & TRN & \\
\hline CHEMBL1518608 & 688422 & 4.45 & 5.0414 & TRN & \\
\hline CHEMBL1423952 & 688422 & 8.3979 & 6.0164 & TST & \\
\hline CHEMBL1319384 & 688422 & 5.0 & 5.114 & TST & \\
\hline CHEMBL1604296 & 688422 & 5.9 & 5.5364 & TRN & \\
\hline CHEMBL1424940 & 688422 & 4.7 & 5.54 & TRN & \\
\hline CHEMBL1307763 & 688422 & 6.5501 & 5.33799 & 9999999999 & TRN \\
\hline CHEMBL1343564 & 688422 & 4.95 & 5.4071 & TRN & \\
\hline CHEMBL1568996 & 688422 & 4.8 & 4.7483 & TST & \\
\hline CHEMBL1398641 & 688422 & 4.45 & 5.1847 & TRN & \\
\hline CHEMBL1498658 & 688422 & 4.65 & 4.6636 & TRN & \\
\hline CHEMBL1316463 & 688422 & 4.8 & 5.0339 & TRN & \\
\hline CHEMBL1402026 & 688422 & 4.45 & 4.9667 & TST & \\
\hline CHEMBL1303227 & 688422 & 4.45 & 5.8843 & TST & \\
\hline CHEMBL1513654 & 688422 & 4.45 & 5.5111 & TST & \\
\hline CHEMBL1393833 & 688422 & 4.5 & 5.3598 & TRN & \\
\hline CHEMBL1418286 & 688422 & 5.45 & 5.4065 & TRN & \\
\hline
\end{tabular}




\begin{tabular}{|c|c|c|c|c|}
\hline \multicolumn{5}{|c|}{ lemental Table $S$} \\
\hline CHEMBL1431142 & 688422 & 4.6 & 5.3445 & TRN \\
\hline CHEMBL1534496 & 688422 & 5.2 & 5.58899 & 99999999995 \\
\hline CHEMBL1568216 & 688422 & 6.45 & 5.416 & TST \\
\hline CHEMBL1502032 & 688422 & 4.65 & 5.2837 & TRN \\
\hline CHEMBL1333628 & 688422 & 6.5501 & 5.3113 & TRN \\
\hline CHEMBL1983581 & 688422 & 4.5 & 4.8497 & TRN \\
\hline CHEMBL3198851 & 688422 & 4.6 & 5.0641 & TST \\
\hline CHEMBL1524786 & 688422 & 4.8 & 5.1481 & TRN \\
\hline CHEMBL1319676 & 688422 & 6.0 & 5.4538 & TRN \\
\hline CHEMBL3198185 & 688422 & 4.45 & 4.7462 & TRN \\
\hline CHEMBL1321955 & 688422 & 4.9 & 5.3305 & TRN \\
\hline CHEMBL1610854 & 688422 & 4.9 & 5.008 & TRN \\
\hline CHEMBL1502682 & 688422 & 6.7501 & 5.2872 & TST \\
\hline CHEMBL1382516 & 688422 & 8.4559 & 4.999 & TRN \\
\hline CHEMBL1418633 & 688422 & 4.85 & 5.1611 & TRN \\
\hline CHEMBL 1422030 & 688422 & 4.45 & 4.966 & TRN \\
\hline CHEMBL1414854 & 688422 & 7.8996 & 6.0883 & TRN \\
\hline CHEMBL1438881 & 688422 & 4.45 & 5.1012 & TRN \\
\hline CHEMBL1374889 & 688422 & 4.65 & 5.0225 & TRN \\
\hline CHEMBL607299 & 688422 & 4.95 & 4.9013 & TST \\
\hline CHEMBL 1517020 & 688422 & 4.9 & 5.0981 & TRN \\
\hline CHEMBL1437508 & 688422 & 4.45 & 5.2321 & TRN \\
\hline CHEMBL1309181 & 688422 & 5.25 & 4.8661 & TRN \\
\hline CHEMBL1493968 & 688422 & 4.85 & 5.1679 & TRN \\
\hline CHEMBL1332201 & 688422 & 5.2 & 5.1736 & TRN \\
\hline CHEMBL1530422 & 688422 & 5.75 & 5.3665 & TST \\
\hline CHEMBL1471247 & 688422 & 5.25 & 4.6504 & TST \\
\hline CHEMBL1401194 & 688422 & 6.3 & 5.3564 & TRN \\
\hline CHEMBL1367267 & 688422 & 4.85 & 4.7253 & TRN \\
\hline CHEMBL1543393 & 688422 & 7.15 & 5.1272 & TRN \\
\hline CHEMBL1494352 & 688422 & 5.2 & 5.0368 & TRN \\
\hline CHEMBL1964480 & 688422 & 4.85 & 5.0409 & TRN \\
\hline CHEMBL1397466 & 688422 & 8.3468 & 6.1509 & TRN \\
\hline CHEMBL3199379 & 688422 & 4.75 & 5.191 & TST \\
\hline CHEMBL1442281 & 688422 & 4.45 & 5.4017 & TST \\
\hline CHEMBL3193228 & 688422 & 4.7 & 5.1664 & TRN \\
\hline CHEMBL1462688 & 688422 & 4.45 & 5.4455 & TST \\
\hline CHEMBL1400519 & 688422 & 4.95 & 4.7845 & TST \\
\hline CHEMBL1411522 & 688422 & 8.4949 & 6.0761 & TST \\
\hline CHEMBL1602982 & 688422 & 4.7 & 5.4127 & TST \\
\hline CHEMBL1503908 & 688422 & 6.7001 & 5.0263 & TRN \\
\hline CHEMBL1546792 & 688422 & 5.75 & 5.0208 & TST \\
\hline CHEMBL 3194682 & 688422 & 5.75 & 5.7584 & TRN \\
\hline CHEMBL1324810 & 688422 & 4.9 & 5.3764 & TRN \\
\hline CHEMBL 2001794 & 688422 & 5.15 & 4.8568 & TST \\
\hline CHEMBL1319737 & 688422 & 4.7 & 5.3739 & TRN \\
\hline CHEMBL22304 & 688422 & 8.301 & 6.2801 & TST \\
\hline CHEMBL1573805 & 688422 & 4.45 & 5.789 & TRN \\
\hline
\end{tabular}




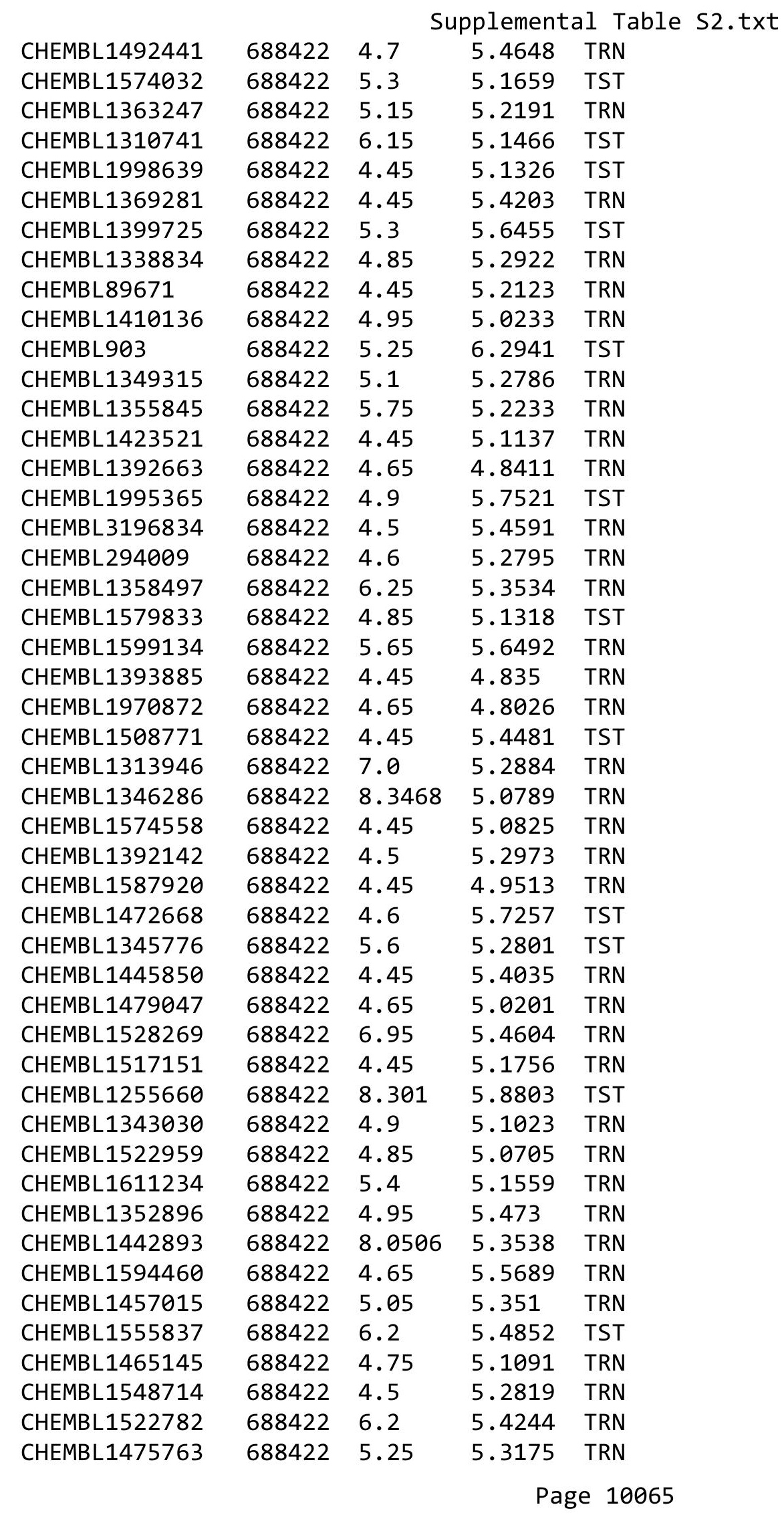




\begin{tabular}{|c|c|c|c|c|c|}
\hline \multicolumn{6}{|c|}{ Supplemental Table S2.txt } \\
\hline CHEMBL250711 & 688422 & 5.0 & 5.0589 & TST & \\
\hline CHEMBL1524015 & 688422 & 4.5 & 5.4632 & TST & \\
\hline CHEMBL1453255 & 688422 & 4.7 & 5.1603 & TRN & \\
\hline CHEMBL1444230 & 688422 & 4.45 & 5.0468 & TRN & \\
\hline CHEMBL1492017 & 688422 & 5.4 & 5.4128 & TRN & \\
\hline CHEMBL3197544 & 688422 & 4.7 & 5.3088 & TRN & \\
\hline CHEMBL1441190 & 688422 & 4.95 & 5.6573 & TRN & \\
\hline CHEMBL1379740 & 688422 & 5.9 & 5.402 & TST & \\
\hline CHEMBL1483326 & 688422 & 4.95 & 5.4821 & TRN & \\
\hline CHEMBL1442404 & 688422 & 4.85 & 5.2573 & TRN & \\
\hline CHEMBL1583495 & 688422 & 4.85 & 5.2483 & TRN & \\
\hline CHEMBL3208413 & 688422 & 4.85 & 5.38399 & 99999999995 & TRN \\
\hline CHEMBL307979 & 688422 & 6.95 & 5.4791 & TST & \\
\hline CHEMBL1529154 & 688422 & 4.5 & 5.1587 & TRN & \\
\hline CHEMBL1527586 & 688422 & 4.95 & 5.0098 & TRN & \\
\hline CHEMBL1514226 & 688422 & 4.95 & 5.4957 & TRN & \\
\hline CHEMBL1372139 & 688422 & 6.25 & 5.3498 & TRN & \\
\hline CHEMBL1981454 & 688422 & 7.5498 & 5.2485 & TRN & \\
\hline CHEMBL1569726 & 688422 & 4.55 & 5.0219 & TRN & \\
\hline CHEMBL1410009 & 688422 & 4.45 & 4.8361 & TRN & \\
\hline CHEMBL1302097 & 688422 & 5.05 & 5.29200 & 0000000001 & TRN \\
\hline CHEMBL1601912 & 688422 & 5.95 & 5.5726 & TRN & \\
\hline CHEMBL1473477 & 688422 & 4.45 & 5.3622 & TRN & \\
\hline CHEMBL246957 & 688422 & 5.35 & 5.2898 & TST & \\
\hline CHEMBL1456503 & 688422 & 4.65 & 5.2134 & TRN & \\
\hline CHEMBL1449082 & 688422 & 5.4 & 5.3277 & TRN & \\
\hline CHEMBL1420712 & 688422 & 6.45 & 5.3572 & TRN & \\
\hline CHEMBL1464220 & 688422 & 4.8 & 5.3595 & TRN & \\
\hline CHEMBL1299537 & 688422 & 6.1 & 5.0277 & TST & \\
\hline CHEMBL1422730 & 688422 & 5.55 & 5.3434 & TRN & \\
\hline CHEMBL1455018 & 688422 & 4.8 & 5.1226 & TRN & \\
\hline CHEMBL1590850 & 688422 & 4.7 & 5.4821 & TRN & \\
\hline CHEMBL1339107 & 688422 & 4.45 & 4.7575 & TRN & \\
\hline CHEMBL1348188 & 688422 & 4.9 & 5.2134 & TRN & \\
\hline CHEMBL1456203 & 688422 & 4.8 & 4.8303 & TRN & \\
\hline CHEMBL2374259 & 688422 & 4.7 & 5.5709 & TRN & \\
\hline CHEMBL1556494 & 688422 & 4.85 & 5.3323 & TST & \\
\hline CHEMBL1511723 & 688422 & 7.5498 & 5.7022 & TST & \\
\hline CHEMBL1304795 & 688422 & 5.6 & 4.97199 & 99999999995 & TRN \\
\hline CHEMBL1587731 & 688422 & 6.8 & 5.1986 & TRN & \\
\hline CHEMBL1612774 & 688422 & 4.65 & 5.1135 & TRN & \\
\hline CHEMBL1597019 & 688422 & 4.9 & 5.0721 & TST & \\
\hline CHEMBL1362013 & 688422 & 6.0 & 5.3876 & TST & \\
\hline CHEMBL1610690 & 688422 & 6.0 & 4.8874 & TRN & \\
\hline CHEMBL1468487 & 688422 & 4.95 & 5.2833 & TRN & \\
\hline CHEMBL1551722 & 688422 & 5.5 & 5.5343 & TRN & \\
\hline CHEMBL1393034 & 688422 & 4.6 & 5.44 & TRN & \\
\hline CHEMBL1313447 & 688422 & 4.6 & 4.965 & TRN & \\
\hline
\end{tabular}




\begin{tabular}{|c|c|c|c|c|c|}
\hline \multirow[b]{2}{*}{ CHEMBL1502755 } & \multirow[b]{2}{*}{688422} & \multicolumn{4}{|c|}{ Supplemental Table S2.txt } \\
\hline & & 7.8508 & 5.2631 & TST & \\
\hline CHEMBL1469540 & 688422 & 5.0 & 4.909 & TRN & \\
\hline CHEMBL3196468 & 688422 & 4.8 & 4.9279 & TST & \\
\hline CHEMBL1362803 & 688422 & 5.35 & 5.7579 & TRN & \\
\hline CHEMBL1562815 & 688422 & 7.5003 & 5.5336 & TST & \\
\hline CHEMBL1382030 & 688422 & 5.15 & 5.426 & TRN & \\
\hline CHEMBL1415409 & 688422 & 4.75 & 5.4307 & TRN & \\
\hline CHEMBL26655 & 688422 & 4.9 & 5.3487 & TRN & \\
\hline CHEMBL1373346 & 688422 & 7.9508 & 5.4334 & TRN & \\
\hline CHEMBL1552131 & 688422 & 4.45 & 5.5754 & TRN & \\
\hline CHEMBL330320 & 688422 & 7.1002 & 6.0318 & TRN & \\
\hline CHEMBL1458518 & 688422 & 4.45 & 4.9869 & TRN & \\
\hline CHEMBL1318863 & 688422 & 5.6 & 5.2454 & TRN & \\
\hline CHEMBL1389453 & 688422 & 4.6 & 4.9479 & TRN & \\
\hline CHEMBL1388987 & 688422 & 5.2 & 4.9739 & TRN & \\
\hline CHEMBL1484101 & 688422 & 4.7 & 5.3566 & TRN & \\
\hline CHEMBL1300443 & 688422 & 4.45 & 5.0339 & TRN & \\
\hline CHEMBL1535806 & 688422 & 4.5 & 4.96 & TST & \\
\hline CHEMBL1545267 & 688422 & 4.6 & 5.1092 & TST & \\
\hline CHEMBL1506477 & 688422 & 5.0 & 5.4407 & TRN & \\
\hline CHEMBL1610841 & 688422 & 5.45 & 5.6986 & TRN & \\
\hline CHEMBL1544331 & 688422 & 4.45 & 5.1538 & TST & \\
\hline CHEMBL1608733 & 688422 & 4.5 & 5.5297 & TRN & \\
\hline CHEMBL1582669 & 688422 & 8.3468 & 5.2308 & TRN & \\
\hline CHEMBL1405078 & 688422 & 4.55 & 5.8424 & TRN & \\
\hline CHEMBL 1440032 & 688422 & 6.0 & 5.3243 & TRN & \\
\hline CHEMBL1455266 & 688422 & 4.8 & 5.1713 & TRN & \\
\hline CHEMBL1445725 & 688422 & 5.45 & 5.3571 & TRN & \\
\hline CHEMBL1547645 & 688422 & 4.95 & 5.2639 & TRN & \\
\hline CHEMBL1586473 & 688422 & 4.7 & 4.7975 & TRN & \\
\hline CHEMBL1423532 & 688422 & 5.75 & 5.1825 & TRN & \\
\hline CHEMBL1505133 & 688422 & 6.2 & 5.3499 & TRN & \\
\hline CHEMBL1514514 & 688422 & 6.9 & 5.8219 & TRN & \\
\hline CHEMBL598679 & 688422 & 4.95 & 4.6888 & TRN & \\
\hline CHEMBL1347002 & 688422 & 4.8 & 5.2473 & TST & \\
\hline CHEMBL1405555 & 688422 & 4.75 & 5.0943 & TRN & \\
\hline CHEMBL1441505 & 688422 & 4.7 & 5.2991 & TRN & \\
\hline CHEMBL1338958 & 688422 & 4.65 & 4.9454 & TRN & \\
\hline CHEMBL1455379 & 688422 & 4.85 & 5.2765 & TRN & \\
\hline CHEMBL1376698 & 688422 & 4.9 & 5.4199 & TRN & \\
\hline CHEMBL512366 & 688422 & 4.45 & 4.5801 & TRN & \\
\hline CHEMBL 3212200 & 688422 & 8.3468 & 5.1623 & TST & \\
\hline CHEMBL1336167 & 688422 & 4.5 & 4.8772 & TRN & \\
\hline CHEMBL1526681 & 688422 & 5.25 & 4.4148 & TST & \\
\hline CHEMBL1585457 & 688422 & 4.85 & 4.9728 & TRN & \\
\hline CHEMBL1562741 & 688422 & 7.5498 & 5.3306 & TRN & \\
\hline CHEMBL1328443 & 688422 & 4.85 & 4.8056 & TRN & \\
\hline CHEMBL1400351 & 688422 & 4.9 & 5.30200 & 00000000005 & TRN \\
\hline & & & & 10067 & \\
\hline
\end{tabular}




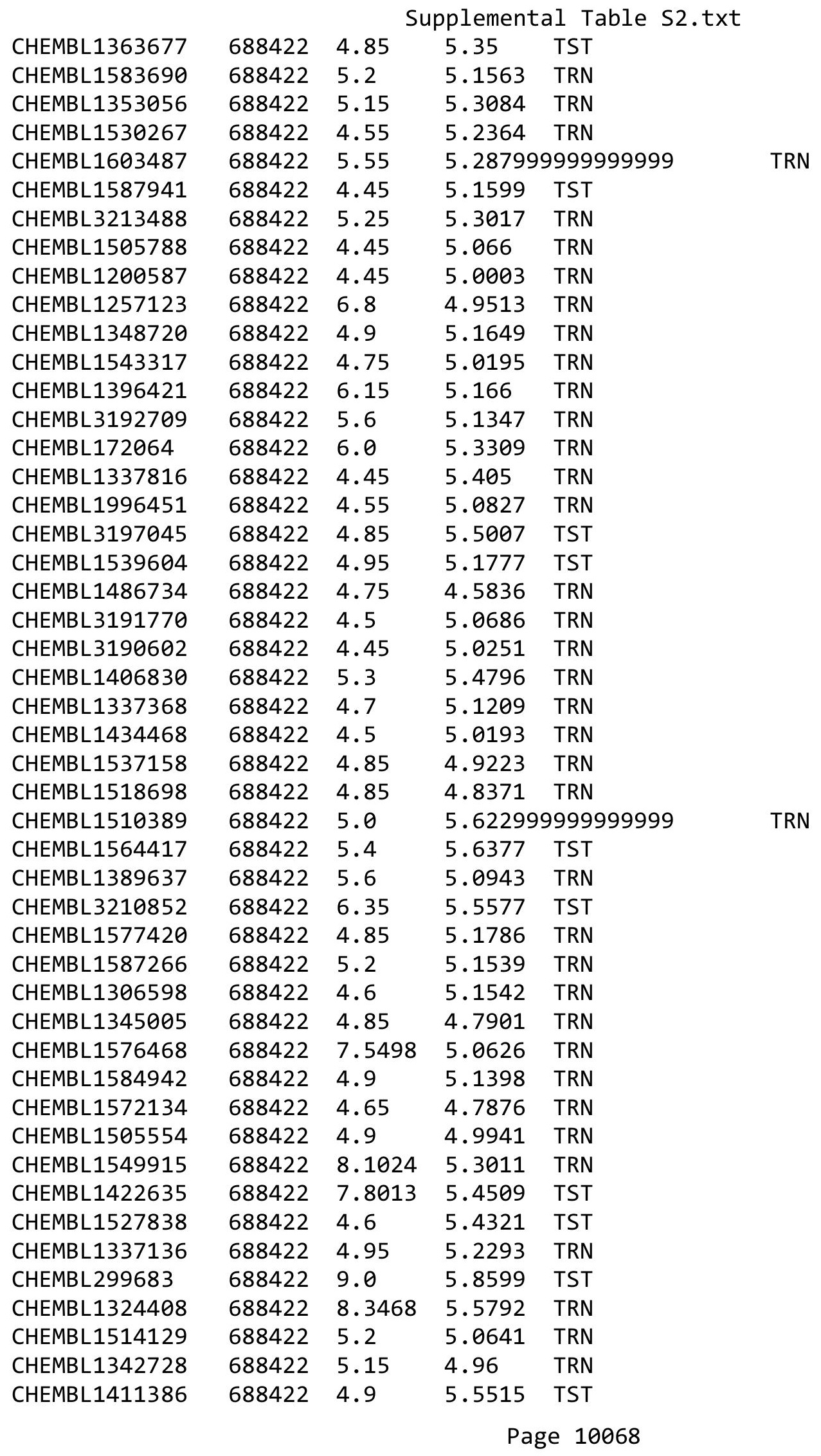




\begin{tabular}{|c|c|c|c|c|c|}
\hline \multirow{3}{*}{$\begin{array}{l}\text { CHEMBL } 2000420 \\
\text { CHEMBL1305970 }\end{array}$} & \multirow{3}{*}{$\begin{array}{l}688422 \\
688422\end{array}$} & \multicolumn{4}{|c|}{ Supplemental Table s2.txt } \\
\hline & & 5.3 & \multicolumn{2}{|c|}{5.111000000000001} & TRN \\
\hline & & 4.9 & 4.9622 & TST & \\
\hline CHEMBL1597993 & 688422 & 8.2518 & 5.654 & TRN & \\
\hline CHEMBL1431433 & 688422 & 4.45 & 5.3358 & TRN & \\
\hline CHEMBL1605204 & 688422 & 4.65 & 5.5578 & TRN & \\
\hline CHEMBL1537905 & 688422 & 4.8 & 5.0492 & TRN & \\
\hline CHEMBL 3214051 & 688422 & 4.65 & 4.9063 & TST & \\
\hline CHEMBL1504963 & 688422 & 5.0 & 4.8723 & TRN & \\
\hline CHEMBL1316201 & 688422 & 4.75 & 4.9929 & TRN & \\
\hline CHEMBL1577844 & 688422 & 8.4949 & 5.4176 & TST & \\
\hline CHEMBL1584763 & 688422 & 4.6 & 5.4082 & TRN & \\
\hline CHEMBL1534610 & 688422 & 4.8 & 5.1157 & TST & \\
\hline CHEMBL1397292 & 688422 & 5.3 & 5.544 & TRN & \\
\hline CHEMBL1365620 & 688422 & 4.8 & 5.1459 & TRN & \\
\hline CHEMBL1316401 & 688422 & 4.75 & 5.9697 & TRN & \\
\hline CHEMBL1351157 & 688422 & 4.95 & 5.0166 & TST & \\
\hline CHEMBL3197461 & 688422 & 4.55 & 4.9331 & TRN & \\
\hline CHEMBL48449 & 688422 & 6.0 & 6.1257 & TST & \\
\hline CHEMBL1982991 & 688422 & 4.45 & 5.1904 & TRN & \\
\hline CHEMBL1326626 & 688422 & 5.3 & 4.8423 & TST & \\
\hline CHEMBL1601899 & 688422 & 4.8 & 4.6767 & TRN & \\
\hline CHEMBL1377676 & 688422 & 6.5 & 4.8185 & TRN & \\
\hline CHEMBL1312153 & 688422 & 4.8 & 5.1168 & TRN & \\
\hline CHEMBL1352851 & 688422 & 7.8013 & 5.4652 & TST & \\
\hline CHEMBL1367962 & 688422 & 5.4 & 5.5233 & TST & \\
\hline CHEMBL3198187 & 688422 & 4.95 & 5.0434 & TRN & \\
\hline CHEMBL1321278 & 688422 & 4.45 & 4.9656 & TRN & \\
\hline CHEMBL1498231 & 688422 & 4.75 & 5.1293 & TRN & \\
\hline CHEMBL1461902 & 688422 & 4.9 & 4.9456 & TRN & \\
\hline CHEMBL3189183 & 688422 & 4.55 & 5.3209 & TRN & \\
\hline CHEMBL1396001 & 688422 & 4.65 & 5.3117 & TRN & \\
\hline CHEMBL1611282 & 688422 & 4.95 & 5.0659 & TRN & \\
\hline CHEMBL1381691 & 688422 & 4.95 & 5.0908 & TST & \\
\hline CHEMBL3213157 & 688422 & 7.4498 & 5.2172 & TST & \\
\hline CHEMBL1526838 & 688422 & 5.2 & 5.4401 & TST & \\
\hline CHEMBL1339825 & 688422 & 7.1002 & 5.3071 & TRN & \\
\hline CHEMBL1586566 & 688422 & 5.2 & 5.1046 & TST & \\
\hline CHEMBL1379480 & 688422 & 4.65 & 4.7791 & TRN & \\
\hline CHEMBL1503342 & 688422 & 5.1 & 4.6939 & TST & \\
\hline CHEMBL1602445 & 688422 & 5.5 & 4.7926 & TRN & \\
\hline CHEMBL1557519 & 688422 & 5.0 & 5.0744 & TST & \\
\hline CHEMBL3199579 & 688422 & 4.45 & 5.2107 & TST & \\
\hline CHEMBL1573220 & 688422 & 4.45 & 5.2007 & TRN & \\
\hline CHEMBL1522316 & 688422 & 5.0 & 5.41700 & 0000000001 & TRN \\
\hline CHEMBL1599549 & 688422 & 4.95 & 5.1103 & TRN & \\
\hline CHEMBL1351254 & 688422 & 4.45 & 5.1682 & TRN & \\
\hline CHEMBL1348077 & 688422 & 4.5 & 5.3209 & TRN & \\
\hline CHEMBL1456321 & 688422 & 5.95 & 5.0487 & TRN & \\
\hline
\end{tabular}




\begin{tabular}{|c|c|c|c|c|}
\hline \multicolumn{5}{|c|}{ Supplemental Table S2.txt } \\
\hline CHEMBL1410975 & 688422 & 4.9 & 5.1391 & TRN \\
\hline CHEMBL1555102 & 688422 & 4.65 & 5.2916 & TRN \\
\hline CHEMBL1438290 & 688422 & 4.75 & 5.5163 & TRN \\
\hline CHEMBL1599370 & 688422 & 5.55 & 4.7729 & TRN \\
\hline CHEMBL1527869 & 688422 & 4.9 & 5.5297 & TST \\
\hline CHEMBL3190060 & 688422 & 5.25 & 5.4561 & TRN \\
\hline CHEMBL1325404 & 688422 & 5.45 & 5.5129 & TST \\
\hline CHEMBL1439482 & 688422 & 6.15 & 5.2543 & TRN \\
\hline CHEMBL1432355 & 688422 & 4.45 & 5.4543 & TST \\
\hline CHEMBL475376 & 688422 & 4.8 & 4.6097 & TRN \\
\hline CHEMBL1423484 & 688422 & 7.0501 & 5.6951 & TRN \\
\hline CHEMBL1469309 & 688422 & 5.45 & 5.4528 & TRN \\
\hline CHEMBL1409944 & 688422 & 4.5 & 5.1211 & TRN \\
\hline CHEMBL1348473 & 688422 & 7.6498 & 5.8964 & TRN \\
\hline CHEMBL1528413 & 688422 & 4.45 & 4.9653 & TRN \\
\hline CHEMBL1370769 & 688422 & 4.5 & 5.0574 & TRN \\
\hline CHEMBL1560074 & 688422 & 4.45 & 4.7969 & TRN \\
\hline CHEMBL1307133 & 688422 & 5.9 & 5.2165 & TRN \\
\hline CHEMBL1340929 & 688422 & 5.5 & 6.0977 & TST \\
\hline CHEMBL1410753 & 688422 & 6.5 & 5.7909 & TRN \\
\hline CHEMBL1478547 & 688422 & 4.6 & 4.8379 & TRN \\
\hline CHEMBL1596872 & 688422 & 4.65 & 5.222 & TRN \\
\hline CHEMBL1523717 & 688422 & 4.45 & 5.5854 & TST \\
\hline CHEMBL1399550 & 688422 & 5.0 & 5.5571 & TRN \\
\hline CHEMBL1319336 & 688422 & 7.9508 & 4.7436 & TST \\
\hline CHEMBL1518393 & 688422 & 4.8 & 4.8402 & TRN \\
\hline CHEMBL1581753 & 688422 & 7.0 & 5.5063 & TST \\
\hline CHEMBL1468832 & 688422 & 6.5 & 5.4343 & TRN \\
\hline CHEMBL1459949 & 688422 & 6.95 & 4.7664 & TRN \\
\hline CHEMBL1511767 & 688422 & 4.9 & 5.2338 & TST \\
\hline CHEMBL1467444 & 688422 & 4.7 & 5.0354 & TRN \\
\hline CHEMBL1386723 & 688422 & 4.8 & 5.3712 & TRN \\
\hline CHEMBL1410423 & 688422 & 4.45 & 5.1515 & TRN \\
\hline CHEMBL1587777 & 688422 & 7.8996 & 5.6358 & TST \\
\hline CHEMBL1576373 & 688422 & 4.7 & 5.4227 & TRN \\
\hline CHEMBL1432465 & 688422 & 4.45 & 5.4178 & TST \\
\hline CHEMBL1327457 & 688422 & 4.65 & 5.1618 & TRN \\
\hline CHEMBL1414080 & 688422 & 6.25 & 5.6269 & TRN \\
\hline CHEMBL1487221 & 688422 & 4.7 & 4.8133 & TRN \\
\hline CHEMBL1596598 & 688422 & 4.8 & 4.9632 & TRN \\
\hline CHEMBL1390702 & 688422 & 5.25 & 5.0406 & TRN \\
\hline CHEMBL1471790 & 688422 & 4.7 & 5.3909 & TRN \\
\hline CHEMBL1431928 & 688422 & 5.05 & 5.2157 & TRN \\
\hline CHEMBL1435913 & 688422 & 8.4559 & 5.4691 & TRN \\
\hline CHEMBL1392675 & 688422 & 4.45 & 5.0959 & TRN \\
\hline CHEMBL1481337 & 688422 & 4.7 & 5.4134 & TRN \\
\hline CHEMBL1525733 & 688422 & 5.85 & 5.1038 & TRN \\
\hline CHEMBL1347233 & 688422 & 4.8 & 5.6177 & TRN \\
\hline
\end{tabular}




\begin{tabular}{|c|c|c|c|c|c|}
\hline & & & & & \\
\hline CHEMBL1328845 & 688422 & 5.3 & 5.2988 & TST & \\
\hline CHEMBL1431662 & 688422 & 4.9 & 4.9188 & TST & \\
\hline CHEMBL1455571 & 688422 & 4.45 & 5.2562 & TRN & \\
\hline CHEMBL1401567 & 688422 & 5.45 & 5.0907 & TRN & \\
\hline CHEMBL1399213 & 688422 & 7.0501 & 5.4528 & TRN & \\
\hline CHEMBL 28328 & 688422 & 4.55 & 6.3312 & TRN & \\
\hline CHEMBL1312546 & 688422 & 4.5 & 5.0429 & TRN & \\
\hline CHEMBL1514228 & 688422 & 5.15 & 5.3405 & TST & \\
\hline CHEMBL1316028 & 688422 & 4.85 & 5.2131 & TRN & \\
\hline CHEMBL1432337 & 688422 & 5.3 & 5.349 & TST & \\
\hline CHEMBL1592607 & 688422 & 7.3497 & 5.36600 & 00000000005 & TRN \\
\hline CHEMBL1493577 & 688422 & 5.1 & 5.0176 & TRN & \\
\hline CHEMBL1410907 & 688422 & 4.9 & 4.7916 & TRN & \\
\hline CHEMBL1558920 & 688422 & 4.95 & 4.9184 & TRN & \\
\hline CHEMBL1389543 & 688422 & 5.25 & 4.793 & TRN & \\
\hline CHEMBL472646 & 688422 & 7.9508 & 5.4937 & TRN & \\
\hline CHEMBL1536807 & 688422 & 5.55 & 5.2451 & TRN & \\
\hline CHEMBL1438803 & 688422 & 5.1 & 4.9951 & TRN & \\
\hline CHEMBL1422567 & 688422 & 4.75 & 5.1237 & TRN & \\
\hline CHEMBL1451752 & 688422 & 4.85 & 5.1712 & TRN & \\
\hline CHEMBL1449086 & 688422 & 5.2 & 5.6823 & TST & \\
\hline CHEMBL1495403 & 688422 & 4.4 & 5.3664 & TRN & \\
\hline CHEMBL1305853 & 688422 & 5.0 & 5.5153 & TRN & \\
\hline CHEMBL1349496 & 688422 & 4.5 & 4.9628 & TST & \\
\hline CHEMBL1610082 & 688422 & 4.8 & 4.8392 & TRN & \\
\hline CHEMBL1598092 & 688422 & 4.45 & 5.4589 & TRN & \\
\hline CHEMBL1308377 & 688422 & 4.95 & 5.0607 & TRN & \\
\hline CHEMBL1595516 & 688422 & 4.6 & 5.0341 & TRN & \\
\hline CHEMBL1374590 & 688422 & 4.45 & 5.0101 & TRN & \\
\hline CHEMBL1610389 & 688422 & 4.45 & 5.1544 & TRN & \\
\hline CHEMBL1969992 & 688422 & 4.9 & 4.9696 & TRN & \\
\hline CHEMBL1421797 & 688422 & 5.25 & 4.6499 & TRN & \\
\hline CHEMBL1411872 & 688422 & 4.85 & 4.9552 & TRN & \\
\hline CHEMBL1386441 & 688422 & 7.0501 & 5.5042 & TST & \\
\hline CHEMBL1535221 & 688422 & 4.75 & 5.0924 & TRN & \\
\hline CHEMBL1558919 & 688422 & 4.9 & 5.4129 & TST & \\
\hline CHEMBL605498 & 688422 & 5.55 & 5.3387 & TST & \\
\hline CHEMBL1449736 & 688422 & 4.95 & 5.28700 & 0000000001 & TST \\
\hline CHEMBL1380342 & 688422 & 7.4001 & 5.5245 & TRN & \\
\hline CHEMBL1592556 & 688422 & 5.3 & 5.13700 & 00000000005 & TRN \\
\hline CHEMBL1461784 & 688422 & 7.8996 & 5.0335 & TRN & \\
\hline CHEMBL1351216 & 688422 & 6.95 & 5.1811 & TST & \\
\hline CHEMBL1313327 & 688422 & 4.9 & 5.0478 & TRN & \\
\hline CHEMBL1382649 & 688422 & 5.75 & 5.49200 & 0000000001 & TRN \\
\hline CHEMBL1349038 & 688422 & 4.65 & 4.9499 & TRN & \\
\hline CHEMBL1392944 & 688422 & 4.85 & 5.3822 & TST & \\
\hline CHEMBL1313565 & 688422 & 4.65 & 5.2321 & TRN & \\
\hline CHEMBL3195654 & 688422 & 4.8 & 5.3712 & TST & \\
\hline
\end{tabular}




\begin{tabular}{|c|c|c|c|c|}
\hline \multicolumn{5}{|c|}{ Supplemental Table S2.txt } \\
\hline CHEMBL1442644 & 688422 & 4.45 & 5.0917 & TRN \\
\hline CHEMBL1501974 & 688422 & 5.25 & 5.1739 & TRN \\
\hline CHEMBL1483422 & 688422 & 4.5 & 5.2052 & TRN \\
\hline CHEMBL1600451 & 688422 & 4.75 & 4.949 & TRN \\
\hline CHEMBL3198125 & 688422 & 4.45 & 5.4016 & TRN \\
\hline CHEMBL1323035 & 688422 & 4.9 & 4.8741 & TST \\
\hline CHEMBL1445570 & 688422 & 4.45 & 5.2844 & TRN \\
\hline CHEMBL1593930 & 688422 & 5.25 & 5.532 & TST \\
\hline CHEMBL1349721 & 688422 & 4.85 & 5.0657 & TST \\
\hline CHEMBL1507954 & 688422 & 6.05 & 5.5116 & TST \\
\hline CHEMBL1448965 & 688422 & 4.5 & 5.2161 & TRN \\
\hline CHEMBL1412779 & 688422 & 4.45 & 5.28 & TRN \\
\hline CHEMBL 3192485 & 688422 & 4.9 & 5.0265 & TST \\
\hline CHEMBL1596722 & 688422 & 4.7 & 5.4734 & TRN \\
\hline CHEMBL1570025 & 688422 & 4.9 & 4.5758 & TRN \\
\hline CHEMBL1517771 & 688422 & 4.45 & 5.0821 & TST \\
\hline CHEMBL1365886 & 688422 & 4.9 & 5.1018 & TRN \\
\hline CHEMBL1375035 & 688422 & 4.55 & 5.3235 & TST \\
\hline CHEMBL1429106 & 688422 & 5.3 & 5.204 & TRN \\
\hline CHEMBL1429326 & 688422 & 4.75 & 5.4303 & TRN \\
\hline CHEMBL1321837 & 688422 & 4.65 & 5.1949 & TRN \\
\hline CHEMBL1537634 & 688422 & 5.15 & 5.4147 & TST \\
\hline CHEMBL1483462 & 688422 & 4.5 & 5.019 & TST \\
\hline CHEMBL1363804 & 688422 & 5.2 & 5.5798 & TRN \\
\hline CHEMBL1412145 & 688422 & 5.35 & 5.341 & TRN \\
\hline CHEMBL3207661 & 688422 & 4.9 & 5.1136 & TRN \\
\hline CHEMBL1393257 & 688422 & 5.2 & 4.6377 & TRN \\
\hline CHEMBL1522464 & 688422 & 5.55 & 5.4491 & TRN \\
\hline CHEMBL1564434 & 688422 & 4.95 & 5.3485 & TRN \\
\hline CHEMBL1458707 & 688422 & 4.95 & 5.4539 & TRN \\
\hline CHEMBL1485094 & 688422 & 4.65 & 5.0183 & TRN \\
\hline CHEMBL1431475 & 688422 & 4.45 & 5.0733 & TST \\
\hline CHEMBL1316070 & 688422 & 5.0 & 5.1034 & TRN \\
\hline CHEMBL1375393 & 688422 & 5.55 & 5.2802 & TRN \\
\hline CHEMBL1525884 & 688422 & 5.1 & 5.3527 & TST \\
\hline CHEMBL1486078 & 688422 & 5.35 & 5.0048 & TRN \\
\hline CHEMBL1509378 & 688422 & 4.85 & 5.1845 & TRN \\
\hline CHEMBL363685 & 688422 & 4.65 & 5.7699 & TRN \\
\hline CHEMBL1312676 & 688422 & 5.75 & 5.3146 & TRN \\
\hline CHEMBL1607352 & 688422 & 4.4 & 4.9955 & TST \\
\hline CHEMBL1555638 & 688422 & 4.75 & 5.0567 & TRN \\
\hline CHEMBL 2002221 & 688422 & 6.6499 & 5.4067 & TRN \\
\hline CHEMBL1539579 & 688422 & 4.85 & 5.3402 & TST \\
\hline CHEMBL1352147 & 688422 & 4.8 & 4.8331 & TRN \\
\hline CHEMBL1345017 & 688422 & 8.3468 & 5.3167 & TRN \\
\hline CHEMBL1371792 & 688422 & 4.5 & 5.3069 & TRN \\
\hline CHEMBL1580641 & 688422 & 5.1 & 4.8884 & TRN \\
\hline CHEMBL3194964 & 688422 & 4.9 & 5.336 & TRN \\
\hline
\end{tabular}




\begin{tabular}{|c|c|c|c|c|}
\hline \multicolumn{5}{|c|}{ Supplemental Table S2.txt } \\
\hline CHEMBL1524426 & 688422 & 5.0 & 5.4341 & TRN \\
\hline CHEMBL1407693 & 688422 & 5.65 & 5.4089 & TRN \\
\hline CHEMBL3145049 & 688422 & 4.75 & 4.9892 & TRN \\
\hline CHEMBL3193989 & 688422 & 5.2 & 5.3656 & TRN \\
\hline CHEMBL1408094 & 688422 & 4.5 & 5.0326 & TRN \\
\hline CHEMBL1416856 & 688422 & 4.5 & 5.3252 & TST \\
\hline CHEMBL1334342 & 688422 & 4.85 & 5.2036 & TRN \\
\hline CHEMBL1437572 & 688422 & 7.6003 & 5.3375 & TRN \\
\hline CHEMBL1300871 & 688422 & 5.0 & 5.1218 & TST \\
\hline CHEMBL1604159 & 688422 & 4.9 & 5.2655 & TRN \\
\hline CHEMBL1460670 & 688422 & 4.8 & 5.4413 & TRN \\
\hline CHEMBL1429662 & 688422 & 4.75 & 5.0928 & TRN \\
\hline CHEMBL1363016 & 688422 & 4.6 & 5.3045 & TRN \\
\hline CHEMBL1601792 & 688422 & 4.75 & 5.681 & TRN \\
\hline CHEMBL1550925 & 688422 & 8.0 & 5.0054 & TRN \\
\hline CHEMBL1583713 & 688422 & 5.3 & 5.8693 & TST \\
\hline CHEMBL1414978 & 688422 & 5.5 & 5.1149 & TRN \\
\hline CHEMBL1506646 & 688422 & 4.45 & 5.2546 & TRN \\
\hline CHEMBL1319973 & 688422 & 4.4 & 5.2099 & TRN \\
\hline CHEMBL1988731 & 688422 & 4.65 & 5.2928 & TST \\
\hline CHEMBL1485925 & 688422 & 4.7 & 5.6714 & TRN \\
\hline CHEMBL3191579 & 688422 & 5.7 & 5.1839 & TRN \\
\hline CHEMBL1445047 & 688422 & 4.85 & 5.4153 & TRN \\
\hline CHEMBL1502502 & 688422 & 4.45 & 5.1687 & TRN \\
\hline CHEMBL1519488 & 688422 & 4.6 & 4.9214 & TRN \\
\hline CHEMBL3190967 & 688422 & 4.9 & 5.2103 & TRN \\
\hline CHEMBL1341138 & 688422 & 4.7 & 5.3674 & TRN \\
\hline CHEMBL1586994 & 688422 & 4.85 & 4.9974 & TRN \\
\hline CHEMBL1379948 & 688422 & 4.95 & 5.1931 & TRN \\
\hline CHEMBL1584440 & 688422 & 4.45 & 5.4816 & TRN \\
\hline CHEMBL1323472 & 688422 & 7.8013 & 5.0797 & TRN \\
\hline CHEMBL1439802 & 688422 & 4.65 & 5.5299 & TST \\
\hline CHEMBL1510779 & 688422 & 4.45 & 5.2311 & TRN \\
\hline CHEMBL1434354 & 688422 & 4.7 & 5.316 & TRN \\
\hline CHEMBL1446929 & 688422 & 5.15 & 5.8309 & TST \\
\hline CHEMBL1604606 & 688422 & 4.45 & 4.8932 & TRN \\
\hline CHEMBL 1587850 & 688422 & 4.45 & 5.2812 & TRN \\
\hline CHEMBL1453208 & 688422 & 5.3 & 5.3901 & TST \\
\hline CHEMBL1607104 & 688422 & 4.8 & 5.2198 & TRN \\
\hline CHEMBL1541779 & 688422 & 5.1 & 5.362 & TRN \\
\hline CHEMBL1433340 & 688422 & 4.45 & 4.8367 & TST \\
\hline CHEMBL1406252 & 688422 & 4.7 & 5.1629 & TRN \\
\hline CHEMBL1587219 & 688422 & 4.75 & 5.2512 & TRN \\
\hline CHEMBL1462073 & 688422 & 4.85 & 5.2388 & TRN \\
\hline CHEMBL1256911 & 688422 & 5.55 & 4.7263 & TST \\
\hline CHEMBL1558755 & 688422 & 5.6 & 5.3108 & TRN \\
\hline CHEMBL1556661 & 688422 & 4.75 & 5.2436 & TST \\
\hline CHEMBL1319301 & 688422 & 4.85 & 5.4222 & TRN \\
\hline
\end{tabular}




\begin{tabular}{|c|c|c|c|c|c|}
\hline \multicolumn{6}{|c|}{ Supplemental Table s2.txt } \\
\hline CHEMBL1502004 & 688422 & 4.45 & 5.0036 & TRN & \\
\hline CHEMBL1370603 & 688422 & 4.75 & 4.9105 & TRN & \\
\hline CHEMBL1514184 & 688422 & 6.8499 & 5.1497 & TST & \\
\hline CHEMBL1545723 & 688422 & 4.45 & 5.0034 & TRN & \\
\hline CHEMBL1382077 & 688422 & 4.8 & 4.6425 & TRN & \\
\hline CHEMBL1601509 & 688422 & 4.45 & 5.2826 & TRN & \\
\hline CHEMBL1586279 & 688422 & 4.75 & 5.2793 & TRN & \\
\hline CHEMBL1559373 & 688422 & 4.45 & 5.0542 & TRN & \\
\hline CHEMBL1560112 & 688422 & 4.8 & 5.2133 & TST & \\
\hline CHEMBL1323007 & 688422 & 4.45 & 5.0296 & TRN & \\
\hline CHEMBL1540036 & 688422 & 4.8 & 5.1679 & TST & \\
\hline CHEMBL1354828 & 688422 & 4.45 & 5.305 & TRN & \\
\hline CHEMBL1520673 & 688422 & 8.0506 & 4.8491 & TRN & \\
\hline CHEMBL1343487 & 688422 & 5.3 & 5.4024 & TRN & \\
\hline CHEMBL1393771 & 688422 & 4.45 & 5.3365 & TRN & \\
\hline CHEMBL1520325 & 688422 & 7.9508 & 5.1282 & TST & \\
\hline CHEMBL1453222 & 688422 & 5.65 & 5.0066 & TRN & \\
\hline CHEMBL1558072 & 688422 & 6.8 & 5.0999 & TST & \\
\hline CHEMBL1465210 & 688422 & 6.05 & 4.9642 & TST & \\
\hline CHEMBL1336346 & 688422 & 4.5 & 5.1191 & TRN & \\
\hline CHEMBL1479408 & 688422 & 4.45 & 5.0704 & TST & \\
\hline CHEMBL 3192084 & 688422 & 6.15 & 5.2227 & TRN & \\
\hline CHEMBL1340639 & 688422 & 4.9 & 5.49100 & 00000000005 & TST \\
\hline CHEMBL1344767 & 688422 & 4.75 & 4.4727 & TRN & \\
\hline CHEMBL1458698 & 688422 & 4.5 & 4.9934 & TRN & \\
\hline CHEMBL1578700 & 688422 & 4.45 & 5.0421 & TRN & \\
\hline CHEMBL1549514 & 688422 & 5.7 & 5.1981 & TST & \\
\hline CHEMBL 2006997 & 688422 & 7.0 & 5.267 & TRN & \\
\hline CHEMBL1302237 & 688422 & 4.7 & 5.80399 & 9999999999 & TRN \\
\hline CHEMBL1966679 & 688422 & 4.85 & 5.3796 & TRN & \\
\hline CHEMBL1427269 & 688422 & 6.8 & 5.3775 & TST & \\
\hline CHEMBL1601851 & 688422 & 4.65 & 4.8215 & TRN & \\
\hline CHEMBL1566955 & 688422 & 4.45 & 5.6337 & TRN & \\
\hline CHEMBL1304408 & 688422 & 4.7 & 4.7084 & TRN & \\
\hline CHEMBL1342349 & 688422 & 4.45 & 5.0837 & TRN & \\
\hline CHEMBL 3209325 & 688422 & 6.0 & 5.2909 & TRN & \\
\hline CHEMBL1384702 & 688422 & 5.3 & 4.9931 & TST & \\
\hline CHEMBL1466193 & 688422 & 4.45 & 5.1618 & TRN & \\
\hline CHEMBL1545202 & 688422 & 6.05 & 5.6876 & TST & \\
\hline CHEMBL3192713 & 688422 & 4.85 & 5.5779 & TRN & \\
\hline CHEMBL1558573 & 688422 & 7.8508 & 5.3221 & TRN & \\
\hline CHEMBL1337152 & 688422 & 4.75 & 4.9834 & TRN & \\
\hline CHEMBL1300648 & 688422 & 6.2 & 5.3981 & TST & \\
\hline CHEMBL1351870 & 688422 & 4.45 & 5.2167 & TST & \\
\hline CHEMBL1508474 & 688422 & 5.05 & 5.4135 & TRN & \\
\hline CHEMBL1442530 & 688422 & 5.25 & 5.1397 & TST & \\
\hline CHEMBL1386586 & 688422 & 5.1 & 4.9173 & TRN & \\
\hline CHEMBL1332441 & 688422 & 5.35 & 5.4468 & TRN & \\
\hline
\end{tabular}




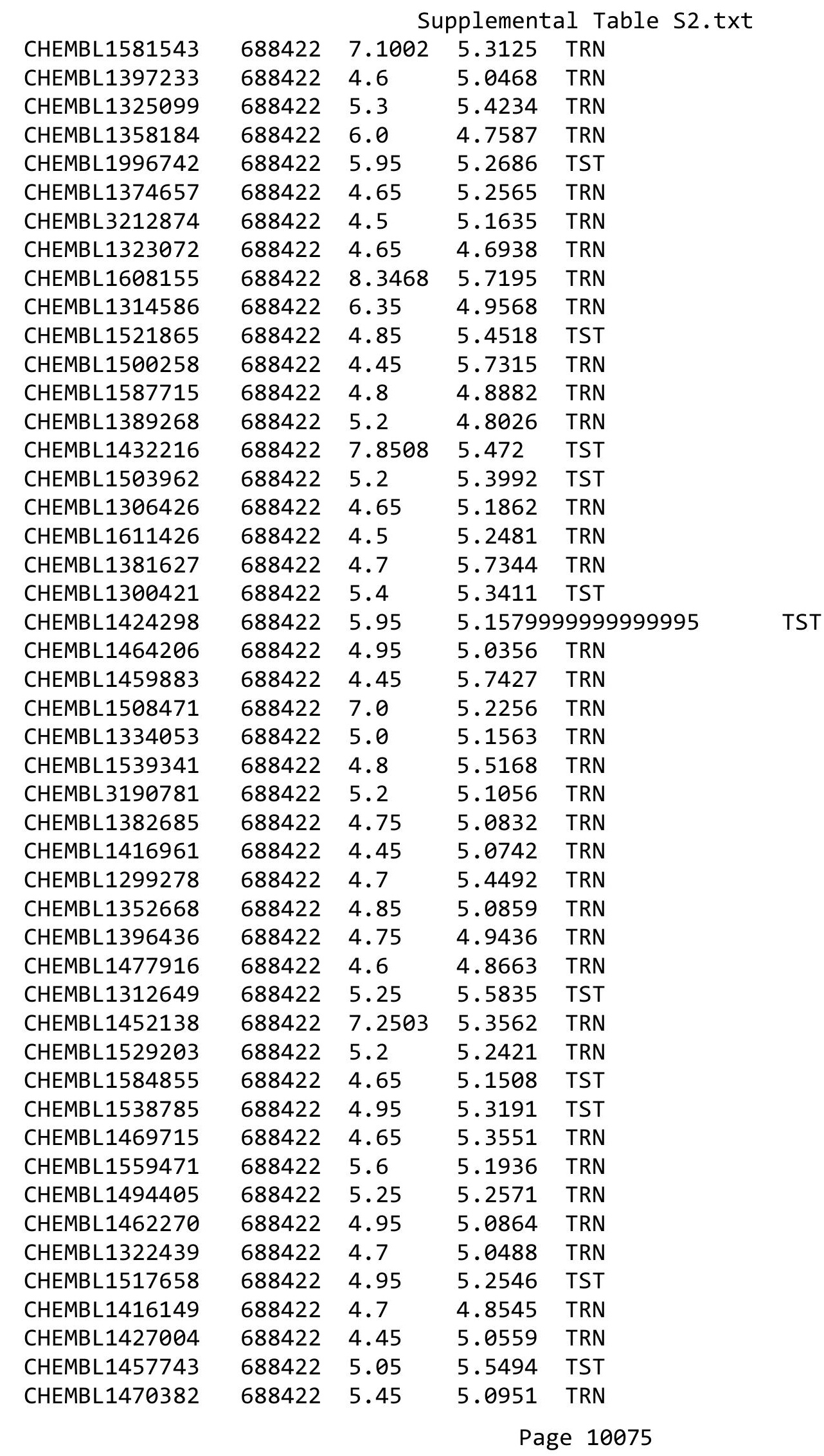




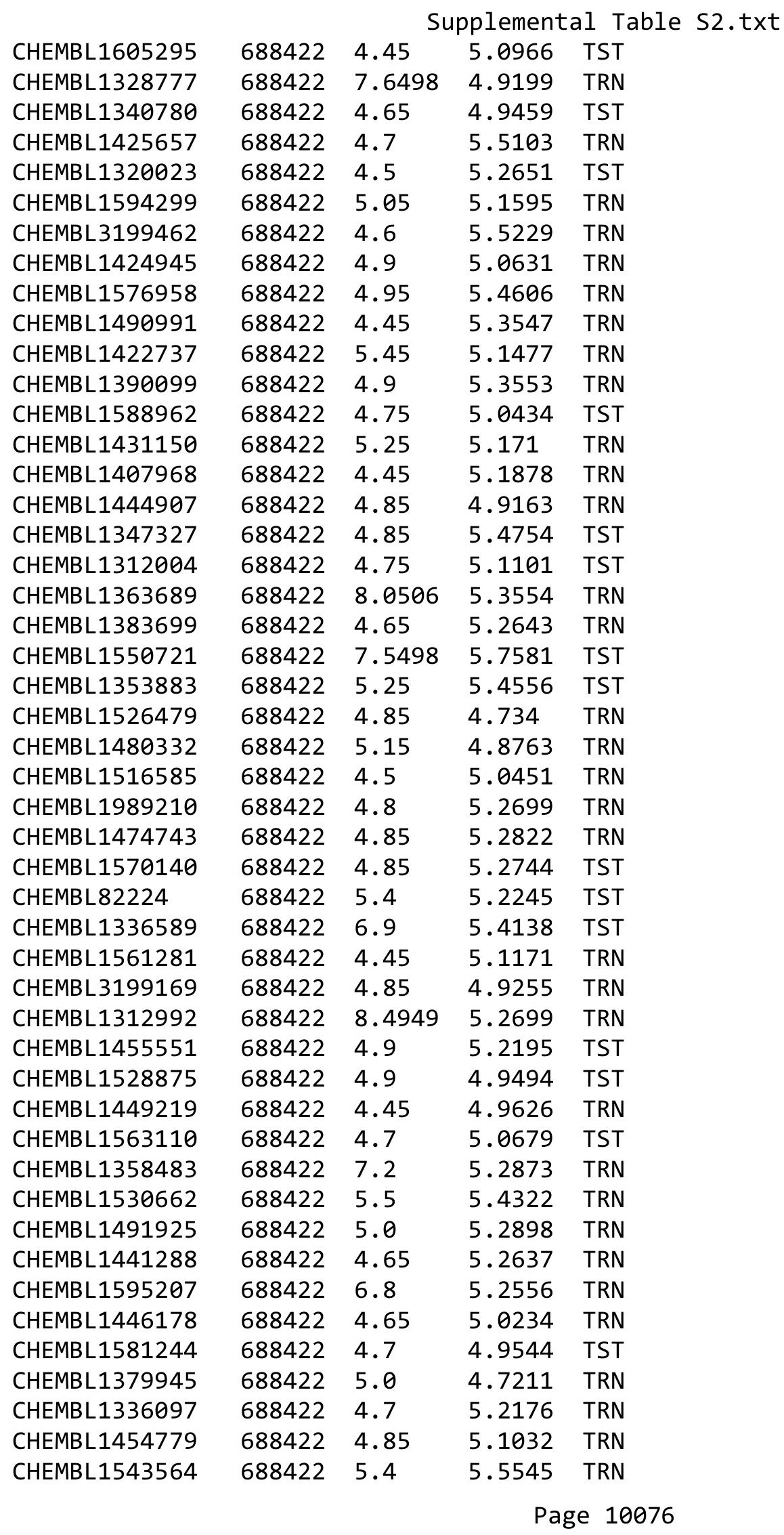




\begin{tabular}{|c|c|c|c|c|}
\hline \multicolumn{5}{|c|}{ Supplemental Table S2.txt } \\
\hline CHEMBL1519457 & 688422 & 7.2503 & 5.2232 & TRN \\
\hline CHEMBL1572014 & 688422 & 4.45 & 5.4078 & TRN \\
\hline CHEMBL1353353 & 688422 & 4.85 & 5.1724 & TRN \\
\hline CHEMBL1469980 & 688422 & 4.45 & 5.0741 & TST \\
\hline CHEMBL1542675 & 688422 & 4.75 & 5.1014 & TRN \\
\hline CHEMBL1484378 & 688422 & 5.6 & 5.1445 & TRN \\
\hline CHEMBL1493159 & 688422 & 4.45 & 4.9252 & TRN \\
\hline CHEMBL1609729 & 688422 & 6.95 & 5.5153 & TRN \\
\hline CHEMBL1547130 & 688422 & 4.65 & 4.8412 & TST \\
\hline CHEMBL1505857 & 688422 & 5.3 & 5.6972 & TST \\
\hline CHEMBL1416115 & 688422 & 4.75 & 5.1387 & TRN \\
\hline CHEMBL369996 & 688422 & 5.45 & 5.3951 & TRN \\
\hline CHEMBL1308672 & 688422 & 4.95 & 5.4446 & TRN \\
\hline CHEMBL1368792 & 688422 & 4.9 & 4.8488 & TRN \\
\hline CHEMBL3193829 & 688422 & 7.2503 & 5.2499 & TRN \\
\hline CHEMBL1579397 & 688422 & 4.45 & 5.776 & TRN \\
\hline CHEMBL1365025 & 688422 & 4.95 & 5.3761 & TRN \\
\hline CHEMBL1422410 & 688422 & 5.3 & 5.5994 & TRN \\
\hline CHEMBL1521874 & 688422 & 6.45 & 5.3457 & TRN \\
\hline CHEMBL1351561 & 688422 & 5.5 & 5.2448 & TST \\
\hline CHEMBL1323736 & 688422 & 4.65 & 4.6891 & TRN \\
\hline CHEMBL1557487 & 688422 & 4.65 & 5.15 & TST \\
\hline CHEMBL1556421 & 688422 & 4.7 & 4.9532 & TRN \\
\hline CHEMBL1310876 & 688422 & 5.4 & 5.2925 & TRN \\
\hline CHEMBL1537893 & 688422 & 6.35 & 5.9788 & TRN \\
\hline CHEMBL1405370 & 688422 & 5.0 & 5.1216 & TST \\
\hline CHEMBL1508733 & 688422 & 4.45 & 4.9922 & TRN \\
\hline CHEMBL1455815 & 688422 & 5.4 & 4.7317 & TRN \\
\hline CHEMBL1381517 & 688422 & 4.45 & 4.7276 & TRN \\
\hline CHEMBL1337146 & 688422 & 4.85 & 5.0535 & TRN \\
\hline CHEMBL1491676 & 688422 & 5.1 & 5.0733 & TRN \\
\hline CHEMBL1453731 & 688422 & 4.95 & 5.2357 & TRN \\
\hline CHEMBL1353831 & 688422 & 4.45 & 5.4653 & TRN \\
\hline CHEMBL1413519 & 688422 & 4.45 & 4.9463 & TRN \\
\hline CHEMBL1303737 & 688422 & 4.95 & 5.0351 & TST \\
\hline CHEMBL1479480 & 688422 & 5.6 & 5.234 & TST \\
\hline CHEMBL1372513 & 688422 & 4.95 & 4.8093 & TRN \\
\hline CHEMBL1588096 & 688422 & 4.65 & 5.46200 & 0000000001 \\
\hline CHEMBL1345466 & 688422 & 4.9 & 5.0224 & TRN \\
\hline CHEMBL1864436 & 688422 & 4.7 & 4.8247 & TST \\
\hline CHEMBL1330879 & 688422 & 5.25 & 5.0887 & TST \\
\hline CHEMBL578915 & 688422 & 5.55 & 5.2868 & TST \\
\hline CHEMBL1379704 & 688422 & 7.0 & 6.1619 & TST \\
\hline CHEMBL1326422 & 688422 & 4.85 & 5.1685 & TRN \\
\hline CHEMBL1503509 & 688422 & 4.75 & 5.0309 & TRN \\
\hline CHEMBL1408816 & 688422 & 5.0 & 5.4966 & TRN \\
\hline CHEMBL 3198178 & 688422 & 4.95 & 5.2847 & TRN \\
\hline CHEMBL1493442 & 688422 & 4.8 & 5.2553 & TRN \\
\hline
\end{tabular}




\begin{tabular}{|c|c|c|c|c|c|}
\hline \multirow[b]{2}{*}{ CHEMBL1537140 } & \multicolumn{5}{|c|}{ Supplemental Table S2.txt } \\
\hline & 688422 & 4.45 & 4.9596 & TRN & \\
\hline CHEMBL1547250 & 688422 & 4.75 & 4.9693 & TRN & \\
\hline CHEMBL1503061 & 688422 & 5.6 & 5.3756 & TRN & \\
\hline CHEMBL1336692 & 688422 & 4.8 & 5.1157 & TRN & \\
\hline CHEMBL1407084 & 688422 & 4.85 & 5.0985 & TST & \\
\hline CHEMBL1242180 & 688422 & 5.75 & 5.4670 & 00000000005 & TRN \\
\hline CHEMBL1488321 & 688422 & 5.45 & 5.2942 & TRN & \\
\hline CHEMBL1352465 & 688422 & 8.301 & 5.6293 & TST & \\
\hline CHEMBL1528493 & 688422 & 4.95 & 5.2494 & TRN & \\
\hline CHEMBL1448985 & 688422 & 4.8 & 5.3158 & TRN & \\
\hline CHEMBL1557869 & 688422 & 4.65 & 4.9173 & TRN & \\
\hline CHEMBL1505053 & 688422 & 4.45 & 5.466 & TRN & \\
\hline CHEMBL1466463 & 688422 & 4.45 & 5.0129 & TRN & \\
\hline CHEMBL1390785 & 688422 & 4.65 & 5.2243 & TST & \\
\hline CHEMBL1400345 & 688422 & 4.55 & 5.1897 & TRN & \\
\hline CHEMBL1369471 & 688422 & 4.95 & 5.2815 & TRN & \\
\hline CHEMBL1904956 & 688422 & 6.15 & 5.1897 & TRN & \\
\hline CHEMBL1463190 & 688422 & 4.8 & 5.4214 & TST & \\
\hline CHEMBL1461935 & 688422 & 5.55 & 5.1044 & TRN & \\
\hline CHEMBL1540358 & 688422 & 4.45 & 5.0673 & TRN & \\
\hline CHEMBL1380459 & 688422 & 5.6 & 5.064 & TRN & \\
\hline CHEMBL1572620 & 688422 & 8.1024 & 5.2942 & TRN & \\
\hline CHEMBL1530122 & 688422 & 4.45 & 5.0166 & TRN & \\
\hline CHEMBL1256719 & 688422 & 4.9 & 5.6979 & 99999999995 & TST \\
\hline CHEMBL1346350 & 688422 & 4.6 & 5.4271 & TRN & \\
\hline CHEMBL1477093 & 688422 & 4.5 & 5.1097 & TRN & \\
\hline CHEMBL1415911 & 688422 & 5.4 & 5.4916 & TRN & \\
\hline CHEMBL1560925 & 688422 & 4.85 & 5.2068 & TRN & \\
\hline CHEMBL1515551 & 688422 & 5.85 & 5.3768 & TRN & \\
\hline CHEMBL1302959 & 688422 & 4.85 & 5.3751 & TRN & \\
\hline CHEMBL1402878 & 688422 & 4.65 & 5.2276 & TRN & \\
\hline CHEMBL1550518 & 688422 & 5.35 & 5.7121 & TRN & \\
\hline CHEMBL1423334 & 688422 & 4.45 & 5.3251 & TST & \\
\hline CHEMBL1372937 & 688422 & 4.45 & 5.0102 & TRN & \\
\hline CHEMBL1323361 & 688422 & 4.45 & 5.3985 & TST & \\
\hline CHEMBL1318643 & 688422 & 8.3979 & 6.2025 & TRN & \\
\hline CHEMBL 1608218 & 688422 & 5.05 & 4.9522 & TRN & \\
\hline CHEMBL1409316 & 688422 & 7.15 & 5.1584 & TRN & \\
\hline CHEMBL3195786 & 688422 & 8.3468 & 5.0507 & TRN & \\
\hline CHEMBL3208111 & 688422 & 4.75 & 5.5498 & TST & \\
\hline CHEMBL1517677 & 688422 & 4.9 & 5.1789 & 9999999999 & TRN \\
\hline CHEMBL1322042 & 688422 & 5.35 & 5.2226 & TRN & \\
\hline CHEMBL1477595 & 688422 & 4.45 & 5.1964 & TRN & \\
\hline CHEMBL1420826 & 688422 & 4.7 & 4.5526 & TRN & \\
\hline CHEMBL1316713 & 688422 & 5.15 & 5.6025 & TRN & \\
\hline CHEMBL1327966 & 688422 & 4.45 & 5.4393 & TRN & \\
\hline CHEMBL1558212 & 688422 & 5.95 & 5.7646 & TRN & \\
\hline CHEMBL 3210212 & 688422 & 5.55 & 5.3667 & TRN & \\
\hline
\end{tabular}




\begin{tabular}{|c|c|c|c|c|c|}
\hline \multicolumn{6}{|c|}{ Supplemental Table S2.txt } \\
\hline CHEMBL1541441 & 688422 & 4.85 & 5.1149 & TRN & \\
\hline CHEMBL1552973 & 688422 & 6.4 & 5.6712 & TST & \\
\hline CHEMBL1370249 & 688422 & 4.8 & 5.0161 & TRN & \\
\hline CHEMBL1413874 & 688422 & 5.0 & 5.2863 & TRN & \\
\hline CHEMBL1432146 & 688422 & 4.7 & 5.2427 & TRN & \\
\hline CHEMBL1542955 & 688422 & 5.8 & 5.2851 & TRN & \\
\hline CHEMBL1329035 & 688422 & 7.2 & 5.3223 & TST & \\
\hline CHEMBL1503340 & 688422 & 4.65 & 5.358 & TRN & \\
\hline CHEMBL1535318 & 688422 & 4.45 & 4.9548 & TRN & \\
\hline CHEMBL1341558 & 688422 & 7.1002 & 5.3461 & TST & \\
\hline CHEMBL1601364 & 688422 & 4.9 & 5.0964 & TRN & \\
\hline CHEMBL1498643 & 688422 & 4.65 & 5.1873 & TST & \\
\hline CHEMBL1576573 & 688422 & 4.45 & 5.6356 & TST & \\
\hline CHEMBL1422448 & 688422 & 4.45 & 5.2599 & TST & \\
\hline CHEMBL1718423 & 688422 & 4.8 & 4.7868 & TST & \\
\hline CHEMBL1993666 & 688422 & 4.9 & 5.2306 & TRN & \\
\hline CHEMBL1990804 & 688422 & 4.8 & 5.5481 & TST & \\
\hline CHEMBL1573791 & 688422 & 4.7 & 5.1253 & TRN & \\
\hline CHEMBL1363276 & 688422 & 6.05 & 5.5319 & TRN & \\
\hline CHEMBL1587931 & 688422 & 4.45 & 5.1859 & TRN & \\
\hline CHEMBL1482597 & 688422 & 4.55 & 4.7582 & TRN & \\
\hline CHEMBL1383515 & 688422 & 7.1002 & 5.265 & TRN & \\
\hline CHEMBL1521316 & 688422 & 6.8499 & 5.5221 & TST & \\
\hline CHEMBL1344481 & 688422 & 4.95 & 4.9867 & TRN & \\
\hline CHEMBL1312788 & 688422 & 5.5 & 5.0242 & TRN & \\
\hline CHEMBL1386033 & 688422 & 5.6 & 5.4751 & TRN & \\
\hline CHEMBL3193369 & 688422 & 4.8 & 4.6634 & TRN & \\
\hline CHEMBL1559704 & 688422 & 5.0 & 5.3147 & TRN & \\
\hline CHEMBL1541981 & 688422 & 4.45 & 5.11100 & 0000000001 & TRN \\
\hline CHEMBL1410712 & 688422 & 4.9 & 5.1776 & TRN & \\
\hline CHEMBL1460146 & 688422 & 4.75 & 4.9976 & TST & \\
\hline CHEMBL1580904 & 688422 & 4.8 & 5.0972 & TST & \\
\hline CHEMBL3199171 & 688422 & 4.8 & 5.152 & TST & \\
\hline CHEMBL1480522 & 688422 & 4.85 & 4.963 & TRN & \\
\hline CHEMBL1588702 & 688422 & 7.4498 & 5.5189 & TRN & \\
\hline CHEMBL1606309 & 688422 & 5.25 & 5.4518 & TRN & \\
\hline CHEMBL1324616 & 688422 & 6.3 & 4.9921 & TRN & \\
\hline CHEMBL1579339 & 688422 & 4.45 & 5.4814 & TRN & \\
\hline CHEMBL1340825 & 688422 & 4.85 & 5.2065 & TST & \\
\hline CHEMBL1543009 & 688422 & 4.7 & 5.28100 & 0000000001 & TRN \\
\hline CHEMBL1422146 & 688422 & 5.0 & 4.9706 & TRN & \\
\hline CHEMBL1467729 & 688422 & 4.65 & 4.7913 & TRN & \\
\hline CHEMBL1459557 & 688422 & 4.55 & 5.225 & TRN & \\
\hline CHEMBL1383015 & 688422 & 4.9 & 5.4159 & TST & \\
\hline CHEMBL1496347 & 688422 & 4.7 & 4.8756 & TRN & \\
\hline CHEMBL1382430 & 688422 & 6.2 & 5.2521 & TRN & \\
\hline CHEMBL 3210087 & 688422 & 4.7 & 5.0727 & TRN & \\
\hline CHEMBL1362426 & 688422 & 4.45 & 5.2774 & TRN & \\
\hline
\end{tabular}




\begin{tabular}{|c|c|c|c|c|c|}
\hline \multicolumn{6}{|c|}{ Supplemental Table S2.txt } \\
\hline CHEMBL 3193203 & 688422 & 4.7 & 5.0552 & TST & \\
\hline CHEMBL1548510 & 688422 & 6.95 & 5.4079 & TST & \\
\hline CHEMBL3196625 & 688422 & 4.7 & 5.2627 & TST & \\
\hline CHEMBL1509703 & 688422 & 4.5 & 5.2919 & TST & \\
\hline CHEMBL 22966 & 688422 & 4.65 & 5.1734 & TST & \\
\hline CHEMBL1527767 & 688422 & 5.25 & 5.8201 & TRN & \\
\hline CHEMBL1378796 & 688422 & 5.7 & 5.6274 & TST & \\
\hline CHEMBL1472651 & 688422 & 5.25 & 5.3968 & TRN & \\
\hline CHEMBL1463120 & 688422 & 4.45 & 5.1961 & TRN & \\
\hline CHEMBL1555128 & 688422 & 6.8 & 5.2214 & TRN & \\
\hline CHEMBL1490262 & 688422 & 5.25 & 5.3864 & TRN & \\
\hline CHEMBL 3193568 & 688422 & 4.6 & 5.0398 & TST & \\
\hline CHEMBL1412039 & 688422 & 5.25 & 4.752 & TST & \\
\hline CHEMBL1383987 & 688422 & 4.95 & 5.1239 & TRN & \\
\hline CHEMBL1341009 & 688422 & 5.45 & 5.2444 & TRN & \\
\hline CHEMBL1568363 & 688422 & 4.45 & 5.0014 & TRN & \\
\hline CHEMBL1550049 & 688422 & 4.5 & 5.1186 & TRN & \\
\hline CHEMBL1613420 & 688422 & 5.8 & 5.5811 & TST & \\
\hline CHEMBL1257106 & 688422 & 9.0458 & 5.3184 & TST & \\
\hline CHEMBL1991112 & 688422 & 5.45 & 5.2982 & TRN & \\
\hline CHEMBL1335945 & 688422 & 5.2 & 5.0248 & TST & \\
\hline CHEMBL1491878 & 688422 & 5.1 & 5.8387 & TRN & \\
\hline CHEMBL1318183 & 688422 & 5.1 & 5.5305 & TRN & \\
\hline CHEMBL1357513 & 688422 & 5.05 & 5.2411 & TRN & \\
\hline CHEMBL1420135 & 688422 & 4.8 & 5.57600 & 00000000005 & TRN \\
\hline CHEMBL1504729 & 688422 & 4.9 & 5.3333 & TRN & \\
\hline CHEMBL1488081 & 688422 & 4.65 & 5.0182 & TRN & \\
\hline CHEMBL1460614 & 688422 & 5.8 & 5.3445 & TST & \\
\hline CHEMBL1312189 & 688422 & 4.75 & 5.1394 & TST & \\
\hline CHEMBL1412550 & 688422 & 6.8 & 5.4843 & TST & \\
\hline CHEMBL1541771 & 688422 & 4.95 & 5.1608 & TRN & \\
\hline CHEMBL1575440 & 688422 & 4.95 & 4.9375 & TRN & \\
\hline CHEMBL1437846 & 688422 & 7.15 & 5.642 & TST & \\
\hline CHEMBL1554159 & 688422 & 4.5 & 4.9883 & TRN & \\
\hline CHEMBL1315572 & 688422 & 4.45 & 5.3778 & TRN & \\
\hline CHEMBL 3208357 & 688422 & 4.45 & 5.7458 & TST & \\
\hline CHEMBL1497562 & 688422 & 7.0501 & 5.4294 & TRN & \\
\hline CHEMBL1507872 & 688422 & 4.85 & 5.0437 & TRN & \\
\hline CHEMBL1308329 & 688422 & 7.4498 & 5.1169 & TST & \\
\hline CHEMBL1482522 & 688422 & 6.35 & 5.3207 & TST & \\
\hline CHEMBL1506508 & 688422 & 4.95 & 5.32100 & 0000000001 & TRN \\
\hline CHEMBL1477224 & 688422 & 4.8 & 5.2936 & TRN & \\
\hline CHEMBL1477013 & 688422 & 4.95 & 5.3777 & TST & \\
\hline CHEMBL1505000 & 688422 & 5.0 & 5.0917 & TRN & \\
\hline CHEMBL1367572 & 688422 & 4.45 & 4.7339 & TST & \\
\hline CHEMBL1309620 & 688422 & 4.6 & 4.6437 & TRN & \\
\hline CHEMBL1329631 & 688422 & 4.7 & 4.7982 & TRN & \\
\hline CHEMBL1395673 & 688422 & 5.05 & 5.4766 & TST & \\
\hline
\end{tabular}




\begin{tabular}{|c|c|c|c|c|c|}
\hline \\
\hline CHEMBL1354197 & 688422 & 4.9 & 5.5965 & TST & \\
\hline CHEMBL1384784 & 688422 & 4.95 & 5.1517 & TRN & \\
\hline CHEMBL1500059 & 688422 & 4.85 & 5.51399 & 9999999999 & TRN \\
\hline CHEMBL1610750 & 688422 & 4.45 & 5.2036 & TRN & \\
\hline CHEMBL1425567 & 688422 & 4.45 & 4.8273 & TST & \\
\hline CHEMBL1327045 & 688422 & 5.4 & 5.7357 & TRN & \\
\hline CHEMBL1347560 & 688422 & 5.5 & 5.1043 & TST & \\
\hline CHEMBL1570596 & 688422 & 8.1024 & 5.4413 & TRN & \\
\hline CHEMBL1448710 & 688422 & 4.95 & 4.9893 & TRN & \\
\hline CHEMBL1487635 & 688422 & 4.75 & 5.2362 & TRN & \\
\hline CHEMBL1543308 & 688422 & 5.55 & 5.0428 & TST & \\
\hline CHEMBL1590719 & 688422 & 7.3002 & 5.6271 & TRN & \\
\hline CHEMBL1444601 & 688422 & 4.45 & 5.0851 & TRN & \\
\hline CHEMBL1556364 & 688422 & 4.65 & 4.9359 & TRN & \\
\hline CHEMBL1596883 & 688422 & 5.35 & 5.8816 & TRN & \\
\hline CHEMBL1599032 & 688422 & 4.45 & 5.0041 & TST & \\
\hline CHEMBL1599151 & 688422 & 4.65 & 5.1039 & TRN & \\
\hline CHEMBL1555802 & 688422 & 5.2 & 5.1393 & TRN & \\
\hline CHEMBL1449878 & 688422 & 4.45 & 5.3884 & TRN & \\
\hline CHEMBL1463718 & 688422 & 4.45 & 4.9155 & TRN & \\
\hline CHEMBL1402668 & 688422 & 5.0 & 5.0889 & TST & \\
\hline CHEMBL1299889 & 688422 & 7.2503 & 5.49100 & 00000000005 & TRN \\
\hline CHEMBL1333993 & 688422 & 4.95 & 4.9779 & TRN & \\
\hline CHEMBL1518606 & 688422 & 4.95 & 5.5113 & TRN & \\
\hline CHEMBL1407754 & 688422 & 4.75 & 5.0083 & TRN & \\
\hline CHEMBL3190831 & 688422 & 7.8013 & 5.2451 & TRN & \\
\hline CHEMBL3199311 & 688422 & 6.1 & 5.4148 & TRN & \\
\hline CHEMBL1506593 & 688422 & 4.5 & 5.7878 & TRN & \\
\hline CHEMBL3196014 & 688422 & 4.95 & 5.0098 & TRN & \\
\hline CHEMBL1503053 & 688422 & 8.0 & 5.4166 & TRN & \\
\hline CHEMBL1499130 & 688422 & 5.6 & 5.5481 & TRN & \\
\hline CHEMBL1337707 & 688422 & 5.6 & 5.4164 & TRN & \\
\hline CHEMBL1406824 & 688422 & 5.25 & 5.0654 & TRN & \\
\hline CHEMBL1163685 & 688422 & 4.85 & 5.6898 & TRN & \\
\hline CHEMBL3196957 & 688422 & 4.85 & 5.0732 & TRN & \\
\hline CHEMBL1572827 & 688422 & 5.5 & 4.8152 & TRN & \\
\hline CHEMBL1349489 & 688422 & 4.9 & 5.4415 & TRN & \\
\hline CHEMBL1582859 & 688422 & 4.6 & 4.8637 & TRN & \\
\hline CHEMBL1987472 & 688422 & 4.45 & 5.1088 & TST & \\
\hline CHEMBL1347851 & 688422 & 4.95 & 5.1371 & TRN & \\
\hline CHEMBL1334129 & 688422 & 5.0 & 5.5476 & TRN & \\
\hline CHEMBL3197447 & 688422 & 5.9 & 5.4946 & TRN & \\
\hline CHEMBL1309086 & 688422 & 5.0 & 5.6065 & TRN & \\
\hline CHEMBL1322677 & 688422 & 4.75 & 5.105 & TRN & \\
\hline CHEMBL1479116 & 688422 & 4.5 & 4.9037 & TST & \\
\hline CHEMBL1367016 & 688422 & 4.45 & 5.3529 & TRN & \\
\hline CHEMBL1330389 & 688422 & 5.0 & 5.1997 & TRN & \\
\hline CHEMBL1472926 & 688422 & 4.8 & 5.0577 & TRN & \\
\hline
\end{tabular}




\begin{tabular}{|c|c|c|c|c|c|}
\hline \multicolumn{6}{|c|}{ Supplemental Table S2.txt } \\
\hline CHEMBL1499951 & 688422 & 4.75 & 5.0727 & TST & \\
\hline CHEMBL1428299 & 688422 & 4.7 & 4.9908 & TRN & \\
\hline CHEMBL1376617 & 688422 & 6.5501 & 5.6883 & TRN & \\
\hline CHEMBL1441337 & 688422 & 4.45 & 5.0207 & TRN & \\
\hline CHEMBL1552720 & 688422 & 4.7 & 4.813 & TST & \\
\hline CHEMBL1403894 & 688422 & 8.4949 & 5.9116 & TST & \\
\hline CHEMBL1490669 & 688422 & 8.1024 & 5.4952 & TRN & \\
\hline CHEMBL1326617 & 688422 & 5.65 & 5.3058 & TST & \\
\hline CHEMBL1483763 & 688422 & 4.7 & 4.9405 & TST & \\
\hline CHEMBL3214413 & 688422 & 5.15 & 5.4165 & TST & \\
\hline CHEMBL1565096 & 688422 & 4.45 & 5.6069 & TRN & \\
\hline CHEMBL1514215 & 688422 & 4.45 & 5.1102 & TRN & \\
\hline CHEMBL1479855 & 688422 & 4.45 & 4.9321 & TRN & \\
\hline CHEMBL1349631 & 688422 & 5.45 & 5.3044 & TRN & \\
\hline CHEMBL1507496 & 688422 & 7.0 & 5.3571 & TST & \\
\hline CHEMBL1576390 & 688422 & 4.7 & 5.2059 & TRN & \\
\hline CHEMBL1325460 & 688422 & 4.85 & 5.0884 & TRN & \\
\hline CHEMBL1436133 & 688422 & 5.25 & 4.9491 & TST & \\
\hline CHEMBL1429217 & 688422 & 4.5 & 5.0981 & TRN & \\
\hline CHEMBL1547720 & 688422 & 7.9508 & 5.1394 & TRN & \\
\hline CHEMBL1432121 & 688422 & 7.4498 & 5.6723 & TRN & \\
\hline CHEMBL1479826 & 688422 & 4.6 & 5.4396 & TRN & \\
\hline CHEMBL1301309 & 688422 & 5.0 & 5.3566 & TRN & \\
\hline CHEMBL1301797 & 688422 & 4.85 & 5.5276 & TRN & \\
\hline CHEMBL1382633 & 688422 & 5.25 & 5.5274 & TRN & \\
\hline CHEMBL1567475 & 688422 & 4.85 & 5.1784 & TRN & \\
\hline CHEMBL1611203 & 688422 & 7.9508 & 5.3686 & TST & \\
\hline CHEMBL1328177 & 688422 & 5.8 & 5.49 & TRN & \\
\hline CHEMBL1362096 & 688422 & 4.6 & 4.8935 & TST & \\
\hline CHEMBL1315096 & 688422 & 5.25 & 5.2433 & TRN & \\
\hline CHEMBL1354855 & 688422 & 6.05 & 5.2613 & TRN & \\
\hline CHEMBL1341186 & 688422 & 5.2 & 5.3628 & TST & \\
\hline CHEMBL1593118 & 688422 & 6.05 & 5.19799 & 99999999995 & TRN \\
\hline CHEMBL1489291 & 688422 & 4.85 & 4.9694 & TST & \\
\hline CHEMBL1522275 & 688422 & 4.45 & 5.38299 & 9999999999 & TST \\
\hline CHEMBL3212945 & 688422 & 5.0 & 5.1111 & TRN & \\
\hline CHEMBL1346438 & 688422 & 5.55 & 5.3334 & TST & \\
\hline CHEMBL3193693 & 688422 & 7.2503 & 5.0266 & TRN & \\
\hline CHEMBL547833 & 688422 & 4.95 & 5.0384 & TRN & \\
\hline CHEMBL1520906 & 688422 & 4.95 & 5.0294 & TRN & \\
\hline CHEMBL1390325 & 688422 & 4.45 & 4.9904 & TRN & \\
\hline CHEMBL1579643 & 688422 & 6.95 & 5.2679 & TST & \\
\hline CHEMBL1413267 & 688422 & 4.85 & 5.4581 & TRN & \\
\hline CHEMBL1578156 & 688422 & 4.5 & 5.3973 & TRN & \\
\hline CHEMBL1354845 & 688422 & 4.9 & 5.5426 & TRN & \\
\hline CHEMBL3193586 & 688422 & 4.8 & 5.2067 & TRN & \\
\hline CHEMBL1562771 & 688422 & 5.0 & 5.1033 & TRN & \\
\hline CHEMBL1494009 & 688422 & 4.85 & 5.1947 & TRN & \\
\hline
\end{tabular}




\begin{tabular}{|c|c|c|c|c|c|}
\hline \multicolumn{6}{|c|}{ Supplemental Table S2.txt } \\
\hline CHEMBL1598502 & 688422 & 5.1 & 5.4128 & TST & \\
\hline CHEMBL1539502 & 688422 & 4.85 & 5.1931 & TRN & \\
\hline CHEMBL1370291 & 688422 & 4.45 & 5.2255 & TRN & \\
\hline CHEMBL1332346 & 688422 & 4.7 & 4.8977 & TRN & \\
\hline CHEMBL1478787 & 688422 & 4.7 & 5.0317 & TST & \\
\hline CHEMBL1465372 & 688422 & 4.85 & 5.1854 & TRN & \\
\hline CHEMBL1415227 & 688422 & 4.95 & 5.0126 & TRN & \\
\hline CHEMBL1576427 & 688422 & 4.45 & 5.4531 & TRN & \\
\hline CHEMBL1410405 & 688422 & 4.8 & 4.9204 & TRN & \\
\hline CHEMBL1976631 & 688422 & 4.45 & 5.0964 & TRN & \\
\hline CHEMBL1441983 & 688422 & 4.65 & 4.8338 & TRN & \\
\hline CHEMBL1528979 & 688422 & 5.0 & 5.1635 & TRN & \\
\hline CHEMBL1491238 & 688422 & 5.7 & 4.7159 & TRN & \\
\hline CHEMBL1423440 & 688422 & 4.45 & 5.3249 & TRN & \\
\hline CHEMBL1589716 & 688422 & 7.4001 & 5.53100 & 0000000001 & TRN \\
\hline CHEMBL1408161 & 688422 & 5.05 & 5.1348 & TRN & \\
\hline CHEMBL1438259 & 688422 & 4.75 & 5.0941 & TRN & \\
\hline CHEMBL1438385 & 688422 & 4.45 & 5.3567 & TRN & \\
\hline CHEMBL1358983 & 688422 & 4.45 & 4.9546 & TRN & \\
\hline CHEMBL1380633 & 688422 & 4.75 & 5.3444 & TRN & \\
\hline CHEMBL1405701 & 688422 & 4.9 & 4.8651 & TRN & \\
\hline CHEMBL1547317 & 688422 & 4.9 & 5.0447 & TRN & \\
\hline CHEMBL1364969 & 688422 & 4.45 & 5.0327 & TST & \\
\hline CHEMBL1492241 & 688422 & 4.85 & 5.1944 & TRN & \\
\hline CHEMBL1588368 & 688422 & 6.0 & 5.0283 & TRN & \\
\hline CHEMBL1333938 & 688422 & 4.45 & 5.1256 & TRN & \\
\hline CHEMBL1596446 & 688422 & 4.8 & 5.1186 & TST & \\
\hline CHEMBL1326768 & 688422 & 4.9 & 5.3934 & TRN & \\
\hline CHEMBL1608640 & 688422 & 4.8 & 5.3238 & TRN & \\
\hline CHEMBL1407488 & 688422 & 4.75 & 5.1874 & TRN & \\
\hline CHEMBL1496876 & 688422 & 5.55 & 5.8088 & TRN & \\
\hline CHEMBL1451307 & 688422 & 4.9 & 4.938 & TRN & \\
\hline CHEMBL1488357 & 688422 & 4.9 & 5.2409 & TRN & \\
\hline CHEMBL1337059 & 688422 & 6.5501 & 6.0402 & TST & \\
\hline CHEMBL1384749 & 688422 & 4.55 & 5.55 & TRN & \\
\hline CHEMBL1552376 & 688422 & 5.8 & 5.1994 & TRN & \\
\hline CHEMBL1564015 & 688422 & 4.6 & 4.7206 & TST & \\
\hline CHEMBL1529142 & 688422 & 4.85 & 4.7571 & TST & \\
\hline CHEMBL1537805 & 688422 & 4.8 & 5.0595 & TRN & \\
\hline CHEMBL1399328 & 688422 & 5.1 & 5.1343 & TRN & \\
\hline CHEMBL1568018 & 688422 & 5.25 & 5.1389 & TRN & \\
\hline CHEMBL3197044 & 688422 & 4.45 & 5.501 & TST & \\
\hline CHEMBL1304770 & 688422 & 4.95 & 5.0325 & TRN & \\
\hline CHEMBL1395846 & 688422 & 6.8 & 5.4509 & TRN & \\
\hline CHEMBL3198633 & 688422 & 4.75 & 5.3575 & TRN & \\
\hline CHEMBL1328452 & 688422 & 4.75 & 5.3927 & TRN & \\
\hline CHEMBL1566347 & 688422 & 5.5 & 4.8853 & TST & \\
\hline CHEMBL1579418 & 688422 & 5.1 & 5.5503 & TST & \\
\hline
\end{tabular}




\begin{tabular}{|c|c|c|c|c|c|}
\hline \multicolumn{6}{|c|}{ Supplemental Table S2.txt } \\
\hline CHEMBL1536562 & 688422 & 4.5 & 4.836 & TRN & \\
\hline CHEMBL1576451 & 688422 & 4.55 & 5.1395 & TRN & \\
\hline CHEMBL1336837 & 688422 & 6.25 & 5.4261 & TST & \\
\hline CHEMBL1299329 & 688422 & 4.65 & 4.9287 & TST & \\
\hline CHEMBL2005302 & 688422 & 4.45 & 5.0464 & TRN & \\
\hline CHEMBL1607682 & 688422 & 4.95 & 5.2151 & TRN & \\
\hline CHEMBL1572390 & 688422 & 7.1002 & 5.0544 & TRN & \\
\hline CHEMBL1606551 & 688422 & 4.45 & 5.188 & TRN & \\
\hline CHEMBL1583996 & 688422 & 4.75 & 5.1747 & TRN & \\
\hline CHEMBL1503366 & 688422 & 4.9 & 5.3195 & TRN & \\
\hline CHEMBL1426512 & 688422 & 4.45 & 5.1495 & TST & \\
\hline CHEMBL1528139 & 688422 & 6.0 & 5.4646 & TST & \\
\hline CHEMBL1422439 & 688422 & 4.65 & 5.0868 & TST & \\
\hline CHEMBL1362201 & 688422 & 5.0 & 5.4637 & TST & \\
\hline CHEMBL1570966 & 688422 & 6.35 & 5.5484 & TRN & \\
\hline CHEMBL1382864 & 688422 & 6.7501 & 5.5276 & TRN & \\
\hline CHEMBL1390384 & 688422 & 4.9 & 5.1279 & TRN & \\
\hline CHEMBL3194752 & 688422 & 4.9 & 4.7464 & TRN & \\
\hline CHEMBL1333600 & 688422 & 5.65 & 5.7926 & TST & \\
\hline CHEMBL1311172 & 688422 & 8.0 & 5.5012 & TRN & \\
\hline CHEMBL1710 & 688422 & 6.0 & 5.0067 & TRN & \\
\hline CHEMBL1576851 & 688422 & 5.5 & 5.1537 & TRN & \\
\hline CHEMBL1531685 & 688422 & 4.95 & 5.1578 & TRN & \\
\hline CHEMBL1418937 & 688422 & 4.45 & 4.85 & TRN & \\
\hline CHEMBL530115 & 688422 & 4.45 & 5.5309 & TRN & \\
\hline CHEMBL1316608 & 688422 & 4.95 & 5.0644 & TRN & \\
\hline CHEMBL1549749 & 688422 & 5.25 & 5.3764 & TST & \\
\hline CHEMBL1424804 & 688422 & 4.9 & 5.2732 & TST & \\
\hline CHEMBL1605706 & 688422 & 4.6 & 5.1433 & TRN & \\
\hline CHEMBL1307661 & 688422 & 5.3 & 5.1679 & TRN & \\
\hline CHEMBL1519692 & 688422 & 4.5 & 5.3988 & TRN & \\
\hline CHEMBL1304514 & 688422 & 4.45 & 4.8083 & TRN & \\
\hline CHEMBL1329719 & 688422 & 6.05 & 4.9819 & TRN & \\
\hline CHEMBL1529183 & 688422 & 4.45 & 5.8178 & TST & \\
\hline CHEMBL1458566 & 688422 & 5.55 & 5.04899 & 99999999995 & TRN \\
\hline CHEMBL1307868 & 688422 & 5.15 & 5.2671 & TRN & \\
\hline CHEMBL1488338 & 688422 & 4.95 & 4.8847 & TRN & \\
\hline CHEMBL1528335 & 688422 & 4.45 & 5.7045 & TRN & \\
\hline CHEMBL1455868 & 688422 & 4.8 & 4.9156 & TRN & \\
\hline CHEMBL1389629 & 688422 & 4.85 & 5.376 & TRN & \\
\hline CHEMBL1343733 & 688422 & 7.15 & 5.2426 & TRN & \\
\hline CHEMBL1304004 & 688422 & 4.45 & 5.4328 & TRN & \\
\hline CHEMBL1388790 & 688422 & 4.6 & 5.1883 & TRN & \\
\hline CHEMBL1301689 & 688422 & 5.8 & 5.3446 & TRN & \\
\hline CHEMBL1327069 & 688422 & 6.05 & 4.9761 & TRN & \\
\hline CHEMBL1308657 & 688422 & 7.15 & 5.1306 & TRN & \\
\hline CHEMBL1572529 & 688422 & 8.0506 & 5.4775 & TST & \\
\hline CHEMBL1378118 & 688422 & 4.7 & 5.1061 & TRN & \\
\hline
\end{tabular}




\begin{tabular}{|c|c|c|c|c|c|}
\hline \multicolumn{6}{|c|}{ Supplemental Table s2.txt } \\
\hline CHEMBL1339737 & 688422 & 5.15 & 5.3623 & TRN & \\
\hline CHEMBL 3211244 & 688422 & 4.95 & 5.5011 & TRN & \\
\hline CHEMBL1459789 & 688422 & 4.95 & 5.686 & TST & \\
\hline CHEMBL1413753 & 688422 & 4.8 & 5.4446 & TST & \\
\hline CHEMBL1312064 & 688422 & 4.95 & 5.0416 & TRN & \\
\hline CHEMBL1340055 & 688422 & 5.55 & 5.0375 & TRN & \\
\hline CHEMBL1418890 & 688422 & 4.45 & 5.7113 & TRN & \\
\hline CHEMBL1526515 & 688422 & 4.5 & 4.6842 & TRN & \\
\hline CHEMBL1416247 & 688422 & 7.3002 & 5.36299 & 99999999995 & TRN \\
\hline CHEMBL1315060 & 688422 & 8.0 & 5.6093 & TRN & \\
\hline CHEMBL1418194 & 688422 & 6.8499 & 5.2466 & TRN & \\
\hline CHEMBL1585220 & 688422 & 4.8 & 4.8525 & TRN & \\
\hline CHEMBL1587169 & 688422 & 5.75 & 5.4167 & TRN & \\
\hline CHEMBL1512265 & 688422 & 5.4 & 5.7844 & TRN & \\
\hline CHEMBL1431387 & 688422 & 6.9 & 5.6326 & TST & \\
\hline CHEMBL1496584 & 688422 & 4.45 & 5.3155 & TRN & \\
\hline CHEMBL1461370 & 688422 & 4.75 & 5.4707 & TRN & \\
\hline CHEMBL1573193 & 688422 & 5.2 & 5.461 & TRN & \\
\hline CHEMBL 3193486 & 688422 & 4.95 & 5.2206 & TRN & \\
\hline CHEMBL1562761 & 688422 & 5.0 & 5.228 & TRN & \\
\hline CHEMBL3207594 & 688422 & 7.3002 & 5.4011 & TRN & \\
\hline CHEMBL 3191354 & 688422 & 4.45 & 5.1285 & TST & \\
\hline CHEMBL1478026 & 688422 & 5.8 & 5.8432 & TST & \\
\hline CHEMBL1457907 & 688422 & 4.45 & 5.058 & TST & \\
\hline CHEMBL3199206 & 688422 & 6.5501 & 5.2005 & TRN & \\
\hline CHEMBL1593060 & 688422 & 4.75 & 5.5828 & TRN & \\
\hline CHEMBL1379231 & 688422 & 5.2 & 5.2856 & TRN & \\
\hline CHEMBL1448920 & 688422 & 4.45 & 5.4301 & TRN & \\
\hline CHEMBL1464178 & 688422 & 4.75 & 5.0717 & TRN & \\
\hline CHEMBL1444182 & 688422 & 4.85 & 5.1375 & TRN & \\
\hline CHEMBL 3213453 & 688422 & 8.3468 & 5.7641 & TST & \\
\hline CHEMBL1451195 & 688422 & 6.4 & 5.2372 & TRN & \\
\hline CHEMBL1348766 & 688422 & 5.4 & 4.9814 & TRN & \\
\hline CHEMBL1343693 & 688422 & 4.45 & 5.2624 & TRN & \\
\hline CHEMBL1446538 & 688422 & 4.45 & 5.1673 & TRN & \\
\hline CHEMBL1464828 & 688422 & 4.7 & 5.5297 & TST & \\
\hline CHEMBL1708832 & 688422 & 5.6 & 5.189 & TRN & \\
\hline CHEMBL1336435 & 688422 & 8.0506 & 5.71700 & 00000000005 & TRN \\
\hline CHEMBL1307027 & 688422 & 6.0 & 5.7828 & TST & \\
\hline CHEMBL1595824 & 688422 & 4.95 & 5.1207 & TRN & \\
\hline CHEMBL1434465 & 688422 & 4.45 & 5.5515 & TRN & \\
\hline CHEMBL1442704 & 688422 & 5.25 & 5.1152 & TRN & \\
\hline CHEMBL1392017 & 688422 & 4.75 & 5.2182 & TRN & \\
\hline CHEMBL1528901 & 688422 & 5.55 & 5.6608 & TST & \\
\hline CHEMBL1454029 & 688422 & 5.1 & 5.495 & TRN & \\
\hline CHEMBL 2068573 & 688422 & 5.0 & 5.6998 & TST & \\
\hline CHEMBL1596474 & 688422 & 7.1002 & 5.2988 & TRN & \\
\hline CHEMBL3198285 & 688422 & 4.6 & 5.1638 & TRN & \\
\hline
\end{tabular}




\begin{tabular}{|c|c|c|c|c|c|}
\hline \multicolumn{6}{|c|}{ Supplemental Table S2.txt } \\
\hline CHEMBL1453935 & 688422 & 6.1 & 5.3264 & TST & \\
\hline CHEMBL 3196362 & 688422 & 4.45 & 4.9698 & TRN & \\
\hline CHEMBL1596772 & 688422 & 4.8 & 5.7146 & TRN & \\
\hline CHEMBL1601688 & 688422 & 5.25 & 5.5407 & TRN & \\
\hline CHEMBL1446648 & 688422 & 7.2 & 5.2076 & TRN & \\
\hline CHEMBL1418397 & 688422 & 4.8 & 5.3767 & TRN & \\
\hline CHEMBL1334189 & 688422 & 4.45 & 4.9796 & TRN & \\
\hline CHEMBL1484859 & 688422 & 4.9 & 4.9645 & TRN & \\
\hline CHEMBL16102 & 688422 & 5.1 & 5.4941 & TST & \\
\hline CHEMBL1583524 & 688422 & 5.0 & 4.7559 & TRN & \\
\hline CHEMBL358580 & 688422 & 4.95 & 5.2528 & TRN & \\
\hline CHEMBL1301769 & 688422 & 4.65 & 5.0278 & TST & \\
\hline CHEMBL1507980 & 688422 & 5.5 & 5.1399 & TST & \\
\hline CHEMBL1358297 & 688422 & 5.45 & 5.5332 & TST & \\
\hline CHEMBL1513841 & 688422 & 4.45 & 5.8853 & TST & \\
\hline CHEMBL1346694 & 688422 & 5.5 & 5.2539 & TRN & \\
\hline CHEMBL1343309 & 688422 & 4.75 & 4.8808 & TRN & \\
\hline CHEMBL1485620 & 688422 & 4.45 & 5.0355 & TST & \\
\hline CHEMBL1568662 & 688422 & 4.5 & 5.1474 & TRN & \\
\hline CHEMBL1304603 & 688422 & 5.2 & 5.1751 & TST & \\
\hline CHEMBL1344470 & 688422 & 4.45 & 5.1902 & TST & \\
\hline CHEMBL1319614 & 688422 & 8.301 & 5.9307 & TRN & \\
\hline CHEMBL1367066 & 688422 & 8.3468 & 5.6173 & TRN & \\
\hline CHEMBL1456745 & 688422 & 4.45 & 5.6055 & TRN & \\
\hline CHEMBL1361308 & 688422 & 5.45 & 4.8288 & TRN & \\
\hline CHEMBL1420334 & 688422 & 4.45 & 5.2429 & TST & \\
\hline CHEMBL1450382 & 688422 & 4.75 & 5.2557 & TRN & \\
\hline CHEMBL3194609 & 688422 & 4.45 & 5.2301 & TRN & \\
\hline CHEMBL1607826 & 688422 & 6.4 & 5.1712 & TRN & \\
\hline CHEMBL1529848 & 688422 & 4.8 & 5.267 & TRN & \\
\hline CHEMBL1513851 & 688422 & 7.6498 & 5.5732 & TRN & \\
\hline CHEMBL1317145 & 688422 & 4.8 & 5.1863 & TRN & \\
\hline CHEMBL1546079 & 688422 & 6.35 & 5.0755 & TST & \\
\hline CHEMBL1568055 & 688422 & 4.9 & 4.7616 & TRN & \\
\hline CHEMBL1425705 & 688422 & 4.85 & $5.1270 e$ & 0000000001 & TST \\
\hline CHEMBL1477455 & 688422 & 7.6498 & $5.1110 e$ & 0000000001 & TRN \\
\hline CHEMBL3197563 & 688422 & 5.6 & 5.2753 & TRN & \\
\hline CHEMBL1414869 & 688422 & 5.6 & 4.9995 & TRN & \\
\hline CHEMBL1586832 & 688422 & 5.4 & 5.6652 & TRN & \\
\hline CHEMBL1613143 & 688422 & 4.85 & 5.2142 & TST & \\
\hline CHEMBL1401152 & 688422 & 4.65 & 5.0148 & TRN & \\
\hline CHEMBL1366395 & 688422 & 4.45 & 4.8 & TRN & \\
\hline CHEMBL1536662 & 688422 & 7.6498 & 5.3711 & TST & \\
\hline CHEMBL1405792 & 688422 & 5.65 & 5.1788 & TRN & \\
\hline CHEMBL1460843 & 688422 & 4.85 & 5.4202 & TST & \\
\hline CHEMBL1498487 & 688422 & 6.2 & 5.5867 & TST & \\
\hline CHEMBL1391217 & 688422 & 4.9 & 5.5116 & TST & \\
\hline CHEMBL1396033 & 688422 & 4.95 & 5.5615 & TRN & \\
\hline
\end{tabular}




\begin{tabular}{|c|c|c|c|c|}
\hline \multicolumn{5}{|c|}{ Supplemental Table s2.txt } \\
\hline CHEMBL1544054 & 688422 & 5.7 & 5.4839 & TRN \\
\hline CHEMBL1570906 & 688422 & 4.45 & 5.6599 & TRN \\
\hline CHEMBL3209027 & 688422 & 4.75 & 5.3051 & TRN \\
\hline CHEMBL1439675 & 688422 & 4.45 & 5.1947 & TRN \\
\hline CHEMBL1356307 & 688422 & 7.3497 & 5.5789 & TST \\
\hline CHEMBL1408519 & 688422 & 5.35 & 5.0616 & TST \\
\hline CHEMBL3194213 & 688422 & 4.6 & 5.1153 & TRN \\
\hline CHEMBL1574014 & 688422 & 5.35 & 5.1089 & TRN \\
\hline CHEMBL 3195222 & 688422 & 4.8 & 4.9839 & TRN \\
\hline CHEMBL 1357157 & 688422 & 5.2 & 5.3681 & TST \\
\hline CHEMBL1585610 & 688422 & 4.95 & 5.3629 & TRN \\
\hline CHEMBL600589 & 688422 & 4.45 & 4.9566 & TRN \\
\hline CHEMBL1413956 & 688422 & 4.9 & 5.2907 & TRN \\
\hline CHEMBL1359261 & 688422 & 7.0501 & 5.8442 & TST \\
\hline CHEMBL1493815 & 688422 & 5.0 & 5.0017 & TRN \\
\hline CHEMBL1362518 & 688422 & 4.55 & 4.7356 & TRN \\
\hline CHEMBL1545406 & 688422 & 4.9 & 4.9146 & TRN \\
\hline CHEMBL1601291 & 688422 & 4.9 & 5.301 & TST \\
\hline CHEMBL1501777 & 688422 & 4.45 & 5.5466 & TST \\
\hline CHEMBL1990792 & 688422 & 5.05 & 5.3753 & TRN \\
\hline CHEMBL1328113 & 688422 & 4.45 & 4.7815 & TRN \\
\hline CHEMBL1376293 & 688422 & 4.9 & 5.093 & TST \\
\hline CHEMBL3190726 & 688422 & 4.45 & 5.4816 & TRN \\
\hline CHEMBL1515194 & 688422 & 4.6 & 4.8903 & TRN \\
\hline CHEMBL1304266 & 688422 & 4.7 & 5.4013 & TRN \\
\hline CHEMBL1503371 & 688422 & 4.6 & 5.0881 & TRN \\
\hline CHEMBL1344007 & 688422 & 4.7 & 5.18 & TRN \\
\hline CHEMBL1414086 & 688422 & 4.65 & 5.6888 & TST \\
\hline CHEMBL1362562 & 688422 & 4.6 & 5.0069 & TST \\
\hline CHEMBL1565678 & 688422 & 5.4 & 5.5438 & TRN \\
\hline CHEMBL1416253 & 688422 & 5.2 & 5.142 & TST \\
\hline CHEMBL1489638 & 688422 & 4.65 & 5.4696 & TRN \\
\hline CHEMBL1520539 & 688422 & 4.6 & 4.8912 & TRN \\
\hline CHEMBL1541681 & 688422 & 4.5 & 4.776 & TST \\
\hline CHEMBL1341582 & 688422 & 4.95 & 5.1039 & TRN \\
\hline CHEMBL1340034 & 688422 & 5.5 & 5.3194 & TST \\
\hline CHEMBL1390928 & 688422 & 4.9 & 5.1199 & TST \\
\hline CHEMBL1447362 & 688422 & 4.8 & 5.3048 & TRN \\
\hline CHEMBL1563561 & 688422 & 4.8 & 5.0634 & TST \\
\hline CHEMBL1600741 & 688422 & 4.45 & 5.2032 & TST \\
\hline CHEMBL1576194 & 688422 & 5.1 & 5.5689 & TRN \\
\hline CHEMBL1389232 & 688422 & 4.9 & 4.992 & TRN \\
\hline CHEMBL1393911 & 688422 & 4.45 & 4.9661 & TRN \\
\hline CHEMBL1591733 & 688422 & 5.7 & 5.2343 & TRN \\
\hline CHEMBL1387067 & 688422 & 4.45 & 5.6179 & TST \\
\hline CHEMBL1340678 & 688422 & 4.65 & 5.2653 & TRN \\
\hline CHEMBL1361515 & 688422 & 4.5 & 5.0843 & TRN \\
\hline CHEMBL1411813 & 688422 & 4.45 & 5.1882 & TRN \\
\hline
\end{tabular}




\begin{tabular}{|c|c|c|c|c|c|}
\hline & & \multicolumn{4}{|c|}{ Supplemental Table S2.txt } \\
\hline CHEMBL1301947 & 688422 & 6.7501 & 5.2893 & TRN & \\
\hline CHEMBL1360735 & 688422 & 4.7 & 4.7771 & TST & \\
\hline CHEMBL1597750 & 688422 & 5.05 & 5.2055 & TRN & \\
\hline CHEMBL1526683 & 688422 & 5.05 & 5.5066 & TRN & \\
\hline CHEMBL1451988 & 688422 & 4.65 & 4.9492 & TRN & \\
\hline CHEMBL1303452 & 688422 & 4.9 & 4.9595 & TRN & \\
\hline CHEMBL1441339 & 688422 & 4.5 & 5.4284 & TRN & \\
\hline CHEMBL1306211 & 688422 & 5.2 & 5.9011 & TST & \\
\hline CHEMBL1612058 & 688422 & 4.95 & 5.7843 & TRN & \\
\hline CHEMBL1457593 & 688422 & 4.65 & 5.1958 & TRN & \\
\hline CHEMBL1429204 & 688422 & 5.8 & 5.3689 & TRN & \\
\hline CHEMBL1521317 & 688422 & 7.5003 & 5.1331 & TRN & \\
\hline CHEMBL1509140 & 688422 & 6.25 & 5.4812 & TRN & \\
\hline CHEMBL1506384 & 688422 & 5.25 & 4.893 & TRN & \\
\hline CHEMBL3195722 & 688422 & 4.45 & 4.8079 & TRN & \\
\hline CHEMBL1429047 & 688422 & 4.85 & 4.8598 & TRN & \\
\hline CHEMBL1485609 & 688422 & 6.2 & 5.2304 & TRN & \\
\hline CHEMBL1439422 & 688422 & 4.6 & 4.5614 & TRN & \\
\hline CHEMBL1484144 & 688422 & 4.65 & 5.4831 & TRN & \\
\hline CHEMBL1334934 & 688422 & 8.0506 & 5.466 & TST & \\
\hline CHEMBL1399542 & 688422 & 6.9 & 5.5483 & TST & \\
\hline CHEMBL1321154 & 688422 & 6.45 & 5.4336 & TST & \\
\hline CHEMBL1516210 & 688422 & 4.95 & 4.8918 & TRN & \\
\hline CHEMBL1490392 & 688422 & 7.0 & 5.8351 & TRN & \\
\hline CHEMBL1353879 & 688422 & 4.9 & 5.1122 & TRN & \\
\hline CHEMBL1543470 & 688422 & 5.2 & 5.21700 & 00000000005 & TRN \\
\hline CHEMBL1299722 & 688422 & 4.45 & 5.3416 & TRN & \\
\hline CHEMBL1423370 & 688422 & 4.45 & 4.6856 & TRN & \\
\hline CHEMBL1588605 & 688422 & 5.15 & 5.11100 & 0000000001 & TRN \\
\hline CHEMBL1339537 & 688422 & 4.65 & 5.0233 & TRN & \\
\hline CHEMBL1486958 & 688422 & 4.9 & 5.3955 & TRN & \\
\hline CHEMBL1444691 & 688422 & 4.8 & 4.7807 & TRN & \\
\hline CHEMBL1326090 & 688422 & 4.55 & 4.8886 & TRN & \\
\hline CHEMBL1540710 & 688422 & 4.95 & 5.3846 & TRN & \\
\hline CHEMBL1414895 & 688422 & 4.6 & 5.4093 & TRN & \\
\hline CHEMBL1445707 & 688422 & 5.35 & 5.2659 & TRN & \\
\hline CHEMBL1516683 & 688422 & 5.45 & 4.8627 & TRN & \\
\hline CHEMBL1971410 & 688422 & 4.85 & 5.2288 & TRN & \\
\hline CHEMBL1558889 & 688422 & 5.15 & 5.4255 & TRN & \\
\hline CHEMBL1493601 & 688422 & 4.45 & 5.8629 & TRN & \\
\hline CHEMBL1339303 & 688422 & 4.45 & 4.85800 & 00000000005 & TRN \\
\hline CHEMBL1340903 & 688422 & 4.45 & 5.0487 & TST & \\
\hline CHEMBL1604078 & 688422 & 5.0 & 5.1583 & TRN & \\
\hline CHEMBL1461514 & 688422 & 7.15 & 5.3667 & TST & \\
\hline CHEMBL1534313 & 688422 & 4.45 & 5.5723 & TST & \\
\hline CHEMBL 1457877 & 688422 & 4.55 & 5.1925 & TRN & \\
\hline CHEMBL1473377 & 688422 & 5.6 & 5.4668 & TRN & \\
\hline CHEMBL2003356 & 688422 & 4.45 & 4.9817 & TRN & \\
\hline
\end{tabular}




\begin{tabular}{|c|c|c|c|c|}
\hline & & & pplement & al Ta \\
\hline CHEMBL1323376 & 688422 & 5.45 & 4.6453 & TRN \\
\hline CHEMBL1411839 & 688422 & 4.85 & 5.4633 & TST \\
\hline CHEMBL1306971 & 688422 & 8.0 & 4.7481 & TRN \\
\hline CHEMBL1527759 & 688422 & 6.25 & 5.2781 & TRN \\
\hline CHEMBL1353597 & 688422 & 4.45 & 4.9582 & TRN \\
\hline CHEMBL1427511 & 688422 & 5.85 & 5.2483 & TST \\
\hline CHEMBL1387047 & 688422 & 4.7 & 4.878 & TRN \\
\hline CHEMBL1567092 & 688422 & 4.5 & 5.1013 & TRN \\
\hline CHEMBL1558962 & 688422 & 5.8 & 5.5519 & TRN \\
\hline CHEMBL1490123 & 688422 & 4.8 & 5.4295 & TST \\
\hline CHEMBL1384090 & 688422 & 4.45 & 4.8396 & TRN \\
\hline CHEMBL1336709 & 688422 & 4.85 & 5.0833 & TRN \\
\hline CHEMBL1602792 & 688422 & 4.45 & 5.5914 & TST \\
\hline CHEMBL1452136 & 688422 & 4.85 & 5.7999 & TST \\
\hline CHEMBL1503636 & 688422 & 4.45 & 5.3183 & TST \\
\hline CHEMBL1304316 & 688422 & 5.45 & 5.3281 & TRN \\
\hline CHEMBL1996858 & 688422 & 4.9 & 5.1114 & TRN \\
\hline CHEMBL1310254 & 688422 & 4.75 & 5.6206 & TST \\
\hline CHEMBL1500062 & 688422 & 4.95 & 5.0209 & TRN \\
\hline CHEMBL1533225 & 688422 & 4.45 & 5.16 & TST \\
\hline CHEMBL1424686 & 688422 & 5.35 & 5.0222 & TST \\
\hline CHEMBL1459419 & 688422 & 8.4559 & 5.1793 & TRN \\
\hline CHEMBL 257856 & 688422 & 5.05 & 5.2133 & TRN \\
\hline CHEMBL1423984 & 688422 & 6.0 & 5.6574 & TST \\
\hline CHEMBL1483034 & 688422 & 5.6 & 5.4558 & TST \\
\hline CHEMBL1498629 & 688422 & 5.0 & 4.7723 & TRN \\
\hline CHEMBL1588180 & 688422 & 7.5003 & 5.1993 & TRN \\
\hline CHEMBL1369414 & 688422 & 6.0 & 5.439 & TRN \\
\hline CHEMBL1492430 & 688422 & 5.25 & 5.1362 & TST \\
\hline CHEMBL1321368 & 688422 & 5.65 & 5.485 & TRN \\
\hline CHEMBL1524390 & 688422 & 5.05 & 4.8709 & TRN \\
\hline CHEMBL1302523 & 688422 & 5.05 & 4.8517 & TRN \\
\hline CHEMBL1487870 & 688422 & 4.85 & 5.1858 & TRN \\
\hline CHEMBL1558605 & 688422 & 4.45 & 5.3581 & TRN \\
\hline CHEMBL1580214 & 688422 & 4.65 & 4.7408 & TRN \\
\hline CHEMBL1551343 & 688422 & 4.65 & 5.0976 & TRN \\
\hline CHEMBL45245 & 688422 & 5.2 & 5.4955 & TST \\
\hline CHEMBL1417856 & 688422 & 6.0 & 5.4299 & TST \\
\hline CHEMBL1525601 & 688422 & 6.4 & 5.3358 & TST \\
\hline CHEMBL1489977 & 688422 & 4.9 & 5.4311 & TRN \\
\hline CHEMBL1587131 & 688422 & 4.85 & 5.2758 & TRN \\
\hline CHEMBL1423387 & 688422 & 5.5 & 5.3424 & TRN \\
\hline CHEMBL1391340 & 688422 & 5.45 & 5.4773 & TRN \\
\hline CHEMBL1492395 & 688422 & 4.45 & 5.1289 & TRN \\
\hline CHEMBL1364432 & 688422 & 4.95 & 5.0104 & TRN \\
\hline CHEMBL3197127 & 688422 & 4.65 & 5.206 & TST \\
\hline CHEMBL1465665 & 688422 & 4.7 & 5.6822 & TST \\
\hline CHEMBL1382615 & 688422 & 8.4559 & 5.307 & TRN \\
\hline
\end{tabular}




\begin{tabular}{|c|c|c|c|c|}
\hline \multicolumn{5}{|c|}{ Supplemental Table S2.txt } \\
\hline CHEMBL1486445 & 688422 & 4.95 & 5.316 & TST \\
\hline CHEMBL1573030 & 688422 & 4.45 & 5.4419 & TST \\
\hline CHEMBL 277498 & 688422 & 4.85 & 5.897 & TST \\
\hline CHEMBL1541883 & 688422 & 4.45 & 5.1098 & TRN \\
\hline CHEMBL1567514 & 688422 & 4.7 & 5.5126 & TRN \\
\hline CHEMBL1384524 & 688422 & 5.45 & 5.2393 & TRN \\
\hline CHEMBL1605924 & 688422 & 4.6 & 5.2494 & TST \\
\hline CHEMBL3199433 & 688422 & 5.6 & 5.4845 & TRN \\
\hline CHEMBL1576138 & 688422 & 4.7 & 4.7552 & TRN \\
\hline CHEMBL1348251 & 688422 & 4.45 & 5.0862 & TRN \\
\hline CHEMBL1323765 & 688422 & 4.55 & 5.0914 & TRN \\
\hline CHEMBL1476539 & 688422 & 4.7 & 5.4287 & TRN \\
\hline CHEMBL1596472 & 688422 & 4.6 & 5.2757 & TRN \\
\hline CHEMBL1425871 & 688422 & 4.45 & 5.2225 & TRN \\
\hline CHEMBL1364983 & 688422 & 4.9 & 5.1465 & TRN \\
\hline CHEMBL1317728 & 688422 & 4.95 & 5.1834 & TRN \\
\hline CHEMBL1555482 & 688422 & 4.5 & 5.1255 & TRN \\
\hline CHEMBL1600664 & 688422 & 7.0501 & 5.6447 & TST \\
\hline CHEMBL1323802 & 688422 & 4.8 & 5.0988 & TRN \\
\hline CHEMBL1437449 & 688422 & 8.301 & 5.539 & TRN \\
\hline CHEMBL1302116 & 688422 & 4.5 & 5.0177 & TRN \\
\hline CHEMBL1588132 & 688422 & 4.85 & 5.2719 & TRN \\
\hline CHEMBL447986 & 688422 & 4.45 & 5.3023 & TRN \\
\hline CHEMBL1478857 & 688422 & 4.45 & 5.3215 & TST \\
\hline CHEMBL1601997 & 688422 & 5.25 & 5.0185 & TST \\
\hline CHEMBL1345620 & 688422 & 5.5 & 4.7987 & TRN \\
\hline CHEMBL1517862 & 688422 & 6.0 & 6.3617 & TRN \\
\hline CHEMBL1481626 & 688422 & 5.6 & 5.0667 & TRN \\
\hline CHEMBL1531454 & 688422 & 4.75 & 5.5845 & TRN \\
\hline CHEMBL1543417 & 688422 & 4.9 & 4.6726 & TST \\
\hline CHEMBL3348827 & 688422 & 7.3002 & 6.1992 & TRN \\
\hline CHEMBL1453691 & 688422 & 4.8 & 5.5048 & TRN \\
\hline CHEMBL1419438 & 688422 & 4.65 & 4.8425 & TRN \\
\hline CHEMBL1322805 & 688422 & 7.8508 & 5.9161 & TST \\
\hline CHEMBL1451774 & 688422 & 4.45 & 4.9278 & TRN \\
\hline CHEMBL1562945 & 688422 & 4.5 & 5.0346 & TRN \\
\hline CHEMBL1340275 & 688422 & 5.9 & 5.8394 & TRN \\
\hline CHEMBL1480422 & 688422 & 4.85 & 5.1781 & TRN \\
\hline CHEMBL1352337 & 688422 & 4.5 & 5.056 & TRN \\
\hline CHEMBL1406265 & 688422 & 4.9 & 5.4776 & TRN \\
\hline CHEMBL1561327 & 688422 & 4.75 & 5.4928 & TRN \\
\hline CHEMBL1379280 & 688422 & 4.75 & 5.1485 & TRN \\
\hline CHEMBL1326547 & 688422 & 5.3 & 5.4253 & TRN \\
\hline CHEMBL1578748 & 688422 & 4.65 & 5.1345 & TST \\
\hline CHEMBL609110 & 688422 & 4.55 & 5.0881 & TRN \\
\hline CHEMBL1467860 & 688422 & 4.45 & 4.7766 & TRN \\
\hline CHEMBL1367260 & 688422 & 5.3 & 5.3672 & TRN \\
\hline CHEMBL1388010 & 688422 & 4.5 & 5.0535 & TRN \\
\hline
\end{tabular}




\begin{tabular}{|c|c|c|c|c|c|}
\hline \multicolumn{6}{|c|}{ Supplemental Table s2.txt } \\
\hline CHEMBL1353484 & 688422 & 5.65 & 5.1897 & TRN & \\
\hline CHEMBL1360823 & 688422 & 4.45 & 5.1855 & TRN & \\
\hline CHEMBL1530266 & 688422 & 4.95 & \multicolumn{2}{|c|}{5.361000000000001} & TRN \\
\hline CHEMBL1400761 & 688422 & 4.9 & 4.6788 & TST & \\
\hline CHEMBL1359648 & 688422 & 4.65 & 5.5018 & TRN & \\
\hline CHEMBL1532113 & 688422 & 4.5 & 5.2046 & TST & \\
\hline CHEMBL1521872 & 688422 & 5.0 & 5.0434 & TST & \\
\hline CHEMBL1525535 & 688422 & 6.05 & 5.4633 & TST & \\
\hline CHEMBL1523322 & 688422 & 5.8 & 5.4177 & TST & \\
\hline CHEMBL3192306 & 688422 & 7.5003 & 5.1636 & TRN & \\
\hline CHEMBL1597650 & 688422 & 4.4 & 5.4365 & TRN & \\
\hline CHEMBL1525497 & 688422 & 4.7 & 5.0857 & TRN & \\
\hline CHEMBL1500772 & 688422 & 4.6 & 5.4158 & TST & \\
\hline CHEMBL1366052 & 688422 & 4.65 & 5.7471 & TRN & \\
\hline CHEMBL1323005 & 688422 & 4.45 & 5.3237 & TRN & \\
\hline CHEMBL1499999 & 688422 & 4.75 & 4.9371 & TRN & \\
\hline CHEMBL1455668 & 688422 & 5.6 & 5.4092 & TST & \\
\hline CHEMBL1513485 & 688422 & 5.05 & 5.0707 & TRN & \\
\hline CHEMBL1336364 & 688422 & 8.1487 & 5.5852 & TST & \\
\hline CHEMBL1389769 & 688422 & 4.75 & 5.0901 & TRN & \\
\hline CHEMBL1541162 & 688422 & 4.9 & 5.1038 & TST & \\
\hline CHEMBL1580066 & 688422 & 4.45 & 4.9501 & TRN & \\
\hline CHEMBL1428528 & 688422 & 4.45 & 5.3522 & TRN & \\
\hline CHEMBL3192048 & 688422 & 5.5 & 5.0451 & TST & \\
\hline CHEMBL1492333 & 688422 & 5.25 & 5.104 & TST & \\
\hline CHEMBL1572094 & 688422 & 5.5 & 5.2986 & TRN & \\
\hline CHEMBL1305791 & 688422 & 8.4949 & 5.3823 & TRN & \\
\hline CHEMBL1377894 & 688422 & 4.65 & 5.2548 & TRN & \\
\hline CHEMBL1493512 & 688422 & 4.75 & 5.6395 & TST & \\
\hline CHEMBL1498138 & 688422 & 4.5 & 5.0174 & TRN & \\
\hline CHEMBL1503489 & 688422 & 5.1 & 5.01699 & 99999999995 & TRN \\
\hline CHEMBL1491462 & 688422 & 4.95 & 5.2678 & TRN & \\
\hline CHEMBL1870697 & 688422 & 4.85 & 5.0564 & TRN & \\
\hline CHEMBL1374807 & 688422 & 4.45 & 5.4361 & TRN & \\
\hline CHEMBL1416488 & 688422 & 4.7 & 5.2738 & TST & \\
\hline CHEMBL1414859 & 688422 & 4.45 & 4.9034 & TRN & \\
\hline CHEMBL504598 & 688422 & 4.45 & 5.3262 & TRN & \\
\hline CHEMBL1391117 & 688422 & 4.7 & 5.7005 & TST & \\
\hline CHEMBL1586600 & 688422 & 4.7 & 4.8157 & TRN & \\
\hline CHEMBL1525883 & 688422 & 4.65 & 5.2987 & TRN & \\
\hline CHEMBL1568330 & 688422 & 7.0501 & 5.5134 & TRN & \\
\hline CHEMBL1413234 & 688422 & 7.1002 & 5.3851 & TRN & \\
\hline CHEMBL1509621 & 688422 & 4.9 & 5.2342 & TRN & \\
\hline CHEMBL478754 & 688422 & 4.95 & 5.5321 & TRN & \\
\hline CHEMBL3192014 & 688422 & 4.9 & 4.8923 & TRN & \\
\hline CHEMBL1604510 & 688422 & 4.45 & 5.2953 & TRN & \\
\hline CHEMBL1449481 & 688422 & 4.85 & 5.2198 & TRN & \\
\hline CHEMBL1256659 & 688422 & 4.9 & 4.96399 & 99999999995 & TRN \\
\hline & & & & 1009 & \\
\hline
\end{tabular}




\begin{tabular}{|c|c|c|c|c|c|}
\hline \multicolumn{6}{|c|}{ Supplemental Table S2.txt } \\
\hline CHEMBL1337592 & 688422 & 4.6 & 4.5839 & TRN & \\
\hline CHEMBL391997 & 688422 & 4.95 & \multicolumn{2}{|c|}{5.167999999999999} & TST \\
\hline CHEMBL1484841 & 688422 & 4.7 & 5.0767 & TST & \\
\hline CHEMBL1365596 & 688422 & 4.45 & \multicolumn{2}{|c|}{5.1610000000000005} & TRN \\
\hline CHEMBL1441216 & 688422 & 4.9 & 5.4257 & TRN & \\
\hline CHEMBL1410988 & 688422 & 6.8 & 4.9412 & TRN & \\
\hline CHEMBL1572844 & 688422 & 4.8 & 5.7452 & TRN & \\
\hline CHEMBL1453546 & 688422 & 4.45 & 5.0343 & TRN & \\
\hline CHEMBL1495663 & 688422 & 4.45 & 5.1427 & TRN & \\
\hline CHEMBL1450412 & 688422 & 4.55 & 4.9976 & TRN & \\
\hline CHEMBL1606244 & 688422 & 4.95 & 5.7036 & TRN & \\
\hline CHEMBL1424534 & 688422 & 5.6 & 5.9651 & TST & \\
\hline CHEMBL1343388 & 688422 & 5.35 & 5.289 & TRN & \\
\hline CHEMBL1444581 & 688422 & 8.0506 & 5.2276 & TST & \\
\hline CHEMBL1417963 & 688422 & 8.3468 & 5.6613 & TST & \\
\hline CHEMBL1418786 & 688422 & 4.85 & 4.7902 & TRN & \\
\hline CHEMBL1445746 & 688422 & 7.2 & 5.5294 & TST & \\
\hline CHEMBL1385396 & 688422 & 4.45 & 5.1387 & TST & \\
\hline CHEMBL1613580 & 688422 & 4.5 & 4.9969 & TRN & \\
\hline CHEMBL1509599 & 688422 & 4.65 & 4.9256 & TRN & \\
\hline CHEMBL1416713 & 688422 & 4.65 & 4.8031 & TRN & \\
\hline CHEMBL1526135 & 688422 & 5.1 & \multicolumn{2}{|c|}{5.513999999999999} & TRN \\
\hline CHEMBL1335761 & 688422 & 4.5 & 5.5115 & TST & \\
\hline CHEMBL1557932 & 688422 & 5.5 & 5.1139 & TRN & \\
\hline CHEMBL1484484 & 688422 & 4.9 & 5.2403 & TRN & \\
\hline CHEMBL1303599 & 688422 & 8.4949 & 5.2187 & TST & \\
\hline CHEMBL1611283 & 688422 & 5.25 & 5.5362 & TRN & \\
\hline CHEMBL1374533 & 688422 & 4.95 & 4.8147 & TRN & \\
\hline CHEMBL1447941 & 688422 & 6.05 & 5.1429 & TST & \\
\hline CHEMBL1489553 & 688422 & 4.85 & 5.0557 & TRN & \\
\hline CHEMBL1566242 & 688422 & 4.45 & 5.1298 & TRN & \\
\hline CHEMBL1548484 & 688422 & 4.45 & 5.2903 & TRN & \\
\hline CHEMBL1371999 & 688422 & 4.7 & 5.0051 & TRN & \\
\hline CHEMBL1530160 & 688422 & 7.5003 & 5.0559 & TST & \\
\hline CHEMBL1986099 & 688422 & 4.8 & 5.2533 & TST & \\
\hline CHEMBL1361741 & 688422 & 4.8 & 5.098 & TRN & \\
\hline CHEMBL1371049 & 688422 & 4.9 & 5.2655 & TRN & \\
\hline CHEMBL1353528 & 688422 & 5.0 & 4.7788 & TRN & \\
\hline CHEMBL1329721 & 688422 & 4.7 & 5.0142 & TRN & \\
\hline CHEMBL1564908 & 688422 & 4.95 & 5.4759 & TRN & \\
\hline CHEMBL1418818 & 688422 & 5.45 & 5.1971 & TRN & \\
\hline CHEMBL1452607 & 688422 & 4.7 & 5.1379 & TRN & \\
\hline CHEMBL1393808 & 688422 & 5.25 & 6.0189 & TRN & \\
\hline CHEMBL1448100 & 688422 & 6.2 & 5.5827 & TST & \\
\hline CHEMBL1310139 & 688422 & 4.7 & 5.2694 & TRN & \\
\hline CHEMBL1586145 & 688422 & 5.0 & 5.2908 & TRN & \\
\hline CHEMBL1337250 & 688422 & 4.45 & 4.998 & TRN & \\
\hline \multirow[t]{2}{*}{ CHEMBL1324095 } & 688422 & 4.45 & 5.2563 & TRN & \\
\hline & & \multicolumn{4}{|c|}{ Page 10092} \\
\hline
\end{tabular}




\begin{tabular}{|c|c|c|c|c|c|}
\hline \multicolumn{6}{|c|}{ Supplemental Table S2.txt } \\
\hline CHEMBL1587170 & 688422 & 4.95 & 5.6621 & TRN & \\
\hline CHEMBL1556868 & 688422 & 4.45 & 5.0882 & TRN & \\
\hline CHEMBL1326205 & 688422 & 6.2 & 5.7753 & TRN & \\
\hline CHEMBL1468000 & 688422 & 4.9 & 5.6463 & TST & \\
\hline CHEMBL1311944 & 688422 & 4.95 & 5.6005 & TRN & \\
\hline CHEMBL1440502 & 688422 & 4.85 & 4.9606 & TRN & \\
\hline CHEMBL1383582 & 688422 & 4.95 & 5.1296 & TRN & \\
\hline CHEMBL1499183 & 688422 & 4.7 & 5.1092 & TST & \\
\hline CHEMBL3193496 & 688422 & 4.45 & 5.3961 & TRN & \\
\hline CHEMBL1410150 & 688422 & 6.8 & 5.7064 & TRN & \\
\hline CHEMBL1582794 & 688422 & 5.65 & 5.0587 & TRN & \\
\hline CHEMBL1300767 & 688422 & 4.45 & 4.811 & TRN & \\
\hline CHEMBL1547010 & 688422 & 4.95 & 5.3871 & TRN & \\
\hline CHEMBL1514090 & 688422 & 8.3979 & 6.3768 & TRN & \\
\hline CHEMBL564979 & 688422 & 5.55 & 5.3169 & TRN & \\
\hline CHEMBL454761 & 688422 & 8.4949 & 6.2846 & TRN & \\
\hline CHEMBL1499328 & 688422 & 4.8 & 5.1604 & TRN & \\
\hline CHEMBL1451217 & 688422 & 4.85 & 5.3933 & TRN & \\
\hline CHEMBL1533030 & 688422 & 4.8 & 4.9816 & TRN & \\
\hline CHEMBL1535109 & 688422 & 4.95 & 4.9868 & TRN & \\
\hline CHEMBL1540584 & 688422 & 4.85 & 5.0796 & TRN & \\
\hline CHEMBL1472240 & 688422 & 4.95 & 4.8502 & TRN & \\
\hline CHEMBL1302314 & 688422 & 4.5 & 5.3379 & TRN & \\
\hline CHEMBL1339084 & 688422 & 5.2 & 4.8967 & TST & \\
\hline CHEMBL1495171 & 688422 & 4.8 & 5.4073 & TRN & \\
\hline CHEMBL1469930 & 688422 & 7.0501 & 5.6572 & TRN & \\
\hline CHEMBL1402289 & 688422 & 4.85 & 5.0361 & TRN & \\
\hline CHEMBL1507595 & 688422 & 4.45 & 4.9767 & TST & \\
\hline CHEMBL1434035 & 688422 & 4.6 & 5.0856 & TRN & \\
\hline CHEMBL3195626 & 688422 & 8.0506 & 5.3362 & TRN & \\
\hline CHEMBL1497165 & 688422 & 5.55 & 4.8239 & TRN & \\
\hline CHEMBL22075 & 688422 & 5.5 & 4.8827 & TST & \\
\hline CHEMBL1549535 & 688422 & 6.6 & 5.1484 & TST & \\
\hline CHEMBL1543644 & 688422 & 4.45 & 5.269 & TRN & \\
\hline CHEMBL1586570 & 688422 & 6.35 & 5.5208 & TST & \\
\hline CHEMBL1342385 & 688422 & 4.45 & 5.2178 & TRN & \\
\hline CHEMBL1592978 & 688422 & 5.9 & 5.1515 & TRN & \\
\hline CHEMBL1563896 & 688422 & 5.0 & 5.6139 & TST & \\
\hline CHEMBL1530097 & 688422 & 6.05 & 5.3732 & TRN & \\
\hline CHEMBL1305380 & 688422 & 4.9 & 5.2865 & TRN & \\
\hline CHEMBL1529576 & 688422 & 4.45 & 5.0395 & TST & \\
\hline CHEMBL3210086 & 688422 & 4.5 & 4.9525 & TRN & \\
\hline CHEMBL1524984 & 688422 & 7.699 & 5.4671 & TRN & \\
\hline CHEMBL1376210 & 688422 & 4.85 & 5.32100 & 2000000001 & TRN \\
\hline CHEMBL1532571 & 688422 & 4.95 & 5.29799 & 9999999999 & TRN \\
\hline CHEMBL1542189 & 688422 & 7.4498 & 4.6885 & TRN & \\
\hline CHEMBL1457503 & 688422 & 4.8 & 5.047 & TRN & \\
\hline CHEMBL1558610 & 688422 & 5.9 & 4.9698 & TRN & \\
\hline
\end{tabular}




\begin{tabular}{|c|c|c|c|c|}
\hline \multicolumn{5}{|c|}{ Supplemental Table S2.txt } \\
\hline CHEMBL63349 & 688422 & 4.9 & 5.9034 & TRN \\
\hline CHEMBL1587834 & 688422 & 5.85 & 4.8154 & TRN \\
\hline CHEMBL1361147 & 688422 & 4.6 & 5.8932 & TRN \\
\hline CHEMBL1592464 & 688422 & 4.45 & 4.8988 & TRN \\
\hline CHEMBL1516504 & 688422 & 4.7 & 5.1224 & TRN \\
\hline CHEMBL1309273 & 688422 & 4.45 & 5.2576 & TRN \\
\hline CHEMBL1358092 & 688422 & 4.45 & 4.6079 & TRN \\
\hline CHEMBL1362308 & 688422 & 4.5 & 5.4279 & TRN \\
\hline CHEMBL1531899 & 688422 & 5.2 & 5.2697 & TRN \\
\hline CHEMBL1458353 & 688422 & 4.7 & 5.3871 & TRN \\
\hline CHEMBL1578956 & 688422 & 4.65 & 5.3256 & TRN \\
\hline CHEMBL1599915 & 688422 & 4.95 & 5.3044 & TRN \\
\hline CHEMBL1599866 & 688422 & 7.15 & 5.1796 & TRN \\
\hline CHEMBL1386402 & 688422 & 4.85 & 5.3871 & TRN \\
\hline CHEMBL1392335 & 688422 & 8.3468 & 5.271 & TST \\
\hline CHEMBL1508393 & 688422 & 4.8 & 5.3179 & TRN \\
\hline CHEMBL1468998 & 688422 & 4.45 & 5.2708 & TRN \\
\hline CHEMBL1365151 & 688422 & 6.2 & 5.5821 & TRN \\
\hline CHEMBL1435205 & 688422 & 6.5501 & 5.4641 & TRN \\
\hline CHEMBL1444536 & 688422 & 4.75 & 5.1855 & TRN \\
\hline CHEMBL1376772 & 688422 & 4.95 & 5.0553 & TRN \\
\hline CHEMBL1301962 & 688422 & 4.8 & 5.018 & TRN \\
\hline CHEMBL604119 & 688422 & 4.9 & 5.4131 & TST \\
\hline CHEMBL1448182 & 688422 & 4.95 & 4.9502 & TRN \\
\hline CHEMBL1318270 & 688422 & 4.8 & 4.7114 & TRN \\
\hline CHEMBL1558220 & 688422 & 4.5 & 5.0166 & TST \\
\hline CHEMBL1397120 & 688422 & 4.45 & 5.2152 & TRN \\
\hline CHEMBL1386017 & 688422 & 4.95 & $5.3370 e$ & 0000000001 \\
\hline CHEMBL1424538 & 688422 & 4.5 & 5.6659 & TRN \\
\hline CHEMBL 1422809 & 688422 & 4.45 & 5.3687 & TRN \\
\hline CHEMBL1518694 & 688422 & 5.55 & 5.4279 & TRN \\
\hline CHEMBL1309594 & 688422 & 4.9 & 4.8815 & TST \\
\hline CHEMBL1366046 & 688422 & 5.35 & 5.192 & TRN \\
\hline CHEMBL530149 & 688422 & 7.8013 & 5.4643 & TRN \\
\hline CHEMBL1405856 & 688422 & 4.45 & 5.1026 & TRN \\
\hline CHEMBL3192756 & 688422 & 4.65 & 5.0423 & TRN \\
\hline CHEMBL1542182 & 688422 & 4.45 & 5.3552 & TRN \\
\hline CHEMBL56897 & 688422 & 6.2 & 5.4974 & TST \\
\hline CHEMBL1576141 & 688422 & 4.45 & 5.1838 & TRN \\
\hline CHEMBL1523855 & 688422 & 4.6 & 5.1969 & TST \\
\hline CHEMBL1498214 & 688422 & 4.95 & 5.3933 & TST \\
\hline CHEMBL1478754 & 688422 & 5.5 & 5.1119 & TRN \\
\hline CHEMBL1534740 & 688422 & 4.45 & 5.3851 & TRN \\
\hline CHEMBL1532226 & 688422 & 4.8 & 5.0237 & TRN \\
\hline CHEMBL1419410 & 688422 & 4.45 & 5.0214 & TRN \\
\hline CHEMBL1504600 & 688422 & 4.7 & 4.8211 & TST \\
\hline CHEMBL1577300 & 688422 & 4.95 & 5.4416 & TST \\
\hline CHEMBL1427991 & 688422 & 5.25 & 4.9709 & TRN \\
\hline
\end{tabular}




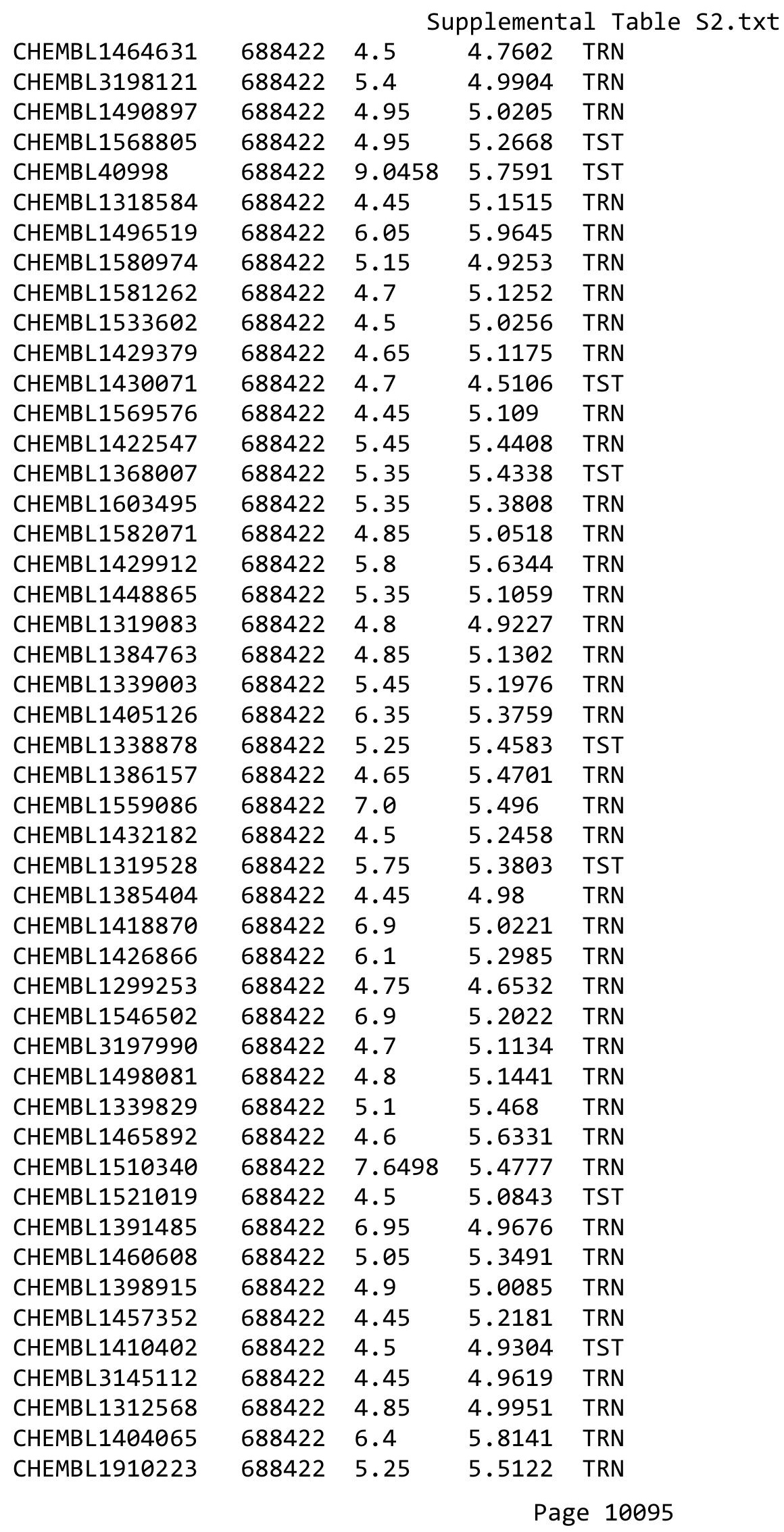




\begin{tabular}{|c|c|c|c|c|}
\hline \multicolumn{5}{|c|}{ Supplemental Table S2.txt } \\
\hline CHEMBL1306290 & 688422 & 4.5 & 5.0244 & TRN \\
\hline CHEMBL1527326 & 688422 & 5.4 & 5.1943 & TRN \\
\hline CHEMBL1446840 & 688422 & 4.7 & 5.2013 & TRN \\
\hline CHEMBL1533790 & 688422 & 6.8 & 5.45799 & 9999999999 \\
\hline CHEMBL1587422 & 688422 & 4.95 & 6.0056 & TRN \\
\hline CHEMBL3191792 & 688422 & 4.45 & 4.8455 & TST \\
\hline CHEMBL1326418 & 688422 & 5.3 & 5.5073 & TRN \\
\hline CHEMBL1319461 & 688422 & 4.85 & 5.1439 & TST \\
\hline CHEMBL1305230 & 688422 & 4.65 & 5.3499 & TST \\
\hline CHEMBL1455029 & 688422 & 4.45 & 5.4348 & TRN \\
\hline CHEMBL1490795 & 688422 & 5.0 & 5.3347 & TRN \\
\hline CHEMBL1506712 & 688422 & 4.45 & 4.8366 & TRN \\
\hline CHEMBL1559029 & 688422 & 4.6 & 4.9392 & TRN \\
\hline CHEMBL1329226 & 688422 & 4.85 & 5.6846 & TRN \\
\hline CHEMBL1308186 & 688422 & 5.1 & 5.0259 & TRN \\
\hline CHEMBL1165028 & 688422 & 4.65 & 5.4951 & TRN \\
\hline CHEMBL1509707 & 688422 & 4.45 & 5.2879 & TRN \\
\hline CHEMBL1608422 & 688422 & 4.45 & 4.9789 & TRN \\
\hline CHEMBL1518892 & 688422 & 4.6 & 4.8619 & TRN \\
\hline CHEMBL1609126 & 688422 & 5.55 & 5.0899 & TRN \\
\hline CHEMBL1546303 & 688422 & 5.6 & 5.1618 & TRN \\
\hline CHEMBL1355377 & 688422 & 7.699 & 5.4425 & TRN \\
\hline CHEMBL1490013 & 688422 & 4.6 & 5.3999 & TRN \\
\hline CHEMBL1517580 & 688422 & 7.5003 & 4.9774 & TST \\
\hline CHEMBL1543219 & 688422 & 7.6498 & 5.3935 & TRN \\
\hline CHEMBL1414020 & 688422 & 7.0501 & 5.4457 & TRN \\
\hline CHEMBL3197910 & 688422 & 4.85 & 5.4921 & TRN \\
\hline CHEMBL1406274 & 688422 & 6.0 & 4.985 & TRN \\
\hline CHEMBL1381462 & 688422 & 4.45 & 5.1419 & TRN \\
\hline CHEMBL1432973 & 688422 & 4.45 & 4.687 & TRN \\
\hline CHEMBL1510124 & 688422 & 4.95 & 5.8575 & TRN \\
\hline CHEMBL608846 & 688422 & 4.45 & 5.0307 & TRN \\
\hline CHEMBL1352005 & 688422 & 5.45 & 5.2752 & TRN \\
\hline CHEMBL1607629 & 688422 & 4.45 & 4.9743 & TRN \\
\hline CHEMBL3208977 & 688422 & 4.9 & 5.0645 & TRN \\
\hline CHEMBL1519751 & 688422 & 5.85 & 5.2849 & TRN \\
\hline CHEMBL1356882 & 688422 & 5.45 & 5.9729 & TRN \\
\hline CHEMBL1403289 & 688422 & 4.6 & 5.4019 & TRN \\
\hline CHEMBL1392473 & 688422 & 5.25 & 4.9227 & TRN \\
\hline CHEMBL1446802 & 688422 & 4.8 & 5.2072 & TST \\
\hline CHEMBL1587272 & 688422 & 4.45 & 4.9022 & TRN \\
\hline CHEMBL1428782 & 688422 & 6.2 & 5.3539 & TRN \\
\hline CHEMBL1381088 & 688422 & 5.05 & 5.2341 & TRN \\
\hline CHEMBL1425297 & 688422 & 4.45 & 5.1856 & TRN \\
\hline CHEMBL1382046 & 688422 & 4.7 & 5.4452 & TST \\
\hline CHEMBL1394829 & 688422 & 4.6 & 5.1901 & TRN \\
\hline CHEMBL1492417 & 688422 & 5.7 & 5.1464 & TRN \\
\hline CHEMBL1369033 & 688422 & 5.4 & 5.3357 & TRN \\
\hline
\end{tabular}




\begin{tabular}{|c|c|c|c|c|}
\hline \multicolumn{5}{|c|}{ Supplemental Table s2.txt } \\
\hline CHEMBL1444767 & 688422 & 4.5 & 4.9274 & TRN \\
\hline CHEMBL1548143 & 688422 & 4.95 & 5.1715 & TRN \\
\hline CHEMBL1449391 & 688422 & 4.5 & 5.0828 & TST \\
\hline CHEMBL1305011 & 688422 & 4.75 & 5.1396 & TST \\
\hline CHEMBL1572778 & 688422 & 8.3468 & 5.5641 & TRN \\
\hline CHEMBL3196754 & 688422 & 4.6 & 4.9287 & TRN \\
\hline CHEMBL1341216 & 688422 & 5.4 & 5.6347 & TST \\
\hline CHEMBL1465807 & 688422 & 4.9 & 5.1361 & TRN \\
\hline CHEMBL1608082 & 688422 & 5.5 & 5.608 & TRN \\
\hline CHEMBL1469464 & 688422 & 4.55 & 4.6956 & TRN \\
\hline CHEMBL1514942 & 688422 & 4.45 & 5.0203 & TRN \\
\hline CHEMBL1307786 & 688422 & 4.9 & 5.3028 & TRN \\
\hline CHEMBL1367732 & 688422 & 5.25 & 5.4874 & TST \\
\hline CHEMBL1612668 & 688422 & 7.4498 & 5.6093 & TRN \\
\hline CHEMBL1477315 & 688422 & 4.85 & 5.5049 & TRN \\
\hline CHEMBL1440967 & 688422 & 4.9 & 5.1954 & TST \\
\hline CHEMBL1484540 & 688422 & 4.65 & 5.3099 & TST \\
\hline CHEMBL1587500 & 688422 & 4.9 & 5.5027 & TRN \\
\hline CHEMBL1424162 & 688422 & 4.5 & 4.6243 & TRN \\
\hline CHEMBL1439984 & 688422 & 6.6 & 5.2501 & TST \\
\hline CHEMBL1403714 & 688422 & 5.15 & 5.1005 & TRN \\
\hline CHEMBL1519472 & 688422 & 5.2 & 4.9189 & TRN \\
\hline CHEMBL1604546 & 688422 & 5.55 & 5.3046 & TRN \\
\hline CHEMBL3208650 & 688422 & 4.45 & 5.2891 & TRN \\
\hline CHEMBL1471846 & 688422 & 5.0 & 5.2565 & TRN \\
\hline CHEMBL1337414 & 688422 & 4.9 & 4.7196 & TST \\
\hline CHEMBL603024 & 688422 & 5.05 & 4.8958 & TST \\
\hline CHEMBL1492860 & 688422 & 7.4001 & 5.2053 & TRN \\
\hline CHEMBL1559913 & 688422 & 4.45 & 5.2003 & TRN \\
\hline CHEMBL1320335 & 688422 & 4.45 & 5.3139 & TRN \\
\hline CHEMBL270299 & 688422 & 5.5 & 4.9013 & TST \\
\hline CHEMBL1369518 & 688422 & 5.7 & 5.0593 & TRN \\
\hline CHEMBL1489071 & 688422 & 6.9 & 5.3643 & TST \\
\hline CHEMBL1595772 & 688422 & 4.95 & 5.0936 & TRN \\
\hline CHEMBL 1475110 & 688422 & 4.95 & 5.2926 & TST \\
\hline CHEMBL1408513 & 688422 & 4.95 & 4.8048 & TRN \\
\hline CHEMBL1323710 & 688422 & 6.5 & 5.4094 & TRN \\
\hline CHEMBL1397773 & 688422 & 8.0 & 5.4912 & TRN \\
\hline CHEMBL1979844 & 688422 & 4.45 & 4.9021 & TRN \\
\hline CHEMBL1595048 & 688422 & 5.4 & 5.1183 & TRN \\
\hline CHEMBL1427504 & 688422 & 4.7 & 5.2717 & TST \\
\hline CHEMBL1407256 & 688422 & 5.55 & 5.0194 & TRN \\
\hline CHEMBL1992346 & 688422 & 6.8 & 5.11600 & 00000000005 \\
\hline CHEMBL1327498 & 688422 & 4.9 & 5.5048 & TRN \\
\hline CHEMBL1329615 & 688422 & 4.4 & 5.3205 & TRN \\
\hline CHEMBL1550455 & 688422 & 5.0 & 5.0009 & TRN \\
\hline CHEMBL1426223 & 688422 & 4.45 & 4.947 & TST \\
\hline CHEMBL1558926 & 688422 & 5.15 & 4.8462 & TRN \\
\hline
\end{tabular}




\begin{tabular}{|c|c|c|c|c|c|}
\hline & & \multicolumn{4}{|c|}{ Supplemental Table S2.txt } \\
\hline CHEMBL1386684 & 688422 & 5.55 & 5.4484 & TRN & \\
\hline CHEMBL 3193682 & 688422 & 6.4 & 5.5179 & TRN & \\
\hline CHEMBL1544997 & 688422 & 4.45 & 4.871 & TRN & \\
\hline CHEMBL1428173 & 688422 & 4.45 & 4.9594 & TRN & \\
\hline CHEMBL1508008 & 688422 & 5.0 & 4.7767 & TRN & \\
\hline CHEMBL 3208882 & 688422 & 4.95 & 5.2183 & TRN & \\
\hline CHEMBL1406297 & 688422 & 4.75 & 4.6421 & TRN & \\
\hline CHEMBL330129 & 688422 & 5.25 & 6.3097 & TST & \\
\hline CHEMBL1464866 & 688422 & 4.9 & 5.0956 & TRN & \\
\hline CHEMBL1365319 & 688422 & 5.25 & 5.2494 & TRN & \\
\hline CHEMBL 269277 & 688422 & 5.3 & 5.2223 & TRN & \\
\hline CHEMBL1535494 & 688422 & 5.3 & 5.0832 & TRN & \\
\hline CHEMBL1382229 & 688422 & 4.45 & 4.7781 & TRN & \\
\hline CHEMBL1531287 & 688422 & 5.2 & 5.4092 & TST & \\
\hline CHEMBL1360595 & 688422 & 4.5 & 5.0872 & TRN & \\
\hline CHEMBL1415065 & 688422 & 4.8 & 5.4283 & TRN & \\
\hline CHEMBL1610401 & 688422 & 5.05 & 5.4807 & TRN & \\
\hline CHEMBL1596936 & 688422 & 5.0 & 5.3948 & TRN & \\
\hline CHEMBL1550973 & 688422 & 4.5 & 5.2207 & TRN & \\
\hline CHEMBL1362088 & 688422 & 5.55 & 5.3528 & TRN & \\
\hline CHEMBL1544330 & 688422 & 4.45 & 5.0484 & TRN & \\
\hline CHEMBL1475118 & 688422 & 6.95 & 5.1477 & TST & \\
\hline CHEMBL 225903 & 688422 & 4.45 & 5.12799 & 9999999999 & TST \\
\hline CHEMBL1417091 & 688422 & 4.45 & 5.766 & TRN & \\
\hline CHEMBL1364704 & 688422 & 5.65 & 5.4875 & TST & \\
\hline CHEMBL1558430 & 688422 & 4.75 & 5.2735 & TRN & \\
\hline CHEMBL1428900 & 688422 & 6.6499 & 5.1845 & TRN & \\
\hline CHEMBL1461006 & 688422 & 4.65 & 5.5514 & TRN & \\
\hline CHEMBL1498824 & 688422 & 4.85 & 5.3976 & TRN & \\
\hline CHEMBL1576023 & 688422 & 4.7 & 5.3189 & TST & \\
\hline CHEMBL1363815 & 688422 & 4.45 & 4.8025 & TRN & \\
\hline CHEMBL1539301 & 688422 & 4.9 & 5.3246 & TST & \\
\hline CHEMBL1571677 & 688422 & 4.8 & 5.2699 & TST & \\
\hline CHEMBL85139 & 688422 & 6.15 & 5.4685 & TST & \\
\hline CHEMBL1409398 & 688422 & 5.7 & 5.50200 & 2000000001 & TRN \\
\hline CHEMBL1540976 & 688422 & 5.45 & 5.4385 & TST & \\
\hline CHEMBL1324212 & 688422 & 4.95 & 5.0111 & TRN & \\
\hline CHEMBL1453140 & 688422 & 4.5 & 4.4478 & TST & \\
\hline CHEMBL1331442 & 688422 & 4.45 & 4.9877 & TRN & \\
\hline CHEMBL3192491 & 688422 & 6.15 & 5.4275 & TRN & \\
\hline CHEMBL1425182 & 688422 & 5.1 & 5.501 & TRN & \\
\hline CHEMBL1344747 & 688422 & 8.0506 & 5.8722 & TST & \\
\hline CHEMBL1561425 & 688422 & 4.75 & 4.694 & TRN & \\
\hline CHEMBL3208369 & 688422 & 7.0 & 5.0216 & TST & \\
\hline CHEMBL1520538 & 688422 & 4.65 & 5.1473 & TST & \\
\hline CHEMBL1375246 & 688422 & 5.25 & 5.1781 & TRN & \\
\hline CHEMBL1610476 & 688422 & 4.7 & 5.2991 & TRN & \\
\hline CHEMBL1560116 & 688422 & 4.75 & 5.3966 & TRN & \\
\hline
\end{tabular}




\begin{tabular}{|c|c|c|c|c|c|}
\hline \multicolumn{6}{|c|}{ Supplemental Table S2.txt } \\
\hline CHEMBL1437430 & 688422 & 4.95 & 4.9094 & TRN & \\
\hline CHEMBL1387386 & 688422 & 4.9 & 5.0271 & TST & \\
\hline CHEMBL1493254 & 688422 & 4.85 & 4.5805 & TRN & \\
\hline CHEMBL 3198115 & 688422 & 4.5 & 5.2545 & TRN & \\
\hline CHEMBL1543627 & 688422 & 4.5 & 4.7104 & TRN & \\
\hline CHEMBL1976549 & 688422 & 4.9 & 5.15799 & 99999999995 & TRN \\
\hline CHEMBL1430780 & 688422 & 5.35 & 5.0499 & TRN & \\
\hline CHEMBL1543937 & 688422 & 4.45 & 4.8992 & TRN & \\
\hline CHEMBL1449540 & 688422 & 4.45 & 5.1823 & TST & \\
\hline CHEMBL1481178 & 688422 & 4.9 & 5.3997 & TST & \\
\hline CHEMBL1423692 & 688422 & 4.65 & 4.9645 & TRN & \\
\hline CHEMBL1593102 & 688422 & 6.15 & 5.0068 & TRN & \\
\hline CHEMBL1997668 & 688422 & 5.15 & 5.4006 & TRN & \\
\hline CHEMBL1347408 & 688422 & 5.15 & 5.4898 & TRN & \\
\hline CHEMBL1539023 & 688422 & 4.45 & 5.5033 & TRN & \\
\hline CHEMBL1582023 & 688422 & 4.45 & 5.1196 & TST & \\
\hline CHEMBL1577366 & 688422 & 5.9 & 5.6462 & TRN & \\
\hline CHEMBL1304055 & 688422 & 4.95 & 5.0886 & TRN & \\
\hline CHEMBL1307218 & 688422 & 4.45 & 5.3177 & TRN & \\
\hline CHEMBL1453365 & 688422 & 4.7 & 5.1151 & TST & \\
\hline CHEMBL1458179 & 688422 & 4.95 & 4.90600 & 0000000001 & TRN \\
\hline CHEMBL1341674 & 688422 & 4.45 & 4.927 & TST & \\
\hline CHEMBL1362209 & 688422 & 4.4 & 5.6618 & TST & \\
\hline CHEMBL1591856 & 688422 & 6.4 & 4.8546 & TRN & \\
\hline CHEMBL1313074 & 688422 & 4.45 & 5.2074 & TST & \\
\hline CHEMBL1493693 & 688422 & 4.5 & 5.2584 & TRN & \\
\hline CHEMBL1441873 & 688422 & 5.25 & 5.0357 & TRN & \\
\hline CHEMBL1533136 & 688422 & 4.8 & 5.2196 & TST & \\
\hline CHEMBL1345701 & 688422 & 4.45 & 5.0767 & TRN & \\
\hline CHEMBL1544971 & 688422 & 4.45 & 5.8177 & TRN & \\
\hline CHEMBL 3214487 & 688422 & 4.7 & 5.0602 & TRN & \\
\hline CHEMBL1350580 & 688422 & 4.75 & 5.4196 & TRN & \\
\hline CHEMBL1311039 & 688422 & 4.5 & 5.1749 & TRN & \\
\hline CHEMBL1306021 & 688422 & 4.95 & 4.7396 & TRN & \\
\hline CHEMBL1359086 & 688422 & 4.8 & 4.9905 & TRN & \\
\hline CHEMBL1599873 & 688422 & 5.15 & 5.54299 & 9999999999 & TST \\
\hline CHEMBL1510953 & 688422 & 4.95 & 5.2723 & TST & \\
\hline CHEMBL1381179 & 688422 & 4.95 & 4.7764 & TRN & \\
\hline CHEMBL1340142 & 688422 & 6.3 & 5.2883 & TRN & \\
\hline CHEMBL1355106 & 688422 & 4.45 & 5.0077 & TRN & \\
\hline CHEMBL1442010 & 688422 & 6.1 & 5.1982 & TRN & \\
\hline CHEMBL1373304 & 688422 & 6.5 & 6.2462 & TST & \\
\hline CHEMBL1415552 & 688422 & 4.75 & 5.4917 & TST & \\
\hline CHEMBL1510858 & 688422 & 4.45 & 5.2463 & TST & \\
\hline CHEMBL1542483 & 688422 & 8.0 & 5.6234 & TRN & \\
\hline CHEMBL1493429 & 688422 & 6.8499 & 5.78 & TRN & \\
\hline CHEMBL1606558 & 688422 & 4.95 & 4.9543 & TRN & \\
\hline CHEMBL3209467 & 688422 & 4.65 & 4.9321 & TST & \\
\hline
\end{tabular}




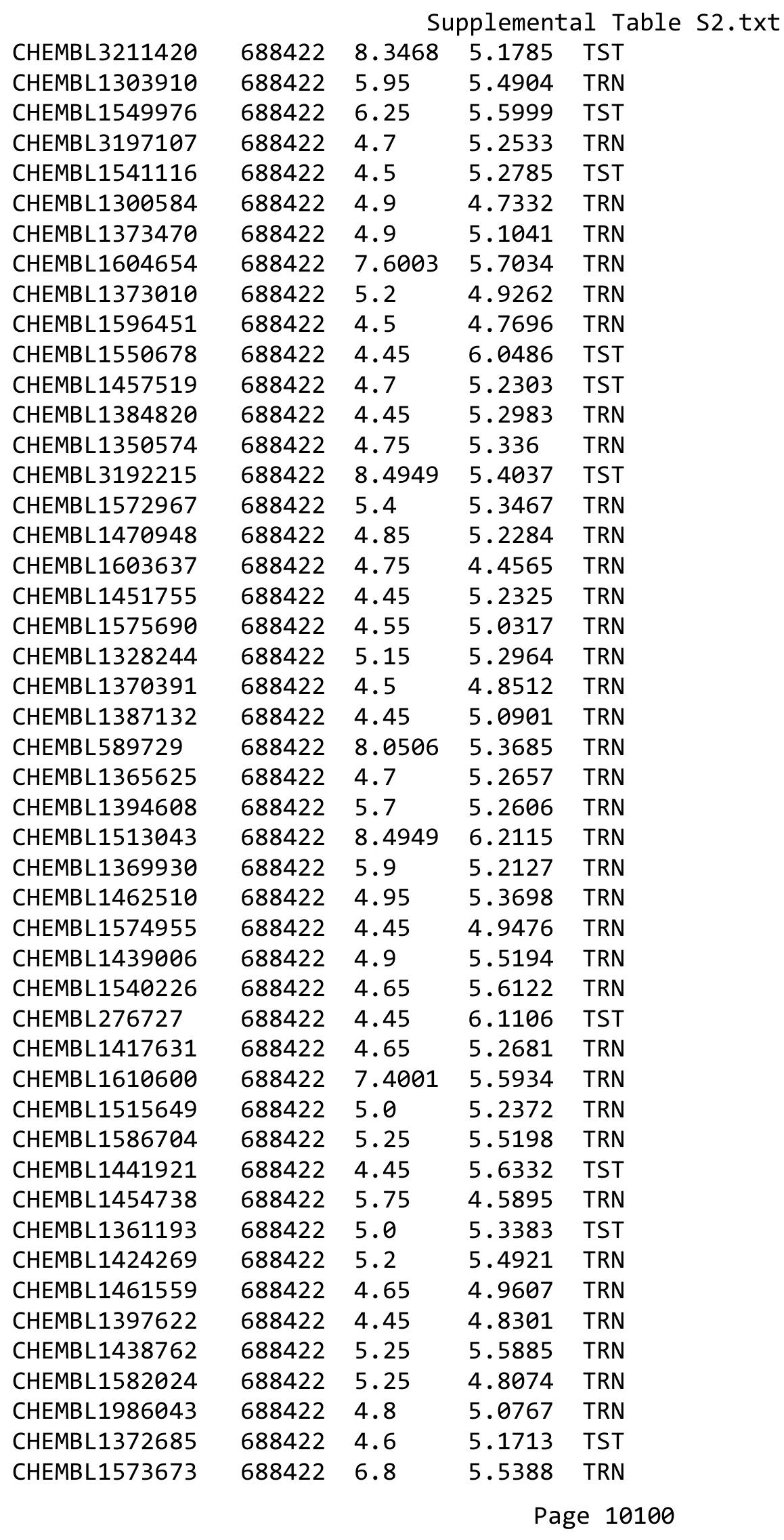




\begin{tabular}{|c|c|c|c|c|c|}
\hline \multicolumn{6}{|c|}{ Supplemental Table s2.txt } \\
\hline CHEMBL1489283 & 688422 & 4.65 & 5.0062 & TRN & \\
\hline CHEMBL1487951 & 688422 & 4.45 & 5.2519 & TRN & \\
\hline CHEMBL1339434 & 688422 & 4.9 & 4.9164 & TRN & \\
\hline CHEMBL597857 & 688422 & 5.15 & 5.1609 & TRN & \\
\hline CHEMBL 1477547 & 688422 & 4.85 & 5.2005 & TRN & \\
\hline CHEMBL1366516 & 688422 & 4.8 & 5.6091 & TST & \\
\hline CHEMBL1594395 & 688422 & 4.65 & 5.3741 & TRN & \\
\hline CHEMBL1345805 & 688422 & 5.5 & 5.3324 & TRN & \\
\hline CHEMBL 3190080 & 688422 & 4.45 & 5.3538 & TRN & \\
\hline CHEMBL1404482 & 688422 & 4.45 & 4.8984 & TRN & \\
\hline CHEMBL1348060 & 688422 & 4.5 & 4.7767 & TRN & \\
\hline CHEMBL1465661 & 688422 & 7.1002 & 5.2438 & TRN & \\
\hline CHEMBL1497230 & 688422 & 5.05 & 5.8271 & TRN & \\
\hline CHEMBL1304169 & 688422 & 4.65 & 5.2618 & TST & \\
\hline CHEMBL1557748 & 688422 & 6.5 & 5.3554 & TRN & \\
\hline CHEMBL1358618 & 688422 & 4.9 & 5.0671 & TRN & \\
\hline CHEMBL1315403 & 688422 & 8.301 & 5.17299 & 9999999999 & TST \\
\hline CHEMBL1498174 & 688422 & 4.45 & 5.7961 & TRN & \\
\hline CHEMBL1557926 & 688422 & 8.3468 & 5.2417 & TRN & \\
\hline CHEMBL1458809 & 688422 & 4.45 & 5.2849 & TRN & \\
\hline CHEMBL1538121 & 688422 & 4.6 & 5.1221 & TRN & \\
\hline CHEMBL1386881 & 688422 & 4.9 & 4.9403 & TRN & \\
\hline CHEMBL1569400 & 688422 & 5.45 & 5.2385 & TRN & \\
\hline CHEMBL1598746 & 688422 & 4.7 & 5.5267 & TRN & \\
\hline CHEMBL1564230 & 688422 & 4.95 & 5.2724 & TST & \\
\hline CHEMBL1370523 & 688422 & 4.45 & 5.2586 & TRN & \\
\hline CHEMBL1460399 & 688422 & 4.7 & 5.0206 & TRN & \\
\hline CHEMBL1500410 & 688422 & 4.8 & 5.2044 & TRN & \\
\hline CHEMBL1598814 & 688422 & 4.5 & 5.1813 & TST & \\
\hline CHEMBL1981928 & 688422 & 4.85 & 5.4921 & TST & \\
\hline CHEMBL1385686 & 688422 & 4.65 & 5.0471 & TST & \\
\hline CHEMBL1421781 & 688422 & 4.95 & 5.2745 & TRN & \\
\hline CHEMBL1362816 & 688422 & 4.45 & 5.2746 & TRN & \\
\hline CHEMBL1506193 & 688422 & 4.45 & 4.8964 & TRN & \\
\hline CHEMBL1300830 & 688422 & 5.4 & 5.0914 & TST & \\
\hline CHEMBL1993613 & 688422 & 5.5 & 5.0316 & TRN & \\
\hline CHEMBL1327519 & 688422 & 7.5498 & 5.7143 & TRN & \\
\hline CHEMBL1408688 & 688422 & 5.2 & 5.237 & TRN & \\
\hline CHEMBL1414297 & 688422 & 4.7 & 4.9773 & TRN & \\
\hline CHEMBL1438092 & 688422 & 4.8 & 5.397 & TRN & \\
\hline CHEMBL1312195 & 688422 & 4.5 & 5.2141 & TRN & \\
\hline CHEMBL1390 & 688422 & 6.0 & 5.8302 & TRN & \\
\hline CHEMBL1322764 & 688422 & 5.4 & 5.1994 & TRN & \\
\hline CHEMBL1302621 & 688422 & 7.4498 & 5.6664 & TST & \\
\hline CHEMBL1330243 & 688422 & 5.55 & 5.4683 & TRN & \\
\hline CHEMBL1346079 & 688422 & 4.5 & 5.09399 & 9999999999 & TRN \\
\hline CHEMBL1414754 & 688422 & 5.0 & 4.8636 & TRN & \\
\hline CHEMBL1444215 & 688422 & 4.45 & 4.8629 & TRN & \\
\hline
\end{tabular}




\begin{tabular}{|c|c|c|c|c|c|}
\hline \multicolumn{6}{|c|}{ Supplemental Table S2.txt } \\
\hline CHEMBL1401670 & 688422 & 4.9 & 5.3645 & TRN & \\
\hline CHEMBL1435638 & 688422 & 4.65 & 4.5601 & TRN & \\
\hline CHEMBL1404058 & 688422 & 4.5 & 5.3898 & TST & \\
\hline CHEMBL1330459 & 688422 & 5.8 & 5.9012 & TST & \\
\hline CHEMBL1457406 & 688422 & 8.301 & 5.0653 & TRN & \\
\hline CHEMBL1460250 & 688422 & 4.6 & 4.9654 & TRN & \\
\hline CHEMBL1469841 & 688422 & 4.5 & 4.9029 & TST & \\
\hline CHEMBL1391202 & 688422 & 8.301 & 5.0681 & TRN & \\
\hline CHEMBL1607959 & 688422 & 4.45 & 4.6934 & TST & \\
\hline CHEMBL1548739 & 688422 & 4.55 & 4.8507 & TRN & \\
\hline CHEMBL1421770 & 688422 & 4.7 & 5.3807 & TRN & \\
\hline CHEMBL1417865 & 688422 & 5.5 & 6.0003 & TST & \\
\hline CHEMBL1542342 & 688422 & 4.9 & 5.069 & TRN & \\
\hline CHEMBL1511246 & 688422 & 5.1 & 5.92299 & 9999999999 & TRN \\
\hline CHEMBL1534566 & 688422 & 8.3468 & 5.3681 & TRN & \\
\hline CHEMBL1418991 & 688422 & 4.85 & 5.082 & TST & \\
\hline CHEMBL1368461 & 688422 & 4.6 & 5.1228 & TRN & \\
\hline CHEMBL1312177 & 688422 & 7.6498 & 5.0954 & TRN & \\
\hline CHEMBL1300473 & 688422 & 8.5528 & 5.2795 & TST & \\
\hline CHEMBL1564406 & 688422 & 8.1024 & 5.526 & TRN & \\
\hline CHEMBL1404132 & 688422 & 4.9 & 5.268 & TRN & \\
\hline CHEMBL1430766 & 688422 & 5.7 & 5.5605 & TST & \\
\hline CHEMBL1352440 & 688422 & 5.3 & 5.4652 & TRN & \\
\hline CHEMBL1390541 & 688422 & 4.9 & 5.1653 & TRN & \\
\hline CHEMBL 2004417 & 688422 & 5.4 & 5.4568 & TRN & \\
\hline CHEMBL1365654 & 688422 & 4.45 & 5.1805 & TST & \\
\hline CHEMBL1552343 & 688422 & 5.25 & 5.1963 & TRN & \\
\hline CHEMBL1978197 & 688422 & 5.45 & 5.3717 & TRN & \\
\hline CHEMBL1317168 & 688422 & 5.25 & 5.2553 & TRN & \\
\hline CHEMBL1453387 & 688422 & 5.25 & 5.3156 & TRN & \\
\hline CHEMBL1501078 & 688422 & 4.6 & 4.7339 & TRN & \\
\hline CHEMBL1370628 & 688422 & 4.95 & 5.1232 & TST & \\
\hline CHEMBL1307195 & 688422 & 4.45 & 5.4126 & TST & \\
\hline CHEMBL1538279 & 688422 & 8.301 & 5.3737 & TRN & \\
\hline CHEMBL1591202 & 688422 & 5.6 & 5.8809 & TRN & \\
\hline CHEMBL1380754 & 688422 & 5.45 & 5.5356 & TRN & \\
\hline CHEMBL1595810 & 688422 & 4.5 & 4.8232 & TRN & \\
\hline CHEMBL1418716 & 688422 & 4.95 & 5.1085 & TRN & \\
\hline CHEMBL1433501 & 688422 & 7.15 & 5.3562 & TRN & \\
\hline CHEMBL1543599 & 688422 & 5.45 & 5.3843 & TRN & \\
\hline CHEMBL1473105 & 688422 & 7.15 & 5.4635 & TRN & \\
\hline CHEMBL577764 & 688422 & 4.45 & 5.3627 & TST & \\
\hline CHEMBL1536677 & 688422 & 5.4 & 5.155 & TST & \\
\hline CHEMBL1373879 & 688422 & 4.95 & 4.9562 & TRN & \\
\hline CHEMBL1534611 & 688422 & 6.3 & 5.46899 & 9999999999 & TRN \\
\hline CHEMBL1360659 & 688422 & 5.2 & 5.2184 & TRN & \\
\hline CHEMBL1301387 & 688422 & 5.35 & 5.6393 & TST & \\
\hline CHEMBL1506263 & 688422 & 4.7 & 5.0513 & TRN & \\
\hline
\end{tabular}




\begin{tabular}{|c|c|c|c|c|c|}
\hline \multicolumn{6}{|c|}{ Supplemental Table S2.txt } \\
\hline CHEMBL1461142 & 688422 & 5.05 & 5.2626 & TRN & \\
\hline CHEMBL1540577 & 688422 & 5.0 & 5.0972 & TRN & \\
\hline CHEMBL1324567 & 688422 & 4.45 & 5.1131 & TRN & \\
\hline CHEMBL1307425 & 688422 & 4.45 & 5.4844 & TST & \\
\hline CHEMBL1579193 & 688422 & 4.8 & 5.0865 & TST & \\
\hline CHEMBL1466712 & 688422 & 4.5 & 4.9547 & TRN & \\
\hline CHEMBL1379566 & 688422 & 5.95 & 5.275 & TRN & \\
\hline CHEMBL1487439 & 688422 & 4.9 & 5.5139 & TRN & \\
\hline CHEMBL1409847 & 688422 & 4.75 & 4.8615 & TRN & \\
\hline CHEMBL1562357 & 688422 & 5.5 & 5.1552 & TST & \\
\hline CHEMBL1412984 & 688422 & 4.8 & 4.7997 & TRN & \\
\hline CHEMBL3195322 & 688422 & 5.0 & 4.8629 & TRN & \\
\hline CHEMBL1540527 & 688422 & 5.25 & 5.5434 & TRN & \\
\hline CHEMBL1344628 & 688422 & 4.8 & 5.3666 & TRN & \\
\hline CHEMBL1404335 & 688422 & 4.65 & 5.6652 & TST & \\
\hline CHEMBL1347277 & 688422 & 4.45 & 5.0594 & TST & \\
\hline CHEMBL1299668 & 688422 & 4.45 & 5.0815 & TRN & \\
\hline CHEMBL1599029 & 688422 & 4.5 & 5.3408 & TRN & \\
\hline CHEMBL1327812 & 688422 & 6.35 & 5.2465 & TRN & \\
\hline CHEMBL1613455 & 688422 & 7.3497 & 5.9027 & TST & \\
\hline CHEMBL1482191 & 688422 & 4.55 & 4.9439 & TRN & \\
\hline CHEMBL1369965 & 688422 & 5.5 & 5.1735 & TRN & \\
\hline CHEMBL1457413 & 688422 & 4.45 & 4.8976 & TRN & \\
\hline CHEMBL1417869 & 688422 & 5.9 & 5.5177 & TRN & \\
\hline CHEMBL1442436 & 688422 & 5.5 & 5.5106 & TRN & \\
\hline CHEMBL1420702 & 688422 & 5.6 & 5.1322 & TRN & \\
\hline CHEMBL1329408 & 688422 & 4.45 & 5.3235 & TRN & \\
\hline CHEMBL1444725 & 688422 & 5.45 & 5.6731 & TRN & \\
\hline CHEMBL1605953 & 688422 & 4.9 & 5.1011 & TRN & \\
\hline CHEMBL1309978 & 688422 & 4.8 & 5.7094 & TST & \\
\hline CHEMBL1526230 & 688422 & 5.9 & 5.1112 & TRN & \\
\hline CHEMBL1508370 & 688422 & 4.85 & 4.7489 & TRN & \\
\hline CHEMBL1387016 & 688422 & 4.75 & 5.0895 & TST & \\
\hline CHEMBL21396 & 688422 & 5.5 & 5.3201 & TST & \\
\hline CHEMBL1541948 & 688422 & 4.9 & 5.369 & TST & \\
\hline CHEMBL1335538 & 688422 & 5.0 & 5.7775 & TST & \\
\hline CHEMBL1486762 & 688422 & 4.5 & 5.3545 & TST & \\
\hline CHEMBL1479475 & 688422 & 5.0 & 4.7537 & TST & \\
\hline CHEMBL1371630 & 688422 & 4.85 & 5.45100 & 00000000005 & TRN \\
\hline CHEMBL1568430 & 688422 & 8.3468 & 5.401 & TST & \\
\hline CHEMBL51697 & 688422 & 4.9 & 5.5103 & TST & \\
\hline CHEMBL1406155 & 688422 & 4.7 & 4.915 & TRN & \\
\hline CHEMBL1465643 & 688422 & 4.45 & 5.3041 & TST & \\
\hline CHEMBL1452558 & 688422 & 4.45 & 4.8776 & TRN & \\
\hline CHEMBL1975069 & 688422 & 4.55 & 5.0351 & TRN & \\
\hline CHEMBL1509573 & 688422 & 8.2518 & 5.5528 & TRN & \\
\hline CHEMBL1588394 & 688422 & 4.45 & 4.9173 & TRN & \\
\hline CHEMBL1580338 & 688422 & 4.9 & 4.7395 & TRN & \\
\hline
\end{tabular}




\begin{tabular}{|c|c|c|c|c|c|}
\hline \multicolumn{6}{|c|}{ Supplemental Table S2.txt } \\
\hline CHEMBL1371147 & 688422 & 4.85 & 4.8311 & TRN & \\
\hline CHEMBL1393783 & 688422 & 5.1 & 5.4592 & TRN & \\
\hline CHEMBL1545931 & 688422 & 8.3979 & 5.9309 & TST & \\
\hline CHEMBL1455566 & 688422 & 5.05 & 4.73300 & 00000000005 & TST \\
\hline CHEMBL137743 & 688422 & 5.25 & 5.4727 & TRN & \\
\hline CHEMBL1458412 & 688422 & 4.7 & 5.1065 & TST & \\
\hline CHEMBL1370998 & 688422 & 7.6003 & 5.164 & TRN & \\
\hline CHEMBL3189670 & 688422 & 4.7 & 5.4346 & TRN & \\
\hline CHEMBL1434812 & 688422 & 6.5 & 5.4929 & TRN & \\
\hline CHEMBL1482917 & 688422 & 4.45 & 5.5254 & TRN & \\
\hline CHEMBL1400998 & 688422 & 4.95 & 5.3035 & TRN & \\
\hline CHEMBL1591201 & 688422 & 4.85 & 5.3757 & TRN & \\
\hline CHEMBL1435433 & 688422 & 5.45 & 4.9964 & TRN & \\
\hline CHEMBL1457919 & 688422 & 4.7 & 5.5681 & TRN & \\
\hline CHEMBL1377924 & 688422 & 5.55 & 5.1745 & TRN & \\
\hline CHEMBL1333493 & 688422 & 8.301 & 5.3587 & TRN & \\
\hline CHEMBL1391541 & 688422 & 4.9 & 4.8058 & TST & \\
\hline CHEMBL1503851 & 688422 & 4.45 & 5.0511 & TRN & \\
\hline CHEMBL585481 & 688422 & 4.85 & 5.4138 & TRN & \\
\hline CHEMBL1417332 & 688422 & 5.05 & 5.0375 & TRN & \\
\hline CHEMBL559612 & 688422 & 4.7 & 4.5801 & TST & \\
\hline CHEMBL1494270 & 688422 & 4.8 & 4.8409 & TRN & \\
\hline CHEMBL1490514 & 688422 & 4.9 & 5.5212 & TRN & \\
\hline CHEMBL1543464 & 688422 & 5.8 & 5.5282 & TST & \\
\hline CHEMBL1367618 & 688422 & 4.5 & 4.9359 & TRN & \\
\hline CHEMBL1605472 & 688422 & 7.5003 & 5.9962 & TRN & \\
\hline CHEMBL322970 & 688422 & 6.45 & 5.3448 & TST & \\
\hline CHEMBL1410597 & 688422 & 5.15 & 5.4298 & TRN & \\
\hline CHEMBL1556527 & 688422 & 6.3 & 5.1333 & TRN & \\
\hline CHEMBL1342156 & 688422 & 4.5 & 5.1988 & TRN & \\
\hline CHEMBL1571397 & 688422 & 6.6499 & 4.9687 & TRN & \\
\hline CHEMBL1558064 & 688422 & 4.95 & 5.0624 & TRN & \\
\hline CHEMBL1471570 & 688422 & 8.0 & 5.0338 & TST & \\
\hline CHEMBL1455785 & 688422 & 5.8 & 5.6305 & TST & \\
\hline CHEMBL456295 & 688422 & 4.95 & 5.4867 & TST & \\
\hline CHEMBL1313626 & 688422 & 4.9 & 5.5113 & TST & \\
\hline CHEMBL1435313 & 688422 & 8.3468 & 6.2858 & TRN & \\
\hline CHEMBL1316486 & 688422 & 7.8996 & 5.24200 & 0000000001 & TRN \\
\hline CHEMBL1611496 & 688422 & 6.2 & 5.1052 & TRN & \\
\hline CHEMBL1430537 & 688422 & 7.8996 & 5.8107 & TST & \\
\hline CHEMBL1592945 & 688422 & 5.75 & 5.3326 & TRN & \\
\hline CHEMBL1538165 & 688422 & 4.45 & 5.0491 & TRN & \\
\hline CHEMBL3194612 & 688422 & 5.2 & 5.1722 & TST & \\
\hline CHEMBL1487107 & 688422 & 5.45 & 4.8116 & TRN & \\
\hline CHEMBL1511331 & 688422 & 4.8 & 5.4451 & TRN & \\
\hline CHEMBL1414123 & 688422 & 4.45 & 5.0604 & TRN & \\
\hline CHEMBL1519257 & 688422 & 4.45 & 4.9845 & TRN & \\
\hline CHEMBL1353274 & 688422 & 5.75 & 5.6162 & TRN & \\
\hline
\end{tabular}




\begin{tabular}{|c|c|c|c|c|}
\hline \multirow[b]{2}{*}{ CHEMBL1358128 } & \multicolumn{4}{|c|}{ Supplemental Table S2.txt } \\
\hline & 688422 & 4.5 & 5.2261 & TRN \\
\hline CHEMBL1443899 & 688422 & 7.699 & 5.5304 & TRN \\
\hline CHEMBL3197831 & 688422 & 5.0 & 5.3755 & TRN \\
\hline CHEMBL1407885 & 688422 & 4.8 & 5.0836 & TRN \\
\hline CHEMBL1487899 & 688422 & 4.45 & 5.7866 & TRN \\
\hline CHEMBL1535126 & 688422 & 4.8 & 5.0949 & TRN \\
\hline CHEMBL1505809 & 688422 & 4.95 & 5.3623 & TRN \\
\hline CHEMBL1523224 & 688422 & 4.95 & 5.0726 & TRN \\
\hline CHEMBL7763 & 688422 & 8.0506 & 6.2578 & TST \\
\hline CHEMBL1302810 & 688422 & 5.2 & 5.205 & TST \\
\hline CHEMBL1547347 & 688422 & 4.8 & 4.9473 & TST \\
\hline CHEMBL1405423 & 688422 & 4.5 & 5.1138 & TRN \\
\hline CHEMBL1364445 & 688422 & 4.5 & 5.225 & TST \\
\hline CHEMBL1466265 & 688422 & 5.05 & 5.1788 & TRN \\
\hline CHEMBL1472107 & 688422 & 4.7 & 5.2437 & TRN \\
\hline CHEMBL1324564 & 688422 & 4.85 & 5.0354 & TRN \\
\hline CHEMBL1491702 & 688422 & 4.6 & 5.0604 & TRN \\
\hline CHEMBL1585376 & 688422 & 7.699 & 4.933 & TST \\
\hline CHEMBL1369587 & 688422 & 4.45 & 4.8547 & TRN \\
\hline CHEMBL1388339 & 688422 & 4.45 & 5.2957 & TRN \\
\hline CHEMBL1302326 & 688422 & 4.8 & 4.8296 & TRN \\
\hline CHEMBL1478579 & 688422 & 4.45 & 5.2809 & TRN \\
\hline CHEMBL1419954 & 688422 & 4.8 & 4.8979 & TRN \\
\hline CHEMBL1488404 & 688422 & 8.301 & 5.4152 & TRN \\
\hline CHEMBL1585019 & 688422 & 4.75 & 5.1998 & TST \\
\hline CHEMBL1522746 & 688422 & 7.9508 & 5.2319 & TRN \\
\hline CHEMBL1564231 & 688422 & 4.6 & 5.3086 & TRN \\
\hline CHEMBL1349510 & 688422 & 5.2 & 5.229 & TST \\
\hline CHEMBL1335940 & 688422 & 5.6 & 5.8517 & TRN \\
\hline CHEMBL1517136 & 688422 & 4.5 & 5.1499 & TST \\
\hline CHEMBL1601272 & 688422 & 5.2 & 5.237 & TRN \\
\hline CHEMBL1311109 & 688422 & 5.25 & 4.9831 & TST \\
\hline CHEMBL1456253 & 688422 & 5.7 & 4.8493 & TRN \\
\hline CHEMBL1544088 & 688422 & 7.6003 & 5.4616 & TRN \\
\hline CHEMBL1580917 & 688422 & 4.95 & 4.9791 & TRN \\
\hline CHEMBL3207993 & 688422 & 4.45 & 5.7274 & TRN \\
\hline CHEMBL1496285 & 688422 & 5.6 & 5.5878 & TST \\
\hline CHEMBL1443679 & 688422 & 4.45 & 4.8716 & TRN \\
\hline CHEMBL1454561 & 688422 & 7.2503 & 5.4259 & TRN \\
\hline CHEMBL1496056 & 688422 & 4.6 & 4.7258 & TST \\
\hline CHEMBL1363368 & 688422 & 6.1 & 5.2668 & TST \\
\hline CHEMBL3190338 & 688422 & 4.95 & 4.6646 & TST \\
\hline CHEMBL373839 & 688422 & 4.55 & 5.2911 & TST \\
\hline CHEMBL1565371 & 688422 & 4.6 & 5.4656 & TRN \\
\hline CHEMBL1516434 & 688422 & 4.45 & 5.3862 & TRN \\
\hline CHEMBL1563201 & 688422 & 6.3 & 5.2469 & TST \\
\hline CHEMBL3210113 & 688422 & 7.699 & 5.6915 & TRN \\
\hline CHEMBL1405004 & 688422 & 5.65 & 5.1783 & TRN \\
\hline
\end{tabular}




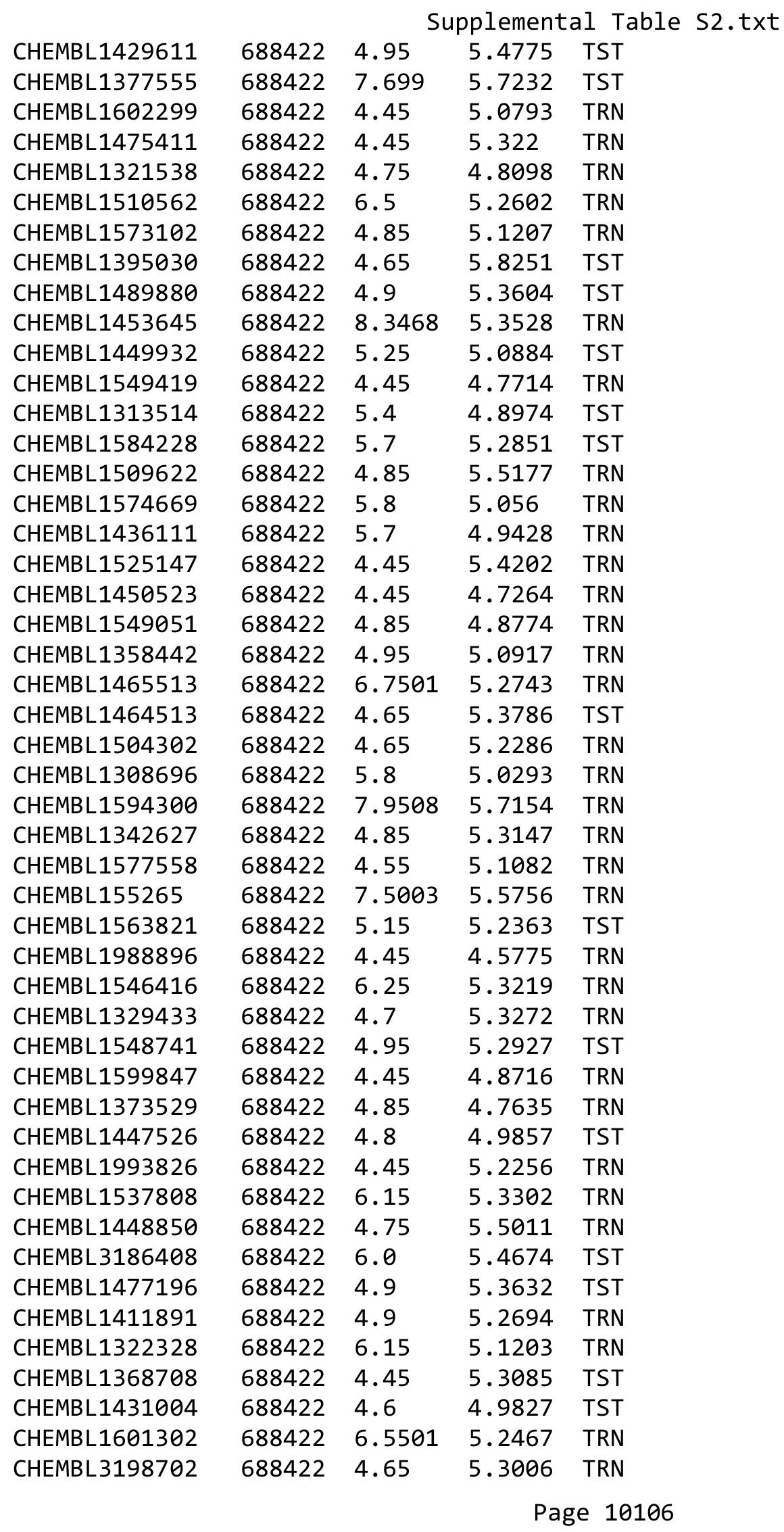




\begin{tabular}{|c|c|c|c|c|}
\hline \multicolumn{5}{|c|}{ Supplemental Table S2.txt } \\
\hline CHEMBL1594989 & 688422 & 4.45 & 5.0923 & TST \\
\hline CHEMBL1512757 & 688422 & 5.45 & 5.2728 & TRN \\
\hline CHEMBL1497516 & 688422 & 4.45 & 5.4699 & TRN \\
\hline CHEMBL1303620 & 688422 & 4.65 & 5.3855 & TRN \\
\hline CHEMBL1576125 & 688422 & 4.85 & 5.4672 & TST \\
\hline CHEMBL1339664 & 688422 & 5.0 & 4.9991 & TRN \\
\hline CHEMBL1427185 & 688422 & 5.15 & 5.2921 & TST \\
\hline CHEMBL1373654 & 688422 & 4.45 & 5.0489 & TST \\
\hline CHEMBL1547579 & 688422 & 8.3468 & 5.4794 & TRN \\
\hline CHEMBL1429544 & 688422 & 4.5 & 5.4424 & TRN \\
\hline CHEMBL1583995 & 688422 & 4.75 & 5.033 & TRN \\
\hline CHEMBL1566950 & 688422 & 4.45 & 4.9759 & TST \\
\hline CHEMBL1567441 & 688422 & 4.7 & 5.2079 & TRN \\
\hline CHEMBL1310317 & 688422 & 4.45 & 5.425 & TST \\
\hline CHEMBL1585628 & 688422 & 5.4 & 5.0816 & TRN \\
\hline CHEMBL1585698 & 688422 & 4.85 & 5.2786 & TRN \\
\hline CHEMBL1564634 & 688422 & 4.45 & 5.6478 & TST \\
\hline CHEMBL1456039 & 688422 & 5.95 & 5.476 & TRN \\
\hline CHEMBL1322754 & 688422 & 4.45 & 4.9553 & TST \\
\hline CHEMBL1332740 & 688422 & 4.8 & 5.3442 & TST \\
\hline CHEMBL1417726 & 688422 & 5.3 & 5.1365 & TRN \\
\hline CHEMBL1378651 & 688422 & 7.5003 & 5.1669 & TRN \\
\hline CHEMBL1431414 & 688422 & 4.45 & 5.157 & TRN \\
\hline CHEMBL1457368 & 688422 & 5.45 & 5.6657 & TRN \\
\hline CHEMBL1403721 & 688422 & 4.8 & 5.4693 & TRN \\
\hline CHEMBL1401007 & 688422 & 4.8 & 5.7252 & TST \\
\hline CHEMBL563306 & 688422 & 4.65 & 5.0635 & TRN \\
\hline CHEMBL1538018 & 688422 & 4.5 & 5.2342 & TRN \\
\hline CHEMBL1313981 & 688422 & 5.6 & 4.9796 & TRN \\
\hline CHEMBL1426362 & 688422 & 6.5501 & 5.1122 & TST \\
\hline CHEMBL1583504 & 688422 & 4.85 & 5.0243 & TRN \\
\hline CHEMBL1316055 & 688422 & 4.65 & 4.6663 & TRN \\
\hline CHEMBL1333752 & 688422 & 6.3 & 5.0485 & TRN \\
\hline CHEMBL1397620 & 688422 & 5.35 & 5.4558 & TRN \\
\hline CHEMBL1483093 & 688422 & 8.3468 & 5.3303 & TRN \\
\hline CHEMBL1349611 & 688422 & 4.45 & 5.5651 & TRN \\
\hline CHEMBL 1405753 & 688422 & 4.7 & 5.3463 & TST \\
\hline CHEMBL1383810 & 688422 & 4.7 & 5.1289 & TRN \\
\hline CHEMBL1595774 & 688422 & 4.5 & 4.9956 & TRN \\
\hline CHEMBL1438073 & 688422 & 4.8 & 4.8472 & TRN \\
\hline CHEMBL1430542 & 688422 & 4.85 & 5.3894 & TRN \\
\hline CHEMBL1965236 & 688422 & 4.9 & 5.18 & TRN \\
\hline CHEMBL1582656 & 688422 & 5.35 & 5.8572 & TRN \\
\hline CHEMBL1526622 & 688422 & 4.45 & 4.7731 & TRN \\
\hline CHEMBL1573629 & 688422 & 4.5 & 5.0362 & TRN \\
\hline CHEMBL1590127 & 688422 & 5.0 & 5.7861 & TRN \\
\hline CHEMBL1561048 & 688422 & 8.1487 & 5.2593 & TRN \\
\hline CHEMBL1395810 & 688422 & 5.25 & 5.8116 & TRN \\
\hline
\end{tabular}




\begin{tabular}{|c|c|c|c|c|}
\hline \multicolumn{5}{|c|}{ Supplemental Table S2.txt } \\
\hline CHEMBL1333322 & 688422 & 4.75 & 5.3542 & TST \\
\hline CHEMBL1547025 & 688422 & 4.9 & 4.7116 & TRN \\
\hline CHEMBL1412236 & 688422 & 5.45 & 5.4581 & TRN \\
\hline CHEMBL1606531 & 688422 & 5.95 & 5.1947 & TRN \\
\hline CHEMBL1541329 & 688422 & 4.7 & 4.9055 & TRN \\
\hline CHEMBL1416834 & 688422 & 4.9 & 5.3643 & TST \\
\hline CHEMBL1439130 & 688422 & 5.25 & 5.606 & TST \\
\hline CHEMBL1536380 & 688422 & 4.5 & 5.472 & TRN \\
\hline CHEMBL 1498210 & 688422 & 5.35 & 5.4281 & TRN \\
\hline CHEMBL1532161 & 688422 & 4.7 & 5.1869 & TRN \\
\hline CHEMBL1410773 & 688422 & 4.95 & 5.0848 & TRN \\
\hline CHEMBL1534476 & 688422 & 4.65 & 5.2303 & TRN \\
\hline CHEMBL1498661 & 688422 & 4.85 & $5.1110 e$ & 0000000001 \\
\hline CHEMBL1600944 & 688422 & 4.85 & 5.3886 & TRN \\
\hline CHEMBL1519674 & 688422 & 4.75 & 5.4357 & TRN \\
\hline CHEMBL1469630 & 688422 & 4.45 & 5.6031 & TRN \\
\hline CHEMBL1371219 & 688422 & 4.6 & 5.3259 & TRN \\
\hline CHEMBL1521217 & 688422 & 7.0 & 5.3728 & TRN \\
\hline CHEMBL1587339 & 688422 & 6.7001 & 5.3743 & TRN \\
\hline CHEMBL1605859 & 688422 & 4.45 & 5.2726 & TRN \\
\hline CHEMBL1455802 & 688422 & 4.65 & 5.1457 & TRN \\
\hline CHEMBL1509441 & 688422 & 4.85 & 5.0313 & TRN \\
\hline CHEMBL1524030 & 688422 & 5.35 & 5.4994 & TST \\
\hline CHEMBL1360100 & 688422 & 5.55 & 5.1743 & TRN \\
\hline CHEMBL1517718 & 688422 & 4.95 & 5.0407 & TRN \\
\hline CHEMBL1444851 & 688422 & 4.5 & 5.2299 & TRN \\
\hline CHEMBL1611002 & 688422 & 5.6 & 5.5671 & TRN \\
\hline CHEMBL1497803 & 688422 & 4.75 & 4.916 & TRN \\
\hline CHEMBL1313113 & 688422 & 5.35 & 5.0141 & TRN \\
\hline CHEMBL1564595 & 688422 & 4.75 & 5.2491 & TRN \\
\hline CHEMBL1493007 & 688422 & 6.5501 & 5.7499 & TST \\
\hline CHEMBL1603564 & 688422 & 4.9 & 4.6664 & TRN \\
\hline CHEMBL1579800 & 688422 & 5.15 & 5.3496 & TRN \\
\hline CHEMBL1377082 & 688422 & 4.7 & 5.2557 & TRN \\
\hline CHEMBL1561461 & 688422 & 6.6 & 5.6339 & TRN \\
\hline CHEMBL1420025 & 688422 & 4.45 & 5.643 & TST \\
\hline CHEMBL1337068 & 688422 & 4.45 & 4.9839 & TST \\
\hline CHEMBL1345865 & 688422 & 4.85 & 4.9429 & TRN \\
\hline CHEMBL1398260 & 688422 & 6.6499 & 6.1501 & TRN \\
\hline CHEMBL1337537 & 688422 & 4.45 & 5.3027 & TST \\
\hline CHEMBL1527476 & 688422 & 4.45 & 4.9112 & TRN \\
\hline CHEMBL1418252 & 688422 & 5.8 & 5.933 & TRN \\
\hline CHEMBL1558751 & 688422 & 5.1 & 5.2297 & TRN \\
\hline CHEMBL1589369 & 688422 & 6.8 & 5.0514 & TRN \\
\hline CHEMBL1520102 & 688422 & 7.2 & 5.8494 & TST \\
\hline CHEMBL1521538 & 688422 & 4.75 & 5.3449 & TRN \\
\hline CHEMBL1511538 & 688422 & 6.9 & 5.2143 & TST \\
\hline CHEMBL1418401 & 688422 & 4.45 & 5.2472 & TST \\
\hline
\end{tabular}




\begin{tabular}{|c|c|c|c|c|c|}
\hline \multirow{3}{*}{$\begin{array}{l}\text { CHEMBL1539520 } \\
\text { CHEMBL1310466 }\end{array}$} & \multirow{3}{*}{$\begin{array}{l}688422 \\
688422\end{array}$} & \multicolumn{4}{|c|}{ Supplemental Table S2.txt } \\
\hline & & 4.45 & \multicolumn{2}{|c|}{4.9639999999999995} & TRN \\
\hline & & 5.3 & 5.2685 & TRN & \\
\hline CHEMBL1554442 & 688422 & 4.45 & 4.8845 & TRN & \\
\hline CHEMBL1393004 & 688422 & 5.2 & 5.0975 & TST & \\
\hline CHEMBL1521744 & 688422 & 6.45 & 5.1542 & TRN & \\
\hline CHEMBL1994446 & 688422 & 4.5 & 5.4138 & TRN & \\
\hline CHEMBL1590217 & 688422 & 4.85 & 4.7834 & TRN & \\
\hline CHEMBL1595192 & 688422 & 4.6 & 5.1267 & TRN & \\
\hline CHEMBL1449354 & 688422 & 4.45 & 5.2811 & TRN & \\
\hline CHEMBL1502890 & 688422 & 7.7496 & 5.7481 & TST & \\
\hline CHEMBL1541996 & 688422 & 4.55 & 5.2709 & TRN & \\
\hline CHEMBL1340977 & 688422 & 7.1002 & 5.059 & TRN & \\
\hline CHEMBL1380594 & 688422 & 6.05 & 5.4525 & TRN & \\
\hline CHEMBL1389702 & 688422 & 5.0 & 5.4721 & TRN & \\
\hline CHEMBL1534808 & 688422 & 4.85 & 5.4642 & TRN & \\
\hline CHEMBL1302407 & 688422 & 6.25 & 5.5925 & TRN & \\
\hline CHEMBL1471517 & 688422 & 4.5 & 5.1581 & TST & \\
\hline CHEMBL1479027 & 688422 & 4.9 & 5.8168 & TRN & \\
\hline CHEMBL1395915 & 688422 & 5.85 & 5.1186 & TRN & \\
\hline CHEMBL1547871 & 688422 & 7.6003 & 5.6752 & TST & \\
\hline CHEMBL1487153 & 688422 & 4.45 & 4.9729 & TRN & \\
\hline CHEMBL1329235 & 688422 & 4.75 & 5.76200 & 00000000005 & TRN \\
\hline CHEMBL1531852 & 688422 & 4.45 & 5.6083 & TRN & \\
\hline CHEMBL1437226 & 688422 & 4.5 & 4.5889 & TRN & \\
\hline CHEMBL3192376 & 688422 & 5.15 & 5.3035 & TRN & \\
\hline CHEMBL1460990 & 688422 & 4.45 & 5.4707 & TRN & \\
\hline CHEMBL1416851 & 688422 & 5.5 & 5.2722 & TRN & \\
\hline CHEMBL1335414 & 688422 & 5.3 & 5.0396 & TRN & \\
\hline CHEMBL1556515 & 688422 & 7.6498 & 5.4254 & TRN & \\
\hline CHEMBL3214338 & 688422 & 5.0 & 5.0996 & TRN & \\
\hline CHEMBL1508723 & 688422 & 4.6 & 4.8372 & TRN & \\
\hline CHEMBL1439774 & 688422 & 4.5 & 5.0029 & TRN & \\
\hline CHEMBL1612809 & 688422 & 5.4 & 5.0295 & TST & \\
\hline CHEMBL1560402 & 688422 & 4.8 & 5.1542 & TRN & \\
\hline CHEMBL1435124 & 688422 & 6.2 & 5.2772 & TRN & \\
\hline CHEMBL1406969 & 688422 & 4.45 & 4.8092 & TRN & \\
\hline CHEMBL1424169 & 688422 & 5.25 & 5.2875 & TRN & \\
\hline CHEMBL3212608 & 688422 & 4.8 & 5.3604 & TST & \\
\hline CHEMBL1367872 & 688422 & 4.9 & 4.8048 & TRN & \\
\hline CHEMBL1437348 & 688422 & 6.15 & 5.3879 & TRN & \\
\hline CHEMBL1306587 & 688422 & 6.5 & 5.5939 & TRN & \\
\hline CHEMBL1523699 & 688422 & 4.95 & 5.0452 & TRN & \\
\hline CHEMBL1422720 & 688422 & 4.45 & 5.1812 & TRN & \\
\hline CHEMBL1596821 & 688422 & 5.0 & 4.8887 & TRN & \\
\hline CHEMBL1461463 & 688422 & 4.85 & 4.8768 & TRN & \\
\hline CHEMBL1354210 & 688422 & 4.5 & 4.9411 & TRN & \\
\hline CHEMBL1460973 & 688422 & 7.4498 & 5.2815 & TRN & \\
\hline CHEMBL388676 & 688422 & 6.1 & 5.7615 & TST & \\
\hline
\end{tabular}




\begin{tabular}{|c|c|c|c|c|}
\hline \multicolumn{5}{|c|}{ Supplemental Table S2.txt } \\
\hline CHEMBL1583097 & 688422 & 4.55 & 4.7765 & TRN \\
\hline CHEMBL1567553 & 688422 & 4.65 & 5.1334 & TRN \\
\hline CHEMBL1533528 & 688422 & 6.5 & 4.9762 & TRN \\
\hline CHEMBL1323295 & 688422 & 6.15 & 5.8221 & TST \\
\hline CHEMBL1350962 & 688422 & 8.5528 & 5.2479 & TRN \\
\hline CHEMBL1339811 & 688422 & 4.45 & 5.347 & TRN \\
\hline CHEMBL1320946 & 688422 & 5.25 & 5.3889 & TST \\
\hline CHEMBL1476808 & 688422 & 4.9 & 5.1715 & TRN \\
\hline CHEMBL1546913 & 688422 & 8.3468 & 5.0933 & TST \\
\hline CHEMBL1585339 & 688422 & 4.6 & 5.0168 & TRN \\
\hline CHEMBL1582184 & 688422 & 4.5 & 4.8713 & TST \\
\hline CHEMBL1552440 & 688422 & 4.65 & 5.4007 & TRN \\
\hline CHEMBL3209779 & 688422 & 4.45 & 4.5987 & TRN \\
\hline CHEMBL1463964 & 688422 & 4.6 & 4.6218 & TRN \\
\hline CHEMBL1430674 & 688422 & 5.15 & 5.1864 & TST \\
\hline CHEMBL1582802 & 688422 & 5.35 & 5.3786 & TRN \\
\hline CHEMBL3144828 & 688422 & 4.65 & 4.9827 & TRN \\
\hline CHEMBL 3197704 & 688422 & 5.95 & 5.1996 & TRN \\
\hline CHEMBL 1439210 & 688422 & 5.25 & 5.2915 & TRN \\
\hline CHEMBL1585777 & 688422 & 4.8 & 4.5278 & TRN \\
\hline CHEMBL1312336 & 688422 & 4.45 & 5.5073 & TRN \\
\hline CHEMBL876 & 688422 & 4.65 & 5.1886 & TRN \\
\hline CHEMBL1326937 & 688422 & 5.55 & 5.078 & TRN \\
\hline CHEMBL1331838 & 688422 & 4.45 & 4.6552 & TRN \\
\hline CHEMBL1495161 & 688422 & 4.7 & 5.5947 & TRN \\
\hline CHEMBL1480747 & 688422 & 4.45 & 5.1244 & TRN \\
\hline CHEMBL1480605 & 688422 & 5.85 & 5.5169 & TRN \\
\hline CHEMBL1368428 & 688422 & 5.5 & 5.5275 & TRN \\
\hline CHEMBL1535931 & 688422 & 4.95 & 5.1283 & TRN \\
\hline CHEMBL1364193 & 688422 & 6.25 & 5.1687 & TRN \\
\hline CHEMBL1400256 & 688422 & 4.6 & 5.0676 & TRN \\
\hline CHEMBL1438778 & 688422 & 5.0 & 5.2605 & TST \\
\hline CHEMBL1493694 & 688422 & 5.2 & 5.038 & TST \\
\hline CHEMBL1511309 & 688422 & 5.45 & 5.7948 & TST \\
\hline CHEMBL1435728 & 688422 & 6.1 & 5.4499 & TRN \\
\hline CHEMBL1987891 & 688422 & 5.1 & 4.9648 & TRN \\
\hline CHEMBL1409217 & 688422 & 4.5 & 5.3358 & TRN \\
\hline CHEMBL1473484 & 688422 & 5.5 & 5.2759 & TRN \\
\hline CHEMBL1324867 & 688422 & 4.6 & 5.3334 & TST \\
\hline CHEMBL1394297 & 688422 & 4.9 & 5.4177 & TRN \\
\hline CHEMBL1407046 & 688422 & 4.6 & 4.9289 & TRN \\
\hline CHEMBL1552854 & 688422 & 4.8 & 4.923 & TRN \\
\hline CHEMBL1328164 & 688422 & 4.45 & 4.6852 & TRN \\
\hline CHEMBL1994902 & 688422 & 4.65 & 5.0657 & TRN \\
\hline CHEMBL1430449 & 688422 & 4.5 & 5.2117 & TST \\
\hline CHEMBL1517902 & 688422 & 4.45 & 4.7921 & TRN \\
\hline CHEMBL1380728 & 688422 & 7.15 & 5.7469 & TRN \\
\hline CHEMBL1514372 & 688422 & 4.45 & 5.3815 & TRN \\
\hline
\end{tabular}




\begin{tabular}{|c|c|c|c|c|}
\hline \multicolumn{5}{|c|}{ Supplemental Table S2.txt } \\
\hline CHEMBL1573956 & 688422 & 4.6 & 5.0723 & TRN \\
\hline CHEMBL1400012 & 688422 & 4.85 & 5.0433 & TST \\
\hline CHEMBL1429064 & 688422 & 4.8 & 4.8288 & TRN \\
\hline CHEMBL1516967 & 688422 & 4.85 & 5.8118 & TRN \\
\hline CHEMBL1521101 & 688422 & 5.7 & 5.749 & TRN \\
\hline CHEMBL1284 & 688422 & 5.45 & 5.4703 & TRN \\
\hline CHEMBL1562517 & 688422 & 4.5 & 4.9356 & TRN \\
\hline CHEMBL1375778 & 688422 & 4.65 & 5.0586 & TRN \\
\hline CHEMBL1338577 & 688422 & 4.5 & 5.2077 & TRN \\
\hline CHEMBL1255778 & 688422 & 5.5 & 5.7774 & TST \\
\hline CHEMBL1540821 & 688422 & 4.95 & 5.2743 & TST \\
\hline CHEMBL1349898 & 688422 & 4.65 & 5.2922 & TRN \\
\hline CHEMBL1539427 & 688422 & 7.4498 & 5.2807 & TST \\
\hline CHEMBL1494142 & 688422 & 4.9 & 5.0994 & TST \\
\hline CHEMBL1536446 & 688422 & 4.65 & 5.3916 & TRN \\
\hline CHEMBL1526617 & 688422 & 8.0 & 5.7691 & TRN \\
\hline CHEMBL1345610 & 688422 & 4.7 & 5.3086 & TST \\
\hline CHEMBL1413117 & 688422 & 4.45 & 5.7161 & TRN \\
\hline CHEMBL1581907 & 688422 & 4.45 & 5.2999 & TRN \\
\hline CHEMBL1574311 & 688422 & 7.7496 & 5.4077 & TRN \\
\hline CHEMBL1607818 & 688422 & 4.85 & 5.0303 & TST \\
\hline CHEMBL1522586 & 688422 & 5.0 & 5.3715 & TRN \\
\hline CHEMBL1543375 & 688422 & 5.7 & 5.0746 & TRN \\
\hline CHEMBL1514272 & 688422 & 4.45 & 4.9285 & TRN \\
\hline CHEMBL1560657 & 688422 & 6.1 & 5.2532 & TRN \\
\hline CHEMBL1304676 & 688422 & 4.9 & 5.396 & TRN \\
\hline CHEMBL1347890 & 688422 & 4.85 & 5.2896 & TST \\
\hline CHEMBL1486433 & 688422 & 5.2 & 5.2999 & TRN \\
\hline CHEMBL491953 & 688422 & 4.8 & 4.6551 & TRN \\
\hline CHEMBL1339243 & 688422 & 4.95 & 5.0638 & TRN \\
\hline CHEMBL1387986 & 688422 & 6.5 & 5.3454 & TRN \\
\hline CHEMBL1436882 & 688422 & 9.0458 & 6.1541 & TRN \\
\hline CHEMBL1974856 & 688422 & 4.9 & 4.7993 & TRN \\
\hline CHEMBL1576657 & 688422 & 5.4 & 4.8738 & TST \\
\hline CHEMBL1600014 & 688422 & 7.6003 & 4.9106 & TRN \\
\hline CHEMBL1562181 & 688422 & 5.0 & 5.282 & TRN \\
\hline CHEMBL1502469 & 688422 & 5.0 & 5.5123 & TST \\
\hline CHEMBL1555583 & 688422 & 4.8 & 5.2891 & TRN \\
\hline CHEMBL1531983 & 688422 & 4.5 & 5.5439 & TRN \\
\hline CHEMBL1470466 & 688422 & 4.7 & 5.4573 & TST \\
\hline CHEMBL81977 & 688422 & 8.8861 & 5.8952 & TST \\
\hline CHEMBL 1478885 & 688422 & 6.5501 & 5.2256 & TST \\
\hline CHEMBL1589556 & 688422 & 5.3 & 5.1666 & TRN \\
\hline CHEMBL1351991 & 688422 & 4.45 & 5.567 & TRN \\
\hline CHEMBL1387629 & 688422 & 4.45 & 5.0733 & TRN \\
\hline CHEMBL1409252 & 688422 & 5.35 & 5.6214 & TST \\
\hline CHEMBL1399198 & 688422 & 5.25 & 5.5855 & TRN \\
\hline CHEMBL1367658 & 688422 & 6.6 & 5.0178 & TRN \\
\hline
\end{tabular}




\begin{tabular}{|c|c|c|c|c|c|}
\hline \multicolumn{6}{|c|}{ Supplemental Table s2.txt } \\
\hline CHEMBL1607203 & 688422 & 4.95 & 5.0468 & TRN & \\
\hline CHEMBL1324002 & 688422 & 5.15 & 4.9261 & TRN & \\
\hline CHEMBL1564657 & 688422 & 7.4001 & 5.5135 & TST & \\
\hline CHEMBL1470046 & 688422 & 5.0 & 4.7875 & TST & \\
\hline CHEMBL1330835 & 688422 & 4.5 & 4.93199 & 99999999995 & TRN \\
\hline CHEMBL1436004 & 688422 & 4.8 & 5.6799 & TST & \\
\hline CHEMBL1388566 & 688422 & 4.85 & 4.9666 & TRN & \\
\hline CHEMBL1475487 & 688422 & 4.9 & 5.32600 & 00000000005 & TRN \\
\hline CHEMBL1511680 & 688422 & 7.6003 & 5.6554 & TRN & \\
\hline CHEMBL1301435 & 688422 & 4.5 & 4.785 & TRN & \\
\hline CHEMBL1371726 & 688422 & 8.0 & 5.6069 & TRN & \\
\hline CHEMBL543557 & 688422 & 7.1002 & 5.5916 & TST & \\
\hline CHEMBL1565244 & 688422 & 4.45 & 5.4569 & TST & \\
\hline CHEMBL1373870 & 688422 & 4.55 & 5.4945 & TST & \\
\hline CHEMBL1320697 & 688422 & 4.95 & 5.3069 & TRN & \\
\hline CHEMBL1588353 & 688422 & 4.5 & 5.5897 & TRN & \\
\hline CHEMBL1576580 & 688422 & 4.9 & 5.0234 & TRN & \\
\hline CHEMBL1427576 & 688422 & 4.45 & 4.8023 & TRN & \\
\hline CHEMBL1585075 & 688422 & 4.95 & 4.7489 & TRN & \\
\hline CHEMBL1568793 & 688422 & 4.75 & 5.4704 & TRN & \\
\hline CHEMBL1402333 & 688422 & 6.35 & 5.4156 & TRN & \\
\hline CHEMBL1209196 & 688422 & 5.0 & 5.4794 & TST & \\
\hline CHEMBL1490513 & 688422 & 5.4 & 5.37799 & 9999999999 & TRN \\
\hline CHEMBL1399513 & 688422 & 4.45 & 5.7829 & TST & \\
\hline CHEMBL1496508 & 688422 & 5.35 & 5.5546 & TRN & \\
\hline CHEMBL1435809 & 688422 & 4.45 & 5.2279 & TRN & \\
\hline CHEMBL1319941 & 688422 & 4.7 & 5.3906 & TST & \\
\hline CHEMBL1494866 & 688422 & 4.45 & 4.8641 & TRN & \\
\hline CHEMBL1318553 & 688422 & 4.85 & 5.3269 & TST & \\
\hline CHEMBL1385534 & 688422 & 4.8 & 4.9543 & TRN & \\
\hline CHEMBL1351164 & 688422 & 5.35 & 5.2063 & TRN & \\
\hline CHEMBL1511300 & 688422 & 4.5 & 4.8398 & TST & \\
\hline CHEMBL1586200 & 688422 & 5.2 & 5.0013 & TRN & \\
\hline CHEMBL1517187 & 688422 & 5.25 & 5.4378 & TRN & \\
\hline CHEMBL1975756 & 688422 & 4.45 & 5.141 & TST & \\
\hline CHEMBL1470446 & 688422 & 4.6 & 4.8298 & TST & \\
\hline CHEMBL1542962 & 688422 & 4.55 & 5.4104 & TST & \\
\hline CHEMBL1568190 & 688422 & 4.45 & 4.8327 & TRN & \\
\hline CHEMBL1324022 & 688422 & 4.75 & 5.1831 & TST & \\
\hline CHEMBL1333459 & 688422 & 5.85 & 4.8919 & TRN & \\
\hline CHEMBL1410181 & 688422 & 4.75 & 5.3244 & TRN & \\
\hline CHEMBL1482974 & 688422 & 5.4 & 5.6804 & TRN & \\
\hline CHEMBL1564135 & 688422 & 4.65 & 5.5437 & TRN & \\
\hline CHEMBL1508375 & 688422 & 6.0 & 5.3183 & TRN & \\
\hline CHEMBL1449689 & 688422 & 5.25 & 5.1275 & TRN & \\
\hline CHEMBL1483513 & 688422 & 4.95 & 5.0474 & TRN & \\
\hline CHEMBL1415914 & 688422 & 7.0 & 5.4304 & TST & \\
\hline CHEMBL1408823 & 688422 & 6.7001 & 4.995 & TRN & \\
\hline
\end{tabular}




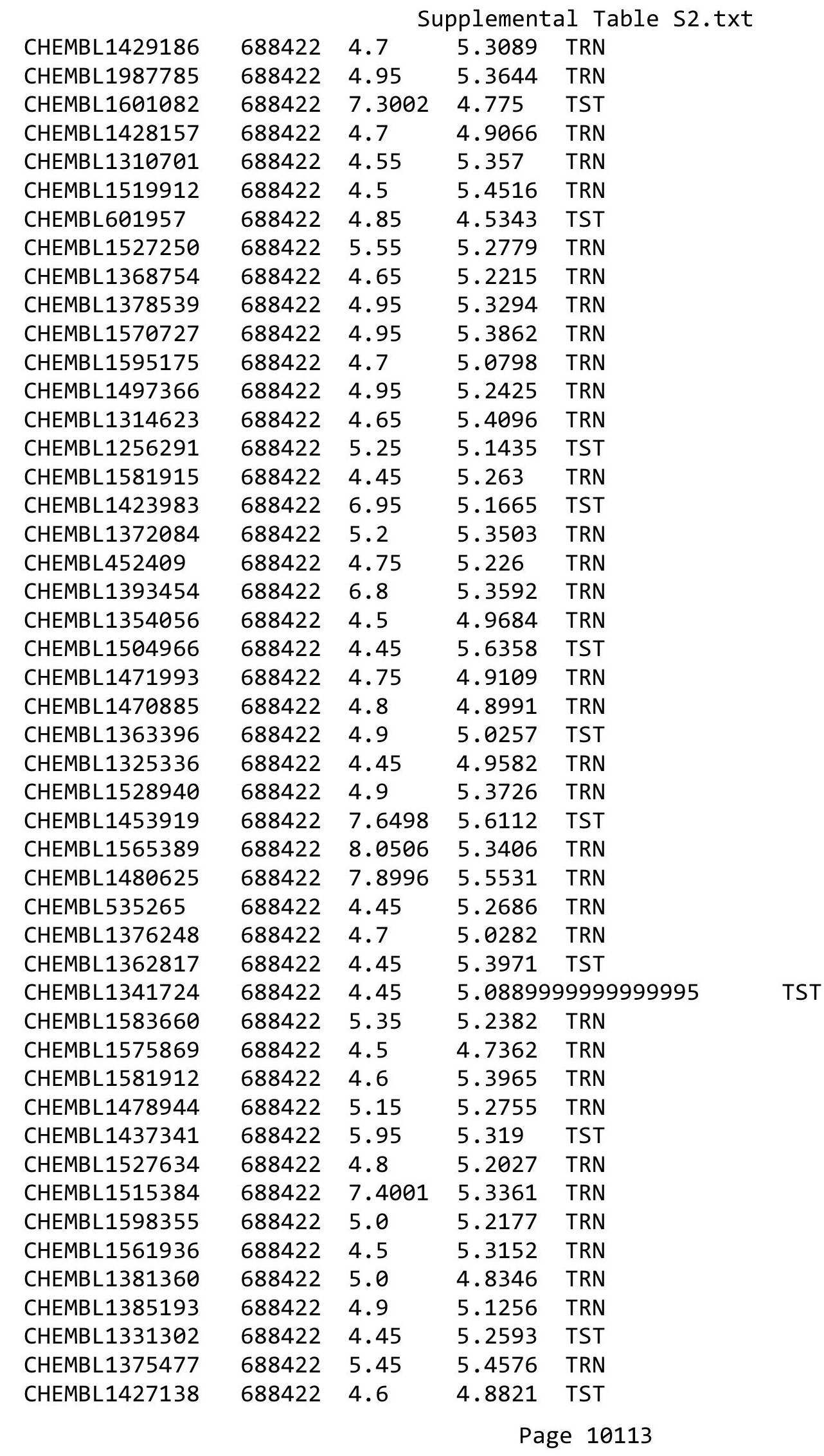




\begin{tabular}{|c|c|c|c|c|}
\hline \multicolumn{5}{|c|}{ Supplemental Table s2.txt } \\
\hline CHEMBL1416809 & 688422 & 6.8 & 5.2249 & TRN \\
\hline CHEMBL1427175 & 688422 & 4.95 & 5.691 & TRN \\
\hline CHEMBL1604675 & 688422 & 7.4498 & 5.4947 & TST \\
\hline CHEMBL1385995 & 688422 & 5.25 & 5.4095 & TST \\
\hline CHEMBL1464577 & 688422 & 5.3 & 5.5076 & TRN \\
\hline CHEMBL1608861 & 688422 & 4.85 & 4.9052 & TRN \\
\hline CHEMBL1371178 & 688422 & 5.35 & 5.331 & TRN \\
\hline CHEMBL1084643 & 688422 & 8.1024 & 5.5858 & TRN \\
\hline CHEMBL1308565 & 688422 & 4.9 & 5.3287 & TRN \\
\hline CHEMBL1408115 & 688422 & 5.25 & 5.5972 & TRN \\
\hline CHEMBL1550334 & 688422 & 4.6 & 5.0561 & TRN \\
\hline CHEMBL1399695 & 688422 & 5.85 & 5.0954 & TST \\
\hline CHEMBL1578235 & 688422 & 4.95 & 5.1999 & TRN \\
\hline CHEMBL1588354 & 688422 & 4.85 & 5.3356 & TRN \\
\hline CHEMBL1391437 & 688422 & 4.65 & 5.0122 & TRN \\
\hline CHEMBL1400659 & 688422 & 5.1 & 5.3595 & TST \\
\hline CHEMBL1307138 & 688422 & 4.8 & 4.907 & TST \\
\hline CHEMBL3207899 & 688422 & 4.95 & 5.3594 & TRN \\
\hline CHEMBL1382581 & 688422 & 5.25 & 5.5649 & TRN \\
\hline CHEMBL1351705 & 688422 & 4.5 & 5.1986 & TRN \\
\hline CHEMBL3199822 & 688422 & 4.45 & 5.1505 & TST \\
\hline CHEMBL1607822 & 688422 & 4.65 & 5.2475 & TST \\
\hline CHEMBL1420629 & 688422 & 5.2 & 5.1061 & TRN \\
\hline CHEMBL1442421 & 688422 & 4.9 & 4.7041 & TRN \\
\hline CHEMBL1462066 & 688422 & 4.5 & 5.2815 & TRN \\
\hline CHEMBL1545060 & 688422 & 7.8996 & 5.3135 & TRN \\
\hline CHEMBL1362994 & 688422 & 4.9 & 4.9884 & TRN \\
\hline CHEMBL1338040 & 688422 & 4.65 & 4.8487 & TRN \\
\hline CHEMBL1588686 & 688422 & 5.55 & 5.6548 & TRN \\
\hline CHEMBL1568257 & 688422 & 4.7 & 5.7898 & TRN \\
\hline CHEMBL3190410 & 688422 & 5.25 & 4.9398 & TRN \\
\hline CHEMBL1470257 & 688422 & 4.55 & 5.2903 & TRN \\
\hline CHEMBL1338703 & 688422 & 5.65 & 5.5066 & TST \\
\hline CHEMBL1497184 & 688422 & 4.55 & 5.5378 & TRN \\
\hline CHEMBL1503167 & 688422 & 5.55 & 5.5269 & TRN \\
\hline CHEMBL3199491 & 688422 & 4.6 & 5.0643 & TST \\
\hline CHEMBL1313157 & 688422 & 4.65 & 5.1172 & TRN \\
\hline CHEMBL3191887 & 688422 & 4.85 & 4.9459 & TRN \\
\hline CHEMBL1437804 & 688422 & 6.5501 & 5.5614 & TST \\
\hline CHEMBL1584757 & 688422 & 6.8 & 5.596 & TST \\
\hline CHEMBL3192482 & 688422 & 6.0 & 4.8893 & TST \\
\hline CHEMBL3193858 & 688422 & 4.75 & 5.1149 & TRN \\
\hline CHEMBL1527752 & 688422 & 4.45 & 5.1832 & TRN \\
\hline CHEMBL1499125 & 688422 & 5.0 & 4.8655 & TST \\
\hline CHEMBL1495238 & 688422 & 4.95 & 4.9764 & TST \\
\hline CHEMBL1511524 & 688422 & 4.8 & 5.0791 & TRN \\
\hline CHEMBL1373769 & 688422 & 4.6 & 5.12200 & 0000000001 \\
\hline CHEMBL1603894 & 688422 & 4.45 & 5.3581 & TRN \\
\hline
\end{tabular}

TRN 


\begin{tabular}{|c|c|c|c|c|c|}
\hline \multicolumn{6}{|c|}{ Supplemental Table S2.txt } \\
\hline CHEMBL1538083 & 688422 & 4.45 & 4.9616 & TST & \\
\hline CHEMBL3199102 & 688422 & 5.2 & 5.6601 & TRN & \\
\hline CHEMBL1368553 & 688422 & 4.85 & 4.6625 & TRN & \\
\hline CHEMBL1528559 & 688422 & 6.8 & 5.3991 & TST & \\
\hline CHEMBL 3194550 & 688422 & 4.45 & 4.8918 & TRN & \\
\hline CHEMBL1366369 & 688422 & 5.45 & 5.2094 & TST & \\
\hline CHEMBL1500273 & 688422 & 5.35 & 5.499 & TST & \\
\hline CHEMBL1342162 & 688422 & 4.8 & 5.3964 & TRN & \\
\hline CHEMBL1519626 & 688422 & 4.45 & 5.0623 & TRN & \\
\hline CHEMBL1361889 & 688422 & 4.5 & 5.2307 & TRN & \\
\hline CHEMBL1396970 & 688422 & 4.45 & 5.4648 & TST & \\
\hline CHEMBL1514223 & 688422 & 4.75 & 4.9104 & TRN & \\
\hline CHEMBL1465041 & 688422 & 5.15 & 5.2295 & TST & \\
\hline CHEMBL1314224 & 688422 & 6.2 & 5.9992 & TRN & \\
\hline CHEMBL1489083 & 688422 & 7.3002 & 5.2345 & TRN & \\
\hline CHEMBL1390295 & 688422 & 4.5 & 5.4977 & TRN & \\
\hline CHEMBL3212987 & 688422 & 5.0 & 5.3272 & TST & \\
\hline CHEMBL1353425 & 688422 & 4.75 & 5.1343 & TRN & \\
\hline CHEMBL16081 & 688422 & 8.2518 & 6.2563 & TST & \\
\hline CHEMBL1567968 & 688422 & 5.25 & 5.0943 & TST & \\
\hline CHEMBL1598792 & 688422 & 6.05 & 5.6437 & TRN & \\
\hline CHEMBL1352428 & 688422 & 4.6 & 5.4009 & TST & \\
\hline CHEMBL1522315 & 688422 & 4.45 & 5.0865 & TRN & \\
\hline CHEMBL1455305 & 688422 & 7.6498 & 5.2039 & TST & \\
\hline CHEMBL1307830 & 688422 & 5.0 & 5.24200 & 0000000001 & TRN \\
\hline CHEMBL1441092 & 688422 & 6.5 & 5.0638 & TRN & \\
\hline CHEMBL1351001 & 688422 & 4.95 & 5.2645 & TRN & \\
\hline CHEMBL1476364 & 688422 & 4.95 & 5.5374 & TRN & \\
\hline CHEMBL1885024 & 688422 & 4.8 & 5.3884 & TRN & \\
\hline CHEMBL1447076 & 688422 & 4.45 & 4.9342 & TRN & \\
\hline CHEMBL1394089 & 688422 & 5.85 & 5.5773 & TRN & \\
\hline CHEMBL1256191 & 688422 & 6.95 & 5.0175 & TST & \\
\hline CHEMBL1512495 & 688422 & 6.8 & 5.3938 & TRN & \\
\hline CHEMBL1391613 & 688422 & 4.9 & 5.3876 & TST & \\
\hline CHEMBL1468129 & 688422 & 4.45 & 5.1239 & TRN & \\
\hline CHEMBL1379288 & 688422 & 4.6 & 5.0696 & TRN & \\
\hline CHEMBL1497813 & 688422 & 4.95 & 5.0483 & TRN & \\
\hline CHEMBL1561288 & 688422 & 7.1002 & 5.8446 & TST & \\
\hline CHEMBL1498944 & 688422 & 4.5 & 5.1483 & TRN & \\
\hline CHEMBL1430749 & 688422 & 4.9 & 4.9041 & TRN & \\
\hline CHEMBL1377041 & 688422 & 4.45 & 5.2511 & TRN & \\
\hline CHEMBL1574230 & 688422 & 4.85 & 5.3767 & TST & \\
\hline CHEMBL1535167 & 688422 & 4.95 & 5.101 & TRN & \\
\hline CHEMBL1467103 & 688422 & 6.5 & 5.4494 & TST & \\
\hline CHEMBL1329927 & 688422 & 4.85 & 5.5134 & TST & \\
\hline CHEMBL1516096 & 688422 & 4.9 & 5.5435 & TST & \\
\hline CHEMBL1481050 & 688422 & 4.8 & 4.8032 & TRN & \\
\hline CHEMBL1354489 & 688422 & 4.7 & 5.3109 & TRN & \\
\hline
\end{tabular}




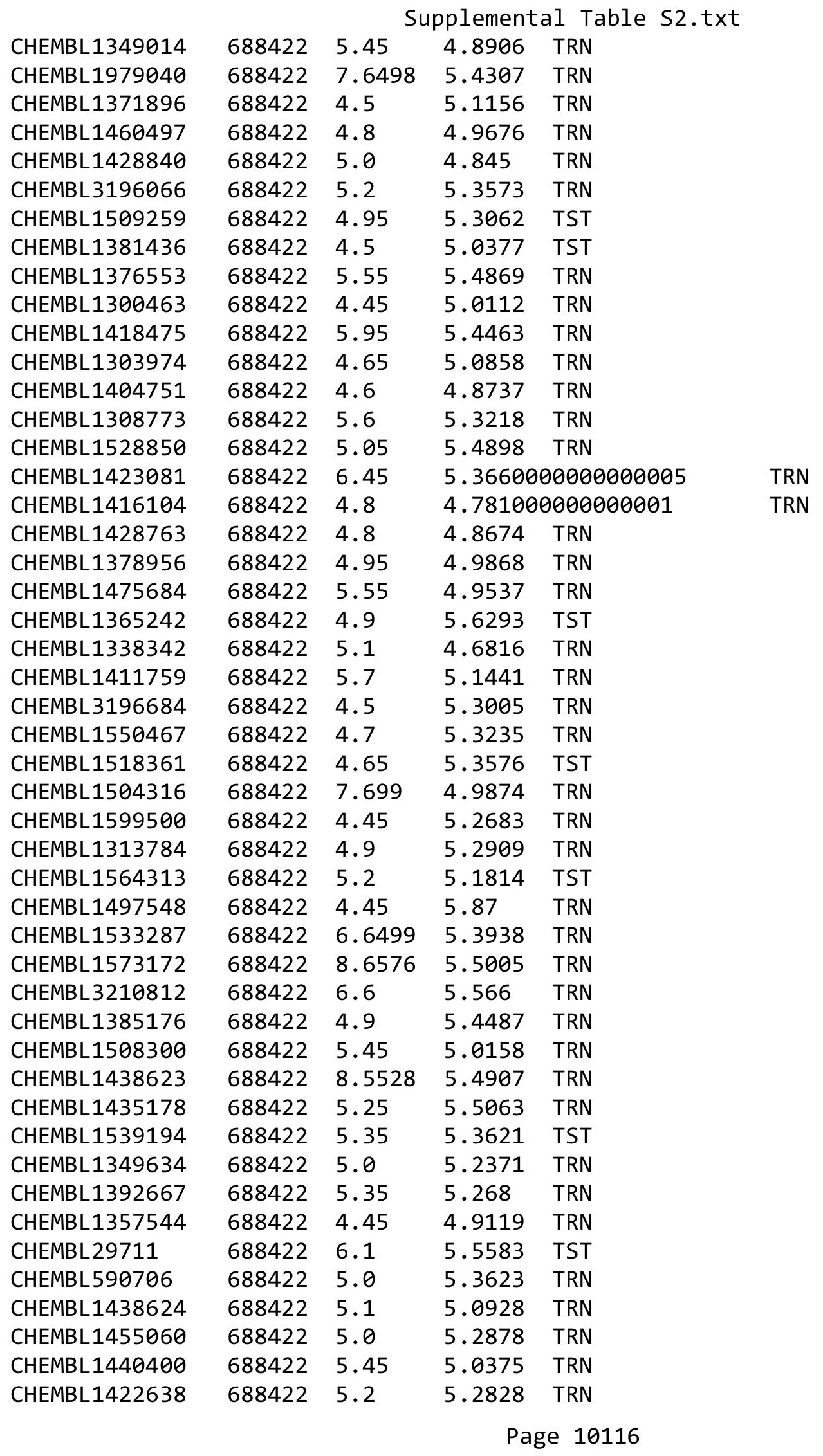




\begin{tabular}{|c|c|c|c|c|c|}
\hline \multicolumn{6}{|c|}{ Supplemental Table S2.txt } \\
\hline CHEMBL1467991 & 688422 & 4.75 & 5.3195 & TRN & \\
\hline CHEMBL1531578 & 688422 & 4.45 & 4.8044 & TRN & \\
\hline CHEMBL1579367 & 688422 & 4.45 & 5.3047 & TRN & \\
\hline CHEMBL1445067 & 688422 & 4.95 & 4.9883 & TRN & \\
\hline CHEMBL1449083 & 688422 & 5.25 & 5.0455 & TRN & \\
\hline CHEMBL1498938 & 688422 & 4.45 & 5.5191 & TRN & \\
\hline CHEMBL3194233 & 688422 & 4.65 & 4.8403 & TRN & \\
\hline CHEMBL1596849 & 688422 & 5.2 & 5.2413 & TRN & \\
\hline CHEMBL1491267 & 688422 & 5.25 & 5.0527 & TST & \\
\hline CHEMBL1564857 & 688422 & 5.3 & 4.7196 & TRN & \\
\hline CHEMBL1579471 & 688422 & 4.95 & 4.7816 & TRN & \\
\hline CHEMBL3212930 & 688422 & 5.95 & 5.1533 & TRN & \\
\hline CHEMBL1563008 & 688422 & 5.95 & 4.9851 & TRN & \\
\hline CHEMBL1531258 & 688422 & 4.45 & 4.6276 & TRN & \\
\hline CHEMBL3209451 & 688422 & 5.45 & 5.19600 & 0000000001 & TRN \\
\hline CHEMBL1471952 & 688422 & 5.35 & 5.3444 & TRN & \\
\hline CHEMBL1456643 & 688422 & 4.75 & 5.7786 & TST & \\
\hline CHEMBL1474910 & 688422 & 6.5 & 5.2955 & TRN & \\
\hline CHEMBL1474016 & 688422 & 4.8 & 4.9436 & TRN & \\
\hline CHEMBL1610273 & 688422 & 8.3979 & 6.075 & TRN & \\
\hline CHEMBL1408808 & 688422 & 6.95 & 5.2124 & TST & \\
\hline CHEMBL1435883 & 688422 & 4.45 & 4.5561 & TRN & \\
\hline CHEMBL1564800 & 688422 & 5.05 & 5.2394 & TRN & \\
\hline CHEMBL1531742 & 688422 & 5.15 & 5.3712 & TRN & \\
\hline CHEMBL1502461 & 688422 & 4.95 & 5.2129 & TRN & \\
\hline CHEMBL1411259 & 688422 & 4.45 & 5.34200 & 00000000005 & TRN \\
\hline CHEMBL1390196 & 688422 & 4.85 & 5.4907 & TRN & \\
\hline CHEMBL3211775 & 688422 & 4.45 & 5.1325 & TRN & \\
\hline CHEMBL1528519 & 688422 & 4.85 & 4.9527 & TST & \\
\hline CHEMBL1390942 & 688422 & 4.7 & 5.0046 & TRN & \\
\hline CHEMBL1463127 & 688422 & 5.25 & 5.71899 & 9999999999 & TST \\
\hline CHEMBL1458562 & 688422 & 5.25 & 5.7084 & TST & \\
\hline CHEMBL1507840 & 688422 & 4.9 & 4.9447 & TRN & \\
\hline CHEMBL1256873 & 688422 & 5.2 & 5.6431 & TST & \\
\hline CHEMBL1482117 & 688422 & 4.5 & 5.2093 & TRN & \\
\hline CHEMBL1558051 & 688422 & 4.9 & 5.4512 & TRN & \\
\hline CHEMBL1334026 & 688422 & 5.1 & 5.0696 & TRN & \\
\hline CHEMBL1307682 & 688422 & 5.15 & 5.13299 & 9999999999 & TRN \\
\hline CHEMBL1466087 & 688422 & 4.9 & 5.2366 & TRN & \\
\hline CHEMBL1536437 & 688422 & 4.45 & 5.1904 & TRN & \\
\hline CHEMBL1324163 & 688422 & 4.9 & 4.9239 & TRN & \\
\hline CHEMBL1592032 & 688422 & 4.45 & 4.9454 & TRN & \\
\hline CHEMBL1441750 & 688422 & 5.0 & 5.2598 & TST & \\
\hline CHEMBL1568677 & 688422 & 5.05 & 5.1941 & TST & \\
\hline CHEMBL1520412 & 688422 & 4.9 & 4.954 & TRN & \\
\hline CHEMBL1470503 & 688422 & 4.45 & 5.3625 & TST & \\
\hline CHEMBL1544186 & 688422 & 5.5 & 4.7958 & TRN & \\
\hline CHEMBL1430583 & 688422 & 5.35 & 5.3821 & TRN & \\
\hline
\end{tabular}




\begin{tabular}{|c|c|c|c|c|c|}
\hline & & \multicolumn{4}{|c|}{ Supplemental Table S2.txt } \\
\hline CHEMBL1412842 & 688422 & 9.0458 & 5.7288 & TRN & \\
\hline CHEMBL1450269 & 688422 & 4.9 & 4.9789 & TRN & \\
\hline CHEMBL1334430 & 688422 & 4.9 & 5.419 & TRN & \\
\hline CHEMBL1564099 & 688422 & 4.8 & 5.4231 & TRN & \\
\hline CHEMBL1602336 & 688422 & 5.0 & 5.1104 & TRN & \\
\hline CHEMBL1328965 & 688422 & 5.3 & 5.436 & TRN & \\
\hline CHEMBL1329608 & 688422 & 4.9 & 5.0051 & TRN & \\
\hline CHEMBL1471312 & 688422 & 4.85 & 4.98 & TRN & \\
\hline CHEMBL1305448 & 688422 & 4.9 & 5.2101 & TRN & \\
\hline CHEMBL1599437 & 688422 & 4.65 & 5.2534 & TST & \\
\hline CHEMBL1582131 & 688422 & 5.1 & 5.6234 & TST & \\
\hline CHEMBL1319586 & 688422 & 5.85 & 5.6472 & TST & \\
\hline CHEMBL1521017 & 688422 & 5.25 & 5.2056 & TRN & \\
\hline CHEMBL1395052 & 688422 & 4.8 & 5.1153 & TRN & \\
\hline CHEMBL1576260 & 688422 & 4.65 & 5.431 & TST & \\
\hline CHEMBL1311527 & 688422 & 4.45 & 4.9471 & TRN & \\
\hline CHEMBL1427641 & 688422 & 5.1 & 5.4317 & TRN & \\
\hline CHEMBL1502967 & 688422 & 5.4 & 5.3237 & TRN & \\
\hline CHEMBL1539272 & 688422 & 4.45 & 5.2743 & TRN & \\
\hline CHEMBL1350275 & 688422 & 4.65 & 5.2698 & TRN & \\
\hline CHEMBL1322702 & 688422 & 5.0 & 5.4159 & TST & \\
\hline CHEMBL1514387 & 688422 & 5.4 & 5.33299 & 9999999999 & TRN \\
\hline CHEMBL3193400 & 688422 & 4.45 & 5.0359 & TRN & \\
\hline CHEMBL1337779 & 688422 & 4.45 & 4.9242 & TRN & \\
\hline CHEMBL1491159 & 688422 & 5.3 & 5.3827 & TST & \\
\hline CHEMBL1411959 & 688422 & 4.45 & 5.1436 & TRN & \\
\hline CHEMBL1525880 & 688422 & 4.65 & 4.8473 & TST & \\
\hline CHEMBL1356361 & 688422 & 6.95 & 5.1751 & TRN & \\
\hline CHEMBL1555986 & 688422 & 4.55 & 5.6396 & TRN & \\
\hline CHEMBL3213455 & 688422 & 6.8499 & 5.3697 & TRN & \\
\hline CHEMBL1561933 & 688422 & 4.75 & 4.979 & TRN & \\
\hline CHEMBL1601643 & 688422 & 4.45 & 4.8443 & TRN & \\
\hline CHEMBL1385019 & 688422 & 7.2 & 5.6901 & TRN & \\
\hline CHEMBL1547895 & 688422 & 4.45 & 5.0912 & TRN & \\
\hline CHEMBL1306614 & 688422 & 4.45 & 5.4779 & TRN & \\
\hline CHEMBL1441374 & 688422 & 4.9 & 5.1402 & TRN & \\
\hline CHEMBL1405781 & 688422 & 4.45 & 5.1293 & TST & \\
\hline CHEMBL1470367 & 688422 & 6.9 & 5.3128 & TST & \\
\hline CHEMBL1322065 & 688422 & 4.45 & 5.4381 & TRN & \\
\hline CHEMBL1374044 & 688422 & 4.65 & 5.6782 & TRN & \\
\hline CHEMBL1368457 & 688422 & 8.0 & 5.7495 & TRN & \\
\hline CHEMBL1375361 & 688422 & 4.45 & 5.5114 & TRN & \\
\hline CHEMBL1492569 & 688422 & 5.7 & 5.2322 & TRN & \\
\hline CHEMBL1557433 & 688422 & 7.1002 & 5.4243 & TRN & \\
\hline CHEMBL1341472 & 688422 & 5.05 & 5.1421 & TRN & \\
\hline CHEMBL1510136 & 688422 & 5.6 & 5.1396 & TRN & \\
\hline CHEMBL1376423 & 688422 & 4.65 & 5.1529 & TST & \\
\hline CHEMBL1404915 & 688422 & 4.45 & 4.8653 & TST & \\
\hline
\end{tabular}




\begin{tabular}{|c|c|c|c|c|c|}
\hline \multicolumn{6}{|c|}{ Supplemental Table S2.txt } \\
\hline CHEMBL1606419 & 688422 & 4.7 & 5.1493 & TRN & \\
\hline CHEMBL1408926 & 688422 & 4.5 & 5.4961 & TRN & \\
\hline CHEMBL1489398 & 688422 & 6.5 & 5.5095 & TST & \\
\hline CHEMBL1575058 & 688422 & 5.8 & 5.9048 & TRN & \\
\hline CHEMBL1573265 & 688422 & 4.55 & 5.4419 & TST & \\
\hline CHEMBL1547818 & 688422 & 4.8 & 5.3756 & TST & \\
\hline CHEMBL1601007 & 688422 & 5.85 & 5.1004 & TRN & \\
\hline CHEMBL1373230 & 688422 & 4.45 & 5.4073 & TRN & \\
\hline CHEMBL1390838 & 688422 & 4.45 & 6.0086 & TRN & \\
\hline CHEMBL3190609 & 688422 & 4.65 & 5.4871 & TST & \\
\hline CHEMBL1386059 & 688422 & 4.45 & 5.7244 & TST & \\
\hline CHEMBL1594310 & 688422 & 4.5 & 5.358 & TRN & \\
\hline CHEMBL187801 & 688422 & 6.5 & 5.3687 & TRN & \\
\hline CHEMBL1420039 & 688422 & 5.85 & 5.2806 & TRN & \\
\hline CHEMBL1588762 & 688422 & 4.95 & 4.7081 & TRN & \\
\hline CHEMBL1485443 & 688422 & 4.65 & 5.1186 & TRN & \\
\hline CHEMBL3191434 & 688422 & 4.85 & 5.251 & TST & \\
\hline CHEMBL3197588 & 688422 & 4.75 & 5.1568 & TST & \\
\hline CHEMBL1480305 & 688422 & 4.45 & 5.1371 & TRN & \\
\hline CHEMBL1609674 & 688422 & 4.95 & 5.1633 & TRN & \\
\hline CHEMBL1607761 & 688422 & 5.5 & 5.266 & TST & \\
\hline CHEMBL1565888 & 688422 & 4.55 & 5.0416 & TRN & \\
\hline CHEMBL3196037 & 688422 & 6.6 & 5.4571 & TRN & \\
\hline CHEMBL1573309 & 688422 & 5.05 & 5.3127 & TRN & \\
\hline CHEMBL3192648 & 688422 & 6.05 & 5.2074 & TRN & \\
\hline CHEMBL1512148 & 688422 & 4.85 & 4.9517 & TRN & \\
\hline CHEMBL1428003 & 688422 & 4.6 & 4.6578 & TRN & \\
\hline CHEMBL1535570 & 688422 & 8.3468 & 5.7255 & TST & \\
\hline CHEMBL466930 & 688422 & 4.45 & 4.9158 & TRN & \\
\hline CHEMBL1458694 & 688422 & 4.9 & 5.6533 & TRN & \\
\hline CHEMBL1501237 & 688422 & 4.45 & $5.4970 e$ & 0000000001 & TRN \\
\hline CHEMBL1465320 & 688422 & 4.45 & $5.8370 e$ & 0000000001 & TRN \\
\hline CHEMBL1455056 & 688422 & 4.65 & 5.1733 & TST & \\
\hline CHEMBL1496821 & 688422 & 4.9 & 5.0713 & TRN & \\
\hline CHEMBL1445742 & 688422 & 4.75 & 4.7754 & TRN & \\
\hline CHEMBL1350614 & 688422 & 5.1 & 5.0763 & TRN & \\
\hline CHEMBL1339338 & 688422 & 4.45 & 4.9976 & TRN & \\
\hline CHEMBL1996068 & 688422 & 5.35 & 5.1438 & TRN & \\
\hline CHEMBL1577395 & 688422 & 5.05 & 5.1657 & TRN & \\
\hline CHEMBL1387010 & 688422 & 4.5 & 4.7993 & TRN & \\
\hline CHEMBL1534949 & 688422 & 7.6498 & 5.2154 & TRN & \\
\hline CHEMBL1305490 & 688422 & 4.45 & 5.226 & TRN & \\
\hline CHEMBL1422476 & 688422 & 4.75 & 4.8863 & TST & \\
\hline CHEMBL1315149 & 688422 & 4.7 & 5.4819 & TRN & \\
\hline CHEMBL400598 & 688422 & 9.3979 & 5.4647 & TST & \\
\hline CHEMBL1529499 & 688422 & 4.95 & 5.0782 & TRN & \\
\hline CHEMBL1390764 & 688422 & 6.05 & 5.2798 & TRN & \\
\hline CHEMBL1444397 & 688422 & 4.45 & $4.9510 e$ & 00000000005 & TRN \\
\hline & & & & 10119 & \\
\hline
\end{tabular}




\begin{tabular}{|c|c|c|c|c|c|}
\hline \multicolumn{6}{|c|}{ Supplemental Table S2.txt } \\
\hline CHEMBL1596683 & 688422 & 4.65 & 5.3303 & TRN & \\
\hline CHEMBL1329557 & 688422 & 4.95 & 5.0353 & TRN & \\
\hline CHEMBL1497396 & 688422 & 5.6 & 4.9624 & TRN & \\
\hline CHEMBL1567282 & 688422 & 4.6 & 5.1241 & TRN & \\
\hline CHEMBL1557939 & 688422 & 4.95 & 5.2686 & TRN & \\
\hline CHEMBL1550302 & 688422 & 5.1 & 5.4152 & TRN & \\
\hline CHEMBL1304001 & 688422 & 4.45 & 5.4196 & TRN & \\
\hline CHEMBL1324834 & 688422 & 4.65 & 4.7144 & TRN & \\
\hline CHEMBL1438294 & 688422 & 5.15 & 5.4551 & TRN & \\
\hline CHEMBL1456336 & 688422 & 4.7 & 5.0710 & 0000000001 & TRN \\
\hline CHEMBL1384997 & 688422 & 4.45 & 5.3455 & TRN & \\
\hline CHEMBL1563910 & 688422 & 5.0 & 5.1139 & TRN & \\
\hline CHEMBL1305663 & 688422 & 4.8 & 4.7786 & TRN & \\
\hline CHEMBL1344324 & 688422 & 4.45 & 5.3232 & TRN & \\
\hline CHEMBL1381800 & 688422 & 5.95 & 5.5929 & TRN & \\
\hline CHEMBL1433970 & 688422 & 6.05 & 5.2588 & TRN & \\
\hline CHEMBL1509195 & 688422 & 5.25 & 5.2523 & TRN & \\
\hline CHEMBL1548785 & 688422 & 4.9 & 4.9273 & TRN & \\
\hline CHEMBL1492763 & 688422 & 4.85 & 5.1809 & TRN & \\
\hline CHEMBL 3193284 & 688422 & 4.95 & 4.8367 & TRN & \\
\hline CHEMBL1390651 & 688422 & 4.9 & 5.0865 & TRN & \\
\hline CHEMBL1457112 & 688422 & 5.25 & 5.4059 & TRN & \\
\hline CHEMBL1518454 & 688422 & 4.8 & 4.9273 & TRN & \\
\hline CHEMBL1598299 & 688422 & 4.5 & 5.0671 & TST & \\
\hline CHEMBL1612211 & 688422 & 6.15 & 5.3081 & TRN & \\
\hline CHEMBL1341697 & 688422 & 4.95 & 4.9607 & TST & \\
\hline CHEMBL1511994 & 688422 & 7.2 & 5.0441 & TRN & \\
\hline CHEMBL1425802 & 688422 & 5.45 & 5.3363 & TRN & \\
\hline CHEMBL1577016 & 688422 & 5.5 & 5.358 & TRN & \\
\hline CHEMBL1555635 & 688422 & 5.35 & 5.4128 & TRN & \\
\hline CHEMBL1419563 & 688422 & 6.6499 & 4.8324 & TRN & \\
\hline CHEMBL1398637 & 688422 & 9.3979 & 5.5892 & TRN & \\
\hline CHEMBL1306153 & 688422 & 5.75 & 5.1487 & TST & \\
\hline CHEMBL 397974 & 688422 & 5.15 & 6.1553 & TRN & \\
\hline CHEMBL1333153 & 688422 & 4.5 & 5.4595 & TRN & \\
\hline CHEMBL1596152 & 688422 & 5.0 & 5.0691 & TRN & \\
\hline CHEMBL 1486878 & 688422 & 4.7 & 4.9915 & TRN & \\
\hline CHEMBL1348025 & 688422 & 4.75 & 5.4054 & TRN & \\
\hline CHEMBL1342451 & 688422 & 5.25 & 5.275 & TRN & \\
\hline CHEMBL1332272 & 688422 & 6.35 & 5.4033 & TRN & \\
\hline CHEMBL1506436 & 688422 & 4.95 & 5.1794 & TRN & \\
\hline CHEMBL1567824 & 688422 & 4.75 & 5.0744 & TST & \\
\hline CHEMBL1304898 & 688422 & 4.45 & 5.1415 & TRN & \\
\hline CHEMBL1542818 & 688422 & 8.4949 & 5.2964 & TRN & \\
\hline CHEMBL1483228 & 688422 & 4.65 & 5.144 & TRN & \\
\hline CHEMBL1480976 & 688422 & 4.85 & 5.5248 & TRN & \\
\hline CHEMBL1412063 & 688422 & 4.8 & 5.1346 & TRN & \\
\hline CHEMBL1406702 & 688422 & 5.95 & 5.5693 & TRN & \\
\hline
\end{tabular}




\begin{tabular}{|c|c|c|c|c|c|}
\hline \multirow{3}{*}{$\begin{array}{l}\text { CHEMBL1399234 } \\
\text { CHEMBL1339613 }\end{array}$} & \multirow{3}{*}{$\begin{array}{l}688422 \\
688422\end{array}$} & \multicolumn{4}{|c|}{ Supplemental Table S2.txt } \\
\hline & & 4.6 & \multicolumn{2}{|c|}{5.422999999999999} & TRN \\
\hline & & 4.5 & 5.2285 & TRN & \\
\hline CHEMBL1422470 & 688422 & 5.3 & 5.1374 & TRN & \\
\hline CHEMBL1413431 & 688422 & 4.65 & 5.0319 & TRN & \\
\hline CHEMBL405912 & 688422 & 4.95 & 5.3052 & TST & \\
\hline CHEMBL1413321 & 688422 & 4.75 & 5.4561 & TRN & \\
\hline CHEMBL1411948 & 688422 & 4.8 & 5.0735 & TST & \\
\hline CHEMBL1589298 & 688422 & 4.8 & 5.4798 & TST & \\
\hline CHEMBL1604680 & 688422 & 4.9 & \multicolumn{2}{|c|}{4.861000000000001} & TRN \\
\hline CHEMBL1520552 & 688422 & 4.45 & 5.1107 & TRN & \\
\hline CHEMBL1601021 & 688422 & 5.9 & 4.9573 & TRN & \\
\hline CHEMBL1611612 & 688422 & 4.85 & 5.0093 & TRN & \\
\hline CHEMBL1427594 & 688422 & 4.7 & 5.2668 & TRN & \\
\hline CHEMBL1411820 & 688422 & 4.9 & 5.0777 & TRN & \\
\hline CHEMBL3144992 & 688422 & 4.5 & 4.91 & TRN & \\
\hline CHEMBL1392244 & 688422 & 4.45 & 5.3563 & TST & \\
\hline CHEMBL1460897 & 688422 & 4.45 & 5.0596 & TRN & \\
\hline CHEMBL1372588 & 688422 & 5.25 & 5.3674 & TST & \\
\hline CHEMBL1527275 & 688422 & 4.85 & 5.1715 & TRN & \\
\hline CHEMBL 3196020 & 688422 & 4.65 & 5.1757 & TRN & \\
\hline CHEMBL1439158 & 688422 & 5.1 & 5.2289 & TRN & \\
\hline CHEMBL1504080 & 688422 & 4.45 & 4.8974 & TRN & \\
\hline CHEMBL1607393 & 688422 & 4.85 & 5.6277 & TRN & \\
\hline CHEMBL1349292 & 688422 & 5.1 & 4.9069 & TST & \\
\hline CHEMBL1485047 & 688422 & 5.9 & 5.4362 & TRN & \\
\hline CHEMBL1546914 & 688422 & 4.45 & 5.0706 & TRN & \\
\hline CHEMBL1530425 & 688422 & 6.3 & 5.7055 & TRN & \\
\hline CHEMBL1498585 & 688422 & 4.45 & 5.5454 & TRN & \\
\hline CHEMBL 2000815 & 688422 & 4.45 & 5.2407 & TRN & \\
\hline CHEMBL1418110 & 688422 & 4.5 & 5.2714 & TST & \\
\hline CHEMBL1525961 & 688422 & 4.5 & 5.2144 & TST & \\
\hline CHEMBL1310822 & 688422 & 4.7 & 5.1076 & TRN & \\
\hline CHEMBL1612671 & 688422 & 4.95 & 5.3664 & TRN & \\
\hline CHEMBL1605512 & 688422 & 4.55 & 5.2051 & TRN & \\
\hline CHEMBL1466156 & 688422 & 4.6 & 4.9927 & TRN & \\
\hline CHEMBL1342771 & 688422 & 4.8 & 5.7757 & TRN & \\
\hline CHEMBL1390746 & 688422 & 4.8 & 4.9505 & TRN & \\
\hline CHEMBL1547042 & 688422 & 6.05 & 5.3257 & TRN & \\
\hline CHEMBL1493956 & 688422 & 4.75 & 5.3121 & TRN & \\
\hline CHEMBL1440953 & 688422 & 4.45 & 5.1386 & TST & \\
\hline CHEMBL1501913 & 688422 & 4.85 & 5.5871 & TRN & \\
\hline CHEMBL1341502 & 688422 & 6.9 & 4.8694 & TST & \\
\hline CHEMBL1338108 & 688422 & 7.0 & 4.7788 & TRN & \\
\hline CHEMBL1612017 & 688422 & 4.7 & 5.4236 & TST & \\
\hline CHEMBL1999451 & 688422 & 5.2 & 5.2053 & TRN & \\
\hline CHEMBL1387929 & 688422 & 4.5 & 5.5518 & TRN & \\
\hline CHEMBL1508593 & 688422 & 7.0501 & 4.8492 & TRN & \\
\hline CHEMBL1505184 & 688422 & 8.3979 & 5.4535 & TRN & \\
\hline
\end{tabular}




\begin{tabular}{|c|c|c|c|c|c|}
\hline \multicolumn{6}{|c|}{ Supplemental Table S2.txt } \\
\hline CHEMBL1574544 & 688422 & 4.45 & 5.2849 & TST & \\
\hline CHEMBL1430572 & 688422 & 4.65 & 4.8232 & TRN & \\
\hline CHEMBL1470494 & 688422 & 5.2 & 5.3074 & TRN & \\
\hline CHEMBL1380692 & 688422 & 6.5 & 5.2466 & TRN & \\
\hline CHEMBL1403182 & 688422 & 4.45 & 5.6529 & TRN & \\
\hline CHEMBL1598864 & 688422 & 4.8 & 4.9722 & TRN & \\
\hline CHEMBL1572662 & 688422 & 4.75 & 5.0826 & TST & \\
\hline CHEMBL1403579 & 688422 & 4.45 & 4.9907 & TST & \\
\hline CHEMBL1312476 & 688422 & 4.6 & 4.954 & TRN & \\
\hline CHEMBL1602083 & 688422 & 5.5 & 4.9681 & TRN & \\
\hline CHEMBL1406534 & 688422 & 5.35 & 4.9859 & TRN & \\
\hline CHEMBL1452062 & 688422 & 6.05 & 5.6393 & TRN & \\
\hline CHEMBL1504625 & 688422 & 6.05 & 5.2315 & TRN & \\
\hline CHEMBL3210139 & 688422 & 5.35 & 5.2811 & TRN & \\
\hline CHEMBL1581570 & 688422 & 4.95 & 5.4255 & TRN & \\
\hline CHEMBL1345747 & 688422 & 4.95 & 5.0265 & TRN & \\
\hline CHEMBL1355029 & 688422 & 4.45 & 5.1443 & TRN & \\
\hline CHEMBL1519116 & 688422 & 4.45 & 4.9633 & TRN & \\
\hline CHEMBL1519151 & 688422 & 4.65 & 5.1121 & TRN & \\
\hline CHEMBL3191657 & 688422 & 4.5 & 5.9415 & TST & \\
\hline CHEMBL1525095 & 688422 & 4.45 & 5.0628 & TRN & \\
\hline CHEMBL1487513 & 688422 & 4.45 & 4.7914 & TRN & \\
\hline CHEMBL 2004144 & 688422 & 4.9 & 5.1576 & TRN & \\
\hline CHEMBL530049 & 688422 & 4.45 & 5.3506 & TST & \\
\hline CHEMBL1600623 & 688422 & 4.45 & 5.0592 & TRN & \\
\hline CHEMBL 2000750 & 688422 & 4.7 & 5.0344 & TRN & \\
\hline CHEMBL3198907 & 688422 & 5.05 & 5.0877 & TRN & \\
\hline CHEMBL1485078 & 688422 & 5.3 & 5.3064 & TRN & \\
\hline CHEMBL1555491 & 688422 & 4.5 & 5.0534 & TRN & \\
\hline CHEMBL1445726 & 688422 & 5.15 & 5.3212 & TRN & \\
\hline CHEMBL1422399 & 688422 & 4.95 & 5.0127 & TST & \\
\hline CHEMBL1326567 & 688422 & 5.0 & 5.109 & TRN & \\
\hline CHEMBL1467599 & 688422 & 7.3497 & 5.91 & TRN & \\
\hline CHEMBL1434997 & 688422 & 4.65 & 4.8765 & TRN & \\
\hline CHEMBL1606685 & 688422 & 4.9 & 5.3652 & TRN & \\
\hline CHEMBL1305761 & 688422 & 4.45 & 5.4697 & TRN & \\
\hline CHEMBL1422625 & 688422 & 5.55 & 5.4217 & TST & \\
\hline CHEMBL1539298 & 688422 & 5.3 & 5.25700 & 0000000001 & TRN \\
\hline CHEMBL 3145303 & 688422 & 4.95 & 5.6706 & TST & \\
\hline CHEMBL1448757 & 688422 & 4.45 & 5.4617 & TST & \\
\hline CHEMBL1381668 & 688422 & 4.95 & 4.8758 & TRN & \\
\hline CHEMBL1342711 & 688422 & 4.9 & 5.6531 & TST & \\
\hline CHEMBL3209840 & 688422 & 6.7501 & 5.6103 & TST & \\
\hline CHEMBL1530268 & 688422 & 7.0 & 5.2229 & TRN & \\
\hline CHEMBL1330586 & 688422 & 4.85 & 4.8417 & TRN & \\
\hline CHEMBL1441053 & 688422 & 4.45 & 5.3126 & TST & \\
\hline CHEMBL1363988 & 688422 & 4.9 & 4.6074 & TRN & \\
\hline CHEMBL1523564 & 688422 & 4.9 & 5.2266 & TST & \\
\hline
\end{tabular}




\begin{tabular}{|c|c|c|c|c|c|}
\hline \multicolumn{6}{|c|}{ Supplemental Table S2.txt } \\
\hline CHEMBL1406787 & 688422 & 4.85 & 5.1494 & TRN & \\
\hline CHEMBL1588812 & 688422 & 5.4 & 5.4328 & TRN & \\
\hline CHEMBL3209375 & 688422 & 6.4 & 5.86100 & 0000000001 & TRN \\
\hline CHEMBL1602084 & 688422 & 4.6 & 4.9821 & TRN & \\
\hline CHEMBL1430772 & 688422 & 4.6 & 5.2952 & TRN & \\
\hline CHEMBL1380334 & 688422 & 7.2503 & 5.0813 & TRN & \\
\hline CHEMBL1966001 & 688422 & 4.95 & 5.3275 & TRN & \\
\hline CHEMBL1327383 & 688422 & 4.5 & 5.0484 & TRN & \\
\hline CHEMBL1558549 & 688422 & 4.7 & 5.1296 & TRN & \\
\hline CHEMBL3211401 & 688422 & 4.45 & 4.9608 & TST & \\
\hline CHEMBL 3196681 & 688422 & 4.95 & 5.3303 & TRN & \\
\hline CHEMBL1433152 & 688422 & 4.45 & 5.0237 & TRN & \\
\hline CHEMBL3214287 & 688422 & 4.6 & 5.0876 & TRN & \\
\hline CHEMBL1441751 & 688422 & 6.25 & 5.2978 & TRN & \\
\hline CHEMBL1401438 & 688422 & 4.45 & 5.0151 & TRN & \\
\hline CHEMBL1570359 & 688422 & 4.45 & 5.2779 & TST & \\
\hline CHEMBL1410085 & 688422 & 5.05 & 4.9393 & TRN & \\
\hline CHEMBL1335691 & 688422 & 4.7 & 5.1848 & TRN & \\
\hline CHEMBL1394331 & 688422 & 5.05 & 5.1103 & TST & \\
\hline CHEMBL1346258 & 688422 & 4.75 & 4.9471 & TRN & \\
\hline CHEMBL1484438 & 688422 & 7.2 & 5.5884 & TRN & \\
\hline CHEMBL1389203 & 688422 & 6.95 & 5.3926 & TRN & \\
\hline CHEMBL1505956 & 688422 & 4.8 & 4.8487 & TRN & \\
\hline CHEMBL1466874 & 688422 & 4.75 & 5.3937 & TRN & \\
\hline CHEMBL1394002 & 688422 & 4.85 & 5.0526 & TRN & \\
\hline CHEMBL1566191 & 688422 & 4.85 & 5.1643 & TRN & \\
\hline CHEMBL1420393 & 688422 & 6.05 & 4.9722 & TST & \\
\hline CHEMBL1419413 & 688422 & 4.85 & 5.2834 & TRN & \\
\hline CHEMBL1524377 & 688422 & 5.6 & 5.3914 & TRN & \\
\hline CHEMBL1333894 & 688422 & 4.45 & 5.2146 & TRN & \\
\hline CHEMBL1567499 & 688422 & 5.1 & 5.49700 & 0000000001 & TRN \\
\hline CHEMBL1336595 & 688422 & 4.85 & 5.5969 & TRN & \\
\hline CHEMBL1342029 & 688422 & 5.25 & 5.1251 & TRN & \\
\hline CHEMBL1351688 & 688422 & 4.9 & 5.0306 & TRN & \\
\hline CHEMBL1584860 & 688422 & 4.8 & 5.2019 & TRN & \\
\hline CHEMBL1592992 & 688422 & 5.2 & 5.0372 & TRN & \\
\hline CHEMBL1422004 & 688422 & 5.45 & 5.0664 & TST & \\
\hline CHEMBL1606837 & 688422 & 4.85 & 5.2209 & TST & \\
\hline CHEMBL1561430 & 688422 & 4.85 & 4.9293 & TST & \\
\hline CHEMBL1329450 & 688422 & 4.7 & 4.7564 & TRN & \\
\hline CHEMBL1319368 & 688422 & 5.7 & 5.1565 & TRN & \\
\hline CHEMBL1330235 & 688422 & 4.45 & 4.8716 & TRN & \\
\hline CHEMBL1499971 & 688422 & 4.5 & 5.7376 & TST & \\
\hline CHEMBL1456659 & 688422 & 4.75 & 4.9399 & TST & \\
\hline CHEMBL1601367 & 688422 & 4.85 & 5.1003 & TRN & \\
\hline CHEMBL1302531 & 688422 & 4.5 & 4.9536 & TRN & \\
\hline CHEMBL1496236 & 688422 & 6.45 & 5.4711 & TRN & \\
\hline CHEMBL1384622 & 688422 & 5.5 & 5.1779 & TST & \\
\hline
\end{tabular}


TRN 


\begin{tabular}{|c|c|c|c|c|c|}
\hline \multicolumn{6}{|c|}{ Supplemental Table S2.txt } \\
\hline CHEMBL1351201 & 688422 & 4.95 & 5.1642 & TRN & \\
\hline CHEMBL3194523 & 688422 & 4.8 & 5.5527 & TRN & \\
\hline CHEMBL1375605 & 688422 & 5.25 & 5.0366 & TRN & \\
\hline CHEMBL1426570 & 688422 & 8.4949 & 5.2897 & TRN & \\
\hline CHEMBL1609063 & 688422 & 4.9 & 5.1008 & TRN & \\
\hline CHEMBL1985354 & 688422 & 6.35 & 5.1964 & TRN & \\
\hline CHEMBL1469644 & 688422 & 4.45 & 5.2428 & TRN & \\
\hline CHEMBL1564072 & 688422 & 5.4 & 5.6933 & TST & \\
\hline CHEMBL1374704 & 688422 & 4.95 & 5.3551 & TST & \\
\hline CHEMBL1303989 & 688422 & 5.35 & 5.0626 & TRN & \\
\hline CHEMBL 3195241 & 688422 & 4.45 & 5.209 & TST & \\
\hline CHEMBL1603466 & 688422 & 5.2 & 5.6205 & TRN & \\
\hline CHEMBL1318475 & 688422 & 7.1002 & 5.4924 & TRN & \\
\hline CHEMBL1533190 & 688422 & 4.45 & 5.0496 & TRN & \\
\hline CHEMBL3210072 & 688422 & 5.2 & 5.4642 & TRN & \\
\hline CHEMBL1328023 & 688422 & 5.05 & 5.8135 & TRN & \\
\hline CHEMBL1482338 & 688422 & 4.9 & 5.1126 & TST & \\
\hline CHEMBL1490011 & 688422 & 4.8 & 5.1196 & TRN & \\
\hline CHEMBL1543671 & 688422 & 4.45 & 5.3158 & TRN & \\
\hline CHEMBL1556474 & 688422 & 4.45 & 5.19600 & 0000000001 & TST \\
\hline CHEMBL1369544 & 688422 & 4.6 & 5.1515 & TST & \\
\hline CHEMBL1493272 & 688422 & 5.1 & 5.1732 & TST & \\
\hline CHEMBL1515923 & 688422 & 5.5 & 5.8524 & TRN & \\
\hline CHEMBL1415228 & 688422 & 7.3002 & 5.2564 & TRN & \\
\hline CHEMBL1552168 & 688422 & 4.7 & 5.359 & TRN & \\
\hline CHEMBL1483117 & 688422 & 4.6 & 4.8548 & TRN & \\
\hline CHEMBL1313346 & 688422 & 5.0 & 5.1255 & TST & \\
\hline CHEMBL1475914 & 688422 & 4.9 & 5.0089 & TRN & \\
\hline CHEMBL1334914 & 688422 & 4.65 & 5.2237 & TST & \\
\hline CHEMBL3197429 & 688422 & 4.6 & 5.4965 & TST & \\
\hline CHEMBL1396372 & 688422 & 6.05 & 5.4251 & TST & \\
\hline CHEMBL1588329 & 688422 & 4.45 & 5.1198 & TRN & \\
\hline CHEMBL1488793 & 688422 & 4.45 & 5.2787 & TRN & \\
\hline CHEMBL1491004 & 688422 & 5.5 & 4.8571 & TRN & \\
\hline CHEMBL1610367 & 688422 & 4.75 & 4.7043 & TRN & \\
\hline CHEMBL1480548 & 688422 & 4.8 & 5.1567 & TRN & \\
\hline CHEMBL1355675 & 688422 & 8.0506 & 5.2357 & TRN & \\
\hline CHEMBL1317869 & 688422 & 4.45 & 5.33700 & 0000000001 & TST \\
\hline CHEMBL1549879 & 688422 & 4.9 & 5.1764 & TRN & \\
\hline CHEMBL1547329 & 688422 & 4.85 & 5.5981 & TST & \\
\hline CHEMBL1377656 & 688422 & 4.45 & 4.6564 & TRN & \\
\hline CHEMBL1315835 & 688422 & 7.0501 & 5.9364 & TRN & \\
\hline CHEMBL1421772 & 688422 & 5.15 & 4.9278 & TST & \\
\hline CHEMBL1483145 & 688422 & 4.85 & 5.2307 & TRN & \\
\hline CHEMBL1386724 & 688422 & 4.65 & 5.3223 & TST & \\
\hline CHEMBL1320005 & 688422 & 4.45 & 5.6929 & TRN & \\
\hline CHEMBL1539597 & 688422 & 5.85 & 5.2971 & TRN & \\
\hline CHEMBL1454500 & 688422 & 4.8 & 4.8502 & TRN & \\
\hline
\end{tabular}




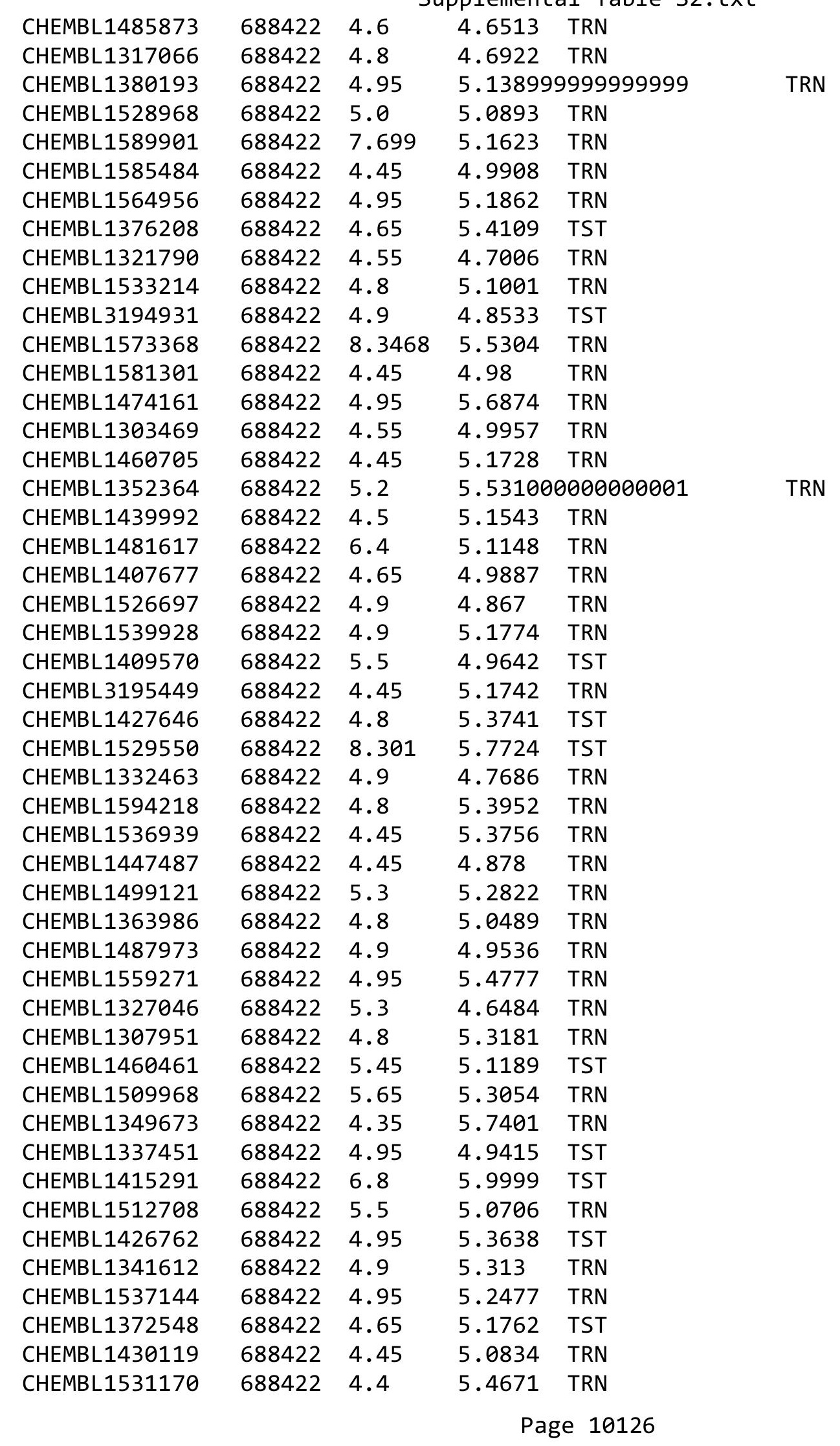




\begin{tabular}{|c|c|c|c|c|c|}
\hline \multicolumn{6}{|c|}{ Supplemental Table S2.txt } \\
\hline CHEMBL1315315 & 688422 & 4.9 & 5.1496 & TRN & \\
\hline CHEMBL1379881 & 688422 & 4.8 & 5.1938 & TRN & \\
\hline CHEMBL1482634 & 688422 & 5.35 & 5.644 & TST & \\
\hline CHEMBL1348135 & 688422 & 4.95 & 5.4086 & TST & \\
\hline CHEMBL1537178 & 688422 & 8.0506 & 4.9435 & TST & \\
\hline CHEMBL1256924 & 688422 & 5.25 & 5.2669 & TRN & \\
\hline CHEMBL1430822 & 688422 & 4.6 & 4.757 & TRN & \\
\hline CHEMBL1423734 & 688422 & 4.95 & 5.3553 & TRN & \\
\hline CHEMBL1509128 & 688422 & 4.8 & 5.3962 & TRN & \\
\hline CHEMBL1387918 & 688422 & 4.45 & 5.0949 & TRN & \\
\hline CHEMBL1311603 & 688422 & 5.0 & 5.8156 & TST & \\
\hline CHEMBL1561366 & 688422 & 4.45 & 4.7144 & TRN & \\
\hline CHEMBL1427270 & 688422 & 4.45 & 5.4933 & TRN & \\
\hline CHEMBL1443184 & 688422 & 4.7 & 5.2304 & TRN & \\
\hline CHEMBL1376391 & 688422 & 5.95 & 6.0692 & TRN & \\
\hline CHEMBL1546412 & 688422 & 4.45 & 4.3423 & TRN & \\
\hline CHEMBL1449911 & 688422 & 4.75 & 5.022 & TRN & \\
\hline CHEMBL1308229 & 688422 & 7.0501 & 5.8639 & TRN & \\
\hline CHEMBL1412029 & 688422 & 4.9 & 5.3453 & TRN & \\
\hline CHEMBL1491425 & 688422 & 5.9 & 5.6262 & TRN & \\
\hline CHEMBL1443128 & 688422 & 4.45 & 5.38700 & 00000000005 & TRN \\
\hline CHEMBL1503950 & 688422 & 5.05 & 5.1258 & TRN & \\
\hline CHEMBL1427361 & 688422 & 4.65 & 5.1365 & TRN & \\
\hline CHEMBL1603871 & 688422 & 4.6 & 5.0824 & TRN & \\
\hline CHEMBL1359842 & 688422 & 4.45 & 5.0446 & TRN & \\
\hline CHEMBL1429456 & 688422 & 4.85 & 5.0292 & TRN & \\
\hline CHEMBL1533542 & 688422 & 4.45 & 5.42700 & 00000000005 & TST \\
\hline CHEMBL3210612 & 688422 & 4.65 & 5.3884 & TST & \\
\hline CHEMBL1456000 & 688422 & 6.3 & 5.4888 & TRN & \\
\hline CHEMBL1493765 & 688422 & 6.5501 & 5.3903 & TRN & \\
\hline CHEMBL1451114 & 688422 & 5.8 & 5.5844 & TRN & \\
\hline CHEMBL1420437 & 688422 & 4.8 & 5.4809 & TRN & \\
\hline CHEMBL1410134 & 688422 & 7.2 & 5.3555 & TST & \\
\hline CHEMBL3191064 & 688422 & 4.5 & 5.1741 & TRN & \\
\hline CHEMBL1553331 & 688422 & 5.2 & 5.3421 & TST & \\
\hline CHEMBL1557948 & 688422 & 4.5 & 5.3485 & TRN & \\
\hline CHEMBL1563757 & 688422 & 4.95 & 5.1261 & TRN & \\
\hline CHEMBL1517426 & 688422 & 5.45 & 5.5842 & TRN & \\
\hline CHEMBL1510517 & 688422 & 4.8 & 5.2988 & TRN & \\
\hline CHEMBL1585036 & 688422 & 4.7 & 4.9858 & TRN & \\
\hline CHEMBL1457342 & 688422 & 4.65 & 5.0511 & TST & \\
\hline CHEMBL1583270 & 688422 & 4.45 & 5.3625 & TRN & \\
\hline CHEMBL3192441 & 688422 & 4.55 & 5.2628 & TST & \\
\hline CHEMBL1402360 & 688422 & 4.6 & 4.9592 & TRN & \\
\hline CHEMBL1540512 & 688422 & 7.3002 & 5.265 & TRN & \\
\hline CHEMBL1508610 & 688422 & 4.9 & 5.1942 & TRN & \\
\hline CHEMBL1377381 & 688422 & 5.55 & 5.4041 & TRN & \\
\hline CHEMBL1972996 & 688422 & 4.5 & 5.4227 & TST & \\
\hline
\end{tabular}




\begin{tabular}{|c|c|c|c|c|c|}
\hline \multicolumn{6}{|c|}{ Supplemental Table S2.txt } \\
\hline CHEMBL1413830 & 688422 & 4.95 & 5.4371 & TRN & \\
\hline CHEMBL1306250 & 688422 & 5.0 & 5.0545 & TRN & \\
\hline CHEMBL1568924 & 688422 & 4.85 & 4.9415 & TST & \\
\hline CHEMBL1533141 & 688422 & 5.0 & 5.3997 & TRN & \\
\hline CHEMBL3195389 & 688422 & 5.7 & 5.3541 & TRN & \\
\hline CHEMBL1364618 & 688422 & 4.85 & 4.7845 & TRN & \\
\hline CHEMBL1428407 & 688422 & 5.05 & 4.7846 & TRN & \\
\hline CHEMBL1556603 & 688422 & 4.75 & 5.0157 & TRN & \\
\hline CHEMBL1576499 & 688422 & 4.45 & 5.44799 & 99999999995 & TST \\
\hline CHEMBL1586183 & 688422 & 7.2 & 5.4012 & TST & \\
\hline CHEMBL1371135 & 688422 & 7.699 & 5.6319 & TST & \\
\hline CHEMBL1347728 & 688422 & 7.5003 & 5.4199 & TRN & \\
\hline CHEMBL1581813 & 688422 & 4.6 & 5.0772 & TRN & \\
\hline CHEMBL1422803 & 688422 & 4.8 & 5.355 & TST & \\
\hline CHEMBL1413873 & 688422 & 5.3 & 5.3439 & TRN & \\
\hline CHEMBL1395913 & 688422 & 8.4949 & 5.4684 & TRN & \\
\hline CHEMBL1409345 & 688422 & 5.55 & 5.3263 & TRN & \\
\hline CHEMBL1303801 & 688422 & 4.95 & 5.1662 & TRN & \\
\hline CHEMBL1392177 & 688422 & 7.4001 & 5.2306 & TRN & \\
\hline CHEMBL1504246 & 688422 & 6.7501 & 5.277 & TRN & \\
\hline CHEMBL1596347 & 688422 & 5.65 & 4.8971 & TST & \\
\hline CHEMBL1355625 & 688422 & 4.4 & 5.3717 & TRN & \\
\hline CHEMBL1390386 & 688422 & 5.55 & 5.1891 & TRN & \\
\hline CHEMBL1312943 & 688422 & 4.9 & 5.1675 & TRN & \\
\hline CHEMBL1324923 & 688422 & 7.0 & 5.2964 & TST & \\
\hline CHEMBL1464440 & 688422 & 4.65 & 4.8461 & TST & \\
\hline CHEMBL 2374027 & 688422 & 5.15 & 5.0216 & TRN & \\
\hline CHEMBL3207736 & 688422 & 5.0 & 4.8321 & TST & \\
\hline CHEMBL1552625 & 688422 & 5.45 & 5.3465 & TRN & \\
\hline CHEMBL1327053 & 688422 & 4.95 & 5.54700 & 0000000001 & TRN \\
\hline CHEMBL1565400 & 688422 & 7.4001 & 5.2913 & TRN & \\
\hline CHEMBL1407976 & 688422 & 4.8 & 5.0842 & TRN & \\
\hline CHEMBL1593765 & 688422 & 6.0 & 5.1273 & TRN & \\
\hline CHEMBL1405221 & 688422 & 4.7 & 4.982 & TRN & \\
\hline CHEMBL1478240 & 688422 & 6.8 & 4.9513 & TRN & \\
\hline CHEMBL1331563 & 688422 & 4.75 & 4.8666 & TRN & \\
\hline CHEMBL1570469 & 688422 & 6.4 & 5.471 & TST & \\
\hline CHEMBL1300431 & 688422 & 4.85 & 4.9843 & TRN & \\
\hline CHEMBL1356908 & 688422 & 8.3468 & 5.3027 & TRN & \\
\hline CHEMBL1397910 & 688422 & 5.0 & 5.1969 & TRN & \\
\hline CHEMBL1374030 & 688422 & 4.6 & 5.0049 & TRN & \\
\hline CHEMBL1579226 & 688422 & 5.05 & 5.2911 & TST & \\
\hline CHEMBL3195849 & 688422 & 4.45 & 4.9236 & TST & \\
\hline CHEMBL1426249 & 688422 & 5.45 & 5.5159 & TRN & \\
\hline CHEMBL1573866 & 688422 & 4.9 & 5.0547 & TRN & \\
\hline CHEMBL1322752 & 688422 & 7.6498 & 4.9844 & TRN & \\
\hline CHEMBL3197076 & 688422 & 4.75 & 5.4896 & TST & \\
\hline CHEMBL1444145 & 688422 & 5.5 & 5.4234 & TST & \\
\hline
\end{tabular}




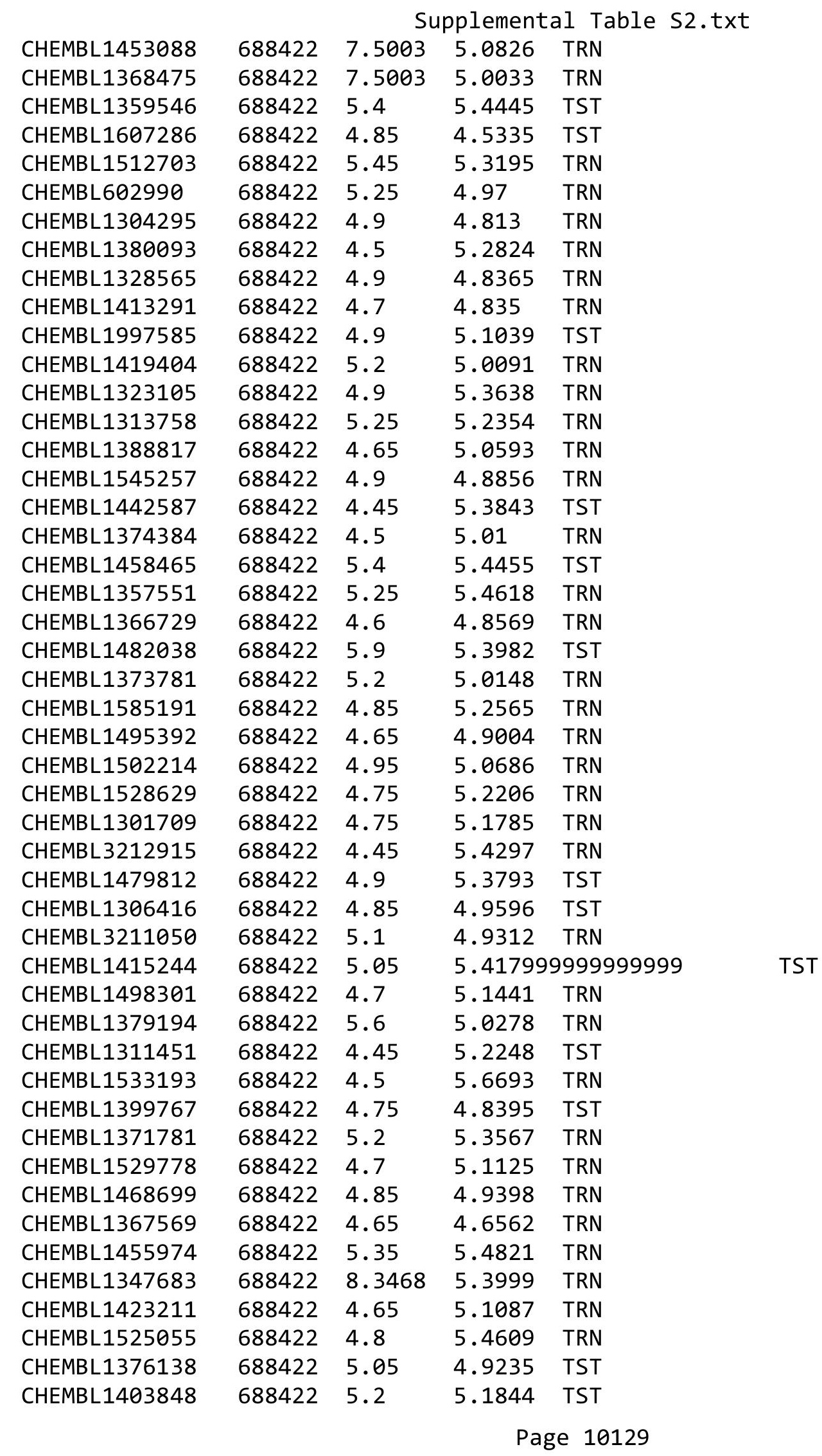




\begin{tabular}{|c|c|c|c|c|c|}
\hline \multicolumn{6}{|c|}{ Supplemental Table S2.txt } \\
\hline CHEMBL1305661 & 688422 & 6.35 & 5.5185 & TST & \\
\hline CHEMBL1341795 & 688422 & 5.2 & 5.2878 & TRN & \\
\hline CHEMBL1347144 & 688422 & 4.8 & 5.0019 & TRN & \\
\hline CHEMBL1555674 & 688422 & 8.0506 & 5.2686 & TST & \\
\hline CHEMBL1533641 & 688422 & 4.45 & 4.9566 & TRN & \\
\hline CHEMBL1383888 & 688422 & 5.0 & 5.145 & TRN & \\
\hline CHEMBL1613188 & 688422 & 5.55 & 5.1877 & TRN & \\
\hline CHEMBL1610793 & 688422 & 6.05 & 5.3409 & TRN & \\
\hline CHEMBL1461841 & 688422 & 4.7 & 5.2715 & TST & \\
\hline CHEMBL1388353 & 688422 & 4.85 & 4.7791 & TRN & \\
\hline CHEMBL1526582 & 688422 & 4.45 & 4.9334 & TRN & \\
\hline CHEMBL1438396 & 688422 & 4.65 & 5.3111 & TRN & \\
\hline CHEMBL1404018 & 688422 & 5.25 & 5.2833 & TRN & \\
\hline CHEMBL1596398 & 688422 & 5.35 & 5.3451 & TRN & \\
\hline CHEMBL1410897 & 688422 & 5.6 & 5.1696 & TRN & \\
\hline CHEMBL1491598 & 688422 & 4.45 & 5.2198 & TRN & \\
\hline CHEMBL1462474 & 688422 & 4.8 & 5.3113 & TST & \\
\hline CHEMBL 2005664 & 688422 & 4.95 & 5.2913 & TRN & \\
\hline CHEMBL1599920 & 688422 & 6.5501 & 5.052 & TRN & \\
\hline CHEMBL1321142 & 688422 & 5.4 & 5.4838 & TST & \\
\hline CHEMBL1601026 & 688422 & 4.45 & 5.1059 & TST & \\
\hline CHEMBL1371058 & 688422 & 6.1 & 5.1865 & TST & \\
\hline CHEMBL1344977 & 688422 & 5.0 & 5.2908 & TST & \\
\hline CHEMBL16687 & 688422 & 5.05 & 5.5773 & TST & \\
\hline CHEMBL1353903 & 688422 & 5.95 & 5.2476 & TST & \\
\hline CHEMBL1569549 & 688422 & 4.95 & 5.07 & TST & \\
\hline CHEMBL1381408 & 688422 & 4.7 & 4.5789 & TRN & \\
\hline CHEMBL1558111 & 688422 & 4.8 & 5.1492 & TST & \\
\hline CHEMBL1476633 & 688422 & 6.8 & 5.0606 & TRN & \\
\hline CHEMBL1331123 & 688422 & 5.2 & 5.46700 & 00000000005 & TST \\
\hline CHEMBL1527407 & 688422 & 4.85 & 5.0612 & TRN & \\
\hline CHEMBL1522868 & 688422 & 5.4 & 5.5 & TRN & \\
\hline CHEMBL1361592 & 688422 & 5.15 & 5.2519 & TST & \\
\hline CHEMBL1470192 & 688422 & 4.45 & 5.3999 & TRN & \\
\hline CHEMBL1458427 & 688422 & 4.45 & 5.5286 & TST & \\
\hline CHEMBL1380963 & 688422 & 4.85 & 5.1252 & TRN & \\
\hline CHEMBL1362107 & 688422 & 4.85 & 5.1123 & TST & \\
\hline CHEMBL1567330 & 688422 & 4.6 & 5.0706 & TRN & \\
\hline CHEMBL1489147 & 688422 & 4.5 & 5.1509 & TRN & \\
\hline CHEMBL1559729 & 688422 & 4.95 & 5.4376 & TRN & \\
\hline CHEMBL1558814 & 688422 & 4.65 & 4.919 & TRN & \\
\hline CHEMBL1334638 & 688422 & 5.2 & 4.8673 & TRN & \\
\hline CHEMBL1566724 & 688422 & 4.8 & 5.2149 & TRN & \\
\hline CHEMBL1307468 & 688422 & 4.45 & 5.0539 & TRN & \\
\hline CHEMBL1299842 & 688422 & 4.45 & 5.2837 & TRN & \\
\hline CHEMBL1444120 & 688422 & 6.45 & 5.356 & TRN & \\
\hline CHEMBL1359798 & 688422 & 4.65 & 5.0364 & TRN & \\
\hline CHEMBL1597046 & 688422 & 4.95 & 5.2331 & TRN & \\
\hline
\end{tabular}




\begin{tabular}{|c|c|c|c|c|c|}
\hline \multicolumn{6}{|c|}{ Supplemental Table S2.txt } \\
\hline CHEMBL1487326 & 688422 & 6.8 & 5.6672 & TRN & \\
\hline CHEMBL1368377 & 688422 & 7.4498 & 6.1932 & TRN & \\
\hline CHEMBL1500519 & 688422 & 4.65 & 5.1199 & TST & \\
\hline CHEMBL1404731 & 688422 & 4.45 & 5.2487 & TST & \\
\hline CHEMBL1528486 & 688422 & 4.5 & 4.92899 & 9999999999 & TRN \\
\hline CHEMBL1334230 & 688422 & 4.95 & 5.2828 & TRN & \\
\hline CHEMBL1425759 & 688422 & 4.45 & 5.5477 & TST & \\
\hline CHEMBL1464375 & 688422 & 4.85 & 5.1041 & TRN & \\
\hline CHEMBL1368971 & 688422 & 4.8 & 5.136 & TRN & \\
\hline CHEMBL1529687 & 688422 & 5.0 & 5.3997 & TRN & \\
\hline CHEMBL1522425 & 688422 & 4.75 & 5.0904 & TRN & \\
\hline CHEMBL1579696 & 688422 & 4.45 & 5.1822 & TRN & \\
\hline CHEMBL1359619 & 688422 & 4.9 & 5.4063 & TST & \\
\hline CHEMBL1343226 & 688422 & 4.8 & 4.9502 & TRN & \\
\hline CHEMBL1373869 & 688422 & 4.95 & 5.1198 & TRN & \\
\hline CHEMBL1488309 & 688422 & 7.4001 & 5.5978 & TRN & \\
\hline CHEMBL1509975 & 688422 & 4.95 & 5.2663 & TRN & \\
\hline CHEMBL 2005246 & 688422 & 4.9 & 4.6391 & TRN & \\
\hline CHEMBL1559035 & 688422 & 4.5 & 4.9029 & TRN & \\
\hline CHEMBL1532959 & 688422 & 4.6 & 5.575 & TST & \\
\hline CHEMBL1592612 & 688422 & 4.6 & 4.857 & TRN & \\
\hline CHEMBL1396180 & 688422 & 4.9 & 5.0518 & TRN & \\
\hline CHEMBL1507967 & 688422 & 4.45 & 5.4406 & TRN & \\
\hline CHEMBL1433001 & 688422 & 7.5498 & 5.3892 & TRN & \\
\hline CHEMBL1509016 & 688422 & 4.7 & 5.0787 & TRN & \\
\hline CHEMBL1463041 & 688422 & 4.5 & 5.1613 & TST & \\
\hline CHEMBL1570111 & 688422 & 4.8 & 4.9225 & TRN & \\
\hline CHEMBL1448364 & 688422 & 4.6 & 5.2215 & TRN & \\
\hline CHEMBL1461003 & 688422 & 6.95 & 5.4064 & TRN & \\
\hline CHEMBL1361887 & 688422 & 4.8 & 4.6375 & TST & \\
\hline CHEMBL1474029 & 688422 & 7.4001 & 5.7149 & TRN & \\
\hline CHEMBL1396037 & 688422 & 5.6 & 5.5538 & TRN & \\
\hline CHEMBL3191194 & 688422 & 4.8 & 5.1395 & TST & \\
\hline CHEMBL1304996 & 688422 & 4.6 & 5.4403 & TRN & \\
\hline CHEMBL1364954 & 688422 & 4.6 & 4.8923 & TRN & \\
\hline CHEMBL1549321 & 688422 & 5.15 & 5.0767 & TRN & \\
\hline CHEMBL1340668 & 688422 & 4.7 & 5.0934 & TRN & \\
\hline CHEMBL1505916 & 688422 & 4.95 & 5.0863 & TRN & \\
\hline CHEMBL1330549 & 688422 & 4.45 & 4.8989 & TRN & \\
\hline CHEMBL1342991 & 688422 & 6.5501 & 5.7041 & TRN & \\
\hline CHEMBL1541737 & 688422 & 4.75 & 5.0262 & TRN & \\
\hline CHEMBL600773 & 688422 & 5.8 & 4.8813 & TRN & \\
\hline CHEMBL1373569 & 688422 & 5.05 & 4.9073 & TRN & \\
\hline CHEMBL1547865 & 688422 & 4.95 & 4.8756 & TRN & \\
\hline CHEMBL1357724 & 688422 & 4.9 & 4.5583 & TRN & \\
\hline CHEMBL1323952 & 688422 & 5.05 & 5.3888 & TST & \\
\hline CHEMBL1323214 & 688422 & 4.85 & 5.1664 & TRN & \\
\hline CHEMBL1422699 & 688422 & 6.1 & 4.9715 & TRN & \\
\hline
\end{tabular}




\begin{tabular}{|c|c|c|c|c|c|}
\hline \multicolumn{6}{|c|}{ Supplemental Table S2.txt } \\
\hline CHEMBL1530864 & 688422 & 4.45 & 5.3796 & TRN & \\
\hline CHEMBL1391311 & 688422 & 5.65 & 5.254 & TST & \\
\hline CHEMBL1301207 & 688422 & 4.95 & 5.5667 & TRN & \\
\hline CHEMBL3208001 & 688422 & 7.4001 & 5.1671 & TRN & \\
\hline CHEMBL1440173 & 688422 & 4.9 & 5.34200 & 00000000005 & TRN \\
\hline CHEMBL1500306 & 688422 & 4.85 & 5.362 & TRN & \\
\hline CHEMBL1516586 & 688422 & 4.95 & 5.178 & TRN & \\
\hline CHEMBL1451252 & 688422 & 4.45 & 5.0219 & TRN & \\
\hline CHEMBL1340340 & 688422 & 7.6498 & 5.3446 & TRN & \\
\hline CHEMBL1535139 & 688422 & 4.8 & 5.6619 & TRN & \\
\hline CHEMBL3190325 & 688422 & 4.45 & 4.9847 & TST & \\
\hline CHEMBL3214213 & 688422 & 7.0501 & 5.4312 & TRN & \\
\hline CHEMBL1521453 & 688422 & 5.35 & 5.5284 & TST & \\
\hline CHEMBL1573652 & 688422 & 8.301 & 5.1562 & TRN & \\
\hline CHEMBL1477450 & 688422 & 7.7496 & 4.8555 & TST & \\
\hline CHEMBL1424375 & 688422 & 4.85 & 5.2413 & TRN & \\
\hline CHEMBL1588956 & 688422 & 4.65 & 5.181 & TRN & \\
\hline CHEMBL1385867 & 688422 & 4.9 & 5.1775 & TST & \\
\hline CHEMBL1533166 & 688422 & 6.4 & 5.3596 & TRN & \\
\hline CHEMBL1501821 & 688422 & 4.85 & 5.2419 & TRN & \\
\hline CHEMBL1389470 & 688422 & 6.0 & 5.2425 & TST & \\
\hline CHEMBL516954 & 688422 & 4.5 & 5.2363 & TRN & \\
\hline CHEMBL1337347 & 688422 & 4.45 & 5.4028 & TRN & \\
\hline CHEMBL1507261 & 688422 & 4.75 & 4.814 & TRN & \\
\hline CHEMBL1332089 & 688422 & 5.0 & 5.1906 & TRN & \\
\hline CHEMBL1469984 & 688422 & 5.25 & 5.0641 & TRN & \\
\hline CHEMBL1520852 & 688422 & 4.45 & 5.1231 & TRN & \\
\hline CHEMBL1462798 & 688422 & 5.1 & 5.1004 & TRN & \\
\hline CHEMBL1481441 & 688422 & 4.45 & 5.3471 & TST & \\
\hline CHEMBL1459265 & 688422 & 4.95 & 5.0257 & TRN & \\
\hline CHEMBL1440540 & 688422 & 5.4 & 5.2419 & TRN & \\
\hline CHEMBL1583857 & 688422 & 5.2 & 5.4057 & TRN & \\
\hline CHEMBL1333268 & 688422 & 5.0 & 5.2311 & TST & \\
\hline CHEMBL1486332 & 688422 & 5.65 & 4.8425 & TRN & \\
\hline CHEMBL1341936 & 688422 & 4.65 & 5.1716 & TRN & \\
\hline CHEMBL1609995 & 688422 & 5.3 & 5.7445 & TST & \\
\hline CHEMBL1419333 & 688422 & 4.9 & 5.3404 & TST & \\
\hline CHEMBL1604781 & 688422 & 4.45 & 5.0799 & TST & \\
\hline CHEMBL3190102 & 688422 & 5.15 & 5.2026 & TRN & \\
\hline CHEMBL1428574 & 688422 & 4.5 & 4.8664 & TRN & \\
\hline CHEMBL1419089 & 688422 & 4.95 & 4.8231 & TRN & \\
\hline CHEMBL1306028 & 688422 & 4.45 & 4.9507 & TRN & \\
\hline CHEMBL1560502 & 688422 & 4.7 & 4.7765 & TRN & \\
\hline CHEMBL1567380 & 688422 & 4.8 & 5.2778 & TRN & \\
\hline CHEMBL1469969 & 688422 & 4.8 & 5.3206 & TRN & \\
\hline CHEMBL1392477 & 688422 & 4.45 & 4.8183 & TRN & \\
\hline CHEMBL1379980 & 688422 & 4.95 & 5.2829 & TST & \\
\hline CHEMBL1339487 & 688422 & 4.45 & 5.3139 & TRN & \\
\hline
\end{tabular}




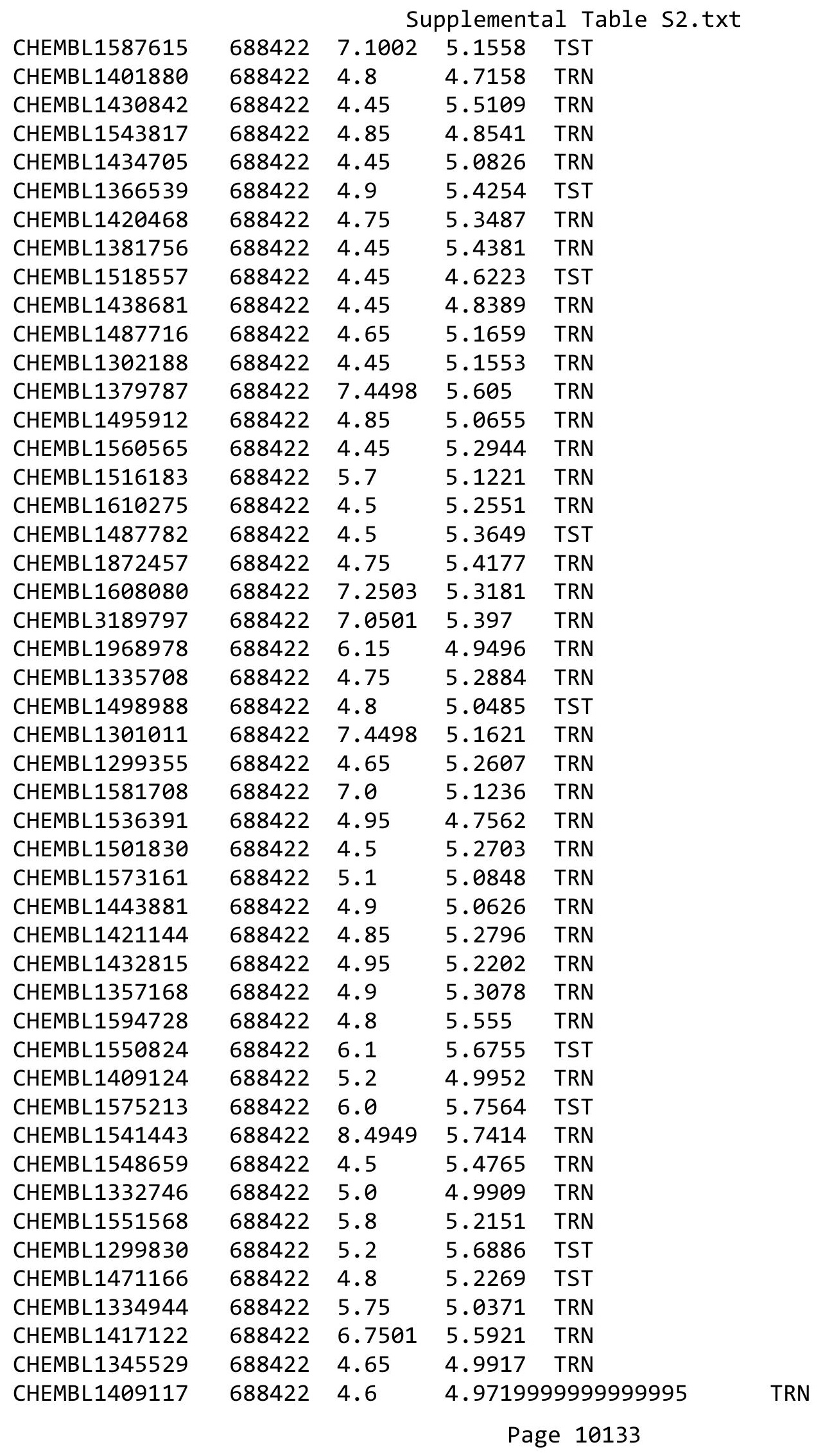




\begin{tabular}{|c|c|c|c|c|}
\hline \multicolumn{5}{|c|}{ Supplemental Table S2.txt } \\
\hline CHEMBL1403505 & 688422 & 4.45 & 4.9979 & TRN \\
\hline CHEMBL1525648 & 688422 & 5.65 & 5.0797 & TRN \\
\hline CHEMBL1586219 & 688422 & 4.75 & 5.1693 & TRN \\
\hline CHEMBL1482736 & 688422 & 4.45 & 5.77 & TRN \\
\hline CHEMBL1425234 & 688422 & 5.2 & 5.6458 & TST \\
\hline CHEMBL1342254 & 688422 & 7.2503 & 5.8038 & TST \\
\hline CHEMBL1340694 & 688422 & 4.85 & 4.891 & TRN \\
\hline CHEMBL1543856 & 688422 & 4.45 & 4.9044 & TRN \\
\hline CHEMBL1471940 & 688422 & 4.7 & 5.2359 & TRN \\
\hline CHEMBL1509995 & 688422 & 4.9 & 5.1096 & TST \\
\hline CHEMBL80155 & 688422 & 4.45 & 5.2565 & TRN \\
\hline CHEMBL1528506 & 688422 & 4.45 & 5.2018 & TRN \\
\hline CHEMBL1458193 & 688422 & 8.3468 & 5.6217 & TRN \\
\hline CHEMBL 288174 & 688422 & 4.8 & 4.6263 & TST \\
\hline CHEMBL1451181 & 688422 & 5.6 & 5.2594 & TRN \\
\hline CHEMBL1570029 & 688422 & 4.5 & 4.974 & TRN \\
\hline CHEMBL1516033 & 688422 & 4.45 & 5.1084 & TRN \\
\hline CHEMBL1527820 & 688422 & 4.8 & 5.1634 & TRN \\
\hline CHEMBL1544770 & 688422 & 4.45 & 4.962 & TRN \\
\hline CHEMBL1490225 & 688422 & 4.95 & 5.3004 & TRN \\
\hline CHEMBL1526207 & 688422 & 4.9 & 5.278 & TRN \\
\hline CHEMBL1577480 & 688422 & 4.75 & 5.5729 & TRN \\
\hline CHEMBL1532037 & 688422 & 4.85 & 5.2455 & TRN \\
\hline CHEMBL1331630 & 688422 & 7.4001 & 5.3423 & TST \\
\hline CHEMBL1385928 & 688422 & 4.9 & 4.998 & TRN \\
\hline CHEMBL1485888 & 688422 & 6.5501 & 5.1773 & TRN \\
\hline CHEMBL1448952 & 688422 & 4.7 & 5.5884 & TRN \\
\hline CHEMBL1452391 & 688422 & 5.3 & 4.8861 & TRN \\
\hline CHEMBL1449311 & 688422 & 4.7 & 5.2764 & TRN \\
\hline CHEMBL1464435 & 688422 & 4.85 & 5.2455 & TST \\
\hline CHEMBL1492912 & 688422 & 5.5 & 4.9956 & TRN \\
\hline CHEMBL1610820 & 688422 & 4.8 & 4.9052 & TRN \\
\hline CHEMBL1310332 & 688422 & 4.45 & 4.9577 & TRN \\
\hline CHEMBL1421901 & 688422 & 4.95 & 5.5977 & TST \\
\hline CHEMBL1452379 & 688422 & 5.5 & 4.6822 & TRN \\
\hline CHEMBL1462403 & 688422 & 4.85 & 5.0812 & TRN \\
\hline CHEMBL1531046 & 688422 & 4.75 & 5.6192 & TRN \\
\hline CHEMBL1382693 & 688422 & 4.8 & 5.7571 & TST \\
\hline CHEMBL1347523 & 688422 & 5.55 & 5.6277 & TRN \\
\hline CHEMBL1550533 & 688422 & 4.65 & 5.4337 & TRN \\
\hline CHEMBL1528425 & 688422 & 5.0 & 5.2981 & TRN \\
\hline CHEMBL3196866 & 688422 & 6.8 & 5.7089 & TRN \\
\hline CHEMBL1376212 & 688422 & 5.0 & 5.1347 & TRN \\
\hline CHEMBL3210959 & 688422 & 4.65 & 5.1707 & TRN \\
\hline CHEMBL153036 & 688422 & 6.0 & 5.2844 & TST \\
\hline CHEMBL1612840 & 688422 & 6.2 & 4.8578 & TRN \\
\hline CHEMBL65374 & 688422 & 5.2 & 5.0542 & TRN \\
\hline CHEMBL1456135 & 688422 & 4.6 & 5.4049 & TRN \\
\hline
\end{tabular}




\begin{tabular}{|c|c|c|c|c|c|}
\hline \multicolumn{6}{|c|}{ Supplemental Table s2.txt } \\
\hline CHEMBL1472139 & 688422 & 4.45 & 5.4595 & TRN & \\
\hline CHEMBL1377146 & 688422 & 4.95 & 5.284 & TRN & \\
\hline CHEMBL1311255 & 688422 & 4.85 & 5.087 & TRN & \\
\hline CHEMBL1371873 & 688422 & 4.85 & 4.8964 & TRN & \\
\hline CHEMBL1432271 & 688422 & 4.8 & 5.1618 & TRN & \\
\hline CHEMBL1385339 & 688422 & 4.95 & 5.1826 & TRN & \\
\hline CHEMBL1518326 & 688422 & 4.45 & 5.1964 & TST & \\
\hline CHEMBL1318348 & 688422 & 4.7 & \multicolumn{2}{|c|}{5.571000000000001} & TRN \\
\hline CHEMBL1503847 & 688422 & 5.0 & 4.9863 & TST & \\
\hline CHEMBL1458210 & 688422 & 4.8 & 5.151 & TST & \\
\hline CHEMBL1412445 & 688422 & 4.7 & 5.1478 & TRN & \\
\hline CHEMBL1568192 & 688422 & 8.0 & 5.1194 & TST & \\
\hline CHEMBL1442405 & 688422 & 4.45 & 5.0071 & TST & \\
\hline CHEMBL1443309 & 688422 & 4.65 & 5.541 & TRN & \\
\hline CHEMBL1379737 & 688422 & 5.45 & 4.6318 & TST & \\
\hline CHEMBL1379398 & 688422 & 5.7 & 4.9253 & TST & \\
\hline CHEMBL1464983 & 688422 & 4.8 & 5.3509 & TRN & \\
\hline CHEMBL1979843 & 688422 & 6.8 & 5.5971 & TRN & \\
\hline CHEMBL1474067 & 688422 & 5.45 & 5.3616 & TRN & \\
\hline CHEMBL 2003921 & 688422 & 4.7 & 5.4409 & TRN & \\
\hline CHEMBL1395599 & 688422 & 5.1 & 5.2177 & TRN & \\
\hline CHEMBL1487212 & 688422 & 4.45 & 4.9213 & TST & \\
\hline CHEMBL1563920 & 688422 & 5.4 & 5.3864 & TRN & \\
\hline CHEMBL1456964 & 688422 & 5.7 & 5.5529 & TRN & \\
\hline CHEMBL1368991 & 688422 & 5.5 & 5.5999 & TRN & \\
\hline CHEMBL1375860 & 688422 & 5.95 & 5.1758 & TRN & \\
\hline CHEMBL3208449 & 688422 & 4.85 & 4.988 & TRN & \\
\hline CHEMBL1570360 & 688422 & 7.15 & 5.7449 & TRN & \\
\hline CHEMBL1444644 & 688422 & 4.8 & 5.2845 & TRN & \\
\hline CHEMBL1997112 & 688422 & 4.95 & 4.7764 & TST & \\
\hline CHEMBL1359380 & 688422 & 4.85 & 5.0899 & TRN & \\
\hline CHEMBL1538321 & 688422 & 5.0 & 5.1492 & TRN & \\
\hline CHEMBL1475398 & 688422 & 5.6 & 5.36 & TST & \\
\hline CHEMBL1384451 & 688422 & 4.9 & 5.1662 & TRN & \\
\hline CHEMBL3190356 & 688422 & 4.95 & 5.1556 & TRN & \\
\hline CHEMBL1563909 & 688422 & 4.75 & 5.0555 & TRN & \\
\hline CHEMBL1539269 & 688422 & 7.2503 & 5.8 & TRN & \\
\hline CHEMBL1497288 & 688422 & 7.0501 & 5.2337 & TST & \\
\hline CHEMBL3212595 & 688422 & 4.75 & 5.8208 & TST & \\
\hline CHEMBL1576273 & 688422 & 6.35 & 5.1366 & TRN & \\
\hline CHEMBL1597536 & 688422 & 5.85 & 5.6457 & TRN & \\
\hline CHEMBL1421906 & 688422 & 4.6 & 5.6379 & TRN & \\
\hline CHEMBL1487657 & 688422 & 4.45 & 4.9959 & TRN & \\
\hline CHEMBL1577117 & 688422 & 4.5 & 5.2252 & TRN & \\
\hline CHEMBL1498397 & 688422 & 4.45 & 5.2702 & TRN & \\
\hline CHEMBL1467739 & 688422 & 5.1 & 5.0095 & TRN & \\
\hline CHEMBL1551852 & 688422 & 6.05 & 5.4783 & TRN & \\
\hline \multirow[t]{2}{*}{ CHEMBL1331447 } & 688422 & 5.1 & 5.21399 & 99999999995 & TRN \\
\hline & & \multicolumn{4}{|c|}{ Page 10135} \\
\hline
\end{tabular}




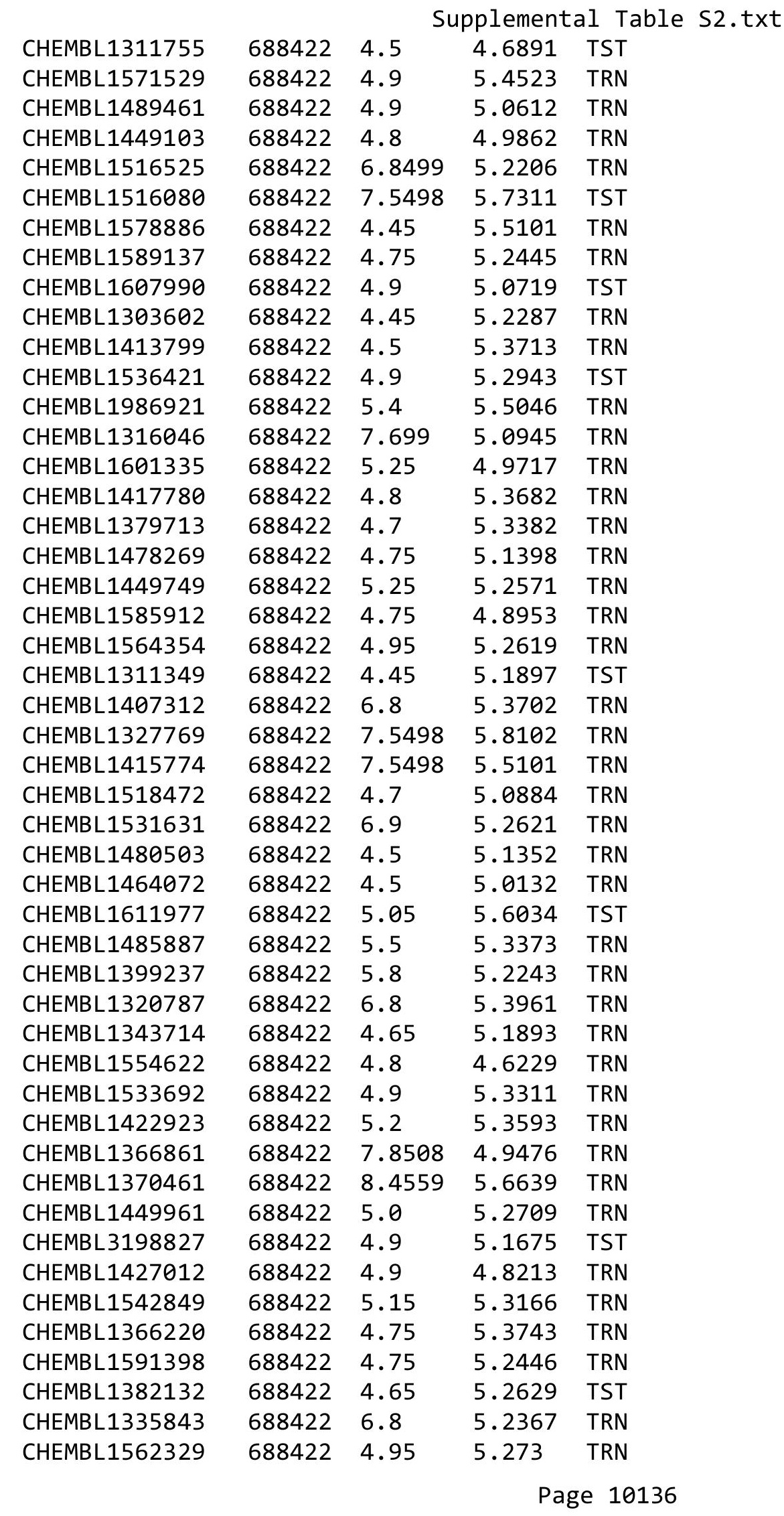




\begin{tabular}{|c|c|c|c|c|}
\hline \multicolumn{5}{|c|}{ Supplemental Table S2.txt } \\
\hline CHEMBL3191835 & 688422 & 4.75 & 5.0803 & TRN \\
\hline CHEMBL1477772 & 688422 & 4.8 & 5.2412 & TST \\
\hline CHEMBL1334751 & 688422 & 4.45 & 5.5769 & TST \\
\hline CHEMBL1382967 & 688422 & 4.5 & 5.16200 & 0000000001 \\
\hline CHEMBL1347794 & 688422 & 4.95 & 5.1699 & TST \\
\hline CHEMBL1303891 & 688422 & 4.95 & 5.3809 & TRN \\
\hline CHEMBL1331018 & 688422 & 4.5 & 5.4422 & TRN \\
\hline CHEMBL1489856 & 688422 & 6.1 & 4.8831 & TST \\
\hline CHEMBL1325689 & 688422 & 4.65 & 4.8399 & TRN \\
\hline CHEMBL1490926 & 688422 & 5.4 & 5.4236 & TRN \\
\hline CHEMBL1310859 & 688422 & 7.4498 & 5.1705 & TRN \\
\hline CHEMBL1567332 & 688422 & 8.4949 & 5.3653 & TST \\
\hline CHEMBL1401775 & 688422 & 4.7 & 5.5006 & TST \\
\hline CHEMBL1423164 & 688422 & 4.5 & 4.6469 & TRN \\
\hline CHEMBL1462657 & 688422 & 5.2 & 4.9774 & TRN \\
\hline CHEMBL1447400 & 688422 & 4.8 & 5.1039 & TRN \\
\hline CHEMBL1604011 & 688422 & 4.45 & 4.8898 & TRN \\
\hline CHEMBL1312037 & 688422 & 4.45 & 5.3174 & TST \\
\hline CHEMBL1414516 & 688422 & 5.9 & 5.0146 & TRN \\
\hline CHEMBL1556649 & 688422 & 4.85 & 4.9113 & TST \\
\hline CHEMBL190259 & 688422 & 9.0458 & 6.0455 & TRN \\
\hline CHEMBL1535587 & 688422 & 4.65 & 4.8981 & TRN \\
\hline CHEMBL436913 & 688422 & 7.6003 & 5.1281 & TST \\
\hline CHEMBL 2007184 & 688422 & 5.15 & 5.6003 & TRN \\
\hline CHEMBL1441016 & 688422 & 5.5 & 5.0559 & TRN \\
\hline CHEMBL1474176 & 688422 & 5.2 & 5.5351 & TRN \\
\hline CHEMBL1342038 & 688422 & 4.9 & 5.4559 & TRN \\
\hline CHEMBL1321945 & 688422 & 5.15 & 5.2967 & TRN \\
\hline CHEMBL1474523 & 688422 & 5.5 & 6.4219 & TRN \\
\hline CHEMBL1339934 & 688422 & 4.75 & 5.029 & TRN \\
\hline CHEMBL3189180 & 688422 & 4.7 & 5.0597 & TRN \\
\hline CHEMBL1391864 & 688422 & 5.35 & 5.403 & TST \\
\hline CHEMBL1343234 & 688422 & 4.4 & 5.478 & TRN \\
\hline CHEMBL1367834 & 688422 & 5.25 & 5.0461 & TRN \\
\hline CHEMBL1399590 & 688422 & 4.7 & 4.904 & TST \\
\hline CHEMBL 3189304 & 688422 & 4.7 & 5.1805 & TRN \\
\hline CHEMBL1350139 & 688422 & 4.45 & 5.2063 & TRN \\
\hline CHEMBL1371533 & 688422 & 4.45 & 4.9429 & TRN \\
\hline CHEMBL1577169 & 688422 & 7.6003 & 5.4774 & TST \\
\hline CHEMBL1400272 & 688422 & 4.9 & 5.3651 & TST \\
\hline CHEMBL1585855 & 688422 & 6.0 & 4.9333 & TST \\
\hline CHEMBL1349509 & 688422 & 4.45 & 5.7796 & TST \\
\hline CHEMBL1365457 & 688422 & 7.5498 & 5.2665 & TST \\
\hline CHEMBL1452612 & 688422 & 5.0 & 5.1436 & TRN \\
\hline CHEMBL1346895 & 688422 & 4.95 & 5.5602 & TRN \\
\hline CHEMBL1561893 & 688422 & 4.45 & 4.7522 & TST \\
\hline CHEMBL1329672 & 688422 & 4.45 & 5.4307 & TRN \\
\hline CHEMBL1535105 & 688422 & 5.0 & 5.2718 & TRN \\
\hline
\end{tabular}




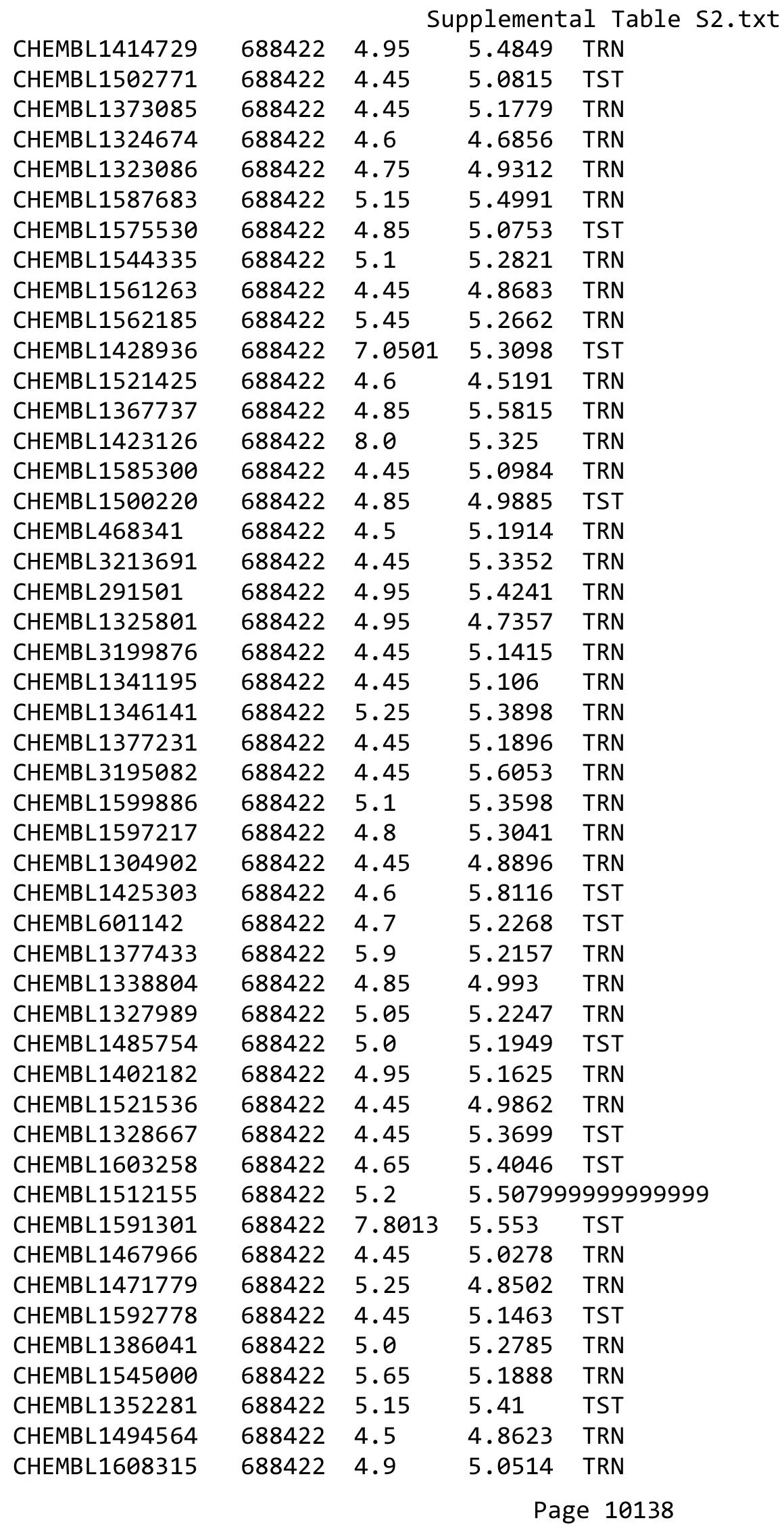




\begin{tabular}{|c|c|c|c|c|c|}
\hline \multicolumn{6}{|c|}{ Supplemental Table s2.txt } \\
\hline CHEMBL1499839 & 688422 & 4.45 & 5.0999 & TRN & \\
\hline CHEMBL1452550 & 688422 & 6.05 & 5.9393 & TRN & \\
\hline CHEMBL1308796 & 688422 & 6.05 & 5.2331 & TST & \\
\hline CHEMBL1605463 & 688422 & 4.9 & 5.2002 & TRN & \\
\hline CHEMBL1373990 & 688422 & 7.6498 & 5.5266 & TRN & \\
\hline CHEMBL578689 & 688422 & 6.05 & 4.5389 & TRN & \\
\hline CHEMBL1369376 & 688422 & 4.45 & 5.0032 & TRN & \\
\hline CHEMBL582444 & 688422 & 6.0 & 5.3069 & TST & \\
\hline CHEMBL1611297 & 688422 & 4.6 & 5.2224 & TRN & \\
\hline CHEMBL1965321 & 688422 & 5.1 & 5.50299 & 9999999999 & TST \\
\hline CHEMBL1513679 & 688422 & 7.2503 & 5.0615 & TST & \\
\hline CHEMBL1372826 & 688422 & 4.5 & 4.6968 & TST & \\
\hline CHEMBL1364131 & 688422 & 4.45 & 5.0872 & TRN & \\
\hline CHEMBL1470754 & 688422 & 4.85 & 5.2888 & TRN & \\
\hline CHEMBL1341981 & 688422 & 4.45 & 4.8847 & TRN & \\
\hline CHEMBL1342746 & 688422 & 5.15 & 5.5361 & TRN & \\
\hline CHEMBL1378342 & 688422 & 4.85 & 5.0522 & TRN & \\
\hline CHEMBL1403985 & 688422 & 4.8 & 5.1565 & TRN & \\
\hline CHEMBL114070 & 688422 & 6.25 & 5.4681 & TRN & \\
\hline CHEMBL1306079 & 688422 & 4.95 & 5.1283 & TRN & \\
\hline CHEMBL1467600 & 688422 & 4.45 & 5.3535 & TRN & \\
\hline CHEMBL1570602 & 688422 & 8.0 & 5.5567 & TRN & \\
\hline CHEMBL1440202 & 688422 & 6.0 & 5.0468 & TRN & \\
\hline CHEMBL1422349 & 688422 & 4.6 & 5.2521 & TST & \\
\hline CHEMBL1506393 & 688422 & 6.1 & 5.3286 & TRN & \\
\hline CHEMBL1434116 & 688422 & 5.6 & 5.2863 & TRN & \\
\hline CHEMBL1355866 & 688422 & 4.6 & 5.516 & TRN & \\
\hline CHEMBL1477778 & 688422 & 4.45 & 4.7585 & TRN & \\
\hline CHEMBL1516719 & 688422 & 4.95 & 5.0266 & TRN & \\
\hline CHEMBL1489310 & 688422 & 4.65 & 5.2922 & TRN & \\
\hline CHEMBL1379882 & 688422 & 5.9 & 5.6896 & TRN & \\
\hline CHEMBL1406194 & 688422 & 4.8 & 5.0462 & TRN & \\
\hline CHEMBL167869 & 688422 & 7.3497 & 4.8222 & TRN & \\
\hline CHEMBL1360850 & 688422 & 5.25 & 5.1141 & TRN & \\
\hline CHEMBL1563687 & 688422 & 5.3 & 5.2576 & TRN & \\
\hline CHEMBL1395738 & 688422 & 6.9 & 5.2448 & TRN & \\
\hline CHEMBL1569488 & 688422 & 4.8 & 5.1071 & TRN & \\
\hline CHEMBL1569543 & 688422 & 6.2 & 5.2866 & TRN & \\
\hline CHEMBL1561858 & 688422 & 5.6 & 5.4732 & TRN & \\
\hline CHEMBL1436752 & 688422 & 4.8 & 5.3357 & TRN & \\
\hline CHEMBL1408497 & 688422 & 4.45 & 5.4226 & TST & \\
\hline CHEMBL1345817 & 688422 & 5.05 & 5.6563 & TRN & \\
\hline CHEMBL3192607 & 688422 & 4.8 & 5.0728 & TST & \\
\hline CHEMBL3192283 & 688422 & 4.75 & 5.3194 & TRN & \\
\hline CHEMBL579919 & 688422 & 4.9 & 4.9356 & TRN & \\
\hline CHEMBL1609540 & 688422 & 4.45 & 5.25899 & 99999999995 & TRN \\
\hline CHEMBL1484774 & 688422 & 4.65 & 5.0031 & TST & \\
\hline CHEMBL1561636 & 688422 & 8.301 & 5.4234 & TRN & \\
\hline
\end{tabular}




\begin{tabular}{|c|c|c|c|c|}
\hline \multicolumn{5}{|c|}{ Supplemental Table S2.txt } \\
\hline CHEMBL1423485 & 688422 & 7.2503 & 5.8333 & TRN \\
\hline CHEMBL171281 & 688422 & 5.55 & 6.2135 & TRN \\
\hline CHEMBL1453819 & 688422 & 4.8 & 4.8071 & TRN \\
\hline CHEMBL1557190 & 688422 & 4.9 & 4.8274 & TRN \\
\hline CHEMBL1476446 & 688422 & 6.45 & 5.875 & TRN \\
\hline CHEMBL1343058 & 688422 & 4.7 & 4.8709 & TRN \\
\hline CHEMBL1599463 & 688422 & 4.8 & 5.8087 & TST \\
\hline CHEMBL1392655 & 688422 & 4.65 & 4.9594 & TRN \\
\hline CHEMBL1400664 & 688422 & 5.0 & 4.8563 & TRN \\
\hline CHEMBL1591314 & 688422 & 4.6 & 5.1269 & TRN \\
\hline CHEMBL 3212014 & 688422 & 5.9 & 5.3628 & TRN \\
\hline CHEMBL1364542 & 688422 & 6.15 & 5.5883 & TRN \\
\hline CHEMBL1474271 & 688422 & 7.6498 & 5.276 & TRN \\
\hline CHEMBL1435381 & 688422 & 5.4 & 5.4378 & TRN \\
\hline CHEMBL1339536 & 688422 & 5.6 & 4.9656 & TRN \\
\hline CHEMBL1369571 & 688422 & 4.45 & 4.9943 & TRN \\
\hline CHEMBL3195844 & 688422 & 4.85 & 5.1505 & TST \\
\hline CHEMBL1562439 & 688422 & 4.9 & 4.833 & TRN \\
\hline CHEMBL1386366 & 688422 & 4.95 & 4.9667 & TRN \\
\hline CHEMBL1371825 & 688422 & 4.9 & 5.0798 & TRN \\
\hline CHEMBL1569760 & 688422 & 6.3 & 5.0804 & TRN \\
\hline CHEMBL1567103 & 688422 & 4.8 & 5.1568 & TST \\
\hline CHEMBL1382724 & 688422 & 4.45 & 5.3551 & TST \\
\hline CHEMBL1518196 & 688422 & 4.5 & 5.5238 & TRN \\
\hline CHEMBL1507032 & 688422 & 6.05 & 5.1731 & TRN \\
\hline CHEMBL1418469 & 688422 & 4.45 & 4.7675 & TRN \\
\hline CHEMBL1547657 & 688422 & 8.4559 & 5.8173 & TRN \\
\hline CHEMBL1452313 & 688422 & 4.45 & 5.2254 & TST \\
\hline CHEMBL1479369 & 688422 & 4.9 & 5.3249 & TRN \\
\hline CHEMBL1431346 & 688422 & 4.8 & 5.4828 & TRN \\
\hline CHEMBL1420715 & 688422 & 5.85 & 5.4919 & TST \\
\hline CHEMBL1428439 & 688422 & 4.75 & 4.8048 & TRN \\
\hline CHEMBL1543404 & 688422 & 4.95 & 5.2392 & TST \\
\hline CHEMBL1573050 & 688422 & 5.1 & 5.5075 & TRN \\
\hline CHEMBL1362182 & 688422 & 5.25 & 5.0037 & TRN \\
\hline CHEMBL1367525 & 688422 & 4.45 & 4.8642 & TRN \\
\hline CHEMBL1374544 & 688422 & 4.45 & 4.987 & TRN \\
\hline CHEMBL1609759 & 688422 & 5.55 & 4.9071 & TRN \\
\hline CHEMBL1521659 & 688422 & 4.9 & 5.7853 & TRN \\
\hline CHEMBL1552640 & 688422 & 4.9 & 5.2904 & TST \\
\hline CHEMBL1576778 & 688422 & 5.45 & 5.4481 & TRN \\
\hline CHEMBL1556352 & 688422 & 4.6 & 5.3769 & TRN \\
\hline CHEMBL1367994 & 688422 & 5.5 & 5.4089 & TST \\
\hline CHEMBL1534716 & 688422 & 4.9 & 4.9055 & TRN \\
\hline CHEMBL1402475 & 688422 & 8.0 & 5.3248 & TST \\
\hline CHEMBL1504140 & 688422 & 5.0 & 5.2838 & TRN \\
\hline CHEMBL1583919 & 688422 & 4.8 & 4.8207 & TRN \\
\hline CHEMBL1573175 & 688422 & 4.75 & 5.4588 & TRN \\
\hline
\end{tabular}




\begin{tabular}{|c|c|c|c|c|c|}
\hline \multicolumn{6}{|c|}{ Supplemental Table s2.txt } \\
\hline CHEMBL1472243 & 688422 & 5.35 & 5.3053 & TST & \\
\hline CHEMBL1419669 & 688422 & 4.65 & 6.0037 & TRN & \\
\hline CHEMBL1335491 & 688422 & 4.75 & 4.9391 & TRN & \\
\hline CHEMBL1508651 & 688422 & 4.65 & 5.5423 & TRN & \\
\hline CHEMBL1311098 & 688422 & 6.5501 & 5.0851 & TRN & \\
\hline CHEMBL1383845 & 688422 & 7.8508 & 5.6235 & TST & \\
\hline CHEMBL1594827 & 688422 & 5.0 & 5.0202 & TST & \\
\hline CHEMBL1610923 & 688422 & 5.0 & 4.7847 & TRN & \\
\hline CHEMBL1365528 & 688422 & 6.7001 & 5.3643 & TRN & \\
\hline CHEMBL1393071 & 688422 & 4.95 & 4.8214 & TRN & \\
\hline CHEMBL1529273 & 688422 & 4.65 & 5.185 & TST & \\
\hline CHEMBL1601466 & 688422 & 4.45 & 5.8385 & TST & \\
\hline CHEMBL1421887 & 688422 & 4.65 & 5.105 & TRN & \\
\hline CHEMBL1404447 & 688422 & 4.45 & 5.0879 & TRN & \\
\hline CHEMBL1458360 & 688422 & 4.6 & 4.9644 & TRN & \\
\hline CHEMBL1562276 & 688422 & 4.75 & 4.5609 & TRN & \\
\hline CHEMBL1377446 & 688422 & 4.95 & 5.1346 & TRN & \\
\hline CHEMBL1311844 & 688422 & 4.6 & 5.3784 & TRN & \\
\hline CHEMBL1608144 & 688422 & 4.55 & 4.7849 & TRN & \\
\hline CHEMBL1372844 & 688422 & 4.45 & 5.1417 & TRN & \\
\hline CHEMBL1430042 & 688422 & 4.9 & 5.2263 & TST & \\
\hline CHEMBL341910 & 688422 & 4.85 & 5.6989 & TST & \\
\hline CHEMBL1341581 & 688422 & 4.75 & 5.046 & TRN & \\
\hline CHEMBL1514722 & 688422 & 5.7 & 5.3894 & TRN & \\
\hline CHEMBL1521905 & 688422 & 5.6 & 5.39 & TRN & \\
\hline CHEMBL1393538 & 688422 & 4.85 & 5.4661 & TST & \\
\hline CHEMBL1606293 & 688422 & 5.2 & 5.4469 & TRN & \\
\hline CHEMBL3191963 & 688422 & 4.95 & 5.4048 & TRN & \\
\hline CHEMBL1593619 & 688422 & 4.9 & 5.3952 & TRN & \\
\hline CHEMBL1348147 & 688422 & 5.0 & 4.9253 & TRN & \\
\hline CHEMBL1609963 & 688422 & 5.55 & 5.2109 & TRN & \\
\hline CHEMBL1525066 & 688422 & 5.25 & 5.3164 & TRN & \\
\hline CHEMBL1398914 & 688422 & 4.95 & 5.2938 & TRN & \\
\hline CHEMBL3207863 & 688422 & 4.85 & 5.2487 & TRN & \\
\hline CHEMBL1499118 & 688422 & 4.95 & 5.1444 & TST & \\
\hline CHEMBL1431953 & 688422 & 4.7 & 5.0557 & TRN & \\
\hline CHEMBL3192745 & 688422 & 4.45 & 4.941 & TRN & \\
\hline CHEMBL1568631 & 688422 & 5.25 & 5.2923 & TRN & \\
\hline CHEMBL1411673 & 688422 & 4.6 & 5.21899 & 9999999999 & TRN \\
\hline CHEMBL1299229 & 688422 & 5.35 & 5.5885 & TST & \\
\hline CHEMBL1340506 & 688422 & 4.75 & 5.3545 & TST & \\
\hline CHEMBL1467082 & 688422 & 4.7 & 4.7009 & TRN & \\
\hline CHEMBL1529302 & 688422 & 6.0 & 5.4115 & TRN & \\
\hline CHEMBL1555935 & 688422 & 4.45 & 5.6603 & TRN & \\
\hline CHEMBL1513498 & 688422 & 4.9 & 5.4374 & TRN & \\
\hline CHEMBL1325622 & 688422 & 5.25 & 4.9601 & TRN & \\
\hline CHEMBL1511526 & 688422 & 4.45 & 4.8522 & TRN & \\
\hline CHEMBL3213601 & 688422 & 5.0 & 5.3926 & TST & \\
\hline
\end{tabular}




\begin{tabular}{|c|c|c|c|c|c|}
\hline \multicolumn{6}{|c|}{ Supplemental Table S2.txt } \\
\hline CHEMBL1610977 & 688422 & 4.55 & 5.4605 & TRN & \\
\hline CHEMBL1367841 & 688422 & 4.75 & 5.2055 & TST & \\
\hline CHEMBL1604613 & 688422 & 5.5 & 5.41700 & 0000000001 & TRN \\
\hline CHEMBL1528391 & 688422 & 4.9 & 5.1066 & TRN & \\
\hline CHEMBL1306978 & 688422 & 4.8 & 5.1711 & TRN & \\
\hline CHEMBL1359820 & 688422 & 7.699 & 5.6229 & TRN & \\
\hline CHEMBL1582746 & 688422 & 5.15 & 5.4525 & TRN & \\
\hline CHEMBL1337903 & 688422 & 4.45 & 4.8792 & TRN & \\
\hline CHEMBL1492245 & 688422 & 4.45 & 5.6792 & TRN & \\
\hline CHEMBL1502327 & 688422 & 5.3 & 4.9458 & TRN & \\
\hline CHEMBL1501640 & 688422 & 4.7 & 4.9587 & TST & \\
\hline CHEMBL1304064 & 688422 & 4.45 & 4.7183 & TRN & \\
\hline CHEMBL1360300 & 688422 & 4.5 & 4.8312 & TRN & \\
\hline CHEMBL1335037 & 688422 & 4.45 & 4.9232 & TRN & \\
\hline CHEMBL1439866 & 688422 & 5.65 & 5.8711 & TRN & \\
\hline CHEMBL1580153 & 688422 & 7.0 & 5.3746 & TRN & \\
\hline CHEMBL1439362 & 688422 & 4.7 & 5.0137 & TST & \\
\hline CHEMBL1524324 & 688422 & 4.95 & 4.6055 & TRN & \\
\hline CHEMBL1588463 & 688422 & 4.65 & 4.9978 & TST & \\
\hline CHEMBL1554579 & 688422 & 4.45 & 5.2539 & TRN & \\
\hline CHEMBL1370701 & 688422 & 4.65 & 5.5549 & TST & \\
\hline CHEMBL1395513 & 688422 & 5.25 & 5.5345 & TST & \\
\hline CHEMBL1381297 & 688422 & 4.45 & 4.8992 & TST & \\
\hline CHEMBL1422900 & 688422 & 7.5003 & 5.3871 & TST & \\
\hline CHEMBL1257041 & 688422 & 4.95 & 5.45100 & 00000000005 & TRN \\
\hline CHEMBL1613140 & 688422 & 4.6 & 5.347 & TRN & \\
\hline CHEMBL1461452 & 688422 & 4.45 & 5.4656 & TST & \\
\hline CHEMBL3145316 & 688422 & 4.7 & 5.0154 & TRN & \\
\hline CHEMBL1332181 & 688422 & 4.45 & 4.8977 & TRN & \\
\hline CHEMBL1563220 & 688422 & 5.45 & 4.97199 & 99999999995 & TRN \\
\hline CHEMBL1388544 & 688422 & 4.45 & 4.6979 & TST & \\
\hline CHEMBL1503318 & 688422 & 5.0 & 5.2221 & TRN & \\
\hline CHEMBL1552093 & 688422 & 6.6 & 5.3169 & TRN & \\
\hline CHEMBL1372606 & 688422 & 7.0 & 5.3239 & TRN & \\
\hline CHEMBL1326543 & 688422 & 4.75 & 4.7702 & TRN & \\
\hline CHEMBL1574908 & 688422 & 5.15 & 4.8282 & TRN & \\
\hline CHEMBL1468990 & 688422 & 4.7 & 5.6638 & TRN & \\
\hline CHEMBL1535551 & 688422 & 4.45 & 5.3346 & TRN & \\
\hline CHEMBL1346656 & 688422 & 4.5 & 5.5618 & TRN & \\
\hline CHEMBL1370241 & 688422 & 5.1 & 5.7211 & TRN & \\
\hline CHEMBL1381257 & 688422 & 8.4559 & 5.1625 & TST & \\
\hline CHEMBL1544445 & 688422 & 4.9 & 5.7667 & TRN & \\
\hline CHEMBL1608221 & 688422 & 6.4 & 5.2682 & TRN & \\
\hline CHEMBL3193502 & 688422 & 6.7001 & 5.3066 & TST & \\
\hline CHEMBL1421135 & 688422 & 4.65 & 5.0028 & TRN & \\
\hline CHEMBL1352070 & 688422 & 4.75 & 5.1103 & TRN & \\
\hline CHEMBL1574989 & 688422 & 5.2 & 5.5634 & TRN & \\
\hline CHEMBL1559811 & 688422 & 4.65 & 5.2776 & TRN & \\
\hline
\end{tabular}




\begin{tabular}{|c|c|c|c|c|c|}
\hline \multicolumn{6}{|c|}{ Supplemental Table S2.txt } \\
\hline CHEMBL1302278 & 688422 & 4.85 & 4.9117 & TST & \\
\hline CHEMBL1508357 & 688422 & 4.85 & 5.2822 & TRN & \\
\hline CHEMBL1451696 & 688422 & 4.95 & 5.2363 & TRN & \\
\hline CHEMBL1471209 & 688422 & 4.7 & 4.6903 & TRN & \\
\hline CHEMBL1533212 & 688422 & 4.45 & 4.7221 & TRN & \\
\hline CHEMBL592712 & 688422 & 4.9 & 4.6003 & TST & \\
\hline CHEMBL1569133 & 688422 & 4.8 & 5.0342 & TRN & \\
\hline CHEMBL1390427 & 688422 & 4.95 & 4.6616 & TST & \\
\hline CHEMBL1310783 & 688422 & 4.45 & 5.4186 & TST & \\
\hline CHEMBL1376438 & 688422 & 4.65 & 5.515 & TST & \\
\hline CHEMBL1512020 & 688422 & 7.699 & 5.271 & TRN & \\
\hline CHEMBL1569974 & 688422 & 4.75 & 5.1725 & TRN & \\
\hline CHEMBL1551217 & 688422 & 4.95 & 5.4186 & TRN & \\
\hline CHEMBL1523574 & 688422 & 5.95 & 5.2044 & TRN & \\
\hline CHEMBL1312261 & 688422 & 4.45 & 5.149 & TRN & \\
\hline CHEMBL1602121 & 688422 & 7.6498 & 4.7676 & TRN & \\
\hline CHEMBL1549034 & 688422 & 4.45 & 5.59399 & 9999999999 & TRN \\
\hline CHEMBL1530409 & 688422 & 4.45 & 4.7868 & TRN & \\
\hline CHEMBL1481896 & 688422 & 5.35 & 5.6385 & TRN & \\
\hline CHEMBL1451756 & 688422 & 8.4949 & 5.4385 & TRN & \\
\hline CHEMBL1470835 & 688422 & 4.85 & 4.8376 & TRN & \\
\hline CHEMBL1454275 & 688422 & 7.2503 & 5.5146 & TRN & \\
\hline CHEMBL1349108 & 688422 & 5.5 & 5.1079 & TRN & \\
\hline CHEMBL1332761 & 688422 & 4.85 & 4.6674 & TRN & \\
\hline CHEMBL1518663 & 688422 & 4.45 & 5.2301 & TRN & \\
\hline CHEMBL1313293 & 688422 & 5.4 & 5.2497 & TST & \\
\hline CHEMBL1376223 & 688422 & 7.699 & 5.2412 & TRN & \\
\hline CHEMBL1337445 & 688422 & 4.8 & 4.6767 & TRN & \\
\hline CHEMBL1337284 & 688422 & 4.55 & 5.2465 & TRN & \\
\hline CHEMBL1388295 & 688422 & 6.1 & 5.2562 & TRN & \\
\hline CHEMBL1398899 & 688422 & 4.45 & 4.7943 & TRN & \\
\hline CHEMBL1390444 & 688422 & 5.9 & 5.1068 & TRN & \\
\hline CHEMBL1551204 & 688422 & 6.15 & 5.6098 & TRN & \\
\hline CHEMBL1533930 & 688422 & 7.0 & 5.2275 & TRN & \\
\hline CHEMBL1320128 & 688422 & 5.9 & 5.0975 & TRN & \\
\hline CHEMBL1452671 & 688422 & 4.8 & 4.8629 & TRN & \\
\hline CHEMBL1438688 & 688422 & 5.55 & 4.8678 & TRN & \\
\hline CHEMBL1382640 & 688422 & 4.9 & 4.85800 & 00000000005 & TRN \\
\hline CHEMBL1443792 & 688422 & 5.55 & 5.2447 & TRN & \\
\hline CHEMBL1423576 & 688422 & 7.1002 & 5.8254 & TST & \\
\hline CHEMBL1360224 & 688422 & 4.45 & 4.8467 & TRN & \\
\hline CHEMBL3209007 & 688422 & 5.0 & 5.6846 & TRN & \\
\hline CHEMBL1376295 & 688422 & 4.5 & 5.6505 & TRN & \\
\hline CHEMBL1334566 & 688422 & 5.1 & 5.6007 & TST & \\
\hline CHEMBL1515636 & 688422 & 7.0 & 5.2075 & TST & \\
\hline CHEMBL1479057 & 688422 & 4.95 & 5.1815 & TRN & \\
\hline CHEMBL1547124 & 688422 & 4.85 & 5.0707 & TRN & \\
\hline CHEMBL1543448 & 688422 & 7.0 & 5.7047 & TRN & \\
\hline
\end{tabular}




\begin{tabular}{|c|c|c|c|c|c|}
\hline & & \multicolumn{4}{|c|}{ Supplemental Table S2.txt } \\
\hline CHEMBL1570721 & 688422 & 6.7501 & 5.5349 & TRN & \\
\hline CHEMBL1469568 & 688422 & 4.45 & 5.4293 & TST & \\
\hline CHEMBL1468929 & 688422 & 4.95 & 5.7273 & TST & \\
\hline CHEMBL1607663 & 688422 & 4.65 & 5.187 & TRN & \\
\hline CHEMBL1461546 & 688422 & 4.45 & 4.9553 & TRN & \\
\hline CHEMBL1565569 & 688422 & 5.55 & 5.7906 & TST & \\
\hline CHEMBL1371216 & 688422 & 4.45 & 5.546 & TRN & \\
\hline CHEMBL1430895 & 688422 & 4.8 & 4.8697 & TRN & \\
\hline CHEMBL1483202 & 688422 & 6.5501 & 5.6219 & TRN & \\
\hline CHEMBL1597697 & 688422 & 5.2 & 5.25799 & 9999999999 & TRN \\
\hline CHEMBL1567682 & 688422 & 4.45 & 5.2909 & TRN & \\
\hline CHEMBL1352481 & 688422 & 5.45 & 5.6396 & TRN & \\
\hline CHEMBL1329703 & 688422 & 4.45 & 5.1407 & TST & \\
\hline CHEMBL1304360 & 688422 & 4.95 & 5.4095 & TRN & \\
\hline CHEMBL216973 & 688422 & 6.1 & 5.5112 & TST & \\
\hline CHEMBL1424317 & 688422 & 6.5 & 5.7647 & TST & \\
\hline CHEMBL1369043 & 688422 & 6.1 & 5.1443 & TST & \\
\hline CHEMBL1449655 & 688422 & 6.7501 & 5.3633 & TST & \\
\hline CHEMBL3195783 & 688422 & 4.45 & 5.3463 & TRN & \\
\hline CHEMBL1396968 & 688422 & 7.2 & 5.8816 & TRN & \\
\hline CHEMBL1429768 & 688422 & 4.45 & 5.2398 & TST & \\
\hline CHEMBL1477586 & 688422 & 4.95 & 5.0192 & TRN & \\
\hline CHEMBL1976466 & 688422 & 4.95 & 5.5099 & TRN & \\
\hline CHEMBL1459127 & 688422 & 6.5 & 5.0169 & TRN & \\
\hline CHEMBL1421485 & 688422 & 5.0 & 5.2976 & TRN & \\
\hline CHEMBL1610051 & 688422 & 4.6 & 5.0906 & TRN & \\
\hline CHEMBL1430650 & 688422 & 5.05 & 5.2288 & TRN & \\
\hline CHEMBL1330293 & 688422 & 4.75 & 5.2863 & TRN & \\
\hline CHEMBL1409350 & 688422 & 4.75 & 4.938 & TRN & \\
\hline CHEMBL1421048 & 688422 & 4.75 & 4.9696 & TRN & \\
\hline CHEMBL1584571 & 688422 & 4.45 & 5.1543 & TRN & \\
\hline CHEMBL1369768 & 688422 & 5.35 & 5.098 & TRN & \\
\hline CHEMBL1609391 & 688422 & 4.45 & 5.3593 & TRN & \\
\hline CHEMBL1593334 & 688422 & 6.05 & 5.1803 & TRN & \\
\hline CHEMBL1338805 & 688422 & 4.8 & 5.0749 & TRN & \\
\hline CHEMBL1439571 & 688422 & 4.8 & 5.3406 & TST & \\
\hline CHEMBL1457469 & 688422 & 5.1 & 5.2945 & TST & \\
\hline CHEMBL1469756 & 688422 & 4.7 & 5.159 & TST & \\
\hline CHEMBL3198970 & 688422 & 6.8 & 5.2126 & TST & \\
\hline CHEMBL1307886 & 688422 & 5.2 & 6.0512 & TST & \\
\hline CHEMBL1309134 & 688422 & 5.35 & 5.2926 & TST & \\
\hline CHEMBL1389285 & 688422 & 4.45 & 5.0729 & TRN & \\
\hline CHEMBL1442120 & 688422 & 5.05 & 5.0773 & TST & \\
\hline CHEMBL1573264 & 688422 & 4.65 & 5.038 & TRN & \\
\hline CHEMBL1602160 & 688422 & 5.0 & 5.1288 & TST & \\
\hline CHEMBL1411636 & 688422 & 4.6 & 4.8661 & TRN & \\
\hline CHEMBL3195475 & 688422 & 4.45 & 4.9652 & TRN & \\
\hline CHEMBL1392651 & 688422 & 4.45 & 5.1597 & TST & \\
\hline
\end{tabular}




\begin{tabular}{|c|c|c|c|c|c|}
\hline \multicolumn{6}{|c|}{ Supplemental Table S2.txt } \\
\hline CHEMBL1344618 & 688422 & 4.7 & 5.1887 & TRN & \\
\hline CHEMBL1605670 & 688422 & 4.65 & 4.8952 & TRN & \\
\hline CHEMBL3193513 & 688422 & 6.15 & 5.4946 & TRN & \\
\hline CHEMBL1576335 & 688422 & 7.0 & 5.1961 & TRN & \\
\hline CHEMBL1371746 & 688422 & 5.0 & 5.3106 & TRN & \\
\hline CHEMBL1451974 & 688422 & 4.6 & 5.0434 & TRN & \\
\hline CHEMBL1603955 & 688422 & 6.7001 & 5.1426 & TRN & \\
\hline CHEMBL1439549 & 688422 & 4.9 & 5.2309 & TRN & \\
\hline CHEMBL1528030 & 688422 & 4.55 & 4.9062 & TST & \\
\hline CHEMBL1426614 & 688422 & 4.85 & 5.1751 & TRN & \\
\hline CHEMBL1322090 & 688422 & 4.9 & 5.2296 & TRN & \\
\hline CHEMBL1507522 & 688422 & 5.8 & 5.2923 & TRN & \\
\hline CHEMBL1310155 & 688422 & 4.45 & 5.7524 & TST & \\
\hline CHEMBL1498511 & 688422 & 5.0 & 5.2084 & TST & \\
\hline CHEMBL3210228 & 688422 & 4.45 & 4.9877 & TRN & \\
\hline CHEMBL1433005 & 688422 & 6.45 & 5.0 & TRN & \\
\hline CHEMBL1441634 & 688422 & 5.45 & 5.4205 & TRN & \\
\hline CHEMBL1445235 & 688422 & 5.9 & 5.3277 & TRN & \\
\hline CHEMBL1578131 & 688422 & 4.5 & 5.4517 & TRN & \\
\hline CHEMBL1467965 & 688422 & 4.45 & 4.9747 & TST & \\
\hline CHEMBL1516720 & 688422 & 7.15 & 5.6156 & TRN & \\
\hline CHEMBL3190521 & 688422 & 5.2 & 5.5391 & TRN & \\
\hline CHEMBL1312703 & 688422 & 4.55 & 4.9908 & TRN & \\
\hline CHEMBL1464366 & 688422 & 4.55 & 5.7029 & TRN & \\
\hline CHEMBL1569156 & 688422 & 5.15 & 5.0488 & TRN & \\
\hline CHEMBL3208021 & 688422 & 4.65 & 5.1011 & TRN & \\
\hline CHEMBL1431231 & 688422 & 4.7 & 5.0357 & TRN & \\
\hline CHEMBL1418509 & 688422 & 5.25 & $5.4910 e$ & 00000000005 & \\
\hline CHEMBL1490377 & 688422 & 5.4 & 5.6138 & TST & \\
\hline CHEMBL1515578 & 688422 & 7.3497 & 5.5547 & TRN & \\
\hline CHEMBL1592622 & 688422 & 4.5 & 5.0601 & TRN & \\
\hline CHEMBL1200792 & 688422 & 4.65 & 5.2424 & TRN & \\
\hline CHEMBL1479699 & 688422 & 4.45 & 4.7312 & TRN & \\
\hline CHEMBL1558728 & 688422 & 6.5501 & 5.5496 & TRN & \\
\hline CHEMBL1336116 & 688422 & 4.85 & 4.8668 & TRN & \\
\hline CHEMBL1301723 & 688422 & 5.5 & 4.9609 & TRN & \\
\hline CHEMBL1451026 & 688422 & 4.9 & 5.0133 & TRN & \\
\hline CHEMBL1535974 & 688422 & 4.65 & 5.0047 & TRN & \\
\hline CHEMBL1466932 & 688422 & 4.9 & 5.2356 & TRN & \\
\hline CHEMBL1358796 & 688422 & 4.45 & 4.6098 & TRN & \\
\hline CHEMBL1376974 & 688422 & 7.1002 & 6.6062 & TST & \\
\hline CHEMBL1413938 & 688422 & 5.15 & 5.1051 & TRN & \\
\hline CHEMBL1324553 & 688422 & 4.45 & 5.085 & TRN & \\
\hline CHEMBL1573747 & 688422 & 5.35 & 5.2164 & TRN & \\
\hline CHEMBL1971935 & 688422 & 5.0 & 5.2013 & TRN & \\
\hline CHEMBL1537475 & 688422 & 7.0 & 5.4167 & TRN & \\
\hline CHEMBL1378295 & 688422 & 4.7 & 5.3541 & TRN & \\
\hline CHEMBL1386531 & 688422 & 4.6 & 5.6422 & TRN & \\
\hline
\end{tabular}




\begin{tabular}{|c|c|c|c|c|}
\hline \multicolumn{5}{|c|}{ Supplemental Table S2.txt } \\
\hline CHEMBL1546492 & 688422 & 4.45 & 5.0291 & TRN \\
\hline CHEMBL1546518 & 688422 & 4.5 & 5.5456 & TRN \\
\hline CHEMBL1394739 & 688422 & 8.301 & 5.7076 & TRN \\
\hline CHEMBL1422386 & 688422 & 5.45 & 5.3842 & TRN \\
\hline CHEMBL1500704 & 688422 & 4.5 & 4.9235 & TRN \\
\hline CHEMBL1511000 & 688422 & 4.85 & 5.1609 & TRN \\
\hline CHEMBL1515858 & 688422 & 4.9 & 4.8242 & TRN \\
\hline CHEMBL1556792 & 688422 & 4.45 & 4.7256 & TRN \\
\hline CHEMBL1499865 & 688422 & 4.85 & 5.2317 & TRN \\
\hline CHEMBL1490763 & 688422 & 4.7 & 4.9716 & TST \\
\hline CHEMBL1332478 & 688422 & 5.9 & 5.7412 & TST \\
\hline CHEMBL1327238 & 688422 & 6.25 & 5.3007 & TST \\
\hline CHEMBL1482828 & 688422 & 4.5 & 5.4922 & TRN \\
\hline CHEMBL1590416 & 688422 & 4.65 & 4.8815 & TRN \\
\hline CHEMBL1359375 & 688422 & 6.4 & 5.4166 & TRN \\
\hline CHEMBL1451436 & 688422 & 4.85 & 5.4452 & TRN \\
\hline CHEMBL1331935 & 688422 & 4.8 & 5.2123 & TST \\
\hline CHEMBL1585098 & 688422 & 4.9 & 4.9392 & TRN \\
\hline CHEMBL1320274 & 688422 & 4.45 & 4.6984 & TRN \\
\hline CHEMBL1398967 & 688422 & 4.5 & 5.4473 & TRN \\
\hline CHEMBL1517737 & 688422 & 4.8 & 5.1518 & TST \\
\hline CHEMBL1407611 & 688422 & 4.75 & 5.4002 & TRN \\
\hline CHEMBL1387155 & 688422 & 4.95 & 4.9205 & TRN \\
\hline CHEMBL1420549 & 688422 & 4.45 & 5.0815 & TRN \\
\hline CHEMBL1422559 & 688422 & 6.35 & 5.3524 & TST \\
\hline CHEMBL1453313 & 688422 & 5.25 & 5.4823 & TRN \\
\hline CHEMBL1584629 & 688422 & 4.95 & 5.8053 & TST \\
\hline CHEMBL1371697 & 688422 & 4.5 & 5.0633 & TRN \\
\hline CHEMBL1422020 & 688422 & 5.0 & 5.4455 & TST \\
\hline CHEMBL1431172 & 688422 & 4.85 & 5.3478 & TRN \\
\hline CHEMBL1365080 & 688422 & 4.6 & 4.9517 & TRN \\
\hline CHEMBL1339740 & 688422 & 5.0 & 5.3987 & TRN \\
\hline CHEMBL3210719 & 688422 & 5.55 & 5.1055 & TST \\
\hline CHEMBL1338891 & 688422 & 4.6 & 5.3289 & TRN \\
\hline CHEMBL1523470 & 688422 & 7.2503 & 5.4932 & TST \\
\hline CHEMBL1399652 & 688422 & 5.1 & 5.205 & TRN \\
\hline CHEMBL3192190 & 688422 & 6.15 & 5.1038 & TRN \\
\hline CHEMBL3199060 & 688422 & 6.45 & 4.9582 & TRN \\
\hline CHEMBL1409077 & 688422 & 4.45 & 5.5973 & TRN \\
\hline CHEMBL1405091 & 688422 & 7.2 & 5.4733 & TRN \\
\hline CHEMBL1305849 & 688422 & 4.8 & 4.6906 & TRN \\
\hline CHEMBL1529434 & 688422 & 5.2 & 5.3532 & TRN \\
\hline CHEMBL1369271 & 688422 & 4.85 & 5.1858 & TST \\
\hline CHEMBL1592950 & 688422 & 5.3 & 5.1172 & TST \\
\hline CHEMBL1399676 & 688422 & 8.3468 & 5.6689 & TST \\
\hline CHEMBL1993220 & 688422 & 8.4949 & 5.4483 & TST \\
\hline CHEMBL1349354 & 688422 & 7.5003 & 5.4943 & TRN \\
\hline CHEMBL1462487 & 688422 & 5.45 & 5.2095 & TRN \\
\hline
\end{tabular}




\begin{tabular}{|c|c|c|c|c|c|}
\hline \multicolumn{6}{|c|}{ Supplemental Table S2.txt } \\
\hline CHEMBL1460098 & 688422 & 4.9 & 5.3903 & TRN & \\
\hline CHEMBL1444573 & 688422 & 5.0 & 5.7566 & TRN & \\
\hline CHEMBL1535571 & 688422 & 4.5 & 5.4108 & TST & \\
\hline CHEMBL1421751 & 688422 & 6.25 & 5.4589 & TST & \\
\hline CHEMBL 3198000 & 688422 & 5.2 & 5.348 & TRN & \\
\hline CHEMBL1372819 & 688422 & 4.75 & 5.2405 & TRN & \\
\hline CHEMBL1376745 & 688422 & 4.7 & 5.9873 & TRN & \\
\hline CHEMBL1330966 & 688422 & 4.6 & 5.0823 & TRN & \\
\hline CHEMBL1320356 & 688422 & 4.45 & 5.2914 & TRN & \\
\hline CHEMBL1336236 & 688422 & 5.65 & 4.7717 & TRN & \\
\hline CHEMBL1587559 & 688422 & 4.95 & 5.0125 & TST & \\
\hline CHEMBL1380326 & 688422 & 4.6 & 5.1669 & TRN & \\
\hline CHEMBL1361043 & 688422 & 4.5 & 5.7194 & TRN & \\
\hline CHEMBL1392524 & 688422 & 4.45 & 5.033 & TRN & \\
\hline CHEMBL1573320 & 688422 & 4.75 & 5.1027 & TRN & \\
\hline CHEMBL1419966 & 688422 & 4.7 & 4.5572 & TRN & \\
\hline CHEMBL1345253 & 688422 & 4.65 & 5.2096 & TRN & \\
\hline CHEMBL1508265 & 688422 & 5.2 & 5.9151 & TST & \\
\hline CHEMBL1376227 & 688422 & 4.95 & 5.4035 & TRN & \\
\hline CHEMBL1477090 & 688422 & 5.6 & 4.8257 & TRN & \\
\hline CHEMBL1436540 & 688422 & 4.7 & 5.0915 & TRN & \\
\hline CHEMBL1576518 & 688422 & 4.85 & 5.2513 & TRN & \\
\hline CHEMBL1611969 & 688422 & 4.7 & 5.38 & TRN & \\
\hline CHEMBL1352775 & 688422 & 4.9 & 4.9844 & TRN & \\
\hline CHEMBL285819 & 688422 & 6.0 & 6.3114 & TRN & \\
\hline CHEMBL1418106 & 688422 & 5.15 & 4.9171 & TRN & \\
\hline CHEMBL1346627 & 688422 & 4.45 & 5.2106 & TST & \\
\hline CHEMBL1426327 & 688422 & 5.7 & 5.1767 & TRN & \\
\hline CHEMBL1591805 & 688422 & 8.3468 & 5.2276 & TST & \\
\hline CHEMBL1613020 & 688422 & 5.1 & 5.5176 & TRN & \\
\hline CHEMBL1559622 & 688422 & 4.45 & 4.9329 & TRN & \\
\hline CHEMBL1395344 & 688422 & 5.35 & 4.9717 & TRN & \\
\hline CHEMBL1358347 & 688422 & 7.6003 & 5.119 & TRN & \\
\hline CHEMBL1528334 & 688422 & 4.7 & 5.1797 & TRN & \\
\hline CHEMBL1398158 & 688422 & 4.5 & 5.2004 & TRN & \\
\hline CHEMBL2358514 & 688422 & 4.45 & 5.2645 & TRN & \\
\hline CHEMBL3196519 & 688422 & 4.85 & 5.4673 & TST & \\
\hline CHEMBL1597195 & 688422 & 4.5 & 5.1755 & TST & \\
\hline CHEMBL1416329 & 688422 & 4.45 & 4.9853 & TRN & \\
\hline CHEMBL1579057 & 688422 & 4.7 & 5.551 & TST & \\
\hline CHEMBL1528812 & 688422 & 4.8 & 5.2498 & TRN & \\
\hline CHEMBL1345456 & 688422 & 4.65 & 5.2198 & TRN & \\
\hline CHEMBL1576765 & 688422 & 6.2 & 5.4187 & TRN & \\
\hline CHEMBL1452430 & 688422 & 4.95 & $5.3770 e$ & 2000000001 & TRN \\
\hline CHEMBL1546532 & 688422 & 5.45 & 5.437 & TST & \\
\hline CHEMBL1611476 & 688422 & 6.6499 & 5.2104 & TRN & \\
\hline CHEMBL1472202 & 688422 & 5.4 & 5.0642 & TST & \\
\hline CHEMBL1518677 & 688422 & 5.6 & 5.2171 & TRN & \\
\hline
\end{tabular}




\begin{tabular}{|c|c|c|c|c|c|}
\hline \multicolumn{6}{|c|}{ Supplemental Table S2.txt } \\
\hline CHEMBL1510973 & 688422 & 5.05 & 5.2187 & TRN & \\
\hline CHEMBL1438584 & 688422 & 4.85 & 5.0322 & TRN & \\
\hline CHEMBL1981150 & 688422 & 4.6 & 4.829 & TRN & \\
\hline CHEMBL1553766 & 688422 & 4.45 & 4.7694 & TRN & \\
\hline CHEMBL1449910 & 688422 & 5.35 & 5.4252 & TRN & \\
\hline CHEMBL1984272 & 688422 & 4.65 & 5.1852 & TRN & \\
\hline CHEMBL1502859 & 688422 & 4.45 & 5.19 & TRN & \\
\hline CHEMBL1349378 & 688422 & 4.8 & 5.4158 & TRN & \\
\hline CHEMBL1540621 & 688422 & 4.9 & 4.9893 & TRN & \\
\hline CHEMBL1347757 & 688422 & 6.1 & 5.7597 & TST & \\
\hline CHEMBL1483312 & 688422 & 4.45 & 4.9747 & TRN & \\
\hline CHEMBL1610070 & 688422 & 4.45 & 4.9338 & TRN & \\
\hline CHEMBL1402547 & 688422 & 5.4 & 4.9863 & TRN & \\
\hline CHEMBL1581364 & 688422 & 4.85 & 5.1207 & TRN & \\
\hline CHEMBL1607113 & 688422 & 4.45 & 5.2349 & TST & \\
\hline CHEMBL1577080 & 688422 & 5.3 & 5.5175 & TST & \\
\hline CHEMBL1557221 & 688422 & 4.7 & 5.3453 & TRN & \\
\hline CHEMBL1394910 & 688422 & 4.45 & 5.20799 & э999999999 & TST \\
\hline CHEMBL1564599 & 688422 & 4.45 & 5.4912 & TRN & \\
\hline CHEMBL1505057 & 688422 & 4.9 & 5.2708 & TRN & \\
\hline CHEMBL1584285 & 688422 & 7.3497 & 5.1334 & TST & \\
\hline CHEMBL1465059 & 688422 & 4.85 & 4.9106 & TRN & \\
\hline CHEMBL1373316 & 688422 & 4.95 & 5.218 & TST & \\
\hline CHEMBL1485936 & 688422 & 4.45 & 5.4524 & TRN & \\
\hline CHEMBL1321782 & 688422 & 7.4001 & 5.9196 & TRN & \\
\hline CHEMBL1315701 & 688422 & 8.7447 & 5.4569 & TST & \\
\hline CHEMBL1483344 & 688422 & 4.8 & 5.2612 & TRN & \\
\hline CHEMBL1526149 & 688422 & 5.0 & 5.1315 & TRN & \\
\hline CHEMBL1487849 & 688422 & 5.55 & 5.2675 & TRN & \\
\hline CHEMBL1426370 & 688422 & 4.85 & 5.1335 & TRN & \\
\hline CHEMBL123 & 688422 & 6.0 & 5.7442 & TST & \\
\hline CHEMBL1594781 & 688422 & 4.9 & 4.9194 & TRN & \\
\hline CHEMBL1527128 & 688422 & 6.2 & 5.4438 & TST & \\
\hline CHEMBL1406673 & 688422 & 4.9 & 5.4551 & TRN & \\
\hline CHEMBL1371914 & 688422 & 8.3468 & 5.1373 & TRN & \\
\hline CHEMBL1598631 & 688422 & 6.05 & 5.3491 & TRN & \\
\hline CHEMBL1379483 & 688422 & 4.95 & 5.0833 & TRN & \\
\hline CHEMBL1442617 & 688422 & 7.6003 & 5.6204 & TRN & \\
\hline CHEMBL1518526 & 688422 & 5.0 & 5.0198 & TRN & \\
\hline CHEMBL1306348 & 688422 & 5.1 & 5.3101 & TRN & \\
\hline CHEMBL1603375 & 688422 & 4.65 & 5.2616 & TRN & \\
\hline CHEMBL1343523 & 688422 & 4.9 & 5.1264 & TRN & \\
\hline CHEMBL1498273 & 688422 & 4.65 & 5.2669 & TRN & \\
\hline CHEMBL1364263 & 688422 & 4.85 & 5.7279 & TRN & \\
\hline CHEMBL1490048 & 688422 & 4.45 & 5.1091 & TRN & \\
\hline CHEMBL1360521 & 688422 & 4.75 & 5.1996 & TRN & \\
\hline CHEMBL1328024 & 688422 & 5.05 & 5.1944 & TRN & \\
\hline CHEMBL1347030 & 688422 & 4.45 & 4.7901 & TST & \\
\hline
\end{tabular}




\begin{tabular}{|c|c|c|c|c|c|}
\hline \multirow[b]{2}{*}{ CHEMBL1412533 } & \multirow[b]{2}{*}{688422} & \multicolumn{4}{|c|}{ Supplemental Table S2.txt } \\
\hline & & 7.0501 & 5.1155 & TST & \\
\hline CHEMBL1412383 & 688422 & 6.45 & 5.6887 & TRN & \\
\hline CHEMBL1533744 & 688422 & 4.9 & 5.30200 & 00000000005 & TRN \\
\hline CHEMBL1545753 & 688422 & 5.2 & 5.6216 & TRN & \\
\hline CHEMBL1347787 & 688422 & 4.75 & 5.2902 & TRN & \\
\hline CHEMBL1418823 & 688422 & 4.9 & 5.0562 & TRN & \\
\hline CHEMBL1559825 & 688422 & 6.7501 & 5.0996 & TST & \\
\hline CHEMBL1468193 & 688422 & 4.9 & 5.2928 & TST & \\
\hline CHEMBL1983389 & 688422 & 4.8 & 5.3153 & TST & \\
\hline CHEMBL1468668 & 688422 & 4.7 & 5.2158 & TST & \\
\hline CHEMBL1449660 & 688422 & 4.9 & 4.8629 & TRN & \\
\hline CHEMBL1303661 & 688422 & 4.45 & 5.4737 & TRN & \\
\hline CHEMBL1604219 & 688422 & 4.75 & 5.1877 & TST & \\
\hline CHEMBL1508454 & 688422 & 4.65 & 5.3678 & TRN & \\
\hline CHEMBL1431420 & 688422 & 4.8 & 5.4329 & TRN & \\
\hline CHEMBL3194178 & 688422 & 4.85 & 4.6578 & TRN & \\
\hline CHEMBL1308733 & 688422 & 4.7 & 5.0606 & TST & \\
\hline CHEMBL1368114 & 688422 & 4.95 & 4.9002 & TRN & \\
\hline CHEMBL1428768 & 688422 & 4.9 & 5.3092 & TST & \\
\hline CHEMBL1611464 & 688422 & 7.8013 & 5.6904 & TST & \\
\hline CHEMBL1386534 & 688422 & 4.8 & 5.2951 & TST & \\
\hline CHEMBL1437957 & 688422 & 4.95 & 5.1966 & TST & \\
\hline CHEMBL1501515 & 688422 & 5.05 & 5.1511 & TRN & \\
\hline CHEMBL1491145 & 688422 & 4.95 & 4.5165 & TRN & \\
\hline CHEMBL3196726 & 688422 & 5.1 & 4.9579 & TRN & \\
\hline CHEMBL 1590657 & 688422 & 4.45 & 5.1504 & TRN & \\
\hline CHEMBL1387077 & 688422 & 4.85 & 4.9865 & TRN & \\
\hline CHEMBL1450403 & 688422 & 5.3 & 5.5829 & TRN & \\
\hline CHEMBL1584420 & 688422 & 4.7 & 5.0076 & TRN & \\
\hline CHEMBL268868 & 688422 & 4.9 & 5.4102 & TST & \\
\hline CHEMBL1483122 & 688422 & 7.0501 & 5.0634 & TRN & \\
\hline CHEMBL1478881 & 688422 & 4.95 & 5.2388 & TST & \\
\hline CHEMBL1371971 & 688422 & 6.2 & 5.3327 & TST & \\
\hline CHEMBL1388876 & 688422 & 4.8 & 5.3246 & TRN & \\
\hline CHEMBL1387320 & 688422 & 4.45 & 4.6962 & TRN & \\
\hline CHEMBL1979306 & 688422 & 4.85 & 5.6968 & TST & \\
\hline CHEMBL1304866 & 688422 & 6.35 & 5.4928 & TRN & \\
\hline CHEMBL1387355 & 688422 & 5.0 & 4.8752 & TRN & \\
\hline CHEMBL576997 & 688422 & 6.0 & 5.5867 & TRN & \\
\hline CHEMBL1255758 & 688422 & 5.2 & 5.70200 & 0000000001 & TST \\
\hline CHEMBL1524980 & 688422 & 4.9 & 5.4882 & TST & \\
\hline CHEMBL1450678 & 688422 & 4.7 & 5.8094 & TST & \\
\hline CHEMBL1451723 & 688422 & 4.85 & 4.9935 & TRN & \\
\hline CHEMBL1512055 & 688422 & 5.55 & 5.1731 & TRN & \\
\hline CHEMBL1390737 & 688422 & 6.5 & 5.222 & TRN & \\
\hline CHEMBL1342543 & 688422 & 5.0 & 5.2 & TRN & \\
\hline CHEMBL1457467 & 688422 & 4.45 & 4.6972 & TRN & \\
\hline CHEMBL1579561 & 688422 & 4.75 & 4.5465 & TRN & \\
\hline
\end{tabular}




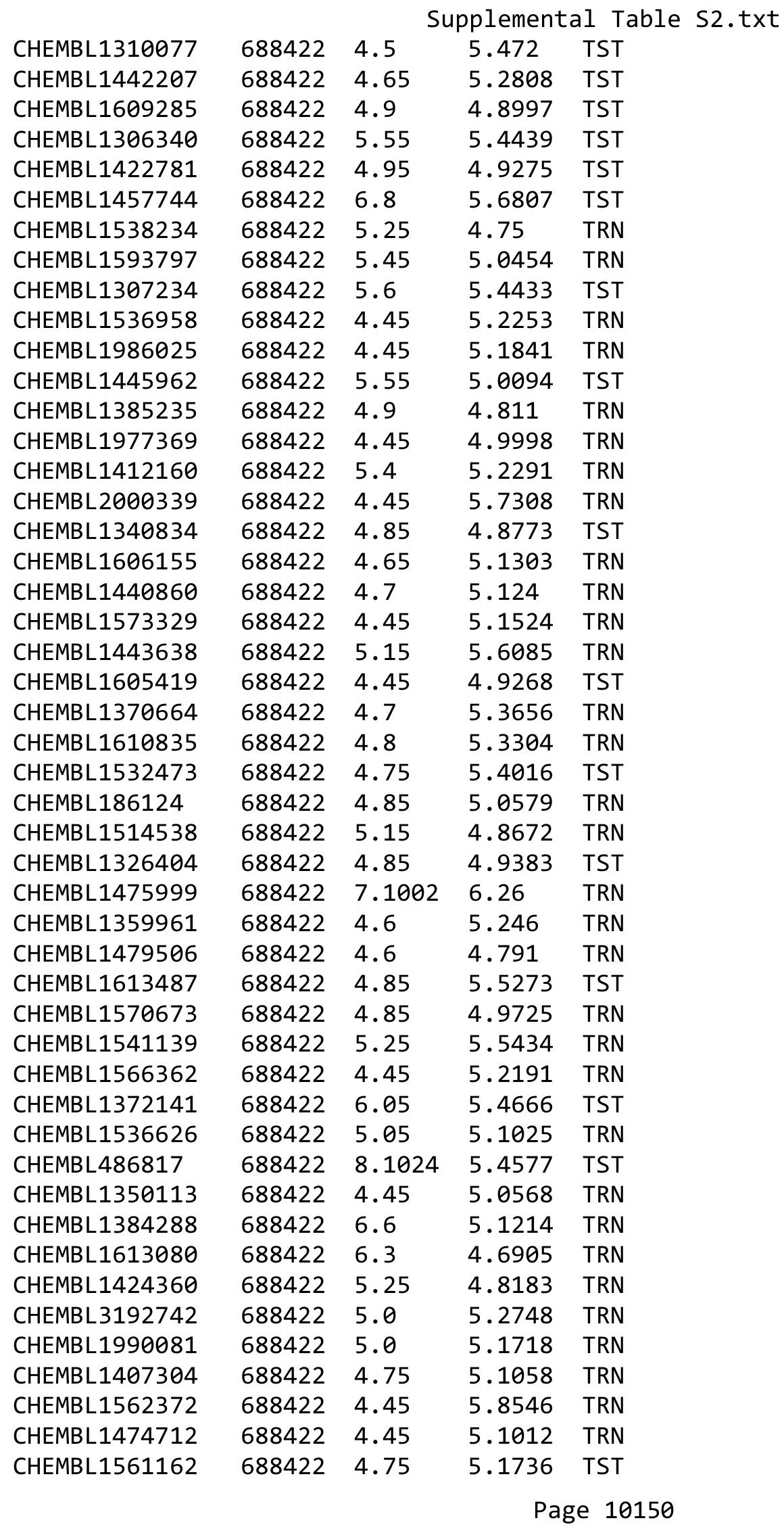




\begin{tabular}{|c|c|c|c|c|c|}
\hline \multicolumn{6}{|c|}{ Supplemental Table s2.txt } \\
\hline CHEMBL1481594 & 688422 & 4.45 & 5.4603 & TRN & \\
\hline CHEMBL1334241 & 688422 & 4.45 & 5.1206 & TRN & \\
\hline CHEMBL1370692 & 688422 & 5.95 & 5.8826 & TRN & \\
\hline CHEMBL1320403 & 688422 & 8.301 & 5.999 & TRN & \\
\hline CHEMBL1604303 & 688422 & 5.05 & 5.2684 & TRN & \\
\hline CHEMBL1329000 & 688422 & 4.85 & 4.8047 & TRN & \\
\hline CHEMBL1453238 & 688422 & 4.55 & 5.4183 & TRN & \\
\hline CHEMBL1322654 & 688422 & 5.9 & 5.8637 & TRN & \\
\hline CHEMBL3144961 & 688422 & 4.45 & 5.2849 & TST & \\
\hline CHEMBL1583145 & 688422 & 7.2 & 5.9287 & TST & \\
\hline CHEMBL1373129 & 688422 & 4.45 & 5.5146 & TRN & \\
\hline CHEMBL1453565 & 688422 & 4.85 & 5.6369 & TRN & \\
\hline CHEMBL3145076 & 688422 & 6.8499 & 5.087 & TRN & \\
\hline CHEMBL1530584 & 688422 & 4.45 & 4.8767 & TRN & \\
\hline CHEMBL3190777 & 688422 & 4.45 & 5.2074 & TST & \\
\hline CHEMBL1534285 & 688422 & 4.45 & 4.8916 & TRN & \\
\hline CHEMBL1369321 & 688422 & 4.65 & 5.0298 & TST & \\
\hline CHEMBL1577092 & 688422 & 5.5 & 4.9107 & TRN & \\
\hline CHEMBL1366242 & 688422 & 5.1 & 5.4758 & TRN & \\
\hline CHEMBL1565212 & 688422 & 5.15 & 5.1339 & TRN & \\
\hline CHEMBL1561554 & 688422 & 5.2 & 5.3315 & TST & \\
\hline CHEMBL1427224 & 688422 & 5.35 & 5.3791 & TST & \\
\hline CHEMBL1506356 & 688422 & 4.85 & 5.2569 & TST & \\
\hline CHEMBL1311395 & 688422 & 7.4001 & 4.867 & TST & \\
\hline CHEMBL1572558 & 688422 & 5.6 & 5.6307 & TRN & \\
\hline CHEMBL1408196 & 688422 & 4.8 & 5.2282 & TRN & \\
\hline CHEMBL1344571 & 688422 & 4.65 & 4.80399 & 9999999999 & TRN \\
\hline CHEMBL1486358 & 688422 & 4.45 & 4.7636 & TRN & \\
\hline CHEMBL1336911 & 688422 & 5.0 & 5.062 & TRN & \\
\hline CHEMBL1349215 & 688422 & 4.7 & 5.1871 & TRN & \\
\hline CHEMBL1578844 & 688422 & 5.4 & 5.4099 & TST & \\
\hline CHEMBL1511826 & 688422 & 4.8 & 5.4961 & TRN & \\
\hline CHEMBL1586632 & 688422 & 7.4498 & 5.4107 & TRN & \\
\hline CHEMBL1375819 & 688422 & 7.3497 & 5.0593 & TRN & \\
\hline CHEMBL1996363 & 688422 & 5.55 & 5.4821 & TST & \\
\hline CHEMBL1421759 & 688422 & 4.95 & 5.0483 & TST & \\
\hline CHEMBL1456573 & 688422 & 5.65 & 5.0055 & TST & \\
\hline CHEMBL1384042 & 688422 & 5.15 & 5.2781 & TRN & \\
\hline CHEMBL1483494 & 688422 & 4.45 & 5.4458 & TRN & \\
\hline CHEMBL1376484 & 688422 & 6.05 & 4.8836 & TRN & \\
\hline CHEMBL1454425 & 688422 & 5.0 & 5.9347 & TRN & \\
\hline CHEMBL1581275 & 688422 & 4.5 & 5.0296 & TRN & \\
\hline CHEMBL1458275 & 688422 & 5.4 & 5.5116 & TRN & \\
\hline CHEMBL1317309 & 688422 & 8.4949 & 5.7391 & TRN & \\
\hline CHEMBL1572243 & 688422 & 4.45 & 5.558 & TRN & \\
\hline CHEMBL1352347 & 688422 & 4.5 & 5.49200 & 0000000001 & TST \\
\hline CHEMBL1381752 & 688422 & 4.45 & 5.1379 & TRN & \\
\hline CHEMBL1364373 & 688422 & 7.8996 & 4.852 & TST & \\
\hline
\end{tabular}




\begin{tabular}{|c|c|c|c|c|}
\hline \multicolumn{5}{|c|}{ Supplemental Table S2.txt } \\
\hline CHEMBL1541241 & 688422 & 4.65 & 5.0449 & TRN \\
\hline CHEMBL1457450 & 688422 & 4.6 & 5.6129 & TRN \\
\hline CHEMBL1594694 & 688422 & 4.5 & 4.8712 & TRN \\
\hline CHEMBL17201 & 688422 & 4.75 & 5.0115 & TRN \\
\hline CHEMBL1350181 & 688422 & 4.95 & 5.109 & TST \\
\hline CHEMBL1588938 & 688422 & 5.75 & 5.9466 & TST \\
\hline CHEMBL1390891 & 688422 & 4.5 & 5.4368 & TST \\
\hline CHEMBL3208281 & 688422 & 7.15 & 5.1726 & TST \\
\hline CHEMBL1599852 & 688422 & 6.2 & 5.1622 & TRN \\
\hline CHEMBL1441978 & 688422 & 4.8 & 5.2128 & TRN \\
\hline CHEMBL1317080 & 688422 & 4.9 & 5.1323 & TRN \\
\hline CHEMBL1452915 & 688422 & 4.45 & 5.3858 & TST \\
\hline CHEMBL1580340 & 688422 & 7.699 & 5.1729 & TRN \\
\hline CHEMBL1500417 & 688422 & 6.2 & 5.4908 & TST \\
\hline CHEMBL1341913 & 688422 & 7.4498 & 5.1016 & TRN \\
\hline CHEMBL1306816 & 688422 & 5.15 & 5.1147 & TST \\
\hline CHEMBL1407114 & 688422 & 5.1 & 5.3169 & TRN \\
\hline CHEMBL1593965 & 688422 & 6.15 & 5.6208 & TRN \\
\hline CHEMBL1441695 & 688422 & 5.5 & 5.9559 & TST \\
\hline CHEMBL1341251 & 688422 & 4.8 & 4.9227 & TRN \\
\hline CHEMBL1378098 & 688422 & 4.45 & 5.5072 & TRN \\
\hline CHEMBL1469747 & 688422 & 5.5 & 5.1681 & TRN \\
\hline CHEMBL1351576 & 688422 & 4.9 & 5.2822 & TRN \\
\hline CHEMBL1358674 & 688422 & 4.9 & 5.1616 & TST \\
\hline CHEMBL1471998 & 688422 & 4.55 & 5.3832 & TRN \\
\hline CHEMBL1425831 & 688422 & 4.7 & 5.3643 & TST \\
\hline CHEMBL1434637 & 688422 & 4.7 & 5.3108 & TRN \\
\hline CHEMBL1558487 & 688422 & 5.7 & 5.2021 & TRN \\
\hline CHEMBL1469134 & 688422 & 4.6 & 4.9471 & TRN \\
\hline CHEMBL3193427 & 688422 & 4.9 & 5.4024 & TRN \\
\hline CHEMBL1518702 & 688422 & 5.2 & 5.1457 & TRN \\
\hline CHEMBL1337683 & 688422 & 4.55 & 5.0276 & TRN \\
\hline CHEMBL1562379 & 688422 & 6.1 & 5.4212 & TRN \\
\hline CHEMBL1550432 & 688422 & 4.45 & 5.3644 & TRN \\
\hline CHEMBL1312565 & 688422 & 5.0 & 5.2194 & TRN \\
\hline CHEMBL1459647 & 688422 & 4.45 & 5.1152 & TRN \\
\hline CHEMBL1460084 & 688422 & 4.6 & 5.0453 & TRN \\
\hline CHEMBL1408909 & 688422 & 4.75 & 5.2356 & TRN \\
\hline CHEMBL1447420 & 688422 & 5.95 & 5.3507 & TRN \\
\hline CHEMBL1543752 & 688422 & 4.65 & 4.6846 & TRN \\
\hline CHEMBL1316722 & 688422 & 5.9 & 5.2535 & TRN \\
\hline CHEMBL1499028 & 688422 & 4.95 & 5.4309 & TRN \\
\hline CHEMBL1335558 & 688422 & 5.2 & 4.971 & TST \\
\hline CHEMBL1360107 & 688422 & 4.9 & 5.5439 & TST \\
\hline CHEMBL1468691 & 688422 & 5.25 & 5.5275 & TRN \\
\hline CHEMBL1355945 & 688422 & 6.8499 & 5.6656 & TRN \\
\hline CHEMBL1456735 & 688422 & 4.5 & 5.6344 & TRN \\
\hline CHEMBL1306058 & 688422 & 4.65 & 5.142 & TRN \\
\hline
\end{tabular}




\begin{tabular}{|c|c|c|c|c|c|}
\hline \multicolumn{6}{|c|}{ Supplemental Table s2.txt } \\
\hline CHEMBL1574265 & 688422 & 6.05 & 5.4604 & TRN & \\
\hline CHEMBL1576837 & 688422 & 4.8 & 4.9155 & TRN & \\
\hline CHEMBL1544633 & 688422 & 6.7501 & 5.3993 & TRN & \\
\hline CHEMBL1426562 & 688422 & 5.35 & 5.3298 & TST & \\
\hline CHEMBL3197902 & 688422 & 4.7 & 5.1311 & TRN & \\
\hline CHEMBL1529215 & 688422 & 7.15 & 5.5024 & TST & \\
\hline CHEMBL1464080 & 688422 & 4.45 & 4.879 & TRN & \\
\hline CHEMBL1571941 & 688422 & 4.45 & 5.1727 & TRN & \\
\hline CHEMBL1412250 & 688422 & 5.1 & 5.1678 & TRN & \\
\hline CHEMBL1489731 & 688422 & 4.95 & 5.4549 & TST & \\
\hline CHEMBL1304885 & 688422 & 4.6 & 5.0968 & TRN & \\
\hline CHEMBL1452488 & 688422 & 4.45 & 5.2804 & TRN & \\
\hline CHEMBL1368809 & 688422 & 4.65 & 4.9119 & TST & \\
\hline CHEMBL1492365 & 688422 & 5.55 & 4.9221 & TRN & \\
\hline CHEMBL3210057 & 688422 & 8.0506 & 4.7437 & TRN & \\
\hline CHEMBL1397820 & 688422 & 5.05 & 5.0577 & TRN & \\
\hline CHEMBL1596707 & 688422 & 4.85 & 5.7829 & TRN & \\
\hline CHEMBL1363127 & 688422 & 5.15 & 5.0403 & TRN & \\
\hline CHEMBL1375553 & 688422 & 4.7 & 5.3199 & TST & \\
\hline CHEMBL1410287 & 688422 & 4.45 & 5.1935 & TRN & \\
\hline CHEMBL3194009 & 688422 & 5.1 & 5.4246 & TST & \\
\hline CHEMBL1557088 & 688422 & 4.75 & 5.2553 & TRN & \\
\hline CHEMBL1526262 & 688422 & 5.0 & 4.8885 & TRN & \\
\hline CHEMBL1316562 & 688422 & 4.9 & 5.2089 & TRN & \\
\hline CHEMBL1524901 & 688422 & 4.5 & 5.1643 & TRN & \\
\hline CHEMBL1255737 & 688422 & 6.0 & 5.1354 & TST & \\
\hline CHEMBL1446159 & 688422 & 4.9 & 5.0096 & TRN & \\
\hline CHEMBL1372035 & 688422 & 4.7 & 5.5519 & TRN & \\
\hline CHEMBL1349490 & 688422 & 4.45 & 5.4764 & TRN & \\
\hline CHEMBL1558266 & 688422 & 4.85 & 5.1106 & TST & \\
\hline CHEMBL1430225 & 688422 & 5.55 & 5.6665 & TST & \\
\hline CHEMBL1508661 & 688422 & 5.8 & 4.864 & TRN & \\
\hline CHEMBL1322247 & 688422 & 4.45 & 5.6937 & TRN & \\
\hline CHEMBL1418104 & 688422 & 4.85 & 5.4206 & TRN & \\
\hline CHEMBL1598432 & 688422 & 4.8 & 4.9206 & TRN & \\
\hline CHEMBL1488544 & 688422 & 6.15 & 6.0407 & TRN & \\
\hline CHEMBL1466558 & 688422 & 4.65 & 4.9566 & TRN & \\
\hline CHEMBL1462779 & 688422 & 5.95 & 5.5663 & TRN & \\
\hline CHEMBL1415794 & 688422 & 4.95 & 5.2488 & TRN & \\
\hline CHEMBL1385696 & 688422 & 6.35 & 5.6891 & TRN & \\
\hline CHEMBL1613381 & 688422 & 4.85 & 5.722 & TST & \\
\hline CHEMBL1299982 & 688422 & 6.05 & 5.1997 & TST & \\
\hline CHEMBL1419925 & 688422 & 5.85 & 5.1301 & TRN & \\
\hline CHEMBL3194091 & 688422 & 5.2 & 4.7525 & TRN & \\
\hline CHEMBL1346822 & 688422 & 4.45 & 5.0944 & TRN & \\
\hline CHEMBL1371242 & 688422 & 4.45 & 5.4684 & TRN & \\
\hline CHEMBL1515729 & 688422 & 4.45 & 4.8663 & TRN & \\
\hline CHEMBL1390984 & 688422 & 4.7 & $5.1220 e$ & 0000000001 & TRN \\
\hline & & & & 10153 & \\
\hline
\end{tabular}




\begin{tabular}{|c|c|c|c|c|c|}
\hline \multicolumn{6}{|c|}{ Supplemental Table S2.txt } \\
\hline CHEMBL1494127 & 688422 & 4.7 & 4.9596 & TRN & \\
\hline CHEMBL1523805 & 688422 & 4.45 & 4.6583 & TRN & \\
\hline CHEMBL1338583 & 688422 & 6.05 & 5.8297 & TST & \\
\hline CHEMBL1455233 & 688422 & 5.45 & 4.6093 & TRN & \\
\hline CHEMBL1378773 & 688422 & 4.8 & 5.6688 & TRN & \\
\hline CHEMBL1307787 & 688422 & 4.45 & 5.1124 & TST & \\
\hline CHEMBL3192364 & 688422 & 4.6 & 5.1707 & TRN & \\
\hline CHEMBL1985350 & 688422 & 5.05 & 5.1232 & TST & \\
\hline CHEMBL1532566 & 688422 & 4.6 & 5.0006 & TRN & \\
\hline CHEMBL1469208 & 688422 & 4.45 & 5.1536 & TRN & \\
\hline CHEMBL1467304 & 688422 & 4.45 & 4.9305 & TST & \\
\hline CHEMBL1421468 & 688422 & 4.45 & 4.8457 & TRN & \\
\hline CHEMBL1436547 & 688422 & 4.75 & 5.7604 & TRN & \\
\hline CHEMBL1544717 & 688422 & 5.15 & 5.9626 & TRN & \\
\hline CHEMBL1568417 & 688422 & 4.45 & 5.6695 & TST & \\
\hline CHEMBL1375019 & 688422 & 5.05 & 5.1016 & TST & \\
\hline CHEMBL1439687 & 688422 & 5.4 & 5.3086 & TST & \\
\hline CHEMBL1492628 & 688422 & 6.5 & 5.2034 & TRN & \\
\hline CHEMBL1305536 & 688422 & 4.45 & 4.9077 & TRN & \\
\hline CHEMBL1459028 & 688422 & 4.45 & 5.312 & TRN & \\
\hline CHEMBL1315187 & 688422 & 8.1487 & 5.3665 & TRN & \\
\hline CHEMBL1411785 & 688422 & 4.45 & 5.4974 & TRN & \\
\hline CHEMBL1348977 & 688422 & 5.35 & 5.5085 & TST & \\
\hline CHEMBL1523240 & 688422 & 7.6498 & 5.4187 & TRN & \\
\hline CHEMBL1529776 & 688422 & 4.45 & 5.5195 & TRN & \\
\hline CHEMBL1506250 & 688422 & 4.75 & 5.045 & TRN & \\
\hline CHEMBL1369392 & 688422 & 4.9 & 5.2285 & TRN & \\
\hline CHEMBL1347544 & 688422 & 4.65 & 5.5611 & TST & \\
\hline CHEMBL1353259 & 688422 & 4.45 & 4.9734 & TRN & \\
\hline CHEMBL3214555 & 688422 & 4.45 & 5.2209 & TST & \\
\hline CHEMBL1486572 & 688422 & 4.95 & 4.8508 & TRN & \\
\hline CHEMBL1362727 & 688422 & 4.9 & 5.1564 & TRN & \\
\hline CHEMBL3213915 & 688422 & 5.0 & 5.561 & TRN & \\
\hline CHEMBL1556066 & 688422 & 5.35 & 5.1928 & TRN & \\
\hline CHEMBL1516568 & 688422 & 5.4 & 5.4762 & TRN & \\
\hline CHEMBL1534875 & 688422 & 4.85 & 4.931 & TRN & \\
\hline CHEMBL599503 & 688422 & 4.8 & 5.0229 & TRN & \\
\hline CHEMBL1325198 & 688422 & 4.9 & $5.1160 e$ & 00000000005 & TRN \\
\hline CHEMBL1536673 & 688422 & 5.05 & 5.2734 & TRN & \\
\hline CHEMBL1527447 & 688422 & 4.75 & 4.9586 & TRN & \\
\hline CHEMBL1595487 & 688422 & 4.6 & 5.1287 & TRN & \\
\hline CHEMBL1989858 & 688422 & 4.7 & 4.8271 & TRN & \\
\hline CHEMBL1611553 & 688422 & 4.45 & 4.9818 & TST & \\
\hline CHEMBL1460708 & 688422 & 5.2 & 5.4517 & TRN & \\
\hline CHEMBL1327196 & 688422 & 8.1024 & 5.26 & TRN & \\
\hline CHEMBL1609114 & 688422 & 8.4949 & 5.61 & TRN & \\
\hline CHEMBL1474978 & 688422 & 5.25 & $5.5820 e$ & 0000000001 & TRN \\
\hline CHEMBL1482924 & 688422 & 4.45 & 5.3074 & TRN & \\
\hline
\end{tabular}




\begin{tabular}{|c|c|c|c|c|}
\hline \multicolumn{5}{|c|}{ Supplemental Table S2.txt } \\
\hline CHEMBL1435046 & 688422 & 7.0 & 5.4623 & TRN \\
\hline CHEMBL1477578 & 688422 & 6.9 & 5.3206 & TRN \\
\hline CHEMBL1360816 & 688422 & 4.5 & 5.3957 & TST \\
\hline CHEMBL1365046 & 688422 & 5.6 & 5.5337 & TRN \\
\hline CHEMBL110739 & 688422 & 6.35 & 5.9724 & TRN \\
\hline CHEMBL1502093 & 688422 & 7.3497 & 6.1125 & TST \\
\hline CHEMBL1435216 & 688422 & 4.45 & 5.1327 & TRN \\
\hline CHEMBL3199489 & 688422 & 4.6 & 5.3868 & TRN \\
\hline CHEMBL1559959 & 688422 & 5.4 & 4.9058 & TRN \\
\hline CHEMBL1299470 & 688422 & 4.9 & 5.2276 & TRN \\
\hline CHEMBL1414491 & 688422 & 4.75 & 5.3254 & TST \\
\hline CHEMBL1342237 & 688422 & 4.45 & 5.1929 & TRN \\
\hline CHEMBL1422788 & 688422 & 4.6 & 5.6122 & TST \\
\hline CHEMBL1596602 & 688422 & 5.05 & 5.1291 & TRN \\
\hline CHEMBL1431209 & 688422 & 4.45 & 5.5349 & TST \\
\hline CHEMBL1490339 & 688422 & 6.4 & 5.6752 & TRN \\
\hline CHEMBL1417984 & 688422 & 4.45 & 5.3071 & TST \\
\hline CHEMBL1562146 & 688422 & 4.35 & 5.444 & TRN \\
\hline CHEMBL1456048 & 688422 & 4.85 & 4.9942 & TST \\
\hline CHEMBL1589808 & 688422 & 4.5 & 4.581 & TRN \\
\hline CHEMBL1484115 & 688422 & 5.7 & 5.2468 & TST \\
\hline CHEMBL1393900 & 688422 & 4.45 & 5.2948 & TST \\
\hline CHEMBL1302706 & 688422 & 4.9 & 5.0649 & TRN \\
\hline CHEMBL1368116 & 688422 & 4.65 & 5.4817 & TRN \\
\hline CHEMBL1427221 & 688422 & 4.45 & 4.877 & TST \\
\hline CHEMBL1351288 & 688422 & 7.1002 & 5.5632 & TST \\
\hline CHEMBL1369593 & 688422 & 4.45 & 4.2435 & TRN \\
\hline CHEMBL1431829 & 688422 & 5.2 & 5.2429 & TST \\
\hline CHEMBL1590071 & 688422 & 6.25 & 5.3 & TRN \\
\hline CHEMBL1507578 & 688422 & 4.85 & 4.9661 & TRN \\
\hline CHEMBL1419798 & 688422 & 6.8499 & 5.4065 & TRN \\
\hline CHEMBL1438343 & 688422 & 4.65 & 5.2737 & TST \\
\hline CHEMBL1568647 & 688422 & 6.0 & 5.0013 & TST \\
\hline CHEMBL3208220 & 688422 & 4.45 & 5.5682 & TRN \\
\hline CHEMBL1465873 & 688422 & 4.45 & 5.0447 & TRN \\
\hline CHEMBL1365523 & 688422 & 6.05 & 5.4352 & TRN \\
\hline CHEMBL1463363 & 688422 & 4.6 & 5.0674 & TST \\
\hline CHEMBL3192561 & 688422 & 5.1 & 5.3058 & TRN \\
\hline CHEMBL1515123 & 688422 & 4.4 & 5.3315 & TRN \\
\hline CHEMBL1464121 & 688422 & 4.9 & 5.5103 & TRN \\
\hline CHEMBL1506932 & 688422 & 4.45 & 5.4774 & TST \\
\hline CHEMBL1255936 & 688422 & 5.6 & 5.1589 & TST \\
\hline CHEMBL1328534 & 688422 & 4.9 & 5.1907 & TRN \\
\hline CHEMBL3194247 & 688422 & 4.95 & 5.2125 & TRN \\
\hline CHEMBL3210537 & 688422 & 4.45 & 5.4075 & TRN \\
\hline CHEMBL1476049 & 688422 & 4.8 & 4.961 & TRN \\
\hline CHEMBL1457591 & 688422 & 6.35 & 5.4117 & TRN \\
\hline CHEMBL1484451 & 688422 & 4.8 & 5.3546 & TRN \\
\hline
\end{tabular}




\begin{tabular}{|c|c|c|c|c|c|}
\hline \multicolumn{6}{|c|}{ Supplemental Table s2.txt } \\
\hline CHEMBL1589157 & 688422 & 5.65 & 5.6104 & TRN & \\
\hline CHEMBL1393375 & 688422 & 4.85 & 4.71899 & 9999999999 & TRN \\
\hline CHEMBL1470256 & 688422 & 5.3 & 5.3652 & TRN & \\
\hline CHEMBL1353792 & 688422 & 6.3 & 5.653 & TRN & \\
\hline CHEMBL1347632 & 688422 & 4.9 & 5.4374 & TRN & \\
\hline CHEMBL1499433 & 688422 & 4.9 & 5.447 & TRN & \\
\hline CHEMBL1342111 & 688422 & 6.8499 & 5.33799 & 9999999999 & TST \\
\hline CHEMBL1343860 & 688422 & 4.95 & 5.2044 & TRN & \\
\hline CHEMBL1326050 & 688422 & 4.45 & 5.0502 & TRN & \\
\hline CHEMBL1444363 & 688422 & 4.45 & 5.0776 & TRN & \\
\hline CHEMBL1353925 & 688422 & 7.6003 & 5.3136 & TST & \\
\hline CHEMBL1406208 & 688422 & 6.15 & 5.1183 & TRN & \\
\hline CHEMBL601335 & 688422 & 6.0 & 5.3844 & TRN & \\
\hline CHEMBL1331573 & 688422 & 5.25 & 5.1528 & TST & \\
\hline CHEMBL3192907 & 688422 & 4.45 & 5.2758 & TRN & \\
\hline CHEMBL127579 & 688422 & 4.45 & 5.2197 & TRN & \\
\hline CHEMBL1544212 & 688422 & 4.85 & 5.0625 & TST & \\
\hline CHEMBL1564647 & 688422 & 4.45 & 5.7402 & TST & \\
\hline CHEMBL1391059 & 688422 & 4.45 & 5.3445 & TRN & \\
\hline CHEMBL1407091 & 688422 & 4.45 & 4.9732 & TRN & \\
\hline CHEMBL1611106 & 688422 & 5.4 & 5.0213 & TRN & \\
\hline CHEMBL1356629 & 688422 & 5.0 & 5.6785 & TRN & \\
\hline CHEMBL1316222 & 688422 & 5.45 & 5.4618 & TST & \\
\hline CHEMBL1422704 & 688422 & 4.45 & 5.1079 & TRN & \\
\hline CHEMBL1389332 & 688422 & 5.25 & 5.2122 & TRN & \\
\hline CHEMBL1561124 & 688422 & 5.3 & 5.8537 & TRN & \\
\hline CHEMBL1460675 & 688422 & 4.9 & 4.8542 & TRN & \\
\hline CHEMBL1547683 & 688422 & 6.5501 & 5.2625 & TRN & \\
\hline CHEMBL1435997 & 688422 & 4.65 & 5.496 & TRN & \\
\hline CHEMBL1584680 & 688422 & 4.5 & 5.4916 & TRN & \\
\hline CHEMBL1385410 & 688422 & 4.7 & 4.9955 & TRN & \\
\hline CHEMBL1381309 & 688422 & 6.25 & 5.1835 & TST & \\
\hline CHEMBL1356563 & 688422 & 8.3468 & 5.2874 & TRN & \\
\hline CHEMBL1447006 & 688422 & 4.45 & 5.6711 & TRN & \\
\hline CHEMBL1605701 & 688422 & 4.75 & 5.2856 & TRN & \\
\hline CHEMBL1402373 & 688422 & 4.7 & 5.2016 & TRN & \\
\hline CHEMBL1458228 & 688422 & 4.75 & 5.2077 & TRN & \\
\hline CHEMBL1342842 & 688422 & 4.45 & 4.944 & TRN & \\
\hline CHEMBL1316707 & 688422 & 4.65 & 4.9097 & TRN & \\
\hline CHEMBL1429202 & 688422 & 4.8 & 5.2635 & TRN & \\
\hline CHEMBL1537402 & 688422 & 8.301 & 5.1817 & TST & \\
\hline CHEMBL1450920 & 688422 & 4.5 & 5.1974 & TST & \\
\hline CHEMBL1397197 & 688422 & 4.45 & 5.9948 & TRN & \\
\hline CHEMBL1453613 & 688422 & 4.45 & 5.0202 & TRN & \\
\hline CHEMBL1378509 & 688422 & 4.9 & 5.6294 & TRN & \\
\hline CHEMBL1465084 & 688422 & 4.9 & 5.1424 & TRN & \\
\hline CHEMBL1596427 & 688422 & 5.25 & 5.3464 & TRN & \\
\hline CHEMBL1591206 & 688422 & 6.4 & 5.3757 & TRN & \\
\hline
\end{tabular}




\begin{tabular}{|c|c|c|c|c|}
\hline \multicolumn{5}{|c|}{ Supplemental Table S2.txt } \\
\hline CHEMBL1546820 & 688422 & 4.95 & 5.7648 & TST \\
\hline CHEMBL1971611 & 688422 & 4.45 & 5.0425 & TRN \\
\hline CHEMBL1318326 & 688422 & 6.05 & 6.1321 & TRN \\
\hline CHEMBL1538704 & 688422 & 7.5498 & 5.3713 & TRN \\
\hline CHEMBL1567797 & 688422 & 6.8 & 5.3132 & TRN \\
\hline CHEMBL1462313 & 688422 & 4.45 & 5.1361 & TRN \\
\hline CHEMBL1594685 & 688422 & 4.45 & 5.2382 & TRN \\
\hline CHEMBL1573731 & 688422 & 4.5 & 5.5912 & TST \\
\hline CHEMBL1463772 & 688422 & 5.2 & 5.0747 & TRN \\
\hline CHEMBL1483908 & 688422 & 4.8 & 4.8438 & TRN \\
\hline CHEMBL1974859 & 688422 & 7.8508 & 5.4014 & TRN \\
\hline CHEMBL 3214178 & 688422 & 5.25 & 5.0778 & TRN \\
\hline CHEMBL1534235 & 688422 & 5.45 & 5.5286 & TRN \\
\hline CHEMBL1392197 & 688422 & 5.25 & 5.4518 & TRN \\
\hline CHEMBL1603054 & 688422 & 5.6 & 4.7091 & TRN \\
\hline CHEMBL1533315 & 688422 & 4.55 & 4.9265 & TRN \\
\hline CHEMBL1561207 & 688422 & 4.45 & 5.121 & TRN \\
\hline CHEMBL1519133 & 688422 & 4.8 & 5.1916 & TST \\
\hline CHEMBL1379272 & 688422 & 4.45 & 5.7863 & TRN \\
\hline CHEMBL 2062343 & 688422 & 6.9 & 5.4964 & TRN \\
\hline CHEMBL74300 & 688422 & 5.35 & 5.1698 & TRN \\
\hline CHEMBL1333529 & 688422 & 4.5 & 4.9139 & TRN \\
\hline CHEMBL1397636 & 688422 & 4.95 & 4.8762 & TRN \\
\hline CHEMBL1540023 & 688422 & 7.9508 & 5.4181 & TST \\
\hline CHEMBL1381281 & 688422 & 4.45 & 5.1322 & TRN \\
\hline CHEMBL1465522 & 688422 & 5.0 & 5.1566 & TST \\
\hline CHEMBL1349566 & 688422 & 4.9 & 4.948 & TRN \\
\hline CHEMBL1387449 & 688422 & 4.8 & 4.9614 & TRN \\
\hline CHEMBL1467042 & 688422 & 4.45 & 5.0526 & TST \\
\hline CHEMBL1349390 & 688422 & 4.45 & 5.5211 & TRN \\
\hline CHEMBL1507324 & 688422 & 4.85 & 5.085 & TRN \\
\hline CHEMBL1497379 & 688422 & 6.25 & 5.2107 & TRN \\
\hline CHEMBL1517796 & 688422 & 5.55 & 5.3241 & TRN \\
\hline CHEMBL1606344 & 688422 & 4.8 & 5.1662 & TRN \\
\hline CHEMBL1498737 & 688422 & 4.45 & 5.1872 & TST \\
\hline CHEMBL1477697 & 688422 & 4.5 & 4.9692 & TRN \\
\hline CHEMBL1553367 & 688422 & 6.5501 & 5.3492 & TST \\
\hline CHEMBL1462050 & 688422 & 4.85 & 5.5513 & TST \\
\hline CHEMBL1585062 & 688422 & 5.1 & 4.8692 & TRN \\
\hline CHEMBL1570546 & 688422 & 5.55 & 5.0641 & TRN \\
\hline CHEMBL1591133 & 688422 & 4.8 & 4.9857 & TRN \\
\hline CHEMBL1522527 & 688422 & 5.45 & 5.0422 & TST \\
\hline CHEMBL1515913 & 688422 & 4.45 & 5.1991 & TRN \\
\hline CHEMBL1535374 & 688422 & 4.45 & 5.3005 & TRN \\
\hline CHEMBL1465113 & 688422 & 4.5 & 4.832 & TST \\
\hline CHEMBL1594656 & 688422 & 4.65 & 5.4615 & TRN \\
\hline CHEMBL1421652 & 688422 & 5.1 & 5.3237 & TRN \\
\hline CHEMBL1437628 & 688422 & 4.65 & 5.3396 & TRN \\
\hline
\end{tabular}




\begin{tabular}{|c|c|c|c|c|c|}
\hline \multicolumn{6}{|c|}{ Supplemental Table S2.txt } \\
\hline CHEMBL1338378 & 688422 & 6.05 & 5.1841 & TST & \\
\hline CHEMBL1362486 & 688422 & 4.95 & 5.3399 & TRN & \\
\hline CHEMBL1604703 & 688422 & 7.6498 & 5.39 & TST & \\
\hline CHEMBL1532182 & 688422 & 4.8 & 5.3097 & TRN & \\
\hline CHEMBL1454937 & 688422 & 4.45 & 5.49799 & 9999999999 & TRN \\
\hline CHEMBL1483726 & 688422 & 6.15 & 5.0177 & TRN & \\
\hline CHEMBL1487469 & 688422 & 4.85 & 5.6117 & TRN & \\
\hline CHEMBL1343685 & 688422 & 5.15 & 5.099 & TRN & \\
\hline CHEMBL1336893 & 688422 & 5.2 & 5.4385 & TRN & \\
\hline CHEMBL1332471 & 688422 & 4.85 & 4.91100 & 00000000005 & TRN \\
\hline CHEMBL1479875 & 688422 & 4.65 & 5.1019 & TRN & \\
\hline CHEMBL1432548 & 688422 & 4.6 & 5.1118 & TRN & \\
\hline CHEMBL1561136 & 688422 & 7.5498 & 5.0551 & TRN & \\
\hline CHEMBL1376160 & 688422 & 4.45 & 4.7675 & TRN & \\
\hline CHEMBL1557350 & 688422 & 4.45 & 5.2873 & TRN & \\
\hline CHEMBL1350286 & 688422 & 4.45 & 5.0357 & TRN & \\
\hline CHEMBL1347927 & 688422 & 4.55 & 5.3712 & TRN & \\
\hline CHEMBL1406971 & 688422 & 5.05 & 5.6033 & TST & \\
\hline CHEMBL1431256 & 688422 & 4.45 & 5.2323 & TRN & \\
\hline CHEMBL1361699 & 688422 & 4.95 & 5.1817 & TRN & \\
\hline CHEMBL1525530 & 688422 & 5.05 & 4.6123 & TRN & \\
\hline CHEMBL1395306 & 688422 & 4.9 & 4.9361 & TRN & \\
\hline CHEMBL1424561 & 688422 & 4.8 & 5.2572 & TST & \\
\hline CHEMBL1332589 & 688422 & 4.45 & 5.104 & TRN & \\
\hline CHEMBL1379408 & 688422 & 7.5498 & 5.0554 & TST & \\
\hline CHEMBL1359361 & 688422 & 4.45 & 5.1046 & TRN & \\
\hline CHEMBL1403746 & 688422 & 6.9 & 5.2516 & TRN & \\
\hline CHEMBL1437947 & 688422 & 4.45 & 5.6199 & TRN & \\
\hline CHEMBL1490887 & 688422 & 4.45 & 4.8464 & TRN & \\
\hline CHEMBL3208530 & 688422 & 4.65 & 5.155 & TRN & \\
\hline CHEMBL1429496 & 688422 & 4.95 & 5.4395 & TRN & \\
\hline CHEMBL1368535 & 688422 & 7.7496 & 5.7063 & TRN & \\
\hline CHEMBL1466721 & 688422 & 7.0 & 5.5362 & TRN & \\
\hline CHEMBL1526645 & 688422 & 4.8 & 5.2588 & TRN & \\
\hline CHEMBL1348442 & 688422 & 4.9 & 5.3539 & TRN & \\
\hline CHEMBL1433703 & 688422 & 4.6 & 4.5502 & TRN & \\
\hline CHEMBL1386403 & 688422 & 5.25 & 5.4004 & TST & \\
\hline CHEMBL1579275 & 688422 & 4.55 & 5.023 & TRN & \\
\hline CHEMBL1481154 & 688422 & 4.45 & 5.232 & TRN & \\
\hline CHEMBL1531595 & 688422 & 4.8 & 4.9226 & TST & \\
\hline CHEMBL3191329 & 688422 & 4.95 & 5.0112 & TRN & \\
\hline CHEMBL1607561 & 688422 & 7.1002 & 5.2242 & TRN & \\
\hline CHEMBL1327251 & 688422 & 5.65 & 5.1 & TRN & \\
\hline CHEMBL569958 & 688422 & 4.7 & 5.2984 & TRN & \\
\hline CHEMBL1347126 & 688422 & 4.95 & 5.4903 & TRN & \\
\hline CHEMBL1596756 & 688422 & 4.45 & 4.6906 & TRN & \\
\hline CHEMBL 1447657 & 688422 & 4.55 & 5.6496 & TST & \\
\hline CHEMBL1516375 & 688422 & 5.15 & 5.2917 & TST & \\
\hline
\end{tabular}




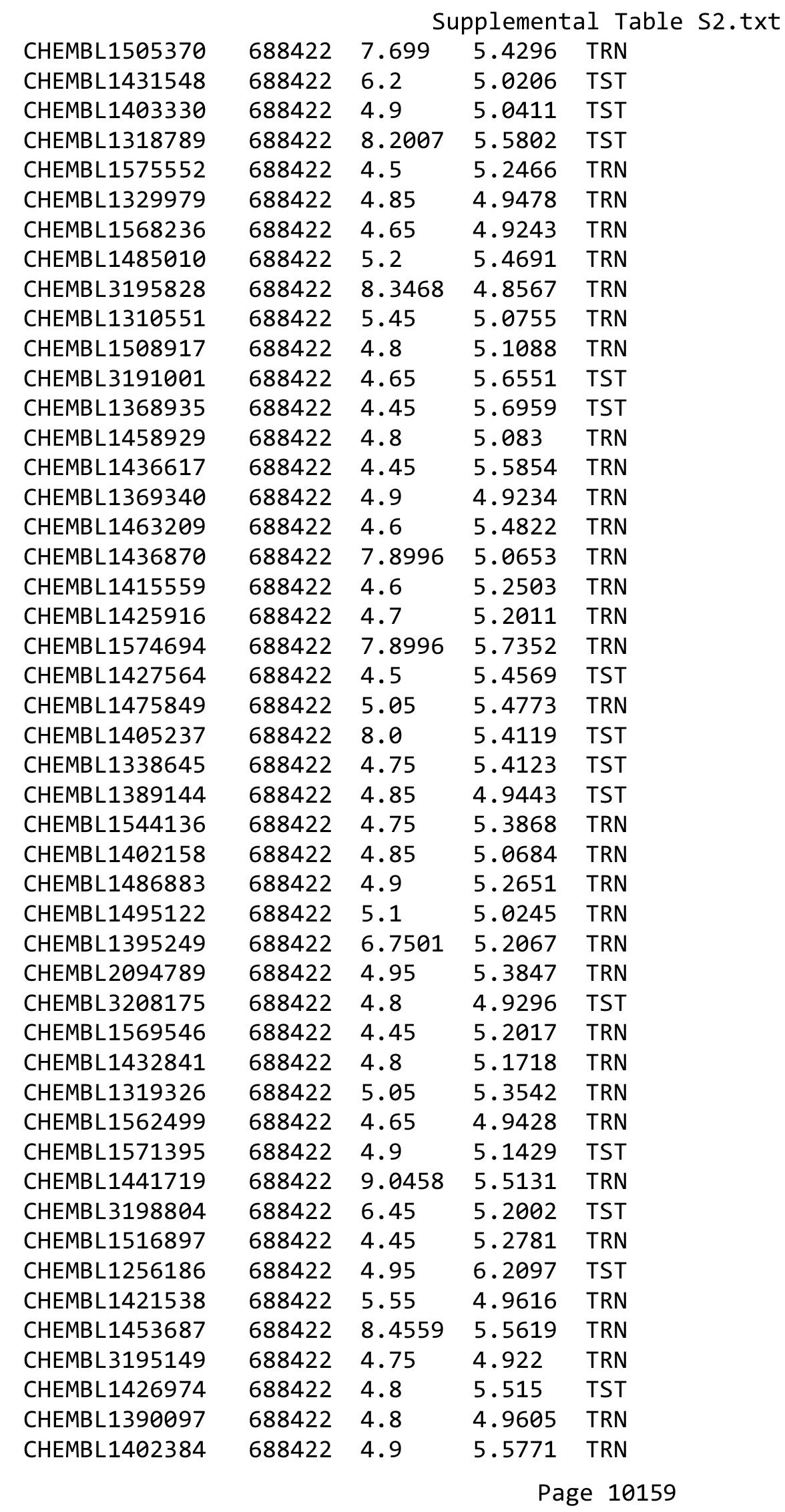




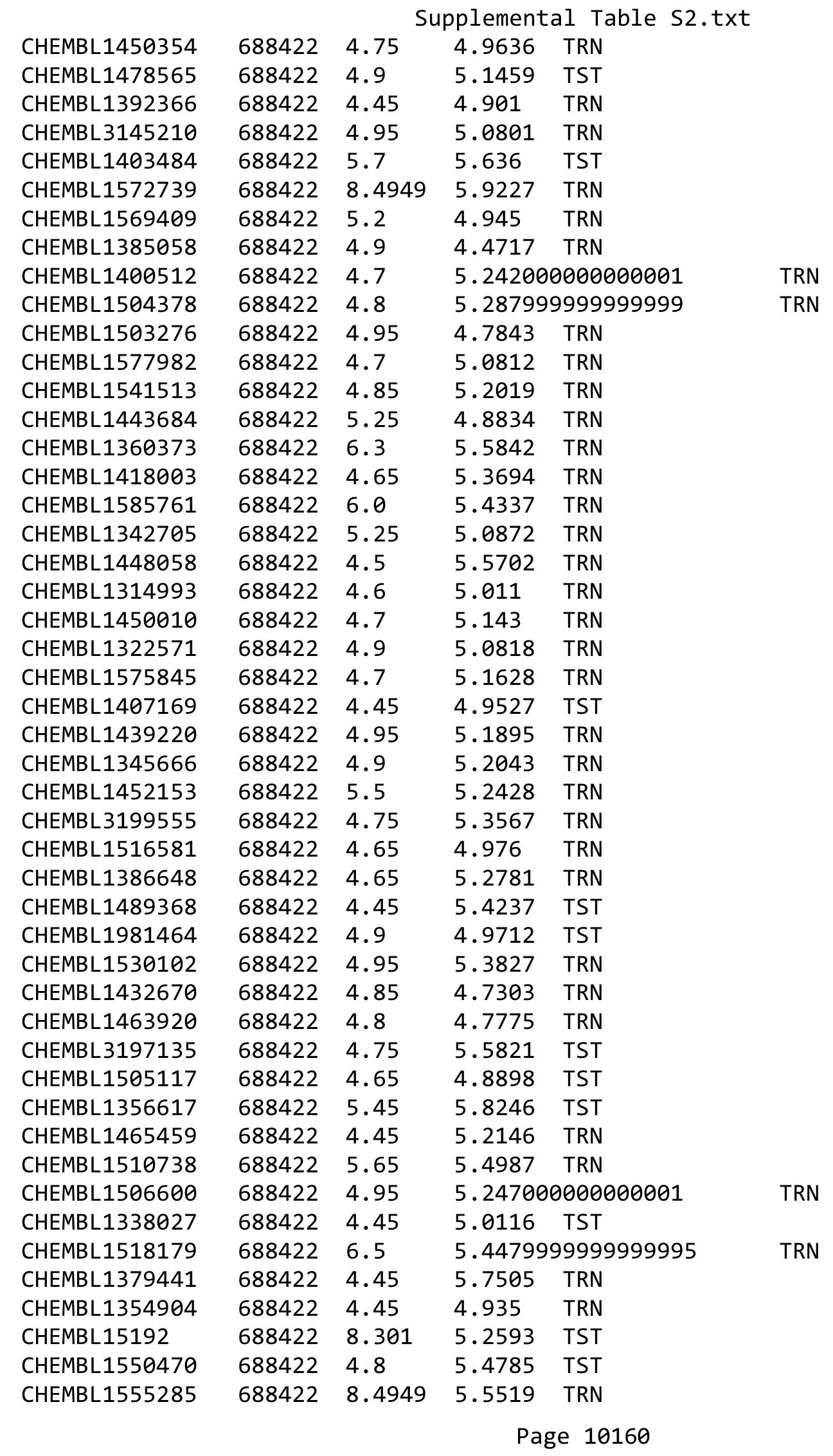




\begin{tabular}{|c|c|c|c|c|}
\hline & & & pplement & al $\mathrm{Ta}$ \\
\hline CHEMBL1470078 & 688422 & 4.7 & 5.1279 & TRN \\
\hline CHEMBL1520019 & 688422 & 4.9 & 5.2408 & TRN \\
\hline CHEMBL1460134 & 688422 & 4.9 & 4.7286 & TST \\
\hline CHEMBL1406765 & 688422 & 4.45 & 4.7908 & TRN \\
\hline CHEMBL1299846 & 688422 & 7.0 & 5.5574 & TRN \\
\hline CHEMBL1346003 & 688422 & 4.7 & 5.1415 & TRN \\
\hline CHEMBL321747 & 688422 & 6.0 & 5.5415 & TRN \\
\hline CHEMBL1458475 & 688422 & 4.95 & 5.1121 & TRN \\
\hline CHEMBL1598055 & 688422 & 4.75 & 5.3355 & TRN \\
\hline CHEMBL3210424 & 688422 & 4.45 & 5.64 & TST \\
\hline CHEMBL1587724 & 688422 & 4.95 & 4.8361 & TRN \\
\hline CHEMBL1551179 & 688422 & 4.35 & 5.2504 & TRN \\
\hline CHEMBL1479321 & 688422 & 5.15 & 5.5654 & TRN \\
\hline CHEMBL1368967 & 688422 & 4.45 & 5.0154 & TRN \\
\hline CHEMBL1458167 & 688422 & 7.699 & 5.4457 & TRN \\
\hline CHEMBL1319344 & 688422 & 4.6 & 4.9424 & TRN \\
\hline CHEMBL1467368 & 688422 & 5.0 & 5.185 & TST \\
\hline CHEMBL1481358 & 688422 & 4.95 & 5.2318 & TRN \\
\hline CHEMBL3190562 & 688422 & 7.2503 & 5.084 & TRN \\
\hline CHEMBL 3194290 & 688422 & 4.9 & 5.4396 & TRN \\
\hline CHEMBL1563558 & 688422 & 4.45 & 4.8747 & TRN \\
\hline CHEMBL1600882 & 688422 & 4.5 & 5.0768 & TRN \\
\hline CHEMBL1369612 & 688422 & 4.75 & 5.4604 & TRN \\
\hline CHEMBL1492376 & 688422 & 4.75 & 5.2132 & TRN \\
\hline CHEMBL1359757 & 688422 & 5.5 & 5.5227 & TST \\
\hline CHEMBL1529082 & 688422 & 8.1024 & 5.6775 & TRN \\
\hline CHEMBL1417539 & 688422 & 6.9 & 5.331 & TRN \\
\hline CHEMBL1484834 & 688422 & 7.6498 & 5.3415 & TRN \\
\hline CHEMBL1479830 & 688422 & 4.9 & 4.8511 & TST \\
\hline CHEMBL1440795 & 688422 & 5.2 & 4.9216 & TST \\
\hline CHEMBL1613064 & 688422 & 4.45 & 5.0043 & TST \\
\hline CHEMBL 3198829 & 688422 & 7.2 & 5.5401 & TRN \\
\hline CHEMBL1458741 & 688422 & 4.9 & 5.2714 & TST \\
\hline CHEMBL1611779 & 688422 & 4.75 & 4.6858 & TRN \\
\hline CHEMBL1613227 & 688422 & 4.85 & 5.2981 & TST \\
\hline CHEMBL1360317 & 688422 & 5.05 & 5.0949 & TRN \\
\hline CHEMBL3195111 & 688422 & 4.9 & 4.9584 & TRN \\
\hline CHEMBL1410056 & 688422 & 4.65 & 5.2435 & TRN \\
\hline CHEMBL1463500 & 688422 & 7.2 & 5.1721 & TST \\
\hline CHEMBL1432210 & 688422 & 5.0 & 5.1532 & TRN \\
\hline CHEMBL1417829 & 688422 & 4.55 & 5.0394 & TRN \\
\hline CHEMBL1588857 & 688422 & 4.9 & 5.58 & TRN \\
\hline CHEMBL1467102 & 688422 & 4.9 & 5.1664 & TRN \\
\hline CHEMBL1499847 & 688422 & 4.5 & 5.0535 & TRN \\
\hline CHEMBL1462028 & 688422 & 4.45 & 5.4614 & TRN \\
\hline CHEMBL1299921 & 688422 & 5.0 & 5.0046 & TRN \\
\hline CHEMBL1391484 & 688422 & 4.85 & 4.5779 & TRN \\
\hline CHEMBL1581065 & 688422 & 4.5 & 5.4482 & TST \\
\hline
\end{tabular}




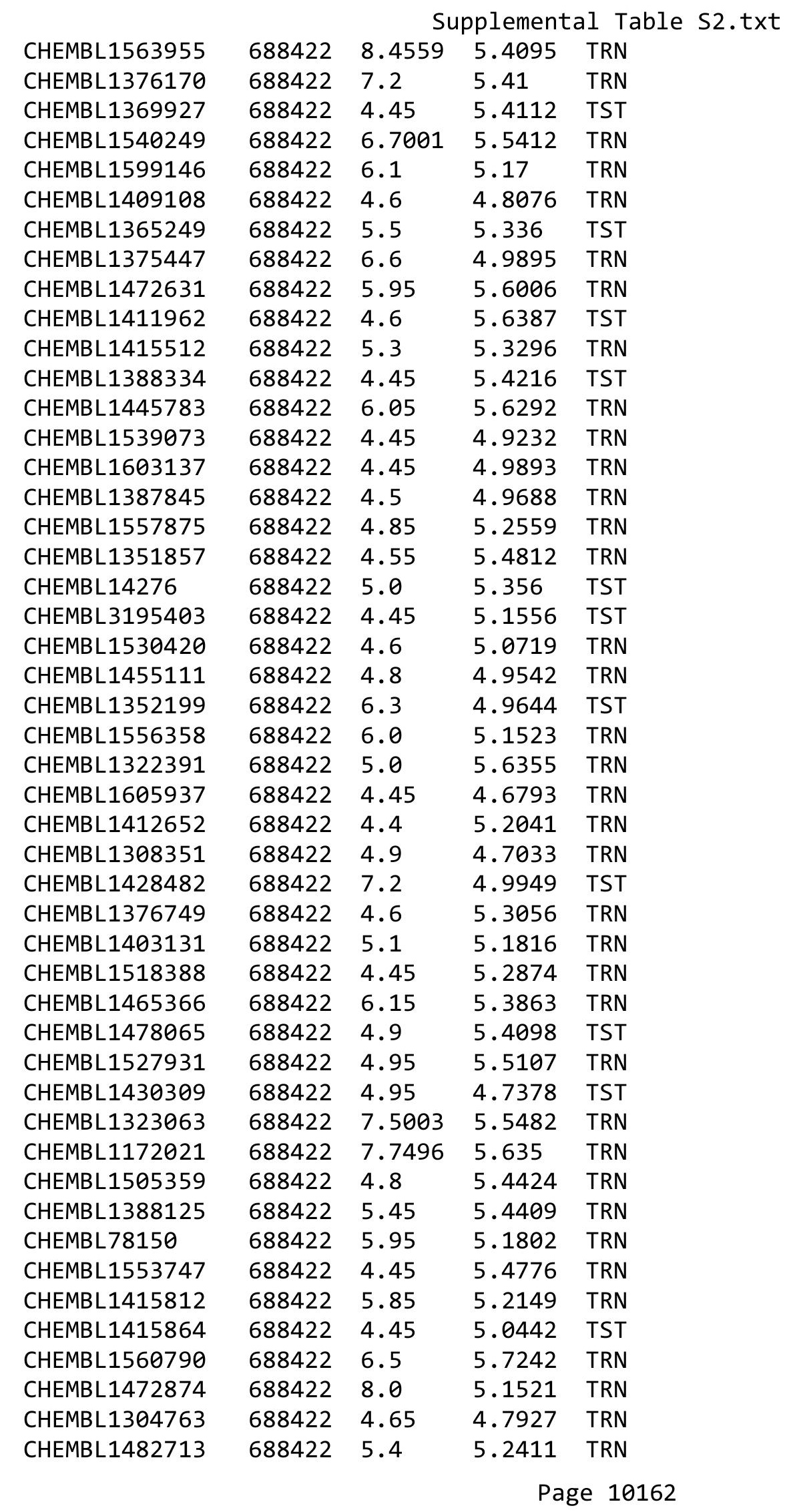




\begin{tabular}{|c|c|c|c|c|c|}
\hline \multicolumn{6}{|c|}{ Supplemental Table S2.txt } \\
\hline CHEMBL1256751 & 688422 & 4.85 & 5.4158 & TRN & \\
\hline CHEMBL1459504 & 688422 & 4.85 & 5.919 & TRN & \\
\hline CHEMBL1389882 & 688422 & 5.1 & 5.3116 & TST & \\
\hline CHEMBL1577779 & 688422 & 8.3468 & 5.1581 & TST & \\
\hline CHEMBL 1467100 & 688422 & 5.85 & 5.4102 & TRN & \\
\hline CHEMBL1391016 & 688422 & 4.8 & 5.1525 & TRN & \\
\hline CHEMBL1611328 & 688422 & 5.0 & 5.0725 & TRN & \\
\hline CHEMBL1568598 & 688422 & 4.5 & 5.4187 & TRN & \\
\hline CHEMBL1364335 & 688422 & 5.5 & 5.2439 & TRN & \\
\hline CHEMBL1345279 & 688422 & 4.85 & 5.05699 & 99999999995 & TRN \\
\hline CHEMBL1537417 & 688422 & 4.65 & 5.50899 & 99999999995 & TST \\
\hline CHEMBL1613546 & 688422 & 4.45 & 5.0884 & TRN & \\
\hline CHEMBL586000 & 688422 & 4.45 & 5.3307 & TST & \\
\hline CHEMBL1992001 & 688422 & 4.6 & 4.8722 & TRN & \\
\hline CHEMBL1425410 & 688422 & 4.5 & 4.746 & TRN & \\
\hline CHEMBL1598065 & 688422 & 4.65 & 4.8506 & TRN & \\
\hline CHEMBL1340025 & 688422 & 4.9 & 5.3462 & TRN & \\
\hline CHEMBL1973429 & 688422 & 5.5 & 5.0696 & TST & \\
\hline CHEMBL1481370 & 688422 & 5.4 & 5.7105 & TRN & \\
\hline CHEMBL1578014 & 688422 & 4.85 & 4.8873 & TRN & \\
\hline CHEMBL1501183 & 688422 & 4.75 & 5.0407 & TRN & \\
\hline CHEMBL1604257 & 688422 & 5.7 & 5.5809 & TST & \\
\hline CHEMBL1556342 & 688422 & 4.6 & 5.3982 & TST & \\
\hline CHEMBL1344112 & 688422 & 4.45 & 5.0418 & TRN & \\
\hline CHEMBL1450705 & 688422 & 5.65 & 5.3515 & TST & \\
\hline CHEMBL1462064 & 688422 & 5.55 & 5.1179 & TRN & \\
\hline CHEMBL1392624 & 688422 & 4.55 & 4.8341 & TST & \\
\hline CHEMBL1560552 & 688422 & 4.9 & 4.803 & TRN & \\
\hline CHEMBL1608118 & 688422 & 5.0 & 5.2956 & TRN & \\
\hline CHEMBL1413762 & 688422 & 6.8 & 5.7687 & TRN & \\
\hline CHEMBL1437693 & 688422 & 7.699 & 5.5502 & TRN & \\
\hline CHEMBL1540599 & 688422 & 5.2 & 6.0393 & TST & \\
\hline CHEMBL1979221 & 688422 & 4.9 & 5.3331 & TRN & \\
\hline CHEMBL1590299 & 688422 & 5.9 & 5.2745 & TRN & \\
\hline CHEMBL1407608 & 688422 & 4.9 & 5.2907 & TRN & \\
\hline CHEMBL1343591 & 688422 & 7.5498 & 5.0453 & TRN & \\
\hline CHEMBL1605039 & 688422 & 5.6 & 5.2437 & TRN & \\
\hline CHEMBL1432778 & 688422 & 5.0 & 5.0111 & TRN & \\
\hline CHEMBL1440253 & 688422 & 4.85 & 4.654 & TRN & \\
\hline CHEMBL1409990 & 688422 & 4.65 & 4.9543 & TRN & \\
\hline CHEMBL582491 & 688422 & 4.6 & 4.8094 & TRN & \\
\hline CHEMBL1453094 & 688422 & 8.3468 & 5.0731 & TST & \\
\hline CHEMBL1501301 & 688422 & 4.9 & 5.4879 & TRN & \\
\hline CHEMBL1455514 & 688422 & 4.8 & 5.3732 & TST & \\
\hline CHEMBL1388629 & 688422 & 4.9 & 4.9782 & TRN & \\
\hline CHEMBL1386313 & 688422 & 4.85 & 4.8029 & TRN & \\
\hline CHEMBL1484341 & 688422 & 4.45 & 4.8817 & TRN & \\
\hline CHEMBL1582152 & 688422 & 5.85 & 5.2157 & TRN & \\
\hline
\end{tabular}




\begin{tabular}{|c|c|c|c|c|c|}
\hline \multicolumn{6}{|c|}{ Supplemental Table S2.txt } \\
\hline CHEMBL1380008 & 688422 & 4.9 & 5.0066 & TRN & \\
\hline CHEMBL1364674 & 688422 & 7.15 & 5.3733 & TRN & \\
\hline CHEMBL3197594 & 688422 & 4.45 & 5.3897 & TRN & \\
\hline CHEMBL1589350 & 688422 & 4.45 & 5.0999 & TRN & \\
\hline CHEMBL1530426 & 688422 & 4.5 & 5.1643 & TRN & \\
\hline CHEMBL1489121 & 688422 & 4.85 & 5.1953 & TRN & \\
\hline CHEMBL1420204 & 688422 & 5.5 & 5.2886 & TRN & \\
\hline CHEMBL1381455 & 688422 & 4.65 & 5.5588 & TRN & \\
\hline CHEMBL1309967 & 688422 & 4.9 & 5.1856 & TST & \\
\hline CHEMBL1525487 & 688422 & 4.65 & 4.7127 & TRN & \\
\hline CHEMBL1500217 & 688422 & 4.45 & 5.1193 & TRN & \\
\hline CHEMBL1420742 & 688422 & 5.2 & 5.3124 & TST & \\
\hline CHEMBL1428935 & 688422 & 5.2 & 4.9217 & TRN & \\
\hline CHEMBL1359808 & 688422 & 4.9 & 5.3121 & TST & \\
\hline CHEMBL1447588 & 688422 & 7.0501 & 5.8627 & TST & \\
\hline CHEMBL1557285 & 688422 & 5.0 & 5.1321 & TRN & \\
\hline CHEMBL1564255 & 688422 & 4.95 & 5.28799 & 9999999999 & TRN \\
\hline CHEMBL1352313 & 688422 & 5.0 & 4.8897 & TRN & \\
\hline CHEMBL1566376 & 688422 & 6.5501 & 6.1873 & TRN & \\
\hline CHEMBL1389854 & 688422 & 5.2 & 5.5893 & TST & \\
\hline CHEMBL1416938 & 688422 & 4.45 & 4.9306 & TRN & \\
\hline CHEMBL1967566 & 688422 & 5.2 & 5.3797 & TST & \\
\hline CHEMBL1588644 & 688422 & 5.2 & 5.7269 & TST & \\
\hline CHEMBL 284742 & 688422 & 4.5 & 5.0816 & TRN & \\
\hline CHEMBL1485209 & 688422 & 5.7 & 5.8191 & TRN & \\
\hline CHEMBL3199758 & 688422 & 4.95 & 5.4643 & TST & \\
\hline CHEMBL1552906 & 688422 & 4.95 & 5.6515 & TRN & \\
\hline CHEMBL1427838 & 688422 & 4.75 & 5.1856 & TRN & \\
\hline CHEMBL1350986 & 688422 & 4.45 & 4.9951 & TRN & \\
\hline CHEMBL1601076 & 688422 & 4.5 & 5.352 & TRN & \\
\hline CHEMBL1470558 & 688422 & 4.85 & 4.9071 & TST & \\
\hline CHEMBL1545872 & 688422 & 4.6 & 4.9453 & TRN & \\
\hline CHEMBL1421686 & 688422 & 5.85 & 5.2151 & TST & \\
\hline CHEMBL3189349 & 688422 & 5.8 & 5.2429 & TRN & \\
\hline CHEMBL1568795 & 688422 & 8.4949 & 4.8921 & TST & \\
\hline CHEMBL1305712 & 688422 & 4.55 & 5.4768 & TRN & \\
\hline CHEMBL1418425 & 688422 & 4.85 & 5.1681 & TRN & \\
\hline CHEMBL1408198 & 688422 & 4.8 & 5.1205 & TST & \\
\hline CHEMBL1340362 & 688422 & 4.45 & 5.0819 & TRN & \\
\hline CHEMBL1494626 & 688422 & 5.5 & 5.6316 & TRN & \\
\hline CHEMBL1359321 & 688422 & 4.9 & 5.3622 & TRN & \\
\hline CHEMBL1300034 & 688422 & 5.25 & 5.5162 & TST & \\
\hline CHEMBL1366130 & 688422 & 4.9 & 5.3086 & TRN & \\
\hline CHEMBL1312163 & 688422 & 4.9 & 5.0884 & TST & \\
\hline CHEMBL 3210700 & 688422 & 5.2 & 5.4252 & TST & \\
\hline CHEMBL1442038 & 688422 & 6.05 & 5.4261 & TST & \\
\hline CHEMBL1370698 & 688422 & 4.45 & 5.1713 & TST & \\
\hline CHEMBL1310486 & 688422 & 4.45 & 4.8973 & TRN & \\
\hline
\end{tabular}




\begin{tabular}{|c|c|c|c|c|c|}
\hline \multicolumn{6}{|c|}{ Supplemental Table s2.txt } \\
\hline CHEMBL1457770 & 688422 & 5.55 & 5.4185 & TST & \\
\hline CHEMBL1530276 & 688422 & 4.5 & 5.6157 & TST & \\
\hline CHEMBL1299610 & 688422 & 5.9 & 5.3124 & TRN & \\
\hline CHEMBL1438337 & 688422 & 4.85 & 5.4878 & TST & \\
\hline CHEMBL1476749 & 688422 & 5.3 & 5.0666 & TRN & \\
\hline CHEMBL1339493 & 688422 & 4.65 & 4.7425 & TRN & \\
\hline CHEMBL1432551 & 688422 & 5.25 & 5.2122 & TRN & \\
\hline CHEMBL 3194857 & 688422 & 4.65 & 5.2952 & TRN & \\
\hline CHEMBL1441977 & 688422 & 4.75 & 5.0823 & TRN & \\
\hline CHEMBL1444937 & 688422 & 5.35 & 5.1295 & TST & \\
\hline CHEMBL1342374 & 688422 & 7.1002 & 5.18 & TST & \\
\hline CHEMBL1449947 & 688422 & 4.7 & 4.8946 & TRN & \\
\hline CHEMBL1531896 & 688422 & 4.6 & 5.7563 & TST & \\
\hline CHEMBL1330568 & 688422 & 4.95 & 4.8904 & TST & \\
\hline CHEMBL1337672 & 688422 & 5.0 & 5.1784 & TRN & \\
\hline CHEMBL1408045 & 688422 & 4.9 & 5.6723 & TRN & \\
\hline CHEMBL1349301 & 688422 & 4.4 & 5.5683 & TRN & \\
\hline CHEMBL1502983 & 688422 & 5.05 & 5.7084 & TRN & \\
\hline CHEMBL1514321 & 688422 & 6.8 & 5.7161 & TRN & \\
\hline CHEMBL1393270 & 688422 & 4.95 & 5.1549 & TRN & \\
\hline CHEMBL1463283 & 688422 & 4.45 & 5.0423 & TRN & \\
\hline CHEMBL1595758 & 688422 & 4.65 & 5.1475 & TRN & \\
\hline CHEMBL1902079 & 688422 & 4.7 & 5.3892 & TRN & \\
\hline CHEMBL1490876 & 688422 & 4.45 & 5.7971 & TRN & \\
\hline CHEMBL1498006 & 688422 & 4.45 & 5.091 & TRN & \\
\hline CHEMBL1443433 & 688422 & 5.15 & 5.0655 & TRN & \\
\hline CHEMBL1368239 & 688422 & 7.8013 & 5.0784 & TST & \\
\hline CHEMBL1368208 & 688422 & 7.9508 & 5.2549 & TRN & \\
\hline CHEMBL1416621 & 688422 & 4.7 & 5.1276 & TRN & \\
\hline CHEMBL1417479 & 688422 & 4.45 & 5.3491 & TRN & \\
\hline CHEMBL1545959 & 688422 & 4.7 & 5.0299 & TRN & \\
\hline CHEMBL1509222 & 688422 & 5.5 & 5.1903 & TRN & \\
\hline CHEMBL1588205 & 688422 & 5.65 & 5.4095 & TRN & \\
\hline CHEMBL1599646 & 688422 & 4.9 & 5.2331 & TRN & \\
\hline CHEMBL1337162 & 688422 & 4.85 & 5.5477 & TRN & \\
\hline CHEMBL 3144954 & 688422 & 4.8 & 5.26399 & 9999999999 & TST \\
\hline CHEMBL3213811 & 688422 & 5.3 & 5.3478 & TRN & \\
\hline CHEMBL1573840 & 688422 & 7.6498 & 5.0985 & TST & \\
\hline CHEMBL1371073 & 688422 & 5.25 & 5.4815 & TRN & \\
\hline CHEMBL1358822 & 688422 & 4.5 & 4.4279 & TRN & \\
\hline CHEMBL1350866 & 688422 & 4.5 & 4.8348 & TRN & \\
\hline CHEMBL3190363 & 688422 & 4.45 & 5.6662 & TRN & \\
\hline CHEMBL1511610 & 688422 & 4.45 & 5.29799 & 9999999999 & TST \\
\hline CHEMBL1585715 & 688422 & 4.8 & 5.251 & TRN & \\
\hline CHEMBL1415501 & 688422 & 5.3 & 4.9597 & TRN & \\
\hline CHEMBL1474675 & 688422 & 4.45 & 5.1577 & TRN & \\
\hline CHEMBL1389396 & 688422 & 7.3002 & 5.3793 & TRN & \\
\hline CHEMBL3210076 & 688422 & 4.45 & 5.1094 & TRN & \\
\hline
\end{tabular}




\begin{tabular}{|c|c|c|c|c|c|}
\hline \multirow[b]{2}{*}{ CHEMBL1528704 } & \multicolumn{5}{|c|}{ Supplemental Table S2.txt } \\
\hline & 688422 & 4.45 & 5.272 & TST & \\
\hline CHEMBL1394659 & 688422 & 4.45 & 5.51200 & 00000000005 & TRN \\
\hline CHEMBL1301948 & 688422 & 4.45 & 4.7812 & TRN & \\
\hline CHEMBL3191365 & 688422 & 4.5 & 4.8912 & TRN & \\
\hline CHEMBL1396959 & 688422 & 6.15 & 5.2603 & TRN & \\
\hline CHEMBL1563218 & 688422 & 7.0501 & 5.2216 & TRN & \\
\hline CHEMBL1353710 & 688422 & 4.8 & 5.0105 & TRN & \\
\hline CHEMBL1534684 & 688422 & 5.5 & 5.513 & TRN & \\
\hline CHEMBL1476835 & 688422 & 8.1024 & 5.3373 & TRN & \\
\hline CHEMBL1416103 & 688422 & 5.15 & 5.1077 & TST & \\
\hline CHEMBL1480448 & 688422 & 4.65 & 5.3589 & TRN & \\
\hline CHEMBL1329690 & 688422 & 5.1 & 5.6794 & TST & \\
\hline CHEMBL1385593 & 688422 & 5.4 & 5.2992 & TRN & \\
\hline CHEMBL1597716 & 688422 & 4.45 & 5.0199 & TRN & \\
\hline CHEMBL1325048 & 688422 & 4.45 & 5.2219 & TRN & \\
\hline CHEMBL1479499 & 688422 & 4.75 & 5.136 & TRN & \\
\hline CHEMBL1530158 & 688422 & 6.25 & 5.7523 & TRN & \\
\hline CHEMBL3190589 & 688422 & 5.45 & 5.6831 & TRN & \\
\hline CHEMBL1596495 & 688422 & 5.85 & 5.5957 & TRN & \\
\hline CHEMBL1299523 & 688422 & 4.5 & 5.3507 & TRN & \\
\hline CHEMBL1346711 & 688422 & 5.2 & 5.4156 & TRN & \\
\hline CHEMBL1444548 & 688422 & 4.6 & 5.0055 & TRN & \\
\hline CHEMBL1303652 & 688422 & 4.55 & 5.2931 & TST & \\
\hline CHEMBL1584765 & 688422 & 5.6 & 5.0807 & TRN & \\
\hline CHEMBL1379130 & 688422 & 5.35 & 5.6884 & TRN & \\
\hline CHEMBL3197969 & 688422 & 5.5 & 5.3934 & TRN & \\
\hline CHEMBL1502432 & 688422 & 4.85 & 4.9603 & TST & \\
\hline CHEMBL1341988 & 688422 & 5.8 & 4.9241 & TRN & \\
\hline CHEMBL1417795 & 688422 & 4.7 & 5.2196 & TRN & \\
\hline CHEMBL1514513 & 688422 & 6.5501 & 5.1 & TRN & \\
\hline CHEMBL1433087 & 688422 & 4.5 & 5.1662 & TRN & \\
\hline CHEMBL1395146 & 688422 & 4.45 & 5.1779 & TRN & \\
\hline CHEMBL1343349 & 688422 & 4.8 & 5.0285 & TRN & \\
\hline CHEMBL3193425 & 688422 & 4.55 & 5.0554 & TRN & \\
\hline CHEMBL1324489 & 688422 & 7.2 & 5.6246 & TRN & \\
\hline CHEMBL1430574 & 688422 & 8.2518 & 4.998 & TRN & \\
\hline CHEMBL1507765 & 688422 & 4.65 & 5.4825 & TST & \\
\hline CHEMBL1399044 & 688422 & 5.25 & 5.2898 & TRN & \\
\hline CHEMBL1316862 & 688422 & 4.45 & 5.3325 & TRN & \\
\hline CHEMBL1547217 & 688422 & 5.85 & 5.2504 & TRN & \\
\hline CHEMBL1974308 & 688422 & 4.8 & 5.2025 & TST & \\
\hline CHEMBL1395478 & 688422 & 7.3497 & 5.2929 & TRN & \\
\hline CHEMBL1587522 & 688422 & 4.75 & 4.8912 & TST & \\
\hline CHEMBL1493233 & 688422 & 4.75 & 5.0532 & TRN & \\
\hline CHEMBL1469463 & 688422 & 4.75 & 4.9847 & TRN & \\
\hline CHEMBL1402539 & 688422 & 5.1 & 5.0606 & TST & \\
\hline CHEMBL1441497 & 688422 & 7.6003 & 5.3913 & TRN & \\
\hline CHEMBL1587116 & 688422 & 5.1 & 5.2722 & TRN & \\
\hline
\end{tabular}




\begin{tabular}{|c|c|c|c|c|c|}
\hline \multicolumn{6}{|c|}{ Supplemental Table S2.txt } \\
\hline CHEMBL1440910 & 688422 & 5.7 & 5.2797 & TST & \\
\hline CHEMBL1399277 & 688422 & 4.65 & 5.0144 & TRN & \\
\hline CHEMBL1435899 & 688422 & 4.45 & 4.9112 & TRN & \\
\hline CHEMBL1438918 & 688422 & 4.85 & 5.1329 & TST & \\
\hline CHEMBL1352365 & 688422 & 4.5 & 5.3378 & TST & \\
\hline CHEMBL1459214 & 688422 & 4.45 & 4.7198 & TRN & \\
\hline CHEMBL1383765 & 688422 & 5.05 & 5.2724 & TST & \\
\hline CHEMBL1487834 & 688422 & 5.25 & 4.8158 & TRN & \\
\hline CHEMBL1503586 & 688422 & 4.5 & 4.8685 & TRN & \\
\hline CHEMBL1305693 & 688422 & 4.6 & 5.3187 & TST & \\
\hline CHEMBL1300802 & 688422 & 5.25 & 5.5447 & TRN & \\
\hline CHEMBL1495475 & 688422 & 8.3468 & 5.0772 & TRN & \\
\hline CHEMBL1983168 & 688422 & 5.45 & 5.1312 & TST & \\
\hline CHEMBL1527068 & 688422 & 5.05 & 5.145 & TST & \\
\hline CHEMBL1567076 & 688422 & 4.45 & 5.2948 & TST & \\
\hline CHEMBL1429366 & 688422 & 8.4559 & 5.58200 & 0000000001 & TST \\
\hline CHEMBL1392449 & 688422 & 4.45 & 5.3807 & TRN & \\
\hline CHEMBL1604496 & 688422 & 5.3 & 5.2087 & TRN & \\
\hline CHEMBL1489684 & 688422 & 4.5 & 5.0132 & TST & \\
\hline CHEMBL1431880 & 688422 & 4.9 & 5.2682 & TRN & \\
\hline CHEMBL1486435 & 688422 & 4.8 & 5.0108 & TRN & \\
\hline CHEMBL1362604 & 688422 & 6.0 & 5.41799 & 9999999999 & TRN \\
\hline CHEMBL1319900 & 688422 & 5.35 & 5.1759 & TRN & \\
\hline CHEMBL1467345 & 688422 & 4.45 & 4.8311 & TRN & \\
\hline CHEMBL1441677 & 688422 & 4.45 & 4.7947 & TRN & \\
\hline CHEMBL1424628 & 688422 & 4.7 & 5.0582 & TRN & \\
\hline CHEMBL1450105 & 688422 & 5.05 & 4.6356 & TRN & \\
\hline CHEMBL1476773 & 688422 & 4.65 & 4.9672 & TRN & \\
\hline CHEMBL1509580 & 688422 & 5.2 & 5.1805 & TST & \\
\hline CHEMBL1478379 & 688422 & 5.95 & 5.5508 & TRN & \\
\hline CHEMBL1542454 & 688422 & 4.45 & 5.3825 & TST & \\
\hline CHEMBL1463634 & 688422 & 5.15 & 4.863 & TST & \\
\hline CHEMBL1521167 & 688422 & 5.25 & 5.8938 & TRN & \\
\hline CHEMBL 3194144 & 688422 & 7.1002 & 5.3813 & TRN & \\
\hline CHEMBL1975892 & 688422 & 4.95 & 5.2885 & TST & \\
\hline CHEMBL1453539 & 688422 & 4.95 & 5.5094 & TRN & \\
\hline CHEMBL1333091 & 688422 & 4.45 & 5.1954 & TRN & \\
\hline CHEMBL1362710 & 688422 & 4.6 & 5.485 & TRN & \\
\hline CHEMBL3196399 & 688422 & 5.2 & 5.5432 & TST & \\
\hline CHEMBL1394825 & 688422 & 6.9 & 5.3495 & TRN & \\
\hline CHEMBL1989817 & 688422 & 5.2 & 5.1198 & TST & \\
\hline CHEMBL1484178 & 688422 & 7.0501 & 5.4915 & TST & \\
\hline CHEMBL1531082 & 688422 & 4.95 & 5.2677 & TST & \\
\hline CHEMBL1432526 & 688422 & 4.95 & 5.0167 & TRN & \\
\hline CHEMBL1485354 & 688422 & 7.1002 & 5.5974 & TRN & \\
\hline CHEMBL1404611 & 688422 & 4.95 & 4.9886 & TRN & \\
\hline CHEMBL1430882 & 688422 & 4.9 & 5.3391 & TST & \\
\hline CHEMBL1536242 & 688422 & 4.5 & 5.0784 & TRN & \\
\hline
\end{tabular}




\begin{tabular}{|c|c|c|c|c|c|}
\hline \multicolumn{6}{|c|}{ Supplemental Table S2.txt } \\
\hline CHEMBL1411921 & 688422 & 4.65 & 5.2862 & TRN & \\
\hline CHEMBL1524159 & 688422 & 4.7 & 5.1589 & TRN & \\
\hline CHEMBL1596923 & 688422 & 4.9 & 5.4643 & TST & \\
\hline CHEMBL1437531 & 688422 & 5.35 & 4.825 & TRN & \\
\hline CHEMBL 3208290 & 688422 & 7.6003 & 4.9213 & TST & \\
\hline CHEMBL1447278 & 688422 & 4.95 & 5.1182 & TST & \\
\hline CHEMBL1403396 & 688422 & 5.05 & 5.2221 & TRN & \\
\hline CHEMBL 3212800 & 688422 & 4.5 & 5.4833 & TRN & \\
\hline CHEMBL1588966 & 688422 & 4.6 & 5.0556 & TRN & \\
\hline CHEMBL1477215 & 688422 & 5.05 & 5.3406 & TRN & \\
\hline CHEMBL1605840 & 688422 & 5.5 & 5.4213 & TRN & \\
\hline CHEMBL1313320 & 688422 & 4.5 & 5.2917 & TRN & \\
\hline CHEMBL1578945 & 688422 & 4.9 & 4.6465 & TRN & \\
\hline CHEMBL 2358182 & 688422 & 4.8 & 4.8185 & TRN & \\
\hline CHEMBL1302435 & 688422 & 7.4498 & 5.351 & TST & \\
\hline CHEMBL1486949 & 688422 & 4.95 & 5.2773 & TRN & \\
\hline CHEMBL1413108 & 688422 & 4.7 & 6.1144 & TRN & \\
\hline CHEMBL1371106 & 688422 & 5.4 & 5.2942 & TRN & \\
\hline CHEMBL1555967 & 688422 & 5.55 & 4.9086 & TRN & \\
\hline CHEMBL1366337 & 688422 & 5.5 & 5.6831 & TST & \\
\hline CHEMBL1570765 & 688422 & 5.45 & 5.2964 & TST & \\
\hline CHEMBL1608133 & 688422 & 4.45 & 4.8161 & TRN & \\
\hline CHEMBL1326403 & 688422 & 4.85 & 4.8305 & TRN & \\
\hline CHEMBL1346142 & 688422 & 4.5 & 5.2694 & TRN & \\
\hline CHEMBL1388322 & 688422 & 5.05 & 5.01699 & 99999999995 & TRN \\
\hline CHEMBL1591417 & 688422 & 4.9 & 5.2849 & TRN & \\
\hline CHEMBL1599983 & 688422 & 5.45 & 5.5144 & TRN & \\
\hline CHEMBL1500150 & 688422 & 4.75 & 5.0794 & TST & \\
\hline CHEMBL1446245 & 688422 & 4.75 & 5.1651 & TST & \\
\hline CHEMBL1328018 & 688422 & 4.9 & 5.5874 & TRN & \\
\hline CHEMBL 3210870 & 688422 & 4.45 & 5.0004 & TRN & \\
\hline CHEMBL1338552 & 688422 & 5.25 & 5.5874 & TRN & \\
\hline CHEMBL1568145 & 688422 & 4.5 & 5.3025 & TST & \\
\hline CHEMBL595369 & 688422 & 4.95 & 5.5424 & TRN & \\
\hline CHEMBL1441916 & 688422 & 4.9 & 5.2574 & TRN & \\
\hline CHEMBL1469087 & 688422 & 5.1 & 5.0287 & TRN & \\
\hline CHEMBL1559510 & 688422 & 4.75 & 5.5184 & TRN & \\
\hline CHEMBL3195358 & 688422 & 4.45 & 5.1676 & TRN & \\
\hline CHEMBL1534981 & 688422 & 5.85 & 4.6772 & TRN & \\
\hline CHEMBL1505821 & 688422 & 4.75 & 4.6929 & TRN & \\
\hline CHEMBL1478772 & 688422 & 4.65 & 5.19799 & 99999999995 & TRN \\
\hline CHEMBL1370817 & 688422 & 4.75 & 4.8439 & TST & \\
\hline CHEMBL1418004 & 688422 & 5.65 & 5.052 & TRN & \\
\hline CHEMBL1430052 & 688422 & 5.35 & 5.1004 & TRN & \\
\hline CHEMBL1419077 & 688422 & 5.05 & 5.4622 & TRN & \\
\hline CHEMBL1556644 & 688422 & 4.9 & 4.7115 & TRN & \\
\hline CHEMBL1323490 & 688422 & 8.3468 & 5.555 & TRN & \\
\hline CHEMBL1555941 & 688422 & 5.0 & 5.3544 & TRN & \\
\hline
\end{tabular}




\begin{tabular}{|c|c|c|c|c|c|}
\hline \multicolumn{6}{|c|}{ Supplemental Table s2.txt } \\
\hline CHEMBL600070 & 688422 & 4.45 & 5.1707 & TST & \\
\hline CHEMBL1372399 & 688422 & 4.75 & 4.9629 & TRN & \\
\hline CHEMBL1549486 & 688422 & 4.45 & 5.28299 & 99999999995 & TST \\
\hline CHEMBL1487642 & 688422 & 4.95 & 4.8511 & TRN & \\
\hline CHEMBL3189464 & 688422 & 4.7 & 4.6546 & TRN & \\
\hline CHEMBL1526517 & 688422 & 8.0 & 5.6657 & TST & \\
\hline CHEMBL1898496 & 688422 & 6.8 & 5.09399 & 9999999999 & TST \\
\hline CHEMBL1362635 & 688422 & 4.75 & 5.1198 & TRN & \\
\hline CHEMBL1482536 & 688422 & 4.85 & 5.3142 & TRN & \\
\hline CHEMBL1561059 & 688422 & 6.05 & 5.047 & TRN & \\
\hline CHEMBL1319544 & 688422 & 4.45 & 5.2165 & TRN & \\
\hline CHEMBL1351455 & 688422 & 4.8 & 5.2077 & TST & \\
\hline CHEMBL1610433 & 688422 & 4.95 & 4.7698 & TRN & \\
\hline CHEMBL1516336 & 688422 & 5.25 & 5.067 & TRN & \\
\hline CHEMBL1440922 & 688422 & 5.0 & 5.2028 & TRN & \\
\hline CHEMBL1314200 & 688422 & 4.45 & 4.8605 & TRN & \\
\hline CHEMBL1540667 & 688422 & 4.85 & 5.2971 & TRN & \\
\hline CHEMBL1447670 & 688422 & 4.45 & 5.6136 & TRN & \\
\hline CHEMBL1580114 & 688422 & 4.8 & 4.6728 & TRN & \\
\hline CHEMBL1579905 & 688422 & 4.7 & 5.7314 & TRN & \\
\hline CHEMBL1331798 & 688422 & 4.7 & 5.0262 & TRN & \\
\hline CHEMBL1352543 & 688422 & 4.7 & 4.9217 & TRN & \\
\hline CHEMBL1428544 & 688422 & 6.25 & 5.5248 & TRN & \\
\hline CHEMBL1421998 & 688422 & 4.45 & 5.0027 & TRN & \\
\hline CHEMBL1596976 & 688422 & 4.45 & 5.2089 & TST & \\
\hline CHEMBL1256024 & 688422 & 6.1 & 5.9046 & TST & \\
\hline CHEMBL1465058 & 688422 & 7.2503 & 5.2552 & TRN & \\
\hline CHEMBL1381495 & 688422 & 4.8 & 5.1496 & TRN & \\
\hline CHEMBL3192477 & 688422 & 4.45 & 4.9578 & TST & \\
\hline CHEMBL1531057 & 688422 & 6.8 & 5.8394 & TRN & \\
\hline CHEMBL1464880 & 688422 & 7.6003 & 5.4873 & TST & \\
\hline CHEMBL1332280 & 688422 & 4.5 & 5.2075 & TRN & \\
\hline CHEMBL1453075 & 688422 & 4.75 & 5.0309 & TRN & \\
\hline CHEMBL1347003 & 688422 & 7.3002 & 6.0896 & TRN & \\
\hline CHEMBL1302041 & 688422 & 4.95 & 5.2421 & TRN & \\
\hline CHEMBL1465932 & 688422 & 4.8 & 5.2644 & TRN & \\
\hline CHEMBL1422935 & 688422 & 8.3468 & 5.2864 & TRN & \\
\hline CHEMBL1509075 & 688422 & 4.5 & 5.2388 & TRN & \\
\hline CHEMBL1561662 & 688422 & 5.55 & 5.1951 & TRN & \\
\hline CHEMBL1976567 & 688422 & 4.5 & 4.9766 & TRN & \\
\hline CHEMBL1496386 & 688422 & 4.9 & 5.1251 & TST & \\
\hline CHEMBL1338372 & 688422 & 4.45 & 5.0802 & TRN & \\
\hline CHEMBL1483220 & 688422 & 5.5 & 5.0728 & TRN & \\
\hline CHEMBL1568674 & 688422 & 7.4001 & 5.1649 & TST & \\
\hline CHEMBL1542231 & 688422 & 4.9 & 5.1644 & TST & \\
\hline CHEMBL1478288 & 688422 & 5.4 & 5.1097 & TRN & \\
\hline CHEMBL1307026 & 688422 & 4.45 & 5.4735 & TRN & \\
\hline CHEMBL1317598 & 688422 & 5.8 & 5.6221 & TRN & \\
\hline
\end{tabular}




\begin{tabular}{|c|c|c|c|c|c|}
\hline \multicolumn{6}{|c|}{ Supplemental Table S2.txt } \\
\hline CHEMBL1578341 & 688422 & 4.95 & 4.8123 & TRN & \\
\hline CHEMBL1499257 & 688422 & 4.65 & 5.2257 & TRN & \\
\hline CHEMBL1345166 & 688422 & 5.5 & 5.0446 & TRN & \\
\hline CHEMBL1492304 & 688422 & 4.9 & 5.3191 & TST & \\
\hline CHEMBL1577397 & 688422 & 4.7 & 5.3978 & TST & \\
\hline CHEMBL1995383 & 688422 & 8.4949 & 5.9438 & TST & \\
\hline CHEMBL1315716 & 688422 & 4.8 & 5.0072 & TRN & \\
\hline CHEMBL1554491 & 688422 & 5.15 & 5.4346 & TRN & \\
\hline CHEMBL1573994 & 688422 & 4.75 & 5.3228 & TRN & \\
\hline CHEMBL1519922 & 688422 & 5.15 & 5.1219 & TRN & \\
\hline CHEMBL1605038 & 688422 & 4.45 & 5.2784 & TRN & \\
\hline CHEMBL1518145 & 688422 & 4.6 & 5.0983 & TRN & \\
\hline CHEMBL1453338 & 688422 & 4.9 & 5.4271 & TST & \\
\hline CHEMBL1515065 & 688422 & 8.0 & 5.7623 & TST & \\
\hline CHEMBL1576346 & 688422 & 4.5 & 5.2309 & TRN & \\
\hline CHEMBL1384061 & 688422 & 4.5 & 4.787 & TRN & \\
\hline CHEMBL1479082 & 688422 & 4.9 & 5.4792 & TRN & \\
\hline CHEMBL1539342 & 688422 & 5.25 & 5.2665 & TST & \\
\hline CHEMBL1449745 & 688422 & 4.8 & 5.2152 & TRN & \\
\hline CHEMBL1551958 & 688422 & 4.9 & 5.3815 & TRN & \\
\hline CHEMBL1461111 & 688422 & 4.6 & 5.1534 & TRN & \\
\hline CHEMBL1361326 & 688422 & 4.45 & 5.4842 & TRN & \\
\hline CHEMBL1471016 & 688422 & 7.8996 & 5.5322 & TST & \\
\hline CHEMBL1307046 & 688422 & 4.6 & 4.7085 & TRN & \\
\hline CHEMBL1500832 & 688422 & 4.45 & 5.16299 & & TRN \\
\hline CHEMBL1451348 & 688422 & 4.5 & 4.765 & TRN & \\
\hline CHEMBL3196502 & 688422 & 4.9 & 5.4163 & TST & \\
\hline CHEMBL1382236 & 688422 & 4.45 & 5.1129 & TRN & \\
\hline CHEMBL1391681 & 688422 & 4.7 & 5.1893 & TRN & \\
\hline CHEMBL1369594 & 688422 & 5.0 & 5.1053 & TRN & \\
\hline CHEMBL1541283 & 688422 & 4.5 & 5.1265 & TRN & \\
\hline CHEMBL1416733 & 688422 & 6.45 & 5.6544 & TRN & \\
\hline CHEMBL3211238 & 688422 & 4.85 & 5.3643 & TRN & \\
\hline CHEMBL1507548 & 688422 & 4.65 & 4.9308 & TRN & \\
\hline CHEMBL 3208066 & 688422 & 5.0 & 4.8589 & TRN & \\
\hline CHEMBL1485568 & 688422 & 4.65 & 5.4089 & TST & \\
\hline CHEMBL1457862 & 688422 & 7.6498 & 5.4904 & TRN & \\
\hline CHEMBL1511861 & 688422 & 4.65 & 5.2151 & TRN & \\
\hline CHEMBL1556233 & 688422 & 4.65 & 5.2927 & TRN & \\
\hline CHEMBL1363757 & 688422 & 4.8 & 5.4497 & TRN & \\
\hline CHEMBL1342753 & 688422 & 5.55 & 5.3958 & TRN & \\
\hline CHEMBL1475065 & 688422 & 4.9 & 5.9142 & TRN & \\
\hline CHEMBL1596496 & 688422 & 5.45 & 5.1209 & TRN & \\
\hline CHEMBL 3208223 & 688422 & 4.95 & 5.416 & TRN & \\
\hline CHEMBL1347904 & 688422 & 4.7 & 5.0143 & TRN & \\
\hline CHEMBL1593939 & 688422 & 4.45 & 5.4441 & TRN & \\
\hline CHEMBL1978755 & 688422 & 4.45 & 5.1532 & TRN & \\
\hline CHEMBL1384836 & 688422 & 4.45 & 5.3407 & TRN & \\
\hline
\end{tabular}




\begin{tabular}{|c|c|c|c|c|c|}
\hline \multicolumn{6}{|c|}{ Supplemental Table S2.txt } \\
\hline CHEMBL1411505 & 688422 & 5.0 & 5.7136 & TRN & \\
\hline CHEMBL1402581 & 688422 & 4.6 & 4.9059 & TRN & \\
\hline CHEMBL1442987 & 688422 & 6.0 & 5.2423 & TRN & \\
\hline CHEMBL1308938 & 688422 & 5.05 & 5.9361 & TST & \\
\hline CHEMBL1466178 & 688422 & 4.45 & 5.4111 & TRN & \\
\hline CHEMBL50378 & 688422 & 4.55 & 5.3891 & TST & \\
\hline CHEMBL1498469 & 688422 & 4.9 & 5.6415 & TRN & \\
\hline CHEMBL1565847 & 688422 & 4.95 & 5.3582 & TST & \\
\hline CHEMBL1427275 & 688422 & 4.9 & 5.2455 & TRN & \\
\hline CHEMBL3189829 & 688422 & 4.9 & 4.9942 & TRN & \\
\hline CHEMBL1384684 & 688422 & 4.5 & 5.1226 & TRN & \\
\hline CHEMBL1361334 & 688422 & 4.45 & 5.5007 & TST & \\
\hline CHEMBL1433716 & 688422 & 5.55 & 5.0404 & TRN & \\
\hline CHEMBL1441291 & 688422 & 4.6 & 5.1799 & TRN & \\
\hline CHEMBL1458939 & 688422 & 8.301 & 5.1717 & TST & \\
\hline CHEMBL1454591 & 688422 & 6.2 & 5.0338 & TRN & \\
\hline CHEMBL1331948 & 688422 & 4.95 & 5.2052 & TST & \\
\hline CHEMBL1310577 & 688422 & 4.65 & 5.3327 & TRN & \\
\hline CHEMBL1483907 & 688422 & 4.9 & 4.6596 & TRN & \\
\hline CHEMBL1518765 & 688422 & 5.0 & 4.5835 & TRN & \\
\hline CHEMBL1556453 & 688422 & 4.7 & 5.1753 & TST & \\
\hline CHEMBL3194994 & 688422 & 4.65 & 5.1436 & TRN & \\
\hline CHEMBL1413739 & 688422 & 4.6 & 5.4276 & TRN & \\
\hline CHEMBL1347628 & 688422 & 8.4949 & 5.25299 & 9999999999 & TRN \\
\hline CHEMBL1313906 & 688422 & 4.45 & 5.0987 & TRN & \\
\hline CHEMBL1521656 & 688422 & 5.25 & 4.904 & TRN & \\
\hline CHEMBL1378722 & 688422 & 5.0 & 4.9438 & TRN & \\
\hline CHEMBL1574033 & 688422 & 4.45 & 5.2753 & TRN & \\
\hline CHEMBL1510033 & 688422 & 4.55 & 5.1377 & TRN & \\
\hline CHEMBL1522635 & 688422 & 7.1002 & 5.1275 & TRN & \\
\hline CHEMBL1427946 & 688422 & 4.5 & 5.7606 & TRN & \\
\hline CHEMBL1547918 & 688422 & 6.7001 & 5.3195 & TRN & \\
\hline CHEMBL1561819 & 688422 & 4.85 & 5.2544 & TRN & \\
\hline CHEMBL1529478 & 688422 & 4.6 & 4.65 & TRN & \\
\hline CHEMBL1609428 & 688422 & 4.9 & 5.0043 & TRN & \\
\hline CHEMBL1304434 & 688422 & 5.0 & 5.0697 & TRN & \\
\hline CHEMBL1522113 & 688422 & 4.9 & 5.5187 & TST & \\
\hline CHEMBL1384170 & 688422 & 4.6 & 5.539 & TST & \\
\hline CHEMBL1335417 & 688422 & 4.7 & 5.007 & TRN & \\
\hline CHEMBL1385768 & 688422 & 4.75 & 5.4153 & TRN & \\
\hline CHEMBL1303271 & 688422 & 4.5 & 5.3656 & TRN & \\
\hline CHEMBL1391475 & 688422 & 4.55 & 4.9566 & TST & \\
\hline CHEMBL1564348 & 688422 & 4.6 & 5.2543 & TRN & \\
\hline CHEMBL1300631 & 688422 & 4.65 & 5.3705 & TRN & \\
\hline CHEMBL1568747 & 688422 & 4.95 & 4.9159 & TRN & \\
\hline CHEMBL1493700 & 688422 & 4.45 & 5.1657 & TRN & \\
\hline CHEMBL3212748 & 688422 & 5.25 & 5.4475 & TRN & \\
\hline CHEMBL1565672 & 688422 & 6.1 & 5.3831 & TST & \\
\hline
\end{tabular}




\begin{tabular}{|c|c|c|c|c|c|}
\hline & & \multicolumn{4}{|c|}{ Supplemental Table S2.txt } \\
\hline CHEMBL1560230 & 688422 & 6.7501 & 5.1588 & TRN & \\
\hline CHEMBL1399785 & 688422 & 5.25 & 4.9296 & TRN & \\
\hline CHEMBL1543306 & 688422 & 4.45 & 5.1152 & TRN & \\
\hline CHEMBL1343823 & 688422 & 5.6 & 5.5615 & TST & \\
\hline CHEMBL1567295 & 688422 & 5.4 & 5.08 & TRN & \\
\hline CHEMBL1484881 & 688422 & 4.9 & 5.1549 & TRN & \\
\hline CHEMBL1346634 & 688422 & 4.65 & 4.8978 & TRN & \\
\hline CHEMBL1585648 & 688422 & 4.45 & 5.4569 & TST & \\
\hline CHEMBL1429297 & 688422 & 4.6 & 5.0071 & TRN & \\
\hline CHEMBL1502902 & 688422 & 4.5 & 5.433 & TRN & \\
\hline CHEMBL1602766 & 688422 & 5.95 & 5.1786 & TRN & \\
\hline CHEMBL1500596 & 688422 & 6.9 & 5.62799 & 9999999999 & TST \\
\hline CHEMBL1407572 & 688422 & 4.75 & 5.2646 & TRN & \\
\hline CHEMBL1323795 & 688422 & 4.9 & 4.8682 & TRN & \\
\hline CHEMBL1383787 & 688422 & 4.8 & 5.261 & TRN & \\
\hline CHEMBL1487022 & 688422 & 6.25 & 5.2568 & TRN & \\
\hline CHEMBL 3084891 & 688422 & 5.2 & 5.5604 & TRN & \\
\hline CHEMBL1406613 & 688422 & 4.7 & 5.785 & TRN & \\
\hline CHEMBL1365538 & 688422 & 4.8 & 4.9029 & TRN & \\
\hline CHEMBL1603623 & 688422 & 4.65 & 5.2789 & TRN & \\
\hline CHEMBL 1466738 & 688422 & 7.0 & 5.1813 & TRN & \\
\hline CHEMBL1471500 & 688422 & 8.1487 & 5.6022 & TRN & \\
\hline CHEMBL1537322 & 688422 & 6.15 & 5.1287 & TRN & \\
\hline CHEMBL1501158 & 688422 & 4.75 & 5.2948 & TRN & \\
\hline CHEMBL1975151 & 688422 & 5.5 & 5.2269 & TRN & \\
\hline CHEMBL1430215 & 688422 & 5.0 & 5.1992 & TRN & \\
\hline CHEMBL1349615 & 688422 & 4.8 & 4.9724 & TST & \\
\hline CHEMBL400912 & 688422 & 4.5 & 5.3266 & TRN & \\
\hline CHEMBL3196249 & 688422 & 4.85 & 5.3562 & TST & \\
\hline CHEMBL1595455 & 688422 & 5.85 & 5.4767 & TRN & \\
\hline CHEMBL1571157 & 688422 & 5.6 & 5.4888 & TRN & \\
\hline CHEMBL1972450 & 688422 & 4.45 & 5.1122 & TST & \\
\hline CHEMBL1331086 & 688422 & 4.85 & 5.2227 & TST & \\
\hline CHEMBL1547738 & 688422 & 4.9 & 5.3069 & TST & \\
\hline CHEMBL1304865 & 688422 & 5.1 & 5.3913 & TRN & \\
\hline CHEMBL1454000 & 688422 & 8.0 & 5.0225 & TRN & \\
\hline CHEMBL1387668 & 688422 & 4.6 & 4.996 & TRN & \\
\hline CHEMBL1386509 & 688422 & 4.95 & 5.0694 & TST & \\
\hline CHEMBL1556914 & 688422 & 4.45 & 5.5355 & TST & \\
\hline CHEMBL1369716 & 688422 & 5.0 & 5.2613 & TRN & \\
\hline CHEMBL1512119 & 688422 & 4.45 & 5.4089 & TST & \\
\hline CHEMBL1402628 & 688422 & 4.8 & 5.0442 & TRN & \\
\hline CHEMBL1319812 & 688422 & 4.6 & 5.4831 & TST & \\
\hline CHEMBL1487134 & 688422 & 7.6003 & 5.5696 & TRN & \\
\hline CHEMBL1531684 & 688422 & 5.3 & 5.2153 & TRN & \\
\hline CHEMBL1420403 & 688422 & 4.9 & 5.5453 & TRN & \\
\hline CHEMBL1501377 & 688422 & 4.45 & 4.8904 & TST & \\
\hline CHEMBL 2000175 & 688422 & 4.95 & 5.2202 & TST & \\
\hline
\end{tabular}




\begin{tabular}{|c|c|c|c|c|}
\hline \multicolumn{5}{|c|}{ Supplemental Table S2.txt } \\
\hline CHEMBL1290347 & 688422 & 4.45 & 5.1626 & TST \\
\hline CHEMBL1401228 & 688422 & 5.4 & 5.0771 & TRN \\
\hline CHEMBL1469028 & 688422 & 5.9 & 4.9699 & TST \\
\hline CHEMBL1460194 & 688422 & 4.8 & 5.0042 & TST \\
\hline CHEMBL1363361 & 688422 & 4.7 & 5.0627 & TRN \\
\hline CHEMBL1312139 & 688422 & 4.65 & 5.0657 & TRN \\
\hline CHEMBL1529127 & 688422 & 4.8 & 5.1617 & TST \\
\hline CHEMBL1584148 & 688422 & 6.1 & 5.0423 & TRN \\
\hline CHEMBL1375791 & 688422 & 4.45 & 5.5292 & TRN \\
\hline CHEMBL1389969 & 688422 & 4.55 & 5.5052 & TRN \\
\hline CHEMBL1604630 & 688422 & 4.45 & 5.0109 & TRN \\
\hline CHEMBL1530900 & 688422 & 4.85 & 5.2323 & TRN \\
\hline CHEMBL1324916 & 688422 & 4.65 & 5.0956 & TST \\
\hline CHEMBL524222 & 688422 & 5.15 & 5.1865 & TRN \\
\hline CHEMBL1557831 & 688422 & 5.45 & 5.1951 & TST \\
\hline CHEMBL167542 & 688422 & 5.8 & 5.7248 & TST \\
\hline CHEMBL1526074 & 688422 & 4.9 & 5.1913 & TRN \\
\hline CHEMBL1329140 & 688422 & 4.7 & 4.9168 & TRN \\
\hline CHEMBL1339742 & 688422 & 4.5 & 5.0486 & TRN \\
\hline CHEMBL1439946 & 688422 & 7.5498 & 5.2862 & TRN \\
\hline CHEMBL1447148 & 688422 & 4.75 & 4.9346 & TRN \\
\hline CHEMBL1346986 & 688422 & 4.5 & 5.2148 & TST \\
\hline CHEMBL1533534 & 688422 & 4.45 & 5.1724 & TST \\
\hline CHEMBL1486661 & 688422 & 5.05 & 4.8168 & TRN \\
\hline CHEMBL1497316 & 688422 & 5.0 & 4.7602 & TRN \\
\hline CHEMBL1559659 & 688422 & 5.1 & 5.2158 & TRN \\
\hline CHEMBL1593996 & 688422 & 7.7496 & 5.4987 & TRN \\
\hline CHEMBL1458208 & 688422 & 4.85 & 5.3618 & TST \\
\hline CHEMBL1607674 & 688422 & 4.45 & 5.0078 & TRN \\
\hline CHEMBL1541235 & 688422 & 5.9 & 5.5974 & TST \\
\hline CHEMBL1516958 & 688422 & 4.65 & 5.2838 & TRN \\
\hline CHEMBL1439345 & 688422 & 4.65 & 5.4302 & TRN \\
\hline CHEMBL1480983 & 688422 & 4.45 & 5.4578 & TST \\
\hline CHEMBL1572016 & 688422 & 4.8 & 5.3961 & TRN \\
\hline CHEMBL1432566 & 688422 & 5.0 & 5.2983 & TRN \\
\hline CHEMBL1401264 & 688422 & 4.65 & 5.1944 & TST \\
\hline CHEMBL1430139 & 688422 & 4.45 & 5.1127 & TRN \\
\hline CHEMBL1529551 & 688422 & 4.5 & 5.3218 & TRN \\
\hline CHEMBL1482431 & 688422 & 4.45 & 5.2645 & TST \\
\hline CHEMBL1333565 & 688422 & 4.6 & 5.5831 & TST \\
\hline CHEMBL1376715 & 688422 & 4.45 & 5.2228 & TRN \\
\hline CHEMBL1434894 & 688422 & 4.8 & 5.3625 & TRN \\
\hline CHEMBL1305844 & 688422 & 7.6498 & 5.5102 & TST \\
\hline CHEMBL1426669 & 688422 & 4.5 & 4.838 & TRN \\
\hline CHEMBL1303557 & 688422 & 4.9 & 5.2417 & TST \\
\hline CHEMBL1355657 & 688422 & 6.7501 & 5.7045 & TRN \\
\hline CHEMBL1579084 & 688422 & 4.45 & 5.3288 & TRN \\
\hline CHEMBL1358604 & 688422 & 4.95 & 4.6233 & TRN \\
\hline
\end{tabular}




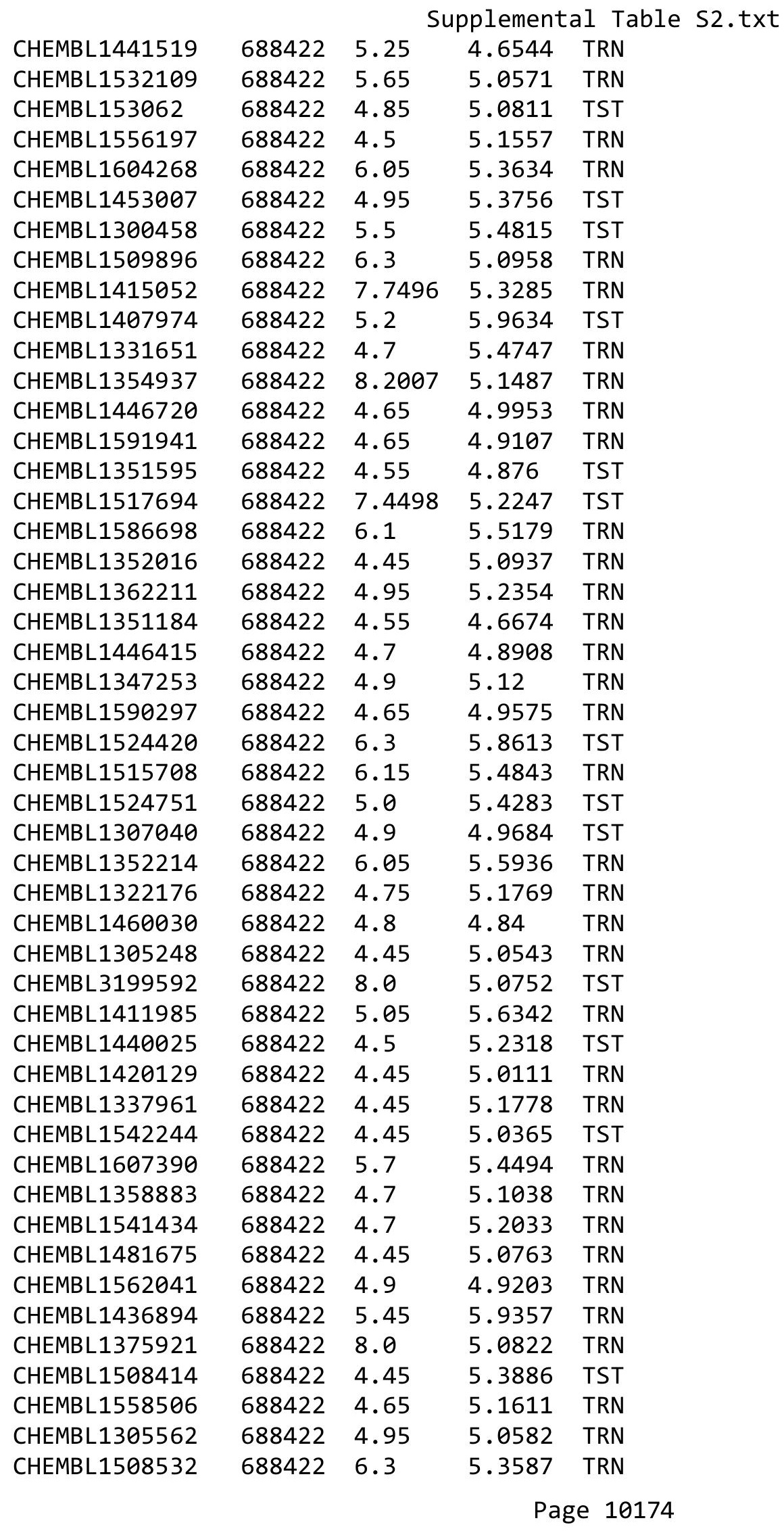




\begin{tabular}{|c|c|c|c|c|}
\hline \multicolumn{5}{|c|}{ Supplemental Table S2.txt } \\
\hline CHEMBL1401692 & 688422 & 6.0 & 5.2704 & TST \\
\hline CHEMBL1255837 & 688422 & 6.0 & 5.6567 & TRN \\
\hline CHEMBL1530492 & 688422 & 4.45 & 5.0686 & TST \\
\hline CHEMBL1484428 & 688422 & 4.45 & 5.51 & TST \\
\hline CHEMBL1575108 & 688422 & 4.45 & 5.1218 & TRN \\
\hline CHEMBL1407071 & 688422 & 4.45 & 5.1127 & TRN \\
\hline CHEMBL1369253 & 688422 & 4.95 & 5.1643 & TST \\
\hline CHEMBL1494854 & 688422 & 4.45 & 4.9054 & TRN \\
\hline CHEMBL1304402 & 688422 & 5.0 & 5.3261 & TST \\
\hline CHEMBL1404016 & 688422 & 5.1 & 5.8695 & TRN \\
\hline CHEMBL1447697 & 688422 & 4.65 & 5.3977 & TRN \\
\hline CHEMBL1341090 & 688422 & 7.15 & 5.9741 & TST \\
\hline CHEMBL1369905 & 688422 & 4.45 & 5.3273 & TRN \\
\hline CHEMBL1331978 & 688422 & 4.45 & 5.1808 & TRN \\
\hline CHEMBL1483855 & 688422 & 4.45 & 4.7619 & TRN \\
\hline CHEMBL1543944 & 688422 & 4.85 & 4.9688 & TST \\
\hline CHEMBL1716038 & 688422 & 5.45 & 5.1808 & TRN \\
\hline CHEMBL1556943 & 688422 & 4.5 & 5.0536 & TRN \\
\hline CHEMBL1310660 & 688422 & 4.5 & 5.4519 & TRN \\
\hline CHEMBL1521557 & 688422 & 4.9 & 5.019 & TRN \\
\hline CHEMBL1469483 & 688422 & 4.75 & 5.3042 & TST \\
\hline CHEMBL1577637 & 688422 & 4.7 & 5.3668 & TRN \\
\hline CHEMBL1600972 & 688422 & 4.75 & 5.5279 & TST \\
\hline CHEMBL1333635 & 688422 & 4.45 & 5.5205 & TRN \\
\hline CHEMBL1583535 & 688422 & 4.85 & 5.3283 & TRN \\
\hline CHEMBL1446539 & 688422 & 5.0 & 4.9754 & TRN \\
\hline CHEMBL1421072 & 688422 & 5.2 & 5.5618 & TST \\
\hline CHEMBL1573754 & 688422 & 4.9 & 5.3593 & TRN \\
\hline CHEMBL1324421 & 688422 & 5.9 & 5.6314 & TRN \\
\hline CHEMBL 3194187 & 688422 & 4.9 & 5.0805 & TRN \\
\hline CHEMBL1525454 & 688422 & 5.8 & 5.2455 & TRN \\
\hline CHEMBL1448584 & 688422 & 4.9 & 5.3204 & TRN \\
\hline CHEMBL1488464 & 688422 & 4.55 & 5.136 & TRN \\
\hline CHEMBL1346533 & 688422 & 5.05 & 4.8599 & TRN \\
\hline CHEMBL1481094 & 688422 & 4.95 & 4.7999 & TRN \\
\hline CHEMBL1320545 & 688422 & 5.6 & 5.6417 & TST \\
\hline CHEMBL1411664 & 688422 & 5.15 & 5.1108 & TRN \\
\hline CHEMBL1549407 & 688422 & 4.45 & 4.7143 & TRN \\
\hline CHEMBL 3193481 & 688422 & 4.6 & 5.4895 & TRN \\
\hline CHEMBL1407184 & 688422 & 4.8 & 5.0237 & TRN \\
\hline CHEMBL1315288 & 688422 & 4.45 & 5.8123 & TST \\
\hline CHEMBL3208755 & 688422 & 4.45 & 5.2445 & TRN \\
\hline CHEMBL1407018 & 688422 & 6.45 & 5.5917 & TST \\
\hline CHEMBL376505 & 688422 & 5.5 & 5.5262 & TST \\
\hline CHEMBL1433734 & 688422 & 4.65 & 5.5824 & TRN \\
\hline CHEMBL1359607 & 688422 & 7.5003 & 5.5685 & TST \\
\hline CHEMBL1385610 & 688422 & 7.6003 & 5.0234 & TST \\
\hline CHEMBL1569072 & 688422 & 4.45 & 5.5391 & TRN \\
\hline
\end{tabular}




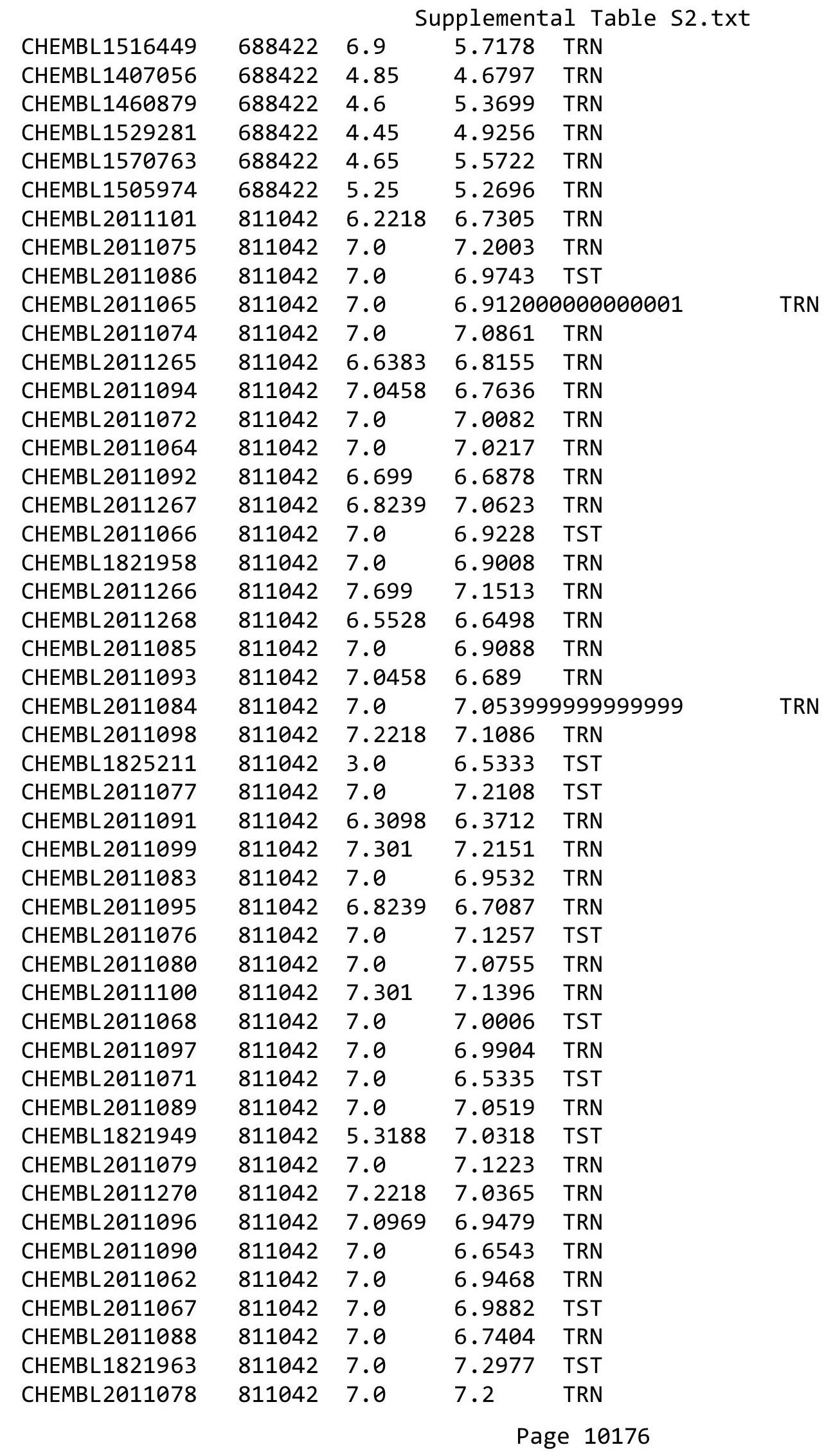




\begin{tabular}{|c|c|c|c|c|c|}
\hline \multicolumn{6}{|c|}{ Supplemental Table S2.txt } \\
\hline CHEMBL2011082 & 811042 & 7.0 & 7.0976 & TRN & \\
\hline CHEMBL 2011087 & 811042 & 5.9586 & 6.7114 & TRN & \\
\hline CHEMBL2011063 & 811042 & 7.0 & 6.8267 & TRN & \\
\hline CHEMBL 2011070 & 811042 & 7.0 & 7.0307 & TST & \\
\hline CHEMBL 2011073 & 811042 & 7.0 & 6.8955 & TST & \\
\hline CHEMBL2011069 & 811042 & 7.0 & 6.7868 & TST & \\
\hline CHEMBL 2011269 & 811042 & 6.5528 & 6.7661 & TRN & \\
\hline CHEMBL 2011081 & 811042 & 7.0 & 7.2081 & TRN & \\
\hline CHEMBL1572233 & 809361 & 5.5287 & 6.0271 & TRN & \\
\hline CHEMBL1605476 & 809361 & 4.3627 & 5.4668 & TRN & \\
\hline CHEMBL1470450 & 809361 & 5.5114 & 5.4018 & TRN & \\
\hline CHEMBL1392611 & 809361 & 6.3809 & 5.7481 & TRN & \\
\hline CHEMBL1529190 & 809361 & 5.7932 & 6.2261 & TRN & \\
\hline CHEMBL1707088 & 809361 & 5.0357 & 5.3029 & TRN & \\
\hline CHEMBL1478826 & 809361 & 5.7305 & 5.84399 & 9999999999 & TRN \\
\hline CHEMBL1453996 & 809361 & 5.5638 & 5.7668 & TRN & \\
\hline CHEMBL1409445 & 809361 & 6.1186 & 5.9202 & TRN & \\
\hline CHEMBL1565371 & 809361 & 5.6021 & 5.7929 & TRN & \\
\hline CHEMBL1425364 & 809361 & 5.4559 & 5.4048 & TRN & \\
\hline CHEMBL1973156 & 809361 & 5.0223 & 5.3613 & TST & \\
\hline CHEMBL1530173 & 809361 & 5.4672 & 5.4341 & TRN & \\
\hline CHEMBL1420175 & 809361 & 5.3526 & 5.3566 & TRN & \\
\hline CHEMBL1302286 & 809361 & 5.0846 & 5.3492 & TRN & \\
\hline CHEMBL1553023 & 809361 & 7.585 & 6.8634 & TST & \\
\hline CHEMBL1338667 & 809361 & 6.067 & 4.8929 & TST & \\
\hline CHEMBL1448282 & 809361 & 6.1524 & $6.4460 e$ & 0000000001 & TRN \\
\hline CHEMBL591370 & 809361 & 5.6364 & 5.5565 & TRN & \\
\hline CHEMBL1532668 & 809361 & 5.27 & 5.8687 & TRN & \\
\hline CHEMBL1714574 & 809361 & 4.2828 & 5.5544 & TST & \\
\hline CHEMBL1518893 & 809361 & 4.9978 & 5.4055 & TRN & \\
\hline CHEMBL1727038 & 809361 & 4.4445 & 4.7082 & TST & \\
\hline CHEMBL1562060 & 809361 & 5.2328 & 5.2235 & TRN & \\
\hline CHEMBL1876725 & 809361 & 5.6055 & 5.4257 & TRN & \\
\hline CHEMBL1331851 & 809361 & 5.4802 & 5.95 & TRN & \\
\hline CHEMBL1885576 & 809361 & 5.2321 & 5.3849 & TRN & \\
\hline CHEMBL1541657 & 809361 & 4.9731 & 5.4187 & TRN & \\
\hline CHEMBL1481192 & 809361 & 5.5143 & 5.2706 & TST & \\
\hline CHEMBL1324616 & 809361 & 5.6635 & 5.6546 & TRN & \\
\hline CHEMBL1385770 & 809361 & 4.3814 & 5.3431 & TRN & \\
\hline CHEMBL1901606 & 809361 & 6.0 & 5.6145 & TRN & \\
\hline CHEMBL1511363 & 809361 & 5.8356 & 5.5576 & TST & \\
\hline CHEMBL1504982 & 809361 & 5.5376 & 5.8797 & TRN & \\
\hline CHEMBL1983274 & 809361 & 4.8074 & 5.5513 & TRN & \\
\hline CHEMBL1364793 & 809361 & 5.7144 & 5.4304 & TRN & \\
\hline CHEMBL203695 & 809361 & 5.6326 & 5.5271 & TRN & \\
\hline CHEMBL1506503 & 809361 & 7.585 & 5.5809 & TRN & \\
\hline CHEMBL1531172 & 809361 & 5.5784 & 5.6269 & TRN & \\
\hline CHEMBL607140 & 809361 & 6.1952 & 5.9489 & TRN & \\
\hline
\end{tabular}




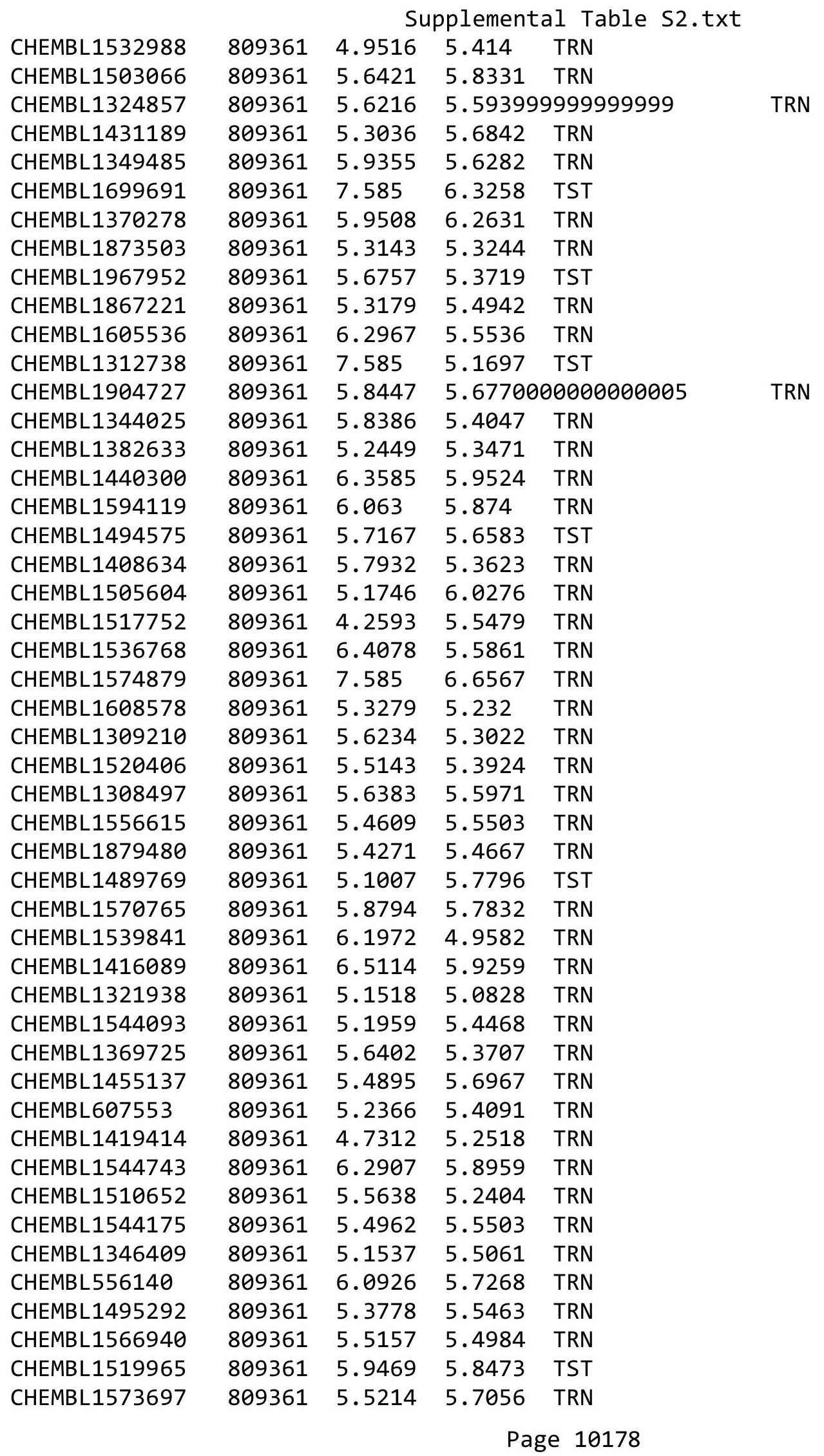




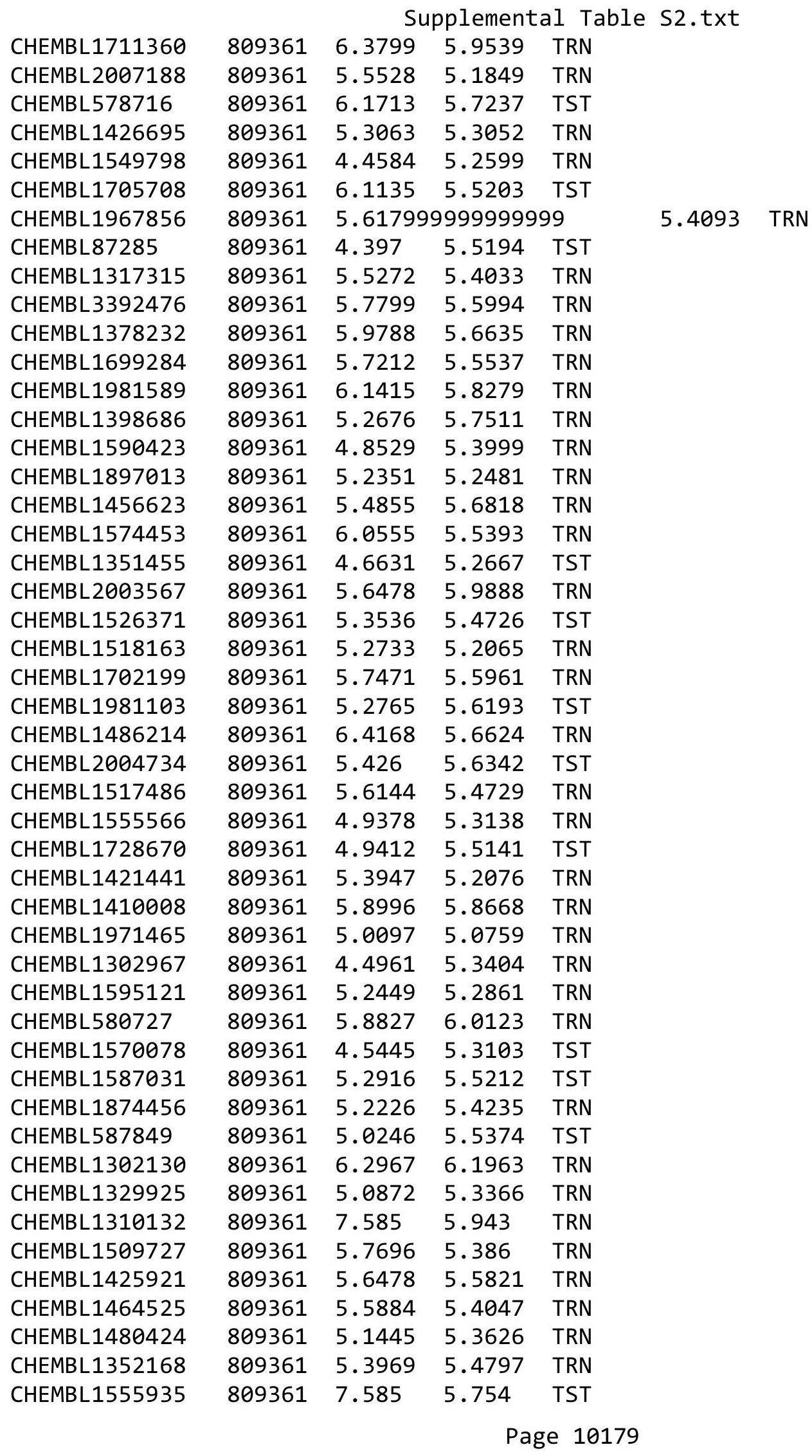




\begin{tabular}{|c|c|c|c|c|c|c|}
\hline & & \multicolumn{5}{|c|}{ Supplemental Table S2.txt } \\
\hline CHEMBL1736634 & 809361 & 5.7055 & 5.1477 & TRN & & \\
\hline CHEMBL1301232 & 809361 & 5.6038 & 5.3297 & TRN & & \\
\hline CHEMBL1422720 & 809361 & 5.2644 & 5.6318 & TRN & & \\
\hline CHEMBL1462692 & 809361 & 5.1599 & 5.3559 & TRN & & \\
\hline CHEMBL1515801 & 809361 & 5.2644 & 5.5172 & TST & & \\
\hline CHEMBL1572169 & 809361 & 5.5003 & 5.3904 & TRN & & \\
\hline CHEMBL1592249 & 809361 & 5.1637 & 5.1249 & TRN & & \\
\hline CHEMBL1349575 & 809361 & 5.475 & 5.381 & TRN & & \\
\hline CHEMBL1580311 & 809361 & 4.8908 & 5.3055 & TRN & & \\
\hline CHEMBL1493936 & 809361 & 5.5498 & 5.8389 & TST & & \\
\hline CHEMBL1586531 & 809361 & 5.0106 & 5.4428 & TRN & & \\
\hline CHEMBL1313978 & 809361 & 5.2518 & 5.3513 & TRN & & \\
\hline CHEMBL1563896 & 809361 & 5.5768 & 5.5292 & TST & & \\
\hline CHEMBL1966192 & 809361 & 5.3478 & 5.4653 & TST & & \\
\hline CHEMBL1302109 & 809361 & 6.153 & 5.3826 & TRN & & \\
\hline CHEMBL588804 & 809361 & 5.9788 & 6.3494 & TRN & & \\
\hline CHEMBL1337570 & 809361 & 5.5751 & 5.3679 & TRN & & \\
\hline CHEMBL1482188 & 809361 & 5.7496 & 5.4192 & TST & & \\
\hline CHEMBL1606837 & 809361 & \multicolumn{3}{|c|}{5.2139999999999995} & 5.5226 & TST \\
\hline CHEMBL1307050 & 809361 & 6.2588 & 5.697 & TRN & & \\
\hline CHEMBL1352607 & 809361 & 5.585 & 5.6412 & TRN & & \\
\hline CHEMBL1300836 & 809361 & 5.3768 & 5.5062 & TRN & & \\
\hline CHEMBL1539505 & 809361 & 4.6609 & 5.3069 & TRN & & \\
\hline CHEMBL1392142 & 809361 & 5.0462 & 5.4893 & TRN & & \\
\hline CHEMBL1374250 & 809361 & 5.062 & 5.2781 & TRN & & \\
\hline CHEMBL1353013 & 809361 & 6.4248 & 5.6606 & TRN & & \\
\hline CHEMBL1311185 & 809361 & 5.8633 & 5.6694 & TRN & & \\
\hline CHEMBL1353317 & 809361 & \multicolumn{3}{|c|}{6.1579999999999995} & 5.3833 & TRN \\
\hline CHEMBL1442973 & 809361 & 5.3233 & 5.4897 & TRN & & \\
\hline CHEMBL1610180 & 809361 & \multicolumn{3}{|c|}{5.617999999999999} & 5.5441 & TRN \\
\hline CHEMBL1610049 & 809361 & 5.3401 & 6.1106 & TRN & & \\
\hline CHEMBL1725424 & 809361 & 4.7747 & 5.3615 & TRN & & \\
\hline CHEMBL1394747 & 809361 & 4.6885 & 5.455 & TST & & \\
\hline CHEMBL1299281 & 809361 & 5.9031 & 5.6028 & TRN & & \\
\hline CHEMBL1375563 & 809361 & 5.6234 & 5.5463 & TRN & & \\
\hline CHEMBL 379300 & 809361 & \multicolumn{3}{|c|}{5.752000000000001} & 5.6317 & TST \\
\hline CHEMBL1483380 & 809361 & 5.4609 & 5.5517 & TRN & & \\
\hline CHEMBL1400787 & 809361 & 5.2541 & 5.3506 & TST & & \\
\hline CHEMBL1450195 & 809361 & 5.2457 & 5.3556 & TRN & & \\
\hline CHEMBL1534387 & 809361 & 6.0768 & 5.7786 & TRN & & \\
\hline CHEMBL1502830 & 809361 & 4.961 & 5.268 & TRN & & \\
\hline CHEMBL1567159 & 809361 & 5.8097 & 5.4703 & TRN & & \\
\hline CHEMBL1323536 & 809361 & 5.1986 & 5.3921 & TRN & & \\
\hline CHEMBL1528275 & 809361 & 5.0969 & 5.1463 & TRN & & \\
\hline CHEMBL1477197 & 809361 & 5.5884 & 5.4749 & TRN & & \\
\hline CHEMBL1985082 & 809361 & 6.1911 & 5.8044 & TRN & & \\
\hline CHEMBL1720610 & 809361 & 5.6576 & 5.1617 & TRN & & \\
\hline CHEMBL1477103 & 809361 & 5.3063 & 5.2628 & TRN & & \\
\hline
\end{tabular}




\begin{tabular}{|c|c|c|c|c|c|c|}
\hline & & \multicolumn{5}{|c|}{ Supplemental Table S2.txt } \\
\hline CHEMBL1512575 & 809361 & 5.4449 & 5.5209 & TRN & & \\
\hline CHEMBL1562575 & 809361 & 6.5817 & 5.6473 & TRN & & \\
\hline CHEMBL1403416 & 809361 & 5.063 & 5.5824 & TRN & & \\
\hline CHEMBL1360774 & 809361 & 5.2255 & 5.2779 & TRN & & \\
\hline CHEMBL1372484 & 809361 & 5.2299 & 5.16200 & 0000000001 & & TRN \\
\hline CHEMBL1570216 & 809361 & 5.8297 & 5.5667 & TRN & & \\
\hline CHEMBL 2007282 & 809361 & 5.0575 & 5.4321 & TRN & & \\
\hline CHEMBL1553738 & 809361 & 5.1158 & 5.0486 & TRN & & \\
\hline CHEMBL1579080 & 809361 & 5.1146 & 5.4776 & TRN & & \\
\hline CHEMBL1379149 & 809361 & 5.6757 & 5.49 & TRN & & \\
\hline CHEMBL1735610 & 809361 & 5.6402 & 5.3465 & TRN & & \\
\hline CHEMBL1524431 & 809361 & 5.7011 & 5.7025 & TRN & & \\
\hline CHEMBL1409554 & 809361 & 5.8697 & 5.8477 & TRN & & \\
\hline CHEMBL1886075 & 809361 & 6.0195 & 5.6767 & TRN & & \\
\hline CHEMBL1531073 & 809361 & 7.585 & 5.7225 & TST & & \\
\hline CHEMBL1529741 & 809361 & 5.4572 & 5.8015 & TST & & \\
\hline CHEMBL1541996 & 809361 & 5.3224 & 5.4166 & TRN & & \\
\hline CHEMBL1522275 & 809361 & 5.0448 & 5.2995 & TRN & & \\
\hline CHEMBL1514790 & 809361 & 5.0926 & 5.6021 & TST & & \\
\hline CHEMBL1414585 & 809361 & 5.3872 & 5.6366 & TRN & & \\
\hline CHEMBL1458022 & 809361 & $5.7520 \ell$ & 30000000 & 01 & 5.7199 & TRN \\
\hline CHEMBL1698492 & 809361 & 5.2708 & 5.5012 & TRN & & \\
\hline CHEMBL1873240 & 809361 & 5.2823 & 5.4362 & TRN & & \\
\hline CHEMBL1438884 & 809361 & 7.585 & 5.7051 & TRN & & \\
\hline CHEMBL1430094 & 809361 & 6.2815 & 5.4051 & TRN & & \\
\hline CHEMBL601135 & 809361 & 5.3969 & 5.4367 & TRN & & \\
\hline CHEMBL1602160 & 809361 & 5.4609 & 5.6562 & TST & & \\
\hline CHEMBL1482468 & 809361 & 6.1798 & 5.7283 & TRN & & \\
\hline CHEMBL1464730 & 809361 & 5.8069 & 5.2438 & TST & & \\
\hline CHEMBL1611695 & 809361 & 5.3497 & 5.3013 & TRN & & \\
\hline CHEMBL1468351 & 809361 & 5.2807 & 5.3308 & TRN & & \\
\hline CHEMBL1463640 & 809361 & 4.6517 & 5.3127 & TRN & & \\
\hline CHEMBL1348931 & 809361 & 5.6576 & 5.2527 & TRN & & \\
\hline CHEMBL1878035 & 809361 & 6.0004 & 5.4269 & TRN & & \\
\hline CHEMBL1893385 & 809361 & 4.8496 & 5.2969 & TRN & & \\
\hline CHEMBL1487952 & 809361 & 6.2426 & 5.6058 & TRN & & \\
\hline CHEMBL1339562 & 809361 & 4.8058 & 5.3218 & TRN & & \\
\hline CHEMBL1349225 & 809361 & 5.3045 & 5.51 & TRN & & \\
\hline CHEMBL1580463 & 809361 & 5.5575 & 5.6654 & TRN & & \\
\hline CHEMBL1421105 & 809361 & 7.585 & 5.4914 & TRN & & \\
\hline CHEMBL1530557 & 809361 & 5.6162 & 5.7244 & TRN & & \\
\hline CHEMBL1593484 & 809361 & 5.0195 & 5.2233 & TRN & & \\
\hline CHEMBL1463930 & 809361 & 5.4881 & 5.1703 & TST & & \\
\hline CHEMBL1526427 & 809361 & 5.3224 & 5.2743 & TRN & & \\
\hline CHEMBL1520753 & 809361 & 5.7595 & 5.6988 & TRN & & \\
\hline CHEMBL1530707 & 809361 & 4.9914 & 5.5406 & TST & & \\
\hline CHEMBL1569058 & 809361 & 5.3107 & 5.38299 & 9999999999 & & TRN \\
\hline CHEMBL1446971 & 809361 & 7.585 & 5.6756 & TRN & & \\
\hline
\end{tabular}




\begin{tabular}{|c|c|c|c|c|c|c|}
\hline \multirow[b]{2}{*}{ CHEMBL1999906 } & & \multicolumn{5}{|c|}{ Supplemental Table S2.txt } \\
\hline & 809361 & 5.2676 & 5.2151 & TST & & \\
\hline CHEMBL1380787 & 809361 & 5.24799 & 99999999 & 99 & 5.5636 & TRN \\
\hline CHEMBL1351584 & 809361 & 5.3706 & 5.2428 & TRN & & \\
\hline CHEMBL1555271 & 809361 & 5.9172 & 6.2241 & TRN & & \\
\hline CHEMBL1541379 & 809361 & 5.8697 & 5.1943 & TRN & & \\
\hline CHEMBL1886345 & 809361 & 5.8697 & 5.4017 & TST & & \\
\hline CHEMBL1702773 & 809361 & 4.82100 & 30000000 & & 5.3731 & TRN \\
\hline CHEMBL1439438 & 809361 & 5.6216 & 5.45100 & 0000000000 & 05 & TRN \\
\hline CHEMBL1481162 & 809361 & 6.0814 & 5.5871 & TRN & & \\
\hline CHEMBL1900730 & 809361 & 5.6038 & 5.54799 & 9999999999 & & TRN \\
\hline CHEMBL1299526 & 809361 & 5.4634 & 5.6366 & TRN & & \\
\hline CHEMBL1491238 & 809361 & 5.0119 & 5.255 & TRN & & \\
\hline CHEMBL 2374050 & 809361 & 5.4815 & 5.7728 & TST & & \\
\hline CHEMBL1391518 & 809361 & 5.8665 & 5.9106 & TRN & & \\
\hline CHEMBL1581141 & 809361 & 5.51 & 5.4452 & TRN & & \\
\hline CHEMBL535307 & 809361 & 7.585 & 6.1126 & TST & & \\
\hline CHEMBL1564958 & 809361 & 5.5918 & 6.2149 & TRN & & \\
\hline CHEMBL1870103 & 809361 & 4.7324 & 5.4583 & TRN & & \\
\hline CHEMBL1523952 & 809361 & 5.585 & 5.476 & TRN & & \\
\hline CHEMBL1460653 & 809361 & 5.056 & 5.4246 & TST & & \\
\hline CHEMBL1421779 & 809361 & 5.6757 & 5.8022 & TST & & \\
\hline CHEMBL268089 & 809361 & 5.3125 & 5.3783 & TRN & & \\
\hline CHEMBL1499127 & 809361 & 5.1113 & 5.4507 & TRN & & \\
\hline CHEMBL1398721 & 809361 & 5.6737 & 5.1957 & TRN & & \\
\hline CHEMBL1458782 & 809361 & 5.7011 & 5.2277 & TRN & & \\
\hline CHEMBL1545677 & 809361 & 6.4413 & 5.7452 & TRN & & \\
\hline CHEMBL1730353 & 809361 & 5.7747 & 5.6757 & TST & & \\
\hline CHEMBL1594821 & 809361 & 5.7011 & 5.7605 & TRN & & \\
\hline CHEMBL1342907 & 809361 & 5.4449 & 5.6224 & TRN & & \\
\hline CHEMBL1708171 & 809361 & 4.6362 & 5.4457 & TRN & & \\
\hline CHEMBL1391921 & 809361 & 6.1945 & 5.3684 & TRN & & \\
\hline CHEMBL1547860 & 809361 & 5.0585 & 5.5225 & TRN & & \\
\hline CHEMBL1430068 & 809361 & 5.2549 & 5.1505 & TRN & & \\
\hline CHEMBL1547169 & 809361 & 5.3737 & 5.26 & TRN & & \\
\hline CHEMBL1339536 & 809361 & 5.2984 & 5.41 & TRN & & \\
\hline CHEMBL1720661 & 809361 & 5.0414 & 5.2472 & TRN & & \\
\hline CHEMBL1493864 & 809361 & 5.5272 & 5.7495 & TRN & & \\
\hline CHEMBL1458483 & 809361 & 4.6861 & 5.5152 & TST & & \\
\hline CHEMBL1373096 & 809361 & 6.3747 & 6.443 & TRN & & \\
\hline CHEMBL1455102 & 809361 & 4.99100 & 30000000 & 005 & 5.2458 & TRN \\
\hline CHEMBL1460871 & 809361 & 5.3152 & 5.693 & TST & & \\
\hline CHEMBL578515 & 809361 & 5.7852 & 5.5274 & TRN & & \\
\hline CHEMBL1700880 & 809361 & 5.9208 & 5.7199 & TRN & & \\
\hline CHEMBL1434912 & 809361 & 5.7471 & 5.6495 & TRN & & \\
\hline CHEMBL1731360 & 809361 & 5.4034 & 5.19799 & 9999999999 & 95 & TRN \\
\hline CHEMBL1727333 & 809361 & 6.0915 & 5.6166 & TRN & & \\
\hline CHEMBL1730684 & 809361 & 4.9382 & 5.4755 & TST & & \\
\hline CHEMBL1322995 & 809361 & 5.5214 & 5.3419 & TRN & & \\
\hline
\end{tabular}




\begin{tabular}{|c|c|c|c|c|c|c|}
\hline & & \multicolumn{5}{|c|}{ Supplemental Table S2.txt } \\
\hline CHEMBL1437997 & 809361 & 5.2351 & 5.5395 & TST & & \\
\hline CHEMBL1376674 & 809361 & 7.585 & 5.8186 & TRN & & \\
\hline CHEMBL1428765 & 809361 & 5.5622 & 5.4778 & TRN & & \\
\hline CHEMBL1307177 & 809361 & 5.2233 & 5.2465 & TRN & & \\
\hline CHEMBL1433325 & 809361 & 5.1403 & 5.2321 & TST & & \\
\hline CHEMBL1573351 & 809361 & 5.644 & 5.3339 & TRN & & \\
\hline CHEMBL1508699 & 809361 & 5.5421 & 5.7242 & TRN & & \\
\hline CHEMBL1448929 & 809361 & \multicolumn{3}{|c|}{5.718999999999999} & 5.5837 & TRN \\
\hline CHEMBL1495310 & 809361 & 5.7799 & 5.4075 & TRN & & \\
\hline CHEMBL1476739 & 809361 & 5.8665 & 5.8177 & TRN & & \\
\hline CHEMBL1598985 & 809361 & 5.5654 & 5.3396 & TRN & & \\
\hline CHEMBL1879303 & 809361 & 5.0757 & 5.4427 & TRN & & \\
\hline CHEMBL1561936 & 809361 & 5.1203 & 5.4436 & TRN & & \\
\hline CHEMBL1612156 & 809361 & 5.4584 & 5.3841 & TRN & & \\
\hline CHEMBL1256655 & 809361 & 5.8794 & 5.4733 & TRN & & \\
\hline CHEMBL1553954 & 809361 & 5.644 & 5.3547 & TRN & & \\
\hline CHEMBL1304363 & 809361 & 6.0878 & 6.061 & TRN & & \\
\hline CHEMBL1487136 & 809361 & 7.585 & 7.2315 & TST & & \\
\hline CHEMBL1729203 & 809361 & 5.5768 & 5.5127 & TST & & \\
\hline CHEMBL1301851 & 809361 & 5.6126 & 5.1685 & TRN & & \\
\hline CHEMBL1897634 & 809361 & 5.5884 & 5.6083 & TST & & \\
\hline CHEMBL1304623 & 809361 & 5.2668 & 5.647 & TRN & & \\
\hline CHEMBL1335610 & 809361 & 4.9739 & 5.3792 & TRN & & \\
\hline CHEMBL1503312 & 809361 & 6.0685 & 5.3402 & TRN & & \\
\hline CHEMBL1712452 & 809361 & 5.1035 & \multicolumn{3}{|c|}{5.207999999999999} & TRN \\
\hline CHEMBL1532293 & 809361 & $5.7520 e$ & 000000000 & 91 & 5.4551 & TRN \\
\hline CHEMBL1415844 & 809361 & 5.8761 & 5.5856 & TRN & & \\
\hline CHEMBL1436518 & 809361 & 5.58 & 5.575 & TST & & \\
\hline CHEMBL1501632 & 809361 & \multicolumn{3}{|c|}{5.757000000000001} & 5.9459 & TRN \\
\hline CHEMBL1367597 & 809361 & 5.7878 & 5.7265 & TRN & & \\
\hline CHEMBL1597777 & 809361 & 5.9666 & 5.8763 & TRN & & \\
\hline CHEMBL1706381 & 809361 & 5.8665 & 6.0893 & TRN & & \\
\hline CHEMBL1594890 & 809361 & 5.4365 & 5.175 & TST & & \\
\hline CHEMBL1881757 & 809361 & 4.8431 & 5.4244 & TST & & \\
\hline CHEMBL1464024 & 809361 & 7.585 & 5.7744 & TRN & & \\
\hline CHEMBL1594475 & 809361 & 5.857 & 6.2229 & TRN & & \\
\hline CHEMBL1447872 & 809361 & 5.3152 & 5.2013 & TRN & & \\
\hline CHEMBL1564709 & 809361 & \multicolumn{3}{|c|}{4.3660000000000005} & 5.3846 & TRN \\
\hline CHEMBL319244 & 809361 & 6.057 & 5.821000 & 0000000001 & & TRN \\
\hline CHEMBL1894069 & 809361 & 4.5666 & 5.5796 & TRN & & \\
\hline CHEMBL1387401 & 809361 & 6.2848 & 5.9892 & TRN & & \\
\hline CHEMBL1527502 & 809361 & 5.5346 & 5.4488 & TRN & & \\
\hline CHEMBL1602759 & 809361 & 5.7696 & 5.7539 & TST & & \\
\hline CHEMBL1389268 & 809361 & 5.9208 & 5.8573 & TRN & & \\
\hline CHEMBL317115 & 809361 & 5.3915 & 5.7027 & TRN & & \\
\hline CHEMBL1732556 & 809361 & 6.1481 & 5.5594 & TRN & & \\
\hline CHEMBL1336527 & 809361 & 5.4711 & 5.2057 & TRN & & \\
\hline CHEMBL1558461 & 809361 & 4.8259 & 5.1525 & TRN & & \\
\hline
\end{tabular}


Supplemental Table S2.txt

\begin{tabular}{|c|c|c|c|c|c|}
\hline CHEMBL1436618 & 809361 & 5.5719 & 5.729 & TRN & \\
\hline CHEMBL1608413 & 809361 & 4.7486 & 5.56 & TRN & \\
\hline CHEMBL1700777 & 809361 & 5.3288 & 5.4092 & TRN & \\
\hline CHEMBL1497597 & 809361 & 5.5391 & 5.4501 & TRN & \\
\hline CHEMBL1340186 & 809361 & 5.0915 & 5.3968 & TRN & \\
\hline CHEMBL1725136 & 809361 & 5.2381 & 5.3804 & TRN & \\
\hline CHEMBL1894588 & 809361 & 4.3298 & 5.4654 & TRN & \\
\hline CHEMBL1502020 & 809361 & 5.5467 & 6.0518 & TRN & \\
\hline CHEMBL1334809 & 809361 & 5.399 & 5.4787 & TRN & \\
\hline CHEMBL1430019 & 809361 & 5.2782 & 5.5109 & TRN & \\
\hline CHEMBL1375155 & 809361 & 5.8761 & 5.4349 & TST & \\
\hline CHEMBL1717484 & 809361 & 4.9154 & 5.4228 & TRN & \\
\hline CHEMBL1884965 & 809361 & 5.4056 & 5.7529 & TRN & \\
\hline CHEMBL1300618 & 809361 & 5.0391 & 5.2935 & TRN & \\
\hline CHEMBL1305254 & 809361 & 5.3768 & 5.6151 & TST & \\
\hline CHEMBL1603615 & 809361 & 5.1938 & 5.565 & TRN & \\
\hline CHEMBL1343392 & 809361 & 5.295 & 5.6038 & TRN & \\
\hline CHEMBL1546018 & 809361 & 3.1549 & 5.2898 & TRN & \\
\hline CHEMBL1513705 & 809361 & 6.45100 & 0000000 & 305 & 6.0251 \\
\hline CHEMBL1516966 & 809361 & 5.4522 & 5.657 & TRN & \\
\hline CHEMBL1720524 & 809361 & 5.6882 & 5.4478 & TST & \\
\hline CHEMBL1541693 & 809361 & 5.2299 & 5.2009 & TRN & \\
\hline CHEMBL1430096 & 809361 & 7.585 & 5.6306 & TST & \\
\hline CHEMBL1452116 & 809361 & 5.3526 & 5.7872 & TST & \\
\hline CHEMBL1560954 & 809361 & 5.1851 & 5.468 & TRN & \\
\hline CHEMBL1352995 & 809361 & 4.8505 & 5.4289 & TRN & \\
\hline CHEMBL1560590 & 809361 & 5.4815 & 5.6165 & TRN & \\
\hline CHEMBL1427185 & 809361 & 6.0237 & 5.5143 & TST & \\
\hline CHEMBL1726266 & 809361 & 5.6737 & 5.7256 & TRN & \\
\hline CHEMBL1716834 & 809361 & 5.0074 & 5.3246 & TST & \\
\hline CHEMBL1502704 & 809361 & 5.032 & 5.4893 & TRN & \\
\hline CHEMBL1370024 & 809361 & 5.7447 & 5.3935 & TRN & \\
\hline CHEMBL1966062 & 809361 & 7.585 & 6.1482 & TST & \\
\hline CHEMBL1571123 & 809361 & 5.466 & 5.664 & TRN & \\
\hline CHEMBL1880232 & 809361 & 5.1669 & 5.4717 & TRN & \\
\hline CHEMBL1433979 & 809361 & 5.1331 & 5.2463 & TRN & \\
\hline CHEMBL1519450 & 809361 & 5.8697 & 6.1735 & TRN & \\
\hline CHEMBL1905195 & 809361 & 4.8105 & 5.2083 & TST & \\
\hline CHEMBL1886629 & 809361 & 4.9698 & 5.3129 & TST & \\
\hline CHEMBL1324082 & 809361 & 5.7235 & 5.4574 & TST & \\
\hline CHEMBL1554511 & 809361 & 3.1549 & 5.444 & TRN & \\
\hline CHEMBL1437030 & 809361 & 6.1605 & 5.4353 & TRN & \\
\hline CHEMBL1561231 & 809361 & 3.1549 & 5.3731 & TRN & \\
\hline CHEMBL1361883 & 809361 & 5.7932 & 5.461 & TRN & \\
\hline CHEMBL1461730 & 809361 & 5.9318 & 5.7285 & TST & \\
\hline CHEMBL1372292 & 809361 & 6.5834 & 5.7729 & TRN & \\
\hline CHEMBL1534781 & 809361 & 5.7375 & 5.9086 & TRN & \\
\hline CHEMBL1896316 & 809361 & 5.3487 & 5.4929 & TRN & \\
\hline
\end{tabular}




\begin{tabular}{|c|c|c|c|c|c|c|}
\hline & & \multicolumn{4}{|c|}{ Supplemental Table S2.txt } & \\
\hline CHEMBL1568022 & 809361 & \multicolumn{3}{|c|}{5.7620000000000005} & 5.7259 & TRN \\
\hline CHEMBL1716472 & 809361 & \multicolumn{3}{|c|}{5.752000000000001} & 5.4708 & TRN \\
\hline CHEMBL1501645 & 809361 & \multicolumn{3}{|c|}{5.327000000000001} & 5.3653 & TRN \\
\hline CHEMBL1983107 & 809361 & 5.2725 & 5.3059 & TRN & & \\
\hline CHEMBL1369965 & 809361 & 5.5498 & 5.4847 & TRN & & \\
\hline CHEMBL1447382 & 809361 & 6.3143 & 5.5819 & TRN & & \\
\hline CHEMBL1370126 & 809361 & 5.6716 & 5.5804 & TST & & \\
\hline CHEMBL1553481 & 809361 & 4.9714 & 5.4031 & TST & & \\
\hline CHEMBL1429108 & 809361 & 5.5058 & 5.2679 & TRN & & \\
\hline CHEMBL1331541 & 809361 & 6.3372 & 6.0346 & TRN & & \\
\hline CHEMBL1464261 & 809361 & 5.1018 & 5.4456 & TRN & & \\
\hline CHEMBL1393972 & 809361 & 5.9547 & 5.6679 & TST & & \\
\hline CHEMBL1834675 & 809361 & 5.3028 & 5.5652 & TST & & \\
\hline CHEMBL1343814 & 809361 & 4.9722 & 5.4231 & TRN & & \\
\hline CHEMBL1699020 & 809361 & 5.0164 & 5.1151 & TRN & & \\
\hline CHEMBL1600150 & 809361 & 5.4202 & 4.6915 & TRN & & \\
\hline CHEMBL1880495 & 809361 & 5.8928 & 5.4886 & TST & & \\
\hline CHEMBL1717328 & 809361 & 5.1979 & 5.3266 & TST & & \\
\hline CHEMBL1497024 & 809361 & 5.6402 & 5.4399 & TRN & & \\
\hline CHEMBL1550676 & 809361 & 5.4828 & 5.6177 & TRN & & \\
\hline CHEMBL1388951 & 809361 & 5.5143 & 5.3355 & TRN & & \\
\hline CHEMBL1339909 & 809361 & \multicolumn{3}{|c|}{5.718999999999999} & 5.5903 & TRN \\
\hline CHEMBL1305380 & 809361 & 5.1662 & 5.4762 & TRN & & \\
\hline CHEMBL1483562 & 809361 & 5.4522 & 5.4813 & TRN & & \\
\hline CHEMBL1455567 & 809361 & 5.6861 & 5.4536 & TST & & \\
\hline CHEMBL1529991 & 809361 & \multicolumn{3}{|c|}{5.718999999999999} & 5.4427 & TRN \\
\hline CHEMBL1531374 & 809361 & 3.1549 & 5.3161 & TST & & \\
\hline CHEMBL1526446 & 809361 & 5.5867 & 5.1921 & TRN & & \\
\hline CHEMBL1378716 & 809361 & 5.644 & 5.355 & TST & & \\
\hline CHEMBL1882159 & 809361 & 5.1986 & 5.4386 & TRN & & \\
\hline CHEMBL1406540 & 809361 & 5.5986 & 5.2841 & TRN & & \\
\hline CHEMBL1722002 & 809361 & 5.8794 & 5.6744 & TST & & \\
\hline CHEMBL1515132 & 809361 & 6.041 & 5.5265 & TST & & \\
\hline CHEMBL1873577 & 809361 & 5.1938 & 5.3379 & TRN & & \\
\hline CHEMBL1357873 & 809361 & 5.8633 & 5.5239 & TST & & \\
\hline CHEMBL453974 & 809361 & 5.1938 & 5.669 & TST & & \\
\hline CHEMBL1502771 & 809361 & 5.4895 & 5.3878 & TRN & & \\
\hline CHEMBL1421029 & 809361 & 5.9508 & 5.5791 & TRN & & \\
\hline CHEMBL1438737 & 809361 & 5.4881 & 5.4425 & TST & & \\
\hline CHEMBL1312371 & 809361 & 5.5157 & 5.3139 & TRN & & \\
\hline CHEMBL1698464 & 809361 & 5.7328 & 6.2978 & TRN & & \\
\hline CHEMBL1469929 & 809361 & 5.5638 & 5.5297 & TRN & & \\
\hline CHEMBL1533399 & 809361 & 5.6778 & 5.5645 & TRN & & \\
\hline CHEMBL1730189 & 809361 & 5.4597 & 5.2199 & TRN & & \\
\hline CHEMBL1388140 & 809361 & 4.9462 & 5.3692 & TRN & & \\
\hline CHEMBL1609391 & 809361 & 5.0223 & 5.5414 & TRN & & \\
\hline CHEMBL1730238 & 809361 & 6.3372 & 5.5508 & TST & & \\
\hline CHEMBL1483252 & 809361 & 5.2565 & 5.7965 & TRN & & \\
\hline
\end{tabular}




\begin{tabular}{|c|c|c|c|c|c|c|}
\hline & & \multicolumn{5}{|c|}{ Supplemental Table S2.txt } \\
\hline CHEMBL1453555 & 809361 & 5.5834 & 5.4716 & TRN & & \\
\hline CHEMBL1369137 & 809361 & 5.6073 & 5.4875 & TST & & \\
\hline CHEMBL1367089 & 809361 & 5.1118 & 5.2201 & TST & & \\
\hline CHEMBL1573534 & 809361 & 5.1959 & 5.2936 & TST & & \\
\hline CHEMBL1972072 & 809361 & 5.4584 & 5.6275 & TRN & & \\
\hline CHEMBL1608757 & 809361 & 4.8033 & 5.4101 & TST & & \\
\hline CHEMBL1567488 & 809361 & 5.38399 & 99999999 & 995 & 5.3205 & TRN \\
\hline CHEMBL1313502 & 809361 & 6.0501 & 5.7254 & TRN & & \\
\hline CHEMBL1904199 & 809361 & 4.6745 & 5.5276 & TST & & \\
\hline CHEMBL1612227 & 809361 & 5.4921 & 5.5291 & TST & & \\
\hline CHEMBL1419529 & 809361 & 5.091 & 5.2227 & TRN & & \\
\hline CHEMBL1423935 & 809361 & 5.7212 & 5.7362 & TRN & & \\
\hline CHEMBL1400084 & 809361 & 3.1549 & 5.3145 & TRN & & \\
\hline CHEMBL1387307 & 809361 & 5.2636 & 5.4439 & TRN & & \\
\hline CHEMBL1360862 & 809361 & 5.4214 & 5.3382 & TRN & & \\
\hline CHEMBL1497797 & 809361 & 5.699 & 5.4062 & TST & & \\
\hline CHEMBL1894067 & 809361 & 5.0209 & 5.2959 & TRN & & \\
\hline CHEMBL590927 & 809361 & 5.9281 & 6.2506 & TRN & & \\
\hline CHEMBL1583441 & 809361 & 5.5867 & 5.4356 & TST & & \\
\hline CHEMBL1328510 & 809361 & 5.6968 & 5.8626 & TRN & & \\
\hline CHEMBL1304647 & 809361 & 5.3468 & 5.6512 & TRN & & \\
\hline CHEMBL1387462 & 809361 & 5.8928 & 5.3531 & TRN & & \\
\hline CHEMBL1901445 & 809361 & 5.1373 & 5.5789 & TRN & & \\
\hline CHEMBL543876 & 809361 & 5.2097 & 5.3376 & TST & & \\
\hline CHEMBL1580472 & 809361 & 5.3458 & 5.5164 & TRN & & \\
\hline CHEMBL1412002 & 809361 & 6.0088 & 5.4962 & TRN & & \\
\hline CHEMBL1472681 & 809361 & 5.4522 & 5.3362 & TRN & & \\
\hline CHEMBL1572468 & 809361 & 6.067 & 5.6071 & TRN & & \\
\hline CHEMBL1584502 & 809361 & 5.5528 & 5.4888 & TRN & & \\
\hline CHEMBL1564737 & 809361 & 5.426 & 5.5948 & TRN & & \\
\hline CHEMBL1903229 & 809361 & 4.5906 & 5.506 & TST & & \\
\hline CHEMBL1299470 & 809361 & 5.3788 & 5.5587 & TRN & & \\
\hline CHEMBL1723391 & 809361 & 5.7986 & 5.3267 & TRN & & \\
\hline CHEMBL1316828 & 809361 & 5.3335 & 5.4598 & TST & & \\
\hline CHEMBL1531933 & 809361 & 5.2055 & 5.595 & TRN & & \\
\hline CHEMBL1550670 & 809361 & 5.6778 & 5.5727 & TRN & & \\
\hline CHEMBL1454819 & 809361 & 5.1884 & 5.3181 & TRN & & \\
\hline CHEMBL1330307 & 809361 & 5.3605 & 6.0828 & TRN & & \\
\hline CHEMBL1560784 & 809361 & 5.1701 & 5.3099 & TRN & & \\
\hline CHEMBL1341970 & 809361 & 5.4572 & 5.2373 & TRN & & \\
\hline CHEMBL592600 & 809361 & 6.2774 & 6.4873 & TRN & & \\
\hline CHEMBL1449794 & 809361 & 5.9101 & 5.4386 & TRN & & \\
\hline CHEMBL1352969 & 809361 & 5.2874 & 5.4572 & TRN & & \\
\hline CHEMBL1312275 & 809361 & 5.3645 & 5.7548 & TRN & & \\
\hline CHEMBL530499 & 809361 & 5.5003 & 6.1974 & TRN & & \\
\hline CHEMBL1342821 & 809361 & 5.8013 & 5.3976 & TRN & & \\
\hline CHEMBL1543473 & 809361 & 5.7959 & 5.6207 & TRN & & \\
\hline CHEMBL1428095 & 809361 & 6.1118 & 5.8424 & TRN & & \\
\hline
\end{tabular}




\begin{tabular}{|c|c|c|c|c|c|c|}
\hline & & \multicolumn{5}{|c|}{ Supplemental Table S2.txt } \\
\hline CHEMBL606532 & 809361 & 5.7258 & 6.2216 & TRN & & \\
\hline CHEMBL1705928 & 809361 & 5.61799 & 99999999 & 99 & 5.5577 & TRN \\
\hline CHEMBL1422668 & 809361 & 4.6126 & 5.5243 & TRN & & \\
\hline CHEMBL1500469 & 809361 & 5.7447 & 5.9891 & TRN & & \\
\hline CHEMBL1449499 & 809361 & 5.2526 & 5.0641 & TRN & & \\
\hline CHEMBL1458479 & 809361 & 5.4789 & 5.6737 & TRN & & \\
\hline CHEMBL1505475 & 809361 & 5.1831 & 5.5124 & TRN & & \\
\hline CHEMBL601614 & 809361 & 7.585 & 5.9979 & TST & & \\
\hline CHEMBL1423564 & 809361 & 5.7375 & 5.5793 & TST & & \\
\hline CHEMBL1305642 & 809361 & 5.3969 & 5.477 & TRN & & \\
\hline CHEMBL1565115 & 809361 & 6.4815 & 5.7982 & TRN & & \\
\hline CHEMBL1354582 & 809361 & 5.8601 & 5.4496 & TRN & & \\
\hline CHEMBL1358740 & 809361 & 5.0964 & 5.5442 & TST & & \\
\hline CHEMBL1408604 & 809361 & 5.4437 & 5.6863 & TRN & & \\
\hline CHEMBL1409423 & 809361 & 5.8041 & 5.5528 & TRN & & \\
\hline CHEMBL604361 & 809361 & 4.5667 & 5.3316 & TRN & & \\
\hline CHEMBL1732831 & 809361 & 6.0 & 5.4937 & TST & & \\
\hline CHEMBL1337862 & 809361 & 5.6498 & 5.2869 & TRN & & \\
\hline CHEMBL1425438 & 809361 & 5.9788 & 5.4821 & TRN & & \\
\hline CHEMBL1375849 & 809361 & 4.4442 & 5.4018 & TST & & \\
\hline CHEMBL1429289 & 809361 & 5.8697 & 5.4571 & TST & & \\
\hline CHEMBL1335944 & 809361 & 4.8918 & 5.2577 & TRN & & \\
\hline CHEMBL1603001 & 809361 & 7.585 & 6.4406 & TRN & & \\
\hline CHEMBL1317160 & 809361 & 5.2882 & 5.5778 & TST & & \\
\hline CHEMBL1722145 & 809361 & 4.9646 & 5.3308 & TRN & & \\
\hline CHEMBL1867903 & 809361 & 5.8013 & 5.5684 & TRN & & \\
\hline CHEMBL1512670 & 809361 & 6.0259 & 5.989 & TRN & & \\
\hline CHEMBL1502550 & 809361 & 5.3556 & 5.4003 & TST & & \\
\hline CHEMBL1308996 & 809361 & 5.3778 & 5.1922 & TRN & & \\
\hline CHEMBL1532068 & 809361 & 5.9245 & 6.0384 & TRN & & \\
\hline CHEMBL1575588 & 809361 & 5.8827 & 5.9169 & TRN & & \\
\hline CHEMBL1503190 & 809361 & 5.1798 & 5.6051 & TST & & \\
\hline CHEMBL1496993 & 809361 & 5.7375 & 5.5439 & TRN & & \\
\hline CHEMBL1385296 & 809361 & 5.4647 & 5.431 & TRN & & \\
\hline CHEMBL1546843 & 809361 & 5.9469 & 5.4268 & TRN & & \\
\hline CHEMBL 2002411 & 809361 & 5.4522 & 5.4365 & TRN & & \\
\hline CHEMBL1463077 & 809361 & 5.4306 & 5.7264 & TRN & & \\
\hline CHEMBL1507537 & 809361 & 5.4737 & 5.4227 & TRN & & \\
\hline CHEMBL120734 & 809361 & 5.8761 & 5.6678 & TRN & & \\
\hline CHEMBL1715327 & 809361 & 4.9337 & 5.3292 & TRN & & \\
\hline CHEMBL1424665 & 809361 & 5.7011 & 6.0232 & TRN & & \\
\hline CHEMBL1340458 & 809361 & 5.2899 & 5.2768 & TRN & & \\
\hline CHEMBL1472321 & 809361 & 4.5685 & 5.4956 & TST & & \\
\hline CHEMBL1341270 & 809361 & 5.8327 & 5.9401 & TST & & \\
\hline CHEMBL1556277 & 809361 & 5.2358 & 6.0539 & TRN & & \\
\hline CHEMBL1352525 & 809361 & 5.61799 & 99999999 & 99 & 5.5062 & TRN \\
\hline CHEMBL1872338 & 809361 & 5.5258 & 5.3305 & TRN & & \\
\hline CHEMBL1473791 & 809361 & 5.5498 & 5.6287 & TRN & & \\
\hline
\end{tabular}


Supplemental Table S2.txt

\begin{tabular}{|c|c|c|c|c|c|}
\hline CHEMBL1343705 & 809361 & 5.3665 & 5.6569 & TRN & \\
\hline CHEMBL1601129 & 809361 & 5.2055 & 5.261 & TRN & \\
\hline CHEMBL1546607 & 809361 & 5.6308 & 5.3215 & TRN & \\
\hline CHEMBL1351099 & 809361 & 5.2336 & 5.4799 & TST & \\
\hline CHEMBL1606613 & 809361 & 5.3915 & 5.4388 & TRN & \\
\hline CHEMBL1387479 & 809361 & 5.4271 & 5.5098 & TRN & \\
\hline CHEMBL472437 & 809361 & 5.8894 & 5.6239 & TST & \\
\hline CHEMBL1470761 & 809361 & 4.2806 & 5.405 & TRN & \\
\hline CHEMBL1590136 & 809361 & 4.1817 & 5.2437 & TST & \\
\hline CHEMBL1531219 & 809361 & 4.6968 & 5.3421 & TRN & \\
\hline CHEMBL1492912 & 809361 & 5.7799 & 5.1937 & TRN & \\
\hline CHEMBL1447263 & 809361 & 4.9825 & 5.4938 & TRN & \\
\hline CHEMBL1439019 & 809361 & 4.4909 & 5.2816 & TRN & \\
\hline CHEMBL1321240 & 809361 & 5.2636 & 5.5989 & TRN & \\
\hline CHEMBL1568897 & 809361 & 5.7905 & 5.4677 & TRN & \\
\hline CHEMBL1317135 & 809361 & 5.7375 & 5.5409 & TST & \\
\hline CHEMBL1524267 & 809361 & 5.3595 & 5.5373 & TRN & \\
\hline CHEMBL1522827 & 809361 & 5.9957 & 5.82700 & 0000000001 & TRN \\
\hline CHEMBL1550749 & 809361 & 4.4662 & 5.4215 & TRN & \\
\hline CHEMBL1863767 & 809361 & 5.4034 & 5.4561 & TRN & \\
\hline CHEMBL1526539 & 809361 & 5.8327 & 5.5314 & TST & \\
\hline CHEMBL1369099 & 809361 & 5.3516 & 5.2313 & TRN & \\
\hline CHEMBL1361493 & 809361 & 5.1746 & 5.4183 & TRN & \\
\hline CHEMBL1699532 & 809361 & 5.0066 & 5.34399 & 9999999999 & TRN \\
\hline CHEMBL601768 & 809361 & 6.0283 & 6.2719 & TRN & \\
\hline CHEMBL1329798 & 809361 & 5.983 & 5.3566 & TRN & \\
\hline CHEMBL1329129 & 809361 & 5.6326 & 5.8661 & TRN & \\
\hline CHEMBL1543453 & 809361 & 5.5143 & 5.3313 & TRN & \\
\hline CHEMBL1524438 & 809361 & 5.426 & 5.5318 & TRN & \\
\hline CHEMBL1332956 & 809361 & 5.1415 & 5.3956 & TST & \\
\hline CHEMBL1431651 & 809361 & 4.765 & 5.3663 & TRN & \\
\hline CHEMBL1325594 & 809361 & 5.3019 & 5.2813 & TRN & \\
\hline CHEMBL1993539 & 809361 & 5.0883 & 5.5953 & TST & \\
\hline CHEMBL1573994 & 809361 & 7.585 & 5.7036 & TST & \\
\hline CHEMBL1441749 & 809361 & 5.3429 & 5.2837 & TRN & \\
\hline CHEMBL1384414 & 809361 & 5.301 & 5.1217 & TRN & \\
\hline CHEMBL1500686 & 809361 & 5.2628 & 5.3498 & TRN & \\
\hline CHEMBL1701330 & 809361 & 5.6198 & 5.3181 & TRN & \\
\hline CHEMBL1889303 & 809361 & 5.2226 & 5.6588 & TST & \\
\hline CHEMBL1728992 & 809361 & 6.0625 & 5.6056 & TST & \\
\hline CHEMBL1602962 & 809361 & 5.5498 & 5.6262 & TRN & \\
\hline CHEMBL1444764 & 809361 & 5.8239 & 5.71299 & 9999999999 & TRN \\
\hline CHEMBL1566084 & 809361 & 5.317 & 5.8928 & TRN & \\
\hline CHEMBL1718231 & 809361 & 5.5867 & 5.5437 & TRN & \\
\hline CHEMBL1707874 & 809361 & 5.5031 & 4.6708 & TRN & \\
\hline CHEMBL1724428 & 809361 & 7.585 & 6.5001 & TST & \\
\hline CHEMBL1721226 & 809361 & 7.585 & 5.8227 & TST & \\
\hline CHEMBL579919 & 809361 & 5.4353 & 5.4765 & TRN & \\
\hline
\end{tabular}


Supplemental Table S2.txt

\begin{tabular}{|c|c|c|c|c|c|}
\hline CHEMBL1314757 & 809361 & 5.4962 & 5.4252 & TRN & \\
\hline CHEMBL1731138 & 809361 & 5.3526 & 5.434 & TST & \\
\hline CHEMBL1413424 & 809361 & 5.9281 & 5.8821 & TRN & \\
\hline CHEMBL1605758 & 809361 & 5.3307 & 5.2625 & TST & \\
\hline CHEMBL1587722 & 809361 & 5.3116 & 5.6181 & TRN & \\
\hline CHEMBL1607286 & 809361 & 4.9602 & 5.439 & TRN & \\
\hline CHEMBL1566610 & 809361 & 6.5346 & 6.4968 & TST & \\
\hline CHEMBL1371706 & 809361 & 6.1226 & 5.9596 & TRN & \\
\hline CHEMBL1540688 & 809361 & 4.8877 & 5.6147 & TST & \\
\hline CHEMBL1629966 & 809361 & 5.58 & 5.6632 & TRN & \\
\hline CHEMBL1366319 & 809361 & 5.5884 & 5.832999 & э999999999 & TRN \\
\hline CHEMBL1310852 & 809361 & 5.3737 & 5.3011 & TRN & \\
\hline CHEMBL1476734 & 809361 & 6.1884 & 5.1273 & TRN & \\
\hline CHEMBL591876 & 809361 & 6.1605 & 6.2445 & TRN & \\
\hline CHEMBL1570879 & 809361 & 5.1415 & 5.3432 & TRN & \\
\hline CHEMBL1712981 & 809361 & 4.3019 & 5.2185 & TST & \\
\hline CHEMBL1461392 & 809361 & 5.1952 & 5.3922 & TRN & \\
\hline CHEMBL1458016 & 809361 & 5.6198 & 5.3838 & TRN & \\
\hline CHEMBL1730045 & 809361 & 7.585 & 5.2475 & TST & \\
\hline CHEMBL1331836 & 809361 & 5.2426 & 5.157 & TST & \\
\hline CHEMBL1329725 & 809361 & 5.3947 & 5.2775 & TRN & \\
\hline CHEMBL1717596 & 809361 & 5.6253 & 5.4875 & TRN & \\
\hline CHEMBL1703043 & 809361 & 7.585 & 5.3835 & TRN & \\
\hline CHEMBL300389 & 809361 & 7.585 & 6.1359 & TRN & \\
\hline CHEMBL1407961 & 809361 & 6.4672 & 5.797000 & 0000000001 & TRN \\
\hline CHEMBL580955 & 809361 & 6.3279 & 6.3721 & TRN & \\
\hline CHEMBL1540682 & 809361 & 7.585 & 5.9536 & TST & \\
\hline CHEMBL1308223 & 809361 & 6.0462 & 5.6269 & TRN & \\
\hline CHEMBL1406419 & 809361 & 5.4056 & 5.377999 & 9999999999 & TRN \\
\hline CHEMBL1425718 & 809361 & 5.475 & 5.2859 & TRN & \\
\hline CHEMBL1526851 & 809361 & 5.295 & 5.3963 & TRN & \\
\hline CHEMBL1324027 & 809361 & 5.7799 & 5.5703 & TRN & \\
\hline CHEMBL1713163 & 809361 & 5.6676 & 5.5325 & TRN & \\
\hline CHEMBL1300171 & 809361 & 5.3054 & 5.4424 & TRN & \\
\hline CHEMBL1323821 & 809361 & 4.9237 & 5.6944 & TRN & \\
\hline CHEMBL1328473 & 809361 & 5.3261 & 5.5138 & TRN & \\
\hline CHEMBL1901126 & 809361 & 5.3925 & 5.5544 & TST & \\
\hline CHEMBL1871319 & 809361 & 5.251 & 5.4012 & TRN & \\
\hline CHEMBL1473160 & 809361 & 5.4989 & 5.3248 & TRN & \\
\hline CHEMBL1555876 & 809361 & 5.2848 & 6.0706 & TRN & \\
\hline CHEMBL1876267 & 809361 & 5.9101 & 5.1672 & TRN & \\
\hline CHEMBL1610300 & 809361 & 6.2299 & 5.7442 & TST & \\
\hline CHEMBL1501755 & 809361 & 5.3536 & 5.1188 & TRN & \\
\hline CHEMBL1422962 & 809361 & 6.0531 & 5.8414 & TST & \\
\hline CHEMBL1416171 & 809361 & 6.21399 & 999999999 & 5.4243 & TRN \\
\hline CHEMBL1491279 & 809361 & 5.3893 & 5.5356 & TRN & \\
\hline CHEMBL1504077 & 809361 & 5.4711 & 5.6049 & TRN & \\
\hline CHEMBL1369262 & 809361 & 6.0353 & 5.8321 & TST & \\
\hline
\end{tabular}




\begin{tabular}{|c|c|c|c|c|c|c|}
\hline & & \multicolumn{5}{|c|}{ Supplemental Table S2.txt } \\
\hline CHEMBL1338958 & 809361 & 5.2388 & 5.3436 & TRN & & \\
\hline CHEMBL590665 & 809361 & 6.1739 & 6.0861 & TRN & & \\
\hline CHEMBL1570080 & 809361 & 5.5719 & 5.8317 & TRN & & \\
\hline CHEMBL268584 & 809361 & 5.4724 & 5.4709 & TRN & & \\
\hline CHEMBL 2002430 & 809361 & 6.1979 & 5.7151 & TST & & \\
\hline CHEMBL1423192 & 809361 & 5.3757 & 5.7129 & TRN & & \\
\hline CHEMBL1334638 & 809361 & 5.6421 & 5.4295 & TRN & & \\
\hline CHEMBL1326083 & 809361 & 5.4425 & 5.8772 & TRN & & \\
\hline CHEMBL1492214 & 809361 & 4.4531 & 5.2712 & TRN & & \\
\hline CHEMBL1398891 & 809361 & 4.5678 & 5.2563 & TRN & & \\
\hline CHEMBL1548492 & 809361 & 6.0381 & 6.1141 & TRN & & \\
\hline CHEMBL1728514 & 809361 & 5.6536 & 5.6347 & TST & & \\
\hline CHEMBL1535665 & 809361 & 6.0367 & 5.7231 & TRN & & \\
\hline CHEMBL1412039 & 809361 & 5.3546 & 5.528 & TRN & & \\
\hline CHEMBL1507490 & 809361 & 5.6882 & 5.7992 & TRN & & \\
\hline CHEMBL1893871 & 809361 & 4.5632 & 5.4801 & TST & & \\
\hline CHEMBL1300908 & 809361 & 5.0429 & 5.2453 & TRN & & \\
\hline CHEMBL1422217 & 809361 & 5.6091 & 5.5902 & TRN & & \\
\hline CHEMBL1506738 & 809361 & $5.8210 e$ & 30000000 & $\partial 1$ & 5.1865 & TRN \\
\hline CHEMBL1724993 & 809361 & 4.8428 & 5.4384 & TRN & & \\
\hline CHEMBL1567592 & 809361 & 5.7328 & 5.7362 & TRN & & \\
\hline CHEMBL1382368 & 809361 & 5.2565 & 5.1553 & TRN & & \\
\hline CHEMBL1363219 & 809361 & 5.4202 & 5.7642 & TRN & & \\
\hline CHEMBL1486664 & 809361 & 5.3072 & 5.3092 & TRN & & \\
\hline CHEMBL1449912 & 809361 & 5.5287 & 5.6017 & TRN & & \\
\hline CHEMBL1448732 & 809361 & 5.2604 & 5.6026 & TRN & & \\
\hline CHEMBL600862 & 809361 & 5.9508 & 6.2829 & TRN & & \\
\hline CHEMBL1524449 & 809361 & 5.4089 & 5.2677 & TRN & & \\
\hline CHEMBL1733422 & 809361 & 5.6383 & 5.6354 & TRN & & \\
\hline CHEMBL1538692 & 809361 & 6.3316 & 5.8203 & TRN & & \\
\hline CHEMBL1503651 & 809361 & 6.0357 & 5.7582 & TST & & \\
\hline CHEMBL1309391 & 809361 & 5.8894 & 5.9202 & TST & & \\
\hline CHEMBL 309474 & 809361 & 5.5735 & 5.5652 & TST & & \\
\hline CHEMBL1543907 & 809361 & 5.2848 & 5.5703 & TRN & & \\
\hline CHEMBL1424801 & 809361 & 5.2218 & 5.4003 & TRN & & \\
\hline CHEMBL1345388 & 809361 & 5.4989 & 5.7014 & TRN & & \\
\hline CHEMBL 2007530 & 809361 & 4.1934 & 5.1454 & TRN & & \\
\hline CHEMBL1889367 & 809361 & 5.6421 & 6.0064 & TRN & & \\
\hline CHEMBL 2000067 & 809361 & 3.1549 & 5.2925 & TST & & \\
\hline CHEMBL1369945 & 809361 & 5.8665 & 5.2956 & TRN & & \\
\hline CHEMBL433680 & 809361 & 7.585 & 7.143 & TST & & \\
\hline CHEMBL1897229 & 809361 & 5.4168 & 5.3471 & TRN & & \\
\hline CHEMBL1330524 & 809361 & 5.5129 & 5.5314 & TRN & & \\
\hline CHEMBL1513651 & 809361 & 5.4067 & 5.2768 & TRN & & \\
\hline CHEMBL1329971 & 809361 & 5.4123 & 5.2985 & TRN & & \\
\hline CHEMBL1612880 & 809361 & 5.0487 & 5.3827 & TRN & & \\
\hline CHEMBL1461774 & 809361 & 5.4841 & 5.4385 & TST & & \\
\hline CHEMBL578929 & 809361 & 7.585 & 6.12 & TST & & \\
\hline
\end{tabular}




\begin{tabular}{|c|c|c|c|c|c|c|}
\hline & & \multicolumn{5}{|c|}{ Supplemental Table S2.txt } \\
\hline CHEMBL1547940 & 809361 & 5.289 & 5.1731 & TRN & & \\
\hline CHEMBL1458376 & 809361 & 5.6861 & 5.5162 & TRN & & \\
\hline CHEMBL1484231 & 809361 & 5.4789 & 5.6967 & TST & & \\
\hline CHEMBL1541840 & 809361 & 5.1824 & 5.3911 & TRN & & \\
\hline CHEMBL1984723 & 809361 & 5.7747 & 5.5172 & TST & & \\
\hline CHEMBL493153 & 809361 & 6.2588 & 5.8679 & TRN & & \\
\hline CHEMBL1547430 & 809361 & 5.301 & 5.3943 & TRN & & \\
\hline CHEMBL1447442 & 809361 & 5.7825 & 5.5975 & TRN & & \\
\hline CHEMBL1361913 & 809361 & 4.7781 & 5.4322 & TRN & & \\
\hline CHEMBL1888851 & 809361 & 5.3487 & 5.2846 & TRN & & \\
\hline CHEMBL1457279 & 809361 & 3.1549 & 4.7756 & TRN & & \\
\hline CHEMBL1580083 & 809361 & 5.567 & 5.2913 & TRN & & \\
\hline CHEMBL1307349 & 809361 & 5.3072 & 4.7313 & TST & & \\
\hline CHEMBL1431684 & 809361 & 4.9727 & 5.4192 & TRN & & \\
\hline CHEMBL1456092 & 809361 & 5.1931 & 5.3866 & TRN & & \\
\hline CHEMBL1428415 & 809361 & 6.2503 & 5.7513 & TRN & & \\
\hline CHEMBL1341999 & 809361 & 5.4123 & 5.3949 & TRN & & \\
\hline CHEMBL1574080 & 809361 & 5.8327 & 5.8951 & TRN & & \\
\hline CHEMBL1571157 & 809361 & 5.5591 & 5.5626 & TRN & & \\
\hline CHEMBL1326110 & 809361 & 5.4486 & 5.5412 & TRN & & \\
\hline CHEMBL47940 & 809361 & 6.1818 & 5.0779 & TST & & \\
\hline CHEMBL1985527 & 809361 & 6.4425 & 5.6689 & TST & & \\
\hline CHEMBL1324564 & 809361 & 4.8687 & 5.2521 & TST & & \\
\hline CHEMBL1901877 & 809361 & 5.1818 & 5.4233 & TRN & & \\
\hline CHEMBL1332454 & 809361 & 6.2993 & 5.8647 & TRN & & \\
\hline CHEMBL1452671 & 809361 & 5.3969 & 5.3613 & TRN & & \\
\hline CHEMBL 1877386 & 809361 & 5.5157 & 5.6523 & TRN & & \\
\hline CHEMBL1712491 & 809361 & $5.7570 e$ & 0000000 & $\partial 1$ & 5.5783 & TRN \\
\hline CHEMBL1594828 & 809361 & 4.9948 & 5.2209 & TRN & & \\
\hline CHEMBL1891071 & 809361 & 5.7328 & 5.3563 & TRN & & \\
\hline CHEMBL1518077 & 809361 & 6.2774 & 5.6293 & TRN & & \\
\hline CHEMBL1396345 & 809361 & 5.5834 & 5.4797 & TRN & & \\
\hline CHEMBL1393568 & 809361 & 5.8097 & 5.3302 & TRN & & \\
\hline CHEMBL1721451 & 809361 & 6.3298 & 5.7082 & TST & & \\
\hline CHEMBL1531670 & 809361 & 5.4248 & 5.3793 & TST & & \\
\hline CHEMBL1613695 & 809361 & 5.6968 & 5.4337 & TRN & & \\
\hline CHEMBL 1725584 & 809361 & 6.3686 & 5.6795 & TST & & \\
\hline CHEMBL3392492 & 809361 & 5.8539 & 5.506 & TRN & & \\
\hline CHEMBL1435226 & 809361 & 5.8477 & 5.899 & TRN & & \\
\hline CHEMBL1312239 & 809361 & 4.7435 & 5.3859 & TRN & & \\
\hline CHEMBL1510332 & 809361 & 5.8097 & 5.9533 & TRN & & \\
\hline CHEMBL1535546 & 809361 & 5.2832 & 5.5995 & TRN & & \\
\hline CHEMBL1424420 & 809361 & 5.5952 & 4.9023 & TRN & & \\
\hline CHEMBL1450616 & 809361 & 5.0691 & 5.5039 & TRN & & \\
\hline CHEMBL1393773 & 809361 & 5.5031 & 5.4374 & TRN & & \\
\hline CHEMBL1493490 & 809361 & 5.7212 & 5.8986 & TRN & & \\
\hline CHEMBL585827 & 809361 & 5.6289 & 6.2904 & TRN & & \\
\hline CHEMBL1510371 & 809361 & 5.6253 & 5.5947 & TST & & \\
\hline
\end{tabular}




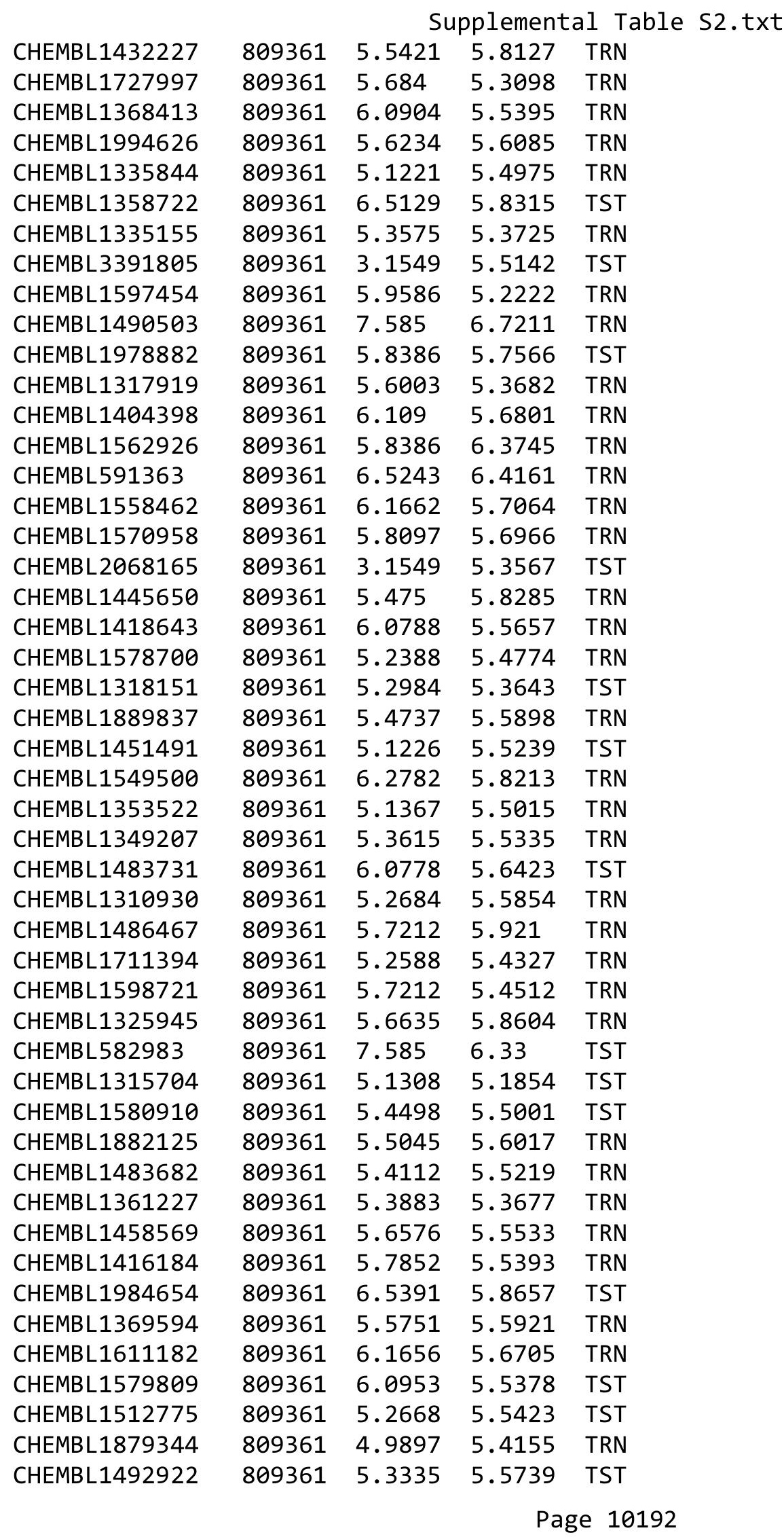


Supplemental Table S2.txt

\begin{tabular}{|c|c|c|c|c|c|}
\hline CHEMBL1344491 & 809361 & 5.5935 & 5.1658 & TRN & \\
\hline CHEMBL1863734 & 809361 & 5.1073 & 5.4642 & TRN & \\
\hline CHEMBL1438624 & 809361 & 5.5361 & 5.4169 & TRN & \\
\hline CHEMBL1570379 & 809361 & 5.8182 & 5.5664 & TRN & \\
\hline CHEMBL1519289 & 809361 & 6.0706 & 5.4168 & TRN & \\
\hline CHEMBL582444 & 809361 & 5.4045 & 5.3786 & TST & \\
\hline CHEMBL1468750 & 809361 & 6.2426 & 5.5563 & TRN & \\
\hline CHEMBL1527986 & 809361 & 6.1203 & 5.7773 & TRN & \\
\hline CHEMBL1718295 & 809361 & 4.6176 & 5.3376 & TRN & \\
\hline CHEMBL1301371 & 809361 & 5.5751 & 5.6325 & TRN & \\
\hline CHEMBL1998498 & 809361 & 5.2062 & 4.7846 & TRN & \\
\hline CHEMBL1606291 & 809361 & 5.7595 & 6.1253 & TRN & \\
\hline CHEMBL1605956 & 809361 & 5.6345 & 5.3892 & TRN & \\
\hline CHEMBL1525735 & 809361 & 5.5482 & 5.7135 & TRN & \\
\hline CHEMBL580340 & 809361 & 5.6882 & \multicolumn{2}{|c|}{5.577999999999999} & TRN \\
\hline CHEMBL1417970 & 809361 & 5.7496 & 5.5813 & TRN & \\
\hline CHEMBL1709472 & 809361 & 5.0278 & 5.4385 & TST & \\
\hline CHEMBL1458873 & 809361 & 5.6536 & 5.3731 & TST & \\
\hline CHEMBL1587117 & 809361 & 6.1878 & 5.4243 & TRN & \\
\hline CHEMBL1438200 & 809361 & 5.5884 & 5.5813 & TRN & \\
\hline CHEMBL1361046 & 809361 & 7.585 & 6.0718 & TRN & \\
\hline CHEMBL1606066 & 809361 & 5.5918 & 5.5844 & TRN & \\
\hline CHEMBL1609580 & 809361 & 5.6635 & 5.314 & TRN & \\
\hline CHEMBL1898348 & 809361 & 5.5171 & 5.5862 & TRN & \\
\hline CHEMBL1347090 & 809361 & 5.4342 & 5.5092 & TRN & \\
\hline CHEMBL2004475 & 809361 & 5.1911 & 5.5468 & TST & \\
\hline CHEMBL600778 & 809361 & 6.3325 & \multicolumn{2}{|c|}{6.4079999999999995} & TRN \\
\hline CHEMBL1537642 & 809361 & 5.5935 & 5.4644 & TRN & \\
\hline CHEMBL1523841 & 809361 & 6.2708 & 5.2256 & TST & \\
\hline CHEMBL1700729 & 809361 & 5.317 & 5.4709 & TST & \\
\hline CHEMBL1459468 & 809361 & 6.0615 & 5.8769 & TRN & \\
\hline CHEMBL1708906 & 809361 & 5.2007 & 5.3137 & TRN & \\
\hline CHEMBL1893162 & 809361 & 5.3809 & 5.4226 & TRN & \\
\hline CHEMBL1352748 & 809361 & 5.4225 & 5.1727 & TRN & \\
\hline CHEMBL1305455 & 809361 & 5.6778 & \multicolumn{2}{|c|}{5.5329999999999995} & TRN \\
\hline CHEMBL1456780 & 809361 & 6.1549 & 5.3456 & TRN & \\
\hline CHEMBL1474553 & 809361 & 5.0329 & 5.7353 & TRN & \\
\hline CHEMBL1401779 & 809361 & 6.2857 & 5.2576 & TRN & \\
\hline CHEMBL1493843 & 809361 & 4.9598 & 5.4214 & TST & \\
\hline CHEMBL1450921 & 809361 & 5.6968 & 5.7909 & TRN & \\
\hline CHEMBL1724645 & 809361 & 6.0106 & 5.7961 & TST & \\
\hline CHEMBL1439210 & 809361 & 5.6253 & 5.6098 & TRN & \\
\hline CHEMBL272945 & 809361 & 5.9914 & 5.3821 & TRN & \\
\hline CHEMBL1491847 & 809361 & 5.2588 & 5.4794 & TST & \\
\hline CHEMBL1470373 & 809361 & 5.2807 & 5.1507 & TST & \\
\hline CHEMBL1504035 & 809361 & 5.2857 & 5.2756 & TRN & \\
\hline CHEMBL1310617 & 809361 & 5.5834 & 5.8991 & TRN & \\
\hline CHEMBL1608247 & 809361 & 5.7055 & 5.5722 & TRN & \\
\hline
\end{tabular}




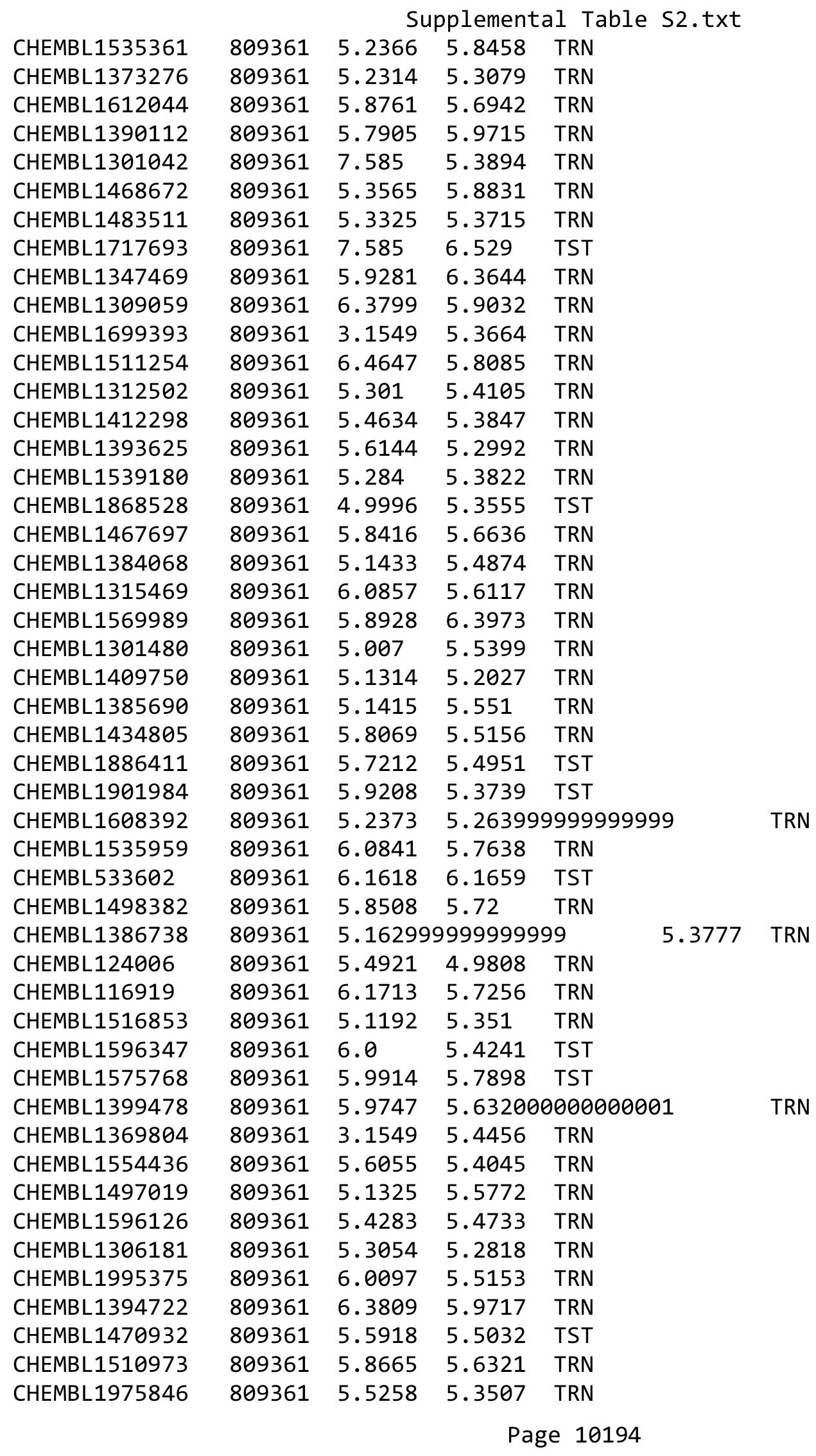




\begin{tabular}{|c|c|c|c|c|c|c|}
\hline & & \multicolumn{5}{|c|}{ Supplemental Table S2.txt } \\
\hline CHEMBL1337614 & 809361 & 5.3382 & 5.7497 & TRN & & \\
\hline CHEMBL1511215 & 809361 & 5.7747 & 5.6341 & TRN & & \\
\hline CHEMBL1340089 & 809361 & 5.4828 & 5.5485 & TRN & & \\
\hline CHEMBL1484306 & 809361 & 5.6326 & 5.4369 & TRN & & \\
\hline CHEMBL1890126 & 809361 & 5.0491 & 5.2825 & TST & & \\
\hline CHEMBL1522618 & 809361 & 5.8729 & 5.6061 & TRN & & \\
\hline CHEMBL1499935 & 809361 & 5.399 & 5.4508 & TRN & & \\
\hline CHEMBL1721568 & 809361 & 5.3585 & 5.6432 & TRN & & \\
\hline CHEMBL578675 & 809361 & 5.5513 & 5.6959 & TRN & & \\
\hline CHEMBL585266 & 809361 & \multicolumn{3}{|c|}{5.757000000000001} & 6.0086 & TRN \\
\hline CHEMBL1551810 & 809361 & 4.6558 & 5.2791 & TST & & \\
\hline CHEMBL1865908 & 809361 & 5.0381 & 5.3414 & TST & & \\
\hline CHEMBL1514042 & 809361 & 5.4214 & 4.6728 & TRN & & \\
\hline CHEMBL1300295 & 809361 & 5.5686 & 5.2782 & TRN & & \\
\hline CHEMBL1714720 & 809361 & 5.4976 & 5.53799 & 9999999999 & & TRN \\
\hline CHEMBL1377352 & 809361 & 5.71 & 5.7107 & TRN & & \\
\hline CHEMBL1343711 & 809361 & 6.2175 & 5.5951 & TRN & & \\
\hline CHEMBL1555866 & 809361 & 5.4881 & 5.1955 & TRN & & \\
\hline CHEMBL1713029 & 809361 & 4.8633 & 5.3173 & TRN & & \\
\hline CHEMBL1368013 & 809361 & 5.7122 & 5.3342 & TRN & & \\
\hline CHEMBL1313241 & 809361 & 5.4283 & 5.3859 & TRN & & \\
\hline CHEMBL1563650 & 809361 & 6.2604 & 5.8032 & TRN & & \\
\hline CHEMBL1534503 & 809361 & 5.5768 & 5.4142 & TRN & & \\
\hline CHEMBL1585527 & 809361 & 5.2388 & 5.7709 & TRN & & \\
\hline CHEMBL581152 & 809361 & 5.2644 & 5.4178 & TRN & & \\
\hline CHEMBL1979212 & 809361 & 5.6799 & 5.7947 & TRN & & \\
\hline CHEMBL1732062 & 809361 & 5.4737 & 5.6724 & TRN & & \\
\hline CHEMBL1464798 & 809361 & 6.0278 & 5.4949 & TRN & & \\
\hline CHEMBL1722300 & 809361 & 6.279 & 5.6942 & TRN & & \\
\hline CHEMBL1722228 & 809361 & 5.1319 & 5.4172 & TST & & \\
\hline CHEMBL599924 & 809361 & 5.5901 & 5.6888 & TRN & & \\
\hline CHEMBL1366622 & 809361 & 6.279 & 6.0202 & TRN & & \\
\hline CHEMBL1613290 & 809361 & 4.8827 & 5.364 & TRN & & \\
\hline CHEMBL1448198 & 809361 & 6.0 & 5.2232 & TRN & & \\
\hline CHEMBL1332450 & 809361 & 5.7167 & 6.1416 & TRN & & \\
\hline CHEMBL1491288 & 809361 & 5.5031 & 5.289 & TRN & & \\
\hline CHEMBL1307901 & 809361 & 4.2015 & 5.0906 & TRN & & \\
\hline CHEMBL1460029 & 809361 & 5.3019 & 5.3174 & TRN & & \\
\hline CHEMBL1361220 & 809361 & 5.279 & 5.6781 & TRN & & \\
\hline CHEMBL1307972 & 809361 & 6.3925 & 5.8932 & TRN & & \\
\hline CHEMBL1383521 & 809361 & 5.7773 & 6.1973 & TRN & & \\
\hline CHEMBL 2003351 & 809361 & 4.8545 & 5.1811 & TRN & & \\
\hline CHEMBL1566205 & 809361 & 6.4597 & 5.6923 & TRN & & \\
\hline CHEMBL1366510 & 809361 & 5.4881 & 5.4014 & TST & & \\
\hline CHEMBL1329255 & 809361 & 3.1549 & 5.4977 & TRN & & \\
\hline CHEMBL1611162 & 809361 & 5.3019 & 5.3147 & TRN & & \\
\hline CHEMBL1699062 & 809361 & 4.6696 & 5.3048 & TST & & \\
\hline CHEMBL1973050 & 809361 & 5.8894 & 5.3948 & TRN & & \\
\hline
\end{tabular}


Supplemental Table S2.txt

\begin{tabular}{|c|c|c|c|c|c|c|}
\hline CHEMBL1352313 & 809361 & 5.6073 & \multicolumn{3}{|c|}{5.587999999999999} & TST \\
\hline CHEMBL1581838 & 809361 & 3.1549 & 5.3773 & TRN & & \\
\hline CHEMBL1458548 & 809361 & 5.4401 & 5.7835 & TRN & & \\
\hline CHEMBL1548439 & 809361 & 5.3635 & 5.5284 & TRN & & \\
\hline CHEMBL1555483 & 809361 & 5.475 & 5.4464 & TRN & & \\
\hline CHEMBL601547 & 809361 & 5.4377 & 5.4261 & TRN & & \\
\hline CHEMBL1722169 & 809361 & 5.8633 & 5.4907 & TST & & \\
\hline CHEMBL1613582 & 809361 & 5.3536 & 5.2993 & TRN & & \\
\hline CHEMBL1395980 & 809361 & 4.757 & 5.232 & TRN & & \\
\hline CHEMBL1327276 & 809361 & 5.5686 & 5.4843 & TRN & & \\
\hline CHEMBL1405318 & 809361 & 5.2076 & 5.3458 & TRN & & \\
\hline CHEMBL1465815 & 809361 & 5.6556 & 5.62 & TRN & & \\
\hline CHEMBL1572920 & 809361 & 5.9666 & 5.3699 & TRN & & \\
\hline CHEMBL1420384 & 809361 & 5.3969 & 5.4835 & TRN & & \\
\hline CHEMBL1336277 & 809361 & 5.7447 & 5.3993 & TRN & & \\
\hline CHEMBL1501567 & 809361 & 5.0531 & 5.5432 & TST & & \\
\hline CHEMBL 2002162 & 809361 & 5.52 & 5.6459 & TST & & \\
\hline CHEMBL1902131 & 809361 & 5.5482 & 5.2778 & TRN & & \\
\hline CHEMBL1561591 & 809361 & 5.6478 & 5.5736 & TRN & & \\
\hline CHEMBL3392223 & 809361 & 5.61799 & 99999999 & 99 & 5.3045 & ST \\
\hline CHEMBL1300831 & 809361 & 5.3737 & 5.6708 & TST & & \\
\hline CHEMBL1711797 & 809361 & 6.1791 & 5.61100 & 000000000 & & \\
\hline CHEMBL1432721 & 809361 & 5.9914 & 5.6971 & TRN & & \\
\hline CHEMBL1347359 & 809361 & 5.0531 & 5.3912 & TRN & & \\
\hline CHEMBL1335491 & 809361 & 5.5901 & 5.9449 & TRN & & \\
\hline CHEMBL1707900 & 809361 & 5.4634 & 5.5758 & TRN & & \\
\hline CHEMBL1496814 & 809361 & 5.7258 & 5.4704 & TRN & & \\
\hline CHEMBL1383742 & 809361 & 5.9872 & 5.5797 & TRN & & \\
\hline CHEMBL1423660 & 809361 & 7.585 & 6.2101 & TRN & & \\
\hline CHEMBL 1488056 & 809361 & 4.8256 & 5.2951 & TRN & & \\
\hline CHEMBL1481061 & 809361 & 5.5302 & 5.5089 & TST & & \\
\hline CHEMBL1513566 & 809361 & 6.0114 & 5.1481 & TRN & & \\
\hline CHEMBL1889898 & 809361 & 5.6696 & 5.6865 & TST & & \\
\hline CHEMBL1456022 & 809361 & 5.2941 & 5.4916 & TRN & & \\
\hline CHEMBL596674 & 809361 & 5.3747 & 5.3524 & TRN & & \\
\hline CHEMBL1715463 & 809361 & 5.5513 & 5.4707 & TST & & \\
\hline CHEMBL1438590 & 809361 & 5.3019 & 5.4254 & TRN & & \\
\hline CHEMBL1518705 & 809361 & 4.9359 & 5.4938 & TST & & \\
\hline CHEMBL1311094 & 809361 & 5.4389 & 5.414 & TST & & \\
\hline CHEMBL 1605875 & 809361 & 5.7696 & 5.8425 & TRN & & \\
\hline CHEMBL1966132 & 809361 & 6.0975 & 5.6095 & TRN & & \\
\hline CHEMBL1497589 & 809361 & 5.6517 & 5.5349 & TRN & & \\
\hline CHEMBL1701308 & 809361 & 5.4828 & 5.5319 & TRN & & \\
\hline CHEMBL1526148 & 809361 & 5.209 & 5.3425 & TRN & & \\
\hline CHEMBL1334550 & 809361 & 5.5317 & 5.5405 & TRN & & \\
\hline CHEMBL1445297 & 809361 & 5.4248 & 5.4655 & TRN & & \\
\hline CHEMBL1349747 & 809361 & 4.702 & 5.2916 & TST & & \\
\hline CHEMBL1869116 & 809361 & 5.1669 & 5.3777 & TRN & & \\
\hline
\end{tabular}

Page 10196 


\begin{tabular}{|c|c|c|c|c|c|}
\hline \multirow{3}{*}{$\begin{array}{l}\text { CHEMBL1405288 } \\
\text { CHEMBL1386344 }\end{array}$} & \multirow{3}{*}{$\begin{array}{l}809361 \\
809361\end{array}$} & \multicolumn{4}{|c|}{ Supplemental Table S2.txt } \\
\hline & & 6.1469 & \multicolumn{2}{|c|}{6.047000000000001} & TRN \\
\hline & & 5.4306 & 5.2785 & TST & \\
\hline CHEMBL1583471 & 809361 & 6.2774 & 5.8643 & TRN & \\
\hline CHEMBL1700186 & 809361 & 5.04 & 5.2343 & TRN & \\
\hline CHEMBL1358447 & 809361 & 5.5575 & 5.4138 & TRN & \\
\hline CHEMBL1452234 & 809361 & 3.1549 & 5.2647 & TRN & \\
\hline CHEMBL1403320 & 809361 & 5.9245 & 5.5979 & TRN & \\
\hline CHEMBL1381809 & 809361 & 5.3335 & 5.3556 & TRN & \\
\hline CHEMBL1522108 & 809361 & 5.9318 & 6.0714 & TRN & \\
\hline CHEMBL595700 & 809361 & 5.983 & 5.6986 & TRN & \\
\hline CHEMBL1425521 & 809361 & 5.8633 & 5.608 & TST & \\
\hline CHEMBL1873644 & 809361 & 7.585 & 5.947 & TST & \\
\hline CHEMBL1709857 & 809361 & 4.3145 & 5.2735 & TRN & \\
\hline CHEMBL1335650 & 809361 & 5.7077 & 5.3795 & TST & \\
\hline CHEMBL1713613 & 809361 & 5.4698 & 5.7677 & TRN & \\
\hline CHEMBL1865123 & 809361 & 5.3507 & 5.3873 & TST & \\
\hline CHEMBL1387231 & 809361 & 4.672 & 5.4644 & TRN & \\
\hline CHEMBL1410758 & 809361 & 5.5901 & 6.1173 & TRN & \\
\hline CHEMBL1705098 & 809361 & 5.8097 & 6.0849 & TRN & \\
\hline CHEMBL1330184 & 809361 & 5.8729 & 5.2897 & TRN & \\
\hline CHEMBL1543839 & 809361 & 5.4486 & 5.6031 & TRN & \\
\hline CHEMBL1473985 & 809361 & 5.3261 & 5.3448 & TST & \\
\hline CHEMBL1711814 & 809361 & 6.0259 & 5.5648 & TRN & \\
\hline CHEMBL1488036 & 809361 & 5.4101 & 5.6018 & TRN & \\
\hline CHEMBL1326053 & 809361 & 5.0915 & 5.3554 & TRN & \\
\hline CHEMBL1310479 & 809361 & 5.9355 & 5.5093 & TST & \\
\hline CHEMBL577660 & 809361 & 5.3862 & 5.4858 & TRN & \\
\hline CHEMBL1452421 & 809361 & 5.9245 & 6.0815 & TRN & \\
\hline CHEMBL1373357 & 809361 & 3.1549 & 5.4502 & TST & \\
\hline CHEMBL1550076 & 809361 & 5.6108 & 5.3247 & TRN & \\
\hline CHEMBL1516044 & 809361 & 5.0141 & 5.181 & TRN & \\
\hline CHEMBL1724177 & 809361 & 5.6038 & 5.5059 & TST & \\
\hline CHEMBL1581280 & 809361 & 5.4921 & 5.6007 & TRN & \\
\hline CHEMBL1313222 & 809361 & 5.1884 & 5.4013 & TRN & \\
\hline CHEMBL1348803 & 809361 & 5.7328 & 5.3797 & TRN & \\
\hline CHEMBL1703510 & 809361 & 5.5171 & 5.584 & TRN & \\
\hline CHEMBL1348057 & 809361 & 5.2716 & 5.4015 & TRN & \\
\hline CHEMBL1563714 & 809361 & 5.2441 & 5.5879 & TST & \\
\hline CHEMBL1345481 & 809361 & 5.8268 & 5.6711 & TRN & \\
\hline CHEMBL1510146 & 809361 & 4.3187 & 5.5785 & TST & \\
\hline CHEMBL1904071 & 809361 & 5.5258 & 5.1526 & TRN & \\
\hline CHEMBL1346587 & 809361 & 6.0477 & 5.5666 & TRN & \\
\hline CHEMBL1447306 & 809361 & 5.0747 & 5.5903 & TRN & \\
\hline CHEMBL1482025 & 809361 & 5.5544 & 5.291 & TRN & \\
\hline CHEMBL1477528 & 809361 & 5.5229 & 5.3738 & TRN & \\
\hline CHEMBL1707745 & 809361 & 6.2 & 5.8234 & TRN & \\
\hline CHEMBL1735624 & 809361 & 5.6383 & 5.6049 & TRN & \\
\hline CHEMBL1522211 & 809361 & 4.6128 & 5.3761 & TRN & \\
\hline
\end{tabular}




\begin{tabular}{|c|c|c|c|c|c|}
\hline & & \multicolumn{4}{|c|}{ Supplemental Table s2.txt } \\
\hline CHEMBL1439337 & 809361 & 5.3242 & 5.5511 & TST & \\
\hline CHEMBL1406670 & 809361 & 3.1549 & 5.2233 & TST & \\
\hline CHEMBL1465706 & 809361 & 6.2403 & 6.2214 & TRN & \\
\hline CHEMBL1539522 & 809361 & 6.3134 & 5.5471 & TRN & \\
\hline CHEMBL589238 & 809361 & 5.5638 & 6.1056 & TRN & \\
\hline CHEMBL1366727 & 809361 & 6.4989 & 5.585 & TRN & \\
\hline CHEMBL1453723 & 809361 & 5.1494 & 5.2676 & TRN & \\
\hline CHEMBL1287980 & 809361 & 5.4815 & 5.6294 & TST & \\
\hline CHEMBL1338922 & 809361 & 4.7062 & 5.1924 & TRN & \\
\hline CHEMBL1564519 & 809361 & 5.3565 & 5.5674 & TRN & \\
\hline CHEMBL1726113 & 809361 & 4.6137 & 5.1603 & TRN & \\
\hline CHEMBL1549594 & 809361 & 5.2924 & 5.2872 & TRN & \\
\hline CHEMBL1970198 & 809361 & 4.5308 & 5.4113 & TRN & \\
\hline CHEMBL1302158 & 809361 & 5.0762 & 5.5456 & TRN & \\
\hline CHEMBL1341696 & 809361 & 5.4828 & 5.4762 & TRN & \\
\hline CHEMBL1425525 & 809361 & 5.266 & 5.5093 & TRN & \\
\hline CHEMBL1599441 & 809361 & 5.7399 & 5.21399 & 99999999995 & TRN \\
\hline CHEMBL1565444 & 809361 & 5.6144 & 5.7385 & TRN & \\
\hline CHEMBL1341560 & 809361 & 5.3497 & 5.45100 & 00000000005 & TRN \\
\hline CHEMBL1518827 & 809361 & 5.1746 & 5.3369 & TRN & \\
\hline CHEMBL1430715 & 809361 & 3.1549 & 5.2398 & TRN & \\
\hline CHEMBL1709973 & 809361 & 6.5157 & 5.5472 & TRN & \\
\hline CHEMBL1442788 & 809361 & 6.1379 & 5.7281 & TRN & \\
\hline CHEMBL1340112 & 809361 & 5.7595 & 5.5562 & TRN & \\
\hline CHEMBL1881663 & 809361 & 5.1439 & 5.3928 & TRN & \\
\hline CHEMBL1424968 & 809361 & 5.3872 & 5.651 & TRN & \\
\hline CHEMBL1530686 & 809361 & 6.2807 & 6.0542 & TRN & \\
\hline CHEMBL1997132 & 809361 & 5.4342 & 5.6453 & TRN & \\
\hline CHEMBL1551233 & 809361 & 5.8327 & 5.5792 & TST & \\
\hline CHEMBL1531328 & 809361 & 6.4318 & 6.0968 & TST & \\
\hline CHEMBL1424697 & 809361 & 5.8861 & 5.5617 & TRN & \\
\hline CHEMBL1412396 & 809361 & 6.308 & 5.6699 & TRN & \\
\hline CHEMBL1454614 & 809361 & 5.1451 & 5.5877 & TRN & \\
\hline CHEMBL1542653 & 809361 & 5.2782 & 5.2457 & TRN & \\
\hline CHEMBL1328541 & 809361 & 5.0092 & 5.3977 & TRN & \\
\hline CHEMBL1598843 & 809361 & 5.15799 & 99999999 & 5.1663 & TRN \\
\hline CHEMBL1879338 & 809361 & 4.8904 & 5.39 & TRN & \\
\hline CHEMBL1462791 & 809361 & 4.7757 & 5.1411 & TRN & \\
\hline CHEMBL1533488 & 809361 & 4.6647 & 5.5684 & TST & \\
\hline CHEMBL1457139 & 809361 & 5.9469 & 6.0701 & TRN & \\
\hline CHEMBL1443900 & 809361 & 6.5482 & 5.8185 & TRN & \\
\hline CHEMBL1447350 & 809361 & 5.7959 & 5.5123 & TRN & \\
\hline CHEMBL1429297 & 809361 & 5.2487 & 5.4487 & TRN & \\
\hline CHEMBL1879461 & 809361 & 5.466 & 5.5338 & TRN & \\
\hline CHEMBL1607013 & 809361 & 5.2526 & 5.492006 & 0000000001 & TRN \\
\hline CHEMBL1988268 & 809361 & 5.4609 & 5.3668 & TRN & \\
\hline CHEMBL1368914 & 809361 & 5.7773 & 5.4734 & TRN & \\
\hline CHEMBL1394624 & 809361 & 5.7773 & 5.9227 & TRN & \\
\hline
\end{tabular}


Supplemental Table S2.txt

\begin{tabular}{|c|c|c|c|c|c|}
\hline CHEMBL1443219 & 809361 & 4.6156 & 5.4892 & TRN & \\
\hline CHEMBL1467940 & 809361 & 5.7747 & 5.9146 & TRN & \\
\hline CHEMBL1465899 & 809361 & 5.4989 & 5.3216 & TRN & \\
\hline CHEMBL1479496 & 809361 & 5.4711 & 5.471 & TRN & \\
\hline CHEMBL1409430 & 809361 & 5.38299 & Э9999999 & 99 & 6.1723 \\
\hline CHEMBL1609419 & 809361 & 5.7305 & 5.6138 & TRN & \\
\hline CHEMBL1727030 & 809361 & 5.4597 & 5.3838 & TRN & \\
\hline CHEMBL395263 & 809361 & 5.5751 & 5.2578 & TST & \\
\hline CHEMBL1700479 & 809361 & 5.7328 & 5.5672 & TST & \\
\hline CHEMBL1524710 & 809361 & 5.5243 & 5.5543 & TRN & \\
\hline CHEMBL1546000 & 809361 & 5.2757 & 5.2309 & TRN & \\
\hline CHEMBL1721017 & 809361 & 5.0565 & 5.4516 & TRN & \\
\hline CHEMBL1332925 & 809361 & 5.2976 & 5.4563 & TRN & \\
\hline CHEMBL1367466 & 809361 & 5.7167 & 5.4442 & TRN & \\
\hline CHEMBL1402371 & 809361 & 5.5654 & 5.6749 & TRN & \\
\hline CHEMBL260148 & 809361 & 5.9666 & 5.4097 & TRN & \\
\hline CHEMBL1395785 & 809361 & 5.5391 & 5.2082 & TRN & \\
\hline CHEMBL1387704 & 809361 & 5.7645 & 5.5195 & TRN & \\
\hline CHEMBL1584329 & 809361 & 5.7423 & 5.6285 & TRN & \\
\hline CHEMBL1504429 & 809361 & 5.3279 & 5.5158 & TRN & \\
\hline CHEMBL1710051 & 809361 & 5.4881 & 5.4371 & TRN & \\
\hline CHEMBL1975935 & 809361 & 4.919 & 5.4148 & TRN & \\
\hline CHEMBL1473402 & 809361 & 5.9031 & 5.8607 & TRN & \\
\hline CHEMBL1329235 & 809361 & 6.27 & 6.3807 & TRN & \\
\hline CHEMBL1522655 & 809361 & 5.4067 & 5.2966 & TRN & \\
\hline CHEMBL1573811 & 809361 & 5.3233 & 5.3487 & TRN & \\
\hline CHEMBL1387563 & 809361 & 5.4815 & 5.2345 & TRN & \\
\hline CHEMBL1359384 & 809361 & 5.1726 & 5.165 & TST & \\
\hline CHEMBL1409883 & 809361 & 5.8996 & 5.6297 & TRN & \\
\hline CHEMBL1319709 & 809361 & 5.2668 & 5.5378 & TRN & \\
\hline CHEMBL1593654 & 809361 & 5.0625 & 5.3331 & TST & \\
\hline CHEMBL1370361 & 809361 & 4.494 & 5.285 & TST & \\
\hline CHEMBL1598785 & 809361 & 5.7011 & 6.269 & TRN & \\
\hline CHEMBL1529783 & 809361 & 6.0635 & 5.3038 & TRN & \\
\hline CHEMBL1733563 & 809361 & 4.9151 & 5.4637 & TST & \\
\hline CHEMBL1501495 & 809361 & 5.2899 & 5.1907 & TRN & \\
\hline CHEMBL548615 & 809361 & 6.0 & 6.23 & TRN & \\
\hline CHEMBL1597561 & 809361 & 3.1549 & 5.3262 & TRN & \\
\hline CHEMBL1716010 & 809361 & 5.2175 & 5.3352 & TRN & \\
\hline CHEMBL1549279 & 809361 & 5.3478 & 5.3923 & TRN & \\
\hline CHEMBL1366948 & 809361 & 5.7167 & 5.5531 & TST & \\
\hline CHEMBL530361 & 809361 & 6.1433 & 5.7568 & TRN & \\
\hline CHEMBL1891470 & 809361 & 3.1549 & 5.443 & TST & \\
\hline CHEMBL1411665 & 809361 & 5.1129 & 5.6195 & TRN & \\
\hline CHEMBL1719155 & 809361 & 5.2299 & 5.5521 & TST & \\
\hline CHEMBL1994355 & 809361 & 4.9788 & 5.4547 & TRN & \\
\hline CHEMBL1354881 & 809361 & 5.0975 & 5.3853 & TST & \\
\hline CHEMBL 2004666 & 809361 & 4.6341 & 5.4074 & TRN & \\
\hline
\end{tabular}


Supplemental Table S2.txt

\begin{tabular}{|c|c|c|c|c|}
\hline - & & & & \\
\hline & & .2848 & 5.3257 & \\
\hline & & & & \\
\hline AEMBL17 & & & 567 & 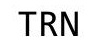 \\
\hline JEMBL15 & 29361 & & & \\
\hline HEMBL1380929 & 09361 & .3686 & 6524 & \\
\hline HEMBL1S & 361 & & & \\
\hline IFMBI 13 & & & & \\
\hline HEMBL13 & 361 & & 4238 & \\
\hline HEMBL17 & 09361 & & 0027 & \\
\hline HEMBL14 & 09361 & & 78 & \\
\hline IEMBL16 & 61 & & 356 & \\
\hline AEMBL15 & & & & \\
\hline HEMBL14 & 61 & & .1228 & \\
\hline AEMBL13 & 61 & & & \\
\hline AEMBL1: & 51 & 57 & 4024 & \\
\hline AEMBL15 & 1 & & & \\
\hline HEMBL58 & & & & \\
\hline HEMBL1S & 61 & & & \\
\hline IEMBL15 & & & & \\
\hline FEMBLI & 51 & & & \\
\hline HEMBL1 & & & & וזנה \\
\hline HEMBL13 & & & & \\
\hline HFMBI 15 & & & & \\
\hline AEMBL19 & & & & (2) \\
\hline HEMBL1 & & & 72 & RN \\
\hline HEMBL1. & & & & Niv \\
\hline HFMBI 1 & & & & \\
\hline HEMBL1C & & & & RIV \\
\hline HEMBL15 & & & & I RN \\
\hline HEMBL1: & & & 43 & RN \\
\hline HEMBL1 & & & & RN \\
\hline 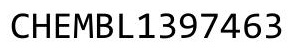 & & & 45 & (ng) \\
\hline HEMBL 18 & & & & is \\
\hline HEMBL1450483 & 51 & & 105 & TRN \\
\hline HEMBL1 & & & 68 & TRN \\
\hline HFMRI 5 & & & & ST \\
\hline HEMBL1 & & & & 「RN \\
\hline HEMBL1538267 & 61 & & 038 & TRN \\
\hline AEMBL1: & & & & -7 \\
\hline HEMBL1 & 1 & & & ונד \\
\hline CHEMBL15 & & & & TST \\
\hline HEMBL13 & & & 3906 & TRN \\
\hline IEMBL15 & 61 & 73 & 141 & TS \\
\hline HEMBL15 & & & 5.7467 & $T$ \\
\hline HEMBL1 & & & & \\
\hline CHEMBL173 & & & 5.3202 & \\
\hline CHEMBL1340698 & 809361 & 5.4157 & 5.8747 & ГRN \\
\hline
\end{tabular}

Page 10200 


\begin{tabular}{|c|c|c|c|c|c|}
\hline & & \multicolumn{4}{|c|}{ Supplemental Table s2.txt } \\
\hline CHEMBL1486109 & 809361 & 5.7167 & 5.7391 & TRN & \\
\hline CHEMBL1458840 & 809361 & 5.7696 & 5.4533 & TRN & \\
\hline CHEMBL1731329 & 809361 & 4.909 & 5.5131 & TRN & \\
\hline CHEMBL1300959 & 809361 & 5.8386 & 5.5904 & TRN & \\
\hline CHEMBL1435655 & 809361 & 4.4432 & 5.2653 & TST & \\
\hline CHEMBL1991164 & 809361 & 5.2874 & 5.4151 & TRN & \\
\hline CHEMBL1533366 & 809361 & 5.2211 & 5.5836 & TRN & \\
\hline CHEMBL1538234 & 809361 & 5.2899 & 5.3761 & TRN & \\
\hline CHEMBL169811 & 809361 & 7.585 & 5.48 & TRN & \\
\hline CHEMBL1490222 & 809361 & 5.6737 & 6.2194 & TRN & \\
\hline CHEMBL1510339 & 809361 & 5.8697 & 5.6134 & TRN & \\
\hline CHEMBL1343966 & 809361 & 5.767 & 5.4076 & TRN & \\
\hline CHEMBL1418818 & 809361 & 5.3325 & 5.6514 & TRN & \\
\hline CHEMBL1444683 & 809361 & 6.0857 & 5.50200 & 0000000001 & TRN \\
\hline CHEMBL1426340 & 809361 & 5.7773 & 6.1563 & TRN & \\
\hline CHEMBL1726140 & 809361 & 4.7268 & 5.3476 & TST & \\
\hline CHEMBL1431608 & 809361 & 5.4145 & 5.539 & TRN & \\
\hline CHEMBL1731275 & 809361 & 5.4547 & 5.4349 & TST & \\
\hline CHEMBL1516692 & 809361 & 5.9666 & 5.6831 & TRN & \\
\hline CHEMBL1557454 & 809361 & 5.5376 & 5.4893 & TRN & \\
\hline CHEMBL1327721 & 809361 & 5.8013 & 5.5584 & TRN & \\
\hline CHEMBL1358184 & 809361 & 5.38399 & 99999999 & 5.1427 & TRN \\
\hline CHEMBL1734534 & 809361 & 5.4001 & 5.7143 & TRN & \\
\hline CHEMBL1550278 & 809361 & 6.4498 & 6.097 & TRN & \\
\hline CHEMBL1439933 & 809361 & 5.15 & 5.5045 & TRN & \\
\hline CHEMBL1588217 & 809361 & 5.9469 & 5.4655 & TRN & \\
\hline CHEMBL1338885 & 809361 & 5.0311 & 5.3321 & TRN & \\
\hline CHEMBL1501300 & 809361 & 5.2526 & 5.2403 & TRN & \\
\hline CHEMBL1516127 & 809361 & 5.8182 & 5.7565 & TRN & \\
\hline CHEMBL1483768 & 809361 & 5.6737 & 5.3619 & TRN & \\
\hline CHEMBL414890 & 809361 & 5.2907 & 5.7746 & TST & \\
\hline CHEMBL1491222 & 809361 & 5.8794 & 6.0707 & TRN & \\
\hline CHEMBL1723968 & 809361 & 5.2628 & 5.3705 & TST & \\
\hline CHEMBL1341789 & 809361 & 5.1141 & 5.5103 & TST & \\
\hline CHEMBL1475774 & 809361 & 5.433 & 5.3705 & TRN & \\
\hline CHEMBL367376 & 809361 & 7.585 & 5.9205 & TST & \\
\hline CHEMBL1728642 & 809361 & 6.0 & 5.6293 & TST & \\
\hline CHEMBL1386580 & 809361 & 4.4819 & 5.2116 & TRN & \\
\hline CHEMBL1432251 & 809361 & 7.585 & 5.7818 & TRN & \\
\hline CHEMBL1352586 & 809361 & 5.1785 & 5.5759 & TRN & \\
\hline CHEMBL1347861 & 809361 & 5.6091 & 5.6741 & TRN & \\
\hline CHEMBL1520276 & 809361 & 5.3197 & 5.563 & TRN & \\
\hline CHEMBL1353983 & 809361 & 6.5467 & 5.9169 & TRN & \\
\hline CHEMBL1473102 & 809361 & 4.5904 & 5.2064 & TRN & \\
\hline CHEMBL1700569 & 809361 & 7.585 & 6.6296 & TST & \\
\hline CHEMBL1353194 & 809361 & 5.3507 & 5.3485 & TRN & \\
\hline CHEMBL1345932 & 809361 & 5.4895 & 5.6583 & TRN & \\
\hline CHEMBL1588579 & 809361 & 5.1568 & 5.1736 & TRN & \\
\hline
\end{tabular}




\begin{tabular}{|c|c|c|c|c|c|}
\hline & & \multicolumn{4}{|c|}{ Supplemental Table S2.txt } \\
\hline CHEMBL1464070 & 809361 & 5.3197 & 5.4124 & TRN & \\
\hline CHEMBL1337235 & 809361 & 5.9172 & 5.5653 & TRN & \\
\hline CHEMBL1459140 & 809361 & 6.0 & 6.1551 & TRN & \\
\hline CHEMBL1529115 & 809361 & 6.2534 & 5.7343 & TRN & \\
\hline CHEMBL1563223 & 809361 & 5.9747 & 5.7871 & TRN & \\
\hline CHEMBL1543258 & 809361 & 6.3054 & 5.7756 & TST & \\
\hline CHEMBL1532525 & 809361 & 5.8268 & 5.7487 & TRN & \\
\hline CHEMBL1717507 & 809361 & 5.857 & 5.5549 & TRN & \\
\hline CHEMBL1590661 & 809361 & 5.8356 & 5.7997 & TRN & \\
\hline CHEMBL1542804 & 809361 & 5.6108 & 5.37700 & 0000000001 & TRN \\
\hline CHEMBL1332013 & 809361 & 5.1255 & 5.8694 & TRN & \\
\hline CHEMBL1439124 & 809361 & 5.3045 & 5.3307 & TRN & \\
\hline CHEMBL1490562 & 809361 & 5.6289 & 5.6021 & TRN & \\
\hline CHEMBL1734661 & 809361 & 4.8601 & 5.2705 & TRN & \\
\hline CHEMBL1734467 & 809361 & 5.6676 & 5.3839 & TRN & \\
\hline CHEMBL1601830 & 809361 & 5.7447 & 5.6761 & TRN & \\
\hline CHEMBL1725385 & 809361 & 4.8413 & 5.0933 & TRN & \\
\hline CHEMBL1464071 & 809361 & 6.2328 & 5.807 & TRN & \\
\hline CHEMBL1408861 & 809361 & 5.6271 & 5.8217 & TRN & \\
\hline CHEMBL1341553 & 809361 & 6.5243 & 5.4682 & TRN & \\
\hline CHEMBL1733910 & 809361 & 5.4157 & 5.3344 & TRN & \\
\hline CHEMBL1410897 & 809361 & 5.52 & 5.676 & TRN & \\
\hline CHEMBL 265686 & 809361 & 5.7033 & 5.6397 & TRN & \\
\hline CHEMBL1727091 & 809361 & 6.1129 & 5.6638 & TST & \\
\hline CHEMBL1453108 & 809361 & 6.0168 & 5.6495 & TRN & \\
\hline CHEMBL1419822 & 809361 & 5.7212 & 5.5735 & TRN & \\
\hline CHEMBL1510389 & 809361 & 5.5421 & 5.6709 & TRN & \\
\hline CHEMBL1436844 & 809361 & 3.1549 & 4.9124 & TRN & \\
\hline CHEMBL1553183 & 809361 & 6.4763 & 5.3756 & TST & \\
\hline CHEMBL1560061 & 809361 & 7.585 & 6.023 & TRN & \\
\hline CHEMBL1510261 & 809361 & 6.2076 & 5.5268 & TRN & \\
\hline CHEMBL1300302 & 809361 & 5.5986 & 5.5888 & TRN & \\
\hline CHEMBL1541828 & 809361 & 6.4425 & 5.3666 & TRN & \\
\hline CHEMBL1428507 & 809361 & 5.4976 & 5.1238 & TRN & \\
\hline CHEMBL1736280 & 809361 & 5.2741 & 4.8139 & TRN & \\
\hline CHEMBL1470712 & 809361 & 5.7799 & 5.7594 & TRN & \\
\hline CHEMBL2001648 & 809361 & 6.0814 & 5.8372 & TST & \\
\hline CHEMBL1734142 & 809361 & 6.0092 & 5.7168 & TST & \\
\hline CHEMBL1395931 & 809361 & 4.4098 & 5.3883 & TST & \\
\hline CHEMBL1379390 & 809361 & 5.0424 & 5.5853 & TRN & \\
\hline CHEMBL1327783 & 809361 & 6.0315 & 5.5864 & TRN & \\
\hline CHEMBL1520214 & 809361 & 5.9626 & 5.5989 & TRN & \\
\hline CHEMBL1570307 & 809361 & 4.8505 & 5.1238 & TRN & \\
\hline CHEMBL1465040 & 809361 & 5.7399 & 5.7246 & TRN & \\
\hline CHEMBL1374797 & 809361 & 5.3098 & 5.6198 & TRN & \\
\hline CHEMBL1402332 & 809361 & 6.0195 & 5.6059 & TRN & \\
\hline CHEMBL1415184 & 809361 & 7.585 & 6.7852 & TST & \\
\hline CHEMBL1331100 & 809361 & 5.2916 & 5.5395 & TRN & \\
\hline
\end{tabular}




\begin{tabular}{|c|c|c|c|c|c|c|}
\hline & & \multicolumn{5}{|c|}{ Supplemental Table S2.txt } \\
\hline CHEMBL1582580 & 809361 & 6.04 & 5.6958 & TRN & & \\
\hline CHEMBL592068 & 809361 & 5.7595 & 5.6252 & TRN & & \\
\hline CHEMBL1499501 & 809361 & \multicolumn{3}{|c|}{6.247999999999999} & 6.3834 & TRN \\
\hline CHEMBL1490987 & 809361 & 6.2692 & 5.2037 & TRN & & \\
\hline CHEMBL1485168 & 809361 & 5.4145 & 5.8759 & TRN & & \\
\hline CHEMBL1405331 & 809361 & 6.1445 & 5.6133 & TST & & \\
\hline CHEMBL1597655 & 809361 & \multicolumn{3}{|c|}{6.172000000000001} & 6.0607 & TRN \\
\hline CHEMBL1449204 & 809361 & 5.466 & 5.6084 & TRN & & \\
\hline CHEMBL1312083 & 809361 & 5.8416 & 5.2548 & TRN & & \\
\hline CHEMBL1472145 & 809361 & 4.8339 & 5.4411 & TRN & & \\
\hline CHEMBL1449349 & 809361 & 5.301 & 5.4791 & TRN & & \\
\hline CHEMBL1354459 & 809361 & 5.0883 & 5.3549 & TST & & \\
\hline CHEMBL1402510 & 809361 & 5.857 & 5.8886 & TRN & & \\
\hline CHEMBL1499893 & 809361 & 5.4271 & 5.4791 & TRN & & \\
\hline CHEMBL1701446 & 809361 & \multicolumn{3}{|c|}{5.757000000000001} & 5.4205 & TRN \\
\hline CHEMBL1583715 & 809361 & 5.58 & 5.3921 & TRN & & \\
\hline CHEMBL1720152 & 809361 & 5.7328 & 5.5746 & TRN & & \\
\hline CHEMBL1887440 & 809361 & 3.1549 & 5.4312 & TRN & & \\
\hline CHEMBL1491654 & 809361 & 5.6946 & 5.2924 & TRN & & \\
\hline CHEMBL1440422 & 809361 & 5.8794 & 5.5122 & TRN & & \\
\hline CHEMBL1392228 & 809361 & 5.6635 & 5.7409 & TRN & & \\
\hline CHEMBL1420393 & 809361 & 6.2262 & 5.2421 & TRN & & \\
\hline CHEMBL1548253 & 809361 & 5.0721 & 5.4539 & TST & & \\
\hline CHEMBL1493442 & 809361 & 6.0899 & 5.5959 & TRN & & \\
\hline CHEMBL1429003 & 809361 & \multicolumn{3}{|c|}{4.9830000000000005} & 5.5226 & TRN \\
\hline CHEMBL1341031 & 809361 & 6.0788 & 5.7199 & TRN & & \\
\hline CHEMBL1417566 & 809361 & 5.6216 & 5.4376 & TRN & & \\
\hline CHEMBL1531272 & 809361 & 5.1169 & 5.4098 & TRN & & \\
\hline CHEMBL1476183 & 809361 & 5.8386 & 5.4278 & TST & & \\
\hline CHEMBL1505780 & 809361 & 5.9172 & 5.8319 & TRN & & \\
\hline CHEMBL1484741 & 809361 & \multicolumn{3}{|c|}{5.821000000000001} & 5.9511 & TRN \\
\hline CHEMBL1585191 & 809361 & 5.1421 & 5.2167 & TRN & & \\
\hline CHEMBL1354085 & 809361 & 5.7077 & 5.7139 & TST & & \\
\hline CHEMBL528791 & 809361 & 5.3468 & 5.3759 & TRN & & \\
\hline CHEMBL579837 & 809361 & 4.9727 & 5.4327 & TRN & & \\
\hline CHEMBL1714315 & 809361 & 5.5086 & 5.3981 & TRN & & \\
\hline CHEMBL1896778 & 809361 & 5.2708 & 5.4479 & TRN & & \\
\hline CHEMBL1478220 & 809361 & 5.6737 & 5.5391 & TRN & & \\
\hline CHEMBL1366942 & 809361 & 7.585 & 5.6857 & TRN & & \\
\hline CHEMBL1388113 & 809361 & 5.4449 & 5.2929 & TRN & & \\
\hline CHEMBL1449470 & 809361 & 5.8125 & 5.8158 & TST & & \\
\hline CHEMBL1565460 & 809361 & 5.8794 & 5.8043 & TRN & & \\
\hline CHEMBL1469029 & 809361 & 6.2441 & 5.749 & TRN & & \\
\hline CHEMBL510650 & 809361 & 7.585 & 6.2335 & TST & & \\
\hline CHEMBL1705201 & 809361 & 5.5017 & 5.7312 & TRN & & \\
\hline CHEMBL1463659 & 809361 & 6.3072 & 6.0976 & TRN & & \\
\hline CHEMBL1452157 & 809361 & 6.5482 & 5.9841 & TRN & & \\
\hline CHEMBL1599776 & 809361 & 5.5452 & 5.4903 & TRN & & \\
\hline
\end{tabular}




\begin{tabular}{|c|c|c|c|c|c|}
\hline \multirow[b]{2}{*}{ CHEMBL1511219 } & & \multicolumn{4}{|c|}{ Supplemental Table s2.txt } \\
\hline & 809361 & 7.585 & 5.8584 & TRN & \\
\hline CHEMBL1482542 & 809361 & 6.1713 & \multicolumn{2}{|c|}{5.8389999999999995} & TRN \\
\hline CHEMBL1482389 & 809361 & 5.0857 & 5.4852 & TST & \\
\hline CHEMBL1507990 & 809361 & 5.6308 & 5.5513 & TRN & \\
\hline CHEMBL588038 & 809361 & 6.3125 & 5.9433 & TST & \\
\hline CHEMBL1413931 & 809361 & 6.4895 & 5.6829 & TRN & \\
\hline CHEMBL1492399 & 809361 & 5.6655 & 5.6118 & TRN & \\
\hline CHEMBL1702031 & 809361 & 5.3458 & 5.559 & TRN & \\
\hline CHEMBL1498599 & 809361 & 5.2495 & 5.4917 & TRN & \\
\hline CHEMBL1373370 & 809361 & 5.8761 & 5.5503 & TRN & \\
\hline CHEMBL1334003 & 809361 & 5.8697 & 5.641 & TRN & \\
\hline CHEMBL1415720 & 809361 & 4.9337 & 5.4058 & TST & \\
\hline CHEMBL1565349 & 809361 & 5.9172 & 5.7211 & TRN & \\
\hline CHEMBL1583665 & 809361 & 5.3696 & 5.3545 & TRN & \\
\hline CHEMBL1607568 & 809361 & \multicolumn{3}{|c|}{5.382000000000001} & TST \\
\hline CHEMBL1372112 & 809361 & 5.0269 & 5.2587 & TRN & \\
\hline CHEMBL1322350 & 809361 & 5.4855 & 5.4572 & TRN & \\
\hline CHEMBL565657 & 809361 & 6.3063 & 5.6446 & TRN & \\
\hline CHEMBL1469557 & 809361 & 5.3063 & \multicolumn{2}{|c|}{5.361000000000001} & TRN \\
\hline CHEMBL1455813 & 809361 & 5.9431 & 5.4168 & TRN & \\
\hline CHEMBL1704518 & 809361 & 5.8928 & 5.5631 & TST & \\
\hline CHEMBL1401989 & 809361 & 4.8111 & 5.7305 & TRN & \\
\hline CHEMBL1473229 & 809361 & 5.7167 & 5.6981 & TRN & \\
\hline CHEMBL1733762 & 809361 & 5.4962 & 5.2655 & TRN & \\
\hline CHEMBL1384550 & 809361 & 5.5952 & 5.5149 & TRN & \\
\hline CHEMBL1702665 & 809361 & 7.585 & 6.2737 & TST & \\
\hline CHEMBL1729345 & 809361 & 5.7399 & 5.5389 & TRN & \\
\hline CHEMBL1509181 & 809361 & 4.8945 & 5.2922 & TRN & \\
\hline CHEMBL1504766 & 809361 & 5.8239 & 4.8695 & TRN & \\
\hline CHEMBL1443802 & 809361 & 5.4134 & 5.2943 & TRN & \\
\hline CHEMBL1403523 & 809361 & 4.9363 & 5.2561 & TRN & \\
\hline CHEMBL1436389 & 809361 & 5.1864 & 5.3705 & TST & \\
\hline CHEMBL603020 & 809361 & 4.6629 & 5.4679 & TRN & \\
\hline CHEMBL1303799 & 809361 & 5.4522 & 5.2853 & TRN & \\
\hline CHEMBL1547516 & 809361 & 5.3706 & 5.5485 & TST & \\
\hline CHEMBL1512747 & 809361 & 5.3645 & 5.0882 & TRN & \\
\hline CHEMBL1540099 & 809361 & 5.8268 & 5.4552 & TST & \\
\hline CHEMBL1536041 & 809361 & 5.426 & 5.2894 & TRN & \\
\hline CHEMBL1480986 & 809361 & 3.1549 & 5.5068 & TRN & \\
\hline CHEMBL1561146 & 809361 & 5.4413 & 5.3473 & TRN & \\
\hline CHEMBL1524692 & 809361 & 5.1073 & 5.4486 & TRN & \\
\hline CHEMBL1871515 & 809361 & 5.6716 & 5.5241 & TST & \\
\hline CHEMBL1407690 & 809361 & 5.5157 & 5.4361 & TRN & \\
\hline CHEMBL1421976 & 809361 & 6.2441 & 5.3511 & TRN & \\
\hline CHEMBL1468075 & 809361 & 5.9101 & 5.6172 & TRN & \\
\hline CHEMBL1470633 & 809361 & 5.3862 & 5.5492 & TRN & \\
\hline CHEMBL1457902 & 809361 & 5.9626 & 6.01200 & 20000000005 & TRN \\
\hline \multirow[t]{2}{*}{ CHEMBL56170 } & 809361 & 7.585 & 5.7164 & TRN & \\
\hline & & \multicolumn{4}{|c|}{ Page 10204} \\
\hline
\end{tabular}




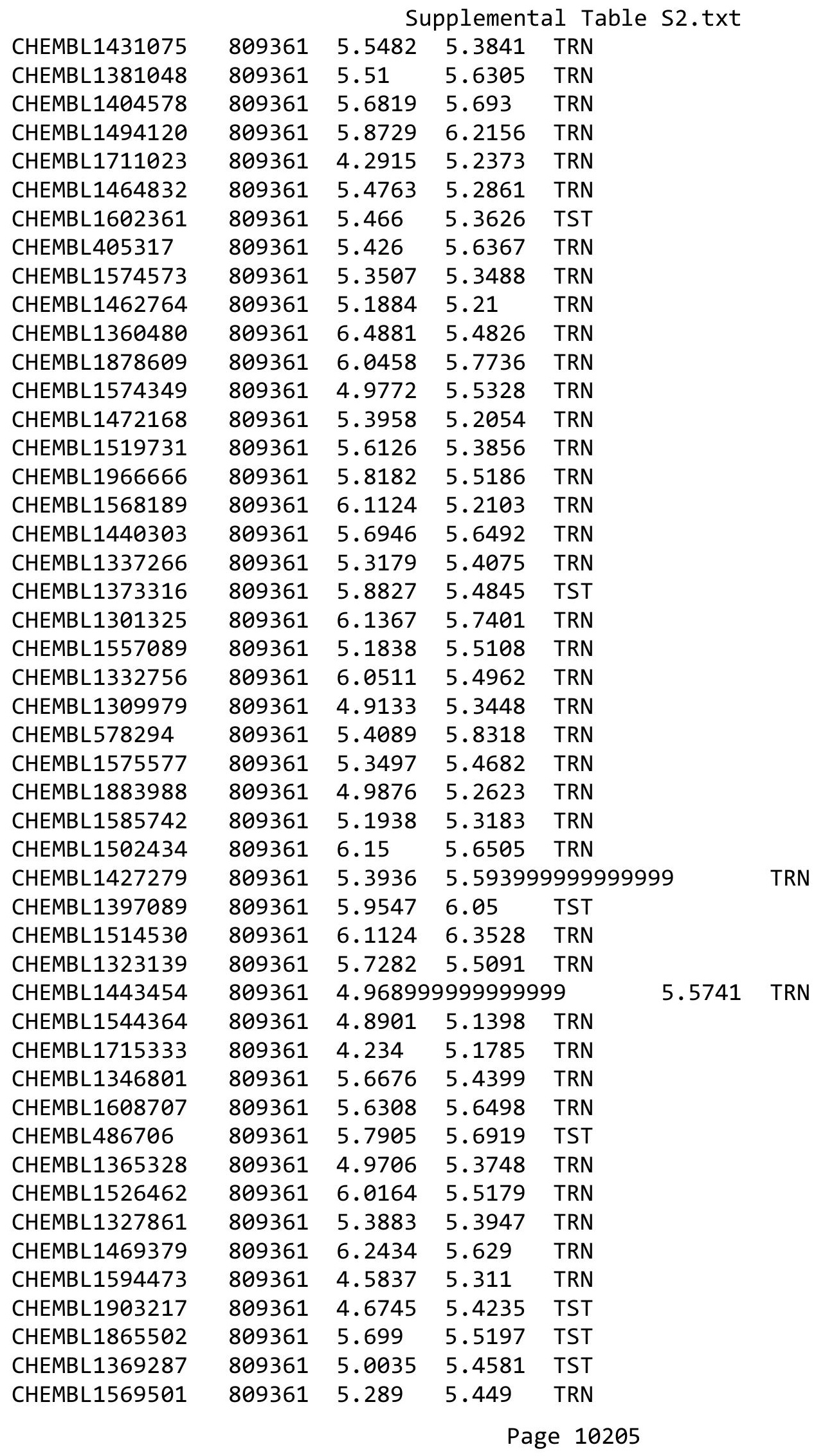


Supplemental Table S2.txt

\begin{tabular}{|c|c|c|c|c|c|}
\hline CHEMBL1474608 & 809361 & 5.317 & 5.5368 & TST & \\
\hline CHEMBL1489033 & 809361 & 5.6676 & 5.2146 & TRN & \\
\hline CHEMBL1301125 & 809361 & 5.7258 & 5.9485 & TST & \\
\hline CHEMBL1507250 & 809361 & 5.8894 & 5.8986 & TRN & \\
\hline CHEMBL1992529 & 809361 & 4.6409 & 5.4081 & TRN & \\
\hline CHEMBL1711326 & 809361 & 5.0391 & 5.303 & TRN & \\
\hline CHEMBL1341870 & 809361 & 6.0575 & 5.4263 & TRN & \\
\hline CHEMBL1714813 & 809361 & 5.0595 & 5.5829 & TST & \\
\hline CHEMBL1477341 & 809361 & 4.4843 & 5.2391 & TST & \\
\hline CHEMBL1332404 & 809361 & 5.4622 & 6.136 & TST & \\
\hline CHEMBL1555449 & 809361 & 5.2027 & 5.3815 & TST & \\
\hline CHEMBL1525157 & 809361 & 5.34200 & 00000000 & 205 & 5.4914 \\
\hline CHEMBL1700347 & 809361 & 7.585 & 5.9135 & TST & \\
\hline CHEMBL1993889 & 809361 & 5.8928 & 5.4758 & TST & \\
\hline CHEMBL1565005 & 809361 & 5.9281 & 5.8376 & TST & \\
\hline CHEMBL1307319 & 809361 & 5.8697 & 5.8098 & TST & \\
\hline CHEMBL1443946 & 809361 & 5.2676 & 5.5214 & TST & \\
\hline CHEMBL1320969 & 809361 & 5.7235 & 5.4892 & TST & \\
\hline CHEMBL1399408 & 809361 & 5.5302 & 5.3522 & TST & \\
\hline CHEMBL1375365 & 809361 & 5.4023 & 5.1801 & TST & \\
\hline CHEMBL1500252 & 809361 & 5.6091 & 5.6614 & TST & \\
\hline CHEMBL1343490 & 809361 & 5.2277 & 5.6624 & TST & \\
\hline CHEMBL 306380 & 809361 & 5.2299 & 5.5866 & TST & \\
\hline CHEMBL1432816 & 809361 & 5.3449 & 5.4148 & TST & \\
\hline CHEMBL1607435 & 809361 & 5.2434 & 5.1429 & TST & \\
\hline CHEMBL1375338 & 809361 & 5.5654 & 5.614 & TST & \\
\hline CHEMBL 2005493 & 809361 & 5.2984 & 5.2704 & TST & \\
\hline CHEMBL1383333 & 809361 & 5.6421 & 5.8971 & TST & \\
\hline CHEMBL1721554 & 809361 & 4.7755 & 5.2825 & TST & \\
\hline CHEMBL1305077 & 809361 & 5.8827 & 5.415 & TST & \\
\hline CHEMBL1882193 & 809361 & 5.4034 & 5.3135 & TST & \\
\hline CHEMBL1531357 & 809361 & 5.3809 & 5.1844 & TST & \\
\hline CHEMBL 2006180 & 809361 & 4.5051 & 5.2552 & TST & \\
\hline CHEMBL1729168 & 809361 & 6.04 & 5.6079 & TST & \\
\hline CHEMBL1336541 & 809361 & 5.9393 & 5.8281 & TST & \\
\hline CHEMBL1487720 & 809361 & 6.3354 & 6.3832 & TST & \\
\hline CHEMBL1314042 & 809361 & 5.52 & 5.4074 & TST & \\
\hline CHEMBL1698348 & 809361 & 4.8608 & 5.2371 & TST & \\
\hline CHEMBL1334026 & 809361 & 5.4191 & 5.6074 & TST & \\
\hline CHEMBL1313883 & 809361 & 5.51 & 5.501 & TST & \\
\hline CHEMBL1377682 & 809361 & 5.0218 & 5.3909 & TST & \\
\hline CHEMBL1521492 & 809361 & 5.6326 & 5.5795 & TST & \\
\hline CHEMBL1997017 & 809361 & 5.4908 & 5.3952 & TST & \\
\hline CHEMBL1316090 & 809361 & 4.8074 & 5.5853 & TST & \\
\hline CHEMBL1383414 & 809361 & 5.857 & 5.6687 & TST & \\
\hline CHEMBL1716540 & 809361 & 5.9626 & 5.8288 & TST & \\
\hline CHEMBL1462900 & 809361 & 5.1475 & 6.0075 & TST & \\
\hline CHEMBL1412196 & 809361 & 3.1549 & 5.2985 & TST & \\
\hline
\end{tabular}


Supplemental Table S2.txt

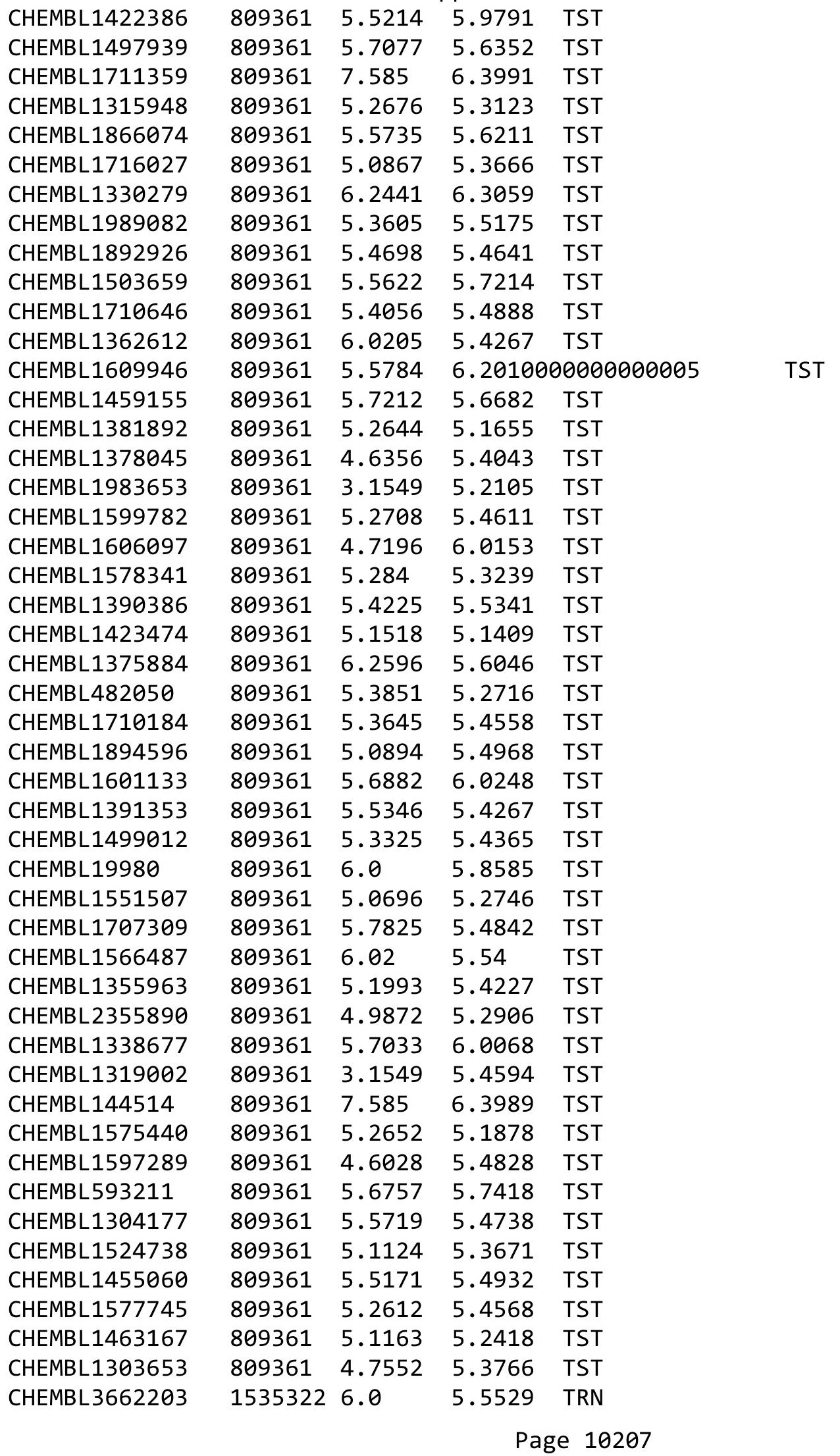


Supplemental Table S2.txt

\begin{tabular}{|c|c|c|c|c|c|}
\hline CHEMBL 3657930 & 1535322 & 7.8153 & 8.2561 & TRN & \\
\hline CHEMBL 3657863 & 1535322 & 7.8125 & 7.4814 & TRN & \\
\hline CHEMBL 3932431 & 1535322 & 6.7212 & 6.5585 & TRN & \\
\hline CHEMBL 3662202 & 1535322 & 6.0 & 6.2138 & TRN & \\
\hline CHEMBL 3662095 & 1535322 & 6.4318 & 6.0785 & TST & \\
\hline CHEMBL 3657914 & 1535322 & 7.5186 & 6.9039 & TRN & \\
\hline CHEMBL 3662145 & 1535322 & 6.8539 & 6.9217 & TRN & \\
\hline CHEMBL 3662182 & 1535322 & 6.4685 & 6.56 & TRN & \\
\hline CHEMBL 3662190 & 1535322 & 8.3979 & 8.33 & TRN & \\
\hline CHEMBL 3658020 & 1535322 & 8.0969 & 7.8596 & TRN & \\
\hline CHEMBL 3662216 & 1535322 & 7.3279 & 7.3842 & TRN & \\
\hline CHEMBL 3662230 & 1535322 & 8.1079 & 7.648 & TRN & \\
\hline CHEMBL 3662174 & 1535322 & 7.0458 & 7.5 & TST & \\
\hline CHEMBL 3657810 & 1535322 & 6.767 & 6.6658 & TRN & \\
\hline CHEMBL 3657817 & 1535322 & 7.6402 & 7.7714 & TRN & \\
\hline CHEMBL 3662122 & 1535322 & 6.0 & 6.6647 & TRN & \\
\hline CHEMBL 3657952 & 1535322 & 8.0362 & 7.9885 & TRN & \\
\hline CHEMBL 3657815 & 1535322 & 7.2495 & 6.9623 & TST & \\
\hline CHEMBL 3657954 & 1535322 & 8.2218 & 8.2338 & TRN & \\
\hline CHEMBL 3657846 & 1535322 & 8.5086 & 8.0815 & TST & \\
\hline CHEMBL 3657808 & 1535322 & 6.0 & 6.1526 & TST & \\
\hline CHEMBL 3658002 & 1535322 & 8.5229 & 8.3132 & TRN & \\
\hline CHEMBL 3662184 & 1535322 & 7.6778 & 7.7527 & TRN & \\
\hline CHEMBL 3657821 & 1535322 & 5.0 & 5.746 & TST & \\
\hline CHEMBL 3662201 & 1535322 & 6.0 & 6.0252 & TRN & \\
\hline CHEMBL 3662099 & 1535322 & 8.2218 & 7.8399 & TRN & \\
\hline CHEMBL 3924008 & 1535322 & 6.0 & 6.0272 & TRN & \\
\hline CHEMBL 3657807 & 1535322 & 8.0605 & 7.9824 & TRN & \\
\hline CHEMBL 3662147 & 1535322 & 5.4815 & 6.2407 & TRN & \\
\hline CHEMBL 3657972 & 1535322 & 8.0458 & 8.339 & TRN & \\
\hline CHEMBL 3657852 & 1535322 & 8.1192 & 6.8266 & TST & \\
\hline CHEMBL 3662155 & 1535322 & 7.1871 & 6.5587 & TRN & \\
\hline CHEMBL 3662189 & 1535322 & 6.0 & 6.4734 & TRN & \\
\hline CHEMBL 3662128 & 1535322 & 7.2076 & 7.269 & TRN & \\
\hline CHEMBL 3662158 & 1535322 & 6.9208 & 6.6572 & TRN & \\
\hline CHEMBL 3662097 & 1535322 & 8.0 & 8.3756 & TRN & \\
\hline CHEMBL 3657979 & 1535322 & 7.699 & 7.525 & TRN & \\
\hline CHEMBL 3639610 & 1535322 & 6.8539 & 6.8232 & TRN & \\
\hline CHEMBL 3662072 & 1535322 & 8.0969 & 8.0712 & TRN & \\
\hline CHEMBL 3662135 & 1535322 & 7.9208 & 7.9931 & TRN & \\
\hline CHEMBL 3662186 & 1535322 & 7.0862 & 7.4337 & TST & \\
\hline CHEMBL 3662205 & 1535322 & 8.5229 & 7.8532 & TRN & \\
\hline CHEMBL 3657921 & 1535322 & 7.5171 & 6.0901 & TST & \\
\hline CHEMBL 3662197 & 1535322 & 6.699 & 6.8304 & TRN & \\
\hline CHEMBL 3939334 & 1535322 & 6.0 & 5.9016 & TST & \\
\hline CHEMBL 3662198 & 1535322 & 5.8861 & 6.197999 & 99999999995 & TRN \\
\hline CHEMBL 3961432 & 1535322 & 6.0 & 6.235 & TRN & \\
\hline CHEMBL 3657805 & 1535322 & 8.2839 & 9999999 & 7.5622 & TRN \\
\hline
\end{tabular}


Supplemental Table S2.txt

\begin{tabular}{|c|c|c|c|c|}
\hline 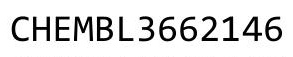 & & .3565 & 5.9024 & \\
\hline & & 6.6576 & 6.8429 & \\
\hline 1 & 322 & & & \\
\hline AEMBL & 322 & $\partial 132$ & & \\
\hline AEMBL3662124 & 35322 & 135 & 5519 & \\
\hline HEMBL3657861 & 535322 & 7.4342 & .7511 & \\
\hline & 322 & 188 & & \\
\hline IEMBL & & & & \\
\hline HEMBL365 & 322 & 3979 & 8.5887 & \\
\hline HEMBL3657931 & 5322 & 739 & 8768 & \\
\hline AEMBL3662162 & 322 & & .7811 & \\
\hline IEMBL & 322 & 721 & .2425 & \\
\hline HEMBL; & & & & \\
\hline HEMBL366 & 322 & 6 . & . 1101 & \\
\hline AEMBL3 & 322 & 7 & & \\
\hline AEMBL365 & 22 & 6. & 96 & \\
\hline HEMBL3S & & & 09 & 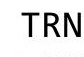 \\
\hline HEMBL3 & & & & \\
\hline HEMBL366 & 322 & 6 . & & \\
\hline HEMBL 366 & & & & \\
\hline HEMBL & 22 & 7. & 38 & Niv \\
\hline AEMBL & & & & 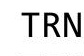 \\
\hline HEMBL & & & & \\
\hline HEMBL & & 8 & & \\
\hline AEMBL 366 & & & & 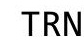 \\
\hline HEMBL3 & & & & I RN \\
\hline HEMBL & & & & RN \\
\hline HFMRI & & 5. & & \\
\hline HEMBL366 & & & & TIV \\
\hline HEMBL 366 & 22 & & & I RIV \\
\hline HEMBL3 & & 6. & & ST \\
\hline HEMBL: & & 9 & & RN \\
\hline HEMBL3 & & 39 & & $\mathrm{RN}$ \\
\hline HEMBL 3662 & & 8 & & IRN \\
\hline HEMBL3662143 & & & & ГRN \\
\hline HEMBL3 & & & 55 & $\mathrm{RN}$ \\
\hline HEMRI & & & & $\Gamma \mathrm{RN}$ \\
\hline HEMBL & & 7.9586 & & $\Gamma \mathrm{RN}$ \\
\hline HEMBL3662126 & 535322 & 6 & 31 & TRN \\
\hline AEMBL3 & & & & TRN \\
\hline HEMBL3 & & 8 . & 79 & \\
\hline CHEMBL 3 & & 9.0 & & TRN \\
\hline HEMBL3 & 535322 & 8.65 & 264 & $\Gamma \mathrm{RN}$ \\
\hline HEMBL 3662 & 535322 & 8.3979 & 366 & TRN \\
\hline $\mathrm{MPI}=$ & & & & th \\
\hline HEMBL3 & & & 5.1865 & \\
\hline CHEMBL 36621 & & 7.0969 & .6703 & \\
\hline CHEMBL3662090 & 1535322 & 8.0969 & 8.4422 & ГRN \\
\hline
\end{tabular}

Page 10209 
Supplemental Table S2.txt

\begin{tabular}{|c|c|c|c|c|c|}
\hline CHEMBL3662130 & 1535322 & 6.8539 & 7.2748 & TST & \\
\hline CHEMBL3662196 & 1535322 & 7.1308 & 6.676 & TRN & \\
\hline CHEMBL3657929 & 1535322 & 8.4437 & 7.695 & TRN & \\
\hline CHEMBL3662191 & 1535322 & 7.7212 & 8.112 & TRN & \\
\hline CHEMBL3657950 & 1535322 & 8.3979 & 8.0297 & TRN & \\
\hline CHEMBL3662226 & 1535322 & 7.8539 & 7.2742 & TST & \\
\hline CHEMBL3662159 & 1535322 & 6.6198 & 6.3942 & TRN & \\
\hline CHEMBL 3662140 & 1535322 & 7.5686 & 7.9576 & TRN & \\
\hline CHEMBL3662169 & 1535322 & 6.0 & 6.1674 & TRN & \\
\hline CHEMBL3662161 & 1535322 & 6.9586 & 6.9529 & TRN & \\
\hline CHEMBL 3657820 & 1535322 & 7.5513 & 7.9112 & TRN & \\
\hline CHEMBL3662171 & 1535322 & 5.8861 & 6.1171 & TRN & \\
\hline CHEMBL3662138 & 1535322 & 7.041 & 7.1305 & TRN & \\
\hline CHEMBL3662194 & 1535322 & 6.284 & 7.2723 & TRN & \\
\hline CHEMBL3662150 & 1535322 & 7.7212 & 7.702006 & 0000000001 & TRN \\
\hline CHEMBL3662154 & 1535322 & 7.585 & 8.0183 & TRN & \\
\hline CHEMBL3662144 & 1535322 & 6.5686 & 6.4719 & TRN & \\
\hline CHEMBL3662117 & 1535322 & 5.284 & 5.3645 & TRN & \\
\hline CHEMBL3662156 & 1535322 & 6.2147 & 6.6461 & TRN & \\
\hline CHEMBL3662192 & 1535322 & 8.699 & 8.3664 & TRN & \\
\hline CHEMBL3662229 & 1535322 & 8.5086 & 8.5273 & TRN & \\
\hline CHEMBL3662173 & 1535322 & 7.1249 & 7.4748 & TST & \\
\hline CHEMBL3657811 & 1535322 & 7.5058 & 7.0274 & TRN & \\
\hline CHEMBL3662236 & 1535322 & 9.0 & 8.8741 & TRN & \\
\hline CHEMBL3658014 & 1535322 & 7.699 & 7.5324 & TRN & \\
\hline CHEMBL3657873 & 1535322 & 7.3809 & 7.1429 & TRN & \\
\hline CHEMBL3662213 & 1535322 & 7.4949 & 7.5479 & TRN & \\
\hline CHEMBL3662104 & 1535322 & 7.4559 & 7.5955 & TRN & \\
\hline CHEMBL 3657887 & 1535322 & 8.1367 & 8.067 & TRN & \\
\hline CHEMBL3662180 & 1535322 & 7.5229 & 7.4812 & TRN & \\
\hline CHEMBL3662102 & 1535322 & 7.2076 & 6.7749 & TRN & \\
\hline CHEMBL3662137 & 1535322 & 7.699 & 7.7978 & TRN & \\
\hline CHEMBL3662153 & 1535322 & 7.1739 & 7.3333 & TRN & \\
\hline CHEMBL3662183 & 1535322 & 7.0969 & 6.9151 & TRN & \\
\hline CHEMBL3662219 & 1535322 & 6.8861 & 7.0911 & TRN & \\
\hline CHEMBL3662177 & 1535322 & 8.699 & 8.4956 & TRN & \\
\hline CHEMBL3657838 & 1535322 & 7.9706 & 8.0697 & TRN & \\
\hline CHEMBL3662172 & 1535322 & 6.1549 & 6.2424 & TRN & \\
\hline CHEMBL3662217 & 1535322 & 7.2291 & 7.3923 & TRN & \\
\hline CHEMBL3657839 & 1535322 & 8.3372 & 8.2364 & TRN & \\
\hline CHEMBL3657882 & 1535322 & 7.2749 & 7.4594 & TRN & \\
\hline CHEMBL3657822 & 1535322 & 5.6478 & 5.8371 & TRN & \\
\hline CHEMBL3662139 & 1535322 & 6.0 & 5.6706 & TRN & \\
\hline CHEMBL3890625 & 1535322 & 7.3872 & 6.7781 & TRN & \\
\hline CHEMBL3662218 & 1535322 & 7.2924 & 7.343 & TRN & \\
\hline CHEMBL3662164 & 1535322 & 7.2076 & 7.2297 & TRN & \\
\hline CHEMBL3662119 & 1535322 & 7.1024 & 7.5757 & TRN & \\
\hline CHEMBL3657845 & 1535322 & 8.4202 & 6.9066 & TST & \\
\hline
\end{tabular}


Supplemental Table S2.txt

\begin{tabular}{|c|c|c|c|c|}
\hline CHEMBL3662163 & 1535322 & 6.9208 & 6.8292 & TRN \\
\hline CHEMBL3953767 & 1535322 & 8.1549 & 7.9942 & TRN \\
\hline CHEMBL3662136 & 1535322 & 7.1549 & 7.2099 & TRN \\
\hline CHEMBL3662098 & 1535322 & 7.6383 & 7.8174 & TRN \\
\hline CHEMBL3662160 & 1535322 & 6.7696 & 6.862 & TRN \\
\hline CHEMBL3662103 & 1535322 & 7.699 & 7.4748 & TRN \\
\hline CHEMBL3662077 & 1535322 & 8.0 & 8.3851 & TRN \\
\hline CHEMBL3658005 & 1535322 & 8.301 & 8.1806 & TRN \\
\hline CHEMBL3657932 & 1535322 & 8.8539 & 8.9711 & TRN \\
\hline CHEMBL3657934 & 1535322 & 8.3665 & 8.23 & TRN \\
\hline CHEMBL3662093 & 1535322 & 8.699 & 8.7491 & TRN \\
\hline CHEMBL3657837 & 1535322 & 8.4815 & 8.2746 & TRN \\
\hline CHEMBL 3662221 & 1535322 & 7.0 & 7.1717 & TRN \\
\hline CHEMBL3894925 & 1535322 & 6.0 & 6.4475 & TST \\
\hline CHEMBL3662121 & 1535322 & 7.2757 & 6.8866 & TRN \\
\hline CHEMBL3662204 & 1535322 & 7.6383 & 7.83 & TRN \\
\hline CHEMBL3662214 & 1535322 & 7.4815 & 7.3495 & TRN \\
\hline CHEMBL3662106 & 1535322 & 6.8539 & 6.2816 & TRN \\
\hline CHEMBL3657982 & 1535322 & 7.8861 & 7.5211 & TRN \\
\hline CHEMBL3662148 & 1535322 & 7.7447 & 7.0653 & TRN \\
\hline CHEMBL3341985 & 1535322 & 8.2596 & 8.102 & TRN \\
\hline CHEMBL3662211 & 1535322 & 7.2366 & 8.06899 & 9999999999 \\
\hline CHEMBL 3657816 & 1535322 & 7.8729 & 6.6541 & TST \\
\hline CHEMBL 3662222 & 1535322 & 7.4949 & 7.6081 & TRN \\
\hline CHEMBL3662170 & 1535322 & 6.5229 & 7.3999 & TRN \\
\hline CHEMBL3657998 & 1535322 & 8.0969 & 8.161 & TRN \\
\hline CHEMBL3662207 & 1535322 & 8.0 & 7.7005 & TRN \\
\hline CHEMBL3662165 & 1535322 & 6.9208 & 7.164 & TRN \\
\hline CHEMBL3961343 & 1535322 & 7.1818 & 6.90799 & 99999999995 \\
\hline CHEMBL3657828 & 1535322 & 8.1135 & 8.1725 & TST \\
\hline CHEMBL3662151 & 1535322 & 8.0458 & 7.7884 & TST \\
\hline CHEMBL3921769 & 1535322 & 6.7447 & 7.3533 & TST \\
\hline CHEMBL 3657870 & 1535322 & 7.0685 & 7.4269 & TST \\
\hline CHEMBL3942782 & 1535322 & 7.6198 & 7.9499 & TST \\
\hline CHEMBL3662195 & 1535322 & 6.4089 & 6.8926 & TST \\
\hline CHEMBL3657834 & 1535322 & 7.7471 & 6.8108 & TST \\
\hline CHEMBL3662125 & 1535322 & 7.7212 & 7.2822 & TST \\
\hline CHEMBL3662115 & 1535322 & 5.8539 & 6.3656 & TST \\
\hline CHEMBL 3662149 & 1535322 & 7.5376 & 6.5735 & TST \\
\hline CHEMBL 3657854 & 1535322 & 8.5229 & 8.2638 & TST \\
\hline CHEMBL3657840 & 1535322 & 8.6576 & 8.475 & TST \\
\hline CHEMBL3662133 & 1535322 & 5.6021 & 5.7545 & TST \\
\hline CHEMBL3662105 & 1535322 & 7.0555 & 6.4474 & TST \\
\hline CHEMBL3935463 & 1535322 & 6.0 & 6.0534 & TST \\
\hline CHEMBL3895995 & 1535322 & 7.5686 & 6.0287 & TST \\
\hline CHEMBL3662167 & 1535322 & 7.2757 & 7.1836 & TST \\
\hline CHEMBL3662100 & 1535322 & 6.0 & 6.1274 & TST \\
\hline CHEMBL3658000 & 1535322 & 8.301 & 7.2801 & TST \\
\hline
\end{tabular}


Supplemental Table S2.txt

\begin{tabular}{|c|c|c|c|c|c|}
\hline CHEMBL 3657860 & 1535322 & 7.4647 & 7.1372 & TST & \\
\hline CHEMBL3662206 & 1535322 & 7.5528 & 7.7132 & TST & \\
\hline CHEMBL3662096 & 1535322 & 7.699 & 7.575 & TST & \\
\hline CHEMBL3910018 & 1535322 & 6.0 & 6.5475 & TST & \\
\hline CHEMBL3657936 & 1535322 & 7.9747 & 7.7596 & TST & \\
\hline CHEMBL 3657824 & 1535322 & 6.8356 & 6.2067 & TST & \\
\hline CHEMBL3731222 & 1537598 & 6.0 & 5.9456 & TRN & \\
\hline CHEMBL3727488 & 1537598 & 7.0 & 6.9374 & TRN & \\
\hline CHEMBL3733000 & 1537598 & 5.0 & 5.0403 & TRN & \\
\hline CHEMBL3732352 & 1537598 & 6.0 & 5.984 & TRN & \\
\hline CHEMBL 3730030 & 1537598 & 7.0 & 6.3791 & TST & \\
\hline CHEMBL3732696 & 1537598 & 6.0 & 6.105 & TRN & \\
\hline CHEMBL3731583 & 1537598 & 8.0 & 7.7052 & TRN & \\
\hline CHEMBL 3732270 & 1537598 & 6.0 & \multicolumn{2}{|c|}{6.337000000000001} & TRN \\
\hline CHEMBL3731633 & 1537598 & 6.0 & 6.2795 & TST & \\
\hline CHEMBL 3728548 & 1537598 & 8.0 & 7.8478 & TRN & \\
\hline CHEMBL3730792 & 1537598 & 5.0 & 5.1374 & TRN & \\
\hline CHEMBL3733186 & 1537598 & 7.0 & 7.1371 & TRN & \\
\hline CHEMBL3731302 & 1537598 & 6.0 & \multicolumn{2}{|c|}{6.252999999999999} & TRN \\
\hline CHEMBL3731848 & 1537598 & 5.0 & 5.1878 & TRN & \\
\hline CHEMBL3727756 & 1537598 & 6.0 & 5.8865 & TRN & \\
\hline CHEMBL3732646 & 1537598 & 5.0 & 6.0765 & TST & \\
\hline CHEMBL3729153 & 1537598 & 5.0 & 5.0863 & TRN & \\
\hline CHEMBL3729925 & 1537598 & 6.0 & \multicolumn{2}{|c|}{5.962999999999999} & TRN \\
\hline CHEMBL3727608 & 1537598 & 5.0 & 4.8592 & TRN & \\
\hline CHEMBL3730803 & 1537598 & 6.0 & 6.0117 & TRN & \\
\hline CHEMBL3727609 & 1537598 & 6.0 & 5.8984 & TRN & \\
\hline CHEMBL3728670 & 1537598 & 6.0 & 5.994 & TRN & \\
\hline CHEMBL 3731554 & 1537598 & 6.0 & 6.2735 & TST & \\
\hline CHEMBL3731825 & 1537598 & 7.0 & 6.6438 & TRN & \\
\hline CHEMBL3731614 & 1537598 & 7.0 & 6.5246 & TST & \\
\hline CHEMBL3727818 & 1537598 & 7.0 & 6.9429 & TRN & \\
\hline CHEMBL3731142 & 1537598 & 5.0 & 4.9629 & TRN & \\
\hline CHEMBL3728474 & 1537598 & 6.0 & 5.9466 & TRN & \\
\hline CHEMBL3732944 & 1537598 & 7.0 & 6.9815 & TRN & \\
\hline CHEMBL3733109 & 1537598 & 6.0 & 5.7164 & TST & \\
\hline CHEMBL3731914 & 1537598 & 5.0 & 5.1115 & TRN & \\
\hline CHEMBL 3728808 & 1537598 & 6.0 & 5.9151 & TRN & \\
\hline CHEMBL3728557 & 1537598 & 5.0 & 6.8186 & TST & \\
\hline CHEMBL3728850 & 1537598 & 5.0 & 4.8424 & TRN & \\
\hline CHEMBL3732255 & 1537598 & 6.0 & 5.9851 & TRN & \\
\hline CHEMBL3730394 & 1537598 & 5.0 & 6.7395 & TST & \\
\hline CHEMBL3731649 & 1537598 & 6.0 & 6.1297 & TRN & \\
\hline CHEMBL3728050 & 1537598 & 7.0 & 6.8056 & TRN & \\
\hline CHEMBL3732699 & 1537598 & 7.0 & 6.9754 & TRN & \\
\hline CHEMBL3731958 & 1537598 & 7.0 & 6.6612 & TRN & \\
\hline CHEMBL3729159 & 1537598 & 7.0 & 7.0967 & TRN & \\
\hline CHEMBL3728284 & 1537598 & 5.0 & 5.935 & TST & \\
\hline
\end{tabular}




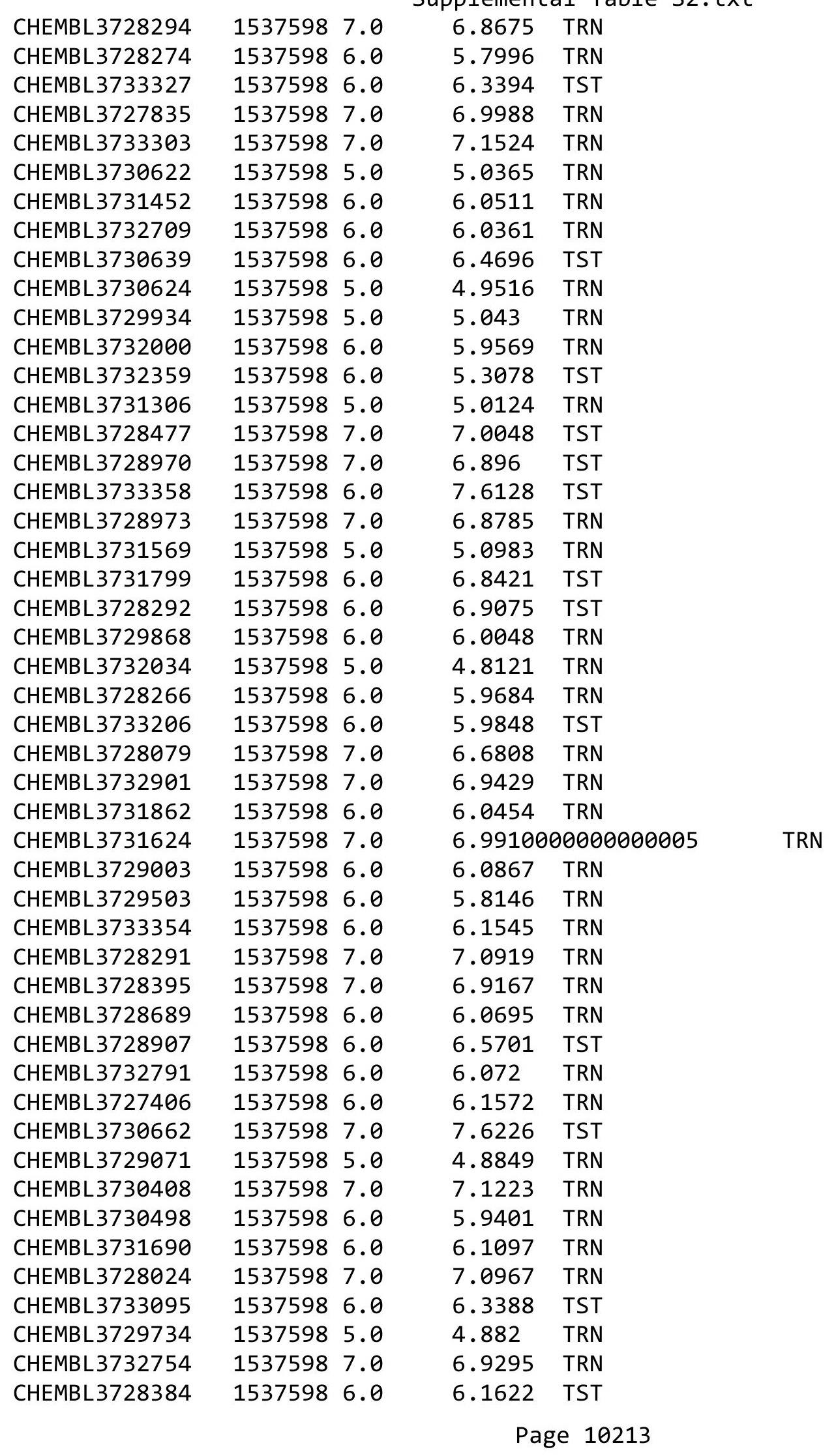




\begin{tabular}{|c|c|c|c|c|}
\hline & & & & \\
\hline CHEMBL 3728703 & 1537598 & 7.0 & 6.9539 & TRN \\
\hline CHEMBL3728146 & 1537598 & 5.0 & 7.1702 & TST \\
\hline CHEMBL3733310 & 1537598 & 6.0 & 5.9984 & TRN \\
\hline CHEMBL3730961 & 1537598 & 6.0 & 6.0303 & TRN \\
\hline CHEMBL3731728 & 1537598 & 7.0 & 6.8372 & TST \\
\hline CHEMBL3728737 & 1537598 & 6.0 & 5.5837 & TRN \\
\hline CHEMBL 3730767 & 1537598 & 6.0 & 6.932 & TST \\
\hline CHEMBL3729930 & 1537598 & 6.0 & 6.0105 & TRN \\
\hline CHEMBL3727805 & 1537598 & 5.0 & 5.0812 & TRN \\
\hline CHEMBL 3729288 & 1537598 & 6.0 & 5.954 & TRN \\
\hline CHEMBL3730597 & 1537598 & 6.0 & 5.9464 & TRN \\
\hline CHEMBL 3728676 & 1537598 & 6.0 & 5.7694 & TRN \\
\hline CHEMBL3729812 & 1537598 & 6.0 & 6.3487 & TRN \\
\hline CHEMBL3727641 & 1537598 & 5.0 & 5.1503 & TRN \\
\hline CHEMBL 3732444 & 1537598 & 7.0 & 6.8771 & TRN \\
\hline CHEMBL 3730226 & 1537598 & 6.0 & 5.8666 & TST \\
\hline CHEMBL 3727783 & 1537598 & 6.0 & 6.9616 & TST \\
\hline CHEMBL3729318 & 1537598 & 6.0 & 6.0402 & TRN \\
\hline CHEMBL3732957 & 1537598 & 6.0 & 6.0454 & TRN \\
\hline CHEMBL 3729122 & 1537598 & 6.0 & 6.0039 & TRN \\
\hline CHEMBL3728576 & 1537598 & 7.0 & 6.9626 & TRN \\
\hline CHEMBL3728068 & 1537598 & 6.0 & 6.0363 & TRN \\
\hline CHEMBL 3730443 & 1537598 & 6.0 & 6.0513 & TRN \\
\hline CHEMBL3727569 & 1537598 & 5.0 & 6.4877 & TST \\
\hline CHEMBL 3730046 & 1537598 & 6.0 & 6.5237 & TST \\
\hline CHEMBL3733036 & 1537598 & 7.0 & 6.9775 & TRN \\
\hline CHEMBL 3733020 & 1537598 & 6.0 & 7.0854 & TST \\
\hline CHEMBL3732036 & 1537598 & 5.0 & 4.9901 & TRN \\
\hline CHEMBL3728698 & 1537598 & 6.0 & 6.1516 & TST \\
\hline CHEMBL 3732346 & 1537598 & 7.0 & 6.9539 & TRN \\
\hline CHEMBL3727951 & 1537598 & 5.0 & 6.4586 & TST \\
\hline CHEMBL 3732827 & 1537598 & 6.0 & 6.0858 & TRN \\
\hline CHEMBL 3733184 & 1537598 & 7.0 & 7.0927 & TRN \\
\hline CHEMBL3732937 & 1537598 & 6.0 & 6.1374 & TRN \\
\hline CHEMBL 3729835 & 1537598 & 5.0 & 5.0695 & TRN \\
\hline CHEMBL3729415 & 1537598 & 6.0 & 6.1155 & TRN \\
\hline CHEMBL 3732226 & 1537598 & 6.0 & 6.3042 & TRN \\
\hline CHEMBL3728311 & 1537598 & 6.0 & 6.0172 & TRN \\
\hline CHEMBL3731709 & 1537598 & 6.0 & 6.126 & TST \\
\hline CHEMBL 3728584 & 1537598 & 7.0 & 6.8295 & TRN \\
\hline CHEMBL3731001 & 1537598 & 7.0 & 6.8652 & TRN \\
\hline CHEMBL3731304 & 1537598 & 6.0 & 5.8675 & TRN \\
\hline CHEMBL3729171 & 1537598 & 5.0 & 4.9907 & TRN \\
\hline CHEMBL3729587 & 1537598 & 6.0 & 6.70200 & 0000000001 \\
\hline CHEMBL 3727537 & 1537598 & 6.0 & 6.4184 & TRN \\
\hline CHEMBL 3731387 & 1537598 & 6.0 & 5.8603 & TRN \\
\hline CHEMBL 3730554 & 1537598 & 6.0 & 6.2098 & TRN \\
\hline CHEMBL3732514 & 1537598 & 7.0 & 7.4873 & TRN \\
\hline
\end{tabular}




\begin{tabular}{|c|c|c|c|c|}
\hline \multicolumn{5}{|c|}{ Supplemental Table S2.txt } \\
\hline CHEMBL3729554 & 1537598 & 6.0 & 5.8298 & TRN \\
\hline CHEMBL 3728773 & 1537598 & 5.0 & 5.0248 & TRN \\
\hline CHEMBL3731552 & 1537598 & 7.0 & 6.3399 & TST \\
\hline CHEMBL3730295 & 1537598 & 6.0 & 6.3675 & TST \\
\hline CHEMBL3731450 & 1537598 & 6.0 & 5.9751 & TST \\
\hline CHEMBL3728060 & 1537598 & 3.2218 & 3.2305 & TRN \\
\hline CHEMBL 3728642 & 1537598 & 5.0 & 5.0472 & TRN \\
\hline CHEMBL3971807 & 1637152 & 6.301 & 5.2354 & TRN \\
\hline CHEMBL3955478 & 1637152 & 5.301 & 5.2334 & TRN \\
\hline CHEMBL3935100 & 1637152 & 6.301 & 5.2651 & TRN \\
\hline CHEMBL3940360 & 1637152 & 4.0 & 4.3853 & TRN \\
\hline CHEMBL 3954978 & 1637152 & 5.301 & 5.1939 & TST \\
\hline CHEMBL3933168 & 1637152 & 6.301 & 5.1688 & TRN \\
\hline CHEMBL3941703 & 1637152 & 4.0 & 4.5302 & TRN \\
\hline CHEMBL3968095 & 1637152 & 5.301 & 5.0658 & TRN \\
\hline CHEMBL 3890467 & 1637152 & 5.301 & 4.4343 & TRN \\
\hline CHEMBL3985717 & 1637152 & 6.301 & 5.1276 & TST \\
\hline CHEMBL3945707 & 1637152 & 5.301 & 4.8936 & TST \\
\hline CHEMBL 3944290 & 1637152 & 4.0 & 4.5104 & TRN \\
\hline CHEMBL3941565 & 1637152 & 4.0 & 5.0863 & TST \\
\hline CHEMBL3958968 & 1637152 & 4.0 & 5.0902 & TST \\
\hline CHEMBL3949599 & 1637152 & 5.301 & 4.3927 & TRN \\
\hline CHEMBL 3919966 & 1637152 & 5.301 & 5.1207 & TRN \\
\hline CHEMBL3968167 & 1637152 & 4.0 & 4.4825 & TRN \\
\hline CHEMBL3904333 & 1637152 & 4.0 & 5.1403 & TRN \\
\hline CHEMBL3942381 & 1637152 & 5.301 & 5.1608 & TRN \\
\hline CHEMBL3928075 & 1637152 & 4.0 & 5.0313 & TRN \\
\hline CHEMBL 3979042 & 1637152 & 5.301 & 4.8852 & TST \\
\hline CHEMBL 3981313 & 1637152 & 4.0 & 4.3689 & TRN \\
\hline CHEMBL3952336 & 1637152 & 6.301 & 4.8988 & TST \\
\hline CHEMBL3977421 & 1637152 & 6.301 & 4.5028 & TRN \\
\hline CHEMBL 3942988 & 1637152 & 4.0 & 4.485 & TRN \\
\hline CHEMBL3956999 & 1637152 & 5.301 & 4.6425 & TRN \\
\hline CHEMBL 3957835 & 1637152 & 4.0 & 4.501 & TRN \\
\hline CHEMBL3911079 & 1637152 & 4.0 & 4.886 & TST \\
\hline CHEMBL3949992 & 1637152 & 5.301 & 5.2105 & TST \\
\hline CHEMBL3928847 & 1637152 & 4.0 & 4.2087 & TRN \\
\hline CHEMBL3917210 & 1637152 & 5.301 & 4.9487 & TST \\
\hline CHEMBL 3899027 & 1637152 & 4.0 & 5.0898 & TRN \\
\hline CHEMBL3912374 & 1637152 & 5.301 & 5.1813 & TRN \\
\hline CHEMBL3904980 & 1637152 & 5.301 & 4.5939 & TRN \\
\hline CHEMBL 3971789 & 1637152 & 4.0 & 4.4358 & TRN \\
\hline CHEMBL3921859 & 1637152 & 5.301 & 5.0821 & TRN \\
\hline CHEMBL3893235 & 1637152 & 4.0 & 4.3037 & TRN \\
\hline CHEMBL 3981784 & 1637152 & 4.0 & 4.9673 & TRN \\
\hline CHEMBL3914107 & 1637152 & 4.0 & 4.2194 & TRN \\
\hline CHEMBL3904681 & 1637152 & 4.0 & 4.4576 & TRN \\
\hline CHEMBL 3918722 & 1637152 & 5.301 & 4.6933 & TRN \\
\hline
\end{tabular}


Supplemental Table S2.txt

\begin{tabular}{|c|c|c|c|c|c|}
\hline CHEMBL3934437 & 1637152 & 4.0 & 4.3679 & TST & \\
\hline CHEMBL 3968497 & 1637152 & 4.0 & 4.5033 & TRN & \\
\hline CHEMBL3907089 & 1637152 & 4.0 & 5.1264 & TRN & \\
\hline CHEMBL3948750 & 1637152 & 6.301 & 4.6116 & TRN & \\
\hline CHEMBL3928507 & 1637152 & 5.301 & 5.1789 & TRN & \\
\hline CHEMBL3969082 & 1637152 & 6.301 & 5.3 & TRN & \\
\hline CHEMBL3896422 & 1637152 & 4.0 & 4.4878 & TST & \\
\hline CHEMBL3903656 & 1637152 & 4.0 & 4.2593 & TRN & \\
\hline CHEMBL3923610 & 1637152 & 5.301 & 5.001 & TRN & \\
\hline CHEMBL3967303 & 1637152 & 4.0 & 4.5441 & TRN & \\
\hline CHEMBL3985076 & 1637152 & 6.301 & 5.1079 & TRN & \\
\hline CHEMBL3916725 & 1637152 & 6.301 & 4.6377 & TRN & \\
\hline CHEMBL3979361 & 1637152 & 5.301 & 5.195 & TRN & \\
\hline CHEMBL3964025 & 1637152 & 4.0 & 5.1635 & TRN & \\
\hline CHEMBL3931676 & 1637152 & 5.301 & 4.5814 & TRN & \\
\hline CHEMBL3945059 & 1637152 & 4.0 & 4.8797 & TRN & \\
\hline CHEMBL3913674 & 1637152 & 6.301 & 4.9939 & TST & \\
\hline CHEMBL 3897700 & 1637152 & 5.301 & 5.1668 & TRN & \\
\hline CHEMBL3896039 & 1637152 & 6.301 & 4.9631 & TST & \\
\hline CHEMBL3899285 & 1637152 & 4.0 & 5.1718 & TRN & \\
\hline CHEMBL3954395 & 1637152 & 6.301 & 4.637 & TRN & \\
\hline CHEMBL3968460 & 1637152 & 6.301 & 5.0626 & TRN & \\
\hline CHEMBL3904645 & 1637152 & 5.301 & 5.1914 & TRN & \\
\hline CHEMBL3951586 & 1637152 & 4.0 & 4.1399 & TST & \\
\hline CHEMBL3926189 & 1637152 & 4.0 & 4.6018 & TST & \\
\hline CHEMBL3948349 & 1637152 & 5.301 & 4.9749 & TST & \\
\hline CHEMBL3981425 & 1637152 & 5.301 & 5.2089 & TRN & \\
\hline CHEMBL3979607 & 1637152 & 4.0 & 4.4871 & TST & \\
\hline CHEMBL3907402 & 1637152 & 6.301 & 5.2594 & TRN & \\
\hline CHEMBL3939013 & 1637152 & 4.0 & 4.4707 & TRN & \\
\hline CHEMBL3947313 & 1637152 & 4.0 & 5.13299 & 9999999999 & TRN \\
\hline CHEMBL3920821 & 1637152 & 5.301 & 5.0138 & TRN & \\
\hline CHEMBL3966021 & 1637152 & 4.0 & 4.1187 & TST & \\
\hline CHEMBL3956565 & 1637152 & 5.301 & 4.2911 & TST & \\
\hline CHEMBL3917962 & 1637152 & 4.0 & 4.7528 & TRN & \\
\hline CHEMBL3919462 & 1637152 & 5.301 & 4.49 & TRN & \\
\hline CHEMBL 3896589 & 1637152 & 4.0 & 5.1388 & TRN & \\
\hline CHEMBL3980636 & 1637152 & 4.0 & 4.4825 & TRN & \\
\hline CHEMBL 3935744 & 1637152 & 4.0 & 4.9231 & TRN & \\
\hline CHEMBL3895266 & 1637152 & 4.0 & 4.3963 & TRN & \\
\hline CHEMBL3890797 & 1637152 & 4.0 & 4.338 & TST & \\
\hline CHEMBL 3899101 & 1637152 & 4.0 & 4.2403 & TST & \\
\hline CHEMBL3986998 & 1637152 & 4.0 & 4.7243 & TRN & \\
\hline CHEMBL3932389 & 1637152 & 4.0 & 5.1286 & TRN & \\
\hline CHEMBL3314930 & 1452898 & 3.5229 & 3.0537 & TRN & \\
\hline CHEMBL3314894 & 1452898 & 4.0 & 4.3423 & TRN & \\
\hline CHEMBL3314872 & 1452898 & 3.5229 & 4.1493 & TRN & \\
\hline CHEMBL3314912 & 1452898 & 4.0 & 3.3122 & TRN & \\
\hline
\end{tabular}


Supplemental Table S2.txt

\begin{tabular}{|c|c|c|c|c|c|}
\hline CHEMBL3314915 & 1452898 & 4.0 & 3.4633 & TRN & \\
\hline CHEMBL3314926 & 1452898 & 3.5229 & 4.0464 & TRN & \\
\hline CHEMBL3314875 & 1452898 & 5.6925 & 5.4941 & TST & \\
\hline CHEMBL324735 & 1452898 & 6.6536 & 4.1658 & TST & \\
\hline CHEMBL 3314904 & 1452898 & 4.0 & 4.4483 & TRN & \\
\hline CHEMBL3314892 & 1452898 & 5.6459 & 4.9411 & TRN & \\
\hline CHEMBL3314880 & 1452898 & 3.5229 & 4.0542 & TRN & \\
\hline CHEMBL3314889 & 1452898 & 4.0 & 4.6566 & TRN & \\
\hline CHEMBL3314895 & 1452898 & 5.6003 & 4.802 & TRN & \\
\hline CHEMBL3314920 & 1452898 & 4.0 & 3.8779 & TST & \\
\hline CHEMBL3314922 & 1452898 & 4.0 & 3.2097 & TRN & \\
\hline CHEMBL3314893 & 1452898 & 5.3354 & 4.7311 & TRN & \\
\hline CHEMBL 3314870 & 1452898 & 3.5229 & 4.3103 & TRN & \\
\hline CHEMBL3314896 & 1452898 & 5.0 & 5.1005 & TRN & \\
\hline CHEMBL 3314916 & 1452898 & 4.0 & 3.9699 & TRN & \\
\hline CHEMBL3314921 & 1452898 & 4.0 & 3.4422 & TST & \\
\hline CHEMBL3314911 & 1452898 & 4.0 & 4.4483 & TRN & \\
\hline CHEMBL3314905 & 1452898 & 4.0 & 4.2358 & TST & \\
\hline CHEMBL3314913 & 1452898 & 5.1457 & 4.9407 & TRN & \\
\hline CHEMBL 3314891 & 1452898 & 4.0 & 4.4304 & TRN & \\
\hline CHEMBL136689 & 1452898 & 4.0 & 5.3487 & TST & \\
\hline CHEMBL3314897 & 1452898 & 5.3179 & 5.0322 & TRN & \\
\hline CHEMBL3314901 & 1452898 & 3.5229 & 4.3679 & TRN & \\
\hline CHEMBL3314910 & 1452898 & 4.0 & 3.6307 & TST & \\
\hline CHEMBL 3314927 & 1452898 & 3.5229 & 3.8624 & TRN & \\
\hline CHEMBL3314899 & 1452898 & 5.7878 & 5.3144 & TRN & \\
\hline CHEMBL3314898 & 1452898 & 5.7055 & 5.2988 & TRN & \\
\hline CHEMBL3314914 & 1452898 & 4.0 & 4.6056 & TRN & \\
\hline CHEMBL3314918 & 1452898 & 4.0 & 3.5128 & TRN & \\
\hline CHEMBL3314881 & 1452898 & 3.5229 & 3.3206 & TRN & \\
\hline CHEMBL3314890 & 1452898 & 5.0 & 4.7731 & TRN & \\
\hline CHEMBL3314906 & 1452898 & 4.0 & 3.8873 & TST & \\
\hline CHEMBL3314873 & 1452898 & 5.6038 & 5.0855 & TRN & \\
\hline CHEMBL 3314882 & 1452898 & 3.5229 & 4.2276 & TRN & \\
\hline CHEMBL 3314887 & 1452898 & 5.6108 & 5.003 & TRN & \\
\hline CHEMBL3314888 & 1452898 & 5.5143 & 5.1612 & TRN & \\
\hline CHEMBL 3314900 & 1452898 & 5.6904 & 5.2441 & TRN & \\
\hline CHEMBL3314928 & 1452898 & 3.5229 & 4.0591 & TRN & \\
\hline CHEMBL3314923 & 1452898 & 4.0 & 3.9106 & TRN & \\
\hline CHEMBL3314925 & 1452898 & 3.5229 & 3.9662 & TRN & \\
\hline CHEMBL 3314876 & 1452898 & 5.9547 & 5.28799 & 9999999999 & TRN \\
\hline CHEMBL 3314871 & 1452898 & 4.8761 & 5.0131 & TRN & \\
\hline CHEMBL3314902 & 1452898 & 3.5229 & 3.9615 & TRN & \\
\hline CHEMBL3314929 & 1452898 & 3.5229 & 3.3286 & TRN & \\
\hline CHEMBL 3314908 & 1452898 & 4.0 & 4.5551 & TRN & \\
\hline CHEMBL3314919 & 1452898 & 4.0 & 3.3316 & TRN & \\
\hline CHEMBL 3314885 & 1452898 & 3.5229 & 3.694 & TRN & \\
\hline CHEMBL 3314903 & 1452898 & 4.5229 & 4.8458 & TRN & \\
\hline
\end{tabular}

Page 10217 
Supplemental Table S2.txt

\begin{tabular}{|c|c|c|c|c|c|}
\hline CHEMBL3314874 & 1452898 & 3.5229 & 4.4851 & TRN & \\
\hline CHEMBL3313941 & 1452898 & 5.2741 & 5.0347 & TRN & \\
\hline CHEMBL3314909 & 1452898 & 4.0 & 4.323 & TRN & \\
\hline CHEMBL3314917 & 1452898 & 4.0 & 3.4126 & TRN & \\
\hline CHEMBL3314884 & 1452898 & 3.5229 & 3.7956 & TST & \\
\hline CHEMBL3314878 & 1452898 & 3.5229 & 3.8221 & TST & \\
\hline CHEMBL3314879 & 1452898 & 5.3152 & 4.4078 & TST & \\
\hline CHEMBL3314907 & 1452898 & 4.0 & 3.8104 & TST & \\
\hline CHEMBL 3314883 & 1452898 & 5.7212 & 4.1864 & TST & \\
\hline CHEMBL3314924 & 1452898 & 4.0 & 4.2212 & TST & \\
\hline CHEMBL3314877 & 1452898 & 5.9281 & 4.2451 & TST & \\
\hline CHEMBL3314886 & 1452898 & 3.5229 & 2.8631 & TST & \\
\hline CHEMBL419884 & 48815 & 7.4089 & 7.4554 & TST & \\
\hline CHEMBL318660 & 48815 & 6.5003 & 6.4899 & TRN & \\
\hline CHEMBL317533 & 48815 & 6.6326 & 6.6464 & TRN & \\
\hline CHEMBL328654 & 48815 & 5.8085 & 5.8632 & TRN & \\
\hline CHEMBL94439 & 48815 & 6.2218 & 5.8953 & TST & \\
\hline CHEMBL94658 & 48815 & 7.3188 & 7.3361 & TRN & \\
\hline CHEMBL415497 & 48815 & 7.0655 & 7.0191 & TRN & \\
\hline CHEMBL97678 & 48815 & 4.0 & 5.0948 & TST & \\
\hline CHEMBL96323 & 48815 & 7.1249 & 7.1327 & TRN & \\
\hline CHEMBL96605 & 48815 & 6.8539 & 6.8684 & TRN & \\
\hline CHEMBL316628 & 48815 & 7.699 & 7.7233 & TRN & \\
\hline CHEMBL419325 & 48815 & 6.9066 & 6.9425 & TRN & \\
\hline CHEMBL91977 & 48815 & 5.9776 & 5.9552 & TRN & \\
\hline CHEMBL92144 & 48815 & 7.2924 & 7.2607 & TRN & \\
\hline CHEMBL94530 & 48815 & 6.5784 & 6.5529 & TRN & \\
\hline CHEMBL96434 & 48815 & 7.7447 & 7.6318 & TRN & \\
\hline CHEMBL96372 & 48815 & 7.5376 & 7.4989 & TRN & \\
\hline CHEMBL420622 & 48815 & 7.5528 & 7.5231 & TRN & \\
\hline CHEMBL421183 & 48815 & 6.2306 & 6.2435 & TRN & \\
\hline CHEMBL94436 & 48815 & 7.3872 & 7.3665 & TRN & \\
\hline CHEMBL97784 & 48815 & 5.6031 & 5.5396 & TRN & \\
\hline CHEMBL315645 & 48815 & 6.3768 & 6.3146 & TRN & \\
\hline CHEMBL98240 & 48815 & 6.6925 & 6.6562 & TRN & \\
\hline CHEMBL330562 & 48815 & 5.4752 & 5.5274 & TRN & \\
\hline CHEMBL327922 & 48815 & 6.0132 & 6.0679 & TRN & \\
\hline CHEMBL317594 & 48815 & 6.5031 & 6.5271 & TRN & \\
\hline CHEMBL432391 & 48815 & 7.4318 & 7.416 & TRN & \\
\hline CHEMBL330141 & 48815 & 7.3872 & 7.492006 & 2000000001 & TRN \\
\hline CHEMBL431419 & 48815 & 7.4318 & 7.4395 & TRN & \\
\hline CHEMBL318015 & 48815 & 5.7537 & 5.7918 & TRN & \\
\hline CHEMBL96651 & 48815 & 7.2147 & 7.2549 & TRN & \\
\hline CHEMBL316481 & 48815 & 5.3368 & 5.3273 & TRN & \\
\hline CHEMBL92928 & 48815 & 7.301 & 7.229 & TRN & \\
\hline CHEMBL94399 & 48815 & 4.0 & 5.0229 & TST & \\
\hline CHEMBL92613 & 48815 & 7.4437 & 7.4291 & TRN & \\
\hline CHEMBL97664 & 48815 & 5.3438 & 5.3287 & TST & \\
\hline
\end{tabular}




\begin{tabular}{|c|c|c|c|c|c|}
\hline & & \multicolumn{4}{|c|}{ Supplemental Table S2.txt } \\
\hline CHEMBL92132 & 48815 & 7.301 & 7.3315 & TRN & \\
\hline CHEMBL318935 & 48815 & 6.58 & 6.5781 & TRN & \\
\hline CHEMBL421560 & 48815 & 6.0223 & 6.0149 & TRN & \\
\hline CHEMBL94721 & 48815 & 6.9586 & 6.9486 & TRN & \\
\hline CHEMBL94651 & 48815 & 6.5129 & 6.5055 & TRN & \\
\hline CHEMBL 318890 & 48815 & 8.0 & 8.0849 & TRN & \\
\hline CHEMBL327161 & 48815 & 7.699 & 7.6304 & TRN & \\
\hline CHEMBL432214 & 48815 & 6.6861 & 6.6457 & TRN & \\
\hline CHEMBL96495 & 48815 & 7.2676 & 7.353 & TRN & \\
\hline CHEMBL94904 & 48815 & 6.9914 & 6.9998 & TRN & \\
\hline CHEMBL420078 & 48815 & 6.9747 & 7.0053 & TST & \\
\hline CHEMBL97341 & 48815 & 4.0 & 5.1452 & TST & \\
\hline CHEMBL92616 & 48815 & 6.9031 & 6.8929 & TRN & \\
\hline CHEMBL97473 & 48815 & 7.1192 & 7.1366 & TRN & \\
\hline CHEMBL318709 & 48815 & 7.2441 & 7.24799 & 9999999999 & TRN \\
\hline CHEMBL328611 & 48815 & 7.1487 & 7.1739 & TRN & \\
\hline CHEMBL 97583 & 48815 & 7.3565 & 7.1681 & TST & \\
\hline CHEMBL94605 & 48815 & 6.1475 & 6.1783 & TST & \\
\hline CHEMBL95148 & 48815 & 7.3979 & 7.1731 & TST & \\
\hline CHEMBL94696 & 48815 & 6.8069 & 6.9627 & TST & \\
\hline CHEMBL97839 & 48815 & 5.7142 & 5.9906 & TST & \\
\hline CHEMBL94781 & 48815 & 6.1871 & 5.9461 & TST & \\
\hline CHEMBL96129 & 48815 & 7.8861 & 7.6377 & TST & \\
\hline CHEMBL 329525 & 48815 & 7.8861 & 7.9822 & TST & \\
\hline CHEMBL327253 & 48815 & 5.8091 & 5.7134 & TST & \\
\hline CHEMBL3899517 & 1641090 & 5.3279 & 4.4548 & TST & \\
\hline CHEMBL 3985122 & 1641090 & 4.0 & 4.3589 & TRN & \\
\hline CHEMBL3965996 & 1641090 & 5.0 & 4.6245 & TRN & \\
\hline CHEMBL 3922983 & 1641090 & 4.0 & 3.9672 & TRN & \\
\hline CHEMBL3905124 & 1641090 & 4.0 & 3.8659 & TRN & \\
\hline CHEMBL 3932405 & 1641090 & 4.0 & 4.3211 & TRN & \\
\hline CHEMBL 3941624 & 1641090 & 4.0 & 3.8039 & TRN & \\
\hline CHEMBL 3900760 & 1641090 & 4.0 & 3.8901 & TRN & \\
\hline CHEMBL3983503 & 1641090 & 5.1249 & 4.4846 & TRN & \\
\hline CHEMBL3904307 & 1641090 & 4.0 & 4.1956 & TRN & \\
\hline CHEMBL3954041 & 1641090 & 5.2518 & 4.5698 & TST & \\
\hline CHEMBL3954882 & 1641090 & 4.0 & 4.3948 & TST & \\
\hline CHEMBL 3972346 & 1641090 & 4.0 & 4.6108 & TRN & \\
\hline CHEMBL3911957 & 1641090 & 5.1135 & 4.3533 & TRN & \\
\hline CHEMBL3915715 & 1641090 & 4.0 & 3.8236 & TRN & \\
\hline CHEMBL 3930487 & 1641090 & 4.0 & 4.3668 & TRN & \\
\hline CHEMBL3979372 & 1641090 & 4.0 & 4.319 & TRN & \\
\hline CHEMBL3976308 & 1641090 & 5.4318 & 4.9591 & TRN & \\
\hline CHEMBL3911020 & 1641090 & 4.0 & 3.946 & TRN & \\
\hline CHEMBL3953778 & 1641090 & 4.0 & 4.4533 & TRN & \\
\hline CHEMBL3901799 & 1641090 & 4.0 & 4.6901 & TRN & \\
\hline CHEMBL 3946450 & 1641090 & 4.0 & 4.1258 & TRN & \\
\hline CHEMBL 3942437 & 1641090 & 4.0 & 4.1416 & TRN & \\
\hline
\end{tabular}




\begin{tabular}{|c|c|c|c|c|}
\hline \multirow[b]{2}{*}{ CHEMBL3909162 } & \multicolumn{4}{|c|}{ Supplemental Table S2.txt } \\
\hline & 1641090 & 4.0 & 5.4973 & TST \\
\hline CHEMBL3937012 & 1641090 & 4.0 & 4.1445 & TRN \\
\hline CHEMBL 3976464 & 1641090 & 4.0 & 4.2303 & TRN \\
\hline CHEMBL3974793 & 1641090 & 4.0 & 4.1579 & TRN \\
\hline CHEMBL3968374 & 1641090 & 4.0 & 3.8919 & TRN \\
\hline CHEMBL3930711 & 1641090 & 4.0 & 3.887 & TRN \\
\hline CHEMBL3938829 & 1641090 & 5.1192 & 4.4734 & TRN \\
\hline CHEMBL3921913 & 1641090 & 4.0 & 3.8731 & TRN \\
\hline CHEMBL3963233 & 1641090 & 5.4437 & 4.7687 & TRN \\
\hline CHEMBL3927690 & 1641090 & 4.0 & 4.2626 & TRN \\
\hline CHEMBL3950563 & 1641090 & 4.0 & 4.0286 & TRN \\
\hline CHEMBL3909215 & 1641090 & 4.0 & 4.0867 & TRN \\
\hline CHEMBL 3916435 & 1641090 & 4.0 & 4.1462 & TRN \\
\hline CHEMBL3924027 & 1641090 & 4.0 & 4.3619 & TRN \\
\hline CHEMBL3952973 & 1641090 & 4.0 & 4.3132 & TST \\
\hline CHEMBL3962551 & 1641090 & 5.5376 & 5.0402 & TST \\
\hline CHEMBL3966756 & 1641090 & 5.1549 & 4.8063 & TRN \\
\hline CHEMBL3909690 & 1641090 & 4.0 & 4.4665 & TRN \\
\hline CHEMBL3980108 & 1641090 & 4.0 & 4.1928 & TRN \\
\hline CHEMBL3956782 & 1641090 & 4.0 & 4.4419 & TRN \\
\hline CHEMBL3919496 & 1641090 & 4.0 & 4.4813 & TRN \\
\hline CHEMBL3899667 & 1641090 & 4.0 & 4.0603 & TRN \\
\hline CHEMBL3906092 & 1641090 & 4.0 & 4.3798 & TST \\
\hline CHEMBL 3960440 & 1641090 & 4.0 & 4.079 & TRN \\
\hline CHEMBL 3924402 & 1641090 & 5.0044 & 4.8263 & TRN \\
\hline CHEMBL3959028 & 1641090 & 5.4202 & 4.5686 & TRN \\
\hline CHEMBL3951729 & 1641090 & 4.0 & 3.6714 & TRN \\
\hline CHEMBL3917930 & 1641090 & 4.0 & 3.8106 & TRN \\
\hline CHEMBL3960146 & 1641090 & 5.6576 & 6.0875 & TRN \\
\hline CHEMBL3906141 & 1641090 & 4.0 & 4.1592 & TRN \\
\hline CHEMBL3976765 & 1641090 & 4.0 & 4.3539 & TRN \\
\hline CHEMBL3931962 & 1641090 & 5.2147 & 4.8017 & TRN \\
\hline CHEMBL3905366 & 1641090 & 4.0 & 4.3759 & TRN \\
\hline CHEMBL 3946201 & 1641090 & 4.0 & 4.0531 & TRN \\
\hline CHEMBL 3944372 & 1641090 & 4.0 & 3.88 & TRN \\
\hline CHEMBL3945385 & 1641090 & 5.1427 & 4.7326 & TRN \\
\hline CHEMBL3933918 & 1641090 & 5.7959 & 5.4893 & TST \\
\hline CHEMBL3893526 & 1641090 & 4.0 & 3.873 & TRN \\
\hline CHEMBL 3933551 & 1641090 & 4.0 & 4.0986 & TRN \\
\hline CHEMBL 3938425 & 1641090 & 5.2007 & 5.1422 & TRN \\
\hline CHEMBL3976494 & 1641090 & 4.0 & 4.032 & TST \\
\hline CHEMBL3938219 & 1641090 & 4.0 & 3.8331 & TRN \\
\hline CHEMBL3982425 & 1641090 & 4.0 & 4.2538 & TRN \\
\hline CHEMBL 3894987 & 1641090 & 4.0 & 4.2519 & TRN \\
\hline CHEMBL3923740 & 1641090 & 4.0 & 4.1997 & TRN \\
\hline CHEMBL3915003 & 1641090 & 4.0 & 4.2146 & TRN \\
\hline CHEMBL3956924 & 1641090 & 5.0458 & 4.3604 & TRN \\
\hline CHEMBL3962188 & 1641090 & 4.0 & 4.1288 & TRN \\
\hline
\end{tabular}




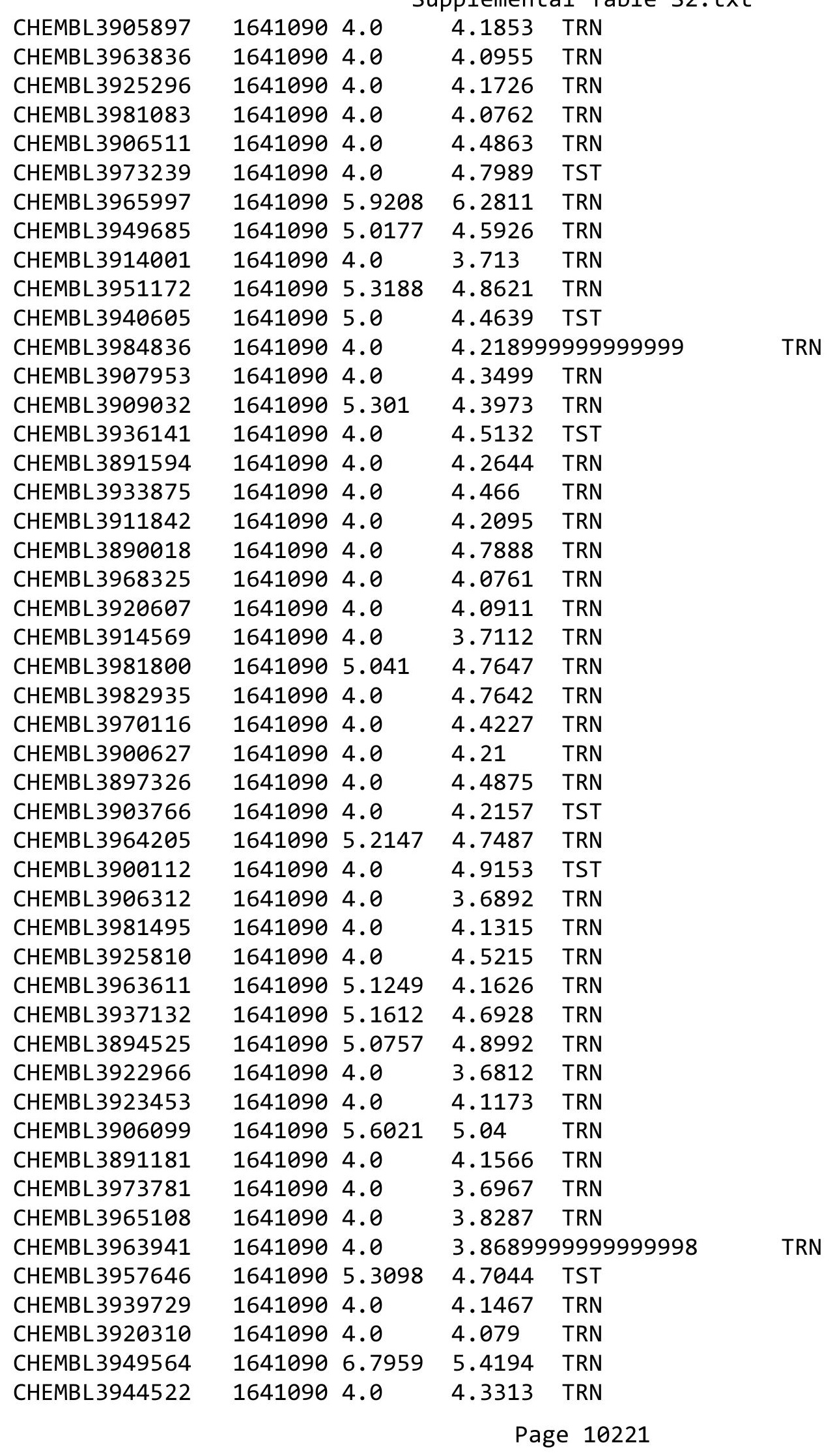


Supplemental Table S2.txt

\begin{tabular}{|c|c|c|c|c|c|}
\hline CHEMBL3946061 & 1641090 & 4.0 & 4.1473 & TRN & \\
\hline CHEMBL3934123 & 1641090 & 5.5376 & 5.4217 & TRN & \\
\hline CHEMBL3945815 & 1641090 & 4.0 & 3.7711 & TRN & \\
\hline CHEMBL3975256 & 1641090 & 4.0 & 4.5011 & TRN & \\
\hline CHEMBL3890122 & 1641090 & 4.0 & 4.715 & TRN & \\
\hline CHEMBL3963051 & 1641090 & 5.4685 & 4.9488 & TRN & \\
\hline CHEMBL 3897600 & 1641090 & 5.2007 & 4.8004 & TRN & \\
\hline CHEMBL3983810 & 1641090 & 4.0 & 3.7219 & TRN & \\
\hline CHEMBL3906296 & 1641090 & 4.0 & 4.4202 & TST & \\
\hline CHEMBL3893772 & 1641090 & 5.0655 & 4.355 & TRN & \\
\hline CHEMBL3967973 & 1641090 & 4.0 & 4.5536 & TST & \\
\hline CHEMBL3975470 & 1641090 & 5.0 & 5.3338 & TRN & \\
\hline CHEMBL3981767 & 1641090 & 4.0 & 3.9687 & TRN & \\
\hline CHEMBL3909665 & 1641090 & 5.0269 & 4.8395 & TRN & \\
\hline CHEMBL3919885 & 1641090 & 4.0 & 4.6341 & TST & \\
\hline CHEMBL3915184 & 1641090 & 4.0 & 4.3057 & TRN & \\
\hline CHEMBL3968476 & 1641090 & 5.1487 & 4.5267 & TRN & \\
\hline CHEMBL3909502 & 1641090 & 4.0 & 4.1901 & TRN & \\
\hline CHEMBL3936497 & 1641090 & 4.0 & 3.8832 & TRN & \\
\hline CHEMBL3939046 & 1641090 & 4.0 & 4.5995 & TST & \\
\hline CHEMBL3931095 & 1641090 & 5.4318 & 5.3995 & TRN & \\
\hline CHEMBL 3948130 & 1641090 & 4.0 & 4.1818 & TRN & \\
\hline CHEMBL3908476 & 1641090 & 4.0 & 4.6242 & TRN & \\
\hline CHEMBL3895464 & 1641090 & 4.0 & 4.0827 & TST & \\
\hline CHEMBL3967957 & 1641090 & 4.0 & 4.2727 & TST & \\
\hline CHEMBL3942375 & 1641090 & 4.0 & 4.1878 & TRN & \\
\hline CHEMBL3981020 & 1641090 & 4.0 & 4.207 & TRN & \\
\hline CHEMBL3952562 & 1641090 & 5.0 & \multicolumn{2}{|c|}{4.9830000000000005} & TST \\
\hline CHEMBL3901266 & 1641090 & 5.0044 & 4.6566 & TRN & \\
\hline CHEMBL3922841 & 1641090 & 4.0 & 4.2674 & TRN & \\
\hline CHEMBL3963612 & 1641090 & 4.0 & 4.8207 & TST & \\
\hline CHEMBL3971915 & 1641090 & 4.0 & 3.8407 & TRN & \\
\hline CHEMBL3959923 & 1641090 & 4.0 & 4.9877 & TST & \\
\hline CHEMBL3960087 & 1641090 & 4.0 & 3.8177 & TRN & \\
\hline CHEMBL3891007 & 1641090 & 4.0 & 4.3067 & TRN & \\
\hline CHEMBL3928260 & 1641090 & 5.0 & 4.4303 & TST & \\
\hline CHEMBL3981977 & 1641090 & 4.0 & 4.1984 & TRN & \\
\hline CHEMBL 3970380 & 1641090 & 4.0 & 4.3701 & TRN & \\
\hline CHEMBL3974980 & 1641090 & 4.0 & \multicolumn{2}{|c|}{3.9130000000000003} & TRN \\
\hline CHEMBL3924046 & 1641090 & 5.2924 & 4.7052 & TRN & \\
\hline CHEMBL3919022 & 1641090 & 4.0 & 4.0327 & TST & \\
\hline CHEMBL3941438 & 1641090 & 5.0315 & 4.4685 & TST & \\
\hline CHEMBL3960197 & 1641090 & 5.0757 & 4.4352 & TST & \\
\hline CHEMBL3898464 & 1641090 & 4.0 & 4.3602 & TST & \\
\hline CHEMBL3983769 & 1641090 & 4.0 & 4.1481 & TST & \\
\hline CHEMBL3920714 & 1641090 & 4.0 & 4.5242 & TST & \\
\hline CHEMBL3920409 & 1641090 & 4.0 & 4.6099 & TST & \\
\hline CHEMBL3966982 & 1641090 & 5.0 & 5.0718 & TST & \\
\hline
\end{tabular}


Supplemental Table S2.txt

\begin{tabular}{|c|c|c|c|c|c|}
\hline CHEMBL3963952 & 1641090 & 4.0 & 4.1649 & TST & \\
\hline CHEMBL3915024 & 1641090 & 4.0 & 4.477 & TST & \\
\hline CHEMBL3972387 & 1641090 & 4.0 & 4.2355 & TST & \\
\hline CHEMBL3982544 & 1641090 & 5.0458 & 4.6937 & TST & \\
\hline CHEMBL3976136 & 1641090 & 5.041 & 4.0584 & TST & \\
\hline CHEMBL3901543 & 1641090 & 4.0 & 4.9054 & TST & \\
\hline CHEMBL3902736 & 1641090 & 5.0223 & 4.0324 & TST & \\
\hline CHEMBL3918639 & 1641090 & 5.4318 & 5.6607 & TST & \\
\hline CHEMBL3907954 & 1641090 & 4.0 & 3.8185 & TST & \\
\hline CHEMBL3926037 & 1641090 & 5.0223 & 4.8813 & TST & \\
\hline CHEMBL 3898924 & 1641090 & 4.0 & 4.3584 & TST & \\
\hline CHEMBL3943822 & 1641090 & 5.3979 & 4.8825 & TST & \\
\hline CHEMBL3699724 & 1528386 & 6.3747 & 6.2101 & TRN & \\
\hline CHEMBL3699762 & 1528386 & 7.2596 & 7.12 & TRN & \\
\hline CHEMBL3699666 & 1528386 & 7.2676 & 6.2935 & TST & \\
\hline CHEMBL3703110 & 1528386 & 7.8861 & 7.8736 & TRN & \\
\hline CHEMBL3639985 & 1528386 & 7.4202 & 7.0095 & TST & \\
\hline CHEMBL3699700 & 1528386 & 7.6576 & 7.8793 & TRN & \\
\hline CHEMBL3699758 & 1528386 & 6.9626 & 6.9778 & TRN & \\
\hline CHEMBL3699664 & 1528386 & 6.2495 & 6.5402 & TST & \\
\hline CHEMBL3699686 & 1528386 & 7.284 & 6.7884 & TST & \\
\hline CHEMBL3699750 & 1528386 & 6.6778 & 6.7322 & TRN & \\
\hline CHEMBL3699746 & 1528386 & 6.5735 & 6.9155 & TST & \\
\hline CHEMBL3699741 & 1528386 & 6.4711 & 6.5741 & TST & \\
\hline CHEMBL3699689 & 1528386 & 6.9355 & 7.0182 & TRN & \\
\hline CHEMBL3699719 & 1528386 & 6.6326 & 6.5813 & TRN & \\
\hline CHEMBL3699720 & 1528386 & 6.5575 & 6.5323 & TRN & \\
\hline CHEMBL3703108 & 1528386 & 8.0969 & 7.832999 & 9999999999 & TRN \\
\hline CHEMBL3703140 & 1528386 & 7.2924 & 7.1784 & TST & \\
\hline CHEMBL3703128 & 1528386 & 6.5406 & 6.5624 & TRN & \\
\hline CHEMBL3699770 & 1528386 & 7.301 & 7.0508 & TRN & \\
\hline CHEMBL3640020 & 1528386 & 6.1637 & 6.117000 & 0000000001 & TRN \\
\hline CHEMBL3699710 & 1528386 & 6.7932 & 6.9119 & TRN & \\
\hline CHEMBL3699684 & 1528386 & 6.617999 & 999999999 & 6.7336 & TRN \\
\hline CHEMBL3703155 & 1528386 & 6.1524 & 6.1759 & TRN & \\
\hline CHEMBL3703107 & 1528386 & 7.6383 & 7.553999 & 7999999999 & TRN \\
\hline CHEMBL3699683 & 1528386 & 6.5045 & 6.3754 & TRN & \\
\hline CHEMBL3703136 & 1528386 & 7.2924 & 7.3775 & TRN & \\
\hline CHEMBL3699774 & 1528386 & 7.4437 & 7.6011 & TRN & \\
\hline CHEMBL3699735 & 1528386 & 6.9281 & 6.8475 & TRN & \\
\hline CHEMBL3703130 & 1528386 & 6.3354 & 6.3587 & TRN & \\
\hline CHEMBL3699769 & 1528386 & 5.8617 & 6.1999 & TRN & \\
\hline CHEMBL3703111 & 1528386 & 8.0458 & 8.0012 & TST & \\
\hline CHEMBL3699727 & 1528386 & 7.1739 & 7.2237 & TRN & \\
\hline CHEMBL3703131 & 1528386 & 7.0555 & 6.8993 & TRN & \\
\hline CHEMBL3699766 & 1528386 & 6.6925 & 6.7813 & TRN & \\
\hline CHEMBL3703115 & 1528386 & 7.284 & 7.252000 & 0000000001 & TRN \\
\hline CHEMBL3703159 & 1528386 & 6.3799 & 6.3518 & TRN & \\
\hline
\end{tabular}


Supplemental Table S2.txt

\begin{tabular}{|c|c|c|c|c|c|}
\hline CHEMBL 3699778 & 1528386 & 6.3233 & 6.3271 & TRN & \\
\hline CHEMBL3699707 & 1528386 & 6.857 & 6.686 & TST & \\
\hline CHEMBL3703112 & 1528386 & 7.6576 & 7.4845 & TRN & \\
\hline CHEMBL3699701 & 1528386 & 6.6904 & 6.6266 & TRN & \\
\hline CHEMBL 3699732 & 1528386 & 6.2882 & 6.2829 & TRN & \\
\hline CHEMBL3699738 & 1528386 & 6.8125 & 6.8098 & TRN & \\
\hline CHEMBL3699740 & 1528386 & 6.1096 & 7.0018 & TST & \\
\hline CHEMBL 3699745 & 1528386 & 6.3188 & 6.1151 & TRN & \\
\hline CHEMBL 3703160 & 1528386 & 5.8801 & 6.1209 & TRN & \\
\hline CHEMBL3699730 & 1528386 & 6.8416 & 6.7715 & TRN & \\
\hline CHEMBL3699667 & 1528386 & 7.4815 & 6.58299 & 9999999999 & TST \\
\hline CHEMBL3703139 & 1528386 & 7.3098 & 7.2901 & TRN & \\
\hline CHEMBL3699696 & 1528386 & 6.7878 & 6.8703 & TRN & \\
\hline CHEMBL 3699668 & 1528386 & 7.0269 & 6.0301 & TST & \\
\hline CHEMBL3703157 & 1528386 & 7.5528 & 7.4969 & TRN & \\
\hline CHEMBL3699734 & 1528386 & 6.6216 & 6.5993 & TRN & \\
\hline CHEMBL3703103 & 1528386 & 6.2069 & 6.364 & TRN & \\
\hline CHEMBL 3703125 & 1528386 & 7.0132 & 6.9308 & TRN & \\
\hline CHEMBL 3703149 & 1528386 & 6.5114 & 6.5255 & TRN & \\
\hline CHEMBL 3703162 & 1528386 & 6.8794 & 6.9454 & TRN & \\
\hline CHEMBL 3699726 & 1528386 & 6.6364 & 6.6881 & TRN & \\
\hline CHEMBL3699715 & 1528386 & 6.7167 & 6.7663 & TRN & \\
\hline CHEMBL3703109 & 1528386 & 7.6576 & 7.7607 & TST & \\
\hline CHEMBL 2035021 & 1528386 & 6.3615 & 6.5152 & TRN & \\
\hline CHEMBL 3699723 & 1528386 & 6.5969 & 6.4918 & TRN & \\
\hline CHEMBL 3703129 & 1528386 & 6.7986 & 6.7232 & TRN & \\
\hline CHEMBL3699752 & 1528386 & 6.7959 & 6.9492 & TRN & \\
\hline CHEMBL3699709 & 1528386 & 7.0706 & 6.5052 & TST & \\
\hline CHEMBL3699733 & 1528386 & 6.5302 & 6.6379 & TRN & \\
\hline CHEMBL 3699718 & 1528386 & 6.2848 & 6.1772 & TRN & \\
\hline CHEMBL 3699755 & 1528386 & 6.9666 & 6.8899 & TST & \\
\hline CHEMBL 3699673 & 1528386 & 6.3706 & 6.3012 & TST & \\
\hline CHEMBL3703113 & 1528386 & 7.5376 & 7.50899 & 99999999995 & TRN \\
\hline CHEMBL 3699704 & 1528386 & 6.3809 & 6.4094 & TST & \\
\hline CHEMBL 3703170 & 1528386 & 5.9614 & 6.5801 & TST & \\
\hline CHEMBL3699777 & 1528386 & 6.8894 & 6.9853 & TRN & \\
\hline CHEMBL3703132 & 1528386 & 6.6925 & 6.921 & TRN & \\
\hline CHEMBL 3703168 & 1528386 & 6.2104 & 6.192 & TRN & \\
\hline CHEMBL 3699693 & 1528386 & 6.4473 & 6.5947 & TRN & \\
\hline CHEMBL 3699675 & 1528386 & 7.4202 & 7.4038 & TRN & \\
\hline CHEMBL3703116 & 1528386 & 7.3565 & 7.2966 & TRN & \\
\hline CHEMBL3699703 & 1528386 & 6.4145 & 6.2306 & TRN & \\
\hline CHEMBL3699669 & 1528386 & 6.5331 & 6.3478 & TRN & \\
\hline CHEMBL3699756 & 1528386 & 7.0315 & 6.8851 & TRN & \\
\hline CHEMBL3699705 & 1528386 & 6.7825 & 6.9851 & TST & \\
\hline CHEMBL 3703163 & 1528386 & 7.0132 & 6.8268 & TRN & \\
\hline CHEMBL3703114 & 1528386 & 7.2757 & 7.3719 & TRN & \\
\hline CHEMBL3703137 & 1528386 & 7.1938 & 7.3227 & TRN & \\
\hline
\end{tabular}

Page 10224 
Supplemental Table S2.txt

\begin{tabular}{|c|c|c|c|}
\hline AEMBL & 86 & 696 & 07 \\
\hline HEMBL 3703122 & 528386 & 6.2976 & 6.4565 \\
\hline HEMBL3699678 & 528386 & 6.3958 & 82 \\
\hline HEMBL3699687 & 528386 & 6.6402 & 6996 \\
\hline HEMBL3703143 & 528386 & 7.0223 & 0371 \\
\hline HEMBL 3703135 & .528386 & 7.1612 & 7.151 \\
\hline HEMBL3699722 & 528386 & 6.4145 & 5.6552 \\
\hline HEMBL3699763 & 528386 & 6.3872 & 549 \\
\hline AEMBL3703165 & 528386 & 6.3134 & 6.5866 \\
\hline HEMBL3703126 & 528386 & 6.6778 & 6.3126 \\
\hline HEMBL 3703102 & .528386 & 7.1549 & 6.9298 \\
\hline HEMBL3699712 & 528386 & 7.1938 & 7.1932 \\
\hline HEMBL3699775 & 386 & 7.0 & 6.9375 \\
\hline HEMBL3699713 & L528386 & 6.7033 & 6.7926 \\
\hline HEMBL3703138 & 528386 & 7.301 & 7.4339 \\
\hline HEMBL3699694 & 1528386 & 6.58 & 6.5642 \\
\hline HEMBL3699761 & 528 & 6.4067 & 5.5916 \\
\hline HEMBL 37 & 86 & 6.8729 & 6.9187 \\
\hline HEMBL3699716 & L528386 & 6.7905 & 6.7449 \\
\hline HEMBL3703171 & 86 & 6.4012 & 6.4436 \\
\hline HEMBL36马 & 52 & 6.9208 & 916 \\
\hline HEMBL37 & 36 & 393 & 7763 \\
\hline HEMBL3 & 86 & 8.1549 & 1091 \\
\hline HEMBL3699711 & 528386 & 7.301 & 7.4145 \\
\hline HEMBL3703154 & 86 & 6.3382 & 6.1262 \\
\hline HEMBL 36 & 86 & 6.5622 & 6. \\
\hline HEMBL36 & 86 & 6.3778 & 058 \\
\hline HEMBL36 & 86 & 7.041 & 1624 \\
\hline HEMBL3699672 & 36 & 6.2596 & 6.2888 \\
\hline HEMBL3703150 & 528 & 6.5045 & 6.5017 \\
\hline HEMBL3699681 & 86 & 6.2487 & 6.3469 \\
\hline HEMBL3 & 36 & 7.3372 & 7.2599 \\
\hline HEMBL3 & 36 & 7.0362 & 6.8867 \\
\hline HEMBL3703161 & 528386 & 7.0862 & 7.0849 \\
\hline HEMBL3703146 & 528386 & 6.2321 & 6.0137 \\
\hline HEMBL3703147 & 36 & 7.0362 & 7.068 \\
\hline CHEMBL3 & 6 & 153 & 74 \\
\hline CHEMBL3703169 & 152 & 7.5229 & 7.4704 \\
\hline CHEMBL3703134 & 528386 & 6.8477 & 7.0163 \\
\hline HEMBL3703166 & 528386 & 6.8729 & 6.8743 \\
\hline CHEMBL3703127 & 1528386 & 7.2518 & 6.9704 \\
\hline CHEMBL3699757 & 1528386 & 7.8239 & 7.0847 \\
\hline CHEMBL3699699 & 1528386 & 7.2757 & 7.0863 \\
\hline CHEMBL3699702 & 1528386 & 5.7082 & 5.5905 \\
\hline CHEMBL3703118 & .528386 & 7.3372 & 7.2643 \\
\hline CHEMBL3703152 & 1528386 & 6.06 & 6.2793 \\
\hline CHEMBL3699728 & 1528386 & 7.7696 & 7.7379 \\
\hline CHEMBL3703119 & 1528386 & 7.3188 & 7.419 \\
\hline
\end{tabular}

Page 10225 
Supplemental Table S2.txt

\begin{tabular}{|c|c|c|c|c|c|}
\hline CHEMBL3699742 & 1528386 & 7.2218 & 7.1559 & TRN & \\
\hline CHEMBL3699739 & 1528386 & 6.8125 & 6.3185 & TST & \\
\hline CHEMBL3699677 & 1528386 & 6.8356 & 6.7078 & TRN & \\
\hline CHEMBL3699748 & 1528386 & 6.1255 & 6.0478 & TRN & \\
\hline CHEMBL3699776 & 1528386 & 6.7212 & 6.9329 & TRN & \\
\hline CHEMBL3703156 & 1528386 & 6.8125 & 6.5341 & TRN & \\
\hline CHEMBL3699751 & 1528386 & 7.1367 & 6.9768 & TST & \\
\hline CHEMBL3699697 & 1528386 & 7.1805 & 7.1268 & TRN & \\
\hline CHEMBL3703120 & 1528386 & 7.2596 & 7.3306 & TRN & \\
\hline CHEMBL3699765 & 1528386 & 6.1331 & 6.3959 & TRN & \\
\hline CHEMBL3699771 & 1528386 & 6.9245 & 6.9845 & TRN & \\
\hline CHEMBL3699670 & 1528386 & 6.5361 & 6.6788 & TRN & \\
\hline CHEMBL3703158 & 1528386 & 6.153 & 6.5041 & TST & \\
\hline CHEMBL3699714 & 1528386 & 6.9957 & 6.5471 & TST & \\
\hline CHEMBL 3703121 & 1528386 & 6.433 & 6.6913 & TST & \\
\hline CHEMBL3703141 & 1528386 & 7.4559 & 7.437 & TST & \\
\hline CHEMBL3699760 & 1528386 & 6.2874 & 6.1303 & TRN & \\
\hline CHEMBL3699674 & 1528386 & 7.8861 & 7.46 & TST & \\
\hline CHEMBL3699743 & 1528386 & 7.1024 & 7.1529 & TRN & \\
\hline CHEMBL3699749 & 1528386 & 7.2518 & 6.8582 & TRN & \\
\hline CHEMBL3699729 & 1528386 & 6.5544 & 6.607 & TRN & \\
\hline CHEMBL3703167 & 1528386 & 5.6934 & 6.0024 & TRN & \\
\hline CHEMBL3699671 & 1528386 & 6.4841 & 6.70700 & 0000000001 & TRN \\
\hline CHEMBL3699725 & 1528386 & 5.7981 & 5.7286 & TRN & \\
\hline CHEMBL 3703104 & 1528386 & 8.0969 & 7.9053 & TRN & \\
\hline CHEMBL3699708 & 1528386 & 6.8601 & 6.5093 & TST & \\
\hline CHEMBL3699768 & 1528386 & 7.6198 & 7.6227 & TRN & \\
\hline CHEMBL3703142 & 1528386 & 6.1481 & 6.3698 & TRN & \\
\hline CHEMBL3703106 & 1528386 & 7.7212 & 7.6942 & TRN & \\
\hline CHEMBL3699772 & 1528386 & 6.9508 & 6.9439 & TRN & \\
\hline CHEMBL3699695 & 1528386 & 6.9957 & 7.0756 & TRN & \\
\hline CHEMBL3703151 & 1528386 & 7.1192 & 6.8874 & TRN & \\
\hline CHEMBL3699767 & 1528386 & 7.3872 & 7.1776 & TST & \\
\hline CHEMBL3699698 & 1528386 & 6.9747 & 6.7552 & TST & \\
\hline CHEMBL 2035022 & 1528386 & 7.301 & 7.3605 & TRN & \\
\hline CHEMBL3703117 & 1528386 & 7.1249 & 6.8137 & TRN & \\
\hline CHEMBL3703145 & 1528386 & 6.5157 & 6.4514 & TRN & \\
\hline CHEMBL3699736 & 1528386 & 6.9355 & 7.1384 & TST & \\
\hline CHEMBL3699691 & 1528386 & 6.9066 & 6.6774 & TST & \\
\hline CHEMBL3699721 & 1528386 & 6.6655 & 6.2456 & TST & \\
\hline CHEMBL3699753 & 1528386 & 6.9914 & 7.5156 & TST & \\
\hline CHEMBL3699754 & 1528386 & 7.2076 & 7.1553 & TST & \\
\hline CHEMBL3699676 & 1528386 & 8.0458 & 7.7849 & TST & \\
\hline CHEMBL3699688 & 1528386 & 7.3279 & 7.2102 & TRN & \\
\hline CHEMBL3699679 & 1528386 & 6.7144 & 6.8267 & TST & \\
\hline CHEMBL3699731 & 1528386 & 6.317 & 6.3731 & TRN & \\
\hline CHEMBL3703164 & 1528386 & 6.8697 & 7.0896 & TRN & \\
\hline CHEMBL3699682 & 1528386 & 6.8297 & 6.9034 & TST & \\
\hline
\end{tabular}


Supplemental Table S2.txt

\begin{tabular}{|c|c|c|c|c|}
\hline CHEMBL 3699737 & 1528386 & 5.8289 & 5.8991 & TRN \\
\hline CHEMBL3699692 & 1528386 & 6.1141 & 6.6935 & TST \\
\hline CHEMBL 3703148 & 1528386 & 6.6556 & 6.7489 & TRN \\
\hline CHEMBL 3699744 & 1528386 & 6.2832 & 6.0925 & TST \\
\hline CHEMBL 3703123 & 1528386 & 6.2248 & 6.3415 & TRN \\
\hline CHEMBL132048 & 831 & 5.0926 & 7.9616 & TST \\
\hline CHEMBL132877 & 831 & 8.1549 & 8.333 & TRN \\
\hline CHEMBL128170 & 831 & 6.8153 & 7.876 & TST \\
\hline CHEMBL130906 & 831 & 7.7447 & 7.7199 & TRN \\
\hline CHEMBL131765 & 831 & 8.699 & 8.3977 & TRN \\
\hline CHEMBL132783 & 831 & 5.8928 & 5.9881 & TRN \\
\hline CHEMBL337292 & 831 & 6.6576 & 7.7493 & TST \\
\hline CHEMBL131364 & 831 & 6.9914 & 7.6375 & TRN \\
\hline CHEMBL339926 & 831 & 7.9208 & 7.9152 & TRN \\
\hline CHEMBL130624 & 831 & 4.9318 & 8.1303 & TST \\
\hline CHEMBL130978 & 831 & 6.4789 & 7.3998 & TST \\
\hline CHEMBL130290 & 831 & 8.2218 & 8.0543 & TRN \\
\hline CHEMBL440162 & 831 & 5.8633 & 7.6645 & TST \\
\hline CHEMBL132500 & 831 & 8.0 & 8.022 & TRN \\
\hline CHEMBL434619 & 831 & 7.585 & 7.6773 & TRN \\
\hline CHEMBL336376 & 831 & 8.5229 & 8.679 & TRN \\
\hline CHEMBL129924 & 831 & 7.2147 & 7.0405 & TRN \\
\hline CHEMBL336721 & 831 & 6.4353 & 7.1562 & TST \\
\hline CHEMBL336967 & 831 & 8.699 & 8.2064 & TRN \\
\hline CHEMBL130822 & 831 & 7.6383 & 7.6516 & TRN \\
\hline CHEMBL130035 & 831 & 6.8539 & 6.9222 & TRN \\
\hline CHEMBL334824 & 831 & 5.5935 & 8.2204 & TST \\
\hline CHEMBL131546 & 831 & 7.041 & 6.5385 & TST \\
\hline CHEMBL131159 & 831 & 5.0443 & 7.9323 & TST \\
\hline CHEMBL132901 & 831 & 7.4202 & 7.4584 & TRN \\
\hline CHEMBL130036 & 831 & 7.8861 & 7.8519 & TRN \\
\hline CHEMBL130070 & 831 & 8.1549 & 8.1406 & TRN \\
\hline CHEMBL338946 & 831 & 7.9586 & 8.0718 & TRN \\
\hline CHEMBL132333 & 831 & 5.76200 & 900000006 & 8.0346 \\
\hline CHEMBL130069 & 831 & 6.068 & 6.147 & TRN \\
\hline CHEMBL128041 & 831 & 7.2441 & 7.2673 & TRN \\
\hline CHEMBL424266 & 831 & 7.9208 & 7.8019 & TRN \\
\hline CHEMBL335554 & 831 & 7.9586 & 7.8842 & TRN \\
\hline CHEMBL131261 & 831 & 8.699 & 8.7278 & TRN \\
\hline CHEMBL134027 & 831 & 8.1549 & 8.1184 & TRN \\
\hline CHEMBL130677 & 831 & 7.4685 & 7.487 & TRN \\
\hline CHEMBL 339852 & 831 & 7.9586 & 7.8045 & TRN \\
\hline CHEMBL339015 & 831 & 6.857 & 6.7917 & TRN \\
\hline CHEMBL 334477 & 831 & 7.284 & 7.1404 & TRN \\
\hline CHEMBL130894 & 831 & 5.6326 & 7.8584 & TST \\
\hline CHEMBL132825 & 831 & 7.0809 & 7.1708 & TRN \\
\hline CHEMBL132736 & 831 & 7.7696 & 7.8175 & TRN \\
\hline CHEMBL339237 & 831 & 8.0 & 7.91799 & 9999999999 \\
\hline
\end{tabular}




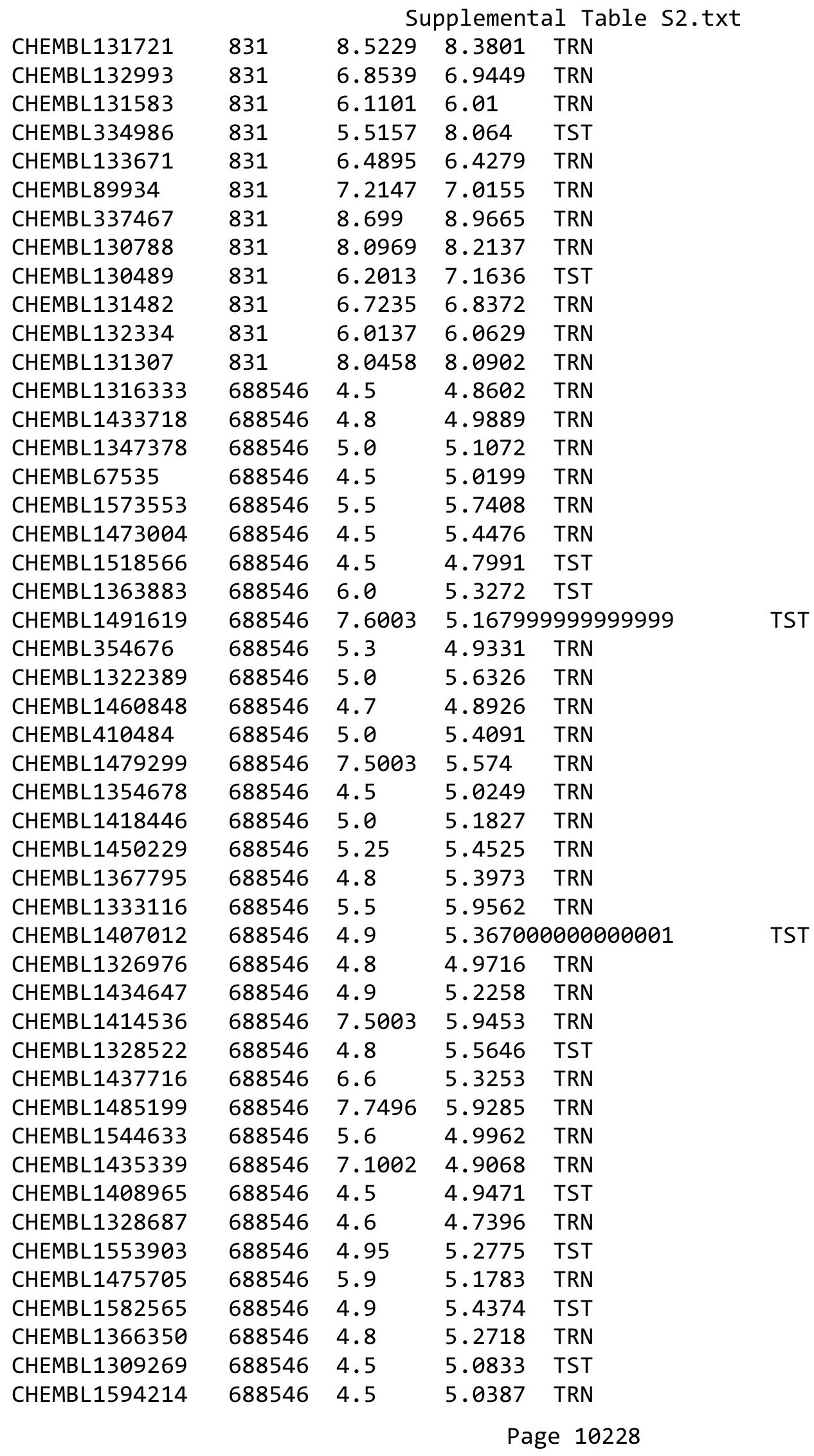




\begin{tabular}{|c|c|c|c|c|}
\hline & & & premer & \\
\hline CHEMBL1555267 & 688546 & 4.9 & 5.4765 & TST \\
\hline CHEMBL1562236 & 688546 & 5.9 & 5.3499 & TRN \\
\hline CHEMBL1398010 & 688546 & 6.2 & 5.1135 & TRN \\
\hline CHEMBL1599062 & 688546 & 5.3 & 5.4703 & TRN \\
\hline CHEMBL1448399 & 688546 & 4.9 & 5.5851 & TRN \\
\hline CHEMBL1395738 & 688546 & 5.35 & 5.6205 & TRN \\
\hline CHEMBL195008 & 688546 & 4.9 & 4.7947 & TST \\
\hline CHEMBL1373601 & 688546 & 4.9 & 5.5508 & TST \\
\hline CHEMBL1322585 & 688546 & 5.0 & 5.4137 & TRN \\
\hline CHEMBL1512657 & 688546 & 4.6 & 5.1405 & TRN \\
\hline CHEMBL1315472 & 688546 & 8.1487 & 5.188 & TST \\
\hline CHEMBL1416355 & 688546 & 5.6 & 5.0219 & TRN \\
\hline CHEMBL1473326 & 688546 & 6.4 & 5.0309 & TRN \\
\hline CHEMBL1514435 & 688546 & 5.6 & 5.4302 & TRN \\
\hline CHEMBL1481567 & 688546 & 4.9 & 5.1914 & TRN \\
\hline CHEMBL1519106 & 688546 & 8.0 & 5.1892 & TRN \\
\hline CHEMBL1563942 & 688546 & 4.5 & 5.2969 & TST \\
\hline CHEMBL1325619 & 688546 & 5.1 & 5.1816 & TRN \\
\hline CHEMBL1355194 & 688546 & 4.5 & 5.3442 & TRN \\
\hline CHEMBL1442050 & 688546 & 4.9 & 5.0973 & TRN \\
\hline CHEMBL1410233 & 688546 & 5.0 & 4.7777 & TRN \\
\hline CHEMBL1568368 & 688546 & 5.25 & 5.1764 & TST \\
\hline CHEMBL1413399 & 688546 & 5.4 & 5.3819 & TRN \\
\hline CHEMBL1387383 & 688546 & 4.7 & 5.0475 & TRN \\
\hline CHEMBL1445596 & 688546 & 5.3 & 5.2377 & TRN \\
\hline CHEMBL1384213 & 688546 & 4.6 & 4.9071 & TRN \\
\hline CHEMBL1434464 & 688546 & 8.0506 & 5.6901 & TRN \\
\hline CHEMBL1463731 & 688546 & 4.9 & 4.9838 & TRN \\
\hline CHEMBL1404257 & 688546 & 5.2 & 4.8969 & TRN \\
\hline CHEMBL1374415 & 688546 & 4.8 & 4.711 & TRN \\
\hline CHEMBL1354577 & 688546 & 5.4 & 5.3757 & TRN \\
\hline CHEMBL1326118 & 688546 & 4.7 & 4.9657 & TRN \\
\hline CHEMBL1600751 & 688546 & 6.2 & 5.6256 & TST \\
\hline CHEMBL1513241 & 688546 & 4.5 & 5.0097 & TRN \\
\hline CHEMBL1377304 & 688546 & 5.0 & 5.3443 & TRN \\
\hline CHEMBL1600274 & 688546 & 5.0 & 5.5335 & TRN \\
\hline CHEMBL1432296 & 688546 & 4.45 & 5.2222 & TST \\
\hline CHEMBL1572395 & 688546 & 4.45 & 4.9027 & TST \\
\hline CHEMBL1529123 & 688546 & 5.2 & 5.9228 & TRN \\
\hline CHEMBL1480189 & 688546 & 4.9 & 4.5245 & TRN \\
\hline CHEMBL1326915 & 688546 & 5.0 & 5.2113 & TRN \\
\hline CHEMBL346516 & 688546 & 4.6 & 5.0492 & TST \\
\hline CHEMBL1303003 & 688546 & 4.9 & 5.3496 & TRN \\
\hline CHEMBL1593090 & 688546 & 5.2 & 5.135 & TRN \\
\hline CHEMBL1570780 & 688546 & 5.1 & 4.9891 & TRN \\
\hline CHEMBL1395727 & 688546 & 4.65 & 5.4617 & TRN \\
\hline CHEMBL1590143 & 688546 & 4.9 & 5.1777 & TRN \\
\hline CHEMBL1513880 & 688546 & 5.2 & 5.1013 & TST \\
\hline
\end{tabular}




\begin{tabular}{|c|c|c|c|c|}
\hline \multicolumn{5}{|c|}{ Supplemental Table S2.txt } \\
\hline CHEMBL344127 & 688546 & 5.5 & 5.1733 & TST \\
\hline CHEMBL1553132 & 688546 & 4.5 & 4.6673 & TST \\
\hline CHEMBL1353957 & 688546 & 4.55 & 5.3394 & TRN \\
\hline CHEMBL1321773 & 688546 & 6.1 & 5.3834 & TRN \\
\hline CHEMBL1409911 & 688546 & 5.0 & 5.7845 & TST \\
\hline CHEMBL1569086 & 688546 & 4.7 & 4.9278 & TRN \\
\hline CHEMBL1535693 & 688546 & 4.5 & 4.9333 & TRN \\
\hline CHEMBL1602663 & 688546 & 4.9 & 4.9004 & TRN \\
\hline CHEMBL1554758 & 688546 & 4.9 & 5.2805 & TRN \\
\hline CHEMBL1319452 & 688546 & 4.5 & 4.9073 & TST \\
\hline CHEMBL1436751 & 688546 & 4.85 & 5.7893 & TRN \\
\hline CHEMBL1337274 & 688546 & 4.8 & 5.3833 & TST \\
\hline CHEMBL1455002 & 688546 & 6.9 & 5.2113 & TRN \\
\hline CHEMBL1488910 & 688546 & 4.9 & 5.3133 & TRN \\
\hline CHEMBL1501960 & 688546 & 5.3 & 5.5853 & TST \\
\hline CHEMBL 294018 & 688546 & 4.9 & 5.4635 & TST \\
\hline CHEMBL1513884 & 688546 & 5.4 & 5.1045 & TRN \\
\hline CHEMBL1356384 & 688546 & 4.5 & 5.3015 & TRN \\
\hline CHEMBL1331907 & 688546 & 4.8 & 5.0584 & TRN \\
\hline CHEMBL1604193 & 688546 & 5.1 & 4.9992 & TRN \\
\hline CHEMBL1552149 & 688546 & 5.7 & 5.42 & TRN \\
\hline CHEMBL1440544 & 688546 & 4.8 & 5.3377 & TRN \\
\hline CHEMBL1364169 & 688546 & 5.15 & 5.5479 & TST \\
\hline CHEMBL1514938 & 688546 & 4.6 & 5.6263 & TST \\
\hline CHEMBL1610028 & 688546 & 5.2 & 6.1139 & TRN \\
\hline CHEMBL1556277 & 688546 & 5.25 & 5.1706 & TST \\
\hline CHEMBL1395440 & 688546 & 4.6 & 5.7319 & TRN \\
\hline CHEMBL1569043 & 688546 & 5.1 & 5.1043 & TRN \\
\hline CHEMBL 3304020 & 688546 & 5.5 & 5.5034 & TST \\
\hline CHEMBL1351610 & 688546 & 4.8 & 5.4126 & TRN \\
\hline CHEMBL134291 & 688546 & 4.9 & 5.0669 & TRN \\
\hline CHEMBL1590398 & 688546 & 4.9 & 5.1211 & TRN \\
\hline CHEMBL1454409 & 688546 & 5.0 & 5.2355 & TRN \\
\hline CHEMBL1317744 & 688546 & 4.8 & 5.1612 & TRN \\
\hline CHEMBL1378106 & 688546 & 4.9 & 4.5023 & TRN \\
\hline CHEMBL1591605 & 688546 & 4.9 & 4.92 & TST \\
\hline CHEMBL1355955 & 688546 & 5.4 & 5.2024 & TST \\
\hline CHEMBL1407828 & 688546 & 4.8 & 5.2889 & TRN \\
\hline CHEMBL1514379 & 688546 & 4.7 & 4.8215 & TRN \\
\hline CHEMBL1373699 & 688546 & 4.6 & 5.8247 & TRN \\
\hline CHEMBL1321958 & 688546 & 5.3 & 5.2215 & TRN \\
\hline CHEMBL1480810 & 688546 & 8.4559 & 5.2631 & TST \\
\hline CHEMBL1610636 & 688546 & 5.0 & 5.1205 & TRN \\
\hline CHEMBL1438659 & 688546 & 5.7 & 4.7127 & TRN \\
\hline CHEMBL1556227 & 688546 & 4.8 & 4.643 & TRN \\
\hline CHEMBL1433987 & 688546 & 5.0 & 5.9488 & TRN \\
\hline CHEMBL1585557 & 688546 & 4.45 & 5.5542 & TRN \\
\hline CHEMBL1591901 & 688546 & 4.7 & 4.7052 & TRN \\
\hline
\end{tabular}




\begin{tabular}{|c|c|c|c|c|c|}
\hline & & & & & \\
\hline CHEMBL1316226 & 688546 & 6.3 & 5.5257 & TRN & \\
\hline CHEMBL1478463 & 688546 & 5.5 & 4.9475 & TRN & \\
\hline CHEMBL1482543 & 688546 & 4.8 & 5.1898 & TRN & \\
\hline CHEMBL1383267 & 688546 & 6.1 & 5.4526 & TRN & \\
\hline CHEMBL1483658 & 688546 & 6.1 & 5.355 & TST & \\
\hline CHEMBL1516244 & 688546 & 5.5 & 5.2193 & TRN & \\
\hline CHEMBL508779 & 688546 & 5.7 & 5.3633 & TST & \\
\hline CHEMBL1591944 & 688546 & 4.8 & 5.4587 & TRN & \\
\hline CHEMBL1369085 & 688546 & 4.6 & 4.8748 & TST & \\
\hline CHEMBL1374363 & 688546 & 5.3 & 4.8247 & TST & \\
\hline CHEMBL1555986 & 688546 & 5.65 & 5.6239 & TRN & \\
\hline CHEMBL3195761 & 688546 & 6.5 & 5.3082 & TST & \\
\hline CHEMBL1524383 & 688546 & 4.45 & 5.0568 & TRN & \\
\hline CHEMBL1444446 & 688546 & 5.0 & 5.3339 & TRN & \\
\hline CHEMBL1476179 & 688546 & 4.9 & 5.1096 & TRN & \\
\hline CHEMBL1411164 & 688546 & 4.5 & 5.3343 & TST & \\
\hline CHEMBL1524774 & 688546 & 4.6 & 4.7388 & TRN & \\
\hline CHEMBL1531549 & 688546 & 4.9 & 5.28700 & $\partial 000000001$ & TRN \\
\hline CHEMBL1556081 & 688546 & 8.1024 & 5.7996 & TRN & \\
\hline CHEMBL1608337 & 688546 & 5.2 & 5.2855 & TST & \\
\hline CHEMBL1611886 & 688546 & 4.8 & 5.3964 & TST & \\
\hline CHEMBL1357181 & 688546 & 4.7 & 5.1588 & TRN & \\
\hline CHEMBL1549940 & 688546 & 4.9 & 4.8289 & TRN & \\
\hline CHEMBL1535800 & 688546 & 6.5 & 5.7295 & TST & \\
\hline CHEMBL600334 & 688546 & 4.8 & 5.0473 & TST & \\
\hline CHEMBL1504575 & 688546 & 4.9 & 4.742 & TRN & \\
\hline CHEMBL1356846 & 688546 & 8.0 & 5.3258 & TRN & \\
\hline CHEMBL1475618 & 688546 & 5.7 & 5.7383 & TRN & \\
\hline CHEMBL1345595 & 688546 & 4.5 & 5.1814 & TST & \\
\hline CHEMBL1360809 & 688546 & 5.1 & 4.9853 & TRN & \\
\hline CHEMBL1408145 & 688546 & 5.1 & 4.7725 & TRN & \\
\hline CHEMBL1318074 & 688546 & 5.0 & 5.3789 & TRN & \\
\hline CHEMBL1374099 & 688546 & 5.0 & 5.562 & TRN & \\
\hline CHEMBL1438626 & 688546 & 4.9 & 5.3517 & TST & \\
\hline CHEMBL1374770 & 688546 & 5.0 & 5.4455 & TRN & \\
\hline CHEMBL1474151 & 688546 & 5.0 & 4.5357 & TRN & \\
\hline CHEMBL1478747 & 688546 & 5.4 & 5.5346 & TRN & \\
\hline CHEMBL1436828 & 688546 & 5.2 & 5.4292 & TRN & \\
\hline CHEMBL1353130 & 688546 & 6.35 & 5.4135 & TST & \\
\hline CHEMBL1478905 & 688546 & 4.9 & 5.3232 & TRN & \\
\hline CHEMBL1453326 & 688546 & 4.8 & 5.3688 & TST & \\
\hline CHEMBL1476944 & 688546 & 6.7001 & 5.7906 & TRN & \\
\hline CHEMBL1539117 & 688546 & 4.7 & 4.9764 & TST & \\
\hline CHEMBL1572391 & 688546 & 4.8 & 4.8044 & TRN & \\
\hline CHEMBL1534030 & 688546 & 4.8 & 4.99100 & 00000000005 & TRN \\
\hline CHEMBL1475959 & 688546 & 5.8 & 5.9612 & TRN & \\
\hline CHEMBL1515993 & 688546 & 4.9 & 5.1272 & TST & \\
\hline CHEMBL1472720 & 688546 & 5.2 & 5.6663 & TRN & \\
\hline & & & & 10231 & \\
\hline
\end{tabular}




\begin{tabular}{|c|c|c|c|c|}
\hline \multicolumn{5}{|c|}{ Supplemental Table S2.txt } \\
\hline CHEMBL1553869 & 688546 & 4.85 & 4.9799 & TRN \\
\hline CHEMBL1371455 & 688546 & 4.8 & 5.0048 & TRN \\
\hline CHEMBL1481495 & 688546 & 5.4 & 5.0633 & TST \\
\hline CHEMBL1418311 & 688546 & 8.4949 & 5.4707 & TST \\
\hline CHEMBL1406781 & 688546 & 4.6 & 4.5517 & TRN \\
\hline CHEMBL472929 & 688546 & 4.5 & 5.3373 & TRN \\
\hline CHEMBL1522114 & 688546 & 4.7 & 5.0094 & TRN \\
\hline CHEMBL1965162 & 688546 & 5.5 & 5.5118 & TRN \\
\hline CHEMBL1474561 & 688546 & 4.5 & 5.0576 & TRN \\
\hline CHEMBL1526060 & 688546 & 6.8 & 6.1054 & TRN \\
\hline CHEMBL1414841 & 688546 & 4.6 & 5.4651 & TRN \\
\hline CHEMBL1317683 & 688546 & 5.5 & 6.0317 & TST \\
\hline CHEMBL1579670 & 688546 & 5.4 & 5.1633 & TRN \\
\hline CHEMBL1606482 & 688546 & 4.9 & 4.9856 & TRN \\
\hline CHEMBL1471820 & 688546 & 7.0 & 5.1697 & TST \\
\hline CHEMBL1455023 & 688546 & 4.5 & 4.5847 & TRN \\
\hline CHEMBL1513307 & 688546 & 4.9 & 4.9899 & TRN \\
\hline CHEMBL1374746 & 688546 & 5.1 & 4.8806 & TST \\
\hline CHEMBL1339111 & 688546 & 4.7 & $4.6560 e$ & 0000000001 \\
\hline CHEMBL1552474 & 688546 & 5.8 & 5.1774 & TRN \\
\hline CHEMBL3194664 & 688546 & 5.0 & 4.9878 & TST \\
\hline CHEMBL3197622 & 688546 & 5.0 & 4.9224 & TST \\
\hline CHEMBL1474507 & 688546 & 4.5 & 5.1932 & TRN \\
\hline CHEMBL1473819 & 688546 & 5.0 & 5.1891 & TRN \\
\hline CHEMBL1433819 & 688546 & 4.7 & 5.0155 & TRN \\
\hline CHEMBL1565733 & 688546 & 4.45 & 5.0658 & TST \\
\hline CHEMBL1566838 & 688546 & 5.4 & 5.2744 & TRN \\
\hline CHEMBL1364494 & 688546 & 5.2 & 4.9877 & TRN \\
\hline CHEMBL1437197 & 688546 & 4.9 & 5.0134 & TRN \\
\hline CHEMBL1526543 & 688546 & 4.5 & 5.591 & TST \\
\hline CHEMBL1610840 & 688546 & 6.1 & 5.2415 & TRN \\
\hline CHEMBL1551915 & 688546 & 4.8 & 5.3858 & TST \\
\hline CHEMBL230056 & 688546 & 4.9 & 4.7813 & TST \\
\hline CHEMBL1436251 & 688546 & 5.5 & 5.0247 & TRN \\
\hline CHEMBL1554976 & 688546 & 4.7 & 4.8763 & TRN \\
\hline CHEMBL1997716 & 688546 & 4.9 & 5.1218 & TRN \\
\hline CHEMBL1512680 & 688546 & 8.1024 & 5.3697 & TRN \\
\hline CHEMBL296407 & 688546 & 4.5 & 4.9265 & TRN \\
\hline CHEMBL1488998 & 688546 & 4.9 & 5.3915 & TST \\
\hline CHEMBL1524331 & 688546 & 4.7 & 5.5395 & TRN \\
\hline CHEMBL1444314 & 688546 & 7.6003 & 5.7641 & TST \\
\hline CHEMBL1584720 & 688546 & 4.6 & 4.5412 & TRN \\
\hline CHEMBL1356346 & 688546 & 4.8 & 5.0315 & TRN \\
\hline CHEMBL1480187 & 688546 & 4.8 & 5.3426 & TRN \\
\hline CHEMBL1478014 & 688546 & 4.5 & 5.4792 & TRN \\
\hline CHEMBL1518807 & 688546 & 4.5 & 5.2261 & TRN \\
\hline CHEMBL1514575 & 688546 & 4.7 & 4.9046 & TRN \\
\hline CHEMBL1573951 & 688546 & 5.5 & 5.8887 & TST \\
\hline
\end{tabular}

TRN 


\begin{tabular}{|c|c|c|c|c|}
\hline \multicolumn{5}{|c|}{ lemental Ta } \\
\hline CHEMBL1366926 & 688546 & 4.9 & 4.7664 & TRN \\
\hline CHEMBL1571479 & 688546 & 4.5 & 5.544 & TRN \\
\hline CHEMBL1551240 & 688546 & 6.1 & 5.3768 & TRN \\
\hline CHEMBL1515137 & 688546 & 4.7 & 4.9419 & TRN \\
\hline CHEMBL1405137 & 688546 & 4.9 & 5.0036 & TRN \\
\hline CHEMBL1590587 & 688546 & 4.5 & 5.5828 & TRN \\
\hline CHEMBL1500220 & 688546 & 4.9 & 4.9173 & TRN \\
\hline CHEMBL1384337 & 688546 & 4.7 & 5.164 & TRN \\
\hline CHEMBL1509104 & 688546 & 5.0 & 5.4544 & TRN \\
\hline CHEMBL1519979 & 688546 & 4.55 & 5.2881 & TST \\
\hline CHEMBL1337231 & 688546 & 4.7 & 4.768 & TRN \\
\hline CHEMBL1348066 & 688546 & 5.0 & 5.3003 & TST \\
\hline CHEMBL1362654 & 688546 & 4.6 & 4.7623 & TRN \\
\hline CHEMBL1356303 & 688546 & 4.8 & 5.0867 & TRN \\
\hline CHEMBL1597447 & 688546 & 4.6 & 5.3491 & TST \\
\hline CHEMBL66953 & 688546 & 4.9 & 5.1309 & TST \\
\hline CHEMBL1389724 & 688546 & 4.9 & 5.0228 & TRN \\
\hline CHEMBL1377126 & 688546 & 5.0 & 5.4799 & TRN \\
\hline CHEMBL1548867 & 688546 & 4.9 & 5.1061 & TRN \\
\hline CHEMBL1315149 & 688546 & 5.5 & 5.6369 & TRN \\
\hline CHEMBL 1601822 & 688546 & 4.9 & 5.21299 & 9999999999 \\
\hline CHEMBL1356407 & 688546 & 4.9 & 5.0172 & TRN \\
\hline CHEMBL8260 & 688546 & 6.2 & 5.1859 & TRN \\
\hline CHEMBL1400942 & 688546 & 4.8 & 5.5293 & TRN \\
\hline CHEMBL1409472 & 688546 & 4.6 & 5.3269 & TRN \\
\hline CHEMBL1323093 & 688546 & 4.7 & 5.3562 & TRN \\
\hline CHEMBL1610691 & 688546 & 5.8 & 5.4565 & TRN \\
\hline CHEMBL1475721 & 688546 & 5.8 & 5.7421 & TRN \\
\hline CHEMBL1369241 & 688546 & 4.8 & 4.8326 & TST \\
\hline CHEMBL1441297 & 688546 & 6.0 & 5.7425 & TRN \\
\hline CHEMBL1532568 & 688546 & 4.9 & 5.0469 & TRN \\
\hline CHEMBL3193638 & 688546 & 4.5 & 5.4483 & TST \\
\hline CHEMBL 37312 & 688546 & 4.6 & 5.4081 & TST \\
\hline CHEMBL585038 & 688546 & 5.4 & 5.3472 & TRN \\
\hline CHEMBL1406156 & 688546 & 4.9 & 5.3408 & TRN \\
\hline CHEMBL1333327 & 688546 & 4.8 & 5.1006 & TRN \\
\hline CHEMBL1592150 & 688546 & 4.9 & 5.1978 & TRN \\
\hline CHEMBL1382648 & 688546 & 4.5 & 4.886 & TST \\
\hline CHEMBL1358524 & 688546 & 4.9 & 5.2036 & TRN \\
\hline CHEMBL1564703 & 688546 & 5.1 & 5.5036 & TST \\
\hline CHEMBL1300405 & 688546 & 4.9 & 5.221 & TRN \\
\hline CHEMBL365374 & 688546 & 6.2 & 4.9378 & TRN \\
\hline CHEMBL 1587117 & 688546 & 5.7 & 5.5124 & TRN \\
\hline CHEMBL1359638 & 688546 & 5.1 & 5.3828 & TRN \\
\hline CHEMBL3199093 & 688546 & 4.6 & 4.9569 & TST \\
\hline CHEMBL56543 & 688546 & 4.7 & 5.3524 & TRN \\
\hline CHEMBL1367224 & 688546 & 4.6 & 5.0456 & TRN \\
\hline CHEMBL 3198047 & 688546 & 5.0 & 5.1707 & TST \\
\hline
\end{tabular}




\begin{tabular}{|c|c|c|c|c|}
\hline \multicolumn{5}{|c|}{ Supplemental Table S2.txt } \\
\hline CHEMBL1397569 & 688546 & 4.7 & 5.0282 & TRN \\
\hline CHEMBL1444023 & 688546 & 5.2 & 5.722 & TRN \\
\hline CHEMBL1450744 & 688546 & 4.5 & 5.3776 & TRN \\
\hline CHEMBL1583952 & 688546 & 5.0 & 4.6691 & TRN \\
\hline CHEMBL1574352 & 688546 & 4.8 & 5.0752 & TRN \\
\hline CHEMBL1493396 & 688546 & 4.5 & 4.9655 & TST \\
\hline CHEMBL1596532 & 688546 & 5.8 & 5.393 & TRN \\
\hline CHEMBL1492671 & 688546 & 6.5 & 5.2025 & TRN \\
\hline CHEMBL1333657 & 688546 & 5.5 & 5.3758 & TST \\
\hline CHEMBL1357897 & 688546 & 5.5 & 5.3064 & TRN \\
\hline CHEMBL1444402 & 688546 & 4.7 & 5.4356 & TST \\
\hline CHEMBL1494345 & 688546 & 4.9 & 4.9626 & TRN \\
\hline CHEMBL1572844 & 688546 & 5.2 & 5.445 & TRN \\
\hline CHEMBL1599968 & 688546 & 4.6 & 5.0584 & TRN \\
\hline CHEMBL1449843 & 688546 & 6.1 & 5.1172 & TRN \\
\hline CHEMBL1472982 & 688546 & 7.3002 & 5.1273 & TST \\
\hline CHEMBL546137 & 688546 & 4.9 & 4.9452 & TRN \\
\hline CHEMBL1551670 & 688546 & 5.2 & 5.8997 & TRN \\
\hline CHEMBL1491541 & 688546 & 4.5 & 5.4286 & TRN \\
\hline CHEMBL1500421 & 688546 & 5.0 & 5.0265 & TRN \\
\hline CHEMBL1602298 & 688546 & 7.0 & 5.5129 & TST \\
\hline CHEMBL1517345 & 688546 & 4.8 & 5.2966 & TRN \\
\hline CHEMBL1401707 & 688546 & 4.9 & 5.2977 & TRN \\
\hline CHEMBL1591622 & 688546 & 5.1 & 5.1267 & TRN \\
\hline CHEMBL599307 & 688546 & 6.15 & 5.584 & TRN \\
\hline CHEMBL1573573 & 688546 & 4.7 & 5.1642 & TST \\
\hline CHEMBL1599636 & 688546 & 4.75 & 4.8806 & TST \\
\hline CHEMBL1473301 & 688546 & 4.85 & 5.6175 & TRN \\
\hline CHEMBL1336053 & 688546 & 5.0 & 5.2653 & TST \\
\hline CHEMBL1456299 & 688546 & 5.6 & 4.9998 & TRN \\
\hline CHEMBL1417232 & 688546 & 4.5 & 5.0021 & TST \\
\hline CHEMBL1591556 & 688546 & 6.0 & 6.2678 & TRN \\
\hline CHEMBL1598007 & 688546 & 5.2 & 5.8839 & TRN \\
\hline CHEMBL1371600 & 688546 & 5.0 & 5.3739 & TRN \\
\hline CHEMBL1591810 & 688546 & 4.5 & 5.1292 & TST \\
\hline CHEMBL1412114 & 688546 & 4.45 & 5.0776 & TRN \\
\hline CHEMBL1534331 & 688546 & 4.9 & 5.3957 & TRN \\
\hline CHEMBL1441523 & 688546 & 5.0 & 4.9659 & TRN \\
\hline CHEMBL1565756 & 688546 & 4.5 & 5.3503 & TST \\
\hline CHEMBL1512411 & 688546 & 4.8 & 5.6543 & TRN \\
\hline CHEMBL1437387 & 688546 & 5.85 & 5.6741 & TRN \\
\hline CHEMBL1611872 & 688546 & 5.0 & 5.0299 & TST \\
\hline CHEMBL1355065 & 688546 & 7.0 & 5.6444 & TRN \\
\hline CHEMBL1606681 & 688546 & 4.9 & 5.2587 & TRN \\
\hline CHEMBL1355607 & 688546 & 8.1024 & 6.3738 & TRN \\
\hline CHEMBL1440044 & 688546 & 5.85 & 5.9966 & TRN \\
\hline CHEMBL1473364 & 688546 & 8.0 & 5.2526 & TRN \\
\hline CHEMBL1562935 & 688546 & 4.65 & 5.4201 & TST \\
\hline
\end{tabular}




\begin{tabular}{|c|c|c|c|c|}
\hline \multicolumn{5}{|c|}{ Supplemental Table S2.txt } \\
\hline CHEMBL1433500 & 688546 & 5.95 & 5.2878 & TST \\
\hline CHEMBL1473410 & 688546 & 5.0 & 5.4664 & TRN \\
\hline CHEMBL1359544 & 688546 & 4.45 & 5.073 & TST \\
\hline CHEMBL1605974 & 688546 & 4.7 & 5.1027 & TRN \\
\hline CHEMBL1358179 & 688546 & 4.7 & 5.0786 & TRN \\
\hline CHEMBL1598128 & 688546 & 5.4 & 5.7198 & TST \\
\hline CHEMBL1474254 & 688546 & 4.7 & 4.6218 & TRN \\
\hline CHEMBL528807 & 688546 & 5.6 & 4.8639 & TRN \\
\hline CHEMBL1519375 & 688546 & 5.3 & 5.0274 & TRN \\
\hline CHEMBL1475586 & 688546 & 4.9 & 5.3305 & TRN \\
\hline CHEMBL1516290 & 688546 & 4.7 & 5.5351 & TRN \\
\hline CHEMBL1337527 & 688546 & 5.8 & 5.2592 & TRN \\
\hline CHEMBL1366018 & 688546 & 7.4001 & 5.4684 & TRN \\
\hline CHEMBL1573195 & 688546 & 5.0 & 5.2726 & TRN \\
\hline CHEMBL1574645 & 688546 & 6.0 & 5.5567 & TRN \\
\hline CHEMBL1342999 & 688546 & 4.5 & 5.2661 & TRN \\
\hline CHEMBL1352436 & 688546 & 4.5 & 5.2466 & TRN \\
\hline CHEMBL239009 & 688546 & 4.8 & 4.6677 & TRN \\
\hline CHEMBL1605551 & 688546 & 4.45 & 5.1095 & TRN \\
\hline CHEMBL1403903 & 688546 & 4.9 & 5.1897 & TRN \\
\hline CHEMBL1380170 & 688546 & 6.0 & 5.2628 & TST \\
\hline CHEMBL1534193 & 688546 & 6.0 & 5.2962 & TRN \\
\hline CHEMBL1437388 & 688546 & 4.5 & 4.9706 & TRN \\
\hline CHEMBL1496871 & 688546 & 5.2 & 5.1787 & TRN \\
\hline CHEMBL1465049 & 688546 & 4.7 & 4.7705 & TRN \\
\hline CHEMBL1509595 & 688546 & 5.05 & 4.8715 & TRN \\
\hline CHEMBL1508377 & 688546 & 4.6 & 5.2585 & TRN \\
\hline CHEMBL1978424 & 688546 & 4.5 & 5.7143 & TST \\
\hline CHEMBL1354758 & 688546 & 4.5 & 5.3041 & TRN \\
\hline CHEMBL1602144 & 688546 & 4.8 & 5.4552 & TRN \\
\hline CHEMBL1354585 & 688546 & 4.6 & 4.8291 & TRN \\
\hline CHEMBL1491294 & 688546 & 4.5 & 5.7126 & TRN \\
\hline CHEMBL1554221 & 688546 & 5.0 & 5.4925 & TRN \\
\hline CHEMBL1978643 & 688546 & 4.75 & 4.8103 & TRN \\
\hline CHEMBL1436189 & 688546 & 5.3 & 5.3625 & TST \\
\hline CHEMBL1467395 & 688546 & 6.5501 & 5.2361 & TST \\
\hline CHEMBL1515046 & 688546 & 4.9 & 5.4123 & TRN \\
\hline CHEMBL1592256 & 688546 & 4.7 & 5.3942 & TRN \\
\hline CHEMBL1317358 & 688546 & 4.9 & 4.5117 & TRN \\
\hline CHEMBL1519387 & 688546 & 5.0 & 4.8669 & TRN \\
\hline CHEMBL1610698 & 688546 & 4.7 & 5.4177 & TRN \\
\hline CHEMBL1401130 & 688546 & 5.25 & 5.2188 & TST \\
\hline CHEMBL1348405 & 688546 & 5.2 & 4.8604 & TST \\
\hline CHEMBL462576 & 688546 & 4.5 & 5.5313 & TST \\
\hline CHEMBL1316423 & 688546 & 6.1 & 5.5594 & TRN \\
\hline CHEMBL1402759 & 688546 & 4.7 & 4.9077 & TRN \\
\hline CHEMBL1573679 & 688546 & 4.7 & 5.6653 & TRN \\
\hline CHEMBL1317535 & 688546 & 4.4 & 5.3246 & TST \\
\hline
\end{tabular}




\begin{tabular}{|c|c|c|c|c|c|}
\hline \\
\hline CHEMBL1408194 & 688546 & 5.0 & 5.1935 & TRN & \\
\hline CHEMBL1466669 & 688546 & 5.0 & 4.9091 & TRN & \\
\hline CHEMBL192627 & 688546 & 4.5 & 5.6128 & TST & \\
\hline CHEMBL1322674 & 688546 & 4.9 & 5.119 & TRN & \\
\hline CHEMBL1398003 & 688546 & 5.2 & 5.6115 & TRN & \\
\hline CHEMBL1318070 & 688546 & 4.9 & 5.3709 & TRN & \\
\hline CHEMBL1457311 & 688546 & 5.0 & 4.7282 & TRN & \\
\hline CHEMBL1434209 & 688546 & 5.9 & 5.6183 & TRN & \\
\hline CHEMBL1402580 & 688546 & 4.6 & 4.7557 & TRN & \\
\hline CHEMBL475908 & 688546 & 5.2 & 5.0269 & TRN & \\
\hline CHEMBL1553025 & 688546 & 4.9 & 4.8864 & TRN & \\
\hline CHEMBL1557832 & 688546 & 5.0 & 5.0186 & TRN & \\
\hline CHEMBL1563695 & 688546 & 5.0 & 5.0299 & TRN & \\
\hline CHEMBL1529479 & 688546 & 4.9 & 5.23600 & 0000000001 & TST \\
\hline CHEMBL1609972 & 688546 & 5.0 & 5.3928 & TRN & \\
\hline CHEMBL1394759 & 688546 & 4.9 & 5.5903 & TRN & \\
\hline CHEMBL1376804 & 688546 & 4.8 & 5.1568 & TRN & \\
\hline CHEMBL1434388 & 688546 & 5.0 & 5.5024 & TRN & \\
\hline CHEMBL1540711 & 688546 & 5.0 & 5.2242 & TRN & \\
\hline CHEMBL1589931 & 688546 & 7.5498 & 5.2871 & TST & \\
\hline CHEMBL1434423 & 688546 & 5.0 & 5.142 & TRN & \\
\hline CHEMBL1362825 & 688546 & 5.25 & 4.6717 & TRN & \\
\hline CHEMBL1350429 & 688546 & 4.7 & 4.9408 & TST & \\
\hline CHEMBL1434057 & 688546 & 4.6 & 5.1295 & TST & \\
\hline CHEMBL1609946 & 688546 & 5.9 & 5.5602 & TRN & \\
\hline CHEMBL1437927 & 688546 & 4.7 & 5.8048 & TRN & \\
\hline CHEMBL1451846 & 688546 & 5.0 & 4.9169 & TRN & \\
\hline CHEMBL1330346 & 688546 & 5.4 & 5.1314 & TRN & \\
\hline CHEMBL1335297 & 688546 & 4.9 & 5.106 & TRN & \\
\hline CHEMBL1475322 & 688546 & 5.0 & 5.6912 & TRN & \\
\hline CHEMBL1331962 & 688546 & 4.9 & 4.9592 & TST & \\
\hline CHEMBL428768 & 688546 & 5.1 & 5.0988 & TST & \\
\hline CHEMBL1526005 & 688546 & 4.85 & 4.801 & TST & \\
\hline CHEMBL1591915 & 688546 & 4.7 & 5.2744 & TRN & \\
\hline CHEMBL1302018 & 688546 & 5.25 & 5.35 & TRN & \\
\hline CHEMBL1491979 & 688546 & 4.9 & 5.4298 & TST & \\
\hline CHEMBL1570216 & 688546 & 4.9 & 5.2317 & TRN & \\
\hline CHEMBL1478663 & 688546 & 4.5 & 4.6293 & TST & \\
\hline CHEMBL1323935 & 688546 & 4.9 & 5.1243 & TRN & \\
\hline CHEMBL1592650 & 688546 & 4.5 & 5.0295 & TRN & \\
\hline CHEMBL1531073 & 688546 & 4.7 & 5.1216 & TRN & \\
\hline CHEMBL1581818 & 688546 & 4.5 & 5.28299 & 99999999995 & TST \\
\hline CHEMBL1435850 & 688546 & 8.3468 & 5.8972 & TRN & \\
\hline CHEMBL1529420 & 688546 & 4.5 & 4.9793 & TRN & \\
\hline CHEMBL1524355 & 688546 & 4.9 & 5.39 & TRN & \\
\hline CHEMBL1519261 & 688546 & 5.0 & 4.6092 & TRN & \\
\hline CHEMBL1489395 & 688546 & 4.6 & 4.5172 & TRN & \\
\hline CHEMBL1515873 & 688546 & 4.95 & 5.5367 & TST & \\
\hline
\end{tabular}




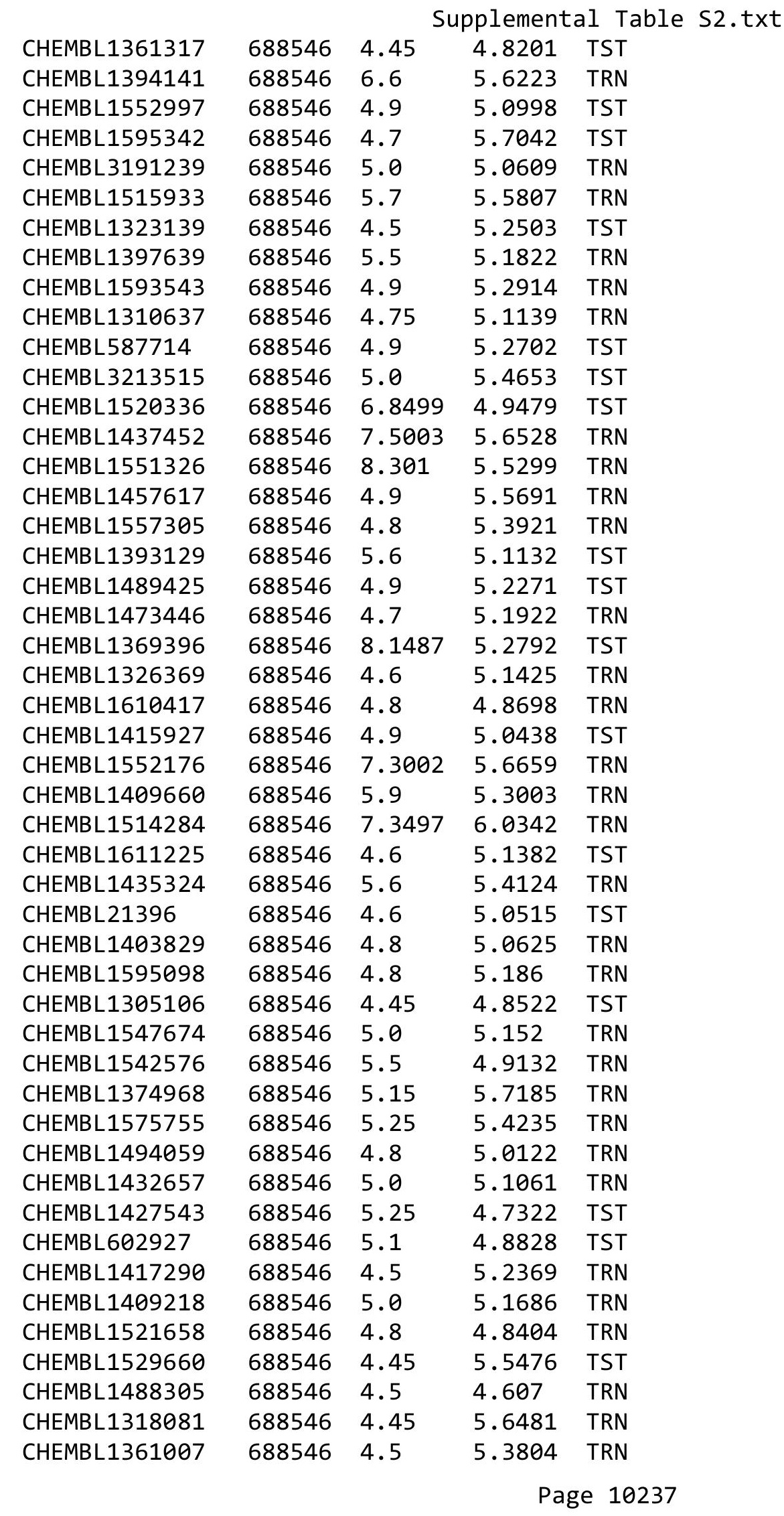




\begin{tabular}{|c|c|c|c|c|c|}
\hline \\
\hline CHEMBL1396824 & 688546 & 4.9 & 5.3449 & TRN & \\
\hline CHEMBL1514097 & 688546 & 5.6 & 5.4224 & TRN & \\
\hline CHEMBL1526938 & 688546 & 5.1 & 5.1854 & TRN & \\
\hline CHEMBL1598544 & 688546 & 4.9 & 4.8443 & TRN & \\
\hline CHEMBL1536842 & 688546 & 4.6 & 4.9287 & TRN & \\
\hline CHEMBL1594720 & 688546 & 4.5 & 4.7478 & TRN & \\
\hline CHEMBL1455349 & 688546 & 5.7 & 5.1603 & TRN & \\
\hline CHEMBL1474106 & 688546 & 4.8 & 4.8088 & TRN & \\
\hline CHEMBL1446121 & 688546 & 4.9 & 5.7075 & TRN & \\
\hline CHEMBL1578404 & 688546 & 4.7 & 4.9528 & TRN & \\
\hline CHEMBL1388146 & 688546 & 5.0 & 4.9427 & TST & \\
\hline CHEMBL1612858 & 688546 & 4.5 & 5.3711 & TST & \\
\hline CHEMBL1321222 & 688546 & 5.0 & 5.4958 & TRN & \\
\hline CHEMBL1590659 & 688546 & 5.0 & 5.3573 & TRN & \\
\hline CHEMBL1400144 & 688546 & 4.9 & 5.221 & TRN & \\
\hline CHEMBL1390221 & 688546 & 5.9 & 5.1411 & TRN & \\
\hline CHEMBL1497555 & 688546 & 4.9 & 5.2388 & TST & \\
\hline CHEMBL1362196 & 688546 & 4.9 & 5.1544 & TRN & \\
\hline CHEMBL1416863 & 688546 & 4.5 & 5.6786 & TST & \\
\hline CHEMBL1568157 & 688546 & 5.0 & 5.29700 & 3000000001 & TRN \\
\hline CHEMBL1562107 & 688546 & 4.5 & 5.2845 & TST & \\
\hline CHEMBL1585520 & 688546 & 5.0 & 4.9884 & TRN & \\
\hline CHEMBL1594897 & 688546 & 4.9 & 5.3325 & TRN & \\
\hline CHEMBL1467184 & 688546 & 4.9 & 5.3392 & TRN & \\
\hline CHEMBL1314512 & 688546 & 4.9 & 5.3489 & TRN & \\
\hline CHEMBL17331 & 688546 & 6.8 & 5.6061 & TST & \\
\hline CHEMBL1377287 & 688546 & 4.9 & 5.26 & TST & \\
\hline CHEMBL1374057 & 688546 & 8.0 & $5.2410 e$ & 20000000005 & TRN \\
\hline CHEMBL1492502 & 688546 & 4.5 & 5.3929 & TRN & \\
\hline CHEMBL1369659 & 688546 & 4.7 & 5.5457 & TRN & \\
\hline CHEMBL1417406 & 688546 & 5.3 & 5.5844 & TRN & \\
\hline CHEMBL1386409 & 688546 & 4.65 & 5.046 & TST & \\
\hline CHEMBL1492648 & 688546 & 4.6 & 4.9431 & TRN & \\
\hline CHEMBL1430353 & 688546 & 4.7 & 5.2182 & TST & \\
\hline CHEMBL1507474 & 688546 & 4.8 & 5.1391 & TRN & \\
\hline CHEMBL1373157 & 688546 & 4.6 & 5.4363 & TRN & \\
\hline CHEMBL1401010 & 688546 & 5.1 & 5.8513 & TRN & \\
\hline CHEMBL1400820 & 688546 & 8.0 & 5.2689 & TRN & \\
\hline CHEMBL1475470 & 688546 & 4.5 & 4.9786 & TRN & \\
\hline CHEMBL1513139 & 688546 & 4.5 & 4.7547 & TRN & \\
\hline CHEMBL1513368 & 688546 & 5.4 & 5.2643 & TRN & \\
\hline CHEMBL601757 & 688546 & 5.7 & 5.6388 & TST & \\
\hline CHEMBL1474984 & 688546 & 4.7 & 5.3807 & TRN & \\
\hline CHEMBL1588726 & 688546 & 4.9 & 4.9669 & TRN & \\
\hline CHEMBL1554400 & 688546 & 5.8 & 5.3199 & TRN & \\
\hline CHEMBL1516545 & 688546 & 4.9 & 5.6664 & TRN & \\
\hline CHEMBL1416853 & 688546 & 5.1 & 5.1051 & TST & \\
\hline CHEMBL1513798 & 688546 & 4.9 & 5.3159 & TRN & \\
\hline
\end{tabular}




\begin{tabular}{|c|c|c|c|c|}
\hline \multicolumn{5}{|c|}{ Supplemental Table S2.txt } \\
\hline CHEMBL1367806 & 688546 & 4.6 & 5.1148 & TRN \\
\hline CHEMBL1453456 & 688546 & 8.0 & 5.7324 & TRN \\
\hline CHEMBL1433988 & 688546 & 4.5 & 5.118 & TST \\
\hline CHEMBL580819 & 688546 & 4.7 & 4.7052 & TRN \\
\hline CHEMBL1494905 & 688546 & 5.6 & 5.1148 & TRN \\
\hline CHEMBL1331895 & 688546 & 5.5 & 5.3537 & TRN \\
\hline CHEMBL1462244 & 688546 & 4.9 & 4.7545 & TRN \\
\hline CHEMBL1555014 & 688546 & 4.9 & 4.7983 & TRN \\
\hline CHEMBL1561152 & 688546 & 6.2 & 5.2221 & TRN \\
\hline CHEMBL1605595 & 688546 & 4.5 & 5.0689 & TRN \\
\hline CHEMBL1390196 & 688546 & 4.8 & 5.4058 & TST \\
\hline CHEMBL1499181 & 688546 & 4.7 & 5.445 & TRN \\
\hline CHEMBL1352792 & 688546 & 4.8 & 5.187 & TST \\
\hline CHEMBL1551193 & 688546 & 4.9 & 5.1465 & TRN \\
\hline CHEMBL1524276 & 688546 & 4.9 & 5.4278 & TRN \\
\hline CHEMBL1314161 & 688546 & 4.9 & 5.0642 & TRN \\
\hline CHEMBL1476763 & 688546 & 7.699 & 5.322 & TRN \\
\hline CHEMBL1327290 & 688546 & 8.1024 & 5.6076 & TRN \\
\hline CHEMBL1476172 & 688546 & 4.9 & 5.7678 & TRN \\
\hline CHEMBL1354521 & 688546 & 5.1 & 4.8755 & TRN \\
\hline CHEMBL1396730 & 688546 & 7.6003 & 5.0995 & TRN \\
\hline CHEMBL1490671 & 688546 & 4.9 & 5.0543 & TST \\
\hline CHEMBL1334995 & 688546 & 8.0 & 4.7755 & TST \\
\hline CHEMBL1409081 & 688546 & 7.8013 & 5.6318 & TRN \\
\hline CHEMBL1604350 & 688546 & 5.3 & 4.856 & TRN \\
\hline CHEMBL1552178 & 688546 & 6.5 & 5.7719 & TST \\
\hline CHEMBL1554627 & 688546 & 6.7001 & 5.4449 & TRN \\
\hline CHEMBL1394253 & 688546 & 6.05 & 5.7813 & TRN \\
\hline CHEMBL1519311 & 688546 & 4.9 & 5.1848 & TST \\
\hline CHEMBL1403311 & 688546 & 4.8 & 5.1637 & TST \\
\hline CHEMBL1366321 & 688546 & 4.9 & 5.2822 & TST \\
\hline CHEMBL1453229 & 688546 & 5.0 & 5.3835 & TRN \\
\hline CHEMBL1477007 & 688546 & 4.5 & 5.9624 & TRN \\
\hline CHEMBL1524085 & 688546 & 4.9 & 4.766 & TST \\
\hline CHEMBL1446113 & 688546 & 5.5 & 5.3465 & TRN \\
\hline CHEMBL22870 & 688546 & 4.6 & 5.0174 & TRN \\
\hline CHEMBL1514213 & 688546 & 6.8 & 5.1062 & TRN \\
\hline CHEMBL1319642 & 688546 & 5.6 & 5.1879 & TRN \\
\hline CHEMBL1385176 & 688546 & 5.0 & 5.3745 & TST \\
\hline CHEMBL1357595 & 688546 & 4.9 & 4.9055 & TRN \\
\hline CHEMBL1358461 & 688546 & 4.7 & 5.0227 & TST \\
\hline CHEMBL1605643 & 688546 & 4.45 & 5.2639 & TST \\
\hline CHEMBL1397120 & 688546 & 4.8 & 5.1043 & TRN \\
\hline CHEMBL1452896 & 688546 & 4.9 & 5.6759 & TRN \\
\hline CHEMBL1378198 & 688546 & 4.9 & 5.3963 & TRN \\
\hline CHEMBL1571968 & 688546 & 5.5 & 5.5675 & TST \\
\hline CHEMBL1440954 & 688546 & 4.9 & 5.0531 & TST \\
\hline CHEMBL1567028 & 688546 & 7.0 & 5.6783 & TST \\
\hline
\end{tabular}




\begin{tabular}{|c|c|c|c|c|c|}
\hline \\
\hline CHEMBL1355218 & 688546 & 5.0 & 5.6805 & TRN & \\
\hline CHEMBL1485841 & 688546 & 8.301 & 5.8493 & TRN & \\
\hline CHEMBL1584661 & 688546 & 4.9 & 5.1736 & TRN & \\
\hline CHEMBL1358573 & 688546 & 7.699 & 5.7386 & TRN & \\
\hline CHEMBL1590641 & 688546 & 5.5 & 5.2804 & TRN & \\
\hline CHEMBL1434971 & 688546 & 5.6 & 5.2233 & TRN & \\
\hline CHEMBL1435700 & 688546 & 4.9 & 5.3518 & TRN & \\
\hline CHEMBL1331486 & 688546 & 5.1 & 5.0151 & TST & \\
\hline CHEMBL1449065 & 688546 & 4.9 & 5.2294 & TST & \\
\hline CHEMBL1611300 & 688546 & 4.9 & 4.8472 & TRN & \\
\hline CHEMBL1444311 & 688546 & 4.9 & 5.7203 & TST & \\
\hline CHEMBL1356176 & 688546 & 4.8 & 5.30399 & 9999999999 & TRN \\
\hline CHEMBL1554153 & 688546 & 5.0 & 5.38200 & 0000000001 & TRN \\
\hline CHEMBL1324601 & 688546 & 6.25 & 5.7079 & TRN & \\
\hline CHEMBL542493 & 688546 & 4.7 & 5.1539 & TRN & \\
\hline CHEMBL1465257 & 688546 & 4.9 & 5.8281 & TST & \\
\hline CHEMBL1446453 & 688546 & 4.45 & 5.9402 & TRN & \\
\hline CHEMBL3193792 & 688546 & 4.5 & 5.3145 & TRN & \\
\hline CHEMBL1590286 & 688546 & 5.1 & 5.20100 & 00000000005 & TRN \\
\hline CHEMBL1398021 & 688546 & 6.0 & 5.2926 & TST & \\
\hline CHEMBL1603055 & 688546 & 4.5 & 5.5 & TRN & \\
\hline CHEMBL1360786 & 688546 & 4.6 & 5.1353 & TRN & \\
\hline CHEMBL3193298 & 688546 & 4.8 & 5.1525 & TRN & \\
\hline CHEMBL1437666 & 688546 & 4.8 & 4.9487 & TRN & \\
\hline CHEMBL1522810 & 688546 & 4.9 & 4.8968 & TRN & \\
\hline CHEMBL1398144 & 688546 & 5.1 & 4.8358 & TRN & \\
\hline CHEMBL1473512 & 688546 & 5.25 & 5.7259 & TRN & \\
\hline CHEMBL1362725 & 688546 & 4.9 & 5.4672 & TST & \\
\hline CHEMBL1517845 & 688546 & 5.0 & 5.13399 & 99999999995 & TRN \\
\hline CHEMBL1413671 & 688546 & 5.3 & 5.141 & TRN & \\
\hline CHEMBL1571028 & 688546 & 6.5 & 6.0916 & TRN & \\
\hline CHEMBL1354327 & 688546 & 4.6 & 4.4282 & TRN & \\
\hline CHEMBL 260213 & 688546 & 5.6 & 5.2045 & TRN & \\
\hline CHEMBL1368492 & 688546 & 8.301 & 5.33899 & 99999999995 & TRN \\
\hline CHEMBL1568250 & 688546 & 4.7 & 5.0729 & TRN & \\
\hline CHEMBL1413237 & 688546 & 4.45 & 5.3575 & TST & \\
\hline CHEMBL1306095 & 688546 & 4.5 & 5.2065 & TST & \\
\hline CHEMBL1433544 & 688546 & 4.7 & 5.1929 & TRN & \\
\hline CHEMBL1343705 & 688546 & 5.1 & 5.1739 & TRN & \\
\hline CHEMBL1494650 & 688546 & 4.7 & 5.3889 & TRN & \\
\hline CHEMBL1487952 & 688546 & 4.9 & 4.9296 & TRN & \\
\hline CHEMBL1529847 & 688546 & 4.9 & 5.2362 & TST & \\
\hline CHEMBL1314706 & 688546 & 4.7 & 5.9264 & TST & \\
\hline CHEMBL1457783 & 688546 & 4.9 & 5.0665 & TST & \\
\hline CHEMBL1598912 & 688546 & 4.7 & 5.36799 & 9999999999 & TRN \\
\hline CHEMBL1441400 & 688546 & 5.0 & 5.0845 & TST & \\
\hline CHEMBL1596472 & 688546 & 4.7 & 5.4954 & TRN & \\
\hline CHEMBL1338800 & 688546 & 4.9 & 5.0839 & TRN & \\
\hline
\end{tabular}




\begin{tabular}{|c|c|c|c|c|}
\hline \multicolumn{5}{|c|}{ Supplemental Table S2. } \\
\hline CHEMBL1395943 & 688546 & 4.8 & 5.0826 & TRN \\
\hline CHEMBL1398405 & 688546 & 4.6 & 5.2842 & TRN \\
\hline CHEMBL1343300 & 688546 & 5.25 & 5.4259 & TST \\
\hline CHEMBL1514372 & 688546 & 4.9 & 5.4214 & TRN \\
\hline CHEMBL1396127 & 688546 & 5.1 & 5.0064 & TRN \\
\hline CHEMBL1586817 & 688546 & 4.5 & 4.7145 & TRN \\
\hline CHEMBL1445576 & 688546 & 4.5 & 5.2629 & TRN \\
\hline CHEMBL1339429 & 688546 & 5.1 & 5.2202 & TRN \\
\hline CHEMBL1501170 & 688546 & 4.8 & 5.3533 & TRN \\
\hline CHEMBL1474723 & 688546 & 5.2 & 5.6309 & TRN \\
\hline CHEMBL1485749 & 688546 & 4.5 & 5.2905 & TRN \\
\hline CHEMBL1477815 & 688546 & 5.3 & 5.647 & TRN \\
\hline CHEMBL1595756 & 688546 & 4.7 & 5.1633 & TRN \\
\hline CHEMBL1489522 & 688546 & 4.8 & 5.154 & TRN \\
\hline CHEMBL1470132 & 688546 & 4.8 & 5.0171 & TRN \\
\hline CHEMBL1445117 & 688546 & 5.4 & 5.9169 & TRN \\
\hline CHEMBL1370740 & 688546 & 5.8 & 5.5809 & TRN \\
\hline CHEMBL1398683 & 688546 & 4.4 & 5.2701 & TST \\
\hline CHEMBL1356278 & 688546 & 5.4 & 5.5058 & TRN \\
\hline CHEMBL1448555 & 688546 & 5.8 & 6.0331 & TRN \\
\hline CHEMBL1360916 & 688546 & 5.5 & 5.4077 & TRN \\
\hline CHEMBL1320019 & 688546 & 4.5 & 5.0881 & TRN \\
\hline CHEMBL1520119 & 688546 & 5.0 & 5.5298 & TRN \\
\hline CHEMBL1358554 & 688546 & 4.8 & 5.3024 & TRN \\
\hline CHEMBL1420550 & 688546 & 4.6 & 5.1904 & TRN \\
\hline CHEMBL1364088 & 688546 & 6.0 & 5.1972 & TRN \\
\hline CHEMBL1516342 & 688546 & 5.0 & 5.0213 & TRN \\
\hline CHEMBL1343533 & 688546 & 5.45 & 4.9916 & TST \\
\hline CHEMBL1527469 & 688546 & 4.9 & 5.2803 & TRN \\
\hline CHEMBL1497939 & 688546 & 6.4 & 5.5816 & TRN \\
\hline CHEMBL1397695 & 688546 & 4.45 & 5.2828 & TST \\
\hline CHEMBL1524821 & 688546 & 5.5 & 5.125 & TRN \\
\hline CHEMBL1591131 & 688546 & 5.0 & 5.395 & TRN \\
\hline CHEMBL1565060 & 688546 & 4.8 & 4.5732 & TRN \\
\hline CHEMBL1450778 & 688546 & 4.9 & 5.0196 & TRN \\
\hline CHEMBL1441225 & 688546 & 4.7 & 5.1262 & TST \\
\hline CHEMBL1498470 & 688546 & 4.95 & 5.2162 & TRN \\
\hline CHEMBL1562252 & 688546 & 6.9 & 5.2071 & TRN \\
\hline CHEMBL1357286 & 688546 & 4.8 & 5.2773 & TRN \\
\hline CHEMBL1454749 & 688546 & 4.9 & 5.1389 & 9999999999 \\
\hline CHEMBL1442646 & 688546 & 5.1 & 5.4694 & TST \\
\hline CHEMBL1598595 & 688546 & 5.8 & 5.3143 & TRN \\
\hline CHEMBL1333767 & 688546 & 4.8 & 4.6451 & TRN \\
\hline CHEMBL1395194 & 688546 & 5.5 & 5.3303 & TST \\
\hline CHEMBL1334116 & 688546 & 6.0 & 5.6693 & TST \\
\hline CHEMBL1337228 & 688546 & 4.7 & 5.4176 & TRN \\
\hline CHEMBL1438451 & 688546 & 5.0 & 5.0834 & TRN \\
\hline CHEMBL1318850 & 688546 & 7.699 & 5.4869 & TRN \\
\hline
\end{tabular}




\begin{tabular}{|c|c|c|c|c|}
\hline & & & pplemen & al $\mathrm{T}$ \\
\hline CHEMBL1397067 & 688546 & 5.0 & 6.0237 & TRN \\
\hline CHEMBL1331228 & 688546 & 4.4 & 5.7224 & TRN \\
\hline CHEMBL1599993 & 688546 & 4.7 & 5.5648 & TST \\
\hline CHEMBL1526445 & 688546 & 7.2 & 5.1651 & TRN \\
\hline CHEMBL1547504 & 688546 & 5.0 & 4.7283 & TRN \\
\hline CHEMBL1434902 & 688546 & 5.0 & 5.7553 & TRN \\
\hline CHEMBL1590583 & 688546 & 4.8 & 4.9792 & TRN \\
\hline CHEMBL1590511 & 688546 & 4.5 & 5.0594 & TRN \\
\hline CHEMBL1608340 & 688546 & 5.5 & 5.4715 & TRN \\
\hline CHEMBL1570047 & 688546 & 5.0 & 5.0563 & TRN \\
\hline CHEMBL1344115 & 688546 & 4.85 & 5.1606 & TST \\
\hline CHEMBL1306966 & 688546 & 4.6 & 5.0149 & TRN \\
\hline CHEMBL1334320 & 688546 & 5.0 & 4.6866 & TRN \\
\hline CHEMBL1394612 & 688546 & 4.9 & 5.0728 & TRN \\
\hline CHEMBL1474269 & 688546 & 6.1 & 5.8263 & TRN \\
\hline CHEMBL1365865 & 688546 & 7.5003 & 4.9938 & TRN \\
\hline CHEMBL1319630 & 688546 & 5.1 & 5.4551 & TRN \\
\hline CHEMBL1591117 & 688546 & 4.7 & 5.1877 & TRN \\
\hline CHEMBL1602790 & 688546 & 4.5 & 5.2249 & TRN \\
\hline CHEMBL1487547 & 688546 & 5.25 & 5.1389 & TST \\
\hline CHEMBL1384594 & 688546 & 4.8 & 4.979 & TRN \\
\hline CHEMBL1513963 & 688546 & 4.8 & 5.0937 & TRN \\
\hline CHEMBL428496 & 688546 & 4.6 & 5.8635 & TST \\
\hline CHEMBL1464555 & 688546 & 5.4 & 5.2538 & TRN \\
\hline CHEMBL1523865 & 688546 & 4.7 & 5.4461 & TRN \\
\hline CHEMBL1597436 & 688546 & 4.8 & 5.3309 & TST \\
\hline CHEMBL1377166 & 688546 & 4.9 & 5.5333 & TRN \\
\hline CHEMBL1318383 & 688546 & 7.5003 & 5.4351 & TRN \\
\hline CHEMBL1513424 & 688546 & 8.301 & 5.6702 & TRN \\
\hline CHEMBL1442492 & 688546 & 4.5 & 5.0149 & TST \\
\hline CHEMBL1331514 & 688546 & 5.6 & 5.4967 & TRN \\
\hline CHEMBL1558822 & 688546 & 5.0 & 5.3763 & TRN \\
\hline CHEMBL1336136 & 688546 & 5.0 & 5.3926 & TST \\
\hline CHEMBL1397092 & 688546 & 5.0 & 5.2544 & TRN \\
\hline CHEMBL1354621 & 688546 & 5.1 & 5.523 & TRN \\
\hline CHEMBL3212141 & 688546 & 4.6 & 5.0105 & TST \\
\hline CHEMBL1593453 & 688546 & 4.6 & 5.1056 & TRN \\
\hline CHEMBL1515365 & 688546 & 5.0 & 5.8528 & TRN \\
\hline CHEMBL1303139 & 688546 & 5.0 & 4.956 & TST \\
\hline CHEMBL1435104 & 688546 & 5.0 & 5.2409 & TRN \\
\hline CHEMBL1442642 & 688546 & 4.9 & 5.2171 & TRN \\
\hline CHEMBL1574936 & 688546 & 4.9 & 4.9908 & TRN \\
\hline CHEMBL1544093 & 688546 & 4.7 & 4.85 & TRN \\
\hline CHEMBL1475918 & 688546 & 4.5 & 4.7685 & TRN \\
\hline CHEMBL85826 & 688546 & 5.0 & 5.2284 & TRN \\
\hline CHEMBL1354491 & 688546 & 4.7 & 4.8117 & TRN \\
\hline CHEMBL1391217 & 688546 & 4.5 & 5.2755 & TST \\
\hline CHEMBL1383022 & 688546 & 4.9 & 5.2962 & TRN \\
\hline
\end{tabular}




\begin{tabular}{|c|c|c|c|c|c|}
\hline \multicolumn{6}{|c|}{ Supplemental Table S2.txt } \\
\hline CHEMBL1348741 & 688546 & 4.95 & 5.3227 & TST & \\
\hline CHEMBL1332160 & 688546 & 7.3002 & 5.2237 & TRN & \\
\hline CHEMBL1302228 & 688546 & 7.3002 & 5.7062 & TRN & \\
\hline CHEMBL1507448 & 688546 & 4.5 & 5.176 & TST & \\
\hline CHEMBL1592142 & 688546 & 4.9 & 5.6378 & TRN & \\
\hline CHEMBL1437262 & 688546 & 5.0 & 5.2975 & TRN & \\
\hline CHEMBL1455411 & 688546 & 4.5 & 4.8199 & TRN & \\
\hline CHEMBL 3197851 & 688546 & 4.9 & 5.4035 & TST & \\
\hline CHEMBL1449490 & 688546 & 5.0 & 5.04899 & 99999999995 & TST \\
\hline CHEMBL1421232 & 688546 & 5.2 & 5.1604 & TRN & \\
\hline CHEMBL1434844 & 688546 & 5.4 & 5.8248 & TRN & \\
\hline CHEMBL1568022 & 688546 & 4.5 & 4.8278 & TRN & \\
\hline CHEMBL1460496 & 688546 & 4.45 & 5.2125 & TST & \\
\hline CHEMBL1332761 & 688546 & 4.5 & 5.0258 & TST & \\
\hline CHEMBL1399667 & 688546 & 4.9 & 5.3711 & TRN & \\
\hline CHEMBL1358756 & 688546 & 4.7 & 4.8149 & TRN & \\
\hline CHEMBL1473245 & 688546 & 5.2 & 5.6423 & TRN & \\
\hline CHEMBL1434038 & 688546 & 5.4 & 5.7075 & TRN & \\
\hline CHEMBL1513498 & 688546 & 4.9 & 5.1546 & TRN & \\
\hline CHEMBL1437759 & 688546 & 4.9 & 4.8771 & TRN & \\
\hline CHEMBL1516043 & 688546 & 5.4 & 5.1437 & TRN & \\
\hline CHEMBL530049 & 688546 & 5.0 & 5.0637 & TST & \\
\hline CHEMBL1365850 & 688546 & 5.1 & 5.1384 & TRN & \\
\hline CHEMBL1355998 & 688546 & 4.8 & 5.4867 & TRN & \\
\hline CHEMBL 3193656 & 688546 & 5.2 & 5.3205 & TST & \\
\hline CHEMBL1522636 & 688546 & 4.8 & 5.3749 & TRN & \\
\hline CHEMBL1495089 & 688546 & 6.1 & 5.9306 & TRN & \\
\hline CHEMBL1314688 & 688546 & 4.9 & 4.8381 & TRN & \\
\hline CHEMBL1506407 & 688546 & 4.9 & 5.3053 & TRN & \\
\hline CHEMBL448847 & 688546 & 4.8 & 4.9809 & TRN & \\
\hline CHEMBL555689 & 688546 & 5.4 & 5.2759 & TST & \\
\hline CHEMBL1406424 & 688546 & 4.9 & 5.1416 & TRN & \\
\hline CHEMBL1474407 & 688546 & 4.7 & 5.6457 & TST & \\
\hline CHEMBL17127 & 688546 & 5.0 & 4.6665 & TST & \\
\hline CHEMBL1491110 & 688546 & 4.9 & 5.13899 & 9999999999 & TRN \\
\hline CHEMBL1595162 & 688546 & 5.0 & 5.0739 & TRN & \\
\hline CHEMBL1333632 & 688546 & 8.301 & 5.1792 & TRN & \\
\hline CHEMBL1551719 & 688546 & 4.7 & 5.2876 & TRN & \\
\hline CHEMBL1578664 & 688546 & 4.45 & 5.3692 & TST & \\
\hline CHEMBL1317817 & 688546 & 4.5 & 5.0632 & TRN & \\
\hline CHEMBL1304938 & 688546 & 5.45 & 5.5494 & TRN & \\
\hline CHEMBL1362737 & 688546 & 5.0 & 4.9482 & TRN & \\
\hline CHEMBL1484159 & 688546 & 4.6 & 5.1251 & TRN & \\
\hline CHEMBL1593486 & 688546 & 5.3 & 5.8231 & TST & \\
\hline CHEMBL1551183 & 688546 & 5.9 & 5.5518 & TRN & \\
\hline CHEMBL1357871 & 688546 & 5.0 & 5.2363 & TRN & \\
\hline CHEMBL1517425 & 688546 & 4.5 & 5.0662 & TRN & \\
\hline CHEMBL1409658 & 688546 & 4.9 & 4.8803 & TRN & \\
\hline
\end{tabular}




\begin{tabular}{|c|c|c|c|c|c|}
\hline \multicolumn{6}{|c|}{ Supplemental Table S2.txt } \\
\hline CHEMBL1600914 & 688546 & 5.0 & 5.0061 & TRN & \\
\hline CHEMBL1397678 & 688546 & 6.25 & 5.3977 & TRN & \\
\hline CHEMBL1413757 & 688546 & 4.9 & 5.2867 & TRN & \\
\hline CHEMBL1591084 & 688546 & 4.5 & 5.0607 & TRN & \\
\hline CHEMBL1317751 & 688546 & 4.5 & 4.8012 & TRN & \\
\hline CHEMBL1445652 & 688546 & 4.9 & 5.0778 & TST & \\
\hline CHEMBL1448418 & 688546 & 6.7501 & 5.6395 & TRN & \\
\hline CHEMBL1370040 & 688546 & 4.4 & 5.3018 & TST & \\
\hline CHEMBL1592284 & 688546 & 4.7 & 5.1951 & TRN & \\
\hline CHEMBL1555279 & 688546 & 6.4 & 5.7599 & TRN & \\
\hline CHEMBL1436381 & 688546 & 6.15 & 5.2857 & TRN & \\
\hline CHEMBL1334073 & 688546 & 5.0 & 5.3575 & TST & \\
\hline CHEMBL1357025 & 688546 & 5.0 & 5.3215 & TRN & \\
\hline CHEMBL1214407 & 688546 & 4.8 & 4.9283 & TRN & \\
\hline CHEMBL1449368 & 688546 & 7.3002 & 5.6097 & TST & \\
\hline CHEMBL1334574 & 688546 & 4.5 & 5.36100 & 0000000001 & TST \\
\hline CHEMBL1512059 & 688546 & 4.8 & 4.9645 & TRN & \\
\hline CHEMBL1418532 & 688546 & 4.7 & 4.6743 & TRN & \\
\hline CHEMBL1553499 & 688546 & 4.6 & 5.2489 & TRN & \\
\hline CHEMBL 248345 & 688546 & 4.7 & 5.4045 & TRN & \\
\hline CHEMBL1316232 & 688546 & 5.0 & 5.5144 & TRN & \\
\hline CHEMBL1375797 & 688546 & 5.8 & 5.0973 & TRN & \\
\hline CHEMBL1467356 & 688546 & 6.5501 & 4.9146 & TST & \\
\hline CHEMBL1609203 & 688546 & 4.5 & 4.8654 & TRN & \\
\hline CHEMBL1409202 & 688546 & 4.5 & 4.8776 & TST & \\
\hline CHEMBL3213064 & 688546 & 7.3497 & 5.4606 & TST & \\
\hline CHEMBL1476790 & 688546 & 4.6 & 5.0967 & TRN & \\
\hline CHEMBL310798 & 688546 & 5.0 & 4.9848 & TST & \\
\hline CHEMBL1474843 & 688546 & 4.8 & 5.7271 & TRN & \\
\hline CHEMBL1464497 & 688546 & 4.7 & 4.886 & TRN & \\
\hline CHEMBL1493139 & 688546 & 5.0 & 4.8567 & TRN & \\
\hline CHEMBL1355143 & 688546 & 7.4001 & 5.0193 & TRN & \\
\hline CHEMBL54804 & 688546 & 4.9 & 5.6451 & TST & \\
\hline CHEMBL1427637 & 688546 & 5.2 & 5.1163 & TST & \\
\hline CHEMBL1396485 & 688546 & 5.2 & 5.2793 & TRN & \\
\hline CHEMBL1592708 & 688546 & 5.0 & 5.5069 & TRN & \\
\hline CHEMBL 1488388 & 688546 & 4.9 & 5.2728 & TRN & \\
\hline CHEMBL1479306 & 688546 & 5.8 & 4.8911 & TRN & \\
\hline CHEMBL1372214 & 688546 & 5.0 & 5.1637 & TRN & \\
\hline CHEMBL1317413 & 688546 & 4.7 & 4.9021 & TST & \\
\hline CHEMBL1529998 & 688546 & 5.1 & 5.6113 & TRN & \\
\hline CHEMBL1484916 & 688546 & 4.6 & 5.1124 & TST & \\
\hline CHEMBL1387313 & 688546 & 4.5 & 4.5772 & TST & \\
\hline CHEMBL1417436 & 688546 & 6.1 & 5.3882 & TRN & \\
\hline CHEMBL1290203 & 688546 & 4.8 & 4.8306 & TRN & \\
\hline CHEMBL1349378 & 688546 & 5.0 & 4.7109 & TRN & \\
\hline CHEMBL1431063 & 688546 & 4.7 & 5.1299 & TST & \\
\hline CHEMBL1590751 & 688546 & 7.8013 & 5.5846 & TST & \\
\hline
\end{tabular}




\begin{tabular}{|c|c|c|c|c|c|}
\hline & & & & & \\
\hline CHEMBL1362278 & 688546 & 6.8 & 5.3797 & TRN & \\
\hline CHEMBL1592791 & 688546 & 5.0 & 5.0997 & TRN & \\
\hline CHEMBL1590492 & 688546 & 5.0 & 4.7095 & TRN & \\
\hline CHEMBL1606349 & 688546 & 8.0 & 5.4703 & TRN & \\
\hline CHEMBL1435633 & 688546 & 4.8 & 5.4698 & TRN & \\
\hline CHEMBL1395477 & 688546 & 5.0 & $5.1770 e$ & 00000000005 & TRN \\
\hline CHEMBL1321646 & 688546 & 4.9 & 5.3462 & TRN & \\
\hline CHEMBL1435880 & 688546 & 5.9 & 5.1735 & TST & \\
\hline CHEMBL1401945 & 688546 & 5.0 & 4.8256 & TRN & \\
\hline CHEMBL1554932 & 688546 & 4.9 & $6.0520 e$ & 00000000005 & TRN \\
\hline CHEMBL1434380 & 688546 & 5.35 & 5.5961 & TRN & \\
\hline CHEMBL1559589 & 688546 & 4.6 & 5.3111 & TRN & \\
\hline CHEMBL1552266 & 688546 & 4.6 & 5.2989 & TRN & \\
\hline CHEMBL1531937 & 688546 & 4.5 & 6.1136 & TRN & \\
\hline CHEMBL1609218 & 688546 & 4.6 & 5.4311 & TRN & \\
\hline CHEMBL1476524 & 688546 & 5.9 & 5.4663 & TRN & \\
\hline CHEMBL1554040 & 688546 & 4.9 & 4.6457 & TRN & \\
\hline CHEMBL1473561 & 688546 & 4.6 & 5.5172 & TRN & \\
\hline CHEMBL1514476 & 688546 & 4.5 & 5.7019 & TST & \\
\hline CHEMBL1342169 & 688546 & 5.25 & 5.3382 & TRN & \\
\hline CHEMBL1407038 & 688546 & 4.5 & 5.1495 & TRN & \\
\hline CHEMBL1488238 & 688546 & 5.45 & 5.5928 & TST & \\
\hline CHEMBL1475950 & 688546 & 5.0 & 5.3049 & TRN & \\
\hline CHEMBL1418581 & 688546 & 4.9 & 4.8193 & TRN & \\
\hline CHEMBL601770 & 688546 & 6.1 & 5.4406 & TRN & \\
\hline CHEMBL1334260 & 688546 & 4.45 & 5.3312 & TST & \\
\hline CHEMBL1471326 & 688546 & 4.9 & 5.2209 & TRN & \\
\hline CHEMBL1366792 & 688546 & 5.5 & 5.495 & TRN & \\
\hline CHEMBL1609892 & 688546 & 4.6 & 5.494 & TRN & \\
\hline CHEMBL1472904 & 688546 & 5.9 & 5.75899 & 99999999995 & TRN \\
\hline CHEMBL1592891 & 688546 & 5.1 & 5.1047 & TRN & \\
\hline CHEMBL1306181 & 688546 & 4.9 & 4.6863 & TRN & \\
\hline CHEMBL1571217 & 688546 & 5.6 & 5.4931 & TRN & \\
\hline CHEMBL1479062 & 688546 & 5.3 & 5.7677 & TRN & \\
\hline CHEMBL1512973 & 688546 & 5.3 & 5.3346 & TRN & \\
\hline CHEMBL1374856 & 688546 & 4.5 & 5.1795 & TST & \\
\hline CHEMBL1542674 & 688546 & 4.8 & 4.8894 & TST & \\
\hline CHEMBL1523779 & 688546 & 6.0 & 5.4853 & TRN & \\
\hline CHEMBL1429637 & 688546 & 4.65 & 4.6643 & TRN & \\
\hline CHEMBL1526572 & 688546 & 5.1 & 5.1699 & TST & \\
\hline CHEMBL1358303 & 688546 & 4.45 & 5.1019 & TRN & \\
\hline CHEMBL1600374 & 688546 & 6.5 & 5.4548 & TRN & \\
\hline CHEMBL1312849 & 688546 & 5.1 & 5.0054 & TST & \\
\hline CHEMBL1366061 & 688546 & 4.5 & 4.9368 & TRN & \\
\hline CHEMBL1365538 & 688546 & 4.6 & 4.5639 & TRN & \\
\hline CHEMBL1375561 & 688546 & 4.9 & 5.1353 & TRN & \\
\hline CHEMBL1551963 & 688546 & 4.7 & 5.1246 & TRN & \\
\hline CHEMBL1485132 & 688546 & 4.6 & 5.0618 & TST & \\
\hline & & & & 10245 & \\
\hline
\end{tabular}




\begin{tabular}{|c|c|c|c|c|c|}
\hline & & \\
\hline CHEMBL1434223 & 688546 & 5.1 & 5.0841 & TRN & \\
\hline CHEMBL1474052 & 688546 & 5.5 & 5.421 & TRN & \\
\hline CHEMBL1540116 & 688546 & 4.85 & 5.8878 & TST & \\
\hline CHEMBL1378033 & 688546 & 4.95 & 5.2785 & TRN & \\
\hline CHEMBL1367899 & 688546 & 4.7 & 4.68199 & 99999999995 & TRN \\
\hline CHEMBL1378161 & 688546 & 7.7496 & 5.16100 & 00000000005 & TRN \\
\hline CHEMBL460518 & 688546 & 4.9 & 5.1578 & TRN & \\
\hline CHEMBL1435132 & 688546 & 4.9 & 4.8795 & TRN & \\
\hline CHEMBL1544544 & 688546 & 4.9 & 5.5127 & TRN & \\
\hline CHEMBL1329038 & 688546 & 4.9 & 4.9363 & TRN & \\
\hline CHEMBL1530560 & 688546 & 4.8 & 5.0586 & TRN & \\
\hline CHEMBL3208043 & 688546 & 4.5 & 5.303 & TST & \\
\hline CHEMBL1554077 & 688546 & 7.7496 & 5.1755 & TRN & \\
\hline CHEMBL1464293 & 688546 & 5.1 & 4.8741 & TRN & \\
\hline CHEMBL1443354 & 688546 & 4.9 & 5.1997 & TST & \\
\hline CHEMBL1335415 & 688546 & 6.8 & 5.1965 & TST & \\
\hline CHEMBL1997899 & 688546 & 5.25 & 5.4121 & TST & \\
\hline CHEMBL1435263 & 688546 & 8.1024 & 5.2769 & TRN & \\
\hline CHEMBL1398005 & 688546 & 8.301 & 5.6605 & TRN & \\
\hline CHEMBL1599897 & 688546 & 5.0 & 4.9396 & TRN & \\
\hline CHEMBL1553046 & 688546 & 4.5 & 4.8897 & TRN & \\
\hline CHEMBL515505 & 688546 & 5.4 & 5.2139 & TST & \\
\hline CHEMBL1593181 & 688546 & 4.9 & 5.3226 & TRN & \\
\hline CHEMBL1523298 & 688546 & 5.35 & 5.1222 & TRN & \\
\hline CHEMBL1501902 & 688546 & 4.45 & 5.4571 & TRN & \\
\hline CHEMBL1390671 & 688546 & 5.0 & 4.9084 & TRN & \\
\hline CHEMBL1560639 & 688546 & 5.9 & 5.7543 & TST & \\
\hline CHEMBL1319883 & 688546 & 5.55 & 5.5941 & TRN & \\
\hline CHEMBL1571874 & 688546 & 4.5 & 4.7788 & TST & \\
\hline CHEMBL1406834 & 688546 & 4.65 & 5.36 & TST & \\
\hline CHEMBL1335967 & 688546 & 5.1 & 4.8751 & TRN & \\
\hline CHEMBL1317317 & 688546 & 6.4 & 5.1916 & TRN & \\
\hline CHEMBL1433866 & 688546 & 4.7 & 5.4366 & TRN & \\
\hline CHEMBL1518097 & 688546 & 4.9 & 5.5156 & TRN & \\
\hline CHEMBL1486766 & 688546 & 5.0 & 5.0622 & TRN & \\
\hline CHEMBL1605053 & 688546 & 8.0506 & 5.6595 & TRN & \\
\hline CHEMBL1437451 & 688546 & 5.4 & 5.0779 & TRN & \\
\hline CHEMBL1474862 & 688546 & 8.301 & 5.3584 & TRN & \\
\hline CHEMBL1363354 & 688546 & 5.25 & 5.5888 & TRN & \\
\hline CHEMBL1436018 & 688546 & 6.7001 & 4.8632 & TRN & \\
\hline CHEMBL1448359 & 688546 & 4.8 & 5.1839 & TRN & \\
\hline CHEMBL1403950 & 688546 & 5.2 & 5.2289 & TRN & \\
\hline CHEMBL1407509 & 688546 & 4.9 & 5.0554 & TST & \\
\hline CHEMBL1593518 & 688546 & 5.4 & 4.6235 & TST & \\
\hline CHEMBL1368118 & 688546 & 4.8 & 4.6578 & TRN & \\
\hline CHEMBL1321491 & 688546 & 6.0 & 5.6958 & TRN & \\
\hline CHEMBL1356232 & 688546 & 7.0 & 5.6146 & TST & \\
\hline CHEMBL1553931 & 688546 & 6.4 & 5.6646 & TRN & \\
\hline
\end{tabular}




\begin{tabular}{|c|c|c|c|c|c|}
\hline \multicolumn{6}{|c|}{ Supplemental Table S2.txt } \\
\hline CHEMBL1361793 & 688546 & 4.6 & 4.8278 & TRN & \\
\hline CHEMBL1591675 & 688546 & 5.75 & 5.6131 & TRN & \\
\hline CHEMBL1426192 & 688546 & 4.5 & 5.1343 & TST & \\
\hline CHEMBL1721986 & 688546 & 5.05 & 5.3738 & TST & \\
\hline CHEMBL1323279 & 688546 & 4.5 & 5.3009 & TRN & \\
\hline CHEMBL1407758 & 688546 & 6.5 & 5.4867 & TRN & \\
\hline CHEMBL1593711 & 688546 & 5.5 & 5.3724 & TST & \\
\hline CHEMBL1368261 & 688546 & 5.0 & 5.1291 & TST & \\
\hline CHEMBL1328411 & 688546 & 6.7001 & 5.4596 & TRN & \\
\hline CHEMBL1507344 & 688546 & 4.5 & 5.2537 & TST & \\
\hline CHEMBL1394538 & 688546 & 4.8 & 5.2274 & TRN & \\
\hline CHEMBL1484528 & 688546 & 4.9 & 5.0398 & TRN & \\
\hline CHEMBL1484818 & 688546 & 4.9 & 4.9586 & TST & \\
\hline CHEMBL1338236 & 688546 & 4.6 & 4.7428 & TRN & \\
\hline CHEMBL1457553 & 688546 & 4.9 & 5.1681 & TRN & \\
\hline CHEMBL1427685 & 688546 & 4.5 & 4.755 & TRN & \\
\hline CHEMBL 39878 & 688546 & 4.5 & 5.1269 & TRN & \\
\hline CHEMBL1554144 & 688546 & 5.5 & 4.9519 & TST & \\
\hline CHEMBL1311534 & 688546 & 4.9 & 5.0947 & TST & \\
\hline CHEMBL1338803 & 688546 & 4.9 & 5.2338 & TST & \\
\hline CHEMBL1358578 & 688546 & 7.8013 & 5.5318 & TRN & \\
\hline CHEMBL1440291 & 688546 & 4.8 & 5.1347 & TRN & \\
\hline CHEMBL1513465 & 688546 & 4.5 & 5.7367 & TRN & \\
\hline CHEMBL1601908 & 688546 & 5.0 & 5.1065 & TRN & \\
\hline CHEMBL1512042 & 688546 & 6.6 & 5.3718 & TRN & \\
\hline CHEMBL1362433 & 688546 & 6.5501 & 5.4442 & TST & \\
\hline CHEMBL1355665 & 688546 & 4.5 & 4.5445 & TRN & \\
\hline CHEMBL1610449 & 688546 & 4.9 & 5.4591 & TRN & \\
\hline CHEMBL1333433 & 688546 & 4.9 & 5.305 & TRN & \\
\hline CHEMBL1596675 & 688546 & 4.5 & 5.3005 & TST & \\
\hline CHEMBL3213953 & 688546 & 4.9 & 5.2298 & TST & \\
\hline CHEMBL1609165 & 688546 & 8.301 & 5.8198 & TRN & \\
\hline CHEMBL1433936 & 688546 & 8.4559 & 4.9775 & TRN & \\
\hline CHEMBL1335830 & 688546 & 5.05 & 5.9316 & TRN & \\
\hline CHEMBL1498591 & 688546 & 5.0 & 5.4056 & TRN & \\
\hline CHEMBL 238873 & 688546 & 5.4 & 5.2245 & TRN & \\
\hline CHEMBL1338749 & 688546 & 7.2 & 5.0725 & TRN & \\
\hline CHEMBL1572122 & 688546 & 4.5 & 5.2888 & TST & \\
\hline CHEMBL1515006 & 688546 & 4.9 & 5.6567 & TRN & \\
\hline CHEMBL260342 & 688546 & 5.1 & 5.1481 & TRN & \\
\hline CHEMBL1398442 & 688546 & 4.7 & 5.7051 & TRN & \\
\hline CHEMBL1476282 & 688546 & 5.45 & 5.6254 & TRN & \\
\hline CHEMBL1565133 & 688546 & 4.6 & 5.2871 & TST & \\
\hline CHEMBL1468497 & 688546 & 4.9 & 4.7405 & TRN & \\
\hline CHEMBL1494495 & 688546 & 6.1 & $5.3670 e$ & 0000000001 & TRN \\
\hline CHEMBL3193533 & 688546 & 4.65 & 5.3301 & TST & \\
\hline CHEMBL1515823 & 688546 & 4.9 & 4.9611 & TRN & \\
\hline CHEMBL3209105 & 688546 & 5.35 & 5.0747 & TST & \\
\hline
\end{tabular}




\begin{tabular}{|c|c|c|c|c|c|}
\hline \multicolumn{6}{|c|}{ Supplemental Table S2.txt } \\
\hline CHEMBL1413419 & 688546 & 4.9 & 5.5516 & TRN & \\
\hline CHEMBL1561742 & 688546 & 6.15 & 5.5095 & TRN & \\
\hline CHEMBL1553528 & 688546 & 4.5 & 5.6272 & TRN & \\
\hline CHEMBL1395004 & 688546 & 5.0 & 5.2806 & TRN & \\
\hline CHEMBL1551403 & 688546 & 8.2007 & 5.8703 & TRN & \\
\hline CHEMBL1475371 & 688546 & 4.5 & 5.6403 & TRN & \\
\hline CHEMBL1374302 & 688546 & 4.7 & 4.8796 & TRN & \\
\hline CHEMBL1537435 & 688546 & 5.5 & 5.3983 & TRN & \\
\hline CHEMBL1410608 & 688546 & 4.5 & 5.3308 & TRN & \\
\hline CHEMBL1397609 & 688546 & 4.8 & 5.5584 & TRN & \\
\hline CHEMBL1512516 & 688546 & 5.5 & 5.4444 & TST & \\
\hline CHEMBL1528902 & 688546 & 7.0501 & 5.9931 & TRN & \\
\hline CHEMBL1425542 & 688546 & 4.9 & 4.9192 & TST & \\
\hline CHEMBL1355406 & 688546 & 5.6 & 4.9907 & TRN & \\
\hline CHEMBL1329768 & 688546 & 5.6 & 5.2582 & TRN & \\
\hline CHEMBL1393934 & 688546 & 4.8 & 5.1171 & TST & \\
\hline CHEMBL1606291 & 688546 & 5.8 & 5.5803 & TST & \\
\hline CHEMBL1435526 & 688546 & 5.1 & 5.2975 & TRN & \\
\hline CHEMBL 259421 & 688546 & 5.4 & 5.4348 & TRN & \\
\hline CHEMBL1552144 & 688546 & 4.8 & 5.37799 & 9999999999 & TRN \\
\hline CHEMBL1563494 & 688546 & 4.6 & 5.8239 & TST & \\
\hline CHEMBL1528640 & 688546 & 4.5 & 4.9784 & TRN & \\
\hline CHEMBL1429512 & 688546 & 4.5 & 4.6408 & TRN & \\
\hline CHEMBL1512614 & 688546 & 4.7 & 4.9414 & TRN & \\
\hline CHEMBL1357113 & 688546 & 4.5 & 4.592 & TRN & \\
\hline CHEMBL1553776 & 688546 & 4.7 & 5.1647 & TST & \\
\hline CHEMBL1372884 & 688546 & 4.8 & 5.0907 & TST & \\
\hline CHEMBL227959 & 688546 & 5.5 & 5.0019 & TRN & \\
\hline CHEMBL1358092 & 688546 & 4.5 & 4.86100 & 0000000001 & TRN \\
\hline CHEMBL1363862 & 688546 & 4.6 & 5.9008 & TST & \\
\hline CHEMBL1305293 & 688546 & 4.9 & 5.2696 & TST & \\
\hline CHEMBL1554272 & 688546 & 6.35 & 5.4378 & TST & \\
\hline CHEMBL1442813 & 688546 & 8.1024 & 5.007 & TRN & \\
\hline CHEMBL1431348 & 688546 & 4.5 & 4.7938 & TRN & \\
\hline CHEMBL1552496 & 688546 & 5.5 & 4.9745 & TRN & \\
\hline CHEMBL1512257 & 688546 & 4.9 & 4.9471 & TRN & \\
\hline CHEMBL1523556 & 688546 & 5.0 & 4.9595 & TST & \\
\hline CHEMBL1593765 & 688546 & 6.0 & 4.9212 & TRN & \\
\hline CHEMBL1374043 & 688546 & 4.9 & 5.4328 & TRN & \\
\hline CHEMBL1555180 & 688546 & 7.0 & 5.2722 & TST & \\
\hline CHEMBL1336482 & 688546 & 5.4 & 4.9128 & TRN & \\
\hline CHEMBL1332503 & 688546 & 4.5 & 5.4928 & TRN & \\
\hline CHEMBL1544315 & 688546 & 4.8 & 5.0441 & TST & \\
\hline CHEMBL1325526 & 688546 & 4.7 & 5.3685 & TRN & \\
\hline CHEMBL1394600 & 688546 & 4.9 & 5.4387 & TRN & \\
\hline CHEMBL1395211 & 688546 & 8.301 & 5.2789 & TRN & \\
\hline CHEMBL1496661 & 688546 & 7.5498 & 5.8726 & TRN & \\
\hline CHEMBL1593007 & 688546 & 4.9 & 4.8558 & TRN & \\
\hline
\end{tabular}




\begin{tabular}{|c|c|c|c|c|c|}
\hline & & & & & \\
\hline CHEMBL1514888 & 688546 & 5.0 & 5.11 & TRN & \\
\hline CHEMBL1541037 & 688546 & 4.5 & 4.9045 & TRN & \\
\hline CHEMBL1552943 & 688546 & 4.5 & 5.034 & TRN & \\
\hline CHEMBL1561098 & 688546 & 7.3002 & 5.4658 & TRN & \\
\hline CHEMBL1553072 & 688546 & 5.3 & 5.4817 & TST & \\
\hline CHEMBL1350867 & 688546 & 4.9 & 5.7151 & TST & \\
\hline CHEMBL1580067 & 688546 & 4.7 & 5.0412 & TRN & \\
\hline CHEMBL1404358 & 688546 & 4.8 & 5.112 & TRN & \\
\hline CHEMBL1395145 & 688546 & 4.9 & 4.9465 & TST & \\
\hline CHEMBL1478874 & 688546 & 4.9 & 5.1068 & TST & \\
\hline CHEMBL1525939 & 688546 & 4.7 & 4.9004 & TRN & \\
\hline CHEMBL1562428 & 688546 & 5.55 & 5.9366 & TRN & \\
\hline CHEMBL1353885 & 688546 & 4.5 & 4.9212 & TRN & \\
\hline CHEMBL1410580 & 688546 & 5.6 & 4.9228 & TRN & \\
\hline CHEMBL1437035 & 688546 & 5.5 & 5.2715 & TRN & \\
\hline CHEMBL1553514 & 688546 & 6.8499 & 6.1032 & TRN & \\
\hline CHEMBL1407693 & 688546 & 5.6 & 5.34200 & 00000000005 & TRN \\
\hline CHEMBL1466843 & 688546 & 4.6 & 4.9804 & TST & \\
\hline CHEMBL1357602 & 688546 & 4.6 & 5.3948 & TRN & \\
\hline CHEMBL1589797 & 688546 & 4.9 & 5.26399 & 9999999999 & TST \\
\hline CHEMBL1395387 & 688546 & 5.0 & 5.7571 & TST & \\
\hline CHEMBL1434994 & 688546 & 4.7 & 4.9433 & TRN & \\
\hline CHEMBL1480983 & 688546 & 4.7 & 4.7537 & TRN & \\
\hline CHEMBL1609698 & 688546 & 5.5 & 5.3095 & TRN & \\
\hline CHEMBL1606513 & 688546 & 5.0 & 5.157 & TRN & \\
\hline CHEMBL2373651 & 688546 & 4.8 & 5.1557 & TST & \\
\hline CHEMBL1561056 & 688546 & 4.8 & 4.8699 & TRN & \\
\hline CHEMBL1407552 & 688546 & 4.8 & 5.365 & TRN & \\
\hline CHEMBL1396635 & 688546 & 5.4 & 5.45100 & 00000000005 & TRN \\
\hline CHEMBL1433555 & 688546 & 4.9 & 4.7888 & TRN & \\
\hline CHEMBL1335173 & 688546 & 4.8 & 5.0742 & TRN & \\
\hline CHEMBL1355509 & 688546 & 5.6 & 5.9885 & TRN & \\
\hline CHEMBL1436460 & 688546 & 6.9 & 5.1621 & TRN & \\
\hline CHEMBL1503016 & 688546 & 4.7 & 5.0502 & TRN & \\
\hline CHEMBL1402612 & 688546 & 5.45 & 5.2428 & TRN & \\
\hline CHEMBL1535510 & 688546 & 4.6 & 5.3985 & TRN & \\
\hline CHEMBL1610336 & 688546 & 4.65 & 4.9782 & TRN & \\
\hline CHEMBL1558875 & 688546 & 4.85 & 5.3287 & TST & \\
\hline CHEMBL1520996 & 688546 & 5.0 & 5.6403 & TRN & \\
\hline CHEMBL 287689 & 688546 & 5.2 & 5.2934 & TST & \\
\hline CHEMBL1486033 & 688546 & 4.8 & 4.8961 & TST & \\
\hline CHEMBL 3145245 & 688546 & 4.8 & 5.5031 & TST & \\
\hline CHEMBL1565324 & 688546 & 5.4 & 4.9805 & TST & \\
\hline CHEMBL1361612 & 688546 & 7.0501 & 5.1862 & TST & \\
\hline CHEMBL1563821 & 688546 & 4.9 & 5.0734 & TRN & \\
\hline CHEMBL1396831 & 688546 & 4.6 & 5.078 & TRN & \\
\hline CHEMBL1532253 & 688546 & 4.5 & 5.0726 & TRN & \\
\hline CHEMBL1590995 & 688546 & 6.6499 & 5.6026 & TRN & \\
\hline
\end{tabular}




\begin{tabular}{|c|c|c|c|c|c|}
\hline \multicolumn{6}{|c|}{ Supplemental Table S2.txt } \\
\hline CHEMBL1329024 & 688546 & 5.0 & 5.8338 & TRN & \\
\hline CHEMBL1335684 & 688546 & 5.45 & 5.4736 & TRN & \\
\hline CHEMBL1592400 & 688546 & 4.6 & 5.0582 & TRN & \\
\hline CHEMBL1512271 & 688546 & 4.8 & 4.7017 & TRN & \\
\hline CHEMBL1518698 & 688546 & 5.1 & 5.1134 & TRN & \\
\hline CHEMBL1394487 & 688546 & 4.6 & 5.7413 & TRN & \\
\hline CHEMBL1515733 & 688546 & 5.45 & 5.5961 & TRN & \\
\hline CHEMBL1593969 & 688546 & 5.9 & 5.2411 & TRN & \\
\hline CHEMBL1398289 & 688546 & 5.0 & 5.0785 & TRN & \\
\hline CHEMBL1493226 & 688546 & 5.0 & 5.1111 & TST & \\
\hline CHEMBL1591114 & 688546 & 4.6 & 4.789 & TRN & \\
\hline CHEMBL1553031 & 688546 & 5.3 & 5.5356 & TRN & \\
\hline CHEMBL1508694 & 688546 & 4.8 & 4.6889 & TRN & \\
\hline CHEMBL1609778 & 688546 & 4.8 & 5.4581 & TRN & \\
\hline CHEMBL1491542 & 688546 & 5.0 & 5.1551 & TRN & \\
\hline CHEMBL1441573 & 688546 & 4.5 & 5.23600 & 0000000001 & TRN \\
\hline CHEMBL1310614 & 688546 & 4.9 & 5.2283 & TRN & \\
\hline CHEMBL1589415 & 688546 & 4.8 & 5.2074 & TST & \\
\hline CHEMBL1317215 & 688546 & 8.301 & 5.3679 & TRN & \\
\hline CHEMBL1389366 & 688546 & 5.3 & 5.6485 & TRN & \\
\hline CHEMBL1487113 & 688546 & 5.2 & 4.9497 & TRN & \\
\hline CHEMBL1357330 & 688546 & 5.0 & 5.5175 & TST & \\
\hline CHEMBL405358 & 688546 & 4.9 & 4.6937 & TST & \\
\hline CHEMBL1396738 & 688546 & 5.4 & 5.5091 & TRN & \\
\hline CHEMBL1333197 & 688546 & 4.6 & 5.3602 & TRN & \\
\hline CHEMBL1592566 & 688546 & 4.5 & 5.8434 & TRN & \\
\hline CHEMBL1398497 & 688546 & 5.0 & 5.1417 & TRN & \\
\hline CHEMBL1565394 & 688546 & 4.9 & 4.9556 & TRN & \\
\hline CHEMBL1433920 & 688546 & 5.0 & 5.5348 & TRN & \\
\hline CHEMBL1356440 & 688546 & 5.3 & 5.3297 & TRN & \\
\hline CHEMBL1556566 & 688546 & 4.9 & 5.5216 & TST & \\
\hline CHEMBL1560700 & 688546 & 4.6 & 5.3369 & TRN & \\
\hline CHEMBL1323619 & 688546 & 4.5 & 5.9358 & TST & \\
\hline CHEMBL1368795 & 688546 & 5.0 & 5.3006 & TRN & \\
\hline CHEMBL1512160 & 688546 & 4.9 & 5.2888 & TRN & \\
\hline CHEMBL1565369 & 688546 & 5.1 & 5.4706 & TRN & \\
\hline CHEMBL1487004 & 688546 & 4.5 & 5.0662 & TRN & \\
\hline CHEMBL1324655 & 688546 & 7.6498 & 5.7475 & TST & \\
\hline CHEMBL1325376 & 688546 & 4.8 & 4.8617 & TST & \\
\hline CHEMBL1416951 & 688546 & 5.0 & 5.4629 & TRN & \\
\hline CHEMBL1380056 & 688546 & 5.0 & 5.1727 & TRN & \\
\hline CHEMBL1437685 & 688546 & 6.7001 & 5.4561 & TRN & \\
\hline CHEMBL1607616 & 688546 & 5.6 & 5.2135 & TST & \\
\hline CHEMBL1594633 & 688546 & 4.5 & 5.2491 & TRN & \\
\hline CHEMBL1590898 & 688546 & 4.9 & 6.1106 & TST & \\
\hline CHEMBL1528565 & 688546 & 5.0 & 4.849 & TST & \\
\hline CHEMBL1327584 & 688546 & 4.8 & 4.8258 & TRN & \\
\hline CHEMBL1455538 & 688546 & 4.9 & 5.3974 & TRN & \\
\hline
\end{tabular}




\begin{tabular}{|c|c|c|c|c|c|}
\hline & & & & & \\
\hline CHEMBL1418230 & 688546 & 5.2 & 5.4528 & TRN & \\
\hline CHEMBL1592185 & 688546 & 5.0 & 5.4503 & TRN & \\
\hline CHEMBL1345047 & 688546 & 5.3 & 5.0687 & TRN & \\
\hline CHEMBL1572201 & 688546 & 4.9 & 5.2016 & TRN & \\
\hline CHEMBL1344196 & 688546 & 4.5 & 5.1215 & TST & \\
\hline CHEMBL1476342 & 688546 & 4.8 & 5.532 & TRN & \\
\hline CHEMBL1355967 & 688546 & 4.8 & 5.0499 & TST & \\
\hline CHEMBL1479106 & 688546 & 5.0 & 4.92899 & 9999999999 & TRN \\
\hline CHEMBL1593661 & 688546 & 4.8 & 4.9506 & TRN & \\
\hline CHEMBL1516542 & 688546 & 4.8 & 5.0185 & TST & \\
\hline CHEMBL1365435 & 688546 & 4.9 & 5.3274 & TRN & \\
\hline CHEMBL1311825 & 688546 & 4.9 & 5.1038 & TRN & \\
\hline CHEMBL1573866 & 688546 & 5.0 & 4.6969 & TST & \\
\hline CHEMBL1436809 & 688546 & 5.5 & 5.7756 & TST & \\
\hline CHEMBL1546623 & 688546 & 5.0 & 5.0255 & TRN & \\
\hline CHEMBL1451617 & 688546 & 4.8 & 5.011 & TRN & \\
\hline CHEMBL1489082 & 688546 & 7.2 & 5.8586 & TRN & \\
\hline CHEMBL1564660 & 688546 & 4.5 & 4.8027 & TST & \\
\hline CHEMBL1427430 & 688546 & 4.45 & 4.9609 & TRN & \\
\hline CHEMBL1355303 & 688546 & 5.1 & 5.4927 & TRN & \\
\hline CHEMBL1518001 & 688546 & 5.0 & 5.385 & TRN & \\
\hline CHEMBL1607894 & 688546 & 4.5 & 5.3383 & TRN & \\
\hline CHEMBL1330741 & 688546 & 5.7 & 5.545 & TST & \\
\hline CHEMBL1452501 & 688546 & 6.0 & 5.3335 & TST & \\
\hline CHEMBL1553380 & 688546 & 5.2 & 5.2399 & TRN & \\
\hline CHEMBL1445421 & 688546 & 5.25 & 5.2141 & TRN & \\
\hline CHEMBL1373043 & 688546 & 4.8 & 5.2268 & TRN & \\
\hline CHEMBL1445351 & 688546 & 6.3 & 5.4587 & TRN & \\
\hline CHEMBL1439212 & 688546 & 7.2 & 5.494 & TRN & \\
\hline CHEMBL1553324 & 688546 & 4.9 & 4.9593 & TRN & \\
\hline CHEMBL1590072 & 688546 & 4.9 & 5.016 & TRN & \\
\hline CHEMBL1403868 & 688546 & 4.6 & 5.2515 & TST & \\
\hline CHEMBL1480926 & 688546 & 6.2 & 5.7853 & TST & \\
\hline CHEMBL1551800 & 688546 & 5.6 & 5.3002 & TRN & \\
\hline CHEMBL1326571 & 688546 & 8.1024 & 5.5081 & TRN & \\
\hline CHEMBL1396812 & 688546 & 4.7 & 5.6038 & TRN & \\
\hline CHEMBL1434689 & 688546 & 7.7496 & 5.4393 & TST & \\
\hline CHEMBL1551877 & 688546 & 6.1 & 5.6703 & TST & \\
\hline CHEMBL1476215 & 688546 & 5.6 & 5.2806 & TRN & \\
\hline CHEMBL 252744 & 688546 & 7.0 & 5.1974 & TST & \\
\hline CHEMBL1499489 & 688546 & 4.8 & 4.9354 & TRN & \\
\hline CHEMBL1328930 & 688546 & 4.6 & 5.2397 & TST & \\
\hline CHEMBL1455814 & 688546 & 4.9 & 4.7931 & TRN & \\
\hline CHEMBL2373615 & 688546 & 5.3 & 5.7387 & TST & \\
\hline CHEMBL1592244 & 688546 & 4.6 & 5.8161 & TRN & \\
\hline CHEMBL1496197 & 688546 & 5.8 & 5.5873 & TRN & \\
\hline CHEMBL1479966 & 688546 & 4.9 & 5.0927 & TRN & \\
\hline CHEMBL1569493 & 688546 & 5.1 & 4.982 & TST & \\
\hline & & & & 10251 & \\
\hline
\end{tabular}




\begin{tabular}{|c|c|c|c|c|c|}
\hline \multirow[b]{2}{*}{ CHEMBL1487872 } & \multicolumn{5}{|c|}{ plemental lable s } \\
\hline & 688546 & 5.0 & 5.1577 & TRN & \\
\hline CHEMBL1535329 & 688546 & 6.2 & 5.57100 & 2000000001 & TRN \\
\hline CHEMBL1573816 & 688546 & 4.8 & 5.4278 & TRN & \\
\hline CHEMBL1534503 & 688546 & 4.5 & 4.8128 & TRN & \\
\hline CHEMBL1610065 & 688546 & 6.2 & 5.6336 & TST & \\
\hline CHEMBL1473009 & 688546 & 4.6 & 4.916 & TRN & \\
\hline CHEMBL1404118 & 688546 & 5.0 & 4.9307 & TRN & \\
\hline CHEMBL1523692 & 688546 & 5.5 & 5.274 & TRN & \\
\hline CHEMBL1433283 & 688546 & 8.1487 & 5.4975 & TRN & \\
\hline CHEMBL3196538 & 688546 & 5.0 & 4.8845 & TRN & \\
\hline CHEMBL1552603 & 688546 & 4.7 & 5.5473 & TRN & \\
\hline CHEMBL1363731 & 688546 & 4.8 & 5.7073 & TRN & \\
\hline CHEMBL1409318 & 688546 & 5.0 & 5.2177 & TRN & \\
\hline CHEMBL1394827 & 688546 & 4.5 & 5.6644 & TST & \\
\hline CHEMBL1498937 & 688546 & 5.1 & 5.4227 & TRN & \\
\hline CHEMBL1335874 & 688546 & 4.9 & 4.9007 & TRN & \\
\hline CHEMBL1384502 & 688546 & 6.25 & 5.4232 & TST & \\
\hline CHEMBL1365211 & 688546 & 4.5 & 4.8464 & TRN & \\
\hline CHEMBL1389540 & 688546 & 5.0 & 5.3184 & TST & \\
\hline CHEMBL1501480 & 688546 & 5.1 & 5.154 & TRN & \\
\hline CHEMBL1563833 & 688546 & 4.5 & 4.9541 & TRN & \\
\hline CHEMBL600103 & 688546 & 4.9 & 5.1722 & TRN & \\
\hline CHEMBL1562179 & 688546 & 5.1 & 5.1198 & TRN & \\
\hline CHEMBL1474166 & 688546 & 7.0501 & 5.0667 & TST & \\
\hline CHEMBL1490017 & 688546 & 4.45 & 5.5353 & TRN & \\
\hline CHEMBL1318907 & 688546 & 6.05 & 5.2672 & TST & \\
\hline CHEMBL1608710 & 688546 & 6.25 & 5.4621 & TRN & \\
\hline CHEMBL1474691 & 688546 & 4.8 & 4.6153 & TRN & \\
\hline CHEMBL1554615 & 688546 & 4.5 & 5.0529 & TRN & \\
\hline CHEMBL1475503 & 688546 & 5.25 & 5.8836 & TRN & \\
\hline CHEMBL406835 & 688546 & 5.7 & 5.1271 & TST & \\
\hline CHEMBL1357505 & 688546 & 8.301 & 5.4277 & TST & \\
\hline CHEMBL 21260 & 688546 & 7.8013 & 5.58799 & 9999999999 & TST \\
\hline CHEMBL1450119 & 688546 & 5.0 & 5.0979 & TRN & \\
\hline CHEMBL1533270 & 688546 & 5.1 & 5.7612 & TRN & \\
\hline CHEMBL1433895 & 688546 & 4.9 & 5.3245 & TRN & \\
\hline CHEMBL1359196 & 688546 & 5.0 & 5.6031 & TST & \\
\hline CHEMBL1473070 & 688546 & 5.6 & 5.1125 & TRN & \\
\hline CHEMBL1611513 & 688546 & 4.6 & 4.8433 & TRN & \\
\hline CHEMBL1569936 & 688546 & 4.5 & 4.5878 & TRN & \\
\hline CHEMBL1529181 & 688546 & 4.9 & 5.24700 & 0000000001 & TRN \\
\hline CHEMBL1435293 & 688546 & 4.7 & 5.1653 & TRN & \\
\hline CHEMBL1513248 & 688546 & 4.6 & 5.3019 & TRN & \\
\hline CHEMBL1403041 & 688546 & 5.0 & 5.0832 & TRN & \\
\hline CHEMBL1569437 & 688546 & 8.0 & 6.1065 & TRN & \\
\hline CHEMBL1377782 & 688546 & 4.5 & 4.9331 & TRN & \\
\hline CHEMBL1515468 & 688546 & 4.8 & 5.0668 & TRN & \\
\hline CHEMBL1401409 & 688546 & 4.9 & 5.3397 & TRN & \\
\hline
\end{tabular}




\begin{tabular}{|c|c|c|c|c|}
\hline \multicolumn{5}{|c|}{ Supplemental Table S2.txt } \\
\hline CHEMBL1551944 & 688546 & 4.8 & 5.1809 & TRN \\
\hline CHEMBL1475106 & 688546 & 4.9 & 5.3022 & TRN \\
\hline CHEMBL1486245 & 688546 & 4.8 & 5.3221 & TRN \\
\hline CHEMBL1321640 & 688546 & 5.5 & 5.3685 & TRN \\
\hline CHEMBL3145108 & 688546 & 4.7 & 5.0814 & TRN \\
\hline CHEMBL1602649 & 688546 & 4.8 & 5.2558 & TRN \\
\hline CHEMBL1413556 & 688546 & 5.9 & 5.434 & TST \\
\hline CHEMBL1403744 & 688546 & 4.9 & 5.0884 & TST \\
\hline CHEMBL1464103 & 688546 & 4.8 & 5.1257 & TST \\
\hline CHEMBL1314784 & 688546 & 5.3 & 5.3809 & TRN \\
\hline CHEMBL1317919 & 688546 & 5.3 & 4.8566 & TRN \\
\hline CHEMBL1396341 & 688546 & 5.0 & 5.4254 & TRN \\
\hline CHEMBL3192873 & 688546 & 5.05 & 5.349 & TST \\
\hline CHEMBL1563785 & 688546 & 4.5 & 6.0392 & TRN \\
\hline CHEMBL1563478 & 688546 & 4.5 & 5.117 & TRN \\
\hline CHEMBL1441816 & 688546 & 4.5 & 5.1961 & TST \\
\hline CHEMBL1376371 & 688546 & 4.8 & 4.9517 & TST \\
\hline CHEMBL1573832 & 688546 & 5.0 & 5.2305 & TRN \\
\hline CHEMBL1340792 & 688546 & 4.45 & 4.8812 & TST \\
\hline CHEMBL1359882 & 688546 & 5.0 & 4.8093 & TST \\
\hline CHEMBL1607223 & 688546 & 5.1 & 4.9929 & TRN \\
\hline CHEMBL1527817 & 688546 & 4.9 & 4.9668 & TST \\
\hline CHEMBL1435037 & 688546 & 5.2 & 4.6997 & TRN \\
\hline CHEMBL1376627 & 688546 & 4.7 & 5.8777 & TST \\
\hline CHEMBL1387107 & 688546 & 6.9 & 4.9869 & TST \\
\hline CHEMBL1449761 & 688546 & 4.9 & 5.3402 & TRN \\
\hline CHEMBL1307923 & 688546 & 4.9 & 5.1516 & TST \\
\hline CHEMBL1563629 & 688546 & 4.9 & 5.1096 & TRN \\
\hline CHEMBL1551035 & 688546 & 4.5 & 5.0639 & TRN \\
\hline CHEMBL1465836 & 688546 & 4.7 & 5.0758 & TRN \\
\hline CHEMBL1341112 & 688546 & 4.9 & 4.8023 & TRN \\
\hline CHEMBL1366347 & 688546 & 5.3 & 5.136 & TRN \\
\hline CHEMBL1409287 & 688546 & 4.5 & 5.4235 & TST \\
\hline CHEMBL1302414 & 688546 & 4.5 & 5.003 & TRN \\
\hline CHEMBL1512460 & 688546 & 4.6 & 5.6089 & TRN \\
\hline CHEMBL1605693 & 688546 & 4.7 & 5.1438 & TRN \\
\hline CHEMBL1357503 & 688546 & 4.7 & 5.1278 & TRN \\
\hline CHEMBL1443065 & 688546 & 4.5 & 5.2133 & TRN \\
\hline CHEMBL1319214 & 688546 & 5.0 & 4.5999 & TST \\
\hline CHEMBL1355617 & 688546 & 7.3497 & 5.3876 & TRN \\
\hline CHEMBL1402105 & 688546 & 4.6 & 5.0939 & TST \\
\hline CHEMBL1554410 & 688546 & 5.2 & 5.5042 & TRN \\
\hline CHEMBL3194665 & 688546 & 4.9 & 5.27 & TST \\
\hline CHEMBL1590543 & 688546 & 6.5501 & 5.3883 & TRN \\
\hline CHEMBL1567904 & 688546 & 4.8 & 4.8221 & TRN \\
\hline CHEMBL1396810 & 688546 & 5.4 & 4.7058 & TRN \\
\hline CHEMBL1409862 & 688546 & 5.0 & 5.4116 & TST \\
\hline CHEMBL1320149 & 688546 & 4.9 & 5.1179 & TRN \\
\hline
\end{tabular}




\begin{tabular}{|c|c|c|c|c|}
\hline & & & pplement & al $\mathrm{Ta}$ \\
\hline CHEMBL1315837 & 688546 & 4.9 & 5.5473 & TST \\
\hline CHEMBL1440848 & 688546 & 5.15 & 4.9998 & TST \\
\hline CHEMBL1554163 & 688546 & 4.5 & 5.4191 & TRN \\
\hline CHEMBL 307893 & 688546 & 4.5 & 5.3731 & TST \\
\hline CHEMBL1554449 & 688546 & 4.8 & 4.9171 & TRN \\
\hline CHEMBL1375740 & 688546 & 5.8 & 5.3634 & TRN \\
\hline CHEMBL1523461 & 688546 & 4.9 & 4.9246 & TRN \\
\hline CHEMBL1354494 & 688546 & 4.8 & 4.7101 & TRN \\
\hline CHEMBL1532745 & 688546 & 4.9 & 5.1915 & TRN \\
\hline CHEMBL1355958 & 688546 & 5.45 & 5.3541 & TRN \\
\hline CHEMBL 1474576 & 688546 & 6.05 & 5.4797 & TRN \\
\hline CHEMBL1487852 & 688546 & 4.5 & 5.1462 & TST \\
\hline CHEMBL1591397 & 688546 & 7.3002 & 5.4694 & TRN \\
\hline CHEMBL1396718 & 688546 & 6.4 & 5.4282 & TRN \\
\hline CHEMBL602575 & 688546 & 7.0 & 5.6579 & TST \\
\hline CHEMBL1412207 & 688546 & 4.45 & 5.5691 & TRN \\
\hline CHEMBL1347831 & 688546 & 5.1 & 4.9238 & TRN \\
\hline CHEMBL1493255 & 688546 & 5.6 & 5.7143 & TRN \\
\hline CHEMBL1255755 & 688546 & 5.0 & 5.2096 & TRN \\
\hline CHEMBL1593187 & 688546 & 5.0 & 5.0019 & TRN \\
\hline CHEMBL1547361 & 688546 & 4.9 & 5.4244 & TST \\
\hline CHEMBL1472708 & 688546 & 4.6 & 5.3058 & TRN \\
\hline CHEMBL1317252 & 688546 & 4.7 & 5.7554 & TST \\
\hline CHEMBL1256661 & 688546 & 4.9 & 5.0658 & TST \\
\hline CHEMBL1330093 & 688546 & 4.7 & 5.2475 & TRN \\
\hline CHEMBL18132 & 688546 & 4.5 & 5.5689 & TST \\
\hline CHEMBL1386609 & 688546 & 4.5 & 5.1257 & TRN \\
\hline CHEMBL1362243 & 688546 & 4.9 & 4.9857 & TRN \\
\hline CHEMBL1417225 & 688546 & 4.7 & 5.0606 & TST \\
\hline CHEMBL1319641 & 688546 & 5.0 & 5.6182 & TRN \\
\hline CHEMBL1383035 & 688546 & 4.5 & 5.4182 & TST \\
\hline CHEMBL1408951 & 688546 & 4.9 & 5.0365 & TRN \\
\hline CHEMBL1552385 & 688546 & 8.3468 & 5.1194 & TRN \\
\hline CHEMBL1453886 & 688546 & 5.0 & 5.7242 & TRN \\
\hline CHEMBL1328771 & 688546 & 4.6 & 5.1093 & TRN \\
\hline CHEMBL1396170 & 688546 & 4.8 & 5.2611 & TST \\
\hline CHEMBL1355720 & 688546 & 6.5 & 5.225 & TRN \\
\hline CHEMBL1319510 & 688546 & 4.7 & 5.2925 & TRN \\
\hline CHEMBL1516475 & 688546 & 7.7496 & 5.7421 & TST \\
\hline CHEMBL1570219 & 688546 & 4.9 & 5.5193 & TST \\
\hline CHEMBL1355142 & 688546 & 4.85 & 4.8614 & TRN \\
\hline CHEMBL1435683 & 688546 & 5.35 & 5.3251 & TRN \\
\hline CHEMBL1359988 & 688546 & 5.4 & 5.4576 & TST \\
\hline CHEMBL 1474432 & 688546 & 4.9 & 5.4017 & TRN \\
\hline CHEMBL1315207 & 688546 & 4.5 & 5.5661 & TST \\
\hline CHEMBL1316171 & 688546 & 5.4 & 4.8685 & TRN \\
\hline CHEMBL1468847 & 688546 & 4.75 & 5.0735 & TST \\
\hline CHEMBL1317823 & 688546 & 4.8 & 5.2675 & TST \\
\hline
\end{tabular}




\begin{tabular}{|c|c|c|c|c|}
\hline & & & prement & \\
\hline CHEMBL1516425 & 688546 & 6.3 & 5.7114 & TRN \\
\hline CHEMBL1356230 & 688546 & 7.0 & 5.2099 & TRN \\
\hline CHEMBL1523094 & 688546 & 4.9 & 5.0593 & TRN \\
\hline CHEMBL1329033 & 688546 & 5.0 & 5.2172 & TST \\
\hline CHEMBL559612 & 688546 & 5.2 & 4.5385 & TST \\
\hline CHEMBL1367304 & 688546 & 4.9 & 5.3298 & TST \\
\hline CHEMBL1327208 & 688546 & 4.7 & 5.277 & TRN \\
\hline CHEMBL1513238 & 688546 & 4.5 & 4.592 & TRN \\
\hline CHEMBL1376571 & 688546 & 4.5 & 4.635 & TRN \\
\hline CHEMBL1316203 & 688546 & 4.45 & 5.1677 & TRN \\
\hline CHEMBL15193 & 688546 & 5.6 & 5.2247 & TST \\
\hline CHEMBL1396826 & 688546 & 4.5 & 4.7104 & TRN \\
\hline CHEMBL1598064 & 688546 & 5.1 & 5.4268 & TRN \\
\hline CHEMBL1604715 & 688546 & 5.0 & 4.9225 & TRN \\
\hline CHEMBL1422233 & 688546 & 4.5 & 5.1178 & TST \\
\hline CHEMBL1552926 & 688546 & 5.4 & 5.276 & TRN \\
\hline CHEMBL1309248 & 688546 & 4.8 & 5.1853 & TRN \\
\hline CHEMBL1375367 & 688546 & 4.9 & 4.8499 & TRN \\
\hline CHEMBL1485715 & 688546 & 5.0 & 5.0225 & TRN \\
\hline CHEMBL1606616 & 688546 & 6.0 & 5.4925 & TRN \\
\hline CHEMBL1394110 & 688546 & 8.0506 & 6.0752 & TRN \\
\hline CHEMBL1592618 & 688546 & 6.0 & 5.3286 & TRN \\
\hline CHEMBL1457898 & 688546 & 5.05 & 5.3332 & TRN \\
\hline CHEMBL1516879 & 688546 & 4.9 & 5.4841 & TRN \\
\hline CHEMBL569088 & 688546 & 4.7 & 4.7216 & TRN \\
\hline CHEMBL1569130 & 688546 & 5.5 & 4.7482 & TST \\
\hline CHEMBL1329451 & 688546 & 7.5003 & 5.6923 & TRN \\
\hline CHEMBL1403324 & 688546 & 5.7 & 5.7836 & TRN \\
\hline CHEMBL1592054 & 688546 & 4.6 & 4.6585 & TRN \\
\hline CHEMBL1397693 & 688546 & 4.9 & 5.265 & TRN \\
\hline CHEMBL1327294 & 688546 & 5.9 & 5.5441 & TRN \\
\hline CHEMBL1553545 & 688546 & 5.4 & 5.2005 & TST \\
\hline CHEMBL 277148 & 688546 & 4.6 & 4.9522 & TRN \\
\hline CHEMBL1323344 & 688546 & 7.9508 & 5.1665 & TST \\
\hline CHEMBL1361552 & 688546 & 4.9 & 4.8612 & TRN \\
\hline CHEMBL1529530 & 688546 & 5.4 & 5.2489 & TRN \\
\hline CHEMBL1555162 & 688546 & 4.65 & 5.2451 & TST \\
\hline CHEMBL1521215 & 688546 & 4.7 & 5.0527 & TRN \\
\hline CHEMBL1320917 & 688546 & 5.0 & 4.9344 & TRN \\
\hline CHEMBL1513214 & 688546 & 4.8 & 4.9058 & TRN \\
\hline CHEMBL1551348 & 688546 & 4.5 & 5.0536 & TST \\
\hline CHEMBL1510399 & 688546 & 4.8 & 5.0811 & TRN \\
\hline CHEMBL 2004809 & 688546 & 4.75 & 4.9527 & TST \\
\hline CHEMBL1442488 & 688546 & 4.5 & 5.2957 & TRN \\
\hline CHEMBL1356591 & 688546 & 5.5 & 5.4374 & TST \\
\hline CHEMBL1514596 & 688546 & 4.7 & 4.8288 & TRN \\
\hline CHEMBL1569717 & 688546 & 4.5 & 5.3845 & TST \\
\hline CHEMBL1484176 & 688546 & 4.5 & 5.1384 & TRN \\
\hline
\end{tabular}




\begin{tabular}{|c|c|c|c|c|}
\hline \multicolumn{5}{|c|}{ Supplemental Table S2.txt } \\
\hline CHEMBL1551608 & 688546 & 5.45 & 5.396 & TRN \\
\hline CHEMBL1608535 & 688546 & 4.5 & 5.2348 & TST \\
\hline CHEMBL1516214 & 688546 & 7.8013 & 5.4989 & TRN \\
\hline CHEMBL1595899 & 688546 & 5.1 & 5.1936 & TRN \\
\hline CHEMBL 1452426 & 688546 & 5.4 & 5.3044 & TRN \\
\hline CHEMBL600715 & 688546 & 4.6 & 5.4373 & TST \\
\hline CHEMBL1554016 & 688546 & 5.0 & 5.4184 & TRN \\
\hline CHEMBL1396362 & 688546 & 4.5 & 4.9925 & TRN \\
\hline CHEMBL1316137 & 688546 & 5.4 & 5.6606 & TST \\
\hline CHEMBL1434537 & 688546 & 7.1002 & 4.9627 & TRN \\
\hline CHEMBL1610881 & 688546 & 4.95 & 4.8265 & TRN \\
\hline CHEMBL1428148 & 688546 & 4.6 & 4.9861 & TRN \\
\hline CHEMBL1613125 & 688546 & 7.5003 & 5.6533 & TRN \\
\hline CHEMBL1596949 & 688546 & 5.4 & 5.2107 & TST \\
\hline CHEMBL 252722 & 688546 & 5.0 & 5.0656 & TRN \\
\hline CHEMBL1429330 & 688546 & 5.3 & 5.0463 & TRN \\
\hline CHEMBL1412448 & 688546 & 4.5 & 4.6537 & TRN \\
\hline CHEMBL1317877 & 688546 & 5.0 & 4.7293 & TRN \\
\hline CHEMBL1555430 & 688546 & 6.0 & 5.3183 & TST \\
\hline CHEMBL1406603 & 688546 & 8.301 & 5.8965 & TRN \\
\hline CHEMBL1373961 & 688546 & 5.0 & 5.1857 & TRN \\
\hline CHEMBL1591075 & 688546 & 4.5 & 5.3479 & TRN \\
\hline CHEMBL1317846 & 688546 & 6.1 & 5.4288 & TRN \\
\hline CHEMBL1526301 & 688546 & 4.9 & 5.033 & TRN \\
\hline CHEMBL1525145 & 688546 & 4.6 & 5.4881 & TRN \\
\hline CHEMBL1314811 & 688546 & 7.1002 & 5.36 & TRN \\
\hline CHEMBL1546068 & 688546 & 4.5 & 5.2043 & TST \\
\hline CHEMBL1487869 & 688546 & 4.7 & 5.2903 & TST \\
\hline CHEMBL1517986 & 688546 & 4.8 & 5.2855 & TST \\
\hline CHEMBL1608443 & 688546 & 7.3002 & 5.7505 & TRN \\
\hline CHEMBL1493117 & 688546 & 4.7 & 5.2927 & TST \\
\hline CHEMBL1563894 & 688546 & 4.9 & 4.9067 & TRN \\
\hline CHEMBL261113 & 688546 & 4.95 & 5.2739 & TST \\
\hline CHEMBL1436241 & 688546 & 5.2 & 5.3085 & TRN \\
\hline CHEMBL1450023 & 688546 & 4.9 & 4.5462 & TRN \\
\hline CHEMBL1316269 & 688546 & 4.8 & 5.1364 & TRN \\
\hline CHEMBL1516816 & 688546 & 5.35 & 5.078 & TRN \\
\hline CHEMBL1590976 & 688546 & 5.4 & 5.4999 & TRN \\
\hline CHEMBL1541257 & 688546 & 4.9 & 4.9641 & TST \\
\hline CHEMBL1590267 & 688546 & 7.6003 & 5.011 & TRN \\
\hline CHEMBL 209149 & 688546 & 4.9 & 4.8923 & TRN \\
\hline CHEMBL1439169 & 688546 & 6.5501 & 5.1413 & TRN \\
\hline CHEMBL518494 & 688546 & 4.9 & 5.4899 & TST \\
\hline CHEMBL1373113 & 688546 & 5.0 & 5.1077 & TRN \\
\hline CHEMBL1309430 & 688546 & 5.0 & 5.5951 & TRN \\
\hline CHEMBL1499436 & 688546 & 4.8 & 4.8777 & TST \\
\hline CHEMBL1496387 & 688546 & 4.4 & 5.4718 & TRN \\
\hline CHEMBL1539867 & 688546 & 4.8 & 5.0914 & TRN \\
\hline
\end{tabular}




\begin{tabular}{|c|c|c|c|c|c|}
\hline \\
\hline CHEMBL3194052 & 688546 & 5.3 & 5.4727 & TRN & \\
\hline CHEMBL1552324 & 688546 & 4.8 & 5.1871 & TRN & \\
\hline CHEMBL1564477 & 688546 & 4.6 & 4.8761 & TRN & \\
\hline CHEMBL1416488 & 688546 & 4.5 & 5.4307 & TST & \\
\hline CHEMBL1438267 & 688546 & 5.1 & 5.1253 & TST & \\
\hline CHEMBL1357265 & 688546 & 4.9 & 4.9477 & TST & \\
\hline CHEMBL3194247 & 688546 & 4.45 & 5.1789 & TST & \\
\hline CHEMBL1598457 & 688546 & 5.0 & 5.3761 & TRN & \\
\hline CHEMBL1375780 & 688546 & 4.5 & 5.1125 & TST & \\
\hline CHEMBL1593986 & 688546 & 6.5 & 5.8869 & TRN & \\
\hline CHEMBL1557508 & 688546 & 4.6 & 5.215 & TST & \\
\hline CHEMBL1474717 & 688546 & 4.5 & 5.2632 & TRN & \\
\hline CHEMBL1553509 & 688546 & 4.9 & 5.2474 & TRN & \\
\hline CHEMBL1474273 & 688546 & 8.301 & 6.1383 & TRN & \\
\hline CHEMBL1451049 & 688546 & 5.35 & 5.6107 & TRN & \\
\hline CHEMBL1437628 & 688546 & 4.7 & 5.5166 & TRN & \\
\hline CHEMBL1369996 & 688546 & 7.3497 & 5.63700 & 00000000005 & TRN \\
\hline CHEMBL1477031 & 688546 & 4.7 & 5.1553 & TRN & \\
\hline CHEMBL1356179 & 688546 & 4.6 & 5.2307 & TST & \\
\hline CHEMBL1425614 & 688546 & 4.9 & 5.059 & TRN & \\
\hline CHEMBL1355963 & 688546 & 6.0 & 6.4716 & TST & \\
\hline CHEMBL1592339 & 688546 & 5.0 & 5.4162 & TST & \\
\hline CHEMBL1481946 & 688546 & 4.8 & 5.643 & TST & \\
\hline CHEMBL1410350 & 688546 & 4.95 & 5.2092 & TST & \\
\hline CHEMBL1397866 & 688546 & 4.6 & 4.8986 & TRN & \\
\hline CHEMBL1434916 & 688546 & 5.1 & 4.9756 & TST & \\
\hline CHEMBL1327990 & 688546 & 4.8 & 5.1115 & TRN & \\
\hline CHEMBL1451139 & 688546 & 5.0 & 5.4528 & TST & \\
\hline CHEMBL1437146 & 688546 & 5.0 & 5.0545 & TRN & \\
\hline CHEMBL 1447576 & 688546 & 4.9 & 4.9002 & TRN & \\
\hline CHEMBL1333086 & 688546 & 7.2 & 5.7483 & TRN & \\
\hline CHEMBL1422039 & 688546 & 4.7 & 5.2259 & TRN & \\
\hline CHEMBL1590429 & 688546 & 5.0 & 5.154 & TRN & \\
\hline CHEMBL1395699 & 688546 & 8.4949 & 5.1667 & TRN & \\
\hline CHEMBL602206 & 688546 & 5.2 & 5.2055 & TRN & \\
\hline CHEMBL1514425 & 688546 & 4.5 & 5.3498 & TST & \\
\hline CHEMBL1446721 & 688546 & 4.5 & 5.9662 & TRN & \\
\hline CHEMBL1591706 & 688546 & 5.0 & 5.1451 & TRN & \\
\hline CHEMBL1533781 & 688546 & 4.5 & 5.4214 & TRN & \\
\hline CHEMBL578420 & 688546 & 5.4 & 5.71700 & 00000000005 & TRN \\
\hline CHEMBL578636 & 688546 & 4.9 & 5.1434 & TRN & \\
\hline CHEMBL1398522 & 688546 & 5.1 & 5.7856 & TRN & \\
\hline CHEMBL1390831 & 688546 & 5.0 & 5.043 & TRN & \\
\hline CHEMBL118109 & 688546 & 4.6 & 5.1494 & TST & \\
\hline CHEMBL1485604 & 688546 & 4.8 & 4.9099 & TRN & \\
\hline CHEMBL1591325 & 688546 & 4.9 & 4.9388 & TRN & \\
\hline CHEMBL1314271 & 688546 & 4.5 & 5.1638 & TST & \\
\hline CHEMBL1472996 & 688546 & 5.0 & 5.06 & TRN & \\
\hline
\end{tabular}




\begin{tabular}{|c|c|c|c|c|c|}
\hline \multicolumn{6}{|c|}{ Supplemental Table S2.txt } \\
\hline CHEMBL429095 & 688546 & 6.1 & 5.1946 & TST & \\
\hline CHEMBL1315084 & 688546 & 5.45 & 5.4131 & TRN & \\
\hline CHEMBL582471 & 688546 & 4.6 & 4.8833 & TRN & \\
\hline CHEMBL1607130 & 688546 & 5.4 & 6.1791 & TRN & \\
\hline CHEMBL1496061 & 688546 & 5.3 & 5.0384 & TRN & \\
\hline CHEMBL1540272 & 688546 & 4.7 & 5.6059 & TRN & \\
\hline CHEMBL1349451 & 688546 & 4.9 & 4.958 & TRN & \\
\hline CHEMBL1313622 & 688546 & 4.75 & 5.0504 & TRN & \\
\hline CHEMBL1551748 & 688546 & 4.7 & 5.1212 & TRN & \\
\hline CHEMBL1609019 & 688546 & 4.5 & 4.7379 & TRN & \\
\hline CHEMBL1314550 & 688546 & 4.5 & 5.10800 & 00000000005 & TRN \\
\hline CHEMBL1460155 & 688546 & 4.5 & 5.0873 & TRN & \\
\hline CHEMBL1446433 & 688546 & 6.7001 & 5.3201 & TRN & \\
\hline CHEMBL1395688 & 688546 & 8.301 & 5.5117 & TRN & \\
\hline CHEMBL1552485 & 688546 & 4.9 & 5.1118 & TRN & \\
\hline CHEMBL1436494 & 688546 & 7.0501 & 5.4069 & TRN & \\
\hline CHEMBL1434051 & 688546 & 4.9 & 4.9808 & TRN & \\
\hline CHEMBL1572558 & 688546 & 4.95 & 5.4472 & TST & \\
\hline CHEMBL1354888 & 688546 & 7.6498 & 5.1643 & TRN & \\
\hline CHEMBL1486437 & 688546 & 5.35 & 5.9595 & TRN & \\
\hline CHEMBL582055 & 688546 & 4.8 & 4.8189 & TRN & \\
\hline CHEMBL1557246 & 688546 & 6.5 & 5.3477 & TRN & \\
\hline CHEMBL1551940 & 688546 & 5.8 & 5.612 & TRN & \\
\hline CHEMBL1565613 & 688546 & 4.5 & 4.9139 & TRN & \\
\hline CHEMBL1513601 & 688546 & 4.7 & 5.0473 & TRN & \\
\hline CHEMBL1434204 & 688546 & 6.0 & 5.4448 & TRN & \\
\hline CHEMBL1355802 & 688546 & 6.5 & 5.9325 & TRN & \\
\hline CHEMBL150924 & 688546 & 4.8 & 4.8717 & TRN & \\
\hline CHEMBL1495730 & 688546 & 4.85 & 4.8173 & TRN & \\
\hline CHEMBL1437640 & 688546 & 4.9 & 4.9148 & TST & \\
\hline CHEMBL1378830 & 688546 & 5.0 & 5.3745 & TRN & \\
\hline CHEMBL1475738 & 688546 & 4.5 & 5.4116 & TRN & \\
\hline CHEMBL1597191 & 688546 & 5.2 & 5.1913 & TRN & \\
\hline CHEMBL1451190 & 688546 & 7.2503 & 6.2542 & TRN & \\
\hline CHEMBL1484713 & 688546 & 4.6 & 4.9298 & TST & \\
\hline CHEMBL1375328 & 688546 & 5.9 & 4.9332 & TRN & \\
\hline CHEMBL1511910 & 688546 & 7.699 & 5.0257 & TRN & \\
\hline CHEMBL1318445 & 688546 & 6.15 & 4.9345 & TRN & \\
\hline CHEMBL259388 & 688546 & 4.5 & 4.8478 & TST & \\
\hline CHEMBL1522063 & 688546 & 4.5 & 5.2519 & TRN & \\
\hline CHEMBL1486218 & 688546 & 4.9 & 5.724 & TRN & \\
\hline CHEMBL1613426 & 688546 & 5.25 & 5.1004 & TRN & \\
\hline CHEMBL1363042 & 688546 & 4.5 & 5.3385 & TRN & \\
\hline CHEMBL1538503 & 688546 & 4.8 & 5.4441 & TRN & \\
\hline CHEMBL1487710 & 688546 & 7.3002 & 5.4776 & TRN & \\
\hline CHEMBL1315021 & 688546 & 4.5 & 4.9554 & TST & \\
\hline CHEMBL1515016 & 688546 & 4.8 & 5.0415 & TRN & \\
\hline CHEMBL1593737 & 688546 & 4.8 & 5.6664 & TRN & \\
\hline
\end{tabular}




\begin{tabular}{|c|c|c|c|c|c|}
\hline \\
\hline CHEMBL1612783 & 688546 & 4.5 & 5.6297 & TRN & \\
\hline CHEMBL1482184 & 688546 & 4.8 & 5.0944 & TST & \\
\hline CHEMBL1378006 & 688546 & 5.7 & 5.0732 & TRN & \\
\hline CHEMBL1594100 & 688546 & 4.9 & 5.255 & TRN & \\
\hline CHEMBL1551417 & 688546 & 6.0 & 5.0661 & TRN & \\
\hline CHEMBL1592701 & 688546 & 5.8 & 4.9132 & TST & \\
\hline CHEMBL1437353 & 688546 & 4.65 & 5.1853 & TRN & \\
\hline CHEMBL1571730 & 688546 & 4.9 & 5.2931 & TST & \\
\hline CHEMBL596633 & 688546 & 4.8 & 4.7278 & TRN & \\
\hline CHEMBL1439391 & 688546 & 5.0 & 5.4064 & TRN & \\
\hline CHEMBL1399872 & 688546 & 8.0 & 5.272 & TRN & \\
\hline CHEMBL1318140 & 688546 & 5.4 & 5.2777 & TST & \\
\hline CHEMBL1435273 & 688546 & 7.1002 & 5.2681 & TRN & \\
\hline CHEMBL1405474 & 688546 & 4.7 & 5.3289 & TRN & \\
\hline CHEMBL1473678 & 688546 & 5.8 & 5.2692 & TRN & \\
\hline CHEMBL1610810 & 688546 & 4.8 & 5.0385 & TRN & \\
\hline CHEMBL1554058 & 688546 & 5.1 & 5.0248 & TRN & \\
\hline CHEMBL1337987 & 688546 & 5.5 & 4.8741 & TRN & \\
\hline CHEMBL1316696 & 688546 & 5.2 & 5.44799 & 99999999995 & TRN \\
\hline CHEMBL1324047 & 688546 & 5.5 & 5.7224 & TRN & \\
\hline CHEMBL1436355 & 688546 & 4.9 & 4.8853 & TRN & \\
\hline CHEMBL1401579 & 688546 & 4.5 & 5.6655 & TRN & \\
\hline CHEMBL600347 & 688546 & 4.95 & 4.5893 & TST & \\
\hline CHEMBL1444750 & 688546 & 5.1 & 5.0213 & TRN & \\
\hline CHEMBL1409506 & 688546 & 5.25 & 5.3601 & TST & \\
\hline CHEMBL1445782 & 688546 & 5.4 & 5.3322 & TST & \\
\hline CHEMBL1590980 & 688546 & 5.4 & 5.3488 & TST & \\
\hline CHEMBL1603681 & 688546 & 4.8 & 5.1427 & TRN & \\
\hline CHEMBL1441480 & 688546 & 4.5 & 4.8685 & TRN & \\
\hline CHEMBL1353241 & 688546 & 4.5 & 4.9929 & TRN & \\
\hline CHEMBL1349430 & 688546 & 4.5 & 4.9854 & TRN & \\
\hline CHEMBL1437014 & 688546 & 5.3 & 5.2234 & TRN & \\
\hline CHEMBL1397952 & 688546 & 5.6 & 5.5369 & TRN & \\
\hline CHEMBL1435877 & 688546 & 4.9 & 5.4155 & TRN & \\
\hline CHEMBL2374055 & 688546 & 4.5 & 5.5206 & TST & \\
\hline CHEMBL1332959 & 688546 & 5.4 & 5.8049 & TRN & \\
\hline CHEMBL1593315 & 688546 & 4.5 & 5.3111 & TST & \\
\hline CHEMBL1529030 & 688546 & 4.6 & 5.2661 & TRN & \\
\hline CHEMBL2095128 & 688546 & 4.95 & 4.9232 & TST & \\
\hline CHEMBL1412694 & 688546 & 8.301 & 5.4545 & TST & \\
\hline CHEMBL1449838 & 688546 & 5.5 & 5.1146 & TST & \\
\hline CHEMBL1552684 & 688546 & 4.8 & 5.4388 & TRN & \\
\hline CHEMBL1600101 & 688546 & 7.0 & 4.9658 & TST & \\
\hline CHEMBL1560630 & 688546 & 4.8 & 5.3457 & TST & \\
\hline CHEMBL1605114 & 688546 & 7.4498 & 5.4789 & TST & \\
\hline CHEMBL1524484 & 688546 & 6.4 & 5.7954 & TRN & \\
\hline CHEMBL1462948 & 688546 & 4.9 & 5.2092 & TRN & \\
\hline CHEMBL1562724 & 688546 & 6.8 & 5.184 & TRN & \\
\hline
\end{tabular}




\begin{tabular}{|c|c|c|c|c|c|}
\hline \multicolumn{6}{|c|}{ Supplemental Table S2.txt } \\
\hline CHEMBL1540114 & 688546 & 5.1 & 5.2273 & TRN & \\
\hline CHEMBL1602456 & 688546 & 5.0 & 5.0031 & TRN & \\
\hline CHEMBL1317740 & 688546 & 7.15 & 5.4637 & TRN & \\
\hline CHEMBL1515731 & 688546 & 4.8 & 5.4262 & TRN & \\
\hline CHEMBL1214519 & 688546 & 5.3 & 5.1482 & TRN & \\
\hline CHEMBL1416722 & 688546 & 4.8 & 5.4629 & TRN & \\
\hline CHEMBL1519867 & 688546 & 6.3 & 6.0789 & TRN & \\
\hline CHEMBL1494009 & 688546 & 4.5 & 5.334 & TRN & \\
\hline CHEMBL1526722 & 688546 & 5.1 & 4.9235 & TRN & \\
\hline CHEMBL1320584 & 688546 & 4.7 & 4.8755 & TRN & \\
\hline CHEMBL1356554 & 688546 & 8.0 & 5.4174 & TRN & \\
\hline CHEMBL1374585 & 688546 & 5.0 & 5.1321 & TRN & \\
\hline CHEMBL1459202 & 688546 & 6.25 & 5.4525 & TRN & \\
\hline CHEMBL571087 & 688546 & 5.4 & 5.1227 & TRN & \\
\hline CHEMBL1497967 & 688546 & 4.7 & 4.7963 & TST & \\
\hline CHEMBL1355140 & 688546 & 4.7 & 5.1033 & TRN & \\
\hline CHEMBL1336119 & 688546 & 4.95 & 5.371 & TST & \\
\hline CHEMBL1515376 & 688546 & 4.45 & 5.8733 & TRN & \\
\hline CHEMBL1388712 & 688546 & 5.3 & 5.3511 & TST & \\
\hline CHEMBL1495406 & 688546 & 4.5 & 5.2316 & TST & \\
\hline CHEMBL1554344 & 688546 & 6.3 & 4.8466 & TRN & \\
\hline CHEMBL1370884 & 688546 & 4.6 & 5.0053 & TRN & \\
\hline CHEMBL1418099 & 688546 & 4.7 & 5.438 & TRN & \\
\hline CHEMBL1507418 & 688546 & 5.4 & 5.2501 & TST & \\
\hline CHEMBL1450905 & 688546 & 5.3 & 5.1849 & TRN & \\
\hline CHEMBL1412082 & 688546 & 5.2 & 5.6549 & TRN & \\
\hline CHEMBL1320063 & 688546 & 5.0 & 4.8594 & TRN & \\
\hline CHEMBL1354280 & 688546 & 4.9 & 4.935 & TRN & \\
\hline CHEMBL1515239 & 688546 & 5.4 & 5.6257 & TRN & \\
\hline CHEMBL1393941 & 688546 & 4.8 & 5.0672 & TRN & \\
\hline CHEMBL388676 & 688546 & 4.5 & 5.4601 & TST & \\
\hline CHEMBL1322327 & 688546 & 5.6 & 4.9804 & TST & \\
\hline CHEMBL1548882 & 688546 & 4.9 & 5.4717 & TST & \\
\hline CHEMBL1606417 & 688546 & 4.6 & 4.7723 & TRN & \\
\hline CHEMBL1395072 & 688546 & 5.35 & 5.5311 & TRN & \\
\hline CHEMBL1476539 & 688546 & 6.6 & 5.1853 & TRN & \\
\hline CHEMBL1445214 & 688546 & 4.7 & 5.801 & TRN & \\
\hline CHEMBL1607045 & 688546 & 8.4949 & 5.5242 & TRN & \\
\hline CHEMBL1401359 & 688546 & 4.8 & $5.5360 e$ & 00000000005 & TRN \\
\hline CHEMBL1597562 & 688546 & 4.9 & 5.186 & TRN & \\
\hline CHEMBL1590485 & 688546 & 7.8996 & 5.8156 & TRN & \\
\hline CHEMBL1424036 & 688546 & 4.5 & 4.735 & TST & \\
\hline CHEMBL1513872 & 688546 & 5.7 & 5.3756 & TRN & \\
\hline CHEMBL1474760 & 688546 & 6.8 & 5.7104 & TRN & \\
\hline CHEMBL1408717 & 688546 & 4.5 & 5.0025 & TRN & \\
\hline CHEMBL1372535 & 688546 & 4.9 & 5.2197 & TRN & \\
\hline CHEMBL591834 & 688546 & 5.4 & 4.9104 & TST & \\
\hline CHEMBL1336921 & 688546 & 6.0 & 5.3919 & TRN & \\
\hline
\end{tabular}




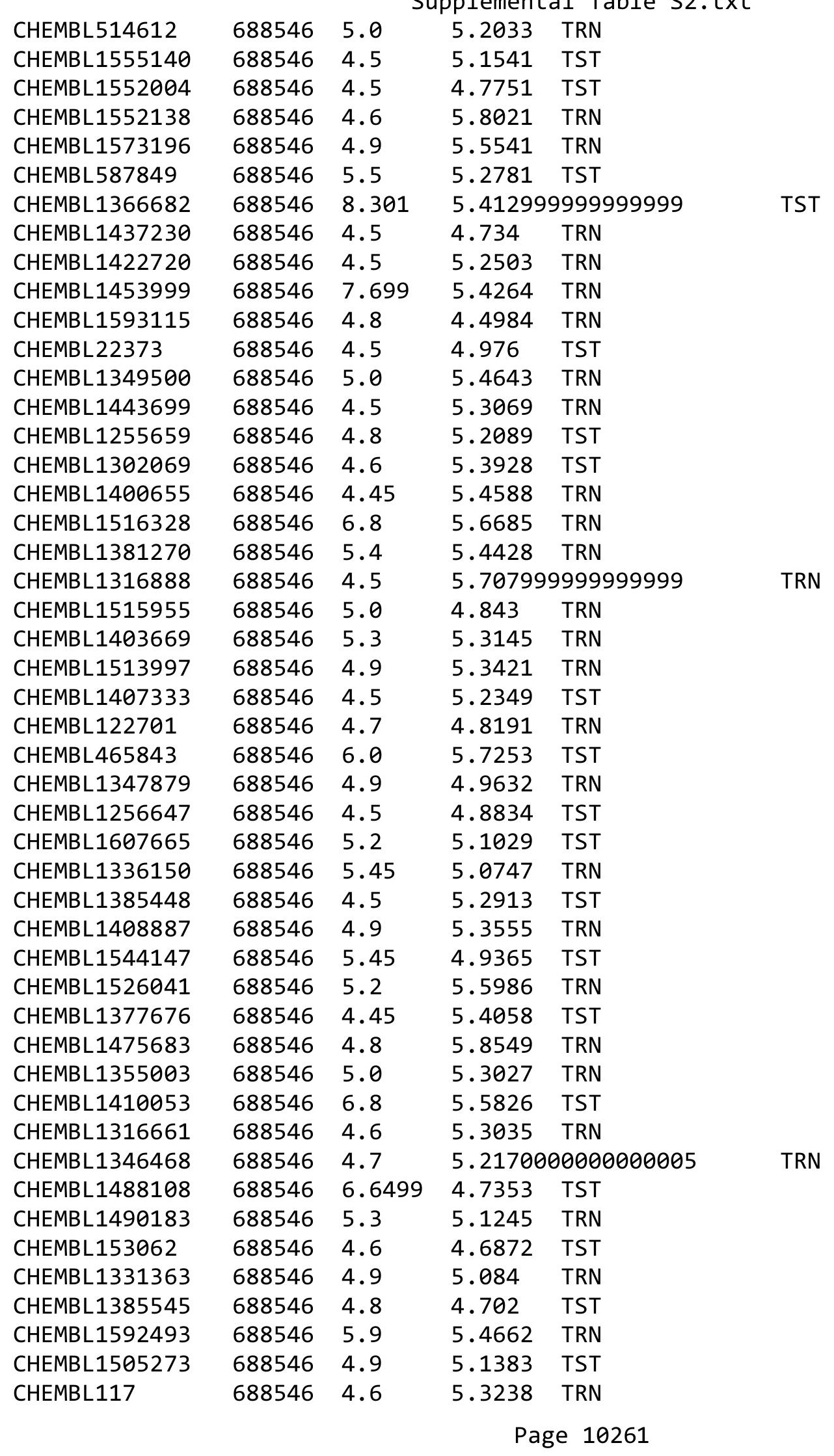




\begin{tabular}{|c|c|c|c|c|}
\hline \multicolumn{5}{|c|}{ Supplemental Table s2.txt } \\
\hline CHEMBL1524853 & 688546 & 8.3979 & 5.5474 & TRN \\
\hline CHEMBL1256660 & 688546 & 4.8 & 5.1853 & TRN \\
\hline CHEMBL1358714 & 688546 & 7.1002 & 5.6556 & TRN \\
\hline CHEMBL1515640 & 688546 & 7.8013 & 5.1855 & TRN \\
\hline CHEMBL1448946 & 688546 & 4.8 & 4.7774 & TRN \\
\hline CHEMBL1485820 & 688546 & 4.8 & 5.6752 & TRN \\
\hline CHEMBL1329986 & 688546 & 4.7 & 5.3814 & TRN \\
\hline CHEMBL1336578 & 688546 & 4.6 & 5.0531 & TRN \\
\hline CHEMBL1407267 & 688546 & 4.5 & 5.2598 & TRN \\
\hline CHEMBL1542533 & 688546 & 5.3 & 4.888 & TST \\
\hline CHEMBL1582814 & 688546 & 5.65 & 5.7897 & TRN \\
\hline CHEMBL1328963 & 688546 & 6.3 & 5.1497 & TST \\
\hline CHEMBL1396960 & 688546 & 6.4 & 5.0771 & TRN \\
\hline CHEMBL1436196 & 688546 & 5.9 & 5.5308 & TRN \\
\hline CHEMBL1514013 & 688546 & 4.9 & 5.2829 & TST \\
\hline CHEMBL 1315400 & 688546 & 5.5 & 4.9354 & TRN \\
\hline CHEMBL1330242 & 688546 & 4.5 & 5.341 & TRN \\
\hline CHEMBL1330516 & 688546 & 4.9 & 4.793 & TRN \\
\hline CHEMBL1398795 & 688546 & 4.5 & 5.7966 & TRN \\
\hline CHEMBL1424253 & 688546 & 4.6 & 5.3264 & TRN \\
\hline CHEMBL1478785 & 688546 & 4.45 & 5.0544 & TRN \\
\hline CHEMBL1454183 & 688546 & 5.0 & 5.2075 & TST \\
\hline CHEMBL1515402 & 688546 & 5.3 & 5.484 & TRN \\
\hline CHEMBL1437398 & 688546 & 5.25 & 4.8459 & TST \\
\hline CHEMBL1472703 & 688546 & 4.8 & 5.0303 & TST \\
\hline CHEMBL 1354952 & 688546 & 4.95 & 5.4909 & TST \\
\hline CHEMBL1357996 & 688546 & 4.8 & 4.9119 & TRN \\
\hline CHEMBL1567170 & 688546 & 4.7 & 5.1634 & TRN \\
\hline CHEMBL1376155 & 688546 & 4.65 & 5.3737 & TRN \\
\hline CHEMBL1561222 & 688546 & 4.7 & 4.7686 & TRN \\
\hline CHEMBL1439989 & 688546 & 5.0 & 5.1628 & TST \\
\hline CHEMBL1418013 & 688546 & 5.3 & 5.3409 & TRN \\
\hline CHEMBL1515183 & 688546 & 5.9 & 5.7048 & TRN \\
\hline CHEMBL1523669 & 688546 & 4.9 & 5.5197 & TRN \\
\hline CHEMBL1437202 & 688546 & 4.5 & 4.7204 & TRN \\
\hline CHEMBL1590828 & 688546 & 4.7 & 5.22 & TRN \\
\hline CHEMBL1309311 & 688546 & 4.6 & 5.024 & TRN \\
\hline CHEMBL1551672 & 688546 & 6.0 & 5.2693 & TRN \\
\hline CHEMBL1516140 & 688546 & 6.0 & 6.0861 & TRN \\
\hline CHEMBL1591927 & 688546 & 5.2 & 5.271 & TRN \\
\hline CHEMBL1594063 & 688546 & 4.6 & 5.1931 & TRN \\
\hline CHEMBL1394264 & 688546 & 5.1 & 5.3576 & TRN \\
\hline CHEMBL1337801 & 688546 & 4.9 & 5.766 & TRN \\
\hline CHEMBL1474639 & 688546 & 4.9 & 5.2379 & TRN \\
\hline CHEMBL1557858 & 688546 & 5.2 & 5.4458 & TRN \\
\hline CHEMBL 1539876 & 688546 & 4.9 & 4.5874 & TST \\
\hline CHEMBL1378402 & 688546 & 5.0 & 5.3072 & TRN \\
\hline CHEMBL 1356530 & 688546 & 5.2 & 5.574 & TRN \\
\hline
\end{tabular}




\begin{tabular}{|c|c|c|c|c|}
\hline \multicolumn{5}{|c|}{ Supplemental Table s2.txt } \\
\hline CHEMBL1437581 & 688546 & 5.0 & 5.2202 & TST \\
\hline CHEMBL1521154 & 688546 & 4.5 & 4.8394 & TST \\
\hline CHEMBL1514611 & 688546 & 4.9 & 5.7208 & TRN \\
\hline CHEMBL1531413 & 688546 & 4.8 & 5.1473 & TRN \\
\hline CHEMBL1444742 & 688546 & 7.2503 & 6.0133 & TRN \\
\hline CHEMBL1165202 & 688546 & 6.3 & 5.3586 & TRN \\
\hline CHEMBL1395128 & 688546 & 5.8 & 5.6218 & TST \\
\hline CHEMBL1442201 & 688546 & 6.1 & 5.1453 & TRN \\
\hline CHEMBL 375629 & 688546 & 4.5 & 4.7484 & TRN \\
\hline CHEMBL1317333 & 688546 & 7.8013 & 5.8392 & TRN \\
\hline CHEMBL1610565 & 688546 & 4.8 & 4.9123 & TRN \\
\hline CHEMBL1515412 & 688546 & 5.2 & 5.5923 & TST \\
\hline CHEMBL1554390 & 688546 & 5.0 & 5.1651 & TRN \\
\hline CHEMBL1474094 & 688546 & 4.8 & 5.0824 & TRN \\
\hline CHEMBL1613308 & 688546 & 4.9 & 5.2883 & TRN \\
\hline CHEMBL1326404 & 688546 & 5.4 & 5.4695 & TST \\
\hline CHEMBL1440316 & 688546 & 4.6 & 5.4021 & TRN \\
\hline CHEMBL1362000 & 688546 & 8.4949 & 5.5983 & TRN \\
\hline CHEMBL1435638 & 688546 & 4.5 & 4.4979 & TRN \\
\hline CHEMBL1315542 & 688546 & 6.4 & 6.1921 & TRN \\
\hline CHEMBL1430213 & 688546 & 4.9 & 5.1768 & TST \\
\hline CHEMBL1363489 & 688546 & 5.35 & 5.4878 & TRN \\
\hline CHEMBL1357166 & 688546 & 4.6 & 5.1523 & TRN \\
\hline CHEMBL1363214 & 688546 & 6.8 & 5.803 & TRN \\
\hline CHEMBL1600515 & 688546 & 4.9 & 5.4026 & TRN \\
\hline CHEMBL1355854 & 688546 & 4.9 & 4.5556 & TRN \\
\hline CHEMBL 228792 & 688546 & 4.9 & 4.67899 & 9999999999 \\
\hline CHEMBL1408676 & 688546 & 4.9 & 5.2073 & TRN \\
\hline CHEMBL1299259 & 688546 & 4.55 & 5.0087 & TST \\
\hline CHEMBL1372514 & 688546 & 5.1 & 5.2964 & TRN \\
\hline CHEMBL1526387 & 688546 & 6.15 & 5.1537 & TRN \\
\hline CHEMBL1416927 & 688546 & 5.1 & 5.2821 & TRN \\
\hline CHEMBL1434672 & 688546 & 8.2518 & 6.0355 & TRN \\
\hline CHEMBL1336959 & 688546 & 4.45 & 5.3471 & TST \\
\hline CHEMBL1554496 & 688546 & 5.4 & 4.9164 & TST \\
\hline CHEMBL1365743 & 688546 & 4.4 & 5.2944 & TRN \\
\hline CHEMBL1414129 & 688546 & 4.9 & 5.3288 & TRN \\
\hline CHEMBL1318060 & 688546 & 5.9 & 5.4793 & TRN \\
\hline CHEMBL1438041 & 688546 & 4.8 & 4.8475 & TRN \\
\hline CHEMBL1551774 & 688546 & 4.7 & 5.019 & TRN \\
\hline CHEMBL1331798 & 688546 & 7.15 & 4.8107 & TST \\
\hline CHEMBL1358212 & 688546 & 4.6 & 4.7823 & TRN \\
\hline CHEMBL1485078 & 688546 & 5.1 & 5.562 & TRN \\
\hline CHEMBL1593313 & 688546 & 7.3497 & 5.4272 & TRN \\
\hline CHEMBL1348675 & 688546 & 5.5 & 5.0809 & TST \\
\hline CHEMBL1399504 & 688546 & 4.5 & 5.061 & TRN \\
\hline CHEMBL1495688 & 688546 & 5.6 & 5.1096 & TRN \\
\hline CHEMBL1596996 & 688546 & 4.5 & 4.6867 & TRN \\
\hline
\end{tabular}




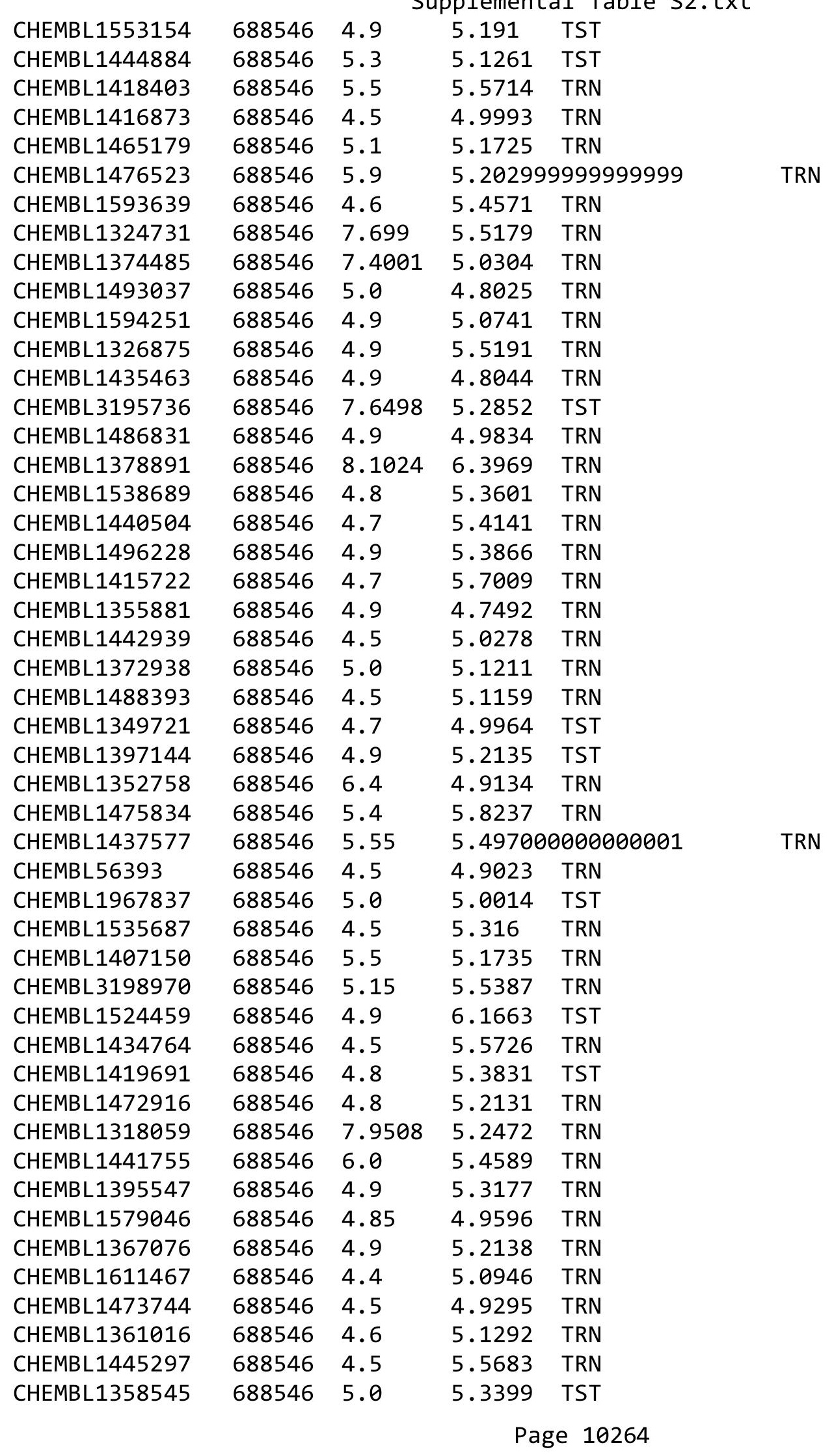




\begin{tabular}{|c|c|c|c|c|c|}
\hline \\
\hline CHEMBL1357687 & 688546 & 6.5 & 5.7584 & TRN & \\
\hline CHEMBL1325310 & 688546 & 5.0 & 4.6716 & TRN & \\
\hline CHEMBL1431184 & 688546 & 5.5 & 5.4035 & TST & \\
\hline CHEMBL1343793 & 688546 & 5.45 & 5.20700 & 0000000001 & TST \\
\hline CHEMBL1599088 & 688546 & 4.9 & 5.0482 & TRN & \\
\hline CHEMBL1570765 & 688546 & 5.7 & 5.4164 & TST & \\
\hline CHEMBL1591941 & 688546 & 4.5 & 5.2102 & TRN & \\
\hline CHEMBL1445273 & 688546 & 4.5 & 5.4608 & TRN & \\
\hline CHEMBL1405215 & 688546 & 6.95 & 5.3465 & TRN & \\
\hline CHEMBL1300080 & 688546 & 4.9 & 5.4062 & TRN & \\
\hline CHEMBL1482765 & 688546 & 4.8 & 5.2415 & TRN & \\
\hline CHEMBL1313979 & 688546 & 5.5 & 5.3155 & TRN & \\
\hline CHEMBL1414943 & 688546 & 6.0 & 5.4767 & TRN & \\
\hline CHEMBL1475129 & 688546 & 7.8508 & 6.0464 & TRN & \\
\hline CHEMBL1594461 & 688546 & 5.1 & 5.1934 & TRN & \\
\hline CHEMBL1395582 & 688546 & 4.5 & 5.4265 & TST & \\
\hline CHEMBL1398015 & 688546 & 4.5 & 5.4313 & TRN & \\
\hline CHEMBL1489290 & 688546 & 5.0 & 5.2605 & TRN & \\
\hline CHEMBL1512156 & 688546 & 4.95 & 5.3237 & TST & \\
\hline CHEMBL1372942 & 688546 & 4.8 & 5.6098 & TRN & \\
\hline CHEMBL509531 & 688546 & 4.9 & 5.777 & TST & \\
\hline CHEMBL1335568 & 688546 & 4.8 & 5.4388 & TST & \\
\hline CHEMBL1530263 & 688546 & 4.5 & 5.2549 & TRN & \\
\hline CHEMBL221219 & 688546 & 4.7 & 4.8221 & TRN & \\
\hline CHEMBL1496402 & 688546 & 4.7 & 4.6834 & TRN & \\
\hline CHEMBL1541001 & 688546 & 4.6 & 5.0375 & TRN & \\
\hline CHEMBL1358480 & 688546 & 5.1 & 5.1339 & TRN & \\
\hline CHEMBL1323217 & 688546 & 4.7 & 4.6773 & TST & \\
\hline CHEMBL1316086 & 688546 & 4.8 & 5.7955 & TRN & \\
\hline CHEMBL1490363 & 688546 & 5.0 & 5.9928 & TST & \\
\hline CHEMBL1450452 & 688546 & 4.5 & 5.3128 & TST & \\
\hline CHEMBL293749 & 688546 & 5.0 & 5.5307 & TRN & \\
\hline CHEMBL1570557 & 688546 & 4.5 & 5.3059 & TST & \\
\hline CHEMBL1354381 & 688546 & 5.0 & 5.29200 & 0000000001 & TRN \\
\hline CHEMBL1472652 & 688546 & 5.2 & 5.1502 & TRN & \\
\hline CHEMBL1581465 & 688546 & 5.0 & 5.2119 & TRN & \\
\hline CHEMBL1515569 & 688546 & 6.3 & 5.4253 & TRN & \\
\hline CHEMBL1329228 & 688546 & 4.9 & 5.1322 & TRN & \\
\hline CHEMBL1433666 & 688546 & 4.7 & 5.1037 & TRN & \\
\hline CHEMBL1518672 & 688546 & 4.8 & 5.0174 & TRN & \\
\hline CHEMBL1358040 & 688546 & 5.2 & 5.4989 & TRN & \\
\hline CHEMBL1406063 & 688546 & 6.0 & 5.8882 & TRN & \\
\hline CHEMBL1512730 & 688546 & 7.2503 & 6.1302 & TRN & \\
\hline CHEMBL1337816 & 688546 & 5.2 & 4.7359 & TRN & \\
\hline CHEMBL1397353 & 688546 & 4.8 & 4.82600 & 00000000005 & TRN \\
\hline CHEMBL1330759 & 688546 & 4.6 & 5.0213 & TRN & \\
\hline CHEMBL1396322 & 688546 & 4.8 & 4.6554 & TRN & \\
\hline CHEMBL1325099 & 688546 & 4.8 & 5.5795 & TRN & \\
\hline
\end{tabular}




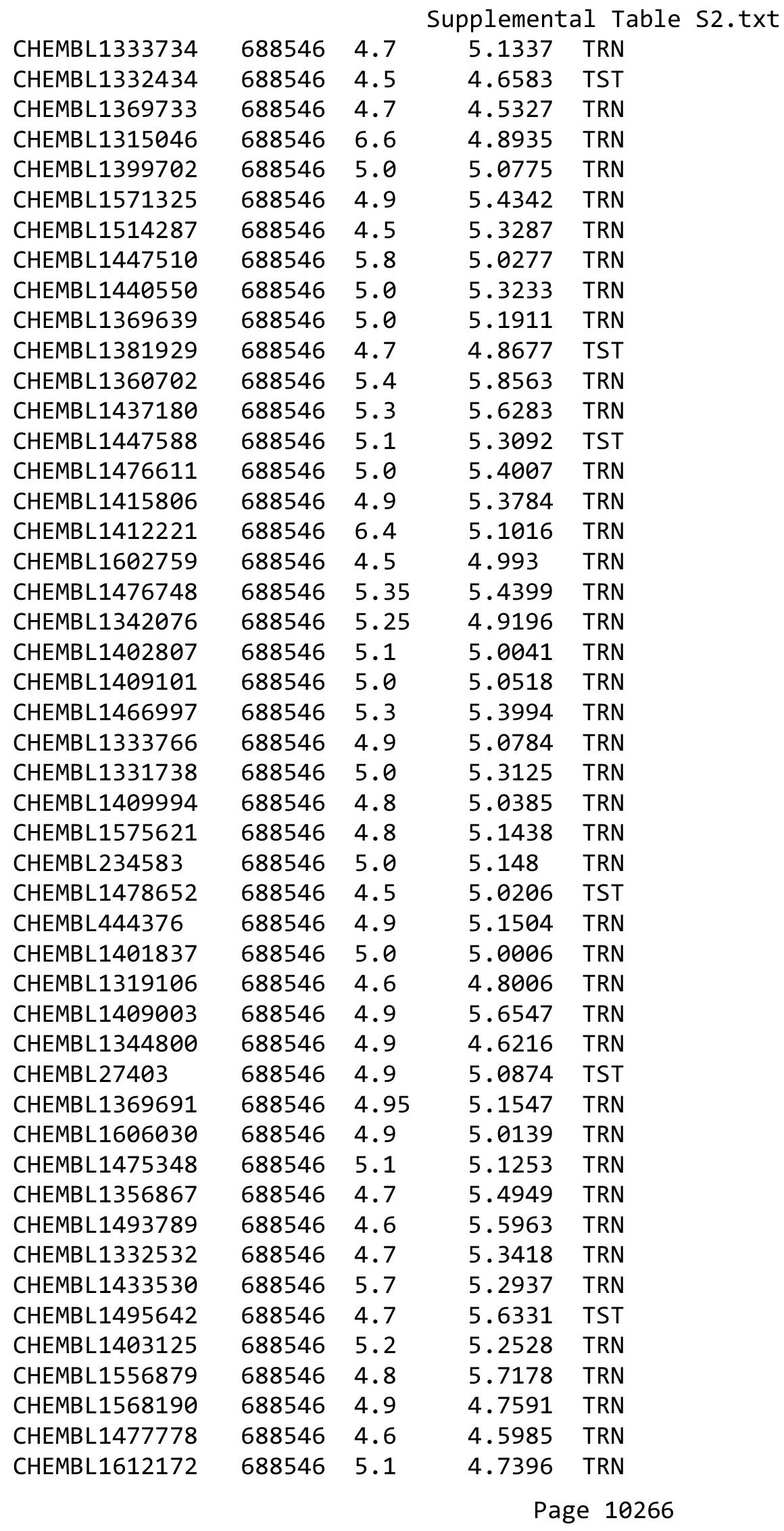




\begin{tabular}{|c|c|c|c|c|}
\hline & & & pplement & al $\mathrm{T}$ \\
\hline CHEMBL1603276 & 688546 & 8.0 & 5.7596 & TRN \\
\hline CHEMBL1401360 & 688546 & 4.9 & 5.1933 & TRN \\
\hline CHEMBL1358584 & 688546 & 4.5 & 4.909 & TRN \\
\hline CHEMBL1475020 & 688546 & 8.0 & 5.4451 & TRN \\
\hline CHEMBL1490887 & 688546 & 4.5 & 5.118 & TRN \\
\hline CHEMBL1484852 & 688546 & 8.1024 & 5.082 & TST \\
\hline CHEMBL137648 & 688546 & 4.5 & 4.8629 & TST \\
\hline CHEMBL1578557 & 688546 & 5.0 & 5.2718 & TRN \\
\hline CHEMBL1396389 & 688546 & 4.9 & 5.7792 & TRN \\
\hline CHEMBL3198449 & 688546 & 4.7 & 5.6028 & TST \\
\hline CHEMBL1437679 & 688546 & 5.1 & 5.4765 & TRN \\
\hline CHEMBL1308118 & 688546 & 4.8 & 5.012 & TST \\
\hline CHEMBL1371323 & 688546 & 4.85 & 5.3241 & TRN \\
\hline CHEMBL1315962 & 688546 & 4.9 & 5.3112 & TRN \\
\hline CHEMBL1379920 & 688546 & 4.9 & 4.8599 & TST \\
\hline CHEMBL408563 & 688546 & 4.9 & 5.1315 & TST \\
\hline CHEMBL1566901 & 688546 & 4.9 & 4.7847 & TRN \\
\hline CHEMBL1577137 & 688546 & 4.9 & 5.5154 & TRN \\
\hline CHEMBL1599227 & 688546 & 4.7 & 5.4393 & TRN \\
\hline CHEMBL1561939 & 688546 & 4.45 & 5.0414 & TRN \\
\hline CHEMBL1460290 & 688546 & 5.25 & 5.0804 & TRN \\
\hline CHEMBL1591160 & 688546 & 7.8013 & 5.9358 & TRN \\
\hline CHEMBL1414873 & 688546 & 4.8 & 4.53 & TRN \\
\hline CHEMBL1337084 & 688546 & 4.8 & 5.4308 & TRN \\
\hline CHEMBL1459485 & 688546 & 4.5 & 4.8021 & TST \\
\hline CHEMBL1472832 & 688546 & 6.2 & 5.6212 & TRN \\
\hline CHEMBL3212311 & 688546 & 4.6 & 5.5103 & TST \\
\hline CHEMBL1552152 & 688546 & 4.6 & 5.3699 & TRN \\
\hline CHEMBL1500607 & 688546 & 7.3497 & 5.3641 & TST \\
\hline CHEMBL1474955 & 688546 & 4.6 & 5.4561 & TRN \\
\hline CHEMBL1538798 & 688546 & 4.5 & 4.9196 & TRN \\
\hline CHEMBL1361233 & 688546 & 5.85 & 5.7699 & TRN \\
\hline CHEMBL1562496 & 688546 & 5.0 & 5.3224 & TRN \\
\hline CHEMBL1373443 & 688546 & 4.8 & 4.8398 & TRN \\
\hline CHEMBL1308887 & 688546 & 4.9 & 5.1968 & TRN \\
\hline CHEMBL1451206 & 688546 & 4.7 & 4.9235 & TRN \\
\hline CHEMBL1354569 & 688546 & 5.0 & 5.0199 & TRN \\
\hline CHEMBL1475565 & 688546 & 5.2 & 5.6491 & TST \\
\hline CHEMBL1589936 & 688546 & 6.45 & 5.2866 & TRN \\
\hline CHEMBL1596843 & 688546 & 5.3 & 5.4438 & TRN \\
\hline CHEMBL1359723 & 688546 & 5.3 & 4.8091 & TRN \\
\hline CHEMBL1476773 & 688546 & 4.8 & 4.5443 & TRN \\
\hline CHEMBL1371815 & 688546 & 5.1 & 5.4693 & TRN \\
\hline CHEMBL1378823 & 688546 & 5.6 & 5.8968 & TRN \\
\hline CHEMBL1441856 & 688546 & 4.5 & 5.1586 & TST \\
\hline CHEMBL1355038 & 688546 & 4.5 & 5.1049 & TRN \\
\hline CHEMBL1407026 & 688546 & 5.5 & 5.0256 & TST \\
\hline CHEMBL1435221 & 688546 & 6.5 & 5.6737 & TST \\
\hline
\end{tabular}




\begin{tabular}{|c|c|c|c|c|}
\hline \multicolumn{5}{|c|}{ Supplemental Table S2.txt } \\
\hline CHEMBL1596917 & 688546 & 4.9 & 5.1886 & TST \\
\hline CHEMBL1610556 & 688546 & 5.4 & 5.5891 & TRN \\
\hline CHEMBL1591015 & 688546 & 8.2007 & 5.4428 & TRN \\
\hline CHEMBL1397616 & 688546 & 4.5 & 5.9623 & TRN \\
\hline CHEMBL1358047 & 688546 & 4.8 & 5.3668 & TRN \\
\hline CHEMBL1488857 & 688546 & 5.5 & 5.7344 & TRN \\
\hline CHEMBL1397913 & 688546 & 4.5 & 5.0526 & TRN \\
\hline CHEMBL1436075 & 688546 & 4.7 & 5.0361 & TRN \\
\hline CHEMBL1378079 & 688546 & 4.75 & 5.6531 & TRN \\
\hline CHEMBL1518688 & 688546 & 4.6 & 5.0993 & TRN \\
\hline CHEMBL1556791 & 688546 & 5.0 & 5.3525 & TRN \\
\hline CHEMBL1610129 & 688546 & 5.6 & 5.6 & TRN \\
\hline CHEMBL1327069 & 688546 & 5.0 & 5.8344 & TST \\
\hline CHEMBL1453953 & 688546 & 5.2 & 4.8522 & TRN \\
\hline CHEMBL1388947 & 688546 & 4.9 & 5.2307 & TST \\
\hline CHEMBL1435630 & 688546 & 6.9 & 5.3666 & TRN \\
\hline CHEMBL1366676 & 688546 & 5.5 & 4.9236 & TRN \\
\hline CHEMBL1536647 & 688546 & 4.9 & 5.1633 & TRN \\
\hline CHEMBL131199 & 688546 & 5.2 & 5.6671 & TST \\
\hline CHEMBL1346967 & 688546 & 4.5 & 4.954 & TRN \\
\hline CHEMBL1435244 & 688546 & 7.699 & 4.984 & TRN \\
\hline CHEMBL1304930 & 688546 & 5.25 & 5.1845 & TRN \\
\hline CHEMBL1592831 & 688546 & 4.5 & 5.7522 & TRN \\
\hline CHEMBL1419647 & 688546 & 4.9 & 5.2926 & TRN \\
\hline CHEMBL3190751 & 688546 & 4.9 & 5.4906 & TRN \\
\hline CHEMBL1418843 & 688546 & 4.5 & 5.556 & TST \\
\hline CHEMBL604119 & 688546 & 4.5 & 4.9007 & TST \\
\hline CHEMBL1553795 & 688546 & 7.15 & 5.5557 & TST \\
\hline CHEMBL1593745 & 688546 & 4.5 & 5.0565 & TRN \\
\hline CHEMBL1519624 & 688546 & 4.9 & 5.4219 & TST \\
\hline CHEMBL1380884 & 688546 & 4.8 & 5.0895 & TST \\
\hline CHEMBL1527485 & 688546 & 4.8 & 4.9313 & TST \\
\hline CHEMBL1409689 & 688546 & 4.5 & 5.3068 & TRN \\
\hline CHEMBL1472819 & 688546 & 5.0 & 4.8837 & TST \\
\hline CHEMBL1476767 & 688546 & 6.6499 & 5.5757 & TST \\
\hline CHEMBL1334997 & 688546 & 5.2 & 4.9678 & TRN \\
\hline CHEMBL1574816 & 688546 & 4.5 & 4.9055 & TRN \\
\hline CHEMBL1338737 & 688546 & 5.0 & 5.0656 & TRN \\
\hline CHEMBL1384832 & 688546 & 4.8 & 5.2837 & TRN \\
\hline CHEMBL1400738 & 688546 & 7.0501 & 5.4232 & TRN \\
\hline CHEMBL1329458 & 688546 & 4.5 & 4.9143 & TRN \\
\hline CHEMBL1535813 & 688546 & 5.2 & 5.7475 & TRN \\
\hline CHEMBL1484606 & 688546 & 7.8013 & 5.5052 & TRN \\
\hline CHEMBL1364980 & 688546 & 4.7 & 5.0165 & TST \\
\hline CHEMBL1328538 & 688546 & 4.5 & 5.0453 & TST \\
\hline CHEMBL1559217 & 688546 & 4.8 & 4.6476 & TRN \\
\hline CHEMBL1459382 & 688546 & 5.2 & 5.5292 & TRN \\
\hline CHEMBL1493935 & 688546 & 7.0 & 5.7087 & TRN \\
\hline
\end{tabular}




\begin{tabular}{|c|c|c|c|c|c|}
\hline \\
\hline CHEMBL1453260 & 688546 & 4.7 & 5.4413 & TRN & \\
\hline CHEMBL1413257 & 688546 & 5.2 & 5.3609 & TRN & \\
\hline CHEMBL1346316 & 688546 & 4.9 & 4.5586 & TST & \\
\hline CHEMBL1528373 & 688546 & 4.8 & 5.0226 & TRN & \\
\hline CHEMBL1395275 & 688546 & 5.0 & 5.3148 & TRN & \\
\hline CHEMBL1473873 & 688546 & 8.0 & 5.36600 & 00000000005 & TRN \\
\hline CHEMBL1474684 & 688546 & 4.7 & 4.8844 & TRN & \\
\hline CHEMBL1401147 & 688546 & 8.4949 & 5.24 & TST & \\
\hline CHEMBL1357125 & 688546 & 6.8499 & 5.6566 & TRN & \\
\hline CHEMBL1302191 & 688546 & 4.9 & 5.7866 & TST & \\
\hline CHEMBL3195514 & 688546 & 4.75 & 5.4393 & TST & \\
\hline CHEMBL1395306 & 688546 & 4.9 & 4.6026 & TRN & \\
\hline CHEMBL1332258 & 688546 & 4.5 & 5.4723 & TST & \\
\hline CHEMBL1201091 & 688546 & 8.2007 & 5.0249 & TST & \\
\hline CHEMBL1370909 & 688546 & 5.0 & 4.8716 & TST & \\
\hline CHEMBL1414546 & 688546 & 4.6 & 5.4234 & TRN & \\
\hline CHEMBL1494755 & 688546 & 5.25 & 4.937 & TRN & \\
\hline CHEMBL1459411 & 688546 & 4.5 & 4.6905 & TRN & \\
\hline CHEMBL1324903 & 688546 & 4.8 & 5.5026 & TST & \\
\hline CHEMBL1470572 & 688546 & 4.9 & 5.1711 & TRN & \\
\hline CHEMBL1474446 & 688546 & 7.5003 & 6.0957 & TRN & \\
\hline CHEMBL1363696 & 688546 & 9.2218 & 5.3361 & TRN & \\
\hline CHEMBL1554848 & 688546 & 5.7 & 5.2814 & TRN & \\
\hline CHEMBL1591997 & 688546 & 4.5 & 5.2282 & TRN & \\
\hline CHEMBL1471476 & 688546 & 4.9 & 4.9272 & TRN & \\
\hline CHEMBL3213398 & 688546 & 7.6003 & 5.3749 & TST & \\
\hline CHEMBL462314 & 688546 & 6.0 & 5.3024 & TST & \\
\hline CHEMBL1591261 & 688546 & 4.5 & 5.3434 & TRN & \\
\hline CHEMBL1394829 & 688546 & 5.3 & 5.0244 & TST & \\
\hline CHEMBL1464602 & 688546 & 5.5 & 5.0686 & TST & \\
\hline CHEMBL1601691 & 688546 & 4.5 & 4.9607 & TST & \\
\hline CHEMBL1586980 & 688546 & 4.7 & 4.9689 & TRN & \\
\hline CHEMBL1313913 & 688546 & 4.95 & 5.2486 & TST & \\
\hline CHEMBL1524998 & 688546 & 4.7 & 4.8847 & TST & \\
\hline CHEMBL1467704 & 688546 & 4.8 & 5.9023 & TRN & \\
\hline CHEMBL1452601 & 688546 & 5.65 & 5.0793 & TRN & \\
\hline CHEMBL1370549 & 688546 & 4.9 & 4.8905 & TRN & \\
\hline CHEMBL1535978 & 688546 & 5.9 & 5.9725 & TRN & \\
\hline CHEMBL1594217 & 688546 & 4.4 & 5.1906 & TST & \\
\hline CHEMBL1436108 & 688546 & 5.0 & 5.2364 & TRN & \\
\hline CHEMBL422942 & 688546 & 5.5 & 5.2381 & TST & \\
\hline CHEMBL1398721 & 688546 & 4.7 & 4.4738 & TRN & \\
\hline CHEMBL1425937 & 688546 & 4.8 & 5.4702 & TRN & \\
\hline CHEMBL1358551 & 688546 & 4.8 & 5.6582 & TRN & \\
\hline CHEMBL1449750 & 688546 & 4.9 & 5.3147 & TRN & \\
\hline CHEMBL1483381 & 688546 & 5.0 & 4.9695 & TRN & \\
\hline CHEMBL1398171 & 688546 & 4.8 & 4.6243 & TRN & \\
\hline CHEMBL1588219 & 688546 & 4.7 & 5.1585 & TST & \\
\hline
\end{tabular}




\begin{tabular}{|c|c|c|c|c|}
\hline \multicolumn{5}{|c|}{ Supplemental Table S2.txt } \\
\hline CHEMBL1376244 & 688546 & 4.6 & 5.1168 & TRN \\
\hline CHEMBL1433652 & 688546 & 5.1 & $5.4220 e$ & 0000000001 \\
\hline CHEMBL1373263 & 688546 & 5.45 & 5.2689 & TRN \\
\hline CHEMBL3194521 & 688546 & 5.0 & 5.1945 & TRN \\
\hline CHEMBL1397987 & 688546 & 4.5 & 5.1366 & TRN \\
\hline CHEMBL1321943 & 688546 & 4.5 & 4.8988 & TRN \\
\hline CHEMBL1533112 & 688546 & 5.4 & 5.8059 & TRN \\
\hline CHEMBL1332770 & 688546 & 4.95 & 5.1188 & TRN \\
\hline CHEMBL491991 & 688546 & 5.0 & 5.1497 & TRN \\
\hline CHEMBL1464836 & 688546 & 5.45 & 5.2204 & TRN \\
\hline CHEMBL1590012 & 688546 & 6.1 & 5.2475 & TRN \\
\hline CHEMBL1478281 & 688546 & 4.45 & 5.5247 & TRN \\
\hline CHEMBL1341870 & 688546 & 5.2 & 4.8561 & TRN \\
\hline CHEMBL1398173 & 688546 & 4.9 & 5.5729 & TRN \\
\hline CHEMBL1476261 & 688546 & 4.7 & 5.3323 & TRN \\
\hline CHEMBL1527187 & 688546 & 5.05 & 5.3398 & TST \\
\hline CHEMBL1514639 & 688546 & 4.5 & 4.979 & TST \\
\hline CHEMBL1422097 & 688546 & 4.95 & 4.7987 & TRN \\
\hline CHEMBL1471435 & 688546 & 4.7 & 4.5488 & TRN \\
\hline CHEMBL1354290 & 688546 & 5.3 & 5.0111 & TRN \\
\hline CHEMBL1370563 & 688546 & 4.9 & 5.2561 & TST \\
\hline CHEMBL1455996 & 688546 & 4.9 & 5.1303 & TST \\
\hline CHEMBL1486030 & 688546 & 6.5 & 5.5738 & TRN \\
\hline CHEMBL1427885 & 688546 & 5.45 & 5.4637 & TRN \\
\hline CHEMBL1592013 & 688546 & 5.9 & 5.0833 & TRN \\
\hline CHEMBL1517172 & 688546 & 4.5 & 4.6667 & TRN \\
\hline CHEMBL1459902 & 688546 & 4.5 & 5.2249 & TST \\
\hline CHEMBL1369899 & 688546 & 5.0 & 4.7384 & TRN \\
\hline CHEMBL1366544 & 688546 & 4.9 & 5.1949 & TST \\
\hline CHEMBL1430634 & 688546 & 4.8 & 4.9119 & TRN \\
\hline CHEMBL1391482 & 688546 & 4.8 & 4.9552 & TST \\
\hline CHEMBL1520687 & 688546 & 7.2 & 5.5276 & TRN \\
\hline CHEMBL1401648 & 688546 & 5.1 & 4.8982 & TRN \\
\hline CHEMBL1419183 & 688546 & 5.0 & 4.6131 & TST \\
\hline CHEMBL1487217 & 688546 & 5.25 & 5.3503 & TRN \\
\hline CHEMBL1489212 & 688546 & 4.6 & 5.1187 & TRN \\
\hline CHEMBL1492968 & 688546 & 4.5 & 5.1661 & TRN \\
\hline CHEMBL473735 & 688546 & 5.2 & 5.4722 & TRN \\
\hline CHEMBL1415176 & 688546 & 4.5 & 4.8152 & TRN \\
\hline CHEMBL1610180 & 688546 & 4.5 & 5.6965 & TRN \\
\hline CHEMBL1591055 & 688546 & 5.4 & 5.1677 & TRN \\
\hline CHEMBL1538538 & 688546 & 6.15 & 4.9428 & TRN \\
\hline CHEMBL1551081 & 688546 & 5.4 & 5.3102 & TRN \\
\hline CHEMBL1603009 & 688546 & 4.8 & 5.2095 & TRN \\
\hline CHEMBL1535582 & 688546 & 7.2503 & 5.596 & TRN \\
\hline CHEMBL1315074 & 688546 & 7.0 & 5.144 & TRN \\
\hline CHEMBL1395970 & 688546 & 4.7 & 5.1937 & TRN \\
\hline CHEMBL 2002776 & 688546 & 4.9 & 5.0556 & TRN \\
\hline
\end{tabular}




\begin{tabular}{|c|c|c|c|c|c|}
\hline \multicolumn{6}{|c|}{ Supplemental Table s2.txt } \\
\hline CHEMBL151 & 688546 & 5.5 & 5.2698 & TRN & \\
\hline CHEMBL1514707 & 688546 & 4.9 & 4.9475 & TRN & \\
\hline CHEMBL1455181 & 688546 & 4.6 & 5.5448 & TRN & \\
\hline CHEMBL1396674 & 688546 & 5.9 & 5.5314 & TRN & \\
\hline CHEMBL1519969 & 688546 & 7.0 & 5.7268 & TRN & \\
\hline CHEMBL34241 & 688546 & 4.9 & 5.1476 & TST & \\
\hline CHEMBL1435656 & 688546 & 5.0 & 4.8794 & TRN & \\
\hline CHEMBL1372213 & 688546 & 4.9 & 5.3056 & TRN & \\
\hline CHEMBL1443840 & 688546 & 5.4 & 5.2274 & TRN & \\
\hline CHEMBL1587679 & 688546 & 6.5501 & 4.9267 & TRN & \\
\hline CHEMBL36296 & 688546 & 4.5 & 4.8299 & TST & \\
\hline CHEMBL1379313 & 688546 & 7.5003 & 4.927 & TST & \\
\hline CHEMBL1605653 & 688546 & 5.0 & 5.1318 & TRN & \\
\hline CHEMBL1324329 & 688546 & 4.8 & 4.6995 & TRN & \\
\hline CHEMBL1400017 & 688546 & 7.8013 & 5.2307 & TRN & \\
\hline CHEMBL1394306 & 688546 & 4.9 & 5.3877 & TRN & \\
\hline CHEMBL1412828 & 688546 & 4.8 & 4.8157 & TRN & \\
\hline CHEMBL1335498 & 688546 & 4.7 & 5.6367 & TRN & \\
\hline CHEMBL1452098 & 688546 & 5.9 & 5.2843 & TRN & \\
\hline CHEMBL1590940 & 688546 & 4.9 & 4.9069 & TRN & \\
\hline CHEMBL1417943 & 688546 & 7.5003 & 5.3873 & TRN & \\
\hline CHEMBL137498 & 688546 & 5.0 & 4.9833 & TRN & \\
\hline CHEMBL1533008 & 688546 & 5.45 & 5.4085 & TRN & \\
\hline CHEMBL1395466 & 688546 & 4.8 & 5.1659 & TRN & \\
\hline CHEMBL1602294 & 688546 & 5.0 & 5.5385 & TRN & \\
\hline CHEMBL1466310 & 688546 & 4.6 & 4.7654 & TRN & \\
\hline CHEMBL1592481 & 688546 & 4.9 & 5.2503 & TST & \\
\hline CHEMBL1357275 & 688546 & 7.4001 & 5.471 & TRN & \\
\hline CHEMBL1528838 & 688546 & 5.6 & 5.6928 & TRN & \\
\hline CHEMBL1449402 & 688546 & 7.699 & 5.3027 & TRN & \\
\hline CHEMBL1608177 & 688546 & 4.5 & 4.8615 & TRN & \\
\hline CHEMBL1412731 & 688546 & 4.7 & 5.1606 & TST & \\
\hline CHEMBL1329446 & 688546 & 5.0 & 5.2861 & TST & \\
\hline CHEMBL1435262 & 688546 & 4.6 & 4.6158 & TRN & \\
\hline CHEMBL1449854 & 688546 & 4.6 & 4.5864 & TRN & \\
\hline CHEMBL1459140 & 688546 & 5.25 & 5.0572 & TST & \\
\hline CHEMBL1436105 & 688546 & 5.2 & 5.0666 & TRN & \\
\hline CHEMBL1442907 & 688546 & 5.2 & 5.3313 & TRN & \\
\hline CHEMBL1487358 & 688546 & 4.6 & 4.458 & TRN & \\
\hline CHEMBL1480256 & 688546 & 6.8499 & 5.7262 & TST & \\
\hline CHEMBL1552456 & 688546 & 4.7 & 5.4462 & TRN & \\
\hline CHEMBL1447419 & 688546 & 5.4 & 4.9241 & TRN & \\
\hline CHEMBL1553824 & 688546 & 5.3 & 5.29299 & 9999999999 & TRN \\
\hline CHEMBL1410006 & 688546 & 5.9 & 5.3512 & TRN & \\
\hline CHEMBL1583267 & 688546 & 5.0 & 5.4732 & TST & \\
\hline CHEMBL3193474 & 688546 & 4.45 & 4.9584 & TST & \\
\hline CHEMBL1476813 & 688546 & 5.0 & 5.1206 & TRN & \\
\hline CHEMBL1512433 & 688546 & 5.1 & 5.3617 & TRN & \\
\hline
\end{tabular}




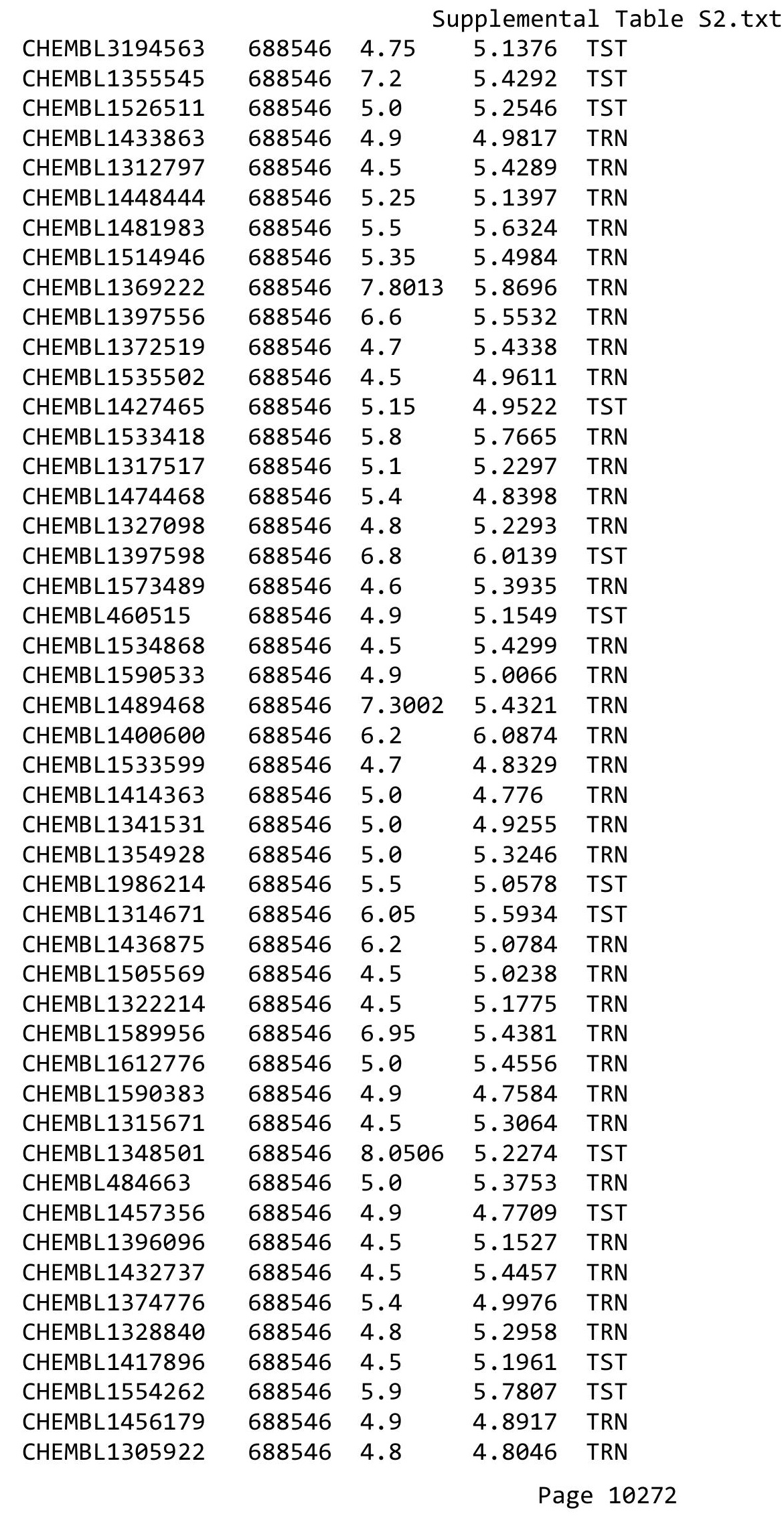




\begin{tabular}{|c|c|c|c|c|c|}
\hline \multirow{3}{*}{$\begin{array}{l}\text { CHEMBL1528272 } \\
\text { CHEMBL } 498770\end{array}$} & \multirow{3}{*}{$\begin{array}{l}688546 \\
688546\end{array}$} & \multicolumn{4}{|c|}{ Supplemental Table S2.txt } \\
\hline & & 5.25 & 5.7860 & 00000000005 & TRN \\
\hline & & 4.9 & 5.0357 & TST & \\
\hline CHEMBL1314906 & 688546 & 4.6 & 4.7067 & TRN & \\
\hline CHEMBL3194517 & 688546 & 4.9 & 5.5801 & TST & \\
\hline CHEMBL3193166 & 688546 & 4.6 & 5.0337 & TRN & \\
\hline CHEMBL1514071 & 688546 & 4.9 & 4.6866 & TRN & \\
\hline CHEMBL1612538 & 688546 & 4.5 & 5.3612 & TRN & \\
\hline CHEMBL1371175 & 688546 & 4.8 & 5.3478 & TRN & \\
\hline CHEMBL1370676 & 688546 & 4.7 & 5.1996 & TRN & \\
\hline CHEMBL1465527 & 688546 & 4.5 & 4.9975 & TST & \\
\hline CHEMBL1449637 & 688546 & 4.7 & 5.33 & TRN & \\
\hline CHEMBL1319634 & 688546 & 5.0 & 5.4554 & TRN & \\
\hline CHEMBL1436176 & 688546 & 4.5 & 4.8247 & TRN & \\
\hline CHEMBL1553360 & 688546 & 4.8 & 5.1207 & TRN & \\
\hline CHEMBL1515691 & 688546 & 4.6 & 5.4226 & TST & \\
\hline CHEMBL1555230 & 688546 & 5.25 & 5.5908 & TRN & \\
\hline CHEMBL2374259 & 688546 & 4.6 & 4.9099 & TRN & \\
\hline CHEMBL1415986 & 688546 & 4.9 & 5.4828 & TRN & \\
\hline CHEMBL1564691 & 688546 & 4.8 & 4.7901 & TRN & \\
\hline CHEMBL1317531 & 688546 & 4.7 & 4.8147 & TRN & \\
\hline CHEMBL1330767 & 688546 & 5.0 & 5.5377 & TRN & \\
\hline CHEMBL1561128 & 688546 & 5.0 & 5.4153 & TRN & \\
\hline CHEMBL1368062 & 688546 & 5.7 & 5.4811 & TRN & \\
\hline CHEMBL1608623 & 688546 & 4.85 & 5.305 & TRN & \\
\hline CHEMBL1394286 & 688546 & 7.4498 & 5.8087 & TRN & \\
\hline CHEMBL1442190 & 688546 & 5.1 & 5.1348 & TRN & \\
\hline CHEMBL1434846 & 688546 & 8.1024 & 5.6235 & TST & \\
\hline CHEMBL188 & 688546 & 8.1024 & 5.3832 & TST & \\
\hline CHEMBL1409113 & 688546 & 5.0 & 5.0313 & TST & \\
\hline CHEMBL1553656 & 688546 & 5.0 & 5.4882 & TRN & \\
\hline CHEMBL1381498 & 688546 & 5.0 & 4.9384 & TST & \\
\hline CHEMBL1331857 & 688546 & 4.9 & 5.0644 & TST & \\
\hline CHEMBL1381551 & 688546 & 4.5 & 4.8097 & TST & \\
\hline CHEMBL1479449 & 688546 & 4.9 & 5.1129 & TST & \\
\hline CHEMBL1363326 & 688546 & 4.8 & 4.9617 & TST & \\
\hline CHEMBL1505353 & 688546 & 4.8 & 5.2691 & TST & \\
\hline CHEMBL192566 & 688546 & 4.9 & 5.4712 & TST & \\
\hline CHEMBL1450386 & 688546 & 5.0 & 4.9159 & TRN & \\
\hline CHEMBL1964614 & 688546 & 5.55 & 5.1109 & TRN & \\
\hline CHEMBL1397541 & 688546 & 4.9 & 5.0909 & TRN & \\
\hline CHEMBL1434055 & 688546 & 5.0 & 5.4661 & TST & \\
\hline CHEMBL1410975 & 688546 & 5.1 & 5.5564 & TRN & \\
\hline CHEMBL1412416 & 688546 & 4.8 & 4.746 & TRN & \\
\hline CHEMBL1318900 & 688546 & 4.9 & 5.0183 & TRN & \\
\hline CHEMBL1473362 & 688546 & 4.9 & 5.2211 & TRN & \\
\hline CHEMBL1475572 & 688546 & 4.8 & 5.16 & TRN & \\
\hline CHEMBL1502876 & 688546 & 4.9 & 5.0396 & TRN & \\
\hline CHEMBL1514509 & 688546 & 4.8 & 5.6778 & TRN & \\
\hline
\end{tabular}




\begin{tabular}{|c|c|c|c|c|}
\hline \multicolumn{5}{|c|}{ Supplemental Table S2.t> } \\
\hline CHEMBL1474413 & 688546 & 5.3 & 5.5193 & TRN \\
\hline CHEMBL 2093214 & 688546 & 4.9 & 5.1342 & TST \\
\hline CHEMBL1474897 & 688546 & 8.301 & 5.9291 & TRN \\
\hline CHEMBL1324957 & 688546 & 5.0 & 4.954 & TRN \\
\hline CHEMBL1443345 & 688546 & 5.45 & 5.2683 & TST \\
\hline CHEMBL1398092 & 688546 & 6.3 & 5.6117 & TRN \\
\hline CHEMBL1381634 & 688546 & 4.5 & 5.1831 & TST \\
\hline CHEMBL1514871 & 688546 & 5.7 & 5.3568 & TRN \\
\hline CHEMBL1513583 & 688546 & 5.8 & 6.1382 & TRN \\
\hline CHEMBL1512397 & 688546 & 7.8996 & 5.5212 & TST \\
\hline CHEMBL1543240 & 688546 & 5.0 & 4.7278 & TRN \\
\hline CHEMBL1445209 & 688546 & 5.0 & 4.6709 & TRN \\
\hline CHEMBL1514672 & 688546 & 5.0 & 5.4521 & TRN \\
\hline CHEMBL1389190 & 688546 & 5.9 & 5.3783 & TRN \\
\hline CHEMBL1344911 & 688546 & 4.5 & 4.7958 & TST \\
\hline CHEMBL1477550 & 688546 & 4.5 & 5.0757 & TRN \\
\hline CHEMBL1530113 & 688546 & 4.9 & 5.0104 & TST \\
\hline CHEMBL1319636 & 688546 & 4.5 & 5.3241 & TRN \\
\hline CHEMBL1733605 & 688546 & 4.6 & 5.4724 & TST \\
\hline CHEMBL1591364 & 688546 & 5.3 & 5.0442 & TRN \\
\hline CHEMBL1394082 & 688546 & 5.4 & 5.9591 & TRN \\
\hline CHEMBL1452817 & 688546 & 4.9 & 5.2899 & TRN \\
\hline CHEMBL1449200 & 688546 & 4.8 & 5.3151 & TRN \\
\hline CHEMBL1434862 & 688546 & 5.0 & 5.3941 & TRN \\
\hline CHEMBL1612390 & 688546 & 4.7 & 4.8904 & TST \\
\hline CHEMBL1364653 & 688546 & 5.8 & 6.2631 & TRN \\
\hline CHEMBL1396203 & 688546 & 4.7 & 4.649 & TRN \\
\hline CHEMBL3197739 & 688546 & 6.4 & 5.1699 & TST \\
\hline CHEMBL1515729 & 688546 & 4.9 & 5.0879 & TRN \\
\hline CHEMBL1554886 & 688546 & 4.9 & 4.9559 & TRN \\
\hline CHEMBL1451063 & 688546 & 6.5 & 5.2386 & TRN \\
\hline CHEMBL1315177 & 688546 & 4.9 & 5.0689 & TRN \\
\hline CHEMBL1551118 & 688546 & 5.4 & 5.0776 & TRN \\
\hline CHEMBL1437226 & 688546 & 4.5 & 4.6673 & TRN \\
\hline CHEMBL1372129 & 688546 & 4.6 & 4.7363 & TRN \\
\hline CHEMBL1334949 & 688546 & 6.0 & 4.9026 & TRN \\
\hline CHEMBL1336940 & 688546 & 6.9 & 5.9812 & TRN \\
\hline CHEMBL1591376 & 688546 & 4.7 & 5.4942 & TRN \\
\hline CHEMBL1591031 & 688546 & 6.9 & 5.6272 & TRN \\
\hline CHEMBL1452108 & 688546 & 4.9 & 5.20200 & 0000000001 \\
\hline CHEMBL3194991 & 688546 & 4.9 & 4.8649 & TRN \\
\hline CHEMBL1356913 & 688546 & 5.0 & 4.902 & TRN \\
\hline CHEMBL1612146 & 688546 & 5.5 & 5.2595 & TRN \\
\hline CHEMBL1545697 & 688546 & 5.5 & 5.2736 & TST \\
\hline CHEMBL1609743 & 688546 & 4.9 & 5.1702 & TRN \\
\hline CHEMBL1531978 & 688546 & 5.0 & 5.1571 & TRN \\
\hline CHEMBL1606641 & 688546 & 5.25 & 5.7631 & TRN \\
\hline CHEMBL1518990 & 688546 & 5.0 & 4.8419 & TRN \\
\hline
\end{tabular}




\begin{tabular}{|c|c|c|c|c|}
\hline \multicolumn{5}{|c|}{ Supplemental Table S2.txt } \\
\hline CHEMBL1357669 & 688546 & 4.9 & 5.3959 & TRN \\
\hline CHEMBL1356697 & 688546 & 6.7001 & 5.4643 & TST \\
\hline CHEMBL1314042 & 688546 & 4.5 & 4.6287 & TRN \\
\hline CHEMBL1314857 & 688546 & 5.7 & 5.1248 & TRN \\
\hline CHEMBL1554106 & 688546 & 5.95 & 5.4649 & TRN \\
\hline CHEMBL1406081 & 688546 & 5.0 & 5.0107 & TRN \\
\hline CHEMBL1363995 & 688546 & 4.6 & 5.4712 & TRN \\
\hline CHEMBL1412695 & 688546 & 5.3 & 5.1158 & TST \\
\hline CHEMBL1363294 & 688546 & 4.5 & 4.9984 & TRN \\
\hline CHEMBL1374552 & 688546 & 4.5 & 4.7276 & TRN \\
\hline CHEMBL1521140 & 688546 & 6.25 & 5.1254 & TST \\
\hline CHEMBL1496616 & 688546 & 5.2 & 5.7269 & TRN \\
\hline CHEMBL1609599 & 688546 & 5.0 & 4.7552 & TRN \\
\hline CHEMBL1559913 & 688546 & 4.9 & 5.2931 & TST \\
\hline CHEMBL1408542 & 688546 & 5.7 & 6.0132 & TRN \\
\hline CHEMBL1336003 & 688546 & 4.5 & 4.9206 & TST \\
\hline CHEMBL1481609 & 688546 & 7.0501 & 5.2358 & TRN \\
\hline CHEMBL1597792 & 688546 & 5.2 & 4.8333 & TRN \\
\hline CHEMBL1438931 & 688546 & 6.5 & 5.3233 & TRN \\
\hline CHEMBL1331003 & 688546 & 4.7 & 5.7995 & TRN \\
\hline CHEMBL1409276 & 688546 & 4.6 & 4.8786 & TRN \\
\hline CHEMBL1555823 & 688546 & 5.5 & 5.2692 & TRN \\
\hline CHEMBL1475994 & 688546 & 5.6 & 5.6056 & TRN \\
\hline CHEMBL1553421 & 688546 & 5.0 & 5.1717 & TST \\
\hline CHEMBL1442093 & 688546 & 4.5 & 5.834 & TRN \\
\hline CHEMBL1475635 & 688546 & 4.8 & 4.9155 & TRN \\
\hline CHEMBL1570633 & 688546 & 4.6 & 4.9269 & TRN \\
\hline CHEMBL1484447 & 688546 & 4.7 & 5.3472 & TRN \\
\hline CHEMBL1453071 & 688546 & 4.8 & 5.4028 & TRN \\
\hline CHEMBL1320479 & 688546 & 4.8 & 5.7113 & TRN \\
\hline CHEMBL1357010 & 688546 & 4.9 & 4.9854 & TRN \\
\hline CHEMBL1609540 & 688546 & 5.0 & 5.2948 & TRN \\
\hline CHEMBL1553123 & 688546 & 4.5 & 4.997 & TRN \\
\hline CHEMBL1396033 & 688546 & 4.7 & 5.7196 & TST \\
\hline CHEMBL1330013 & 688546 & 4.6 & 4.9426 & TST \\
\hline CHEMBL1468639 & 688546 & 4.9 & 5.2569 & TRN \\
\hline CHEMBL1476973 & 688546 & 5.4 & 5.6618 & TRN \\
\hline CHEMBL1554140 & 688546 & 5.0 & 5.2518 & TRN \\
\hline CHEMBL1514212 & 688546 & 5.15 & 5.8554 & TRN \\
\hline CHEMBL1500520 & 688546 & 5.75 & 5.2196 & TRN \\
\hline CHEMBL1588503 & 688546 & 4.9 & 5.4228 & TRN \\
\hline CHEMBL1328466 & 688546 & 4.6 & 5.1333 & TRN \\
\hline CHEMBL1473728 & 688546 & 4.7 & 5.3114 & TRN \\
\hline CHEMBL1180 & 688546 & 4.6 & 5.0918 & TST \\
\hline CHEMBL1475098 & 688546 & 4.9 & 5.5179 & TRN \\
\hline CHEMBL153036 & 688546 & 6.0 & 5.2727 & TST \\
\hline CHEMBL1514677 & 688546 & 5.5 & 5.3248 & TRN \\
\hline CHEMBL1553397 & 688546 & 8.4559 & 5.2396 & TRN \\
\hline
\end{tabular}




\begin{tabular}{|c|c|c|c|c|c|}
\hline \multicolumn{6}{|c|}{ Supplemental Table s2.txt } \\
\hline CHEMBL1594122 & 688546 & 6.45 & 5.6721 & TRN & \\
\hline CHEMBL1553175 & 688546 & 5.5 & 4.9975 & TRN & \\
\hline CHEMBL1613049 & 688546 & 4.7 & 5.1133 & TRN & \\
\hline CHEMBL1576166 & 688546 & 6.1 & 5.0521 & TRN & \\
\hline CHEMBL1456423 & 688546 & 8.301 & 5.46 & TST & \\
\hline CHEMBL1517614 & 688546 & 7.3497 & 4.9479 & TST & \\
\hline CHEMBL1368675 & 688546 & 4.7 & 5.6451 & TRN & \\
\hline CHEMBL1514555 & 688546 & 5.0 & 5.0912 & TRN & \\
\hline CHEMBL1435396 & 688546 & 5.35 & 4.8754 & TRN & \\
\hline CHEMBL1351326 & 688546 & 5.55 & 5.0336 & TST & \\
\hline CHEMBL1429472 & 688546 & 5.0 & 5.0373 & TRN & \\
\hline CHEMBL1397409 & 688546 & 7.0 & 5.0981 & TST & \\
\hline CHEMBL1515000 & 688546 & 4.9 & 5.5414 & TRN & \\
\hline CHEMBL1397964 & 688546 & 8.4949 & 5.245 & TRN & \\
\hline CHEMBL1531041 & 688546 & 4.9 & 4.9854 & TRN & \\
\hline CHEMBL1516985 & 688546 & 4.8 & 5.0451 & TRN & \\
\hline CHEMBL1375273 & 688546 & 5.0 & 5.0094 & TRN & \\
\hline CHEMBL3195756 & 688546 & 5.45 & 5.26 & TRN & \\
\hline CHEMBL1318345 & 688546 & 4.95 & 4.9029 & TRN & \\
\hline CHEMBL1520981 & 688546 & 4.9 & 5.0252 & TRN & \\
\hline CHEMBL1454340 & 688546 & 4.9 & 5.2773 & TRN & \\
\hline CHEMBL1580295 & 688546 & 4.9 & 5.5093 & TST & \\
\hline CHEMBL1591259 & 688546 & 6.8 & 5.4777 & TRN & \\
\hline CHEMBL1553793 & 688546 & 5.1 & 5.2717 & TRN & \\
\hline CHEMBL3207748 & 688546 & 5.25 & 5.0165 & TST & \\
\hline CHEMBL1436282 & 688546 & 4.5 & 5.0824 & TRN & \\
\hline CHEMBL1455403 & 688546 & 4.6 & 5.1372 & TST & \\
\hline CHEMBL1324120 & 688546 & 8.301 & 4.9949 & TRN & \\
\hline CHEMBL1461750 & 688546 & 4.6 & 5.343 & TST & \\
\hline CHEMBL1315684 & 688546 & 4.5 & 5.0746 & TRN & \\
\hline CHEMBL1527704 & 688546 & 4.9 & 4.8811 & TST & \\
\hline CHEMBL1575456 & 688546 & 5.3 & 5.7873 & TRN & \\
\hline CHEMBL1373194 & 688546 & 5.1 & 4.9093 & TRN & \\
\hline CHEMBL1394591 & 688546 & 7.699 & 5.5551 & TST & \\
\hline CHEMBL 2007403 & 688546 & 4.9 & 4.8762 & TST & \\
\hline CHEMBL 363332 & 688546 & 5.7 & 5.1845 & TST & \\
\hline CHEMBL1512528 & 688546 & 7.2 & 5.2992 & TRN & \\
\hline CHEMBL1514444 & 688546 & 5.35 & 5.0545 & TRN & \\
\hline CHEMBL1433994 & 688546 & 8.301 & 5.6964 & TST & \\
\hline CHEMBL1377517 & 688546 & 4.5 & 5.13399 & 99999999995 & TRN \\
\hline CHEMBL1601695 & 688546 & 4.7 & 4.8166 & TRN & \\
\hline CHEMBL1584812 & 688546 & 5.35 & 5.6349 & TST & \\
\hline CHEMBL1395873 & 688546 & 5.35 & 5.25299 & 9999999999 & TRN \\
\hline CHEMBL1474792 & 688546 & 5.0 & 5.8856 & TRN & \\
\hline CHEMBL1316293 & 688546 & 5.1 & 5.4362 & TST & \\
\hline CHEMBL288096 & 688546 & 4.6 & 5.3549 & TRN & \\
\hline CHEMBL1317688 & 688546 & 5.85 & 5.4569 & TRN & \\
\hline CHEMBL1552826 & 688546 & 4.8 & 4.8398 & TRN & \\
\hline
\end{tabular}




\begin{tabular}{|c|c|c|c|c|c|}
\hline & & & & & \\
\hline CHEMBL1534496 & 688546 & 4.8 & 5.1329 & TRN & \\
\hline CHEMBL1593253 & 688546 & 5.0 & 5.756 & TRN & \\
\hline CHEMBL38576 & 688546 & 4.8 & 4.8705 & TRN & \\
\hline CHEMBL602150 & 688546 & 4.8 & 5.3377 & TRN & \\
\hline CHEMBL 1452352 & 688546 & 4.45 & 5.3557 & TST & \\
\hline CHEMBL1333540 & 688546 & 5.0 & 5.04899 & 99999999995 & TRN \\
\hline CHEMBL1490254 & 688546 & 6.6 & 4.9343 & TRN & \\
\hline CHEMBL1360106 & 688546 & 7.8013 & 5.9173 & TRN & \\
\hline CHEMBL1552309 & 688546 & 7.1002 & 5.0129 & TRN & \\
\hline CHEMBL1442780 & 688546 & 5.4 & 5.7974 & TRN & \\
\hline CHEMBL1427423 & 688546 & 4.9 & 5.261 & TRN & \\
\hline CHEMBL1472693 & 688546 & 5.0 & 5.2137 & TRN & \\
\hline CHEMBL1565457 & 688546 & 5.25 & 4.9926 & TST & \\
\hline CHEMBL1422539 & 688546 & 4.5 & 4.9945 & TST & \\
\hline CHEMBL1434727 & 688546 & 4.6 & 5.1332 & TRN & \\
\hline CHEMBL1334486 & 688546 & 4.5 & 6.0356 & TRN & \\
\hline CHEMBL456446 & 688546 & 5.0 & 5.0391 & TRN & \\
\hline CHEMBL1495736 & 688546 & 7.6003 & 5.7367 & TRN & \\
\hline CHEMBL1592957 & 688546 & 5.2 & 5.9878 & TRN & \\
\hline CHEMBL1342109 & 688546 & 4.9 & 4.7871 & TRN & \\
\hline CHEMBL1534542 & 688546 & 7.3497 & 5.7029 & TST & \\
\hline CHEMBL1318532 & 688546 & 5.35 & 5.0988 & TRN & \\
\hline CHEMBL1419993 & 688546 & 4.45 & 4.9563 & TST & \\
\hline CHEMBL1314438 & 688546 & 5.1 & 5.4594 & TRN & \\
\hline CHEMBL3351080 & 688546 & 5.2 & 5.1552 & TST & \\
\hline CHEMBL1400726 & 688546 & 6.0 & 5.6087 & TRN & \\
\hline CHEMBL1592122 & 688546 & 5.55 & 5.2868 & TRN & \\
\hline CHEMBL1351997 & 688546 & 4.95 & 4.6361 & TRN & \\
\hline CHEMBL1322112 & 688546 & 4.9 & 4.97 & TRN & \\
\hline CHEMBL1563323 & 688546 & 4.9 & 4.9339 & TRN & \\
\hline CHEMBL1343751 & 688546 & 5.5 & 5.5525 & TRN & \\
\hline CHEMBL1554447 & 688546 & 5.9 & 5.3671 & TRN & \\
\hline CHEMBL1461491 & 688546 & 6.0 & 4.9722 & TST & \\
\hline CHEMBL1454868 & 688546 & 4.9 & 4.8489 & TST & \\
\hline CHEMBL1434638 & 688546 & 5.15 & 5.4501 & TRN & \\
\hline CHEMBL229887 & 688546 & 5.0 & 4.9578 & TRN & \\
\hline CHEMBL1554580 & 688546 & 4.5 & 5.1467 & TST & \\
\hline CHEMBL1367449 & 688546 & 5.0 & 4.6466 & TRN & \\
\hline CHEMBL1357586 & 688546 & 5.15 & 5.4451 & TRN & \\
\hline CHEMBL1319071 & 688546 & 4.6 & 5.5027 & TRN & \\
\hline CHEMBL1593951 & 688546 & 4.5 & 4.8094 & TST & \\
\hline CHEMBL1318154 & 688546 & 7.2 & 5.761 & TRN & \\
\hline CHEMBL1581798 & 688546 & 4.5 & 4.9061 & TST & \\
\hline CHEMBL1339120 & 688546 & 5.0 & 5.3098 & TST & \\
\hline CHEMBL1581337 & 688546 & 4.6 & 4.5806 & TRN & \\
\hline CHEMBL1357441 & 688546 & 4.7 & 4.7609 & TRN & \\
\hline CHEMBL1522332 & 688546 & 4.5 & 4.7412 & TRN & \\
\hline CHEMBL1535173 & 688546 & 4.5 & 5.3025 & TRN & \\
\hline & & & $P$ & 10277 & \\
\hline
\end{tabular}




\begin{tabular}{|c|c|c|c|c|c|}
\hline \multicolumn{6}{|c|}{ Supplemental Table S2.txt } \\
\hline CHEMBL1338461 & 688546 & 4.6 & 5.2634 & TRN & \\
\hline CHEMBL1413931 & 688546 & 5.5 & 5.0122 & TRN & \\
\hline CHEMBL1555890 & 688546 & 4.7 & 4.6473 & TRN & \\
\hline CHEMBL1519214 & 688546 & 4.8 & 5.2112 & TRN & \\
\hline CHEMBL1562385 & 688546 & 5.1 & 5.2768 & TRN & \\
\hline CHEMBL1550518 & 688546 & 6.3 & 5.5604 & TRN & \\
\hline CHEMBL1433339 & 688546 & 5.35 & 5.2505 & TRN & \\
\hline CHEMBL1316988 & 688546 & 7.8996 & 4.883 & TRN & \\
\hline CHEMBL1356895 & 688546 & 8.4949 & 5.2017 & TRN & \\
\hline CHEMBL1378063 & 688546 & 4.9 & 5.3587 & TST & \\
\hline CHEMBL1523139 & 688546 & 4.6 & 4.9485 & TRN & \\
\hline CHEMBL1412539 & 688546 & 4.8 & 5.0542 & TRN & \\
\hline CHEMBL1358508 & 688546 & 7.9508 & 6.2191 & TRN & \\
\hline CHEMBL1529595 & 688546 & 5.0 & 5.2296 & TRN & \\
\hline CHEMBL1330711 & 688546 & 6.5 & 5.4908 & TRN & \\
\hline CHEMBL1354262 & 688546 & 4.5 & 4.7882 & TRN & \\
\hline CHEMBL1361321 & 688546 & 4.9 & 5.0236 & TRN & \\
\hline CHEMBL 3194854 & 688546 & 4.7 & 4.5826 & TRN & \\
\hline CHEMBL1348360 & 688546 & 4.5 & 4.9821 & TRN & \\
\hline CHEMBL1517117 & 688546 & 5.1 & $5.6560 e$ & 0000000001 & TRN \\
\hline CHEMBL1591467 & 688546 & 4.7 & 5.4245 & TST & \\
\hline CHEMBL1525712 & 688546 & 4.55 & 5.2531 & TST & \\
\hline CHEMBL1481594 & 688546 & 5.25 & 5.5136 & TRN & \\
\hline CHEMBL1610876 & 688546 & 4.7 & 5.1957 & TRN & \\
\hline CHEMBL1355164 & 688546 & 6.0 & 5.8929 & TRN & \\
\hline CHEMBL1475236 & 688546 & 4.9 & 5.3464 & TRN & \\
\hline CHEMBL1486465 & 688546 & 5.6 & 5.5785 & TST & \\
\hline CHEMBL1316255 & 688546 & 5.1 & 5.1651 & TRN & \\
\hline CHEMBL1300632 & 688546 & 4.8 & 5.1499 & TRN & \\
\hline CHEMBL1317806 & 688546 & 7.699 & 6.1788 & TRN & \\
\hline CHEMBL1331148 & 688546 & 4.8 & 5.1734 & TRN & \\
\hline CHEMBL1407945 & 688546 & 5.0 & 4.8166 & TRN & \\
\hline CHEMBL1346466 & 688546 & 4.9 & 5.4916 & TST & \\
\hline CHEMBL1488040 & 688546 & 5.0 & 5.5304 & TRN & \\
\hline CHEMBL1318943 & 688546 & 4.7 & 5.1099 & TST & \\
\hline CHEMBL1553504 & 688546 & 4.8 & 5.4635 & TRN & \\
\hline CHEMBL1381537 & 688546 & 5.25 & 4.8625 & TRN & \\
\hline CHEMBL1375970 & 688546 & 5.1 & 4.7414 & TRN & \\
\hline CHEMBL1519360 & 688546 & 5.9 & 5.7513 & TRN & \\
\hline CHEMBL1555350 & 688546 & 7.2 & 5.1319 & TRN & \\
\hline CHEMBL1451058 & 688546 & 5.1 & 4.9269 & TRN & \\
\hline CHEMBL1519435 & 688546 & 4.8 & 4.7029 & TRN & \\
\hline CHEMBL1328681 & 688546 & 7.4498 & 6.1253 & TRN & \\
\hline CHEMBL1321606 & 688546 & 4.85 & 4.8588 & TRN & \\
\hline CHEMBL1349964 & 688546 & 5.0 & 5.2845 & TST & \\
\hline CHEMBL1566939 & 688546 & 4.8 & 5.3251 & TST & \\
\hline CHEMBL1400667 & 688546 & 4.5 & 5.2238 & TST & \\
\hline CHEMBL1435906 & 688546 & 7.8508 & 5.9442 & TRN & \\
\hline
\end{tabular}




\begin{tabular}{|c|c|c|c|c|c|}
\hline \multicolumn{6}{|c|}{ Supplemental Table S2.txt } \\
\hline CHEMBL1396715 & 688546 & 5.4 & 5.3108 & TRN & \\
\hline CHEMBL1436221 & 688546 & 5.25 & 5.6662 & TRN & \\
\hline CHEMBL1552070 & 688546 & 6.8 & 5.7333 & TRN & \\
\hline CHEMBL1472468 & 688546 & 4.9 & 5.2445 & TRN & \\
\hline CHEMBL1480333 & 688546 & 7.1002 & 5.3602 & TRN & \\
\hline CHEMBL1591505 & 688546 & 4.8 & 4.9621 & TRN & \\
\hline CHEMBL1568597 & 688546 & 4.8 & 5.1563 & TRN & \\
\hline CHEMBL1610849 & 688546 & 4.7 & 5.6627 & TRN & \\
\hline CHEMBL1315312 & 688546 & 6.6 & 4.8667 & TRN & \\
\hline CHEMBL1559279 & 688546 & 4.7 & 4.8811 & TRN & \\
\hline CHEMBL1256816 & 688546 & 4.7 & 5.1336 & TST & \\
\hline CHEMBL1593119 & 688546 & 5.8 & 5.0993 & TRN & \\
\hline CHEMBL1367014 & 688546 & 8.3468 & 6.1994 & TRN & \\
\hline CHEMBL 289277 & 688546 & 4.5 & 5.4266 & TST & \\
\hline CHEMBL1395894 & 688546 & 5.1 & 5.0351 & TRN & \\
\hline CHEMBL1438122 & 688546 & 6.1 & 4.944 & TRN & \\
\hline CHEMBL1398472 & 688546 & 5.0 & 5.3513 & TRN & \\
\hline CHEMBL1409836 & 688546 & 4.9 & 5.3003 & TRN & \\
\hline CHEMBL1525062 & 688546 & 7.2 & 5.6575 & TRN & \\
\hline CHEMBL1433970 & 688546 & 7.0 & 5.4691 & TRN & \\
\hline CHEMBL1475910 & 688546 & 4.9 & 5.8091 & TRN & \\
\hline CHEMBL1613286 & 688546 & 6.5 & 5.3375 & TST & \\
\hline CHEMBL1512319 & 688546 & 5.0 & 4.7053 & TRN & \\
\hline CHEMBL1364042 & 688546 & 7.0 & 5.7764 & TRN & \\
\hline CHEMBL1493310 & 688546 & 8.0 & 5.0032 & TST & \\
\hline CHEMBL501701 & 688546 & 4.9 & 5.2726 & TST & \\
\hline CHEMBL1554808 & 688546 & 5.0 & 5.2032 & TRN & \\
\hline CHEMBL1515044 & 688546 & 4.5 & 5.3064 & TRN & \\
\hline CHEMBL1454607 & 688546 & 7.8996 & 5.471 & TRN & \\
\hline CHEMBL1357544 & 688546 & 4.5 & 5.1148 & TRN & \\
\hline CHEMBL1602417 & 688546 & 4.9 & 5.4157 & TRN & \\
\hline CHEMBL1435174 & 688546 & 4.7 & 5.6188 & TRN & \\
\hline CHEMBL1396009 & 688546 & 5.7 & 5.6329 & TRN & \\
\hline CHEMBL1338464 & 688546 & 6.6499 & 6.2523 & TRN & \\
\hline CHEMBL1439281 & 688546 & 4.9 & 5.6079 & TRN & \\
\hline CHEMBL1546601 & 688546 & 4.8 & 4.8817 & TST & \\
\hline CHEMBL1555296 & 688546 & 6.95 & 5.3011 & TRN & \\
\hline CHEMBL1520616 & 688546 & 7.699 & 5.58700 & 2000000001 & TST \\
\hline CHEMBL526673 & 688546 & 4.9 & 5.1518 & TST & \\
\hline CHEMBL1596719 & 688546 & 4.9 & 5.1858 & TRN & \\
\hline CHEMBL1570993 & 688546 & 5.3 & 5.6497 & TRN & \\
\hline CHEMBL1597278 & 688546 & 4.7 & 5.0627 & TRN & \\
\hline CHEMBL1320977 & 688546 & 4.9 & 5.1637 & TRN & \\
\hline CHEMBL1592735 & 688546 & 6.3 & 5.2958 & TRN & \\
\hline CHEMBL1478539 & 688546 & 4.9 & 5.0805 & TRN & \\
\hline CHEMBL1317417 & 688546 & 4.7 & 5.1767 & TRN & \\
\hline CHEMBL1551467 & 688546 & 7.1002 & 5.88200 & 0000000001 & TRN \\
\hline CHEMBL1572565 & 688546 & 4.9 & 5.282 & TRN & \\
\hline
\end{tabular}




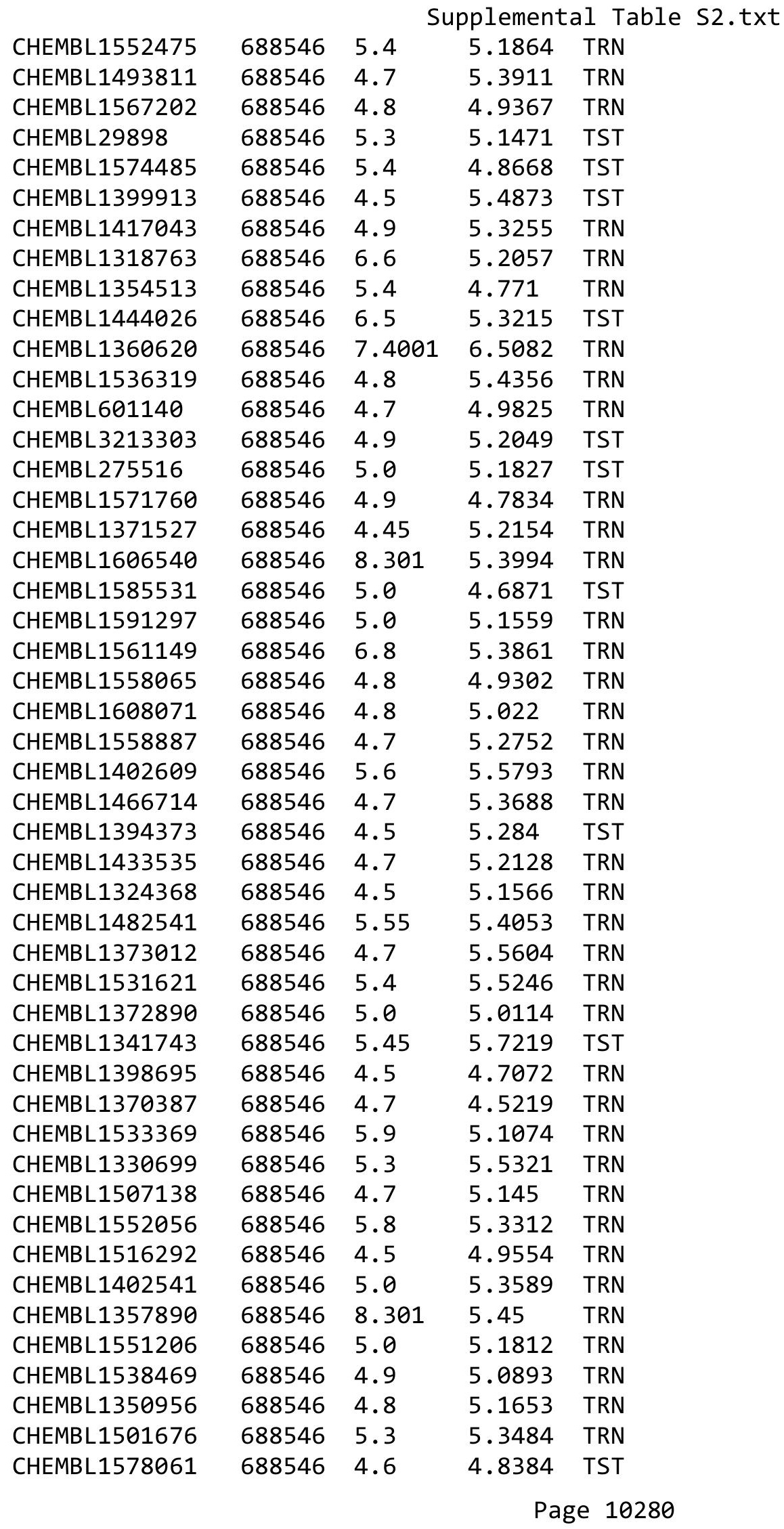




\begin{tabular}{|c|c|c|c|c|}
\hline & & & pplement & al $\mathrm{Ta}$ \\
\hline CHEMBL1356408 & 688546 & 4.9 & 5.1916 & TRN \\
\hline CHEMBL1603890 & 688546 & 4.5 & 5.1511 & TST \\
\hline CHEMBL1500265 & 688546 & 5.4 & 5.3634 & TRN \\
\hline CHEMBL1439137 & 688546 & 5.0 & 5.0178 & TST \\
\hline CHEMBL1487238 & 688546 & 4.9 & 4.9367 & TRN \\
\hline CHEMBL1314366 & 688546 & 5.5 & 5.7173 & TRN \\
\hline CHEMBL1394961 & 688546 & 5.3 & 5.2689 & TRN \\
\hline CHEMBL1417596 & 688546 & 5.0 & 5.0339 & TRN \\
\hline CHEMBL1543317 & 688546 & 4.9 & 5.2788 & TRN \\
\hline CHEMBL1338613 & 688546 & 4.6 & 4.9581 & TST \\
\hline CHEMBL1450497 & 688546 & 6.2 & 5.4899 & TRN \\
\hline CHEMBL1417686 & 688546 & 4.5 & 4.6151 & TRN \\
\hline CHEMBL1390301 & 688546 & 5.35 & 5.1882 & TRN \\
\hline CHEMBL1591704 & 688546 & 4.95 & 5.1423 & TRN \\
\hline CHEMBL1594614 & 688546 & 4.6 & 5.5913 & TRN \\
\hline CHEMBL1376277 & 688546 & 5.2 & 5.1919 & TST \\
\hline CHEMBL1554520 & 688546 & 4.5 & 4.9674 & TRN \\
\hline CHEMBL1594061 & 688546 & 4.6 & 5.1424 & TRN \\
\hline CHEMBL1362964 & 688546 & 4.9 & 4.9448 & TRN \\
\hline CHEMBL1612493 & 688546 & 5.0 & 4.9215 & TRN \\
\hline CHEMBL1598247 & 688546 & 4.5 & 5.195 & TST \\
\hline CHEMBL1574951 & 688546 & 4.6 & 5.4422 & TRN \\
\hline CHEMBL1446142 & 688546 & 5.0 & 5.2972 & TRN \\
\hline CHEMBL1360143 & 688546 & 5.2 & 5.2328 & TRN \\
\hline CHEMBL1318128 & 688546 & 4.8 & 5.3379 & TRN \\
\hline CHEMBL1578476 & 688546 & 4.6 & 5.1599 & TRN \\
\hline CHEMBL1596486 & 688546 & 5.0 & 5.2509 & TRN \\
\hline CHEMBL1382022 & 688546 & 4.75 & 4.6694 & TRN \\
\hline CHEMBL1411653 & 688546 & 4.5 & 5.4048 & TRN \\
\hline CHEMBL1475912 & 688546 & 5.0 & 5.3498 & TRN \\
\hline CHEMBL1476582 & 688546 & 4.7 & 5.1829 & TRN \\
\hline CHEMBL1436181 & 688546 & 4.6 & 4.7398 & TRN \\
\hline CHEMBL1610097 & 688546 & 4.9 & 5.1022 & TRN \\
\hline CHEMBL1400055 & 688546 & 5.3 & 5.02 & TRN \\
\hline CHEMBL1512265 & 688546 & 5.1 & 5.8799 & TRN \\
\hline CHEMBL1395369 & 688546 & 6.95 & 5.6347 & TRN \\
\hline CHEMBL1356044 & 688546 & 5.3 & 5.7638 & TRN \\
\hline CHEMBL1491367 & 688546 & 7.4001 & 5.4791 & TRN \\
\hline CHEMBL1515379 & 688546 & 4.6 & 4.9632 & TRN \\
\hline CHEMBL1516452 & 688546 & 4.5 & 5.8148 & TRN \\
\hline CHEMBL1353418 & 688546 & 5.4 & 5.8357 & TST \\
\hline CHEMBL1605613 & 688546 & 4.9 & 5.265 & TST \\
\hline CHEMBL 2002008 & 688546 & 5.15 & 4.9776 & TST \\
\hline CHEMBL1434706 & 688546 & 4.5 & 5.4403 & TRN \\
\hline CHEMBL1388376 & 688546 & 4.5 & 5.3213 & TST \\
\hline CHEMBL1557234 & 688546 & 4.9 & 4.7896 & TRN \\
\hline CHEMBL1507092 & 688546 & 5.0 & 4.9667 & TRN \\
\hline CHEMBL1314667 & 688546 & 4.8 & 5.2398 & TST \\
\hline
\end{tabular}




\begin{tabular}{|c|c|c|c|c|}
\hline & & & & al Table S \\
\hline CHEMBL1521740 & 688546 & 5.2 & 5.2749 & TRN \\
\hline CHEMBL1439893 & 688546 & 4.8 & 4.8535 & TRN \\
\hline CHEMBL1357715 & 688546 & 5.1 & 5.54799 & 9999999999 \\
\hline CHEMBL3191023 & 688546 & 4.9 & 5.4437 & TST \\
\hline CHEMBL1512842 & 688546 & 6.0 & 5.7047 & TRN \\
\hline CHEMBL1417752 & 688546 & 5.0 & 5.0287 & TRN \\
\hline CHEMBL1593151 & 688546 & 4.9 & 5.099 & TRN \\
\hline CHEMBL1473491 & 688546 & 4.5 & 5.143 & TRN \\
\hline CHEMBL1316644 & 688546 & 5.0 & 5.454 & TRN \\
\hline CHEMBL1407950 & 688546 & 5.0 & 4.7412 & TRN \\
\hline CHEMBL1599294 & 688546 & 5.5 & 4.9913 & TRN \\
\hline CHEMBL1596294 & 688546 & 4.5 & 5.2098 & TRN \\
\hline CHEMBL1356919 & 688546 & 4.5 & 5.1648 & TRN \\
\hline CHEMBL1447109 & 688546 & 5.4 & 5.1212 & TRN \\
\hline CHEMBL1397571 & 688546 & 4.8 & 5.1817 & TRN \\
\hline CHEMBL1447409 & 688546 & 3.65 & 5.751 & TRN \\
\hline CHEMBL1332372 & 688546 & 4.5 & 5.0787 & TRN \\
\hline CHEMBL1358453 & 688546 & 4.8 & 4.7857 & TRN \\
\hline CHEMBL1472953 & 688546 & 4.9 & 4.7975 & TRN \\
\hline CHEMBL1512094 & 688546 & 4.9 & 5.7723 & TRN \\
\hline CHEMBL1315072 & 688546 & 4.9 & 5.1254 & TRN \\
\hline CHEMBL1357429 & 688546 & 4.7 & 5.0212 & TRN \\
\hline CHEMBL1592615 & 688546 & 4.6 & 5.1024 & TRN \\
\hline CHEMBL1396008 & 688546 & 6.1 & 5.4804 & TRN \\
\hline CHEMBL1556755 & 688546 & 6.0 & 5.8924 & TRN \\
\hline CHEMBL1592183 & 688546 & 4.9 & 5.5941 & TRN \\
\hline CHEMBL3192913 & 688546 & 5.1 & 5.0807 & TRN \\
\hline CHEMBL1513443 & 688546 & 4.7 & 5.2598 & TST \\
\hline CHEMBL1606629 & 688546 & 5.2 & 5.5122 & TRN \\
\hline CHEMBL1435533 & 688546 & 4.9 & 5.2593 & TRN \\
\hline CHEMBL1397130 & 688546 & 5.1 & 5.6365 & TRN \\
\hline CHEMBL1579153 & 688546 & 4.9 & 5.334 & TST \\
\hline CHEMBL1513354 & 688546 & 6.4 & 5.5917 & TRN \\
\hline CHEMBL1573911 & 688546 & 4.6 & 5.426 & TRN \\
\hline CHEMBL1590871 & 688546 & 4.7 & 5.5916 & TRN \\
\hline CHEMBL1366941 & 688546 & 5.2 & 5.4929 & TRN \\
\hline CHEMBL1481911 & 688546 & 4.8 & 4.9757 & TRN \\
\hline CHEMBL1434499 & 688546 & 4.9 & 5.2719 & TST \\
\hline CHEMBL1593449 & 688546 & 4.7 & 5.2736 & TRN \\
\hline CHEMBL1558014 & 688546 & 4.9 & 5.2638 & TRN \\
\hline CHEMBL1537790 & 688546 & 4.5 & 5.1569 & TST \\
\hline CHEMBL1358433 & 688546 & 5.4 & 4.9699 & TRN \\
\hline CHEMBL1457100 & 688546 & 5.5 & 5.0049 & TST \\
\hline CHEMBL1400609 & 688546 & 5.0 & 4.8817 & TRN \\
\hline CHEMBL1573442 & 688546 & 4.6 & 5.4681 & TRN \\
\hline CHEMBL1371479 & 688546 & 4.5 & 5.0447 & TRN \\
\hline CHEMBL1601364 & 688546 & 4.8 & 4.9104 & TRN \\
\hline CHEMBL14276 & 688546 & 5.0 & 5.3908 & TST \\
\hline
\end{tabular}

TRN 


\begin{tabular}{|c|c|c|c|c|}
\hline \multicolumn{5}{|c|}{ Supplemental Table S2.txt } \\
\hline CHEMBL1436762 & 688546 & 7.0 & 5.7501 & TRN \\
\hline CHEMBL1551846 & 688546 & 5.4 & 5.2798 & TRN \\
\hline CHEMBL1543924 & 688546 & 4.9 & 4.9495 & TST \\
\hline CHEMBL1518667 & 688546 & 7.699 & 4.9506 & TRN \\
\hline CHEMBL1439634 & 688546 & 4.5 & 5.5608 & TST \\
\hline CHEMBL1471418 & 688546 & 4.55 & 5.329 & TST \\
\hline CHEMBL1553494 & 688546 & 4.8 & 5.0519 & TRN \\
\hline CHEMBL1495154 & 688546 & 4.85 & 5.3507 & TRN \\
\hline CHEMBL1361800 & 688546 & 4.5 & 5.3956 & TRN \\
\hline CHEMBL1567682 & 688546 & 4.9 & 4.9942 & TRN \\
\hline CHEMBL1358681 & 688546 & 4.6 & 5.0438 & TRN \\
\hline CHEMBL1327176 & 688546 & 5.5 & 5.6669 & TRN \\
\hline CHEMBL1321213 & 688546 & 5.1 & 4.8963 & TRN \\
\hline CHEMBL3197612 & 688546 & 4.45 & 4.9655 & TRN \\
\hline CHEMBL1413793 & 688546 & 4.9 & 5.1246 & TRN \\
\hline CHEMBL1332403 & 688546 & 4.9 & 5.3266 & TST \\
\hline CHEMBL1315604 & 688546 & 4.5 & 5.8541 & TRN \\
\hline CHEMBL1552712 & 688546 & 5.1 & 4.904 & TRN \\
\hline CHEMBL1452203 & 688546 & 5.8 & 5.2693 & TRN \\
\hline CHEMBL1455781 & 688546 & 4.7 & 5.5288 & TRN \\
\hline CHEMBL1343524 & 688546 & 4.45 & 5.2088 & TST \\
\hline CHEMBL1598906 & 688546 & 5.9 & 5.6439 & TRN \\
\hline CHEMBL1489706 & 688546 & 4.9 & 5.0098 & TRN \\
\hline CHEMBL1341130 & 688546 & 4.9 & 5.3052 & TST \\
\hline CHEMBL1303942 & 688546 & 5.4 & 5.651 & TST \\
\hline CHEMBL1612039 & 688546 & 4.9 & 5.6722 & TRN \\
\hline CHEMBL1560504 & 688546 & 4.8 & 5.5764 & TRN \\
\hline CHEMBL1316590 & 688546 & 5.0 & 5.6818 & TRN \\
\hline CHEMBL1302523 & 688546 & 4.6 & 4.4833 & TRN \\
\hline CHEMBL1342524 & 688546 & 5.0 & 4.9895 & TST \\
\hline CHEMBL1590202 & 688546 & 4.9 & 4.9776 & TRN \\
\hline CHEMBL1339835 & 688546 & 4.9 & 4.8296 & TRN \\
\hline CHEMBL1312255 & 688546 & 4.9 & 5.3355 & TRN \\
\hline CHEMBL1480548 & 688546 & 4.75 & 5.1783 & TST \\
\hline CHEMBL1393698 & 688546 & 4.8 & 4.5447 & TRN \\
\hline CHEMBL1368089 & 688546 & 4.7 & 4.8132 & TRN \\
\hline CHEMBL1532571 & 688546 & 4.45 & 5.4064 & TST \\
\hline CHEMBL1476419 & 688546 & 5.7 & 5.1964 & TST \\
\hline CHEMBL1490898 & 688546 & 4.9 & 5.2768 & TRN \\
\hline CHEMBL1360872 & 688546 & 4.9 & 4.9905 & TST \\
\hline CHEMBL1316314 & 688546 & 4.8 & 4.9989 & TST \\
\hline CHEMBL1437466 & 688546 & 4.7 & 5.8579 & TRN \\
\hline CHEMBL1564109 & 688546 & 6.0 & 4.9762 & TRN \\
\hline CHEMBL1448387 & 688546 & 4.5 & 4.9058 & TST \\
\hline CHEMBL1519826 & 688546 & 6.45 & 5.1959 & TST \\
\hline CHEMBL1315838 & 688546 & 8.5528 & 5.7167 & TST \\
\hline CHEMBL1501724 & 688546 & 5.0 & 5.0685 & TRN \\
\hline CHEMBL1433083 & 688546 & 4.8 & 5.2 & TST \\
\hline
\end{tabular}




\begin{tabular}{|c|c|c|c|c|c|}
\hline \multicolumn{6}{|c|}{ Supplemental Table S2.txt } \\
\hline CHEMBL1503006 & 688546 & 5.7 & 5.6585 & TRN & \\
\hline CHEMBL406557 & 688546 & 5.0 & 5.3191 & TRN & \\
\hline CHEMBL1354599 & 688546 & 6.2 & 5.1682 & TRN & \\
\hline CHEMBL1609120 & 688546 & 4.5 & 4.9797 & TRN & \\
\hline CHEMBL1570954 & 688546 & 4.6 & 5.1275 & TRN & \\
\hline CHEMBL1610601 & 688546 & 4.9 & 5.1567 & TRN & \\
\hline CHEMBL1320369 & 688546 & 5.25 & 5.29299 & 9999999999 & TRN \\
\hline CHEMBL1596320 & 688546 & 4.6 & 6.0243 & TRN & \\
\hline CHEMBL1318397 & 688546 & 4.9 & 4.8652 & TRN & \\
\hline CHEMBL602922 & 688546 & 5.0 & 4.9329 & TRN & \\
\hline CHEMBL1435923 & 688546 & 7.699 & 5.2493 & TRN & \\
\hline CHEMBL1363596 & 688546 & 7.4498 & 5.1441 & TRN & \\
\hline CHEMBL1597618 & 688546 & 4.7 & 5.2717 & TRN & \\
\hline CHEMBL1314733 & 688546 & 7.8013 & 5.9392 & TRN & \\
\hline CHEMBL1526054 & 688546 & 4.7 & 5.1407 & TRN & \\
\hline CHEMBL1595874 & 688546 & 4.8 & 5.4337 & TST & \\
\hline CHEMBL1476351 & 688546 & 4.9 & 5.3479 & TST & \\
\hline CHEMBL1476305 & 688546 & 4.5 & 5.043 & TRN & \\
\hline CHEMBL1395352 & 688546 & 4.6 & 5.3684 & TRN & \\
\hline CHEMBL1452330 & 688546 & 6.35 & 5.6597 & TST & \\
\hline CHEMBL1408115 & 688546 & 5.75 & 5.2682 & TST & \\
\hline CHEMBL1555300 & 688546 & 5.65 & 5.4028 & TRN & \\
\hline CHEMBL1445865 & 688546 & 4.6 & 4.7076 & TRN & \\
\hline CHEMBL1569710 & 688546 & 5.3 & 5.4468 & TRN & \\
\hline CHEMBL1384524 & 688546 & 4.8 & 5.1631 & TRN & \\
\hline CHEMBL1486479 & 688546 & 5.2 & 5.3483 & TRN & \\
\hline CHEMBL1594589 & 688546 & 4.5 & 4.9582 & TRN & \\
\hline CHEMBL1513969 & 688546 & 4.9 & 5.3895 & TRN & \\
\hline CHEMBL1398074 & 688546 & 4.5 & 5.9693 & TRN & \\
\hline CHEMBL1355715 & 688546 & 5.8 & 5.3384 & TRN & \\
\hline CHEMBL1543947 & 688546 & 4.7 & 4.941 & TRN & \\
\hline CHEMBL1610268 & 688546 & 5.0 & 5.2666 & TST & \\
\hline CHEMBL261123 & 688546 & 5.1 & 5.4737 & TRN & \\
\hline CHEMBL1409447 & 688546 & 4.6 & 5.3141 & TST & \\
\hline CHEMBL1357369 & 688546 & 7.4001 & 6.6501 & TRN & \\
\hline CHEMBL1574464 & 688546 & 4.8 & 5.4691 & TRN & \\
\hline CHEMBL1529126 & 688546 & 5.0 & 4.9756 & TRN & \\
\hline CHEMBL1364810 & 688546 & 4.5 & 5.318 & TRN & \\
\hline CHEMBL1561023 & 688546 & 4.8 & 5.0294 & TRN & \\
\hline CHEMBL1395248 & 688546 & 4.7 & 5.2882 & TRN & \\
\hline CHEMBL1396853 & 688546 & 5.4 & 5.1731 & TRN & \\
\hline CHEMBL1560183 & 688546 & 5.25 & 5.4481 & TRN & \\
\hline CHEMBL1393017 & 688546 & 4.7 & 5.4707 & TRN & \\
\hline CHEMBL1351516 & 688546 & 4.5 & 5.1926 & TRN & \\
\hline CHEMBL1443282 & 688546 & 7.6003 & 5.5183 & TRN & \\
\hline CHEMBL1484934 & 688546 & 5.4 & 4.7529 & TST & \\
\hline CHEMBL1555492 & 688546 & 5.2 & 5.261 & TST & \\
\hline CHEMBL1565174 & 688546 & 8.0 & 5.5842 & TRN & \\
\hline
\end{tabular}




\begin{tabular}{|c|c|c|c|c|}
\hline \multicolumn{5}{|r|}{1 Table } \\
\hline CHEMBL1412246 & 688546 & 6.2 & 5.7325 & TRN \\
\hline CHEMBL1556966 & 688546 & 5.9 & 5.2429 & TST \\
\hline CHEMBL1550895 & 688546 & 4.85 & 4.8185 & TRN \\
\hline CHEMBL1349869 & 688546 & 5.0 & 4.9757 & TRN \\
\hline CHEMBL1523729 & 688546 & 7.699 & 5.6627 & TRN \\
\hline CHEMBL388931 & 688546 & 5.0 & 5.4582 & TRN \\
\hline CHEMBL1413190 & 688546 & 6.35 & 5.5601 & TRN \\
\hline CHEMBL1609351 & 688546 & 4.5 & 6.1848 & TRN \\
\hline CHEMBL1374854 & 688546 & 4.9 & 4.9025 & TST \\
\hline CHEMBL1592274 & 688546 & 4.6 & 5.3582 & TRN \\
\hline CHEMBL1586590 & 688546 & 5.2 & 5.4524 & TRN \\
\hline CHEMBL1478086 & 688546 & 5.3 & 5.1689 & TRN \\
\hline CHEMBL1325198 & 688546 & 4.5 & 4.548 & TRN \\
\hline CHEMBL1566685 & 688546 & 4.9 & 5.3297 & TRN \\
\hline CHEMBL1403851 & 688546 & 4.75 & 5.8023 & TRN \\
\hline CHEMBL1475367 & 688546 & 4.9 & 4.7974 & TRN \\
\hline CHEMBL1531352 & 688546 & 4.9 & 5.4148 & TRN \\
\hline CHEMBL1417238 & 688546 & 4.7 & 5.0412 & TRN \\
\hline CHEMBL1515877 & 688546 & 5.4 & 6.3876 & TST \\
\hline CHEMBL1481939 & 688546 & 5.0 & 5.4792 & TRN \\
\hline CHEMBL1316738 & 688546 & 5.9 & 5.7239 & TST \\
\hline CHEMBL1475780 & 688546 & 4.7 & 5.2768 & TRN \\
\hline CHEMBL1488770 & 688546 & 5.1 & 4.8759 & TRN \\
\hline CHEMBL1456771 & 688546 & 4.5 & 5.0798 & TRN \\
\hline CHEMBL1397116 & 688546 & 4.8 & 4.8733 & TRN \\
\hline CHEMBL1443184 & 688546 & 4.6 & 5.8045 & TRN \\
\hline CHEMBL1432070 & 688546 & 4.9 & 5.2859 & TST \\
\hline CHEMBL1317872 & 688546 & 5.0 & 5.2747 & TRN \\
\hline CHEMBL1357966 & 688546 & 6.8499 & 5.9174 & TST \\
\hline CHEMBL1322440 & 688546 & 4.6 & 5.0177 & TST \\
\hline CHEMBL126077 & 688546 & 4.6 & 4.7463 & TST \\
\hline CHEMBL1514268 & 688546 & 6.0 & 5.5234 & TRN \\
\hline CHEMBL1365553 & 688546 & 5.0 & 5.3778 & TST \\
\hline CHEMBL1606022 & 688546 & 4.6 & 5.7119 & TST \\
\hline CHEMBL1555381 & 688546 & 8.1487 & 5.6521 & TRN \\
\hline CHEMBL1525547 & 688546 & 8.0 & 5.2738 & TRN \\
\hline CHEMBL 1440288 & 688546 & 6.5 & 5.6878 & TRN \\
\hline CHEMBL1546303 & 688546 & 5.5 & 5.3215 & TST \\
\hline CHEMBL1383658 & 688546 & 4.7 & 5.4892 & TRN \\
\hline CHEMBL1592792 & 688546 & 5.0 & 5.148 & TRN \\
\hline CHEMBL1552986 & 688546 & 5.1 & 5.62299 & 9999999999 \\
\hline CHEMBL1513530 & 688546 & 5.0 & 5.5884 & TRN \\
\hline CHEMBL1507852 & 688546 & 5.0 & 5.0795 & TST \\
\hline CHEMBL1319708 & 688546 & 6.2 & 5.2032 & TRN \\
\hline CHEMBL1514781 & 688546 & 4.8 & 5.886 & TRN \\
\hline CHEMBL1314707 & 688546 & 4.6 & 5.0111 & TRN \\
\hline CHEMBL1525371 & 688546 & 5.5 & 5.6683 & TRN \\
\hline CHEMBL1435471 & 688546 & 8.0506 & 5.8905 & TRN \\
\hline
\end{tabular}




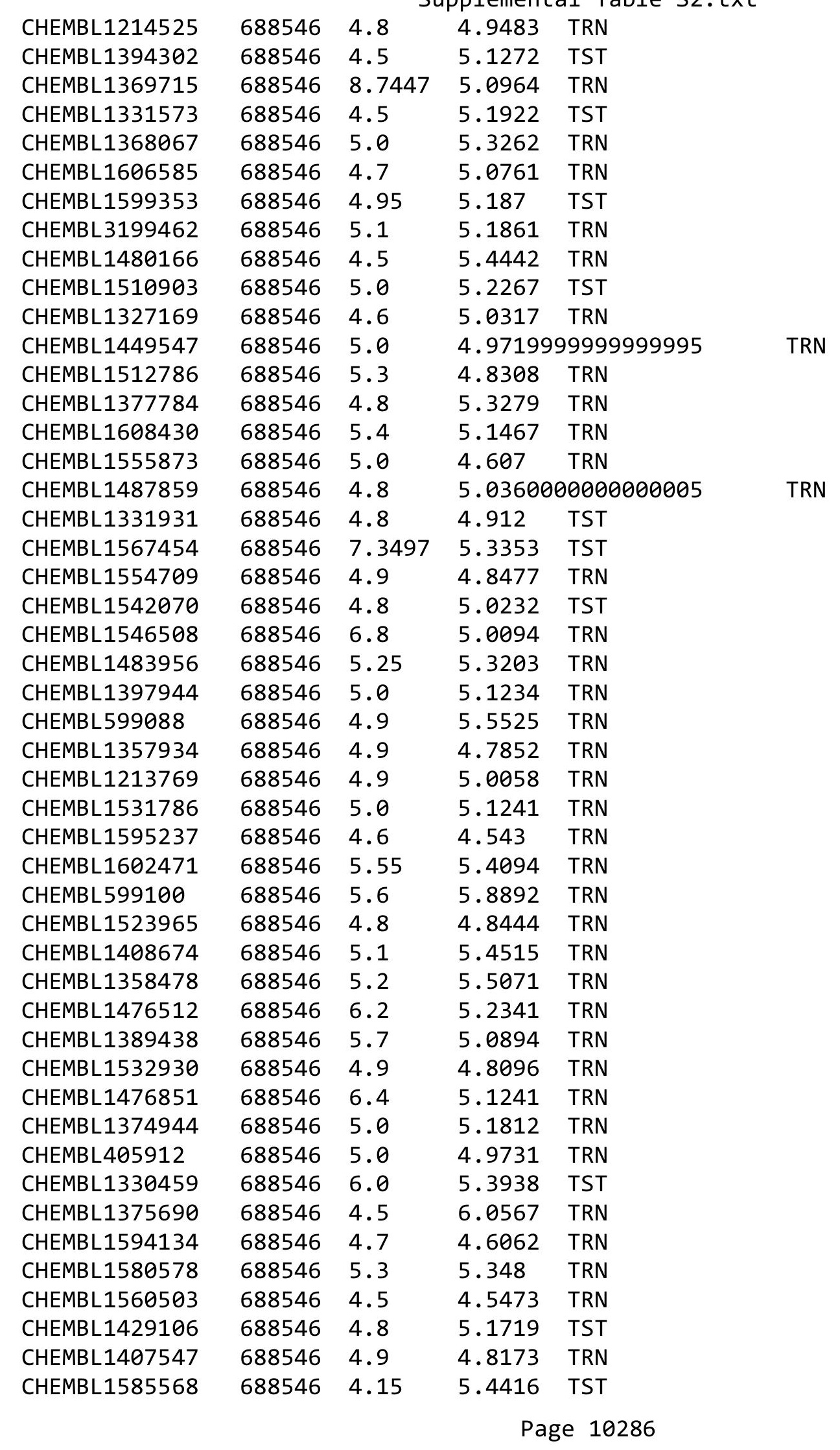




\begin{tabular}{|c|c|c|c|c|}
\hline & & & olemen & \\
\hline CHEMBL1583786 & 688546 & 4.75 & 5.3537 & TST \\
\hline CHEMBL1488499 & 688546 & 4.9 & 5.0625 & TRN \\
\hline CHEMBL1321846 & 688546 & 4.5 & 4.6234 & TRN \\
\hline CHEMBL1451916 & 688546 & 5.0 & 4.8504 & TST \\
\hline CHEMBL 258465 & 688546 & 4.9 & 5.1607 & TST \\
\hline CHEMBL1477937 & 688546 & 4.9 & 5.8577 & TRN \\
\hline CHEMBL1321669 & 688546 & 5.0 & 5.4428 & TRN \\
\hline CHEMBL1434160 & 688546 & 8.3468 & 4.5473 & TRN \\
\hline CHEMBL1479647 & 688546 & 5.0 & 4.8167 & TRN \\
\hline CHEMBL1442794 & 688546 & 7.15 & 5.651 & TRN \\
\hline CHEMBL1394244 & 688546 & 4.75 & 5.0079 & TRN \\
\hline CHEMBL1582784 & 688546 & 4.6 & 5.1318 & TST \\
\hline CHEMBL1299517 & 688546 & 5.35 & 5.3727 & TRN \\
\hline CHEMBL1560860 & 688546 & 5.4 & 5.5373 & TRN \\
\hline CHEMBL1453463 & 688546 & 5.3 & 5.0712 & TST \\
\hline CHEMBL1358312 & 688546 & 4.8 & 5.6702 & TRN \\
\hline CHEMBL1609970 & 688546 & 5.0 & 5.138 & TRN \\
\hline CHEMBL1568028 & 688546 & 5.0 & 4.8073 & TRN \\
\hline CHEMBL599943 & 688546 & 4.9 & 4.9071 & TRN \\
\hline CHEMBL3186408 & 688546 & 6.0 & 5.7195 & TST \\
\hline CHEMBL1318006 & 688546 & 4.9 & 5.7335 & TRN \\
\hline CHEMBL1560213 & 688546 & 4.7 & 4.9041 & TRN \\
\hline CHEMBL1363291 & 688546 & 4.5 & 5.3265 & TRN \\
\hline CHEMBL1356126 & 688546 & 4.9 & 4.8335 & TST \\
\hline CHEMBL1319250 & 688546 & 8.2518 & 5.4785 & TRN \\
\hline CHEMBL1320525 & 688546 & 4.7 & 5.0459 & TRN \\
\hline CHEMBL118752 & 688546 & 4.45 & 4.7157 & TRN \\
\hline CHEMBL1455438 & 688546 & 4.8 & 4.8167 & TRN \\
\hline CHEMBL1496421 & 688546 & 5.35 & 5.2178 & TST \\
\hline CHEMBL1591205 & 688546 & 6.8 & 6.5488 & TRN \\
\hline CHEMBL1309678 & 688546 & 4.7 & 4.8436 & TST \\
\hline CHEMBL1357703 & 688546 & 4.8 & 5.6249 & TRN \\
\hline CHEMBL1317890 & 688546 & 5.55 & 5.4818 & TRN \\
\hline CHEMBL1599945 & 688546 & 4.5 & 4.9939 & TRN \\
\hline CHEMBL1453271 & 688546 & 7.9508 & 5.5978 & TST \\
\hline CHEMBL1592806 & 688546 & 4.8 & 4.7164 & TRN \\
\hline CHEMBL1479255 & 688546 & 4.7 & 4.8376 & TRN \\
\hline CHEMBL1316037 & 688546 & 5.6 & 5.0821 & TRN \\
\hline CHEMBL1491008 & 688546 & 8.2007 & 6.0767 & TRN \\
\hline CHEMBL1996730 & 688546 & 5.25 & 5.2628 & TST \\
\hline CHEMBL1418457 & 688546 & 7.699 & 5.2726 & TST \\
\hline CHEMBL1471212 & 688546 & 4.5 & 5.402 & TRN \\
\hline CHEMBL1592110 & 688546 & 4.6 & 4.9279 & TRN \\
\hline CHEMBL1396361 & 688546 & 4.8 & 5.4067 & TRN \\
\hline CHEMBL1489045 & 688546 & 5.0 & 5.2842 & TRN \\
\hline CHEMBL1370448 & 688546 & 4.8 & 5.3639 & TRN \\
\hline CHEMBL1306237 & 688546 & 5.25 & 5.2699 & TRN \\
\hline CHEMBL1545556 & 688546 & 6.2 & 5.4947 & TRN \\
\hline
\end{tabular}




\begin{tabular}{|c|c|c|c|c|}
\hline \multicolumn{5}{|c|}{ Supplemental Table S2.txt } \\
\hline CHEMBL1366362 & 688546 & 4.6 & 5.3388 & TRN \\
\hline CHEMBL407501 & 688546 & 5.4 & 5.2258 & TRN \\
\hline CHEMBL1434392 & 688546 & 5.4 & 5.141 & TRN \\
\hline CHEMBL1591887 & 688546 & 5.0 & 5.0609 & TST \\
\hline CHEMBL1317352 & 688546 & 4.9 & 4.6771 & TRN \\
\hline CHEMBL1513270 & 688546 & 5.9 & 5.4085 & TRN \\
\hline CHEMBL1456417 & 688546 & 4.9 & 5.0777 & TST \\
\hline CHEMBL1512686 & 688546 & 5.0 & 5.5164 & TRN \\
\hline CHEMBL1435677 & 688546 & 4.9 & 5.0669 & TST \\
\hline CHEMBL1314650 & 688546 & 4.45 & 5.0642 & TST \\
\hline CHEMBL1486826 & 688546 & 4.5 & 5.5417 & TRN \\
\hline CHEMBL1442326 & 688546 & 5.3 & 5.0371 & TRN \\
\hline CHEMBL1477874 & 688546 & 5.1 & 5.6743 & TRN \\
\hline CHEMBL1401696 & 688546 & 5.0 & 4.7717 & TRN \\
\hline CHEMBL1481006 & 688546 & 7.2 & 6.1319 & TRN \\
\hline CHEMBL1592612 & 688546 & 4.5 & 4.8019 & TST \\
\hline CHEMBL1397063 & 688546 & 7.15 & 5.5694 & TRN \\
\hline CHEMBL1356563 & 688546 & 5.5 & 5.5998 & TST \\
\hline CHEMBL1606046 & 688546 & 4.9 & 5.5442 & TRN \\
\hline CHEMBL1471031 & 688546 & 6.45 & 5.5034 & TRN \\
\hline CHEMBL1394209 & 688546 & 4.5 & 4.4914 & TRN \\
\hline CHEMBL1307769 & 688546 & 4.6 & 5.1979 & TST \\
\hline CHEMBL1363516 & 688546 & 4.7 & 4.8999 & TRN \\
\hline CHEMBL1566192 & 688546 & 5.35 & 5.0778 & TRN \\
\hline CHEMBL1455446 & 688546 & 4.8 & 5.2665 & TRN \\
\hline CHEMBL1593297 & 688546 & 4.5 & 5.3729 & TST \\
\hline CHEMBL1515562 & 688546 & 4.8 & 5.6576 & TRN \\
\hline CHEMBL1611263 & 688546 & 5.1 & 5.2279 & TRN \\
\hline CHEMBL1316753 & 688546 & 5.4 & 4.8831 & TRN \\
\hline CHEMBL1438336 & 688546 & 4.5 & 5.2859 & TRN \\
\hline CHEMBL1323976 & 688546 & 7.2 & 5.7612 & TST \\
\hline CHEMBL1333924 & 688546 & 4.5 & 5.2995 & TST \\
\hline CHEMBL1493092 & 688546 & 5.4 & 5.5178 & TRN \\
\hline CHEMBL1515853 & 688546 & 5.4 & 5.2624 & TRN \\
\hline CHEMBL1397424 & 688546 & 6.0 & 5.0313 & TST \\
\hline CHEMBL1397099 & 688546 & 6.7001 & 5.0108 & TRN \\
\hline CHEMBL1591989 & 688546 & 4.6 & 5.6208 & TRN \\
\hline CHEMBL1421271 & 688546 & 4.9 & 5.0142 & TRN \\
\hline CHEMBL1553759 & 688546 & 4.9 & 5.1633 & TRN \\
\hline CHEMBL1464342 & 688546 & 4.7 & 5.0054 & TRN \\
\hline CHEMBL1415698 & 688546 & 8.301 & 5.395 & TST \\
\hline CHEMBL1443124 & 688546 & 5.0 & 4.9612 & TRN \\
\hline CHEMBL1434004 & 688546 & 4.8 & 5.2307 & TRN \\
\hline CHEMBL1508699 & 688546 & 4.6 & 5.1855 & TRN \\
\hline CHEMBL1593678 & 688546 & 4.9 & 4.6621 & TRN \\
\hline CHEMBL1479020 & 688546 & 4.95 & 5.0039 & TST \\
\hline CHEMBL1438722 & 688546 & 7.15 & 5.4857 & TRN \\
\hline CHEMBL1365070 & 688546 & 4.9 & 5.1839 & TST \\
\hline
\end{tabular}




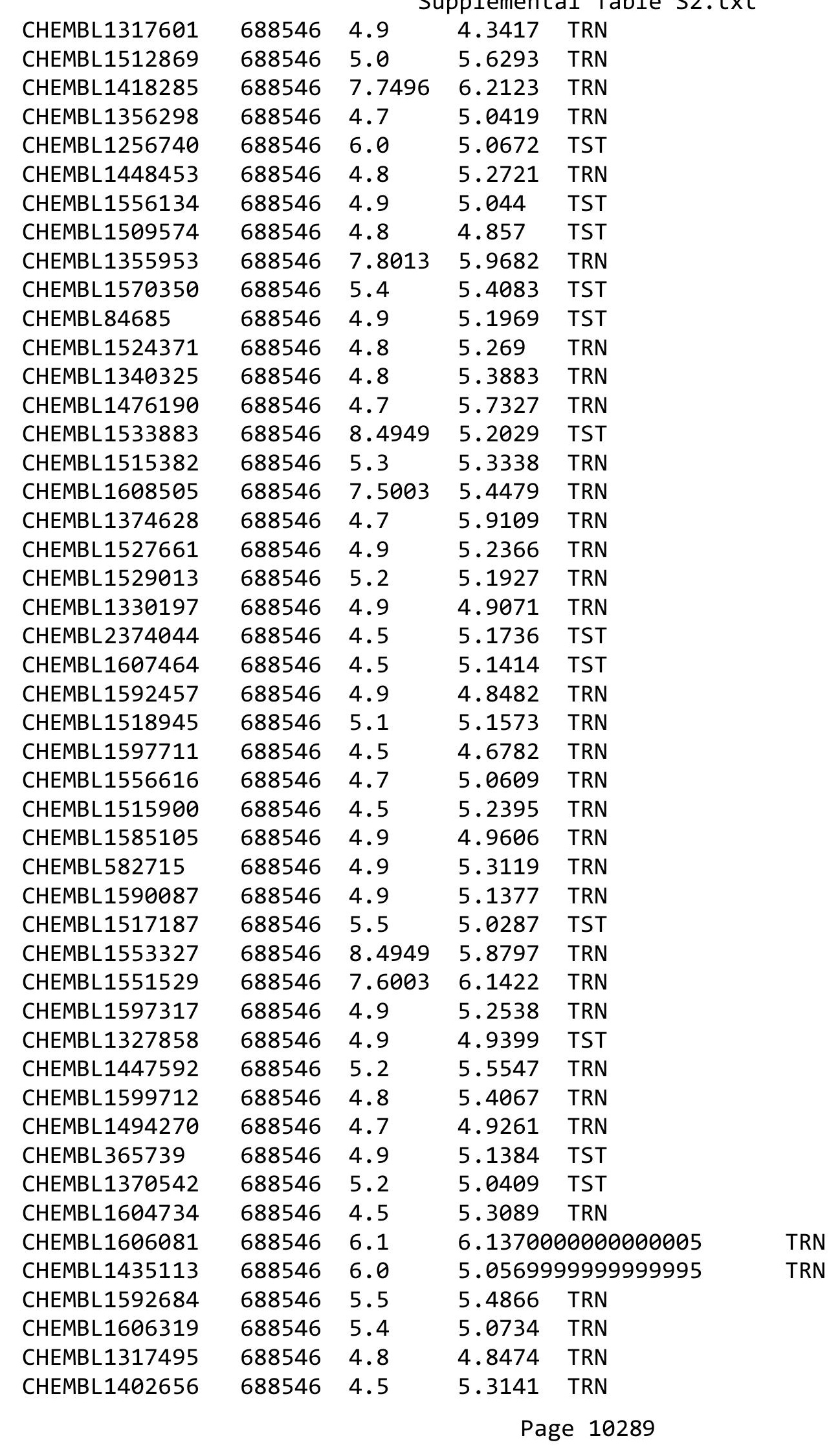




\begin{tabular}{|c|c|c|c|c|c|}
\hline \multirow[b]{2}{*}{ CHEMBL1565595 } & \multicolumn{5}{|c|}{ olemental } \\
\hline & 688546 & 4.9 & 5.1241 & TST & \\
\hline CHEMBL1453505 & 688546 & 4.9 & 5.42899 & 9999999999 & TST \\
\hline CHEMBL1519100 & 688546 & 4.5 & 5.5849 & TRN & \\
\hline CHEMBL1515858 & 688546 & 4.8 & 5.0343 & TRN & \\
\hline CHEMBL429711 & 688546 & 5.0 & 4.9544 & TST & \\
\hline CHEMBL1564760 & 688546 & 4.5 & 4.6416 & TST & \\
\hline CHEMBL1554626 & 688546 & 4.9 & 5.1637 & TRN & \\
\hline CHEMBL1525014 & 688546 & 4.8 & 5.0105 & TST & \\
\hline CHEMBL1564573 & 688546 & 4.9 & 5.0398 & TRN & \\
\hline CHEMBL1474310 & 688546 & 6.5 & 4.9824 & TRN & \\
\hline CHEMBL1399330 & 688546 & 8.301 & 6.1125 & TRN & \\
\hline CHEMBL1316261 & 688546 & 4.6 & 5.0096 & TRN & \\
\hline CHEMBL1432842 & 688546 & 4.5 & 4.5987 & TST & \\
\hline CHEMBL1523699 & 688546 & 4.7 & 5.0551 & TRN & \\
\hline CHEMBL1361939 & 688546 & 4.6 & 5.07100 & 2000000001 & TRN \\
\hline CHEMBL1502775 & 688546 & 5.25 & 5.3463 & TRN & \\
\hline CHEMBL1475417 & 688546 & 7.3497 & 5.7459 & TRN & \\
\hline CHEMBL1597995 & 688546 & 5.2 & 5.6444 & TRN & \\
\hline CHEMBL1591692 & 688546 & 8.3468 & 5.2403 & TRN & \\
\hline CHEMBL1358149 & 688546 & 7.5003 & 5.8881 & TRN & \\
\hline CHEMBL1553251 & 688546 & 4.6 & 4.9511 & TRN & \\
\hline CHEMBL1472876 & 688546 & 6.7001 & 5.5949 & TRN & \\
\hline CHEMBL1335188 & 688546 & 4.7 & 4.8403 & TRN & \\
\hline CHEMBL1557195 & 688546 & 4.9 & 4.3888 & TRN & \\
\hline CHEMBL1527024 & 688546 & 5.0 & 5.2177 & TRN & \\
\hline CHEMBL1329414 & 688546 & 4.9 & 5.33299 & 9999999999 & TRN \\
\hline CHEMBL1524072 & 688546 & 5.5 & 5.1523 & TRN & \\
\hline CHEMBL1515959 & 688546 & 4.8 & 5.5726 & TRN & \\
\hline CHEMBL1472651 & 688546 & 4.8 & 5.3002 & TRN & \\
\hline CHEMBL1591406 & 688546 & 5.7 & 5.33700 & $\partial 000000001$ & TRN \\
\hline CHEMBL1191361 & 688546 & 5.3 & 5.3032 & TST & \\
\hline CHEMBL1214345 & 688546 & 4.9 & 5.0406 & TRN & \\
\hline CHEMBL126804 & 688546 & 4.5 & 5.0849 & TRN & \\
\hline CHEMBL1540682 & 688546 & 4.95 & 5.2906 & TRN & \\
\hline CHEMBL1434028 & 688546 & 5.4 & 5.4685 & TST & \\
\hline CHEMBL1448732 & 688546 & 4.45 & 4.9414 & TST & \\
\hline CHEMBL1551282 & 688546 & 5.2 & 5.1031 & TRN & \\
\hline CHEMBL1591323 & 688546 & 4.6 & 5.5692 & TST & \\
\hline CHEMBL1592892 & 688546 & 5.9 & 5.5024 & TRN & \\
\hline CHEMBL1318807 & 688546 & 6.3 & 5.2855 & TRN & \\
\hline CHEMBL1434234 & 688546 & 5.0 & 5.4168 & TRN & \\
\hline CHEMBL1325504 & 688546 & 4.8 & 5.067 & TRN & \\
\hline CHEMBL1551722 & 688546 & 4.4 & 5.2489 & TST & \\
\hline CHEMBL1316532 & 688546 & 8.301 & 5.2446 & TRN & \\
\hline CHEMBL1521043 & 688546 & 6.2 & 5.2582 & TST & \\
\hline CHEMBL1437162 & 688546 & 5.45 & 4.8789 & TRN & \\
\hline CHEMBL1364729 & 688546 & 4.6 & 5.1174 & TST & \\
\hline CHEMBL1397946 & 688546 & 5.4 & 5.6729 & TRN & \\
\hline
\end{tabular}




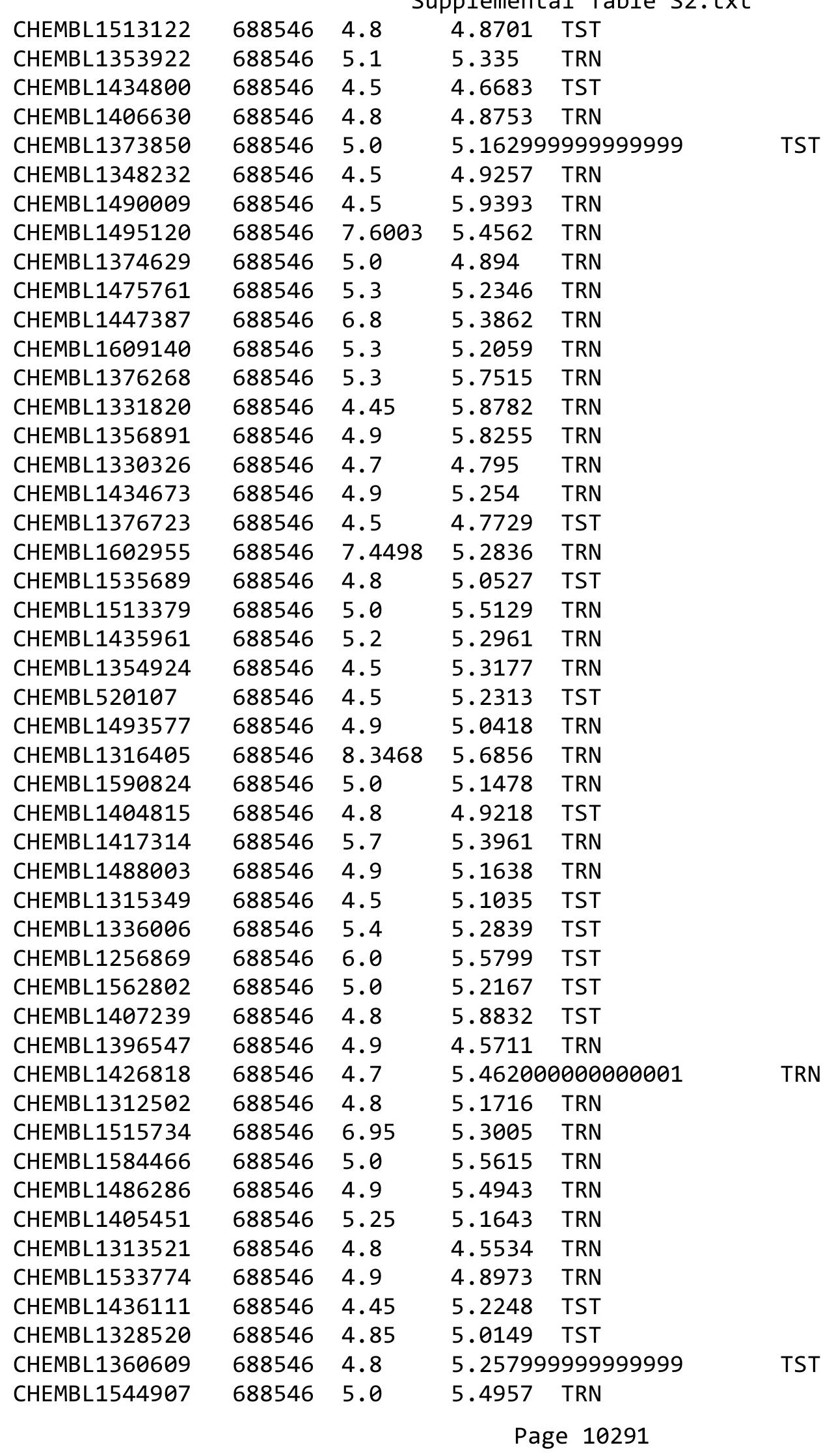




\begin{tabular}{|c|c|c|c|c|}
\hline \multicolumn{5}{|c|}{ Supplemental Table S2.txt } \\
\hline CHEMBL1365820 & 688546 & 4.9 & 4.8032 & TRN \\
\hline CHEMBL1544832 & 688546 & 4.9 & 5.2581 & TST \\
\hline CHEMBL1553381 & 688546 & 4.5 & 4.9988 & TST \\
\hline CHEMBL1315625 & 688546 & 7.6498 & 5.6525 & TRN \\
\hline CHEMBL1413171 & 688546 & 4.8 & 4.9137 & TRN \\
\hline CHEMBL1436942 & 688546 & 4.8 & 4.9725 & TRN \\
\hline CHEMBL1516021 & 688546 & 5.0 & 5.4495 & TRN \\
\hline CHEMBL105739 & 688546 & 5.6 & 4.8986 & TRN \\
\hline CHEMBL1379970 & 688546 & 6.6 & 5.7217 & TRN \\
\hline CHEMBL1423417 & 688546 & 6.5 & 5.0986 & TRN \\
\hline CHEMBL1358721 & 688546 & 4.5 & 4.9326 & TRN \\
\hline CHEMBL1589670 & 688546 & 5.0 & 4.9537 & TRN \\
\hline CHEMBL1553088 & 688546 & 5.7 & 5.8824 & TRN \\
\hline CHEMBL1530540 & 688546 & 6.2 & 5.99 & TRN \\
\hline CHEMBL1597921 & 688546 & 4.9 & 5.2954 & TST \\
\hline CHEMBL1476286 & 688546 & 8.4949 & 6.1128 & TRN \\
\hline CHEMBL1474704 & 688546 & 4.5 & 5.3043 & TRN \\
\hline CHEMBL1394183 & 688546 & 4.6 & 5.1992 & TRN \\
\hline CHEMBL1318096 & 688546 & 6.95 & 5.4205 & TST \\
\hline CHEMBL1337902 & 688546 & 7.3002 & 5.6376 & TRN \\
\hline CHEMBL1564282 & 688546 & 5.0 & 5.37799 & 9999999999 \\
\hline CHEMBL1574559 & 688546 & 5.1 & 4.7877 & TRN \\
\hline CHEMBL1526479 & 688546 & 4.45 & 5.1227 & TST \\
\hline CHEMBL1378556 & 688546 & 4.5 & 5.2054 & TRN \\
\hline CHEMBL1384437 & 688546 & 8.301 & 5.7292 & TST \\
\hline CHEMBL1329825 & 688546 & 6.6 & 5.9253 & TRN \\
\hline CHEMBL1305169 & 688546 & 4.9 & 5.1502 & TRN \\
\hline CHEMBL1082160 & 688546 & 5.0 & 5.6465 & TRN \\
\hline CHEMBL1474027 & 688546 & 4.8 & 5.4754 & TST \\
\hline CHEMBL3189405 & 688546 & 5.55 & 5.2934 & TST \\
\hline CHEMBL1535847 & 688546 & 5.0 & 5.3195 & TRN \\
\hline CHEMBL1365577 & 688546 & 4.45 & 5.2892 & TRN \\
\hline CHEMBL1490048 & 688546 & 4.5 & 4.6242 & TRN \\
\hline CHEMBL 259018 & 688546 & 4.6 & 5.1721 & TRN \\
\hline CHEMBL1357389 & 688546 & 5.0 & 5.3317 & TRN \\
\hline CHEMBL1374828 & 688546 & 4.7 & 5.2433 & TRN \\
\hline CHEMBL1364829 & 688546 & 6.0 & 5.4011 & TRN \\
\hline CHEMBL1524846 & 688546 & 7.699 & 5.3908 & TRN \\
\hline CHEMBL1395113 & 688546 & 4.8 & 5.0909 & TRN \\
\hline CHEMBL1563970 & 688546 & 6.5 & 6.206 & TRN \\
\hline CHEMBL1541692 & 688546 & 5.45 & 5.0497 & TRN \\
\hline CHEMBL1366434 & 688546 & 6.1 & 5.3954 & TRN \\
\hline CHEMBL1301287 & 688546 & 5.2 & 5.3482 & TST \\
\hline CHEMBL1409043 & 688546 & 4.8 & 5.0627 & TRN \\
\hline CHEMBL1472662 & 688546 & 4.9 & 4.9271 & TRN \\
\hline CHEMBL1476840 & 688546 & 5.0 & 5.2987 & TRN \\
\hline CHEMBL1496084 & 688546 & 5.45 & 5.0215 & TRN \\
\hline CHEMBL1480522 & 688546 & 4.95 & 4.7677 & TRN \\
\hline
\end{tabular}




\begin{tabular}{|c|c|c|c|c|}
\hline \multicolumn{5}{|c|}{ Supplement } \\
\hline CHEMBL1361203 & 688546 & 5.6 & 5.5994 & TRN \\
\hline CHEMBL1536124 & 688546 & 6.5 & 6.7928 & TRN \\
\hline CHEMBL1605632 & 688546 & 5.0 & 4.9289 & TRN \\
\hline CHEMBL1457966 & 688546 & 4.8 & 5.1201 & TST \\
\hline CHEMBL1591231 & 688546 & 4.7 & 4.8848 & TRN \\
\hline CHEMBL1316891 & 688546 & 4.6 & 4.8978 & TRN \\
\hline CHEMBL1710 & 688546 & 5.4 & 4.8606 & TRN \\
\hline CHEMBL1334915 & 688546 & 4.7 & 4.9687 & TRN \\
\hline CHEMBL1349063 & 688546 & 6.2 & 5.8309 & TST \\
\hline CHEMBL1623028 & 688546 & 4.9 & 5.1672 & TRN \\
\hline CHEMBL1326633 & 688546 & 6.3 & 5.2542 & TST \\
\hline CHEMBL1591696 & 688546 & 5.5 & 5.8024 & TRN \\
\hline CHEMBL1475915 & 688546 & 7.6498 & 5.7407 & TRN \\
\hline CHEMBL1441350 & 688546 & 5.0 & 4.9601 & TRN \\
\hline CHEMBL1404034 & 688546 & 4.5 & 4.3804 & TRN \\
\hline CHEMBL 272005 & 688546 & 5.1 & 4.7882 & TRN \\
\hline CHEMBL1334688 & 688546 & 5.4 & 5.6838 & TRN \\
\hline CHEMBL1593542 & 688546 & 5.35 & 5.5159 & TRN \\
\hline CHEMBL1523358 & 688546 & 4.9 & 6.0854 & TRN \\
\hline CHEMBL1363458 & 688546 & 7.5498 & 5.4282 & TRN \\
\hline CHEMBL1422296 & 688546 & 5.3 & 5.1438 & TST \\
\hline CHEMBL1553108 & 688546 & 4.9 & 5.0327 & TRN \\
\hline CHEMBL1476510 & 688546 & 5.8 & 5.7204 & TRN \\
\hline CHEMBL1501238 & 688546 & 5.3 & 5.1135 & TRN \\
\hline CHEMBL1356968 & 688546 & 8.301 & 5.5986 & TRN \\
\hline CHEMBL1467411 & 688546 & 5.0 & 5.0682 & TRN \\
\hline CHEMBL3196123 & 688546 & 5.1 & 5.5286 & TRN \\
\hline CHEMBL1514533 & 688546 & 4.5 & 4.9089 & TRN \\
\hline CHEMBL1435206 & 688546 & 4.9 & 5.6245 & TRN \\
\hline CHEMBL1436547 & 688546 & 8.0 & 5.2812 & TRN \\
\hline CHEMBL1398505 & 688546 & 4.9 & 5.402 & TRN \\
\hline CHEMBL1593426 & 688546 & 4.9 & 5.4218 & TRN \\
\hline CHEMBL1541530 & 688546 & 4.45 & 4.5808 & TST \\
\hline CHEMBL1367940 & 688546 & 5.5 & 5.0242 & TST \\
\hline CHEMBL1515089 & 688546 & 7.4498 & 5.6463 & TST \\
\hline CHEMBL1592358 & 688546 & 4.5 & 5.5659 & TST \\
\hline CHEMBL1408656 & 688546 & 4.6 & 4.9003 & TRN \\
\hline CHEMBL1593786 & 688546 & 5.3 & 5.4965 & TRN \\
\hline CHEMBL1556212 & 688546 & 5.95 & 5.2795 & TRN \\
\hline CHEMBL1331636 & 688546 & 5.0 & 4.6413 & TRN \\
\hline CHEMBL1305537 & 688546 & 4.8 & 5.0768 & TRN \\
\hline CHEMBL1499433 & 688546 & 4.9 & 5.1869 & TRN \\
\hline CHEMBL1512564 & 688546 & 6.0 & 5.4272 & TRN \\
\hline CHEMBL1610234 & 688546 & 4.5 & 5.1582 & TRN \\
\hline CHEMBL1365124 & 688546 & 7.1002 & 5.0666 & TRN \\
\hline CHEMBL1528201 & 688546 & 4.8 & 5.2908 & TRN \\
\hline CHEMBL1325462 & 688546 & 4.6 & 5.3052 & TRN \\
\hline CHEMBL1355106 & 688546 & 5.9 & 5.1862 & TRN \\
\hline
\end{tabular}




\begin{tabular}{|c|c|c|c|c|c|}
\hline \multicolumn{6}{|c|}{ Supplemental Table S2.txt } \\
\hline CHEMBL1592126 & 688546 & 5.1 & 5.2901 & TRN & \\
\hline CHEMBL1475396 & 688546 & 4.8 & 4.9858 & TRN & \\
\hline CHEMBL1593221 & 688546 & 4.95 & 5.3573 & TRN & \\
\hline CHEMBL1608401 & 688546 & 4.8 & 5.0977 & TRN & \\
\hline CHEMBL1532326 & 688546 & 5.45 & 5.7152 & TRN & \\
\hline CHEMBL1582803 & 688546 & 5.3 & 5.0429 & TST & \\
\hline CHEMBL1552620 & 688546 & 4.5 & 5.6911 & TRN & \\
\hline CHEMBL1443946 & 688546 & 4.6 & 4.8726 & TRN & \\
\hline CHEMBL1440063 & 688546 & 4.5 & 4.6645 & TRN & \\
\hline CHEMBL1477187 & 688546 & 4.8 & 5.053 & TRN & \\
\hline CHEMBL1314555 & 688546 & 4.7 & 5.279 & TRN & \\
\hline CHEMBL1488094 & 688546 & 6.4 & 5.7795 & TRN & \\
\hline CHEMBL1593692 & 688546 & 6.2 & 5.4017 & TRN & \\
\hline CHEMBL1435594 & 688546 & 4.5 & 5.71899 & 9999999999 & TRN \\
\hline CHEMBL1325495 & 688546 & 4.9 & 4.9101 & TRN & \\
\hline CHEMBL1448296 & 688546 & 5.0 & 5.5348 & TRN & \\
\hline CHEMBL1317831 & 688546 & 4.9 & 4.9591 & TRN & \\
\hline CHEMBL1552181 & 688546 & 4.6 & 4.868 & TRN & \\
\hline CHEMBL1526774 & 688546 & 4.5 & 4.9418 & TRN & \\
\hline CHEMBL1610783 & 688546 & 5.0 & 4.9087 & TRN & \\
\hline CHEMBL1606770 & 688546 & 7.1002 & 5.4987 & TRN & \\
\hline CHEMBL1513202 & 688546 & 4.5 & 4.9862 & TRN & \\
\hline CHEMBL1402450 & 688546 & 6.45 & 5.1428 & TRN & \\
\hline CHEMBL1321287 & 688546 & 5.8 & 5.3954 & TRN & \\
\hline CHEMBL1594527 & 688546 & 4.9 & 5.2546 & TST & \\
\hline CHEMBL1513326 & 688546 & 4.7 & 4.6915 & TRN & \\
\hline CHEMBL1428325 & 688546 & 4.8 & 5.2183 & TRN & \\
\hline CHEMBL1356773 & 688546 & 4.9 & 4.6399 & TRN & \\
\hline CHEMBL1404304 & 688546 & 8.0 & 6.2024 & TRN & \\
\hline CHEMBL1311704 & 688546 & 4.45 & 5.34200 & 00000000005 & TST \\
\hline CHEMBL1520611 & 688546 & 8.1024 & 5.7408 & TRN & \\
\hline CHEMBL1591562 & 688546 & 4.5 & 5.3649 & TST & \\
\hline CHEMBL1593842 & 688546 & 4.9 & 6.1072 & TRN & \\
\hline CHEMBL328710 & 688546 & 5.0 & 4.9682 & TRN & \\
\hline CHEMBL1597435 & 688546 & 4.9 & 5.42899 & 9999999999 & TRN \\
\hline CHEMBL1435001 & 688546 & 4.9 & 5.6044 & TRN & \\
\hline CHEMBL1323290 & 688546 & 5.4 & 5.48 & TRN & \\
\hline CHEMBL1473545 & 688546 & 4.5 & 5.2736 & TRN & \\
\hline CHEMBL1455127 & 688546 & 7.1002 & 5.0263 & TST & \\
\hline CHEMBL1440299 & 688546 & 5.6 & 5.4286 & TRN & \\
\hline CHEMBL3145107 & 688546 & 4.6 & 5.0289 & TRN & \\
\hline CHEMBL1558670 & 688546 & 6.4 & 5.4488 & TRN & \\
\hline CHEMBL1563914 & 688546 & 7.0501 & 5.2254 & TRN & \\
\hline CHEMBL1512847 & 688546 & 4.45 & 5.5183 & TRN & \\
\hline CHEMBL1474403 & 688546 & 6.9 & 5.3211 & TRN & \\
\hline CHEMBL1452743 & 688546 & 5.25 & 5.1742 & TRN & \\
\hline CHEMBL1454850 & 688546 & 4.9 & 5.2713 & TRN & \\
\hline CHEMBL1332908 & 688546 & 4.9 & 4.8549 & TRN & \\
\hline
\end{tabular}




\begin{tabular}{|c|c|c|c|c|}
\hline \multicolumn{5}{|c|}{ Supplemental Table S2.txt } \\
\hline CHEMBL1572202 & 688546 & 4.6 & 5.0562 & TRN \\
\hline CHEMBL1365284 & 688546 & 5.15 & 4.8433 & TST \\
\hline CHEMBL1444351 & 688546 & 4.5 & 5.2313 & TST \\
\hline CHEMBL1533990 & 688546 & 4.9 & 5.5577 & TRN \\
\hline CHEMBL1607194 & 688546 & 5.0 & 4.9787 & TRN \\
\hline CHEMBL1554885 & 688546 & 6.6 & 5.2309 & TRN \\
\hline CHEMBL1579518 & 688546 & 5.0 & 5.5073 & TRN \\
\hline CHEMBL1412975 & 688546 & 7.7496 & 5.2116 & TRN \\
\hline CHEMBL1491767 & 688546 & 5.0 & 5.0422 & TST \\
\hline CHEMBL1556599 & 688546 & 5.0 & 5.4987 & TRN \\
\hline CHEMBL1551238 & 688546 & 5.3 & 5.5948 & TRN \\
\hline CHEMBL1492461 & 688546 & 4.8 & 4.973 & TRN \\
\hline CHEMBL1499028 & 688546 & 5.8 & 4.883 & TRN \\
\hline CHEMBL1356546 & 688546 & 4.7 & 5.1539 & TRN \\
\hline CHEMBL1612618 & 688546 & 4.9 & 5.194 & TRN \\
\hline CHEMBL1330428 & 688546 & 4.5 & 5.1227 & TRN \\
\hline CHEMBL1362445 & 688546 & 6.3 & 5.8756 & TST \\
\hline CHEMBL1496115 & 688546 & 6.3 & 5.4636 & TRN \\
\hline CHEMBL 3189751 & 688546 & 4.9 & 4.716 & TRN \\
\hline CHEMBL1213966 & 688546 & 4.9 & 5.3836 & TRN \\
\hline CHEMBL3209131 & 688546 & 5.0 & 5.2973 & TST \\
\hline CHEMBL1439295 & 688546 & 4.8 & 5.1214 & TRN \\
\hline CHEMBL3194422 & 688546 & 5.1 & 5.035 & TRN \\
\hline CHEMBL1408787 & 688546 & 8.301 & 6.2965 & TRN \\
\hline CHEMBL1318522 & 688546 & 4.5 & 5.3847 & TRN \\
\hline CHEMBL1417654 & 688546 & 5.15 & 5.9108 & TST \\
\hline CHEMBL1475807 & 688546 & 4.95 & 5.148 & TRN \\
\hline CHEMBL1597643 & 688546 & 6.5 & 5.3798 & TRN \\
\hline CHEMBL1358039 & 688546 & 4.9 & 4.9921 & TRN \\
\hline CHEMBL1568660 & 688546 & 4.45 & 5.1356 & TST \\
\hline CHEMBL1456524 & 688546 & 5.0 & 5.3016 & TRN \\
\hline CHEMBL1214410 & 688546 & 4.8 & 4.708 & TRN \\
\hline CHEMBL1396509 & 688546 & 4.5 & 5.4379 & TST \\
\hline CHEMBL1522769 & 688546 & 5.0 & 5.8447 & TRN \\
\hline CHEMBL554041 & 688546 & 6.0 & 5.0227 & TST \\
\hline CHEMBL579749 & 688546 & 4.9 & 5.3353 & TRN \\
\hline CHEMBL1553915 & 688546 & 4.8 & 5.2483 & TRN \\
\hline CHEMBL1597186 & 688546 & 5.0 & 5.1876 & TRN \\
\hline CHEMBL1318177 & 688546 & 7.8996 & 5.5443 & TST \\
\hline CHEMBL1433082 & 688546 & 6.3 & 5.0911 & TRN \\
\hline CHEMBL1315543 & 688546 & 4.9 & 5.0773 & TST \\
\hline CHEMBL1525773 & 688546 & 4.9 & 5.1281 & TRN \\
\hline CHEMBL1606549 & 688546 & 5.0 & 5.0071 & TRN \\
\hline CHEMBL1603081 & 688546 & 5.6 & 5.3407 & TRN \\
\hline CHEMBL1568035 & 688546 & 5.25 & 5.1726 & TST \\
\hline CHEMBL1315303 & 688546 & 4.5 & 5.4165 & TST \\
\hline CHEMBL1377307 & 688546 & 5.0 & 4.9489 & TRN \\
\hline CHEMBL1357413 & 688546 & 4.5 & 5.2753 & TRN \\
\hline
\end{tabular}




\begin{tabular}{|c|c|c|c|c|c|}
\hline & & & & & \\
\hline CHEMBL1355586 & 688546 & 4.6 & 5.2488 & TRN & \\
\hline CHEMBL1314200 & 688546 & 4.7 & 4.99100 & 00000000005 & TRN \\
\hline CHEMBL1476431 & 688546 & 4.9 & 5.34 & TRN & \\
\hline CHEMBL1525495 & 688546 & 4.7 & 4.8575 & TST & \\
\hline CHEMBL1569989 & 688546 & 5.5 & 5.1577 & TRN & \\
\hline CHEMBL1608241 & 688546 & 4.5 & 4.5511 & TRN & \\
\hline CHEMBL1497932 & 688546 & 5.2 & 5.3029 & TRN & \\
\hline CHEMBL1571290 & 688546 & 4.6 & 5.8289 & TRN & \\
\hline CHEMBL1611165 & 688546 & 4.9 & 5.3638 & TRN & \\
\hline CHEMBL1571414 & 688546 & 5.4 & 5.3801 & TST & \\
\hline CHEMBL1571724 & 688546 & 4.6 & 5.004 & TRN & \\
\hline CHEMBL1516194 & 688546 & 4.5 & 5.7761 & TRN & \\
\hline CHEMBL1515641 & 688546 & 4.6 & 5.4315 & TRN & \\
\hline CHEMBL1474281 & 688546 & 4.9 & 4.7711 & TRN & \\
\hline CHEMBL1423211 & 688546 & 8.3468 & 4.9559 & TST & \\
\hline CHEMBL1464080 & 688546 & 4.6 & 5.1757 & TRN & \\
\hline CHEMBL1435675 & 688546 & 5.3 & 5.4634 & TRN & \\
\hline CHEMBL1354367 & 688546 & 7.3002 & 5.3625 & TRN & \\
\hline CHEMBL1339717 & 688546 & 4.9 & 5.1396 & TRN & \\
\hline CHEMBL1519715 & 688546 & 5.7 & 5.1078 & TST & \\
\hline CHEMBL1476819 & 688546 & 4.5 & 5.0753 & TRN & \\
\hline CHEMBL79014 & 688546 & 4.45 & 5.2247 & TST & \\
\hline CHEMBL1483314 & 688546 & 4.5 & 5.8893 & TRN & \\
\hline CHEMBL1337042 & 688546 & 4.5 & 4.9173 & TST & \\
\hline CHEMBL1475331 & 688546 & 4.45 & 5.4548 & TRN & \\
\hline CHEMBL1419438 & 688546 & 4.5 & 5.16100 & 00000000005 & TRN \\
\hline CHEMBL1417455 & 688546 & 4.9 & 4.8904 & TRN & \\
\hline CHEMBL1472696 & 688546 & 5.5 & 5.33200 & 0000000001 & TRN \\
\hline CHEMBL1332323 & 688546 & 8.301 & 6.2076 & TRN & \\
\hline CHEMBL1481451 & 688546 & 4.9 & 5.5886 & TRN & \\
\hline CHEMBL1355029 & 688546 & 5.0 & 5.4213 & TRN & \\
\hline CHEMBL1518629 & 688546 & 5.0 & 4.9335 & TRN & \\
\hline CHEMBL1465114 & 688546 & 4.5 & 4.823 & TRN & \\
\hline CHEMBL1434098 & 688546 & 4.9 & 5.3029 & TRN & \\
\hline CHEMBL1395133 & 688546 & 5.1 & 5.2589 & TRN & \\
\hline CHEMBL1413831 & 688546 & 4.5 & 5.2181 & TST & \\
\hline CHEMBL1454312 & 688546 & 5.4 & 5.2466 & TRN & \\
\hline CHEMBL1516180 & 688546 & 4.5 & 5.2733 & TRN & \\
\hline CHEMBL1329917 & 688546 & 5.4 & 5.5622 & TRN & \\
\hline CHEMBL1399747 & 688546 & 5.3 & 4.8905 & TST & \\
\hline CHEMBL1598184 & 688546 & 5.6 & 5.3198 & TRN & \\
\hline CHEMBL1558751 & 688546 & 4.9 & 5.317 & TRN & \\
\hline CHEMBL1495849 & 688546 & 5.0 & 5.1071 & TRN & \\
\hline CHEMBL1554387 & 688546 & 7.1002 & 5.853 & TRN & \\
\hline CHEMBL1513624 & 688546 & 5.6 & 5.1551 & TRN & \\
\hline CHEMBL1307871 & 688546 & 4.85 & 5.1256 & TST & \\
\hline CHEMBL1583863 & 688546 & 4.5 & 5.1422 & TRN & \\
\hline CHEMBL1605762 & 688546 & 5.2 & 5.0183 & TRN & \\
\hline
\end{tabular}




\begin{tabular}{|c|c|c|c|c|c|}
\hline \multicolumn{6}{|c|}{ Supplemental Table S2.txt } \\
\hline CHEMBL1429821 & 688546 & 4.5 & 5.8867 & TRN & \\
\hline CHEMBL1351643 & 688546 & 4.8 & 5.3311 & TST & \\
\hline CHEMBL1425330 & 688546 & 4.9 & 5.2637 & TRN & \\
\hline CHEMBL1519811 & 688546 & 3.7 & 5.6633 & TRN & \\
\hline CHEMBL399491 & 688546 & 4.5 & 5.5374 & TST & \\
\hline CHEMBL1429038 & 688546 & 4.5 & 4.8732 & TST & \\
\hline CHEMBL1514048 & 688546 & 5.0 & 5.2457 & TRN & \\
\hline CHEMBL1320414 & 688546 & 5.0 & 5.3232 & TRN & \\
\hline CHEMBL1404237 & 688546 & 4.6 & 5.2893 & TRN & \\
\hline CHEMBL1555692 & 688546 & 5.2 & 5.5391 & TRN & \\
\hline CHEMBL486817 & 688546 & 4.6 & 5.3323 & TST & \\
\hline CHEMBL1574688 & 688546 & 5.1 & 5.1522 & TRN & \\
\hline CHEMBL1601966 & 688546 & 5.5 & 5.112 & TRN & \\
\hline CHEMBL1435102 & 688546 & 4.9 & 5.1879 & TRN & \\
\hline CHEMBL1590037 & 688546 & 8.3979 & 5.2686 & TRN & \\
\hline CHEMBL1438717 & 688546 & 4.85 & 5.0803 & TRN & \\
\hline CHEMBL1563482 & 688546 & 4.8 & 5.3375 & TRN & \\
\hline CHEMBL1356811 & 688546 & 6.1 & 5.4386 & TRN & \\
\hline CHEMBL1395957 & 688546 & 5.25 & 5.9699 & TRN & \\
\hline CHEMBL1358801 & 688546 & 4.75 & 4.91100 & 00000000005 & TST \\
\hline CHEMBL1353804 & 688546 & 5.4 & 5.353 & TST & \\
\hline CHEMBL1593002 & 688546 & 5.4 & 5.6781 & TRN & \\
\hline CHEMBL1552783 & 688546 & 4.9 & 5.1053 & TRN & \\
\hline CHEMBL1444513 & 688546 & 5.0 & 4.716 & TST & \\
\hline CHEMBL1567987 & 688546 & 6.0 & 5.4177 & TST & \\
\hline CHEMBL6291 & 688546 & 4.5 & 4.87 & TST & \\
\hline CHEMBL1578536 & 688546 & 5.5 & 5.375 & TRN & \\
\hline CHEMBL1554378 & 688546 & 7.6003 & 5.5265 & TRN & \\
\hline CHEMBL1316622 & 688546 & 6.5 & 5.3472 & TRN & \\
\hline CHEMBL1315044 & 688546 & 4.6 & 5.0806 & TRN & \\
\hline CHEMBL576349 & 688546 & 5.4 & 5.0841 & TRN & \\
\hline CHEMBL1525916 & 688546 & 4.5 & 5.2183 & TRN & \\
\hline CHEMBL1396849 & 688546 & 4.5 & 5.3961 & TST & \\
\hline CHEMBL1564728 & 688546 & 4.5 & 4.7309 & TRN & \\
\hline CHEMBL1395740 & 688546 & 7.2503 & 5.3302 & TST & \\
\hline CHEMBL3213220 & 688546 & 4.95 & 5.1915 & TST & \\
\hline CHEMBL1404816 & 688546 & 4.5 & 5.2094 & TRN & \\
\hline CHEMBL1552629 & 688546 & 6.5 & 5.9931 & TRN & \\
\hline CHEMBL1355174 & 688546 & 8.0 & 5.641 & TST & \\
\hline CHEMBL1554310 & 688546 & 6.6 & 5.5241 & TST & \\
\hline CHEMBL1325004 & 688546 & 6.9 & 5.6934 & TRN & \\
\hline CHEMBL1473796 & 688546 & 5.6 & 5.231 & TST & \\
\hline CHEMBL1602693 & 688546 & 4.9 & 5.3832 & TST & \\
\hline CHEMBL1256697 & 688546 & 4.5 & 4.6112 & TST & \\
\hline CHEMBL1448039 & 688546 & 4.45 & 5.7933 & TRN & \\
\hline CHEMBL1516311 & 688546 & 7.5003 & 5.0475 & TRN & \\
\hline CHEMBL1449812 & 688546 & 5.45 & 5.7181 & TRN & \\
\hline CHEMBL1352138 & 688546 & 4.5 & 5.1742 & TST & \\
\hline
\end{tabular}




\begin{tabular}{|c|c|c|c|c|}
\hline \multicolumn{5}{|c|}{ Supplemental Table S2.txt } \\
\hline CHEMBL1317390 & 688546 & 7.4001 & 5.314 & TRN \\
\hline CHEMBL1319286 & 688546 & 4.5 & 4.7779 & TRN \\
\hline CHEMBL1345845 & 688546 & 6.1 & 5.4875 & TRN \\
\hline CHEMBL1363628 & 688546 & 5.15 & 5.4082 & TRN \\
\hline CHEMBL1358308 & 688546 & 4.6 & 5.4376 & TRN \\
\hline CHEMBL1359022 & 688546 & 7.0501 & 5.4715 & TRN \\
\hline CHEMBL1300237 & 688546 & 4.9 & 5.1922 & TRN \\
\hline CHEMBL1393994 & 688546 & 4.9 & 4.9115 & TST \\
\hline CHEMBL1493169 & 688546 & 5.0 & 5.5452 & TRN \\
\hline CHEMBL1532037 & 688546 & 4.5 & 5.0304 & TRN \\
\hline CHEMBL1477136 & 688546 & 4.9 & 4.9438 & TRN \\
\hline CHEMBL1609181 & 688546 & 4.9 & 5.2224 & TRN \\
\hline CHEMBL1430680 & 688546 & 4.8 & 5.6773 & TST \\
\hline CHEMBL265715 & 688546 & 5.8 & 5.4965 & TRN \\
\hline CHEMBL1598734 & 688546 & 5.0 & 5.2457 & TRN \\
\hline CHEMBL1473803 & 688546 & 5.2 & 5.4727 & TRN \\
\hline CHEMBL1554881 & 688546 & 4.8 & 5.5096 & TRN \\
\hline CHEMBL1514366 & 688546 & 4.5 & 5.1536 & TST \\
\hline CHEMBL1593943 & 688546 & 6.6 & 5.6569 & TST \\
\hline CHEMBL1310517 & 688546 & 4.5 & 4.6771 & TST \\
\hline CHEMBL1480047 & 688546 & 5.0 & 5.1079 & TST \\
\hline CHEMBL1531896 & 688546 & 4.5 & 5.2585 & TST \\
\hline CHEMBL1552022 & 688546 & 5.2 & 5.4596 & TRN \\
\hline CHEMBL1555511 & 688546 & 8.2007 & 5.0252 & TRN \\
\hline CHEMBL3195233 & 688546 & 4.9 & 5.2135 & TST \\
\hline CHEMBL1526488 & 688546 & 5.1 & 4.9863 & TRN \\
\hline CHEMBL1466155 & 688546 & 4.5 & 5.4449 & TRN \\
\hline CHEMBL1474632 & 688546 & 5.4 & 5.3739 & TST \\
\hline CHEMBL1433614 & 688546 & 5.5 & 5.2876 & TST \\
\hline CHEMBL1552347 & 688546 & 5.7 & 5.6669 & TRN \\
\hline CHEMBL1547933 & 688546 & 5.3 & 5.5871 & TST \\
\hline CHEMBL1412086 & 688546 & 4.5 & 5.2792 & TRN \\
\hline CHEMBL3199576 & 688546 & 4.9 & 5.2818 & TST \\
\hline CHEMBL1551622 & 688546 & 5.8 & 5.0573 & TRN \\
\hline CHEMBL1398801 & 688546 & 5.1 & 5.2813 & TRN \\
\hline CHEMBL292477 & 688546 & 4.8 & 5.1301 & TST \\
\hline CHEMBL1482664 & 688546 & 4.5 & 5.2142 & TST \\
\hline CHEMBL1473514 & 688546 & 7.3002 & 4.9066 & TRN \\
\hline CHEMBL1435075 & 688546 & 4.9 & 5.7076 & TST \\
\hline CHEMBL1454833 & 688546 & 6.0 & 5.6985 & TRN \\
\hline CHEMBL1592109 & 688546 & 4.5 & 4.822 & TRN \\
\hline CHEMBL1611890 & 688546 & 4.6 & 5.239 & TRN \\
\hline CHEMBL1435197 & 688546 & 5.5 & 5.5601 & TRN \\
\hline CHEMBL1530921 & 688546 & 4.9 & 5.1479 & TRN \\
\hline CHEMBL1316914 & 688546 & 4.7 & 5.9021 & TRN \\
\hline CHEMBL1531077 & 688546 & 8.301 & 5.3558 & TRN \\
\hline CHEMBL1315253 & 688546 & 4.9 & 5.6619 & TRN \\
\hline CHEMBL1457225 & 688546 & 5.3 & 5.082 & TRN \\
\hline
\end{tabular}




\begin{tabular}{|c|c|c|c|c|}
\hline \multicolumn{5}{|c|}{ Supplemental Table S2.txt } \\
\hline CHEMBL1529929 & 688546 & 4.9 & 5.4486 & TRN \\
\hline CHEMBL1508146 & 688546 & 5.0 & 4.8262 & TRN \\
\hline CHEMBL1592241 & 688546 & 5.3 & 5.3143 & TRN \\
\hline CHEMBL1434520 & 688546 & 5.4 & 5.3178 & TRN \\
\hline CHEMBL1610407 & 688546 & 5.0 & 5.3824 & TST \\
\hline CHEMBL1335003 & 688546 & 4.9 & 4.8601 & TRN \\
\hline CHEMBL1467405 & 688546 & 5.95 & 5.4169 & TRN \\
\hline CHEMBL1357538 & 688546 & 4.6 & 5.3045 & TRN \\
\hline CHEMBL1518975 & 688546 & 4.9 & 5.3039 & TRN \\
\hline CHEMBL1336496 & 688546 & 4.8 & 4.9519 & TRN \\
\hline CHEMBL1481671 & 688546 & 5.5 & 4.9919 & TST \\
\hline CHEMBL1529989 & 688546 & 5.9 & 4.7737 & TRN \\
\hline CHEMBL1568005 & 688546 & 4.7 & 5.3487 & TRN \\
\hline CHEMBL1493662 & 688546 & 6.1 & 4.8253 & TRN \\
\hline CHEMBL1557000 & 688546 & 4.7 & 5.5197 & TRN \\
\hline CHEMBL1551644 & 688546 & 4.9 & 5.375 & TRN \\
\hline CHEMBL1454795 & 688546 & 7.1002 & 5.1249 & TRN \\
\hline CHEMBL1435185 & 688546 & 4.9 & 5.0277 & TRN \\
\hline CHEMBL1502512 & 688546 & 4.5 & 5.0062 & TST \\
\hline CHEMBL1443866 & 688546 & 4.7 & 5.4269 & TST \\
\hline CHEMBL1482591 & 688546 & 6.5501 & 5.2256 & TST \\
\hline CHEMBL1514025 & 688546 & 4.6 & 4.527 & TRN \\
\hline CHEMBL1326465 & 688546 & 7.8996 & 5.4369 & TRN \\
\hline CHEMBL1354237 & 688546 & 8.0 & 5.1851 & TST \\
\hline CHEMBL1529009 & 688546 & 6.0 & 4.877 & TST \\
\hline CHEMBL1406296 & 688546 & 7.3002 & 4.9632 & TST \\
\hline CHEMBL1357392 & 688546 & 4.7 & 4.8698 & TRN \\
\hline CHEMBL1173475 & 688546 & 6.0 & 5.1783 & TRN \\
\hline CHEMBL1304798 & 688546 & 5.0 & 5.0463 & TRN \\
\hline CHEMBL1452791 & 688546 & 4.9 & 5.0125 & TRN \\
\hline CHEMBL1583096 & 688546 & 4.6 & 5.2144 & TST \\
\hline CHEMBL1315620 & 688546 & 4.8 & 5.0659 & TRN \\
\hline CHEMBL1443526 & 688546 & 5.4 & 5.813 & TRN \\
\hline CHEMBL1394540 & 688546 & 4.8 & 5.4492 & TST \\
\hline CHEMBL3197115 & 688546 & 4.95 & 5.1101 & TST \\
\hline CHEMBL1607701 & 688546 & 4.85 & 5.3794 & TST \\
\hline CHEMBL1356339 & 688546 & 4.8 & 5.3209 & TRN \\
\hline CHEMBL1527929 & 688546 & 4.8 & 5.2509 & TRN \\
\hline CHEMBL1553148 & 688546 & 5.2 & 5.3033 & TRN \\
\hline CHEMBL1412673 & 688546 & 4.5 & 5.0896 & TST \\
\hline CHEMBL1366714 & 688546 & 4.5 & 4.6182 & TRN \\
\hline CHEMBL1594218 & 688546 & 4.9 & 4.9412 & TRN \\
\hline CHEMBL1561693 & 688546 & 4.5 & 5.0408 & TRN \\
\hline CHEMBL1566891 & 688546 & 5.0 & 5.092 & TRN \\
\hline CHEMBL1552761 & 688546 & 4.5 & 5.5235 & TRN \\
\hline CHEMBL1319432 & 688546 & 4.9 & 5.2087 & TRN \\
\hline CHEMBL182653 & 688546 & 4.7 & 5.2941 & TRN \\
\hline CHEMBL1397329 & 688546 & 4.7 & 4.8011 & TRN \\
\hline
\end{tabular}




\begin{tabular}{|c|c|c|c|c|c|}
\hline \multicolumn{6}{|c|}{ Supplemental Table S2.txt } \\
\hline CHEMBL1403598 & 688546 & 5.25 & 5.1022 & TRN & \\
\hline CHEMBL1357853 & 688546 & 4.5 & 5.0691 & TRN & \\
\hline CHEMBL1513052 & 688546 & 4.9 & 5.3304 & TRN & \\
\hline CHEMBL1338138 & 688546 & 4.9 & 4.92899 & 9999999999 & TST \\
\hline CHEMBL1329054 & 688546 & 4.5 & 4.9805 & TST & \\
\hline CHEMBL1437275 & 688546 & 4.8 & 5.4903 & TRN & \\
\hline CHEMBL1484722 & 688546 & 6.0 & 5.7453 & TRN & \\
\hline CHEMBL1449162 & 688546 & 4.6 & 5.33899 & 99999999995 & TST \\
\hline CHEMBL1556855 & 688546 & 4.7 & 5.5932 & TRN & \\
\hline CHEMBL1484167 & 688546 & 4.8 & 5.25 & TST & \\
\hline CHEMBL1988883 & 688546 & 4.85 & 4.9242 & TRN & \\
\hline CHEMBL1405293 & 688546 & 4.6 & 5.5672 & TRN & \\
\hline CHEMBL1474369 & 688546 & 4.95 & 5.1731 & TRN & \\
\hline CHEMBL1389728 & 688546 & 4.5 & 4.6327 & TRN & \\
\hline CHEMBL1574088 & 688546 & 4.5 & 5.4267 & TRN & \\
\hline CHEMBL1407408 & 688546 & 4.5 & 5.3608 & TRN & \\
\hline CHEMBL1449126 & 688546 & 5.25 & 5.0918 & TRN & \\
\hline CHEMBL1535354 & 688546 & 4.5 & 5.0445 & TRN & \\
\hline CHEMBL1401065 & 688546 & 4.5 & 5.024 & TRN & \\
\hline CHEMBL1480121 & 688546 & 5.0 & 5.529 & TRN & \\
\hline CHEMBL1427636 & 688546 & 5.2 & 5.3952 & TST & \\
\hline CHEMBL1354584 & 688546 & 5.1 & 4.9858 & TRN & \\
\hline CHEMBL1316778 & 688546 & 5.65 & 5.2896 & TST & \\
\hline CHEMBL1443872 & 688546 & 4.5 & 5.3041 & TST & \\
\hline CHEMBL1338747 & 688546 & 4.6 & 5.0594 & TST & \\
\hline CHEMBL1430185 & 688546 & 4.5 & 5.3116 & TST & \\
\hline CHEMBL1554531 & 688546 & 4.5 & 5.1916 & TST & \\
\hline CHEMBL1367058 & 688546 & 4.45 & 5.6939 & TST & \\
\hline CHEMBL1520107 & 688546 & 4.9 & 5.3274 & TRN & \\
\hline CHEMBL1476025 & 688546 & 4.9 & 5.1547 & TRN & \\
\hline CHEMBL1555202 & 688546 & 8.3468 & 5.6754 & TRN & \\
\hline CHEMBL1375686 & 688546 & 4.65 & 5.88399 & 99999999995 & TRN \\
\hline CHEMBL1358167 & 688546 & 5.4 & 5.1292 & TRN & \\
\hline CHEMBL1529386 & 688546 & 5.0 & 5.2716 & TST & \\
\hline CHEMBL1364477 & 688546 & 4.6 & 5.0747 & TRN & \\
\hline CHEMBL1491757 & 688546 & 4.7 & 5.2788 & TRN & \\
\hline CHEMBL1535698 & 688546 & 6.0 & 5.6704 & TST & \\
\hline CHEMBL1444259 & 688546 & 5.3 & 5.6186 & TRN & \\
\hline CHEMBL1354461 & 688546 & 5.9 & 5.6003 & TST & \\
\hline CHEMBL1523199 & 688546 & 5.0 & 5.0992 & TRN & \\
\hline CHEMBL1402424 & 688546 & 4.8 & 5.7517 & TRN & \\
\hline CHEMBL1314036 & 688546 & 4.9 & 4.6691 & TRN & \\
\hline CHEMBL1600438 & 688546 & 4.5 & 5.0415 & TRN & \\
\hline CHEMBL3195088 & 688546 & 6.8499 & 5.1697 & TRN & \\
\hline CHEMBL1355387 & 688546 & 4.9 & 5.0113 & TRN & \\
\hline CHEMBL1608086 & 688546 & 4.9 & 5.1536 & TRN & \\
\hline CHEMBL1436024 & 688546 & 5.0 & 4.842 & TRN & \\
\hline CHEMBL1567494 & 688546 & 8.0 & 4.9748 & TRN & \\
\hline
\end{tabular}




\begin{tabular}{|c|c|c|c|c|c|}
\hline \multicolumn{6}{|c|}{ Supplemental Table S2.txt } \\
\hline CHEMBL1502502 & 688546 & 5.2 & 5.1632 & TST & \\
\hline CHEMBL1356311 & 688546 & 4.5 & 5.8949 & TRN & \\
\hline CHEMBL1441375 & 688546 & 5.4 & 4.8617 & TRN & \\
\hline CHEMBL1413906 & 688546 & 7.699 & 5.7912 & TRN & \\
\hline CHEMBL1499120 & 688546 & 4.5 & 5.2437 & TST & \\
\hline CHEMBL1590010 & 688546 & 5.0 & 5.0415 & TRN & \\
\hline CHEMBL1474836 & 688546 & 5.6 & 5.46 & TRN & \\
\hline CHEMBL1480233 & 688546 & 4.6 & 5.1204 & TRN & \\
\hline CHEMBL1493921 & 688546 & 5.2 & 4.8875 & TST & \\
\hline CHEMBL1529961 & 688546 & 6.45 & 5.9542 & TRN & \\
\hline CHEMBL1395190 & 688546 & 4.6 & 5.3947 & TST & \\
\hline CHEMBL1526022 & 688546 & 4.45 & 5.2964 & TST & \\
\hline CHEMBL1397133 & 688546 & 7.3002 & 5.0935 & TST & \\
\hline CHEMBL1416737 & 688546 & 4.9 & $5.2410 e$ & 00000000005 & TRN \\
\hline CHEMBL1358526 & 688546 & 4.7 & 5.3634 & TRN & \\
\hline CHEMBL1600827 & 688546 & 5.9 & 5.27 & TRN & \\
\hline CHEMBL1608213 & 688546 & 5.4 & 5.5317 & TRN & \\
\hline CHEMBL1611962 & 688546 & 4.9 & 5.71 & TRN & \\
\hline CHEMBL1474109 & 688546 & 4.6 & 5.2314 & TST & \\
\hline CHEMBL1494103 & 688546 & 5.7 & 5.8741 & TRN & \\
\hline CHEMBL1459538 & 688546 & 4.9 & 4.8689 & TRN & \\
\hline CHEMBL1529007 & 688546 & 5.5 & 5.1754 & TRN & \\
\hline CHEMBL1442632 & 688546 & 5.1 & 5.0487 & TRN & \\
\hline CHEMBL1613327 & 688546 & 4.5 & 4.7295 & TRN & \\
\hline CHEMBL1377592 & 688546 & 4.5 & 4.8641 & TRN & \\
\hline CHEMBL1589870 & 688546 & 6.4 & 5.3453 & TRN & \\
\hline CHEMBL1363920 & 688546 & 4.5 & 4.8653 & TRN & \\
\hline CHEMBL405914 & 688546 & 6.2 & 5.1734 & TRN & \\
\hline CHEMBL1474721 & 688546 & 6.8 & 5.5886 & TRN & \\
\hline CHEMBL1491139 & 688546 & 4.5 & 6.1707 & TRN & \\
\hline CHEMBL1256737 & 688546 & 6.0 & 5.5661 & TRN & \\
\hline CHEMBL1338106 & 688546 & 5.3 & 5.5607 & TRN & \\
\hline CHEMBL1325133 & 688546 & 7.0 & 4.9716 & TST & \\
\hline CHEMBL1357146 & 688546 & 5.1 & 5.6468 & TST & \\
\hline CHEMBL1315118 & 688546 & 7.4001 & 4.83899 & 99999999995 & TST \\
\hline CHEMBL1555658 & 688546 & 4.5 & 4.8766 & TST & \\
\hline CHEMBL1478870 & 688546 & 5.5 & 4.7553 & TRN & \\
\hline CHEMBL1400530 & 688546 & 4.9 & 5.6802 & TRN & \\
\hline CHEMBL1554330 & 688546 & 7.1002 & 5.664 & TRN & \\
\hline CHEMBL1551733 & 688546 & 7.8996 & 5.9155 & TRN & \\
\hline CHEMBL1517068 & 688546 & 4.9 & 5.3449 & TRN & \\
\hline CHEMBL1557282 & 688546 & 5.1 & 5.6494 & TRN & \\
\hline CHEMBL1357058 & 688546 & 4.9 & 5.3106 & TRN & \\
\hline CHEMBL1516145 & 688546 & 4.8 & 5.9364 & TRN & \\
\hline CHEMBL1407912 & 688546 & 4.5 & 4.87 & TST & \\
\hline CHEMBL1515876 & 688546 & 5.5 & 5.4652 & TRN & \\
\hline CHEMBL1361722 & 688546 & 4.8 & 5.4889 & TRN & \\
\hline CHEMBL1475293 & 688546 & 6.0 & 5.4759 & TRN & \\
\hline
\end{tabular}




\begin{tabular}{|c|c|c|c|c|c|}
\hline \multicolumn{6}{|c|}{ Supplemental Table s2.txt } \\
\hline CHEMBL1300243 & 688546 & 4.65 & 5.5024 & TST & \\
\hline CHEMBL1591740 & 688546 & 5.1 & 4.9393 & TRN & \\
\hline CHEMBL1526910 & 688546 & 5.0 & 4.882 & TRN & \\
\hline CHEMBL1355043 & 688546 & 4.7 & 5.1983 & TRN & \\
\hline CHEMBL1396946 & 688546 & 4.5 & 5.0418 & TRN & \\
\hline CHEMBL1367616 & 688546 & 4.8 & 4.9676 & TRN & \\
\hline CHEMBL1443596 & 688546 & 5.5 & 5.1451 & TRN & \\
\hline CHEMBL1434517 & 688546 & 4.9 & 5.4042 & TRN & \\
\hline CHEMBL1472959 & 688546 & 4.9 & 5.2567 & TRN & \\
\hline CHEMBL1595820 & 688546 & 5.6 & 5.5832 & TRN & \\
\hline CHEMBL1561654 & 688546 & 6.1 & 5.4396 & TST & \\
\hline CHEMBL1395425 & 688546 & 4.9 & 5.3252 & TRN & \\
\hline CHEMBL1603878 & 688546 & 4.9 & 5.218 & TRN & \\
\hline CHEMBL1369164 & 688546 & 7.1002 & 5.7859 & TRN & \\
\hline CHEMBL1475403 & 688546 & 6.9 & 5.1752 & TRN & \\
\hline CHEMBL1314816 & 688546 & 4.7 & 5.5683 & TRN & \\
\hline CHEMBL1409486 & 688546 & 4.7 & 4.6265 & TRN & \\
\hline CHEMBL1365608 & 688546 & 4.7 & 5.2171 & TST & \\
\hline CHEMBL1377385 & 688546 & 4.7 & 5.3248 & TRN & \\
\hline CHEMBL1511983 & 688546 & 4.5 & 5.3563 & TRN & \\
\hline CHEMBL1453210 & 688546 & 4.5 & 4.7687 & TST & \\
\hline CHEMBL1530521 & 688546 & 4.5 & 4.8485 & TRN & \\
\hline CHEMBL1476493 & 688546 & 4.5 & 5.4186 & TRN & \\
\hline CHEMBL1524464 & 688546 & 7.6498 & 5.1408 & TST & \\
\hline CHEMBL1590932 & 688546 & 5.35 & 5.669 & TRN & \\
\hline CHEMBL1332382 & 688546 & 5.0 & 5.6048 & TRN & \\
\hline CHEMBL1569671 & 688546 & 4.9 & 5.0186 & TRN & \\
\hline CHEMBL582444 & 688546 & 4.9 & 5.1764 & TST & \\
\hline CHEMBL1398899 & 688546 & 4.5 & 4.9598 & TRN & \\
\hline CHEMBL1323981 & 688546 & 5.25 & 4.74100 & 00000000005 & TST \\
\hline CHEMBL1397994 & 688546 & 5.3 & 5.9304 & TST & \\
\hline CHEMBL1412163 & 688546 & 4.5 & 5.4153 & TST & \\
\hline CHEMBL1400406 & 688546 & 4.9 & 5.2611 & TRN & \\
\hline CHEMBL1499536 & 688546 & 4.8 & 5.1921 & TST & \\
\hline CHEMBL1515564 & 688546 & 6.7501 & 5.407 & TRN & \\
\hline CHEMBL1370731 & 688546 & 4.9 & 5.4826 & TRN & \\
\hline CHEMBL1304996 & 688546 & 5.15 & 5.6744 & TRN & \\
\hline CHEMBL1404107 & 688546 & 5.0 & 4.9179 & TRN & \\
\hline CHEMBL1328077 & 688546 & 5.9 & 5.1187 & TRN & \\
\hline CHEMBL1379297 & 688546 & 4.5 & 5.1267 & TRN & \\
\hline CHEMBL1317606 & 688546 & 4.5 & 5.711 & TRN & \\
\hline CHEMBL1401550 & 688546 & 4.95 & 5.7267 & TST & \\
\hline CHEMBL1515854 & 688546 & 4.7 & 5.5296 & TRN & \\
\hline CHEMBL66654 & 688546 & 6.0 & 5.4314 & TST & \\
\hline CHEMBL1327335 & 688546 & 4.9 & 4.7931 & TRN & \\
\hline CHEMBL1420935 & 688546 & 5.4 & 5.0753 & TST & \\
\hline CHEMBL1577389 & 688546 & 4.8 & 5.2392 & TST & \\
\hline CHEMBL1509206 & 688546 & 6.1 & 5.4052 & TST & \\
\hline
\end{tabular}




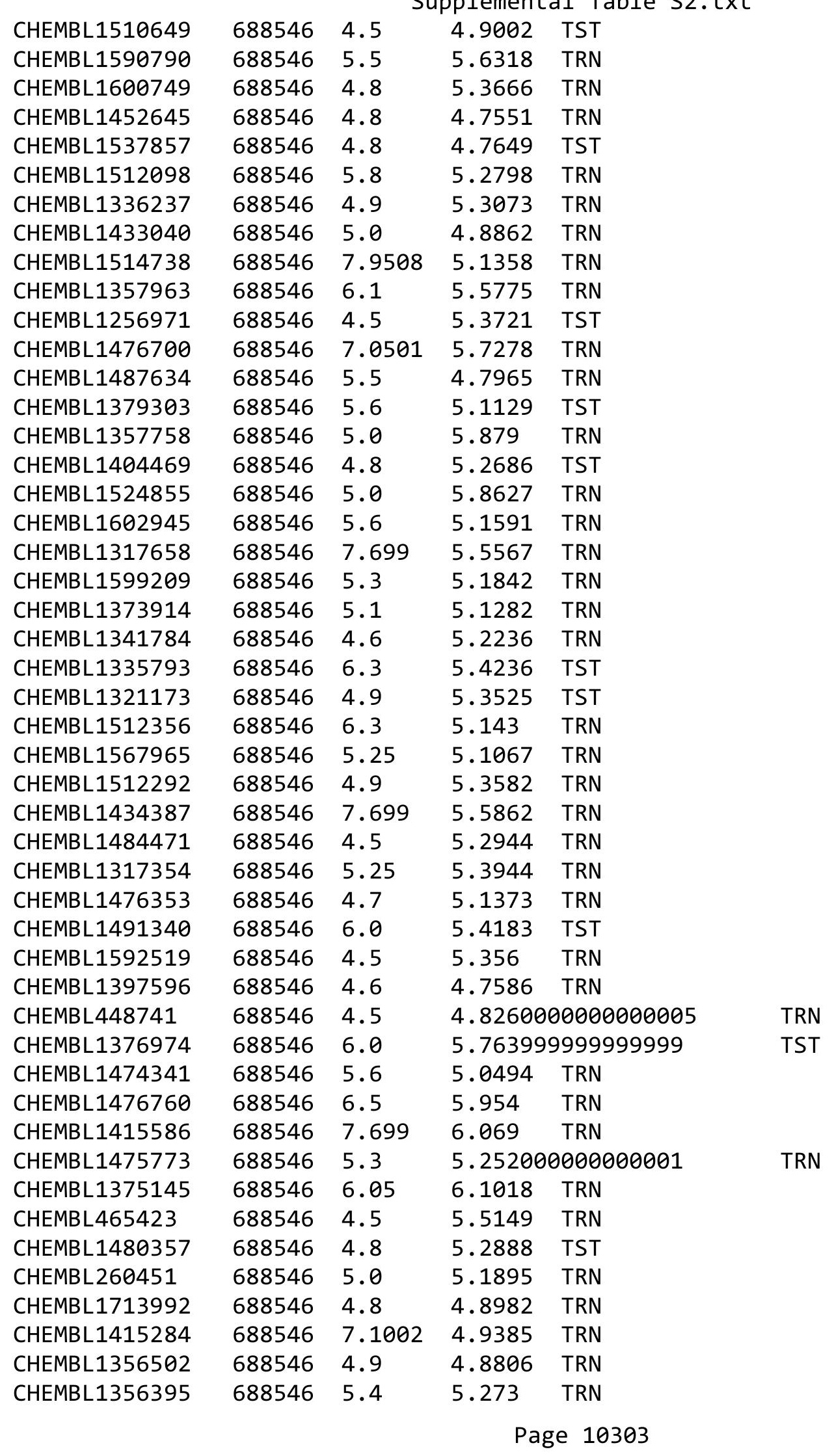




\begin{tabular}{|c|c|c|c|c|}
\hline \multicolumn{5}{|c|}{ Supplemental Ta } \\
\hline CHEMBL1316318 & 688546 & 6.9 & 5.6818 & TRN \\
\hline CHEMBL 269550 & 688546 & 4.8 & 5.11 & TST \\
\hline CHEMBL1356623 & 688546 & 5.2 & 5.1881 & TST \\
\hline CHEMBL1583874 & 688546 & 4.5 & 4.8259 & TST \\
\hline CHEMBL1587744 & 688546 & 5.0 & 5.2059 & TRN \\
\hline CHEMBL1357081 & 688546 & 4.5 & 5.1143 & TRN \\
\hline CHEMBL1347526 & 688546 & 5.9 & 5.3516 & TRN \\
\hline CHEMBL1551592 & 688546 & 5.0 & 5.1807 & TRN \\
\hline CHEMBL1424816 & 688546 & 4.5 & 5.1944 & TST \\
\hline CHEMBL1544371 & 688546 & 5.6 & 5.1991 & TRN \\
\hline CHEMBL1354859 & 688546 & 5.2 & 5.0809 & TRN \\
\hline CHEMBL1574027 & 688546 & 5.3 & 5.2346 & TRN \\
\hline CHEMBL1535951 & 688546 & 5.0 & 5.0541 & TRN \\
\hline CHEMBL 283196 & 688546 & 4.5 & 5.2295 & TRN \\
\hline CHEMBL16685 & 688546 & 5.1 & 5.0741 & TRN \\
\hline CHEMBL1326299 & 688546 & 4.9 & 5.0137 & TRN \\
\hline CHEMBL1565416 & 688546 & 4.9 & 5.088 & TRN \\
\hline CHEMBL1498199 & 688546 & 5.65 & 5.4699 & TRN \\
\hline CHEMBL1484559 & 688546 & 4.9 & 5.1749 & TRN \\
\hline CHEMBL1313919 & 688546 & 5.35 & 5.0401 & TRN \\
\hline CHEMBL1420598 & 688546 & 4.7 & 5.37 & TRN \\
\hline CHEMBL1361514 & 688546 & 4.9 & 5.0097 & TRN \\
\hline CHEMBL1433452 & 688546 & 4.9 & 5.1772 & TRN \\
\hline CHEMBL1520796 & 688546 & 5.3 & 5.4559 & TRN \\
\hline CHEMBL1445316 & 688546 & 4.9 & 5.066 & TRN \\
\hline CHEMBL1565524 & 688546 & 4.5 & 5.3963 & TRN \\
\hline CHEMBL 300814 & 688546 & 5.7 & 4.9348 & TRN \\
\hline CHEMBL1415719 & 688546 & 4.5 & 5.1331 & TRN \\
\hline CHEMBL1592767 & 688546 & 5.7 & 5.204 & TRN \\
\hline CHEMBL1472671 & 688546 & 4.5 & 5.767 & TST \\
\hline CHEMBL1591209 & 688546 & 4.5 & 5.3586 & TRN \\
\hline CHEMBL1554595 & 688546 & 7.8013 & 5.585 & TRN \\
\hline CHEMBL1343219 & 688546 & 4.9 & 4.8276 & TRN \\
\hline CHEMBL1598926 & 688546 & 5.4 & 5.6978 & TRN \\
\hline CHEMBL1591652 & 688546 & 6.2 & 5.4825 & TST \\
\hline CHEMBL1427061 & 688546 & 4.8 & 5.3052 & TRN \\
\hline CHEMBL1554756 & 688546 & 4.6 & 4.7166 & TRN \\
\hline CHEMBL1544498 & 688546 & 5.0 & 5.1 & TRN \\
\hline CHEMBL44 & 688546 & 6.0 & 5.3302 & TRN \\
\hline CHEMBL1995040 & 688546 & 8.301 & 5.3999 & TST \\
\hline CHEMBL1335490 & 688546 & 5.0 & 5.1161 & TST \\
\hline CHEMBL 259103 & 688546 & 5.1 & 5.6196 & TRN \\
\hline CHEMBL1344260 & 688546 & 4.9 & 4.5878 & TRN \\
\hline CHEMBL1396983 & 688546 & 5.0 & 5.0809 & TRN \\
\hline CHEMBL1612774 & 688546 & 4.7 & 5.042 & TST \\
\hline CHEMBL1475354 & 688546 & 4.6 & 5.2913 & TRN \\
\hline CHEMBL1520733 & 688546 & 5.2 & 5.2054 & TRN \\
\hline CHEMBL1505212 & 688546 & 4.5 & 4.9906 & TRN \\
\hline
\end{tabular}




\begin{tabular}{|c|c|c|c|c|}
\hline \multicolumn{5}{|c|}{ Supplemental Table s2.txt } \\
\hline CHEMBL1323968 & 688546 & 5.2 & 5.5336 & TRN \\
\hline CHEMBL1360721 & 688546 & 4.9 & 5.6792 & TRN \\
\hline CHEMBL1318160 & 688546 & 8.1024 & 5.1079 & TST \\
\hline CHEMBL 3190400 & 688546 & 5.0 & 5.0912 & TRN \\
\hline CHEMBL1538611 & 688546 & 4.9 & 4.631 & TRN \\
\hline CHEMBL1473664 & 688546 & 5.4 & 5.5198 & TRN \\
\hline CHEMBL1480144 & 688546 & 5.2 & 5.0157 & TRN \\
\hline CHEMBL1441481 & 688546 & 4.9 & 5.11100 & 0000000001 \\
\hline CHEMBL1434798 & 688546 & 5.1 & 5.3361 & TRN \\
\hline CHEMBL1313085 & 688546 & 8.0 & 6.2261 & TRN \\
\hline CHEMBL1552026 & 688546 & 5.9 & 5.5995 & TRN \\
\hline CHEMBL1603527 & 688546 & 5.7 & 6.2227 & TRN \\
\hline CHEMBL1595617 & 688546 & 5.1 & 5.7389 & TST \\
\hline CHEMBL1328648 & 688546 & 4.9 & 5.0534 & TRN \\
\hline CHEMBL1481729 & 688546 & 8.301 & 5.7776 & TRN \\
\hline CHEMBL1605651 & 688546 & 5.25 & 5.0644 & TST \\
\hline CHEMBL1433900 & 688546 & 5.0 & 5.5273 & TST \\
\hline CHEMBL1394895 & 688546 & 4.6 & 4.8075 & TST \\
\hline CHEMBL1530084 & 688546 & 4.9 & 5.2815 & TRN \\
\hline CHEMBL1495399 & 688546 & 5.9 & 5.6479 & TRN \\
\hline CHEMBL1554759 & 688546 & 4.6 & 5.4704 & TRN \\
\hline CHEMBL1609598 & 688546 & 5.05 & 5.8876 & TRN \\
\hline CHEMBL1606564 & 688546 & 4.8 & 5.42 & TRN \\
\hline CHEMBL1591080 & 688546 & 4.8 & 5.0171 & TRN \\
\hline CHEMBL3198496 & 688546 & 5.2 & 5.0388 & TRN \\
\hline CHEMBL1525573 & 688546 & 5.4 & 5.125 & TRN \\
\hline CHEMBL1606953 & 688546 & 8.2518 & 6.0278 & TRN \\
\hline CHEMBL1512889 & 688546 & 5.2 & 5.9562 & TRN \\
\hline CHEMBL1437139 & 688546 & 6.0 & 6.3147 & TRN \\
\hline CHEMBL1434344 & 688546 & 4.8 & 4.9876 & TST \\
\hline CHEMBL1488667 & 688546 & 4.9 & 4.8552 & TRN \\
\hline CHEMBL1336110 & 688546 & 4.5 & 4.9595 & TRN \\
\hline CHEMBL1368181 & 688546 & 4.7 & 4.8055 & TRN \\
\hline CHEMBL1566928 & 688546 & 5.0 & 5.2213 & TRN \\
\hline CHEMBL1359799 & 688546 & 4.5 & 5.5716 & TRN \\
\hline CHEMBL329872 & 688546 & 5.0 & 5.1561 & TRN \\
\hline CHEMBL1608995 & 688546 & 7.3002 & 5.2273 & TRN \\
\hline CHEMBL1377197 & 688546 & 8.0506 & 5.3947 & TST \\
\hline CHEMBL1379136 & 688546 & 4.8 & 4.8159 & TST \\
\hline CHEMBL1533452 & 688546 & 4.5 & 5.2755 & TST \\
\hline CHEMBL1521047 & 688546 & 5.4 & 5.2381 & TST \\
\hline CHEMBL1567823 & 688546 & 5.25 & 5.1109 & TST \\
\hline CHEMBL1390237 & 688546 & 4.8 & 5.0669 & TST \\
\hline CHEMBL1316742 & 688546 & 6.1 & 5.1889 & TRN \\
\hline CHEMBL1520027 & 688546 & 5.0 & 5.5083 & TRN \\
\hline CHEMBL 3195214 & 688546 & 4.45 & 5.7124 & TST \\
\hline CHEMBL1609183 & 688546 & 5.0 & 5.3252 & TST \\
\hline CHEMBL1520170 & 688546 & 6.05 & 5.1737 & TST \\
\hline
\end{tabular}




\begin{tabular}{|c|c|c|c|c|c|}
\hline \multicolumn{6}{|c|}{ Supplemental Table S2.txt } \\
\hline CHEMBL1468355 & 688546 & 5.7 & 5.3796 & TRN & \\
\hline CHEMBL1355474 & 688546 & 4.7 & 5.0284 & TST & \\
\hline CHEMBL1366227 & 688546 & 5.5 & 5.5573 & TRN & \\
\hline CHEMBL1533253 & 688546 & 6.1 & 5.7852 & TRN & \\
\hline CHEMBL1332052 & 688546 & 5.2 & 5.7171 & TRN & \\
\hline CHEMBL1344123 & 688546 & 5.2 & 5.3248 & TRN & \\
\hline CHEMBL1326949 & 688546 & 4.6 & 5.2857 & TRN & \\
\hline CHEMBL1612191 & 688546 & 4.5 & 5.1929 & TRN & \\
\hline CHEMBL1347477 & 688546 & 5.7 & 5.2644 & TRN & \\
\hline CHEMBL1592036 & 688546 & 4.6 & 6.1074 & TRN & \\
\hline CHEMBL1511042 & 688546 & 4.7 & 5.4214 & TRN & \\
\hline CHEMBL1407870 & 688546 & 5.9 & 5.6278 & TRN & \\
\hline CHEMBL1561059 & 688546 & 4.6 & \multicolumn{2}{|c|}{5.127000000000001} & TRN \\
\hline CHEMBL1590850 & 688546 & 5.55 & 5.3054 & TRN & \\
\hline CHEMBL1370834 & 688546 & 4.8 & 5.1419 & TST & \\
\hline CHEMBL1394749 & 688546 & 5.9 & 5.6736 & TST & \\
\hline CHEMBL1358227 & 688546 & 6.8 & 5.7628 & TRN & \\
\hline CHEMBL1326968 & 688546 & 4.6 & 5.2498 & TRN & \\
\hline CHEMBL1592596 & 688546 & 5.0 & 5.2356 & TST & \\
\hline CHEMBL1315373 & 688546 & 4.9 & 4.6744 & TRN & \\
\hline CHEMBL1355543 & 688546 & 4.9 & 5.1174 & TRN & \\
\hline CHEMBL1324999 & 688546 & 4.8 & 5.0545 & TRN & \\
\hline CHEMBL1329382 & 688546 & 4.9 & 4.8863 & TRN & \\
\hline CHEMBL1601672 & 688546 & 5.0 & 5.3103 & TRN & \\
\hline CHEMBL1595464 & 688546 & 6.1 & 5.5403 & TRN & \\
\hline CHEMBL1373821 & 688546 & 4.8 & 5.0323 & TST & \\
\hline CHEMBL1365810 & 688546 & 4.8 & 5.0109 & TRN & \\
\hline CHEMBL1590360 & 688546 & 4.9 & 5.0489 & TRN & \\
\hline CHEMBL1316015 & 688546 & 5.45 & 5.0458 & TRN & \\
\hline CHEMBL1430757 & 688546 & 4.9 & 5.3334 & TST & \\
\hline CHEMBL1514565 & 688546 & 5.7 & 5.2726 & TRN & \\
\hline CHEMBL1442167 & 688546 & 4.5 & 4.8688 & TRN & \\
\hline CHEMBL1475102 & 688546 & 4.5 & 5.0296 & TST & \\
\hline CHEMBL1397487 & 688546 & 4.6 & 5.1067 & TRN & \\
\hline CHEMBL1520957 & 688546 & 4.5 & 5.3908 & TRN & \\
\hline CHEMBL1389089 & 688546 & 5.25 & 5.2665 & TST & \\
\hline CHEMBL1594867 & 688546 & 4.9 & 5.0554 & TRN & \\
\hline CHEMBL601180 & 688546 & 4.5 & 4.7533 & TRN & \\
\hline CHEMBL1354848 & 688546 & 5.1 & 5.1941 & TRN & \\
\hline CHEMBL1356677 & 688546 & 5.0 & 5.2609 & TRN & \\
\hline CHEMBL1366805 & 688546 & 6.2 & 5.4227 & TRN & \\
\hline CHEMBL1437159 & 688546 & 4.7 & 4.868 & TRN & \\
\hline CHEMBL1477241 & 688546 & 4.45 & 5.1593 & TST & \\
\hline CHEMBL1447831 & 688546 & 5.0 & 5.3998 & TRN & \\
\hline CHEMBL1558361 & 688546 & 4.7 & 5.0676 & TRN & \\
\hline CHEMBL1423635 & 688546 & 5.1 & 5.0905 & TRN & \\
\hline CHEMBL1348758 & 688546 & 8.0 & $5.0710 e$ & 0000000001 & TST \\
\hline CHEMBL1366312 & 688546 & 5.85 & 5.3805 & TRN & \\
\hline
\end{tabular}




\begin{tabular}{|c|c|c|c|c|c|}
\hline \\
\hline CHEMBL1381328 & 688546 & 5.7 & 5.2522 & TRN & \\
\hline CHEMBL1564644 & 688546 & 5.7 & 6.0104 & TRN & \\
\hline CHEMBL1590642 & 688546 & 5.0 & 5.2085 & TRN & \\
\hline CHEMBL1302953 & 688546 & 4.9 & 4.8497 & TRN & \\
\hline CHEMBL1436810 & 688546 & 5.0 & 4.9132 & TRN & \\
\hline CHEMBL1597911 & 688546 & 4.6 & 5.1104 & TST & \\
\hline CHEMBL1515968 & 688546 & 6.6 & 5.1699 & TRN & \\
\hline CHEMBL1494309 & 688546 & 5.0 & 4.9624 & TRN & \\
\hline CHEMBL1569127 & 688546 & 4.5 & 5.6307 & TRN & \\
\hline CHEMBL1559897 & 688546 & 7.6003 & 5.4154 & TRN & \\
\hline CHEMBL1595336 & 688546 & 4.9 & 5.2861 & TRN & \\
\hline CHEMBL1400882 & 688546 & 8.1024 & 5.9156 & TRN & \\
\hline CHEMBL1357949 & 688546 & 4.6 & 5.7362 & TRN & \\
\hline CHEMBL1394997 & 688546 & 5.8 & 5.142 & TRN & \\
\hline CHEMBL1318197 & 688546 & 4.7 & 5.2106 & TRN & \\
\hline CHEMBL1365845 & 688546 & 7.699 & 5.6356 & TRN & \\
\hline CHEMBL1612427 & 688546 & 5.4 & 5.7026 & TRN & \\
\hline CHEMBL15192 & 688546 & 5.3 & 5.369 & TST & \\
\hline CHEMBL1472799 & 688546 & 4.9 & 5.0451 & TRN & \\
\hline CHEMBL1314574 & 688546 & 4.5 & 5.5041 & TRN & \\
\hline CHEMBL1555219 & 688546 & 4.6 & 4.8891 & TST & \\
\hline CHEMBL1418703 & 688546 & 4.6 & 4.8654 & TRN & \\
\hline CHEMBL1390641 & 688546 & 4.8 & 5.2921 & TRN & \\
\hline CHEMBL1401530 & 688546 & 4.7 & 4.894 & TRN & \\
\hline CHEMBL1315389 & 688546 & 5.9 & 4.8343 & TRN & \\
\hline CHEMBL1323768 & 688546 & 4.5 & 5.0235 & TRN & \\
\hline CHEMBL1526649 & 688546 & 4.6 & 5.223 & TRN & \\
\hline CHEMBL1345505 & 688546 & 5.2 & 5.1149 & TRN & \\
\hline CHEMBL1456370 & 688546 & 5.3 & 5.73799 & 99999999995 & TRN \\
\hline CHEMBL3190720 & 688546 & 4.8 & 5.005 & TRN & \\
\hline CHEMBL1514449 & 688546 & 4.65 & 5.1133 & TRN & \\
\hline CHEMBL1307284 & 688546 & 4.6 & 5.6409 & TRN & \\
\hline CHEMBL3392072 & 688546 & 4.9 & 4.9858 & TRN & \\
\hline CHEMBL1476249 & 688546 & 6.6 & 5.3598 & TRN & \\
\hline CHEMBL1610343 & 688546 & 5.0 & 5.3205 & TST & \\
\hline CHEMBL1362096 & 688546 & 4.5 & 4.9738 & TST & \\
\hline CHEMBL1355518 & 688546 & 4.5 & 5.439 & TRN & \\
\hline CHEMBL1318909 & 688546 & 4.5 & 5.1074 & TRN & \\
\hline CHEMBL1527303 & 688546 & 4.5 & 5.1138 & TST & \\
\hline CHEMBL1312587 & 688546 & 4.5 & 5.50799 & 9999999999 & TST \\
\hline CHEMBL1341543 & 688546 & 4.9 & 5.2607 & TRN & \\
\hline CHEMBL1317058 & 688546 & 4.9 & 5.1418 & TRN & \\
\hline CHEMBL1407162 & 688546 & 4.9 & 5.532 & TST & \\
\hline CHEMBL1457402 & 688546 & 4.7 & 4.9051 & TRN & \\
\hline CHEMBL1592463 & 688546 & 5.2 & 5.603 & TRN & \\
\hline CHEMBL1485067 & 688546 & 5.95 & 5.10800 & 00000000005 & TST \\
\hline CHEMBL1369051 & 688546 & 6.2 & 5.7833 & TRN & \\
\hline CHEMBL1475163 & 688546 & 4.8 & 5.4014 & TRN & \\
\hline
\end{tabular}




\begin{tabular}{|c|c|c|c|c|c|}
\hline \\
\hline CHEMBL1410610 & 688546 & 4.9 & 5.5994 & TRN & \\
\hline CHEMBL1476260 & 688546 & 5.7 & 5.5517 & TRN & \\
\hline CHEMBL1363938 & 688546 & 5.0 & 5.2569 & TRN & \\
\hline CHEMBL1328464 & 688546 & 5.25 & 5.6066 & TRN & \\
\hline CHEMBL1540318 & 688546 & 7.5003 & 5.3189 & TST & \\
\hline CHEMBL1492655 & 688546 & 4.9 & 5.0662 & TRN & \\
\hline CHEMBL1479369 & 688546 & 5.35 & 5.23799 & 99999999995 & TRN \\
\hline CHEMBL1414154 & 688546 & 4.4 & 4.9414 & TRN & \\
\hline CHEMBL 242385 & 688546 & 4.9 & 5.1252 & TRN & \\
\hline CHEMBL1320457 & 688546 & 4.6 & 5.2152 & TRN & \\
\hline CHEMBL1411570 & 688546 & 4.8 & 4.8481 & TRN & \\
\hline CHEMBL1394226 & 688546 & 4.5 & 5.0127 & TRN & \\
\hline CHEMBL1598907 & 688546 & 4.8 & 5.0635 & TST & \\
\hline CHEMBL1474472 & 688546 & 8.0 & 6.0286 & TRN & \\
\hline CHEMBL1363964 & 688546 & 7.3002 & 5.6638 & TRN & \\
\hline CHEMBL1339310 & 688546 & 4.7 & 5.0463 & TRN & \\
\hline CHEMBL1343612 & 688546 & 5.0 & 5.1573 & TST & \\
\hline CHEMBL1514543 & 688546 & 8.301 & 5.6465 & TRN & \\
\hline CHEMBL1360267 & 688546 & 4.9 & 5.7653 & TST & \\
\hline CHEMBL1434173 & 688546 & 7.1002 & 5.4604 & TST & \\
\hline CHEMBL1526115 & 688546 & 4.8 & 5.8079 & TST & \\
\hline CHEMBL1611027 & 688546 & 4.8 & 5.3567 & TRN & \\
\hline CHEMBL1540894 & 688546 & 4.8 & 5.1053 & TRN & \\
\hline CHEMBL1598419 & 688546 & 4.9 & 5.0792 & TRN & \\
\hline CHEMBL1590446 & 688546 & 4.5 & 5.0833 & TRN & \\
\hline CHEMBL264931 & 688546 & 5.3 & 5.9257 & TST & \\
\hline CHEMBL1483098 & 688546 & 7.8996 & 5.3244 & TST & \\
\hline CHEMBL1437245 & 688546 & 4.6 & 4.9412 & TRN & \\
\hline CHEMBL1369731 & 688546 & 4.9 & 5.1117 & TRN & \\
\hline CHEMBL1359288 & 688546 & 6.2 & 5.2456 & TRN & \\
\hline CHEMBL1512875 & 688546 & 6.1 & 5.3542 & TRN & \\
\hline CHEMBL1361681 & 688546 & 4.8 & 5.0928 & TRN & \\
\hline CHEMBL374632 & 688546 & 6.4 & 5.5236 & TRN & \\
\hline CHEMBL1463580 & 688546 & 5.8 & 5.7031 & TST & \\
\hline CHEMBL1437846 & 688546 & 4.5 & 5.5831 & TRN & \\
\hline CHEMBL1429775 & 688546 & 4.7 & 5.0527 & TRN & \\
\hline CHEMBL1551835 & 688546 & 4.9 & 4.8332 & TRN & \\
\hline CHEMBL1321812 & 688546 & 7.699 & 5.3296 & TRN & \\
\hline CHEMBL1409580 & 688546 & 5.1 & 5.3505 & TRN & \\
\hline CHEMBL1334699 & 688546 & 4.8 & 5.0858 & TRN & \\
\hline CHEMBL1376305 & 688546 & 6.9 & 5.0495 & TST & \\
\hline CHEMBL1475763 & 688546 & 4.9 & 5.4244 & TRN & \\
\hline CHEMBL605077 & 688546 & 4.5 & 5.1775 & TST & \\
\hline CHEMBL1501898 & 688546 & 4.6 & 5.0441 & TST & \\
\hline CHEMBL1316734 & 688546 & 7.8996 & 5.2104 & TRN & \\
\hline CHEMBL1410911 & 688546 & 4.5 & 6.278 & TRN & \\
\hline CHEMBL1593600 & 688546 & 5.0 & 5.4734 & TRN & \\
\hline CHEMBL1455646 & 688546 & 4.85 & 4.7495 & TRN & \\
\hline
\end{tabular}




\begin{tabular}{|c|c|c|c|c|c|}
\hline \multicolumn{6}{|c|}{ Supplemental Table S2.txt } \\
\hline CHEMBL1369535 & 688546 & 5.1 & 6.1802 & TRN & \\
\hline CHEMBL1437468 & 688546 & 7.3002 & 5.4458 & TST & \\
\hline CHEMBL1586428 & 688546 & 6.6 & 5.5179 & TRN & \\
\hline CHEMBL1467999 & 688546 & 4.7 & 5.1088 & TRN & \\
\hline CHEMBL1482509 & 688546 & 4.8 & 5.7062 & TRN & \\
\hline CHEMBL1395245 & 688546 & 4.7 & 5.5754 & TRN & \\
\hline CHEMBL1473991 & 688546 & 4.6 & 5.6814 & TRN & \\
\hline CHEMBL1593510 & 688546 & 5.5 & 5.431 & TRN & \\
\hline CHEMBL1442840 & 688546 & 5.0 & 5.1329 & TST & \\
\hline CHEMBL1397914 & 688546 & 4.8 & 4.8371 & TRN & \\
\hline CHEMBL1473047 & 688546 & 8.301 & 5.2784 & TRN & \\
\hline CHEMBL1548014 & 688546 & 4.7 & $4.9060 e$ & 0000000001 & TRN \\
\hline CHEMBL1597836 & 688546 & 4.8 & 4.8641 & TRN & \\
\hline CHEMBL1570590 & 688546 & 4.8 & 5.4024 & TST & \\
\hline CHEMBL1317110 & 688546 & 4.5 & 5.4823 & TST & \\
\hline CHEMBL1476629 & 688546 & 5.0 & 5.426 & TRN & \\
\hline CHEMBL1316329 & 688546 & 6.6 & 5.2579 & TRN & \\
\hline CHEMBL1316849 & 688546 & 6.1 & 4.9221 & TST & \\
\hline CHEMBL1354845 & 688546 & 4.5 & $5.3670 e$ & 0000000001 & TRN \\
\hline CHEMBL1591988 & 688546 & 6.8 & 5.3345 & TST & \\
\hline CHEMBL1515160 & 688546 & 4.6 & 4.7923 & TRN & \\
\hline CHEMBL1317977 & 688546 & 4.5 & 5.409 & TRN & \\
\hline CHEMBL1405898 & 688546 & 5.0 & 5.4632 & TRN & \\
\hline CHEMBL1437729 & 688546 & 4.8 & 5.3364 & TRN & \\
\hline CHEMBL1552471 & 688546 & 5.4 & 5.655 & TRN & \\
\hline CHEMBL1370437 & 688546 & 5.1 & 5.0556 & TST & \\
\hline CHEMBL1397311 & 688546 & 5.6 & 5.6192 & TRN & \\
\hline CHEMBL1369358 & 688546 & 4.9 & 4.7519 & TST & \\
\hline CHEMBL1599417 & 688546 & 7.6003 & 6.2236 & TRN & \\
\hline CHEMBL1318421 & 688546 & 5.5 & 5.2665 & TST & \\
\hline CHEMBL1460264 & 688546 & 5.5 & 5.3855 & TST & \\
\hline CHEMBL1398551 & 688546 & 4.9 & 5.5157 & TRN & \\
\hline CHEMBL20377 & 688546 & 4.6 & 4.9575 & TRN & \\
\hline CHEMBL1563583 & 688546 & 4.9 & 5.3407 & TRN & \\
\hline CHEMBL1487030 & 688546 & 8.0 & 5.4981 & TRN & \\
\hline CHEMBL1531920 & 688546 & 5.3 & 4.931 & TRN & \\
\hline CHEMBL1487886 & 688546 & 5.6 & 5.1445 & TRN & \\
\hline CHEMBL1316868 & 688546 & 4.5 & 5.6753 & TRN & \\
\hline CHEMBL1438512 & 688546 & 5.1 & 5.1637 & TRN & \\
\hline CHEMBL1080861 & 688546 & 4.9 & 5.4283 & TST & \\
\hline CHEMBL567175 & 688546 & 4.7 & 4.7774 & TRN & \\
\hline CHEMBL1344582 & 688546 & 5.0 & 5.4104 & TRN & \\
\hline CHEMBL1599909 & 688546 & 4.5 & 5.683 & TRN & \\
\hline CHEMBL1592161 & 688546 & 5.8 & 5.1884 & TRN & \\
\hline CHEMBL1536041 & 688546 & 5.2 & 4.6249 & TRN & \\
\hline CHEMBL1433703 & 688546 & 4.45 & 4.9128 & TRN & \\
\hline CHEMBL24983 & 688546 & 4.9 & 5.0224 & TST & \\
\hline CHEMBL1478339 & 688546 & 5.0 & 5.1764 & TRN & \\
\hline
\end{tabular}




\begin{tabular}{|c|c|c|c|c|}
\hline \multicolumn{5}{|c|}{ Supplemental Table S2.txt } \\
\hline CHEMBL1437677 & 688546 & 4.8 & 4.745 & TRN \\
\hline CHEMBL1546139 & 688546 & 4.45 & 5.1471 & TST \\
\hline CHEMBL1607122 & 688546 & 4.6 & 5.1893 & TRN \\
\hline CHEMBL1434397 & 688546 & 6.1 & 4.9819 & TRN \\
\hline CHEMBL1436339 & 688546 & 4.5 & 5.6528 & TRN \\
\hline CHEMBL1436597 & 688546 & 7.9508 & 6.1636 & TRN \\
\hline CHEMBL1324486 & 688546 & 4.9 & 4.9793 & TRN \\
\hline CHEMBL1442799 & 688546 & 4.9 & 5.8691 & TRN \\
\hline CHEMBL1256654 & 688546 & 5.4 & 5.1669 & TST \\
\hline CHEMBL1338463 & 688546 & 5.1 & 5.0957 & TRN \\
\hline CHEMBL1490744 & 688546 & 4.9 & 5.03 & TRN \\
\hline CHEMBL1401242 & 688546 & 4.9 & 4.9862 & TRN \\
\hline CHEMBL1608356 & 688546 & 5.4 & 5.4336 & TRN \\
\hline CHEMBL1452128 & 688546 & 4.8 & 4.877 & TRN \\
\hline CHEMBL1485673 & 688546 & 5.1 & 5.3033 & TRN \\
\hline CHEMBL 235891 & 688546 & 4.7 & 4.7756 & TST \\
\hline CHEMBL1430881 & 688546 & 4.5 & 5.2797 & TST \\
\hline CHEMBL1590327 & 688546 & 5.4 & 5.0018 & TRN \\
\hline CHEMBL1417840 & 688546 & 5.2 & 5.0525 & TRN \\
\hline CHEMBL1562420 & 688546 & 4.9 & 5.4313 & TST \\
\hline CHEMBL1553805 & 688546 & 4.5 & 5.2152 & TST \\
\hline CHEMBL1403908 & 688546 & 5.1 & 5.2327 & TRN \\
\hline CHEMBL1373852 & 688546 & 4.9 & 5.0144 & TRN \\
\hline CHEMBL1435201 & 688546 & 5.7 & 5.7213 & TRN \\
\hline CHEMBL1328778 & 688546 & 5.0 & 4.9915 & TST \\
\hline CHEMBL528712 & 688546 & 4.9 & 4.7512 & TRN \\
\hline CHEMBL1530605 & 688546 & 4.5 & 5.596 & TRN \\
\hline CHEMBL1355522 & 688546 & 7.5003 & 6.6004 & TRN \\
\hline CHEMBL1592148 & 688546 & 8.4949 & 5.2855 & TRN \\
\hline CHEMBL1358264 & 688546 & 4.7 & 4.7337 & TRN \\
\hline CHEMBL1398130 & 688546 & 5.0 & 5.4757 & TRN \\
\hline CHEMBL1559605 & 688546 & 4.9 & 5.1182 & TRN \\
\hline CHEMBL1397450 & 688546 & 5.9 & 4.9555 & TRN \\
\hline CHEMBL1537051 & 688546 & 5.0 & 5.1244 & TRN \\
\hline CHEMBL1554336 & 688546 & 7.8508 & 5.0925 & TST \\
\hline CHEMBL1395156 & 688546 & 5.0 & 5.1455 & TRN \\
\hline CHEMBL1574793 & 688546 & 5.25 & 5.2063 & TST \\
\hline CHEMBL 1355746 & 688546 & 8.3979 & 5.468 & TST \\
\hline CHEMBL1613036 & 688546 & 9.5229 & 5.2024 & TRN \\
\hline CHEMBL1512119 & 688546 & 5.1 & 4.961 & TRN \\
\hline CHEMBL1336439 & 688546 & 6.4 & 4.8268 & TRN \\
\hline CHEMBL 277127 & 688546 & 4.4 & 5.1232 & TST \\
\hline CHEMBL74913 & 688546 & 5.0 & 5.1652 & TRN \\
\hline CHEMBL3208361 & 688546 & 4.6 & 5.1738 & TST \\
\hline CHEMBL1553369 & 688546 & 4.7 & 5.1627 & TRN \\
\hline CHEMBL1357673 & 688546 & 5.0 & 5.0451 & TRN \\
\hline CHEMBL1315535 & 688546 & 4.9 & 4.6661 & TRN \\
\hline CHEMBL1317757 & 688546 & 4.8 & 5.6797 & TRN \\
\hline
\end{tabular}




\begin{tabular}{|c|c|c|c|c|}
\hline \multicolumn{5}{|c|}{ Supplemental Table S2.txt } \\
\hline CHEMBL1474584 & 688546 & 5.0 & 5.2409 & TRN \\
\hline CHEMBL37708 & 688546 & 4.5 & 5.2593 & TST \\
\hline CHEMBL1551594 & 688546 & 4.9 & 5.6175 & TRN \\
\hline CHEMBL1370316 & 688546 & 5.6 & 5.1165 & TRN \\
\hline CHEMBL 1318320 & 688546 & 5.5 & 5.5228 & TRN \\
\hline CHEMBL1447833 & 688546 & 5.0 & 5.0431 & TRN \\
\hline CHEMBL1450263 & 688546 & 4.8 & 4.9804 & TRN \\
\hline CHEMBL1473403 & 688546 & 4.8 & 5.4387 & TRN \\
\hline CHEMBL1481651 & 688546 & 5.3 & 5.0157 & TRN \\
\hline CHEMBL1516537 & 688546 & 5.1 & 5.4499 & TRN \\
\hline CHEMBL1494878 & 688546 & 4.9 & 4.9416 & TST \\
\hline CHEMBL1552653 & 688546 & 7.5003 & 5.9729 & TRN \\
\hline CHEMBL1321178 & 688546 & 5.5 & 5.5201 & TRN \\
\hline CHEMBL1522725 & 688546 & 8.0 & 5.6763 & TRN \\
\hline CHEMBL1348813 & 688546 & 4.5 & 4.9288 & TST \\
\hline CHEMBL1523507 & 688546 & 4.9 & 5.1692 & TRN \\
\hline CHEMBL1528740 & 688546 & 6.4 & 5.6718 & TST \\
\hline CHEMBL1482409 & 688546 & 6.1 & 5.2965 & TST \\
\hline CHEMBL1555531 & 688546 & 5.0 & 5.5799 & TRN \\
\hline CHEMBL1328565 & 688546 & 4.5 & 4.971 & TRN \\
\hline CHEMBL1464620 & 688546 & 4.9 & 5.02 & TST \\
\hline CHEMBL1348608 & 688546 & 4.7 & 5.0969 & TRN \\
\hline CHEMBL1592540 & 688546 & 5.2 & 5.7605 & TRN \\
\hline CHEMBL1315271 & 688546 & 6.2 & 6.0864 & TRN \\
\hline CHEMBL1453741 & 688546 & 5.4 & 5.7514 & TRN \\
\hline CHEMBL1570677 & 688546 & 5.0 & 5.0791 & TRN \\
\hline CHEMBL 225230 & 688546 & 4.6 & 5.3217 & TRN \\
\hline CHEMBL1433752 & 688546 & 4.5 & 4.6406 & TRN \\
\hline CHEMBL1357581 & 688546 & 4.8 & 5.2824 & TRN \\
\hline CHEMBL1311383 & 688546 & 4.45 & 5.2494 & TST \\
\hline CHEMBL1495505 & 688546 & 4.9 & 5.1652 & TRN \\
\hline CHEMBL1367274 & 688546 & 4.6 & 4.5589 & TST \\
\hline CHEMBL1588024 & 688546 & 4.5 & 5.1881 & TRN \\
\hline CHEMBL1324022 & 688546 & 4.9 & 5.0798 & TST \\
\hline CHEMBL14690 & 688546 & 4.7 & 4.9401 & TST \\
\hline CHEMBL586135 & 688546 & 5.9 & 5.0023 & TRN \\
\hline CHEMBL1372686 & 688546 & 4.8 & 5.2324 & TRN \\
\hline CHEMBL1326212 & 688546 & 5.9 & 5.1551 & TRN \\
\hline CHEMBL1476100 & 688546 & 4.8 & 4.856 & TRN \\
\hline CHEMBL1515472 & 688546 & 5.5 & 5.3657 & TRN \\
\hline CHEMBL1316265 & 688546 & 4.5 & 5.1645 & TST \\
\hline CHEMBL1380723 & 688546 & 5.25 & 5.5681 & TRN \\
\hline CHEMBL546257 & 688546 & 6.0 & 5.5376 & TST \\
\hline CHEMBL1395022 & 688546 & 4.5 & 5.2095 & TRN \\
\hline CHEMBL1433343 & 688546 & 4.9 & 5.0749 & TRN \\
\hline CHEMBL1559944 & 688546 & 5.9 & 5.987 & TRN \\
\hline CHEMBL1315319 & 688546 & 4.5 & 5.5685 & TRN \\
\hline CHEMBL1486922 & 688546 & 4.9 & 5.2958 & TRN \\
\hline
\end{tabular}




\begin{tabular}{|c|c|c|c|c|c|}
\hline \multicolumn{6}{|c|}{ Supplemental Table S2.txt } \\
\hline CHEMBL225513 & 688546 & 4.6 & 4.798 & TST & \\
\hline CHEMBL1485544 & 688546 & 4.5 & 5.4549 & TRN & \\
\hline CHEMBL1367121 & 688546 & 5.1 & 5.3675 & TRN & \\
\hline CHEMBL1377867 & 688546 & 4.6 & 5.7064 & TRN & \\
\hline CHEMBL1452842 & 688546 & 4.5 & 4.6993 & TRN & \\
\hline CHEMBL131921 & 688546 & 5.0 & 5.1493 & TRN & \\
\hline CHEMBL1473549 & 688546 & 5.0 & 4.8589 & TRN & \\
\hline CHEMBL1561989 & 688546 & 4.9 & 4.8873 & TRN & \\
\hline CHEMBL1375932 & 688546 & 4.6 & 4.6132 & TST & \\
\hline CHEMBL1472636 & 688546 & 4.85 & 5.0733 & TRN & \\
\hline CHEMBL1582368 & 688546 & 4.8 & 4.8668 & TRN & \\
\hline CHEMBL1394295 & 688546 & 4.7 & 5.3371 & TRN & \\
\hline CHEMBL1592179 & 688546 & 4.7 & 5.3994 & TRN & \\
\hline CHEMBL2369223 & 688546 & 5.0 & 5.3702 & TST & \\
\hline CHEMBL1326785 & 688546 & 4.9 & 5.118 & TRN & \\
\hline CHEMBL1487059 & 688546 & 5.4 & 5.6372 & TRN & \\
\hline CHEMBL1498868 & 688546 & 4.5 & 4.9954 & TRN & \\
\hline CHEMBL1376740 & 688546 & 4.7 & 4.977 & TRN & \\
\hline CHEMBL1446073 & 688546 & 5.4 & 4.9575 & TRN & \\
\hline CHEMBL1312186 & 688546 & 4.9 & 5.24299 & 9999999999 & TST \\
\hline CHEMBL1440902 & 688546 & 4.5 & 4.8014 & TRN & \\
\hline CHEMBL1555006 & 688546 & 4.8 & 5.6685 & TST & \\
\hline CHEMBL1475185 & 688546 & 7.5498 & 5.9323 & TRN & \\
\hline CHEMBL1583496 & 688546 & 4.7 & 5.1048 & TRN & \\
\hline CHEMBL1516282 & 688546 & 4.75 & 5.4624 & TRN & \\
\hline CHEMBL1518592 & 688546 & 5.0 & 5.0345 & TRN & \\
\hline CHEMBL1494536 & 688546 & 4.5 & 5.4485 & TRN & \\
\hline CHEMBL1493184 & 688546 & 4.6 & 5.5632 & TST & \\
\hline CHEMBL1444724 & 688546 & 4.9 & 5.0249 & TRN & \\
\hline CHEMBL1578607 & 688546 & 5.2 & 5.1019 & TRN & \\
\hline CHEMBL1357561 & 688546 & 4.6 & 5.2326 & TRN & \\
\hline CHEMBL1363142 & 688546 & 4.8 & 4.93199 & 99999999995 & TRN \\
\hline CHEMBL1521300 & 688546 & 8.0 & 5.3542 & TRN & \\
\hline CHEMBL1256686 & 688546 & 5.5 & 5.2905 & TST & \\
\hline CHEMBL1541000 & 688546 & 4.8 & 4.9922 & TRN & \\
\hline CHEMBL1321045 & 688546 & 6.5501 & 5.0839 & TRN & \\
\hline CHEMBL1533114 & 688546 & 5.5 & 5.0078 & TRN & \\
\hline CHEMBL1436178 & 688546 & 4.9 & 4.7053 & TRN & \\
\hline CHEMBL1316795 & 688546 & 4.9 & 4.7711 & TRN & \\
\hline CHEMBL1356771 & 688546 & 4.5 & 4.8685 & TRN & \\
\hline CHEMBL1412712 & 688546 & 5.6 & 5.2008 & TRN & \\
\hline CHEMBL1535158 & 688546 & 4.6 & 5.0417 & TRN & \\
\hline CHEMBL1355626 & 688546 & 4.9 & 4.974 & TRN & \\
\hline CHEMBL1357951 & 688546 & 5.0 & 5.2822 & TRN & \\
\hline CHEMBL1608018 & 688546 & 4.9 & 5.2107 & TRN & \\
\hline CHEMBL1465065 & 688546 & 8.4949 & 5.1023 & TST & \\
\hline CHEMBL1552213 & 688546 & 7.8013 & 5.8395 & TRN & \\
\hline CHEMBL1566071 & 688546 & 4.8 & 5.4697 & TRN & \\
\hline
\end{tabular}




\begin{tabular}{|c|c|c|c|c|c|}
\hline & & \\
\hline CHEMBL1303653 & 688546 & 4.5 & 4.5398 & TRN & \\
\hline CHEMBL1356007 & 688546 & 4.95 & 5.5296 & TRN & \\
\hline CHEMBL1363495 & 688546 & 4.6 & 5.5805 & TRN & \\
\hline CHEMBL1589823 & 688546 & 6.5 & 5.7136 & TST & \\
\hline CHEMBL1521694 & 688546 & 5.4 & 5.843 & TRN & \\
\hline CHEMBL1404788 & 688546 & 5.5 & 4.9697 & TRN & \\
\hline CHEMBL1325515 & 688546 & 4.9 & 5.26399 & 9999999999 & TRN \\
\hline CHEMBL1397186 & 688546 & 4.8 & 5.1424 & TRN & \\
\hline CHEMBL1301125 & 688546 & 4.95 & 5.5534 & TRN & \\
\hline CHEMBL1534088 & 688546 & 7.699 & 5.9106 & TRN & \\
\hline CHEMBL1591003 & 688546 & 8.0 & 5.7232 & TRN & \\
\hline CHEMBL1318029 & 688546 & 4.5 & 5.0641 & TST & \\
\hline CHEMBL1394115 & 688546 & 7.6003 & 5.2776 & TRN & \\
\hline CHEMBL1314606 & 688546 & 4.5 & 5.2567 & TST & \\
\hline CHEMBL1394918 & 688546 & 5.0 & 5.0335 & TRN & \\
\hline CHEMBL1454417 & 688546 & 4.9 & 5.1627 & TRN & \\
\hline CHEMBL1529262 & 688546 & 6.1 & 5.4394 & TST & \\
\hline CHEMBL1491228 & 688546 & 6.6 & 5.2128 & TRN & \\
\hline CHEMBL1491944 & 688546 & 4.9 & 5.1769 & TRN & \\
\hline CHEMBL1315730 & 688546 & 5.0 & 5.4419 & TRN & \\
\hline CHEMBL1571157 & 688546 & 4.8 & 4.8545 & TST & \\
\hline CHEMBL1437427 & 688546 & 7.6498 & 6.2512 & TST & \\
\hline CHEMBL1513782 & 688546 & 7.4001 & 5.7991 & TRN & \\
\hline CHEMBL1397197 & 688546 & 4.7 & 4.9229 & TRN & \\
\hline CHEMBL1522486 & 688546 & 5.5 & 5.3935 & TST & \\
\hline CHEMBL1594647 & 688546 & 4.9 & 5.2899 & TRN & \\
\hline CHEMBL1354484 & 688546 & 4.5 & 4.4281 & TRN & \\
\hline CHEMBL1322233 & 688546 & 5.0 & 4.8529 & TRN & \\
\hline CHEMBL1328834 & 688546 & 5.0 & 5.5442 & TRN & \\
\hline CHEMBL602234 & 688546 & 5.0 & 4.6549 & TRN & \\
\hline CHEMBL1516506 & 688546 & 5.0 & 4.901 & TRN & \\
\hline CHEMBL1432443 & 688546 & 4.9 & 5.0436 & TRN & \\
\hline CHEMBL1318886 & 688546 & 4.5 & 5.1717 & TRN & \\
\hline CHEMBL1479784 & 688546 & 7.1002 & 5.4156 & TST & \\
\hline CHEMBL1321763 & 688546 & 5.4 & 5.59399 & 9999999999 & TRN \\
\hline CHEMBL1445586 & 688546 & 5.3 & 5.5397 & TRN & \\
\hline CHEMBL1437508 & 688546 & 5.0 & 5.0906 & TRN & \\
\hline CHEMBL1356246 & 688546 & 4.7 & 4.8843 & TRN & \\
\hline CHEMBL1375116 & 688546 & 5.1 & 5.1579 & TRN & \\
\hline CHEMBL1588513 & 688546 & 5.5 & 5.2495 & TRN & \\
\hline CHEMBL1327181 & 688546 & 6.2 & 5.9006 & TRN & \\
\hline CHEMBL1324485 & 688546 & 8.4559 & 5.2939 & TRN & \\
\hline CHEMBL1397959 & 688546 & 4.9 & 4.7496 & TRN & \\
\hline CHEMBL1456673 & 688546 & 8.301 & 5.7746 & TRN & \\
\hline CHEMBL1361126 & 688546 & 8.0 & 4.89 & TST & \\
\hline CHEMBL1355057 & 688546 & 4.9 & 5.0185 & TRN & \\
\hline CHEMBL1518789 & 688546 & 7.6498 & 5.21200 & 2000000001 & TST \\
\hline CHEMBL1593528 & 688546 & 5.2 & 5.3508 & TRN & \\
\hline & & & & 10313 & \\
\hline
\end{tabular}




\begin{tabular}{|c|c|c|c|c|c|}
\hline \multirow[b]{2}{*}{ CHEMBL1573345 } & \multirow[b]{2}{*}{688546} & \\
\hline & & 4.7 & 4.6747 & TRN & \\
\hline CHEMBL1593148 & 688546 & 5.25 & 5.5046 & TRN & \\
\hline CHEMBL1571463 & 688546 & 4.9 & 5.0967 & TRN & \\
\hline CHEMBL1552332 & 688546 & 5.1 & 5.0807 & TRN & \\
\hline CHEMBL1450277 & 688546 & 4.5 & 4.9748 & TST & \\
\hline CHEMBL1416255 & 688546 & 4.7 & 5.0149 & TRN & \\
\hline CHEMBL1490638 & 688546 & 4.7 & 5.2847 & TRN & \\
\hline CHEMBL1339340 & 688546 & 4.8 & 5.0704 & TRN & \\
\hline CHEMBL1443734 & 688546 & 4.95 & 5.2722 & TRN & \\
\hline CHEMBL1362643 & 688546 & 4.8 & \multicolumn{2}{|c|}{5.412999999999999} & TRN \\
\hline CHEMBL1374788 & 688546 & 5.5 & 5.3373 & TRN & \\
\hline CHEMBL1435266 & 688546 & 5.8 & 5.5854 & TST & \\
\hline CHEMBL1408864 & 688546 & 5.0 & 5.1015 & TST & \\
\hline CHEMBL1316562 & 688546 & 4.9 & 4.7702 & TRN & \\
\hline CHEMBL1359428 & 688546 & 4.5 & 5.2377 & TRN & \\
\hline CHEMBL1398897 & 688546 & 4.6 & 5.2927 & TRN & \\
\hline CHEMBL1516887 & 688546 & 5.0 & 5.4072 & TST & \\
\hline CHEMBL1329766 & 688546 & 4.7 & 5.2329 & TRN & \\
\hline CHEMBL1554855 & 688546 & 4.9 & \multicolumn{2}{|c|}{4.9110000000000005} & TRN \\
\hline CHEMBL1333686 & 688546 & 5.8 & 5.4558 & TRN & \\
\hline CHEMBL1401402 & 688546 & 4.7 & 4.7403 & TRN & \\
\hline CHEMBL1590820 & 688546 & 5.0 & 4.8993 & TRN & \\
\hline CHEMBL1312836 & 688546 & 6.2 & 5.2532 & TST & \\
\hline CHEMBL1591133 & 688546 & 4.5 & 5.2836 & TRN & \\
\hline CHEMBL1558843 & 688546 & 5.0 & 5.0146 & TRN & \\
\hline CHEMBL1492524 & 688546 & 5.4 & 5.0981 & TRN & \\
\hline CHEMBL1524101 & 688546 & 4.9 & 5.1022 & TRN & \\
\hline CHEMBL1559088 & 688546 & 5.4 & 4.74 & TRN & \\
\hline CHEMBL1398957 & 688546 & 4.8 & 5.0858 & TST & \\
\hline CHEMBL1591689 & 688546 & 5.1 & 5.3007 & TRN & \\
\hline CHEMBL1399458 & 688546 & 4.9 & 5.2597 & TRN & \\
\hline CHEMBL1451162 & 688546 & 4.9 & 5.0396 & TRN & \\
\hline CHEMBL1461857 & 688546 & 5.3 & 4.864 & TST & \\
\hline CHEMBL1608159 & 688546 & 4.9 & \multicolumn{2}{|c|}{5.462000000000001} & TRN \\
\hline CHEMBL1417994 & 688546 & 4.9 & 5.3925 & TRN & \\
\hline CHEMBL1319000 & 688546 & 4.7 & 5.1761 & TRN & \\
\hline CHEMBL1593766 & 688546 & 4.5 & 5.04 & TRN & \\
\hline CHEMBL1524845 & 688546 & 4.9 & 5.0892 & TST & \\
\hline CHEMBL1341981 & 688546 & 4.5 & 5.2962 & TRN & \\
\hline CHEMBL1357904 & 688546 & 4.8 & 5.0385 & TRN & \\
\hline CHEMBL1372701 & 688546 & 5.0 & 4.7306 & TRN & \\
\hline CHEMBL1496428 & 688546 & 4.8 & 4.8206 & TRN & \\
\hline CHEMBL1517748 & 688546 & 4.5 & \multicolumn{2}{|c|}{5.343999999999999} & TRN \\
\hline CHEMBL1573365 & 688546 & 5.05 & 5.1555 & TST & \\
\hline CHEMBL1447019 & 688546 & 4.9 & 5.3822 & TST & \\
\hline CHEMBL1578888 & 688546 & 4.9 & 5.1412 & TRN & \\
\hline CHEMBL1315626 & 688546 & 5.6 & 5.1313 & TRN & \\
\hline \multirow[t]{2}{*}{ CHEMBL1299689 } & 688546 & 8.301 & 5.3257 & TST & \\
\hline & & \multicolumn{4}{|c|}{ Page 10314} \\
\hline
\end{tabular}




\begin{tabular}{|c|c|c|c|c|c|}
\hline \\
\hline CHEMBL1590279 & 688546 & 4.5 & 5.0064 & TRN & \\
\hline CHEMBL1479365 & 688546 & 5.1 & 5.7101 & TRN & \\
\hline CHEMBL1314681 & 688546 & 8.0506 & 5.4187 & TST & \\
\hline CHEMBL1303674 & 688546 & 4.6 & 5.4443 & TST & \\
\hline CHEMBL260028 & 688546 & 5.1 & 5.6042 & TRN & \\
\hline CHEMBL1398141 & 688546 & 5.8 & 5.7789 & TRN & \\
\hline CHEMBL1393932 & 688546 & 4.5 & 5.2786 & TST & \\
\hline CHEMBL1441415 & 688546 & 5.1 & 4.8255 & TRN & \\
\hline CHEMBL1589986 & 688546 & 4.7 & 5.5503 & TST & \\
\hline CHEMBL1368802 & 688546 & 4.5 & 5.2192 & TRN & \\
\hline CHEMBL1325305 & 688546 & 8.0 & 5.324 & TRN & \\
\hline CHEMBL1561389 & 688546 & 4.9 & 4.9992 & TRN & \\
\hline CHEMBL1474741 & 688546 & 4.8 & 5.3605 & TRN & \\
\hline CHEMBL1571426 & 688546 & 4.85 & 5.4816 & TRN & \\
\hline CHEMBL310396 & 688546 & 4.5 & 4.98300 & 00000000005 & TST \\
\hline CHEMBL1597164 & 688546 & 4.8 & 5.2512 & TRN & \\
\hline CHEMBL1383967 & 688546 & 5.6 & 5.5129 & TRN & \\
\hline CHEMBL591126 & 688546 & 5.0 & 5.1119 & TRN & \\
\hline CHEMBL 261118 & 688546 & 6.0 & 5.6662 & TRN & \\
\hline CHEMBL1314864 & 688546 & 4.8 & 4.7686 & TRN & \\
\hline CHEMBL1375977 & 688546 & 5.0 & 5.2103 & TRN & \\
\hline CHEMBL1548327 & 688546 & 4.95 & 5.2806 & TST & \\
\hline CHEMBL1516210 & 688546 & 5.55 & 5.8758 & TRN & \\
\hline CHEMBL1472778 & 688546 & 5.0 & 5.0939 & TRN & \\
\hline CHEMBL1403689 & 688546 & 6.2 & 6.1103 & TRN & \\
\hline CHEMBL112597 & 688546 & 4.7 & 5.0526 & TST & \\
\hline CHEMBL1438442 & 688546 & 4.6 & 5.0291 & TST & \\
\hline CHEMBL1474358 & 688546 & 5.7 & 5.682 & TRN & \\
\hline CHEMBL1344000 & 688546 & 4.95 & 4.4814 & TRN & \\
\hline CHEMBL1381538 & 688546 & 5.4 & 5.3596 & TST & \\
\hline CHEMBL1484454 & 688546 & 5.5 & 5.0279 & TRN & \\
\hline CHEMBL1396076 & 688546 & 5.2 & 5.4227 & TRN & \\
\hline CHEMBL1594733 & 688546 & 4.8 & 5.0637 & TRN & \\
\hline CHEMBL1436493 & 688546 & 6.0 & 5.4729 & TRN & \\
\hline CHEMBL1332454 & 688546 & 5.5 & 4.8858 & TRN & \\
\hline CHEMBL1315732 & 688546 & 4.8 & 4.687 & TRN & \\
\hline CHEMBL1486073 & 688546 & 4.6 & 4.9326 & TRN & \\
\hline CHEMBL1976304 & 688546 & 4.45 & 5.1074 & TST & \\
\hline CHEMBL1325908 & 688546 & 4.8 & 4.7207 & TRN & \\
\hline CHEMBL1426379 & 688546 & 4.5 & 4.967 & TRN & \\
\hline CHEMBL1498407 & 688546 & 4.95 & 5.5287 & TRN & \\
\hline CHEMBL1596829 & 688546 & 4.9 & 5.6212 & TST & \\
\hline CHEMBL1561100 & 688546 & 4.5 & 4.7939 & TRN & \\
\hline CHEMBL1438675 & 688546 & 5.2 & 5.7356 & TRN & \\
\hline CHEMBL1332931 & 688546 & 5.3 & 4.9242 & TST & \\
\hline CHEMBL1318493 & 688546 & 5.15 & 5.3712 & TRN & \\
\hline CHEMBL1593971 & 688546 & 4.9 & 5.704 & TRN & \\
\hline CHEMBL1434411 & 688546 & 4.5 & 4.8194 & TRN & \\
\hline & & & & 10315 & \\
\hline
\end{tabular}




\begin{tabular}{|c|c|c|c|c|c|}
\hline \multicolumn{6}{|c|}{ Supplemental Table S2. } \\
\hline CHEMBL1514086 & 688546 & 4.9 & 5.3005 & TRN & \\
\hline CHEMBL1598836 & 688546 & 8.1024 & 5.7933 & TRN & \\
\hline CHEMBL1329888 & 688546 & 8.0506 & 5.5452 & TST & \\
\hline CHEMBL1334932 & 688546 & 6.8 & 5.34399 & 9999999999 & TRN \\
\hline CHEMBL1414621 & 688546 & 5.6 & 5.3092 & TST & \\
\hline CHEMBL1413081 & 688546 & 4.8 & 5.1631 & TRN & \\
\hline CHEMBL1407161 & 688546 & 5.3 & 5.0034 & TRN & \\
\hline CHEMBL1446909 & 688546 & 4.9 & 4.9438 & TRN & \\
\hline CHEMBL1484019 & 688546 & 6.0 & 5.4431 & TRN & \\
\hline CHEMBL1569110 & 688546 & 6.5 & 5.5663 & TST & \\
\hline CHEMBL1409327 & 688546 & 4.7 & 5.0637 & TRN & \\
\hline CHEMBL1590935 & 688546 & 5.1 & 4.8222 & TRN & \\
\hline CHEMBL1311052 & 688546 & 4.45 & 5.0463 & TST & \\
\hline CHEMBL1405217 & 688546 & 7.699 & 5.9445 & TRN & \\
\hline CHEMBL1534458 & 688546 & 4.5 & 4.8364 & TRN & \\
\hline CHEMBL1566498 & 688546 & 5.6 & 6.0062 & TRN & \\
\hline CHEMBL1591380 & 688546 & 4.7 & 4.7479 & TRN & \\
\hline CHEMBL1319263 & 688546 & 4.8 & 5.0902 & TRN & \\
\hline CHEMBL1467024 & 688546 & 6.5501 & 5.0738 & TRN & \\
\hline CHEMBL1477009 & 688546 & 4.35 & 4.98 & TRN & \\
\hline CHEMBL1356479 & 688546 & 4.9 & 5.3312 & TRN & \\
\hline CHEMBL1483297 & 688546 & 4.5 & 5.2103 & TRN & \\
\hline CHEMBL1474038 & 688546 & 4.5 & 5.6493 & TRN & \\
\hline CHEMBL1513916 & 688546 & 8.301 & 5.5266 & TRN & \\
\hline CHEMBL1554213 & 688546 & 4.5 & 5.5532 & TRN & \\
\hline CHEMBL1455689 & 688546 & 5.3 & 5.041 & TRN & \\
\hline CHEMBL1603840 & 688546 & 5.25 & 5.0263 & TRN & \\
\hline CHEMBL1518016 & 688546 & 5.0 & 5.3754 & TST & \\
\hline CHEMBL1567067 & 688546 & 5.4 & 5.4478 & TRN & \\
\hline CHEMBL1371542 & 688546 & 4.5 & 5.4244 & TRN & \\
\hline CHEMBL1394275 & 688546 & 5.3 & 5.0269 & TRN & \\
\hline CHEMBL1557815 & 688546 & 8.0506 & 4.9292 & TRN & \\
\hline CHEMBL1512462 & 688546 & 5.0 & 5.4195 & TRN & \\
\hline CHEMBL1354749 & 688546 & 4.9 & 5.2208 & TST & \\
\hline CHEMBL1591621 & 688546 & 7.9508 & 5.3214 & TRN & \\
\hline CHEMBL1529641 & 688546 & 5.9 & 5.5899 & TRN & \\
\hline CHEMBL1358158 & 688546 & 5.25 & 5.0194 & TRN & \\
\hline CHEMBL1516229 & 688546 & 4.9 & 5.28299 & 99999999995 & TST \\
\hline CHEMBL1434185 & 688546 & 4.6 & 4.9615 & TRN & \\
\hline CHEMBL1435409 & 688546 & 4.5 & 5.2036 & TRN & \\
\hline CHEMBL1395924 & 688546 & 5.55 & 5.2536 & TRN & \\
\hline CHEMBL1326206 & 688546 & 4.8 & 5.2317 & TRN & \\
\hline CHEMBL1530319 & 688546 & 5.2 & 5.7663 & TRN & \\
\hline CHEMBL1491676 & 688546 & 4.5 & 5.0294 & TST & \\
\hline CHEMBL1605782 & 688546 & 7.8996 & 5.4505 & TRN & \\
\hline CHEMBL1434937 & 688546 & 4.5 & 4.9682 & TRN & \\
\hline CHEMBL 201325 & 688546 & 5.1 & 4.9909 & TRN & \\
\hline CHEMBL1601485 & 688546 & 4.6 & 4.9431 & TRN & \\
\hline
\end{tabular}




\begin{tabular}{|c|c|c|c|c|}
\hline \multicolumn{5}{|c|}{ Supplemental Table S2.txt } \\
\hline CHEMBL1503644 & 688546 & 4.7 & 4.9495 & TRN \\
\hline CHEMBL1487674 & 688546 & 4.8 & 5.2036 & TRN \\
\hline CHEMBL1314910 & 688546 & 4.5 & 5.0773 & TRN \\
\hline CHEMBL1320426 & 688546 & 4.8 & 5.5226 & TRN \\
\hline CHEMBL89445 & 688546 & 6.1 & 5.1664 & TRN \\
\hline CHEMBL1454681 & 688546 & 4.5 & 5.3745 & TST \\
\hline CHEMBL1371753 & 688546 & 4.9 & 5.1318 & TRN \\
\hline CHEMBL1406804 & 688546 & 4.5 & 5.4126 & TST \\
\hline CHEMBL1525585 & 688546 & 4.9 & 5.1805 & TRN \\
\hline CHEMBL1331965 & 688546 & 5.4 & 5.3736 & TRN \\
\hline CHEMBL1473470 & 688546 & 5.9 & 5.1971 & TRN \\
\hline CHEMBL1412054 & 688546 & 5.0 & 5.4184 & TRN \\
\hline CHEMBL1592098 & 688546 & 4.5 & 6.0343 & TRN \\
\hline CHEMBL1526754 & 688546 & 4.8 & 5.2122 & TRN \\
\hline CHEMBL1256656 & 688546 & 6.0 & 5.4988 & TST \\
\hline CHEMBL1562227 & 688546 & 7.8013 & 5.9868 & TRN \\
\hline CHEMBL1513677 & 688546 & 4.9 & 5.4192 & TST \\
\hline CHEMBL1365293 & 688546 & 4.5 & 5.2587 & TRN \\
\hline CHEMBL1605201 & 688546 & 5.0 & 5.3936 & TST \\
\hline CHEMBL579550 & 688546 & 4.9 & 5.3156 & TRN \\
\hline CHEMBL1573834 & 688546 & 4.4 & 4.9481 & TRN \\
\hline CHEMBL1349014 & 688546 & 4.5 & 5.2597 & TRN \\
\hline CHEMBL1568194 & 688546 & 7.6003 & 5.9602 & TRN \\
\hline CHEMBL 337173 & 688546 & 5.3 & 5.2141 & TST \\
\hline CHEMBL1567024 & 688546 & 6.8 & 6.1563 & TRN \\
\hline CHEMBL1414871 & 688546 & 5.0 & 4.816 & TRN \\
\hline CHEMBL1487567 & 688546 & 5.5 & 5.2221 & TRN \\
\hline CHEMBL250711 & 688546 & 4.9 & 4.6142 & TRN \\
\hline CHEMBL1604166 & 688546 & 4.5 & 5.1835 & TRN \\
\hline CHEMBL1315673 & 688546 & 4.5 & 4.8881 & TRN \\
\hline CHEMBL1308876 & 688546 & 5.25 & 5.072 & TST \\
\hline CHEMBL1396475 & 688546 & 4.9 & 4.853 & TRN \\
\hline CHEMBL1309260 & 688546 & 5.0 & 4.8958 & TST \\
\hline CHEMBL1613725 & 688546 & 5.0 & 4.6855 & TRN \\
\hline CHEMBL1608422 & 688546 & 6.05 & 4.6716 & TST \\
\hline CHEMBL1527400 & 688546 & 5.15 & 5.3961 & TRN \\
\hline CHEMBL1574638 & 688546 & 4.5 & 4.8125 & TRN \\
\hline CHEMBL1342039 & 688546 & 4.8 & 5.0576 & TRN \\
\hline CHEMBL1333430 & 688546 & 5.0 & 4.9969 & TRN \\
\hline CHEMBL563919 & 688546 & 5.3 & 5.1918 & TRN \\
\hline CHEMBL1521128 & 688546 & 4.8 & 4.9409 & TRN \\
\hline CHEMBL1599943 & 688546 & 4.8 & 5.2922 & TRN \\
\hline CHEMBL1534823 & 688546 & 5.6 & 5.3129 & TRN \\
\hline CHEMBL1528905 & 688546 & 5.0 & 5.0401 & TRN \\
\hline CHEMBL1548175 & 688546 & 6.1 & 4.8732 & TRN \\
\hline CHEMBL1449859 & 688546 & 6.95 & 5.8888 & TST \\
\hline CHEMBL1514215 & 688546 & 4.8 & 5.8039 & TRN \\
\hline CHEMBL1359200 & 688546 & 4.7 & 5.6559 & TRN \\
\hline
\end{tabular}




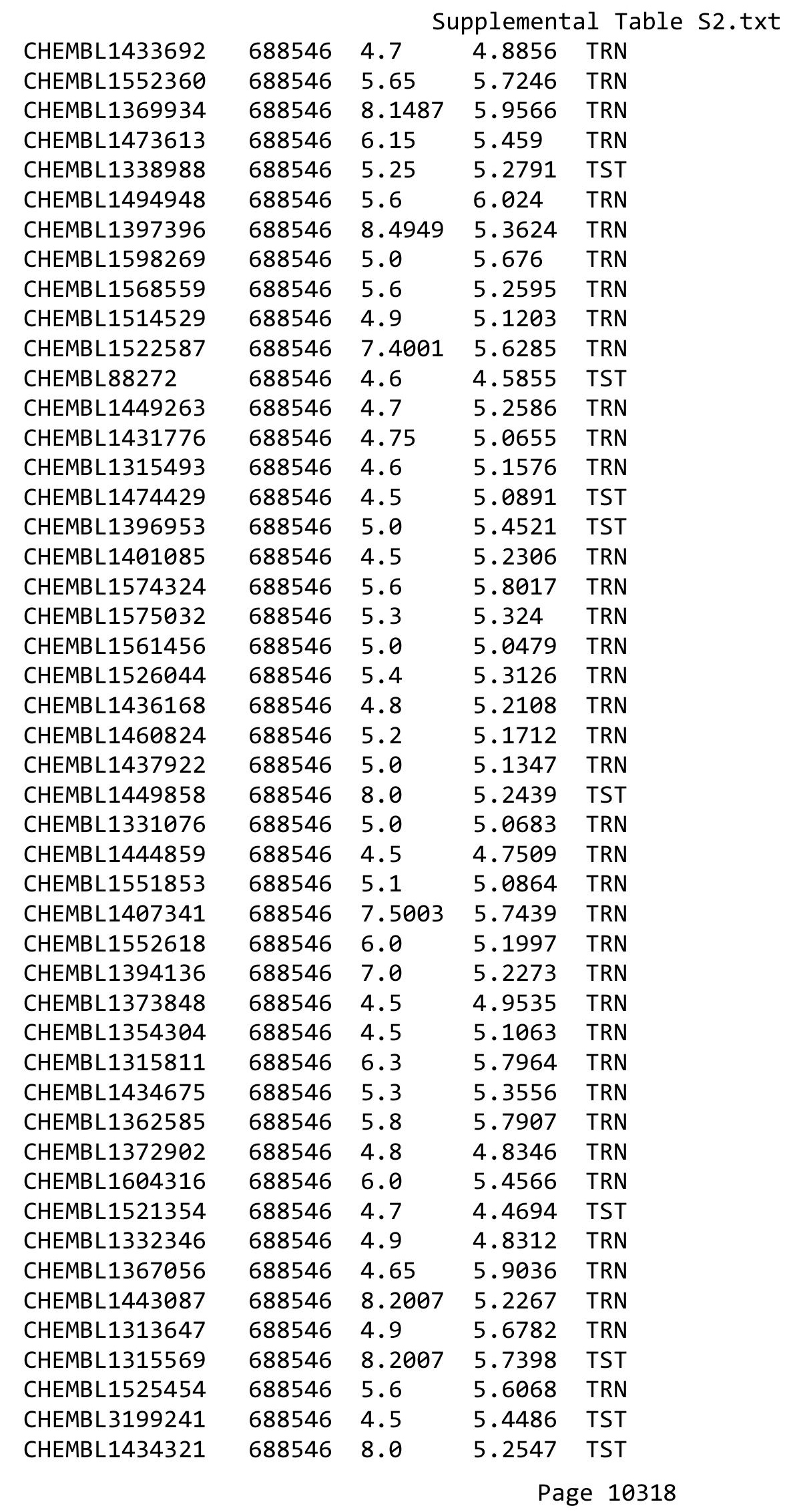




\begin{tabular}{|c|c|c|c|c|c|}
\hline \multicolumn{6}{|c|}{ Supplemental Table S2.txt } \\
\hline CHEMBL1484915 & 688546 & 5.25 & 5.3248 & TRN & \\
\hline CHEMBL1497602 & 688546 & 6.3 & 5.5651 & TRN & \\
\hline CHEMBL1508351 & 688546 & 7.15 & 5.2464 & TST & \\
\hline CHEMBL1316813 & 688546 & 4.7 & 4.9073 & TRN & \\
\hline CHEMBL1412693 & 688546 & 4.5 & 5.0033 & TRN & \\
\hline CHEMBL1401717 & 688546 & 5.2 & 4.9389 & TST & \\
\hline CHEMBL1593798 & 688546 & 7.3002 & 5.5377 & TRN & \\
\hline CHEMBL1485418 & 688546 & 5.0 & 5.2143 & TRN & \\
\hline CHEMBL1553756 & 688546 & 4.5 & 5.7424 & TRN & \\
\hline CHEMBL1611321 & 688546 & 4.5 & 5.2998 & TRN & \\
\hline CHEMBL1412874 & 688546 & 5.0 & 5.1471 & TRN & \\
\hline CHEMBL1351624 & 688546 & 4.7 & 5.1716 & TRN & \\
\hline CHEMBL1513968 & 688546 & 4.9 & 5.216 & TRN & \\
\hline CHEMBL1378851 & 688546 & 4.5 & 4.7834 & TST & \\
\hline CHEMBL1450909 & 688546 & 5.4 & 5.229 & TRN & \\
\hline CHEMBL1604095 & 688546 & 4.8 & 5.3016 & TST & \\
\hline CHEMBL1590971 & 688546 & 4.5 & 4.9945 & TRN & \\
\hline CHEMBL1519086 & 688546 & 7.4498 & 5.17399 & 99999999995 & TST \\
\hline CHEMBL1478490 & 688546 & 4.8 & 5.1236 & TST & \\
\hline CHEMBL1497953 & 688546 & 4.5 & 5.0397 & TST & \\
\hline CHEMBL1514486 & 688546 & 4.9 & 5.1458 & TST & \\
\hline CHEMBL1515952 & 688546 & 6.0 & 5.8127 & TRN & \\
\hline CHEMBL1985598 & 688546 & 4.8 & 5.4242 & TST & \\
\hline CHEMBL1437049 & 688546 & 4.5 & 5.2257 & TST & \\
\hline CHEMBL1434745 & 688546 & 4.5 & 5.7254 & TRN & \\
\hline CHEMBL3189627 & 688546 & 5.05 & 4.9794 & TST & \\
\hline CHEMBL1366055 & 688546 & 5.1 & 5.0895 & TRN & \\
\hline CHEMBL1402086 & 688546 & 4.5 & 5.2446 & TRN & \\
\hline CHEMBL1319405 & 688546 & 5.1 & 5.1307 & TST & \\
\hline CHEMBL1486224 & 688546 & 5.2 & 5.7723 & TRN & \\
\hline CHEMBL1365057 & 688546 & 4.8 & 5.0474 & TRN & \\
\hline CHEMBL1397814 & 688546 & 4.8 & 5.8558 & TRN & \\
\hline CHEMBL1607286 & 688546 & 4.45 & 5.0687 & TST & \\
\hline CHEMBL1405249 & 688546 & 4.6 & 5.0133 & TRN & \\
\hline CHEMBL1566193 & 688546 & 4.5 & 5.2545 & TST & \\
\hline CHEMBL1608208 & 688546 & 4.6 & 5.0443 & TRN & \\
\hline CHEMBL1442377 & 688546 & 4.5 & 5.4139 & TST & \\
\hline CHEMBL1562104 & 688546 & 4.5 & 5.0481 & TST & \\
\hline CHEMBL1421907 & 688546 & 4.5 & 5.5258 & TRN & \\
\hline CHEMBL1561385 & 688546 & 4.9 & 5.3116 & TST & \\
\hline CHEMBL1380072 & 688546 & 4.9 & 5.3396 & TST & \\
\hline CHEMBL1354561 & 688546 & 4.5 & 4.9074 & TRN & \\
\hline CHEMBL1386253 & 688546 & 5.4 & 5.0871 & TST & \\
\hline CHEMBL1436125 & 688546 & 4.6 & 5.0858 & TRN & \\
\hline CHEMBL1315059 & 688546 & 5.4 & 5.5418 & TRN & \\
\hline CHEMBL1390986 & 688546 & 4.9 & 5.5375 & TRN & \\
\hline CHEMBL1316328 & 688546 & 4.8 & 5.0991 & TRN & \\
\hline CHEMBL1518080 & 688546 & 4.9 & 4.7997 & TST & \\
\hline
\end{tabular}




\begin{tabular}{|c|c|c|c|c|c|}
\hline & & & & & \\
\hline CHEMBL1390578 & 688546 & 4.6 & 5.0984 & TST & \\
\hline CHEMBL26320 & 688546 & 6.0 & 4.6847 & TRN & \\
\hline CHEMBL1612880 & 688546 & 4.6 & 5.2865 & TST & \\
\hline CHEMBL1503124 & 688546 & 5.2 & 5.0817 & TRN & \\
\hline CHEMBL1559062 & 688546 & 4.7 & 5.0462 & TST & \\
\hline CHEMBL1560327 & 688546 & 8.6021 & 5.7197 & TRN & \\
\hline CHEMBL1330082 & 688546 & 4.9 & 5.5179 & TRN & \\
\hline CHEMBL1386099 & 688546 & 4.9 & 4.9789 & TRN & \\
\hline CHEMBL1396595 & 688546 & 4.5 & 5.15799 & 99999999995 & TRN \\
\hline CHEMBL1371671 & 688546 & 4.8 & 4.8169 & TRN & \\
\hline CHEMBL408850 & 688546 & 5.1 & 4.9822 & TRN & \\
\hline CHEMBL1478719 & 688546 & 4.5 & 6.1142 & TRN & \\
\hline CHEMBL1477081 & 688546 & 5.2 & 5.3836 & TRN & \\
\hline CHEMBL1484143 & 688546 & 4.9 & 5.0838 & TRN & \\
\hline CHEMBL1436307 & 688546 & 5.0 & 5.5082 & TST & \\
\hline CHEMBL1395485 & 688546 & 4.8 & 4.8695 & TRN & \\
\hline CHEMBL1566979 & 688546 & 8.1024 & 5.4653 & TRN & \\
\hline CHEMBL1208903 & 688546 & 4.5 & 5.3587 & TRN & \\
\hline CHEMBL1395542 & 688546 & 4.9 & 5.117 & TRN & \\
\hline CHEMBL1558782 & 688546 & 4.9 & 6.1266 & TRN & \\
\hline CHEMBL1415784 & 688546 & 4.5 & 4.9747 & TST & \\
\hline CHEMBL1317165 & 688546 & 4.6 & 5.8302 & TRN & \\
\hline CHEMBL1347687 & 688546 & 5.2 & 5.0448 & TRN & \\
\hline CHEMBL1456031 & 688546 & 4.5 & 5.3612 & TRN & \\
\hline CHEMBL1593150 & 688546 & 5.1 & 5.5087 & TRN & \\
\hline CHEMBL1255936 & 688546 & 4.8 & 5.3092 & TST & \\
\hline CHEMBL1474011 & 688546 & 6.0 & 5.1839 & TRN & \\
\hline CHEMBL1481978 & 688546 & 4.9 & 5.1779 & TRN & \\
\hline CHEMBL3196400 & 688546 & 4.9 & 5.1395 & TRN & \\
\hline CHEMBL1518712 & 688546 & 4.5 & 4.845 & TRN & \\
\hline CHEMBL1403379 & 688546 & 4.5 & 5.0182 & TRN & \\
\hline CHEMBL1446542 & 688546 & 4.9 & 5.313 & TRN & \\
\hline CHEMBL3216928 & 688546 & 4.9 & 4.9406 & TST & \\
\hline CHEMBL1373577 & 688546 & 5.5 & 5.1959 & TST & \\
\hline CHEMBL1374371 & 688546 & 4.7 & 5.2683 & TRN & \\
\hline CHEMBL1317401 & 688546 & 4.5 & 5.1053 & TRN & \\
\hline CHEMBL1582077 & 688546 & 4.4 & 4.7772 & TST & \\
\hline CHEMBL1435100 & 688546 & 4.9 & 5.2644 & TRN & \\
\hline CHEMBL1518166 & 688546 & 4.9 & 5.0893 & TRN & \\
\hline CHEMBL1500885 & 688546 & 4.65 & 5.24700 & 0000000001 & TRN \\
\hline CHEMBL3193515 & 688546 & 4.45 & 4.7863 & TRN & \\
\hline CHEMBL1593293 & 688546 & 4.9 & 5.0017 & TRN & \\
\hline CHEMBL1359050 & 688546 & 4.5 & 5.1775 & TRN & \\
\hline CHEMBL1591340 & 688546 & 4.8 & 4.6526 & TRN & \\
\hline CHEMBL1396924 & 688546 & 4.5 & 5.2738 & TRN & \\
\hline CHEMBL 8747 & 688546 & 4.5 & 5.0605 & TST & \\
\hline CHEMBL1550909 & 688546 & 5.95 & 5.8969 & TRN & \\
\hline CHEMBL1545531 & 688546 & 4.45 & 5.1774 & TST & \\
\hline & & & & 10320 & \\
\hline
\end{tabular}




\begin{tabular}{|c|c|c|c|c|c|}
\hline \multicolumn{6}{|c|}{ Supplemental Table S2.txt } \\
\hline CHEMBL1496514 & 688546 & 4.6 & 5.2848 & TST & \\
\hline CHEMBL1591671 & 688546 & 4.6 & 5.4263 & TRN & \\
\hline CHEMBL1374794 & 688546 & 5.55 & 5.4594 & TRN & \\
\hline CHEMBL1406859 & 688546 & 4.9 & 5.2736 & TST & \\
\hline CHEMBL1375757 & 688546 & 6.5 & 5.0713 & TRN & \\
\hline CHEMBL1493000 & 688546 & 4.65 & 5.2073 & TST & \\
\hline CHEMBL1503548 & 688546 & 4.8 & 4.9065 & TRN & \\
\hline CHEMBL1513833 & 688546 & 4.7 & 4.7899 & TRN & \\
\hline CHEMBL276618 & 688546 & 4.5 & 4.9001 & TST & \\
\hline CHEMBL1388109 & 688546 & 6.2 & 6.0068 & TRN & \\
\hline CHEMBL1506175 & 688546 & 4.95 & 4.8728 & TRN & \\
\hline CHEMBL1538192 & 688546 & 6.4 & 4.8943 & TST & \\
\hline CHEMBL1479422 & 688546 & 5.4 & 4.9632 & TRN & \\
\hline CHEMBL1551039 & 688546 & 5.2 & 4.9615 & TRN & \\
\hline CHEMBL1599350 & 688546 & 4.6 & 5.1834 & TRN & \\
\hline CHEMBL1539118 & 688546 & 4.8 & 5.0951 & TST & \\
\hline CHEMBL1601638 & 688546 & 5.0 & 5.0732 & TRN & \\
\hline CHEMBL1409241 & 688546 & 5.0 & 5.2298 & TRN & \\
\hline CHEMBL1415308 & 688546 & 4.45 & 5.4058 & TST & \\
\hline CHEMBL1396045 & 688546 & 4.5 & 5.6364 & TRN & \\
\hline CHEMBL1475366 & 688546 & 4.7 & 4.5178 & TRN & \\
\hline CHEMBL1359565 & 688546 & 5.0 & 5.0123 & TRN & \\
\hline CHEMBL1604870 & 688546 & 5.1 & $5.9860 e$ & 3000000001 & TRN \\
\hline CHEMBL1456742 & 688546 & 6.0 & 5.1953 & TRN & \\
\hline CHEMBL1477547 & 688546 & 4.75 & 5.232 & TRN & \\
\hline CHEMBL1333653 & 688546 & 4.9 & 5.336 & TST & \\
\hline CHEMBL1395207 & 688546 & 4.9 & 5.1595 & TRN & \\
\hline CHEMBL1363307 & 688546 & 4.5 & 5.329 & TRN & \\
\hline CHEMBL1513536 & 688546 & 5.25 & 5.6294 & TRN & \\
\hline CHEMBL1356543 & 688546 & 4.7 & 5.0765 & TRN & \\
\hline CHEMBL1314856 & 688546 & 6.5 & 5.4378 & TRN & \\
\hline CHEMBL1395686 & 688546 & 5.9 & 5.3108 & TRN & \\
\hline CHEMBL1441782 & 688546 & 5.0 & 5.1624 & TRN & \\
\hline CHEMBL1362640 & 688546 & 4.6 & 5.8101 & TRN & \\
\hline CHEMBL1567019 & 688546 & 4.9 & 4.7927 & TST & \\
\hline CHEMBL1395326 & 688546 & 5.95 & 5.03 & TRN & \\
\hline CHEMBL1505118 & 688546 & 5.1 & 5.5094 & TRN & \\
\hline CHEMBL1337452 & 688546 & 4.5 & 5.4023 & TRN & \\
\hline CHEMBL1558864 & 688546 & 4.5 & 5.4751 & TST & \\
\hline CHEMBL1549823 & 688546 & 5.1 & 5.2878 & TST & \\
\hline CHEMBL1305131 & 688546 & 4.9 & 5.0779 & TST & \\
\hline CHEMBL1552375 & 688546 & 4.95 & 5.0776 & TRN & \\
\hline CHEMBL1446661 & 688546 & 4.8 & 5.3937 & TRN & \\
\hline CHEMBL1359636 & 688546 & 6.4 & 4.9779 & TST & \\
\hline CHEMBL186366 & 688546 & 5.1 & 5.0752 & TRN & \\
\hline CHEMBL1512969 & 688546 & 5.7 & 5.1752 & TRN & \\
\hline CHEMBL3199050 & 688546 & 4.85 & 5.1937 & TST & \\
\hline CHEMBL1476210 & 688546 & 4.5 & 4.9349 & TRN & \\
\hline
\end{tabular}




\begin{tabular}{|c|c|c|c|c|c|}
\hline & & \multicolumn{4}{|c|}{ Supplemental Table S2.txt } \\
\hline CHEMBL1392106 & 688546 & 7.4498 & 5.4374 & TST & \\
\hline CHEMBL3192555 & 688546 & 5.15 & 5.6523 & TST & \\
\hline CHEMBL1449683 & 688546 & 8.0506 & 5.6901 & TRN & \\
\hline CHEMBL1533300 & 688546 & 6.5501 & 5.3373 & TRN & \\
\hline CHEMBL1197976 & 688546 & 4.9 & 4.4525 & TRN & \\
\hline CHEMBL1558658 & 688546 & 4.6 & 5.2273 & TRN & \\
\hline CHEMBL1333047 & 688546 & 5.5 & 5.2254 & TRN & \\
\hline CHEMBL1516709 & 688546 & 6.3 & 5.2266 & TST & \\
\hline CHEMBL1593295 & 688546 & 4.6 & 5.3947 & TRN & \\
\hline CHEMBL1435211 & 688546 & 6.15 & 5.4671 & TRN & \\
\hline CHEMBL1570711 & 688546 & 4.9 & 5.1704 & TRN & \\
\hline CHEMBL1311623 & 688546 & 5.05 & 5.2512 & TST & \\
\hline CHEMBL1320607 & 688546 & 4.7 & 5.0401 & TRN & \\
\hline CHEMBL1420595 & 688546 & 4.85 & 5.0323 & TST & \\
\hline CHEMBL1515197 & 688546 & 4.5 & 5.3038 & TRN & \\
\hline CHEMBL1513649 & 688546 & 5.5 & 5.5769 & TST & \\
\hline CHEMBL1450532 & 688546 & 8.301 & 5.5845 & TRN & \\
\hline CHEMBL1603181 & 688546 & 8.2007 & 5.221 & TRN & \\
\hline CHEMBL1417152 & 688546 & 5.3 & 5.601 & TST & \\
\hline CHEMBL194594 & 688546 & 5.3 & 5.3101 & TRN & \\
\hline CHEMBL1436335 & 688546 & 5.7 & 5.3386 & TST & \\
\hline CHEMBL1329715 & 688546 & 5.0 & 4.9076 & TST & \\
\hline CHEMBL1456959 & 688546 & 6.5 & 5.5218 & TRN & \\
\hline CHEMBL1355991 & 688546 & 4.5 & 5.4463 & TRN & \\
\hline CHEMBL1551641 & 688546 & 5.0 & 4.9965 & TRN & \\
\hline CHEMBL1512329 & 688546 & 5.1 & 5.181 & TRN & \\
\hline CHEMBL1612231 & 688546 & 4.5 & 4.7944 & TRN & \\
\hline CHEMBL1357624 & 688546 & 8.2007 & 5.4159 & TRN & \\
\hline CHEMBL1503002 & 688546 & 5.0 & 5.2122 & TRN & \\
\hline CHEMBL1524893 & 688546 & 4.9 & 5.3506 & TRN & \\
\hline CHEMBL1316928 & 688546 & 4.7 & 4.7921 & TRN & \\
\hline CHEMBL1528709 & 688546 & 5.4 & 5.1684 & TRN & \\
\hline CHEMBL1513468 & 688546 & 4.5 & 5.74799 & 9999999999 & TRN \\
\hline CHEMBL1576840 & 688546 & 5.1 & 4.9491 & TRN & \\
\hline CHEMBL1397743 & 688546 & 4.8 & 5.2335 & TRN & \\
\hline CHEMBL1593195 & 688546 & 4.8 & 5.8175 & TRN & \\
\hline CHEMBL1551583 & 688546 & 4.9 & 4.8264 & TST & \\
\hline CHEMBL1512431 & 688546 & 4.5 & 5.3573 & TRN & \\
\hline CHEMBL1321056 & 688546 & 5.0 & 5.2852 & TRN & \\
\hline CHEMBL1489809 & 688546 & 7.5003 & 5.1246 & TRN & \\
\hline CHEMBL1366712 & 688546 & 5.6 & 5.4273 & TRN & \\
\hline CHEMBL1515741 & 688546 & 5.0 & 5.6188 & TRN & \\
\hline CHEMBL1437017 & 688546 & 7.4001 & 5.3668 & TRN & \\
\hline CHEMBL1355042 & 688546 & 5.25 & 5.0997 & TST & \\
\hline CHEMBL1331074 & 688546 & 4.5 & 5.3036 & TRN & \\
\hline CHEMBL1480630 & 688546 & 4.5 & 4.7874 & TRN & \\
\hline CHEMBL1593915 & 688546 & 4.5 & 5.2977 & TRN & \\
\hline CHEMBL1453606 & 688546 & 5.0 & 5.5786 & TRN & \\
\hline
\end{tabular}




\begin{tabular}{|c|c|c|c|c|}
\hline \multicolumn{5}{|c|}{ Supplemental Table S2.txt } \\
\hline CHEMBL1488093 & 688546 & 5.0 & 4.9645 & TRN \\
\hline CHEMBL1396518 & 688546 & 8.1024 & 5.7946 & TRN \\
\hline CHEMBL1553910 & 688546 & 4.7 & 5.4801 & TST \\
\hline CHEMBL1566148 & 688546 & 4.9 & 5.4022 & TST \\
\hline CHEMBL1437755 & 688546 & 5.25 & 5.3668 & TRN \\
\hline CHEMBL1386036 & 688546 & 4.7 & 5.2401 & TRN \\
\hline CHEMBL1315739 & 688546 & 8.5528 & 5.4882 & TRN \\
\hline CHEMBL1513737 & 688546 & 4.75 & 5.4209 & TRN \\
\hline CHEMBL1361554 & 688546 & 4.7 & 5.2769 & TRN \\
\hline CHEMBL1442502 & 688546 & 4.9 & 5.0291 & TRN \\
\hline CHEMBL1392200 & 688546 & 5.0 & 5.2087 & TRN \\
\hline CHEMBL1553974 & 688546 & 5.6 & 4.8248 & TRN \\
\hline CHEMBL1437454 & 688546 & 4.5 & 5.7155 & TRN \\
\hline CHEMBL1591208 & 688546 & 4.45 & 5.8014 & TRN \\
\hline CHEMBL1324812 & 688546 & 7.699 & 6.7029 & TRN \\
\hline CHEMBL1442255 & 688546 & 8.4949 & 5.5782 & TRN \\
\hline CHEMBL1487228 & 688546 & 7.0 & 5.4243 & TRN \\
\hline CHEMBL1492205 & 688546 & 4.7 & 4.9584 & TRN \\
\hline CHEMBL1513494 & 688546 & 4.8 & 5.2951 & TRN \\
\hline CHEMBL1436703 & 688546 & 4.8 & 5.5417 & TRN \\
\hline CHEMBL1514813 & 688546 & 7.8996 & 5.5884 & TRN \\
\hline CHEMBL1371801 & 688546 & 5.1 & 4.9445 & TRN \\
\hline CHEMBL1429728 & 688546 & 5.0 & 5.0095 & TST \\
\hline CHEMBL1376533 & 688546 & 6.6 & 5.6632 & TRN \\
\hline CHEMBL1368212 & 688546 & 5.4 & 5.1781 & TRN \\
\hline CHEMBL1333484 & 688546 & 4.9 & 5.1965 & TRN \\
\hline CHEMBL1478602 & 688546 & 4.5 & 4.9822 & TRN \\
\hline CHEMBL1474500 & 688546 & 4.8 & 5.0245 & TRN \\
\hline CHEMBL1358080 & 688546 & 4.45 & 5.7436 & TRN \\
\hline CHEMBL1483465 & 688546 & 5.0 & 5.2695 & TRN \\
\hline CHEMBL1494073 & 688546 & 5.3 & 5.2289 & TRN \\
\hline CHEMBL1558691 & 688546 & 5.4 & 5.5135 & TRN \\
\hline CHEMBL1406186 & 688546 & 4.5 & 5.4005 & TST \\
\hline CHEMBL1356402 & 688546 & 5.7 & 5.9555 & TRN \\
\hline CHEMBL393417 & 688546 & 6.0 & 5.601 & TST \\
\hline CHEMBL1578599 & 688546 & 5.5 & 5.6266 & TRN \\
\hline CHEMBL1475164 & 688546 & 5.5 & 5.3861 & TRN \\
\hline CHEMBL1600906 & 688546 & 4.8 & 5.1633 & TRN \\
\hline CHEMBL1309219 & 688546 & 4.9 & 4.6345 & TST \\
\hline CHEMBL1481378 & 688546 & 4.6 & 5.311 & TRN \\
\hline CHEMBL1407683 & 688546 & 5.3 & 5.2446 & TRN \\
\hline CHEMBL1429722 & 688546 & 5.0 & 4.8888 & TST \\
\hline CHEMBL1599675 & 688546 & 5.25 & 4.9549 & TST \\
\hline CHEMBL1521069 & 688546 & 4.5 & 5.2871 & TST \\
\hline CHEMBL1472990 & 688546 & 4.5 & 5.2854 & TRN \\
\hline CHEMBL1543238 & 688546 & 5.6 & 5.0485 & TRN \\
\hline CHEMBL 1377820 & 688546 & 5.0 & 5.0814 & TST \\
\hline CHEMBL1315300 & 688546 & 8.301 & 5.3515 & TRN \\
\hline
\end{tabular}




\begin{tabular}{|c|c|c|c|c|}
\hline \multicolumn{5}{|c|}{ Supplemental Table } \\
\hline CHEMBL1489655 & 688546 & 6.8499 & 5.6152 & TST \\
\hline CHEMBL1515811 & 688546 & 8.0 & 5.392 & TRN \\
\hline CHEMBL1590952 & 688546 & 4.5 & 5.3491 & TRN \\
\hline CHEMBL1395065 & 688546 & 4.85 & 5.2942 & TRN \\
\hline CHEMBL1474085 & 688546 & 4.5 & 5.0043 & TRN \\
\hline CHEMBL1362424 & 688546 & 5.2 & 6.0417 & TRN \\
\hline CHEMBL90882 & 688546 & 4.5 & 5.0458 & TRN \\
\hline CHEMBL1330357 & 688546 & 4.6 & 5.7123 & TST \\
\hline CHEMBL1329725 & 688546 & 4.7 & 5.2244 & TST \\
\hline CHEMBL1479909 & 688546 & 4.6 & 4.7516 & TRN \\
\hline CHEMBL1317521 & 688546 & 4.5 & 5.4142 & TRN \\
\hline CHEMBL1495616 & 688546 & 7.5003 & 5.3254 & TRN \\
\hline CHEMBL1519404 & 688546 & 4.9 & 4.8623 & TST \\
\hline CHEMBL1314776 & 688546 & 4.5 & 5.136 & TRN \\
\hline CHEMBL1473989 & 688546 & 4.5 & 5.39 & TRN \\
\hline CHEMBL1362100 & 688546 & 4.5 & 5.3249 & TST \\
\hline CHEMBL1492086 & 688546 & 4.7 & 5.5851 & TRN \\
\hline CHEMBL1372889 & 688546 & 6.5 & 5.8047 & TRN \\
\hline CHEMBL1567235 & 688546 & 4.9 & 5.1709 & TRN \\
\hline CHEMBL1394268 & 688546 & 4.9 & 5.2073 & TRN \\
\hline CHEMBL1611998 & 688546 & 4.9 & 5.0635 & TRN \\
\hline CHEMBL1395429 & 688546 & 4.5 & 4.7524 & TRN \\
\hline CHEMBL1452048 & 688546 & 4.5 & 5.4644 & TRN \\
\hline CHEMBL1545560 & 688546 & 4.6 & 5.4192 & TRN \\
\hline CHEMBL1515235 & 688546 & 5.0 & 5.0002 & TRN \\
\hline CHEMBL1477025 & 688546 & 4.5 & 4.465 & TRN \\
\hline CHEMBL 8145 & 688546 & 6.0 & 5.6498 & TRN \\
\hline CHEMBL1595747 & 688546 & 5.3 & 5.3866 & TST \\
\hline CHEMBL1315037 & 688546 & 4.9 & 5.4125 & TRN \\
\hline CHEMBL1435582 & 688546 & 5.0 & 5.1135 & TST \\
\hline CHEMBL1473207 & 688546 & 4.8 & 5.5717 & TRN \\
\hline CHEMBL1311916 & 688546 & 5.9 & 5.3419 & TRN \\
\hline CHEMBL1332014 & 688546 & 4.8 & 5.4216 & TRN \\
\hline CHEMBL1562505 & 688546 & 5.9 & 5.3763 & TRN \\
\hline CHEMBL1472860 & 688546 & 5.8 & 5.6834 & TRN \\
\hline CHEMBL1486507 & 688546 & 5.4 & 5.3642 & TST \\
\hline CHEMBL1492738 & 688546 & 4.9 & 5.0466 & TRN \\
\hline CHEMBL1373990 & 688546 & 8.4949 & 6.2377 & TRN \\
\hline CHEMBL258767 & 688546 & 6.0 & 5.1809 & TRN \\
\hline CHEMBL1497004 & 688546 & 5.5 & 5.3903 & TRN \\
\hline CHEMBL1372212 & 688546 & 4.9 & 5.0328 & TRN \\
\hline CHEMBL1434541 & 688546 & 5.35 & 5.499 & TRN \\
\hline CHEMBL1349067 & 688546 & 4.9 & 4.9286 & TRN \\
\hline CHEMBL3214565 & 688546 & 5.0 & 5.1368 & TRN \\
\hline CHEMBL1362432 & 688546 & 4.8 & 5.1072 & TRN \\
\hline CHEMBL1306522 & 688546 & 5.0 & 5.1453 & TRN \\
\hline CHEMBL1569303 & 688546 & 5.0 & 5.2674 & TRN \\
\hline CHEMBL1607905 & 688546 & 4.8 & 5.2072 & TST \\
\hline
\end{tabular}




\begin{tabular}{|c|c|c|c|c|c|}
\hline \multirow[b]{2}{*}{ CHEMBL1606088 } & \multicolumn{5}{|c|}{ Supplemental Table s2.txt } \\
\hline & 688546 & 4.9 & 5.3736 & TRN & \multirow{3}{*}{ TRN } \\
\hline CHEMBL1420628 & 688546 & 4.9 & \multicolumn{2}{|c|}{ 4.7139999999999995 } & \\
\hline CHEMBL1366134 & 688546 & 7.699 & 5.822 & TST & \\
\hline CHEMBL1552368 & 688546 & 7.8013 & 5.5135 & TRN & \\
\hline CHEMBL99408 & 688546 & 5.5 & 5.1823 & TST & \\
\hline CHEMBL1487251 & 688546 & 4.9 & 5.3745 & TRN & \\
\hline CHEMBL1560301 & 688546 & 5.0 & 5.56 & TRN & \\
\hline CHEMBL1432396 & 688546 & 4.9 & 5.6482 & TRN & \\
\hline CHEMBL1496799 & 688546 & 4.5 & 5.3576 & TRN & \\
\hline CHEMBL1516772 & 688546 & 4.5 & 4.5391 & TRN & \\
\hline CHEMBL1513292 & 688546 & 4.9 & 4.8244 & TRN & \\
\hline CHEMBL1499803 & 688546 & 4.9 & 4.7316 & TRN & \\
\hline CHEMBL199194 & 688546 & 6.2 & 5.311 & TRN & \\
\hline CHEMBL465226 & 688546 & 4.9 & 5.4852 & TRN & \\
\hline CHEMBL1524621 & 688546 & 4.5 & 5.4823 & TRN & \\
\hline CHEMBL1552875 & 688546 & 7.4001 & 5.7259 & TRN & \\
\hline CHEMBL1561695 & 688546 & 4.45 & 5.3929 & TST & \\
\hline CHEMBL1592486 & 688546 & 5.8 & 5.313 & TRN & \\
\hline CHEMBL1314972 & 688546 & 6.0 & 5.5866 & TRN & \\
\hline CHEMBL1595955 & 688546 & 4.9 & 5.4892 & TRN & \\
\hline CHEMBL 308688 & 688546 & 5.0 & 5.0479 & TRN & \\
\hline CHEMBL370256 & 688546 & 4.8 & 5.4125 & TST & \\
\hline CHEMBL1377689 & 688546 & 4.5 & 5.1961 & TRN & \\
\hline CHEMBL1573167 & 688546 & 4.85 & 5.3703 & TST & \\
\hline CHEMBL1331122 & 688546 & 5.3 & 5.3677 & TST & \\
\hline CHEMBL1483365 & 688546 & 5.2 & 5.0248 & TST & \\
\hline CHEMBL1981990 & 688546 & 4.5 & 5.779 & TST & \\
\hline CHEMBL1523579 & 688546 & 4.9 & 4.706 & TRN & \\
\hline CHEMBL1476265 & 688546 & 5.1 & \multicolumn{2}{|c|}{5.702999999999999} & TRN \\
\hline CHEMBL1444059 & 688546 & 4.6 & \multicolumn{2}{|c|}{5.242999999999999} & TRN \\
\hline CHEMBL1512992 & 688546 & 4.8 & 5.2135 & TRN & \\
\hline CHEMBL1334962 & 688546 & 5.3 & 5.6696 & TRN & \\
\hline CHEMBL1598473 & 688546 & 4.5 & 5.434 & TRN & \\
\hline CHEMBL1356714 & 688546 & 4.7 & 5.4291 & TRN & \\
\hline CHEMBL1515677 & 688546 & 5.7 & 5.8425 & TST & \\
\hline CHEMBL1437484 & 688546 & 4.9 & 5.2016 & TRN & \\
\hline CHEMBL1522834 & 688546 & 4.6 & 5.2062 & TRN & \\
\hline CHEMBL1485379 & 688546 & 5.3 & 5.9415 & TRN & \\
\hline CHEMBL1332609 & 688546 & 4.5 & 5.2709 & TRN & \\
\hline CHEMBL1593169 & 688546 & 5.0 & 5.197 & TRN & \\
\hline CHEMBL1398240 & 688546 & 4.6 & 5.3693 & TRN & \\
\hline CHEMBL1592195 & 688546 & 7.8996 & 5.1384 & TRN & \\
\hline CHEMBL1516121 & 688546 & 4.8 & 4.9675 & TRN & \\
\hline CHEMBL1478232 & 688546 & 4.5 & 4.762 & TST & \\
\hline CHEMBL1310221 & 688546 & 5.15 & 5.2706 & TRN & \\
\hline CHEMBL1518138 & 688546 & 6.9 & 5.0744 & TRN & \\
\hline CHEMBL1316613 & 688546 & 7.5003 & 5.5641 & TRN & \\
\hline CHEMBL1451322 & 688546 & 8.301 & 5.53 & TRN & \\
\hline & & & & 10325 & \\
\hline
\end{tabular}




\begin{tabular}{|c|c|c|c|c|}
\hline & & & pplement & al $\mathrm{T}$ \\
\hline CHEMBL1396195 & 688546 & 4.6 & 5.2933 & TRN \\
\hline CHEMBL1473576 & 688546 & 4.8 & 5.7436 & TRN \\
\hline CHEMBL1590419 & 688546 & 5.0 & 5.0399 & TRN \\
\hline CHEMBL1512208 & 688546 & 4.9 & 4.9173 & TRN \\
\hline CHEMBL1338563 & 688546 & 4.9 & 5.237 & TRN \\
\hline CHEMBL1583513 & 688546 & 4.8 & 5.2758 & TRN \\
\hline CHEMBL3196464 & 688546 & 4.9 & 5.0417 & TST \\
\hline CHEMBL1306666 & 688546 & 4.9 & 5.2034 & TRN \\
\hline CHEMBL1317768 & 688546 & 5.6 & 5.777 & TRN \\
\hline CHEMBL1417970 & 688546 & 4.5 & 4.8551 & TRN \\
\hline CHEMBL1533107 & 688546 & 4.9 & 4.8456 & TRN \\
\hline CHEMBL1474327 & 688546 & 4.6 & 5.1168 & TST \\
\hline CHEMBL1415517 & 688546 & 4.45 & 5.1486 & TRN \\
\hline CHEMBL1591534 & 688546 & 5.9 & 4.8883 & TRN \\
\hline CHEMBL1306324 & 688546 & 4.9 & 5.4464 & TST \\
\hline CHEMBL1594207 & 688546 & 4.7 & 4.6769 & TRN \\
\hline CHEMBL1457345 & 688546 & 5.3 & 5.1693 & TRN \\
\hline CHEMBL1594460 & 688546 & 4.5 & 5.473 & TRN \\
\hline CHEMBL1513378 & 688546 & 5.1 & 5.5116 & TRN \\
\hline CHEMBL449690 & 688546 & 4.5 & 5.6264 & TST \\
\hline CHEMBL1594032 & 688546 & 7.699 & 5.6486 & TRN \\
\hline CHEMBL1355447 & 688546 & 4.5 & 5.275 & TRN \\
\hline CHEMBL1553798 & 688546 & 4.5 & 4.5956 & TRN \\
\hline CHEMBL1547156 & 688546 & 4.9 & 5.1258 & TST \\
\hline CHEMBL1409420 & 688546 & 5.0 & 5.3672 & TRN \\
\hline CHEMBL1333699 & 688546 & 4.9 & 5.0066 & TST \\
\hline CHEMBL1358579 & 688546 & 4.45 & 5.4787 & TST \\
\hline CHEMBL1602282 & 688546 & 4.5 & 5.4366 & TRN \\
\hline CHEMBL1473912 & 688546 & 5.3 & 5.3285 & TST \\
\hline CHEMBL1526094 & 688546 & 5.4 & 5.4557 & TRN \\
\hline CHEMBL1502228 & 688546 & 4.7 & 4.662 & TST \\
\hline CHEMBL1433561 & 688546 & 4.8 & 4.9976 & TST \\
\hline CHEMBL1330020 & 688546 & 5.6 & 5.5377 & TRN \\
\hline CHEMBL1335587 & 688546 & 4.7 & 4.6831 & TRN \\
\hline CHEMBL1317848 & 688546 & 4.7 & 4.7811 & TRN \\
\hline CHEMBL1514008 & 688546 & 4.9 & 5.0391 & TRN \\
\hline CHEMBL1345626 & 688546 & 4.5 & 5.1718 & TRN \\
\hline CHEMBL1300317 & 688546 & 4.6 & 4.8777 & TST \\
\hline CHEMBL1593100 & 688546 & 4.75 & 5.4056 & TST \\
\hline CHEMBL1455592 & 688546 & 6.8 & 5.5653 & TRN \\
\hline CHEMBL1473497 & 688546 & 5.0 & 5.5933 & TRN \\
\hline CHEMBL1413274 & 688546 & 5.0 & 4.9962 & TRN \\
\hline CHEMBL1576405 & 688546 & 4.6 & 5.6837 & TST \\
\hline CHEMBL1599961 & 688546 & 6.2 & 5.3778 & TRN \\
\hline CHEMBL1534168 & 688546 & 4.9 & 5.2587 & TRN \\
\hline CHEMBL1544834 & 688546 & 5.0 & 5.0566 & TRN \\
\hline CHEMBL1334548 & 688546 & 7.5003 & 5.3748 & TRN \\
\hline CHEMBL1318046 & 688546 & 5.7 & 5.2471 & TRN \\
\hline
\end{tabular}




\begin{tabular}{|c|c|c|c|c|c|}
\hline & & & & & \\
\hline CHEMBL1559578 & 688546 & 4.9 & 5.118 & TST & \\
\hline CHEMBL1527186 & 688546 & 4.95 & 4.7162 & TRN & \\
\hline CHEMBL1476664 & 688546 & 4.9 & 4.8973 & TRN & \\
\hline CHEMBL1473983 & 688546 & 5.25 & 5.9148 & TRN & \\
\hline CHEMBL1478012 & 688546 & 4.8 & 4.7321 & TRN & \\
\hline CHEMBL1590519 & 688546 & 5.5 & 5.2685 & TRN & \\
\hline CHEMBL1316719 & 688546 & 4.8 & 5.4771 & TRN & \\
\hline CHEMBL1447232 & 688546 & 5.45 & 5.6524 & TRN & \\
\hline CHEMBL1515224 & 688546 & 4.9 & 5.4668 & TRN & \\
\hline CHEMBL1590689 & 688546 & 4.8 & 5.2696 & TST & \\
\hline CHEMBL1394507 & 688546 & 7.0 & 5.1815 & TRN & \\
\hline CHEMBL1333526 & 688546 & 4.9 & 5.3983 & TST & \\
\hline CHEMBL1593924 & 688546 & 5.2 & 5.0383 & TRN & \\
\hline CHEMBL1314815 & 688546 & 4.5 & 5.7982 & TST & \\
\hline CHEMBL1319873 & 688546 & 4.7 & 4.9366 & TRN & \\
\hline CHEMBL1569370 & 688546 & 4.9 & 4.6838 & TRN & \\
\hline CHEMBL1403548 & 688546 & 5.0 & 6.0078 & TRN & \\
\hline CHEMBL1514929 & 688546 & 4.5 & 5.6503 & TRN & \\
\hline CHEMBL1397045 & 688546 & 5.1 & 5.0742 & TRN & \\
\hline CHEMBL1531398 & 688546 & 4.8 & 5.4106 & TRN & \\
\hline CHEMBL1504324 & 688546 & 5.3 & 5.0991 & TST & \\
\hline CHEMBL545050 & 688546 & 6.7001 & 5.277 & TST & \\
\hline CHEMBL1412891 & 688546 & 5.0 & 5.3611 & TRN & \\
\hline CHEMBL1406161 & 688546 & 4.9 & 5.3043 & TRN & \\
\hline CHEMBL1434928 & 688546 & 4.8 & 4.9533 & TRN & \\
\hline CHEMBL1084441 & 688546 & 4.7 & 4.9778 & TRN & \\
\hline CHEMBL77098 & 688546 & 5.0 & 4.8932 & TRN & \\
\hline CHEMBL1477674 & 688546 & 8.0506 & 4.9862 & TST & \\
\hline CHEMBL1324842 & 688546 & 5.4 & 5.0618 & TST & \\
\hline CHEMBL1354836 & 688546 & 5.7 & 5.38700 & 00000000005 & TRN \\
\hline CHEMBL1608823 & 688546 & 4.9 & 5.2756 & TST & \\
\hline CHEMBL1508884 & 688546 & 4.9 & 5.141 & TRN & \\
\hline CHEMBL1332340 & 688546 & 4.9 & 5.25700 & 3000000001 & TST \\
\hline CHEMBL1361796 & 688546 & 6.0 & 5.61299 & 99999999995 & TRN \\
\hline CHEMBL1492780 & 688546 & 4.9 & 5.0395 & TRN & \\
\hline CHEMBL1395831 & 688546 & 8.2007 & 5.9445 & TST & \\
\hline CHEMBL1502184 & 688546 & 4.7 & 5.0906 & TST & \\
\hline CHEMBL1518405 & 688546 & 4.9 & 5.3711 & TRN & \\
\hline CHEMBL1430921 & 688546 & 5.3 & 5.3963 & TRN & \\
\hline CHEMBL1374301 & 688546 & 4.9 & $6.0760 e$ & 30000000005 & TRN \\
\hline CHEMBL1356051 & 688546 & 6.2 & $5.5820 e$ & 0000000001 & TRN \\
\hline CHEMBL1414269 & 688546 & 5.0 & 4.6786 & TRN & \\
\hline CHEMBL1570613 & 688546 & 5.0 & 5.3833 & TRN & \\
\hline CHEMBL1531156 & 688546 & 4.9 & 4.958 & TRN & \\
\hline CHEMBL1412795 & 688546 & 5.0 & 5.1332 & TRN & \\
\hline CHEMBL1362173 & 688546 & 6.5 & 5.4669 & TRN & \\
\hline CHEMBL1496957 & 688546 & 4.5 & 5.3217 & TRN & \\
\hline CHEMBL1396434 & 688546 & 4.9 & 4.8211 & TRN & \\
\hline & & & & 10327 & \\
\hline
\end{tabular}




\begin{tabular}{|c|c|c|c|c|c|}
\hline CHEMBL1322000 & 688546 & 4.5 & \multicolumn{2}{|c|}{5.093999999999999} & TRN \\
\hline CHEMBL1567403 & 688546 & 4.7 & 5.2156 & TST & \\
\hline CHEMBL1398282 & 688546 & 4.8 & 5.1579 & TRN & \\
\hline CHEMBL1555137 & 688546 & 8.3468 & 5.8244 & TRN & \\
\hline CHEMBL1361668 & 688546 & 7.699 & 5.6431 & TRN & \\
\hline CHEMBL1434724 & 688546 & 5.65 & 5.5263 & TRN & \\
\hline CHEMBL1534334 & 688546 & 4.9 & 5.4035 & TRN & \\
\hline CHEMBL1333966 & 688546 & 7.3002 & 5.0915 & TST & \\
\hline CHEMBL1372850 & 688546 & 5.6 & \multicolumn{2}{|c|}{5.257999999999999} & TST \\
\hline CHEMBL1454544 & 688546 & 4.9 & 4.6391 & TRN & \\
\hline CHEMBL1536135 & 688546 & 4.9 & 4.9013 & TRN & \\
\hline CHEMBL1483849 & 688546 & 5.0 & 5.3548 & TRN & \\
\hline CHEMBL1433261 & 688546 & 7.8013 & 5.4936 & TST & \\
\hline CHEMBL1394461 & 688546 & 7.0501 & 5.5915 & TRN & \\
\hline CHEMBL1486830 & 688546 & 7.0 & 5.3989 & TST & \\
\hline CHEMBL1317571 & 688546 & 4.5 & 5.0793 & TRN & \\
\hline CHEMBL1429218 & 688546 & 5.0 & 4.8017 & TRN & \\
\hline CHEMBL1317586 & 688546 & 4.9 & 5.0483 & TRN & \\
\hline CHEMBL1500193 & 688546 & 4.7 & 4.8457 & TRN & \\
\hline CHEMBL1410565 & 688546 & 5.0 & 5.8808 & TRN & \\
\hline CHEMBL1521501 & 688546 & 6.4 & 5.8664 & TRN & \\
\hline CHEMBL1436415 & 688546 & 4.7 & 4.8872 & TRN & \\
\hline CHEMBL1333641 & 688546 & 4.5 & 6.2101 & TRN & \\
\hline CHEMBL1608066 & 688546 & 5.2 & 5.3278 & TRN & \\
\hline CHEMBL1516450 & 688546 & 8.301 & 5.7339 & TRN & \\
\hline CHEMBL1318539 & 688546 & 4.5 & 5.6991 & TRN & \\
\hline CHEMBL1502259 & 688546 & 4.7 & 4.989 & TST & \\
\hline CHEMBL1364432 & 688546 & 5.1 & 4.698 & TRN & \\
\hline CHEMBL1321245 & 688546 & 4.8 & 5.4052 & TRN & \\
\hline CHEMBL1473583 & 688546 & 4.5 & 5.4224 & TRN & \\
\hline CHEMBL1317822 & 688546 & 5.2 & 5.5258 & TRN & \\
\hline CHEMBL1434506 & 688546 & 5.85 & \multicolumn{2}{|c|}{5.287999999999999} & TRN \\
\hline CHEMBL1488229 & 688546 & 6.6 & 5.3861 & TRN & \\
\hline CHEMBL1578976 & 688546 & 6.45 & 5.5452 & TST & \\
\hline CHEMBL1474673 & 688546 & 7.9508 & 5.9873 & TRN & \\
\hline CHEMBL1555689 & 688546 & 4.8 & 5.1617 & TRN & \\
\hline CHEMBL1562181 & 688546 & 4.5 & 5.0846 & TRN & \\
\hline CHEMBL1370284 & 688546 & 4.7 & 5.1335 & TST & \\
\hline CHEMBL1436726 & 688546 & 4.8 & 5.5097 & TST & \\
\hline CHEMBL1560690 & 688546 & 4.9 & 5.5979 & TST & \\
\hline CHEMBL1488104 & 688546 & 4.6 & 4.9292 & TRN & \\
\hline CHEMBL1488141 & 688546 & 5.0 & 4.9464 & TRN & \\
\hline CHEMBL1354563 & 688546 & 4.9 & 4.9748 & TRN & \\
\hline CHEMBL1553868 & 688546 & 4.5 & 4.7028 & TST & \\
\hline CHEMBL1599764 & 688546 & 4.8 & 5.4076 & TRN & \\
\hline CHEMBL1378375 & 688546 & 4.9 & 5.2365 & TRN & \\
\hline CHEMBL1418216 & 688546 & 4.6 & 4.7687 & TRN & \\
\hline CHEMBL1364723 & 688546 & 4.5 & 5.4151 & TST & \\
\hline & & & & 10328 & \\
\hline
\end{tabular}




\begin{tabular}{|c|c|c|c|c|c|}
\hline & & & & & \\
\hline CHEMBL1472824 & 688546 & 5.5 & 4.7221 & TRN & \\
\hline CHEMBL1341668 & 688546 & 4.5 & 5.2372 & TRN & \\
\hline CHEMBL1323331 & 688546 & 5.9 & 5.5386 & TRN & \\
\hline CHEMBL1572924 & 688546 & 4.9 & 5.2692 & TRN & \\
\hline CHEMBL1542091 & 688546 & 4.9 & 5.4211 & TRN & \\
\hline CHEMBL1359251 & 688546 & 4.9 & 4.8584 & TRN & \\
\hline CHEMBL1361708 & 688546 & 4.8 & 4.9179 & TRN & \\
\hline CHEMBL1601522 & 688546 & 4.7 & 5.3218 & TRN & \\
\hline CHEMBL1332610 & 688546 & 5.5 & 5.8813 & TRN & \\
\hline CHEMBL1357454 & 688546 & 4.8 & 5.1466 & TRN & \\
\hline CHEMBL1451675 & 688546 & 5.0 & 4.7192 & TRN & \\
\hline CHEMBL1490334 & 688546 & 5.1 & 5.0525 & TRN & \\
\hline CHEMBL1443381 & 688546 & 4.5 & 4.8296 & TRN & \\
\hline CHEMBL1394510 & 688546 & 4.9 & 5.2951 & TRN & \\
\hline CHEMBL3199337 & 688546 & 4.7 & 4.96899 & 9999999999 & TRN \\
\hline CHEMBL1494088 & 688546 & 4.8 & 5.3222 & TST & \\
\hline CHEMBL1571692 & 688546 & 5.0 & 5.2338 & TST & \\
\hline CHEMBL1395967 & 688546 & 6.1 & 5.6199 & TRN & \\
\hline CHEMBL1526223 & 688546 & 4.7 & 5.5166 & TST & \\
\hline CHEMBL1324115 & 688546 & 4.6 & 5.26 & TRN & \\
\hline CHEMBL1397903 & 688546 & 5.0 & 4.9418 & TRN & \\
\hline CHEMBL1398475 & 688546 & 4.9 & 5.227 & TST & \\
\hline CHEMBL1486603 & 688546 & 4.7 & 5.3703 & TST & \\
\hline CHEMBL1598680 & 688546 & 4.7 & 5.2437 & TST & \\
\hline CHEMBL65 & 688546 & 6.0 & 6.8858 & TST & \\
\hline CHEMBL1544460 & 688546 & 4.6 & 4.8702 & TRN & \\
\hline CHEMBL1521882 & 688546 & 4.7 & 5.83700 & 0000000001 & TST \\
\hline CHEMBL1334916 & 688546 & 5.1 & 5.44600 & 2000000001 & TST \\
\hline CHEMBL1413052 & 688546 & 4.9 & 4.7499 & TRN & \\
\hline CHEMBL1529383 & 688546 & 5.25 & 5.2611 & TST & \\
\hline CHEMBL1474165 & 688546 & 5.1 & 4.8857 & TRN & \\
\hline CHEMBL1357235 & 688546 & 5.9 & 5.2044 & TRN & \\
\hline CHEMBL1551751 & 688546 & 5.0 & 5.5274 & TRN & \\
\hline CHEMBL1339702 & 688546 & 4.9 & 5.1206 & TRN & \\
\hline CHEMBL1396408 & 688546 & 4.3 & 5.2736 & TST & \\
\hline CHEMBL1310144 & 688546 & 6.0 & 5.1544 & TRN & \\
\hline CHEMBL1395010 & 688546 & 6.7001 & 5.1916 & TST & \\
\hline CHEMBL1475937 & 688546 & 5.4 & 4.8948 & TRN & \\
\hline CHEMBL1561048 & 688546 & 4.5 & 5.3276 & TRN & \\
\hline CHEMBL1358452 & 688546 & 5.8 & 5.3562 & TRN & \\
\hline CHEMBL1306949 & 688546 & 4.9 & 4.8206 & TRN & \\
\hline CHEMBL1509065 & 688546 & 5.0 & 5.357 & TST & \\
\hline CHEMBL1358435 & 688546 & 7.0 & 5.3159 & TRN & \\
\hline CHEMBL1612368 & 688546 & 4.6 & 5.1011 & TRN & \\
\hline CHEMBL1397848 & 688546 & 4.6 & 4.65600 & 3000000001 & TRN \\
\hline CHEMBL1598938 & 688546 & 4.5 & 4.8308 & TRN & \\
\hline CHEMBL1401145 & 688546 & 5.5 & 5.394 & TRN & \\
\hline CHEMBL1603889 & 688546 & 4.7 & 5.5808 & TRN & \\
\hline & & & & 10329 & \\
\hline
\end{tabular}




\begin{tabular}{|c|c|c|c|c|}
\hline & & & & \\
\hline CHEMBL1519975 & 688546 & 5.6 & 5.3199 & TRN \\
\hline CHEMBL1474978 & 688546 & 4.5 & 5.149 & TRN \\
\hline CHEMBL1483007 & 688546 & 4.7 & 4.9545 & TRN \\
\hline CHEMBL1463381 & 688546 & 4.8 & 5.2196 & TST \\
\hline CHEMBL1418503 & 688546 & 6.2 & 5.0802 & TRN \\
\hline CHEMBL1688558 & 688546 & 5.3 & 5.2981 & TRN \\
\hline CHEMBL1487271 & 688546 & 4.5 & 4.6812 & TRN \\
\hline CHEMBL1564629 & 688546 & 5.0 & 6.0064 & TRN \\
\hline CHEMBL1474139 & 688546 & 4.7 & 5.4442 & TRN \\
\hline CHEMBL1351707 & 688546 & 4.9 & 5.5359 & TST \\
\hline CHEMBL1394550 & 688546 & 4.6 & 5.1401 & TRN \\
\hline CHEMBL1314737 & 688546 & 5.1 & 5.4295 & TRN \\
\hline CHEMBL1523114 & 688546 & 4.8 & 5.0089 & TRN \\
\hline CHEMBL1568548 & 688546 & 6.5 & 5.938 & TRN \\
\hline CHEMBL1322960 & 688546 & 4.6 & 5.3731 & TRN \\
\hline CHEMBL1525915 & 688546 & 6.9 & 5.5574 & TRN \\
\hline CHEMBL1503705 & 688546 & 5.0 & 5.4758 & TST \\
\hline CHEMBL1423811 & 688546 & 4.9 & 4.9837 & TST \\
\hline CHEMBL1395297 & 688546 & 4.8 & 4.7968 & TRN \\
\hline CHEMBL1568306 & 688546 & 5.2 & 5.1003 & TRN \\
\hline CHEMBL1435272 & 688546 & 5.3 & 5.1636 & TRN \\
\hline CHEMBL43612 & 688546 & 5.0 & 4.7827 & TST \\
\hline CHEMBL1370940 & 688546 & 4.45 & 5.7718 & TRN \\
\hline CHEMBL1592325 & 688546 & 6.8 & 5.16 & TRN \\
\hline CHEMBL1451013 & 688546 & 5.2 & 5.6126 & TST \\
\hline CHEMBL 3197885 & 688546 & 4.9 & 4.7224 & TRN \\
\hline CHEMBL1568558 & 688546 & 5.0 & 5.5591 & TST \\
\hline CHEMBL1607640 & 688546 & 4.7 & 4.9594 & TRN \\
\hline CHEMBL1455176 & 688546 & 5.45 & 4.9987 & TRN \\
\hline CHEMBL1311346 & 688546 & 4.8 & 5.2274 & TST \\
\hline CHEMBL1336575 & 688546 & 4.9 & 5.4314 & TRN \\
\hline CHEMBL1436631 & 688546 & 4.9 & 4.5777 & TRN \\
\hline CHEMBL1514145 & 688546 & 4.7 & 5.4432 & TRN \\
\hline CHEMBL1320926 & 688546 & 7.5003 & 5.2705 & TST \\
\hline CHEMBL1518325 & 688546 & 8.0 & 5.4333 & TST \\
\hline CHEMBL1508674 & 688546 & 4.7 & 4.9257 & TRN \\
\hline CHEMBL1512483 & 688546 & 4.9 & 5.2088 & TST \\
\hline CHEMBL1603687 & 688546 & 4.6 & 5.9835 & TRN \\
\hline CHEMBL1545699 & 688546 & 6.8 & 5.7093 & TST \\
\hline CHEMBL1563146 & 688546 & 4.9 & 5.849 & TRN \\
\hline CHEMBL1395146 & 688546 & 4.9 & 5.2211 & TRN \\
\hline CHEMBL1443889 & 688546 & 5.0 & 4.9015 & TRN \\
\hline CHEMBL1523356 & 688546 & 4.7 & 5.6825 & TRN \\
\hline CHEMBL1314454 & 688546 & 5.8 & 5.6641 & TRN \\
\hline CHEMBL1327810 & 688546 & 5.0 & 5.4158 & TRN \\
\hline CHEMBL1512692 & 688546 & 4.8 & 5.0582 & TRN \\
\hline CHEMBL1553576 & 688546 & 5.2 & 5.694 & TRN \\
\hline CHEMBL1454373 & 688546 & 4.8 & 5.1687 & TRN \\
\hline
\end{tabular}




\begin{tabular}{|c|c|c|c|c|}
\hline \multicolumn{5}{|c|}{ Supplemental Table S2. } \\
\hline CHEMBL1316465 & 688546 & 4.5 & 5.6563 & TRN \\
\hline CHEMBL1517996 & 688546 & 5.0 & 5.22 & TST \\
\hline CHEMBL1586846 & 688546 & 4.9 & 5.2039 & TRN \\
\hline CHEMBL1596781 & 688546 & 4.8 & 5.3898 & TST \\
\hline CHEMBL1515714 & 688546 & 4.5 & 5.121 & TRN \\
\hline CHEMBL1519886 & 688546 & 5.55 & 5.2838 & TRN \\
\hline CHEMBL1481415 & 688546 & 4.8 & 5.3597 & TRN \\
\hline CHEMBL1590608 & 688546 & 6.25 & 5.3646 & TRN \\
\hline CHEMBL1528904 & 688546 & 4.5 & 4.6255 & TRN \\
\hline CHEMBL1362206 & 688546 & 4.5 & 5.0404 & TST \\
\hline CHEMBL1412478 & 688546 & 4.9 & 5.3983 & TRN \\
\hline CHEMBL1555739 & 688546 & 4.5 & 4.7015 & TRN \\
\hline CHEMBL1475317 & 688546 & 8.4949 & 6.3388 & TRN \\
\hline CHEMBL1564938 & 688546 & 6.3 & 5.9421 & TRN \\
\hline CHEMBL1321323 & 688546 & 4.9 & 5.0111 & TRN \\
\hline CHEMBL1326401 & 688546 & 5.0 & 5.4713 & TRN \\
\hline CHEMBL1398376 & 688546 & 4.8 & 5.1494 & TRN \\
\hline CHEMBL1550877 & 688546 & 5.0 & 5.4161 & TST \\
\hline CHEMBL1559064 & 688546 & 4.35 & 5.5078 & TRN \\
\hline CHEMBL1973226 & 688546 & 4.8 & 4.9822 & TRN \\
\hline CHEMBL406120 & 688546 & 4.7 & 5.3265 & TST \\
\hline CHEMBL1380457 & 688546 & 4.6 & 5.7 & TST \\
\hline CHEMBL1560366 & 688546 & 4.5 & 5.0748 & TST \\
\hline CHEMBL1323237 & 688546 & 4.5 & 5.336 & TST \\
\hline CHEMBL1473957 & 688546 & 4.8 & 5.1468 & TRN \\
\hline CHEMBL1566790 & 688546 & 5.1 & 4.9393 & TST \\
\hline CHEMBL1396497 & 688546 & 5.3 & 5.4354 & TRN \\
\hline CHEMBL1566340 & 688546 & 5.0 & 5.194 & TRN \\
\hline CHEMBL1435212 & 688546 & 4.7 & 5.3224 & TRN \\
\hline CHEMBL1435757 & 688546 & 4.7 & 5.4726 & TRN \\
\hline CHEMBL1453336 & 688546 & 7.8508 & 5.3419 & TST \\
\hline CHEMBL1396790 & 688546 & 7.5003 & 5.0628 & TRN \\
\hline CHEMBL1589316 & 688546 & 4.45 & 5.9061 & TST \\
\hline CHEMBL1395459 & 688546 & 5.5 & 5.6491 & TRN \\
\hline CHEMBL1439236 & 688546 & 4.5 & 5.3875 & TST \\
\hline CHEMBL3208847 & 688546 & 5.6 & 5.30399 & 9999999999 \\
\hline CHEMBL1552414 & 688546 & 4.9 & 5.2059 & TRN \\
\hline CHEMBL1487735 & 688546 & 4.8 & 4.6021 & TRN \\
\hline CHEMBL388757 & 688546 & 5.0 & 5.3767 & TRN \\
\hline CHEMBL1377384 & 688546 & 5.7 & 5.1139 & TRN \\
\hline CHEMBL1573926 & 688546 & 5.0 & 5.2182 & TRN \\
\hline CHEMBL1315098 & 688546 & 5.2 & 5.7418 & TRN \\
\hline CHEMBL1445958 & 688546 & 4.7 & 4.7126 & TRN \\
\hline CHEMBL1547000 & 688546 & 4.9 & 5.4822 & TRN \\
\hline CHEMBL1318988 & 688546 & 4.9 & 4.8905 & TRN \\
\hline CHEMBL1332328 & 688546 & 4.5 & 5.4165 & TST \\
\hline CHEMBL1525456 & 688546 & 4.5 & 5.4482 & TRN \\
\hline CHEMBL1330251 & 688546 & 4.8 & 5.3881 & TRN \\
\hline
\end{tabular}




\begin{tabular}{|c|c|c|c|c|}
\hline \multicolumn{5}{|c|}{ Supplemental Table s2.txt } \\
\hline CHEMBL1324899 & 688546 & 4.7 & 5.0697 & TST \\
\hline CHEMBL285480 & 688546 & 4.5 & 5.0541 & TST \\
\hline CHEMBL1589846 & 688546 & 4.5 & 5.3174 & TRN \\
\hline CHEMBL1373552 & 688546 & 4.8 & 5.3693 & TRN \\
\hline CHEMBL1446926 & 688546 & 4.5 & 5.1104 & TST \\
\hline CHEMBL1357131 & 688546 & 7.1002 & 5.4096 & TRN \\
\hline CHEMBL1594042 & 688546 & 5.3 & 5.105 & TRN \\
\hline CHEMBL1539797 & 688546 & 5.25 & 5.1016 & TRN \\
\hline CHEMBL1452463 & 688546 & 5.9 & 5.154 & TRN \\
\hline CHEMBL1611559 & 688546 & 5.7 & 4.6465 & TRN \\
\hline CHEMBL1403318 & 688546 & 5.25 & 5.0314 & TRN \\
\hline CHEMBL 3197426 & 688546 & 4.45 & 5.7342 & TST \\
\hline CHEMBL1590671 & 688546 & 4.5 & 4.7614 & TRN \\
\hline CHEMBL1488285 & 688546 & 5.5 & 4.4397 & TRN \\
\hline CHEMBL1593285 & 688546 & 4.9 & 4.5141 & TRN \\
\hline CHEMBL1484785 & 688546 & 5.6 & 5.9776 & TRN \\
\hline CHEMBL1552204 & 688546 & 4.5 & 5.5207 & TRN \\
\hline CHEMBL1411108 & 688546 & 4.7 & 5.2718 & TRN \\
\hline CHEMBL1384654 & 688546 & 5.0 & 5.0408 & TRN \\
\hline CHEMBL1319178 & 688546 & 4.9 & 5.0463 & TRN \\
\hline CHEMBL1475346 & 688546 & 4.6 & 4.8255 & TRN \\
\hline CHEMBL1545671 & 688546 & 6.45 & 5.3604 & TST \\
\hline CHEMBL1399313 & 688546 & 6.1 & 4.9895 & TRN \\
\hline CHEMBL1355698 & 688546 & 7.0 & 5.7579 & TRN \\
\hline CHEMBL1488172 & 688546 & 5.0 & 4.8864 & TRN \\
\hline CHEMBL1516237 & 688546 & 5.0 & 5.5175 & TRN \\
\hline CHEMBL1460356 & 688546 & 4.8 & 4.8752 & TRN \\
\hline CHEMBL1318769 & 688546 & 4.9 & 4.9451 & TRN \\
\hline CHEMBL1520422 & 688546 & 4.9 & 5.4059 & TST \\
\hline CHEMBL592611 & 688546 & 5.7 & 5.347 & TRN \\
\hline CHEMBL1417432 & 688546 & 4.6 & 5.1278 & TRN \\
\hline CHEMBL1332924 & 688546 & 5.4 & 5.3804 & TRN \\
\hline CHEMBL1325279 & 688546 & 5.8 & 5.4544 & TRN \\
\hline CHEMBL1410147 & 688546 & 4.5 & 5.1016 & TST \\
\hline CHEMBL1347729 & 688546 & 4.5 & 5.0853 & TRN \\
\hline CHEMBL1438462 & 688546 & 4.9 & 5.3989 & TST \\
\hline CHEMBL1463234 & 688546 & 4.5 & 4.8995 & TRN \\
\hline CHEMBL1474746 & 688546 & 4.8 & 5.5051 & TRN \\
\hline CHEMBL1414277 & 688546 & 4.8 & 5.4054 & TRN \\
\hline CHEMBL1435894 & 688546 & 4.9 & 4.9846 & TRN \\
\hline CHEMBL1590457 & 688546 & 4.7 & 4.8345 & TRN \\
\hline CHEMBL1322253 & 688546 & 7.5003 & 5.8505 & TRN \\
\hline CHEMBL1333724 & 688546 & 6.9 & 5.1157 & TST \\
\hline CHEMBL1574599 & 688546 & 5.3 & 5.0794 & TRN \\
\hline CHEMBL1516388 & 688546 & 6.0 & 5.2837 & TST \\
\hline CHEMBL1606243 & 688546 & 8.4949 & 5.2984 & TRN \\
\hline CHEMBL1546037 & 688546 & 4.8 & 4.9326 & TST \\
\hline CHEMBL1571018 & 688546 & 5.1 & 5.1125 & TRN \\
\hline
\end{tabular}




\begin{tabular}{|c|c|c|c|c|c|}
\hline & & & & & \\
\hline CHEMBL1414599 & 688546 & 5.9 & 5.0613 & TRN & \\
\hline CHEMBL1452363 & 688546 & 5.55 & 5.3114 & TRN & \\
\hline CHEMBL1435271 & 688546 & 4.7 & 5.1909 & TRN & \\
\hline CHEMBL1611207 & 688546 & 4.7 & 6.0586 & TRN & \\
\hline CHEMBL1332450 & 688546 & 5.6 & 5.2027 & TRN & \\
\hline CHEMBL1331097 & 688546 & 5.0 & 5.0706 & TRN & \\
\hline CHEMBL1374110 & 688546 & 4.7 & 4.9314 & TRN & \\
\hline CHEMBL1446987 & 688546 & 5.0 & 5.21399 & 99999999995 & TRN \\
\hline CHEMBL1314674 & 688546 & 4.8 & 4.7058 & TRN & \\
\hline CHEMBL1359595 & 688546 & 4.9 & 5.6378 & TRN & \\
\hline CHEMBL1328437 & 688546 & 6.2 & 4.8276 & TST & \\
\hline CHEMBL1590708 & 688546 & 4.6 & 5.1223 & TRN & \\
\hline CHEMBL1410065 & 688546 & 4.5 & 5.2539 & TRN & \\
\hline CHEMBL1451926 & 688546 & 4.9 & 5.1767 & TRN & \\
\hline CHEMBL1449971 & 688546 & 4.5 & 4.6661 & TRN & \\
\hline CHEMBL1487321 & 688546 & 4.5 & 5.0951 & TRN & \\
\hline CHEMBL1398864 & 688546 & 4.9 & 5.6111 & TRN & \\
\hline CHEMBL129795 & 688546 & 4.5 & 5.385 & TRN & \\
\hline CHEMBL1469885 & 688546 & 4.5 & 5.3291 & TST & \\
\hline CHEMBL1534845 & 688546 & 4.9 & 5.2915 & TRN & \\
\hline CHEMBL1320173 & 688546 & 4.8 & 4.8514 & TRN & \\
\hline CHEMBL1528818 & 688546 & 7.4001 & 5.5565 & TST & \\
\hline CHEMBL1336900 & 688546 & 7.9508 & 5.4652 & TST & \\
\hline CHEMBL1409244 & 688546 & 6.2 & 5.3845 & TRN & \\
\hline CHEMBL1515334 & 688546 & 4.5 & 5.1237 & TRN & \\
\hline CHEMBL1513615 & 688546 & 7.5498 & 5.392 & TRN & \\
\hline CHEMBL1439783 & 688546 & 4.7 & 4.9628 & TST & \\
\hline CHEMBL462880 & 688546 & 4.5 & 5.1734 & TRN & \\
\hline CHEMBL1398546 & 688546 & 4.5 & 5.3732 & TRN & \\
\hline CHEMBL1450676 & 688546 & 5.6 & 5.409 & TRN & \\
\hline CHEMBL1512937 & 688546 & 4.5 & 4.9131 & TRN & \\
\hline CHEMBL3214164 & 688546 & 5.4 & 5.3319 & TRN & \\
\hline CHEMBL 1256876 & 688546 & 6.0 & 4.8368 & TST & \\
\hline CHEMBL1427972 & 688546 & 5.5 & 5.3332 & TRN & \\
\hline CHEMBL1318259 & 688546 & 4.5 & 5.1666 & TST & \\
\hline CHEMBL1596997 & 688546 & 5.35 & 5.1953 & TST & \\
\hline CHEMBL1463686 & 688546 & 4.5 & 5.0977 & TRN & \\
\hline CHEMBL195350 & 688546 & 5.1 & 4.8872 & TRN & \\
\hline CHEMBL1435378 & 688546 & 4.8 & 5.7049 & TRN & \\
\hline CHEMBL1514262 & 688546 & 4.9 & 5.3033 & TRN & \\
\hline CHEMBL1479626 & 688546 & 4.8 & 4.8012 & TRN & \\
\hline CHEMBL1611082 & 688546 & 5.4 & 5.8393 & TRN & \\
\hline CHEMBL1579777 & 688546 & 5.0 & 5.084 & TST & \\
\hline CHEMBL1397147 & 688546 & 5.0 & 5.5111 & TST & \\
\hline CHEMBL1354611 & 688546 & 5.5 & 5.5492 & TRN & \\
\hline CHEMBL1402878 & 688546 & 4.7 & 5.2418 & TST & \\
\hline CHEMBL1591050 & 688546 & 4.5 & 4.94600 & 0000000001 & TRN \\
\hline CHEMBL1516160 & 688546 & 4.5 & 4.8517 & TRN & \\
\hline & & & & 10333 & \\
\hline
\end{tabular}




\begin{tabular}{|c|c|c|c|c|}
\hline \multicolumn{5}{|c|}{ Supplemental Table S2.txt } \\
\hline CHEMBL1448621 & 688546 & 4.6 & 5.4511 & TRN \\
\hline CHEMBL1578075 & 688546 & 4.8 & 5.2403 & TST \\
\hline CHEMBL1381824 & 688546 & 5.0 & 5.0536 & TRN \\
\hline CHEMBL3193678 & 688546 & 5.95 & 5.3491 & TST \\
\hline CHEMBL1360064 & 688546 & 4.9 & 5.2823 & TRN \\
\hline CHEMBL1541343 & 688546 & 4.9 & 5.3619 & TST \\
\hline CHEMBL1554845 & 688546 & 5.4 & 5.2072 & TST \\
\hline CHEMBL1325491 & 688546 & 4.5 & 4.965 & TRN \\
\hline CHEMBL1417215 & 688546 & 4.8 & 5.4758 & TRN \\
\hline CHEMBL1508245 & 688546 & 4.45 & 4.882 & TST \\
\hline CHEMBL1493828 & 688546 & 7.6003 & 6.0405 & TRN \\
\hline CHEMBL1330642 & 688546 & 5.1 & 5.2145 & TST \\
\hline CHEMBL1555401 & 688546 & 7.0 & 6.6116 & TRN \\
\hline CHEMBL1318451 & 688546 & 5.4 & 5.9741 & TRN \\
\hline CHEMBL1395456 & 688546 & 4.6 & 4.973 & TRN \\
\hline CHEMBL1313788 & 688546 & 4.9 & 4.6603 & TRN \\
\hline CHEMBL1399555 & 688546 & 8.2007 & 6.1227 & TRN \\
\hline CHEMBL1458873 & 688546 & 4.9 & 5.234 & TRN \\
\hline CHEMBL1494306 & 688546 & 4.5 & 5.852 & TRN \\
\hline CHEMBL1513673 & 688546 & 6.9 & 6.1541 & TRN \\
\hline CHEMBL1475377 & 688546 & 4.9 & 5.2119 & TRN \\
\hline CHEMBL1314431 & 688546 & 5.0 & 4.6376 & TRN \\
\hline CHEMBL1556254 & 688546 & 4.95 & 4.7869 & TRN \\
\hline CHEMBL1612534 & 688546 & 6.0 & 5.4856 & TRN \\
\hline CHEMBL596836 & 688546 & 4.6 & 4.7046 & TRN \\
\hline CHEMBL1525394 & 688546 & 4.8 & 5.0501 & TRN \\
\hline CHEMBL1519229 & 688546 & 4.5 & 4.9526 & TRN \\
\hline CHEMBL1449409 & 688546 & 4.8 & 4.8112 & TRN \\
\hline CHEMBL1337955 & 688546 & 4.8 & 5.205 & TRN \\
\hline CHEMBL1568511 & 688546 & 7.699 & 5.5017 & TRN \\
\hline CHEMBL1409817 & 688546 & 4.5 & 5.07100 & 0000000001 \\
\hline CHEMBL1486646 & 688546 & 4.5 & 4.9944 & TRN \\
\hline CHEMBL1610429 & 688546 & 4.8 & 5.0397 & TST \\
\hline CHEMBL1474951 & 688546 & 4.5 & 5.746 & TST \\
\hline CHEMBL1323991 & 688546 & 8.0 & 5.1876 & TRN \\
\hline CHEMBL1397645 & 688546 & 4.5 & 5.1077 & TRN \\
\hline CHEMBL1552786 & 688546 & 4.5 & 5.544 & TST \\
\hline CHEMBL1357882 & 688546 & 5.85 & 5.2772 & TRN \\
\hline CHEMBL1399316 & 688546 & 5.2 & 5.3612 & TRN \\
\hline CHEMBL1565346 & 688546 & 4.9 & 5.3456 & TRN \\
\hline CHEMBL1567047 & 688546 & 5.1 & 5.8603 & TRN \\
\hline CHEMBL1568664 & 688546 & 4.45 & 5.7305 & TRN \\
\hline CHEMBL1611178 & 688546 & 5.2 & 5.6221 & TRN \\
\hline CHEMBL1516944 & 688546 & 4.5 & 5.4849 & TRN \\
\hline CHEMBL1609339 & 688546 & 5.0 & 5.0959 & TRN \\
\hline CHEMBL1355857 & 688546 & 4.6 & 4.9275 & TRN \\
\hline CHEMBL1311577 & 688546 & 4.7 & 5.6498 & TST \\
\hline CHEMBL1590378 & 688546 & 6.0 & 5.4147 & TST \\
\hline
\end{tabular}




\begin{tabular}{|c|c|c|c|c|}
\hline \multicolumn{5}{|c|}{ Supplemental Table S2.txt } \\
\hline CHEMBL1330604 & 688546 & 7.5003 & 5.6897 & TRN \\
\hline CHEMBL1353069 & 688546 & 4.9 & 4.7937 & TRN \\
\hline CHEMBL1549834 & 688546 & 6.5 & 5.0996 & TST \\
\hline CHEMBL16312 & 688546 & 5.0 & 5.1251 & TRN \\
\hline CHEMBL7463 & 688546 & 4.6 & 4.8764 & TST \\
\hline CHEMBL1400825 & 688546 & 4.7 & 4.9296 & TRN \\
\hline CHEMBL1396394 & 688546 & 6.7001 & 5.5713 & TRN \\
\hline CHEMBL1317436 & 688546 & 4.5 & 4.995 & TST \\
\hline CHEMBL1404026 & 688546 & 8.3979 & 5.2952 & TST \\
\hline CHEMBL1468781 & 688546 & 5.25 & 5.5434 & TST \\
\hline CHEMBL1544951 & 688546 & 4.5 & 4.9479 & TST \\
\hline CHEMBL540848 & 688546 & 4.5 & 5.0034 & TST \\
\hline CHEMBL1314978 & 688546 & 4.5 & 4.8392 & TRN \\
\hline CHEMBL1422597 & 688546 & 5.1 & 5.6927 & TST \\
\hline CHEMBL1590235 & 688546 & 5.0 & 5.2913 & TST \\
\hline CHEMBL1445523 & 688546 & 5.0 & 5.1944 & TRN \\
\hline CHEMBL1396467 & 688546 & 5.4 & 4.9724 & TRN \\
\hline CHEMBL1611406 & 688546 & 4.8 & $5.2410 e$ & 00000000005 \\
\hline CHEMBL1587098 & 688546 & 5.25 & 5.3626 & TST \\
\hline CHEMBL1495072 & 688546 & 5.3 & 5.033 & TRN \\
\hline CHEMBL 3207845 & 688546 & 4.95 & 5.3991 & TST \\
\hline CHEMBL1368218 & 688546 & 5.5 & 5.1883 & TST \\
\hline CHEMBL1570241 & 688546 & 5.6 & 5.1922 & TRN \\
\hline CHEMBL1515336 & 688546 & 5.25 & 5.4048 & TRN \\
\hline CHEMBL1314804 & 688546 & 8.301 & 5.7621 & TRN \\
\hline CHEMBL1496337 & 688546 & 4.9 & 5.2081 & TRN \\
\hline CHEMBL1520849 & 688546 & 5.0 & 4.7921 & TST \\
\hline CHEMBL1513327 & 688546 & 4.9 & 5.2056 & TRN \\
\hline CHEMBL1594817 & 688546 & 4.9 & 5.4693 & TRN \\
\hline CHEMBL1394421 & 688546 & 4.5 & 4.9794 & TRN \\
\hline CHEMBL1558102 & 688546 & 5.4 & 5.0629 & TRN \\
\hline CHEMBL1346382 & 688546 & 5.8 & 5.2146 & TST \\
\hline CHEMBL1361507 & 688546 & 4.7 & 5.4067 & TRN \\
\hline CHEMBL1455750 & 688546 & 4.8 & 5.0114 & TRN \\
\hline CHEMBL1552911 & 688546 & 4.9 & 5.1758 & TRN \\
\hline CHEMBL1362115 & 688546 & 5.6 & 5.4928 & TRN \\
\hline CHEMBL1518774 & 688546 & 4.8 & 5.1334 & TRN \\
\hline CHEMBL1373107 & 688546 & 4.9 & $5.3270 e$ & 0000000001 \\
\hline CHEMBL1355398 & 688546 & 6.2 & $5.6320 e$ & 0000000001 \\
\hline CHEMBL3208365 & 688546 & 6.1 & 5.0921 & TRN \\
\hline CHEMBL1518444 & 688546 & 4.9 & 5.9682 & TRN \\
\hline CHEMBL1477163 & 688546 & 4.5 & 4.8799 & TRN \\
\hline CHEMBL1490042 & 688546 & 4.8 & 5.2541 & TRN \\
\hline CHEMBL1396243 & 688546 & 4.8 & 5.1252 & TRN \\
\hline CHEMBL1612025 & 688546 & 4.7 & 4.9014 & TRN \\
\hline CHEMBL1318804 & 688546 & 4.8 & 5.3531 & TRN \\
\hline CHEMBL1607496 & 688546 & 5.3 & 5.0483 & TRN \\
\hline CHEMBL1593318 & 688546 & 6.3 & 5.1033 & TRN \\
\hline
\end{tabular}




\begin{tabular}{|c|c|c|c|c|}
\hline \multicolumn{5}{|c|}{ Supplemental Table S2.txt } \\
\hline CHEMBL1335161 & 688546 & 4.9 & 5.9263 & TST \\
\hline CHEMBL1399633 & 688546 & 4.45 & 5.3535 & TRN \\
\hline CHEMBL1412101 & 688546 & 4.5 & 5.5938 & TRN \\
\hline CHEMBL1557782 & 688546 & 4.5 & 4.6668 & TRN \\
\hline CHEMBL1454512 & 688546 & 5.3 & 5.4931 & TST \\
\hline CHEMBL1473541 & 688546 & 4.5 & 5.1426 & TRN \\
\hline CHEMBL1590566 & 688546 & 4.5 & 5.8979 & TRN \\
\hline CHEMBL1447053 & 688546 & 7.699 & 5.9136 & TRN \\
\hline CHEMBL1395703 & 688546 & 5.1 & 5.1567 & TRN \\
\hline CHEMBL1323807 & 688546 & 6.1 & 5.0381 & TST \\
\hline CHEMBL1485127 & 688546 & 4.95 & 5.0593 & TST \\
\hline CHEMBL1356910 & 688546 & 4.9 & 5.2894 & TRN \\
\hline CHEMBL1404188 & 688546 & 8.0 & 5.329 & TRN \\
\hline CHEMBL1530447 & 688546 & 8.1024 & 5.6821 & TRN \\
\hline CHEMBL1466652 & 688546 & 4.8 & 4.9311 & TRN \\
\hline CHEMBL1476121 & 688546 & 4.8 & 5.4965 & TRN \\
\hline CHEMBL1476730 & 688546 & 7.6003 & 5.1905 & TRN \\
\hline CHEMBL1603952 & 688546 & 4.5 & 5.4759 & TRN \\
\hline CHEMBL1432420 & 688546 & 5.2 & 5.1265 & TRN \\
\hline CHEMBL3198987 & 688546 & 4.6 & 4.9664 & TST \\
\hline CHEMBL1418010 & 688546 & 4.5 & 5.2416 & TST \\
\hline CHEMBL1411953 & 688546 & 4.9 & 4.891 & TRN \\
\hline CHEMBL1455767 & 688546 & 4.9 & 5.4423 & TST \\
\hline CHEMBL1475255 & 688546 & 4.9 & 5.2251 & TRN \\
\hline CHEMBL1514197 & 688546 & 5.2 & 5.3798 & TST \\
\hline CHEMBL1336727 & 688546 & 4.8 & 5.2959 & TRN \\
\hline CHEMBL1471358 & 688546 & 4.8 & 4.9071 & TST \\
\hline CHEMBL1396284 & 688546 & 6.3 & 5.521 & TST \\
\hline CHEMBL1574539 & 688546 & 4.8 & 4.9747 & TRN \\
\hline CHEMBL1494401 & 688546 & 6.7001 & 5.7171 & TST \\
\hline CHEMBL1475002 & 688546 & 4.9 & 5.2327 & TRN \\
\hline CHEMBL1354271 & 688546 & 5.0 & 5.1715 & TRN \\
\hline CHEMBL1456320 & 688546 & 6.25 & 5.1798 & TRN \\
\hline CHEMBL1365570 & 688546 & 5.1 & 5.0306 & TRN \\
\hline CHEMBL1612481 & 688546 & 5.0 & 5.0345 & TST \\
\hline CHEMBL1325327 & 688546 & 4.9 & 5.4644 & TRN \\
\hline CHEMBL 1315747 & 688546 & 5.75 & 5.806 & TRN \\
\hline CHEMBL1300493 & 688546 & 5.4 & 5.1298 & TRN \\
\hline CHEMBL1380027 & 688546 & 4.7 & 5.5014 & TST \\
\hline CHEMBL1410196 & 688546 & 4.5 & 5.8474 & TRN \\
\hline CHEMBL1368674 & 688546 & 4.7 & 5.1373 & TRN \\
\hline CHEMBL1395023 & 688546 & 4.8 & 4.8562 & TRN \\
\hline CHEMBL1496869 & 688546 & 5.6 & 5.697 & TRN \\
\hline CHEMBL1394897 & 688546 & 5.4 & 5.8241 & TRN \\
\hline CHEMBL1364944 & 688546 & 4.9 & 5.2912 & TRN \\
\hline CHEMBL1488720 & 688546 & 4.6 & 5.1421 & TRN \\
\hline CHEMBL1573615 & 688546 & 4.7 & 5.0605 & TRN \\
\hline CHEMBL1483112 & 688546 & 4.5 & 4.9871 & TST \\
\hline
\end{tabular}




\begin{tabular}{|c|c|c|c|c|}
\hline \multicolumn{5}{|c|}{ Supplemental Table S2.txt } \\
\hline CHEMBL1593118 & 688546 & 5.15 & 5.1319 & TRN \\
\hline CHEMBL1327328 & 688546 & 5.1 & 5.0416 & TRN \\
\hline CHEMBL1592258 & 688546 & 4.5 & 5.3511 & TST \\
\hline CHEMBL1515147 & 688546 & 4.8 & 5.1878 & TRN \\
\hline CHEMBL1474126 & 688546 & 5.1 & 5.176 & TRN \\
\hline CHEMBL1549175 & 688546 & 4.5 & 5.2807 & TRN \\
\hline CHEMBL1519327 & 688546 & 4.8 & 5.1918 & TST \\
\hline CHEMBL1439533 & 688546 & 4.7 & 4.9067 & TRN \\
\hline CHEMBL1472874 & 688546 & 4.9 & 5.9662 & TRN \\
\hline CHEMBL1435052 & 688546 & 6.45 & 5.5687 & TRN \\
\hline CHEMBL1606598 & 688546 & 4.95 & 5.3848 & TRN \\
\hline CHEMBL1398545 & 688546 & 5.9 & 5.2564 & TRN \\
\hline CHEMBL1460126 & 688546 & 4.9 & 5.4823 & TRN \\
\hline CHEMBL1414709 & 688546 & 4.5 & 5.2911 & TRN \\
\hline CHEMBL1606986 & 688546 & 4.9 & 5.2366 & TRN \\
\hline CHEMBL1382277 & 688546 & 4.6 & 4.7206 & TRN \\
\hline CHEMBL1531877 & 688546 & 4.5 & 5.7455 & TRN \\
\hline CHEMBL1322635 & 688546 & 4.7 & 5.1368 & TRN \\
\hline CHEMBL1385193 & 688546 & 4.9 & 5.2219 & TRN \\
\hline CHEMBL1303068 & 688546 & 4.5 & 4.6563 & TRN \\
\hline CHEMBL1596278 & 688546 & 4.75 & 4.8513 & TRN \\
\hline CHEMBL1611539 & 688546 & 7.8508 & 5.5177 & TRN \\
\hline CHEMBL1584502 & 688546 & 4.5 & 4.6725 & TST \\
\hline CHEMBL1320318 & 688546 & 5.6 & 5.6114 & TRN \\
\hline CHEMBL1605700 & 688546 & 4.7 & 5.3822 & TRN \\
\hline CHEMBL1356667 & 688546 & 5.2 & 6.0143 & TRN \\
\hline CHEMBL1468774 & 688546 & 4.7 & 4.8079 & TRN \\
\hline CHEMBL1517141 & 688546 & 4.6 & 5.2362 & TST \\
\hline CHEMBL 377583 & 688546 & 5.4 & 5.2956 & TRN \\
\hline CHEMBL1580031 & 688546 & 5.1 & 5.2299 & TST \\
\hline CHEMBL1311783 & 688546 & 4.8 & 5.1248 & TRN \\
\hline CHEMBL1447008 & 688546 & 4.9 & 5.5436 & TRN \\
\hline CHEMBL1428415 & 688546 & 5.5 & 5.0217 & TRN \\
\hline CHEMBL1327439 & 688546 & 5.1 & 5.2959 & TRN \\
\hline CHEMBL1333744 & 688546 & 4.8 & 5.6821 & TRN \\
\hline CHEMBL1577295 & 688546 & 4.8 & 5.58299 & 9999999999 \\
\hline CHEMBL1378681 & 688546 & 4.9 & 5.0561 & TRN \\
\hline CHEMBL1395862 & 688546 & 5.0 & 5.3623 & TST \\
\hline CHEMBL1602114 & 688546 & 5.0 & 4.7307 & TRN \\
\hline CHEMBL1590551 & 688546 & 5.0 & 4.966 & TRN \\
\hline CHEMBL1426762 & 688546 & 4.5 & 5.551 & TST \\
\hline CHEMBL1347923 & 688546 & 4.45 & 5.6043 & TST \\
\hline CHEMBL1356552 & 688546 & 8.301 & 5.3491 & TRN \\
\hline CHEMBL1357938 & 688546 & 4.9 & 5.5791 & TST \\
\hline CHEMBL1593142 & 688546 & 4.9 & 5.7916 & TRN \\
\hline CHEMBL1549966 & 688546 & 4.5 & 5.4323 & TST \\
\hline CHEMBL233194 & 688546 & 5.0 & 4.9199 & TRN \\
\hline CHEMBL325238 & 688546 & 4.6 & 4.8199 & TRN \\
\hline
\end{tabular}




\begin{tabular}{|c|c|c|c|c|c|}
\hline \\
\hline CHEMBL1356506 & 688546 & 4.8 & 4.9388 & TRN & \\
\hline CHEMBL1445701 & 688546 & 4.6 & 5.7204 & TRN & \\
\hline CHEMBL1528536 & 688546 & 5.3 & 4.8624 & TRN & \\
\hline CHEMBL1399106 & 688546 & 4.45 & 5.7317 & TST & \\
\hline CHEMBL1451375 & 688546 & 5.0 & 5.3433 & TRN & \\
\hline CHEMBL1315532 & 688546 & 5.0 & 5.5888 & TRN & \\
\hline CHEMBL1361138 & 688546 & 5.0 & 5.2251 & TRN & \\
\hline CHEMBL1412669 & 688546 & 4.6 & 5.1688 & TRN & \\
\hline CHEMBL1080897 & 688546 & 8.0 & 5.4274 & TRN & \\
\hline CHEMBL1365503 & 688546 & 6.8 & 5.6606 & TST & \\
\hline CHEMBL1402683 & 688546 & 4.5 & 5.6964 & TRN & \\
\hline CHEMBL1554903 & 688546 & 4.8 & 4.8365 & TRN & \\
\hline CHEMBL606166 & 688546 & 4.5 & 4.9667 & TST & \\
\hline CHEMBL1470448 & 688546 & 5.3 & 5.2628 & TRN & \\
\hline CHEMBL 270299 & 688546 & 4.7 & 5.1426 & TST & \\
\hline CHEMBL1410208 & 688546 & 4.6 & 6.0913 & TRN & \\
\hline CHEMBL528165 & 688546 & 5.0 & 5.0892 & TST & \\
\hline CHEMBL1410321 & 688546 & 4.5 & 5.0574 & TST & \\
\hline CHEMBL1320698 & 688546 & 4.5 & 6.0111 & TRN & \\
\hline CHEMBL1357752 & 688546 & 5.0 & 5.3093 & TRN & \\
\hline CHEMBL1524927 & 688546 & 4.9 & 5.1464 & TST & \\
\hline CHEMBL1413843 & 688546 & 4.8 & 5.6209 & TRN & \\
\hline CHEMBL1477014 & 688546 & 5.5 & 5.2266 & TRN & \\
\hline CHEMBL3199262 & 688546 & 4.8 & 5.0449 & TST & \\
\hline CHEMBL 1454572 & 688546 & 6.5 & 5.5642 & TRN & \\
\hline CHEMBL428258 & 688546 & 4.9 & 5.4939 & TRN & \\
\hline CHEMBL1594794 & 688546 & 5.1 & 5.3341 & TRN & \\
\hline CHEMBL1495164 & 688546 & 4.85 & 5.0368 & TRN & \\
\hline CHEMBL1371452 & 688546 & 5.4 & 5.2946 & TRN & \\
\hline CHEMBL1526751 & 688546 & 4.5 & 4.8491 & TRN & \\
\hline CHEMBL1396032 & 688546 & 4.6 & 5.2592 & TST & \\
\hline CHEMBL1508370 & 688546 & 4.8 & 4.9393 & TRN & \\
\hline CHEMBL1356074 & 688546 & 5.25 & 5.1275 & TRN & \\
\hline CHEMBL1434131 & 688546 & 4.5 & $5.7920 e$ & 0000000001 & TRN \\
\hline CHEMBL1473104 & 688546 & 4.6 & 4.683 & TRN & \\
\hline CHEMBL1427103 & 688546 & 5.4 & 5.1226 & TRN & \\
\hline CHEMBL1605091 & 688546 & 6.0 & 5.0413 & TRN & \\
\hline CHEMBL1356861 & 688546 & 5.0 & 5.4794 & TST & \\
\hline CHEMBL1606495 & 688546 & 4.5 & 5.0112 & TRN & \\
\hline CHEMBL1424200 & 688546 & 4.8 & 5.3678 & TST & \\
\hline CHEMBL1600646 & 688546 & 5.0 & 5.1857 & TRN & \\
\hline CHEMBL1318885 & 688546 & 5.3 & 5.2637 & TRN & \\
\hline CHEMBL1456420 & 688546 & 4.5 & 4.7438 & TRN & \\
\hline CHEMBL1609036 & 688546 & 7.6003 & 5.3122 & TRN & \\
\hline CHEMBL1532990 & 688546 & 4.9 & 5.4219 & TRN & \\
\hline CHEMBL1590189 & 688546 & 4.8 & 5.1612 & TRN & \\
\hline CHEMBL1366713 & 688546 & 5.3 & 5.1442 & TRN & \\
\hline CHEMBL1435820 & 688546 & 4.7 & 5.5575 & TRN & \\
\hline & & & & 8 & \\
\hline
\end{tabular}




\begin{tabular}{|c|c|c|c|c|c|}
\hline & & \multicolumn{4}{|c|}{ Supplemental Table S2.txt } \\
\hline CHEMBL1444592 & 688546 & 7.5003 & 5.5336 & TRN & \\
\hline CHEMBL1309549 & 688546 & 4.45 & 5.4589 & TRN & \\
\hline CHEMBL1448584 & 688546 & 5.1 & 5.4904 & TST & \\
\hline CHEMBL1377351 & 688546 & 4.5 & 5.1253 & TRN & \\
\hline CHEMBL1564932 & 688546 & 4.9 & 4.92899 & 9999999999 & TST \\
\hline CHEMBL1496343 & 688546 & 5.8 & 5.3863 & TRN & \\
\hline CHEMBL1429579 & 688546 & 5.0 & 4.5433 & TST & \\
\hline CHEMBL1472800 & 688546 & 4.4 & 5.5738 & TRN & \\
\hline CHEMBL1355559 & 688546 & 7.5003 & 5.4282 & TRN & \\
\hline CHEMBL1437506 & 688546 & 8.4949 & 5.75200 & 0000000001 & TRN \\
\hline CHEMBL1597445 & 688546 & 5.0 & 4.9358 & TST & \\
\hline CHEMBL1433924 & 688546 & 5.8 & 5.7088 & TRN & \\
\hline CHEMBL3208413 & 688546 & 4.45 & 5.0569 & TST & \\
\hline CHEMBL1429633 & 688546 & 4.9 & 5.1348 & TRN & \\
\hline CHEMBL1334344 & 688546 & 4.5 & 5.1803 & TRN & \\
\hline CHEMBL1336039 & 688546 & 4.9 & 5.1285 & TST & \\
\hline CHEMBL1352072 & 688546 & 4.7 & 4.9851 & TST & \\
\hline CHEMBL1564777 & 688546 & 4.8 & 5.0394 & TST & \\
\hline CHEMBL1496110 & 688546 & 4.9 & 4.9736 & TST & \\
\hline CHEMBL1600473 & 688546 & 6.2 & 5.5713 & TRN & \\
\hline CHEMBL1320183 & 688546 & 4.9 & 4.5766 & TST & \\
\hline CHEMBL1553713 & 688546 & 7.6003 & 5.3763 & TST & \\
\hline CHEMBL1597594 & 688546 & 5.3 & 5.1607 & TST & \\
\hline CHEMBL1592739 & 688546 & 4.5 & 5.2674 & TRN & \\
\hline CHEMBL1496640 & 688546 & 5.2 & 5.0406 & TST & \\
\hline CHEMBL1415756 & 688546 & 5.0 & 4.8424 & TRN & \\
\hline CHEMBL1410152 & 688546 & 5.0 & 5.0008 & TST & \\
\hline CHEMBL1609118 & 688546 & 5.3 & 5.4329 & TRN & \\
\hline CHEMBL1594135 & 688546 & 4.5 & 4.9639 & TRN & \\
\hline CHEMBL1359129 & 688546 & 4.9 & 4.9161 & TST & \\
\hline CHEMBL1354701 & 688546 & 4.6 & 4.3572 & TRN & \\
\hline CHEMBL1454247 & 688546 & 4.9 & 5.3959 & TRN & \\
\hline CHEMBL1396193 & 688546 & 4.6 & 5.0925 & TRN & \\
\hline CHEMBL1515662 & 688546 & 5.4 & 5.4743 & TST & \\
\hline CHEMBL1355340 & 688546 & 4.9 & 5.5073 & TST & \\
\hline CHEMBL1397746 & 688546 & 4.5 & 5.3138 & TST & \\
\hline CHEMBL 242384 & 688546 & 5.1 & 5.1761 & TRN & \\
\hline CHEMBL1315421 & 688546 & 4.5 & 5.0325 & TRN & \\
\hline CHEMBL1326800 & 688546 & 5.95 & 5.7258 & TRN & \\
\hline CHEMBL1435188 & 688546 & 4.9 & 5.4496 & TST & \\
\hline CHEMBL1355135 & 688546 & 4.5 & 5.0541 & TST & \\
\hline CHEMBL1222385 & 688546 & 4.9 & 5.189 & TRN & \\
\hline CHEMBL1478507 & 688546 & 5.9 & 5.2739 & TRN & \\
\hline CHEMBL1524482 & 688546 & 4.9 & 5.0092 & TRN & \\
\hline CHEMBL1594331 & 688546 & 5.2 & 5.6546 & TRN & \\
\hline CHEMBL1474417 & 688546 & 5.8 & 5.7171 & TRN & \\
\hline CHEMBL1981612 & 688546 & 4.45 & 4.7028 & TST & \\
\hline CHEMBL1364598 & 688546 & 4.7 & 5.088 & TRN & \\
\hline
\end{tabular}




\begin{tabular}{|c|c|c|c|c|c|}
\hline \multicolumn{6}{|c|}{ Supplemental Table S2.txt } \\
\hline CHEMBL598688 & 688546 & 8.4949 & 4.8078 & TST & \\
\hline CHEMBL1407850 & 688546 & 4.9 & 5.2457 & TRN & \\
\hline CHEMBL1553177 & 688546 & 6.3 & 5.2742 & TST & \\
\hline CHEMBL1436533 & 688546 & 8.0506 & 4.9717 & TRN & \\
\hline CHEMBL1548553 & 688546 & 4.7 & 5.3344 & TRN & \\
\hline CHEMBL1593932 & 688546 & 4.9 & 4.9745 & TST & \\
\hline CHEMBL1600151 & 688546 & 4.5 & 4.8386 & TRN & \\
\hline CHEMBL1418527 & 688546 & 4.8 & 5.3968 & TRN & \\
\hline CHEMBL1531697 & 688546 & 4.9 & 4.801 & TST & \\
\hline CHEMBL1539115 & 688546 & 4.6 & 5.7298 & TST & \\
\hline CHEMBL1317891 & 688546 & 5.0 & 5.8075 & TRN & \\
\hline CHEMBL1555411 & 688546 & 5.6 & 5.86700 & 0000000001 & TRN \\
\hline CHEMBL1447183 & 688546 & 8.0 & 5.3223 & TST & \\
\hline CHEMBL1367325 & 688546 & 6.4 & 5.1087 & TRN & \\
\hline CHEMBL1567220 & 688546 & 5.4 & 5.5247 & TST & \\
\hline CHEMBL1435405 & 688546 & 5.5 & 4.9784 & TST & \\
\hline CHEMBL1319437 & 688546 & 4.9 & 4.7725 & TRN & \\
\hline CHEMBL1527299 & 688546 & 5.4 & 4.8669 & TST & \\
\hline CHEMBL1356683 & 688546 & 8.301 & 5.4172 & TRN & \\
\hline CHEMBL1489449 & 688546 & 4.6 & 5.0915 & TST & \\
\hline CHEMBL1302979 & 688546 & 5.4 & 4.9775 & TRN & \\
\hline CHEMBL1436476 & 688546 & 4.5 & 4.9658 & TRN & \\
\hline CHEMBL1359385 & 688546 & 4.5 & 5.269 & TST & \\
\hline CHEMBL1598807 & 688546 & 4.8 & 5.2181 & TST & \\
\hline CHEMBL 3198291 & 688546 & 5.0 & 4.9268 & TRN & \\
\hline CHEMBL 1400590 & 688546 & 5.25 & 5.5324 & TRN & \\
\hline CHEMBL1440798 & 688546 & 4.8 & 5.1068 & TRN & \\
\hline CHEMBL1487548 & 688546 & 5.7 & 5.7008 & TST & \\
\hline CHEMBL1401953 & 688546 & 4.9 & 5.0976 & TRN & \\
\hline CHEMBL1593018 & 688546 & 4.5 & 5.2836 & TRN & \\
\hline CHEMBL1552906 & 688546 & 5.5 & 5.5651 & TRN & \\
\hline CHEMBL1603509 & 688546 & 4.9 & 4.8787 & TRN & \\
\hline CHEMBL1592479 & 688546 & 5.6 & 5.5203 & TRN & \\
\hline CHEMBL1487369 & 688546 & 8.0 & 5.4247 & TRN & \\
\hline CHEMBL1475246 & 688546 & 5.9 & 5.0327 & TRN & \\
\hline CHEMBL1337183 & 688546 & 4.5 & 4.9836 & TRN & \\
\hline CHEMBL1443649 & 688546 & 4.7 & 4.882 & TRN & \\
\hline CHEMBL1433634 & 688546 & 5.1 & 5.0761 & TRN & \\
\hline CHEMBL1514737 & 688546 & 7.5003 & 5.6972 & TRN & \\
\hline CHEMBL1420286 & 688546 & 4.8 & 4.6633 & TRN & \\
\hline CHEMBL1568835 & 688546 & 4.5 & 5.2933 & TRN & \\
\hline CHEMBL3198373 & 688546 & 5.0 & 5.2304 & TST & \\
\hline CHEMBL1434258 & 688546 & 5.0 & 5.0917 & TRN & \\
\hline CHEMBL1324637 & 688546 & 5.0 & 5.2486 & TRN & \\
\hline CHEMBL1317281 & 688546 & 4.9 & 4.8854 & TRN & \\
\hline CHEMBL1477057 & 688546 & 4.9 & 4.9256 & TRN & \\
\hline CHEMBL1535780 & 688546 & 4.5 & 5.1611 & TRN & \\
\hline CHEMBL1398457 & 688546 & 5.0 & 4.9101 & TRN & \\
\hline
\end{tabular}




\begin{tabular}{|c|c|c|c|c|}
\hline \multicolumn{5}{|c|}{ Supplemental Table S2.txt } \\
\hline CHEMBL1360231 & 688546 & 5.7 & 5.4776 & TRN \\
\hline CHEMBL1536497 & 688546 & 4.7 & 5.0971 & TST \\
\hline CHEMBL1532428 & 688546 & 4.8 & 5.1546 & TRN \\
\hline CHEMBL1571629 & 688546 & 5.0 & 5.1427 & TRN \\
\hline CHEMBL1315991 & 688546 & 4.8 & 4.7499 & TRN \\
\hline CHEMBL1515648 & 688546 & 4.5 & 5.0277 & TRN \\
\hline CHEMBL1515532 & 688546 & 6.3 & 5.5954 & TRN \\
\hline CHEMBL1519461 & 688546 & 7.3002 & 5.4956 & TRN \\
\hline CHEMBL1307831 & 688546 & 5.3 & 5.5113 & TST \\
\hline CHEMBL1415760 & 688546 & 4.5 & 4.7732 & TRN \\
\hline CHEMBL1436656 & 688546 & 5.2 & 5.0842 & TRN \\
\hline CHEMBL1378843 & 688546 & 4.5 & 5.1781 & TRN \\
\hline CHEMBL1317742 & 688546 & 4.6 & 5.2788 & TRN \\
\hline CHEMBL1402619 & 688546 & 8.1024 & 6.3213 & TRN \\
\hline CHEMBL1332159 & 688546 & 4.6 & 5.3205 & TRN \\
\hline CHEMBL1485168 & 688546 & 4.9 & 5.1704 & TRN \\
\hline CHEMBL1575036 & 688546 & 5.0 & 4.9843 & TRN \\
\hline CHEMBL1552916 & 688546 & 8.4949 & 5.2869 & TRN \\
\hline CHEMBL1558621 & 688546 & 4.5 & 5.6265 & TST \\
\hline CHEMBL1475614 & 688546 & 7.5003 & 5.6167 & TST \\
\hline CHEMBL1565737 & 688546 & 4.7 & 5.2138 & TRN \\
\hline CHEMBL1424508 & 688546 & 4.6 & 5.1677 & TST \\
\hline CHEMBL1592180 & 688546 & 4.9 & 5.8341 & TRN \\
\hline CHEMBL1493332 & 688546 & 4.5 & 5.5726 & TRN \\
\hline CHEMBL1610228 & 688546 & 4.7 & 4.7123 & TRN \\
\hline CHEMBL1363804 & 688546 & 7.8013 & 5.6175 & TRN \\
\hline CHEMBL1560908 & 688546 & 5.8 & 5.7526 & TRN \\
\hline CHEMBL1415167 & 688546 & 4.5 & 5.1772 & TRN \\
\hline CHEMBL3212069 & 688546 & 5.45 & 5.5377 & TST \\
\hline CHEMBL1396070 & 688546 & 4.7 & 5.9478 & TRN \\
\hline CHEMBL1317141 & 688546 & 5.9 & 4.8636 & TRN \\
\hline CHEMBL1514377 & 688546 & 4.8 & 4.8831 & TRN \\
\hline CHEMBL1609392 & 688546 & 6.15 & 5.4988 & TRN \\
\hline CHEMBL1315725 & 688546 & 5.2 & 5.4254 & TST \\
\hline CHEMBL1475970 & 688546 & 5.0 & 5.307 & TRN \\
\hline CHEMBL1353747 & 688546 & 4.8 & 5.26 & TRN \\
\hline CHEMBL1302596 & 688546 & 4.9 & 5.2038 & TRN \\
\hline CHEMBL1389239 & 688546 & 4.5 & 5.4723 & TST \\
\hline CHEMBL1573665 & 688546 & 4.8 & 5.2275 & TRN \\
\hline CHEMBL1512794 & 688546 & 5.8 & 5.1532 & TRN \\
\hline CHEMBL3193065 & 688546 & 4.5 & 5.222 & TST \\
\hline CHEMBL3214343 & 688546 & 7.6498 & 5.1235 & TST \\
\hline CHEMBL1426676 & 688546 & 4.9 & 4.9282 & TST \\
\hline CHEMBL1394738 & 688546 & 5.0 & 5.4937 & TRN \\
\hline CHEMBL1403448 & 688546 & 4.9 & 5.4286 & TST \\
\hline CHEMBL1456626 & 688546 & 4.7 & 5.2507 & TST \\
\hline CHEMBL1589682 & 688546 & 5.0 & 5.4511 & TRN \\
\hline CHEMBL1523446 & 688546 & 4.8 & 5.1297 & TRN \\
\hline
\end{tabular}




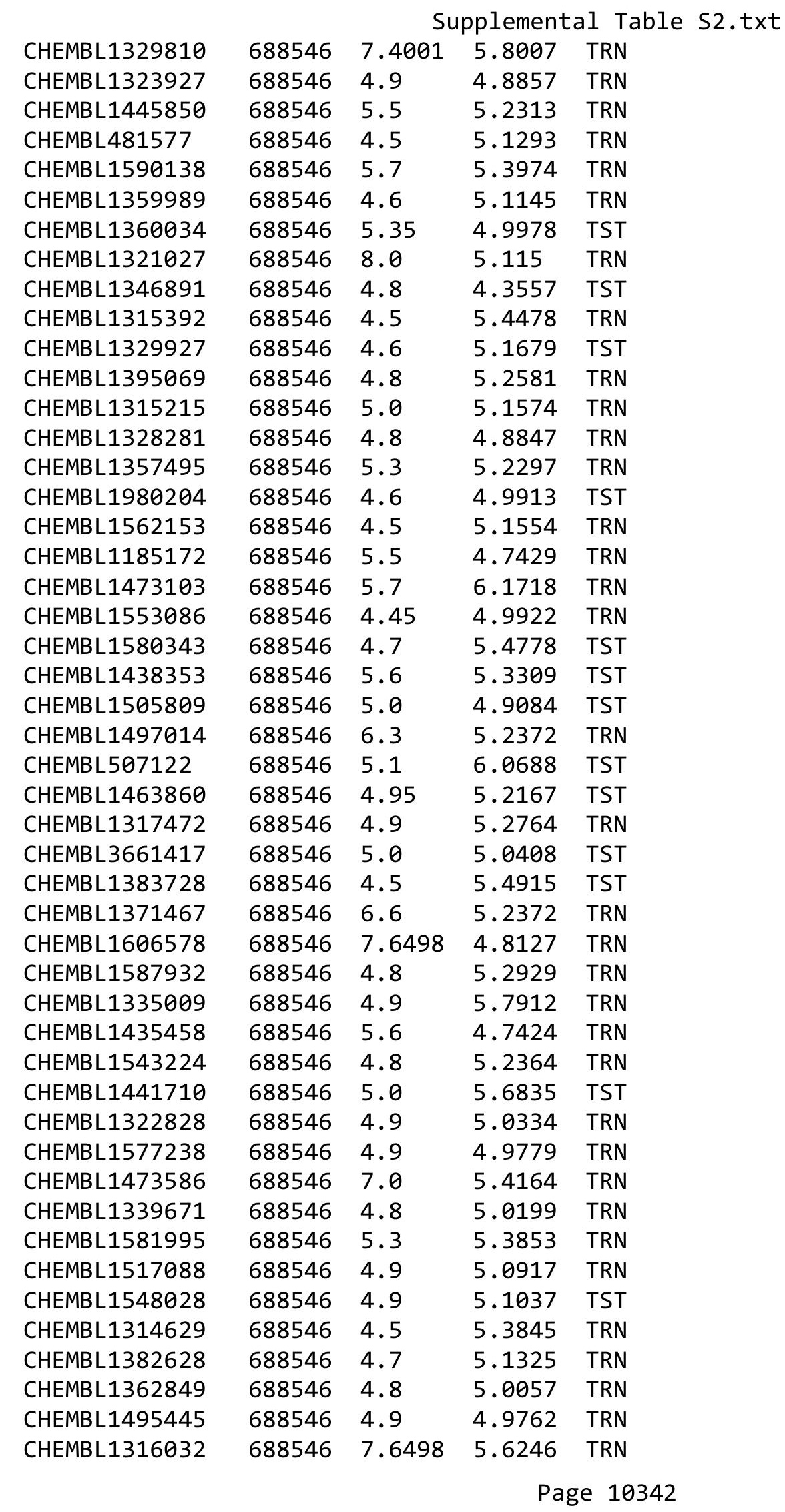




\begin{tabular}{|c|c|c|c|c|}
\hline \multicolumn{5}{|c|}{ Supplemental Table S2.txt } \\
\hline CHEMBL1437931 & 688546 & 5.0 & 5.3387 & TRN \\
\hline CHEMBL143360 & 688546 & 4.5 & 5.0238 & TRN \\
\hline CHEMBL1609212 & 688546 & 5.25 & 5.0156 & TST \\
\hline CHEMBL1487676 & 688546 & 4.8 & 4.8875 & TRN \\
\hline CHEMBL1440279 & 688546 & 4.8 & 5.4655 & TRN \\
\hline CHEMBL1489934 & 688546 & 4.7 & 5.4309 & TRN \\
\hline CHEMBL1477172 & 688546 & 4.7 & 4.8654 & TRN \\
\hline CHEMBL1401524 & 688546 & 4.9 & 4.8614 & TRN \\
\hline CHEMBL1463272 & 688546 & 5.0 & 4.73 & TRN \\
\hline CHEMBL1362329 & 688546 & 4.6 & 4.8231 & TRN \\
\hline CHEMBL1553191 & 688546 & 4.7 & 4.9147 & TRN \\
\hline CHEMBL1430893 & 688546 & 5.0 & 4.9065 & TST \\
\hline CHEMBL1479550 & 688546 & 4.9 & 5.4232 & TRN \\
\hline CHEMBL1354613 & 688546 & 8.1487 & 5.3174 & TRN \\
\hline CHEMBL258893 & 688546 & 4.9 & 5.4732 & TST \\
\hline CHEMBL1449540 & 688546 & 4.6 & 4.9641 & TRN \\
\hline CHEMBL1394691 & 688546 & 5.2 & 5.2415 & TRN \\
\hline CHEMBL424581 & 688546 & 4.9 & 4.8781 & TRN \\
\hline CHEMBL1314323 & 688546 & 4.8 & 5.1051 & TRN \\
\hline CHEMBL1491000 & 688546 & 5.0 & 5.0318 & TRN \\
\hline CHEMBL1481374 & 688546 & 5.0 & 5.0203 & TRN \\
\hline CHEMBL1437322 & 688546 & 4.9 & 5.0367 & TRN \\
\hline CHEMBL1367394 & 688546 & 5.0 & 5.3674 & TRN \\
\hline CHEMBL1588416 & 688546 & 4.6 & 4.7277 & TRN \\
\hline CHEMBL1512632 & 688546 & 5.6 & 5.709 & TRN \\
\hline CHEMBL1325980 & 688546 & 5.6 & 5.2134 & TRN \\
\hline CHEMBL1337279 & 688546 & 4.7 & 4.9784 & TRN \\
\hline CHEMBL1408100 & 688546 & 4.5 & 5.4434 & TRN \\
\hline CHEMBL1409439 & 688546 & 4.8 & 5.3011 & TRN \\
\hline CHEMBL1499545 & 688546 & 4.8 & 5.1241 & TST \\
\hline CHEMBL1348280 & 688546 & 4.9 & 5.041 & TRN \\
\hline CHEMBL1366467 & 688546 & 5.5 & 5.3985 & TRN \\
\hline CHEMBL1586297 & 688546 & 4.9 & 5.0352 & TST \\
\hline CHEMBL1333076 & 688546 & 4.5 & 4.9432 & TST \\
\hline CHEMBL1518418 & 688546 & 4.5 & 5.6597 & TRN \\
\hline CHEMBL1374179 & 688546 & 4.5 & 5.3193 & TST \\
\hline CHEMBL1434432 & 688546 & 5.9 & 5.3015 & TST \\
\hline CHEMBL1329798 & 688546 & 5.4 & 5.3766 & TRN \\
\hline CHEMBL1548696 & 688546 & 4.6 & 5.1279 & TST \\
\hline CHEMBL1416440 & 688546 & 4.5 & 4.9715 & TST \\
\hline CHEMBL1358195 & 688546 & 4.5 & 5.3529 & TRN \\
\hline CHEMBL35482 & 688546 & 5.3 & 4.9705 & TRN \\
\hline CHEMBL1525160 & 688546 & 4.8 & 5.2048 & TRN \\
\hline CHEMBL1555072 & 688546 & 5.65 & 5.5106 & TRN \\
\hline CHEMBL1483427 & 688546 & 5.0 & 4.6685 & TRN \\
\hline CHEMBL1472148 & 688546 & 5.2 & 5.4785 & TST \\
\hline CHEMBL1398285 & 688546 & 5.4 & 5.2295 & TRN \\
\hline CHEMBL1596342 & 688546 & 5.5 & 5.0784 & TRN \\
\hline
\end{tabular}




\begin{tabular}{|c|c|c|c|c|c|}
\hline \multirow{2}{*}{ CHEMBL1437598 } & \multirow{2}{*}{688546} & \\
\hline & & 4.5 & 4.58 & TRN & \\
\hline CHEMBL1406316 & 688546 & 6.3 & 5.25 & TST & \\
\hline CHEMBL1454776 & 688546 & 4.9 & 5.2812 & TRN & \\
\hline CHEMBL1410766 & 688546 & 5.3 & 5.2094 & TRN & \\
\hline CHEMBL1397338 & 688546 & 4.95 & 5.118 & TRN & \\
\hline CHEMBL1591137 & 688546 & 7.9508 & 5.2161 & TRN & \\
\hline CHEMBL1495119 & 688546 & 4.9 & 5.0228 & TRN & \\
\hline CHEMBL1516098 & 688546 & 5.1 & 5.2201 & TRN & \\
\hline CHEMBL1596633 & 688546 & 4.9 & 5.2311 & TRN & \\
\hline CHEMBL1416801 & 688546 & 4.5 & 5.034 & TRN & \\
\hline CHEMBL1397745 & 688546 & 4.9 & 5.5943 & TRN & \\
\hline CHEMBL1369212 & 688546 & 5.5 & 5.3145 & TST & \\
\hline CHEMBL591618 & 688546 & 5.6 & 4.9784 & TRN & \\
\hline CHEMBL1437375 & 688546 & 8.0 & 4.8927 & TST & \\
\hline CHEMBL1362919 & 688546 & 5.7 & 5.4516 & TRN & \\
\hline CHEMBL1314951 & 688546 & 4.7 & 4.8163 & TRN & \\
\hline CHEMBL1551080 & 688546 & 4.5 & 4.7588 & TRN & \\
\hline CHEMBL1416417 & 688546 & 5.1 & 4.8143 & TST & \\
\hline CHEMBL1316706 & 688546 & 5.9 & 5.8474 & TRN & \\
\hline CHEMBL441282 & 688546 & 4.6 & 5.2441 & TST & \\
\hline CHEMBL1435814 & 688546 & 5.0 & 5.4091 & TRN & \\
\hline CHEMBL3190644 & 688546 & 4.65 & 5.1196 & TST & \\
\hline CHEMBL1318255 & 688546 & 5.1 & 5.2498 & TRN & \\
\hline CHEMBL1362965 & 688546 & 4.6 & 5.7593 & TST & \\
\hline CHEMBL1300553 & 688546 & 7.8508 & 6.1587 & TRN & \\
\hline CHEMBL1415141 & 688546 & 4.8 & 5.1716 & TRN & \\
\hline CHEMBL1319193 & 688546 & 5.2 & 5.1118 & TRN & \\
\hline CHEMBL1388790 & 688546 & 4.5 & 5.0808 & TRN & \\
\hline CHEMBL1598178 & 688546 & 5.2 & 4.8862 & TST & \\
\hline CHEMBL1467762 & 688546 & 5.5 & 5.1741 & TST & \\
\hline CHEMBL1495242 & 688546 & 4.9 & 4.9275 & TST & \\
\hline CHEMBL1590122 & 688546 & 4.8 & 5.5033 & TRN & \\
\hline CHEMBL 1600520 & 688546 & 4.9 & 5.1947 & TRN & \\
\hline CHEMBL1593096 & 688546 & 4.9 & 4.8838 & TST & \\
\hline CHEMBL1436923 & 688546 & 5.4 & 5.2428 & TST & \\
\hline CHEMBL1334054 & 688546 & 4.9 & 5.2222 & TRN & \\
\hline CHEMBL1359244 & 688546 & 4.8 & 5.0024 & TRN & \\
\hline CHEMBL1450040 & 688546 & 4.7 & 5.4021 & TRN & \\
\hline CHEMBL 296586 & 688546 & 5.1 & 4.9071 & TST & \\
\hline CHEMBL1338958 & 688546 & 4.5 & 5.0588 & TRN & \\
\hline CHEMBL1438414 & 688546 & 5.0 & 5.1143 & TRN & \\
\hline CHEMBL1477043 & 688546 & 8.0 & $5.7170 e$ & 00000000005 & TRN \\
\hline CHEMBL1605182 & 688546 & 4.6 & 5.1903 & TRN & \\
\hline CHEMBL1413108 & 688546 & 6.2 & 5.5959 & TRN & \\
\hline CHEMBL1606330 & 688546 & 4.5 & 5.2879 & TRN & \\
\hline CHEMBL1488668 & 688546 & 4.8 & 4.9607 & TST & \\
\hline CHEMBL323356 & 688546 & 4.8 & 4.95 & TRN & \\
\hline CHEMBL1435408 & 688546 & 5.0 & 5.3457 & TRN & \\
\hline & & & & 10344 & \\
\hline
\end{tabular}




\begin{tabular}{|c|c|c|c|c|c|}
\hline \\
\hline CHEMBL1592093 & 688546 & 6.8 & 5.6581 & TRN & \\
\hline CHEMBL1480445 & 688546 & 4.7 & 5.0365 & TRN & \\
\hline CHEMBL1373872 & 688546 & 4.5 & 5.154 & TRN & \\
\hline CHEMBL1553216 & 688546 & 4.6 & 5.1654 & TRN & \\
\hline CHEMBL1591844 & 688546 & 7.8013 & 5.1007 & TRN & \\
\hline CHEMBL2005317 & 688546 & 4.95 & 5.0372 & TRN & \\
\hline CHEMBL1593126 & 688546 & 4.5 & 5.2885 & TRN & \\
\hline CHEMBL1330176 & 688546 & 5.2 & 4.7546 & TRN & \\
\hline CHEMBL1530839 & 688546 & 4.7 & 5.6464 & TST & \\
\hline CHEMBL1564993 & 688546 & 7.8996 & 5.3519 & TRN & \\
\hline CHEMBL1553965 & 688546 & 5.4 & 5.5515 & TRN & \\
\hline CHEMBL1564546 & 688546 & 5.0 & 4.7498 & TRN & \\
\hline CHEMBL1602165 & 688546 & 8.4559 & 5.7153 & TRN & \\
\hline CHEMBL1317016 & 688546 & 4.5 & 5.2609 & TST & \\
\hline CHEMBL1357307 & 688546 & 5.6 & 5.0938 & TRN & \\
\hline CHEMBL3199594 & 688546 & 4.55 & 4.8146 & TST & \\
\hline CHEMBL1358424 & 688546 & 4.9 & 5.1694 & TRN & \\
\hline CHEMBL1475660 & 688546 & 5.6 & 5.5468 & TRN & \\
\hline CHEMBL1523002 & 688546 & 5.4 & 5.2603 & TRN & \\
\hline CHEMBL1396418 & 688546 & 4.6 & 5.6224 & TRN & \\
\hline CHEMBL1354541 & 688546 & 6.9 & 5.527 & TRN & \\
\hline CHEMBL1482231 & 688546 & 4.9 & 5.0079 & TST & \\
\hline CHEMBL1339106 & 688546 & 4.5 & 5.1433 & TST & \\
\hline CHEMBL1320991 & 688546 & 6.0 & 5.80200 & 00000000005 & TRN \\
\hline CHEMBL1366009 & 688546 & 4.95 & 4.9274 & TRN & \\
\hline CHEMBL1522172 & 688546 & 5.2 & 5.0324 & TRN & \\
\hline CHEMBL1515132 & 688546 & 4.5 & 5.4483 & TST & \\
\hline CHEMBL1609950 & 688546 & 7.699 & 5.0525 & TRN & \\
\hline CHEMBL1477182 & 688546 & 7.1002 & 6.6425 & TRN & \\
\hline CHEMBL1374953 & 688546 & 5.5 & 5.0213 & TRN & \\
\hline CHEMBL1342911 & 688546 & 4.9 & 5.2161 & TST & \\
\hline CHEMBL1337040 & 688546 & 4.9 & 5.1466 & TST & \\
\hline CHEMBL1440703 & 688546 & 5.1 & 5.197 & TST & \\
\hline CHEMBL1551502 & 688546 & 5.3 & 5.1662 & TRN & \\
\hline CHEMBL1338453 & 688546 & 7.6498 & 5.5601 & TRN & \\
\hline CHEMBL1436413 & 688546 & 5.0 & 5.2809 & TRN & \\
\hline CHEMBL1450585 & 688546 & 4.6 & 5.1806 & TST & \\
\hline CHEMBL1501554 & 688546 & 4.8 & 5.1615 & TST & \\
\hline CHEMBL1574232 & 688546 & 4.5 & 5.443 & TRN & \\
\hline CHEMBL1591480 & 688546 & 4.9 & 5.1434 & TRN & \\
\hline CHEMBL1484738 & 688546 & 4.6 & 5.4392 & TST & \\
\hline CHEMBL1553510 & 688546 & 4.9 & 5.28299 & 99999999995 & TRN \\
\hline CHEMBL494891 & 688546 & 4.9 & 5.1572 & TST & \\
\hline CHEMBL1590140 & 688546 & 5.1 & 5.2113 & TRN & \\
\hline CHEMBL1356040 & 688546 & 4.8 & 4.85 & TRN & \\
\hline CHEMBL1395406 & 688546 & 5.1 & 5.2214 & TRN & \\
\hline CHEMBL1417496 & 688546 & 5.25 & 4.7007 & TRN & \\
\hline CHEMBL1471728 & 688546 & 5.0 & 5.1732 & TRN & \\
\hline
\end{tabular}




\begin{tabular}{|c|c|c|c|c|}
\hline \multicolumn{5}{|c|}{ Supplement } \\
\hline CHEMBL1337337 & 688546 & 4.7 & 4.7782 & TRN \\
\hline CHEMBL1396964 & 688546 & 4.5 & 5.0343 & TRN \\
\hline CHEMBL1549879 & 688546 & 4.8 & 5.3364 & TST \\
\hline CHEMBL1446657 & 688546 & 5.1 & 5.3788 & TRN \\
\hline CHEMBL1462683 & 688546 & 4.8 & 4.5502 & TRN \\
\hline CHEMBL1335945 & 688546 & 5.0 & 5.2546 & TST \\
\hline CHEMBL1451905 & 688546 & 4.9 & 5.07 & TST \\
\hline CHEMBL3192101 & 688546 & 4.7 & 4.8717 & TST \\
\hline CHEMBL1429877 & 688546 & 5.45 & 5.21200 & 0000000001 \\
\hline CHEMBL1476607 & 688546 & 5.0 & 5.3551 & TRN \\
\hline CHEMBL1375371 & 688546 & 5.0 & 5.4551 & TST \\
\hline CHEMBL1393692 & 688546 & 4.5 & 5.4871 & TST \\
\hline CHEMBL1402249 & 688546 & 4.9 & 5.3337 & TRN \\
\hline CHEMBL1388344 & 688546 & 5.0 & 5.4709 & TST \\
\hline CHEMBL1512312 & 688546 & 5.6 & 5.1246 & TRN \\
\hline CHEMBL1318549 & 688546 & 4.9 & 5.215 & TRN \\
\hline CHEMBL1591250 & 688546 & 8.0 & 5.2534 & TRN \\
\hline CHEMBL1610709 & 688546 & 5.5 & 5.2251 & TRN \\
\hline CHEMBL1476756 & 688546 & 4.9 & 5.4868 & TRN \\
\hline CHEMBL1317551 & 688546 & 4.95 & 5.1669 & TRN \\
\hline CHEMBL1486098 & 688546 & 5.1 & 5.6798 & TRN \\
\hline CHEMBL1410437 & 688546 & 4.7 & 5.0294 & TRN \\
\hline CHEMBL1593880 & 688546 & 4.5 & 5.5656 & TRN \\
\hline CHEMBL1375735 & 688546 & 4.9 & 4.9523 & TRN \\
\hline CHEMBL1319810 & 688546 & 4.9 & 5.0053 & TRN \\
\hline CHEMBL1311772 & 688546 & 5.0 & 5.348 & TRN \\
\hline CHEMBL1514084 & 688546 & 4.8 & 5.1923 & TRN \\
\hline CHEMBL1256749 & 688546 & 6.0 & 5.2358 & TST \\
\hline CHEMBL1419320 & 688546 & 4.9 & 5.4041 & TST \\
\hline CHEMBL1354759 & 688546 & 7.3002 & 5.1772 & TRN \\
\hline CHEMBL1363477 & 688546 & 4.9 & 5.9675 & TRN \\
\hline CHEMBL1331925 & 688546 & 5.25 & 5.2113 & TST \\
\hline CHEMBL1591472 & 688546 & 4.9 & 5.2216 & TRN \\
\hline CHEMBL1491386 & 688546 & 5.2 & 5.5758 & TST \\
\hline CHEMBL1481221 & 688546 & 4.7 & 5.595 & TRN \\
\hline CHEMBL1369780 & 688546 & 5.0 & 5.3994 & TRN \\
\hline CHEMBL1433811 & 688546 & 4.9 & 5.6078 & TRN \\
\hline CHEMBL1438577 & 688546 & 5.4 & 5.218 & TRN \\
\hline CHEMBL1479897 & 688546 & 8.5528 & 5.4055 & TST \\
\hline CHEMBL299613 & 688546 & 5.6 & 5.3884 & TRN \\
\hline CHEMBL1407895 & 688546 & 4.8 & 5.8151 & TRN \\
\hline CHEMBL460517 & 688546 & 4.8 & 5.4891 & TRN \\
\hline CHEMBL393136 & 688546 & 4.5 & 4.9078 & TST \\
\hline CHEMBL1496920 & 688546 & 5.0 & 5.0594 & TRN \\
\hline CHEMBL1593774 & 688546 & 4.8 & 4.8934 & TRN \\
\hline CHEMBL1320831 & 688546 & 4.5 & 5.5568 & TRN \\
\hline CHEMBL1528626 & 688546 & 5.0 & 4.9922 & TRN \\
\hline CHEMBL1443326 & 688546 & 5.85 & 4.9081 & TRN \\
\hline
\end{tabular}




\begin{tabular}{|c|c|c|c|c|}
\hline \multicolumn{5}{|c|}{ Supplemental Table S2.txt } \\
\hline CHEMBL1459207 & 688546 & 4.5 & 5.5137 & TST \\
\hline CHEMBL1431620 & 688546 & 4.7 & 4.8468 & TST \\
\hline CHEMBL1489418 & 688546 & 4.9 & 5.3323 & TRN \\
\hline CHEMBL1516483 & 688546 & 4.85 & 5.3348 & TRN \\
\hline CHEMBL1535735 & 688546 & 8.1024 & 5.1263 & TST \\
\hline CHEMBL1553780 & 688546 & 4.5 & 5.0616 & TRN \\
\hline CHEMBL1317870 & 688546 & 5.1 & 5.0984 & TRN \\
\hline CHEMBL1372117 & 688546 & 4.9 & 4.9662 & TRN \\
\hline CHEMBL3197626 & 688546 & 4.7 & 5.1215 & TRN \\
\hline CHEMBL1396544 & 688546 & 4.5 & 4.9035 & TRN \\
\hline CHEMBL1449328 & 688546 & 4.7 & 4.9911 & TST \\
\hline CHEMBL1601814 & 688546 & 4.5 & 5.1757 & TRN \\
\hline CHEMBL1559040 & 688546 & 4.5 & 5.5715 & TRN \\
\hline CHEMBL1524214 & 688546 & 4.5 & 5.0081 & TRN \\
\hline CHEMBL1417827 & 688546 & 7.7496 & 5.7144 & TRN \\
\hline CHEMBL1581158 & 688546 & 4.8 & 5.3202 & TST \\
\hline CHEMBL1320971 & 688546 & 5.5 & 5.5465 & TRN \\
\hline CHEMBL1320103 & 688546 & 4.9 & 4.95 & TRN \\
\hline CHEMBL589912 & 688546 & 5.0 & 5.4219 & TRN \\
\hline CHEMBL1327001 & 688546 & 4.7 & 5.135 & TRN \\
\hline CHEMBL1384011 & 688546 & 5.0 & 5.0432 & TST \\
\hline CHEMBL1301630 & 688546 & 5.0 & 4.7559 & TRN \\
\hline CHEMBL1396817 & 688546 & 4.7 & 4.8985 & TRN \\
\hline CHEMBL1543818 & 688546 & 5.9 & 5.0592 & TST \\
\hline CHEMBL1399495 & 688546 & 4.5 & 5.0991 & TRN \\
\hline CHEMBL1443752 & 688546 & 4.9 & 4.7416 & TST \\
\hline CHEMBL1552327 & 688546 & 5.3 & 5.3683 & TRN \\
\hline CHEMBL1494331 & 688546 & 4.85 & 5.1991 & TRN \\
\hline CHEMBL1525923 & 688546 & 4.9 & 5.4219 & TRN \\
\hline CHEMBL1563855 & 688546 & 5.3 & 5.2979 & TRN \\
\hline CHEMBL1463288 & 688546 & 4.7 & 5.0765 & TRN \\
\hline CHEMBL1554425 & 688546 & 4.9 & 5.1173 & TRN \\
\hline CHEMBL1564170 & 688546 & 8.301 & 5.2729 & TRN \\
\hline CHEMBL1354564 & 688546 & 4.7 & 5.0072 & TRN \\
\hline CHEMBL1504505 & 688546 & 4.8 & 4.5041 & TRN \\
\hline CHEMBL1563526 & 688546 & 8.0 & 5.2319 & TRN \\
\hline CHEMBL1440457 & 688546 & 4.8 & 4.7776 & TRN \\
\hline CHEMBL1592201 & 688546 & 5.6 & 5.2658 & TRN \\
\hline CHEMBL1596375 & 688546 & 8.5528 & 5.9753 & TST \\
\hline CHEMBL1427823 & 688546 & 4.95 & 4.8063 & TRN \\
\hline CHEMBL1593075 & 688546 & 4.7 & 5.1358 & TRN \\
\hline CHEMBL1572707 & 688546 & 5.2 & 5.3202 & TRN \\
\hline CHEMBL1516934 & 688546 & 5.4 & 5.3587 & TST \\
\hline CHEMBL1474246 & 688546 & 4.5 & 5.1219 & TRN \\
\hline CHEMBL177809 & 688546 & 4.5 & 5.0248 & TST \\
\hline CHEMBL1512956 & 688546 & 5.0 & 4.7275 & TST \\
\hline CHEMBL1318014 & 688546 & 5.1 & 5.0099 & TRN \\
\hline CHEMBL1591427 & 688546 & 4.6 & 5.2897 & TST \\
\hline
\end{tabular}




\begin{tabular}{|c|c|c|c|c|c|}
\hline & & & & & \\
\hline CHEMBL1474376 & 688546 & 5.2 & 5.2144 & TRN & \\
\hline CHEMBL1355245 & 688546 & 4.9 & 4.93199 & 99999999995 & TRN \\
\hline CHEMBL1323124 & 688546 & 4.7 & 4.6785 & TRN & \\
\hline CHEMBL1414451 & 688546 & 5.0 & 5.26 & TRN & \\
\hline CHEMBL1590542 & 688546 & 4.6 & 5.2713 & TRN & \\
\hline CHEMBL1515713 & 688546 & 6.0 & 5.5298 & TST & \\
\hline CHEMBL1554423 & 688546 & 5.0 & 5.1104 & TST & \\
\hline CHEMBL1608659 & 688546 & 4.8 & 5.1561 & TST & \\
\hline CHEMBL1400681 & 688546 & 4.9 & 5.1565 & TRN & \\
\hline CHEMBL1366490 & 688546 & 4.45 & 5.4197 & TRN & \\
\hline CHEMBL1547533 & 688546 & 5.4 & 5.0341 & TRN & \\
\hline CHEMBL1549430 & 688546 & 4.9 & 5.0112 & TRN & \\
\hline CHEMBL1368837 & 688546 & 7.7496 & 5.3874 & TRN & \\
\hline CHEMBL1559914 & 688546 & 5.5 & 5.8389 & TRN & \\
\hline CHEMBL1481317 & 688546 & 5.1 & 4.8069 & TRN & \\
\hline CHEMBL86931 & 688546 & 4.8 & 4.9016 & TST & \\
\hline CHEMBL1475861 & 688546 & 5.0 & 5.4084 & TRN & \\
\hline CHEMBL1515692 & 688546 & 4.9 & 5.0446 & TRN & \\
\hline CHEMBL1331302 & 688546 & 4.6 & 5.2512 & TRN & \\
\hline CHEMBL1338007 & 688546 & 4.5 & 5.2807 & TRN & \\
\hline CHEMBL1374736 & 688546 & 4.5 & 4.749 & TRN & \\
\hline CHEMBL1568666 & 688546 & 5.0 & 4.9779 & TRN & \\
\hline CHEMBL3195747 & 688546 & 5.3 & 5.55399 & 9999999999 & TRN \\
\hline CHEMBL1323613 & 688546 & 4.8 & 4.9706 & TRN & \\
\hline CHEMBL1358643 & 688546 & 5.3 & 5.8877 & TRN & \\
\hline CHEMBL1456099 & 688546 & 4.9 & 4.912 & TRN & \\
\hline CHEMBL1446827 & 688546 & 5.6 & 5.2145 & TRN & \\
\hline CHEMBL1579773 & 688546 & 4.9 & 5.1184 & TRN & \\
\hline CHEMBL193747 & 688546 & 4.7 & 4.9415 & TST & \\
\hline CHEMBL1519620 & 688546 & 5.0 & 5.08 & TRN & \\
\hline CHEMBL1409577 & 688546 & 6.9 & 5.7212 & TRN & \\
\hline CHEMBL1410947 & 688546 & 4.5 & 5.0355 & TST & \\
\hline CHEMBL1330055 & 688546 & 4.6 & 4.905 & TST & \\
\hline CHEMBL1416468 & 688546 & 4.9 & 6.0517 & TRN & \\
\hline CHEMBL1300327 & 688546 & 4.5 & 4.6884 & TST & \\
\hline CHEMBL1497878 & 688546 & 4.8 & 4.7335 & TRN & \\
\hline CHEMBL1521428 & 688546 & 5.3 & 5.2229 & TRN & \\
\hline CHEMBL1568767 & 688546 & 4.8 & 4.9445 & TRN & \\
\hline CHEMBL1511809 & 688546 & 4.9 & 5.2569 & TRN & \\
\hline CHEMBL1354812 & 688546 & 4.7 & 4.9931 & TRN & \\
\hline CHEMBL578512 & 688546 & 5.3 & 5.6173 & TST & \\
\hline CHEMBL1355799 & 688546 & 4.8 & 5.7274 & TRN & \\
\hline CHEMBL1563782 & 688546 & 4.6 & 5.3882 & TRN & \\
\hline CHEMBL1362715 & 688546 & 4.85 & 5.1496 & TRN & \\
\hline CHEMBL1350152 & 688546 & 4.9 & 4.962 & TRN & \\
\hline CHEMBL1443342 & 688546 & 4.5 & 5.0395 & TST & \\
\hline CHEMBL1430895 & 688546 & 4.5 & 4.6902 & TRN & \\
\hline CHEMBL1477540 & 688546 & 4.9 & 5.2782 & TRN & \\
\hline
\end{tabular}




\begin{tabular}{|c|c|c|c|c|c|}
\hline & & \multicolumn{4}{|c|}{ Supplemental Table S2.txt } \\
\hline CHEMBL1437872 & 688546 & 7.5003 & 5.2501 & TST & \\
\hline CHEMBL1534210 & 688546 & 5.0 & 5.0315 & TRN & \\
\hline CHEMBL1577459 & 688546 & 4.8 & 4.9694 & TST & \\
\hline CHEMBL1383533 & 688546 & 4.9 & 5.4406 & TRN & \\
\hline CHEMBL1568928 & 688546 & 5.4 & 5.3229 & TRN & \\
\hline CHEMBL1593398 & 688546 & 4.9 & 5.4553 & TRN & \\
\hline CHEMBL1316114 & 688546 & 4.5 & 5.5556 & TST & \\
\hline CHEMBL581196 & 688546 & 4.5 & 5.2209 & TST & \\
\hline CHEMBL1315491 & 688546 & 4.5 & 5.2718 & TRN & \\
\hline CHEMBL1484617 & 688546 & 5.3 & 5.8646 & TRN & \\
\hline CHEMBL1576748 & 688546 & 4.8 & 4.7626 & TRN & \\
\hline CHEMBL1532790 & 688546 & 5.0 & 5.2451 & TRN & \\
\hline CHEMBL1563091 & 688546 & 4.9 & 5.5436 & TRN & \\
\hline CHEMBL1434980 & 688546 & 4.7 & 5.2818 & TRN & \\
\hline CHEMBL30432 & 688546 & 5.8 & 4.9723 & TST & \\
\hline CHEMBL1530348 & 688546 & 4.6 & 5.2722 & TRN & \\
\hline CHEMBL1434853 & 688546 & 4.6 & 5.4765 & TST & \\
\hline CHEMBL1532020 & 688546 & 4.8 & 5.0912 & TRN & \\
\hline CHEMBL1486036 & 688546 & 4.9 & 5.1661 & TRN & \\
\hline CHEMBL1607899 & 688546 & 4.45 & 5.7332 & TST & \\
\hline CHEMBL1593131 & 688546 & 5.2 & 5.1302 & TRN & \\
\hline CHEMBL1454996 & 688546 & 4.8 & 5.12799 & 9999999999 & TRN \\
\hline CHEMBL1310134 & 688546 & 5.55 & 5.0941 & TRN & \\
\hline CHEMBL1356267 & 688546 & 6.8 & 5.4858 & TRN & \\
\hline CHEMBL1458702 & 688546 & 7.3002 & 5.6542 & TST & \\
\hline CHEMBL1516079 & 688546 & 4.9 & 5.2306 & TST & \\
\hline CHEMBL504598 & 688546 & 4.9 & 4.8892 & TRN & \\
\hline CHEMBL1407952 & 688546 & 6.0 & 5.1851 & TRN & \\
\hline CHEMBL1392364 & 688546 & 4.9 & 5.5243 & TRN & \\
\hline CHEMBL1592723 & 688546 & 4.9 & 4.9314 & TRN & \\
\hline CHEMBL1609586 & 688546 & 7.1002 & 5.5851 & TRN & \\
\hline CHEMBL1398232 & 688546 & 8.301 & 5.7421 & TST & \\
\hline CHEMBL1305287 & 688546 & 5.1 & 4.7791 & TRN & \\
\hline CHEMBL1334550 & 688546 & 5.3 & 5.1003 & TRN & \\
\hline CHEMBL1591328 & 688546 & 4.9 & 5.5033 & TST & \\
\hline CHEMBL1395219 & 688546 & 4.6 & 4.6929 & TRN & \\
\hline CHEMBL1575885 & 688546 & 5.25 & 5.1534 & TRN & \\
\hline CHEMBL1478389 & 688546 & 4.9 & 4.9735 & TRN & \\
\hline CHEMBL1452666 & 688546 & 4.9 & 5.7868 & TRN & \\
\hline CHEMBL1314748 & 688546 & 4.9 & 5.13399 & 99999999995 & TRN \\
\hline CHEMBL3212751 & 688546 & 4.9 & 5.0253 & TST & \\
\hline CHEMBL3191725 & 688546 & 4.5 & 5.1489 & TST & \\
\hline CHEMBL1549411 & 688546 & 4.9 & 4.9925 & TRN & \\
\hline CHEMBL1373521 & 688546 & 4.9 & 5.2193 & TRN & \\
\hline CHEMBL1527993 & 688546 & 4.9 & 5.0389 & TST & \\
\hline CHEMBL1467234 & 688546 & 4.9 & 5.8968 & TRN & \\
\hline CHEMBL1441891 & 688546 & 5.0 & 4.7231 & TRN & \\
\hline CHEMBL1545634 & 688546 & 4.9 & 5.0231 & TST & \\
\hline
\end{tabular}




\begin{tabular}{|c|c|c|c|c|}
\hline \multicolumn{5}{|c|}{ Supplemental Table S2.txt } \\
\hline CHEMBL1317162 & 688546 & 7.699 & 5.6997 & TRN \\
\hline CHEMBL1368228 & 688546 & 5.1 & 5.2163 & TRN \\
\hline CHEMBL1487995 & 688546 & 5.3 & 5.1932 & TRN \\
\hline CHEMBL1360959 & 688546 & 4.7 & 4.9156 & TST \\
\hline CHEMBL1493200 & 688546 & 4.9 & 5.0554 & TST \\
\hline CHEMBL1478746 & 688546 & 4.5 & 5.2972 & TST \\
\hline CHEMBL1519059 & 688546 & 5.0 & 4.994 & TRN \\
\hline CHEMBL1316309 & 688546 & 5.8 & 4.9411 & TRN \\
\hline CHEMBL1405306 & 688546 & 4.8 & 5.0701 & TRN \\
\hline CHEMBL1445291 & 688546 & 7.8996 & 5.4311 & TRN \\
\hline CHEMBL1552994 & 688546 & 5.3 & 5.3404 & TRN \\
\hline CHEMBL1551513 & 688546 & 6.8 & 5.1149 & TRN \\
\hline CHEMBL1529796 & 688546 & 5.0 & 5.4197 & TRN \\
\hline CHEMBL1475155 & 688546 & 5.0 & 5.225 & TRN \\
\hline CHEMBL1522880 & 688546 & 6.5 & 5.0067 & TRN \\
\hline CHEMBL1464561 & 688546 & 4.85 & 5.3872 & TST \\
\hline CHEMBL1552836 & 688546 & 8.2518 & 5.8823 & TRN \\
\hline CHEMBL1593821 & 688546 & 5.0 & 5.197 & TST \\
\hline CHEMBL1466948 & 688546 & 4.9 & 5.0074 & TRN \\
\hline CHEMBL1406397 & 688546 & 5.0 & 5.1635 & TRN \\
\hline CHEMBL1418531 & 688546 & 4.7 & 5.1347 & TRN \\
\hline CHEMBL1351433 & 688546 & 5.3 & 5.3199 & TRN \\
\hline CHEMBL1591421 & 688546 & 6.5 & 5.4952 & TRN \\
\hline CHEMBL 1455760 & 688546 & 8.301 & 5.3747 & TST \\
\hline CHEMBL1436681 & 688546 & 4.8 & 4.9795 & TRN \\
\hline CHEMBL1577902 & 688546 & 5.1 & 4.9094 & TRN \\
\hline CHEMBL1437356 & 688546 & 4.7 & 5.5805 & TRN \\
\hline CHEMBL1473089 & 688546 & 4.5 & 5.2377 & TRN \\
\hline CHEMBL1315511 & 688546 & 4.9 & 5.6654 & TRN \\
\hline CHEMBL1591073 & 688546 & 5.0 & 5.4174 & TRN \\
\hline CHEMBL1536605 & 688546 & 6.15 & 5.6045 & TST \\
\hline CHEMBL1356135 & 688546 & 5.3 & 4.9245 & TRN \\
\hline CHEMBL1605430 & 688546 & 4.5 & 5.0572 & TST \\
\hline CHEMBL1320556 & 688546 & 4.5 & 4.5105 & TRN \\
\hline CHEMBL1437802 & 688546 & 5.1 & 5.9433 & TRN \\
\hline CHEMBL1984604 & 688546 & 4.65 & 5.0833 & TST \\
\hline CHEMBL1361177 & 688546 & 4.5 & 4.8506 & TST \\
\hline CHEMBL1360474 & 688546 & 4.5 & 5.1273 & TRN \\
\hline CHEMBL1983418 & 688546 & 5.2 & 5.2163 & TRN \\
\hline CHEMBL 243664 & 688546 & 4.5 & 5.2933 & TRN \\
\hline CHEMBL1965873 & 688546 & 4.85 & 5.175 & TST \\
\hline CHEMBL1515844 & 688546 & 5.9 & 5.4834 & TST \\
\hline CHEMBL1367788 & 688546 & 4.9 & 5.029 & TRN \\
\hline CHEMBL 2374031 & 688546 & 4.5 & 5.6006 & TST \\
\hline CHEMBL1512629 & 688546 & 4.8 & 5.1478 & TRN \\
\hline CHEMBL1316478 & 688546 & 4.5 & 5.6821 & TST \\
\hline CHEMBL1500986 & 688546 & 4.8 & 5.3527 & TRN \\
\hline CHEMBL1590160 & 688546 & 5.45 & 5.3527 & TRN \\
\hline
\end{tabular}




\begin{tabular}{|c|c|c|c|c|}
\hline \multicolumn{5}{|r|}{11 Iabı } \\
\hline CHEMBL1327547 & 688546 & 4.9 & 4.9781 & TRN \\
\hline CHEMBL1395226 & 688546 & 4.7 & 4.7806 & TRN \\
\hline CHEMBL1483180 & 688546 & 5.0 & 5.7947 & TRN \\
\hline CHEMBL1496409 & 688546 & 4.6 & 5.5061 & TRN \\
\hline CHEMBL1517524 & 688546 & 7.15 & 5.0406 & TRN \\
\hline CHEMBL1590663 & 688546 & 4.9 & 4.789 & TRN \\
\hline CHEMBL1437690 & 688546 & 4.6 & 4.5688 & TRN \\
\hline CHEMBL1408060 & 688546 & 6.8 & 5.3381 & TRN \\
\hline CHEMBL1315634 & 688546 & 6.6 & 5.8142 & TRN \\
\hline CHEMBL1541880 & 688546 & 4.55 & 5.2128 & TST \\
\hline CHEMBL1474698 & 688546 & 6.1 & 5.7077 & TST \\
\hline CHEMBL1574597 & 688546 & 4.5 & 5.1081 & TRN \\
\hline CHEMBL1551166 & 688546 & 5.0 & 5.4815 & TST \\
\hline CHEMBL1317002 & 688546 & 5.6 & 5.8619 & TRN \\
\hline CHEMBL1404823 & 688546 & 4.6 & 5.2421 & TRN \\
\hline CHEMBL1574208 & 688546 & 4.5 & 5.1004 & TRN \\
\hline CHEMBL1590606 & 688546 & 7.5498 & 5.7314 & TRN \\
\hline CHEMBL 1458503 & 688546 & 4.5 & 5.3439 & TST \\
\hline CHEMBL259784 & 688546 & 5.9 & 5.3163 & TRN \\
\hline CHEMBL1332916 & 688546 & 4.55 & 5.3941 & TRN \\
\hline CHEMBL1471945 & 688546 & 5.0 & 5.0314 & TST \\
\hline CHEMBL1398137 & 688546 & 5.0 & 4.6538 & TRN \\
\hline CHEMBL1564239 & 688546 & 5.0 & 5.3712 & TRN \\
\hline CHEMBL1372145 & 688546 & 5.5 & 5.545 & TRN \\
\hline CHEMBL1361690 & 688546 & 4.8 & 5.0968 & TRN \\
\hline CHEMBL1404519 & 688546 & 8.301 & 4.9009 & TST \\
\hline CHEMBL1321310 & 688546 & 5.2 & 4.8028 & TRN \\
\hline CHEMBL1486638 & 688546 & 4.5 & 5.3132 & TRN \\
\hline CHEMBL428789 & 688546 & 5.0 & 5.0864 & TRN \\
\hline CHEMBL1529427 & 688546 & 4.5 & 4.7043 & TRN \\
\hline CHEMBL1434203 & 688546 & 4.9 & 5.2652 & TRN \\
\hline CHEMBL1316544 & 688546 & 5.1 & 5.4456 & TRN \\
\hline CHEMBL1374200 & 688546 & 4.95 & 5.1469 & TST \\
\hline CHEMBL1414513 & 688546 & 4.7 & 4.8898 & TST \\
\hline CHEMBL1362013 & 688546 & 5.7 & 5.2481 & TRN \\
\hline CHEMBL1341852 & 688546 & 4.6 & 5.0806 & TST \\
\hline CHEMBL1603853 & 688546 & 5.5 & 5.2519 & TRN \\
\hline CHEMBL1464645 & 688546 & 6.2 & 5.33299 & 9999999999 \\
\hline CHEMBL1304625 & 688546 & 4.8 & 4.9775 & TRN \\
\hline CHEMBL 389162 & 688546 & 4.8 & 4.9452 & TRN \\
\hline CHEMBL1325470 & 688546 & 4.5 & 4.8296 & TRN \\
\hline CHEMBL1447542 & 688546 & 4.9 & 5.1204 & TRN \\
\hline CHEMBL1554108 & 688546 & 5.4 & 5.596 & TRN \\
\hline CHEMBL1406801 & 688546 & 4.8 & 4.8568 & TRN \\
\hline CHEMBL1559836 & 688546 & 5.0 & 6.0518 & TRN \\
\hline CHEMBL1512097 & 688546 & 4.6 & 5.2426 & TRN \\
\hline CHEMBL1601738 & 688546 & 5.1 & 5.2237 & TRN \\
\hline CHEMBL1329019 & 688546 & 4.5 & 5.2999 & TST \\
\hline
\end{tabular}




\begin{tabular}{|c|c|c|c|c|}
\hline \multicolumn{5}{|c|}{ iental Table S } \\
\hline CHEMBL1529975 & 688546 & 5.0 & 5.2326 & TST \\
\hline CHEMBL1434736 & 688546 & 4.5 & 5.3047 & TRN \\
\hline CHEMBL1488219 & 688546 & 5.1 & 5.4257 & TRN \\
\hline CHEMBL 1317950 & 688546 & 4.9 & 5.3084 & TST \\
\hline CHEMBL1404372 & 688546 & 4.8 & 5.2621 & TST \\
\hline CHEMBL1314624 & 688546 & 4.9 & 5.3962 & TST \\
\hline CHEMBL1496190 & 688546 & 7.4001 & 5.3807 & TRN \\
\hline CHEMBL1528874 & 688546 & 4.9 & 4.9951 & TST \\
\hline CHEMBL1410697 & 688546 & 5.05 & 5.3211 & TST \\
\hline CHEMBL1473907 & 688546 & 5.1 & 5.1316 & TST \\
\hline CHEMBL1572197 & 688546 & 4.9 & 5.7806 & TRN \\
\hline CHEMBL1569756 & 688546 & 6.0 & 5.4105 & TRN \\
\hline CHEMBL1440998 & 688546 & 7.699 & 5.325 & TST \\
\hline CHEMBL 1410688 & 688546 & 6.9 & 4.4157 & TRN \\
\hline CHEMBL1551920 & 688546 & 4.5 & 5.0624 & TRN \\
\hline CHEMBL 1314318 & 688546 & 8.0 & 6.0725 & TRN \\
\hline CHEMBL1476503 & 688546 & 6.4 & 5.6531 & TRN \\
\hline CHEMBL1604447 & 688546 & 4.6 & 5.4601 & TRN \\
\hline CHEMBL1371789 & 688546 & 5.1 & 5.2148 & TRN \\
\hline CHEMBL1485627 & 688546 & 5.3 & 5.1219 & TRN \\
\hline CHEMBL 1445898 & 688546 & 5.1 & 5.5056 & TST \\
\hline CHEMBL1514498 & 688546 & 5.3 & 4.8543 & TRN \\
\hline CHEMBL1365162 & 688546 & 5.0 & 4.8432 & TRN \\
\hline CHEMBL1384800 & 688546 & 4.9 & 5.2083 & TRN \\
\hline CHEMBL1554717 & 688546 & 5.0 & 4.7873 & TST \\
\hline CHEMBL1495009 & 688546 & 6.1 & 5.3929 & TRN \\
\hline CHEMBL1597607 & 688546 & 5.2 & 5.6945 & TRN \\
\hline CHEMBL 2374058 & 688546 & 6.0 & 5.3573 & TST \\
\hline CHEMBL1501458 & 688546 & 4.9 & 5.6431 & TST \\
\hline CHEMBL1512966 & 688546 & 5.6 & 5.0057 & TRN \\
\hline CHEMBL1315638 & 688546 & 5.0 & 5.1514 & TRN \\
\hline CHEMBL1317313 & 688546 & 4.9 & 5.7588 & TRN \\
\hline CHEMBL 1400872 & 688546 & 4.5 & 5.6216 & TRN \\
\hline CHEMBL1534744 & 688546 & 4.5 & 5.3868 & TRN \\
\hline CHEMBL1439471 & 688546 & 6.7001 & 5.4454 & TRN \\
\hline CHEMBL1383591 & 688546 & 4.5 & 5.3718 & TST \\
\hline CHEMBL1495345 & 688546 & 4.9 & 5.1538 & TST \\
\hline CHEMBL1553703 & 688546 & 4.4 & 5.1212 & TRN \\
\hline CHEMBL1320898 & 688546 & 5.0 & 5.0787 & TRN \\
\hline CHEMBL1562777 & 688546 & 5.7 & 5.112 & TRN \\
\hline CHEMBL1552960 & 688546 & 5.85 & 5.3677 & TRN \\
\hline CHEMBL3190063 & 688546 & 4.95 & 4.978 & TST \\
\hline CHEMBL1491157 & 688546 & 4.6 & 5.5154 & TST \\
\hline CHEMBL1450695 & 688546 & 4.55 & 5.55399 & 9999999999 \\
\hline CHEMBL1598814 & 688546 & 4.6 & 4.9996 & TRN \\
\hline CHEMBL1558099 & 688546 & 4.8 & 5.0196 & TRN \\
\hline CHEMBL1442586 & 688546 & 4.5 & 4.9157 & TRN \\
\hline CHEMBL 1600087 & 688546 & 4.5 & 5.1209 & TRN \\
\hline
\end{tabular}

TRN 


\begin{tabular}{|c|c|c|c|c|c|}
\hline & & \multicolumn{4}{|c|}{ Supplemental Table S2.txt } \\
\hline CHEMBL1330328 & 688546 & 8.0506 & 5.0827 & TRN & \\
\hline CHEMBL1443979 & 688546 & 4.7 & 4.7252 & TST & \\
\hline CHEMBL1398164 & 688546 & 4.75 & 5.78600 & 00000000005 & TRN \\
\hline CHEMBL237253 & 688546 & 4.9 & 4.8356 & TRN & \\
\hline CHEMBL1736254 & 688546 & 5.5 & 5.6671 & TST & \\
\hline CHEMBL1361692 & 688546 & 4.8 & 5.0107 & TRN & \\
\hline CHEMBL1316434 & 688546 & 4.5 & 4.9189 & TRN & \\
\hline CHEMBL1551701 & 688546 & 4.9 & 5.2221 & TRN & \\
\hline CHEMBL1315924 & 688546 & 6.6 & 5.52 & TRN & \\
\hline CHEMBL1602496 & 688546 & 4.9 & 4.8143 & TRN & \\
\hline CHEMBL1405493 & 688546 & 5.0 & 5.3613 & TRN & \\
\hline CHEMBL1399455 & 688546 & 4.5 & 5.0715 & TRN & \\
\hline CHEMBL582473 & 688546 & 5.0 & 4.9844 & TRN & \\
\hline CHEMBL1304631 & 688546 & 4.8 & 5.1497 & TRN & \\
\hline CHEMBL1600209 & 688546 & 4.8 & 4.9484 & TRN & \\
\hline CHEMBL1474601 & 688546 & 5.0 & 5.7346 & TRN & \\
\hline CHEMBL1436190 & 688546 & 4.5 & 5.2331 & TRN & \\
\hline CHEMBL1430763 & 688546 & 4.65 & 5.4703 & TRN & \\
\hline CHEMBL1330138 & 688546 & 4.6 & 5.2632 & TST & \\
\hline CHEMBL1345939 & 688546 & 5.7 & 5.4367 & TRN & \\
\hline CHEMBL1401105 & 688546 & 4.5 & 5.291 & TRN & \\
\hline CHEMBL1358644 & 688546 & 7.4001 & 5.4 & TRN & \\
\hline CHEMBL1481981 & 688546 & 7.4001 & 5.7445 & TST & \\
\hline CHEMBL1315466 & 688546 & 6.7001 & 5.3703 & TRN & \\
\hline CHEMBL1304407 & 688546 & 4.9 & 5.3658 & TRN & \\
\hline CHEMBL1328533 & 688546 & 4.7 & 5.1457 & TRN & \\
\hline CHEMBL1427203 & 688546 & 4.5 & 5.2088 & TST & \\
\hline CHEMBL1455455 & 688546 & 6.4 & 5.5163 & TRN & \\
\hline CHEMBL1415801 & 688546 & 4.5 & 5.5586 & TRN & \\
\hline CHEMBL1594506 & 688546 & 4.45 & 5.2893 & TRN & \\
\hline CHEMBL1480392 & 688546 & 5.1 & 5.3019 & TRN & \\
\hline CHEMBL1377235 & 688546 & 6.25 & 5.9596 & TRN & \\
\hline CHEMBL1585004 & 688546 & 6.0 & 5.2366 & TST & \\
\hline CHEMBL1555114 & 688546 & 5.5 & 5.6617 & TRN & \\
\hline CHEMBL1368371 & 688546 & 4.65 & 5.105 & TRN & \\
\hline CHEMBL1328855 & 688546 & 6.5 & 5.9558 & TRN & \\
\hline CHEMBL1592254 & 688546 & 4.7 & 5.8991 & TRN & \\
\hline CHEMBL1595686 & 688546 & 6.9 & 5.7619 & TST & \\
\hline CHEMBL1453407 & 688546 & 4.7 & 5.0416 & TRN & \\
\hline CHEMBL1551473 & 688546 & 5.5 & 5.3613 & TRN & \\
\hline CHEMBL1492011 & 688546 & 6.95 & 5.2952 & TST & \\
\hline CHEMBL1551977 & 688546 & 4.8 & 5.6013 & TST & \\
\hline CHEMBL1434115 & 688546 & 7.3002 & 5.7566 & TRN & \\
\hline CHEMBL1524798 & 688546 & 5.3 & 5.0497 & TST & \\
\hline CHEMBL1613230 & 688546 & 4.9 & 5.3491 & TRN & \\
\hline CHEMBL1590089 & 688546 & 4.9 & 5.5318 & TRN & \\
\hline CHEMBL1400780 & 688546 & 4.95 & 5.7662 & TRN & \\
\hline CHEMBL1353513 & 688546 & 4.5 & 5.4037 & TST & \\
\hline
\end{tabular}




\begin{tabular}{|c|c|c|c|c|c|}
\hline \multicolumn{6}{|c|}{ Supplemental Table S2.txt } \\
\hline CHEMBL165 & 688546 & 6.0 & 5.79 & TRN & \\
\hline CHEMBL468167 & 688546 & 5.2 & 5.4415 & TST & \\
\hline CHEMBL1554119 & 688546 & 4.7 & 5.0628 & TRN & \\
\hline CHEMBL1513971 & 688546 & 6.3 & 5.2887 & TRN & \\
\hline CHEMBL1308557 & 688546 & 4.5 & 5.0349 & TRN & \\
\hline CHEMBL1506077 & 688546 & 4.5 & 5.9374 & TRN & \\
\hline CHEMBL1593674 & 688546 & 4.8 & 4.824 & TRN & \\
\hline CHEMBL3196267 & 688546 & 4.9 & 4.9826 & TST & \\
\hline CHEMBL1516125 & 688546 & 4.9 & 5.2064 & TRN & \\
\hline CHEMBL1478141 & 688546 & 4.45 & 5.3118 & TST & \\
\hline CHEMBL1561173 & 688546 & 4.7 & 5.3343 & TRN & \\
\hline CHEMBL3198502 & 688546 & 4.95 & 5.3504 & TST & \\
\hline CHEMBL1355269 & 688546 & 4.6 & 4.9269 & TRN & \\
\hline CHEMBL1327703 & 688546 & 5.3 & 5.1241 & TRN & \\
\hline CHEMBL1555204 & 688546 & 4.8 & 5.7733 & TRN & \\
\hline CHEMBL1551557 & 688546 & 5.5 & 5.0102 & TRN & \\
\hline CHEMBL1512331 & 688546 & 5.1 & 4.9484 & TRN & \\
\hline CHEMBL1437539 & 688546 & 4.5 & 5.5583 & TRN & \\
\hline CHEMBL1327845 & 688546 & 4.9 & 4.9085 & TRN & \\
\hline CHEMBL1560215 & 688546 & 5.0 & 4.9711 & TRN & \\
\hline CHEMBL1395118 & 688546 & 4.5 & 5.8223 & TRN & \\
\hline CHEMBL1514409 & 688546 & 5.0 & 5.1628 & TRN & \\
\hline CHEMBL 3190834 & 688546 & 5.0 & 4.9049 & TRN & \\
\hline CHEMBL1548306 & 688546 & 4.95 & 4.9773 & TRN & \\
\hline CHEMBL1397030 & 688546 & 4.9 & 4.9095 & TRN & \\
\hline CHEMBL1321836 & 688546 & 5.1 & 5.0611 & TRN & \\
\hline CHEMBL1452348 & 688546 & 4.9 & 6.0752 & TRN & \\
\hline CHEMBL1318281 & 688546 & 4.65 & 5.5929 & TRN & \\
\hline CHEMBL1602281 & 688546 & 4.9 & 4.7718 & TRN & \\
\hline CHEMBL1356144 & 688546 & 4.9 & 4.9071 & TRN & \\
\hline CHEMBL1519105 & 688546 & 5.45 & 5.2509 & TST & \\
\hline CHEMBL1512687 & 688546 & 4.8 & 4.8885 & TRN & \\
\hline CHEMBL140 & 688546 & 4.4 & 5.0036 & TRN & \\
\hline CHEMBL1315698 & 688546 & 5.0 & $5.2120 e$ & 0000000001 & TRN \\
\hline CHEMBL1592030 & 688546 & 5.1 & 5.3135 & TRN & \\
\hline CHEMBL1608542 & 688546 & 4.5 & 5.4947 & TRN & \\
\hline CHEMBL1491238 & 688546 & 4.65 & 5.1502 & TRN & \\
\hline CHEMBL1470754 & 688546 & 5.0 & 4.8704 & TRN & \\
\hline CHEMBL560020 & 688546 & 4.5 & $5.3320 e$ & 2000000001 & TST \\
\hline CHEMBL1556482 & 688546 & 7.7496 & 5.8492 & TST & \\
\hline CHEMBL1516275 & 688546 & 5.55 & 5.2237 & TRN & \\
\hline CHEMBL1590450 & 688546 & 5.4 & 4.9122 & TRN & \\
\hline CHEMBL1555182 & 688546 & 5.6 & 5.8746 & TRN & \\
\hline CHEMBL1395944 & 688546 & 6.8499 & 5.2854 & TRN & \\
\hline CHEMBL1437584 & 688546 & 8.3979 & 5.4311 & TRN & \\
\hline CHEMBL1483196 & 688546 & 4.5 & 5.3912 & TRN & \\
\hline CHEMBL1559360 & 688546 & 6.1 & 5.4192 & TRN & \\
\hline CHEMBL1310612 & 688546 & 6.8 & 4.9292 & TST & \\
\hline
\end{tabular}




\begin{tabular}{|c|c|c|c|c|c|}
\hline \\
\hline CHEMBL1363210 & 688546 & 4.9 & 5.1658 & TRN & \\
\hline CHEMBL1436234 & 688546 & 4.9 & 5.0874 & TRN & \\
\hline CHEMBL1410978 & 688546 & 5.0 & 5.00899 & 99999999995 & TRN \\
\hline CHEMBL1363651 & 688546 & 4.7 & 5.0481 & TRN & \\
\hline CHEMBL1478233 & 688546 & 4.8 & 5.3709 & TRN & \\
\hline CHEMBL1358237 & 688546 & 4.45 & 6.2066 & TRN & \\
\hline CHEMBL1375672 & 688546 & 5.6 & 5.4334 & TRN & \\
\hline CHEMBL1473411 & 688546 & 4.7 & 4.7083 & TRN & \\
\hline CHEMBL1553584 & 688546 & 5.1 & 5.1302 & TRN & \\
\hline CHEMBL1591968 & 688546 & 4.5 & 5.1075 & TRN & \\
\hline CHEMBL1437602 & 688546 & 4.7 & 5.3152 & TRN & \\
\hline CHEMBL1396455 & 688546 & 4.6 & 4.6272 & TRN & \\
\hline CHEMBL1535176 & 688546 & 4.9 & 5.2266 & TRN & \\
\hline CHEMBL1328902 & 688546 & 4.5 & 5.6617 & TST & \\
\hline CHEMBL1402344 & 688546 & 7.699 & 5.5118 & TST & \\
\hline CHEMBL1438651 & 688546 & 5.25 & 5.8233 & TRN & \\
\hline CHEMBL1453589 & 688546 & 4.9 & 5.466 & TRN & \\
\hline CHEMBL1410792 & 688546 & 5.5 & 5.3926 & TRN & \\
\hline CHEMBL1551780 & 688546 & 6.3 & 5.9814 & TRN & \\
\hline CHEMBL1338376 & 688546 & 6.5501 & 4.9519 & TST & \\
\hline CHEMBL1590900 & 688546 & 5.3 & 5.1541 & TRN & \\
\hline CHEMBL1395778 & 688546 & 4.5 & 5.48600 & 0000000001 & TRN \\
\hline CHEMBL1407247 & 688546 & 4.7 & 4.967 & TST & \\
\hline CHEMBL1600154 & 688546 & 5.3 & 5.1731 & TRN & \\
\hline CHEMBL1521883 & 688546 & 6.1 & 5.3817 & TST & \\
\hline CHEMBL1476639 & 688546 & 4.8 & 5.0817 & TRN & \\
\hline CHEMBL1328811 & 688546 & 4.8 & 5.0936 & TRN & \\
\hline CHEMBL1394358 & 688546 & 7.5003 & 5.4372 & TRN & \\
\hline CHEMBL1449841 & 688546 & 4.6 & 4.6368 & TRN & \\
\hline CHEMBL1431763 & 688546 & 4.8 & 5.2985 & TRN & \\
\hline CHEMBL1476795 & 688546 & 6.5501 & 5.2027 & TRN & \\
\hline CHEMBL1360011 & 688546 & 4.8 & 4.93199 & 99999999995 & TRN \\
\hline CHEMBL1411594 & 688546 & 5.4 & 5.0701 & TRN & \\
\hline CHEMBL1337235 & 688546 & 4.5 & 5.166 & TRN & \\
\hline CHEMBL1487612 & 688546 & 5.0 & 5.4238 & TRN & \\
\hline CHEMBL1415894 & 688546 & 4.6 & 4.7583 & TST & \\
\hline CHEMBL1347431 & 688546 & 4.9 & 5.6379 & TST & \\
\hline CHEMBL1593734 & 688546 & 4.55 & 5.0569 & TRN & \\
\hline CHEMBL1476758 & 688546 & 5.1 & 4.7769 & TRN & \\
\hline CHEMBL1449120 & 688546 & 5.0 & 5.0331 & TRN & \\
\hline CHEMBL1544647 & 688546 & 5.0 & 4.6048 & TRN & \\
\hline CHEMBL1494240 & 688546 & 5.5 & 5.6589 & TRN & \\
\hline CHEMBL1535935 & 688546 & 4.5 & 5.3505 & TRN & \\
\hline CHEMBL1533477 & 688546 & 5.0 & 5.4378 & TRN & \\
\hline CHEMBL1315148 & 688546 & 4.8 & 5.1398 & TRN & \\
\hline CHEMBL1418494 & 688546 & 4.6 & 4.9632 & TST & \\
\hline CHEMBL1527768 & 688546 & 4.5 & 5.0574 & TST & \\
\hline CHEMBL1475274 & 688546 & 5.1 & 5.4195 & TRN & \\
\hline
\end{tabular}




\begin{tabular}{|c|c|c|c|c|}
\hline \multicolumn{5}{|c|}{ Supplemental Table s2.txt } \\
\hline CHEMBL64119 & 688546 & 4.5 & 5.0835 & TST \\
\hline CHEMBL1367834 & 688546 & 4.8 & 4.9975 & TRN \\
\hline CHEMBL1593290 & 688546 & 5.0 & 5.3011 & TRN \\
\hline CHEMBL1489337 & 688546 & 4.9 & 5.1439 & TRN \\
\hline CHEMBL1518159 & 688546 & 5.2 & 4.6337 & TST \\
\hline CHEMBL1607320 & 688546 & 5.2 & 5.1871 & TST \\
\hline CHEMBL1345494 & 688546 & 5.0 & 5.0712 & TST \\
\hline CHEMBL1552079 & 688546 & 5.1 & 5.1144 & TRN \\
\hline CHEMBL1563483 & 688546 & 4.6 & 5.3717 & TST \\
\hline CHEMBL1373222 & 688546 & 4.5 & 5.5198 & TRN \\
\hline CHEMBL1337116 & 688546 & 5.3 & 5.3667 & TRN \\
\hline CHEMBL478 & 688546 & 4.9 & 5.0247 & TST \\
\hline CHEMBL1318075 & 688546 & 6.0 & 5.5268 & TST \\
\hline CHEMBL1322492 & 688546 & 8.3979 & 5.517 & TRN \\
\hline CHEMBL1361298 & 688546 & 5.1 & 5.4961 & TRN \\
\hline CHEMBL1435555 & 688546 & 5.5 & 5.2741 & TRN \\
\hline CHEMBL1342520 & 688546 & 4.6 & 4.9306 & TST \\
\hline CHEMBL1571703 & 688546 & 4.9 & 5.8091 & TST \\
\hline CHEMBL1566989 & 688546 & 5.2 & 5.0746 & TRN \\
\hline CHEMBL1405945 & 688546 & 6.1 & 5.7593 & TRN \\
\hline CHEMBL1604951 & 688546 & 5.3 & 5.225 & TRN \\
\hline CHEMBL1356290 & 688546 & 4.9 & 5.0765 & TRN \\
\hline CHEMBL1317491 & 688546 & 4.95 & 5.109 & TRN \\
\hline CHEMBL 246957 & 688546 & 5.6 & 5.2739 & TST \\
\hline CHEMBL1495999 & 688546 & 4.9 & 5.7128 & TRN \\
\hline CHEMBL1341087 & 688546 & 4.5 & 5.1099 & TRN \\
\hline CHEMBL3199152 & 688546 & 4.9 & 5.0109 & TRN \\
\hline CHEMBL1563086 & 688546 & 5.0 & 5.2075 & TST \\
\hline CHEMBL1605576 & 688546 & 6.35 & 5.309 & TRN \\
\hline CHEMBL 1410586 & 688546 & 6.0 & 4.9673 & TRN \\
\hline CHEMBL1356845 & 688546 & 4.9 & 5.2947 & TRN \\
\hline CHEMBL1515130 & 688546 & 5.2 & 5.1648 & TRN \\
\hline CHEMBL1592153 & 688546 & 4.9 & 5.0822 & TST \\
\hline CHEMBL1321421 & 688546 & 5.9 & 4.7015 & TST \\
\hline CHEMBL1324518 & 688546 & 4.5 & 5.2377 & TRN \\
\hline CHEMBL1256995 & 688546 & 6.0 & 5.0307 & TRN \\
\hline CHEMBL548444 & 688546 & 4.6 & 5.4875 & TST \\
\hline CHEMBL1556281 & 688546 & 6.35 & 5.5398 & TST \\
\hline CHEMBL1417353 & 688546 & 6.1 & 5.5105 & TRN \\
\hline CHEMBL1330067 & 688546 & 4.5 & 5.3047 & TRN \\
\hline CHEMBL1375580 & 688546 & 5.4 & 5.4579 & TRN \\
\hline CHEMBL1535546 & 688546 & 4.6 & 4.9186 & TRN \\
\hline CHEMBL1394547 & 688546 & 4.8 & 5.5853 & TRN \\
\hline CHEMBL1358415 & 688546 & 4.7 & 5.4388 & TRN \\
\hline CHEMBL1409884 & 688546 & 5.3 & 5.8939 & TST \\
\hline CHEMBL1356399 & 688546 & 6.9 & 5.3178 & TRN \\
\hline CHEMBL1355195 & 688546 & 4.7 & 5.3712 & TRN \\
\hline CHEMBL15927 & 688546 & 4.5 & 4.864 & TST \\
\hline
\end{tabular}




\begin{tabular}{|c|c|c|c|c|c|}
\hline \\
\hline CHEMBL1600268 & 688546 & 4.9 & 5.0266 & TST & \\
\hline CHEMBL1370603 & 688546 & 4.5 & 4.7983 & TST & \\
\hline CHEMBL1497673 & 688546 & 4.5 & 4.9869 & TRN & \\
\hline CHEMBL1308000 & 688546 & 4.5 & 4.9005 & TRN & \\
\hline CHEMBL1443849 & 688546 & 7.1002 & 4.8785 & TRN & \\
\hline CHEMBL1397459 & 688546 & 5.0 & 4.9182 & TRN & \\
\hline CHEMBL1429150 & 688546 & 4.5 & 5.2147 & TST & \\
\hline CHEMBL1554989 & 688546 & 7.3002 & 5.8322 & TRN & \\
\hline CHEMBL1517627 & 688546 & 4.7 & 4.8228 & TRN & \\
\hline CHEMBL1593427 & 688546 & 5.3 & 5.7503 & TRN & \\
\hline CHEMBL1442619 & 688546 & 4.9 & 4.9127 & TRN & \\
\hline CHEMBL1485582 & 688546 & 5.2 & 5.0921 & TRN & \\
\hline CHEMBL1386871 & 688546 & 5.0 & 5.12700 & 0000000001 & TST \\
\hline CHEMBL1519770 & 688546 & 4.6 & 5.4267 & TST & \\
\hline CHEMBL1457964 & 688546 & 7.2503 & 5.3587 & TST & \\
\hline CHEMBL1093507 & 688546 & 4.9 & 5.1156 & TST & \\
\hline CHEMBL1476278 & 688546 & 5.1 & 5.2587 & TRN & \\
\hline CHEMBL1598809 & 688546 & 4.5 & 4.8248 & TRN & \\
\hline CHEMBL1338977 & 688546 & 4.8 & 5.4012 & TST & \\
\hline CHEMBL174588 & 688546 & 5.0 & 5.2429 & TST & \\
\hline CHEMBL1324882 & 688546 & 4.6 & 4.8566 & TRN & \\
\hline CHEMBL1581345 & 688546 & 4.9 & 4.8959 & TST & \\
\hline CHEMBL1395725 & 688546 & 4.9 & 5.2942 & TST & \\
\hline CHEMBL1445067 & 688546 & 4.9 & 5.0711 & TRN & \\
\hline CHEMBL1532820 & 688546 & 6.7001 & 5.7289 & TRN & \\
\hline CHEMBL1541834 & 688546 & 5.4 & 5.1356 & TRN & \\
\hline CHEMBL1413504 & 688546 & 4.9 & 4.6407 & TST & \\
\hline CHEMBL1526702 & 688546 & 6.9 & 4.9552 & TRN & \\
\hline CHEMBL1606755 & 688546 & 4.5 & 5.0591 & TRN & \\
\hline CHEMBL1586416 & 688546 & 4.9 & 5.2323 & TST & \\
\hline CHEMBL1554525 & 688546 & 8.0 & 5.2354 & TRN & \\
\hline CHEMBL1476619 & 688546 & 5.0 & 5.4011 & TRN & \\
\hline CHEMBL1320515 & 688546 & 4.5 & 5.2614 & TST & \\
\hline CHEMBL1610894 & 688546 & 4.9 & 4.7643 & TRN & \\
\hline CHEMBL1610997 & 688546 & 6.45 & 4.5858 & TST & \\
\hline CHEMBL1477532 & 688546 & 7.4001 & 6.0101 & TRN & \\
\hline CHEMBL1487433 & 688546 & 5.8 & 5.4948 & TRN & \\
\hline CHEMBL1457262 & 688546 & 4.5 & 4.7073 & TRN & \\
\hline CHEMBL1514189 & 688546 & 4.85 & 5.0899 & TRN & \\
\hline CHEMBL1354311 & 688546 & 4.8 & 5.5216 & TRN & \\
\hline CHEMBL1449413 & 688546 & 7.8996 & 5.4121 & TRN & \\
\hline CHEMBL1398241 & 688546 & 4.7 & 5.1957 & TRN & \\
\hline CHEMBL1478914 & 688546 & 4.7 & 5.3818 & TRN & \\
\hline CHEMBL1467363 & 688546 & 5.25 & 5.53700 & 0000000001 & TRN \\
\hline CHEMBL1599457 & 688546 & 4.8 & 5.244 & TRN & \\
\hline CHEMBL1593576 & 688546 & 4.7 & 5.687 & TRN & \\
\hline CHEMBL1492074 & 688546 & 4.9 & 4.9512 & TRN & \\
\hline CHEMBL1590628 & 688546 & 5.15 & 5.067 & TRN & \\
\hline
\end{tabular}




\begin{tabular}{|c|c|c|c|c|c|}
\hline \\
\hline CHEMBL1600535 & 688546 & 4.9 & 5.4265 & TST & \\
\hline CHEMBL1322478 & 688546 & 4.6 & 5.0613 & TRN & \\
\hline CHEMBL1389753 & 688546 & 5.0 & 4.6509 & TST & \\
\hline CHEMBL1552871 & 688546 & 5.05 & 5.3882 & TRN & \\
\hline CHEMBL1555613 & 688546 & 4.5 & 5.511 & TRN & \\
\hline CHEMBL597251 & 688546 & 4.5 & 4.988 & TST & \\
\hline CHEMBL1325549 & 688546 & 4.6 & 4.897 & TST & \\
\hline CHEMBL1424968 & 688546 & 4.8 & 5.1086 & TRN & \\
\hline CHEMBL1579693 & 688546 & 4.7 & 5.2273 & TST & \\
\hline CHEMBL570345 & 688546 & 4.5 & 5.1454 & TST & \\
\hline CHEMBL1398402 & 688546 & 5.0 & 5.3689 & TRN & \\
\hline CHEMBL1495062 & 688546 & 7.3497 & 5.1949 & TRN & \\
\hline CHEMBL1516041 & 688546 & 4.5 & 5.4944 & TRN & \\
\hline CHEMBL1551400 & 688546 & 4.9 & 5.3017 & TRN & \\
\hline CHEMBL1567282 & 688546 & 4.9 & 5.0248 & TST & \\
\hline CHEMBL1513351 & 688546 & 4.5 & 4.8964 & TRN & \\
\hline CHEMBL1527282 & 688546 & 4.9 & 4.965 & TST & \\
\hline CHEMBL1553461 & 688546 & 4.8 & 5.2979 & TRN & \\
\hline CHEMBL281622 & 688546 & 4.8 & 4.8354 & TST & \\
\hline CHEMBL34450 & 688546 & 4.9 & 5.1596 & TST & \\
\hline CHEMBL1565686 & 688546 & 5.0 & 5.3227 & TRN & \\
\hline CHEMBL1593957 & 688546 & 4.5 & 5.5822 & TRN & \\
\hline CHEMBL1608077 & 688546 & 4.9 & 5.4262 & TRN & \\
\hline CHEMBL1473551 & 688546 & 5.3 & 5.70299 & 9999999999 & TRN \\
\hline CHEMBL1408045 & 688546 & 6.6 & 5.7995 & TRN & \\
\hline CHEMBL1370071 & 688546 & 4.9 & 5.4984 & TRN & \\
\hline CHEMBL1563876 & 688546 & 5.9 & 5.0768 & TRN & \\
\hline CHEMBL1317451 & 688546 & 4.6 & 4.6762 & TRN & \\
\hline CHEMBL1564326 & 688546 & 6.3 & 5.5712 & TRN & \\
\hline CHEMBL1517102 & 688546 & 4.5 & 5.1007 & TRN & \\
\hline CHEMBL1396447 & 688546 & 8.0 & 4.8476 & TRN & \\
\hline CHEMBL1588326 & 688546 & 4.9 & 5.1168 & TST & \\
\hline CHEMBL104264 & 688546 & 4.8 & 5.329 & TST & \\
\hline CHEMBL1336977 & 688546 & 4.5 & 4.7973 & TRN & \\
\hline CHEMBL3195220 & 688546 & 4.9 & 4.9517 & TST & \\
\hline CHEMBL1600964 & 688546 & 5.1 & 5.0186 & TRN & \\
\hline CHEMBL1514951 & 688546 & 5.0 & $5.3370 e$ & 0000000001 & TRN \\
\hline CHEMBL1400250 & 688546 & 4.6 & 5.2264 & TRN & \\
\hline CHEMBL1534449 & 688546 & 8.301 & 5.0536 & TRN & \\
\hline CHEMBL1456229 & 688546 & 8.0 & 5.3999 & TRN & \\
\hline CHEMBL1309802 & 688546 & 4.5 & 5.3231 & TST & \\
\hline CHEMBL1613324 & 688546 & 4.45 & 5.6173 & TST & \\
\hline CHEMBL1596864 & 688546 & 4.7 & 4.6959 & TRN & \\
\hline CHEMBL1463869 & 688546 & 4.9 & 5.0154 & TST & \\
\hline CHEMBL1611371 & 688546 & 5.0 & 5.1505 & TRN & \\
\hline CHEMBL1417600 & 688546 & 4.5 & 5.4586 & TST & \\
\hline CHEMBL1336709 & 688546 & 4.7 & 4.8365 & TRN & \\
\hline CHEMBL1435593 & 688546 & 4.7 & 4.9208 & TRN & \\
\hline
\end{tabular}




\begin{tabular}{|c|c|c|c|c|c|}
\hline & & & & & \\
\hline CHEMBL1380186 & 688546 & 5.1 & 4.6931 & TRN & \\
\hline CHEMBL1508357 & 688546 & 5.15 & 5.2501 & TST & \\
\hline CHEMBL1604017 & 688546 & 4.9 & 5.2632 & TST & \\
\hline CHEMBL1513844 & 688546 & 4.5 & 4.8354 & TST & \\
\hline CHEMBL1407668 & 688546 & 4.6 & 5.1425 & TRN & \\
\hline CHEMBL1319095 & 688546 & 5.5 & 5.1921 & TRN & \\
\hline CHEMBL1317834 & 688546 & 5.1 & 5.539 & TRN & \\
\hline CHEMBL 77030 & 688546 & 4.6 & 4.9769 & TRN & \\
\hline CHEMBL1592393 & 688546 & 5.0 & 5.3532 & TST & \\
\hline CHEMBL1394916 & 688546 & 5.0 & 5.0158 & TRN & \\
\hline CHEMBL68534 & 688546 & 5.0 & 4.79899 & 99999999995 & TST \\
\hline CHEMBL1560392 & 688546 & 7.0 & 4.7329 & TST & \\
\hline CHEMBL1397549 & 688546 & 8.301 & 5.8046 & TRN & \\
\hline CHEMBL1315394 & 688546 & 4.9 & 5.2337 & TRN & \\
\hline CHEMBL1348657 & 688546 & 4.45 & 5.3238 & TRN & \\
\hline CHEMBL1488204 & 688546 & 4.9 & 4.94300 & 00000000005 & TRN \\
\hline CHEMBL1419335 & 688546 & 4.6 & 4.9686 & TST & \\
\hline CHEMBL1337629 & 688546 & 5.3 & 4.9602 & TST & \\
\hline CHEMBL1394859 & 688546 & 7.5003 & 5.7514 & TRN & \\
\hline CHEMBL1591101 & 688546 & 8.4949 & 5.522 & TRN & \\
\hline CHEMBL1317200 & 688546 & 4.8 & 5.4455 & TRN & \\
\hline CHEMBL1534466 & 688546 & 4.9 & 5.4207 & TRN & \\
\hline CHEMBL1461275 & 688546 & 5.0 & 5.5146 & TST & \\
\hline CHEMBL1553428 & 688546 & 4.7 & 5.3899 & TRN & \\
\hline CHEMBL1545040 & 688546 & 4.8 & 5.0558 & TRN & \\
\hline CHEMBL1551888 & 688546 & 4.5 & 5.4449 & TRN & \\
\hline CHEMBL1537418 & 688546 & 5.4 & 4.8528 & TST & \\
\hline CHEMBL1396586 & 688546 & 4.9 & 5.3238 & TRN & \\
\hline CHEMBL1513469 & 688546 & 7.9508 & 5.2433 & TRN & \\
\hline CHEMBL1358422 & 688546 & 4.4 & 5.2653 & TRN & \\
\hline CHEMBL1575766 & 688546 & 4.7 & 4.96899 & 9999999999 & TRN \\
\hline CHEMBL1464453 & 688546 & 4.9 & 5.1775 & TRN & \\
\hline CHEMBL1558889 & 688546 & 4.9 & 5.0107 & TRN & \\
\hline CHEMBL1319326 & 688546 & 4.7 & 4.5714 & TRN & \\
\hline CHEMBL1559751 & 688546 & 7.15 & 5.3761 & TRN & \\
\hline CHEMBL1455824 & 688546 & 4.95 & 5.2703 & TST & \\
\hline CHEMBL543467 & 688546 & 4.5 & 5.0463 & TST & \\
\hline CHEMBL1438256 & 688546 & 4.8 & 5.0621 & TRN & \\
\hline CHEMBL1531231 & 688546 & 4.9 & 5.4861 & TRN & \\
\hline CHEMBL1434768 & 688546 & 8.4559 & 5.7088 & TRN & \\
\hline CHEMBL1592032 & 688546 & 5.0 & 4.6015 & TRN & \\
\hline CHEMBL1314184 & 688546 & 7.8996 & 5.737 & TRN & \\
\hline CHEMBL1539824 & 688546 & 4.9 & 5.1274 & TRN & \\
\hline CHEMBL1397780 & 688546 & 7.1002 & 5.4992 & TRN & \\
\hline CHEMBL1552195 & 688546 & 5.3 & 5.2908 & TRN & \\
\hline CHEMBL1534136 & 688546 & 4.9 & 4.9182 & TRN & \\
\hline CHEMBL1589849 & 688546 & 5.0 & 5.3868 & TRN & \\
\hline CHEMBL1363534 & 688546 & 4.9 & 5.08899 & 99999999995 & TRN \\
\hline & & & & 10359 & \\
\hline
\end{tabular}




\begin{tabular}{|c|c|c|c|c|}
\hline & & & pplement & al $\mathrm{Ta}$ \\
\hline CHEMBL1391000 & 688546 & 4.7 & 5.2717 & TST \\
\hline CHEMBL1304856 & 688546 & 5.0 & 4.8859 & TST \\
\hline CHEMBL1437680 & 688546 & 4.9 & 4.6659 & TRN \\
\hline CHEMBL1608496 & 688546 & 4.5 & 5.3523 & TST \\
\hline CHEMBL1431955 & 688546 & 5.25 & 4.9607 & TST \\
\hline CHEMBL1473106 & 688546 & 4.6 & 4.6962 & TRN \\
\hline CHEMBL1594590 & 688546 & 5.0 & 5.2703 & TRN \\
\hline CHEMBL238188 & 688546 & 4.5 & 5.1201 & TST \\
\hline CHEMBL1320105 & 688546 & 8.2518 & 5.3192 & TRN \\
\hline CHEMBL1398330 & 688546 & 4.8 & 5.4516 & TST \\
\hline CHEMBL1435504 & 688546 & 5.2 & 5.2948 & TRN \\
\hline CHEMBL1993627 & 688546 & 5.2 & 5.125 & TRN \\
\hline CHEMBL1592361 & 688546 & 4.8 & 5.2132 & TST \\
\hline CHEMBL1553674 & 688546 & 5.4 & 4.7076 & TRN \\
\hline CHEMBL1359181 & 688546 & 4.5 & 4.7693 & TST \\
\hline CHEMBL1315116 & 688546 & 7.1002 & 5.8679 & TRN \\
\hline CHEMBL1367222 & 688546 & 4.5 & 5.107 & TRN \\
\hline CHEMBL1338121 & 688546 & 4.8 & 5.405 & TRN \\
\hline CHEMBL1352326 & 688546 & 4.65 & 5.1636 & TRN \\
\hline CHEMBL1490940 & 688546 & 4.6 & 5.0842 & TST \\
\hline CHEMBL1574222 & 688546 & 4.9 & 5.1459 & TRN \\
\hline CHEMBL1513739 & 688546 & 6.4 & 4.7642 & TRN \\
\hline CHEMBL1394758 & 688546 & 4.6 & 4.9147 & TRN \\
\hline CHEMBL1475026 & 688546 & 5.8 & 5.3874 & TRN \\
\hline CHEMBL1511985 & 688546 & 5.0 & 5.6779 & TRN \\
\hline CHEMBL198759 & 688546 & 5.8 & 5.3245 & TST \\
\hline CHEMBL1589819 & 688546 & 5.7 & 5.6398 & TRN \\
\hline CHEMBL1532190 & 688546 & 4.8 & 5.1641 & TRN \\
\hline CHEMBL1487273 & 688546 & 7.6498 & 5.1976 & TRN \\
\hline CHEMBL1395731 & 688546 & 4.9 & 5.454 & TRN \\
\hline CHEMBL1416732 & 688546 & 5.0 & 5.0591 & TRN \\
\hline CHEMBL51085 & 688546 & 5.1 & 5.9832 & TST \\
\hline CHEMBL1476691 & 688546 & 7.5003 & 5.7181 & TST \\
\hline CHEMBL1317728 & 688546 & 5.1 & 5.2624 & TRN \\
\hline CHEMBL1518713 & 688546 & 6.9 & 5.7625 & TST \\
\hline CHEMBL1317719 & 688546 & 4.9 & 4.2709 & TRN \\
\hline CHEMBL1397179 & 688546 & 5.0 & 4.9746 & TRN \\
\hline CHEMBL1595834 & 688546 & 8.1487 & 5.4452 & TRN \\
\hline CHEMBL1350119 & 688546 & 5.0 & 5.2999 & TST \\
\hline CHEMBL1520884 & 688546 & 5.3 & 6.2677 & TRN \\
\hline CHEMBL1480214 & 688546 & 5.4 & 5.5171 & TRN \\
\hline CHEMBL1447595 & 688546 & 5.7 & 5.8371 & TRN \\
\hline CHEMBL1353522 & 688546 & 4.6 & 5.2748 & TST \\
\hline CHEMBL1514681 & 688546 & 4.8 & 4.9832 & TRN \\
\hline CHEMBL1367553 & 688546 & 5.0 & 5.4437 & TRN \\
\hline CHEMBL1554476 & 688546 & 5.1 & 5.322 & TRN \\
\hline CHEMBL1394570 & 688546 & 4.9 & 5.0196 & TRN \\
\hline CHEMBL1473293 & 688546 & 4.8 & 5.2313 & TRN \\
\hline
\end{tabular}




\begin{tabular}{|c|c|c|c|c|}
\hline & & & pplement & al $\mathrm{Ta}$ \\
\hline CHEMBL1571404 & 688546 & 6.5 & 5.4533 & TRN \\
\hline CHEMBL1385107 & 688546 & 4.5 & 4.9896 & TRN \\
\hline CHEMBL1499754 & 688546 & 5.25 & 4.8197 & TRN \\
\hline CHEMBL1418147 & 688546 & 4.8 & 4.7468 & TRN \\
\hline CHEMBL1328112 & 688546 & 4.9 & 5.3767 & TST \\
\hline CHEMBL1592561 & 688546 & 5.2 & 5.5375 & TRN \\
\hline CHEMBL1556431 & 688546 & 4.8 & 4.666 & TRN \\
\hline CHEMBL1557474 & 688546 & 5.2 & 5.2991 & TRN \\
\hline CHEMBL1509254 & 688546 & 5.2 & 5.4149 & TRN \\
\hline CHEMBL1355404 & 688546 & 6.4 & 4.9024 & TRN \\
\hline CHEMBL1416430 & 688546 & 8.6021 & 5.5488 & TRN \\
\hline CHEMBL1520414 & 688546 & 4.8 & 5.0147 & TRN \\
\hline CHEMBL1396839 & 688546 & 5.9 & 5.2335 & TRN \\
\hline CHEMBL1397308 & 688546 & 4.9 & 5.1899 & TRN \\
\hline CHEMBL1322696 & 688546 & 4.8 & 5.0987 & TRN \\
\hline CHEMBL1498728 & 688546 & 5.1 & 5.0779 & TRN \\
\hline CHEMBL1389101 & 688546 & 5.3 & 5.5905 & TRN \\
\hline CHEMBL1379634 & 688546 & 5.7 & 4.7004 & TST \\
\hline CHEMBL1594868 & 688546 & 4.9 & 4.8785 & TRN \\
\hline CHEMBL1319037 & 688546 & 4.8 & 5.4414 & TRN \\
\hline CHEMBL1476050 & 688546 & 4.8 & 5.1311 & TRN \\
\hline CHEMBL1516076 & 688546 & 4.45 & 4.878 & TRN \\
\hline CHEMBL1519338 & 688546 & 4.45 & 4.6324 & TRN \\
\hline CHEMBL1566189 & 688546 & 4.6 & 5.5689 & TRN \\
\hline CHEMBL1408742 & 688546 & 4.9 & 5.2236 & TRN \\
\hline CHEMBL1340189 & 688546 & 4.5 & 5.2519 & TST \\
\hline CHEMBL1371147 & 688546 & 4.5 & 4.7226 & TST \\
\hline CHEMBL1572957 & 688546 & 4.5 & 5.2595 & TRN \\
\hline CHEMBL1472780 & 688546 & 4.8 & 5.3439 & TRN \\
\hline CHEMBL1370019 & 688546 & 4.5 & 5.2299 & TRN \\
\hline CHEMBL1554129 & 688546 & 4.85 & 5.9392 & TRN \\
\hline CHEMBL1592969 & 688546 & 4.8 & 5.2661 & TRN \\
\hline CHEMBL1529677 & 688546 & 4.8 & 5.2631 & TST \\
\hline CHEMBL1442681 & 688546 & 4.9 & 5.2474 & TRN \\
\hline CHEMBL1590465 & 688546 & 4.8 & 5.0492 & TRN \\
\hline CHEMBL1369740 & 688546 & 4.9 & 5.1384 & TRN \\
\hline CHEMBL1555091 & 688546 & 5.1 & 4.6506 & TRN \\
\hline CHEMBL1406415 & 688546 & 4.7 & 5.1938 & TST \\
\hline CHEMBL1356013 & 688546 & 5.15 & 5.7551 & TRN \\
\hline CHEMBL1534227 & 688546 & 4.5 & 5.5403 & TRN \\
\hline CHEMBL1386123 & 688546 & 5.35 & 5.1356 & TST \\
\hline CHEMBL1435883 & 688546 & 4.9 & 4.6082 & TRN \\
\hline CHEMBL1402026 & 688546 & 4.5 & 4.7487 & TST \\
\hline CHEMBL1513621 & 688546 & 5.5 & 5.1459 & TRN \\
\hline CHEMBL1389304 & 688546 & 4.9 & 5.1053 & TRN \\
\hline CHEMBL1512962 & 688546 & 4.9 & 5.3765 & TRN \\
\hline CHEMBL1412283 & 688546 & 5.1 & 5.0977 & TRN \\
\hline CHEMBL1433908 & 688546 & 8.4559 & 5.0474 & TST \\
\hline
\end{tabular}




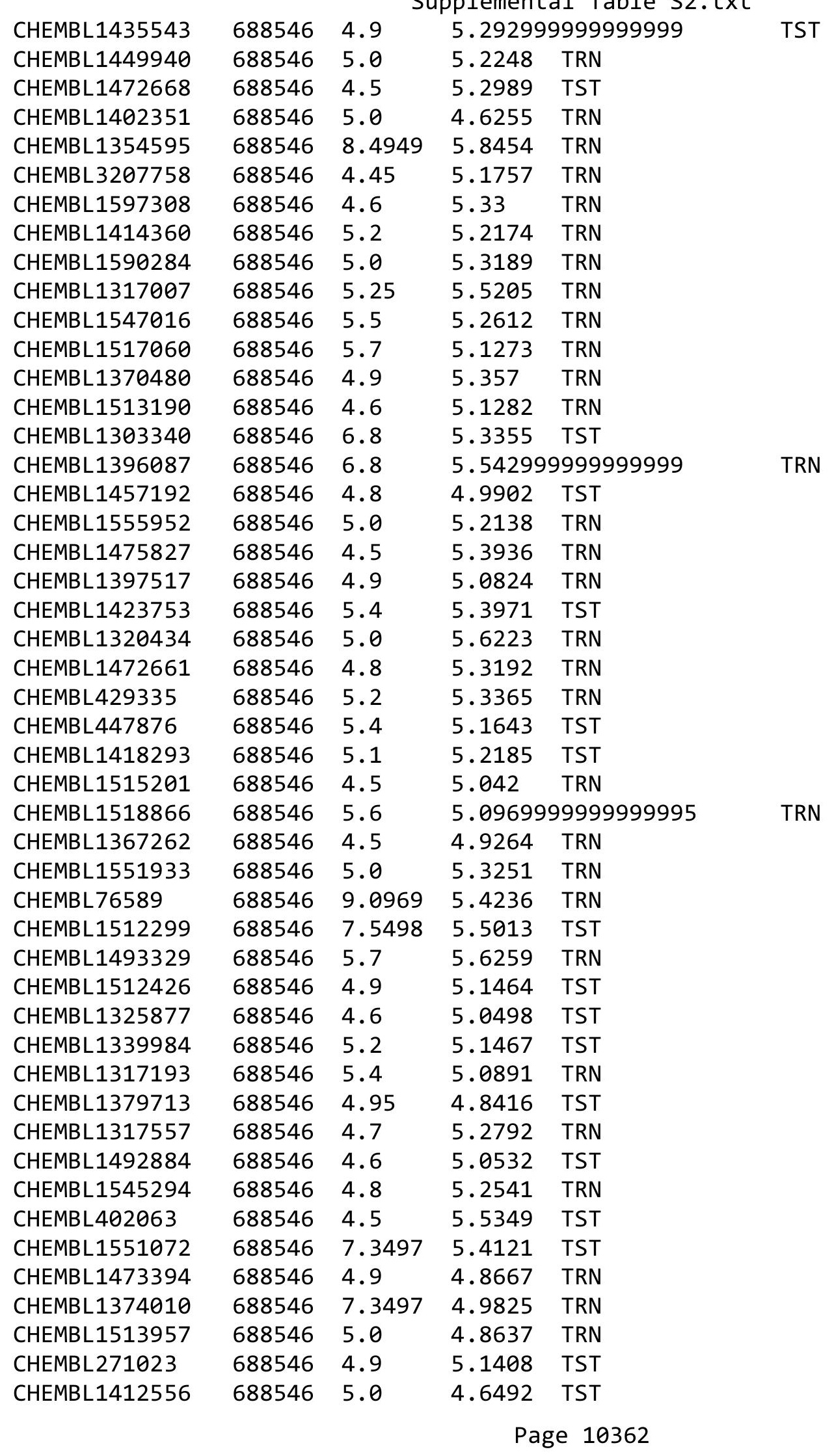




\begin{tabular}{|c|c|c|c|c|c|}
\hline \multirow[b]{2}{*}{ CHEMBL1308088 } & \\
\hline & 688546 & 5.0 & 4.7207 & TRN & \\
\hline CHEMBL1366459 & 688546 & 4.8 & 5.49799 & 9999999999 & TST \\
\hline CHEMBL1489124 & 688546 & 8.301 & 5.54299 & 9999999999 & TRN \\
\hline CHEMBL1443678 & 688546 & 5.6 & 6.0284 & TRN & \\
\hline CHEMBL1357050 & 688546 & 5.4 & 5.2616 & TRN & \\
\hline CHEMBL1612125 & 688546 & 5.0 & 4.8765 & TRN & \\
\hline CHEMBL1355668 & 688546 & 5.3 & 5.3139 & TRN & \\
\hline CHEMBL1573511 & 688546 & 4.9 & 5.1407 & TRN & \\
\hline CHEMBL1532613 & 688546 & 4.5 & 5.4926 & TST & \\
\hline CHEMBL1551969 & 688546 & 4.5 & 4.9458 & TST & \\
\hline CHEMBL1451302 & 688546 & 5.3 & 5.0168 & TST & \\
\hline CHEMBL1512316 & 688546 & 4.9 & 5.0583 & TRN & \\
\hline CHEMBL1363039 & 688546 & 4.5 & 5.0618 & TST & \\
\hline CHEMBL1375897 & 688546 & 4.9 & 5.4582 & TST & \\
\hline CHEMBL1477933 & 688546 & 5.4 & 5.4722 & TRN & \\
\hline CHEMBL1394065 & 688546 & 6.2 & 5.6201 & TRN & \\
\hline CHEMBL1575028 & 688546 & 5.0 & 4.902 & TRN & \\
\hline CHEMBL1569585 & 688546 & 5.5 & 5.3639 & TRN & \\
\hline CHEMBL1256916 & 688546 & 4.7 & 5.1018 & TST & \\
\hline CHEMBL1557564 & 688546 & 4.9 & 5.2076 & TST & \\
\hline CHEMBL1470714 & 688546 & 4.9 & 5.1134 & TRN & \\
\hline CHEMBL1356739 & 688546 & 5.4 & 5.2354 & TRN & \\
\hline CHEMBL1593502 & 688546 & 4.9 & 5.4697 & TST & \\
\hline CHEMBL1431242 & 688546 & 4.9 & 4.9581 & TRN & \\
\hline CHEMBL1318279 & 688546 & 5.7 & 5.3687 & TRN & \\
\hline CHEMBL1407052 & 688546 & 4.9 & 4.9682 & TRN & \\
\hline CHEMBL1589969 & 688546 & 4.9 & 5.4067 & TRN & \\
\hline CHEMBL1370516 & 688546 & 4.6 & 5.2016 & TRN & \\
\hline CHEMBL1333282 & 688546 & 4.5 & 5.5399 & TRN & \\
\hline CHEMBL1398448 & 688546 & 4.9 & 5.0378 & TRN & \\
\hline CHEMBL1348548 & 688546 & 4.8 & 5.0301 & TRN & \\
\hline CHEMBL1447400 & 688546 & 4.7 & 5.0703 & TST & \\
\hline CHEMBL1547108 & 688546 & 4.9 & 5.4762 & TRN & \\
\hline CHEMBL1553370 & 688546 & 4.9 & 5.2198 & TRN & \\
\hline CHEMBL1473767 & 688546 & 4.5 & 5.4485 & TST & \\
\hline CHEMBL1524637 & 688546 & 4.5 & 4.3959 & TRN & \\
\hline CHEMBL1439644 & 688546 & 4.5 & 5.4818 & TRN & \\
\hline CHEMBL1405116 & 688546 & 5.0 & 5.4074 & TRN & \\
\hline CHEMBL1563305 & 688546 & 4.7 & 5.1203 & TRN & \\
\hline CHEMBL1446555 & 688546 & 4.9 & 5.3968 & TRN & \\
\hline CHEMBL1359048 & 688546 & 4.9 & 5.6412 & TRN & \\
\hline CHEMBL1453649 & 688546 & 4.5 & 4.5902 & TST & \\
\hline CHEMBL1578779 & 688546 & 5.1 & 5.0955 & TRN & \\
\hline CHEMBL1593338 & 688546 & 5.6 & 5.1132 & TST & \\
\hline CHEMBL1494263 & 688546 & 4.75 & 4.935 & TRN & \\
\hline CHEMBL1317201 & 688546 & 5.1 & 5.474 & TRN & \\
\hline CHEMBL1354693 & 688546 & 4.5 & 4.7161 & TRN & \\
\hline CHEMBL1593141 & 688546 & 4.9 & 5.2481 & TST & \\
\hline & & & & 10363 & \\
\hline
\end{tabular}




\begin{tabular}{|c|c|c|c|c|c|}
\hline \\
\hline CHEMBL1551012 & 688546 & 4.9 & 5.0885 & TRN & \\
\hline CHEMBL1514741 & 688546 & 5.5 & 4.9314 & TRN & \\
\hline CHEMBL1553366 & 688546 & 4.6 & 4.7502 & TRN & \\
\hline CHEMBL1516250 & 688546 & 4.9 & 4.7635 & TRN & \\
\hline CHEMBL1333313 & 688546 & 4.8 & 5.343 & TRN & \\
\hline CHEMBL192509 & 688546 & 5.1 & 5.3982 & TST & \\
\hline CHEMBL1592972 & 688546 & 4.7 & 4.4832 & TRN & \\
\hline CHEMBL1365045 & 688546 & 4.5 & 4.4857 & TRN & \\
\hline CHEMBL1488035 & 688546 & 5.4 & 5.4276 & TST & \\
\hline CHEMBL1402602 & 688546 & 5.5 & 5.3951 & TRN & \\
\hline CHEMBL1304981 & 688546 & 4.5 & 5.3116 & TST & \\
\hline CHEMBL1395956 & 688546 & 4.7 & 5.269 & TRN & \\
\hline CHEMBL1396136 & 688546 & 5.0 & 5.2618 & TRN & \\
\hline CHEMBL1393885 & 688546 & 5.3 & 5.3821 & TRN & \\
\hline CHEMBL265686 & 688546 & 6.2 & 5.921 & TRN & \\
\hline CHEMBL1407077 & 688546 & 5.1 & 5.0855 & TRN & \\
\hline CHEMBL1505810 & 688546 & 7.4498 & 5.5125 & TRN & \\
\hline CHEMBL1445545 & 688546 & 4.5 & 5.32100 & 0000000001 & TRN \\
\hline CHEMBL1590348 & 688546 & 4.7 & 5.0541 & TRN & \\
\hline CHEMBL1332489 & 688546 & 5.25 & 4.891 & TST & \\
\hline CHEMBL1357962 & 688546 & 5.5 & 5.4385 & TRN & \\
\hline CHEMBL595227 & 688546 & 5.0 & 5.003 & TST & \\
\hline CHEMBL524407 & 688546 & 4.9 & 4.9086 & TRN & \\
\hline CHEMBL1523589 & 688546 & 7.6003 & 5.2476 & TRN & \\
\hline CHEMBL1475971 & 688546 & 4.8 & 5.4311 & TRN & \\
\hline CHEMBL1514050 & 688546 & 7.8996 & 5.7221 & TST & \\
\hline CHEMBL1325481 & 688546 & 4.9 & 5.5373 & TRN & \\
\hline CHEMBL1551391 & 688546 & 4.9 & 5.1195 & TRN & \\
\hline CHEMBL1424280 & 688546 & 5.0 & 5.0423 & TST & \\
\hline CHEMBL1551108 & 688546 & 4.9 & 5.1774 & TST & \\
\hline CHEMBL1445590 & 688546 & 4.8 & 5.3057 & TRN & \\
\hline CHEMBL1417366 & 688546 & 4.5 & 5.3226 & TRN & \\
\hline CHEMBL1493472 & 688546 & 4.95 & 5.2204 & TST & \\
\hline CHEMBL1406438 & 688546 & 4.9 & 4.6167 & TRN & \\
\hline CHEMBL3196791 & 688546 & 4.75 & 5.2382 & TST & \\
\hline CHEMBL1552673 & 688546 & 7.2503 & 5.849 & TRN & \\
\hline CHEMBL1370515 & 688546 & 7.15 & 5.4388 & TRN & \\
\hline CHEMBL1317440 & 688546 & 7.699 & 5.9972 & TRN & \\
\hline CHEMBL1436006 & 688546 & 5.0 & 4.8769 & TRN & \\
\hline CHEMBL1603779 & 688546 & 4.8 & 4.9366 & TST & \\
\hline CHEMBL1513187 & 688546 & 4.9 & 5.1363 & TRN & \\
\hline CHEMBL1495177 & 688546 & 4.6 & 5.3763 & TRN & \\
\hline CHEMBL1368760 & 688546 & 5.6 & 5.6183 & TRN & \\
\hline CHEMBL1346883 & 688546 & 4.45 & 5.0724 & TRN & \\
\hline CHEMBL1518438 & 688546 & 4.9 & 5.0833 & TRN & \\
\hline CHEMBL1344657 & 688546 & 5.35 & 5.3233 & TST & \\
\hline CHEMBL1316733 & 688546 & 5.3 & 6.0302 & TRN & \\
\hline CHEMBL1439954 & 688546 & 4.5 & 5.3854 & TRN & \\
\hline
\end{tabular}




\begin{tabular}{|c|c|c|c|c|c|}
\hline \\
\hline CHEMBL1604474 & 688546 & 4.9 & 5.0416 & TST & \\
\hline CHEMBL1524206 & 688546 & 5.0 & 5.3132 & TRN & \\
\hline CHEMBL1575869 & 688546 & 4.9 & 5.1542 & TST & \\
\hline CHEMBL1593009 & 688546 & 4.9 & 5.4738 & TRN & \\
\hline CHEMBL1504945 & 688546 & 4.9 & 5.1849 & TRN & \\
\hline CHEMBL1323943 & 688546 & 5.0 & 5.3373 & TRN & \\
\hline CHEMBL1435951 & 688546 & 5.6 & 5.6651 & TRN & \\
\hline CHEMBL1358675 & 688546 & 5.8 & 6.0544 & TRN & \\
\hline CHEMBL1520778 & 688546 & 5.0 & 5.481 & TRN & \\
\hline CHEMBL1337984 & 688546 & 6.2 & 5.3258 & TRN & \\
\hline CHEMBL1457597 & 688546 & 4.8 & 5.4443 & TST & \\
\hline CHEMBL1356789 & 688546 & 8.4949 & 5.2484 & TRN & \\
\hline CHEMBL1465286 & 688546 & 5.4 & 5.34200 & 00000000005 & TRN \\
\hline CHEMBL1376919 & 688546 & 5.2 & 5.1224 & TRN & \\
\hline CHEMBL1329594 & 688546 & 4.6 & 4.864 & TRN & \\
\hline CHEMBL1591979 & 688546 & 4.7 & 5.21 & TRN & \\
\hline CHEMBL1395664 & 688546 & 6.7001 & 5.9683 & TRN & \\
\hline CHEMBL1599306 & 688546 & 5.2 & 5.4161 & TRN & \\
\hline CHEMBL1317931 & 688546 & 6.0 & 5.8295 & TST & \\
\hline CHEMBL1541014 & 688546 & 7.3002 & 5.0174 & TST & \\
\hline CHEMBL1433633 & 688546 & 5.65 & 5.1301 & TRN & \\
\hline CHEMBL1531140 & 688546 & 5.3 & 4.9595 & TRN & \\
\hline CHEMBL1578082 & 688546 & 4.9 & 5.09699 & 99999999995 & TST \\
\hline CHEMBL1606006 & 688546 & 7.5003 & 5.7533 & TRN & \\
\hline CHEMBL1490349 & 688546 & 4.8 & 5.4582 & TRN & \\
\hline CHEMBL1356312 & 688546 & 4.5 & 4.671 & TRN & \\
\hline CHEMBL1450965 & 688546 & 4.5 & 5.2593 & TST & \\
\hline CHEMBL1600282 & 688546 & 5.0 & 5.2433 & TST & \\
\hline CHEMBL1488330 & 688546 & 5.1 & 5.6316 & TST & \\
\hline CHEMBL1554727 & 688546 & 5.0 & 5.3876 & TST & \\
\hline CHEMBL1394902 & 688546 & 5.6 & 5.9611 & TRN & \\
\hline CHEMBL1335397 & 688546 & 5.8 & 4.9564 & TST & \\
\hline CHEMBL1568299 & 688546 & 5.6 & 5.721 & TRN & \\
\hline CHEMBL1522293 & 688546 & 4.9 & 5.5722 & TRN & \\
\hline CHEMBL1572255 & 688546 & 5.35 & 5.1733 & TRN & \\
\hline CHEMBL1315622 & 688546 & 5.0 & 5.0395 & TRN & \\
\hline CHEMBL1402966 & 688546 & 6.9 & 5.9036 & TRN & \\
\hline CHEMBL1604983 & 688546 & 5.5 & 6.1948 & TRN & \\
\hline CHEMBL1396662 & 688546 & 5.8 & 5.6795 & TRN & \\
\hline CHEMBL1513822 & 688546 & 8.0506 & 5.2994 & TRN & \\
\hline CHEMBL1434376 & 688546 & 5.4 & 5.4089 & TRN & \\
\hline CHEMBL1551858 & 688546 & 6.2 & 5.4517 & TST & \\
\hline CHEMBL1475873 & 688546 & 5.2 & 5.2036 & TRN & \\
\hline CHEMBL1444350 & 688546 & 4.8 & 4.8827 & TRN & \\
\hline CHEMBL1401610 & 688546 & 4.5 & 5.1692 & TRN & \\
\hline CHEMBL1532765 & 688546 & 4.6 & 5.3497 & TRN & \\
\hline CHEMBL1315580 & 688546 & 4.9 & 5.3806 & TRN & \\
\hline CHEMBL1626274 & 688546 & 5.5 & 5.3413 & TST & \\
\hline
\end{tabular}




\begin{tabular}{|c|c|c|c|c|c|}
\hline \multicolumn{6}{|c|}{ Supplemental Table S2.txt } \\
\hline CHEMBL1396034 & 688546 & 5.0 & 5.2642 & TRN & \\
\hline CHEMBL1517268 & 688546 & 8.3979 & 5.2216 & TST & \\
\hline CHEMBL1515356 & 688546 & 4.7 & 5.2567 & TRN & \\
\hline CHEMBL3190958 & 688546 & 4.85 & 5.3972 & TRN & \\
\hline CHEMBL1356045 & 688546 & 5.6 & 5.6696 & TRN & \\
\hline CHEMBL1482873 & 688546 & 4.9 & 4.8616 & TRN & \\
\hline CHEMBL1522922 & 688546 & 4.7 & 5.0033 & TRN & \\
\hline CHEMBL1497019 & 688546 & 5.9 & 5.4521 & TRN & \\
\hline CHEMBL1585034 & 688546 & 5.0 & 5.0358 & TRN & \\
\hline CHEMBL1476621 & 688546 & 6.3 & 5.3309 & TRN & \\
\hline CHEMBL1486645 & 688546 & 4.7 & 5.1619 & TST & \\
\hline CHEMBL1487599 & 688546 & 4.9 & 5.4424 & TRN & \\
\hline CHEMBL1531322 & 688546 & 5.0 & 5.3768 & TST & \\
\hline CHEMBL1436623 & 688546 & 4.5 & 5.0372 & TRN & \\
\hline CHEMBL1524494 & 688546 & 5.35 & 5.2978 & TST & \\
\hline CHEMBL1080687 & 688546 & 5.1 & 5.6072 & TRN & \\
\hline CHEMBL1377371 & 688546 & 4.9 & 5.1887 & TRN & \\
\hline CHEMBL1511133 & 688546 & 4.7 & 4.9662 & TST & \\
\hline CHEMBL1532490 & 688546 & 6.5501 & 6.0421 & TRN & \\
\hline CHEMBL1343248 & 688546 & 4.8 & 5.5376 & TRN & \\
\hline CHEMBL1561980 & 688546 & 4.9 & 4.9817 & TRN & \\
\hline CHEMBL1476379 & 688546 & 5.0 & 5.5393 & TRN & \\
\hline CHEMBL1440123 & 688546 & 5.1 & 5.2885 & TRN & \\
\hline CHEMBL1496103 & 688546 & 4.5 & 5.0125 & TRN & \\
\hline CHEMBL1316447 & 688546 & 4.6 & 5.0675 & TRN & \\
\hline CHEMBL1600930 & 688546 & 5.0 & 5.1547 & TRN & \\
\hline CHEMBL1434743 & 688546 & 4.6 & 5.3975 & TST & \\
\hline CHEMBL1376023 & 688546 & 4.9 & 5.1288 & TRN & \\
\hline CHEMBL1418579 & 688546 & 6.9 & 5.2659 & TRN & \\
\hline CHEMBL1434405 & 688546 & 4.7 & 6.1402 & TRN & \\
\hline CHEMBL1409918 & 688546 & 4.7 & $5.7620 e$ & 00000000005 & TRN \\
\hline CHEMBL1305004 & 688546 & 4.85 & 5.4353 & TST & \\
\hline CHEMBL1551364 & 688546 & 7.8996 & 5.176 & TRN & \\
\hline CHEMBL1365625 & 688546 & 4.9 & 5.25206 & 0000000001 & TRN \\
\hline CHEMBL1524617 & 688546 & 4.4 & 5.5085 & TST & \\
\hline CHEMBL1415276 & 688546 & 4.7 & 4.9119 & TRN & \\
\hline CHEMBL1328462 & 688546 & 5.5 & 4.7109 & TRN & \\
\hline CHEMBL1307141 & 688546 & 8.0506 & 5.4622 & TRN & \\
\hline CHEMBL1369023 & 688546 & 4.5 & 5.2922 & TST & \\
\hline CHEMBL1474766 & 688546 & 4.9 & 4.7149 & TRN & \\
\hline CHEMBL1529419 & 688546 & 4.7 & 5.5229 & TRN & \\
\hline CHEMBL1314527 & 688546 & 4.8 & 4.6492 & TRN & \\
\hline CHEMBL1512165 & 688546 & 5.2 & 5.2913 & TRN & \\
\hline CHEMBL 1557416 & 688546 & 8.1024 & 6.1436 & TRN & \\
\hline CHEMBL3195763 & 688546 & 4.95 & 5.3834 & TRN & \\
\hline CHEMBL1436583 & 688546 & 4.7 & 5.2254 & TST & \\
\hline CHEMBL1540956 & 688546 & 4.9 & 5.0924 & TRN & \\
\hline CHEMBL1338078 & 688546 & 5.4 & 5.7616 & TRN & \\
\hline
\end{tabular}




\begin{tabular}{|c|c|c|c|c|}
\hline & & & & \\
\hline CHEMBL1407257 & 688546 & 4.9 & 4.9352 & TRN \\
\hline CHEMBL1499272 & 688546 & 5.5 & 4.8194 & TRN \\
\hline CHEMBL1591130 & 688546 & 6.7501 & 5.9643 & TRN \\
\hline CHEMBL1357573 & 688546 & 5.4 & 5.245 & TRN \\
\hline CHEMBL1434035 & 688546 & 6.35 & 5.0114 & TRN \\
\hline CHEMBL1317343 & 688546 & 5.0 & 5.2604 & TST \\
\hline CHEMBL1326839 & 688546 & 4.5 & 5.38200 & 0000000001 \\
\hline CHEMBL1512965 & 688546 & 4.9 & 5.1653 & TRN \\
\hline CHEMBL1356854 & 688546 & 5.7 & 5.2557 & TRN \\
\hline CHEMBL1521950 & 688546 & 4.9 & 4.8595 & TRN \\
\hline CHEMBL1333006 & 688546 & 4.85 & 5.5816 & TRN \\
\hline CHEMBL1438355 & 688546 & 4.6 & 5.2723 & TRN \\
\hline CHEMBL1541840 & 688546 & 4.5 & 4.8114 & TRN \\
\hline CHEMBL1572095 & 688546 & 4.45 & 4.9579 & TST \\
\hline CHEMBL1410881 & 688546 & 7.1002 & 4.8739 & TRN \\
\hline CHEMBL1405113 & 688546 & 5.4 & 5.6659 & TRN \\
\hline CHEMBL1591595 & 688546 & 4.8 & 5.3892 & TRN \\
\hline CHEMBL1394511 & 688546 & 4.6 & 5.1872 & TRN \\
\hline CHEMBL1324157 & 688546 & 4.9 & 5.0427 & TST \\
\hline CHEMBL1450286 & 688546 & 4.9 & 5.3494 & TRN \\
\hline CHEMBL1497853 & 688546 & 4.6 & 5.0992 & TRN \\
\hline CHEMBL1329481 & 688546 & 4.9 & 5.7115 & TST \\
\hline CHEMBL1322766 & 688546 & 4.8 & 5.0595 & TRN \\
\hline CHEMBL1314376 & 688546 & 4.6 & 5.3596 & TST \\
\hline CHEMBL1479847 & 688546 & 5.5 & 5.0536 & TRN \\
\hline CHEMBL1366426 & 688546 & 4.6 & 5.49 & TRN \\
\hline CHEMBL1545746 & 688546 & 4.8 & 5.1512 & TRN \\
\hline CHEMBL1512474 & 688546 & 5.4 & 5.3022 & TRN \\
\hline CHEMBL1532670 & 688546 & 7.3002 & 5.8725 & TRN \\
\hline CHEMBL1356323 & 688546 & 4.8 & 5.2958 & TRN \\
\hline CHEMBL1318620 & 688546 & 4.65 & 5.0099 & TRN \\
\hline CHEMBL1569355 & 688546 & 4.7 & 5.2125 & TRN \\
\hline CHEMBL1430370 & 688546 & 5.7 & 5.2936 & TRN \\
\hline CHEMBL1370224 & 688546 & 5.0 & 5.148 & TRN \\
\hline CHEMBL1610955 & 688546 & 4.5 & 5.0657 & TRN \\
\hline CHEMBL1449350 & 688546 & 4.8 & 4.5716 & TRN \\
\hline CHEMBL1581439 & 688546 & 4.9 & 5.8717 & TRN \\
\hline CHEMBL1397658 & 688546 & 5.0 & 5.0213 & TRN \\
\hline CHEMBL1512931 & 688546 & 4.7 & 5.1631 & TRN \\
\hline CHEMBL1447402 & 688546 & 4.9 & 5.204 & TRN \\
\hline CHEMBL1358144 & 688546 & 5.8 & 5.567 & TRN \\
\hline CHEMBL1365455 & 688546 & 9.0969 & 5.3386 & TST \\
\hline CHEMBL1516163 & 688546 & 4.6 & 5.2151 & TRN \\
\hline CHEMBL1368503 & 688546 & 4.8 & 5.1138 & TRN \\
\hline CHEMBL1357002 & 688546 & 4.7 & 5.4626 & TRN \\
\hline CHEMBL1476144 & 688546 & 7.8996 & 4.8994 & TRN \\
\hline CHEMBL 72365 & 688546 & 4.9 & 5.0923 & TST \\
\hline CHEMBL472930 & 688546 & 4.9 & 5.4266 & TRN \\
\hline
\end{tabular}

TRN 


\begin{tabular}{|c|c|c|c|c|c|}
\hline \multirow{2}{*}{ CHEMBL1453796 } & \multirow{2}{*}{688546} & \\
\hline & & 5.1 & 5.6586 & TST & \\
\hline CHEMBL1314777 & 688546 & 4.5 & 5.8096 & TRN & \\
\hline CHEMBL1315928 & 688546 & 4.5 & 4.8548 & TST & \\
\hline CHEMBL276727 & 688546 & 5.3 & 4.9744 & TST & \\
\hline CHEMBL1435649 & 688546 & 5.4 & 5.7234 & TRN & \\
\hline CHEMBL1472816 & 688546 & 7.6003 & 6.103 & TRN & \\
\hline CHEMBL1316402 & 688546 & 5.1 & 5.0818 & TRN & \\
\hline CHEMBL1396870 & 688546 & 8.3979 & 5.2994 & TST & \\
\hline CHEMBL1531919 & 688546 & 4.6 & 5.0542 & TRN & \\
\hline CHEMBL1420106 & 688546 & 4.9 & 5.1189 & TRN & \\
\hline CHEMBL1605522 & 688546 & 4.7 & \multicolumn{2}{|c|}{5.287000000000001} & TRN \\
\hline CHEMBL1562710 & 688546 & 5.0 & 5.1369 & TRN & \\
\hline CHEMBL1512720 & 688546 & 4.5 & 4.9629 & TRN & \\
\hline CHEMBL1403265 & 688546 & 4.8 & 5.1929 & TRN & \\
\hline CHEMBL1453691 & 688546 & 5.0 & 5.1127 & TRN & \\
\hline CHEMBL1396898 & 688546 & 5.1 & 5.0157 & TRN & \\
\hline CHEMBL1484020 & 688546 & 4.5 & 5.5956 & TST & \\
\hline CHEMBL1476125 & 688546 & 4.5 & 5.5793 & TRN & \\
\hline CHEMBL1592971 & 688546 & 4.5 & 6.2735 & TST & \\
\hline CHEMBL1591021 & 688546 & 4.5 & 4.9674 & TRN & \\
\hline CHEMBL1557392 & 688546 & 4.8 & 5.1999 & TRN & \\
\hline CHEMBL1394695 & 688546 & 4.9 & 5.0652 & TRN & \\
\hline CHEMBL1397016 & 688546 & 4.6 & 5.3755 & TRN & \\
\hline CHEMBL1317423 & 688546 & 4.8 & 4.919 & TST & \\
\hline CHEMBL1385254 & 688546 & 4.5 & 4.9632 & TRN & \\
\hline CHEMBL1081075 & 688546 & 4.8 & 5.6249 & TRN & \\
\hline CHEMBL1607281 & 688546 & 4.8 & 5.2042 & TRN & \\
\hline CHEMBL1568567 & 688546 & 4.5 & 5.6251 & TST & \\
\hline CHEMBL1576300 & 688546 & 4.8 & 5.1987 & TRN & \\
\hline CHEMBL1569816 & 688546 & 6.1 & \multicolumn{2}{|c|}{5.287999999999999} & TRN \\
\hline CHEMBL1472861 & 688546 & 4.5 & 5.5639 & TRN & \\
\hline CHEMBL1378049 & 688546 & 4.6 & 5.0993 & TRN & \\
\hline CHEMBL1560148 & 688546 & 5.25 & 5.4877 & TST & \\
\hline CHEMBL1513081 & 688546 & 4.6 & 5.1606 & TRN & \\
\hline CHEMBL1317655 & 688546 & 5.1 & 5.2244 & TRN & \\
\hline CHEMBL546597 & 688546 & 4.6 & 5.2924 & TST & \\
\hline CHEMBL1397888 & 688546 & 4.6 & 5.5327 & TRN & \\
\hline CHEMBL1324065 & 688546 & 4.5 & 5.3656 & TST & \\
\hline CHEMBL1447287 & 688546 & 5.2 & 4.7946 & TST & \\
\hline CHEMBL1435461 & 688546 & 5.8 & 5.2705 & TRN & \\
\hline CHEMBL1350528 & 688546 & 4.5 & 4.7942 & TST & \\
\hline CHEMBL1328486 & 688546 & 8.3979 & 5.2327 & TRN & \\
\hline CHEMBL1564173 & 688546 & 4.8 & 5.2615 & TRN & \\
\hline CHEMBL1527184 & 688546 & 6.6 & 5.9697 & TRN & \\
\hline CHEMBL1597738 & 688546 & 4.6 & 5.9392 & TRN & \\
\hline CHEMBL56731 & 688546 & 5.0 & 5.1145 & TRN & \\
\hline CHEMBL 1437967 & 688546 & 4.8 & 5.1067 & TRN & \\
\hline \multirow[t]{2}{*}{ CHEMBL1362890 } & 688546 & 4.8 & 5.24799 & 9999999999 & TRN \\
\hline & & & \multicolumn{2}{|c|}{$\begin{array}{c}\text { Page } 10368 \\
\text { Pag }\end{array}$} & \\
\hline
\end{tabular}




\begin{tabular}{|c|c|c|c|c|c|}
\hline \multicolumn{6}{|c|}{ Supplemental Table S2.txt } \\
\hline CHEMBL1566251 & 688546 & 5.25 & 5.4112 & TST & \\
\hline CHEMBL1339993 & 688546 & 4.9 & 5.3072 & TRN & \\
\hline CHEMBL1513360 & 688546 & 4.5 & 5.54799 & 9999999999 & TRN \\
\hline CHEMBL1493823 & 688546 & 7.699 & 5.2391 & TRN & \\
\hline CHEMBL1326645 & 688546 & 5.0 & 5.75700 & 0000000001 & TRN \\
\hline CHEMBL1445044 & 688546 & 6.4 & 5.1591 & TRN & \\
\hline CHEMBL1599168 & 688546 & 4.9 & 4.9761 & TRN & \\
\hline CHEMBL1455745 & 688546 & 7.8996 & 6.2421 & TRN & \\
\hline CHEMBL1507162 & 688546 & 4.9 & 4.8702 & TRN & \\
\hline CHEMBL1597683 & 688546 & 4.5 & 5.2216 & TRN & \\
\hline CHEMBL1360886 & 688546 & 6.7001 & 5.2582 & TRN & \\
\hline CHEMBL1404398 & 688546 & 5.6 & 5.7253 & TRN & \\
\hline CHEMBL1489948 & 688546 & 4.5 & 4.9446 & TRN & \\
\hline CHEMBL1494432 & 688546 & 5.3 & 4.8654 & TRN & \\
\hline CHEMBL1438100 & 688546 & 4.9 & 5.0018 & TST & \\
\hline CHEMBL1441810 & 688546 & 4.9 & 4.9837 & TRN & \\
\hline CHEMBL1374482 & 688546 & 4.7 & 4.934 & TST & \\
\hline CHEMBL1522726 & 688546 & 4.7 & 5.0597 & TRN & \\
\hline CHEMBL1551255 & 688546 & 4.9 & 5.088 & TRN & \\
\hline CHEMBL1363622 & 688546 & 4.7 & 4.6416 & TRN & \\
\hline CHEMBL1524816 & 688546 & 5.4 & 5.2868 & TRN & \\
\hline CHEMBL1613253 & 688546 & 4.9 & 5.1234 & TRN & \\
\hline CHEMBL1493501 & 688546 & 4.9 & 5.33799 & 9999999999 & TRN \\
\hline CHEMBL1404430 & 688546 & 4.5 & 5.0481 & TRN & \\
\hline CHEMBL1514111 & 688546 & 4.5 & 4.8404 & TRN & \\
\hline CHEMBL1478160 & 688546 & 5.9 & 5.1578 & TST & \\
\hline CHEMBL1590852 & 688546 & 4.8 & 5.1743 & TRN & \\
\hline CHEMBL1472666 & 688546 & 4.9 & 4.9521 & TRN & \\
\hline CHEMBL1368418 & 688546 & 4.9 & 4.875 & TRN & \\
\hline CHEMBL1535483 & 688546 & 5.5 & 5.8497 & TRN & \\
\hline CHEMBL1436409 & 688546 & 8.0 & 5.4254 & TRN & \\
\hline CHEMBL1436184 & 688546 & 7.699 & 5.3851 & TRN & \\
\hline CHEMBL1369506 & 688546 & 4.8 & 5.37700 & 0000000001 & TRN \\
\hline CHEMBL1554254 & 688546 & 5.0 & 4.7097 & TRN & \\
\hline CHEMBL1610972 & 688546 & 5.1 & 5.2108 & TST & \\
\hline CHEMBL1593631 & 688546 & 5.0 & 5.9021 & TST & \\
\hline CHEMBL1555111 & 688546 & 4.9 & 5.3951 & TRN & \\
\hline CHEMBL1367089 & 688546 & 4.8 & 5.3544 & TST & \\
\hline CHEMBL1431131 & 688546 & 4.7 & 4.9176 & TRN & \\
\hline CHEMBL1524754 & 688546 & 4.8 & 5.4888 & TRN & \\
\hline CHEMBL1314211 & 688546 & 4.5 & 4.6858 & TRN & \\
\hline CHEMBL1403488 & 688546 & 4.6 & 4.574 & TRN & \\
\hline CHEMBL1355643 & 688546 & 5.2 & 5.4071 & TRN & \\
\hline CHEMBL1370293 & 688546 & 5.0 & 5.3649 & TRN & \\
\hline CHEMBL1590798 & 688546 & 4.8 & 5.0947 & TRN & \\
\hline CHEMBL1355332 & 688546 & 6.35 & 5.5928 & TRN & \\
\hline CHEMBL239276 & 688546 & 5.5 & 4.7778 & TST & \\
\hline CHEMBL1405122 & 688546 & 8.1024 & 6.3207 & TST & \\
\hline
\end{tabular}




\begin{tabular}{|c|c|c|c|c|c|}
\hline \multirow{2}{*}{\multicolumn{2}{|c|}{ CHEMBL1358598 }} & \\
\hline & & 4.5 & 4.9893 & TRN & \\
\hline CHEMBL1592458 & 688546 & 4.8 & 5.1077 & TRN & \\
\hline CHEMBL1389542 & 688546 & 4.9 & 5.1311 & TST & \\
\hline CHEMBL1608062 & 688546 & 5.3 & 5.9129 & TRN & \\
\hline CHEMBL1515343 & 688546 & 4.8 & 4.9629 & TRN & \\
\hline CHEMBL1454891 & 688546 & 4.8 & 4.9326 & TRN & \\
\hline CHEMBL 242341 & 688546 & 6.0 & 5.4579 & TRN & \\
\hline CHEMBL1531241 & 688546 & 4.6 & 4.7405 & TRN & \\
\hline CHEMBL1354714 & 688546 & 4.8 & 5.0476 & TRN & \\
\hline CHEMBL1557062 & 688546 & 5.5 & 5.6476 & TRN & \\
\hline CHEMBL1574308 & 688546 & 5.0 & 4.981 & TRN & \\
\hline CHEMBL1563581 & 688546 & 5.6 & 5.1962 & TRN & \\
\hline CHEMBL1343777 & 688546 & 5.45 & 5.1869 & TST & \\
\hline CHEMBL1332720 & 688546 & 5.65 & 5.3819 & TST & \\
\hline CHEMBL1419597 & 688546 & 5.0 & 5.3505 & TRN & \\
\hline CHEMBL1355981 & 688546 & 6.8 & 5.1854 & TRN & \\
\hline CHEMBL1567913 & 688546 & 5.4 & 5.1597 & TST & \\
\hline CHEMBL86676 & 688546 & 4.5 & 5.4268 & TST & \\
\hline CHEMBL1396542 & 688546 & 4.9 & 5.072 & TRN & \\
\hline CHEMBL1552341 & 688546 & 4.8 & 5.0375 & TST & \\
\hline CHEMBL1443434 & 688546 & 5.25 & 5.5025 & TRN & \\
\hline CHEMBL1315315 & 688546 & 4.9 & 5.2097 & TRN & \\
\hline CHEMBL1481384 & 688546 & 4.9 & 4.9679 & TRN & \\
\hline CHEMBL1972346 & 688546 & 5.0 & 5.3796 & TST & \\
\hline CHEMBL60718 & 688546 & 5.5 & 5.3073 & TRN & \\
\hline CHEMBL1370625 & 688546 & 4.5 & 5.277 & TRN & \\
\hline CHEMBL1336966 & 688546 & 5.35 & 5.3878 & TRN & \\
\hline CHEMBL3199917 & 688546 & 5.85 & 5.37299 & 9999999999 & TST \\
\hline CHEMBL1366168 & 688546 & 5.5 & 5.027 & TRN & \\
\hline CHEMBL1436104 & 688546 & 4.8 & 5.8761 & TRN & \\
\hline CHEMBL1496933 & 688546 & 4.8 & 4.9813 & TRN & \\
\hline CHEMBL1516908 & 688546 & 4.9 & 5.0531 & TRN & \\
\hline CHEMBL1415585 & 688546 & 5.7 & 4.8895 & TST & \\
\hline CHEMBL1495339 & 688546 & 5.0 & 5.2067 & TRN & \\
\hline CHEMBL1473755 & 688546 & 5.3 & 4.7381 & TRN & \\
\hline CHEMBL1368390 & 688546 & 5.6 & 5.58799 & 9999999999 & TRN \\
\hline CHEMBL1365973 & 688546 & 6.0 & 4.958 & TRN & \\
\hline CHEMBL1444828 & 688546 & 5.0 & 5.0991 & TRN & \\
\hline CHEMBL1471745 & 688546 & 4.6 & 5.2366 & TST & \\
\hline CHEMBL1355597 & 688546 & 7.15 & 5.5568 & TST & \\
\hline CHEMBL1606236 & 688546 & 5.9 & 5.4297 & TRN & \\
\hline CHEMBL1554658 & 688546 & 4.5 & 5.1348 & TRN & \\
\hline CHEMBL1420320 & 688546 & 4.5 & 4.7185 & TST & \\
\hline CHEMBL1476284 & 688546 & 4.5 & 5.0271 & TRN & \\
\hline CHEMBL1369197 & 688546 & 4.5 & 5.6967 & TST & \\
\hline CHEMBL1474329 & 688546 & 4.9 & 5.4225 & TRN & \\
\hline CHEMBL512908 & 688546 & 5.3 & 5.37299 & 9999999999 & TST \\
\hline CHEMBL1474753 & 688546 & 4.5 & 5.1959 & TRN & \\
\hline & & & & 10370 & \\
\hline
\end{tabular}




\begin{tabular}{|c|c|c|c|c|c|}
\hline \multicolumn{6}{|c|}{ Supplemental Table S2.txt } \\
\hline CHEMBL1344580 & 688546 & 5.45 & 5.1902 & TST & \\
\hline CHEMBL1493497 & 688546 & 5.0 & 5.1065 & TRN & \\
\hline CHEMBL1583136 & 688546 & 4.5 & 4.9657 & TRN & \\
\hline CHEMBL1355094 & 688546 & 5.0 & 5.0471 & TRN & \\
\hline CHEMBL1434157 & 688546 & 4.9 & 5.02800 & 00000000005 & TST \\
\hline CHEMBL1412815 & 688546 & 4.8 & 4.7373 & TRN & \\
\hline CHEMBL1355824 & 688546 & 5.35 & 6.0264 & TRN & \\
\hline CHEMBL1604357 & 688546 & 5.4 & 5.4227 & TRN & \\
\hline CHEMBL1329009 & 688546 & 5.0 & 5.1206 & TRN & \\
\hline CHEMBL1454845 & 688546 & 4.6 & 5.0139 & TRN & \\
\hline CHEMBL1532008 & 688546 & 4.6 & 4.5812 & TRN & \\
\hline CHEMBL1556955 & 688546 & 6.0 & 4.6289 & TRN & \\
\hline CHEMBL1357178 & 688546 & 4.8 & 4.8941 & TRN & \\
\hline CHEMBL1478817 & 688546 & 4.9 & 5.2734 & TRN & \\
\hline CHEMBL1313247 & 688546 & 4.5 & 5.2042 & TST & \\
\hline CHEMBL1358552 & 688546 & 4.9 & 4.9643 & TRN & \\
\hline CHEMBL1515042 & 688546 & 4.8 & 5.3748 & TRN & \\
\hline CHEMBL1602423 & 688546 & 4.7 & 5.5771 & TRN & \\
\hline CHEMBL1411314 & 688546 & 5.5 & 5.6124 & TRN & \\
\hline CHEMBL1358505 & 688546 & 4.5 & 5.3789 & TST & \\
\hline CHEMBL1346510 & 688546 & 4.5 & 4.7594 & TRN & \\
\hline CHEMBL1382028 & 688546 & 5.15 & 5.1051 & TRN & \\
\hline CHEMBL1581589 & 688546 & 4.9 & 5.4506 & TRN & \\
\hline CHEMBL1518647 & 688546 & 4.8 & 4.6117 & TST & \\
\hline CHEMBL1514896 & 688546 & 4.5 & 5.4218 & TRN & \\
\hline CHEMBL1592283 & 688546 & 5.1 & 5.1602 & TRN & \\
\hline CHEMBL1476181 & 688546 & 4.7 & 4.6543 & TRN & \\
\hline CHEMBL1329173 & 688546 & 4.9 & 5.0094 & TRN & \\
\hline CHEMBL1586111 & 688546 & 5.7 & 5.5387 & TST & \\
\hline CHEMBL1315721 & 688546 & 5.1 & 5.2369 & TRN & \\
\hline CHEMBL1317212 & 688546 & 8.301 & 5.8773 & TRN & \\
\hline CHEMBL1516494 & 688546 & 6.9 & 5.5252 & TRN & \\
\hline CHEMBL1554794 & 688546 & 4.5 & 5.1212 & TRN & \\
\hline CHEMBL1564037 & 688546 & 4.5 & 5.6947 & TRN & \\
\hline CHEMBL1556792 & 688546 & 4.5 & 4.5801 & TRN & \\
\hline CHEMBL1311453 & 688546 & 4.45 & 5.0727 & TST & \\
\hline CHEMBL1437546 & 688546 & 7.1002 & 5.8776 & TRN & \\
\hline CHEMBL1495381 & 688546 & 5.3 & 4.968 & TST & \\
\hline CHEMBL1545467 & 688546 & 5.0 & 4.9793 & TRN & \\
\hline CHEMBL1318033 & 688546 & 4.8 & 4.6535 & TRN & \\
\hline CHEMBL1443755 & 688546 & 6.1 & 5.3741 & TRN & \\
\hline CHEMBL1398504 & 688546 & 4.7 & 5.1888 & TRN & \\
\hline CHEMBL1532792 & 688546 & 4.5 & 5.2542 & TST & \\
\hline CHEMBL1400743 & 688546 & 4.5 & 4.8347 & TRN & \\
\hline CHEMBL1435976 & 688546 & 7.8013 & 5.9225 & TRN & \\
\hline CHEMBL1438339 & 688546 & 4.9 & 5.1345 & TRN & \\
\hline CHEMBL1256291 & 688546 & 4.5 & 5.1095 & TST & \\
\hline CHEMBL1592811 & 688546 & 6.7001 & 5.8588 & TRN & \\
\hline
\end{tabular}




\begin{tabular}{|c|c|c|c|c|}
\hline & & & pplement & al $\mathrm{T}$ \\
\hline CHEMBL1445486 & 688546 & 4.9 & 5.1093 & TRN \\
\hline CHEMBL1315992 & 688546 & 4.6 & 4.8438 & TRN \\
\hline CHEMBL1485622 & 688546 & 4.5 & 5.0379 & TRN \\
\hline CHEMBL355496 & 688546 & 4.9 & 4.8982 & TST \\
\hline CHEMBL1611710 & 688546 & 4.9 & 4.9315 & TRN \\
\hline CHEMBL1475021 & 688546 & 7.6003 & 5.6362 & TRN \\
\hline CHEMBL1328363 & 688546 & 5.4 & 4.6844 & TST \\
\hline CHEMBL1546412 & 688546 & 5.0 & 4.7486 & TRN \\
\hline CHEMBL1591933 & 688546 & 6.8 & 5.3673 & TRN \\
\hline CHEMBL1408238 & 688546 & 5.4 & 5.0049 & TRN \\
\hline CHEMBL1368106 & 688546 & 4.75 & 5.3666 & TST \\
\hline CHEMBL1353065 & 688546 & 4.95 & 4.9699 & TST \\
\hline CHEMBL1524762 & 688546 & 4.9 & 5.0587 & TRN \\
\hline CHEMBL1358845 & 688546 & 6.3 & 5.7389 & TRN \\
\hline CHEMBL1473235 & 688546 & 5.0 & 5.4072 & TRN \\
\hline CHEMBL1336155 & 688546 & 5.4 & 5.3046 & TST \\
\hline CHEMBL1482054 & 688546 & 5.4 & 4.9716 & TRN \\
\hline CHEMBL1551700 & 688546 & 4.9 & 4.9695 & TRN \\
\hline CHEMBL1494313 & 688546 & 4.7 & 4.9109 & TRN \\
\hline CHEMBL1476637 & 688546 & 4.5 & 5.6847 & TRN \\
\hline CHEMBL1379677 & 688546 & 4.8 & 5.3764 & TST \\
\hline CHEMBL1548616 & 688546 & 4.5 & 4.9605 & TST \\
\hline CHEMBL1315605 & 688546 & 4.8 & 5.1352 & TRN \\
\hline CHEMBL1431130 & 688546 & 5.0 & 5.1449 & TST \\
\hline CHEMBL1438649 & 688546 & 5.1 & 4.6441 & TRN \\
\hline CHEMBL512749 & 688546 & 5.3 & 5.2923 & TRN \\
\hline CHEMBL1439277 & 688546 & 4.9 & 4.8768 & TRN \\
\hline CHEMBL1476964 & 688546 & 5.0 & 4.7634 & TRN \\
\hline CHEMBL1483444 & 688546 & 4.9 & 5.305 & TRN \\
\hline CHEMBL1437252 & 688546 & 5.5 & 5.3106 & TRN \\
\hline CHEMBL1541951 & 688546 & 4.6 & 5.2618 & TRN \\
\hline CHEMBL1600428 & 688546 & 7.4498 & 5.8861 & TRN \\
\hline CHEMBL303579 & 688546 & 5.5 & 4.9993 & TST \\
\hline CHEMBL1519929 & 688546 & 5.2 & 5.2537 & TRN \\
\hline CHEMBL1435838 & 688546 & 4.5 & 5.0915 & TRN \\
\hline CHEMBL1482635 & 688546 & 5.2 & 5.5573 & TST \\
\hline CHEMBL38832 & 688546 & 4.8 & 5.499 & TST \\
\hline CHEMBL1372187 & 688546 & 6.8499 & 5.1925 & TRN \\
\hline CHEMBL1480485 & 688546 & 6.1 & 5.4575 & TST \\
\hline CHEMBL1315978 & 688546 & 4.8 & 5.4427 & TRN \\
\hline CHEMBL1494259 & 688546 & 4.75 & 5.7784 & TST \\
\hline CHEMBL1408042 & 688546 & 4.9 & 5.8035 & TST \\
\hline CHEMBL1594795 & 688546 & 4.8 & 5.3895 & TRN \\
\hline CHEMBL1425250 & 688546 & 5.35 & 5.2272 & TST \\
\hline CHEMBL1380847 & 688546 & 5.4 & 5.0546 & TST \\
\hline CHEMBL1397042 & 688546 & 4.5 & 5.7741 & TRN \\
\hline CHEMBL1610569 & 688546 & 4.5 & 5.7759 & TRN \\
\hline CHEMBL1601272 & 688546 & 4.8 & 4.8999 & TRN \\
\hline
\end{tabular}




\begin{tabular}{|c|c|c|c|c|}
\hline \multicolumn{5}{|c|}{ Supplemental Table S2.txt } \\
\hline CHEMBL1463808 & 688546 & 5.7 & 5.3985 & TRN \\
\hline CHEMBL1592494 & 688546 & 6.3 & 5.4307 & TRN \\
\hline CHEMBL1091971 & 688546 & 5.3 & 5.2993 & TST \\
\hline CHEMBL1427979 & 688546 & 5.1 & 5.2737 & TRN \\
\hline CHEMBL1316323 & 688546 & 6.3 & 5.5053 & TRN \\
\hline CHEMBL1366181 & 688546 & 4.9 & 5.0248 & TRN \\
\hline CHEMBL1480977 & 688546 & 5.35 & 5.9178 & TRN \\
\hline CHEMBL1362937 & 688546 & 5.6 & 5.4652 & TRN \\
\hline CHEMBL1515157 & 688546 & 5.3 & 5.1029 & TRN \\
\hline CHEMBL1316771 & 688546 & 5.9 & 5.3785 & TRN \\
\hline CHEMBL1316864 & 688546 & 8.301 & 5.9697 & TRN \\
\hline CHEMBL1447436 & 688546 & 5.3 & 5.699 & TRN \\
\hline CHEMBL1534566 & 688546 & 4.5 & 5.1479 & TST \\
\hline CHEMBL1606551 & 688546 & 4.8 & 5.1277 & TRN \\
\hline CHEMBL1381205 & 688546 & 4.9 & 5.1687 & TRN \\
\hline CHEMBL1552896 & 688546 & 5.0 & 5.4677 & TRN \\
\hline CHEMBL546576 & 688546 & 4.7 & 5.2352 & TST \\
\hline CHEMBL1452891 & 688546 & 5.0 & 5.9742 & TRN \\
\hline CHEMBL1555647 & 688546 & 5.1 & 4.976 & TST \\
\hline CHEMBL1598438 & 688546 & 4.7 & 4.3892 & TRN \\
\hline CHEMBL1513560 & 688546 & 4.8 & 5.3908 & TRN \\
\hline CHEMBL1329298 & 688546 & 4.8 & 5.6831 & TRN \\
\hline CHEMBL1595564 & 688546 & 4.7 & 5.1774 & TST \\
\hline CHEMBL1522905 & 688546 & 5.2 & 5.5062 & TST \\
\hline CHEMBL1604405 & 688546 & 4.8 & 5.0176 & TRN \\
\hline CHEMBL1512473 & 688546 & 6.5501 & 5.7089 & TRN \\
\hline CHEMBL16223 & 688546 & 5.3 & 4.9196 & TST \\
\hline CHEMBL1445249 & 688546 & 5.4 & 5.4606 & TST \\
\hline CHEMBL1446548 & 688546 & 4.7 & 4.9275 & TRN \\
\hline CHEMBL1593939 & 688546 & 4.5 & 4.9806 & TRN \\
\hline CHEMBL1574642 & 688546 & 6.8 & 5.1808 & TRN \\
\hline CHEMBL1534413 & 688546 & 4.9 & 4.8485 & TRN \\
\hline CHEMBL1555009 & 688546 & 4.8 & 5.0436 & TRN \\
\hline CHEMBL1331144 & 688546 & 4.7 & 5.3005 & TRN \\
\hline CHEMBL1594569 & 688546 & 7.6003 & 5.9409 & TRN \\
\hline CHEMBL1601099 & 688546 & 6.1 & 5.7801 & TRN \\
\hline CHEMBL1366697 & 688546 & 4.5 & 5.4966 & TST \\
\hline CHEMBL1315520 & 688546 & 4.8 & 5.5966 & TRN \\
\hline CHEMBL1325324 & 688546 & 4.9 & 5.3228 & TRN \\
\hline CHEMBL1394808 & 688546 & 4.7 & 5.4118 & TRN \\
\hline CHEMBL1436244 & 688546 & 4.5 & 4.8622 & TRN \\
\hline CHEMBL1360691 & 688546 & 5.05 & 5.8512 & TRN \\
\hline CHEMBL3192857 & 688546 & 4.6 & 5.2178 & TST \\
\hline CHEMBL1522302 & 688546 & 4.9 & 5.3892 & TRN \\
\hline CHEMBL1555110 & 688546 & 7.4001 & 5.8546 & TST \\
\hline CHEMBL1440450 & 688546 & 6.2 & 5.9599 & TRN \\
\hline CHEMBL1517112 & 688546 & 4.5 & 5.4386 & TRN \\
\hline CHEMBL1354894 & 688546 & 5.1 & 5.109 & TRN \\
\hline
\end{tabular}




\begin{tabular}{|c|c|c|c|c|c|}
\hline \multicolumn{6}{|c|}{ splement } \\
\hline CHEMBL1601841 & 688546 & 4.8 & 6.0052 & TRN & \\
\hline CHEMBL1482179 & 688546 & 5.0 & 5.2256 & TRN & \\
\hline CHEMBL1877767 & 688546 & 5.5 & 5.1065 & TST & \\
\hline CHEMBL1510242 & 688546 & 4.8 & 5.0232 & TST & \\
\hline CHEMBL1436873 & 688546 & 4.9 & 5.2123 & TRN & \\
\hline CHEMBL1474024 & 688546 & 6.1 & 5.7924 & TRN & \\
\hline CHEMBL1468116 & 688546 & 6.05 & 5.3131 & TRN & \\
\hline CHEMBL1417488 & 688546 & 4.9 & 5.4885 & TRN & \\
\hline CHEMBL1373275 & 688546 & 4.8 & 4.6919 & TRN & \\
\hline CHEMBL1590599 & 688546 & 7.5498 & 5.4905 & TRN & \\
\hline CHEMBL1350768 & 688546 & 5.9 & 5.21700 & 00000000005 & TST \\
\hline CHEMBL1483218 & 688546 & 4.5 & 5.3915 & TRN & \\
\hline CHEMBL1575411 & 688546 & 4.8 & 5.3087 & TRN & \\
\hline CHEMBL1512706 & 688546 & 5.2 & 5.047 & TRN & \\
\hline CHEMBL1594990 & 688546 & 8.6021 & 5.441 & TRN & \\
\hline CHEMBL1513511 & 688546 & 4.8 & 4.851 & TRN & \\
\hline CHEMBL1428244 & 688546 & 5.0 & 5.2045 & TRN & \\
\hline CHEMBL180162 & 688546 & 4.8 & 5.6227 & TST & \\
\hline CHEMBL1443851 & 688546 & 4.7 & 5.0032 & TRN & \\
\hline CHEMBL1486179 & 688546 & 5.9 & 5.3674 & TRN & \\
\hline CHEMBL1448223 & 688546 & 5.0 & 5.3382 & TRN & \\
\hline CHEMBL1503880 & 688546 & 5.6 & 5.8033 & TST & \\
\hline CHEMBL1315597 & 688546 & 4.9 & 5.3632 & TST & \\
\hline CHEMBL1314746 & 688546 & 7.4001 & 5.0138 & TRN & \\
\hline CHEMBL1476350 & 688546 & 5.3 & 5.5364 & TRN & \\
\hline CHEMBL1368943 & 688546 & 4.8 & 5.6179 & TRN & \\
\hline CHEMBL1437652 & 688546 & 5.0 & 5.343 & TRN & \\
\hline CHEMBL1327180 & 688546 & 8.301 & 5.5611 & TRN & \\
\hline CHEMBL1558629 & 688546 & 7.1002 & 5.8024 & TRN & \\
\hline CHEMBL123 & 688546 & 6.0 & 4.9376 & TST & \\
\hline CHEMBL1471899 & 688546 & 5.4 & 5.1115 & TRN & \\
\hline CHEMBL1594046 & 688546 & 4.7 & 5.6569 & TRN & \\
\hline CHEMBL1515779 & 688546 & 5.3 & 5.362 & TRN & \\
\hline CHEMBL1499069 & 688546 & 4.8 & 4.7993 & TRN & \\
\hline CHEMBL1434925 & 688546 & 4.9 & 5.5479 & TRN & \\
\hline CHEMBL1488131 & 688546 & 4.5 & 5.1638 & TST & \\
\hline CHEMBL1555344 & 688546 & 4.7 & 4.6904 & TST & \\
\hline CHEMBL1418568 & 688546 & 4.9 & 5.4233 & TST & \\
\hline CHEMBL1476020 & 688546 & 4.9 & 4.761 & TRN & \\
\hline CHEMBL1322288 & 688546 & 9.1549 & 5.9432 & TRN & \\
\hline CHEMBL1610184 & 688546 & 5.5 & 4.78100 & 0000000001 & TST \\
\hline CHEMBL1431303 & 688546 & 4.5 & 5.1886 & TRN & \\
\hline CHEMBL1356263 & 688546 & 7.4001 & 5.5064 & TRN & \\
\hline CHEMBL1590107 & 688546 & 4.7 & 4.8512 & TRN & \\
\hline CHEMBL1594699 & 688546 & 4.9 & 4.5661 & TRN & \\
\hline CHEMBL1360109 & 688546 & 4.95 & 5.0431 & TRN & \\
\hline CHEMBL1406684 & 688546 & 4.9 & 5.6036 & TRN & \\
\hline CHEMBL1360816 & 688546 & 4.5 & 4.8369 & TRN & \\
\hline
\end{tabular}




\begin{tabular}{|c|c|c|c|c|}
\hline & & & pplement & al $\mathrm{T}$ \\
\hline CHEMBL1775009 & 688546 & 4.8 & 5.0938 & TRN \\
\hline CHEMBL1529092 & 688546 & 5.0 & 4.9547 & TRN \\
\hline CHEMBL601952 & 688546 & 4.6 & 5.1736 & TST \\
\hline CHEMBL1300373 & 688546 & 4.8 & 5.1316 & TRN \\
\hline CHEMBL1355297 & 688546 & 4.9 & 5.0758 & TRN \\
\hline CHEMBL1481422 & 688546 & 5.0 & 5.5132 & TST \\
\hline CHEMBL1513704 & 688546 & 7.8013 & 6.2432 & TRN \\
\hline CHEMBL1394120 & 688546 & 5.25 & 5.6265 & TRN \\
\hline CHEMBL1373167 & 688546 & 4.8 & 5.0826 & TRN \\
\hline CHEMBL1322862 & 688546 & 4.7 & 4.9436 & TRN \\
\hline CHEMBL1461150 & 688546 & 4.8 & 5.2958 & TRN \\
\hline CHEMBL1490452 & 688546 & 4.5 & 5.9099 & TRN \\
\hline CHEMBL1609028 & 688546 & 5.1 & 4.9509 & TRN \\
\hline CHEMBL1573247 & 688546 & 4.8 & 5.2488 & TST \\
\hline CHEMBL1435981 & 688546 & 5.3 & 4.9309 & TRN \\
\hline CHEMBL1320219 & 688546 & 4.7 & 4.8758 & TRN \\
\hline CHEMBL1513697 & 688546 & 5.8 & 5.5149 & TRN \\
\hline CHEMBL1466554 & 688546 & 5.0 & 5.3866 & TST \\
\hline CHEMBL1542600 & 688546 & 4.5 & 5.2856 & TRN \\
\hline CHEMBL1357628 & 688546 & 5.0 & 5.0549 & TRN \\
\hline CHEMBL1314513 & 688546 & 8.4559 & 6.2232 & TST \\
\hline CHEMBL1318880 & 688546 & 8.3979 & 5.6887 & TRN \\
\hline CHEMBL1455626 & 688546 & 5.4 & 5.261 & TRN \\
\hline CHEMBL10284 & 688546 & 5.0 & 5.0511 & TST \\
\hline CHEMBL1358133 & 688546 & 5.35 & 5.0123 & TRN \\
\hline CHEMBL1318468 & 688546 & 4.5 & 5.2888 & TRN \\
\hline CHEMBL1411473 & 688546 & 4.8 & 4.7642 & TRN \\
\hline CHEMBL1339052 & 688546 & 4.9 & 4.7178 & TST \\
\hline CHEMBL1344731 & 688546 & 5.0 & 4.9264 & TST \\
\hline CHEMBL1314724 & 688546 & 4.8 & 5.2452 & TRN \\
\hline CHEMBL1397543 & 688546 & 4.8 & 5.7663 & TRN \\
\hline CHEMBL1593433 & 688546 & 5.3 & 5.585 & TRN \\
\hline CHEMBL1551395 & 688546 & 5.0 & 5.0389 & TRN \\
\hline CHEMBL1314611 & 688546 & 4.5 & 5.0252 & TRN \\
\hline CHEMBL1556882 & 688546 & 4.9 & 5.0695 & TST \\
\hline CHEMBL1446541 & 688546 & 5.3 & 5.0583 & TRN \\
\hline CHEMBL1601233 & 688546 & 5.45 & 5.2061 & TRN \\
\hline CHEMBL29097 & 688546 & 4.5 & 4.8493 & TST \\
\hline CHEMBL1405163 & 688546 & 4.5 & 5.0315 & TRN \\
\hline CHEMBL1398793 & 688546 & 4.9 & 4.998 & TRN \\
\hline CHEMBL573524 & 688546 & 4.9 & 5.2152 & TRN \\
\hline CHEMBL1352955 & 688546 & 5.1 & 5.0899 & TRN \\
\hline CHEMBL1525438 & 688546 & 5.2 & 5.7619 & TST \\
\hline CHEMBL1514405 & 688546 & 4.45 & 5.112 & TST \\
\hline CHEMBL1475630 & 688546 & 5.5 & 5.9806 & TRN \\
\hline CHEMBL601826 & 688546 & 5.9 & 5.3106 & TRN \\
\hline CHEMBL399121 & 688546 & 4.9 & 5.4811 & TST \\
\hline CHEMBL1602756 & 688546 & 4.8 & 5.0129 & TST \\
\hline
\end{tabular}




\begin{tabular}{|c|c|c|c|c|c|}
\hline \\
\hline CHEMBL1304004 & 688546 & 4.8 & 5.4 & TST & \\
\hline CHEMBL1353661 & 688546 & 5.1 & 5.1865 & TRN & \\
\hline CHEMBL1553386 & 688546 & 5.35 & 5.7793 & TST & \\
\hline CHEMBL 297784 & 688546 & 6.0 & 5.711 & TRN & \\
\hline CHEMBL1702181 & 688546 & 5.0 & 5.1228 & TRN & \\
\hline CHEMBL1423070 & 688546 & 4.5 & 5.484 & TST & \\
\hline CHEMBL544713 & 688546 & 5.2 & 5.0872 & TST & \\
\hline CHEMBL1566730 & 688546 & 5.0 & 5.2361 & TRN & \\
\hline CHEMBL1557619 & 688546 & 4.7 & 5.0181 & TST & \\
\hline CHEMBL1444434 & 688546 & 4.8 & 5.5716 & TST & \\
\hline CHEMBL1398259 & 688546 & 5.0 & 5.9897 & TRN & \\
\hline CHEMBL16751 & 688546 & 4.9 & 5.2776 & TRN & \\
\hline CHEMBL1336151 & 688546 & 4.45 & 5.2175 & TRN & \\
\hline CHEMBL1533227 & 688546 & 5.3 & 5.2881 & TRN & \\
\hline CHEMBL1356020 & 688546 & 4.5 & 5.1821 & TRN & \\
\hline CHEMBL1532699 & 688546 & 4.9 & 5.45200 & 0000000001 & TRN \\
\hline CHEMBL1592757 & 688546 & 8.0 & 5.2403 & TST & \\
\hline CHEMBL1518624 & 688546 & 4.9 & 4.7722 & TRN & \\
\hline CHEMBL1574899 & 688546 & 4.8 & 5.0543 & TRN & \\
\hline CHEMBL1592769 & 688546 & 7.8996 & 5.7725 & TRN & \\
\hline CHEMBL1446882 & 688546 & 7.699 & 5.7825 & TRN & \\
\hline CHEMBL1593750 & 688546 & 4.45 & 5.4873 & TRN & \\
\hline CHEMBL1318869 & 688546 & 4.9 & 4.6919 & TRN & \\
\hline CHEMBL1505797 & 688546 & 4.5 & 5.5621 & TST & \\
\hline CHEMBL1514437 & 688546 & 4.4 & 5.4425 & TST & \\
\hline CHEMBL1315854 & 688546 & 4.5 & 5.5513 & TRN & \\
\hline CHEMBL1511217 & 688546 & 5.3 & 5.5826 & TRN & \\
\hline CHEMBL1358577 & 688546 & 6.7001 & 4.5587 & TST & \\
\hline CHEMBL1367118 & 688546 & 4.7 & 5.0757 & TRN & \\
\hline CHEMBL1463491 & 688546 & 4.9 & 5.3799 & TRN & \\
\hline CHEMBL1420358 & 688546 & 4.9 & 5.1586 & TRN & \\
\hline CHEMBL1474565 & 688546 & 4.5 & 5.4382 & TRN & \\
\hline CHEMBL448515 & 688546 & 4.8 & 5.3645 & TST & \\
\hline CHEMBL1373889 & 688546 & 4.9 & 5.0663 & TST & \\
\hline CHEMBL1452714 & 688546 & 5.4 & 5.1571 & TRN & \\
\hline CHEMBL1317785 & 688546 & 4.9 & 5.0636 & TRN & \\
\hline CHEMBL1512190 & 688546 & 5.0 & 4.6301 & TRN & \\
\hline CHEMBL1474846 & 688546 & 4.9 & 5.2014 & TRN & \\
\hline CHEMBL1308898 & 688546 & 4.6 & 4.7969 & TRN & \\
\hline CHEMBL1525589 & 688546 & 5.4 & 5.2725 & TRN & \\
\hline CHEMBL1396098 & 688546 & 4.8 & 5.1783 & TRN & \\
\hline CHEMBL1448941 & 688546 & 4.5 & 5.0519 & TRN & \\
\hline CHEMBL1602155 & 688546 & 4.6 & 5.5572 & TRN & \\
\hline CHEMBL1440408 & 688546 & 5.1 & 5.2772 & TRN & \\
\hline CHEMBL1513392 & 688546 & 4.6 & 5.14 & TRN & \\
\hline CHEMBL1536091 & 688546 & 5.0 & 5.4727 & TRN & \\
\hline CHEMBL1495025 & 688546 & 5.1 & 5.1864 & TST & \\
\hline CHEMBL1486352 & 688546 & 4.95 & 5.0212 & TST & \\
\hline
\end{tabular}




\begin{tabular}{|c|c|c|c|c|c|}
\hline \multicolumn{6}{|c|}{ Supplemental Table S2.txt } \\
\hline CHEMBL1338736 & 688546 & 4.9 & 5.563 & TST & \\
\hline CHEMBL1362420 & 688546 & 4.8 & 5.2938 & TRN & \\
\hline CHEMBL1593170 & 688546 & 5.3 & 5.4285 & TRN & \\
\hline CHEMBL1483908 & 688546 & 4.5 & 4.6051 & TST & \\
\hline CHEMBL1572805 & 688546 & 4.8 & 4.8587 & TRN & \\
\hline CHEMBL1322071 & 688546 & 5.25 & 5.8008 & TRN & \\
\hline CHEMBL1325991 & 688546 & 5.5 & 5.055 & TRN & \\
\hline CHEMBL1386896 & 688546 & 4.55 & 5.1884 & TST & \\
\hline CHEMBL1562267 & 688546 & 4.9 & 5.1076 & TRN & \\
\hline CHEMBL1541441 & 688546 & 4.75 & 5.1562 & TRN & \\
\hline CHEMBL1476045 & 688546 & 5.0 & 5.0731 & TRN & \\
\hline CHEMBL1493726 & 688546 & 5.25 & 5.3427 & TRN & \\
\hline CHEMBL1386546 & 688546 & 4.9 & 5.3369 & TRN & \\
\hline CHEMBL1531385 & 688546 & 4.7 & 4.7907 & TST & \\
\hline CHEMBL1575148 & 688546 & 4.55 & 4.898 & TST & \\
\hline CHEMBL1551744 & 688546 & 8.0506 & 5.816 & TRN & \\
\hline CHEMBL1524492 & 688546 & 5.0 & 5.0656 & TST & \\
\hline CHEMBL1480654 & 688546 & 7.0 & 5.0874 & TRN & \\
\hline CHEMBL1400947 & 688546 & 5.8 & 5.4157 & TRN & \\
\hline CHEMBL1449964 & 688546 & 5.0 & 5.4003 & TRN & \\
\hline CHEMBL1417180 & 688546 & 4.9 & 4.8826 & TRN & \\
\hline CHEMBL1315227 & 688546 & 4.9 & 4.8774 & TRN & \\
\hline CHEMBL1436860 & 688546 & 5.2 & 5.7034 & TRN & \\
\hline CHEMBL1401545 & 688546 & 4.9 & 5.6879 & TRN & \\
\hline CHEMBL1562837 & 688546 & 4.5 & 4.6472 & TRN & \\
\hline CHEMBL1435597 & 688546 & 4.7 & $5.4860 e$ & 0000000001 & TRN \\
\hline CHEMBL1567011 & 688546 & 4.8 & 5.2382 & TRN & \\
\hline CHEMBL1315557 & 688546 & 8.0 & 5.3442 & TRN & \\
\hline CHEMBL1348334 & 688546 & 5.0 & 5.5081 & TRN & \\
\hline CHEMBL1443693 & 688546 & 5.0 & 5.4687 & TRN & \\
\hline CHEMBL1535554 & 688546 & 7.699 & 5.5886 & TRN & \\
\hline CHEMBL1457164 & 688546 & 4.5 & 5.6464 & TRN & \\
\hline CHEMBL1496984 & 688546 & 6.5 & 6.1865 & TRN & \\
\hline CHEMBL1521547 & 688546 & 8.5528 & 5.541 & TRN & \\
\hline CHEMBL1397607 & 688546 & 5.3 & 5.2377 & TRN & \\
\hline CHEMBL1408655 & 688546 & 4.5 & 5.2577 & TRN & \\
\hline CHEMBL547833 & 688546 & 4.6 & 5.0381 & TST & \\
\hline CHEMBL1365098 & 688546 & 5.0 & 4.9426 & TRN & \\
\hline CHEMBL1524950 & 688546 & 5.6 & 5.0329 & TRN & \\
\hline CHEMBL1573688 & 688546 & 4.75 & 5.5698 & TRN & \\
\hline CHEMBL1335814 & 688546 & 4.5 & 5.3048 & TRN & \\
\hline CHEMBL1314886 & 688546 & 6.0 & 5.2489 & TRN & \\
\hline CHEMBL1384151 & 688546 & 4.9 & 5.2244 & TST & \\
\hline CHEMBL1317024 & 688546 & 4.5 & 5.2504 & TRN & \\
\hline CHEMBL1310041 & 688546 & 4.8 & 5.008 & TRN & \\
\hline CHEMBL1445543 & 688546 & 4.7 & 5.2158 & TRN & \\
\hline CHEMBL1554642 & 688546 & 4.5 & 5.5729 & TRN & \\
\hline CHEMBL1423455 & 688546 & 4.7 & 5.4037 & TRN & \\
\hline
\end{tabular}




\begin{tabular}{|c|c|c|c|c|c|}
\hline \\
\hline CHEMBL1502936 & 688546 & 5.3 & 5.2095 & TRN & \\
\hline CHEMBL1443129 & 688546 & 4.6 & 6.1133 & TRN & \\
\hline CHEMBL1310986 & 688546 & 5.1 & 5.3816 & TST & \\
\hline CHEMBL605548 & 688546 & 4.5 & 5.3173 & TRN & \\
\hline CHEMBL1552832 & 688546 & 4.8 & 4.8117 & TRN & \\
\hline CHEMBL1315751 & 688546 & 5.0 & 5.2752 & TST & \\
\hline CHEMBL1610702 & 688546 & 4.9 & 5.4882 & TRN & \\
\hline CHEMBL1436531 & 688546 & 4.8 & 5.4378 & TRN & \\
\hline CHEMBL1598581 & 688546 & 4.65 & 5.081 & TRN & \\
\hline CHEMBL1525198 & 688546 & 4.5 & 5.1348 & TRN & \\
\hline CHEMBL1594961 & 688546 & 5.7 & 5.1204 & TRN & \\
\hline CHEMBL1473283 & 688546 & 4.7 & 5.6852 & TRN & \\
\hline CHEMBL1510089 & 688546 & 4.95 & 5.7425 & TRN & \\
\hline CHEMBL1355385 & 688546 & 5.2 & 5.0012 & TRN & \\
\hline CHEMBL1358104 & 688546 & 5.1 & 5.0859 & TRN & \\
\hline CHEMBL1446802 & 688546 & 4.6 & 5.0856 & TST & \\
\hline CHEMBL1375781 & 688546 & 4.5 & 5.3296 & TST & \\
\hline CHEMBL1343389 & 688546 & 5.0 & 5.4737 & TRN & \\
\hline CHEMBL1338273 & 688546 & 4.5 & 5.5848 & TRN & \\
\hline CHEMBL1398865 & 688546 & 5.1 & 5.6929 & TRN & \\
\hline CHEMBL1476071 & 688546 & 5.1 & 6.0557 & TRN & \\
\hline CHEMBL1365615 & 688546 & 5.3 & 5.5233 & TRN & \\
\hline CHEMBL1437350 & 688546 & 4.5 & 5.6867 & TRN & \\
\hline CHEMBL323197 & 688546 & 6.0 & 5.2756 & TST & \\
\hline CHEMBL1481050 & 688546 & 4.5 & 4.6363 & TRN & \\
\hline CHEMBL1413505 & 688546 & 7.699 & 5.4285 & TRN & \\
\hline CHEMBL1331045 & 688546 & 4.6 & 5.2318 & TST & \\
\hline CHEMBL1373291 & 688546 & 5.2 & 5.7843 & TRN & \\
\hline CHEMBL1576110 & 688546 & 4.45 & 5.2463 & TST & \\
\hline CHEMBL1314894 & 688546 & 4.8 & 4.8241 & TRN & \\
\hline CHEMBL1434565 & 688546 & 4.4 & 4.8714 & TRN & \\
\hline CHEMBL1433498 & 688546 & 4.9 & 5.17200 & 3000000001 & TST \\
\hline CHEMBL1526991 & 688546 & 4.9 & 5.129 & TRN & \\
\hline CHEMBL1573005 & 688546 & 4.9 & 5.0969 & TRN & \\
\hline CHEMBL1605266 & 688546 & 5.0 & 5.6723 & TRN & \\
\hline CHEMBL1313648 & 688546 & 4.7 & 5.0461 & TST & \\
\hline CHEMBL1326644 & 688546 & 5.0 & 4.7291 & TRN & \\
\hline CHEMBL1475922 & 688546 & 4.9 & 5.0687 & TRN & \\
\hline CHEMBL1356094 & 688546 & 4.9 & 5.1317 & TRN & \\
\hline CHEMBL1545280 & 688546 & 4.6 & 4.9458 & TRN & \\
\hline CHEMBL1563138 & 688546 & 8.301 & 6.0529 & TRN & \\
\hline CHEMBL1328176 & 688546 & 5.0 & 5.3278 & TRN & \\
\hline CHEMBL1605177 & 688546 & 6.5 & 5.8142 & TRN & \\
\hline CHEMBL1597827 & 688546 & 4.5 & 4.7303 & TST & \\
\hline CHEMBL1486349 & 688546 & 4.8 & 5.2789 & TRN & \\
\hline CHEMBL1459688 & 688546 & 5.3 & 5.205 & TRN & \\
\hline CHEMBL1601724 & 688546 & 4.9 & 4.8471 & TRN & \\
\hline CHEMBL1564578 & 688546 & 5.2 & 5.1093 & TRN & \\
\hline
\end{tabular}




\begin{tabular}{|c|c|c|c|c|c|}
\hline \\
\hline CHEMBL1368392 & 688546 & 5.3 & 5.2154 & TRN & \\
\hline CHEMBL1536547 & 688546 & 5.0 & 5.1183 & TRN & \\
\hline CHEMBL1320237 & 688546 & 4.45 & 5.1765 & TRN & \\
\hline CHEMBL1553225 & 688546 & 4.5 & 5.6323 & TRN & \\
\hline CHEMBL1377687 & 688546 & 5.7 & 5.4327 & TRN & \\
\hline CHEMBL1543893 & 688546 & 4.9 & 5.2672 & TST & \\
\hline CHEMBL1516680 & 688546 & 5.3 & 5.2158 & TST & \\
\hline CHEMBL333985 & 688546 & 4.7 & 4.6538 & TST & \\
\hline CHEMBL1571810 & 688546 & 5.0 & 5.7286 & TRN & \\
\hline CHEMBL1315041 & 688546 & 4.45 & 4.842 & TRN & \\
\hline CHEMBL1522919 & 688546 & 5.45 & 5.104 & TST & \\
\hline CHEMBL1486533 & 688546 & 4.5 & 5.3473 & TST & \\
\hline CHEMBL1519146 & 688546 & 4.5 & 4.9165 & TRN & \\
\hline CHEMBL1441621 & 688546 & 4.5 & 5.8571 & TRN & \\
\hline CHEMBL1484369 & 688546 & 5.9 & 4.7972 & TRN & \\
\hline CHEMBL1515322 & 688546 & 4.7 & 5.2676 & TRN & \\
\hline CHEMBL1538317 & 688546 & 4.7 & 5.2314 & TRN & \\
\hline CHEMBL1569635 & 688546 & 5.0 & 4.8687 & TRN & \\
\hline CHEMBL1557753 & 688546 & 6.4 & 5.1234 & TRN & \\
\hline CHEMBL1480128 & 688546 & 4.5 & 5.1227 & TRN & \\
\hline CHEMBL1397227 & 688546 & 5.6 & 5.7583 & TRN & \\
\hline CHEMBL578284 & 688546 & 4.75 & 5.2222 & TRN & \\
\hline CHEMBL1333386 & 688546 & 4.9 & 4.8295 & TRN & \\
\hline CHEMBL1553757 & 688546 & 4.6 & 5.4572 & TRN & \\
\hline CHEMBL1399385 & 688546 & 6.8 & 5.6058 & TST & \\
\hline CHEMBL1516188 & 688546 & 5.3 & 5.0249 & TRN & \\
\hline CHEMBL1381063 & 688546 & 5.0 & 5.2308 & TRN & \\
\hline CHEMBL1601962 & 688546 & 5.0 & 5.6608 & TRN & \\
\hline CHEMBL1473234 & 688546 & 5.9 & 5.5935 & TRN & \\
\hline CHEMBL1504492 & 688546 & 4.6 & 5.022 & TST & \\
\hline CHEMBL1473639 & 688546 & 7.8013 & 5.7787 & TRN & \\
\hline CHEMBL 20963 & 688546 & 5.1 & 5.3196 & TST & \\
\hline CHEMBL1407036 & 688546 & 5.0 & 5.42700 & 30000000005 & TRN \\
\hline CHEMBL1394351 & 688546 & 5.8 & 5.96899 & 9999999999 & TST \\
\hline CHEMBL1503636 & 688546 & 5.0 & 4.7439 & TRN & \\
\hline CHEMBL1397689 & 688546 & 6.9 & 5.5025 & TRN & \\
\hline CHEMBL 83552 & 688546 & 4.8 & 4.7954 & TST & \\
\hline CHEMBL1403830 & 688546 & 5.7 & 5.2171 & TRN & \\
\hline CHEMBL1357006 & 688546 & 4.8 & 5.6199 & TRN & \\
\hline CHEMBL585820 & 688546 & 5.7 & 5.3223 & TRN & \\
\hline CHEMBL1509287 & 688546 & 4.85 & 4.9506 & TRN & \\
\hline CHEMBL1375585 & 688546 & 4.8 & 5.6322 & TRN & \\
\hline CHEMBL1354517 & 688546 & 4.5 & 5.2511 & TRN & \\
\hline CHEMBL1488209 & 688546 & 4.9 & 5.5926 & TRN & \\
\hline CHEMBL1401486 & 688546 & 4.5 & 5.246 & TST & \\
\hline CHEMBL1476626 & 688546 & 6.7001 & 5.5623 & TRN & \\
\hline CHEMBL1080915 & 688546 & 6.5 & 5.605 & TRN & \\
\hline CHEMBL1360562 & 688546 & 4.5 & 4.6707 & TRN & \\
\hline & & & & 1037 & \\
\hline
\end{tabular}




\begin{tabular}{|c|c|c|c|c|c|}
\hline & & & & & \\
\hline CHEMBL1515919 & 688546 & 5.4 & 5.9305 & TRN & \\
\hline CHEMBL1521414 & 688546 & 4.7 & 4.90300 & 00000000005 & TRN \\
\hline CHEMBL1606451 & 688546 & 4.9 & 5.2552 & TRN & \\
\hline CHEMBL1473865 & 688546 & 5.1 & 5.2693 & TRN & \\
\hline CHEMBL1513260 & 688546 & 5.0 & 5.5574 & TST & \\
\hline CHEMBL1573636 & 688546 & 4.9 & 5.2321 & TRN & \\
\hline CHEMBL1554960 & 688546 & 4.9 & 4.8408 & TRN & \\
\hline CHEMBL1436008 & 688546 & 6.5 & 6.2584 & TRN & \\
\hline CHEMBL1592169 & 688546 & 8.1024 & 5.176 & TRN & \\
\hline CHEMBL63426 & 688546 & 4.5 & 4.9959 & TST & \\
\hline CHEMBL1394393 & 688546 & 4.7 & 5.2436 & TRN & \\
\hline CHEMBL1545361 & 688546 & 4.6 & 4.4799 & TRN & \\
\hline CHEMBL1356931 & 688546 & 4.7 & 5.0269 & TRN & \\
\hline CHEMBL1611268 & 688546 & 8.301 & 5.3299 & TRN & \\
\hline CHEMBL1343768 & 688546 & 4.7 & 5.5599 & TRN & \\
\hline CHEMBL1416187 & 688546 & 5.5 & 5.2696 & TST & \\
\hline CHEMBL1434114 & 688546 & 4.9 & 5.0622 & TRN & \\
\hline CHEMBL1477249 & 688546 & 4.6 & 5.32600 & 00000000005 & TRN \\
\hline CHEMBL1417747 & 688546 & 4.5 & 4.9367 & TRN & \\
\hline CHEMBL1489769 & 688546 & 6.0 & 5.3113 & TST & \\
\hline CHEMBL1413840 & 688546 & 5.0 & 5.731 & TRN & \\
\hline CHEMBL1372732 & 688546 & 4.9 & 4.7975 & TST & \\
\hline CHEMBL1515958 & 688546 & 4.8 & 5.6035 & TRN & \\
\hline CHEMBL1475786 & 688546 & 4.8 & 5.38299 & 9999999999 & TRN \\
\hline CHEMBL1473287 & 688546 & 5.0 & 5.1196 & TRN & \\
\hline CHEMBL1478691 & 688546 & 5.1 & 5.0058 & TRN & \\
\hline CHEMBL1484817 & 688546 & 4.6 & 5.4043 & TRN & \\
\hline CHEMBL1590879 & 688546 & 4.7 & 4.7925 & TRN & \\
\hline CHEMBL1612418 & 688546 & 8.1024 & 5.7263 & TRN & \\
\hline CHEMBL1397511 & 688546 & 8.2007 & 5.4581 & TST & \\
\hline CHEMBL1521937 & 688546 & 4.7 & 4.963 & TRN & \\
\hline CHEMBL1337864 & 688546 & 4.7 & 5.6429 & TST & \\
\hline CHEMBL1607093 & 688546 & 5.85 & 5.2112 & TRN & \\
\hline CHEMBL1551412 & 688546 & 4.7 & 5.4048 & TRN & \\
\hline CHEMBL1416027 & 688546 & 5.0 & 5.6507 & TRN & \\
\hline CHEMBL1607094 & 688546 & 8.301 & 5.4715 & TST & \\
\hline CHEMBL1364482 & 688546 & 4.5 & 5.2954 & TRN & \\
\hline CHEMBL1564019 & 688546 & 5.1 & 5.2957 & TST & \\
\hline CHEMBL1438667 & 688546 & 4.9 & 5.1053 & TST & \\
\hline CHEMBL1591304 & 688546 & 5.0 & 5.3641 & TRN & \\
\hline CHEMBL1395497 & 688546 & 5.1 & 5.0059 & TRN & \\
\hline CHEMBL1380514 & 688546 & 5.0 & 4.9324 & TRN & \\
\hline CHEMBL1472892 & 688546 & 4.5 & 5.3224 & TRN & \\
\hline CHEMBL1487466 & 688546 & 5.1 & 5.2791 & TRN & \\
\hline CHEMBL1592694 & 688546 & 4.5 & 4.6588 & TRN & \\
\hline CHEMBL1530946 & 688546 & 4.8 & 5.3487 & TST & \\
\hline CHEMBL1395139 & 688546 & 4.6 & 5.4585 & TRN & \\
\hline CHEMBL1315042 & 688546 & 4.8 & 5.7292 & TRN & \\
\hline
\end{tabular}




\begin{tabular}{|c|c|c|c|c|c|}
\hline \multicolumn{6}{|c|}{ Supplemental Table s2.txt } \\
\hline CHEMBL1610732 & 688546 & 5.85 & 5.2729 & TRN & \\
\hline CHEMBL1380914 & 688546 & 4.8 & 5.1729 & TST & \\
\hline CHEMBL1509634 & 688546 & 4.6 & 5.601 & TRN & \\
\hline CHEMBL1407088 & 688546 & 5.0 & 5.1247 & TRN & \\
\hline CHEMBL1442969 & 688546 & 5.0 & 5.3124 & TST & \\
\hline CHEMBL1466087 & 688546 & 5.0 & 5.1146 & TRN & \\
\hline CHEMBL1486453 & 688546 & 6.2 & 5.3074 & TRN & \\
\hline CHEMBL1350157 & 688546 & 4.9 & 5.2292 & TRN & \\
\hline CHEMBL1437774 & 688546 & 8.1024 & 5.3977 & TST & \\
\hline CHEMBL1476762 & 688546 & 4.9 & 4.9422 & TRN & \\
\hline CHEMBL1526840 & 688546 & 4.5 & 5.3066 & TRN & \\
\hline CHEMBL1490765 & 688546 & 4.9 & 4.9084 & TST & \\
\hline CHEMBL1316013 & 688546 & 7.3002 & 5.3377 & TRN & \\
\hline CHEMBL1400646 & 688546 & 5.0 & 5.4867 & TRN & \\
\hline CHEMBL1590933 & 688546 & 6.1 & 5.72 & TRN & \\
\hline CHEMBL1357554 & 688546 & 4.5 & 5.2024 & TRN & \\
\hline CHEMBL1585192 & 688546 & 4.7 & 5.3966 & TST & \\
\hline CHEMBL1593363 & 688546 & 4.5 & 5.4961 & TRN & \\
\hline CHEMBL1579254 & 688546 & 4.9 & 5.394 & TST & \\
\hline CHEMBL1329237 & 688546 & 4.6 & 5.1864 & TST & \\
\hline CHEMBL1601133 & 688546 & 5.4 & 5.2661 & TRN & \\
\hline CHEMBL1330705 & 688546 & 6.0 & 5.3335 & TRN & \\
\hline CHEMBL1326807 & 688546 & 4.7 & 5.8686 & TRN & \\
\hline CHEMBL1413754 & 688546 & 6.0 & 5.4929 & TRN & \\
\hline CHEMBL1598796 & 688546 & 5.7 & 5.38899 & 9999999999 & TRN \\
\hline CHEMBL1591653 & 688546 & 4.9 & 4.7925 & TRN & \\
\hline CHEMBL1424069 & 688546 & 4.6 & 5.3151 & TST & \\
\hline CHEMBL1447506 & 688546 & 6.2 & 5.4345 & TRN & \\
\hline CHEMBL1081842 & 688546 & 7.8996 & 5.5163 & TRN & \\
\hline CHEMBL1545965 & 688546 & 4.85 & 4.8818 & TRN & \\
\hline CHEMBL85194 & 688546 & 4.8 & 5.1736 & TRN & \\
\hline CHEMBL1529733 & 688546 & 4.9 & 5.5424 & TRN & \\
\hline CHEMBL1483133 & 688546 & 4.5 & 5.1971 & TRN & \\
\hline CHEMBL1436148 & 688546 & 4.5 & 5.3229 & TRN & \\
\hline CHEMBL1323978 & 688546 & 5.0 & 5.04899 & 99999999995 & TST \\
\hline CHEMBL1474479 & 688546 & 4.9 & 5.369 & TRN & \\
\hline CHEMBL580421 & 688546 & 6.0 & 5.2656 & TST & \\
\hline CHEMBL1563727 & 688546 & 4.5 & 5.0348 & TST & \\
\hline CHEMBL1451087 & 688546 & 4.5 & 5.0048 & TRN & \\
\hline CHEMBL54918 & 688546 & 4.6 & 5.645 & TST & \\
\hline CHEMBL1311136 & 688546 & 4.9 & 5.1818 & TRN & \\
\hline CHEMBL1597663 & 688546 & 4.5 & 5.7669 & TRN & \\
\hline CHEMBL1394944 & 688546 & 5.2 & 5.3332 & TRN & \\
\hline CHEMBL1322400 & 688546 & 4.8 & 4.72199 & 99999999995 & TRN \\
\hline CHEMBL1439096 & 688546 & 7.6498 & 5.711 & TRN & \\
\hline CHEMBL1512211 & 688546 & 5.3 & 5.3014 & TRN & \\
\hline CHEMBL1580304 & 688546 & 4.5 & 5.0358 & TST & \\
\hline CHEMBL1311597 & 688546 & 5.0 & 4.8566 & TST & \\
\hline
\end{tabular}




\begin{tabular}{|c|c|c|c|c|}
\hline & & & pplement & al $\mathrm{T}$ \\
\hline CHEMBL1436950 & 688546 & 6.8 & 5.7016 & TRN \\
\hline CHEMBL1428456 & 688546 & 4.9 & 4.6663 & TRN \\
\hline CHEMBL1512508 & 688546 & 8.301 & 5.6066 & TRN \\
\hline CHEMBL1565928 & 688546 & 4.95 & 5.6371 & TRN \\
\hline CHEMBL1389037 & 688546 & 4.6 & 5.114 & TRN \\
\hline CHEMBL1352280 & 688546 & 4.9 & 4.8154 & TRN \\
\hline CHEMBL1314657 & 688546 & 4.6 & 5.2402 & TRN \\
\hline CHEMBL1331383 & 688546 & 4.8 & 5.3961 & TRN \\
\hline CHEMBL1404221 & 688546 & 5.5 & 5.0952 & TST \\
\hline CHEMBL1409103 & 688546 & 4.9 & 5.1909 & TRN \\
\hline CHEMBL1552435 & 688546 & 5.0 & 5.5259 & TRN \\
\hline CHEMBL1474303 & 688546 & 4.85 & 5.6674 & TST \\
\hline CHEMBL1357396 & 688546 & 5.6 & 5.596 & TRN \\
\hline CHEMBL1394444 & 688546 & 4.5 & 5.7174 & TRN \\
\hline CHEMBL1453427 & 688546 & 7.5498 & 6.1373 & TRN \\
\hline CHEMBL1337982 & 688546 & 4.65 & 5.2124 & TRN \\
\hline CHEMBL1327766 & 688546 & 4.5 & 5.0189 & TST \\
\hline CHEMBL1589137 & 688546 & 4.7 & 4.7844 & TRN \\
\hline CHEMBL1485094 & 688546 & 4.8 & 5.1487 & TRN \\
\hline CHEMBL1318185 & 688546 & 5.2 & 5.0303 & TRN \\
\hline CHEMBL1315468 & 688546 & 6.0 & 5.5973 & TRN \\
\hline CHEMBL1321266 & 688546 & 6.4 & 5.5622 & TRN \\
\hline CHEMBL1513885 & 688546 & 6.15 & 5.652 & TRN \\
\hline CHEMBL1379039 & 688546 & 5.7 & 5.5787 & TRN \\
\hline CHEMBL1521365 & 688546 & 5.7 & 5.6387 & TRN \\
\hline CHEMBL1302359 & 688546 & 6.15 & 5.4976 & TST \\
\hline CHEMBL1325362 & 688546 & 5.9 & 5.159 & TRN \\
\hline CHEMBL1464533 & 688546 & 4.45 & 5.506 & TRN \\
\hline CHEMBL1487391 & 688546 & 8.3979 & 5.6721 & TRN \\
\hline CHEMBL1511690 & 688546 & 4.7 & 4.7759 & TST \\
\hline CHEMBL1512043 & 688546 & 4.9 & 4.9652 & TRN \\
\hline CHEMBL1315457 & 688546 & 4.9 & 4.7108 & TST \\
\hline CHEMBL1506771 & 688546 & 5.3 & 4.9375 & TRN \\
\hline CHEMBL1600002 & 688546 & 7.8996 & 5.5129 & TRN \\
\hline CHEMBL1518205 & 688546 & 4.9 & 5.1842 & TRN \\
\hline CHEMBL1428659 & 688546 & 5.0 & 5.228 & TRN \\
\hline CHEMBL1564151 & 688546 & 4.7 & 5.2548 & TST \\
\hline CHEMBL1488608 & 688546 & 5.3 & 5.5255 & TRN \\
\hline CHEMBL1478283 & 688546 & 5.5 & 4.9396 & TRN \\
\hline CHEMBL1385529 & 688546 & 4.8 & 5.1084 & TRN \\
\hline CHEMBL1581420 & 688546 & 4.7 & 4.4764 & TST \\
\hline CHEMBL1347369 & 688546 & 5.2 & 5.1805 & TST \\
\hline CHEMBL1409641 & 688546 & 4.7 & 4.9644 & TRN \\
\hline CHEMBL1451144 & 688546 & 4.5 & 5.7687 & TRN \\
\hline CHEMBL1716991 & 688546 & 4.7 & 5.3537 & TST \\
\hline CHEMBL1376210 & 688546 & 4.9 & 4.9613 & TRN \\
\hline CHEMBL1370256 & 688546 & 4.85 & 5.063 & TST \\
\hline CHEMBL1592569 & 688546 & 4.45 & 5.0425 & TRN \\
\hline
\end{tabular}




\begin{tabular}{|c|c|c|c|c|c|}
\hline & & \multicolumn{4}{|c|}{ Supplemental Table S2.txt } \\
\hline CHEMBL1390531 & 688546 & 5.0 & 5.2103 & TRN & \\
\hline CHEMBL1592681 & 688546 & 8.301 & 5.5981 & TRN & \\
\hline CHEMBL1339243 & 688546 & 4.5 & 5.1541 & TST & \\
\hline CHEMBL1516291 & 688546 & 6.25 & 5.724 & TST & \\
\hline CHEMBL1358288 & 688546 & 5.1 & 5.539 & TRN & \\
\hline CHEMBL1526748 & 688546 & 5.15 & 5.3372 & TRN & \\
\hline CHEMBL1513638 & 688546 & 4.8 & 5.0518 & TRN & \\
\hline CHEMBL1530221 & 688546 & 4.7 & 5.272 & TST & \\
\hline CHEMBL259389 & 688546 & 4.5 & 4.8322 & TST & \\
\hline CHEMBL1554087 & 688546 & 5.5 & 5.6178 & TRN & \\
\hline CHEMBL1591057 & 688546 & 4.9 & 5.1492 & TRN & \\
\hline CHEMBL1320262 & 688546 & 5.45 & 5.4843 & TRN & \\
\hline CHEMBL1395948 & 688546 & 4.9 & 5.09699 & 99999999995 & TRN \\
\hline CHEMBL1315325 & 688546 & 4.9 & 5.336 & TRN & \\
\hline CHEMBL1553676 & 688546 & 5.4 & 5.9462 & TRN & \\
\hline CHEMBL579224 & 688546 & 4.9 & 5.6195 & TST & \\
\hline CHEMBL1553929 & 688546 & 6.3 & 5.9087 & TRN & \\
\hline CHEMBL1417981 & 688546 & 4.8 & 4.8236 & TRN & \\
\hline CHEMBL1310825 & 688546 & 4.8 & 4.8026 & TST & \\
\hline CHEMBL1554238 & 688546 & 4.5 & 5.5183 & TRN & \\
\hline CHEMBL1378956 & 688546 & 4.9 & 5.544 & TRN & \\
\hline CHEMBL1346281 & 688546 & 4.6 & 4.9658 & TST & \\
\hline CHEMBL1613249 & 688546 & 8.0 & 5.1995 & TST & \\
\hline CHEMBL1435183 & 688546 & 5.0 & 5.3364 & TRN & \\
\hline CHEMBL1349094 & 688546 & 4.8 & 5.0115 & TRN & \\
\hline CHEMBL1398633 & 688546 & 5.0 & 4.981 & TRN & \\
\hline CHEMBL1535988 & 688546 & 5.0 & 4.9596 & TRN & \\
\hline CHEMBL1343527 & 688546 & 4.9 & 5.4499 & TRN & \\
\hline CHEMBL1600347 & 688546 & 4.7 & 4.5925 & TST & \\
\hline CHEMBL1513185 & 688546 & 4.5 & 5.1337 & TRN & \\
\hline CHEMBL1566105 & 688546 & 5.5 & 5.4929 & TST & \\
\hline CHEMBL1468661 & 688546 & 4.45 & 5.2251 & TST & \\
\hline CHEMBL1442875 & 688546 & 4.5 & 5.136 & TRN & \\
\hline CHEMBL1553932 & 688546 & 7.9508 & 5.0666 & TST & \\
\hline CHEMBL1586964 & 688546 & 4.5 & 5.2485 & TRN & \\
\hline CHEMBL1394980 & 688546 & 4.9 & 4.699 & TRN & \\
\hline CHEMBL1381044 & 688546 & 4.8 & 4.825 & TST & \\
\hline CHEMBL497781 & 688546 & 4.9 & 4.9531 & TST & \\
\hline CHEMBL1505359 & 688546 & 4.8 & 5.3527 & TST & \\
\hline CHEMBL1603836 & 688546 & 4.5 & 5.4696 & TRN & \\
\hline CHEMBL3199273 & 688546 & 4.45 & 5.3747 & TST & \\
\hline CHEMBL600554 & 688546 & 4.9 & 5.0197 & TRN & \\
\hline CHEMBL1495690 & 688546 & 5.0 & 5.1908 & TRN & \\
\hline CHEMBL1566277 & 688546 & 6.6 & 5.9236 & TRN & \\
\hline CHEMBL1511685 & 688546 & 4.8 & 5.3888 & TRN & \\
\hline CHEMBL1556477 & 688546 & 5.3 & 4.8692 & TRN & \\
\hline CHEMBL1325234 & 688546 & 5.8 & 5.0764 & TRN & \\
\hline CHEMBL531043 & 688546 & 4.5 & 5.1485 & TRN & \\
\hline
\end{tabular}




\begin{tabular}{|c|c|c|c|c|c|}
\hline & \\
\hline CHEMBL1330215 & 688546 & 4.8 & 4.8048 & TRN & \\
\hline CHEMBL1490076 & 688546 & 4.5 & 5.4698 & TRN & \\
\hline CHEMBL1435433 & 688546 & 4.9 & 4.8148 & TRN & \\
\hline CHEMBL1355462 & 688546 & 5.1 & 5.3503 & TRN & \\
\hline CHEMBL1396214 & 688546 & 7.7496 & 5.4805 & TRN & \\
\hline CHEMBL1492364 & 688546 & 5.4 & 5.5554 & TRN & \\
\hline CHEMBL1331692 & 688546 & 4.9 & 5.5917 & TRN & \\
\hline CHEMBL1480826 & 688546 & 5.2 & 4.8883 & TRN & \\
\hline CHEMBL1513311 & 688546 & 5.2 & 5.3989 & TRN & \\
\hline CHEMBL1590482 & 688546 & 5.4 & 5.3143 & TRN & \\
\hline CHEMBL1492189 & 688546 & 6.3 & 5.4583 & TRN & \\
\hline CHEMBL1611214 & 688546 & 4.6 & 5.2746 & TRN & \\
\hline CHEMBL1437970 & 688546 & 4.7 & 5.9267 & TRN & \\
\hline CHEMBL1603200 & 688546 & 4.7 & 5.3483 & TRN & \\
\hline CHEMBL1373866 & 688546 & 5.65 & 5.3595 & TST & \\
\hline CHEMBL303846 & 688546 & 4.5 & 5.2646 & TST & \\
\hline CHEMBL1476095 & 688546 & 4.8 & 5.0155 & TRN & \\
\hline CHEMBL1589821 & 688546 & 5.2 & 5.1983 & TRN & \\
\hline CHEMBL45068 & 688546 & 4.5 & 5.4924 & TST & \\
\hline CHEMBL1526627 & 688546 & 4.9 & 5.4277 & TRN & \\
\hline CHEMBL1302571 & 688546 & 4.9 & 5.3849 & TST & \\
\hline CHEMBL1567368 & 688546 & 4.9 & 5.2071 & TST & \\
\hline CHEMBL28626 & 688546 & 5.4 & 5.4106 & TRN & \\
\hline CHEMBL1402959 & 688546 & 4.9 & 4.8892 & TRN & \\
\hline CHEMBL1414516 & 688546 & 5.4 & $5.0280 e$ & 20000000005 & TRN \\
\hline CHEMBL1332487 & 688546 & 5.4 & 5.5282 & TRN & \\
\hline CHEMBL1379927 & 688546 & 5.0 & 5.2574 & TST & \\
\hline CHEMBL1590864 & 688546 & 4.7 & 5.6354 & TRN & \\
\hline CHEMBL1324998 & 688546 & 4.8 & 5.2284 & TRN & \\
\hline CHEMBL1480704 & 688546 & 5.0 & 4.9041 & TRN & \\
\hline CHEMBL1438469 & 688546 & 4.9 & 5.63399 & 99999999995 & TST \\
\hline CHEMBL1395953 & 688546 & 6.95 & 5.0003 & TRN & \\
\hline CHEMBL1489292 & 688546 & 4.5 & 5.0943 & TRN & \\
\hline CHEMBL1458840 & 688546 & 4.5 & 4.4483 & TST & \\
\hline CHEMBL1598592 & 688546 & 4.8 & 5.246 & TST & \\
\hline CHEMBL1534577 & 688546 & 4.8 & 5.1483 & TRN & \\
\hline CHEMBL1356628 & 688546 & 4.5 & 5.1682 & TRN & \\
\hline CHEMBL1357087 & 688546 & 4.9 & 5.2825 & TRN & \\
\hline CHEMBL1515126 & 688546 & 5.15 & 5.6056 & TRN & \\
\hline CHEMBL1316301 & 688546 & 5.2 & 5.1401 & TRN & \\
\hline CHEMBL1442434 & 688546 & 5.0 & 5.4052 & TST & \\
\hline CHEMBL1397326 & 688546 & 8.301 & 5.1511 & TST & \\
\hline CHEMBL1307720 & 688546 & 5.1 & 5.1921 & TRN & \\
\hline CHEMBL1333029 & 688546 & 5.3 & 5.374 & TRN & \\
\hline CHEMBL1339159 & 688546 & 5.6 & 5.5809 & TRN & \\
\hline CHEMBL1309656 & 688546 & 6.8 & 4.835 & TST & \\
\hline CHEMBL1552395 & 688546 & 4.6 & 4.9282 & TRN & \\
\hline CHEMBL1369025 & 688546 & 8.0 & 5.5716 & TRN & \\
\hline & & & & 1038 & \\
\hline
\end{tabular}




\begin{tabular}{|c|c|c|c|c|}
\hline \multicolumn{5}{|c|}{ Supplemental Table s2.txt } \\
\hline CHEMBL1590410 & 688546 & 6.0 & 5.5905 & TRN \\
\hline CHEMBL1545888 & 688546 & 4.8 & 5.058 & TST \\
\hline CHEMBL1564426 & 688546 & 5.5 & 5.1754 & TST \\
\hline CHEMBL1476263 & 688546 & 4.8 & 5.3015 & TRN \\
\hline CHEMBL1358168 & 688546 & 7.4001 & 5.7196 & TST \\
\hline CHEMBL1363449 & 688546 & 4.7 & 5.3189 & TST \\
\hline CHEMBL1395604 & 688546 & 5.9 & 6.045 & TRN \\
\hline CHEMBL1475180 & 688546 & 4.5 & 4.7942 & TRN \\
\hline CHEMBL1314441 & 688546 & 6.5 & 5.348 & TRN \\
\hline CHEMBL1515418 & 688546 & 4.7 & 4.3854 & TRN \\
\hline CHEMBL1472973 & 688546 & 5.4 & 5.3635 & TRN \\
\hline CHEMBL1353518 & 688546 & 4.7 & 5.3851 & TRN \\
\hline CHEMBL1440282 & 688546 & 5.1 & 5.353 & TRN \\
\hline CHEMBL1355079 & 688546 & 7.5003 & 5.7955 & TST \\
\hline CHEMBL85139 & 688546 & 4.9 & 5.1448 & TST \\
\hline CHEMBL1435792 & 688546 & 4.9 & 4.914 & TRN \\
\hline CHEMBL1604546 & 688546 & 5.2 & 5.0185 & TST \\
\hline CHEMBL 3197234 & 688546 & 5.0 & 4.811 & TRN \\
\hline CHEMBL1553422 & 688546 & 4.8 & 5.2886 & TST \\
\hline CHEMBL1365534 & 688546 & 6.7001 & 5.3598 & TRN \\
\hline CHEMBL1423359 & 688546 & 4.9 & 4.8926 & TST \\
\hline CHEMBL1513820 & 688546 & 4.9 & 5.3391 & TRN \\
\hline CHEMBL1333395 & 688546 & 4.45 & 5.185 & TST \\
\hline CHEMBL1513915 & 688546 & 4.7 & 5.4099 & TRN \\
\hline CHEMBL1603131 & 688546 & 5.2 & 5.5598 & TRN \\
\hline CHEMBL1514945 & 688546 & 5.6 & 5.6574 & TRN \\
\hline CHEMBL1346595 & 688546 & 4.8 & 5.0564 & TRN \\
\hline CHEMBL1403862 & 688546 & 4.8 & 5.3431 & TRN \\
\hline CHEMBL1591858 & 688546 & 4.9 & 5.4104 & TRN \\
\hline CHEMBL1197859 & 688546 & 4.8 & 4.7484 & TRN \\
\hline CHEMBL1314847 & 688546 & 5.0 & 5.7994 & TRN \\
\hline CHEMBL1612169 & 688546 & 4.45 & 5.2935 & TST \\
\hline CHEMBL1499632 & 688546 & 5.2 & 4.9716 & TRN \\
\hline CHEMBL1351105 & 688546 & 4.7 & 5.3816 & TST \\
\hline CHEMBL1519275 & 688546 & 7.0 & 5.0305 & TRN \\
\hline CHEMBL1395020 & 688546 & 4.8 & 5.3281 & TRN \\
\hline CHEMBL 1444261 & 688546 & 4.9 & 4.9704 & TRN \\
\hline CHEMBL1356308 & 688546 & 4.8 & 5.244 & TRN \\
\hline CHEMBL1441000 & 688546 & 6.6 & 6.1824 & TRN \\
\hline CHEMBL1580319 & 688546 & 4.9 & 5.2213 & TRN \\
\hline CHEMBL1521574 & 688546 & 5.4 & 5.1122 & TRN \\
\hline CHEMBL1347099 & 688546 & 5.5 & 4.9017 & TRN \\
\hline CHEMBL1414743 & 688546 & 4.8 & 5.3301 & TRN \\
\hline CHEMBL1399165 & 688546 & 5.0 & 4.8704 & TST \\
\hline CHEMBL1332728 & 688546 & 4.9 & 5.3914 & TRN \\
\hline CHEMBL1531582 & 688546 & 4.8 & 4.5985 & TRN \\
\hline CHEMBL53898 & 688546 & 6.1 & 5.2385 & TRN \\
\hline CHEMBL1479440 & 688546 & 5.2 & 5.1934 & TST \\
\hline
\end{tabular}




\begin{tabular}{|c|c|c|c|c|}
\hline \multicolumn{5}{|c|}{ Supplemental Table S2.txt } \\
\hline CHEMBL1473749 & 688546 & 4.95 & 5.6108 & TRN \\
\hline CHEMBL1415442 & 688546 & 4.6 & 4.9411 & TRN \\
\hline CHEMBL1516980 & 688546 & 5.6 & 4.9426 & TRN \\
\hline CHEMBL1591942 & 688546 & 4.5 & 4.8078 & TRN \\
\hline CHEMBL1476101 & 688546 & 5.5 & 5.54 & TRN \\
\hline CHEMBL1395966 & 688546 & 5.2 & 5.2284 & TRN \\
\hline CHEMBL1515667 & 688546 & 5.0 & 4.971 & TRN \\
\hline CHEMBL3190499 & 688546 & 4.5 & 4.7997 & TRN \\
\hline CHEMBL1358546 & 688546 & 4.5 & 5.5407 & TRN \\
\hline CHEMBL611494 & 688546 & 5.6 & 5.3954 & TST \\
\hline CHEMBL1484443 & 688546 & 7.699 & 6.0409 & TRN \\
\hline CHEMBL1506068 & 688546 & 4.7 & 5.0678 & TRN \\
\hline CHEMBL1574753 & 688546 & 4.5 & 5.3314 & TST \\
\hline CHEMBL1515004 & 688546 & 4.9 & 4.9122 & TRN \\
\hline CHEMBL1437045 & 688546 & 5.2 & 5.5027 & TRN \\
\hline CHEMBL1396482 & 688546 & 4.5 & 5.5095 & TRN \\
\hline CHEMBL1340574 & 688546 & 5.25 & 5.0821 & TST \\
\hline CHEMBL3196369 & 688546 & 4.45 & 5.1127 & TRN \\
\hline CHEMBL1563645 & 688546 & 4.5 & 5.608 & TRN \\
\hline CHEMBL1539502 & 688546 & 5.4 & 5.1312 & TRN \\
\hline CHEMBL74675 & 688546 & 4.8 & 5.0942 & TRN \\
\hline CHEMBL1355647 & 688546 & 5.1 & 5.3057 & TRN \\
\hline CHEMBL3211816 & 688546 & 7.1002 & 5.3653 & TST \\
\hline CHEMBL1554596 & 688546 & 4.5 & 5.2528 & TRN \\
\hline CHEMBL1552636 & 688546 & 5.2 & 5.2653 & TRN \\
\hline CHEMBL1476373 & 688546 & 4.5 & 5.9827 & TRN \\
\hline CHEMBL1479942 & 688546 & 5.1 & 5.0796 & TRN \\
\hline CHEMBL1316850 & 688546 & 4.8 & 5.3794 & TRN \\
\hline CHEMBL1568082 & 688546 & 5.55 & 5.0291 & TRN \\
\hline CHEMBL1410798 & 688546 & 4.9 & 5.0093 & TRN \\
\hline CHEMBL1448337 & 688546 & 5.5 & 5.4981 & TRN \\
\hline CHEMBL1602746 & 688546 & 4.5 & 5.1836 & TRN \\
\hline CHEMBL1438708 & 688546 & 4.9 & 5.7287 & TRN \\
\hline CHEMBL1465615 & 688546 & 5.25 & 5.4056 & TST \\
\hline CHEMBL1345820 & 688546 & 4.9 & 4.9698 & TRN \\
\hline CHEMBL1403562 & 688546 & 5.0 & 4.916 & TRN \\
\hline CHEMBL 1447319 & 688546 & 6.5 & 5.8771 & TRN \\
\hline CHEMBL259615 & 688546 & 6.1 & 5.0767 & TRN \\
\hline CHEMBL1434361 & 688546 & 5.0 & 5.7015 & TRN \\
\hline CHEMBL1434569 & 688546 & 4.5 & 5.4429 & TRN \\
\hline CHEMBL1356155 & 688546 & 4.5 & 5.0105 & TRN \\
\hline CHEMBL1413940 & 688546 & 4.7 & 4.7341 & TRN \\
\hline CHEMBL1434682 & 688546 & 7.8996 & 5.6569 & TRN \\
\hline CHEMBL1518684 & 688546 & 4.8 & 5.1249 & TRN \\
\hline CHEMBL1448245 & 688546 & 4.9 & 5.0459 & TRN \\
\hline CHEMBL1409223 & 688546 & 7.15 & 5.8044 & TST \\
\hline CHEMBL1566436 & 688546 & 4.5 & 5.0919 & TRN \\
\hline CHEMBL1470647 & 688546 & 5.5 & 5.4668 & TRN \\
\hline
\end{tabular}




\begin{tabular}{|c|c|c|c|c|c|}
\hline \\
\hline CHEMBL1592795 & 688546 & 4.9 & 5.0042 & TRN & \\
\hline CHEMBL1440172 & 688546 & 5.2 & 5.2018 & TST & \\
\hline CHEMBL310310 & 688546 & 6.0 & 5.2396 & TST & \\
\hline CHEMBL1321036 & 688546 & 4.8 & 4.982 & TRN & \\
\hline CHEMBL1552542 & 688546 & 4.5 & 4.6461 & TRN & \\
\hline CHEMBL1410374 & 688546 & 4.5 & 5.1317 & TRN & \\
\hline CHEMBL1579513 & 688546 & 5.0 & 4.9605 & TST & \\
\hline CHEMBL1568897 & 688546 & 5.3 & 4.9136 & TRN & \\
\hline CHEMBL1552569 & 688546 & 5.0 & 5.4588 & TRN & \\
\hline CHEMBL1354417 & 688546 & 5.3 & 4.9339 & TRN & \\
\hline CHEMBL1395876 & 688546 & 4.7 & 4.9197 & TRN & \\
\hline CHEMBL1553487 & 688546 & 7.6003 & 6.0244 & TRN & \\
\hline CHEMBL1525708 & 688546 & 7.5003 & 5.6988 & TRN & \\
\hline CHEMBL1440474 & 688546 & 4.9 & 5.3699 & TRN & \\
\hline CHEMBL1399234 & 688546 & 5.0 & 4.9259 & TRN & \\
\hline CHEMBL1533333 & 688546 & 8.3979 & 5.2701 & TST & \\
\hline CHEMBL1550087 & 688546 & 4.9 & 5.1021 & TRN & \\
\hline CHEMBL1433837 & 688546 & 5.15 & 5.2097 & TRN & \\
\hline CHEMBL111951 & 688546 & 5.1 & 4.7912 & TRN & \\
\hline CHEMBL1411665 & 688546 & 4.9 & 5.0302 & TRN & \\
\hline CHEMBL1542791 & 688546 & 4.9 & 4.8649 & TRN & \\
\hline CHEMBL1515802 & 688546 & 4.5 & 5.0614 & TST & \\
\hline CHEMBL1563085 & 688546 & 4.8 & 5.0096 & TRN & \\
\hline CHEMBL1316091 & 688546 & 5.55 & 5.0179 & TRN & \\
\hline CHEMBL1991126 & 688546 & 4.5 & 4.8506 & TRN & \\
\hline CHEMBL1537329 & 688546 & 5.0 & 5.3695 & TRN & \\
\hline CHEMBL1394617 & 688546 & 7.2503 & 5.8824 & TRN & \\
\hline CHEMBL1395274 & 688546 & 5.0 & 5.4278 & TRN & \\
\hline CHEMBL1434284 & 688546 & 5.2 & 5.3553 & TRN & \\
\hline CHEMBL1367659 & 688546 & 6.4 & 5.4301 & TRN & \\
\hline CHEMBL1475556 & 688546 & 4.8 & 5.9134 & TRN & \\
\hline CHEMBL1357497 & 688546 & 4.8 & 5.2977 & TRN & \\
\hline CHEMBL1477695 & 688546 & 4.9 & 5.3068 & TRN & \\
\hline CHEMBL1510845 & 688546 & 7.8508 & 5.4893 & TRN & \\
\hline CHEMBL260560 & 688546 & 5.1 & 5.0876 & TRN & \\
\hline CHEMBL1336808 & 688546 & 5.0 & 5.0278 & TRN & \\
\hline CHEMBL1332306 & 688546 & 7.4001 & 5.5414 & TRN & \\
\hline CHEMBL1329631 & 688546 & 4.6 & 5.3015 & TST & \\
\hline CHEMBL1612049 & 688546 & 5.1 & 5.1863 & TRN & \\
\hline CHEMBL1569504 & 688546 & 6.4 & 5.6493 & TRN & \\
\hline CHEMBL1591995 & 688546 & 7.1002 & 4.8888 & TST & \\
\hline CHEMBL1607304 & 688546 & 5.0 & 5.1723 & TRN & \\
\hline CHEMBL3191091 & 688546 & 7.3002 & 5.46899 & 9999999999 & TRN \\
\hline CHEMBL1454730 & 688546 & 5.4 & 5.2727 & TRN & \\
\hline CHEMBL1374844 & 688546 & 4.7 & 5.2324 & TRN & \\
\hline CHEMBL1551922 & 688546 & 7.6003 & 5.9138 & TRN & \\
\hline CHEMBL580381 & 688546 & 5.6 & 5.1904 & TRN & \\
\hline CHEMBL1398199 & 688546 & 7.1002 & 5.7942 & TRN & \\
\hline
\end{tabular}

Supplemental Table S2.txt

Page 10387 


\begin{tabular}{|c|c|c|c|c|}
\hline \multicolumn{5}{|c|}{ Supplement } \\
\hline CHEMBL1520216 & 688546 & 4.6 & 4.6826 & TST \\
\hline CHEMBL1590637 & 688546 & 4.9 & 5.2525 & TRN \\
\hline CHEMBL1331389 & 688546 & 4.5 & 5.0231 & TRN \\
\hline CHEMBL1521924 & 688546 & 4.8 & 5.5057 & TRN \\
\hline CHEMBL1317124 & 688546 & 4.6 & 4.8514 & TST \\
\hline CHEMBL1473032 & 688546 & 6.7001 & 5.62200 & 0000000001 \\
\hline CHEMBL1607620 & 688546 & 4.9 & 5.4544 & TST \\
\hline CHEMBL1320885 & 688546 & 4.8 & 4.98 & TRN \\
\hline CHEMBL1395746 & 688546 & 4.5 & 5.6265 & TST \\
\hline CHEMBL1514685 & 688546 & 4.8 & 4.936 & TRN \\
\hline CHEMBL1437404 & 688546 & 5.55 & 5.5837 & TST \\
\hline CHEMBL1970265 & 688546 & 4.95 & 5.0187 & TST \\
\hline CHEMBL1317630 & 688546 & 4.5 & 5.3472 & TRN \\
\hline CHEMBL1604341 & 688546 & 5.1 & 5.6362 & TRN \\
\hline CHEMBL1447547 & 688546 & 5.0 & 5.1987 & TRN \\
\hline CHEMBL1536045 & 688546 & 5.4 & 5.7636 & TRN \\
\hline CHEMBL1316206 & 688546 & 4.5 & 4.9499 & TRN \\
\hline CHEMBL3208627 & 688546 & 4.8 & 4.8829 & TST \\
\hline CHEMBL1439977 & 688546 & 4.7 & 5.0479 & TRN \\
\hline CHEMBL1315106 & 688546 & 7.8996 & 6.1135 & TRN \\
\hline CHEMBL1471980 & 688546 & 4.9 & 4.8106 & TRN \\
\hline CHEMBL1355421 & 688546 & 4.4 & 4.8279 & TST \\
\hline CHEMBL1365069 & 688546 & 5.3 & 5.4043 & TRN \\
\hline CHEMBL1395945 & 688546 & 6.1 & 6.0932 & TRN \\
\hline CHEMBL1557315 & 688546 & 4.7 & 5.1895 & TRN \\
\hline CHEMBL1559934 & 688546 & 7.4001 & 5.5495 & TRN \\
\hline CHEMBL1395501 & 688546 & 5.6 & 5.3278 & TRN \\
\hline CHEMBL1403048 & 688546 & 5.0 & 5.2185 & TST \\
\hline CHEMBL1355005 & 688546 & 4.5 & 4.898 & TRN \\
\hline CHEMBL1596321 & 688546 & 7.699 & 5.8468 & TRN \\
\hline CHEMBL1479763 & 688546 & 5.45 & 5.2714 & TRN \\
\hline CHEMBL1394564 & 688546 & 4.5 & 5.0146 & TRN \\
\hline CHEMBL1391437 & 688546 & 4.9 & 5.0537 & TRN \\
\hline CHEMBL1479632 & 688546 & 5.0 & 5.1958 & TRN \\
\hline CHEMBL1474756 & 688546 & 7.5003 & 5.7708 & TRN \\
\hline CHEMBL1321919 & 688546 & 5.3 & 5.121 & TST \\
\hline CHEMBL1368245 & 688546 & 4.6 & 5.5145 & TST \\
\hline CHEMBL1524365 & 688546 & 4.5 & 4.9017 & TST \\
\hline CHEMBL1446795 & 688546 & 5.0 & 5.1114 & TST \\
\hline CHEMBL1552586 & 688546 & 4.8 & 5.2576 & TRN \\
\hline CHEMBL1512662 & 688546 & 5.0 & 5.1536 & TRN \\
\hline CHEMBL1456103 & 688546 & 4.7 & 5.1221 & TRN \\
\hline CHEMBL1405267 & 688546 & 5.85 & 5.0719 & TRN \\
\hline CHEMBL1314497 & 688546 & 8.1024 & 5.1427 & TRN \\
\hline CHEMBL1385119 & 688546 & 4.45 & 5.0713 & TRN \\
\hline CHEMBL1476692 & 688546 & 5.0 & 5.2918 & TRN \\
\hline CHEMBL1412927 & 688546 & 5.1 & 5.3249 & TRN \\
\hline CHEMBL1593565 & 688546 & 4.9 & 5.2793 & TRN \\
\hline
\end{tabular}




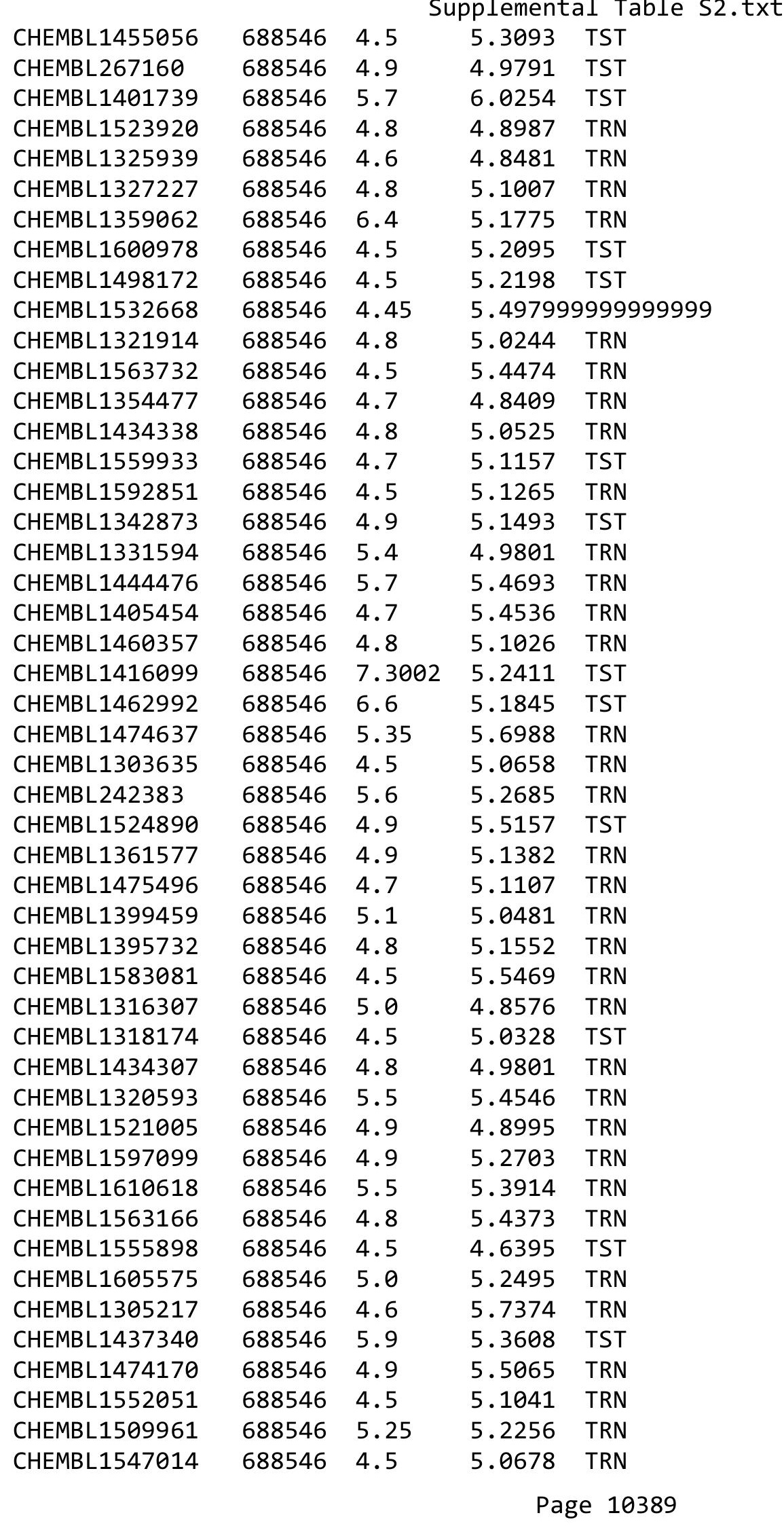




\begin{tabular}{|c|c|c|c|c|}
\hline \multicolumn{5}{|c|}{ Supplement } \\
\hline CHEMBL1422346 & 688546 & 5.1 & 5.3409 & TRN \\
\hline CHEMBL1300779 & 688546 & 5.0 & 4.7857 & TRN \\
\hline CHEMBL1481085 & 688546 & 4.5 & 4.6713 & TRN \\
\hline CHEMBL1599842 & 688546 & 5.9 & 5.5373 & TRN \\
\hline CHEMBL1460920 & 688546 & 5.0 & 5.0698 & TST \\
\hline CHEMBL1413802 & 688546 & 4.8 & 5.0193 & TRN \\
\hline CHEMBL1346439 & 688546 & 4.6 & 5.3383 & TRN \\
\hline CHEMBL154580 & 688546 & 5.0 & 5.2974 & TST \\
\hline CHEMBL1511065 & 688546 & 4.8 & 4.8771 & TST \\
\hline CHEMBL1551923 & 688546 & 4.9 & 4.997 & TST \\
\hline CHEMBL435392 & 688546 & 4.9 & 4.9218 & TST \\
\hline CHEMBL1311219 & 688546 & 4.5 & 5.191 & TRN \\
\hline CHEMBL 73711 & 688546 & 4.5 & 5.1922 & TST \\
\hline CHEMBL1307970 & 688546 & 5.4 & 5.0722 & TST \\
\hline CHEMBL1357326 & 688546 & 5.1 & 5.2461 & TRN \\
\hline CHEMBL1474493 & 688546 & 4.5 & 6.0464 & TRN \\
\hline CHEMBL1596612 & 688546 & 5.5 & 5.3328 & TRN \\
\hline CHEMBL1612935 & 688546 & 4.45 & 5.1158 & TRN \\
\hline CHEMBL1366360 & 688546 & 4.9 & 4.7132 & TRN \\
\hline CHEMBL1436163 & 688546 & 7.6003 & 5.0842 & TST \\
\hline CHEMBL3190220 & 688546 & 4.5 & 4.8976 & TST \\
\hline CHEMBL1592342 & 688546 & 5.2 & 5.1165 & TRN \\
\hline CHEMBL1356240 & 688546 & 6.7001 & 5.0053 & TRN \\
\hline CHEMBL1337912 & 688546 & 4.8 & 5.0297 & TRN \\
\hline CHEMBL1593524 & 688546 & 5.0 & 5.49 & TRN \\
\hline CHEMBL1370166 & 688546 & 4.7 & 5.14 & TRN \\
\hline CHEMBL1354555 & 688546 & 6.1 & 5.0861 & TRN \\
\hline CHEMBL1534672 & 688546 & 4.5 & 5.0329 & TRN \\
\hline CHEMBL1358256 & 688546 & 5.0 & 4.9819 & TRN \\
\hline CHEMBL1476187 & 688546 & 6.1 & 5.1395 & TRN \\
\hline CHEMBL1375660 & 688546 & 5.0 & 4.9938 & TRN \\
\hline CHEMBL1520284 & 688546 & 4.9 & 5.3241 & TRN \\
\hline CHEMBL1361602 & 688546 & 4.5 & 5.4012 & TRN \\
\hline CHEMBL1991885 & 688546 & 4.7 & 5.0881 & TST \\
\hline CHEMBL1397285 & 688546 & 7.6003 & 6.1151 & TRN \\
\hline CHEMBL1412137 & 688546 & 5.3 & 5.2809 & TRN \\
\hline CHEMBL1390244 & 688546 & 4.9 & 5.1935 & TRN \\
\hline CHEMBL1789998 & 688546 & 5.4 & 4.9224 & TST \\
\hline CHEMBL1563170 & 688546 & 4.9 & 5.5674 & TRN \\
\hline CHEMBL1526810 & 688546 & 4.9 & 5.0218 & TRN \\
\hline CHEMBL1413624 & 688546 & 4.8 & 5.0231 & TRN \\
\hline CHEMBL1533715 & 688546 & 4.5 & 5.2994 & TRN \\
\hline CHEMBL1476141 & 688546 & 4.9 & 5.4227 & TRN \\
\hline CHEMBL1366922 & 688546 & 8.0 & 5.9677 & TRN \\
\hline CHEMBL 3197489 & 688546 & 4.9 & 4.7128 & TST \\
\hline CHEMBL1442163 & 688546 & 4.5 & 4.7099 & TRN \\
\hline CHEMBL1317587 & 688546 & 4.5 & 4.9227 & TRN \\
\hline CHEMBL1562649 & 688546 & 4.9 & 5.9652 & TRN \\
\hline
\end{tabular}




\begin{tabular}{|c|c|c|c|c|}
\hline \multicolumn{5}{|c|}{ Supplemental Table S2.txt } \\
\hline CHEMBL1492491 & 688546 & 4.95 & 5.3911 & TST \\
\hline CHEMBL1475359 & 688546 & 6.3 & 5.612 & TRN \\
\hline CHEMBL1403798 & 688546 & 4.9 & 5.3621 & TRN \\
\hline CHEMBL1603334 & 688546 & 6.4 & 5.4537 & TRN \\
\hline CHEMBL1317734 & 688546 & 6.05 & 5.5001 & TST \\
\hline CHEMBL1354681 & 688546 & 5.0 & 5.4814 & TRN \\
\hline CHEMBL1444031 & 688546 & 5.5 & 5.4514 & TRN \\
\hline CHEMBL1456630 & 688546 & 5.2 & 5.0927 & TRN \\
\hline CHEMBL1576714 & 688546 & 7.8508 & 5.2801 & TRN \\
\hline CHEMBL1490421 & 688546 & 6.4 & 5.4288 & TRN \\
\hline CHEMBL1567859 & 688546 & 4.5 & 5.0003 & TRN \\
\hline CHEMBL1409173 & 688546 & 6.0 & 5.01399 & 9999999999 \\
\hline CHEMBL1398260 & 688546 & 6.0 & 6.3701 & TRN \\
\hline CHEMBL1552720 & 688546 & 4.5 & 4.9435 & TRN \\
\hline CHEMBL1411382 & 688546 & 7.699 & 5.3594 & TRN \\
\hline CHEMBL1332051 & 688546 & 4.7 & 4.8849 & TST \\
\hline CHEMBL1332375 & 688546 & 4.5 & 5.3786 & TRN \\
\hline CHEMBL1349756 & 688546 & 4.5 & 5.197 & TST \\
\hline CHEMBL1329632 & 688546 & 5.0 & 5.1587 & TRN \\
\hline CHEMBL545900 & 688546 & 7.5498 & 5.095 & TRN \\
\hline CHEMBL1599249 & 688546 & 4.6 & 4.7857 & TST \\
\hline CHEMBL1474989 & 688546 & 4.5 & 4.8215 & TRN \\
\hline CHEMBL1495368 & 688546 & 4.8 & 5.4601 & TRN \\
\hline CHEMBL1590295 & 688546 & 4.9 & 5.6221 & TRN \\
\hline CHEMBL1331442 & 688546 & 4.8 & 5.1388 & TST \\
\hline CHEMBL1543890 & 688546 & 4.45 & 5.4642 & TST \\
\hline CHEMBL1509691 & 688546 & 4.9 & 5.1044 & TST \\
\hline CHEMBL1315097 & 688546 & 5.0 & 5.3116 & TRN \\
\hline CHEMBL1355454 & 688546 & 4.8 & 4.7944 & TRN \\
\hline CHEMBL1554039 & 688546 & 5.0 & 4.9431 & TRN \\
\hline CHEMBL1530679 & 688546 & 6.95 & 5.5309 & TRN \\
\hline CHEMBL1365525 & 688546 & 4.7 & 4.9217 & TRN \\
\hline CHEMBL1475923 & 688546 & 4.9 & 5.8424 & TRN \\
\hline CHEMBL1519201 & 688546 & 4.5 & 4.9578 & TST \\
\hline CHEMBL1479571 & 688546 & 5.0 & 5.3541 & TRN \\
\hline CHEMBL1396684 & 688546 & 4.5 & 6.0539 & TRN \\
\hline CHEMBL1530115 & 688546 & 7.5003 & 5.6129 & TRN \\
\hline CHEMBL1401957 & 688546 & 5.6 & 5.2108 & TRN \\
\hline CHEMBL1521327 & 688546 & 4.7 & 4.8675 & TRN \\
\hline CHEMBL1440382 & 688546 & 4.9 & 5.0402 & TRN \\
\hline CHEMBL1372997 & 688546 & 4.8 & 5.6251 & TST \\
\hline CHEMBL1473742 & 688546 & 5.0 & 5.6313 & TRN \\
\hline CHEMBL1362998 & 688546 & 5.0 & 5.4017 & TRN \\
\hline CHEMBL1376736 & 688546 & 4.9 & 4.7906 & TRN \\
\hline CHEMBL1433827 & 688546 & 5.1 & 4.9221 & TRN \\
\hline CHEMBL1476044 & 688546 & 5.0 & 6.3619 & TRN \\
\hline CHEMBL1317046 & 688546 & 5.5 & 4.8818 & TRN \\
\hline CHEMBL1493930 & 688546 & 5.85 & 5.504 & TST \\
\hline
\end{tabular}




\begin{tabular}{|c|c|c|c|c|c|}
\hline \multicolumn{6}{|c|}{ Supplemental Table S2.txt } \\
\hline CHEMBL1518622 & 688546 & 5.0 & 5.0518 & TRN & \\
\hline CHEMBL1357509 & 688546 & 7.2503 & 5.8319 & TRN & \\
\hline CHEMBL1587270 & 688546 & 4.9 & 5.1737 & TRN & \\
\hline CHEMBL1552511 & 688546 & 4.9 & 4.9952 & TRN & \\
\hline CHEMBL1541182 & 688546 & 5.5 & 4.9058 & TRN & \\
\hline CHEMBL1357829 & 688546 & 5.6 & \multicolumn{2}{|c|}{5.236000000000001} & TRN \\
\hline CHEMBL1592872 & 688546 & 5.0 & 5.1874 & TRN & \\
\hline CHEMBL1605871 & 688546 & 5.6 & 5.1626 & TRN & \\
\hline CHEMBL1397876 & 688546 & 4.5 & 5.2989 & TRN & \\
\hline CHEMBL1494394 & 688546 & 4.6 & 5.8536 & TRN & \\
\hline CHEMBL1395137 & 688546 & 4.5 & 4.7053 & TRN & \\
\hline CHEMBL1369925 & 688546 & 4.5 & 5.4453 & TST & \\
\hline CHEMBL3210131 & 688546 & 5.0 & 5.3006 & TRN & \\
\hline CHEMBL1378077 & 688546 & 7.8013 & 5.4293 & TRN & \\
\hline CHEMBL1368219 & 688546 & 5.0 & 5.2256 & TRN & \\
\hline CHEMBL1323536 & 688546 & 4.7 & 5.6937 & TRN & \\
\hline CHEMBL1307028 & 688546 & 4.9 & 5.1549 & TRN & \\
\hline CHEMBL1558607 & 688546 & 4.7 & 5.3302 & TST & \\
\hline CHEMBL1432234 & 688546 & 5.0 & 5.0821 & TRN & \\
\hline CHEMBL1371559 & 688546 & 4.6 & 5.1057 & TST & \\
\hline CHEMBL1606481 & 688546 & 5.5 & 5.2405 & TRN & \\
\hline CHEMBL1478440 & 688546 & 4.9 & 5.2433 & TRN & \\
\hline CHEMBL1358788 & 688546 & 4.9 & 4.9503 & TST & \\
\hline CHEMBL1436403 & 688546 & 4.7 & 5.1981 & TRN & \\
\hline CHEMBL1397921 & 688546 & 4.9 & 5.1605 & TRN & \\
\hline CHEMBL1432063 & 688546 & 5.0 & 5.1777 & TRN & \\
\hline CHEMBL1592789 & 688546 & 4.5 & 4.7404 & TRN & \\
\hline CHEMBL1591418 & 688546 & 4.7 & 5.1888 & TRN & \\
\hline CHEMBL1474701 & 688546 & 4.8 & 5.0135 & TST & \\
\hline CHEMBL1491122 & 688546 & 8.0506 & 5.5943 & TRN & \\
\hline CHEMBL1388233 & 688546 & 4.9 & 5.1989 & TRN & \\
\hline CHEMBL1415527 & 688546 & 5.7 & 4.974 & TRN & \\
\hline CHEMBL1551120 & 688546 & 5.0 & 5.4621 & TRN & \\
\hline CHEMBL1428417 & 688546 & 4.5 & 4.7064 & TRN & \\
\hline CHEMBL1327072 & 688546 & 4.6 & 4.9706 & TRN & \\
\hline CHEMBL1590804 & 688546 & 5.1 & 5.1655 & TRN & \\
\hline CHEMBL1255733 & 688546 & 6.1 & 5.9019 & TST & \\
\hline CHEMBL1255837 & 688546 & 6.0 & 5.684 & TST & \\
\hline CHEMBL1370787 & 688546 & 5.0 & $5.1560 e$ & 2000000001 & TRN \\
\hline CHEMBL1593707 & 688546 & 4.8 & 4.809 & TRN & \\
\hline CHEMBL187734 & 688546 & 4.7 & 5.1153 & TST & \\
\hline CHEMBL1415598 & 688546 & 5.4 & 5.1966 & TRN & \\
\hline CHEMBL1532569 & 688546 & 4.7 & 5.1952 & TRN & \\
\hline CHEMBL1514570 & 688546 & 4.5 & 5.0086 & TRN & \\
\hline CHEMBL1474696 & 688546 & 4.5 & 5.5474 & TRN & \\
\hline CHEMBL1477199 & 688546 & 4.5 & 5.9972 & TRN & \\
\hline CHEMBL1394243 & 688546 & 4.5 & 5.0523 & TRN & \\
\hline CHEMBL1256751 & 688546 & 4.9 & 4.8233 & TST & \\
\hline
\end{tabular}




\begin{tabular}{|c|c|c|c|c|c|}
\hline \multicolumn{6}{|c|}{ oplemental Table S } \\
\hline CHEMBL1331520 & 688546 & 4.8 & 5.1174 & TST & \\
\hline CHEMBL1321400 & 688546 & 4.95 & 5.0724 & TRN & \\
\hline CHEMBL1318268 & 688546 & 5.0 & 5.4208 & TST & \\
\hline CHEMBL 2374266 & 688546 & 4.5 & 4.7395 & TRN & \\
\hline CHEMBL1513840 & 688546 & 4.8 & 5.3736 & TRN & \\
\hline CHEMBL1356735 & 688546 & 4.9 & 5.2276 & TRN & \\
\hline CHEMBL1595724 & 688546 & 4.5 & 5.1833 & TST & \\
\hline CHEMBL1401331 & 688546 & 4.9 & 5.2743 & TRN & \\
\hline CHEMBL1565074 & 688546 & 4.7 & 5.69 & TRN & \\
\hline CHEMBL1475717 & 688546 & 4.5 & 5.5492 & TRN & \\
\hline CHEMBL1371865 & 688546 & 5.0 & 4.9767 & TRN & \\
\hline CHEMBL1437027 & 688546 & 5.5 & 4.9734 & TRN & \\
\hline CHEMBL1403565 & 688546 & 5.1 & 5.4751 & TRN & \\
\hline CHEMBL1448609 & 688546 & 4.7 & 5.0101 & TRN & \\
\hline CHEMBL1578187 & 688546 & 4.5 & 5.4714 & TST & \\
\hline CHEMBL1339420 & 688546 & 4.7 & 5.7297 & TRN & \\
\hline CHEMBL1397533 & 688546 & 4.7 & 5.2557 & TRN & \\
\hline CHEMBL1480958 & 688546 & 5.75 & 4.9495 & TRN & \\
\hline CHEMBL1368680 & 688546 & 5.15 & 5.4841 & TST & \\
\hline CHEMBL1417342 & 688546 & 4.9 & 5.2422 & TRN & \\
\hline CHEMBL1308100 & 688546 & 4.5 & 5.2899 & TRN & \\
\hline CHEMBL1327558 & 688546 & 7.3002 & 5.3288 & TRN & \\
\hline CHEMBL1613718 & 688546 & 5.0 & 4.6882 & TRN & \\
\hline CHEMBL1328459 & 688546 & 4.8 & 5.3912 & TRN & \\
\hline CHEMBL1557368 & 688546 & 5.1 & 5.6611 & TRN & \\
\hline CHEMBL1474284 & 688546 & 5.1 & 5.1596 & TST & \\
\hline CHEMBL1327218 & 688546 & 5.4 & 5.5528 & TST & \\
\hline CHEMBL1378608 & 688546 & 8.0 & 5.7675 & TRN & \\
\hline CHEMBL1559517 & 688546 & 7.6498 & 5.2348 & TST & \\
\hline CHEMBL 1256360 & 688546 & 4.8 & 4.8324 & TST & \\
\hline CHEMBL1364404 & 688546 & 6.1 & 5.5493 & TRN & \\
\hline CHEMBL1408631 & 688546 & 5.6 & 5.4988 & TRN & \\
\hline CHEMBL1394218 & 688546 & 7.3497 & 5.8149 & TRN & \\
\hline CHEMBL1374108 & 688546 & 4.6 & 5.1229 & TRN & \\
\hline CHEMBL1482687 & 688546 & 4.6 & 5.83700 & 0000000001 & TRN \\
\hline CHEMBL1400731 & 688546 & 4.9 & 5.0899 & TRN & \\
\hline CHEMBL1550430 & 688546 & 4.9 & 5.1568 & TRN & \\
\hline CHEMBL1366627 & 688546 & 5.0 & 4.7401 & TRN & \\
\hline CHEMBL1429292 & 688546 & 4.9 & 5.3796 & TRN & \\
\hline CHEMBL1366151 & 688546 & 6.25 & 5.4899 & TRN & \\
\hline CHEMBL1554455 & 688546 & 4.9 & 5.1881 & TRN & \\
\hline CHEMBL1256484 & 688546 & 4.7 & 4.7199 & TRN & \\
\hline CHEMBL1567236 & 688546 & 4.5 & 5.1189 & TRN & \\
\hline CHEMBL1474365 & 688546 & 8.1024 & 6.187 & TRN & \\
\hline CHEMBL1399654 & 688546 & 4.8 & 4.9408 & TRN & \\
\hline CHEMBL1543998 & 688546 & 4.5 & 5.1943 & TRN & \\
\hline CHEMBL1476652 & 688546 & 4.9 & 5.7554 & TRN & \\
\hline CHEMBL1425919 & 688546 & 5.2 & 4.9281 & TRN & \\
\hline
\end{tabular}




\begin{tabular}{|c|c|c|c|c|c|}
\hline \multicolumn{6}{|c|}{ plemental } \\
\hline CHEMBL1367944 & 688546 & 4.9 & 4.9662 & TST & \\
\hline CHEMBL1473495 & 688546 & 4.9 & 5.455 & TRN & \\
\hline CHEMBL1474815 & 688546 & 5.5 & 5.4095 & TRN & \\
\hline CHEMBL1395420 & 688546 & 4.5 & 5.9366 & TRN & \\
\hline CHEMBL1363246 & 688546 & 5.0 & 5.7352 & TRN & \\
\hline CHEMBL1337548 & 688546 & 4.8 & 4.8567 & TST & \\
\hline CHEMBL1412578 & 688546 & 4.9 & 5.4805 & TRN & \\
\hline CHEMBL1324088 & 688546 & 4.5 & 5.921 & TRN & \\
\hline CHEMBL1435346 & 688546 & 4.8 & 5.4325 & TRN & \\
\hline CHEMBL1456514 & 688546 & 5.1 & 5.2855 & TRN & \\
\hline CHEMBL1554493 & 688546 & 6.6 & 5.7711 & TRN & \\
\hline CHEMBL1472906 & 688546 & 6.1 & 5.2478 & TRN & \\
\hline CHEMBL1491164 & 688546 & 4.9 & 4.9339 & TRN & \\
\hline CHEMBL1481190 & 688546 & 4.8 & 5.149 & TRN & \\
\hline CHEMBL1332688 & 688546 & 5.0 & 5.2009 & TRN & \\
\hline CHEMBL1314849 & 688546 & 4.9 & 5.2358 & TRN & \\
\hline CHEMBL1417802 & 688546 & 5.15 & 5.3512 & TST & \\
\hline CHEMBL1415335 & 688546 & 8.301 & 5.9548 & TRN & \\
\hline CHEMBL1553164 & 688546 & 5.85 & 5.5928 & TRN & \\
\hline CHEMBL1567967 & 688546 & 5.2 & 5.042 & TRN & \\
\hline CHEMBL1324604 & 688546 & 4.9 & 4.9218 & TST & \\
\hline CHEMBL54782 & 688546 & 4.9 & 4.9178 & TRN & \\
\hline CHEMBL1591419 & 688546 & 5.0 & 5.489 & TST & \\
\hline CHEMBL1365046 & 688546 & 8.301 & 5.9979 & TRN & \\
\hline CHEMBL1475818 & 688546 & 5.2 & 5.17299 & 9999999999 & TRN \\
\hline CHEMBL1475049 & 688546 & 4.6 & 5.6368 & TRN & \\
\hline CHEMBL1596330 & 688546 & 4.5 & 5.3467 & TRN & \\
\hline CHEMBL1366307 & 688546 & 5.0 & 4.9636 & TRN & \\
\hline CHEMBL1513809 & 688546 & 4.9 & 4.9844 & TRN & \\
\hline CHEMBL1325032 & 688546 & 7.5003 & 5.7558 & TRN & \\
\hline CHEMBL1590926 & 688546 & 4.5 & 4.9591 & TRN & \\
\hline CHEMBL1591685 & 688546 & 5.0 & 5.80399 & 9999999999 & TRN \\
\hline CHEMBL1417736 & 688546 & 4.5 & 4.9777 & TRN & \\
\hline CHEMBL1435318 & 688546 & 5.7 & 5.058 & TRN & \\
\hline CHEMBL1393189 & 688546 & 4.9 & 5.5766 & TST & \\
\hline CHEMBL1360568 & 688546 & 5.0 & 5.50299 & 9999999999 & TRN \\
\hline CHEMBL1356410 & 688546 & 4.9 & 5.4793 & TST & \\
\hline CHEMBL1548291 & 688546 & 4.7 & 5.4028 & TST & \\
\hline CHEMBL1353376 & 688546 & 6.45 & 5.1391 & TRN & \\
\hline CHEMBL1378707 & 688546 & 5.0 & 4.69600 & 0000000001 & TRN \\
\hline CHEMBL1465410 & 688546 & 4.6 & 5.1927 & TST & \\
\hline CHEMBL1394881 & 688546 & 4.8 & 4.7562 & TRN & \\
\hline CHEMBL1326593 & 688546 & 4.8 & 5.4325 & TRN & \\
\hline CHEMBL1436383 & 688546 & 6.8 & 5.6363 & TRN & \\
\hline CHEMBL1602958 & 688546 & 5.3 & 5.6076 & TRN & \\
\hline CHEMBL1326725 & 688546 & 4.9 & 5.0733 & TRN & \\
\hline CHEMBL1493292 & 688546 & 4.5 & 4.9466 & TRN & \\
\hline CHEMBL1372039 & 688546 & 4.8 & 5.11 & TRN & \\
\hline
\end{tabular}




\begin{tabular}{|c|c|c|c|c|}
\hline \multicolumn{5}{|c|}{ Supplemental Table S2.txt } \\
\hline CHEMBL1387290 & 688546 & 4.7 & 5.021 & TST \\
\hline CHEMBL1407035 & 688546 & 5.0 & 4.9013 & TRN \\
\hline CHEMBL1598204 & 688546 & 8.2007 & 5.2729 & TRN \\
\hline CHEMBL1611117 & 688546 & 5.8 & 5.3298 & TRN \\
\hline CHEMBL1444242 & 688546 & 4.5 & 5.8312 & TST \\
\hline CHEMBL1512915 & 688546 & 4.5 & 6.0754 & TRN \\
\hline CHEMBL1513172 & 688546 & 4.8 & 5.9433 & TRN \\
\hline CHEMBL1589331 & 688546 & 4.45 & 5.3193 & TST \\
\hline CHEMBL1590613 & 688546 & 5.2 & 5.5716 & TST \\
\hline CHEMBL1582048 & 688546 & 5.45 & 5.0885 & TRN \\
\hline CHEMBL1354707 & 688546 & 8.301 & 5.5871 & TRN \\
\hline CHEMBL1395837 & 688546 & 4.8 & 4.9699 & TRN \\
\hline CHEMBL1513147 & 688546 & 5.4 & 5.0582 & TRN \\
\hline CHEMBL1481361 & 688546 & 4.6 & 5.1097 & TRN \\
\hline CHEMBL1424060 & 688546 & 5.0 & 5.0566 & TST \\
\hline CHEMBL1394562 & 688546 & 4.5 & 5.4587 & TRN \\
\hline CHEMBL1571058 & 688546 & 5.0 & 5.1457 & TRN \\
\hline CHEMBL1513894 & 688546 & 4.9 & 5.3276 & TRN \\
\hline CHEMBL1320182 & 688546 & 8.301 & 5.5697 & TRN \\
\hline CHEMBL1403028 & 688546 & 5.0 & 4.8746 & TRN \\
\hline CHEMBL1384533 & 688546 & 4.9 & 5.2212 & TRN \\
\hline CHEMBL1338421 & 688546 & 4.8 & 5.0607 & TRN \\
\hline CHEMBL1324885 & 688546 & 5.0 & 4.853 & TST \\
\hline CHEMBL1567985 & 688546 & 5.0 & 5.4011 & TRN \\
\hline CHEMBL1345338 & 688546 & 4.5 & 4.9524 & TST \\
\hline CHEMBL356688 & 688546 & 4.8 & 4.976 & TRN \\
\hline CHEMBL1551951 & 688546 & 5.0 & 5.5863 & TRN \\
\hline CHEMBL1337932 & 688546 & 4.6 & 6.0715 & TRN \\
\hline CHEMBL1516002 & 688546 & 4.6 & 5.4733 & TRN \\
\hline CHEMBL1425522 & 688546 & 5.35 & 5.51 & TST \\
\hline CHEMBL1406753 & 688546 & 5.0 & 5.1044 & TRN \\
\hline CHEMBL1529150 & 688546 & 4.45 & 5.1255 & TRN \\
\hline CHEMBL1353113 & 688546 & 4.9 & 5.1795 & TRN \\
\hline CHEMBL1416089 & 688546 & 5.5 & 4.9887 & TRN \\
\hline CHEMBL1435525 & 688546 & 4.8 & 5.2103 & TRN \\
\hline CHEMBL1410037 & 688546 & 5.4 & 5.1444 & TST \\
\hline CHEMBL1436904 & 688546 & 4.5 & 4.945 & TRN \\
\hline CHEMBL1449209 & 688546 & 5.0 & 5.1047 & TRN \\
\hline CHEMBL1355945 & 688546 & 5.1 & 5.96 & TRN \\
\hline CHEMBL 2374027 & 688546 & 4.9 & 4.9812 & TRN \\
\hline CHEMBL1568543 & 688546 & 4.8 & 5.1228 & TRN \\
\hline CHEMBL1378262 & 688546 & 4.5 & 5.041 & TRN \\
\hline CHEMBL1406702 & 688546 & 6.5 & 5.5096 & TRN \\
\hline CHEMBL1570927 & 688546 & 4.5 & 5.4324 & TRN \\
\hline CHEMBL1363038 & 688546 & 4.9 & 5.9462 & TST \\
\hline CHEMBL1396975 & 688546 & 4.7 & 4.7409 & TST \\
\hline CHEMBL1450598 & 688546 & 6.6 & 4.8392 & TRN \\
\hline CHEMBL1396734 & 688546 & 5.4 & 4.9401 & TRN \\
\hline
\end{tabular}




\begin{tabular}{|c|c|c|c|c|}
\hline & & & pplement & al $\mathrm{T}$ \\
\hline CHEMBL1319614 & 688546 & 5.0 & 5.7799 & TRN \\
\hline CHEMBL1333339 & 688546 & 4.9 & 5.4957 & TRN \\
\hline CHEMBL1435578 & 688546 & 5.9 & 5.4143 & TRN \\
\hline CHEMBL1340089 & 688546 & 4.45 & 5.0646 & TST \\
\hline CHEMBL1513514 & 688546 & 5.35 & 5.3031 & TRN \\
\hline CHEMBL1434124 & 688546 & 4.8 & 4.8999 & TST \\
\hline CHEMBL1456607 & 688546 & 4.5 & 4.8974 & TRN \\
\hline CHEMBL1396720 & 688546 & 4.9 & 5.1327 & TST \\
\hline CHEMBL1500049 & 688546 & 5.7 & 5.2395 & TRN \\
\hline CHEMBL1566898 & 688546 & 5.6 & 5.1962 & TRN \\
\hline CHEMBL1476177 & 688546 & 5.1 & 5.4621 & TRN \\
\hline CHEMBL1577977 & 688546 & 4.8 & 4.8434 & TST \\
\hline CHEMBL1355525 & 688546 & 4.6 & 5.2855 & TRN \\
\hline CHEMBL1325252 & 688546 & 4.8 & 5.5793 & TRN \\
\hline CHEMBL1366140 & 688546 & 5.95 & 5.4404 & TRN \\
\hline CHEMBL1323214 & 688546 & 4.8 & 4.8405 & TRN \\
\hline CHEMBL1590272 & 688546 & 4.9 & 5.4059 & TRN \\
\hline CHEMBL1371242 & 688546 & 4.6 & 5.4845 & TRN \\
\hline CHEMBL1366573 & 688546 & 4.5 & 5.1626 & TRN \\
\hline CHEMBL1525845 & 688546 & 5.2 & 5.3176 & TRN \\
\hline CHEMBL1399241 & 688546 & 4.75 & 4.5437 & TRN \\
\hline CHEMBL1490465 & 688546 & 4.8 & 5.1232 & TRN \\
\hline CHEMBL1581560 & 688546 & 4.9 & 5.1725 & TST \\
\hline CHEMBL1396144 & 688546 & 4.6 & 4.9888 & TRN \\
\hline CHEMBL1356510 & 688546 & 5.4 & 6.0825 & TRN \\
\hline CHEMBL1512726 & 688546 & 5.4 & 5.2104 & TRN \\
\hline CHEMBL1352911 & 688546 & 5.0 & 5.2751 & TST \\
\hline CHEMBL1564197 & 688546 & 4.5 & 4.816 & TRN \\
\hline CHEMBL1554873 & 688546 & 4.9 & 5.1197 & TRN \\
\hline CHEMBL1373463 & 688546 & 5.4 & 4.9846 & TRN \\
\hline CHEMBL1612043 & 688546 & 5.2 & 5.391 & TRN \\
\hline CHEMBL1404153 & 688546 & 6.0 & 5.5388 & TRN \\
\hline CHEMBL1591493 & 688546 & 6.1 & 5.6856 & TRN \\
\hline CHEMBL1328137 & 688546 & 6.8 & 5.9496 & TRN \\
\hline CHEMBL1484097 & 688546 & 4.8 & 4.7727 & TST \\
\hline CHEMBL1438621 & 688546 & 4.9 & 4.9623 & TST \\
\hline CHEMBL1327116 & 688546 & 4.7 & 5.3408 & TRN \\
\hline CHEMBL1458755 & 688546 & 4.8 & 4.8423 & TST \\
\hline CHEMBL1415980 & 688546 & 4.9 & 5.1204 & TRN \\
\hline CHEMBL1369231 & 688546 & 4.9 & 5.6042 & TST \\
\hline CHEMBL1483183 & 688546 & 4.9 & 5.0758 & TRN \\
\hline CHEMBL1593436 & 688546 & 4.5 & 5.2135 & TRN \\
\hline CHEMBL1363486 & 688546 & 7.7496 & 5.9403 & TRN \\
\hline CHEMBL1318243 & 688546 & 5.1 & 5.5604 & TRN \\
\hline CHEMBL1328311 & 688546 & 5.3 & 4.9733 & TRN \\
\hline CHEMBL1475759 & 688546 & 5.0 & 5.7327 & TRN \\
\hline CHEMBL1582610 & 688546 & 5.1 & 5.4226 & TST \\
\hline CHEMBL1397275 & 688546 & 8.4949 & 5.5921 & TRN \\
\hline
\end{tabular}




\begin{tabular}{|c|c|c|c|c|}
\hline & & & pplement & al $\mathrm{T}$ \\
\hline CHEMBL1411257 & 688546 & 5.3 & 5.3164 & TRN \\
\hline CHEMBL1491462 & 688546 & 4.8 & 5.0168 & TRN \\
\hline CHEMBL1427801 & 688546 & 5.25 & 5.1185 & TRN \\
\hline CHEMBL1372744 & 688546 & 4.7 & 4.7797 & TST \\
\hline CHEMBL1343727 & 688546 & 4.9 & 5.197 & TRN \\
\hline CHEMBL1437187 & 688546 & 5.4 & 5.1416 & TRN \\
\hline CHEMBL1444452 & 688546 & 5.05 & 4.9036 & TRN \\
\hline CHEMBL1461634 & 688546 & 5.25 & 4.7433 & TST \\
\hline CHEMBL1523206 & 688546 & 4.8 & 5.0753 & TRN \\
\hline CHEMBL1426830 & 688546 & 4.9 & 5.2895 & TRN \\
\hline CHEMBL1552968 & 688546 & 4.9 & 5.322 & TST \\
\hline CHEMBL1590400 & 688546 & 4.7 & 5.2341 & TRN \\
\hline CHEMBL1523844 & 688546 & 4.5 & 4.8685 & TST \\
\hline CHEMBL1514074 & 688546 & 4.8 & 5.4616 & TRN \\
\hline CHEMBL1314762 & 688546 & 4.9 & 5.2261 & TRN \\
\hline CHEMBL1497015 & 688546 & 5.55 & 5.3875 & TST \\
\hline CHEMBL601968 & 688546 & 4.9 & 4.9465 & TST \\
\hline CHEMBL1355058 & 688546 & 5.2 & 4.8611 & TRN \\
\hline CHEMBL1399937 & 688546 & 4.8 & 5.3048 & TRN \\
\hline CHEMBL1316207 & 688546 & 5.6 & 5.4304 & TRN \\
\hline CHEMBL1476764 & 688546 & 4.9 & 4.9592 & TRN \\
\hline CHEMBL1491866 & 688546 & 4.9 & 5.1976 & TRN \\
\hline CHEMBL1591154 & 688546 & 4.6 & 5.2533 & TRN \\
\hline CHEMBL1333795 & 688546 & 4.9 & 5.3645 & TRN \\
\hline CHEMBL1407292 & 688546 & 5.6 & 5.3873 & TRN \\
\hline CHEMBL1567692 & 688546 & 4.9 & 4.8882 & TRN \\
\hline CHEMBL1378620 & 688546 & 5.6 & 5.4368 & TRN \\
\hline CHEMBL1470063 & 688546 & 4.5 & 5.3845 & TRN \\
\hline CHEMBL1369635 & 688546 & 5.0 & 5.5615 & TST \\
\hline CHEMBL1373256 & 688546 & 5.0 & 4.9598 & TRN \\
\hline CHEMBL1606325 & 688546 & 4.9 & 5.29 & TST \\
\hline CHEMBL1397271 & 688546 & 4.5 & 5.4949 & TST \\
\hline CHEMBL1365104 & 688546 & 4.9 & 5.1033 & TST \\
\hline CHEMBL1515431 & 688546 & 4.5 & 5.5603 & TRN \\
\hline CHEMBL1552579 & 688546 & 4.6 & 4.6387 & TST \\
\hline CHEMBL375126 & 688546 & 5.2 & 5.3262 & TST \\
\hline CHEMBL1479682 & 688546 & 5.5 & 5.4342 & TRN \\
\hline CHEMBL1370379 & 688546 & 4.7 & 5.2973 & TRN \\
\hline CHEMBL1371504 & 688546 & 5.0 & 5.4924 & TRN \\
\hline CHEMBL1396634 & 688546 & 4.9 & 5.0918 & TRN \\
\hline CHEMBL1170871 & 688546 & 4.5 & 5.4187 & TRN \\
\hline CHEMBL1445402 & 688546 & 5.6 & 5.7108 & TRN \\
\hline CHEMBL1440056 & 688546 & 4.9 & 5.5993 & TRN \\
\hline CHEMBL 3190963 & 688546 & 4.75 & 4.9862 & TST \\
\hline CHEMBL 1455472 & 688546 & 8.4949 & 5.5839 & TRN \\
\hline CHEMBL1516287 & 688546 & 4.9 & 5.2536 & TRN \\
\hline CHEMBL1315329 & 688546 & 4.9 & 6.086 & TRN \\
\hline CHEMBL1532286 & 688546 & 4.8 & 5.0255 & TRN \\
\hline
\end{tabular}




\begin{tabular}{|c|c|c|c|c|c|}
\hline \\
\hline CHEMBL1396707 & 688546 & 5.0 & 5.2374 & TRN & \\
\hline CHEMBL1437923 & 688546 & 4.7 & 5.0528 & TRN & \\
\hline CHEMBL1515852 & 688546 & 6.0 & 5.2143 & TRN & \\
\hline CHEMBL1476360 & 688546 & 4.9 & 5.6732 & TRN & \\
\hline CHEMBL1595264 & 688546 & 5.0 & 5.1641 & TRN & \\
\hline CHEMBL1327357 & 688546 & 5.9 & 5.4151 & TRN & \\
\hline CHEMBL1426732 & 688546 & 4.5 & 5.4488 & TRN & \\
\hline CHEMBL15594 & 688546 & 4.5 & 5.2479 & TST & \\
\hline CHEMBL1531857 & 688546 & 4.8 & 4.7987 & TRN & \\
\hline CHEMBL1317959 & 688546 & 4.6 & 5.1908 & TRN & \\
\hline CHEMBL1585127 & 688546 & 5.0 & 4.9828 & TST & \\
\hline CHEMBL1722765 & 688546 & 6.8 & 5.1582 & TST & \\
\hline CHEMBL1552842 & 688546 & 5.45 & 5.6729 & TRN & \\
\hline CHEMBL1446849 & 688546 & 5.0 & 5.1869 & TRN & \\
\hline CHEMBL1327137 & 688546 & 4.8 & 4.6227 & TST & \\
\hline CHEMBL1422210 & 688546 & 4.8 & 5.1951 & TRN & \\
\hline CHEMBL1395100 & 688546 & 4.6 & 4.4092 & TST & \\
\hline CHEMBL1514180 & 688546 & 4.5 & 4.904 & TRN & \\
\hline CHEMBL1356205 & 688546 & 5.5 & 5.1011 & TRN & \\
\hline CHEMBL1436439 & 688546 & 5.25 & 5.73799 & 99999999995 & TRN \\
\hline CHEMBL587620 & 688546 & 5.6 & 4.8888 & TRN & \\
\hline CHEMBL1400508 & 688546 & 5.0 & 5.147 & TRN & \\
\hline CHEMBL1450655 & 688546 & 4.5 & 5.3773 & TST & \\
\hline CHEMBL1414582 & 688546 & 4.7 & 5.1099 & TRN & \\
\hline CHEMBL1382209 & 688546 & 4.9 & 4.7518 & TRN & \\
\hline CHEMBL1591038 & 688546 & 4.5 & 5.1168 & TRN & \\
\hline CHEMBL186526 & 688546 & 5.1 & 5.29799 & 9999999999 & TRN \\
\hline CHEMBL1481890 & 688546 & 5.0 & 5.0738 & TRN & \\
\hline CHEMBL1355560 & 688546 & 4.5 & 5.1977 & TRN & \\
\hline CHEMBL1593093 & 688546 & 5.0 & 5.3784 & TRN & \\
\hline CHEMBL1528690 & 688546 & 4.8 & 5.0561 & TRN & \\
\hline CHEMBL1320214 & 688546 & 5.4 & 5.46399 & 99999999995 & TRN \\
\hline CHEMBL1973647 & 688546 & 4.8 & 4.9576 & TST & \\
\hline CHEMBL1400112 & 688546 & 4.7 & 5.269 & TRN & \\
\hline CHEMBL405386 & 688546 & 4.5 & 5.54299 & 9999999999 & TRN \\
\hline CHEMBL1396884 & 688546 & 4.65 & 5.0733 & TRN & \\
\hline CHEMBL 212242 & 688546 & 4.9 & 5.4638 & TRN & \\
\hline CHEMBL1493507 & 688546 & 4.6 & 5.2895 & TST & \\
\hline CHEMBL327708 & 688546 & 4.5 & 5.4826 & TST & \\
\hline CHEMBL1560920 & 688546 & 5.0 & 5.2647 & TST & \\
\hline CHEMBL1360117 & 688546 & 4.7 & 5.0696 & TRN & \\
\hline CHEMBL1611534 & 688546 & 5.4 & 5.9644 & TRN & \\
\hline CHEMBL1601416 & 688546 & 5.0 & 4.7886 & TRN & \\
\hline CHEMBL1424915 & 688546 & 5.4 & 5.3862 & TRN & \\
\hline CHEMBL1437502 & 688546 & 6.3 & 5.3663 & TRN & \\
\hline CHEMBL1397991 & 688546 & 6.05 & 5.7878 & TST & \\
\hline CHEMBL1444896 & 688546 & 4.5 & 5.0269 & TRN & \\
\hline CHEMBL1480615 & 688546 & 4.6 & 5.0749 & TRN & \\
\hline
\end{tabular}




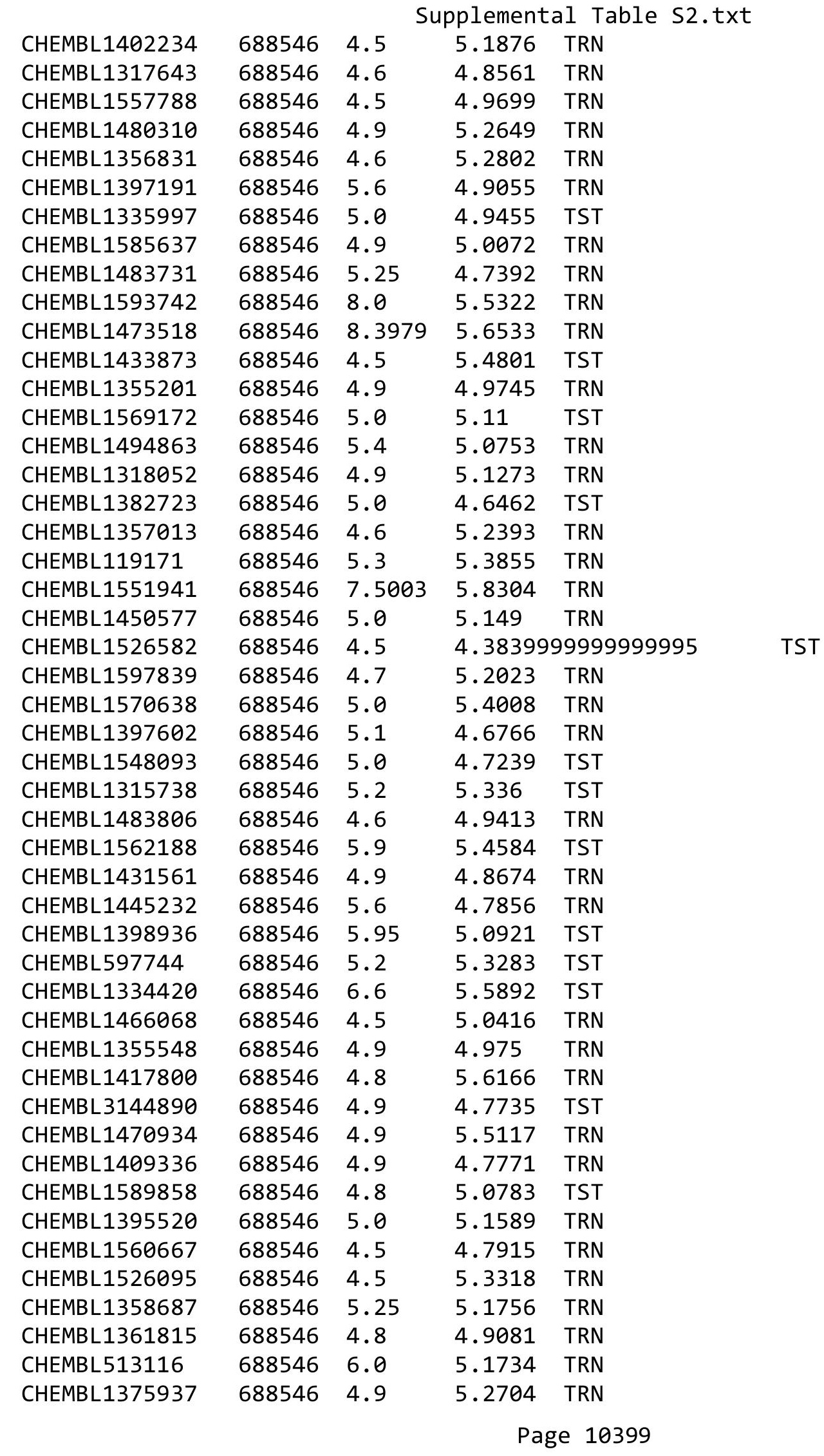




\begin{tabular}{|c|c|c|c|c|c|}
\hline & & & & & \\
\hline CHEMBL1420039 & 688546 & 4.7 & 5.1519 & TST & \\
\hline CHEMBL1448090 & 688546 & 4.9 & 5.4416 & TST & \\
\hline CHEMBL1398550 & 688546 & 4.7 & 5.0005 & TRN & \\
\hline CHEMBL1495888 & 688546 & 4.9 & 5.2671 & TRN & \\
\hline CHEMBL28 & 688546 & 6.0 & 5.5419 & TRN & \\
\hline CHEMBL1488682 & 688546 & 5.0 & 5.0231 & TRN & \\
\hline CHEMBL1313421 & 688546 & 4.8 & 4.9786 & TST & \\
\hline CHEMBL1611060 & 688546 & 5.55 & 4.8984 & TRN & \\
\hline CHEMBL1474454 & 688546 & 5.3 & 5.5413 & TST & \\
\hline CHEMBL1495306 & 688546 & 5.3 & 5.1967 & TRN & \\
\hline CHEMBL1357947 & 688546 & 4.5 & 5.1209 & TRN & \\
\hline CHEMBL1357828 & 688546 & 5.6 & 5.7361 & TRN & \\
\hline CHEMBL1363812 & 688546 & 4.5 & 5.1501 & TRN & \\
\hline CHEMBL1512633 & 688546 & 5.0 & 4.8504 & TRN & \\
\hline CHEMBL1589556 & 688546 & 4.9 & 5.008 & TRN & \\
\hline CHEMBL1434827 & 688546 & 4.6 & 5.3837 & TRN & \\
\hline CHEMBL1570213 & 688546 & 5.0 & 5.0177 & TRN & \\
\hline CHEMBL1436712 & 688546 & 5.8 & 5.2993 & TRN & \\
\hline CHEMBL1316017 & 688546 & 4.7 & 5.9163 & TRN & \\
\hline CHEMBL1565318 & 688546 & 4.6 & 4.7493 & TRN & \\
\hline CHEMBL1407995 & 688546 & 5.7 & 5.3114 & TRN & \\
\hline CHEMBL1712082 & 688546 & 5.5 & 5.6297 & TRN & \\
\hline CHEMBL1415890 & 688546 & 5.4 & 5.9472 & TRN & \\
\hline CHEMBL1484068 & 688546 & 7.6003 & 5.5089 & TRN & \\
\hline CHEMBL1369105 & 688546 & 7.5498 & 5.6769 & TRN & \\
\hline CHEMBL1301425 & 688546 & 4.85 & 5.1525 & TRN & \\
\hline CHEMBL1352023 & 688546 & 5.0 & 5.1336 & TRN & \\
\hline CHEMBL1437736 & 688546 & 4.8 & 5.5216 & TRN & \\
\hline CHEMBL1395162 & 688546 & 5.0 & 4.7966 & TRN & \\
\hline CHEMBL1302338 & 688546 & 4.7 & 5.1003 & TRN & \\
\hline CHEMBL1402362 & 688546 & 5.0 & 5.3429 & TRN & \\
\hline CHEMBL1396384 & 688546 & 4.6 & 4.762 & TRN & \\
\hline CHEMBL1375806 & 688546 & 4.8 & 5.3774 & TRN & \\
\hline CHEMBL1327840 & 688546 & 4.75 & 5.0207 & TST & \\
\hline CHEMBL1442623 & 688546 & 6.7501 & 5.9787 & TRN & \\
\hline CHEMBL1591263 & 688546 & 4.5 & 5.33299 & 9999999999 & TRN \\
\hline CHEMBL1449808 & 688546 & 4.9 & 5.4764 & TRN & \\
\hline CHEMBL1321398 & 688546 & 4.6 & 5.0044 & TST & \\
\hline CHEMBL1434732 & 688546 & 4.6 & 4.6224 & TRN & \\
\hline CHEMBL1515065 & 688546 & 5.4 & 6.1529 & TST & \\
\hline CHEMBL1568343 & 688546 & 5.2 & 5.15799 & 99999999995 & TRN \\
\hline CHEMBL1330618 & 688546 & 4.7 & 4.6825 & TRN & \\
\hline CHEMBL1343568 & 688546 & 4.9 & 5.0948 & TRN & \\
\hline CHEMBL1597642 & 688546 & 6.8 & 5.36299 & 99999999995 & TRN \\
\hline CHEMBL1512716 & 688546 & 6.5 & 5.0875 & TST & \\
\hline CHEMBL1569543 & 688546 & 4.9 & 5.1455 & TRN & \\
\hline CHEMBL1323460 & 688546 & 6.0 & 5.2035 & TRN & \\
\hline CHEMBL1578425 & 688546 & 4.8 & 5.24200 & 0000000001 & TRN \\
\hline & & & & 10400 & \\
\hline
\end{tabular}




\begin{tabular}{|c|c|c|c|c|}
\hline \multicolumn{5}{|c|}{ Supplemental Table S2.txt } \\
\hline CHEMBL1365239 & 688546 & 4.8 & 4.9996 & TRN \\
\hline CHEMBL1415793 & 688546 & 4.7 & 5.4368 & TRN \\
\hline CHEMBL1473238 & 688546 & 4.7 & 4.746 & TRN \\
\hline CHEMBL1318407 & 688546 & 4.8 & 5.0831 & TRN \\
\hline CHEMBL1480312 & 688546 & 5.9 & 5.5809 & TRN \\
\hline CHEMBL3193405 & 688546 & 4.95 & 5.3881 & TST \\
\hline CHEMBL1482401 & 688546 & 4.7 & 4.9006 & TRN \\
\hline CHEMBL577455 & 688546 & 7.1002 & 5.5541 & TST \\
\hline CHEMBL1462403 & 688546 & 4.5 & 5.2688 & TRN \\
\hline CHEMBL1590364 & 688546 & 5.4 & 6.1944 & TRN \\
\hline CHEMBL1307919 & 688546 & 6.1 & 5.1214 & TST \\
\hline CHEMBL1456371 & 688546 & 4.55 & 5.185 & TST \\
\hline CHEMBL1418707 & 688546 & 4.9 & 5.3106 & TRN \\
\hline CHEMBL592712 & 688546 & 4.5 & 4.6087 & TST \\
\hline CHEMBL1473833 & 688546 & 5.1 & 5.4564 & TRN \\
\hline CHEMBL1512994 & 688546 & 5.0 & 5.6981 & TRN \\
\hline CHEMBL1407248 & 688546 & 4.9 & 5.66 & TRN \\
\hline CHEMBL1435759 & 688546 & 6.3 & 5.2592 & TRN \\
\hline CHEMBL1368609 & 688546 & 4.45 & 4.795 & TST \\
\hline CHEMBL1531320 & 688546 & 4.8 & 5.3311 & TRN \\
\hline CHEMBL1556960 & 688546 & 5.9 & 5.5501 & TRN \\
\hline CHEMBL1350251 & 688546 & 4.8 & 5.5699 & TST \\
\hline CHEMBL1515135 & 688546 & 4.5 & 4.7118 & TRN \\
\hline CHEMBL1516336 & 688546 & 5.0 & 5.3943 & TRN \\
\hline CHEMBL1604794 & 688546 & 4.6 & 4.9486 & TRN \\
\hline CHEMBL1455413 & 688546 & 5.4 & 5.3399 & TRN \\
\hline CHEMBL1537967 & 688546 & 4.9 & 5.2383 & TST \\
\hline CHEMBL1486433 & 688546 & 7.6498 & 5.2214 & TRN \\
\hline CHEMBL1592221 & 688546 & 4.8 & 5.2434 & TRN \\
\hline CHEMBL1441360 & 688546 & 5.0 & 5.8946 & TRN \\
\hline CHEMBL 273103 & 688546 & 4.8 & 4.9261 & TRN \\
\hline CHEMBL1549692 & 688546 & 4.7 & 4.7015 & TST \\
\hline CHEMBL1477803 & 688546 & 5.5 & 4.8293 & TRN \\
\hline CHEMBL1336384 & 688546 & 5.3 & 5.3503 & TRN \\
\hline CHEMBL1512137 & 688546 & 4.7 & 5.0022 & TRN \\
\hline CHEMBL1333254 & 688546 & 4.9 & 4.8554 & TRN \\
\hline CHEMBL1416859 & 688546 & 5.0 & 5.3597 & TRN \\
\hline CHEMBL1377435 & 688546 & 5.0 & 5.7303 & TRN \\
\hline CHEMBL1415560 & 688546 & 5.1 & 4.6346 & TRN \\
\hline CHEMBL1362247 & 688546 & 4.8 & 5.1135 & TRN \\
\hline CHEMBL1397302 & 688546 & 4.9 & 5.2683 & TRN \\
\hline CHEMBL1595524 & 688546 & 4.9 & 5.0187 & TST \\
\hline CHEMBL1434092 & 688546 & 4.9 & 5.306 & TRN \\
\hline CHEMBL1316767 & 688546 & 4.8 & 5.0281 & TRN \\
\hline CHEMBL1604894 & 688546 & 5.1 & 5.3175 & TST \\
\hline CHEMBL1436000 & 688546 & 4.7 & 5.5726 & TRN \\
\hline CHEMBL1315331 & 688546 & 5.4 & 5.2539 & TRN \\
\hline CHEMBL1372068 & 688546 & 6.6499 & 5.6297 & TRN \\
\hline
\end{tabular}




\begin{tabular}{|c|c|c|c|c|}
\hline & & & pplement & al $\mathrm{Ta}$ \\
\hline CHEMBL1546213 & 688546 & 4.5 & 4.5837 & TRN \\
\hline CHEMBL1361775 & 688546 & 4.9 & 4.9472 & TRN \\
\hline CHEMBL1353378 & 688546 & 4.5 & 5.347 & TST \\
\hline CHEMBL1368561 & 688546 & 5.3 & 5.6317 & TRN \\
\hline CHEMBL1532162 & 688546 & 5.4 & 5.4913 & TRN \\
\hline CHEMBL1433782 & 688546 & 6.6 & 4.9239 & TRN \\
\hline CHEMBL1529932 & 688546 & 4.8 & 5.2438 & TRN \\
\hline CHEMBL1522274 & 688546 & 4.9 & 5.7009 & TRN \\
\hline CHEMBL1556048 & 688546 & 5.95 & 5.5693 & TST \\
\hline CHEMBL1395764 & 688546 & 4.9 & 5.2662 & TRN \\
\hline CHEMBL1304398 & 688546 & 5.1 & 5.2289 & TRN \\
\hline CHEMBL3193652 & 688546 & 5.25 & 5.1719 & TRN \\
\hline CHEMBL1331065 & 688546 & 4.85 & 4.9635 & TRN \\
\hline CHEMBL1590365 & 688546 & 4.9 & 5.1861 & TRN \\
\hline CHEMBL1318023 & 688546 & 4.5 & 4.8456 & TRN \\
\hline CHEMBL1504458 & 688546 & 5.0 & 5.7241 & TST \\
\hline CHEMBL1327028 & 688546 & 4.8 & 5.1085 & TRN \\
\hline CHEMBL1338469 & 688546 & 4.5 & 5.3947 & TRN \\
\hline CHEMBL1394780 & 688546 & 6.2 & 5.8841 & TRN \\
\hline CHEMBL1436242 & 688546 & 5.0 & 5.001 & TRN \\
\hline CHEMBL1409056 & 688546 & 4.5 & 5.6106 & TST \\
\hline CHEMBL1478129 & 688546 & 8.0 & 5.5088 & TRN \\
\hline CHEMBL1442465 & 688546 & 4.9 & 4.7595 & TRN \\
\hline CHEMBL1407095 & 688546 & 4.9 & 4.9185 & TRN \\
\hline CHEMBL3198964 & 688546 & 5.0 & 5.2814 & TRN \\
\hline CHEMBL1534666 & 688546 & 4.9 & 4.9439 & TST \\
\hline CHEMBL1606108 & 688546 & 4.6 & 4.9244 & TST \\
\hline CHEMBL1422129 & 688546 & 5.3 & 5.49 & TRN \\
\hline CHEMBL1257075 & 688546 & 6.0 & 5.5213 & TST \\
\hline CHEMBL1477366 & 688546 & 4.7 & 5.4205 & TRN \\
\hline CHEMBL1314449 & 688546 & 6.9 & 5.5969 & TST \\
\hline CHEMBL1555310 & 688546 & 6.5 & 5.3497 & TRN \\
\hline CHEMBL1474556 & 688546 & 4.6 & 5.0707 & TRN \\
\hline CHEMBL1319960 & 688546 & 4.9 & 4.9945 & TRN \\
\hline CHEMBL1520615 & 688546 & 4.5 & 4.8758 & TST \\
\hline CHEMBL1476242 & 688546 & 4.5 & 5.5305 & TRN \\
\hline CHEMBL440287 & 688546 & 4.5 & 5.3507 & TST \\
\hline CHEMBL1410576 & 688546 & 4.7 & 5.3561 & TST \\
\hline CHEMBL1414344 & 688546 & 5.0 & 5.4354 & TRN \\
\hline CHEMBL1567475 & 688546 & 4.8 & 5.2587 & TRN \\
\hline CHEMBL265177 & 688546 & 5.9 & 5.2792 & TST \\
\hline CHEMBL1354951 & 688546 & 5.0 & 4.95 & TRN \\
\hline CHEMBL1591775 & 688546 & 7.8996 & 5.9045 & TST \\
\hline CHEMBL1331179 & 688546 & 4.5 & 5.7385 & TRN \\
\hline CHEMBL1561340 & 688546 & 7.5003 & 5.7291 & TRN \\
\hline CHEMBL1357534 & 688546 & 5.45 & 5.1658 & TRN \\
\hline CHEMBL1474904 & 688546 & 4.9 & 4.9279 & TRN \\
\hline CHEMBL1410284 & 688546 & 4.5 & 5.2621 & TST \\
\hline
\end{tabular}




\begin{tabular}{|c|c|c|c|c|}
\hline & & & pplement & $\mathrm{a} \perp \mathrm{Ta}$ \\
\hline CHEMBL1609850 & 688546 & 4.8 & 5.5915 & TRN \\
\hline CHEMBL1605488 & 688546 & 5.0 & 5.1397 & TRN \\
\hline CHEMBL1178 & 688546 & 4.5 & 5.0343 & TST \\
\hline CHEMBL1506065 & 688546 & 5.0 & 5.4354 & TRN \\
\hline CHEMBL1098658 & 688546 & 4.9 & 5.5518 & TST \\
\hline CHEMBL1454626 & 688546 & 4.7 & 5.1025 & TRN \\
\hline CHEMBL1512029 & 688546 & 8.0 & 5.6447 & TRN \\
\hline CHEMBL1473242 & 688546 & 5.0 & 5.1917 & TRN \\
\hline CHEMBL1363415 & 688546 & 4.9 & 4.9598 & TRN \\
\hline CHEMBL1354597 & 688546 & 4.5 & 5.6453 & TST \\
\hline CHEMBL1592502 & 688546 & 4.5 & 5.1608 & TRN \\
\hline CHEMBL1606484 & 688546 & 4.5 & 5.21 & TRN \\
\hline CHEMBL1314209 & 688546 & 4.5 & 5.1843 & TRN \\
\hline CHEMBL1323603 & 688546 & 4.5 & 4.8827 & TRN \\
\hline CHEMBL533577 & 688546 & 4.8 & 5.5285 & TST \\
\hline CHEMBL1360225 & 688546 & 4.5 & 4.9659 & TRN \\
\hline CHEMBL1394362 & 688546 & 4.8 & 4.9002 & TRN \\
\hline CHEMBL1554005 & 688546 & 5.0 & 5.7758 & TST \\
\hline CHEMBL1442682 & 688546 & 5.0 & 4.5111 & TST \\
\hline CHEMBL1559532 & 688546 & 4.6 & 5.138 & TRN \\
\hline CHEMBL1434813 & 688546 & 5.7 & 5.4602 & TRN \\
\hline CHEMBL1402233 & 688546 & 4.7 & 4.9651 & TST \\
\hline CHEMBL3199142 & 688546 & 4.9 & 5.2488 & TST \\
\hline CHEMBL1501061 & 688546 & 5.0 & 5.1643 & TRN \\
\hline CHEMBL1440188 & 688546 & 5.0 & 5.0035 & TRN \\
\hline CHEMBL1376853 & 688546 & 5.2 & 5.1835 & TRN \\
\hline CHEMBL1367487 & 688546 & 5.8 & 5.2526 & TRN \\
\hline CHEMBL1315378 & 688546 & 7.699 & 5.5584 & TRN \\
\hline CHEMBL1468103 & 688546 & 4.9 & 5.4982 & TRN \\
\hline CHEMBL1255866 & 688546 & 4.5 & 4.9706 & TST \\
\hline CHEMBL1416781 & 688546 & 4.45 & 5.1066 & TRN \\
\hline CHEMBL1473929 & 688546 & 5.8 & 5.95 & TRN \\
\hline CHEMBL1441920 & 688546 & 4.9 & 5.3037 & TST \\
\hline CHEMBL1398429 & 688546 & 4.7 & 4.9619 & TRN \\
\hline CHEMBL1433419 & 688546 & 6.2 & 5.7455 & TST \\
\hline CHEMBL1611441 & 688546 & 4.5 & 5.4072 & TRN \\
\hline CHEMBL1384725 & 688546 & 4.9 & 5.0653 & TRN \\
\hline CHEMBL1407986 & 688546 & 5.1 & 5.3839 & TRN \\
\hline CHEMBL1474489 & 688546 & 4.6 & 4.8837 & TRN \\
\hline CHEMBL1455239 & 688546 & 5.4 & 5.4417 & TST \\
\hline CHEMBL1388197 & 688546 & 4.9 & 4.9001 & TRN \\
\hline CHEMBL1516173 & 688546 & 5.1 & 5.3489 & TRN \\
\hline CHEMBL1515860 & 688546 & 4.5 & 5.6638 & TRN \\
\hline CHEMBL1395413 & 688546 & 4.7 & 5.2326 & TRN \\
\hline CHEMBL1976446 & 688546 & 4.5 & 5.1121 & TST \\
\hline CHEMBL1475684 & 688546 & 4.8 & 5.4788 & TRN \\
\hline CHEMBL1318399 & 688546 & 4.9 & 5.6255 & TRN \\
\hline CHEMBL1357763 & 688546 & 4.9 & 5.4723 & TRN \\
\hline
\end{tabular}




\begin{tabular}{|c|c|c|c|c|c|}
\hline \multirow[b]{2}{*}{ CHEMBL1515148 } & \multicolumn{5}{|c|}{ plementas re } \\
\hline & 688546 & 4.7 & 5.3251 & TRN & \\
\hline CHEMBL1569243 & 688546 & 4.9 & 5.3723 & TST & \\
\hline CHEMBL1398929 & 688546 & 5.6 & 5.4279 & TRN & \\
\hline CHEMBL1444684 & 688546 & 5.25 & 5.41299 & 9999999999 & TRN \\
\hline CHEMBL1515629 & 688546 & 4.9 & 5.4716 & TRN & \\
\hline CHEMBL1563222 & 688546 & 5.7 & 5.36799 & 9999999999 & TRN \\
\hline CHEMBL1586489 & 688546 & 4.5 & 5.1814 & TST & \\
\hline CHEMBL1595519 & 688546 & 5.65 & 5.1699 & TST & \\
\hline CHEMBL1592002 & 688546 & 7.4001 & 5.3174 & TRN & \\
\hline CHEMBL1555409 & 688546 & 5.3 & 5.3464 & TRN & \\
\hline CHEMBL1595394 & 688546 & 6.6 & 5.6165 & TRN & \\
\hline CHEMBL1406922 & 688546 & 4.6 & 5.0511 & TRN & \\
\hline CHEMBL1408789 & 688546 & 5.1 & 5.149 & TRN & \\
\hline CHEMBL1435166 & 688546 & 4.7 & 5.5524 & TST & \\
\hline CHEMBL1512490 & 688546 & 4.6 & 4.8522 & TRN & \\
\hline CHEMBL1484854 & 688546 & 4.9 & 4.9689 & TRN & \\
\hline CHEMBL1403819 & 688546 & 5.3 & 4.9322 & TST & \\
\hline CHEMBL1417084 & 688546 & 5.25 & 5.0525 & TST & \\
\hline CHEMBL1553427 & 688546 & 5.0 & 5.218 & TRN & \\
\hline CHEMBL1502721 & 688546 & 5.0 & 4.9799 & TRN & \\
\hline CHEMBL1316451 & 688546 & 5.8 & 5.4405 & TRN & \\
\hline CHEMBL1514210 & 688546 & 5.0 & 5.449 & TRN & \\
\hline CHEMBL1380845 & 688546 & 7.6498 & 5.1833 & TST & \\
\hline CHEMBL1404601 & 688546 & 4.9 & 5.20700 & 0000000001 & TRN \\
\hline CHEMBL585769 & 688546 & 4.45 & 5.3811 & TRN & \\
\hline CHEMBL1493857 & 688546 & 5.6 & 5.15799 & 99999999995 & TRN \\
\hline CHEMBL1356824 & 688546 & 5.3 & 5.0056 & TST & \\
\hline CHEMBL 76904 & 688546 & 4.8 & 4.9745 & TRN & \\
\hline CHEMBL1356652 & 688546 & 4.6 & 5.1071 & TRN & \\
\hline CHEMBL1353194 & 688546 & 4.7 & 5.1195 & TRN & \\
\hline CHEMBL1487152 & 688546 & 5.0 & 5.2145 & TRN & \\
\hline CHEMBL1455160 & 688546 & 5.0 & 5.54799 & 9999999999 & TRN \\
\hline CHEMBL1363070 & 688546 & 5.3 & 5.4998 & TRN & \\
\hline CHEMBL1607849 & 688546 & 4.9 & 5.5042 & TRN & \\
\hline CHEMBL1489944 & 688546 & 5.0 & 4.9654 & TST & \\
\hline CHEMBL1475830 & 688546 & 5.1 & 5.505 & TRN & \\
\hline CHEMBL1316981 & 688546 & 5.4 & 5.971 & TRN & \\
\hline CHEMBL1572004 & 688546 & 7.5003 & 6.3853 & TRN & \\
\hline CHEMBL1331288 & 688546 & 4.7 & 5.1061 & TRN & \\
\hline CHEMBL1328299 & 688546 & 4.8 & 4.9029 & TRN & \\
\hline CHEMBL1513406 & 688546 & 5.0 & 5.1596 & TRN & \\
\hline CHEMBL1561266 & 688546 & 4.5 & 5.1237 & TRN & \\
\hline CHEMBL1567968 & 688546 & 4.6 & 5.1383 & TRN & \\
\hline CHEMBL1328696 & 688546 & 4.9 & 5.6888 & TRN & \\
\hline CHEMBL3213585 & 688546 & 4.7 & 5.3992 & TST & \\
\hline CHEMBL1369299 & 688546 & 5.1 & 5.5949 & TRN & \\
\hline CHEMBL1514877 & 688546 & 8.1024 & 5.7548 & TRN & \\
\hline CHEMBL1557071 & 688546 & 4.45 & 5.4006 & TST & \\
\hline
\end{tabular}




\begin{tabular}{|c|c|c|c|c|c|}
\hline & & & & & \\
\hline CHEMBL1354442 & 688546 & 4.9 & 4.8309 & TRN & \\
\hline CHEMBL1543167 & 688546 & 5.0 & 5.0588 & TRN & \\
\hline CHEMBL1554253 & 688546 & 5.5 & 4.7148 & TRN & \\
\hline CHEMBL1554051 & 688546 & 5.7 & 5.8106 & TRN & \\
\hline CHEMBL1318311 & 688546 & 4.5 & 5.2958 & TRN & \\
\hline CHEMBL1394285 & 688546 & 4.6 & 5.526 & TRN & \\
\hline CHEMBL1595981 & 688546 & 7.3002 & 5.3213 & TRN & \\
\hline CHEMBL1475987 & 688546 & 6.5 & 5.2498 & TRN & \\
\hline CHEMBL1526680 & 688546 & 5.0 & 5.0917 & TST & \\
\hline CHEMBL1552699 & 688546 & 4.9 & 5.34399 & 9999999999 & TRN \\
\hline CHEMBL1470485 & 688546 & 4.9 & 5.4659 & TST & \\
\hline CHEMBL1314968 & 688546 & 5.4 & 5.2189 & TRN & \\
\hline CHEMBL1431591 & 688546 & 4.5 & 5.1746 & TRN & \\
\hline CHEMBL1325479 & 688546 & 4.8 & 5.0551 & TRN & \\
\hline CHEMBL1611663 & 688546 & 4.85 & 5.7802 & TRN & \\
\hline CHEMBL1552723 & 688546 & 4.8 & 4.98600 & 0000000001 & TRN \\
\hline CHEMBL1457612 & 688546 & 4.45 & 4.715 & TRN & \\
\hline CHEMBL3199665 & 688546 & 5.4 & 5.3659 & TST & \\
\hline CHEMBL1401277 & 688546 & 5.7 & 5.567 & TRN & \\
\hline CHEMBL1390863 & 688546 & 4.8 & 5.0345 & TST & \\
\hline CHEMBL1531552 & 688546 & 4.8 & 5.0177 & TRN & \\
\hline CHEMBL1433411 & 688546 & 5.45 & 4.9829 & TST & \\
\hline CHEMBL1456865 & 688546 & 7.5003 & 5.8843 & TST & \\
\hline CHEMBL1592591 & 688546 & 5.1 & 5.2226 & TRN & \\
\hline CHEMBL1446335 & 688546 & 4.9 & 4.8564 & TRN & \\
\hline CHEMBL1512004 & 688546 & 8.301 & 5.3907 & TRN & \\
\hline CHEMBL1395481 & 688546 & 4.5 & 5.5413 & TST & \\
\hline CHEMBL1378764 & 688546 & 4.5 & 5.0344 & TRN & \\
\hline CHEMBL1477629 & 688546 & 5.85 & 4.89 & TRN & \\
\hline CHEMBL1398471 & 688546 & 6.6 & 4.8368 & TRN & \\
\hline CHEMBL1521232 & 688546 & 4.9 & 5.7092 & TRN & \\
\hline CHEMBL1356019 & 688546 & 4.5 & 5.045 & TRN & \\
\hline CHEMBL1478841 & 688546 & 4.9 & 5.4764 & TST & \\
\hline CHEMBL1587568 & 688546 & 4.9 & 5.2249 & TRN & \\
\hline CHEMBL1593498 & 688546 & 7.699 & 5.6668 & TRN & \\
\hline CHEMBL1521620 & 688546 & 4.7 & 5.8066 & TRN & \\
\hline CHEMBL1512279 & 688546 & 5.0 & 5.2001 & TRN & \\
\hline CHEMBL1327253 & 688546 & 5.0 & 4.9052 & TST & \\
\hline CHEMBL1533566 & 688546 & 5.0 & 5.5956 & TRN & \\
\hline CHEMBL 275311 & 688546 & 4.9 & 5.4299 & TST & \\
\hline CHEMBL1497557 & 688546 & 4.9 & 5.0208 & TRN & \\
\hline CHEMBL1519056 & 688546 & 4.9 & 5.5298 & TRN & \\
\hline CHEMBL1476953 & 688546 & 5.6 & 5.2909 & TRN & \\
\hline CHEMBL1447819 & 688546 & 4.5 & 5.4431 & TRN & \\
\hline CHEMBL1554471 & 688546 & 4.9 & 5.3913 & TRN & \\
\hline CHEMBL1604420 & 688546 & 4.5 & 5.3694 & TST & \\
\hline CHEMBL1449954 & 688546 & 4.9 & 5.3004 & TRN & \\
\hline CHEMBL1513001 & 688546 & 4.6 & 5.6199 & TRN & \\
\hline
\end{tabular}




\begin{tabular}{|c|c|c|c|c|c|}
\hline \\
\hline CHEMBL1455934 & 688546 & 5.3 & 4.7258 & TRN & \\
\hline CHEMBL1513396 & 688546 & 4.9 & 4.8423 & TRN & \\
\hline CHEMBL1555938 & 688546 & 5.2 & 5.0596 & TST & \\
\hline CHEMBL282489 & 688546 & 4.9 & 5.1316 & TST & \\
\hline CHEMBL1394187 & 688546 & 4.5 & 5.1831 & TRN & \\
\hline CHEMBL1394906 & 688546 & 4.7 & 5.4925 & TRN & \\
\hline CHEMBL1317851 & 688546 & 4.8 & 5.4697 & TRN & \\
\hline CHEMBL1553105 & 688546 & 4.8 & 4.8141 & TRN & \\
\hline CHEMBL1331263 & 688546 & 5.0 & 5.113 & TRN & \\
\hline CHEMBL1591417 & 688546 & 5.7 & 5.7777 & TRN & \\
\hline CHEMBL1455275 & 688546 & 8.4559 & 5.0958 & TRN & \\
\hline CHEMBL1512027 & 688546 & 4.7 & 5.4686 & TRN & \\
\hline CHEMBL1455630 & 688546 & 5.0 & 5.1768 & TST & \\
\hline CHEMBL1552547 & 688546 & 6.4 & 5.3158 & TST & \\
\hline CHEMBL294009 & 688546 & 4.9 & 4.8248 & TRN & \\
\hline CHEMBL1308331 & 688546 & 5.2 & 5.0584 & TRN & \\
\hline CHEMBL1372601 & 688546 & 4.9 & 5.0704 & TRN & \\
\hline CHEMBL1590154 & 688546 & 6.7001 & 5.8042 & TRN & \\
\hline CHEMBL1337500 & 688546 & 4.5 & 5.3476 & TST & \\
\hline CHEMBL1512414 & 688546 & 5.2 & 5.05 & TRN & \\
\hline CHEMBL1480213 & 688546 & 6.2 & 5.3829 & TRN & \\
\hline CHEMBL1528759 & 688546 & 6.1 & 4.9577 & TRN & \\
\hline CHEMBL1579152 & 688546 & 4.65 & 5.0507 & TST & \\
\hline CHEMBL1602608 & 688546 & 5.0 & 4.8125 & TRN & \\
\hline CHEMBL1350195 & 688546 & 4.7 & 4.7621 & TRN & \\
\hline CHEMBL1452558 & 688546 & 5.0 & 5.1164 & TST & \\
\hline CHEMBL1397115 & 688546 & 4.9 & 5.4017 & TRN & \\
\hline CHEMBL1357804 & 688546 & 4.7 & 5.2346 & TRN & \\
\hline CHEMBL1473450 & 688546 & 6.3 & 4.8141 & TRN & \\
\hline CHEMBL1328073 & 688546 & 5.0 & 5.1923 & TST & \\
\hline CHEMBL1409268 & 688546 & 4.8 & 5.136 & TRN & \\
\hline CHEMBL1555645 & 688546 & 4.5 & 5.4295 & TST & \\
\hline CHEMBL1542436 & 688546 & 4.9 & 4.7834 & TST & \\
\hline CHEMBL1591135 & 688546 & 5.0 & 5.0864 & TRN & \\
\hline CHEMBL1368023 & 688546 & 5.25 & 5.3875 & TRN & \\
\hline CHEMBL1488592 & 688546 & 4.6 & 5.5387 & TST & \\
\hline CHEMBL1476724 & 688546 & 4.6 & 5.0727 & TRN & \\
\hline CHEMBL1533731 & 688546 & 4.45 & $5.2070 e$ & 0000000001 & TRN \\
\hline CHEMBL1356313 & 688546 & 5.0 & 5.7846 & TRN & \\
\hline CHEMBL1478843 & 688546 & 5.0 & 5.2975 & TST & \\
\hline CHEMBL1572836 & 688546 & 4.6 & 4.9554 & TRN & \\
\hline CHEMBL1361689 & 688546 & 5.1 & 5.0698 & TRN & \\
\hline CHEMBL1567796 & 688546 & 7.699 & 5.2538 & TRN & \\
\hline CHEMBL1533813 & 688546 & 4.8 & 4.7849 & TRN & \\
\hline CHEMBL1418686 & 688546 & 5.4 & 4.48 & TRN & \\
\hline CHEMBL1474458 & 688546 & 5.0 & 4.885 & TRN & \\
\hline CHEMBL1335489 & 688546 & 5.0 & 4.8446 & TRN & \\
\hline CHEMBL1394885 & 688546 & 5.9 & 5.6389 & TRN & \\
\hline & & & & 24 & \\
\hline
\end{tabular}




\begin{tabular}{|c|c|c|c|c|}
\hline \multicolumn{5}{|c|}{ Supplemental Table S2.txt } \\
\hline CHEMBL150 & 688546 & 6.0 & 5.4759 & TRN \\
\hline CHEMBL1458833 & 688546 & 4.85 & 5.4497 & TST \\
\hline CHEMBL1354476 & 688546 & 6.5501 & 6.0663 & TRN \\
\hline CHEMBL1475006 & 688546 & 4.9 & 5.4387 & TRN \\
\hline CHEMBL1397995 & 688546 & 4.5 & 5.3842 & TST \\
\hline CHEMBL1398454 & 688546 & 5.4 & 4.7513 & TRN \\
\hline CHEMBL1574649 & 688546 & 4.5 & 5.2108 & TRN \\
\hline CHEMBL1593540 & 688546 & 5.5 & 5.9957 & TRN \\
\hline CHEMBL1436250 & 688546 & 5.0 & 4.8538 & TRN \\
\hline CHEMBL1327026 & 688546 & 5.9 & 5.2306 & TRN \\
\hline CHEMBL1317173 & 688546 & 4.9 & 5.4003 & TST \\
\hline CHEMBL1478181 & 688546 & 5.05 & 5.7572 & TST \\
\hline CHEMBL1208858 & 688546 & 4.8 & 5.2204 & TST \\
\hline CHEMBL1256180 & 688546 & 4.5 & 5.1879 & TST \\
\hline CHEMBL1612118 & 688546 & 4.65 & 5.0935 & TST \\
\hline CHEMBL47940 & 688546 & 4.8 & 4.872 & TST \\
\hline CHEMBL1489306 & 688546 & 4.7 & 4.7038 & TRN \\
\hline CHEMBL1299399 & 688546 & 4.5 & 4.9359 & TRN \\
\hline CHEMBL1435387 & 688546 & 4.8 & 4.7258 & TRN \\
\hline CHEMBL1582178 & 688546 & 7.4001 & 5.081 & TST \\
\hline CHEMBL1338533 & 688546 & 4.8 & 5.0981 & TST \\
\hline CHEMBL550826 & 688546 & 4.7 & 4.9955 & TST \\
\hline CHEMBL1343178 & 688546 & 5.3 & 4.668 & TRN \\
\hline CHEMBL1485895 & 688546 & 4.9 & 5.1835 & TRN \\
\hline CHEMBL1569404 & 688546 & 6.0 & 5.0217 & TST \\
\hline CHEMBL1338853 & 688546 & 5.0 & 5.1849 & TRN \\
\hline CHEMBL1501302 & 688546 & 4.6 & 4.9324 & TRN \\
\hline CHEMBL1592763 & 688546 & 4.8 & 5.4685 & TRN \\
\hline CHEMBL1318220 & 688546 & 5.0 & 5.3418 & TRN \\
\hline CHEMBL1438452 & 688546 & 4.9 & 5.1239 & TRN \\
\hline CHEMBL1364512 & 688546 & 5.2 & 5.3009 & TRN \\
\hline CHEMBL1371318 & 688546 & 5.5 & 5.9134 & TRN \\
\hline CHEMBL1560217 & 688546 & 4.5 & 4.7704 & TRN \\
\hline CHEMBL1551621 & 688546 & 4.9 & 5.0719 & TRN \\
\hline CHEMBL1609632 & 688546 & 4.8 & 5.3064 & TRN \\
\hline CHEMBL1335190 & 688546 & 4.9 & 5.0879 & TST \\
\hline CHEMBL1565641 & 688546 & 5.0 & 4.8347 & TRN \\
\hline CHEMBL1556372 & 688546 & 5.0 & 5.1036 & TRN \\
\hline CHEMBL1406513 & 688546 & 4.9 & 5.2615 & TRN \\
\hline CHEMBL1417032 & 688546 & 6.7001 & 5.5823 & TRN \\
\hline CHEMBL1552010 & 688546 & 7.3497 & 5.5564 & TRN \\
\hline CHEMBL1354317 & 688546 & 5.1 & 5.7664 & TRN \\
\hline CHEMBL1312086 & 688546 & 5.25 & 5.3788 & TST \\
\hline CHEMBL1362127 & 688546 & 5.0 & 5.4712 & TST \\
\hline CHEMBL1425634 & 688546 & 5.3 & 6.0205 & TST \\
\hline CHEMBL1567097 & 688546 & 4.9 & 4.6352 & TRN \\
\hline CHEMBL3198339 & 688546 & 5.0 & 5.2934 & TST \\
\hline CHEMBL1523468 & 688546 & 4.9 & 5.1308 & TRN \\
\hline
\end{tabular}




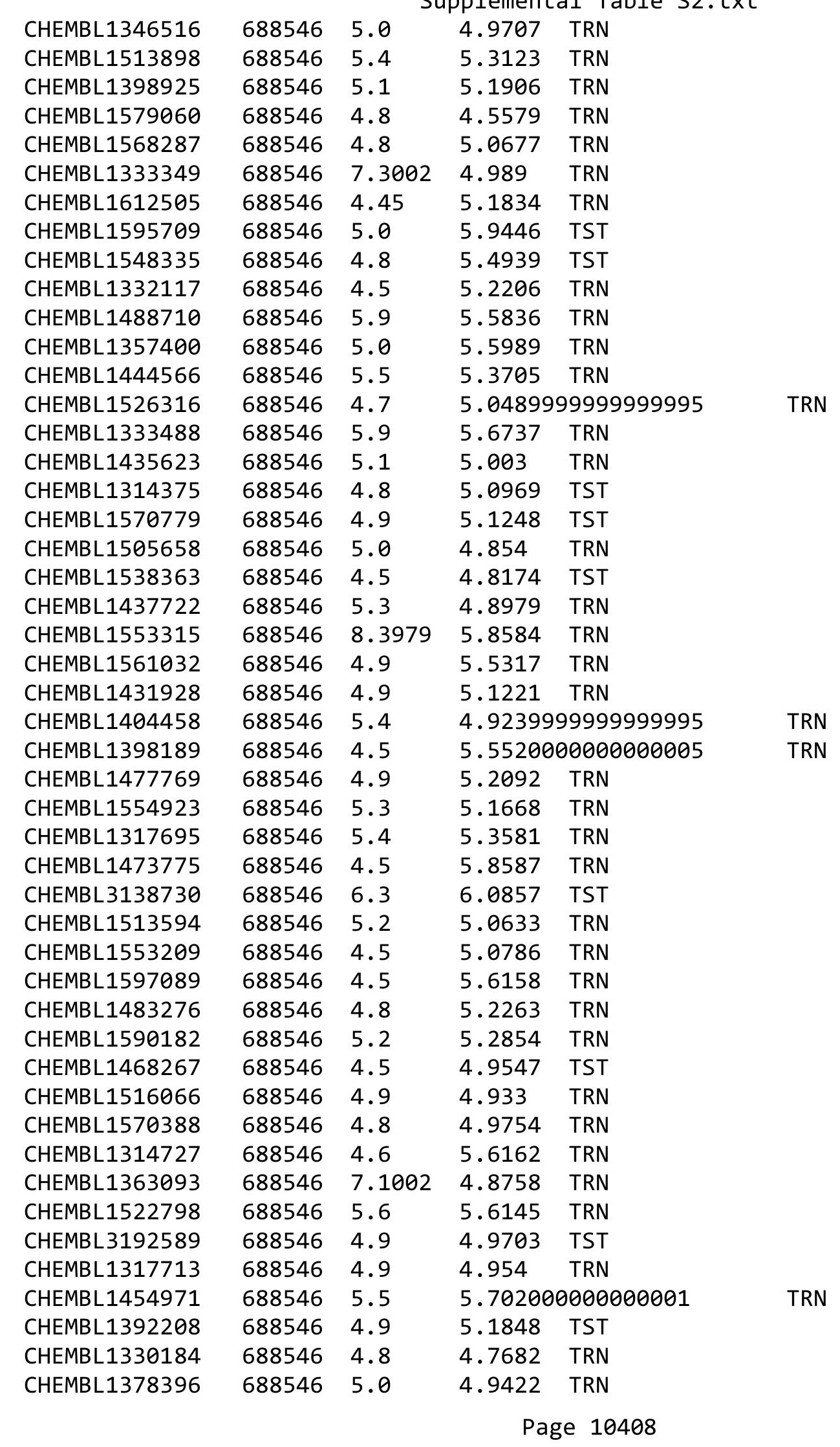




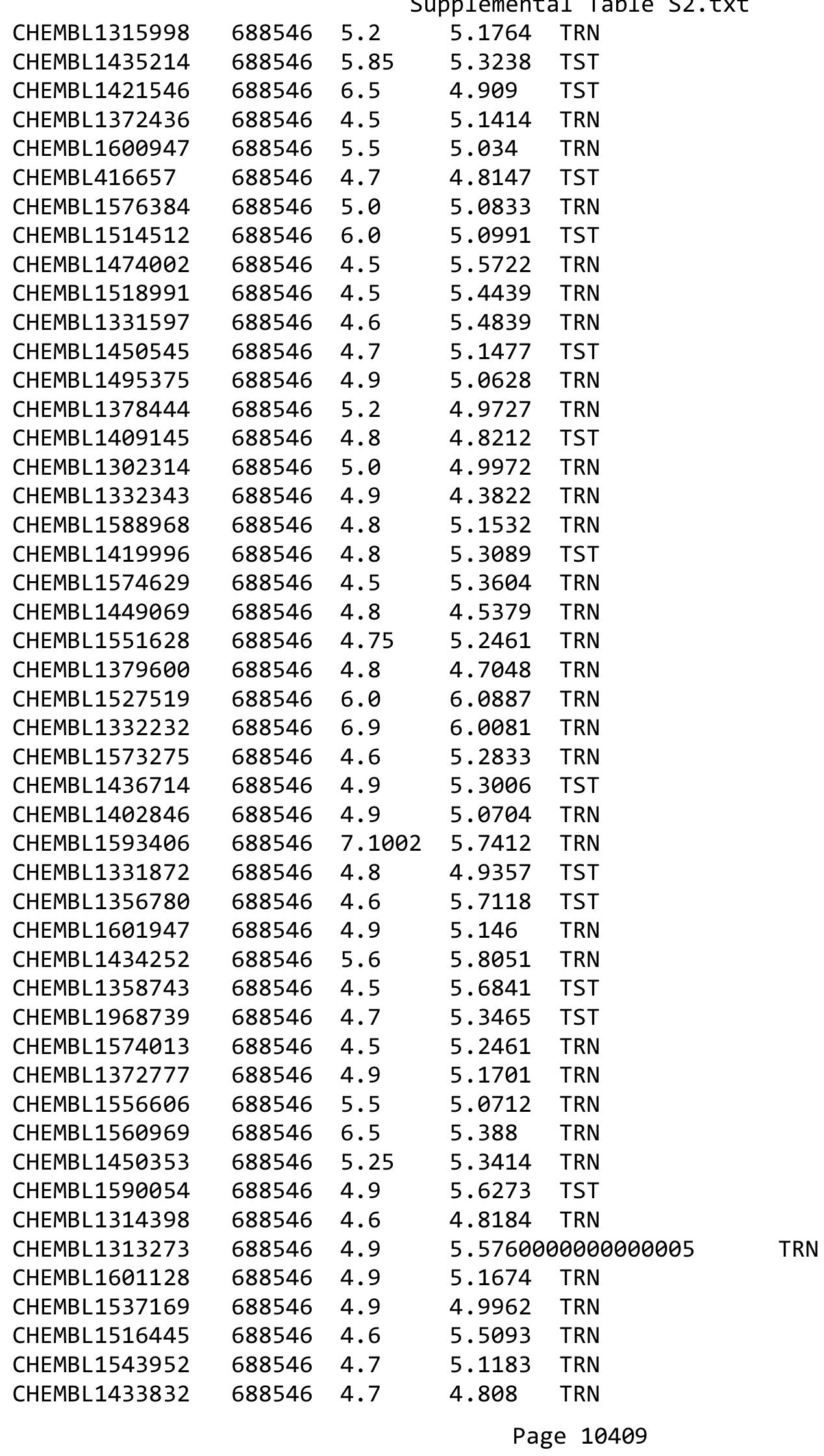




\begin{tabular}{|c|c|c|c|c|c|}
\hline \multirow{2}{*}{ CHEMBL1453812 } & \multirow{2}{*}{688546} & \\
\hline & & 5.0 & 4.999 & TRN & \\
\hline CHEMBL1366852 & 688546 & 6.45 & 5.4004 & TRN & \\
\hline CHEMBL1569155 & 688546 & 5.2 & 5.6217 & TRN & \\
\hline CHEMBL1447280 & 688546 & 5.1 & 4.9965 & TRN & \\
\hline CHEMBL1356139 & 688546 & 5.0 & 4.8706 & TRN & \\
\hline CHEMBL1424917 & 688546 & 4.9 & 5.4443 & TST & \\
\hline CHEMBL1554178 & 688546 & 6.3 & 5.0843 & TRN & \\
\hline CHEMBL1434522 & 688546 & 5.45 & 5.5289 & TRN & \\
\hline CHEMBL 393287 & 688546 & 5.0 & 5.0168 & TRN & \\
\hline CHEMBL1441934 & 688546 & 4.6 & \multicolumn{2}{|c|}{5.297999999999999} & TST \\
\hline CHEMBL1358604 & 688546 & 4.5 & 4.9964 & TRN & \\
\hline CHEMBL1396242 & 688546 & 4.6 & 5.1814 & TRN & \\
\hline CHEMBL1395152 & 688546 & 4.5 & 5.1157 & TRN & \\
\hline CHEMBL1524018 & 688546 & 4.6 & 5.5394 & TRN & \\
\hline CHEMBL1593855 & 688546 & 6.8 & 5.3331 & TST & \\
\hline CHEMBL1435698 & 688546 & 4.8 & 4.8279 & TRN & \\
\hline CHEMBL1422976 & 688546 & 4.5 & 4.9759 & TRN & \\
\hline CHEMBL1487415 & 688546 & 5.1 & 4.992 & TRN & \\
\hline CHEMBL1565001 & 688546 & 4.5 & 4.849 & TRN & \\
\hline CHEMBL1341192 & 688546 & 4.8 & 4.7515 & TRN & \\
\hline CHEMBL1355230 & 688546 & 4.9 & 5.0027 & TST & \\
\hline CHEMBL1416129 & 688546 & 4.5 & 5.3571 & TST & \\
\hline CHEMBL1445772 & 688546 & 4.6 & \multicolumn{2}{|c|}{5.1579999999999995} & TRN \\
\hline CHEMBL1411970 & 688546 & 5.8 & 4.8549 & TRN & \\
\hline CHEMBL1302048 & 688546 & 4.6 & 5.5511 & TRN & \\
\hline CHEMBL1514165 & 688546 & 5.4 & 5.2849 & TRN & \\
\hline CHEMBL1317342 & 688546 & 5.8 & 5.6405 & TRN & \\
\hline CHEMBL1441221 & 688546 & 5.7 & 5.4156 & TRN & \\
\hline CHEMBL1355653 & 688546 & 7.5003 & 5.8401 & TRN & \\
\hline CHEMBL1585521 & 688546 & 5.6 & 5.0781 & TRN & \\
\hline CHEMBL1387162 & 688546 & 4.9 & \multicolumn{2}{|c|}{4.968999999999999} & TST \\
\hline CHEMBL1525065 & 688546 & 4.7 & 5.0632 & TST & \\
\hline CHEMBL1447501 & 688546 & 4.9 & 4.9685 & TST & \\
\hline CHEMBL1304647 & 688546 & 5.35 & 5.2827 & TST & \\
\hline CHEMBL1317149 & 688546 & 7.7496 & 5.2687 & TRN & \\
\hline CHEMBL1603379 & 688546 & 8.0 & 5.9457 & TRN & \\
\hline CHEMBL1324409 & 688546 & 4.9 & 5.1383 & TRN & \\
\hline CHEMBL1526002 & 688546 & 6.8 & 5.3895 & TRN & \\
\hline CHEMBL1428977 & 688546 & 4.5 & 5.301 & TST & \\
\hline CHEMBL1330568 & 688546 & 4.9 & 4.8972 & TST & \\
\hline CHEMBL1447744 & 688546 & 4.5 & 4.9774 & TRN & \\
\hline CHEMBL1513428 & 688546 & 4.5 & 5.0365 & TRN & \\
\hline CHEMBL1559717 & 688546 & 6.0 & 4.8822 & TST & \\
\hline CHEMBL1394119 & 688546 & 4.9 & 5.0926 & TRN & \\
\hline CHEMBL1485611 & 688546 & 7.0 & 5.4142 & TRN & \\
\hline CHEMBL1522806 & 688546 & 5.9 & 5.6202 & TRN & \\
\hline CHEMBL1533443 & 688546 & 6.6499 & 5.7593 & TRN & \\
\hline CHEMBL1590325 & 688546 & 6.9 & 5.3854 & TST & \\
\hline
\end{tabular}




\begin{tabular}{|c|c|c|c|c|c|}
\hline \\
\hline CHEMBL1397496 & 688546 & 4.9 & 4.7756 & TRN & \\
\hline CHEMBL1433869 & 688546 & 4.5 & 4.9569 & TST & \\
\hline CHEMBL1396037 & 688546 & 5.2 & 5.2546 & TRN & \\
\hline CHEMBL1396881 & 688546 & 5.5 & 5.2131 & TRN & \\
\hline CHEMBL1396723 & 688546 & 4.6 & 5.1619 & TRN & \\
\hline CHEMBL1496742 & 688546 & 4.5 & 5.6695 & TRN & \\
\hline CHEMBL1550642 & 688546 & 4.5 & 4.6932 & TST & \\
\hline CHEMBL1475707 & 688546 & 4.9 & 4.9621 & TRN & \\
\hline CHEMBL1474009 & 688546 & 5.9 & 5.6036 & TRN & \\
\hline CHEMBL1594948 & 688546 & 4.7 & 5.3845 & TST & \\
\hline CHEMBL1462696 & 688546 & 4.6 & 5.1702 & TST & \\
\hline CHEMBL1555208 & 688546 & 4.6 & 4.7606 & TRN & \\
\hline CHEMBL1383282 & 688546 & 5.0 & 4.8519 & TST & \\
\hline CHEMBL104255 & 688546 & 4.5 & 4.8558 & TRN & \\
\hline CHEMBL1314355 & 688546 & 5.2 & 5.5331 & TST & \\
\hline CHEMBL1554135 & 688546 & 4.7 & 4.7264 & TRN & \\
\hline CHEMBL1315996 & 688546 & 5.2 & 5.2065 & TRN & \\
\hline CHEMBL1599618 & 688546 & 4.5 & 5.4231 & TRN & \\
\hline CHEMBL1436838 & 688546 & 4.5 & 5.2886 & TRN & \\
\hline CHEMBL1543804 & 688546 & 4.45 & 5.3602 & TRN & \\
\hline CHEMBL1461532 & 688546 & 5.0 & 5.2998 & TST & \\
\hline CHEMBL1609759 & 688546 & 4.9 & 5.0503 & TST & \\
\hline CHEMBL1331382 & 688546 & 4.7 & 5.0474 & TRN & \\
\hline CHEMBL1316980 & 688546 & 6.0 & 5.1543 & TST & \\
\hline CHEMBL1608009 & 688546 & 5.0 & 5.0081 & TRN & \\
\hline CHEMBL1325803 & 688546 & 4.8 & 5.2637 & TRN & \\
\hline CHEMBL1317673 & 688546 & 4.5 & 4.6577 & TRN & \\
\hline CHEMBL1412549 & 688546 & 4.9 & 4.8193 & TRN & \\
\hline CHEMBL1597136 & 688546 & 5.3 & $5.4510 e$ & 00000000005 & TRN \\
\hline CHEMBL1408725 & 688546 & 4.5 & 5.0598 & TRN & \\
\hline CHEMBL1552608 & 688546 & 4.7 & 5.7047 & TRN & \\
\hline CHEMBL1357859 & 688546 & 6.8 & 5.3027 & TRN & \\
\hline CHEMBL1551602 & 688546 & 6.5 & 5.5665 & TRN & \\
\hline CHEMBL1540695 & 688546 & 5.25 & 5.1475 & TST & \\
\hline CHEMBL1399037 & 688546 & 4.8 & 4.8721 & TRN & \\
\hline CHEMBL1333087 & 688546 & 5.35 & 5.2004 & TRN & \\
\hline CHEMBL1473769 & 688546 & 5.4 & 5.6689 & TST & \\
\hline CHEMBL1359010 & 688546 & 4.5 & 5.2154 & TRN & \\
\hline CHEMBL1604007 & 688546 & 4.7 & 4.8566 & TST & \\
\hline CHEMBL1505916 & 688546 & 4.5 & 5.0914 & TRN & \\
\hline CHEMBL1315064 & 688546 & 8.2007 & 5.8949 & TRN & \\
\hline CHEMBL1399528 & 688546 & 4.5 & 4.5215 & TST & \\
\hline CHEMBL1434775 & 688546 & 4.5 & 5.5088 & TRN & \\
\hline CHEMBL1374636 & 688546 & 7.3497 & 5.8439 & TRN & \\
\hline CHEMBL1324344 & 688546 & 8.1024 & 5.4107 & TRN & \\
\hline CHEMBL1513654 & 688546 & 4.7 & 5.3756 & TST & \\
\hline CHEMBL1331418 & 688546 & 5.1 & 4.9571 & TRN & \\
\hline CHEMBL1339742 & 688546 & 4.65 & 4.9444 & TRN & \\
\hline
\end{tabular}




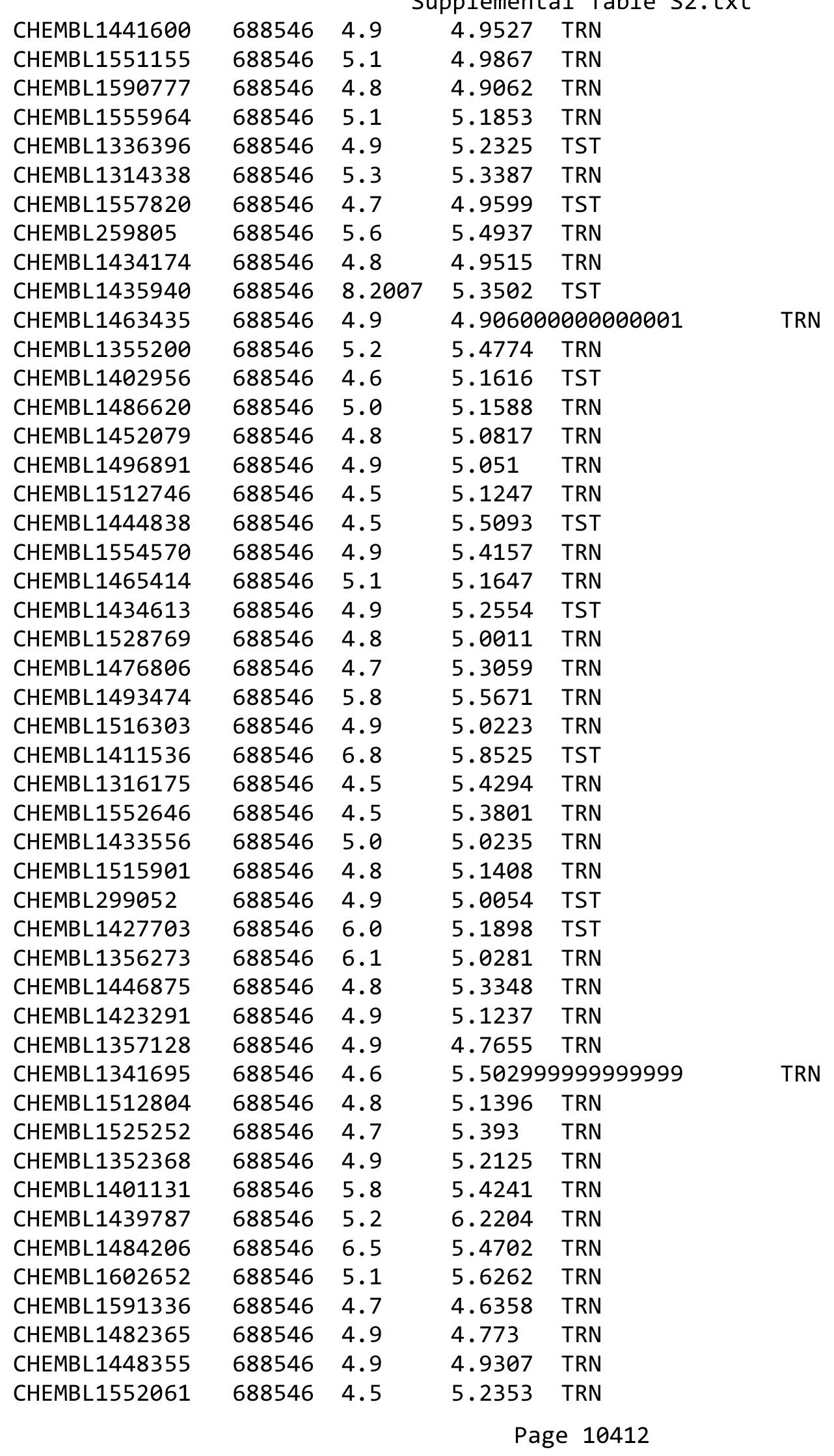




\begin{tabular}{|c|c|c|c|c|c|}
\hline \\
\hline CHEMBL1317572 & 688546 & 5.8 & 6.1855 & TRN & \\
\hline CHEMBL1589734 & 688546 & 4.9 & 4.6031 & TRN & \\
\hline CHEMBL1434373 & 688546 & 4.5 & 4.3798 & TRN & \\
\hline CHEMBL1468159 & 688546 & 4.5 & 5.5558 & TRN & \\
\hline CHEMBL1516882 & 688546 & 4.8 & 5.3289 & TRN & \\
\hline CHEMBL1473430 & 688546 & 4.9 & 5.0721 & TRN & \\
\hline CHEMBL1367003 & 688546 & 6.5501 & 5.2817 & TST & \\
\hline CHEMBL1513333 & 688546 & 6.1 & 5.4679 & TRN & \\
\hline CHEMBL1526086 & 688546 & 5.25 & 5.1273 & TST & \\
\hline CHEMBL1609081 & 688546 & 4.9 & 5.2262 & TRN & \\
\hline CHEMBL1593037 & 688546 & 5.3 & 5.3191 & TRN & \\
\hline CHEMBL1320504 & 688546 & 4.9 & 5.0108 & TST & \\
\hline CHEMBL402468 & 688546 & 5.4 & 4.915 & TRN & \\
\hline CHEMBL1591422 & 688546 & 4.9 & 4.8007 & TRN & \\
\hline CHEMBL1522912 & 688546 & 4.9 & 4.8223 & TRN & \\
\hline CHEMBL1478849 & 688546 & 6.7501 & 5.1239 & TST & \\
\hline CHEMBL1444953 & 688546 & 4.9 & 5.1522 & TRN & \\
\hline CHEMBL1559647 & 688546 & 4.8 & 5.2952 & TRN & \\
\hline CHEMBL1317934 & 688546 & 4.8 & 5.2529 & TRN & \\
\hline CHEMBL1461196 & 688546 & 5.0 & 5.0894 & TRN & \\
\hline CHEMBL1518248 & 688546 & 4.5 & 5.5547 & TST & \\
\hline CHEMBL1492465 & 688546 & 4.5 & 5.0296 & TST & \\
\hline CHEMBL1516492 & 688546 & 5.9 & 5.34 & TRN & \\
\hline CHEMBL1315137 & 688546 & 8.0 & 4.776 & TST & \\
\hline CHEMBL1525813 & 688546 & 5.6 & 5.37799 & 9999999999 & TRN \\
\hline CHEMBL1354998 & 688546 & 4.8 & 4.9855 & TRN & \\
\hline CHEMBL1513961 & 688546 & 4.5 & 4.63 & TRN & \\
\hline CHEMBL1609978 & 688546 & 5.2 & 5.0017 & TRN & \\
\hline CHEMBL1549365 & 688546 & 7.9508 & 5.7807 & TRN & \\
\hline CHEMBL1511197 & 688546 & 4.7 & 5.1729 & TRN & \\
\hline CHEMBL1335413 & 688546 & 4.7 & 5.2456 & TRN & \\
\hline CHEMBL1330307 & 688546 & 5.4 & 5.3766 & TRN & \\
\hline CHEMBL1552582 & 688546 & 4.7 & 5.1075 & TST & \\
\hline CHEMBL1553059 & 688546 & 4.7 & 5.2319 & TRN & \\
\hline CHEMBL1433606 & 688546 & 5.4 & 5.0136 & TRN & \\
\hline CHEMBL1508455 & 688546 & 4.45 & 5.1903 & TST & \\
\hline CHEMBL1553296 & 688546 & 6.5501 & 5.2566 & TST & \\
\hline CHEMBL1377868 & 688546 & 4.6 & 4.7528 & TRN & \\
\hline CHEMBL1380684 & 688546 & 6.0 & 5.5075 & TRN & \\
\hline CHEMBL1315128 & 688546 & 5.3 & 5.08899 & 99999999995 & TRN \\
\hline CHEMBL1337544 & 688546 & 7.2 & 5.8319 & TST & \\
\hline CHEMBL1601915 & 688546 & 5.0 & 5.0994 & TRN & \\
\hline CHEMBL1354835 & 688546 & 5.9 & 5.6495 & TRN & \\
\hline CHEMBL3197259 & 688546 & 5.5 & 5.4418 & TST & \\
\hline CHEMBL1481277 & 688546 & 7.3002 & 5.254 & TRN & \\
\hline CHEMBL1451936 & 688546 & 4.9 & 4.7853 & TRN & \\
\hline CHEMBL1436561 & 688546 & 7.4001 & 5.7123 & TRN & \\
\hline CHEMBL1561361 & 688546 & 4.6 & 5.3427 & TRN & \\
\hline
\end{tabular}




\begin{tabular}{|c|c|c|c|c|}
\hline & & & EII & al Table s \\
\hline CHEMBL1571094 & 688546 & 4.9 & 5.4465 & TRN \\
\hline CHEMBL1322076 & 688546 & 5.8 & 5.5995 & TRN \\
\hline CHEMBL1474256 & 688546 & 5.3 & 4.7296 & TRN \\
\hline CHEMBL1432964 & 688546 & 4.6 & 5.029 & TRN \\
\hline CHEMBL1319189 & 688546 & 4.5 & 5.2857 & TRN \\
\hline CHEMBL1363977 & 688546 & 4.7 & 4.8342 & TRN \\
\hline CHEMBL1572441 & 688546 & 5.0 & 5.1799 & TRN \\
\hline CHEMBL1547823 & 688546 & 4.9 & 5.2902 & TRN \\
\hline CHEMBL1448747 & 688546 & 5.1 & 4.7625 & TRN \\
\hline CHEMBL1364205 & 688546 & 5.0 & 5.067 & TRN \\
\hline CHEMBL1352318 & 688546 & 5.4 & 5.3719 & TST \\
\hline CHEMBL1358182 & 688546 & 5.4 & 5.0939 & TRN \\
\hline CHEMBL1358113 & 688546 & 8.1487 & 5.5287 & TST \\
\hline CHEMBL1514806 & 688546 & 4.5 & 5.1525 & TRN \\
\hline CHEMBL 3212690 & 688546 & 4.9 & 5.499 & TST \\
\hline CHEMBL1507817 & 688546 & 5.25 & 4.5167 & TST \\
\hline CHEMBL1531705 & 688546 & 4.9 & 5.0229 & TRN \\
\hline CHEMBL1437067 & 688546 & 5.0 & 5.2575 & TRN \\
\hline CHEMBL1402153 & 688546 & 4.7 & 5.2529 & TRN \\
\hline CHEMBL1516370 & 688546 & 4.7 & 5.1366 & TRN \\
\hline CHEMBL1474426 & 688546 & 6.9 & 5.024 & TRN \\
\hline CHEMBL1573812 & 688546 & 4.8 & 4.3599 & TRN \\
\hline CHEMBL1417229 & 688546 & 7.2 & 5.2395 & TRN \\
\hline CHEMBL1601125 & 688546 & 5.1 & 5.4692 & TST \\
\hline CHEMBL1597350 & 688546 & 5.5 & 4.8116 & TRN \\
\hline CHEMBL1334195 & 688546 & 6.0 & 4.9127 & TRN \\
\hline CHEMBL1586047 & 688546 & 8.6576 & 5.2092 & TST \\
\hline CHEMBL1339007 & 688546 & 5.4 & 5.0501 & TRN \\
\hline CHEMBL1608194 & 688546 & 5.7 & 5.2111 & TRN \\
\hline CHEMBL1417926 & 688546 & 4.7 & 5.0718 & TST \\
\hline CHEMBL1475620 & 688546 & 4.5 & 4.8306 & TRN \\
\hline CHEMBL1513119 & 688546 & 4.8 & 5.5268 & TST \\
\hline CHEMBL1593097 & 688546 & 5.8 & 5.744 & TRN \\
\hline CHEMBL1610141 & 688546 & 4.8 & 5.4335 & TRN \\
\hline CHEMBL1572191 & 688546 & 4.9 & 5.2625 & TRN \\
\hline CHEMBL1594554 & 688546 & 4.8 & 5.2844 & TRN \\
\hline CHEMBL1418093 & 688546 & 5.7 & 5.1584 & TRN \\
\hline CHEMBL1333249 & 688546 & 5.8 & 5.276 & TST \\
\hline CHEMBL1394165 & 688546 & 4.5 & 6.00799 & 9999999999 \\
\hline CHEMBL1535263 & 688546 & 5.7 & 5.0609 & TRN \\
\hline CHEMBL1473574 & 688546 & 5.6 & 5.2339 & TRN \\
\hline CHEMBL1412832 & 688546 & 4.6 & 5.0401 & TRN \\
\hline CHEMBL1377888 & 688546 & 4.9 & 4.6483 & TRN \\
\hline CHEMBL1452967 & 688546 & 4.9 & 5.5058 & TRN \\
\hline CHEMBL1593414 & 688546 & 5.0 & 5.8087 & TRN \\
\hline CHEMBL1373600 & 688546 & 4.9 & 5.6529 & TRN \\
\hline CHEMBL1499966 & 688546 & 4.8 & 4.9935 & TST \\
\hline CHEMBL1391564 & 688546 & 4.5 & 5.6012 & TST \\
\hline
\end{tabular}




\begin{tabular}{|c|c|c|c|c|}
\hline & & & pplement & al $\mathrm{T}$ \\
\hline CHEMBL1561928 & 688546 & 4.95 & 5.0061 & TST \\
\hline CHEMBL1374258 & 688546 & 5.0 & 5.4351 & TRN \\
\hline CHEMBL1594370 & 688546 & 5.6 & 5.4821 & TRN \\
\hline CHEMBL1413181 & 688546 & 5.4 & 5.4422 & TRN \\
\hline CHEMBL1551349 & 688546 & 4.6 & 4.8223 & TRN \\
\hline CHEMBL1605454 & 688546 & 5.2 & 4.9644 & TRN \\
\hline CHEMBL1213834 & 688546 & 5.4 & 5.1999 & TRN \\
\hline CHEMBL1355127 & 688546 & 6.0 & 5.0455 & TRN \\
\hline CHEMBL1563852 & 688546 & 6.1 & 5.3323 & TRN \\
\hline CHEMBL1344348 & 688546 & 4.6 & 5.3096 & TST \\
\hline CHEMBL1434348 & 688546 & 4.85 & 5.1601 & TRN \\
\hline CHEMBL1396271 & 688546 & 4.5 & 5.3347 & TRN \\
\hline CHEMBL1315095 & 688546 & 5.0 & 5.4449 & TRN \\
\hline CHEMBL1402941 & 688546 & 5.3 & 5.2143 & TRN \\
\hline CHEMBL1553598 & 688546 & 5.2 & 5.6384 & TRN \\
\hline CHEMBL1554819 & 688546 & 4.5 & 5.0579 & TRN \\
\hline CHEMBL1517710 & 688546 & 6.6 & 6.0431 & TRN \\
\hline CHEMBL 274844 & 688546 & 4.5 & 5.1916 & TST \\
\hline CHEMBL1365696 & 688546 & 4.5 & 5.0766 & TRN \\
\hline CHEMBL1408847 & 688546 & 4.5 & 5.0164 & TST \\
\hline CHEMBL1436280 & 688546 & 6.3 & 5.5997 & TRN \\
\hline CHEMBL1409293 & 688546 & 4.6 & 5.0146 & TRN \\
\hline CHEMBL1591054 & 688546 & 4.5 & 5.0002 & TRN \\
\hline CHEMBL1312582 & 688546 & 4.9 & 5.0503 & TRN \\
\hline CHEMBL1418018 & 688546 & 5.4 & 5.1061 & TRN \\
\hline CHEMBL1583650 & 688546 & 4.9 & 5.1498 & TRN \\
\hline CHEMBL1512536 & 688546 & 4.7 & 5.2087 & TST \\
\hline CHEMBL1306407 & 688546 & 4.9 & 5.2594 & TST \\
\hline CHEMBL1597750 & 688546 & 5.1 & 5.0113 & TRN \\
\hline CHEMBL1434351 & 688546 & 4.5 & 5.7809 & TRN \\
\hline CHEMBL1557770 & 688546 & 4.95 & 5.4516 & TRN \\
\hline CHEMBL1318205 & 688546 & 4.75 & 5.3933 & TRN \\
\hline CHEMBL1442775 & 688546 & 5.0 & 6.1033 & TRN \\
\hline CHEMBL1538398 & 688546 & 4.6 & 4.9524 & TST \\
\hline CHEMBL1604876 & 688546 & 5.3 & 5.1008 & TST \\
\hline CHEMBL1375390 & 688546 & 4.9 & 5.4981 & TST \\
\hline CHEMBL1326787 & 688546 & 4.5 & 4.8593 & TRN \\
\hline CHEMBL274619 & 688546 & 7.5003 & 5.9836 & TST \\
\hline CHEMBL1434142 & 688546 & 8.301 & 5.4013 & TRN \\
\hline CHEMBL1390645 & 688546 & 4.6 & 4.9074 & TST \\
\hline CHEMBL1462568 & 688546 & 4.7 & 5.5711 & TST \\
\hline CHEMBL1394378 & 688546 & 4.5 & 5.2702 & TRN \\
\hline CHEMBL1373818 & 688546 & 4.5 & 5.2746 & TST \\
\hline CHEMBL1591062 & 688546 & 5.0 & 5.0508 & TRN \\
\hline CHEMBL1512330 & 688546 & 4.6 & 5.1622 & TRN \\
\hline CHEMBL1373823 & 688546 & 4.9 & 5.4216 & TRN \\
\hline CHEMBL1319796 & 688546 & 4.5 & 5.1931 & TRN \\
\hline CHEMBL1356882 & 688546 & 4.5 & 5.2514 & TRN \\
\hline
\end{tabular}




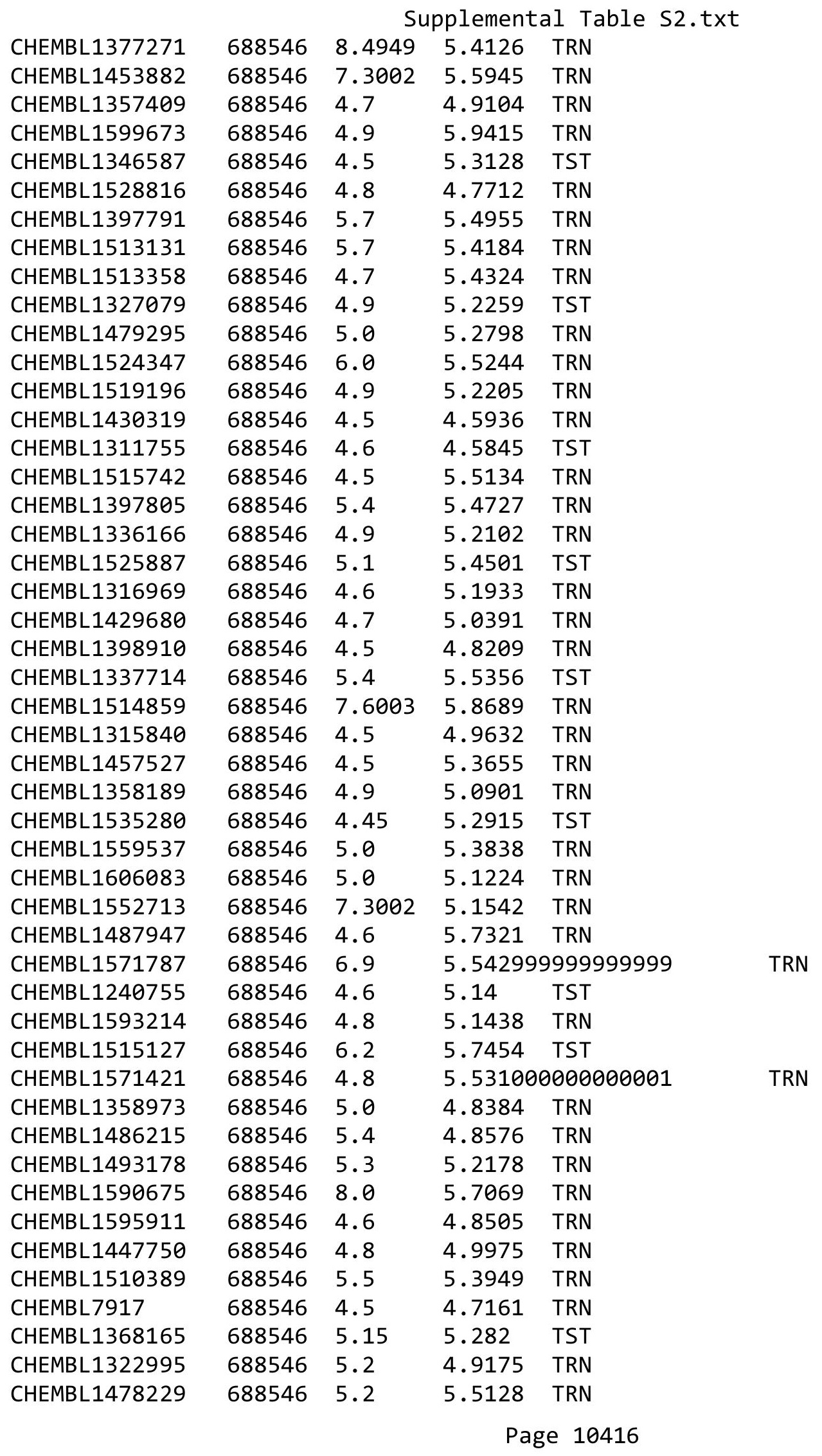




\begin{tabular}{|c|c|c|c|c|c|}
\hline & & \\
\hline CHEMBL1408374 & 688546 & 4.8 & 5.1138 & TRN & \\
\hline CHEMBL1434254 & 688546 & 4.9 & 5.1522 & TRN & \\
\hline CHEMBL1597519 & 688546 & 4.5 & 5.006 & TST & \\
\hline CHEMBL1327697 & 688546 & 4.6 & 4.7732 & TRN & \\
\hline CHEMBL1403348 & 688546 & 5.05 & 4.918 & TRN & \\
\hline CHEMBL584849 & 688546 & 4.9 & 5.1266 & TST & \\
\hline CHEMBL3191151 & 688546 & 5.65 & 5.3229 & TST & \\
\hline CHEMBL1464550 & 688546 & 4.7 & 5.4806 & TRN & \\
\hline CHEMBL1433741 & 688546 & 4.7 & 5.0276 & TRN & \\
\hline CHEMBL1364763 & 688546 & 4.8 & 5.4371 & TRN & \\
\hline CHEMBL1565909 & 688546 & 4.8 & 5.11 & TRN & \\
\hline CHEMBL1453801 & 688546 & 4.8 & 4.90300 & 00000000005 & TST \\
\hline CHEMBL1515850 & 688546 & 4.8 & 4.8697 & TRN & \\
\hline CHEMBL528256 & 688546 & 4.9 & 4.9305 & TRN & \\
\hline CHEMBL1473034 & 688546 & 8.1024 & 5.7424 & TRN & \\
\hline CHEMBL1324137 & 688546 & 4.6 & 5.4712 & TRN & \\
\hline CHEMBL1471225 & 688546 & 4.9 & 5.2997 & TRN & \\
\hline CHEMBL1584930 & 688546 & 4.6 & 5.0938 & TRN & \\
\hline CHEMBL1321672 & 688546 & 4.5 & 4.8296 & TRN & \\
\hline CHEMBL1587655 & 688546 & 4.6 & 4.9069 & TST & \\
\hline CHEMBL1321321 & 688546 & 4.6 & 6.225 & TRN & \\
\hline CHEMBL1439781 & 688546 & 5.0 & 5.1975 & TRN & \\
\hline CHEMBL1597357 & 688546 & 4.8 & 5.1385 & TST & \\
\hline CHEMBL1591435 & 688546 & 4.7 & 4.8836 & TRN & \\
\hline CHEMBL1515325 & 688546 & 4.7 & 5.2345 & TRN & \\
\hline CHEMBL567422 & 688546 & 4.6 & 5.074 & TST & \\
\hline CHEMBL1517560 & 688546 & 5.7 & 5.3166 & TST & \\
\hline CHEMBL1379132 & 688546 & 5.9 & 5.0563 & TRN & \\
\hline CHEMBL1466028 & 688546 & 5.0 & 5.2346 & TST & \\
\hline CHEMBL1440617 & 688546 & 5.0 & 5.2091 & TRN & \\
\hline CHEMBL1612140 & 688546 & 5.45 & 5.4081 & TST & \\
\hline CHEMBL1324449 & 688546 & 5.2 & 5.1591 & TST & \\
\hline CHEMBL1568148 & 688546 & 4.4 & 5.2765 & TRN & \\
\hline CHEMBL1357946 & 688546 & 4.7 & 4.7445 & TRN & \\
\hline CHEMBL1336755 & 688546 & 7.3002 & 5.1916 & TRN & \\
\hline CHEMBL1527737 & 688546 & 5.1 & 5.1249 & TST & \\
\hline CHEMBL1389480 & 688546 & 4.6 & 4.9803 & TST & \\
\hline CHEMBL1446474 & 688546 & 4.8 & 5.205 & TST & \\
\hline CHEMBL1530097 & 688546 & 4.9 & 5.4278 & TRN & \\
\hline CHEMBL1330772 & 688546 & 4.9 & 5.4993 & TRN & \\
\hline CHEMBL1474675 & 688546 & 5.3 & 4.8736 & TRN & \\
\hline CHEMBL1484698 & 688546 & 6.0 & 5.7028 & TRN & \\
\hline CHEMBL1554305 & 688546 & 5.6 & 5.3463 & TRN & \\
\hline CHEMBL1568662 & 688546 & 8.301 & 5.1234 & TRN & \\
\hline CHEMBL1357448 & 688546 & 5.0 & 4.91100 & 00000000005 & TRN \\
\hline CHEMBL1526319 & 688546 & 4.8 & 4.8455 & TST & \\
\hline CHEMBL1493015 & 688546 & 5.15 & 4.8802 & TRN & \\
\hline CHEMBL1491327 & 688546 & 5.3 & 5.4175 & TRN & \\
\hline & & & & 10417 & \\
\hline
\end{tabular}




\begin{tabular}{|c|c|c|c|c|}
\hline \multicolumn{5}{|c|}{ Supplemental Table S2.txt } \\
\hline CHEMBL408653 & 688546 & 5.5 & 5.4675 & TRN \\
\hline CHEMBL1500106 & 688546 & 4.6 & 5.2302 & TRN \\
\hline CHEMBL1551266 & 688546 & 4.7 & 5.0601 & TRN \\
\hline CHEMBL1331805 & 688546 & 5.5 & 5.2916 & TRN \\
\hline CHEMBL1578945 & 688546 & 4.6 & 5.2003 & TST \\
\hline CHEMBL1456683 & 688546 & 5.0 & 4.7602 & TST \\
\hline CHEMBL1497245 & 688546 & 4.9 & 5.2605 & TRN \\
\hline CHEMBL1600051 & 688546 & 6.95 & 5.2179 & TST \\
\hline CHEMBL1447259 & 688546 & 4.9 & 4.9695 & TRN \\
\hline CHEMBL1376120 & 688546 & 4.8 & 5.1205 & TRN \\
\hline CHEMBL1513663 & 688546 & 4.9 & 5.604 & TRN \\
\hline CHEMBL1396673 & 688546 & 5.3 & 5.5511 & TST \\
\hline CHEMBL1337475 & 688546 & 7.4001 & 5.6077 & TRN \\
\hline CHEMBL1594069 & 688546 & 5.2 & 5.7707 & TRN \\
\hline CHEMBL1554931 & 688546 & 4.9 & 5.3178 & TRN \\
\hline CHEMBL1545979 & 688546 & 4.8 & 5.8054 & TST \\
\hline CHEMBL1444626 & 688546 & 5.0 & 5.0613 & TRN \\
\hline CHEMBL1356400 & 688546 & 8.4559 & 5.4784 & TRN \\
\hline CHEMBL1437358 & 688546 & 4.8 & 5.0105 & TRN \\
\hline CHEMBL1522750 & 688546 & 4.6 & 5.3618 & TST \\
\hline CHEMBL1446340 & 688546 & 6.7001 & 5.8672 & TRN \\
\hline CHEMBL1601301 & 688546 & 4.5 & 5.4361 & TRN \\
\hline CHEMBL1478852 & 688546 & 4.7 & 5.2045 & TST \\
\hline CHEMBL1302243 & 688546 & 4.75 & 5.0943 & TST \\
\hline CHEMBL1512997 & 688546 & 4.8 & 5.1872 & TRN \\
\hline CHEMBL1364407 & 688546 & 5.0 & 5.183 & TRN \\
\hline CHEMBL1335581 & 688546 & 5.0 & 4.9381 & TST \\
\hline CHEMBL1434249 & 688546 & 4.6 & 5.5893 & TST \\
\hline CHEMBL1524192 & 688546 & 5.1 & 5.1739 & TRN \\
\hline CHEMBL1319380 & 688546 & 7.5003 & 5.6518 & TRN \\
\hline CHEMBL1574935 & 688546 & 4.9 & 5.0943 & TRN \\
\hline CHEMBL1727680 & 688546 & 5.7 & 5.5791 & TST \\
\hline CHEMBL1305429 & 688546 & 4.6 & 5.2452 & TRN \\
\hline CHEMBL1569738 & 688546 & 5.0 & 5.2996 & TRN \\
\hline CHEMBL1396641 & 688546 & 5.0 & 5.1793 & TRN \\
\hline CHEMBL1554536 & 688546 & 5.6 & 5.0286 & TRN \\
\hline CHEMBL1532839 & 688546 & 4.5 & 5.0394 & TRN \\
\hline CHEMBL1333545 & 688546 & 5.1 & 5.135 & TRN \\
\hline CHEMBL1518720 & 688546 & 4.6 & 5.3324 & TRN \\
\hline CHEMBL1436542 & 688546 & 7.7496 & 5.7428 & TRN \\
\hline CHEMBL1402604 & 688546 & 4.8 & 4.914 & TRN \\
\hline CHEMBL994 & 688546 & 4.9 & 5.6783 & TST \\
\hline CHEMBL1423890 & 688546 & 4.6 & 5.0888 & TRN \\
\hline CHEMBL1376258 & 688546 & 5.0 & 5.0388 & TRN \\
\hline CHEMBL1613446 & 688546 & 6.3 & 5.2199 & TRN \\
\hline CHEMBL1523960 & 688546 & 4.5 & 5.3222 & TRN \\
\hline CHEMBL1526325 & 688546 & 4.5 & 5.0127 & TRN \\
\hline CHEMBL1434964 & 688546 & 8.0 & 5.4204 & TRN \\
\hline
\end{tabular}




\begin{tabular}{|c|c|c|c|c|}
\hline \multicolumn{5}{|c|}{ Supplemental Table s2.txt } \\
\hline CHEMBL1584460 & 688546 & 4.8 & 5.1104 & TRN \\
\hline CHEMBL1314850 & 688546 & 5.0 & 5.1085 & TRN \\
\hline CHEMBL1573276 & 688546 & 5.0 & 4.9607 & TRN \\
\hline CHEMBL1593489 & 688546 & 4.5 & 5.1491 & TRN \\
\hline CHEMBL1343646 & 688546 & 4.8 & 5.20200 & 0000000001 \\
\hline CHEMBL1324398 & 688546 & 5.1 & 5.192 & TRN \\
\hline CHEMBL1356026 & 688546 & 5.85 & 5.519 & TRN \\
\hline CHEMBL1433727 & 688546 & 6.1 & 5.1832 & TRN \\
\hline CHEMBL1522330 & 688546 & 4.9 & 4.9597 & TRN \\
\hline CHEMBL1485566 & 688546 & 5.3 & 5.3819 & TRN \\
\hline CHEMBL1395302 & 688546 & 5.0 & 5.1609 & TRN \\
\hline CHEMBL1433571 & 688546 & 5.6 & 5.4243 & TRN \\
\hline CHEMBL1515770 & 688546 & 4.5 & 5.7906 & TRN \\
\hline CHEMBL606675 & 688546 & 4.5 & 4.7526 & TRN \\
\hline CHEMBL411085 & 688546 & 4.9 & 5.2593 & TRN \\
\hline CHEMBL1557656 & 688546 & 5.1 & 5.4956 & TRN \\
\hline CHEMBL1397577 & 688546 & 4.8 & 5.4787 & TRN \\
\hline CHEMBL1584571 & 688546 & 4.9 & 4.854 & TRN \\
\hline CHEMBL1600851 & 688546 & 5.6 & 5.1551 & TRN \\
\hline CHEMBL91900 & 688546 & 5.1 & 5.5606 & TST \\
\hline CHEMBL1415681 & 688546 & 7.3002 & 5.0661 & TST \\
\hline CHEMBL1455966 & 688546 & 4.5 & 5.4217 & TRN \\
\hline CHEMBL1565462 & 688546 & 4.5 & 4.747 & TRN \\
\hline CHEMBL1584663 & 688546 & 4.9 & 5.0541 & TRN \\
\hline CHEMBL1565441 & 688546 & 5.0 & 5.0432 & TRN \\
\hline CHEMBL1526240 & 688546 & 5.3 & 5.3981 & TRN \\
\hline CHEMBL1318035 & 688546 & 5.0 & 5.7294 & TRN \\
\hline CHEMBL1525639 & 688546 & 4.8 & 5.0393 & TRN \\
\hline CHEMBL1434786 & 688546 & 5.0 & 5.0378 & TRN \\
\hline CHEMBL1492729 & 688546 & 4.5 & 5.3217 & TRN \\
\hline CHEMBL1359442 & 688546 & 4.5 & 5.126 & TRN \\
\hline CHEMBL 259422 & 688546 & 6.0 & 5.3787 & TST \\
\hline CHEMBL1453291 & 688546 & 5.0 & 4.9913 & TRN \\
\hline CHEMBL1552434 & 688546 & 6.1 & 5.8744 & TRN \\
\hline CHEMBL373137 & 688546 & 4.9 & 5.3404 & TST \\
\hline CHEMBL1434393 & 688546 & 5.4 & 5.5538 & TRN \\
\hline CHEMBL1402510 & 688546 & 5.3 & 5.4151 & TRN \\
\hline CHEMBL1478605 & 688546 & 4.5 & 5.3307 & TST \\
\hline CHEMBL1435897 & 688546 & 4.7 & 5.4785 & TRN \\
\hline CHEMBL1306756 & 688546 & 5.5 & 5.5985 & TST \\
\hline CHEMBL1506017 & 688546 & 5.0 & 4.9335 & TST \\
\hline CHEMBL1589914 & 688546 & 5.2 & 5.2544 & TRN \\
\hline CHEMBL1591644 & 688546 & 5.1 & 5.2042 & TRN \\
\hline CHEMBL1373404 & 688546 & 5.1 & 5.2641 & TRN \\
\hline CHEMBL1472667 & 688546 & 4.8 & 5.165 & TRN \\
\hline CHEMBL1534295 & 688546 & 4.5 & 5.043 & TRN \\
\hline CHEMBL1513762 & 688546 & 6.0 & 5.8039 & TRN \\
\hline CHEMBL1397330 & 688546 & 4.7 & 5.2459 & TRN \\
\hline
\end{tabular}

TRN 


\begin{tabular}{|c|c|c|c|c|c|}
\hline \multirow{3}{*}{$\begin{array}{l}\text { CHEMBL1379646 } \\
\text { CHEMBL1516341 }\end{array}$} & \multirow{3}{*}{$\begin{array}{l}688546 \\
688546\end{array}$} & \multicolumn{4}{|c|}{ Supplemental Table S2.txt } \\
\hline & & 4.8 & \multicolumn{2}{|c|}{4.8389999999999995} & \multirow{2}{*}{ TRN } \\
\hline & & 7.4001 & 5.8328 & TRN & \\
\hline CHEMBL1406675 & 688546 & 4.8 & 5.0329 & TRN & \\
\hline CHEMBL1200471 & 688546 & 5.6 & 5.3267 & TST & \\
\hline CHEMBL1317335 & 688546 & 5.0 & 4.6515 & TRN & \\
\hline CHEMBL1494302 & 688546 & 8.0 & 5.0293 & TRN & \\
\hline CHEMBL 3189415 & 688546 & 4.5 & 5.1671 & TST & \\
\hline CHEMBL405317 & 688546 & 5.5 & 5.5579 & TRN & \\
\hline CHEMBL1323375 & 688546 & 4.5 & 5.5843 & TRN & \\
\hline CHEMBL2002522 & 688546 & 4.6 & 5.2612 & TST & \\
\hline CHEMBL1514710 & 688546 & 5.3 & 5.1157 & TST & \\
\hline CHEMBL1967431 & 688546 & 5.0 & 5.1632 & TST & \\
\hline CHEMBL1404867 & 688546 & 6.7501 & 5.0123 & TRN & \\
\hline CHEMBL1605942 & 688546 & 4.7 & 4.9993 & TRN & \\
\hline CHEMBL1518894 & 688546 & 5.4 & 5.4813 & TST & \\
\hline CHEMBL1534283 & 688546 & 4.9 & 5.1562 & TRN & \\
\hline CHEMBL1599862 & 688546 & 4.7 & \multicolumn{2}{|c|}{5.3229999999999995} & TRN \\
\hline CHEMBL343732 & 688546 & 4.9 & 4.6702 & TST & \\
\hline CHEMBL1556303 & 688546 & 4.8 & 5.1441 & TRN & \\
\hline CHEMBL1440577 & 688546 & 4.9 & 5.0978 & TRN & \\
\hline CHEMBL1532501 & 688546 & 7.1002 & 5.2475 & TRN & \\
\hline CHEMBL1320762 & 688546 & 4.6 & 5.3185 & TRN & \\
\hline CHEMBL1531535 & 688546 & 4.9 & 5.425 & TST & \\
\hline CHEMBL1173570 & 688546 & 5.9 & 5.329 & TRN & \\
\hline CHEMBL1437287 & 688546 & 5.45 & 5.2911 & TRN & \\
\hline CHEMBL1558388 & 688546 & 4.8 & 5.2547 & TRN & \\
\hline CHEMBL1534248 & 688546 & 6.0 & 4.9904 & TST & \\
\hline CHEMBL492010 & 688546 & 4.8 & 5.0644 & TRN & \\
\hline CHEMBL1557524 & 688546 & 4.9 & 4.7796 & TRN & \\
\hline CHEMBL1412657 & 688546 & 4.8 & 4.9606 & TRN & \\
\hline CHEMBL1317032 & 688546 & 5.0 & 5.1482 & TRN & \\
\hline CHEMBL1417719 & 688546 & 4.9 & 5.31 & TRN & \\
\hline CHEMBL1579548 & 688546 & 4.45 & 5.2203 & TST & \\
\hline CHEMBL1424065 & 688546 & 5.7 & 4.9783 & TRN & \\
\hline CHEMBL600881 & 688546 & 5.5 & 5.1692 & TRN & \\
\hline CHEMBL1389592 & 688546 & 4.5 & 4.4728 & TST & \\
\hline CHEMBL1498547 & 688546 & 5.3 & 5.0291 & TST & \\
\hline CHEMBL1486729 & 688546 & 4.5 & 5.5317 & TST & \\
\hline CHEMBL1513609 & 688546 & 5.5 & 5.4572 & TRN & \\
\hline CHEMBL1415516 & 688546 & 4.8 & 5.0034 & TRN & \\
\hline CHEMBL1481112 & 688546 & 7.699 & 5.7927 & TRN & \\
\hline CHEMBL1434386 & 688546 & 4.9 & 5.3581 & TST & \\
\hline CHEMBL1485288 & 688546 & 5.2 & 5.8208 & TRN & \\
\hline CHEMBL1473643 & 688546 & 7.1002 & 5.5973 & TRN & \\
\hline CHEMBL1320271 & 688546 & 6.6 & 5.73600 & 0000000001 & TRN \\
\hline CHEMBL1397552 & 688546 & 4.6 & 5.346 & TRN & \\
\hline CHEMBL3191307 & 688546 & 4.9 & 5.3531 & TRN & \\
\hline CHEMBL1483928 & 688546 & 7.5003 & 5.3335 & TRN & \\
\hline
\end{tabular}




\begin{tabular}{|c|c|c|c|c|c|}
\hline & & & oplement & al lable & \\
\hline CHEMBL1327499 & 688546 & 8.301 & 5.4755 & TRN & \\
\hline CHEMBL1553561 & 688546 & 5.9 & 5.49200 & 2000000001 & TRN \\
\hline CHEMBL1475867 & 688546 & 7.2 & 5.369 & TRN & \\
\hline CHEMBL1599634 & 688546 & 5.0 & 4.9188 & TRN & \\
\hline CHEMBL1530272 & 688546 & 4.9 & 4.7541 & TRN & \\
\hline CHEMBL1555899 & 688546 & 4.8 & 4.4736 & TRN & \\
\hline CHEMBL1337191 & 688546 & 4.9 & 5.1879 & TRN & \\
\hline CHEMBL1473902 & 688546 & 4.8 & 5.6961 & TRN & \\
\hline CHEMBL1444575 & 688546 & 4.6 & 4.78100 & 0000000001 & TRN \\
\hline CHEMBL1566877 & 688546 & 5.5 & 4.9689 & TRN & \\
\hline CHEMBL1401025 & 688546 & 4.9 & 5.88 & TRN & \\
\hline CHEMBL1398931 & 688546 & 4.8 & 4.9351 & TRN & \\
\hline CHEMBL1325661 & 688546 & 4.6 & 5.3859 & TRN & \\
\hline CHEMBL1514885 & 688546 & 4.8 & 4.742 & TRN & \\
\hline CHEMBL1358268 & 688546 & 5.25 & 5.3403 & TRN & \\
\hline CHEMBL1512943 & 688546 & 5.7 & 5.2685 & TRN & \\
\hline CHEMBL1356030 & 688546 & 4.8 & 4.9348 & TRN & \\
\hline CHEMBL1394429 & 688546 & 4.7 & 4.9819 & TRN & \\
\hline CHEMBL1565543 & 688546 & 7.3497 & 5.0841 & TST & \\
\hline CHEMBL1300736 & 688546 & 4.8 & 4.8982 & TST & \\
\hline CHEMBL1522191 & 688546 & 5.0 & 5.1138 & TRN & \\
\hline CHEMBL1490987 & 688546 & 4.6 & 4.9341 & TRN & \\
\hline CHEMBL1569103 & 688546 & 6.1 & 5.4438 & TRN & \\
\hline CHEMBL1561176 & 688546 & 6.1 & 5.3964 & TRN & \\
\hline CHEMBL1408430 & 688546 & 5.4 & 5.1155 & TST & \\
\hline CHEMBL1500450 & 688546 & 4.45 & 5.2401 & TST & \\
\hline CHEMBL1356146 & 688546 & 4.6 & 4.8684 & TRN & \\
\hline CHEMBL1593614 & 688546 & 7.699 & 5.6636 & TRN & \\
\hline CHEMBL1364285 & 688546 & 5.1 & 5.5438 & TRN & \\
\hline CHEMBL1554426 & 688546 & 5.2 & 4.9963 & TRN & \\
\hline CHEMBL1990214 & 688546 & 4.85 & 4.8883 & TRN & \\
\hline CHEMBL3190739 & 688546 & 4.6 & 5.2646 & TRN & \\
\hline CHEMBL1372359 & 688546 & 5.2 & 5.2104 & TRN & \\
\hline CHEMBL1302503 & 688546 & 4.7 & 5.1514 & TST & \\
\hline CHEMBL1373546 & 688546 & 4.8 & 5.1441 & TST & \\
\hline CHEMBL1440011 & 688546 & 4.9 & 4.9229 & TRN & \\
\hline CHEMBL1468597 & 688546 & 4.8 & 4.8896 & TST & \\
\hline CHEMBL1486734 & 688546 & 4.5 & 5.0731 & TRN & \\
\hline CHEMBL1492105 & 688546 & 5.0 & 4.6904 & TRN & \\
\hline CHEMBL1593522 & 688546 & 4.9 & 4.6585 & TST & \\
\hline CHEMBL1367340 & 688546 & 4.9 & 5.3787 & TRN & \\
\hline CHEMBL1527656 & 688546 & 5.0 & 5.1155 & TRN & \\
\hline CHEMBL1396728 & 688546 & 4.6 & 5.3584 & TRN & \\
\hline CHEMBL1514761 & 688546 & 5.6 & 5.1782 & TRN & \\
\hline CHEMBL1363115 & 688546 & 5.4 & 5.3134 & TRN & \\
\hline CHEMBL1544962 & 688546 & 4.8 & 4.99 & TRN & \\
\hline CHEMBL1606230 & 688546 & 4.7 & 5.1778 & TST & \\
\hline CHEMBL1357563 & 688546 & 8.0 & 5.3646 & TST & \\
\hline
\end{tabular}




\begin{tabular}{|c|c|c|c|c|}
\hline \multicolumn{5}{|r|}{1} \\
\hline CHEMBL1514320 & 688546 & 5.0 & 4.8307 & TST \\
\hline CHEMBL1448086 & 688546 & 5.0 & 5.0299 & TRN \\
\hline CHEMBL1552437 & 688546 & 5.2 & 5.3531 & TRN \\
\hline CHEMBL1472796 & 688546 & 6.8 & 5.4269 & TRN \\
\hline CHEMBL1307515 & 688546 & 7.6498 & 5.6495 & TRN \\
\hline CHEMBL1474791 & 688546 & 5.0 & 5.3122 & TRN \\
\hline CHEMBL1523440 & 688546 & 5.5 & 5.0733 & TRN \\
\hline CHEMBL1365620 & 688546 & 4.8 & 4.7427 & TRN \\
\hline CHEMBL1452611 & 688546 & 5.25 & 5.1159 & TST \\
\hline CHEMBL1472867 & 688546 & 4.9 & 5.2827 & TRN \\
\hline CHEMBL1323791 & 688546 & 5.4 & 5.1864 & TRN \\
\hline CHEMBL1597315 & 688546 & 4.6 & 4.9901 & TRN \\
\hline CHEMBL1317327 & 688546 & 4.5 & 4.8784 & TRN \\
\hline CHEMBL1412017 & 688546 & 4.5 & 5.1457 & TST \\
\hline CHEMBL412010 & 688546 & 4.6 & 5.0117 & TRN \\
\hline CHEMBL 1456175 & 688546 & 5.1 & 5.0828 & TRN \\
\hline CHEMBL1435875 & 688546 & 5.0 & 5.2191 & TRN \\
\hline CHEMBL1553468 & 688546 & 4.8 & 5.1988 & TRN \\
\hline CHEMBL1401305 & 688546 & 4.45 & 5.3205 & TRN \\
\hline CHEMBL1350574 & 688546 & 4.65 & 5.5067 & TST \\
\hline CHEMBL1327089 & 688546 & 5.1 & 5.1304 & TST \\
\hline CHEMBL1580861 & 688546 & 5.5 & 5.3598 & TST \\
\hline CHEMBL1478736 & 688546 & 4.5 & 5.1684 & TRN \\
\hline CHEMBL1504619 & 688546 & 4.5 & 5.3485 & TRN \\
\hline CHEMBL 1314653 & 688546 & 5.0 & 5.1342 & TRN \\
\hline CHEMBL1433852 & 688546 & 4.65 & 5.6064 & TRN \\
\hline CHEMBL1552887 & 688546 & 5.0 & 4.7589 & TRN \\
\hline CHEMBL1488251 & 688546 & 5.0 & 5.4343 & TST \\
\hline CHEMBL1436407 & 688546 & 4.9 & 4.9394 & TRN \\
\hline CHEMBL 1483703 & 688546 & 6.1 & 5.2944 & TRN \\
\hline CHEMBL1324713 & 688546 & 5.9 & 5.3506 & TRN \\
\hline CHEMBL1333839 & 688546 & 4.5 & 5.0357 & TRN \\
\hline CHEMBL1399631 & 688546 & 5.1 & 5.3067 & TST \\
\hline CHEMBL1516030 & 688546 & 5.6 & 5.9184 & TRN \\
\hline CHEMBL1516925 & 688546 & 4.9 & 5.0329 & TRN \\
\hline CHEMBL574181 & 688546 & 5.0 & 5.5257 & TST \\
\hline CHEMBL1452502 & 688546 & 5.0 & 5.0614 & TRN \\
\hline CHEMBL1608260 & 688546 & 7.699 & 5.854 & TRN \\
\hline CHEMBL1300039 & 688546 & 4.7 & 5.3053 & TST \\
\hline CHEMBL1310104 & 688546 & 4.9 & 4.9808 & TST \\
\hline CHEMBL 1477877 & 688546 & 5.8 & 5.3762 & TRN \\
\hline CHEMBL1553242 & 688546 & 4.65 & 5.3338 & TRN \\
\hline CHEMBL1474627 & 688546 & 5.3 & 5.0322 & TRN \\
\hline CHEMBL1386201 & 688546 & 4.5 & 5.5505 & TRN \\
\hline CHEMBL 18115 & 688546 & 4.6 & 5.1169 & TRN \\
\hline CHEMBL1327046 & 688546 & 4.9 & 4.9505 & TRN \\
\hline CHEMBL1413999 & 688546 & 4.9 & 5.1322 & TRN \\
\hline CHEMBL1408247 & 688546 & 4.9 & 5.7831 & TST \\
\hline
\end{tabular}




\begin{tabular}{|c|c|c|c|c|}
\hline \multicolumn{5}{|c|}{ Supplemental Table S2.txt } \\
\hline CHEMBL1554535 & 688546 & 4.5 & 5.4484 & TRN \\
\hline CHEMBL1552938 & 688546 & 5.1 & 4.8507 & TRN \\
\hline CHEMBL1396994 & 688546 & 4.5 & 5.5271 & TRN \\
\hline CHEMBL1369178 & 688546 & 7.1002 & 5.9478 & TRN \\
\hline CHEMBL445969 & 688546 & 5.4 & 5.3483 & TST \\
\hline CHEMBL1488109 & 688546 & 4.6 & 5.8274 & TRN \\
\hline CHEMBL1552937 & 688546 & 4.6 & 5.3557 & TRN \\
\hline CHEMBL1438111 & 688546 & 4.6 & 5.3027 & TRN \\
\hline CHEMBL1500966 & 688546 & 4.7 & 4.7718 & TRN \\
\hline CHEMBL1562139 & 688546 & 4.9 & 4.9687 & TST \\
\hline CHEMBL3195995 & 688546 & 5.0 & 5.2307 & TRN \\
\hline CHEMBL1574310 & 688546 & 4.75 & 5.2078 & TST \\
\hline CHEMBL1520105 & 688546 & 4.7 & 4.8382 & TRN \\
\hline CHEMBL1388206 & 688546 & 4.9 & 5.246 & TRN \\
\hline CHEMBL1356974 & 688546 & 5.6 & 5.5835 & TRN \\
\hline CHEMBL1381938 & 688546 & 5.0 & 5.0568 & TRN \\
\hline CHEMBL1401298 & 688546 & 4.5 & 5.0201 & TRN \\
\hline CHEMBL1444124 & 688546 & 5.5 & 5.1923 & TST \\
\hline CHEMBL1473740 & 688546 & 4.9 & 5.347 & TRN \\
\hline CHEMBL1476430 & 688546 & 4.6 & 4.8466 & TRN \\
\hline CHEMBL1413823 & 688546 & 4.9 & 5.3179 & TRN \\
\hline CHEMBL1555017 & 688546 & 4.5 & 5.5384 & TRN \\
\hline CHEMBL565755 & 688546 & 4.8 & 5.0285 & TRN \\
\hline CHEMBL1611819 & 688546 & 4.6 & 4.9499 & TST \\
\hline CHEMBL1372307 & 688546 & 6.2 & 5.678 & TRN \\
\hline CHEMBL1601677 & 688546 & 7.8508 & 5.4374 & TRN \\
\hline CHEMBL1569027 & 688546 & 5.0 & 4.9335 & TST \\
\hline CHEMBL1610712 & 688546 & 7.3002 & 5.5477 & TRN \\
\hline CHEMBL1315614 & 688546 & 6.5 & 5.8715 & TST \\
\hline CHEMBL1435917 & 688546 & 4.5 & 4.9588 & TST \\
\hline CHEMBL336467 & 688546 & 4.8 & 5.0174 & TST \\
\hline CHEMBL1474926 & 688546 & 4.8 & 5.2529 & TRN \\
\hline CHEMBL1321028 & 688546 & 6.5 & 5.8503 & TST \\
\hline CHEMBL1394193 & 688546 & 4.6 & 5.4485 & TRN \\
\hline CHEMBL1398413 & 688546 & 5.1 & 5.9895 & TRN \\
\hline CHEMBL1350167 & 688546 & 4.6 & 4.8671 & TRN \\
\hline CHEMBL1317735 & 688546 & 7.6003 & 6.1666 & TRN \\
\hline CHEMBL1521741 & 688546 & 4.9 & 5.295 & TRN \\
\hline CHEMBL1388257 & 688546 & 5.3 & 4.8257 & TRN \\
\hline CHEMBL1470420 & 688546 & 4.7 & 5.1707 & TST \\
\hline CHEMBL1523200 & 688546 & 4.9 & 5.0912 & TRN \\
\hline CHEMBL1318576 & 688546 & 5.3 & 5.3448 & TRN \\
\hline CHEMBL1605879 & 688546 & 4.8 & 5.2405 & TRN \\
\hline CHEMBL1440777 & 688546 & 6.2 & 6.2256 & TRN \\
\hline CHEMBL1399401 & 688546 & 4.5 & 4.4107 & TRN \\
\hline CHEMBL1597194 & 688546 & 4.6 & 4.811 & TST \\
\hline CHEMBL1358083 & 688546 & 8.6021 & 5.386 & TST \\
\hline CHEMBL1442997 & 688546 & 5.0 & 5.1909 & TRN \\
\hline
\end{tabular}




\begin{tabular}{|c|c|c|c|c|c|}
\hline \\
\hline CHEMBL1417788 & 688546 & 4.9 & 4.8559 & TRN & \\
\hline CHEMBL1555125 & 688546 & 4.5 & 5.1459 & TRN & \\
\hline CHEMBL1531257 & 688546 & 5.0 & 4.8669 & TRN & \\
\hline CHEMBL1610384 & 688546 & 4.6 & 5.1334 & TRN & \\
\hline CHEMBL1611208 & 688546 & 4.8 & 4.7951 & TRN & \\
\hline CHEMBL1593122 & 688546 & 5.0 & 5.1588 & TST & \\
\hline CHEMBL1354586 & 688546 & 4.4 & 5.9379 & TRN & \\
\hline CHEMBL1383843 & 688546 & 5.65 & 5.5441 & TRN & \\
\hline CHEMBL1308582 & 688546 & 5.1 & 5.032 & TRN & \\
\hline CHEMBL1555153 & 688546 & 5.0 & 5.5907 & TRN & \\
\hline CHEMBL1522311 & 688546 & 4.55 & 5.4662 & TRN & \\
\hline CHEMBL1457443 & 688546 & 4.9 & 4.9971 & TRN & \\
\hline CHEMBL1449116 & 688546 & 4.45 & 5.1492 & TRN & \\
\hline CHEMBL1602331 & 688546 & 5.6 & 5.2181 & TRN & \\
\hline CHEMBL48310 & 688546 & 4.9 & 4.9583 & TST & \\
\hline CHEMBL1551317 & 688546 & 6.2 & 5.2684 & TRN & \\
\hline CHEMBL1318348 & 688546 & 4.9 & 5.1767 & TRN & \\
\hline CHEMBL1451237 & 688546 & 4.9 & 5.0581 & TRN & \\
\hline CHEMBL1309434 & 688546 & 4.5 & 5.0333 & TST & \\
\hline CHEMBL1539301 & 688546 & 4.7 & 5.5305 & TST & \\
\hline CHEMBL149322 & 688546 & 5.0 & 4.8653 & TRN & \\
\hline CHEMBL1330897 & 688546 & 8.1024 & 5.5189 & TRN & \\
\hline CHEMBL1336651 & 688546 & 4.5 & 4.9904 & TRN & \\
\hline CHEMBL1330058 & 688546 & 5.6 & 5.53100 & 0000000001 & TRN \\
\hline CHEMBL1331809 & 688546 & 4.5 & 5.0 & TST & \\
\hline CHEMBL1519396 & 688546 & 4.7 & 5.3107 & TRN & \\
\hline CHEMBL1590918 & 688546 & 4.9 & 5.3474 & TRN & \\
\hline CHEMBL1486765 & 688546 & 4.8 & 4.9116 & TRN & \\
\hline CHEMBL1551503 & 688546 & 4.8 & 4.8139 & TRN & \\
\hline CHEMBL418509 & 688546 & 4.7 & 5.6832 & TRN & \\
\hline CHEMBL1546534 & 688546 & 5.3 & 5.0662 & TST & \\
\hline CHEMBL1519978 & 688546 & 4.5 & 4.8046 & TRN & \\
\hline CHEMBL1407418 & 688546 & 5.1 & 5.1639 & TRN & \\
\hline CHEMBL1350749 & 688546 & 4.65 & 5.1318 & TST & \\
\hline CHEMBL 1377148 & 688546 & 4.9 & 5.2402 & TRN & \\
\hline CHEMBL 2374050 & 688546 & 5.5 & 5.5409 & TST & \\
\hline CHEMBL1468845 & 688546 & 5.25 & 5.1631 & TST & \\
\hline CHEMBL1597728 & 688546 & 5.0 & 5.1387 & TRN & \\
\hline CHEMBL1552671 & 688546 & 6.3 & 5.8586 & TRN & \\
\hline CHEMBL1442957 & 688546 & 7.699 & 5.87 & TRN & \\
\hline CHEMBL1596974 & 688546 & 5.0 & 4.6742 & TRN & \\
\hline CHEMBL1325702 & 688546 & 5.2 & 5.16700 & 0000000001 & TRN \\
\hline CHEMBL1513861 & 688546 & 4.7 & 4.9724 & TRN & \\
\hline CHEMBL1396219 & 688546 & 4.5 & 5.1721 & TST & \\
\hline CHEMBL1591679 & 688546 & 6.5 & 5.9402 & TRN & \\
\hline CHEMBL1524628 & 688546 & 4.5 & 5.6622 & TRN & \\
\hline CHEMBL1369969 & 688546 & 4.95 & 6.0296 & TST & \\
\hline CHEMBL1572372 & 688546 & 5.2 & 5.1444 & TRN & \\
\hline
\end{tabular}




\begin{tabular}{|c|c|c|c|c|}
\hline & & & pplement & al $\mathrm{T}$ \\
\hline CHEMBL1446936 & 688546 & 4.5 & 4.9597 & TRN \\
\hline CHEMBL1596724 & 688546 & 5.0 & 5.0162 & TRN \\
\hline CHEMBL1605337 & 688546 & 8.301 & 5.4892 & TRN \\
\hline CHEMBL1475520 & 688546 & 6.1 & 6.1467 & TRN \\
\hline CHEMBL1439556 & 688546 & 5.6 & 5.2626 & TST \\
\hline CHEMBL1318573 & 688546 & 5.5 & 5.4133 & TRN \\
\hline CHEMBL1553740 & 688546 & 5.1 & 5.1326 & TST \\
\hline CHEMBL1609428 & 688546 & 5.1 & 5.0282 & TRN \\
\hline CHEMBL1364490 & 688546 & 6.05 & 5.7385 & TRN \\
\hline CHEMBL1565400 & 688546 & 4.45 & 5.6174 & TRN \\
\hline CHEMBL1452641 & 688546 & 5.1 & 5.4215 & TRN \\
\hline CHEMBL1589288 & 688546 & 5.0 & 5.3388 & TST \\
\hline CHEMBL1491288 & 688546 & 5.6 & 5.0352 & TRN \\
\hline CHEMBL1454216 & 688546 & 6.0 & 5.5518 & TRN \\
\hline CHEMBL1590260 & 688546 & 6.5 & 5.8643 & TRN \\
\hline CHEMBL1452394 & 688546 & 8.1024 & 5.5754 & TST \\
\hline CHEMBL1360889 & 688546 & 4.9 & 5.4748 & TRN \\
\hline CHEMBL1313936 & 688546 & 5.6 & 5.2209 & TRN \\
\hline CHEMBL1521901 & 688546 & 4.6 & 4.9135 & TRN \\
\hline CHEMBL1434395 & 688546 & 5.0 & 5.4528 & TRN \\
\hline CHEMBL1553483 & 688546 & 4.8 & 5.2433 & TRN \\
\hline CHEMBL1399075 & 688546 & 6.7001 & 5.8107 & TRN \\
\hline CHEMBL1338425 & 688546 & 4.8 & 4.8286 & TRN \\
\hline CHEMBL1365677 & 688546 & 5.0 & 4.9644 & TRN \\
\hline CHEMBL1325144 & 688546 & 5.8 & 5.223 & TRN \\
\hline CHEMBL1397518 & 688546 & 5.0 & 5.3077 & TRN \\
\hline CHEMBL1595079 & 688546 & 6.6 & 5.541 & TRN \\
\hline CHEMBL1320735 & 688546 & 4.6 & 5.0976 & TRN \\
\hline CHEMBL1399507 & 688546 & 4.8 & 5.083 & TST \\
\hline CHEMBL1368894 & 688546 & 4.45 & 5.3408 & TRN \\
\hline CHEMBL 1256024 & 688546 & 5.2 & 5.6711 & TST \\
\hline CHEMBL1610945 & 688546 & 5.5 & 5.3531 & TST \\
\hline CHEMBL1529687 & 688546 & 4.7 & 4.8896 & TRN \\
\hline CHEMBL 3207874 & 688546 & 4.9 & 5.0165 & TST \\
\hline CHEMBL1592526 & 688546 & 7.9508 & 5.9086 & TRN \\
\hline CHEMBL1344611 & 688546 & 4.5 & 5.0346 & TRN \\
\hline CHEMBL1475327 & 688546 & 4.9 & 4.8226 & TRN \\
\hline CHEMBL1397510 & 688546 & 4.9 & 5.4829 & TRN \\
\hline CHEMBL1327196 & 688546 & 4.6 & 5.8698 & TRN \\
\hline CHEMBL1610124 & 688546 & 5.0 & 5.5578 & TRN \\
\hline CHEMBL1515903 & 688546 & 4.9 & 5.0228 & TRN \\
\hline CHEMBL1594088 & 688546 & 4.5 & 4.6352 & TRN \\
\hline CHEMBL1613149 & 688546 & 4.9 & 5.6006 & TRN \\
\hline CHEMBL1453355 & 688546 & 4.8 & 4.7643 & TRN \\
\hline CHEMBL1301928 & 688546 & 8.1024 & 4.7821 & TST \\
\hline CHEMBL1581396 & 688546 & 4.45 & 5.1924 & TST \\
\hline CHEMBL1554101 & 688546 & 4.5 & 5.351 & TRN \\
\hline CHEMBL1514865 & 688546 & 5.0 & 4.8384 & TRN \\
\hline
\end{tabular}




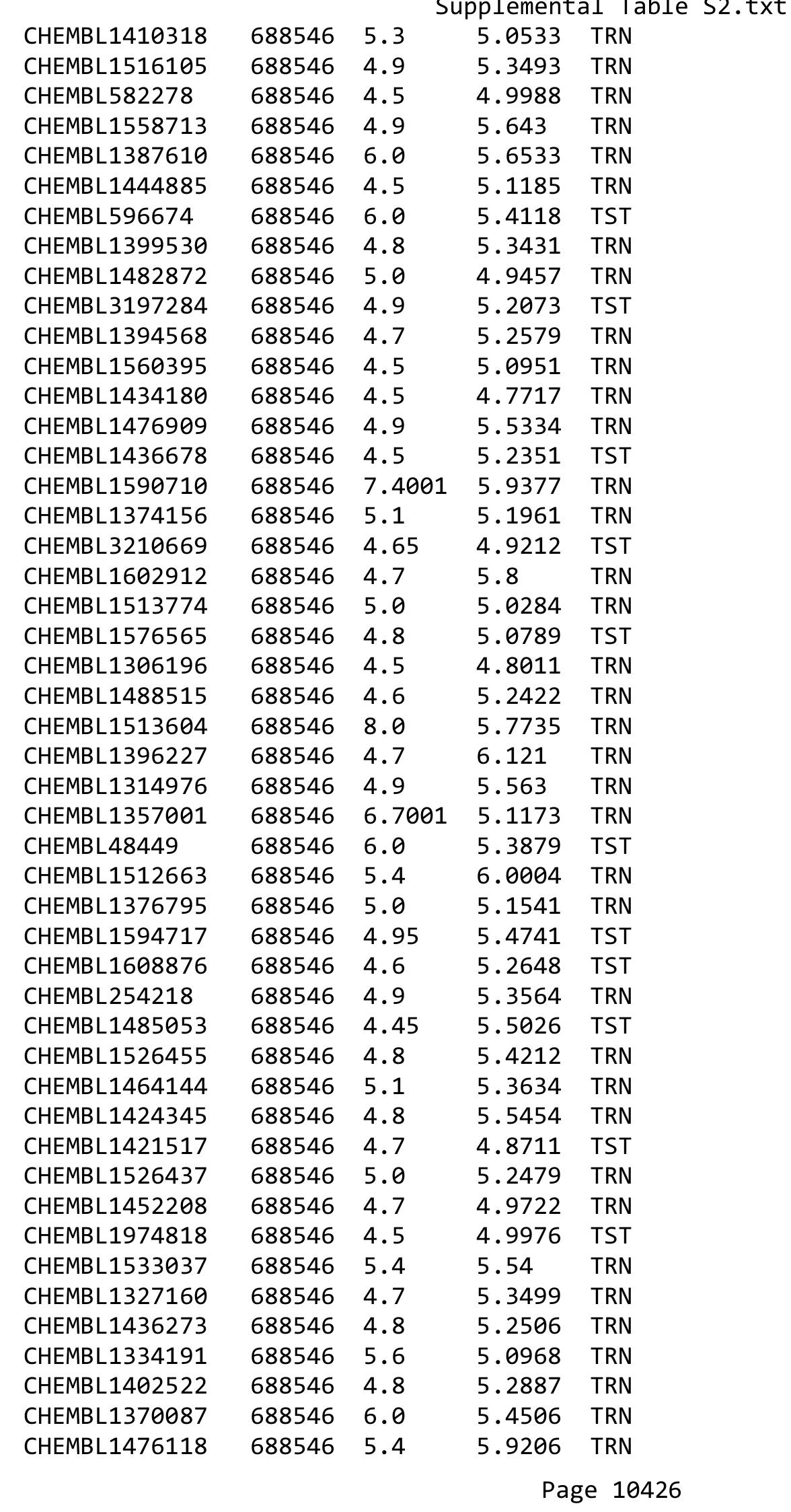




\begin{tabular}{|c|c|c|c|c|c|}
\hline \\
\hline CHEMBL1315225 & 688546 & 4.9 & 5.1501 & TST & \\
\hline CHEMBL1359086 & 688546 & 4.5 & 5.16 & TST & \\
\hline CHEMBL1513625 & 688546 & 4.5 & 5.1719 & TRN & \\
\hline CHEMBL1515582 & 688546 & 4.5 & 5.3855 & TST & \\
\hline CHEMBL1518055 & 688546 & 4.9 & 5.2712 & TRN & \\
\hline CHEMBL1434265 & 688546 & 7.3002 & 5.3611 & TRN & \\
\hline CHEMBL1481949 & 688546 & 4.9 & 4.8913 & TST & \\
\hline CHEMBL1406814 & 688546 & 7.699 & 5.8322 & TRN & \\
\hline CHEMBL1342330 & 688546 & 4.9 & 4.917 & TST & \\
\hline CHEMBL1468913 & 688546 & 7.1002 & 5.4039 & TRN & \\
\hline CHEMBL1406920 & 688546 & 4.6 & 5.2404 & TRN & \\
\hline CHEMBL1564752 & 688546 & 8.4949 & 5.3334 & TST & \\
\hline CHEMBL1594744 & 688546 & 5.35 & 5.15 & TRN & \\
\hline CHEMBL1367341 & 688546 & 4.5 & 5.0649 & TRN & \\
\hline CHEMBL1514375 & 688546 & 4.5 & 5.1453 & TST & \\
\hline CHEMBL1591409 & 688546 & 4.5 & 5.6516 & TRN & \\
\hline CHEMBL1476326 & 688546 & 4.6 & 5.4497 & TRN & \\
\hline CHEMBL1551353 & 688546 & 7.8013 & 5.13899 & 9999999999 & TRN \\
\hline CHEMBL1525468 & 688546 & 4.8 & 4.9308 & TRN & \\
\hline CHEMBL 1357558 & 688546 & 4.9 & 5.431 & TST & \\
\hline CHEMBL1508424 & 688546 & 4.8 & 5.0492 & TRN & \\
\hline CHEMBL529205 & 688546 & 4.6 & 5.0881 & TRN & \\
\hline CHEMBL1491272 & 688546 & 4.9 & 4.9906 & TRN & \\
\hline CHEMBL1301175 & 688546 & 4.5 & 4.9984 & TRN & \\
\hline CHEMBL1552965 & 688546 & 4.8 & 5.34399 & 9999999999 & TST \\
\hline CHEMBL1555529 & 688546 & 5.1 & 5.3157 & TST & \\
\hline CHEMBL1515038 & 688546 & 4.8 & 5.0156 & TRN & \\
\hline CHEMBL1553949 & 688546 & 5.45 & 5.5398 & TRN & \\
\hline CHEMBL21241 & 688546 & 4.5 & 5.1881 & TST & \\
\hline CHEMBL1516211 & 688546 & 4.9 & 4.9649 & TRN & \\
\hline CHEMBL1451470 & 688546 & 4.8 & 5.7977 & TRN & \\
\hline CHEMBL1486154 & 688546 & 4.7 & 5.1247 & TRN & \\
\hline CHEMBL46703 & 688546 & 5.0 & 5.2849 & TRN & \\
\hline CHEMBL 2006909 & 688546 & 5.7 & 5.3444 & TST & \\
\hline CHEMBL1414686 & 688546 & 4.8 & 5.1201 & TRN & \\
\hline CHEMBL1576870 & 688546 & 5.0 & 4.8889 & TRN & \\
\hline CHEMBL1473368 & 688546 & 4.6 & 4.8706 & TRN & \\
\hline CHEMBL1395188 & 688546 & 4.9 & 5.2464 & TRN & \\
\hline CHEMBL1611705 & 688546 & 6.05 & 5.739 & TRN & \\
\hline CHEMBL1593953 & 688546 & 7.5003 & 5.5811 & TRN & \\
\hline CHEMBL1318141 & 688546 & 6.2 & 5.3648 & TRN & \\
\hline CHEMBL1482019 & 688546 & 6.8 & 5.5334 & TRN & \\
\hline CHEMBL1314528 & 688546 & 5.7 & 4.9218 & TRN & \\
\hline CHEMBL1514150 & 688546 & 6.6 & 5.2572 & TST & \\
\hline CHEMBL 1450751 & 688546 & 4.9 & 5.3064 & TRN & \\
\hline CHEMBL1560430 & 688546 & 4.6 & 5.4512 & TRN & \\
\hline CHEMBL1433623 & 688546 & 4.8 & 5.2375 & TST & \\
\hline CHEMBL1357688 & 688546 & 6.0 & 5.3525 & TRN & \\
\hline
\end{tabular}




\begin{tabular}{|c|c|c|c|c|c|}
\hline \multicolumn{6}{|c|}{ Supplemental Table S2.txt } \\
\hline CHEMBL1359067 & 688546 & 5.0 & 5.2563 & TRN & \\
\hline CHEMBL1596344 & 688546 & 4.55 & 5.0902 & TRN & \\
\hline CHEMBL1397233 & 688546 & 4.8 & 5.4887 & TRN & \\
\hline CHEMBL1551338 & 688546 & 4.9 & 5.0618 & TRN & \\
\hline CHEMBL1345366 & 688546 & 5.4 & 5.1521 & TRN & \\
\hline CHEMBL1473481 & 688546 & 4.9 & 5.135 & TRN & \\
\hline CHEMBL1552919 & 688546 & 8.9586 & 5.3725 & TST & \\
\hline CHEMBL1578877 & 688546 & 4.9 & 5.2162 & TRN & \\
\hline CHEMBL1397782 & 688546 & 4.5 & 5.3954 & TRN & \\
\hline CHEMBL1396894 & 688546 & 4.7 & 5.02 & TRN & \\
\hline CHEMBL1609026 & 688546 & 5.35 & 5.3313 & TRN & \\
\hline CHEMBL1385588 & 688546 & 4.9 & 4.7793 & TRN & \\
\hline CHEMBL1570943 & 688546 & 4.6 & 5.61100 & 0000000001 & TRN \\
\hline CHEMBL1529582 & 688546 & 4.5 & 4.8755 & TRN & \\
\hline CHEMBL1394326 & 688546 & 5.2 & 5.591 & TRN & \\
\hline CHEMBL1515108 & 688546 & 4.5 & 4.9987 & TRN & \\
\hline CHEMBL1476585 & 688546 & 4.5 & 5.6858 & TRN & \\
\hline CHEMBL582699 & 688546 & 4.5 & 5.3103 & TRN & \\
\hline CHEMBL1366485 & 688546 & 4.9 & 5.0139 & TRN & \\
\hline CHEMBL1318622 & 688546 & 4.6 & 4.9497 & TRN & \\
\hline CHEMBL1476307 & 688546 & 4.9 & 5.2088 & TRN & \\
\hline CHEMBL1302618 & 688546 & 4.8 & 5.0056 & TST & \\
\hline CHEMBL1323874 & 688546 & 4.5 & 5.0593 & TRN & \\
\hline CHEMBL1386288 & 688546 & 4.6 & 5.0014 & TST & \\
\hline CHEMBL1317047 & 688546 & 6.2 & 5.4403 & TST & \\
\hline CHEMBL1401187 & 688546 & 5.0 & 5.0611 & TRN & \\
\hline CHEMBL1570412 & 688546 & 5.2 & 5.518 & TRN & \\
\hline CHEMBL1477548 & 688546 & 4.9 & 5.2881 & TRN & \\
\hline CHEMBL1607826 & 688546 & 5.8 & 5.5226 & TRN & \\
\hline CHEMBL1502549 & 688546 & 4.5 & 5.2559 & TST & \\
\hline CHEMBL1568678 & 688546 & 5.3 & 5.9602 & TRN & \\
\hline CHEMBL1516339 & 688546 & 5.9 & 5.4983 & TRN & \\
\hline CHEMBL1454397 & 688546 & 4.8 & 5.3774 & TST & \\
\hline CHEMBL1475859 & 688546 & 5.4 & 5.2305 & TRN & \\
\hline CHEMBL 242171 & 688546 & 5.0 & 4.9051 & TRN & \\
\hline CHEMBL1412319 & 688546 & 5.0 & 5.6456 & TRN & \\
\hline CHEMBL1472513 & 688546 & 4.5 & 5.2366 & TST & \\
\hline CHEMBL1459932 & 688546 & 5.6 & 5.2653 & TST & \\
\hline CHEMBL1563333 & 688546 & 5.0 & 5.3105 & TST & \\
\hline CHEMBL1436786 & 688546 & 4.8 & 4.539 & TRN & \\
\hline CHEMBL1357180 & 688546 & 4.5 & 4.9244 & TRN & \\
\hline CHEMBL1554259 & 688546 & 6.5501 & 5.8659 & TRN & \\
\hline CHEMBL1355197 & 688546 & 4.8 & 5.0512 & TRN & \\
\hline CHEMBL1435501 & 688546 & 6.8 & 5.1703 & TRN & \\
\hline CHEMBL1338795 & 688546 & 5.0 & 5.003 & TRN & \\
\hline CHEMBL1527850 & 688546 & 4.8 & 5.5232 & TRN & \\
\hline CHEMBL1398045 & 688546 & 7.4498 & 5.5828 & TRN & \\
\hline CHEMBL1316581 & 688546 & 7.3002 & 5.3942 & TST & \\
\hline
\end{tabular}




\begin{tabular}{|c|c|c|c|c|c|}
\hline \multicolumn{6}{|c|}{ Supplemental Table S2.txt } \\
\hline CHEMBL1433897 & 688546 & 6.1 & 5.6962 & TST & \\
\hline CHEMBL1599197 & 688546 & 4.9 & 5.7383 & TRN & \\
\hline CHEMBL1590131 & 688546 & 4.8 & 4.9887 & TRN & \\
\hline CHEMBL1517928 & 688546 & 4.9 & 5.1333 & TRN & \\
\hline CHEMBL1531367 & 688546 & 8.301 & 5.7652 & TRN & \\
\hline CHEMBL1395568 & 688546 & 8.5528 & 5.3905 & TRN & \\
\hline CHEMBL1491064 & 688546 & 4.6 & 5.3645 & TST & \\
\hline CHEMBL1315202 & 688546 & 5.0 & 5.2276 & TRN & \\
\hline CHEMBL1315406 & 688546 & 7.5003 & 4.7307 & TRN & \\
\hline CHEMBL1368116 & 688546 & 4.9 & 5.1515 & TST & \\
\hline CHEMBL1407930 & 688546 & 5.0 & 5.2792 & TRN & \\
\hline CHEMBL1526068 & 688546 & 4.5 & 4.9705 & TST & \\
\hline CHEMBL1440950 & 688546 & 7.1002 & 5.4796 & TRN & \\
\hline CHEMBL1586958 & 688546 & 5.05 & 5.4265 & TST & \\
\hline CHEMBL1439324 & 688546 & 4.9 & 5.5846 & TST & \\
\hline CHEMBL1434679 & 688546 & 4.6 & 5.2512 & TRN & \\
\hline CHEMBL1546299 & 688546 & 4.9 & 5.4054 & TRN & \\
\hline CHEMBL1423466 & 688546 & 4.8 & 4.9566 & TRN & \\
\hline CHEMBL1366812 & 688546 & 5.2 & 5.3761 & TST & \\
\hline CHEMBL3197870 & 688546 & 4.85 & 5.2334 & TST & \\
\hline CHEMBL1450120 & 688546 & 5.0 & 4.9344 & TST & \\
\hline CHEMBL1320387 & 688546 & 4.5 & 4.9742 & TRN & \\
\hline CHEMBL1554164 & 688546 & 5.7 & 5.1899 & TRN & \\
\hline CHEMBL1427239 & 688546 & 5.0 & 5.3239 & TRN & \\
\hline CHEMBL1505992 & 688546 & 5.25 & 5.2549 & TST & \\
\hline CHEMBL1365830 & 688546 & 4.6 & 4.901 & TRN & \\
\hline CHEMBL1594038 & 688546 & 5.1 & 5.029 & TRN & \\
\hline CHEMBL1613708 & 688546 & 4.5 & 5.2007 & TST & \\
\hline CHEMBL1452456 & 688546 & 5.7 & 5.7841 & TRN & \\
\hline CHEMBL536950 & 688546 & 5.0 & 5.1692 & TST & \\
\hline CHEMBL1399789 & 688546 & 5.2 & 5.7153 & TRN & \\
\hline CHEMBL1317258 & 688546 & 4.8 & 5.69 & TRN & \\
\hline CHEMBL1403985 & 688546 & 4.45 & 4.7478 & TRN & \\
\hline CHEMBL1613344 & 688546 & 4.6 & 5.1773 & TST & \\
\hline CHEMBL1607781 & 688546 & 6.2 & 5.2774 & TRN & \\
\hline CHEMBL1494038 & 688546 & 4.5 & 4.9559 & TST & \\
\hline CHEMBL1434889 & 688546 & 5.0 & 4.9368 & TRN & \\
\hline CHEMBL1346881 & 688546 & 4.85 & 4.9066 & TRN & \\
\hline CHEMBL1475225 & 688546 & 5.0 & 4.9332 & TRN & \\
\hline CHEMBL1553264 & 688546 & 7.4001 & 5.8055 & TST & \\
\hline CHEMBL1520905 & 688546 & 4.6 & 5.04899 & 99999999995 & TRN \\
\hline CHEMBL1611939 & 688546 & 5.0 & 5.0316 & TST & \\
\hline CHEMBL1533594 & 688546 & 4.9 & 5.1287 & TRN & \\
\hline CHEMBL1440132 & 688546 & 8.301 & 5.7896 & TRN & \\
\hline CHEMBL1358032 & 688546 & 4.9 & 5.1382 & TRN & \\
\hline CHEMBL1564308 & 688546 & 4.9 & 5.0187 & TRN & \\
\hline CHEMBL1441198 & 688546 & 5.5 & 5.3575 & TRN & \\
\hline CHEMBL1316561 & 688546 & 4.8 & 4.9155 & TRN & \\
\hline
\end{tabular}




\begin{tabular}{|c|c|c|c|c|c|}
\hline \multirow{2}{*}{\multicolumn{2}{|c|}{ CHEMBL1436779 }} & \\
\hline & & 4.5 & 5.1651 & TRN & \\
\hline CHEMBL1594065 & 688546 & 5.5 & 5.1412 & TRN & \\
\hline CHEMBL1473246 & 688546 & 4.9 & 5.1298 & TRN & \\
\hline CHEMBL1529046 & 688546 & 5.0 & 4.7395 & TRN & \\
\hline CHEMBL1324811 & 688546 & 5.6 & 5.7308 & TRN & \\
\hline CHEMBL1591063 & 688546 & 5.2 & 5.9308 & TRN & \\
\hline CHEMBL1513881 & 688546 & 5.0 & 5.5018 & TRN & \\
\hline CHEMBL1608441 & 688546 & 4.7 & 4.7675 & TRN & \\
\hline CHEMBL1482799 & 688546 & 5.0 & 4.7552 & TRN & \\
\hline CHEMBL1608293 & 688546 & 5.1 & 5.2818 & TRN & \\
\hline CHEMBL1436153 & 688546 & 4.8 & 5.4192 & TRN & \\
\hline CHEMBL1465004 & 688546 & 4.9 & 4.9699 & TST & \\
\hline CHEMBL1356025 & 688546 & 5.0 & 5.1538 & TRN & \\
\hline CHEMBL1359157 & 688546 & 4.5 & 4.7831 & TST & \\
\hline CHEMBL 75267 & 688546 & 4.9 & 4.7536 & TRN & \\
\hline CHEMBL1445595 & 688546 & 4.9 & 4.8509 & TRN & \\
\hline CHEMBL1418563 & 688546 & 5.1 & 5.0093 & TRN & \\
\hline CHEMBL1256709 & 688546 & 5.0 & 5.4502 & TST & \\
\hline CHEMBL1478628 & 688546 & 4.8 & 5.267 & TRN & \\
\hline CHEMBL1523108 & 688546 & 4.8 & 5.0637 & TRN & \\
\hline CHEMBL1434616 & 688546 & 8.6021 & 5.6008 & TRN & \\
\hline CHEMBL1413428 & 688546 & 8.1024 & 5.3343 & TRN & \\
\hline CHEMBL1446354 & 688546 & 4.45 & 6.1341 & TRN & \\
\hline CHEMBL1354402 & 688546 & 5.7 & 5.2967 & TRN & \\
\hline CHEMBL1488418 & 688546 & 4.5 & 5.1054 & TRN & \\
\hline CHEMBL1357204 & 688546 & 6.9 & 5.5436 & TRN & \\
\hline CHEMBL1396463 & 688546 & 4.4 & 4.8239 & TST & \\
\hline CHEMBL1540645 & 688546 & 4.9 & 4.9893 & TRN & \\
\hline CHEMBL1455443 & 688546 & 7.5003 & 5.3296 & TST & \\
\hline CHEMBL1551083 & 688546 & 7.4001 & 5.9763 & TRN & \\
\hline CHEMBL3145067 & 688546 & 4.5 & 5.0624 & TRN & \\
\hline CHEMBL1409985 & 688546 & 5.2 & 4.9581 & TST & \\
\hline CHEMBL1499384 & 688546 & 4.9 & 5.6926 & TRN & \\
\hline CHEMBL1484911 & 688546 & 4.5 & 5.05 & TRN & \\
\hline CHEMBL1373435 & 688546 & 4.9 & 5.1702 & TRN & \\
\hline CHEMBL1474482 & 688546 & 4.6 & 5.7399 & TRN & \\
\hline CHEMBL1335079 & 688546 & 7.15 & 5.38299 & 9999999999 & TRN \\
\hline CHEMBL1514022 & 688546 & 8.4949 & 5.6952 & TRN & \\
\hline CHEMBL1480801 & 688546 & 5.1 & 5.1064 & TRN & \\
\hline CHEMBL1421833 & 688546 & 5.9 & 5.6358 & TRN & \\
\hline CHEMBL1358605 & 688546 & 8.0 & 5.0804 & TST & \\
\hline CHEMBL1419082 & 688546 & 5.7 & 5.0373 & TRN & \\
\hline CHEMBL1444230 & 688546 & 4.7 & 5.2412 & TRN & \\
\hline CHEMBL1399264 & 688546 & 6.5 & 5.6267 & TRN & \\
\hline CHEMBL3198616 & 688546 & 5.7 & 5.2465 & TST & \\
\hline CHEMBL1395178 & 688546 & 4.9 & 5.26200 & 00000000005 & TRN \\
\hline CHEMBL1397677 & 688546 & 5.6 & 5.9045 & TRN & \\
\hline CHEMBL1378158 & 688546 & 4.9 & 4.8132 & TRN & \\
\hline & & & & 10430 & \\
\hline
\end{tabular}




\begin{tabular}{|c|c|c|c|c|}
\hline \multicolumn{5}{|c|}{ Supplemental Table S2.txt } \\
\hline CHEMBL1355136 & 688546 & 5.0 & 5.6676 & TRN \\
\hline CHEMBL1317325 & 688546 & 4.9 & 5.4192 & TRN \\
\hline CHEMBL1512309 & 688546 & 4.8 & 5.0141 & TRN \\
\hline CHEMBL1452881 & 688546 & 4.5 & 5.8665 & TST \\
\hline CHEMBL546170 & 688546 & 5.3 & 5.0677 & TRN \\
\hline CHEMBL1474475 & 688546 & 4.7 & 4.6387 & TRN \\
\hline CHEMBL1395660 & 688546 & 4.7 & 5.1146 & TRN \\
\hline CHEMBL1535245 & 688546 & 5.0 & 5.2345 & TST \\
\hline CHEMBL1303411 & 688546 & 4.8 & 5.3947 & TRN \\
\hline CHEMBL1501547 & 688546 & 5.0 & 5.0813 & TRN \\
\hline CHEMBL1511557 & 688546 & 4.9 & 5.2025 & TRN \\
\hline CHEMBL589924 & 688546 & 4.9 & 5.1442 & TRN \\
\hline CHEMBL1398099 & 688546 & 5.1 & 5.1719 & TRN \\
\hline CHEMBL1437015 & 688546 & 5.35 & 5.8984 & TRN \\
\hline CHEMBL1592924 & 688546 & 4.5 & 5.8034 & TST \\
\hline CHEMBL1518942 & 688546 & 6.3 & 5.4477 & TRN \\
\hline CHEMBL1595310 & 688546 & 6.4 & 5.4193 & TRN \\
\hline CHEMBL1558449 & 688546 & 4.8 & 5.5651 & TST \\
\hline CHEMBL1480266 & 688546 & 7.3002 & 5.3146 & TRN \\
\hline CHEMBL1475296 & 688546 & 4.6 & 6.1356 & TRN \\
\hline CHEMBL1423491 & 688546 & 5.25 & 5.0155 & TRN \\
\hline CHEMBL1572280 & 688546 & 4.5 & 5.7666 & TST \\
\hline CHEMBL1342739 & 688546 & 5.8 & 5.3662 & TST \\
\hline CHEMBL454746 & 688546 & 5.0 & 5.3409 & TRN \\
\hline CHEMBL1474467 & 688546 & 8.4559 & 5.9095 & TRN \\
\hline CHEMBL1398428 & 688546 & 4.45 & 6.1469 & TRN \\
\hline CHEMBL1608078 & 688546 & 4.6 & 5.1813 & TRN \\
\hline CHEMBL1355390 & 688546 & 4.9 & 5.1644 & TRN \\
\hline CHEMBL1437286 & 688546 & 4.5 & 5.3523 & TRN \\
\hline CHEMBL1380091 & 688546 & 4.9 & 4.7841 & TRN \\
\hline CHEMBL1446815 & 688546 & 4.8 & 4.6688 & TRN \\
\hline CHEMBL1592910 & 688546 & 4.6 & 4.5956 & TRN \\
\hline CHEMBL1472951 & 688546 & 5.0 & 6.0441 & TRN \\
\hline CHEMBL1485112 & 688546 & 4.5 & 5.3018 & TRN \\
\hline CHEMBL58033 & 688546 & 6.0 & 5.365 & TRN \\
\hline CHEMBL1533267 & 688546 & 5.5 & 5.2978 & TRN \\
\hline CHEMBL1552568 & 688546 & 4.6 & 4.9151 & TRN \\
\hline CHEMBL1591458 & 688546 & 5.2 & 5.3292 & TRN \\
\hline CHEMBL406119 & 688546 & 4.7 & 5.3118 & TST \\
\hline CHEMBL1488661 & 688546 & 4.5 & 5.0598 & TRN \\
\hline CHEMBL1521563 & 688546 & 4.8 & 5.0344 & TST \\
\hline CHEMBL1421398 & 688546 & 5.2 & 5.1234 & TRN \\
\hline CHEMBL1567944 & 688546 & 4.5 & 5.6856 & TST \\
\hline CHEMBL1318605 & 688546 & 5.0 & 5.1603 & TRN \\
\hline CHEMBL1317793 & 688546 & 4.5 & 5.0201 & TRN \\
\hline CHEMBL1520683 & 688546 & 7.0 & 5.4919 & TST \\
\hline CHEMBL1473853 & 688546 & 4.9 & 5.5558 & TRN \\
\hline CHEMBL1331379 & 688546 & 5.0 & 4.977 & TRN \\
\hline
\end{tabular}




\begin{tabular}{|c|c|c|c|c|c|}
\hline \multirow[b]{2}{*}{ CHEMBL1448856 } & \multicolumn{5}{|c|}{ plemer } \\
\hline & 688546 & 4.9 & 5.0701 & TST & \\
\hline CHEMBL1405548 & 688546 & 4.9 & 5.4017 & TRN & \\
\hline CHEMBL400777 & 688546 & 5.2 & 5.06800 & 00000000005 & TRN \\
\hline CHEMBL1346885 & 688546 & 5.5 & 5.0611 & TRN & \\
\hline CHEMBL1590297 & 688546 & 4.7 & 5.0712 & TRN & \\
\hline CHEMBL1342119 & 688546 & 5.6 & 5.0069 & TRN & \\
\hline CHEMBL1483161 & 688546 & 4.55 & 4.7004 & TRN & \\
\hline CHEMBL1414391 & 688546 & 4.95 & 4.9844 & TRN & \\
\hline CHEMBL1363772 & 688546 & 4.9 & 4.779 & TRN & \\
\hline CHEMBL1359337 & 688546 & 5.2 & 5.3179 & TRN & \\
\hline CHEMBL1325385 & 688546 & 8.3468 & 5.1157 & TRN & \\
\hline CHEMBL1591179 & 688546 & 5.1 & 5.3082 & TRN & \\
\hline CHEMBL1401320 & 688546 & 5.5 & 5.0015 & TRN & \\
\hline CHEMBL1481616 & 688546 & 5.3 & 5.4112 & TST & \\
\hline CHEMBL465339 & 688546 & 4.6 & 5.4246 & TRN & \\
\hline CHEMBL1518161 & 688546 & 5.2 & 5.2394 & TRN & \\
\hline CHEMBL1434194 & 688546 & 4.5 & 4.9619 & TRN & \\
\hline CHEMBL1604884 & 688546 & 5.0 & 5.3866 & TRN & \\
\hline CHEMBL1592160 & 688546 & 4.9 & 5.0038 & TRN & \\
\hline CHEMBL1411897 & 688546 & 4.9 & 4.8672 & TST & \\
\hline CHEMBL1595601 & 688546 & 5.0 & 4.9967 & TST & \\
\hline CHEMBL1394383 & 688546 & 4.65 & 5.4987 & TRN & \\
\hline CHEMBL1332982 & 688546 & 4.8 & 5.5413 & TST & \\
\hline CHEMBL1516016 & 688546 & 4.7 & 5.2355 & TRN & \\
\hline CHEMBL1336171 & 688546 & 5.1 & 5.4637 & TRN & \\
\hline CHEMBL1490523 & 688546 & 4.8 & 4.7285 & TRN & \\
\hline CHEMBL1299756 & 688546 & 5.0 & 4.9614 & TST & \\
\hline CHEMBL1495889 & 688546 & 4.6 & 5.2203 & TRN & \\
\hline CHEMBL1503585 & 688546 & 8.6021 & 5.9243 & TRN & \\
\hline CHEMBL1325260 & 688546 & 4.5 & 5.2421 & TRN & \\
\hline CHEMBL1314277 & 688546 & 5.6 & 5.9579 & TRN & \\
\hline CHEMBL529138 & 688546 & 4.9 & 5.1708 & TRN & \\
\hline CHEMBL1513918 & 688546 & 4.5 & 5.1381 & TRN & \\
\hline CHEMBL1343759 & 688546 & 4.5 & 5.513 & TST & \\
\hline CHEMBL1513355 & 688546 & 5.1 & 5.3725 & TRN & \\
\hline CHEMBL1336262 & 688546 & 5.5 & 5.4887 & TRN & \\
\hline CHEMBL1336245 & 688546 & 4.5 & 4.6977 & TRN & \\
\hline CHEMBL1414984 & 688546 & 4.6 & 5.6967 & TRN & \\
\hline CHEMBL1489960 & 688546 & 4.8 & 5.4562 & TRN & \\
\hline CHEMBL1412825 & 688546 & 4.9 & 5.5544 & TRN & \\
\hline CHEMBL 261693 & 688546 & 6.4 & 5.444 & TST & \\
\hline CHEMBL1338385 & 688546 & 4.7 & 5.0003 & TRN & \\
\hline CHEMBL1448023 & 688546 & 4.5 & 5.2279 & TRN & \\
\hline CHEMBL1564854 & 688546 & 5.25 & 5.5169 & TST & \\
\hline CHEMBL1369348 & 688546 & 5.3 & 5.3556 & TST & \\
\hline CHEMBL1325689 & 688546 & 4.5 & 5.4023 & TRN & \\
\hline CHEMBL1593184 & 688546 & 5.5 & 5.356 & TRN & \\
\hline CHEMBL41794 & 688546 & 5.35 & 4.8644 & TST & \\
\hline & & & & 10432 & \\
\hline
\end{tabular}




\begin{tabular}{|c|c|c|c|c|c|}
\hline \\
\hline CHEMBL1555386 & 688546 & 6.2 & 5.7213 & TRN & \\
\hline CHEMBL1336277 & 688546 & 5.9 & 5.2744 & TRN & \\
\hline CHEMBL1524888 & 688546 & 8.1024 & 5.5986 & TRN & \\
\hline CHEMBL1552890 & 688546 & 4.6 & 5.2042 & TST & \\
\hline CHEMBL1558930 & 688546 & 5.1 & 5.0411 & TRN & \\
\hline CHEMBL1596914 & 688546 & 8.4949 & 5.4731 & TST & \\
\hline CHEMBL1306822 & 688546 & 4.5 & 4.8213 & TRN & \\
\hline CHEMBL1604646 & 688546 & 4.5 & 5.0287 & TST & \\
\hline CHEMBL1325611 & 688546 & 4.7 & 5.8407 & TRN & \\
\hline CHEMBL1396919 & 688546 & 5.1 & 5.25700 & $\partial 000000001$ & TRN \\
\hline CHEMBL1442396 & 688546 & 4.6 & 5.2286 & TST & \\
\hline CHEMBL1395086 & 688546 & 4.9 & 5.4549 & TST & \\
\hline CHEMBL1331613 & 688546 & 4.6 & 5.2588 & TRN & \\
\hline CHEMBL1403320 & 688546 & 5.1 & 5.04 & TRN & \\
\hline CHEMBL1609312 & 688546 & 5.3 & 5.5514 & TST & \\
\hline CHEMBL1324101 & 688546 & 7.699 & 6.1063 & TRN & \\
\hline CHEMBL1553727 & 688546 & 4.9 & 5.2331 & TST & \\
\hline CHEMBL1553321 & 688546 & 4.6 & 4.7094 & TRN & \\
\hline CHEMBL1420031 & 688546 & 4.5 & 4.8605 & TRN & \\
\hline CHEMBL1357097 & 688546 & 7.15 & 5.44 & TST & \\
\hline CHEMBL1519019 & 688546 & 5.3 & 5.3054 & TRN & \\
\hline CHEMBL1589889 & 688546 & 5.6 & 5.2035 & TRN & \\
\hline CHEMBL1436831 & 688546 & 7.7496 & 6.0384 & TRN & \\
\hline CHEMBL1472629 & 688546 & 5.0 & 5.4006 & TST & \\
\hline CHEMBL1453042 & 688546 & 4.9 & 4.95 & TRN & \\
\hline CHEMBL1437205 & 688546 & 6.2 & 5.8544 & TRN & \\
\hline CHEMBL1492557 & 688546 & 6.9 & 5.0553 & TRN & \\
\hline CHEMBL1476299 & 688546 & 8.301 & 5.5006 & TRN & \\
\hline CHEMBL1593455 & 688546 & 5.0 & 5.528 & TRN & \\
\hline CHEMBL1516550 & 688546 & 6.25 & 5.1818 & TRN & \\
\hline CHEMBL1518935 & 688546 & 5.3 & 6.0911 & TRN & \\
\hline CHEMBL1517347 & 688546 & 5.5 & 5.6506 & TRN & \\
\hline CHEMBL1371134 & 688546 & 5.45 & 5.7057 & TRN & \\
\hline CHEMBL1561182 & 688546 & 5.1 & 4.8664 & TRN & \\
\hline CHEMBL1315608 & 688546 & 8.1024 & 5.38200 & 2000000001 & TRN \\
\hline CHEMBL1338662 & 688546 & 4.8 & 5.5171 & TRN & \\
\hline CHEMBL597452 & 688546 & 5.45 & 5.1741 & TRN & \\
\hline CHEMBL1398382 & 688546 & 4.5 & 4.8448 & TRN & \\
\hline CHEMBL1405891 & 688546 & 5.25 & 5.3072 & TRN & \\
\hline CHEMBL1544015 & 688546 & 6.2 & 5.1475 & TRN & \\
\hline CHEMBL1550809 & 688546 & 5.2 & 4.9814 & TRN & \\
\hline CHEMBL1416809 & 688546 & 5.0 & 4.9753 & TRN & \\
\hline CHEMBL1554951 & 688546 & 5.1 & 5.2461 & TRN & \\
\hline CHEMBL533959 & 688546 & 5.5 & 5.0786 & TRN & \\
\hline CHEMBL1546185 & 688546 & 4.9 & 5.0584 & TST & \\
\hline CHEMBL1516624 & 688546 & 5.55 & 5.0873 & TRN & \\
\hline CHEMBL1516995 & 688546 & 4.6 & 4.8295 & TRN & \\
\hline CHEMBL3199095 & 688546 & 4.9 & 5.4885 & TST & \\
\hline
\end{tabular}




\begin{tabular}{|c|c|c|c|c|c|}
\hline \multicolumn{6}{|c|}{ oplemental Table s } \\
\hline CHEMBL1320008 & 688546 & 5.2 & 5.4538 & TRN & \\
\hline CHEMBL1550445 & 688546 & 6.5 & 5.1141 & TRN & \\
\hline CHEMBL1377224 & 688546 & 5.1 & 5.2506 & TRN & \\
\hline CHEMBL1564134 & 688546 & 4.8 & 4.8866 & TRN & \\
\hline CHEMBL3199915 & 688546 & 4.9 & 5.2167 & TST & \\
\hline CHEMBL1474689 & 688546 & 4.9 & 5.2571 & TRN & \\
\hline CHEMBL1533872 & 688546 & 7.6003 & 5.1941 & TST & \\
\hline CHEMBL1391746 & 688546 & 4.9 & 5.2068 & TRN & \\
\hline CHEMBL1592809 & 688546 & 4.5 & 6.0817 & TRN & \\
\hline CHEMBL1485405 & 688546 & 5.2 & 4.8666 & TRN & \\
\hline CHEMBL1359476 & 688546 & 5.2 & 4.9812 & TRN & \\
\hline CHEMBL1592483 & 688546 & 4.5 & 4.7293 & TRN & \\
\hline CHEMBL1315327 & 688546 & 4.7 & 5.1978 & TRN & \\
\hline CHEMBL1441446 & 688546 & 4.8 & 4.8004 & TRN & \\
\hline CHEMBL1433507 & 688546 & 6.6499 & 5.8392 & TST & \\
\hline CHEMBL1401057 & 688546 & 4.45 & 5.0967 & TST & \\
\hline CHEMBL1331875 & 688546 & 5.3 & 5.0468 & TRN & \\
\hline CHEMBL1580990 & 688546 & 4.5 & 5.0737 & TRN & \\
\hline CHEMBL1386936 & 688546 & 4.8 & 5.271 & TRN & \\
\hline CHEMBL1402163 & 688546 & 4.5 & 5.1485 & TST & \\
\hline CHEMBL1324774 & 688546 & 7.3497 & 5.0609 & TRN & \\
\hline CHEMBL1520410 & 688546 & 5.4 & 6.1312 & TRN & \\
\hline CHEMBL1492865 & 688546 & 4.5 & 5.3124 & TST & \\
\hline CHEMBL1368872 & 688546 & 4.45 & 5.2026 & TRN & \\
\hline CHEMBL1475362 & 688546 & 5.3 & 5.6973 & TRN & \\
\hline CHEMBL1548237 & 688546 & 4.5 & 5.2829 & TRN & \\
\hline CHEMBL1494966 & 688546 & 4.65 & 5.3551 & TST & \\
\hline CHEMBL1375955 & 688546 & 4.5 & 4.6116 & TRN & \\
\hline CHEMBL1408650 & 688546 & 5.4 & 5.3375 & TST & \\
\hline CHEMBL1366565 & 688546 & 7.699 & 5.1115 & TRN & \\
\hline CHEMBL1441246 & 688546 & 4.9 & 5.1753 & TRN & \\
\hline CHEMBL1410505 & 688546 & 7.8013 & 5.82700 & 0000000001 & TRN \\
\hline CHEMBL1256911 & 688546 & 4.9 & 5.0244 & TST & \\
\hline CHEMBL1434263 & 688546 & 6.0 & 5.4423 & TRN & \\
\hline CHEMBL1592927 & 688546 & 4.8 & 5.1597 & TRN & \\
\hline CHEMBL1520944 & 688546 & 5.0 & 5.2518 & TST & \\
\hline CHEMBL1375608 & 688546 & 5.25 & 5.5976 & TRN & \\
\hline CHEMBL1370271 & 688546 & 4.9 & 5.2876 & TRN & \\
\hline CHEMBL1604810 & 688546 & 5.3 & 5.1524 & TRN & \\
\hline CHEMBL1320243 & 688546 & 4.6 & 4.8487 & TRN & \\
\hline CHEMBL1445636 & 688546 & 4.9 & 5.4369 & TRN & \\
\hline CHEMBL1334808 & 688546 & 4.9 & 4.7865 & TRN & \\
\hline CHEMBL1444098 & 688546 & 7.3002 & 5.5241 & TST & \\
\hline CHEMBL1604273 & 688546 & 5.0 & 5.341 & TRN & \\
\hline CHEMBL1536823 & 688546 & 4.9 & 5.3385 & TST & \\
\hline CHEMBL1565734 & 688546 & 5.5 & 4.9584 & TRN & \\
\hline CHEMBL1398481 & 688546 & 5.6 & 5.3738 & TRN & \\
\hline CHEMBL1314693 & 688546 & 4.8 & 5.1602 & TRN & \\
\hline
\end{tabular}




\begin{tabular}{|c|c|c|c|c|c|}
\hline & & \multicolumn{4}{|c|}{ Supplemental Table S2.txt } \\
\hline CHEMBL1517058 & 688546 & 6.6499 & 5.4102 & TRN & \\
\hline CHEMBL1314749 & 688546 & 4.6 & 5.4401 & TRN & \\
\hline CHEMBL1437726 & 688546 & 5.4 & 5.0852 & TRN & \\
\hline CHEMBL1474999 & 688546 & 5.4 & 4.9485 & TST & \\
\hline CHEMBL1322597 & 688546 & 4.9 & 5.5163 & TST & \\
\hline CHEMBL1515645 & 688546 & 5.6 & 5.524 & TRN & \\
\hline CHEMBL1333387 & 688546 & 5.1 & 5.397 & TST & \\
\hline CHEMBL3392050 & 688546 & 4.8 & 4.9858 & TRN & \\
\hline CHEMBL1378090 & 688546 & 4.9 & 5.3595 & TST & \\
\hline CHEMBL1529502 & 688546 & 4.5 & 5.57 & TRN & \\
\hline CHEMBL1435472 & 688546 & 4.5 & 5.4097 & TRN & \\
\hline CHEMBL1551874 & 688546 & 4.9 & 5.3289 & TRN & \\
\hline CHEMBL1447785 & 688546 & 8.1024 & 5.815 & TRN & \\
\hline CHEMBL1475081 & 688546 & 4.5 & 5.461 & TRN & \\
\hline CHEMBL1324670 & 688546 & 5.1 & 5.353 & TRN & \\
\hline CHEMBL1418048 & 688546 & 5.1 & 5.2149 & TRN & \\
\hline CHEMBL1472817 & 688546 & 5.4 & 5.7116 & TRN & \\
\hline CHEMBL1570906 & 688546 & 7.8996 & 5.3575 & TRN & \\
\hline CHEMBL1551011 & 688546 & 5.1 & 5.1205 & TRN & \\
\hline CHEMBL1337566 & 688546 & 4.7 & 5.4515 & TRN & \\
\hline CHEMBL1395912 & 688546 & 4.7 & 5.1482 & TRN & \\
\hline CHEMBL1318625 & 688546 & 5.05 & 5.6203 & TRN & \\
\hline CHEMBL1324613 & 688546 & 4.7 & 5.9241 & TRN & \\
\hline CHEMBL1394280 & 688546 & 4.6 & 4.9795 & TRN & \\
\hline CHEMBL1565955 & 688546 & 4.95 & 4.7173 & TRN & \\
\hline CHEMBL1317251 & 688546 & 8.2007 & 5.5814 & TST & \\
\hline CHEMBL1372402 & 688546 & 7.4001 & 5.3562 & TRN & \\
\hline CHEMBL1453208 & 688546 & 4.5 & 4.9633 & TRN & \\
\hline CHEMBL1574795 & 688546 & 4.5 & 4.7241 & TRN & \\
\hline CHEMBL1594290 & 688546 & 4.8 & 5.1148 & TRN & \\
\hline CHEMBL1557043 & 688546 & 5.35 & 5.4896 & TRN & \\
\hline CHEMBL1361294 & 688546 & 4.7 & 5.2332 & TST & \\
\hline CHEMBL1322652 & 688546 & 7.2 & 5.3247 & TRN & \\
\hline CHEMBL1610968 & 688546 & 5.0 & 5.1362 & TST & \\
\hline CHEMBL1519341 & 688546 & 4.9 & 4.5647 & TRN & \\
\hline CHEMBL1372083 & 688546 & 6.5 & 5.3648 & TST & \\
\hline CHEMBL1473789 & 688546 & 4.6 & 5.4898 & TRN & \\
\hline CHEMBL1397890 & 688546 & 4.9 & 4.8809 & TRN & \\
\hline CHEMBL1538973 & 688546 & 4.9 & 5.018 & TRN & \\
\hline CHEMBL3208787 & 688546 & 4.7 & 4.8867 & TST & \\
\hline CHEMBL1309183 & 688546 & 4.45 & 5.319 & TST & \\
\hline CHEMBL1435797 & 688546 & 8.301 & 5.3941 & TRN & \\
\hline CHEMBL1512621 & 688546 & 5.0 & 5.63899 & 9999999999 & TRN \\
\hline CHEMBL 1415790 & 688546 & 4.9 & 4.5329 & TRN & \\
\hline CHEMBL1422079 & 688546 & 4.8 & 5.3314 & TRN & \\
\hline CHEMBL1398009 & 688546 & 7.5498 & 5.8481 & TRN & \\
\hline CHEMBL1409504 & 688546 & 4.7 & 4.8765 & TRN & \\
\hline CHEMBL1434029 & 688546 & 4.5 & 5.1766 & TST & \\
\hline
\end{tabular}




\begin{tabular}{|c|c|c|c|c|}
\hline \multicolumn{5}{|c|}{ Supplemental Table S2.txt } \\
\hline CHEMBL1470598 & 688546 & 5.2 & 4.9757 & TRN \\
\hline CHEMBL1592700 & 688546 & 8.2007 & 5.7702 & TRN \\
\hline CHEMBL1575054 & 688546 & 4.9 & 5.0857 & TRN \\
\hline CHEMBL1491324 & 688546 & 5.0 & 4.7784 & TRN \\
\hline CHEMBL 1604826 & 688546 & 5.0 & 5.2077 & TRN \\
\hline CHEMBL1320451 & 688546 & 5.0 & 5.3472 & TRN \\
\hline CHEMBL1553723 & 688546 & 5.05 & 5.2523 & TRN \\
\hline CHEMBL1514773 & 688546 & 5.5 & 5.4662 & TRN \\
\hline CHEMBL1514491 & 688546 & 5.0 & 5.305 & TRN \\
\hline CHEMBL1476302 & 688546 & 4.7 & 5.8854 & TRN \\
\hline CHEMBL1567149 & 688546 & 4.5 & 5.5608 & TRN \\
\hline CHEMBL1525404 & 688546 & 4.8 & 5.1284 & TRN \\
\hline CHEMBL1396642 & 688546 & 4.7 & 5.3289 & TRN \\
\hline CHEMBL1324618 & 688546 & 4.9 & 4.8627 & TRN \\
\hline CHEMBL1464435 & 688546 & 4.7 & 4.8731 & TST \\
\hline CHEMBL1307549 & 688546 & 4.5 & 5.5148 & TRN \\
\hline CHEMBL1436874 & 688546 & 4.8 & 5.2152 & TRN \\
\hline CHEMBL1315594 & 688546 & 7.4498 & 6.0526 & TRN \\
\hline CHEMBL1608433 & 688546 & 5.0 & 5.3828 & TRN \\
\hline CHEMBL221137 & 688546 & 4.9 & 5.1464 & TST \\
\hline CHEMBL3199884 & 688546 & 4.7 & 5.1329 & TRN \\
\hline CHEMBL1553227 & 688546 & 4.9 & 4.9598 & TRN \\
\hline CHEMBL1435628 & 688546 & 4.5 & 5.7764 & TRN \\
\hline CHEMBL586946 & 688546 & 4.5 & 5.1663 & TST \\
\hline CHEMBL52 & 688546 & 6.0 & 4.7545 & TRN \\
\hline CHEMBL1492440 & 688546 & 5.0 & 5.4737 & TST \\
\hline CHEMBL1301407 & 688546 & 4.6 & 5.4749 & TST \\
\hline CHEMBL1336380 & 688546 & 4.5 & 4.944 & TRN \\
\hline CHEMBL319244 & 688546 & 4.9 & 4.9574 & TST \\
\hline CHEMBL1474849 & 688546 & 6.8 & 5.6339 & TRN \\
\hline CHEMBL1571921 & 688546 & 5.7 & 5.105 & TRN \\
\hline CHEMBL1533329 & 688546 & 4.5 & 5.7029 & TRN \\
\hline CHEMBL1488604 & 688546 & 5.1 & 5.3168 & TRN \\
\hline CHEMBL1309497 & 688546 & 4.9 & 4.6365 & TRN \\
\hline CHEMBL1311501 & 688546 & 5.0 & 5.9078 & TRN \\
\hline CHEMBL1324347 & 688546 & 5.0 & 4.9092 & TST \\
\hline CHEMBL1406466 & 688546 & 5.8 & 5.6799 & TRN \\
\hline CHEMBL1575995 & 688546 & 5.25 & 5.2396 & TST \\
\hline CHEMBL1602699 & 688546 & 4.9 & 5.138 & TRN \\
\hline CHEMBL1397148 & 688546 & 4.9 & 5.5626 & TST \\
\hline CHEMBL1416902 & 688546 & 5.1 & 5.2062 & TRN \\
\hline CHEMBL320247 & 688546 & 5.5 & 5.2065 & TRN \\
\hline CHEMBL1610032 & 688546 & 4.8 & 5.5022 & TRN \\
\hline CHEMBL1435119 & 688546 & 5.1 & 5.1064 & TRN \\
\hline CHEMBL1377981 & 688546 & 5.4 & 5.2733 & TRN \\
\hline CHEMBL1554800 & 688546 & 4.8 & 5.2532 & TRN \\
\hline CHEMBL1434896 & 688546 & 4.5 & 4.9202 & TRN \\
\hline CHEMBL1450423 & 688546 & 5.0 & 5.5431 & TRN \\
\hline
\end{tabular}




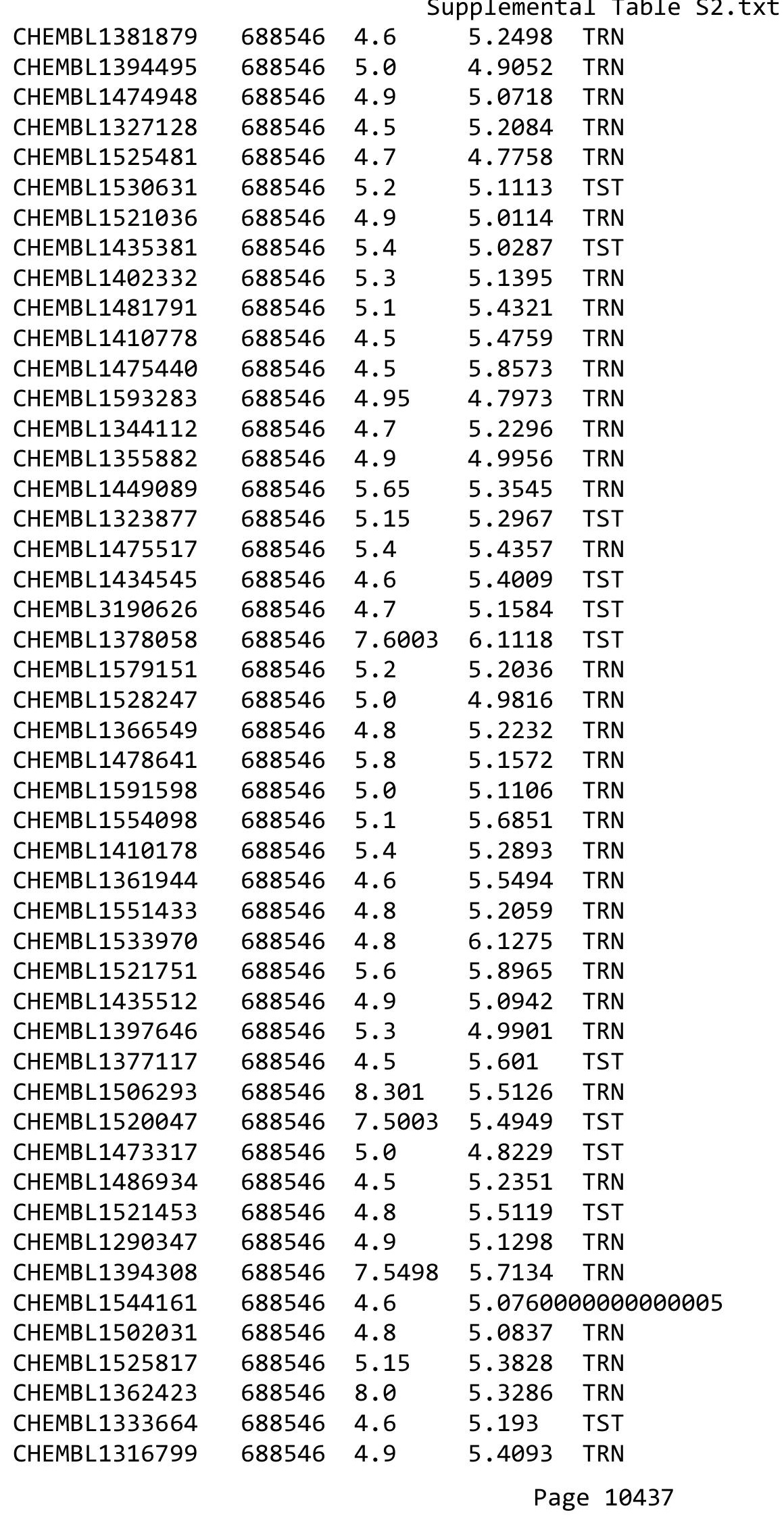




\begin{tabular}{|c|c|c|c|c|c|}
\hline CHEMBL1404717 & 688546 & 4.7 & \multicolumn{2}{|c|}{ 4.9319999999999995 } & TRN \\
\hline CHEMBL1445710 & 688546 & 4.8 & 4.9548 & TST & \\
\hline CHEMBL1365867 & 688546 & 4.9 & 5.1904 & TRN & \\
\hline CHEMBL1436050 & 688546 & 6.8 & 5.9857 & TST & \\
\hline CHEMBL1359221 & 688546 & 6.2 & 5.7509 & TRN & \\
\hline CHEMBL1582448 & 688546 & 5.0 & 5.4805 & TST & \\
\hline CHEMBL1595693 & 688546 & 4.5 & 6.0097 & TRN & \\
\hline CHEMBL1485101 & 688546 & 4.9 & 5.3894 & TRN & \\
\hline CHEMBL1481309 & 688546 & 4.5 & 5.312 & TRN & \\
\hline CHEMBL1410491 & 688546 & 4.6 & 5.2996 & TRN & \\
\hline CHEMBL1436211 & 688546 & 5.2 & 5.5552 & TRN & \\
\hline CHEMBL1541391 & 688546 & 4.5 & 5.1791 & TST & \\
\hline CHEMBL1536493 & 688546 & 4.5 & 5.3369 & TST & \\
\hline CHEMBL1533158 & 688546 & 4.9 & 5.0706 & TRN & \\
\hline CHEMBL1390081 & 688546 & 4.9 & 5.0854 & TRN & \\
\hline CHEMBL1591309 & 688546 & 4.7 & 5.4673 & TRN & \\
\hline CHEMBL1321297 & 688546 & 6.0 & 4.662 & TRN & \\
\hline CHEMBL1607804 & 688546 & 5.4 & 5.4702 & TRN & \\
\hline CHEMBL 3145304 & 688546 & 4.85 & 5.4233 & TST & \\
\hline CHEMBL1529777 & 688546 & 4.9 & 5.1006 & TRN & \\
\hline CHEMBL1301607 & 688546 & 4.8 & 5.3193 & TRN & \\
\hline CHEMBL1428196 & 688546 & 5.0 & 5.2718 & TRN & \\
\hline CHEMBL1368808 & 688546 & 6.0 & 5.3834 & TRN & \\
\hline CHEMBL1478321 & 688546 & 4.5 & 5.0627 & TRN & \\
\hline CHEMBL1590819 & 688546 & 6.45 & 5.7252 & TST & \\
\hline CHEMBL1595518 & 688546 & 4.9 & 5.2199 & TRN & \\
\hline CHEMBL1551519 & 688546 & 5.2 & 4.8849 & TRN & \\
\hline CHEMBL1330739 & 688546 & 4.5 & 4.8966 & TST & \\
\hline CHEMBL592123 & 688546 & 4.8 & 5.4392 & TRN & \\
\hline CHEMBL1081635 & 688546 & 5.7 & 5.6466 & TRN & \\
\hline CHEMBL549562 & 577227 & 4.1805 & 4.0234 & TST & \\
\hline CHEMBL570306 & 577227 & 4.585 & 4.6326 & TRN & \\
\hline CHEMBL551710 & 577227 & 4.3468 & 4.3792 & TRN & \\
\hline CHEMBL563032 & 577227 & 4.5528 & 4.284 & TRN & \\
\hline CHEMBL538961 & 577227 & 4.2218 & 4.311 & TRN & \\
\hline CHEMBL552105 & 577227 & 4.5376 & 4.4001 & TRN & \\
\hline CHEMBL557905 & 577227 & 4.3468 & 4.1856 & TRN & \\
\hline CHEMBL559716 & 577227 & 4.4815 & 4.3512 & TRN & \\
\hline CHEMBL539139 & 577227 & 3.0 & 3.0262 & TRN & \\
\hline CHEMBL559717 & 577227 & 4.5686 & 4.5135 & TRN & \\
\hline CHEMBL561569 & 577227 & 4.2007 & 4.0825 & TST & \\
\hline CHEMBL550752 & 577227 & 4.8539 & 4.7841 & TRN & \\
\hline CHEMBL539393 & 577227 & 4.4202 & 4.2383 & TRN & \\
\hline CHEMBL563804 & 577227 & 4.6198 & 4.4513 & TRN & \\
\hline CHEMBL564464 & 577227 & 4.2147 & 4.3113 & TRN & \\
\hline CHEMBL551244 & 577227 & 3.0 & 2.8167 & TST & \\
\hline CHEMBL560369 & 577227 & 4.5086 & 4.4429 & TRN & \\
\hline CHEMBL550768 & 577227 & 3.9706 & 4.0166 & TRN & \\
\hline
\end{tabular}




\begin{tabular}{|c|c|c|c|c|c|}
\hline & & & & & \\
\hline CHEMBL559521 & 577227 & 4.2076 & 4.3792 & TRN & \\
\hline CHEMBL560148 & 577227 & 3.0 & 2.9065 & TRN & \\
\hline CHEMBL562247 & 577227 & 4.7696 & 4.5642 & TRN & \\
\hline CHEMBL559520 & 577227 & 4.4949 & 4.2116 & TRN & \\
\hline CHEMBL550767 & 577227 & 4.0088 & 4.0396 & TRN & \\
\hline CHEMBL560309 & 577227 & 4.2676 & 3.2976 & TST & \\
\hline CHEMBL558107 & 577227 & 4.3665 & 4.3154 & TRN & \\
\hline CHEMBL551385 & 577227 & 4.585 & 4.6148 & TRN & \\
\hline CHEMBL540227 & 577227 & 2.8861 & 3.1041 & TST & \\
\hline CHEMBL561051 & 577227 & 4.4949 & 4.5663 & TRN & \\
\hline CHEMBL551046 & 577227 & 2.8861 & 2.9779 & TRN & \\
\hline CHEMBL561648 & 577227 & 3.0 & 3.5024 & TST & \\
\hline CHEMBL552742 & 577227 & 3.0 & 3.1596 & TRN & \\
\hline CHEMBL550766 & 577227 & 4.5686 & 2.87899 & 99999999996 & TST \\
\hline CHEMBL553190 & 577227 & 4.4685 & 4.2316 & TST & \\
\hline CHEMBL560972 & 577227 & 4.4685 & 4.577 & TRN & \\
\hline CHEMBL539718 & 577227 & 4.4437 & 4.47199 & 99999999995 & TRN \\
\hline CHEMBL570307 & 577227 & 4.2518 & 2.7028 & TST & \\
\hline CHEMBL551791 & 577227 & 4.2676 & 4.4021 & TRN & \\
\hline CHEMBL556270 & 577227 & 4.5528 & 4.5895 & TRN & \\
\hline CHEMBL549557 & 577227 & 3.0 & 4.0232 & TRN & \\
\hline CHEMBL552185 & 577227 & 4.4202 & 4.0417 & TST & \\
\hline CHEMBL561649 & 577227 & 4.5376 & 4.2763 & TST & \\
\hline CHEMBL560568 & 577227 & 4.2076 & 4.4786 & TST & \\
\hline CHEMBL550765 & 577227 & 4.2076 & 2.8157 & TST & \\
\hline CHEMBL561446 & 577227 & 4.2676 & 4.3995 & TST & \\
\hline CHEMBL551975 & 577227 & 4.3279 & 4.3361 & TRN & \\
\hline CHEMBL562250 & 577227 & 4.1739 & 3.9059 & TRN & \\
\hline CHEMBL551976 & 577227 & 4.4685 & 4.5157 & TRN & \\
\hline CHEMBL562173 & 577227 & 4.4559 & 4.1633 & TRN & \\
\hline CHEMBL561650 & 577227 & 4.4089 & 4.3675 & TRN & \\
\hline CHEMBL558108 & 577227 & 4.7959 & 4.6728 & TRN & \\
\hline CHEMBL552456 & 577227 & 4.5086 & 4.5676 & TRN & \\
\hline CHEMBL560675 & 577227 & 3.0 & 2.6787 & TST & \\
\hline CHEMBL561850 & 577227 & 4.2676 & 3.7617 & TST & \\
\hline CHEMBL560310 & 577227 & 3.0 & 2.8022 & TST & \\
\hline CHEMBL550759 & 577227 & 4.3188 & 4.4777 & TRN & \\
\hline CHEMBL565150 & 577227 & 4.2596 & 4.3395 & TRN & \\
\hline CHEMBL563871 & 577227 & 4.7447 & 4.8302 & TRN & \\
\hline CHEMBL550846 & 577227 & 4.4559 & 4.68 & TRN & \\
\hline CHEMBL552048 & 577227 & 4.5528 & 4.4346 & TRN & \\
\hline CHEMBL561050 & 577227 & 4.5086 & 4.391 & TRN & \\
\hline CHEMBL570776 & 577227 & 4.2924 & 4.26699 & 99999999995 & TRN \\
\hline CHEMBL550758 & 577227 & 4.7447 & 4.6785 & TRN & \\
\hline CHEMBL562584 & 577227 & 4.3279 & 4.4006 & TRN & \\
\hline CHEMBL562251 & 577227 & 4.0862 & 4.0325 & TRN & \\
\hline CHEMBL563181 & 577227 & 4.2757 & 4.3717 & TRN & \\
\hline CHEMBL550760 & 577227 & 4.6021 & 4.6484 & TRN & \\
\hline
\end{tabular}




\begin{tabular}{|c|c|c|c|c|}
\hline & & & oplement & al $\mathrm{Tc}$ \\
\hline CHEMBL564112 & 577227 & 4.0044 & 3.9182 & TRN \\
\hline CHEMBL560510 & 577227 & 3.0 & 3.8119 & TST \\
\hline CHEMBL549482 & 577227 & 4.3872 & 4.0404 & TRN \\
\hline CHEMBL551184 & 577227 & 4.0 & 4.1662 & TRN \\
\hline CHEMBL541737 & 577227 & 4.585 & 4.6227 & TRN \\
\hline CHEMBL552392 & 577227 & 4.9208 & 4.5973 & TST \\
\hline CHEMBL550497 & 577227 & 4.6021 & 4.5734 & TRN \\
\hline CHEMBL561574 & 577227 & 4.0 & 4.1073 & TRN \\
\hline CHEMBL560108 & 577227 & 3.9957 & 4.0034 & TRN \\
\hline CHEMBL559522 & 577227 & 4.699 & 4.6008 & TRN \\
\hline CHEMBL560311 & 577227 & 4.5086 & 4.5261 & TST \\
\hline CHEMBL555749 & 577227 & 4.8539 & 4.7815 & TST \\
\hline CHEMBL541227 & 577227 & 2.8861 & 2.8067 & TRN \\
\hline CHEMBL569845 & 577227 & 4.6198 & 4.4577 & TRN \\
\hline CHEMBL561975 & 577227 & 4.0132 & 4.1311 & TRN \\
\hline CHEMBL558106 & 577227 & 5.0 & 4.7952 & TRN \\
\hline CHEMBL560911 & 577227 & 4.3188 & 4.0639 & TRN \\
\hline CHEMBL562445 & 577227 & 4.2676 & 4.3131 & TRN \\
\hline CHEMBL562507 & 577227 & 4.2596 & 4.3417 & TRN \\
\hline CHEMBL561653 & 577227 & 3.0 & 3.0459 & TRN \\
\hline CHEMBL561170 & 577227 & 4.5376 & 4.683 & TRN \\
\hline CHEMBL550954 & 577227 & 4.2518 & 4.1679 & TRN \\
\hline CHEMBL557906 & 577227 & 4.8861 & 4.848 & TRN \\
\hline CHEMBL538150 & 577227 & 4.1871 & 3.9087 & TRN \\
\hline CHEMBL572342 & 577227 & 4.4559 & 4.4992 & TRN \\
\hline CHEMBL559854 & 577227 & 4.4089 & 4.4454 & TRN \\
\hline CHEMBL541478 & 577227 & 4.301 & 4.1583 & TRN \\
\hline CHEMBL558297 & 577227 & 4.1367 & 4.2116 & TRN \\
\hline CHEMBL563943 & 577227 & 4.2441 & 4.3013 & TRN \\
\hline CHEMBL540471 & 577227 & 4.5528 & 4.4116 & TRN \\
\hline CHEMBL551778 & 577227 & 4.3665 & 4.4394 & TRN \\
\hline CHEMBL541481 & 577227 & 4.4318 & 4.5141 & TRN \\
\hline CHEMBL558298 & 577227 & 4.9208 & 4.8491 & TRN \\
\hline CHEMBL551106 & 577227 & 4.4685 & 4.5793 & TRN \\
\hline CHEMBL550845 & 577227 & 4.2076 & 4.4796 & TRN \\
\hline CHEMBL560512 & 577227 & 4.7959 & 3.9508 & TST \\
\hline CHEMBL563368 & 577227 & 4.0915 & 4.3063 & TRN \\
\hline CHEMBL549685 & 577227 & 4.6198 & 3.7395 & TST \\
\hline CHEMBL551779 & 577227 & 4.5528 & 4.542 & TRN \\
\hline CHEMBL560569 & 577227 & 4.6383 & 4.5114 & TRN \\
\hline CHEMBL551450 & 577227 & 4.2676 & 4.2515 & TRN \\
\hline CHEMBL552517 & 577227 & 4.1079 & 4.3072 & TRN \\
\hline CHEMBL552106 & 577227 & 3.0 & 4.3606 & TST \\
\hline CHEMBL557091 & 577227 & 4.4089 & 4.5955 & TRN \\
\hline CHEMBL560114 & 577227 & 4.585 & 4.2912 & TST \\
\hline CHEMBL572348 & 577227 & 4.4949 & 4.316 & TST \\
\hline CHEMBL550094 & 577227 & 4.9208 & 4.6654 & TST \\
\hline CHEMBL561570 & 577227 & 4.1427 & 4.0916 & TRN \\
\hline
\end{tabular}




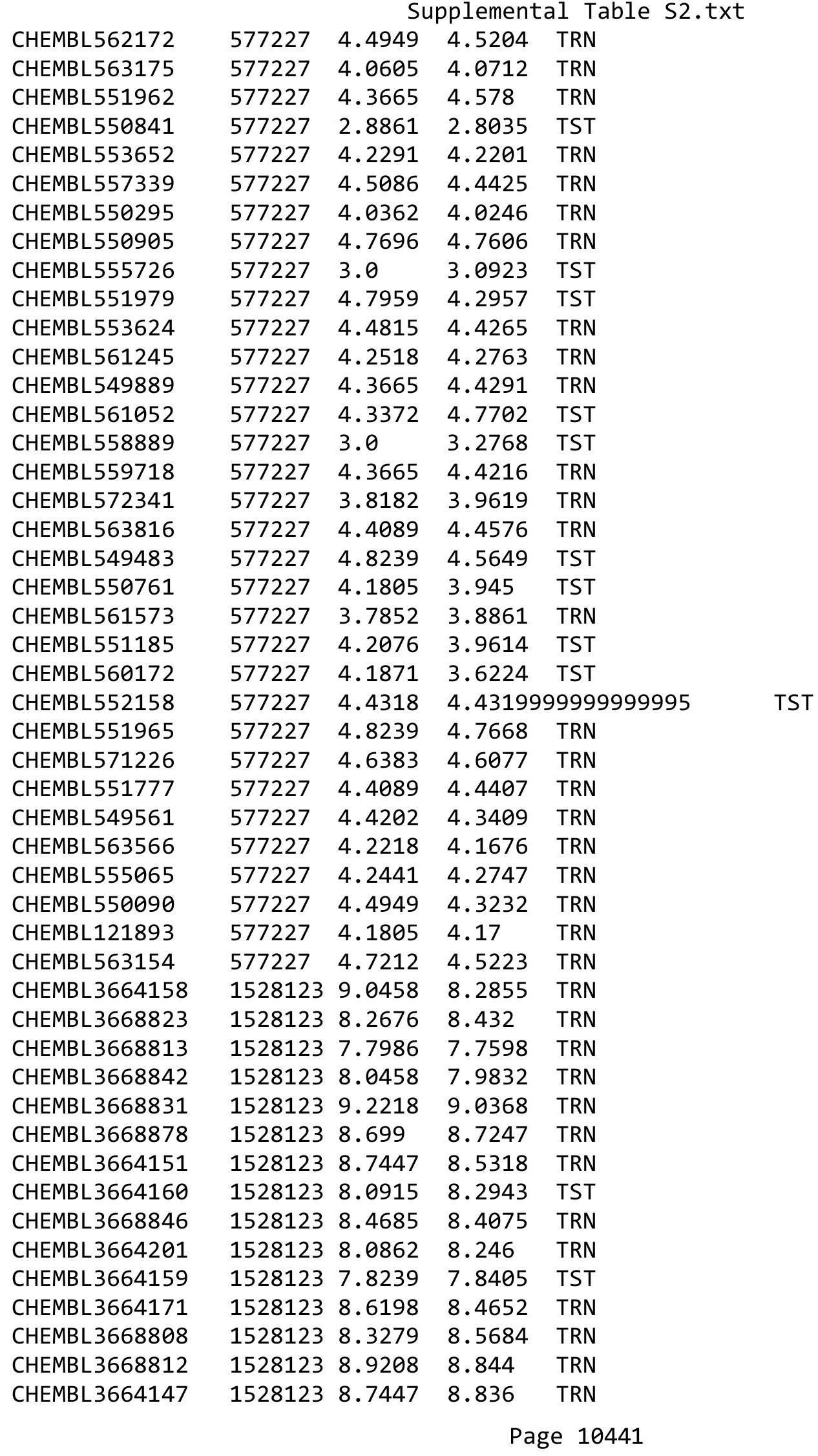


Supplemental Table S2.txt

\begin{tabular}{|c|c|c|c|c|}
\hline CHEMBL3668880 & 1528123 & 8.5528 & 8.5034 & TRN \\
\hline CHEMBL3668883 & 1528123 & 9.301 & 9.1885 & TST \\
\hline CHEMBL3668787 & 1528123 & 8.4089 & 7.9874 & TST \\
\hline CHEMBL3639630 & 1528123 & 7.0947 & 7.5602 & TST \\
\hline CHEMBL3664167 & 1528123 & 7.6308 & 8.0404 & TST \\
\hline CHEMBL3668876 & 1528123 & 8.1249 & 8.003 & TRN \\
\hline CHEMBL3664149 & 1528123 & 9.0458 & 9.0552 & TRN \\
\hline CHEMBL3664145 & 1528123 & 9.301 & 9.1407 & TRN \\
\hline CHEMBL3668873 & 1528123 & 8.8239 & 8.9176 & TRN \\
\hline CHEMBL3668818 & 1528123 & 9.2218 & 9.0391 & TRN \\
\hline CHEMBL 3668822 & 1528123 & 7.8539 & 7.83799 & 9999999999 \\
\hline CHEMBL3664142 & 1528123 & 8.1308 & 8.1893 & TRN \\
\hline CHEMBL3664169 & 1528123 & 9.0458 & 8.9553 & TRN \\
\hline CHEMBL 3668835 & 1528123 & 8.7447 & 8.8928 & TRN \\
\hline CHEMBL3664208 & 1528123 & 8.3098 & 8.0809 & TRN \\
\hline CHEMBL3664211 & 1528123 & 7.8928 & 8.338 & TRN \\
\hline CHEMBL3668826 & 1528123 & 8.7212 & 9.0827 & TRN \\
\hline CHEMBL3664162 & 1528123 & 6.9176 & 7.2701 & TRN \\
\hline CHEMBL 3668825 & 1528123 & 8.4559 & 8.612 & TRN \\
\hline CHEMBL3668882 & 1528123 & 8.6576 & 8.7832 & TRN \\
\hline CHEMBL3668837 & 1528123 & 8.4815 & 8.6861 & TRN \\
\hline CHEMBL3668874 & 1528123 & 7.8761 & 7.7484 & TRN \\
\hline CHEMBL3668804 & 1528123 & 8.8539 & 8.4172 & TRN \\
\hline CHEMBL3668881 & 1528123 & 8.8539 & 8.8429 & TST \\
\hline CHEMBL3668821 & 1528123 & 8.1192 & 7.9338 & TRN \\
\hline CHEMBL3668857 & 1528123 & 7.1599 & 7.4531 & TST \\
\hline CHEMBL3664207 & 1528123 & 8.1024 & 8.2839 & TRN \\
\hline CHEMBL3668872 & 1528123 & 8.2007 & 8.1178 & TST \\
\hline CHEMBL 3668824 & 1528123 & 8.1024 & 8.2354 & TRN \\
\hline CHEMBL3639676 & 1528123 & 8.8539 & 8.9088 & TRN \\
\hline CHEMBL3668877 & 1528123 & 8.2924 & 8.126 & TRN \\
\hline CHEMBL3664168 & 1528123 & 7.0706 & 7.6246 & TST \\
\hline CHEMBL3668811 & 1528123 & 8.2924 & 8.4337 & TRN \\
\hline CHEMBL 3664146 & 1528123 & 7.6968 & 7.9911 & TRN \\
\hline CHEMBL3668853 & 1528123 & 8.9208 & 8.8145 & TRN \\
\hline CHEMBL3668807 & 1528123 & 8.5528 & 8.5598 & TRN \\
\hline CHEMBL3668879 & 1528123 & 8.8539 & 8.728 & TST \\
\hline CHEMBL3668851 & 1528123 & 8.4559 & 8.2497 & TST \\
\hline CHEMBL 3668868 & 1528123 & 7.6716 & 7.8122 & TST \\
\hline CHEMBL3664163 & 1528123 & 7.1694 & 7.7724 & TRN \\
\hline CHEMBL3668810 & 1528123 & 8.7447 & 8.8908 & TRN \\
\hline CHEMBL3668863 & 1528123 & 7.9469 & 7.8522 & TST \\
\hline CHEMBL3664165 & 1528123 & 7.0501 & 7.2808 & TRN \\
\hline CHEMBL3668816 & 1528123 & 8.0969 & 8.2061 & TRN \\
\hline CHEMBL3664170 & 1528123 & 8.7959 & 8.1509 & TRN \\
\hline CHEMBL3668852 & 1528123 & 7.9172 & 7.9169 & TRN \\
\hline CHEMBL3664164 & 1528123 & 7.0516 & 7.1738 & TRN \\
\hline CHEMBL 3668840 & 1528123 & 7.9066 & 7.8814 & TST \\
\hline
\end{tabular}




$$
\text { Supplemental Table S2.txt }
$$

\begin{tabular}{|c|c|c|c|c|c|}
\hline CHEMBL 3664166 & 1528123 & 6.9638 & 7.1871 & TST & \\
\hline CHEMBL 3668806 & 1528123 & 8.6021 & 8.3215 & TRN & \\
\hline CHEMBL 3668829 & 1528123 & 9.0969 & 9.1905 & TRN & \\
\hline CHEMBL 3668805 & 1528123 & 7.098 & 7.7613 & TST & \\
\hline CHEMBL3664156 & 1528123 & 8.9586 & 8.6953 & TRN & \\
\hline CHEMBL3668793 & 1528123 & 8.6576 & 8.024 & TST & \\
\hline CHEMBL 3668864 & 1528123 & 9.301 & 9.4659 & TRN & \\
\hline CHEMBL 3664161 & 1528123 & 7.8794 & 7.6137 & TRN & \\
\hline CHEMBL 3668820 & 1528123 & 9.0458 & 8.9509 & TRN & \\
\hline CHEMBL 3664200 & 1528123 & 7.9547 & 7.916 & TRN & \\
\hline CHEMBL3668847 & 1528123 & 8.301 & 8.1883 & TRN & \\
\hline CHEMBL3668866 & 1528123 & 8.1612 & 8.1643 & TRN & \\
\hline CHEMBL 3664157 & 1528123 & 6.2979 & 7.1374 & TST & \\
\hline CHEMBL 3668834 & 1528123 & 7.7773 & 7.7452 & TST & \\
\hline CHEMBL 3664144 & 1528123 & 8.7212 & 9.0326 & TRN & \\
\hline CHEMBL3668809 & 1528123 & 8.3279 & 8.2204 & TRN & \\
\hline CHEMBL1974998 & 809265 & 4.2 & 4.0966 & TRN & \\
\hline CHEMBL1980142 & 809265 & 5.1 & 4.7331 & TRN & \\
\hline CHEMBL41783 & 809265 & 5.1 & 4.9733 & TRN & \\
\hline CHEMBL 2004438 & 809265 & 4.5 & 4.291 & TRN & \\
\hline CHEMBL191003 & 809265 & 4.2 & 5.3577 & TRN & \\
\hline CHEMBL271381 & 809265 & 6.5 & 6.2732 & TRN & \\
\hline CHEMBL 2006785 & 809265 & 5.1 & 4.9764 & TRN & \\
\hline CHEMBL1982466 & 809265 & 8.3 & 7.3142 & TRN & \\
\hline CHEMBL1973359 & 809265 & 5.7 & 5.4116 & TST & \\
\hline CHEMBL1994638 & 809265 & 6.3 & 6.4015 & TRN & \\
\hline CHEMBL1995740 & 809265 & 5.1 & 4.7161 & TRN & \\
\hline CHEMBL1985888 & 809265 & 6.3 & 6.13299 & 9999999999 & TRN \\
\hline CHEMBL1986943 & 809265 & 5.1 & 5.2278 & TRN & \\
\hline CHEMBL1979690 & 809265 & 6.8 & 7.0889 & TRN & \\
\hline CHEMBL 234085 & 809265 & 4.3 & 4.6151 & TRN & \\
\hline CHEMBL1995832 & 809265 & 5.1 & 5.3759 & TRN & \\
\hline CHEMBL1969042 & 809265 & 5.1 & 5.3939 & TRN & \\
\hline CHEMBL 2000345 & 809265 & 5.1 & 5.1417 & TRN & \\
\hline CHEMBL1999931 & 809265 & 6.4 & 5.74 & TRN & \\
\hline CHEMBL1976376 & 809265 & 8.9 & 7.5115 & TRN & \\
\hline CHEMBL1983575 & 809265 & 4.2 & 5.35 & TRN & \\
\hline CHEMBL1968868 & 809265 & 4.2 & 4.4175 & TRN & \\
\hline CHEMBL 302449 & 809265 & 5.1 & 5.6563 & TST & \\
\hline CHEMBL2007064 & 809265 & 5.1 & 5.6711 & TRN & \\
\hline CHEMBL1981047 & 809265 & 7.3 & 7.9376 & TRN & \\
\hline CHEMBL 229968 & 809265 & 5.1 & 5.0558 & TRN & \\
\hline CHEMBL1976196 & 809265 & 4.2 & 4.0555 & TST & \\
\hline CHEMBL1976240 & 809265 & 5.1 & 4.9946 & TRN & \\
\hline CHEMBL1997197 & 809265 & 4.2 & 4.4142 & TRN & \\
\hline CHEMBL1979093 & 809265 & 6.2 & 5.9299 & TRN & \\
\hline CHEMBL1968151 & 809265 & 5.1 & 4.7042 & TST & \\
\hline CHEMBL1381197 & 809265 & 6.1 & 6.3204 & TRN & \\
\hline
\end{tabular}




\begin{tabular}{|c|c|c|c|c|c|}
\hline \\
\hline CHEMBL1987009 & 809265 & 5.1 & 5.1945 & TRN & \\
\hline CHEMBL379218 & 809265 & 5.1 & 5.2318 & TRN & \\
\hline CHEMBL2003817 & 809265 & 5.1 & 4.8865 & TRN & \\
\hline CHEMBL336961 & 809265 & 7.0 & 5.9499 & TRN & \\
\hline CHEMBL1994830 & 809265 & 5.1 & 5.3479 & TRN & \\
\hline CHEMBL1987054 & 809265 & 7.6 & 8.061 & TRN & \\
\hline CHEMBL1970083 & 809265 & 7.6 & $7.5420 e$ & $\partial 000000001$ & TRN \\
\hline CHEMBL226403 & 809265 & 5.1 & 4.8056 & TRN & \\
\hline CHEMBL 2005631 & 809265 & 5.1 & 7.5321 & TRN & \\
\hline CHEMBL1994938 & 809265 & 9.4 & 9.2302 & TRN & \\
\hline CHEMBL1977223 & 809265 & 5.1 & 4.9624 & TRN & \\
\hline CHEMBL1995765 & 809265 & 4.3 & 4.3467 & TST & \\
\hline CHEMBL1966279 & 809265 & 5.1 & 5.1951 & TRN & \\
\hline CHEMBL1997846 & 809265 & 5.1 & 4.8258 & TRN & \\
\hline CHEMBL1984760 & 809265 & 4.2 & 4.3964 & TRN & \\
\hline CHEMBL 2004419 & 809265 & 5.1 & 5.4531 & TRN & \\
\hline CHEMBL360847 & 809265 & 4.2 & 4.2208 & TST & \\
\hline CHEMBL2007073 & 809265 & 4.2 & 4.2864 & TRN & \\
\hline CHEMBL1995811 & 809265 & 4.2 & 4.7804 & TRN & \\
\hline CHEMBL1975787 & 809265 & 5.4 & 5.1822 & TRN & \\
\hline CHEMBL 2002407 & 809265 & 6.2 & 5.4219 & TRN & \\
\hline CHEMBL1992937 & 809265 & 4.4 & 4.2618 & TST & \\
\hline CHEMBL1985566 & 809265 & 5.1 & 4.8934 & TRN & \\
\hline CHEMBL1972119 & 809265 & 5.1 & 4.5211 & TRN & \\
\hline CHEMBL95692 & 809265 & 5.1 & 5.142 & TRN & \\
\hline CHEMBL1090356 & 809265 & 7.0 & 5.7332 & TRN & \\
\hline CHEMBL1976455 & 809265 & 5.1 & 4.7018 & TRN & \\
\hline CHEMBL261849 & 809265 & 4.2 & $4.3580 e$ & 00000000005 & TST \\
\hline CHEMBL1983923 & 809265 & 5.4 & 6.7558 & TRN & \\
\hline CHEMBL1983534 & 809265 & 5.1 & 5.23 & TRN & \\
\hline CHEMBL1982361 & 809265 & 5.1 & 5.1546 & TRN & \\
\hline CHEMBL1999112 & 809265 & 6.4 & 6.1243 & TST & \\
\hline CHEMBL1982122 & 809265 & 5.1 & 5.1717 & TRN & \\
\hline CHEMBL 2000801 & 809265 & 5.1 & 4.8773 & TRN & \\
\hline CHEMBL1682546 & 809265 & 5.2 & 5.1687 & TRN & \\
\hline CHEMBL1988872 & 809265 & 4.2 & 4.7209 & TRN & \\
\hline CHEMBL1991395 & 809265 & 5.1 & 5.1372 & TRN & \\
\hline CHEMBL1971245 & 809265 & 5.1 & 5.5909 & TRN & \\
\hline CHEMBL1987648 & 809265 & 5.1 & 5.0869 & TRN & \\
\hline CHEMBL1996780 & 809265 & 5.1 & 4.73 & TST & \\
\hline CHEMBL1993634 & 809265 & 4.2 & 4.4481 & TRN & \\
\hline CHEMBL1972142 & 809265 & 5.1 & 5.3166 & TRN & \\
\hline CHEMBL1966514 & 809265 & 6.8 & 6.8724 & TRN & \\
\hline CHEMBL 2003638 & 809265 & 6.4 & 5.6767 & TRN & \\
\hline CHEMBL 296586 & 809265 & 7.2 & 6.4537 & TRN & \\
\hline CHEMBL1996066 & 809265 & 5.1 & 6.379 & TST & \\
\hline CHEMBL1983393 & 809265 & 4.2 & 4.5456 & TRN & \\
\hline CHEMBL516429 & 809265 & 5.1 & 5.3873 & TRN & \\
\hline
\end{tabular}




\begin{tabular}{|c|c|c|c|c|}
\hline \multicolumn{5}{|c|}{ Supplemental Table s2.tx } \\
\hline CHEMBL1993722 & 809265 & 5.1 & 4.6914 & TRN \\
\hline CHEMBL 2006674 & 809265 & 4.2 & 4.8237 & TST \\
\hline CHEMBL1984236 & 809265 & 4.2 & 4.2592 & TST \\
\hline CHEMBL1992371 & 809265 & 4.2 & 4.0225 & TRN \\
\hline CHEMBL1375640 & 809265 & 5.1 & 5.1594 & TST \\
\hline CHEMBL1979970 & 809265 & 5.1 & 5.2467 & TRN \\
\hline CHEMBL 2002599 & 809265 & 4.2 & 4.3963 & TRN \\
\hline CHEMBL249282 & 809265 & 5.1 & 4.7939 & TRN \\
\hline CHEMBL1967252 & 809265 & 4.1 & 4.2843 & TRN \\
\hline CHEMBL1992473 & 809265 & 4.2 & 5.1721 & TRN \\
\hline CHEMBL 2004637 & 809265 & 5.4 & 4.8898 & TRN \\
\hline CHEMBL1993374 & 809265 & 4.2 & 4.5567 & TST \\
\hline CHEMBL1969264 & 809265 & 5.1 & 5.1635 & TRN \\
\hline CHEMBL1994318 & 809265 & 4.2 & 4.2183 & TRN \\
\hline CHEMBL1999506 & 809265 & 4.2 & 4.3556 & TRN \\
\hline CHEMBL1967720 & 809265 & 7.3 & 7.4879 & TRN \\
\hline CHEMBL1572266 & 809265 & 5.1 & 4.9606 & TST \\
\hline CHEMBL1979516 & 809265 & 7.5 & 7.0439 & TRN \\
\hline CHEMBL1605605 & 809265 & 4.2 & 4.1415 & TRN \\
\hline CHEMBL1989029 & 809265 & 5.1 & 5.225 & TRN \\
\hline CHEMBL392642 & 809265 & 5.1 & 5.041 & TRN \\
\hline CHEMBL 2000652 & 809265 & 6.4 & 6.8062 & TRN \\
\hline CHEMBL514499 & 809265 & 5.1 & 6.2707 & TST \\
\hline CHEMBL1970352 & 809265 & 5.6 & 4.7992 & TST \\
\hline CHEMBL1965631 & 809265 & 5.1 & 5.0255 & TRN \\
\hline CHEMBL1980144 & 809265 & 5.1 & 4.89 & TRN \\
\hline CHEMBL1991188 & 809265 & 5.1 & 4.6592 & TRN \\
\hline CHEMBL1980167 & 809265 & 4.2 & 4.5965 & TST \\
\hline CHEMBL377408 & 809265 & 5.1 & 4.7641 & TRN \\
\hline CHEMBL215152 & 809265 & 4.6 & 5.7571 & TRN \\
\hline CHEMBL231209 & 809265 & 5.1 & 5.024 & TRN \\
\hline CHEMBL1976220 & 809265 & 5.1 & 5.1112 & TRN \\
\hline CHEMBL 2006765 & 809265 & 6.2 & 5.5824 & TRN \\
\hline CHEMBL259922 & 809265 & 5.4 & 5.9057 & TST \\
\hline CHEMBL1969301 & 809265 & 5.1 & 5.1062 & TRN \\
\hline CHEMBL1982383 & 809265 & 5.1 & 5.0533 & TRN \\
\hline CHEMBL17370 & 809265 & 5.1 & 5.2329 & TRN \\
\hline CHEMBL1980246 & 809265 & 4.2 & 4.3798 & TST \\
\hline CHEMBL374044 & 809265 & 6.6 & 6.2335 & TRN \\
\hline CHEMBL1987910 & 809265 & 5.1 & 4.9255 & TRN \\
\hline CHEMBL1983932 & 809265 & 5.1 & 4.9646 & TRN \\
\hline CHEMBL1983980 & 809265 & 5.7 & 5.313 & TRN \\
\hline CHEMBL1999484 & 809265 & 5.9 & 5.0361 & TRN \\
\hline CHEMBL404366 & 809265 & 5.1 & 6.0485 & TRN \\
\hline CHEMBL1966069 & 809265 & 5.1 & 5.0402 & TRN \\
\hline CHEMBL1986899 & 809265 & 4.2 & 5.1134 & TST \\
\hline CHEMBL1991285 & 809265 & 5.1 & 5.329 & TRN \\
\hline CHEMBL1997822 & 809265 & 6.8 & 6.2591 & TRN \\
\hline
\end{tabular}




\begin{tabular}{|c|c|c|c|c|c|}
\hline \multicolumn{6}{|c|}{ Supplemental Table s2.txt } \\
\hline CHEMBL243088 & 809265 & 5.1 & 5.942 & TRN & \\
\hline CHEMBL1984038 & 809265 & 4.5 & 4.4001 & TRN & \\
\hline CHEMBL1968606 & 809265 & 4.2 & 4.2139 & TRN & \\
\hline CHEMBL1974416 & 809265 & 7.0 & 7.0795 & TRN & \\
\hline CHEMBL1993661 & 809265 & 6.5 & 6.7434 & TRN & \\
\hline CHEMBL1964290 & 809265 & 5.1 & 5.0832 & TRN & \\
\hline CHEMBL2001398 & 809265 & 4.2 & 4.6395 & TRN & \\
\hline CHEMBL 213505 & 809265 & 5.1 & 5.7906 & TRN & \\
\hline CHEMBL 202721 & 809265 & 7.1 & 6.211 & TRN & \\
\hline CHEMBL1987034 & 809265 & 7.6 & 7.3603 & TRN & \\
\hline CHEMBL1993941 & 809265 & 7.7 & 7.7652 & TRN & \\
\hline CHEMBL 377383 & 809265 & 5.1 & 5.1146 & TRN & \\
\hline CHEMBL 2005886 & 809265 & 7.6 & 7.5525 & TRN & \\
\hline CHEMBL481491 & 809265 & 5.1 & 5.2473 & TST & \\
\hline CHEMBL1682345 & 809265 & 5.1 & 5.1244 & TRN & \\
\hline CHEMBL1973142 & 809265 & 5.1 & 5.1548 & TRN & \\
\hline CHEMBL388311 & 809265 & 6.4 & 5.9246 & TRN & \\
\hline CHEMBL1973145 & 809265 & 5.1 & 4.9652 & TRN & \\
\hline CHEMBL1982924 & 809265 & 5.1 & 5.7888 & TRN & \\
\hline CHEMBL2005936 & 809265 & 5.1 & 5.0211 & TRN & \\
\hline CHEMBL1807515 & 809265 & 5.1 & 5.1264 & TRN & \\
\hline CHEMBL1964948 & 809265 & 4.2 & 4.1487 & TRN & \\
\hline CHEMBL1971141 & 809265 & 5.1 & 5.1638 & TRN & \\
\hline CHEMBL1995813 & 809265 & 5.1 & 5.0987 & TRN & \\
\hline CHEMBL 206236 & 809265 & 5.1 & 4.833 & TRN & \\
\hline CHEMBL1989834 & 809265 & 3.4 & 4.2482 & TRN & \\
\hline CHEMBL523823 & 809265 & 5.1 & 5.03100 & 2000000001 & TST \\
\hline CHEMBL1973178 & 809265 & 7.1 & 6.8834 & TRN & \\
\hline CHEMBL1987430 & 809265 & 4.2 & 4.1247 & TRN & \\
\hline CHEMBL 244378 & 809265 & 5.1 & 5.4466 & TRN & \\
\hline CHEMBL1988778 & 809265 & 6.8 & 6.1129 & TRN & \\
\hline CHEMBL2001957 & 809265 & 5.1 & 5.0462 & TRN & \\
\hline CHEMBL1969372 & 809265 & 5.1 & 5.0993 & TRN & \\
\hline CHEMBL1993413 & 809265 & 4.2 & 4.3439 & TRN & \\
\hline CHEMBL1990583 & 809265 & 6.4 & 5.979 & TRN & \\
\hline CHEMBL1993584 & 809265 & 5.1 & 4.8499 & TRN & \\
\hline CHEMBL1986263 & 809265 & 5.1 & 5.3486 & TRN & \\
\hline CHEMBL 2000114 & 809265 & 5.1 & 5.5807 & TRN & \\
\hline CHEMBL210618 & 809265 & 5.1 & 5.0593 & TRN & \\
\hline CHEMBL1986265 & 809265 & 4.2 & 3.9696 & TRN & \\
\hline CHEMBL1975647 & 809265 & 5.1 & 5.1257 & TRN & \\
\hline CHEMBL1968380 & 809265 & 5.1 & 5.0691 & TRN & \\
\hline CHEMBL1964644 & 809265 & 5.1 & 5.2516 & TRN & \\
\hline CHEMBL1991734 & 809265 & 5.7 & 5.5225 & TST & \\
\hline CHEMBL1981782 & 809265 & 5.1 & 5.3848 & TRN & \\
\hline CHEMBL1970142 & 809265 & 7.8 & 7.2143 & TRN & \\
\hline CHEMBL1990912 & 809265 & 5.1 & 5.12200 & 0000000001 & TRN \\
\hline CHEMBL1983348 & 809265 & 4.2 & 5.1967 & TRN & \\
\hline
\end{tabular}




\begin{tabular}{|c|c|c|c|c|}
\hline & & & pplement & \\
\hline CHEMBL1968394 & 809265 & 4.7 & 5.0043 & TRN \\
\hline CHEMBL1988163 & 809265 & 7.0 & 6.7656 & TRN \\
\hline CHEMBL1974480 & 809265 & 5.4 & 5.5709 & TRN \\
\hline CHEMBL1986177 & 809265 & 5.3 & 5.1066 & TRN \\
\hline CHEMBL1969735 & 809265 & 5.1 & 5.1197 & TRN \\
\hline CHEMBL 2003524 & 809265 & 5.1 & 5.1662 & TST \\
\hline CHEMBL 2002649 & 809265 & 5.1 & 5.2557 & TRN \\
\hline CHEMBL1985367 & 809265 & 5.5 & 5.3332 & TST \\
\hline CHEMBL1996510 & 809265 & 4.2 & 4.3882 & TST \\
\hline CHEMBL437747 & 809265 & 5.1 & 5.1559 & TRN \\
\hline CHEMBL1995172 & 809265 & 4.5 & 4.7314 & TST \\
\hline CHEMBL 2001584 & 809265 & 4.2 & 5.2185 & TST \\
\hline CHEMBL507936 & 809265 & 5.1 & 5.2289 & TRN \\
\hline CHEMBL104264 & 809265 & 5.1 & 5.1025 & TST \\
\hline CHEMBL1967998 & 809265 & 6.7 & 7.1979 & TRN \\
\hline CHEMBL1994321 & 809265 & 6.8 & 6.1716 & TRN \\
\hline CHEMBL1978562 & 809265 & 5.5 & 4.7035 & TST \\
\hline CHEMBL1997129 & 809265 & 5.1 & 4.9105 & TRN \\
\hline CHEMBL1964307 & 809265 & 5.1 & 5.3983 & TRN \\
\hline CHEMBL1989471 & 809265 & 5.8 & 5.7989 & TST \\
\hline CHEMBL 2000508 & 809265 & 5.1 & 5.1034 & TRN \\
\hline CHEMBL 2001547 & 809265 & 5.1 & 4.9447 & TRN \\
\hline CHEMBL210928 & 809265 & 5.1 & 5.0271 & TRN \\
\hline CHEMBL1978195 & 809265 & 4.2 & 4.5873 & TRN \\
\hline CHEMBL1994361 & 809265 & 5.1 & 5.0588 & TRN \\
\hline CHEMBL1972840 & 809265 & 5.1 & 5.104 & TRN \\
\hline CHEMBL1977148 & 809265 & 8.2 & 7.6235 & TRN \\
\hline CHEMBL1966842 & 809265 & 5.8 & 5.4058 & TRN \\
\hline CHEMBL 2003286 & 809265 & 5.1 & 5.0472 & TRN \\
\hline CHEMBL1992306 & 809265 & 6.6 & 6.0062 & TRN \\
\hline CHEMBL 2002165 & 809265 & 7.6 & 7.8314 & TRN \\
\hline CHEMBL1998585 & 809265 & 7.1 & 6.5254 & TRN \\
\hline CHEMBL519697 & 809265 & 5.1 & 4.9227 & TRN \\
\hline CHEMBL 2004934 & 809265 & 5.1 & 5.0774 & TRN \\
\hline CHEMBL1996345 & 809265 & 4.2 & 5.0519 & TST \\
\hline CHEMBL1975128 & 809265 & 5.1 & 5.3225 & TRN \\
\hline CHEMBL 2004025 & 809265 & 5.8 & 4.7356 & TRN \\
\hline CHEMBL1996048 & 809265 & 5.5 & 4.9999 & TST \\
\hline CHEMBL1976158 & 809265 & 4.5 & 4.8877 & TST \\
\hline CHEMBL461876 & 809265 & 4.2 & 4.2831 & TRN \\
\hline CHEMBL1965033 & 809265 & 4.2 & 3.9991 & TRN \\
\hline CHEMBL 2001485 & 809265 & 7.1 & 7.1597 & TRN \\
\hline CHEMBL504950 & 809265 & 6.2 & 5.2278 & TRN \\
\hline CHEMBL1997335 & 809265 & 4.2 & 4.5917 & TRN \\
\hline CHEMBL1984363 & 809265 & 5.1 & 5.0119 & TRN \\
\hline CHEMBL1978099 & 809265 & 6.5 & 6.0887 & TRN \\
\hline CHEMBL1977041 & 809265 & 7.8 & 6.3672 & TRN \\
\hline CHEMBL1968070 & 809265 & 5.1 & 5.15 & TRN \\
\hline
\end{tabular}




\begin{tabular}{|c|c|c|c|c|c|}
\hline \\
\hline CHEMBL1988608 & 809265 & 5.1 & 5.3053 & TRN & \\
\hline CHEMBL184847 & 809265 & 5.1 & 5.3174 & TRN & \\
\hline CHEMBL1971132 & 809265 & 4.2 & 4.0092 & TRN & \\
\hline CHEMBL1984367 & 809265 & 5.1 & 5.1942 & TRN & \\
\hline CHEMBL226898 & 809265 & 5.1 & 5.4619 & TRN & \\
\hline CHEMBL1982563 & 809265 & 5.1 & 5.0272 & TRN & \\
\hline CHEMBL1991377 & 809265 & 4.2 & 4.4292 & TRN & \\
\hline CHEMBL539474 & 809265 & 6.1 & 6.4383 & TST & \\
\hline CHEMBL575824 & 809265 & 5.1 & 5.0162 & TRN & \\
\hline CHEMBL1988387 & 809265 & 8.2 & 8.3232 & TRN & \\
\hline CHEMBL1973868 & 809265 & 4.2 & 3.99 & TRN & \\
\hline CHEMBL1972462 & 809265 & 4.2 & 4.1597 & TRN & \\
\hline CHEMBL1990288 & 809265 & 5.1 & 5.064 & TRN & \\
\hline CHEMBL1970074 & 809265 & 5.1 & 5.1186 & TRN & \\
\hline CHEMBL1986970 & 809265 & 5.1 & 4.7807 & TRN & \\
\hline CHEMBL1958401 & 809265 & 5.1 & 5.1849 & TRN & \\
\hline CHEMBL2003456 & 809265 & 5.1 & 4.8443 & TRN & \\
\hline CHEMBL1966816 & 809265 & 5.1 & 5.0602 & TRN & \\
\hline CHEMBL1972584 & 809265 & 5.4 & 6.7125 & TRN & \\
\hline CHEMBL2002992 & 809265 & 4.4 & 4.0244 & TRN & \\
\hline CHEMBL1982700 & 809265 & 4.2 & 4.7762 & TST & \\
\hline CHEMBL1968791 & 809265 & 5.1 & 5.3788 & TRN & \\
\hline CHEMBL 326282 & 809265 & 5.1 & 5.0229 & TST & \\
\hline CHEMBL1977634 & 809265 & 4.2 & 4.3617 & TRN & \\
\hline CHEMBL1992732 & 809265 & 5.1 & 4.6737 & TST & \\
\hline CHEMBL1971186 & 809265 & 5.1 & 5.1368 & TRN & \\
\hline CHEMBL1969156 & 809265 & 4.8 & 5.0289 & TST & \\
\hline CHEMBL1973211 & 809265 & 6.5 & 6.0166 & TRN & \\
\hline CHEMBL1984700 & 809265 & 5.1 & 5.0308 & TRN & \\
\hline CHEMBL 2007151 & 809265 & 6.1 & 5.9019 & TRN & \\
\hline CHEMBL1971606 & 809265 & 4.2 & 4.2994 & TRN & \\
\hline CHEMBL1972125 & 809265 & 5.1 & 4.8896 & TRN & \\
\hline CHEMBL1976134 & 809265 & 6.5 & 5.5095 & TRN & \\
\hline CHEMBL1972158 & 809265 & 5.1 & 4.9684 & TRN & \\
\hline CHEMBL1981215 & 809265 & 4.2 & 4.1701 & TRN & \\
\hline CHEMBL1999414 & 809265 & 6.4 & 6.7516 & TRN & \\
\hline CHEMBL1967336 & 809265 & 4.2 & 4.3677 & TRN & \\
\hline CHEMBL 2001228 & 809265 & 6.7 & 5.7807 & TRN & \\
\hline CHEMBL 2006581 & 809265 & 5.1 & 4.9955 & TRN & \\
\hline CHEMBL 1970340 & 809265 & 4.1 & 3.9638 & TRN & \\
\hline CHEMBL1967992 & 809265 & 4.2 & 4.1042 & TRN & \\
\hline CHEMBL1981671 & 809265 & 4.2 & 4.71399 & 99999999995 & TRN \\
\hline CHEMBL 2006450 & 809265 & 4.2 & 4.007 & TRN & \\
\hline CHEMBL1975534 & 809265 & 5.1 & 5.2286 & TRN & \\
\hline CHEMBL1993424 & 809265 & 7.2 & 7.3808 & TRN & \\
\hline CHEMBL1966703 & 809265 & 5.1 & 5.0621 & TST & \\
\hline CHEMBL 2001987 & 809265 & 4.2 & 4.1013 & TRN & \\
\hline CHEMBL1969561 & 809265 & 5.1 & 4.9806 & TRN & \\
\hline
\end{tabular}




\begin{tabular}{|c|c|c|c|c|c|}
\hline \\
\hline CHEMBL1994555 & 809265 & 5.4 & 4.823 & TRN & \\
\hline CHEMBL1975121 & 809265 & 4.2 & 4.5849 & TRN & \\
\hline CHEMBL1983640 & 809265 & 5.7 & 5.3226 & TRN & \\
\hline CHEMBL1997023 & 809265 & 5.1 & 4.8196 & TST & \\
\hline CHEMBL1964687 & 809265 & 5.2 & 5.2692 & TRN & \\
\hline CHEMBL1971943 & 809265 & 4.5 & 4.3451 & TRN & \\
\hline CHEMBL1999918 & 809265 & 5.1 & 5.6065 & TRN & \\
\hline CHEMBL1974254 & 809265 & 7.9 & 8.3115 & TRN & \\
\hline CHEMBL1997924 & 809265 & 8.0 & 7.5633 & TRN & \\
\hline CHEMBL1988537 & 809265 & 5.1 & 4.9942 & TST & \\
\hline CHEMBL1969049 & 809265 & 5.1 & 4.9769 & TRN & \\
\hline CHEMBL 2005828 & 809265 & 5.1 & 5.9044 & TRN & \\
\hline CHEMBL1978267 & 809265 & 4.2 & 4.1503 & TRN & \\
\hline CHEMBL1971485 & 809265 & 4.2 & 4.5399 & TRN & \\
\hline CHEMBL485556 & 809265 & 5.1 & 5.5817 & TRN & \\
\hline CHEMBL1975900 & 809265 & 5.1 & 5.2756 & TRN & \\
\hline CHEMBL1992334 & 809265 & 4.2 & 4.4445 & TRN & \\
\hline CHEMBL255822 & 809265 & 5.1 & 5.0826 & TRN & \\
\hline CHEMBL1972221 & 809265 & 5.1 & 5.1141 & TRN & \\
\hline CHEMBL 2006778 & 809265 & 7.4 & 8.4195 & TRN & \\
\hline CHEMBL378627 & 809265 & 5.1 & 4.9353 & TRN & \\
\hline CHEMBL1996979 & 809265 & 8.5 & 8.0793 & TRN & \\
\hline CHEMBL1968406 & 809265 & 5.1 & 5.7374 & TRN & \\
\hline CHEMBL1975921 & 809265 & 4.0 & 4.5134 & TRN & \\
\hline CHEMBL1982476 & 809265 & 9.2 & 7.71299 & 9999999999 & TRN \\
\hline CHEMBL1998545 & 809265 & 5.1 & 5.0239 & TRN & \\
\hline CHEMBL1986869 & 809265 & 5.1 & 4.9837 & TRN & \\
\hline CHEMBL 2004033 & 809265 & 5.3 & 5.2424 & TST & \\
\hline CHEMBL1975923 & 809265 & 5.7 & 5.3681 & TST & \\
\hline CHEMBL2005449 & 809265 & 5.8 & 5.7373 & TRN & \\
\hline CHEMBL1987998 & 809265 & 4.2 & 3.9111 & TRN & \\
\hline CHEMBL1682558 & 809265 & 5.1 & 4.9191 & TRN & \\
\hline CHEMBL1990496 & 809265 & 4.7 & 4.8088 & TRN & \\
\hline CHEMBL2002799 & 809265 & 4.2 & 4.401 & TST & \\
\hline CHEMBL 242865 & 809265 & 4.2 & 4.8722 & TRN & \\
\hline CHEMBL1997623 & 809265 & 6.4 & 5.6289 & TRN & \\
\hline CHEMBL 2002479 & 809265 & 5.1 & 5.6373 & TRN & \\
\hline CHEMBL1967094 & 809265 & 5.1 & 5.1496 & TRN & \\
\hline CHEMBL2003341 & 809265 & 5.1 & 5.1683 & TRN & \\
\hline CHEMBL1998110 & 809265 & 4.2 & 4.2763 & TRN & \\
\hline CHEMBL1999590 & 809265 & 6.5 & 6.1449 & TST & \\
\hline CHEMBL1981079 & 809265 & 5.1 & 4.9539 & TRN & \\
\hline CHEMBL1978166 & 809265 & 6.1 & 6.28700 & 0000000001 & TRN \\
\hline CHEMBL1980489 & 809265 & 5.1 & 5.1379 & TRN & \\
\hline CHEMBL 2000832 & 809265 & 5.1 & 5.2103 & TRN & \\
\hline CHEMBL1967116 & 809265 & 8.2 & 8.0098 & TRN & \\
\hline CHEMBL1990590 & 809265 & 4.2 & 4.136 & TRN & \\
\hline CHEMBL1970709 & 809265 & 5.1 & 5.3308 & TRN & \\
\hline
\end{tabular}




\begin{tabular}{|c|c|c|c|c|c|}
\hline \\
\hline CHEMBL1965660 & 809265 & 5.1 & 5.2064 & TRN & \\
\hline CHEMBL1992125 & 809265 & 5.3 & 5.6378 & TRN & \\
\hline CHEMBL1998112 & 809265 & 5.1 & 6.0719 & TRN & \\
\hline CHEMBL1993996 & 809265 & 6.5 & 6.4066 & TRN & \\
\hline CHEMBL1969126 & 809265 & 5.1 & 5.188 & TRN & \\
\hline CHEMBL1980896 & 809265 & 6.6 & 6.6786 & TRN & \\
\hline CHEMBL1970104 & 809265 & 6.6 & 6.395 & TRN & \\
\hline CHEMBL1991429 & 809265 & 6.6 & 6.1124 & TRN & \\
\hline CHEMBL1999714 & 809265 & 5.1 & 4.9974 & TRN & \\
\hline CHEMBL1994040 & 809265 & 5.1 & 5.13299 & 9999999999 & TRN \\
\hline CHEMBL 388978 & 809265 & 7.3 & 7.1245 & TST & \\
\hline CHEMBL579246 & 809265 & 5.1 & 5.0189 & TRN & \\
\hline CHEMBL398951 & 809265 & 4.4 & 4.5787 & TRN & \\
\hline CHEMBL1982506 & 809265 & 5.1 & 5.3622 & TST & \\
\hline CHEMBL2004716 & 809265 & 7.6 & 7.4411 & TRN & \\
\hline CHEMBL1968127 & 809265 & 5.1 & 4.86 & TRN & \\
\hline CHEMBL1975233 & 809265 & 5.1 & 5.2588 & TRN & \\
\hline CHEMBL1985406 & 809265 & 5.1 & 5.1537 & TRN & \\
\hline CHEMBL 207400 & 809265 & 5.1 & 5.1104 & TST & \\
\hline CHEMBL2000894 & 809265 & 5.1 & 4.8612 & TST & \\
\hline CHEMBL1421720 & 809265 & 5.3 & 5.1644 & TRN & \\
\hline CHEMBL1982135 & 809265 & 5.1 & 4.9449 & TRN & \\
\hline CHEMBL1976090 & 809265 & 5.1 & 5.1074 & TRN & \\
\hline CHEMBL1993243 & 809265 & 8.7 & 8.5755 & TRN & \\
\hline CHEMBL2004771 & 809265 & 5.1 & 4.6896 & TRN & \\
\hline CHEMBL1992922 & 809265 & 6.2 & 5.7492 & TRN & \\
\hline CHEMBL399021 & 809265 & 5.1 & 5.7338 & TRN & \\
\hline CHEMBL1997597 & 809265 & 5.1 & 5.0294 & TRN & \\
\hline CHEMBL1969537 & 809265 & 7.0 & 5.7004 & TST & \\
\hline CHEMBL576113 & 809265 & 4.2 & 4.6933 & TRN & \\
\hline CHEMBL1976093 & 809265 & 5.1 & 4.7833 & TRN & \\
\hline CHEMBL1975256 & 809265 & 5.1 & 4.7976 & TST & \\
\hline CHEMBL508928 & 809265 & 8.3 & 8.3228 & TRN & \\
\hline CHEMBL116070 & 809265 & 6.2 & 5.4856 & TRN & \\
\hline CHEMBL1990223 & 809265 & 4.2 & 3.9677 & TRN & \\
\hline CHEMBL1969879 & 809265 & 5.1 & 5.0398 & TRN & \\
\hline CHEMBL2006149 & 809265 & 4.2 & 4.4197 & TRN & \\
\hline CHEMBL1964382 & 809265 & 4.2 & 4.4454 & TST & \\
\hline CHEMBL101311 & 809265 & 6.3 & 5.9588 & TRN & \\
\hline CHEMBL1981720 & 809265 & 5.1 & 4.9252 & TRN & \\
\hline CHEMBL419932 & 809265 & 5.1 & 5.0269 & TRN & \\
\hline CHEMBL262433 & 809265 & 6.3 & 5.6364 & TRN & \\
\hline CHEMBL373798 & 809265 & 6.2 & 6.4273 & TRN & \\
\hline CHEMBL 306380 & 809265 & 7.5 & 8.2345 & TRN & \\
\hline CHEMBL1988581 & 809265 & 6.6 & 6.2491 & TST & \\
\hline CHEMBL2005699 & 809265 & 4.2 & 4.2304 & TRN & \\
\hline CHEMBL1975500 & 809265 & 6.2 & 5.4802 & TRN & \\
\hline CHEMBL394619 & 809265 & 5.1 & 5.4374 & TRN & \\
\hline & & & & 10450 & \\
\hline
\end{tabular}




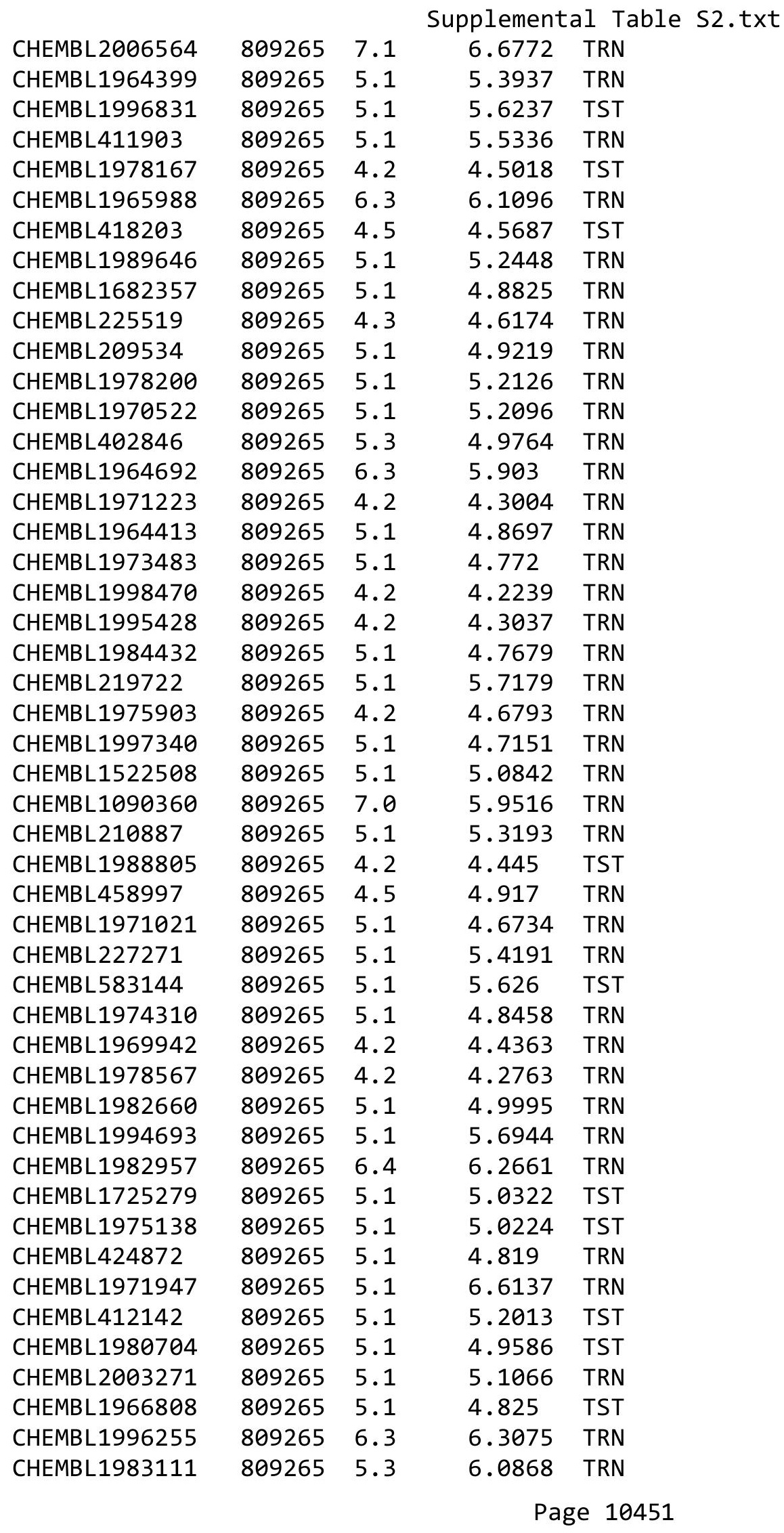




\begin{tabular}{|c|c|c|c|c|c|}
\hline \multicolumn{6}{|c|}{ Supplemental Table s2.txt } \\
\hline CHEMBL 260135 & 809265 & 5.1 & 4.9563 & TRN & \\
\hline CHEMBL 220241 & 809265 & 5.1 & 5.3738 & TRN & \\
\hline CHEMBL1988141 & 809265 & 6.1 & 5.3348 & TST & \\
\hline CHEMBL1982610 & 809265 & 6.1 & 5.2672 & TST & \\
\hline CHEMBL1977134 & 809265 & 6.5 & 6.9295 & TRN & \\
\hline CHEMBL 2006933 & 809265 & 5.1 & 5.1628 & TST & \\
\hline CHEMBL1985206 & 809265 & 4.2 & 3.5368 & TRN & \\
\hline CHEMBL1988300 & 809265 & 6.8 & 7.5274 & TRN & \\
\hline CHEMBL1991078 & 809265 & 6.6 & 5.9753 & TRN & \\
\hline CHEMBL1987359 & 809265 & 5.1 & 4.9185 & TST & \\
\hline CHEMBL1977749 & 809265 & 4.2 & 3.8112 & TST & \\
\hline CHEMBL 2000685 & 809265 & 5.1 & 5.3183 & TRN & \\
\hline CHEMBL1997275 & 809265 & 4.2 & 4.2549 & TRN & \\
\hline CHEMBL1993904 & 809265 & 4.2 & 5.0577 & TRN & \\
\hline CHEMBL1980376 & 809265 & 4.1 & 4.5291 & TRN & \\
\hline CHEMBL1967513 & 809265 & 4.2 & 4.3285 & TRN & \\
\hline CHEMBL 2000724 & 809265 & 4.2 & 3.82899 & 99999999997 & TRN \\
\hline CHEMBL1985311 & 809265 & 5.1 & 5.585 & TRN & \\
\hline CHEMBL1982413 & 809265 & 5.3 & 4.7273 & TST & \\
\hline CHEMBL1969502 & 809265 & 7.4 & 7.5323 & TST & \\
\hline CHEMBL1965910 & 809265 & 5.1 & 5.9373 & TRN & \\
\hline CHEMBL1682553 & 809265 & 5.1 & 4.9372 & TRN & \\
\hline CHEMBL1983963 & 809265 & 6.6 & 6.474 & TRN & \\
\hline CHEMBL1997764 & 809265 & 5.1 & 5.4551 & TRN & \\
\hline CHEMBL 2000271 & 809265 & 5.1 & 5.2534 & TRN & \\
\hline CHEMBL1981792 & 809265 & 4.2 & 4.1312 & TRN & \\
\hline CHEMBL1987535 & 809265 & 4.2 & 4.1643 & TRN & \\
\hline CHEMBL1985092 & 809265 & 5.1 & 5.3018 & TRN & \\
\hline CHEMBL1981410 & 809265 & 5.1 & 5.1324 & TRN & \\
\hline CHEMBL 2002586 & 809265 & 5.7 & 5.3136 & TRN & \\
\hline CHEMBL1996234 & 809265 & 5.1 & 4.9296 & TST & \\
\hline CHEMBL383264 & 809265 & 4.2 & 4.4777 & TRN & \\
\hline CHEMBL 2007421 & 809265 & 6.4 & 6.0388 & TST & \\
\hline CHEMBL1967544 & 809265 & 5.1 & 4.6638 & TRN & \\
\hline CHEMBL1973138 & 809265 & 4.2 & 4.9337 & TST & \\
\hline CHEMBL 223367 & 809265 & 5.1 & 5.6468 & TST & \\
\hline CHEMBL340384 & 809265 & 5.1 & 4.7688 & TST & \\
\hline CHEMBL1969151 & 809265 & 4.2 & 4.0254 & TRN & \\
\hline CHEMBL1996587 & 809265 & 5.1 & 5.1625 & TRN & \\
\hline CHEMBL1993335 & 809265 & 6.1 & 5.1082 & TST & \\
\hline CHEMBL1988692 & 809265 & 6.3 & 5.7468 & TRN & \\
\hline CHEMBL 2007574 & 809265 & 4.2 & 4.2247 & TRN & \\
\hline CHEMBL1964804 & 809265 & 5.1 & 4.715 & TRN & \\
\hline CHEMBL 2000354 & 809265 & 5.1 & 5.1905 & TRN & \\
\hline CHEMBL1965507 & 809265 & 5.4 & 5.0543 & TRN & \\
\hline CHEMBL 274064 & 809265 & 5.1 & 5.6911 & TRN & \\
\hline CHEMBL1998680 & 809265 & 4.2 & 4.2233 & TRN & \\
\hline CHEMBL1967564 & 809265 & 5.1 & 5.3456 & TRN & \\
\hline
\end{tabular}




\begin{tabular}{|c|c|c|c|c|c|}
\hline \\
\hline CHEMBL592030 & 809265 & 4.5 & 4.5024 & TST & \\
\hline CHEMBL 2000071 & 809265 & 6.6 & 5.7251 & TRN & \\
\hline CHEMBL1979176 & 809265 & 5.1 & 4.927 & TRN & \\
\hline CHEMBL1970317 & 809265 & 8.0 & 7.8996 & TRN & \\
\hline CHEMBL1985491 & 809265 & 5.1 & 4.9758 & TRN & \\
\hline CHEMBL 2000408 & 809265 & 5.1 & 5.1218 & TRN & \\
\hline CHEMBL 248757 & 809265 & 5.1 & 5.5275 & TST & \\
\hline CHEMBL1978014 & 809265 & 5.1 & 4.9167 & TRN & \\
\hline CHEMBL 2002736 & 809265 & 4.2 & 4.4516 & TRN & \\
\hline CHEMBL1997007 & 809265 & 4.2 & 4.4151 & TRN & \\
\hline CHEMBL1994538 & 809265 & 5.1 & 5.0342 & TRN & \\
\hline CHEMBL1964444 & 809265 & 5.1 & 4.4264 & TRN & \\
\hline CHEMBL2002690 & 809265 & 4.2 & 4.4406 & TRN & \\
\hline CHEMBL1986139 & 809265 & 5.1 & 5.5039 & TRN & \\
\hline CHEMBL 383527 & 809265 & 5.1 & 5.0752 & TRN & \\
\hline CHEMBL1980540 & 809265 & 5.1 & 4.9767 & TRN & \\
\hline CHEMBL 278041 & 809265 & 4.2 & 4.0838 & TRN & \\
\hline CHEMBL1979883 & 809265 & 6.7 & 6.2227 & TRN & \\
\hline CHEMBL1984162 & 809265 & 8.1 & 8.4071 & TRN & \\
\hline CHEMBL1997051 & 809265 & 5.6 & 5.6565 & TRN & \\
\hline CHEMBL491758 & 809265 & 6.9 & 6.7511 & TRN & \\
\hline CHEMBL1986590 & 809265 & 5.4 & 4.3964 & TRN & \\
\hline CHEMBL549730 & 809265 & 5.1 & 4.9401 & TRN & \\
\hline CHEMBL1970189 & 809265 & 5.1 & 4.8084 & TRN & \\
\hline CHEMBL1870106 & 809265 & 4.2 & 4.3451 & TRN & \\
\hline CHEMBL1996791 & 809265 & 6.4 & 5.7572 & TRN & \\
\hline CHEMBL371206 & 809265 & 6.7 & 6.8404 & TRN & \\
\hline CHEMBL1974664 & 809265 & 7.9 & 7.5606 & TRN & \\
\hline CHEMBL406845 & 809265 & 7.5 & 7.5363 & TRN & \\
\hline CHEMBL1974288 & 809265 & 5.1 & 5.09399 & 9999999999 & TRN \\
\hline CHEMBL1984296 & 809265 & 4.2 & 5.0801 & TST & \\
\hline CHEMBL196363 & 809265 & 6.6 & 6.6122 & TRN & \\
\hline CHEMBL1190711 & 809265 & 5.1 & 5.0712 & TRN & \\
\hline CHEMBL1968705 & 809265 & 4.5 & 4.8518 & TRN & \\
\hline CHEMBL1964441 & 809265 & 5.6 & 5.5239 & TRN & \\
\hline CHEMBL1991410 & 809265 & 4.2 & 4.5993 & TRN & \\
\hline CHEMBL546797 & 809265 & 5.3 & 5.1062 & TRN & \\
\hline CHEMBL404367 & 809265 & 5.3 & 5.0182 & TRN & \\
\hline CHEMBL1966343 & 809265 & 5.1 & 5.1737 & TRN & \\
\hline CHEMBL1978271 & 809265 & 4.2 & 4.3801 & TRN & \\
\hline CHEMBL1967887 & 809265 & 5.1 & 5.2312 & TRN & \\
\hline CHEMBL 2007266 & 809265 & 4.2 & 3.9665 & TRN & \\
\hline CHEMBL1985469 & 809265 & 4.2 & 4.5845 & TST & \\
\hline CHEMBL 2000568 & 809265 & 4.5 & 4.0085 & TRN & \\
\hline CHEMBL1994308 & 809265 & 4.2 & 4.7075 & TST & \\
\hline CHEMBL2000335 & 809265 & 6.3 & 6.5989 & TRN & \\
\hline CHEMBL1988717 & 809265 & 8.1 & 8.1758 & TRN & \\
\hline CHEMBL1974328 & 809265 & 6.2 & 5.8598 & TRN & \\
\hline & & & & 2453 & \\
\hline
\end{tabular}




\begin{tabular}{|c|c|c|c|c|c|}
\hline \\
\hline CHEMBL509032 & 809265 & 6.3 & 6.4575 & TRN & \\
\hline CHEMBL1973808 & 809265 & 5.1 & 5.2819 & TRN & \\
\hline CHEMBL2000429 & 809265 & 5.1 & 5.1138 & TRN & \\
\hline CHEMBL1972576 & 809265 & 5.1 & 4.8962 & TRN & \\
\hline CHEMBL1992342 & 809265 & 5.1 & 4.9305 & TRN & \\
\hline CHEMBL1988173 & 809265 & 5.1 & 5.2454 & TST & \\
\hline CHEMBL1973013 & 809265 & 5.4 & 5.4188 & TST & \\
\hline CHEMBL1164265 & 809265 & 4.2 & 5.1586 & TST & \\
\hline CHEMBL1965423 & 809265 & 5.3 & 5.2884 & TRN & \\
\hline CHEMBL1983025 & 809265 & 5.1 & 5.9175 & TRN & \\
\hline CHEMBL1975927 & 809265 & 5.5 & 6.0174 & TRN & \\
\hline CHEMBL 205415 & 809265 & 4.5 & 4.8962 & TRN & \\
\hline CHEMBL1977135 & 809265 & 5.1 & 5.0582 & TRN & \\
\hline CHEMBL2001920 & 809265 & 5.1 & 5.2062 & TRN & \\
\hline CHEMBL1997119 & 809265 & 4.2 & 4.6784 & TST & \\
\hline CHEMBL1980904 & 809265 & 7.0 & 6.8647 & TRN & \\
\hline CHEMBL1977138 & 809265 & 6.4 & 5.7295 & TST & \\
\hline CHEMBL2002323 & 809265 & 5.1 & 5.505 & TRN & \\
\hline CHEMBL1241473 & 809265 & 7.9 & 6.8332 & TRN & \\
\hline CHEMBL1978448 & 809265 & 4.5 & 5.4789 & TST & \\
\hline CHEMBL1969483 & 809265 & 4.2 & 3.948 & TRN & \\
\hline CHEMBL1980329 & 809265 & 4.2 & 4.8498 & TRN & \\
\hline CHEMBL2001257 & 809265 & 6.1 & 5.57299 & 99999999995 & TRN \\
\hline CHEMBL1992042 & 809265 & 4.2 & 5.6878 & TST & \\
\hline CHEMBL2005548 & 809265 & 5.1 & 5.2912 & TRN & \\
\hline CHEMBL 271441 & 809265 & 6.9 & 6.2016 & TRN & \\
\hline CHEMBL1992536 & 809265 & 5.1 & 5.0774 & TRN & \\
\hline CHEMBL21156 & 809265 & 4.2 & 4.3477 & TST & \\
\hline CHEMBL1992740 & 809265 & 5.1 & 5.2131 & TRN & \\
\hline CHEMBL1994724 & 809265 & 4.2 & 4.3687 & TRN & \\
\hline CHEMBL1989267 & 809265 & 8.4 & 8.5568 & TRN & \\
\hline CHEMBL1974574 & 809265 & 4.2 & 4.566 & TST & \\
\hline CHEMBL2006188 & 809265 & 5.1 & 4.724 & TRN & \\
\hline CHEMBL1970290 & 809265 & 5.5 & 5.4376 & TRN & \\
\hline CHEMBL1967531 & 809265 & 6.3 & 5.7364 & TRN & \\
\hline CHEMBL1970913 & 809265 & 5.1 & 5.2172 & TRN & \\
\hline CHEMBL1973893 & 809265 & 5.1 & 5.1444 & TRN & \\
\hline CHEMBL1997534 & 809265 & 5.1 & 5.1563 & TRN & \\
\hline CHEMBL1993877 & 809265 & 5.3 & 5.559 & TRN & \\
\hline CHEMBL1996500 & 809265 & 4.3 & 4.5297 & TRN & \\
\hline CHEMBL1985095 & 809265 & 5.1 & 4.8669 & TST & \\
\hline CHEMBL273187 & 809265 & 7.1 & 6.5846 & TRN & \\
\hline CHEMBL1973363 & 809265 & 5.3 & 5.0564 & TRN & \\
\hline CHEMBL1991180 & 809265 & 5.1 & 5.0041 & TST & \\
\hline CHEMBL1682540 & 809265 & 5.1 & 4.7956 & TRN & \\
\hline CHEMBL1976420 & 809265 & 5.8 & 5.7195 & TRN & \\
\hline CHEMBL1986979 & 809265 & 5.1 & 6.4068 & TRN & \\
\hline CHEMBL1998253 & 809265 & 4.2 & 4.2447 & TST & \\
\hline
\end{tabular}




\begin{tabular}{|c|c|c|c|c|c|}
\hline \\
\hline CHEMBL413779 & 809265 & 5.1 & 5.4722 & TST & \\
\hline CHEMBL1981744 & 809265 & 4.2 & 4.649 & TRN & \\
\hline CHEMBL2002446 & 809265 & 6.2 & 6.0193 & TRN & \\
\hline CHEMBL497151 & 809265 & 5.1 & 5.3445 & TRN & \\
\hline CHEMBL2000029 & 809265 & 4.2 & 4.0004 & TRN & \\
\hline CHEMBL1973961 & 809265 & 4.2 & 4.5314 & TRN & \\
\hline CHEMBL246970 & 809265 & 5.1 & 5.082 & TRN & \\
\hline CHEMBL340921 & 809265 & 5.1 & 4.6969 & TST & \\
\hline CHEMBL1994977 & 809265 & 4.2 & 4.365 & TRN & \\
\hline CHEMBL373598 & 809265 & 5.1 & 5.4667 & TST & \\
\hline CHEMBL2001149 & 809265 & 4.2 & 4.4886 & TRN & \\
\hline CHEMBL1999718 & 809265 & 5.1 & 4.8902 & TRN & \\
\hline CHEMBL 2000078 & 809265 & 4.2 & 4.7485 & TRN & \\
\hline CHEMBL 2005478 & 809265 & 6.4 & 4.7173 & TST & \\
\hline CHEMBL1276446 & 809265 & 6.7 & 6.4858 & TST & \\
\hline CHEMBL1996646 & 809265 & 5.6 & 5.7311 & TRN & \\
\hline CHEMBL1979773 & 809265 & 4.2 & 4.1501 & TRN & \\
\hline CHEMBL1977346 & 809265 & 5.1 & 4.9227 & TRN & \\
\hline CHEMBL 2003657 & 809265 & 7.1 & 5.5381 & TRN & \\
\hline CHEMBL1971649 & 809265 & 5.1 & 4.9876 & TRN & \\
\hline CHEMBL 2005482 & 809265 & 6.1 & 5.6261 & TRN & \\
\hline CHEMBL1996702 & 809265 & 4.2 & 5.1473 & TRN & \\
\hline CHEMBL1997909 & 809265 & 4.2 & 4.1065 & TRN & \\
\hline CHEMBL 2007124 & 809265 & 4.2 & 4.4185 & TRN & \\
\hline CHEMBL2006439 & 809265 & 5.1 & 5.1013 & TRN & \\
\hline CHEMBL1985681 & 809265 & 4.2 & 4.082 & TST & \\
\hline CHEMBL1969190 & 809265 & 6.5 & 5.91299 & 9999999999 & TRN \\
\hline CHEMBL 2002660 & 809265 & 4.2 & 4.2168 & TRN & \\
\hline CHEMBL1973937 & 809265 & 5.1 & 5.4451 & TRN & \\
\hline CHEMBL1991674 & 809265 & 5.1 & 4.9198 & TRN & \\
\hline CHEMBL1982711 & 809265 & 4.4 & 4.7332 & TRN & \\
\hline CHEMBL1984842 & 809265 & 4.5 & 4.6667 & TRN & \\
\hline CHEMBL1969102 & 809265 & 9.5 & 7.5192 & TRN & \\
\hline CHEMBL 2004118 & 809265 & 4.2 & 4.41100 & 00000000005 & TRN \\
\hline CHEMBL1682346 & 809265 & 5.1 & 5.1358 & TRN & \\
\hline CHEMBL1996795 & 809265 & 4.2 & 4.7834 & TST & \\
\hline CHEMBL 2007044 & 809265 & 5.1 & 4.7831 & TRN & \\
\hline CHEMBL2001998 & 809265 & 5.1 & 5.0906 & TRN & \\
\hline CHEMBL1994241 & 809265 & 5.1 & 5.2534 & TRN & \\
\hline CHEMBL 223460 & 809265 & 5.1 & 5.3451 & TST & \\
\hline CHEMBL1998829 & 809265 & 6.2 & 5.9152 & TRN & \\
\hline CHEMBL50894 & 809265 & 4.5 & 5.6199 & TRN & \\
\hline CHEMBL1995211 & 809265 & 4.2 & 4.7794 & TRN & \\
\hline CHEMBL1988838 & 809265 & 7.2 & 7.1708 & TRN & \\
\hline CHEMBL1981725 & 809265 & 7.7 & 6.9228 & TRN & \\
\hline CHEMBL 375284 & 809265 & 5.1 & 5.2201 & TRN & \\
\hline CHEMBL 2006299 & 809265 & 4.2 & 4.3978 & TRN & \\
\hline CHEMBL1965169 & 809265 & 4.2 & 4.6629 & TST & \\
\hline
\end{tabular}




\begin{tabular}{|c|c|c|c|c|}
\hline & & & plement & al \\
\hline CHEMBL1991818 & 809265 & 4.2 & 4.7546 & TST \\
\hline CHEMBL1081312 & 809265 & 7.1 & 7.3769 & TRN \\
\hline CHEMBL1965170 & 809265 & 6.0 & 7.2293 & TRN \\
\hline CHEMBL1982866 & 809265 & 5.1 & 4.8761 & TRN \\
\hline CHEMBL2005792 & 809265 & 4.5 & 4.8003 & TRN \\
\hline CHEMBL1984206 & 809265 & 5.1 & 4.9639 & TRN \\
\hline CHEMBL1986503 & 809265 & 4.2 & 4.8256 & TST \\
\hline CHEMBL1965570 & 809265 & 6.9 & 6.7201 & TRN \\
\hline CHEMBL1972355 & 809265 & 5.7 & 5.4163 & TRN \\
\hline CHEMBL1997892 & 809265 & 4.2 & 4.4101 & TRN \\
\hline CHEMBL2001641 & 809265 & 4.0 & 5.0235 & TRN \\
\hline CHEMBL1997193 & 809265 & 5.5 & 4.5713 & TST \\
\hline CHEMBL210963 & 809265 & 5.1 & 5.0115 & TRN \\
\hline CHEMBL1964902 & 809265 & 4.2 & 4.1442 & TRN \\
\hline CHEMBL1082440 & 809265 & 5.1 & 5.3884 & TST \\
\hline CHEMBL1972362 & 809265 & 5.1 & 4.7668 & TRN \\
\hline CHEMBL1984633 & 809265 & 5.1 & 5.0613 & TRN \\
\hline CHEMBL1965845 & 809265 & 5.1 & 4.7773 & TRN \\
\hline CHEMBL1983715 & 809265 & 6.2 & 5.7901 & TRN \\
\hline CHEMBL1971017 & 809265 & 5.1 & 5.1406 & TRN \\
\hline CHEMBL 2006715 & 809265 & 7.5 & 6.9857 & TRN \\
\hline CHEMBL1990482 & 809265 & 5.1 & 4.8132 & TRN \\
\hline CHEMBL1990904 & 809265 & 5.1 & 5.0407 & TRN \\
\hline CHEMBL2000104 & 809265 & 5.1 & 4.6871 & TRN \\
\hline CHEMBL2005475 & 809265 & 5.1 & 5.2982 & TRN \\
\hline CHEMBL183844 & 809265 & 5.1 & 5.0976 & TRN \\
\hline CHEMBL220057 & 809265 & 5.1 & 5.7108 & TRN \\
\hline CHEMBL 383541 & 809265 & 5.1 & 5.0934 & TRN \\
\hline CHEMBL2001224 & 809265 & 5.1 & 5.2774 & TRN \\
\hline CHEMBL10 & 809265 & 4.4 & 4.6349 & TRN \\
\hline CHEMBL1964937 & 809265 & 5.1 & 4.7867 & TRN \\
\hline CHEMBL1980763 & 809265 & 4.2 & 4.7316 & TRN \\
\hline CHEMBL590109 & 809265 & 5.1 & 5.0409 & TST \\
\hline CHEMBL1970879 & 809265 & 9.0 & 7.5068 & TRN \\
\hline CHEMBL1989856 & 809265 & 6.4 & 5.5457 & TST \\
\hline CHEMBL 2005899 & 809265 & 5.1 & 4.9035 & TRN \\
\hline CHEMBL1682552 & 809265 & 5.1 & 5.0785 & TRN \\
\hline CHEMBL259850 & 809265 & 5.1 & 5.0503 & TRN \\
\hline CHEMBL2007479 & 809265 & 4.2 & 4.3676 & TRN \\
\hline CHEMBL229799 & 809265 & 5.1 & 5.0942 & TRN \\
\hline CHEMBL105739 & 809265 & 6.1 & 5.4869 & TRN \\
\hline CHEMBL1972220 & 809265 & 7.2 & 7.7122 & TRN \\
\hline CHEMBL 379300 & 809265 & 5.1 & 5.2159 & TRN \\
\hline CHEMBL1973720 & 809265 & 4.2 & 4.5412 & TRN \\
\hline CHEMBL1969523 & 809265 & 5.1 & 5.227 & TRN \\
\hline CHEMBL207995 & 809265 & 5.1 & 4.9934 & TRN \\
\hline CHEMBL2001923 & 809265 & 4.5 & 4.3525 & TRN \\
\hline CHEMBL1986781 & 809265 & 5.1 & 5.0696 & TRN \\
\hline
\end{tabular}




\begin{tabular}{|c|c|c|c|c|}
\hline & & & IETh & \\
\hline CHEMBL1983070 & 809265 & 4.2 & 4.301 & TRN \\
\hline CHEMBL526133 & 809265 & 5.1 & 5.1331 & TRN \\
\hline CHEMBL 2003514 & 809265 & 4.2 & 3.9942 & TRN \\
\hline CHEMBL1966836 & 809265 & 5.1 & 6.2526 & TRN \\
\hline CHEMBL1989043 & 809265 & 4.2 & 4.8028 & TRN \\
\hline CHEMBL1979057 & 809265 & 5.1 & 4.8809 & TRN \\
\hline CHEMBL1981045 & 809265 & 5.1 & 4.9966 & TRN \\
\hline CHEMBL 387971 & 809265 & 5.1 & 6.2232 & TRN \\
\hline CHEMBL1975418 & 809265 & 5.1 & 4.8941 & TRN \\
\hline CHEMBL1164180 & 809265 & 4.2 & 4.7565 & TST \\
\hline CHEMBL 223257 & 809265 & 5.1 & 5.3878 & TST \\
\hline CHEMBL1999428 & 809265 & 5.1 & 5.2373 & TRN \\
\hline CHEMBL1967560 & 809265 & 5.1 & 5.2448 & TRN \\
\hline CHEMBL1997611 & 809265 & 4.2 & 4.442 & TST \\
\hline CHEMBL1516890 & 809265 & 5.1 & 5.4502 & TRN \\
\hline CHEMBL1982465 & 809265 & 5.1 & 6.154 & TRN \\
\hline CHEMBL 2001751 & 809265 & 6.4 & 6.5555 & TRN \\
\hline CHEMBL1984586 & 809265 & 5.1 & 5.0567 & TRN \\
\hline CHEMBL272938 & 809265 & 7.0 & 6.4612 & TRN \\
\hline CHEMBL1972659 & 809265 & 5.1 & 4.8055 & TST \\
\hline CHEMBL 2002723 & 809265 & 5.5 & 5.4715 & TST \\
\hline CHEMBL1973395 & 809265 & 6.1 & 5.3596 & TRN \\
\hline CHEMBL 272453 & 809265 & 5.1 & 5.8707 & TRN \\
\hline CHEMBL1970217 & 809265 & 5.1 & 4.9409 & TRN \\
\hline CHEMBL 2005528 & 809265 & 5.1 & 5.2529 & TRN \\
\hline CHEMBL1984686 & 809265 & 4.2 & 4.4661 & TRN \\
\hline CHEMBL185569 & 809265 & 5.1 & 5.4754 & TRN \\
\hline CHEMBL1969843 & 809265 & 5.1 & 5.1972 & TRN \\
\hline CHEMBL 2007002 & 809265 & 5.1 & 5.1704 & TRN \\
\hline CHEMBL1973793 & 809265 & 4.2 & 4.4619 & TST \\
\hline CHEMBL1969588 & 809265 & 8.0 & 6.5112 & TRN \\
\hline CHEMBL1984711 & 809265 & 7.8 & 6.4472 & TRN \\
\hline CHEMBL1992073 & 809265 & 4.2 & 5.0367 & TRN \\
\hline CHEMBL484390 & 809265 & 5.1 & 4.9889 & TRN \\
\hline CHEMBL1979252 & 809265 & 5.1 & 5.2403 & TRN \\
\hline CHEMBL1986143 & 809265 & 4.2 & 4.4041 & TRN \\
\hline CHEMBL1972934 & 809265 & 4.1 & 4.6048 & TRN \\
\hline CHEMBL 2007559 & 809265 & 4.2 & 4.7765 & TRN \\
\hline CHEMBL1992581 & 809265 & 5.8 & 5.5437 & TRN \\
\hline CHEMBL1682341 & 809265 & 5.1 & 5.1072 & TRN \\
\hline CHEMBL 2004290 & 809265 & 6.6 & 7.0459 & TST \\
\hline CHEMBL1986499 & 809265 & 5.1 & 5.1262 & TST \\
\hline CHEMBL1972937 & 809265 & 5.1 & 5.091 & TST \\
\hline CHEMBL1972250 & 809265 & 5.1 & 4.5235 & TST \\
\hline CHEMBL 2000393 & 809265 & 6.6 & 6.5772 & TST \\
\hline CHEMBL403402 & 809265 & 6.7 & 6.5426 & TST \\
\hline CHEMBL1983573 & 809265 & 5.0 & 4.6991 & TST \\
\hline CHEMBL 2004311 & 809265 & 5.1 & 5.1645 & TST \\
\hline
\end{tabular}




\begin{tabular}{|c|c|c|c|c|}
\hline & & & pplement & al $\mathrm{Ta}$ \\
\hline CHEMBL1992634 & 809265 & 5.1 & 5.2754 & TST \\
\hline CHEMBL1242373 & 809265 & 5.1 & 5.8052 & TST \\
\hline CHEMBL1984847 & 809265 & 4.2 & 4.76 & TST \\
\hline CHEMBL316264 & 809265 & 5.1 & 4.7137 & TST \\
\hline CHEMBL1988075 & 809265 & 6.3 & 6.2402 & TST \\
\hline CHEMBL1996576 & 809265 & 4.2 & 4.8012 & TST \\
\hline CHEMBL1988076 & 809265 & 4.2 & 4.7165 & TST \\
\hline CHEMBL1991678 & 809265 & 4.3 & 4.6588 & TST \\
\hline CHEMBL 2001239 & 809265 & 5.1 & 5.9962 & TST \\
\hline CHEMBL1988594 & 809265 & 5.1 & 5.3504 & TST \\
\hline CHEMBL 2001288 & 809265 & 5.1 & 5.1198 & TST \\
\hline CHEMBL260092 & 809265 & 5.1 & 5.8344 & TST \\
\hline CHEMBL1999811 & 809265 & 7.0 & 4.8965 & TST \\
\hline CHEMBL1965495 & 809265 & 5.1 & 5.1329 & TST \\
\hline CHEMBL235157 & 809265 & 4.2 & 4.1737 & TST \\
\hline CHEMBL 2000481 & 809265 & 5.1 & 5.1517 & TST \\
\hline CHEMBL1982874 & 809265 & 5.1 & 5.5961 & TST \\
\hline CHEMBL1991725 & 809265 & 5.1 & 5.1236 & TST \\
\hline CHEMBL1992242 & 809265 & 5.1 & 5.0608 & TST \\
\hline CHEMBL 2007296 & 809265 & 5.1 & 4.7538 & TST \\
\hline CHEMBL 2004159 & 809265 & 4.2 & 4.2973 & TST \\
\hline CHEMBL396523 & 809265 & 5.1 & 6.1034 & TST \\
\hline CHEMBL1978371 & 809265 & 4.2 & 5.4384 & TST \\
\hline CHEMBL1970203 & 809265 & 5.1 & 4.8059 & TST \\
\hline CHEMBL1986530 & 809265 & 5.1 & 5.0712 & TST \\
\hline CHEMBL440084 & 809265 & 4.2 & 4.6369 & TST \\
\hline CHEMBL1999321 & 809265 & 5.1 & 5.5393 & TST \\
\hline CHEMBL1968590 & 809265 & 7.5 & 8.1174 & TST \\
\hline CHEMBL1999749 & 809265 & 8.6 & 6.4984 & TST \\
\hline CHEMBL 2005375 & 809265 & 5.1 & 5.4042 & TST \\
\hline CHEMBL1984191 & 809265 & 5.1 & 4.7729 & TST \\
\hline CHEMBL1983006 & 809265 & 5.1 & 5.0376 & TST \\
\hline CHEMBL1966501 & 809265 & 4.2 & 4.019 & TST \\
\hline CHEMBL1971029 & 809265 & 7.6 & 6.7213 & TST \\
\hline CHEMBL394790 & 809265 & 5.1 & 5.0189 & TST \\
\hline CHEMBL226471 & 809265 & 5.1 & 4.4648 & TST \\
\hline CHEMBL1974702 & 809265 & 5.1 & 5.2367 & TST \\
\hline CHEMBL1996111 & 809265 & 5.1 & 4.7308 & TST \\
\hline CHEMBL1966175 & 809265 & 4.2 & 4.8242 & TST \\
\hline CHEMBL1965589 & 809265 & 5.1 & 5.2133 & TST \\
\hline CHEMBL 2007375 & 809265 & 4.2 & 4.3749 & TST \\
\hline CHEMBL1998193 & 809265 & 5.1 & 4.9762 & TST \\
\hline CHEMBL379975 & 809265 & 5.4 & 5.5575 & TST \\
\hline CHEMBL474432 & 809265 & 6.4 & 6.1603 & TST \\
\hline CHEMBL1973016 & 809265 & 4.2 & 4.6713 & TST \\
\hline CHEMBL1965387 & 809265 & 4.2 & 4.0702 & TST \\
\hline CHEMBL1988153 & 809265 & 5.1 & 5.2561 & TST \\
\hline CHEMBL550418 & 809265 & 4.2 & 4.4402 & TST \\
\hline
\end{tabular}




\begin{tabular}{|c|c|c|c|c|c|}
\hline \\
\hline CHEMBL1971289 & 809265 & 4.2 & 4.5531 & TST & \\
\hline CHEMBL1988437 & 809265 & 5.0 & 5.0887 & TST & \\
\hline CHEMBL1968245 & 809265 & 6.6 & 5.1616 & TST & \\
\hline CHEMBL1979577 & 809265 & 6.4 & 6.0416 & TST & \\
\hline CHEMBL1998121 & 809265 & 6.5 & 5.3226 & TST & \\
\hline CHEMBL1233887 & 809265 & 4.2 & 4.7542 & TST & \\
\hline CHEMBL1991800 & 809265 & 5.1 & 5.075 & TST & \\
\hline CHEMBL2003689 & 809265 & 4.2 & 4.4176 & TST & \\
\hline CHEMBL1979357 & 809265 & 5.1 & 5.0206 & TST & \\
\hline CHEMBL1980802 & 809265 & 5.1 & 5.2465 & TST & \\
\hline CHEMBL1996649 & 809265 & 6.3 & 6.5273 & TST & \\
\hline CHEMBL1996817 & 809265 & 6.8 & 5.7625 & TST & \\
\hline CHEMBL1979554 & 809265 & 5.1 & 5.2454 & TST & \\
\hline CHEMBL1986756 & 809265 & 4.2 & 3.9122 & TST & \\
\hline CHEMBL409349 & 809265 & 6.5 & 6.3603 & TST & \\
\hline CHEMBL 2004355 & 809265 & 5.1 & 4.963 & TST & \\
\hline CHEMBL468280 & 809265 & 5.1 & 5.1804 & TST & \\
\hline CHEMBL1990884 & 809265 & 7.2 & 6.0875 & TST & \\
\hline CHEMBL3109278 & 809265 & 6.6 & 6.2064 & TST & \\
\hline CHEMBL256835 & 809265 & 5.1 & 5.5632 & TST & \\
\hline CHEMBL1682032 & 727386 & 4.0706 & 3.9627 & TRN & \\
\hline CHEMBL1682056 & 727386 & 3.0 & 3.1138 & TRN & \\
\hline CHEMBL1685082 & 727386 & 4.5528 & 4.3165 & TRN & \\
\hline CHEMBL1682043 & 727386 & 4.4815 & 4.6073 & TRN & \\
\hline CHEMBL1682059 & 727386 & 4.3098 & 4.2691 & TRN & \\
\hline CHEMBL1682045 & 727386 & 3.0 & 2.9262 & TRN & \\
\hline CHEMBL1682033 & 727386 & 3.0 & 3.2791 & TRN & \\
\hline CHEMBL1685081 & 727386 & 4.1612 & 3.969 & TRN & \\
\hline CHEMBL1682053 & 727386 & 4.0362 & 3.878 & TRN & \\
\hline CHEMBL1682060 & 727386 & 4.7212 & 4.6592 & TRN & \\
\hline CHEMBL1682034 & 727386 & 4.0 & 3.9288 & TRN & \\
\hline CHEMBL1682064 & 727386 & 2.4776 & 3.1967 & TST & \\
\hline CHEMBL1685076 & 727386 & 4.284 & 4.1813 & TRN & \\
\hline CHEMBL1682028 & 727386 & 4.284 & 4.4616 & TRN & \\
\hline CHEMBL1685084 & 727386 & 4.2076 & 4.189 & TRN & \\
\hline CHEMBL1682042 & 727386 & 4.301 & 4.1961 & TRN & \\
\hline CHEMBL1682039 & 727386 & 4.4437 & 4.3269 & TRN & \\
\hline CHEMBL1682054 & 727386 & 4.2676 & 4.0985 & TRN & \\
\hline CHEMBL1682029 & 727386 & 4.5686 & 4.4975 & TRN & \\
\hline CHEMBL1682030 & 727386 & 4.699 & 4.578 & TRN & \\
\hline CHEMBL1682067 & 727386 & 3.0 & 3.7238 & TST & \\
\hline CHEMBL1682063 & 727386 & 3.0 & 2.8514 & TRN & \\
\hline CHEMBL1682055 & 727386 & 4.6383 & 4.8065 & TRN & \\
\hline CHEMBL1682048 & 727386 & 4.6778 & 4.7232 & TRN & \\
\hline CHEMBL1682065 & 727386 & 4.4437 & 3.7053 & TST & \\
\hline CHEMBL1682035 & 727386 & 4.1249 & 3.99399 & 99999999998 & TRN \\
\hline CHEMBL1682068 & 727386 & 3.0 & 4.1248 & TST & \\
\hline CHEMBL1682046 & 727386 & 3.0 & 3.4301 & TRN & \\
\hline
\end{tabular}




\begin{tabular}{|c|c|c|c|c|c|}
\hline \multicolumn{6}{|c|}{ Supplemental Table S2.txt } \\
\hline CHEMBL1682047 & 727386 & 3.0 & 3.3204 & TRN & \\
\hline CHEMBL1685075 & 727386 & 4.1249 & 4.3807 & TRN & \\
\hline CHEMBL1685080 & 727386 & 4.9586 & 4.9158 & TRN & \\
\hline CHEMBL1682044 & 727386 & 4.0862 & 4.0551 & TRN & \\
\hline CHEMBL1682040 & 727386 & 4.284 & 4.131 & TRN & \\
\hline CHEMBL1682041 & 727386 & 4.2596 & 4.1912 & TRN & \\
\hline CHEMBL1682037 & 727386 & 4.1135 & 4.045 & TRN & \\
\hline CHEMBL1685078 & 727386 & 4.3468 & 4.4681 & TRN & \\
\hline CHEMBL1685079 & 727386 & 4.0915 & 4.3455 & TRN & \\
\hline CHEMBL1682070 & 727386 & 3.0 & 2.9755 & TST & \\
\hline CHEMBL1682057 & 727386 & 4.1024 & 4.168 & TRN & \\
\hline CHEMBL1682069 & 727386 & 3.0 & 1.8804 & TST & \\
\hline CHEMBL1685083 & 727386 & 4.2366 & 4.2593 & TRN & \\
\hline CHEMBL1682027 & 727386 & 4.3279 & 4.2627 & TRN & \\
\hline CHEMBL1682038 & 727386 & 4.0605 & 4.1178 & TRN & \\
\hline CHEMBL1682026 & 727386 & 4.0706 & 3.7982 & TRN & \\
\hline CHEMBL1682051 & 727386 & 4.5229 & 4.5249 & TRN & \\
\hline CHEMBL1682031 & 727386 & 4.6383 & 4.9298 & TRN & \\
\hline CHEMBL1682049 & 727386 & 4.6021 & 4.5233 & TRN & \\
\hline CHEMBL1682062 & 727386 & 3.0 & 2.9754 & TRN & \\
\hline CHEMBL1682066 & 727386 & 3.0 & 4.0326 & TST & \\
\hline CHEMBL1682052 & 727386 & 4.0 & 3.8446 & TST & \\
\hline CHEMBL1682061 & 727386 & 4.1487 & 4.2607 & TST & \\
\hline CHEMBL1685077 & 727386 & 4.1308 & 4.3843 & TST & \\
\hline CHEMBL1682050 & 727386 & 4.6576 & 4.4213 & TST & \\
\hline CHEMBL218227 & 727386 & 4.9586 & 4.9283 & TST & \\
\hline CHEMBL1682036 & 727386 & 4.2596 & 4.405 & TST & \\
\hline CHEMBL1682058 & 727386 & 3.0 & 4.4778 & TST & \\
\hline CHEMBL37639 & 158035 & 7.82 & 7.5597 & TRN & \\
\hline CHEMBL288513 & 158035 & 8.21 & 7.6825 & TRN & \\
\hline CHEMBL284942 & 158035 & 10.7 & 10.8828 & TRN & \\
\hline CHEMBL37033 & 158035 & 7.96 & 7.9578 & TRN & \\
\hline CHEMBL 290074 & 158035 & 9.89 & 10.0597 & TRN & \\
\hline CHEMBL416783 & 158035 & 10.7 & 10.5179 & 99999999999 & TRN \\
\hline CHEMBL39747 & 158035 & 6.73 & 6.6797 & TRN & \\
\hline CHEMBL289934 & 158035 & 7.48 & 7.2494 & TRN & \\
\hline CHEMBL290331 & 158035 & 10.22 & 9.8382 & TRN & \\
\hline CHEMBL366576 & 158035 & 10.22 & 10.3525 & TRN & \\
\hline CHEMBL416612 & 158035 & 10.22 & 10.0566 & TRN & \\
\hline CHEMBL37701 & 158035 & 7.85 & 7.9375 & TRN & \\
\hline CHEMBL446395 & 158035 & 10.0 & 10.0358 & TRN & \\
\hline CHEMBL39979 & 158035 & 7.0 & 6.6646 & TRN & \\
\hline CHEMBL40052 & 158035 & 6.27 & 6.2294 & TRN & \\
\hline CHEMBL286596 & 158035 & 7.64 & 7.45700 & 0000000001 & TRN \\
\hline CHEMBL416964 & 158035 & 8.85 & 8.9494 & TRN & \\
\hline CHEMBL116517 & 158035 & 10.7 & 10.7311 & TRN & \\
\hline CHEMBL36900 & 158035 & 11.0 & 10.9546 & TRN & \\
\hline CHEMBL287520 & 158035 & 7.4 & 7.2494 & TRN & \\
\hline
\end{tabular}




\begin{tabular}{|c|c|c|c|c|c|}
\hline \multicolumn{6}{|c|}{ Supplemental Table S2.txt } \\
\hline CHEMBL289907 & 158035 & 8.85 & 8.984 & TRN & \\
\hline CHEMBL 291004 & 158035 & 10.52 & 10.1856 & TRN & \\
\hline CHEMBL 286390 & 158035 & 9.6 & 9.1965 & TRN & \\
\hline CHEMBL432093 & 158035 & 9.39 & 9.715 & TST & \\
\hline CHEMBL 289762 & 158035 & 9.52 & 9.638 & TRN & \\
\hline CHEMBL36437 & 158035 & 9.42 & 9.0506 & TRN & \\
\hline CHEMBL37313 & 158035 & 7.92 & 8.0064 & TRN & \\
\hline CHEMBL 290362 & 158035 & 10.1 & 9.7561 & TRN & \\
\hline CHEMBL 290254 & 158035 & 10.0 & 9.8759 & TRN & \\
\hline CHEMBL431321 & 158035 & 9.19 & 9.7165 & TRN & \\
\hline CHEMBL 36862 & 158035 & 8.77 & 8.964 & TRN & \\
\hline CHEMBL39592 & 158035 & 8.1 & 8.4432 & TRN & \\
\hline CHEMBL36581 & 158035 & 9.55 & 9.7165 & TRN & \\
\hline CHEMBL37618 & 158035 & 7.36 & 7.8467 & TRN & \\
\hline CHEMBL36939 & 158035 & 8.59 & 8.6692 & TRN & \\
\hline CHEMBL37593 & 158035 & 10.0 & 9.7561 & TRN & \\
\hline CHEMBL38339 & 158035 & 7.96 & 8.1791 & TRN & \\
\hline CHEMBL 286794 & 158035 & 6.8 & 7.8051 & TRN & \\
\hline CHEMBL 264852 & 158035 & 10.0 & 9.8964 & TST & \\
\hline CHEMBL288239 & 158035 & 7.18 & 6.9898 & TRN & \\
\hline CHEMBL 285871 & 158035 & 9.31 & 9.252 & TRN & \\
\hline CHEMBL 39749 & 158035 & 7.82 & 7.8717 & TRN & \\
\hline CHEMBL 289715 & 158035 & 7.64 & 7.7882 & TRN & \\
\hline CHEMBL 285282 & 158035 & 8.31 & 8.34799 & & TRN \\
\hline CHEMBL 37083 & 158035 & 7.85 & 8.0482 & TRN & \\
\hline CHEMBL36481 & 158035 & 6.01 & 6.479 & TST & \\
\hline CHEMBL 286693 & 158035 & 9.04 & 9.0372 & TRN & \\
\hline CHEMBL 324293 & 158035 & 10.52 & 9.6326 & TST & \\
\hline CHEMBL 39432 & 158035 & 6.49 & 6.3199 & TST & \\
\hline CHEMBL 38281 & 158035 & 8.25 & 8.3393 & TRN & \\
\hline CHEMBL 289393 & 158035 & 8.8 & 8.6302 & TST & \\
\hline CHEMBL 288254 & 158035 & 10.7 & 9.5547 & TST & \\
\hline CHEMBL 37472 & 158035 & 8.92 & 8.1782 & TST & \\
\hline CHEMBL 284941 & 158035 & 9.51 & 9.3522 & TST & \\
\hline CHEMBL287818 & 158035 & 6.96 & 6.8383 & TST & \\
\hline CHEMBL286159 & 158035 & 9.62 & 9.3691 & TST & \\
\hline CHEMBL38059 & 158035 & 6.34 & 7.2739 & TST & \\
\hline CHEMBL113884 & 158035 & 10.1 & 9.4413 & TST & \\
\hline CHEMBL 284340 & 158035 & 10.05 & 9.7113 & TST & \\
\hline CHEMBL 288261 & 158035 & 9.82 & 9.5875 & TST & \\
\hline CHEMBL3911957 & 1641089 & 5.8539 & 6.273 & TRN & \\
\hline CHEMBL 3920310 & 1641089 & 6.4685 & 6.5313 & TRN & \\
\hline CHEMBL 3959028 & 1641089 & 7.8539 & 7.6998 & TRN & \\
\hline CHEMBL 3893772 & 1641089 & 7.4202 & 6.7697 & TRN & \\
\hline CHEMBL 3901266 & 1641089 & 7.3565 & 7.5333 & TRN & \\
\hline CHEMBL 3944522 & 1641089 & 7.2147 & 6.4914 & TRN & \\
\hline CHEMBL 3928260 & 1641089 & 7.0506 & 6.5342 & TST & \\
\hline CHEMBL 3975256 & 1641089 & 6.2832 & 5.9847 & TRN & \\
\hline
\end{tabular}




\begin{tabular}{|c|c|c|c|c|c|c|}
\hline \multicolumn{7}{|c|}{ Supplemental Table s2.txt } \\
\hline CHEMBL 3889807 & 1641089 & 5.0 & 6.3106 & TRN & & \\
\hline CHEMBL 3975470 & 1641089 & 6.0 & 6.5374 & TRN & & \\
\hline CHEMBL3963941 & 1641089 & 7.6021 & 7.4588 & TRN & & \\
\hline CHEMBL 3920607 & 1641089 & 5.0862 & 5.7874 & TRN & & \\
\hline CHEMBL3981800 & 1641089 & 8.1549 & 7.633999 & 999999999 & 95 & TRN \\
\hline CHEMBL3976464 & 1641089 & 6.6345 & 6.7371 & TRN & & \\
\hline CHEMBL3911020 & 1641089 & 6.4001 & 6.5389 & TRN & & \\
\hline CHEMBL 3901543 & 1641089 & 6.055 & 6.8102 & TRN & & \\
\hline CHEMBL 3905124 & 1641089 & 8.0458 & 7.04899 & 999999999 & 95 & TRN \\
\hline CHEMBL3938091 & 1641089 & 6.7696 & 6.7493 & TRN & & \\
\hline CHEMBL3945815 & 1641089 & 5.0 & 5.6548 & TRN & & \\
\hline CHEMBL3891594 & 1641089 & 6.5591 & 6.4903 & TRN & & \\
\hline CHEMBL3963051 & 1641089 & 6.1221 & 6.2983 & TRN & & \\
\hline CHEMBL 3965108 & 1641089 & 6.2757 & 6.3367 & TRN & & \\
\hline CHEMBL3983810 & 1641089 & 7.4437 & 7.664 & TRN & & \\
\hline CHEMBL3952201 & 1641089 & 7.0809 & 6.5542 & TRN & & \\
\hline CHEMBL3906099 & 1641089 & 5.8861 & 6.576006 & 000000000 & 05 & TRN \\
\hline CHEMBL3966756 & 1641089 & 8.0 & 7.0725 & TRN & & \\
\hline CHEMBL3984836 & 1641089 & 7.3372 & 6.6282 & TRN & & \\
\hline CHEMBL3909215 & 1641089 & 8.0 & 8.073 & TRN & & \\
\hline CHEMBL3952973 & 1641089 & 5.7959 & 6.6431 & TST & & \\
\hline CHEMBL3939046 & 1641089 & 6.699 & 6.7367 & TST & & \\
\hline CHEMBL3963611 & 1641089 & 6.8996 & 7.3747 & TRN & & \\
\hline CHEMBL 3897953 & 1641089 & 7.1079 & 6.7617 & TRN & & \\
\hline CHEMBL3906511 & 1641089 & 5.699 & 6.38899 & 999999999 & & TST \\
\hline CHEMBL3936141 & 1641089 & 6.5952 & 6.9241 & TST & & \\
\hline CHEMBL3930487 & 1641089 & 5.707999 & 99999999 & 99 & 6.136 & TRN \\
\hline CHEMBL3897326 & 1641089 & 7.6021 & 7.4933 & TRN & & \\
\hline CHEMBL 3899517 & 1641089 & 6.617999 & 99999999 & 99 & 6.6612 & TST \\
\hline CHEMBL3918639 & 1641089 & 6.3979 & 6.7654 & TRN & & \\
\hline CHEMBL3905897 & 1641089 & 7.2924 & 7.2502 & TRN & & \\
\hline CHEMBL3891007 & 1641089 & 6.2366 & 5.8971 & TRN & & \\
\hline CHEMBL3965996 & 1641089 & 5.699 & 5.7613 & TRN & & \\
\hline CHEMBL3921913 & 1641089 & 5.1226 & 6.348 & TRN & & \\
\hline CHEMBL3941438 & 1641089 & 7.6021 & 7.0265 & TRN & & \\
\hline CHEMBL3976136 & 1641089 & 7.3372 & 6.9646 & TRN & & \\
\hline CHEMBL3904307 & 1641089 & 5.0 & 6.1881 & TRN & & \\
\hline CHEMBL3900164 & 1641089 & 5.0 & 6.4767 & TRN & & \\
\hline CHEMBL3899667 & 1641089 & 8.0 & 7.3311 & TRN & & \\
\hline CHEMBL3971915 & 1641089 & 8.0 & 7.7545 & TRN & & \\
\hline CHEMBL3934123 & 1641089 & 6.3242 & 6.2089 & TRN & & \\
\hline CHEMBL3946450 & 1641089 & 7.3468 & 7.5483 & TRN & & \\
\hline CHEMBL3944372 & 1641089 & 5.9927 & 6.3084 & TRN & & \\
\hline CHEMBL3920714 & 1641089 & 6.7328 & 6.975 & TRN & & \\
\hline CHEMBL3970116 & 1641089 & 8.0 & 7.7039 & TRN & & \\
\hline CHEMBL3939729 & 1641089 & 5.0 & 6.5251 & TRN & & \\
\hline CHEMBL3915184 & 1641089 & 5.0 & 5.7358 & TRN & & \\
\hline CHEMBL3938425 & 1641089 & 6.4685 & 6.407 & TRN & & \\
\hline
\end{tabular}


Supplemental Table S2.txt

\begin{tabular}{|c|c|c|c|c|c|}
\hline CHEMBL3915715 & 1641089 & 7.6383 & 7.7702 & TRN & \\
\hline CHEMBL3907953 & 1641089 & 8.0 & 8.2924 & TRN & \\
\hline CHEMBL3892833 & 1641089 & 6.0 & 6.3904 & TRN & \\
\hline CHEMBL3950563 & 1641089 & 6.6383 & 5.7375 & TRN & \\
\hline CHEMBL3981767 & 1641089 & 6.2676 & 6.6318 & TRN & \\
\hline CHEMBL3916435 & 1641089 & 6.3726 & 6.0169 & TRN & \\
\hline CHEMBL3890018 & 1641089 & 6.3737 & 6.2586 & TRN & \\
\hline CHEMBL3940605 & 1641089 & 7.1308 & 6.8372 & TST & \\
\hline CHEMBL3903766 & 1641089 & 6.2684 & 6.8234 & TST & \\
\hline CHEMBL3906141 & 1641089 & 7.0223 & 6.6424 & TRN & \\
\hline CHEMBL3959264 & 1641089 & 6.0862 & 6.0894 & TRN & \\
\hline CHEMBL3926037 & 1641089 & 6.0655 & 5.6173 & TRN & \\
\hline CHEMBL3963836 & 1641089 & 5.3279 & 5.8963 & TRN & \\
\hline CHEMBL3957646 & 1641089 & 7.2757 & 7.0851 & TST & \\
\hline CHEMBL3922841 & 1641089 & 7.6576 & 6.4859 & TRN & \\
\hline CHEMBL3933918 & 1641089 & 5.0555 & 6.0757 & TST & \\
\hline CHEMBL3919496 & 1641089 & 6.2069 & 6.2354 & TRN & \\
\hline CHEMBL3960087 & 1641089 & 6.5229 & 5.9821 & TRN & \\
\hline CHEMBL3907954 & 1641089 & 7.1192 & 7.2462 & TRN & \\
\hline CHEMBL3976308 & 1641089 & 7.0044 & 6.6401 & TRN & \\
\hline CHEMBL3894987 & 1641089 & 5.9427 & 5.6497 & TRN & \\
\hline CHEMBL3924402 & 1641089 & 7.4949 & 7.3774 & TRN & \\
\hline CHEMBL3960440 & 1641089 & 7.3768 & 7.7261 & TRN & \\
\hline CHEMBL3909162 & 1641089 & 5.9535 & 6.4993 & TST & \\
\hline CHEMBL3972387 & 1641089 & 7.2924 & 7.6874 & TST & \\
\hline CHEMBL3982935 & 1641089 & 6.5086 & 6.4479 & TRN & \\
\hline CHEMBL3952562 & 1641089 & 5.2924 & 6.53100 & 0000000001 & TST \\
\hline CHEMBL3964205 & 1641089 & 7.3188 & 7.1972 & TRN & \\
\hline CHEMBL3911842 & 1641089 & 7.9208 & 6.8173 & TRN & \\
\hline CHEMBL3968476 & 1641089 & 7.8861 & 7.5403 & TRN & \\
\hline CHEMBL3920409 & 1641089 & 6.7447 & 6.4014 & TRN & \\
\hline CHEMBL3945385 & 1641089 & 7.6576 & 7.1842 & TRN & \\
\hline CHEMBL3983503 & 1641089 & 6.8761 & 6.9333 & TRN & \\
\hline CHEMBL3909502 & 1641089 & 7.2366 & 7.2169 & TRN & \\
\hline CHEMBL 3895464 & 1641089 & 6.5817 & 7.197 & TST & \\
\hline CHEMBL3890122 & 1641089 & 5.7447 & 6.0535 & TRN & \\
\hline CHEMBL3973781 & 1641089 & 7.9208 & 7.7768 & TRN & \\
\hline CHEMBL3969147 & 1641089 & 5.1427 & 5.777 & TRN & \\
\hline CHEMBL3956924 & 1641089 & 6.3799 & 7.0536 & TRN & \\
\hline CHEMBL3931095 & 1641089 & 6.1367 & 6.2261 & TRN & \\
\hline CHEMBL3893526 & 1641089 & 7.3098 & 7.3906 & TRN & \\
\hline CHEMBL3963612 & 1641089 & 6.2636 & 6.3634 & TST & \\
\hline CHEMBL3976494 & 1641089 & 5.0506 & 5.5324 & TST & \\
\hline CHEMBL3902736 & 1641089 & 7.3979 & 6.3918 & TRN & \\
\hline CHEMBL3981495 & 1641089 & 7.8239 & 6.8534 & TRN & \\
\hline CHEMBL3900627 & 1641089 & 7.4949 & 6.7106 & TRN & \\
\hline CHEMBL3966982 & 1641089 & 6.1308 & 5.6321 & TRN & \\
\hline CHEMBL3967957 & 1641089 & $6.3420 e$ & 0000000 & 6.8078 & TST \\
\hline
\end{tabular}


Supplemental Table S2.txt

\begin{tabular}{|c|c|c|c|c|}
\hline Th & 1089 & 6.7986 & & \\
\hline UГMDI & 641089 & 7.6576 & 8266 & \\
\hline & & 24 & & \\
\hline JEMBL 38 & 089 & 7447 & & $2 \mathrm{~N}$ \\
\hline AEMBL3901799 & 089 & 586 & & \\
\hline HEMBL3949685 & 641089 & 5.0 & 5237 & \\
\hline 32 & 889 & 65 & & \\
\hline IFMRI 393 & & & & \\
\hline HEMBL397 & 089 & 6.0 & 7023 & \\
\hline HEMBL389 & 089 & 528 & 6179 & \\
\hline HEMBL 389 & 089 & 7.699 & 14 & \\
\hline IEMBL391 & 889 & & 3966 & \\
\hline AEMBL 389 & & & & \\
\hline HEMBL 392 & 089 & 6.23 & 5.4774 & \\
\hline AEMBL 394 & 889 & & 316 & \\
\hline AEMBL390 & 899 & 9666 & 18 & \\
\hline AEMBL39 & 89 & 39 & 86 & \\
\hline HEMBL39 & & & & \\
\hline HEMBL 398 & & 086 & & \\
\hline AEMBL393 & 89 & & & \\
\hline HEIMBLSS & 39 & 4 & 63 & $\mathrm{IRIV}$ \\
\hline AEMBL3S & & & & RN \\
\hline AEMBL3S & & 279 & & \\
\hline 23 & 389 & 5 . & 5042 & \\
\hline AEMBL39 & & & & TST \\
\hline HEMBL3S & 89 & 7. & & ГRN \\
\hline HEMBL3 & & & & 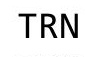 \\
\hline HFMBI 36 & 39 & & 58 & \\
\hline HEMBL39८ & & & & $\ln$ \\
\hline HEMBL 393 & & & & IK \\
\hline HEMBL 39 & 39 & 5 & 537 & RN \\
\hline HEMBL3 & 39 & 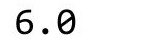 & - & RN \\
\hline HEMBL3 & & 58 & 807 & ST \\
\hline HEMBL393 & 89 & & 307 & IRN \\
\hline HEMBL3976181 & & 7.5086 & 6.6969 & TRN \\
\hline HEMBL396 & & & 3883 & \\
\hline HFMRI 3 & & & 78 & $\Gamma \mathrm{RN}$ \\
\hline HEMBL3 & & & & RN \\
\hline HEMBL397 & 889 & 7. & 6.7155 & TRN \\
\hline HEMBL 394 & & & 4809 & TRN \\
\hline HEMBL395 & 89 & 7. & 6.8644 & TST \\
\hline CHEMBL390 & & & 7.402 & TRN \\
\hline HEMBL397 & & 7.1367 & .7796 & TRN \\
\hline HEMBL 390 & 089 & 6.065 & .1472 & TRN \\
\hline $1=2+3+2$ & & 2 & 1966 & $\mathrm{~N}$ \\
\hline HEMBL 39 & & 229 & .3572 & \\
\hline CHEMBL392 & & .0177 & .8042 & \\
\hline CHEMBL3938219 & 1641089 & 7.9208 & 6.1885 & \\
\hline
\end{tabular}

Page 10464 
Supplemental Table S2.txt

\begin{tabular}{|c|c|c|c|c|c|}
\hline CHEMBL3914569 & 1641089 & 7.301 & 7.166 & TRN & \\
\hline CHEMBL3922966 & 1641089 & 7.3468 & 7.0012 & TRN & \\
\hline CHEMBL3906296 & 1641089 & 7.699 & 6.7672 & TST & \\
\hline CHEMBL3985122 & 1641089 & 6.041 & 5.7855 & TRN & \\
\hline CHEMBL3968325 & 1641089 & 7.1938 & 7.1455 & TRN & \\
\hline CHEMBL3983769 & 1641089 & 6.0297 & 6.6027 & TRN & \\
\hline CHEMBL3951172 & 1641089 & 6.2848 & 7.164 & TRN & \\
\hline CHEMBL3973239 & 1641089 & 5.6813 & 6.622006 & 0000000001 & TST \\
\hline CHEMBL3954882 & 1641089 & 6.6345 & 6.9187 & TST & \\
\hline CHEMBL3981977 & 1641089 & 7.3279 & 6.6662 & TRN & \\
\hline CHEMBL3925296 & 1641089 & 6.5086 & 6.1848 & TRN & \\
\hline CHEMBL3951729 & 1641089 & 7.5528 & 6.9615 & TRN & \\
\hline CHEMBL3919022 & 1641089 & 6.6696 & 6.915 & TRN & \\
\hline CHEMBL3963233 & 1641089 & 6.3449 & 6.2637 & TRN & \\
\hline CHEMBL3940075 & 1641089 & 5.7696 & 5.6913 & TRN & \\
\hline CHEMBL3900112 & 1641089 & 5.0 & 6.3691 & TST & \\
\hline CHEMBL3931962 & 1641089 & 7.8239 & 7.2614 & TRN & \\
\hline CHEMBL3962188 & 1641089 & 6.5467 & 7.2126 & TRN & \\
\hline CHEMBL3972346 & 1641089 & 6.8097 & 6.2731 & TST & \\
\hline CHEMBL3967973 & 1641089 & 7.0915 & 6.455 & TST & \\
\hline CHEMBL3962551 & 1641089 & 6.3143 & 6.4392 & TST & \\
\hline CHEMBL3951067 & 1641089 & 6.5376 & 6.8291 & TST & \\
\hline CHEMBL3923453 & 1641089 & 7.1549 & 7.175 & TST & \\
\hline CHEMBL3933551 & 1641089 & 6.3696 & 6.9398 & TST & \\
\hline CHEMBL3981020 & 1641089 & 6.1871 & 5.9663 & TST & \\
\hline CHEMBL3942375 & 1641089 & 5.8861 & 6.8523 & TST & \\
\hline CHEMBL3942437 & 1641089 & 5.697 & 6.4725 & TST & \\
\hline CHEMBL3915003 & 1641089 & 6.6716 & 7.7365 & TST & \\
\hline CHEMBL3956782 & 1641089 & 7.2596 & 6.8435 & TST & \\
\hline CHEMBL3906312 & 1641089 & 7.6383 & 7.115 & TST & \\
\hline CHEMBL3982544 & 1641089 & 5.0 & 6.6169 & TST & \\
\hline CHEMBL 3892428 & 1641089 & 6.0 & 6.4754 & TST & \\
\hline CHEMBL3965997 & 1641089 & 6.6596 & 6.4175 & TST & \\
\hline CHEMBL3905366 & 1641089 & 7.1135 & 7.0073 & TST & \\
\hline CHEMBL3917930 & 1641089 & 5.6036 & 6.3888 & TST & \\
\hline CHEMBL3960197 & 1641089 & 6.5918 & 6.8174 & TST & \\
\hline CHEMBL3900760 & 1641089 & 8.0 & 7.6666 & TST & \\
\hline CHEMBL3976765 & 1641089 & \multicolumn{3}{|c|}{6.757000000000001} & 1 \\
\hline CHEMBL3937012 & 1641089 & 5.3965 & 5.9061 & TST & \\
\hline CHEMBL3914001 & 1641089 & 7.3279 & 7.1226 & TST & \\
\hline CHEMBL1269807 & 674827 & 6.2366 & 5.5069 & TRN & \\
\hline CHEMBL1271473 & 674827 & 4.0 & 3.9356 & TRN & \\
\hline CHEMBL1271913 & 674827 & 7.0555 & 7.1902 & TRN & \\
\hline CHEMBL1272184 & 674827 & 7.2518 & 7.1704 & TRN & \\
\hline CHEMBL1272293 & 674827 & 4.0 & 4.7968 & TRN & \\
\hline CHEMBL1272023 & 674827 & 8.0458 & 7.7748 & TRN & \\
\hline CHEMBL1271857 & 674827 & 5.4157 & 4.5009 & TRN & \\
\hline CHEMBL1271855 & 674827 & 4.0 & 3.9141 & TST & \\
\hline
\end{tabular}




\begin{tabular}{|c|c|c|c|c|c|}
\hline \multicolumn{6}{|c|}{ Supplemental Table S2.txt } \\
\hline CHEMBL1269065 & 674827 & 4.0 & 3.7358 & TST & \\
\hline CHEMBL1271800 & 674827 & 7.4437 & 7.13399 & 99999999995 & TRN \\
\hline CHEMBL1271526 & 674827 & 5.7959 & 6.61 & TRN & \\
\hline CHEMBL1271525 & 674827 & 7.0315 & 6.8957 & TRN & \\
\hline CHEMBL 1271740 & 674827 & 6.2007 & 5.8869 & TRN & \\
\hline CHEMBL1271737 & 674827 & 6.7959 & 6.2166 & TRN & \\
\hline CHEMBL1271856 & 674827 & 4.0 & 4.2837 & TRN & \\
\hline CHEMBL1271854 & 674827 & 4.0 & 4.0579 & TST & \\
\hline CHEMBL1271684 & 674827 & 4.0 & 3.7839 & TRN & \\
\hline CHEMBL1271738 & 674827 & 4.0 & 4.2788 & TRN & \\
\hline CHEMBL1269043 & 674827 & 5.0 & 5.7616 & TRN & \\
\hline CHEMBL1271911 & 674827 & 4.0 & 4.2187 & TST & \\
\hline CHEMBL1271914 & 674827 & 6.7905 & 6.6541 & TRN & \\
\hline CHEMBL1271968 & 674827 & 7.5086 & 7.2695 & TRN & \\
\hline CHEMBL1271967 & 674827 & 7.5229 & 7.4415 & TRN & \\
\hline CHEMBL1271739 & 674827 & 4.0 & 3.8864 & TRN & \\
\hline CHEMBL1272292 & 674827 & 4.0 & 4.4198 & TST & \\
\hline CHEMBL1272131 & 674827 & 5.4089 & 5.3097 & TRN & \\
\hline CHEMBL1271799 & 674827 & 4.0 & 3.8363 & TST & \\
\hline CHEMBL1272183 & 674827 & 7.0862 & 7.4449 & TRN & \\
\hline CHEMBL1271741 & 674827 & 4.0 & 4.0201 & TRN & \\
\hline CHEMBL1271633 & 674827 & 4.0 & 4.1568 & TRN & \\
\hline CHEMBL1271581 & 674827 & 4.0 & 4.1531 & TRN & \\
\hline CHEMBL1271970 & 674827 & 6.7167 & 6.0924 & TST & \\
\hline CHEMBL1269064 & 674827 & 4.0 & 3.7542 & TRN & \\
\hline CHEMBL1271801 & 674827 & 6.9469 & 6.8275 & TST & \\
\hline CHEMBL1271579 & 674827 & 5.0 & 5.0114 & TRN & \\
\hline CHEMBL1271912 & 674827 & 6.6882 & 7.1062 & TRN & \\
\hline CHEMBL1272129 & 674827 & 7.3665 & 7.6731 & TRN & \\
\hline CHEMBL1271797 & 674827 & 5.5528 & 5.0478 & TRN & \\
\hline CHEMBL1272239 & 674827 & 6.9469 & 6.6664 & TRN & \\
\hline CHEMBL1272079 & 674827 & 5.3188 & 4.7741 & TRN & \\
\hline CHEMBL1271969 & 674827 & 7.2596 & 7.2616 & TST & \\
\hline CHEMBL1269808 & 674827 & 4.0 & 3.9705 & TRN & \\
\hline CHEMBL1271798 & 674827 & 4.0 & 4.1681 & TRN & \\
\hline CHEMBL1272027 & 674827 & 4.0 & 4.0312 & TST & \\
\hline CHEMBL1272130 & 674827 & 7.284 & 6.9945 & TRN & \\
\hline CHEMBL1271474 & 674827 & 5.284 & 5.8856 & TRN & \\
\hline CHEMBL1271685 & 674827 & 4.0 & 4.3183 & TST & \\
\hline CHEMBL1272081 & 674827 & 4.0 & 4.3531 & TST & \\
\hline CHEMBL1272080 & 674827 & 4.0 & 4.5974 & TRN & \\
\hline CHEMBL1272026 & 674827 & 6.0177 & 5.8319 & TST & \\
\hline CHEMBL1271580 & 674827 & 6.7878 & 6.8071 & TRN & \\
\hline CHEMBL1272082 & 674827 & 7.1938 & 7.2059 & TST & \\
\hline CHEMBL1269063 & 674827 & 4.0 & 4.3 & TRN & \\
\hline CHEMBL570059 & 787655 & 5.4976 & 5.6588 & TRN & \\
\hline CHEMBL1917833 & 787655 & 4.994 & 4.7201 & TST & \\
\hline CHEMBL1917664 & 787655 & 3.0 & 3.4682 & TRN & \\
\hline
\end{tabular}




\begin{tabular}{|c|c|c|c|c|c|}
\hline \multicolumn{6}{|c|}{ Supplemental Table S2.txt } \\
\hline CHEMBL572236 & 787655 & 3.0 & 3.2037 & TRN & \\
\hline CHEMBL569338 & 787655 & 5.4145 & 4.9024 & TRN & \\
\hline CHEMBL572026 & 787655 & 4.0389 & 3.8098 & TRN & \\
\hline CHEMBL571146 & 787655 & 5.3206 & 5.3722 & TRN & \\
\hline CHEMBL570465 & 787655 & 3.0 & 3.0284 & TRN & \\
\hline CHEMBL576070 & 787655 & 5.3507 & 4.8389 & TRN & \\
\hline CHEMBL1917654 & 787655 & 5.9245 & 5.8674 & TRN & \\
\hline CHEMBL569557 & 787655 & 4.0546 & 3.8512 & TRN & \\
\hline CHEMBL1917839 & 787655 & 3.0 & 2.7004 & TST & \\
\hline CHEMBL1917669 & 787655 & 3.0 & 3.2758 & TRN & \\
\hline CHEMBL1917671 & 787655 & 4.7263 & 4.3163 & TRN & \\
\hline CHEMBL1917666 & 787655 & 4.6647 & 4.7803 & TRN & \\
\hline CHEMBL1917829 & 787655 & 4.3903 & 3.3278 & TST & \\
\hline CHEMBL1917830 & 787655 & 3.0 & 3.1105 & TST & \\
\hline CHEMBL1917663 & 787655 & 5.1046 & 4.6878 & TRN & \\
\hline CHEMBL1917662 & 787655 & 3.0 & 2.7719 & TRN & \\
\hline CHEMBL1917827 & 787655 & 3.0 & 2.8437 & TRN & \\
\hline CHEMBL1917832 & 787655 & 4.4516 & 4.3628 & TST & \\
\hline CHEMBL1917661 & 787655 & 4.5063 & 4.4006 & TRN & \\
\hline CHEMBL1917665 & 787655 & 3.0 & 2.9342 & TRN & \\
\hline CHEMBL1917838 & 787655 & 3.0 & 2.7884 & TST & \\
\hline CHEMBL1917667 & 787655 & 4.1171 & 3.8732 & TRN & \\
\hline CHEMBL572024 & 787655 & 5.8069 & 5.7872 & TRN & \\
\hline CHEMBL1917656 & 787655 & 4.4472 & 4.4808 & TRN & \\
\hline CHEMBL1917835 & 787655 & 4.7183 & 4.7382 & TST & \\
\hline CHEMBL578814 & 787655 & 5.6655 & 5.7327 & TRN & \\
\hline CHEMBL1917837 & 787655 & 3.0 & 3.6217 & TST & \\
\hline CHEMBL570511 & 787655 & 4.0598 & 3.7315 & TRN & \\
\hline CHEMBL1917660 & 787655 & 4.9307 & 5.0448 & TRN & \\
\hline CHEMBL1917828 & 787655 & 4.9329 & 5.0403 & TRN & \\
\hline CHEMBL570510 & 787655 & 4.1832 & 4.7054 & TRN & \\
\hline CHEMBL1917834 & 787655 & 3.0 & 3.0951 & TST & \\
\hline CHEMBL571359 & 787655 & 5.0137 & 4.1207 & TRN & \\
\hline CHEMBL1914493 & 787655 & 4.9944 & 5.045 & TST & \\
\hline CHEMBL1917836 & 787655 & 3.0 & 3.6089 & TST & \\
\hline CHEMBL569558 & 787655 & 3.0 & 4.1207 & TRN & \\
\hline CHEMBL1917670 & 787655 & 3.0 & 3.57800 & 00000000003 & TRN \\
\hline CHEMBL1917655 & 787655 & 5.4855 & 5.4261 & TRN & \\
\hline CHEMBL583335 & 787655 & 4.9289 & 5.1968 & TRN & \\
\hline CHEMBL584953 & 787655 & 4.5872 & 4.6796 & TRN & \\
\hline CHEMBL1917659 & 787655 & 5.5969 & 5.106 & TRN & \\
\hline CHEMBL569115 & 787655 & 5.8729 & 6.2209 & TRN & \\
\hline CHEMBL570466 & 787655 & 5.4622 & 5.1303 & TRN & \\
\hline CHEMBL1917668 & 787655 & 3.0 & 2.7606 & TST & \\
\hline CHEMBL1917657 & 787655 & 5.2541 & 5.5939 & TRN & \\
\hline CHEMBL1917658 & 787655 & 3.0 & 3.3673 & TRN & \\
\hline CHEMBL1917831 & 787655 & 3.0 & 3.1101 & TST & \\
\hline CHEMBL 2041800 & 823824 & 6.4283 & 6.4391 & TST & \\
\hline
\end{tabular}




\begin{tabular}{|c|c|c|c|c|c|}
\hline & & \multicolumn{4}{|c|}{ Supplemental Table S2.txt } \\
\hline CHEMBL2041804 & 823824 & 5.2636 & 5.3806 & TRN & \\
\hline CHEMBL2041826 & 823824 & 7.6198 & 7.4036 & TRN & \\
\hline CHEMBL2041820 & 823824 & 6.9031 & 6.9536 & TRN & \\
\hline CHEMBL2041842 & 823824 & 7.1938 & 7.1854 & TRN & \\
\hline CHEMBL2041809 & 823824 & 4.7773 & 5.1419 & TRN & \\
\hline CHEMBL601707 & 823824 & 5.5817 & 5.4618 & TRN & \\
\hline CHEMBL2041622 & 823824 & 6.0706 & 6.182 & TRN & \\
\hline CHEMBL601069 & 823824 & 4.433 & 5.0691 & TST & \\
\hline CHEMBL2041797 & 823824 & 6.4815 & 6.4382 & TRN & \\
\hline CHEMBL2041816 & 823824 & 3.0 & 2.8135 & TRN & \\
\hline CHEMBL2041618 & 823824 & 7.0969 & 7.0615 & TRN & \\
\hline CHEMBL 2041824 & 823824 & 6.0 & 6.0432 & TRN & \\
\hline CHEMBL590504 & 823824 & 5.8153 & 5.5733 & TRN & \\
\hline CHEMBL2041839 & 823824 & 6.7959 & 6.9348 & TST & \\
\hline CHEMBL2041835 & 823824 & 3.0 & 3.3026 & TST & \\
\hline CHEMBL 2041621 & 823824 & 6.4949 & 6.614 & TRN & \\
\hline CHEMBL2041801 & 823824 & 5.8962 & 5.8044 & TRN & \\
\hline CHEMBL601706 & 823824 & 6.3188 & 6.3401 & TRN & \\
\hline CHEMBL2041836 & 823824 & 3.0 & 3.3603 & TST & \\
\hline CHEMBL2041620 & 823824 & 6.6198 & 6.7321 & TRN & \\
\hline CHEMBL2041815 & 823824 & 6.8239 & 6.7228 & TRN & \\
\hline CHEMBL2041843 & 823824 & 7.8239 & 7.8694 & TRN & \\
\hline CHEMBL 2041810 & 823824 & 6.2291 & 6.1482 & TRN & \\
\hline CHEMBL601066 & 823824 & 6.6198 & 6.5342 & TRN & \\
\hline CHEMBL2041828 & 823824 & 6.4949 & 7.0776 & TST & \\
\hline CHEMBL2041829 & 823824 & 6.8539 & 6.8987 & TRN & \\
\hline CHEMBL2041814 & 823824 & 5.2291 & 5.2339 & TRN & \\
\hline CHEMBL2041819 & 823824 & 4.3696 & 4.2765 & TRN & \\
\hline CHEMBL2041624 & 823824 & 7.0862 & 7.1893 & TRN & \\
\hline CHEMBL2041619 & 823824 & 6.9586 & 6.8977 & TRN & \\
\hline CHEMBL2041812 & 823824 & 4.4377 & 4.5758 & TRN & \\
\hline CHEMBL598176 & 823824 & 5.066 & 5.155 & TRN & \\
\hline CHEMBL590385 & 823824 & 6.6198 & 6.6573 & TST & \\
\hline CHEMBL601068 & 823824 & 6.699 & 6.7678 & TRN & \\
\hline CHEMBL2041838 & 823824 & 6.8539 & 6.879 & TST & \\
\hline CHEMBL2041623 & 823824 & 6.0269 & 5.9955 & TRN & \\
\hline CHEMBL 2041837 & 823824 & 6.7447 & 6.61600 & 00000000005 & TST \\
\hline CHEMBL2041845 & 823824 & 7.2518 & 7.2025 & TRN & \\
\hline CHEMBL601065 & 823824 & 6.0132 & 5.8696 & TRN & \\
\hline CHEMBL601708 & 823824 & 6.8539 & 6.4807 & TST & \\
\hline CHEMBL539632 & 823824 & 6.699 & 7.0043 & TRN & \\
\hline CHEMBL605979 & 823824 & 4.7049 & 4.8177 & TRN & \\
\hline CHEMBL2041970 & 823824 & 6.6383 & 6.7443 & TRN & \\
\hline CHEMBL2041830 & 823824 & 7.2441 & 7.121 & TRN & \\
\hline CHEMBL590266 & 823824 & 7.3768 & 7.4146 & TRN & \\
\hline CHEMBL596744 & 823824 & 3.0 & 3.1314 & TRN & \\
\hline CHEMBL2041827 & 823824 & 6.6383 & 6.3668 & TRN & \\
\hline CHEMBL2041798 & 823824 & 6.3565 & 6.4621 & TRN & \\
\hline
\end{tabular}


Supplemental Table S2.txt

\begin{tabular}{|c|c|c|c|c|c|}
\hline CHEMBL2041817 & 823824 & 6.6778 & 6.5932 & TRN & \\
\hline CHEMBL 2041821 & 823824 & 7.1135 & 6.9154 & TRN & \\
\hline CHEMBL2041844 & 823824 & 6.7696 & 6.7101 & TRN & \\
\hline CHEMBL 2041803 & 823824 & 5.1415 & 5.2711 & TRN & \\
\hline CHEMBL2041840 & 823824 & 6.0 & 5.9565 & TRN & \\
\hline CHEMBL 2041795 & 823824 & 6.6198 & 6.722 & TRN & \\
\hline CHEMBL 2041802 & 823824 & 5.5867 & 5.527 & TRN & \\
\hline CHEMBL2041805 & 823824 & 7.4318 & 7.4672 & TRN & \\
\hline CHEMBL 2041833 & 823824 & 5.5719 & 5.428 & TST & \\
\hline CHEMBL2041813 & 823824 & 4.6676 & 4.6195 & TRN & \\
\hline CHEMBL2041831 & 823824 & 6.4815 & 6.5603 & TST & \\
\hline CHEMBL596746 & 823824 & 3.0 & 3.2685 & TRN & \\
\hline CHEMBL2041971 & 823824 & 6.6198 & 6.7513 & TRN & \\
\hline CHEMBL 2041617 & 823824 & 7.0969 & 6.9928 & TRN & \\
\hline CHEMBL598801 & 823824 & 4.6872 & 4.4441 & TRN & \\
\hline CHEMBL 2041616 & 823824 & 7.5528 & 7.6728 & TRN & \\
\hline CHEMBL2041811 & 823824 & 6.1549 & 6.2455 & TRN & \\
\hline CHEMBL 2041807 & 823824 & 7.4202 & 7.4146 & TRN & \\
\hline CHEMBL605561 & 823824 & 4.7174 & 4.4692 & TRN & \\
\hline CHEMBL2041806 & 823824 & 7.4815 & 7.4494 & TRN & \\
\hline CHEMBL 2041799 & 823824 & 6.6021 & 6.504 & TST & \\
\hline CHEMBL2041832 & 823824 & 6.0915 & 6.0678 & TST & \\
\hline CHEMBL 2041834 & 823824 & 4.6345 & 5.4184 & TST & \\
\hline CHEMBL2041846 & 823824 & 5.2967 & 6.1032 & TST & \\
\hline CHEMBL601067 & 823824 & 6.1549 & 6.4215 & TST & \\
\hline CHEMBL 2041818 & 823824 & 7.9586 & 7.4269 & TST & \\
\hline CHEMBL 2041796 & 823824 & 6.5229 & 6.5486 & TST & \\
\hline CHEMBL590505 & 823824 & 6.7447 & 6.6435 & TST & \\
\hline CHEMBL1417888 & 737277 & 5.1955 & 4.5283 & TRN & \\
\hline CHEMBL1376176 & 737277 & 4.4961 & 4.7702 & TRN & \\
\hline CHEMBL1349755 & 737277 & 4.6413 & 4.8291 & TRN & \\
\hline CHEMBL1486538 & 737277 & 5.2249 & 5.2163 & TRN & \\
\hline CHEMBL1404407 & 737277 & 5.3309 & 4.5974 & TRN & \\
\hline CHEMBL1729477 & 737277 & 5.0339 & 4.846 & TRN & \\
\hline CHEMBL1331598 & 737277 & 5.5722 & 5.4274 & TST & \\
\hline CHEMBL1346143 & 737277 & 4.9458 & 4.6557 & TRN & \\
\hline CHEMBL1328939 & 737277 & 4.8739 & 4.9825 & TRN & \\
\hline CHEMBL1544647 & 737277 & 5.1517 & 5.0823 & TRN & \\
\hline CHEMBL295786 & 737277 & 4.1669 & 4.4876 & TRN & \\
\hline CHEMBL1582509 & 737277 & 5.3913 & 4.8465 & TRN & \\
\hline CHEMBL3193389 & 737277 & 6.0875 & 5.7369 & TRN & \\
\hline CHEMBL1537034 & 737277 & 4.6556 & 4.9811 & TRN & \\
\hline CHEMBL 3212840 & 737277 & 5.3669 & 5.3047 & TRN & \\
\hline CHEMBL1544333 & 737277 & 4.8027 & 5.0693 & TRN & \\
\hline CHEMBL1388639 & 737277 & 5.6123 & 5.2816 & TRN & \\
\hline CHEMBL1603416 & 737277 & 6.1981 & 5.2166 & TST & \\
\hline CHEMBL1550601 & 737277 & \multicolumn{3}{|c|}{4.9830000000000005} & 4.5635 \\
\hline CHEMBL486706 & 737277 & 4.8935 & 4.6724 & TRN & \\
\hline
\end{tabular}




\begin{tabular}{|c|c|c|c|c|c|}
\hline \multicolumn{6}{|c|}{ Supplemental Table S2.txt } \\
\hline CHEMBL1429210 & 737277 & 3.0 & 4.836 & TRN & \\
\hline CHEMBL217920 & 737277 & 4.4441 & 4.4322 & TRN & \\
\hline CHEMBL1502929 & 737277 & 5.0545 & 4.8924 & TRN & \\
\hline CHEMBL1575796 & 737277 & 4.9809 & 5.0264 & TST & \\
\hline CHEMBL1543510 & 737277 & 5.2226 & 5.0267 & TRN & \\
\hline CHEMBL1709692 & 737277 & 3.0 & 4.7833 & TRN & \\
\hline CHEMBL1589129 & 737277 & 5.2093 & 4.8289 & TRN & \\
\hline CHEMBL1735225 & 737277 & 3.0 & 4.7905 & TST & \\
\hline CHEMBL1388596 & 737277 & 3.0 & 4.5949 & TST & \\
\hline CHEMBL1903762 & 737277 & 6.8499 & 6.0969 & TRN & \\
\hline CHEMBL539027 & 737277 & 5.4564 & 4.9499 & TRN & \\
\hline CHEMBL1604346 & 737277 & 4.6455 & 4.7088 & TST & \\
\hline CHEMBL1560731 & 737277 & 4.8225 & 5.069 & TRN & \\
\hline CHEMBL1580969 & 737277 & 4.5945 & 4.6113 & TRN & \\
\hline CHEMBL1495632 & 737277 & 6.0164 & 5.1276 & TRN & \\
\hline CHEMBL1517146 & 737277 & 4.7095 & 4.6613 & TRN & \\
\hline CHEMBL1984138 & 737277 & 5.8413 & 6.12200 & 0000000001 & TRN \\
\hline CHEMBL1506661 & 737277 & 3.0 & 4.9657 & TST & \\
\hline CHEMBL1386650 & 737277 & 4.7307 & 4.5903 & TRN & \\
\hline CHEMBL1425691 & 737277 & 4.856 & 4.6479 & TRN & \\
\hline CHEMBL1605241 & 737277 & 4.1628 & 4.8418 & TRN & \\
\hline CHEMBL1572384 & 737277 & 4.2027 & 4.4945 & TRN & \\
\hline CHEMBL443231 & 737277 & 4.9462 & 4.5054 & TRN & \\
\hline CHEMBL1556020 & 737277 & 5.3683 & 4.9686 & TST & \\
\hline CHEMBL1723343 & 737277 & 4.7749 & 4.5986 & TRN & \\
\hline CHEMBL1468612 & 737277 & 4.7496 & 5.2721 & TRN & \\
\hline CHEMBL1714722 & 737277 & 4.6761 & 5.2617 & TRN & \\
\hline CHEMBL1523485 & 737277 & 4.9889 & 4.5723 & TRN & \\
\hline CHEMBL1424968 & 737277 & 4.9374 & 5.1898 & TRN & \\
\hline CHEMBL1381508 & 737277 & 4.6117 & 4.671 & TRN & \\
\hline CHEMBL1441475 & 737277 & 4.4955 & 4.5709 & TRN & \\
\hline CHEMBL1587031 & 737277 & 5.0854 & 5.2219 & TST & \\
\hline CHEMBL1468750 & 737277 & 5.0242 & 5.0338 & TRN & \\
\hline CHEMBL1560044 & 737277 & 3.0 & 5.0101 & TRN & \\
\hline CHEMBL579287 & 737277 & 5.0819 & 4.61600 & 00000000005 & TRN \\
\hline CHEMBL1338004 & 737277 & 4.1856 & 4.7917 & TRN & \\
\hline CHEMBL1606939 & 737277 & 4.5077 & 4.5835 & TST & \\
\hline CHEMBL1501755 & 737277 & 5.1024 & 4.8115 & TRN & \\
\hline CHEMBL1410678 & 737277 & 4.8041 & 4.86100 & 2000000001 & TRN \\
\hline CHEMBL1707746 & 737277 & 5.0799 & 4.6994 & TRN & \\
\hline CHEMBL3190182 & 737277 & 5.2593 & 5.9454 & TRN & \\
\hline CHEMBL1385576 & 737277 & 4.5427 & 4.9669 & TRN & \\
\hline CHEMBL1368371 & 737277 & 5.3704 & 5.0479 & TRN & \\
\hline CHEMBL1510964 & 737277 & 5.0811 & 4.7837 & TRN & \\
\hline CHEMBL1475888 & 737277 & 5.2773 & 5.1336 & TST & \\
\hline CHEMBL3197434 & 737277 & 5.5289 & 5.8176 & TRN & \\
\hline CHEMBL1379745 & 737277 & 5.0745 & 4.8879 & TRN & \\
\hline CHEMBL1464645 & 737277 & 3.0 & 4.3865 & TRN & \\
\hline
\end{tabular}




\begin{tabular}{|c|c|c|c|c|c|c|}
\hline \multicolumn{7}{|c|}{ } \\
\hline CHEMBL1900830 & 737277 & 6.8674 & 6.334 & TRN & & \\
\hline CHEMBL1699711 & 737277 & 6.4454 & 5.0396 & TST & & \\
\hline CHEMBL578944 & 737277 & 5.0953 & 4.8498 & TRN & & \\
\hline CHEMBL3198833 & 737277 & 5.0455 & 5.9716 & TRN & & \\
\hline CHEMBL1445474 & 737277 & 5.4129 & 5.1643 & TRN & & \\
\hline CHEMBL1429574 & 737277 & 5.3823 & 4.5745 & TRN & & \\
\hline CHEMBL1417419 & 737277 & 5.2342 & 4.9249 & TRN & & \\
\hline CHEMBL1306696 & 737277 & 4.8386 & 5.0201 & TST & & \\
\hline CHEMBL1561078 & 737277 & 5.3729 & 5.2002 & TRN & & \\
\hline CHEMBL1568729 & 737277 & 4.0094 & 4.6936 & TRN & & \\
\hline CHEMBL1559673 & 737277 & 5.3106 & 4.7775 & TRN & & \\
\hline CHEMBL1561245 & 737277 & 4.7862 & 4.963 & TRN & & \\
\hline CHEMBL1568487 & 737277 & 4.9889 & 4.556 & TRN & & \\
\hline CHEMBL1449269 & 737277 & 6.0045 & 4.9103 & TRN & & \\
\hline CHEMBL1527323 & 737277 & 4.8601 & 4.6561 & TRN & & \\
\hline CHEMBL1518304 & 737277 & 4.6929 & 4.6298 & TRN & & \\
\hline CHEMBL1540876 & 737277 & 4.9492 & 4.5094 & TRN & & \\
\hline CHEMBL1431263 & 737277 & 4.6415 & 4.8711 & TRN & & \\
\hline CHEMBL1456502 & 737277 & 5.3565 & 5.2971 & TRN & & \\
\hline CHEMBL1400666 & 737277 & 4.0732 & 4.5196 & TRN & & \\
\hline CHEMBL1343490 & 737277 & 5.0357 & 4.883 & TST & & \\
\hline CHEMBL1312974 & 737277 & 4.9784 & 4.6839 & TST & & \\
\hline CHEMBL1728120 & 737277 & 5.40799 & و9999999 & 995 & 5.245 & TRN \\
\hline CHEMBL1885808 & 737277 & 6.9311 & 5.8955 & TRN & & \\
\hline CHEMBL1449029 & 737277 & 4.7438 & 4.8373 & TRN & & \\
\hline CHEMBL1451569 & 737277 & 4.9165 & 5.2098 & TRN & & \\
\hline CHEMBL1371583 & 737277 & 5.275 & 4.5498 & TRN & & \\
\hline CHEMBL1300631 & 737277 & 4.71899 & 99999999 & 99 & 4.5212 & TRN \\
\hline CHEMBL1398902 & 737277 & 4.1685 & 4.6478 & TRN & & \\
\hline CHEMBL1601093 & 737277 & 5.2284 & 4.521 & TRN & & \\
\hline CHEMBL1522697 & 737277 & 4.2826 & 4.9327 & TST & & \\
\hline CHEMBL1545639 & 737277 & 5.3785 & 5.1519 & TRN & & \\
\hline CHEMBL1404438 & 737277 & 5.0185 & 4.5672 & TRN & & \\
\hline CHEMBL1376776 & 737277 & 5.1646 & 4.5706 & TRN & & \\
\hline CHEMBL1376600 & 737277 & 4.7953 & 4.772 & TRN & & \\
\hline CHEMBL1466598 & 737277 & 5.1259 & 4.8087 & TRN & & \\
\hline CHEMBL1548086 & 737277 & 5.1869 & 5.1261 & TST & & \\
\hline CHEMBL1533031 & 737277 & 5.055 & 5.0765 & TRN & & \\
\hline CHEMBL1390613 & 737277 & 5.9551 & 4.8028 & TRN & & \\
\hline CHEMBL1584128 & 737277 & 6.2211 & 5.1561 & TRN & & \\
\hline CHEMBL1508257 & 737277 & 4.7897 & 4.7417 & TST & & \\
\hline CHEMBL1502451 & 737277 & 4.3105 & 4.6927 & TRN & & \\
\hline CHEMBL1568189 & 737277 & 4.4547 & 4.8441 & TRN & & \\
\hline CHEMBL1505044 & 737277 & 5.6889 & 4.8253 & TRN & & \\
\hline CHEMBL1547025 & 737277 & 4.40300 & 30000000 & 205 & 4.6731 & TRN \\
\hline CHEMBL 3209825 & 737277 & 4.2439 & 5.2401 & TST & & \\
\hline CHEMBL1339887 & 737277 & 4.3937 & 5.0574 & TST & & \\
\hline CHEMBL1606910 & 737277 & 5.3088 & 5.289 & TRN & & \\
\hline
\end{tabular}




\begin{tabular}{|c|c|c|c|c|c|c|}
\hline & & \multicolumn{5}{|c|}{ Supplemental Table S2.txt } \\
\hline CHEMBL1346802 & 737277 & 4.9201 & 4.7994 & TRN & & \\
\hline CHEMBL1391813 & 737277 & 5.1562 & 4.7994 & TRN & & \\
\hline CHEMBL1351650 & 737277 & 4.4617 & 4.7556 & TRN & & \\
\hline CHEMBL1581582 & 737277 & 4.8499 & 4.9087 & TRN & & \\
\hline CHEMBL3208522 & 737277 & 4.5246 & 5.6881 & TRN & & \\
\hline CHEMBL1346897 & 737277 & 3.0 & 4.2777 & TRN & & \\
\hline CHEMBL1414655 & 737277 & 3.0 & 4.8414 & TRN & & \\
\hline CHEMBL3189676 & 737277 & 4.8542 & 5.2881 & TRN & & \\
\hline CHEMBL1392763 & 737277 & \multicolumn{3}{|c|}{5.837999999999999} & 4.9255 & TRN \\
\hline CHEMBL1384282 & 737277 & 4.8548 & 4.8613 & TRN & & \\
\hline CHEMBL 3210528 & 737277 & \multicolumn{3}{|c|}{5.156000000000001} & 5.2661 & TRN \\
\hline CHEMBL1349960 & 737277 & 5.5193 & 4.8364 & TRN & & \\
\hline CHEMBL1305118 & 737277 & 4.8539 & 5.0327 & TRN & & \\
\hline CHEMBL1546422 & 737277 & 5.0175 & 4.6608 & TRN & & \\
\hline CHEMBL1480163 & 737277 & 4.6712 & 4.7575 & TRN & & \\
\hline CHEMBL1305158 & 737277 & 5.2829 & 4.6319 & TRN & & \\
\hline CHEMBL1360994 & 737277 & 4.5832 & 4.8452 & TRN & & \\
\hline CHEMBL1580495 & 737277 & 3.0 & 5.4444 & TST & & \\
\hline CHEMBL1530208 & 737277 & 5.2028 & 5.0429 & TRN & & \\
\hline CHEMBL1388124 & 737277 & 4.9169 & 4.5416 & TST & & \\
\hline CHEMBL1509494 & 737277 & 5.1965 & 4.5355 & TRN & & \\
\hline CHEMBL1444904 & 737277 & 4.6576 & 4.7158 & TRN & & \\
\hline CHEMBL1717382 & 737277 & 5.4288 & 4.8444 & TST & & \\
\hline CHEMBL1325657 & 737277 & 4.8564 & 4.9894 & TRN & & \\
\hline CHEMBL1867074 & 737277 & 6.5265 & 5.9112 & TRN & & \\
\hline CHEMBL1526266 & 737277 & 4.8422 & 5.0249 & TRN & & \\
\hline CHEMBL1303255 & 737277 & 3.0 & 4.6334 & TST & & \\
\hline CHEMBL1518071 & 737277 & 4.0881 & 4.7138 & TRN & & \\
\hline CHEMBL3194374 & 737277 & 4.6647 & 5.4407 & TRN & & \\
\hline CHEMBL1306389 & 737277 & 4.8604 & 4.8233 & TST & & \\
\hline CHEMBL1478000 & 737277 & 4.7418 & 4.7154 & TRN & & \\
\hline CHEMBL1340346 & 737277 & 4.2384 & 4.8833 & TST & & \\
\hline CHEMBL1309874 & 737277 & \multicolumn{3}{|c|}{5.9670000000000005} & 5.1217 & TRN \\
\hline CHEMBL1442384 & 737277 & 3.0 & 4.7662 & TRN & & \\
\hline CHEMBL3190972 & 737277 & 5.0976 & 5.4977 & TRN & & \\
\hline CHEMBL1590447 & 737277 & 5.4627 & 4.8721 & TRN & & \\
\hline CHEMBL1465215 & 737277 & 3.0 & 4.7082 & TRN & & \\
\hline CHEMBL3207669 & 737277 & 6.4652 & 6.0135 & TRN & & \\
\hline CHEMBL1333924 & 737277 & 4.3824 & 4.4189 & TRN & & \\
\hline CHEMBL1405851 & 737277 & 4.2618 & 4.42899 & 9999999999 & & S \\
\hline CHEMBL1302410 & 737277 & 4.7562 & 5.1984 & TST & & \\
\hline CHEMBL1559767 & 737277 & 4.1088 & 4.8159 & TRN & & \\
\hline CHEMBL1541709 & 737277 & 4.739 & 4.8516 & TRN & & \\
\hline CHEMBL1402907 & 737277 & 5.1066 & 4.7288 & TST & & \\
\hline CHEMBL1470818 & 737277 & 5.1912 & 4.7598 & TRN & & \\
\hline CHEMBL1496705 & 737277 & 5.2591 & 4.8115 & TRN & & \\
\hline CHEMBL1392552 & 737277 & 4.8761 & 4.5095 & TST & & \\
\hline CHEMBL1894168 & 737277 & 5.815 & 5.9426 & TRN & & \\
\hline
\end{tabular}




\begin{tabular}{|c|c|c|c|c|c|c|}
\hline & & \multicolumn{5}{|c|}{ Supplemental Table S2.txt } \\
\hline CHEMBL1419182 & 737277 & 4.1615 & 4.8076 & TST & & \\
\hline CHEMBL1437987 & 737277 & 4.5436 & 4.6388 & TRN & & \\
\hline CHEMBL1697956 & 737277 & 5.3447 & 5.1544 & TRN & & \\
\hline CHEMBL3212885 & 737277 & 5.1283 & 5.3923 & TRN & & \\
\hline CHEMBL1542752 & 737277 & 3.0 & 4.746 & TST & & \\
\hline CHEMBL1499778 & 737277 & 4.1955 & 4.4136 & TRN & & \\
\hline CHEMBL1417218 & 737277 & 4.1217 & 4.8753 & TRN & & \\
\hline CHEMBL1412977 & 737277 & 4.1501 & 4.6448 & TRN & & \\
\hline CHEMBL1549261 & 737277 & 4.3382 & 5.1823 & TRN & & \\
\hline CHEMBL1457199 & 737277 & 4.512 & 4.9601 & TRN & & \\
\hline CHEMBL1723099 & 737277 & 3.0 & 4.6306 & TRN & & \\
\hline CHEMBL3209467 & 737277 & 5.5564 & 5.3754 & TRN & & \\
\hline CHEMBL1356140 & 737277 & 4.96899 & 99999999 & 99 & 4.8382 & TRN \\
\hline CHEMBL1305371 & 737277 & 4.584 & 4.6779 & TRN & & \\
\hline CHEMBL1370471 & 737277 & 5.0593 & 4.8099 & TRN & & \\
\hline CHEMBL1579772 & 737277 & 5.41200 & 30000000 & & 4.6831 & TRN \\
\hline CHEMBL1330113 & 737277 & 4.6364 & 4.8946 & TST & & \\
\hline CHEMBL1589425 & 737277 & 5.3043 & 5.1261 & TST & & \\
\hline CHEMBL1424834 & 737277 & 4.5278 & 4.3948 & TRN & & \\
\hline CHEMBL1584109 & 737277 & 5.5902 & 4.9537 & TRN & & \\
\hline CHEMBL1611833 & 737277 & 3.0 & 4.7429 & TST & & \\
\hline CHEMBL1491892 & 737277 & 5.2518 & 4.7487 & TRN & & \\
\hline CHEMBL1402502 & 737277 & 4.9772 & 4.822 & TRN & & \\
\hline CHEMBL1462919 & 737277 & 4.8601 & 5.152 & TRN & & \\
\hline CHEMBL1546194 & 737277 & 6.2593 & 5.2258 & TRN & & \\
\hline CHEMBL3197063 & 737277 & 5.3206 & 5.2507 & TRN & & \\
\hline CHEMBL1561659 & 737277 & 4.8102 & 4.4529 & TRN & & \\
\hline CHEMBL1587028 & 737277 & 4.7042 & 4.973 & TRN & & \\
\hline CHEMBL1356182 & 737277 & 4.4018 & 4.721 & TRN & & \\
\hline CHEMBL1574523 & 737277 & 4.9582 & 4.7508 & TRN & & \\
\hline CHEMBL1731938 & 737277 & 4.704 & 4.9028 & TRN & & \\
\hline CHEMBL1444617 & 737277 & 3.0 & 4.7578 & TRN & & \\
\hline CHEMBL1471351 & 737277 & 5.1096 & 5.1461 & TRN & & \\
\hline CHEMBL1419900 & 737277 & 4.823 & 4.9089 & TRN & & \\
\hline CHEMBL3197667 & 737277 & 5.6821 & 6.1702 & TRN & & \\
\hline CHEMBL1612826 & 737277 & 4.8058 & 4.6584 & TRN & & \\
\hline CHEMBL1398181 & 737277 & 5.6916 & 5.0515 & TRN & & \\
\hline CHEMBL1582665 & 737277 & 4.3206 & 4.961 & TRN & & \\
\hline CHEMBL1588722 & 737277 & 5.5572 & 4.7798 & TRN & & \\
\hline CHEMBL1370674 & 737277 & 4.4908 & 4.4489 & TRN & & \\
\hline CHEMBL1299782 & 737277 & 6.1683 & 5.104 & TRN & & \\
\hline CHEMBL1536483 & 737277 & 4.6035 & 4.5461 & TRN & & \\
\hline CHEMBL1720297 & 737277 & 5.3447 & 4.9171 & TRN & & \\
\hline CHEMBL1329111 & 737277 & 4.9255 & 4.883 & TRN & & \\
\hline CHEMBL1449107 & 737277 & 4.63 & 4.718 & TRN & & \\
\hline CHEMBL1359445 & 737277 & 5.3216 & 4.7813 & TRN & & \\
\hline CHEMBL1464388 & 737277 & 4.7937 & 4.5313 & TRN & & \\
\hline CHEMBL1384948 & 737277 & 4.555 & 5.0861 & TRN & & \\
\hline
\end{tabular}


Supplemental Table S2.txt

\begin{tabular}{|c|c|c|c|c|}
\hline CHEMBL1496095 & 737277 & 4.6402 & 4.7691 & TRN \\
\hline CHEMBL1578493 & 737277 & 4.6323 & 4.855 & TRN \\
\hline CHEMBL3190356 & 737277 & 4.6052 & 5.254 & TRN \\
\hline CHEMBL1586238 & 737277 & 5.7149 & 4.9748 & TST \\
\hline CHEMBL1430785 & 737277 & 4.4333 & 4.654 & TRN \\
\hline CHEMBL1388853 & 737277 & 5.7951 & 4.6697 & TRN \\
\hline CHEMBL1392642 & 737277 & 5.2289 & 5.0499 & TRN \\
\hline CHEMBL 2006620 & 737277 & 5.1081 & 5.767 & TRN \\
\hline CHEMBL1714370 & 737277 & 4.9183 & 4.8398 & TRN \\
\hline CHEMBL1508547 & 737277 & 4.6511 & 4.5608 & TRN \\
\hline CHEMBL1351626 & 737277 & 4.9755 & 4.7566 & TRN \\
\hline CHEMBL1545902 & 737277 & 4.5654 & 5.0363 & TRN \\
\hline CHEMBL1434375 & 737277 & 5.2075 & 5.13700 & 00000000005 \\
\hline CHEMBL1453858 & 737277 & 3.0 & 4.5077 & TRN \\
\hline CHEMBL1716272 & 737277 & 5.0389 & 5.1082 & TST \\
\hline CHEMBL1327850 & 737277 & 4.9582 & 5.1751 & TRN \\
\hline CHEMBL1407834 & 737277 & 5.0089 & 4.5963 & TRN \\
\hline CHEMBL1437660 & 737277 & 4.9352 & 4.8304 & TRN \\
\hline CHEMBL 86464 & 737277 & 5.169 & 5.1558 & TRN \\
\hline CHEMBL1326318 & 737277 & 5.4853 & 5.0412 & TRN \\
\hline CHEMBL1503289 & 737277 & 5.374 & 4.6057 & TRN \\
\hline CHEMBL3195299 & 737277 & 6.5945 & 6.1254 & TRN \\
\hline CHEMBL1726052 & 737277 & 3.0 & 4.9635 & TST \\
\hline CHEMBL1320148 & 737277 & 6.9905 & 4.977 & TRN \\
\hline CHEMBL1706291 & 737277 & 4.8706 & 4.8157 & TRN \\
\hline CHEMBL1306962 & 737277 & 5.1321 & 4.8388 & TRN \\
\hline CHEMBL1372494 & 737277 & 4.4885 & 4.8197 & TRN \\
\hline CHEMBL1413681 & 737277 & 4.5711 & 4.4675 & TRN \\
\hline CHEMBL1312600 & 737277 & 5.3332 & 5.3387 & TRN \\
\hline CHEMBL1520777 & 737277 & 5.041 & 4.9897 & TRN \\
\hline CHEMBL1303197 & 737277 & 4.9694 & 5.0474 & TRN \\
\hline CHEMBL1363179 & 737277 & 4.4408 & 4.7581 & TRN \\
\hline CHEMBL1448901 & 737277 & 4.6617 & 4.9031 & TRN \\
\hline CHEMBL1382643 & 737277 & 4.7577 & 4.9184 & TRN \\
\hline CHEMBL1338580 & 737277 & 4.1197 & 4.5179 & TRN \\
\hline CHEMBL1411065 & 737277 & 5.1631 & 4.3726 & TST \\
\hline CHEMBL1523678 & 737277 & 5.2328 & 5.0957 & TRN \\
\hline CHEMBL1436748 & 737277 & 5.1202 & 4.9135 & TRN \\
\hline CHEMBL1403346 & 737277 & 4.8207 & 4.5964 & TST \\
\hline CHEMBL1438058 & 737277 & 5.4621 & 5.0713 & TRN \\
\hline CHEMBL1419155 & 737277 & 4.6438 & 4.7789 & TRN \\
\hline CHEMBL1442955 & 737277 & 5.1225 & 5.0743 & TRN \\
\hline CHEMBL1566885 & 737277 & 4.8811 & 4.3877 & TST \\
\hline CHEMBL1415031 & 737277 & 3.0 & 4.9462 & TRN \\
\hline CHEMBL1388239 & 737277 & 5.6872 & 5.1721 & TRN \\
\hline CHEMBL1336545 & 737277 & 5.6767 & 5.0814 & TST \\
\hline CHEMBL1365001 & 737277 & 5.3364 & 4.8428 & TRN \\
\hline CHEMBL1494764 & 737277 & 4.8536 & 4.5776 & TRN \\
\hline
\end{tabular}




\begin{tabular}{|c|c|c|c|c|c|c|}
\hline \multicolumn{7}{|c|}{ Supplemental Table S2.txt } \\
\hline CHEMBL1427189 & 737277 & 4.8841 & 5.2447 & TRN & & \\
\hline CHEMBL1611686 & 737277 & 4.5363 & 4.3758 & TRN & & \\
\hline CHEMBL1362012 & 737277 & 4.1677 & 4.7125 & TST & & \\
\hline CHEMBL1610081 & 737277 & 6.2661 & 5.348 & TRN & & \\
\hline CHEMBL1494350 & 737277 & 4.5583 & 4.7696 & TRN & & \\
\hline CHEMBL1339987 & 737277 & 5.3267 & 4.5465 & TST & & \\
\hline CHEMBL1483899 & 737277 & 5.29899 & 99999999 & 995 & 4.6434 & TST \\
\hline CHEMBL1409121 & 737277 & 4.2803 & 4.6592 & TST & & \\
\hline CHEMBL1417963 & 737277 & 3.0 & 4.3645 & TST & & \\
\hline CHEMBL1387237 & 737277 & 4.447 & 4.6459 & TST & & \\
\hline CHEMBL1601826 & 737277 & 4.9682 & 5.3401 & TST & & \\
\hline CHEMBL1320465 & 737277 & 5.1502 & 4.7356 & TST & & \\
\hline CHEMBL1518653 & 737277 & 5.4561 & 5.1761 & TST & & \\
\hline CHEMBL1573779 & 737277 & 4.78600 & 000000000 & 205 & 4.9876 & TST \\
\hline CHEMBL1554625 & 737277 & 4.45 & 5.172000 & 0000000001 & & \\
\hline CHEMBL1378435 & 737277 & 5.0236 & 4.7484 & TST & & \\
\hline CHEMBL1453099 & 737277 & 5.716 & 4.9613 & TST & & \\
\hline CHEMBL1339993 & 737277 & 6.2531 & 5.0901 & TST & & \\
\hline CHEMBL1389745 & 737277 & 5.4614 & 5.073 & TST & & \\
\hline CHEMBL1978082 & 737277 & 5.2833 & 5.1664 & TST & & \\
\hline CHEMBL1546248 & 737277 & 5.0382 & 4.7653 & TST & & \\
\hline CHEMBL1577620 & 737277 & 4.8598 & 5.2021 & TST & & \\
\hline CHEMBL1388369 & 737277 & 5.7291 & 4.7183 & TST & & \\
\hline CHEMBL1601256 & 737277 & 4.5799 & 5.2585 & TST & & \\
\hline CHEMBL3210824 & 737277 & 6.0607 & 5.9295 & TST & & \\
\hline CHEMBL1425125 & 737277 & 4.2819 & 4.8876 & TST & & \\
\hline CHEMBL1376937 & 737277 & 4.7883 & 4.8201 & TST & & \\
\hline CHEMBL1736903 & 737277 & 5.1052 & 4.7118 & TST & & \\
\hline CHEMBL1387741 & 737277 & 4.1372 & 4.9093 & TST & & \\
\hline CHEMBL1359684 & 737277 & 4.6627 & 4.8677 & TST & & \\
\hline CHEMBL1340445 & 737277 & 4.6089 & 4.822 & TST & & \\
\hline CHEMBL1576645 & 737277 & 4.0297 & 4.8944 & TST & & \\
\hline CHEMBL1532635 & 737277 & 4.863 & 4.8679 & TST & & \\
\hline CHEMBL1422664 & 737277 & 5.4324 & 4.7363 & TST & & \\
\hline CHEMBL1594238 & 737277 & 5.0442 & 4.6542 & TST & & \\
\hline CHEMBL1710673 & 737277 & 4.7457 & 4.3266 & TST & & \\
\hline CHEMBL1499903 & 737277 & 4.8419 & 4.8233 & TST & & \\
\hline CHEMBL3732283 & 1537606 & 8.1319 & 8.1913 & TRN & & \\
\hline CHEMBL 3727672 & 1537606 & 8.4425 & 8.1522 & TRN & & \\
\hline CHEMBL3730914 & 1537606 & 7.0404 & 7.7359 & TST & & \\
\hline CHEMBL3729256 & 1537606 & 8.1403 & 6.8705 & TST & & \\
\hline CHEMBL3731960 & 1537606 & 5.7794 & 6.4777 & TST & & \\
\hline CHEMBL3732151 & 1537606 & 8.7959 & 8.607000 & 0000000001 & & TRN \\
\hline CHEMBL3733315 & 1537606 & 8.6073 & 8.464 & TRN & & \\
\hline CHEMBL 3730090 & 1537606 & 7.803 & 7.7926 & TRN & & \\
\hline CHEMBL3733017 & 1537606 & 6.2935 & 7.0062 & TST & & \\
\hline CHEMBL 3732840 & 1537606 & 8.3288 & 8.3068 & TRN & & \\
\hline CHEMBL3727709 & 1537606 & 6.1054 & 6.3364 & TRN & & \\
\hline
\end{tabular}


Supplemental Table S2.txt

\begin{tabular}{|c|c|c|c|c|c|}
\hline CHEMBL3732951 & 1537606 & 7.4047 & 7.2887 & TRN & \\
\hline CHEMBL 3730357 & 1537606 & 6.1541 & 6.4915 & TRN & \\
\hline CHEMBL 3733313 & 1537606 & 6.6914 & 7.4184 & TST & \\
\hline CHEMBL 3727768 & 1537606 & 8.1385 & 8.3026 & TRN & \\
\hline CHEMBL 3732433 & 1537606 & 6.2213 & 6.0737 & TRN & \\
\hline CHEMBL 3727495 & 1537606 & 7.8901 & 6.8738 & TST & \\
\hline CHEMBL3729523 & 1537606 & 7.4166 & 8.336 & TRN & \\
\hline CHEMBL 3729948 & 1537606 & 6.2193 & \multicolumn{2}{|c|}{6.292000000000001} & TRN \\
\hline CHEMBL3729530 & 1537606 & 8.719 & 8.6212 & TRN & \\
\hline CHEMBL 3728637 & 1537606 & 6.0 & 5.609 & TST & \\
\hline CHEMBL 3728013 & 1537606 & 8.7799 & 8.5166 & TRN & \\
\hline CHEMBL3729406 & 1537606 & 6.8548 & 7.1298 & TRN & \\
\hline CHEMBL 3729464 & 1537606 & 6.5442 & 6.2878 & TRN & \\
\hline CHEMBL 3732817 & 1537606 & 7.6381 & 7.8158 & TRN & \\
\hline CHEMBL3730607 & 1537606 & 7.1451 & \multicolumn{2}{|c|}{8.107000000000001} & TRN \\
\hline CHEMBL 3727779 & 1537606 & 6.6494 & 6.7375 & TRN & \\
\hline CHEMBL3732152 & 1537606 & 6.2481 & 6.5766 & TST & \\
\hline CHEMBL 3730074 & 1537606 & 7.4106 & 7.4798 & TRN & \\
\hline CHEMBL 3728779 & 1537606 & 7.7122 & 7.0687 & TRN & \\
\hline CHEMBL 3729878 & 1537606 & 6.3339 & 5.9147 & TST & \\
\hline CHEMBL 3732619 & 1537606 & 7.0947 & 6.6897 & TRN & \\
\hline CHEMBL3731014 & 1537606 & 6.7778 & \multicolumn{2}{|c|}{6.5920000000000005} & TRN \\
\hline CHEMBL 3727432 & 1537606 & 8.1013 & 8.4809 & TRN & \\
\hline CHEMBL 3731858 & 1537606 & 6.1127 & 7.2523 & TST & \\
\hline CHEMBL 3727707 & 1537606 & 7.0396 & 7.2684 & TST & \\
\hline CHEMBL 3732314 & 1537606 & 7.0915 & 7.1494 & TRN & \\
\hline CHEMBL 3729647 & 1537606 & 7.3048 & 7.2119 & TRN & \\
\hline CHEMBL 3728053 & 1537606 & 6.209 & 7.937 & TST & \\
\hline CHEMBL 3732971 & 1537606 & 5.8911 & 6.4495 & TRN & \\
\hline CHEMBL 3733272 & 1537606 & 8.3179 & 8.4149 & TRN & \\
\hline CHEMBL 3730564 & 1537606 & 5.3265 & 6.5681 & TST & \\
\hline CHEMBL 3730935 & 1537606 & 7.7064 & 7.2267 & TRN & \\
\hline CHEMBL 3732887 & 1537606 & 7.942 & 7.7801 & TRN & \\
\hline CHEMBL 3728462 & 1537606 & 8.9136 & 8.3558 & TRN & \\
\hline CHEMBL3731476 & 1537606 & 8.7825 & 9.0213 & TRN & \\
\hline CHEMBL3732089 & 1537606 & 9.4949 & 8.5793 & TRN & \\
\hline CHEMBL 3730974 & 1537606 & 7.6645 & 7.2671 & TST & \\
\hline CHEMBL3729018 & 1537606 & 9.1427 & 8.538 & TRN & \\
\hline CHEMBL 3727816 & 1537606 & 8.1215 & 8.1417 & TRN & \\
\hline CHEMBL 3730079 & 1537606 & 6.8386 & 7.2449 & TRN & \\
\hline CHEMBL 3729637 & 1537606 & 6.4685 & 6.5706 & TRN & \\
\hline CHEMBL 3729379 & 1537606 & 6.8259 & 6.0963 & TRN & \\
\hline CHEMBL 3728147 & 1537606 & 6.8265 & 7.5047 & TRN & \\
\hline CHEMBL 3728113 & 1537606 & 7.1767 & 6.6555 & TRN & \\
\hline CHEMBL 3730076 & 1537606 & 6.2953 & 5.9993 & TRN & \\
\hline CHEMBL 3731529 & 1537606 & 5.9776 & 7.5874 & TST & \\
\hline CHEMBL 3730712 & 1537606 & 8.3288 & 8.4007 & TRN & \\
\hline CHEMBL 3728803 & 1537606 & 6.9119 & 7.0176 & TRN & \\
\hline
\end{tabular}

Page 10476 
Supplemental Table S2.txt

\begin{tabular}{|c|c|c|c|c|c|c|}
\hline CHEMBL3727627 & 1537606 & \multicolumn{3}{|c|}{6.0360000000000005} & \multirow[t]{19}{*}{7.2059} & \multirow[t]{3}{*}{ TST } \\
\hline CHEMBL3729033 & 1537606 & 7.2548 & 6.7857 & TRN & & \\
\hline CHEMBL3732471 & 1537606 & 6.4987 & 6.7097 & TRN & & \\
\hline CHEMBL3728936 & 1537606 & 5.6586 & 7.8229 & TST & & \\
\hline CHEMBL3727710 & 1537606 & 6.2072 & 6.1055 & TRN & & \\
\hline CHEMBL 3728202 & 1537606 & 6.2404 & 6.3483 & TRN & & \\
\hline CHEMBL3732858 & 1537606 & 7.1063 & 6.8707 & TRN & & \\
\hline CHEMBL3728620 & 1537606 & 8.6162 & 8.7733 & TRN & & \\
\hline CHEMBL3731269 & 1537606 & 8.2306 & 7.8861 & TST & & \\
\hline CHEMBL3731010 & 1537606 & 6.7194 & 6.7491 & TRN & & \\
\hline CHEMBL3731508 & 1537606 & 8.6757 & 8.5463 & TRN & & \\
\hline CHEMBL3733169 & 1537606 & 6.2313 & 6.2017 & TRN & & \\
\hline CHEMBL3727781 & 1537606 & 8.6162 & 8.6507 & TRN & & \\
\hline CHEMBL3730715 & 1537606 & 8.2993 & 7.5785 & TRN & & \\
\hline CHEMBL3729532 & 1537606 & 7.3115 & 7.104 & TST & & \\
\hline CHEMBL3729338 & 1537606 & 8.3686 & 7.9825 & TRN & & \\
\hline CHEMBL3732411 & 1537606 & 8.6517 & 8.2085 & TRN & & \\
\hline CHEMBL3731210 & 1537606 & 6.9884 & 6.6017 & TRN & & \\
\hline CHEMBL3731928 & 1537606 & 8.1244 & 7.7937 & TRN & & \\
\hline CHEMBL3731504 & 1537606 & \multicolumn{3}{|c|}{7.3839999999999995} & 6.9794 & TRN \\
\hline CHEMBL3731424 & 1537606 & 6.4916 & 7.0113 & TRN & & \\
\hline CHEMBL3730704 & 1537606 & 6.7844 & 8.2031 & TRN & & \\
\hline CHEMBL3727956 & 1537606 & 8.5186 & 8.4909 & TRN & & \\
\hline CHEMBL3727735 & 1537606 & 6.3467 & 6.4743 & TRN & & \\
\hline CHEMBL3731621 & 1537606 & 7.1253 & 6.9676 & TRN & & \\
\hline CHEMBL3728966 & 1537606 & 6.8684 & 6.57 & TRN & & \\
\hline CHEMBL 3732482 & 1537606 & 7.6521 & 7.5578 & TRN & & \\
\hline CHEMBL3731134 & 1537606 & 7.2966 & 7.7395 & TRN & & \\
\hline CHEMBL3731932 & 1537606 & 8.0867 & 7.2648 & TST & & \\
\hline CHEMBL3729621 & 1537606 & 7.3979 & 7.4127 & TRN & & \\
\hline CHEMBL3731190 & 1537606 & 8.0013 & 8.3419 & TRN & & \\
\hline CHEMBL3729842 & 1537606 & 7.3458 & 6.9947 & TST & & \\
\hline CHEMBL3729581 & 1537606 & 8.1057 & 8.3436 & TRN & & \\
\hline CHEMBL3728283 & 1537606 & 7.6607 & 7.6415 & TRN & & \\
\hline CHEMBL3730813 & 1537606 & 7.4222 & 7.31 & TST & & \\
\hline CHEMBL3729809 & 1537606 & 6.0 & 5.2833 & TST & & \\
\hline CHEMBL3731454 & 1537606 & 6.3361 & 6.6525 & TRN & & \\
\hline CHEMBL3732354 & 1537606 & 6.4065 & 6.3219 & TRN & & \\
\hline CHEMBL3730595 & 1537606 & 6.0 & 4.8742 & TST & & \\
\hline CHEMBL3731020 & 1537606 & 8.1232 & 7.9347 & TRN & & \\
\hline CHEMBL3728491 & 1537606 & 7.5464 & 7.544 & TRN & & \\
\hline CHEMBL3730692 & 1537606 & 5.7051 & 6.4529 & TST & & \\
\hline CHEMBL3733129 & 1537606 & 7.141 & 7.7206 & TRN & & \\
\hline CHEMBL3732661 & 1537606 & 6.4618 & 6.7416 & TRN & & \\
\hline CHEMBL3732925 & 1537606 & 7.3178 & 6.8117 & TRN & & \\
\hline CHEMBL3729955 & 1537606 & 6.6373 & 6.5237 & TRN & & \\
\hline CHEMBL3728473 & 1537606 & 7.5127 & 7.289 & TST & & \\
\hline CHEMBL3732386 & 1537606 & 8.1163 & 7.6746 & TRN & & \\
\hline
\end{tabular}


Supplemental Table S2.txt

\begin{tabular}{|c|c|c|c|c|c|}
\hline CHEMBL3727531 & 1537606 & 9.1367 & 8.8367 & TRN & \\
\hline CHEMBL3730606 & 1537606 & 5.4684 & 5.811 & TRN & \\
\hline CHEMBL3732750 & 1537606 & 6.9535 & 7.3014 & TRN & \\
\hline CHEMBL3728293 & 1537606 & 6.2285 & 6.4519 & TRN & \\
\hline CHEMBL3732594 & 1537606 & 5.7445 & 6.5816 & TRN & \\
\hline CHEMBL3730124 & 1537606 & 6.9948 & 6.7815 & TRN & \\
\hline CHEMBL3730060 & 1537606 & 8.0778 & 8.0219 & TRN & \\
\hline CHEMBL3731702 & 1537606 & 7.2937 & 7.8432 & TRN & \\
\hline CHEMBL3728158 & 1537606 & 8.2865 & 8.2866 & TRN & \\
\hline CHEMBL3732785 & 1537606 & 8.0545 & 8.5948 & TRN & \\
\hline CHEMBL3728167 & 1537606 & 6.8579 & 7.0294 & TST & \\
\hline CHEMBL3730812 & 1537606 & 6.8422 & 7.0013 & TRN & \\
\hline CHEMBL3728990 & 1537606 & 7.5546 & 7.586 & TRN & \\
\hline CHEMBL3728622 & 1537606 & 7.3713 & 6.655 & TST & \\
\hline CHEMBL3731032 & 1537606 & 7.6444 & 7.633999 & 99999999995 & TRN \\
\hline CHEMBL3727463 & 1537606 & 7.1618 & 6.9567 & TRN & \\
\hline CHEMBL3728918 & 1537606 & 5.6308 & 6.1462 & TST & \\
\hline CHEMBL 3729837 & 1537606 & 5.9404 & 6.3568 & TST & \\
\hline CHEMBL3732993 & 1537606 & 5.8716 & 6.3775 & TRN & \\
\hline CHEMBL3729596 & 1537606 & 7.7126 & 7.2853 & TST & \\
\hline CHEMBL3728507 & 1537606 & 7.8545 & 7.7357 & TRN & \\
\hline CHEMBL 3730244 & 1537606 & 8.9508 & 8.0941 & TRN & \\
\hline CHEMBL3732137 & 1537606 & 7.4032 & 7.4498 & TRN & \\
\hline CHEMBL3729892 & 1537606 & 6.6641 & 7.5142 & TRN & \\
\hline CHEMBL 3727848 & 1537606 & 6.9473 & 7.6627 & TRN & \\
\hline CHEMBL3732637 & 1537606 & 8.4535 & 8.2813 & TRN & \\
\hline CHEMBL3733083 & 1537606 & 6.57299 & 999999999 & 6.3891 & TRN \\
\hline CHEMBL3728873 & 1537606 & 6.3405 & 6.8357 & TRN & \\
\hline CHEMBL3727807 & 1537606 & 8.0159 & 7.3627 & TST & \\
\hline CHEMBL 3730470 & 1537606 & 8.4737 & 8.1911 & TRN & \\
\hline CHEMBL3731063 & 1537606 & 9.0605 & 7.4502 & TST & \\
\hline CHEMBL3732629 & 1537606 & 5.5677 & 6.7532 & TST & \\
\hline CHEMBL3728281 & 1537606 & 7.1398 & 7.5995 & TRN & \\
\hline CHEMBL3729823 & 1537606 & 8.5258 & 8.2468 & TRN & \\
\hline CHEMBL3731644 & 1537606 & 8.9547 & 8.7783 & TRN & \\
\hline CHEMBL3728319 & 1537606 & 5.9161 & 5.8191 & TRN & \\
\hline CHEMBL3729938 & 1537606 & 6.6718 & 6.9023 & TRN & \\
\hline CHEMBL3729347 & 1537606 & 6.0964 & 6.0746 & TRN & \\
\hline CHEMBL3730719 & 1537606 & 8.6459 & 8.8052 & TRN & \\
\hline CHEMBL3728199 & 1537606 & 8.308 & 8.7642 & TRN & \\
\hline CHEMBL3728680 & 1537606 & 8.3468 & 8.6926 & TRN & \\
\hline CHEMBL 3730848 & 1537606 & 7.7667 & 7.782999 & 99999999995 & TRN \\
\hline CHEMBL3729385 & 1537606 & 6.9179 & 6.8291 & TRN & \\
\hline CHEMBL3732987 & 1537606 & 8.4789 & 7.9305 & TRN & \\
\hline CHEMBL3728503 & 1537606 & 6.9462 & 6.7397 & TRN & \\
\hline CHEMBL3732954 & 1537606 & 6.2912 & 6.3758 & TST & \\
\hline CHEMBL 3728788 & 1537606 & 7.9566 & 8.6756 & TRN & \\
\hline CHEMBL3729067 & 1537606 & 5.7503 & 6.829 & TST & \\
\hline
\end{tabular}


Supplemental Table S2.txt

\begin{tabular}{|c|c|c|c|c|c|}
\hline CHEMBL3732783 & 1537606 & 6.1843 & 6.4913 & TRN & \\
\hline CHEMBL3731161 & 1537606 & 7.6842 & 7.6359 & TRN & \\
\hline CHEMBL3732777 & 1537606 & 7.8874 & 7.5513 & TRN & \\
\hline CHEMBL3729245 & 1537606 & 7.1803 & 6.9212 & TRN & \\
\hline CHEMBL3727533 & 1537606 & 6.5375 & 7.0026 & TRN & \\
\hline CHEMBL3728010 & 1537606 & 7.7314 & 7.2428 & TST & \\
\hline CHEMBL3729525 & 1537606 & 8.3439 & 8.5266 & TRN & \\
\hline CHEMBL3731404 & 1537606 & 6.3351 & 7.2782 & TST & \\
\hline CHEMBL3731667 & 1537606 & 8.5045 & 8.2753 & TRN & \\
\hline CHEMBL3730129 & 1537606 & 6.9423 & 7.1599 & TRN & \\
\hline CHEMBL3729520 & 1537606 & 5.4305 & 6.6571 & TRN & \\
\hline CHEMBL3731060 & 1537606 & 7.1037 & 7.1844 & TRN & \\
\hline CHEMBL3729859 & 1537606 & 7.857 & 7.6347 & TST & \\
\hline CHEMBL 3732678 & 1537606 & 8.2757 & 8.1625 & TRN & \\
\hline CHEMBL3732656 & 1537606 & 6.2431 & 6.1615 & TRN & \\
\hline CHEMBL3732593 & 1537606 & 8.4855 & 8.2466 & TRN & \\
\hline CHEMBL3732786 & 1537606 & 8.7167 & 8.7212 & TRN & \\
\hline CHEMBL3730242 & 1537606 & 7.2992 & 7.5603 & TRN & \\
\hline CHEMBL3728406 & 1537606 & 6.0045 & \multicolumn{2}{|c|}{6.962000000000001} & TST \\
\hline CHEMBL3727965 & 1537606 & 8.5952 & 8.7768 & TRN & \\
\hline CHEMBL3732187 & 1537606 & 6.7091 & 6.8097 & TRN & \\
\hline CHEMBL3732986 & 1537606 & 5.8636 & 5.8806 & TRN & \\
\hline CHEMBL3730711 & 1537606 & 7.556 & 7.1713 & TRN & \\
\hline CHEMBL3729475 & 1537606 & 7.9718 & 7.5411 & TRN & \\
\hline CHEMBL3732288 & 1537606 & 6.4697 & 6.6821 & TRN & \\
\hline CHEMBL3733243 & 1537606 & 6.0406 & 6.2432 & TRN & \\
\hline CHEMBL3728130 & 1537606 & 6.697 & 6.3868 & TST & \\
\hline CHEMBL3728638 & 1537606 & 8.5622 & 8.2289 & TRN & \\
\hline CHEMBL 3727478 & 1537606 & 6.5594 & 6.3116 & TST & \\
\hline CHEMBL3731836 & 1537606 & 8.6383 & 8.5751 & TRN & \\
\hline CHEMBL3728466 & 1537606 & 6.7989 & 6.3356 & TRN & \\
\hline CHEMBL3729386 & 1537606 & 8.2604 & 8.4186 & TRN & \\
\hline CHEMBL3728211 & 1537606 & 6.3775 & 7.3315 & TST & \\
\hline CHEMBL3728411 & 1537606 & 5.4582 & 6.4234 & TST & \\
\hline CHEMBL3729358 & 1537606 & 5.9516 & 6.1565 & TST & \\
\hline CHEMBL3730440 & 1537606 & 6.2038 & 6.2221 & TST & \\
\hline CHEMBL3732202 & 1537606 & 7.6688 & \multicolumn{2}{|c|}{7.8870000000000005} & TRN \\
\hline CHEMBL3731547 & 1537606 & 8.4225 & 8.3333 & TRN & \\
\hline CHEMBL3733319 & 1537606 & 8.9066 & 8.0919 & TRN & \\
\hline CHEMBL3732794 & 1537606 & 7.4181 & 7.0257 & TST & \\
\hline CHEMBL3728869 & 1537606 & 7.8199 & 8.0676 & TRN & \\
\hline CHEMBL 3727624 & 1537606 & 6.4051 & 6.2139 & TRN & \\
\hline CHEMBL3727676 & 1537606 & 8.2993 & 7.8746 & TRN & \\
\hline CHEMBL3729522 & 1537606 & 5.8336 & 5.4579 & TRN & \\
\hline CHEMBL3729770 & 1537606 & 6.767 & 7.1062 & TRN & \\
\hline CHEMBL3728215 & 1537606 & 8.5575 & 8.8572 & TRN & \\
\hline CHEMBL3728180 & 1537606 & 6.1735 & 6.2014 & TRN & \\
\hline CHEMBL3733324 & 1537606 & 8.9136 & 8.6491 & TRN & \\
\hline
\end{tabular}


Supplemental Table S2.txt

\begin{tabular}{|c|c|c|c|c|c|}
\hline CHEMBL3727486 & 1537606 & 6.7457 & 7.0358 & TRN & \\
\hline CHEMBL 3731380 & 1537606 & 8.4647 & \multicolumn{2}{|c|}{7.952999999999999} & TRN \\
\hline CHEMBL3729432 & 1537606 & 7.0973 & 7.0179 & TRN & \\
\hline CHEMBL 3731050 & 1537606 & 9.1192 & 8.1494 & TRN & \\
\hline CHEMBL3730494 & 1537606 & 8.6696 & 8.1608 & TRN & \\
\hline CHEMBL 3731548 & 1537606 & 6.2397 & 6.3492 & TRN & \\
\hline CHEMBL 3728326 & 1537606 & 9.0655 & 8.6256 & TRN & \\
\hline CHEMBL 3731794 & 1537606 & 7.3872 & 7.3235 & TRN & \\
\hline CHEMBL 3731160 & 1537606 & 8.6126 & 8.3783 & TRN & \\
\hline CHEMBL3732020 & 1537606 & 6.5322 & 5.9408 & TRN & \\
\hline CHEMBL 3731355 & 1537606 & 6.266 & 6.7249 & TRN & \\
\hline CHEMBL 3728800 & 1537606 & 6.6855 & 6.978 & TRN & \\
\hline CHEMBL3732805 & 1537606 & 8.5817 & \multicolumn{2}{|c|}{8.267000000000001} & TRN \\
\hline CHEMBL 3730850 & 1537606 & 6.8948 & 7.0469 & TRN & \\
\hline CHEMBL3731766 & 1537606 & 8.7747 & 8.6229 & TRN & \\
\hline CHEMBL 3732492 & 1537606 & 7.3199 & 7.1697 & TRN & \\
\hline CHEMBL3727806 & 1537606 & 5.7817 & 6.3058 & TRN & \\
\hline CHEMBL3732521 & 1537606 & 6.856 & 6.3988 & TRN & \\
\hline CHEMBL 3731720 & 1537606 & 7.5812 & 7.9336 & TRN & \\
\hline CHEMBL3729599 & 1537606 & 8.4522 & 8.4504 & TRN & \\
\hline CHEMBL 3728288 & 1537606 & 6.3544 & 6.3289 & TRN & \\
\hline CHEMBL3727464 & 1537606 & 8.0516 & 8.3257 & TRN & \\
\hline CHEMBL 3730035 & 1537606 & 8.7399 & 7.9778 & TRN & \\
\hline CHEMBL 3728702 & 1537606 & 5.6386 & 5.8682 & TRN & \\
\hline CHEMBL3731275 & 1537606 & 6.9363 & 7.2131 & TRN & \\
\hline CHEMBL3731983 & 1537606 & 8.3458 & 8.5971 & TRN & \\
\hline CHEMBL 3729775 & 1537606 & 5.7817 & 6.5466 & TRN & \\
\hline CHEMBL3728008 & 1537606 & 8.2076 & 8.2776 & TRN & \\
\hline CHEMBL 3730384 & 1537606 & 7.7109 & 7.6739 & TRN & \\
\hline CHEMBL3730526 & 1537606 & 8.1605 & 8.443 & TRN & \\
\hline CHEMBL 3730863 & 1537606 & 8.9136 & 8.4794 & TRN & \\
\hline CHEMBL3732453 & 1537606 & 6.9735 & 6.8257 & TST & \\
\hline CHEMBL3730866 & 1537606 & 7.3047 & 7.4818 & TRN & \\
\hline CHEMBL 3729435 & 1537606 & 8.644 & 8.0974 & TRN & \\
\hline CHEMBL3729499 & 1537606 & 8.1785 & 7.87 & TRN & \\
\hline CHEMBL3731802 & 1537606 & 5.5643 & 6.4904 & TST & \\
\hline CHEMBL3731383 & 1537606 & 8.7773 & 8.1658 & TRN & \\
\hline CHEMBL3729143 & 1537606 & 8.4056 & 8.2487 & TRN & \\
\hline CHEMBL3728096 & 1537606 & 7.279 & 7.5316 & TST & \\
\hline CHEMBL3729282 & 1537606 & 7.1676 & 7.2976 & TST & \\
\hline CHEMBL3732554 & 1537606 & 6.1016 & 7.5241 & TST & \\
\hline CHEMBL3731719 & 1537606 & 5.7981 & 5.7418 & TRN & \\
\hline CHEMBL3728882 & 1537606 & 7.9069 & 7.6489 & TRN & \\
\hline CHEMBL3728380 & 1537606 & 5.9974 & 6.1608 & TRN & \\
\hline CHEMBL3729919 & 1537606 & 8.6716 & 8.8353 & TRN & \\
\hline CHEMBL3728697 & 1537606 & 8.4622 & 8.8748 & TRN & \\
\hline CHEMBL3731108 & 1537606 & 8.2967 & 8.4729 & TRN & \\
\hline CHEMBL3728088 & 1537606 & 5.9923 & 5.8424 & TRN & \\
\hline
\end{tabular}


Supplemental Table S2.txt

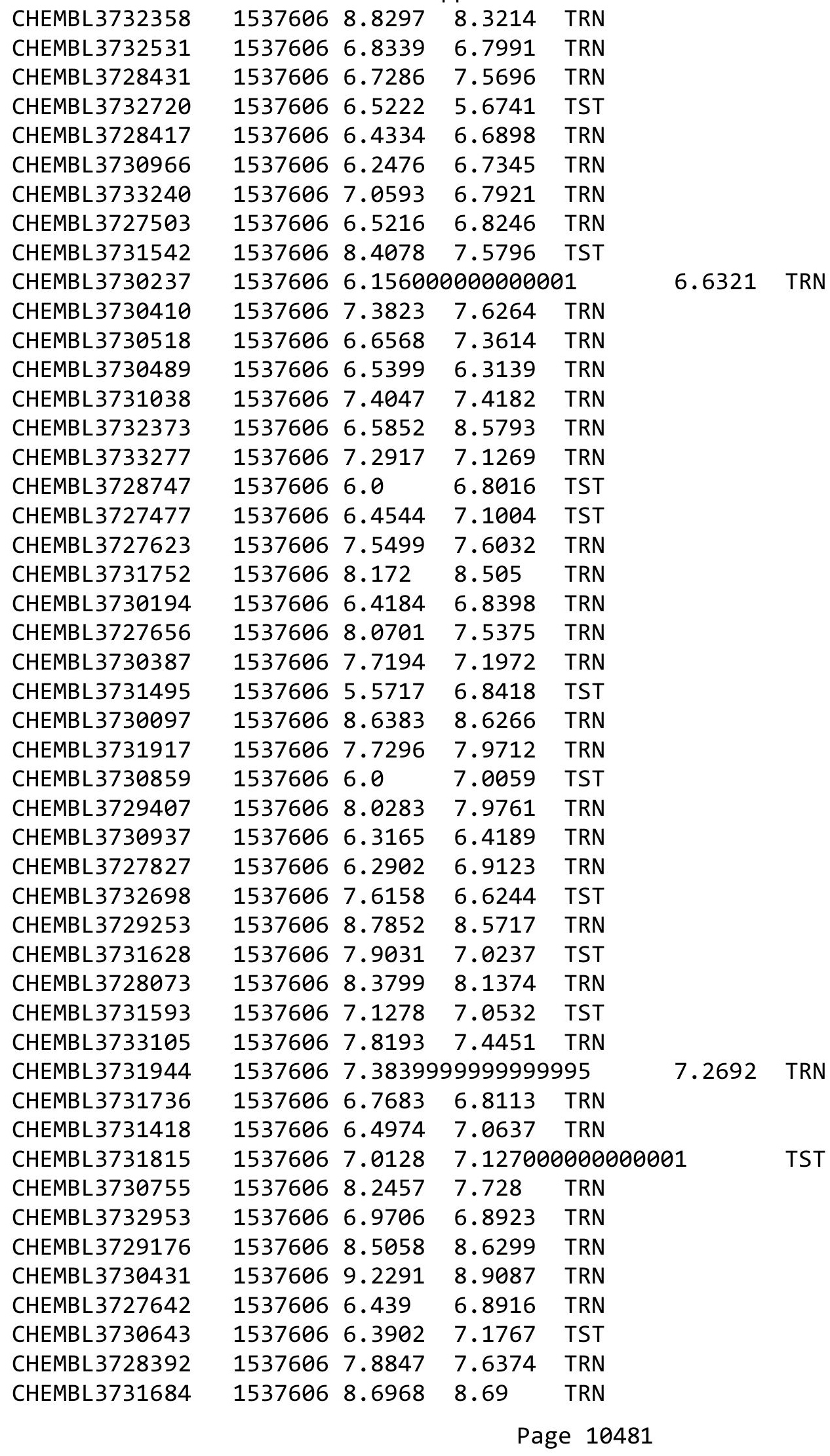


Supplemental Table S2.txt

\begin{tabular}{|c|c|c|c|c|c|c|}
\hline CHEMBL3730192 & 1537606 & 7.3105 & 7.1646 & TRN & & \\
\hline CHEMBL3728059 & 1537606 & 7.5364 & \multicolumn{2}{|c|}{7.031000000000001} & & TST \\
\hline CHEMBL3729657 & 1537606 & 6.4425 & \multicolumn{3}{|c|}{6.622000000000001} & TRN \\
\hline CHEMBL3732079 & 1537606 & 7.8674 & 6.8991 & TST & & \\
\hline CHEMBL3732276 & 1537606 & 8.3279 & 8.6016 & TRN & & \\
\hline CHEMBL3727889 & 1537606 & 6.7284 & 6.3597 & TRN & & \\
\hline CHEMBL3729701 & 1537606 & 5.581 & 5.5916 & TRN & & \\
\hline CHEMBL3733348 & 1537606 & 6.4931 & 6.9607 & TRN & & \\
\hline CHEMBL3731203 & 1537606 & 8.6861 & 8.3546 & TRN & & \\
\hline CHEMBL3730957 & 1537606 & 7.6101 & 7.4596 & TRN & & \\
\hline CHEMBL 3730469 & 1537606 & 8.6478 & 8.7643 & TRN & & \\
\hline CHEMBL3727802 & 1537606 & 6.1718 & 6.4403 & TRN & & \\
\hline CHEMBL 3732490 & 1537606 & 7.8216 & 8.0488 & TRN & & \\
\hline CHEMBL 3728563 & 1537606 & 7.8133 & 7.8466 & TRN & & \\
\hline CHEMBL3732170 & 1537606 & 7.0264 & 6.3214 & TST & & \\
\hline CHEMBL 3730846 & 1537606 & 7.1464 & 5.8292 & TST & & \\
\hline CHEMBL3732636 & 1537606 & 8.3925 & 8.0028 & TRN & & \\
\hline CHEMBL3730778 & 1537606 & 8.2596 & 7.3699 & TST & & \\
\hline CHEMBL3731961 & 1537606 & 6.5986 & 6.3385 & TST & & \\
\hline CHEMBL 3732032 & 1537606 & 7.9158 & 7.6065 & TST & & \\
\hline CHEMBL3733053 & 1537606 & 8.5513 & 6.8628 & TST & & \\
\hline CHEMBL3731871 & 1537606 & 6.6535 & 6.5879 & TRN & & \\
\hline CHEMBL3729992 & 1537606 & 8.0888 & 6.749 & TST & & \\
\hline CHEMBL3730069 & 1537606 & 8.4609 & 8.2556 & TRN & & \\
\hline CHEMBL3731102 & 1537606 & 8.8416 & 8.5136 & TRN & & \\
\hline CHEMBL3732525 & 1537606 & 7.6356 & 7.1448 & TST & & \\
\hline CHEMBL3731940 & 1537606 & 5.9594 & 5.9397 & TST & & \\
\hline CHEMBL3730688 & 1537606 & 8.8697 & 8.3777 & TRN & & \\
\hline CHEMBL3728653 & 1537606 & 8.4342 & 8.2665 & TRN & & \\
\hline CHEMBL3729754 & 1537606 & 6.8187 & 6.6454 & TRN & & \\
\hline CHEMBL3730275 & 1537606 & 7.8658 & 8.2637 & TRN & & \\
\hline CHEMBL3731085 & 1537606 & 8.3883 & 8.2077 & TRN & & \\
\hline CHEMBL3728728 & 1537606 & 7.4451 & 8.1337 & TRN & & \\
\hline CHEMBL3730270 & 1537606 & 8.752 & 8.53 & TRN & & \\
\hline CHEMBL3731888 & 1537606 & 7.9784 & 7.7658 & TRN & & \\
\hline CHEMBL3733175 & 1537606 & 8.3439 & 7.8029 & TST & & \\
\hline CHEMBL3732891 & 1537606 & 8.4461 & 8.3731 & TRN & & \\
\hline CHEMBL3728285 & 1537606 & \multicolumn{3}{|c|}{7.611000000000001} & 7.1774 & TRN \\
\hline CHEMBL3731049 & 1537606 & 5.9846 & \multicolumn{3}{|c|}{6.162999999999999} & TST \\
\hline CHEMBL 3732437 & 1537606 & 8.0348 & 8.3002 & TRN & & \\
\hline CHEMBL 3731434 & 1537606 & 8.3161 & 7.8421 & TRN & & \\
\hline CHEMBL3732006 & 1537606 & 7.9763 & \multicolumn{3}{|c|}{7.757000000000001} & TRN \\
\hline CHEMBL3733239 & 1537606 & 7.7768 & 7.7301 & TRN & & \\
\hline CHEMBL3728707 & 1537606 & 8.9626 & 8.5718 & TRN & & \\
\hline CHEMBL3732266 & 1537606 & 8.9508 & 8.3365 & TRN & & \\
\hline CHEMBL3731484 & 1537606 & 6.1668 & 6.0966 & TRN & & \\
\hline CHEMBL3729720 & 1537606 & 7.9834 & 7.1332 & TRN & & \\
\hline CHEMBL3728724 & 1537606 & 9.0044 & 8.4622 & TRN & & \\
\hline
\end{tabular}

Page 10482 
Supplemental Table S2.txt

\begin{tabular}{|c|c|c|c|c|c|c|}
\hline CHEMBL3729340 & 1537606 & 7.4951 & 7.9899 & TST & & \\
\hline CHEMBL3729641 & 1537606 & 8.8928 & 8.4875 & TRN & & \\
\hline CHEMBL3729588 & 1537606 & 6.2054 & 5.6622 & TRN & & \\
\hline CHEMBL3730239 & 1537606 & 7.6576 & 6.9676 & TST & & \\
\hline CHEMBL3732565 & 1537606 & 8.3585 & 7.3621 & TST & & \\
\hline CHEMBL3731148 & 1537606 & 6.9194 & 6.845 & TRN & & \\
\hline CHEMBL3731491 & 1537606 & 8.5017 & 7.547999 & 999999999 & TST & \\
\hline CHEMBL3728858 & 1537606 & 6.4913 & 6.3539 & TRN & & \\
\hline CHEMBL3730143 & 1537606 & 6.8592 & 7.3355 & TST & & \\
\hline CHEMBL3729962 & 1537606 & $8.3410 e$ & 000000000 & & 8.7533 TRN & \\
\hline CHEMBL3728886 & 1537606 & 6.7245 & 6.834 & TST & & \\
\hline CHEMBL3732884 & 1537606 & 7.5532 & 7.4888 & TRN & & \\
\hline CHEMBL3728067 & 1537606 & 7.1594 & 7.8167 & TRN & & \\
\hline CHEMBL3732797 & 1537606 & 8.1175 & 8.3758 & TRN & & \\
\hline CHEMBL3729726 & 1537606 & 7.7122 & 7.8322 & TRN & & \\
\hline CHEMBL3730121 & 1537606 & 7.3156 & 7.6977 & TRN & & \\
\hline CHEMBL3727598 & 1537606 & 7.9702 & 7.3904 & TRN & & \\
\hline CHEMBL3732445 & 1537606 & 6.5129 & 7.4273 & TST & & \\
\hline CHEMBL 3728244 & 1537606 & 6.3274 & 7.4007 & TRN & & \\
\hline CHEMBL3728256 & 1537606 & 7.152 & 6.5261 & TRN & & \\
\hline CHEMBL3733049 & 1537606 & 7.5412 & 7.4287 & TRN & & \\
\hline CHEMBL3727643 & 1537606 & 6.3985 & 7.0756 & TRN & & \\
\hline CHEMBL 3732045 & 1537606 & 8.1085 & 7.8745 & TRN & & \\
\hline CHEMBL3733155 & 1537606 & 6.6476 & 6.499 & TST & & \\
\hline CHEMBL3728367 & 1537606 & 8.064 & 6.8905 & TST & & \\
\hline CHEMBL3729564 & 1537606 & 6.1583 & 5.7597 & TRN & & \\
\hline CHEMBL3728343 & 1537606 & 7.6212 & 7.1435 & TRN & & \\
\hline CHEMBL3730981 & 1537606 & 7.2574 & 6.6625 & TST & & \\
\hline CHEMBL3731536 & 1537606 & 6.1577 & 7.2987 & TST & & \\
\hline CHEMBL3728153 & 1537606 & 8.0615 & 8.7733 & TRN & & \\
\hline CHEMBL3727854 & 1537606 & 7.3657 & 7.4249 & TRN & & \\
\hline CHEMBL3731626 & 1537606 & 8.1267 & 8.4026 & TRN & & \\
\hline CHEMBL3729088 & 1537606 & 8.5086 & 8.0029 & TRN & & \\
\hline CHEMBL 3732890 & 1537606 & 8.0362 & 8.3287 & TRN & & \\
\hline CHEMBL 3727674 & 1537606 & 7.5281 & 7.0744 & TST & & \\
\hline CHEMBL3732642 & 1537606 & 7.655 & 8.4539 & TST & & \\
\hline CHEMBL3728188 & 1537606 & 5.6167 & 7.5498 & TST & & \\
\hline CHEMBL3732304 & 1537606 & 6.6851 & 6.1072 & TST & & \\
\hline CHEMBL3730335 & 1537606 & \multicolumn{3}{|c|}{6.417000000000001} & 7.3839999999999995 & TST \\
\hline CHEMBL3731072 & 1537606 & 8.0615 & 8.12 & TST & & \\
\hline CHEMBL3732836 & 1537606 & 8.4584 & 7.0169 & TST & & \\
\hline CHEMBL3730373 & 1537606 & 6.3847 & 6.1962 & TST & & \\
\hline CHEMBL3728864 & 1537606 & 8.1618 & 7.3846 & TST & & \\
\hline CHEMBL3733298 & 1537606 & 6.0892 & 7.2572 & TST & & \\
\hline CHEMBL 3727514 & 1537606 & 8.3516 & 7.6882 & TST & & \\
\hline CHEMBL1256570 & 665349 & 3.4306 & 3.3405 & TRN & & \\
\hline CHEMBL1258013 & 665349 & 3.4306 & 4.1621 & TRN & & \\
\hline CHEMBL1256318 & 665349 & 5.0506 & 4.3389 & TRN & & \\
\hline
\end{tabular}




\begin{tabular}{|c|c|c|c|c|c|}
\hline \multicolumn{6}{|c|}{ Supplemental Table S2.txt } \\
\hline CHEMBL1257661 & 665349 & 3.4461 & 3.6106 & TRN & \\
\hline CHEMBL1257427 & 665349 & 3.3979 & 4.0452 & TST & \\
\hline CHEMBL529769 & 665349 & 5.2924 & 4.2171 & TST & \\
\hline CHEMBL1257542 & 665349 & 4.9508 & 3.803 & TRN & \\
\hline CHEMBL 1258248 & 665349 & 3.5436 & 3.87600 & 00000000003 & TST \\
\hline CHEMBL1255621 & 665349 & 3.4828 & 3.3658 & TRN & \\
\hline CHEMBL1256507 & 665349 & 3.4535 & 3.5425 & TRN & \\
\hline CHEMBL1258132 & 665349 & 3.4855 & 3.8595 & TRN & \\
\hline CHEMBL1258014 & 665349 & 3.5421 & 4.1621 & TRN & \\
\hline CHEMBL582429 & 665349 & 3.3768 & 4.045 & TRN & \\
\hline CHEMBL1257543 & 665349 & 3.6253 & 3.5156 & TRN & \\
\hline CHEMBL1256346 & 665349 & 3.4134 & 4.1102 & TRN & \\
\hline CHEMBL1256345 & 665349 & 3.4401 & 4.1303 & TRN & \\
\hline CHEMBL1256317 & 665349 & 3.4342 & 4.0622 & TRN & \\
\hline CHEMBL1255728 & 665349 & 5.0269 & 4.1494 & TRN & \\
\hline CHEMBL1258012 & 665349 & 3.5361 & 3.4715 & TRN & \\
\hline CHEMBL1256509 & 665349 & 3.4306 & 3.3572 & TRN & \\
\hline CHEMBL1256613 & 665349 & 3.4828 & 3.3084 & TRN & \\
\hline CHEMBL1256381 & 665349 & 3.4237 & 3.2796 & TRN & \\
\hline CHEMBL1256166 & 665349 & 3.383 & 4.0085 & TST & \\
\hline CHEMBL1257313 & 665349 & 4.0501 & 4.4407 & TRN & \\
\hline CHEMBL 1257902 & 665349 & 3.4522 & 3.4601 & TRN & \\
\hline CHEMBL1256445 & 665349 & 3.4535 & 3.5912 & TRN & \\
\hline CHEMBL1256247 & 665349 & 3.4283 & 3.7988 & TRN & \\
\hline CHEMBL1255731 & 665349 & 4.9136 & 3.8849 & TRN & \\
\hline CHEMBL1255775 & 665349 & 3.4473 & 3.9522 & TRN & \\
\hline CHEMBL1256167 & 665349 & 3.3716 & 3.5354 & TRN & \\
\hline CHEMBL1256569 & 665349 & 3.4306 & 3.3541 & TRN & \\
\hline CHEMBL1256108 & 665349 & 3.2774 & 3.6468 & TST & \\
\hline CHEMBL1256168 & 665349 & 3.3969 & 3.8201 & TRN & \\
\hline CHEMBL1256443 & 665349 & 3.4535 & 3.7202 & TRN & \\
\hline CHEMBL 1256347 & 665349 & 3.4237 & 3.5423 & TRN & \\
\hline CHEMBL1258133 & 665349 & 3.4962 & 3.5766 & TRN & \\
\hline CHEMBL1257312 & 665349 & 4.5528 & 4.3789 & TRN & \\
\hline CHEMBL1257429 & 665349 & 3.4425 & 3.9554 & TST & \\
\hline CHEMBL528486 & 665349 & 4.7077 & 4.1134 & TRN & \\
\hline CHEMBL1257903 & 665349 & 3.4763 & 3.3351 & TRN & \\
\hline CHEMBL1255776 & 665349 & 3.3497 & 3.7612 & TRN & \\
\hline CHEMBL1256109 & 665349 & 3.202 & 3.8519 & TST & \\
\hline CHEMBL1256246 & 665349 & 3.4401 & 3.8753 & TST & \\
\hline CHEMBL1258134 & 665349 & 4.8239 & 4.1412 & TRN & \\
\hline CHEMBL1256614 & 665349 & 3.4828 & 3.3697 & TRN & \\
\hline CHEMBL1256444 & 665349 & 3.4535 & 3.5906 & TRN & \\
\hline CHEMBL1256571 & 665349 & 3.4828 & 3.4595 & TRN & \\
\hline CHEMBL1256615 & 665349 & 3.4828 & 3.3377 & TRN & \\
\hline CHEMBL1258246 & 665349 & 4.7235 & 4.2183 & TRN & \\
\hline CHEMBL537807 & 665349 & 5.5528 & 4.383 & TRN & \\
\hline CHEMBL1257314 & 665349 & 4.3143 & 4.3795 & TRN & \\
\hline
\end{tabular}




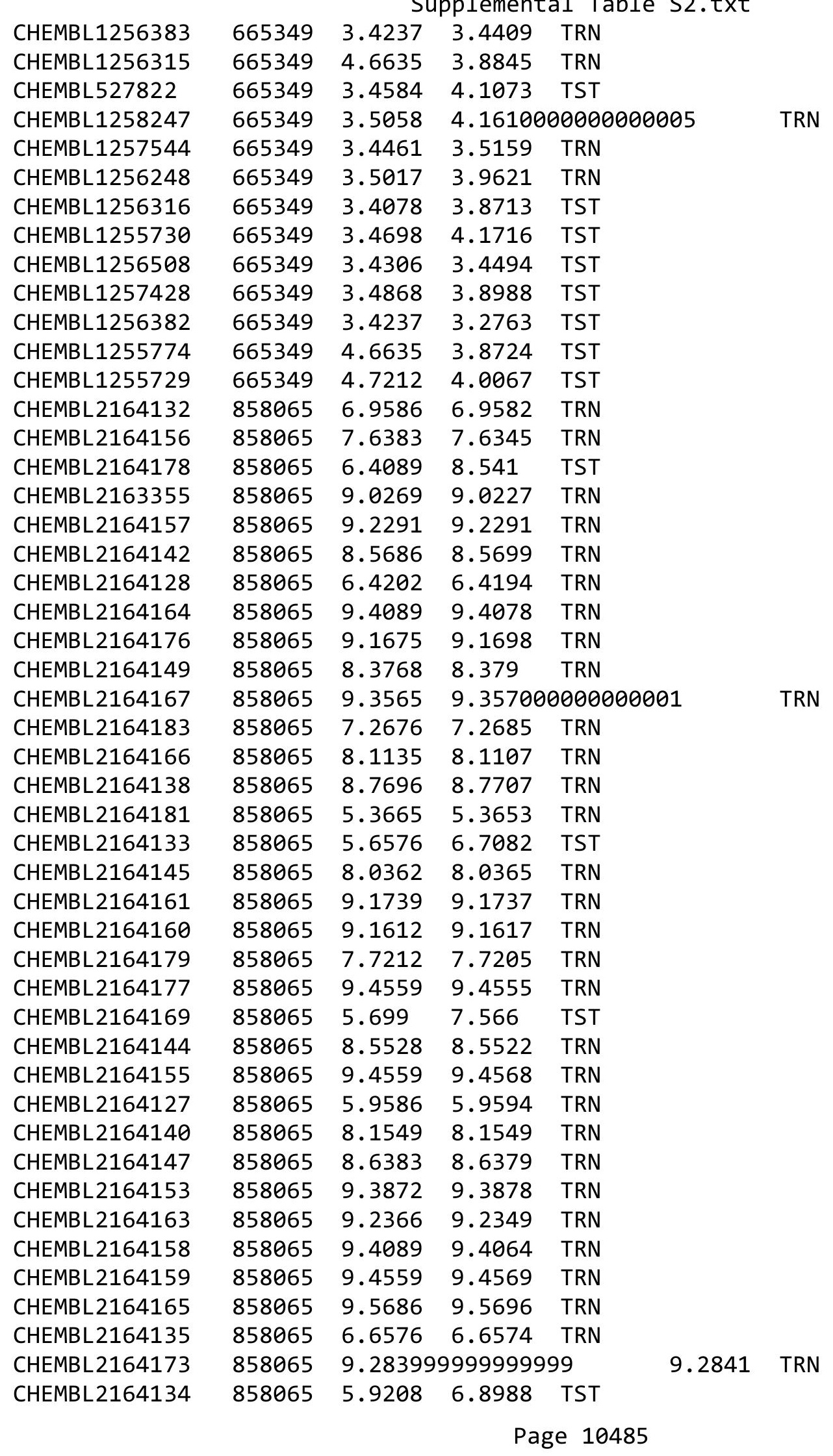




\begin{tabular}{|c|c|c|c|c|c|}
\hline \multicolumn{6}{|c|}{ Supplemental Table S2.txt } \\
\hline CHEMBL 2164143 & 858065 & 9.3468 & 9.3464 & TRN & \\
\hline CHEMBL 2164150 & 858065 & 8.0044 & 7.6799 & TST & \\
\hline CHEMBL 2164170 & 858065 & 8.2757 & 8.2759 & TRN & \\
\hline CHEMBL 2164154 & 858065 & 9.1024 & 9.104 & TRN & \\
\hline CHEMBL 2164151 & 858065 & 8.4559 & 7.795 & TST & \\
\hline CHEMBL 2164182 & 858065 & 7.3188 & 7.3175 & TRN & \\
\hline CHEMBL 2164174 & 858065 & 9.0 & 9.0016 & TRN & \\
\hline CHEMBL 2164175 & 858065 & 8.8539 & 8.8542 & TRN & \\
\hline CHEMBL 2164171 & 858065 & 8.3565 & 8.3587 & TRN & \\
\hline CHEMBL 2164152 & 858065 & 8.3098 & 8.2328 & TST & \\
\hline CHEMBL 2164162 & 858065 & 9.3665 & 9.3658 & TRN & \\
\hline CHEMBL 2164180 & 858065 & 5.7447 & 5.7471 & TRN & \\
\hline CHEMBL 2164129 & 858065 & 7.7212 & 7.7218 & TRN & \\
\hline CHEMBL 2164131 & 858065 & 7.2757 & 7.2772 & TRN & \\
\hline CHEMBL 2164168 & 858065 & 9.2076 & 9.1654 & TST & \\
\hline CHEMBL 2164137 & 858065 & 5.9586 & 7.4964 & TST & \\
\hline CHEMBL 2164148 & 858065 & 7.7696 & 8.8115 & TST & \\
\hline CHEMBL 2164141 & 858065 & 9.585 & 8.9913 & TST & \\
\hline CHEMBL 2164130 & 858065 & 6.7959 & 6.0476 & TST & \\
\hline CHEMBL 2164172 & 858065 & 8.585 & 8.333 & TST & \\
\hline CHEMBL 2164146 & 858065 & 9.5686 & 9.3061 & TST & \\
\hline CHEMBL 2164139 & 858065 & 9.8239 & 9.7342 & TST & \\
\hline CHEMBL1760082 & 741329 & 5.4976 & 5.8213 & TRN & \\
\hline CHEMBL1760086 & 741329 & 4.0 & 5.7274 & TRN & \\
\hline CHEMBL1760233 & 741329 & 4.0 & 5.5557 & TRN & \\
\hline CHEMBL1760241 & 741329 & 4.0 & 4.7653 & TRN & \\
\hline CHEMBL1760003 & 741329 & 6.5086 & 6.4885 & TRN & \\
\hline CHEMBL1760075 & 741329 & 4.0 & 4.6116 & TRN & \\
\hline CHEMBL1760065 & 741329 & 5.9914 & 5.2601 & TRN & \\
\hline CHEMBL1760231 & 741329 & 5.5817 & 6.4668 & TRN & \\
\hline CHEMBL1760068 & 741329 & 7.0 & 4.92899 & 9999999999 & TRN \\
\hline CHEMBL1760060 & 741329 & 6.7959 & 5.1153 & TRN & \\
\hline CHEMBL1760080 & 741329 & 6.4437 & 5.8662 & TRN & \\
\hline CHEMBL1760077 & 741329 & 6.8539 & 5.961 & TRN & \\
\hline CHEMBL1760070 & 741329 & 6.3872 & 4.9147 & TRN & \\
\hline CHEMBL1760245 & 741329 & 7.8539 & 5.7942 & TST & \\
\hline CHEMBL1760232 & 741329 & 4.0 & 5.1457 & TRN & \\
\hline CHEMBL1760069 & 741329 & 4.0 & 4.6036 & TRN & \\
\hline CHEMBL1760079 & 741329 & 6.7696 & 6.0353 & TRN & \\
\hline CHEMBL1760243 & 741329 & 7.041 & 5.0825 & TST & \\
\hline CHEMBL1760221 & 741329 & 4.0 & 5.9106 & TST & \\
\hline CHEMBL1760081 & 741329 & 5.585 & 5.8226 & TRN & \\
\hline CHEMBL1760229 & 741329 & 6.4559 & 6.4433 & TRN & \\
\hline CHEMBL1760227 & 741329 & 6.0757 & 6.2511 & TRN & \\
\hline CHEMBL1760083 & 741329 & 5.4949 & 5.7879 & TRN & \\
\hline CHEMBL1760066 & 741329 & 4.0 & 4.4972 & TRN & \\
\hline CHEMBL1760067 & 741329 & 4.0 & 4.5886 & TRN & \\
\hline CHEMBL1760239 & 741329 & 5.6576 & 4.9959 & TRN & \\
\hline
\end{tabular}




\begin{tabular}{|c|c|c|c|c|c|}
\hline \multicolumn{6}{|c|}{ Supplemental Table S2.txt } \\
\hline CHEMBL1760247 & 741329 & 8.0458 & 5.6971 & TST & \\
\hline CHEMBL1760074 & 741329 & 4.0 & 4.2422 & TRN & \\
\hline CHEMBL1760237 & 741329 & 7.3872 & 5.9699 & TRN & \\
\hline CHEMBL1760061 & 741329 & 6.2757 & 5.3711 & TRN & \\
\hline CHEMBL1760078 & 741329 & 6.7696 & 5.9307 & TRN & \\
\hline CHEMBL1760063 & 741329 & 5.9469 & 5.1454 & TRN & \\
\hline CHEMBL1760072 & 741329 & 4.0 & 4.7142 & TRN & \\
\hline CHEMBL1760240 & 741329 & 4.0 & 5.0579 & TRN & \\
\hline CHEMBL1760236 & 741329 & 6.1938 & 5.1751 & TRN & \\
\hline CHEMBL1760246 & 741329 & 7.6198 & 5.7468 & TST & \\
\hline CHEMBL1760248 & 741329 & 7.6021 & 5.6978 & TST & \\
\hline CHEMBL1760244 & 741329 & 5.5058 & 4.9581 & TST & \\
\hline CHEMBL1760084 & 741329 & 5.3188 & 5.7883 & TRN & \\
\hline CHEMBL1760251 & 741329 & 7.5686 & 5.58799 & 9999999999 & TST \\
\hline CHEMBL1760238 & 741329 & 5.3372 & 6.011 & TRN & \\
\hline CHEMBL1760071 & 741329 & 5.4202 & 4.6377 & TRN & \\
\hline CHEMBL1760220 & 741329 & 4.0 & 5.7589 & TRN & \\
\hline CHEMBL1760228 & 741329 & 6.0269 & 6.393 & TRN & \\
\hline CHEMBL1760222 & 741329 & 5.8182 & 5.975 & TRN & \\
\hline CHEMBL1760224 & 741329 & 6.6021 & 5.9281 & TRN & \\
\hline CHEMBL1760223 & 741329 & 7.5086 & 5.9496 & TRN & \\
\hline CHEMBL1760226 & 741329 & 6.7696 & 6.3054 & TRN & \\
\hline CHEMBL1760225 & 741329 & 5.6882 & 6.3028 & TRN & \\
\hline CHEMBL1760073 & 741329 & 4.0 & 4.3052 & TRN & \\
\hline CHEMBL1760250 & 741329 & 7.9208 & 5.6219 & TST & \\
\hline CHEMBL1760242 & 741329 & 6.8239 & 5.0572 & TST & \\
\hline CHEMBL1760249 & 741329 & 7.3565 & 5.6559 & TST & \\
\hline CHEMBL1760230 & 741329 & 5.8182 & 6.4431 & TRN & \\
\hline CHEMBL1760235 & 741329 & 5.7959 & 5.21399 & 99999999995 & TST \\
\hline CHEMBL1760064 & 741329 & 4.0 & 4.921 & TRN & \\
\hline CHEMBL1760076 & 741329 & 4.0 & 4.3418 & TST & \\
\hline CHEMBL1760062 & 741329 & 6.1739 & 5.0704 & TST & \\
\hline CHEMBL1760085 & 741329 & 5.6383 & 5.8053 & TST & \\
\hline CHEMBL1731664 & 1479004 & 5.5 & 4.5696 & TRN & \\
\hline CHEMBL3431013 & 1479004 & 5.8 & 5.9983 & TRN & \\
\hline CHEMBL3431014 & 1479004 & 4.7 & 4.8022 & TRN & \\
\hline CHEMBL3431015 & 1479004 & 5.5 & 5.2229 & TRN & \\
\hline CHEMBL3431016 & 1479004 & 6.5 & 6.6893 & TRN & \\
\hline CHEMBL3431017 & 1479004 & 5.6 & 5.8574 & TRN & \\
\hline CHEMBL3431018 & 1479004 & 5.9 & 6.2193 & TRN & \\
\hline CHEMBL3431019 & 1479004 & 3.3 & 4.7894 & TRN & \\
\hline CHEMBL 3431020 & 1479004 & 6.4 & 6.4961 & TRN & \\
\hline CHEMBL3431021 & 1479004 & 5.1 & 5.0492 & TRN & \\
\hline CHEMBL3431022 & 1479004 & 6.3 & 6.024 & TRN & \\
\hline CHEMBL3431023 & 1479004 & 6.5 & 6.3595 & TST & \\
\hline CHEMBL3431024 & 1479004 & 6.8 & 6.6017 & TRN & \\
\hline CHEMBL3431025 & 1479004 & 7.7 & 7.5341 & TRN & \\
\hline CHEMBL3431026 & 1479004 & 5.5 & 5.5216 & TST & \\
\hline
\end{tabular}




\begin{tabular}{|c|c|c|c|c|}
\hline & & & 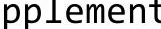 & \\
\hline CHEMBL3431027 & 1479004 & 5.2 & 5.0434 & TRN \\
\hline CHEMBL3431028 & 1479004 & 6.7 & 7.0151 & TRN \\
\hline CHEMBL3431029 & 1479004 & 6.9 & 7.1751 & TRN \\
\hline CHEMBL3431030 & 1479004 & 5.5 & 5.4321 & TRN \\
\hline CHEMBL3431031 & 1479004 & 5.4 & 5.7549 & TRN \\
\hline CHEMBL3431032 & 1479004 & 5.9 & 5.8473 & TRN \\
\hline CHEMBL1527364 & 1479004 & 4.8 & 4.3343 & TRN \\
\hline CHEMBL3430914 & 1479004 & 5.9 & 6.0114 & TRN \\
\hline CHEMBL3431033 & 1479004 & 7.4 & 6.8407 & TRN \\
\hline CHEMBL3431034 & 1479004 & 6.2 & 6.1532 & TRN \\
\hline CHEMBL3431035 & 1479004 & 5.9 & 5.606 & TRN \\
\hline CHEMBL3431036 & 1479004 & 6.2 & 6.1331 & TRN \\
\hline CHEMBL3431037 & 1479004 & 5.8 & 5.6976 & TRN \\
\hline CHEMBL3431038 & 1479004 & 6.3 & 5.8742 & TRN \\
\hline CHEMBL3431039 & 1479004 & 6.4 & 6.7759 & TRN \\
\hline CHEMBL3431040 & 1479004 & 5.7 & 5.8117 & TRN \\
\hline CHEMBL1354075 & 1479004 & 5.2 & 5.9672 & TRN \\
\hline CHEMBL3431041 & 1479004 & 5.2 & 4.0353 & TRN \\
\hline CHEMBL3431042 & 1479004 & 6.8 & 6.7785 & TRN \\
\hline CHEMBL3431043 & 1479004 & 4.9 & 5.1474 & TST \\
\hline CHEMBL3431044 & 1479004 & 6.8 & 6.4772 & TST \\
\hline CHEMBL3431045 & 1479004 & 4.7 & 4.77 & TRN \\
\hline CHEMBL3431046 & 1479004 & 4.6 & 4.7563 & TRN \\
\hline CHEMBL3431047 & 1479004 & 5.5 & 5.8849 & TRN \\
\hline CHEMBL3431048 & 1479004 & 5.6 & 5.9135 & TRN \\
\hline CHEMBL3431049 & 1479004 & 5.7 & 5.7866 & TRN \\
\hline CHEMBL3431050 & 1479004 & 5.6 & 5.8352 & TRN \\
\hline CHEMBL3431051 & 1479004 & 5.1 & 5.7928 & TRN \\
\hline CHEMBL3431052 & 1479004 & 5.9 & 5.5975 & TRN \\
\hline CHEMBL3431053 & 1479004 & 6.5 & 5.9712 & TRN \\
\hline CHEMBL2356808 & 1479004 & 5.9 & 5.9673 & TRN \\
\hline CHEMBL3431054 & 1479004 & 5.6 & 5.8053 & TRN \\
\hline CHEMBL3431055 & 1479004 & 7.0 & 6.7411 & TST \\
\hline CHEMBL3431056 & 1479004 & 7.1 & 7.1013 & TRN \\
\hline CHEMBL3431057 & 1479004 & 5.6 & 4.9132 & TST \\
\hline CHEMBL2093320 & 1479004 & 6.4 & 6.4621 & TRN \\
\hline CHEMBL3431058 & 1479004 & 3.3 & 2.9687 & TRN \\
\hline CHEMBL3431059 & 1479004 & 3.3 & 2.9646 & TRN \\
\hline CHEMBL3431060 & 1479004 & 3.3 & 2.9425 & TRN \\
\hline CHEMBL3431061 & 1479004 & 3.3 & 2.9086 & TRN \\
\hline CHEMBL3431062 & 1479004 & 3.3 & 2.8827 & TRN \\
\hline CHEMBL3431063 & 1479004 & 3.3 & 2.9784 & TRN \\
\hline CHEMBL3431064 & 1479004 & 6.0 & 5.8286 & TRN \\
\hline CHEMBL3431065 & 1479004 & 6.1 & 6.0706 & TST \\
\hline CHEMBL3431066 & 1479004 & 6.1 & 6.1044 & TRN \\
\hline CHEMBL3431067 & 1479004 & 4.9 & 5.0939 & TRN \\
\hline CHEMBL3431068 & 1479004 & 6.8 & 6.8223 & TRN \\
\hline CHEMBL3431069 & 1479004 & 5.8 & 5.7386 & TRN \\
\hline
\end{tabular}




\begin{tabular}{|c|c|c|c|c|c|}
\hline & & & & & \\
\hline CHEMBL3431070 & 1479004 & 7.3 & 6.9288 & TRN & \\
\hline CHEMBL3431071 & 1479004 & 5.3 & 5.4495 & TST & \\
\hline CHEMBL3431072 & 1479004 & 6.3 & 5.9107 & TRN & \\
\hline CHEMBL3431073 & 1479004 & 4.9 & 3.969 & TST & \\
\hline CHEMBL 3431074 & 1479004 & 5.9 & 4.8436 & TRN & \\
\hline CHEMBL3431075 & 1479004 & 3.3 & 4.1232 & TST & \\
\hline CHEMBL3431076 & 1479004 & 6.0 & 6.3833 & TRN & \\
\hline CHEMBL3431077 & 1479004 & 6.0 & 6.1643 & TRN & \\
\hline CHEMBL3431078 & 1479004 & 6.2 & 5.8473 & TRN & \\
\hline CHEMBL3431079 & 1479004 & 4.6 & 3.9506 & TRN & \\
\hline CHEMBL3431080 & 1479004 & 5.9 & 6.4244 & TRN & \\
\hline CHEMBL3431081 & 1479004 & 6.5 & 6.4387 & TRN & \\
\hline CHEMBL3431082 & 1479004 & 5.5 & 5.6175 & TRN & \\
\hline CHEMBL 3431083 & 1479004 & 5.4 & 5.16200 & $\partial 000000001$ & TRN \\
\hline CHEMBL 3431084 & 1479004 & 6.6 & 6.3291 & TST & \\
\hline CHEMBL1585368 & 1479004 & 5.0 & 4.371 & TRN & \\
\hline CHEMBL3431085 & 1479004 & 6.3 & 6.5943 & TRN & \\
\hline CHEMBL3431086 & 1479004 & 5.0 & 5.2609 & TRN & \\
\hline CHEMBL3431087 & 1479004 & 6.1 & 5.7775 & TRN & \\
\hline CHEMBL3431088 & 1479004 & 6.0 & 5.8664 & TRN & \\
\hline CHEMBL3431089 & 1479004 & 6.8 & 6.6444 & TRN & \\
\hline CHEMBL3431090 & 1479004 & 6.5 & 6.3623 & TRN & \\
\hline CHEMBL3431091 & 1479004 & 5.2 & 5.2921 & TRN & \\
\hline CHEMBL3431092 & 1479004 & 5.1 & 5.385 & TRN & \\
\hline CHEMBL3431093 & 1479004 & 5.2 & 5.5999 & TRN & \\
\hline CHEMBL3431094 & 1479004 & 6.1 & 6.0645 & TRN & \\
\hline CHEMBL3431095 & 1479004 & 5.9 & 5.8216 & TRN & \\
\hline CHEMBL3431096 & 1479004 & 3.3 & 3.8139 & TRN & \\
\hline CHEMBL3431097 & 1479004 & 5.9 & 5.8435 & TRN & \\
\hline CHEMBL3431098 & 1479004 & 6.0 & 5.7914 & TRN & \\
\hline CHEMBL3431099 & 1479004 & 4.4 & 4.1907 & TST & \\
\hline CHEMBL3431100 & 1479004 & 6.0 & 5.86799 & 9999999999 & TRN \\
\hline CHEMBL3431101 & 1479004 & 5.5 & 5.5608 & TST & \\
\hline CHEMBL3431102 & 1479004 & 5.1 & 5.1193 & TST & \\
\hline CHEMBL3431103 & 1479004 & 4.7 & 4.6583 & TST & \\
\hline CHEMBL3431104 & 1479004 & 6.4 & 6.7768 & TRN & \\
\hline CHEMBL3431105 & 1479004 & 6.5 & 6.0968 & TRN & \\
\hline CHEMBL3431106 & 1479004 & 6.9 & 6.3822 & TST & \\
\hline CHEMBL3431107 & 1479004 & 6.7 & 7.0415 & TRN & \\
\hline CHEMBL 3431108 & 1479004 & 6.0 & 6.2994 & TRN & \\
\hline CHEMBL3431109 & 1479004 & 5.6 & 5.5015 & TRN & \\
\hline CHEMBL3431110 & 1479004 & 5.4 & 5.4515 & TRN & \\
\hline CHEMBL3431111 & 1479004 & 5.9 & 5.9774 & TRN & \\
\hline CHEMBL3431112 & 1479004 & 4.8 & 5.0442 & TRN & \\
\hline CHEMBL3431113 & 1479004 & 5.8 & 5.4474 & TRN & \\
\hline CHEMBL 3431114 & 1479004 & 6.3 & 6.0179 & TRN & \\
\hline CHEMBL3431115 & 1479004 & 4.6 & 5.0376 & TST & \\
\hline CHEMBL3431116 & 1479004 & 6.3 & 5.9444 & TRN & \\
\hline & & & & 10489 & \\
\hline
\end{tabular}




\begin{tabular}{|c|c|c|c|c|c|}
\hline \multirow{3}{*}{ CHEMBL 3431117} & \multirow{2}{*}{1479004} & \\
\hline & & 8.0 & 7.7461 & \multicolumn{2}{|l|}{ TRN } \\
\hline & 1479004 & 6.6 & 6.0897 & \multicolumn{2}{|l|}{ TRN } \\
\hline CHEMBL3431119 & 1479004 & 6.7 & 6.2517 & \multicolumn{2}{|l|}{ TRN } \\
\hline CHEMBL3431120 & 1479004 & 6.4 & 6.5556 & \multicolumn{2}{|l|}{ TRN } \\
\hline CHEMBL3431121 & 1479004 & 6.1 & 6.0844 & \multicolumn{2}{|l|}{ TST } \\
\hline CHEMBL3431122 & 1479004 & 6.5 & 6.3959 & \multicolumn{2}{|l|}{ TRN } \\
\hline CHEMBL3431123 & 1479004 & 6.4 & 5.5527 & \multicolumn{2}{|l|}{ TRN } \\
\hline CHEMBL 3431124 & 1479004 & 6.0 & 5.9196 & \multicolumn{2}{|l|}{ TRN } \\
\hline CHEMBL3431125 & 1479004 & 6.5 & 6.2809 & \multicolumn{2}{|l|}{ TST } \\
\hline CHEMBL3431126 & 1479004 & 3.3 & 4.6135 & \multicolumn{2}{|l|}{ TRN } \\
\hline CHEMBL3431128 & 1479004 & 8.0 & 7.8021 & \multicolumn{2}{|l|}{ TST } \\
\hline CHEMBL3431129 & 1479004 & 9.0 & 8.1231 & \multicolumn{2}{|l|}{ TST } \\
\hline CHEMBL3431130 & 1479004 & 7.2 & 7.4039 & \multicolumn{2}{|l|}{ TST } \\
\hline CHEMBL 3431131 & 1479004 & 7.4 & 6.4631 & \multicolumn{2}{|l|}{ TRN } \\
\hline CHEMBL3430915 & 1479004 & 7.1 & 7.0083 & \multicolumn{2}{|l|}{ TRN } \\
\hline CHEMBL3431132 & 1479004 & 6.9 & 6.5987 & \multicolumn{2}{|l|}{ TRN } \\
\hline CHEMBL3431133 & 1479004 & 7.0 & 6.9067 & \multicolumn{2}{|l|}{ TRN } \\
\hline CHEMBL 3431134 & 1479004 & 5.1 & 5.3652 & \multicolumn{2}{|l|}{ TRN } \\
\hline CHEMBL3431135 & 1479004 & 6.3 & 6.65799 & 99999999995 & TRN \\
\hline CHEMBL3431136 & 1479004 & 5.4 & $5.5360 e$ & 00000000005 & TRN \\
\hline CHEMBL3431137 & 1479004 & 5.6 & 5.6948 & TRN & \\
\hline CHEMBL3431138 & 1479004 & 5.3 & 4.6493 & TST & \\
\hline CHEMBL3431139 & 1479004 & 6.7 & 6.7352 & TST & \\
\hline CHEMBL3431140 & 1479004 & 7.4 & 7.45299 & 9999999999 & TST \\
\hline CHEMBL3431141 & 1479004 & 6.5 & 5.9631 & TRN & \\
\hline CHEMBL3431142 & 1479004 & 5.2 & 5.5273 & TST & \\
\hline CHEMBL3431143 & 1479004 & 4.9 & 5.3384 & TRN & \\
\hline CHEMBL3431144 & 1479004 & 5.6 & 5.5406 & TRN & \\
\hline CHEMBL3431145 & 1479004 & 6.0 & 5.9098 & TRN & \\
\hline CHEMBL3431146 & 1479004 & 7.0 & 6.5088 & TRN & \\
\hline CHEMBL3431147 & 1479004 & 5.0 & 5.2413 & TST & \\
\hline CHEMBL3431148 & 1479004 & 6.3 & 6.4447 & TRN & \\
\hline CHEMBL3431149 & 1479004 & 5.2 & 5.2108 & TRN & \\
\hline CHEMBL3431150 & 1479004 & 6.9 & 6.6772 & TRN & \\
\hline CHEMBL3431151 & 1479004 & 7.1 & 7.0 & TRN & \\
\hline CHEMBL3431152 & 1479004 & 6.5 & 6.8113 & TRN & \\
\hline CHEMBL3431153 & 1479004 & 6.6 & 6.7194 & TRN & \\
\hline CHEMBL3431154 & 1479004 & 5.1 & 5.0894 & TST & \\
\hline CHEMBL3431155 & 1479004 & 7.4 & 7.4624 & TRN & \\
\hline CHEMBL3431156 & 1479004 & 6.5 & 6.6441 & TRN & \\
\hline CHEMBL3431157 & 1479004 & 3.3 & 4.2316 & TST & \\
\hline CHEMBL3431158 & 1479004 & 3.3 & 3.7332 & TST & \\
\hline CHEMBL3431159 & 1479004 & 6.1 & 5.5269 & TST & \\
\hline CHEMBL1593679 & 1479004 & 7.2 & 7.051 & TRN & \\
\hline CHEMBL3431160 & 1479004 & 5.5 & 5.1239 & TRN & \\
\hline CHEMBL 3431161 & 1479004 & 6.3 & 5.7478 & TST & \\
\hline CHEMBL3431162 & 1479004 & 6.6 & 6.4833 & TST & \\
\hline CHEMBL3431163 & 1479004 & 6.4 & 6.3309 & TRN & \\
\hline & & & & 10490 & \\
\hline
\end{tabular}




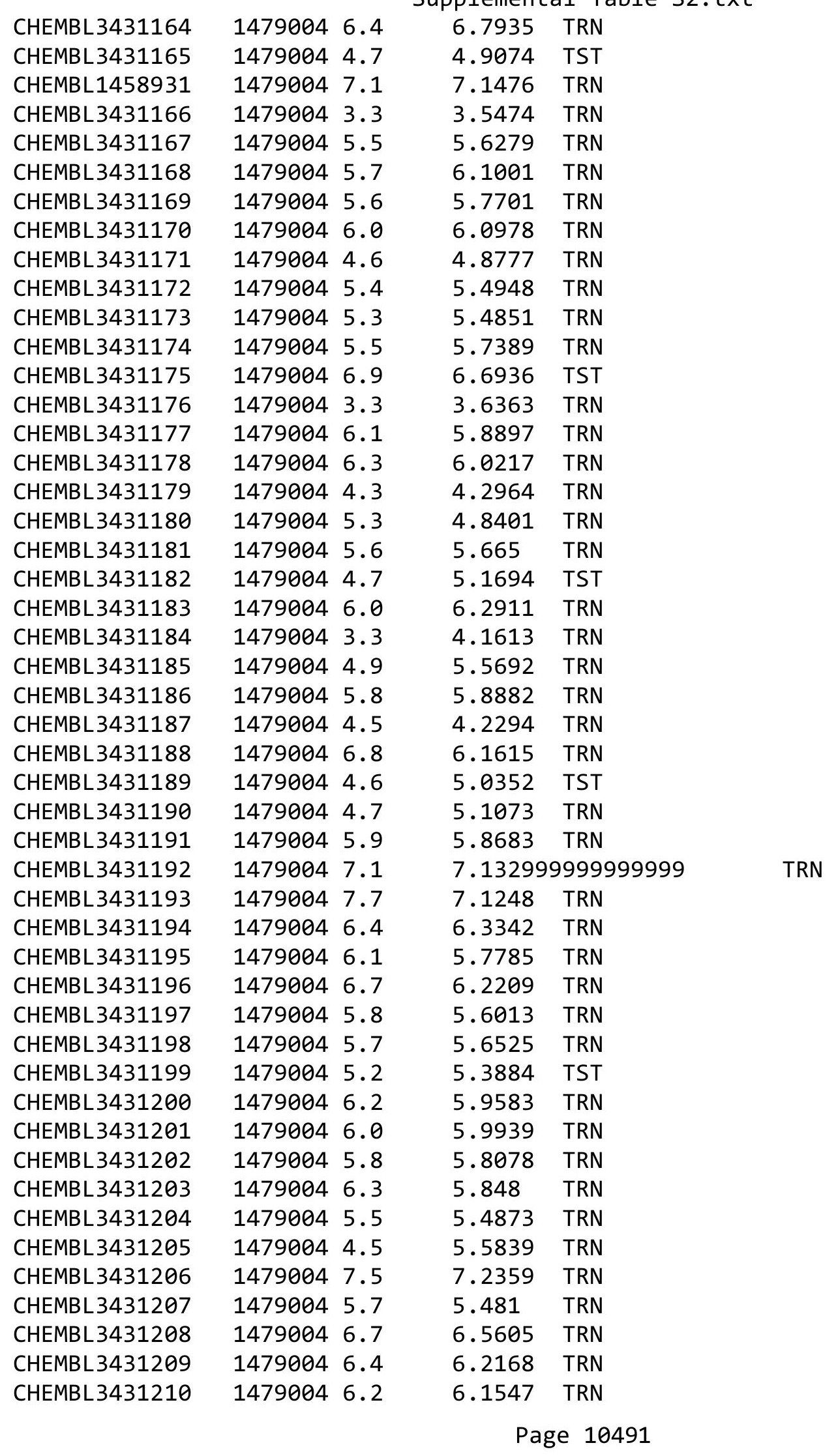




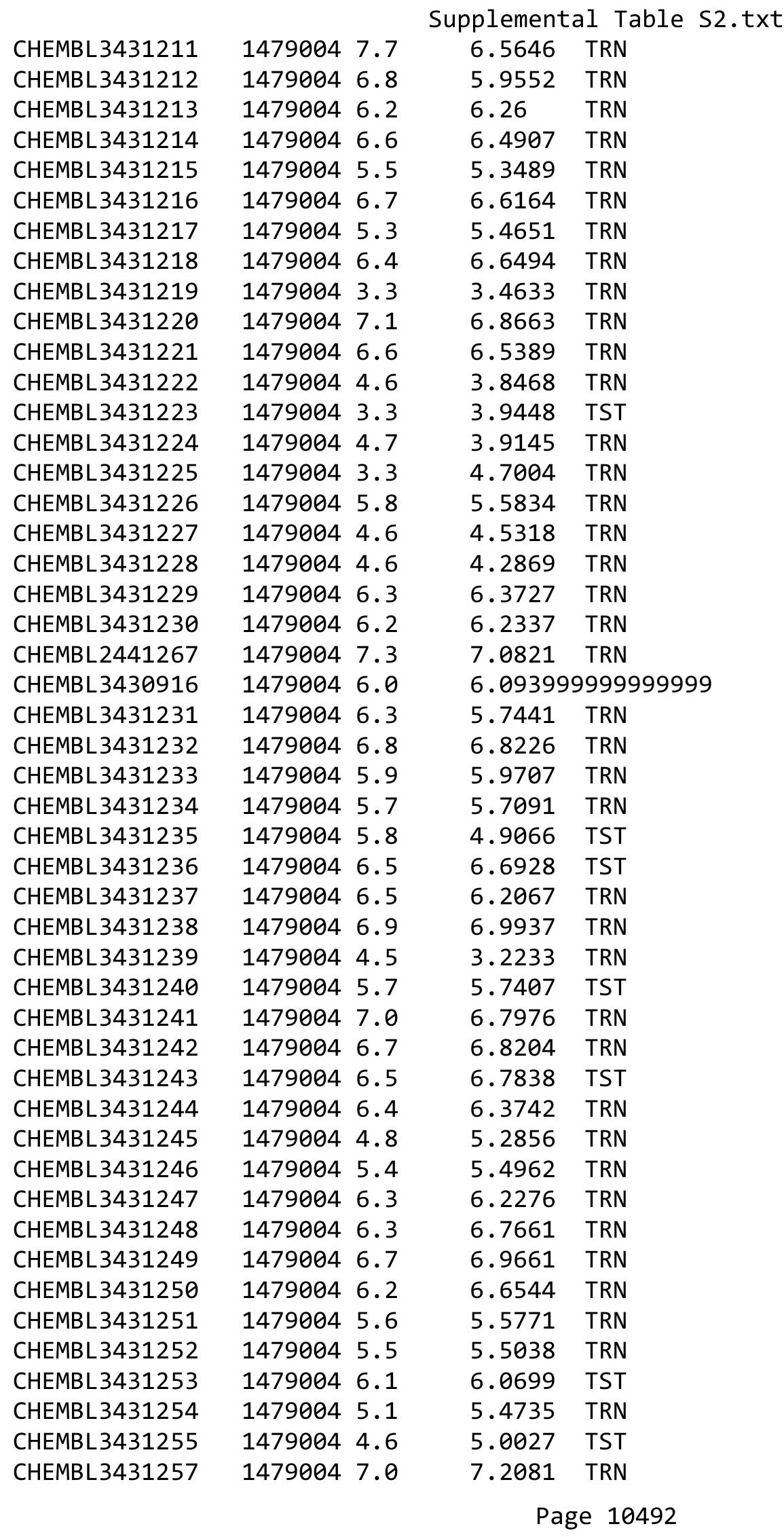




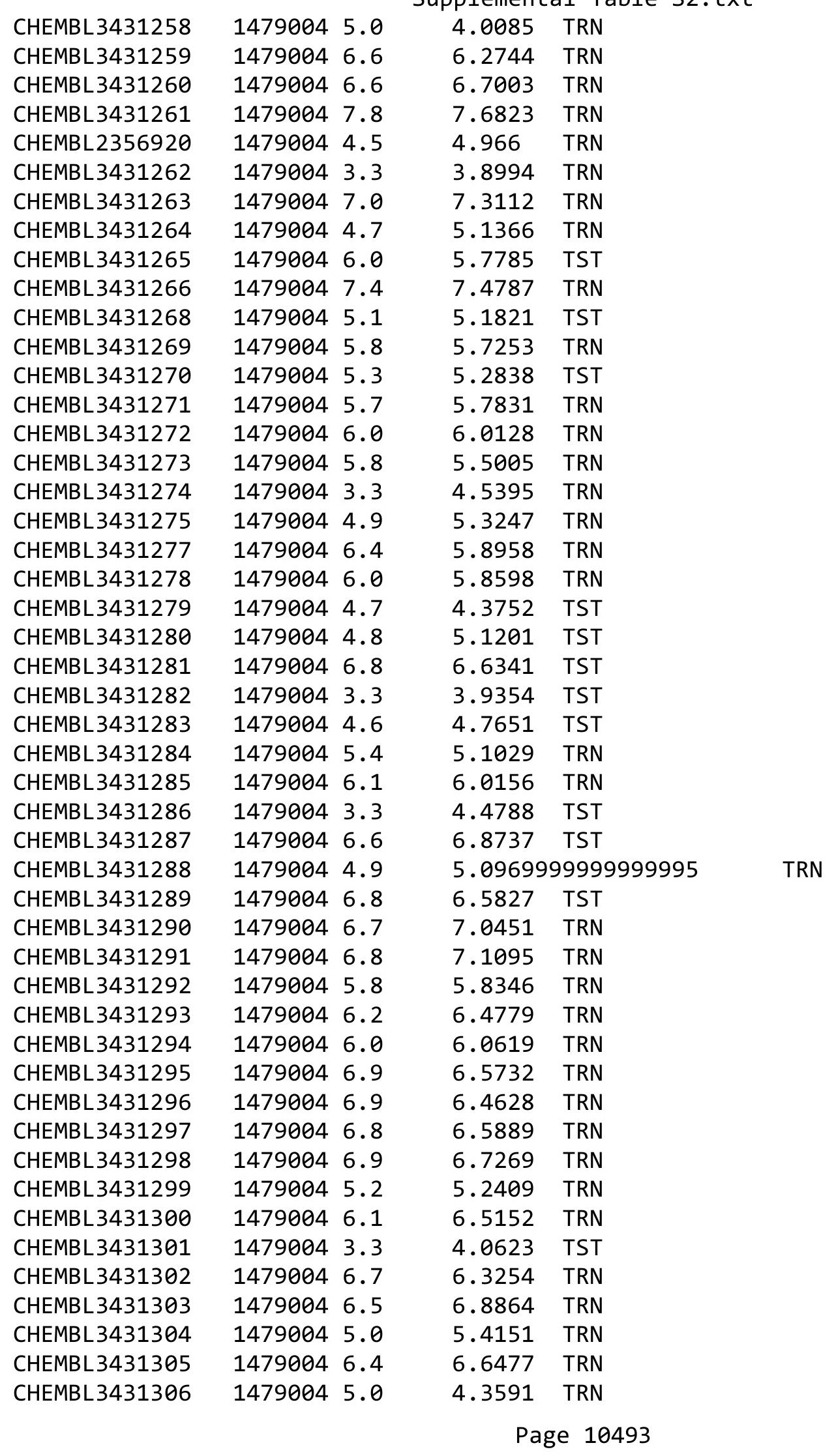




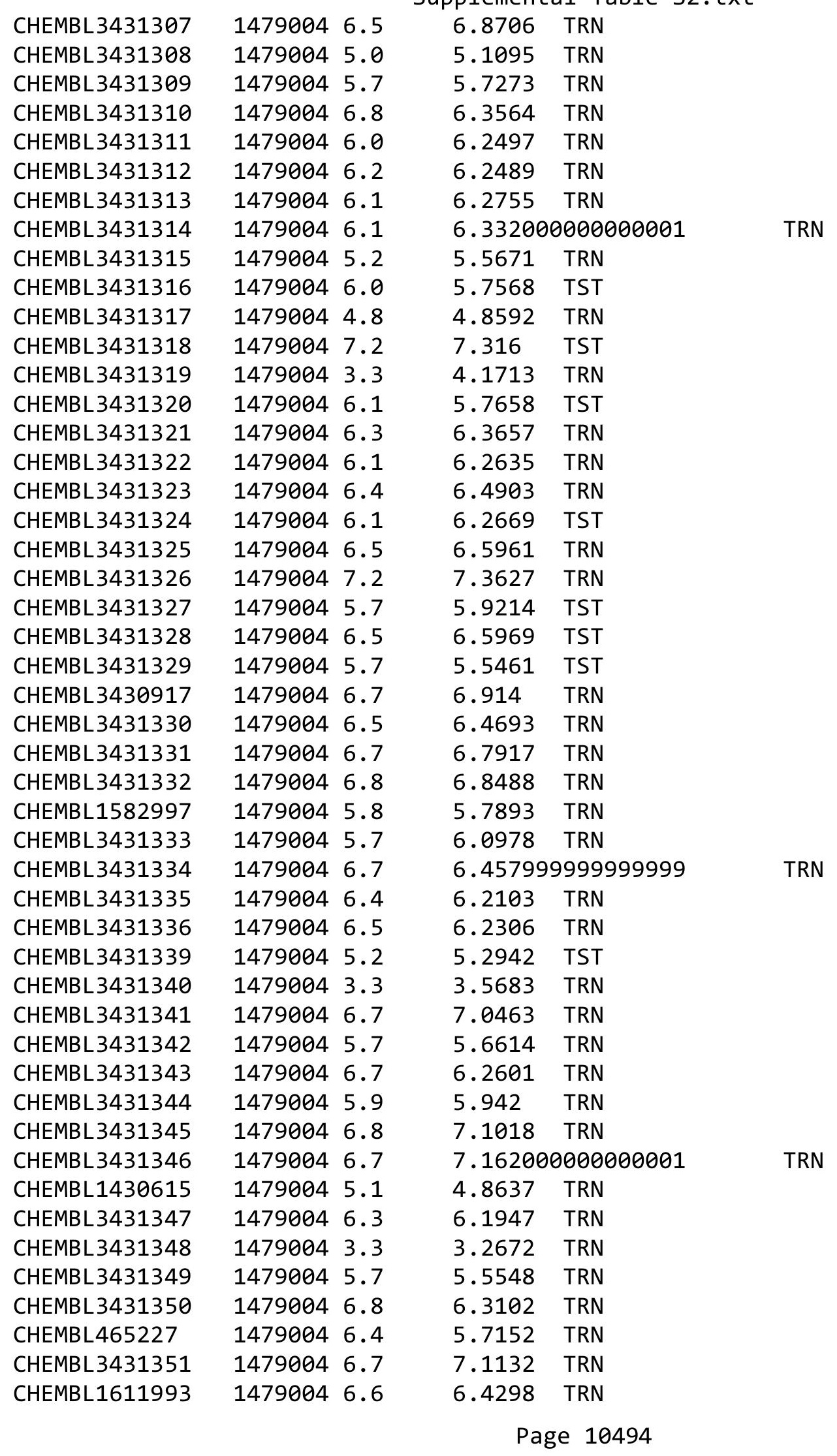




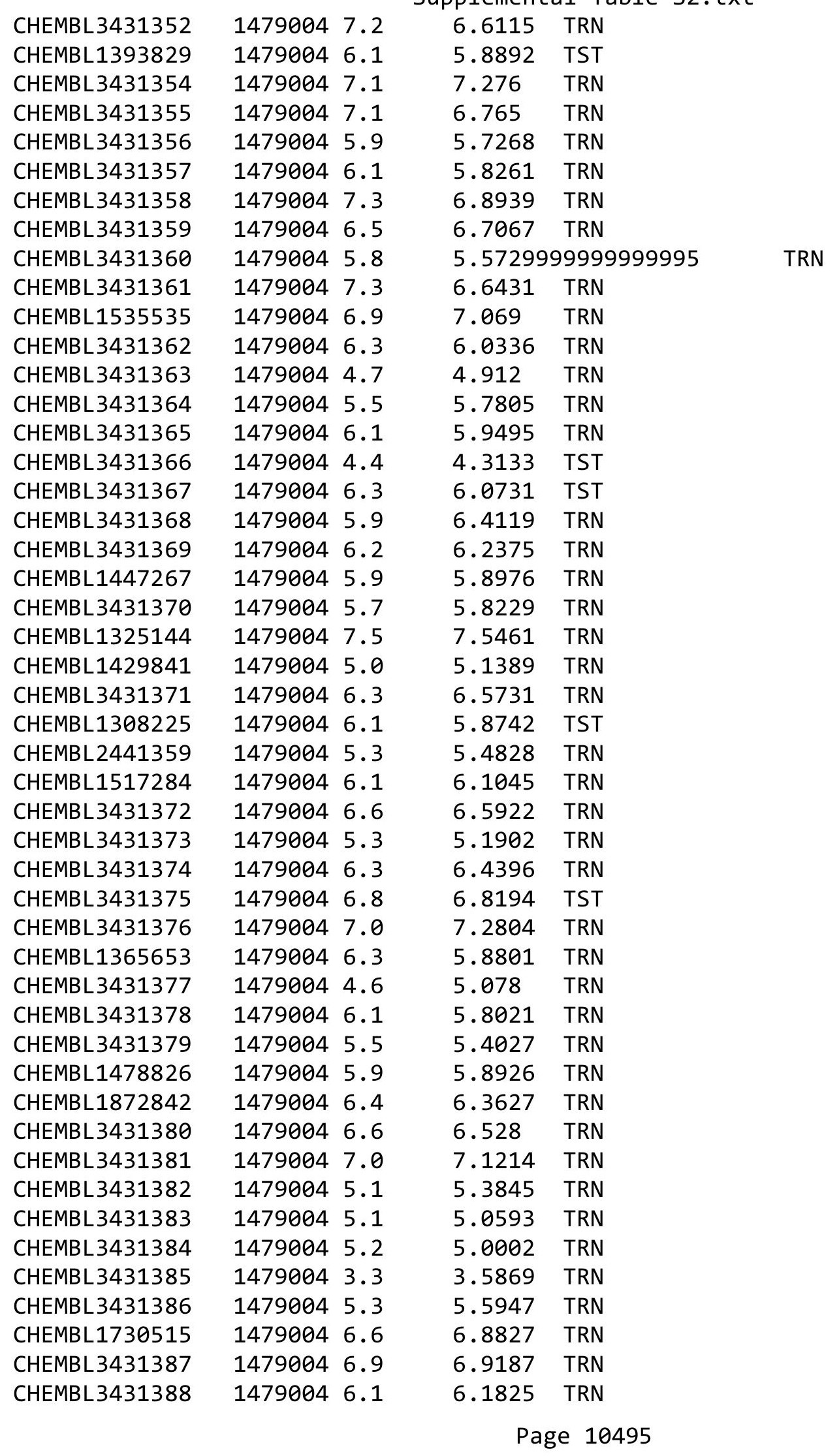




\begin{tabular}{|c|c|c|c|c|c|}
\hline CHEMBL1566898 & 1479004 & 5.0 & 4.7919 & TRN & \\
\hline CHEMBL3431389 & 1479004 & 4.6 & 4.6279 & TRN & \\
\hline CHEMBL3431390 & 1479004 & 4.8 & 5.0858 & TST & \\
\hline CHEMBL3431391 & 1479004 & 4.5 & 3.82800 & 00000000003 & TRN \\
\hline CHEMBL1489081 & 1479004 & 6.4 & 6.29899 & 99999999995 & TRN \\
\hline CHEMBL3431392 & 1479004 & 3.3 & 3.5889 & TRN & \\
\hline CHEMBL3431393 & 1479004 & 6.1 & 5.9562 & TRN & \\
\hline CHEMBL3431394 & 1479004 & 4.7 & 5.1826 & TST & \\
\hline CHEMBL3431395 & 1479004 & 5.7 & 5.5974 & TRN & \\
\hline CHEMBL3431396 & 1479004 & 3.3 & 4.6322 & TRN & \\
\hline CHEMBL3431397 & 1479004 & 6.5 & 6.68 & TRN & \\
\hline CHEMBL3431398 & 1479004 & 5.2 & 4.6437 & TRN & \\
\hline CHEMBL3431399 & 1479004 & 5.9 & 5.8601 & TRN & \\
\hline CHEMBL3431400 & 1479004 & 7.3 & 7.3041 & TRN & \\
\hline CHEMBL1418463 & 1479004 & 6.5 & 6.2575 & TRN & \\
\hline CHEMBL3431401 & 1479004 & 5.1 & 5.2025 & TRN & \\
\hline CHEMBL3431402 & 1479004 & 4.9 & 4.9532 & TST & \\
\hline CHEMBL3431403 & 1479004 & 4.6 & 5.3783 & TRN & \\
\hline CHEMBL3431404 & 1479004 & 6.1 & 5.8224 & TRN & \\
\hline CHEMBL3431405 & 1479004 & 7.1 & 6.9135 & TRN & \\
\hline CHEMBL3431406 & 1479004 & 6.3 & 6.1681 & TST & \\
\hline CHEMBL3431407 & 1479004 & 6.6 & 6.2868 & TST & \\
\hline CHEMBL3431408 & 1479004 & 7.0 & 7.1463 & TRN & \\
\hline CHEMBL3431409 & 1479004 & 6.0 & 5.7969 & TRN & \\
\hline CHEMBL3431410 & 1479004 & 6.6 & 6.4635 & TST & \\
\hline CHEMBL 3431411 & 1479004 & 6.0 & 5.6539 & TRN & \\
\hline CHEMBL3431412 & 1479004 & 7.1 & 6.5404 & TST & \\
\hline CHEMBL3431413 & 1479004 & 4.5 & 4.4462 & TST & \\
\hline CHEMBL3431414 & 1479004 & 6.9 & 6.5267 & TRN & \\
\hline CHEMBL3431415 & 1479004 & 7.2 & 6.4806 & TRN & \\
\hline CHEMBL3431416 & 1479004 & 6.9 & 6.59 & TST & \\
\hline CHEMBL291721 & 1479004 & 5.5 & 5.5939 & TST & \\
\hline CHEMBL3431417 & 1479004 & 5.7 & 5.7884 & TRN & \\
\hline CHEMBL3431418 & 1479004 & 7.9 & 7.2317 & TST & \\
\hline CHEMBL487186 & 1479004 & 6.7 & 6.915 & TST & \\
\hline CHEMBL3431419 & 1479004 & 6.4 & 6.475 & TRN & \\
\hline CHEMBL3431420 & 1479004 & 6.5 & 6.2191 & TRN & \\
\hline CHEMBL3431421 & 1479004 & 6.0 & 6.1225 & TRN & \\
\hline CHEMBL3431422 & 1479004 & 5.1 & 5.0305 & TRN & \\
\hline CHEMBL3431423 & 1479004 & 3.3 & 3.5214 & TRN & \\
\hline CHEMBL3431424 & 1479004 & 6.7 & 6.7934 & TRN & \\
\hline CHEMBL3431425 & 1479004 & 5.1 & 5.4873 & TRN & \\
\hline CHEMBL3431426 & 1479004 & 6.3 & 6.2527 & TRN & \\
\hline CHEMBL3431427 & 1479004 & 6.6 & 6.3283 & TRN & \\
\hline CHEMBL3431428 & 1479004 & 4.6 & 4.8766 & TST & \\
\hline CHEMBL1725748 & 1479004 & 6.4 & 6.1172 & TRN & \\
\hline CHEMBL3430918 & 1479004 & 6.6 & 6.7511 & TST & \\
\hline \multirow[t]{2}{*}{ CHEMBL 3431429} & 1479004 & 3.3 & 4.89199 & 99999999995 & TRN \\
\hline & & \multicolumn{4}{|c|}{ Page 10496} \\
\hline
\end{tabular}




\begin{tabular}{|c|c|c|c|c|}
\hline \\
\hline CHEMBL3431430 & 1479004 & 6.6 & 6.7643 & TRN \\
\hline CHEMBL128672 & 1479004 & 5.9 & 6.1265 & TRN \\
\hline CHEMBL491149 & 1479004 & 6.7 & 6.8346 & TRN \\
\hline CHEMBL 3431431 & 1479004 & 6.1 & 5.48799 & 99999999995 \\
\hline CHEMBL3431432 & 1479004 & 6.0 & 5.4393 & TRN \\
\hline CHEMBL3431433 & 1479004 & 6.7 & 6.7023 & TRN \\
\hline CHEMBL3431434 & 1479004 & 7.7 & 7.5215 & TST \\
\hline CHEMBL3431435 & 1479004 & 7.5 & 7.1483 & TRN \\
\hline CHEMBL3431436 & 1479004 & 5.3 & 5.6419 & TRN \\
\hline CHEMBL3431437 & 1479004 & 3.3 & 4.0256 & TRN \\
\hline CHEMBL3431438 & 1479004 & 6.4 & 6.0832 & TST \\
\hline CHEMBL3431439 & 1479004 & 4.5 & 3.9983 & TST \\
\hline CHEMBL3431440 & 1479004 & 6.3 & 5.9487 & TST \\
\hline CHEMBL 3431441 & 1479004 & 5.5 & 5.4455 & TRN \\
\hline CHEMBL3431442 & 1479004 & 5.3 & 4.5925 & TST \\
\hline CHEMBL3431443 & 1479004 & 6.9 & 6.5129 & TRN \\
\hline CHEMBL3431444 & 1479004 & 5.9 & 5.7522 & TST \\
\hline CHEMBL 3431445 & 1479004 & 4.4 & 4.9527 & TRN \\
\hline CHEMBL549020 & 1479004 & 6.3 & 6.3176 & TRN \\
\hline CHEMBL526199 & 1479004 & 5.1 & 5.2064 & TRN \\
\hline CHEMBL3430919 & 1479004 & 3.3 & 3.765 & TRN \\
\hline CHEMBL528583 & 1479004 & 8.3 & 8.1882 & TRN \\
\hline CHEMBL530358 & 1479004 & 6.1 & 6.0405 & TRN \\
\hline CHEMBL534517 & 1479004 & 5.9 & 6.0689 & TRN \\
\hline CHEMBL3430921 & 1479004 & 6.8 & 6.2887 & TST \\
\hline CHEMBL3430922 & 1479004 & 6.3 & 6.0174 & TST \\
\hline CHEMBL 2098124 & 1479004 & 6.8 & 6.307 & TRN \\
\hline CHEMBL 2098408 & 1479004 & 5.8 & 5.9299 & TRN \\
\hline CHEMBL1578482 & 1479004 & 6.1 & 6.0595 & TRN \\
\hline CHEMBL 2098276 & 1479004 & 6.0 & 5.9049 & TRN \\
\hline CHEMBL3430923 & 1479004 & 6.4 & 6.3748 & TST \\
\hline CHEMBL3430924 & 1479004 & 5.9 & 6.0106 & TRN \\
\hline CHEMBL3430925 & 1479004 & 7.2 & 5.3917 & TST \\
\hline CHEMBL3430926 & 1479004 & 7.1 & 6.2865 & TST \\
\hline CHEMBL 2165401 & 1479004 & 4.7 & 4.4184 & TST \\
\hline CHEMBL3430928 & 1479004 & 5.6 & 5.6028 & TRN \\
\hline CHEMBL3430929 & 1479004 & 4.9 & 5.2121 & TRN \\
\hline CHEMBL3430930 & 1479004 & 4.4 & 4.6269 & TRN \\
\hline CHEMBL 305686 & 1479004 & 5.9 & 5.9678 & TST \\
\hline CHEMBL3430931 & 1479004 & 6.5 & 6.6091 & TST \\
\hline CHEMBL3430932 & 1479004 & 6.0 & 6.4944 & TST \\
\hline CHEMBL1232777 & 1479004 & 6.5 & 6.4285 & TST \\
\hline CHEMBL3430933 & 1479004 & 6.3 & 6.5321 & TRN \\
\hline CHEMBL3430913 & 1479004 & 5.7 & 5.6475 & TRN \\
\hline CHEMBL3430934 & 1479004 & 4.7 & 5.3207 & TRN \\
\hline CHEMBL3430935 & 1479004 & 6.6 & 6.2562 & TST \\
\hline CHEMBL3430936 & 1479004 & 6.0 & 5.7669 & TRN \\
\hline CHEMBL3430937 & 1479004 & 4.9 & 5.144 & TST \\
\hline
\end{tabular}

TRN 


\begin{tabular}{|c|c|c|c|c|c|}
\hline CHEMBL 3430938 & 1479004 & 5.2 & 5.0671 & TRN & \\
\hline CHEMBL3430939 & 1479004 & 5.2 & 5.1999 & TRN & \\
\hline CHEMBL3430940 & 1479004 & 5.5 & 5.3674 & TRN & \\
\hline CHEMBL 3430941 & 1479004 & 5.2 & \multicolumn{2}{|c|}{5.1339999999999995} & TRN \\
\hline CHEMBL 3430942 & 1479004 & 5.6 & 5.2984 & TRN & \\
\hline CHEMBL3430943 & 1479004 & 5.5 & 5.3142 & TRN & \\
\hline CHEMBL 3430944 & 1479004 & 5.1 & 4.8593 & TRN & \\
\hline CHEMBL3430945 & 1479004 & 5.7 & 5.7961 & TRN & \\
\hline CHEMBL3430946 & 1479004 & 5.6 & 5.5013 & TRN & \\
\hline CHEMBL3430947 & 1479004 & 6.2 & 5.6355 & TRN & \\
\hline CHEMBL 3430948 & 1479004 & 4.7 & 4.6884 & TRN & \\
\hline CHEMBL3430949 & 1479004 & 6.2 & 6.2435 & TRN & \\
\hline CHEMBL1388922 & 1479004 & 5.7 & 5.5291 & TRN & \\
\hline CHEMBL3430950 & 1479004 & 5.9 & 5.7565 & TRN & \\
\hline CHEMBL3430951 & 1479004 & 6.8 & \multicolumn{2}{|c|}{6.446000000000001} & TST \\
\hline CHEMBL1321334 & 1479004 & 6.7 & 6.5204 & TRN & \\
\hline CHEMBL3430953 & 1479004 & 3.3 & 3.8985 & TRN & \\
\hline CHEMBL3430954 & 1479004 & 6.3 & 6.2102 & TRN & \\
\hline CHEMBL3430955 & 1479004 & 6.3 & 5.9631 & TST & \\
\hline CHEMBL3430956 & 1479004 & 6.0 & 6.2529 & TRN & \\
\hline CHEMBL3430957 & 1479004 & 4.8 & 5.3935 & TRN & \\
\hline CHEMBL3430958 & 1479004 & 5.1 & 5.5685 & TRN & \\
\hline CHEMBL3430959 & 1479004 & 5.7 & 5.8304 & TRN & \\
\hline CHEMBL3430960 & 1479004 & 6.8 & 7.0587 & TRN & \\
\hline CHEMBL3430961 & 1479004 & 5.7 & 5.5899 & TRN & \\
\hline CHEMBL3430962 & 1479004 & 4.5 & 4.3444 & TRN & \\
\hline CHEMBL3430963 & 1479004 & 5.7 & 6.0367 & TRN & \\
\hline CHEMBL 3430964 & 1479004 & 5.7 & 5.8942 & TRN & \\
\hline CHEMBL3430965 & 1479004 & 4.6 & 4.9556 & TRN & \\
\hline CHEMBL3430966 & 1479004 & 6.4 & 6.7192 & TRN & \\
\hline CHEMBL 3430967 & 1479004 & 5.1 & 5.4331 & TRN & \\
\hline CHEMBL 3430968 & 1479004 & 6.6 & 6.3506 & TRN & \\
\hline CHEMBL3430969 & 1479004 & 6.0 & \multicolumn{2}{|c|}{6.0489999999999995} & TRN \\
\hline CHEMBL3430970 & 1479004 & 5.0 & 5.2646 & TRN & \\
\hline CHEMBL1482137 & 1479004 & 6.6 & 6.3359 & TRN & \\
\hline CHEMBL3430971 & 1479004 & 6.9 & 6.4988 & TRN & \\
\hline CHEMBL3430972 & 1479004 & 6.2 & 6.1403 & TRN & \\
\hline CHEMBL3430973 & 1479004 & 5.5 & 5.7146 & TRN & \\
\hline CHEMBL3430974 & 1479004 & 3.3 & 3.9068 & TRN & \\
\hline CHEMBL3430975 & 1479004 & 6.0 & 5.744 & TRN & \\
\hline CHEMBL3430976 & 1479004 & 5.7 & 5.6302 & TRN & \\
\hline CHEMBL 3430977 & 1479004 & 4.8 & 4.5555 & TST & \\
\hline CHEMBL164422 & 1479004 & 6.2 & 6.1675 & TRN & \\
\hline CHEMBL3430978 & 1479004 & 3.3 & 4.4557 & TST & \\
\hline CHEMBL3430979 & 1479004 & 6.3 & 5.8116 & TST & \\
\hline CHEMBL 3430980 & 1479004 & 8.3 & 7.0265 & TST & \\
\hline CHEMBL1487481 & 1479004 & 5.7 & 5.7457 & TST & \\
\hline CHEMBL1487467 & 1479004 & 5.9 & 6.0173 & TST & \\
\hline
\end{tabular}




\begin{tabular}{|c|c|c|c|c|c|}
\hline \\
\hline CHEMBL3430981 & 1479004 & 4.8 & 4.5243 & TST & \\
\hline CHEMBL3430982 & 1479004 & 3.3 & 4.0291 & TST & \\
\hline CHEMBL3430983 & 1479004 & 3.3 & 4.1615 & TST & \\
\hline CHEMBL592827 & 1479004 & 6.7 & 6.8515 & TST & \\
\hline CHEMBL3430984 & 1479004 & 5.9 & 5.879 & TST & \\
\hline CHEMBL3430985 & 1479004 & 5.3 & 5.4333 & TST & \\
\hline CHEMBL1466712 & 1479004 & 5.4 & 5.4994 & TST & \\
\hline CHEMBL3430986 & 1479004 & 4.8 & 5.0292 & TST & \\
\hline CHEMBL3430987 & 1479004 & 5.4 & 5.3281 & TST & \\
\hline CHEMBL3430988 & 1479004 & 6.5 & 6.4448 & TST & \\
\hline CHEMBL3430989 & 1479004 & 6.2 & 6.3014 & TST & \\
\hline CHEMBL3430990 & 1479004 & 6.7 & 6.2357 & TST & \\
\hline CHEMBL3430991 & 1479004 & 6.9 & 6.506 & TST & \\
\hline CHEMBL3430992 & 1479004 & 7.4 & 6.8493 & TST & \\
\hline CHEMBL3430993 & 1479004 & 6.1 & 6.0275 & TST & \\
\hline CHEMBL3430994 & 1479004 & 5.2 & 5.1752 & TST & \\
\hline CHEMBL3430995 & 1479004 & 5.8 & 5.7531 & TST & \\
\hline CHEMBL3430996 & 1479004 & 7.1 & 6.8414 & TST & \\
\hline CHEMBL3430997 & 1479004 & 5.9 & 5.7238 & TST & \\
\hline CHEMBL3430998 & 1479004 & 6.5 & 6.3183 & TST & \\
\hline CHEMBL3430999 & 1479004 & 6.9 & 7.0736 & TST & \\
\hline CHEMBL3431000 & 1479004 & 4.8 & 5.20299 & 9999999999 & TST \\
\hline CHEMBL3431001 & 1479004 & 6.7 & 6.82 & TST & \\
\hline CHEMBL3431002 & 1479004 & 6.0 & 6.2175 & TST & \\
\hline CHEMBL3431003 & 1479004 & 7.1 & 7.2768 & TST & \\
\hline CHEMBL 3431004 & 1479004 & 7.0 & 7.2377 & TST & \\
\hline CHEMBL3431005 & 1479004 & 6.3 & 6.6587 & TST & \\
\hline CHEMBL3431006 & 1479004 & 6.6 & 6.9164 & TST & \\
\hline CHEMBL3431007 & 1479004 & 4.4 & 4.2689 & TST & \\
\hline CHEMBL3431008 & 1479004 & 5.3 & 5.6742 & TST & \\
\hline CHEMBL3431009 & 1479004 & 6.7 & 6.9892 & TST & \\
\hline CHEMBL2355685 & 1479004 & 6.3 & 5.9013 & TST & \\
\hline CHEMBL3431010 & 1479004 & 5.0 & 5.3557 & TST & \\
\hline CHEMBL3431011 & 1479004 & 6.2 & 6.1426 & TST & \\
\hline CHEMBL3431012 & 1479004 & 4.5 & 4.8786 & TST & \\
\hline CHEMBL3941662 & 1641585 & 7.5086 & 7.2166 & TRN & \\
\hline CHEMBL3923412 & 1641585 & 8.9208 & 8.6045 & TRN & \\
\hline CHEMBL3982552 & 1641585 & 9.5229 & 8.2399 & TRN & \\
\hline CHEMBL3965671 & 1641585 & 7.6576 & 8.1715 & TRN & \\
\hline CHEMBL3926555 & 1641585 & 7.5686 & 8.198 & TRN & \\
\hline CHEMBL3926819 & 1641585 & 7.3098 & 7.9695 & TRN & \\
\hline CHEMBL3921051 & 1641585 & 8.0506 & 8.6497 & TRN & \\
\hline CHEMBL3950095 & 1641585 & 6.1649 & 7.0864 & TRN & \\
\hline CHEMBL3977121 & 1641585 & 9.5229 & 8.5867 & TRN & \\
\hline CHEMBL3945358 & 1641585 & 8.5229 & 8.2254 & TRN & \\
\hline CHEMBL3964661 & 1641585 & 8.4685 & 9.0317 & TRN & \\
\hline CHEMBL3981592 & 1641585 & 8.7212 & 7.7407 & TST & \\
\hline CHEMBL3941523 & 1641585 & 8.4949 & 8.8777 & TRN & \\
\hline
\end{tabular}


Supplemental Table S2.txt

\begin{tabular}{|c|c|c|c|c|c|}
\hline CHEMBL3898997 & 1641585 & 9.5229 & 8.2605 & TST & \\
\hline CHEMBL3952623 & 1641585 & 8.0605 & 8.6972 & TRN & \\
\hline CHEMBL3970195 & 1641585 & 8.4815 & 8.1126 & TST & \\
\hline CHEMBL3935589 & 1641585 & 7.8861 & 7.8211 & TRN & \\
\hline CHEMBL3930248 & 1641585 & 8.301 & 7.5474 & TRN & \\
\hline CHEMBL3948857 & 1641585 & 7.6383 & 7.7141 & TRN & \\
\hline CHEMBL3981919 & 1641585 & 9.0 & 8.4916 & TRN & \\
\hline CHEMBL3953423 & 1641585 & 7.4437 & 7.2637 & TRN & \\
\hline CHEMBL3946836 & 1641585 & 8.3098 & 7.4625 & TRN & \\
\hline CHEMBL3979404 & 1641585 & 8.3979 & 8.1817 & TST & \\
\hline CHEMBL3917389 & 1641585 & 8.5229 & 8.6258 & TRN & \\
\hline CHEMBL3908521 & 1641585 & 9.5229 & 9.3562 & TRN & \\
\hline CHEMBL3932245 & 1641585 & 8.0 & 8.0469 & TRN & \\
\hline CHEMBL 3962584 & 1641585 & 7.9208 & 8.3943 & TRN & \\
\hline CHEMBL 3973934 & 1641585 & 8.1871 & 7.8361 & TRN & \\
\hline CHEMBL3965050 & 1641585 & 7.699 & 7.5351 & TRN & \\
\hline CHEMBL3945503 & 1641585 & 6.1445 & 7.01399 & 9999999999 & TRN \\
\hline CHEMBL3903055 & 1641585 & 8.1549 & 7.8991 & TRN & \\
\hline CHEMBL3936180 & 1641585 & 7.3565 & 7.4155 & TRN & \\
\hline CHEMBL3935043 & 1641585 & 8.0706 & 8.5825 & TRN & \\
\hline CHEMBL3950377 & 1641585 & 8.5229 & 8.3772 & TRN & \\
\hline CHEMBL3957513 & 1641585 & 8.3768 & 7.8108 & TRN & \\
\hline CHEMBL3890053 & 1641585 & 8.4949 & 8.042 & TRN & \\
\hline CHEMBL3974522 & 1641585 & 7.4559 & 7.9891 & TRN & \\
\hline CHEMBL3962532 & 1641585 & 8.3979 & 8.1482 & TRN & \\
\hline CHEMBL3975996 & 1641585 & 6.1871 & 7.75 & TST & \\
\hline CHEMBL3987130 & 1641585 & 8.2218 & 8.5801 & TRN & \\
\hline CHEMBL3944484 & 1641585 & 8.4089 & 8.1606 & TRN & \\
\hline CHEMBL3898136 & 1641585 & 7.5086 & 7.6083 & TRN & \\
\hline CHEMBL3966024 & 1641585 & 7.8861 & 7.6229 & TRN & \\
\hline CHEMBL3978018 & 1641585 & 8.5086 & 7.8645 & TRN & \\
\hline CHEMBL3912888 & 1641585 & 8.0915 & 8.5614 & TRN & \\
\hline CHEMBL3979039 & 1641585 & 8.4559 & 7.8796 & TRN & \\
\hline CHEMBL3959348 & 1641585 & 9.5229 & 9.5316 & TRN & \\
\hline CHEMBL3986601 & 1641585 & 9.5229 & 8.242 & TRN & \\
\hline CHEMBL3959105 & 1641585 & 6.6326 & 7.7238 & TRN & \\
\hline CHEMBL3936467 & 1641585 & 7.8861 & 8.2587 & TRN & \\
\hline CHEMBL3922918 & 1641585 & 8.4685 & 8.979 & TRN & \\
\hline CHEMBL3918819 & 1641585 & 7.2924 & 7.3277 & TRN & \\
\hline CHEMBL3913939 & 1641585 & 8.1675 & 7.7928 & TST & \\
\hline CHEMBL3915183 & 1641585 & 9.5229 & 9.3306 & TRN & \\
\hline CHEMBL3941239 & 1641585 & 7.1612 & 8.0374 & TRN & \\
\hline CHEMBL3959861 & 1641585 & 9.5229 & 8.6597 & TRN & \\
\hline CHEMBL3939263 & 1641585 & 7.8861 & 8.4526 & TRN & \\
\hline CHEMBL3928833 & 1641585 & 9.5229 & 8.6413 & TRN & \\
\hline CHEMBL3933477 & 1641585 & 7.2007 & 8.0135 & TRN & \\
\hline CHEMBL3950645 & 1641585 & 8.4437 & 9.4221 & TST & \\
\hline CHEMBL3969764 & 1641585 & 6.9431 & 7.8258 & TST & \\
\hline
\end{tabular}


Supplemental Table S2.txt

\begin{tabular}{|c|c|c|c|c|c|}
\hline CHEMBL3937862 & 1641585 & 6.1805 & 7.4946 & TST & \\
\hline CHEMBL3970802 & 1641585 & 7.1135 & 7.6562 & TST & \\
\hline CHEMBL3944685 & 1641585 & 8.0044 & 9.0573 & TST & \\
\hline CHEMBL 3893615 & 1641585 & 8.5229 & 8.8099 & TST & \\
\hline CHEMBL 3967484 & 1641585 & 7.8861 & 8.3424 & TST & \\
\hline CHEMBL 3953864 & 1641585 & 8.0223 & 8.2308 & TST & \\
\hline CHEMBL3889746 & 1641585 & 8.0605 & 7.7103 & TST & \\
\hline CHEMBL3935357 & 1641585 & 9.5229 & 8.5201 & TST & \\
\hline CHEMBL3908038 & 1641585 & 7.6576 & 7.9487 & TST & \\
\hline CHEMBL3956542 & 1641585 & 8.2518 & 8.2063 & TST & \\
\hline CHEMBL 2314330 & 936637 & 4.9355 & 5.8689 & TST & \\
\hline CHEMBL2314290 & 936637 & 5.3565 & 5.3499 & TRN & \\
\hline CHEMBL2314320 & 936637 & 6.8539 & 6.2791 & TRN & \\
\hline CHEMBL2314294 & 936637 & 5.2596 & 4.8118 & TRN & \\
\hline CHEMBL1972527 & 936637 & 6.9208 & 6.0109 & TRN & \\
\hline CHEMBL 2314620 & 936637 & 6.2366 & 5.7694 & TST & \\
\hline CHEMBL2314288 & 936637 & 6.3665 & 6.0831 & TRN & \\
\hline CHEMBL 2314331 & 936637 & 5.7212 & 6.1453 & TST & \\
\hline CHEMBL 2314314 & 936637 & 5.0269 & 5.80200 & 00000000005 & TRN \\
\hline CHEMBL2314293 & 936637 & 6.6021 & 5.5272 & TRN & \\
\hline CHEMBL1970441 & 936637 & 5.7447 & 6.3429 & TRN & \\
\hline CHEMBL2314312 & 936637 & 6.2147 & 6.3034 & TRN & \\
\hline CHEMBL 2314324 & 936637 & 6.4559 & 6.5989 & TRN & \\
\hline CHEMBL2314297 & 936637 & 6.2147 & 6.2843 & TRN & \\
\hline CHEMBL2314304 & 936637 & 5.4318 & 6.1642 & TST & \\
\hline CHEMBL2314621 & 936637 & 6.4318 & 6.2934 & TST & \\
\hline CHEMBL1979763 & 936637 & 6.0088 & 6.0326 & TRN & \\
\hline CHEMBL 2314296 & 936637 & 3.699 & 5.0884 & TRN & \\
\hline CHEMBL1985845 & 936637 & 5.8539 & 6.1136 & TRN & \\
\hline CHEMBL2314307 & 936637 & 5.8539 & 6.1649 & TRN & \\
\hline CHEMBL2314326 & 936637 & 6.4318 & 6.5657 & TRN & \\
\hline CHEMBL1736481 & 936637 & 5.7696 & 6.1194 & TRN & \\
\hline CHEMBL1965488 & 936637 & 6.5376 & 6.4345 & TRN & \\
\hline CHEMBL2314309 & 936637 & 5.7447 & 5.3603 & TRN & \\
\hline CHEMBL 2314295 & 936637 & 6.2757 & 5.8749 & TRN & \\
\hline CHEMBL1981304 & 936637 & 6.6576 & 6.4012 & TRN & \\
\hline CHEMBL1994128 & 936637 & 5.0706 & 5.5236 & TRN & \\
\hline CHEMBL2314619 & 936637 & 4.7447 & 6.1002 & TST & \\
\hline CHEMBL2314302 & 936637 & 3.699 & 4.4618 & TRN & \\
\hline CHEMBL 2314313 & 936637 & 5.4202 & 6.0088 & TRN & \\
\hline CHEMBL1980609 & 936637 & 6.1938 & 6.3601 & TRN & \\
\hline CHEMBL1977515 & 936637 & 6.1938 & 6.3978 & TRN & \\
\hline CHEMBL2314305 & 936637 & 6.1079 & 6.1271 & TRN & \\
\hline CHEMBL2314327 & 936637 & 5.4685 & 6.0862 & TRN & \\
\hline CHEMBL2314299 & 936637 & 6.3665 & \multicolumn{2}{|c|}{5.872000000000001} & TRN \\
\hline CHEMBL2314292 & 936637 & 5.9586 & 5.9774 & TRN & \\
\hline CHEMBL2314300 & 936637 & 6.6021 & 5.6973 & TST & \\
\hline CHEMBL2314321 & 936637 & 5.3768 & 6.2111 & TRN & \\
\hline
\end{tabular}




\begin{tabular}{|c|c|c|c|c|c|}
\hline & & \multicolumn{4}{|c|}{ Supplemental Table S2.txt } \\
\hline CHEMBL2314622 & 936637 & 6.3098 & 6.2873 & TST & \\
\hline CHEMBL2314303 & 936637 & 3.699 & 5.6342 & TST & \\
\hline CHEMBL1995776 & 936637 & 6.1739 & 6.5901 & TRN & \\
\hline CHEMBL2314318 & 936637 & 6.4949 & 6.393 & TRN & \\
\hline CHEMBL1973416 & 936637 & 5.5086 & 6.1024 & TST & \\
\hline CHEMBL1987422 & 936637 & 6.6198 & 6.5917 & TRN & \\
\hline CHEMBL1968640 & 936637 & 6.1079 & 5.9159 & TST & \\
\hline CHEMBL 2314298 & 936637 & 6.0862 & 5.6536 & TRN & \\
\hline CHEMBL 2000954 & 936637 & 6.3665 & 5.8794 & TRN & \\
\hline CHEMBL2314310 & 936637 & 6.0 & 5.2888 & TRN & \\
\hline CHEMBL2314289 & 936637 & 6.1367 & 5.75700 & 0000000001 & TST \\
\hline CHEMBL2314325 & 936637 & 5.699 & 6.2692 & TRN & \\
\hline CHEMBL2314319 & 936637 & 5.8239 & 6.0321 & TRN & \\
\hline CHEMBL2314317 & 936637 & 6.2676 & 6.1507 & TRN & \\
\hline CHEMBL1977658 & 936637 & 5.9208 & 5.7762 & TRN & \\
\hline CHEMBL 2314291 & 936637 & 7.0 & 6.0398 & TRN & \\
\hline CHEMBL 2314328 & 936637 & 6.3468 & 6.1072 & TST & \\
\hline CHEMBL1964671 & 936637 & 6.585 & 6.4168 & TRN & \\
\hline CHEMBL1729021 & 936637 & 6.5686 & 6.5389 & TRN & \\
\hline CHEMBL2314623 & 936637 & 3.6021 & 6.2291 & TST & \\
\hline CHEMBL1980803 & 936637 & 5.6576 & 6.081 & TST & \\
\hline CHEMBL2314308 & 936637 & 6.4318 & 5.949 & TRN & \\
\hline CHEMBL 2314322 & 936637 & 6.4437 & 6.249 & TRN & \\
\hline CHEMBL2314311 & 936637 & 6.3872 & 6.2958 & TRN & \\
\hline CHEMBL2314315 & 936637 & 5.0 & 5.8504 & TRN & \\
\hline CHEMBL 2005648 & 936637 & 6.4437 & 6.3647 & TRN & \\
\hline CHEMBL2002956 & 936637 & 6.2757 & 6.0417 & TST & \\
\hline CHEMBL2314316 & 936637 & 6.2291 & 5.9756 & TRN & \\
\hline CHEMBL 2314306 & 936637 & 6.4318 & 6.5965 & TRN & \\
\hline CHEMBL 2314323 & 936637 & 6.6576 & 6.5836 & TRN & \\
\hline CHEMBL2314301 & 936637 & 6.6198 & 5.1881 & TST & \\
\hline CHEMBL2001553 & 936637 & 6.0809 & 5.7374 & TRN & \\
\hline CHEMBL2314329 & 936637 & 5.6021 & 6.0082 & TST & \\
\hline CHEMBL1977285 & 936637 & 4.7447 & 5.9799 & TST & \\
\hline CHEMBL1969065 & 936637 & 6.5528 & 6.1725 & TRN & \\
\hline CHEMBL2348914 & 950588 & 3.2218 & 3.1872 & TRN & \\
\hline CHEMBL 2348909 & 950588 & 3.2218 & 3.516 & TRN & \\
\hline CHEMBL2348877 & 950588 & 3.2218 & 3.5189 & TRN & \\
\hline CHEMBL 2348925 & 950588 & 3.2218 & 3.0858 & TRN & \\
\hline CHEMBL 2349037 & 950588 & 3.2218 & 3.2103 & TRN & \\
\hline CHEMBL 2348888 & 950588 & 3.2218 & 3.5907 & TRN & \\
\hline CHEMBL 2348913 & 950588 & 3.2218 & 3.2882 & TRN & \\
\hline CHEMBL 2348872 & 950588 & 3.2218 & 4.2362 & TRN & \\
\hline CHEMBL 2349049 & 950588 & 3.2218 & 3.4548 & TST & \\
\hline CHEMBL 2348873 & 950588 & 3.2218 & 3.8647 & TRN & \\
\hline CHEMBL2349057 & 950588 & 3.2218 & 3.2247 & TRN & \\
\hline CHEMBL 2348892 & 950588 & 3.2218 & 3.3637 & TRN & \\
\hline CHEMBL2348896 & 950588 & 3.2218 & 3.2318 & TRN & \\
\hline
\end{tabular}


Supplemental Table S2.txt

\begin{tabular}{|c|c|c|c|c|}
\hline HEMBL2348912 & & & & \\
\hline HEMBL 2348879 & & & & \\
\hline & & & & \\
\hline FMRI 231 & & & & \\
\hline IEMBL234 & 50588 & & & \\
\hline HEMBL2348869 & 50588 & 212 & & \\
\hline 39 & 38 & & & \\
\hline & & & & \\
\hline IEMBL234 & 505 & & & \\
\hline HEMBL 234 & 50588 & & & \\
\hline HEMBL 234 & 50588 & & & \\
\hline IEMBL234 & 88 & & & \\
\hline 58 & & & & ST \\
\hline HEMBL 234 & 38 & & & \\
\hline IEMBL234 & 38 & & & \\
\hline IEMBL234 & 50 & & & ות \\
\hline 29 & 38 & & & 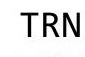 \\
\hline 43 & 8 & & & ST \\
\hline 91 & 8 & & & \\
\hline 87 & 8 & & & \\
\hline IEIMBLL 234 & 8 & & & \\
\hline 27 & 8 & & 3. & RN \\
\hline 83 & 8 & & & RN \\
\hline & & & & \\
\hline 84 & & & & SI \\
\hline IEIMBEL & 38 & & 4 . & $\mathrm{KI}$ \\
\hline 18 & 8 & & & 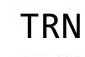 \\
\hline & & & & RN \\
\hline & & & & RN \\
\hline & & & & RN \\
\hline MBL234 & 8 & & & RI \\
\hline 55 & 8 & & & ST \\
\hline & & & & RN \\
\hline & & & & RN \\
\hline HEMBL234 & 50 & & & RN \\
\hline MBL & 0 & & & $\cdots$ \\
\hline 90 & 8 & & & RN \\
\hline & & & & ST \\
\hline & & & & RN \\
\hline IEMBL234 & 5 & & & $S T$ \\
\hline MBL & 8 & & & RN \\
\hline & & & & (1) \\
\hline & & & & ST \\
\hline IEMBL234 & 8 & & & ST \\
\hline MBL234 & 505 & & 93 & $S T$ \\
\hline 7 & & & & wr \\
\hline CHEMBL234 & & & 3.2847 & $\mathrm{R}$ \\
\hline CHEMBL 23 & 50588 & 3.2218 & 3.1977 & \\
\hline
\end{tabular}

Page 10503 


\begin{tabular}{|c|c|c|c|c|}
\hline & & & oplement & al $\mathrm{Tc}$ \\
\hline CHEMBL 2348915 & 950588 & 3.2218 & 3.0696 & TRN \\
\hline CHEMBL 2349038 & 950588 & 3.2218 & 3.1261 & TRN \\
\hline CHEMBL2348886 & 950588 & 4.4318 & 3.7841 & TRN \\
\hline CHEMBL2348880 & 950588 & 3.2218 & 3.4519 & TRN \\
\hline CHEMBL2349036 & 950588 & 3.2218 & 3.2024 & TRN \\
\hline CHEMBL2348878 & 950588 & 3.2218 & 3.4813 & TRN \\
\hline CHEMBL 2349050 & 950588 & 3.2218 & 3.2952 & TST \\
\hline CHEMBL2349033 & 950588 & 3.2218 & 3.0908 & TRN \\
\hline CHEMBL 2349034 & 950588 & 3.2218 & 3.093 & TRN \\
\hline CHEMBL2349054 & 950588 & 3.2218 & 3.3575 & TST \\
\hline CHEMBL2348920 & 950588 & 3.2218 & 3.2598 & TRN \\
\hline CHEMBL2348919 & 950588 & 3.2218 & 3.2384 & TRN \\
\hline CHEMBL2349031 & 950588 & 3.2218 & 3.1353 & TRN \\
\hline CHEMBL 2349035 & 950588 & 3.2218 & 3.0874 & TRN \\
\hline CHEMBL2349056 & 950588 & 3.2218 & 3.2887 & TST \\
\hline CHEMBL2349040 & 950588 & 3.2218 & 3.2411 & TST \\
\hline CHEMBL 2349045 & 950588 & 3.2218 & 3.2831 & TST \\
\hline CHEMBL 2348907 & 950588 & 3.2218 & 3.6188 & TRN \\
\hline CHEMBL2348921 & 950588 & 3.2218 & 3.1912 & TRN \\
\hline CHEMBL2348905 & 950588 & 3.2218 & 4.3109 & TST \\
\hline CHEMBL 2348882 & 950588 & 4.4815 & 4.0167 & TRN \\
\hline CHEMBL 2348906 & 950588 & 3.2218 & 3.1276 & TRN \\
\hline CHEMBL2348916 & 950588 & 3.2218 & 3.1539 & TRN \\
\hline CHEMBL 2349044 & 950588 & 3.2218 & 3.4035 & TST \\
\hline CHEMBL2348910 & 950588 & 3.2218 & 3.3662 & TRN \\
\hline CHEMBL 2348889 & 950588 & 3.2218 & 3.5 & TRN \\
\hline CHEMBL2348899 & 950588 & 3.2218 & 3.3318 & TRN \\
\hline CHEMBL 2348876 & 950588 & 3.2218 & 4.0091 & TST \\
\hline CHEMBL2348897 & 950588 & 3.2218 & 3.2197 & TRN \\
\hline CHEMBL 2349030 & 950588 & 3.2218 & 3.225 & TRN \\
\hline CHEMBL2348911 & 950588 & 3.2218 & 3.3804 & TRN \\
\hline CHEMBL2348926 & 950588 & 3.2218 & 3.6601 & TRN \\
\hline CHEMBL 2349047 & 950588 & 3.2218 & 3.5186 & TST \\
\hline CHEMBL2348903 & 950588 & 3.2218 & 3.3947 & TST \\
\hline CHEMBL1344330 & 737039 & 4.4966 & 3.6488 & TRN \\
\hline CHEMBL1993173 & 737039 & 5.7466 & 4.2792 & TRN \\
\hline CHEMBL1527903 & 737039 & 4.144 & 4.1714 & TRN \\
\hline CHEMBL1559707 & 737039 & 2.699 & 3.3633 & TRN \\
\hline CHEMBL1301828 & 737039 & 2.699 & 3.4243 & TST \\
\hline CHEMBL1380232 & 737039 & 5.1906 & 3.6595 & TRN \\
\hline CHEMBL1672292 & 737039 & 2.699 & 2.653 & TRN \\
\hline CHEMBL1320481 & 737039 & 3.7757 & 4.1887 & TRN \\
\hline CHEMBL1578893 & 737039 & 2.699 & 3.2245 & TST \\
\hline CHEMBL1354019 & 737039 & 5.6901 & 5.1812 & TRN \\
\hline CHEMBL1447326 & 737039 & 2.699 & 2.1806 & TRN \\
\hline CHEMBL1550672 & 737039 & 2.699 & 2.9919 & TRN \\
\hline CHEMBL1411702 & 737039 & 5.1488 & 3.9332 & TRN \\
\hline CHEMBL1309682 & 737039 & 3.887 & 3.5029 & TST \\
\hline
\end{tabular}




\begin{tabular}{|c|c|c|c|c|c|c|}
\hline & & \multicolumn{5}{|c|}{ Supplemental Table S2.txt } \\
\hline CHEMBL1308195 & 737039 & 5.3945 & 4.3146 & TRN & & \\
\hline CHEMBL1612112 & 737039 & 6.8069 & 5.4793 & TRN & & \\
\hline CHEMBL1605743 & 737039 & 2.699 & 4.6318 & TRN & & \\
\hline CHEMBL1363428 & 737039 & 2.699 & 3.6706 & TRN & & \\
\hline CHEMBL1469472 & 737039 & 2.699 & 3.2319 & TRN & & \\
\hline CHEMBL1447803 & 737039 & 5.37 & 4.5183 & TRN & & \\
\hline CHEMBL1443623 & 737039 & 2.699 & 3.9455 & TST & & \\
\hline CHEMBL1312953 & 737039 & 2.699 & 2.9217 & TST & & \\
\hline CHEMBL1602055 & 737039 & 4.9748 & 4.9377 & TRN & & \\
\hline CHEMBL 1457702 & 737039 & 5.0032 & 4.6347 & TRN & & \\
\hline CHEMBL 2003304 & 737039 & 2.699 & 3.56600 & 20000 & 003 & TRN \\
\hline CHEMBL3190895 & 737039 & 5.5947 & 4.6909 & TRN & & \\
\hline CHEMBL1585746 & 737039 & 5.7228 & 4.2789 & TRN & & \\
\hline CHEMBL1445259 & 737039 & 4.9512 & 4.1215 & TRN & & \\
\hline CHEMBL1438567 & 737039 & 5.3455 & 4.507 & TRN & & \\
\hline CHEMBL1300620 & 737039 & \multicolumn{3}{|c|}{5.6370000000000005} & 5.5834 & TRN \\
\hline CHEMBL1427838 & 737039 & 2.699 & 3.2323 & TRN & & \\
\hline CHEMBL1304979 & 737039 & 5.6646 & 5.3873 & TRN & & \\
\hline CHEMBL3192206 & 737039 & 2.699 & 4.6326 & TRN & & \\
\hline CHEMBL3211983 & 737039 & 2.699 & 3.4191 & TST & & \\
\hline CHEMBL1572208 & 737039 & 4.8369 & 4.0283 & TRN & & \\
\hline CHEMBL1455832 & 737039 & \multicolumn{3}{|c|}{5.3420000000000005} & 4.2044 & TRN \\
\hline CHEMBL1527528 & 737039 & 2.699 & 3.1019 & TRN & & \\
\hline CHEMBL1458402 & 737039 & 2.699 & 2.3153 & TRN & & \\
\hline CHEMBL1521960 & 737039 & 2.699 & 3.175 & TRN & & \\
\hline CHEMBL1451931 & 737039 & 4.8071 & 4.725 & TRN & & \\
\hline CHEMBL1545384 & 737039 & 5.1743 & 5.314 & TRN & & \\
\hline CHEMBL1512862 & 737039 & 2.699 & 3.6632 & TRN & & \\
\hline CHEMBL1594257 & 737039 & 2.699 & 4.0145 & TRN & & \\
\hline CHEMBL1466913 & 737039 & 2.699 & 3.3818 & TST & & \\
\hline CHEMBL1480087 & 737039 & 2.699 & 4.3492 & TRN & & \\
\hline CHEMBL1603305 & 737039 & 3.9796 & 2.8287 & TRN & & \\
\hline CHEMBL1563488 & 737039 & 2.699 & 3.5342 & TRN & & \\
\hline CHEMBL1352196 & 737039 & 2.699 & 3.2448 & TST & & \\
\hline CHEMBL1433943 & 737039 & 2.699 & 2.5651 & TRN & & \\
\hline CHEMBL1999473 & 737039 & 4.7387 & 4.5702 & TRN & & \\
\hline CHEMBL1351543 & 737039 & 5.1161 & 3.1828 & TRN & & \\
\hline CHEMBL1362538 & 737039 & 2.699 & 2.8744 & TRN & & \\
\hline CHEMBL 2028186 & 737039 & 5.67 & 3.2852 & TST & & \\
\hline CHEMBL1587842 & 737039 & 2.699 & 3.7345 & TST & & \\
\hline CHEMBL1379309 & 737039 & 2.699 & 2.1229 & TRN & & \\
\hline CHEMBL1427763 & 737039 & 6.8069 & 3.9504 & TRN & & \\
\hline CHEMBL3208613 & 737039 & 2.699 & 3.8121 & TST & & \\
\hline CHEMBL1529584 & 737039 & 5.3583 & 4.3381 & TRN & & \\
\hline CHEMBL1302539 & 737039 & 2.699 & 2.4089 & TRN & & \\
\hline CHEMBL1964978 & 737039 & 4.7203 & 3.5313 & TRN & & \\
\hline CHEMBL1995336 & 737039 & 2.699 & 3.4379 & TRN & & \\
\hline CHEMBL1360857 & 737039 & 5.0702 & 3.8456 & TRN & & \\
\hline
\end{tabular}




\begin{tabular}{|c|c|c|c|c|c|}
\hline & & \multicolumn{4}{|c|}{ Supplemental Table S2.txt } \\
\hline CHEMBL1405964 & 737039 & 5.7959 & 5.4786 & TRN & \\
\hline CHEMBL1320537 & 737039 & 5.3594 & 5.4154 & TRN & \\
\hline CHEMBL1522307 & 737039 & 2.699 & 4.3662 & TST & \\
\hline CHEMBL1575065 & 737039 & 2.699 & 3.0064 & TRN & \\
\hline CHEMBL418068 & 737039 & 2.699 & 4.5391 & TRN & \\
\hline CHEMBL1503962 & 737039 & 2.699 & 4.1228 & TRN & \\
\hline CHEMBL1502870 & 737039 & 2.699 & 2.7075 & TRN & \\
\hline CHEMBL1440277 & 737039 & 5.4078 & 4.3884 & TRN & \\
\hline CHEMBL1532953 & 737039 & 5.4679 & 5.4786 & TRN & \\
\hline CHEMBL1388952 & 737039 & 2.699 & 3.2488 & TST & \\
\hline CHEMBL1384253 & 737039 & 2.699 & 3.5804 & TRN & \\
\hline CHEMBL1558097 & 737039 & 2.699 & 3.6637 & TRN & \\
\hline CHEMBL1462636 & 737039 & 5.0409 & 4.8587 & TRN & \\
\hline CHEMBL1379737 & 737039 & 2.699 & 3.2071 & TRN & \\
\hline CHEMBL1548790 & 737039 & 2.699 & 3.6162 & TRN & \\
\hline CHEMBL1608791 & 737039 & 4.5362 & 3.9697 & TST & \\
\hline CHEMBL1344245 & 737039 & 2.699 & 3.4635 & TRN & \\
\hline CHEMBL269122 & 737039 & 2.699 & 4.8894 & TRN & \\
\hline CHEMBL1323252 & 737039 & 6.8069 & 5.975 & TRN & \\
\hline CHEMBL1303641 & 737039 & 2.699 & 4.0201 & TRN & \\
\hline CHEMBL1568206 & 737039 & 2.699 & 4.1184 & TRN & \\
\hline CHEMBL1511181 & 737039 & 6.8069 & 6.3771 & TRN & \\
\hline CHEMBL1302747 & 737039 & 2.699 & 3.1717 & TRN & \\
\hline CHEMBL1990694 & 737039 & 2.699 & 3.804 & TRN & \\
\hline CHEMBL1390860 & 737039 & 5.2064 & 4.3785 & TRN & \\
\hline CHEMBL1352903 & 737039 & 4.622 & 3.7566 & TRN & \\
\hline CHEMBL1367787 & 737039 & 2.699 & 4.1721 & TRN & \\
\hline CHEMBL1308037 & 737039 & 2.699 & 5.4864 & TRN & \\
\hline CHEMBL1348090 & 737039 & 5.6214 & 5.1411 & TRN & \\
\hline CHEMBL1509938 & 737039 & 2.699 & 3.6452 & TST & \\
\hline CHEMBL3210910 & 737039 & 2.699 & 3.2061 & TRN & \\
\hline CHEMBL1308993 & 737039 & 4.9754 & 3.9503 & TRN & \\
\hline CHEMBL1423844 & 737039 & 2.699 & 2.7808 & TRN & \\
\hline CHEMBL1415156 & 737039 & 5.4278 & 5.3495 & TRN & \\
\hline CHEMBL1447211 & 737039 & 2.699 & 4.1388 & TST & \\
\hline CHEMBL1505642 & 737039 & 2.699 & 3.1412 & TRN & \\
\hline CHEMBL3193946 & 737039 & 5.5329 & 4.301 & TRN & \\
\hline CHEMBL1569997 & 737039 & 4.9286 & 3.5101 & TRN & \\
\hline CHEMBL1546183 & 737039 & 5.3318 & 3.7481 & TRN & \\
\hline CHEMBL88326 & 737039 & 6.8069 & 4.6991 & TRN & \\
\hline CHEMBL1455712 & 737039 & 2.699 & 2.79 & TST & \\
\hline CHEMBL1325241 & 737039 & 4.2948 & 4.0564 & TRN & \\
\hline CHEMBL1462687 & 737039 & 4.9354 & 5.2918 & TRN & \\
\hline CHEMBL1446738 & 737039 & 2.699 & 3.1391 & TRN & \\
\hline CHEMBL1466263 & 737039 & 2.699 & 2.5255 & TRN & \\
\hline CHEMBL1420123 & 737039 & 2.699 & 4.0753 & TRN & \\
\hline CHEMBL1367225 & 737039 & 2.699 & $2.6660 e$ & 00000000004 & TST \\
\hline CHEMBL1526865 & 737039 & 2.699 & 3.1693 & TRN & \\
\hline
\end{tabular}




\begin{tabular}{|c|c|c|c|c|c|c|}
\hline & & \multicolumn{5}{|c|}{ Supplemental Table S2.txt } \\
\hline CHEMBL3195851 & 737039 & 2.699 & 2.6872 & TRN & & \\
\hline CHEMBL1389315 & 737039 & 5.67899 & 79999999 & 99 & 5.185 & TRN \\
\hline CHEMBL1304114 & 737039 & 2.699 & 2.3471 & TRN & & \\
\hline CHEMBL1564363 & 737039 & 2.699 & 3.1998 & TRN & & \\
\hline CHEMBL1346753 & 737039 & 5.4025 & 4.5307 & TRN & & \\
\hline CHEMBL1469444 & 737039 & 2.699 & 3.3489 & TRN & & \\
\hline CHEMBL1334670 & 737039 & 5.2666 & 4.3263 & TRN & & \\
\hline CHEMBL1310325 & 737039 & 2.699 & 4.436 & TRN & & \\
\hline CHEMBL1533336 & 737039 & 4.2263 & 4.6966 & TRN & & \\
\hline CHEMBL1410750 & 737039 & 2.699 & 3.3836 & TRN & & \\
\hline CHEMBL1300769 & 737039 & 2.699 & 4.7134 & TRN & & \\
\hline CHEMBL1503523 & 737039 & 5.7517 & 6.2138 & TRN & & \\
\hline CHEMBL1454269 & 737039 & 5.2916 & 4.3408 & TRN & & \\
\hline CHEMBL1302170 & 737039 & 5.2182 & 4.2866 & TRN & & \\
\hline CHEMBL1548333 & 737039 & 5.1371 & 5.0739 & TRN & & \\
\hline CHEMBL1598597 & 737039 & 2.699 & 3.1815 & TRN & & \\
\hline CHEMBL1483823 & 737039 & 2.699 & 3.5842 & TRN & & \\
\hline CHEMBL1481369 & 737039 & 2.699 & 2.1852 & TRN & & \\
\hline CHEMBL1416360 & 737039 & 3.9982 & 3.1219 & TRN & & \\
\hline CHEMBL1452593 & 737039 & 2.699 & 3.2585 & TRN & & \\
\hline CHEMBL1343560 & 737039 & 2.699 & 3.4487 & TRN & & \\
\hline CHEMBL2000670 & 737039 & 5.4267 & 5.155 & TRN & & \\
\hline CHEMBL1368362 & 737039 & 4.678 & 4.618 & TST & & \\
\hline CHEMBL1998038 & 737039 & 4.0117 & 3.4617 & TST & & \\
\hline CHEMBL1340316 & 737039 & 2.699 & 3.0161 & TST & & \\
\hline CHEMBL1370375 & 737039 & 5.2262 & 3.8513 & TST & & \\
\hline CHEMBL1323674 & 737039 & 6.8069 & 4.537 & TST & & \\
\hline CHEMBL1490594 & 737039 & 2.699 & 4.0267 & TST & & \\
\hline CHEMBL1440953 & 737039 & 2.699 & 3.8445 & TST & & \\
\hline CHEMBL1365210 & 737039 & 4.7657 & 3.3614 & TST & & \\
\hline CHEMBL1536144 & 737039 & 4.3682 & 3.6368 & TST & & \\
\hline CHEMBL1459861 & 737039 & 2.699 & 3.3371 & TST & & \\
\hline CHEMBL3195461 & 737039 & 4.827 & 4.28 & TST & & \\
\hline CHEMBL1416302 & 737039 & 5.2976 & 4.1715 & TST & & \\
\hline CHEMBL1334149 & 737039 & 5.7324 & 3.5085 & TST & & \\
\hline CHEMBL1369492 & 737039 & 5.052 & 4.0865 & TST & & \\
\hline CHEMBL1985649 & 737039 & 5.2512 & 3.7904 & TST & & \\
\hline CHEMBL1351935 & 737039 & 5.2003 & 3.3877 & TST & & \\
\hline CHEMBL1300876 & 737039 & 2.699 & 4.7059 & TST & & \\
\hline CHEMBL1360708 & 737039 & 2.699 & 2.5441 & TST & & \\
\hline CHEMBL1478085 & 737039 & 5.1966 & 4.2362 & TST & & \\
\hline CHEMBL1433585 & 737039 & 4.9421 & 4.3294 & TST & & \\
\hline CHEMBL1094352 & 629724 & 7.2366 & 7.0429 & TST & & \\
\hline CHEMBL1097880 & 629724 & 8.0 & 8.019 & TRN & & \\
\hline CHEMBL1097657 & 629724 & 7.6576 & 7.3444 & TRN & & \\
\hline CHEMBL1098841 & 629724 & 7.4202 & 7.3767 & TRN & & \\
\hline CHEMBL1098063 & 629724 & 6.2147 & 6.1599 & TRN & & \\
\hline CHEMBL1096160 & 629724 & 6.9547 & 6.8705 & TRN & & \\
\hline
\end{tabular}


Supplemental Table S2.txt

\begin{tabular}{|c|c|c|c|c|}
\hline CHEMBL1098802 & 629724 & 7.6576 & 7.7491 & TRN \\
\hline CHEMBL1097858 & 629724 & 7.6778 & 7.7013 & TRN \\
\hline CHEMBL1097873 & 629724 & 5.6653 & 6.4709 & TST \\
\hline CHEMBL1097879 & 629724 & 6.2596 & 6.2389 & TRN \\
\hline CHEMBL1097472 & 629724 & 6.5686 & 6.6285 & TRN \\
\hline CHEMBL1099188 & 629724 & 8.0 & 7.7487 & TST \\
\hline CHEMBL1096201 & 629724 & 5.6354 & 6.2687 & TST \\
\hline CHEMBL1098871 & 629724 & 7.9586 & 7.5937 & TRN \\
\hline CHEMBL1098209 & 629724 & 7.8239 & 7.8961 & TRN \\
\hline CHEMBL1098856 & 629724 & 7.9208 & 7.8846 & TRN \\
\hline CHEMBL1096501 & 629724 & 7.4202 & 7.5687 & TRN \\
\hline CHEMBL1096976 & 629724 & 4.857 & 4.9518 & TRN \\
\hline CHEMBL1098062 & 629724 & 6.2111 & 6.0643 & TRN \\
\hline CHEMBL1099070 & 629724 & 6.9318 & 6.9711 & TRN \\
\hline CHEMBL1098210 & 629724 & 8.0 & 7.8949 & TRN \\
\hline CHEMBL1094406 & 629724 & 7.2757 & 7.3179 & TRN \\
\hline CHEMBL1097285 & 629724 & 6.8861 & 6.9332 & TRN \\
\hline CHEMBL1096377 & 629724 & 6.1024 & 6.0086 & TRN \\
\hline CHEMBL1095558 & 629724 & 8.0 & 7.8828 & TRN \\
\hline CHEMBL1095559 & 629724 & 7.8239 & 7.4508 & TRN \\
\hline CHEMBL1098515 & 629724 & 6.0315 & 6.1445 & TRN \\
\hline CHEMBL1086836 & 629724 & 7.4559 & 7.5619 & TST \\
\hline CHEMBL1095557 & 629724 & 6.8539 & 7.0297 & TRN \\
\hline CHEMBL1099189 & 629724 & 5.9393 & 6.4201 & TST \\
\hline CHEMBL1098803 & 629724 & 7.8239 & 7.8707 & TRN \\
\hline CHEMBL30392 & 629724 & 5.6364 & 5.6463 & TST \\
\hline CHEMBL1096843 & 629724 & 7.3372 & 7.5061 & TRN \\
\hline CHEMBL1097157 & 629724 & 7.5528 & 7.4967 & TRN \\
\hline CHEMBL1094566 & 629724 & 5.7156 & 5.5069 & TRN \\
\hline CHEMBL1097473 & 629724 & 5.295 & 5.2935 & TRN \\
\hline CHEMBL1094989 & 629724 & 7.699 & 7.17399 & 79999999995 \\
\hline CHEMBL1098474 & 629724 & 7.6778 & 7.63299 & э999999999 \\
\hline CHEMBL1095231 & 629724 & 7.4685 & 7.5181 & TRN \\
\hline CHEMBL1098804 & 629724 & 7.6383 & 7.6931 & TRN \\
\hline CHEMBL1094560 & 629724 & 7.3279 & 7.52 & TRN \\
\hline CHEMBL1099060 & 629724 & 6.7696 & 6.5778 & TRN \\
\hline CHEMBL1094404 & 629724 & 6.4559 & 6.9082 & TRN \\
\hline CHEMBL1098491 & 629724 & 5.6696 & 6.5078 & TST \\
\hline CHEMBL1095532 & 629724 & 7.1308 & 7.2736 & TRN \\
\hline CHEMBL1099222 & 629724 & 7.8239 & 7.5077 & TST \\
\hline CHEMBL1096376 & 629724 & 6.9788 & 7.3715 & TRN \\
\hline CHEMBL1094740 & 629724 & 7.4318 & 7.5395 & TRN \\
\hline CHEMBL1095092 & 629724 & 5.6872 & 5.6402 & TRN \\
\hline CHEMBL1094565 & 629724 & 4.3979 & 4.544 & TRN \\
\hline CHEMBL1097464 & 629724 & 7.3979 & 7.3628 & TRN \\
\hline CHEMBL1096378 & 629724 & 7.0177 & 7.2597 & TRN \\
\hline CHEMBL1096518 & 629724 & 7.8239 & 7.8134 & TRN \\
\hline CHEMBL1094892 & 629724 & 7.3665 & 7.3515 & TRN \\
\hline
\end{tabular}




\begin{tabular}{|c|c|c|c|c|c|}
\hline \multicolumn{6}{|c|}{ Supplemental Table s2.txt } \\
\hline CHEMBL1094405 & 629724 & 7.3468 & 7.1818 & TRN & \\
\hline CHEMBL1099071 & 629724 & 7.1024 & 7.2338 & TRN & \\
\hline CHEMBL1096841 & 629724 & 7.4089 & 8.2233 & TST & \\
\hline CHEMBL1095091 & 629724 & 6.6716 & 6.4945 & TST & \\
\hline CHEMBL1097857 & 629724 & 7.0862 & 8.075 & TST & \\
\hline CHEMBL1098840 & 629724 & 7.9586 & 6.8248 & TST & \\
\hline CHEMBL1098064 & 629724 & 7.3468 & 6.0997 & TST & \\
\hline CHEMBL1098864 & 629724 & 7.699 & 7.6413 & TST & \\
\hline CHEMBL1098001 & 629724 & 7.4559 & 6.8503 & TST & \\
\hline CHEMBL455192 & 511069 & 8.699 & 8.8723 & TRN & \\
\hline CHEMBL508515 & 511069 & 7.6778 & 7.6471 & TRN & \\
\hline CHEMBL459889 & 511069 & 5.3565 & 5.3396 & TRN & \\
\hline CHEMBL508516 & 511069 & 7.0177 & 6.5517 & TRN & \\
\hline CHEMBL452829 & 511069 & 5.8861 & 6.0105 & TRN & \\
\hline CHEMBL452078 & 511069 & 5.7696 & 5.4958 & TRN & \\
\hline CHEMBL488054 & 511069 & 6.7447 & 6.835 & TRN & \\
\hline CHEMBL511992 & 511069 & 6.9208 & 5.7359 & TRN & \\
\hline CHEMBL515352 & 511069 & 5.0969 & 5.0302 & TRN & \\
\hline CHEMBL520240 & 511069 & 6.6383 & 6.7873 & TRN & \\
\hline CHEMBL 209388 & 511069 & 6.6576 & 6.5175 & TRN & \\
\hline CHEMBL519891 & 511069 & 7.2676 & 7.2421 & TRN & \\
\hline CHEMBL452079 & 511069 & 6.6778 & 6.7873 & TRN & \\
\hline CHEMBL529897 & 511069 & 6.5686 & 6.1882 & TRN & \\
\hline CHEMBL513079 & 511069 & 6.3768 & 6.50200 & 3000000001 & TST \\
\hline CHEMBL487891 & 511069 & 6.699 & 6.8095 & TRN & \\
\hline CHEMBL 214253 & 511069 & 7.3279 & 7.1174 & TST & \\
\hline CHEMBL472542 & 511069 & 7.2676 & 7.2194 & TRN & \\
\hline CHEMBL488899 & 511069 & 6.6021 & 6.8582 & TRN & \\
\hline CHEMBL508294 & 511069 & 5.4685 & 5.7821 & TRN & \\
\hline CHEMBL472209 & 511069 & 7.1135 & 6.3033 & TST & \\
\hline CHEMBL519238 & 511069 & 7.4437 & 7.0828 & TRN & \\
\hline CHEMBL462170 & 511069 & 6.3872 & 6.2815 & TRN & \\
\hline CHEMBL512342 & 511069 & 5.8539 & 6.3766 & TST & \\
\hline CHEMBL512341 & 511069 & 7.7447 & 7.7814 & TRN & \\
\hline CHEMBL460939 & 511069 & 4.0 & 4.8453 & TRN & \\
\hline CHEMBL 215900 & 511069 & 4.4559 & 5.6767 & TRN & \\
\hline CHEMBL486828 & 511069 & 5.2291 & 5.3913 & TRN & \\
\hline CHEMBL472208 & 511069 & 6.9208 & 6.675 & TST & \\
\hline CHEMBL471156 & 511069 & 7.0555 & 7.1009 & TRN & \\
\hline CHEMBL214005 & 511069 & 7.2518 & 7.1712 & TST & \\
\hline CHEMBL512012 & 511069 & 7.4559 & 7.86299 & 99999999995 & TRN \\
\hline CHEMBL511991 & 511069 & 6.3768 & 6.5401 & TRN & \\
\hline CHEMBL411662 & 511069 & 6.7696 & 6.7102 & TRN & \\
\hline CHEMBL470113 & 511069 & 6.4437 & 6.7386 & TRN & \\
\hline CHEMBL471329 & 511069 & 6.2007 & 6.5682 & TST & \\
\hline CHEMBL 213593 & 511069 & 5.9208 & 6.0797 & TST & \\
\hline CHEMBL460940 & 511069 & 5.6021 & 5.8669 & TRN & \\
\hline CHEMBL520071 & 511069 & 5.3665 & 5.2831 & TRN & \\
\hline
\end{tabular}




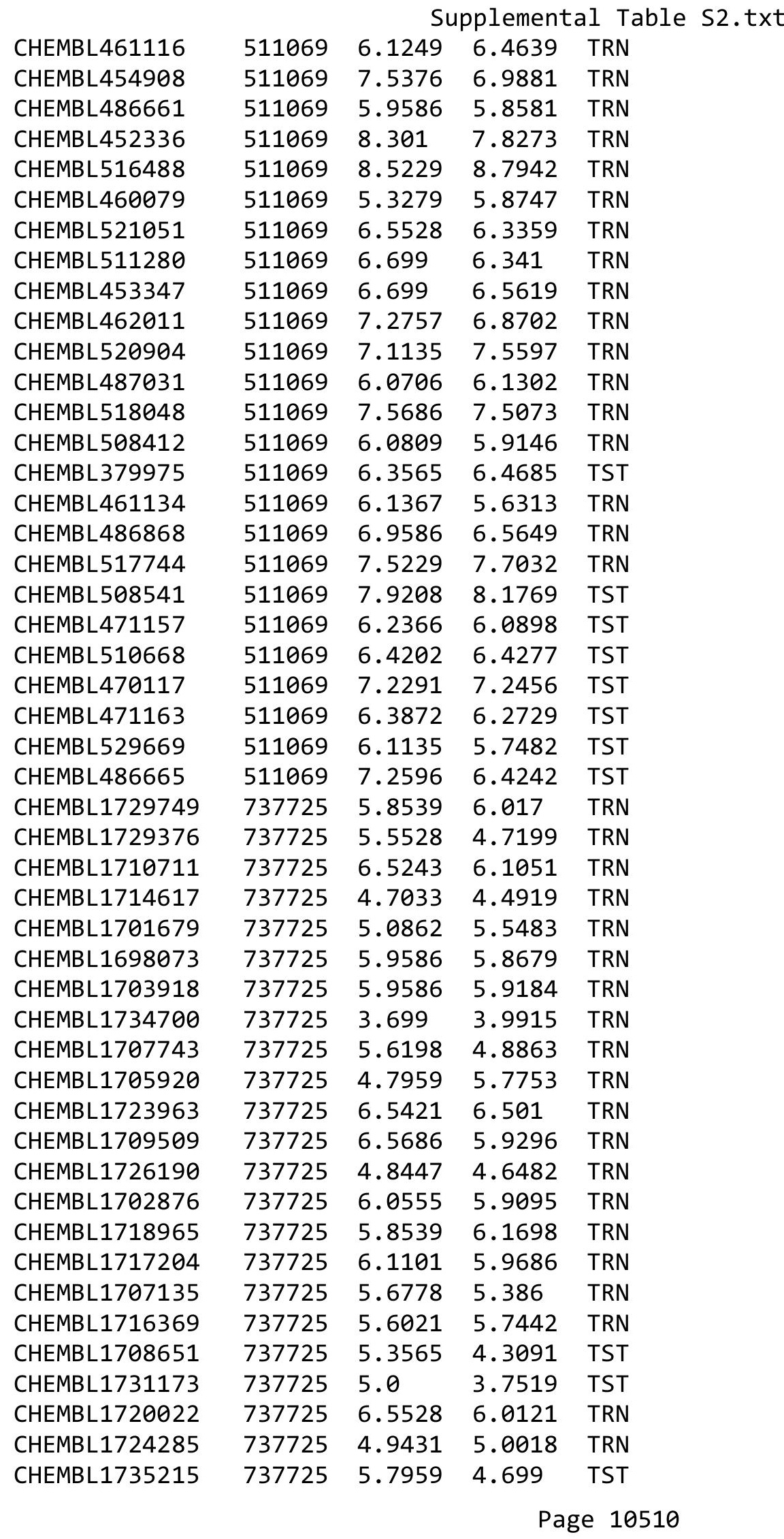


Supplemental Table S2.txt

\begin{tabular}{|c|c|c|c|c|c|}
\hline CHEMBL1311692 & 737725 & 3.699 & 4.2637 & TST & \\
\hline CHEMBL1697929 & 737725 & 6.0 & 6.0899 & TRN & \\
\hline CHEMBL1703562 & 737725 & 6.1675 & 6.1766 & TRN & \\
\hline CHEMBL1713683 & 737725 & 5.0132 & 4.8173 & TRN & \\
\hline CHEMBL1584538 & 737725 & 5.6576 & 6.0703 & TRN & \\
\hline CHEMBL1715364 & 737725 & 3.699 & 3.7197 & TRN & \\
\hline CHEMBL1718881 & 737725 & 3.699 & 3.8785 & TRN & \\
\hline CHEMBL1725011 & 737725 & 5.6383 & 4.7911 & TST & \\
\hline CHEMBL1700476 & 737725 & 6.3872 & 6.1816 & TRN & \\
\hline CHEMBL1727473 & 737725 & 4.9706 & 5.0778 & TRN & \\
\hline CHEMBL1710542 & 737725 & 3.699 & 4.848 & TRN & \\
\hline CHEMBL1729911 & 737725 & 5.6383 & 5.8792 & TRN & \\
\hline CHEMBL1708907 & 737725 & 5.0605 & 5.2875 & TRN & \\
\hline CHEMBL1706988 & 737725 & 6.1688 & 6.0953 & TRN & \\
\hline CHEMBL1710048 & 737725 & 4.9586 & 3.2925 & TST & \\
\hline CHEMBL1716158 & 737725 & 4.9136 & 5.57600 & 00000000005 & TRN \\
\hline CHEMBL1699198 & 737725 & 6.1618 & 6.2644 & TRN & \\
\hline CHEMBL1712328 & 737725 & 4.7399 & 4.8567 & TRN & \\
\hline CHEMBL1724571 & 737725 & 5.7959 & 5.5535 & TRN & \\
\hline CHEMBL1698337 & 737725 & 5.2076 & 4.9039 & TRN & \\
\hline CHEMBL1719118 & 737725 & 5.0 & 4.9989 & TRN & \\
\hline CHEMBL1734525 & 737725 & 5.2596 & 4.7426 & TRN & \\
\hline CHEMBL1706758 & 737725 & 6.0074 & 6.00700 & 0000000001 & TRN \\
\hline CHEMBL1350024 & 737725 & 3.699 & 3.9994 & TST & \\
\hline CHEMBL1723067 & 737725 & 5.5528 & 6.0143 & TRN & \\
\hline CHEMBL1456577 & 737725 & 3.699 & 3.1706 & TST & \\
\hline CHEMBL1729021 & 737725 & 6.5654 & 6.3671 & TRN & \\
\hline CHEMBL1705499 & 737725 & 6.1864 & 5.8288 & TRN & \\
\hline CHEMBL1729987 & 737725 & 4.7932 & 4.684 & TRN & \\
\hline CHEMBL1715946 & 737725 & 5.2007 & 5.4357 & TRN & \\
\hline CHEMBL1710499 & 737725 & 5.3768 & 5.0554 & TRN & \\
\hline CHEMBL1722551 & 737725 & 4.7959 & 4.7451 & TST & \\
\hline CHEMBL1720787 & 737725 & 6.1403 & 5.4246 & TRN & \\
\hline CHEMBL1707830 & 737725 & 5.9208 & 6.1877 & TRN & \\
\hline CHEMBL1730555 & 737725 & 5.9208 & 5.853 & TRN & \\
\hline CHEMBL1710120 & 737725 & 3.699 & 4.3314 & TRN & \\
\hline CHEMBL1705448 & 737725 & 6.1864 & 6.1846 & TRN & \\
\hline CHEMBL1701301 & 737725 & 3.699 & 5.3059 & TST & \\
\hline CHEMBL1728621 & 737725 & 5.2076 & 4.9888 & TRN & \\
\hline CHEMBL1731906 & 737725 & 5.5528 & 4.4569 & TST & \\
\hline CHEMBL1706556 & 737725 & 5.3872 & 5.6348 & TRN & \\
\hline CHEMBL1716381 & 737725 & 5.1249 & 5.0177 & TRN & \\
\hline CHEMBL1703414 & 737725 & 5.5376 & 5.4328 & TRN & \\
\hline CHEMBL1736481 & 737725 & 5.7696 & 6.3821 & TRN & \\
\hline CHEMBL1733129 & 737725 & 6.2403 & 6.2208 & TRN & \\
\hline CHEMBL1708047 & 737725 & 5.3872 & 3.7095 & TST & \\
\hline CHEMBL1702161 & 737725 & 5.2676 & 5.1029 & TST & \\
\hline CHEMBL1728485 & 737725 & 5.1549 & 5.4582 & TRN & \\
\hline
\end{tabular}


Supplemental Table S2.txt

\begin{tabular}{|c|c|c|c|c|}
\hline CHEMBL1458112 & 737725 & 5.2366 & 5.1363 & TST \\
\hline CHEMBL1701512 & 737725 & 5.4815 & 4.3598 & TST \\
\hline CHEMBL1728794 & 737725 & 6.2426 & 6.1276 & TRN \\
\hline CHEMBL1713871 & 737725 & 5.2518 & 4.9546 & TRN \\
\hline CHEMBL1703306 & 737725 & 5.7959 & 5.40799 & 99999999995 \\
\hline CHEMBL1717450 & 737725 & 6.1871 & 5.9543 & TRN \\
\hline CHEMBL1698879 & 737725 & 5.6576 & 5.921 & TRN \\
\hline CHEMBL1710128 & 737725 & 6.1871 & 5.7819 & TRN \\
\hline CHEMBL1723453 & 737725 & 3.699 & 4.4692 & TRN \\
\hline CHEMBL1735852 & 737725 & 6.1427 & 5.4736 & TST \\
\hline CHEMBL1734822 & 737725 & 4.7905 & 4.0962 & TST \\
\hline CHEMBL1721648 & 737725 & 6.4449 & 5.6316 & TST \\
\hline CHEMBL1726382 & 737725 & 5.8861 & 5.9106 & TST \\
\hline CHEMBL1699874 & 737725 & 5.1549 & 4.3545 & TST \\
\hline CHEMBL1733974 & 737725 & 5.0458 & 4.2512 & TST \\
\hline CHEMBL1732922 & 737725 & 5.5686 & 4.7265 & TST \\
\hline CHEMBL1580338 & 688631 & 3.1003 & 3.0429 & TRN \\
\hline CHEMBL1388862 & 688631 & 4.0546 & 3.6244 & TST \\
\hline CHEMBL1607604 & 688631 & 3.1003 & 3.674 & TRN \\
\hline CHEMBL1537230 & 688631 & 3.1003 & 3.1219 & TRN \\
\hline CHEMBL1450791 & 688631 & 3.1003 & 3.2904 & TRN \\
\hline CHEMBL1398693 & 688631 & 3.1003 & 3.1804 & TST \\
\hline CHEMBL1420204 & 688631 & 3.1003 & 3.0385 & TRN \\
\hline CHEMBL1446907 & 688631 & 3.1003 & 3.0474 & TRN \\
\hline CHEMBL1412367 & 688631 & 4.0546 & 3.1552 & TRN \\
\hline CHEMBL1542120 & 688631 & 3.1003 & 3.1899 & TRN \\
\hline CHEMBL1409776 & 688631 & 3.1003 & 3.6702 & TST \\
\hline CHEMBL1594622 & 688631 & 3.1003 & 3.0513 & TRN \\
\hline CHEMBL1349621 & 688631 & 4.6625 & 3.8474 & TST \\
\hline CHEMBL1568508 & 688631 & 3.1003 & 3.2808 & TRN \\
\hline CHEMBL1303028 & 688631 & 4.3021 & 3.5961 & TRN \\
\hline CHEMBL3196920 & 688631 & 3.1003 & 3.4293 & TRN \\
\hline CHEMBL1388589 & 688631 & 3.1003 & 3.7694 & TRN \\
\hline CHEMBL1454677 & 688631 & 4.5318 & 3.5661 & TRN \\
\hline CHEMBL1332040 & 688631 & 3.1003 & 3.4883 & TST \\
\hline CHEMBL1164316 & 688631 & 3.1003 & 3.5367 & TRN \\
\hline CHEMBL1362711 & 688631 & 3.1003 & 3.4815 & TRN \\
\hline CHEMBL1490285 & 688631 & 3.1003 & 3.0488 & TRN \\
\hline CHEMBL1531023 & 688631 & 3.1003 & 3.0413 & TRN \\
\hline CHEMBL1301494 & 688631 & 3.1003 & 3.109 & TRN \\
\hline CHEMBL1423531 & 688631 & 3.1003 & 3.1207 & TRN \\
\hline CHEMBL1484186 & 688631 & 3.1003 & 3.5501 & TST \\
\hline CHEMBL1318957 & 688631 & 3.1003 & 3.4375 & TRN \\
\hline CHEMBL1586211 & 688631 & 3.1003 & 3.4201 & TRN \\
\hline CHEMBL1305440 & 688631 & 3.1003 & 3.1239 & TRN \\
\hline CHEMBL1392806 & 688631 & 4.2314 & 3.4818 & TRN \\
\hline CHEMBL1587890 & 688631 & 3.1003 & 3.0421 & TRN \\
\hline CHEMBL1587044 & 688631 & 4.0803 & 3.5091 & TRN \\
\hline
\end{tabular}

Page 10512 
Supplemental Table S2.txt

\begin{tabular}{|c|c|c|c|c|}
\hline CHEMBL1604196 & 688631 & 3.1003 & 3.4012 & TRN \\
\hline CHEMBL1322491 & 688631 & 3.1003 & 3.2827 & TRN \\
\hline CHEMBL1521960 & 688631 & 3.1003 & 3.5717 & TST \\
\hline CHEMBL1313532 & 688631 & 3.1003 & 3.0385 & TRN \\
\hline CHEMBL1488460 & 688631 & 3.1003 & 3.6498 & TRN \\
\hline CHEMBL1425009 & 688631 & 3.1003 & 3.1071 & TRN \\
\hline CHEMBL1557028 & 688631 & 3.1003 & 3.1914 & TRN \\
\hline CHEMBL1490470 & 688631 & 3.1003 & 3.5136 & TRN \\
\hline CHEMBL3196830 & 688631 & 3.1003 & 3.5885 & TRN \\
\hline CHEMBL1547204 & 688631 & 3.1003 & 3.1188 & TRN \\
\hline CHEMBL1359775 & 688631 & 5.4866 & 3.6149 & TRN \\
\hline CHEMBL1370794 & 688631 & 3.1003 & 3.5012 & TRN \\
\hline CHEMBL1366593 & 688631 & 3.1003 & 3.42199 & 99999999997 \\
\hline CHEMBL1490437 & 688631 & 3.1003 & 3.0477 & TRN \\
\hline CHEMBL1444315 & 688631 & 3.5774 & 3.5142 & TST \\
\hline CHEMBL3198000 & 688631 & 3.1003 & 3.7148 & TRN \\
\hline CHEMBL1575051 & 688631 & 3.1003 & 3.1455 & TRN \\
\hline CHEMBL1271059 & 688631 & 3.1003 & 3.6875 & TRN \\
\hline CHEMBL1378944 & 688631 & 3.1003 & 3.0885 & TRN \\
\hline CHEMBL1488394 & 688631 & 3.1003 & 3.0438 & TRN \\
\hline CHEMBL1381564 & 688631 & 3.1003 & 3.3345 & TRN \\
\hline CHEMBL1535864 & 688631 & 3.1003 & 3.1348 & TRN \\
\hline CHEMBL3199401 & 688631 & 3.1003 & 3.5484 & TRN \\
\hline CHEMBL1351418 & 688631 & 3.1003 & 3.6558 & TRN \\
\hline CHEMBL1450163 & 688631 & 3.1003 & 3.3929 & TRN \\
\hline CHEMBL1352830 & 688631 & 3.1003 & 3.1726 & TRN \\
\hline CHEMBL1328113 & 688631 & 3.1003 & 3.0439 & TRN \\
\hline CHEMBL1305201 & 688631 & 3.1003 & 3.0591 & TRN \\
\hline CHEMBL1587764 & 688631 & 3.1003 & 3.2232 & TRN \\
\hline CHEMBL3196468 & 688631 & 3.1003 & 3.4752 & TRN \\
\hline CHEMBL1351746 & 688631 & 3.1003 & 3.1089 & TST \\
\hline CHEMBL1529744 & 688631 & 3.5774 & 3.6716 & TRN \\
\hline CHEMBL1574065 & 688631 & 3.1003 & 3.2318 & TRN \\
\hline CHEMBL1451957 & 688631 & 3.1003 & 3.1097 & TRN \\
\hline CHEMBL1351361 & 688631 & 3.1003 & 3.4283 & TST \\
\hline CHEMBL1369067 & 688631 & 3.1003 & 3.0385 & TRN \\
\hline CHEMBL1462838 & 688631 & 4.3209 & 3.6546 & TRN \\
\hline CHEMBL1501406 & 688631 & 3.1003 & 3.3682 & TRN \\
\hline CHEMBL1606315 & 688631 & 3.1003 & 3.1448 & TRN \\
\hline CHEMBL1588950 & 688631 & 4.0402 & 3.3641 & TRN \\
\hline CHEMBL1556190 & 688631 & 4.4378 & 3.6314 & TRN \\
\hline CHEMBL1408111 & 688631 & 3.1003 & 3.6371 & TRN \\
\hline CHEMBL1485914 & 688631 & 3.1003 & 3.0896 & TRN \\
\hline CHEMBL1569232 & 688631 & 3.1003 & 3.1428 & TRN \\
\hline CHEMBL 1305732 & 688631 & 3.1003 & 3.1016 & TRN \\
\hline CHEMBL1389338 & 688631 & 3.1003 & 3.1254 & TRN \\
\hline CHEMBL1465040 & 688631 & 3.1003 & 3.18600 & 00000000004 \\
\hline CHEMBL1354197 & 688631 & 3.1003 & 3.1868 & TST \\
\hline
\end{tabular}


Supplemental Table S2.txt

\begin{tabular}{|c|c|c|c|c|}
\hline CHEMBL1485988 & 688631 & 3.1003 & 3.0509 & TRN \\
\hline CHEMBL1547468 & 688631 & 3.1003 & 3.1294 & TST \\
\hline CHEMBL1517409 & 688631 & 3.1003 & 3.1743 & TRN \\
\hline CHEMBL1493043 & 688631 & 3.1003 & 3.4806 & TRN \\
\hline CHEMBL1603319 & 688631 & 3.1003 & 3.5674 & TRN \\
\hline CHEMBL1342815 & 688631 & 3.1003 & 3.5871 & TRN \\
\hline CHEMBL1302000 & 688631 & 3.1003 & 3.0385 & TRN \\
\hline CHEMBL1489863 & 688631 & 3.1003 & 3.5479 & TRN \\
\hline CHEMBL1398596 & 688631 & 3.1003 & 3.1611 & TRN \\
\hline CHEMBL1418633 & 688631 & 3.1003 & \multicolumn{2}{|c|}{3.4930000000000003} \\
\hline CHEMBL1452842 & 688631 & 3.1003 & 3.0825 & TRN \\
\hline CHEMBL1325591 & 688631 & 5.0828 & 3.1478 & TRN \\
\hline CHEMBL1428640 & 688631 & 3.1003 & 3.6154 & TST \\
\hline CHEMBL1448422 & 688631 & 3.1003 & 3.0417 & TRN \\
\hline CHEMBL1350426 & 688631 & 5.1456 & 3.5927 & TST \\
\hline CHEMBL1450246 & 688631 & 3.1003 & 3.0385 & TRN \\
\hline CHEMBL1495560 & 688631 & 3.1003 & 3.2821 & TRN \\
\hline CHEMBL1495948 & 688631 & 3.1003 & 3.227 & TRN \\
\hline CHEMBL1350581 & 688631 & 3.1003 & 3.6192 & TRN \\
\hline CHEMBL1536363 & 688631 & 3.1003 & 3.1496 & TRN \\
\hline CHEMBL1423537 & 688631 & 3.1003 & 3.52 & TRN \\
\hline CHEMBL1966612 & 688631 & 4.7421 & 3.5976 & TRN \\
\hline CHEMBL1364957 & 688631 & 4.0896 & 3.1277 & TRN \\
\hline CHEMBL1448856 & 688631 & 3.1003 & 3.4831 & TRN \\
\hline CHEMBL1492585 & 688631 & 3.1003 & 3.6278 & TST \\
\hline CHEMBL1331978 & 688631 & 4.4037 & 3.694 & TRN \\
\hline CHEMBL1978236 & 688631 & 3.5774 & 3.7735 & TST \\
\hline CHEMBL1494694 & 688631 & 3.1003 & 3.5884 & TRN \\
\hline CHEMBL1404472 & 688631 & 3.1003 & 3.112 & TRN \\
\hline CHEMBL3192653 & 688631 & 3.1003 & \multicolumn{2}{|c|}{3.5410000000000004} \\
\hline CHEMBL1494683 & 688631 & 3.1003 & 3.1467 & TRN \\
\hline CHEMBL1418971 & 688631 & 3.1003 & 3.1645 & TRN \\
\hline CHEMBL1401856 & 688631 & 3.1003 & 3.0547 & TRN \\
\hline CHEMBL3194616 & 688631 & 3.1003 & 3.2128 & TRN \\
\hline CHEMBL1507312 & 688631 & 3.1003 & 3.4957 & TRN \\
\hline CHEMBL1500449 & 688631 & 4.095 & 3.6586 & TRN \\
\hline CHEMBL1491688 & 688631 & 3.1003 & 3.1702 & TST \\
\hline CHEMBL1338266 & 688631 & 3.1003 & 3.3724 & TRN \\
\hline CHEMBL1551015 & 688631 & 3.1003 & 2.9722 & TST \\
\hline CHEMBL1525902 & 688631 & 3.1003 & 3.4442 & TRN \\
\hline CHEMBL1471229 & 688631 & 3.1003 & 3.0412 & TRN \\
\hline CHEMBL1322190 & 688631 & 3.1003 & 3.0405 & TRN \\
\hline CHEMBL1601197 & 688631 & 3.1003 & 3.4087 & TRN \\
\hline CHEMBL1569119 & 688631 & 3.1003 & 3.1285 & TRN \\
\hline CHEMBL1496299 & 688631 & 3.1003 & 3.1649 & TST \\
\hline CHEMBL1449966 & 688631 & 4.3192 & 3.5403 & TRN \\
\hline CHEMBL1337428 & 688631 & 3.1003 & 3.5106 & TRN \\
\hline CHEMBL1312613 & 688631 & 3.1003 & 3.4557 & TRN \\
\hline
\end{tabular}

Page 10514 
Supplemental Table S2.txt

\begin{tabular}{|c|c|c|c|c|}
\hline CHEMBL1444293 & 688631 & 3.1003 & 3.0456 & TRN \\
\hline CHEMBL1304590 & 688631 & 3.1003 & 3.0436 & TRN \\
\hline CHEMBL504791 & 688631 & 4.1364 & 3.6385 & TST \\
\hline CHEMBL1312424 & 688631 & 4.4692 & 3.7363 & TRN \\
\hline CHEMBL1370669 & 688631 & 3.1003 & 3.1823 & TST \\
\hline CHEMBL1528008 & 688631 & 3.1003 & 3.1479 & TRN \\
\hline CHEMBL1362149 & 688631 & 3.1003 & 3.0747 & TRN \\
\hline CHEMBL1601252 & 688631 & 3.1003 & 3.1496 & TRN \\
\hline CHEMBL1405838 & 688631 & 3.1003 & 3.0458 & TRN \\
\hline CHEMBL1579464 & 688631 & 3.1003 & 3.8047 & TRN \\
\hline CHEMBL1324305 & 688631 & 3.1003 & 3.1062 & TRN \\
\hline CHEMBL1454187 & 688631 & 4.7552 & 3.5592 & TRN \\
\hline CHEMBL1448603 & 688631 & 3.1003 & 3.5506 & TRN \\
\hline CHEMBL1428882 & 688631 & 3.1003 & 3.074 & TRN \\
\hline CHEMBL1494589 & 688631 & 3.1003 & 3.0397 & TRN \\
\hline CHEMBL1539264 & 688631 & 3.1003 & 3.4373 & TRN \\
\hline CHEMBL1556424 & 688631 & 3.1003 & 3.0477 & TRN \\
\hline CHEMBL1304062 & 688631 & 4.2087 & 3.2866 & TRN \\
\hline CHEMBL1469528 & 688631 & 3.1003 & 3.1632 & TRN \\
\hline CHEMBL1383396 & 688631 & 3.1003 & 3.0385 & TRN \\
\hline CHEMBL1515768 & 688631 & 3.1003 & 3.0462 & TRN \\
\hline CHEMBL1564280 & 688631 & 4.2004 & 3.6294 & TRN \\
\hline CHEMBL1386873 & 688631 & 3.1003 & 3.136 & TRN \\
\hline CHEMBL1412448 & 688631 & 3.1003 & 3.0973 & TRN \\
\hline CHEMBL1530194 & 688631 & 3.1003 & 3.493999 & 99999999998 \\
\hline CHEMBL1547272 & 688631 & 3.1003 & 3.1131 & TRN \\
\hline CHEMBL1386916 & 688631 & 5.1008 & 3.7305 & TRN \\
\hline CHEMBL1498444 & 688631 & 3.1003 & 3.0965 & TRN \\
\hline CHEMBL417727 & 688631 & 3.1003 & 3.5699 & TRN \\
\hline CHEMBL1596917 & 688631 & 4.8748 & 3.2239 & TRN \\
\hline CHEMBL1427022 & 688631 & 4.8164 & 3.7021 & TRN \\
\hline CHEMBL3198706 & 688631 & 3.1003 & 3.5243 & TST \\
\hline CHEMBL1545863 & 688631 & 4.7176 & 3.6511 & TRN \\
\hline CHEMBL1568260 & 688631 & 4.2344 & 3.5937 & TRN \\
\hline CHEMBL1349902 & 688631 & 3.1003 & 3.0453 & TRN \\
\hline CHEMBL1558411 & 688631 & 3.1003 & 3.1372 & TST \\
\hline CHEMBL602163 & 688631 & 3.1003 & 3.2609 & TRN \\
\hline CHEMBL1347130 & 688631 & 3.1003 & 3.2708 & TRN \\
\hline CHEMBL1583996 & 688631 & 3.1003 & 3.0882 & TRN \\
\hline CHEMBL1597383 & 688631 & 3.1003 & 3.177 & TRN \\
\hline CHEMBL1352840 & 688631 & 3.1003 & 3.1528 & TRN \\
\hline CHEMBL1464872 & 688631 & 3.1003 & 3.1401 & TRN \\
\hline CHEMBL1521813 & 688631 & 3.1003 & 3.3257 & TST \\
\hline CHEMBL1366942 & 688631 & 4.0673 & 3.5974 & TST \\
\hline CHEMBL1526553 & 688631 & 4.6558 & 3.6469 & TRN \\
\hline CHEMBL1543177 & 688631 & 3.1003 & 3.4995 & TRN \\
\hline CHEMBL1567207 & 688631 & 3.1003 & 3.431 & TRN \\
\hline CHEMBL1604626 & 688631 & 3.1003 & 3.0385 & TRN \\
\hline
\end{tabular}


Supplemental Table S2.txt

\begin{tabular}{|c|c|c|c|c|}
\hline 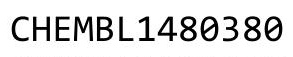 & & & & \\
\hline HEMBL1382616 & 88631 & .1003 & .1544 & \\
\hline & & & & \\
\hline 3060 & 8631 & 1003 & 56 & \\
\hline IEMBL1347385 & 38631 & 1003 & 09 & \\
\hline AEMBL1499411 & 88631 & 1003 & 1441 & \\
\hline HEMBL1431563 & 88631 & 1003 & 1689 & \\
\hline EM & 8631 & 779 & & \\
\hline EMBL1464093 & 88631 & .2392 & 5318 & \\
\hline AEMBL1510387 & 88631 & 1003 & 0397 & \\
\hline HEMBL1613238 & 88631 & 0918 & .7861 & \\
\hline AEMBL1585275 & 88631 & 1003 & 1588 & \\
\hline IEMBL60 & 8631 & 234 & 298 & \\
\hline AEMBL1556161 & 88631 & 215 & 8562 & \\
\hline AEMBL1605444 & 88631 & 1003 & 5011 & \\
\hline AEMBL1335392 & 88631 & 1003 & 5024 & \\
\hline AEMBL1385709 & 88631 & 003 & 421 & \\
\hline HEMBL129 & 31 & 293 & 358 & \\
\hline HEMBL1307254 & 88631 & 003 & & \\
\hline AEMBL1416815 & 88631 & 989 & & 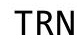 \\
\hline EEMBL3199612 & 88631 & 003 & 1516 & KIV \\
\hline HEMBL1374054 & 38631 & 003 & 7123 & $\mathrm{RN}$ \\
\hline HEMBL $13 \angle$ & 38631 & 003 & 2142 & \\
\hline 89 & 31 & 003 & 169 & ST \\
\hline IEMBL133 & 38631 & 003 & 864 & RN \\
\hline IEMBL1586131 & 38631 & $\partial 3$ & 816 & KIV \\
\hline HEMBL1588879 & 88631 & 003 & 542 & 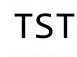 \\
\hline HEMBL 319 & 8631 & 03 & 545 & ST \\
\hline 37 & 31 & 03 & 993 & RN \\
\hline IEMBL13: & 31 & & & RIN \\
\hline JEMBL1301572 & 88631 & 003 & 682 & ST \\
\hline HEMBL1337652 & 88631 & 003 & 1477 & RN \\
\hline HFMBI 13 & 38631 & 03 & 59 & RN \\
\hline & & & 249 & ST \\
\hline IEMBL1413736 & 88631 & 03 & .772 & RN \\
\hline IEMBL1380640 & 88631 & 003 & 847 & ST \\
\hline HEMBL1402874 & 88631 & 003 & 208 & RN \\
\hline 1,1010 & & & & $\mathrm{RN}$ \\
\hline HEMBL1587976 & & 873 & 7827 & RN \\
\hline HEMBL1600188 & 88631 & 003 & 408 & RN \\
\hline HEMBL1491054 & 88631 & 003 & 739 & RN \\
\hline HEMBL1432472 & 588631 & 003 & 1822 & \\
\hline HEMBL1509659 & & & & ST \\
\hline HEMBL1486010 & 38631 & 003 & 1273 & RN \\
\hline AEMBL1427926 & 88631 & 374 & 749 & 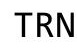 \\
\hline MBL14 & 38631 & & & \\
\hline 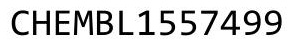 & & & 926 & \\
\hline 101 & 000 & 03 & & \\
\hline
\end{tabular}

Page 10516 
Supplemental Table S2.txt

\begin{tabular}{|c|c|c|c|c|}
\hline CHEMBL1374897 & 688631 & 3.1003 & 3.5711 & TRN \\
\hline CHEMBL1582392 & 688631 & 3.1003 & 3.0814 & TRN \\
\hline CHEMBL1300912 & 688631 & 3.1003 & 3.5621 & TRN \\
\hline CHEMBL153072 & 688631 & 3.1003 & 3.4616 & TRN \\
\hline CHEMBL1497668 & 688631 & 3.1003 & 3.5622 & TRN \\
\hline CHEMBL1589053 & 688631 & 4.2695 & 3.5527 & TRN \\
\hline CHEMBL1587683 & 688631 & 3.1003 & 3.1429 & TRN \\
\hline CHEMBL1508025 & 688631 & 3.1003 & 3.2627 & TRN \\
\hline CHEMBL1442411 & 688631 & 3.1003 & 3.0965 & TRN \\
\hline CHEMBL1412520 & 688631 & 4.5527 & 3.5853 & TRN \\
\hline CHEMBL3213646 & 688631 & 3.1003 & 3.1368 & TRN \\
\hline CHEMBL1306312 & 688631 & 3.1003 & 3.4256 & TRN \\
\hline CHEMBL1564547 & 688631 & 3.1003 & 3.398999 & 99999999996 \\
\hline CHEMBL1492686 & 688631 & 3.1003 & 3.1963 & TRN \\
\hline CHEMBL1461424 & 688631 & 3.1003 & 3.0441 & TRN \\
\hline CHEMBL1559168 & 688631 & 3.1003 & 3.552 & TRN \\
\hline CHEMBL1366562 & 688631 & 4.7289 & 3.5578 & TRN \\
\hline CHEMBL1491062 & 688631 & 3.1003 & 3.534 & TRN \\
\hline CHEMBL1578127 & 688631 & 3.1003 & 3.5144 & TST \\
\hline CHEMBL1418881 & 688631 & 3.1003 & 3.5308 & TST \\
\hline CHEMBL1498247 & 688631 & 3.1003 & 3.1361 & TRN \\
\hline CHEMBL1587518 & 688631 & 3.1003 & 3.2271 & TST \\
\hline CHEMBL405110 & 688631 & 5.5148 & 3.8533 & TST \\
\hline CHEMBL1431341 & 688631 & 3.1003 & 3.5597 & TRN \\
\hline CHEMBL1484500 & 688631 & 3.1003 & 3.5731 & TRN \\
\hline CHEMBL1501761 & 688631 & 3.1003 & 3.5925 & TST \\
\hline CHEMBL1503047 & 688631 & 4.6863 & 3.6154 & TRN \\
\hline CHEMBL1528753 & 688631 & 3.1003 & 3.0385 & TRN \\
\hline CHEMBL1409901 & 688631 & 3.1003 & 3.2049 & TRN \\
\hline CHEMBL1568732 & 688631 & 3.1003 & 3.06 & TRN \\
\hline CHEMBL1523661 & 688631 & 3.1003 & 3.2135 & TST \\
\hline CHEMBL1571111 & 688631 & 3.1003 & 3.1677 & TRN \\
\hline CHEMBL1447245 & 688631 & 3.1003 & 3.6128 & TRN \\
\hline CHEMBL1576788 & 688631 & 3.1003 & 3.1581 & TRN \\
\hline CHEMBL1612100 & 688631 & 3.1003 & 3.6547 & TRN \\
\hline CHEMBL1427304 & 688631 & 3.1003 & 3.0514 & TRN \\
\hline CHEMBL1417090 & 688631 & 3.1003 & 3.0506 & TRN \\
\hline CHEMBL1385904 & 688631 & 3.1003 & 3.5708 & TRN \\
\hline CHEMBL1529930 & 688631 & 4.1967 & 3.5701 & TRN \\
\hline CHEMBL1324024 & 688631 & 4.8035 & 3.7742 & TRN \\
\hline CHEMBL1424191 & 688631 & 3.1003 & 3.1304 & TRN \\
\hline CHEMBL1368099 & 688631 & 3.1003 & 3.1083 & TRN \\
\hline CHEMBL1362262 & 688631 & 3.1003 & 3.1999 & TRN \\
\hline CHEMBL1389774 & 688631 & 3.1003 & 3.0385 & TRN \\
\hline CHEMBL1417458 & 688631 & 4.8604 & 3.282 & TRN \\
\hline CHEMBL1546847 & 688631 & 3.1003 & 3.076 & TRN \\
\hline CHEMBL1480312 & 688631 & 3.1003 & 3.0385 & TRN \\
\hline CHEMBL1499884 & 688631 & 3.1003 & 3.4488 & TST \\
\hline
\end{tabular}


Supplemental Table S2.txt

\begin{tabular}{|c|c|c|c|c|c|}
\hline CHEMBL1329300 & 688631 & 4.3887 & 3.6261 & TRN & \\
\hline CHEMBL1456701 & 688631 & 3.1003 & 3.637 & TRN & \\
\hline CHEMBL1545051 & 688631 & 4.3175 & 3.4787 & TST & \\
\hline CHEMBL1412417 & 688631 & 3.1003 & 3.1933 & TRN & \\
\hline CHEMBL1408514 & 688631 & 3.1003 & 3.4634 & TRN & \\
\hline CHEMBL1567568 & 688631 & 3.1003 & 3.4828 & TST & \\
\hline CHEMBL1403983 & 688631 & 3.1003 & 3.136 & TRN & \\
\hline CHEMBL1572461 & 688631 & 3.1003 & 3.0975 & TRN & \\
\hline CHEMBL1426396 & 688631 & 3.1003 & 3.0962 & TRN & \\
\hline CHEMBL1470505 & 688631 & 3.1003 & 3.0441 & TRN & \\
\hline CHEMBL3198489 & 688631 & 3.1003 & 3.1832 & TRN & \\
\hline CHEMBL1336564 & 688631 & 3.1003 & 3.0954 & TRN & \\
\hline CHEMBL1409912 & 688631 & 3.1003 & 3.0512 & TRN & \\
\hline CHEMBL1535116 & 688631 & 3.1003 & 3.1369 & TRN & \\
\hline CHEMBL1503781 & 688631 & 3.1003 & 3.0573 & TRN & \\
\hline CHEMBL1351686 & 688631 & 3.1003 & 3.6468 & TRN & \\
\hline CHEMBL1376488 & 688631 & 4.0668 & 3.5347 & TRN & \\
\hline CHEMBL1393172 & 688631 & 3.1003 & 3.7313 & TRN & \\
\hline CHEMBL1328473 & 688631 & 3.1003 & 3.6717 & TRN & \\
\hline CHEMBL1380975 & 688631 & 3.1003 & 3.3588 & TRN & \\
\hline CHEMBL1327088 & 688631 & 3.1003 & 3.042 & TRN & \\
\hline CHEMBL1603238 & 688631 & 3.1003 & 3.1812 & TST & \\
\hline CHEMBL1505364 & 688631 & 3.1003 & 3.1926 & TRN & \\
\hline CHEMBL1441823 & 688631 & 3.1003 & 3.6216 & TRN & \\
\hline CHEMBL1535724 & 688631 & 3.1003 & 3.1762 & TRN & \\
\hline CHEMBL1575003 & 688631 & 3.1003 & 3.3866 & TRN & \\
\hline CHEMBL1485010 & 688631 & 3.1003 & 3.1613 & TRN & \\
\hline CHEMBL1608905 & 688631 & 3.1003 & 3.0545 & TRN & \\
\hline CHEMBL1543192 & 688631 & 3.1003 & 3.176 & TRN & \\
\hline CHEMBL1321356 & 688631 & 3.1003 & 3.6611 & TRN & \\
\hline CHEMBL1388510 & 688631 & 3.1003 & 3.168 & TST & \\
\hline CHEMBL1331930 & 688631 & 4.2709 & 3.8753 & TST & \\
\hline CHEMBL1543903 & 688631 & 3.1003 & 3.0452 & TRN & \\
\hline CHEMBL1583070 & 688631 & 3.1003 & 3.0414 & TRN & \\
\hline CHEMBL1494982 & 688631 & 3.1003 & \multicolumn{2}{|c|}{3.0469999999999997} & TRN \\
\hline CHEMBL1414671 & 688631 & 3.1003 & 3.19 & TRN & \\
\hline CHEMBL1562431 & 688631 & 3.1003 & 3.042 & TRN & \\
\hline CHEMBL1326901 & 688631 & 3.1003 & 3.5226 & TRN & \\
\hline CHEMBL1538790 & 688631 & 4.3977 & 3.8289 & TRN & \\
\hline CHEMBL1505300 & 688631 & 3.1003 & 3.4575 & TRN & \\
\hline CHEMBL1222145 & 688631 & 3.1003 & 3.4382 & TRN & \\
\hline CHEMBL1375544 & 688631 & 3.1003 & \multicolumn{2}{|c|}{3.0410000000000004} & TRN \\
\hline CHEMBL1607932 & 688631 & 3.1003 & 3.6518 & TRN & \\
\hline CHEMBL1530807 & 688631 & 3.1003 & 3.6539 & TRN & \\
\hline CHEMBL1303333 & 688631 & 3.1003 & 3.4588 & TST & \\
\hline CHEMBL1417249 & 688631 & 3.5774 & 3.5942 & TST & \\
\hline CHEMBL1582769 & 688631 & 3.1003 & 3.5299 & TRN & \\
\hline CHEMBL1440872 & 688631 & 3.1003 & 3.1419 & TRN & \\
\hline
\end{tabular}


Supplemental Table S2.txt

\begin{tabular}{|c|c|c|c|c|}
\hline CHEMBL1405142 & 688631 & 3.1003 & 3.5556 & TRN \\
\hline CHEMBL1462764 & 688631 & 3.1003 & 3.5653 & TRN \\
\hline CHEMBL1343508 & 688631 & 3.1003 & 3.0585 & TRN \\
\hline CHEMBL1448094 & 688631 & 4.1223 & 3.3752 & TRN \\
\hline CHEMBL1399754 & 688631 & 3.5774 & 3.5528 & TRN \\
\hline CHEMBL3193785 & 688631 & 4.0546 & 3.7266 & TST \\
\hline CHEMBL1338781 & 688631 & 3.1003 & 3.0458 & TRN \\
\hline CHEMBL1501928 & 688631 & 3.1003 & 3.2156 & TRN \\
\hline CHEMBL391877 & 688631 & 3.1003 & 3.1596 & TRN \\
\hline CHEMBL1363571 & 688631 & 4.7552 & 3.6708 & TRN \\
\hline CHEMBL1583741 & 688631 & 3.1003 & \multicolumn{2}{|c|}{3.1069999999999998} \\
\hline CHEMBL1587301 & 688631 & 3.1003 & 3.5979 & TRN \\
\hline CHEMBL1542650 & 688631 & 3.1003 & 3.1333 & TST \\
\hline CHEMBL1347350 & 688631 & 3.1003 & 3.0385 & TRN \\
\hline CHEMBL1498284 & 688631 & 3.1003 & 3.3736 & TRN \\
\hline CHEMBL1506268 & 688631 & 3.1003 & 3.1402 & TST \\
\hline CHEMBL1380526 & 688631 & 3.1003 & 3.4118 & TRN \\
\hline CHEMBL1589567 & 688631 & 4.0892 & 3.6883 & TRN \\
\hline CHEMBL1417231 & 688631 & 4.9884 & 3.7003 & TRN \\
\hline CHEMBL1385747 & 688631 & 3.1003 & 3.5631 & TRN \\
\hline CHEMBL1449640 & 688631 & 3.1003 & 3.4572 & TRN \\
\hline CHEMBL1471965 & 688631 & 3.1003 & 3.2086 & TST \\
\hline CHEMBL1604187 & 688631 & 3.1003 & 3.1298 & TRN \\
\hline CHEMBL1561641 & 688631 & 3.1003 & 3.4883 & TRN \\
\hline CHEMBL1603373 & 688631 & 3.1003 & 3.5543 & TRN \\
\hline CHEMBL1548720 & 688631 & 3.1003 & 3.0451 & TRN \\
\hline CHEMBL1511437 & 688631 & 4.8404 & 3.7081 & TRN \\
\hline CHEMBL1404376 & 688631 & 3.1003 & 3.1202 & TRN \\
\hline CHEMBL1428877 & 688631 & 3.1003 & 3.0435 & TRN \\
\hline CHEMBL1416266 & 688631 & 3.1003 & 3.7806 & TRN \\
\hline CHEMBL1540717 & 688631 & 5.3319 & 3.6092 & TST \\
\hline CHEMBL1596518 & 688631 & 3.1003 & 3.0385 & TRN \\
\hline CHEMBL1414215 & 688631 & 4.7932 & 3.6438 & TRN \\
\hline CHEMBL1481844 & 688631 & 3.1003 & \multicolumn{2}{|c|}{3.1289999999999996} \\
\hline CHEMBL1318943 & 688631 & 3.1003 & 3.5778 & TST \\
\hline CHEMBL1568611 & 688631 & 3.1003 & 3.154 & TRN \\
\hline CHEMBL1526978 & 688631 & 3.1003 & 3.0759 & TRN \\
\hline CHEMBL1573867 & 688631 & 3.1003 & 3.1636 & TST \\
\hline CHEMBL1345018 & 688631 & 3.1003 & 3.0459 & TST \\
\hline CHEMBL1370184 & 688631 & 3.1003 & 3.5064 & TST \\
\hline CHEMBL1543169 & 688631 & 3.1003 & 3.5098 & TST \\
\hline CHEMBL1348813 & 688631 & 3.1003 & 3.4399 & TST \\
\hline CHEMBL1360098 & 688631 & 3.1003 & 3.2823 & TST \\
\hline CHEMBL3194658 & 688631 & 3.1003 & 3.5533 & TST \\
\hline CHEMBL1426003 & 688631 & 5.096 & 3.8199 & TST \\
\hline CHEMBL1494018 & 688631 & 3.1003 & 3.0385 & TST \\
\hline CHEMBL1484562 & 688631 & 3.1003 & 3.5566 & TST \\
\hline CHEMBL1340538 & 688631 & 3.1003 & 3.0867 & TST \\
\hline
\end{tabular}

Page 10519 
Supplemental Table S2.txt

\begin{tabular}{|c|c|c|c|c|}
\hline CHEMBL1380276 & 688631 & 3.1003 & 3.1268 & TST \\
\hline CHEMBL1467309 & 688631 & 4.3789 & 3.6119 & TST \\
\hline CHEMBL1466134 & 688631 & 3.1003 & 3.1689 & TST \\
\hline CHEMBL1580375 & 688631 & 4.8658 & 3.6979 & TST \\
\hline CHEMBL1510509 & 688631 & 3.1003 & 3.5552 & TST \\
\hline CHEMBL1505452 & 688631 & 3.1003 & 3.0385 & TST \\
\hline CHEMBL1304332 & 688631 & 4.3905 & 3.5784 & TST \\
\hline CHEMBL1497688 & 688631 & 3.1003 & 3.0482 & TST \\
\hline CHEMBL1380232 & 688631 & 5.0701 & 3.8194 & TST \\
\hline CHEMBL1604975 & 688631 & 3.1003 & 3.7218 & TST \\
\hline CHEMBL1348824 & 688631 & 3.1003 & 3.0385 & TST \\
\hline CHEMBL1330273 & 688631 & 3.1003 & 3.0413 & TST \\
\hline CHEMBL1365146 & 688631 & 4.6955 & 3.7687 & TST \\
\hline CHEMBL1467138 & 688631 & 3.1003 & 3.118006 & 0000000003 \\
\hline CHEMBL1556602 & 688631 & 4.1594 & 3.656 & TST \\
\hline CHEMBL1390336 & 688631 & 4.5481 & 3.7411 & TST \\
\hline CHEMBL 3195488 & 688631 & 4.4573 & 3.5919 & TST \\
\hline CHEMBL1403337 & 688631 & 3.1003 & 3.1717 & TST \\
\hline CHEMBL1426930 & 688631 & 4.6895 & 3.6565 & TST \\
\hline CHEMBL 3189713 & 688631 & 3.1003 & 3.1533 & TST \\
\hline CHEMBL1485384 & 688631 & 3.1003 & 3.1235 & TST \\
\hline CHEMBL1399076 & 688631 & 3.1003 & 3.0417 & TST \\
\hline CHEMBL1605635 & 688631 & 3.1003 & 3.1127 & TST \\
\hline CHEMBL1611123 & 688631 & 4.4562 & 3.6194 & TST \\
\hline CHEMBL1310248 & 688631 & 3.1003 & 3.0915 & TST \\
\hline CHEMBL1546820 & 688631 & 3.1003 & 3.202 & TST \\
\hline CHEMBL1515913 & 688631 & 3.1003 & 3.1935 & TST \\
\hline CHEMBL1528299 & 688631 & 3.1003 & 3.1512 & TST \\
\hline CHEMBL1510408 & 688631 & 4.0396 & 3.7722 & TST \\
\hline CHEMBL1547257 & 688631 & 3.1003 & 3.6517 & TST \\
\hline CHEMBL1563062 & 688631 & 3.1003 & 3.0397 & TST \\
\hline CHEMBL1414033 & 688631 & 3.1003 & 3.0385 & TST \\
\hline CHEMBL445658 & 366821 & 1.699 & 1.663 & TRN \\
\hline CHEMBL219066 & 366821 & 2.4776 & 3.0616 & TRN \\
\hline CHEMBL414084 & 366821 & 3.0 & 3.1468 & TRN \\
\hline CHEMBL 211751 & 366821 & 3.301 & 3.2433 & TRN \\
\hline CHEMBL213959 & 366821 & 1.699 & 0.7046 & TST \\
\hline CHEMBL384894 & 366821 & 4.7959 & 3.9399 & TRN \\
\hline CHEMBL413690 & 366821 & 1.699 & 1.7073 & TRN \\
\hline CHEMBL 374420 & 366821 & 4.0969 & 4.197 & TRN \\
\hline CHEMBL377971 & 366821 & 4.699 & 4.663 & TRN \\
\hline CHEMBL429024 & 366821 & 2.0 & 1.9057 & TST \\
\hline CHEMBL414785 & 366821 & 2.4776 & 2.4577 & TRN \\
\hline CHEMBL412938 & 366821 & 4.3279 & 4.428999 & 999999999 \\
\hline CHEMBL 211346 & 366821 & 2.0 & 1.1667 & TST \\
\hline CHEMBL414863 & 366821 & 3.5072 & 3.4211 & TRN \\
\hline CHEMBL219359 & 366821 & 3.9245 & 4.2974 & TRN \\
\hline CHEMBL373670 & 366821 & 5.5229 & 5.4861 & TRN \\
\hline
\end{tabular}




\begin{tabular}{|c|c|c|c|c|c|}
\hline \multicolumn{6}{|c|}{ Supplemental Table S2.txt } \\
\hline CHEMBL377022 & 366821 & 3.0 & 3.0366 & TRN & \\
\hline CHEMBL267212 & 366821 & 5.3979 & 5.473 & TRN & \\
\hline CHEMBL427057 & 366821 & 4.9586 & 4.8649 & TRN & \\
\hline CHEMBL438564 & 366821 & 2.4776 & 2.4616 & TRN & \\
\hline CHEMBL409975 & 366821 & 4.2924 & 3.9399 & TRN & \\
\hline CHEMBL424924 & 366821 & 4.7212 & 4.9173 & TRN & \\
\hline CHEMBL383932 & 366821 & 1.699 & 1.5944 & TRN & \\
\hline CHEMBL211490 & 366821 & 4.2218 & 4.2161 & TRN & \\
\hline CHEMBL409955 & 366821 & 2.4776 & 3.3895 & TRN & \\
\hline CHEMBL406897 & 366821 & 4.4685 & 3.3895 & TRN & \\
\hline CHEMBL265611 & 366821 & 1.699 & 1.73699 & 99999999999 & TRN \\
\hline CHEMBL437254 & 366821 & 3.9747 & 3.9399 & TRN & \\
\hline CHEMBL263689 & 366821 & 2.0 & 1.9322 & TRN & \\
\hline CHEMBL375326 & 366821 & 2.0 & 2.2357 & TRN & \\
\hline CHEMBL437253 & 366821 & 3.6861 & 3.5401 & TRN & \\
\hline CHEMBL414784 & 366821 & 4.2596 & 4.0997 & TRN & \\
\hline CHEMBL413479 & 366821 & 4.2518 & 4.4353 & TRN & \\
\hline CHEMBL411159 & 366821 & 2.4776 & 2.67199 & 99999999997 & TRN \\
\hline CHEMBL379730 & 366821 & 1.699 & 1.6189 & TRN & \\
\hline CHEMBL436489 & 366821 & 4.2518 & 4.1884 & TRN & \\
\hline CHEMBL378468 & 366821 & 3.0 & 2.8804 & TRN & \\
\hline CHEMBL415577 & 366821 & 3.7878 & 4.003 & TRN & \\
\hline CHEMBL262829 & 366821 & 2.4776 & 2.5458 & TRN & \\
\hline CHEMBL409617 & 366821 & 1.699 & 1.6827 & TRN & \\
\hline CHEMBL380069 & 366821 & 1.699 & 1.6001 & TST & \\
\hline CHEMBL273566 & 366821 & 1.699 & 1.9589 & TST & \\
\hline CHEMBL211491 & 366821 & 3.0 & 2.4674 & TST & \\
\hline CHEMBL219853 & 366821 & 2.4776 & 3.2412 & TST & \\
\hline CHEMBL438244 & 366821 & 4.7959 & 4.5177 & TST & \\
\hline CHEMBL426172 & 366821 & 2.4776 & 3.9399 & TST & \\
\hline CHEMBL412724 & 366821 & 1.699 & 2.5195 & TST & \\
\hline CHEMBL436517 & 366821 & 2.4776 & 3.1268 & TST & \\
\hline CHEMBL374671 & 366821 & 4.4202 & 3.3092 & TST & \\
\hline CHEMBL434367 & 366821 & 4.3665 & 4.2645 & TST & \\
\hline CHEMBL119732 & 89057 & 7.699 & 7.4257 & TRN & \\
\hline CHEMBL325893 & 89057 & 6.1135 & 6.1476 & TRN & \\
\hline CHEMBL115637 & 89057 & 7.6021 & 8.0017 & TRN & \\
\hline CHEMBL331055 & 89057 & 6.4437 & 6.9692 & TRN & \\
\hline CHEMBL118300 & 89057 & 7.2757 & 7.4157 & TRN & \\
\hline CHEMBL118358 & 89057 & 6.2366 & 5.3688 & TRN & \\
\hline CHEMBL119335 & 89057 & 8.4202 & 8.1928 & TRN & \\
\hline CHEMBL118518 & 89057 & 8.0458 & 7.931 & TRN & \\
\hline CHEMBL326271 & 89057 & 8.301 & 8.2141 & TRN & \\
\hline CHEMBL117279 & 89057 & 8.301 & 8.3883 & TRN & \\
\hline CHEMBL115971 & 89057 & 7.7447 & 7.9425 & TRN & \\
\hline CHEMBL117452 & 89057 & 5.0453 & 5.8853 & TRN & \\
\hline CHEMBL118299 & 89057 & 7.3979 & 7.6769 & TRN & \\
\hline CHEMBL326771 & 89057 & 7.7696 & 8.022 & TRN & \\
\hline
\end{tabular}




\begin{tabular}{|c|c|c|c|c|c|}
\hline \multirow[b]{2}{*}{ CHEMBL325651 } & & \multicolumn{4}{|c|}{ Supplemental Table s2.txt } \\
\hline & 89057 & 7.4949 & 6.9096 & TRN & \\
\hline CHEMBL324133 & 89057 & 6.7447 & 6.9918 & TRN & \\
\hline CHEMBL115462 & 89057 & 6.1675 & 5.9657 & TRN & \\
\hline CHEMBL119815 & 89057 & 6.9586 & 6.8479 & TRN & \\
\hline CHEMBL117198 & 89057 & 8.699 & 8.333 & TRN & \\
\hline CHEMBL115815 & 89057 & 7.0862 & 6.99700 & 0000000001 & TRN \\
\hline CHEMBL325184 & 89057 & 8.2218 & 8.4513 & TRN & \\
\hline CHEMBL117668 & 89057 & 8.2218 & 8.4242 & TRN & \\
\hline CHEMBL118114 & 89057 & 5.0 & 4.7424 & TRN & \\
\hline CHEMBL434222 & 89057 & 6.8239 & 6.5543 & TRN & \\
\hline CHEMBL325033 & 89057 & 7.2757 & 6.9444 & TST & \\
\hline CHEMBL119733 & 89057 & 8.699 & 8.4921 & TRN & \\
\hline CHEMBL325618 & 89057 & 5.0 & 5.3446 & TRN & \\
\hline CHEMBL118074 & 89057 & 7.7696 & 8.0027 & TRN & \\
\hline CHEMBL117453 & 89057 & 7.699 & 7.3859 & TRN & \\
\hline CHEMBL119522 & 89057 & 6.0862 & 5.8982 & TST & \\
\hline CHEMBL323832 & 89057 & 6.1675 & 6.159 & TRN & \\
\hline CHEMBL119599 & 89057 & 6.5229 & 6.669 & TRN & \\
\hline CHEMBL117936 & 89057 & 7.3768 & 7.3978 & TRN & \\
\hline CHEMBL117093 & 89057 & 7.1024 & 7.141 & TST & \\
\hline CHEMBL116363 & 89057 & 7.2291 & 7.7564 & TRN & \\
\hline CHEMBL119901 & 89057 & 5.0 & 4.7271 & TST & \\
\hline CHEMBL118113 & 89057 & 8.8539 & 8.2601 & TST & \\
\hline CHEMBL 6370 & 89057 & 4.3979 & 4.8172 & TST & \\
\hline CHEMBL115431 & 89057 & 7.585 & 7.1289 & TRN & \\
\hline CHEMBL324824 & 89057 & 6.4949 & 6.8237 & TRN & \\
\hline CHEMBL116454 & 89057 & 7.6576 & 7.4324 & TST & \\
\hline CHEMBL115742 & 89057 & 6.7959 & 7.0435 & TRN & \\
\hline CHEMBL326360 & 89057 & 5.0 & 4.9646 & TST & \\
\hline CHEMBL119711 & 89057 & 6.1739 & 6.2608 & TST & \\
\hline CHEMBL119501 & 89057 & 9.0 & 8.7477 & TRN & \\
\hline CHEMBL331584 & 89057 & 8.0969 & 8.3463 & TRN & \\
\hline CHEMBL419046 & 89057 & 7.7959 & 7.336 & TST & \\
\hline CHEMBL119886 & 89057 & 7.1249 & 6.7661 & TRN & \\
\hline CHEMBL116152 & 89057 & 8.3979 & 8.0954 & TRN & \\
\hline CHEMBL115981 & 89057 & 6.8239 & 6.5812 & TRN & \\
\hline CHEMBL116958 & 89057 & 6.2218 & 5.9267 & TST & \\
\hline CHEMBL324158 & 89057 & 7.3279 & 6.9933 & TRN & \\
\hline CHEMBL331662 & 89057 & 6.9208 & 7.022 & TRN & \\
\hline CHEMBL119039 & 89057 & 8.3979 & 8.2643 & TRN & \\
\hline CHEMBL117367 & 89057 & 6.0809 & 5.8861 & TST & \\
\hline CHEMBL325286 & 89057 & 6.1079 & 5.949 & TST & \\
\hline CHEMBL6320 & 89057 & 4.3979 & 4.4541 & TST & \\
\hline CHEMBL115534 & 89057 & 6.1192 & 6.0926 & TRN & \\
\hline CHEMBL117565 & 89057 & 5.0132 & 6.7799 & TST & \\
\hline CHEMBL117292 & 89057 & 6.9208 & 6.8176 & TST & \\
\hline CHEMBL421231 & 89057 & 6.1024 & 4.7813 & TST & \\
\hline CHEMBL115966 & 89057 & 7.5086 & 7.5375 & TRN & \\
\hline
\end{tabular}




\begin{tabular}{|c|c|c|c|c|c|}
\hline & & \multicolumn{4}{|c|}{ Supplemental Table S2.txt } \\
\hline CHEMBL326712 & 89057 & 6.9208 & 6.9547 & TST & \\
\hline CHEMBL119183 & 89057 & 7.7959 & 7.8511 & TRN & \\
\hline CHEMBL116070 & 89057 & 8.301 & 8.2422 & TRN & \\
\hline CHEMBL119532 & 89057 & 6.3665 & 7.0191 & TRN & \\
\hline CHEMBL268567 & 89057 & 7.3188 & 7.2925 & TST & \\
\hline CHEMBL116089 & 89057 & 7.8861 & 7.7394 & TRN & \\
\hline CHEMBL119523 & 89057 & 6.4685 & 6.5644 & TRN & \\
\hline CHEMBL119861 & 89057 & 6.3098 & 6.3798 & TRN & \\
\hline CHEMBL117671 & 89057 & 6.9355 & 6.725 & TST & \\
\hline CHEMBL326120 & 89057 & 8.301 & 8.0613 & TRN & \\
\hline CHEMBL331248 & 89057 & 5.0 & 5.2998 & TRN & \\
\hline CHEMBL117571 & 89057 & 6.9586 & 7.2331 & TRN & \\
\hline CHEMBL115432 & 89057 & 6.2366 & 6.2347 & TRN & \\
\hline CHEMBL118022 & 89057 & 7.6383 & 7.4008 & TRN & \\
\hline CHEMBL117746 & 89057 & 8.3979 & 8.453 & TRN & \\
\hline CHEMBL119705 & 89057 & 6.7959 & 7.04899 & 99999999995 & TRN \\
\hline CHEMBL116307 & 89057 & 7.7447 & 7.3987 & TRN & \\
\hline CHEMBL118034 & 89057 & 8.301 & 8.2585 & TRN & \\
\hline CHEMBL115960 & 89057 & 6.8861 & 7.0626 & TRN & \\
\hline CHEMBL118089 & 89057 & 7.3372 & 7.2186 & TRN & \\
\hline CHEMBL117894 & 89057 & 8.2218 & 8.2713 & TRN & \\
\hline CHEMBL119091 & 89057 & 7.4685 & 7.3369 & TRN & \\
\hline CHEMBL118886 & 89057 & 8.0 & 7.7648 & TRN & \\
\hline CHEMBL267678 & 89057 & 7.6021 & 6.6455 & TST & \\
\hline CHEMBL119348 & 89057 & 6.1367 & 5.705 & TST & \\
\hline CHEMBL1964290 & 809278 & 7.6 & 7.3864 & TRN & \\
\hline CHEMBL 2003768 & 809278 & 6.3 & 5.5204 & TRN & \\
\hline CHEMBL 213505 & 809278 & 5.7 & 5.012 & TRN & \\
\hline CHEMBL1982880 & 809278 & 4.2 & 5.4751 & TRN & \\
\hline CHEMBL1993941 & 809278 & 4.2 & 4.591 & TRN & \\
\hline CHEMBL1989293 & 809278 & 6.8 & 6.3276 & TRN & \\
\hline CHEMBL377383 & 809278 & 4.2 & 3.991 & TRN & \\
\hline CHEMBL1973142 & 809278 & 5.3 & 5.2351 & TST & \\
\hline CHEMBL1973145 & 809278 & 4.2 & 4.03100 & 0000000001 & TRN \\
\hline CHEMBL1982924 & 809278 & 6.3 & 5.4537 & TRN & \\
\hline CHEMBL1964948 & 809278 & 4.4 & 4.71399 & 99999999995 & TRN \\
\hline CHEMBL1971141 & 809278 & 4.2 & 4.0641 & TRN & \\
\hline CHEMBL1995813 & 809278 & 6.7 & 7.3786 & TRN & \\
\hline CHEMBL1979718 & 809278 & 6.2 & 5.6364 & TRN & \\
\hline CHEMBL206236 & 809278 & 5.2 & 5.6798 & TRN & \\
\hline CHEMBL1990583 & 809278 & 5.4 & 5.3129 & TRN & \\
\hline CHEMBL1986943 & 809278 & 7.3 & 7.1418 & TRN & \\
\hline CHEMBL 2006263 & 809278 & 7.0 & 5.8972 & TST & \\
\hline CHEMBL 2001646 & 809278 & 5.7 & 4.7563 & TRN & \\
\hline CHEMBL1993584 & 809278 & 6.1 & 6.2986 & TRN & \\
\hline CHEMBL 2000114 & 809278 & 5.6 & 5.2252 & TRN & \\
\hline CHEMBL210618 & 809278 & 4.2 & 4.2637 & TRN & \\
\hline CHEMBL1971172 & 809278 & 5.8 & 6.6114 & TRN & \\
\hline
\end{tabular}




\begin{tabular}{|c|c|c|c|c|c|}
\hline & & & & & \\
\hline CHEMBL1975647 & 809278 & 8.3 & 8.8992 & TRN & \\
\hline CHEMBL1968380 & 809278 & 4.2 & 3.9434 & TRN & \\
\hline CHEMBL1997643 & 809278 & 8.3 & 8.0768 & TRN & \\
\hline CHEMBL1991734 & 809278 & 5.9 & 5.6195 & TST & \\
\hline CHEMBL1990912 & 809278 & 6.0 & 5.3443 & TRN & \\
\hline CHEMBL1991782 & 809278 & 3.1 & 3.8545 & TRN & \\
\hline CHEMBL1988163 & 809278 & 7.0 & 6.72 & TRN & \\
\hline CHEMBL1974480 & 809278 & 6.0 & 5.3229 & TST & \\
\hline CHEMBL1980671 & 809278 & 5.3 & 5.745 & TRN & \\
\hline CHEMBL 2006493 & 809278 & 4.2 & 4.4268 & TST & \\
\hline CHEMBL1996923 & 809278 & 4.2 & 4.4901 & TST & \\
\hline CHEMBL1969735 & 809278 & 5.5 & 4.49 & TRN & \\
\hline CHEMBL 2003524 & 809278 & 7.1 & 6.9286 & TST & \\
\hline CHEMBL 2002649 & 809278 & 6.8 & 6.7218 & TRN & \\
\hline CHEMBL1985367 & 809278 & 6.5 & 6.3897 & TST & \\
\hline CHEMBL1971227 & 809278 & 5.8 & 5.3011 & TST & \\
\hline CHEMBL1994321 & 809278 & 5.7 & 4.7255 & TRN & \\
\hline CHEMBL1978562 & 809278 & 6.2 & 5.7872 & TST & \\
\hline CHEMBL1964307 & 809278 & 4.2 & 4.3426 & TRN & \\
\hline CHEMBL1989471 & 809278 & 6.6 & 5.9853 & TST & \\
\hline CHEMBL 2000508 & 809278 & 5.8 & 4.9658 & TRN & \\
\hline CHEMBL1971694 & 809278 & 4.2 & 4.3404 & TST & \\
\hline CHEMBL1978195 & 809278 & 7.0 & 7.274 & TRN & \\
\hline CHEMBL1986603 & 809278 & 4.2 & 4.947 & TST & \\
\hline CHEMBL1977148 & 809278 & 5.7 & 4.7424 & TRN & \\
\hline CHEMBL1966842 & 809278 & 5.8 & 5.2254 & TRN & \\
\hline CHEMBL 2004443 & 809278 & 6.3 & 5.5145 & TRN & \\
\hline CHEMBL 2003286 & 809278 & 5.4 & 5.0621 & TRN & \\
\hline CHEMBL1992306 & 809278 & 4.2 & 4.82 & TRN & \\
\hline CHEMBL 2002165 & 809278 & 4.2 & 4.7536 & TRN & \\
\hline CHEMBL1979318 & 809278 & 5.5 & 4.3753 & TRN & \\
\hline CHEMBL 206382 & 809278 & 4.2 & 4.3563 & TRN & \\
\hline CHEMBL127898 & 809278 & 5.6 & 4.5082 & TST & \\
\hline CHEMBL519697 & 809278 & 5.3 & 4.4744 & TRN & \\
\hline CHEMBL1968459 & 809278 & 7.3 & 6.8361 & TRN & \\
\hline CHEMBL1996345 & 809278 & 4.4 & 4.7604 & TST & \\
\hline CHEMBL1975128 & 809278 & 7.7 & 7.7668 & TRN & \\
\hline CHEMBL1970369 & 809278 & 4.2 & 3.9653 & TRN & \\
\hline CHEMBL1965033 & 809278 & 4.4 & $4.4510 e$ & 00000000005 & TRN \\
\hline CHEMBL 2001485 & 809278 & 5.2 & 4.8598 & TRN & \\
\hline CHEMBL504950 & 809278 & 4.2 & 5.0708 & TRN & \\
\hline CHEMBL1966425 & 809278 & 4.2 & 4.6599 & TRN & \\
\hline CHEMBL1988608 & 809278 & 7.1 & 5.9672 & TRN & \\
\hline CHEMBL184847 & 809278 & 5.2 & 4.8636 & TRN & \\
\hline CHEMBL1982563 & 809278 & 6.0 & 5.3215 & TRN & \\
\hline CHEMBL539474 & 809278 & 7.3 & 6.4892 & TST & \\
\hline CHEMBL575824 & 809278 & 6.2 & 6.3447 & TRN & \\
\hline CHEMBL1988387 & 809278 & 6.7 & 5.5587 & TRN & \\
\hline & & & & 10524 & \\
\hline
\end{tabular}




\begin{tabular}{|c|c|c|c|c|c|}
\hline CHEMBL1973868 & 809278 & 4.4 & \multicolumn{2}{|c|}{ 4.888999999999999 } & TRN \\
\hline CHEMBL1972462 & 809278 & 4.4 & 4.3969 & TST & \\
\hline CHEMBL1965702 & 809278 & 4.4 & 6.0009 & TRN & \\
\hline CHEMBL1986970 & 809278 & 7.0 & 7.3141 & TRN & \\
\hline CHEMBL 2002456 & 809278 & 6.2 & 6.2341 & TRN & \\
\hline CHEMBL1958401 & 809278 & 6.7 & 7.3675 & TRN & \\
\hline CHEMBL1984044 & 809278 & 4.2 & 4.9836 & TRN & \\
\hline CHEMBL1972584 & 809278 & 4.2 & 4.1592 & TRN & \\
\hline CHEMBL1982700 & 809278 & 4.4 & 4.5549 & TST & \\
\hline CHEMBL326282 & 809278 & 4.2 & 4.5469 & TST & \\
\hline CHEMBL1992732 & 809278 & 7.4 & 6.9177 & TST & \\
\hline CHEMBL1971186 & 809278 & 6.7 & 5.6191 & TRN & \\
\hline CHEMBL 2003482 & 809278 & 6.7 & 6.0778 & TRN & \\
\hline CHEMBL 2006456 & 809278 & 6.2 & 6.5388 & TRN & \\
\hline CHEMBL1973211 & 809278 & 6.1 & 4.5264 & TRN & \\
\hline CHEMBL1964340 & 809278 & 6.9 & 6.2417 & TRN & \\
\hline CHEMBL1976134 & 809278 & 5.3 & 4.7886 & TRN & \\
\hline CHEMBL1965131 & 809278 & 5.4 & 5.1074 & TST & \\
\hline CHEMBL1981215 & 809278 & 7.9 & 8.2328 & TRN & \\
\hline CHEMBL1974457 & 809278 & 6.6 & 6.6625 & TRN & \\
\hline CHEMBL1967662 & 809278 & 7.5 & \multicolumn{2}{|c|}{6.367000000000001} & TRN \\
\hline CHEMBL 2006580 & 809278 & 5.9 & 4.6483 & TRN & \\
\hline CHEMBL 2001228 & 809278 & 4.4 & 5.1092 & TRN & \\
\hline CHEMBL2006581 & 809278 & 4.2 & 3.9259 & TRN & \\
\hline CHEMBL1979855 & 809278 & 5.9 & 4.1793 & TRN & \\
\hline CHEMBL1970340 & 809278 & 3.3 & 3.627 & TRN & \\
\hline CHEMBL 2005186 & 809278 & 4.2 & 4.336 & TRN & \\
\hline CHEMBL1995927 & 809278 & 6.3 & 4.3317 & TST & \\
\hline CHEMBL 2006450 & 809278 & 4.4 & 4.2137 & TRN & \\
\hline CHEMBL 2001987 & 809278 & 8.1 & 7.9187 & TRN & \\
\hline CHEMBL 243518 & 809278 & 8.5 & 7.9239 & TRN & \\
\hline CHEMBL1994555 & 809278 & 6.1 & 5.9336 & TST & \\
\hline CHEMBL1997023 & 809278 & 6.4 & 5.081 & TST & \\
\hline CHEMBL1971943 & 809278 & 4.8 & 4.6696 & TRN & \\
\hline CHEMBL1997924 & 809278 & 8.1 & 6.2408 & TRN & \\
\hline CHEMBL1969049 & 809278 & 7.0 & 6.6117 & TRN & \\
\hline CHEMBL 2005828 & 809278 & 5.3 & 5.3103 & TRN & \\
\hline CHEMBL1991143 & 809278 & 5.5 & 4.1495 & TRN & \\
\hline CHEMBL1998611 & 809278 & 5.6 & 5.7291 & TST & \\
\hline CHEMBL1975900 & 809278 & 7.2 & 6.9865 & TRN & \\
\hline CHEMBL255822 & 809278 & 6.1 & 5.3028 & TRN & \\
\hline CHEMBL 2006778 & 809278 & 4.2 & 4.8531 & TRN & \\
\hline CHEMBL378627 & 809278 & 4.2 & \multicolumn{2}{|c|}{4.156000000000001} & TRN \\
\hline CHEMBL1996979 & 809278 & 6.3 & 5.7711 & TRN & \\
\hline CHEMBL1997025 & 809278 & 4.2 & 4.4776 & TRN & \\
\hline CHEMBL1968406 & 809278 & 6.0 & 5.4291 & TRN & \\
\hline CHEMBL1975921 & 809278 & 4.2 & 4.5722 & TRN & \\
\hline CHEMBL1982476 & 809278 & 4.2 & 5.5285 & TRN & \\
\hline
\end{tabular}




\begin{tabular}{|c|c|c|c|c|}
\hline & & & ipplement & al $\mathrm{T}$ \\
\hline CHEMBL1975923 & 809278 & 4.7 & 4.9715 & TST \\
\hline CHEMBL 2005449 & 809278 & 7.3 & 6.2045 & TRN \\
\hline CHEMBL1682558 & 809278 & 4.2 & 4.6925 & TRN \\
\hline CHEMBL1990496 & 809278 & 4.3 & 4.6903 & TST \\
\hline CHEMBL1998068 & 809278 & 6.6 & 6.3052 & TRN \\
\hline CHEMBL1993166 & 809278 & 4.2 & 4.3748 & TRN \\
\hline CHEMBL1967094 & 809278 & 4.2 & 4.5465 & TRN \\
\hline CHEMBL 2003341 & 809278 & 6.0 & 6.0428 & TRN \\
\hline CHEMBL1992644 & 809278 & 6.6 & 5.3925 & TRN \\
\hline CHEMBL1992645 & 809278 & 4.2 & 4.8723 & TST \\
\hline CHEMBL1998110 & 809278 & 5.7 & 5.0953 & TRN \\
\hline CHEMBL1999590 & 809278 & 7.0 & 5.9422 & TST \\
\hline CHEMBL1981079 & 809278 & 7.6 & 7.5872 & TRN \\
\hline CHEMBL1978166 & 809278 & 6.2 & 5.7547 & TRN \\
\hline CHEMBL1980489 & 809278 & 6.5 & 6.8238 & TRN \\
\hline CHEMBL 2000832 & 809278 & 6.6 & 6.1632 & TRN \\
\hline CHEMBL1967116 & 809278 & 4.2 & 4.7179 & TRN \\
\hline CHEMBL1990590 & 809278 & 4.4 & 4.3946 & TRN \\
\hline CHEMBL1977814 & 809278 & 4.3 & 4.7844 & TRN \\
\hline CHEMBL513846 & 809278 & 5.5 & 5.5633 & TRN \\
\hline CHEMBL1974617 & 809278 & 5.5 & 5.3277 & TRN \\
\hline CHEMBL1965660 & 809278 & 8.2 & 8.0952 & TRN \\
\hline CHEMBL1998112 & 809278 & 4.2 & 5.2304 & TRN \\
\hline CHEMBL1969126 & 809278 & 5.9 & 6.3054 & TRN \\
\hline CHEMBL1980896 & 809278 & 4.2 & 4.2782 & TRN \\
\hline CHEMBL1975208 & 809278 & 4.2 & 4.001 & TST \\
\hline CHEMBL1991429 & 809278 & 7.3 & 6.5726 & TRN \\
\hline CHEMBL1971149 & 809278 & 5.7 & 4.5635 & TRN \\
\hline CHEMBL1999714 & 809278 & 4.2 & 4.2245 & TRN \\
\hline CHEMBL1994040 & 809278 & 5.2 & 4.7846 & TRN \\
\hline CHEMBL388978 & 809278 & 7.5 & 6.6169 & TST \\
\hline CHEMBL 2004716 & 809278 & 4.5 & 4.2499 & TRN \\
\hline CHEMBL1975233 & 809278 & 5.7 & 4.902 & TRN \\
\hline CHEMBL1421720 & 809278 & 6.3 & 5.2573 & TRN \\
\hline CHEMBL1982135 & 809278 & 5.7 & 5.0467 & TRN \\
\hline CHEMBL1976090 & 809278 & 5.8 & 5.8212 & TRN \\
\hline CHEMBL 2004771 & 809278 & 5.5 & 5.3962 & TRN \\
\hline CHEMBL1992922 & 809278 & 5.8 & 5.8092 & TRN \\
\hline CHEMBL1997597 & 809278 & 4.2 & 4.8901 & TRN \\
\hline CHEMBL1976093 & 809278 & 5.2 & 4.7733 & TRN \\
\hline CHEMBL1996543 & 809278 & 5.7 & 6.3154 & TRN \\
\hline CHEMBL1975256 & 809278 & 6.8 & 6.6886 & TST \\
\hline CHEMBL1949855 & 809278 & 4.7 & 4.9425 & TST \\
\hline CHEMBL1999126 & 809278 & 5.8 & 4.3622 & TST \\
\hline CHEMBL1997503 & 809278 & 4.2 & 4.448 & TST \\
\hline CHEMBL116070 & 809278 & 6.8 & 7.6687 & TRN \\
\hline CHEMBL1990821 & 809278 & 4.2 & 4.3544 & TRN \\
\hline CHEMBL 2004871 & 809278 & 4.2 & 4.7808 & TRN \\
\hline
\end{tabular}




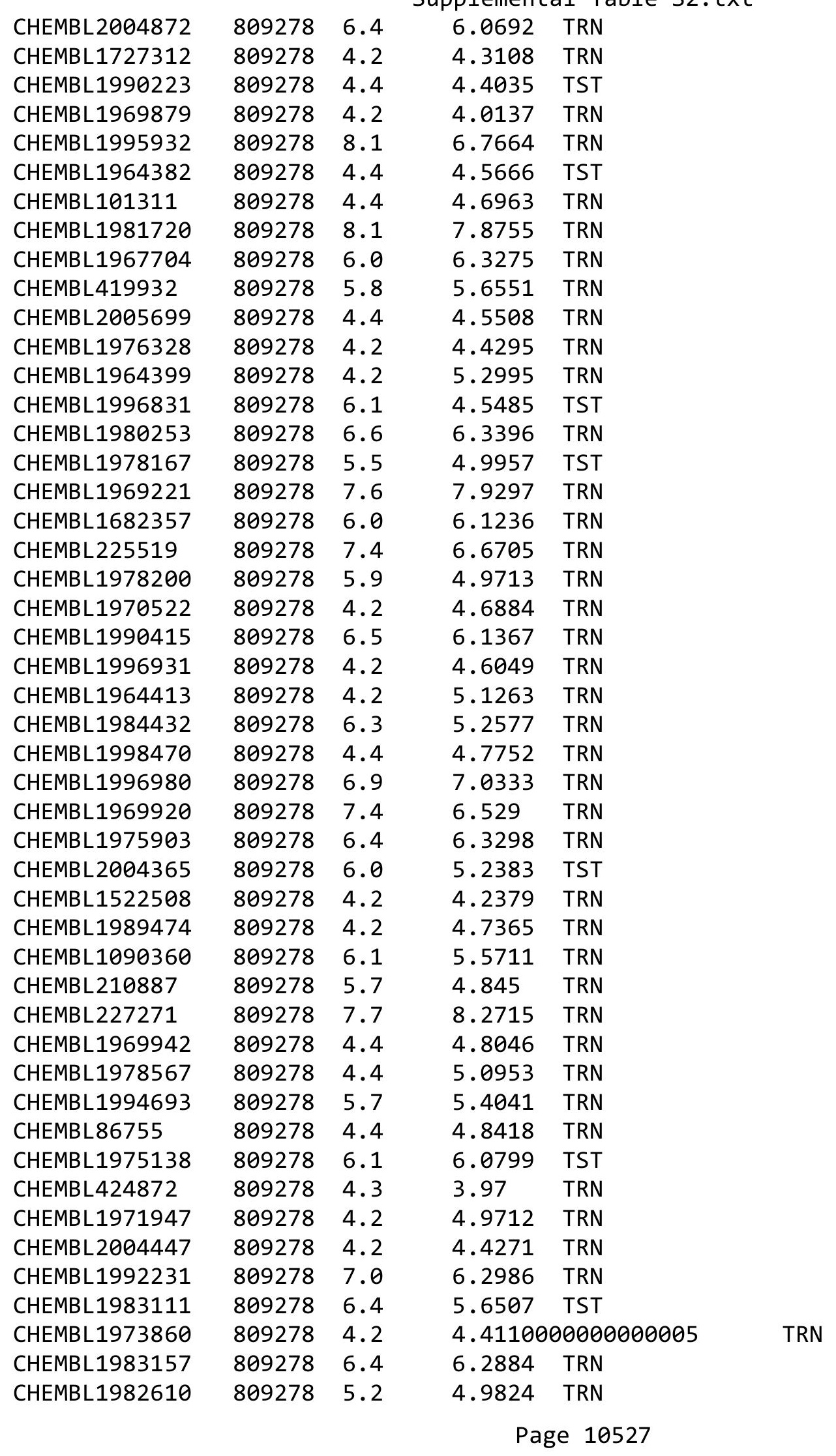




\begin{tabular}{|c|c|c|c|c|}
\hline & & & ient & al Ta \\
\hline CHEMBL1999496 & 809278 & 6.4 & 5.3438 & TRN \\
\hline CHEMBL1988300 & 809278 & 4.2 & 4.7492 & TRN \\
\hline CHEMBL1975212 & 809278 & 4.4 & 4.8194 & TRN \\
\hline CHEMBL 2001613 & 809278 & 4.7 & 4.607 & TRN \\
\hline CHEMBL1997275 & 809278 & 4.4 & 4.7522 & TRN \\
\hline CHEMBL1993904 & 809278 & 6.2 & 6.237 & TRN \\
\hline CHEMBL1989265 & 809278 & 5.8 & 5.3528 & TST \\
\hline CHEMBL1965910 & 809278 & 4.2 & 3.969 & TRN \\
\hline CHEMBL1996447 & 809278 & 6.2 & 5.9112 & TRN \\
\hline CHEMBL1983963 & 809278 & 4.2 & 4.9626 & TRN \\
\hline CHEMBL1985092 & 809278 & 5.2 & 4.4593 & TRN \\
\hline CHEMBL1981410 & 809278 & 4.2 & 4.0382 & TRN \\
\hline CHEMBL383264 & 809278 & 6.8 & 6.7438 & TRN \\
\hline CHEMBL 2007421 & 809278 & 4.4 & 4.4901 & TST \\
\hline CHEMBL1991434 & 809278 & 4.2 & 4.755 & TST \\
\hline CHEMBL1973138 & 809278 & 4.4 & 4.2713 & TRN \\
\hline CHEMBL340384 & 809278 & 6.9 & 6.6841 & TRN \\
\hline CHEMBL1969151 & 809278 & 5.8 & 6.8139 & TRN \\
\hline CHEMBL1996587 & 809278 & 4.2 & 5.3422 & TRN \\
\hline CHEMBL1988692 & 809278 & 4.4 & 4.8163 & TRN \\
\hline CHEMBL592030 & 809278 & 6.5 & 6.3157 & TST \\
\hline CHEMBL 2000071 & 809278 & 5.8 & 5.9828 & TRN \\
\hline CHEMBL 2002613 & 809278 & 7.4 & 7.2116 & TRN \\
\hline CHEMBL1983195 & 809278 & 6.3 & 6.0377 & TST \\
\hline CHEMBL 278041 & 809278 & 4.6 & 4.9537 & TRN \\
\hline CHEMBL1984162 & 809278 & 7.1 & 6.6283 & TRN \\
\hline CHEMBL1998432 & 809278 & 5.5 & 6.0942 & TRN \\
\hline CHEMBL1870106 & 809278 & 6.3 & 5.8095 & TRN \\
\hline CHEMBL1996791 & 809278 & 5.5 & 5.0247 & TRN \\
\hline CHEMBL371206 & 809278 & 5.7 & 4.5944 & TRN \\
\hline CHEMBL1974664 & 809278 & 6.9 & 6.9436 & TST \\
\hline CHEMBL1998477 & 809278 & 5.9 & 5.4593 & TRN \\
\hline CHEMBL1970104 & 809278 & 5.9 & 5.6479 & TRN \\
\hline CHEMBL1984296 & 809278 & 5.8 & 5.2952 & TST \\
\hline CHEMBL196363 & 809278 & 4.2 & 4.6435 & TRN \\
\hline CHEMBL1190711 & 809278 & 7.7 & 7.3565 & TRN \\
\hline CHEMBL1964441 & 809278 & 4.4 & 4.7721 & TRN \\
\hline CHEMBL546797 & 809278 & 5.9 & 5.5311 & TRN \\
\hline CHEMBL404367 & 809278 & 4.2 & 4.7351 & TRN \\
\hline CHEMBL1966343 & 809278 & 5.9 & 5.1734 & TRN \\
\hline CHEMBL1967887 & 809278 & 5.6 & 6.1856 & TRN \\
\hline CHEMBL 2000568 & 809278 & 4.3 & 4.084 & TRN \\
\hline CHEMBL2000335 & 809278 & 6.5 & 5.2007 & TRN \\
\hline CHEMBL 2007097 & 809278 & 4.4 & 4.529 & TRN \\
\hline CHEMBL1993648 & 809278 & 5.7 & 6.0869 & TRN \\
\hline CHEMBL 243298 & 809278 & 7.5 & 8.2485 & TRN \\
\hline CHEMBL1971951 & 809278 & 6.0 & 6.0425 & TRN \\
\hline CHEMBL1973808 & 809278 & 4.2 & 4.7159 & TRN \\
\hline
\end{tabular}




\begin{tabular}{|c|c|c|c|c|}
\hline & & & CIIC & al Ta \\
\hline CHEMBL 2000429 & 809278 & 5.6 & 4.7244 & TRN \\
\hline CHEMBL1972576 & 809278 & 4.2 & 5.4361 & TRN \\
\hline CHEMBL1992555 & 809278 & 4.2 & 4.3668 & TRN \\
\hline CHEMBL 2003682 & 809278 & 6.7 & 6.9268 & TRN \\
\hline CHEMBL1988173 & 809278 & 6.1 & 7.0013 & TST \\
\hline CHEMBL535331 & 809278 & 4.2 & 4.9957 & TRN \\
\hline CHEMBL1989805 & 809278 & 6.6 & 5.9622 & TST \\
\hline CHEMBL1982980 & 809278 & 4.2 & 4.1398 & TRN \\
\hline CHEMBL1983025 & 809278 & 5.8 & 5.0019 & TRN \\
\hline CHEMBL1975927 & 809278 & 4.4 & 4.527 & TRN \\
\hline CHEMBL 2002322 & 809278 & 7.0 & 7.2596 & TRN \\
\hline CHEMBL1985654 & 809278 & 6.0 & 6.131 & TRN \\
\hline CHEMBL1997119 & 809278 & 4.7 & 4.5168 & TRN \\
\hline CHEMBL 2002323 & 809278 & 4.2 & 5.348 & TST \\
\hline CHEMBL2000879 & 809278 & 4.2 & 4.3628 & TST \\
\hline CHEMBL1983855 & 809278 & 5.6 & 6.3546 & TRN \\
\hline CHEMBL1987793 & 809278 & 5.6 & 4.3728 & TRN \\
\hline CHEMBL21156 & 809278 & 4.4 & 4.7421 & TST \\
\hline CHEMBL1992740 & 809278 & 7.6 & 6.5205 & TRN \\
\hline CHEMBL1989267 & 809278 & 5.5 & 4.88 & TRN \\
\hline CHEMBL 2002373 & 809278 & 5.4 & 5.062 & TRN \\
\hline CHEMBL439340 & 809278 & 4.2 & 4.6014 & TRN \\
\hline CHEMBL 2006188 & 809278 & 5.9 & 5.7678 & TRN \\
\hline CHEMBL1973893 & 809278 & 6.6 & 6.5835 & TRN \\
\hline CHEMBL 2004631 & 809278 & 8.1 & 7.7891 & TRN \\
\hline CHEMBL1995736 & 809278 & 4.2 & 4.2067 & TRN \\
\hline CHEMBL1985095 & 809278 & 7.0 & 7.1268 & TST \\
\hline CHEMBL1996500 & 809278 & 4.4 & 4.7494 & TRN \\
\hline CHEMBL1973363 & 809278 & 5.5 & 5.2032 & TRN \\
\hline CHEMBL1682540 & 809278 & 7.2 & 6.775 & TRN \\
\hline CHEMBL1998253 & 809278 & 4.4 & 4.6928 & TST \\
\hline CHEMBL413779 & 809278 & 6.7 & 5.2914 & TST \\
\hline CHEMBL497151 & 809278 & 7.5 & 7.4419 & TRN \\
\hline CHEMBL 2000029 & 809278 & 6.9 & 7.3711 & TRN \\
\hline CHEMBL1973961 & 809278 & 4.4 & 4.5702 & TRN \\
\hline CHEMBL1994977 & 809278 & 4.4 & 4.312 & TRN \\
\hline CHEMBL 373598 & 809278 & 6.6 & 5.1141 & TST \\
\hline CHEMBL2001149 & 809278 & 4.4 & 4.5886 & TRN \\
\hline CHEMBL1999718 & 809278 & 8.4 & 7.3395 & TRN \\
\hline CHEMBL 2000078 & 809278 & 4.4 & 5.0457 & TRN \\
\hline CHEMBL1996646 & 809278 & 5.9 & 5.7476 & TRN \\
\hline CHEMBL1979773 & 809278 & 4.4 & 4.6989 & TRN \\
\hline CHEMBL1977346 & 809278 & 7.0 & 7.0993 & TRN \\
\hline CHEMBL1996702 & 809278 & 4.4 & 5.1667 & TRN \\
\hline CHEMBL1975440 & 809278 & 6.8 & 6.0717 & TRN \\
\hline CHEMBL1998435 & 809278 & 5.2 & 4.8779 & TRN \\
\hline CHEMBL1969190 & 809278 & 4.2 & 4.8151 & TRN \\
\hline CHEMBL1973937 & 809278 & 4.2 & 4.7443 & TRN \\
\hline
\end{tabular}




\begin{tabular}{|c|c|c|c|c|}
\hline & & & ipplement & al $\mathrm{T}$ \\
\hline CHEMBL1982711 & 809278 & 6.1 & 5.8535 & TRN \\
\hline CHEMBL1987982 & 809278 & 4.2 & 4.2322 & TST \\
\hline CHEMBL1969102 & 809278 & 4.2 & 4.64 & TRN \\
\hline CHEMBL 2004118 & 809278 & 4.4 & 4.4374 & TRN \\
\hline CHEMBL1994241 & 809278 & 6.3 & 6.7967 & TRN \\
\hline CHEMBL 2007044 & 809278 & 4.2 & 4.7007 & TST \\
\hline CHEMBL 2001998 & 809278 & 4.2 & 4.0026 & TST \\
\hline CHEMBL2003119 & 809278 & 5.5 & 5.2304 & TST \\
\hline CHEMBL50894 & 809278 & 7.8 & 7.5972 & TRN \\
\hline CHEMBL1995211 & 809278 & 6.2 & 5.8157 & TRN \\
\hline CHEMBL1988838 & 809278 & 5.7 & 5.9208 & TRN \\
\hline CHEMBL1981725 & 809278 & 4.2 & 4.4962 & TRN \\
\hline CHEMBL1982753 & 809278 & 4.4 & 4.7176 & TRN \\
\hline CHEMBL1965169 & 809278 & 4.4 & 4.5138 & TST \\
\hline CHEMBL1081312 & 809278 & 4.7 & 5.3949 & TRN \\
\hline CHEMBL1965170 & 809278 & 5.6 & 4.8811 & TRN \\
\hline CHEMBL 2004156 & 809278 & 5.7 & 5.4293 & TRN \\
\hline CHEMBL 2005792 & 809278 & 4.4 & 4.76 & TRN \\
\hline CHEMBL1984206 & 809278 & 4.2 & 4.0756 & TRN \\
\hline CHEMBL462120 & 809278 & 5.6 & 5.2667 & TST \\
\hline CHEMBL1991577 & 809278 & 4.2 & 4.4571 & TRN \\
\hline CHEMBL 2007592 & 809278 & 4.2 & 5.6547 & TRN \\
\hline CHEMBL1997892 & 809278 & 4.4 & 4.4794 & TRN \\
\hline CHEMBL1976936 & 809278 & 7.0 & 6.8956 & TRN \\
\hline CHEMBL 210963 & 809278 & 4.2 & 4.0136 & TRN \\
\hline CHEMBL1984633 & 809278 & 6.2 & 5.7276 & TRN \\
\hline CHEMBL1982400 & 809278 & 7.7 & 7.8208 & TRN \\
\hline CHEMBL1965845 & 809278 & 6.6 & 7.2864 & TRN \\
\hline CHEMBL1983715 & 809278 & 5.8 & 5.8152 & TRN \\
\hline CHEMBL402846 & 809278 & 4.2 & 4.7762 & TRN \\
\hline CHEMBL1682545 & 809278 & 6.2 & 5.9229 & TRN \\
\hline CHEMBL1976732 & 809278 & 6.2 & 4.5359 & TRN \\
\hline CHEMBL1982982 & 809278 & 6.1 & 6.1192 & TRN \\
\hline CHEMBL1980163 & 809278 & 4.2 & 4.4429 & TRN \\
\hline CHEMBL1989856 & 809278 & 5.5 & 5.0622 & TST \\
\hline CHEMBL1972568 & 809278 & 4.2 & 4.4802 & TRN \\
\hline CHEMBL259850 & 809278 & 7.6 & 7.0922 & TRN \\
\hline CHEMBL1986851 & 809278 & 4.4 & 5.3227 & TRN \\
\hline CHEMBL1987745 & 809278 & 6.6 & 6.0188 & TRN \\
\hline CHEMBL1971223 & 809278 & 4.4 & 4.3198 & TRN \\
\hline CHEMBL105739 & 809278 & 4.2 & 4.1755 & TRN \\
\hline CHEMBL203673 & 809278 & 5.3 & 6.0579 & TRN \\
\hline CHEMBL 2003785 & 809278 & 4.3 & 4.5335 & TRN \\
\hline CHEMBL1983070 & 809278 & 4.4 & 4.3435 & TRN \\
\hline CHEMBL 2002470 & 809278 & 5.5 & 5.3208 & TST \\
\hline CHEMBL1981045 & 809278 & 6.2 & 4.2399 & TRN \\
\hline CHEMBL387971 & 809278 & 4.2 & 4.3167 & TST \\
\hline CHEMBL1992796 & 809278 & 5.5 & 5.1519 & TST \\
\hline
\end{tabular}




\begin{tabular}{|c|c|c|c|c|c|}
\hline \\
\hline CHEMBL1968515 & 809278 & 4.5 & 4.5924 & TST & \\
\hline CHEMBL1164180 & 809278 & 4.4 & 4.9934 & TST & \\
\hline CHEMBL223257 & 809278 & 5.4 & 5.0487 & TST & \\
\hline CHEMBL1997611 & 809278 & 4.4 & 4.8317 & TST & \\
\hline CHEMBL1516890 & 809278 & 5.7 & 4.8461 & TRN & \\
\hline CHEMBL2001751 & 809278 & 7.2 & 6.8184 & TRN & \\
\hline CHEMBL1984586 & 809278 & 4.2 & 4.9693 & TRN & \\
\hline CHEMBL1999774 & 809278 & 4.2 & 4.0995 & TST & \\
\hline CHEMBL1972659 & 809278 & 4.2 & 4.4265 & TST & \\
\hline CHEMBL1973395 & 809278 & 5.8 & 5.4719 & TRN & \\
\hline CHEMBL1984686 & 809278 & 4.4 & 5.3562 & TRN & \\
\hline CHEMBL1969843 & 809278 & 6.1 & 5.3916 & TRN & \\
\hline CHEMBL 2007002 & 809278 & 6.4 & 5.3841 & TRN & \\
\hline CHEMBL1992073 & 809278 & 4.4 & 3.8649 & TRN & \\
\hline CHEMBL484390 & 809278 & 4.2 & 4.4096 & TRN & \\
\hline CHEMBL 2007559 & 809278 & 4.4 & 4.4767 & TRN & \\
\hline CHEMBL 2004290 & 809278 & 4.3 & 5.2347 & TRN & \\
\hline CHEMBL2000393 & 809278 & 5.3 & 5.0937 & TST & \\
\hline CHEMBL 2004072 & 809278 & 6.2 & 6.2301 & TRN & \\
\hline CHEMBL1983573 & 809278 & 4.9 & 4.988 & TRN & \\
\hline CHEMBL1242373 & 809278 & 5.5 & 5.2324 & TRN & \\
\hline CHEMBL56543 & 809278 & 5.9 & 5.3433 & TST & \\
\hline CHEMBL1984402 & 809278 & 5.9 & 4.82600 & 00000000005 & TRN \\
\hline CHEMBL1988075 & 809278 & 4.2 & 4.9567 & TRN & \\
\hline CHEMBL1988076 & 809278 & 4.4 & 4.9931 & TRN & \\
\hline CHEMBL 2001239 & 809278 & 4.2 & 4.7019 & TST & \\
\hline CHEMBL 2001288 & 809278 & 4.2 & 4.4384 & TRN & \\
\hline CHEMBL1999811 & 809278 & 6.0 & 5.0772 & TRN & \\
\hline CHEMBL 235157 & 809278 & 4.4 & 4.7993 & TST & \\
\hline CHEMBL 2000481 & 809278 & 5.7 & 5.0427 & TRN & \\
\hline CHEMBL1992242 & 809278 & 4.2 & 3.9372 & TRN & \\
\hline CHEMBL1982271 & 809278 & 6.6 & 6.7864 & TRN & \\
\hline CHEMBL2007138 & 809278 & 6.0 & 4.9158 & TST & \\
\hline CHEMBL2004159 & 809278 & 4.4 & 4.7319 & TRN & \\
\hline CHEMBL1986530 & 809278 & 4.2 & 4.8735 & TST & \\
\hline CHEMBL440084 & 809278 & 4.4 & 4.7632 & TRN & \\
\hline CHEMBL1999321 & 809278 & 4.2 & 4.8914 & TRN & \\
\hline CHEMBL1968590 & 809278 & 4.2 & 4.5535 & TRN & \\
\hline CHEMBL 2005375 & 809278 & 4.2 & 4.1878 & TRN & \\
\hline CHEMBL1972183 & 809278 & 4.2 & 4.2775 & TRN & \\
\hline CHEMBL1995391 & 809278 & 6.1 & 4.9632 & TRN & \\
\hline CHEMBL1980592 & 809278 & 6.2 & 5.7209 & TRN & \\
\hline CHEMBL1974702 & 809278 & 5.7 & 5.5788 & TST & \\
\hline CHEMBL474432 & 809278 & 5.8 & 5.077 & TST & \\
\hline CHEMBL1965387 & 809278 & 4.4 & 4.4313 & TRN & \\
\hline CHEMBL2001539 & 809278 & 4.2 & 4.7657 & TST & \\
\hline CHEMBL1997041 & 809278 & 5.2 & 4.6473 & TRN & \\
\hline CHEMBL1487428 & 809278 & 5.0 & 5.447 & TRN & \\
\hline
\end{tabular}




\begin{tabular}{|c|c|c|c|c|c|}
\hline \\
\hline CHEMBL550418 & 809278 & 4.4 & 4.7628 & TRN & \\
\hline CHEMBL 2003637 & 809278 & 7.4 & 6.2864 & TST & \\
\hline CHEMBL1986666 & 809278 & 7.8 & 6.5968 & TRN & \\
\hline CHEMBL1971289 & 809278 & 4.4 & 4.476 & TRN & \\
\hline CHEMBL1999556 & 809278 & 7.0 & 7.2823 & TRN & \\
\hline CHEMBL1988437 & 809278 & 4.5 & 5.1537 & TRN & \\
\hline CHEMBL1998121 & 809278 & 6.1 & 5.735 & TRN & \\
\hline CHEMBL2003689 & 809278 & 4.4 & 4.5782 & TRN & \\
\hline CHEMBL379835 & 809278 & 4.2 & 4.3433 & TRN & \\
\hline CHEMBL1980802 & 809278 & 5.2 & 4.8976 & TST & \\
\hline CHEMBL1996649 & 809278 & 4.5 & 4.8317 & TRN & \\
\hline CHEMBL1986756 & 809278 & 7.5 & 7.9427 & TRN & \\
\hline CHEMBL3197315 & 809278 & 5.4 & 5.9335 & TST & \\
\hline CHEMBL468280 & 809278 & 4.2 & 4.9867 & TST & \\
\hline CHEMBL1990884 & 809278 & 4.2 & 5.13399 & 99999999995 & TRN \\
\hline CHEMBL3109278 & 809278 & 4.6 & 4.1573 & TRN & \\
\hline CHEMBL 2006276 & 809278 & 4.2 & 4.8387 & TRN & \\
\hline CHEMBL191003 & 809278 & 6.8 & 6.273 & TRN & \\
\hline CHEMBL 2006785 & 809278 & 4.2 & 4.5406 & TST & \\
\hline CHEMBL1973359 & 809278 & 6.4 & 6.3414 & TST & \\
\hline CHEMBL1995740 & 809278 & 6.3 & 6.5174 & TRN & \\
\hline CHEMBL1979690 & 809278 & 4.4 & 4.9812 & TRN & \\
\hline CHEMBL1995832 & 809278 & 4.2 & 4.8431 & TRN & \\
\hline CHEMBL 2000345 & 809278 & 5.8 & 6.1317 & TRN & \\
\hline CHEMBL1983575 & 809278 & 6.1 & 5.9658 & TRN & \\
\hline CHEMBL1375418 & 809278 & 5.3 & 4.7284 & TRN & \\
\hline CHEMBL302449 & 809278 & 7.8 & 6.6107 & TST & \\
\hline CHEMBL1981047 & 809278 & 4.7 & 4.787 & TRN & \\
\hline CHEMBL229968 & 809278 & 7.5 & 7.5729 & TRN & \\
\hline CHEMBL1976196 & 809278 & 5.5 & 4.6753 & TST & \\
\hline CHEMBL1976240 & 809278 & 7.1 & 6.4535 & TRN & \\
\hline CHEMBL1987948 & 809278 & 6.1 & 6.2323 & TRN & \\
\hline CHEMBL1983630 & 809278 & 4.8 & 5.0968 & TRN & \\
\hline CHEMBL1979093 & 809278 & 5.2 & 4.8706 & TRN & \\
\hline CHEMBL336961 & 809278 & 8.0 & 7.7346 & TRN & \\
\hline CHEMBL1970083 & 809278 & 6.0 & 5.5053 & TRN & \\
\hline CHEMBL1994938 & 809278 & 4.2 & 5.0232 & TRN & \\
\hline CHEMBL1977223 & 809278 & 8.6 & 7.8617 & TRN & \\
\hline CHEMBL1976290 & 809278 & 4.1 & 4.8403 & TRN & \\
\hline CHEMBL1236126 & 809278 & 4.2 & 4.4423 & TRN & \\
\hline CHEMBL1997846 & 809278 & 5.9 & 5.9927 & TRN & \\
\hline CHEMBL 2004419 & 809278 & 4.2 & 4.3822 & TRN & \\
\hline CHEMBL1992937 & 809278 & 5.6 & 4.8167 & TST & \\
\hline CHEMBL1985566 & 809278 & 4.2 & 4.2961 & TRN & \\
\hline CHEMBL1972119 & 809278 & 8.0 & 7.0909 & TRN & \\
\hline CHEMBL95692 & 809278 & 4.2 & 4.7396 & TRN & \\
\hline CHEMBL1976455 & 809278 & 8.4 & 7.9863 & TRN & \\
\hline CHEMBL1983923 & 809278 & 5.9 & 5.2111 & TRN & \\
\hline & & & & 10532 & \\
\hline
\end{tabular}




\begin{tabular}{|c|c|c|c|c|c|}
\hline \multirow[b]{2}{*}{ CHEMBL1983534 } & \multirow[b]{2}{*}{809278} & \multirow[b]{2}{*}{4.2} & \\
\hline & & & 5.5237 & TRN & \\
\hline CHEMBL1982361 & 809278 & 6.8 & 6.5011 & TRN & \\
\hline CHEMBL2000801 & 809278 & 4.2 & 4.276 & TRN & \\
\hline CHEMBL1991395 & 809278 & 4.3 & 4.9595 & TRN & \\
\hline CHEMBL1971245 & 809278 & 5.8 & 5.1961 & TRN & \\
\hline CHEMBL2003545 & 809278 & 4.1 & 5.1786 & TST & \\
\hline CHEMBL1972142 & 809278 & 4.2 & 4.4009 & TRN & \\
\hline CHEMBL1966514 & 809278 & 4.2 & 4.9105 & TRN & \\
\hline CHEMBL1983393 & 809278 & 4.4 & 4.9612 & TRN & \\
\hline CHEMBL516429 & 809278 & 7.9 & 7.2527 & TRN & \\
\hline CHEMBL1970806 & 809278 & 4.2 & 5.4263 & TRN & \\
\hline CHEMBL1992371 & 809278 & 6.0 & 6.62799 & 9999999999 & TRN \\
\hline CHEMBL1967252 & 809278 & 5.4 & 5.9845 & TRN & \\
\hline CHEMBL1970821 & 809278 & 7.0 & 6.4687 & TRN & \\
\hline CHEMBL2004637 & 809278 & 5.7 & 5.2754 & TRN & \\
\hline CHEMBL1993374 & 809278 & 4.4 & 4.2779 & TST & \\
\hline CHEMBL1969264 & 809278 & 6.4 & 5.63399 & 99999999995 & TRN \\
\hline CHEMBL2006237 & 809278 & 4.2 & 5.2446 & TRN & \\
\hline CHEMBL1999506 & 809278 & 4.4 & 4.4072 & TRN & \\
\hline CHEMBL2005509 & 809278 & 7.0 & 6.9272 & TRN & \\
\hline CHEMBL1572266 & 809278 & 7.5 & 4.3508 & TST & \\
\hline CHEMBL1979516 & 809278 & 4.2 & 4.6754 & TRN & \\
\hline CHEMBL1972820 & 809278 & 4.2 & 4.3389 & TST & \\
\hline CHEMBL1605605 & 809278 & 4.4 & 4.6579 & TRN & \\
\hline CHEMBL1989029 & 809278 & 5.2 & 5.553 & TRN & \\
\hline CHEMBL392642 & 809278 & 5.7 & 6.7584 & TRN & \\
\hline CHEMBL1682554 & 809278 & 7.8 & 7.4637 & TRN & \\
\hline CHEMBL1980167 & 809278 & 6.5 & 5.9292 & TST & \\
\hline CHEMBL1972849 & 809278 & 4.2 & 4.702 & TRN & \\
\hline CHEMBL1986855 & 809278 & 7.5 & 7.1141 & TRN & \\
\hline CHEMBL1975357 & 809278 & 4.2 & 4.2662 & TST & \\
\hline CHEMBL1989136 & 809278 & 6.4 & 5.9624 & TRN & \\
\hline CHEMBL259922 & 809278 & 4.2 & 4.2847 & TST & \\
\hline CHEMBL1997617 & 809278 & 4.2 & 3.8627 & TRN & \\
\hline CHEMBL1969301 & 809278 & 5.3 & 4.3845 & TRN & \\
\hline CHEMBL1987910 & 809278 & 4.2 & 4.615 & TRN & \\
\hline CHEMBL1983980 & 809278 & 6.2 & 5.9812 & TRN & \\
\hline CHEMBL1986899 & 809278 & 4.4 & 4.6913 & TRN & \\
\hline CHEMBL243088 & 809278 & 7.9 & 7.9931 & TRN & \\
\hline CHEMBL1993661 & 809278 & 5.1 & 5.8789 & TRN & \\
\hline CHEMBL1230164 & 809278 & 5.3 & 4.9799 & TRN & \\
\hline CHEMBL202721 & 809278 & 4.7 & 4.6063 & TRN & \\
\hline CHEMBL1987034 & 809278 & 6.9 & 6.5366 & TRN & \\
\hline CHEMBL2005886 & 809278 & 5.5 & 5.0862 & TST & \\
\hline CHEMBL1682345 & 809278 & 6.7 & 7.1225 & TRN & \\
\hline CHEMBL481491 & 809278 & 4.2 & 4.717 & TST & \\
\hline CHEMBL388311 & 809278 & 8.6 & 7.8821 & TRN & \\
\hline CHEMBL1807515 & 809278 & 6.7 & 7.4555 & TRN & \\
\hline & & & & 10533 & \\
\hline
\end{tabular}




\begin{tabular}{|c|c|c|c|c|c|}
\hline \multirow[b]{2}{*}{ CHEMBL2005936 } & \multirow[b]{2}{*}{809278} & \multirow[b]{2}{*}{8.5} & \\
\hline & & & 8.2548 & TRN & \\
\hline CHEMBL1999778 & 809278 & 5.6 & 5.3062 & TST & \\
\hline CHEMBL1987430 & 809278 & 8.2 & 8.3957 & TRN & \\
\hline CHEMBL1562756 & 809278 & 5.6 & 5.2183 & TST & \\
\hline CHEMBL1993413 & 809278 & 4.4 & 4.3011 & TRN & \\
\hline CHEMBL1969372 & 809278 & 6.2 & 5.9052 & TRN & \\
\hline CHEMBL2001957 & 809278 & 4.2 & 4.6418 & TRN & \\
\hline CHEMBL1988662 & 809278 & 5.2 & 5.4816 & TRN & \\
\hline CHEMBL1986263 & 809278 & 7.9 & 5.8516 & TRN & \\
\hline CHEMBL1986265 & 809278 & 4.4 & 4.6901 & TST & \\
\hline CHEMBL1964644 & 809278 & 6.7 & 7.2382 & TRN & \\
\hline CHEMBL1981782 & 809278 & 5.5 & 5.1675 & TRN & \\
\hline CHEMBL1970142 & 809278 & 5.3 & 4.7998 & TRN & \\
\hline CHEMBL1977681 & 809278 & 6.1 & 5.6904 & TRN & \\
\hline CHEMBL1983348 & 809278 & 6.3 & 6.0538 & TRN & \\
\hline CHEMBL1995592 & 809278 & 5.7 & 5.0466 & TRN & \\
\hline CHEMBL1982541 & 809278 & 5.8 & 4.5963 & TRN & \\
\hline CHEMBL1986177 & 809278 & 4.4 & 4.4629 & TRN & \\
\hline CHEMBL1992323 & 809278 & 5.2 & 5.0712 & TST & \\
\hline CHEMBL1983449 & 809278 & 6.8 & 6.1453 & TRN & \\
\hline CHEMBL1983589 & 809278 & 6.1 & 7.3101 & TRN & \\
\hline CHEMBL1996510 & 809278 & 4.4 & 7.1194 & TST & \\
\hline CHEMBL2005718 & 809278 & 6.4 & 6.3247 & TRN & \\
\hline CHEMBL437747 & 809278 & 5.6 & 5.88399 & 99999999995 & TRN \\
\hline CHEMBL507936 & 809278 & 4.2 & 4.3705 & TRN & \\
\hline CHEMBL2001584 & 809278 & 4.4 & 4.1815 & TRN & \\
\hline CHEMBL1995172 & 809278 & 4.3 & 4.0559 & TST & \\
\hline CHEMBL1967998 & 809278 & 4.4 & 5.0651 & TRN & \\
\hline CHEMBL104264 & 809278 & 4.2 & 4.5328 & TRN & \\
\hline CHEMBL1997129 & 809278 & 5.5 & 6.1986 & TRN & \\
\hline CHEMBL1984788 & 809278 & 4.2 & 4.7967 & TRN & \\
\hline CHEMBL1974875 & 809278 & 4.3 & 4.7229 & TST & \\
\hline CHEMBL2001547 & 809278 & 4.2 & 4.789 & TRN & \\
\hline CHEMBL210928 & 809278 & 4.2 & 4.0412 & TRN & \\
\hline CHEMBL1972840 & 809278 & 6.7 & 6.9373 & TRN & \\
\hline CHEMBL2001668 & 809278 & 4.2 & 4.9026 & TRN & \\
\hline CHEMBL1998585 & 809278 & 6.0 & 5.3638 & TRN & \\
\hline CHEMBL 2004934 & 809278 & 6.9 & 6.694 & TRN & \\
\hline CHEMBL1987261 & 809278 & 5.7 & 6.5653 & TRN & \\
\hline CHEMBL1996048 & 809278 & 4.4 & 4.9439 & TST & \\
\hline CHEMBL 2004025 & 809278 & 6.4 & 5.78799 & 9999999999 & TST \\
\hline CHEMBL461876 & 809278 & 4.4 & 4.7243 & TST & \\
\hline CHEMBL1971519 & 809278 & 4.7 & $4.5760 e$ & 20000000005 & TRN \\
\hline CHEMBL1997335 & 809278 & 4.4 & 5.6752 & TRN & \\
\hline CHEMBL1978099 & 809278 & 6.1 & 5.782 & TRN & \\
\hline CHEMBL1984363 & 809278 & 5.3 & 4.6751 & TRN & \\
\hline CHEMBL1977041 & 809278 & 6.0 & 5.5685 & TRN & \\
\hline CHEMBL1968070 & 809278 & 7.0 & 7.2251 & TRN & \\
\hline & & & & 10534 & \\
\hline
\end{tabular}




\begin{tabular}{|c|c|c|c|c|c|}
\hline \multirow[b]{2}{*}{ CHEMBL1994808 } & \multirow[b]{2}{*}{809278} & \\
\hline & & 4.0 & 4.6544 & TRN & \\
\hline CHEMBL1985723 & 809278 & 4.4 & 6.1801 & TRN & \\
\hline CHEMBL1984367 & 809278 & 5.3 & 4.4964 & TRN & \\
\hline CHEMBL1977128 & 809278 & 8.4 & 7.6758 & TRN & \\
\hline CHEMBL1997759 & 809278 & 4.2 & 4.9632 & TRN & \\
\hline CHEMBL1970074 & 809278 & 4.2 & 4.9565 & TRN & \\
\hline CHEMBL1974803 & 809278 & 5.5 & 4.3896 & TST & \\
\hline CHEMBL1984500 & 809278 & 3.1 & 3.6296 & TRN & \\
\hline CHEMBL 2005112 & 809278 & 4.2 & 4.4746 & TST & \\
\hline CHEMBL2003456 & 809278 & 5.6 & 5.6423 & TRN & \\
\hline CHEMBL 2002992 & 809278 & 4.3 & 4.3966 & TRN & \\
\hline CHEMBL560813 & 809278 & 5.5 & 5.1366 & TRN & \\
\hline CHEMBL1890036 & 809278 & 5.7 & 5.5861 & TST & \\
\hline CHEMBL207253 & 809278 & 4.2 & $4.6930 e$ & 00000000005 & TRN \\
\hline CHEMBL1968791 & 809278 & 4.2 & 3.6461 & TRN & \\
\hline CHEMBL 2002682 & 809278 & 4.2 & 4.3991 & TRN & \\
\hline CHEMBL1977634 & 809278 & 4.4 & 4.5825 & TRN & \\
\hline CHEMBL1984700 & 809278 & 5.6 & 4.7643 & TRN & \\
\hline CHEMBL1998953 & 809278 & 4.4 & 4.7475 & TRN & \\
\hline CHEMBL 2007151 & 809278 & 4.2 & 3.9498 & TRN & \\
\hline CHEMBL1971606 & 809278 & 5.6 & 5.8938 & TRN & \\
\hline CHEMBL1972125 & 809278 & 4.4 & 5.4537 & TRN & \\
\hline CHEMBL1461728 & 809278 & 4.2 & 4.4058 & TRN & \\
\hline CHEMBL1999279 & 809278 & 6.9 & 7.2074 & TRN & \\
\hline CHEMBL1995448 & 809278 & 4.2 & 4.6444 & TRN & \\
\hline CHEMBL1972158 & 809278 & 7.9 & 8.1122 & TRN & \\
\hline CHEMBL1999414 & 809278 & 4.5 & 4.8526 & TRN & \\
\hline CHEMBL1967336 & 809278 & 7.6 & 7.7353 & TRN & \\
\hline CHEMBL2006481 & 809278 & 4.2 & 3.89399 & 99999999997 & TRN \\
\hline CHEMBL1978645 & 809278 & 5.4 & 4.71399 & 99999999995 & TRN \\
\hline CHEMBL1967992 & 809278 & 6.3 & 6.0967 & TRN & \\
\hline CHEMBL1993424 & 809278 & 6.3 & 6.455 & TRN & \\
\hline CHEMBL1975534 & 809278 & 4.2 & 4.0958 & TRN & \\
\hline CHEMBL1966703 & 809278 & 7.7 & $6.6770 e$ & 00000000005 & TST \\
\hline CHEMBL1969561 & 809278 & 7.8 & 7.7486 & TRN & \\
\hline CHEMBL1983640 & 809278 & 5.5 & 4.9651 & TRN & \\
\hline CHEMBL1964687 & 809278 & 5.8 & 5.1598 & TRN & \\
\hline CHEMBL1999918 & 809278 & 8.2 & 7.6888 & TRN & \\
\hline CHEMBL1974254 & 809278 & 4.2 & 4.916 & TRN & \\
\hline CHEMBL1988537 & 809278 & 5.3 & 5.1677 & TST & \\
\hline CHEMBL 2002240 & 809278 & 5.9 & 4.4405 & TRN & \\
\hline CHEMBL1978267 & 809278 & 4.4 & 4.6625 & TRN & \\
\hline CHEMBL1980178 & 809278 & 6.1 & 6.0099 & TRN & \\
\hline CHEMBL485556 & 809278 & 4.2 & 4.3273 & TRN & \\
\hline CHEMBL1981511 & 809278 & 6.2 & 5.6818 & TRN & \\
\hline CHEMBL1972221 & 809278 & 7.2 & 6.9072 & TRN & \\
\hline CHEMBL1984274 & 809278 & 4.2 & 5.3467 & TST & \\
\hline CHEMBL1998545 & 809278 & 5.7 & 5.1705 & TRN & \\
\hline & & & & 105 & \\
\hline
\end{tabular}




\begin{tabular}{|c|c|c|c|c|}
\hline & & & & al \\
\hline CHEMBL 2004033 & 809278 & 5.5 & 5.2789 & TST \\
\hline CHEMBL1986869 & 809278 & 4.2 & 4.5909 & TRN \\
\hline CHEMBL1987998 & 809278 & 4.4 & 4.5364 & TST \\
\hline CHEMBL1971534 & 809278 & 5.3 & 5.9315 & TRN \\
\hline CHEMBL242865 & 809278 & 8.0 & 7.7362 & TRN \\
\hline CHEMBL1997623 & 809278 & 4.2 & 4.5981 & TRN \\
\hline CHEMBL 2002479 & 809278 & 4.2 & 4.1948 & TRN \\
\hline CHEMBL1966035 & 809278 & 6.4 & 5.7793 & TRN \\
\hline CHEMBL1990708 & 809278 & 6.5 & 5.9371 & TRN \\
\hline CHEMBL1982992 & 809278 & 5.4 & 4.8047 & TRN \\
\hline CHEMBL1972276 & 809278 & 4.2 & 5.7211 & TRN \\
\hline CHEMBL1970709 & 809278 & 4.2 & 4.4396 & TRN \\
\hline CHEMBL1992125 & 809278 & 5.6 & 5.4851 & TRN \\
\hline CHEMBL1972290 & 809278 & 6.1 & 6.0362 & TRN \\
\hline CHEMBL1964777 & 809278 & 6.6 & 7.5316 & TRN \\
\hline CHEMBL1987533 & 809278 & 4.2 & 4.2073 & TRN \\
\hline CHEMBL1984548 & 809278 & 8.1 & 8.2233 & TRN \\
\hline CHEMBL579246 & 809278 & 7.0 & 6.4089 & TRN \\
\hline CHEMBL398951 & 809278 & 4.3 & 4.1705 & TST \\
\hline CHEMBL1982506 & 809278 & 6.9 & 6.85 & TST \\
\hline CHEMBL1968127 & 809278 & 5.3 & 4.6454 & TRN \\
\hline CHEMBL1985406 & 809278 & 8.6 & 7.0806 & TRN \\
\hline CHEMBL 2000894 & 809278 & 6.2 & 6.0461 & TRN \\
\hline CHEMBL 207400 & 809278 & 4.2 & 4.3979 & TRN \\
\hline CHEMBL1968130 & 809278 & 4.5 & 4.6393 & TRN \\
\hline CHEMBL1993243 & 809278 & 4.2 & 4.7888 & TRN \\
\hline CHEMBL399021 & 809278 & 4.2 & 3.8212 & TRN \\
\hline CHEMBL1969537 & 809278 & 6.5 & 5.0324 & TST \\
\hline CHEMBL 210032 & 809278 & 4.2 & 4.9024 & TRN \\
\hline CHEMBL508928 & 809278 & 4.2 & 4.1841 & TRN \\
\hline CHEMBL1991356 & 809278 & 4.2 & 5.0574 & TST \\
\hline CHEMBL1983309 & 809278 & 6.3 & 5.8025 & TRN \\
\hline CHEMBL 2004892 & 809278 & 4.2 & 4.9254 & TRN \\
\hline CHEMBL1972339 & 809278 & 7.7 & 7.7615 & TRN \\
\hline CHEMBL1970314 & 809278 & 4.2 & 4.676 & TRN \\
\hline CHEMBL262433 & 809278 & 5.3 & 4.5685 & TRN \\
\hline CHEMBL 306380 & 809278 & 4.2 & 4.7626 & TRN \\
\hline CHEMBL1966722 & 809278 & 6.3 & 6.1932 & TST \\
\hline CHEMBL1983595 & 809278 & 8.4 & 7.4804 & TRN \\
\hline CHEMBL1988581 & 809278 & 7.1 & 6.0374 & TST \\
\hline CHEMBL1975500 & 809278 & 6.3 & 5.2872 & TRN \\
\hline CHEMBL394619 & 809278 & 4.2 & 4.6065 & TRN \\
\hline CHEMBL 2006564 & 809278 & 5.7 & 5.1512 & TRN \\
\hline CHEMBL411903 & 809278 & 5.2 & 4.9816 & TRN \\
\hline CHEMBL1965988 & 809278 & 5.5 & 5.0546 & TRN \\
\hline CHEMBL418203 & 809278 & 6.4 & 5.7747 & TST \\
\hline CHEMBL1989646 & 809278 & 7.2 & 7.5335 & TRN \\
\hline CHEMBL 209534 & 809278 & 4.2 & 4.2439 & TRN \\
\hline
\end{tabular}




\begin{tabular}{|c|c|c|c|c|}
\hline & & & pplement & al $\mathrm{Ta}$ \\
\hline CHEMBL1994159 & 809278 & 4.6 & 4.4321 & TRN \\
\hline CHEMBL1966087 & 809278 & 4.2 & 4.4536 & TRN \\
\hline CHEMBL1964692 & 809278 & 5.7 & 5.2784 & TRN \\
\hline CHEMBL1986767 & 809278 & 6.9 & 6.1807 & TRN \\
\hline CHEMBL1973483 & 809278 & 8.1 & 8.2852 & TRN \\
\hline CHEMBL 219722 & 809278 & 5.4 & 5.2179 & TRN \\
\hline CHEMBL1970735 & 809278 & 4.2 & 4.4339 & TRN \\
\hline CHEMBL1997340 & 809278 & 4.2 & 3.8522 & TRN \\
\hline CHEMBL1994669 & 809278 & 8.3 & 8.6439 & TRN \\
\hline CHEMBL226232 & 809278 & 6.1 & 6.2402 & TRN \\
\hline CHEMBL458997 & 809278 & 4.3 & 3.8526 & TRN \\
\hline CHEMBL1988805 & 809278 & 4.4 & 4.6544 & TST \\
\hline CHEMBL1971021 & 809278 & 4.2 & 4.2042 & TRN \\
\hline CHEMBL1974310 & 809278 & 7.1 & 7.5472 & TRN \\
\hline CHEMBL583144 & 809278 & 5.4 & 5.6958 & TST \\
\hline CHEMBL1982957 & 809278 & 6.8 & 6.3008 & TRN \\
\hline CHEMBL1725279 & 809278 & 6.5 & 5.7285 & TST \\
\hline CHEMBL 2002346 & 809278 & 8.1 & 7.2036 & TRN \\
\hline CHEMBL 2006836 & 809278 & 5.3 & 4.2408 & TST \\
\hline CHEMBL412142 & 809278 & 8.4 & 6.7698 & TST \\
\hline CHEMBL1985153 & 809278 & 5.2 & 5.9266 & TRN \\
\hline CHEMBL2003271 & 809278 & 5.4 & 5.6302 & TST \\
\hline CHEMBL1980704 & 809278 & 4.2 & 5.1683 & TST \\
\hline CHEMBL1966808 & 809278 & 6.9 & 6.3819 & TRN \\
\hline CHEMBL260135 & 809278 & 6.8 & 6.7865 & TRN \\
\hline CHEMBL 220241 & 809278 & 7.2 & 6.6965 & TRN \\
\hline CHEMBL 2004544 & 809278 & 6.2 & 5.7137 & TST \\
\hline CHEMBL1966040 & 809278 & 7.0 & 6.7569 & TRN \\
\hline CHEMBL1988141 & 809278 & 7.0 & 5.6823 & TST \\
\hline CHEMBL1977134 & 809278 & 4.4 & 4.5341 & TRN \\
\hline CHEMBL1985206 & 809278 & 4.4 & 4.5187 & TST \\
\hline CHEMBL2006933 & 809278 & 6.9 & 6.1426 & TST \\
\hline CHEMBL1991078 & 809278 & 6.0 & 7.8276 & TRN \\
\hline CHEMBL1987359 & 809278 & 4.2 & 4.1325 & TST \\
\hline CHEMBL1977749 & 809278 & 4.4 & 5.1721 & TST \\
\hline CHEMBL 2000685 & 809278 & 4.2 & 4.4687 & TRN \\
\hline CHEMBL1994438 & 809278 & 4.4 & 6.273 & TRN \\
\hline CHEMBL1967513 & 809278 & 7.4 & 7.6404 & TRN \\
\hline CHEMBL1980376 & 809278 & 4.4 & 4.2572 & TRN \\
\hline CHEMBL1985311 & 809278 & 4.2 & 4.9931 & TRN \\
\hline CHEMBL 2000724 & 809278 & 4.4 & 4.7564 & TRN \\
\hline CHEMBL1982413 & 809278 & 5.6 & 4.9283 & TST \\
\hline CHEMBL1682553 & 809278 & 7.4 & 7.3649 & TRN \\
\hline CHEMBL1969502 & 809278 & 5.3 & 5.4951 & TRN \\
\hline CHEMBL1971430 & 809278 & 4.2 & 4.6802 & TST \\
\hline CHEMBL 2000271 & 809278 & 6.1 & 6.774 & TRN \\
\hline CHEMBL1997764 & 809278 & 5.7 & 5.1478 & TRN \\
\hline CHEMBL1987535 & 809278 & 5.5 & 5.1627 & TRN \\
\hline
\end{tabular}




\begin{tabular}{|c|c|c|c|c|}
\hline & & & EI & al Ta \\
\hline CHEMBL1981792 & 809278 & 7.6 & 8.0185 & TRN \\
\hline CHEMBL 2002586 & 809278 & 4.4 & 4.1589 & TRN \\
\hline CHEMBL 2004692 & 809278 & 5.9 & 6.1935 & TST \\
\hline CHEMBL1987815 & 809278 & 4.4 & 4.7316 & TST \\
\hline CHEMBL1996234 & 809278 & 4.2 & 4.3115 & TRN \\
\hline CHEMBL1967544 & 809278 & 4.2 & 4.7692 & TRN \\
\hline CHEMBL1992673 & 809278 & 4.4 & 4.4137 & TST \\
\hline CHEMBL223367 & 809278 & 6.8 & 5.442 & TST \\
\hline CHEMBL1993335 & 809278 & 6.4 & 5.9196 & TST \\
\hline CHEMBL 2007574 & 809278 & 7.5 & 6.9281 & TRN \\
\hline CHEMBL1964804 & 809278 & 6.2 & 5.5159 & TRN \\
\hline CHEMBL1996282 & 809278 & 5.3 & 5.4672 & TRN \\
\hline CHEMBL443962 & 809278 & 5.5 & 5.9207 & TST \\
\hline CHEMBL1965507 & 809278 & 4.2 & 4.5088 & TRN \\
\hline CHEMBL 2000354 & 809278 & 5.5 & 5.1843 & TRN \\
\hline CHEMBL1998680 & 809278 & 4.4 & 4.5647 & TRN \\
\hline CHEMBL 274064 & 809278 & 4.2 & 5.3259 & TRN \\
\hline CHEMBL1967564 & 809278 & 6.8 & 7.2059 & TRN \\
\hline CHEMBL1970317 & 809278 & 4.2 & 4.6214 & TRN \\
\hline CHEMBL 2000408 & 809278 & 5.5 & 4.8776 & TRN \\
\hline CHEMBL1978014 & 809278 & 7.5 & 5.983 & TRN \\
\hline CHEMBL248757 & 809278 & 4.2 & 5.9062 & TST \\
\hline CHEMBL1974250 & 809278 & 8.6 & 7.0937 & TRN \\
\hline CHEMBL1997007 & 809278 & 4.4 & 4.3786 & TRN \\
\hline CHEMBL1994538 & 809278 & 7.8 & 8.2406 & TRN \\
\hline CHEMBL1975490 & 809278 & 4.2 & 4.6754 & TRN \\
\hline CHEMBL 2002690 & 809278 & 4.4 & 4.7932 & TRN \\
\hline CHEMBL383527 & 809278 & 4.2 & 5.5026 & TRN \\
\hline CHEMBL1986139 & 809278 & 4.2 & 4.5894 & TRN \\
\hline CHEMBL 2006567 & 809278 & 4.2 & 4.337 & TRN \\
\hline CHEMBL 2003229 & 809278 & 5.9 & 5.9728 & TRN \\
\hline CHEMBL1979883 & 809278 & 5.6 & 4.7264 & TRN \\
\hline CHEMBL1997051 & 809278 & 4.4 & 5.1905 & TRN \\
\hline CHEMBL1988331 & 809278 & 7.6 & 6.4676 & TRN \\
\hline CHEMBL491758 & 809278 & 5.7 & 5.853 & TRN \\
\hline CHEMBL1986590 & 809278 & 4.4 & 4.9206 & TRN \\
\hline CHEMBL1998826 & 809278 & 6.4 & 5.9649 & TRN \\
\hline CHEMBL549730 & 809278 & 5.6 & 5.1377 & TRN \\
\hline CHEMBL1970189 & 809278 & 5.2 & 4.2997 & TRN \\
\hline CHEMBL406845 & 809278 & 4.4 & 4.379 & TRN \\
\hline CHEMBL1974288 & 809278 & 6.8 & 6.8178 & TRN \\
\hline CHEMBL 213207 & 809278 & 6.9 & 7.0903 & TRN \\
\hline CHEMBL1990346 & 809278 & 4.2 & 4.2528 & TRN \\
\hline CHEMBL1991410 & 809278 & 4.4 & 3.8982 & TRN \\
\hline CHEMBL1968705 & 809278 & 4.4 & 4.2519 & TRN \\
\hline CHEMBL1978271 & 809278 & 4.4 & 4.4094 & TRN \\
\hline CHEMBL 2007266 & 809278 & 4.4 & 4.613 & TRN \\
\hline CHEMBL1994308 & 809278 & 4.4 & 4.6797 & TRN \\
\hline
\end{tabular}




\begin{tabular}{|c|c|c|c|c|}
\hline & & & ipplement & al Table S \\
\hline CHEMBL1974328 & 809278 & 4.5 & 4.9712 & TRN \\
\hline CHEMBL1988717 & 809278 & 4.2 & 4.6356 & TRN \\
\hline CHEMBL509032 & 809278 & 4.4 & 4.0064 & TRN \\
\hline CHEMBL1992342 & 809278 & 4.2 & 5.0206 & TRN \\
\hline CHEMBL2002202 & 809278 & 4.2 & 4.8564 & TRN \\
\hline CHEMBL1973013 & 809278 & 5.6 & 5.4796 & TST \\
\hline CHEMBL1965423 & 809278 & 4.2 & 4.3606 & TRN \\
\hline CHEMBL 205415 & 809278 & 5.7 & 5.3576 & TRN \\
\hline CHEMBL1977135 & 809278 & 6.7 & 5.9507 & TRN \\
\hline CHEMBL1969473 & 809278 & 8.0 & 7.9806 & TRN \\
\hline CHEMBL1999153 & 809278 & 7.9 & 7.6412 & TRN \\
\hline CHEMBL2001920 & 809278 & 6.3 & 5.1856 & TST \\
\hline CHEMBL1977138 & 809278 & 6.2 & 6.5279 & TST \\
\hline CHEMBL1241473 & 809278 & 8.2 & 8.3343 & TRN \\
\hline CHEMBL1978448 & 809278 & 4.7 & 4.5206 & TST \\
\hline CHEMBL2004513 & 809278 & 5.5 & 4.989 & TRN \\
\hline CHEMBL1972258 & 809278 & 4.2 & 4.2996 & TRN \\
\hline CHEMBL1969483 & 809278 & 4.4 & 4.9584 & TRN \\
\hline CHEMBL2001257 & 809278 & 4.5 & 4.2816 & TRN \\
\hline CHEMBL2004515 & 809278 & 4.6 & 4.6392 & TRN \\
\hline CHEMBL1980329 & 809278 & 6.3 & 6.3169 & TRN \\
\hline CHEMBL1992042 & 809278 & 6.4 & 5.3942 & TST \\
\hline CHEMBL1992536 & 809278 & 7.2 & 6.415 & TRN \\
\hline CHEMBL1994724 & 809278 & 5.9 & 6.1851 & TRN \\
\hline CHEMBL1970290 & 809278 & 5.9 & 5.2341 & TRN \\
\hline CHEMBL1967531 & 809278 & 5.2 & 4.9156 & TRN \\
\hline CHEMBL1970913 & 809278 & 6.9 & 6.8591 & TRN \\
\hline CHEMBL1997534 & 809278 & 7.3 & 7.3243 & TRN \\
\hline CHEMBL1993877 & 809278 & 4.4 & 5.1842 & TRN \\
\hline CHEMBL1977374 & 809278 & 4.2 & 4.51 & TRN \\
\hline CHEMBL1998551 & 809278 & 4.2 & 4.5742 & TRN \\
\hline CHEMBL1991180 & 809278 & 6.4 & 6.1827 & TST \\
\hline CHEMBL1983315 & 809278 & 7.9 & 7.7374 & TRN \\
\hline CHEMBL1978656 & 809278 & 4.2 & 5.3418 & TRN \\
\hline CHEMBL1976420 & 809278 & 5.7 & 5.7871 & TST \\
\hline CHEMBL1981744 & 809278 & 8.1 & 7.88299 & 9999999999 \\
\hline CHEMBL1994864 & 809278 & 6.4 & 6.3682 & TRN \\
\hline CHEMBL2002446 & 809278 & 5.6 & 4.579 & TST \\
\hline CHEMBL246970 & 809278 & 6.2 & 6.6853 & TRN \\
\hline CHEMBL340921 & 809278 & 5.5 & 6.032 & TRN \\
\hline CHEMBL2005478 & 809278 & 6.4 & 5.9347 & TST \\
\hline CHEMBL1276446 & 809278 & 8.5 & 6.3921 & TST \\
\hline CHEMBL1995712 & 809278 & 6.1 & 5.8151 & TRN \\
\hline CHEMBL1971649 & 809278 & 4.2 & 4.814 & TRN \\
\hline CHEMBL2003657 & 809278 & 4.2 & 4.3107 & TRN \\
\hline CHEMBL2005482 & 809278 & 4.4 & 5.2636 & TRN \\
\hline CHEMBL2007124 & 809278 & 4.4 & 4.607 & TRN \\
\hline CHEMBL1997909 & 809278 & 4.4 & 4.9514 & TRN \\
\hline
\end{tabular}




\begin{tabular}{|c|c|c|c|c|}
\hline & & & 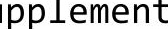 & al Table \\
\hline CHEMBL 2006439 & 809278 & 5.0 & 5.8386 & TRN \\
\hline CHEMBL 2006156 & 809278 & 4.2 & 4.8671 & TST \\
\hline CHEMBL1985681 & 809278 & 7.5 & 6.66799 & 9999999999 \\
\hline CHEMBL1991674 & 809278 & 7.2 & 7.5421 & TRN \\
\hline CHEMBL 262623 & 809278 & 4.3 & 4.6138 & TRN \\
\hline CHEMBL1984842 & 809278 & 4.4 & 4.5888 & TRN \\
\hline CHEMBL 223460 & 809278 & 6.1 & 5.0286 & TST \\
\hline CHEMBL1998829 & 809278 & 4.2 & 4.7263 & TRN \\
\hline CHEMBL 2006299 & 809278 & 5.7 & 5.4924 & TRN \\
\hline CHEMBL375284 & 809278 & 4.2 & 4.5035 & TRN \\
\hline CHEMBL1972346 & 809278 & 6.0 & 5.0834 & TST \\
\hline CHEMBL1980562 & 809278 & 7.1 & 6.7663 & TRN \\
\hline CHEMBL1982866 & 809278 & 4.2 & 4.6297 & TRN \\
\hline CHEMBL1968926 & 809278 & 4.2 & 5.3565 & TRN \\
\hline CHEMBL2006609 & 809278 & 5.2 & 5.5231 & TST \\
\hline CHEMBL1979933 & 809278 & 7.3 & 6.9445 & TRN \\
\hline CHEMBL1965570 & 809278 & 4.2 & 5.6552 & TRN \\
\hline CHEMBL1986503 & 809278 & 4.4 & 4.6415 & TST \\
\hline CHEMBL 2001641 & 809278 & 4.9 & 5.2162 & TRN \\
\hline CHEMBL1972355 & 809278 & 6.4 & 6.1423 & TST \\
\hline CHEMBL1997193 & 809278 & 6.5 & 5.3097 & TST \\
\hline CHEMBL1964902 & 809278 & 4.4 & 4.6947 & TRN \\
\hline CHEMBL 2005387 & 809278 & 6.5 & 6.1933 & TRN \\
\hline CHEMBL1082440 & 809278 & 4.2 & 4.7301 & TST \\
\hline CHEMBL1614705 & 809278 & 4.2 & 4.6541 & TRN \\
\hline CHEMBL1972988 & 809278 & 6.1 & 5.9421 & TRN \\
\hline CHEMBL 2007372 & 809278 & 4.2 & 4.3476 & TRN \\
\hline CHEMBL1982167 & 809278 & 4.2 & 5.3895 & TRN \\
\hline CHEMBL1986597 & 809278 & 5.2 & 5.6212 & TRN \\
\hline CHEMBL 2006715 & 809278 & 6.3 & 6.1673 & TRN \\
\hline CHEMBL1971017 & 809278 & 7.7 & 7.6271 & TRN \\
\hline CHEMBL1990482 & 809278 & 4.2 & 5.0049 & TRN \\
\hline CHEMBL1990904 & 809278 & 6.4 & 6.1138 & TRN \\
\hline CHEMBL1987448 & 809278 & 6.3 & 6.5716 & TRN \\
\hline CHEMBL 2005475 & 809278 & 5.3 & 4.1541 & TRN \\
\hline CHEMBL 2000104 & 809278 & 7.4 & 7.4579 & TRN \\
\hline CHEMBL183844 & 809278 & 4.2 & 4.163 & TRN \\
\hline CHEMBL1997349 & 809278 & 6.1 & 5.3019 & TST \\
\hline CHEMBL220057 & 809278 & 5.4 & 4.171 & TRN \\
\hline CHEMBL383541 & 809278 & 5.9 & 6.4225 & TRN \\
\hline CHEMBL 2001224 & 809278 & 4.2 & 4.5339 & TRN \\
\hline CHEMBL10 & 809278 & 5.8 & 5.0685 & TRN \\
\hline CHEMBL2005216 & 809278 & 7.8 & 6.9804 & TRN \\
\hline CHEMBL1964937 & 809278 & 5.8 & 6.3384 & TRN \\
\hline CHEMBL1980763 & 809278 & 4.4 & 4.3347 & TRN \\
\hline CHEMBL1969506 & 809278 & 5.6 & 4.9601 & TRN \\
\hline CHEMBL590109 & 809278 & 6.0 & 6.6108 & TST \\
\hline CHEMBL1977931 & 809278 & 4.2 & 4.3609 & TRN \\
\hline
\end{tabular}




\begin{tabular}{|c|c|c|c|c|}
\hline & & & pplement & 0 \\
\hline CHEMBL1970879 & 809278 & 4.2 & 4.1802 & TRN \\
\hline CHEMBL 2005899 & 809278 & 5.3 & 5.3507 & TRN \\
\hline CHEMBL1682552 & 809278 & 7.0 & 7.1246 & TRN \\
\hline CHEMBL 2007479 & 809278 & 6.8 & 6.1795 & TRN \\
\hline CHEMBL1996155 & 809278 & 4.2 & 4.0724 & TRN \\
\hline CHEMBL229799 & 809278 & 7.8 & 7.9497 & TRN \\
\hline CHEMBL 379300 & 809278 & 8.0 & 7.4503 & TRN \\
\hline CHEMBL1972220 & 809278 & 5.9 & 5.4629 & TRN \\
\hline CHEMBL1973720 & 809278 & 6.4 & 6.9437 & TRN \\
\hline CHEMBL1969523 & 809278 & 6.1 & 5.9138 & TRN \\
\hline CHEMBL 2005214 & 809278 & 5.4 & 4.4193 & TRN \\
\hline CHEMBL207995 & 809278 & 5.8 & 5.6806 & TRN \\
\hline CHEMBL1988995 & 809278 & 4.2 & 4.6664 & TRN \\
\hline CHEMBL1986781 & 809278 & 7.1 & 5.9957 & TRN \\
\hline CHEMBL2001923 & 809278 & 4.3 & 4.5478 & TRN \\
\hline CHEMBL526133 & 809278 & 7.4 & 7.6189 & TRN \\
\hline CHEMBL 2003514 & 809278 & 5.8 & 5.6598 & TRN \\
\hline CHEMBL1989043 & 809278 & 5.5 & 5.0669 & TRN \\
\hline CHEMBL1979057 & 809278 & 5.3 & 5.5396 & TRN \\
\hline CHEMBL1967538 & 809278 & 4.4 & 4.5728 & TST \\
\hline CHEMBL1999428 & 809278 & 6.8 & 6.8268 & TRN \\
\hline CHEMBL1967560 & 809278 & 4.2 & 3.9071 & TRN \\
\hline CHEMBL1682358 & 809278 & 6.8 & 6.1749 & TRN \\
\hline CHEMBL211378 & 809278 & 4.2 & 4.421 & TRN \\
\hline CHEMBL1982465 & 809278 & 4.2 & 4.1782 & TRN \\
\hline CHEMBL 2003420 & 809278 & 4.2 & 4.5468 & TRN \\
\hline CHEMBL 2002723 & 809278 & 5.9 & 5.2318 & TST \\
\hline CHEMBL 272453 & 809278 & 4.2 & 4.5598 & TRN \\
\hline CHEMBL1971801 & 809278 & 5.8 & 6.6093 & TRN \\
\hline CHEMBL1970217 & 809278 & 6.6 & 6.7722 & TRN \\
\hline CHEMBL1968850 & 809278 & 6.7 & 7.2052 & TRN \\
\hline CHEMBL 2005528 & 809278 & 5.4 & 5.5306 & TST \\
\hline CHEMBL185569 & 809278 & 4.2 & 4.4165 & TRN \\
\hline CHEMBL1987007 & 809278 & 4.2 & 4.3216 & TRN \\
\hline CHEMBL1973793 & 809278 & 4.4 & 4.7981 & TST \\
\hline CHEMBL1969588 & 809278 & 8.0 & 6.6443 & TRN \\
\hline CHEMBL1984711 & 809278 & 5.6 & 5.2907 & TRN \\
\hline CHEMBL1990212 & 809278 & 4.2 & 5.2943 & TRN \\
\hline CHEMBL1986143 & 809278 & 5.9 & 6.3657 & TRN \\
\hline CHEMBL1979252 & 809278 & 6.6 & 6.5388 & TRN \\
\hline CHEMBL1972934 & 809278 & 4.8 & 4.5793 & TRN \\
\hline CHEMBL1992581 & 809278 & 4.4 & 4.9767 & TRN \\
\hline CHEMBL1972250 & 809278 & 4.2 & 4.663 & TST \\
\hline CHEMBL1972937 & 809278 & 4.2 & 4.3954 & TRN \\
\hline CHEMBL1986499 & 809278 & 7.9 & 7.8494 & TRN \\
\hline CHEMBL2001477 & 809278 & 5.8 & 6.0679 & TRN \\
\hline CHEMBL 2004311 & 809278 & 4.2 & 4.2381 & TRN \\
\hline CHEMBL1992634 & 809278 & 4.2 & 4.8306 & TRN \\
\hline
\end{tabular}




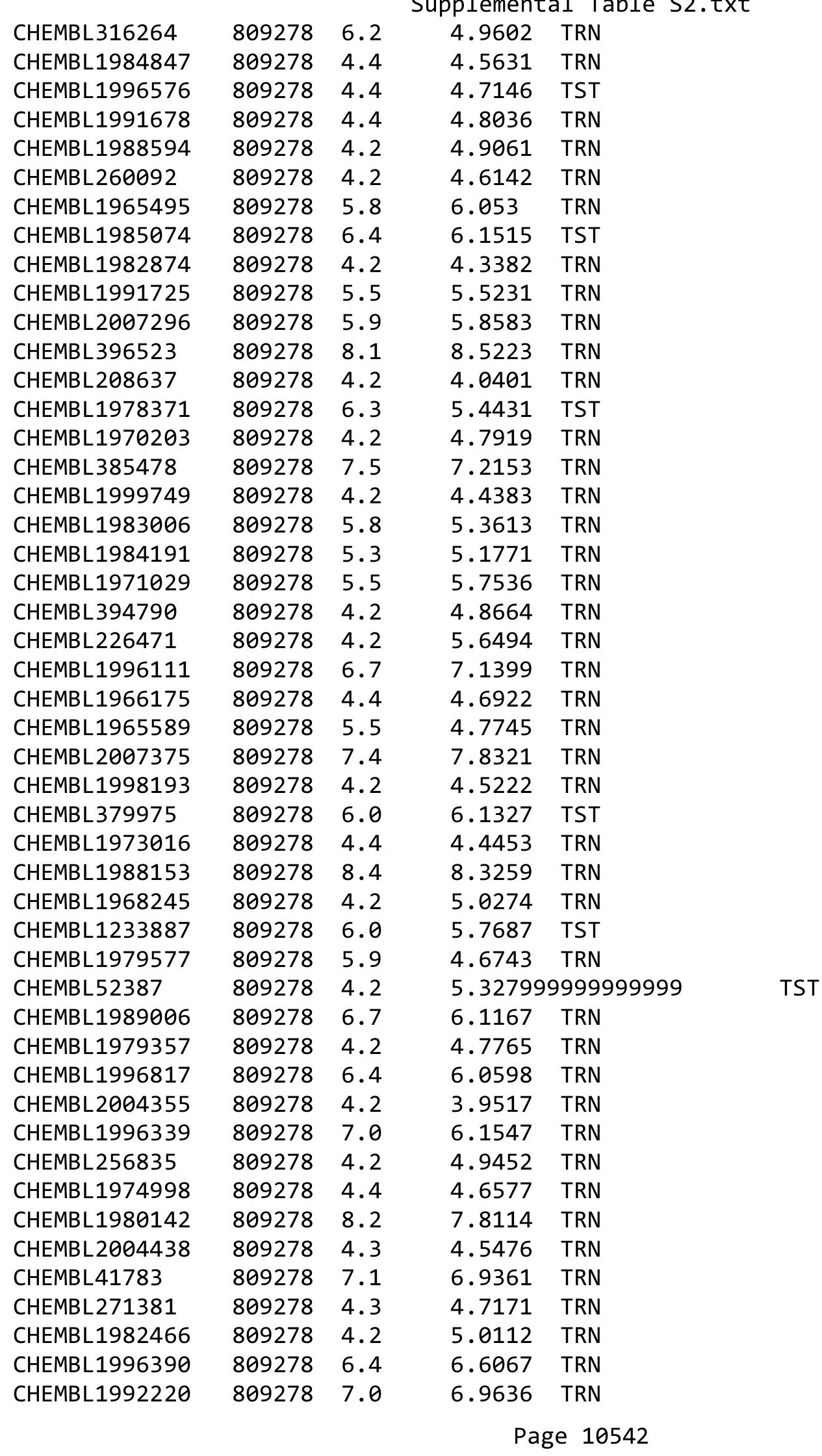




\begin{tabular}{|c|c|c|c|c|}
\hline & & & Supplement & a] \\
\hline CHEMBL234085 & 809278 & 4.4 & 4.1748 & TRN \\
\hline CHEMBL1998414 & 809278 & 4.2 & 5.1311 & TRN \\
\hline CHEMBL1969042 & 809278 & 5.4 & 4.7598 & TST \\
\hline CHEMBL1976376 & 809278 & 4.4 & 4.1661 & TST \\
\hline CHEMBL1991640 & 809278 & 4.2 & 5.4218 & TST \\
\hline CHEMBL1968868 & 809278 & 7.6 & 7.4339 & TST \\
\hline CHEMBL 2007064 & 809278 & 5.8 & 4.3979 & TST \\
\hline CHEMBL1997197 & 809278 & 5.6 & 5.6957 & TST \\
\hline CHEMBL1968151 & 809278 & 6.6 & 5.9331 & TST \\
\hline CHEMBL1381197 & 809278 & 4.2 & 4.8398 & TST \\
\hline CHEMBL1987009 & 809278 & 5.7 & 5.6586 & TST \\
\hline CHEMBL379218 & 809278 & 7.2 & 7.4583 & TST \\
\hline CHEMBL2003817 & 809278 & 7.2 & 7.8903 & TST \\
\hline CHEMBL1994830 & 809278 & 8.5 & 8.7287 & TST \\
\hline CHEMBL1987054 & 809278 & 6.9 & 6.4448 & TST \\
\hline CHEMBL226403 & 809278 & 4.2 & 4.3289 & TST \\
\hline CHEMBL2005631 & 809278 & 4.2 & 5.1889 & TST \\
\hline CHEMBL1995765 & 809278 & 4.7 & 4.9086 & TST \\
\hline CHEMBL1966279 & 809278 & 4.2 & 4.8331 & TST \\
\hline CHEMBL1984760 & 809278 & 4.4 & 4.3914 & TST \\
\hline CHEMBL1991728 & 809278 & 4.2 & 4.2945 & TST \\
\hline CHEMBL360847 & 809278 & 6.1 & 5.5489 & TST \\
\hline CHEMBL1995811 & 809278 & 8.7 & 8.2069 & TST \\
\hline CHEMBL1975787 & 809278 & 6.7 & 7.6011 & TST \\
\hline CHEMBL 2002407 & 809278 & 5.9 & 5.2254 & TST \\
\hline CHEMBL1995916 & 809278 & 6.0 & 5.0143 & TST \\
\hline CHEMBL1972489 & 809278 & 4.2 & 4.3946 & TST \\
\hline CHEMBL1994074 & 809278 & 4.2 & 4.9896 & TST \\
\hline CHEMBL1990541 & 809278 & 5.4 & 5.976 & TST \\
\hline CHEMBL1968930 & 809278 & 5.9 & 6.5531 & TST \\
\hline CHEMBL1090356 & 809278 & 4.2 & 4.7336 & TST \\
\hline CHEMBL1986328 & 809278 & 6.2 & 5.4545 & TST \\
\hline CHEMBL 2002450 & 809278 & 4.5 & 4.3635 & TST \\
\hline CHEMBL261849 & 809278 & 4.4 & 4.4954 & TST \\
\hline CHEMBL1970950 & 809278 & 5.9 & 6.7013 & TST \\
\hline CHEMBL1982122 & 809278 & 4.2 & 6.5926 & TST \\
\hline CHEMBL1999112 & 809278 & 5.2 & 5.4125 & TST \\
\hline CHEMBL1682546 & 809278 & 5.2 & 5.8382 & TST \\
\hline CHEMBL1996780 & 809278 & 4.2 & 5.409 & TST \\
\hline CHEMBL1996066 & 809278 & 4.2 & 4.5506 & TST \\
\hline CHEMBL296586 & 809278 & 7.7 & 7.48 & TST \\
\hline CHEMBL1993722 & 809278 & 5.7 & 5.6664 & TST \\
\hline CHEMBL 2006674 & 809278 & 5.9 & 5.5928 & TST \\
\hline CHEMBL1984236 & 809278 & 4.4 & 4.5164 & TST \\
\hline CHEMBL 2002599 & 809278 & 8.1 & 7.2124 & TST \\
\hline CHEMBL1375640 & 809278 & 4.2 & 5.4756 & TST \\
\hline CHEMBL 249282 & 809278 & 4.2 & 4.3442 & TST \\
\hline CHEMBL1994318 & 809278 & 4.4 & 4.5386 & TST \\
\hline
\end{tabular}




\begin{tabular}{|c|c|c|c|c|c|c|}
\hline \multicolumn{7}{|c|}{ Supplemental Table S2.txt } \\
\hline CHEMBL1973711 & 809278 & 6.6 & 5.8624 & TST & & \\
\hline CHEMBL1967720 & 809278 & 5.3 & 4.5375 & TST & & \\
\hline CHEMBL1967719 & 809278 & 5.7 & 5.4145 & TST & & \\
\hline CHEMBL1969755 & 809278 & 5.6 & 4.5529 & TST & & \\
\hline CHEMBL1991138 & 809278 & 4.2 & 4.1031 & TST & & \\
\hline CHEMBL1996208 & 809278 & 4.3 & 4.5341 & TST & & \\
\hline CHEMBL514499 & 809278 & 5.7 & 4.9784 & TST & & \\
\hline CHEMBL1970352 & 809278 & 5.5 & 4.7062 & TST & & \\
\hline CHEMBL1965631 & 809278 & 8.2 & 7.5455 & TST & & \\
\hline CHEMBL1980144 & 809278 & 5.6 & 5.0505 & TST & & \\
\hline CHEMBL1991188 & 809278 & 7.4 & 6.9602 & TST & & \\
\hline CHEMBL 377408 & 809278 & 4.4 & 3.9804 & TST & & \\
\hline CHEMBL215152 & 809278 & 4.7 & 4.7423 & TST & & \\
\hline CHEMBL231209 & 809278 & 4.2 & 4.8305 & TST & & \\
\hline CHEMBL 2006765 & 809278 & 4.4 & 4.6271 & TST & & \\
\hline CHEMBL1976220 & 809278 & 4.2 & 4.7838 & TST & & \\
\hline CHEMBL1982383 & 809278 & 4.2 & 4.7154 & TST & & \\
\hline CHEMBL17370 & 809278 & 6.8 & 5.5158 & TST & & \\
\hline CHEMBL1980246 & 809278 & 4.4 & 5.0733 & TST & & \\
\hline CHEMBL1999484 & 809278 & 4.4 & 4.7233 & TST & & \\
\hline CHEMBL1997822 & 809278 & 4.2 & 4.7496 & TST & & \\
\hline CHEMBL1991285 & 809278 & 5.9 & 4.7804 & TST & & \\
\hline CHEMBL1984038 & 809278 & 4.4 & 5.2662 & TST & & \\
\hline CHEMBL1974416 & 809278 & 6.1 & 5.6321 & TST & & \\
\hline CHEMBL1984039 & 809278 & 4.2 & 4.3749 & TST & & \\
\hline CHEMBL 2004615 & 809278 & 4.2 & 4.5745 & TST & & \\
\hline CHEMBL1997872 & 809278 & 4.2 & 4.2824 & TST & & \\
\hline CHEMBL3933051 & 1640803 & 7.2291 & 6.0935 & TST & & \\
\hline CHEMBL3897951 & 1640803 & 7.6778 & 7.63 & TRN & & \\
\hline CHEMBL 3904557 & 1640803 & $6.8210 e$ & 00000000 & $\partial 1$ & 6.6426 & TRN \\
\hline CHEMBL 3920812 & 1640803 & 8.1367 & 8.0122 & TRN & & \\
\hline CHEMBL 3908015 & 1640803 & 8.1249 & 8.0746 & TRN & & \\
\hline CHEMBL 3889765 & 1640803 & 6.0 & 6.3421 & TRN & & \\
\hline CHEMBL3939428 & 1640803 & 7.4001 & 7.8855 & TRN & & \\
\hline CHEMBL 3929982 & 1640803 & 7.6421 & 7.6355 & TRN & & \\
\hline CHEMBL3927962 & 1640803 & 6.0 & 6.1061 & TRN & & \\
\hline CHEMBL 3943458 & 1640803 & 7.8633 & 7.9009 & TRN & & \\
\hline CHEMBL 3902341 & 1640803 & 7.58 & 7.6056 & TRN & & \\
\hline CHEMBL3923647 & 1640803 & 6.6799 & 6.8281 & TST & & \\
\hline CHEMBL 3940098 & 1640803 & 8.2366 & 8.1516 & TRN & & \\
\hline CHEMBL3981510 & 1640803 & 7.4318 & 7.5909 & TRN & & \\
\hline CHEMBL 3954500 & 1640803 & 7.3979 & 7.3043 & TRN & & \\
\hline CHEMBL3892941 & 1640803 & 7.3605 & 6.6716 & TRN & & \\
\hline CHEMBL3891874 & 1640803 & 8.1367 & 8.5199 & TRN & & \\
\hline CHEMBL 3914946 & 1640803 & 6.3098 & 6.5805 & TST & & \\
\hline CHEMBL 3979451 & 1640803 & 6.0 & 5.9027 & TRN & & \\
\hline CHEMBL3923719 & 1640803 & 7.3002 & 7.5319 & TRN & & \\
\hline CHEMBL3931970 & 1640803 & 8.0757 & 7.8248 & TRN & & \\
\hline
\end{tabular}


Supplemental Table S2.txt

\begin{tabular}{|c|c|c|c|c|c|}
\hline CHEMBL3891961 & 1640803 & 6.0 & 6.1798 & TRN & \\
\hline CHEMBL3924867 & 1640803 & 6.0 & 5.1745 & TST & \\
\hline CHEMBL 3938363 & 1640803 & 6.6021 & 7.8897 & TST & \\
\hline CHEMBL3922593 & 1640803 & 7.9957 & 8.0747 & TRN & \\
\hline CHEMBL3956078 & 1640803 & 8.3565 & 8.2462 & TRN & \\
\hline CHEMBL 3925248 & 1640803 & 7.1798 & 6.9789 & TRN & \\
\hline CHEMBL3977687 & 1640803 & 7.8097 & 7.48799 & 99999999995 & TRN \\
\hline CHEMBL3960988 & 1640803 & 8.3665 & 8.0984 & TRN & \\
\hline CHEMBL3928160 & 1640803 & 7.2716 & 7.4271 & TRN & \\
\hline CHEMBL3897203 & 1640803 & 7.0799 & 7.2717 & TRN & \\
\hline CHEMBL 3972323 & 1640803 & 8.4318 & 8.4565 & TRN & \\
\hline CHEMBL3962275 & 1640803 & 7.2321 & 7.1396 & TRN & \\
\hline CHEMBL3947417 & 1640803 & 7.6696 & 7.8618 & TRN & \\
\hline CHEMBL 3963910 & 1640803 & 6.8309 & 6.9689 & TRN & \\
\hline CHEMBL3975016 & 1640803 & 6.0 & 7.1533 & TRN & \\
\hline CHEMBL3917251 & 1640803 & 6.0 & 6.1457 & TRN & \\
\hline CHEMBL3912297 & 1640803 & 8.2291 & 8.4734 & TRN & \\
\hline CHEMBL3945692 & 1640803 & 8.4815 & 8.8084 & TRN & \\
\hline CHEMBL3929892 & 1640803 & 7.4318 & 7.5645 & TRN & \\
\hline CHEMBL3967040 & 1640803 & 6.7836 & 6.7284 & TRN & \\
\hline CHEMBL3930388 & 1640803 & 7.1945 & 7.4723 & TRN & \\
\hline CHEMBL3982193 & 1640803 & 7.4318 & 7.6702 & TRN & \\
\hline CHEMBL3954315 & 1640803 & 7.7696 & 7.8464 & TRN & \\
\hline CHEMBL3938745 & 1640803 & 8.2291 & 8.0854 & TRN & \\
\hline CHEMBL3985227 & 1640803 & \multicolumn{2}{|c|}{7.757000000000001} & 8.0317 & TRN \\
\hline CHEMBL3966439 & 1640803 & 6.9586 & 6.9164 & TRN & \\
\hline CHEMBL3912941 & 1640803 & 7.5086 & 6.876 & TRN & \\
\hline CHEMBL3984014 & 1640803 & 8.2147 & 7.8875 & TRN & \\
\hline CHEMBL3924553 & 1640803 & 6.9586 & 7.7259 & TST & \\
\hline CHEMBL3898209 & 1640803 & 6.8539 & 7.0171 & TRN & \\
\hline CHEMBL3953785 & 1640803 & 8.699 & 8.4988 & TRN & \\
\hline CHEMBL3909152 & 1640803 & \multicolumn{3}{|c|}{7.821000000000001} & TST \\
\hline CHEMBL3958062 & 1640803 & 8.1675 & 8.1306 & TRN & \\
\hline CHEMBL 3951475 & 1640803 & 8.301 & 8.411 & TRN & \\
\hline CHEMBL3904905 & 1640803 & 7.6536 & \multicolumn{2}{|c|}{7.672000000000001} & TRN \\
\hline CHEMBL3896637 & 1640803 & 7.9469 & 8.5256 & TST & \\
\hline CHEMBL3971650 & 1640803 & 8.3372 & 8.2461 & TRN & \\
\hline CHEMBL 3891029 & 1640803 & 7.7282 & 7.6954 & TRN & \\
\hline CHEMBL 3973726 & 1640803 & 7.8097 & 7.6651 & TRN & \\
\hline CHEMBL3956756 & 1640803 & 7.4012 & 7.5912 & TRN & \\
\hline CHEMBL3946918 & 1640803 & 6.4318 & 7.0271 & TST & \\
\hline CHEMBL3901795 & 1640803 & 7.5229 & 7.4278 & TRN & \\
\hline CHEMBL3891728 & 1640803 & 7.7825 & 7.7651 & TRN & \\
\hline CHEMBL3962673 & 1640803 & 8.4559 & 8.0647 & TRN & \\
\hline CHEMBL3891561 & 1640803 & \multicolumn{3}{|c|}{8.283999999999999} & TRN \\
\hline CHEMBL3940286 & 1640803 & 7.5686 & 7.8144 & TRN & \\
\hline CHEMBL3956510 & 1640803 & 7.9208 & 8.0537 & TRN & \\
\hline CHEMBL 3963550 & 1640803 & 7.4815 & 7.2479 & TRN & \\
\hline
\end{tabular}

Page 10545 
Supplemental Table S2.txt

\begin{tabular}{|c|c|c|c|c|}
\hline . & 540803 & 739 & & \\
\hline ב & 640803 & 6.0 & 5.8635 & \\
\hline$=0$ & 303 & 8 & & \\
\hline AEMBL & 0803 & 393 & & \\
\hline AEMBL3905962 & 540803 & 8.041 & & \\
\hline HEMBL3912552 & 640803 & 6.0 & 9375 & \\
\hline 65 & 803 & 34 & 064 & \\
\hline 584 & 803 & & & \\
\hline AEMBL3952963 & 640803 & 3268 & 4912 & \\
\hline HEMBL3942704 & 640803 & 7.5072 & 7552 & \\
\hline HEMBL3921979 & 640803 & 8.2007 & 5598 & \\
\hline IEMBL38 & 803 & 6.0 & & \\
\hline AEMBL3 & & 7 & & \\
\hline HEMBL39 & 640803 & 8.1135 & 1359 & \\
\hline HEMBL392 & 640803 & 6.0 & & \\
\hline AEMBL39 & 803 & 362 & 78 & \\
\hline AEMBL3S & 93 & 83 & 802 & \\
\hline HEMBL3\& & & & & \\
\hline HEMBL39 & 803 & 6.0 & 149 & \\
\hline AEMBL3S & 303 & 8 & & \\
\hline HEMBL= & 03 & 22 & 67 & Niv \\
\hline AEMBL: & 3 & 706 & 072 & 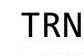 \\
\hline HEMBL; & 03 & 6 . & 256 & \\
\hline 328 & 303 & 5 . & 2357 & \\
\hline AEMBL3S & & 8 & & 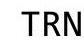 \\
\hline HEMBL3S & 03 & 6 & 3084 & RN \\
\hline HEMBL; & 13 & & 753 & RN \\
\hline$H F M B I=$ & 33 & 82 & 588 & \\
\hline HEMBL3S & & 696 & 1628 & TIV \\
\hline HEMBL 391 & 33 & 7. & 886 & 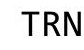 \\
\hline HEMBL3E & 03 & 85 & 278 & RN \\
\hline HEMBL & 33 & $\partial 6$ & 191 & RN \\
\hline$\triangle 5 M P$ & 33 & 25 & 163 & RN \\
\hline HEMBL393. & & & 1896 & IRN \\
\hline HEMBL3952206 & 640803 & 356 & 5188 & TST \\
\hline HEMBL3 & $\partial 3$ & 528 & 216 & TRN \\
\hline HCMP - & 3 & 76 & 95 & \\
\hline HEMBL & & 78 & 827 & IRN \\
\hline HEMBL3900640 & 640803 & 8.3979 & 3751 & TRN \\
\hline JEMBL3980398 & 803 & 67 & 149 & $\mathrm{RN}$ \\
\hline HEMBL39 & 640803 & & 133 & \\
\hline HEMBL 39 & & & & RIV \\
\hline HEMBL3984775 & 1640803 & 7.2941 & 4182 & RN \\
\hline AEMBL3946323 & 640803 & 8.1249 & 9631 & TRN \\
\hline $1=8$ & & & 807 & 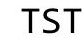 \\
\hline HEMBL3S & 640803 & 208 & 8973 & \\
\hline LHEMBL3917726 & & .1871 & .0701 & \\
\hline CHEMBL3915098 & 1640803 & 7.7447 & 7.7194 & \\
\hline
\end{tabular}

Page 10546 


$$
\text { Supplemental Table S2.txt }
$$

\begin{tabular}{|c|c|c|c|c|c|c|}
\hline CHEMBL 3927037 & 1640803 & 7.699 & 7.6513 & TRN & & \\
\hline CHEMBL 3902456 & 1640803 & 7.1278 & 7.3361 & TST & & \\
\hline CHEMBL3958416 & 1640803 & 7.3872 & 7.7555 & TRN & & \\
\hline CHEMBL 3986593 & 1640803 & 5.0 & 5.5534 & TRN & & \\
\hline CHEMBL3900566 & 1640803 & 7.9586 & 7.73 & TRN & & \\
\hline CHEMBL 3949070 & 1640803 & \multicolumn{3}{|c|}{7.4510000000000005} & 7.4139 & TRN \\
\hline CHEMBL 3948808 & 1640803 & 6.3098 & 6.3321 & TRN & & \\
\hline CHEMBL 3968689 & 1640803 & \multicolumn{3}{|c|}{7.7620000000000005} & 7.391 & TST \\
\hline CHEMBL 3980375 & 1640803 & 7.8097 & 8.1011 & TRN & & \\
\hline CHEMBL3897329 & 1640803 & 8.2676 & 8.1575 & TRN & & \\
\hline CHEMBL 3965658 & 1640803 & 7.3233 & 7.6319 & TST & & \\
\hline CHEMBL 3924458 & 1640803 & 8.4949 & 8.3766 & TRN & & \\
\hline CHEMBL 3961066 & 1640803 & 7.6459 & 7.4276 & TRN & & \\
\hline CHEMBL 3924719 & 1640803 & 7.0195 & 7.0977 & TRN & & \\
\hline CHEMBL 3896825 & 1640803 & 8.2924 & 8.1976 & TRN & & \\
\hline CHEMBL 3939231 & 1640803 & 7.7077 & 6.4948 & TST & & \\
\hline CHEMBL3952190 & 1640803 & 8.5086 & 8.4903 & TRN & & \\
\hline CHEMBL 3901051 & 1640803 & 8.0362 & 7.8568 & TRN & & \\
\hline CHEMBL 3895048 & 1640803 & 8.1612 & 8.122 & TRN & & \\
\hline CHEMBL3953287 & 1640803 & 6.5086 & 6.5666 & TRN & & \\
\hline CHEMBL 3902112 & 1640803 & 7.4789 & 7.4792 & TRN & & \\
\hline CHEMBL3911753 & 1640803 & 7.9136 & 7.9394 & TRN & & \\
\hline CHEMBL 3909704 & 1640803 & 5.0 & 5.2681 & TRN & & \\
\hline CHEMBL 3953935 & 1640803 & 5.0 & 8.3987 & TST & & \\
\hline CHEMBL 3966246 & 1640803 & 7.6198 & 7.4263 & TRN & & \\
\hline CHEMBL 3985417 & 1640803 & 7.2041 & 7.2059 & TRN & & \\
\hline CHEMBL 3934445 & 1640803 & 6.0 & 6.0844 & TRN & & \\
\hline CHEMBL 3951520 & 1640803 & 6.5293 & 6.4666 & TRN & & \\
\hline CHEMBL 3945154 & 1640803 & 6.0 & 5.9222 & TRN & & \\
\hline CHEMBL 3900634 & 1640803 & 7.699 & 7.8055 & TRN & & \\
\hline CHEMBL 3964259 & 1640803 & 8.2441 & 7.8751 & TRN & & \\
\hline CHEMBL 3961657 & 1640803 & \multicolumn{3}{|c|}{8.283999999999999} & 8.5904 & 17 \\
\hline CHEMBL 3975913 & 1640803 & 7.0458 & 6.4661 & TRN & & \\
\hline CHEMBL 3937454 & 1640803 & 8.4437 & 8.3474 & TRN & & \\
\hline CHEMBL 3915878 & 1640803 & 6.3719 & 6.59 & TRN & & \\
\hline CHEMBL 3938380 & 1640803 & 6.5686 & 6.3651 & TRN & & \\
\hline CHEMBL 3892086 & 1640803 & 7.6289 & 7.3463 & TRN & & \\
\hline CHEMBL 3941535 & 1640803 & 7.3468 & 7.1806 & TRN & & \\
\hline CHEMBL 3945433 & 1640803 & 7.3625 & 7.44 & TRN & & \\
\hline CHEMBL 3918374 & 1640803 & 7.9586 & 7.9413 & TRN & & \\
\hline CHEMBL 3900254 & 1640803 & 6.6021 & 6.6236 & TRN & & \\
\hline CHEMBL 3900387 & 1640803 & 7.6861 & 7.6103 & TRN & & \\
\hline CHEMBL3938157 & 1640803 & 8.0177 & 8.0626 & TST & & \\
\hline CHEMBL 3920458 & 1640803 & 7.3143 & 7.2204 & TRN & & \\
\hline CHEMBL 3946850 & 1640803 & 7.6003 & 8.1201 & TRN & & \\
\hline CHEMBL 3901922 & 1640803 & 7.9586 & 8.3518 & TST & & \\
\hline CHEMBL 3973050 & 1640803 & 6.4263 & 6.3125 & TRN & & \\
\hline CHEMBL 3902834 & 1640803 & 8.1427 & 8.4233 & TRN & & \\
\hline
\end{tabular}


Supplemental Table S2.txt

\begin{tabular}{|c|c|c|c|c|c|}
\hline CHEMBL 3933271 & 1640803 & 7.0799 & 8.4195 & TST & \\
\hline CHEMBL 3945833 & 1640803 & 7.9626 & 7.9238 & TRN & \\
\hline CHEMBL 3953972 & 1640803 & 6.9208 & 7.3243 & TRN & \\
\hline CHEMBL 3926926 & 1640803 & 6.98799 & 999999999 & 7.0409 & TRN \\
\hline CHEMBL 3946891 & 1640803 & 6.8327 & 7.3259 & TST & \\
\hline CHEMBL 3898801 & 1640803 & 7.4559 & 7.4334 & TRN & \\
\hline CHEMBL 3912488 & 1640803 & 6.0 & 5.9035 & TST & \\
\hline CHEMBL 3948634 & 1640803 & 7.9355 & 7.9902 & TRN & \\
\hline CHEMBL 3931071 & 1640803 & 8.0132 & 7.1225 & TST & \\
\hline CHEMBL 3921614 & 1640803 & 7.3565 & 7.423999 & 99999999995 & TRN \\
\hline CHEMBL 3905589 & 1640803 & 7.8447 & 7.5244 & TRN & \\
\hline CHEMBL 3977562 & 1640803 & 7.8097 & 7.9408 & TRN & \\
\hline CHEMBL 3893385 & 1640803 & 8.3372 & 8.2427 & TRN & \\
\hline CHEMBL 3975874 & 1640803 & 6.0 & 6.1874 & TRN & \\
\hline CHEMBL 3954864 & 1640803 & 7.7721 & 7.4223 & TRN & \\
\hline CHEMBL 3965258 & 1640803 & 7.9957 & 8.025 & TRN & \\
\hline CHEMBL 3959385 & 1640803 & 7.1421 & 7.1294 & TST & \\
\hline CHEMBL 3927321 & 1640803 & 7.9136 & 7.842000 & 00000000005 & \\
\hline CHEMBL 3957762 & 1640803 & 7.7696 & 7.8087 & TRN & \\
\hline CHEMBL 3968019 & 1640803 & 8.28399 & 999999999 & 8.1282 & TKIV \\
\hline CHEMBL 3935185 & 1640803 & 7.9208 & 5.6021 & TST & \\
\hline CHEMBL 3930692 & 1640803 & 8.2676 & 8.23 & TRN & \\
\hline CHEMBL 3982358 & 1640803 & 7.9208 & 7.6547 & TRN & \\
\hline CHEMBL 3925664 & 1640803 & 7.6556 & 8.021 & TRN & \\
\hline CHEMBL 3951224 & 1640803 & 6.4685 & 6.8034 & TST & \\
\hline CHEMBL 3937386 & 1640803 & 8.0 & 7.756 & TRN & \\
\hline CHEMBL 3911894 & 1640803 & 6.2076 & 6.4617 & TRN & \\
\hline CHEMBL 3899854 & 1640803 & 6.0 & 5.9488 & TRN & \\
\hline CHEMBL 3949692 & 1640803 & 8.28399 & 999999999 & 7.9548 & \\
\hline CHEMBL 3927907 & 1640803 & 8.0458 & 7.7221 & TRN & \\
\hline CHEMBL 3938097 & 1640803 & 6.0 & 5.8068 & TRN & \\
\hline CHEMBL 3907242 & 1640803 & 8.2757 & 8.6534 & TRN & \\
\hline CHEMBL 3968542 & 1640803 & 6.6038 & 6.7829 & TRN & \\
\hline CHEMBL 3909359 & 1640803 & 7.8297 & 7.8125 & TRN & \\
\hline CHEMBL 3980149 & 1640803 & 7.3768 & 7.4267 & TRN & \\
\hline CHEMBL 3893531 & 1640803 & 8.2007 & 8.24 & TRN & \\
\hline CHEMBL 3891562 & 1640803 & 8.1487 & 7.8692 & TRN & \\
\hline CHEMBL 3915535 & 1640803 & 7.9431 & 7.8227 & TRN & \\
\hline CHEMBL 3928523 & 1640803 & 6.0 & 6.1394 & TRN & \\
\hline CHEMBL 3967809 & 1640803 & 7.767 & 8.0823 & TRN & \\
\hline CHEMBL 3953880 & 1640803 & 8.3872 & 8.1695 & TRN & \\
\hline CHEMBL 3901026 & 1640803 & 7.1891 & 7.2489 & TRN & \\
\hline CHEMBL 3976688 & 1640803 & 7.0991 & 7.1089 & TRN & \\
\hline CHEMBL 3968560 & 1640803 & 7.3768 & 7.2221 & TRN & \\
\hline CHEMBL 3973514 & 1640803 & 7.7033 & 7.6092 & TRN & \\
\hline CHEMBL 3960330 & 1640803 & 7.4425 & 7.4504 & TRN & \\
\hline CHEMBL 3917618 & 1640803 & 6.8116 & 7.5126 & TST & \\
\hline CHEMBL 3965514 & 1640803 & 6.0 & 6.3266 & TRN & \\
\hline
\end{tabular}


Supplemental Table S2.txt

\begin{tabular}{|c|c|c|c|c|c|c|}
\hline CHEMBL 3938698 & 1640803 & 6.0 & 6.079 & TRN & & \\
\hline CHEMBL 3946550 & 1640803 & 7.7212 & 7.5349 & TRN & & \\
\hline CHEMBL3953473 & 1640803 & 7.4572 & 7.6124 & TRN & & \\
\hline CHEMBL 3906298 & 1640803 & 7.8601 & 7.9823 & TRN & & \\
\hline CHEMBL 3929726 & 1640803 & 6.8861 & 7.0087 & TRN & & \\
\hline CHEMBL3919117 & 1640803 & 7.4437 & 7.3756 & TST & & \\
\hline CHEMBL3916886 & 1640803 & 7.2411 & 8.2308 & TST & & \\
\hline CHEMBL 3983631 & 1640803 & 7.9355 & 7.9747 & TRN & & \\
\hline CHEMBL3967734 & 1640803 & 8.4949 & 8.6606 & TRN & & \\
\hline CHEMBL 3944672 & 1640803 & 8.2218 & 8.1266 & TRN & & \\
\hline CHEMBL 3944830 & 1640803 & 6.0 & 6.3963 & TRN & & \\
\hline CHEMBL 3960079 & 1640803 & 8.699 & 8.6608 & TRN & & \\
\hline CHEMBL 3942356 & 1640803 & 8.0655 & 8.40200 & 0000000001 & & TRN \\
\hline CHEMBL 3942729 & 1640803 & 8.5086 & 7.3443 & TST & & \\
\hline CHEMBL 3938943 & 1640803 & 7.76200 & 00000000 & 305 & 7.0997 & TST \\
\hline CHEMBL 3957069 & 1640803 & 8.0605 & 7.9391 & TST & & \\
\hline CHEMBL 3908602 & 1640803 & 7.6308 & 8.476 & TST & & \\
\hline CHEMBL 3971477 & 1640803 & 8.5686 & 7.7996 & TST & & \\
\hline CHEMBL 3919056 & 1640803 & 7.71 & 7.2454 & TST & & \\
\hline CHEMBL 3975375 & 1640803 & 7.1024 & 7.3749 & TST & & \\
\hline CHEMBL 3936076 & 1640803 & 5.0 & 7.359 & TST & & \\
\hline CHEMBL 3953657 & 1640803 & 7.8125 & 8.1649 & TST & & \\
\hline CHEMBL 3945057 & 1640803 & 6.0 & 6.8719 & TST & & \\
\hline CHEMBL 3911456 & 1640803 & 7.8125 & 8.2528 & TST & & \\
\hline CHEMBL 3954158 & 1640803 & 7.684 & 7.4125 & TST & & \\
\hline CHEMBL 3947420 & 1640803 & 7.8297 & 7.3765 & TST & & \\
\hline CHEMBL 3926683 & 1640803 & 8.2366 & 8.0347 & TST & & \\
\hline CHEMBL 3965459 & 1640803 & 8.2147 & 8.4367 & TST & & \\
\hline CHEMBL3968477 & 1640803 & 8.0969 & 8.7328 & TST & & \\
\hline CHEMBL 3914685 & 1640803 & 7.1707 & 5.7185 & TST & & \\
\hline CHEMBL 3922977 & 1640803 & 6.7703 & 6.8017 & TST & & \\
\hline CHEMBL 3912933 & 1640803 & 8.0655 & 5.5062 & TST & & \\
\hline CHEMBL 3985614 & 1640803 & 7.7375 & 7.273 & TST & & \\
\hline CHEMBL3931640 & 1640803 & 7.5686 & 6.7696 & TST & & \\
\hline CHEMBL3951898 & 1640803 & 7.8861 & 6.5765 & TST & & \\
\hline CHEMBL3913595 & 1640803 & 7.0472 & 6.7649 & TST & & \\
\hline CHEMBL3908295 & 1640803 & 7.6576 & 7.9562 & TST & & \\
\hline CHEMBL 3977047 & 1640803 & 7.3143 & 6.5369 & TST & & \\
\hline CHEMBL 3985120 & 1640803 & 7.1838 & 7.7282 & TST & & \\
\hline CHEMBL 3937308 & 1640803 & 7.7447 & 6.3755 & TST & & \\
\hline CHEMBL 3918302 & 1640803 & 8.4437 & 8.5481 & TST & & \\
\hline CHEMBL 3954945 & 1640803 & 7.3799 & 7.74200 & 0000000001 & & TST \\
\hline CHEMBL 2159461 & 855538 & 7.1079 & 7.2728 & TRN & & \\
\hline CHEMBL 2159315 & 855538 & 7.2291 & 7.2261 & TRN & & \\
\hline CHEMBL 2159478 & 855538 & 7.9586 & 7.7502 & TRN & & \\
\hline CHEMBL 2159477 & 855538 & 8.0 & 7.8831 & TRN & & \\
\hline CHEMBL 2158030 & 855538 & \multicolumn{3}{|c|}{6.382000000000001} & 6407 & \\
\hline CHEMBL 2158033 & 855538 & 7.5686 & 7.4033 & TRN & & \\
\hline
\end{tabular}

Page 10549 
Supplemental Table S2.txt

\begin{tabular}{|c|c|c|c|c|c|}
\hline CHEMBL 2159476 & 855538 & 6.9172 & 7.4083 & TRN & \\
\hline CHEMBL 2159456 & 855538 & 5.6533 & 5.6892 & TRN & \\
\hline CHEMBL 2159454 & 855538 & 7.0132 & 7.2217 & TRN & \\
\hline CHEMBL 2158028 & 855538 & 5.5728 & 5.8873 & TST & \\
\hline CHEMBL 2158031 & 855538 & 6.4763 & 6.8095 & TRN & \\
\hline CHEMBL 2159472 & 855538 & 7.5686 & 7.3102 & TRN & \\
\hline CHEMBL 2158036 & 855538 & 6.0888 & 5.9417 & TRN & \\
\hline CHEMBL522691 & 855538 & 9.2366 & 6.7647 & TST & \\
\hline CHEMBL 2159306 & 855538 & 5.9416 & 6.3844 & TRN & \\
\hline CHEMBL 2159311 & 855538 & 6.6904 & 6.909 & TRN & \\
\hline CHEMBL 2159475 & 855538 & 7.2366 & 7.3323 & TRN & \\
\hline CHEMBL 2159457 & 855538 & 7.2218 & 7.3895 & TRN & \\
\hline CHEMBL 2159482 & 855538 & 6.5331 & 6.346 & TRN & \\
\hline CHEMBL 2159473 & 855538 & 5.8422 & 6.051 & TRN & \\
\hline CHEMBL 2158039 & 855538 & 6.059 & 6.1232 & TRN & \\
\hline CHEMBL 2159485 & 855538 & 8.3979 & 7.7433 & TRN & \\
\hline CHEMBL 2158035 & 855538 & 6.4828 & 6.8279 & TRN & \\
\hline CHEMBL 2159480 & 855538 & 7.7959 & 7.351 & TRN & \\
\hline CHEMBL 2159320 & 855538 & 6.7932 & 6.1054 & TST & \\
\hline CHEMBL 2158025 & 855538 & 6.063 & 6.457999 & 999999999 & TRN \\
\hline CHEMBL 2159458 & 855538 & 7.8861 & 7.6666 & TRN & \\
\hline CHEMBL 2159463 & 855538 & 5.6243 & 5.4224 & TRN & \\
\hline CHEMBL 2158034 & 855538 & 6.5072 & 6.6791 & TRN & \\
\hline CHEMBL 2159466 & 855538 & 8.1549 & 7.7987 & TRN & \\
\hline CHEMBL 2159317 & 855538 & 6.1494 & 5.5899 & TRN & \\
\hline CHEMBL2159459 & 855538 & 5.8658 & 6.044 & TRN & \\
\hline CHEMBL 2159309 & 855538 & 7.9208 & 8.0085 & TRN & \\
\hline CHEMBL 2159484 & 855538 & 7.7959 & 6.9975 & TRN & \\
\hline CHEMBL 2158038 & 855538 & 6.4078 & 6.2541 & TRN & \\
\hline CHEMBL 2159318 & 855538 & 5.6529 & 6.0161 & TRN & \\
\hline CHEMBL 2159479 & 855538 & 8.0458 & 7.3279 & TRN & \\
\hline CHEMBL 2159469 & 855538 & 7.3872 & 7.0241 & TRN & \\
\hline CHEMBL 2159471 & 855538 & 8.0 & 7.9673 & TRN & \\
\hline CHEMBL 2159323 & 855538 & 6.0 & 8.0346 & TRN & \\
\hline CHEMBL 2158029 & 855538 & 6.3883 & 6.5115 & TST & \\
\hline CHEMBL95104 & 855538 & 8.4949 & 6.8611 & TST & \\
\hline CHEMBL1256844 & 855538 & 8.9208 & 6.7923 & TST & \\
\hline CHEMBL 2158027 & 855538 & 5.8239 & 6.5115 & TST & \\
\hline CHEMBL 2159468 & 855538 & 6.7496 & 6.76 & TRN & \\
\hline CHEMBL 2159464 & 855538 & 6.8097 & 7.0198 & TRN & \\
\hline CHEMBL 2159455 & 855538 & 7.699 & 7.8068 & TRN & \\
\hline CHEMBL 2159313 & 855538 & 7.0706 & 7.2103 & TRN & \\
\hline CHEMBL 2159467 & 855538 & 7.6778 & 6.8924 & TRN & \\
\hline CHEMBL 2159462 & 855538 & 5.6586 & 5.932 & TRN & \\
\hline CHEMBL 2158032 & 855538 & 6.3904 & 6.5161 & TRN & \\
\hline CHEMBL 2159483 & 855538 & 8.0458 & 7.6551 & TRN & \\
\hline CHEMBL 2159319 & 855538 & 5.9555 & 5.9797 & TRN & \\
\hline CHEMBL 2159460 & 855538 & 7.3372 & 7.3664 & TRN & \\
\hline
\end{tabular}




\begin{tabular}{|c|c|c|c|c|c|c|}
\hline \multirow[b]{2}{*}{ CHEMBL 2159310} & & \multicolumn{5}{|c|}{ Supplemental Table S2.txt } \\
\hline & 855538 & 7.0315 & 7.4278 & TRN & & \\
\hline CHEMBL 2159316 & 855538 & 6.3696 & 6.1758 & TRN & & \\
\hline CHEMBL 2159314 & 855538 & $5.9570 e$ & 00000000 & 01 & 6.2435 & TRN \\
\hline CHEMBL 2159322 & 855538 & 8.301 & 7.8236 & TRN & & \\
\hline CHEMBL 2159486 & 855538 & 7.8239 & 7.6495 & TRN & & \\
\hline CHEMBL 2158037 & 855538 & 5.7768 & 5.9215 & TST & & \\
\hline CHEMBL 2159308 & 855538 & 7.7696 & 7.6569 & TST & & \\
\hline CHEMBL 2159474 & 855538 & 7.8539 & 7.3474 & TST & & \\
\hline CHEMBL 2159481 & 855538 & 8.1549 & 7.9561 & TST & & \\
\hline CHEMBL 2159312 & 855538 & 5.4721 & 6.0633 & TST & & \\
\hline CHEMBL 2158026 & 855538 & 5.9252 & 6.6083 & TST & & \\
\hline CHEMBL 2159307 & 855538 & 6.5591 & 6.7528 & TST & & \\
\hline CHEMBL 2159470 & 855538 & 7.5376 & 7.7069 & TST & & \\
\hline CHEMBL 2159465 & 855538 & 9.5229 & 7.6019 & TST & & \\
\hline CHEMBL3703980 & 1528574 & 9.0 & 8.9143 & TRN & & \\
\hline CHEMBL3703944 & 1528574 & 8.5229 & 8.4584 & TRN & & \\
\hline CHEMBL3703956 & 1528574 & 8.699 & 8.6356 & TRN & & \\
\hline CHEMBL 3704023 & 1528574 & 7.3188 & 7.2364 & TRN & & \\
\hline CHEMBL3704012 & 1528574 & 8.2218 & 8.5887 & TST & & \\
\hline CHEMBL3703975 & 1528574 & 7.6383 & 7.6463 & TRN & & \\
\hline CHEMBL3703982 & 1528574 & 8.301 & 8.2154 & TRN & & \\
\hline CHEMBL3703993 & 1528574 & 8.5229 & 8.4819 & TRN & & \\
\hline CHEMBL3703972 & 1528574 & 8.3979 & 8.5996 & TRN & & \\
\hline CHEMBL3703959 & 1528574 & 8.699 & 8.7064 & TRN & & \\
\hline CHEMBL3703938 & 1528574 & 8.0458 & 8.0116 & TRN & & \\
\hline CHEMBL3704020 & 1528574 & 8.301 & 8.2218 & TST & & \\
\hline CHEMBL3704014 & 1528574 & 8.0969 & 8.0618 & TST & & \\
\hline CHEMBL3703955 & 1528574 & 7.8239 & 7.9652 & TRN & & \\
\hline CHEMBL3704006 & 1528574 & 7.6198 & 7.6666 & TRN & & \\
\hline CHEMBL3703945 & 1528574 & 9.0 & 8.8774 & TRN & & \\
\hline CHEMBL 3651404 & 1528574 & 8.2218 & 8.1158 & TST & & \\
\hline CHEMBL3704021 & 1528574 & 6.5058 & 8.34799 & 9999999999 & & TST \\
\hline CHEMBL3704015 & 1528574 & 8.0969 & 8.104 & TST & & \\
\hline CHEMBL3703998 & 1528574 & 8.0969 & 8.4425 & TRN & & \\
\hline CHEMBL3704010 & 1528574 & 7.0809 & 7.7037 & TST & & \\
\hline CHEMBL3703947 & 1528574 & 8.5229 & 8.4544 & TRN & & \\
\hline CHEMBL3703939 & 1528574 & 8.301 & 8.5343 & TRN & & \\
\hline CHEMBL3703940 & 1528574 & 8.699 & 8.7657 & TRN & & \\
\hline CHEMBL3703974 & 1528574 & 8.699 & 8.7137 & TRN & & \\
\hline CHEMBL3704007 & 1528574 & 8.1549 & 8.3989 & TST & & \\
\hline CHEMBL3704013 & 1528574 & 8.2218 & 8.6848 & TST & & \\
\hline CHEMBL3703988 & 1528574 & 9.0 & 7.8818 & TST & & \\
\hline CHEMBL3703997 & 1528574 & 8.2218 & 8.3257 & TRN & & \\
\hline CHEMBL3703996 & 1528574 & 8.3979 & 8.5555 & TRN & & \\
\hline CHEMBL3703976 & 1528574 & 9.0 & 8.7474 & TRN & & \\
\hline CHEMBL3704019 & 1528574 & 8.5229 & 8.6878 & TRN & & \\
\hline CHEMBL3704011 & 1528574 & 7.4815 & 7.8599 & TST & & \\
\hline CHEMBL3703967 & 1528574 & 8.3979 & 8.4939 & TRN & & \\
\hline
\end{tabular}


Supplemental Table S2.txt

\begin{tabular}{|c|c|c|c|c|}
\hline |EI & 574 & 01 & 52 & $\mathrm{~T}$ \\
\hline & 528574 & 8.2218 & & \\
\hline & 3574 & 3979 & & \\
\hline AEMBL3 & 28574 & 301 & & \\
\hline AEMBL3703978 & 528574 & 3979 & 5869 & \\
\hline HEMBL3703968 & 528574 & 7.3468 & .2551 & \\
\hline 985 & 574 & 79 & & \\
\hline 954 & 528574 & & & \\
\hline AEMBL3 & 528574 & 8.301 & .1778 & \\
\hline HEMBL37 & 528574 & 8.699 & 3861 & \\
\hline HEMBL3 & 528574 & 5229 & 95 & \\
\hline IEMBL & 28574 & 99 & 72 & \\
\hline AEMBL & & & & \\
\hline HEMBL3 & 528574 & 7 & 6.9784 & \\
\hline AEMBL3 & 528574 & 9 & & \\
\hline AEMBL3 & 528574 & 7.9208 & 7.8572 & \\
\hline AEMBL & 28574 & 9 & 87 & \\
\hline HEMBL & 8574 & 99 & & \\
\hline HEMBL3 & 528574 & 39 & 8.5139 & \\
\hline AEMBL & 574 & 2 & & RN \\
\hline AEMIBL & 74 & 7 & 84 & \\
\hline HEMBL & 74 & 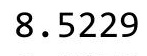 & 85 & \\
\hline HEMBL & 74 & 79 & 88 & RN \\
\hline 999 & 528574 & 9. & & $\mathrm{RN}$ \\
\hline AEMBL3 & & 0 & & II \\
\hline HEMBL & 74 & 9 & 29 & IRN \\
\hline HEMBL & 74 & & & 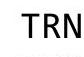 \\
\hline 942 & 74 & & 74 & RN \\
\hline HEMBL3 & 528574 & & & RIV \\
\hline HEMBL3 & 528574 & 7. & 63 & I RN \\
\hline HEMBL & 74 & & & TRN \\
\hline HFMBI & & & 54 & RIV \\
\hline HEMBL. & & 7 & 45 & $\mathrm{RN}$ \\
\hline HEMBL3 & 528574 & 8 . & 96 & $\Gamma \mathrm{RN}$ \\
\hline HEMBL37 & 528574 & 7.82 & 7.6 & $\Gamma \mathrm{RN}$ \\
\hline HEMBL & 574 & & 75 & \\
\hline HEMRI & & & & RN \\
\hline HEMBL & & & & RN \\
\hline HEMBL37 & 528574 & 8.69 & 3.6917 & $\Gamma \mathrm{RN}$ \\
\hline IEMBL: & 528574 & 7. & 8.7606 & ST \\
\hline HEMBL3 & 528574 & & 6.6846 & \\
\hline CHEMBL3 & & & & RN \\
\hline HEMBL3 & 528574 & 8.5229 & 8.4229 & TRN \\
\hline HEMBL3 & 528574 & 8.699 & 8.1824 & ГST \\
\hline EMBL & $1 / 4$ & 1 & 7.8 & \\
\hline CHEMBL 3 & & 8.3979 & 8.4637 & \\
\hline CHEMBL3 & 5285 & 8.5229 & 8.4325 & \\
\hline CHEMBL370395 & 1528574 & 8.5229 & 8.4814 & ГRN \\
\hline
\end{tabular}

Page 10552 
Supplemental Table S2.txt

\begin{tabular}{|c|c|c|c|c|c|}
\hline CHEMBL3703963 & 1528574 & 8.3979 & 7.7589 & TST & \\
\hline CHEMBL3703965 & 1528574 & 8.5229 & 8.6324 & TST & \\
\hline CHEMBL3704001 & 1528574 & 8.5229 & 8.2399 & TST & \\
\hline CHEMBL3703992 & 1528574 & 8.699 & 8.2538 & TST & \\
\hline CHEMBL509032 & 954943 & 3.4202 & 3.1911 & TRN & \\
\hline CHEMBL472940 & 954943 & 2.5976 & 2.7137 & TRN & \\
\hline CHEMBL1516890 & 954943 & 4.2563 & 4.2045 & TRN & \\
\hline CHEMBL392695 & 954943 & 3.1045 & 3.3214 & TRN & \\
\hline CHEMBL379975 & 954943 & 5.8443 & 5.8422 & TRN & \\
\hline CHEMBL1643959 & 954943 & 2.6361 & 2.7842 & TRN & \\
\hline CHEMBL412142 & 954943 & 3.7024 & 3.5664 & TRN & \\
\hline CHEMBL573107 & 954943 & 5.5132 & 5.5491 & TRN & \\
\hline CHEMBL483847 & 954943 & 3.7212 & 3.8241 & TRN & \\
\hline CHEMBL1909414 & 954943 & 4.9175 & 4.9044 & TRN & \\
\hline CHEMBL222102 & 954943 & 4.6477 & 4.4225 & TRN & \\
\hline CHEMBL3186408 & 954943 & 3.4703 & 3.2128 & TST & \\
\hline CHEMBL300389 & 954943 & 5.0039 & 5.148 & TRN & \\
\hline CHEMBL189584 & 954943 & 4.356 & 4.4847 & TRN & \\
\hline CHEMBL220241 & 954943 & 3.5084 & 3.4223 & TRN & \\
\hline CHEMBL 9470 & 954943 & 3.0394 & 4.1608 & TST & \\
\hline CHEMBL 92309 & 954943 & 2.0816 & 2.1589 & TST & \\
\hline CHEMBL259181 & 954943 & 2.7347 & 2.8304 & TRN & \\
\hline CHEMBL 202721 & 954943 & 5.561 & 5.4802 & TRN & \\
\hline CHEMBL373751 & 954943 & 3.2377 & 3.3457 & TRN & \\
\hline CHEMBL3392440 & 954943 & 3.3532 & 3.4968 & TRN & \\
\hline CHEMBL514499 & 954943 & 5.7256 & 5.6383 & TRN & \\
\hline CHEMBL1242367 & 954943 & 2.9974 & 2.8543 & TRN & \\
\hline CHEMBL1590308 & 954943 & 2.5544 & 2.9588 & TST & \\
\hline CHEMBL 240954 & 954943 & 3.6008 & 4.0702 & TST & \\
\hline CHEMBL 2005886 & 954943 & 3.0253 & 2.8987 & TRN & \\
\hline CHEMBL483849 & 954943 & 2.555 & 2.6978 & TRN & \\
\hline CHEMBL192566 & 954943 & 7.473 & 6.3702 & TST & \\
\hline CHEMBL515416 & 954943 & 3.4862 & 3.5887 & TRN & \\
\hline CHEMBL585951 & 954943 & 4.1524 & 4.308 & TRN & \\
\hline CHEMBL1230020 & 954943 & 5.0191 & 5.20799 & 9999999999 & TRN \\
\hline CHEMBL1357247 & 954943 & 2.3661 & 2.3637 & TRN & \\
\hline CHEMBL 258844 & 954943 & 3.2605 & 3.1771 & TRN & \\
\hline CHEMBL1256459 & 954943 & 5.2798 & 5.4221 & TRN & \\
\hline CHEMBL3349342 & 954943 & 5.3586 & 5.215 & TRN & \\
\hline CHEMBL1970879 & 954943 & 2.9392 & 2.8775 & TRN & \\
\hline CHEMBL 210618 & 954943 & 3.5985 & 3.5746 & TRN & \\
\hline CHEMBL1404918 & 954943 & 3.2208 & 3.1363 & TRN & \\
\hline CHEMBL135561 & 954943 & 3.7907 & 3.6584 & TRN & \\
\hline CHEMBL393929 & 954943 & 4.8458 & 4.9619 & TRN & \\
\hline CHEMBL3199475 & 954943 & 3.7879 & 3.7016 & TRN & \\
\hline CHEMBL449158 & 954943 & 5.9096 & 5.7831 & TST & \\
\hline CHEMBL65 & 954943 & 8.6014 & 8.6469 & TRN & \\
\hline CHEMBL180127 & 954943 & 2.8423 & 2.8936 & TRN & \\
\hline
\end{tabular}

Page 10553 
Supplemental Table S2.txt

\begin{tabular}{|c|c|c|c|c|}
\hline CHEMBL191334 & 954943 & 5.5862 & 5.4199 & TRN \\
\hline CHEMBL512504 & 954943 & 4.0796 & 3.9211 & TRN \\
\hline CHEMBL1673039 & 954943 & 2.7281 & 2.8854 & TRN \\
\hline CHEMBL102714 & 954943 & 4.3083 & 4.4412 & TRN \\
\hline CHEMBL577784 & 954943 & 5.7293 & 5.6879 & TRN \\
\hline CHEMBL1190711 & 954943 & 4.3953 & 4.329 & TRN \\
\hline CHEMBL1788116 & 954943 & 4.0531 & 3.8096 & TRN \\
\hline CHEMBL558642 & 954943 & 2.7477 & 2.7495 & TST \\
\hline CHEMBL213100 & 954943 & 2.9871 & 3.4291 & TST \\
\hline CHEMBL221137 & 954943 & 3.8592 & 3.7727 & TST \\
\hline CHEMBL188678 & 954943 & 5.4583 & 4.7322 & TST \\
\hline CHEMBL 2363137 & 954943 & 3.3413 & 3.8834 & TST \\
\hline CHEMBL209148 & 954943 & 2.6966 & 3.6029 & TST \\
\hline CHEMBL 2144069 & 954943 & 2.9882 & 4.8652 & TST \\
\hline CHEMBL 379300 & 954943 & 5.83 & 4.8515 & TST \\
\hline CHEMBL 2218412 & 887762 & 6.6 & 6.6874 & TST \\
\hline CHEMBL 2218413 & 887762 & 6.3 & 7.232 & TRN \\
\hline CHEMBL 2218414 & 887762 & 7.2 & 6.7297 & TRN \\
\hline CHEMBL 2218415 & 887762 & 6.2 & 6.7858 & TRN \\
\hline CHEMBL 2218416 & 887762 & 6.2 & 6.8197 & TRN \\
\hline CHEMBL 2218417 & 887762 & 6.7 & 6.6913 & TRN \\
\hline CHEMBL 2218418 & 887762 & 7.0 & 6.7245 & TRN \\
\hline CHEMBL 2218419 & 887762 & 6.6 & 6.6589 & TRN \\
\hline CHEMBL 2218420 & 887762 & 6.9 & 6.8423 & TRN \\
\hline CHEMBL 2218421 & 887762 & 6.5 & 6.8186 & TRN \\
\hline CHEMBL 2218422 & 887762 & 6.4 & 6.9255 & TST \\
\hline CHEMBL 2218423 & 887762 & 7.8 & 6.9082 & TST \\
\hline CHEMBL 2218424 & 887762 & 6.6 & 6.7247 & TRN \\
\hline CHEMBL 2218425 & 887762 & 6.3 & 6.9094 & TRN \\
\hline CHEMBL 2218426 & 887762 & 5.9 & 6.727 & TRN \\
\hline CHEMBL 2218427 & 887762 & 5.9 & 6.9217 & TST \\
\hline CHEMBL 2218428 & 887762 & 6.2 & 6.6229 & TRN \\
\hline CHEMBL 2218429 & 887762 & 5.9 & 6.805 & TRN \\
\hline CHEMBL 2218430 & 887762 & 6.3 & 6.7652 & TRN \\
\hline CHEMBL 2218431 & 887762 & 6.5 & 6.8182 & TRN \\
\hline CHEMBL 2218432 & 887762 & 6.7 & 6.6974 & TRN \\
\hline CHEMBL 2218433 & 887762 & 6.4 & 7.0676 & TST \\
\hline CHEMBL 2218434 & 887762 & 6.6 & 6.7567 & TRN \\
\hline CHEMBL 2218435 & 887762 & 6.4 & 6.8913 & TRN \\
\hline CHEMBL 2218436 & 887762 & 6.4 & 6.9223 & TRN \\
\hline CHEMBL 2218437 & 887762 & 6.6 & 6.4723 & TRN \\
\hline CHEMBL 2218438 & 887762 & 6.4 & 6.6685 & TRN \\
\hline CHEMBL 2218439 & 887762 & 6.4 & 6.8507 & TRN \\
\hline CHEMBL 2218440 & 887762 & 6.5 & 6.7621 & TRN \\
\hline CHEMBL 2218441 & 887762 & 6.7 & 6.7803 & TRN \\
\hline CHEMBL 2218442 & 887762 & 7.3 & 6.5939 & TRN \\
\hline CHEMBL 2218443 & 887762 & 6.9 & 6.5905 & TRN \\
\hline CHEMBL 2218444 & 887762 & 6.2 & 6.8509 & TST \\
\hline
\end{tabular}




\begin{tabular}{|c|c|c|c|c|c|}
\hline \multirow[b]{2}{*}{ CHEMBL2218445 } & \multirow[b]{2}{*}{887762} & \\
\hline & & 6.6 & 6.9478 & TST & \\
\hline CHEMBL2218446 & 887762 & 7.5 & 7.0515 & TST & \\
\hline CHEMBL2218447 & 887762 & 6.6 & 6.7242 & TST & \\
\hline CHEMBL2218448 & 887762 & 7.2 & 6.8221 & TST & \\
\hline CHEMBL2218595 & 887762 & 6.1 & 6.5923 & TST & \\
\hline CHEMBL2218596 & 887762 & 6.9 & 6.8715 & TST & \\
\hline CHEMBL2218597 & 887762 & 7.4 & \multicolumn{2}{|c|}{7.002999999999999} & TST \\
\hline CHEMBL2218598 & 887762 & 7.4 & 6.7133 & TRN & \\
\hline CHEMBL 2218070 & 887762 & 7.2 & 6.7319 & TST & \\
\hline CHEMBL2218599 & 887762 & 7.1 & 6.8432 & TRN & \\
\hline CHEMBL2218600 & 887762 & 6.5 & 6.7911 & TRN & \\
\hline CHEMBL2218601 & 887762 & 7.0 & 6.6874 & TRN & \\
\hline CHEMBL2218602 & 887762 & 6.7 & 6.864 & TRN & \\
\hline CHEMBL2218603 & 887762 & 6.9 & 6.7589 & TRN & \\
\hline CHEMBL2218604 & 887762 & 7.2 & 7.1156 & TRN & \\
\hline CHEMBL2218605 & 887762 & 6.8 & 6.6999 & TRN & \\
\hline CHEMBL2218606 & 887762 & 6.4 & 6.7631 & TRN & \\
\hline CHEMBL2218607 & 887762 & 6.2 & 6.9696 & TST & \\
\hline CHEMBL2218608 & 887762 & 6.9 & 6.8745 & TRN & \\
\hline CHEMBL2218609 & 887762 & 6.5 & 6.7855 & TRN & \\
\hline CHEMBL2218610 & 887762 & 6.1 & 6.9271 & TST & \\
\hline CHEMBL2218611 & 887762 & 6.8 & \multicolumn{2}{|c|}{7.122000000000001} & TRN \\
\hline CHEMBL2218612 & 887762 & 6.7 & 7.0978 & TRN & \\
\hline CHEMBL1222671 & 887762 & 6.4 & 7.0364 & TST & \\
\hline CHEMBL2218613 & 887762 & 5.9 & 7.0984 & TST & \\
\hline CHEMBL2218614 & 887762 & 7.1 & 6.9223 & TST & \\
\hline CHEMBL2218615 & 887762 & 6.7 & 6.9943 & TST & \\
\hline CHEMBL 2218616 & 887762 & 6.4 & 7.0465 & TST & \\
\hline CHEMBL2218617 & 887762 & 6.2 & 7.0642 & TST & \\
\hline CHEMBL2218618 & 887762 & 6.1 & 7.1547 & TST & \\
\hline CHEMBL2218619 & 887762 & 6.4 & 6.7205 & TST & \\
\hline CHEMBL2218620 & 887762 & 6.6 & 6.7752 & TRN & \\
\hline CHEMBL 2218621 & 887762 & 6.4 & 6.8319 & TRN & \\
\hline CHEMBL2218622 & 887762 & 6.6 & 6.8829 & TRN & \\
\hline CHEMBL2218623 & 887762 & 5.9 & 7.0021 & TST & \\
\hline CHEMBL2218624 & 887762 & 5.9 & 7.0061 & TST & \\
\hline CHEMBL2218625 & 887762 & 6.1 & 6.8728 & TST & \\
\hline CHEMBL 2218626 & 887762 & 6.1 & 7.0522 & TST & \\
\hline CHEMBL2218627 & 887762 & 6.8 & 7.1564 & TRN & \\
\hline CHEMBL2218754 & 887762 & 6.6 & 7.0931 & TRN & \\
\hline CHEMBL2218755 & 887762 & 6.0 & 7.1286 & TRN & \\
\hline CHEMBL1222741 & 887762 & 6.0 & 6.9985 & TRN & \\
\hline CHEMBL1222742 & 887762 & 6.2 & 7.0515 & TRN & \\
\hline CHEMBL1222744 & 887762 & 6.2 & 7.3336 & TRN & \\
\hline CHEMBL2218757 & 887762 & 7.3 & 7.0866 & TRN & \\
\hline CHEMBL2218758 & 887762 & 6.1 & 7.255 & TRN & \\
\hline CHEMBL1222740 & 887762 & 6.2 & 7.2603 & TRN & \\
\hline \multirow[t]{2}{*}{ CHEMBL2218761 } & 887762 & 6.6 & 6.9574 & TRN & \\
\hline & & \multicolumn{4}{|c|}{ Page 10555} \\
\hline
\end{tabular}




\begin{tabular}{|c|c|c|c|c|}
\hline & & & & al lable \\
\hline CHEMBL2218763 & 887762 & 6.8 & 7.0441 & TRN \\
\hline CHEMBL2218765 & 887762 & 6.8 & 7.2106 & TRN \\
\hline CHEMBL2218766 & 887762 & 6.1 & 6.9918 & TRN \\
\hline CHEMBL2218767 & 887762 & 7.8 & 7.3898 & TRN \\
\hline CHEMBL 2218768 & 887762 & 6.4 & 7.1224 & TRN \\
\hline CHEMBL 2218770 & 887762 & 7.1 & 7.1234 & TRN \\
\hline CHEMBL 2218772 & 887762 & 6.7 & 7.0038 & TRN \\
\hline CHEMBL2218773 & 887762 & 7.4 & 7.2356 & TST \\
\hline CHEMBL 2218774 & 887762 & 6.1 & 6.9458 & TRN \\
\hline CHEMBL2218778 & 887762 & 7.0 & 7.3445 & TST \\
\hline CHEMBL1222743 & 887762 & 7.0 & 6.9666 & TRN \\
\hline CHEMBL2218181 & 887762 & 6.7 & 7.3493 & TST \\
\hline CHEMBL2218182 & 887762 & 7.4 & 7.3643 & TRN \\
\hline CHEMBL 2218183 & 887762 & 8.0 & 7.7812 & TRN \\
\hline CHEMBL2218186 & 887762 & 7.6 & 7.3489 & TRN \\
\hline CHEMBL 2218189 & 887762 & 6.9 & 7.3686 & TST \\
\hline CHEMBL2218192 & 887762 & 6.9 & 7.2855 & TST \\
\hline CHEMBL2218193 & 887762 & 6.4 & 7.7216 & TST \\
\hline CHEMBL2218194 & 887762 & 7.1 & 8.0575 & TST \\
\hline CHEMBL2218195 & 887762 & 6.9 & 7.7281 & TST \\
\hline CHEMBL2218196 & 887762 & 6.5 & 7.3387 & TST \\
\hline CHEMBL2218197 & 887762 & 7.8 & 8.1214 & TST \\
\hline CHEMBL2218198 & 887762 & 7.0 & 7.2501 & TST \\
\hline CHEMBL2218199 & 887762 & 6.7 & 7.3646 & TST \\
\hline CHEMBL2218200 & 887762 & 8.0 & 7.28700 & 0000000001 \\
\hline CHEMBL2218201 & 887762 & 8.5 & 7.584 & TRN \\
\hline CHEMBL 2218202 & 887762 & 6.7 & 7.2663 & TST \\
\hline CHEMBL2218211 & 887762 & 7.7 & 7.2545 & TRN \\
\hline CHEMBL2218247 & 887762 & 6.3 & 7.2414 & TST \\
\hline CHEMBL 2218248 & 887762 & 7.8 & 7.921 & TRN \\
\hline CHEMBL2218250 & 887762 & 6.1 & 7.3148 & TRN \\
\hline CHEMBL 2218251 & 887762 & 6.2 & 7.598 & TST \\
\hline CHEMBL 2218252 & 887762 & 8.5 & 7.5441 & TRN \\
\hline CHEMBL 2218253 & 887762 & 7.4 & 7.0862 & TST \\
\hline CHEMBL 2218254 & 887762 & 6.7 & 7.4835 & TRN \\
\hline CHEMBL2218256 & 887762 & 7.0 & 7.1313 & TST \\
\hline CHEMBL 2218257 & 887762 & 8.5 & 7.352 & TRN \\
\hline CHEMBL 2218258 & 887762 & 8.9 & 7.9344 & TRN \\
\hline CHEMBL2218261 & 887762 & 8.9 & 7.3669 & TST \\
\hline CHEMBL 2218262 & 887762 & 8.8 & 7.1218 & TST \\
\hline CHEMBL2218263 & 887762 & 7.7 & 7.5988 & TRN \\
\hline CHEMBL2218265 & 887762 & 8.8 & 8.2415 & TRN \\
\hline CHEMBL2218268 & 887762 & 8.6 & 7.8261 & TRN \\
\hline CHEMBL 2218269 & 887762 & 7.4 & 7.49 & TRN \\
\hline CHEMBL 2218270 & 887762 & 7.6 & 7.5047 & TST \\
\hline CHEMBL 2218271 & 887762 & 7.1 & 7.1222 & TST \\
\hline CHEMBL 2218272 & 887762 & 7.5 & 7.8516 & TRN \\
\hline CHEMBL2218273 & 887762 & 7.7 & 7.9345 & TRN \\
\hline
\end{tabular}




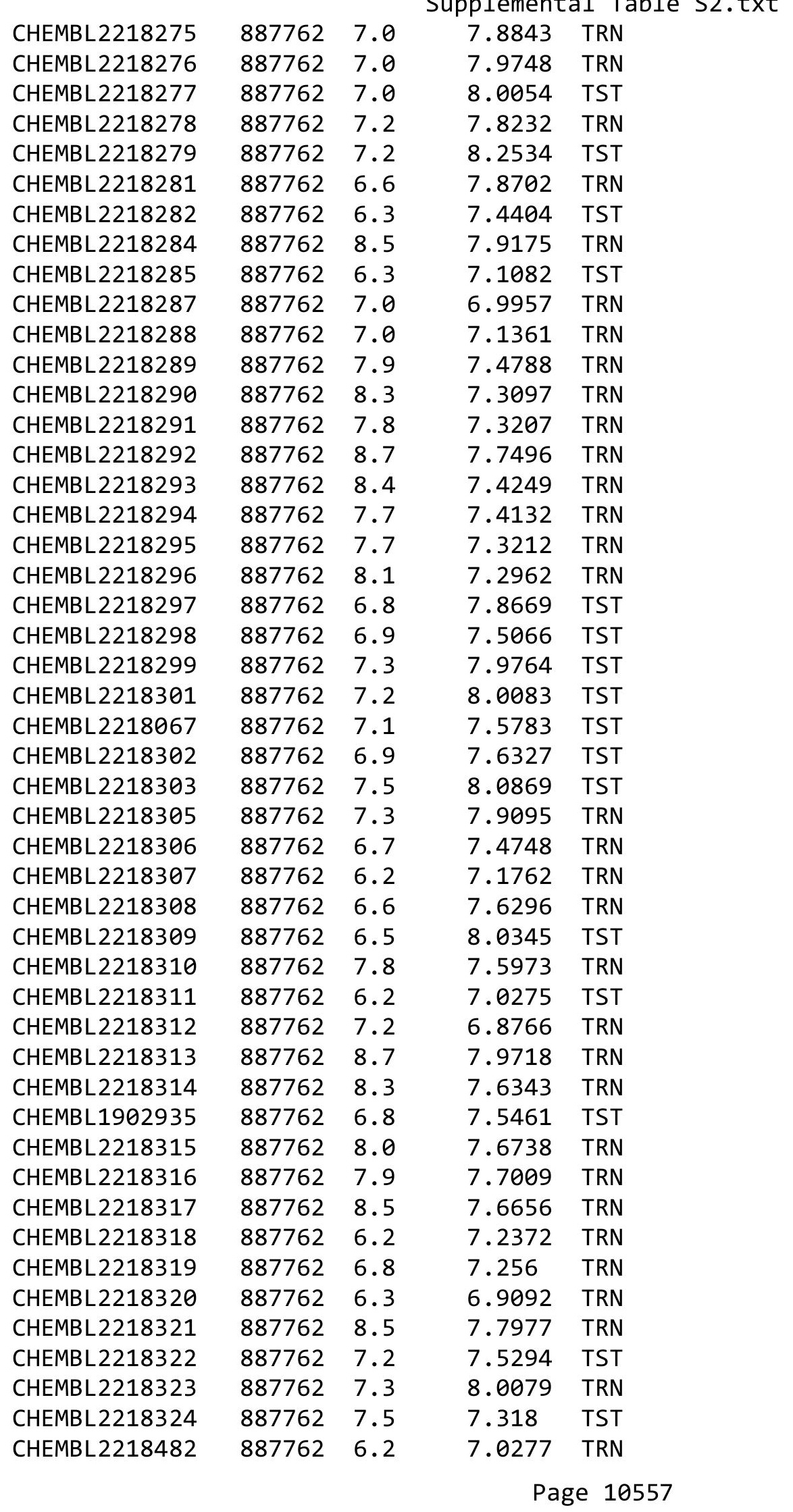




\begin{tabular}{|c|c|c|c|c|c|}
\hline & & & & & \\
\hline CHEMBL2218483 & 887762 & 8.5 & 7.3853 & TRN & \\
\hline CHEMBL 2218488 & 887762 & 6.3 & 7.4965 & TRN & \\
\hline CHEMBL2218489 & 887762 & 6.2 & 7.5155 & TRN & \\
\hline CHEMBL 2218490 & 887762 & 6.9 & 7.0083 & TRN & \\
\hline CHEMBL2218491 & 887762 & 7.2 & 7.9725 & TRN & \\
\hline CHEMBL2218492 & 887762 & 6.4 & 7.3705 & TRN & \\
\hline CHEMBL 2218493 & 887762 & 7.5 & 7.3781 & TRN & \\
\hline CHEMBL2218494 & 887762 & 8.1 & 7.9339 & TRN & \\
\hline CHEMBL2218495 & 887762 & 7.5 & 7.565 & TRN & \\
\hline CHEMBL2218496 & 887762 & 7.3 & 7.624 & TRN & \\
\hline CHEMBL2218497 & 887762 & 8.0 & 7.4813 & TRN & \\
\hline CHEMBL 2218498 & 887762 & 6.3 & 7.1978 & TRN & \\
\hline CHEMBL2218499 & 887762 & 6.2 & 7.011 & TRN & \\
\hline CHEMBL2218069 & 887762 & 6.1 & 7.2761 & TRN & \\
\hline CHEMBL 2218500 & 887762 & 6.4 & 7.1008 & TRN & \\
\hline CHEMBL 2218501 & 887762 & 7.3 & 7.3956 & TST & \\
\hline CHEMBL2218502 & 887762 & 8.5 & 7.6761 & TRN & \\
\hline CHEMBL2218503 & 887762 & 6.6 & 7.0326 & TRN & \\
\hline CHEMBL2218504 & 887762 & 7.0 & 7.4207 & TRN & \\
\hline CHEMBL 2218505 & 887762 & 6.6 & 7.3248 & TRN & \\
\hline CHEMBL 2218506 & 887762 & 7.3 & 7.3323 & TRN & \\
\hline CHEMBL 2218507 & 887762 & 6.9 & 7.0726 & TRN & \\
\hline CHEMBL 2218508 & 887762 & 6.7 & 6.8664 & TRN & \\
\hline CHEMBL2218509 & 887762 & 6.3 & 7.0326 & TRN & \\
\hline CHEMBL 2218510 & 887762 & 7.8 & 7.2686 & TRN & \\
\hline CHEMBL 2218511 & 887762 & 7.3 & 7.2543 & TRN & \\
\hline CHEMBL 2218514 & 887762 & 7.8 & 7.8622 & TST & \\
\hline CHEMBL 2218515 & 887762 & 7.1 & 7.4143 & TRN & \\
\hline CHEMBL2218516 & 887762 & 7.5 & 7.86299 & 99999999995 & TST \\
\hline CHEMBL 2218693 & 887762 & 7.1 & 7.2766 & TRN & \\
\hline CHEMBL 2218694 & 887762 & 8.0 & 7.7381 & TST & \\
\hline CHEMBL2218695 & 887762 & 8.2 & 7.4809 & TRN & \\
\hline CHEMBL 2218696 & 887762 & 7.6 & 7.671 & TST & \\
\hline CHEMBL2218697 & 887762 & 8.3 & 7.9435 & TST & \\
\hline CHEMBL 2218071 & 887762 & 7.3 & 7.1174 & TST & \\
\hline CHEMBL2218698 & 887762 & 7.4 & 7.461 & TST & \\
\hline CHEMBL2218699 & 887762 & 7.1 & 7.6471 & TST & \\
\hline CHEMBL 2218700 & 887762 & 6.4 & 6.9549 & TRN & \\
\hline CHEMBL2218701 & 887762 & 8.0 & 7.1789 & TRN & \\
\hline CHEMBL2218702 & 887762 & 7.0 & 6.8588 & TRN & \\
\hline CHEMBL 2218703 & 887762 & 6.9 & 7.07299 & 99999999995 & TRN \\
\hline CHEMBL 2218704 & 887762 & 8.3 & 6.9076 & TRN & \\
\hline CHEMBL2218705 & 887762 & 7.3 & 7.0712 & TRN & \\
\hline CHEMBL2218706 & 887762 & 6.8 & 6.9907 & TRN & \\
\hline CHEMBL2218707 & 887762 & 6.8 & 7.0378 & TRN & \\
\hline CHEMBL 2218708 & 887762 & 7.7 & 6.9752 & TRN & \\
\hline CHEMBL2218709 & 887762 & 7.3 & 6.807 & TRN & \\
\hline CHEMBL 2218710 & 887762 & 6.9 & 7.0912 & TRN & \\
\hline & & & & 10558 & \\
\hline
\end{tabular}




\begin{tabular}{|c|c|c|c|c|c|}
\hline \\
\hline CHEMBL2218711 & 887762 & 6.0 & 6.9336 & TRN & \\
\hline CHEMBL2218712 & 887762 & 6.6 & 6.8305 & TRN & \\
\hline CHEMBL2218713 & 887762 & 6.6 & 6.8847 & TST & \\
\hline CHEMBL2218714 & 887762 & 6.8 & 7.2562 & TST & \\
\hline CHEMBL2218715 & 887762 & 6.9 & 7.284 & TST & \\
\hline CHEMBL2218716 & 887762 & 7.5 & 7.3596 & TST & \\
\hline CHEMBL2218717 & 887762 & 7.9 & 7.2935 & TST & \\
\hline CHEMBL2218718 & 887762 & 7.6 & 7.3286 & TRN & \\
\hline CHEMBL2218719 & 887762 & 6.9 & 6.8904 & TST & \\
\hline CHEMBL2218720 & 887762 & 7.0 & 7.3333 & TST & \\
\hline CHEMBL2218721 & 887762 & 7.3 & 7.2153 & TST & \\
\hline CHEMBL2218722 & 887762 & 6.9 & 6.8533 & TRN & \\
\hline CHEMBL 2218723 & 887762 & 7.4 & 7.6551 & TRN & \\
\hline CHEMBL2218449 & 887762 & 7.3 & 6.9242 & TST & \\
\hline CHEMBL 2218450 & 887762 & 6.6 & 6.8601 & TRN & \\
\hline CHEMBL 2218451 & 887762 & 6.9 & 6.8641 & TRN & \\
\hline CHEMBL2218452 & 887762 & 8.5 & 8.3774 & TRN & \\
\hline CHEMBL2218453 & 887762 & 6.0 & 7.1676 & TRN & \\
\hline CHEMBL2218454 & 887762 & 7.5 & 7.2888 & TST & \\
\hline CHEMBL2218455 & 887762 & 7.5 & 8.0512 & TST & \\
\hline CHEMBL 2218456 & 887762 & 7.4 & 7.4197 & TST & \\
\hline CHEMBL2218457 & 887762 & 6.7 & 6.841 & TST & \\
\hline CHEMBL2218458 & 887762 & 6.0 & 7.0619 & TST & \\
\hline CHEMBL2218459 & 887762 & 7.1 & 6.8064 & TRN & \\
\hline CHEMBL2218460 & 887762 & 8.1 & 6.8157 & TRN & \\
\hline CHEMBL 2218461 & 887762 & 6.3 & 6.86100 & 2000000001 & TRN \\
\hline CHEMBL2218462 & 887762 & 6.0 & 6.8546 & TRN & \\
\hline CHEMBL2218464 & 887762 & 7.9 & 8.1468 & TRN & \\
\hline CHEMBL 2218465 & 887762 & 8.3 & 7.2177 & TST & \\
\hline CHEMBL2218466 & 887762 & 6.3 & 6.7276 & TRN & \\
\hline CHEMBL2218467 & 887762 & 6.4 & 7.0521 & TRN & \\
\hline CHEMBL2218468 & 887762 & 6.0 & 7.0843 & TRN & \\
\hline CHEMBL2218469 & 887762 & 6.8 & 6.6625 & TRN & \\
\hline CHEMBL 2218470 & 887762 & 7.0 & 6.9919 & TRN & \\
\hline CHEMBL 2218471 & 887762 & 7.1 & 6.9486 & TRN & \\
\hline CHEMBL2218472 & 887762 & 7.4 & 6.8021 & TRN & \\
\hline CHEMBL 2218473 & 887762 & 7.3 & 6.9157 & TRN & \\
\hline CHEMBL2218474 & 887762 & 8.0 & 6.8555 & TRN & \\
\hline CHEMBL 2218475 & 887762 & 7.0 & 7.0121 & TRN & \\
\hline CHEMBL2218476 & 887762 & 7.8 & 7.4056 & TRN & \\
\hline CHEMBL 2218477 & 887762 & 6.2 & 6.8533 & TRN & \\
\hline CHEMBL 2218478 & 887762 & 6.6 & 7.2207 & TRN & \\
\hline CHEMBL2218479 & 887762 & 6.7 & 7.4084 & TRN & \\
\hline CHEMBL2218480 & 887762 & 6.3 & 7.4899 & TRN & \\
\hline CHEMBL 2218481 & 887762 & 6.1 & 7.4339 & TRN & \\
\hline CHEMBL2218517 & 887762 & 7.0 & 7.1367 & TRN & \\
\hline CHEMBL 2218518 & 887762 & 6.4 & 7.1795 & TRN & \\
\hline CHEMBL2218519 & 887762 & 8.0 & 8.0357 & TRN & \\
\hline
\end{tabular}




\begin{tabular}{|c|c|c|c|c|}
\hline \multicolumn{5}{|c|}{ Supplemental Table S2.txt } \\
\hline CHEMBL 2218520 & 887762 & 7.2 & 7.1084 & TRN \\
\hline CHEMBL 2218521 & 887762 & 6.4 & 6.9984 & TRN \\
\hline CHEMBL 2218522 & 887762 & 7.3 & 7.31 & TRN \\
\hline CHEMBL 2218523 & 887762 & 7.4 & 7.4674 & TRN \\
\hline CHEMBL 2218525 & 887762 & 7.1 & 7.3884 & TRN \\
\hline CHEMBL 2218526 & 887762 & 7.3 & 7.2242 & TRN \\
\hline CHEMBL 2218527 & 887762 & 6.3 & 7.0204 & TRN \\
\hline CHEMBL 2218528 & 887762 & 7.6 & 7.0718 & TRN \\
\hline CHEMBL 2218529 & 887762 & 7.9 & 6.9771 & TRN \\
\hline CHEMBL 2218530 & 887762 & 6.3 & 7.0268 & TRN \\
\hline CHEMBL 2218531 & 887762 & 7.3 & 6.9346 & TRN \\
\hline CHEMBL 2218532 & 887762 & 7.4 & 7.0136 & TRN \\
\hline CHEMBL 2218533 & 887762 & 7.5 & 6.7312 & TRN \\
\hline CHEMBL 2218534 & 887762 & 6.7 & 6.8082 & TRN \\
\hline CHEMBL 2218535 & 887762 & 7.2 & 7.4313 & TRN \\
\hline CHEMBL 2218536 & 887762 & 7.0 & 7.2141 & TRN \\
\hline CHEMBL 2218537 & 887762 & 7.0 & 6.7551 & TRN \\
\hline CHEMBL 2218538 & 887762 & 6.2 & 7.0138 & TRN \\
\hline CHEMBL 2218539 & 887762 & 8.0 & 7.6711 & TRN \\
\hline CHEMBL 2218540 & 887762 & 7.0 & 7.5405 & TRN \\
\hline CHEMBL 2218541 & 887762 & 6.2 & 7.0583 & TRN \\
\hline CHEMBL 2218542 & 887762 & 8.2 & 7.9469 & TRN \\
\hline CHEMBL 2218543 & 887762 & 7.6 & 7.472 & TRN \\
\hline CHEMBL 2218544 & 887762 & 8.1 & 7.9325 & TRN \\
\hline CHEMBL 2218545 & 887762 & 7.3 & 7.0459 & TRN \\
\hline CHEMBL 2218546 & 887762 & 6.9 & 7.5106 & TRN \\
\hline CHEMBL 2218547 & 887762 & 8.1 & 7.9895 & TRN \\
\hline CHEMBL 2218548 & 887762 & 7.0 & 6.8844 & TRN \\
\hline CHEMBL 2218549 & 887762 & 7.7 & 7.7883 & TST \\
\hline CHEMBL 2218550 & 887762 & 7.5 & 6.9133 & TRN \\
\hline CHEMBL 2218551 & 887762 & 7.3 & 6.8429 & TRN \\
\hline CHEMBL 2218552 & 887762 & 8.3 & 8.2077 & TRN \\
\hline CHEMBL 2218553 & 887762 & 7.8 & 7.8183 & TRN \\
\hline CHEMBL 2218554 & 887762 & 7.6 & 7.8473 & TRN \\
\hline CHEMBL 2218555 & 887762 & 7.4 & 7.039 & TRN \\
\hline CHEMBL 2218628 & 887762 & 7.4 & 7.1164 & TRN \\
\hline CHEMBL 2218629 & 887762 & 7.6 & 7.5459 & TRN \\
\hline CHEMBL 2218630 & 887762 & 7.5 & 7.2193 & TRN \\
\hline CHEMBL 2218631 & 887762 & 8.3 & 7.7309 & TRN \\
\hline CHEMBL 2218632 & 887762 & 7.5 & 7.7888 & TRN \\
\hline CHEMBL 2218633 & 887762 & 7.4 & 7.8098 & TRN \\
\hline CHEMBL 2218634 & 887762 & 7.2 & 6.9632 & TRN \\
\hline CHEMBL 2218635 & 887762 & 7.9 & 6.8475 & TRN \\
\hline CHEMBL 2218636 & 887762 & 7.8 & 7.5148 & TRN \\
\hline CHEMBL 2218637 & 887762 & 7.5 & 7.6002 & TRN \\
\hline CHEMBL 2218638 & 887762 & 6.7 & 7.4957 & TST \\
\hline CHEMBL 2218639 & 887762 & 7.6 & 7.5403 & TRN \\
\hline CHEMBL 2218640 & 887762 & 6.7 & 7.9572 & TST \\
\hline
\end{tabular}




\begin{tabular}{|c|c|c|c|c|}
\hline & & & ipplement & al lable s \\
\hline CHEMBL2218641 & 887762 & 7.5 & 6.8888 & TRN \\
\hline CHEMBL 2218642 & 887762 & 7.3 & 7.0386 & TRN \\
\hline CHEMBL2218643 & 887762 & 8.0 & 6.9029 & TRN \\
\hline CHEMBL 2218644 & 887762 & 6.7 & 7.21 & TRN \\
\hline CHEMBL 2218645 & 887762 & 6.8 & 7.0724 & TST \\
\hline CHEMBL 2218646 & 887762 & 7.2 & 7.2208 & TRN \\
\hline CHEMBL 2218647 & 887762 & 6.9 & 7.3947 & TRN \\
\hline CHEMBL 2218648 & 887762 & 8.1 & 6.75299 & 9999999999 \\
\hline CHEMBL 2218649 & 887762 & 7.8 & 6.8207 & TRN \\
\hline CHEMBL2218650 & 887762 & 8.0 & 7.0024 & TRN \\
\hline CHEMBL 2218651 & 887762 & 6.6 & 6.8735 & TST \\
\hline CHEMBL2218652 & 887762 & 6.8 & 7.0466 & TRN \\
\hline CHEMBL2218653 & 887762 & 7.7 & 7.0516 & TRN \\
\hline CHEMBL 2218654 & 887762 & 7.0 & 6.9987 & TRN \\
\hline CHEMBL2218655 & 887762 & 6.8 & 6.9186 & TRN \\
\hline CHEMBL 2218656 & 887762 & 7.5 & 7.0848 & TRN \\
\hline CHEMBL2218657 & 887762 & 6.9 & 7.215 & TRN \\
\hline CHEMBL2218724 & 887762 & 6.1 & 7.2217 & TRN \\
\hline CHEMBL 2218725 & 887762 & 7.1 & 7.1441 & TRN \\
\hline CHEMBL2218726 & 887762 & 7.2 & 7.4719 & TRN \\
\hline CHEMBL 2218727 & 887762 & 6.7 & 6.869 & TRN \\
\hline CHEMBL2218728 & 887762 & 6.3 & 6.8401 & TRN \\
\hline CHEMBL2218729 & 887762 & 6.8 & 6.9531 & TRN \\
\hline CHEMBL 2218730 & 887762 & 8.5 & 6.9243 & TRN \\
\hline CHEMBL2218731 & 887762 & 8.1 & 6.9088 & TRN \\
\hline CHEMBL2218733 & 887762 & 6.6 & 6.812 & TRN \\
\hline CHEMBL 2218734 & 887762 & 7.8 & 7.6445 & TRN \\
\hline CHEMBL2218735 & 887762 & 7.4 & 7.6617 & TRN \\
\hline CHEMBL 2218736 & 887762 & 7.7 & 7.5333 & TRN \\
\hline CHEMBL 2218737 & 887762 & 7.2 & 8.2418 & TST \\
\hline CHEMBL2218738 & 887762 & 6.1 & 7.3901 & TST \\
\hline CHEMBL 2218739 & 887762 & 7.6 & 7.1648 & TRN \\
\hline CHEMBL 2218740 & 887762 & 6.6 & 7.3605 & TST \\
\hline CHEMBL 2218741 & 887762 & 7.8 & 7.1809 & TRN \\
\hline CHEMBL 2218742 & 887762 & 7.8 & 7.1238 & TRN \\
\hline CHEMBL 2218743 & 887762 & 7.3 & 6.9215 & TRN \\
\hline CHEMBL 2218744 & 887762 & 7.9 & 7.4759 & TRN \\
\hline CHEMBL 2218745 & 887762 & 6.9 & 7.0271 & TRN \\
\hline CHEMBL 2218746 & 887762 & 7.3 & 7.1159 & TRN \\
\hline CHEMBL 2218747 & 887762 & 6.7 & 6.9595 & TRN \\
\hline CHEMBL 2218748 & 887762 & 7.6 & 7.7435 & TST \\
\hline CHEMBL2218749 & 887762 & 8.1 & 7.5258 & TRN \\
\hline CHEMBL 2218750 & 887762 & 7.1 & 7.3462 & TRN \\
\hline CHEMBL 2218751 & 887762 & 7.8 & 7.4239 & TRN \\
\hline CHEMBL 2218752 & 887762 & 6.6 & 6.8628 & TRN \\
\hline CHEMBL2218753 & 887762 & 7.5 & 6.9441 & TRN \\
\hline CHEMBL 2218072 & 887762 & 8.0 & 7.2732 & TRN \\
\hline CHEMBL 2218073 & 887762 & 7.3 & 7.2588 & TRN \\
\hline
\end{tabular}

TRN 


\begin{tabular}{|c|c|c|c|c|}
\hline & & & ient & al 1 \\
\hline CHEMBL 2218074 & 887762 & 7.4 & 6.8879 & TRN \\
\hline CHEMBL 2218075 & 887762 & 7.9 & 7.1234 & TRN \\
\hline CHEMBL2218076 & 887762 & 7.3 & 7.5904 & TRN \\
\hline CHEMBL 2218077 & 887762 & 7.3 & 7.3125 & TRN \\
\hline CHEMBL2218078 & 887762 & 6.5 & 6.9525 & TRN \\
\hline CHEMBL 2218079 & 887762 & 7.8 & 7.598 & TRN \\
\hline CHEMBL2218080 & 887762 & 7.9 & 8.1908 & TRN \\
\hline CHEMBL2218081 & 887762 & 7.3 & 7.7311 & TRN \\
\hline CHEMBL 2218082 & 887762 & 6.6 & 7.3432 & TRN \\
\hline CHEMBL2218083 & 887762 & 7.3 & 7.7596 & TST \\
\hline CHEMBL 2218084 & 887762 & 7.1 & 6.9726 & TRN \\
\hline CHEMBL2218085 & 887762 & 7.2 & 6.8989 & TRN \\
\hline CHEMBL2218086 & 887762 & 8.2 & 7.7487 & TRN \\
\hline CHEMBL 2218087 & 887762 & 8.2 & 7.4465 & TRN \\
\hline CHEMBL2218088 & 887762 & 7.4 & 6.9966 & TRN \\
\hline CHEMBL 2218089 & 887762 & 8.1 & 7.0067 & TRN \\
\hline CHEMBL2218090 & 887762 & 8.8 & 7.3237 & TRN \\
\hline CHEMBL2218091 & 887762 & 7.9 & 7.059 & TRN \\
\hline CHEMBL 2218092 & 887762 & 7.2 & 7.3781 & TRN \\
\hline CHEMBL2218093 & 887762 & 7.1 & 6.9263 & TRN \\
\hline CHEMBL 2218094 & 887762 & 7.8 & 8.332 & TRN \\
\hline CHEMBL2218095 & 887762 & 7.5 & 7.9152 & TRN \\
\hline CHEMBL 2218096 & 887762 & 7.0 & 7.5464 & TRN \\
\hline CHEMBL2218097 & 887762 & 7.3 & 7.0759 & TRN \\
\hline CHEMBL2218098 & 887762 & 8.1 & 7.9019 & TRN \\
\hline CHEMBL2218099 & 887762 & 7.8 & 7.4676 & TRN \\
\hline CHEMBL 2218100 & 887762 & 7.2 & 7.0942 & TRN \\
\hline CHEMBL2218101 & 887762 & 7.6 & 6.9127 & TRN \\
\hline CHEMBL2218102 & 887762 & 7.5 & 7.1885 & TRN \\
\hline CHEMBL 2218103 & 887762 & 7.9 & 6.8613 & TRN \\
\hline CHEMBL2218065 & 887762 & 7.6 & 7.0872 & TRN \\
\hline CHEMBL 2218104 & 887762 & 7.7 & 7.0873 & TRN \\
\hline CHEMBL 2218105 & 887762 & 7.2 & 7.1175 & TRN \\
\hline CHEMBL2218106 & 887762 & 7.2 & 7.2059 & TRN \\
\hline CHEMBL 2218107 & 887762 & 8.0 & 7.553 & TRN \\
\hline CHEMBL2218108 & 887762 & 7.8 & 7.2797 & TRN \\
\hline CHEMBL2218109 & 887762 & 8.1 & 7.6539 & TRN \\
\hline CHEMBL 2218141 & 887762 & 7.4 & 7.1583 & TRN \\
\hline CHEMBL 2218142 & 887762 & 6.5 & 7.0998 & TRN \\
\hline CHEMBL 2218143 & 887762 & 6.2 & 7.2523 & TRN \\
\hline CHEMBL 2218144 & 887762 & 6.8 & 7.1849 & TRN \\
\hline CHEMBL 2218145 & 887762 & 7.0 & 7.2284 & TRN \\
\hline CHEMBL 2218146 & 887762 & 7.2 & 8.2193 & TRN \\
\hline CHEMBL 2218147 & 887762 & 6.6 & 8.0334 & TST \\
\hline CHEMBL 2218148 & 887762 & 8.0 & 7.6143 & TRN \\
\hline CHEMBL2218149 & 887762 & 8.3 & 8.083 & TRN \\
\hline CHEMBL2218150 & 887762 & 6.3 & 7.4986 & TST \\
\hline CHEMBL2218151 & 887762 & 8.4 & 7.1629 & TRN \\
\hline
\end{tabular}




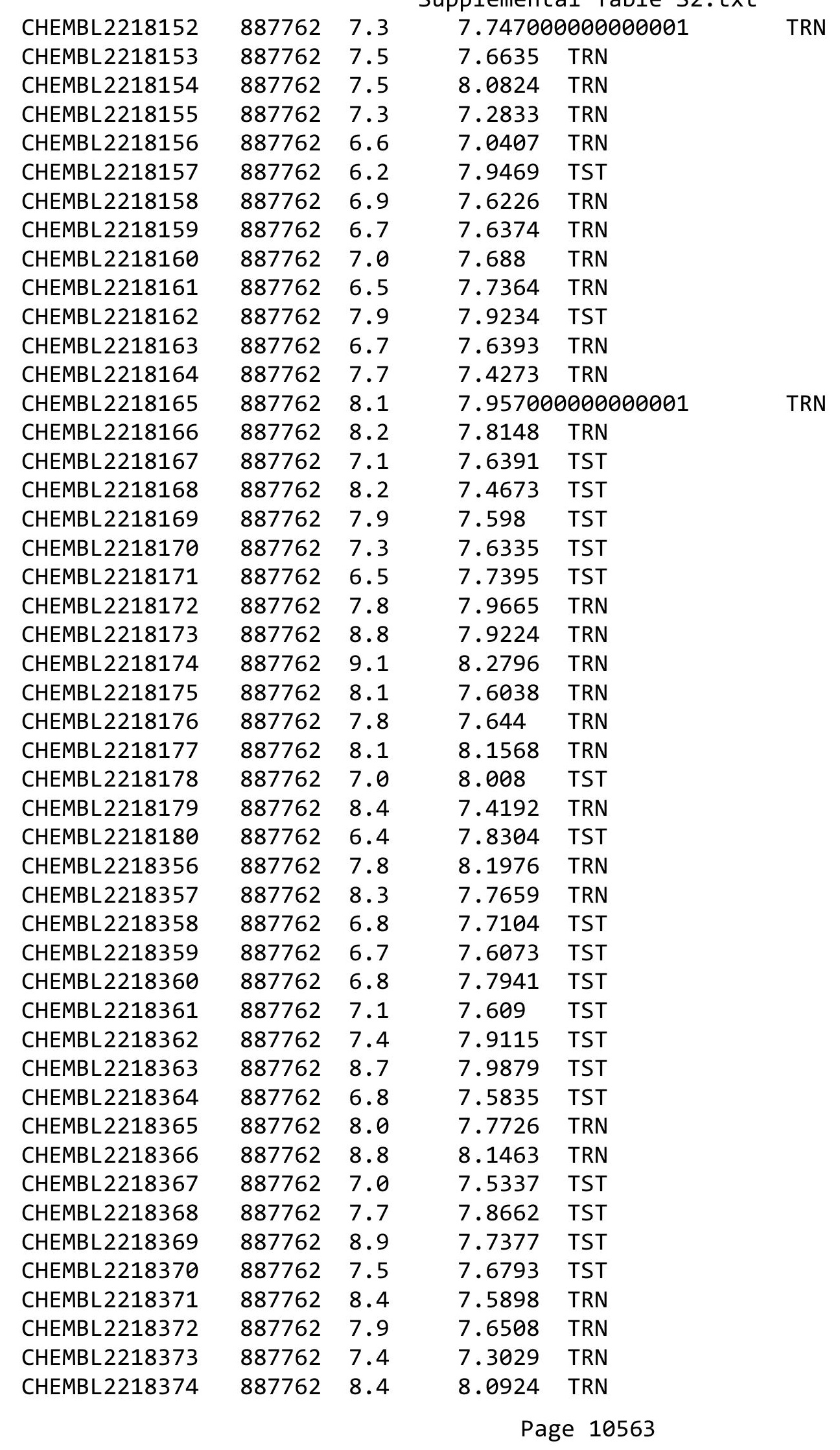




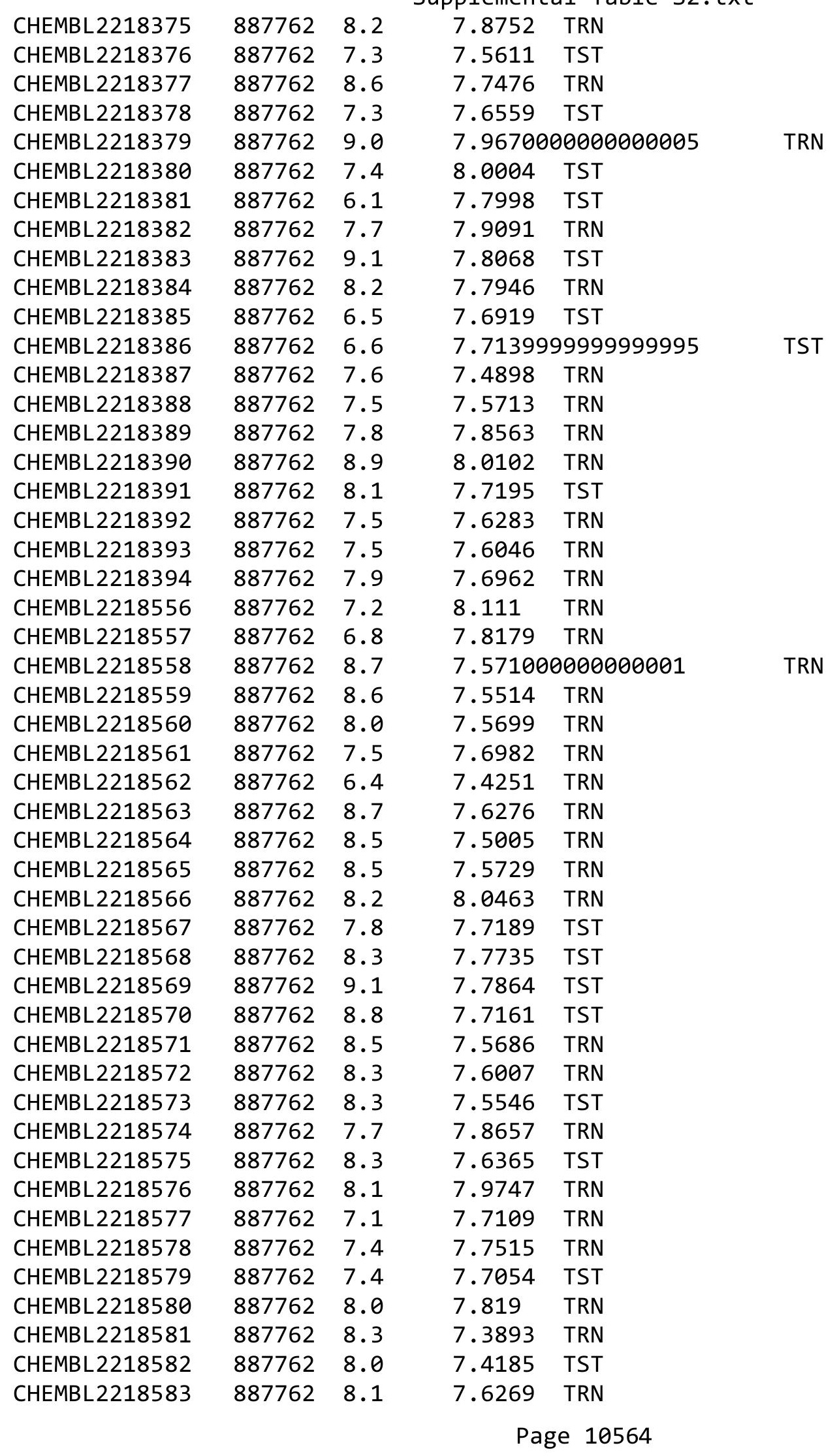




\begin{tabular}{|c|c|c|c|c|c|}
\hline \\
\hline CHEMBL2218584 & 887762 & 8.5 & 8.0067 & TRN & \\
\hline CHEMBL 2218585 & 887762 & 7.8 & 7.9767 & TRN & \\
\hline CHEMBL2218586 & 887762 & 7.3 & 7.6943 & TRN & \\
\hline CHEMBL 2218587 & 887762 & 8.3 & 7.8094 & TRN & \\
\hline CHEMBL 2218588 & 887762 & 7.8 & 7.3637 & TRN & \\
\hline CHEMBL2218589 & 887762 & 8.4 & 7.7669 & TRN & \\
\hline CHEMBL2218590 & 887762 & 7.9 & 7.8406 & TRN & \\
\hline CHEMBL2218591 & 887762 & 6.6 & 7.8689 & TRN & \\
\hline CHEMBL2218592 & 887762 & 7.7 & 7.8393 & TRN & \\
\hline CHEMBL2218593 & 887762 & 7.9 & 7.7173 & TRN & \\
\hline CHEMBL2218594 & 887762 & 7.9 & 7.7694 & TRN & \\
\hline CHEMBL2218658 & 887762 & 7.8 & 7.4985 & TRN & \\
\hline CHEMBL2218659 & 887762 & 7.9 & 7.7409 & TRN & \\
\hline CHEMBL 2218660 & 887762 & 7.4 & 7.5832 & TRN & \\
\hline CHEMBL 2218661 & 887762 & 7.5 & 7.9692 & TRN & \\
\hline CHEMBL 2218662 & 887762 & 8.0 & 7.7876 & TRN & \\
\hline CHEMBL2218663 & 887762 & 7.3 & 7.7703 & TST & \\
\hline CHEMBL2218664 & 887762 & 7.5 & 7.7631 & TRN & \\
\hline CHEMBL2218665 & 887762 & 8.0 & 7.9845 & TRN & \\
\hline CHEMBL2218666 & 887762 & 8.2 & 8.1356 & TRN & \\
\hline CHEMBL 2218667 & 887762 & 7.0 & 7.8941 & TRN & \\
\hline CHEMBL2218668 & 887762 & 7.1 & 7.9967 & TRN & \\
\hline CHEMBL2218669 & 887762 & 6.6 & 7.8756 & TRN & \\
\hline CHEMBL2218670 & 887762 & 7.6 & 8.0082 & TRN & \\
\hline CHEMBL2218671 & 887762 & 7.0 & 7.9821 & TRN & \\
\hline CHEMBL 2218672 & 887762 & 7.5 & 7.8658 & TST & \\
\hline CHEMBL2218673 & 887762 & 8.2 & 7.8797 & TRN & \\
\hline CHEMBL 2218674 & 887762 & 7.6 & 8.029 & TRN & \\
\hline CHEMBL2218675 & 887762 & 8.4 & 7.9267 & TRN & \\
\hline CHEMBL 2218676 & 887762 & 7.3 & 8.0015 & TRN & \\
\hline CHEMBL 2218677 & 887762 & 8.3 & 7.9124 & TRN & \\
\hline CHEMBL2218678 & 887762 & 7.3 & $7.6720 e$ & 3000000001 & TRN \\
\hline CHEMBL2218679 & 887762 & 7.3 & 7.8545 & TRN & \\
\hline CHEMBL2218680 & 887762 & 8.5 & 8.2258 & TRN & \\
\hline CHEMBL2218681 & 887762 & 6.7 & 7.7485 & TST & \\
\hline CHEMBL2218682 & 887762 & 6.4 & 7.6794 & TST & \\
\hline CHEMBL 2218683 & 887762 & 7.1 & 7.7142 & TRN & \\
\hline CHEMBL2218684 & 887762 & 6.9 & 7.9595 & TST & \\
\hline CHEMBL2218685 & 887762 & 6.5 & 7.7743 & TST & \\
\hline CHEMBL 2218686 & 887762 & 6.2 & 7.9582 & TRN & \\
\hline CHEMBL 2218687 & 887762 & 6.6 & 8.0476 & TRN & \\
\hline CHEMBL 2218688 & 887762 & 6.2 & 7.9507 & TST & \\
\hline CHEMBL2218689 & 887762 & 6.5 & 7.8799 & TST & \\
\hline CHEMBL2218690 & 887762 & 6.2 & 7.5946 & TST & \\
\hline CHEMBL2218691 & 887762 & 7.9 & 8.0395 & TRN & \\
\hline CHEMBL2218692 & 887762 & 7.8 & 7.7482 & TRN & \\
\hline CHEMBL 2218111 & 887762 & 6.7 & 7.9405 & TRN & \\
\hline CHEMBL2218112 & 887762 & 7.9 & 7.3712 & TRN & \\
\hline
\end{tabular}




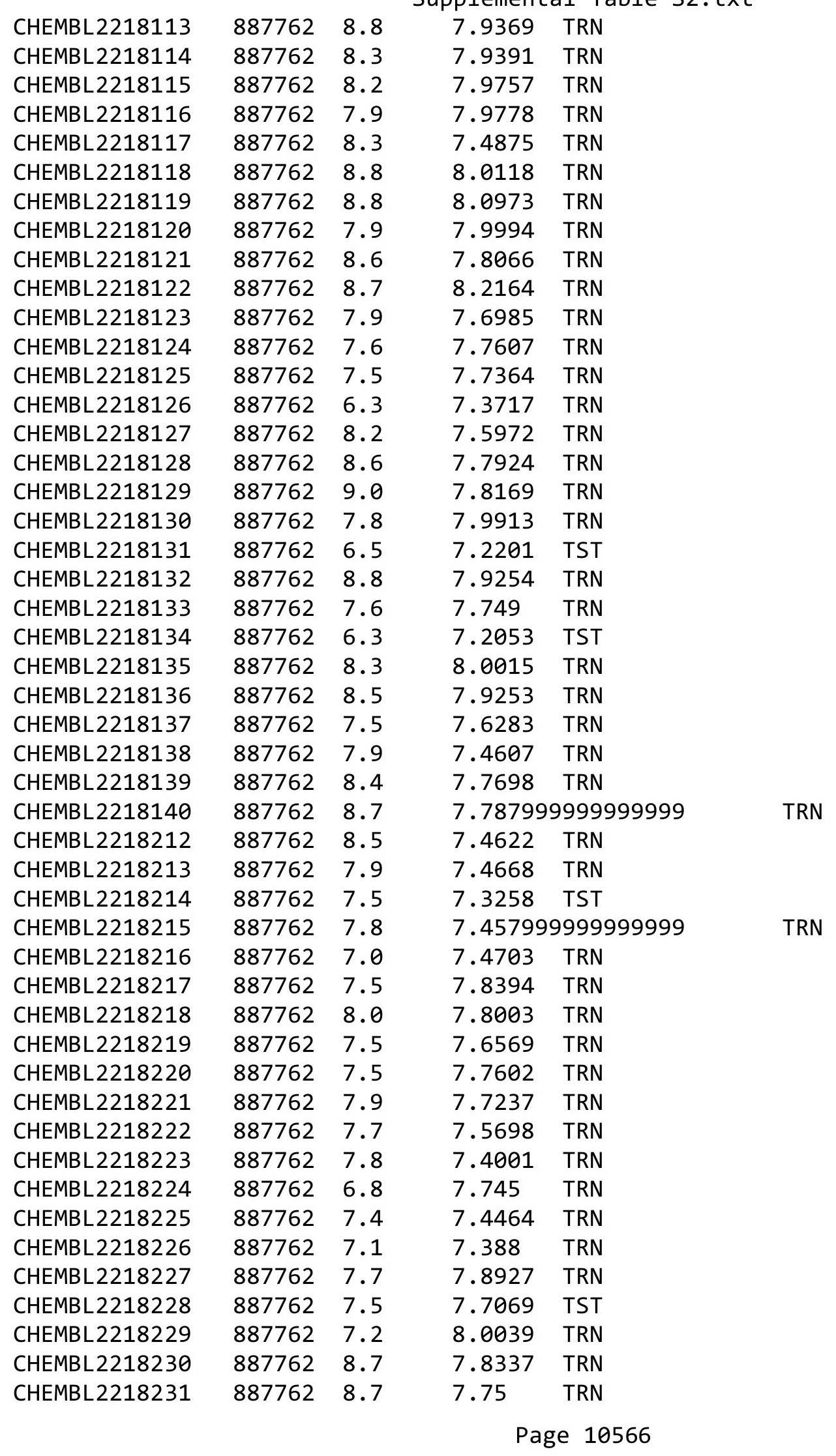




\begin{tabular}{|c|c|c|c|c|c|}
\hline & & & & & \\
\hline CHEMBL2218232 & 887762 & 7.7 & 7.5876 & TRN & \\
\hline CHEMBL2218233 & 887762 & 7.8 & 7.4101 & TRN & \\
\hline CHEMBL2218234 & 887762 & 7.3 & 7.4477 & TRN & \\
\hline CHEMBL2218235 & 887762 & 8.6 & 7.9016 & TRN & \\
\hline CHEMBL2218236 & 887762 & 7.5 & 7.7125 & TRN & \\
\hline CHEMBL2218237 & 887762 & 7.6 & 7.4664 & TRN & \\
\hline CHEMBL2218238 & 887762 & 7.9 & 7.4878 & TRN & \\
\hline CHEMBL2218239 & 887762 & 6.8 & 7.4186 & TRN & \\
\hline CHEMBL 2218240 & 887762 & 8.8 & 7.4764 & TRN & \\
\hline CHEMBL2218241 & 887762 & 7.1 & 7.638 & TRN & \\
\hline CHEMBL2218242 & 887762 & 6.8 & 7.4263 & TST & \\
\hline CHEMBL2218243 & 887762 & 6.6 & 7.489 & TRN & \\
\hline CHEMBL 2218244 & 887762 & 7.0 & 7.5008 & TRN & \\
\hline CHEMBL 2218245 & 887762 & 7.4 & 7.3412 & TRN & \\
\hline CHEMBL2218246 & 887762 & 7.9 & 8.0471 & TRN & \\
\hline CHEMBL 2218325 & 887762 & 8.4 & 7.3689 & TRN & \\
\hline CHEMBL2218326 & 887762 & 6.7 & 7.7273 & TRN & \\
\hline CHEMBL2218327 & 887762 & 8.7 & 8.2015 & TRN & \\
\hline CHEMBL2218328 & 887762 & 7.5 & 7.3602 & TRN & \\
\hline CHEMBL2218329 & 887762 & 8.5 & 7.8553 & TRN & \\
\hline CHEMBL 2218330 & 887762 & 7.4 & 7.6047 & TST & \\
\hline CHEMBL2218331 & 887762 & 8.8 & 8.0493 & TRN & \\
\hline CHEMBL 2218332 & 887762 & 7.6 & 7.1558 & TRN & \\
\hline CHEMBL2218333 & 887762 & 7.5 & 8.0669 & TRN & \\
\hline CHEMBL2218334 & 887762 & 7.6 & 7.7741 & TRN & \\
\hline CHEMBL2218335 & 887762 & 7.3 & 8.0406 & TRN & \\
\hline CHEMBL2218336 & 887762 & 6.8 & 7.612 & TST & \\
\hline CHEMBL2218337 & 887762 & 7.0 & $7.8420 e$ & 00000000005 & TRN \\
\hline CHEMBL2218338 & 887762 & 8.6 & 7.9814 & TRN & \\
\hline CHEMBL2218339 & 887762 & 8.8 & 8.1426 & TRN & \\
\hline CHEMBL2218340 & 887762 & 8.9 & 8.087 & TRN & \\
\hline CHEMBL2218341 & 887762 & 7.6 & 8.0271 & TRN & \\
\hline CHEMBL 2218342 & 887762 & 6.5 & 7.3254 & TST & \\
\hline CHEMBL2218343 & 887762 & 6.7 & 7.3372 & TRN & \\
\hline CHEMBL 2218344 & 887762 & 7.7 & 7.9163 & TRN & \\
\hline CHEMBL2218345 & 887762 & 6.9 & 7.6429 & TRN & \\
\hline CHEMBL2218346 & 887762 & 6.5 & 6.7292 & TST & \\
\hline CHEMBL 2218347 & 887762 & 6.5 & 6.7489 & TST & \\
\hline CHEMBL 2218348 & 887762 & 6.5 & 6.8244 & TST & \\
\hline CHEMBL2218349 & 887762 & 6.3 & 6.9891 & TST & \\
\hline CHEMBL 2218350 & 887762 & 6.3 & 6.8521 & TST & \\
\hline CHEMBL2218351 & 887762 & 7.2 & 6.9503 & TST & \\
\hline CHEMBL2218352 & 887762 & 6.2 & 6.9671 & TST & \\
\hline CHEMBL 2218353 & 887762 & 6.8 & 6.8041 & TST & \\
\hline CHEMBL 2218354 & 887762 & 7.3 & 6.7556 & TRN & \\
\hline CHEMBL 2218355 & 887762 & 6.7 & 6.7998 & TRN & \\
\hline CHEMBL2218395 & 887762 & 6.5 & 6.8659 & TRN & \\
\hline CHEMBL2218396 & 887762 & 6.3 & 6.8002 & TRN & \\
\hline & & & & 10567 & \\
\hline
\end{tabular}




\begin{tabular}{|c|c|c|c|c|}
\hline \multicolumn{5}{|c|}{ Supplemental Table S2.txt } \\
\hline CHEMBL2218397 & 887762 & 6.8 & 6.9232 & TRN \\
\hline CHEMBL 2218398 & 887762 & 7.0 & 6.7974 & TRN \\
\hline CHEMBL2218399 & 887762 & 6.3 & 6.8735 & TRN \\
\hline CHEMBL 2218400 & 887762 & 6.9 & 6.6936 & TRN \\
\hline CHEMBL 2218068 & 887762 & 6.8 & 6.5978 & TRN \\
\hline CHEMBL1096029 & 887762 & 6.8 & 6.7008 & TST \\
\hline CHEMBL 2218401 & 887762 & 7.0 & 7.0025 & TRN \\
\hline CHEMBL2218402 & 887762 & 6.6 & 6.7531 & TST \\
\hline CHEMBL 2218403 & 887762 & 6.2 & 6.7 & TST \\
\hline CHEMBL 2218404 & 887762 & 7.2 & 6.7049 & TRN \\
\hline CHEMBL2218405 & 887762 & 6.1 & 6.7911 & TRN \\
\hline CHEMBL 2218406 & 887762 & 6.7 & 6.9541 & TRN \\
\hline CHEMBL 2218407 & 887762 & 7.2 & 6.7734 & TRN \\
\hline CHEMBL 2218408 & 887762 & 6.6 & 6.8841 & TRN \\
\hline CHEMBL2218409 & 887762 & 6.5 & 6.8749 & TST \\
\hline CHEMBL 2218410 & 887762 & 6.8 & 6.6472 & TST \\
\hline CHEMBL2218411 & 887762 & 6.5 & 6.9187 & TST \\
\hline CHEMBL 3656204 & 1528021 & 6.2831 & 6.3437 & TRN \\
\hline CHEMBL 3656242 & 1528021 & 6.8268 & 7.1167 & TST \\
\hline CHEMBL3964102 & 1528021 & 7.2373 & 7.2287 & TRN \\
\hline CHEMBL3656205 & 1528021 & 7.4089 & 7.3941 & TRN \\
\hline CHEMBL 3961260 & 1528021 & 6.7721 & 6.6624 & TRN \\
\hline CHEMBL3974295 & 1528021 & 7.2757 & 7.0649 & TRN \\
\hline CHEMBL 3656210 & 1528021 & 7.3188 & 7.3051 & TRN \\
\hline CHEMBL 3952491 & 1528021 & 7.6021 & 7.6264 & TRN \\
\hline CHEMBL3986229 & 1528021 & 6.6012 & 6.7107 & TRN \\
\hline CHEMBL3656196 & 1528021 & 7.2652 & 7.1843 & TRN \\
\hline CHEMBL 3924654 & 1528021 & 6.3947 & 6.6413 & TRN \\
\hline CHEMBL 3969581 & 1528021 & 6.2623 & 6.2689 & TRN \\
\hline CHEMBL 3978446 & 1528021 & 6.0 & 5.7945 & TRN \\
\hline CHEMBL3889795 & 1528021 & 6.9393 & 6.9021 & TRN \\
\hline CHEMBL 3982045 & 1528021 & 7.4647 & 7.4139 & TRN \\
\hline CHEMBL 3656226 & 1528021 & 6.7645 & 7.1505 & TRN \\
\hline CHEMBL3966983 & 1528021 & 6.9586 & 6.9438 & TRN \\
\hline CHEMBL 3981271 & 1528021 & 7.4685 & 7.4149 & TRN \\
\hline CHEMBL 3925344 & 1528021 & 8.0269 & 8.0175 & TRN \\
\hline CHEMBL 3902306 & 1528021 & 6.4949 & 6.585 & TRN \\
\hline CHEMBL3975135 & 1528021 & 7.567 & 7.3265 & TRN \\
\hline CHEMBL 3656189 & 1528021 & 7.06 & 7.0087 & TRN \\
\hline CHEMBL 3656148 & 1528021 & 8.2757 & 7.5359 & TST \\
\hline CHEMBL 3983234 & 1528021 & 6.9788 & 6.99700 & 0000000001 \\
\hline CHEMBL3656212 & 1528021 & 7.2147 & 7.4244 & TST \\
\hline CHEMBL3656186 & 1528021 & 6.5629 & 6.6201 & TRN \\
\hline CHEMBL 3908843 & 1528021 & 8.2218 & 7.8372 & TRN \\
\hline CHEMBL 3907597 & 1528021 & 7.9208 & 7.7483 & TRN \\
\hline CHEMBL3656218 & 1528021 & 6.057 & 6.1267 & TST \\
\hline CHEMBL 3907808 & 1528021 & 6.8271 & 6.7879 & TRN \\
\hline CHEMBL3656216 & 1528021 & 8.0969 & 7.8893 & TRN \\
\hline
\end{tabular}


Supplemental Table S2.txt

\begin{tabular}{|c|c|c|c|c|c|}
\hline CHEMBL3916361 & 1528021 & 8.3468 & 8.6367 & TST & \\
\hline CHEMBL 3656245 & 1528021 & 6.0 & 6.2773 & TST & \\
\hline CHEMBL3939788 & 1528021 & 6.8601 & 7.0169 & TRN & \\
\hline CHEMBL3956802 & 1528021 & 6.9654 & 7.04899 & 99999999995 & TRN \\
\hline CHEMBL 3978126 & 1528021 & 7.8239 & 7.569 & TST & \\
\hline CHEMBL 3656239 & 1528021 & 7.1135 & 7.0931 & TST & \\
\hline CHEMBL3656202 & 1528021 & 6.7005 & 6.7067 & TRN & \\
\hline CHEMBL3979180 & 1528021 & 8.301 & 8.432 & TST & \\
\hline CHEMBL3656195 & 1528021 & 7.5258 & 7.2874 & TRN & \\
\hline CHEMBL 3898784 & 1528021 & 6.0 & 7.6751 & TRN & \\
\hline CHEMBL 3656260 & 1528021 & 6.5722 & 6.7579 & TST & \\
\hline CHEMBL 3889964 & 1528021 & 6.8407 & 6.8884 & TRN & \\
\hline CHEMBL 3893841 & 1528021 & 6.6737 & 6.6755 & TRN & \\
\hline CHEMBL 3891866 & 1528021 & 7.1046 & 6.2156 & TST & \\
\hline CHEMBL 3915571 & 1528021 & 6.8928 & 6.874 & TRN & \\
\hline CHEMBL 3913272 & 1528021 & 6.768 & 6.8791 & TRN & \\
\hline CHEMBL3656225 & 1528021 & 6.8928 & 7.1414 & TRN & \\
\hline CHEMBL3909616 & 1528021 & 6.5735 & 6.5957 & TRN & \\
\hline CHEMBL3929053 & 1528021 & 6.8928 & 6.8807 & TRN & \\
\hline CHEMBL 3983108 & 1528021 & 6.0931 & 6.6392 & TRN & \\
\hline CHEMBL3985399 & 1528021 & 7.1068 & 7.0247 & TRN & \\
\hline CHEMBL3969552 & 1528021 & 7.1379 & 7.0151 & TRN & \\
\hline CHEMBL3922739 & 1528021 & 7.6383 & 7.25899 & 99999999995 & \\
\hline CHEMBL3909450 & 1528021 & 6.4089 & 6.489 & TRN & \\
\hline CHEMBL 3954597 & 1528021 & 7.0044 & 7.0587 & TRN & \\
\hline CHEMBL 3656277 & 1528021 & 6.9914 & 7.2885 & TRN & \\
\hline CHEMBL 3656252 & 1528021 & 4.8697 & 4.8876 & TST & \\
\hline CHEMBL3938356 & 1528021 & 5.3894 & 6.1989 & TST & \\
\hline CHEMBL3979334 & 1528021 & 7.3536 & 7.0123 & TRN & \\
\hline CHEMBL 3923021 & 1528021 & 6.8041 & 6.7654 & TRN & \\
\hline CHEMBL3910301 & 1528021 & 7.1175 & 6.7403 & TRN & \\
\hline CHEMBL 3917982 & 1528021 & 6.7263 & 6.8689 & TRN & \\
\hline CHEMBL 3656253 & 1528021 & 6.9519 & 7.1093 & TRN & \\
\hline CHEMBL3915238 & 1528021 & 7.9586 & 8.2849 & TST & \\
\hline CHEMBL 3656187 & 1528021 & 7.3686 & 7.1948 & TRN & \\
\hline CHEMBL3656188 & 1528021 & 7.0039 & 7.0843 & TRN & \\
\hline CHEMBL 3923832 & 1528021 & 7.5086 & 7.4986 & TRN & \\
\hline CHEMBL 3982284 & 1528021 & 8.1549 & 7.8898 & TRN & \\
\hline CHEMBL3959903 & 1528021 & \multicolumn{3}{|c|}{6.3420000000000005} & TST \\
\hline CHEMBL3953496 & 1528021 & 6.8722 & 6.6827 & TRN & \\
\hline CHEMBL3980458 & 1528021 & 5.3741 & 5.3262 & TRN & \\
\hline CHEMBL3919628 & 1528021 & 7.1135 & 7.0883 & TRN & \\
\hline CHEMBL 3656276 & 1528021 & 8.2076 & 7.9808 & TRN & \\
\hline CHEMBL3930777 & 1528021 & 6.2118 & 6.2246 & TRN & \\
\hline CHEMBL3639551 & 1528021 & \multicolumn{2}{|c|}{6.75299999999999} & 6.9784 & וב \\
\hline CHEMBL 3941774 & 1528021 & 6.0506 & 5.9382 & TRN & \\
\hline CHEMBL 3656227 & 1528021 & 7.0555 & 7.05200 & 00000000005 & $\mathbf{K}$ \\
\hline CHEMBL3986110 & 1528021 & 7.6778 & 8.0791 & TST & \\
\hline
\end{tabular}


Supplemental Table S2.txt

\begin{tabular}{|c|c|c|c|c|}
\hline AEMB & 021 & 2 & 6.6336 & TRN \\
\hline HEMBL 3934938 & 528021 & 8.0458 & 7.8165 & \\
\hline HEMBL3905966 & 528021 & 6.5331 & 505 & \\
\hline HEMBL3656261 & 528021 & 6.3728 & 0637 & \\
\hline HEMBL3656215 & 528021 & 8.0458 & 9038 & \\
\hline HEMBL3967914 & 528021 & 7.9318 & 7.898 & \\
\hline HEMBL3656191 & 528021 & 7.0325 & 8603 & \\
\hline HEMBL3890041 & 528021 & 6.0 & .7861 & \\
\hline HEMBL3656174 & 528021 & 6.68 & 6.1924 & \\
\hline HEMBL3894384 & 528021 & 7.0655 & 6.6871 & ST \\
\hline HEMBL3949349 & 528021 & 5.6739 & 5.6385 & \\
\hline HEMBL 3902793 & 528021 & 5.6126 & .3003 & \\
\hline HEMBL134002 & 3668 & & 6.517 & RN \\
\hline HEMBL132773 & 43668 & 6.7959 & 6.4756 & \\
\hline HEMBL337462 & 3668 & 39 & 5.6948 & ST \\
\hline HEMBL131540 & 43668 & 6.5229 & 6.5348 & \\
\hline HEMBL130722 & 43668 & 61 & 5.7034 & \\
\hline HEMBL132839 & 43668 & 872 & 6.4448 & RN \\
\hline HEMBL339869 & 43668 & 5.0 & 5.5218 & \\
\hline HEMBL134142 & 3668 & 36 & 6 . & N \\
\hline HEMBL130580 & 43668 & 59 & 5.6728 & וג \\
\hline HEMBL37 & 436 & & 6.5069 & RN \\
\hline HEMBL 130 & 43668 & & 6.3257 & $\mathrm{RN}$ \\
\hline HEMBL420872 & 43668 & & 6.3395 & RN \\
\hline HEMBL133521 & 43668 & 59 & 6.7076 & RN \\
\hline HEMBL 337684 & 43668 & 8 & 657 & RN \\
\hline HEMBL131319 & 4 & & 056 & RN \\
\hline HEMBL119622 & 43668 & 69 & 6.5077 & RN \\
\hline HEMBL131866 & 43668 & 6. & 6.3691 & TRN \\
\hline HEMBL131707 & 43668 & 6 & 5.6914 & TST \\
\hline HEMBL133106 & 43668 & 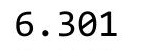 & 6 & $\Gamma \mathrm{RN}$ \\
\hline HEMBL1: & 10 & 6. & 295 & RN \\
\hline HEMBL132526 & 43 & 6 & 5.4755 & RN \\
\hline HEMBL133243 & 43668 & & 6.1984 & TRN \\
\hline HEMBL 337608 & 43668 & 4. & 5.8784 & TRN \\
\hline HEMBL273817 & 43668 & 71 & 6.4746 & TST \\
\hline CHEMBL13 & 8 & & 6.6269 & $\Gamma \mathrm{RN}$ \\
\hline CHEMBL131779 & 43668 & & 5.3844 & TRN \\
\hline HEMBL130345 & 43668 & 6.69 & 6.3792 & TRN \\
\hline HEMBL132587 & 3668 & 192 & 5.7737 & TRN \\
\hline LHEMBL131002 & 43668 & 7. & 6.6209 & $\Gamma \mathrm{RN}$ \\
\hline CHEMBL331850 & & $7.2 \varepsilon$ & 6.4827 & TRN \\
\hline CHEMBL134508 & 43668 & 5.9208 & 6.4171 & TRN \\
\hline CHEMBL424074 & 43668 & 6.0969 & 6.2218 & TRN \\
\hline CHEMBL132732 & 43668 & $6.2+x-2$ & 6.3218 & $1 \pi$ \\
\hline CHEMBL338957 & 43668 & 5.1024 & 5.7333 & \\
\hline CHEMBL134092 & 43668 & 7.1549 & 6.8153 & $\mathrm{RN}$ \\
\hline CHEMBL132566 & 43668 & 6.6576 & 6.482 & TST \\
\hline
\end{tabular}

Page 10570 


\begin{tabular}{|c|c|c|c|c|}
\hline & & & oplement & al $\mathrm{Tc}$ \\
\hline CHEMBL3706739 & 43668 & 6.4318 & 6.5153 & TRN \\
\hline CHEMBL339174 & 43668 & 6.1549 & 6.4739 & TRN \\
\hline CHEMBL131781 & 43668 & 6.3768 & 6.4616 & TST \\
\hline CHEMBL335293 & 43668 & 5.6383 & 6.4307 & TRN \\
\hline CHEMBL3706738 & 43668 & 6.5086 & 6.4974 & TRN \\
\hline CHEMBL130107 & 43668 & 6.0 & 6.447 & TRN \\
\hline CHEMBL133806 & 43668 & 6.3188 & 6.5441 & TRN \\
\hline CHEMBL 3706740 & 43668 & 6.4202 & 6.521 & TRN \\
\hline CHEMBL132987 & 43668 & 6.9208 & 6.4749 & TRN \\
\hline CHEMBL435203 & 43668 & 6.3372 & 6.6182 & TRN \\
\hline CHEMBL423704 & 43668 & 6.301 & 5.4424 & TRN \\
\hline CHEMBL133970 & 43668 & 6.8861 & 6.3223 & TRN \\
\hline CHEMBL116477 & 43668 & 6.4559 & 6.3885 & TRN \\
\hline CHEMBL130114 & 43668 & 6.1938 & 6.3181 & TRN \\
\hline CHEMBL336649 & 43668 & 6.6021 & 6.4842 & TRN \\
\hline CHEMBL325147 & 43668 & 6.6021 & 6.3255 & TRN \\
\hline CHEMBL130756 & 43668 & 6.8861 & 6.5733 & TRN \\
\hline CHEMBL130753 & 43668 & 6.4202 & 6.5231 & TRN \\
\hline CHEMBL130146 & 43668 & 6.6383 & 6.5531 & TRN \\
\hline CHEMBL133936 & 43668 & 6.699 & 6.6237 & TRN \\
\hline CHEMBL341219 & 43668 & 6.0458 & 6.5614 & TRN \\
\hline CHEMBL134121 & 43668 & 6.0969 & 6.3965 & TRN \\
\hline CHEMBL133634 & 43668 & 6.5376 & 6.3934 & TRN \\
\hline CHEMBL133749 & 43668 & 6.4559 & 6.3626 & TRN \\
\hline CHEMBL129933 & 43668 & 6.1871 & 6.2982 & TRN \\
\hline CHEMBL421910 & 43668 & 6.4559 & 6.5233 & TRN \\
\hline CHEMBL335706 & 43668 & 5.7212 & 5.8377 & TST \\
\hline CHEMBL133707 & 43668 & 6.2291 & 6.6605 & TRN \\
\hline CHEMBL130506 & 43668 & 5.9586 & 6.29 & TRN \\
\hline CHEMBL335291 & 43668 & 6.9208 & 6.5101 & TRN \\
\hline CHEMBL129831 & 43668 & 7.301 & 6.4782 & TRN \\
\hline CHEMBL117888 & 43668 & 6.1675 & 6.3968 & TRN \\
\hline CHEMBL130599 & 43668 & 6.6198 & 6.5821 & TRN \\
\hline CHEMBL130338 & 43668 & 6.9586 & 6.7329 & TRN \\
\hline CHEMBL413308 & 43668 & 6.7447 & 6.8111 & TRN \\
\hline CHEMBL337830 & 43668 & 6.699 & 6.7014 & TRN \\
\hline CHEMBL334744 & 43668 & 6.301 & 6.3848 & TRN \\
\hline CHEMBL132586 & 43668 & 7.7212 & 6.2709 & TST \\
\hline CHEMBL130215 & 43668 & 6.5229 & 5.7857 & TST \\
\hline CHEMBL131264 & 43668 & 6.1871 & 6.4115 & TST \\
\hline CHEMBL131639 & 43668 & 6.5686 & 6.6468 & TST \\
\hline CHEMBL130359 & 43668 & 6.4202 & 6.487 & TST \\
\hline CHEMBL134179 & 43668 & 5.8861 & 6.2766 & TST \\
\hline CHEMBL117336 & 43668 & 6.699 & 6.4843 & TST \\
\hline CHEMBL134173 & 43668 & 6.9208 & 6.7213 & TST \\
\hline CHEMBL131257 & 43668 & 6.0706 & 5.6495 & TST \\
\hline CHEMBL132886 & 43668 & 6.0969 & 5.6805 & TST \\
\hline CHEMBL422260 & 43668 & 6.6021 & 6.3419 & TST \\
\hline
\end{tabular}




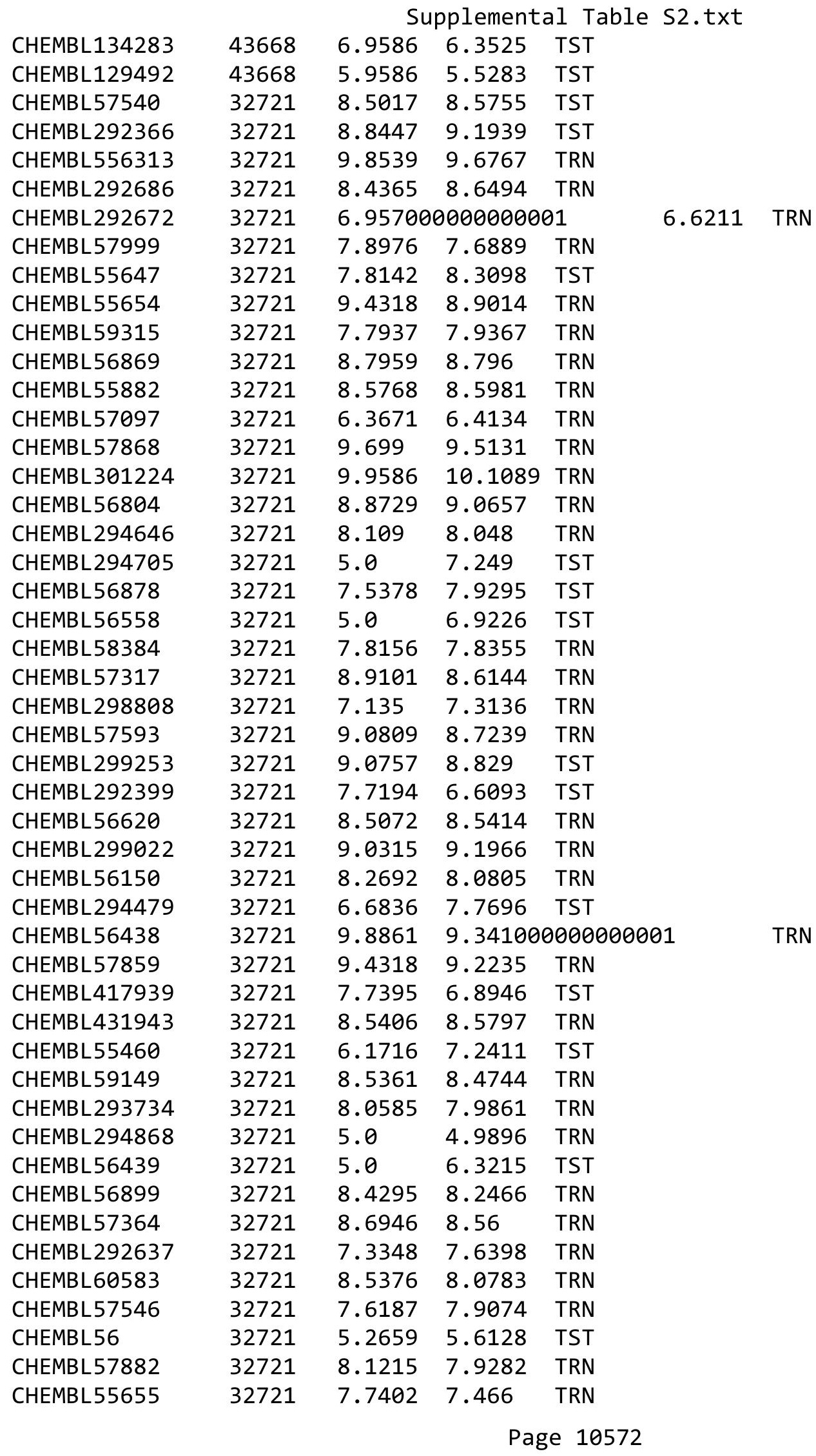




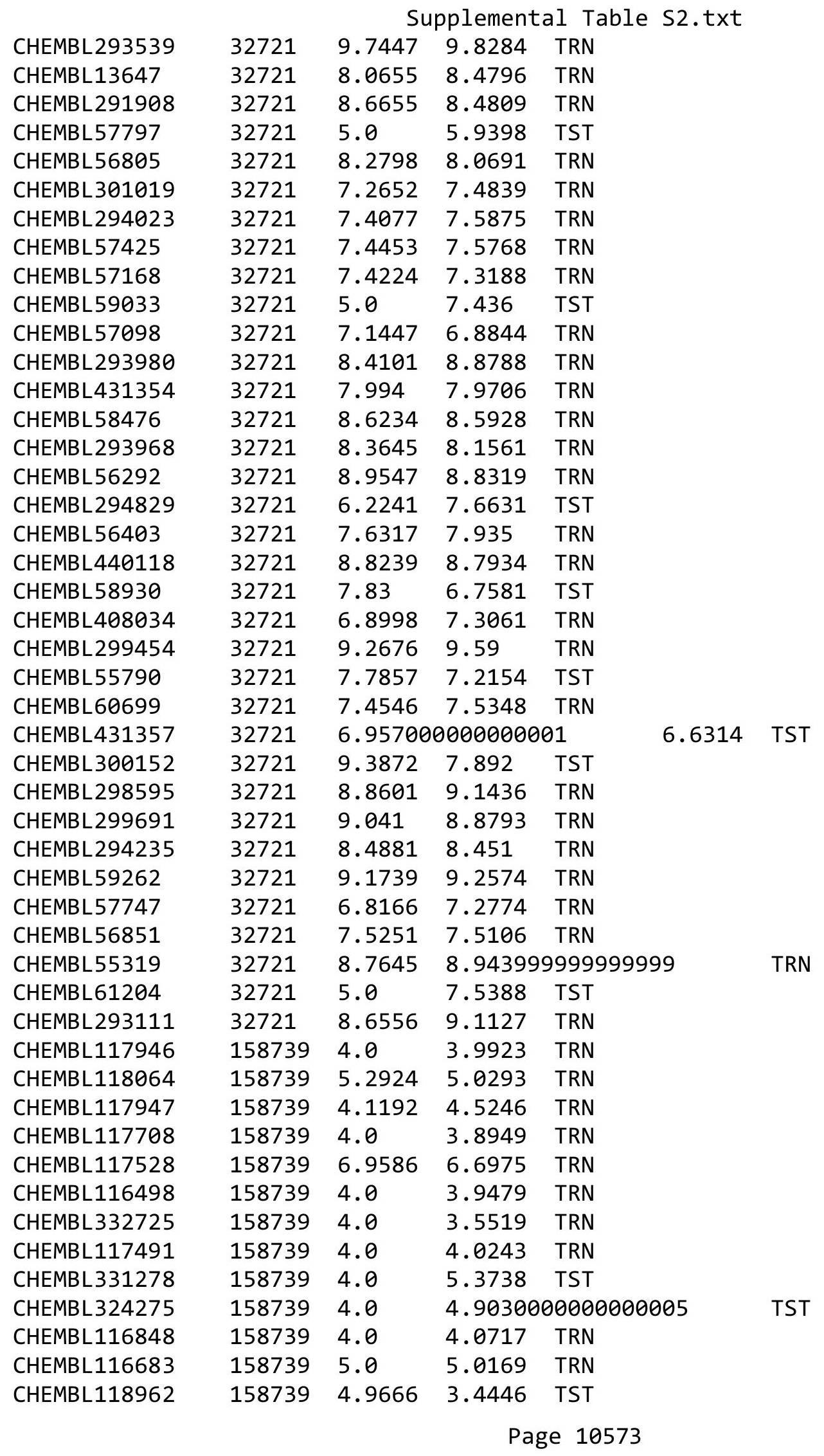




\begin{tabular}{|c|c|c|c|c|}
\hline & & & plement & \\
\hline CHEMBL117917 & 158739 & 4.8097 & 4.9138 & TRN \\
\hline CHEMBL331148 & 158739 & 4.0 & 3.8471 & TRN \\
\hline CHEMBL324700 & 158739 & 4.0 & 3.8664 & TRN \\
\hline CHEMBL333084 & 158739 & 4.0 & 4.158 & TRN \\
\hline CHEMBL119852 & 158739 & 4.0 & 4.0292 & TRN \\
\hline CHEMBL325298 & 158739 & 4.0 & 4.0706 & TRN \\
\hline CHEMBL119076 & 158739 & 4.0 & 3.8187 & TRN \\
\hline CHEMBL333170 & 158739 & 4.0 & 4.1149 & TRN \\
\hline CHEMBL324826 & 158739 & 5.0458 & 5.0529 & TRN \\
\hline CHEMBL325437 & 158739 & 4.0 & 3.9218 & TRN \\
\hline CHEMBL324957 & 158739 & 4.0 & 3.9327 & TRN \\
\hline CHEMBL324312 & 158739 & 5.6576 & 5.5365 & TRN \\
\hline CHEMBL119089 & 158739 & 4.0 & 4.3306 & TRN \\
\hline CHEMBL117306 & 158739 & 4.0 & 4.3372 & TRN \\
\hline CHEMBL115979 & 158739 & 5.9208 & 5.5711 & TRN \\
\hline CHEMBL115752 & 158739 & 4.6234 & 4.8846 & TRN \\
\hline CHEMBL326577 & 158739 & 4.0 & 3.8172 & TRN \\
\hline CHEMBL324093 & 158739 & 4.0 & 4.1315 & TRN \\
\hline CHEMBL117618 & 158739 & 4.0 & 4.0268 & TRN \\
\hline CHEMBL115458 & 158739 & 4.0 & 2.9854 & TST \\
\hline CHEMBL116253 & 158739 & 3.0 & 4.9587 & TST \\
\hline CHEMBL117862 & 158739 & 4.0 & 3.8606 & TRN \\
\hline CHEMBL116199 & 158739 & 4.0 & 4.2 & TST \\
\hline CHEMBL333651 & 158739 & 5.8861 & 5.8083 & TRN \\
\hline CHEMBL420869 & 158739 & 4.0 & 4.2102 & TRN \\
\hline CHEMBL118936 & 158739 & 4.0 & 3.8406 & TRN \\
\hline CHEMBL324509 & 158739 & 4.0 & 4.061 & TRN \\
\hline CHEMBL418859 & 158739 & 4.0 & 4.3306 & TRN \\
\hline CHEMBL118067 & 158739 & 4.0 & 3.8561 & TRN \\
\hline CHEMBL117146 & 158739 & 4.0 & 4.1096 & TST \\
\hline CHEMBL116933 & 158739 & 4.0 & 4.0529 & TST \\
\hline CHEMBL419407 & 158739 & 6.2218 & 6.2114 & TRN \\
\hline CHEMBL117650 & 158739 & 4.0 & 3.8409 & TRN \\
\hline CHEMBL324472 & 158739 & 4.0 & 3.91 & TRN \\
\hline CHEMBL117547 & 158739 & 4.0 & 4.0845 & TRN \\
\hline CHEMBL119853 & 158739 & 4.0 & 3.8172 & TRN \\
\hline CHEMBL114162 & 158739 & 4.0 & 3.9454 & TST \\
\hline CHEMBL324825 & 158739 & 4.0 & 4.0104 & TRN \\
\hline CHEMBL115864 & 158739 & 4.0 & 4.2514 & TST \\
\hline CHEMBL326291 & 158739 & 5.3979 & 5.3519 & TRN \\
\hline CHEMBL115905 & 158739 & 5.0 & 3.6198 & TST \\
\hline CHEMBL325894 & 158739 & 6.9586 & 7.0793 & TRN \\
\hline CHEMBL116252 & 158739 & 4.0 & 5.2102 & TST \\
\hline CHEMBL114783 & 158739 & 4.0 & 3.9923 & TRN \\
\hline CHEMBL115410 & 158739 & 6.0458 & 6.0175 & TRN \\
\hline CHEMBL117852 & 158739 & 4.0 & 3.9673 & TRN \\
\hline CHEMBL324823 & 158739 & 4.0 & 4.6703 & TST \\
\hline CHEMBL117855 & 158739 & 4.0 & 3.7073 & TRN \\
\hline
\end{tabular}




\begin{tabular}{|c|c|c|c|c|}
\hline \multicolumn{5}{|c|}{ Supplemental Table S2.txt } \\
\hline CHEMBL118081 & 158739 & 4.0 & 3.8204 & TRN \\
\hline CHEMBL332251 & 158739 & 5.5686 & 5.5816 & TRN \\
\hline CHEMBL326270 & 158739 & 5.5086 & 5.4194 & TRN \\
\hline CHEMBL324048 & 158739 & 5.7212 & 5.289 & TRN \\
\hline CHEMBL116016 & 158739 & 4.0 & 4.5242 & TRN \\
\hline CHEMBL325297 & 158739 & 4.0 & 5.3738 & TST \\
\hline CHEMBL324580 & 158739 & 4.0 & 3.8211 & TRN \\
\hline CHEMBL326335 & 158739 & 4.0 & 4.332 & TRN \\
\hline CHEMBL442018 & 158739 & 4.0 & 4.1291 & TRN \\
\hline CHEMBL333755 & 158739 & 4.0 & 4.0529 & TST \\
\hline CHEMBL327150 & 158739 & 4.0 & 3.9312 & TRN \\
\hline CHEMBL324923 & 158739 & 4.0 & 4.1171 & TRN \\
\hline CHEMBL119002 & 158739 & 4.0 & 4.0268 & TRN \\
\hline CHEMBL333505 & 158739 & 4.0 & 4.1441 & TST \\
\hline CHEMBL117295 & 158739 & 4.0 & 4.4408 & TRN \\
\hline CHEMBL324042 & 158739 & 4.0 & 4.1885 & TST \\
\hline CHEMBL331135 & 158739 & 4.0 & 4.012 & TRN \\
\hline CHEMBL116365 & 158739 & 4.0 & 4.1832 & TRN \\
\hline CHEMBL116343 & 158739 & 4.0 & 4.1807 & TST \\
\hline CHEMBL119001 & 158739 & 4.0 & 4.2275 & TST \\
\hline CHEMBL326097 & 158739 & 4.0 & 4.0382 & TRN \\
\hline CHEMBL324841 & 158739 & 5.0 & 5.0339 & TST \\
\hline CHEMBL325492 & 158739 & 4.0 & 3.9454 & TST \\
\hline CHEMBL141674 & 105812 & 8.0458 & 7.4744 & TRN \\
\hline CHEMBL343547 & 105812 & 5.699 & 5.7743 & TRN \\
\hline CHEMBL142071 & 105812 & 7.699 & 7.4595 & TRN \\
\hline CHEMBL424472 & 105812 & 7.5229 & 7.0855 & TRN \\
\hline CHEMBL138613 & 105812 & 8.699 & 8.1705 & TRN \\
\hline CHEMBL342710 & 105812 & 7.5229 & 7.2221 & TRN \\
\hline CHEMBL140863 & 105812 & 8.301 & 8.2049 & TRN \\
\hline CHEMBL337761 & 105812 & 7.5229 & 7.5722 & TRN \\
\hline CHEMBL138535 & 105812 & 5.5229 & 5.6801 & TRN \\
\hline CHEMBL60624 & 105812 & 6.0 & 7.9582 & TRN \\
\hline CHEMBL424473 & 105812 & 7.699 & 7.4653 & TRN \\
\hline CHEMBL262264 & 105812 & 8.0 & 7.9747 & TRN \\
\hline CHEMBL141339 & 105812 & 5.699 & 5.727 & TRN \\
\hline CHEMBL138338 & 105812 & 8.0969 & 7.5509 & TST \\
\hline CHEMBL141504 & 105812 & 5.5229 & 6.273 & TRN \\
\hline CHEMBL 337793 & 105812 & 8.3979 & 8.0613 & TST \\
\hline CHEMBL138814 & 105812 & 9.0 & 8.3591 & TRN \\
\hline CHEMBL141835 & 105812 & 7.3979 & 7.43 & TRN \\
\hline CHEMBL142095 & 105812 & 7.699 & 7.6412 & TRN \\
\hline CHEMBL423366 & 105812 & 6.5229 & 6.6014 & TRN \\
\hline CHEMBL 291758 & 105812 & 8.5229 & 8.6093 & TST \\
\hline CHEMBL141675 & 105812 & 7.699 & 7.2997 & TRN \\
\hline CHEMBL137929 & 105812 & 6.699 & 6.6539 & TRN \\
\hline CHEMBL140335 & 105812 & 6.5229 & 6.3699 & TRN \\
\hline CHEMBL141534 & 105812 & 8.699 & 8.535 & TRN \\
\hline
\end{tabular}




\begin{tabular}{|c|c|c|c|c|c|}
\hline \multicolumn{6}{|c|}{ Supplemental Table S2.txt } \\
\hline CHEMBL141038 & 105812 & 8.0 & 7.8795 & TRN & \\
\hline CHEMBL443478 & 105812 & 7.0 & 7.2377 & TST & \\
\hline CHEMBL342374 & 105812 & 6.5229 & 6.2525 & TRN & \\
\hline CHEMBL141359 & 105812 & 8.0969 & 8.071 & TRN & \\
\hline CHEMBL141471 & 105812 & 7.1549 & 7.3941 & TRN & \\
\hline CHEMBL141340 & 105812 & 7.699 & 6.1485 & TST & \\
\hline CHEMBL140543 & 105812 & 9.0 & 8.2591 & TRN & \\
\hline CHEMBL337585 & 105812 & 7.0969 & 7.7681 & TRN & \\
\hline CHEMBL140426 & 105812 & 6.301 & 5.6611 & TST & \\
\hline CHEMBL141673 & 105812 & 8.5229 & 8.9731 & TRN & \\
\hline CHEMBL138264 & 105812 & 6.2218 & 6.2319 & TST & \\
\hline CHEMBL142134 & 105812 & 8.699 & 8.7745 & TRN & \\
\hline CHEMBL141475 & 105812 & 8.0 & 7.8078 & TRN & \\
\hline CHEMBL138696 & 105812 & 7.301 & 7.6004 & TRN & \\
\hline CHEMBL343326 & 105812 & 6.0969 & 6.4503 & TRN & \\
\hline CHEMBL344587 & 105812 & 6.699 & 5.8651 & TRN & \\
\hline CHEMBL137966 & 105812 & 5.699 & 5.9258 & TRN & \\
\hline CHEMBL141560 & 105812 & 8.0 & 8.1042 & TRN & \\
\hline CHEMBL 343775 & 105812 & 6.2218 & 6.5348 & TRN & \\
\hline CHEMBL 292636 & 105812 & 5.0 & 5.5129 & TST & \\
\hline CHEMBL140305 & 105812 & 7.0969 & 6.5832 & TST & \\
\hline CHEMBL 344410 & 105812 & 8.0 & 7.4823 & TRN & \\
\hline CHEMBL141672 & 105812 & 6.0 & 5.5044 & TST & \\
\hline CHEMBL435820 & 105812 & 5.5229 & 6.0148 & TRN & \\
\hline CHEMBL140454 & 105812 & 7.2218 & 6.5629 & TRN & \\
\hline CHEMBL57725 & 105812 & 8.5229 & 7.855 & TST & \\
\hline CHEMBL 294680 & 105812 & 7.1549 & 8.1496 & TST & \\
\hline CHEMBL137900 & 105812 & 7.5229 & 7.4117 & TRN & \\
\hline CHEMBL140439 & 105812 & 8.1549 & 8.0879 & TRN & \\
\hline CHEMBL334709 & 105812 & 7.0 & 6.8477 & TRN & \\
\hline CHEMBL343392 & 105812 & 7.3979 & 8.4068 & TRN & \\
\hline CHEMBL424106 & 105812 & 5.1549 & 5.7494 & TRN & \\
\hline CHEMBL344029 & 105812 & 6.699 & 6.32600 & 00000000005 & TRN \\
\hline CHEMBL140368 & 105812 & 8.0 & 7.3615 & TRN & \\
\hline CHEMBL434446 & 105812 & 8.699 & 8.3973 & TRN & \\
\hline CHEMBL344827 & 105812 & 7.3979 & 7.556 & TST & \\
\hline CHEMBL423001 & 105812 & 7.5229 & 7.6101 & TRN & \\
\hline CHEMBL138858 & 105812 & 7.699 & 7.5442 & TRN & \\
\hline CHEMBL342889 & 105812 & 6.0969 & 7.2375 & TRN & \\
\hline CHEMBL138273 & 105812 & 7.0969 & 7.0212 & TRN & \\
\hline CHEMBL141470 & 105812 & 7.0458 & 6.79700 & 0000000001 & TRN \\
\hline CHEMBL343818 & 105812 & 6.699 & 7.2249 & TST & \\
\hline CHEMBL138400 & 105812 & 8.699 & 9.1144 & TRN & \\
\hline CHEMBL140602 & 105812 & 8.699 & 8.1648 & TST & \\
\hline CHEMBL336243 & 105812 & 8.699 & 8.9012 & TRN & \\
\hline CHEMBL341604 & 105812 & 8.699 & 8.2826 & TRN & \\
\hline CHEMBL335118 & 105812 & 7.699 & 7.8492 & TRN & \\
\hline CHEMBL422105 & 105812 & 8.5229 & 8.3144 & TRN & \\
\hline
\end{tabular}




\begin{tabular}{|c|c|c|c|c|c|}
\hline \multicolumn{6}{|c|}{ Supplemental Table S2.txt } \\
\hline CHEMBL141098 & 105812 & 7.0 & 7.6233 & TRN & \\
\hline CHEMBL434655 & 105812 & 6.301 & 6.3496 & TRN & \\
\hline CHEMBL137835 & 105812 & 8.699 & 8.7088 & TRN & \\
\hline CHEMBL139542 & 105812 & 8.699 & 8.5502 & TRN & \\
\hline CHEMBL138181 & 105812 & 7.0458 & 6.0482 & TST & \\
\hline CHEMBL138953 & 105812 & 8.5229 & 8.038 & TRN & \\
\hline CHEMBL140888 & 105812 & 7.5229 & 7.6365 & TST & \\
\hline CHEMBL141589 & 105812 & 7.3979 & 7.2599 & TST & \\
\hline CHEMBL138656 & 105812 & 8.699 & 8.3768 & TST & \\
\hline CHEMBL141283 & 105812 & 7.699 & 7.63299 & 9999999999 & TST \\
\hline CHEMBL138643 & 105812 & 8.0969 & 8.054 & TST & \\
\hline CHEMBL3216082 & 766794 & 6.3382 & 6.6499 & TRN & \\
\hline CHEMBL3216499 & 766794 & 6.8962 & 7.191 & TRN & \\
\hline CHEMBL3217172 & 766794 & 6.2545 & 6.3624 & TRN & \\
\hline CHEMBL 3215848 & 766794 & 6.7328 & 6.983 & TRN & \\
\hline CHEMBL3217169 & 766794 & 6.7135 & 6.6966 & TRN & \\
\hline CHEMBL3215846 & 766794 & 7.1938 & 6.5097 & TRN & \\
\hline CHEMBL3216498 & 766794 & 6.6402 & 6.4778 & TRN & \\
\hline CHEMBL1852552 & 766794 & 7.1487 & 6.8491 & TRN & \\
\hline CHEMBL 3215847 & 766794 & 6.215 & 6.4044 & TRN & \\
\hline CHEMBL1852505 & 766794 & 7.0287 & 6.9262 & TRN & \\
\hline CHEMBL1852666 & 766794 & 7.0255 & 6.7668 & TRN & \\
\hline CHEMBL3216290 & 766794 & 5.8374 & 6.3063 & TRN & \\
\hline CHEMBL3216959 & 766794 & 5.6499 & 6.7042 & TRN & \\
\hline CHEMBL 3217183 & 766794 & 6.9626 & 7.0494 & TRN & \\
\hline CHEMBL3216965 & 766794 & 6.4908 & 6.4312 & TRN & \\
\hline CHEMBL1852362 & 766794 & 6.3716 & 6.0595 & TRN & \\
\hline CHEMBL3216508 & 766794 & 6.21899 & 99999999 & 6.5658 & TRN \\
\hline CHEMBL3215862 & 766794 & 6.6326 & 6.7902 & TRN & \\
\hline CHEMBL 3217170 & 766794 & 5.8222 & 6.763 & TRN & \\
\hline CHEMBL 3216084 & 766794 & 6.2154 & 6.3157 & TRN & \\
\hline CHEMBL3216078 & 766794 & 6.6234 & 6.5252 & TST & \\
\hline CHEMBL3216754 & 766794 & 6.6289 & 6.5456 & TRN & \\
\hline CHEMBL3216285 & 766794 & 6.1846 & 6.2186 & TRN & \\
\hline CHEMBL3216303 & 766794 & 6.857 & 7.0621 & TST & \\
\hline CHEMBL3217171 & 766794 & 6.5482 & 6.5641 & TRN & \\
\hline CHEMBL3215638 & 766794 & 7.1675 & 6.8031 & TST & \\
\hline CHEMBL1852339 & 766794 & 7.2076 & 7.019 & TRN & \\
\hline CHEMBL3216964 & 766794 & 7.1135 & 6.834 & TRN & \\
\hline CHEMBL 3215627 & 766794 & 5.9266 & 6.3141 & TRN & \\
\hline CHEMBL 2447952 & 766794 & 5.9996 & 5.9538 & TRN & \\
\hline CHEMBL1852333 & 766794 & 6.9872 & 6.5992 & TST & \\
\hline CHEMBL1852777 & 766794 & 6.2588 & 6.5737 & TRN & \\
\hline CHEMBL3216291 & 766794 & 7.0177 & 6.77 & TRN & \\
\hline CHEMBL1852359 & 766794 & 6.699 & 6.8462 & TRN & \\
\hline CHEMBL1852774 & 766794 & 6.2644 & 6.3575 & TRN & \\
\hline CHEMBL1852503 & 766794 & 7.8356 & 7.249 & TST & \\
\hline CHEMBL1852659 & 766794 & 6.8356 & 6.8713 & TRN & \\
\hline
\end{tabular}




\begin{tabular}{|c|c|c|c|c|c|}
\hline & & & & & \\
\hline CHEMBL1852372 & 766794 & 6.7235 & 6.8205 & TRN & \\
\hline CHEMBL1852466 & 766794 & 7.4271 & 7.01200 & 00000000005 & TRN \\
\hline CHEMBL3216507 & 766794 & 6.279 & 6.3936 & TRN & \\
\hline CHEMBL3681368 & 766794 & 6.0676 & 6.356 & TST & \\
\hline CHEMBL3216075 & 766794 & 6.0209 & 6.1305 & TST & \\
\hline CHEMBL3216757 & 766794 & 6.1314 & 6.3266 & TRN & \\
\hline CHEMBL 3215864 & 766794 & 5.3984 & 6.8966 & TST & \\
\hline CHEMBL3215624 & 766794 & 6.7235 & 6.778 & TRN & \\
\hline CHEMBL3215628 & 766794 & 6.7192 & 6.8458 & TRN & \\
\hline CHEMBL1852346 & 766794 & 6.8356 & 6.8666 & TRN & \\
\hline CHEMBL1852373 & 766794 & 6.983 & 6.8417 & TST & \\
\hline CHEMBL3215618 & 766794 & 7.1675 & 6.4428 & TRN & \\
\hline CHEMBL1852617 & 766794 & 6.5376 & 6.6698 & TRN & \\
\hline CHEMBL3216974 & 766794 & 6.9562 & 6.79 & TRN & \\
\hline CHEMBL3216286 & 766794 & 6.3251 & 6.6626 & TRN & \\
\hline CHEMBL3216737 & 766794 & 7.1931 & 6.6735 & TRN & \\
\hline CHEMBL1852345 & 766794 & 6.8861 & 6.53700 & 0000000001 & TRN \\
\hline CHEMBL1852341 & 766794 & 7.9172 & 7.24 & TRN & \\
\hline CHEMBL3215851 & 766794 & 6.2269 & 6.1257 & TRN & \\
\hline CHEMBL3215622 & 766794 & 7.1938 & 7.0926 & TRN & \\
\hline CHEMBL3215849 & 766794 & 7.4609 & 6.8649 & TST & \\
\hline CHEMBL 3215863 & 766794 & 6.4353 & 6.6268 & TST & \\
\hline CHEMBL1852811 & 766794 & 6.8539 & 6.98799 & 99999999995 & TRN \\
\hline CHEMBL3217176 & 766794 & 6.7696 & 6.8272 & TRN & \\
\hline CHEMBL1852418 & 766794 & 5.6535 & 6.5527 & TST & \\
\hline CHEMBL1852361 & 766794 & 7.4214 & 6.6057 & TST & \\
\hline CHEMBL3216284 & 766794 & 6.4168 & 6.91 & TRN & \\
\hline CHEMBL3216073 & 766794 & 5.8213 & 6.2463 & TRN & \\
\hline CHEMBL3216979 & 766794 & 6.7033 & 6.8638 & TST & \\
\hline CHEMBL1852779 & 766794 & 6.7986 & 6.7916 & TRN & \\
\hline CHEMBL1852472 & 766794 & 6.9626 & 6.8327 & TRN & \\
\hline CHEMBL1852370 & 766794 & 7.2941 & 7.1351 & TRN & \\
\hline CHEMBL3216975 & 766794 & 7.2147 & 6.6448 & TST & \\
\hline CHEMBL3216742 & 766794 & 6.9469 & 6.8041 & TRN & \\
\hline CHEMBL3216504 & 766794 & 6.5467 & 6.20799 & 9999999999 & TRN \\
\hline CHEMBL3216961 & 766794 & 5.359 & 6.7815 & TST & \\
\hline CHEMBL 3217175 & 766794 & 6.3224 & 6.4888 & TRN & \\
\hline CHEMBL1852517 & 766794 & 6.6904 & 6.6078 & TRN & \\
\hline CHEMBL1852587 & 766794 & 4.994 & 6.4052 & TST & \\
\hline CHEMBL1852420 & 766794 & 4.0 & 5.9018 & TST & \\
\hline CHEMBL3216966 & 766794 & 5.8649 & 6.1351 & TRN & \\
\hline CHEMBL3216756 & 766794 & 6.4001 & 6.0994 & TRN & \\
\hline CHEMBL3216085 & 766794 & 6.5436 & 6.5071 & TRN & \\
\hline CHEMBL3215850 & 766794 & 5.8639 & 6.7622 & TST & \\
\hline CHEMBL1852387 & 766794 & 6.2798 & 6.2427 & TRN & \\
\hline CHEMBL1852485 & 766794 & 7.0555 & 7.1971 & TRN & \\
\hline CHEMBL3216956 & 766794 & 6.1798 & 6.0065 & TRN & \\
\hline CHEMBL3216282 & 766794 & 6.2715 & 6.2951 & TRN & \\
\hline
\end{tabular}


Supplemental Table S2.txt

\begin{tabular}{|c|c|c|c|c|c|}
\hline CHEMBL1852514 & 766794 & 6.2252 & 6.0959 & TST & \\
\hline CHEMBL 3216738 & 766794 & 6.8097 & 7.2374 & TRN & \\
\hline CHEMBL3216506 & 766794 & 6.2625 & 6.3382 & TRN & \\
\hline CHEMBL3216518 & 766794 & 6.6253 & 6.5879 & TST & \\
\hline CHEMBL 3216755 & 766794 & 6.9747 & 6.9737 & TST & \\
\hline CHEMBL 3216288 & 766794 & 6.1113 & 6.3832 & TRN & \\
\hline CHEMBL 3216501 & 766794 & 6.9355 & 6.7594 & TST & \\
\hline CHEMBL1852665 & 766794 & 7.1158 & 6.7523 & TRN & \\
\hline CHEMBL 3217173 & 766794 & 6.4899 & 6.7509 & TRN & \\
\hline CHEMBL1852422 & 766794 & 7.5935 & 7.2897 & TRN & \\
\hline CHEMBL 3216741 & 766794 & 6.9066 & 6.7599 & TRN & \\
\hline CHEMBL 3216083 & 766794 & 6.5272 & 6.8948 & TST & \\
\hline CHEMBL3216093 & 766794 & 7.4089 & 6.8908 & TRN & \\
\hline CHEMBL 3216074 & 766794 & 6.7338 & 6.2131 & TRN & \\
\hline CHEMBL 3215626 & 766794 & 6.5072 & 6.3721 & TRN & \\
\hline CHEMBL1852516 & 766794 & 7.1805 & 7.197 & TRN & \\
\hline CHEMBL3216957 & 766794 & 6.1785 & 6.51200 & 00000000005 & TST \\
\hline CHEMBL 3216505 & 766794 & 6.7791 & 6.3126 & TST & \\
\hline CHEMBL1797354 & 753895 & 5.4535 & 5.3764 & TRN & \\
\hline CHEMBL1797472 & 753895 & 3.0 & 4.467 & TRN & \\
\hline CHEMBL1795365 & 753895 & 5.3565 & 5.3216 & TRN & \\
\hline CHEMBL1797490 & 753895 & 4.9408 & 4.1677 & TRN & \\
\hline CHEMBL1797356 & 753895 & 5.5901 & 5.2064 & TRN & \\
\hline CHEMBL1773239 & 753895 & 5.8633 & 5.6488 & TST & \\
\hline CHEMBL1797494 & 753895 & 5.4001 & 5.8385 & TST & \\
\hline CHEMBL1773244 & 753895 & 5.7423 & 5.4044 & TST & \\
\hline CHEMBL1797466 & 753895 & 5.5452 & 4.7856 & TRN & \\
\hline CHEMBL1797368 & 753895 & 4.8536 & 4.9936 & TRN & \\
\hline CHEMBL1797492 & 753895 & 5.1007 & 5.4342 & TST & \\
\hline CHEMBL1797355 & 753895 & 5.3799 & 5.6729 & TRN & \\
\hline CHEMBL1797497 & 753895 & 5.6459 & 5.9184 & TST & \\
\hline CHEMBL1797491 & 753895 & 4.9431 & 5.4485 & TST & \\
\hline CHEMBL1797365 & 753895 & 5.5045 & 5.4659 & TRN & \\
\hline CHEMBL1797482 & 753895 & 3.0 & 4.2255 & TRN & \\
\hline CHEMBL1797336 & 753895 & 5.3883 & 4.7905 & TRN & \\
\hline CHEMBL1797480 & 753895 & 5.3936 & 5.1022 & TRN & \\
\hline CHEMBL1797196 & 753895 & 3.0 & 4.7743 & TRN & \\
\hline CHEMBL1797477 & 753895 & 3.0 & 3.1872 & TRN & \\
\hline CHEMBL1797458 & 753895 & 5.3125 & 5.6663 & TRN & \\
\hline CHEMBL1797348 & 753895 & 5.1986 & 5.0525 & TRN & \\
\hline CHEMBL1797456 & 753895 & 5.3799 & 5.3361 & TRN & \\
\hline CHEMBL1797475 & 753895 & 3.0 & 4.8725 & TST & \\
\hline CHEMBL1797465 & 753895 & 5.2708 & 4.3908 & TRN & \\
\hline CHEMBL1797353 & 753895 & 5.5243 & 5.3499 & TRN & \\
\hline CHEMBL1797349 & 753895 & 4.8407 & 5.0525 & TRN & \\
\hline CHEMBL1797333 & 753895 & 5.6038 & 4.6552 & TRN & \\
\hline CHEMBL1797489 & 753895 & 4.9367 & 4.3456 & TRN & \\
\hline CHEMBL1797483 & 753895 & 4.7138 & 4.6404 & TRN & \\
\hline
\end{tabular}




\begin{tabular}{|c|c|c|c|c|c|}
\hline & & \multicolumn{4}{|c|}{ Supplemental Table S2.txt } \\
\hline CHEMBL1797599 & 753895 & 5.5884 & 5.6427 & TST & \\
\hline CHEMBL1797366 & 753895 & 5.4306 & 5.5441 & TRN & \\
\hline CHEMBL1797481 & 753895 & 4.5042 & 4.6505 & TRN & \\
\hline CHEMBL1797370 & 753895 & 4.9292 & 5.3369 & TRN & \\
\hline CHEMBL1797484 & 753895 & 5.8416 & 4.7427 & TST & \\
\hline CHEMBL1797469 & 753895 & 3.0 & 2.8063 & TRN & \\
\hline CHEMBL1797457 & 753895 & 5.2076 & 5.3617 & TRN & \\
\hline CHEMBL1797487 & 753895 & 3.0 & 4.4779 & TRN & \\
\hline CHEMBL1797364 & 753895 & 5.1637 & 5.7878 & TRN & \\
\hline CHEMBL1797473 & 753895 & 3.0 & 4.0223 & TRN & \\
\hline CHEMBL1797363 & 753895 & 5.6655 & 5.4852 & TRN & \\
\hline CHEMBL1797190 & 753895 & 4.9698 & 5.0207 & TRN & \\
\hline CHEMBL1797478 & 753895 & 5.5817 & 5.1034 & TRN & \\
\hline CHEMBL1797357 & 753895 & 4.9817 & 5.216 & TRN & \\
\hline CHEMBL1797479 & 753895 & 5.5045 & 5.3667 & TRN & \\
\hline CHEMBL1797342 & 753895 & 5.3116 & 5.3507 & TRN & \\
\hline CHEMBL1797194 & 753895 & 4.9978 & 4.774 & TRN & \\
\hline CHEMBL1797346 & 753895 & 6.0088 & 5.5483 & TRN & \\
\hline CHEMBL1797351 & 753895 & 5.466 & 5.0982 & TRN & \\
\hline CHEMBL1773235 & 753895 & 5.8477 & 5.5956 & TST & \\
\hline CHEMBL1797474 & 753895 & 4.9496 & 4.7499 & TRN & \\
\hline CHEMBL1797468 & 753895 & 3.0 & 3.6547 & TRN & \\
\hline CHEMBL1797493 & 753895 & 6.0605 & 5.8774 & TST & \\
\hline CHEMBL1797327 & 753895 & 5.0195 & 5.2247 & TRN & \\
\hline CHEMBL1797460 & 753895 & 5.3893 & 5.42299 & 9999999999 & TRN \\
\hline CHEMBL1797359 & 753895 & 5.3851 & 5.1168 & TRN & \\
\hline CHEMBL1797471 & 753895 & 5.2823 & 4.8336 & TRN & \\
\hline CHEMBL1797343 & 753895 & 5.4473 & 5.6749 & TRN & \\
\hline CHEMBL1797367 & 753895 & 5.5467 & 5.8398 & TRN & \\
\hline CHEMBL1797199 & 753895 & 6.0 & 5.1367 & TRN & \\
\hline CHEMBL1797459 & 753895 & 4.8911 & 5.3972 & TRN & \\
\hline CHEMBL1797347 & 753895 & 5.4123 & 5.8706 & TRN & \\
\hline CHEMBL1797345 & 753895 & $5.7620 e$ & 0000000 & 5.4605 & TRN \\
\hline CHEMBL1797369 & 753895 & 5.04 & 5.0821 & TRN & \\
\hline CHEMBL1797600 & 753895 & 5.3382 & 5.6296 & TST & \\
\hline CHEMBL1797495 & 753895 & 5.8508 & 6.171 & TST & \\
\hline CHEMBL1797602 & 753895 & 5.0343 & 5.4271 & TST & \\
\hline CHEMBL1797339 & 753895 & 5.3936 & 4.7443 & TRN & \\
\hline CHEMBL1797603 & 753895 & 5.8601 & 5.6173 & TST & \\
\hline CHEMBL1797322 & 753895 & 5.3391 & 5.0259 & TRN & \\
\hline CHEMBL1797358 & 753895 & 5.5867 & 5.5672 & TRN & \\
\hline CHEMBL1797350 & 753895 & 5.1649 & 5.3622 & TRN & \\
\hline CHEMBL1797344 & 753895 & 5.4283 & 5.1419 & TST & \\
\hline CHEMBL1797326 & 753895 & 4.9731 & 4.8911 & TRN & \\
\hline CHEMBL1797496 & 753895 & 5.4522 & 5.6649 & TST & \\
\hline CHEMBL1797498 & 753895 & 4.8636 & 5.2415 & TST & \\
\hline CHEMBL1797352 & 753895 & 5.6536 & 5.2909 & TRN & \\
\hline CHEMBL1797360 & 753895 & 5.0721 & 5.1179 & TRN & \\
\hline
\end{tabular}


Supplemental Table S2.txt

\begin{tabular}{|c|c|c|c|c|c|}
\hline CHEMBL1797470 & 753895 & 5.1959 & 4.6113 & TRN & \\
\hline CHEMBL1797463 & 753895 & 5.7799 & 4.7746 & TST & \\
\hline CHEMBL1797488 & 753895 & 5.7747 & 4.6664 & TRN & \\
\hline CHEMBL1797361 & 753895 & 5.3958 & 5.4754 & TRN & \\
\hline CHEMBL1797601 & 753895 & 5.8356 & 5.8969 & TST & \\
\hline CHEMBL1797323 & 753895 & 4.7462 & 5.0647 & TRN & \\
\hline CHEMBL1797362 & 753895 & 5.3737 & 5.3712 & TRN & \\
\hline CHEMBL1797324 & 753895 & 5.2291 & 5.4081 & TRN & \\
\hline CHEMBL1797598 & 753895 & 5.0482 & 5.3327 & TST & \\
\hline CHEMBL1652176 & 753895 & 5.7721 & 5.2879 & TRN & \\
\hline CHEMBL1797462 & 753895 & 6.7212 & 4.7158 & TST & \\
\hline CHEMBL1797188 & 753895 & 4.8901 & 4.8118 & TRN & \\
\hline CHEMBL1797461 & 753895 & 5.2676 & 5.7253 & TRN & \\
\hline CHEMBL1773232 & 753895 & 5.6737 & 5.8215 & TST & \\
\hline CHEMBL 2170622 & 862405 & 7.5229 & 7.6191 & TRN & \\
\hline CHEMBL 2170619 & 862405 & 6.8794 & 6.8955 & TRN & \\
\hline CHEMBL 2170608 & 862405 & 8.0 & 8.0066 & TRN & \\
\hline CHEMBL 2170643 & 862405 & 6.9626 & 6.9404 & TRN & \\
\hline CHEMBL 2170649 & 862405 & 6.9914 & 6.9718 & TRN & \\
\hline CHEMBL 2170642 & 862405 & 7.1675 & 7.1417 & TRN & \\
\hline CHEMBL 2170638 & 862405 & 7.585 & 7.5708 & TRN & \\
\hline CHEMBL 2170616 & 862405 & 7.5686 & 7.6051 & TST & \\
\hline CHEMBL 2170646 & 862405 & 6.4145 & 6.4079 & TRN & \\
\hline CHEMBL 2170639 & 862405 & 7.7212 & 7.6776 & TRN & \\
\hline CHEMBL 2170610 & 862405 & 8.2218 & 8.1842 & TRN & \\
\hline CHEMBL 2170607 & 862405 & 7.7959 & 7.7999 & TRN & \\
\hline CHEMBL 2170617 & 862405 & 7.8539 & 7.6624 & TST & \\
\hline CHEMBL 2170620 & 862405 & 7.284 & 7.2256 & TRN & \\
\hline CHEMBL 2170623 & 862405 & 7.4437 & 7.4438 & TRN & \\
\hline CHEMBL 2170628 & 862405 & 7.6778 & 7.6548 & TRN & \\
\hline CHEMBL 2170614 & 862405 & 7.6576 & 8.416 & TST & \\
\hline CHEMBL 2170606 & 862405 & 7.5528 & 7.5381 & TRN & \\
\hline CHEMBL 2170635 & 862405 & 7.7447 & 7.7451 & TRN & \\
\hline CHEMBL 2170624 & 862405 & 7.1938 & 7.218999 & 9999999999 & TRN \\
\hline CHEMBL 2170611 & 862405 & 8.301 & 8.0088 & TST & \\
\hline CHEMBL 2170615 & 862405 & 7.8539 & 7.9168 & TRN & \\
\hline CHEMBL 2170632 & 862405 & 7.8239 & 7.7278 & TRN & \\
\hline CHEMBL 2170637 & 862405 & 7.7447 & 7.7396 & TRN & \\
\hline CHEMBL 2170640 & 862405 & 7.3872 & 6.9792 & TST & \\
\hline CHEMBL 2170618 & 862405 & 7.7447 & 7.7678 & TRN & \\
\hline CHEMBL 2170634 & 862405 & 7.2366 & 7.2569 & TRN & \\
\hline CHEMBL 2170641 & 862405 & 7.3468 & 7.3713 & TRN & \\
\hline CHEMBL 2170629 & 862405 & 7.6198 & 7.6331 & TRN & \\
\hline CHEMBL 2170612 & 862405 & 7.7212 & 8.3307 & TST & \\
\hline CHEMBL 2170633 & 862405 & 7.2218 & 7.3443 & TRN & \\
\hline CHEMBL 2170636 & 862405 & 7.7447 & 7.7253 & TRN & \\
\hline CHEMBL 2170621 & 862405 & 7.301 & 7.3204 & TRN & \\
\hline CHEMBL 2170650 & 862405 & 7.4437 & 7.0309 & TST & \\
\hline
\end{tabular}




\begin{tabular}{|c|c|c|c|c|c|c|}
\hline \multicolumn{7}{|c|}{ Supplemental Table S2.txt } \\
\hline CHEMBL 2170651 & 862405 & 6.7645 & 6.8773 & TST & & \\
\hline CHEMBL 2170631 & 862405 & 7.2147 & 7.2268 & TRN & & \\
\hline CHEMBL 2170648 & 862405 & 5.3274 & 5.3356 & TRN & & \\
\hline CHEMBL 2170644 & 862405 & 6.4949 & 6.4635 & TRN & & \\
\hline CHEMBL 2170627 & 862405 & 7.1871 & 7.1884 & TRN & & \\
\hline CHEMBL 2170613 & 862405 & 7.5376 & 8.1338 & TST & & \\
\hline CHEMBL 2170604 & 862405 & 7.5376 & 7.4886 & TRN & & \\
\hline CHEMBL 2170630 & 862405 & 7.4559 & 7.4297 & TRN & & \\
\hline CHEMBL 2170605 & 862405 & 7.1427 & 7.1143 & TRN & & \\
\hline CHEMBL2169894 & 862405 & 7.8239 & 8.2178 & TST & & \\
\hline CHEMBL 2170645 & 862405 & 6.5143 & 6.5323 & TRN & & \\
\hline CHEMBL2170609 & 862405 & 7.9586 & 7.9709 & TRN & & \\
\hline CHEMBL 2170625 & 862405 & 7.3279 & 7.3628 & TRN & & \\
\hline CHEMBL 2170626 & 862405 & 7.4815 & 6.7464 & TST & & \\
\hline CHEMBL 2170603 & 862405 & 7.8239 & 8.5096 & TST & & \\
\hline CHEMBL 2170647 & 862405 & 6.9666 & 6.9454 & TST & & \\
\hline CHEMBL1256459 & 955041 & 7.551 & 7.6981 & TRN & & \\
\hline CHEMBL 2144069 & 955041 & 5.0477 & 4.9726 & TRN & & \\
\hline CHEMBL573107 & 955041 & 4.0782 & 3.9873 & TRN & & \\
\hline CHEMBL188678 & 955041 & 4.0172 & 3.9832 & TRN & & \\
\hline CHEMBL1970879 & 955041 & 5.9374 & 5.9965 & TRN & & \\
\hline CHEMBL412142 & 955041 & 3.8824 & 3.762 & TRN & & \\
\hline CHEMBL1788116 & 955041 & 4.5484 & 4.4708 & TRN & & \\
\hline CHEMBL3392440 & 955041 & 3.7634 & 3.7145 & TRN & & \\
\hline CHEMBL1404918 & 955041 & 2.7977 & 2.8427 & TRN & & \\
\hline CHEMBL221137 & 955041 & 5.25299 & 99999999 & 99 & 5.2306 & TST \\
\hline CHEMBL1190711 & 955041 & 4.2249 & 4.3029 & TRN & & \\
\hline CHEMBL1643959 & 955041 & 4.9493 & 4.8133 & TRN & & \\
\hline CHEMBL192566 & 955041 & 8.8784 & 9.3684 & TST & & \\
\hline CHEMBL472940 & 955041 & 3.1568 & 3.0776 & TRN & & \\
\hline CHEMBL509032 & 955041 & 6.4878 & 6.3837 & TRN & & \\
\hline CHEMBL558642 & 955041 & 5.7019 & 5.6814 & TRN & & \\
\hline CHEMBL392695 & 955041 & 6.3267 & 6.2997 & TRN & & \\
\hline CHEMBL 379300 & 955041 & 6.62799 & 99999999 & 99 & 6.8093 & TRN \\
\hline CHEMBL135561 & 955041 & 4.0636 & 4.2668 & TRN & & \\
\hline CHEMBL 373751 & 955041 & 3.9636 & 3.9963 & TRN & & \\
\hline CHEMBL1673039 & 955041 & 5.0965 & 5.1716 & TRN & & \\
\hline CHEMBL258844 & 955041 & 4.2399 & 4.1788 & TRN & & \\
\hline CHEMBL 222102 & 955041 & 3.0369 & 3.2804 & TRN & & \\
\hline CHEMBL3199475 & 955041 & 3.8049 & 3.6241 & TRN & & \\
\hline CHEMBL449158 & 955041 & 6.4368 & 7.3635 & TST & & \\
\hline CHEMBL65 & 955041 & 7.5674 & 7.501 & TRN & & \\
\hline CHEMBL 240954 & 955041 & 3.4129 & 3.2933 & TRN & & \\
\hline CHEMBL 102714 & 955041 & 2.9239 & 2.9335 & TRN & & \\
\hline CHEMBL 2005886 & 955041 & 6.4639 & 6.4101 & TRN & & \\
\hline CHEMBL483849 & 955041 & 0.9822 & 1.1524 & TRN & & \\
\hline CHEMBL1242367 & 955041 & 4.1401 & 4.245 & TRN & & \\
\hline CHEMBL514499 & 955041 & 7.4494 & 7.6803 & TRN & & \\
\hline
\end{tabular}


Supplemental Table S2.txt

\begin{tabular}{|c|c|c|c|c|}
\hline 04 & & 4.4272 & 4.444 & 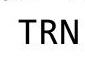 \\
\hline HEMBL 3186408 & & 4.2003 & 4.1305 & \\
\hline HFMRI 2 & 1 & & 0565 & \\
\hline AEMBL2: & 1 & 78 & 5068 & \\
\hline HEMBL1230020 & 55041 & .9271 & 8976 & \\
\hline HEMBL1 & 55041 & 74 & 6035 & \\
\hline 7247 & & & 2508 & \\
\hline AEMBL2 & & & 3292 & 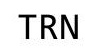 \\
\hline HEMBL9470 & 55041 & 636 & .2576 & \\
\hline HEMBL 300389 & 55041 & 32 & 8446 & \\
\hline HEMBL1 & 1 & 596 & 4814 & \\
\hline IEMBL & 41 & & 8876 & \\
\hline AEMBL9 & & & 9569 & \\
\hline HEMBL151689 & 55041 & & 7349 & \\
\hline HEMBL 210618 & 41 & & 1236 & \\
\hline HEMBL 2 & 1 & & 255 & \\
\hline HEMBL: & & & 299 & ו \\
\hline HEMBL 2 & & & 495 & \\
\hline HEMBL 5 & 41 & & 801 & IST \\
\hline HEMBL 2393263 & 36 & & 1373 & I KIV \\
\hline HEMBL & 36 & & & ГRN \\
\hline HEMBL & & & 397 & RN \\
\hline HEMBL 2 & 36 & & 681 & RN \\
\hline HEMBL 2 & & & 041 & I KIV \\
\hline HEMBL2 & 63836 & & 432 & RN \\
\hline HEMBL2 & 36 & & 765 & RN \\
\hline HEMBL 2 & & & 706 & RN \\
\hline 243 & & & 421 & IST \\
\hline HEMBL 2 & & & 582 & $\Gamma \mathrm{RN}$ \\
\hline HEMBL 2393265 & 53836 & & 196 & TRN \\
\hline HEMBL 2 & 36 & & 656 & ST \\
\hline 0 & & & 14 & 「RN \\
\hline 250 & & & & RN \\
\hline HEMBL2393255 & & & 085 & 「RN \\
\hline HEMBL 2393268 & 36 & & 7214 & RN \\
\hline 278 & 36 & & 34 & TRN \\
\hline 47 & & & 292 & IST \\
\hline HEMBL2 & & & 3171 & TRN \\
\hline HEMBL2 & 36 & & 455 & $\Gamma R$ \\
\hline CTIDL & & & 453 & RN \\
\hline HEMBL 2 & & & 346 & ГST \\
\hline HEMBL2 & 36 & & 9992 & TRN \\
\hline HEMBL2393404 & & & 1495 & TRN \\
\hline HEMBL2 & 63 & & 431 & TR \\
\hline CHEMBL2393262 & & & & \\
\hline 93244 & & 1 & 2279 & \\
\hline CHEMBL 2393257 & 963836 & 4.0 & 4.0201 & RN \\
\hline CHEMBL 2393238 & 963836 & 5.8989 & 4.7453 & S \\
\hline
\end{tabular}

Page 10583 


\begin{tabular}{|c|c|c|c|c|c|c|}
\hline & & \multicolumn{5}{|c|}{ Supplemental Table S2.txt } \\
\hline CHEMBL 2393256 & 963836 & 5.1086 & 4.6422 & TRN & & \\
\hline CHEMBL 2393230 & 963836 & 4.0 & 4.459 & TST & & \\
\hline CHEMBL2393234 & 963836 & 4.0 & 4.0676 & TRN & & \\
\hline CHEMBL 2393266 & 963836 & 4.0 & 3.8294 & TRN & & \\
\hline CHEMBL 2393403 & 963836 & 5.9646 & 6.3395 & TRN & & \\
\hline CHEMBL 2393248 & 963836 & 6.5702 & 5.8826 & TST & & \\
\hline CHEMBL 2393241 & 963836 & 6.1085 & 6.0768 & TRN & & \\
\hline CHEMBL2393252 & 963836 & \multicolumn{3}{|c|}{5.071000000000001} & 5.6386 & TRN \\
\hline CHEMBL 2393274 & 963836 & 6.3063 & 6.2376 & TRN & & \\
\hline CHEMBL 2393236 & 963836 & 4.0 & 4.0653 & TST & & \\
\hline CHEMBL 2393402 & 963836 & 8.1079 & 7.2349 & TRN & & \\
\hline CHEMBL 2393237 & 963836 & 4.0 & 4.1401 & TRN & & \\
\hline CHEMBL 2393249 & 963836 & 4.0 & 4.1483 & TRN & & \\
\hline CHEMBL 2393245 & 963836 & 8.6383 & 6.3375 & TST & & \\
\hline CHEMBL 2393231 & 963836 & 4.0 & 4.2817 & TRN & & \\
\hline CHEMBL 2393232 & 963836 & 4.0 & 4.0093 & TRN & & \\
\hline CHEMBL 2393264 & 963836 & \multicolumn{3}{|c|}{5.587000000000001} & 5.2915 & TRN \\
\hline CHEMBL2393239 & 963836 & 5.5449 & 5.2369 & TRN & & \\
\hline CHEMBL 2393270 & 963836 & 5.8861 & 5.8345 & TRN & & \\
\hline CHEMBL 2393276 & 963836 & 6.3809 & 6.87 & TRN & & \\
\hline CHEMBL 2393275 & 963836 & 6.0778 & 6.6848 & TST & & \\
\hline CHEMBL 2393235 & 963836 & 4.0 & 3.8495 & TST & & \\
\hline CHEMBL 2393258 & 963836 & 4.0 & 3.855 & TST & & \\
\hline CHEMBL 2393254 & 963836 & 7.5317 & 7.2024 & TST & & \\
\hline CHEMBL340589 & 211078 & 3.0 & 2.7441 & TRN & & \\
\hline CHEMBL341339 & 211078 & 4.0506 & 4.2176 & TRN & & \\
\hline CHEMBL340465 & 211078 & 4.0 & 4.145 & TRN & & \\
\hline CHEMBL 341108 & 211078 & 3.0 & 3.4162 & TRN & & \\
\hline CHEMBL127957 & 211078 & 4.0 & 3.8344 & TRN & & \\
\hline CHEMBL338757 & 211078 & 4.0 & 4.0522 & TRN & & \\
\hline CHEMBL129031 & 211078 & 4.0 & 3.8487 & TRN & & \\
\hline CHEMBL129498 & 211078 & 4.0 & 4.1347 & TRN & & \\
\hline CHEMBL341119 & 211078 & 4.0 & 3.6051 & TRN & & \\
\hline CHEMBL340695 & 211078 & 3.0 & 2.9933 & TRN & & \\
\hline CHEMBL341077 & 211078 & 4.0 & 3.5816 & TRN & & \\
\hline CHEMBL339472 & 211078 & 3.0 & 2.9492 & TRN & & \\
\hline CHEMBL126025 & 211078 & 3.0 & 3.2779 & TRN & & \\
\hline CHEMBL338235 & 211078 & 5.3565 & 4.9806 & TRN & & \\
\hline CHEMBL341482 & 211078 & 3.0 & 3.0746 & TRN & & \\
\hline CHEMBL126232 & 211078 & 3.0 & 3.2207 & TST & & \\
\hline CHEMBL340531 & 211078 & 3.0 & 3.0171 & TRN & & \\
\hline CHEMBL419422 & 211078 & 3.0 & 3.6236 & TRN & & \\
\hline CHEMBL125350 & 211078 & 4.0 & 3.6983 & TRN & & \\
\hline CHEMBL126371 & 211078 & 4.0 & 3.9348 & TRN & & \\
\hline CHEMBL340153 & 211078 & 5.0 & 4.6441 & TRN & & \\
\hline CHEMBL127117 & 211078 & 4.0969 & 3.6818 & TRN & & \\
\hline CHEMBL338170 & 211078 & 4.0 & 4.132 & TRN & & \\
\hline CHEMBL129708 & 211078 & 3.0 & 2.4908 & TRN & & \\
\hline
\end{tabular}




\begin{tabular}{|c|c|c|c|c|c|}
\hline & & & & & \\
\hline CHEMBL338409 & 211078 & 4.0 & 3.8596 & TRN & \\
\hline CHEMBL126824 & 211078 & 4.0 & 4.4408 & TRN & \\
\hline CHEMBL340581 & 211078 & 4.0 & 3.8571 & TRN & \\
\hline CHEMBL126773 & 211078 & 3.0 & 3.2455 & TRN & \\
\hline CHEMBL269624 & 211078 & 4.0 & 4.3783 & TRN & \\
\hline CHEMBL131499 & 211078 & 4.0 & 4.5425 & TRN & \\
\hline CHEMBL127063 & 211078 & 5.0 & 4.4644 & TRN & \\
\hline CHEMBL125343 & 211078 & 3.0 & 2.92199 & 99999999997 & TRN \\
\hline CHEMBL13477 & 211078 & 3.0 & 3.0114 & TRN & \\
\hline CHEMBL126717 & 211078 & 5.1024 & 4.7538 & TRN & \\
\hline CHEMBL128978 & 211078 & 4.0 & 4.1783 & TRN & \\
\hline CHEMBL407977 & 211078 & 4.0 & 3.8236 & TST & \\
\hline CHEMBL129268 & 211078 & 4.0 & 4.4172 & TRN & \\
\hline CHEMBL341021 & 211078 & 4.0 & 4.0813 & TST & \\
\hline CHEMBL126381 & 211078 & 3.0 & 2.1685 & TST & \\
\hline CHEMBL126194 & 211078 & 3.0 & 3.2055 & TST & \\
\hline CHEMBL130695 & 211078 & 5.0 & 4.6713 & TRN & \\
\hline CHEMBL126785 & 211078 & 4.0 & 3.9111 & TRN & \\
\hline CHEMBL340920 & 211078 & 3.0 & 3.1157 & TRN & \\
\hline CHEMBL338814 & 211078 & 4.0 & 2.576 & TST & \\
\hline CHEMBL129246 & 211078 & 3.0 & 4.167 & TST & \\
\hline CHEMBL126883 & 211078 & 3.5229 & 2.4145 & TST & \\
\hline CHEMBL126708 & 211078 & 6.1024 & 5.3039 & TRN & \\
\hline CHEMBL340588 & 211078 & 4.0 & 4.1193 & TRN & \\
\hline CHEMBL341039 & 211078 & 4.0 & 4.3328 & TRN & \\
\hline CHEMBL130186 & 211078 & 3.0 & 2.7934 & TST & \\
\hline CHEMBL125748 & 211078 & 4.0 & 4.9723 & TRN & \\
\hline CHEMBL339093 & 211078 & 4.0 & 3.9438 & TST & \\
\hline CHEMBL129104 & 211078 & 5.0 & 4.662 & TRN & \\
\hline CHEMBL341490 & 211078 & 4.4559 & 3.8646 & TST & \\
\hline CHEMBL434825 & 211078 & 3.0 & 3.0213 & TST & \\
\hline CHEMBL126999 & 211078 & 4.3468 & 4.3353 & TRN & \\
\hline CHEMBL129647 & 211078 & 4.0 & 3.0317 & TST & \\
\hline CHEMBL338605 & 211078 & 4.0 & 4.0595 & TST & \\
\hline CHEMBL126195 & 211078 & 3.0 & 3.1362 & TST & \\
\hline CHEMBL338470 & 211078 & 3.0 & 3.8224 & TST & \\
\hline CHEMBL129581 & 211078 & 4.0 & 4.0508 & TRN & \\
\hline CHEMBL340897 & 211078 & 3.0 & 2.9885 & TRN & \\
\hline CHEMBL126029 & 211078 & 3.0 & 3.4442 & TRN & \\
\hline CHEMBL550094 & 577226 & 5.7959 & 4.8758 & TST & \\
\hline CHEMBL550841 & 577226 & 3.301 & 3.2984 & TST & \\
\hline CHEMBL558108 & 577226 & 5.7696 & 5.8082 & TRN & \\
\hline CHEMBL550845 & 577226 & 6.2218 & 6.1569 & TRN & \\
\hline CHEMBL557091 & 577226 & 5.3979 & 5.3615 & TRN & \\
\hline CHEMBL551779 & 577226 & 5.699 & 5.7448 & TRN & \\
\hline CHEMBL565150 & 577226 & 5.6778 & 5.724 & TRN & \\
\hline CHEMBL558297 & 577226 & 6.0458 & 6.1126 & TRN & \\
\hline CHEMBL570776 & 577226 & 5.3372 & 5.1392 & TRN & \\
\hline
\end{tabular}




\begin{tabular}{|c|c|c|c|c|c|}
\hline \multirow[b]{2}{*}{ CHEMBL550295 } & \multicolumn{5}{|c|}{ Supplemental Table S2.txt } \\
\hline & 577226 & 6.0969 & 6.1576 & TRN & \\
\hline CHEMBL561170 & 577226 & 5.6198 & 5.3971 & TRN & \\
\hline CHEMBL551791 & 577226 & 5.8539 & 5.8581 & TRN & \\
\hline CHEMBL559522 & 577226 & 5.8861 & 6.0354 & TRN & \\
\hline CHEMBL549685 & 577226 & 3.301 & 3.2937 & TRN & \\
\hline CHEMBL541481 & 577226 & 6.0969 & 5.9238 & TRN & \\
\hline CHEMBL561653 & 577226 & 3.301 & 3.2953 & TRN & \\
\hline CHEMBL561570 & 577226 & 6.0458 & 6.0405 & TRN & \\
\hline CHEMBL561050 & 577226 & 5.5686 & 5.5448 & TRN & \\
\hline CHEMBL563032 & 577226 & 5.9208 & 5.9637 & TRN & \\
\hline CHEMBL560369 & 577226 & 6.2218 & 6.0858 & TRN & \\
\hline CHEMBL563181 & 577226 & 5.7447 & 5.7234 & TRN & \\
\hline CHEMBL563871 & 577226 & 6.0969 & 6.0179 & TRN & \\
\hline CHEMBL550497 & 577226 & 6.1549 & 6.0865 & TRN & \\
\hline CHEMBL551046 & 577226 & 3.301 & 3.2952 & TRN & \\
\hline CHEMBL563368 & 577226 & 5.4202 & 5.4388 & TRN & \\
\hline CHEMBL550905 & 577226 & 6.0969 & 6.1189 & TRN & \\
\hline CHEMBL551450 & 577226 & 5.2518 & 5.2353 & TRN & \\
\hline CHEMBL552185 & 577226 & 5.3979 & 5.7621 & TST & \\
\hline CHEMBL538150 & 577226 & 3.301 & 3.3085 & TRN & \\
\hline CHEMBL549483 & 577226 & 6.1549 & 6.1336 & TRN & \\
\hline CHEMBL560114 & 577226 & 5.7471 & 5.544 & TST & \\
\hline CHEMBL550766 & 577226 & 3.301 & 3.2656 & TST & \\
\hline CHEMBL563175 & 577226 & 6.0969 & 6.155 & TRN & \\
\hline CHEMBL121893 & 577226 & 5.041 & 4.9162 & TRN & \\
\hline CHEMBL556270 & 577226 & 5.9208 & 5.9275 & TRN & \\
\hline CHEMBL552392 & 577226 & 5.6383 & 4.6811 & TST & \\
\hline CHEMBL551778 & 577226 & 5.9208 & 5.9014 & TRN & \\
\hline CHEMBL562251 & 577226 & 5.9208 & 5.7822 & TRN & \\
\hline CHEMBL563154 & 577226 & 6.0 & 6.0773 & TRN & \\
\hline CHEMBL561574 & 577226 & 6.3979 & 6.2979 & TRN & \\
\hline CHEMBL557905 & 577226 & 5.6198 & 5.6174 & TRN & \\
\hline CHEMBL569845 & 577226 & 6.0969 & 6.0814 & TRN & \\
\hline CHEMBL551710 & 577226 & 5.1487 & 5.1098 & TRN & \\
\hline CHEMBL549562 & 577226 & 5.5376 & 6.2216 & TST & \\
\hline CHEMBL541227 & 577226 & 3.301 & 3.3351 & TRN & \\
\hline CHEMBL550759 & 577226 & 4.9508 & 4.9692 & TRN & \\
\hline CHEMBL560568 & 577226 & 5.8861 & 5.79700 & $\partial 000000001$ & TST \\
\hline CHEMBL551979 & 577226 & 5.301 & 5.3054 & TRN & \\
\hline CHEMBL549557 & 577226 & 5.0757 & 5.149 & TRN & \\
\hline CHEMBL555749 & 577226 & 5.7696 & 4.8638 & TST & \\
\hline CHEMBL555726 & 577226 & 3.301 & 5.0859 & TST & \\
\hline CHEMBL550846 & 577226 & 5.7959 & 5.7753 & TRN & \\
\hline CHEMBL558889 & 577226 & 4.9066 & 4.933 & TST & \\
\hline CHEMBL552105 & 577226 & 5.2924 & 5.3033 & TRN & \\
\hline CHEMBL539393 & 577226 & 4.9957 & 5.0448 & TRN & \\
\hline CHEMBL560911 & 577226 & 5.5686 & 5.4909 & TRN & \\
\hline CHEMBL561650 & 577226 & 5.301 & 5.3986 & TRN & \\
\hline
\end{tabular}




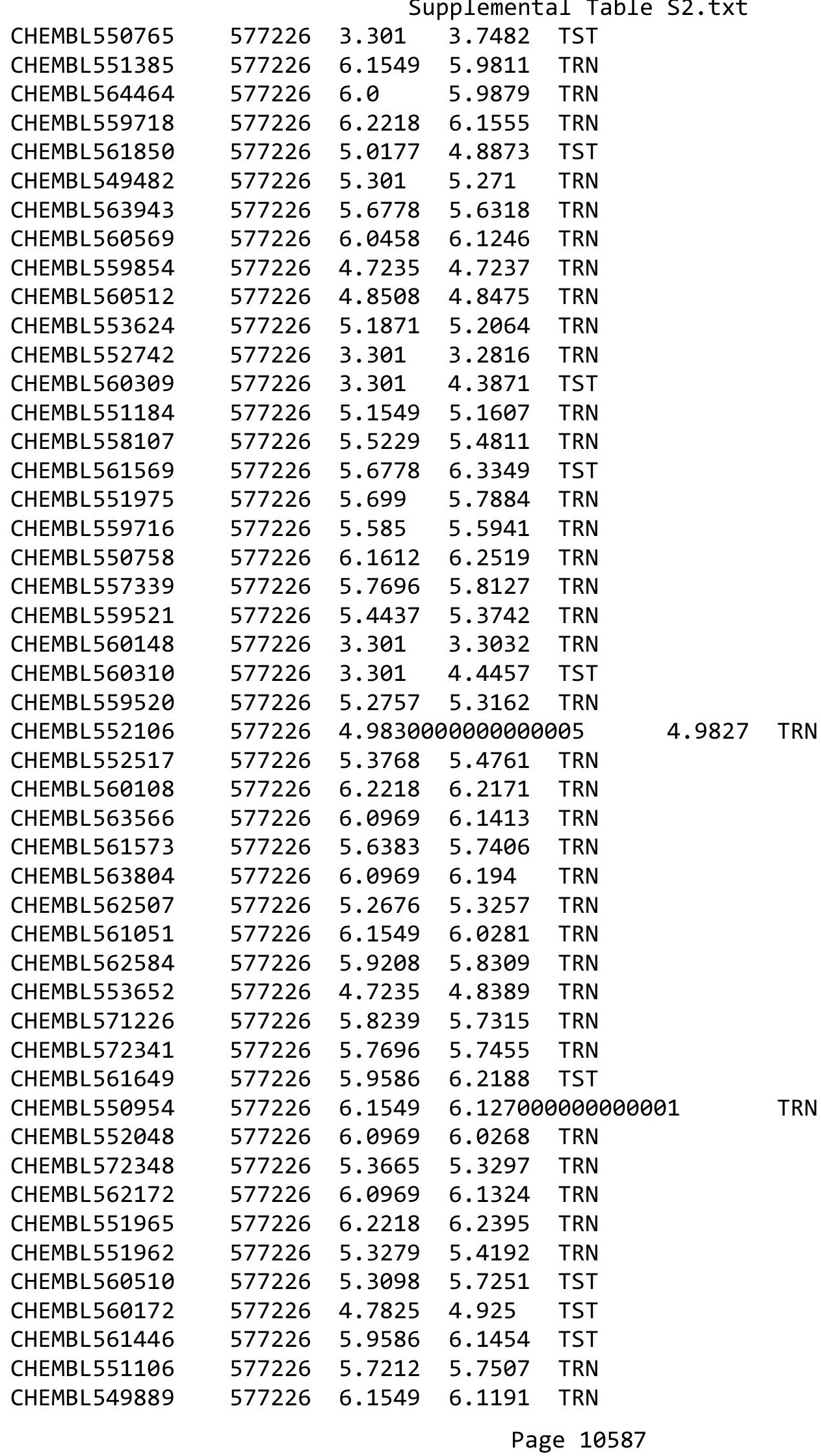




\begin{tabular}{|c|c|c|c|c|c|}
\hline \multirow[b]{2}{*}{ CHEMBL553190 } & \multicolumn{5}{|c|}{ Supplemental Table S2.txt } \\
\hline & 577226 & 5.2291 & 5.1223 & TST & \\
\hline CHEMBL555065 & 577226 & 5.301 & 5.3592 & TRN & \\
\hline CHEMBL550767 & 577226 & 6.2218 & 6.1997 & TRN & \\
\hline CHEMBL562247 & 577226 & 6.2218 & 6.2429 & TRN & \\
\hline CHEMBL539718 & 577226 & 5.8239 & 5.8398 & TST & \\
\hline CHEMBL550761 & 577226 & 5.4437 & 6.2834 & TST & \\
\hline CHEMBL560675 & 577226 & 3.301 & 3.2899 & TST & \\
\hline CHEMBL570307 & 577226 & 3.301 & 3.7633 & TST & \\
\hline CHEMBL541478 & 577226 & 5.2676 & 5.1874 & TRN & \\
\hline CHEMBL561245 & 577226 & 5.3872 & 5.4208 & TRN & \\
\hline CHEMBL550760 & 577226 & 5.3979 & 5.47 & TRN & \\
\hline CHEMBL560311 & 577226 & 5.9586 & 6.1162 & TST & \\
\hline CHEMBL559717 & 577226 & 5.9208 & 6.187 & TST & \\
\hline CHEMBL558106 & 577226 & 5.7212 & 5.9589 & TST & \\
\hline CHEMBL561052 & 577226 & 5.7696 & 5.8756 & TST & \\
\hline CHEMBL572342 & 577226 & 5.2757 & 5.3326 & TRN & \\
\hline CHEMBL539139 & 577226 & 3.301 & 4.2195 & TST & \\
\hline CHEMBL563816 & 577226 & 6.0969 & 6.1226 & TRN & \\
\hline CHEMBL550752 & 577226 & 5.9586 & 6.1361 & TRN & \\
\hline CHEMBL549561 & 577226 & 5.8239 & 5.7783 & TRN & \\
\hline CHEMBL570306 & 577226 & 6.0458 & 5.8744 & TRN & \\
\hline CHEMBL562250 & 577226 & 4.6576 & 4.6883 & TRN & \\
\hline CHEMBL561975 & 577226 & 6.0 & 6.0622 & TRN & \\
\hline CHEMBL558298 & 577226 & 5.8861 & 5.862 & TRN & \\
\hline CHEMBL551185 & 577226 & 4.5969 & 4.82100 & 0000000001 & TST \\
\hline CHEMBL561648 & 577226 & 5.0915 & 3.8934 & TST & \\
\hline CHEMBL551976 & 577226 & 5.7696 & 5.8503 & TRN & \\
\hline CHEMBL564112 & 577226 & 6.1549 & 6.2019 & TRN & \\
\hline CHEMBL562445 & 577226 & 5.699 & 5.7165 & TRN & \\
\hline CHEMBL552456 & 577226 & 5.699 & 5.6993 & TRN & \\
\hline CHEMBL540471 & 577226 & 5.8539 & 5.8851 & TRN & \\
\hline CHEMBL550090 & 577226 & 6.0458 & 5.9817 & TRN & \\
\hline CHEMBL551244 & 577226 & 3.301 & 3.3104 & TST & \\
\hline CHEMBL550768 & 577226 & 6.301 & 6.2957 & TRN & \\
\hline CHEMBL551777 & 577226 & 5.7447 & 5.7537 & TRN & \\
\hline CHEMBL560972 & 577226 & 5.5686 & 5.5086 & TST & \\
\hline CHEMBL541737 & 577226 & 5.8239 & 5.9949 & TST & \\
\hline CHEMBL540227 & 577226 & 3.301 & 3.2954 & TST & \\
\hline CHEMBL557906 & 577226 & 5.9586 & 6.001 & TRN & \\
\hline CHEMBL538961 & 577226 & 5.3188 & 5.4325 & TRN & \\
\hline CHEMBL562173 & 577226 & 5.4559 & 5.5818 & TRN & \\
\hline CHEMBL552158 & 577226 & 5.3279 & 5.3083 & TST & \\
\hline CHEMBL3956608 & 1641575 & 9.0 & 7.5392 & TRN & \\
\hline CHEMBL3968668 & 1641575 & 7.3279 & 7.0544 & TRN & \\
\hline CHEMBL 3902352 & 1641575 & 6.9101 & 6.8383 & TRN & \\
\hline CHEMBL3934356 & 1641575 & 6.7545 & 6.95700 & 0000000001 & TRN \\
\hline CHEMBL3956464 & 1641575 & 5.0761 & 4.7527 & TRN & \\
\hline CHEMBL3948247 & 1641575 & 7.3565 & 6.59399 & 9999999999 & TRN \\
\hline & & & & 10588 & \\
\hline
\end{tabular}


Supplemental Table S2.txt

\begin{tabular}{|c|c|c|c|c|c|c|}
\hline CHEMBL 3967679 & 1641575 & 5.7144 & 6.522 & TRN & & \\
\hline CHEMBL 3914182 & 1641575 & 6.6861 & 6.4296 & TRN & & \\
\hline CHEMBL 3958178 & 1641575 & 5.0511 & 5.3981 & TRN & & \\
\hline CHEMBL 3925239 & 1641575 & 5.0184 & 6.775 & TST & & \\
\hline CHEMBL 3934072 & 1641575 & 8.0458 & 7.3436 & TRN & & \\
\hline CHEMBL 3909409 & 1641575 & 8.3979 & 7.58 & TRN & & \\
\hline CHEMBL 3901111 & 1641575 & 5.7852 & 5.732 & TRN & & \\
\hline CHEMBL 3893088 & 1641575 & 6.0635 & 6.4029 & TRN & & \\
\hline CHEMBL 3974711 & 1641575 & 6.0227 & 7.1697 & TRN & & \\
\hline CHEMBL 3931671 & 1641575 & 5.8416 & 6.0525 & TST & & \\
\hline CHEMBL 3979637 & 1641575 & 7.1079 & 6.7763 & TRN & & \\
\hline CHEMBL 3903597 & 1641575 & 7.699 & 7.2814 & TRN & & \\
\hline CHEMBL 3903887 & 1641575 & 7.8861 & 7.8314 & TRN & & \\
\hline CHEMBL 3895085 & 1641575 & 5.5482 & 5.6745 & TRN & & \\
\hline CHEMBL 3941363 & 1641575 & 5.7645 & 6.3576 & TST & & \\
\hline CHEMBL 3918137 & 1641575 & 6.6635 & 5.4638 & TRN & & \\
\hline CHEMBL 3962780 & 1641575 & 7.3565 & 7.1744 & TRN & & \\
\hline CHEMBL 3951883 & 1641575 & 5.7423 & 5.5612 & TST & & \\
\hline CHEMBL 3949024 & 1641575 & 6.20200 & 00000000 & 1 & 6.3012 & TRA \\
\hline CHEMBL 3957139 & 1641575 & 8.3979 & 7.4333 & TRN & & \\
\hline CHEMBL 3965386 & 1641575 & 5.4283 & 6.2564 & TST & & \\
\hline CHEMBL 3938805 & 1641575 & 6.0 & 6.8862 & TST & & \\
\hline CHEMBL 3890039 & 1641575 & 8.0458 & 6.9395 & TRN & & \\
\hline CHEMBL 3893083 & 1641575 & 6.2343 & 5.9353 & TST & & \\
\hline CHEMBL 3897144 & 1641575 & 6.4828 & 5.3495 & TRN & & \\
\hline CHEMBL 3917572 & 1641575 & 7.3565 & 6.8097 & TRN & & \\
\hline CHEMBL 3891093 & 1641575 & 7.8539 & 7.2689 & TRN & & \\
\hline CHEMBL 3908514 & 1641575 & 5.9805 & 6.1583 & TRN & & \\
\hline CHEMBL 3962108 & 1641575 & 7.6576 & 6.8382 & TRN & & \\
\hline CHEMBL 3953260 & 1641575 & 5.7089 & 6.609 & TST & & \\
\hline CHEMBL 3910316 & 1641575 & 5.0 & 6.0969 & TST & & \\
\hline CHEMBL 3897384 & 1641575 & 6.3737 & 5.7896 & TST & & \\
\hline CHEMBL 3899664 & 1641575 & 7.5229 & 7.3856 & TRN & & \\
\hline CHEMBL 3966215 & 1641575 & 5.1758 & 5.9735 & TST & & \\
\hline CHEMBL 3970736 & 1641575 & 6.3925 & 6.5695 & TRN & & \\
\hline CHEMBL 3947926 & 1641575 & 7.2147 & 6.8223 & TRN & & \\
\hline CHEMBL 3978984 & 1641575 & 6.8601 & 6.6795 & TRN & & \\
\hline CHEMBL 3921613 & 1641575 & 6.24799 & 999999999 & 99 & 7.2484 & TST \\
\hline CHEMBL 3892756 & 1641575 & 6.0 & 7.5543 & TRN & & \\
\hline CHEMBL 3917679 & 1641575 & 5.063 & 5.6915 & TRN & & \\
\hline CHEMBL 3967462 & 1641575 & 6.3179 & 6.9353 & TRN & & \\
\hline CHEMBL 3964095 & 1641575 & 6.4802 & 6.4749 & TST & & \\
\hline CHEMBL 3908253 & 1641575 & 6.9208 & 7.0375 & TRN & & \\
\hline CHEMBL 3972688 & 1641575 & 7.4202 & 6.4247 & TST & & \\
\hline CHEMBL 3920427 & 1641575 & 5.5513 & 5.3014 & TST & & \\
\hline CHEMBL 3966991 & 1641575 & 6.0 & 7.0265 & TRN & & \\
\hline CHEMBL 3910841 & 1641575 & 6.0 & 6.7091 & TRN & & \\
\hline CHEMBL 3980819 & 1641575 & 6.0 & 7.0878 & TRN & & \\
\hline
\end{tabular}


Supplemental Table S2.txt

\begin{tabular}{|c|c|c|c|c|c|}
\hline CHEMBL3902493 & 1641575 & 7.5229 & 6.6806 & TRN & \\
\hline CHEMBL3912613 & 1641575 & 8.301 & 7.4928 & TRN & \\
\hline CHEMBL3916239 & 1641575 & 6.0013 & 6.4278 & TRN & \\
\hline CHEMBL3958373 & 1641575 & 5.7055 & 6.0015 & TST & \\
\hline CHEMBL3935318 & 1641575 & 6.0 & 7.0658 & TRN & \\
\hline CHEMBL3961651 & 1641575 & 6.0 & 6.2461 & TST & \\
\hline CHEMBL 3927684 & 1641575 & 6.0 & 5.8701 & TRN & \\
\hline CHEMBL3941582 & 1641575 & 7.2441 & 6.6702 & TRN & \\
\hline CHEMBL3956267 & 1641575 & 5.0595 & 6.4645 & TRN & \\
\hline CHEMBL3950388 & 1641575 & 7.699 & 7.5304 & TRN & \\
\hline CHEMBL3986397 & 1641575 & 7.9586 & 7.1289 & TRN & \\
\hline CHEMBL3946029 & 1641575 & 5.4724 & 6.1349 & TRN & \\
\hline CHEMBL3901600 & 1641575 & 6.0 & 5.9416 & TST & \\
\hline CHEMBL3937507 & 1641575 & 6.0 & 7.42700 & 00000000005 & TRN \\
\hline CHEMBL3923061 & 1641575 & 5.8545 & 5.6154 & TRN & \\
\hline CHEMBL3972873 & 1641575 & 6.0 & 7.0585 & TRN & \\
\hline CHEMBL3909203 & 1641575 & 6.0227 & 6.1334 & TST & \\
\hline CHEMBL3894168 & 1641575 & 6.5686 & 6.6933 & TRN & \\
\hline CHEMBL3916633 & 1641575 & 7.5086 & 7.0899 & TRN & \\
\hline CHEMBL3965617 & 1641575 & 7.585 & 7.3523 & TRN & \\
\hline CHEMBL3966015 & 1641575 & 7.3098 & 7.142 & TRN & \\
\hline CHEMBL3946745 & 1641575 & 5.4441 & 6.0457 & TST & \\
\hline CHEMBL3929073 & 1641575 & 6.0 & 6.7024 & TRN & \\
\hline CHEMBL3916930 & 1641575 & 5.3575 & 6.7705 & TRN & \\
\hline CHEMBL3947569 & 1641575 & 5.1772 & 5.7415 & TRN & \\
\hline CHEMBL3968349 & 1641575 & 5.4949 & 6.546 & TST & \\
\hline CHEMBL3976878 & 1641575 & 5.2924 & 5.8495 & TST & \\
\hline CHEMBL3961860 & 1641575 & 7.6778 & 7.4858 & TRN & \\
\hline CHEMBL3953230 & 1641575 & 6.0 & 6.9863 & TRN & \\
\hline CHEMBL3909728 & 1641575 & 6.8477 & 6.1107 & TRN & \\
\hline CHEMBL3903672 & 1641575 & 6.0 & 7.692 & TRN & \\
\hline CHEMBL3952929 & 1641575 & 6.6737 & 6.7396 & TRN & \\
\hline CHEMBL3958465 & 1641575 & 7.8239 & 7.194 & TRN & \\
\hline CHEMBL 3964188 & 1641575 & 6.8182 & 6.9336 & TRN & \\
\hline CHEMBL3893005 & 1641575 & 6.0 & 6.6813 & TST & \\
\hline CHEMBL3890057 & 1641575 & 7.3565 & 7.0849 & TRN & \\
\hline CHEMBL3938042 & 1641575 & 9.0 & 7.689 & TRN & \\
\hline CHEMBL3974510 & 1641575 & 8.3979 & 7.4184 & TRN & \\
\hline CHEMBL3944213 & 1641575 & 5.7783 & \multicolumn{2}{|c|}{6.452000000000001} & TST \\
\hline CHEMBL3913028 & 1641575 & 6.1785 & 6.8986 & TRN & \\
\hline CHEMBL3908632 & 1641575 & 6.9066 & 6.6187 & TRN & \\
\hline CHEMBL416394 & 159768 & 3.0 & 4.4554 & TRN & \\
\hline CHEMBL 29472 & 159768 & 7.9208 & 7.479 & TRN & \\
\hline CHEMBL282084 & 159768 & 6.4685 & 7.524 & TRN & \\
\hline CHEMBL29424 & 159768 & 7.5376 & 6.8131 & TRN & \\
\hline CHEMBL 287170 & 159768 & 5.9626 & 5.6559 & TST & \\
\hline CHEMBL29439 & 159768 & 7.7959 & 7.0574 & TRN & \\
\hline CHEMBL430728 & 159768 & 3.0 & 3.843 & TRN & \\
\hline
\end{tabular}




\begin{tabular}{|c|c|c|c|c|c|}
\hline \multirow[b]{2}{*}{ CHEMBL280636 } & \multicolumn{5}{|c|}{ suppte } \\
\hline & 159768 & 8.2757 & 8.2906 & TST & \\
\hline CHEMBL28084 & 159768 & 3.0 & 4.797 & TRN & \\
\hline CHEMBL 29423 & 159768 & 7.0 & 7.2297 & TRN & \\
\hline CHEMBL29456 & 159768 & 6.4559 & 5.9953 & TRN & \\
\hline CHEMBL 29920 & 159768 & 7.4949 & 5.9939 & TRN & \\
\hline CHEMBL282390 & 159768 & 3.0 & 4.5767 & TRN & \\
\hline CHEMBL283388 & 159768 & 6.1938 & 6.6634 & TRN & \\
\hline CHEMBL 29333 & 159768 & 3.0 & 3.6492 & TRN & \\
\hline CHEMBL283633 & 159768 & 7.284 & 6.1305 & TST & \\
\hline CHEMBL29133 & 159768 & 7.6576 & 8.0045 & TST & \\
\hline CHEMBL282301 & 159768 & 7.3098 & 5.7143 & TST & \\
\hline CHEMBL29899 & 159768 & 8.2441 & 8.2991 & TRN & \\
\hline CHEMBL284914 & 159768 & 5.3197 & 5.1187 & TRN & \\
\hline CHEMBL 28664 & 159768 & 5.58 & 5.5576 & TRN & \\
\hline CHEMBL29839 & 159768 & 8.0969 & 8.9122 & TRN & \\
\hline CHEMBL274990 & 159768 & 7.0 & 3.3325 & TRN & \\
\hline CHEMBL282752 & 159768 & 5.4461 & 4.5343 & TST & \\
\hline CHEMBL30084 & 159768 & 7.5686 & 7.7266 & TRN & \\
\hline CHEMBL29562 & 159768 & 6.0506 & 6.00200 & 0000000001 & TRN \\
\hline CHEMBL 743 & 159768 & 4.9508 & 3.8525 & TRN & \\
\hline CHEMBL29083 & 159768 & 7.5528 & 7.00299 & 9999999999 & TST \\
\hline CHEMBL287447 & 159768 & 6.4685 & 6.8138 & TST & \\
\hline CHEMBL280772 & 159768 & 3.0 & 5.2882 & TRN & \\
\hline CHEMBL 29844 & 159768 & 7.1805 & 6.7146 & TRN & \\
\hline CHEMBL29620 & 159768 & 5.1118 & 6.1263 & TRN & \\
\hline CHEMBL 745 & 159768 & 4.0301 & 4.0747 & TRN & \\
\hline CHEMBL29445 & 159768 & 6.8861 & 5.5881 & TRN & \\
\hline CHEMBL29943 & 159768 & 3.0 & 4.0217 & TRN & \\
\hline CHEMBL29766 & 159768 & 8.7696 & 6.8094 & TST & \\
\hline CHEMBL29583 & 159768 & 8.1739 & 8.9122 & TRN & \\
\hline CHEMBL281001 & 159768 & 4.7033 & 5.91200 & 0000000001 & TST \\
\hline CHEMBL281694 & 159768 & 7.6198 & 8.1825 & TRN & \\
\hline CHEMBL 29575 & 159768 & 3.0 & 4.2475 & TRN & \\
\hline CHEMBL281504 & 159768 & 4.5272 & 4.9541 & TRN & \\
\hline CHEMBL 28801 & 159768 & 6.0655 & 6.3581 & TRN & \\
\hline CHEMBL29075 & 159768 & 4.341 & 5.2312 & TRN & \\
\hline CHEMBL280573 & 159768 & 4.327 & 4.6472 & TST & \\
\hline CHEMBL282838 & 159768 & 6.0809 & 4.8103 & TRN & \\
\hline CHEMBL 29492 & 159768 & 4.202 & 4.7355 & TRN & \\
\hline CHEMBL29942 & 159768 & 6.5376 & 5.4671 & TRN & \\
\hline CHEMBL29697 & 159768 & 3.0 & 4.2553 & TRN & \\
\hline CHEMBL30011 & 159768 & 6.1249 & 6.3477 & TRN & \\
\hline CHEMBL28881 & 159768 & 8.3279 & 8.0248 & TRN & \\
\hline CHEMBL283086 & 159768 & 7.5528 & 6.9801 & TST & \\
\hline CHEMBL29469 & 159768 & 6.6383 & 7.2799 & TRN & \\
\hline CHEMBL27975 & 159768 & 7.5086 & 6.4386 & TST & \\
\hline CHEMBL 29842 & 159768 & 7.0969 & 4.9583 & TST & \\
\hline CHEMBL29662 & 159768 & 3.0 & 5.0284 & TST & \\
\hline & & & & 10591 & \\
\hline
\end{tabular}




\begin{tabular}{|c|c|c|c|c|}
\hline & & & oplement & al $\mathrm{T}$ \\
\hline CHEMBL286756 & 159768 & 6.9208 & 5.5682 & TRN \\
\hline CHEMBL282839 & 159768 & 7.6778 & 8.5412 & TRN \\
\hline CHEMBL 27733 & 159768 & 4.8447 & 5.8953 & TRN \\
\hline CHEMBL281978 & 159768 & 7.2518 & 6.3928 & TRN \\
\hline CHEMBL433428 & 159768 & 8.0 & 6.9041 & TRN \\
\hline CHEMBL282085 & 159768 & 7.8239 & 7.0063 & TRN \\
\hline CHEMBL 29576 & 159768 & 4.0 & 4.4728 & TRN \\
\hline CHEMBL281975 & 159768 & 7.8861 & 6.5973 & TRN \\
\hline CHEMBL 29717 & 159768 & 7.8239 & 7.3562 & TRN \\
\hline CHEMBL28491 & 159768 & 6.7959 & 6.6328 & TST \\
\hline CHEMBL406140 & 159768 & 4.3468 & 4.8499 & TRN \\
\hline CHEMBL 29887 & 159768 & 8.0315 & 7.3249 & TRN \\
\hline CHEMBL29403 & 159768 & 7.284 & 7.3772 & TST \\
\hline CHEMBL 282360 & 159768 & 6.2218 & 6.1991 & TRN \\
\hline CHEMBL283497 & 159768 & 7.2518 & 7.12 & TRN \\
\hline CHEMBL287646 & 159768 & 7.6778 & 6.3312 & TRN \\
\hline CHEMBL29136 & 159768 & 6.4685 & 5.1521 & TRN \\
\hline CHEMBL280601 & 159768 & 6.5376 & 5.4615 & TST \\
\hline CHEMBL28662 & 159768 & 3.0 & 3.5621 & TRN \\
\hline CHEMBL30091 & 159768 & 7.0757 & 5.1659 & TST \\
\hline CHEMBL29941 & 159768 & 3.0 & 5.4677 & TST \\
\hline CHEMBL 29840 & 159768 & 8.0 & 7.3136 & TST \\
\hline CHEMBL285335 & 159768 & 6.699 & 5.0642 & TRN \\
\hline CHEMBL29397 & 159768 & 6.4559 & 6.2058 & TRN \\
\hline CHEMBL28487 & 159768 & 4.5272 & 5.6516 & TST \\
\hline CHEMBL28528 & 159768 & 7.1192 & 4.6816 & TST \\
\hline CHEMBL283038 & 159768 & 6.9208 & 6.0645 & TRN \\
\hline CHEMBL28599 & 159768 & 7.1612 & 5.9834 & TRN \\
\hline CHEMBL29204 & 159768 & 6.1249 & 5.5953 & TRN \\
\hline CHEMBL285567 & 159768 & 3.0 & 1.6689 & TRN \\
\hline CHEMBL283178 & 159768 & 8.0458 & 7.8483 & TRN \\
\hline CHEMBL 28913 & 159768 & 8.4318 & 8.3652 & TRN \\
\hline CHEMBL283177 & 159768 & 7.585 & 7.3761 & TRN \\
\hline CHEMBL29257 & 159768 & 8.0 & 7.9792 & TRN \\
\hline CHEMBL282391 & 159768 & 3.0 & 4.2215 & TRN \\
\hline CHEMBL285831 & 159768 & 5.0846 & 5.0244 & TRN \\
\hline CHEMBL282093 & 159768 & 8.0 & 7.271 & TRN \\
\hline CHEMBL440798 & 159768 & 4.3298 & 3.4311 & TRN \\
\hline CHEMBL26915 & 159768 & 4.1255 & 6.3477 & TRN \\
\hline CHEMBL283425 & 159768 & 4.1891 & 4.7357 & TRN \\
\hline CHEMBL29923 & 159768 & 6.9586 & 6.9454 & TRN \\
\hline CHEMBL286277 & 159768 & 5.3316 & 5.4116 & TST \\
\hline CHEMBL 30200 & 159768 & 3.0 & 4.306 & TRN \\
\hline CHEMBL29533 & 159768 & 7.2518 & 6.569 & TRN \\
\hline CHEMBL286256 & 159768 & 3.0 & 5.4106 & TRN \\
\hline CHEMBL29847 & 159768 & 5.4828 & 5.1178 & TRN \\
\hline CHEMBL29500 & 159768 & 7.5086 & 7.21 & TRN \\
\hline CHEMBL28545 & 159768 & 4.1549 & 4.8884 & TST \\
\hline
\end{tabular}




\begin{tabular}{|c|c|c|c|c|c|}
\hline \multicolumn{6}{|c|}{ Supplemental Table S2.txt } \\
\hline CHEMBL30236 & 159768 & 6.3665 & 6.9618 & TRN & \\
\hline CHEMBL418574 & 159768 & 7.2366 & 6.23 & TST & \\
\hline CHEMBL286953 & 159768 & 7.5686 & 7.2019 & TST & \\
\hline CHEMBL612000 & 436468 & 4.301 & 4.2254 & TST & \\
\hline CHEMBL227929 & 436468 & 3.0 & 4.2385 & TRN & \\
\hline CHEMBL390528 & 436468 & 5.2218 & 5.439 & TRN & \\
\hline CHEMBL226156 & 436468 & 4.301 & 3.6977 & TRN & \\
\hline CHEMBL611733 & 436468 & 4.3979 & $3.85699 \mathrm{~s}$ & 99999999998 & TST \\
\hline CHEMBL438657 & 436468 & 4.1549 & 4.6581 & TST & \\
\hline CHEMBL226157 & 436468 & 4.0458 & 4.3367 & TST & \\
\hline CHEMBL226813 & 436468 & 4.4559 & 5.3747 & TRN & \\
\hline CHEMBL227820 & 436468 & 3.0 & 3.8117 & TRN & \\
\hline CHEMBL228097 & 436468 & 7.4559 & 4.6684 & TRN & \\
\hline CHEMBL389008 & 436468 & 3.0 & 3.3378 & TRN & \\
\hline CHEMBL226187 & 436468 & 4.2596 & 4.3539 & TST & \\
\hline CHEMBL374386 & 436468 & 4.5452 & 5.2444 & TRN & \\
\hline CHEMBL227873 & 436468 & 3.0 & 3.8194 & TRN & \\
\hline CHEMBL227191 & 436468 & 4.301 & 4.4256 & TST & \\
\hline CHEMBL389850 & 436468 & 3.0 & 3.305 & TRN & \\
\hline CHEMBL376617 & 436468 & 5.0 & 4.1449 & TRN & \\
\hline CHEMBL390063 & 436468 & 3.0 & 3.0219 & TRN & \\
\hline CHEMBL227300 & 436468 & 4.2218 & 4.2268 & TST & \\
\hline CHEMBL376618 & 436468 & 6.0605 & 4.4244 & TRN & \\
\hline CHEMBL227982 & 436468 & 3.301 & 3.6358 & TRN & \\
\hline CHEMBL227563 & 436468 & 6.0605 & 5.3853 & TRN & \\
\hline CHEMBL227536 & 436468 & 3.0 & 3.3639 & TRN & \\
\hline CHEMBL227299 & 436468 & 4.2218 & 4.3411 & TST & \\
\hline CHEMBL228154 & 436468 & 3.0 & 4.2672 & TRN & \\
\hline CHEMBL390086 & 436468 & 3.0 & 3.8999 & TRN & \\
\hline CHEMBL227535 & 436468 & 3.0 & 3.0868 & TRN & \\
\hline CHEMBL390087 & 436468 & 3.0 & 4.2353 & TRN & \\
\hline CHEMBL227534 & 436468 & 3.0 & 3.6583 & TRN & \\
\hline CHEMBL228041 & 436468 & 4.6021 & 4.8226 & TRN & \\
\hline CHEMBL226052 & 436468 & 4.1249 & 4.7118 & TST & \\
\hline CHEMBL228040 & 436468 & 5.8239 & 3.8979 & TRN & \\
\hline CHEMBL390064 & 436468 & 3.0 & 3.9877 & TRN & \\
\hline CHEMBL227243 & 436468 & 4.284 & 4.3956 & TST & \\
\hline CHEMBL227620 & 436468 & 5.2147 & 5.3503 & TRN & \\
\hline CHEMBL228039 & 436468 & 6.0605 & 4.7828 & TRN & \\
\hline CHEMBL388950 & 436468 & 3.0 & 4.7473 & TRN & \\
\hline CHEMBL228098 & 436468 & 6.0605 & 4.9171 & TRN & \\
\hline CHEMBL227930 & 436468 & 3.301 & 3.8513 & TRN & \\
\hline CHEMBL227675 & 436468 & 4.699 & 4.254 & TRN & \\
\hline CHEMBL227593 & 436468 & 3.0 & 3.2735 & TRN & \\
\hline CHEMBL222215 & 436468 & 4.0 & 3.5797 & TRN & \\
\hline CHEMBL227874 & 436468 & 3.0 & 3.8794 & TRN & \\
\hline CHEMBL227981 & 436468 & 6.0605 & 4.0921 & TRN & \\
\hline CHEMBL388951 & 436468 & 3.0 & 4.6891 & TRN & \\
\hline
\end{tabular}




\begin{tabular}{|c|c|c|c|c|}
\hline \multicolumn{5}{|c|}{ Supplemental Table S2.txt } \\
\hline CHEMBL374387 & 436468 & 3.0 & 4.6666 & TRN \\
\hline CHEMBL226812 & 436468 & 4.5193 & 4.6909 & TRN \\
\hline CHEMBL425480 & 436468 & 5.1871 & 3.6477 & TRN \\
\hline CHEMBL 228100 & 436468 & 6.0605 & 4.8037 & TRN \\
\hline CHEMBL228189 & 436468 & 3.0 & 3.3233 & TRN \\
\hline CHEMBL227647 & 436468 & 5.1549 & 3.3378 & TRN \\
\hline CHEMBL227619 & 436468 & 5.7696 & 5.2597 & TRN \\
\hline CHEMBL227618 & 436468 & 6.0088 & 5.2963 & TST \\
\hline CHEMBL227592 & 436468 & 4.3468 & 3.3568 & TST \\
\hline CHEMBL227591 & 436468 & 3.0 & 4.2336 & TST \\
\hline CHEMBL228099 & 436468 & 6.0605 & 4.7758 & TST \\
\hline CHEMBL1972840 & 809282 & 5.8 & 5.8592 & TRN \\
\hline CHEMBL1977148 & 809282 & 4.1 & 4.4271 & TRN \\
\hline CHEMBL 2003286 & 809282 & 4.1 & 4.1936 & TRN \\
\hline CHEMBL1992306 & 809282 & 4.1 & 4.4934 & TRN \\
\hline CHEMBL 2002165 & 809282 & 6.4 & 6.4979 & TRN \\
\hline CHEMBL2001668 & 809282 & 4.1 & 4.1733 & TST \\
\hline CHEMBL1979318 & 809282 & 4.1 & 4.9673 & TRN \\
\hline CHEMBL206382 & 809282 & 4.1 & 4.101 & TRN \\
\hline CHEMBL1998585 & 809282 & 6.4 & 7.1751 & TRN \\
\hline CHEMBL519697 & 809282 & 5.3 & 4.7368 & TST \\
\hline CHEMBL 2004934 & 809282 & 4.1 & 4.2168 & TRN \\
\hline CHEMBL1975128 & 809282 & 6.5 & 6.6329 & TRN \\
\hline CHEMBL1970369 & 809282 & 4.1 & 4.0883 & TRN \\
\hline CHEMBL2001485 & 809282 & 5.4 & 4.9359 & TRN \\
\hline CHEMBL504950 & 809282 & 5.3 & 5.0988 & TRN \\
\hline CHEMBL1984363 & 809282 & 5.6 & 5.437 & TRN \\
\hline CHEMBL1978099 & 809282 & 5.6 & 5.7268 & TRN \\
\hline CHEMBL1977041 & 809282 & 6.1 & 5.9001 & TRN \\
\hline CHEMBL1968070 & 809282 & 4.1 & 4.1915 & TRN \\
\hline CHEMBL1988608 & 809282 & 5.2 & 4.4774 & TRN \\
\hline CHEMBL184847 & 809282 & 4.1 & 4.4394 & TRN \\
\hline CHEMBL1984367 & 809282 & 4.1 & 4.6559 & TRN \\
\hline CHEMBL178737 & 809282 & 4.1 & 4.3648 & TST \\
\hline CHEMBL226898 & 809282 & 7.1 & 7.2156 & TRN \\
\hline CHEMBL1982563 & 809282 & 4.1 & 4.1398 & TRN \\
\hline CHEMBL575824 & 809282 & 4.2 & 4.5529 & TRN \\
\hline CHEMBL1988387 & 809282 & 6.4 & 6.2171 & TRN \\
\hline CHEMBL1997759 & 809282 & 4.1 & 4.2711 & TRN \\
\hline CHEMBL1990288 & 809282 & 4.1 & 4.002 & TRN \\
\hline CHEMBL1974803 & 809282 & 4.1 & 4.5708 & TST \\
\hline CHEMBL1970074 & 809282 & 5.2 & 5.2696 & TRN \\
\hline CHEMBL1986970 & 809282 & 5.6 & 5.4656 & TRN \\
\hline CHEMBL 2005112 & 809282 & 4.1 & 4.1034 & TST \\
\hline CHEMBL1984044 & 809282 & 5.5 & 4.8671 & TRN \\
\hline CHEMBL 2003456 & 809282 & 5.4 & 5.2012 & TRN \\
\hline CHEMBL1966816 & 809282 & 4.1 & 4.8922 & TRN \\
\hline CHEMBL1972584 & 809282 & 5.9 & 5.5837 & TRN \\
\hline
\end{tabular}




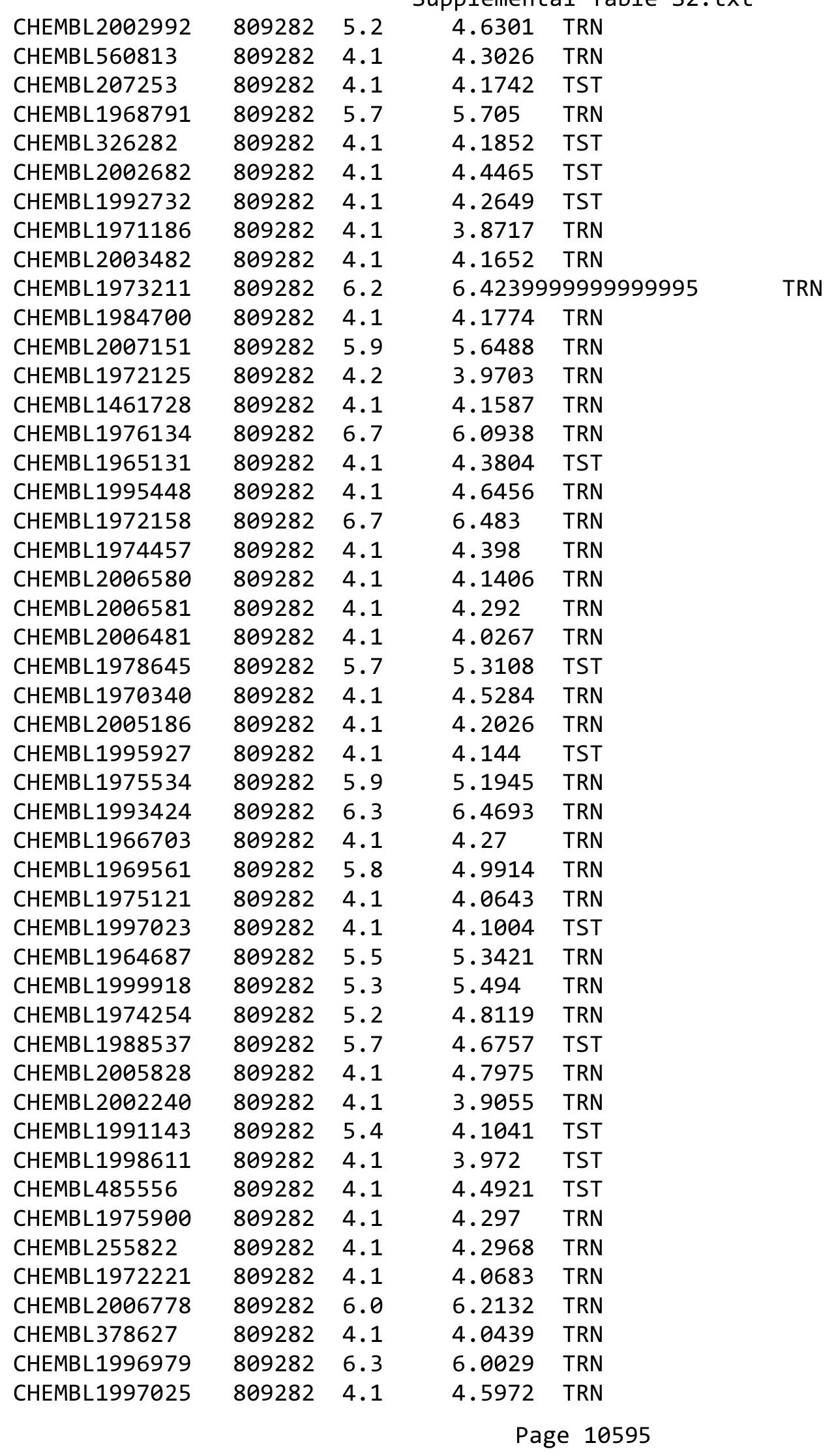




\begin{tabular}{|c|c|c|c|c|}
\hline \multicolumn{5}{|c|}{ Supplemental Table s2.txt } \\
\hline CHEMBL1968406 & 809282 & 6.0 & 5.6782 & TRN \\
\hline CHEMBL1982476 & 809282 & 6.4 & 6.4684 & TRN \\
\hline CHEMBL1984274 & 809282 & 5.5 & 5.09399 & 9999999999 \\
\hline CHEMBL1998545 & 809282 & 4.1 & 3.9387 & TRN \\
\hline CHEMBL1986869 & 809282 & 4.1 & 4.0362 & TST \\
\hline CHEMBL1682558 & 809282 & 4.1 & 4.2305 & TRN \\
\hline CHEMBL1990496 & 809282 & 4.1 & 4.0459 & TRN \\
\hline CHEMBL1997623 & 809282 & 5.2 & 4.8218 & TRN \\
\hline CHEMBL1993166 & 809282 & 4.1 & 4.9005 & TRN \\
\hline CHEMBL1967094 & 809282 & 5.6 & 5.6604 & TRN \\
\hline CHEMBL1966035 & 809282 & 4.1 & 3.9668 & TRN \\
\hline CHEMBL2003341 & 809282 & 4.1 & 4.0204 & TRN \\
\hline CHEMBL1992644 & 809282 & 5.2 & 4.7306 & TRN \\
\hline CHEMBL1992645 & 809282 & 5.5 & 4.2285 & TST \\
\hline CHEMBL1982992 & 809282 & 4.1 & 4.0345 & TRN \\
\hline CHEMBL1999590 & 809282 & 4.1 & 4.244 & TST \\
\hline CHEMBL1972276 & 809282 & 4.1 & 4.2262 & TRN \\
\hline CHEMBL1980489 & 809282 & 4.1 & 4.1502 & TRN \\
\hline CHEMBL1967116 & 809282 & 6.8 & 6.5603 & TRN \\
\hline CHEMBL2000832 & 809282 & 4.1 & 5.3695 & TRN \\
\hline CHEMBL1977814 & 809282 & 4.1 & 4.2336 & TST \\
\hline CHEMBL1970709 & 809282 & 4.1 & 4.1625 & TRN \\
\hline CHEMBL1969126 & 809282 & 4.1 & 4.209 & TRN \\
\hline CHEMBL1980896 & 809282 & 4.1 & 4.5114 & TRN \\
\hline CHEMBL1975208 & 809282 & 4.1 & 4.05 & TST \\
\hline CHEMBL1970104 & 809282 & 7.1 & 6.0302 & TRN \\
\hline CHEMBL1991429 & 809282 & 4.1 & 4.6601 & TRN \\
\hline CHEMBL1964777 & 809282 & 4.1 & 4.5978 & TRN \\
\hline CHEMBL1971149 & 809282 & 4.1 & 4.1454 & TRN \\
\hline CHEMBL1999714 & 809282 & 4.1 & 4.105 & TRN \\
\hline CHEMBL1987533 & 809282 & 4.1 & 4.1826 & TRN \\
\hline CHEMBL1994040 & 809282 & 4.1 & 4.0201 & TRN \\
\hline CHEMBL 388978 & 809282 & 8.1 & 8.8161 & TST \\
\hline CHEMBL579246 & 809282 & 5.5 & 5.3772 & TRN \\
\hline CHEMBL398951 & 809282 & 6.6 & 5.9858 & TST \\
\hline CHEMBL1982506 & 809282 & 5.2 & 4.4777 & TST \\
\hline CHEMBL2004716 & 809282 & 6.3 & 6.806 & TRN \\
\hline CHEMBL1968127 & 809282 & 4.1 & 3.9301 & TRN \\
\hline CHEMBL1975233 & 809282 & 4.2 & 3.9948 & TRN \\
\hline CHEMBL1985406 & 809282 & 5.6 & 4.7662 & TRN \\
\hline CHEMBL 207400 & 809282 & 4.1 & 4.143 & TST \\
\hline CHEMBL 2000894 & 809282 & 5.2 & 3.988 & TST \\
\hline CHEMBL1982135 & 809282 & 4.1 & 4.6495 & TRN \\
\hline CHEMBL1976090 & 809282 & 5.5 & 5.2058 & TRN \\
\hline CHEMBL1993243 & 809282 & 6.0 & 5.9277 & TRN \\
\hline CHEMBL1992922 & 809282 & 6.7 & 6.3118 & TRN \\
\hline CHEMBL399021 & 809282 & 5.9 & 5.8733 & TRN \\
\hline CHEMBL1997597 & 809282 & 5.3 & 5.184 & TRN \\
\hline
\end{tabular}




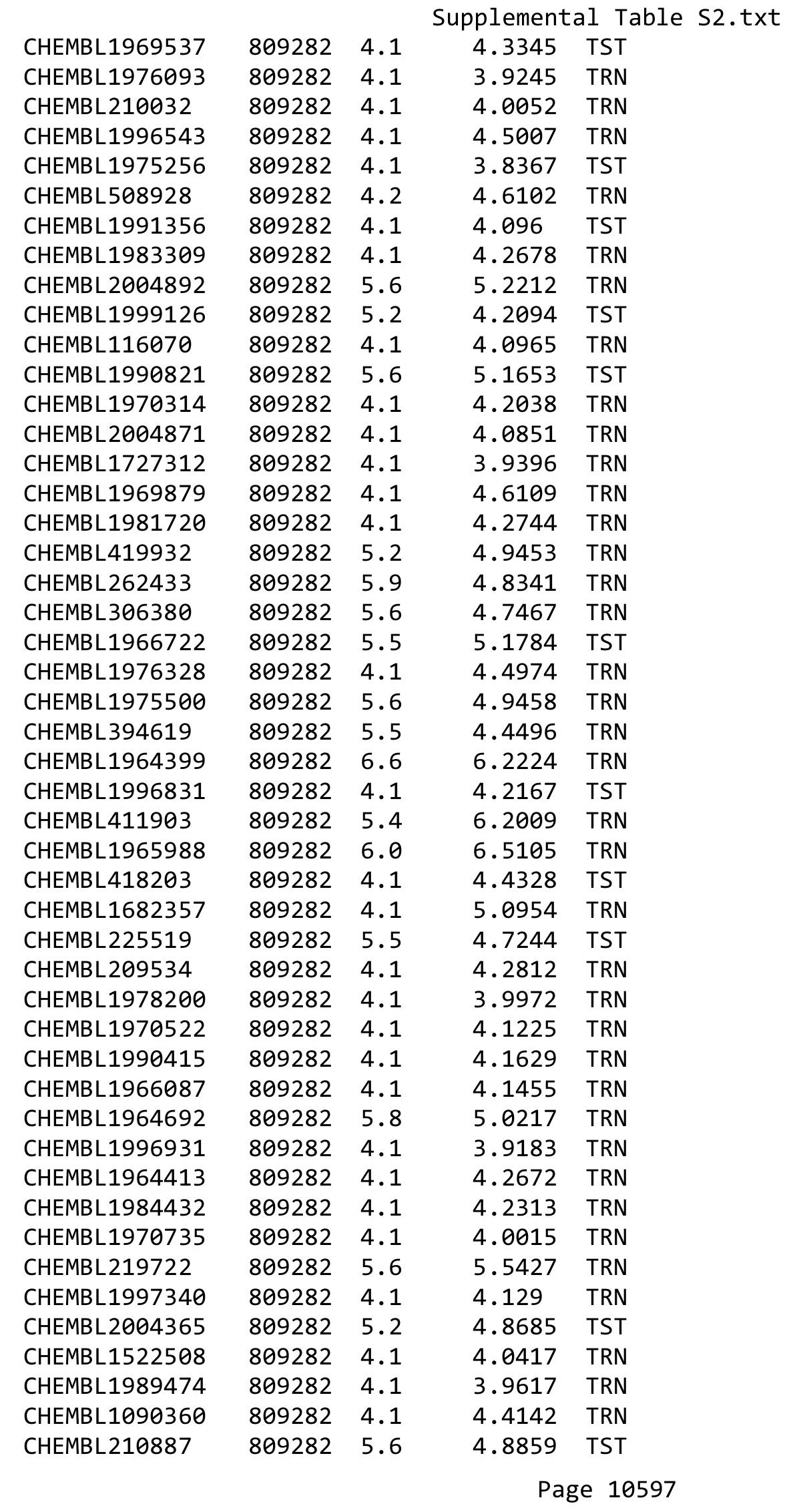




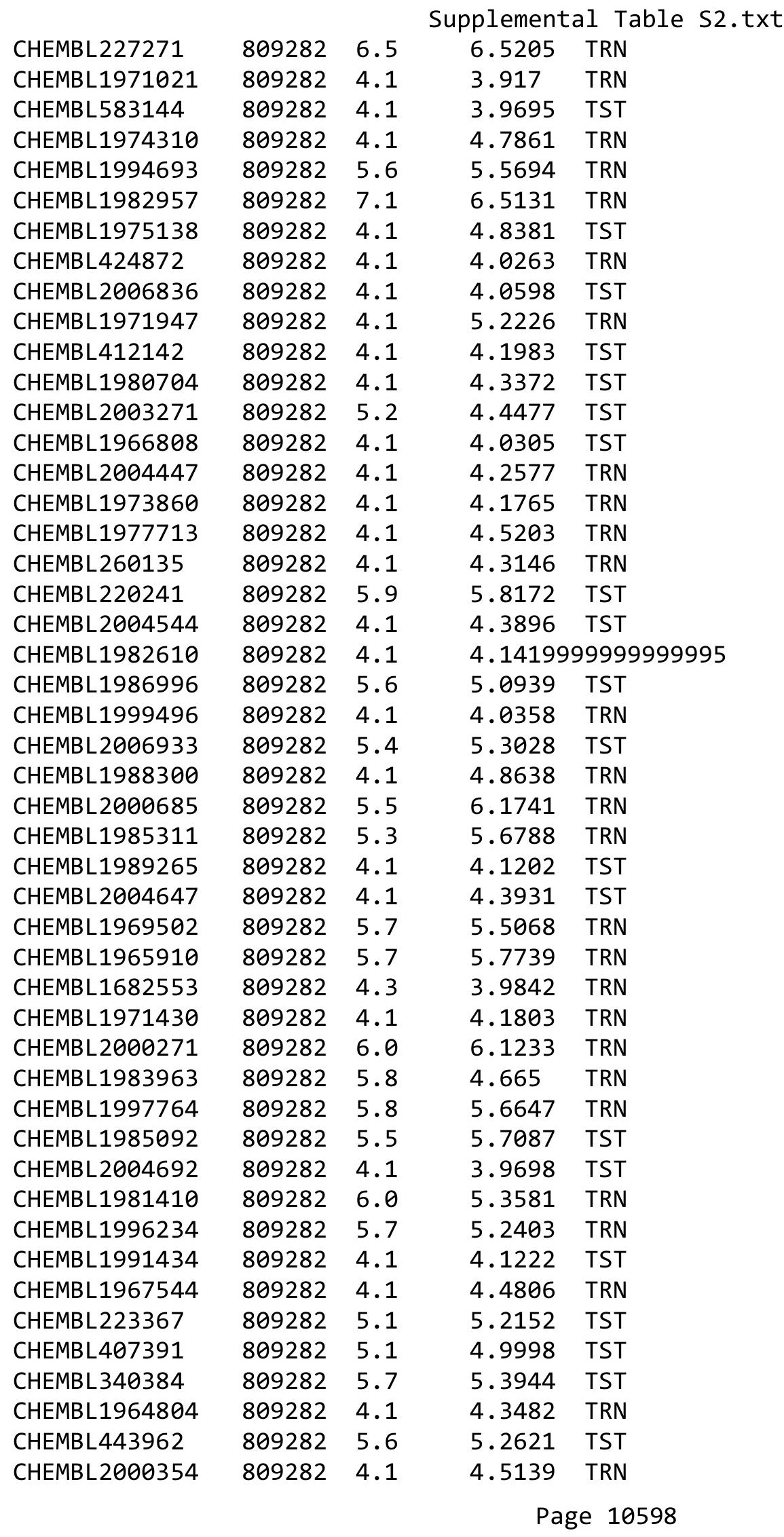




\begin{tabular}{|c|c|c|c|c|c|}
\hline \multicolumn{6}{|c|}{ Supplemental Table S2.txt } \\
\hline CHEMBL1965507 & 809282 & 6.6 & 6.2852 & TRN & \\
\hline CHEMBL274064 & 809282 & 4.1 & 4.521 & TRN & \\
\hline CHEMBL1967564 & 809282 & 4.1 & 3.9238 & TRN & \\
\hline CHEMBL592030 & 809282 & 7.3 & 7.267 & TST & \\
\hline CHEMBL 2000071 & 809282 & 6.4 & 6.1945 & TRN & \\
\hline CHEMBL1970317 & 809282 & 7.4 & 5.4746 & TRN & \\
\hline CHEMBL 2000408 & 809282 & 4.1 & 4.1304 & TRN & \\
\hline CHEMBL248757 & 809282 & 5.4 & 4.8479 & TST & \\
\hline CHEMBL1978014 & 809282 & 4.1 & 4.1975 & TRN & \\
\hline CHEMBL1990179 & 809282 & 5.8 & 4.4323 & TRN & \\
\hline CHEMBL1994538 & 809282 & 4.1 & 3.8716 & TRN & \\
\hline CHEMBL1983195 & 809282 & 4.1 & 4.109 & TST & \\
\hline CHEMBL1964444 & 809282 & 4.1 & 4.07600 & 00000000005 & TRN \\
\hline CHEMBL1989957 & 809282 & 4.1 & 4.1266 & TRN & \\
\hline CHEMBL 2006567 & 809282 & 4.1 & 3.9696 & TRN & \\
\hline CHEMBL1986139 & 809282 & 4.1 & 4.1344 & TRN & \\
\hline CHEMBL383527 & 809282 & 4.1 & 4.1063 & TRN & \\
\hline CHEMBL1980540 & 809282 & 4.1 & 3.9669 & TRN & \\
\hline CHEMBL1979883 & 809282 & 6.1 & 6.4386 & TRN & \\
\hline CHEMBL1984162 & 809282 & 7.8 & 7.5373 & TRN & \\
\hline CHEMBL491758 & 809282 & 5.6 & 5.7351 & TRN & \\
\hline CHEMBL549730 & 809282 & 4.3 & 4.2825 & TRN & \\
\hline CHEMBL1970189 & 809282 & 4.1 & 5.0374 & TRN & \\
\hline CHEMBL1996791 & 809282 & 4.1 & 5.1645 & TRN & \\
\hline CHEMBL371206 & 809282 & 6.0 & 4.9657 & TRN & \\
\hline CHEMBL1974664 & 809282 & 4.1 & 3.9687 & TST & \\
\hline CHEMBL1974288 & 809282 & 4.1 & 4.1712 & TRN & \\
\hline CHEMBL196363 & 809282 & 5.5 & 5.8782 & TRN & \\
\hline CHEMBL1990346 & 809282 & 5.7 & 5.5195 & TRN & \\
\hline CHEMBL404367 & 809282 & 4.1 & 4.2848 & TRN & \\
\hline CHEMBL1966343 & 809282 & 6.4 & 5.8739 & TRN & \\
\hline CHEMBL1967887 & 809282 & 5.4 & 5.1749 & TRN & \\
\hline CHEMBL 2000568 & 809282 & 5.8 & 5.4408 & TRN & \\
\hline CHEMBL 2000335 & 809282 & 6.7 & 6.3854 & TRN & \\
\hline CHEMBL1977604 & 809282 & 4.1 & 4.0513 & TST & \\
\hline CHEMBL1988717 & 809282 & 4.1 & 4.5037 & TRN & \\
\hline CHEMBL1985507 & 809282 & 5.4 & 4.7567 & TRN & \\
\hline CHEMBL573339 & 809282 & 4.1 & 4.7854 & TRN & \\
\hline CHEMBL1973808 & 809282 & 4.1 & 3.9843 & TRN & \\
\hline CHEMBL 2000429 & 809282 & 4.1 & 4.2812 & TRN & \\
\hline CHEMBL1972576 & 809282 & 6.3 & 6.2122 & TRN & \\
\hline CHEMBL1992555 & 809282 & 4.1 & 4.0639 & TST & \\
\hline CHEMBL1989069 & 809282 & 5.4 & 4.7357 & TST & \\
\hline CHEMBL1992342 & 809282 & 5.3 & 5.0749 & TRN & \\
\hline CHEMBL1988173 & 809282 & 5.3 & 5.282 & TST & \\
\hline CHEMBL535331 & 809282 & 4.1 & 4.12 & TRN & \\
\hline CHEMBL1989805 & 809282 & 5.2 & 3.8894 & TST & \\
\hline CHEMBL1965423 & 809282 & 4.1 & 4.1588 & TRN & \\
\hline
\end{tabular}




\begin{tabular}{|c|c|c|c|c|}
\hline & & & ipplement & al Table S \\
\hline CHEMBL1982980 & 809282 & 5.7 & 5.1844 & TST \\
\hline CHEMBL1983025 & 809282 & 6.3 & 6.3128 & TRN \\
\hline CHEMBL 205415 & 809282 & 5.6 & 4.18 & TRN \\
\hline CHEMBL1977135 & 809282 & 4.1 & 4.1099 & TRN \\
\hline CHEMBL2001920 & 809282 & 5.6 & 5.1995 & TRN \\
\hline CHEMBL2002322 & 809282 & 4.1 & 4.4919 & TRN \\
\hline CHEMBL1241473 & 809282 & 7.8 & 7.8569 & TRN \\
\hline CHEMBL2002323 & 809282 & 4.1 & 4.1687 & TST \\
\hline CHEMBL 2004513 & 809282 & 4.1 & 4.3149 & TRN \\
\hline CHEMBL1972258 & 809282 & 4.1 & 4.0637 & TRN \\
\hline CHEMBL2001257 & 809282 & 6.0 & 6.0843 & TRN \\
\hline CHEMBL1992536 & 809282 & 4.1 & 4.0659 & TRN \\
\hline CHEMBL1987793 & 809282 & 5.7 & 5.32700 & 0000000001 \\
\hline CHEMBL1992740 & 809282 & 4.1 & 3.983 & TRN \\
\hline CHEMBL2002373 & 809282 & 4.1 & 4.1946 & TRN \\
\hline CHEMBL2006188 & 809282 & 4.1 & 4.751 & TRN \\
\hline CHEMBL1967531 & 809282 & 6.2 & 6.1059 & TRN \\
\hline CHEMBL1970913 & 809282 & 4.1 & 3.9865 & TRN \\
\hline CHEMBL1973893 & 809282 & 4.1 & 4.0968 & TRN \\
\hline CHEMBL1995736 & 809282 & 4.1 & 4.166 & TRN \\
\hline CHEMBL1996500 & 809282 & 4.1 & 4.1623 & TRN \\
\hline CHEMBL1985095 & 809282 & 6.7 & 6.655 & TST \\
\hline CHEMBL1998551 & 809282 & 4.1 & 3.9999 & TRN \\
\hline CHEMBL1977374 & 809282 & 4.1 & 4.056 & TRN \\
\hline CHEMBL1991180 & 809282 & 6.3 & 5.8596 & TST \\
\hline CHEMBL1682540 & 809282 & 4.1 & 4.2303 & TRN \\
\hline CHEMBL1978656 & 809282 & 4.1 & 4.2826 & TRN \\
\hline CHEMBL1994864 & 809282 & 4.1 & 4.1444 & TRN \\
\hline CHEMBL413779 & 809282 & 5.8 & 6.609 & TST \\
\hline CHEMBL 2002446 & 809282 & 4.1 & 4.9079 & TST \\
\hline CHEMBL497151 & 809282 & 5.2 & 5.2803 & TRN \\
\hline CHEMBL 246970 & 809282 & 5.2 & 4.6591 & TRN \\
\hline CHEMBL 340921 & 809282 & 4.1 & 4.1427 & TST \\
\hline CHEMBL373598 & 809282 & 4.1 & 6.681 & TST \\
\hline CHEMBL1276446 & 809282 & 7.2 & 6.8632 & TST \\
\hline CHEMBL1977346 & 809282 & 4.1 & 4.8293 & TRN \\
\hline CHEMBL1971649 & 809282 & 4.1 & 4.0568 & TRN \\
\hline CHEMBL2003657 & 809282 & 4.1 & 4.1474 & TRN \\
\hline CHEMBL1998435 & 809282 & 4.1 & 3.9651 & TRN \\
\hline CHEMBL2006156 & 809282 & 5.3 & 4.2517 & TST \\
\hline CHEMBL1969190 & 809282 & 6.2 & 5.7377 & TRN \\
\hline CHEMBL1973937 & 809282 & 5.5 & 5.4707 & TRN \\
\hline CHEMBL1982711 & 809282 & 6.8 & 6.0106 & TRN \\
\hline CHEMBL1969102 & 809282 & 6.1 & 6.4332 & TRN \\
\hline CHEMBL 2007044 & 809282 & 5.6 & 5.5811 & TST \\
\hline CHEMBL2001998 & 809282 & 6.6 & 5.938 & TST \\
\hline CHEMBL1994241 & 809282 & 5.2 & 4.9961 & TRN \\
\hline CHEMBL223460 & 809282 & 4.1 & 4.8673 & TST \\
\hline
\end{tabular}




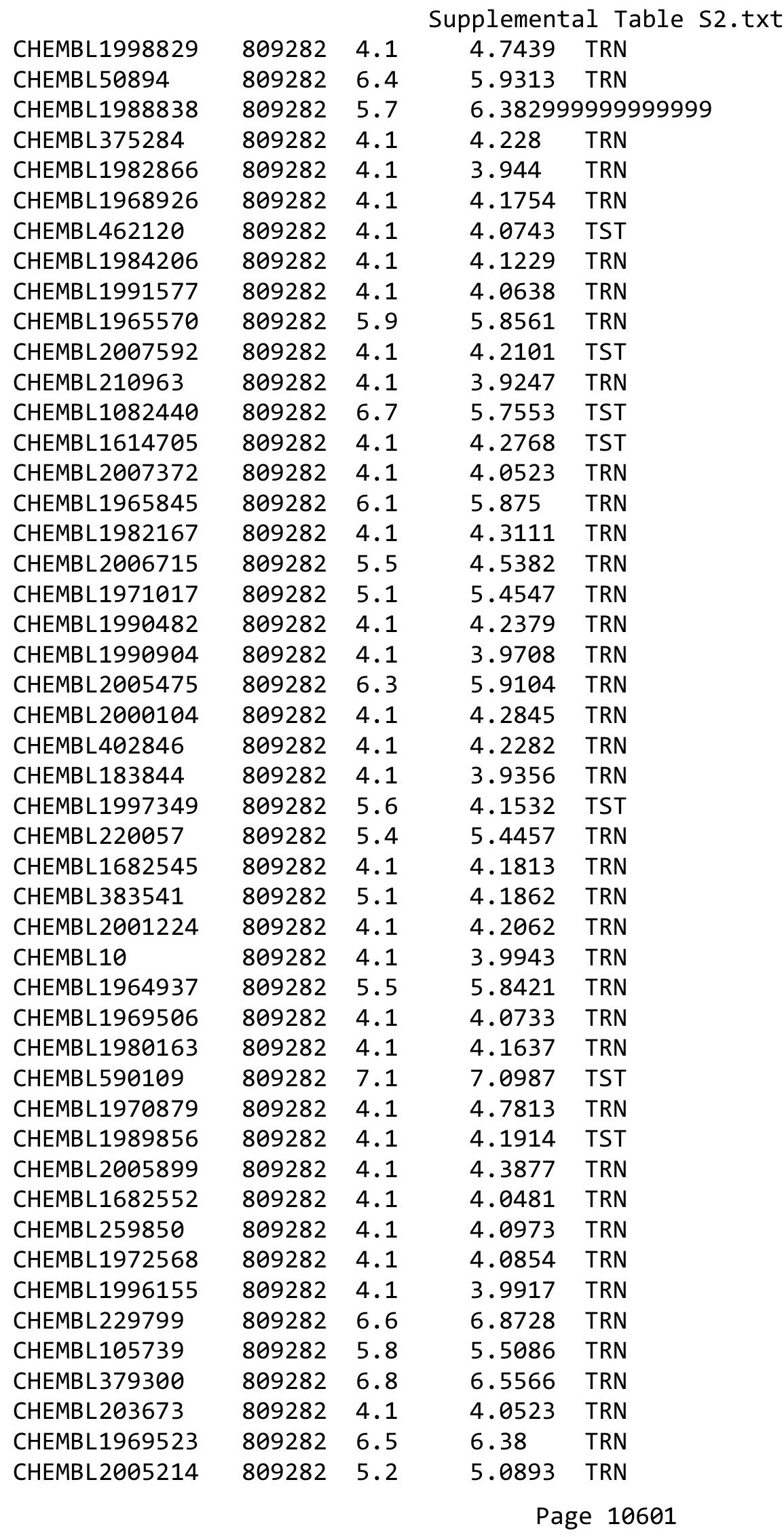

TRN 


\begin{tabular}{|c|c|c|c|c|}
\hline & & & $p l$ & \\
\hline CHEMBL207995 & 809282 & 4.1 & 3.9682 & TRN \\
\hline CHEMBL1988995 & 809282 & 4.1 & 4.1552 & TRN \\
\hline CHEMBL 2001923 & 809282 & 4.1 & 4.5983 & TRN \\
\hline CHEMBL1986781 & 809282 & 4.1 & 3.8365 & TRN \\
\hline CHEMBL526133 & 809282 & 4.1 & 4.4558 & TRN \\
\hline CHEMBL1981045 & 809282 & 5.4 & 5.0711 & TRN \\
\hline CHEMBL387971 & 809282 & 4.1 & 4.6391 & TST \\
\hline CHEMBL1979057 & 809282 & 5.5 & 4.6557 & TRN \\
\hline CHEMBL1992796 & 809282 & 4.1 & 4.1664 & TST \\
\hline CHEMBL1999428 & 809282 & 4.1 & 3.9319 & TRN \\
\hline CHEMBL223257 & 809282 & 4.1 & 5.8679 & TST \\
\hline CHEMBL1967560 & 809282 & 4.1 & 4.1852 & TST \\
\hline CHEMBL211378 & 809282 & 4.1 & 4.3739 & TRN \\
\hline CHEMBL1516890 & 809282 & 5.8 & 5.6027 & TRN \\
\hline CHEMBL1982465 & 809282 & 6.2 & 6.1651 & TRN \\
\hline CHEMBL 2001751 & 809282 & 7.1 & 6.9523 & TRN \\
\hline CHEMBL1984586 & 809282 & 5.2 & 4.7699 & TRN \\
\hline CHEMBL1999774 & 809282 & 4.1 & 4.1503 & TST \\
\hline CHEMBL1972659 & 809282 & 4.1 & 4.1785 & TST \\
\hline CHEMBL1973395 & 809282 & 6.9 & 6.6544 & TRN \\
\hline CHEMBL 272453 & 809282 & 4.1 & 4.9235 & TRN \\
\hline CHEMBL1970217 & 809282 & 4.1 & 4.2637 & TRN \\
\hline CHEMBL1971801 & 809282 & 4.1 & 4.1968 & TRN \\
\hline CHEMBL1968850 & 809282 & 4.1 & 4.1783 & TRN \\
\hline CHEMBL 2005528 & 809282 & 4.1 & 4.3381 & TST \\
\hline CHEMBL185569 & 809282 & 4.1 & 4.3585 & TRN \\
\hline CHEMBL1969843 & 809282 & 4.1 & 4.1386 & TRN \\
\hline CHEMBL 2007002 & 809282 & 5.4 & 5.2418 & TRN \\
\hline CHEMBL1987007 & 809282 & 4.1 & 4.2782 & TRN \\
\hline CHEMBL1984711 & 809282 & 5.4 & 5.5317 & TRN \\
\hline CHEMBL1990212 & 809282 & 4.1 & 4.1231 & TRN \\
\hline CHEMBL484390 & 809282 & 4.1 & 4.8761 & TST \\
\hline CHEMBL1979252 & 809282 & 4.1 & 4.4225 & TRN \\
\hline CHEMBL 2004290 & 809282 & 4.1 & 4.7042 & TRN \\
\hline CHEMBL1972937 & 809282 & 4.1 & 4.1344 & TRN \\
\hline CHEMBL1972250 & 809282 & 4.1 & 5.3327 & TST \\
\hline CHEMBL 2000393 & 809282 & 7.1 & 6.4866 & TST \\
\hline CHEMBL 2004072 & 809282 & 4.1 & 4.5561 & TRN \\
\hline CHEMBL 2004311 & 809282 & 4.1 & 4.1823 & TRN \\
\hline CHEMBL1992634 & 809282 & 6.1 & 6.3762 & TRN \\
\hline CHEMBL1242373 & 809282 & 5.3 & 5.5568 & TRN \\
\hline CHEMBL1984869 & 809282 & 5.9 & 4.3557 & TRN \\
\hline CHEMBL 2000433 & 809282 & 4.1 & 4.5448 & TST \\
\hline CHEMBL56543 & 809282 & 5.9 & 4.5636 & TRN \\
\hline CHEMBL1988075 & 809282 & 5.4 & 5.5963 & TRN \\
\hline CHEMBL316264 & 809282 & 4.1 & 3.9768 & TRN \\
\hline CHEMBL1991678 & 809282 & 4.1 & 4.0518 & TRN \\
\hline CHEMBL 2001239 & 809282 & 5.6 & 5.2641 & TST \\
\hline
\end{tabular}




\begin{tabular}{|c|c|c|c|c|c|}
\hline & & & & & \\
\hline CHEMBL1988594 & 809282 & 6.5 & 6.3637 & TRN & \\
\hline CHEMBL 2001288 & 809282 & 4.1 & 4.6231 & TRN & \\
\hline CHEMBL260092 & 809282 & 6.2 & 6.4891 & TRN & \\
\hline CHEMBL1999811 & 809282 & 5.6 & 5.3081 & TST & \\
\hline CHEMBL1965495 & 809282 & 5.6 & 5.4111 & TRN & \\
\hline CHEMBL1985074 & 809282 & 4.1 & 4.0917 & TST & \\
\hline CHEMBL1982874 & 809282 & 4.1 & 4.3447 & TRN & \\
\hline CHEMBL 2000481 & 809282 & 5.2 & 4.4557 & TRN & \\
\hline CHEMBL1991725 & 809282 & 4.1 & 4.3271 & TRN & \\
\hline CHEMBL1992242 & 809282 & 4.1 & 4.0947 & TRN & \\
\hline CHEMBL2007138 & 809282 & 3.7 & 3.8357 & TRN & \\
\hline CHEMBL208637 & 809282 & 4.1 & 3.9069 & TRN & \\
\hline CHEMBL1970203 & 809282 & 4.1 & 5.8061 & TRN & \\
\hline CHEMBL1968590 & 809282 & 5.2 & 4.9403 & TRN & \\
\hline CHEMBL1999749 & 809282 & 4.1 & 4.2733 & TRN & \\
\hline CHEMBL2005375 & 809282 & 4.1 & 4.1319 & TST & \\
\hline CHEMBL1984191 & 809282 & 4.1 & 4.2973 & TRN & \\
\hline CHEMBL1983006 & 809282 & 4.1 & 4.0083 & TRN & \\
\hline CHEMBL1972183 & 809282 & 4.1 & 4.082 & TRN & \\
\hline CHEMBL1971029 & 809282 & 7.8 & 7.29899 & 99999999995 & TRN \\
\hline CHEMBL1995391 & 809282 & 3.7 & 4.175 & TRN & \\
\hline CHEMBL394790 & 809282 & 5.4 & 4.4857 & TRN & \\
\hline CHEMBL226471 & 809282 & 4.1 & 4.9916 & TST & \\
\hline CHEMBL1974702 & 809282 & 4.1 & 3.9673 & TST & \\
\hline CHEMBL1996111 & 809282 & 5.6 & 5.7884 & TRN & \\
\hline CHEMBL1965589 & 809282 & 4.1 & 3.9716 & TRN & \\
\hline CHEMBL474432 & 809282 & 6.0 & 5.5584 & TST & \\
\hline CHEMBL1988153 & 809282 & 4.1 & 4.132 & TRN & \\
\hline CHEMBL1999556 & 809282 & 5.4 & 5.2588 & TRN & \\
\hline CHEMBL1988437 & 809282 & 6.3 & 5.5534 & TST & \\
\hline CHEMBL1968245 & 809282 & 4.1 & 4.2507 & TRN & \\
\hline CHEMBL1998121 & 809282 & 7.3 & 6.7516 & TRN & \\
\hline CHEMBL1979577 & 809282 & 6.4 & 6.5688 & TRN & \\
\hline CHEMBL1985566 & 809282 & 4.1 & 4.3497 & TRN & \\
\hline CHEMBL52387 & 809282 & 4.1 & 4.2613 & TST & \\
\hline CHEMBL379835 & 809282 & 4.1 & 4.1694 & TST & \\
\hline CHEMBL1980802 & 809282 & 4.1 & 4.6809 & TST & \\
\hline CHEMBL1979357 & 809282 & 4.1 & 4.1073 & TRN & \\
\hline CHEMBL1996817 & 809282 & 6.5 & 6.5268 & TRN & \\
\hline CHEMBL 3197315 & 809282 & 4.1 & 4.0421 & TST & \\
\hline CHEMBL2004355 & 809282 & 4.1 & 4.072 & TRN & \\
\hline CHEMBL468280 & 809282 & 4.1 & 4.0326 & TST & \\
\hline CHEMBL1990884 & 809282 & 4.1 & 4.3423 & TRN & \\
\hline CHEMBL3109278 & 809282 & 6.7 & 5.9391 & TRN & \\
\hline CHEMBL256835 & 809282 & 4.1 & 4.3451 & TRN & \\
\hline CHEMBL41783 & 809282 & 4.1 & 3.9066 & TRN & \\
\hline CHEMBL 2004438 & 809282 & 4.1 & 4.3919 & TRN & \\
\hline CHEMBL2006276 & 809282 & 4.1 & 4.1692 & TRN & \\
\hline & & & & 10603 & \\
\hline
\end{tabular}




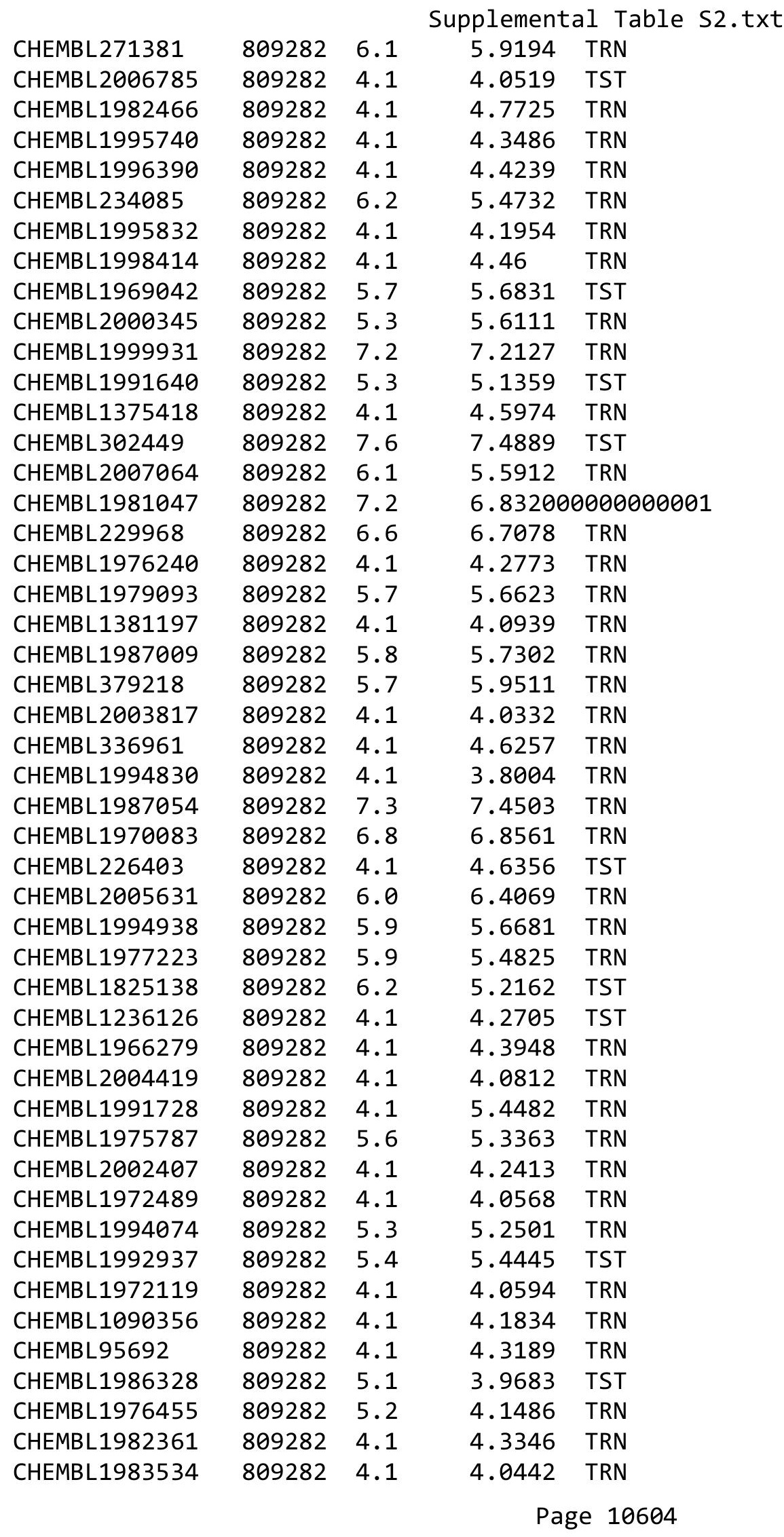




\begin{tabular}{|c|c|c|c|c|c|}
\hline \multicolumn{6}{|c|}{ Supplemental Table S2.txt } \\
\hline CHEMBL1999112 & 809282 & 4.1 & 4.2624 & TST & \\
\hline CHEMBL1982122 & 809282 & 4.1 & 4.1235 & TRN & \\
\hline CHEMBL 2000801 & 809282 & 4.1 & 4.0415 & TRN & \\
\hline CHEMBL1682546 & 809282 & 4.1 & 4.3227 & TRN & \\
\hline CHEMBL1991395 & 809282 & 4.1 & 4.0243 & TRN & \\
\hline CHEMBL1996780 & 809282 & 5.2 & 3.9835 & TST & \\
\hline CHEMBL1972142 & 809282 & 6.1 & 4.5244 & TRN & \\
\hline CHEMBL1966514 & 809282 & 5.9 & 5.9454 & TRN & \\
\hline CHEMBL 296586 & 809282 & 6.0 & 5.6633 & TRN & \\
\hline CHEMBL516429 & 809282 & 6.5 & 6.2595 & TRN & \\
\hline CHEMBL1993722 & 809282 & 5.7 & 5.54299 & 9999999999 & TRN \\
\hline CHEMBL1970806 & 809282 & 4.1 & 4.1129 & TST & \\
\hline CHEMBL1375640 & 809282 & 5.3 & 5.11600 & 00000000005 & TST \\
\hline CHEMBL1979970 & 809282 & 4.1 & 3.8082 & TRN & \\
\hline CHEMBL 249282 & 809282 & 5.5 & 5.699 & TST & \\
\hline CHEMBL1969264 & 809282 & 4.1 & 4.3565 & TRN & \\
\hline CHEMBL1973711 & 809282 & 4.1 & 4.0921 & TST & \\
\hline CHEMBL 2006237 & 809282 & 4.1 & 4.1802 & TRN & \\
\hline CHEMBL1967720 & 809282 & 6.5 & 6.4705 & TRN & \\
\hline CHEMBL1991138 & 809282 & 4.1 & 4.5622 & TRN & \\
\hline CHEMBL1969755 & 809282 & 4.1 & 3.9746 & TRN & \\
\hline CHEMBL1979516 & 809282 & 6.4 & 5.6775 & TRN & \\
\hline CHEMBL1605605 & 809282 & 4.1 & 4.0198 & TRN & \\
\hline CHEMBL1972820 & 809282 & 4.1 & 4.1981 & TST & \\
\hline CHEMBL1989029 & 809282 & 4.1 & 4.3143 & TRN & \\
\hline CHEMBL392642 & 809282 & 4.1 & 4.6786 & TRN & \\
\hline CHEMBL514499 & 809282 & 4.1 & 4.9782 & TST & \\
\hline CHEMBL1965631 & 809282 & 4.1 & 4.7831 & TRN & \\
\hline CHEMBL1980144 & 809282 & 5.2 & 5.7279 & TRN & \\
\hline CHEMBL1991188 & 809282 & 4.1 & 4.8962 & TRN & \\
\hline CHEMBL 377408 & 809282 & 5.2 & 4.4325 & TRN & \\
\hline CHEMBL231209 & 809282 & 4.1 & 4.4641 & TRN & \\
\hline CHEMBL1976220 & 809282 & 5.4 & 4.494 & TRN & \\
\hline CHEMBL259922 & 809282 & 4.1 & 4.1084 & TST & \\
\hline CHEMBL1997617 & 809282 & 6.6 & 6.3088 & TRN & \\
\hline CHEMBL1982383 & 809282 & 4.1 & 4.1983 & TRN & \\
\hline CHEMBL1969301 & 809282 & 5.7 & 5.2378 & TST & \\
\hline CHEMBL17370 & 809282 & 4.1 & 4.0116 & TRN & \\
\hline CHEMBL1987910 & 809282 & 4.1 & 4.2814 & TRN & \\
\hline CHEMBL1997822 & 809282 & 4.1 & 4.9471 & TRN & \\
\hline CHEMBL1991285 & 809282 & 4.3 & 4.1511 & TRN & \\
\hline CHEMBL1984038 & 809282 & 4.1 & 4.3928 & TRN & \\
\hline CHEMBL1974416 & 809282 & 5.9 & 5.9723 & TRN & \\
\hline CHEMBL 2004615 & 809282 & 4.1 & 4.3014 & TST & \\
\hline CHEMBL1984039 & 809282 & 5.4 & 5.2313 & TST & \\
\hline CHEMBL1997872 & 809282 & 4.1 & 5.2547 & TRN & \\
\hline CHEMBL 2003768 & 809282 & 4.1 & 4.1077 & TRN & \\
\hline CHEMBL213505 & 809282 & 5.7 & 5.3931 & TRN & \\
\hline
\end{tabular}




\begin{tabular}{|c|c|c|c|c|c|}
\hline \\
\hline CHEMBL1982880 & 809282 & 4.1 & 4.2029 & TRN & \\
\hline CHEMBL1987034 & 809282 & 7.4 & 7.6149 & TRN & \\
\hline CHEMBL1993941 & 809282 & 6.2 & 6.1498 & TRN & \\
\hline CHEMBL377383 & 809282 & 4.1 & 3.9969 & TRN & \\
\hline CHEMBL578061 & 809282 & 5.4 & 5.5697 & TRN & \\
\hline CHEMBL 2005886 & 809282 & 7.1 & 6.8059 & TST & \\
\hline CHEMBL481491 & 809282 & 4.1 & 4.462 & TST & \\
\hline CHEMBL1682345 & 809282 & 5.9 & 5.5311 & TRN & \\
\hline CHEMBL1973142 & 809282 & 4.1 & 4.4095 & TST & \\
\hline CHEMBL1973145 & 809282 & 4.1 & 4.1084 & TRN & \\
\hline CHEMBL1982924 & 809282 & 5.9 & 5.9329 & TRN & \\
\hline CHEMBL 2005936 & 809282 & 6.2 & 5.7438 & TRN & \\
\hline CHEMBL1971141 & 809282 & 4.1 & 4.0055 & TRN & \\
\hline CHEMBL1979718 & 809282 & 4.1 & 4.4831 & TRN & \\
\hline CHEMBL206236 & 809282 & 4.1 & 4.1204 & TRN & \\
\hline CHEMBL1562756 & 809282 & 4.1 & 4.3653 & TST & \\
\hline CHEMBL 2001957 & 809282 & 4.1 & 4.1103 & TRN & \\
\hline CHEMBL1969372 & 809282 & 4.1 & 3.846 & TRN & \\
\hline CHEMBL1990583 & 809282 & 7.1 & 6.2783 & TRN & \\
\hline CHEMBL 2006263 & 809282 & 4.1 & 4.5437 & TST & \\
\hline CHEMBL 2001646 & 809282 & 5.8 & 5.4029 & TST & \\
\hline CHEMBL1993584 & 809282 & 4.1 & 4.1449 & TRN & \\
\hline CHEMBL1986263 & 809282 & 6.2 & 5.7562 & TRN & \\
\hline CHEMBL 2000114 & 809282 & 5.4 & 5.4819 & TRN & \\
\hline CHEMBL 210618 & 809282 & 4.1 & 4.002 & TRN & \\
\hline CHEMBL1975647 & 809282 & 4.1 & 4.1274 & TRN & \\
\hline CHEMBL1968380 & 809282 & 4.1 & 4.3459 & TST & \\
\hline CHEMBL1964644 & 809282 & 4.1 & 4.1254 & TRN & \\
\hline CHEMBL1981782 & 809282 & 5.4 & 4.8955 & TRN & \\
\hline CHEMBL1977681 & 809282 & 5.9 & 5.6874 & TRN & \\
\hline CHEMBL1970142 & 809282 & 4.1 & $4.5760 e$ & 20000000005 & TRN \\
\hline CHEMBL1990912 & 809282 & 5.6 & 4.197 & TRN & \\
\hline CHEMBL1988163 & 809282 & 6.1 & 6.7521 & TRN & \\
\hline CHEMBL1995592 & 809282 & 5.9 & 5.1503 & TST & \\
\hline CHEMBL 2006493 & 809282 & 4.1 & 4.1038 & TST & \\
\hline CHEMBL1982541 & 809282 & 4.1 & 4.3096 & TRN & \\
\hline CHEMBL1996923 & 809282 & 4.1 & 4.1098 & TST & \\
\hline CHEMBL1983449 & 809282 & 4.1 & 4.1132 & TRN & \\
\hline CHEMBL1992323 & 809282 & 4.1 & 4.08 & TST & \\
\hline CHEMBL1969735 & 809282 & 4.1 & 4.1805 & TRN & \\
\hline CHEMBL 2003524 & 809282 & 4.1 & 4.8713 & TST & \\
\hline CHEMBL 2002649 & 809282 & 6.3 & 5.9242 & TRN & \\
\hline CHEMBL437747 & 809282 & 4.1 & 4.8496 & TRN & \\
\hline CHEMBL1995172 & 809282 & 4.1 & 4.9397 & TST & \\
\hline CHEMBL507936 & 809282 & 4.1 & 4.0264 & TRN & \\
\hline CHEMBL104264 & 809282 & 5.5 & 5.24799 & 9999999999 & TST \\
\hline CHEMBL1994321 & 809282 & 6.1 & 6.6189 & TRN & \\
\hline CHEMBL1997129 & 809282 & 7.1 & 6.7789 & TST & \\
\hline
\end{tabular}




\begin{tabular}{|c|c|c|c|c|c|}
\hline \multicolumn{6}{|c|}{ Supplemental Table s2.txt } \\
\hline CHEMBL1984788 & 809282 & 4.1 & 4.6057 & TRN & \\
\hline CHEMBL1964307 & 809282 & 5.6 & 5.6515 & TRN & \\
\hline CHEMBL2000508 & 809282 & 4.1 & 4.122 & TST & \\
\hline CHEMBL1971694 & 809282 & 4.1 & 4.1512 & TST & \\
\hline CHEMBL 2001547 & 809282 & 4.1 & 4.0026 & TST & \\
\hline CHEMBL 210928 & 809282 & 4.1 & 3.97300 & 00000000003 & TST \\
\hline CHEMBL1652721 & 714645 & 5.9706 & 6.3083 & TST & \\
\hline CHEMBL1652702 & 714645 & 7.9586 & 7.9565 & TRN & \\
\hline CHEMBL1649765 & 714645 & 5.301 & 5.3022 & TRN & \\
\hline CHEMBL1652713 & 714645 & 3.6021 & 3.7906 & TST & \\
\hline CHEMBL1652728 & 714645 & 6.2874 & 6.2954 & TRN & \\
\hline CHEMBL1652695 & 714645 & 5.301 & 5.3404 & TRN & \\
\hline CHEMBL1652739 & 714645 & 8.3979 & 8.3854 & TRN & \\
\hline CHEMBL1652701 & 714645 & 7.7959 & 7.8032 & TRN & \\
\hline CHEMBL1652704 & 714645 & 8.5229 & 8.5039 & TRN & \\
\hline CHEMBL1652716 & 714645 & 6.1249 & 5.7504 & TST & \\
\hline CHEMBL1652736 & 714645 & 6.8894 & 6.8753 & TRN & \\
\hline CHEMBL1652707 & 714645 & 8.3979 & 8.3936 & TRN & \\
\hline CHEMBL1649758 & 714645 & 5.301 & 5.3012 & TRN & \\
\hline CHEMBL1652737 & 714645 & 8.1549 & 8.1526 & TRN & \\
\hline CHEMBL1649761 & 714645 & 6.3799 & 6.3889 & TRN & \\
\hline CHEMBL1652724 & 714645 & 4.6021 & 4.5914 & TRN & \\
\hline CHEMBL1652692 & 714645 & 6.8894 & 6.853 & TRN & \\
\hline CHEMBL1652705 & 714645 & 7.7959 & 7.8021 & TRN & \\
\hline CHEMBL1652706 & 714645 & 8.3979 & 8.4183 & TRN & \\
\hline CHEMBL1652694 & 714645 & 5.301 & 5.2901 & TRN & \\
\hline CHEMBL1652720 & 714645 & 7.0362 & 7.0442 & TRN & \\
\hline CHEMBL1649763 & 714645 & 8.2218 & 8.1986 & TRN & \\
\hline CHEMBL1649767 & 714645 & 5.301 & 5.2477 & TRN & \\
\hline CHEMBL1652727 & 714645 & 5.0 & 4.9944 & TRN & \\
\hline CHEMBL1649766 & 714645 & 5.301 & 5.3255 & TRN & \\
\hline CHEMBL1652726 & 714645 & 7.0177 & 7.0261 & TRN & \\
\hline CHEMBL1652741 & 714645 & 7.7212 & 7.7077 & TRN & \\
\hline CHEMBL1652700 & 714645 & 8.0969 & 8.0937 & TRN & \\
\hline CHEMBL92361 & 714645 & 7.0969 & 3.74899 & 99999999997 & TST \\
\hline CHEMBL1652742 & 714645 & 7.3665 & 7.3849 & TRN & \\
\hline CHEMBL1649764 & 714645 & 5.301 & 5.3133 & TRN & \\
\hline CHEMBL1652708 & 714645 & 8.301 & 8.3021 & TRN & \\
\hline CHEMBL1652712 & 714645 & 3.6021 & 4.2061 & TST & \\
\hline CHEMBL1649759 & 714645 & 5.301 & 5.3022 & TRN & \\
\hline CHEMBL1649586 & 714645 & 6.4559 & 6.4698 & TRN & \\
\hline CHEMBL1652722 & 714645 & 6.0132 & 6.0084 & TRN & \\
\hline CHEMBL1652709 & 714645 & 8.0969 & 8.1187 & TRN & \\
\hline CHEMBL1652697 & 714645 & 8.2218 & 8.2051 & TRN & \\
\hline CHEMBL1649614 & 714645 & 7.1249 & 7.1415 & TRN & \\
\hline CHEMBL1652719 & 714645 & 5.7496 & 5.6667 & TST & \\
\hline CHEMBL1649769 & 714645 & 6.6576 & 6.6484 & TRN & \\
\hline CHEMBL1652710 & 714645 & 9.0 & 8.9978 & TRN & \\
\hline
\end{tabular}




\begin{tabular}{|c|c|c|c|c|c|c|}
\hline \\
\hline CHEMBL1652732 & 714645 & 7.4949 & 7.5055 & TRN & & \\
\hline CHEMBL1652715 & 714645 & 6.0044 & 5.3097 & TST & & \\
\hline CHEMBL1649762 & 714645 & 5.301 & 5.3 & TRN & & \\
\hline CHEMBL1652703 & 714645 & 8.0458 & 8.0647 & TRN & & \\
\hline CHEMBL1652693 & 714645 & 5.0 & 5.003 & TRN & & \\
\hline CHEMBL1652729 & 714645 & 6.6596 & 6.6599 & TRN & & \\
\hline CHEMBL1652734 & 714645 & 7.5528 & 7.5629 & TRN & & \\
\hline CHEMBL1652711 & 714645 & 5.6778 & 5.6584 & TST & & \\
\hline CHEMBL1652735 & 714645 & 6.4034 & 6.4767 & TST & & \\
\hline CHEMBL1652718 & 714645 & 6.9914 & 6.2242 & TST & & \\
\hline CHEMBL1649760 & 714645 & 5.301 & 5.3011 & TRN & & \\
\hline CHEMBL1652714 & 714645 & 5.8239 & 5.3484 & TST & & \\
\hline CHEMBL1652738 & 714645 & 8.5229 & 8.5352 & TRN & & \\
\hline CHEMBL1649770 & 714645 & 7.1549 & 7.1531 & TRN & & \\
\hline CHEMBL1652696 & 714645 & 5.301 & 5.2768 & TRN & & \\
\hline CHEMBL1649768 & 714645 & 5.301 & 5.3276 & TRN & & \\
\hline CHEMBL1652731 & 714645 & 6.7496 & 7.6821 & TST & & \\
\hline CHEMBL1652740 & 714645 & 7.1612 & 7.147 & TRN & & \\
\hline CHEMBL1652717 & 714645 & 5.8996 & 5.4841 & TST & & \\
\hline CHEMBL1652725 & 714645 & 5.0 & 6.6917 & TST & & \\
\hline CHEMBL1652730 & 714645 & 7.1675 & 7.5333 & TST & & \\
\hline CHEMBL1652723 & 714645 & 4.6021 & 6.1942 & TST & & \\
\hline CHEMBL1652699 & 714645 & 7.5686 & 7.5615 & TRN & & \\
\hline CHEMBL1652698 & 714645 & 7.6021 & 7.595 & TRN & & \\
\hline CHEMBL1652733 & 714645 & 7.1135 & 7.9222 & TST & & \\
\hline CHEMBL 210436 & 376788 & 6.7447 & 6.7479 & TRN & & \\
\hline CHEMBL384676 & 376788 & 7.0044 & 7.0101 & TRN & & \\
\hline CHEMBL 210408 & 376788 & 6.1612 & 6.1618 & TRN & & \\
\hline CHEMBL 210818 & 376788 & 6.5513 & 6.5499 & TRN & & \\
\hline CHEMBL378180 & 376788 & 7.6383 & 7.6492 & TRN & & \\
\hline CHEMBL 209059 & 376788 & 6.6038 & 6.602 & TRN & & \\
\hline CHEMBL211166 & 376788 & 7.3372 & 8.5602 & TST & & \\
\hline CHEMBL379797 & 376788 & 6.617999 & 99999999 & 99 & 6.6193 & TRN \\
\hline CHEMBL377976 & 376788 & 7.2007 & 7.1961 & TRN & & \\
\hline CHEMBL 209504 & 376788 & 8.2218 & 8.2148 & TRN & & \\
\hline CHEMBL376976 & 376788 & 7.699 & 8.0041 & TST & & \\
\hline CHEMBL210255 & 376788 & 5.7781 & 5.7747 & TRN & & \\
\hline CHEMBL 210274 & 376788 & 8.699 & 8.7044 & TRN & & \\
\hline CHEMBL209935 & 376788 & 7.1192 & 7.1199 & TRN & & \\
\hline CHEMBL 210344 & 376788 & 6.7496 & 6.7486 & TRN & & \\
\hline CHEMBL413578 & 376788 & 7.3098 & 7.3106 & TRN & & \\
\hline CHEMBL 210715 & 376788 & 8.5229 & 8.5086 & TRN & & \\
\hline CHEMBL 211005 & 376788 & 7.3468 & 7.3435 & TRN & & \\
\hline CHEMBL379489 & 376788 & 7.7959 & 7.8018 & TRN & & \\
\hline CHEMBL378269 & 376788 & 6.8928 & 6.8779 & TRN & & \\
\hline CHEMBL 211058 & 376788 & 7.2924 & 7.2913 & TRN & & \\
\hline CHEMBL 211335 & 376788 & 7.0362 & 7.7421 & TST & & \\
\hline CHEMBL 212330 & 376788 & 7.7212 & 7.7311 & TRN & & \\
\hline
\end{tabular}


Supplemental Table S2.txt

\begin{tabular}{|c|c|c|c|c|}
\hline CHEMBL209050 & 376788 & 7.6021 & 7.6056 & TRN \\
\hline CHEMBL378994 & 376788 & 8.0458 & 8.042 & TRN \\
\hline CHEMBL210857 & 376788 & 5.8453 & 5.8432 & TRN \\
\hline CHEMBL 377321 & 376788 & 8.9208 & 8.3805 & TST \\
\hline CHEMBL208275 & 376788 & 7.7959 & 7.7794 & TRN \\
\hline CHEMBL212671 & 376788 & 6.7144 & 6.7126 & TRN \\
\hline CHEMBL 379789 & 376788 & 7.4089 & 7.9533 & TST \\
\hline CHEMBL208081 & 376788 & 7.585 & 7.8371 & TST \\
\hline CHEMBL361392 & 376788 & 8.6021 & 8.5988 & TRN \\
\hline CHEMBL209510 & 376788 & 7.8539 & 8.1152 & TST \\
\hline CHEMBL212750 & 376788 & 6.8508 & 6.8449 & TRN \\
\hline CHEMBL210481 & 376788 & 7.2147 & 7.2222 & TRN \\
\hline CHEMBL380275 & 376788 & 7.5229 & 7.5414 & TRN \\
\hline CHEMBL 212210 & 376788 & 5.4885 & 5.4916 & TRN \\
\hline CHEMBL212265 & 376788 & 8.0969 & 8.093 & TRN \\
\hline CHEMBL377738 & 376788 & 7.7447 & 7.7583 & TRN \\
\hline CHEMBL211285 & 376788 & 8.3979 & 8.3908 & TRN \\
\hline CHEMBL209828 & 376788 & 8.5229 & 8.5353 & TRN \\
\hline CHEMBL212159 & 376788 & 8.5229 & 8.5233 & TRN \\
\hline CHEMBL209089 & 376788 & 7.8861 & 7.8731 & TRN \\
\hline CHEMBL211504 & 376788 & 6.1046 & 6.1055 & TRN \\
\hline CHEMBL380371 & 376788 & 9.0 & 8.2712 & TST \\
\hline CHEMBL212093 & 376788 & 7.284 & 7.285 & TRN \\
\hline CHEMBL210531 & 376788 & 7.6778 & 7.6825 & TRN \\
\hline CHEMBL211139 & 376788 & 7.1135 & 7.1132 & TRN \\
\hline CHEMBL210343 & 376788 & 7.3768 & 7.6559 & TST \\
\hline CHEMBL378009 & 376788 & 6.2815 & 7.6795 & TST \\
\hline CHEMBL211311 & 376788 & 7.3188 & 7.8025 & TST \\
\hline CHEMBL208970 & 376788 & 5.6651 & 6.6673 & TST \\
\hline CHEMBL210532 & 376788 & 6.7212 & 7.125 & TST \\
\hline CHEMBL378972 & 376788 & 7.3979 & 7.6654 & TST \\
\hline CHEMBL3647060 & 1528151 & 6.0 & 5.8771 & TRN \\
\hline CHEMBL3890287 & 1528151 & 8.699 & 8.6558 & TST \\
\hline CHEMBL3639487 & 1528151 & 6.0 & 6.0949 & TRN \\
\hline CHEMBL3650012 & 1528151 & 7.699 & 7.8853 & TRN \\
\hline CHEMBL3649839 & 1528151 & 7.7696 & 7.9626 & TRN \\
\hline CHEMBL3649879 & 1528151 & 8.699 & 8.5105 & TRN \\
\hline CHEMBL3649962 & 1528151 & 6.0 & 6.2573 & TRN \\
\hline CHEMBL3649980 & 1528151 & 6.0 & 6.5688 & TST \\
\hline CHEMBL3971691 & 1528151 & 9.0 & 8.8957 & TRN \\
\hline CHEMBL3944856 & 1528151 & 8.3979 & 8.2463 & TRN \\
\hline CHEMBL3653332 & 1528151 & 7.4318 & 7.5168 & TRN \\
\hline CHEMBL3654193 & 1528151 & 7.2757 & \multicolumn{2}{|c|}{ 7. 372999999999999} \\
\hline CHEMBL3898360 & 1528151 & 7.9586 & 8.0217 & TRN \\
\hline CHEMBL3649926 & 1528151 & 9.0 & 8.6184 & TRN \\
\hline CHEMBL3649848 & 1528151 & 6.0 & 7.6856 & TRN \\
\hline CHEMBL3654184 & 1528151 & 10.0 & 9.6952 & TRN \\
\hline CHEMBL3942858 & 1528151 & 8.5229 & 8.5362 & TRN \\
\hline
\end{tabular}




\begin{tabular}{|c|c|c|c|c|c|}
\hline \multicolumn{6}{|c|}{ Supplemental Table S2.txt } \\
\hline CHEMBL 3650020 & 1528151 & 6.0 & 7.8282 & TRN & \\
\hline CHEMBL3647055 & 1528151 & 6.0 & 5.8139 & TRN & \\
\hline CHEMBL3649874 & 1528151 & 8.0458 & 7.9262 & TRN & \\
\hline CHEMBL3949967 & 1528151 & 9.0 & 8.1694 & TRN & \\
\hline CHEMBL3653318 & 1528151 & 6.0 & 5.7019 & TRN & \\
\hline CHEMBL3649875 & 1528151 & 9.0 & 8.8966 & TRN & \\
\hline CHEMBL3649998 & 1528151 & 8.301 & 8.1458 & TRN & \\
\hline CHEMBL 3649970 & 1528151 & 6.0 & 6.3554 & TRN & \\
\hline CHEMBL3971319 & 1528151 & 9.0 & 8.9896 & TST & \\
\hline CHEMBL3649995 & 1528151 & 8.0969 & 7.6487 & TRN & \\
\hline CHEMBL3650010 & 1528151 & 6.9136 & 7.25200 & 0000000001 & TST \\
\hline CHEMBL3650019 & 1528151 & 6.0 & 6.0998 & TRN & \\
\hline CHEMBL3916078 & 1528151 & 8.3979 & 8.4324 & TRN & \\
\hline CHEMBL3649816 & 1528151 & 7.3665 & 6.8901 & TRN & \\
\hline CHEMBL3649843 & 1528151 & 8.5229 & 8.5915 & TRN & \\
\hline CHEMBL3649960 & 1528151 & 6.0 & 5.86600 & 00000000005 & TRN \\
\hline CHEMBL3649910 & 1528151 & 7.7696 & 7.8767 & TRN & \\
\hline CHEMBL3909218 & 1528151 & 8.301 & 8.3753 & TRN & \\
\hline CHEMBL3946174 & 1528151 & 8.5229 & 8.4377 & TRN & \\
\hline CHEMBL3649880 & 1528151 & 6.0 & 6.3022 & TRN & \\
\hline CHEMBL3653315 & 1528151 & 6.0 & 5.8319 & TRN & \\
\hline CHEMBL3936690 & 1528151 & 7.5376 & 7.5098 & TST & \\
\hline CHEMBL3649918 & 1528151 & 7.6383 & 7.6994 & TRN & \\
\hline CHEMBL3952519 & 1528151 & 8.3979 & 8.4461 & TRN & \\
\hline CHEMBL3649976 & 1528151 & 6.0 & 6.235 & TRN & \\
\hline CHEMBL3938767 & 1528151 & 8.2218 & 8.22200 & 0000000001 & TRN \\
\hline CHEMBL3649959 & 1528151 & 8.699 & 5.6838 & TRN & \\
\hline CHEMBL3649863 & 1528151 & 9.0 & 8.8771 & TRN & \\
\hline CHEMBL 3649871 & 1528151 & 8.1549 & 8.1171 & TRN & \\
\hline CHEMBL3944443 & 1528151 & 9.0 & 8.9865 & TRN & \\
\hline CHEMBL 3650011 & 1528151 & 10.0 & 9.9674 & TST & \\
\hline CHEMBL3647058 & 1528151 & 8.3979 & 8.3949 & TRN & \\
\hline CHEMBL3649869 & 1528151 & 9.0 & 8.8053 & TRN & \\
\hline CHEMBL3984635 & 1528151 & 8.3979 & 8.0928 & TRN & \\
\hline CHEMBL3649914 & 1528151 & 7.7212 & 7.7957 & TRN & \\
\hline CHEMBL3959078 & 1528151 & 9.0 & 9.0583 & TST & \\
\hline CHEMBL3647061 & 1528151 & 8.699 & 8.8295 & TRN & \\
\hline CHEMBL3649877 & 1528151 & 7.9586 & 7.9767 & TRN & \\
\hline CHEMBL3649868 & 1528151 & 6.0 & 6.3938 & TRN & \\
\hline CHEMBL3938875 & 1528151 & 7.2218 & 7.2306 & TST & \\
\hline CHEMBL3649966 & 1528151 & 8.0458 & 7.6417 & TRN & \\
\hline CHEMBL3965668 & 1528151 & 8.699 & 8.8007 & TRN & \\
\hline CHEMBL3926337 & 1528151 & 6.8894 & 6.9303 & TST & \\
\hline CHEMBL3649817 & 1528151 & 6.0 & 6.1735 & TRN & \\
\hline CHEMBL3959820 & 1528151 & 9.0 & 8.3214 & TST & \\
\hline CHEMBL3979460 & 1528151 & 8.5229 & 8.6871 & TRN & \\
\hline CHEMBL3948683 & 1528151 & 8.3979 & 8.5701 & TRN & \\
\hline CHEMBL3649819 & 1528151 & 9.0 & 8.8635 & TRN & \\
\hline
\end{tabular}




$$
\text { Supplemental Table S2.txt }
$$

\begin{tabular}{|c|c|c|c|c|c|}
\hline CHEMBL 3649992 & 1528151 & 8.1549 & 8.296 & TST & \\
\hline CHEMBL 3649860 & 1528151 & 6.0 & 6.3997 & TRN & \\
\hline CHEMBL 3647053 & 1528151 & 9.0 & 9.119 & TRN & \\
\hline CHEMBL 3653335 & 1528151 & 8.301 & 8.1825 & TRN & \\
\hline CHEMBL3649990 & 1528151 & 8.699 & 8.6237 & TST & \\
\hline CHEMBL 3947091 & 1528151 & 7.4202 & 7.4686 & TRN & \\
\hline CHEMBL 3942009 & 1528151 & 8.699 & 8.6166 & TST & \\
\hline CHEMBL 3653326 & 1528151 & 9.0 & 8.7125 & TRN & \\
\hline CHEMBL 3971378 & 1528151 & 9.0 & 8.7952 & TST & \\
\hline CHEMBL3927923 & 1528151 & 6.0 & 6.3336 & TRN & \\
\hline CHEMBL 3945283 & 1528151 & 6.0 & 6.1691 & TRN & \\
\hline CHEMBL 3965113 & 1528151 & 8.0 & 8.2231 & TRN & \\
\hline CHEMBL 3649989 & 1528151 & 8.699 & 8.4165 & TRN & \\
\hline CHEMBL 3649847 & 1528151 & 8.5229 & 8.459 & TST & \\
\hline CHEMBL3647059 & 1528151 & 6.0 & 5.7154 & TRN & \\
\hline CHEMBL 3650015 & 1528151 & 7.5528 & 7.5502 & TST & \\
\hline CHEMBL 3649964 & 1528151 & 8.5229 & 7.9056 & TRN & \\
\hline CHEMBL 3653329 & 1528151 & 7.1427 & 7.312 & TRN & \\
\hline CHEMBL 3954453 & 1528151 & 8.5229 & 8.699 & TRN & \\
\hline CHEMBL 3907252 & 1528151 & 6.0 & 6.522 & TRN & \\
\hline CHEMBL3649814 & 1528151 & 7.4949 & 7.7624 & TRN & \\
\hline CHEMBL 3649891 & 1528151 & 9.0 & 8.8831 & TRN & \\
\hline CHEMBL 3649912 & 1528151 & 8.301 & 8.1955 & TRN & \\
\hline CHEMBL 3963317 & 1528151 & 8.301 & 8.3942 & TRN & \\
\hline CHEMBL 3649972 & 1528151 & 8.699 & 8.4961 & TST & \\
\hline CHEMBL3949194 & 1528151 & 8.5229 & 8.627 & TRN & \\
\hline CHEMBL 3649850 & 1528151 & 7.9208 & 8.0263 & TRN & \\
\hline CHEMBL 3649865 & 1528151 & 9.0 & 8.6787 & TRN & \\
\hline CHEMBL 3639488 & 1528151 & 6.0 & 6.3198 & TRN & \\
\hline CHEMBL 3654194 & 1528151 & 7.1549 & 8.0936 & TRN & \\
\hline CHEMBL 3911237 & 1528151 & 9.0 & 8.9174 & TRN & \\
\hline CHEMBL 3971741 & 1528151 & 8.699 & 8.7827 & TST & \\
\hline CHEMBL 3649849 & 1528151 & 9.0 & 8.7854 & TRN & \\
\hline CHEMBL3941220 & 1528151 & 6.0 & 6.0801 & TRN & \\
\hline CHEMBL 3909594 & 1528151 & 9.0 & 8.664 & TRN & \\
\hline CHEMBL 3653324 & 1528151 & 6.0 & 5.756 & TRN & \\
\hline CHEMBL 3649878 & 1528151 & 8.0458 & 7.9822 & TRN & \\
\hline CHEMBL 3647046 & 1528151 & 10.0 & 9.4544 & TRN & \\
\hline CHEMBL3930337 & 1528151 & 8.0 & 8.3062 & TRN & \\
\hline CHEMBL 3649872 & 1528151 & 9.0 & 8.7532 & TRN & \\
\hline CHEMBL 3649974 & 1528151 & 6.0 & 6.327006 & 0000000001 & TRN \\
\hline CHEMBL3649981 & 1528151 & 8.699 & 7.8417 & TST & \\
\hline CHEMBL 3894230 & 1528151 & 8.5229 & 8.6032 & TRN & \\
\hline CHEMBL 3649977 & 1528151 & 8.5229 & 7.8437 & TRN & \\
\hline CHEMBL 3654192 & 1528151 & 8.5229 & 6.072999 & 99999999995 & TRN \\
\hline CHEMBL 3647070 & 1528151 & 6.0 & 6.7227 & TRN & \\
\hline CHEMBL3942694 & 1528151 & 8.5229 & 8.6957 & TRN & \\
\hline CHEMBL3649898 & 1528151 & 9.0 & 8.9642 & TRN & \\
\hline
\end{tabular}


Supplemental Table S2.txt

\begin{tabular}{|c|c|c|c|c|c|}
\hline CHEMBL3649943 & 1528151 & 7.0862 & 6.9898 & TRN & \\
\hline CHEMBL3939191 & 1528151 & 9.0 & 9.1527 & TRN & \\
\hline CHEMBL3649876 & 1528151 & 7.3872 & 7.5258 & TRN & \\
\hline CHEMBL 3653334 & 1528151 & 8.1549 & 8.16 & TRN & \\
\hline CHEMBL3649911 & 1528151 & 8.5229 & 7.5145 & TRN & \\
\hline CHEMBL3649896 & 1528151 & 8.0458 & 8.0787 & TRN & \\
\hline CHEMBL 3647049 & 1528151 & 8.5229 & 8.5136 & TRN & \\
\hline CHEMBL3649997 & 1528151 & 8.0969 & 7.8744 & TRN & \\
\hline CHEMBL3649971 & 1528151 & 7.7212 & 7.9518 & TST & \\
\hline CHEMBL3915460 & 1528151 & 6.9136 & 7.0462 & TST & \\
\hline CHEMBL 3653321 & 1528151 & 6.0 & 5.8406 & TRN & \\
\hline CHEMBL3649986 & 1528151 & 7.6778 & 7.5428 & TST & \\
\hline CHEMBL3649991 & 1528151 & 6.0 & 6.563 & TRN & \\
\hline CHEMBL3966104 & 1528151 & 8.699 & 8.792 & TRN & \\
\hline CHEMBL3649834 & 1528151 & 6.0 & 6.1166 & TRN & \\
\hline CHEMBL3966426 & 1528151 & 10.0 & 10.0844 & TRN & \\
\hline CHEMBL3952705 & 1528151 & 10.0 & 9.1913 & TRN & \\
\hline CHEMBL 3647048 & 1528151 & 8.5229 & 8.2436 & TRN & \\
\hline CHEMBL3649881 & 1528151 & 8.699 & 8.5474 & TRN & \\
\hline CHEMBL3931299 & 1528151 & 9.0 & 9.0992 & TRN & \\
\hline CHEMBL3649892 & 1528151 & 8.5229 & 8.5231 & TRN & \\
\hline CHEMBL3653338 & 1528151 & 7.5528 & 7.4294 & TST & \\
\hline CHEMBL 3982716 & 1528151 & 9.0 & 8.663 & TRN & \\
\hline CHEMBL3649979 & 1528151 & 8.699 & 8.6135 & TST & \\
\hline CHEMBL3984644 & 1528151 & 8.699 & 8.8378 & TST & \\
\hline CHEMBL3649824 & 1528151 & 8.0458 & 7.7333 & TRN & \\
\hline CHEMBL3968578 & 1528151 & 8.699 & 8.7231 & TRN & \\
\hline CHEMBL 3649827 & 1528151 & 8.0969 & 8.1797 & TST & \\
\hline CHEMBL 3649867 & 1528151 & 7.8861 & 8.0053 & TRN & \\
\hline CHEMBL3647069 & 1528151 & 6.0 & 6.5405 & TRN & \\
\hline CHEMBL3649978 & 1528151 & 8.5229 & 8.0298 & TRN & \\
\hline CHEMBL3650008 & 1528151 & 6.7959 & 7.2334 & TST & \\
\hline CHEMBL 3649825 & 1528151 & 9.0 & 8.3176 & TRN & \\
\hline CHEMBL3649815 & 1528151 & 8.5229 & 8.5307 & TRN & \\
\hline CHEMBL3978308 & 1528151 & 9.0 & 9.1567 & TRN & \\
\hline CHEMBL3958237 & 1528151 & 9.0 & 9.0816 & TRN & \\
\hline CHEMBL3649833 & 1528151 & 8.5229 & 8.5527 & TST & \\
\hline CHEMBL3649963 & 1528151 & 6.0 & \multicolumn{2}{|c|}{6.367000000000001} & TRN \\
\hline CHEMBL 3653327 & 1528151 & 7.1871 & 7.5335 & TRN & \\
\hline CHEMBL3982496 & 1528151 & 7.585 & 7.751 & TST & \\
\hline CHEMBL3916778 & 1528151 & 7.6021 & 7.5232 & TST & \\
\hline CHEMBL3649961 & 1528151 & 6.0 & 6.2795 & TRN & \\
\hline CHEMBL3649983 & 1528151 & 6.0 & 6.3544 & TST & \\
\hline CHEMBL3649922 & 1528151 & 7.7447 & 7.854 & TRN & \\
\hline CHEMBL 3649999 & 1528151 & 8.3979 & 8.299 & TST & \\
\hline CHEMBL3957580 & 1528151 & 6.0 & 5.8617 & TRN & \\
\hline CHEMBL3649919 & 1528151 & 7.3979 & 7.5309 & TST & \\
\hline CHEMBL3914761 & 1528151 & 7.7959 & 7.8061 & TRN & \\
\hline
\end{tabular}

Page 10612 
Supplemental Table S2.txt

\begin{tabular}{|c|c|c|c|c|}
\hline CHEMBL 3649994 & 1528151 & 8.0969 & 7.6931 & TRN \\
\hline CHEMBL 3649967 & 1528151 & 6.0 & 5.6228 & TRN \\
\hline CHEMBL 3649987 & 1528151 & 8.3979 & 8.4599 & TST \\
\hline CHEMBL 3649845 & 1528151 & 6.0 & 6.4553 & TRN \\
\hline CHEMBL 3649846 & 1528151 & 8.2218 & 8.1337 & TST \\
\hline CHEMBL3649818 & 1528151 & 7.7959 & 7.7497 & TRN \\
\hline CHEMBL 3906549 & 1528151 & 8.699 & 8.845 & TST \\
\hline CHEMBL 3957470 & 1528151 & 8.699 & 8.7636 & TST \\
\hline CHEMBL 3649853 & 1528151 & 8.699 & 8.6528 & TRN \\
\hline CHEMBL 3647067 & 1528151 & 9.0 & 8.4993 & TST \\
\hline CHEMBL3649821 & 1528151 & 9.0 & 9.2684 & TST \\
\hline CHEMBL 3649823 & 1528151 & 6.0 & 6.5853 & TRN \\
\hline CHEMBL 3649965 & 1528151 & 7.8239 & 7.4652 & TRN \\
\hline CHEMBL 3933957 & 1528151 & 6.0 & 6.4191 & TST \\
\hline CHEMBL 3649890 & 1528151 & 7.8539 & 7.6511 & TRN \\
\hline CHEMBL3647066 & 1528151 & 8.699 & 8.9349 & TRN \\
\hline CHEMBL3654187 & 1528151 & 6.0 & 7.2219 & TRN \\
\hline CHEMBL 3934510 & 1528151 & 7.6198 & 7.8486 & TST \\
\hline CHEMBL 3649921 & 1528151 & 7.0655 & 7.1986 & TST \\
\hline CHEMBL 3923676 & 1528151 & 8.3979 & 8.6277 & TRN \\
\hline CHEMBL 3649913 & 1528151 & 7.8539 & 7.8746 & TRN \\
\hline CHEMBL3649975 & 1528151 & 8.301 & 7.6113 & TRN \\
\hline CHEMBL 3649859 & 1528151 & 8.0969 & 8.0891 & TRN \\
\hline CHEMBL3649851 & 1528151 & 7.6778 & 7.8631 & TRN \\
\hline CHEMBL 3649870 & 1528151 & 8.5229 & 8.39 & TRN \\
\hline CHEMBL 3927925 & 1528151 & 6.4522 & 7.1608 & TRN \\
\hline CHEMBL 3653328 & 1528151 & 6.9245 & 7.0754 & TRN \\
\hline CHEMBL 3649973 & 1528151 & 8.301 & 8.0219 & TST \\
\hline CHEMBL3979791 & 1528151 & 6.0 & 6.4414 & TST \\
\hline CHEMBL 3650000 & 1528151 & 8.699 & 8.853 & TRN \\
\hline CHEMBL 3931087 & 1528151 & 8.1549 & 7.9356 & TST \\
\hline CHEMBL 3952603 & 1528151 & 7.9586 & 8.1442 & TRN \\
\hline CHEMBL 3969880 & 1528151 & 6.0 & 6.54 & TRN \\
\hline CHEMBL3649969 & 1528151 & 6.0 & 5.897 & TRN \\
\hline CHEMBL 3653330 & 1528151 & 6.9508 & 7.0314 & TRN \\
\hline CHEMBL3895119 & 1528151 & 8.3979 & 8.4068 & TST \\
\hline CHEMBL3978215 & 1528151 & 8.301 & 8.4759 & TRN \\
\hline CHEMBL 3933691 & 1528151 & 8.3979 & 8.6498 & TRN \\
\hline CHEMBL3649917 & 1528151 & 7.3768 & 7.4723 & TRN \\
\hline CHEMBL 3649844 & 1528151 & 9.0 & 8.8894 & TRN \\
\hline CHEMBL 3653333 & 1528151 & 8.699 & 8.5842 & TRN \\
\hline CHEMBL 3649826 & 1528151 & 8.5229 & 8.8037 & TRN \\
\hline CHEMBL 3647051 & 1528151 & 9.0 & 8.9658 & TRN \\
\hline CHEMBL 3650013 & 1528151 & 8.0 & 8.173 & TRN \\
\hline CHEMBL 3649915 & 1528151 & 6.0 & \multicolumn{2}{|c|}{6.303999999999999} \\
\hline CHEMBL 3954821 & 1528151 & 6.6021 & 6.9172 & TST \\
\hline CHEMBL 3649841 & 1528151 & 8.1549 & 8.3153 & TRN \\
\hline CHEMBL 3653337 & 1528151 & 7.4318 & 7.4156 & TST \\
\hline
\end{tabular}




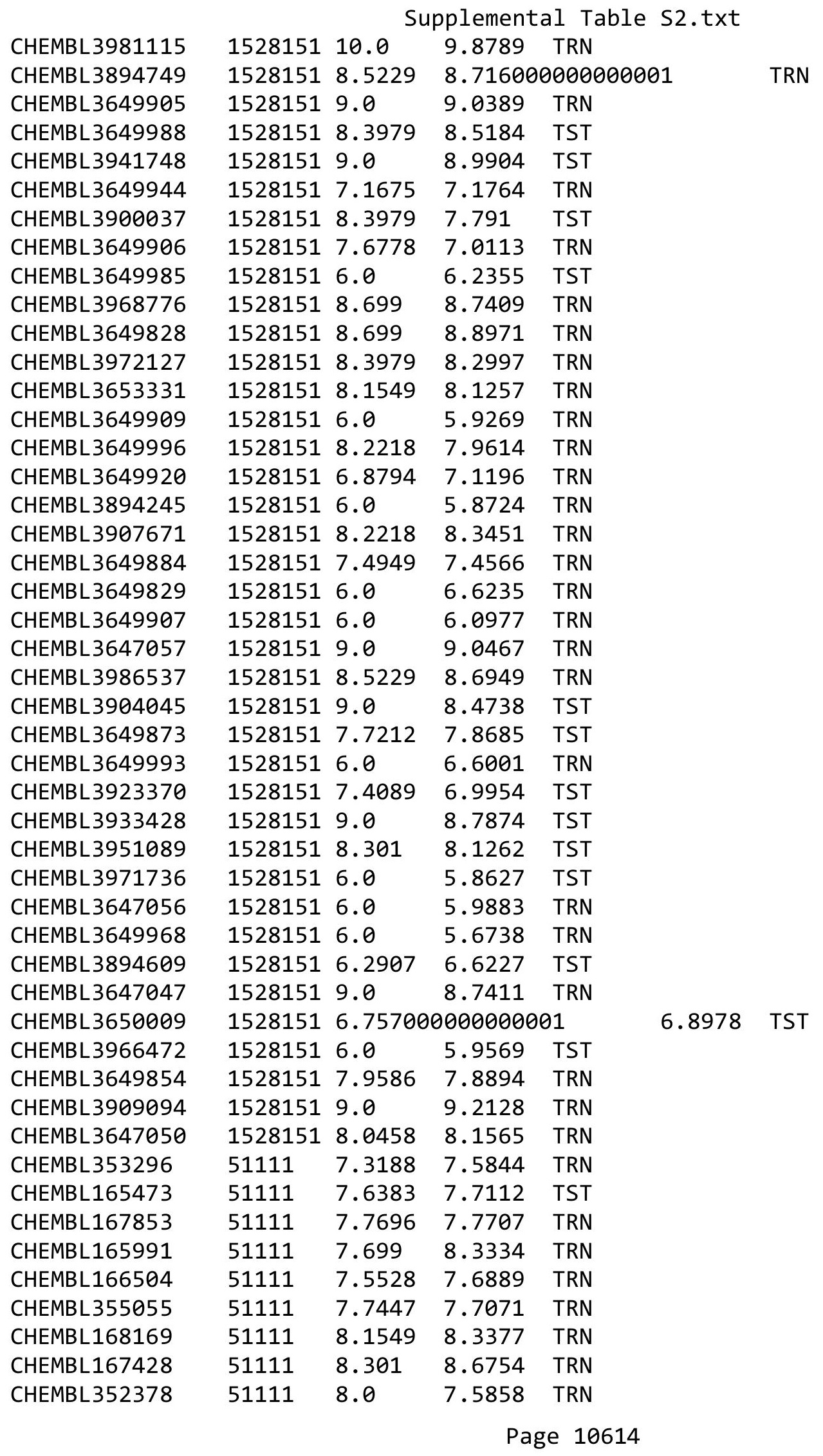




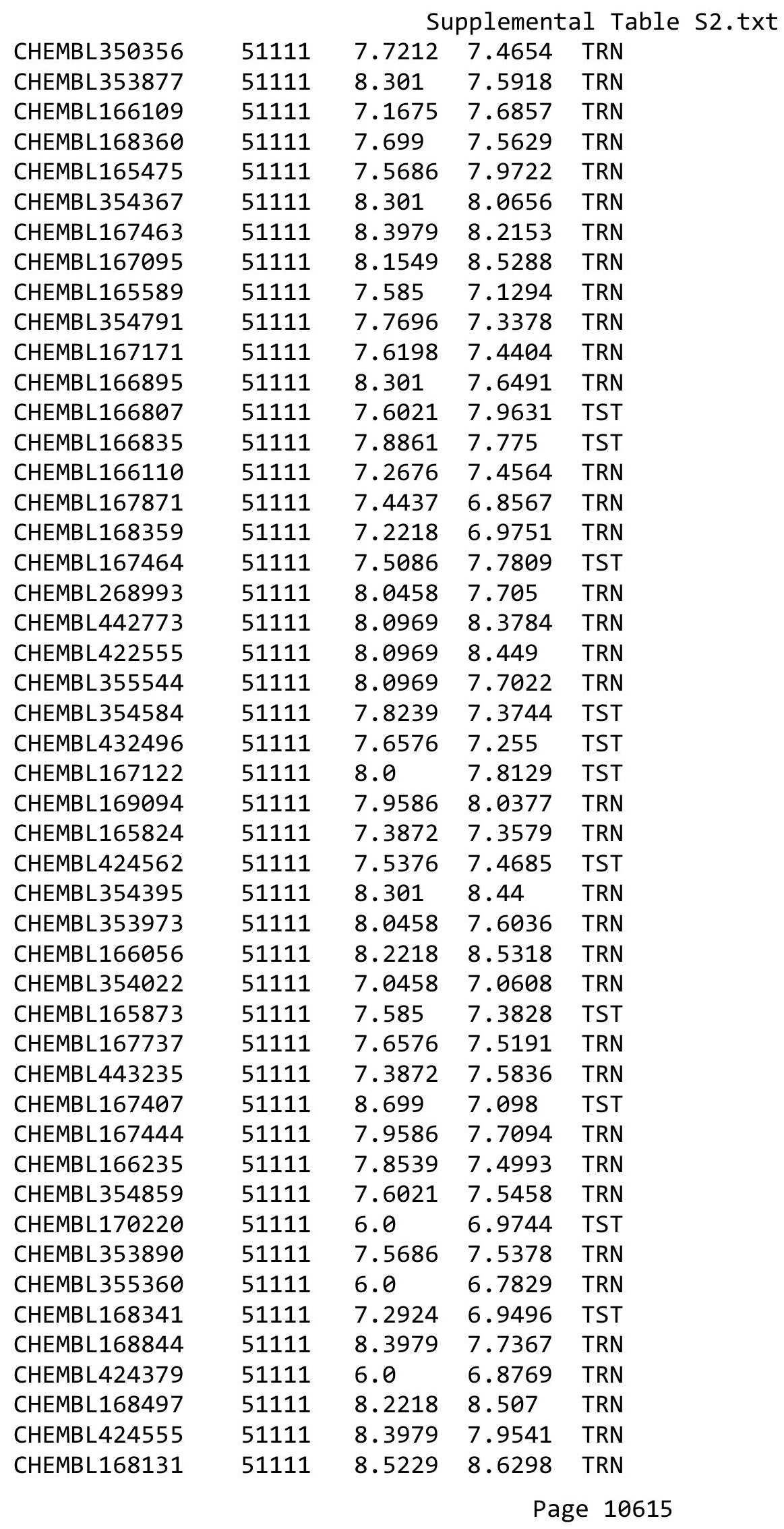




\begin{tabular}{|c|c|c|c|c|c|}
\hline \multirow[b]{2}{*}{ CHEMBL166388 } & \multicolumn{5}{|c|}{ Supplemental Table S2.txt } \\
\hline & 51111 & 8.301 & 7.7381 & TRN & \\
\hline CHEMBL166238 & 51111 & 7.6198 & 7.3586 & TST & \\
\hline CHEMBL166897 & 51111 & 7.4815 & 7.63700 & 00000000005 & TRN \\
\hline CHEMBL46479 & 51111 & 7.9208 & 7.1447 & TST & \\
\hline CHEMBL167177 & 51111 & 8.301 & 7.5785 & TRN & \\
\hline CHEMBL167195 & 51111 & 7.6198 & 7.3977 & TRN & \\
\hline CHEMBL168824 & 51111 & 7.4559 & 6.9318 & TRN & \\
\hline CHEMBL424204 & 51111 & 7.4949 & 7.4149 & TST & \\
\hline CHEMBL165531 & 51111 & 7.8539 & 7.7405 & TRN & \\
\hline CHEMBL424538 & 51111 & 8.2218 & 8.2464 & TRN & \\
\hline CHEMBL167870 & 51111 & 5.0 & 6.8653 & TST & \\
\hline CHEMBL167738 & 51111 & 7.3565 & 7.2141 & TST & \\
\hline CHEMBL10203 & 51111 & 8.0458 & 7.5355 & TRN & \\
\hline CHEMBL 354871 & 51111 & 5.0 & 6.6374 & TRN & \\
\hline CHEMBL 354178 & 51111 & 8.301 & 8.6782 & TRN & \\
\hline CHEMBL166345 & 51111 & 8.301 & 7.8556 & TRN & \\
\hline CHEMBL168748 & 51111 & 5.0 & 7.3741 & TST & \\
\hline CHEMBL166734 & 51111 & 5.0 & 7.0669 & TRN & \\
\hline CHEMBL166776 & 51111 & 7.5086 & 7.5844 & TST & \\
\hline CHEMBL79885 & 31628 & 4.0 & 2.5321 & TST & \\
\hline CHEMBL78661 & 31628 & 3.0 & 2.9218 & TRN & \\
\hline CHEMBL81109 & 31628 & 6.0 & 6.0886 & TRN & \\
\hline CHEMBL 309290 & 31628 & 3.0 & 3.0535 & TRN & \\
\hline CHEMBL419474 & 31628 & 8.0 & 7.9913 & TRN & \\
\hline CHEMBL 309684 & 31628 & 4.0 & 4.0889 & TRN & \\
\hline CHEMBL310572 & 31628 & 6.0 & 6.2559 & TRN & \\
\hline CHEMBL81972 & 31628 & 5.0 & 4.2336 & TST & \\
\hline CHEMBL82185 & 31628 & 5.0 & 5.2272 & TRN & \\
\hline CHEMBL81303 & 31628 & 5.0 & 4.7705 & TRN & \\
\hline CHEMBL82425 & 31628 & 4.0 & 3.77100 & 00000000004 & TST \\
\hline CHEMBL 309965 & 31628 & 4.0 & 4.1575 & TRN & \\
\hline CHEMBL312671 & 31628 & 5.0 & 6.6448 & TST & \\
\hline CHEMBL310099 & 31628 & 4.0 & 3.6383 & TRN & \\
\hline CHEMBL81606 & 31628 & 3.0 & 3.1415 & TST & \\
\hline CHEMBL81625 & 31628 & 4.0 & 3.5101 & TST & \\
\hline CHEMBL79251 & 31628 & 3.0 & 3.8607 & TST & \\
\hline CHEMBL 312005 & 31628 & 5.0 & 4.9475 & TRN & \\
\hline CHEMBL82772 & 31628 & 3.0 & 3.1455 & TRN & \\
\hline CHEMBL311644 & 31628 & 3.0 & 2.9648 & TRN & \\
\hline CHEMBL420773 & 31628 & 4.0 & 4.2589 & TRN & \\
\hline CHEMBL81682 & 31628 & 5.0 & 4.9771 & TRN & \\
\hline CHEMBL81981 & 31628 & 5.0 & 5.2578 & TRN & \\
\hline CHEMBL78776 & 31628 & 4.0 & 3.9324 & TRN & \\
\hline CHEMBL 82608 & 31628 & 7.0 & 7.004 & TRN & \\
\hline CHEMBL82300 & 31628 & 5.0 & 4.9973 & TRN & \\
\hline CHEMBL 311584 & 31628 & 6.0 & 6.2454 & TRN & \\
\hline CHEMBL 77679 & 31628 & 8.0 & 7.8621 & TRN & \\
\hline CHEMBL421713 & 31628 & 3.0 & 3.1295 & TRN & \\
\hline
\end{tabular}




\begin{tabular}{|c|c|c|c|c|c|}
\hline & & & & & \\
\hline CHEMBL309387 & 31628 & 7.0 & 6.9519 & TRN & \\
\hline CHEMBL 82424 & 31628 & 6.0 & 6.3436 & TST & \\
\hline CHEMBL79006 & 31628 & 4.0 & 3.9133 & TRN & \\
\hline CHEMBL79115 & 31628 & 5.0 & 4.7334 & TRN & \\
\hline CHEMBL 79787 & 31628 & 3.0 & 4.1815 & TST & \\
\hline CHEMBL 80881 & 31628 & 4.0 & 3.9541 & TRN & \\
\hline CHEMBL 78305 & 31628 & 4.0 & 2.9431 & TST & \\
\hline CHEMBL 78583 & 31628 & 4.0 & 4.0787 & TRN & \\
\hline CHEMBL79461 & 31628 & 8.0 & 7.6061 & TRN & \\
\hline CHEMBL81536 & 31628 & 8.0 & 7.9641 & TRN & \\
\hline CHEMBL 77447 & 31628 & 4.0 & 4.8736 & TST & \\
\hline CHEMBL84176 & 31628 & 4.0 & $4.1160 e$ & 00000000005 & TRN \\
\hline CHEMBL432927 & 31628 & 8.0 & 8.2683 & TRN & \\
\hline CHEMBL 78544 & 31628 & 4.0 & 4.2692 & TRN & \\
\hline CHEMBL268961 & 31628 & 6.0 & 6.5331 & TRN & \\
\hline CHEMBL420766 & 31628 & 5.0 & 5.4888 & TRN & \\
\hline CHEMBL79015 & 31628 & 5.0 & 4.8231 & TRN & \\
\hline CHEMBL39377 & 31628 & 3.0 & 3.2667 & TRN & \\
\hline CHEMBL312031 & 31628 & 3.0 & 3.15 & TRN & \\
\hline CHEMBL 81718 & 31628 & 5.0 & 4.8521 & TRN & \\
\hline CHEMBL285628 & 31628 & 5.0 & 4.976 & TRN & \\
\hline CHEMBL 78706 & 31628 & 6.0 & 5.7475 & TRN & \\
\hline CHEMBL421333 & 31628 & 5.0 & 5.1022 & TRN & \\
\hline CHEMBL79198 & 31628 & 7.0 & 7.2097 & TRN & \\
\hline CHEMBL 79353 & 31628 & 3.0 & 3.0171 & TRN & \\
\hline CHEMBL431587 & 31628 & 4.0 & 3.8369 & TRN & \\
\hline CHEMBL 82713 & 31628 & 3.0 & 2.7124 & TRN & \\
\hline CHEMBL310791 & 31628 & 3.0 & $2.7310 e$ & j0000000003 & TRN \\
\hline CHEMBL310383 & 31628 & 4.0 & 4.0078 & TRN & \\
\hline CHEMBL309288 & 31628 & 8.0 & 8.0595 & TRN & \\
\hline CHEMBL81709 & 31628 & 4.0 & 3.6877 & TST & \\
\hline CHEMBL 81049 & 31628 & 6.0 & 5.731 & TRN & \\
\hline CHEMBL 78819 & 31628 & 8.0 & 7.7248 & TRN & \\
\hline CHEMBL 79228 & 31628 & 5.0 & 5.80399 & 9999999999 & TST \\
\hline CHEMBL 81453 & 31628 & 3.0 & 3.0971 & TRN & \\
\hline CHEMBL314044 & 31628 & 3.0 & 3.0687 & TRN & \\
\hline CHEMBL 81171 & 31628 & 5.0 & 6.4481 & TST & \\
\hline CHEMBL79831 & 31628 & 3.0 & 2.9424 & TRN & \\
\hline CHEMBL 309524 & 31628 & 5.0 & 5.0685 & TRN & \\
\hline CHEMBL 79199 & 31628 & 6.0 & 5.7868 & TRN & \\
\hline CHEMBL311334 & 31628 & 5.0 & 4.8017 & TRN & \\
\hline CHEMBL 81353 & 31628 & 5.0 & 4.8683 & TRN & \\
\hline CHEMBL 82493 & 31628 & 5.0 & 4.922 & TRN & \\
\hline CHEMBL312053 & 31628 & 3.0 & 3.0798 & TRN & \\
\hline CHEMBL 81471 & 31628 & 3.0 & 2.5464 & TST & \\
\hline CHEMBL81558 & 31628 & 4.0 & 2.9961 & TST & \\
\hline CHEMBL 81242 & 31628 & 3.0 & 2.9611 & TRN & \\
\hline CHEMBL78821 & 31628 & 5.0 & 5.1162 & TRN & \\
\hline & & & & 10617 & \\
\hline
\end{tabular}




\begin{tabular}{|c|c|c|c|c|c|c|}
\hline \multicolumn{7}{|c|}{ Supplemental Table S2.txt } \\
\hline CHEMBL78963 & 31628 & 7.0 & 6.5468 & TRN & & \\
\hline CHEMBL 79484 & 31628 & 3.0 & 3.4009 & TST & & \\
\hline CHEMBL309998 & 31628 & 7.0 & 5.0504 & TST & & \\
\hline CHEMBL82299 & 31628 & 3.0 & 3.6884 & TST & & \\
\hline CHEMBL312712 & 31628 & 4.0 & 4.5244 & TST & & \\
\hline CHEMBL 81250 & 31628 & 3.0 & 4.5545 & TST & & \\
\hline CHEMBL1704002 & 737406 & 3.0 & 3.2799 & TRN & & \\
\hline CHEMBL1532240 & 737406 & 3.0 & 2.9242 & TST & & \\
\hline CHEMBL1732183 & 737406 & 3.0 & 2.8807 & TRN & & \\
\hline CHEMBL1704720 & 737406 & \multicolumn{3}{|c|}{4.821000000000001} & 4.6064 & TRN \\
\hline CHEMBL1304974 & 737406 & 4.9101 & 3.9015 & TST & & \\
\hline CHEMBL1719539 & 737406 & 4.0022 & 3.4786 & TRN & & \\
\hline CHEMBL1445488 & 737406 & 6.6615 & 3.951 & TST & & \\
\hline CHEMBL1373210 & 737406 & 5.4498 & 4.3895 & TRN & & \\
\hline CHEMBL1411223 & 737406 & 3.0 & 3.2088 & TRN & & \\
\hline CHEMBL1730304 & 737406 & 5.3161 & 4.7851 & TRN & & \\
\hline CHEMBL1708762 & 737406 & 4.7905 & 3.9643 & TST & & \\
\hline CHEMBL1714887 & 737406 & 4.1445 & 4.2329 & TRN & & \\
\hline CHEMBL1391676 & 737406 & 3.0 & 3.4406 & TST & & \\
\hline CHEMBL1704444 & 737406 & 4.5157 & 5.157 & TRN & & \\
\hline CHEMBL1702302 & 737406 & 4.2161 & 4.439 & TRN & & \\
\hline CHEMBL1728483 & 737406 & 3.0 & 2.9118 & TRN & & \\
\hline CHEMBL1422255 & 737406 & 3.0 & 3.7708 & TST & & \\
\hline CHEMBL1605172 & 737406 & 6.3958 & 6.0016 & TST & & \\
\hline CHEMBL1536896 & 737406 & 7.71 & 3.8254 & TST & & \\
\hline CHEMBL1385949 & 737406 & 6.6655 & 5.5583 & TST & & \\
\hline CHEMBL1425948 & 737406 & 3.0 & 3.4532 & TRN & & \\
\hline CHEMBL1699305 & 737406 & 4.3883 & \multicolumn{3}{|c|}{4.531000000000001} & TRN \\
\hline CHEMBL1416769 & 737406 & 3.0 & 3.4847 & TRN & & \\
\hline CHEMBL1452827 & 737406 & 3.0 & 2.679 & TST & & \\
\hline CHEMBL1729688 & 737406 & 3.0 & 4.3623 & TRN & & \\
\hline CHEMBL1477806 & 737406 & 3.0 & 3.4392 & TST & & \\
\hline CHEMBL1710618 & 737406 & 3.0 & 3.0601 & TRN & & \\
\hline CHEMBL1301020 & 737406 & \multicolumn{3}{|c|}{4.0680000000000005} & 3.5418 & TST \\
\hline CHEMBL1733159 & 737406 & 4.3152 & 4.1538 & TRN & & \\
\hline CHEMBL1736524 & 737406 & 3.0 & 2.6471 & TRN & & \\
\hline CHEMBL1735969 & 737406 & 4.3279 & 3.9203 & TRN & & \\
\hline CHEMBL1505246 & 737406 & 6.0177 & 5.5508 & TST & & \\
\hline CHEMBL1452898 & 737406 & 3.0 & 4.0794 & TRN & & \\
\hline CHEMBL1721258 & 737406 & 3.0 & 3.7974 & TRN & & \\
\hline CHEMBL1724547 & 737406 & 4.3862 & 4.6776 & TRN & & \\
\hline CHEMBL1461661 & 737406 & 4.0458 & 4.1428 & TRN & & \\
\hline CHEMBL1735408 & 737406 & 3.0 & 2.7442 & TRN & & \\
\hline CHEMBL1462768 & 737406 & 3.0 & 2.6587 & TRN & & \\
\hline CHEMBL1447397 & 737406 & 5.7721 & 4.7171 & TRN & & \\
\hline CHEMBL1569076 & 737406 & 5.2692 & 5.5497 & TRN & & \\
\hline CHEMBL1723513 & 737406 & 4.1726 & 3.8438 & TRN & & \\
\hline CHEMBL1470219 & 737406 & 3.0 & 2.7329 & TRN & & \\
\hline
\end{tabular}




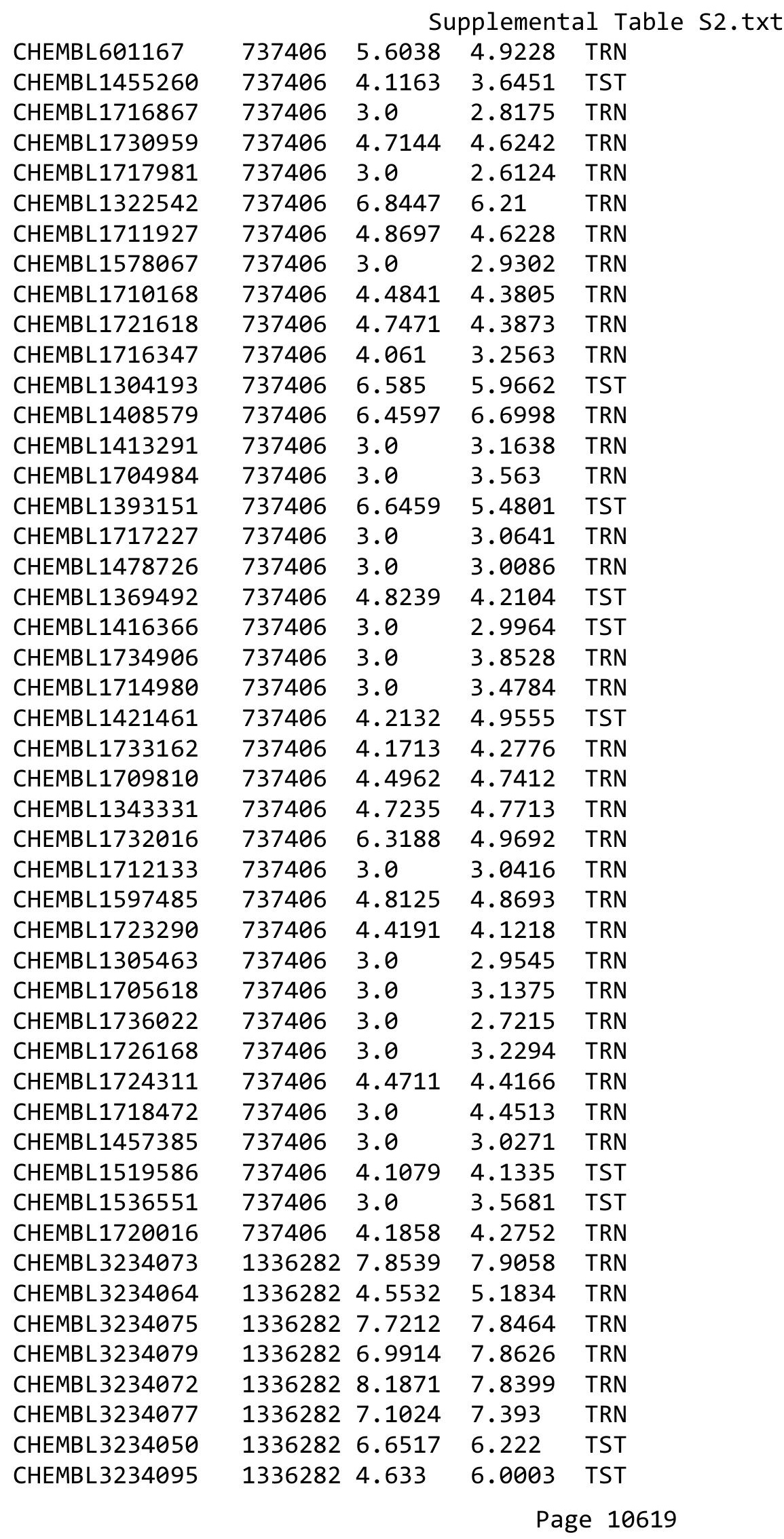


Supplemental Table S2.txt

\begin{tabular}{|c|c|c|c|c|}
\hline 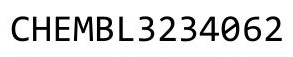 & & 881 & & \\
\hline HEMBL3234045 & 336282 & 7.0223 & 7.2164 & \\
\hline 61 & 282 & & 593 & \\
\hline 067 & 36282 & 1805 & 8974 & \\
\hline IEMBL3234098 & 36282 & 1175 & 9895 & \\
\hline AEMBL3234096 & 336282 & 6863 & 8326 & \\
\hline HEMBL3234041 & 336282 & 7959 & 523 & \\
\hline EMBL & 36282 & 952 & 9387 & \\
\hline EMBL3234058 & 36282 & 743 & .5761 & \\
\hline AEMBL3234081 & 336282 & 6.9318 & .3869 & \\
\hline HEMBL3234097 & 336282 & 1169 & 0302 & \\
\hline AEMBL3234060 & 336282 & 268 & 3573 & \\
\hline IEMBL: & & & & \\
\hline HEMBL3 & 282 & 949 & 8795 & \\
\hline AEMBL3234043 & 336282 & 5867 & 8957 & \\
\hline AEMBL3234 & 336282 & 239 & & \\
\hline AEMBL3 & 336282 & 654 & 273 & \\
\hline AEMBL & 82 & & & \\
\hline HEMBL3 & 282 & 235 & 302 & \\
\hline HEMBL 32 & 336282 & 925 & 7654 & RN \\
\hline EMABL 323 & 336282 & .7447 & .9702 & NIV \\
\hline HEMBL3 & 336282 & 565 & 027 & RN \\
\hline HEMBL3 & 82 & & 89 & \\
\hline 42 & 82 & 59 & 386 & S \\
\hline AEMBL32 & 282 & 71 & & RN \\
\hline EMBL323 & 82 & 15 & 732 & KIN \\
\hline HEMBL 32 & 82 & 33 & 7118 & RN \\
\hline HEMBL3 & 82 & & 949 & \\
\hline 86 & 82 & 75 & 73 & RN \\
\hline IEMBL32 & 82 & 97 & 119 & KIV \\
\hline MBL32 & 32 & 82 & 353 & ГRN \\
\hline HEMBL 32 & 336282 & 14 & .76 & Niv \\
\hline HEMBL3 & 32 & & & RN \\
\hline & & & 7866 & RN \\
\hline AEMBL323 & 36282 & 84 & 6.17 & ST \\
\hline EMBL32 & 36282 & 67 & 86 & rRN \\
\hline HEMBL 323 & 336282 & 45 & & RIV \\
\hline & & & & RN \\
\hline HEMBL32 & 336282 & 045 & 3225 & RN \\
\hline AEMBL32 & 36282 & 372 & 868 & RN \\
\hline IEMBL32 & 336282 & 47 & 644 & \\
\hline HEMBL323 & & 391 & 6.7574 & \\
\hline (2) & & & .7106 & ST \\
\hline HEMBL32 & 336282 & 7305 & 5.3721 & TST \\
\hline AEMBL32 & 336282 & 559 & 7.85 & ST \\
\hline & & & 4814 & \\
\hline - & 年 & & 6.2161 & ו \\
\hline 23407 & 1336 & & 7.8 & \\
\hline
\end{tabular}

Page 10620 
Supplemental Table S2.txt

\begin{tabular}{|c|c|c|c|c|}
\hline CHEMBL3234066 & 1336282 & 4.4974 & 5.5641 & TST \\
\hline CHEMBL3234080 & 1336282 & 6.9706 & 7.5323 & TST \\
\hline CHEMBL172 & 1336282 & 7.9208 & 7.2918 & TST \\
\hline CHEMBL 2003768 & 809285 & 4.0 & 5.1301 & TRN \\
\hline CHEMBL213505 & 809285 & 6.6 & 5.8879 & TRN \\
\hline CHEMBL202721 & 809285 & 4.9 & 5.5999 & TRN \\
\hline CHEMBL1982881 & 809285 & 5.7 & 5.7739 & TRN \\
\hline CHEMBL1993941 & 809285 & 4.0 & 4.5115 & TRN \\
\hline CHEMBL1989293 & 809285 & 7.6 & 6.4767 & TRN \\
\hline CHEMBL377383 & 809285 & 4.0 & 4.332 & TRN \\
\hline CHEMBL 2005886 & 809285 & 7.3 & 6.3827 & TRN \\
\hline CHEMBL481491 & 809285 & 6.0 & 4.9351 & TST \\
\hline CHEMBL1973142 & 809285 & 7.1 & 7.5602 & TRN \\
\hline CHEMBL388311 & 809285 & 9.5 & 10.0122 & TRN \\
\hline CHEMBL1973145 & 809285 & 5.4 & 4.5981 & TRN \\
\hline CHEMBL1982924 & 809285 & 6.7 & 7.0271 & TRN \\
\hline CHEMBL 2005936 & 809285 & 8.2 & 8.2098 & TRN \\
\hline CHEMBL1964948 & 809285 & 4.6 & 4.9566 & TRN \\
\hline CHEMBL1999778 & 809285 & 5.1 & 5.3152 & TST \\
\hline CHEMBL1971141 & 809285 & 4.0 & 4.6196 & TRN \\
\hline CHEMBL1995813 & 809285 & 8.2 & 8.883 & TRN \\
\hline CHEMBL206236 & 809285 & 6.4 & 7.095 & TRN \\
\hline CHEMBL1989834 & 809285 & 6.0 & 5.4842 & TRN \\
\hline CHEMBL1987430 & 809285 & 6.8 & 5.8655 & TRN \\
\hline CHEMBL244378 & 809285 & 7.0 & 7.5545 & TRN \\
\hline CHEMBL 2001957 & 809285 & 4.0 & 4.2324 & TRN \\
\hline CHEMBL1969372 & 809285 & 6.7 & 5.8898 & TRN \\
\hline CHEMBL1993413 & 809285 & 7.6 & 6.1795 & TRN \\
\hline CHEMBL289959 & 809285 & 6.0 & 5.4683 & TRN \\
\hline CHEMBL 2006263 & 809285 & 4.0 & 6.0055 & TST \\
\hline CHEMBL1988662 & 809285 & 7.1 & 7.0254 & TRN \\
\hline CHEMBL1993584 & 809285 & 7.8 & 7.7359 & TRN \\
\hline CHEMBL 2000114 & 809285 & 7.4 & 6.9961 & TRN \\
\hline CHEMBL210618 & 809285 & 4.0 & 4.2259 & TRN \\
\hline CHEMBL1986265 & 809285 & 4.6 & 4.6419 & TRN \\
\hline CHEMBL1971172 & 809285 & 8.3 & 7.8204 & TRN \\
\hline CHEMBL1975647 & 809285 & 6.6 & 7.2378 & TRN \\
\hline CHEMBL1968380 & 809285 & 5.6 & 5.3494 & TRN \\
\hline CHEMBL1997643 & 809285 & 8.4 & 7.9413 & TRN \\
\hline CHEMBL1967211 & 809285 & 6.1 & 5.3454 & TRN \\
\hline CHEMBL1964644 & 809285 & 5.1 & 5.2506 & TRN \\
\hline CHEMBL1991734 & 809285 & 7.6 & 5.8644 & TST \\
\hline CHEMBL1981782 & 809285 & 6.7 & 6.9913 & TRN \\
\hline CHEMBL1977681 & 809285 & 6.9 & 5.9468 & TRN \\
\hline CHEMBL1970142 & 809285 & 4.0 & 4.9165 & TRN \\
\hline CHEMBL1990912 & 809285 & 8.5 & 7.7336 & TRN \\
\hline CHEMBL1991782 & 809285 & 5.4 & 4.6377 & TRN \\
\hline CHEMBL2002105 & 809285 & 5.6 & 5.7874 & TRN \\
\hline
\end{tabular}




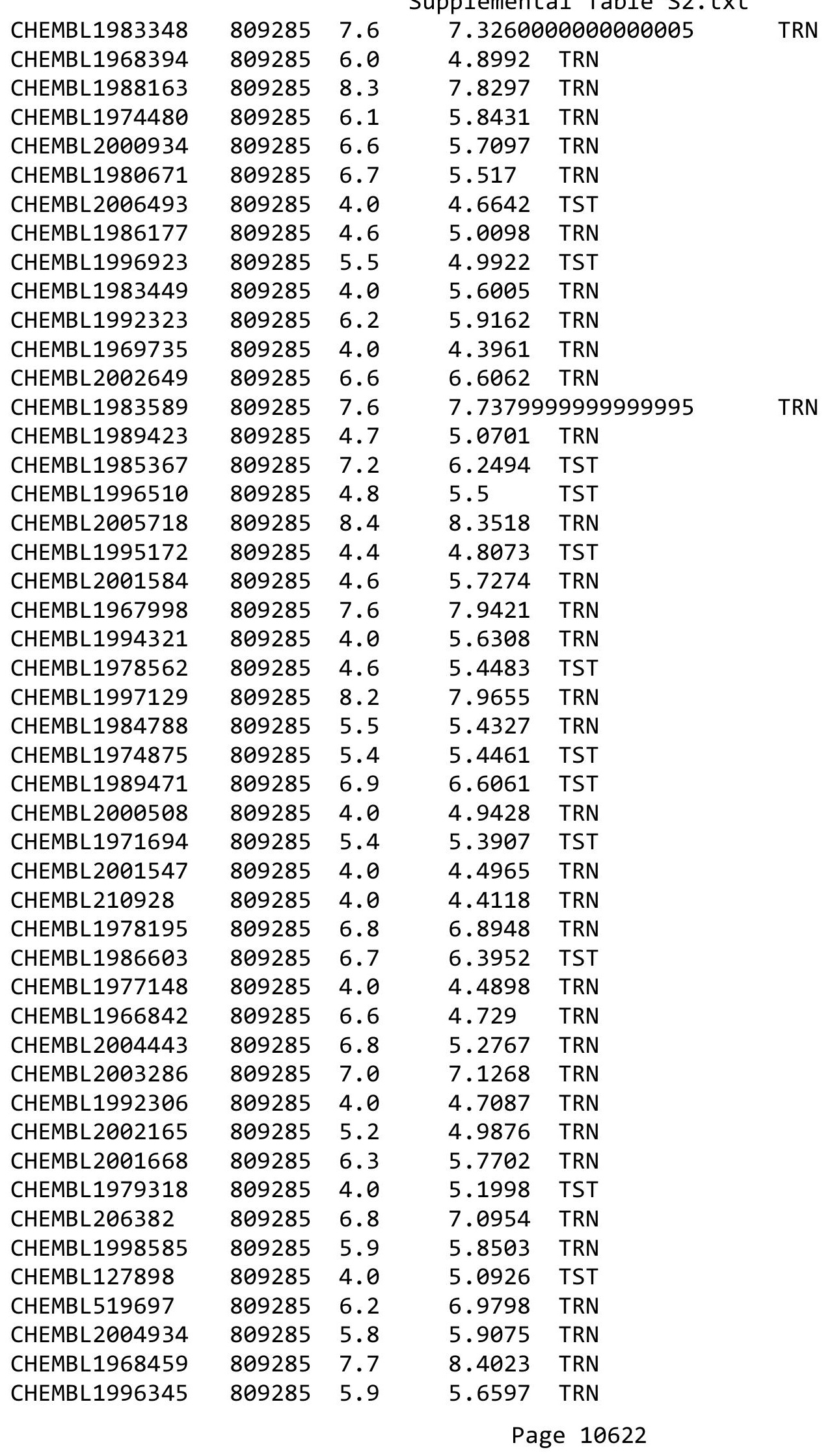




\begin{tabular}{|c|c|c|c|c|c|}
\hline \multirow[b]{2}{*}{ CHEMBL1975128 } & \multirow[b]{2}{*}{809285} & \multirow[b]{2}{*}{7.9} & \\
\hline & & & 8.3758 & TRN & \\
\hline CHEMBL 2004025 & 809285 & 6.3 & 5.5371 & TRN & \\
\hline CHEMBL1996048 & 809285 & 4.6 & 6.1326 & TRN & \\
\hline CHEMBL1970369 & 809285 & 6.4 & 5.3737 & TRN & \\
\hline CHEMBL1976158 & 809285 & 5.9 & 5.3817 & TST & \\
\hline CHEMBL461876 & 809285 & 7.7 & 6.9541 & TRN & \\
\hline CHEMBL1965033 & 809285 & 4.6 & 5.0428 & TRN & \\
\hline CHEMBL2001485 & 809285 & 4.0 & 4.9266 & TRN & \\
\hline CHEMBL1971519 & 809285 & 7.4 & \multicolumn{2}{|c|}{6.7989999999999995} & TRN \\
\hline CHEMBL1997335 & 809285 & 7.2 & 7.3516 & TRN & \\
\hline CHEMBL1966425 & 809285 & 6.1 & 5.2558 & TRN & \\
\hline CHEMBL1984363 & 809285 & 7.1 & 6.9467 & TRN & \\
\hline CHEMBL1978099 & 809285 & 6.5 & 6.4662 & TRN & \\
\hline CHEMBL1988608 & 809285 & 7.2 & 7.1862 & TRN & \\
\hline CHEMBL184847 & 809285 & 4.0 & 5.185 & TRN & \\
\hline CHEMBL1994808 & 809285 & 4.1 & 5.1183 & TRN & \\
\hline CHEMBL1984367 & 809285 & 5.4 & 5.0721 & TRN & \\
\hline CHEMBL1985723 & 809285 & 8.3 & 8.1072 & TRN & \\
\hline CHEMBL178737 & 809285 & 6.5 & 5.8267 & TST & \\
\hline CHEMBL1982563 & 809285 & 4.0 & 4.7077 & TRN & \\
\hline CHEMBL539474 & 809285 & 4.0 & 5.5367 & TST & \\
\hline CHEMBL575824 & 809285 & 8.3 & 9.1377 & TRN & \\
\hline CHEMBL1988387 & 809285 & 4.0 & \multicolumn{2}{|c|}{4.5280000000000005} & TRN \\
\hline CHEMBL1973868 & 809285 & 7.6 & 7.2468 & TRN & \\
\hline CHEMBL1977128 & 809285 & 8.4 & 8.3921 & TRN & \\
\hline CHEMBL1974803 & 809285 & 6.4 & 5.6462 & TRN & \\
\hline CHEMBL1970074 & 809285 & 6.0 & 5.4314 & TRN & \\
\hline CHEMBL399434 & 809285 & 6.1 & 5.8177 & TRN & \\
\hline CHEMBL1965702 & 809285 & 7.9 & 8.0626 & TRN & \\
\hline CHEMBL1984500 & 809285 & 5.2 & 4.675 & TRN & \\
\hline CHEMBL1986970 & 809285 & 6.1 & 7.0724 & TRN & \\
\hline CHEMBL2002456 & 809285 & 7.9 & 7.3156 & TRN & \\
\hline CHEMBL 2005112 & 809285 & 6.2 & 5.1792 & TST & \\
\hline CHEMBL1958401 & 809285 & 7.7 & 7.528 & TRN & \\
\hline CHEMBL1984044 & 809285 & 5.9 & 5.8363 & TRN & \\
\hline CHEMBL2003456 & 809285 & 5.2 & 5.3583 & TRN & \\
\hline CHEMBL1966816 & 809285 & 7.9 & 6.6737 & TRN & \\
\hline CHEMBL1972584 & 809285 & 5.3 & 4.721 & TRN & \\
\hline CHEMBL2002992 & 809285 & 6.8 & 6.7411 & TRN & \\
\hline CHEMBL560813 & 809285 & 6.2 & 5.9304 & TRN & \\
\hline CHEMBL 207253 & 809285 & 5.9 & $4.9460 e$ & 0000000001 & TST \\
\hline CHEMBL1982700 & 809285 & 4.6 & 5.2596 & TST & \\
\hline CHEMBL1968791 & 809285 & 4.0 & 4.5364 & TRN & \\
\hline CHEMBL2002682 & 809285 & 4.0 & 5.1068 & TST & \\
\hline CHEMBL1997495 & 809285 & 5.8 & 5.4974 & TRN & \\
\hline CHEMBL1977634 & 809285 & 4.6 & 4.7865 & TRN & \\
\hline CHEMBL1971186 & 809285 & 4.0 & 5.309 & TRN & \\
\hline \multirow[t]{2}{*}{ CHEMBL2003482 } & 809285 & 4.0 & 5.2855 & TRN & \\
\hline & & \multicolumn{4}{|c|}{ Page 10623} \\
\hline
\end{tabular}




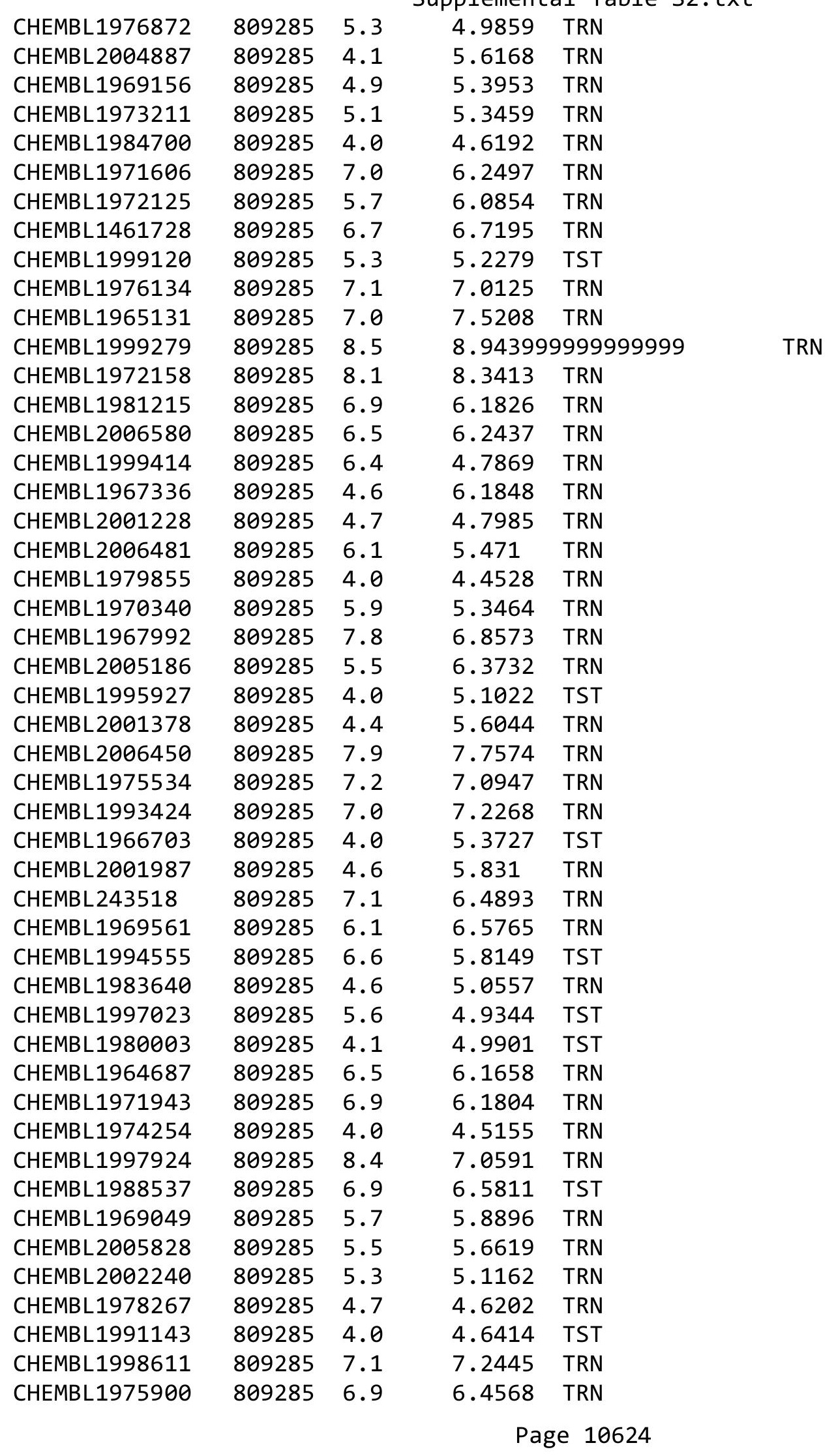




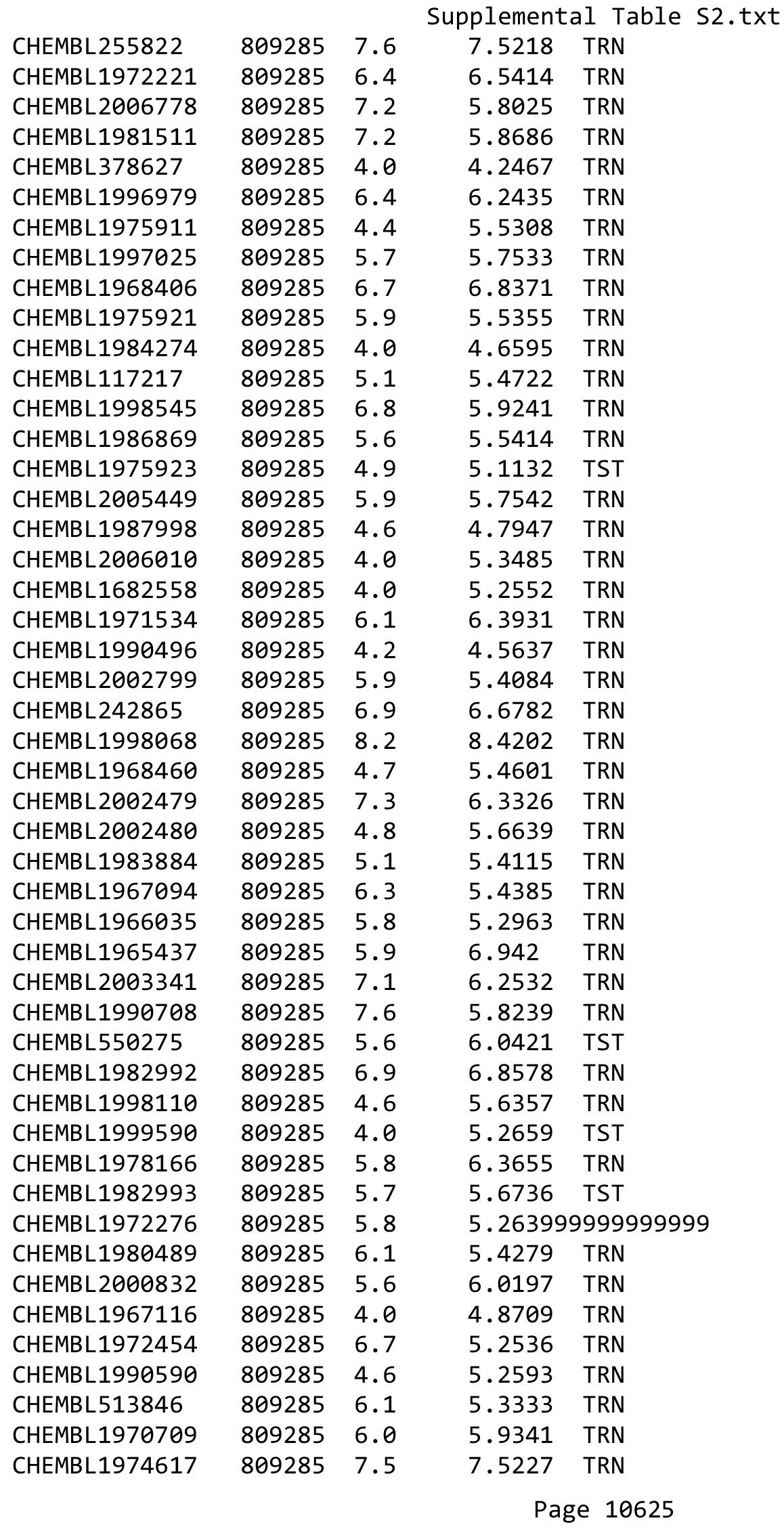




\begin{tabular}{|c|c|c|c|c|}
\hline & & & EII & al Table \\
\hline CHEMBL1965660 & 809285 & 9.2 & 9.003 & TRN \\
\hline CHEMBL1992125 & 809285 & 6.0 & 6.086 & TRN \\
\hline CHEMBL1998112 & 809285 & 4.0 & 4.9953 & TRN \\
\hline CHEMBL1972290 & 809285 & 8.3 & 8.6884 & TRN \\
\hline CHEMBL1969126 & 809285 & 4.0 & 5.0225 & TRN \\
\hline CHEMBL1980896 & 809285 & 6.0 & 5.6415 & TRN \\
\hline CHEMBL1975208 & 809285 & 4.0 & 4.4052 & TST \\
\hline CHEMBL1178727 & 809285 & 4.8 & 5.3393 & TRN \\
\hline CHEMBL1970104 & 809285 & 7.1 & 7.4182 & TRN \\
\hline CHEMBL1991429 & 809285 & 4.0 & 4.4178 & TRN \\
\hline CHEMBL1967612 & 809285 & 4.2 & 5.6464 & TST \\
\hline CHEMBL1964777 & 809285 & 6.1 & 6.6413 & TRN \\
\hline CHEMBL1971149 & 809285 & 4.0 & 4.4253 & TRN \\
\hline CHEMBL1999714 & 809285 & 4.0 & 4.4004 & TRN \\
\hline CHEMBL1987533 & 809285 & 6.4 & 5.4481 & TRN \\
\hline CHEMBL1994040 & 809285 & 4.0 & 4.5817 & TRN \\
\hline CHEMBL 388978 & 809285 & 8.7 & 7.03700 & 0000000001 \\
\hline CHEMBL398951 & 809285 & 4.6 & 4.3337 & TST \\
\hline CHEMBL1982506 & 809285 & 6.4 & 5.9762 & TST \\
\hline CHEMBL2004716 & 809285 & 4.0 & 4.5802 & TRN \\
\hline CHEMBL1968127 & 809285 & 4.0 & 4.5433 & TRN \\
\hline CHEMBL1975233 & 809285 & 4.0 & 5.1347 & TRN \\
\hline CHEMBL1985406 & 809285 & 7.7 & 7.7572 & TRN \\
\hline CHEMBL 2007603 & 809285 & 7.0 & 6.1208 & TRN \\
\hline CHEMBL 207400 & 809285 & 6.1 & 4.8324 & TST \\
\hline CHEMBL 2000894 & 809285 & 6.8 & 7.022 & TRN \\
\hline CHEMBL1421720 & 809285 & 6.3 & 5.8774 & TRN \\
\hline CHEMBL1968130 & 809285 & 6.3 & 5.568 & TRN \\
\hline CHEMBL 2002553 & 809285 & 5.8 & 4.7808 & TST \\
\hline CHEMBL1982135 & 809285 & 6.7 & 6.5324 & TRN \\
\hline CHEMBL1976090 & 809285 & 7.9 & 7.9023 & TRN \\
\hline CHEMBL1993243 & 809285 & 5.4 & 4.8223 & TRN \\
\hline CHEMBL 2004771 & 809285 & 6.1 & 5.6008 & TRN \\
\hline CHEMBL1992922 & 809285 & 8.1 & 7.937 & TRN \\
\hline CHEMBL1997597 & 809285 & 6.4 & 6.2892 & TRN \\
\hline CHEMBL1969537 & 809285 & 4.0 & 5.2627 & TST \\
\hline CHEMBL1972466 & 809285 & 5.6 & 5.6471 & TST \\
\hline CHEMBL576113 & 809285 & 5.7 & 5.6193 & TST \\
\hline CHEMBL1976093 & 809285 & 5.4 & 4.5538 & TRN \\
\hline CHEMBL 210032 & 809285 & 6.0 & 5.0809 & TRN \\
\hline CHEMBL1975256 & 809285 & 5.1 & 5.1316 & TRN \\
\hline CHEMBL508928 & 809285 & 6.7 & 5.1866 & TRN \\
\hline CHEMBL1991356 & 809285 & 6.6 & 4.9907 & TST \\
\hline CHEMBL1983309 & 809285 & 6.0 & 5.0206 & TRN \\
\hline CHEMBL 2004892 & 809285 & 6.7 & 6.3815 & TRN \\
\hline CHEMBL1949855 & 809285 & 6.3 & 5.8787 & TRN \\
\hline CHEMBL1999126 & 809285 & 5.7 & 4.7946 & TST \\
\hline CHEMBL1997503 & 809285 & 4.0 & 4.9361 & TST \\
\hline
\end{tabular}




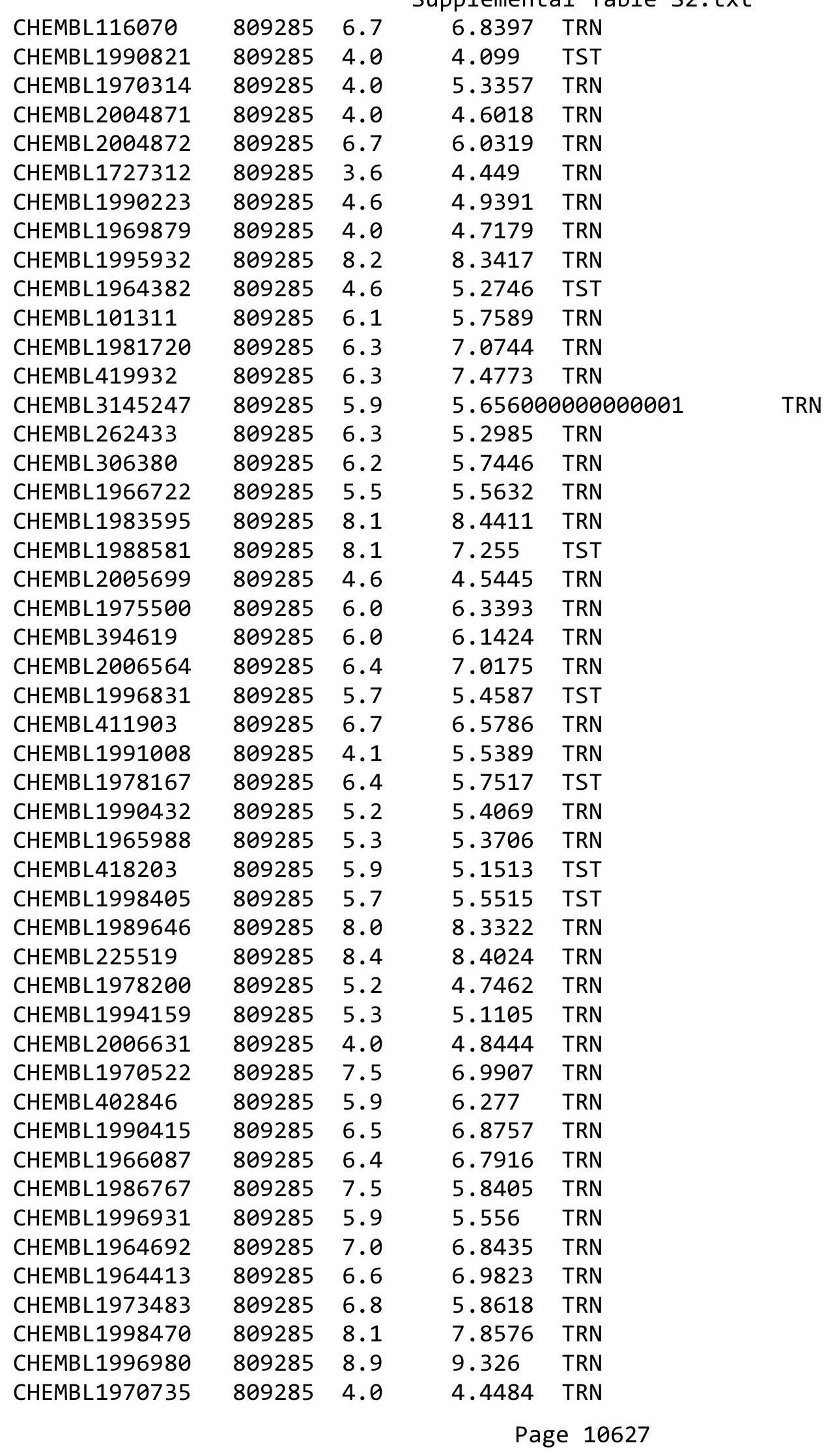




\begin{tabular}{|c|c|c|c|c|}
\hline & & & & $a \perp \mid a b \perp \epsilon$ \\
\hline CHEMBL1975903 & 809285 & 6.3 & 5.6042 & TRN \\
\hline CHEMBL1997340 & 809285 & 6.2 & 5.5196 & TRN \\
\hline CHEMBL2004365 & 809285 & 5.7 & 5.345 & TST \\
\hline CHEMBL1522508 & 809285 & 6.0 & 5.3417 & TRN \\
\hline CHEMBL1989474 & 809285 & 4.0 & 4.879 & TRN \\
\hline CHEMBL1090360 & 809285 & 4.0 & 4.3507 & TRN \\
\hline CHEMBL226232 & 809285 & 8.0 & 7.5345 & TRN \\
\hline CHEMBL210887 & 809285 & 7.8 & 7.1613 & TRN \\
\hline CHEMBL1988805 & 809285 & 6.7 & 6.1611 & TRN \\
\hline CHEMBL458997 & 809285 & 7.8 & 7.0134 & TRN \\
\hline CHEMBL1971021 & 809285 & 4.0 & 4.9402 & TRN \\
\hline CHEMBL583144 & 809285 & 7.0 & 6.6288 & TRN \\
\hline CHEMBL1974310 & 809285 & 6.8 & 6.968 & TRN \\
\hline CHEMBL1969942 & 809285 & 4.6 & 5.6778 & TRN \\
\hline CHEMBL1978567 & 809285 & 4.6 & 5.6357 & TRN \\
\hline CHEMBL1982660 & 809285 & 7.6 & 7.4934 & TRN \\
\hline CHEMBL1994693 & 809285 & 7.3 & 6.9207 & TRN \\
\hline CHEMBL1965838 & 809285 & 4.5 & 5.8341 & TST \\
\hline CHEMBL1982957 & 809285 & 7.8 & 7.6681 & TRN \\
\hline CHEMBL1725279 & 809285 & 7.2 & 6.9747 & TST \\
\hline CHEMBL 2002346 & 809285 & 8.3 & 8.5479 & TRN \\
\hline CHEMBL1975138 & 809285 & 6.1 & 4.9535 & TRN \\
\hline CHEMBL424872 & 809285 & 4.0 & 4.376 & TRN \\
\hline CHEMBL 2006836 & 809285 & 5.6 & 4.5915 & TST \\
\hline CHEMBL412142 & 809285 & 5.8 & 5.2976 & TST \\
\hline CHEMBL1988000 & 809285 & 5.3 & 5.5931 & TST \\
\hline CHEMBL2002802 & 809285 & 4.6 & 5.6757 & TRN \\
\hline CHEMBL1985153 & 809285 & 4.0 & 5.8293 & TRN \\
\hline CHEMBL1980704 & 809285 & 5.1 & 4.8563 & TST \\
\hline CHEMBL 2003271 & 809285 & 7.0 & 7.5279 & TRN \\
\hline CHEMBL1966808 & 809285 & 6.3 & 5.6696 & TRN \\
\hline CHEMBL 2004447 & 809285 & 4.0 & 4.4475 & TST \\
\hline CHEMBL1992231 & 809285 & 4.6 & 5.5477 & TRN \\
\hline CHEMBL1983111 & 809285 & 6.7 & 6.8501 & TRN \\
\hline CHEMBL1973860 & 809285 & 6.5 & 6.1696 & TRN \\
\hline CHEMBL1977713 & 809285 & 6.1 & 5.2765 & TRN \\
\hline CHEMBL260135 & 809285 & 6.2 & 6.7004 & TRN \\
\hline CHEMBL 220241 & 809285 & 6.2 & 5.2995 & TRN \\
\hline CHEMBL2004544 & 809285 & 6.0 & 5.8916 & TST \\
\hline CHEMBL1983157 & 809285 & 8.5 & 7.4303 & TRN \\
\hline CHEMBL1988141 & 809285 & 7.4 & $6.2020 e$ & 0000000001 \\
\hline CHEMBL1982610 & 809285 & 7.3 & 6.584 & TRN \\
\hline CHEMBL1989569 & 809285 & 5.2 & 6.0025 & TRN \\
\hline CHEMBL1966040 & 809285 & 7.2 & 8.0458 & TRN \\
\hline CHEMBL1977134 & 809285 & 4.6 & 4.8038 & TRN \\
\hline CHEMBL1999496 & 809285 & 4.0 & 5.0152 & TRN \\
\hline CHEMBL1970873 & 809285 & 3.3 & 4.4623 & TRN \\
\hline CHEMBL1985206 & 809285 & 6.3 & 5.1746 & TST \\
\hline
\end{tabular}




\begin{tabular}{|c|c|c|c|c|c|}
\hline \\
\hline CHEMBL375293 & 809285 & 5.5 & 6.0747 & TST & \\
\hline CHEMBL1988300 & 809285 & 6.2 & 5.4152 & TRN & \\
\hline CHEMBL1987359 & 809285 & 4.0 & 4.8037 & TST & \\
\hline CHEMBL1977749 & 809285 & 7.6 & 5.7288 & TST & \\
\hline CHEMBL1975212 & 809285 & 5.8 & 5.6317 & TRN & \\
\hline CHEMBL 2001613 & 809285 & 5.9 & 5.9423 & TRN & \\
\hline CHEMBL1997275 & 809285 & 6.1 & 5.6364 & TRN & \\
\hline CHEMBL1993904 & 809285 & 7.7 & 6.1819 & TRN & \\
\hline CHEMBL1994438 & 809285 & 7.5 & 8.0101 & TRN & \\
\hline CHEMBL1980376 & 809285 & 5.3 & 5.32299 & 99999999995 & TRN \\
\hline CHEMBL1967513 & 809285 & 6.8 & 6.1604 & TRN & \\
\hline CHEMBL 2000724 & 809285 & 4.6 & 5.0802 & TRN & \\
\hline CHEMBL 2002418 & 809285 & 5.9 & 5.7903 & TRN & \\
\hline CHEMBL1989265 & 809285 & 4.0 & 4.8977 & TST & \\
\hline CHEMBL1982413 & 809285 & 7.3 & 5.7476 & TRN & \\
\hline CHEMBL1965909 & 809285 & 5.4 & 5.3549 & TRN & \\
\hline CHEMBL 2004647 & 809285 & 4.0 & 4.53 & TST & \\
\hline CHEMBL1969502 & 809285 & 6.3 & 6.1068 & TRN & \\
\hline CHEMBL1996447 & 809285 & 8.0 & 7.2173 & TRN & \\
\hline CHEMBL1682553 & 809285 & 7.5 & 8.5965 & TRN & \\
\hline CHEMBL1971430 & 809285 & 4.0 & 4.5131 & TRN & \\
\hline CHEMBL1983963 & 809285 & 6.1 & 5.79 & TRN & \\
\hline CHEMBL1997764 & 809285 & 6.7 & 6.5568 & TRN & \\
\hline CHEMBL1985042 & 809285 & 5.0 & 5.4253 & TRN & \\
\hline CHEMBL1981792 & 809285 & 4.6 & 5.6323 & TRN & \\
\hline CHEMBL1987535 & 809285 & 7.8 & 7.6906 & TRN & \\
\hline CHEMBL354676 & 809285 & 5.1 & 4.7613 & TRN & \\
\hline CHEMBL1985092 & 809285 & 6.3 & 6.3643 & TRN & \\
\hline CHEMBL 2004692 & 809285 & 5.9 & 4.5955 & TRN & \\
\hline CHEMBL1981410 & 809285 & 5.6 & 5.4615 & TRN & \\
\hline CHEMBL 2002586 & 809285 & 6.2 & 5.6133 & TRN & \\
\hline CHEMBL1987815 & 809285 & 5.4 & 5.2283 & TRN & \\
\hline CHEMBL1996234 & 809285 & 4.0 & 4.7787 & TRN & \\
\hline CHEMBL383264 & 809285 & 9.0 & 9.2841 & TRN & \\
\hline CHEMBL 2007421 & 809285 & 6.3 & 5.8985 & TST & \\
\hline CHEMBL1991434 & 809285 & 4.0 & 5.1511 & TST & \\
\hline CHEMBL1967544 & 809285 & 7.0 & 7.0018 & TRN & \\
\hline CHEMBL1973138 & 809285 & 4.6 & 5.2924 & TRN & \\
\hline CHEMBL223367 & 809285 & 4.0 & 4.3511 & TST & \\
\hline CHEMBL1992673 & 809285 & 4.7 & 5.4139 & TRN & \\
\hline CHEMBL340384 & 809285 & 7.7 & 8.1662 & TRN & \\
\hline CHEMBL1969151 & 809285 & 8.6 & 8.7215 & TRN & \\
\hline CHEMBL1996587 & 809285 & 6.4 & 5.1967 & TRN & \\
\hline CHEMBL1981492 & 809285 & 5.4 & 5.0477 & TRN & \\
\hline CHEMBL1993335 & 809285 & 6.8 & 5.7551 & TST & \\
\hline CHEMBL1988692 & 809285 & 4.6 & 5.5807 & TRN & \\
\hline CHEMBL 2007574 & 809285 & 9.2 & 9.1466 & TRN & \\
\hline CHEMBL1964804 & 809285 & 8.3 & 8.1375 & TRN & \\
\hline
\end{tabular}




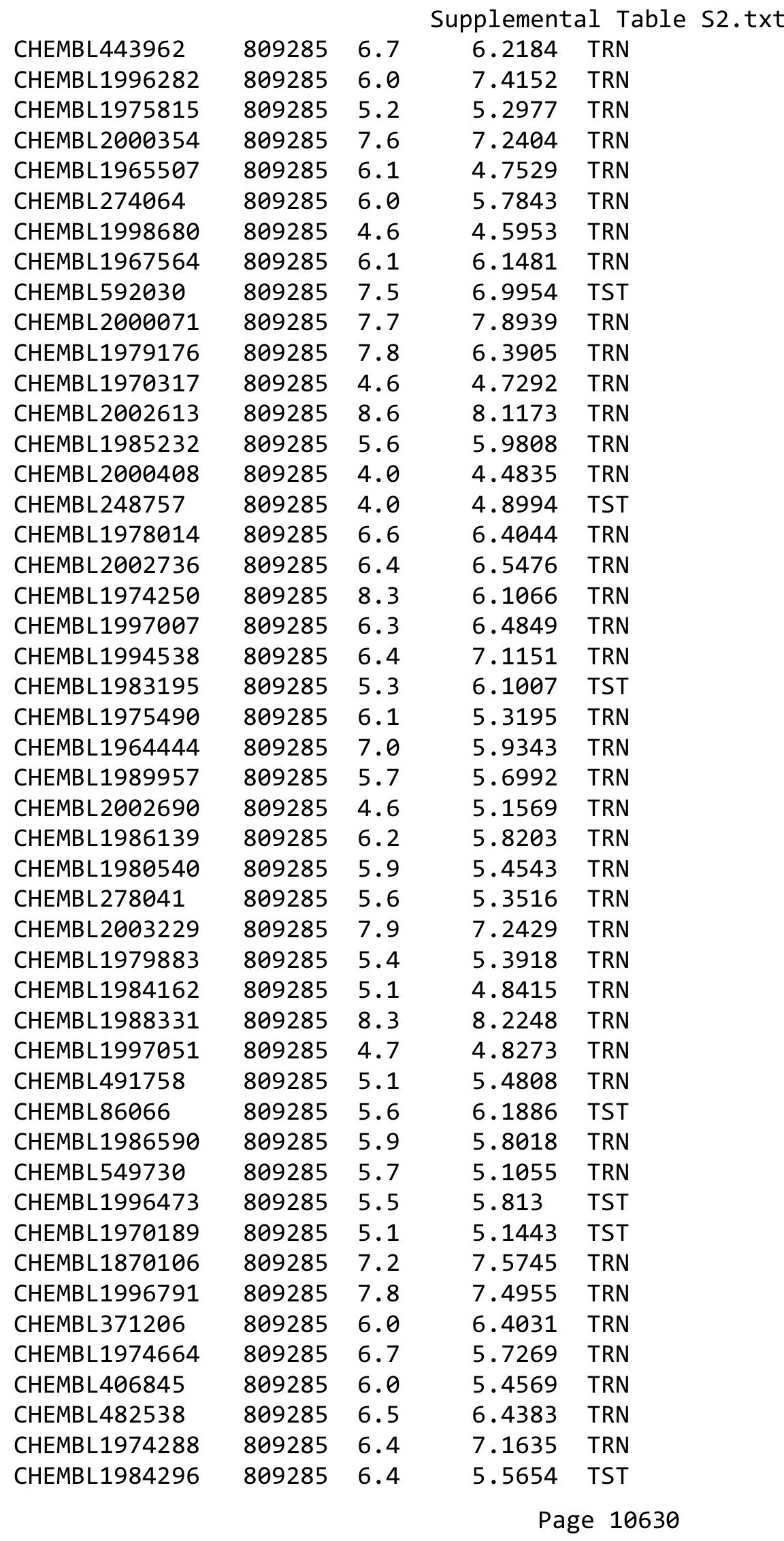




\begin{tabular}{|c|c|c|c|c|c|}
\hline \\
\hline CHEMBL196363 & 809285 & 6.9 & 5.5311 & TRN & \\
\hline CHEMBL1996837 & 809285 & 6.0 & 5.8321 & TRN & \\
\hline CHEMBL1190711 & 809285 & 8.0 & 7.1882 & TRN & \\
\hline CHEMBL1964718 & 809285 & 5.5 & 5.178 & TST & \\
\hline CHEMBL1968705 & 809285 & 6.4 & 5.82799 & 9999999999 & TRN \\
\hline CHEMBL1991410 & 809285 & 8.0 & 6.3791 & TRN & \\
\hline CHEMBL1964441 & 809285 & 4.6 & 5.1776 & TRN & \\
\hline CHEMBL1986684 & 809285 & 6.0 & 4.9 & TST & \\
\hline CHEMBL546797 & 809285 & 6.6 & 5.9608 & TRN & \\
\hline CHEMBL404367 & 809285 & 5.9 & 6.7832 & TRN & \\
\hline CHEMBL1966343 & 809285 & 7.9 & 7.5567 & TRN & \\
\hline CHEMBL1978271 & 809285 & 4.8 & 4.6777 & TRN & \\
\hline CHEMBL2007266 & 809285 & 4.6 & 5.0439 & TRN & \\
\hline CHEMBL 2000568 & 809285 & 6.2 & 6.2542 & TRN & \\
\hline CHEMBL 2000335 & 809285 & 6.2 & 6.1449 & TRN & \\
\hline CHEMBL1977604 & 809285 & 4.0 & 4.5123 & TST & \\
\hline CHEMBL2007097 & 809285 & 5.5 & 5.4672 & TRN & \\
\hline CHEMBL1993648 & 809285 & 7.4 & 7.7105 & TRN & \\
\hline CHEMBL1988717 & 809285 & 4.0 & 4.4404 & TRN & \\
\hline CHEMBL1974328 & 809285 & 7.1 & 6.6143 & TRN & \\
\hline CHEMBL509032 & 809285 & 7.7 & 7.1269 & TRN & \\
\hline CHEMBL 243298 & 809285 & 7.3 & 6.9067 & TRN & \\
\hline CHEMBL573339 & 809285 & 6.1 & 5.768 & TRN & \\
\hline CHEMBL1971951 & 809285 & 8.5 & 6.5677 & TRN & \\
\hline CHEMBL1973808 & 809285 & 7.3 & 7.0176 & TRN & \\
\hline CHEMBL 2000429 & 809285 & 4.0 & 4.2656 & TRN & \\
\hline CHEMBL1972576 & 809285 & 5.3 & 4.7727 & TRN & \\
\hline CHEMBL1992555 & 809285 & 4.0 & 5.2249 & TRN & \\
\hline CHEMBL1990254 & 809285 & 6.9 & 6.9509 & TRN & \\
\hline CHEMBL1992342 & 809285 & 6.3 & 6.6041 & TRN & \\
\hline CHEMBL 2003682 & 809285 & 7.9 & 6.6951 & TRN & \\
\hline CHEMBL1980853 & 809285 & 4.3 & 5.4748 & TST & \\
\hline CHEMBL1988173 & 809285 & 6.3 & 6.0689 & TRN & \\
\hline CHEMBL1973013 & 809285 & 6.2 & 5.9997 & TST & \\
\hline CHEMBL1164265 & 809285 & 7.0 & 5.7564 & TST & \\
\hline CHEMBL535331 & 809285 & 5.7 & 5.195 & TRN & \\
\hline CHEMBL1989805 & 809285 & 6.2 & 5.59399 & 9999999999 & TST \\
\hline CHEMBL1982980 & 809285 & 4.0 & 4.1293 & TST & \\
\hline CHEMBL1965423 & 809285 & 5.3 & 4.805 & TRN & \\
\hline CHEMBL1983025 & 809285 & 5.1 & 5.4066 & TRN & \\
\hline CHEMBL1975927 & 809285 & 6.8 & 6.1781 & TRN & \\
\hline CHEMBL 205415 & 809285 & 7.1 & 7.6081 & TRN & \\
\hline CHEMBL1969473 & 809285 & 8.3 & 7.7221 & TRN & \\
\hline CHEMBL1977135 & 809285 & 6.2 & 6.2833 & TRN & \\
\hline CHEMBL 2001920 & 809285 & 6.2 & 5.9858 & TRN & \\
\hline CHEMBL1985654 & 809285 & 8.0 & 8.169 & TRN & \\
\hline CHEMBL1997119 & 809285 & 4.8 & 5.3888 & TRN & \\
\hline CHEMBL1977138 & 809285 & 9.0 & 7.8042 & TST & \\
\hline
\end{tabular}




\begin{tabular}{|c|c|c|c|c|c|}
\hline & & & 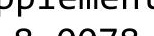 & 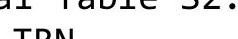 & \\
\hline CHEMBL1241473 & 809285 & 7.9 & 8.0078 & TRN & \\
\hline CHEMBL2000879 & 809285 & 4.6 & 5.2336 & TST & \\
\hline CHEMBL1978448 & 809285 & 4.2 & 4.7001 & TST & \\
\hline CHEMBL1972258 & 809285 & 6.6 & 7.0613 & TRN & \\
\hline CHEMBL 2004513 & 809285 & 4.0 & 5.2322 & TRN & \\
\hline CHEMBL1991251 & 809285 & 4.2 & 5.6331 & TST & \\
\hline CHEMBL1969483 & 809285 & 4.7 & 4.57600 & 00000000005 & TRN \\
\hline CHEMBL1983855 & 809285 & 8.0 & 7.9614 & TRN & \\
\hline CHEMBL1980329 & 809285 & 5.9 & 5.5354 & TRN & \\
\hline CHEMBL2004515 & 809285 & 7.3 & 7.3542 & TRN & \\
\hline CHEMBL2001257 & 809285 & 4.0 & 4.8646 & TRN & \\
\hline CHEMBL1971785 & 809285 & 4.7 & 5.2528 & TRN & \\
\hline CHEMBL1992042 & 809285 & 6.0 & 5.4197 & TRN & \\
\hline CHEMBL 2001704 & 809285 & 4.5 & 5.67 & TRN & \\
\hline CHEMBL1987793 & 809285 & 4.0 & 4.2469 & TST & \\
\hline CHEMBL1992536 & 809285 & 7.1 & 6.316 & TRN & \\
\hline CHEMBL21156 & 809285 & 7.1 & 5.5279 & TST & \\
\hline CHEMBL1992740 & 809285 & 6.0 & 7.0156 & TRN & \\
\hline CHEMBL1994724 & 809285 & 6.5 & 6.2384 & TRN & \\
\hline CHEMBL1989267 & 809285 & 5.6 & 5.2733 & TRN & \\
\hline CHEMBL2002373 & 809285 & 4.0 & 4.90300 & 00000000005 & TRN \\
\hline CHEMBL439340 & 809285 & 4.0 & 5.1624 & TRN & \\
\hline CHEMBL1974574 & 809285 & 6.3 & 5.5787 & TST & \\
\hline CHEMBL2006188 & 809285 & 5.5 & 6.0795 & TRN & \\
\hline CHEMBL1967531 & 809285 & 6.4 & 6.0117 & TRN & \\
\hline CHEMBL1970913 & 809285 & 5.8 & 5.7905 & TRN & \\
\hline CHEMBL1973893 & 809285 & 6.8 & 6.2491 & TRN & \\
\hline CHEMBL 2004631 & 809285 & 7.6 & 8.0682 & TRN & \\
\hline CHEMBL1995736 & 809285 & 5.5 & 5.5118 & TRN & \\
\hline CHEMBL1997534 & 809285 & 7.5 & 6.0677 & TRN & \\
\hline CHEMBL1993877 & 809285 & 8.2 & 7.3073 & TRN & \\
\hline CHEMBL1985095 & 809285 & 7.6 & 7.4689 & TST & \\
\hline CHEMBL1996500 & 809285 & 4.4 & 4.4533 & TRN & \\
\hline CHEMBL1998551 & 809285 & 4.0 & 4.6283 & TRN & \\
\hline CHEMBL1977374 & 809285 & 4.0 & 4.507 & TRN & \\
\hline CHEMBL1973363 & 809285 & 5.6 & 6.0205 & TRN & \\
\hline CHEMBL2005352 & 809285 & 5.8 & 5.9229 & TRN & \\
\hline CHEMBL1682540 & 809285 & 7.9 & 8.5822 & TRN & \\
\hline CHEMBL1983315 & 809285 & 8.1 & 7.8767 & TRN & \\
\hline CHEMBL1976420 & 809285 & 4.5 & 5.5619 & TST & \\
\hline CHEMBL1998253 & 809285 & 6.1 & 5.3912 & TST & \\
\hline CHEMBL1981744 & 809285 & 5.9 & 5.9055 & TRN & \\
\hline CHEMBL1994864 & 809285 & 6.1 & 5.1755 & TRN & \\
\hline CHEMBL 2002446 & 809285 & 5.5 & 4.9133 & TST & \\
\hline CHEMBL497151 & 809285 & 6.9 & 6.5814 & TRN & \\
\hline CHEMBL 2000029 & 809285 & 7.6 & 7.8016 & TRN & \\
\hline CHEMBL1973961 & 809285 & 4.7 & 5.3849 & TRN & \\
\hline \multirow[t]{2}{*}{ CHEMBL246970 } & 809285 & 4.0 & 6.3561 & TRN & \\
\hline & & \multicolumn{4}{|c|}{ Page 10632} \\
\hline
\end{tabular}




\begin{tabular}{|c|c|c|c|c|c|}
\hline \multicolumn{6}{|c|}{ Supplemental Table S2.txt } \\
\hline CHEMBL340921 & 809285 & 7.2 & 7.185 & TRN & \\
\hline CHEMBL1994977 & 809285 & 4.6 & 4.6933 & TRN & \\
\hline CHEMBL 2001149 & 809285 & 6.5 & 6.1834 & TRN & \\
\hline CHEMBL1999718 & 809285 & 6.5 & 6.03600 & 00000000005 & TRN \\
\hline CHEMBL 2000078 & 809285 & 4.7 & 4.6781 & TRN & \\
\hline CHEMBL 2005478 & 809285 & 6.7 & 5.4637 & TST & \\
\hline CHEMBL1276446 & 809285 & 8.2 & 7.6193 & TST & \\
\hline CHEMBL1996646 & 809285 & 4.6 & 5.7355 & TST & \\
\hline CHEMBL1995712 & 809285 & 8.2 & 8.0101 & TRN & \\
\hline CHEMBL1979773 & 809285 & 8.3 & 5.01699 & 99999999995 & TRN \\
\hline CHEMBL1977346 & 809285 & 6.6 & 6.3428 & TRN & \\
\hline CHEMBL1971649 & 809285 & 5.4 & 5.0729 & TRN & \\
\hline CHEMBL 2005482 & 809285 & 4.7 & 4.7431 & TRN & \\
\hline CHEMBL1996702 & 809285 & 7.1 & 5.9605 & TRN & \\
\hline CHEMBL1997909 & 809285 & 4.7 & 4.3341 & TRN & \\
\hline CHEMBL 2007124 & 809285 & 4.6 & 5.1996 & TRN & \\
\hline CHEMBL1975440 & 809285 & 8.0 & 7.7948 & TRN & \\
\hline CHEMBL1998435 & 809285 & 6.3 & 6.4161 & TRN & \\
\hline CHEMBL 2006156 & 809285 & 5.8 & 5.3253 & TST & \\
\hline CHEMBL1985681 & 809285 & 7.5 & 7.4524 & TST & \\
\hline CHEMBL1969190 & 809285 & 5.4 & 5.3668 & TRN & \\
\hline CHEMBL1973937 & 809285 & 5.2 & 5.6017 & TRN & \\
\hline CHEMBL1991674 & 809285 & 7.7 & 7.2664 & TRN & \\
\hline CHEMBL262623 & 809285 & 6.4 & 6.251 & TRN & \\
\hline CHEMBL1987982 & 809285 & 4.0 & 4.7605 & TST & \\
\hline CHEMBL1984842 & 809285 & 4.6 & 4.4131 & TRN & \\
\hline CHEMBL 2004118 & 809285 & 5.8 & 5.5419 & TRN & \\
\hline CHEMBL 2007044 & 809285 & 4.0 & 4.3371 & TST & \\
\hline CHEMBL1994241 & 809285 & 6.9 & 7.2891 & TRN & \\
\hline CHEMBL 223460 & 809285 & 4.0 & 4.6127 & TST & \\
\hline CHEMBL1998829 & 809285 & 6.5 & 5.7943 & TRN & \\
\hline CHEMBL50894 & 809285 & 4.9 & 5.0521 & TRN & \\
\hline CHEMBL1995211 & 809285 & 7.5 & 7.5547 & TRN & \\
\hline CHEMBL1988838 & 809285 & 6.6 & 7.227 & TRN & \\
\hline CHEMBL1981725 & 809285 & 4.0 & 4.4627 & TRN & \\
\hline CHEMBL 2006299 & 809285 & 7.2 & 6.3599 & TRN & \\
\hline CHEMBL1980562 & 809285 & 8.7 & 8.589 & TRN & \\
\hline CHEMBL1965169 & 809285 & 7.0 & 5.7353 & TST & \\
\hline CHEMBL1991818 & 809285 & 6.4 & 5.9299 & TST & \\
\hline CHEMBL1081312 & 809285 & 6.1 & 6.961 & TRN & \\
\hline CHEMBL1965170 & 809285 & 4.6 & 4.9863 & TRN & \\
\hline CHEMBL1982866 & 809285 & 4.0 & 4.8412 & TRN & \\
\hline CHEMBL1393571 & 809285 & 5.0 & 5.5598 & TRN & \\
\hline CHEMBL 2004156 & 809285 & 6.8 & 5.2034 & TRN & \\
\hline CHEMBL 2005792 & 809285 & 4.6 & 4.5066 & TRN & \\
\hline CHEMBL1968926 & 809285 & 5.1 & 5.4063 & TRN & \\
\hline CHEMBL462120 & 809285 & 6.3 & 5.7252 & TRN & \\
\hline CHEMBL1991867 & 809285 & 5.3 & 5.6444 & TST & \\
\hline
\end{tabular}




\begin{tabular}{|c|c|c|c|c|}
\hline & & & 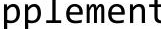 & al Ta \\
\hline CHEMBL1979933 & 809285 & 6.3 & 5.8789 & TRN \\
\hline CHEMBL1986503 & 809285 & 5.6 & 5.4314 & TST \\
\hline CHEMBL 2007592 & 809285 & 5.5 & 5.0811 & TRN \\
\hline CHEMBL1965570 & 809285 & 6.6 & 5.4955 & TRN \\
\hline CHEMBL1972355 & 809285 & 7.1 & 6.2839 & TRN \\
\hline CHEMBL1997892 & 809285 & 4.6 & 4.9135 & TRN \\
\hline CHEMBL 2001641 & 809285 & 7.1 & 6.6078 & TRN \\
\hline CHEMBL1976936 & 809285 & 7.4 & 7.2606 & TRN \\
\hline CHEMBL1997193 & 809285 & 4.6 & 5.871 & TST \\
\hline CHEMBL 210963 & 809285 & 4.0 & 4.296 & TRN \\
\hline CHEMBL1964902 & 809285 & 4.6 & 4.5061 & TRN \\
\hline CHEMBL 2005387 & 809285 & 8.3 & 8.2613 & TRN \\
\hline CHEMBL1082440 & 809285 & 6.0 & 6.3506 & TST \\
\hline CHEMBL1614705 & 809285 & 4.0 & 4.9952 & TST \\
\hline CHEMBL1982400 & 809285 & 8.4 & 8.2409 & TRN \\
\hline CHEMBL1984633 & 809285 & 6.2 & 6.5829 & TRN \\
\hline CHEMBL1972988 & 809285 & 7.2 & 8.0039 & TRN \\
\hline CHEMBL1965845 & 809285 & 7.1 & 7.6565 & TRN \\
\hline CHEMBL 2007372 & 809285 & 4.0 & 4.2228 & TRN \\
\hline CHEMBL1998228 & 809285 & 4.2 & 5.146 & TRN \\
\hline CHEMBL1983715 & 809285 & 8.0 & 7.5313 & TRN \\
\hline CHEMBL 2006715 & 809285 & 4.0 & 4.3779 & TRN \\
\hline CHEMBL1986597 & 809285 & 6.2 & 6.2172 & TRN \\
\hline CHEMBL1990482 & 809285 & 7.1 & 6.8401 & TRN \\
\hline CHEMBL1990904 & 809285 & 5.8 & 5.2114 & TRN \\
\hline CHEMBL 2005475 & 809285 & 6.4 & 5.21 & TRN \\
\hline CHEMBL1987448 & 809285 & 8.8 & 9.3079 & TRN \\
\hline CHEMBL1997349 & 809285 & 5.6 & 5.5533 & TST \\
\hline CHEMBL183844 & 809285 & 4.0 & 4.7631 & TRN \\
\hline CHEMBL 220057 & 809285 & 7.1 & 7.0324 & TRN \\
\hline CHEMBL1682545 & 809285 & 7.1 & 7.5198 & TRN \\
\hline CHEMBL 383541 & 809285 & 8.5 & 8.9121 & TRN \\
\hline CHEMBL 2001224 & 809285 & 4.0 & 4.5892 & TRN \\
\hline CHEMBL1966799 & 809285 & 4.2 & 5.3049 & TRN \\
\hline CHEMBL10 & 809285 & 4.6 & 5.3534 & TRN \\
\hline CHEMBL1976732 & 809285 & 4.0 & 4.7721 & TRN \\
\hline CHEMBL1982982 & 809285 & 7.0 & 6.0296 & TRN \\
\hline CHEMBL2005216 & 809285 & 7.2 & 7.1659 & TRN \\
\hline CHEMBL1969506 & 809285 & 6.3 & 6.01 & TRN \\
\hline CHEMBL1980763 & 809285 & 5.7 & 5.3189 & TRN \\
\hline CHEMBL1964937 & 809285 & 7.2 & 7.3251 & TRN \\
\hline CHEMBL1980163 & 809285 & 5.3 & 4.934 & TRN \\
\hline CHEMBL1977931 & 809285 & 5.6 & 5.5812 & TRN \\
\hline CHEMBL 2005899 & 809285 & 5.8 & 5.2679 & TRN \\
\hline CHEMBL1972568 & 809285 & 6.4 & 6.2217 & TRN \\
\hline CHEMBL1682552 & 809285 & 8.0 & 8.7468 & TRN \\
\hline CHEMBL 2007479 & 809285 & 6.5 & 6.7501 & TRN \\
\hline CHEMBL2004601 & 809285 & 5.6 & 5.8385 & TST \\
\hline
\end{tabular}




\begin{tabular}{|c|c|c|c|c|c|}
\hline \\
\hline CHEMBL1987745 & 809285 & 7.2 & 6.5816 & TRN & \\
\hline CHEMBL105739 & 809285 & 6.4 & 6.2642 & TRN & \\
\hline CHEMBL1972220 & 809285 & 4.6 & 4.9803 & TRN & \\
\hline CHEMBL1972583 & 809285 & 5.4 & 5.3617 & TRN & \\
\hline CHEMBL2003785 & 809285 & 5.8 & 5.6993 & TRN & \\
\hline CHEMBL1973720 & 809285 & 9.0 & 9.1892 & TRN & \\
\hline CHEMBL 2005214 & 809285 & 5.3 & 5.1948 & TST & \\
\hline CHEMBL1969523 & 809285 & 6.2 & 5.6335 & TRN & \\
\hline CHEMBL1988995 & 809285 & 4.0 & 4.3024 & TRN & \\
\hline CHEMBL2001923 & 809285 & 4.6 & 5.0555 & TRN & \\
\hline CHEMBL1986781 & 809285 & 5.0 & 5.038 & TRN & \\
\hline CHEMBL1983070 & 809285 & 4.6 & 5.1149 & TRN & \\
\hline CHEMBL526133 & 809285 & 7.2 & 7.8149 & TRN & \\
\hline CHEMBL 2003514 & 809285 & 4.6 & 6.2698 & TRN & \\
\hline CHEMBL1989043 & 809285 & 5.8 & 6.4903 & TRN & \\
\hline CHEMBL1967538 & 809285 & 5.5 & 5.7716 & TRN & \\
\hline CHEMBL1979057 & 809285 & 5.7 & 5.9198 & TRN & \\
\hline CHEMBL387971 & 809285 & 5.5 & 5.0599 & TST & \\
\hline CHEMBL1968515 & 809285 & 5.4 & 5.3842 & TST & \\
\hline CHEMBL1164180 & 809285 & 4.7 & 5.5888 & TST & \\
\hline CHEMBL1999428 & 809285 & 6.2 & 6.2572 & TRN & \\
\hline CHEMBL1967560 & 809285 & 4.0 & 4.8901 & TRN & \\
\hline CHEMBL1997611 & 809285 & 6.6 & 5.5896 & TRN & \\
\hline CHEMBL1516890 & 809285 & 6.8 & 7.0772 & TRN & \\
\hline CHEMBL 211378 & 809285 & 6.5 & 5.5818 & TRN & \\
\hline CHEMBL1682358 & 809285 & 8.0 & 7.8005 & TRN & \\
\hline CHEMBL1982465 & 809285 & 5.2 & 5.0181 & TRN & \\
\hline CHEMBL 2003420 & 809285 & 5.8 & 5.03100 & 0000000001 & TRN \\
\hline CHEMBL1984586 & 809285 & 5.3 & 5.1914 & TRN & \\
\hline CHEMBL1972659 & 809285 & 4.0 & 4.8284 & TST & \\
\hline CHEMBL 2002723 & 809285 & 6.1 & 5.9706 & TST & \\
\hline CHEMBL 272453 & 809285 & 4.0 & 4.842 & TRN & \\
\hline CHEMBL1970217 & 809285 & 6.1 & 6.6697 & TRN & \\
\hline CHEMBL 2005528 & 809285 & 7.1 & 6.5781 & TRN & \\
\hline CHEMBL1984686 & 809285 & 6.4 & 5.7542 & TRN & \\
\hline CHEMBL185569 & 809285 & 5.8 & 5.0645 & TRN & \\
\hline CHEMBL1969843 & 809285 & 7.5 & 7.5667 & TRN & \\
\hline CHEMBL 2007002 & 809285 & 8.0 & 7.3559 & TRN & \\
\hline CHEMBL1987007 & 809285 & 6.1 & 4.598 & TRN & \\
\hline CHEMBL1973793 & 809285 & 4.6 & 5.1788 & TST & \\
\hline CHEMBL1984711 & 809285 & 5.7 & 5.9749 & TRN & \\
\hline CHEMBL1992073 & 809285 & 4.8 & 5.5951 & TRN & \\
\hline CHEMBL484390 & 809285 & 6.1 & 6.7808 & TRN & \\
\hline CHEMBL1979252 & 809285 & 6.6 & 6.0796 & TRN & \\
\hline CHEMBL1986143 & 809285 & 6.5 & 6.7091 & TRN & \\
\hline CHEMBL1972934 & 809285 & 5.8 & 5.7201 & TRN & \\
\hline CHEMBL 2007559 & 809285 & 6.8 & 5.5831 & TRN & \\
\hline CHEMBL1992581 & 809285 & 6.6 & 6.0333 & TRN & \\
\hline
\end{tabular}




\begin{tabular}{|c|c|c|c|c|c|}
\hline \multicolumn{6}{|c|}{ plemental } \\
\hline CHEMBL 2004290 & 809285 & 4.2 & 4.7364 & TRN & \\
\hline CHEMBL1986499 & 809285 & 8.2 & 8.0797 & TRN & \\
\hline CHEMBL1972937 & 809285 & 5.4 & 5.0307 & TRN & \\
\hline CHEMBL2000393 & 809285 & 6.6 & 5.945 & TST & \\
\hline CHEMBL2001477 & 809285 & 6.5 & 6.2214 & TRN & \\
\hline CHEMBL 2004311 & 809285 & 5.1 & 5.0428 & TRN & \\
\hline CHEMBL1992634 & 809285 & 7.1 & 7.2899 & TRN & \\
\hline CHEMBL1242373 & 809285 & 6.9 & 6.7185 & TRN & \\
\hline CHEMBL56543 & 809285 & 4.2 & 4.8553 & TRN & \\
\hline CHEMBL1984847 & 809285 & 4.6 & 5.4091 & TST & \\
\hline CHEMBL1984402 & 809285 & 5.1 & 4.9132 & TRN & \\
\hline CHEMBL316264 & 809285 & 5.4 & 5.1767 & TRN & \\
\hline CHEMBL1988075 & 809285 & 4.0 & 4.9519 & TRN & \\
\hline CHEMBL1996576 & 809285 & 4.6 & 4.9981 & TST & \\
\hline CHEMBL1988076 & 809285 & 4.7 & 4.6868 & TRN & \\
\hline CHEMBL1991678 & 809285 & 4.5 & 4.288 & TRN & \\
\hline CHEMBL2001239 & 809285 & 5.8 & 5.3379 & TRN & \\
\hline CHEMBL1988594 & 809285 & 6.2 & 5.4523 & TRN & \\
\hline CHEMBL 2001288 & 809285 & 7.5 & 6.6194 & TRN & \\
\hline CHEMBL1992363 & 809285 & 7.4 & 8.6484 & TRN & \\
\hline CHEMBL1999811 & 809285 & 7.9 & 7.5672 & TRN & \\
\hline CHEMBL235157 & 809285 & 4.6 & 5.7502 & TST & \\
\hline CHEMBL1985074 & 809285 & 6.1 & 6.1741 & TRN & \\
\hline CHEMBL 2000481 & 809285 & 5.9 & $6.2410 e$ & 00000000005 & TRN \\
\hline CHEMBL1982874 & 809285 & 5.1 & 4.9566 & TRN & \\
\hline CHEMBL1991725 & 809285 & 7.6 & 8.0047 & TRN & \\
\hline CHEMBL1992242 & 809285 & 4.0 & 4.2884 & TRN & \\
\hline CHEMBL1982271 & 809285 & 8.7 & 9.0561 & TRN & \\
\hline CHEMBL2007296 & 809285 & 7.2 & 6.3848 & TRN & \\
\hline CHEMBL208637 & 809285 & 4.0 & 4.2654 & TRN & \\
\hline CHEMBL2004159 & 809285 & 4.6 & 5.8618 & TRN & \\
\hline CHEMBL396523 & 809285 & 7.9 & 8.1385 & TRN & \\
\hline CHEMBL1978371 & 809285 & 6.1 & 5.1948 & TST & \\
\hline CHEMBL 2003952 & 809285 & 4.5 & 5.3433 & TRN & \\
\hline CHEMBL1970203 & 809285 & 4.0 & 4.6214 & TRN & \\
\hline CHEMBL1986530 & 809285 & 7.2 & 5.9628 & TST & \\
\hline CHEMBL440084 & 809285 & 4.6 & $5.5920 e$ & 00000000005 & TRN \\
\hline CHEMBL1999321 & 809285 & 4.0 & 4.7167 & TRN & \\
\hline CHEMBL 2007336 & 809285 & 5.4 & 5.7834 & TRN & \\
\hline CHEMBL1968590 & 809285 & 5.1 & 4.7382 & TRN & \\
\hline CHEMBL 2005375 & 809285 & 4.0 & 5.3718 & TRN & \\
\hline CHEMBL1984191 & 809285 & 5.8 & 5.471 & TRN & \\
\hline CHEMBL1972183 & 809285 & 4.0 & 4.893 & TST & \\
\hline CHEMBL1971029 & 809285 & 7.6 & 7.1307 & TRN & \\
\hline CHEMBL1971679 & 809285 & 4.4 & 5.0261 & TST & \\
\hline CHEMBL1980592 & 809285 & 5.9 & 5.6385 & TRN & \\
\hline CHEMBL394790 & 809285 & 6.1 & 6.0199 & TRN & \\
\hline CHEMBL226471 & 809285 & 6.5 & 7.066 & TRN & \\
\hline
\end{tabular}




\begin{tabular}{|c|c|c|c|c|}
\hline \multicolumn{5}{|c|}{ )lemental T } \\
\hline CHEMBL1974702 & 809285 & 6.1 & 5.8205 & TRN \\
\hline CHEMBL1996111 & 809285 & 6.3 & 6.7558 & TRN \\
\hline CHEMBL1966175 & 809285 & 4.6 & 5.3728 & TRN \\
\hline CHEMBL1965589 & 809285 & 5.5 & 4.615 & TRN \\
\hline CHEMBL 2007375 & 809285 & 7.1 & 6.2182 & TRN \\
\hline CHEMBL1998193 & 809285 & 4.0 & 4.8567 & TRN \\
\hline CHEMBL379975 & 809285 & 4.8 & 6.1717 & TRN \\
\hline CHEMBL474432 & 809285 & 6.1 & 5.7931 & TST \\
\hline CHEMBL1973016 & 809285 & 6.5 & 6.3694 & TRN \\
\hline CHEMBL1965387 & 809285 & 4.6 & 5.0442 & TRN \\
\hline CHEMBL 2001539 & 809285 & 5.5 & 5.3266 & TST \\
\hline CHEMBL1997041 & 809285 & 7.1 & 6.7247 & TRN \\
\hline CHEMBL1988153 & 809285 & 6.5 & 6.4177 & TRN \\
\hline CHEMBL550418 & 809285 & 6.3 & 5.5737 & TRN \\
\hline CHEMBL 2003637 & 809285 & 8.0 & 5.4784 & TST \\
\hline CHEMBL1986666 & 809285 & 6.9 & 6.7626 & TRN \\
\hline CHEMBL1971289 & 809285 & 7.7 & 7.1767 & TRN \\
\hline CHEMBL1988437 & 809285 & 4.7 & 5.7096 & TRN \\
\hline CHEMBL1968646 & 809285 & 5.9 & 5.5959 & TRN \\
\hline CHEMBL1979577 & 809285 & 5.3 & 5.6459 & TRN \\
\hline CHEMBL1998121 & 809285 & 8.3 & 7.8593 & TRN \\
\hline CHEMBL1233887 & 809285 & 4.6 & 5.6777 & TST \\
\hline CHEMBL1992607 & 809285 & 4.6 & 5.7127 & TRN \\
\hline CHEMBL1991800 & 809285 & 5.4 & 4.6926 & TRN \\
\hline CHEMBL 52387 & 809285 & 6.3 & 6.2784 & TST \\
\hline CHEMBL379835 & 809285 & 5.6 & 4.532 & TST \\
\hline CHEMBL1979357 & 809285 & 6.0 & 6.0352 & TRN \\
\hline CHEMBL1996649 & 809285 & 6.0 & 4.4873 & TRN \\
\hline CHEMBL1986756 & 809285 & 7.2 & 5.8241 & TRN \\
\hline CHEMBL3197315 & 809285 & 4.0 & 4.9938 & TRN \\
\hline CHEMBL468280 & 809285 & 4.2 & 4.5843 & TST \\
\hline CHEMBL1990884 & 809285 & 5.2 & 5.1852 & TRN \\
\hline CHEMBL1996339 & 809285 & 8.4 & 8.6953 & TRN \\
\hline CHEMBL3109278 & 809285 & 5.0 & 5.6055 & TRN \\
\hline CHEMBL256835 & 809285 & 4.0 & 4.8246 & TRN \\
\hline CHEMBL1970006 & 809285 & 5.9 & 5.9742 & TST \\
\hline CHEMBL1980142 & 809285 & 4.0 & 5.5862 & TRN \\
\hline CHEMBL41783 & 809285 & 6.7 & 7.0486 & TRN \\
\hline CHEMBL 2004438 & 809285 & 4.6 & 4.8902 & TRN \\
\hline CHEMBL 2006276 & 809285 & 4.0 & 4.9144 & TRN \\
\hline CHEMBL191003 & 809285 & 6.7 & 6.3394 & TRN \\
\hline CHEMBL271381 & 809285 & 5.7 & 5.473 & TRN \\
\hline CHEMBL 2006785 & 809285 & 6.3 & 5.0761 & TRN \\
\hline CHEMBL1982466 & 809285 & 4.0 & 4.7047 & TRN \\
\hline CHEMBL1973359 & 809285 & 7.7 & 7.1962 & TST \\
\hline CHEMBL1995740 & 809285 & 4.0 & 4.8999 & TRN \\
\hline CHEMBL1990162 & 809285 & 8.9 & 8.2869 & TRN \\
\hline CHEMBL1979690 & 809285 & 7.6 & 7.9401 & TRN \\
\hline
\end{tabular}




\begin{tabular}{|c|c|c|c|c|c|}
\hline & & & & & \\
\hline CHEMBL234085 & 809285 & 4.5 & 5.0818 & TRN & \\
\hline CHEMBL1998414 & 809285 & 6.2 & 5.934 & TRN & \\
\hline CHEMBL1995832 & 809285 & 4.0 & 4.2018 & TRN & \\
\hline CHEMBL1969042 & 809285 & 5.9 & 6.1545 & TRN & \\
\hline CHEMBL 2000345 & 809285 & 6.9 & 7.1139 & TRN & \\
\hline CHEMBL1976376 & 809285 & 4.6 & 5.0578 & TRN & \\
\hline CHEMBL1988622 & 809285 & 5.4 & 5.6561 & TRN & \\
\hline CHEMBL1983575 & 809285 & 8.8 & 7.6745 & TRN & \\
\hline CHEMBL1968868 & 809285 & 7.1 & 6.7381 & TRN & \\
\hline CHEMBL1375418 & 809285 & 4.0 & 4.5417 & TRN & \\
\hline CHEMBL2007064 & 809285 & 6.6 & 6.0304 & TRN & \\
\hline CHEMBL1981047 & 809285 & 5.8 & 5.4894 & TRN & \\
\hline CHEMBL1976196 & 809285 & 4.6 & 4.9326 & TST & \\
\hline CHEMBL1976240 & 809285 & 6.5 & 6.8922 & TRN & \\
\hline CHEMBL1987948 & 809285 & 8.5 & 8.4128 & TRN & \\
\hline CHEMBL1997197 & 809285 & 6.5 & 6.061 & TRN & \\
\hline CHEMBL1983630 & 809285 & 5.2 & 5.23799 & 99999999995 & TRN \\
\hline CHEMBL1968151 & 809285 & 5.6 & 5.9167 & TRN & \\
\hline CHEMBL1979093 & 809285 & 5.4 & 5.624 & TRN & \\
\hline CHEMBL1973795 & 809285 & 5.8 & 4.9629 & TRN & \\
\hline CHEMBL1987009 & 809285 & 6.4 & 5.7823 & TRN & \\
\hline CHEMBL 2003817 & 809285 & 7.4 & 7.4375 & TRN & \\
\hline CHEMBL1994830 & 809285 & 7.5 & 7.4779 & TRN & \\
\hline CHEMBL226403 & 809285 & 7.2 & 6.9685 & TRN & \\
\hline CHEMBL 2005631 & 809285 & 5.9 & 5.0574 & TRN & \\
\hline CHEMBL1994938 & 809285 & 5.6 & 4.7427 & TRN & \\
\hline CHEMBL1977223 & 809285 & 8.0 & 8.2827 & TRN & \\
\hline CHEMBL1995765 & 809285 & 6.3 & 5.6141 & TST & \\
\hline CHEMBL1976290 & 809285 & 5.6 & 4.9711 & TRN & \\
\hline CHEMBL1966279 & 809285 & 5.3 & 5.6228 & TRN & \\
\hline CHEMBL1236126 & 809285 & 6.1 & 6.2128 & TRN & \\
\hline CHEMBL1997846 & 809285 & 6.8 & $6.4570 e$ & 0000000001 & TRN \\
\hline CHEMBL1984760 & 809285 & 6.4 & 6.2539 & TRN & \\
\hline CHEMBL 2004419 & 809285 & 4.0 & 4.5905 & TRN & \\
\hline CHEMBL360847 & 809285 & 6.9 & 6.0605 & TST & \\
\hline CHEMBL1995811 & 809285 & 8.0 & 8.2136 & TRN & \\
\hline CHEMBL1995916 & 809285 & 4.9 & 5.0787 & TRN & \\
\hline CHEMBL1972489 & 809285 & 6.8 & 5.9224 & TST & \\
\hline CHEMBL1994074 & 809285 & 5.8 & 6.2233 & TST & \\
\hline CHEMBL1992937 & 809285 & 8.0 & 7.1496 & TST & \\
\hline CHEMBL451401 & 809285 & 5.9 & 5.4324 & TST & \\
\hline CHEMBL1968930 & 809285 & 8.2 & 8.666 & TST & \\
\hline CHEMBL1972119 & 809285 & 5.7 & 5.6486 & TST & \\
\hline CHEMBL1986328 & 809285 & 5.2 & 6.1235 & TST & \\
\hline CHEMBL 95692 & 809285 & 4.0 & 5.0385 & TST & \\
\hline CHEMBL1090356 & 809285 & 4.0 & 4.2226 & TST & \\
\hline CHEMBL 2002450 & 809285 & 5.1 & 5.0201 & TST & \\
\hline CHEMBL1976455 & 809285 & 7.7 & 7.99299 & 9999999999 & TST \\
\hline & & & & 10638 & \\
\hline
\end{tabular}




\begin{tabular}{|c|c|c|c|c|c|}
\hline \\
\hline CHEMBL261849 & 809285 & 4.6 & 5.3491 & TST & \\
\hline CHEMBL1983923 & 809285 & 6.3 & 5.5512 & TST & \\
\hline CHEMBL1983534 & 809285 & 7.5 & 8.0437 & TST & \\
\hline CHEMBL1970950 & 809285 & 5.3 & 6.17700 & 00000000005 & TST \\
\hline CHEMBL1982361 & 809285 & 4.0 & 5.3544 & TST & \\
\hline CHEMBL1999112 & 809285 & 5.4 & 5.2229 & TST & \\
\hline CHEMBL1982122 & 809285 & 6.0 & 7.2801 & TST & \\
\hline CHEMBL 2000801 & 809285 & 4.0 & 4.4783 & TST & \\
\hline CHEMBL1682546 & 809285 & 6.6 & 7.07700 & 0000000001 & TST \\
\hline CHEMBL1988872 & 809285 & 6.3 & 6.3352 & TST & \\
\hline CHEMBL1991395 & 809285 & 5.5 & 4.5413 & TST & \\
\hline CHEMBL1971245 & 809285 & 5.1 & 5.3342 & TST & \\
\hline CHEMBL 2003545 & 809285 & 4.9 & 5.34399 & 9999999999 & TST \\
\hline CHEMBL1972142 & 809285 & 4.0 & 5.5754 & TST & \\
\hline CHEMBL 2002182 & 809285 & 5.0 & 5.032 & TST & \\
\hline CHEMBL1966514 & 809285 & 6.3 & 5.4575 & TST & \\
\hline CHEMBL1996066 & 809285 & 8.0 & 6.5937 & TST & \\
\hline CHEMBL1983393 & 809285 & 6.1 & 6.1696 & TST & \\
\hline CHEMBL1972152 & 809285 & 5.9 & 5.2201 & TST & \\
\hline CHEMBL1970806 & 809285 & 4.0 & 5.0619 & TST & \\
\hline CHEMBL1993722 & 809285 & 7.6 & 7.1244 & TST & \\
\hline CHEMBL 2006674 & 809285 & 6.3 & 5.4947 & TST & \\
\hline CHEMBL1984236 & 809285 & 4.6 & 5.683 & TST & \\
\hline CHEMBL1992371 & 809285 & 6.9 & 7.0027 & TST & \\
\hline CHEMBL1375640 & 809285 & 8.4 & 7.8802 & TST & \\
\hline CHEMBL1979970 & 809285 & 6.8 & 7.4316 & TST & \\
\hline CHEMBL2002599 & 809285 & 7.0 & 6.38899 & 9999999999 & TST \\
\hline CHEMBL 249282 & 809285 & 4.0 & 4.2777 & TST & \\
\hline CHEMBL1967252 & 809285 & 8.7 & 8.1358 & TST & \\
\hline CHEMBL1993374 & 809285 & 5.7 & 5.6861 & TST & \\
\hline CHEMBL 2006237 & 809285 & 6.8 & 5.795 & TST & \\
\hline CHEMBL1967719 & 809285 & 5.8 & 6.1903 & TST & \\
\hline CHEMBL1967720 & 809285 & 5.2 & 5.6008 & TST & \\
\hline CHEMBL1572266 & 809285 & 4.0 & 4.8224 & TST & \\
\hline CHEMBL1991138 & 809285 & 4.0 & 4.7945 & TST & \\
\hline CHEMBL1979516 & 809285 & 4.0 & 4.5146 & TST & \\
\hline CHEMBL1969755 & 809285 & 6.2 & 5.6308 & TST & \\
\hline CHEMBL1972820 & 809285 & 4.0 & 4.5894 & TST & \\
\hline CHEMBL1605605 & 809285 & 6.5 & 5.6757 & TST & \\
\hline CHEMBL1989029 & 809285 & 5.9 & 5.7001 & TST & \\
\hline CHEMBL392642 & 809285 & 5.5 & 6.1091 & TST & \\
\hline CHEMBL514499 & 809285 & 6.4 & 5.1716 & TST & \\
\hline CHEMBL1970352 & 809285 & 6.1 & 5.2832 & TST & \\
\hline CHEMBL1965631 & 809285 & 7.1 & 8.134 & TST & \\
\hline CHEMBL1980144 & 809285 & 5.5 & 5.0026 & TST & \\
\hline CHEMBL1991188 & 809285 & 6.5 & 6.4054 & TST & \\
\hline CHEMBL1682554 & 809285 & 8.4 & 8.513 & TST & \\
\hline CHEMBL1980167 & 809285 & 4.6 & 5.4607 & TST & \\
\hline
\end{tabular}




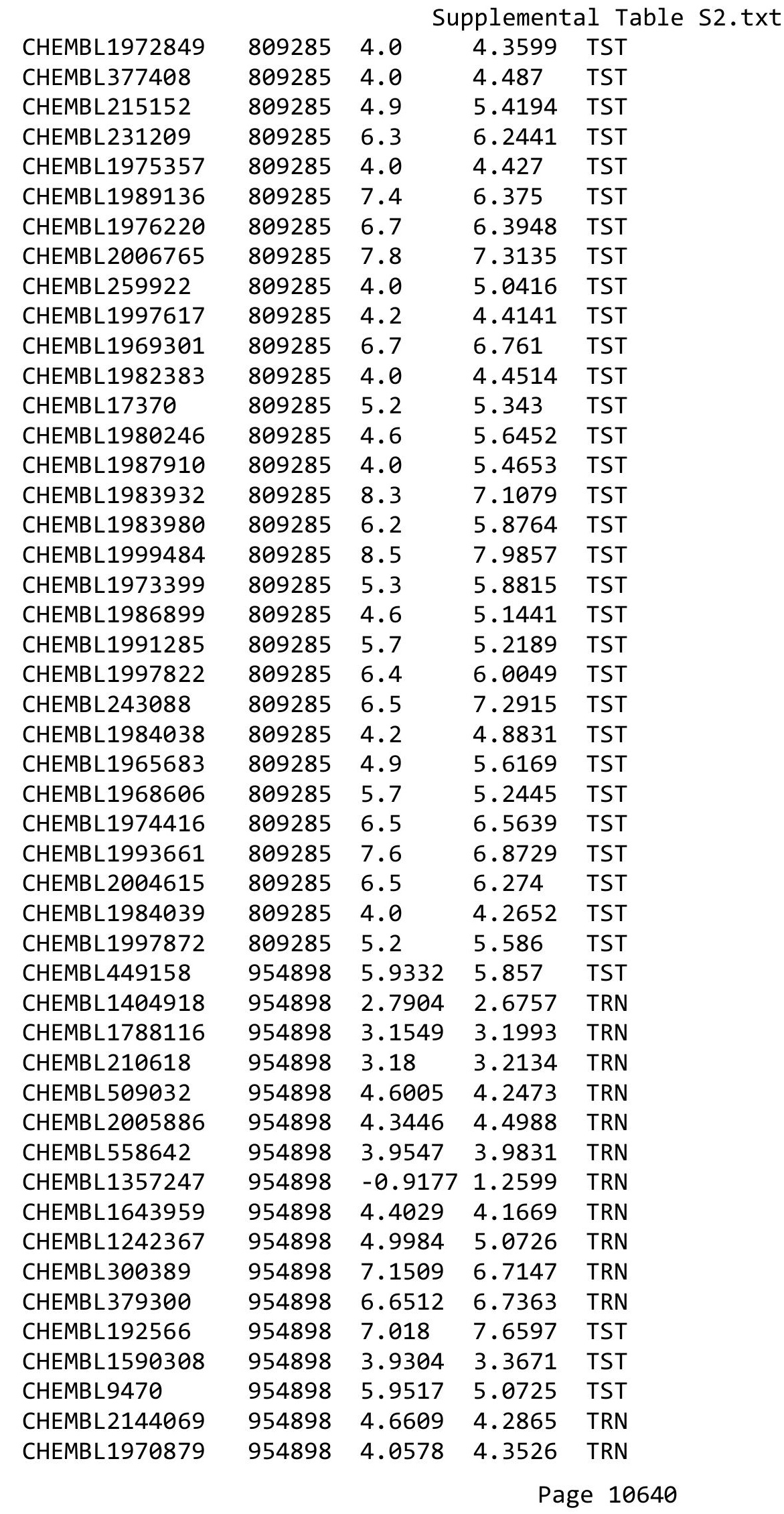




\begin{tabular}{|c|c|c|c|c|c|c|}
\hline & & \multicolumn{5}{|c|}{ Supplemental Table S2.txt } \\
\hline CHEMBL483849 & 954898 & 3.6337 & 4.2821 & TRN & & \\
\hline CHEMBL515416 & 954898 & 4.4253 & 4.4825 & TRN & & \\
\hline CHEMBL577784 & 954898 & 5.3327 & 5.2769 & TRN & & \\
\hline CHEMBL3349342 & 954898 & 4.1267 & 4.0196 & TRN & & \\
\hline CHEMBL65 & 954898 & 7.869 & 7.8592 & TRN & & \\
\hline CHEMBL1256459 & 954898 & 6.8685 & 7.5654 & TRN & & \\
\hline CHEMBL 3186408 & 954898 & 3.5087 & 3.6918 & TST & & \\
\hline CHEMBL472940 & 954898 & 4.9677 & 4.6599 & TRN & & \\
\hline CHEMBL258844 & 954898 & 4.9845 & 4.0932 & TRN & & \\
\hline CHEMBL3392440 & 954898 & 4.3614 & 3.8506 & TRN & & \\
\hline CHEMBL 209148 & 954898 & 4.6879 & 4.6673 & TRN & & \\
\hline CHEMBL514499 & 954898 & 7.0051 & 7.6119 & TRN & & \\
\hline CHEMBL102714 & 954898 & 3.6618 & 3.9828 & TRN & & \\
\hline CHEMBL483847 & 954898 & 3.716 & 4.0674 & TRN & & \\
\hline CHEMBL3199475 & 954898 & 5.5494 & 5.1514 & TRN & & \\
\hline CHEMBL180127 & 954898 & 4.1436 & 4.4744 & TRN & & \\
\hline CHEMBL222102 & 954898 & 5.0821 & 4.7293 & TRN & & \\
\hline CHEMBL213100 & 954898 & 3.7164 & 3.9761 & TRN & & \\
\hline CHEMBL259181 & 954898 & 4.6071 & 4.3971 & TRN & & \\
\hline CHEMBL188678 & 954898 & 5.9278 & 5.2882 & TRN & & \\
\hline CHEMBL1190711 & 954898 & 4.9653 & 5.0276 & TRN & & \\
\hline CHEMBL392695 & 954898 & 5.4544 & 5.4027 & TRN & & \\
\hline CHEMBL1516890 & 954898 & 3.9224 & 3.6072 & TRN & & \\
\hline CHEMBL 221137 & 954898 & 4.4429 & 4.5509 & TST & & \\
\hline CHEMBL1230020 & 954898 & 4.5966 & 4.7289 & TRN & & \\
\hline CHEMBL 202721 & 954898 & 5.26 & 5.3101 & TRN & & \\
\hline CHEMBL512504 & 954898 & 6.3396 & 6.8593 & TRN & & \\
\hline CHEMBL189584 & 954898 & 5.4588 & 5.5884 & TRN & & \\
\hline CHEMBL 373751 & 954898 & 3.2937 & 3.1915 & TRN & & \\
\hline CHEMBL585951 & 954898 & 4.6348 & 5.1428 & TRN & & \\
\hline CHEMBL135561 & 954898 & 4.1071 & 3.7237 & TRN & & \\
\hline CHEMBL2363137 & 954898 & 4.8182 & 3.9865 & TRN & & \\
\hline CHEMBL92309 & 954898 & 4.4682 & 2.5959 & TST & & \\
\hline CHEMBL 240954 & 954898 & 4.1333 & 4.7463 & TST & & \\
\hline CHEMBL412142 & 954898 & 3.7598 & 2.8957 & TRN & & \\
\hline CHEMBL379975 & 954898 & 5.7861 & 5.8592 & TST & & \\
\hline CHEMBL1673039 & 954898 & 5.3394 & 4.7303 & TST & & \\
\hline CHEMBL191334 & 954898 & 4.2915 & 4.3623 & TST & & \\
\hline CHEMBL1909414 & 954898 & 3.9776 & 5.1743 & TST & & \\
\hline CHEMBL573107 & 954898 & 5.5528 & 5.6219 & TST & & \\
\hline CHEMBL220241 & 954898 & 4.1582 & 4.1231 & TST & & \\
\hline CHEMBL393929 & 954898 & 4.22199 & 99999999 & 995 & 3.603 & TST \\
\hline CHEMBL21156 & 809247 & 4.6 & 5.3524 & TST & & \\
\hline CHEMBL1994724 & 809247 & 4.6 & 4.941 & TRN & & \\
\hline CHEMBL1989267 & 809247 & 5.8 & 5.3047 & TRN & & \\
\hline CHEMBL1991782 & 809247 & 3.3 & 3.9079 & TRN & & \\
\hline CHEMBL 2002105 & 809247 & 4.9 & 5.0643 & TRN & & \\
\hline CHEMBL1983348 & 809247 & 6.3 & 6.7695 & TRN & & \\
\hline
\end{tabular}




\begin{tabular}{|c|c|c|c|c|}
\hline & & & 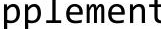 & al Ta \\
\hline CHEMBL1970290 & 809247 & 6.2 & 5.1305 & TRN \\
\hline CHEMBL1968394 & 809247 & 4.7 & 4.1955 & TRN \\
\hline CHEMBL1993877 & 809247 & 7.0 & 6.4373 & TRN \\
\hline CHEMBL1974480 & 809247 & 6.1 & 5.7088 & TRN \\
\hline CHEMBL 2000934 & 809247 & 4.6 & 5.1008 & TRN \\
\hline CHEMBL1996500 & 809247 & 4.6 & 4.57 & TRN \\
\hline CHEMBL1980671 & 809247 & 4.2 & 4.6543 & TRN \\
\hline CHEMBL1973363 & 809247 & 5.6 & 5.6513 & TRN \\
\hline CHEMBL1986177 & 809247 & 4.6 & 5.021 & TRN \\
\hline CHEMBL1989708 & 809247 & 4.6 & 4.7958 & TRN \\
\hline CHEMBL1976420 & 809247 & 4.6 & 4.6086 & TRN \\
\hline CHEMBL1981744 & 809247 & 4.6 & 4.6729 & TRN \\
\hline CHEMBL1989423 & 809247 & 4.3 & 4.1099 & TST \\
\hline CHEMBL1985367 & 809247 & 4.6 & 5.5289 & TRN \\
\hline CHEMBL1996510 & 809247 & 4.7 & 5.5647 & TRN \\
\hline CHEMBL 2000029 & 809247 & 6.8 & 7.2934 & TRN \\
\hline CHEMBL1995172 & 809247 & 4.6 & 4.1546 & TST \\
\hline CHEMBL 2001584 & 809247 & 4.6 & 4.5755 & TRN \\
\hline CHEMBL1973961 & 809247 & 5.6 & 5.2741 & TRN \\
\hline CHEMBL1971227 & 809247 & 5.6 & 5.6645 & TST \\
\hline CHEMBL1967998 & 809247 & 6.8 & 6.8534 & TRN \\
\hline CHEMBL1978562 & 809247 & 4.6 & 4.9469 & TRN \\
\hline CHEMBL1994977 & 809247 & 4.6 & 4.5942 & TRN \\
\hline CHEMBL 2001149 & 809247 & 6.0 & 6.0337 & TRN \\
\hline CHEMBL1974875 & 809247 & 5.0 & 4.9931 & TRN \\
\hline CHEMBL 2005478 & 809247 & 4.6 & 5.1153 & TRN \\
\hline CHEMBL1996646 & 809247 & 6.1 & 5.3106 & TRN \\
\hline CHEMBL1979773 & 809247 & 4.6 & 5.1739 & TRN \\
\hline CHEMBL1989471 & 809247 & 6.2 & 6.053 & TST \\
\hline CHEMBL1992723 & 809247 & 4.2 & 4.1245 & TRN \\
\hline CHEMBL1996702 & 809247 & 7.0 & 6.7938 & TRN \\
\hline CHEMBL 2007124 & 809247 & 4.6 & 4.5033 & TRN \\
\hline CHEMBL1978195 & 809247 & 6.4 & 6.6716 & TRN \\
\hline CHEMBL 2006439 & 809247 & 8.1 & 7.6216 & TRN \\
\hline CHEMBL1985681 & 809247 & 6.9 & 6.4208 & TRN \\
\hline CHEMBL1991674 & 809247 & 6.5 & 6.4284 & TRN \\
\hline CHEMBL1982711 & 809247 & 8.4 & 6.9152 & TRN \\
\hline CHEMBL262623 & 809247 & 5.7 & 5.0509 & TRN \\
\hline CHEMBL1984842 & 809247 & 4.6 & 4.8312 & TRN \\
\hline CHEMBL 2004118 & 809247 & 4.6 & 4.9622 & TRN \\
\hline CHEMBL2003119 & 809247 & 5.6 & 5.2165 & TST \\
\hline CHEMBL1996345 & 809247 & 5.7 & 5.3371 & TRN \\
\hline CHEMBL 2004025 & 809247 & 6.2 & 5.7426 & TRN \\
\hline CHEMBL1996048 & 809247 & 4.6 & 4.7926 & TRN \\
\hline CHEMBL50894 & 809247 & 4.6 & 4.7934 & TRN \\
\hline CHEMBL1995211 & 809247 & 6.4 & 5.8172 & TRN \\
\hline CHEMBL1965033 & 809247 & 4.6 & 4.542 & TRN \\
\hline CHEMBL461876 & 809247 & 5.9 & 6.3671 & TRN \\
\hline
\end{tabular}




\begin{tabular}{|c|c|c|c|c|}
\hline & & & plement & al lable s \\
\hline CHEMBL1982753 & 809247 & 5.6 & 5.5821 & TRN \\
\hline CHEMBL2006299 & 809247 & 4.6 & 4.98600 & 0000000001 \\
\hline CHEMBL1972346 & 809247 & 7.0 & 6.3991 & TST \\
\hline CHEMBL1971519 & 809247 & 5.2 & 5.3603 & TRN \\
\hline CHEMBL1997335 & 809247 & 6.5 & 7.0048 & TRN \\
\hline CHEMBL1965169 & 809247 & 4.6 & 5.3098 & TRN \\
\hline CHEMBL1991818 & 809247 & 5.6 & 5.3844 & TST \\
\hline CHEMBL1081312 & 809247 & 4.9 & 5.5519 & TRN \\
\hline CHEMBL1965170 & 809247 & 4.6 & 4.4056 & TRN \\
\hline CHEMBL1994808 & 809247 & 4.1 & 4.3498 & TST \\
\hline CHEMBL 2005792 & 809247 & 4.6 & 4.9349 & TRN \\
\hline CHEMBL1991867 & 809247 & 4.8 & 4.8607 & TRN \\
\hline CHEMBL1972355 & 809247 & 6.4 & 6.9804 & TRN \\
\hline CHEMBL1997892 & 809247 & 4.6 & 4.6023 & TRN \\
\hline CHEMBL2001641 & 809247 & 5.7 & 5.6495 & TRN \\
\hline CHEMBL1997193 & 809247 & 6.1 & 5.3665 & TST \\
\hline CHEMBL1964902 & 809247 & 4.6 & 4.5216 & TRN \\
\hline CHEMBL1973868 & 809247 & 7.3 & 6.4777 & TRN \\
\hline CHEMBL1825138 & 809247 & 4.6 & 5.1972 & TST \\
\hline CHEMBL1998228 & 809247 & 4.1 & 4.553 & TRN \\
\hline CHEMBL1983715 & 809247 & 7.0 & 7.5872 & TRN \\
\hline CHEMBL1984500 & 809247 & 4.5 & 3.6801 & TRN \\
\hline CHEMBL 2002992 & 809247 & 6.8 & 5.7363 & TRN \\
\hline CHEMBL1982700 & 809247 & 4.6 & 4.7484 & TRN \\
\hline CHEMBL1966799 & 809247 & 4.2 & 4.5114 & TRN \\
\hline CHEMBL10 & 809247 & 4.6 & 4.7176 & TRN \\
\hline CHEMBL1980763 & 809247 & 4.6 & 4.6934 & TRN \\
\hline CHEMBL1977634 & 809247 & 4.6 & 4.6322 & TRN \\
\hline CHEMBL1977931 & 809247 & 4.7 & 4.7188 & TRN \\
\hline CHEMBL1976872 & 809247 & 4.2 & 4.1997 & TRN \\
\hline CHEMBL1969156 & 809247 & 4.1 & 4.0963 & TRN \\
\hline CHEMBL 2007479 & 809247 & 6.7 & 5.6038 & TRN \\
\hline CHEMBL1998953 & 809247 & 4.6 & 5.125 & TRN \\
\hline CHEMBL1971606 & 809247 & 4.6 & 4.6959 & TRN \\
\hline CHEMBL1999120 & 809247 & 4.8 & 4.5334 & TRN \\
\hline CHEMBL1972220 & 809247 & 4.6 & 4.4871 & TRN \\
\hline CHEMBL1972583 & 809247 & 4.8 & 4.5233 & TRN \\
\hline CHEMBL1981215 & 809247 & 4.6 & 4.9474 & TRN \\
\hline CHEMBL 2003785 & 809247 & 4.9 & 4.916 & TRN \\
\hline CHEMBL1973720 & 809247 & 7.8 & 8.7538 & TRN \\
\hline CHEMBL1987003 & 809247 & 4.3 & 4.8479 & TRN \\
\hline CHEMBL1999414 & 809247 & 4.6 & 4.931 & TRN \\
\hline CHEMBL1967336 & 809247 & 5.8 & 5.4466 & TRN \\
\hline CHEMBL 2001923 & 809247 & 4.6 & 4.8637 & TRN \\
\hline CHEMBL 2003514 & 809247 & 4.6 & 4.2105 & TRN \\
\hline CHEMBL1970340 & 809247 & 5.5 & 5.1682 & TRN \\
\hline CHEMBL1967992 & 809247 & 6.5 & 6.2428 & TRN \\
\hline CHEMBL1989043 & 809247 & 4.6 & 5.7349 & TRN \\
\hline
\end{tabular}

TRN 


\begin{tabular}{|c|c|c|c|c|}
\hline & & & & \\
\hline CHEMBL 2006450 & 809247 & 7.4 & 7.2536 & TRN \\
\hline CHEMBL1967538 & 809247 & 4.9 & 4.7393 & TRN \\
\hline CHEMBL2001987 & 809247 & 4.6 & 4.4749 & TRN \\
\hline CHEMBL1994555 & 809247 & 4.6 & 5.3931 & TRN \\
\hline CHEMBL1968515 & 809247 & 4.5 & 4.8007 & TST \\
\hline CHEMBL1164180 & 809247 & 4.6 & 5.0019 & TST \\
\hline CHEMBL1975121 & 809247 & 4.6 & 4.502 & TRN \\
\hline CHEMBL1983640 & 809247 & 4.6 & 4.9177 & TRN \\
\hline CHEMBL1997611 & 809247 & 6.0 & 5.9743 & TRN \\
\hline CHEMBL1971943 & 809247 & 4.9 & 5.395 & TRN \\
\hline CHEMBL 2002723 & 809247 & 5.9 & 5.6726 & TRN \\
\hline CHEMBL1984686 & 809247 & 4.6 & 5.4151 & TST \\
\hline CHEMBL1973793 & 809247 & 4.6 & 4.4555 & TRN \\
\hline CHEMBL1992073 & 809247 & 4.6 & 4.3971 & TRN \\
\hline CHEMBL1990254 & 809247 & 5.8 & 5.0976 & TRN \\
\hline CHEMBL1986143 & 809247 & 4.6 & 4.8139 & TRN \\
\hline CHEMBL1972934 & 809247 & 5.5 & 5.1286 & TRN \\
\hline CHEMBL2007559 & 809247 & 4.6 & 4.9687 & TRN \\
\hline CHEMBL1975911 & 809247 & 4.1 & 4.382 & TRN \\
\hline CHEMBL1992581 & 809247 & 5.9 & 5.5993 & TRN \\
\hline CHEMBL 2004290 & 809247 & 4.6 & 4.223 & TRN \\
\hline CHEMBL1975921 & 809247 & 5.0 & 5.2687 & TRN \\
\hline CHEMBL1983573 & 809247 & 4.0 & 4.6194 & TRN \\
\hline CHEMBL1975923 & 809247 & 4.9 & 5.3788 & TST \\
\hline CHEMBL1984402 & 809247 & 4.1 & 4.1349 & TRN \\
\hline CHEMBL 2005449 & 809247 & 5.8 & 5.273 & TRN \\
\hline CHEMBL1996576 & 809247 & 4.6 & 4.9482 & TST \\
\hline CHEMBL1991678 & 809247 & 4.6 & 4.6152 & TRN \\
\hline CHEMBL1987998 & 809247 & 4.6 & 4.3627 & TRN \\
\hline CHEMBL1971534 & 809247 & 5.9 & 5.9257 & TRN \\
\hline CHEMBL1990496 & 809247 & 4.6 & 4.44 & TRN \\
\hline CHEMBL 242865 & 809247 & 6.4 & 6.8202 & TRN \\
\hline CHEMBL 235157 & 809247 & 4.6 & 4.9692 & TRN \\
\hline CHEMBL 2002480 & 809247 & 4.5 & 4.5654 & TRN \\
\hline CHEMBL1983884 & 809247 & 4.7 & 4.5863 & TRN \\
\hline CHEMBL2004159 & 809247 & 4.6 & 4.65 & TRN \\
\hline CHEMBL1978371 & 809247 & 6.0 & 5.7073 & TST \\
\hline CHEMBL440084 & 809247 & 4.6 & 5.0935 & TRN \\
\hline CHEMBL550275 & 809247 & 5.7 & 5.4124 & TST \\
\hline CHEMBL1998110 & 809247 & 4.6 & 4.1092 & TRN \\
\hline CHEMBL1978166 & 809247 & 6.2 & 6.0219 & TRN \\
\hline CHEMBL1972454 & 809247 & 6.2 & 4.8052 & TRN \\
\hline CHEMBL1974617 & 809247 & 7.0 & 6.4773 & TRN \\
\hline CHEMBL1965660 & 809247 & 9.2 & 8.4995 & TRN \\
\hline CHEMBL1992125 & 809247 & 5.7 & 5.8428 & TRN \\
\hline CHEMBL1966175 & 809247 & 4.6 & 4.2724 & TRN \\
\hline CHEMBL 2007375 & 809247 & 4.6 & 5.2272 & TRN \\
\hline CHEMBL1178727 & 809247 & 4.4 & 4.4263 & TST \\
\hline
\end{tabular}




\begin{tabular}{|c|c|c|c|c|c|}
\hline \\
\hline CHEMBL379975 & 809247 & 6.0 & 5.5834 & TST & \\
\hline CHEMBL1967612 & 809247 & 4.7 & 4.4911 & TRN & \\
\hline CHEMBL1965387 & 809247 & 4.6 & 4.785 & TRN & \\
\hline CHEMBL2001539 & 809247 & 5.2 & 4.9394 & TST & \\
\hline CHEMBL 388978 & 809247 & 8.3 & 7.4744 & TST & \\
\hline CHEMBL1997041 & 809247 & 6.1 & 5.2856 & TRN & \\
\hline CHEMBL550418 & 809247 & 6.5 & 6.4556 & TRN & \\
\hline CHEMBL398951 & 809247 & 4.6 & 4.3458 & TST & \\
\hline CHEMBL1971289 & 809247 & 7.8 & 7.0598 & TST & \\
\hline CHEMBL1988437 & 809247 & 4.9 & 4.7478 & TRN & \\
\hline CHEMBL2007603 & 809247 & 5.7 & 5.2784 & TRN & \\
\hline CHEMBL1421720 & 809247 & 6.1 & 6.4025 & TRN & \\
\hline CHEMBL1233887 & 809247 & 4.6 & 4.6619 & TRN & \\
\hline CHEMBL1968130 & 809247 & 5.5 & 5.3296 & TRN & \\
\hline CHEMBL1992607 & 809247 & 4.4 & 4.7041 & TRN & \\
\hline CHEMBL1996649 & 809247 & 4.6 & 4.6306 & TRN & \\
\hline CHEMBL1986756 & 809247 & 4.6 & 4.83899 & 99999999995 & TRN \\
\hline CHEMBL1949855 & 809247 & 5.5 & 5.6128 & TRN & \\
\hline CHEMBL3109278 & 809247 & 4.7 & 4.7184 & TRN & \\
\hline CHEMBL1727312 & 809247 & 4.2 & 3.4338 & TRN & \\
\hline CHEMBL1990223 & 809247 & 4.6 & 4.5098 & TRN & \\
\hline CHEMBL2004438 & 809247 & 4.6 & 4.7132 & TRN & \\
\hline CHEMBL1964382 & 809247 & 4.6 & 4.921 & TST & \\
\hline CHEMBL101311 & 809247 & 5.6 & 5.7406 & TRN & \\
\hline CHEMBL191003 & 809247 & 4.7 & 5.4868 & TRN & \\
\hline CHEMBL1973359 & 809247 & 7.1 & 7.3958 & TST & \\
\hline CHEMBL1988581 & 809247 & 7.8 & 7.7072 & TST & \\
\hline CHEMBL2005699 & 809247 & 4.6 & 4.4908 & TRN & \\
\hline CHEMBL2006564 & 809247 & 5.8 & 5.7027 & TRN & \\
\hline CHEMBL1986943 & 809247 & 8.6 & 8.5352 & TRN & \\
\hline CHEMBL1979690 & 809247 & 7.0 & 6.9546 & TRN & \\
\hline CHEMBL1991008 & 809247 & 4.3 & 4.4747 & TRN & \\
\hline CHEMBL 234085 & 809247 & 4.6 & 4.3394 & TRN & \\
\hline CHEMBL1978167 & 809247 & 4.6 & 5.0254 & TRN & \\
\hline CHEMBL418203 & 809247 & 6.9 & 6.3749 & TST & \\
\hline CHEMBL225519 & 809247 & 8.0 & 7.6016 & TRN & \\
\hline CHEMBL1994159 & 809247 & 4.5 & 4.2853 & TRN & \\
\hline CHEMBL1976376 & 809247 & 4.6 & 4.7252 & TRN & \\
\hline CHEMBL1983575 & 809247 & 7.7 & 7.0515 & TST & \\
\hline CHEMBL1968868 & 809247 & 5.6 & 5.4259 & TRN & \\
\hline CHEMBL1981047 & 809247 & 4.6 & 4.9561 & TRN & \\
\hline CHEMBL1998470 & 809247 & 7.8 & 7.4885 & TRN & \\
\hline CHEMBL1976196 & 809247 & 4.6 & 5.1197 & TRN & \\
\hline CHEMBL1997197 & 809247 & 6.4 & 5.8705 & TRN & \\
\hline CHEMBL1975903 & 809247 & 6.1 & 5.3589 & TRN & \\
\hline CHEMBL1983630 & 809247 & 4.3 & 4.511 & TRN & \\
\hline CHEMBL1522508 & 809247 & 6.1 & 4.9104 & TRN & \\
\hline CHEMBL1973795 & 809247 & 4.0 & 4.1611 & TRN & \\
\hline
\end{tabular}




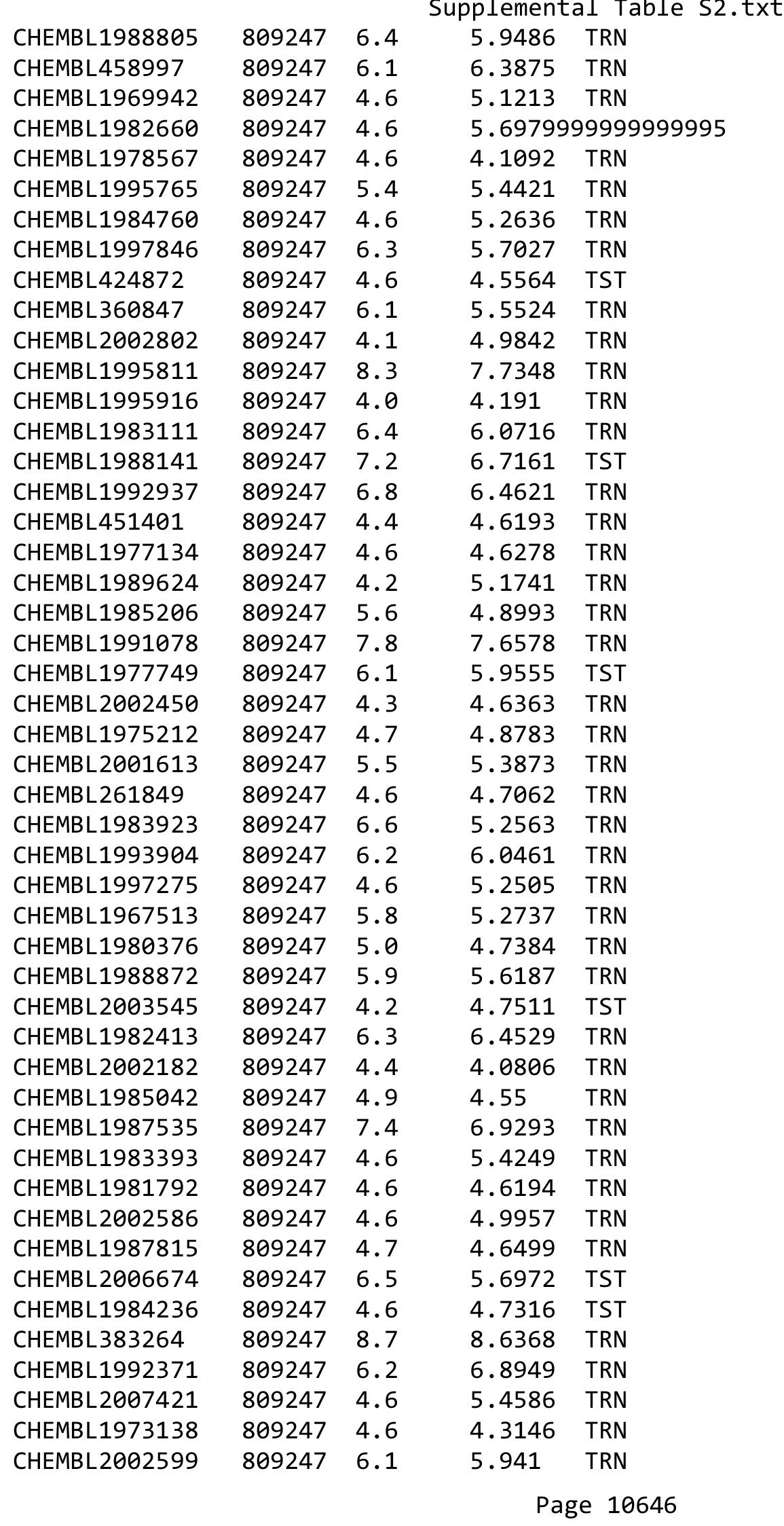

TRN 


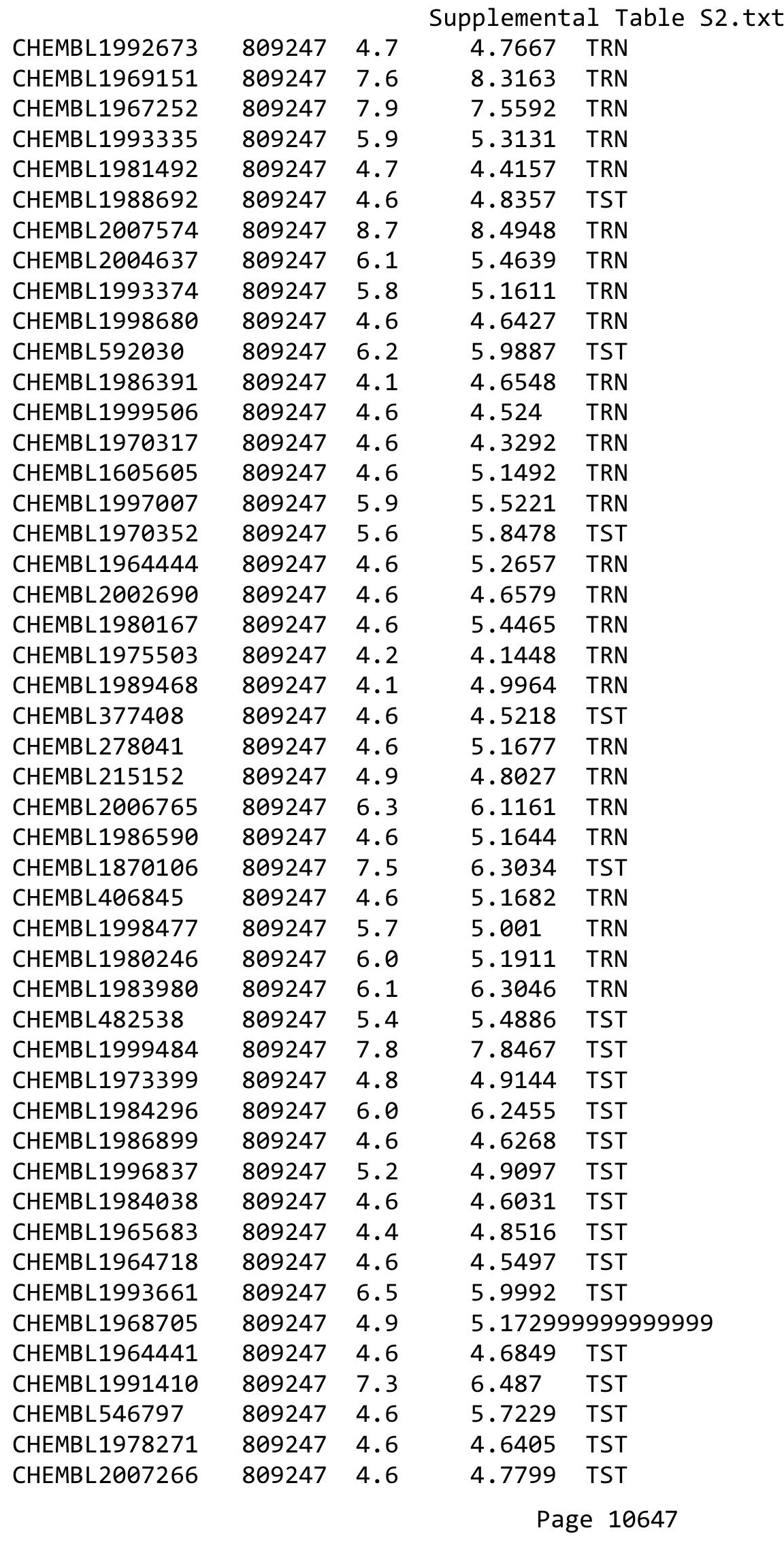




\begin{tabular}{|c|c|c|c|c|c|}
\hline \\
\hline CHEMBL 202721 & 809247 & 4.9 & 4.836 & TST & \\
\hline CHEMBL 2000568 & 809247 & 6.1 & 5.0831 & TST & \\
\hline CHEMBL2007097 & 809247 & 5.1 & 4.9371 & TST & \\
\hline CHEMBL1974328 & 809247 & 6.1 & 5.5617 & TST & \\
\hline CHEMBL509032 & 809247 & 5.8 & 5.8773 & TST & \\
\hline CHEMBL388311 & 809247 & 9.0 & 8.6513 & TST & \\
\hline CHEMBL1964948 & 809247 & 4.6 & 4.8807 & TST & \\
\hline CHEMBL1973013 & 809247 & 5.9 & 5.595 & TST & \\
\hline CHEMBL1987430 & 809247 & 4.6 & 5.0461 & TST & \\
\hline CHEMBL1993413 & 809247 & 6.5 & 6.4517 & TST & \\
\hline CHEMBL205415 & 809247 & 6.6 & 6.6423 & TST & \\
\hline CHEMBL1975927 & 809247 & 5.6 & 5.4056 & TST & \\
\hline CHEMBL289959 & 809247 & 4.8 & 4.6715 & TST & \\
\hline CHEMBL1997119 & 809247 & 4.4 & 4.2636 & TST & \\
\hline CHEMBL1977138 & 809247 & 7.6 & 7.50299 & 9999999999 & TST \\
\hline CHEMBL 2000879 & 809247 & 4.6 & 4.445 & TST & \\
\hline CHEMBL1978448 & 809247 & 4.6 & 4.541 & TST & \\
\hline CHEMBL1980329 & 809247 & 6.4 & 5.8691 & TST & \\
\hline CHEMBL 2004515 & 809247 & 6.6 & 5.9469 & TST & \\
\hline CHEMBL1992042 & 809247 & 4.6 & 5.7087 & TST & \\
\hline CHEMBL1986265 & 809247 & 4.6 & 4.2632 & TST & \\
\hline CHEMBL 2001704 & 809247 & 4.2 & 4.838 & TST & \\
\hline CHEMBL1967211 & 809247 & 4.8 & 4.646 & TST & \\
\hline CHEMBL1991734 & 809247 & 6.8 & 6.5701 & TST & \\
\hline CHEMBL3945995 & 1642254 & 6.4949 & 6.5637 & TRN & \\
\hline CHEMBL3911823 & 1642254 & 7.3565 & 7.5464 & TRN & \\
\hline CHEMBL3952687 & 1642254 & 7.0269 & 7.1881 & TST & \\
\hline CHEMBL3954972 & 1642254 & 7.3768 & 7.4851 & TRN & \\
\hline CHEMBL3903013 & 1642254 & 6.3565 & 7.09399 & 9999999999 & TRN \\
\hline CHEMBL3933162 & 1642254 & 7.9208 & 7.3842 & TRN & \\
\hline CHEMBL3967497 & 1642254 & 6.8239 & 6.9882 & TST & \\
\hline CHEMBL 3935402 & 1642254 & 7.585 & 7.4655 & TRN & \\
\hline CHEMBL3962961 & 1642254 & 5.6253 & 6.737 & TST & \\
\hline CHEMBL3892973 & 1642254 & 7.3872 & 7.1963 & TRN & \\
\hline CHEMBL 3985397 & 1642254 & 6.5376 & 7.2048 & TST & \\
\hline CHEMBL3921234 & 1642254 & 7.3665 & 6.8672 & TRN & \\
\hline CHEMBL 3986060 & 1642254 & 7.5229 & 6.709 & TST & \\
\hline CHEMBL3891794 & 1642254 & 8.0 & 7.4122 & TRN & \\
\hline CHEMBL3919942 & 1642254 & 5.9281 & 6.3435 & TST & \\
\hline CHEMBL3892601 & 1642254 & 7.3979 & 7.5342 & TRN & \\
\hline CHEMBL3932624 & 1642254 & 7.7696 & 7.9159 & TRN & \\
\hline CHEMBL 3894044 & 1642254 & 7.9586 & 7.5377 & TRN & \\
\hline CHEMBL3976321 & 1642254 & 4.301 & 6.1644 & TST & \\
\hline CHEMBL3889485 & 1642254 & 6.0 & 6.7682 & TST & \\
\hline CHEMBL3970635 & 1642254 & 7.3188 & 7.9034 & TRN & \\
\hline CHEMBL3932114 & 1642254 & 7.1938 & 7.6436 & TRN & \\
\hline CHEMBL 3984353 & 1642254 & 6.6778 & 7.6597 & TRN & \\
\hline CHEMBL3983729 & 1642254 & 6.8697 & 6.8434 & TST & \\
\hline
\end{tabular}


Supplemental Table S2.txt

\begin{tabular}{|c|c|c|c|c|c|}
\hline CHEMBL3899694 & 1642254 & 7.8539 & 7.6859 & TRN & \\
\hline CHEMBL3943160 & 1642254 & 5.7721 & \multicolumn{2}{|c|}{6.617999999999999} & TRN \\
\hline CHEMBL3922296 & 1642254 & 7.3188 & 7.6115 & TRN & \\
\hline CHEMBL3962035 & 1642254 & 6.3768 & 6.2012 & TST & \\
\hline CHEMBL3984143 & 1642254 & 7.0 & 7.2825 & TRN & \\
\hline CHEMBL3968574 & 1642254 & 6.8239 & 6.7347 & TRN & \\
\hline CHEMBL3905078 & 1642254 & 7.6198 & 7.425 & TRN & \\
\hline CHEMBL3907287 & 1642254 & 7.4318 & 7.024 & TRN & \\
\hline CHEMBL3911464 & 1642254 & 7.6383 & 7.5724 & TRN & \\
\hline CHEMBL3954321 & 1642254 & 7.7212 & 7.391 & TRN & \\
\hline CHEMBL3928810 & 1642254 & 7.3188 & 7.2315 & TRN & \\
\hline CHEMBL3915719 & 1642254 & 7.6383 & 7.3348 & TRN & \\
\hline CHEMBL3926590 & 1642254 & 7.4815 & 7.1062 & TRN & \\
\hline CHEMBL3984313 & 1642254 & 6.9586 & 7.1226 & TRN & \\
\hline CHEMBL 3923917 & 1642254 & 6.7328 & 6.6732 & TST & \\
\hline CHEMBL3891564 & 1642254 & 7.2596 & 6.6628 & TST & \\
\hline CHEMBL3950209 & 1642254 & 7.2076 & 7.3002 & TRN & \\
\hline CHEMBL3977044 & 1642254 & 7.9586 & \multicolumn{2}{|c|}{7.5089999999999995} & TRN \\
\hline CHEMBL3894905 & 1642254 & 6.2757 & 6.7652 & TST & \\
\hline CHEMBL3971866 & 1642254 & 7.9208 & 7.4593 & TRN & \\
\hline CHEMBL3948079 & 1642254 & 7.6778 & 7.9334 & TRN & \\
\hline CHEMBL3945221 & 1642254 & 7.6778 & 7.2602 & TRN & \\
\hline CHEMBL3903102 & 1642254 & 7.1871 & 7.5696 & TRN & \\
\hline CHEMBL3986980 & 1642254 & 7.9208 & 7.5448 & TRN & \\
\hline CHEMBL3962560 & 1642254 & 7.7959 & 7.4661 & TRN & \\
\hline CHEMBL3917458 & 1642254 & 7.7696 & 7.5878 & TRN & \\
\hline CHEMBL3960328 & 1642254 & 7.0862 & 6.6869 & TST & \\
\hline CHEMBL3893117 & 1642254 & 7.7447 & 7.3165 & TRN & \\
\hline CHEMBL3964640 & 1642254 & 4.301 & 6.7213 & TST & \\
\hline CHEMBL 3938541 & 1642254 & 7.0 & 6.9876 & TRN & \\
\hline CHEMBL3930427 & 1642254 & 7.1079 & 7.0499 & TRN & \\
\hline CHEMBL3975955 & 1642254 & 8.2218 & 7.8823 & TRN & \\
\hline CHEMBL3919963 & 1642254 & 7.7696 & 7.5586 & TRN & \\
\hline CHEMBL3962982 & 1642254 & 5.6038 & 6.6797 & TST & \\
\hline CHEMBL3983969 & 1642254 & 7.6198 & 7.568 & TRN & \\
\hline CHEMBL3943541 & 1642254 & 6.6778 & 7.1194 & TRN & \\
\hline CHEMBL3975014 & 1642254 & 7.4949 & 7.1676 & TRN & \\
\hline CHEMBL3906251 & 1642254 & 8.0 & 7.5996 & TRN & \\
\hline CHEMBL3941006 & 1642254 & 7.0655 & 7.3854 & TST & \\
\hline CHEMBL3901443 & 1642254 & 7.301 & 6.4311 & TST & \\
\hline CHEMBL3959794 & 1642254 & 7.6198 & 7.4869 & TRN & \\
\hline CHEMBL 3894320 & 1642254 & 6.2676 & 6.9928 & TRN & \\
\hline CHEMBL3901281 & 1642254 & 7.8861 & 7.7843 & TRN & \\
\hline CHEMBL3917301 & 1642254 & 7.699 & 7.1902 & TST & \\
\hline CHEMBL3922349 & 1642254 & 7.3468 & 7.1149 & TRN & \\
\hline CHEMBL3924969 & 1642254 & 7.7212 & 7.5098 & TRN & \\
\hline CHEMBL3972130 & 1642254 & 6.7696 & 7.1047 & TST & \\
\hline CHEMBL3971369 & 1642254 & 7.4202 & 7.4552 & TRN & \\
\hline
\end{tabular}


Supplemental Table S2.txt

\begin{tabular}{|c|c|c|c|c|}
\hline CHEMBL3915342 & 1642254 & 7.6198 & 7.5272 & TRN \\
\hline CHEMBL 3972640 & 1642254 & 7.7212 & 7.4863 & TRN \\
\hline CHEMBL3971978 & 1642254 & 7.7447 & 7.5481 & TRN \\
\hline CHEMBL 3959472 & 1642254 & 7.3872 & 7.1532 & TRN \\
\hline CHEMBL 3923704 & 1642254 & 7.2218 & 7.1368 & TRN \\
\hline CHEMBL3962297 & 1642254 & 6.0088 & 6.3798 & TRN \\
\hline CHEMBL 3933584 & 1642254 & 6.0605 & 7.2553 & TRN \\
\hline CHEMBL3918933 & 1642254 & 7.4949 & 7.2561 & TRN \\
\hline CHEMBL 3978130 & 1642254 & 6.9208 & 7.269 & TST \\
\hline CHEMBL 3933387 & 1642254 & 6.3768 & 6.4929 & TST \\
\hline CHEMBL 3949269 & 1642254 & 7.8539 & 7.6961 & TRN \\
\hline CHEMBL 3922048 & 1642254 & 8.0458 & 7.9021 & TRN \\
\hline CHEMBL3915492 & 1642254 & 7.2007 & 7.1264 & TST \\
\hline CHEMBL 3899214 & 1642254 & 7.2147 & 7.1293 & TRN \\
\hline CHEMBL 3970222 & 1642254 & 6.9208 & 6.7527 & TST \\
\hline CHEMBL 3915660 & 1642254 & 8.2218 & 7.7464 & TRN \\
\hline CHEMBL3961046 & 1642254 & 7.2676 & 7.5366 & TRN \\
\hline CHEMBL3962197 & 1642254 & 8.301 & 7.6211 & TRN \\
\hline CHEMBL3951619 & 1642254 & 6.6778 & 7.0576 & TST \\
\hline CHEMBL 3916597 & 1642254 & 7.6198 & 7.3293 & TRN \\
\hline CHEMBL 3959628 & 1642254 & 7.4815 & 7.1408 & TRN \\
\hline CHEMBL3896166 & 1642254 & 7.4202 & 7.3488 & TRN \\
\hline CHEMBL 3925152 & 1642254 & 7.2291 & 7.6668 & TRN \\
\hline CHEMBL3929509 & 1642254 & 6.9586 & 7.1624 & TRN \\
\hline CHEMBL 3928445 & 1642254 & 6.8539 & 6.9781 & TRN \\
\hline CHEMBL3954686 & 1642254 & 6.5528 & 6.7735 & TST \\
\hline CHEMBL 3980686 & 1642254 & 7.585 & 7.5523 & TRN \\
\hline CHEMBL3931603 & 1642254 & 6.0 & 7.2689 & TRN \\
\hline CHEMBL3910741 & 1642254 & 7.0969 & 7.1564 & TRN \\
\hline CHEMBL 3941358 & 1642254 & 7.699 & 7.5419 & TRN \\
\hline CHEMBL 3960855 & 1642254 & 6.5229 & 6.9122 & TST \\
\hline CHEMBL 3970537 & 1642254 & 7.2757 & 7.1421 & TRN \\
\hline CHEMBL3947691 & 1642254 & 7.1612 & 6.4484 & TST \\
\hline CHEMBL 3921231 & 1642254 & 4.301 & 6.8198 & TRN \\
\hline CHEMBL 3907446 & 1642254 & 7.1427 & 7.7049 & TRN \\
\hline CHEMBL3899622 & 1642254 & 7.3979 & 7.0571 & TRN \\
\hline CHEMBL 3979542 & 1642254 & 6.9626 & 6.4925 & TRN \\
\hline CHEMBL 3943679 & 1642254 & 7.3979 & 7.3229 & TRN \\
\hline CHEMBL 3891688 & 1642254 & 6.9586 & 7.3862 & TRN \\
\hline CHEMBL 3898969 & 1642254 & 7.699 & 7.5211 & TRN \\
\hline CHEMBL 3905739 & 1642254 & 4.301 & 6.117999 & 9999999999 \\
\hline CHEMBL 3924864 & 1642254 & 6.0 & 6.5531 & TST \\
\hline CHEMBL 3982738 & 1642254 & 7.041 & 7.5089 & TRN \\
\hline CHEMBL 3939437 & 1642254 & 7.5086 & 7.5658 & TRN \\
\hline CHEMBL 3894429 & 1642254 & 6.983 & 6.6943 & TST \\
\hline CHEMBL 3922703 & 1642254 & 7.1871 & 6.5903 & TST \\
\hline CHEMBL 3898437 & 1642254 & 7.7212 & 7.6594 & TRN \\
\hline CHEMBL 3930576 & 1642254 & 7.3665 & 7.7132 & TRN \\
\hline
\end{tabular}


Supplemental Table S2.txt

\begin{tabular}{|c|c|c|c|c|}
\hline HEMBL 3966134 & & 7.7212 & & \\
\hline HEMBL3971921 & 642254 & 6.684 & 6.8565 & \\
\hline & 254 & & & \\
\hline 932 & 54 & 65 & & \\
\hline UEMBL3929938 & 042254 & 4318 & 301 & \\
\hline AEMBL3892113 & 642254 & 7.5376 & .4008 & \\
\hline HEMBL3949302 & 254 & 7.6198 & .541 & \\
\hline 347 & & & 505 & \\
\hline IEMBL 394 & 254 & 599 & 7.3135 & \\
\hline HEMBL3970842 & 254 & 7.3098 & 5504 & \\
\hline HEMBL3967912 & 254 & 7.585 & 4261 & \\
\hline HEMBL397 & 54 & 367 & 428 & \\
\hline AEMBL. & & & & \\
\hline HEMBL; & 54 & 599 & 5805 & \\
\hline AEMBL3944348 & 54 & 862 & 753 & \\
\hline HEMBL3907017 & 84 & 99 & 83 & \\
\hline HEMBL3S & 4 & 539 & 524 & \\
\hline HEMBL3S & & & & \\
\hline HEMBL3S & & 3188 & 951 & \\
\hline AEMBL39 & & 291 & & \\
\hline HEMBL 3893529 & 84 & 539 & 265 & KIN \\
\hline HEMBL39 & 4 & 21 & 79 & \\
\hline HEMBL3S & & 98 & 66 & \\
\hline 06 & & 38 & 844 & \\
\hline AEMBL39 & 54 & 57 & 76 & SI \\
\hline L38 & & 9 & 76 & RN \\
\hline HEMBL39 & 4 & 86 & 33 & RN \\
\hline 34 & & & & \\
\hline AEMBL3S & & & & $\mathrm{RN}$ \\
\hline AEMBL39 & 64 & -9 & 93 & RN \\
\hline AEMBL 38 & 4 & 87 & 225 & ST \\
\hline 9 & & 361 & 89 & RN \\
\hline 20 & & & & RN \\
\hline HEMBL3965791 & & & & RN \\
\hline AEMBL3930975 & 64 & 655 & 367 & IST \\
\hline HEMBL3 & 6 & 778 & 479 & ST \\
\hline HEMRI 3 & & 7. & & ST \\
\hline 05 & & & 048 & ST \\
\hline HEMBL3956186 & 54 & 5 . & 6.7853 & TRN \\
\hline AEMBL39 & 6 & 18 & 986 & RN \\
\hline HEMBL393 & 6 & 586 & 7.6113 & 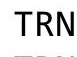 \\
\hline HEMBL394 & & & 7.4153 & RN \\
\hline HEMBL3972102 & & 7.3468 & 7114 & ST \\
\hline HEMBL3979428 & 254 & 8.0969 & 7.5245 & RN \\
\hline 20 & & 85 & & KIV \\
\hline HEMBL 3963875 & & & 6.9108 & \\
\hline HEMBL 39 & & .4559 & 7.6026 & \\
\hline CHEMBL3935073 & 1642254 & 8.0 & 7.5012 & \\
\hline
\end{tabular}

Page 10651 
Supplemental Table S2.txt

\begin{tabular}{|c|c|c|c|c|c|}
\hline CHEMBL3965407 & 1642254 & 7.6198 & 7.615 & TRN & \\
\hline CHEMBL3934732 & 1642254 & 7.4949 & 7.2997 & TRN & \\
\hline CHEMBL3971732 & 1642254 & 7.7959 & 7.8581 & TRN & \\
\hline CHEMBL3893270 & 1642254 & 6.1675 & 6.6397 & TRN & \\
\hline CHEMBL3938900 & 1642254 & 6.6882 & 6.7193 & TST & \\
\hline CHEMBL3940149 & 1642254 & 8.0458 & 7.7287 & TRN & \\
\hline CHEMBL3960022 & 1642254 & 7.8861 & 7.591 & TRN & \\
\hline CHEMBL3918324 & 1642254 & 7.4685 & 7.6754 & TRN & \\
\hline CHEMBL3935004 & 1642254 & 7.699 & 7.5596 & TRN & \\
\hline CHEMBL3985588 & 1642254 & 7.7447 & 7.2471 & TRN & \\
\hline CHEMBL3894066 & 1642254 & 7.2924 & 7.428 & TRN & \\
\hline CHEMBL3896474 & 1642254 & 6.6383 & 6.3155 & TRN & \\
\hline CHEMBL3917227 & 1642254 & 7.5686 & 7.433 & TST & \\
\hline CHEMBL3908611 & 1642254 & 7.9586 & 7.6976 & TRN & \\
\hline CHEMBL 3945625 & 1642254 & 8.0458 & 7.6165 & TRN & \\
\hline CHEMBL3946637 & 1642254 & 7.3979 & 6.8697 & TRN & \\
\hline CHEMBL3962746 & 1642254 & 5.8861 & 5.8743 & TRN & \\
\hline CHEMBL3927639 & 1642254 & 7.9208 & 7.3053 & TRN & \\
\hline CHEMBL3901975 & 1642254 & 7.5376 & 7.3157 & TRN & \\
\hline CHEMBL3965774 & 1642254 & 6.0757 & 6.7499 & TST & \\
\hline CHEMBL3900209 & 1642254 & 7.6198 & 7.42399 & э99999999995 & TRN \\
\hline CHEMBL3940532 & 1642254 & 7.5686 & 7.5271 & TRN & \\
\hline CHEMBL3972894 & 1642254 & 6.0 & 6.7404 & TST & \\
\hline CHEMBL3976943 & 1642254 & 6.2076 & 6.7957 & TST & \\
\hline CHEMBL3985124 & 1642254 & 7.699 & 7.5529 & TRN & \\
\hline CHEMBL3923523 & 1642254 & 7.1675 & 7.5767 & TRN & \\
\hline CHEMBL3914145 & 1642254 & 6.9586 & 7.4808 & TRN & \\
\hline CHEMBL3982115 & 1642254 & 7.0223 & 7.3732 & TST & \\
\hline CHEMBL3896687 & 1642254 & 7.0969 & 6.9942 & TRN & \\
\hline CHEMBL 3894295 & 1642254 & 7.4437 & 7.1281 & TRN & \\
\hline CHEMBL3933902 & 1642254 & 7.2757 & 7.5201 & TRN & \\
\hline CHEMBL3906844 & 1642254 & 6.9914 & 7.2287 & TST & \\
\hline CHEMBL3977322 & 1642254 & 7.0132 & 6.7816 & TRN & \\
\hline CHEMBL3947026 & 1642254 & 7.0044 & 6.5518 & TST & \\
\hline CHEMBL3902090 & 1642254 & 5.8254 & 6.5172 & TRN & \\
\hline CHEMBL3929921 & 1642254 & 7.5376 & 6.9432 & TRN & \\
\hline CHEMBL3939407 & 1642254 & 7.4559 & 7.2877 & TRN & \\
\hline CHEMBL3927497 & 1642254 & 8.0458 & 7.501 & TRN & \\
\hline CHEMBL3936432 & 1642254 & 7.2441 & 6.7832 & TRN & \\
\hline CHEMBL3952389 & 1642254 & 7.6576 & 7.4956 & TRN & \\
\hline CHEMBL3938270 & 1642254 & 7.9586 & 7.42299 & 9999999999 & TRN \\
\hline CHEMBL3909325 & 1642254 & 6.4685 & 6.7161 & TST & \\
\hline CHEMBL3953388 & 1642254 & 7.2441 & 7.2376 & TST & \\
\hline CHEMBL3938945 & 1642254 & 7.2291 & 7.4017 & TRN & \\
\hline CHEMBL3902171 & 1642254 & 7.9586 & 7.9492 & TRN & \\
\hline CHEMBL3914318 & 1642254 & 6.9586 & 7.2714 & TRN & \\
\hline CHEMBL3956069 & 1642254 & 7.4815 & 7.3366 & TRN & \\
\hline CHEMBL3916218 & 1642254 & 7.3979 & 7.1894 & TST & \\
\hline
\end{tabular}


Supplemental Table S2.txt

\begin{tabular}{|c|c|c|c|c|}
\hline CHEMBL3905299 & 1642254 & 8.0 & 7.5232 & TRN \\
\hline CHEMBL3952119 & 1642254 & 7.5376 & 7.3302 & TRN \\
\hline CHEMBL3895704 & 1642254 & 8.0458 & 8.005 & TRN \\
\hline CHEMBL3959137 & 1642254 & 6.7496 & 7.396 & TST \\
\hline CHEMBL3927245 & 1642254 & 7.5376 & 7.6115 & TRN \\
\hline CHEMBL3915984 & 1642254 & 7.1739 & 7.388 & TRN \\
\hline CHEMBL3914043 & 1642254 & 7.7447 & 7.5016 & TRN \\
\hline CHEMBL3959828 & 1642254 & 6.3372 & 6.1122 & TST \\
\hline CHEMBL3936004 & 1642254 & 7.9208 & 7.8392 & TRN \\
\hline CHEMBL3958510 & 1642254 & 7.5376 & 7.2818 & TRN \\
\hline CHEMBL3952848 & 1642254 & 7.301 & 7.7273 & TRN \\
\hline CHEMBL3897245 & 1642254 & 5.3487 & 5.9751 & TRN \\
\hline CHEMBL3933878 & 1642254 & 7.7959 & 7.894 & TST \\
\hline CHEMBL3940841 & 1642254 & 7.4559 & 7.4184 & TRN \\
\hline CHEMBL3944366 & 1642254 & 7.6778 & 7.5785 & TRN \\
\hline CHEMBL3981007 & 1642254 & 7.5229 & 7.0753 & TRN \\
\hline CHEMBL3893984 & 1642254 & 7.6198 & 7.2826 & TRN \\
\hline CHEMBL3906726 & 1642254 & 7.6778 & 7.4556 & TRN \\
\hline CHEMBL3933609 & 1642254 & 7.7447 & 7.7304 & TRN \\
\hline CHEMBL3956986 & 1642254 & 7.4437 & 7.57600 & 00000000005 \\
\hline CHEMBL3911741 & 1642254 & 5.4306 & 6.7928 & TST \\
\hline CHEMBL3949713 & 1642254 & 7.4089 & 7.7625 & TRN \\
\hline CHEMBL3917729 & 1642254 & 6.8386 & 7.4454 & TRN \\
\hline CHEMBL3911196 & 1642254 & 7.6198 & 7.6408 & TRN \\
\hline CHEMBL3894268 & 1642254 & 7.1024 & 7.6353 & TRN \\
\hline CHEMBL3892817 & 1642254 & 7.2676 & 6.8792 & TRN \\
\hline CHEMBL3893018 & 1642254 & 7.3979 & 7.4566 & TRN \\
\hline CHEMBL3895933 & 1642254 & 7.6778 & 7.3414 & TRN \\
\hline CHEMBL3976292 & 1642254 & 6.2291 & 7.0814 & TST \\
\hline CHEMBL3985033 & 1642254 & 6.0 & 6.4361 & TST \\
\hline CHEMBL3889787 & 1642254 & 6.0506 & 6.9338 & TST \\
\hline CHEMBL3902566 & 1642254 & 7.1249 & 6.7922 & TRN \\
\hline CHEMBL3961981 & 1642254 & 7.1805 & 7.3021 & TRN \\
\hline CHEMBL3957597 & 1642254 & 6.9586 & 7.0712 & TST \\
\hline CHEMBL3971018 & 1642254 & 6.8539 & 6.7445 & TST \\
\hline CHEMBL3978403 & 1642254 & 7.7959 & 7.3761 & TRN \\
\hline CHEMBL3908483 & 1642254 & 7.2291 & 6.7835 & TRN \\
\hline CHEMBL3921854 & 1642254 & 7.1427 & 7.2602 & TRN \\
\hline CHEMBL3955152 & 1642254 & 7.0088 & 6.796 & TST \\
\hline CHEMBL3969478 & 1642254 & 7.284 & 7.5703 & TRN \\
\hline CHEMBL3938476 & 1642254 & 7.4437 & 7.1082 & TST \\
\hline CHEMBL3948207 & 1642254 & 7.0555 & 7.5493 & TRN \\
\hline CHEMBL3902887 & 1642254 & 7.5686 & 7.4759 & TRN \\
\hline CHEMBL3929307 & 1642254 & 5.9172 & 6.8692 & TST \\
\hline CHEMBL3975941 & 1642254 & 8.0458 & 7.8734 & TRN \\
\hline CHEMBL3923912 & 1642254 & 7.2291 & 7.5071 & TRN \\
\hline CHEMBL3890268 & 1642254 & 7.0506 & 6.8651 & TRN \\
\hline CHEMBL3908194 & 1642254 & 6.3565 & 7.4654 & TRN \\
\hline
\end{tabular}


Supplemental Table S2.txt

CHEMBL3936764

CHEMBL3931107

CHEMBL3908686

CHEMBL3923215

CHEMBL3960666

CHEMBL3981901

CHEMBL3933279

CHEMBL3964060

CHEMBL3948957

CHEMBL3942630

CHEMBL3954707

CHEMBL3905229

CHEMBL3936710

CHEMBL3951892

CHEMBL3944341

CHEMBL3912957

CHEMBL3953558

CHEMBL3981989

CHEMBL3981322

CHEMBL3975312

CHEMBL3939411

CHEMBL3941141

CHEMBL3928845

CHEMBL3909855

CHEMBL3921137

CHEMBL3919638

CHEMBL 3908480

CHEMBL3932303

CHEMBL3920956

CHEMBL3901802

CHEMBL3957367

CHEMBL3957719

CHEMBL 3983146

CHEMBL3943938

CHEMBL3899430

CHEMBL3911378

CHEMBL3926883

CHEMBL3949918

CHEMBL3969857

CHEMBL3927676

CHEMBL3947610

CHEMBL3932119

CHEMBL3932646

CHEMBL3915942

CHEMBL3961413

CHEMBL3928165

CHEMBL3938486

CHEMBL3907499
16422547.0

16422545.4353

16422546.0

16422547.8539

16422548.0458

16422546.9788

16422547.2366

16422546.0

16422546.1871

16422547.2007

16422547.1871

16422547.585

16422547.2924

16422547.2147

16422545.8097

16422547.2757

16422547.1871

16422546.6108

16422547.0132

16422547.6778

16422547.2518

16422547.0757

16422547.6198

16422547.284

16422546.5086

16422547.7447

16422546.0701

16422547.3098

16422547.7447

16422547.6778

16422545.4634

16422547.4318

16422546.0

16422546.7212

16422547.2596

16422547.0269

16422546.0

16422548.1549

16422546.3372

16422547.9586

16422547.699

16422547.699

16422547.2757

16422546.9586

16422547.6021

16422547.3979

16422547.4559

16422547.2441
7.0689 TRN

6.0329999999999995

7.2676 TRN

7.7593 TRN

7.3061 TRN

7.0773 TST

7.1369 TRN

6.612 TST

6.06 TST

7.4432 TRN

7.5742 TRN

7.1919 TRN

7.0434 TST

7.5662 TRN

6.1493 TST

7.4985 TRN

7.5443 TRN

7.0666 TST

7.0028 TRN

7.4362 TRN

7.3186 TRN

7.0415 TRN

7.082000000000001

7.4357 TRN

6.7445 TRN

7.9257 TRN

6.9542 TRN

6.6992 TST

7.8485 TRN

7.6515 TRN

6.796 TST

7.0748 TRN

7.4937 TRN

7.1055 TRN

7.105 TRN

7.0694 TST

7.4056 TST

7.9110000000000005

6.9734 TRN

7.624 TRN

7.6686 TRN

7.4061 TRN

7.4399 TRN

6.7773 TRN

7.2604 TRN

7.4519 TRN

7.6326 TRN

6.9259 TRN 
Supplemental Table S2.txt

\begin{tabular}{|c|c|c|c|c|}
\hline HEMBL3923173 & 1642254 & 7.3372 & 7.3571 & \\
\hline CHEMBL 3914523 & 642254 & 7.4437 & 7.2851 & \\
\hline AEMBL & 642254 & 7.7212 & 522 & \\
\hline IEMBL 3961523 & 642254 & 7.1549 & 34 & \\
\hline IEMBL3936191 & 642254 & 4.301 & 4939 & \\
\hline AEMBL3944896 & 642254 & 6.8539 & 6.6841 & \\
\hline HEMBL3901552 & 642254 & 7.2518 & 7.1388 & \\
\hline AEMBL3983307 & 642254 & 4.9578 & 451 & \\
\hline AEMBL3961371 & 1642254 & 7.7447 & 7.9242 & \\
\hline AEMBL3930059 & 1642254 & 7.6021 & 6.8537 & \\
\hline AEMBL3953567 & 1642254 & 7.5686 & 4542 & \\
\hline AEMBL3907415 & 1642254 & 6.7825 & 7.0614 & \\
\hline AEMBL3934120 & 254 & 4.301 & 112 & \\
\hline AEMBL93833 & 760 & 169 & 539 & \\
\hline HEMBL93824 & 76067 & 5.6383 & 5.6176 & \\
\hline IEMBL327489 & 76067 & 6.6198 & 6.608 & \\
\hline JEMBL92999 & 760 & 4.9914 & 641 & \\
\hline HEMBL93274 & 760 & 06 & 506 & \\
\hline HEMBL92947 & 760 & & 834 & \\
\hline HEMBL 330622 & 760 & 18 & 523 & \\
\hline L94314 & 6067 & 6. & 934 & \\
\hline L319376 & 760 & 6.1 & 883 & \\
\hline HEMBL89982 & 760 & & 16 & \\
\hline HEMBL91706 & 766 & & 879 & \\
\hline HEMBL 328687 & 760 & 5 . & 22 & \\
\hline L9. & 60 & 5 . & 56 & \\
\hline L92980 & 760 & 5 . & 97 & \\
\hline 740 & 760 & & 813 & \\
\hline L328661 & 766 & & 772 & \\
\hline HEMBL92034 & 760 & 5 . & 88 & TR \\
\hline L 327557 & 760 & 78 & 69 & \\
\hline 641 & 766 & 12 & 93 & \\
\hline L329854 & & 24 & 886 & \\
\hline CHEMBL328134 & 760 & & 526 & \\
\hline CHEMBL323532 & 760 & 6 . & 6.105 & \\
\hline L420065 & 760 & & 366 & \\
\hline $\mathrm{CHE}$ & 76 & & & 11 \\
\hline L91849 & 760 & 61 & 5.8826 & \\
\hline CHEMBL96437 & 76067 & 5.2291 & 5.2049 & TR \\
\hline L276675 & 760 & 6. & 027 & T \\
\hline CHEMBL93533 & 760 & 5. & 5.4889 & \\
\hline & & & 5.3923 & $\mathrm{k}$ \\
\hline CHEMBL94540 & 76067 & 5.1427 & 5.1398 & $\Gamma R$ \\
\hline CHEMBL92734 & 76067 & 7.1487 & 7.1613 & TR \\
\hline 10360 & 760 & 5. & 5.4955 & 3 \\
\hline CHEMBL 92294 & 760 & 5.6 & 5.6387 & \\
\hline CHEMBL93248 & 76067 & 5.7447 & 5.7463 & \\
\hline CHEMBL329364 & 76067 & 5.1549 & 5.1326 & \\
\hline
\end{tabular}

Page 10655 


\begin{tabular}{|c|c|c|c|c|c|}
\hline & & \multicolumn{4}{|c|}{ Supplemental Table s2.txt } \\
\hline CHEMBL92574 & 76067 & 5.2596 & 5.2778 & TRN & \\
\hline CHEMBL92236 & 76067 & 6.2596 & 6.3763 & TRN & \\
\hline CHEMBL94166 & 76067 & 5.6778 & 5.6651 & TRN & \\
\hline CHEMBL92979 & 76067 & 6.6778 & 6.6617 & TRN & \\
\hline CHEMBL96344 & 76067 & 5.3372 & 5.3283 & TRN & \\
\hline CHEMBL94063 & 76067 & 6.301 & 6.3136 & TRN & \\
\hline CHEMBL93091 & 76067 & 5.4437 & 6.3027 & TST & \\
\hline CHEMBL93409 & 76067 & 5.6383 & 5.6247 & TRN & \\
\hline CHEMBL273561 & 76067 & 5.7696 & 6.0503 & TST & \\
\hline CHEMBL95038 & 76067 & 5.3979 & 5.4325 & TRN & \\
\hline CHEMBL92280 & 76067 & 4.4437 & 5.8647 & TST & \\
\hline CHEMBL328612 & 76067 & 5.5686 & \multicolumn{2}{|c|}{5.712000000000001} & TST \\
\hline CHEMBL96810 & 76067 & 5.2007 & 5.1713 & TRN & \\
\hline CHEMBL328101 & 76067 & 5.8861 & 5.8819 & TRN & \\
\hline CHEMBL93597 & 76067 & 6.4089 & 6.4051 & TRN & \\
\hline CHEMBL327491 & 76067 & 6.0655 & 6.0321 & TRN & \\
\hline CHEMBL91868 & 76067 & 6.7959 & 5.4138 & TST & \\
\hline CHEMBL92895 & 76067 & 6.1871 & 6.178 & TRN & \\
\hline CHEMBL329200 & 76067 & 5.8239 & 5.7447 & TRN & \\
\hline CHEMBL93938 & 76067 & 5.9172 & 5.9308 & TRN & \\
\hline CHEMBL327863 & 76067 & 4.2218 & 4.1676 & TRN & \\
\hline CHEMBL327824 & 76067 & 5.5376 & 5.5857 & TRN & \\
\hline CHEMBL93138 & 76067 & 6.0862 & 6.1767 & TRN & \\
\hline CHEMBL96549 & 76067 & 7.4437 & 7.3173 & TRN & \\
\hline CHEMBL316322 & 76067 & 7.2147 & 7.2178 & TRN & \\
\hline CHEMBL328304 & 76067 & 5.7959 & 5.8411 & TRN & \\
\hline CHEMBL420433 & 76067 & 5.8539 & 5.8622 & TRN & \\
\hline CHEMBL93063 & 76067 & 5.3279 & 5.9991 & TST & \\
\hline CHEMBL92935 & 76067 & 5.5686 & \multicolumn{2}{|c|}{5.6129999999999995} & TRN \\
\hline CHEMBL414409 & 76067 & 5.5528 & 5.5519 & TRN & \\
\hline CHEMBL96944 & 76067 & 4.7352 & 4.7666 & TRN & \\
\hline CHEMBL93039 & 76067 & 5.6198 & 5.7299 & TRN & \\
\hline CHEMBL93019 & 76067 & 5.9208 & 5.8904 & TRN & \\
\hline CHEMBL92467 & 76067 & 6.1739 & 6.1847 & TRN & \\
\hline CHEMBL94104 & 76067 & 5.585 & 6.0413 & TST & \\
\hline CHEMBL421003 & 76067 & 5.6778 & 5.6472 & TRN & \\
\hline CHEMBL329877 & 76067 & 6.0044 & 5.9637 & TRN & \\
\hline CHEMBL96507 & 76067 & 5.2676 & 5.2714 & TRN & \\
\hline CHEMBL96826 & 76067 & 6.0458 & 6.0323 & TRN & \\
\hline CHEMBL92877 & 76067 & 6.284 & 6.2739 & TRN & \\
\hline CHEMBL89989 & 76067 & 5.7696 & 5.7605 & TRN & \\
\hline CHEMBL92399 & 76067 & 5.5086 & 5.5477 & TRN & \\
\hline CHEMBL93288 & 76067 & 4.4685 & \multicolumn{2}{|c|}{5.593999999999999} & TST \\
\hline CHEMBL317924 & 76067 & 5.5229 & 5.5064 & TRN & \\
\hline CHEMBL420811 & 76067 & 4.4685 & 5.8007 & TST & \\
\hline CHEMBL92177 & 76067 & 6.1308 & 6.1143 & TRN & \\
\hline CHEMBL328136 & 76067 & 5.8539 & 5.8705 & TRN & \\
\hline CHEMBL91558 & 76067 & 5.699 & 5.7343 & TRN & \\
\hline
\end{tabular}




\begin{tabular}{|c|c|c|c|c|c|}
\hline \multirow[b]{2}{*}{ CHEMBL442693 } & \multicolumn{5}{|c|}{ Supplemental Table S2.txt } \\
\hline & 76067 & 5.7212 & 5.71399 & 99999999995 & TRN \\
\hline CHEMBL316116 & 76067 & 6.7447 & 6.8315 & TRN & \\
\hline CHEMBL93197 & 76067 & 5.8539 & 7.1675 & TST & \\
\hline CHEMBL 92862 & 76067 & 5.5086 & 5.4808 & TRN & \\
\hline CHEMBL91967 & 76067 & 6.0506 & 5.9979 & TRN & \\
\hline CHEMBL93015 & 76067 & 4.9208 & 4.9246 & TRN & \\
\hline CHEMBL92190 & 76067 & 5.7696 & 5.7843 & TRN & \\
\hline CHEMBL329853 & 76067 & 5.3565 & 5.3738 & TRN & \\
\hline CHEMBL 94222 & 76067 & 5.6021 & 5.6182 & TRN & \\
\hline CHEMBL96296 & 76067 & 6.301 & 6.2896 & TRN & \\
\hline CHEMBL432569 & 76067 & 5.2366 & 5.4431 & TST & \\
\hline CHEMBL92176 & 76067 & 6.2218 & 6.6168 & TST & \\
\hline CHEMBL 92249 & 76067 & 5.1192 & 5.2476 & TST & \\
\hline CHEMBL93191 & 76067 & 5.585 & 5.6659 & TST & \\
\hline CHEMBL92989 & 76067 & 6.4202 & 6.36299 & 99999999995 & ST \\
\hline CHEMBL 93358 & 76067 & 5.6778 & 6.0469 & TST & \\
\hline CHEMBL95150 & 76067 & 5.1805 & 5.4269 & TST & \\
\hline CHEMBL316603 & 76067 & 5.6345 & 6.0392 & TST & \\
\hline CHEMBL 93373 & 76067 & 6.0132 & 5.9189 & TST & \\
\hline CHEMBL91057 & 76067 & 5.7959 & 5.8471 & TST & \\
\hline CHEMBL 327717 & 76067 & 5.7696 & 5.9014 & TST & \\
\hline CHEMBL92645 & 76067 & 6.1487 & 6.1382 & TST & \\
\hline CHEMBL 93525 & 76067 & 5.8239 & 5.8 & TST & \\
\hline CHEMBL329671 & 76067 & 6.2366 & 5.5171 & TST & \\
\hline CHEMBL92781 & 76067 & 6.1079 & 6.0122 & TST & \\
\hline CHEMBL92666 & 76067 & 6.7447 & 7.2308 & TST & \\
\hline CHEMBL328913 & 76067 & 5.2218 & 5.4046 & TST & \\
\hline CHEMBL525392 & 498612 & 8.1675 & 7.8151 & TRN & \\
\hline CHEMBL524675 & 498612 & 6.4101 & 7.6138 & TST & \\
\hline CHEMBL525591 & 498612 & 6.9586 & 6.9332 & TRN & \\
\hline CHEMBL526315 & 498612 & 8.9586 & 8.6906 & TRN & \\
\hline CHEMBL501240 & 498612 & 7.6861 & 7.8264 & TRN & \\
\hline CHEMBL507480 & 498612 & 9.0 & 8.4955 & TRN & \\
\hline CHEMBL524683 & 498612 & 8.585 & 8.6315 & TRN & \\
\hline CHEMBL525566 & 498612 & 6.2487 & 6.5753 & TST & \\
\hline CHEMBL525453 & 498612 & 7.4559 & 6.4748 & TST & \\
\hline CHEMBL526000 & 498612 & 7.4248 & 7.9011 & TRN & \\
\hline CHEMBL501224 & 498612 & 5.9957 & 5.5766 & TRN & \\
\hline CHEMBL503123 & 498612 & 8.8539 & 8.9471 & TRN & \\
\hline CHEMBL526360 & 498612 & 8.5686 & 8.0368 & TRN & \\
\hline CHEMBL526004 & 498612 & 5.0 & 7.4781 & TRN & \\
\hline CHEMBL502352 & 498612 & 7.2823 & 7.8184 & TRN & \\
\hline CHEMBL526328 & 498612 & 5.6737 & 5.1231 & TRN & \\
\hline CHEMBL498867 & 498612 & 8.1135 & 7.5339 & TRN & \\
\hline CHEMBL501268 & 498612 & 5.6055 & 6.9188 & TST & \\
\hline CHEMBL1187422 & 498612 & 7.3063 & 7.6635 & TRN & \\
\hline CHEMBL500280 & 498612 & 8.2924 & 7.8184 & TRN & \\
\hline CHEMBL525613 & 498612 & 9.1549 & 8.7033 & TRN & \\
\hline
\end{tabular}

Page 10657 


\begin{tabular}{|c|c|c|c|c|c|c|}
\hline & & \multicolumn{5}{|c|}{ Supplemental Table S2.txt } \\
\hline CHEMBL525419 & 498612 & 9.0969 & 8.2346 & TRN & & \\
\hline CHEMBL525817 & 498612 & 7.76200 & 00000000 & 005 & 8.0368 & TRN \\
\hline CHEMBL525258 & 498612 & 7.3116 & 6.6225 & TRN & & \\
\hline CHEMBL524528 & 498612 & 5.9872 & 6.5043 & TST & & \\
\hline CHEMBL499507 & 498612 & 9.1549 & 8.146 & TST & & \\
\hline CHEMBL525611 & 498612 & 6.7595 & 7.0529 & TRN & & \\
\hline CHEMBL524471 & 498612 & 8.0757 & 8.2177 & TRN & & \\
\hline CHEMBL526899 & 498612 & 7.6819 & 7.6143 & TRN & & \\
\hline CHEMBL508607 & 498612 & 7.4248 & 8.0118 & TST & & \\
\hline CHEMBL506840 & 498612 & 8.3872 & 7.2563 & TST & & \\
\hline CHEMBL530563 & 498612 & 8.3565 & 8.2031 & TRN & & \\
\hline CHEMBL526552 & 498612 & 6.8539 & 7.2675 & TRN & & \\
\hline CHEMBL498948 & 498612 & 8.6198 & 8.0517 & TST & & \\
\hline CHEMBL524495 & 498612 & 8.6383 & 7.8641 & TST & & \\
\hline CHEMBL502619 & 498612 & 6.6596 & 6.79799 & 9999999999 & & TRN \\
\hline CHEMBL525957 & 498612 & 5.3969 & 6.9174 & TST & & \\
\hline CHEMBL525639 & 498612 & 7.4001 & 7.4316 & TRN & & \\
\hline CHEMBL524672 & 498612 & 8.1308 & 7.1034 & TST & & \\
\hline CHEMBL524494 & 498612 & 8.8239 & 8.0603 & TRN & & \\
\hline CHEMBL525951 & 498612 & 5.7423 & 5.3619 & TRN & & \\
\hline CHEMBL526154 & 498612 & 8.0177 & 7.7372 & TRN & & \\
\hline CHEMBL525207 & 498612 & 6.3788 & 6.3234 & TRN & & \\
\hline CHEMBL501487 & 498612 & 7.9586 & 7.6241 & TRN & & \\
\hline CHEMBL445530 & 498612 & 8.058 & 7.8806 & TRN & & \\
\hline CHEMBL506517 & 498612 & 8.3665 & 8.374 & TRN & & \\
\hline CHEMBL505046 & 498612 & 8.0132 & 7.9343 & TRN & & \\
\hline CHEMBL500706 & 498612 & 6.2692 & 6.8892 & TRN & & \\
\hline CHEMBL501257 & 498612 & 6.0788 & 7.0917 & TRN & & \\
\hline CHEMBL525091 & 498612 & 8.1308 & 7.8184 & TRN & & \\
\hline CHEMBL526131 & 498612 & 7.2798 & 7.6871 & TST & & \\
\hline CHEMBL524521 & 498612 & 6.3354 & 7.5339 & TRN & & \\
\hline CHEMBL500227 & 498612 & 7.9957 & 8.0482 & TRN & & \\
\hline CHEMBL499665 & 498612 & 8.4815 & 8.27799 & 9999999999 & & TST \\
\hline CHEMBL506101 & 560532 & 8.7212 & 8.7214 & TRN & & \\
\hline CHEMBL260557 & 560532 & 7.3188 & 6.9225 & TST & & \\
\hline CHEMBL516800 & 560532 & 8.4559 & 8.4554 & TRN & & \\
\hline CHEMBL468256 & 560532 & 8.9586 & 8.9592 & TRN & & \\
\hline CHEMBL449469 & 560532 & 8.0706 & 8.07 & TRN & & \\
\hline CHEMBL461650 & 560532 & 8.0555 & 8.0539 & TRN & & \\
\hline CHEMBL517886 & 560532 & 9.1549 & 9.1556 & TRN & & \\
\hline CHEMBL517277 & 560532 & 6.9136 & 6.9156 & TRN & & \\
\hline CHEMBL443665 & 560532 & 8.2676 & 8.2658 & TRN & & \\
\hline CHEMBL404447 & 560532 & 6.5834 & 6.9264 & TST & & \\
\hline CHEMBL442670 & 560532 & 7.9245 & 7.9255 & TRN & & \\
\hline CHEMBL467245 & 560532 & 8.6576 & 8.6608 & TRN & & \\
\hline CHEMBL506511 & 560532 & 8.3979 & 8.3988 & TRN & & \\
\hline CHEMBL462488 & 560532 & 8.6383 & 8.6383 & TRN & & \\
\hline CHEMBL510134 & 560532 & 8.7959 & 8.797 & TRN & & \\
\hline
\end{tabular}




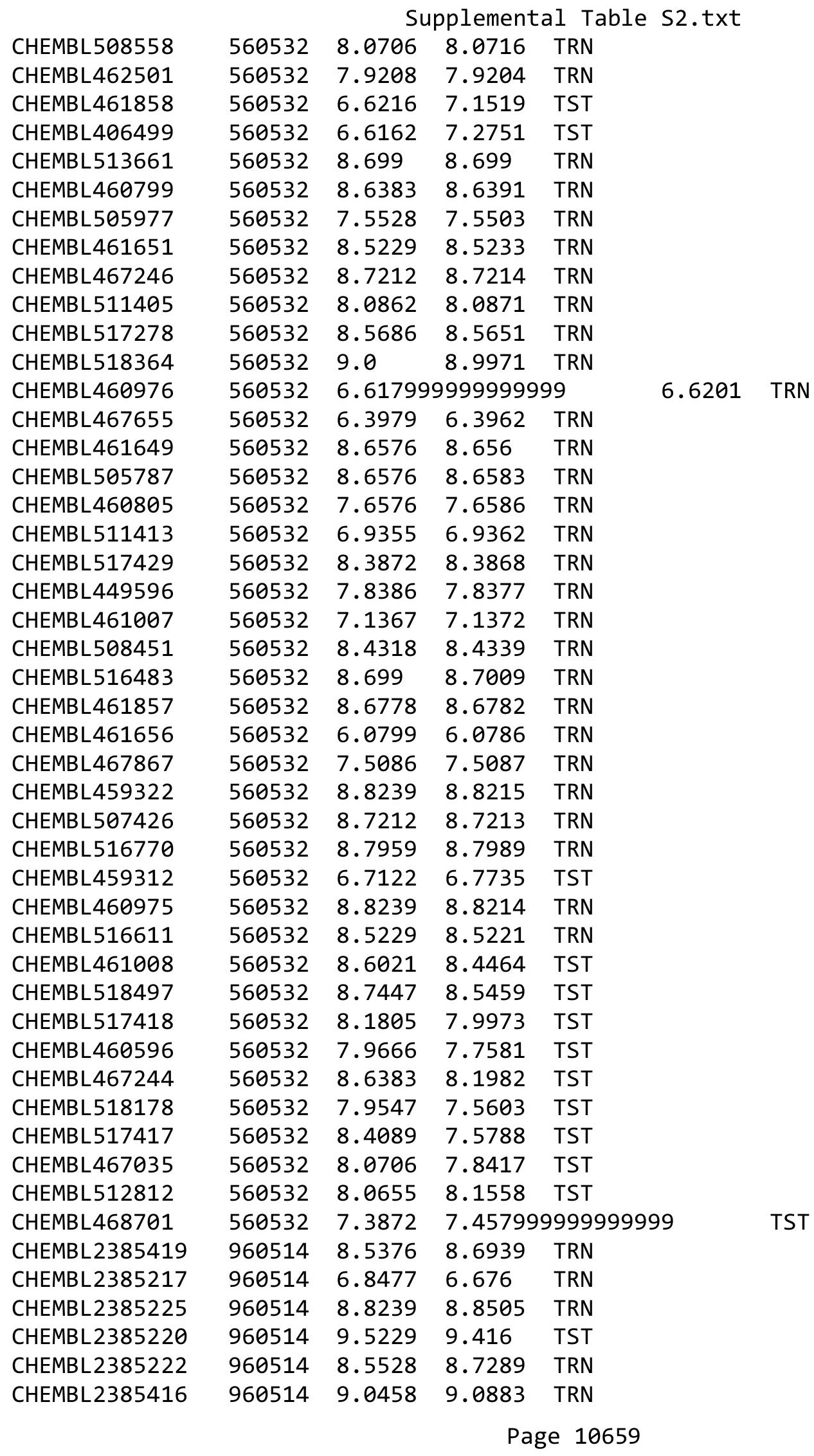




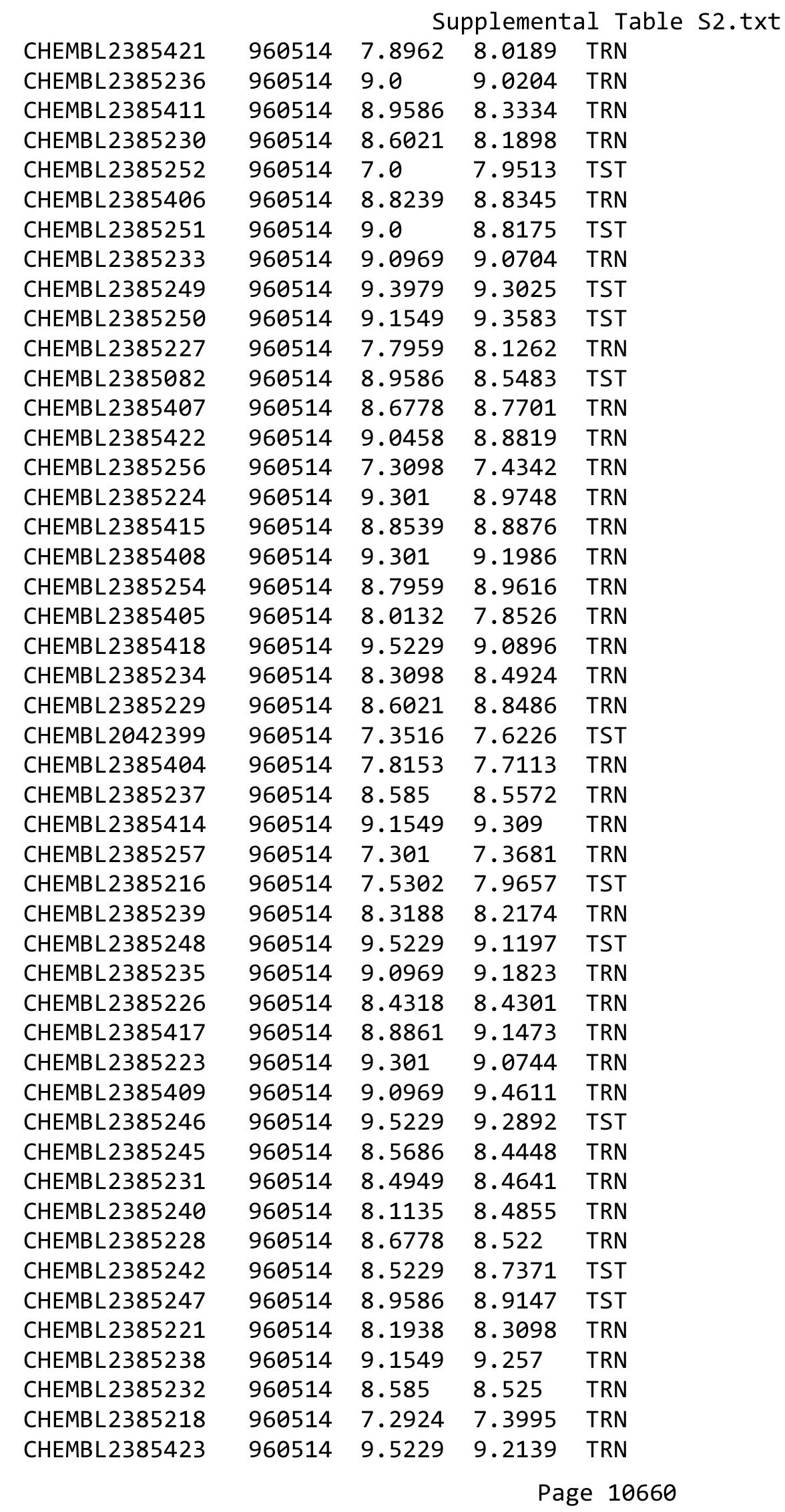




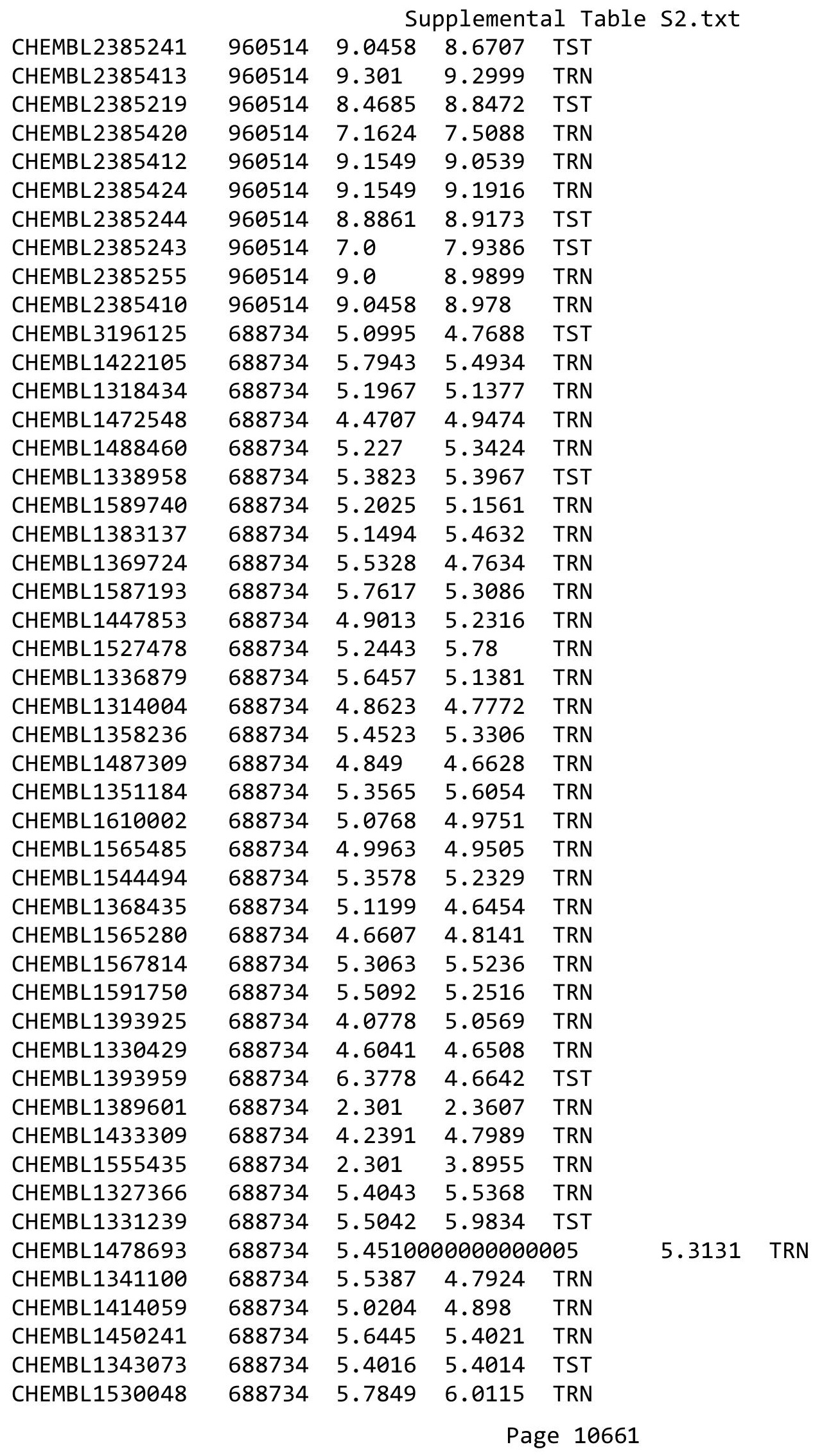


Supplemental Table S2.txt

\begin{tabular}{|c|c|c|c|c|}
\hline CHEMBL1415312 & 688734 & 4.6264 & 4.7471 & TRN \\
\hline CHEMBL1394006 & 688734 & 5.3877 & 4.8812 & TRN \\
\hline CHEMBL1407961 & 688734 & 5.9337 & 5.4158 & TRN \\
\hline CHEMBL1589702 & 688734 & 5.0402 & 4.715 & TRN \\
\hline CHEMBL1332241 & 688734 & 5.2662 & 4.9758 & TST \\
\hline CHEMBL1380929 & 688734 & 5.4719 & 5.0535 & TRN \\
\hline CHEMBL1475828 & 688734 & 5.1846 & 5.0125 & TRN \\
\hline CHEMBL1240975 & 688734 & 5.0773 & 4.5949 & TRN \\
\hline CHEMBL1333583 & 688734 & 5.4405 & 5.6931 & TRN \\
\hline CHEMBL1449558 & 688734 & 5.2293 & 4.774 & TRN \\
\hline CHEMBL1533974 & 688734 & 5.0371 & 5.5246 & TRN \\
\hline CHEMBL1305704 & 688734 & 5.4375 & 5.8418 & TRN \\
\hline CHEMBL397100 & 688734 & 4.3322 & 4.7376 & TRN \\
\hline CHEMBL1528869 & 688734 & 4.688 & 4.6414 & TST \\
\hline CHEMBL1394162 & 688734 & 5.1789 & 5.559 & TST \\
\hline CHEMBL1302315 & 688734 & 5.1755 & 5.9629 & TST \\
\hline CHEMBL1606526 & 688734 & 4.0053 & 4.7855 & TST \\
\hline CHEMBL1511808 & 688734 & 4.7398 & 5.1133 & TST \\
\hline CHEMBL1471371 & 688734 & 4.8252 & 4.9026 & TST \\
\hline CHEMBL1429121 & 688734 & 5.3952 & 4.6365 & TST \\
\hline CHEMBL1437208 & 688734 & 5.3976 & 5.6549 & TST \\
\hline CHEMBL1528266 & 688734 & 4.9848 & 5.41799 & 9999999999 \\
\hline CHEMBL1555362 & 688734 & 2.301 & 5.7657 & TST \\
\hline CHEMBL116438 & 737630 & 5.1302 & 4.7262 & TRN \\
\hline CHEMBL 70501 & 737630 & 5.6635 & 5.7451 & TRN \\
\hline CHEMBL1449443 & 737630 & 4.7144 & 4.4474 & TRN \\
\hline CHEMBL1578178 & 737630 & 5.1778 & 4.8473 & TST \\
\hline CHEMBL1420033 & 737630 & 5.9101 & 4.935 & TRN \\
\hline CHEMBL1492396 & 737630 & 4.8962 & 5.1161 & TRN \\
\hline CHEMBL1561802 & 737630 & 3.0 & 4.0209 & TRN \\
\hline CHEMBL 3195180 & 737630 & 3.0 & 3.4005 & TRN \\
\hline CHEMBL1399134 & 737630 & 3.0 & 3.2383 & TRN \\
\hline CHEMBL1428985 & 737630 & 4.8327 & 5.1638 & TRN \\
\hline CHEMBL1431219 & 737630 & 3.0 & 2.96199 & 99999999997 \\
\hline CHEMBL1548525 & 737630 & 3.0 & 3.3839 & TRN \\
\hline CHEMBL1313987 & 737630 & 3.0 & 3.487 & TRN \\
\hline CHEMBL35228 & 737630 & 5.251 & 4.5626 & TRN \\
\hline CHEMBL1486470 & 737630 & 4.5952 & 5.1001 & TRN \\
\hline CHEMBL1331373 & 737630 & 3.0 & 3.0087 & TRN \\
\hline CHEMBL1382917 & 737630 & 4.7932 & 5.2206 & TST \\
\hline CHEMBL1587916 & 737630 & 3.0 & 3.074 & TRN \\
\hline CHEMBL1709293 & 737630 & 3.0 & 3.1147 & TRN \\
\hline CHEMBL1597471 & 737630 & 3.0 & 3.6381 & TST \\
\hline CHEMBL1588557 & 737630 & 4.752 & 4.9988 & TRN \\
\hline CHEMBL1457387 & 737630 & 3.0 & 3.5674 & TRN \\
\hline CHEMBL1698040 & 737630 & 3.0 & 3.2748 & TST \\
\hline CHEMBL1464067 & 737630 & 3.0 & 3.0371 & TRN \\
\hline CHEMBL1585156 & 737630 & 5.2857 & 5.3254 & TRN \\
\hline
\end{tabular}




\begin{tabular}{|c|c|c|c|c|c|}
\hline & & \multicolumn{4}{|c|}{ Supplemental Table S2.txt } \\
\hline CHEMBL3144972 & 737630 & 5.5498 & 5.5329 & TRN & \\
\hline CHEMBL1724264 & 737630 & 3.0 & 3.2399 & TRN & \\
\hline CHEMBL1516715 & 737630 & 3.0 & 3.1072 & TRN & \\
\hline CHEMBL1607222 & 737630 & 3.0 & 3.04399 & 99999999996 & TRN \\
\hline CHEMBL607979 & 737630 & 5.0996 & 5.3227 & TRN & \\
\hline CHEMBL1587439 & 737630 & 3.0 & 3.4888 & TRN & \\
\hline CHEMBL1303388 & 737630 & 3.0 & 3.2942 & TRN & \\
\hline CHEMBL1514592 & 737630 & 4.5513 & 3.8788 & TRN & \\
\hline CHEMBL1611306 & 737630 & 3.0 & 2.9628 & TRN & \\
\hline CHEMBL1379827 & 737630 & 4.2549 & 3.8772 & TRN & \\
\hline CHEMBL1506682 & 737630 & 5.5017 & 5.06800 & 00000000005 & TRN \\
\hline CHEMBL1525848 & 737630 & 3.0 & 2.8582 & TRN & \\
\hline CHEMBL1610513 & 737630 & 3.0 & 2.7272 & TRN & \\
\hline CHEMBL3207974 & 737630 & 4.1574 & 4.1044 & TRN & \\
\hline CHEMBL1432850 & 737630 & 3.0 & 3.263 & TRN & \\
\hline CHEMBL1352939 & 737630 & 3.0 & 2.6833 & TRN & \\
\hline CHEMBL 2006168 & 737630 & 3.0 & 3.6531 & TST & \\
\hline CHEMBL1721630 & 737630 & 3.0 & 3.0128 & TRN & \\
\hline CHEMBL 1446800 & 737630 & 3.0 & 3.1879 & TRN & \\
\hline CHEMBL1604431 & 737630 & 3.0 & 3.1619 & TRN & \\
\hline CHEMBL1499077 & 737630 & 4.6364 & 4.3889 & TST & \\
\hline CHEMBL1541110 & 737630 & 3.0 & 3.0402 & TRN & \\
\hline CHEMBL1553368 & 737630 & 3.0 & 3.5956 & TRN & \\
\hline CHEMBL1350396 & 737630 & 4.7747 & 4.6735 & TRN & \\
\hline CHEMBL1382032 & 737630 & 3.0 & 4.2967 & TST & \\
\hline CHEMBL1445765 & 737630 & 3.0 & 2.8837 & TRN & \\
\hline CHEMBL1329826 & 737630 & 5.9245 & 5.4994 & TRN & \\
\hline CHEMBL3198247 & 737630 & 3.0 & 3.1246 & TRN & \\
\hline CHEMBL1975298 & 737630 & 3.0 & 2.9856 & TRN & \\
\hline CHEMBL1529932 & 737630 & 5.7545 & 5.9126 & TRN & \\
\hline CHEMBL 250450 & 737630 & 5.2798 & 5.4626 & TRN & \\
\hline CHEMBL1713569 & 737630 & 3.0 & 3.8815 & TST & \\
\hline CHEMBL1452961 & 737630 & 3.0 & 2.8668 & TRN & \\
\hline CHEMBL1541861 & 737630 & 5.0164 & 4.7229 & TST & \\
\hline CHEMBL1525328 & 737630 & 3.0 & 2.8339 & TRN & \\
\hline CHEMBL1379048 & 737630 & 3.0 & 4.1355 & TST & \\
\hline CHEMBL1547704 & 737630 & 3.0 & 2.9956 & TRN & \\
\hline CHEMBL1376200 & 737630 & 5.4535 & 5.4971 & TRN & \\
\hline CHEMBL1537821 & 737630 & 3.0 & 2.9463 & TRN & \\
\hline CHEMBL1490932 & 737630 & 3.0 & 3.3576 & TRN & \\
\hline CHEMBL1489553 & 737630 & 3.0 & 2.9059 & TRN & \\
\hline CHEMBL1405443 & 737630 & 3.0 & 2.8096 & TRN & \\
\hline CHEMBL1567826 & 737630 & 3.0 & 2.945 & TRN & \\
\hline CHEMBL1720410 & 737630 & 3.0 & 2.8029 & TRN & \\
\hline CHEMBL1392848 & 737630 & 4.8386 & 5.3552 & TRN & \\
\hline CHEMBL1323839 & 737630 & 3.0 & 2.6006 & TRN & \\
\hline CHEMBL1534166 & 737630 & 3.0 & 2.6233 & TRN & \\
\hline CHEMBL1724929 & 737630 & 4.9788 & 4.415 & TRN & \\
\hline
\end{tabular}




\begin{tabular}{|c|c|c|c|c|}
\hline \multicolumn{5}{|c|}{ Supplemental Table S2.txt } \\
\hline CHEMBL1704015 & 737630 & 3.0 & 2.6326 & TRN \\
\hline CHEMBL1491038 & 737630 & 3.0 & 3.5951 & TRN \\
\hline CHEMBL1711448 & 737630 & 3.0 & 2.5689 & TRN \\
\hline CHEMBL1719402 & 737630 & 3.0 & 3.4962 & TRN \\
\hline CHEMBL1387654 & 737630 & 3.0 & 3.1461 & TRN \\
\hline CHEMBL1731731 & 737630 & 3.0 & 2.6891 & TRN \\
\hline CHEMBL1351855 & 737630 & 3.0 & 2.9547 & TRN \\
\hline CHEMBL1306327 & 737630 & 3.0 & 4.0863 & TST \\
\hline CHEMBL1369513 & 737630 & 4.7986 & 4.5333 & TRN \\
\hline CHEMBL1509671 & 737630 & 4.8861 & 3.8991 & TRN \\
\hline CHEMBL 3144928 & 737630 & 5.9706 & 5.5861 & TRN \\
\hline CHEMBL56393 & 737630 & 5.3556 & 5.0072 & TRN \\
\hline CHEMBL1585882 & 737630 & 3.0 & 3.6898 & TRN \\
\hline CHEMBL1715135 & 737630 & 3.0 & 3.5647 & TST \\
\hline CHEMBL1495138 & 737630 & 4.8827 & 5.18 & TST \\
\hline CHEMBL1570083 & 737630 & 3.0 & 3.7954 & TST \\
\hline CHEMBL1574441 & 737630 & 3.0 & 3.9435 & TST \\
\hline CHEMBL1344216 & 737630 & 3.0 & 2.9522 & TST \\
\hline CHEMBL1509470 & 737630 & 3.0 & 2.8399 & TST \\
\hline CHEMBL1470848 & 737630 & 3.0 & 2.1997 & TST \\
\hline CHEMBL1303380 & 737630 & 3.0 & 3.4151 & TST \\
\hline CHEMBL1502258 & 737630 & 3.0 & 3.3746 & TST \\
\hline CHEMBL1489864 & 737630 & 3.0 & 5.0404 & TST \\
\hline CHEMBL1577632 & 737630 & 4.3224 & 4.1514 & TST \\
\hline CHEMBL1376258 & 737630 & 3.0 & 3.6558 & TST \\
\hline CHEMBL1257003 & 737630 & 5.1361 & 4.4196 & TST \\
\hline CHEMBL1613123 & 737630 & 3.0 & 3.5963 & TST \\
\hline CHEMBL1368187 & 737630 & 3.0 & 3.435 & TST \\
\hline CHEMBL 2007266 & 809273 & 4.4 & 4.3107 & TRN \\
\hline CHEMBL 202721 & 809273 & 4.4 & 4.6949 & TRN \\
\hline CHEMBL1985469 & 809273 & 4.4 & 4.7676 & TRN \\
\hline CHEMBL 2000568 & 809273 & 5.5 & 4.1829 & TRN \\
\hline CHEMBL1994308 & 809273 & 4.4 & 4.1333 & TRN \\
\hline CHEMBL 2007097 & 809273 & 4.0 & 4.3544 & TRN \\
\hline CHEMBL1973516 & 809273 & 7.1 & 7.1954 & TRN \\
\hline CHEMBL1974328 & 809273 & 6.8 & 6.2478 & TRN \\
\hline CHEMBL 243298 & 809273 & 4.4 & 5.6129 & TRN \\
\hline CHEMBL509032 & 809273 & 7.1 & 7.9384 & TRN \\
\hline CHEMBL1980435 & 809273 & 6.9 & 6.7211 & TRN \\
\hline CHEMBL 388311 & 809273 & 8.0 & 7.9862 & TRN \\
\hline CHEMBL1807515 & 809273 & 8.4 & 7.7965 & TRN \\
\hline CHEMBL1964948 & 809273 & 4.4 & 4.5393 & TRN \\
\hline CHEMBL1973013 & 809273 & 6.7 & 6.6733 & TRN \\
\hline CHEMBL1995813 & 809273 & 8.2 & 7.5904 & TRN \\
\hline CHEMBL1966204 & 809273 & 7.6 & 7.0984 & TRN \\
\hline CHEMBL1989834 & 809273 & 4.0 & 3.5368 & TRN \\
\hline CHEMBL1987430 & 809273 & 4.4 & 4.3442 & TRN \\
\hline CHEMBL 244378 & 809273 & 4.6 & 5.0422 & TRN \\
\hline
\end{tabular}




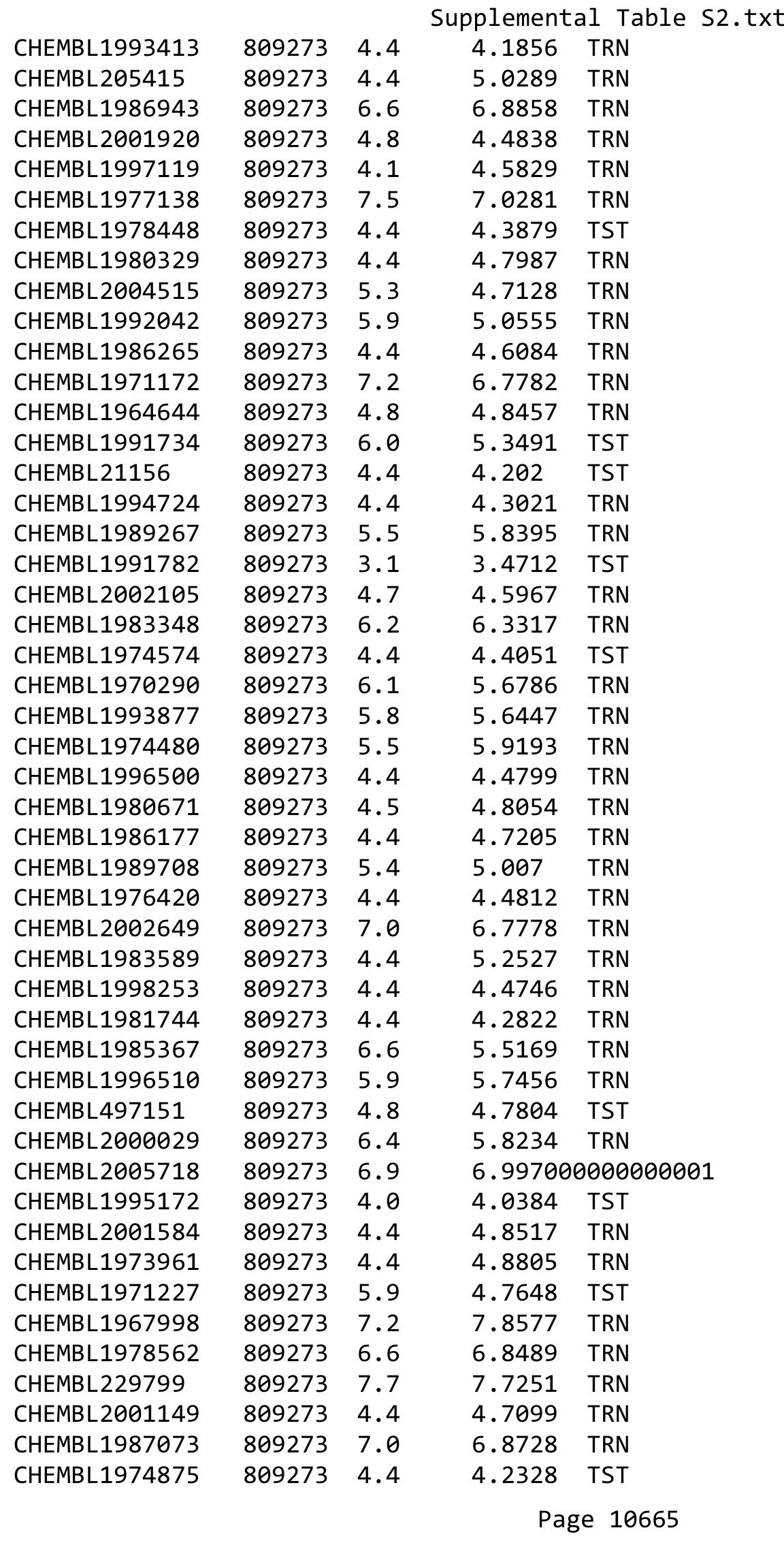




\begin{tabular}{|c|c|c|c|c|c|}
\hline & & & & & \\
\hline CHEMBL2005478 & 809273 & 7.5 & 7.0 & TRN & \\
\hline CHEMBL1996646 & 809273 & 5.7 & 5.6201 & TRN & \\
\hline CHEMBL1979773 & 809273 & 4.4 & 4.7333 & TRN & \\
\hline CHEMBL1995712 & 809273 & 7.2 & 6.8158 & TRN & \\
\hline CHEMBL1989471 & 809273 & 6.6 & 5.516 & TST & \\
\hline CHEMBL1977346 & 809273 & 4.8 & 5.3897 & TRN & \\
\hline CHEMBL 2002099 & 809273 & 4.4 & 4.8124 & TRN & \\
\hline CHEMBL1996702 & 809273 & 4.4 & 4.1565 & TRN & \\
\hline CHEMBL 2007124 & 809273 & 4.4 & 4.2533 & TRN & \\
\hline CHEMBL1978195 & 809273 & 5.9 & 5.5037 & TRN & \\
\hline CHEMBL2006439 & 809273 & 4.2 & 4.999 & TRN & \\
\hline CHEMBL1985681 & 809273 & 7.4 & 6.3403 & TRN & \\
\hline CHEMBL 2002660 & 809273 & 4.4 & 4.7414 & TRN & \\
\hline CHEMBL1991674 & 809273 & 4.2 & 4.1605 & TRN & \\
\hline CHEMBL1982711 & 809273 & 6.2 & 5.6578 & TRN & \\
\hline CHEMBL 262623 & 809273 & 4.4 & 4.3572 & TRN & \\
\hline CHEMBL1984842 & 809273 & 4.4 & 4.4125 & TRN & \\
\hline CHEMBL 2004118 & 809273 & 4.4 & 4.6761 & TRN & \\
\hline CHEMBL1987261 & 809273 & 6.4 & 7.1215 & TRN & \\
\hline CHEMBL52387 & 809273 & 7.1 & $6.3770 e$ & 0000000001 & TRN \\
\hline CHEMBL1996345 & 809273 & 4.4 & 4.7783 & TRN & \\
\hline CHEMBL 2004025 & 809273 & 5.8 & 5.4083 & TRN & \\
\hline CHEMBL1996048 & 809273 & 4.4 & 5.0368 & TRN & \\
\hline CHEMBL50894 & 809273 & 4.4 & 4.4284 & TRN & \\
\hline CHEMBL1976158 & 809273 & 4.7 & 5.1055 & TRN & \\
\hline CHEMBL1995211 & 809273 & 4.4 & 5.5675 & TRN & \\
\hline CHEMBL1965033 & 809273 & 4.4 & 4.5088 & TRN & \\
\hline CHEMBL461876 & 809273 & 5.6 & 5.2373 & TRN & \\
\hline CHEMBL2006299 & 809273 & 4.4 & 4.2815 & TRN & \\
\hline CHEMBL1971519 & 809273 & 4.7 & 4.4023 & TRN & \\
\hline CHEMBL1980562 & 809273 & 6.7 & 7.0521 & TRN & \\
\hline CHEMBL1997335 & 809273 & 4.4 & 5.1084 & TRN & \\
\hline CHEMBL1965169 & 809273 & 6.8 & 5.8475 & TRN & \\
\hline CHEMBL1991818 & 809273 & 4.4 & 4.6423 & TST & \\
\hline CHEMBL1081312 & 809273 & 4.4 & 5.2449 & TRN & \\
\hline CHEMBL1971132 & 809273 & 4.4 & 4.4808 & TRN & \\
\hline CHEMBL1965170 & 809273 & 4.4 & 4.6619 & TRN & \\
\hline CHEMBL1985723 & 809273 & 6.8 & 7.1542 & TRN & \\
\hline CHEMBL 2005792 & 809273 & 4.4 & 4.3868 & TRN & \\
\hline CHEMBL1991867 & 809273 & 4.4 & 4.6616 & TRN & \\
\hline CHEMBL1979933 & 809273 & 5.8 & 5.1992 & TRN & \\
\hline CHEMBL1986503 & 809273 & 4.4 & 4.3397 & TST & \\
\hline CHEMBL1972355 & 809273 & 6.3 & $5.7620 e$ & 00000000005 & TRN \\
\hline CHEMBL1997892 & 809273 & 4.4 & 4.9645 & TRN & \\
\hline CHEMBL 2001641 & 809273 & 5.0 & 4.811 & TRN & \\
\hline CHEMBL1976936 & 809273 & 4.4 & 4.5863 & TRN & \\
\hline CHEMBL1997193 & 809273 & 4.4 & 5.7237 & TST & \\
\hline CHEMBL1964902 & 809273 & 4.4 & 4.2399 & TRN & \\
\hline
\end{tabular}




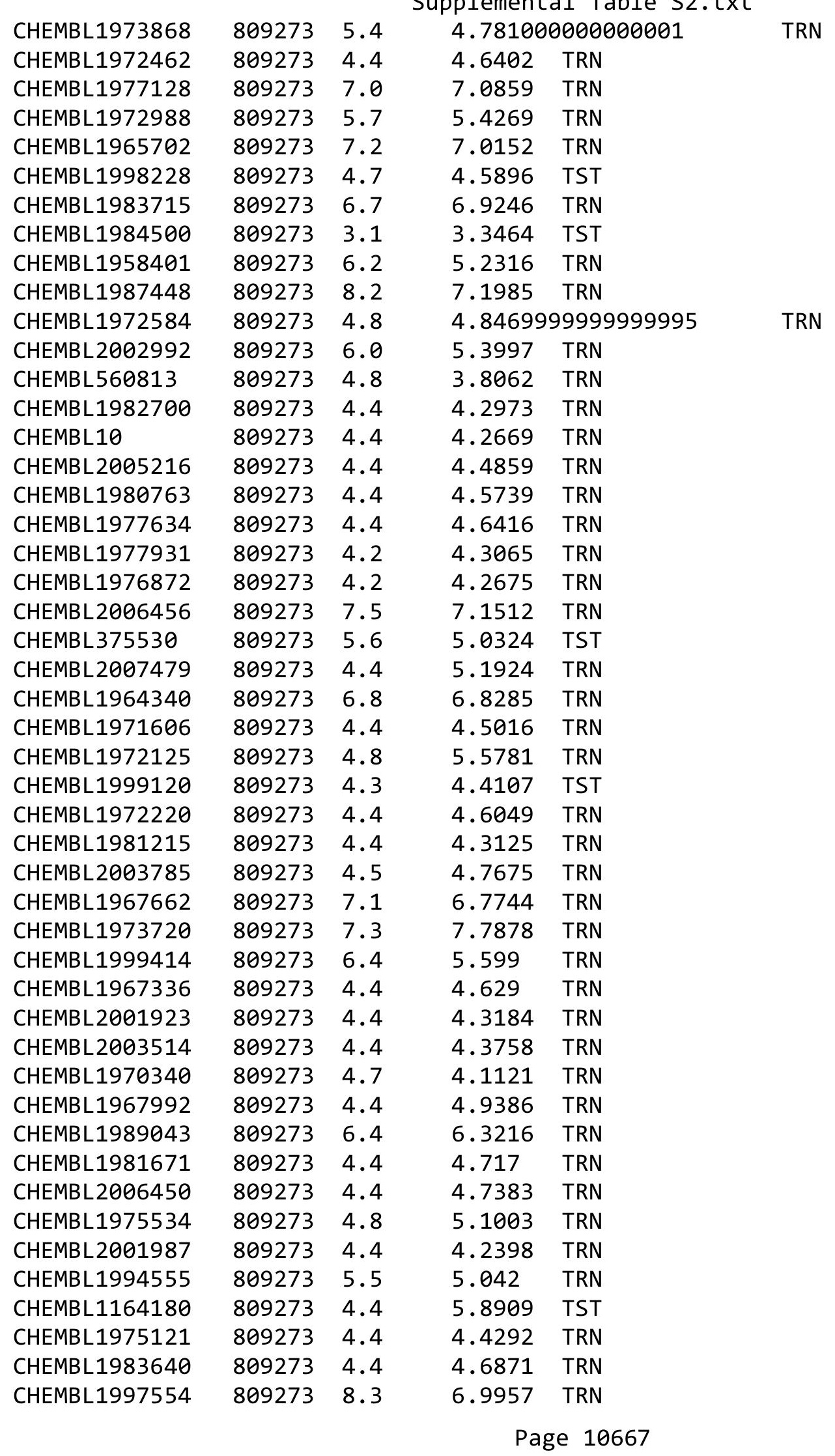




\begin{tabular}{|c|c|c|c|c|c|}
\hline & & & & & \\
\hline CHEMBL1997611 & 809273 & 4.4 & 5.2098 & TST & \\
\hline CHEMBL1971943 & 809273 & 4.4 & 4.4363 & TRN & \\
\hline CHEMBL 2002723 & 809273 & 5.6 & 5.1667 & TRN & \\
\hline CHEMBL1984686 & 809273 & 4.4 & 5.2628 & TST & \\
\hline CHEMBL1973793 & 809273 & 4.4 & 4.2241 & TST & \\
\hline CHEMBL1980178 & 809273 & 6.6 & 6.5768 & TRN & \\
\hline CHEMBL1969588 & 809273 & 7.6 & 7.8275 & TRN & \\
\hline CHEMBL1992073 & 809273 & 4.4 & 4.8737 & TRN & \\
\hline CHEMBL1990254 & 809273 & 4.4 & 4.9819 & TRN & \\
\hline CHEMBL1986143 & 809273 & 4.4 & 4.4824 & TRN & \\
\hline CHEMBL1972934 & 809273 & 4.4 & 4.3112 & TRN & \\
\hline CHEMBL 2007559 & 809273 & 4.4 & 4.8657 & TRN & \\
\hline CHEMBL1992581 & 809273 & 6.7 & 5.3793 & TRN & \\
\hline CHEMBL 2004290 & 809273 & 4.4 & 4.1352 & TRN & \\
\hline CHEMBL1986499 & 809273 & 4.6 & 5.1493 & TRN & \\
\hline CHEMBL1975921 & 809273 & 4.9 & 4.8046 & TRN & \\
\hline CHEMBL1992634 & 809273 & 4.8 & 5.1238 & TRN & \\
\hline CHEMBL1975923 & 809273 & 4.7 & 4.4118 & TST & \\
\hline CHEMBL 2005449 & 809273 & 5.6 & 6.0066 & TRN & \\
\hline CHEMBL1996576 & 809273 & 4.4 & 4.4671 & TST & \\
\hline CHEMBL1991678 & 809273 & 4.4 & 4.3078 & TRN & \\
\hline CHEMBL1987998 & 809273 & 4.4 & 4.5365 & TRN & \\
\hline CHEMBL1971534 & 809273 & 4.9 & 4.8772 & TRN & \\
\hline CHEMBL1990496 & 809273 & 4.4 & 4.4228 & TRN & \\
\hline CHEMBL1992363 & 809273 & 7.0 & 6.8881 & TRN & \\
\hline CHEMBL 242865 & 809273 & 4.4 & 4.7377 & TRN & \\
\hline CHEMBL1982271 & 809273 & 7.4 & 7.3384 & TRN & \\
\hline CHEMBL1991725 & 809273 & 6.6 & 5.99799 & 9999999999 & TRN \\
\hline CHEMBL1983884 & 809273 & 3.1 & 4.2695 & TRN & \\
\hline CHEMBL2004159 & 809273 & 4.4 & 4.2749 & TRN & \\
\hline CHEMBL396523 & 809273 & 4.6 & 5.2485 & TRN & \\
\hline CHEMBL1978371 & 809273 & 5.9 & 4.5685 & TST & \\
\hline CHEMBL440084 & 809273 & 4.4 & 4.9033 & TRN & \\
\hline CHEMBL1998110 & 809273 & 4.4 & 4.308 & TRN & \\
\hline CHEMBL1966501 & 809273 & 5.6 & 4.5786 & TRN & \\
\hline CHEMBL1978166 & 809273 & 6.3 & 5.9298 & TRN & \\
\hline CHEMBL1981079 & 809273 & 7.1 & 6.3965 & TRN & \\
\hline CHEMBL 2000832 & 809273 & 4.8 & 4.2503 & TRN & \\
\hline CHEMBL1977814 & 809273 & 4.4 & 4.856 & TST & \\
\hline CHEMBL 86755 & 809273 & 5.7 & 4.6902 & TRN & \\
\hline CHEMBL1974617 & 809273 & 4.9 & 5.0033 & TRN & \\
\hline CHEMBL1965660 & 809273 & 6.8 & 6.4233 & TRN & \\
\hline CHEMBL1992125 & 809273 & 5.7 & 5.6431 & TRN & \\
\hline CHEMBL1974702 & 809273 & 4.8 & 5.1891 & TST & \\
\hline CHEMBL1972290 & 809273 & 7.0 & 7.2377 & TRN & \\
\hline CHEMBL1966175 & 809273 & 4.4 & 4.3525 & TRN & \\
\hline CHEMBL1965589 & 809273 & 4.8 & 4.8815 & TRN & \\
\hline CHEMBL 2007375 & 809273 & 4.4 & 4.47 & TRN & \\
\hline & & & & 10668 & \\
\hline
\end{tabular}




\begin{tabular}{|c|c|c|c|c|c|}
\hline \\
\hline CHEMBL1970104 & 809273 & 6.7 & 6.4824 & TRN & \\
\hline CHEMBL379975 & 809273 & 4.4 & 5.2846 & TST & \\
\hline CHEMBL1973016 & 809273 & 4.4 & 5.4585 & TRN & \\
\hline CHEMBL1965387 & 809273 & 4.4 & 4.3533 & TRN & \\
\hline CHEMBL2001539 & 809273 & 4.5 & 4.5409 & TST & \\
\hline CHEMBL388978 & 809273 & 7.2 & 7.4168 & TST & \\
\hline CHEMBL1997041 & 809273 & 5.2 & 4.7285 & TRN & \\
\hline CHEMBL1984548 & 809273 & 8.2 & $8.6520 e$ & 0000000001 & TRN \\
\hline CHEMBL550418 & 809273 & 4.4 & 4.2887 & TRN & \\
\hline CHEMBL1986666 & 809273 & 5.8 & 5.5356 & TRN & \\
\hline CHEMBL398951 & 809273 & 4.4 & 5.1706 & TST & \\
\hline CHEMBL1971289 & 809273 & 4.4 & 5.1174 & TRN & \\
\hline CHEMBL1988437 & 809273 & 4.4 & 5.2282 & TST & \\
\hline CHEMBL1985406 & 809273 & 4.8 & 5.3179 & TRN & \\
\hline CHEMBL1421720 & 809273 & 6.0 & 5.528 & TRN & \\
\hline CHEMBL1233887 & 809273 & 5.8 & 5.3091 & TRN & \\
\hline CHEMBL1968130 & 809273 & 4.5 & 4.3333 & TST & \\
\hline CHEMBL1992607 & 809273 & 4.2 & 4.4797 & TRN & \\
\hline CHEMBL 2003689 & 809273 & 4.4 & 4.6382 & TRN & \\
\hline CHEMBL576113 & 809273 & 4.4 & 4.834 & TRN & \\
\hline CHEMBL1996649 & 809273 & 5.7 & 5.0956 & TRN & \\
\hline CHEMBL1986756 & 809273 & 4.4 & 4.5134 & TRN & \\
\hline CHEMBL1949855 & 809273 & 4.7 & 5.0174 & TRN & \\
\hline CHEMBL1972339 & 809273 & 6.7 & 6.1476 & TRN & \\
\hline CHEMBL3109278 & 809273 & 7.7 & 6.7532 & TRN & \\
\hline CHEMBL1990223 & 809273 & 4.4 & 4.7131 & TRN & \\
\hline CHEMBL 2004438 & 809273 & 4.4 & 4.3581 & TRN & \\
\hline CHEMBL1964382 & 809273 & 4.4 & 4.4664 & TST & \\
\hline CHEMBL101311 & 809273 & 4.4 & 5.2494 & TRN & \\
\hline CHEMBL191003 & 809273 & 6.2 & 6.1531 & TRN & \\
\hline CHEMBL1973359 & 809273 & 6.2 & 6.2656 & TST & \\
\hline CHEMBL1983595 & 809273 & 6.8 & 6.8043 & TRN & \\
\hline CHEMBL1995740 & 809273 & 4.2 & 4.5106 & TRN & \\
\hline CHEMBL1988581 & 809273 & 6.7 & 6.6166 & TST & \\
\hline CHEMBL1990162 & 809273 & 7.6 & 7.2119 & TRN & \\
\hline CHEMBL1975500 & 809273 & 4.8 & 3.7891 & TRN & \\
\hline CHEMBL2005699 & 809273 & 4.4 & 4.3718 & TRN & \\
\hline CHEMBL1992220 & 809273 & 6.3 & 7.2096 & TRN & \\
\hline CHEMBL 2006564 & 809273 & 5.7 & 5.896 & TRN & \\
\hline CHEMBL1980253 & 809273 & 6.6 & 6.1497 & TRN & \\
\hline CHEMBL1979690 & 809273 & 7.1 & 7.9349 & TRN & \\
\hline CHEMBL 234085 & 809273 & 4.4 & 4.0481 & TRN & \\
\hline CHEMBL1978167 & 809273 & 6.3 & 6.3991 & TRN & \\
\hline CHEMBL418203 & 809273 & 7.0 & 5.9297 & TST & \\
\hline CHEMBL 225519 & 809273 & 4.6 & 5.5428 & TRN & \\
\hline CHEMBL1976376 & 809273 & 4.4 & 4.4269 & TRN & \\
\hline CHEMBL1983575 & 809273 & 5.5 & 5.5205 & TRN & \\
\hline CHEMBL1986722 & 809273 & 4.6 & 4.7495 & TRN & \\
\hline
\end{tabular}




\begin{tabular}{|c|c|c|c|c|c|}
\hline \\
\hline CHEMBL1968868 & 809273 & 4.4 & 4.7628 & TRN & \\
\hline CHEMBL1981047 & 809273 & 8.0 & 7.1538 & TRN & \\
\hline CHEMBL229968 & 809273 & 7.7 & 7.7785 & TRN & \\
\hline CHEMBL1998470 & 809273 & 6.4 & 5.1621 & TRN & \\
\hline CHEMBL1996980 & 809273 & 7.4 & 7.4178 & TRN & \\
\hline CHEMBL1976196 & 809273 & 4.4 & 4.4201 & TST & \\
\hline CHEMBL2002432 & 809273 & 5.8 & 5.5217 & TRN & \\
\hline CHEMBL1987948 & 809273 & 7.1 & 6.8435 & TRN & \\
\hline CHEMBL1997197 & 809273 & 4.4 & 5.4195 & TRN & \\
\hline CHEMBL1983630 & 809273 & 4.4 & 4.4713 & TRN & \\
\hline CHEMBL1994669 & 809273 & 8.5 & 8.8088 & TRN & \\
\hline CHEMBL1975903 & 809273 & 4.4 & 5.1635 & TRN & \\
\hline CHEMBL1522508 & 809273 & 4.2 & 4.0281 & TRN & \\
\hline CHEMBL458997 & 809273 & 6.4 & 6.4052 & TRN & \\
\hline CHEMBL1988805 & 809273 & 4.4 & 5.0329 & TRN & \\
\hline CHEMBL1969942 & 809273 & 4.4 & 4.2716 & TRN & \\
\hline CHEMBL1974310 & 809273 & 4.8 & 5.7506 & TRN & \\
\hline CHEMBL1982660 & 809273 & 4.4 & $4.9460 e$ & 0000000001 & TRN \\
\hline CHEMBL1978567 & 809273 & 4.4 & 4.308 & TRN & \\
\hline CHEMBL1977223 & 809273 & 7.9 & 7.1931 & TRN & \\
\hline CHEMBL1995765 & 809273 & 4.7 & 4.5738 & TRN & \\
\hline CHEMBL1975138 & 809273 & 4.8 & 4.7689 & TRN & \\
\hline CHEMBL1984760 & 809273 & 4.4 & 4.887 & TRN & \\
\hline CHEMBL 2003856 & 809273 & 4.6 & 6.1659 & TRN & \\
\hline CHEMBL1997846 & 809273 & 4.2 & 3.293 & TRN & \\
\hline CHEMBL360847 & 809273 & 5.6 & 5.5622 & TRN & \\
\hline CHEMBL1995811 & 809273 & 6.7 & 6.45 & TRN & \\
\hline CHEMBL1992231 & 809273 & 4.4 & 4.6426 & TRN & \\
\hline CHEMBL1983111 & 809273 & 7.0 & 6.8445 & TRN & \\
\hline CHEMBL1988141 & 809273 & 6.2 & 6.2676 & TST & \\
\hline CHEMBL1992937 & 809273 & 6.7 & 6.3582 & TRN & \\
\hline CHEMBL1977134 & 809273 & 4.4 & 4.9451 & TRN & \\
\hline CHEMBL1968930 & 809273 & 6.8 & 7.3113 & TRN & \\
\hline CHEMBL1985206 & 809273 & 4.4 & 5.1763 & TST & \\
\hline CHEMBL1991078 & 809273 & 6.9 & 6.7261 & TRN & \\
\hline CHEMBL1090356 & 809273 & 4.8 & 4.4737 & TRN & \\
\hline CHEMBL1977749 & 809273 & 4.4 & 4.5244 & TST & \\
\hline CHEMBL1975212 & 809273 & 4.6 & 5.0228 & TRN & \\
\hline CHEMBL2001613 & 809273 & 4.7 & 4.2999 & TRN & \\
\hline CHEMBL 261849 & 809273 & 4.4 & 4.737 & TST & \\
\hline CHEMBL1983923 & 809273 & 7.3 & 6.6273 & TRN & \\
\hline CHEMBL1997275 & 809273 & 6.0 & 5.3915 & TRN & \\
\hline CHEMBL1993904 & 809273 & 5.8 & 5.3424 & TRN & \\
\hline CHEMBL1999112 & 809273 & 4.8 & 4.5876 & TST & \\
\hline CHEMBL1994438 & 809273 & 7.1 & 6.7692 & TRN & \\
\hline CHEMBL1967513 & 809273 & 4.4 & 4.2873 & TRN & \\
\hline CHEMBL1980376 & 809273 & 4.3 & 4.0826 & TRN & \\
\hline CHEMBL1982413 & 809273 & 5.7 & 5.4369 & TRN & \\
\hline
\end{tabular}




\begin{tabular}{|c|c|c|c|c|}
\hline & & & & $a+1 a$ \\
\hline CHEMBL2003638 & 809273 & 7.0 & 7.0376 & TRN \\
\hline CHEMBL1983393 & 809273 & 4.4 & 4.8034 & TRN \\
\hline CHEMBL1987535 & 809273 & 6.0 & 5.70100 & 00000000005 \\
\hline CHEMBL1981792 & 809273 & 4.4 & 4.1688 & TRN \\
\hline CHEMBL 2002586 & 809273 & 5.5 & 5.2224 & TRN \\
\hline CHEMBL 2006674 & 809273 & 7.4 & 5.995 & TST \\
\hline CHEMBL1984236 & 809273 & 4.4 & 4.9008 & TST \\
\hline CHEMBL1992371 & 809273 & 5.4 & 5.5022 & TRN \\
\hline CHEMBL 2007421 & 809273 & 6.5 & 7.5175 & TRN \\
\hline CHEMBL1973138 & 809273 & 4.4 & 4.8337 & TST \\
\hline CHEMBL 2002599 & 809273 & 4.4 & 4.7988 & TST \\
\hline CHEMBL1992673 & 809273 & 4.1 & 4.3498 & TST \\
\hline CHEMBL1969151 & 809273 & 7.0 & 7.3142 & TST \\
\hline CHEMBL1967252 & 809273 & 5.1 & 5.8962 & TST \\
\hline CHEMBL1981492 & 809273 & 4.2 & 4.3816 & TST \\
\hline CHEMBL1993335 & 809273 & 7.2 & 6.9461 & TST \\
\hline CHEMBL1988692 & 809273 & 4.4 & 5.4118 & TST \\
\hline CHEMBL 2007574 & 809273 & 7.6 & 6.5738 & TST \\
\hline CHEMBL 2004637 & 809273 & 5.8 & 5.1769 & TST \\
\hline CHEMBL1993374 & 809273 & 6.0 & 6.0986 & TST \\
\hline CHEMBL1994318 & 809273 & 5.7 & 4.8332 & TST \\
\hline CHEMBL 2000354 & 809273 & 4.8 & 4.4447 & TST \\
\hline CHEMBL1998680 & 809273 & 4.4 & 4.3207 & TST \\
\hline CHEMBL1999506 & 809273 & 4.4 & 4.2371 & TST \\
\hline CHEMBL1967719 & 809273 & 5.8 & 4.8603 & TST \\
\hline CHEMBL 2002613 & 809273 & 6.4 & 6.3279 & TST \\
\hline CHEMBL 2005509 & 809273 & 7.0 & 7.2066 & TST \\
\hline CHEMBL1605605 & 809273 & 4.4 & 4.298 & TST \\
\hline CHEMBL1996208 & 809273 & 4.4 & 5.4823 & TST \\
\hline CHEMBL1989029 & 809273 & 4.8 & 4.5428 & TST \\
\hline CHEMBL 2002736 & 809273 & 4.4 & 4.7924 & TST \\
\hline CHEMBL1997007 & 809273 & 4.4 & 4.4966 & TST \\
\hline CHEMBL1970352 & 809273 & 5.4 & 4.7554 & TST \\
\hline CHEMBL 2002690 & 809273 & 4.4 & 4.1801 & TST \\
\hline CHEMBL1980167 & 809273 & 5.5 & 5.7209 & TST \\
\hline CHEMBL 278041 & 809273 & 4.4 & 4.3913 & TST \\
\hline CHEMBL 2003229 & 809273 & 6.7 & 5.2005 & TST \\
\hline CHEMBL1986855 & 809273 & 6.8 & 7.3783 & TST \\
\hline CHEMBL215152 & 809273 & 4.4 & 4.8467 & TST \\
\hline CHEMBL1998432 & 809273 & 7.6 & 7.2679 & TST \\
\hline CHEMBL 2006765 & 809273 & 6.4 & 5.3498 & TST \\
\hline CHEMBL1986590 & 809273 & 5.7 & 5.2133 & TST \\
\hline CHEMBL1870106 & 809273 & 5.6 & 5.7047 & TST \\
\hline CHEMBL406845 & 809273 & 4.4 & 4.9587 & TST \\
\hline CHEMBL1980246 & 809273 & 4.4 & 4.9138 & TST \\
\hline CHEMBL1983980 & 809273 & 6.2 & 5.7372 & TST \\
\hline CHEMBL1999484 & 809273 & 6.5 & 7.365 & TST \\
\hline CHEMBL482538 & 809273 & 4.6 & 4.83 & TST \\
\hline
\end{tabular}

TRN 


\begin{tabular}{|c|c|c|c|c|c|}
\hline & & & & & \\
\hline CHEMBL1984296 & 809273 & 5.4 & 5.6047 & TST & \\
\hline CHEMBL1986899 & 809273 & 4.4 & 4.6162 & TST & \\
\hline CHEMBL1984038 & 809273 & 4.4 & 4.4243 & TST & \\
\hline CHEMBL1964718 & 809273 & 4.1 & 4.5545 & TST & \\
\hline CHEMBL1993661 & 809273 & 7.5 & 7.2477 & TST & \\
\hline CHEMBL1968705 & 809273 & 4.4 & 5.2141 & TST & \\
\hline CHEMBL1991410 & 809273 & 4.4 & 4.2834 & TST & \\
\hline CHEMBL1964441 & 809273 & 4.4 & 5.0437 & TST & \\
\hline CHEMBL546797 & 809273 & 5.5 & 5.6744 & TST & \\
\hline CHEMBL1084616 & 634304 & 9.1612 & 9.3079 & TRN & \\
\hline CHEMBL1083462 & 634304 & 9.7212 & 9.5608 & TRN & \\
\hline CHEMBL1085572 & 634304 & 8.6021 & 8.8556 & TRN & \\
\hline CHEMBL1085866 & 634304 & 9.4685 & 9.2247 & TRN & \\
\hline CHEMBL1083274 & 634304 & 9.2518 & 9.2928 & TRN & \\
\hline CHEMBL1085560 & 634304 & 9.5528 & 9.3674 & TRN & \\
\hline CHEMBL1084294 & 634304 & 7.5528 & 7.8157 & TRN & \\
\hline CHEMBL1083463 & 634304 & 9.1308 & 9.344 & TRN & \\
\hline CHEMBL1085124 & 634304 & 7.6778 & 8.079 & TRN & \\
\hline CHEMBL1085829 & 634304 & 9.0 & 9.0216 & TRN & \\
\hline CHEMBL1085337 & 634304 & 10.3009 & 99999999 & 9.9942 & TRN \\
\hline CHEMBL1083448 & 634304 & 9.3979 & 9.1594 & TRN & \\
\hline CHEMBL351231 & 634304 & 9.3468 & 9.0125 & TST & \\
\hline CHEMBL1086074 & 634304 & 9.0809 & 9.1692 & TRN & \\
\hline CHEMBL237394 & 634304 & 9.7212 & 9.8236 & TRN & \\
\hline CHEMBL1086032 & 634304 & 8.1308 & 8.0687 & TRN & \\
\hline CHEMBL1085591 & 634304 & 8.4202 & 8.5503 & TST & \\
\hline CHEMBL1083406 & 634304 & 9.6576 & 9.4111 & TRN & \\
\hline CHEMBL1086073 & 634304 & 9.0506 & 8.5962 & TRN & \\
\hline CHEMBL1086521 & 634304 & 9.3565 & 9.2207 & TRN & \\
\hline CHEMBL1082496 & 634304 & 9.1192 & 8.94700 & 0000000001 & TRN \\
\hline CHEMBL1084582 & 634304 & 9.0506 & 9.0154 & TRN & \\
\hline CHEMBL1084383 & 634304 & 10.0 & 10.137 & TST & \\
\hline CHEMBL1086514 & 634304 & 9.9208 & 9.9299 & TRN & \\
\hline CHEMBL1086520 & 634304 & 8.7447 & 8.8137 & TST & \\
\hline CHEMBL1085326 & 634304 & 8.2924 & 8.5176 & TRN & \\
\hline CHEMBL1084826 & 634304 & 9.0315 & 8.9476 & TRN & \\
\hline CHEMBL1084560 & 634304 & 9.9586 & 9.9174 & TRN & \\
\hline CHEMBL1084384 & 634304 & 9.0706 & 8.9189 & TST & \\
\hline CHEMBL1084877 & 634304 & 8.9586 & 8.7832 & TRN & \\
\hline CHEMBL1084584 & 634304 & 9.1487 & 8.7321 & TST & \\
\hline CHEMBL1082488 & 634304 & 8.7696 & 9.4622 & TRN & \\
\hline CHEMBL1084827 & 634304 & 9.7959 & 9.8435 & TRN & \\
\hline CHEMBL263101 & 634304 & 9.4685 & 9.3897 & TRN & \\
\hline CHEMBL1085783 & 634304 & 6.6383 & 7.0693 & TST & \\
\hline CHEMBL393581 & 634304 & 9.585 & 9.6724 & TRN & \\
\hline CHEMBL1084878 & 634304 & 8.1675 & 8.0313 & TRN & \\
\hline CHEMBL1082606 & 634304 & 9.4559 & 9.4635 & TRN & \\
\hline CHEMBL1082447 & 634304 & 9.4437 & 9.3257 & TRN & \\
\hline
\end{tabular}


Supplemental Table S2.txt

\begin{tabular}{|c|c|c|c|c|}
\hline HEMBL2 & & 6 & 23 & \\
\hline HEMRI 1984582 & & & 8.4863 & \\
\hline HEMBL10860 & & & & \\
\hline AEMBL442242 & 304 & 468 & - & \\
\hline HEMBL1084314 & 34304 & 699 & .4141 & \\
\hline HEMBL10 & 304 & $a$ & 1932 & \\
\hline AEMBL3S & & 8 & & \\
\hline HEMBL108 & & 021 & 7091 & \\
\hline HEMBL1085828 & 304 & .7212 & 7891 & \\
\hline HEMBL1085800 & 304 & .1612 & 9.1561 & \\
\hline HEMBL1e & 04 & 696 & 67 & \\
\hline HEMBL1€ & & & & \\
\hline HEMBL1C & & 49 & & \\
\hline AEMBL108 & & 021 & & \\
\hline AEMBL10 & 04 & 08 & 553 & \\
\hline AEMBL1 & & 71 & 73 & \\
\hline AEMBL1 & & & & \\
\hline HEMBL16 & & 586 & 3633 & \\
\hline AEMBL1€ & & & & \\
\hline AEMBL1e & & 23 & 23 & NIV \\
\hline IEMBL1 & & & & RIN \\
\hline IEMBL] & & & & NIV \\
\hline HEMBL 1 & & & 942 & \\
\hline AEMBL16 & & & & \\
\hline HEMBL1€ & & 383 & 56 & RN \\
\hline IEMBL1 & & & 217 & RN \\
\hline IEMBL' & & & & RN \\
\hline 52 & & & & \\
\hline IEMBL1 & & & & IST \\
\hline AEMBL10 & & & 37 & ST \\
\hline EMBL1 & & & 03 & ST \\
\hline 5 & & & & ST \\
\hline & & & & 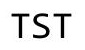 \\
\hline AEMBL10 & & & & ST \\
\hline AEMBL108 & & & 11 & ST \\
\hline AFMRI 1 & & & & ST \\
\hline & & & & RN \\
\hline HEMBL13 & & & & RN \\
\hline AEMBL15e & & & & RN \\
\hline EBL1 1 & & & & RN \\
\hline HEMBL1C & & & 3822 & \\
\hline & & & & RN \\
\hline HEMBL156 & & 5.857 & 5.8277 & RN \\
\hline AEMBL13 & & & 3034 & $\mathrm{R}$ \\
\hline MBL1 & & & & ST \\
\hline HEMBL 155 & & & 5.0005 & \\
\hline CHEMBL130 & & 5.2676 & 5.2211 & \\
\hline CHEMBL1410897 & 737339 & 5.3152 & 5.2922 & RN \\
\hline
\end{tabular}

Page 10673 
Supplemental Table S2.txt

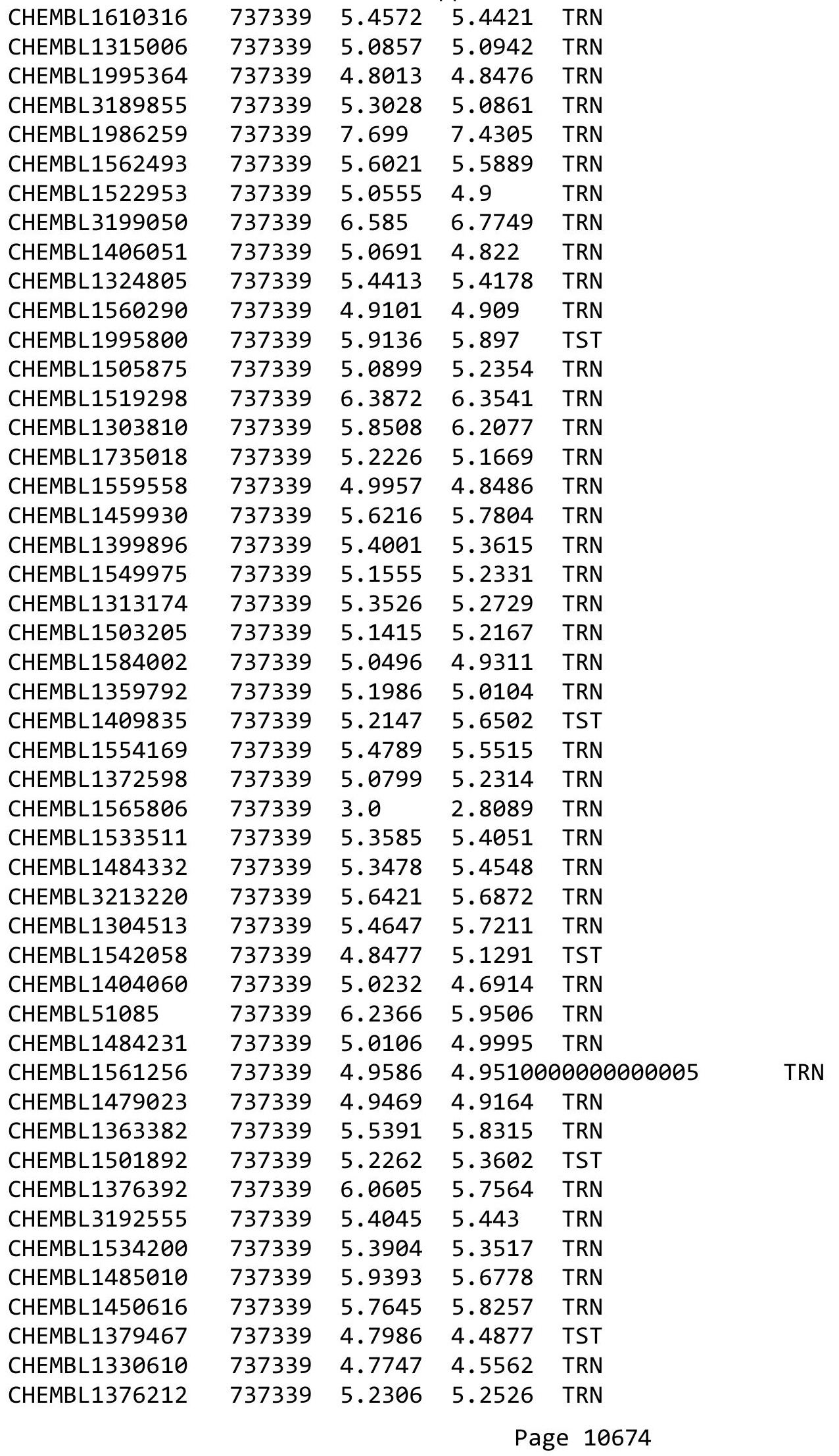




\begin{tabular}{|c|c|c|c|c|c|}
\hline & & & & & \\
\hline CHEMBL1572280 & 737339 & 5.4067 & 5.4512 & TST & \\
\hline CHEMBL1541034 & 737339 & 5.3507 & 5.3712 & TRN & \\
\hline CHEMBL1447783 & 737339 & 5.5834 & 5.7355 & TRN & \\
\hline CHEMBL1964878 & 737339 & 5.4191 & 5.1837 & TRN & \\
\hline CHEMBL1345116 & 737339 & 4.7077 & 4.7484 & TRN & \\
\hline CHEMBL1315414 & 737339 & 5.2708 & 5.1412 & TRN & \\
\hline CHEMBL1384531 & 737339 & 4.6576 & 4.7547 & TRN & \\
\hline CHEMBL1546440 & 737339 & 4.9914 & 4.9745 & TRN & \\
\hline CHEMBL1302758 & 737339 & 5.0462 & 5.4449 & TST & \\
\hline CHEMBL1424945 & 737339 & 5.0052 & 4.9538 & TRN & \\
\hline CHEMBL1453108 & 737339 & 5.1124 & 5.0532 & TRN & \\
\hline CHEMBL1549738 & 737339 & 5.7033 & 5.7284 & TRN & \\
\hline CHEMBL1419625 & 737339 & 5.0114 & 4.9706 & TRN & \\
\hline CHEMBL1408586 & 737339 & 5.1506 & 5.2232 & TRN & \\
\hline CHEMBL1567402 & 737339 & 5.0825 & 5.1434 & TRN & \\
\hline CHEMBL1581799 & 737339 & 4.2464 & 4.409 & TRN & \\
\hline CHEMBL1470485 & 737339 & 5.8962 & 5.5337 & TST & \\
\hline CHEMBL1389702 & 737339 & 4.9172 & 4.9364 & TRN & \\
\hline CHEMBL1510030 & 737339 & 5.4001 & 5.4418 & TRN & \\
\hline CHEMBL1466519 & 737339 & 5.4034 & 5.5694 & TRN & \\
\hline CHEMBL1407254 & 737339 & 5.8268 & 5.8544 & TRN & \\
\hline CHEMBL1515506 & 737339 & 6.1805 & 6.3532 & TRN & \\
\hline CHEMBL1342598 & 737339 & 5.3298 & 5.3999 & TRN & \\
\hline CHEMBL1980581 & 737339 & 4.9355 & 4.9286 & TRN & \\
\hline CHEMBL1447350 & 737339 & 5.3605 & 5.459 & TRN & \\
\hline CHEMBL1574219 & 737339 & 5.5654 & 5.6325 & TRN & \\
\hline CHEMBL1334612 & 737339 & 5.1373 & 4.9957 & TRN & \\
\hline CHEMBL1554002 & 737339 & 5.0362 & 5.0842 & TST & \\
\hline CHEMBL1322943 & 737339 & 5.1778 & 4.8833 & TRN & \\
\hline CHEMBL1392140 & 737339 & 5.1811 & 5.3171 & TRN & \\
\hline CHEMBL1489205 & 737339 & 4.98300 & 30000000 & 4.6287 & TST \\
\hline CHEMBL1304750 & 737339 & 5.1637 & 5.2058 & TST & \\
\hline CHEMBL1549334 & 737339 & 4.567 & 4.44300 & 00000000005 & TRN \\
\hline CHEMBL1469305 & 737339 & 5.0119 & 5.0531 & TRN & \\
\hline CHEMBL211969 & 737339 & 5.8761 & 5.7979 & TRN & \\
\hline CHEMBL1364072 & 737339 & 5.2993 & 5.1754 & TST & \\
\hline CHEMBL1518799 & 737339 & 5.7212 & 5.7796 & TRN & \\
\hline CHEMBL1717912 & 737339 & 4.8386 & 4.8427 & TRN & \\
\hline CHEMBL1978997 & 737339 & 5.1062 & 5.11600 & 00000000005 & TRN \\
\hline CHEMBL1598934 & 737339 & 5.2299 & 5.0368 & TRN & \\
\hline CHEMBL1366037 & 737339 & 5.3063 & 4.9924 & TRN & \\
\hline CHEMBL1400960 & 737339 & 5.3045 & 5.3113 & TST & \\
\hline CHEMBL1586425 & 737339 & 4.8894 & 4.8216 & TRN & \\
\hline CHEMBL1487135 & 737339 & 5.082 & 5.1185 & TRN & \\
\hline CHEMBL1390546 & 737339 & 4.9957 & 4.8378 & TRN & \\
\hline CHEMBL1471900 & 737339 & 5.7595 & 5.61700 & 2000000001 & TRN \\
\hline CHEMBL1988138 & 737339 & 5.4365 & 5.5569 & TRN & \\
\hline CHEMBL1421736 & 737339 & 6.585 & 6.5136 & TRN & \\
\hline
\end{tabular}


Supplemental Table S2.txt

\begin{tabular}{|c|c|c|c|c|}
\hline CHEMBL1485605 & 737339 & 6.1612 & 6.1071 & TRN \\
\hline CHEMBL1303152 & 737339 & 4.8928 & 4.9688 & TRN \\
\hline CHEMBL1392552 & 737339 & 5.224 & 5.3693 & TST \\
\hline CHEMBL1527341 & 737339 & 5.0937 & 5.0838 & TRN \\
\hline CHEMBL1583997 & 737339 & 5.2306 & 5.038 & TRN \\
\hline CHEMBL1553717 & 737339 & 4.9666 & 4.9284 & TRN \\
\hline CHEMBL1391098 & 737339 & 5.8928 & 6.0949 & TRN \\
\hline CHEMBL1200847 & 737339 & 5.3605 & 5.2622 & TST \\
\hline CHEMBL1544036 & 737339 & 5.4134 & 5.4297 & TRN \\
\hline CHEMBL1702079 & 737339 & 5.3288 & 5.4199 & TRN \\
\hline CHEMBL1318817 & 737339 & 5.5017 & 5.2939 & TRN \\
\hline CHEMBL1463422 & 737339 & 5.6421 & 5.8675 & TST \\
\hline CHEMBL1984894 & 737339 & 5.7282 & 5.7916 & TRN \\
\hline CHEMBL1533040 & 737339 & 3.0 & 3.8434 & TRN \\
\hline CHEMBL1969492 & 737339 & 4.9666 & 4.5394 & TST \\
\hline CHEMBL1353110 & 737339 & 6.0969 & 5.9303 & TRN \\
\hline CHEMBL1368514 & 737339 & 5.4962 & 5.4777 & TRN \\
\hline CHEMBL1521188 & 737339 & 3.0 & 3.655 & TRN \\
\hline CHEMBL3198175 & 737339 & 5.5317 & 5.784 & TRN \\
\hline CHEMBL1401698 & 737339 & 5.6289 & 5.3002 & TST \\
\hline CHEMBL1300391 & 737339 & 5.1637 & 5.0415 & TST \\
\hline CHEMBL1549175 & 737339 & 5.9245 & 6.2098 & TST \\
\hline CHEMBL1547145 & 737339 & 4.9066 & 5.0815 & TST \\
\hline CHEMBL1463480 & 737339 & 4.7799 & 5.01 & TST \\
\hline CHEMBL1495590 & 737339 & 5.6162 & 4.5984 & TST \\
\hline CHEMBL1892270 & 737339 & 5.2916 & 5.2752 & TST \\
\hline CHEMBL546576 & 737339 & 5.059 & 4.5079 & TST \\
\hline CHEMBL1369392 & 737339 & 7.699 & 6.0624 & TST \\
\hline CHEMBL1331798 & 737339 & 5.0424 & 5.1316 & TST \\
\hline CHEMBL1608787 & 737339 & 5.2132 & 4.644 & TST \\
\hline CHEMBL1371138 & 737339 & 5.7399 & 5.7193 & TST \\
\hline CHEMBL1439210 & 737339 & 5.3063 & 5.4872 & TST \\
\hline CHEMBL1303703 & 737339 & 5.4112 & 5.1934 & TST \\
\hline CHEMBL1503238 & 737339 & 5.51 & 4.7343 & TST \\
\hline CHEMBL1494336 & 737339 & 4.9208 & 4.8071 & TST \\
\hline CHEMBL3192609 & 737339 & 5.3979 & 5.2094 & TST \\
\hline CHEMBL1467732 & 737339 & 5.644 & 5.5952 & TST \\
\hline CHEMBL1197424 & 1592870 & 3.4948 & 3.4176 & TRN \\
\hline CHEMBL3637895 & 1592870 & 5.5952 & 5.5343 & TRN \\
\hline CHEMBL1683016 & 1592870 & 3.4948 & 3.9496 & TST \\
\hline CHEMBL466426 & 1592870 & 4.3497 & 4.5097 & TST \\
\hline CHEMBL1197563 & 1592870 & 3.4948 & 3.736 & TRN \\
\hline CHEMBL3637897 & 1592870 & 4.7625 & 4.7994 & TRN \\
\hline CHEMBL1230468 & 1592870 & 5.9957 & 5.9019 & TRN \\
\hline CHEMBL474899 & 1592870 & 5.3947 & \multirow{2}{*}{\multicolumn{2}{|c|}{$\begin{array}{l}5.513999999999999 \\
3.4210000000000003\end{array}$}} \\
\hline CHEMBL 3637893 & 1592870 & 3.4948 & & \\
\hline CHEMBL1197423 & 1592870 & 3.4948 & 3.2449 & TRN \\
\hline CHEMBL 3115821 & 1592870 & 6.7959 & 6.7 & TRN \\
\hline
\end{tabular}


Supplemental Table S2.txt

\begin{tabular}{|c|c|c|c|c|c|}
\hline CHEMBL3431099 & 1592870 & 3.1938 & 4.276 & TST & \\
\hline CHEMBL 3431191 & 1592870 & 5.7986 & 5.9086 & TRN & \\
\hline CHEMBL3637896 & 1592870 & 6.2007 & 6.2172 & TRN & \\
\hline CHEMBL472854 & 1592870 & 3.4948 & 3.747 & TRN & \\
\hline CHEMBL 2441383 & 1592870 & 5.8508 & 5.666 & TRN & \\
\hline CHEMBL 3431323 & 1592870 & 4.4949 & 4.5674 & TRN & \\
\hline CHEMBL3637899 & 1592870 & 3.1938 & 3.1234 & TRN & \\
\hline CHEMBL45843 & 1592870 & 5.9957 & 4.4156 & TST & \\
\hline CHEMBL 3431223 & 1592870 & 3.1938 & 3.1088 & TRN & \\
\hline CHEMBL238442 & 1592870 & 5.3915 & 5.3918 & TRN & \\
\hline CHEMBL1308225 & 1592870 & 4.2977 & 4.1918 & TRN & \\
\hline CHEMBL 3431084 & 1592870 & 4.3563 & 4.2676 & TRN & \\
\hline CHEMBL 3431105 & 1592870 & 5.16299 & 99999999 & 99 & 5.1558 \\
\hline CHEMBL241427 & 1592870 & 3.4948 & 3.6549 & TRN & \\
\hline CHEMBL1872842 & 1592870 & 3.1938 & 3.2299 & TRN & \\
\hline CHEMBL1198787 & 1592870 & 3.4948 & 3.3473 & TRN & \\
\hline CHEMBL3431322 & 1592870 & 4.2823 & 4.109 & TRN & \\
\hline CHEMBL 3431127 & 1592870 & 7.5229 & 5.1596 & TST & \\
\hline CHEMBL511692 & 1592870 & 4.7897 & 4.8161 & TRN & \\
\hline CHEMBL 3637892 & 1592870 & 3.4948 & 3.4702 & TRN & \\
\hline CHEMBL 3431129 & 1592870 & 6.2676 & 5.2118 & TST & \\
\hline CHEMBL1683021 & 1592870 & 4.7897 & 3.81 & TST & \\
\hline CHEMBL1836611 & 1592870 & 5.3915 & 5.8403 & TST & \\
\hline CHEMBL3431294 & 1592870 & 3.1938 & 3.0271 & TRN & \\
\hline CHEMBL520654 & 1592870 & 3.4948 & 3.5344 & TRN & \\
\hline CHEMBL 3431330 & 1592870 & 3.1938 & 3.2001 & TRN & \\
\hline CHEMBL 3431007 & 1592870 & 3.1938 & 3.1665 & TRN & \\
\hline CHEMBL 2229099 & 1592870 & 4.3407 & 4.4903 & TRN & \\
\hline CHEMBL3431128 & 1592870 & 6.3279 & 4.7888 & TST & \\
\hline CHEMBL 3637894 & 1592870 & 3.4948 & 3.5387 & TRN & \\
\hline CHEMBL1094051 & 1592870 & 4.5952 & 4.614 & TRN & \\
\hline CHEMBL 2171461 & 1592870 & 3.4948 & 3.4963 & TRN & \\
\hline CHEMBL393580 & 1592870 & 4.8655 & 4.9789 & TRN & \\
\hline CHEMBL394241 & 1592870 & 4.9931 & 5.1113 & TRN & \\
\hline CHEMBL458799 & 1592870 & 3.4948 & 3.6248 & TRN & \\
\hline CHEMBL227667 & 1592870 & 3.4948 & 3.9164 & TRN & \\
\hline CHEMBL1566634 & 1592870 & 3.1938 & 3.2127 & TRN & \\
\hline CHEMBL 3431272 & 1592870 & 3.1938 & 3.093 & TRN & \\
\hline CHEMBL241634 & 1592870 & 4.667 & 4.296 & TRN & \\
\hline CHEMBL394474 & 1592870 & 3.4948 & 3.6357 & TRN & \\
\hline CHEMBL472881 & 1592870 & 5.3915 & 5.4863 & TRN & \\
\hline CHEMBL1836562 & 1592870 & 4.9948 & 4.8094 & TST & \\
\hline CHEMBL519040 & 1592870 & 3.4948 & 3.5752 & TRN & \\
\hline CHEMBL 227240 & 1592870 & 5.5952 & 5.3512 & TRN & \\
\hline CHEMBL 3431166 & 1592870 & 3.1938 & 3.1311 & TST & \\
\hline CHEMBL 3431411 & 1592870 & 3.1938 & 3.3007 & TST & \\
\hline CHEMBL 3637898 & 1592870 & 3.4948 & 4.7181 & TST & \\
\hline CHEMBL413331 & 1592870 & 4.9931 & 4.651 & TST & \\
\hline
\end{tabular}


Supplemental Table S2.txt

\begin{tabular}{|c|c|c|c|c|}
\hline CHEMBL3431063 & 1592870 & 3.1938 & 3.0147 & TST \\
\hline CHEMBL3963054 & 1642415 & 6.6576 & 6.3809 & TRN \\
\hline CHEMBL3897084 & 1642415 & 6.5086 & 6.1615 & TRN \\
\hline CHEMBL3939699 & 1642415 & 6.9586 & 6.1139 & TST \\
\hline CHEMBL3913669 & 1642415 & 8.9586 & 8.7534 & TRN \\
\hline CHEMBL3963114 & 1642415 & 6.6198 & 6.1671 & TRN \\
\hline CHEMBL3906546 & 1642415 & 8.3768 & 8.3158 & TRN \\
\hline CHEMBL3947976 & 1642415 & 6.2924 & 5.885 & TRN \\
\hline CHEMBL3948065 & 1642415 & 9.4949 & 7.9468 & TST \\
\hline CHEMBL3969979 & 1642415 & 6.3098 & 6.3592 & TRN \\
\hline CHEMBL3977729 & 1642415 & 6.0 & 7.7246 & TRN \\
\hline CHEMBL3984082 & 1642415 & 8.7696 & 8.5793 & TRN \\
\hline CHEMBL3944698 & 1642415 & 8.4559 & 7.8056 & TST \\
\hline CHEMBL3940423 & 1642415 & 9.1739 & 8.1226 & TRN \\
\hline CHEMBL 3928597 & 1642415 & 6.585 & 5.5785 & TRN \\
\hline CHEMBL3950138 & 1642415 & 7.1135 & 6.0432 & TRN \\
\hline CHEMBL3897911 & 1642415 & 8.3279 & 8.2516 & TRN \\
\hline CHEMBL3902892 & 1642415 & 5.5229 & 8.006 & TRN \\
\hline CHEMBL3906926 & 1642415 & 8.7696 & 8.4102 & TRN \\
\hline CHEMBL3921373 & 1642415 & 6.0655 & 7.6976 & TST \\
\hline CHEMBL3902845 & 1642415 & 9.0915 & 9.0698 & TRN \\
\hline CHEMBL3910506 & 1642415 & 6.9066 & 7.1516 & TRN \\
\hline CHEMBL3895077 & 1642415 & 6.0 & 7.7542 & TST \\
\hline CHEMBL3896850 & 1642415 & 4.0 & 5.6356 & TST \\
\hline CHEMBL 3969173 & 1642415 & 8.8539 & 8.8437 & TRN \\
\hline CHEMBL3966567 & 1642415 & 6.0809 & 5.78700 & 0000000001 \\
\hline CHEMBL3939337 & 1642415 & 5.5229 & 4.9138 & TRN \\
\hline CHEMBL3953696 & 1642415 & 7.301 & 6.1777 & TST \\
\hline CHEMBL3942135 & 1642415 & 5.7212 & 7.3314 & TST \\
\hline CHEMBL 3918154 & 1642415 & 8.5686 & 8.2526 & TRN \\
\hline CHEMBL3897152 & 1642415 & 6.5229 & 7.87200 & 0000000001 \\
\hline CHEMBL3947816 & 1642415 & 5.699 & 6.2737 & TRN \\
\hline CHEMBL3939090 & 1642415 & 6.4949 & 6.4332 & TST \\
\hline CHEMBL3976076 & 1642415 & 8.3279 & 7.7457 & TRN \\
\hline CHEMBL 3968870 & 1642415 & 8.3665 & 7.3058 & TRN \\
\hline CHEMBL3945485 & 1642415 & 9.0 & 7.8763 & TRN \\
\hline CHEMBL 3890068 & 1642415 & 8.5686 & 8.1073 & TRN \\
\hline CHEMBL3955025 & 1642415 & 7.7212 & 6.9188 & TST \\
\hline CHEMBL3954730 & 1642415 & 9.8239 & 8.644 & TRN \\
\hline CHEMBL3961123 & 1642415 & 6.8539 & 7.8131 & TRN \\
\hline CHEMBL3941460 & 1642415 & 5.2757 & 5.0135 & TRN \\
\hline CHEMBL3984995 & 1642415 & 5.8239 & 5.1053 & TRN \\
\hline CHEMBL3901100 & 1642415 & 9.0506 & 8.0138 & TST \\
\hline CHEMBL3985855 & 1642415 & 9.3565 & 8.5264 & TRN \\
\hline CHEMBL3916950 & 1642415 & 8.9586 & 7.977 & TRN \\
\hline CHEMBL3978821 & 1642415 & 7.2596 & 6.5974 & TST \\
\hline CHEMBL 3973566 & 1642415 & 9.7212 & 9.1074 & TRN \\
\hline CHEMBL3983090 & 1642415 & 8.9586 & 8.6763 & TRN \\
\hline
\end{tabular}


Supplemental Table S2.txt

\begin{tabular}{|c|c|c|}
\hline & & \\
\hline HEMBL3974343 & 1642415 & \\
\hline HEMBL3904180 & 642415 & \\
\hline 154 & & \\
\hline AEMBL3918344 & 642415 & \\
\hline AEMBL3964695 & 1642415 & \\
\hline HEMBL3930480 & 1642415 & 7.02 \\
\hline HEMBL3954461 & 164 & \\
\hline AEMBL395 & 16 & \\
\hline HEMBL396 & & \\
\hline HEMBL3926833 & 1642415 & \\
\hline HEMBL3954175 & 1642415 & \\
\hline HEMBL3894 & 16 & \\
\hline IEMBL 391 & 16 & \\
\hline HEMBL 393 & 16 & \\
\hline HEMBL3900591 & 164 & \\
\hline HEMBL3983966 & 16 & \\
\hline HEMBL396 & 16 & \\
\hline IEMBL397 & 16 & \\
\hline HEMBL 389 & 16 & \\
\hline HEMBL394 & 16 & \\
\hline HEMBL397 & 16 & \\
\hline HEMBL394 & 16 & \\
\hline IEMBL 394 & 16 & \\
\hline JEMBL389 & 16 & \\
\hline HEMBL3959393 & 16 & \\
\hline HEMBL3905984 & 16 & \\
\hline HEMBL393 & 16 & \\
\hline HEMBL3S & 16 & \\
\hline HFMRI 30 & 16 & \\
\hline HEMBL3924383 & 16 & \\
\hline HEMBL3965262 & 16 & \\
\hline AEMBL39 & & \\
\hline HEMBL & 16 & 6. \\
\hline HEM & 16 & 6 . \\
\hline HEMBL3904488 & 164 & \\
\hline HEMBL3968222 & 164 & \\
\hline 1 & & \\
\hline 4 HEM 30 & 16 & 4. \\
\hline CHEMBL389 & 16 & 7.49 \\
\hline HEMBL3961487 & 164 & \\
\hline HEMBL3968704 & 164 & \\
\hline & & 4. \\
\hline CHEMBL3894176 & 164 & 8.58 \\
\hline CHEMBL 3959301 & 164 & 5.721 \\
\hline HEMBL 3983632 & 164 & 4.0 \\
\hline CHEMBL3940428 & 1642 & \\
\hline 200 & & \\
\hline
\end{tabular}

6.1958 TST

5.4474 TRN

5.9382 TRN

7.4467 TRN

8.0641 TRN

8.0489 TRN

7.2233 TRN

6.2375 TRN

9.1136 TRN

6.2199 TRN

6.2997 TST

7.954 TRN

8.2548 TRN

8.1296 TRN

6.2293 TRN

8.5311 TRN

8.7529 TRN

9.0146 TRN

7.6423 TRN

7.8883 TRN

8.115 TRN

8.1011 TRN

8.4193 TRN

7.1419 TRN

8.2363 TRN

8.5791 TRN

9.3587 TRN

8.2645 TST

8.0996 TRN

8.3441 TST

5.6847 TST

8.4277 TRN

8.0427 TRN

8.4781 TRN

8.1153 TRN

8.3323 TRN

8.7298 TRN

8.8304 TRN

6.9627 TST

7.3684 TST

6.0654 TST

7.287999999999999

TST

5.3851 TRN

7.3998 TRN

6.37 TST

5.7986 TST

7.7464 TST

7.0496 TRN

Page 10679 
Supplemental Table S2.txt

\begin{tabular}{|c|c|c|}
\hline 70 & & \\
\hline HEMBL393 & 62015 & 4.0 \\
\hline & & \\
\hline 617 & 15 & ח \\
\hline IEMBL 3969976 & 642415 & 04 \\
\hline AEMBL 3895268 & 642415 & 958 \\
\hline IEMBL3C & & 6.82 \\
\hline & & 494 \\
\hline 18101 & 415 & \\
\hline IEMBL3940696 & 415 & 8.795 \\
\hline AEMBL 3893163 & 15 & 58 \\
\hline IEMBL3977236 & 15 & 8.301 \\
\hline 8314 & & 886 \\
\hline IEMBL 38 & 15 & 5.5086 \\
\hline IEMBL3978173 & 15 & $\partial 315$ \\
\hline IEMBL3931363 & 15 & $2 \angle 9]$ \\
\hline IEMBL3S & 15 & .420 \\
\hline IEMBL39 & & 823 \\
\hline IEMBL39. & & 619 \\
\hline IEMBL 3926191 & & 721 \\
\hline AEMBL3895210 & 15 & $38 / 4$ \\
\hline IEMBL39 & 16 & 318 \\
\hline IEMBL3C & 15 & .8535 \\
\hline 8115 & & 327 \\
\hline IEMBL 3891285 & & 8.677 \\
\hline IEMBL 3895297 & 16 & 99 \\
\hline IEMBL394 & 16 & 3872 \\
\hline 095 & 15 & \\
\hline 3899 & 15 & 318 \\
\hline IEMBL 389 & 5 & 107 \\
\hline IEMBL395 & 16 & \\
\hline EMBL38 & 16 & 208 \\
\hline 60 & 16 & 86 \\
\hline IEMBL3925102 & 15 & 8861 \\
\hline IEMBL 3982878 & 15 & 8.537 \\
\hline IEMBL39 & 16 & 7.522 \\
\hline EMBL39 & 16 & 8.9208 \\
\hline IEMBL3S & 16 & 8.3279 \\
\hline AEMBL3962583 & 16 & 6.0 \\
\hline IEMBL 3945892 & 16 & 5.221 \\
\hline AEMBL3977187 & 16 & 7.853 \\
\hline HEMBL3912307 & 164 & 5.769 \\
\hline HEMBL3929088 & 15 & 7.7212 \\
\hline IEMBL3974534 & 15 & .958 \\
\hline HEMBL392 & 6 & .958 \\
\hline CHEMBL3891595 & 164 & 250 \\
\hline CHEMBL3930626 & 642415 & .494 \\
\hline CHEMBL3908127 & 1642415 & 4.0 \\
\hline
\end{tabular}

\begin{tabular}{ll}
8.5362 & TRN \\
6.1934 & TST \\
8.3768 & TRN \\
8.7816 & TRN \\
8.2624 & TRN \\
8.177 & TRN \\
8.1208 & TST \\
5.3967 & TRN \\
5.2324 & TRN \\
8.2677 & TRN \\
7.2105 & TRN \\
8.1706 & TRN \\
8.186 & TRN \\
5.7827 & TRN \\
6.6609 & TST \\
8.5897 & TST \\
8.583 & TRN \\
8.5214 & TST \\
7.1134 & TRN \\
8.1829 & TRN \\
8.606 & TST \\
8.8656 & TRN \\
8.2883 & TRN \\
6.8003 & TRN \\
8.63 & TRN \\
7.9443 & TRN \\
8.4784 & TST \\
5.7085 & TRN \\
8.3067 & TRN \\
9.1075 & TRN \\
4.8757 & TRN \\
8.3412 & TRN \\
8.1261 & TST \\
8.5982 & TST \\
8.785 & TRN \\
8.531 & TRN \\
8.638 & TRN \\
8.7759 & TRN \\
7.5214 & TRN \\
8.0989 & TRN \\
6.0629 & TRN \\
5.9707 & TST \\
5.9082 & TRN \\
8.0467 & TRN \\
\hline .3986 & TRN \\
\hline 8207 & TRN \\
\hline
\end{tabular}

Page 10680 
Supplemental Table S2.txt

\begin{tabular}{|c|c|c|c|c|}
\hline IE & 15 & 51 & & $\mathrm{~T}$ \\
\hline & & 8.8861 & 8.7158 & \\
\hline 56 & & & 877 & \\
\hline AEMBL3908157 & 15 & 696 & 6773 & \\
\hline AEMBL3916800 & 15 & 3872 & 7575 & \\
\hline HEMBL3904241 & 642415 & 6.3872 & 0947 & \\
\hline 623 & & 686 & 111 & \\
\hline IEMBL 392 & & & & \\
\hline AEMBL3892137 & 6 & & 8677 & \\
\hline HEMBL3946624 & 64 & 147 & 8551 & \\
\hline HEMBL3949083 & 64 & 6.699 & 5033 & \\
\hline IEMBL392 & 5 & 239 & 781 & \\
\hline AEMBL39 & & & 804 & \\
\hline HEMBL397 & 15 & 7959 & 1508 & \\
\hline AEMBL389 & 15 & 8.6576 & 165 & \\
\hline AEMBL394 & כ & 3768 & 7541 & \\
\hline AEMBL39 & כ & 18 & 652 & \\
\hline HEMBL39 & & & 22 & \\
\hline HEMBL 395 & & & 5054 & \\
\hline HEMBL 394 & & & & \\
\hline AEMBL & 62 & 5. & 374 & וכ \\
\hline AEMBL39 & & 78 & 275 & 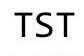 \\
\hline AEMBL39 & & 37 & 04 & \\
\hline HEMBL 394 & & 18 & 9597 & \\
\hline HEMBL 397 & & & & I RIV \\
\hline HEMBL3S & 6 & & 348 & SI \\
\hline HEMBL3\& & J & & 71 & RN \\
\hline HEMBL3S & & & 61 & DN \\
\hline HEMBL396 & & 383 & & TST \\
\hline HEMBL396 & & 372 & 121 & TST \\
\hline HEMBL39 & 6 & 696 & 254 & RN \\
\hline HEMBL 3 & & & 518 & ST \\
\hline HEMBL3 & & 6 & 83 & $\mathrm{R}$ \\
\hline HEMBL 388 & 5 & 8 . & 3875 & RN \\
\hline HEMBL 391 & 62 & & 7476 & 「RN \\
\hline JEMBL39 & 6 & 2 & 814 & ST \\
\hline HFMRI 3 & & & & RN \\
\hline HEMBL3 & & & 961 & RN \\
\hline HEMBL397 & 5 & 8.9208 & 381 & RN \\
\hline IEMBL39 & 6 & 778 & 915 & RN \\
\hline HEMBL 395 & 64 & 447 & 7124 & BA \\
\hline CHEMBL39 & & & & ו \\
\hline HEMBL394 & & 5.4685 & .7132 & RN \\
\hline HEMBL 392 & 5 & 5.0862 & 3134 & TR \\
\hline EMBL39 & & 586 & 68 & RN \\
\hline CHEMBL389 & & & & \\
\hline CHEMBL 398 & 16 & .5686 & .5413 & \\
\hline HEMBL3973435 & 1642415 & 6.0 & 8.7404 & RN \\
\hline
\end{tabular}

Page 10681 
Supplemental Table S2.txt

\begin{tabular}{|c|c|c|c|c|c|c|}
\hline CHEMBL3979645 & 1642415 & 8.2441 & 7.5847 & TRN & & \\
\hline CHEMBL149146 & 156187 & 5.6882 & 5.2187 & TST & & \\
\hline CHEMBL149538 & 156187 & 5.8601 & 5.9945 & TST & & \\
\hline CHEMBL149265 & 156187 & 4.1518 & 4.2678 & TRN & & \\
\hline CHEMBL147652 & 156187 & 5.8665 & 5.8891 & TRN & & \\
\hline CHEMBL342307 & 156187 & 5.3645 & 5.3237 & TRN & & \\
\hline CHEMBL356616 & 156187 & 5.6271 & 5.6055 & TRN & & \\
\hline CHEMBL346855 & 156187 & 6.0757 & 6.2462 & TRN & & \\
\hline CHEMBL436423 & 156187 & 3.9363 & 3.8948 & TRN & & \\
\hline CHEMBL149310 & 156187 & 5.821006 & 300000000 & $\partial 1$ & 5.8566 & TRN \\
\hline CHEMBL357984 & 156187 & 5.6289 & 5.7966 & TRN & & \\
\hline CHEMBL434129 & 156187 & 6.4089 & 6.3435 & TRN & & \\
\hline CHEMBL343225 & 156187 & 4.4191 & 4.2794 & TRN & & \\
\hline CHEMBL150004 & 156187 & 4.4862 & 4.4913 & TRN & & \\
\hline CHEMBL151159 & 156187 & 4.6977 & 4.6453 & TRN & & \\
\hline CHEMBL149547 & 156187 & 5.4318 & 5.705 & TST & & \\
\hline CHEMBL430348 & 156187 & 5.6271 & 6.2427 & TST & & \\
\hline CHEMBL148670 & 156187 & 4.1891 & 4.164 & TRN & & \\
\hline CHEMBL436265 & 156187 & 3.8483 & 3.9171 & TRN & & \\
\hline CHEMBL150166 & 156187 & 6.6021 & 6.6584 & TRN & & \\
\hline CHEMBL148659 & 156187 & 6.4089 & 6.4218 & TRN & & \\
\hline CHEMBL347313 & 156187 & 6.4437 & 6.4394 & TRN & & \\
\hline CHEMBL358906 & 156187 & 4.4179 & 5.5431 & TST & & \\
\hline CHEMBL359337 & 156187 & 6.0655 & 6.1216 & TRN & & \\
\hline CHEMBL149731 & 156187 & 6.3768 & 6.2038 & TRN & & \\
\hline CHEMBL148929 & 156187 & 6.6383 & 6.6651 & TRN & & \\
\hline CHEMBL148041 & 156187 & 5.752006 & 300000000 & $\partial 1$ & 5.7659 & $\mathrm{kN}$ \\
\hline CHEMBL149128 & 156187 & 6.4737 & 6.5171 & TRN & & \\
\hline CHEMBL149430 & 156187 & 6.2596 & 6.0654 & TST & & \\
\hline CHEMBL344787 & 156187 & 4.6162 & 4.6566 & TRN & & \\
\hline CHEMBL445382 & 156187 & 3.9176 & 3.9174 & TRN & & \\
\hline CHEMBL358457 & 156187 & 5.2741 & 5.461 & TST & & \\
\hline CHEMBL148940 & 156187 & 5.1421 & 6.4749 & TST & & \\
\hline CHEMBL150101 & 156187 & 6.0269 & 5.9982 & TRN & & \\
\hline CHEMBL342329 & 156187 & 6.6383 & 5.8307 & TST & & \\
\hline CHEMBL346893 & 156187 & 6.3468 & 6.385 & TRN & & \\
\hline CHEMBL358908 & 156187 & 6.041 & 6.0017 & TRN & & \\
\hline CHEMBL147402 & 156187 & 5.0237 & 5.0346 & TRN & & \\
\hline CHEMBL149602 & 156187 & 6.0655 & 6.0322 & TRN & & \\
\hline CHEMBL356032 & 156187 & 6.2076 & 6.182 & TRN & & \\
\hline CHEMBL356859 & 156187 & 6.585 & 6.5004 & TRN & & \\
\hline CHEMBL149709 & 156187 & 5.6737 & 5.6986 & TRN & & \\
\hline CHEMBL149595 & 156187 & 4.2757 & 4.5197 & TST & & \\
\hline CHEMBL356708 & 156187 & 4.6704 & 4.6204 & TRN & & \\
\hline CHEMBL150058 & 156187 & 4.8176 & 4.8545 & TRN & & \\
\hline CHEMBL148614 & 156187 & 4.9535 & 4.944 & TRN & & \\
\hline CHEMBL358417 & 156187 & 4.3979 & 4.3414 & TRN & & \\
\hline CHEMBL345539 & 156187 & 5.0325 & 5.0235 & TRN & & \\
\hline
\end{tabular}




\begin{tabular}{|c|c|c|c|c|c|}
\hline \multicolumn{6}{|c|}{ Supplemental Table S2.txt } \\
\hline CHEMBL148613 & 156187 & 5.9101 & 5.8655 & TRN & \\
\hline CHEMBL148756 & 156187 & 4.8665 & 4.8149 & TRN & \\
\hline CHEMBL358458 & 156187 & 6.585 & 6.5151 & TRN & \\
\hline CHEMBL149319 & 156187 & 4.7773 & 4.8636 & TRN & \\
\hline CHEMBL436024 & 156187 & 6.2596 & 5.58700 & 0000000001 & TST \\
\hline CHEMBL149613 & 156187 & 4.5513 & 4.5772 & TRN & \\
\hline CHEMBL151669 & 156187 & 5.5918 & 5.5879 & TRN & \\
\hline CHEMBL422127 & 156187 & 6.2147 & 6.1947 & TRN & \\
\hline CHEMBL146318 & 156187 & 5.9914 & 6.0066 & TRN & \\
\hline CHEMBL150531 & 156187 & 4.0721 & 3.1074 & TST & \\
\hline CHEMBL356438 & 156187 & 5.9281 & 6.55 & TST & \\
\hline CHEMBL146814 & 156187 & 3.9948 & 4.0128 & TRN & \\
\hline CHEMBL148443 & 156187 & 4.1302 & 4.1909 & TRN & \\
\hline CHEMBL149658 & 156187 & 4.3958 & 5.8973 & TST & \\
\hline CHEMBL347543 & 156187 & 5.9101 & 5.8881 & TRN & \\
\hline CHEMBL148455 & 156187 & 5.0255 & 4.9827 & TRN & \\
\hline CHEMBL359258 & 156187 & 4.3372 & 4.3274 & TRN & \\
\hline CHEMBL148881 & 156187 & 5.3098 & 6.0382 & TST & \\
\hline CHEMBL356083 & 156187 & 5.767 & 5.6669 & TRN & \\
\hline CHEMBL356397 & 156187 & 6.1938 & 6.2528 & TRN & \\
\hline CHEMBL439993 & 156187 & 4.5658 & 4.5758 & TRN & \\
\hline CHEMBL356180 & 156187 & 5.0273 & 5.0676 & TRN & \\
\hline CHEMBL359416 & 156187 & 6.9208 & 6.9236 & TRN & \\
\hline CHEMBL151023 & 156187 & 6.3665 & 6.4227 & TST & \\
\hline CHEMBL348681 & 156187 & 5.5229 & 5.5522 & TST & \\
\hline CHEMBL149150 & 156187 & 4.4225 & 4.928 & TST & \\
\hline CHEMBL343213 & 156187 & 5.7932 & 6.1471 & TST & \\
\hline CHEMBL2372883 & 207592 & 3.5229 & 4.5125 & TRN & \\
\hline CHEMBL 295944 & 207592 & 5.8861 & 5.8514 & TRN & \\
\hline CHEMBL51235 & 207592 & 3.5229 & 6.0302 & TST & \\
\hline CHEMBL 2372867 & 207592 & 3.5229 & 4.1705 & TRN & \\
\hline CHEMBL2372879 & 207592 & 3.5229 & 3.5065 & TRN & \\
\hline CHEMBL2372849 & 207592 & 4.9586 & 5.0464 & TRN & \\
\hline CHEMBL49990 & 207592 & 5.8239 & 6.3454 & TST & \\
\hline CHEMBL51637 & 207592 & 5.4559 & 6.0108 & TST & \\
\hline CHEMBL417727 & 207592 & 6.699 & 6.7274 & TRN & \\
\hline CHEMBL52347 & 207592 & 5.1549 & 6.39 & TST & \\
\hline CHEMBL51257 & 207592 & 5.9586 & 6.0339 & TRN & \\
\hline CHEMBL52047 & 207592 & 5.1079 & 5.0614 & TRN & \\
\hline CHEMBL 2372880 & 207592 & 3.5229 & 3.2871 & TRN & \\
\hline CHEMBL2372891 & 207592 & 4.6696 & 4.6858 & TRN & \\
\hline CHEMBL300680 & 207592 & 6.301 & 6.1799 & TST & \\
\hline CHEMBL50505 & 207592 & 3.5229 & 3.5135 & TRN & \\
\hline CHEMBL 2372854 & 207592 & 5.5229 & 5.0464 & TRN & \\
\hline CHEMBL 2372878 & 207592 & 3.5229 & 3.5142 & TRN & \\
\hline CHEMBL50973 & 207592 & 6.699 & 6.3838 & TST & \\
\hline CHEMBL 2372873 & 207592 & 4.8539 & 4.6707 & TRN & \\
\hline CHEMBL51776 & 207592 & 5.9586 & 5.9418 & TRN & \\
\hline
\end{tabular}




\begin{tabular}{|c|c|c|c|c|c|}
\hline \multicolumn{6}{|c|}{ Supplemental Table S2.txt } \\
\hline CHEMBL54165 & 207592 & 6.699 & 6.7041 & TRN & \\
\hline CHEMBL52388 & 207592 & 6.2218 & 6.2489 & TRN & \\
\hline CHEMBL2372894 & 207592 & 5.0555 & 5.0565 & TRN & \\
\hline CHEMBL300663 & 207592 & 6.1549 & 6.9409 & TST & \\
\hline CHEMBL2372892 & 207592 & 5.0458 & 4.7051 & TRN & \\
\hline CHEMBL 299154 & 207592 & 5.6576 & 5.5841 & TRN & \\
\hline CHEMBL 2372866 & 207592 & 4.8386 & 4.7738 & TRN & \\
\hline CHEMBL2372869 & 207592 & 3.5229 & 4.2819 & TRN & \\
\hline CHEMBL51322 & 207592 & 5.8239 & 5.8256 & TRN & \\
\hline CHEMBL54131 & 207592 & 6.4949 & 6.4531 & TRN & \\
\hline CHEMBL51007 & 207592 & 3.5229 & 7.20299 & 9999999999 & TST \\
\hline CHEMBL52491 & 207592 & 6.2218 & 6.2457 & TRN & \\
\hline CHEMBL38066 & 207592 & 6.2218 & 6.2389 & TRN & \\
\hline CHEMBL2372898 & 207592 & 3.5229 & 3.4625 & TRN & \\
\hline CHEMBL2372864 & 207592 & 4.9788 & 4.5125 & TRN & \\
\hline CHEMBL 2372865 & 207592 & 5.1549 & 4.8977 & TRN & \\
\hline CHEMBL51781 & 207592 & 6.0 & 6.0229 & TRN & \\
\hline CHEMBL 300260 & 207592 & 3.5229 & 6.6726 & TST & \\
\hline CHEMBL2372848 & 207592 & 4.7959 & 4.5552 & TRN & \\
\hline CHEMBL298582 & 207592 & 6.5229 & 6.5672 & TRN & \\
\hline CHEMBL51529 & 207592 & 4.9586 & 4.4217 & TST & \\
\hline CHEMBL51039 & 207592 & 5.6778 & 7.5451 & TST & \\
\hline CHEMBL51948 & 207592 & 5.7696 & 6.6691 & TST & \\
\hline CHEMBL51636 & 207592 & 5.1487 & 5.8895 & TST & \\
\hline CHEMBL300664 & 207592 & 5.8861 & 5.9404 & TST & \\
\hline CHEMBL300241 & 207592 & 5.3565 & 5.2386 & TRN & \\
\hline CHEMBL2372871 & 207592 & 4.7144 & 4.9734 & TRN & \\
\hline CHEMBL51317 & 207592 & 5.5376 & 5.4976 & TRN & \\
\hline CHEMBL49992 & 207592 & 6.3979 & 6.4562 & TRN & \\
\hline CHEMBL54154 & 207592 & 5.1938 & 6.7298 & TST & \\
\hline CHEMBL 2372875 & 207592 & 5.2596 & 4.7923 & TRN & \\
\hline CHEMBL51547 & 207592 & 3.5229 & 3.4752 & TRN & \\
\hline CHEMBL 2372868 & 207592 & 4.7212 & 5.0464 & TRN & \\
\hline CHEMBL2372881 & 207592 & 3.5229 & 3.7387 & TRN & \\
\hline CHEMBL417021 & 207592 & 3.5229 & 3.5297 & TRN & \\
\hline CHEMBL 2372874 & 207592 & 4.6383 & 5.1512 & TRN & \\
\hline CHEMBL 2372886 & 207592 & 5.301 & 4.1705 & TRN & \\
\hline CHEMBL50347 & 207592 & 5.8861 & 5.8954 & TRN & \\
\hline CHEMBL 2372863 & 207592 & 4.6383 & 4.7041 & TRN & \\
\hline CHEMBL50161 & 207592 & 5.7959 & 5.812 & TRN & \\
\hline CHEMBL50878 & 207592 & 5.5086 & 5.5607 & TRN & \\
\hline CHEMBL54164 & 207592 & 6.0969 & 6.2623 & TST & \\
\hline CHEMBL298384 & 207592 & 5.8861 & 5.8688 & TRN & \\
\hline CHEMBL2372889 & 207592 & 3.5229 & 3.5912 & TRN & \\
\hline CHEMBL53966 & 207592 & 6.0 & 6.053 & TRN & \\
\hline CHEMBL50187 & 207592 & 6.3979 & 6.4486 & TST & \\
\hline CHEMBL2372876 & 207592 & 5.301 & 5.0464 & TRN & \\
\hline CHEMBL51583 & 207592 & 5.7696 & 6.7401 & TST & \\
\hline
\end{tabular}




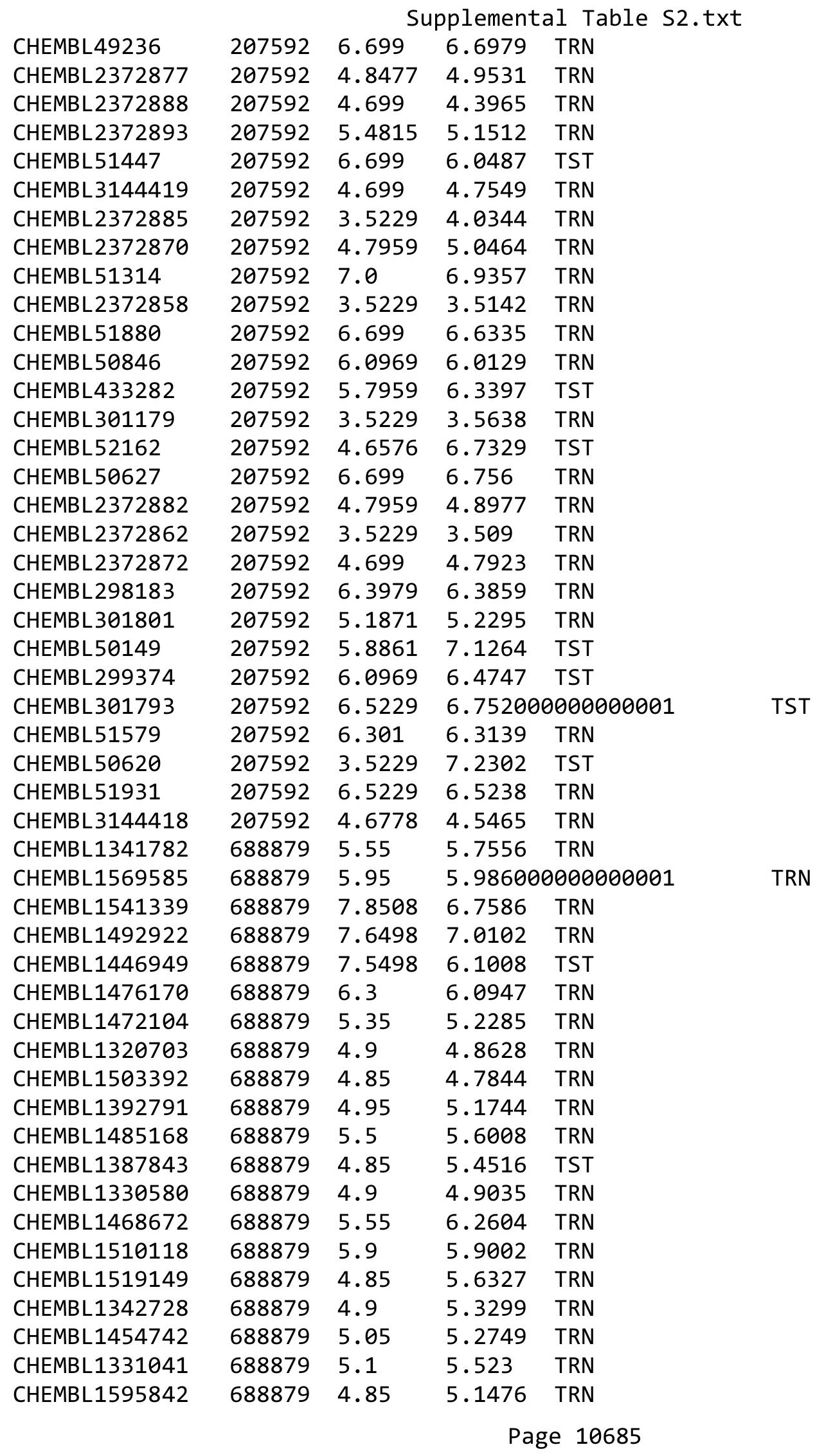




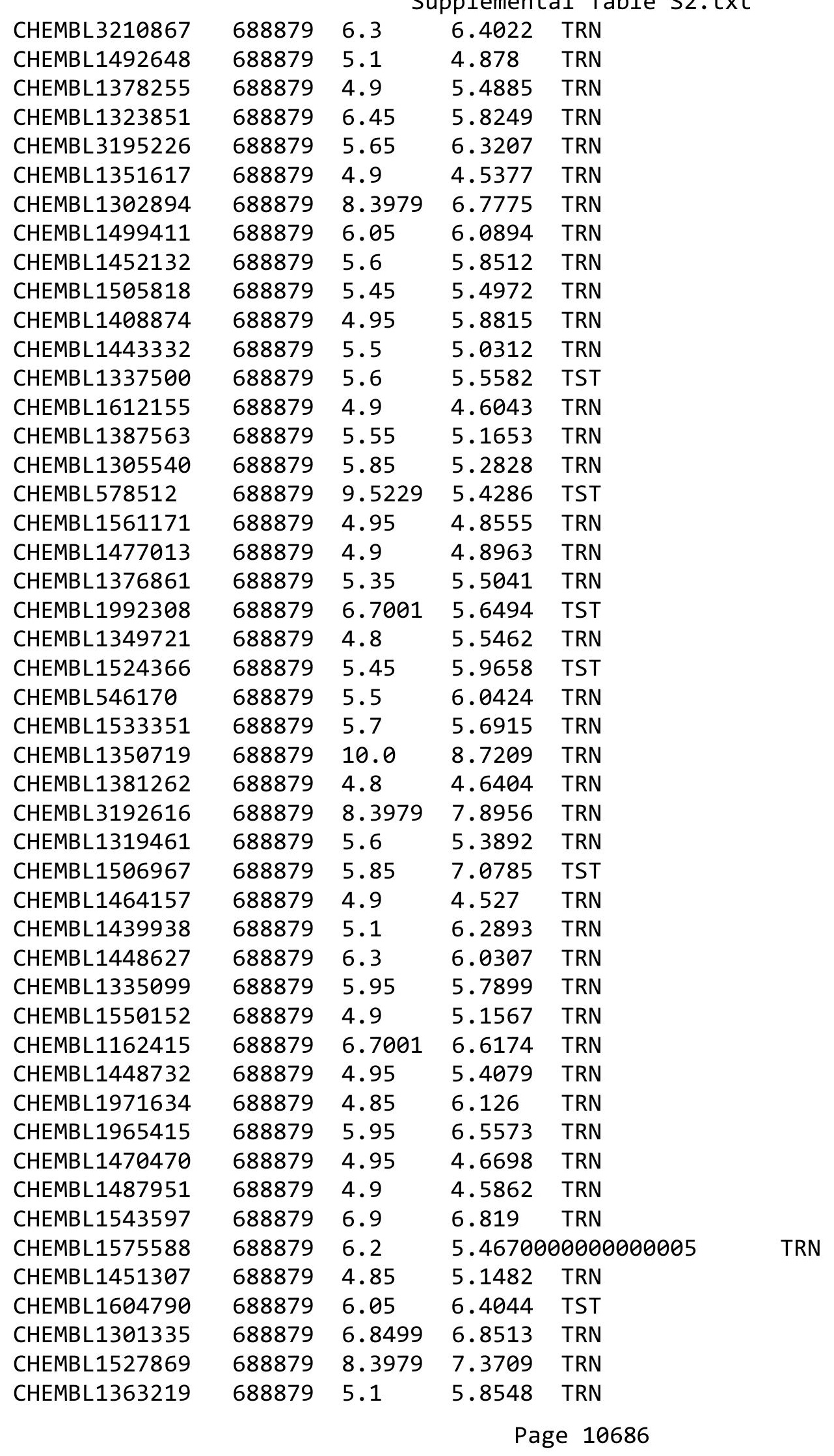




\begin{tabular}{|c|c|c|c|c|}
\hline \multicolumn{5}{|c|}{ Supplemental Table } \\
\hline CHEMBL1522836 & 688879 & 6.5501 & 6.9083 & TRN \\
\hline CHEMBL1330510 & 688879 & 6.5 & 6.2651 & TRN \\
\hline CHEMBL1534919 & 688879 & 5.55 & 7.2106 & TRN \\
\hline CHEMBL1386409 & 688879 & 4.95 & 4.1876 & TRN \\
\hline CHEMBL534353 & 688879 & 5.45 & 5.3893 & TRN \\
\hline CHEMBL1371924 & 688879 & 6.45 & 5.3829 & TRN \\
\hline CHEMBL428064 & 688879 & 5.65 & 5.7371 & TRN \\
\hline CHEMBL1537810 & 688879 & 6.5 & 6.6848 & TRN \\
\hline CHEMBL1461818 & 688879 & 5.2 & 5.0056 & TRN \\
\hline CHEMBL1597146 & 688879 & 4.9 & 4.643 & TRN \\
\hline CHEMBL1403026 & 688879 & 5.15 & 4.4664 & TRN \\
\hline CHEMBL1302946 & 688879 & 5.0 & 4.9502 & TRN \\
\hline CHEMBL1306305 & 688879 & 4.85 & 5.7482 & TRN \\
\hline CHEMBL1612486 & 688879 & 5.15 & 4.8469 & TRN \\
\hline CHEMBL528694 & 688879 & 8.3468 & 6.481 & TRN \\
\hline CHEMBL1331050 & 688879 & 4.95 & 5.62 & TRN \\
\hline CHEMBL112597 & 688879 & 6.7501 & 7.0347 & TRN \\
\hline CHEMBL1255837 & 688879 & 5.0 & 5.4798 & TRN \\
\hline CHEMBL1456412 & 688879 & 6.8 & 6.0053 & TST \\
\hline CHEMBL1346587 & 688879 & 5.15 & 5.0712 & TRN \\
\hline CHEMBL1334291 & 688879 & 5.7 & 6.0229 & TRN \\
\hline CHEMBL1464371 & 688879 & 5.05 & 4.9573 & TRN \\
\hline CHEMBL1976308 & 688879 & 5.6 & 5.9976 & TRN \\
\hline CHEMBL1335176 & 688879 & 5.7 & 5.8225 & TRN \\
\hline CHEMBL1349829 & 688879 & 5.3 & 5.726 & TST \\
\hline CHEMBL1517187 & 688879 & 5.2 & 6.3606 & TST \\
\hline CHEMBL 2002150 & 688879 & 6.7001 & 6.9794 & TRN \\
\hline CHEMBL1584777 & 688879 & 5.2 & 5.1466 & TRN \\
\hline CHEMBL1458353 & 688879 & 5.35 & 5.2393 & TRN \\
\hline CHEMBL1369594 & 688879 & 5.05 & 4.81 & TST \\
\hline CHEMBL1385840 & 688879 & 8.0 & 5.983 & TST \\
\hline CHEMBL1529460 & 688879 & 5.05 & 5.517 & TST \\
\hline CHEMBL1338432 & 688879 & 5.8 & 5.8882 & TST \\
\hline CHEMBL1981951 & 688879 & 5.35 & 5.8419 & TST \\
\hline CHEMBL1467893 & 688879 & 5.65 & 5.942 & TST \\
\hline CHEMBL1344225 & 688879 & 5.65 & 5.8291 & TST \\
\hline CHEMBL1340359 & 688879 & 5.1 & 5.0994 & TST \\
\hline CHEMBL1571839 & 688879 & 7.8996 & 6.5457 & TST \\
\hline CHEMBL111750 & 688879 & 6.5501 & 6.1905 & TST \\
\hline CHEMBL1566610 & 688879 & 7.0501 & 6.8611 & TST \\
\hline CHEMBL1445748 & 688879 & 5.45 & 7.0459 & TST \\
\hline CHEMBL3209511 & 688879 & 5.65 & 5.9753 & TST \\
\hline CHEMBL1978331 & 688879 & 9.0 & 6.5858 & TST \\
\hline CHEMBL1562139 & 688879 & 5.05 & 4.5041 & TST \\
\hline CHEMBL1712181 & 688879 & 5.3 & 5.6819 & TST \\
\hline CHEMBL1349510 & 688879 & 5.0 & 4.9122 & TST \\
\hline CHEMBL1537850 & 688879 & 4.95 & 4.6175 & TST \\
\hline CHEMBL 307307 & 28532 & 4.3098 & 5.9748 & TST \\
\hline
\end{tabular}




\begin{tabular}{|c|c|c|c|c|c|}
\hline \multicolumn{6}{|c|}{ Supplemental Table S2.txt } \\
\hline CHEMBL 308768 & 28532 & 5.0315 & 4.9305 & TRN & \\
\hline CHEMBL72084 & 28532 & 4.301 & 5.5062 & TST & \\
\hline CHEMBL302511 & 28532 & 5.4949 & 5.6084 & TRN & \\
\hline CHEMBL72051 & 28532 & 6.9586 & 6.9395 & TRN & \\
\hline CHEMBL421117 & 28532 & 6.6383 & 6.2308 & TRN & \\
\hline CHEMBL306316 & 28532 & 3.0 & 5.2023 & TST & \\
\hline CHEMBL73152 & 28532 & 4.0 & 5.3004 & TST & \\
\hline CHEMBL72953 & 28532 & 6.5528 & 6.6291 & TRN & \\
\hline CHEMBL16687 & 28532 & 8.2218 & 6.73799 & 99999999995 & TST \\
\hline CHEMBL70810 & 28532 & 6.0 & 6.2047 & TRN & \\
\hline CHEMBL 306850 & 28532 & 6.7696 & 6.7324 & TRN & \\
\hline CHEMBL 74681 & 28532 & 6.1487 & 6.2905 & TRN & \\
\hline CHEMBL 312744 & 28532 & 5.8539 & 5.6971 & TST & \\
\hline CHEMBL73006 & 28532 & 6.7447 & 6.6275 & TRN & \\
\hline CHEMBL 308728 & 28532 & 4.0 & 5.4744 & TST & \\
\hline CHEMBL269318 & 28532 & 5.3872 & 5.2772 & TRN & \\
\hline CHEMBL 306907 & 28532 & 4.5528 & 6.0498 & TST & \\
\hline CHEMBL 304769 & 28532 & 6.3565 & 6.2369 & TRN & \\
\hline CHEMBL 303883 & 28532 & 5.0 & 6.1992 & TST & \\
\hline CHEMBL433313 & 28532 & 4.7212 & 4.6074 & TRN & \\
\hline CHEMBL311481 & 28532 & 6.5376 & 6.6607 & TRN & \\
\hline CHEMBL311616 & 28532 & 7.6198 & 7.5372 & TRN & \\
\hline CHEMBL72766 & 28532 & 4.0 & 4.6548 & TRN & \\
\hline CHEMBL306596 & 28532 & 5.6576 & 5.8665 & TRN & \\
\hline CHEMBL420368 & 28532 & 7.6198 & 7.9411 & TRN & \\
\hline CHEMBL70435 & 28532 & 7.0 & 7.0204 & TRN & \\
\hline CHEMBL 307102 & 28532 & 3.0 & 5.6447 & TST & \\
\hline CHEMBL70434 & 28532 & 4.0 & 4.1835 & TRN & \\
\hline CHEMBL431376 & 28532 & 6.8539 & 6.808 & TRN & \\
\hline CHEMBL 310041 & 28532 & 5.1308 & 4.7364 & TRN & \\
\hline CHEMBL464859 & 28532 & 8.0 & 7.5455 & TST & \\
\hline CHEMBL 72177 & 28532 & 7.2218 & 7.1962 & TRN & \\
\hline CHEMBL 308975 & 28532 & 3.0 & 2.9196 & TRN & \\
\hline CHEMBL 73132 & 28532 & 4.5376 & 4.5504 & TRN & \\
\hline CHEMBL 74403 & 28532 & 5.2147 & 5.4926 & TST & \\
\hline CHEMBL69722 & 28532 & 4.9586 & 4.976 & TRN & \\
\hline CHEMBL312449 & 28532 & 6.9586 & 6.7235 & TRN & \\
\hline CHEMBL73478 & 28532 & 7.5528 & 7.4223 & TRN & \\
\hline CHEMBL 73682 & 28532 & 6.0757 & 5.6971 & TRN & \\
\hline CHEMBL 72903 & 28532 & 5.3372 & 5.421 & TST & \\
\hline CHEMBL442176 & 28532 & 7.2441 & 7.151 & TRN & \\
\hline CHEMBL 306351 & 28532 & 7.4949 & 7.3968 & TRN & \\
\hline CHEMBL70359 & 28532 & 6.1367 & 6.1931 & TRN & \\
\hline CHEMBL 73210 & 28532 & 5.7447 & 5.9665 & TRN & \\
\hline CHEMBL305707 & 28532 & 5.4559 & 6.184 & TST & \\
\hline CHEMBL 304621 & 28532 & 6.0706 & 6.1387 & TRN & \\
\hline CHEMBL 70735 & 28532 & 4.7696 & 4.2004 & TRN & \\
\hline CHEMBL72290 & 28532 & 5.1871 & 4.6919 & TRN & \\
\hline
\end{tabular}




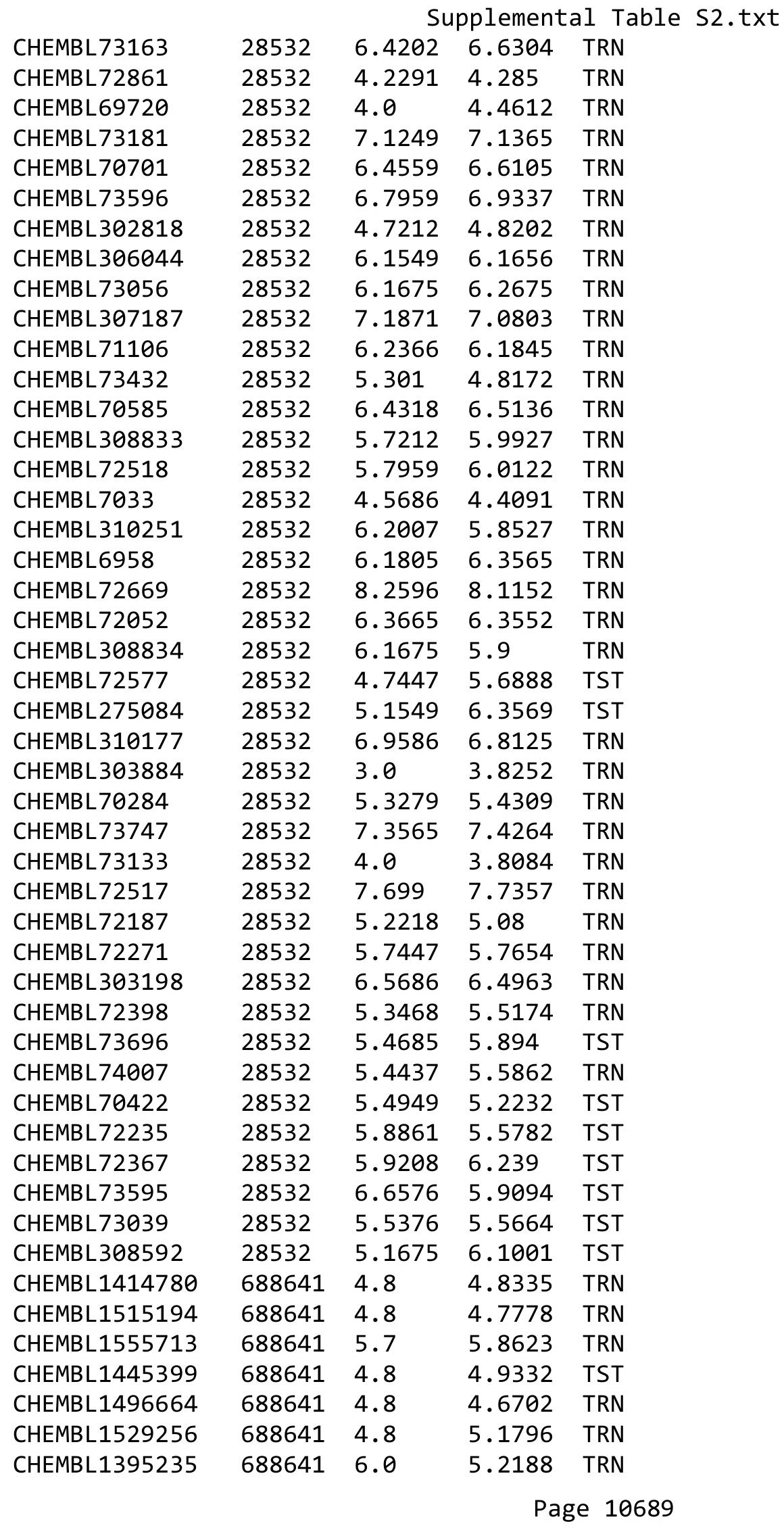




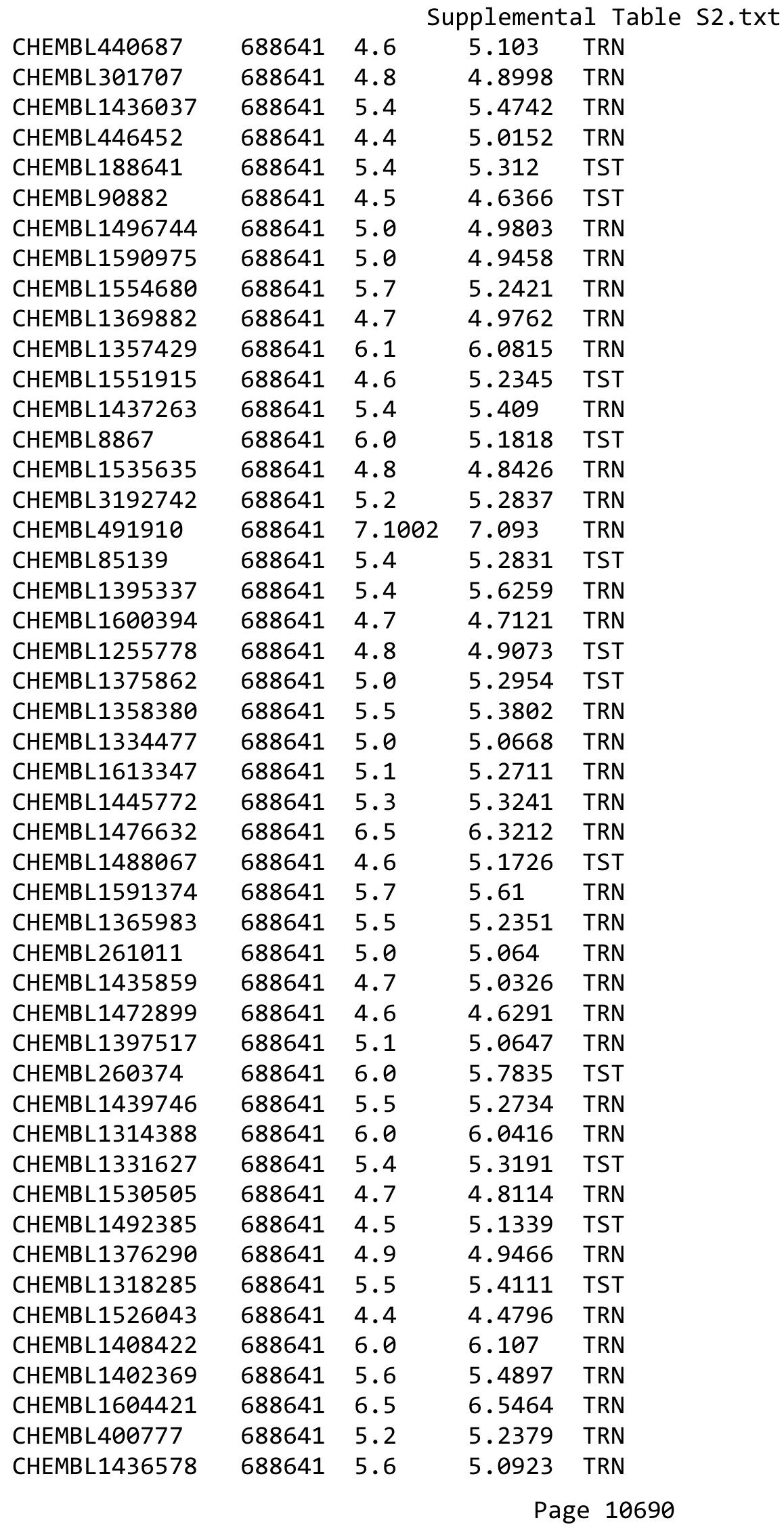




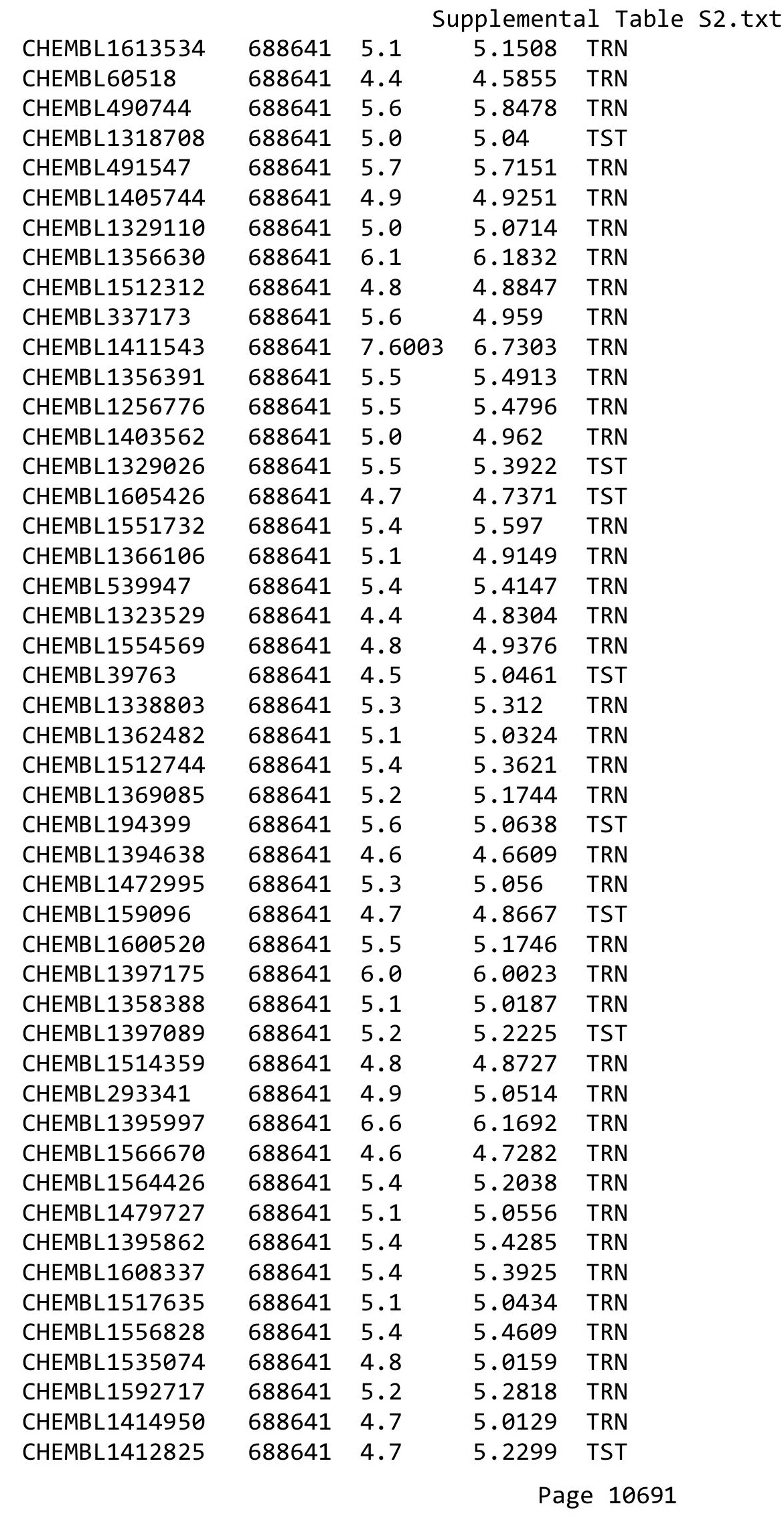




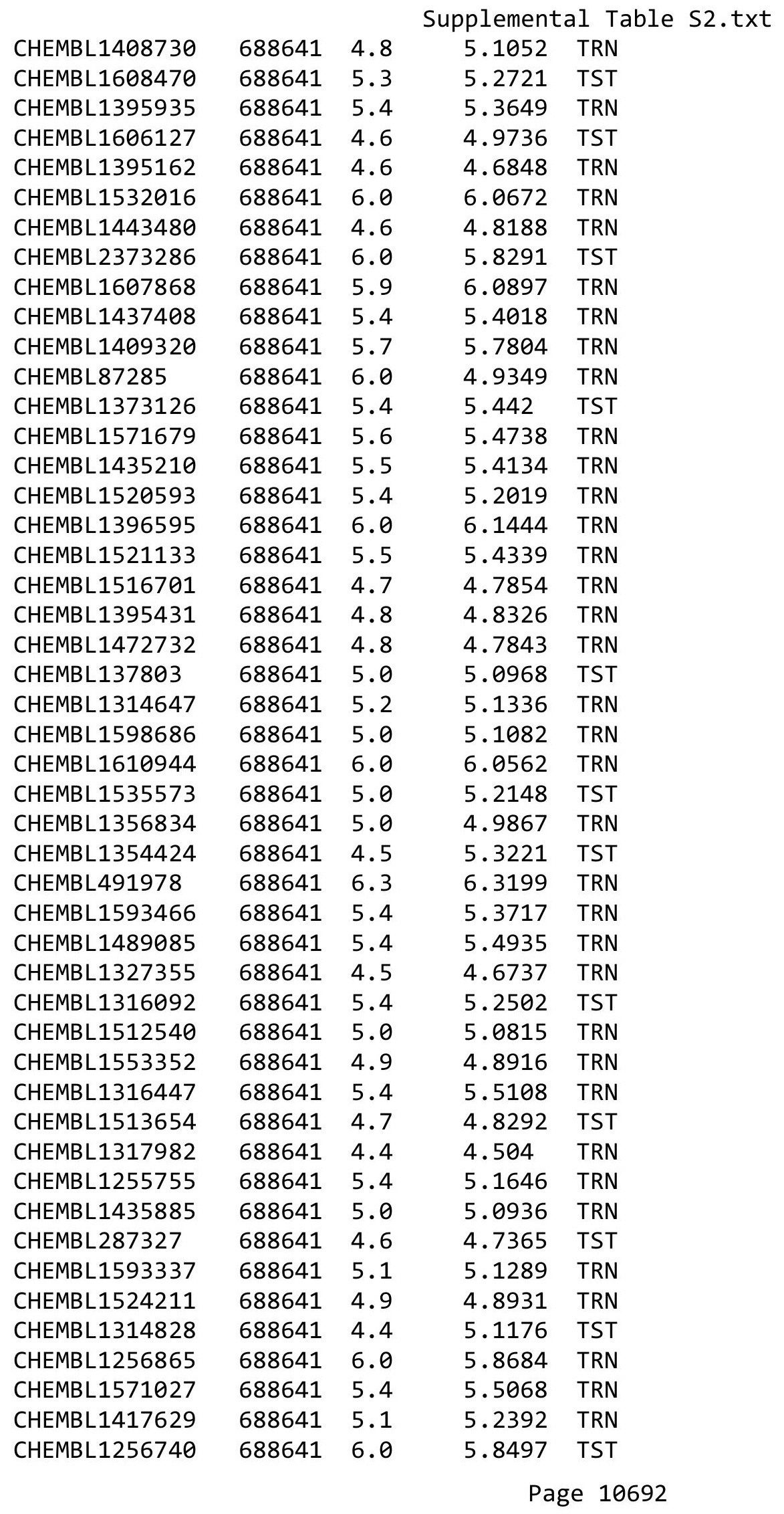




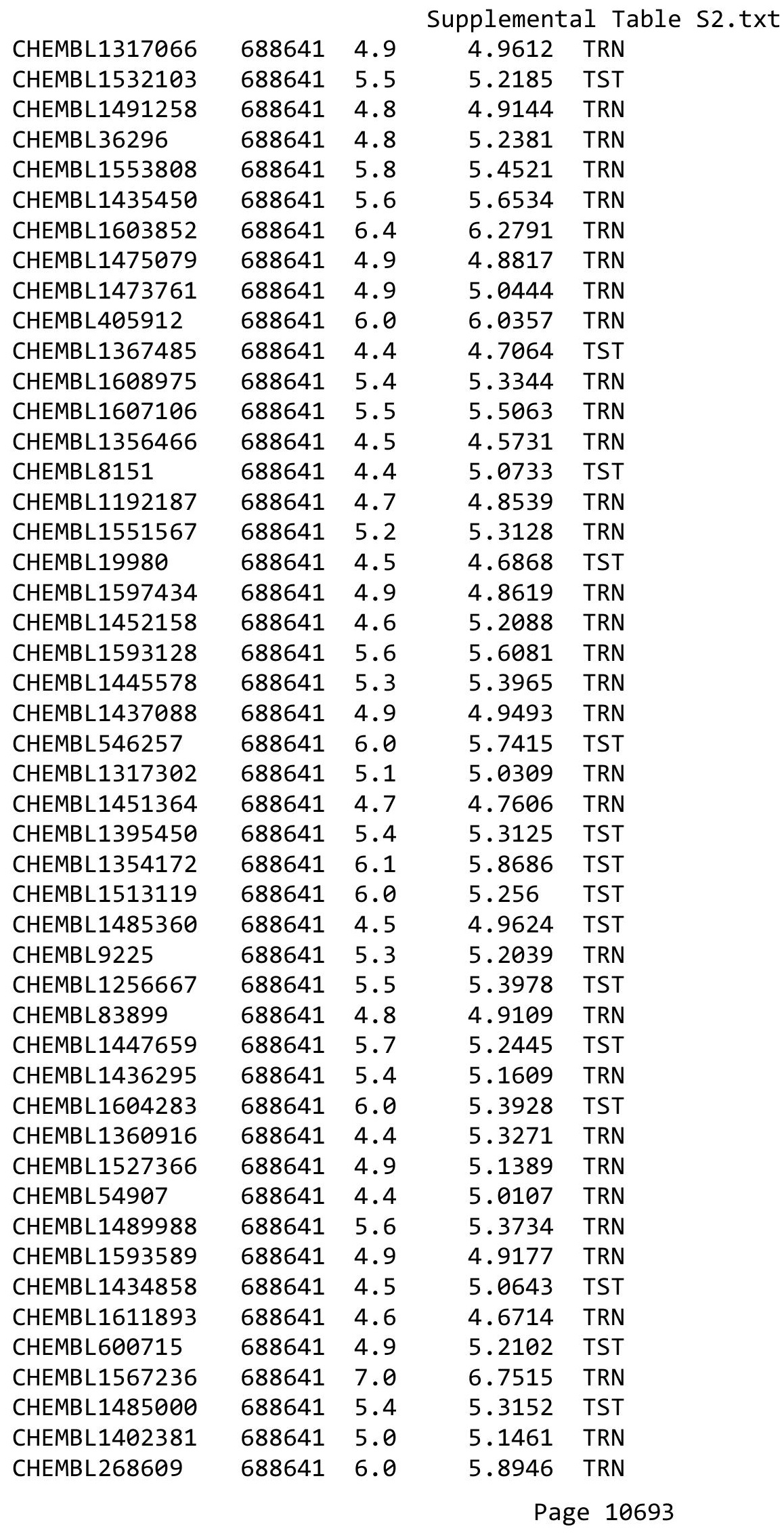




\begin{tabular}{|c|c|c|c|c|}
\hline \multicolumn{5}{|c|}{ plemental } \\
\hline CHEMBL1492577 & 688641 & 5.8 & 5.2059 & TRN \\
\hline CHEMBL1475627 & 688641 & 4.8 & 4.9491 & TRN \\
\hline CHEMBL491991 & 688641 & 5.4 & 5.0986 & TRN \\
\hline CHEMBL1408520 & 688641 & 4.9 & 4.9931 & TRN \\
\hline CHEMBL221300 & 688641 & 4.8 & 4.9576 & TRN \\
\hline CHEMBL1450619 & 688641 & 5.5 & 5.6107 & TRN \\
\hline CHEMBL1513030 & 688641 & 5.1 & 5.0527 & TRN \\
\hline CHEMBL1441891 & 688641 & 5.1 & 5.0547 & TRN \\
\hline CHEMBL1236872 & 688641 & 4.9 & 5.5204 & TRN \\
\hline CHEMBL433461 & 688641 & 6.1 & 5.8421 & TRN \\
\hline CHEMBL1551515 & 688641 & 4.7 & 4.773 & TRN \\
\hline CHEMBL25230 & 688641 & 4.9 & 5.1698 & TST \\
\hline CHEMBL1447909 & 688641 & 5.7 & 5.8962 & TRN \\
\hline CHEMBL1523822 & 688641 & 5.4 & 5.4573 & TST \\
\hline CHEMBL1231544 & 688641 & 5.1 & 4.8526 & TRN \\
\hline CHEMBL1483855 & 688641 & 5.5 & 5.6124 & TRN \\
\hline CHEMBL1396403 & 688641 & 4.6 & 4.6471 & TRN \\
\hline CHEMBL1440617 & 688641 & 4.8 & 4.84399 & 9999999999 \\
\hline CHEMBL1474313 & 688641 & 5.5 & 5.4879 & TRN \\
\hline CHEMBL1516007 & 688641 & 4.7 & 4.993 & TRN \\
\hline CHEMBL495068 & 688641 & 5.5 & 5.4709 & TRN \\
\hline CHEMBL1529361 & 688641 & 5.1 & 5.0756 & TRN \\
\hline CHEMBL1534710 & 688641 & 4.9 & 4.8281 & TRN \\
\hline CHEMBL1552181 & 688641 & 5.0 & 4.9827 & TRN \\
\hline CHEMBL1610929 & 688641 & 5.4 & 4.9197 & TRN \\
\hline CHEMBL1472786 & 688641 & 5.4 & 5.1391 & TST \\
\hline CHEMBL1256816 & 688641 & 4.8 & 4.9056 & TST \\
\hline CHEMBL1366393 & 688641 & 4.9 & 5.0698 & TRN \\
\hline CHEMBL1375525 & 688641 & 6.0 & 5.3689 & TRN \\
\hline CHEMBL462880 & 688641 & 4.7 & 4.9671 & TRN \\
\hline CHEMBL1331657 & 688641 & 4.6 & 4.878 & TRN \\
\hline CHEMBL1592465 & 688641 & 4.8 & 4.795 & TRN \\
\hline CHEMBL1590354 & 688641 & 5.7 & 5.7956 & TRN \\
\hline CHEMBL1518164 & 688641 & 4.9 & 5.06 & TRN \\
\hline CHEMBL 1605510 & 688641 & 5.0 & 4.9498 & TRN \\
\hline CHEMBL 2373622 & 688641 & 4.8 & 4.9511 & TST \\
\hline CHEMBL552439 & 688641 & 5.4 & 5.3222 & TST \\
\hline CHEMBL1493308 & 688641 & 5.8 & 5.237 & TRN \\
\hline CHEMBL1408343 & 688641 & 5.4 & 5.4388 & TRN \\
\hline CHEMBL1441920 & 688641 & 6.0 & 5.8292 & TST \\
\hline CHEMBL1316456 & 688641 & 5.4 & 5.3232 & TRN \\
\hline CHEMBL445969 & 688641 & 5.8 & 5.3082 & TST \\
\hline CHEMBL1515401 & 688641 & 4.9 & 4.9513 & TRN \\
\hline CHEMBL1559465 & 688641 & 4.9 & 4.974 & TRN \\
\hline CHEMBL1477557 & 688641 & 4.8 & 4.8251 & TRN \\
\hline CHEMBL1414251 & 688641 & 5.1 & 5.4382 & TRN \\
\hline CHEMBL1374108 & 688641 & 5.1 & 5.1641 & TRN \\
\hline CHEMBL1330251 & 688641 & 5.7 & 5.6646 & TRN \\
\hline
\end{tabular}




\begin{tabular}{|c|c|c|c|c|}
\hline \multicolumn{5}{|c|}{ Supplemental Table S2.txt } \\
\hline CHEMBL1318222 & 688641 & 4.5 & 4.8051 & TRN \\
\hline CHEMBL1515361 & 688641 & 4.8 & 4.9418 & TRN \\
\hline CHEMBL1519326 & 688641 & 4.8 & 4.8047 & TRN \\
\hline CHEMBL1368261 & 688641 & 4.8 & 5.1211 & TST \\
\hline CHEMBL1601908 & 688641 & 4.9 & 5.273 & TRN \\
\hline CHEMBL1440619 & 688641 & 5.0 & 5.1254 & TRN \\
\hline CHEMBL1612893 & 688641 & 4.7 & 4.7756 & TRN \\
\hline CHEMBL1436979 & 688641 & 4.9 & 4.838 & TRN \\
\hline CHEMBL1591487 & 688641 & 4.5 & 4.5452 & TRN \\
\hline CHEMBL1573862 & 688641 & 4.9 & 4.9549 & TRN \\
\hline CHEMBL1327459 & 688641 & 5.5 & 5.4739 & TRN \\
\hline CHEMBL1397079 & 688641 & 4.6 & 4.6753 & TRN \\
\hline CHEMBL1599647 & 688641 & 6.7001 & 5.1932 & TST \\
\hline CHEMBL1333287 & 688641 & 4.9 & 4.8414 & TRN \\
\hline CHEMBL1573319 & 688641 & 4.9 & 5.1197 & TRN \\
\hline CHEMBL 290914 & 688641 & 4.8 & 5.107 & TRN \\
\hline CHEMBL1395415 & 688641 & 4.9 & 4.9407 & TRN \\
\hline CHEMBL1369013 & 688641 & 5.1 & 4.9359 & TRN \\
\hline CHEMBL1473755 & 688641 & 5.6 & 5.5498 & TRN \\
\hline CHEMBL1355849 & 688641 & 5.5 & 5.1097 & TST \\
\hline CHEMBL1396170 & 688641 & 4.4 & 5.1043 & TRN \\
\hline CHEMBL1358738 & 688641 & 5.5 & 5.3947 & TRN \\
\hline CHEMBL1447239 & 688641 & 6.1 & 5.4851 & TRN \\
\hline CHEMBL1355263 & 688641 & 5.2 & 5.0882 & TRN \\
\hline CHEMBL454761 & 688641 & 5.5 & 5.3115 & TRN \\
\hline CHEMBL1474318 & 688641 & 5.1 & 5.0873 & TRN \\
\hline CHEMBL1473793 & 688641 & 4.6 & 4.5998 & TRN \\
\hline CHEMBL492127 & 688641 & 6.5 & 6.7041 & TRN \\
\hline CHEMBL1403333 & 688641 & 5.3 & 5.1722 & TRN \\
\hline CHEMBL1394499 & 688641 & 4.8 & 4.8446 & TRN \\
\hline CHEMBL1256191 & 688641 & 4.8 & 4.8357 & TRN \\
\hline CHEMBL1314745 & 688641 & 4.9 & 4.9688 & TRN \\
\hline CHEMBL1409369 & 688641 & 5.5 & 5.4037 & TRN \\
\hline CHEMBL1256360 & 688641 & 5.0 & 4.9819 & TRN \\
\hline CHEMBL521971 & 688641 & 6.6 & 6.6977 & TRN \\
\hline CHEMBL1417139 & 688641 & 5.7 & 5.346 & TRN \\
\hline CHEMBL1435886 & 688641 & 4.9 & 4.9026 & TRN \\
\hline CHEMBL1400280 & 688641 & 5.0 & 5.4599 & TRN \\
\hline CHEMBL1416639 & 688641 & 4.6 & 4.6531 & TRN \\
\hline CHEMBL1316461 & 688641 & 5.9 & 5.6896 & TRN \\
\hline CHEMBL1317913 & 688641 & 5.2 & 5.0857 & TRN \\
\hline CHEMBL1439665 & 688641 & 4.8 & 4.9335 & TRN \\
\hline CHEMBL575073 & 688641 & 4.6 & 4.9272 & TRN \\
\hline CHEMBL1611678 & 688641 & 5.4 & 5.425 & TRN \\
\hline CHEMBL1356138 & 688641 & 5.5 & 5.4727 & TRN \\
\hline CHEMBL402063 & 688641 & 6.0 & 5.2421 & TRN \\
\hline CHEMBL1437226 & 688641 & 5.9 & 5.9183 & TRN \\
\hline CHEMBL1448490 & 688641 & 6.0 & 5.1295 & TRN \\
\hline
\end{tabular}


Supplemental Table S2.txt

\begin{tabular}{|c|c|c|c|c|c|}
\hline CHEMBL1475924 & 688641 & 7.1002 & 6.6208 & TRN & \\
\hline CHEMBL1475151 & 688641 & 5.5 & 5.5236 & TRN & \\
\hline CHEMBL1324493 & 688641 & 4.8 & 4.9173 & TST & \\
\hline CHEMBL1512850 & 688641 & 4.6 & 4.6566 & TRN & \\
\hline CHEMBL489737 & 688641 & 6.7001 & 6.7691 & TRN & \\
\hline CHEMBL1400594 & 688641 & 6.0 & 5.6986 & TRN & \\
\hline CHEMBL1437804 & 688641 & 4.8 & 4.8871 & TST & \\
\hline CHEMBL1435544 & 688641 & 4.8 & 4.7847 & TRN & \\
\hline CHEMBL1335332 & 688641 & 4.8 & 4.8499 & TRN & \\
\hline CHEMBL1703229 & 688641 & 5.1 & 5.0763 & TRN & \\
\hline CHEMBL1597612 & 688641 & 4.9 & 5.008 & TRN & \\
\hline CHEMBL1372282 & 688641 & 5.4 & 5.3134 & TST & \\
\hline CHEMBL1396822 & 688641 & 5.5 & 5.4279 & TST & \\
\hline CHEMBL1478 & 688641 & 4.5 & 5.564 & TRN & \\
\hline CHEMBL1315083 & 688641 & 5.7 & 5.6844 & TRN & \\
\hline CHEMBL1356304 & 688641 & 5.5 & 5.2745 & TST & \\
\hline CHEMBL319244 & 688641 & 6.0 & 4.8556 & TRN & \\
\hline CHEMBL1476184 & 688641 & 4.9 & 4.8248 & TRN & \\
\hline CHEMBL1514931 & 688641 & 4.5 & 4.6473 & TST & \\
\hline CHEMBL1165239 & 688641 & 5.6 & 5.0319 & TST & \\
\hline CHEMBL1559127 & 688641 & 5.1 & 5.2139 & TRN & \\
\hline CHEMBL1551284 & 688641 & 5.0 & 5.1195 & TRN & \\
\hline CHEMBL1406513 & 688641 & 4.9 & 5.1297 & TRN & \\
\hline CHEMBL1569638 & 688641 & 5.5 & 5.4343 & TRN & \\
\hline CHEMBL1332636 & 688641 & 5.4 & 5.4502 & TRN & \\
\hline CHEMBL1396615 & 688641 & 4.8 & 4.9146 & TRN & \\
\hline CHEMBL1395523 & 688641 & 6.0 & 6.0365 & TRN & \\
\hline CHEMBL574181 & 688641 & 5.5 & 5.3945 & TRN & \\
\hline CHEMBL1562777 & 688641 & 5.2 & 4.9605 & TRN & \\
\hline CHEMBL1489438 & 688641 & 4.8 & 4.8407 & TRN & \\
\hline CHEMBL 2373647 & 688641 & 5.2 & 5.2794 & TST & \\
\hline CHEMBL1362657 & 688641 & 5.4 & 5.4132 & TST & \\
\hline CHEMBL245121 & 688641 & 4.9 & 5.2473 & TRN & \\
\hline CHEMBL573524 & 688641 & 5.9 & 5.2228 & TRN & \\
\hline CHEMBL1448728 & 688641 & 4.9 & 4.8375 & TRN & \\
\hline CHEMBL1200765 & 688641 & 6.0 & 5.081 & TST & \\
\hline CHEMBL1527132 & 688641 & 5.7 & 5.7563 & TRN & \\
\hline CHEMBL1612363 & 688641 & 5.0 & 5.0159 & TRN & \\
\hline CHEMBL329673 & 688641 & 4.9 & 5.16200 & 3000000001 & TRN \\
\hline CHEMBL1370480 & 688641 & 4.5 & 4.723 & TRN & \\
\hline CHEMBL1355387 & 688641 & 5.4 & 5.3799 & TRN & \\
\hline CHEMBL1394854 & 688641 & 6.3 & 6.3385 & TRN & \\
\hline CHEMBL1477443 & 688641 & 5.0 & 4.811 & TRN & \\
\hline CHEMBL1439455 & 688641 & 5.4 & 5.2695 & TST & \\
\hline CHEMBL1255659 & 688641 & 4.6 & 4.7435 & TRN & \\
\hline CHEMBL1603113 & 688641 & 5.6 & 5.5795 & TRN & \\
\hline CHEMBL98572 & 688641 & 4.9 & 5.1085 & TST & \\
\hline CHEMBL1365616 & 688641 & 4.9 & 5.0321 & TRN & \\
\hline
\end{tabular}




\begin{tabular}{|c|c|c|c|c|}
\hline \multicolumn{5}{|c|}{ Supplemental Table S2.txt } \\
\hline CHEMBL1433486 & 688641 & 5.0 & 4.9396 & TRN \\
\hline CHEMBL389390 & 688641 & 6.0 & 4.8731 & TRN \\
\hline CHEMBL1454751 & 688641 & 5.1 & 5.2296 & TRN \\
\hline CHEMBL1600620 & 688641 & 5.3 & 5.1986 & TRN \\
\hline CHEMBL1594078 & 688641 & 4.9 & 5.0052 & TRN \\
\hline CHEMBL1334106 & 688641 & 6.0 & 6.0298 & TRN \\
\hline CHEMBL194805 & 688641 & 4.7 & 5.078 & TRN \\
\hline CHEMBL539027 & 688641 & 5.0 & 5.0116 & TRN \\
\hline CHEMBL1434272 & 688641 & 5.0 & 5.0136 & TRN \\
\hline CHEMBL1610387 & 688641 & 4.9 & 4.9652 & TRN \\
\hline CHEMBL 242385 & 688641 & 5.4 & 5.433 & TRN \\
\hline CHEMBL428496 & 688641 & 5.1 & 5.1176 & TST \\
\hline CHEMBL1355111 & 688641 & 4.8 & 4.8393 & TRN \\
\hline CHEMBL362863 & 688641 & 6.5 & 6.187 & TST \\
\hline CHEMBL1355515 & 688641 & 5.4 & 5.4802 & TRN \\
\hline CHEMBL1405187 & 688641 & 5.4 & 5.2382 & TST \\
\hline CHEMBL 28449 & 688641 & 6.0 & 5.8488 & TRN \\
\hline CHEMBL1490307 & 688641 & 4.4 & 4.6121 & TRN \\
\hline CHEMBL1594612 & 688641 & 6.5 & 6.5113 & TRN \\
\hline CHEMBL1597873 & 688641 & 5.3 & 5.2075 & TST \\
\hline CHEMBL1520681 & 688641 & 5.3 & 5.1763 & TRN \\
\hline CHEMBL1598394 & 688641 & 4.9 & 5.1215 & TRN \\
\hline CHEMBL1590974 & 688641 & 5.4 & 5.2903 & TRN \\
\hline CHEMBL1411411 & 688641 & 6.0 & 5.1831 & TRN \\
\hline CHEMBL1367020 & 688641 & 4.7 & 4.7073 & TRN \\
\hline CHEMBL1362935 & 688641 & 4.4 & 5.0952 & TRN \\
\hline CHEMBL1606380 & 688641 & 6.0 & 5.9805 & TRN \\
\hline CHEMBL1317016 & 688641 & 5.6 & 5.2663 & TST \\
\hline CHEMBL150 & 688641 & 6.0 & 5.3516 & TRN \\
\hline CHEMBL12129 & 688641 & 6.2 & 6.0497 & TRN \\
\hline CHEMBL1399553 & 688641 & 5.0 & 5.2921 & TST \\
\hline CHEMBL1437436 & 688641 & 5.4 & 5.4029 & TST \\
\hline CHEMBL1446649 & 688641 & 5.3 & 5.2458 & TRN \\
\hline CHEMBL1406485 & 688641 & 4.7 & 4.7835 & TRN \\
\hline CHEMBL1554453 & 688641 & 5.1 & 5.1621 & TRN \\
\hline CHEMBL1374903 & 688641 & 5.4 & 5.1127 & TRN \\
\hline CHEMBL1256693 & 688641 & 5.1 & 5.1043 & TST \\
\hline CHEMBL1479767 & 688641 & 5.0 & 5.1119 & TRN \\
\hline CHEMBL1322958 & 688641 & 5.4 & 4.9698 & TST \\
\hline CHEMBL1435823 & 688641 & 5.0 & 4.9447 & TRN \\
\hline CHEMBL1475255 & 688641 & 6.2 & 6.183 & TRN \\
\hline CHEMBL 242341 & 688641 & 4.8 & 4.975 & TRN \\
\hline CHEMBL1525886 & 688641 & 5.4 & 5.3365 & TST \\
\hline CHEMBL1367995 & 688641 & 4.4 & 4.5121 & TRN \\
\hline CHEMBL1491397 & 688641 & 4.8 & 4.9861 & TST \\
\hline CHEMBL1522460 & 688641 & 4.8 & 4.8446 & TRN \\
\hline CHEMBL104255 & 688641 & 4.8 & 5.0646 & TRN \\
\hline CHEMBL1557657 & 688641 & 4.9 & 4.8745 & TRN \\
\hline
\end{tabular}




\begin{tabular}{|c|c|c|c|c|c|}
\hline \multicolumn{6}{|c|}{ Supplemental Table s2.txt } \\
\hline CHEMBL1553488 & 688641 & 5.5 & 5.0532 & TST & \\
\hline CHEMBL343732 & 688641 & 4.5 & 4.9527 & TST & \\
\hline CHEMBL1436917 & 688641 & 5.2 & 5.181 & TRN & \\
\hline CHEMBL1364182 & 688641 & 5.4 & 5.4612 & TRN & \\
\hline CHEMBL2373587 & 688641 & 5.6 & 5.2347 & TRN & \\
\hline CHEMBL1449834 & 688641 & 4.8 & 5.1487 & TRN & \\
\hline CHEMBL1492558 & 688641 & 4.5 & 4.5427 & TRN & \\
\hline CHEMBL286077 & 688641 & 6.8 & 6.1832 & TST & \\
\hline CHEMBL1528648 & 688641 & 4.8 & \multicolumn{2}{|c|}{5.1370000000000005} & TRN \\
\hline CHEMBL1591238 & 688641 & 5.9 & 5.9897 & TRN & \\
\hline CHEMBL1512434 & 688641 & 6.0 & 6.0304 & TRN & \\
\hline CHEMBL1318560 & 688641 & 5.7 & 5.4687 & TRN & \\
\hline CHEMBL1435754 & 688641 & 6.0 & 5.4859 & TST & \\
\hline CHEMBL6634 & 688641 & 7.4001 & 6.4535 & TST & \\
\hline CHEMBL1607885 & 688641 & 5.9 & 6.0014 & TRN & \\
\hline CHEMBL164660 & 688641 & 4.5 & 4.9428 & TRN & \\
\hline CHEMBL1472955 & 688641 & 5.4 & 5.4623 & TRN & \\
\hline CHEMBL1595524 & 688641 & 4.4 & 4.5706 & TST & \\
\hline CHEMBL1452881 & 688641 & 6.0 & 5.7858 & TST & \\
\hline CHEMBL1439625 & 688641 & 4.4 & 5.4648 & TRN & \\
\hline CHEMBL1591635 & 688641 & 4.8 & 4.8675 & TRN & \\
\hline CHEMBL1318419 & 688641 & 5.4 & 5.1157 & TRN & \\
\hline CHEMBL363506 & 688641 & 6.0 & 5.0235 & TST & \\
\hline CHEMBL1415927 & 688641 & 5.5 & 5.2227 & TST & \\
\hline CHEMBL1318310 & 688641 & 5.4 & 5.4623 & TRN & \\
\hline CHEMBL1372037 & 688641 & 6.1 & 6.2438 & TRN & \\
\hline CHEMBL1552095 & 688641 & 6.0 & 5.9438 & TST & \\
\hline CHEMBL1562093 & 688641 & 5.6 & 5.2004 & TST & \\
\hline CHEMBL457583 & 688641 & 4.6 & 5.0658 & TRN & \\
\hline CHEMBL1394258 & 688641 & 4.9 & 4.9488 & TRN & \\
\hline CHEMBL1327681 & 688641 & 4.7 & \multicolumn{2}{|c|}{4.8660000000000005} & TRN \\
\hline CHEMBL1730100 & 688641 & 6.0 & 5.1189 & TST & \\
\hline CHEMBL1611630 & 688641 & 7.8996 & 4.7558 & TRN & \\
\hline CHEMBL332898 & 688641 & 5.1 & 5.0858 & TRN & \\
\hline CHEMBL1440943 & 688641 & 6.3 & 6.4467 & TRN & \\
\hline CHEMBL1456906 & 688641 & 4.8 & 5.3323 & TST & \\
\hline CHEMBL1405339 & 688641 & 4.9 & 5.1392 & TRN & \\
\hline CHEMBL1079421 & 688641 & 4.6 & 4.8544 & TRN & \\
\hline CHEMBL475375 & 688641 & 5.4 & 5.5162 & TRN & \\
\hline CHEMBL1325766 & 688641 & 5.5 & 5.4368 & TRN & \\
\hline CHEMBL1356843 & 688641 & 4.4 & 4.5503 & TRN & \\
\hline CHEMBL1557167 & 688641 & 4.9 & 4.9283 & TST & \\
\hline CHEMBL1316190 & 688641 & 4.8 & 5.0285 & TRN & \\
\hline CHEMBL1440157 & 688641 & 6.7001 & 6.7607 & TRN & \\
\hline CHEMBL1314641 & 688641 & 5.3 & 5.1207 & TST & \\
\hline CHEMBL1377706 & 688641 & 4.6 & 4.7995 & TRN & \\
\hline CHEMBL1558153 & 688641 & 4.6 & 5.115 & TST & \\
\hline CHEMBL1358586 & 688641 & 4.8 & 4.8038 & TRN & \\
\hline
\end{tabular}




\begin{tabular}{|c|c|c|c|c|c|}
\hline \multirow{2}{*}{ CHEMBL1565169 } & \multirow{2}{*}{688641} & \\
\hline & & 5.4 & 5.2369 & TRN & \\
\hline CHEMBL1551962 & 688641 & 5.6 & 5.4781 & TRN & \\
\hline CHEMBL1516254 & 688641 & 4.8 & 4.7221 & TRN & \\
\hline CHEMBL1561691 & 688641 & 5.4 & 5.0418 & TRN & \\
\hline CHEMBL1435902 & 688641 & 5.9 & 5.3536 & TRN & \\
\hline CHEMBL 228132 & 688641 & 5.5 & 5.1052 & TRN & \\
\hline CHEMBL1591965 & 688641 & 5.2 & 5.1384 & TRN & \\
\hline CHEMBL1356069 & 688641 & 5.0 & 5.2667 & TRN & \\
\hline CHEMBL1475075 & 688641 & 5.8 & 5.7167 & TRN & \\
\hline CHEMBL1474987 & 688641 & 4.7 & 5.1284 & TRN & \\
\hline CHEMBL1481399 & 688641 & 4.9 & 4.8562 & TRN & \\
\hline CHEMBL1552066 & 688641 & 5.4 & 5.4016 & TRN & \\
\hline CHEMBL10347 & 688641 & 6.0 & 5.8126 & TST & \\
\hline CHEMBL1605399 & 688641 & 5.2 & 4.8176 & TRN & \\
\hline CHEMBL1570285 & 688641 & 5.6 & 5.6088 & TRN & \\
\hline CHEMBL1372363 & 688641 & 4.8 & 4.8187 & TRN & \\
\hline CHEMBL1437012 & 688641 & 5.5 & 5.3729 & TST & \\
\hline CHEMBL1366020 & 688641 & 5.7 & 5.6011 & TRN & \\
\hline CHEMBL1314897 & 688641 & 5.5 & 5.3367 & TRN & \\
\hline CHEMBL1512198 & 688641 & 4.9 & 4.9577 & TST & \\
\hline CHEMBL1316108 & 688641 & 4.6 & 4.6437 & TRN & \\
\hline CHEMBL1255832 & 688641 & 4.9 & 4.9691 & TRN & \\
\hline CHEMBL 243664 & 688641 & 6.0 & 5.5876 & TRN & \\
\hline CHEMBL1317069 & 688641 & 5.0 & 5.2289 & TST & \\
\hline CHEMBL1326092 & 688641 & 4.9 & 5.0007 & TRN & \\
\hline CHEMBL1396384 & 688641 & 5.3 & 5.5596 & TRN & \\
\hline CHEMBL 309490 & 688641 & 4.8 & 5.4682 & TRN & \\
\hline CHEMBL1355835 & 688641 & 6.3 & 6.0808 & TRN & \\
\hline CHEMBL144530 & 688641 & 4.6 & 4.8761 & TST & \\
\hline CHEMBL1408954 & 688641 & 5.6 & 5.4475 & TST & \\
\hline CHEMBL1330057 & 688641 & 5.5 & 5.4207 & TST & \\
\hline CHEMBL1527579 & 688641 & 5.4 & 5.4552 & TRN & \\
\hline CHEMBL1733652 & 688641 & 6.4 & 5.0752 & TST & \\
\hline CHEMBL1335465 & 688641 & 4.8 & 4.8067 & TRN & \\
\hline CHEMBL1612347 & 688641 & 4.8 & 5.0545 & TRN & \\
\hline CHEMBL1557007 & 688641 & 5.4 & 5.3123 & TRN & \\
\hline CHEMBL1486638 & 688641 & 5.7 & 5.6569 & TST & \\
\hline CHEMBL1590266 & 688641 & 5.1 & 5.0882 & TRN & \\
\hline CHEMBL1358120 & 688641 & 5.4 & 5.3606 & TRN & \\
\hline CHEMBL1511972 & 688641 & 4.4 & 4.5177 & TRN & \\
\hline CHEMBL1338909 & 688641 & 4.9 & 5.1014 & TRN & \\
\hline CHEMBL1521440 & 688641 & 5.4 & 5.7170 & 00000000005 & TRN \\
\hline CHEMBL1514110 & 688641 & 5.1 & 5.0341 & TRN & \\
\hline CHEMBL1451823 & 688641 & 5.5 & 5.0198 & TRN & \\
\hline CHEMBL161343 & 688641 & 4.6 & 4.7056 & TRN & \\
\hline CHEMBL1487381 & 688641 & 6.0 & 5.1116 & TRN & \\
\hline CHEMBL583849 & 688641 & 5.0 & 5.0805 & TRN & \\
\hline CHEMBL1600586 & 688641 & 5.3 & 5.3453 & TRN & \\
\hline & & & & 10699 & \\
\hline
\end{tabular}




\begin{tabular}{|c|c|c|c|c|}
\hline & & & plement & \\
\hline CHEMBL1372870 & 688641 & 4.8 & 5.2465 & TST \\
\hline CHEMBL1476267 & 688641 & 5.4 & 5.2652 & TRN \\
\hline CHEMBL1560764 & 688641 & 6.0 & 5.8371 & TRN \\
\hline CHEMBL1482908 & 688641 & 5.3 & 5.1629 & TRN \\
\hline CHEMBL196537 & 688641 & 4.8 & 5.0175 & TST \\
\hline CHEMBL1397279 & 688641 & 5.7 & 5.3615 & TRN \\
\hline CHEMBL1434535 & 688641 & 5.1 & 5.3387 & TRN \\
\hline CHEMBL1601166 & 688641 & 4.6 & 5.0057 & TRN \\
\hline CHEMBL1405627 & 688641 & 6.1 & 6.1894 & TRN \\
\hline CHEMBL1594132 & 688641 & 5.0 & 5.1447 & TRN \\
\hline CHEMBL1362420 & 688641 & 5.4 & 4.9923 & TRN \\
\hline CHEMBL 291536 & 688641 & 5.0 & 5.0246 & TST \\
\hline CHEMBL1371397 & 688641 & 5.1 & 5.2197 & TST \\
\hline CHEMBL1332726 & 688641 & 4.8 & 4.9137 & TRN \\
\hline CHEMBL1407887 & 688641 & 5.4 & 5.2185 & TST \\
\hline CHEMBL515916 & 688641 & 5.0 & 5.0351 & TST \\
\hline CHEMBL258728 & 688641 & 5.1 & 4.9673 & TRN \\
\hline CHEMBL1612620 & 688641 & 5.2 & 5.0919 & TRN \\
\hline CHEMBL1367222 & 688641 & 5.5 & 5.6084 & TRN \\
\hline CHEMBL1484120 & 688641 & 5.4 & 5.1998 & TRN \\
\hline CHEMBL1400043 & 688641 & 4.8 & 4.8858 & TRN \\
\hline CHEMBL1488845 & 688641 & 5.0 & 4.891 & TST \\
\hline CHEMBL1591847 & 688641 & 4.8 & 4.8264 & TRN \\
\hline CHEMBL 287045 & 688641 & 4.5 & 4.6907 & TRN \\
\hline CHEMBL1486465 & 688641 & 5.6 & 5.0643 & TRN \\
\hline CHEMBL1559023 & 688641 & 4.8 & 4.8245 & TRN \\
\hline CHEMBL1410627 & 688641 & 5.4 & 5.2984 & TST \\
\hline CHEMBL86676 & 688641 & 5.9 & 5.7185 & TST \\
\hline CHEMBL1394661 & 688641 & 5.5 & 5.4791 & TRN \\
\hline CHEMBL1322976 & 688641 & 5.4 & 5.1273 & TST \\
\hline CHEMBL1439400 & 688641 & 6.0 & 5.1198 & TRN \\
\hline CHEMBL1513876 & 688641 & 5.2 & 5.0445 & TRN \\
\hline CHEMBL1601163 & 688641 & 6.4 & 6.5898 & TRN \\
\hline CHEMBL393136 & 688641 & 4.5 & 5.0885 & TRN \\
\hline CHEMBL1442538 & 688641 & 4.5 & 4.6333 & TRN \\
\hline CHEMBL1533335 & 688641 & 5.5 & 5.4921 & TRN \\
\hline CHEMBL1516276 & 688641 & 4.5 & 4.5808 & TRN \\
\hline CHEMBL1552727 & 688641 & 4.7 & 4.789 & TRN \\
\hline CHEMBL1358628 & 688641 & 6.0 & 5.7282 & TRN \\
\hline CHEMBL1526429 & 688641 & 6.0 & 5.9029 & TRN \\
\hline CHEMBL1474890 & 688641 & 5.0 & 5.0407 & TRN \\
\hline CHEMBL1493002 & 688641 & 5.2 & 5.088 & TRN \\
\hline CHEMBL1415957 & 688641 & 5.5 & 5.4401 & TRN \\
\hline CHEMBL1316656 & 688641 & 5.4 & 5.3867 & TRN \\
\hline CHEMBL1474625 & 688641 & 6.0 & 5.7263 & TRN \\
\hline CHEMBL1473307 & 688641 & 4.5 & 5.2237 & TST \\
\hline CHEMBL1375285 & 688641 & 6.0 & 6.0082 & TRN \\
\hline CHEMBL1366296 & 688641 & 7.6003 & 6.9006 & TRN \\
\hline
\end{tabular}




\begin{tabular}{|c|c|c|c|c|c|}
\hline \multirow{3}{*}{$\begin{array}{l}\text { CHEMBL1438690 } \\
\text { CHEMBL1488668 }\end{array}$} & \multirow{3}{*}{$\begin{array}{l}688641 \\
688641\end{array}$} & \multicolumn{4}{|c|}{ Supplemental Table S2.txt } \\
\hline & & 6.0 & \multicolumn{2}{|c|}{6.2379999999999995} & TRN \\
\hline & & 4.9 & 4.9655 & TRN & \\
\hline CHEMBL1317603 & 688641 & 5.4 & 5.1507 & TRN & \\
\hline CHEMBL1371095 & 688641 & 5.0 & 5.153 & TST & \\
\hline CHEMBL491748 & 688641 & 5.1 & 5.1956 & TRN & \\
\hline CHEMBL1401780 & 688641 & 5.7 & 5.1496 & TRN & \\
\hline CHEMBL1611806 & 688641 & 5.3 & 5.1824 & TRN & \\
\hline CHEMBL1374696 & 688641 & 4.8 & 4.8594 & TRN & \\
\hline CHEMBL1434655 & 688641 & 4.5 & 4.5983 & TRN & \\
\hline CHEMBL1515792 & 688641 & 4.8 & 5.1816 & TST & \\
\hline CHEMBL1437273 & 688641 & 5.2 & 5.0513 & TRN & \\
\hline CHEMBL1559912 & 688641 & 5.4 & 5.2669 & TRN & \\
\hline CHEMBL1337755 & 688641 & 6.0 & 5.7454 & TST & \\
\hline CHEMBL1414592 & 688641 & 4.7 & 4.7296 & TRN & \\
\hline CHEMBL1335634 & 688641 & 6.0 & 5.1446 & TRN & \\
\hline CHEMBL1553941 & 688641 & 4.8 & 4.9148 & TRN & \\
\hline CHEMBL1529205 & 688641 & 5.4 & 5.2034 & TRN & \\
\hline CHEMBL1595291 & 688641 & 5.1 & 5.0954 & TRN & \\
\hline CHEMBL1555314 & 688641 & 5.6 & 5.6906 & TRN & \\
\hline CHEMBL 78150 & 688641 & 5.5 & 5.3528 & TRN & \\
\hline CHEMBL1087126 & 688641 & 4.4 & 5.0645 & TRN & \\
\hline CHEMBL1358197 & 688641 & 5.9 & 5.994 & TRN & \\
\hline CHEMBL260316 & 688641 & 4.8 & 5.2533 & TRN & \\
\hline CHEMBL1527944 & 688641 & 4.4 & 5.5467 & TRN & \\
\hline CHEMBL1476426 & 688641 & 4.7 & 5.3164 & TRN & \\
\hline CHEMBL310798 & 688641 & 5.0 & 4.9494 & TRN & \\
\hline CHEMBL1356196 & 688641 & 5.3 & 5.2844 & TRN & \\
\hline CHEMBL1270169 & 688641 & 5.7 & 5.5556 & TST & \\
\hline CHEMBL1452520 & 688641 & 6.3 & 5.2084 & TRN & \\
\hline CHEMBL418068 & 688641 & 5.0 & 4.9626 & TRN & \\
\hline CHEMBL1447808 & 688641 & 4.8 & 5.1715 & TRN & \\
\hline CHEMBL1321094 & 688641 & 4.9 & 4.8529 & TRN & \\
\hline CHEMBL1328319 & 688641 & 5.1 & 5.3033 & TRN & \\
\hline CHEMBL1317802 & 688641 & 4.9 & 4.9345 & TRN & \\
\hline CHEMBL1474532 & 688641 & 4.6 & 5.0873 & TST & \\
\hline CHEMBL1574966 & 688641 & 6.0 & 5.9153 & TRN & \\
\hline CHEMBL1561132 & 688641 & 5.4 & 5.34200 & 00000000005 & TST \\
\hline CHEMBL 24909 & 688641 & 6.2 & 6.1215 & TRN & \\
\hline CHEMBL1434057 & 688641 & 5.0 & 5.0504 & TRN & \\
\hline CHEMBL 2373557 & 688641 & 6.0 & 5.2069 & TRN & \\
\hline CHEMBL1552303 & 688641 & 5.3 & 5.3961 & TRN & \\
\hline CHEMBL1232207 & 688641 & 4.9 & 5.025 & TST & \\
\hline CHEMBL3965817 & 688641 & 4.5 & 5.0267 & TRN & \\
\hline CHEMBL1407497 & 688641 & 4.9 & 5.0681 & TRN & \\
\hline CHEMBL1593861 & 688641 & 4.8 & 4.8436 & TRN & \\
\hline CHEMBL1476293 & 688641 & 5.0 & 4.9213 & TRN & \\
\hline CHEMBL1454049 & 688641 & 5.9 & 5.9476 & TRN & \\
\hline CHEMBL1487126 & 688641 & 5.3 & 5.3313 & TRN & \\
\hline
\end{tabular}




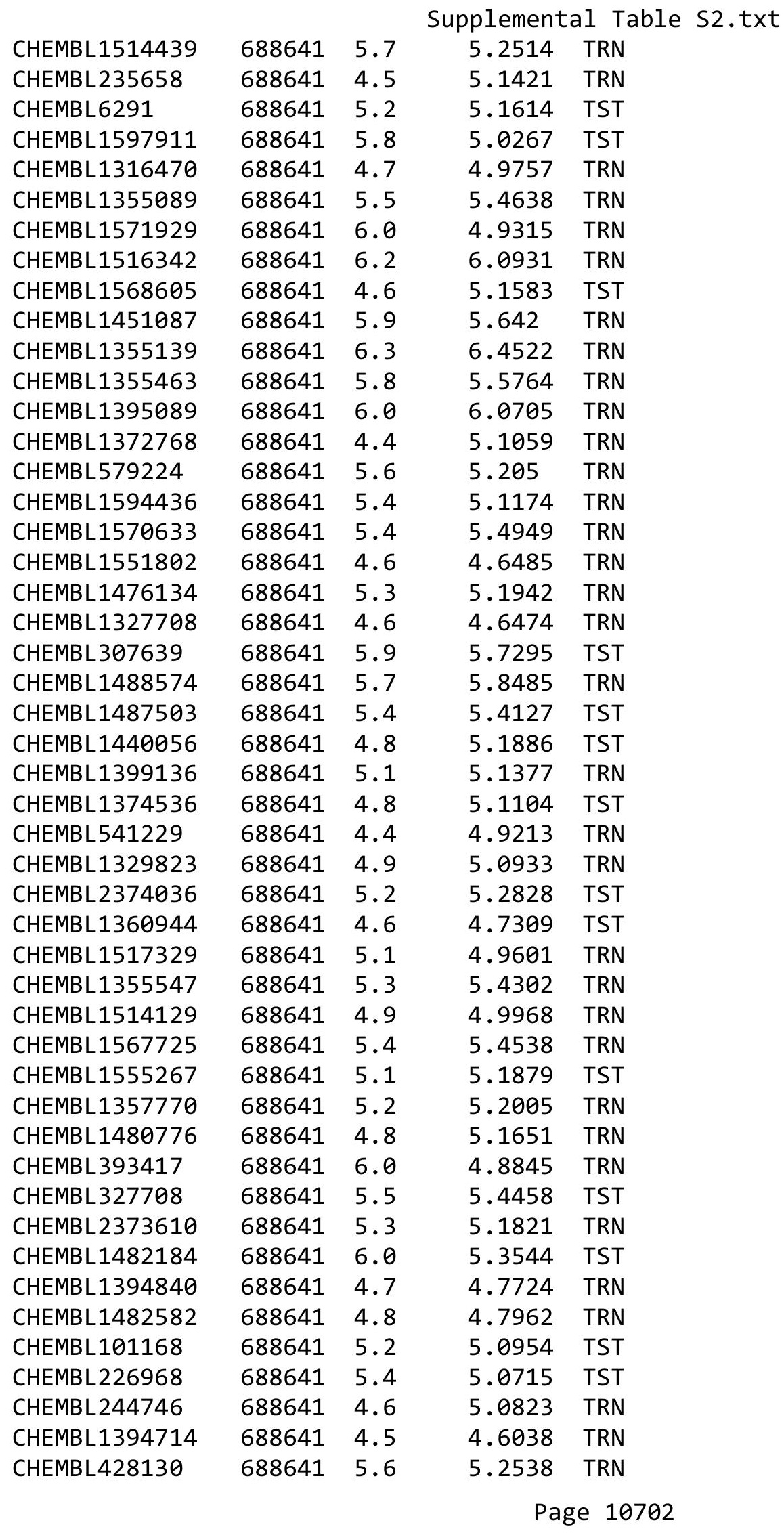




\begin{tabular}{|c|c|c|c|c|}
\hline \multicolumn{5}{|c|}{ Supplemental Table S2.txt } \\
\hline CHEMBL1593859 & 688641 & 4.6 & 4.6642 & TRN \\
\hline CHEMBL1455942 & 688641 & 5.5 & 5.3502 & TRN \\
\hline CHEMBL1396698 & 688641 & 4.6 & 4.6491 & TRN \\
\hline CHEMBL 36148 & 688641 & 6.0 & 5.966 & TRN \\
\hline CHEMBL1593796 & 688641 & 5.4 & 5.3805 & TRN \\
\hline CHEMBL243676 & 688641 & 4.9 & 5.0849 & TRN \\
\hline CHEMBL1448138 & 688641 & 5.3 & 4.9021 & TRN \\
\hline CHEMBL1416646 & 688641 & 4.5 & 5.1518 & TRN \\
\hline CHEMBL1554637 & 688641 & 4.6 & 4.7 & TRN \\
\hline CHEMBL1573712 & 688641 & 4.9 & 5.1278 & TRN \\
\hline CHEMBL1491242 & 688641 & 5.9 & 5.3338 & TST \\
\hline CHEMBL1337781 & 688641 & 5.4 & 5.3568 & TRN \\
\hline CHEMBL1408519 & 688641 & 5.0 & 5.0479 & TST \\
\hline CHEMBL368700 & 688641 & 5.0 & 5.0271 & TST \\
\hline CHEMBL1398031 & 688641 & 4.6 & 4.7893 & TST \\
\hline CHEMBL1592041 & 688641 & 4.9 & 5.1111 & TRN \\
\hline CHEMBL1357016 & 688641 & 4.7 & 4.7628 & TRN \\
\hline CHEMBL1454280 & 688641 & 5.5 & 4.9816 & TRN \\
\hline CHEMBL1412047 & 688641 & 4.8 & 5.0831 & TRN \\
\hline CHEMBL1473753 & 688641 & 5.3 & 5.2447 & TRN \\
\hline CHEMBL1317300 & 688641 & 6.0 & 4.9116 & TST \\
\hline CHEMBL1487898 & 688641 & 5.0 & 5.105 & TRN \\
\hline CHEMBL1318710 & 688641 & 5.5 & 5.0437 & TST \\
\hline CHEMBL1411009 & 688641 & 5.8 & 5.2443 & TRN \\
\hline CHEMBL146855 & 688641 & 6.0 & 4.9275 & TST \\
\hline CHEMBL1436925 & 688641 & 5.8 & 5.7473 & TRN \\
\hline CHEMBL1476082 & 688641 & 4.8 & 4.7667 & TRN \\
\hline CHEMBL1335961 & 688641 & 5.9 & 5.0683 & TRN \\
\hline CHEMBL1395219 & 688641 & 4.8 & 4.8007 & TRN \\
\hline CHEMBL1358810 & 688641 & 5.5 & 5.3221 & TRN \\
\hline CHEMBL1331351 & 688641 & 4.8 & 4.8982 & TRN \\
\hline CHEMBL45244 & 688641 & 4.5 & 4.6752 & TRN \\
\hline CHEMBL1316045 & 688641 & 5.3 & 5.2531 & TRN \\
\hline CHEMBL1368395 & 688641 & 5.3 & 5.2733 & TRN \\
\hline CHEMBL1602263 & 688641 & 5.4 & 5.0638 & TST \\
\hline CHEMBL1396989 & 688641 & 4.9 & 4.8884 & TRN \\
\hline CHEMBL118902 & 688641 & 6.0 & 5.7082 & TST \\
\hline CHEMBL3212645 & 688641 & 5.5 & 5.4584 & TRN \\
\hline CHEMBL 2374027 & 688641 & 6.0 & 5.7674 & TST \\
\hline CHEMBL490718 & 688641 & 6.2 & 6.3762 & TRN \\
\hline CHEMBL1591121 & 688641 & 4.8 & 4.8418 & TRN \\
\hline CHEMBL1358007 & 688641 & 5.5 & 5.397 & TST \\
\hline CHEMBL1602508 & 688641 & 4.6 & 4.7691 & TRN \\
\hline CHEMBL1318588 & 688641 & 4.5 & 5.0138 & TRN \\
\hline CHEMBL1256876 & 688641 & 6.0 & 5.6617 & TST \\
\hline CHEMBL1433725 & 688641 & 4.6 & 4.619 & TRN \\
\hline CHEMBL1356870 & 688641 & 6.0 & 5.7213 & TRN \\
\hline CHEMBL1592371 & 688641 & 5.1 & 5.1079 & TRN \\
\hline
\end{tabular}




\begin{tabular}{|c|c|c|c|c|c|}
\hline \multicolumn{6}{|c|}{ Supplemental Table S2.txt } \\
\hline CHEMBL399121 & 688641 & 6.0 & 5.0341 & TRN & \\
\hline CHEMBL1356439 & 688641 & 5.2 & 5.2998 & TRN & \\
\hline CHEMBL1391326 & 688641 & 5.0 & 5.103 & TRN & \\
\hline CHEMBL1475509 & 688641 & 5.4 & 5.4052 & TRN & \\
\hline CHEMBL1590038 & 688641 & 5.1 & 5.1773 & TRN & \\
\hline CHEMBL1377111 & 688641 & 6.0 & 5.8367 & TST & \\
\hline CHEMBL1332504 & 688641 & 6.4 & 6.0878 & TRN & \\
\hline CHEMBL1365271 & 688641 & 5.0 & 5.0514 & TRN & \\
\hline CHEMBL1565578 & 688641 & 4.8 & 4.8098 & TRN & \\
\hline CHEMBL1315093 & 688641 & 4.9 & 4.7504 & TRN & \\
\hline CHEMBL1553161 & 688641 & 5.4 & 5.4993 & TRN & \\
\hline CHEMBL1321891 & 688641 & 4.8 & 5.0138 & TRN & \\
\hline CHEMBL1591674 & 688641 & 4.6 & 4.6426 & TRN & \\
\hline CHEMBL1396975 & 688641 & 5.1 & 5.0138 & TRN & \\
\hline CHEMBL1514804 & 688641 & 4.8 & 4.6908 & TRN & \\
\hline CHEMBL1452221 & 688641 & 5.6 & 5.6607 & TRN & \\
\hline CHEMBL1515034 & 688641 & 5.7 & 5.9028 & TRN & \\
\hline CHEMBL1256291 & 688641 & 4.7 & 4.7597 & TST & \\
\hline CHEMBL1415406 & 688641 & 5.1 & 5.2253 & TRN & \\
\hline CHEMBL491977 & 688641 & 6.4 & 6.4272 & TRN & \\
\hline CHEMBL1318349 & 688641 & 4.9 & 4.9951 & TRN & \\
\hline CHEMBL1445979 & 688641 & 5.1 & 4.7239 & TRN & \\
\hline CHEMBL1565342 & 688641 & 6.0 & 5.9995 & TRN & \\
\hline CHEMBL1366408 & 688641 & 5.0 & 4.9672 & TRN & \\
\hline CHEMBL1512780 & 688641 & 5.0 & 5.0721 & TRN & \\
\hline CHEMBL1434801 & 688641 & 4.9 & 4.9857 & TRN & \\
\hline CHEMBL3199282 & 688641 & 5.4 & 5.4796 & TRN & \\
\hline CHEMBL1354154 & 688641 & 5.7 & 5.8875 & TRN & \\
\hline CHEMBL1555164 & 688641 & 5.4 & 5.4672 & TRN & \\
\hline CHEMBL1316956 & 688641 & 6.9 & 6.8845 & TRN & \\
\hline CHEMBL1338613 & 688641 & 4.8 & 5.0143 & TST & \\
\hline CHEMBL1558420 & 688641 & 4.8 & 4.7407 & TRN & \\
\hline CHEMBL391997 & 688641 & 5.5 & 5.36600 & 00000000005 & TST \\
\hline CHEMBL1436121 & 688641 & 6.9 & 5.0923 & TST & \\
\hline CHEMBL145725 & 688641 & 4.5 & 5.15 & TST & \\
\hline CHEMBL1435638 & 688641 & 5.7 & 5.7517 & TRN & \\
\hline CHEMBL1513247 & 688641 & 4.9 & 5.1314 & TRN & \\
\hline CHEMBL1512083 & 688641 & 5.1 & 5.0272 & TRN & \\
\hline CHEMBL1357500 & 688641 & 4.8 & 4.8395 & TRN & \\
\hline CHEMBL1373634 & 688641 & 5.4 & 5.3512 & TRN & \\
\hline CHEMBL1371756 & 688641 & 5.0 & 5.165 & TRN & \\
\hline CHEMBL1530314 & 688641 & 5.5 & 5.4662 & TST & \\
\hline CHEMBL1377908 & 688641 & 4.9 & 4.8909 & TRN & \\
\hline CHEMBL1483700 & 688641 & 5.5 & 5.4857 & TRN & \\
\hline CHEMBL1476139 & 688641 & 4.9 & 4.8547 & TRN & \\
\hline CHEMBL1256998 & 688641 & 5.5 & 5.4208 & TRN & \\
\hline CHEMBL1603627 & 688641 & 4.7 & 4.7632 & TRN & \\
\hline CHEMBL1437002 & 688641 & 5.4 & 5.2606 & TST & \\
\hline
\end{tabular}




\begin{tabular}{|c|c|c|c|c|c|}
\hline \multicolumn{6}{|c|}{ Supplemental Table S2.txt } \\
\hline CHEMBL1568854 & 688641 & 5.0 & 5.1118 & TRN & \\
\hline CHEMBL1405759 & 688641 & 4.9 & 4.9591 & TST & \\
\hline CHEMBL260283 & 688641 & 5.0 & 5.0598 & TRN & \\
\hline CHEMBL1366629 & 688641 & 5.3 & 5.1306 & TRN & \\
\hline CHEMBL1478552 & 688641 & 4.4 & 4.919 & TRN & \\
\hline CHEMBL1496203 & 688641 & 5.5 & 5.3663 & TRN & \\
\hline CHEMBL490913 & 688641 & 6.8 & 6.7743 & TRN & \\
\hline CHEMBL1571975 & 688641 & 5.8 & 5.7002 & TST & \\
\hline CHEMBL1456454 & 688641 & 5.4 & 5.5794 & TRN & \\
\hline CHEMBL1592202 & 688641 & 4.9 & 4.8926 & TRN & \\
\hline CHEMBL1433785 & 688641 & 4.5 & 4.6718 & TRN & \\
\hline CHEMBL1513562 & 688641 & 4.8 & 5.1042 & TRN & \\
\hline CHEMBL518252 & 688641 & 5.5 & 5.1133 & TRN & \\
\hline CHEMBL1606094 & 688641 & 6.0 & 5.849 & TST & \\
\hline CHEMBL1529384 & 688641 & 5.4 & 5.4579 & TRN & \\
\hline CHEMBL1568233 & 688641 & 5.5 & 5.433 & TRN & \\
\hline CHEMBL3209999 & 688641 & 5.4 & 5.4389 & TRN & \\
\hline CHEMBL1535431 & 688641 & 4.9 & 4.914 & TRN & \\
\hline CHEMBL1330385 & 688641 & 5.6 & 5.6515 & TRN & \\
\hline CHEMBL1595371 & 688641 & 5.5 & 5.3398 & TRN & \\
\hline CHEMBL1330422 & 688641 & 5.5 & 5.4383 & TRN & \\
\hline CHEMBL1561408 & 688641 & 4.4 & 5.0032 & TRN & \\
\hline CHEMBL 70582 & 688641 & 4.7 & 4.834 & TRN & \\
\hline CHEMBL1476107 & 688641 & 5.5 & 4.9711 & TST & \\
\hline CHEMBL1552277 & 688641 & 5.6 & 5.6545 & TRN & \\
\hline CHEMBL1407527 & 688641 & 5.4 & 5.3944 & TRN & \\
\hline CHEMBL1317373 & 688641 & 5.9 & 5.9269 & TRN & \\
\hline CHEMBL1567101 & 688641 & 5.6 & 5.325 & TRN & \\
\hline CHEMBL1443360 & 688641 & 5.0 & 4.963 & TRN & \\
\hline CHEMBL1326944 & 688641 & 5.1 & 5.13299 & 9999999999 & TRN \\
\hline CHEMBL1590601 & 688641 & 5.5 & 5.5739 & TRN & \\
\hline CHEMBL1256775 & 688641 & 4.4 & 4.6032 & TRN & \\
\hline CHEMBL1401324 & 688641 & 5.5 & 5.5821 & TST & \\
\hline CHEMBL1397177 & 688641 & 5.5 & 5.5059 & TRN & \\
\hline CHEMBL43612 & 688641 & 4.4 & 4.9609 & TRN & \\
\hline CHEMBL1321846 & 688641 & 5.5 & 5.6368 & TRN & \\
\hline CHEMBL 2373630 & 688641 & 5.3 & 5.2303 & TST & \\
\hline CHEMBL1319049 & 688641 & 6.0 & 6.0658 & TRN & \\
\hline CHEMBL1434108 & 688641 & 5.5 & 5.2033 & TST & \\
\hline CHEMBL1332667 & 688641 & 5.7 & 5.3723 & TRN & \\
\hline CHEMBL441618 & 688641 & 5.0 & 5.0429 & TST & \\
\hline CHEMBL1354626 & 688641 & 5.5 & 5.444 & TRN & \\
\hline CHEMBL1356395 & 688641 & 5.5 & 5.4144 & TST & \\
\hline CHEMBL1590321 & 688641 & 4.7 & 4.752 & TRN & \\
\hline CHEMBL1591903 & 688641 & 5.4 & 5.4317 & TRN & \\
\hline CHEMBL1420719 & 688641 & 4.5 & 4.9879 & TRN & \\
\hline CHEMBL534084 & 688641 & 5.1 & 5.2423 & TRN & \\
\hline CHEMBL1518718 & 688641 & 4.4 & 4.5911 & TRN & \\
\hline
\end{tabular}




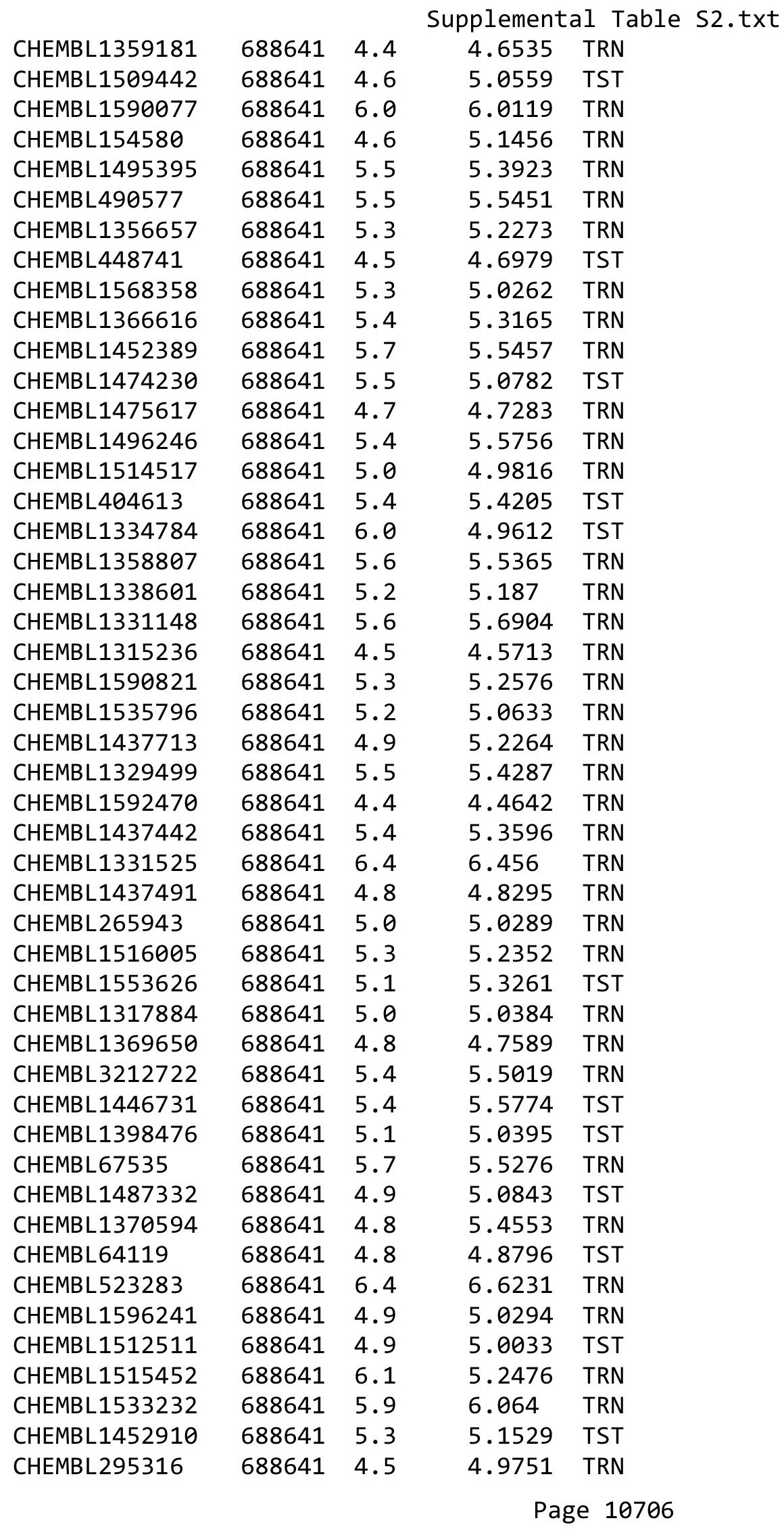




\begin{tabular}{|c|c|c|c|c|c|}
\hline \multicolumn{6}{|c|}{ Supplemental Table S2.txt } \\
\hline CHEMBL291057 & 688641 & 4.5 & 5.0824 & TST & \\
\hline CHEMBL1475574 & 688641 & 5.6 & 4.8154 & TRN & \\
\hline CHEMBL1523959 & 688641 & 4.6 & 4.7159 & TRN & \\
\hline CHEMBL1515280 & 688641 & 4.8 & 4.8027 & TRN & \\
\hline CHEMBL1395009 & 688641 & 5.3 & 5.2627 & TST & \\
\hline CHEMBL56543 & 688641 & 4.8 & 4.9875 & TRN & \\
\hline CHEMBL1448839 & 688641 & 4.9 & 4.878 & TRN & \\
\hline CHEMBL1354734 & 688641 & 4.9 & 5.0214 & TST & \\
\hline CHEMBL1406851 & 688641 & 6.4 & 6.4371 & TRN & \\
\hline CHEMBL1485541 & 688641 & 4.6 & 5.0819 & TRN & \\
\hline CHEMBL1330394 & 688641 & 6.0 & 6.0039 & TRN & \\
\hline CHEMBL1592364 & 688641 & 5.0 & 4.9907 & TRN & \\
\hline CHEMBL1317314 & 688641 & 5.1 & 5.0854 & TRN & \\
\hline CHEMBL1474326 & 688641 & 5.1 & 5.0078 & TRN & \\
\hline CHEMBL1389138 & 688641 & 5.4 & 5.25 & TRN & \\
\hline CHEMBL1570894 & 688641 & 5.4 & 5.2818 & TRN & \\
\hline CHEMBL1591548 & 688641 & 5.1 & 5.1375 & TRN & \\
\hline CHEMBL1322979 & 688641 & 5.5 & 5.1325 & TST & \\
\hline CHEMBL16687 & 688641 & 5.1 & 5.0595 & TST & \\
\hline CHEMBL1317932 & 688641 & 5.8 & 5.57299 & 99999999995 & TRN \\
\hline CHEMBL1477833 & 688641 & 6.0 & 6.0162 & TRN & \\
\hline CHEMBL1473405 & 688641 & 5.3 & 5.2115 & TRN & \\
\hline CHEMBL356688 & 688641 & 5.0 & 5.053 & TRN & \\
\hline CHEMBL1488728 & 688641 & 4.4 & 5.1322 & TRN & \\
\hline CHEMBL1442106 & 688641 & 4.8 & 4.8151 & TRN & \\
\hline CHEMBL1594425 & 688641 & 5.2 & 5.2049 & TST & \\
\hline CHEMBL1401243 & 688641 & 5.0 & 5.07100 & 0000000001 & TRN \\
\hline CHEMBL1355410 & 688641 & 4.5 & 5.3821 & TST & \\
\hline CHEMBL1398425 & 688641 & 4.8 & 4.9606 & TRN & \\
\hline CHEMBL1398713 & 688641 & 5.2 & 5.2079 & TST & \\
\hline CHEMBL1354455 & 688641 & 4.5 & 4.6007 & TRN & \\
\hline CHEMBL1602710 & 688641 & 5.1 & 5.2358 & TRN & \\
\hline CHEMBL1516262 & 688641 & 4.8 & 4.7897 & TRN & \\
\hline CHEMBL1397552 & 688641 & 4.9 & 5.2567 & TRN & \\
\hline CHEMBL1334278 & 688641 & 5.1 & 5.2805 & TRN & \\
\hline CHEMBL1595401 & 688641 & 4.4 & 5.0085 & TRN & \\
\hline CHEMBL1493496 & 688641 & 5.8 & 5.9153 & TRN & \\
\hline CHEMBL1512614 & 688641 & 6.3 & 5.4227 & TRN & \\
\hline CHEMBL1595328 & 688641 & 4.6 & 4.6258 & TRN & \\
\hline CHEMBL 2373679 & 688641 & 6.2 & 5.2368 & TST & \\
\hline CHEMBL44628 & 688641 & 7.3002 & 4.8127 & TRN & \\
\hline CHEMBL1474056 & 688641 & 5.6 & 5.4661 & TRN & \\
\hline CHEMBL1474681 & 688641 & 6.3 & 6.4593 & TRN & \\
\hline CHEMBL1489446 & 688641 & 4.7 & 4.7323 & TRN & \\
\hline CHEMBL1452868 & 688641 & 5.4 & 5.0895 & TRN & \\
\hline CHEMBL1333711 & 688641 & 4.8 & 4.9902 & TRN & \\
\hline CHEMBL1411081 & 688641 & 6.0 & 6.0137 & TRN & \\
\hline CHEMBL1316831 & 688641 & 4.8 & 4.8567 & TST & \\
\hline
\end{tabular}




\begin{tabular}{|c|c|c|c|c|}
\hline \multicolumn{5}{|c|}{ Supplemental Table S2.txt } \\
\hline CHEMBL1476298 & 688641 & 5.6 & 5.6749 & TRN \\
\hline CHEMBL 267373 & 688641 & 8.301 & 4.8067 & TRN \\
\hline CHEMBL1591956 & 688641 & 5.6 & 5.6997 & TRN \\
\hline CHEMBL1532555 & 688641 & 4.9 & 4.8612 & TRN \\
\hline CHEMBL1445893 & 688641 & 4.9 & 4.9826 & TRN \\
\hline CHEMBL1356292 & 688641 & 5.4 & 5.3955 & TRN \\
\hline CHEMBL1363077 & 688641 & 5.1 & 5.3775 & TRN \\
\hline CHEMBL434063 & 688641 & 5.5 & 5.0651 & TST \\
\hline CHEMBL1255664 & 688641 & 5.6 & 5.0712 & TRN \\
\hline CHEMBL1436054 & 688641 & 4.9 & 4.9756 & TRN \\
\hline CHEMBL1605941 & 688641 & 5.6 & 5.3067 & TST \\
\hline CHEMBL1436865 & 688641 & 4.9 & 4.8479 & TRN \\
\hline CHEMBL1256656 & 688641 & 6.1 & 5.0841 & TST \\
\hline CHEMBL1358758 & 688641 & 5.2 & 5.4032 & TRN \\
\hline CHEMBL1441981 & 688641 & 6.0 & 6.0636 & TRN \\
\hline CHEMBL1534082 & 688641 & 5.3 & 5.3389 & TRN \\
\hline CHEMBL1354398 & 688641 & 4.5 & 4.7046 & TST \\
\hline CHEMBL1512317 & 688641 & 4.7 & 4.7222 & TRN \\
\hline CHEMBL1344070 & 688641 & 5.1 & 5.072 & TRN \\
\hline CHEMBL1335889 & 688641 & 4.6 & 4.8042 & TRN \\
\hline CHEMBL1514836 & 688641 & 4.5 & 4.6726 & TRN \\
\hline CHEMBL1372368 & 688641 & 5.3 & 5.2506 & TRN \\
\hline CHEMBL1318765 & 688641 & 6.0 & 5.3313 & TRN \\
\hline CHEMBL1446539 & 688641 & 4.9 & 4.8608 & TRN \\
\hline CHEMBL1520292 & 688641 & 5.9 & 6.1547 & TRN \\
\hline CHEMBL1336796 & 688641 & 6.2 & 5.8868 & TST \\
\hline CHEMBL490743 & 688641 & 5.7 & 5.9506 & TRN \\
\hline CHEMBL406376 & 688641 & 5.7 & 5.2701 & TRN \\
\hline CHEMBL1573532 & 688641 & 5.5 & 5.5616 & TRN \\
\hline CHEMBL1375363 & 688641 & 5.0 & 5.2439 & TST \\
\hline CHEMBL3213210 & 688641 & 5.5 & 5.4884 & TRN \\
\hline CHEMBL1322702 & 688641 & 5.4 & 5.3499 & TST \\
\hline CHEMBL1320485 & 688641 & 5.0 & 5.0523 & TRN \\
\hline CHEMBL1482880 & 688641 & 4.5 & 4.6448 & TRN \\
\hline CHEMBL1611999 & 688641 & 5.5 & 5.0258 & TRN \\
\hline CHEMBL1256647 & 688641 & 5.4 & 5.2679 & TRN \\
\hline CHEMBL1320903 & 688641 & 5.4 & 5.4302 & TRN \\
\hline CHEMBL1474195 & 688641 & 5.0 & 5.0013 & TRN \\
\hline CHEMBL1553530 & 688641 & 4.7 & 4.8066 & TRN \\
\hline CHEMBL1316219 & 688641 & 5.3 & 5.2655 & TST \\
\hline CHEMBL1337108 & 688641 & 5.3 & 5.1905 & TRN \\
\hline CHEMBL310396 & 688641 & 4.5 & 4.9009 & TRN \\
\hline CHEMBL1434146 & 688641 & 5.4 & 5.5146 & TRN \\
\hline CHEMBL1398537 & 688641 & 6.0 & 5.6543 & TRN \\
\hline CHEMBL1366737 & 688641 & 4.8 & 4.7745 & TRN \\
\hline CHEMBL1452413 & 688641 & 5.1 & 5.0866 & TRN \\
\hline CHEMBL1513800 & 688641 & 4.6 & 4.7428 & TRN \\
\hline CHEMBL1330459 & 688641 & 6.0 & 5.2391 & TRN \\
\hline
\end{tabular}




\begin{tabular}{|c|c|c|c|c|}
\hline \multicolumn{5}{|c|}{ Supplemental Table S2.txt } \\
\hline CHEMBL1367159 & 688641 & 4.6 & 5.1009 & TRN \\
\hline CHEMBL1256851 & 688641 & 6.4 & 6.0161 & TRN \\
\hline CHEMBL1528491 & 688641 & 5.5 & 5.4529 & TRN \\
\hline CHEMBL1611496 & 688641 & 5.3 & 5.4205 & TRN \\
\hline CHEMBL1611225 & 688641 & 5.3 & 5.3429 & TRN \\
\hline CHEMBL1409830 & 688641 & 5.7 & 5.9053 & TRN \\
\hline CHEMBL1515033 & 688641 & 5.1 & 5.0809 & TRN \\
\hline CHEMBL1330334 & 688641 & 4.9 & 4.9333 & TRN \\
\hline CHEMBL1496596 & 688641 & 4.8 & 4.8182 & TRN \\
\hline CHEMBL1333834 & 688641 & 5.1 & 5.1626 & TST \\
\hline CHEMBL1257080 & 688641 & 5.0 & 5.1332 & TST \\
\hline CHEMBL44201 & 688641 & 4.9 & 5.0037 & TRN \\
\hline CHEMBL1602394 & 688641 & 5.5 & 5.4976 & TRN \\
\hline CHEMBL1362517 & 688641 & 4.9 & 4.9338 & TRN \\
\hline CHEMBL 582444 & 688641 & 5.0 & 5.0074 & TST \\
\hline CHEMBL194400 & 688641 & 6.0 & 5.0113 & TST \\
\hline CHEMBL1357221 & 688641 & 4.8 & 4.8414 & TRN \\
\hline CHEMBL1255653 & 688641 & 6.5 & 6.1673 & TST \\
\hline CHEMBL1473430 & 688641 & 5.9 & 5.7533 & TRN \\
\hline CHEMBL1358200 & 688641 & 4.9 & 5.1199 & TRN \\
\hline CHEMBL265699 & 688641 & 5.4 & 5.2903 & TST \\
\hline CHEMBL1605356 & 688641 & 5.6 & 5.7074 & TRN \\
\hline CHEMBL1253351 & 688641 & 5.7 & 5.5421 & TST \\
\hline CHEMBL1396561 & 688641 & 5.8 & 5.7707 & TRN \\
\hline CHEMBL1334016 & 688641 & 5.2 & 5.1634 & TRN \\
\hline CHEMBL1404703 & 688641 & 4.9 & 4.9132 & TRN \\
\hline CHEMBL1372371 & 688641 & 5.0 & 4.9607 & TRN \\
\hline CHEMBL1476705 & 688641 & 4.6 & 5.2012 & TST \\
\hline CHEMBL1592974 & 688641 & 4.8 & 5.0745 & TRN \\
\hline CHEMBL3207899 & 688641 & 5.5 & 5.5236 & TRN \\
\hline CHEMBL1513149 & 688641 & 5.8 & 5.2011 & TST \\
\hline CHEMBL394171 & 688641 & 4.8 & 4.9336 & TRN \\
\hline CHEMBL1456755 & 688641 & 5.4 & 5.3402 & TST \\
\hline CHEMBL1371677 & 688641 & 4.8 & 5.6624 & TRN \\
\hline CHEMBL1603692 & 688641 & 4.6 & 4.6778 & TRN \\
\hline CHEMBL1436821 & 688641 & 4.4 & 5.2382 & TST \\
\hline CHEMBL1256869 & 688641 & 4.5 & 4.7095 & TST \\
\hline CHEMBL1363413 & 688641 & 6.0 & 6.0594 & TRN \\
\hline CHEMBL1363367 & 688641 & 5.4 & 5.3429 & TRN \\
\hline CHEMBL586058 & 688641 & 5.0 & 5.2179 & TST \\
\hline CHEMBL1436110 & 688641 & 4.6 & 5.0572 & TRN \\
\hline CHEMBL1556035 & 688641 & 4.8 & 5.0025 & TRN \\
\hline CHEMBL1435996 & 688641 & 5.5 & 5.1215 & TRN \\
\hline CHEMBL1456388 & 688641 & 4.8 & 5.0286 & TRN \\
\hline CHEMBL1574608 & 688641 & 4.8 & 4.8988 & TRN \\
\hline CHEMBL1449350 & 688641 & 4.6 & 4.8935 & TRN \\
\hline CHEMBL1473715 & 688641 & 4.8 & 5.2695 & TRN \\
\hline CHEMBL1602112 & 688641 & 5.9 & 5.9396 & TRN \\
\hline
\end{tabular}




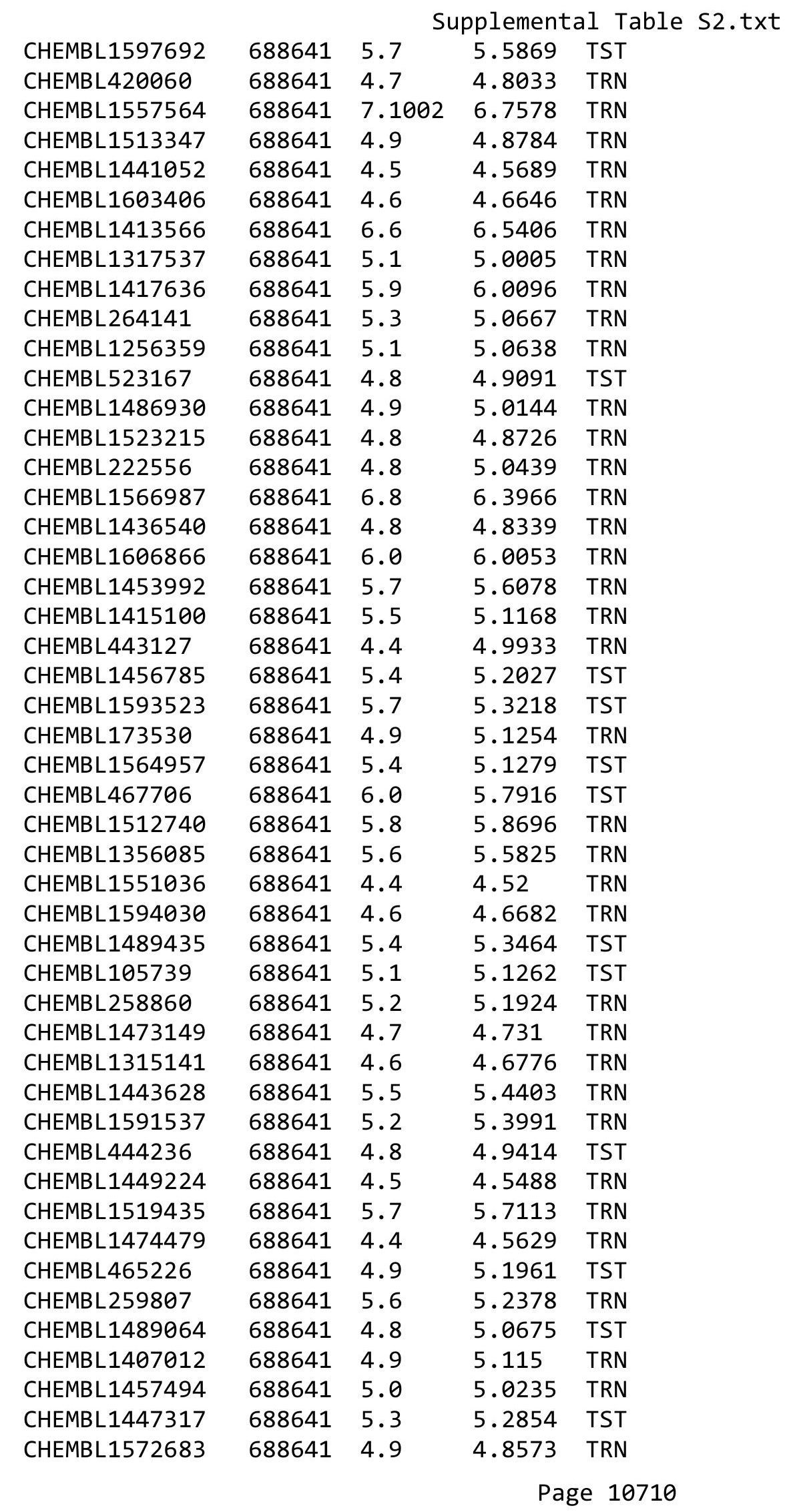




\begin{tabular}{|c|c|c|c|c|c|}
\hline & & \multicolumn{4}{|c|}{ Supplemental Table S2.txt } \\
\hline CHEMBL1394765 & 688641 & 5.0 & 5.0096 & TRN & \\
\hline CHEMBL1590605 & 688641 & 4.6 & 4.8208 & TRN & \\
\hline CHEMBL1515315 & 688641 & 5.3 & 5.3938 & TRN & \\
\hline CHEMBL1445323 & 688641 & 5.1 & 4.962 & TST & \\
\hline CHEMBL1491574 & 688641 & 5.6 & 5.6142 & TRN & \\
\hline CHEMBL1354864 & 688641 & 5.5 & 5.3812 & TRN & \\
\hline CHEMBL1478761 & 688641 & 5.3 & 5.1758 & TRN & \\
\hline CHEMBL1370510 & 688641 & 5.5 & 5.1254 & TRN & \\
\hline CHEMBL1554976 & 688641 & 6.2 & 6.0012 & TRN & \\
\hline CHEMBL151 & 688641 & 6.0 & 5.4361 & TRN & \\
\hline CHEMBL1315457 & 688641 & 5.0 & 5.0528 & TST & \\
\hline CHEMBL107251 & 688641 & 5.0 & 4.9883 & TRN & \\
\hline CHEMBL1433596 & 688641 & 4.8 & 4.9542 & TRN & \\
\hline CHEMBL1611906 & 688641 & 5.5 & 5.426 & TRN & \\
\hline CHEMBL1491776 & 688641 & 5.4 & 5.4095 & TRN & \\
\hline CHEMBL 254348 & 688641 & 6.0 & 5.3456 & TRN & \\
\hline CHEMBL1418420 & 688641 & 5.4 & 5.38299 & 9999999999 & TRN \\
\hline CHEMBL1475541 & 688641 & 5.0 & 5.1942 & TRN & \\
\hline CHEMBL1318020 & 688641 & 5.2 & 5.1366 & TRN & \\
\hline CHEMBL1321338 & 688641 & 4.8 & 4.9838 & TRN & \\
\hline CHEMBL1558135 & 688641 & 4.8 & 4.8988 & TRN & \\
\hline CHEMBL1358588 & 688641 & 5.3 & 5.1742 & TRN & \\
\hline CHEMBL1561544 & 688641 & 4.4 & 5.091 & TST & \\
\hline CHEMBL508030 & 688641 & 6.0 & 5.0213 & TST & \\
\hline CHEMBL1521010 & 688641 & 6.0 & 5.8658 & TRN & \\
\hline CHEMBL1436024 & 688641 & 4.6 & 4.7115 & TRN & \\
\hline CHEMBL1435296 & 688641 & 4.8 & 4.875 & TRN & \\
\hline CHEMBL1377805 & 688641 & 6.0 & 5.1311 & TRN & \\
\hline CHEMBL16685 & 688641 & 4.5 & 5.1275 & TRN & \\
\hline CHEMBL1325964 & 688641 & 4.8 & 4.9342 & TRN & \\
\hline CHEMBL1322608 & 688641 & 6.0 & 4.9216 & TRN & \\
\hline CHEMBL1511986 & 688641 & 5.7 & 5.5862 & TRN & \\
\hline CHEMBL1317998 & 688641 & 5.3 & 5.3185 & TRN & \\
\hline CHEMBL1527209 & 688641 & 6.0 & 6.0371 & TRN & \\
\hline CHEMBL1515804 & 688641 & 5.3 & 5.2615 & TRN & \\
\hline CHEMBL1527622 & 688641 & 5.8 & 5.5926 & TST & \\
\hline CHEMBL1401214 & 688641 & 5.5 & 5.6913 & TRN & \\
\hline CHEMBL1314367 & 688641 & 6.3 & 6.4134 & TRN & \\
\hline CHEMBL1601305 & 688641 & 5.1 & 5.0216 & TRN & \\
\hline CHEMBL1520216 & 688641 & 5.5 & 5.6253 & TRN & \\
\hline CHEMBL371811 & 688641 & 4.5 & 4.5963 & TST & \\
\hline CHEMBL119264 & 688641 & 5.9 & 5.8185 & TST & \\
\hline CHEMBL1454793 & 688641 & 5.2 & 5.2803 & TRN & \\
\hline CHEMBL1570996 & 688641 & 5.6 & 5.5908 & TRN & \\
\hline CHEMBL1513308 & 688641 & 5.1 & 5.3015 & TST & \\
\hline CHEMBL1515568 & 688641 & 5.6 & 5.4238 & TRN & \\
\hline CHEMBL1449821 & 688641 & 4.9 & 4.9384 & TST & \\
\hline CHEMBL16751 & 688641 & 5.1 & 5.2088 & TRN & \\
\hline
\end{tabular}




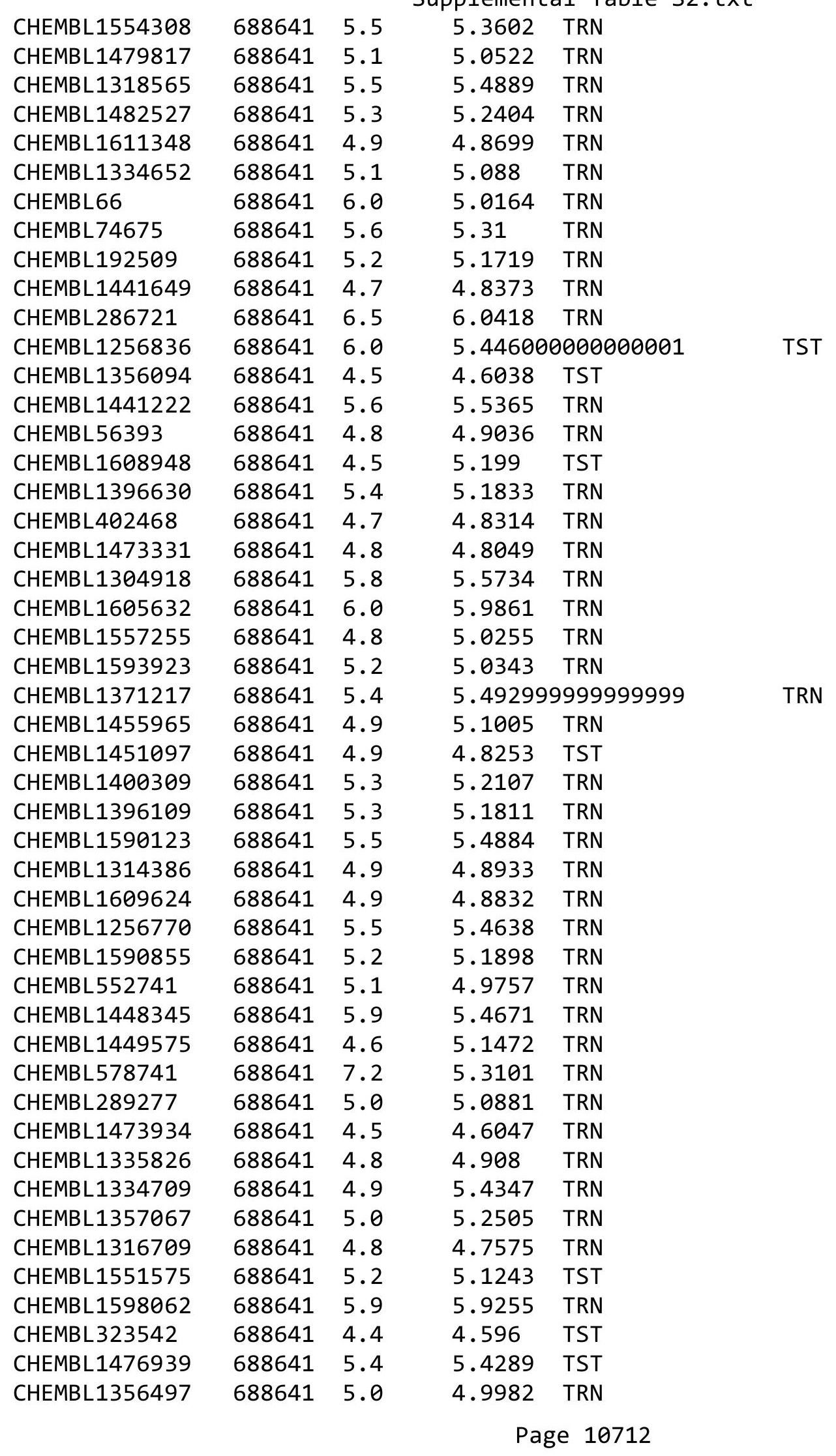




\begin{tabular}{|c|c|c|c|c|c|}
\hline \multirow{2}{*}{ CHEMBL1590909 } & \multirow{2}{*}{688641} & \\
\hline & & 5.5 & 5.5744 & TRN & \\
\hline CHEMBL1568080 & 688641 & 5.5 & 5.4893 & TRN & \\
\hline CHEMBL1492454 & 688641 & 4.7 & 5.0993 & TST & \\
\hline CHEMBL1332998 & 688641 & 6.0 & 5.0831 & TRN & \\
\hline CHEMBL328710 & 688641 & 5.0 & 5.0903 & TST & \\
\hline CHEMBL1366762 & 688641 & 5.3 & 5.3813 & TRN & \\
\hline CHEMBL 267476 & 688641 & 4.5 & 4.6725 & TRN & \\
\hline CHEMBL1404315 & 688641 & 5.4 & \multicolumn{2}{|c|}{5.412000000000001} & TRN \\
\hline CHEMBL1336727 & 688641 & 4.9 & 4.9839 & TST & \\
\hline CHEMBL1567365 & 688641 & 5.5 & 5.4712 & TRN & \\
\hline CHEMBL1488230 & 688641 & 6.0 & 5.0853 & TRN & \\
\hline CHEMBL471225 & 688641 & 5.1 & 5.1223 & TST & \\
\hline CHEMBL1316463 & 688641 & 4.9 & 4.9077 & TRN & \\
\hline CHEMBL1380684 & 688641 & 6.0 & 5.5876 & TRN & \\
\hline CHEMBL369142 & 688641 & 4.8 & 5.0027 & TRN & \\
\hline CHEMBL1551981 & 688641 & 5.1 & 5.1054 & TRN & \\
\hline CHEMBL1317039 & 688641 & 5.7 & 5.8337 & TRN & \\
\hline CHEMBL1475788 & 688641 & 4.9 & 4.8781 & TRN & \\
\hline CHEMBL1418542 & 688641 & 5.6 & 5.4869 & TRN & \\
\hline CHEMBL1551847 & 688641 & 4.5 & 5.085 & TST & \\
\hline CHEMBL1405043 & 688641 & 5.4 & 5.3124 & TRN & \\
\hline CHEMBL 38288 & 688641 & 6.1 & 5.7313 & TRN & \\
\hline CHEMBL1484447 & 688641 & 4.8 & 4.7893 & TST & \\
\hline CHEMBL1596246 & 688641 & 5.6 & \multicolumn{2}{|c|}{4.968999999999999} & TRN \\
\hline CHEMBL1567251 & 688641 & 4.6 & 4.6729 & TRN & \\
\hline CHEMBL1364859 & 688641 & 4.9 & 4.902 & TRN & \\
\hline CHEMBL1323759 & 688641 & 4.8 & 4.8273 & TRN & \\
\hline CHEMBL1443163 & 688641 & 5.6 & 5.4203 & TST & \\
\hline CHEMBL1438164 & 688641 & 4.8 & 4.9921 & TRN & \\
\hline CHEMBL1456420 & 688641 & 5.4 & 5.3908 & TRN & \\
\hline CHEMBL1436661 & 688641 & 5.0 & 4.9791 & TRN & \\
\hline CHEMBL1618718 & 688641 & 4.7 & 4.7964 & TST & \\
\hline CHEMBL1335890 & 688641 & 6.0 & 6.1062 & TRN & \\
\hline CHEMBL1592500 & 688641 & 6.0 & 5.2983 & TRN & \\
\hline CHEMBL1592803 & 688641 & 6.1 & 6.0707 & TRN & \\
\hline CHEMBL1520783 & 688641 & 4.6 & 5.0781 & TST & \\
\hline CHEMBL323356 & 688641 & 4.9 & 4.9412 & TST & \\
\hline CHEMBL1378731 & 688641 & 5.3 & 5.2828 & TST & \\
\hline CHEMBL1532000 & 688641 & 5.3 & 5.37 & TRN & \\
\hline CHEMBL1473055 & 688641 & 4.9 & 4.9021 & TRN & \\
\hline CHEMBL430893 & 688641 & 6.0 & 5.8098 & TST & \\
\hline CHEMBL1551444 & 688641 & 4.6 & 4.7476 & TRN & \\
\hline CHEMBL1415701 & 688641 & 4.9 & 5.1468 & TRN & \\
\hline CHEMBL1356501 & 688641 & 4.7 & 4.9449 & TRN & \\
\hline CHEMBL1590262 & 688641 & 4.8 & 4.8210 & 2000000001 & TRN \\
\hline CHEMBL1329033 & 688641 & 5.5 & 5.4275 & TST & \\
\hline CHEMBL44 & 688641 & 6.0 & 5.0028 & TRN & \\
\hline \multirow[t]{2}{*}{ CHEMBL1530445 } & 688641 & 5.5 & 5.484 & TRN & \\
\hline & & \multicolumn{4}{|c|}{ Page 10713} \\
\hline
\end{tabular}




\begin{tabular}{|c|c|c|c|c|c|}
\hline \multicolumn{6}{|c|}{ Supplemental Table S2.txt } \\
\hline CHEMBL259851 & 688641 & 5.0 & 5.2474 & TRN & \\
\hline CHEMBL1569497 & 688641 & 5.4 & 5.5082 & TRN & \\
\hline CHEMBL1412842 & 688641 & 6.0 & 5.934 & TRN & \\
\hline CHEMBL1407769 & 688641 & 4.9 & 5.0147 & TRN & \\
\hline CHEMBL1454052 & 688641 & 4.9 & 4.9755 & TRN & \\
\hline CHEMBL1552984 & 688641 & 5.5 & 5.3573 & TST & \\
\hline CHEMBL1474272 & 688641 & 5.1 & 5.1863 & TRN & \\
\hline CHEMBL1399301 & 688641 & 4.6 & 4.6942 & TRN & \\
\hline CHEMBL1447143 & 688641 & 5.2 & 5.2605 & TRN & \\
\hline CHEMBL297687 & 688641 & 5.0 & 5.1875 & TRN & \\
\hline CHEMBL553503 & 688641 & 6.0 & 4.9155 & TRN & \\
\hline CHEMBL1524305 & 688641 & 4.9 & 4.8804 & TRN & \\
\hline CHEMBL 275097 & 688641 & 5.1 & 5.206 & TRN & \\
\hline CHEMBL1338520 & 688641 & 4.9 & 5.2158 & TST & \\
\hline CHEMBL1513463 & 688641 & 4.8 & 5.125 & TST & \\
\hline CHEMBL1255655 & 688641 & 4.9 & 4.9491 & TST & \\
\hline CHEMBL134291 & 688641 & 5.0 & 5.0099 & TRN & \\
\hline CHEMBL1553768 & 688641 & 6.0 & 5.8767 & TST & \\
\hline CHEMBL1493740 & 688641 & 4.4 & 5.5312 & TRN & \\
\hline CHEMBL261642 & 688641 & 4.7 & 5.129 & TST & \\
\hline CHEMBL1593602 & 688641 & 5.2 & 5.26 & TST & \\
\hline CHEMBL1574160 & 688641 & 5.3 & 5.1074 & TRN & \\
\hline CHEMBL1315743 & 688641 & 6.0 & 5.6994 & TST & \\
\hline CHEMBL1517982 & 688641 & 4.7 & 5.09699 & 99999999995 & TRN \\
\hline CHEMBL1592215 & 688641 & 5.0 & 4.9425 & TRN & \\
\hline CHEMBL1565125 & 688641 & 5.4 & 5.3227 & TST & \\
\hline CHEMBL1605950 & 688641 & 5.5 & 5.2982 & TRN & \\
\hline CHEMBL1593827 & 688641 & 5.7 & 5.6953 & TRN & \\
\hline CHEMBL1437578 & 688641 & 4.9 & 4.8745 & TRN & \\
\hline CHEMBL1396462 & 688641 & 4.5 & 4.5493 & TRN & \\
\hline CHEMBL1482847 & 688641 & 4.9 & 4.8761 & TRN & \\
\hline CHEMBL1590886 & 688641 & 5.0 & 4.9362 & TRN & \\
\hline CHEMBL1514976 & 688641 & 4.9 & 4.8396 & TRN & \\
\hline CHEMBL1554842 & 688641 & 5.3 & 5.4932 & TRN & \\
\hline CHEMBL1472900 & 688641 & 4.6 & 4.663 & TRN & \\
\hline CHEMBL263893 & 688641 & 4.8 & 5.1035 & TRN & \\
\hline CHEMBL1365609 & 688641 & 4.8 & 4.8826 & TRN & \\
\hline CHEMBL1356106 & 688641 & 4.9 & 4.9581 & TRN & \\
\hline CHEMBL299052 & 688641 & 5.5 & 5.5136 & TST & \\
\hline CHEMBL1553136 & 688641 & 5.1 & 5.1494 & TRN & \\
\hline CHEMBL542700 & 688641 & 4.9 & 5.118 & TRN & \\
\hline CHEMBL1409461 & 688641 & 4.5 & $4.6610 e$ & 00000000005 & TST \\
\hline CHEMBL1495541 & 688641 & 4.8 & 5.0845 & TRN & \\
\hline CHEMBL1318220 & 688641 & 4.5 & 5.2011 & TST & \\
\hline CHEMBL50112 & 688641 & 5.1 & 4.9894 & TRN & \\
\hline CHEMBL1355467 & 688641 & 5.6 & 5.0562 & TRN & \\
\hline CHEMBL1369212 & 688641 & 6.0 & 6.0565 & TRN & \\
\hline CHEMBL1451788 & 688641 & 5.5 & 5.7136 & TRN & \\
\hline
\end{tabular}




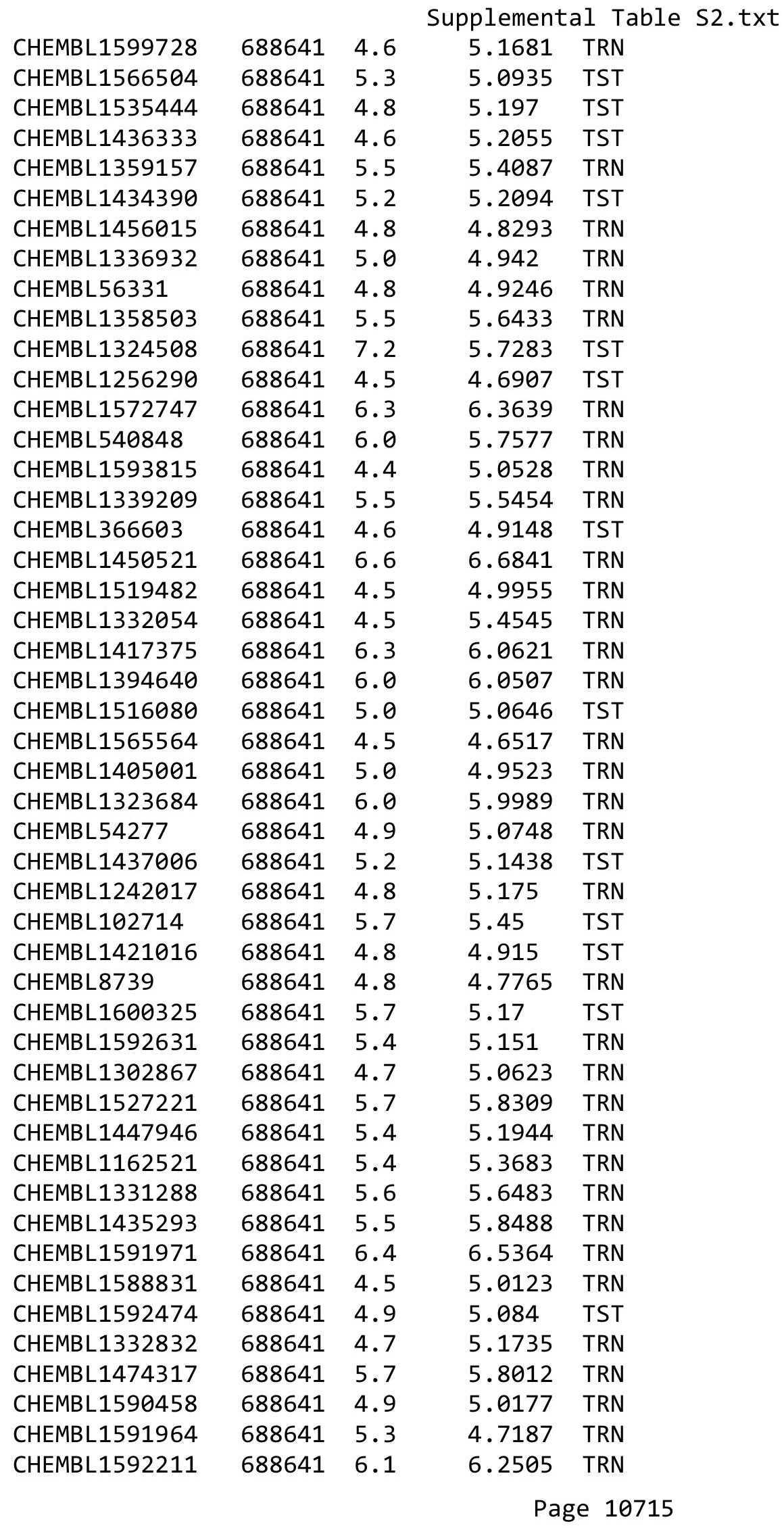




\begin{tabular}{|c|c|c|c|c|c|}
\hline \\
\hline CHEMBL1365122 & 688641 & 5.4 & 5.1557 & TRN & \\
\hline CHEMBL126804 & 688641 & 5.8 & 5.2961 & TRN & \\
\hline CHEMBL406119 & 688641 & 5.1 & 5.32700 & $\partial 000000001$ & TRN \\
\hline CHEMBL1552519 & 688641 & 4.8 & 4.8806 & TRN & \\
\hline CHEMBL1450209 & 688641 & 5.2 & 5.178 & TST & \\
\hline CHEMBL1373151 & 688641 & 5.0 & 4.94 & TRN & \\
\hline CHEMBL1566650 & 688641 & 4.6 & 5.2822 & TRN & \\
\hline CHEMBL1595166 & 688641 & 6.5 & 6.282 & TRN & \\
\hline CHEMBL1371789 & 688641 & 5.4 & 5.181 & TRN & \\
\hline CHEMBL1612582 & 688641 & 5.1 & 5.1042 & TRN & \\
\hline CHEMBL1551049 & 688641 & 5.3 & 5.2116 & TRN & \\
\hline CHEMBL1536007 & 688641 & 4.9 & 4.956 & TRN & \\
\hline CHEMBL1552098 & 688641 & 4.5 & 4.5926 & TRN & \\
\hline CHEMBL1328533 & 688641 & 6.1 & 6.1022 & TRN & \\
\hline CHEMBL1415080 & 688641 & 4.7 & 4.7351 & TRN & \\
\hline CHEMBL1329372 & 688641 & 5.3 & 4.94 & TRN & \\
\hline CHEMBL489935 & 688641 & 6.5 & 6.5934 & TRN & \\
\hline CHEMBL1527943 & 688641 & 4.6 & 5.1539 & TST & \\
\hline CHEMBL1327247 & 688641 & 6.1 & 5.8663 & TRN & \\
\hline CHEMBL1328879 & 688641 & 5.5 & 5.15600 & 0000000001 & TRN \\
\hline CHEMBL1473205 & 688641 & 4.7 & 5.2634 & TRN & \\
\hline CHEMBL1417646 & 688641 & 6.7001 & 6.6303 & TRN & \\
\hline CHEMBL1533853 & 688641 & 6.1 & 6.1844 & TRN & \\
\hline CHEMBL1360401 & 688641 & 5.2 & 5.1564 & TRN & \\
\hline CHEMBL1518035 & 688641 & 4.8 & 4.8451 & TRN & \\
\hline CHEMBL1331980 & 688641 & 6.0 & 5.8126 & TST & \\
\hline CHEMBL1611590 & 688641 & 5.2 & 4.9961 & TST & \\
\hline CHEMBL1323411 & 688641 & 4.5 & 5.1628 & TST & \\
\hline CHEMBL1417789 & 688641 & 5.4 & 5.4302 & TRN & \\
\hline CHEMBL1397559 & 688641 & 5.4 & 5.3462 & TRN & \\
\hline CHEMBL1370296 & 688641 & 5.4 & 5.4412 & TRN & \\
\hline CHEMBL1357422 & 688641 & 4.9 & 4.83 & TRN & \\
\hline CHEMBL1435319 & 688641 & 4.4 & 5.095 & TST & \\
\hline CHEMBL1590968 & 688641 & 4.8 & 4.80399 & 9999999999 & TRN \\
\hline CHEMBL93403 & 688641 & 4.8 & 4.8545 & TRN & \\
\hline CHEMBL 2374266 & 688641 & 4.6 & 4.9358 & TRN & \\
\hline CHEMBL1317009 & 688641 & 5.0 & 4.9776 & TRN & \\
\hline CHEMBL1512722 & 688641 & 5.1 & 5.0282 & TRN & \\
\hline CHEMBL195953 & 688641 & 5.5 & 5.0488 & TST & \\
\hline CHEMBL1479912 & 688641 & 5.5 & 5.5141 & TRN & \\
\hline CHEMBL1331112 & 688641 & 5.3 & 5.2093 & TST & \\
\hline CHEMBL1436222 & 688641 & 4.9 & 4.8894 & TRN & \\
\hline CHEMBL1373326 & 688641 & 4.9 & 4.8594 & TRN & \\
\hline CHEMBL1355831 & 688641 & 5.0 & 4.9326 & TRN & \\
\hline CHEMBL1518418 & 688641 & 5.7 & 5.0719 & TST & \\
\hline CHEMBL299613 & 688641 & 6.0 & 5.7427 & TRN & \\
\hline CHEMBL1480516 & 688641 & 6.0 & 5.8565 & TST & \\
\hline CHEMBL1397454 & 688641 & 4.8 & 4.7851 & TRN & \\
\hline
\end{tabular}




\begin{tabular}{|c|c|c|c|c|c|}
\hline \multicolumn{6}{|c|}{ Supplemental Table S2.txt } \\
\hline CHEMBL1376143 & 688641 & 4.8 & 4.8367 & TRN & \\
\hline CHEMBL16671 & 688641 & 6.0 & 4.8324 & TST & \\
\hline CHEMBL1514016 & 688641 & 4.6 & 4.6463 & TRN & \\
\hline CHEMBL34155 & 688641 & 5.7 & 5.0023 & TST & \\
\hline CHEMBL1554579 & 688641 & 6.3 & 6.3128 & TRN & \\
\hline CHEMBL1562088 & 688641 & 5.3 & 5.2872 & TST & \\
\hline CHEMBL1592672 & 688641 & 4.8 & 4.8534 & TRN & \\
\hline CHEMBL77971 & 688641 & 6.4 & 6.0556 & TST & \\
\hline CHEMBL1452057 & 688641 & 4.9 & 5.0604 & TRN & \\
\hline CHEMBL1333264 & 688641 & 5.4 & 5.1143 & TRN & \\
\hline CHEMBL1364473 & 688641 & 4.9 & 4.9142 & TRN & \\
\hline CHEMBL186784 & 688641 & 4.9 & 5.0429 & TRN & \\
\hline CHEMBL1593430 & 688641 & 4.8 & 4.7891 & TRN & \\
\hline CHEMBL1591544 & 688641 & 4.5 & 4.5237 & TRN & \\
\hline CHEMBL1398197 & 688641 & 4.5 & 5.1656 & TST & \\
\hline CHEMBL313737 & 688641 & 5.3 & 5.3266 & TST & \\
\hline CHEMBL497781 & 688641 & 4.9 & 5.066 & TRN & \\
\hline CHEMBL1319047 & 688641 & 4.5 & 4.92899 & 9999999999 & TRN \\
\hline CHEMBL1331037 & 688641 & 5.7 & 5.8325 & TRN & \\
\hline CHEMBL551154 & 688641 & 4.7 & 5.0184 & TRN & \\
\hline CHEMBL1592493 & 688641 & 6.0 & 5.5612 & TST & \\
\hline CHEMBL1473338 & 688641 & 4.6 & 4.6619 & TRN & \\
\hline CHEMBL1517852 & 688641 & 5.4 & 4.8217 & TRN & \\
\hline CHEMBL1490024 & 688641 & 4.9 & 4.8896 & TRN & \\
\hline CHEMBL 88147 & 688641 & 5.5 & 5.3942 & TST & \\
\hline CHEMBL69710 & 688641 & 4.5 & 4.7437 & TST & \\
\hline CHEMBL1393926 & 688641 & 5.3 & 5.0903 & TRN & \\
\hline CHEMBL484663 & 688641 & 5.5 & 5.1774 & TRN & \\
\hline CHEMBL1552270 & 688641 & 5.6 & 5.5667 & TRN & \\
\hline CHEMBL1569529 & 688641 & 4.9 & 4.9811 & TRN & \\
\hline CHEMBL22373 & 688641 & 5.1 & 5.1176 & TST & \\
\hline CHEMBL1368566 & 688641 & 4.8 & 4.8374 & TRN & \\
\hline CHEMBL1592452 & 688641 & 4.8 & 4.8654 & TRN & \\
\hline CHEMBL1555348 & 688641 & 4.8 & 4.9931 & TRN & \\
\hline CHEMBL1554278 & 688641 & 5.5 & 5.1802 & TST & \\
\hline CHEMBL1315268 & 688641 & 4.9 & 4.9006 & TRN & \\
\hline CHEMBL1314587 & 688641 & 5.3 & 5.4116 & TRN & \\
\hline CHEMBL1433752 & 688641 & 5.4 & 5.4938 & TRN & \\
\hline CHEMBL1599096 & 688641 & 4.8 & 5.1881 & TST & \\
\hline CHEMBL1613233 & 688641 & 4.5 & 4.6533 & TRN & \\
\hline CHEMBL1598994 & 688641 & 4.7 & 4.9102 & TRN & \\
\hline CHEMBL1320765 & 688641 & 4.9 & 4.9466 & TRN & \\
\hline CHEMBL422942 & 688641 & 6.0 & 5.2055 & TST & \\
\hline CHEMBL1482575 & 688641 & 6.1 & 6.0879 & TRN & \\
\hline CHEMBL1333653 & 688641 & 4.6 & 5.0243 & TRN & \\
\hline CHEMBL1597690 & 688641 & 4.9 & 5.303 & TST & \\
\hline CHEMBL1410635 & 688641 & 5.5 & 5.6688 & TRN & \\
\hline CHEMBL1558834 & 688641 & 4.6 & 4.7113 & TRN & \\
\hline
\end{tabular}




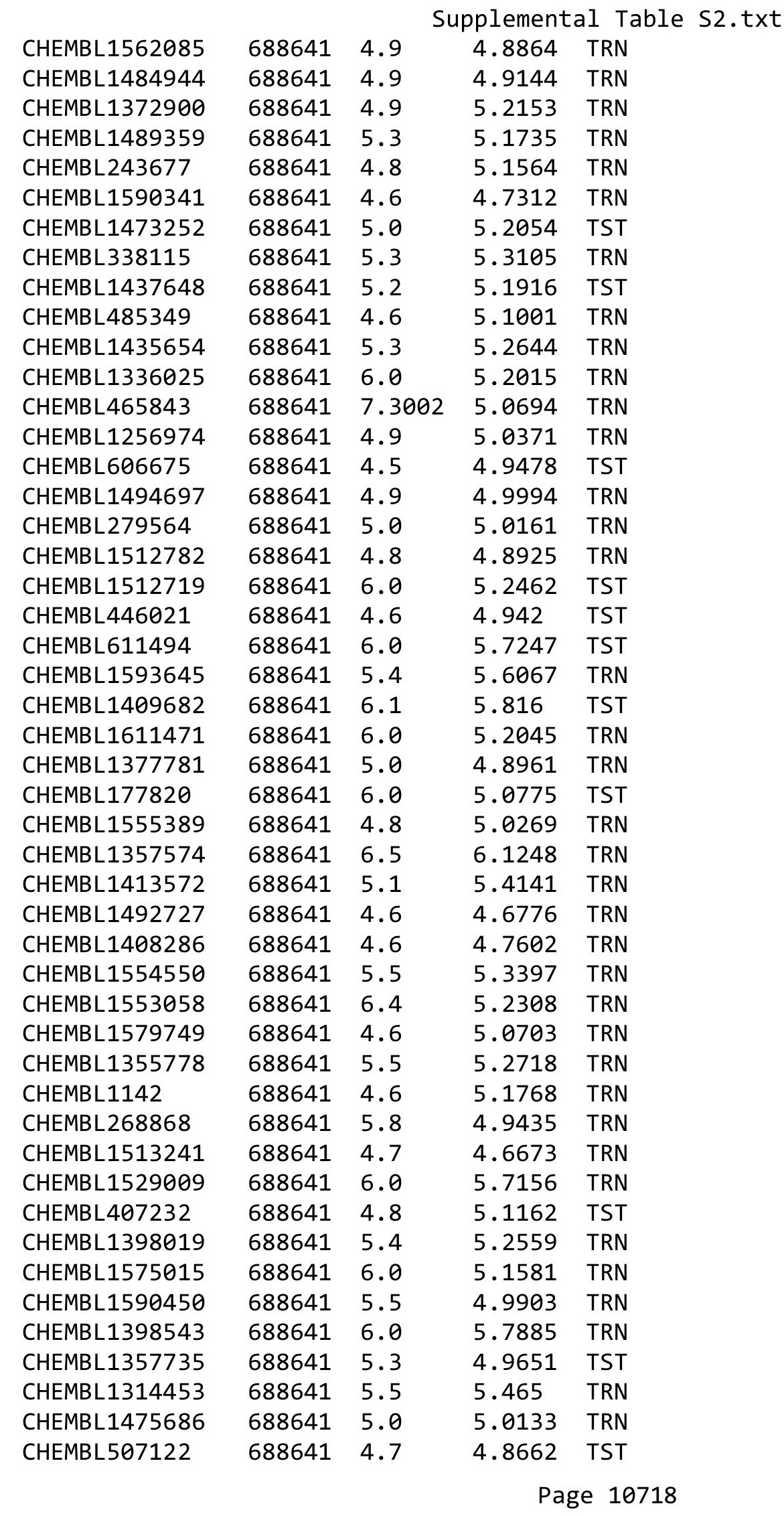




\begin{tabular}{|c|c|c|c|c|c|}
\hline \multicolumn{6}{|c|}{ Supplemental Table S2.txt } \\
\hline CHEMBL325238 & 688641 & 4.5 & 5.0025 & TRN & \\
\hline CHEMBL1358456 & 688641 & 4.9 & 4.8446 & TRN & \\
\hline CHEMBL1437778 & 688641 & 4.8 & 4.8503 & TRN & \\
\hline CHEMBL1590818 & 688641 & 4.5 & 4.6257 & TRN & \\
\hline CHEMBL1403769 & 688641 & 4.5 & 4.6099 & TRN & \\
\hline CHEMBL1562791 & 688641 & 5.3 & 5.3499 & TRN & \\
\hline CHEMBL1476996 & 688641 & 4.8 & 5.2242 & TST & \\
\hline CHEMBL1354600 & 688641 & 4.6 & 4.6518 & TRN & \\
\hline CHEMBL1590060 & 688641 & 4.9 & 4.8344 & TRN & \\
\hline CHEMBL1371510 & 688641 & 5.5 & 5.3302 & TST & \\
\hline CHEMBL1480740 & 688641 & 4.8 & 5.2302 & TST & \\
\hline CHEMBL1355712 & 688641 & 5.8 & 5.8929 & TRN & \\
\hline CHEMBL1256687 & 688641 & 6.1 & 5.7484 & TST & \\
\hline CHEMBL1552286 & 688641 & 4.8 & 5.046 & TRN & \\
\hline CHEMBL1512307 & 688641 & 5.4 & 5.4557 & TRN & \\
\hline CHEMBL1457268 & 688641 & 4.8 & 5.019 & TRN & \\
\hline CHEMBL1341844 & 688641 & 4.8 & 4.942 & TRN & \\
\hline CHEMBL1435276 & 688641 & 5.0 & 5.02 & TRN & \\
\hline CHEMBL1355982 & 688641 & 5.3 & 5.29 & TST & \\
\hline CHEMBL1315109 & 688641 & 5.1 & 5.0794 & TRN & \\
\hline CHEMBL1362729 & 688641 & 5.4 & 5.4627 & TRN & \\
\hline CHEMBL1410926 & 688641 & 5.2 & 5.1976 & TRN & \\
\hline CHEMBL1395338 & 688641 & 7.1002 & 6.4101 & TRN & \\
\hline CHEMBL1450553 & 688641 & 6.0 & 5.8427 & TRN & \\
\hline CHEMBL1328109 & 688641 & 5.5 & 5.3728 & TRN & \\
\hline CHEMBL1373007 & 688641 & 7.5003 & 5.2943 & TRN & \\
\hline CHEMBL1485850 & 688641 & 4.8 & 4.8246 & TRN & \\
\hline CHEMBL1438688 & 688641 & 5.5 & 5.5611 & TRN & \\
\hline CHEMBL1604074 & 688641 & 5.0 & 5.1407 & TST & \\
\hline CHEMBL1475166 & 688641 & 5.0 & 5.2663 & TRN & \\
\hline CHEMBL1591876 & 688641 & 4.8 & 4.7872 & TRN & \\
\hline CHEMBL1526121 & 688641 & 4.8 & 5.0305 & TRN & \\
\hline CHEMBL258512 & 688641 & 5.3 & 5.3156 & TRN & \\
\hline CHEMBL131171 & 688641 & 5.5 & 5.3752 & TST & \\
\hline CHEMBL1442011 & 688641 & 5.7 & 5.57799 & 9999999999 & TRN \\
\hline CHEMBL13790 & 688641 & 6.0 & 4.292 & TRN & \\
\hline CHEMBL1356336 & 688641 & 5.8 & 5.8746 & TRN & \\
\hline CHEMBL1605366 & 688641 & 6.1 & 5.4539 & TRN & \\
\hline CHEMBL1404317 & 688641 & 5.5 & 5.4797 & TRN & \\
\hline CHEMBL1474209 & 688641 & 5.4 & 5.5864 & TRN & \\
\hline CHEMBL1316075 & 688641 & 5.7 & 5.6035 & TRN & \\
\hline CHEMBL1567295 & 688641 & 6.8 & 6.7605 & TRN & \\
\hline CHEMBL1357930 & 688641 & 6.0 & 5.0407 & TST & \\
\hline CHEMBL1414358 & 688641 & 5.3 & 5.5139 & TRN & \\
\hline CHEMBL 286204 & 688641 & 5.8 & 4.833 & TST & \\
\hline CHEMBL1568825 & 688641 & 4.8 & 5.101 & TRN & \\
\hline CHEMBL1628207 & 688641 & 5.1 & 5.1516 & TRN & \\
\hline CHEMBL1373621 & 688641 & 4.8 & 4.7927 & TRN & \\
\hline
\end{tabular}




\begin{tabular}{|c|c|c|c|c|c|}
\hline \\
\hline CHEMBL1417552 & 688641 & 4.9 & 5.0897 & TRN & \\
\hline CHEMBL1320619 & 688641 & 5.0 & 4.9249 & TRN & \\
\hline CHEMBL1551503 & 688641 & 4.9 & 4.9265 & TRN & \\
\hline CHEMBL1516054 & 688641 & 5.9 & 5.944 & TRN & \\
\hline CHEMBL323354 & 688641 & 5.3 & 5.4216 & TST & \\
\hline CHEMBL1554888 & 688641 & 5.6 & 5.6182 & TRN & \\
\hline CHEMBL1322414 & 688641 & 5.6 & 5.558 & TRN & \\
\hline CHEMBL303516 & 688641 & 4.8 & 4.9104 & TST & \\
\hline CHEMBL1443713 & 688641 & 4.6 & 4.6884 & TRN & \\
\hline CHEMBL1357182 & 688641 & 4.9 & 4.7535 & TRN & \\
\hline CHEMBL1363467 & 688641 & 4.8 & 4.7731 & TRN & \\
\hline CHEMBL1333783 & 688641 & 6.1 & 5.9577 & TRN & \\
\hline CHEMBL1473191 & 688641 & 5.4 & 5.4006 & TST & \\
\hline CHEMBL1397634 & 688641 & 5.5 & 5.5035 & TRN & \\
\hline CHEMBL1329526 & 688641 & 5.0 & 5.0436 & TRN & \\
\hline CHEMBL1317214 & 688641 & 5.5 & 5.57600 & 00000000005 & TRN \\
\hline CHEMBL 274438 & 688641 & 5.9 & 5.6948 & TRN & \\
\hline CHEMBL1486304 & 688641 & 5.4 & 5.3309 & TRN & \\
\hline CHEMBL1397192 & 688641 & 4.8 & 4.9203 & TRN & \\
\hline CHEMBL1338095 & 688641 & 5.4 & 5.3919 & TRN & \\
\hline CHEMBL1320525 & 688641 & 5.0 & 5.1286 & TRN & \\
\hline CHEMBL1489212 & 688641 & 6.3 & 5.3021 & TST & \\
\hline CHEMBL1448010 & 688641 & 5.9 & 4.9859 & TST & \\
\hline CHEMBL 2374058 & 688641 & 4.6 & 4.7832 & TST & \\
\hline CHEMBL1456417 & 688641 & 5.1 & 5.1376 & TRN & \\
\hline CHEMBL1455699 & 688641 & 5.5 & 5.0726 & TST & \\
\hline CHEMBL1553262 & 688641 & 4.5 & 4.659 & TRN & \\
\hline CHEMBL1440534 & 688641 & 5.4 & 5.4361 & TRN & \\
\hline CHEMBL1476170 & 688641 & 6.0 & 5.8416 & TST & \\
\hline CHEMBL1528479 & 688641 & 4.9 & 4.8966 & TRN & \\
\hline CHEMBL1474498 & 688641 & 5.0 & 5.2356 & TRN & \\
\hline CHEMBL1601768 & 688641 & 4.4 & 5.2405 & TRN & \\
\hline CHEMBL1406936 & 688641 & 4.7 & 4.7398 & TRN & \\
\hline CHEMBL167513 & 688641 & 4.6 & 4.9701 & TRN & \\
\hline CHEMBL1491744 & 688641 & 5.4 & 5.5249 & TRN & \\
\hline CHEMBL1554018 & 688641 & 6.0 & 6.0737 & TRN & \\
\hline CHEMBL1450162 & 688641 & 5.2 & 5.13299 & 9999999999 & TRN \\
\hline CHEMBL1201074 & 688641 & 5.0 & 5.067 & TST & \\
\hline CHEMBL1570971 & 688641 & 5.4 & 5.3404 & TRN & \\
\hline CHEMBL1318425 & 688641 & 4.5 & 5.3004 & TST & \\
\hline CHEMBL1332346 & 688641 & 5.9 & 6.0242 & TRN & \\
\hline CHEMBL1496494 & 688641 & 5.0 & 5.1046 & TRN & \\
\hline CHEMBL1553700 & 688641 & 6.0 & 5.737 & TST & \\
\hline CHEMBL1521453 & 688641 & 6.0 & 5.7852 & TST & \\
\hline CHEMBL1591712 & 688641 & 4.9 & 4.8951 & TRN & \\
\hline CHEMBL77456 & 688641 & 4.7 & 4.7357 & TRN & \\
\hline CHEMBL1474695 & 688641 & 5.2 & 5.2593 & TRN & \\
\hline CHEMBL1172911 & 688641 & 5.4 & 5.2234 & TST & \\
\hline
\end{tabular}




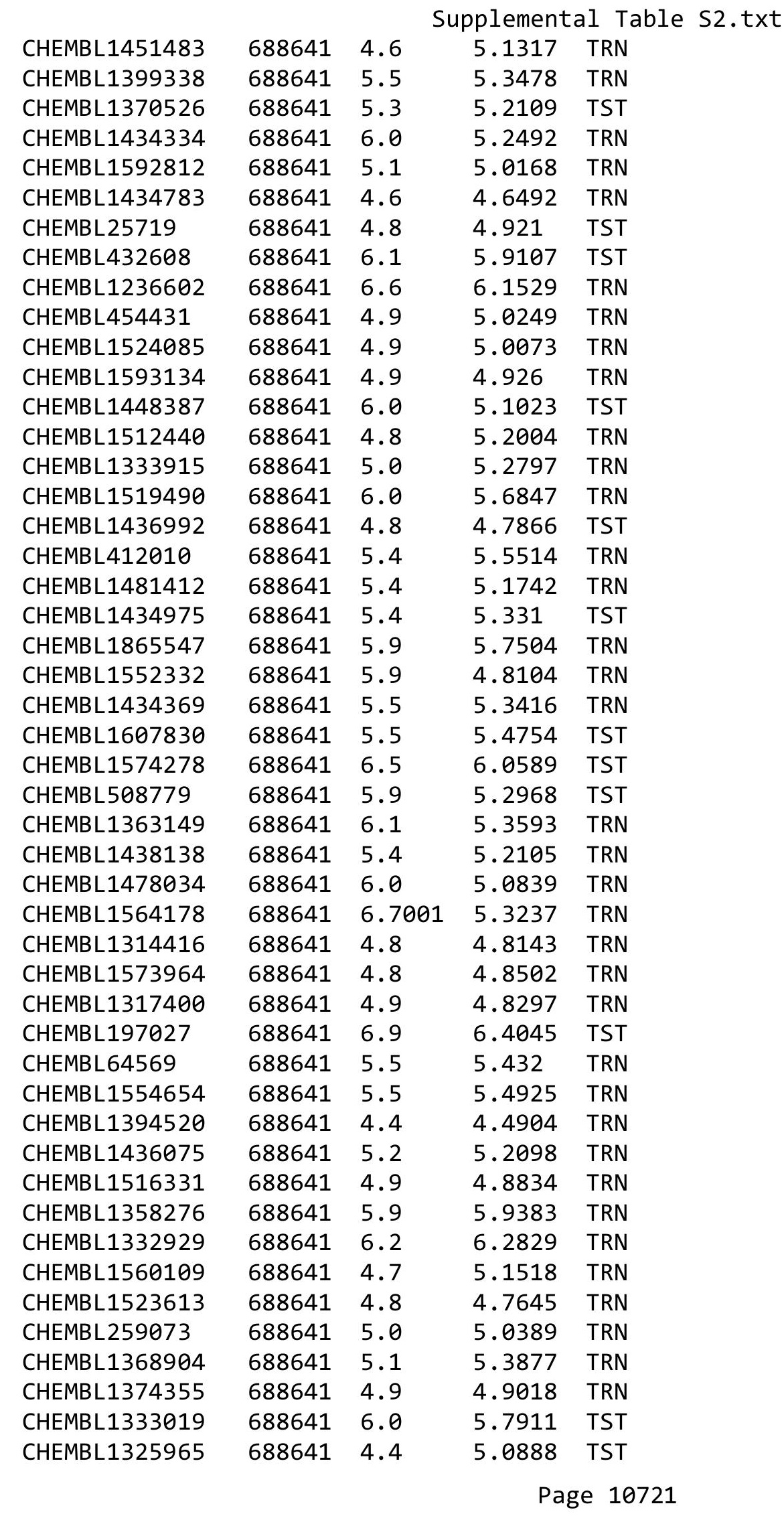




\begin{tabular}{|c|c|c|c|c|c|}
\hline \\
\hline CHEMBL1356690 & 688641 & 4.6 & 4.6282 & TRN & \\
\hline CHEMBL1402957 & 688641 & 6.0 & 5.53799 & 9999999999 & TST \\
\hline CHEMBL3348827 & 688641 & 4.8 & $5.3870 e$ & 00000000005 & TRN \\
\hline CHEMBL1512786 & 688641 & 5.2 & 4.9531 & TRN & \\
\hline CHEMBL1514735 & 688641 & 5.4 & 5.2472 & TST & \\
\hline CHEMBL1516388 & 688641 & 4.5 & 4.743 & TST & \\
\hline CHEMBL16807 & 688641 & 6.0 & 5.0821 & TRN & \\
\hline CHEMBL1560633 & 688641 & 4.5 & 5.0754 & TRN & \\
\hline CHEMBL1355762 & 688641 & 4.4 & 4.9706 & TRN & \\
\hline CHEMBL1320607 & 688641 & 4.8 & 4.769 & TRN & \\
\hline CHEMBL1395252 & 688641 & 4.8 & 4.885 & TRN & \\
\hline CHEMBL1607228 & 688641 & 6.0 & 5.7438 & TRN & \\
\hline CHEMBL1319286 & 688641 & 4.9 & 4.9751 & TRN & \\
\hline CHEMBL1336787 & 688641 & 5.1 & 5.1169 & TRN & \\
\hline CHEMBL1601630 & 688641 & 4.9 & 4.9159 & TRN & \\
\hline CHEMBL1434411 & 688641 & 4.8 & 4.7401 & TRN & \\
\hline CHEMBL184450 & 688641 & 4.8 & 4.9808 & TRN & \\
\hline CHEMBL1567098 & 688641 & 6.0 & 5.94799 & 99999999995 & TRN \\
\hline CHEMBL1438226 & 688641 & 4.9 & 5.1305 & TRN & \\
\hline CHEMBL1527443 & 688641 & 5.7 & 5.7919 & TRN & \\
\hline CHEMBL1394223 & 688641 & 4.8 & 4.8028 & TRN & \\
\hline CHEMBL1256674 & 688641 & 4.8 & 5.0672 & TST & \\
\hline CHEMBL1375753 & 688641 & 5.5 & 5.4298 & TRN & \\
\hline CHEMBL1555153 & 688641 & 5.7 & 5.2093 & TST & \\
\hline CHEMBL1476280 & 688641 & 5.4 & 5.6876 & TRN & \\
\hline CHEMBL1477383 & 688641 & 5.3 & 5.2394 & TST & \\
\hline CHEMBL1368860 & 688641 & 6.0 & 5.9386 & TRN & \\
\hline CHEMBL1434460 & 688641 & 5.5 & 5.6518 & TRN & \\
\hline CHEMBL1602812 & 688641 & 5.9 & 5.9952 & TRN & \\
\hline CHEMBL441282 & 688641 & 5.6 & 5.45 & TST & \\
\hline CHEMBL1327203 & 688641 & 6.4 & 6.5432 & TRN & \\
\hline CHEMBL169233 & 688641 & 4.9 & 4.9349 & TST & \\
\hline CHEMBL1444270 & 688641 & 5.8 & 5.9011 & TRN & \\
\hline CHEMBL1322711 & 688641 & 5.5 & 5.1507 & TRN & \\
\hline CHEMBL 1454270 & 688641 & 4.8 & 4.7783 & TRN & \\
\hline CHEMBL1397283 & 688641 & 5.3 & 5.2602 & TRN & \\
\hline CHEMBL1395915 & 688641 & 5.5 & 5.4042 & TRN & \\
\hline CHEMBL1437846 & 688641 & 5.4 & 5.2491 & TST & \\
\hline CHEMBL1609209 & 688641 & 4.7 & 4.7627 & TRN & \\
\hline CHEMBL1600561 & 688641 & 4.8 & 4.7897 & TRN & \\
\hline CHEMBL1514626 & 688641 & 4.8 & 4.8412 & TRN & \\
\hline CHEMBL1436179 & 688641 & 4.8 & 4.8945 & TRN & \\
\hline CHEMBL1552478 & 688641 & 4.5 & 4.7133 & TRN & \\
\hline CHEMBL1589923 & 688641 & 4.7 & 4.8757 & TRN & \\
\hline CHEMBL 1455767 & 688641 & 4.4 & 4.4749 & TRN & \\
\hline CHEMBL1566012 & 688641 & 5.8 & 5.6056 & TRN & \\
\hline CHEMBL1563066 & 688641 & 5.4 & 5.3298 & TRN & \\
\hline CHEMBL1358659 & 688641 & 4.5 & 4.7337 & TST & \\
\hline
\end{tabular}




\begin{tabular}{|c|c|c|c|c|c|}
\hline \multicolumn{6}{|c|}{ Supplemental Table S2.txt } \\
\hline CHEMBL429095 & 688641 & 4.6 & 4.6883 & TST & \\
\hline CHEMBL1481741 & 688641 & 4.5 & 4.7121 & TRN & \\
\hline CHEMBL1255837 & 688641 & 6.0 & 5.9268 & TST & \\
\hline CHEMBL1316368 & 688641 & 5.0 & 5.0502 & TST & \\
\hline CHEMBL1435384 & 688641 & 5.6 & 5.6233 & TRN & \\
\hline CHEMBL1418097 & 688641 & 5.3 & 5.2244 & TST & \\
\hline CHEMBL1357044 & 688641 & 5.4 & 5.121 & TST & \\
\hline CHEMBL1453980 & 688641 & 4.8 & 4.8044 & TRN & \\
\hline CHEMBL1612050 & 688641 & 5.5 & 5.5274 & TRN & \\
\hline CHEMBL1562729 & 688641 & 4.6 & 5.2337 & TST & \\
\hline CHEMBL1555368 & 688641 & 5.5 & 5.6585 & TRN & \\
\hline CHEMBL1597037 & 688641 & 5.5 & 5.4291 & TRN & \\
\hline CHEMBL286615 & 688641 & 5.1 & 5.2658 & TRN & \\
\hline CHEMBL1474185 & 688641 & 4.9 & 4.8405 & TRN & \\
\hline CHEMBL1404112 & 688641 & 5.4 & 5.3571 & TRN & \\
\hline CHEMBL1338985 & 688641 & 5.1 & 5.126 & TRN & \\
\hline CHEMBL1490495 & 688641 & 4.4 & 5.0714 & TRN & \\
\hline CHEMBL1367917 & 688641 & 5.8 & 5.5494 & TRN & \\
\hline CHEMBL1521490 & 688641 & 6.1 & 6.0882 & TRN & \\
\hline CHEMBL1435899 & 688641 & 4.8 & 4.7282 & TRN & \\
\hline CHEMBL1395429 & 688641 & 4.9 & 4.9608 & TRN & \\
\hline CHEMBL37312 & 688641 & 5.4 & 5.3765 & TRN & \\
\hline CHEMBL 2373608 & 688641 & 6.0 & 5.1932 & TRN & \\
\hline CHEMBL1326341 & 688641 & 5.0 & 4.9962 & TRN & \\
\hline CHEMBL1358178 & 688641 & 5.6 & 5.4337 & TST & \\
\hline CHEMBL 3189483 & 688641 & 6.0 & 5.9331 & TRN & \\
\hline CHEMBL251647 & 688641 & 6.0 & 5.8569 & TST & \\
\hline CHEMBL136906 & 688641 & 5.5 & 5.2885 & TST & \\
\hline CHEMBL95431 & 688641 & 5.5 & 5.3927 & TST & \\
\hline CHEMBL1483285 & 688641 & 5.5 & 5.70100 & 00000000005 & TRN \\
\hline CHEMBL1358654 & 688641 & 5.6 & 5.4569 & TRN & \\
\hline CHEMBL1396559 & 688641 & 5.1 & 5.0954 & TRN & \\
\hline CHEMBL1436682 & 688641 & 5.0 & 5.1368 & TRN & \\
\hline CHEMBL1395137 & 688641 & 4.9 & 4.8229 & TRN & \\
\hline CHEMBL1473868 & 688641 & 5.4 & 5.4299 & TRN & \\
\hline CHEMBL312163 & 688641 & 4.4 & 5.4543 & TRN & \\
\hline CHEMBL1480779 & 688641 & 5.9 & 5.6465 & TRN & \\
\hline CHEMBL1486459 & 688641 & 5.6 & 5.2523 & TRN & \\
\hline CHEMBL1334817 & 688641 & 4.5 & 4.6658 & TST & \\
\hline CHEMBL1396309 & 688641 & 5.0 & 5.3392 & TST & \\
\hline CHEMBL 2373653 & 688641 & 5.4 & 5.1775 & TRN & \\
\hline CHEMBL418971 & 688641 & 6.0 & 5.0516 & TRN & \\
\hline CHEMBL83954 & 688641 & 4.6 & 4.7423 & TRN & \\
\hline CHEMBL1590645 & 688641 & 5.2 & 5.2634 & TRN & \\
\hline CHEMBL1532517 & 688641 & 4.7 & 4.7565 & TRN & \\
\hline CHEMBL1555122 & 688641 & 4.8 & 4.8598 & TRN & \\
\hline CHEMBL1604807 & 688641 & 5.4 & 5.3737 & TRN & \\
\hline CHEMBL1434447 & 688641 & 5.4 & 5.4457 & TRN & \\
\hline
\end{tabular}




\begin{tabular}{|c|c|c|c|c|}
\hline \multicolumn{5}{|c|}{ plemental } \\
\hline CHEMBL1406764 & 688641 & 5.4 & 5.2668 & TRN \\
\hline CHEMBL1368643 & 688641 & 4.6 & 4.6935 & TRN \\
\hline CHEMBL1418190 & 688641 & 5.8 & 5.5373 & TRN \\
\hline CHEMBL 367741 & 688641 & 4.6 & 4.9758 & TRN \\
\hline CHEMBL1998893 & 688641 & 5.4 & 5.3288 & TRN \\
\hline CHEMBL1085765 & 688641 & 6.0 & 4.9284 & TRN \\
\hline CHEMBL1484422 & 688641 & 5.5 & 5.4946 & TRN \\
\hline CHEMBL1473029 & 688641 & 5.5 & 5.1322 & TST \\
\hline CHEMBL1512624 & 688641 & 5.3 & 5.3365 & TRN \\
\hline CHEMBL1316357 & 688641 & 6.2 & 5.1216 & TRN \\
\hline CHEMBL1574106 & 688641 & 6.3 & 6.3837 & TRN \\
\hline CHEMBL1500995 & 688641 & 4.5 & 5.012 & TRN \\
\hline CHEMBL448966 & 688641 & 6.6 & 6.7199 & TRN \\
\hline CHEMBL1442425 & 688641 & 4.6 & 4.6974 & TRN \\
\hline CHEMBL1406078 & 688641 & 4.9 & 4.8115 & TRN \\
\hline CHEMBL1553274 & 688641 & 4.4 & 5.2314 & TST \\
\hline CHEMBL1499330 & 688641 & 5.2 & 5.1994 & TRN \\
\hline CHEMBL1593850 & 688641 & 4.9 & 5.0755 & TST \\
\hline CHEMBL1551051 & 688641 & 5.4 & 5.3961 & TRN \\
\hline CHEMBL1551308 & 688641 & 4.8 & 4.8301 & TRN \\
\hline CHEMBL1489528 & 688641 & 5.9 & 5.9655 & TRN \\
\hline CHEMBL3209943 & 688641 & 5.4 & 5.4559 & TRN \\
\hline CHEMBL1561383 & 688641 & 4.9 & 4.8376 & TRN \\
\hline CHEMBL1394089 & 688641 & 6.0 & 4.9944 & TST \\
\hline CHEMBL1441237 & 688641 & 5.1 & 4.9956 & TRN \\
\hline CHEMBL1523827 & 688641 & 5.0 & 4.9659 & TST \\
\hline CHEMBL 242383 & 688641 & 4.4 & 5.0637 & TRN \\
\hline CHEMBL1477982 & 688641 & 5.3 & 5.4377 & TRN \\
\hline CHEMBL1593335 & 688641 & 5.0 & 5.1977 & TRN \\
\hline CHEMBL1451477 & 688641 & 5.8 & 5.397 & TRN \\
\hline CHEMBL1490299 & 688641 & 4.5 & 5.0965 & TRN \\
\hline CHEMBL1594008 & 688641 & 5.5 & 5.4757 & TRN \\
\hline CHEMBL1483739 & 688641 & 4.8 & 5.0194 & TRN \\
\hline CHEMBL577455 & 688641 & 4.8 & 4.9652 & TST \\
\hline CHEMBL1552667 & 688641 & 5.4 & 5.1436 & TRN \\
\hline CHEMBL1592352 & 688641 & 5.0 & 5.1705 & TST \\
\hline CHEMBL3207783 & 688641 & 5.4 & 5.4776 & TRN \\
\hline CHEMBL1368965 & 688641 & 5.8 & 5.9344 & TRN \\
\hline CHEMBL1315820 & 688641 & 4.8 & 4.808 & TRN \\
\hline CHEMBL1437962 & 688641 & 5.4 & 5.3294 & TST \\
\hline CHEMBL1476099 & 688641 & 4.4 & 5.0812 & TRN \\
\hline CHEMBL1595377 & 688641 & 5.0 & 4.9904 & TRN \\
\hline CHEMBL1436817 & 688641 & 4.9 & 4.956 & TRN \\
\hline CHEMBL1514953 & 688641 & 5.4 & 5.376 & TRN \\
\hline CHEMBL1515410 & 688641 & 5.1 & 4.8736 & TRN \\
\hline CHEMBL17127 & 688641 & 4.5 & 5.0645 & TST \\
\hline CHEMBL1256971 & 688641 & 4.8 & 4.9417 & TST \\
\hline CHEMBL83154 & 688641 & 4.8 & 5.1131 & TRN \\
\hline
\end{tabular}




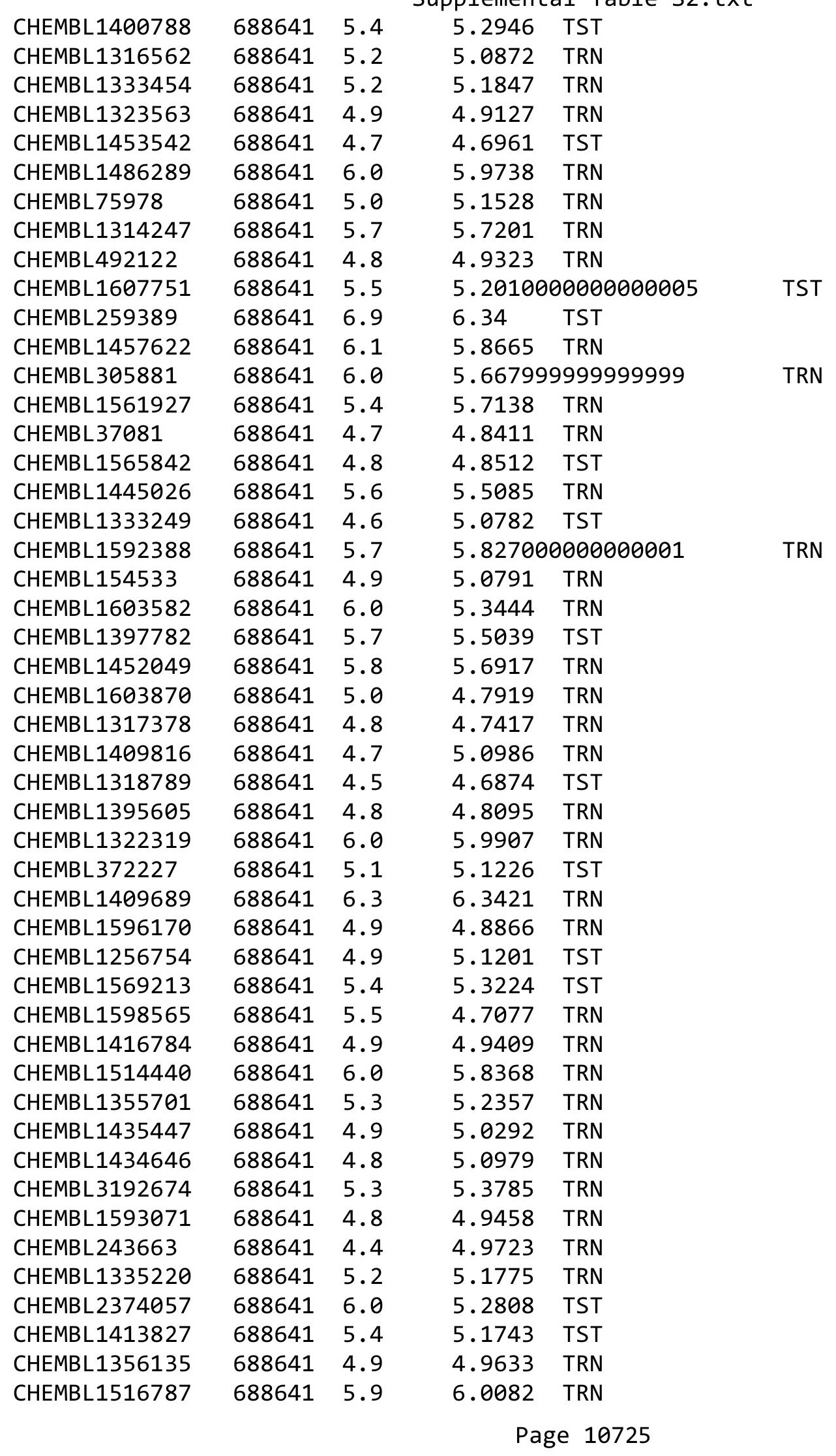




\begin{tabular}{|c|c|c|c|c|c|}
\hline \multicolumn{6}{|c|}{ Supplemental Table S2.txt } \\
\hline CHEMBL487186 & 688641 & 6.3 & 5.232 & TST & \\
\hline CHEMBL1317498 & 688641 & 4.8 & 4.7829 & TRN & \\
\hline CHEMBL1488393 & 688641 & 4.7 & 5.0883 & TRN & \\
\hline CHEMBL1506225 & 688641 & 4.7 & 4.9027 & TST & \\
\hline CHEMBL1330087 & 688641 & 6.0 & 6.0666 & TRN & \\
\hline CHEMBL1551610 & 688641 & 4.4 & 5.3465 & TST & \\
\hline CHEMBL1447894 & 688641 & 5.4 & 5.3975 & TRN & \\
\hline CHEMBL1256760 & 688641 & 6.0 & 5.6922 & TRN & \\
\hline CHEMBL1331312 & 688641 & 4.9 & 5.07100 & 2000000001 & TRN \\
\hline CHEMBL1433883 & 688641 & 4.9 & 4.9216 & TRN & \\
\hline CHEMBL63426 & 688641 & 5.2 & 5.2067 & TST & \\
\hline CHEMBL1610144 & 688641 & 4.8 & 5.0819 & TRN & \\
\hline CHEMBL1556431 & 688641 & 4.8 & 4.7601 & TRN & \\
\hline CHEMBL1591381 & 688641 & 4.8 & 4.7521 & TRN & \\
\hline CHEMBL1516675 & 688641 & 4.8 & 5.0483 & TST & \\
\hline CHEMBL1590550 & 688641 & 6.4 & 6.53 & TRN & \\
\hline CHEMBL18785 & 688641 & 5.9 & 5.6972 & TRN & \\
\hline CHEMBL1486447 & 688641 & 4.6 & 4.9811 & TRN & \\
\hline CHEMBL198159 & 688641 & 4.9 & 4.9883 & TRN & \\
\hline CHEMBL1451208 & 688641 & 4.5 & 5.0058 & TRN & \\
\hline CHEMBL1553422 & 688641 & 5.5 & 5.4282 & TRN & \\
\hline CHEMBL1355840 & 688641 & 6.5 & 6.4838 & TRN & \\
\hline CHEMBL1554844 & 688641 & 6.0 & 5.155 & TST & \\
\hline CHEMBL261836 & 688641 & 5.4 & 5.2299 & TRN & \\
\hline CHEMBL1394738 & 688641 & 4.4 & 5.2557 & TRN & \\
\hline CHEMBL1369824 & 688641 & 5.4 & 5.2758 & TRN & \\
\hline CHEMBL1436521 & 688641 & 5.1 & 5.1508 & TRN & \\
\hline CHEMBL1456346 & 688641 & 4.9 & 5.0046 & TST & \\
\hline CHEMBL1568744 & 688641 & 6.0 & 5.8776 & TRN & \\
\hline CHEMBL1473760 & 688641 & 5.2 & 5.2235 & TRN & \\
\hline CHEMBL1358384 & 688641 & 8.8861 & 7.8132 & TST & \\
\hline CHEMBL1396460 & 688641 & 6.0 & 5.3286 & TRN & \\
\hline CHEMBL1517581 & 688641 & 5.4 & 5.1836 & TRN & \\
\hline CHEMBL1613544 & 688641 & 5.5 & 5.1252 & TRN & \\
\hline CHEMBL12014 & 688641 & 5.4 & 5.2926 & TRN & \\
\hline CHEMBL1321421 & 688641 & 4.7 & 4.8895 & TST & \\
\hline CHEMBL 845 & 688641 & 5.3 & 5.2245 & TRN & \\
\hline CHEMBL1407783 & 688641 & 5.5 & 5.5372 & TRN & \\
\hline CHEMBL1553404 & 688641 & 5.1 & 5.0076 & TRN & \\
\hline CHEMBL173395 & 688641 & 4.9 & 5.0709 & TRN & \\
\hline CHEMBL1325732 & 688641 & 6.2 & 5.9336 & TST & \\
\hline CHEMBL1606591 & 688641 & 4.9 & 4.8578 & TRN & \\
\hline CHEMBL1565373 & 688641 & 4.9 & 5.2666 & TRN & \\
\hline CHEMBL90769 & 688641 & 4.7 & 4.7287 & TST & \\
\hline CHEMBL585481 & 688641 & 4.5 & 5.0867 & TRN & \\
\hline CHEMBL1327881 & 688641 & 5.0 & 4.9845 & TRN & \\
\hline CHEMBL1474435 & 688641 & 5.5 & 5.4503 & TRN & \\
\hline CHEMBL1596952 & 688641 & 5.3 & 5.1717 & TRN & \\
\hline
\end{tabular}




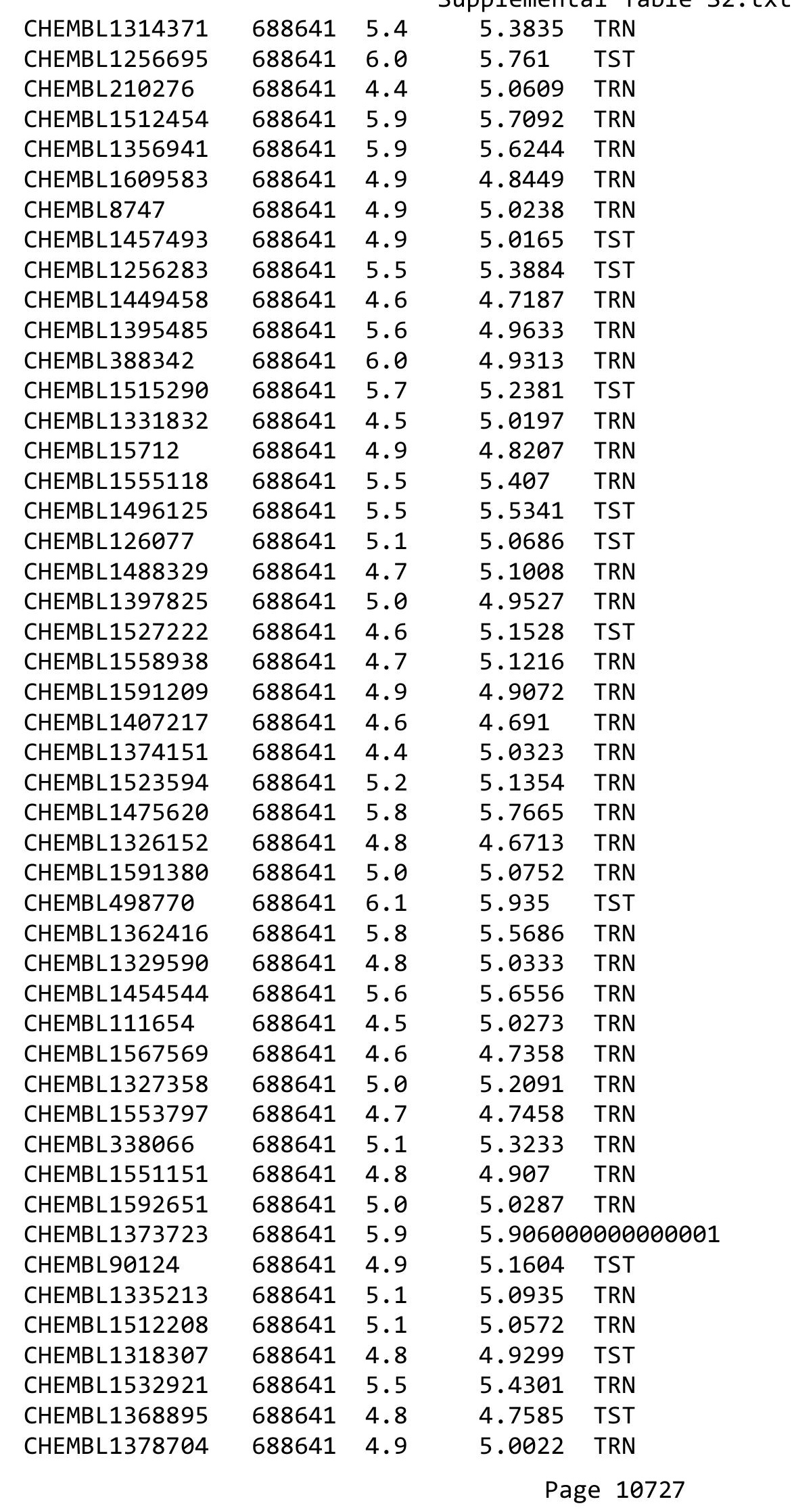




\begin{tabular}{|c|c|c|c|c|c|}
\hline \multicolumn{6}{|c|}{ Supplemental Table S2.txt } \\
\hline CHEMBL491771 & 688641 & 5.8 & 5.7628 & TRN & \\
\hline CHEMBL 2373284 & 688641 & 5.5 & 5.4033 & TST & \\
\hline CHEMBL1513633 & 688641 & 6.3 & 6.32700 & 0000000001 & TRN \\
\hline CHEMBL1529879 & 688641 & 5.4 & 5.4062 & TRN & \\
\hline CHEMBL1325119 & 688641 & 5.0 & 5.1464 & TST & \\
\hline CHEMBL1482426 & 688641 & 5.2 & 5.3305 & TRN & \\
\hline CHEMBL518494 & 688641 & 4.4 & 5.1766 & TST & \\
\hline CHEMBL1447149 & 688641 & 5.3 & 5.1841 & TRN & \\
\hline CHEMBL1395107 & 688641 & 4.4 & 4.5894 & TRN & \\
\hline CHEMBL1514505 & 688641 & 4.8 & 4.8133 & TRN & \\
\hline CHEMBL1355351 & 688641 & 4.9 & 4.9608 & TRN & \\
\hline CHEMBL1445094 & 688641 & 5.0 & 5.1426 & TRN & \\
\hline CHEMBL1437776 & 688641 & 4.9 & 4.9267 & TRN & \\
\hline CHEMBL1320569 & 688641 & 5.7 & 5.29299 & 7999999999 & TRN \\
\hline CHEMBL258893 & 688641 & 4.5 & 4.8024 & TST & \\
\hline CHEMBL1531982 & 688641 & 4.8 & 5.2107 & TST & \\
\hline CHEMBL1396693 & 688641 & 5.8 & 5.7572 & TRN & \\
\hline CHEMBL1404451 & 688641 & 5.9 & 5.892 & TRN & \\
\hline CHEMBL1558245 & 688641 & 5.4 & 5.4764 & TRN & \\
\hline CHEMBL307341 & 688641 & 4.4 & 5.0825 & TRN & \\
\hline CHEMBL1554745 & 688641 & 5.6 & 5.7217 & TRN & \\
\hline CHEMBL1316317 & 688641 & 4.8 & 4.8214 & TRN & \\
\hline CHEMBL1589893 & 688641 & 5.1 & 4.9744 & TRN & \\
\hline CHEMBL536480 & 688641 & 5.2 & 5.1392 & TRN & \\
\hline CHEMBL1528540 & 688641 & 5.4 & 5.1976 & TRN & \\
\hline CHEMBL1551633 & 688641 & 4.6 & 4.6628 & TRN & \\
\hline CHEMBL1358297 & 688641 & 5.0 & 5.0422 & TST & \\
\hline CHEMBL14276 & 688641 & 5.6 & 5.5163 & TST & \\
\hline CHEMBL1554982 & 688641 & 5.5 & 5.6799 & TRN & \\
\hline CHEMBL1553179 & 688641 & 5.3 & 5.15 & TRN & \\
\hline CHEMBL398363 & 688641 & 4.9 & 4.9277 & TRN & \\
\hline CHEMBL1551415 & 688641 & 5.4 & 5.1447 & TRN & \\
\hline CHEMBL1553990 & 688641 & 4.8 & 4.9336 & TRN & \\
\hline CHEMBL1514458 & 688641 & 4.7 & 5.7635 & TRN & \\
\hline CHEMBL1590493 & 688641 & 5.4 & 5.1553 & TRN & \\
\hline CHEMBL1323768 & 688641 & 4.5 & 5.1776 & TST & \\
\hline CHEMBL1397196 & 688641 & 5.7 & 5.28799 & 9999999999 & TRN \\
\hline CHEMBL1489769 & 688641 & 6.0 & 5.1293 & TST & \\
\hline CHEMBL1592220 & 688641 & 5.3 & 5.0855 & TRN & \\
\hline CHEMBL 258767 & 688641 & 6.0 & 5.7066 & TRN & \\
\hline CHEMBL1416203 & 688641 & 4.7 & 5.0697 & TRN & \\
\hline CHEMBL1366732 & 688641 & 5.8 & 5.9816 & TRN & \\
\hline CHEMBL2373639 & 688641 & 5.5 & 5.3831 & TST & \\
\hline CHEMBL1474402 & 688641 & 5.3 & 5.3983 & TRN & \\
\hline CHEMBL1512895 & 688641 & 4.8 & 4.7278 & TRN & \\
\hline CHEMBL3351063 & 688641 & 5.5 & 5.1989 & TRN & \\
\hline CHEMBL516616 & 688641 & 5.4 & 5.3552 & TST & \\
\hline CHEMBL1411438 & 688641 & 5.5 & 5.5919 & TRN & \\
\hline
\end{tabular}




\begin{tabular}{|c|c|c|c|c|c|}
\hline \multicolumn{6}{|c|}{ Supplemental Table S2.txt } \\
\hline CHEMBL318275 & 688641 & 4.5 & 5.0437 & TRN & \\
\hline CHEMBL 2373626 & 688641 & 4.8 & 5.1947 & TST & \\
\hline CHEMBL1441737 & 688641 & 5.1 & 5.141 & TRN & \\
\hline CHEMBL1439183 & 688641 & 4.8 & 4.913 & TRN & \\
\hline CHEMBL1476662 & 688641 & 5.0 & 5.0453 & TRN & \\
\hline CHEMBL1454730 & 688641 & 5.7 & 5.6018 & TST & \\
\hline CHEMBL1303139 & 688641 & 4.9 & 5.0335 & TRN & \\
\hline CHEMBL29097 & 688641 & 4.8 & 4.7819 & TRN & \\
\hline CHEMBL1400342 & 688641 & 4.8 & 4.8256 & TRN & \\
\hline CHEMBL1316893 & 688641 & 5.1 & 5.0609 & TRN & \\
\hline CHEMBL1569972 & 688641 & 5.7 & 5.8224 & TRN & \\
\hline CHEMBL1473472 & 688641 & 5.4 & 5.4557 & TRN & \\
\hline CHEMBL1255934 & 688641 & 5.9 & 5.6638 & TST & \\
\hline CHEMBL1529543 & 688641 & 5.4 & 5.3943 & TRN & \\
\hline CHEMBL1443393 & 688641 & 4.8 & 4.8454 & TRN & \\
\hline CHEMBL1314211 & 688641 & 5.6 & 5.6774 & TRN & \\
\hline CHEMBL1380212 & 688641 & 5.9 & 5.94600 & 0000000001 & TRN \\
\hline CHEMBL1371221 & 688641 & 5.4 & 5.3124 & TRN & \\
\hline CHEMBL1594372 & 688641 & 6.7001 & 6.7557 & TRN & \\
\hline CHEMBL1514923 & 688641 & 6.6 & 6.1505 & TRN & \\
\hline CHEMBL 275260 & 688641 & 4.6 & 4.9039 & TRN & \\
\hline CHEMBL1435727 & 688641 & 7.1002 & 5.0956 & TRN & \\
\hline CHEMBL1416207 & 688641 & 5.0 & 4.898 & TRN & \\
\hline CHEMBL1527565 & 688641 & 5.8 & 5.5054 & TST & \\
\hline CHEMBL1399058 & 688641 & 5.1 & 5.16299 & 9999999999 & TRN \\
\hline CHEMBL1331923 & 688641 & 5.4 & 5.2161 & TST & \\
\hline CHEMBL1593001 & 688641 & 4.9 & 4.907 & TRN & \\
\hline CHEMBL1512277 & 688641 & 5.0 & 5.0806 & TRN & \\
\hline CHEMBL1450413 & 688641 & 4.8 & 5.2666 & TRN & \\
\hline CHEMBL1594020 & 688641 & 4.8 & 4.8991 & TRN & \\
\hline CHEMBL153062 & 688641 & 4.5 & 5.0071 & TRN & \\
\hline CHEMBL1414477 & 688641 & 5.4 & 5.4327 & TRN & \\
\hline CHEMBL1358395 & 688641 & 5.4 & 5.3442 & TST & \\
\hline CHEMBL1374610 & 688641 & 5.5 & 5.2143 & TRN & \\
\hline CHEMBL1326787 & 688641 & 5.8 & 5.2289 & TST & \\
\hline CHEMBL1476043 & 688641 & 5.1 & 5.1658 & TRN & \\
\hline CHEMBL1594704 & 688641 & 5.1 & 5.2166 & TRN & \\
\hline CHEMBL1565927 & 688641 & 4.8 & 4.9137 & TRN & \\
\hline CHEMBL1572745 & 688641 & 4.8 & 5.0777 & TRN & \\
\hline CHEMBL1320565 & 688641 & 5.1 & 5.0121 & TRN & \\
\hline CHEMBL1475366 & 688641 & 5.9 & 5.8947 & TRN & \\
\hline CHEMBL 2374062 & 688641 & 6.0 & 5.6674 & TST & \\
\hline CHEMBL1160544 & 688641 & 6.3 & 5.8896 & TRN & \\
\hline CHEMBL1560118 & 688641 & 5.1 & 5.2257 & TRN & \\
\hline CHEMBL1256873 & 688641 & 4.9 & 4.9627 & TST & \\
\hline CHEMBL13647 & 688641 & 6.0 & 5.7216 & TRN & \\
\hline CHEMBL1557383 & 688641 & 6.0 & 4.9822 & TRN & \\
\hline CHEMBL267014 & 688641 & 4.9 & 4.8567 & TRN & \\
\hline
\end{tabular}




\begin{tabular}{|c|c|c|c|c|c|}
\hline \multirow{2}{*}{\multicolumn{2}{|c|}{ CHEMBL3198273 }} & \\
\hline & & 5.4 & 5.4401 & TRN & \\
\hline CHEMBL1317353 & 688641 & 5.2 & 5.3115 & TST & \\
\hline CHEMBL1396611 & 688641 & 4.9 & 4.9846 & TRN & \\
\hline CHEMBL1325833 & 688641 & 5.7 & 5.6011 & TRN & \\
\hline CHEMBL1517073 & 688641 & 5.4 & 5.3995 & TRN & \\
\hline CHEMBL1517965 & 688641 & 5.5 & 5.0817 & TST & \\
\hline CHEMBL1394118 & 688641 & 4.9 & 4.8957 & TRN & \\
\hline CHEMBL1394833 & 688641 & 4.7 & 4.743 & TRN & \\
\hline CHEMBL1487944 & 688641 & 5.7 & 5.6527 & TST & \\
\hline CHEMBL1355432 & 688641 & 4.5 & 4.6266 & TRN & \\
\hline CHEMBL1445799 & 688641 & 5.5 & 4.9922 & TRN & \\
\hline CHEMBL1597410 & 688641 & 6.0 & 6.0705 & TRN & \\
\hline CHEMBL1434441 & 688641 & 6.3 & 5.1468 & TST & \\
\hline CHEMBL1314833 & 688641 & 5.4 & 5.5867 & TRN & \\
\hline CHEMBL1408854 & 688641 & 5.5 & 4.8247 & TRN & \\
\hline CHEMBL1568019 & 688641 & 5.5 & 5.5589 & TRN & \\
\hline CHEMBL486193 & 688641 & 4.6 & 5.3386 & TST & \\
\hline CHEMBL1590919 & 688641 & 4.5 & 4.5553 & TRN & \\
\hline CHEMBL1528756 & 688641 & 5.1 & 5.2087 & TRN & \\
\hline CHEMBL1594044 & 688641 & 5.9 & 5.629 & TRN & \\
\hline CHEMBL1397169 & 688641 & 4.8 & 5.151 & TRN & \\
\hline CHEMBL1397225 & 688641 & 6.0 & 6.0616 & TRN & \\
\hline CHEMBL538965 & 688641 & 4.8 & 4.931 & TRN & \\
\hline CHEMBL1324334 & 688641 & 5.1 & 5.1675 & TRN & \\
\hline CHEMBL1356748 & 688641 & 5.6 & 5.2812 & TRN & \\
\hline CHEMBL1457256 & 688641 & 5.1 & 5.1468 & TRN & \\
\hline CHEMBL 70880 & 688641 & 6.2 & 5.968 & TRN & \\
\hline CHEMBL1593219 & 688641 & 5.0 & 4.96899 & 9999999999 & TRN \\
\hline CHEMBL1514153 & 688641 & 4.9 & 4.8608 & TRN & \\
\hline CHEMBL1372744 & 688641 & 5.1 & 5.1009 & TRN & \\
\hline CHEMBL406255 & 688641 & 5.5 & 5.2776 & TRN & \\
\hline CHEMBL1475395 & 688641 & 5.2 & 5.3715 & TRN & \\
\hline CHEMBL13662 & 688641 & 4.5 & 4.598 & TST & \\
\hline CHEMBL1332204 & 688641 & 4.8 & 5.1836 & TRN & \\
\hline CHEMBL604119 & 688641 & 5.6 & 5.4643 & TST & \\
\hline CHEMBL1515508 & 688641 & 4.5 & 4.5829 & TRN & \\
\hline CHEMBL 261782 & 688641 & 5.5 & 5.2657 & TRN & \\
\hline CHEMBL1317237 & 688641 & 5.4 & 5.2256 & TRN & \\
\hline CHEMBL1417837 & 688641 & 5.4 & 5.3369 & TRN & \\
\hline CHEMBL1332074 & 688641 & 5.2 & 5.157 & TRN & \\
\hline CHEMBL1452716 & 688641 & 6.0 & 5.2159 & TST & \\
\hline CHEMBL1355090 & 688641 & 4.6 & 4.7126 & TRN & \\
\hline CHEMBL1489659 & 688641 & 6.2 & 6.1327 & TRN & \\
\hline CHEMBL1490786 & 688641 & 5.8 & 5.8832 & TRN & \\
\hline CHEMBL1370938 & 688641 & 5.4 & 5.0886 & TRN & \\
\hline CHEMBL1433762 & 688641 & 4.9 & 5.0201 & TRN & \\
\hline CHEMBL1569400 & 688641 & 4.7 & 4.7461 & TRN & \\
\hline CHEMBL1476430 & 688641 & 5.3 & 5.4164 & TRN & \\
\hline & & & & 10730 & \\
\hline
\end{tabular}




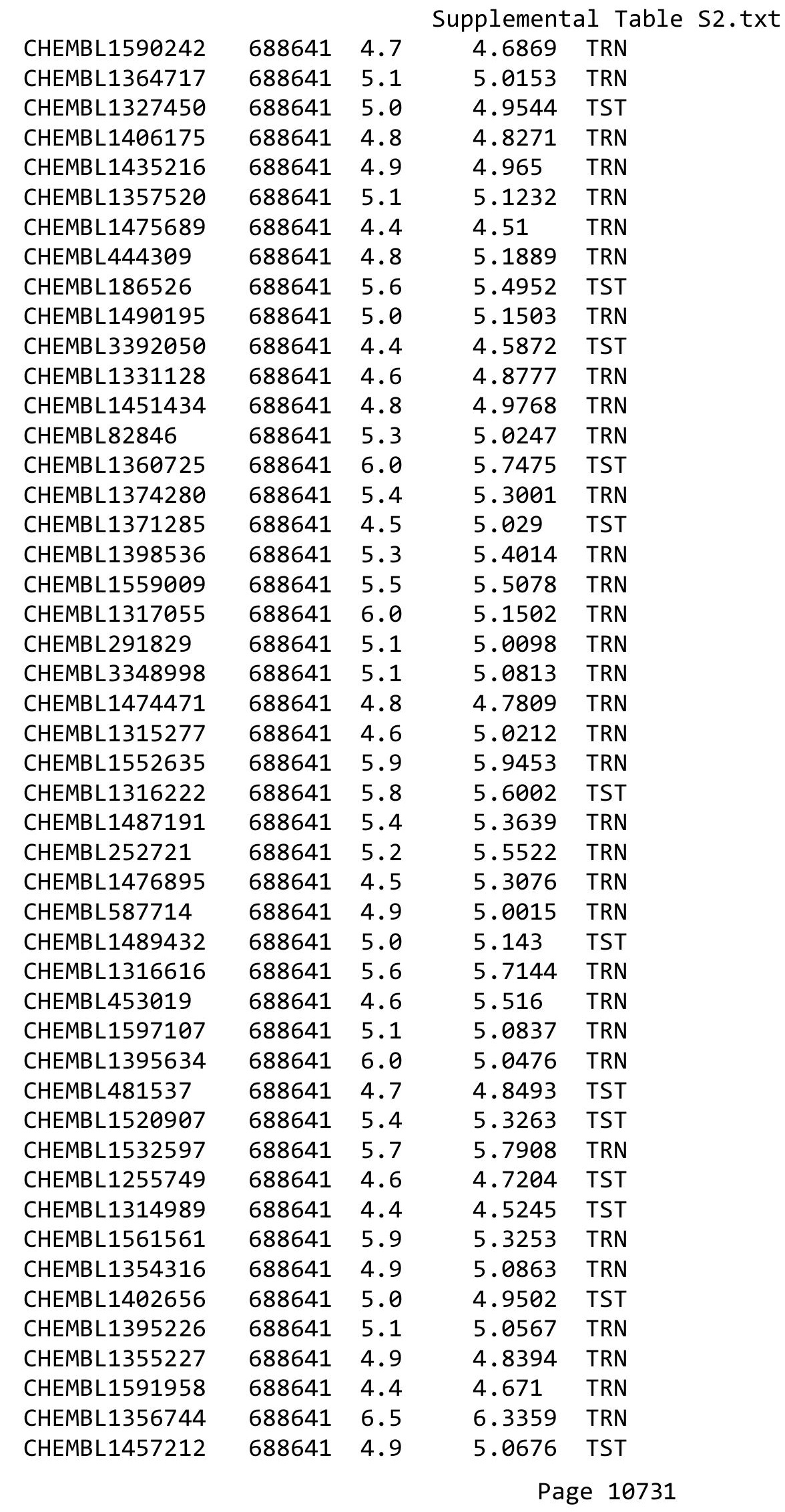




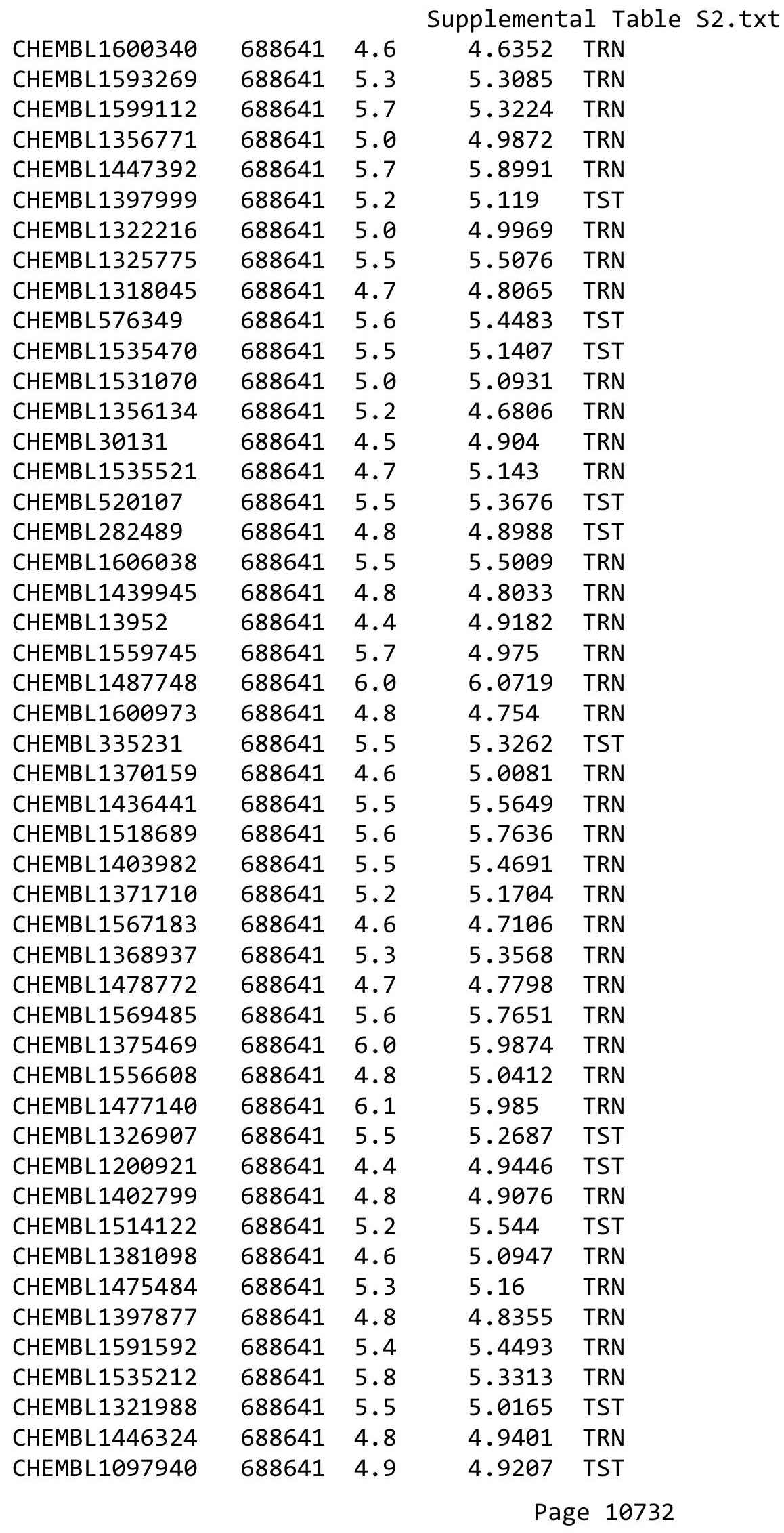




\begin{tabular}{|c|c|c|c|c|c|}
\hline \multirow[b]{2}{*}{ CHEMBL1455661 } & \multirow{2}{*}{688641} & \\
\hline & & 5.0 & 5.081 & TRN & \\
\hline CHEMBL1394698 & 688641 & 5.7 & 5.3215 & TRN & \\
\hline CHEMBL1361133 & 688641 & 5.4 & \multicolumn{2}{|c|}{5.422000000000001} & TST \\
\hline CHEMBL1592160 & 688641 & 4.9 & 5.0766 & TRN & \\
\hline CHEMBL1354672 & 688641 & 4.6 & 5.0112 & TRN & \\
\hline CHEMBL1396809 & 688641 & 5.6 & 5.4585 & TRN & \\
\hline CHEMBL123040 & 688641 & 4.4 & 4.9807 & TST & \\
\hline CHEMBL3189190 & 688641 & 5.4 & 5.4722 & TRN & \\
\hline CHEMBL1329927 & 688641 & 6.0 & 4.9774 & TST & \\
\hline CHEMBL1358272 & 688641 & 5.0 & 5.05 & TRN & \\
\hline CHEMBL1362630 & 688641 & 4.9 & 4.9258 & TST & \\
\hline CHEMBL574985 & 688641 & 4.4 & 4.6241 & TST & \\
\hline CHEMBL1400637 & 688641 & 5.1 & 5.0504 & TRN & \\
\hline CHEMBL1402827 & 688641 & 4.6 & 4.7353 & TRN & \\
\hline CHEMBL1436686 & 688641 & 4.4 & 5.2172 & TST & \\
\hline CHEMBL1403310 & 688641 & 5.9 & 5.2293 & TRN & \\
\hline CHEMBL2374087 & 688641 & 5.4 & 5.224 & TRN & \\
\hline CHEMBL1483625 & 688641 & 4.9 & 4.9036 & TRN & \\
\hline CHEMBL1435558 & 688641 & 5.2 & 5.1176 & TRN & \\
\hline CHEMBL1513050 & 688641 & 5.9 & 5.3022 & TST & \\
\hline CHEMBL1605255 & 688641 & 5.0 & 5.0307 & TRN & \\
\hline CHEMBL1405649 & 688641 & 5.3 & 5.0754 & TRN & \\
\hline CHEMBL1320141 & 688641 & 5.3 & 5.4372 & TRN & \\
\hline CHEMBL1357465 & 688641 & 4.7 & 5.2058 & TRN & \\
\hline CHEMBL994 & 688641 & 4.9 & 4.9921 & TST & \\
\hline CHEMBL1512817 & 688641 & 4.9 & 5.0359 & TRN & \\
\hline CHEMBL1453749 & 688641 & 5.1 & 5.3518 & TRN & \\
\hline CHEMBL 276618 & 688641 & 4.6 & 5.0533 & TRN & \\
\hline CHEMBL3207894 & 688641 & 6.0 & 5.9618 & TRN & \\
\hline CHEMBL1394983 & 688641 & 4.8 & 4.8071 & TRN & \\
\hline CHEMBL1521278 & 688641 & 5.6 & 5.3292 & TST & \\
\hline CHEMBL1552588 & 688641 & 5.0 & 4.9524 & TRN & \\
\hline CHEMBL1316314 & 688641 & 5.7 & 5.5197 & TST & \\
\hline CHEMBL1530684 & 688641 & 4.6 & 5.0113 & TST & \\
\hline CHEMBL1565192 & 688641 & 4.5 & 5.0056 & TRN & \\
\hline CHEMBL15901 & 688641 & 4.6 & 5.06800 & 20000000005 & TRN \\
\hline CHEMBL1559654 & 688641 & 5.6 & 5.8422 & TRN & \\
\hline CHEMBL1525813 & 688641 & 5.5 & 5.5218 & TST & \\
\hline CHEMBL1442440 & 688641 & 6.3 & 6.2404 & TRN & \\
\hline CHEMBL1334657 & 688641 & 4.6 & 4.7072 & TRN & \\
\hline CHEMBL1474125 & 688641 & 4.4 & 4.4819 & TRN & \\
\hline CHEMBL1466168 & 688641 & 4.5 & 4.9774 & TRN & \\
\hline CHEMBL1363873 & 688641 & 5.0 & 4.841 & TRN & \\
\hline CHEMBL1357231 & 688641 & 5.4 & 5.4194 & TRN & \\
\hline CHEMBL1514023 & 688641 & 5.4 & 5.38899 & 9999999999 & TRN \\
\hline CHEMBL 254218 & 688641 & 4.8 & 5.0732 & TRN & \\
\hline CHEMBL1454224 & 688641 & 4.9 & 4.8545 & TRN & \\
\hline CHEMBL1317058 & 688641 & 4.4 & 5.1552 & TST & \\
\hline & & & & 10733 & \\
\hline
\end{tabular}




\begin{tabular}{|c|c|c|c|c|}
\hline \multicolumn{5}{|c|}{ Supplemental Table S2.txt } \\
\hline CHEMBL1358743 & 688641 & 6.4 & 5.2358 & TST \\
\hline CHEMBL1314911 & 688641 & 5.5 & 5.2516 & TRN \\
\hline CHEMBL1434022 & 688641 & 4.8 & 4.8174 & TRN \\
\hline CHEMBL1515787 & 688641 & 5.4 & 5.2981 & TRN \\
\hline CHEMBL3207903 & 688641 & 5.5 & 5.5388 & TRN \\
\hline CHEMBL1608876 & 688641 & 5.7 & 5.2187 & TRN \\
\hline CHEMBL1409536 & 688641 & 5.5 & 5.32600 & 00000000005 \\
\hline CHEMBL1572834 & 688641 & 6.1 & 6.2539 & TRN \\
\hline CHEMBL503938 & 688641 & 4.5 & 5.0619 & TST \\
\hline CHEMBL1520727 & 688641 & 6.0 & 6.0845 & TRN \\
\hline CHEMBL1447746 & 688641 & 5.5 & 5.4319 & TST \\
\hline CHEMBL116438 & 688641 & 4.6 & 4.9337 & TRN \\
\hline CHEMBL1355970 & 688641 & 4.6 & 4.5654 & TRN \\
\hline CHEMBL1322757 & 688641 & 5.2 & 5.2201 & TRN \\
\hline CHEMBL1527332 & 688641 & 5.6 & 5.4995 & TRN \\
\hline CHEMBL1356998 & 688641 & 5.0 & 4.915 & TRN \\
\hline CHEMBL1335862 & 688641 & 5.9 & 5.653 & TST \\
\hline CHEMBL313244 & 688641 & 4.8 & 5.0397 & TRN \\
\hline CHEMBL1473842 & 688641 & 4.4 & 5.4389 & TRN \\
\hline CHEMBL1401793 & 688641 & 5.4 & 5.2889 & TST \\
\hline CHEMBL1484032 & 688641 & 5.8 & 5.5945 & TST \\
\hline CHEMBL1602568 & 688641 & 5.0 & 4.9888 & TRN \\
\hline CHEMBL1315318 & 688641 & 5.4 & 5.4971 & TRN \\
\hline CHEMBL1318509 & 688641 & 4.9 & 5.0492 & TRN \\
\hline CHEMBL1356166 & 688641 & 5.4 & 5.2987 & TRN \\
\hline CHEMBL1316056 & 688641 & 5.5 & 5.4121 & TRN \\
\hline CHEMBL1569421 & 688641 & 5.5 & 4.7357 & TRN \\
\hline CHEMBL1551380 & 688641 & 4.7 & 4.7382 & TRN \\
\hline CHEMBL1475550 & 688641 & 4.8 & 5.1676 & TST \\
\hline CHEMBL1456767 & 688641 & 5.1 & 5.1059 & TRN \\
\hline CHEMBL1474578 & 688641 & 4.9 & 4.8346 & TRN \\
\hline CHEMBL1476051 & 688641 & 6.2 & 6.2145 & TRN \\
\hline CHEMBL1330763 & 688641 & 5.5 & 5.425 & TRN \\
\hline CHEMBL 216504 & 688641 & 5.8 & 5.6085 & TST \\
\hline CHEMBL1357184 & 688641 & 5.5 & 5.5187 & TRN \\
\hline CHEMBL1355201 & 688641 & 5.2 & 5.2566 & TRN \\
\hline CHEMBL479014 & 688641 & 4.9 & 4.9044 & TRN \\
\hline CHEMBL1513537 & 688641 & 4.6 & 5.2271 & TST \\
\hline CHEMBL1399528 & 688641 & 4.9 & 4.8665 & TRN \\
\hline CHEMBL1515706 & 688641 & 5.5 & 5.4748 & TRN \\
\hline CHEMBL1552540 & 688641 & 5.0 & 5.0968 & TRN \\
\hline CHEMBL489738 & 688641 & 6.7001 & 6.7013 & TRN \\
\hline CHEMBL1316165 & 688641 & 4.9 & 4.7395 & TRN \\
\hline CHEMBL1599248 & 688641 & 4.9 & 5.2008 & TRN \\
\hline CHEMBL1555316 & 688641 & 4.8 & 4.803 & TRN \\
\hline CHEMBL1589897 & 688641 & 5.6 & 4.8839 & TRN \\
\hline CHEMBL1488390 & 688641 & 5.0 & 5.1754 & TST \\
\hline CHEMBL1592963 & 688641 & 5.4 & 5.3987 & TRN \\
\hline
\end{tabular}




\begin{tabular}{|c|c|c|c|c|c|}
\hline \multicolumn{6}{|c|}{ Supplemental Table S2.txt } \\
\hline CHEMBL1439262 & 688641 & 4.6 & 4.9927 & TRN & \\
\hline CHEMBL1551913 & 688641 & 5.4 & 5.3388 & TRN & \\
\hline CHEMBL3213748 & 688641 & 5.4 & 5.4368 & TRN & \\
\hline CHEMBL491555 & 688641 & 6.3 & 6.4862 & TRN & \\
\hline CHEMBL1725279 & 688641 & 5.4 & 5.2834 & TST & \\
\hline CHEMBL1314564 & 688641 & 5.4 & 5.2715 & TRN & \\
\hline CHEMBL1475487 & 688641 & 6.0 & 5.7744 & TRN & \\
\hline CHEMBL124267 & 688641 & 5.3 & 5.2266 & TRN & \\
\hline CHEMBL1610228 & 688641 & 4.6 & 4.6328 & TRN & \\
\hline CHEMBL1372077 & 688641 & 4.9 & 5.0053 & TRN & \\
\hline CHEMBL55814 & 688641 & 6.0 & 5.0682 & TRN & \\
\hline CHEMBL1315091 & 688641 & 4.8 & 4.9155 & TRN & \\
\hline CHEMBL25308 & 688641 & 4.9 & 4.9253 & TST & \\
\hline CHEMBL1394899 & 688641 & 5.4 & 5.46 & TRN & \\
\hline CHEMBL1256924 & 688641 & 5.4 & 5.2792 & TRN & \\
\hline CHEMBL1339340 & 688641 & 4.5 & 5.2486 & TST & \\
\hline CHEMBL1332463 & 688641 & 6.0 & 6.0698 & TRN & \\
\hline CHEMBL1397466 & 688641 & 4.9 & 4.9697 & TRN & \\
\hline CHEMBL295652 & 688641 & 4.6 & 5.0442 & TRN & \\
\hline CHEMBL1493835 & 688641 & 5.0 & 5.0015 & TST & \\
\hline CHEMBL1555537 & 688641 & 5.3 & 5.2214 & TST & \\
\hline CHEMBL1322818 & 688641 & 4.6 & 4.9597 & TRN & \\
\hline CHEMBL1608410 & 688641 & 5.5 & 5.1532 & TRN & \\
\hline CHEMBL66953 & 688641 & 4.5 & 5.1611 & TST & \\
\hline CHEMBL1400050 & 688641 & 6.0 & 5.9891 & TRN & \\
\hline CHEMBL492121 & 688641 & 4.9 & 4.9655 & TRN & \\
\hline CHEMBL1413770 & 688641 & 4.9 & 4.8902 & TRN & \\
\hline CHEMBL1355718 & 688641 & 4.8 & 4.8835 & TRN & \\
\hline CHEMBL1475036 & 688641 & 6.0 & 6.00799 & 9999999999 & TRN \\
\hline CHEMBL1394135 & 688641 & 4.9 & 4.9869 & TST & \\
\hline CHEMBL1554960 & 688641 & 4.8 & 4.8119 & TRN & \\
\hline CHEMBL1336443 & 688641 & 6.0 & 6.063 & TRN & \\
\hline CHEMBL1516476 & 688641 & 6.0 & 5.812 & TRN & \\
\hline CHEMBL580421 & 688641 & 4.5 & 4.6669 & TST & \\
\hline CHEMBL1357089 & 688641 & 5.3 & 5.1447 & TRN & \\
\hline CHEMBL1365512 & 688641 & 5.5 & 5.5871 & TRN & \\
\hline CHEMBL1554721 & 688641 & 5.8 & 5.904 & TRN & \\
\hline CHEMBL1605130 & 688641 & 5.0 & 4.8386 & TRN & \\
\hline CHEMBL1316158 & 688641 & 4.7 & 4.6922 & TRN & \\
\hline CHEMBL1593998 & 688641 & 4.7 & 5.0806 & TRN & \\
\hline CHEMBL1551009 & 688641 & 5.1 & 5.0866 & TRN & \\
\hline CHEMBL1450327 & 688641 & 5.0 & 5.0594 & TRN & \\
\hline CHEMBL1434739 & 688641 & 4.9 & 5.0508 & TRN & \\
\hline CHEMBL1375046 & 688641 & 4.9 & 4.9209 & TRN & \\
\hline CHEMBL1337092 & 688641 & 4.7 & 4.7943 & TRN & \\
\hline CHEMBL1368942 & 688641 & 5.7 & 5.6997 & TRN & \\
\hline CHEMBL1595973 & 688641 & 5.8 & 5.1166 & TRN & \\
\hline CHEMBL311158 & 688641 & 6.0 & 5.0281 & TRN & \\
\hline
\end{tabular}




\begin{tabular}{|c|c|c|c|c|}
\hline & & & Supplement & \\
\hline CHEMBL1610400 & 688641 & 4.9 & 4.803 & TRN \\
\hline CHEMBL397209 & 688641 & 4.4 & 4.605 & TST \\
\hline CHEMBL1363319 & 688641 & 4.9 & 5.0342 & TRN \\
\hline CHEMBL1566552 & 688641 & 4.8 & 5.2829 & TRN \\
\hline CHEMBL1475789 & 688641 & 6.2 & 6.3198 & TRN \\
\hline CHEMBL1515835 & 688641 & 4.6 & 5.001 & TRN \\
\hline CHEMBL1232474 & 688641 & 6.5 & 6.5893 & TRN \\
\hline CHEMBL1558729 & 688641 & 4.8 & 5.1211 & TRN \\
\hline CHEMBL1518686 & 688641 & 5.8 & 5.7584 & TRN \\
\hline CHEMBL1593601 & 688641 & 5.9 & 5.9655 & TRN \\
\hline CHEMBL1555369 & 688641 & 5.4 & 5.4126 & TRN \\
\hline CHEMBL1590103 & 688641 & 4.4 & 5.1998 & TST \\
\hline CHEMBL1564545 & 688641 & 4.8 & 4.8129 & TRN \\
\hline CHEMBL1476712 & 688641 & 5.5 & 5.3364 & TRN \\
\hline CHEMBL1377526 & 688641 & 5.4 & 5.3781 & TRN \\
\hline CHEMBL1354281 & 688641 & 5.8 & 5.7447 & TRN \\
\hline CHEMBL1713992 & 688641 & 4.5 & 4.6327 & TST \\
\hline CHEMBL1318316 & 688641 & 5.4 & 5.3772 & TST \\
\hline CHEMBL1358467 & 688641 & 5.6 & 5.1254 & TRN \\
\hline CHEMBL1557091 & 688641 & 4.9 & 4.9416 & TST \\
\hline CHEMBL1457550 & 688641 & 6.0 & 5.8512 & TRN \\
\hline CHEMBL1437354 & 688641 & 5.4 & 5.1954 & TRN \\
\hline CHEMBL1434111 & 688641 & 4.8 & 4.7953 & TRN \\
\hline CHEMBL1571138 & 688641 & 5.6 & 5.5633 & TRN \\
\hline CHEMBL1355855 & 688641 & 5.5 & 5.4269 & TST \\
\hline CHEMBL1449218 & 688641 & 5.7 & 5.5798 & TRN \\
\hline CHEMBL1408822 & 688641 & 5.3 & 5.4616 & TRN \\
\hline CHEMBL80155 & 688641 & 5.0 & 4.9753 & TRN \\
\hline CHEMBL253998 & 688641 & 4.9 & 5.0373 & TRN \\
\hline CHEMBL1357956 & 688641 & 4.8 & 4.8157 & TRN \\
\hline CHEMBL1369062 & 688641 & 4.6 & 4.6936 & TRN \\
\hline CHEMBL1317010 & 688641 & 5.4 & 5.4453 & TRN \\
\hline CHEMBL1515221 & 688641 & 4.9 & 5.0273 & TRN \\
\hline CHEMBL1593707 & 688641 & 5.1 & 4.9796 & TRN \\
\hline CHEMBL1533055 & 688641 & 5.1 & 5.1052 & TRN \\
\hline CHEMBL1554348 & 688641 & 4.9 & 4.9647 & TRN \\
\hline CHEMBL1398299 & 688641 & 5.4 & 5.2765 & TRN \\
\hline CHEMBL1409985 & 688641 & 4.8 & 4.9666 & TRN \\
\hline CHEMBL1515985 & 688641 & 4.6 & 4.7773 & TRN \\
\hline CHEMBL1591729 & 688641 & 4.9 & 5.2425 & TST \\
\hline CHEMBL 269362 & 688641 & 6.0 & 5.7621 & TST \\
\hline CHEMBL1438566 & 688641 & 6.0 & 5.9636 & TRN \\
\hline CHEMBL1395275 & 688641 & 4.6 & 5.2779 & TST \\
\hline CHEMBL563919 & 688641 & 4.4 & 5.0305 & TRN \\
\hline CHEMBL1481984 & 688641 & 4.9 & 4.9666 & TST \\
\hline CHEMBL470671 & 688641 & 4.9 & 4.9914 & TRN \\
\hline CHEMBL1553555 & 688641 & 5.7 & 5.0968 & TRN \\
\hline CHEMBL1395408 & 688641 & 4.8 & 5.1644 & TST \\
\hline
\end{tabular}




\begin{tabular}{|c|c|c|c|c|}
\hline \multicolumn{5}{|c|}{ plementa } \\
\hline CHEMBL1553428 & 688641 & 5.0 & 5.0749 & TRN \\
\hline CHEMBL342375 & 688641 & 6.3 & 6.1055 & TST \\
\hline CHEMBL1514416 & 688641 & 5.1 & 5.2036 & TRN \\
\hline CHEMBL1528170 & 688641 & 4.9 & 4.9019 & TRN \\
\hline CHEMBL1331363 & 688641 & 7.2 & 6.8163 & TRN \\
\hline CHEMBL1314971 & 688641 & 5.3 & 5.2062 & TRN \\
\hline CHEMBL1568735 & 688641 & 5.6 & 5.5289 & TRN \\
\hline CHEMBL1553173 & 688641 & 5.6 & 5.5614 & TRN \\
\hline CHEMBL1417771 & 688641 & 6.3 & 6.4022 & TRN \\
\hline CHEMBL1574390 & 688641 & 4.5 & 4.5721 & TRN \\
\hline CHEMBL1557129 & 688641 & 6.0 & 5.1808 & TST \\
\hline CHEMBL3198657 & 688641 & 6.0 & 6.0052 & TRN \\
\hline CHEMBL1601019 & 688641 & 4.9 & 5.1102 & TRN \\
\hline CHEMBL1529093 & 688641 & 5.6 & 5.0871 & TRN \\
\hline CHEMBL1435889 & 688641 & 4.6 & 4.621 & TRN \\
\hline CHEMBL1317946 & 688641 & 4.6 & 5.1656 & TRN \\
\hline CHEMBL1551021 & 688641 & 5.3 & 5.3631 & TRN \\
\hline CHEMBL1334847 & 688641 & 5.0 & 4.8548 & TRN \\
\hline CHEMBL1497006 & 688641 & 4.8 & 5.0665 & TRN \\
\hline CHEMBL1448542 & 688641 & 4.8 & 4.9517 & TRN \\
\hline CHEMBL1519261 & 688641 & 5.6 & 5.6294 & TRN \\
\hline CHEMBL1481921 & 688641 & 5.5 & 5.2047 & TRN \\
\hline CHEMBL1514779 & 688641 & 4.8 & 4.7548 & TRN \\
\hline CHEMBL1407035 & 688641 & 5.1 & 5.0894 & TRN \\
\hline CHEMBL1371160 & 688641 & 5.2 & 5.1483 & TST \\
\hline CHEMBL1410859 & 688641 & 5.1 & 5.088 & TRN \\
\hline CHEMBL1571785 & 688641 & 6.1 & 5.1357 & TRN \\
\hline CHEMBL 243250 & 688641 & 5.4 & 5.0646 & TRN \\
\hline CHEMBL1323956 & 688641 & 4.6 & 4.6005 & TRN \\
\hline CHEMBL1475241 & 688641 & 4.7 & 4.668 & TRN \\
\hline CHEMBL1476722 & 688641 & 4.9 & 5.4373 & TRN \\
\hline CHEMBL1356132 & 688641 & 5.3 & 5.2244 & TRN \\
\hline CHEMBL1457332 & 688641 & 5.6 & 5.5903 & TRN \\
\hline CHEMBL1450993 & 688641 & 4.7 & 4.7146 & TRN \\
\hline CHEMBL1317461 & 688641 & 6.3 & 6.2796 & TRN \\
\hline CHEMBL1593545 & 688641 & 4.7 & 4.7638 & TRN \\
\hline CHEMBL1531699 & 688641 & 5.6 & 5.5819 & TRN \\
\hline CHEMBL1314434 & 688641 & 4.8 & 4.7861 & TRN \\
\hline CHEMBL1355359 & 688641 & 5.6 & 5.1831 & TST \\
\hline CHEMBL1398540 & 688641 & 4.8 & 4.8227 & TRN \\
\hline CHEMBL1323524 & 688641 & 4.9 & 4.7443 & TRN \\
\hline CHEMBL1559341 & 688641 & 4.6 & 5.2544 & TST \\
\hline CHEMBL1490477 & 688641 & 5.5 & 5.454 & TRN \\
\hline CHEMBL1473925 & 688641 & 4.8 & 4.8366 & TRN \\
\hline CHEMBL1457544 & 688641 & 5.0 & 5.0163 & TRN \\
\hline CHEMBL1358033 & 688641 & 5.0 & 5.038 & TRN \\
\hline CHEMBL1435086 & 688641 & 4.8 & 4.8131 & TRN \\
\hline CHEMBL1592876 & 688641 & 5.4 & 5.4504 & TRN \\
\hline
\end{tabular}




\begin{tabular}{|c|c|c|c|c|c|}
\hline \multicolumn{6}{|c|}{ Supplemental Table S2.txt } \\
\hline CHEMBL1452517 & 688641 & 4.8 & 5.4146 & TRN & \\
\hline CHEMBL1602699 & 688641 & 5.1 & 5.2568 & TST & \\
\hline CHEMBL1561922 & 688641 & 5.1 & 4.7465 & TRN & \\
\hline CHEMBL1357834 & 688641 & 5.4 & 5.2484 & TST & \\
\hline CHEMBL1610778 & 688641 & 6.0 & 5.401 & TST & \\
\hline CHEMBL440084 & 688641 & 5.0 & 5.1587 & TRN & \\
\hline CHEMBL77387 & 688641 & 5.8 & 5.4493 & TRN & \\
\hline CHEMBL1491435 & 688641 & 5.8 & 5.2805 & TRN & \\
\hline CHEMBL189438 & 688641 & 5.3 & 5.3351 & TST & \\
\hline CHEMBL1574476 & 688641 & 5.1 & 5.0511 & TRN & \\
\hline CHEMBL1555238 & 688641 & 4.7 & 4.7116 & TRN & \\
\hline CHEMBL1407923 & 688641 & 4.8 & 5.2353 & TST & \\
\hline CHEMBL1371604 & 688641 & 5.6 & 5.4937 & TRN & \\
\hline CHEMBL1515449 & 688641 & 6.2 & 6.2528 & TRN & \\
\hline CHEMBL1358708 & 688641 & 4.9 & 4.9744 & TST & \\
\hline CHEMBL1395974 & 688641 & 4.5 & 4.605 & TRN & \\
\hline CHEMBL1366433 & 688641 & 5.1 & 5.08899 & 99999999995 & TRN \\
\hline CHEMBL418509 & 688641 & 4.7 & 5.0083 & TRN & \\
\hline CHEMBL1449517 & 688641 & 5.4 & 5.3195 & TRN & \\
\hline CHEMBL1331734 & 688641 & 5.1 & 5.1188 & TST & \\
\hline CHEMBL1338311 & 688641 & 6.1 & 5.0026 & TRN & \\
\hline CHEMBL1406971 & 688641 & 5.5 & 5.1467 & TRN & \\
\hline CHEMBL1487070 & 688641 & 5.6 & 5.7175 & TRN & \\
\hline CHEMBL1317712 & 688641 & 4.6 & 4.6839 & TRN & \\
\hline CHEMBL1435313 & 688641 & 5.4 & 5.4762 & TRN & \\
\hline CHEMBL1338358 & 688641 & 5.5 & 5.0965 & TRN & \\
\hline CHEMBL1517884 & 688641 & 5.5 & 4.8261 & TRN & \\
\hline CHEMBL1406879 & 688641 & 4.8 & 4.8727 & TRN & \\
\hline CHEMBL1437667 & 688641 & 5.8 & 5.676 & TRN & \\
\hline CHEMBL1515614 & 688641 & 4.8 & 4.9828 & TRN & \\
\hline CHEMBL1475284 & 688641 & 4.6 & 4.7068 & TRN & \\
\hline CHEMBL 2373669 & 688641 & 5.9 & 5.2083 & TRN & \\
\hline CHEMBL1256186 & 688641 & 5.5 & 5.3966 & TST & \\
\hline CHEMBL1597449 & 688641 & 4.6 & 4.9697 & TRN & \\
\hline CHEMBL1592760 & 688641 & 5.0 & 4.9854 & TRN & \\
\hline CHEMBL1482953 & 688641 & 4.8 & 5.0975 & TRN & \\
\hline CHEMBL1400902 & 688641 & 4.9 & 5.0768 & TRN & \\
\hline CHEMBL1490740 & 688641 & 5.0 & 5.3533 & TRN & \\
\hline CHEMBL1408176 & 688641 & 5.4 & 5.3315 & TRN & \\
\hline CHEMBL 250892 & 688641 & 5.0 & 5.0499 & TRN & \\
\hline CHEMBL1525767 & 688641 & 4.4 & 4.5341 & TRN & \\
\hline CHEMBL444422 & 688641 & 5.7 & 5.145 & TRN & \\
\hline CHEMBL1555991 & 688641 & 4.8 & 4.8294 & TRN & \\
\hline CHEMBL545523 & 688641 & 6.0 & 6.0397 & TRN & \\
\hline CHEMBL1364808 & 688641 & 4.7 & 4.8317 & TST & \\
\hline CHEMBL1554693 & 688641 & 6.2 & 6.1163 & TRN & \\
\hline CHEMBL1512123 & 688641 & 5.1 & 5.1485 & TRN & \\
\hline CHEMBL1318480 & 688641 & 4.9 & 4.9786 & TRN & \\
\hline
\end{tabular}




\begin{tabular}{|c|c|c|c|c|c|}
\hline & & & & & \\
\hline CHEMBL1591619 & 688641 & 5.0 & 5.0391 & TRN & \\
\hline CHEMBL1448896 & 688641 & 5.3 & 5.1722 & TRN & \\
\hline CHEMBL1359691 & 688641 & 5.3 & 5.3217 & TRN & \\
\hline CHEMBL1473489 & 688641 & 5.5 & 5.3138 & TRN & \\
\hline CHEMBL1736254 & 688641 & 5.5 & 5.4569 & TST & \\
\hline CHEMBL11348 & 688641 & 5.4 & 5.3946 & TST & \\
\hline CHEMBL1315913 & 688641 & 5.3 & 5.1585 & TRN & \\
\hline CHEMBL1374591 & 688641 & 4.8 & 5.1922 & TST & \\
\hline CHEMBL1554199 & 688641 & 5.7 & 5.2032 & TRN & \\
\hline CHEMBL1563840 & 688641 & 5.4 & 5.3586 & TRN & \\
\hline CHEMBL1474876 & 688641 & 5.2 & 5.1125 & TRN & \\
\hline CHEMBL1565914 & 688641 & 5.4 & 5.2991 & TST & \\
\hline CHEMBL1331122 & 688641 & 5.4 & 5.2985 & TST & \\
\hline CHEMBL1591758 & 688641 & 4.9 & 4.8891 & TRN & \\
\hline CHEMBL1475951 & 688641 & 5.9 & 6.0664 & TRN & \\
\hline CHEMBL1473099 & 688641 & 6.2 & 6.3579 & TRN & \\
\hline CHEMBL1490386 & 688641 & 5.8 & 5.8301 & TRN & \\
\hline CHEMBL375270 & 688641 & 4.6 & 4.7228 & TRN & \\
\hline CHEMBL1565567 & 688641 & 5.4 & 5.2323 & TRN & \\
\hline CHEMBL3208052 & 688641 & 5.5 & 5.2752 & TST & \\
\hline CHEMBL1596872 & 688641 & 4.8 & 4.7911 & TRN & \\
\hline CHEMBL1439788 & 688641 & 4.8 & 4.9854 & TRN & \\
\hline CHEMBL1257123 & 688641 & 5.1 & 5.019 & TRN & \\
\hline CHEMBL1475200 & 688641 & 6.0 & 5.9946 & TRN & \\
\hline CHEMBL1488612 & 688641 & 4.8 & 5.2069 & TST & \\
\hline CHEMBL1555610 & 688641 & 4.6 & 4.6373 & TRN & \\
\hline CHEMBL1416812 & 688641 & 5.5 & 5.45299 & 9999999999 & TRN \\
\hline CHEMBL1591992 & 688641 & 4.8 & 4.843 & TRN & \\
\hline CHEMBL93655 & 688641 & 6.3 & 5.7314 & TST & \\
\hline CHEMBL28626 & 688641 & 4.5 & 5.5034 & TRN & \\
\hline CHEMBL1434198 & 688641 & 4.9 & 4.9468 & TRN & \\
\hline CHEMBL1398800 & 688641 & 4.9 & 4.9681 & TRN & \\
\hline CHEMBL1492229 & 688641 & 5.4 & 5.2759 & TRN & \\
\hline CHEMBL1410419 & 688641 & 5.5 & 5.0556 & TRN & \\
\hline CHEMBL36028 & 688641 & 4.6 & 4.8419 & TRN & \\
\hline CHEMBL1594487 & 688641 & 5.4 & 5.45 & TRN & \\
\hline CHEMBL1327772 & 688641 & 5.3 & 5.106 & TRN & \\
\hline CHEMBL1435744 & 688641 & 4.9 & 5.1986 & TRN & \\
\hline CHEMBL1437128 & 688641 & 6.5 & 6.0243 & TRN & \\
\hline CHEMBL1435381 & 688641 & 4.6 & 4.5598 & TST & \\
\hline CHEMBL334378 & 688641 & 5.0 & 5.1351 & TST & \\
\hline CHEMBL1373464 & 688641 & 6.0 & 6.0593 & TRN & \\
\hline CHEMBL1369966 & 688641 & 5.8 & 5.9426 & TRN & \\
\hline CHEMBL1514149 & 688641 & 4.9 & 4.9723 & TRN & \\
\hline CHEMBL1525856 & 688641 & 4.8 & 5.2481 & TRN & \\
\hline CHEMBL1446743 & 688641 & 5.1 & 5.1622 & TST & \\
\hline CHEMBL1332709 & 688641 & 5.9 & 5.2141 & TRN & \\
\hline CHEMBL1399481 & 688641 & 5.9 & 6.0642 & TRN & \\
\hline & & & & 10739 & \\
\hline
\end{tabular}




\begin{tabular}{|c|c|c|c|c|c|}
\hline \multicolumn{6}{|c|}{ Supplemental Table S2.txt } \\
\hline CHEMBL1611235 & 688641 & 4.8 & 4.8855 & TRN & \\
\hline CHEMBL1455018 & 688641 & 4.7 & 4.7988 & TRN & \\
\hline CHEMBL1594439 & 688641 & 5.3 & 5.1447 & TST & \\
\hline CHEMBL1413161 & 688641 & 4.8 & 5.0859 & TRN & \\
\hline CHEMBL1566621 & 688641 & 4.8 & 4.758 & TRN & \\
\hline CHEMBL1479593 & 688641 & 4.6 & 5.1277 & TRN & \\
\hline CHEMBL1522552 & 688641 & 6.0 & 5.0589 & TRN & \\
\hline CHEMBL278164 & 688641 & 4.9 & 5.1174 & TRN & \\
\hline CHEMBL1411246 & 688641 & 4.6 & 4.9979 & TST & \\
\hline CHEMBL1590382 & 688641 & 5.0 & 4.962 & TRN & \\
\hline CHEMBL1437294 & 688641 & 5.2 & 5.3202 & TRN & \\
\hline CHEMBL228281 & 688641 & 4.4 & 5.1249 & TRN & \\
\hline CHEMBL598952 & 688641 & 5.0 & 4.6695 & TST & \\
\hline CHEMBL1566452 & 688641 & 5.4 & 5.0957 & TRN & \\
\hline CHEMBL1515948 & 688641 & 4.9 & 5.0089 & TST & \\
\hline CHEMBL1520512 & 688641 & 4.4 & 5.1548 & TRN & \\
\hline CHEMBL259331 & 688641 & 6.0 & 5.26 & TRN & \\
\hline CHEMBL 7463 & 688641 & 4.9 & 4.9414 & TST & \\
\hline CHEMBL1377727 & 688641 & 6.2 & 6.0722 & TRN & \\
\hline CHEMBL1328324 & 688641 & 6.0 & 4.9675 & TST & \\
\hline CHEMBL1381 & 688641 & 4.6 & 4.8442 & TRN & \\
\hline CHEMBL1468832 & 688641 & 4.9 & 4.9197 & TRN & \\
\hline CHEMBL1377507 & 688641 & 6.0 & 5.8012 & TRN & \\
\hline CHEMBL1512413 & 688641 & 5.1 & 5.0123 & TRN & \\
\hline CHEMBL1415180 & 688641 & 6.1 & 6.1196 & TRN & \\
\hline CHEMBL1599299 & 688641 & 6.3 & 5.1198 & TRN & \\
\hline CHEMBL1451411 & 688641 & 6.1 & 5.86600 & 00000000005 & TRN \\
\hline CHEMBL1446815 & 688641 & 4.9 & 4.9031 & TRN & \\
\hline CHEMBL1335436 & 688641 & 5.6 & 5.4655 & TST & \\
\hline CHEMBL1591459 & 688641 & 5.4 & 5.4301 & TRN & \\
\hline CHEMBL1363622 & 688641 & 4.5 & 4.6316 & TRN & \\
\hline CHEMBL1339099 & 688641 & 5.4 & 5.3293 & TRN & \\
\hline CHEMBL1516249 & 688641 & 5.1 & 4.7471 & TRN & \\
\hline CHEMBL1515137 & 688641 & 4.5 & 5.2054 & TST & \\
\hline CHEMBL1453764 & 688641 & 4.6 & 4.80399 & 9999999999 & TRN \\
\hline CHEMBL1255662 & 688641 & 6.0 & 5.5088 & TST & \\
\hline CHEMBL17331 & 688641 & 6.8 & 5.8643 & TST & \\
\hline CHEMBL 2373593 & 688641 & 5.4 & 5.2043 & TRN & \\
\hline CHEMBL1530091 & 688641 & 4.8 & 4.8507 & TRN & \\
\hline CHEMBL1356113 & 688641 & 5.5 & 5.523 & TRN & \\
\hline CHEMBL1396301 & 688641 & 4.9 & 5.1306 & TRN & \\
\hline CHEMBL1476504 & 688641 & 5.3 & 5.2294 & TRN & \\
\hline CHEMBL1356733 & 688641 & 4.9 & 4.8919 & TRN & \\
\hline CHEMBL1496350 & 688641 & 6.0 & 5.7715 & TRN & \\
\hline CHEMBL1476049 & 688641 & 4.6 & 4.6552 & TRN & \\
\hline CHEMBL1256697 & 688641 & 5.6 & 5.4213 & TRN & \\
\hline CHEMBL1256923 & 688641 & 5.2 & 5.1748 & TST & \\
\hline CHEMBL1452894 & 688641 & 5.5 & 5.6247 & TRN & \\
\hline
\end{tabular}




\begin{tabular}{|c|c|c|c|c|}
\hline \multicolumn{5}{|c|}{ lemental T } \\
\hline CHEMBL1562477 & 688641 & 4.5 & 4.5295 & TRN \\
\hline CHEMBL1304407 & 688641 & 5.7 & 5.1111 & TRN \\
\hline CHEMBL1607202 & 688641 & 4.8 & 5.0396 & TRN \\
\hline CHEMBL1358525 & 688641 & 4.5 & 4.6545 & TRN \\
\hline CHEMBL1343453 & 688641 & 5.1 & 5.1006 & TRN \\
\hline CHEMBL1513174 & 688641 & 5.6 & 4.8659 & TRN \\
\hline CHEMBL517186 & 688641 & 5.5 & 5.4045 & TST \\
\hline CHEMBL1552677 & 688641 & 4.5 & 4.7668 & TRN \\
\hline CHEMBL1532895 & 688641 & 4.9 & 5.2767 & TST \\
\hline CHEMBL1487121 & 688641 & 4.9 & 4.9779 & TRN \\
\hline CHEMBL395808 & 688641 & 4.8 & 5.0797 & TRN \\
\hline CHEMBL429711 & 688641 & 4.4 & 4.5391 & TRN \\
\hline CHEMBL1446716 & 688641 & 6.2 & 6.3284 & TRN \\
\hline CHEMBL1374863 & 688641 & 5.5 & 5.3998 & TRN \\
\hline CHEMBL1316292 & 688641 & 4.9 & 5.1339 & TRN \\
\hline CHEMBL1513511 & 688641 & 6.3 & 6.1485 & TRN \\
\hline CHEMBL1519225 & 688641 & 5.4 & 5.2906 & TRN \\
\hline CHEMBL1440653 & 688641 & 4.6 & 5.4722 & TRN \\
\hline CHEMBL1327915 & 688641 & 4.8 & 4.8504 & TRN \\
\hline CHEMBL1523894 & 688641 & 4.8 & 4.8927 & TST \\
\hline CHEMBL1472761 & 688641 & 5.7 & 5.4007 & TRN \\
\hline CHEMBL1436053 & 688641 & 4.9 & 5.2465 & TST \\
\hline CHEMBL1369871 & 688641 & 4.8 & 4.9065 & TRN \\
\hline CHEMBL1556456 & 688641 & 5.1 & 5.1221 & TRN \\
\hline CHEMBL1552607 & 688641 & 4.8 & 4.7574 & TRN \\
\hline CHEMBL1515355 & 688641 & 6.2 & 6.1719 & TRN \\
\hline CHEMBL1319992 & 688641 & 5.6 & 5.3698 & TRN \\
\hline CHEMBL1257002 & 688641 & 6.0 & 5.8233 & TST \\
\hline CHEMBL1397596 & 688641 & 4.9 & 4.9042 & TRN \\
\hline CHEMBL1323927 & 688641 & 4.5 & 4.6344 & TRN \\
\hline CHEMBL1516545 & 688641 & 4.8 & 5.2301 & TST \\
\hline CHEMBL 315348 & 688641 & 4.7 & 4.9085 & TRN \\
\hline CHEMBL497939 & 688641 & 6.0 & 4.7241 & TST \\
\hline CHEMBL1366302 & 688641 & 5.0 & 4.7595 & TRN \\
\hline CHEMBL1411201 & 688641 & 5.7 & 5.7902 & TRN \\
\hline CHEMBL1555208 & 688641 & 5.6 & 5.2735 & TRN \\
\hline CHEMBL1596756 & 688641 & 5.7 & 5.5889 & TRN \\
\hline CHEMBL1368340 & 688641 & 4.4 & 4.5626 & TST \\
\hline CHEMBL1412863 & 688641 & 4.9 & 5.0927 & TRN \\
\hline CHEMBL1592547 & 688641 & 6.1 & 5.77 & TRN \\
\hline CHEMBL1594054 & 688641 & 5.5 & 5.4929 & TRN \\
\hline CHEMBL1486596 & 688641 & 5.1 & 5.1328 & TRN \\
\hline CHEMBL276473 & 688641 & 4.4 & 5.1165 & TRN \\
\hline CHEMBL1318544 & 688641 & 5.6 & 5.7939 & TRN \\
\hline CHEMBL405358 & 688641 & 5.3 & 4.9523 & TST \\
\hline CHEMBL1568178 & 688641 & 5.9 & 5.9561 & TRN \\
\hline CHEMBL1522015 & 688641 & 5.5 & 5.2365 & TST \\
\hline CHEMBL1516154 & 688641 & 4.9 & 5.489 & TRN \\
\hline
\end{tabular}




\begin{tabular}{|c|c|c|c|c|}
\hline \multicolumn{5}{|c|}{ Supplemental Table S2.txt } \\
\hline CHEMBL1363408 & 688641 & 5.1 & 5.0118 & TRN \\
\hline CHEMBL1474561 & 688641 & 5.3 & 5.1333 & TRN \\
\hline CHEMBL1436997 & 688641 & 5.6 & 5.1006 & TRN \\
\hline CHEMBL1441255 & 688641 & 5.3 & 5.2478 & TST \\
\hline CHEMBL 8618 & 688641 & 6.0 & 5.7093 & TRN \\
\hline CHEMBL1315926 & 688641 & 5.6 & 4.9496 & TRN \\
\hline CHEMBL1603803 & 688641 & 6.0 & 5.9742 & TRN \\
\hline CHEMBL1321343 & 688641 & 4.8 & 5.1551 & TRN \\
\hline CHEMBL348856 & 688641 & 4.9 & 5.1032 & TRN \\
\hline CHEMBL1357401 & 688641 & 4.6 & 4.7271 & TRN \\
\hline CHEMBL1437013 & 688641 & 5.0 & 5.1291 & TRN \\
\hline CHEMBL1337381 & 688641 & 4.8 & 5.0077 & TRN \\
\hline CHEMBL491960 & 688641 & 6.2 & 5.9273 & TST \\
\hline CHEMBL133930 & 688641 & 4.9 & 5.0918 & TST \\
\hline CHEMBL 239047 & 688641 & 4.4 & 5.4712 & TRN \\
\hline CHEMBL1362068 & 688641 & 5.5 & 5.4991 & TRN \\
\hline CHEMBL1529625 & 688641 & 4.8 & 4.8497 & TST \\
\hline CHEMBL1559269 & 688641 & 4.8 & 5.02 & TRN \\
\hline CHEMBL1365367 & 688641 & 5.4 & 5.541 & TRN \\
\hline CHEMBL1565133 & 688641 & 4.9 & 5.0533 & TST \\
\hline CHEMBL1394731 & 688641 & 5.1 & 5.1165 & TRN \\
\hline CHEMBL1473188 & 688641 & 5.0 & 4.9891 & TRN \\
\hline CHEMBL1534811 & 688641 & 4.6 & 4.9742 & TRN \\
\hline CHEMBL1563047 & 688641 & 4.4 & 4.625 & TRN \\
\hline CHEMBL478 & 688641 & 7.4001 & 6.7611 & TRN \\
\hline CHEMBL1404882 & 688641 & 5.6 & 5.6504 & TRN \\
\hline CHEMBL445102 & 688641 & 5.6 & 5.0878 & TRN \\
\hline CHEMBL1516170 & 688641 & 6.7001 & 6.6089 & TRN \\
\hline CHEMBL1517935 & 688641 & 5.5 & 5.4957 & TRN \\
\hline CHEMBL1397595 & 688641 & 4.9 & 5.3417 & TRN \\
\hline CHEMBL1597366 & 688641 & 4.9 & 5.0175 & TRN \\
\hline CHEMBL1357724 & 688641 & 5.3 & 5.3927 & TRN \\
\hline CHEMBL182653 & 688641 & 5.6 & 5.3023 & TRN \\
\hline CHEMBL53898 & 688641 & 5.6 & 5.5951 & TRN \\
\hline CHEMBL1555884 & 688641 & 5.1 & 5.178 & TST \\
\hline CHEMBL399249 & 688641 & 4.9 & 5.0881 & TRN \\
\hline CHEMBL1448331 & 688641 & 4.4 & 4.9214 & TST \\
\hline CHEMBL1478614 & 688641 & 5.5 & 5.4318 & TRN \\
\hline CHEMBL1490209 & 688641 & 4.5 & 4.8237 & TRN \\
\hline CHEMBL1561363 & 688641 & 5.2 & 5.1366 & TRN \\
\hline CHEMBL1499 & 688641 & 5.0 & 5.072 & TRN \\
\hline CHEMBL50378 & 688641 & 6.0 & 5.862 & TST \\
\hline CHEMBL522121 & 688641 & 6.0 & 5.9195 & TRN \\
\hline CHEMBL1605496 & 688641 & 5.1 & 5.0098 & TRN \\
\hline CHEMBL1433726 & 688641 & 5.0 & 5.0841 & TST \\
\hline CHEMBL1350617 & 688641 & 4.5 & 5.1248 & TRN \\
\hline CHEMBL1318553 & 688641 & 6.0 & 5.7734 & TST \\
\hline CHEMBL1314808 & 688641 & 5.0 & 5.4493 & TRN \\
\hline
\end{tabular}




\begin{tabular}{|c|c|c|c|c|}
\hline \multicolumn{5}{|c|}{ lemental Table s } \\
\hline CHEMBL1358012 & 688641 & 5.5 & 5.4112 & TRN \\
\hline CHEMBL1438719 & 688641 & 4.8 & 5.37799 & 9999999999 \\
\hline CHEMBL49247 & 688641 & 4.6 & 5.1045 & TST \\
\hline CHEMBL1369373 & 688641 & 5.2 & 5.4864 & TRN \\
\hline CHEMBL1435261 & 688641 & 4.6 & 5.2364 & TST \\
\hline CHEMBL1395215 & 688641 & 5.6 & 5.1607 & TST \\
\hline CHEMBL1455073 & 688641 & 5.4 & 5.2928 & TST \\
\hline CHEMBL1472926 & 688641 & 5.7 & 5.5052 & TRN \\
\hline CHEMBL399705 & 688641 & 4.9 & 4.9644 & TST \\
\hline CHEMBL1568539 & 688641 & 5.7 & 5.2283 & TRN \\
\hline CHEMBL489534 & 688641 & 6.3 & 6.4826 & TRN \\
\hline CHEMBL1400491 & 688641 & 5.6 & 5.4653 & TRN \\
\hline CHEMBL1590213 & 688641 & 5.4 & 5.2702 & TRN \\
\hline CHEMBL1408334 & 688641 & 6.0 & 6.0793 & TRN \\
\hline CHEMBL1448398 & 688641 & 5.5 & 5.4341 & TRN \\
\hline CHEMBL1333038 & 688641 & 4.6 & 4.956 & TRN \\
\hline CHEMBL1445084 & 688641 & 4.8 & 5.0255 & TRN \\
\hline CHEMBL1599118 & 688641 & 5.0 & 5.0475 & TRN \\
\hline CHEMBL1524650 & 688641 & 5.0 & 4.9621 & TRN \\
\hline CHEMBL1512023 & 688641 & 4.8 & 4.8263 & TRN \\
\hline CHEMBL1551643 & 688641 & 4.8 & 4.9912 & TST \\
\hline CHEMBL1523957 & 688641 & 5.3 & 5.2695 & TRN \\
\hline CHEMBL1443491 & 688641 & 6.1 & 5.8912 & TRN \\
\hline CHEMBL1531056 & 688641 & 4.6 & 4.7484 & TRN \\
\hline CHEMBL 76904 & 688641 & 4.5 & 4.6778 & TRN \\
\hline CHEMBL1354319 & 688641 & 5.4 & 5.3228 & TRN \\
\hline CHEMBL1566017 & 688641 & 5.1 & 5.2728 & TRN \\
\hline CHEMBL1355935 & 688641 & 4.8 & 4.9407 & TRN \\
\hline CHEMBL1315666 & 688641 & 5.5 & 5.187 & TRN \\
\hline CHEMBL1514272 & 688641 & 4.8 & 4.8265 & TRN \\
\hline CHEMBL 1443376 & 688641 & 5.1 & 5.0931 & TST \\
\hline CHEMBL1452052 & 688641 & 6.0 & 6.0437 & TRN \\
\hline CHEMBL1552897 & 688641 & 4.6 & 4.9531 & TRN \\
\hline CHEMBL1493476 & 688641 & 4.5 & 4.5668 & TRN \\
\hline CHEMBL1332453 & 688641 & 5.5 & 5.1147 & TRN \\
\hline CHEMBL1395869 & 688641 & 5.5 & 5.4862 & TRN \\
\hline CHEMBL1531754 & 688641 & 6.0 & 5.6865 & TRN \\
\hline CHEMBL1316432 & 688641 & 5.4 & 5.0405 & TRN \\
\hline CHEMBL1598680 & 688641 & 6.0 & 5.8834 & TRN \\
\hline CHEMBL1517234 & 688641 & 5.8 & 5.5179 & TRN \\
\hline CHEMBL1569718 & 688641 & 4.7 & 4.7364 & TRN \\
\hline CHEMBL1409720 & 688641 & 5.2 & 5.2493 & TRN \\
\hline CHEMBL1551639 & 688641 & 5.0 & 5.1237 & TRN \\
\hline CHEMBL1563032 & 688641 & 4.8 & 4.9879 & TRN \\
\hline CHEMBL1435198 & 688641 & 5.7 & 5.3729 & TRN \\
\hline CHEMBL1534413 & 688641 & 4.9 & 5.1188 & TRN \\
\hline CHEMBL1409148 & 688641 & 6.0 & 6.0439 & TRN \\
\hline CHEMBL1319432 & 688641 & 5.7 & 5.68 & TST \\
\hline
\end{tabular}

TRN 
Supplemental Table S2.txt

\begin{tabular}{|c|c|c|c|c|c|}
\hline CHEMBL1451739 & 688641 & 7.3002 & 4.9891 & TST & \\
\hline CHEMBL1593547 & 688641 & 4.7 & 4.8594 & TRN & \\
\hline CHEMBL1330623 & 688641 & 6.0 & \multicolumn{2}{|c|}{6.0329999999999995} & TRN \\
\hline CHEMBL1552623 & 688641 & 6.3 & 6.3852 & TRN & \\
\hline CHEMBL1514455 & 688641 & 5.5 & 5.3497 & TRN & \\
\hline CHEMBL1515334 & 688641 & 6.0 & 5.7315 & TRN & \\
\hline CHEMBL1476055 & 688641 & 5.2 & 5.1835 & TRN & \\
\hline CHEMBL3208021 & 688641 & 5.4 & 5.4588 & TRN & \\
\hline CHEMBL1325197 & 688641 & 5.6 & 5.2484 & TRN & \\
\hline CHEMBL1571692 & 688641 & 6.0 & 5.7115 & TST & \\
\hline CHEMBL17468 & 688641 & 4.8 & 4.9144 & TST & \\
\hline CHEMBL1357598 & 688641 & 4.8 & 5.1851 & TRN & \\
\hline CHEMBL153 & 688641 & 4.9 & 4.9093 & TST & \\
\hline CHEMBL1591543 & 688641 & 5.4 & 5.3258 & TRN & \\
\hline CHEMBL1354713 & 688641 & 5.2 & 5.1098 & TRN & \\
\hline CHEMBL1446323 & 688641 & 4.7 & 4.789 & TRN & \\
\hline CHEMBL520992 & 688641 & 5.6 & 5.1358 & TRN & \\
\hline CHEMBL118109 & 688641 & 5.4 & 5.3631 & TRN & \\
\hline CHEMBL1355881 & 688641 & 4.5 & 4.5857 & TRN & \\
\hline CHEMBL1336060 & 688641 & 4.8 & 4.8596 & TRN & \\
\hline CHEMBL1475698 & 688641 & 6.0 & 5.2748 & TRN & \\
\hline CHEMBL1516514 & 688641 & 5.4 & \multicolumn{2}{|c|}{5.172000000000001} & TRN \\
\hline CHEMBL1444367 & 688641 & 4.8 & 5.0599 & TRN & \\
\hline CHEMBL280065 & 688641 & 4.5 & 4.5647 & TRN & \\
\hline CHEMBL1609324 & 688641 & 4.9 & 4.8728 & TRN & \\
\hline CHEMBL1435028 & 688641 & 4.9 & 4.931 & TRN & \\
\hline CHEMBL3197283 & 688641 & 5.4 & 5.4267 & TRN & \\
\hline CHEMBL1472898 & 688641 & 5.4 & 5.3842 & TRN & \\
\hline CHEMBL239276 & 688641 & 4.9 & 5.1262 & TRN & \\
\hline CHEMBL1493284 & 688641 & 4.6 & 4.6462 & TRN & \\
\hline CHEMBL1318041 & 688641 & 4.9 & 4.8676 & TRN & \\
\hline CHEMBL1435200 & 688641 & 5.3 & 5.1767 & TRN & \\
\hline CHEMBL1516477 & 688641 & 6.0 & 5.7415 & TRN & \\
\hline CHEMBL1525602 & 688641 & 5.1 & 5.1179 & TRN & \\
\hline CHEMBL1571634 & 688641 & 5.5 & 5.1315 & TRN & \\
\hline CHEMBL111545 & 688641 & 5.0 & 5.0198 & TST & \\
\hline CHEMBL1590789 & 688641 & 5.0 & 4.9311 & TRN & \\
\hline CHEMBL283196 & 688641 & 4.9 & 5.1036 & TRN & \\
\hline CHEMBL1411045 & 688641 & 5.5 & 5.591 & TST & \\
\hline CHEMBL1408836 & 688641 & 5.4 & 5.3112 & TST & \\
\hline CHEMBL1520285 & 688641 & 5.9 & 5.6862 & TRN & \\
\hline CHEMBL1555037 & 688641 & 5.6 & 5.2519 & TRN & \\
\hline CHEMBL250711 & 688641 & 5.5 & 5.3538 & TRN & \\
\hline CHEMBL479689 & 688641 & 6.4 & 5.2217 & TRN & \\
\hline CHEMBL2112207 & 688641 & 5.0 & 5.2105 & TST & \\
\hline CHEMBL1513643 & 688641 & 5.4 & 5.3713 & TST & \\
\hline CHEMBL1560835 & 688641 & 4.5 & 5.1599 & TRN & \\
\hline \multirow[t]{2}{*}{ CHEMBL1409852 } & 688641 & 4.9 & 4.93199 & 99999999995 & TRN \\
\hline & & & \multicolumn{2}{|c|}{ Page 10744} & \\
\hline
\end{tabular}




\begin{tabular}{|c|c|c|c|c|c|}
\hline \\
\hline CHEMBL1525456 & 688641 & 5.3 & 5.3125 & TRN & \\
\hline CHEMBL1495004 & 688641 & 5.4 & 5.4323 & TRN & \\
\hline CHEMBL1333968 & 688641 & 4.9 & 4.9049 & TRN & \\
\hline CHEMBL1363331 & 688641 & 5.3 & 5.2799 & TRN & \\
\hline CHEMBL1359613 & 688641 & 4.8 & 5.0098 & TRN & \\
\hline CHEMBL1517765 & 688641 & 5.4 & 5.5604 & TRN & \\
\hline CHEMBL1364990 & 688641 & 5.1 & 5.3509 & TRN & \\
\hline CHEMBL16312 & 688641 & 5.7 & 5.0887 & TRN & \\
\hline CHEMBL1529330 & 688641 & 6.4 & 6.0375 & TRN & \\
\hline CHEMBL63154 & 688641 & 5.6 & 5.3873 & TST & \\
\hline CHEMBL1357530 & 688641 & 4.7 & 4.7535 & TRN & \\
\hline CHEMBL408982 & 688641 & 4.6 & 5.1178 & TST & \\
\hline CHEMBL1474475 & 688641 & 5.3 & 5.2826 & TRN & \\
\hline CHEMBL1492669 & 688641 & 5.4 & 5.3192 & TST & \\
\hline CHEMBL21241 & 688641 & 5.4 & 5.2967 & TST & \\
\hline CHEMBL1449987 & 688641 & 5.0 & 5.1246 & TST & \\
\hline CHEMBL1568722 & 688641 & 4.7 & 5.0638 & TRN & \\
\hline CHEMBL1516163 & 688641 & 5.1 & 5.0539 & 9999999999 & TRN \\
\hline CHEMBL247484 & 688641 & 4.7 & 5.5433 & TRN & \\
\hline CHEMBL 72410 & 688641 & 4.6 & 4.7803 & TRN & \\
\hline CHEMBL1436049 & 688641 & 5.2 & 5.271 & TRN & \\
\hline CHEMBL470881 & 688641 & 5.6 & 5.2249 & TST & \\
\hline CHEMBL1325879 & 688641 & 4.9 & 4.9661 & TRN & \\
\hline CHEMBL1334895 & 688641 & 4.6 & 5.0012 & TST & \\
\hline CHEMBL1379031 & 688641 & 4.9 & 4.7503 & TRN & \\
\hline CHEMBL1325701 & 688641 & 5.3 & 5.1848 & TRN & \\
\hline CHEMBL1378901 & 688641 & 4.6 & 4.6766 & TRN & \\
\hline CHEMBL1371458 & 688641 & 5.1 & 4.9487 & TRN & \\
\hline CHEMBL1433886 & 688641 & 5.4 & 5.4234 & TRN & \\
\hline CHEMBL1515324 & 688641 & 5.4 & 5.4032 & TRN & \\
\hline CHEMBL1570413 & 688641 & 4.8 & 4.7117 & TRN & \\
\hline CHEMBL1446139 & 688641 & 5.2 & 5.3501 & TRN & \\
\hline CHEMBL1371587 & 688641 & 4.7 & 5.124 & TRN & \\
\hline CHEMBL1496345 & 688641 & 4.8 & 4.9502 & TRN & \\
\hline CHEMBL1435908 & 688641 & 6.0 & 6.0256 & TRN & \\
\hline CHEMBL1315374 & 688641 & 5.5 & 5.1318 & TST & \\
\hline CHEMBL1435444 & 688641 & 4.8 & 5.0524 & TRN & \\
\hline CHEMBL1513392 & 688641 & 5.3 & 5.2011 & TST & \\
\hline CHEMBL1374028 & 688641 & 5.4 & 5.3121 & TST & \\
\hline CHEMBL1317451 & 688641 & 4.8 & 4.7839 & TRN & \\
\hline CHEMBL1489140 & 688641 & 4.7 & 4.7427 & TST & \\
\hline CHEMBL 3210244 & 688641 & 5.4 & 5.439 & TRN & \\
\hline CHEMBL1590106 & 688641 & 4.7 & 4.9958 & TRN & \\
\hline CHEMBL1592227 & 688641 & 5.7 & 5.8326 & TRN & \\
\hline CHEMBL1566780 & 688641 & 6.1 & 6.2425 & TRN & \\
\hline CHEMBL1442770 & 688641 & 4.7 & 4.7847 & TST & \\
\hline CHEMBL1370726 & 688641 & 5.5 & 5.3045 & TST & \\
\hline CHEMBL1366586 & 688641 & 5.1 & 5.3131 & TRN & \\
\hline & & & & 107 & \\
\hline
\end{tabular}




\begin{tabular}{|c|c|c|c|c|c|}
\hline & & & & & \\
\hline CHEMBL1414673 & 688641 & 5.4 & 5.5268 & TRN & \\
\hline CHEMBL1484614 & 688641 & 4.6 & 4.7513 & TRN & \\
\hline CHEMBL1512190 & 688641 & 5.3 & 5.1826 & TRN & \\
\hline CHEMBL1554622 & 688641 & 5.5 & 5.4103 & TRN & \\
\hline CHEMBL1559578 & 688641 & 5.4 & 5.3193 & TRN & \\
\hline CHEMBL1396146 & 688641 & 4.8 & 4.893 & TRN & \\
\hline CHEMBL1317931 & 688641 & 6.0 & 5.2006 & TST & \\
\hline CHEMBL1358983 & 688641 & 5.9 & 5.9856 & TRN & \\
\hline CHEMBL1435765 & 688641 & 5.3 & 5.0262 & TST & \\
\hline CHEMBL1484196 & 688641 & 5.9 & 5.9467 & TRN & \\
\hline CHEMBL1493707 & 688641 & 5.5 & 5.4922 & TST & \\
\hline CHEMBL566899 & 688641 & 6.0 & 6.0158 & TRN & \\
\hline CHEMBL1515246 & 688641 & 5.7 & 5.5024 & TRN & \\
\hline CHEMBL1316974 & 688641 & 4.8 & 5.0648 & TRN & \\
\hline CHEMBL1397325 & 688641 & 4.9 & 4.9398 & TRN & \\
\hline CHEMBL1399561 & 688641 & 4.9 & 4.8426 & TRN & \\
\hline CHEMBL1571391 & 688641 & 5.5 & $5.1320 e$ & 0000000001 & TRN \\
\hline CHEMBL39 & 688641 & 6.0 & 4.7509 & TRN & \\
\hline CHEMBL1358602 & 688641 & 5.4 & 5.1245 & TRN & \\
\hline CHEMBL1374784 & 688641 & 5.4 & 5.4657 & TRN & \\
\hline CHEMBL1256625 & 688641 & 4.6 & 4.7206 & TRN & \\
\hline CHEMBL1554408 & 688641 & 6.9 & 5.2118 & TRN & \\
\hline CHEMBL1592964 & 688641 & 5.2 & 5.2559 & TRN & \\
\hline CHEMBL1394113 & 688641 & 5.1 & 5.1618 & TRN & \\
\hline CHEMBL1358215 & 688641 & 5.1 & 4.9828 & TRN & \\
\hline CHEMBL1476791 & 688641 & 5.1 & 5.1761 & TRN & \\
\hline CHEMBL1552720 & 688641 & 5.3 & 5.1873 & TRN & \\
\hline CHEMBL 8145 & 688641 & 6.0 & 4.8424 & TRN & \\
\hline CHEMBL1490268 & 688641 & 4.9 & 5.0244 & TST & \\
\hline CHEMBL1472651 & 688641 & 4.6 & 4.5916 & TRN & \\
\hline CHEMBL1590261 & 688641 & 4.8 & 4.8942 & TRN & \\
\hline CHEMBL1488918 & 688641 & 6.1 & 6.0499 & TRN & \\
\hline CHEMBL1594405 & 688641 & 6.2 & 6.4587 & TRN & \\
\hline CHEMBL 28517 & 688641 & 4.5 & 5.1485 & TST & \\
\hline CHEMBL1604877 & 688641 & 4.8 & 5.0605 & TRN & \\
\hline CHEMBL1316628 & 688641 & 4.8 & 4.895 & TRN & \\
\hline CHEMBL1474568 & 688641 & 6.2 & 5.8327 & TRN & \\
\hline CHEMBL1444844 & 688641 & 6.1 & 5.843 & TRN & \\
\hline CHEMBL419045 & 688641 & 4.8 & 5.1754 & TST & \\
\hline CHEMBL1434625 & 688641 & 5.1 & 4.8157 & TRN & \\
\hline CHEMBL1554465 & 688641 & 5.4 & 5.2565 & TRN & \\
\hline CHEMBL1376200 & 688641 & 4.7 & 5.0677 & TRN & \\
\hline CHEMBL1256914 & 688641 & 5.0 & 5.0208 & TRN & \\
\hline CHEMBL1440650 & 688641 & 5.2 & 5.0448 & TRN & \\
\hline CHEMBL1486915 & 688641 & 5.4 & 5.5173 & TRN & \\
\hline CHEMBL1449490 & 688641 & 6.0 & 5.2293 & TST & \\
\hline CHEMBL1395165 & 688641 & 5.7 & 5.8142 & TRN & \\
\hline CHEMBL70141 & 688641 & 5.0 & 5.0753 & TRN & \\
\hline & & & & 10746 & \\
\hline
\end{tabular}




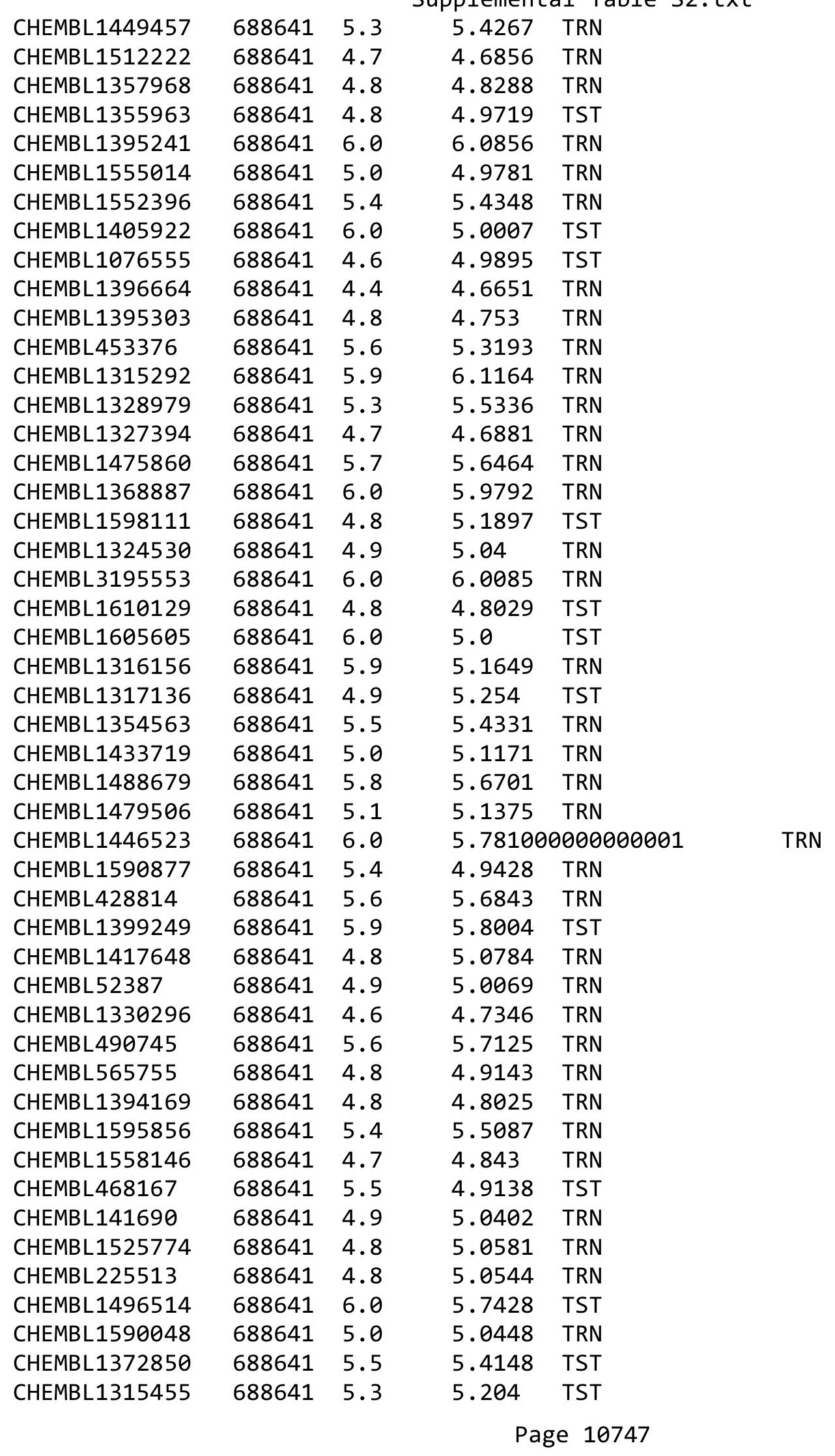




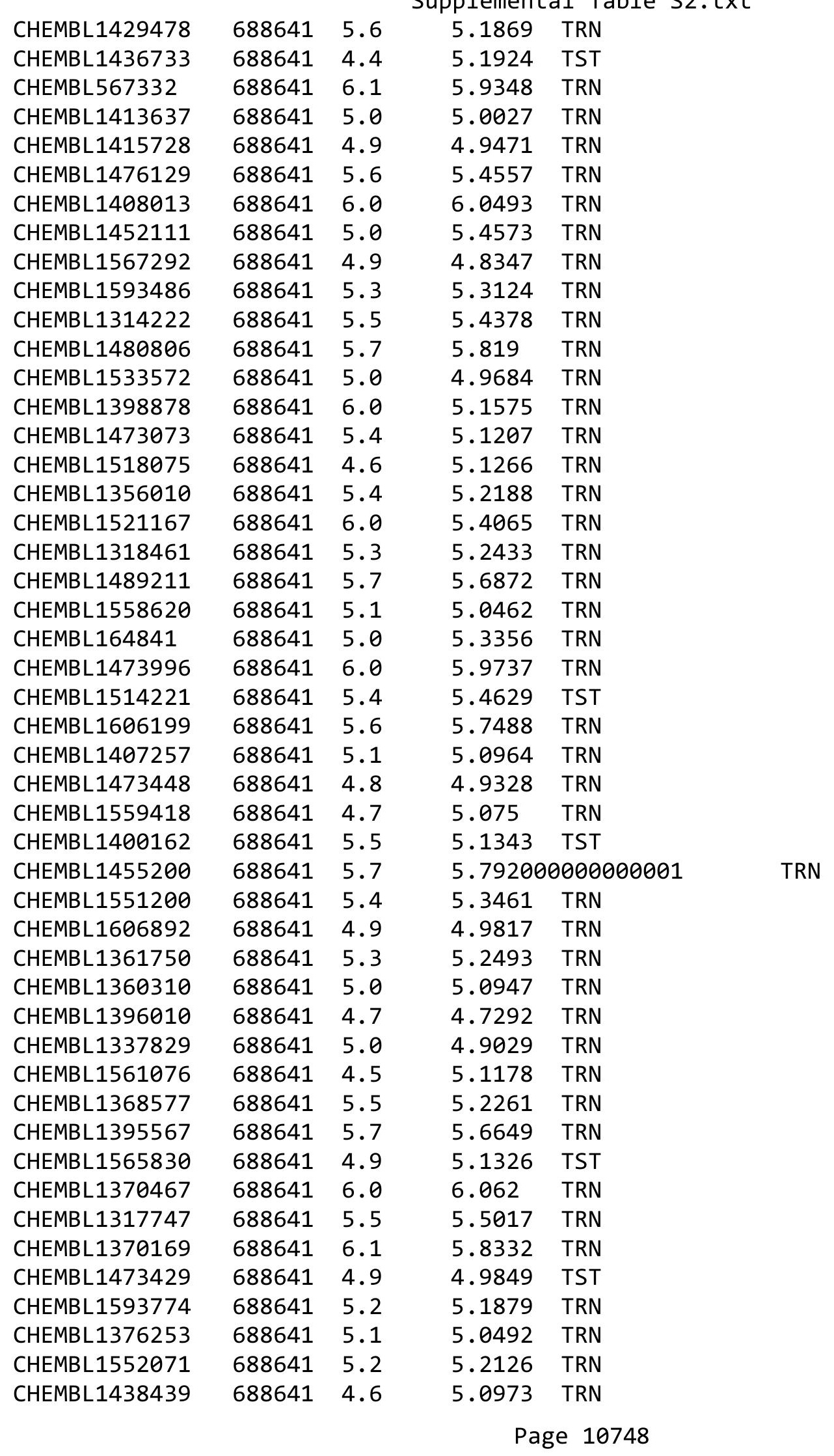




\begin{tabular}{|c|c|c|c|c|c|}
\hline \multicolumn{6}{|c|}{ Supplemental Table S2.txt } \\
\hline CHEMBL1445473 & 688641 & 4.9 & 4.8432 & TRN & \\
\hline CHEMBL115225 & 688641 & 8.4949 & 7.603 & TST & \\
\hline CHEMBL1318104 & 688641 & 4.8 & 4.881 & TRN & \\
\hline CHEMBL47529 & 688641 & 4.8 & 4.9039 & TRN & \\
\hline CHEMBL1520025 & 688641 & 6.0 & 5.1578 & TRN & \\
\hline CHEMBL1356794 & 688641 & 5.2 & 5.1876 & TRN & \\
\hline CHEMBL1315833 & 688641 & 5.3 & 5.3608 & TRN & \\
\hline CHEMBL1314799 & 688641 & 5.6 & 5.51399 & 9999999999 & TRN \\
\hline CHEMBL1480687 & 688641 & 4.6 & 4.6516 & TRN & \\
\hline CHEMBL1524453 & 688641 & 6.0 & 5.9704 & TRN & \\
\hline CHEMBL1321439 & 688641 & 4.8 & 4.8191 & TRN & \\
\hline CHEMBL1356842 & 688641 & 6.3 & 5.9524 & TRN & \\
\hline CHEMBL1485406 & 688641 & 4.6 & 5.1496 & TRN & \\
\hline CHEMBL1484261 & 688641 & 6.3 & 6.3734 & TRN & \\
\hline CHEMBL1396124 & 688641 & 4.8 & 5.2605 & TRN & \\
\hline CHEMBL1491099 & 688641 & 5.8 & 5.1118 & TST & \\
\hline CHEMBL1418449 & 688641 & 5.6 & 5.222 & TST & \\
\hline CHEMBL465423 & 688641 & 5.4 & 5.1864 & TST & \\
\hline CHEMBL1368286 & 688641 & 5.4 & 5.3405 & TRN & \\
\hline CHEMBL1535201 & 688641 & 4.9 & 5.1555 & TST & \\
\hline CHEMBL1553123 & 688641 & 4.8 & 5.1014 & TRN & \\
\hline CHEMBL1316745 & 688641 & 4.5 & 4.602 & TRN & \\
\hline CHEMBL1355224 & 688641 & 4.9 & 4.9967 & TRN & \\
\hline CHEMBL1476642 & 688641 & 4.6 & 5.0741 & TRN & \\
\hline CHEMBL1590391 & 688641 & 4.3 & 5.0119 & TST & \\
\hline CHEMBL540294 & 688641 & 6.0 & 5.8064 & TST & \\
\hline CHEMBL1513686 & 688641 & 5.1 & 5.1079 & TRN & \\
\hline CHEMBL1579501 & 688641 & 5.3 & 5.1945 & TST & \\
\hline CHEMBL1535689 & 688641 & 5.1 & 5.0398 & TRN & \\
\hline CHEMBL1337995 & 688641 & 4.9 & 5.48799 & 99999999995 & TRN \\
\hline CHEMBL1551139 & 688641 & 5.2 & 5.2248 & TRN & \\
\hline CHEMBL1552294 & 688641 & 4.8 & 4.941 & TRN & \\
\hline CHEMBL 279218 & 688641 & 4.9 & 5.0566 & TST & \\
\hline CHEMBL1437906 & 688641 & 4.9 & 4.9607 & TRN & \\
\hline CHEMBL1518159 & 688641 & 4.7 & 4.8164 & TRN & \\
\hline CHEMBL1476227 & 688641 & 4.6 & 4.5904 & TRN & \\
\hline CHEMBL1513439 & 688641 & 4.9 & 4.9325 & TRN & \\
\hline CHEMBL1566325 & 688641 & 5.3 & 5.1544 & TST & \\
\hline CHEMBL1451526 & 688641 & 5.5 & 5.3855 & TRN & \\
\hline CHEMBL1318512 & 688641 & 4.4 & 5.30399 & 9999999999 & TRN \\
\hline CHEMBL1512385 & 688641 & 5.4 & 5.425 & TRN & \\
\hline CHEMBL1435252 & 688641 & 4.8 & 5.1133 & TRN & \\
\hline CHEMBL1322719 & 688641 & 5.8 & 5.7503 & TST & \\
\hline CHEMBL1355002 & 688641 & 4.9 & 4.8966 & TRN & \\
\hline CHEMBL1607289 & 688641 & 4.5 & 5.29299 & 9999999999 & TRN \\
\hline CHEMBL1487677 & 688641 & 4.9 & 5.0803 & TRN & \\
\hline CHEMBL1406556 & 688641 & 5.6 & 5.5623 & TRN & \\
\hline CHEMBL1488771 & 688641 & 5.4 & 5.3632 & TST & \\
\hline
\end{tabular}




\begin{tabular}{|c|c|c|c|c|c|}
\hline \\
\hline CHEMBL1474875 & 688641 & 4.8 & 4.8099 & TRN & \\
\hline CHEMBL1610003 & 688641 & 4.6 & 4.5864 & TRN & \\
\hline CHEMBL1433704 & 688641 & 4.5 & 4.6098 & TRN & \\
\hline CHEMBL1601416 & 688641 & 4.5 & 4.5338 & TRN & \\
\hline CHEMBL573214 & 688641 & 5.7 & 5.6597 & TST & \\
\hline CHEMBL273807 & 688641 & 6.0 & 5.8187 & TST & \\
\hline CHEMBL487603 & 688641 & 4.6 & 5.3953 & TRN & \\
\hline CHEMBL1394855 & 688641 & 5.4 & 5.4634 & TRN & \\
\hline CHEMBL 398755 & 688641 & 4.5 & 4.9048 & TRN & \\
\hline CHEMBL491940 & 688641 & 5.8 & 5.6756 & TRN & \\
\hline CHEMBL1395088 & 688641 & 5.4 & $5.2860 e$ & 00000000005 & TRN \\
\hline CHEMBL1613209 & 688641 & 6.1 & 4.9575 & TRN & \\
\hline CHEMBL202752 & 688641 & 5.8 & $5.5870 e$ & 0000000001 & TST \\
\hline CHEMBL1318448 & 688641 & 5.2 & 5.2556 & TRN & \\
\hline CHEMBL1517051 & 688641 & 4.6 & 4.6796 & TRN & \\
\hline CHEMBL34704 & 688641 & 6.0 & 5.7127 & TST & \\
\hline CHEMBL1316760 & 688641 & 5.3 & 5.2871 & TRN & \\
\hline CHEMBL1473632 & 688641 & 5.9 & 5.3848 & TRN & \\
\hline CHEMBL1590616 & 688641 & 4.6 & 4.7738 & TRN & \\
\hline CHEMBL1595914 & 688641 & 4.5 & 4.9781 & TRN & \\
\hline CHEMBL1490313 & 688641 & 4.8 & 5.2257 & TRN & \\
\hline CHEMBL1529147 & 688641 & 4.5 & 5.2211 & TST & \\
\hline CHEMBL1557498 & 688641 & 5.6 & 5.355 & TRN & \\
\hline CHEMBL34241 & 688641 & 5.2 & 4.9734 & TRN & \\
\hline CHEMBL1414353 & 688641 & 4.6 & 5.0171 & TRN & \\
\hline CHEMBL 1450079 & 688641 & 5.5 & 5.197 & TRN & \\
\hline CHEMBL1609913 & 688641 & 4.8 & 5.2466 & TST & \\
\hline CHEMBL 1534872 & 688641 & 5.6 & 5.3568 & TST & \\
\hline CHEMBL1474114 & 688641 & 6.1 & 6.2697 & TRN & \\
\hline CHEMBL 2374045 & 688641 & 5.5 & 5.1841 & TRN & \\
\hline CHEMBL1394757 & 688641 & 6.0 & 5.8313 & TST & \\
\hline CHEMBL1372635 & 688641 & 6.0 & 6.1602 & TRN & \\
\hline CHEMBL1606751 & 688641 & 4.7 & 5.0653 & TRN & \\
\hline CHEMBL1378440 & 688641 & 5.6 & 5.4939 & TRN & \\
\hline CHEMBL1376952 & 688641 & 5.5 & 5.3994 & TRN & \\
\hline CHEMBL1553001 & 688641 & 4.8 & 4.7401 & TRN & \\
\hline CHEMBL1489663 & 688641 & 5.4 & 5.3498 & TST & \\
\hline CHEMBL1373918 & 688641 & 5.4 & 5.1146 & TRN & \\
\hline CHEMBL1490863 & 688641 & 5.5 & 5.3252 & TRN & \\
\hline CHEMBL1317494 & 688641 & 5.7 & 5.7348 & TRN & \\
\hline CHEMBL 208484 & 688641 & 5.5 & 5.0188 & TRN & \\
\hline CHEMBL1364404 & 688641 & 5.2 & 5.1352 & TST & \\
\hline CHEMBL1354262 & 688641 & 4.9 & 4.9245 & TRN & \\
\hline CHEMBL1411743 & 688641 & 5.6 & 5.7671 & TRN & \\
\hline CHEMBL1574231 & 688641 & 5.3 & 5.4219 & TRN & \\
\hline CHEMBL1403488 & 688641 & 5.6 & 5.4754 & TRN & \\
\hline CHEMBL1358018 & 688641 & 5.5 & 5.1875 & TRN & \\
\hline CHEMBL164921 & 688641 & 4.6 & 5.1058 & TRN & \\
\hline
\end{tabular}




\begin{tabular}{|c|c|c|c|c|}
\hline \multicolumn{5}{|c|}{ Supplemental Table S2.txt } \\
\hline CHEMBL1395417 & 688641 & 5.0 & 4.9572 & TRN \\
\hline CHEMBL1394353 & 688641 & 6.0 & 6.1695 & TRN \\
\hline CHEMBL1363568 & 688641 & 4.6 & 4.6146 & TRN \\
\hline CHEMBL1512025 & 688641 & 5.4 & 5.2249 & TST \\
\hline CHEMBL1571545 & 688641 & 4.8 & 5.1553 & TRN \\
\hline CHEMBL 384903 & 688641 & 4.8 & 4.9078 & TST \\
\hline CHEMBL1158 & 688641 & 4.4 & 4.9111 & TST \\
\hline CHEMBL1449726 & 688641 & 5.5 & 5.5098 & TRN \\
\hline CHEMBL1394348 & 688641 & 6.0 & 5.8269 & TRN \\
\hline CHEMBL1495893 & 688641 & 5.6 & 5.0375 & TST \\
\hline CHEMBL1589925 & 688641 & 4.8 & 4.8176 & TRN \\
\hline CHEMBL1354186 & 688641 & 5.5 & 5.1138 & TRN \\
\hline CHEMBL1554723 & 688641 & 5.4 & 5.3041 & TRN \\
\hline CHEMBL1315690 & 688641 & 4.7 & 4.694 & TRN \\
\hline CHEMBL1529490 & 688641 & 6.0 & 5.4556 & TRN \\
\hline CHEMBL1554459 & 688641 & 5.4 & 5.4295 & TRN \\
\hline CHEMBL1552949 & 688641 & 5.4 & 5.4748 & TRN \\
\hline CHEMBL1408878 & 688641 & 5.1 & 5.0507 & TRN \\
\hline CHEMBL1574543 & 688641 & 7.5003 & 5.1891 & TRN \\
\hline CHEMBL1354913 & 688641 & 5.2 & 5.2141 & TST \\
\hline CHEMBL340807 & 688641 & 6.0 & 5.4766 & TRN \\
\hline CHEMBL1530645 & 688641 & 6.3 & 6.4677 & TRN \\
\hline CHEMBL323197 & 688641 & 4.4 & 5.1567 & TRN \\
\hline CHEMBL1318847 & 688641 & 4.6 & 4.6959 & TRN \\
\hline CHEMBL1434006 & 688641 & 4.8 & 4.9249 & TRN \\
\hline CHEMBL 277525 & 688641 & 6.2 & 6.1702 & TRN \\
\hline CHEMBL1592464 & 688641 & 6.4 & 6.5522 & TRN \\
\hline CHEMBL1558184 & 688641 & 4.6 & 4.6209 & TRN \\
\hline CHEMBL 281622 & 688641 & 4.8 & 4.876 & TST \\
\hline CHEMBL1357498 & 688641 & 4.8 & 4.8105 & TRN \\
\hline CHEMBL1394923 & 688641 & 4.8 & 4.872 & TRN \\
\hline CHEMBL1436488 & 688641 & 5.1 & 5.0098 & TRN \\
\hline CHEMBL1450493 & 688641 & 5.3 & 5.2125 & TST \\
\hline CHEMBL190259 & 688641 & 6.0 & 5.0794 & TRN \\
\hline CHEMBL472994 & 688641 & 6.5 & 6.2265 & TST \\
\hline CHEMBL1417025 & 688641 & 4.7 & 4.7821 & TRN \\
\hline CHEMBL1529538 & 688641 & 4.9 & 4.947 & TST \\
\hline CHEMBL 247378 & 688641 & 4.4 & 4.5684 & TRN \\
\hline CHEMBL1356003 & 688641 & 4.5 & 4.6251 & TRN \\
\hline CHEMBL326958 & 688641 & 4.6 & 4.794 & TRN \\
\hline CHEMBL1551122 & 688641 & 5.7 & 5.8117 & TRN \\
\hline CHEMBL1514819 & 688641 & 4.8 & 4.8816 & TRN \\
\hline CHEMBL1408138 & 688641 & 6.2 & 5.9379 & TST \\
\hline CHEMBL1323385 & 688641 & 5.1 & 5.1258 & TRN \\
\hline CHEMBL1354388 & 688641 & 4.9 & 4.8937 & TRN \\
\hline CHEMBL370152 & 688641 & 5.1 & 5.0122 & TRN \\
\hline CHEMBL1601121 & 688641 & 5.6 & 5.5409 & TRN \\
\hline CHEMBL1315373 & 688641 & 5.4 & 5.4948 & TRN \\
\hline
\end{tabular}




\begin{tabular}{|c|c|c|c|c|c|}
\hline \multirow{2}{*}{ CHEMBL1473442 } & \multirow{2}{*}{688641} & \\
\hline & & 5.4 & 5.4357 & TRN & \\
\hline CHEMBL1398216 & 688641 & 5.5 & 5.5295 & TRN & \\
\hline CHEMBL1533197 & 688641 & 5.1 & 5.0878 & TRN & \\
\hline CHEMBL1515858 & 688641 & 4.9 & 4.8549 & TRN & \\
\hline CHEMBL1481847 & 688641 & 5.0 & 5.0228 & TRN & \\
\hline CHEMBL484901 & 688641 & 4.9 & 4.9578 & TRN & \\
\hline CHEMBL1474241 & 688641 & 5.5 & 5.4131 & TRN & \\
\hline CHEMBL1396090 & 688641 & 4.8 & 4.7765 & TRN & \\
\hline CHEMBL366861 & 688641 & 4.4 & 5.2663 & TRN & \\
\hline CHEMBL1721226 & 688641 & 4.6 & 5.0775 & TRN & \\
\hline CHEMBL1483693 & 688641 & 6.0 & \multicolumn{2}{|c|}{6.042999999999999} & TRN \\
\hline CHEMBL1374337 & 688641 & 4.9 & 5.0058 & TRN & \\
\hline CHEMBL1436125 & 688641 & 6.1 & 6.0352 & TRN & \\
\hline CHEMBL1481781 & 688641 & 5.5 & 5.4189 & TRN & \\
\hline CHEMBL1316353 & 688641 & 4.8 & 4.8003 & TRN & \\
\hline CHEMBL1515366 & 688641 & 5.3 & 5.1758 & TRN & \\
\hline CHEMBL1332033 & 688641 & 4.6 & 4.6881 & TRN & \\
\hline CHEMBL 75773 & 688641 & 4.9 & \multicolumn{2}{|c|}{5.053999999999999} & TRN \\
\hline CHEMBL355496 & 688641 & 5.1 & 5.0433 & TST & \\
\hline CHEMBL1479372 & 688641 & 4.7 & 4.8302 & TRN & \\
\hline CHEMBL1370610 & 688641 & 6.0 & 5.0143 & TST & \\
\hline CHEMBL1413787 & 688641 & 5.3 & 5.0327 & TRN & \\
\hline CHEMBL1528606 & 688641 & 6.0 & 5.9468 & TRN & \\
\hline CHEMBL1290409 & 688641 & 4.7 & 4.7797 & TRN & \\
\hline CHEMBL1446922 & 688641 & 5.0 & 5.039 & TRN & \\
\hline CHEMBL1551231 & 688641 & 4.6 & 4.6827 & TRN & \\
\hline CHEMBL1373004 & 688641 & 5.6 & 5.5237 & TRN & \\
\hline CHEMBL1610892 & 688641 & 5.0 & 4.9658 & TRN & \\
\hline CHEMBL1396936 & 688641 & 5.7 & 5.8108 & TRN & \\
\hline CHEMBL1566458 & 688641 & 5.4 & 5.0281 & TRN & \\
\hline CHEMBL1366157 & 688641 & 4.6 & \multicolumn{2}{|c|}{4.6610000000000005} & TRN \\
\hline CHEMBL1316496 & 688641 & 7.5003 & 6.7528 & TRN & \\
\hline CHEMBL1406307 & 688641 & 5.5 & 5.3676 & TST & \\
\hline CHEMBL1396754 & 688641 & 5.4 & 5.0523 & TRN & \\
\hline CHEMBL1317344 & 688641 & 5.0 & 5.1247 & TRN & \\
\hline CHEMBL1474410 & 688641 & 5.1 & 5.029 & TRN & \\
\hline CHEMBL1256814 & 688641 & 5.0 & 4.9476 & TRN & \\
\hline CHEMBL1410676 & 688641 & 6.9 & 6.8923 & TRN & \\
\hline CHEMBL1552542 & 688641 & 5.4 & 5.2986 & TRN & \\
\hline CHEMBL1442250 & 688641 & 4.9 & 4.9411 & TRN & \\
\hline CHEMBL 77030 & 688641 & 6.0 & 5.6737 & TRN & \\
\hline CHEMBL1612590 & 688641 & 5.4 & 5.1255 & TST & \\
\hline CHEMBL1396583 & 688641 & 5.3 & 5.092 & TRN & \\
\hline CHEMBL 34730 & 688641 & 4.8 & 4.8481 & TRN & \\
\hline CHEMBL1443413 & 688641 & 4.4 & 4.9936 & TRN & \\
\hline CHEMBL1473707 & 688641 & 5.5 & 5.1356 & TRN & \\
\hline CHEMBL1358234 & 688641 & 5.8 & 5.8888 & TRN & \\
\hline CHEMBL1611261 & 688641 & 4.8 & 4.8574 & TRN & \\
\hline
\end{tabular}




\begin{tabular}{|c|c|c|c|c|c|}
\hline \multicolumn{6}{|c|}{ Supplemental Table S2.txt } \\
\hline CHEMBL1476362 & 688641 & 4.5 & 5.1669 & TST & \\
\hline CHEMBL1452816 & 688641 & 4.6 & 5.1735 & TRN & \\
\hline CHEMBL1405546 & 688641 & 5.5 & 5.4137 & TRN & \\
\hline CHEMBL1439401 & 688641 & 5.7 & 5.7564 & TRN & \\
\hline CHEMBL10 & 688641 & 6.0 & 5.97 & TST & \\
\hline CHEMBL1566571 & 688641 & 5.0 & 4.9915 & TRN & \\
\hline CHEMBL1403793 & 688641 & 5.1 & 5.17899 & 9999999999 & TRN \\
\hline CHEMBL1411094 & 688641 & 5.6 & 5.7299 & TRN & \\
\hline CHEMBL1435713 & 688641 & 4.8 & 4.879 & TRN & \\
\hline CHEMBL1437732 & 688641 & 5.4 & 5.4587 & TRN & \\
\hline CHEMBL1402241 & 688641 & 5.4 & 5.425 & TRN & \\
\hline CHEMBL1494408 & 688641 & 5.5 & 5.7344 & TRN & \\
\hline CHEMBL1609440 & 688641 & 4.7 & 4.6458 & TRN & \\
\hline CHEMBL1527567 & 688641 & 5.0 & 4.7634 & TRN & \\
\hline CHEMBL1414185 & 688641 & 6.5 & 6.28 & TST & \\
\hline CHEMBL1514075 & 688641 & 4.8 & 4.8656 & TRN & \\
\hline CHEMBL1331579 & 688641 & 5.5 & 5.4652 & TRN & \\
\hline CHEMBL1558777 & 688641 & 4.8 & 4.9424 & TRN & \\
\hline CHEMBL1408703 & 688641 & 4.8 & 4.8181 & TRN & \\
\hline CHEMBL601534 & 688641 & 4.7 & 5.33299 & 9999999999 & TRN \\
\hline CHEMBL1474244 & 688641 & 4.7 & 4.7311 & TRN & \\
\hline CHEMBL1437054 & 688641 & 5.8 & 5.5209 & TST & \\
\hline CHEMBL48310 & 688641 & 6.2 & 5.0892 & TST & \\
\hline CHEMBL1573058 & 688641 & 4.8 & 4.7445 & TRN & \\
\hline CHEMBL565856 & 688641 & 5.7 & 5.8295 & TRN & \\
\hline CHEMBL1602633 & 688641 & 5.7 & 5.7233 & TRN & \\
\hline CHEMBL1594947 & 688641 & 5.6 & 5.6738 & TRN & \\
\hline CHEMBL1436536 & 688641 & 4.6 & 4.8854 & TRN & \\
\hline CHEMBL1555567 & 688641 & 5.4 & 5.5048 & TRN & \\
\hline CHEMBL1515666 & 688641 & 4.4 & 5.2033 & TST & \\
\hline CHEMBL1474795 & 688641 & 4.8 & 4.8374 & TRN & \\
\hline CHEMBL1593511 & 688641 & 5.5 & 5.3804 & TRN & \\
\hline CHEMBL171064 & 688641 & 4.5 & 4.6324 & TST & \\
\hline CHEMBL1357850 & 688641 & 6.0 & 6.09399 & 9999999999 & TRN \\
\hline CHEMBL597744 & 688641 & 5.0 & 5.0923 & TRN & \\
\hline CHEMBL1606292 & 688641 & 5.9 & 5.9805 & TRN & \\
\hline CHEMBL1325152 & 688641 & 4.6 & 5.1173 & TRN & \\
\hline CHEMBL1439202 & 688641 & 4.5 & 5.1051 & TST & \\
\hline CHEMBL500996 & 688641 & 5.0 & 5.0109 & TRN & \\
\hline CHEMBL1513063 & 688641 & 4.8 & 4.8663 & TRN & \\
\hline CHEMBL1452080 & 688641 & 4.9 & 5.0935 & TRN & \\
\hline CHEMBL1333011 & 688641 & 4.8 & 5.2404 & TRN & \\
\hline CHEMBL1256844 & 688641 & 6.0 & 5.716 & TST & \\
\hline CHEMBL1491809 & 688641 & 5.0 & 4.9789 & TRN & \\
\hline CHEMBL195008 & 688641 & 5.2 & 5.1497 & TRN & \\
\hline CHEMBL1569985 & 688641 & 5.5 & 5.4179 & TRN & \\
\hline CHEMBL1436507 & 688641 & 5.5 & 5.5256 & TRN & \\
\hline CHEMBL1600347 & 688641 & 4.9 & 4.9435 & TRN & \\
\hline
\end{tabular}




\begin{tabular}{|c|c|c|c|c|c|}
\hline & & & & & \\
\hline CHEMBL1554725 & 688641 & 5.5 & 5.4944 & TRN & \\
\hline CHEMBL1330272 & 688641 & 6.1 & 6.2605 & TRN & \\
\hline CHEMBL1526213 & 688641 & 5.9 & 5.6763 & TRN & \\
\hline CHEMBL876 & 688641 & 6.0 & 4.9931 & TST & \\
\hline CHEMBL1371686 & 688641 & 7.0 & 5.0591 & TRN & \\
\hline CHEMBL1256668 & 688641 & 4.8 & 4.9825 & TST & \\
\hline CHEMBL1408475 & 688641 & 4.8 & 5.0226 & TRN & \\
\hline CHEMBL86931 & 688641 & 4.5 & 4.6705 & TST & \\
\hline CHEMBL1331060 & 688641 & 4.8 & 4.916 & TRN & \\
\hline CHEMBL1319626 & 688641 & 5.4 & 5.32 & TRN & \\
\hline CHEMBL73933 & 688641 & 4.6 & 5.1413 & TRN & \\
\hline CHEMBL1551970 & 688641 & 4.8 & 5.2641 & TRN & \\
\hline CHEMBL1324022 & 688641 & 4.8 & 4.9 & TST & \\
\hline CHEMBL1529478 & 688641 & 5.4 & 5.3485 & TRN & \\
\hline CHEMBL1332532 & 688641 & 5.8 & 5.3928 & TRN & \\
\hline CHEMBL1366539 & 688641 & 4.7 & 5.2199 & TST & \\
\hline CHEMBL1408808 & 688641 & 4.4 & 5.2416 & TST & \\
\hline CHEMBL1319213 & 688641 & 4.4 & 4.9325 & TRN & \\
\hline CHEMBL1370284 & 688641 & 5.8 & 5.2503 & TST & \\
\hline CHEMBL1590059 & 688641 & 5.2 & 4.982 & TRN & \\
\hline CHEMBL1404598 & 688641 & 6.2 & 6.3219 & TRN & \\
\hline CHEMBL1401672 & 688641 & 4.8 & 4.8527 & TRN & \\
\hline CHEMBL1447383 & 688641 & 6.0 & 5.1818 & TST & \\
\hline CHEMBL1317358 & 688641 & 4.6 & 4.6919 & TRN & \\
\hline CHEMBL244707 & 688641 & 4.5 & 5.0188 & TRN & \\
\hline CHEMBL1526411 & 688641 & 5.5 & 5.45299 & 9999999999 & TRN \\
\hline CHEMBL1474633 & 688641 & 5.7 & 5.7663 & TRN & \\
\hline CHEMBL410873 & 688641 & 4.8 & 4.9594 & TRN & \\
\hline CHEMBL1332719 & 688641 & 5.4 & 5.3802 & TST & \\
\hline CHEMBL1357551 & 688641 & 4.7 & 4.7897 & TRN & \\
\hline CHEMBL28 & 688641 & 6.0 & 5.7929 & TRN & \\
\hline CHEMBL523464 & 688641 & 6.2 & 6.13899 & 9999999999 & TRN \\
\hline CHEMBL1552293 & 688641 & 4.7 & 4.7304 & TRN & \\
\hline CHEMBL10009 & 688641 & 5.6 & 5.5884 & TRN & \\
\hline CHEMBL1519649 & 688641 & 6.3 & 6.0496 & TRN & \\
\hline CHEMBL1514640 & 688641 & 4.6 & 4.6121 & TRN & \\
\hline CHEMBL1452250 & 688641 & 5.9 & 5.9494 & TRN & \\
\hline CHEMBL1368892 & 688641 & 5.4 & 5.3045 & TRN & \\
\hline CHEMBL97797 & 688641 & 4.5 & 4.952 & TRN & \\
\hline CHEMBL363207 & 688641 & 5.1 & 4.8653 & TST & \\
\hline CHEMBL2373604 & 688641 & 5.8 & 5.0426 & TST & \\
\hline CHEMBL1559246 & 688641 & 4.8 & 4.7871 & TRN & \\
\hline CHEMBL1397914 & 688641 & 4.6 & 4.699 & TRN & \\
\hline CHEMBL1400667 & 688641 & 5.1 & 5.0743 & TST & \\
\hline CHEMBL1590724 & 688641 & 5.3 & 5.1991 & TST & \\
\hline CHEMBL1553740 & 688641 & 5.3 & 5.2733 & TRN & \\
\hline CHEMBL1493851 & 688641 & 5.5 & 5.4831 & TRN & \\
\hline CHEMBL1325975 & 688641 & 5.1 & 5.0684 & TRN & \\
\hline & & & & 10754 & \\
\hline
\end{tabular}




\begin{tabular}{|c|c|c|c|c|c|}
\hline \multicolumn{6}{|c|}{ plemerticas rave } \\
\hline CHEMMLI315380 & 688641 & 5.6 & 5.4206 & TRN & \\
\hline CHEMBL1558526 & 688641 & 5.0 & 5.0503 & TRN & \\
\hline CHEMBL1358731 & 688641 & 5.4 & 5.2371 & TRN & \\
\hline CHEMBL1378800 & 688641 & 5.4 & 5.3641 & TST & \\
\hline CHEMBL1359108 & 688641 & 6.6 & 6.3948 & TRN & \\
\hline CHEMBL1359780 & 688641 & 4.9 & 5.1917 & TRN & \\
\hline CHEMBL1404884 & 688641 & 5.1 & 5.1078 & TRN & \\
\hline CHEMBL1314288 & 688641 & 5.6 & 5.7535 & TRN & \\
\hline CHEMBL1453347 & 688641 & 4.4 & 4.9982 & TST & \\
\hline CHEMBL1440857 & 688641 & 5.1 & 5.119 & TST & \\
\hline CHEMBL1435647 & 688641 & 4.6 & 4.6723 & TST & \\
\hline CHEMBL1327945 & 688641 & 6.3 & 6.4219 & TRN & \\
\hline CHEMBL1371311 & 688641 & 5.4 & 5.3576 & TST & \\
\hline CHEMBL1568575 & 688641 & 4.7 & 4.852 & TRN & \\
\hline CHEMBL227725 & 688641 & 5.7 & 5.5864 & TST & \\
\hline CHEMBL1366754 & 688641 & 4.9 & 4.8725 & TRN & \\
\hline CHEMBL1512845 & 688641 & 4.7 & 5.3013 & TRN & \\
\hline CHEMBL1481745 & 688641 & 5.7 & 5.3913 & TRN & \\
\hline CHEMBL1475562 & 688641 & 4.9 & 4.91 & TRN & \\
\hline CHEMBL1484438 & 688641 & 6.6 & 5.2147 & TST & \\
\hline CHEMBL1357168 & 688641 & 5.5 & 5.5265 & TRN & \\
\hline CHEMBL1487219 & 688641 & 5.5 & 5.5342 & TST & \\
\hline CHEMBL1414885 & 688641 & 4.9 & 5.2277 & TRN & \\
\hline CHEMBL1435373 & 688641 & 6.6 & 6.5246 & TRN & \\
\hline CHEMBL1473990 & 688641 & 6.0 & 5.7986 & TRN & \\
\hline CHEMBL490706 & 688641 & 5.7 & 5.6769 & TRN & \\
\hline CHEMBL1551979 & 688641 & 4.8 & 4.8664 & TRN & \\
\hline CHEMBL1326251 & 688641 & 5.4 & 5.2828 & TRN & \\
\hline CHEMBL1592557 & 688641 & 5.7 & 5.4869 & TRN & \\
\hline CHEMBL1522104 & 688641 & 5.7 & 5.0244 & TST & \\
\hline CHEMBL1473752 & 688641 & 4.7 & 4.6874 & TRN & \\
\hline CHEMBL275006 & 688641 & 6.0 & 5.9209 & TST & \\
\hline CHEMBL1326015 & 688641 & 4.9 & 4.9481 & TST & \\
\hline CHEMBL409902 & 688641 & 5.0 & 5.006 & TRN & \\
\hline CHEMBL1475258 & 688641 & 4.7 & 4.7555 & TRN & \\
\hline CHEMBL1533465 & 688641 & 4.8 & 4.9168 & TRN & \\
\hline CHEMBL1315991 & 688641 & 4.8 & 4.8609 & TRN & \\
\hline CHEMBL1520347 & 688641 & 5.6 & 4.8056 & TRN & \\
\hline CHEMBL1590132 & 688641 & 4.9 & 4.9017 & TRN & \\
\hline CHEMBL1318400 & 688641 & 6.0 & 6.0987 & TRN & \\
\hline CHEMBL1335973 & 688641 & 4.9 & 5.14 & TRN & \\
\hline CHEMBL1491545 & 688641 & 5.3 & 5.4721 & TRN & \\
\hline CHEMBL52 & 688641 & 6.0 & 5.2646 & TRN & \\
\hline CHEMBL1317626 & 688641 & 4.8 & 4.82100 & 0000000001 & TRN \\
\hline CHEMBL1606176 & 688641 & 5.7 & 5.3567 & TST & \\
\hline CHEMBL1490938 & 688641 & 4.8 & 5.4298 & TRN & \\
\hline CHEMBL1551254 & 688641 & 5.5 & 5.4199 & TST & \\
\hline CHEMBL1374849 & 688641 & 5.8 & 5.8441 & TRN & \\
\hline & & & & 10755 & \\
\hline
\end{tabular}




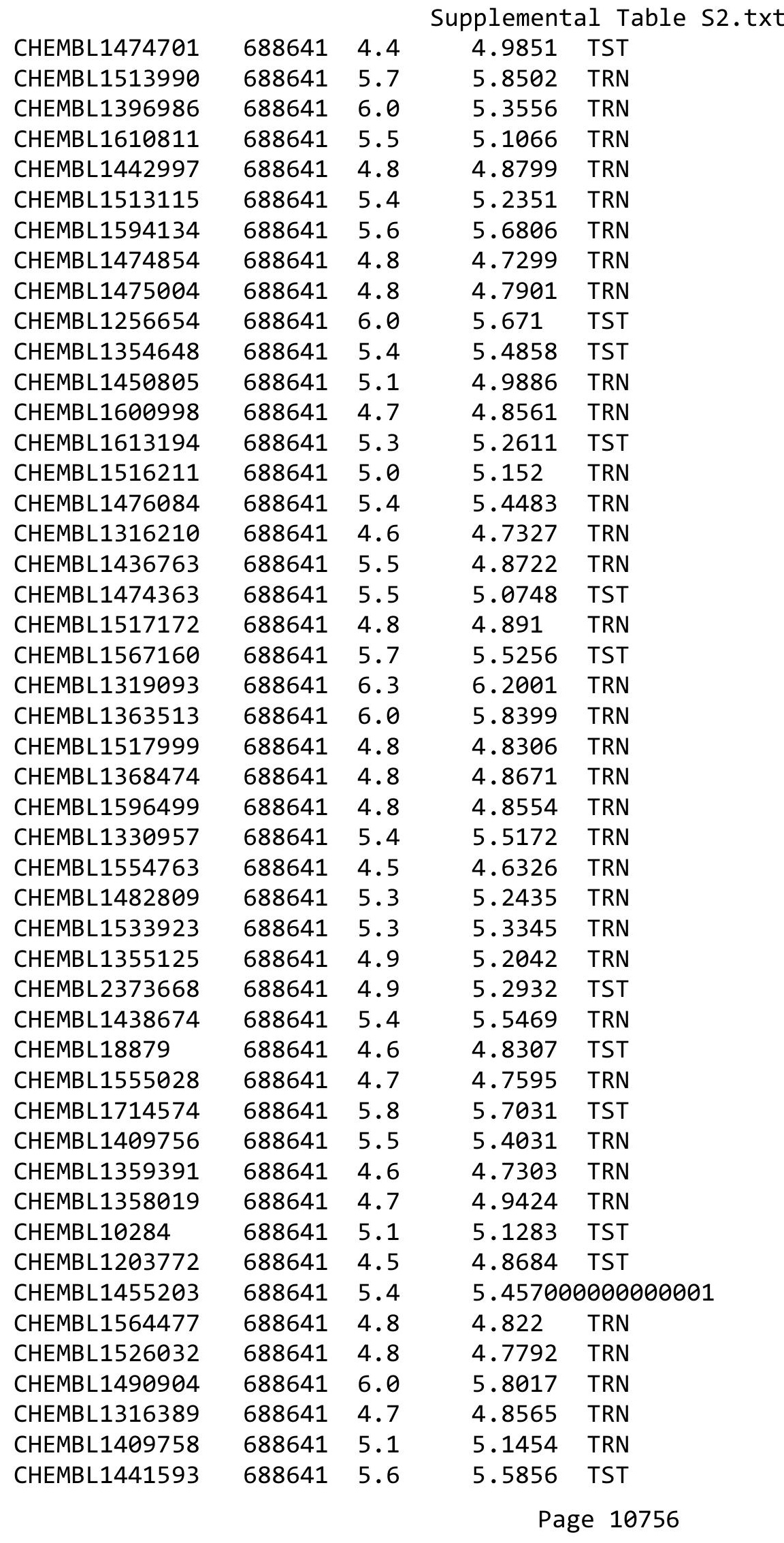

TRN 


\begin{tabular}{|c|c|c|c|c|c|}
\hline \multicolumn{6}{|c|}{ Supplemental Table S2.txt } \\
\hline CHEMBL137648 & 688641 & 4.5 & 4.6479 & TRN & \\
\hline CHEMBL1592571 & 688641 & 5.1 & 5.0806 & TRN & \\
\hline CHEMBL 388676 & 688641 & 6.0 & 5.0926 & TST & \\
\hline CHEMBL1255747 & 688641 & 4.4 & 5.2048 & TRN & \\
\hline CHEMBL1414232 & 688641 & 6.0 & 5.9589 & TRN & \\
\hline CHEMBL1593068 & 688641 & 5.1 & 5.0649 & TRN & \\
\hline CHEMBL607536 & 688641 & 4.4 & 5.0368 & TRN & \\
\hline CHEMBL1481378 & 688641 & 5.4 & 5.6093 & TRN & \\
\hline CHEMBL1358009 & 688641 & 5.3 & 5.2564 & TRN & \\
\hline CHEMBL1355665 & 688641 & 5.9 & 5.5452 & TRN & \\
\hline CHEMBL1256148 & 688641 & 6.0 & 5.8621 & TST & \\
\hline CHEMBL1325511 & 688641 & 5.4 & 5.2938 & TST & \\
\hline CHEMBL1604672 & 688641 & 5.9 & 5.2819 & TST & \\
\hline CHEMBL461903 & 688641 & 4.5 & 5.0483 & TST & \\
\hline CHEMBL1395138 & 688641 & 6.0 & 5.0828 & TRN & \\
\hline CHEMBL1552922 & 688641 & 4.6 & 4.6715 & TRN & \\
\hline CHEMBL1475737 & 688641 & 5.2 & 5.2796 & TRN & \\
\hline CHEMBL172064 & 688641 & 6.0 & 4.9815 & TST & \\
\hline CHEMBL1565333 & 688641 & 5.5 & 5.2756 & TST & \\
\hline CHEMBL1592323 & 688641 & 5.8 & 5.3576 & TRN & \\
\hline CHEMBL1551834 & 688641 & 4.9 & 4.977 & TRN & \\
\hline CHEMBL1476546 & 688641 & 4.9 & 5.4526 & TST & \\
\hline CHEMBL67378 & 688641 & 6.0 & 5.7907 & TST & \\
\hline CHEMBL1483133 & 688641 & 4.6 & 4.6575 & TRN & \\
\hline CHEMBL1518067 & 688641 & 4.8 & 4.8629 & TRN & \\
\hline CHEMBL1335406 & 688641 & 4.8 & 4.919 & TST & \\
\hline CHEMBL1398066 & 688641 & 4.9 & 4.9972 & TRN & \\
\hline CHEMBL1358796 & 688641 & 5.7 & 5.7333 & TRN & \\
\hline CHEMBL1553785 & 688641 & 4.7 & 4.721999 & 99999999995 & TRN \\
\hline CHEMBL1529308 & 688641 & 5.6 & 5.5422 & TRN & \\
\hline CHEMBL1314516 & 688641 & 4.8 & 5.0969 & TRN & \\
\hline CHEMBL1478279 & 688641 & 4.9 & 4.8359 & TRN & \\
\hline CHEMBL1480554 & 688641 & 5.5 & 4.8943 & TRN & \\
\hline CHEMBL1557696 & 688641 & 4.9 & 4.9118 & TRN & \\
\hline CHEMBL1161461 & 688641 & 4.7 & 5.1385 & TST & \\
\hline CHEMBL428768 & 688641 & 6.0 & 5.7911 & TRN & \\
\hline CHEMBL1322864 & 688641 & 5.5 & 5.3559 & TST & \\
\hline CHEMBL1356060 & 688641 & 6.1 & 6.2341 & TRN & \\
\hline CHEMBL1372133 & 688641 & 4.6 & 4.5893 & TRN & \\
\hline CHEMBL 274844 & 688641 & 4.6 & 4.7455 & TRN & \\
\hline CHEMBL605003 & 688641 & 5.3 & 5.3168 & TST & \\
\hline CHEMBL 292477 & 688641 & 4.5 & 4.9481 & TRN & \\
\hline CHEMBL1562420 & 688641 & 4.4 & 4.5538 & TST & \\
\hline CHEMBL1397902 & 688641 & 5.4 & 5.4689 & TST & \\
\hline CHEMBL164 & 688641 & 6.0 & 5.8012 & TRN & \\
\hline CHEMBL 3213163 & 688641 & 5.5 & 5.5246 & TRN & \\
\hline CHEMBL1515777 & 688641 & 4.9 & 4.897 & TRN & \\
\hline CHEMBL1365882 & 688641 & 5.5 & 5.3261 & TRN & \\
\hline
\end{tabular}




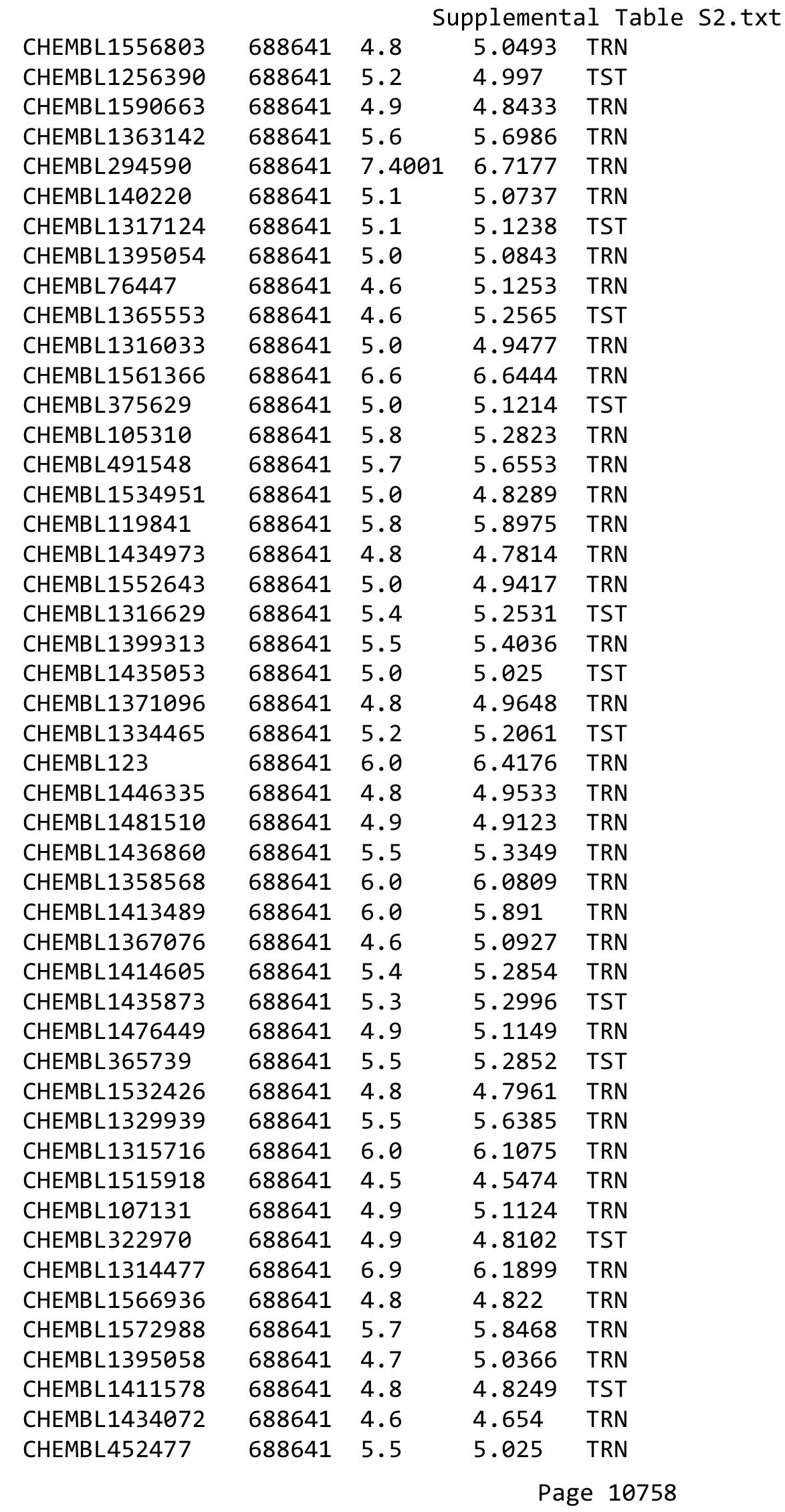




\begin{tabular}{|c|c|c|c|c|}
\hline \multicolumn{5}{|c|}{ plemental } \\
\hline CHEMBL1453655 & 688641 & 5.4 & 5.0204 & TRN \\
\hline CHEMBL1532230 & 688641 & 4.5 & 4.7176 & TRN \\
\hline CHEMBL510009 & 688641 & 5.6 & 5.5052 & TRN \\
\hline CHEMBL1318163 & 688641 & 4.8 & 4.9799 & TST \\
\hline CHEMBL1257003 & 688641 & 4.9 & 4.9961 & TRN \\
\hline CHEMBL1361226 & 688641 & 6.0 & 5.9963 & TRN \\
\hline CHEMBL1526987 & 688641 & 4.8 & 5.149 & TST \\
\hline CHEMBL88272 & 688641 & 4.8 & 4.8732 & TST \\
\hline CHEMBL1483801 & 688641 & 5.4 & 5.4509 & TRN \\
\hline CHEMBL585861 & 688641 & 5.6 & 5.6946 & TRN \\
\hline CHEMBL1402894 & 688641 & 5.4 & 5.3952 & TRN \\
\hline CHEMBL1609459 & 688641 & 4.9 & 5.2047 & TST \\
\hline CHEMBL1355242 & 688641 & 4.9 & 4.9888 & TRN \\
\hline CHEMBL1398321 & 688641 & 4.9 & 4.9422 & TST \\
\hline CHEMBL1443614 & 688641 & 6.0 & 5.0607 & TRN \\
\hline CHEMBL1410012 & 688641 & 4.8 & 4.83 & TRN \\
\hline CHEMBL1560095 & 688641 & 4.5 & 4.6528 & TRN \\
\hline CHEMBL1607517 & 688641 & 4.4 & 5.1914 & TRN \\
\hline CHEMBL1323167 & 688641 & 5.5 & 5.3245 & TST \\
\hline CHEMBL326967 & 688641 & 4.6 & 4.7472 & TST \\
\hline CHEMBL1484176 & 688641 & 4.9 & 5.2358 & TRN \\
\hline CHEMBL1318067 & 688641 & 4.8 & 4.7707 & TRN \\
\hline CHEMBL73310 & 688641 & 4.9 & 4.9726 & TRN \\
\hline CHEMBL1479224 & 688641 & 4.7 & 5.0873 & TRN \\
\hline CHEMBL1556023 & 688641 & 6.4 & 6.0306 & TRN \\
\hline CHEMBL1522370 & 688641 & 4.6 & 4.6789 & TRN \\
\hline CHEMBL1489220 & 688641 & 4.6 & 5.2296 & TST \\
\hline CHEMBL1565160 & 688641 & 5.4 & 5.3508 & TRN \\
\hline CHEMBL1452710 & 688641 & 4.6 & 5.079 & TRN \\
\hline CHEMBL1552864 & 688641 & 4.9 & 5.125 & TRN \\
\hline CHEMBL1520442 & 688641 & 5.5 & 5.5126 & TRN \\
\hline CHEMBL42485 & 688641 & 4.7 & 4.7810 & 0000000001 \\
\hline CHEMBL313833 & 688641 & 5.1 & 5.0594 & TST \\
\hline CHEMBL241858 & 688641 & 4.9 & 5.2296 & TRN \\
\hline CHEMBL1434552 & 688641 & 4.6 & 5.038 & TRN \\
\hline CHEMBL1491455 & 688641 & 5.4 & 5.3211 & TST \\
\hline CHEMBL242384 & 688641 & 4.8 & 5.2379 & TRN \\
\hline CHEMBL1306920 & 688641 & 6.0 & 5.2142 & TRN \\
\hline CHEMBL1451119 & 688641 & 5.2 & 5.1466 & TRN \\
\hline CHEMBL1439635 & 688641 & 6.0 & 5.272 & TST \\
\hline CHEMBL1597572 & 688641 & 5.6 & 5.3472 & TRN \\
\hline CHEMBL1454153 & 688641 & 4.7 & 4.739 & TRN \\
\hline CHEMBL1475377 & 688641 & 5.5 & 4.7868 & TRN \\
\hline CHEMBL1487735 & 688641 & 4.8 & 4.7843 & TRN \\
\hline CHEMBL1601477 & 688641 & 5.1 & 5.0031 & TRN \\
\hline CHEMBL1592117 & 688641 & 5.1 & 5.0316 & TRN \\
\hline CHEMBL1256719 & 688641 & 5.0 & 4.9984 & TST \\
\hline CHEMBL1515961 & 688641 & 5.5 & 5.4288 & TST \\
\hline
\end{tabular}




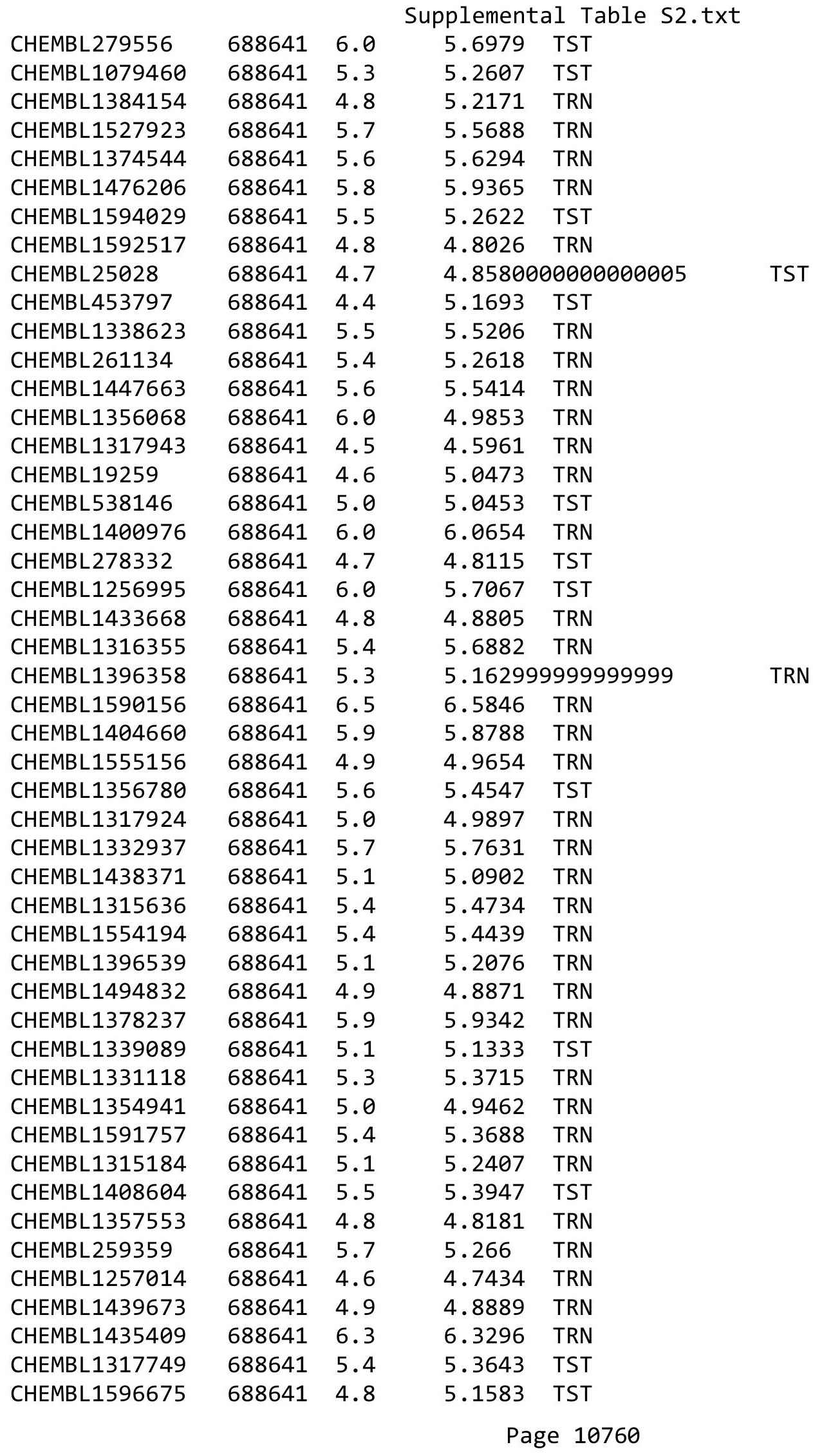




\begin{tabular}{|c|c|c|c|c|c|}
\hline \multicolumn{6}{|c|}{ Supplemental Table S2.txt } \\
\hline CHEMBL1355537 & 688641 & 4.9 & 4.9264 & TRN & \\
\hline CHEMBL1565867 & 688641 & 5.6 & 5.1836 & TRN & \\
\hline CHEMBL258942 & 688641 & 5.6 & 5.234 & TRN & \\
\hline CHEMBL490717 & 688641 & 6.2 & 6.3547 & TRN & \\
\hline CHEMBL1494064 & 688641 & 5.7 & 5.1596 & TST & \\
\hline CHEMBL1590982 & 688641 & 5.5 & 5.32 & TRN & \\
\hline CHEMBL1514071 & 688641 & 5.0 & 4.968 & TRN & \\
\hline CHEMBL15134 & 688641 & 4.6 & 5.0584 & TST & \\
\hline CHEMBL1399702 & 688641 & 5.5 & 5.0681 & TRN & \\
\hline CHEMBL87385 & 688641 & 4.9 & 5.0701 & TST & \\
\hline CHEMBL405760 & 688641 & 5.1 & 5.3263 & TRN & \\
\hline CHEMBL1376723 & 688641 & 4.6 & 4.7657 & TRN & \\
\hline CHEMBL1434220 & 688641 & 5.9 & 5.1643 & TST & \\
\hline CHEMBL1410816 & 688641 & 5.0 & 5.1643 & TRN & \\
\hline CHEMBL1476521 & 688641 & 5.2 & 5.1669 & TRN & \\
\hline CHEMBL1595002 & 688641 & 5.3 & 4.8694 & TRN & \\
\hline CHEMBL1173475 & 688641 & 6.0 & 5.8102 & TRN & \\
\hline CHEMBL1330729 & 688641 & 4.8 & 5.2565 & TRN & \\
\hline CHEMBL1357676 & 688641 & 5.1 & 5.1595 & TRN & \\
\hline CHEMBL1558796 & 688641 & 4.6 & 5.0421 & TRN & \\
\hline CHEMBL1604387 & 688641 & 5.3 & 5.1016 & TST & \\
\hline CHEMBL1255583 & 688641 & 4.4 & 4.6587 & TRN & \\
\hline CHEMBL1517986 & 688641 & 5.3 & 5.0506 & TST & \\
\hline CHEMBL1405325 & 688641 & 5.2 & 5.1627 & TST & \\
\hline CHEMBL1436475 & 688641 & 4.9 & 5.1434 & TRN & \\
\hline CHEMBL1603393 & 688641 & 4.8 & 4.9521 & TRN & \\
\hline CHEMBL1601824 & 688641 & 7.8013 & 5.1924 & TRN & \\
\hline CHEMBL1526543 & 688641 & 6.0 & 5.7557 & TRN & \\
\hline CHEMBL1592580 & 688641 & 5.1 & 5.1105 & TRN & \\
\hline CHEMBL1554088 & 688641 & 4.9 & 4.9505 & TRN & \\
\hline CHEMBL1590397 & 688641 & 5.5 & $5.5420 e$ & 0000000001 & TRN \\
\hline CHEMBL1499545 & 688641 & 4.9 & 4.8744 & TST & \\
\hline CHEMBL1317056 & 688641 & 5.9 & 5.9399 & TRN & \\
\hline CHEMBL48278 & 688641 & 4.6 & 4.7552 & TRN & \\
\hline CHEMBL7162 & 688641 & 4.7 & 4.8489 & TST & \\
\hline CHEMBL1482759 & 688641 & 5.1 & 5.0308 & TRN & \\
\hline CHEMBL45281 & 688641 & 4.9 & 4.8431 & TST & \\
\hline CHEMBL1515899 & 688641 & 6.0 & 5.9414 & TRN & \\
\hline CHEMBL1515018 & 688641 & 5.4 & 5.1452 & TST & \\
\hline CHEMBL1481747 & 688641 & 4.8 & 4.8948 & TRN & \\
\hline CHEMBL490756 & 688641 & 5.9 & 5.8737 & TRN & \\
\hline CHEMBL1402049 & 688641 & 5.5 & 5.4236 & TRN & \\
\hline CHEMBL1314982 & 688641 & 6.7001 & 5.5633 & TRN & \\
\hline CHEMBL1526849 & 688641 & 5.3 & 5.2876 & TST & \\
\hline CHEMBL1526486 & 688641 & 5.0 & 4.9598 & TST & \\
\hline CHEMBL1316858 & 688641 & 5.6 & 5.1365 & TST & \\
\hline CHEMBL1496378 & 688641 & 6.0 & 5.0319 & TRN & \\
\hline CHEMBL9352 & 688641 & 6.0 & 5.1757 & TRN & \\
\hline
\end{tabular}




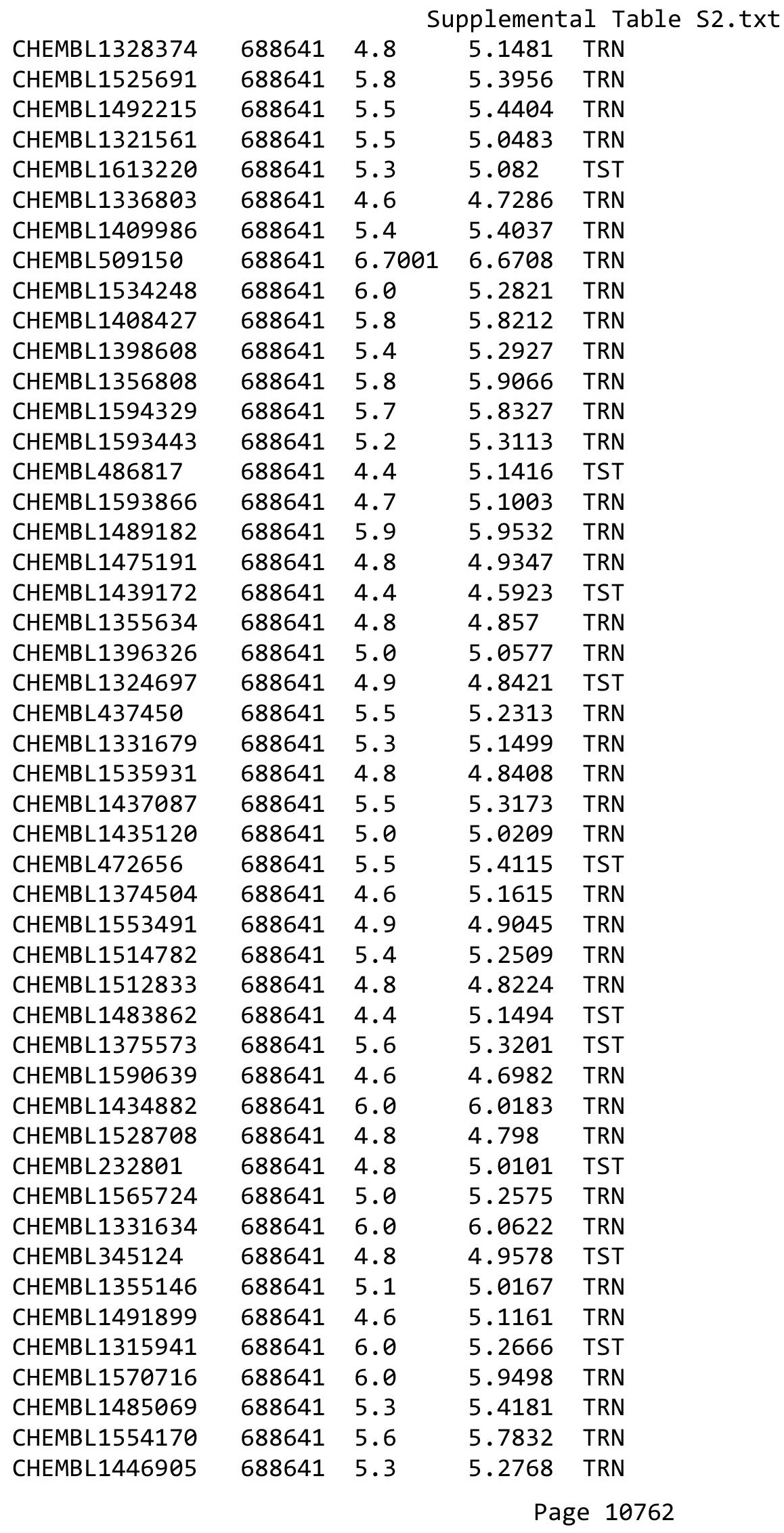




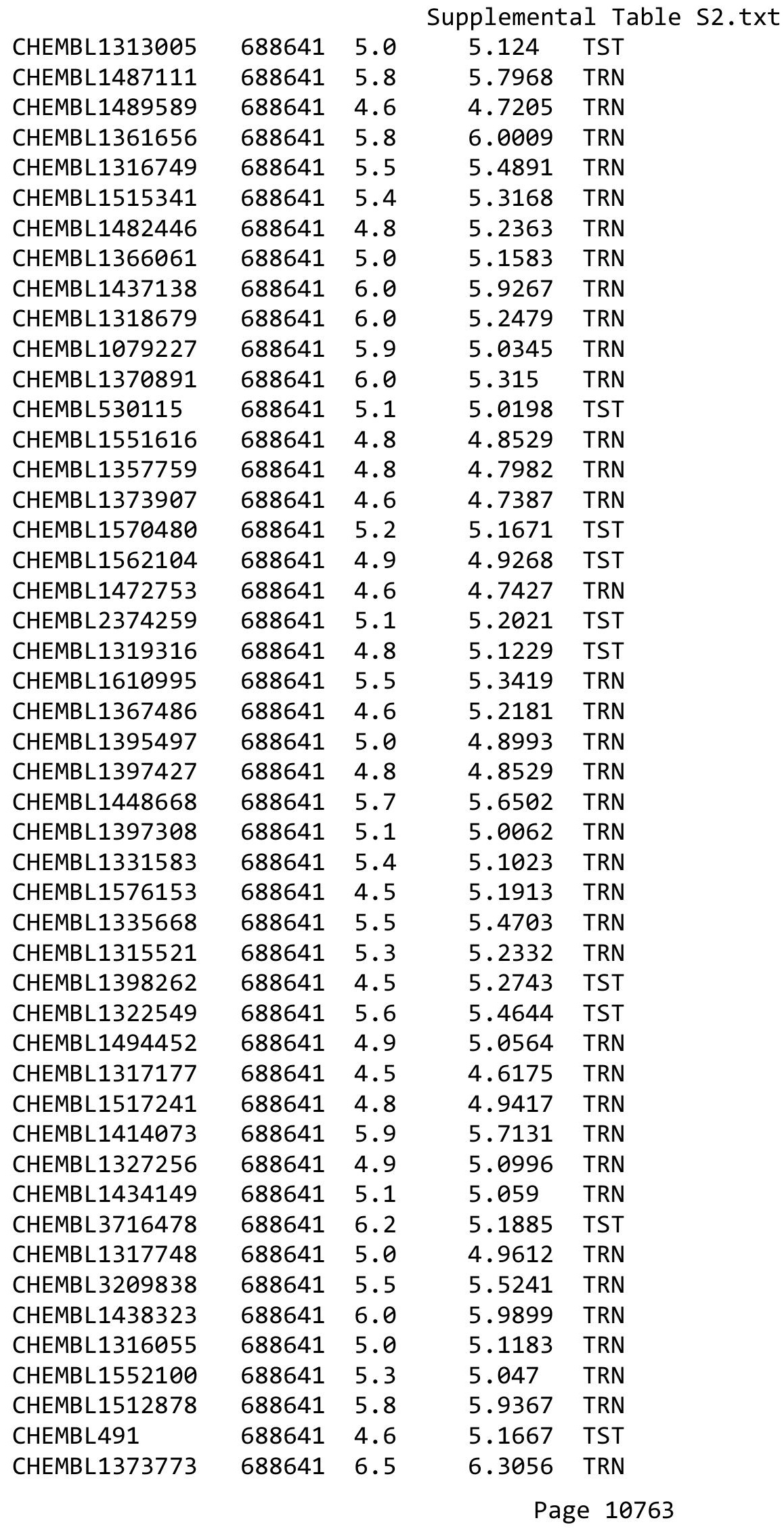




\begin{tabular}{|c|c|c|c|c|c|}
\hline & & & & & \\
\hline CHEMBL1325931 & 688641 & 4.4 & 5.0682 & TRN & \\
\hline CHEMBL1320947 & 688641 & 6.2 & 5.9374 & TRN & \\
\hline CHEMBL56731 & 688641 & 4.8 & 4.8929 & TRN & \\
\hline CHEMBL1318622 & 688641 & 5.6 & $5.5520 e$ & 00000000005 & TRN \\
\hline CHEMBL1364980 & 688641 & 5.5 & 5.4876 & TRN & \\
\hline CHEMBL1475131 & 688641 & 6.4 & 6.3441 & TRN & \\
\hline CHEMBL1552707 & 688641 & 6.2 & 6.0649 & TRN & \\
\hline CHEMBL1445173 & 688641 & 4.9 & 5.1744 & TST & \\
\hline CHEMBL1332759 & 688641 & 6.2 & 6.2684 & TRN & \\
\hline CHEMBL1324529 & 688641 & 4.6 & 4.6892 & TRN & \\
\hline CHEMBL1433898 & 688641 & 5.0 & 4.9541 & TRN & \\
\hline CHEMBL544115 & 688641 & 4.8 & 5.0697 & TRN & \\
\hline CHEMBL1447538 & 688641 & 6.0 & $5.9510 e$ & 00000000005 & TRN \\
\hline CHEMBL1439866 & 688641 & 4.5 & $5.1960 e$ & 0000000001 & TRN \\
\hline CHEMBL1516107 & 688641 & 5.5 & 5.1048 & TRN & \\
\hline CHEMBL1494196 & 688641 & 4.5 & 4.712 & TRN & \\
\hline CHEMBL1356234 & 688641 & 4.8 & 4.8567 & TRN & \\
\hline CHEMBL1213187 & 688641 & 4.5 & 4.7449 & TST & \\
\hline CHEMBL1337713 & 688641 & 5.2 & 5.1693 & TRN & \\
\hline CHEMBL1553328 & 688641 & 5.3 & 5.0677 & TRN & \\
\hline CHEMBL1483672 & 688641 & 6.0 & 5.6156 & TRN & \\
\hline CHEMBL1443390 & 688641 & 4.8 & 4.9186 & TRN & \\
\hline CHEMBL551842 & 688641 & 4.6 & 5.2297 & TST & \\
\hline CHEMBL1512562 & 688641 & 5.3 & 5.2397 & TRN & \\
\hline CHEMBL278755 & 688641 & 4.8 & 4.8691 & TRN & \\
\hline CHEMBL1371597 & 688641 & 5.2 & 5.1022 & TRN & \\
\hline CHEMBL1333104 & 688641 & 5.1 & 5.1207 & TRN & \\
\hline CHEMBL1491288 & 688641 & 5.5 & 5.4005 & TRN & \\
\hline CHEMBL1603595 & 688641 & 4.8 & 4.8527 & TRN & \\
\hline CHEMBL1436644 & 688641 & 4.8 & 4.8079 & TRN & \\
\hline CHEMBL1361449 & 688641 & 5.3 & 5.4229 & TRN & \\
\hline CHEMBL1552957 & 688641 & 4.6 & 4.8106 & TRN & \\
\hline CHEMBL1356512 & 688641 & 4.7 & 5.0546 & TRN & \\
\hline CHEMBL1363362 & 688641 & 4.8 & 5.0629 & TRN & \\
\hline CHEMBL1357674 & 688641 & 4.5 & 4.6932 & TST & \\
\hline CHEMBL1532720 & 688641 & 4.9 & 4.8867 & TRN & \\
\hline CHEMBL45068 & 688641 & 6.0 & 5.0529 & TRN & \\
\hline CHEMBL3190029 & 688641 & 5.6 & 5.2219 & TST & \\
\hline CHEMBL1593440 & 688641 & 5.2 & 5.1224 & TRN & \\
\hline CHEMBL1436743 & 688641 & 5.4 & 5.6138 & TRN & \\
\hline CHEMBL1449417 & 688641 & 4.9 & 4.8904 & TRN & \\
\hline CHEMBL1358116 & 688641 & 6.0 & 5.148 & TST & \\
\hline CHEMBL1318635 & 688641 & 5.4 & 5.3274 & TST & \\
\hline CHEMBL1569962 & 688641 & 5.5 & 5.4158 & TRN & \\
\hline CHEMBL98350 & 688641 & 6.0 & 5.7614 & TRN & \\
\hline CHEMBL1480136 & 688641 & 4.7 & 4.8054 & TST & \\
\hline CHEMBL1473117 & 688641 & 4.7 & 4.8063 & TRN & \\
\hline CHEMBL158507 & 688641 & 5.6 & 5.53799 & 9999999999 & TST \\
\hline & & & & 10764 & \\
\hline
\end{tabular}




\begin{tabular}{|c|c|c|c|c|c|}
\hline \multicolumn{6}{|c|}{ Supplemental Table S2.txt } \\
\hline CHEMBL1418387 & 688641 & 4.7 & 4.7233 & TRN & \\
\hline CHEMBL1454855 & 688641 & 5.8 & 5.7347 & TRN & \\
\hline CHEMBL1487604 & 688641 & 6.0 & 5.0898 & TRN & \\
\hline CHEMBL1355293 & 688641 & 5.5 & 5.3255 & TST & \\
\hline CHEMBL1414988 & 688641 & 4.9 & 5.23 & TRN & \\
\hline CHEMBL1567472 & 688641 & 5.3 & 5.37700 & 0000000001 & TRN \\
\hline CHEMBL1354547 & 688641 & 5.7 & 5.7318 & TRN & \\
\hline CHEMBL1612246 & 688641 & 4.8 & 5.1108 & TRN & \\
\hline CHEMBL 285480 & 688641 & 4.7 & 5.0084 & TRN & \\
\hline CHEMBL1613260 & 688641 & 4.9 & 5.1269 & TRN & \\
\hline CHEMBL1449914 & 688641 & 5.6 & 5.2607 & TRN & \\
\hline CHEMBL1574924 & 688641 & 5.5 & 5.2015 & TRN & \\
\hline CHEMBL1517998 & 688641 & 4.8 & 5.4538 & TRN & \\
\hline CHEMBL1492205 & 688641 & 5.5 & 5.6249 & TRN & \\
\hline CHEMBL1593321 & 688641 & 5.7 & 5.343 & TRN & \\
\hline CHEMBL1514748 & 688641 & 5.6 & 5.3994 & TRN & \\
\hline CHEMBL1513821 & 688641 & 4.9 & 5.1689 & TST & \\
\hline CHEMBL1566428 & 688641 & 5.0 & 5.1248 & TRN & \\
\hline CHEMBL1397151 & 688641 & 5.6 & 5.153 & TRN & \\
\hline CHEMBL 220087 & 688641 & 4.8 & 4.9218 & TRN & \\
\hline CHEMBL495069 & 688641 & 5.5 & 5.4294 & TRN & \\
\hline CHEMBL1475902 & 688641 & 4.9 & 4.9825 & TRN & \\
\hline CHEMBL1590763 & 688641 & 4.7 & 4.7879 & TRN & \\
\hline CHEMBL1316294 & 688641 & 5.5 & 5.4969 & TRN & \\
\hline CHEMBL 276140 & 688641 & 5.4 & 5.4397 & TST & \\
\hline CHEMBL404313 & 688641 & 4.8 & 5.2695 & TST & \\
\hline CHEMBL1606022 & 688641 & 5.1 & 5.1312 & TRN & \\
\hline CHEMBL1401483 & 688641 & 5.2 & 4.9828 & TRN & \\
\hline CHEMBL1320922 & 688641 & 5.3 & 5.4 & TST & \\
\hline CHEMBL1396377 & 688641 & 4.6 & 4.7811 & TRN & \\
\hline CHEMBL84685 & 688641 & 5.6 & 5.2377 & TRN & \\
\hline CHEMBL1461491 & 688641 & 7.3002 & 6.4915 & TRN & \\
\hline CHEMBL1398013 & 688641 & 5.1 & 5.077 & TRN & \\
\hline CHEMBL1413165 & 688641 & 6.4 & 6.3026 & TRN & \\
\hline CHEMBL1437488 & 688641 & 6.0 & 6.0207 & TRN & \\
\hline CHEMBL1444856 & 688641 & 4.7 & 4.718 & TRN & \\
\hline CHEMBL1515540 & 688641 & 5.1 & 4.9648 & TRN & \\
\hline CHEMBL475376 & 688641 & 5.2 & 5.1952 & TRN & \\
\hline CHEMBL1444914 & 688641 & 6.5 & 6.5747 & TRN & \\
\hline CHEMBL1434848 & 688641 & 5.5 & 5.6631 & TRN & \\
\hline CHEMBL1474196 & 688641 & 5.9 & 5.2425 & TST & \\
\hline CHEMBL1512570 & 688641 & 4.6 & 5.1514 & TST & \\
\hline CHEMBL1451973 & 688641 & 4.6 & 5.2271 & TRN & \\
\hline CHEMBL289233 & 688641 & 4.8 & 4.8839 & TRN & \\
\hline CHEMBL1356004 & 688641 & 4.9 & 4.853 & TRN & \\
\hline CHEMBL1332471 & 688641 & 5.6 & 5.7446 & TRN & \\
\hline CHEMBL75967 & 688641 & 5.6 & 4.8638 & TRN & \\
\hline CHEMBL1356844 & 688641 & 4.6 & 4.7176 & TRN & \\
\hline
\end{tabular}




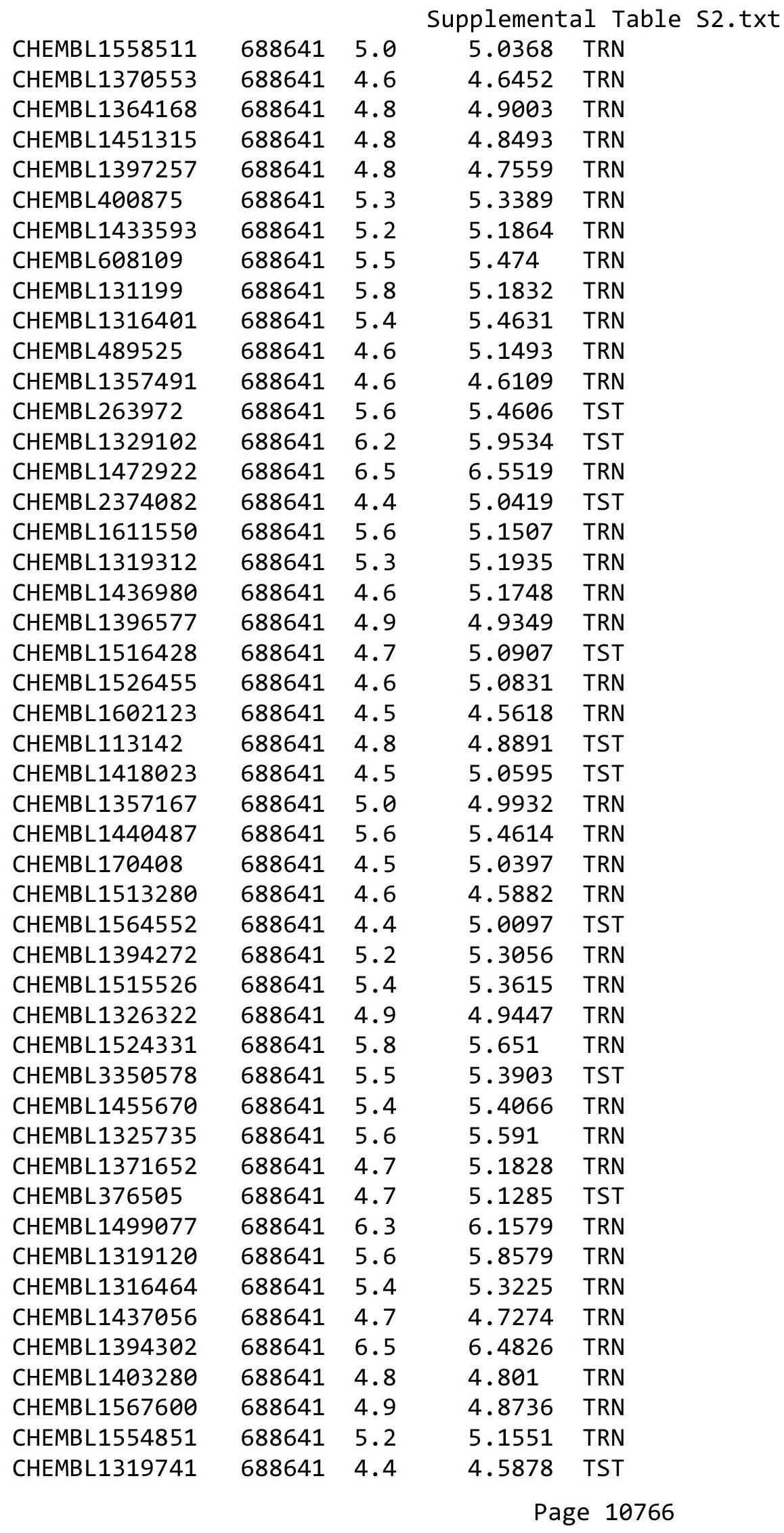




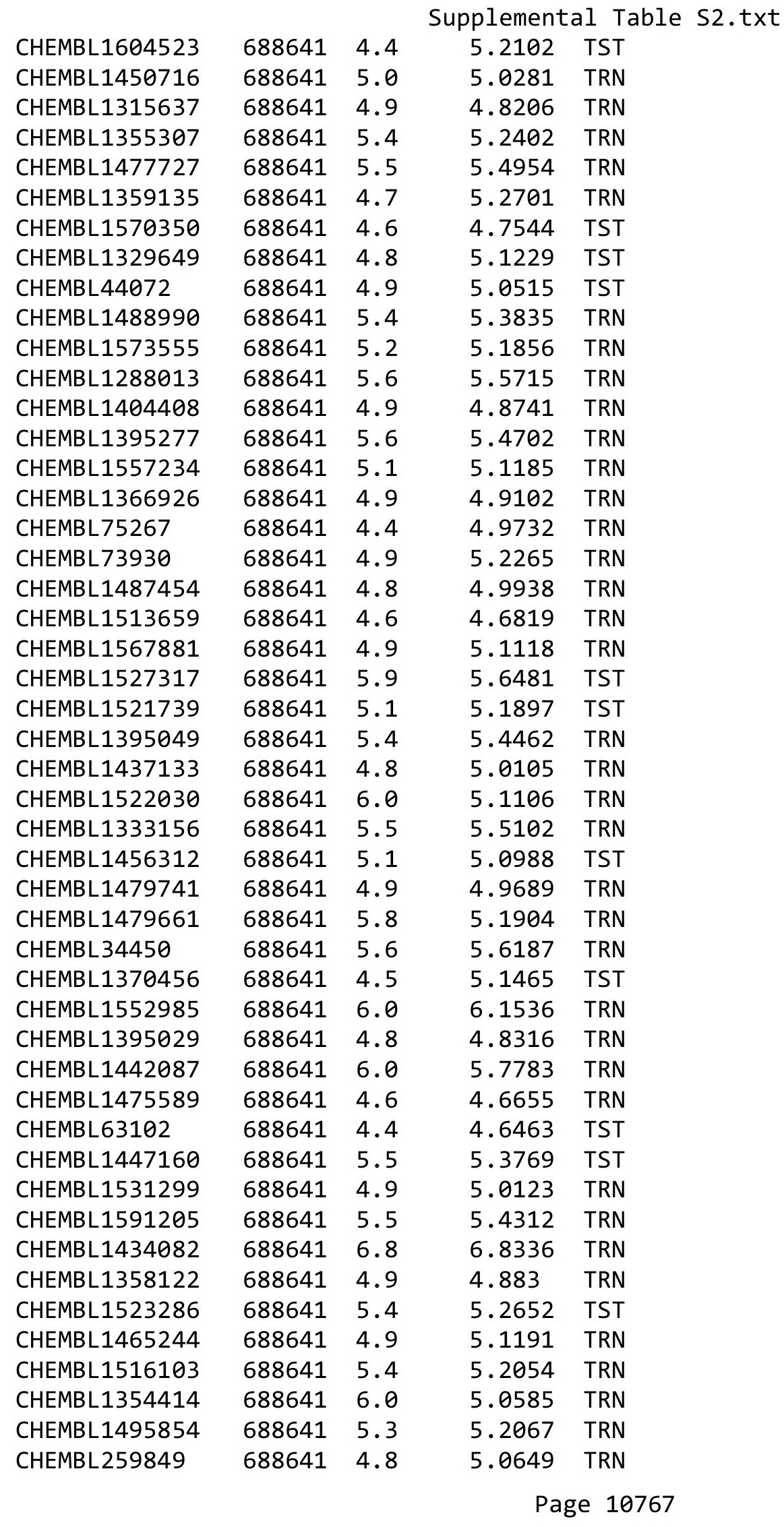




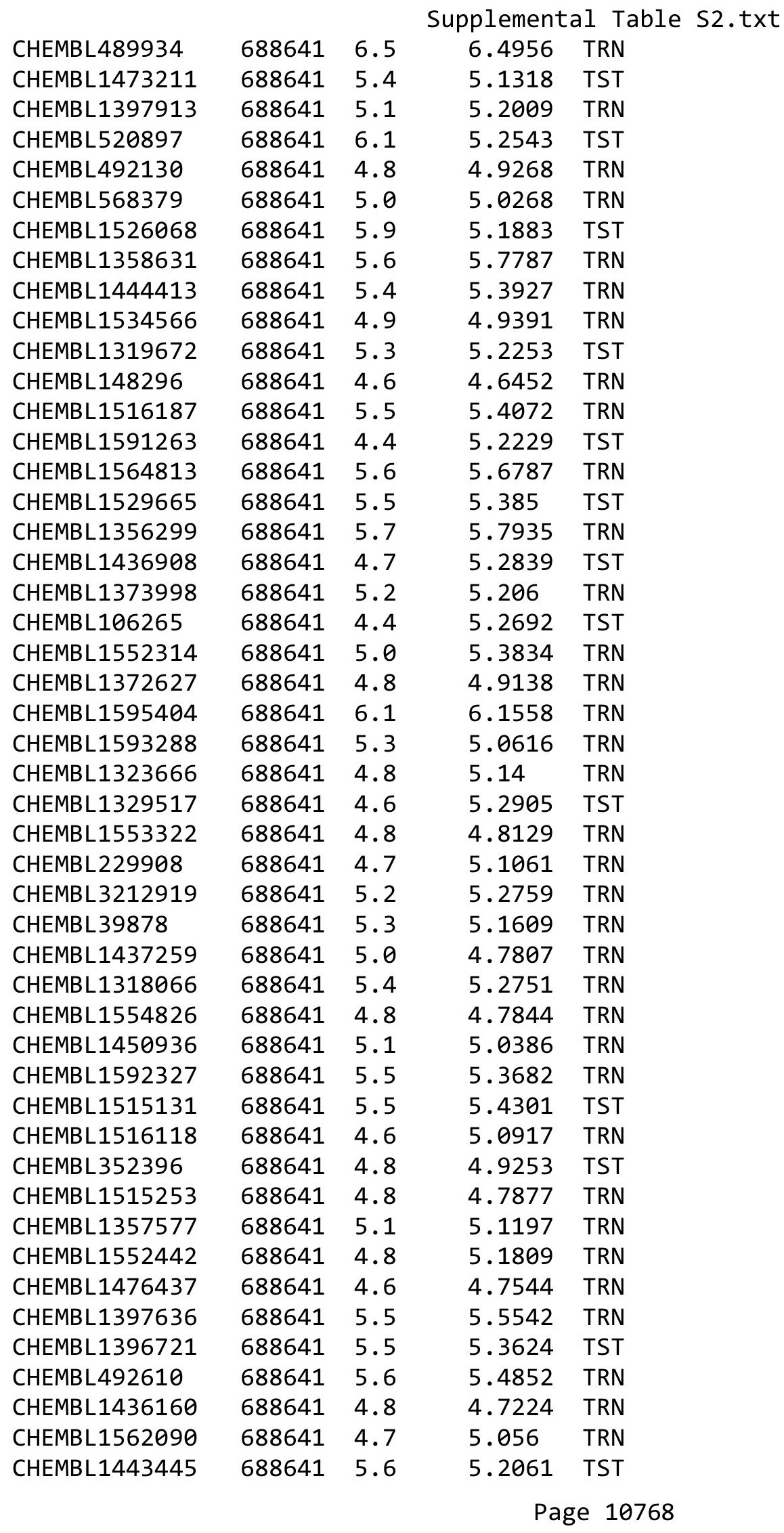




\begin{tabular}{|c|c|c|c|c|c|}
\hline & & & & & \\
\hline CHEMBL1496576 & 688641 & 6.2 & 6.271 & TRN & \\
\hline CHEMBL1592213 & 688641 & 4.8 & 4.854 & TRN & \\
\hline CHEMBL1319789 & 688641 & 5.0 & 5.3811 & TRN & \\
\hline CHEMBL1396108 & 688641 & 4.9 & 5.05 & TRN & \\
\hline CHEMBL3196930 & 688641 & 5.7 & 5.3199 & TST & \\
\hline CHEMBL42115 & 688641 & 4.5 & 5.0974 & TRN & \\
\hline CHEMBL 2373658 & 688641 & 5.1 & 5.1016 & TST & \\
\hline CHEMBL1437047 & 688641 & 4.7 & 5.1954 & TST & \\
\hline CHEMBL1476383 & 688641 & 5.2 & 5.2284 & TRN & \\
\hline CHEMBL1526572 & 688641 & 5.6 & 5.5129 & TRN & \\
\hline CHEMBL1338367 & 688641 & 4.8 & 5.1875 & TRN & \\
\hline CHEMBL1317059 & 688641 & 4.8 & 5.096 & TST & \\
\hline CHEMBL1403505 & 688641 & 5.8 & 5.9538 & TRN & \\
\hline CHEMBL1256839 & 688641 & 6.0 & 5.8583 & TRN & \\
\hline CHEMBL1435809 & 688641 & 4.6 & 4.8247 & TRN & \\
\hline CHEMBL1528565 & 688641 & 5.7 & 5.6004 & TST & \\
\hline CHEMBL1372997 & 688641 & 5.5 & 5.4103 & TST & \\
\hline CHEMBL1378167 & 688641 & 4.7 & 5.40799 & 99999999995 & TRN \\
\hline CHEMBL1371726 & 688641 & 6.0 & 6.0344 & TRN & \\
\hline CHEMBL1568917 & 688641 & 5.5 & 5.1882 & TRN & \\
\hline CHEMBL1416476 & 688641 & 5.6 & 5.6032 & TRN & \\
\hline CHEMBL1436045 & 688641 & 6.1 & 6.1971 & TRN & \\
\hline CHEMBL1399760 & 688641 & 4.8 & 4.8587 & TRN & \\
\hline CHEMBL1566105 & 688641 & 5.3 & 5.2134 & TST & \\
\hline CHEMBL1528531 & 688641 & 6.1 & 5.0344 & TST & \\
\hline CHEMBL489943 & 688641 & 6.5 & 6.7514 & TRN & \\
\hline CHEMBL1317232 & 688641 & 4.8 & 4.8391 & TRN & \\
\hline CHEMBL1591772 & 688641 & 5.2 & 5.08899 & 99999999995 & TRN \\
\hline CHEMBL1370189 & 688641 & 5.7 & 5.5267 & TRN & \\
\hline CHEMBL1378235 & 688641 & 5.2 & 5.4699 & TRN & \\
\hline CHEMBL23731 & 688641 & 6.0 & 5.763 & TST & \\
\hline CHEMBL1444266 & 688641 & 5.6 & 5.0629 & TRN & \\
\hline CHEMBL1378755 & 688641 & 5.9 & 6.0 & TRN & \\
\hline CHEMBL1452888 & 688641 & 5.4 & 5.2304 & TST & \\
\hline CHEMBL1403626 & 688641 & 5.5 & 5.4722 & TRN & \\
\hline CHEMBL376103 & 688641 & 6.0 & 5.2421 & TST & \\
\hline CHEMBL1552172 & 688641 & 5.5 & 5.5613 & TRN & \\
\hline CHEMBL1435435 & 688641 & 4.8 & 5.0343 & TRN & \\
\hline CHEMBL541543 & 688641 & 4.7 & 4.967 & TST & \\
\hline CHEMBL1450334 & 688641 & 4.8 & 4.9158 & TST & \\
\hline CHEMBL1435477 & 688641 & 6.0 & 5.7113 & TST & \\
\hline CHEMBL1593765 & 688641 & 4.5 & 4.7584 & TRN & \\
\hline CHEMBL1450903 & 688641 & 5.7 & 5.7921 & TRN & \\
\hline CHEMBL1603860 & 688641 & 5.0 & 5.0966 & TRN & \\
\hline CHEMBL1394181 & 688641 & 5.0 & 4.9387 & TRN & \\
\hline CHEMBL1455438 & 688641 & 4.6 & 4.6411 & TRN & \\
\hline CHEMBL1494481 & 688641 & 5.2 & 5.0458 & TRN & \\
\hline CHEMBL1433731 & 688641 & 5.2 & 4.9633 & TRN & \\
\hline
\end{tabular}




\begin{tabular}{|c|c|c|c|c|}
\hline \multicolumn{5}{|c|}{ Supplemental Table s2.txt } \\
\hline CHEMBL1473809 & 688641 & 4.9 & 4.9074 & TRN \\
\hline CHEMBL1362931 & 688641 & 5.5 & 5.3861 & TRN \\
\hline CHEMBL1357941 & 688641 & 4.8 & 4.9116 & TRN \\
\hline CHEMBL1565302 & 688641 & 5.8 & 5.7712 & TRN \\
\hline CHEMBL1484360 & 688641 & 5.3 & 5.1204 & TRN \\
\hline CHEMBL1322064 & 688641 & 5.4 & 5.1228 & TRN \\
\hline CHEMBL 20963 & 688641 & 4.8 & 4.9008 & TST \\
\hline CHEMBL1489424 & 688641 & 6.5 & 6.0806 & TST \\
\hline CHEMBL1435916 & 688641 & 5.3 & 5.4598 & TRN \\
\hline CHEMBL1318799 & 688641 & 5.5 & 5.7838 & TRN \\
\hline CHEMBL1358266 & 688641 & 4.8 & 4.9539 & TRN \\
\hline CHEMBL1188431 & 688641 & 5.2 & 5.2449 & TRN \\
\hline CHEMBL 274189 & 688641 & 4.4 & 5.1095 & TST \\
\hline CHEMBL1593596 & 688641 & 5.5 & 5.0979 & TST \\
\hline CHEMBL411481 & 688641 & 5.4 & 5.1181 & TRN \\
\hline CHEMBL1573844 & 688641 & 4.7 & 5.1526 & TST \\
\hline CHEMBL1515209 & 688641 & 5.4 & 5.3128 & TST \\
\hline CHEMBL1442173 & 688641 & 5.8 & 5.9017 & TRN \\
\hline CHEMBL1515675 & 688641 & 6.7001 & 5.2303 & TRN \\
\hline CHEMBL1486474 & 688641 & 4.8 & 5.25299 & 9999999999 \\
\hline CHEMBL1314185 & 688641 & 4.4 & 4.5712 & TRN \\
\hline CHEMBL495067 & 688641 & 4.8 & 5.0824 & TST \\
\hline CHEMBL1553114 & 688641 & 5.3 & 5.2865 & TRN \\
\hline CHEMBL1437075 & 688641 & 5.0 & 5.0336 & TRN \\
\hline CHEMBL3213894 & 688641 & 6.0 & 6.061 & TRN \\
\hline CHEMBL1413858 & 688641 & 5.1 & 5.0686 & TRN \\
\hline CHEMBL1398600 & 688641 & 5.5 & 5.3622 & TRN \\
\hline CHEMBL1512460 & 688641 & 5.6 & 5.1722 & TST \\
\hline CHEMBL48449 & 688641 & 6.0 & 5.7564 & TST \\
\hline CHEMBL516075 & 688641 & 5.3 & 5.2808 & TRN \\
\hline CHEMBL1412519 & 688641 & 5.4 & 5.3379 & TRN \\
\hline CHEMBL1561374 & 688641 & 5.6 & 5.1628 & TST \\
\hline CHEMBL1592804 & 688641 & 5.1 & 4.9596 & TRN \\
\hline CHEMBL1570196 & 688641 & 5.6 & 5.4891 & TRN \\
\hline CHEMBL1331105 & 688641 & 5.4 & 5.358 & TRN \\
\hline CHEMBL1494609 & 688641 & 4.8 & 4.8382 & TRN \\
\hline CHEMBL1256750 & 688641 & 4.6 & 4.8077 & TRN \\
\hline CHEMBL1590738 & 688641 & 5.1 & 5.0144 & TRN \\
\hline CHEMBL1397406 & 688641 & 4.8 & 5.0135 & TRN \\
\hline CHEMBL1412710 & 688641 & 5.9 & 5.012 & TRN \\
\hline CHEMBL66654 & 688641 & 6.0 & 4.9595 & TST \\
\hline CHEMBL1437314 & 688641 & 5.4 & 5.4842 & TRN \\
\hline CHEMBL 24510 & 688641 & 4.6 & 4.7236 & TRN \\
\hline CHEMBL1316402 & 688641 & 5.5 & 5.4591 & TRN \\
\hline CHEMBL104264 & 688641 & 5.8 & 5.723 & TRN \\
\hline CHEMBL1365082 & 688641 & 5.3 & 5.2971 & TST \\
\hline CHEMBL1435080 & 688641 & 4.9 & 4.9368 & TRN \\
\hline CHEMBL1525024 & 688641 & 5.4 & 5.3663 & TST \\
\hline
\end{tabular}




\begin{tabular}{|c|c|c|c|c|c|}
\hline \multirow{2}{*}{ CHEMBL1364372 } & \multirow{2}{*}{688641} & \\
\hline & & 5.5 & 5.5117 & TRN & \\
\hline CHEMBL1480008 & 688641 & 5.7 & 5.4381 & TRN & \\
\hline CHEMBL1972346 & 688641 & 4.7 & 5.0088 & TRN & \\
\hline CHEMBL1415790 & 688641 & 4.9 & 4.8805 & TRN & \\
\hline CHEMBL1434643 & 688641 & 5.1 & 5.1623 & TRN & \\
\hline CHEMBL1366591 & 688641 & 5.4 & 5.4199 & TRN & \\
\hline CHEMBL1474294 & 688641 & 6.2 & 5.8739 & TRN & \\
\hline CHEMBL309917 & 688641 & 4.5 & 4.9416 & TRN & \\
\hline CHEMBL510539 & 688641 & 5.1 & 5.2162 & TRN & \\
\hline CHEMBL1443425 & 688641 & 4.6 & 4.5825 & TRN & \\
\hline CHEMBL1594058 & 688641 & 6.7001 & 6.3664 & TRN & \\
\hline CHEMBL1597812 & 688641 & 6.0 & 5.7527 & TST & \\
\hline CHEMBL166161 & 688641 & 4.5 & 4.7654 & TST & \\
\hline CHEMBL1603825 & 688641 & 4.7 & 5.0847 & TRN & \\
\hline CHEMBL1434308 & 688641 & 5.8 & 4.8509 & TRN & \\
\hline CHEMBL1324032 & 688641 & 5.3 & 5.2407 & TST & \\
\hline CHEMBL1551925 & 688641 & 5.3 & 5.2929 & TRN & \\
\hline CHEMBL1405464 & 688641 & 5.3 & 5.2422 & TRN & \\
\hline CHEMBL1446009 & 688641 & 4.9 & 4.9452 & TRN & \\
\hline CHEMBL1433598 & 688641 & 5.5 & 5.3098 & TRN & \\
\hline CHEMBL1318042 & 688641 & 5.4 & 5.5563 & TRN & \\
\hline CHEMBL1354678 & 688641 & 4.6 & 4.6155 & TRN & \\
\hline CHEMBL57394 & 688641 & 4.5 & 5.1372 & TRN & \\
\hline CHEMBL1377189 & 688641 & 4.5 & 5.24100 & 00000000005 & TST \\
\hline CHEMBL1316979 & 688641 & 5.9 & 5.9977 & TRN & \\
\hline CHEMBL 1476670 & 688641 & 4.9 & 5.0427 & TRN & \\
\hline CHEMBL1317163 & 688641 & 4.8 & 4.871 & TRN & \\
\hline CHEMBL1316408 & 688641 & 5.5 & 5.5955 & TRN & \\
\hline CHEMBL1480885 & 688641 & 5.4 & 5.4013 & TRN & \\
\hline CHEMBL1521527 & 688641 & 5.0 & 4.9979 & TRN & \\
\hline CHEMBL1532023 & 688641 & 5.4 & 5.4192 & TRN & \\
\hline CHEMBL1554590 & 688641 & 5.5 & 5.0679 & TRN & \\
\hline CHEMBL1476789 & 688641 & 4.8 & 4.9928 & TRN & \\
\hline CHEMBL565654 & 688641 & 5.1 & 5.1773 & TRN & \\
\hline CHEMBL 38508 & 688641 & 5.1 & 5.2616 & TST & \\
\hline CHEMBL1314625 & 688641 & 5.6 & 5.7347 & TRN & \\
\hline CHEMBL1607623 & 688641 & 5.5 & 5.5313 & TRN & \\
\hline CHEMBL1330357 & 688641 & 6.0 & 4.9849 & TST & \\
\hline CHEMBL1531342 & 688641 & 5.5 & 5.4831 & TST & \\
\hline CHEMBL1398586 & 688641 & 5.4 & 5.4521 & TRN & \\
\hline CHEMBL1609007 & 688641 & 4.8 & 5.0353 & TRN & \\
\hline CHEMBL1456714 & 688641 & 5.1 & 4.9883 & TRN & \\
\hline CHEMBL1410841 & 688641 & 5.3 & 5.3423 & TST & \\
\hline CHEMBL1316178 & 688641 & 6.0 & 5.2044 & TST & \\
\hline CHEMBL464176 & 688641 & 5.0 & 5.2864 & TST & \\
\hline CHEMBL238188 & 688641 & 4.6 & 5.0658 & TRN & \\
\hline CHEMBL344127 & 688641 & 4.8 & 4.96899 & 9999999999 & TRN \\
\hline CHEMBL1374763 & 688641 & 5.5 & 5.4101 & TRN & \\
\hline
\end{tabular}




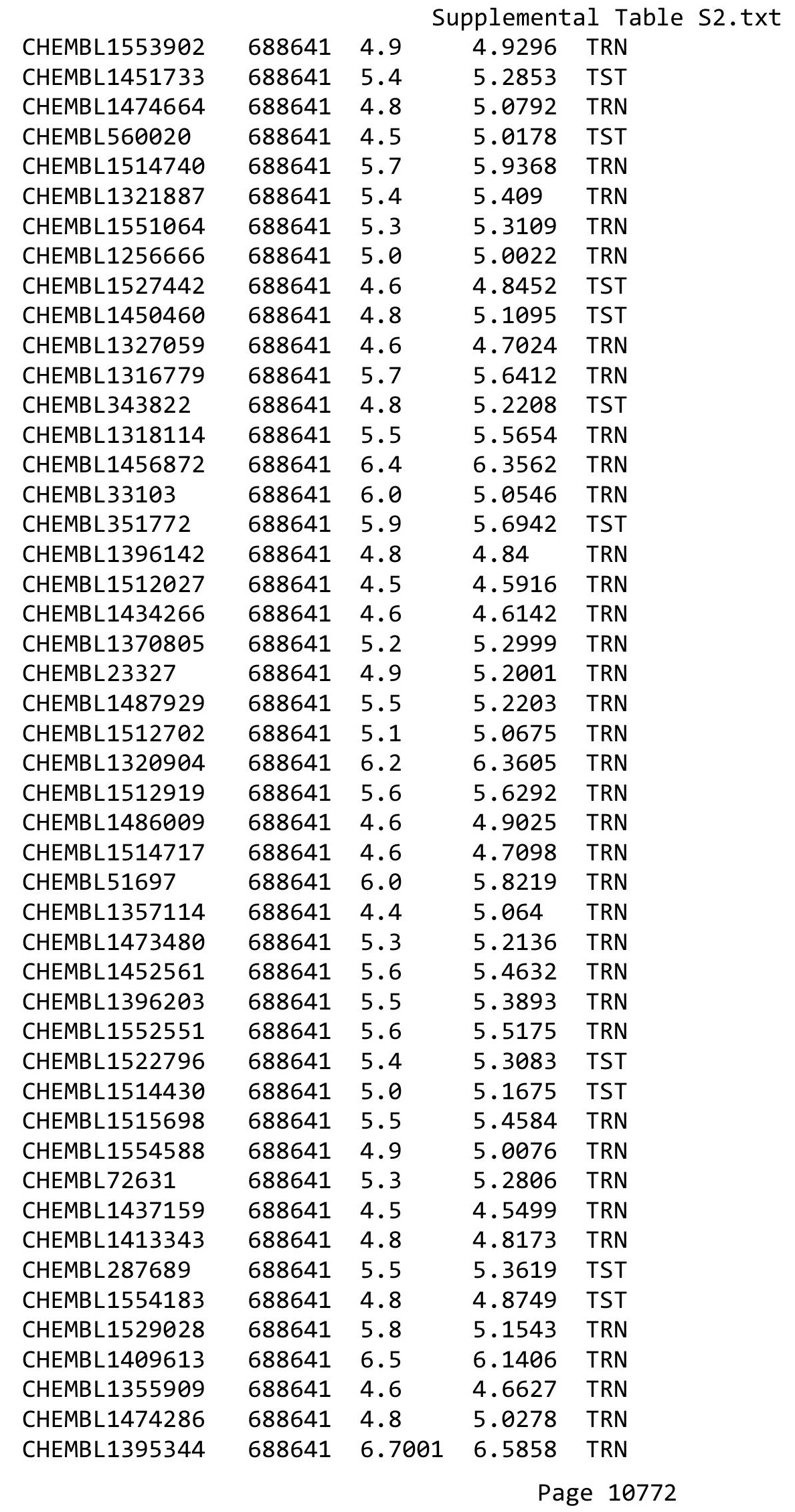




\begin{tabular}{|c|c|c|c|c|c|}
\hline \multicolumn{6}{|c|}{ Supplemental Table S2.txt } \\
\hline CHEMBL1455301 & 688641 & 4.9 & 5.1905 & TST & \\
\hline CHEMBL1554817 & 688641 & 5.5 & 5.499 & TRN & \\
\hline CHEMBL1489708 & 688641 & 4.9 & 4.999 & TRN & \\
\hline CHEMBL1355262 & 688641 & 5.0 & 4.9768 & TRN & \\
\hline CHEMBL1410491 & 688641 & 5.6 & 5.5375 & TRN & \\
\hline CHEMBL1478153 & 688641 & 5.5 & 5.1708 & TRN & \\
\hline CHEMBL1475108 & 688641 & 5.4 & 5.0748 & TRN & \\
\hline CHEMBL1605152 & 688641 & 5.5 & 5.506 & TRN & \\
\hline CHEMBL1328943 & 688641 & 5.3 & 5.3795 & TRN & \\
\hline CHEMBL1317339 & 688641 & 4.9 & 5.2787 & TST & \\
\hline CHEMBL1449371 & 688641 & 5.8 & 5.5538 & TRN & \\
\hline CHEMBL1594610 & 688641 & 4.8 & 5.4375 & TST & \\
\hline CHEMBL1447959 & 688641 & 5.1 & 5.061 & TRN & \\
\hline CHEMBL1404907 & 688641 & 5.3 & 5.1811 & TRN & \\
\hline CHEMBL78573 & 688641 & 4.6 & 5.0914 & TRN & \\
\hline CHEMBL1332518 & 688641 & 4.6 & 5.0616 & TST & \\
\hline CHEMBL 2374044 & 688641 & 6.5 & 5.1769 & TST & \\
\hline CHEMBL117405 & 688641 & 5.1 & 5.0688 & TST & \\
\hline CHEMBL 324642 & 688641 & 4.5 & 4.9542 & TRN & \\
\hline CHEMBL493032 & 688641 & 4.4 & 5.0154 & TRN & \\
\hline CHEMBL1551477 & 688641 & 5.1 & 5.0481 & TRN & \\
\hline CHEMBL75035 & 688641 & 4.5 & 4.7095 & TST & \\
\hline CHEMBL1315079 & 688641 & 4.6 & 4.6111 & TRN & \\
\hline CHEMBL1256746 & 688641 & 4.9 & 5.051 & TRN & \\
\hline CHEMBL1552165 & 688641 & 5.0 & 5.1092 & TRN & \\
\hline CHEMBL1533388 & 688641 & 5.4 & 5.2399 & TST & \\
\hline CHEMBL1413956 & 688641 & 5.1 & 5.2048 & TST & \\
\hline CHEMBL1551557 & 688641 & 4.8 & 4.755 & TRN & \\
\hline CHEMBL1567238 & 688641 & 6.0 & 5.9426 & TRN & \\
\hline CHEMBL1435079 & 688641 & 5.0 & 5.1329 & TRN & \\
\hline CHEMBL1337479 & 688641 & 4.9 & 4.8494 & TRN & \\
\hline CHEMBL491909 & 688641 & 7.1002 & 7.1011 & TRN & \\
\hline CHEMBL1355135 & 688641 & 5.3 & 5.21399 & 99999999995 & TRN \\
\hline CHEMBL1494966 & 688641 & 4.6 & 5.1285 & TRN & \\
\hline CHEMBL1515295 & 688641 & 4.9 & 5.0073 & TRN & \\
\hline CHEMBL1475083 & 688641 & 5.6 & 5.6488 & TRN & \\
\hline CHEMBL1359917 & 688641 & 6.7001 & 6.5303 & TRN & \\
\hline CHEMBL1411049 & 688641 & 5.6 & 5.7561 & TRN & \\
\hline CHEMBL1515417 & 688641 & 5.2 & 5.1487 & TRN & \\
\hline CHEMBL59532 & 688641 & 4.9 & 4.934 & TST & \\
\hline CHEMBL1321919 & 688641 & 6.4 & 5.465 & TRN & \\
\hline CHEMBL1371140 & 688641 & 5.0 & 4.963 & TRN & \\
\hline CHEMBL1329889 & 688641 & 5.1 & 5.1265 & TRN & \\
\hline CHEMBL1512708 & 688641 & 5.8 & 6.0107 & TRN & \\
\hline CHEMBL1330317 & 688641 & 4.8 & 4.7838 & TRN & \\
\hline CHEMBL1434747 & 688641 & 5.6 & 5.3994 & TRN & \\
\hline CHEMBL1478221 & 688641 & 4.8 & 4.8493 & TRN & \\
\hline CHEMBL1415804 & 688641 & 5.1 & 5.2593 & TRN & \\
\hline
\end{tabular}




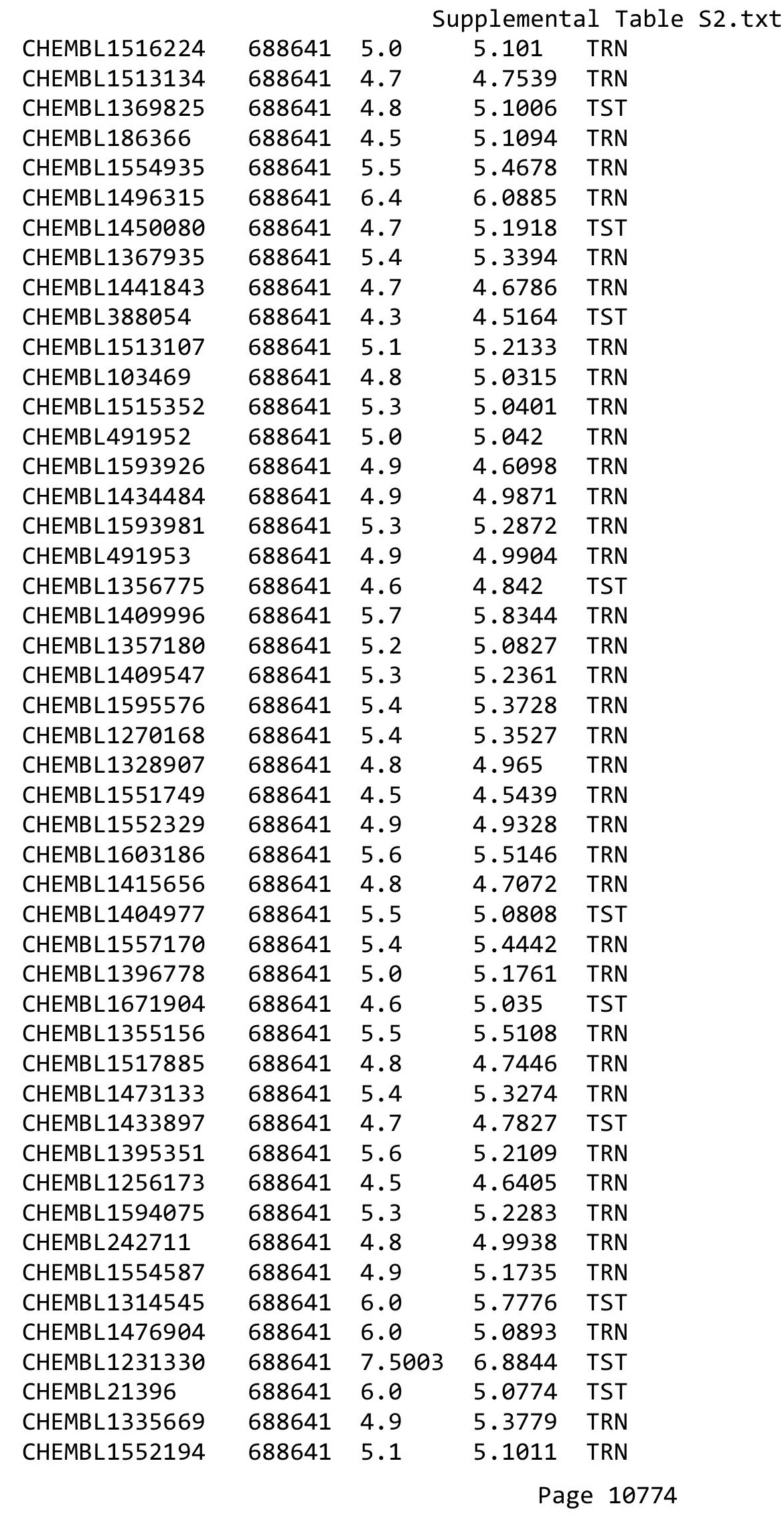




\begin{tabular}{|c|c|c|c|c|c|}
\hline \multirow[b]{2}{*}{ CHEMBL1554743 } & \multirow[b]{2}{*}{688641} & \multicolumn{4}{|c|}{ Supplemental Table S2.txt } \\
\hline & & 4.8 & 4.7913 & TRN & \\
\hline CHEMBL1324151 & 688641 & 4.9 & 4.8798 & TRN & \\
\hline CHEMBL1360778 & 688641 & 4.6 & 5.1178 & TRN & \\
\hline CHEMBL1357872 & 688641 & 4.6 & 4.6837 & TRN & \\
\hline CHEMBL1368062 & 688641 & 5.8 & 5.1796 & TRN & \\
\hline CHEMBL1512391 & 688641 & 4.6 & 4.8953 & TRN & \\
\hline CHEMBL1316796 & 688641 & 4.9 & 4.8872 & TRN & \\
\hline CHEMBL554041 & 688641 & 4.6 & 5.1415 & TRN & \\
\hline CHEMBL1395753 & 688641 & 5.4 & 5.4747 & TRN & \\
\hline CHEMBL1456923 & 688641 & 4.6 & 5.2203 & TRN & \\
\hline CHEMBL1326815 & 688641 & 5.5 & 5.5029 & TRN & \\
\hline CHEMBL1354751 & 688641 & 5.3 & 5.2508 & TRN & \\
\hline CHEMBL1453944 & 688641 & 6.0 & 5.2787 & TST & \\
\hline CHEMBL1317810 & 688641 & 5.4 & 5.1768 & TST & \\
\hline CHEMBL509256 & 688641 & 5.0 & 5.1959 & TRN & \\
\hline CHEMBL1572915 & 688641 & 5.4 & 5.3355 & TRN & \\
\hline CHEMBL1437448 & 688641 & 4.9 & 4.8713 & TST & \\
\hline CHEMBL1396261 & 688641 & 6.4 & 6.5713 & TRN & \\
\hline CHEMBL1574626 & 688641 & 4.8 & 4.8816 & TRN & \\
\hline CHEMBL1481608 & 688641 & 5.3 & 5.1633 & TRN & \\
\hline CHEMBL1406622 & 688641 & 5.5 & 5.4461 & TRN & \\
\hline CHEMBL1357090 & 688641 & 4.7 & 5.12700 & 0000000001 & TRN \\
\hline CHEMBL1314286 & 688641 & 6.0 & 5.7039 & TST & \\
\hline CHEMBL1413967 & 688641 & 5.4 & 5.3837 & TRN & \\
\hline CHEMBL 224214 & 688641 & 5.9 & 5.1445 & TRN & \\
\hline CHEMBL1256984 & 688641 & 5.6 & 5.66200 & 0000000001 & TST \\
\hline CHEMBL1534630 & 688641 & 5.0 & 5.0265 & TST & \\
\hline CHEMBL1358161 & 688641 & 4.8 & 4.9836 & TRN & \\
\hline CHEMBL106437 & 688641 & 4.9 & 5.0613 & TRN & \\
\hline CHEMBL1594011 & 688641 & 6.0 & 5.8546 & TRN & \\
\hline CHEMBL1396407 & 688641 & 5.9 & 5.9695 & TRN & \\
\hline CHEMBL1533214 & 688641 & 5.2 & 5.138 & TRN & \\
\hline CHEMBL586946 & 688641 & 5.7 & 5.5006 & TRN & \\
\hline CHEMBL1519978 & 688641 & 5.4 & 5.4149 & TRN & \\
\hline CHEMBL1337934 & 688641 & 5.5 & 5.5333 & TRN & \\
\hline CHEMBL1467058 & 688641 & 5.1 & 5.3244 & TST & \\
\hline CHEMBL1553745 & 688641 & 5.2 & 5.2488 & TST & \\
\hline CHEMBL1440774 & 688641 & 4.8 & 5.4459 & TRN & \\
\hline CHEMBL1363411 & 688641 & 4.5 & 4.8064 & TRN & \\
\hline CHEMBL1323905 & 688641 & 5.0 & 5.0718 & TRN & \\
\hline CHEMBL1288014 & 688641 & 5.4 & 5.4864 & TST & \\
\hline CHEMBL1403101 & 688641 & 5.3 & 5.2315 & TRN & \\
\hline CHEMBL1371435 & 688641 & 4.6 & 5.2036 & TRN & \\
\hline CHEMBL1367976 & 688641 & 4.6 & 5.1806 & TRN & \\
\hline CHEMBL513116 & 688641 & 6.0 & 5.6904 & TRN & \\
\hline CHEMBL1408735 & 688641 & 5.8 & 5.8566 & TRN & \\
\hline CHEMBL1489223 & 688641 & 5.0 & 5.0893 & TRN & \\
\hline CHEMBL454173 & 688641 & 6.0 & 5.1129 & TST & \\
\hline
\end{tabular}




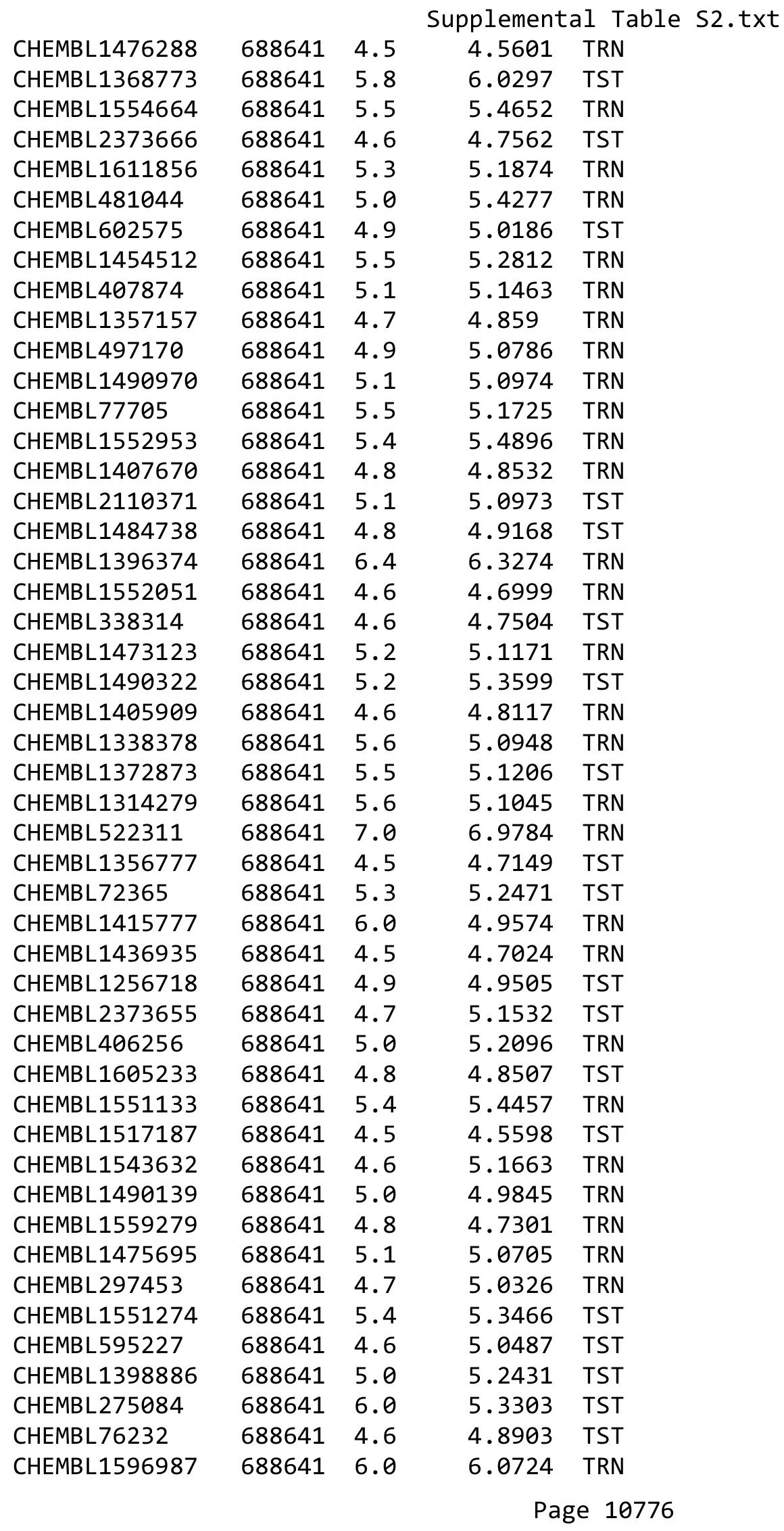




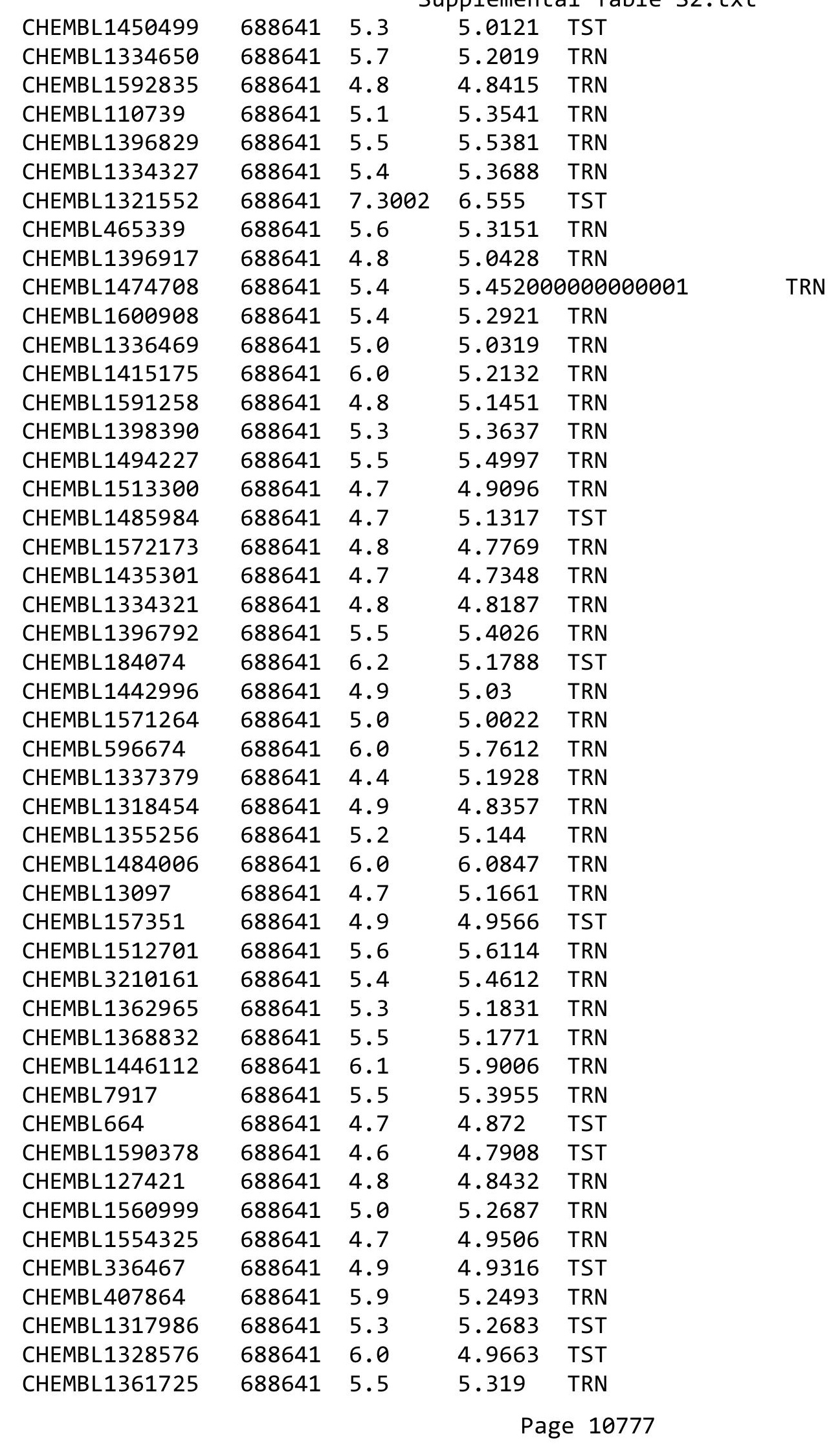




\begin{tabular}{|c|c|c|c|c|}
\hline & & & pplement & \\
\hline CHEMBL1290347 & 688641 & 4.5 & 5.0306 & TRN \\
\hline CHEMBL1591714 & 688641 & 6.0 & 5.4797 & TRN \\
\hline CHEMBL1325297 & 688641 & 4.9 & 5.0605 & TRN \\
\hline CHEMBL55285 & 688641 & 4.6 & 4.9106 & TST \\
\hline CHEMBL1473171 & 688641 & 5.6 & 5.3149 & TST \\
\hline CHEMBL140 & 688641 & 6.0 & 5.0695 & TRN \\
\hline CHEMBL1330951 & 688641 & 5.3 & 5.2954 & TRN \\
\hline CHEMBL1593754 & 688641 & 6.0 & 5.2689 & TST \\
\hline CHEMBL1512594 & 688641 & 5.1 & 5.1395 & TRN \\
\hline CHEMBL1476155 & 688641 & 4.6 & 5.0913 & TST \\
\hline CHEMBL1413340 & 688641 & 5.7 & 5.6168 & TRN \\
\hline CHEMBL1591368 & 688641 & 6.0 & 6.0617 & TRN \\
\hline CHEMBL1436361 & 688641 & 5.8 & 5.8702 & TRN \\
\hline CHEMBL448515 & 688641 & 4.6 & 5.0507 & TST \\
\hline CHEMBL1361855 & 688641 & 5.5 & 5.4166 & TST \\
\hline CHEMBL1417349 & 688641 & 5.5 & 5.6374 & TRN \\
\hline CHEMBL 280822 & 688641 & 6.0 & 5.7106 & TST \\
\hline CHEMBL1579130 & 688641 & 6.0 & 5.4178 & TST \\
\hline CHEMBL1316337 & 688641 & 5.3 & 5.2115 & TRN \\
\hline CHEMBL1435481 & 688641 & 4.7 & 4.7293 & TRN \\
\hline CHEMBL 2374076 & 688641 & 4.4 & 5.2561 & TST \\
\hline CHEMBL1515717 & 688641 & 5.4 & 5.3905 & TRN \\
\hline CHEMBL1595910 & 688641 & 5.5 & 5.2966 & TRN \\
\hline CHEMBL1594258 & 688641 & 5.4 & 5.0372 & TRN \\
\hline CHEMBL1315504 & 688641 & 6.1 & 6.0634 & TRN \\
\hline CHEMBL1552854 & 688641 & 5.7 & 5.6816 & TRN \\
\hline CHEMBL1334021 & 688641 & 4.6 & 4.6887 & TRN \\
\hline CHEMBL109037 & 688641 & 4.8 & 5.1315 & TRN \\
\hline CHEMBL1551479 & 688641 & 6.1 & 5.8494 & TRN \\
\hline CHEMBL1519167 & 688641 & 5.4 & 5.2601 & TRN \\
\hline CHEMBL117 & 688641 & 6.0 & 5.4808 & TRN \\
\hline CHEMBL1596743 & 688641 & 5.2 & 5.2154 & TRN \\
\hline CHEMBL1316213 & 688641 & 5.3 & 5.3948 & TRN \\
\hline CHEMBL1327492 & 688641 & 6.1 & 5.1661 & TST \\
\hline CHEMBL457504 & 688641 & 5.3 & 5.1041 & TRN \\
\hline CHEMBL1590173 & 688641 & 5.5 & 5.5109 & TRN \\
\hline CHEMBL1330355 & 688641 & 6.8 & 5.0579 & TRN \\
\hline CHEMBL1398810 & 688641 & 4.8 & 4.8236 & TRN \\
\hline CHEMBL1396862 & 688641 & 5.4 & 5.36 & TRN \\
\hline CHEMBL1562290 & 688641 & 4.8 & 5.0736 & TRN \\
\hline CHEMBL1409097 & 688641 & 5.9 & 5.6553 & TST \\
\hline CHEMBL346516 & 688641 & 5.4 & 5.0105 & TST \\
\hline CHEMBL1256916 & 688641 & 4.6 & 5.0361 & TRN \\
\hline CHEMBL1330388 & 688641 & 5.5 & 5.1826 & TST \\
\hline CHEMBL1255936 & 688641 & 6.7001 & 6.232 & TST \\
\hline CHEMBL1374218 & 688641 & 5.4 & 5.3756 & TRN \\
\hline CHEMBL1488477 & 688641 & 4.7 & 4.7202 & TRN \\
\hline CHEMBL1593592 & 688641 & 5.8 & 5.731 & TRN \\
\hline
\end{tabular}


Supplemental Table S2.txt

\begin{tabular}{|c|c|c|c|c|}
\hline CHEMBL522600 & 688641 & 6.7001 & 6.8078 & TRN \\
\hline CHEMBL1568520 & 688641 & 4.9 & 5.042 & TRN \\
\hline CHEMBL1436272 & 688641 & 4.8 & 4.9899 & TRN \\
\hline CHEMBL1396080 & 688641 & 4.9 & 4.8946 & TRN \\
\hline CHEMBL1526170 & 688641 & 5.4 & 5.544 & TRN \\
\hline CHEMBL1518338 & 688641 & 4.8 & 4.8203 & TRN \\
\hline CHEMBL1322756 & 688641 & 4.8 & 4.8377 & TRN \\
\hline CHEMBL1367960 & 688641 & 4.7 & 5.23 & TRN \\
\hline CHEMBL1436355 & 688641 & 5.3 & 5.3051 & TRN \\
\hline CHEMBL1531250 & 688641 & 6.0 & 5.3731 & TRN \\
\hline CHEMBL1355644 & 688641 & 6.0 & 6.0522 & TRN \\
\hline CHEMBL1357982 & 688641 & 5.7 & 5.8657 & TRN \\
\hline CHEMBL1565107 & 688641 & 4.5 & 5.0596 & TST \\
\hline CHEMBL1435947 & 688641 & 4.7 & 4.7997 & TRN \\
\hline CHEMBL1323124 & 688641 & 4.8 & 4.8345 & TRN \\
\hline CHEMBL1484861 & 688641 & 5.6 & 5.6599 & TRN \\
\hline CHEMBL1485048 & 688641 & 7.2 & 5.234 & TST \\
\hline CHEMBL1410175 & 688641 & 5.4 & 5.3308 & TST \\
\hline CHEMBL1551286 & 688641 & 4.8 & 5.34399 & 9999999999 \\
\hline CHEMBL1495773 & 688641 & 4.6 & 4.6853 & TRN \\
\hline CHEMBL1332314 & 688641 & 4.7 & 5.1147 & TST \\
\hline CHEMBL1455972 & 688641 & 5.3 & 5.2284 & TST \\
\hline CHEMBL1336812 & 688641 & 4.9 & 5.0149 & TST \\
\hline CHEMBL1317769 & 688641 & 5.0 & 4.9585 & TRN \\
\hline CHEMBL1318580 & 688641 & 4.8 & 4.8188 & TRN \\
\hline CHEMBL1336793 & 688641 & 5.0 & 4.9797 & TRN \\
\hline CHEMBL1355216 & 688641 & 5.4 & 5.2605 & TRN \\
\hline CHEMBL1395737 & 688641 & 4.6 & 4.7487 & TRN \\
\hline CHEMBL1554531 & 688641 & 4.7 & 5.2227 & TRN \\
\hline CHEMBL1362553 & 688641 & 5.4 & 5.15799 & Э99999999995 \\
\hline CHEMBL406120 & 688641 & 5.0 & 5.23 & TRN \\
\hline CHEMBL1474483 & 688641 & 5.3 & 5.1449 & TRN \\
\hline CHEMBL1531108 & 688641 & 4.7 & 4.8579 & TRN \\
\hline CHEMBL1591190 & 688641 & 4.8 & 4.9216 & TRN \\
\hline CHEMBL1323164 & 688641 & 6.0 & 6.0601 & TRN \\
\hline CHEMBL1524520 & 688641 & 6.2 & 6.1151 & TRN \\
\hline CHEMBL1256364 & 688641 & 4.8 & 4.9168 & TRN \\
\hline CHEMBL 2373582 & 688641 & 5.4 & 4.8455 & TST \\
\hline CHEMBL1574956 & 688641 & 5.3 & 5.3692 & TRN \\
\hline CHEMBL1437650 & 688641 & 4.6 & 4.6861 & TRN \\
\hline CHEMBL1512676 & 688641 & 4.9 & 4.9071 & TRN \\
\hline CHEMBL1436169 & 688641 & 6.2 & 6.099 & TRN \\
\hline CHEMBL1333445 & 688641 & 5.6 & 5.7311 & TRN \\
\hline CHEMBL 283130 & 688641 & 4.8 & 4.8553 & TRN \\
\hline CHEMBL15927 & 688641 & 4.3 & 4.5226 & TRN \\
\hline CHEMBL1600269 & 688641 & 4.9 & 4.9387 & TRN \\
\hline CHEMBL1592560 & 688641 & 4.4 & 4.5014 & TRN \\
\hline CHEMBL1599378 & 688641 & 4.9 & 5.1322 & TRN \\
\hline
\end{tabular}




\begin{tabular}{|c|c|c|c|c|c|}
\hline \multicolumn{6}{|c|}{ Supplemental Table S2.txt } \\
\hline CHEMBL1534237 & 688641 & 4.9 & 4.9577 & TRN & \\
\hline CHEMBL280998 & 688641 & 5.0 & 4.8037 & TST & \\
\hline CHEMBL1573756 & 688641 & 5.5 & 5.1713 & TST & \\
\hline CHEMBL1592966 & 688641 & 4.6 & 4.7033 & TRN & \\
\hline CHEMBL1554236 & 688641 & 4.7 & 4.6721 & TRN & \\
\hline CHEMBL1435509 & 688641 & 5.4 & 5.3573 & TRN & \\
\hline CHEMBL1450573 & 688641 & 6.4 & 6.1007 & TRN & \\
\hline CHEMBL1479744 & 688641 & 5.0 & 5.0524 & TRN & \\
\hline CHEMBL19032 & 688641 & 5.9 & 5.2366 & TRN & \\
\hline CHEMBL1358402 & 688641 & 6.0 & 5.7701 & TST & \\
\hline CHEMBL448602 & 688641 & 5.5 & 5.4999 & TRN & \\
\hline CHEMBL1514671 & 688641 & 4.6 & 5.1907 & TST & \\
\hline CHEMBL1315250 & 688641 & 5.5 & 5.5085 & TRN & \\
\hline CHEMBL1512693 & 688641 & 4.8 & 4.8149 & TRN & \\
\hline CHEMBL1369940 & 688641 & 5.0 & 5.0425 & TRN & \\
\hline CHEMBL1593751 & 688641 & 7.6003 & 5.2432 & TRN & \\
\hline CHEMBL1516459 & 688641 & 4.4 & 5.0523 & TST & \\
\hline CHEMBL1476407 & 688641 & 4.8 & 4.8292 & TRN & \\
\hline CHEMBL1433724 & 688641 & 6.2 & $6.2020 e$ & 2000000001 & TRN \\
\hline CHEMBL1521391 & 688641 & 6.0 & 6.0485 & TRN & \\
\hline CHEMBL362051 & 688641 & 4.8 & 5.0179 & TRN & \\
\hline CHEMBL1474977 & 688641 & 5.0 & 5.033 & TRN & \\
\hline CHEMBL408501 & 688641 & 5.4 & 5.2388 & TRN & \\
\hline CHEMBL1590556 & 688641 & 4.8 & 4.9379 & TRN & \\
\hline CHEMBL1256660 & 688641 & 4.7 & 4.9488 & TST & \\
\hline CHEMBL1361406 & 688641 & 4.9 & 4.9521 & TRN & \\
\hline CHEMBL1402495 & 688641 & 5.4 & 5.4455 & TRN & \\
\hline CHEMBL1484689 & 688641 & 5.4 & 5.5625 & TRN & \\
\hline CHEMBL1474151 & 688641 & 4.5 & 4.63 & TRN & \\
\hline CHEMBL52229 & 688641 & 4.8 & 5.0062 & TRN & \\
\hline CHEMBL1567483 & 688641 & 4.8 & 5.2524 & TRN & \\
\hline CHEMBL1487836 & 688641 & 5.4 & 5.21899 & 9999999999 & TRN \\
\hline CHEMBL1365537 & 688641 & 5.4 & 5.4294 & TRN & \\
\hline CHEMBL1590813 & 688641 & 4.8 & 4.8769 & TRN & \\
\hline CHEMBL1354190 & 688641 & 5.5 & 5.3597 & TST & \\
\hline CHEMBL1475990 & 688641 & 5.2 & 5.2885 & TRN & \\
\hline CHEMBL1480574 & 688641 & 5.4 & 5.138 & TRN & \\
\hline CHEMBL576997 & 688641 & 6.0 & 5.0556 & TST & \\
\hline CHEMBL1447438 & 688641 & 5.6 & 5.5177 & TRN & \\
\hline CHEMBL1590270 & 688641 & 4.8 & 5.062 & TRN & \\
\hline CHEMBL1472703 & 688641 & 6.0 & 5.1835 & TRN & \\
\hline CHEMBL1255940 & 688641 & 4.8 & 4.8639 & TRN & \\
\hline CHEMBL2373656 & 688641 & 5.8 & 5.2398 & TST & \\
\hline CHEMBL1315508 & 688641 & 4.8 & 4.8301 & TRN & \\
\hline CHEMBL553181 & 688641 & 4.5 & 4.8866 & TRN & \\
\hline CHEMBL1436575 & 688641 & 5.5 & 4.7781 & TRN & \\
\hline CHEMBL1496934 & 688641 & 5.5 & 4.7909 & TRN & \\
\hline CHEMBL1256659 & 688641 & 4.7 & 5.1041 & TRN & \\
\hline
\end{tabular}




\begin{tabular}{|c|c|c|c|c|}
\hline & & & plem & \\
\hline CHEMBL85811 & 688641 & 4.5 & 4.9438 & TRN \\
\hline CHEMBL1434817 & 688641 & 4.6 & 4.738 & TRN \\
\hline CHEMBL1323619 & 688641 & 6.2 & 5.0345 & TST \\
\hline CHEMBL1208858 & 688641 & 4.8 & 4.9473 & TRN \\
\hline CHEMBL1597474 & 688641 & 5.4 & 5.2785 & TRN \\
\hline CHEMBL1369140 & 688641 & 5.5 & 5.3596 & TST \\
\hline CHEMBL1603100 & 688641 & 5.4 & 5.3813 & TRN \\
\hline CHEMBL 2374020 & 688641 & 4.7 & 5.1475 & TST \\
\hline CHEMBL1484480 & 688641 & 4.9 & 4.9561 & TRN \\
\hline CHEMBL 85728 & 688641 & 4.6 & 5.1747 & TRN \\
\hline CHEMBL1523816 & 688641 & 4.6 & 4.9204 & TRN \\
\hline CHEMBL1455462 & 688641 & 5.5 & 5.4684 & TRN \\
\hline CHEMBL1486578 & 688641 & 5.4 & 5.3029 & TST \\
\hline CHEMBL18132 & 688641 & 5.8 & 5.5764 & TRN \\
\hline CHEMBL1514398 & 688641 & 5.4 & 5.5822 & TRN \\
\hline CHEMBL1553751 & 688641 & 5.1 & 5.3981 & TRN \\
\hline CHEMBL1565311 & 688641 & 6.0 & 6.0174 & TRN \\
\hline CHEMBL502044 & 688641 & 4.5 & 4.6552 & TST \\
\hline CHEMBL1434156 & 688641 & 4.8 & 4.7883 & TRN \\
\hline CHEMBL93353 & 688641 & 6.0 & 5.4314 & TST \\
\hline CHEMBL1315207 & 688641 & 4.6 & 4.8659 & TST \\
\hline CHEMBL1591731 & 688641 & 5.6 & 5.5346 & TST \\
\hline CHEMBL1404954 & 688641 & 4.5 & 4.5862 & TRN \\
\hline CHEMBL1488225 & 688641 & 4.8 & 5.0537 & TRN \\
\hline CHEMBL1610735 & 688641 & 6.0 & 5.5379 & TRN \\
\hline CHEMBL1476604 & 688641 & 4.8 & 4.7602 & TRN \\
\hline CHEMBL1435912 & 688641 & 4.9 & 5.0565 & TRN \\
\hline CHEMBL1437164 & 688641 & 4.8 & 4.8635 & TRN \\
\hline CHEMBL1357356 & 688641 & 4.4 & 5.1388 & TST \\
\hline CHEMBL1318262 & 688641 & 4.7 & 4.7349 & TRN \\
\hline CHEMBL122701 & 688641 & 4.5 & 5.1636 & TRN \\
\hline CHEMBL1315845 & 688641 & 4.7 & 4.6848 & TRN \\
\hline CHEMBL1483422 & 688641 & 5.6 & 5.2385 & TRN \\
\hline CHEMBL1395863 & 688641 & 5.4 & 5.2186 & TST \\
\hline CHEMBL32579 & 688641 & 5.5 & 5.36 & TRN \\
\hline CHEMBL1499536 & 688641 & 4.8 & 4.9889 & TRN \\
\hline CHEMBL1514027 & 688641 & 4.5 & 4.5931 & TRN \\
\hline CHEMBL1533537 & 688641 & 4.8 & 4.7773 & TRN \\
\hline CHEMBL1435788 & 688641 & 5.4 & 5.246 & TRN \\
\hline CHEMBL1411360 & 688641 & 6.0 & 5.851 & TST \\
\hline CHEMBL1474816 & 688641 & 5.0 & 4.8929 & TRN \\
\hline CHEMBL1357018 & 688641 & 6.0 & 6.1122 & TRN \\
\hline CHEMBL1559163 & 688641 & 5.4 & 5.3881 & TRN \\
\hline CHEMBL1474989 & 688641 & 5.2 & 5.1387 & TRN \\
\hline CHEMBL1573063 & 688641 & 5.9 & 6.013 & TRN \\
\hline CHEMBL1710 & 688641 & 4.5 & 5.1364 & TST \\
\hline CHEMBL1366297 & 688641 & 4.9 & 5.0556 & TRN \\
\hline CHEMBL1553731 & 688641 & 5.4 & 5.1684 & TST \\
\hline
\end{tabular}




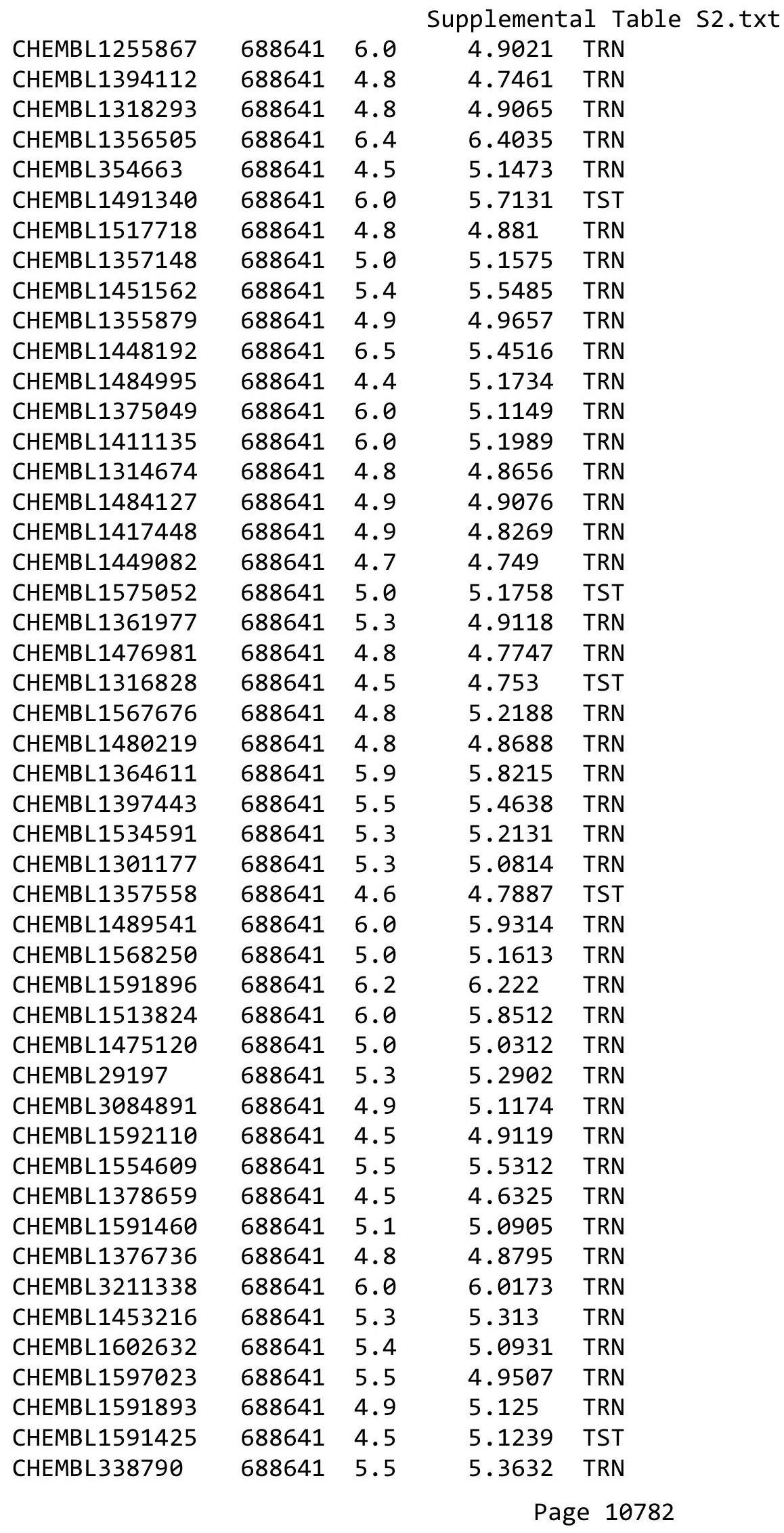




\begin{tabular}{|c|c|c|c|c|}
\hline & & & & $a \perp 1 a$ \\
\hline CHEMBL1316557 & 688641 & 5.4 & 5.3471 & TRN \\
\hline CHEMBL1317620 & 688641 & 4.7 & 4.6939 & TRN \\
\hline CHEMBL1365979 & 688641 & 4.9 & 4.9162 & TRN \\
\hline CHEMBL1457317 & 688641 & 5.1 & 5.1926 & TRN \\
\hline CHEMBL1472837 & 688641 & 5.2 & 5.2832 & TRN \\
\hline CHEMBL1516252 & 688641 & 4.8 & 5.0374 & TRN \\
\hline CHEMBL544713 & 688641 & 5.6 & 5.5593 & TRN \\
\hline CHEMBL1591874 & 688641 & 4.9 & 4.8297 & TRN \\
\hline CHEMBL1269022 & 688641 & 5.6 & 5.5435 & TRN \\
\hline CHEMBL1474684 & 688641 & 4.6 & 5.2366 & TST \\
\hline CHEMBL1596796 & 688641 & 5.5 & 5.3717 & TST \\
\hline CHEMBL1331031 & 688641 & 5.5 & 5.5233 & TRN \\
\hline CHEMBL166112 & 688641 & 5.0 & 5.0054 & TST \\
\hline CHEMBL1369863 & 688641 & 5.0 & 4.9231 & TRN \\
\hline CHEMBL1317761 & 688641 & 4.8 & 4.7819 & TRN \\
\hline CHEMBL12998 & 688641 & 5.1 & 5.3064 & TST \\
\hline CHEMBL26915 & 688641 & 4.4 & 4.6169 & TST \\
\hline CHEMBL1320919 & 688641 & 5.4 & 5.0013 & TRN \\
\hline CHEMBL1396225 & 688641 & 4.9 & 4.8269 & TRN \\
\hline CHEMBL371523 & 688641 & 4.9 & 4.8871 & TRN \\
\hline CHEMBL1411146 & 688641 & 5.1 & 5.095 & TRN \\
\hline CHEMBL333985 & 688641 & 4.9 & 4.9161 & TST \\
\hline CHEMBL1415465 & 688641 & 4.7 & 4.716 & TRN \\
\hline CHEMBL1358547 & 688641 & 5.8 & 5.3509 & TRN \\
\hline CHEMBL1361758 & 688641 & 5.0 & 5.0909 & TRN \\
\hline CHEMBL1433930 & 688641 & 5.8 & 5.6378 & TRN \\
\hline CHEMBL1358756 & 688641 & 4.8 & 4.7423 & TRN \\
\hline CHEMBL1437007 & 688641 & 4.8 & 4.8159 & TRN \\
\hline CHEMBL1474927 & 688641 & 5.7 & 5.6909 & TRN \\
\hline CHEMBL1514719 & 688641 & 4.6 & 4.7056 & TRN \\
\hline CHEMBL1256835 & 688641 & 6.0 & 5.8251 & TRN \\
\hline CHEMBL1445754 & 688641 & 4.7 & 5.1818 & TRN \\
\hline CHEMBL559612 & 688641 & 5.3 & 5.3127 & TST \\
\hline CHEMBL1433805 & 688641 & 4.8 & 4.8041 & TRN \\
\hline CHEMBL1561023 & 688641 & 5.2 & 5.1507 & TRN \\
\hline CHEMBL252744 & 688641 & 4.5 & 5.4724 & TST \\
\hline CHEMBL1568071 & 688641 & 5.8 & 5.8717 & TRN \\
\hline CHEMBL1514639 & 688641 & 5.6 & 5.4737 & TST \\
\hline CHEMBL1474281 & 688641 & 4.8 & 4.7824 & TRN \\
\hline CHEMBL164269 & 688641 & 5.5 & 5.4431 & TST \\
\hline CHEMBL1475428 & 688641 & 5.2 & 5.0091 & TRN \\
\hline CHEMBL1486734 & 688641 & 5.8 & 5.9279 & TRN \\
\hline CHEMBL77098 & 688641 & 4.7 & 5.1168 & TRN \\
\hline CHEMBL1410006 & 688641 & 5.5 & 5.1666 & TRN \\
\hline CHEMBL1331410 & 688641 & 5.7 & 5.7848 & TRN \\
\hline CHEMBL1315530 & 688641 & 4.7 & 4.6954 & TRN \\
\hline CHEMBL1357338 & 688641 & 4.9 & 4.8485 & TRN \\
\hline CHEMBL1597277 & 688641 & 4.4 & 4.5533 & TRN \\
\hline
\end{tabular}




\begin{tabular}{|c|c|c|c|c|c|}
\hline \multicolumn{6}{|c|}{ Supplemental Table S2.txt } \\
\hline CHEMBL227298 & 688641 & 5.3 & 5.2398 & TST & \\
\hline CHEMBL1440509 & 688641 & 5.0 & 5.0354 & TRN & \\
\hline CHEMBL1361596 & 688641 & 6.0 & 5.7235 & TST & \\
\hline CHEMBL1515024 & 688641 & 4.8 & 4.8069 & TRN & \\
\hline CHEMBL1572239 & 688641 & 5.2 & 5.3232 & TRN & \\
\hline CHEMBL1436042 & 688641 & 4.7 & 4.6944 & TRN & \\
\hline CHEMBL1406230 & 688641 & 4.6 & 5.1027 & TRN & \\
\hline CHEMBL1490528 & 688641 & 4.8 & 4.7636 & TRN & \\
\hline CHEMBL1354355 & 688641 & 4.8 & 4.9344 & TRN & \\
\hline CHEMBL450288 & 688641 & 4.6 & 5.056 & TRN & \\
\hline CHEMBL1533516 & 688641 & 4.5 & 4.6211 & TRN & \\
\hline CHEMBL1411519 & 688641 & 5.0 & 5.0689 & TRN & \\
\hline CHEMBL1518618 & 688641 & 4.8 & 4.7536 & TRN & \\
\hline CHEMBL1611820 & 688641 & 4.8 & 4.8089 & TRN & \\
\hline CHEMBL1335595 & 688641 & 6.3 & 5.9156 & TRN & \\
\hline CHEMBL1451874 & 688641 & 4.9 & 5.0738 & TRN & \\
\hline CHEMBL1397369 & 688641 & 4.8 & 5.4096 & TST & \\
\hline CHEMBL1357347 & 688641 & 5.0 & 5.1439 & TRN & \\
\hline CHEMBL510698 & 688641 & 5.9 & 5.5506 & TRN & \\
\hline CHEMBL1530832 & 688641 & 5.6 & 5.7582 & TRN & \\
\hline CHEMBL1551919 & 688641 & 5.0 & 4.9475 & TRN & \\
\hline CHEMBL1523579 & 688641 & 4.8 & 4.7606 & TRN & \\
\hline CHEMBL1489016 & 688641 & 4.5 & 4.648 & TRN & \\
\hline CHEMBL1608125 & 688641 & 5.6 & 5.5189 & TRN & \\
\hline CHEMBL1327793 & 688641 & 5.4 & 5.318 & TRN & \\
\hline CHEMBL1554098 & 688641 & 6.0 & 5.0988 & TST & \\
\hline CHEMBL1480350 & 688641 & 4.8 & 4.8706 & TRN & \\
\hline CHEMBL1412847 & 688641 & 5.5 & 5.4446 & TRN & \\
\hline CHEMBL1447318 & 688641 & 5.6 & 5.276 & TST & \\
\hline CHEMBL1372514 & 688641 & 4.9 & 5.0046 & TRN & \\
\hline CHEMBL1435604 & 688641 & 4.8 & 4.8187 & TRN & \\
\hline CHEMBL1433798 & 688641 & 5.1 & 5.0864 & TRN & \\
\hline CHEMBL1369008 & 688641 & 6.0 & 5.9606 & TRN & \\
\hline CHEMBL1256646 & 688641 & 4.8 & 4.8926 & TRN & \\
\hline CHEMBL1320206 & 688641 & 4.9 & 4.9379 & TRN & \\
\hline CHEMBL1515565 & 688641 & 4.6 & 4.6692 & TRN & \\
\hline CHEMBL1436811 & 688641 & 4.8 & 4.7892 & TRN & \\
\hline CHEMBL1396236 & 688641 & 5.3 & 5.2483 & TST & \\
\hline CHEMBL80941 & 688641 & 4.9 & 4.9343 & TRN & \\
\hline CHEMBL54804 & 688641 & 4.5 & 5.1744 & TST & \\
\hline CHEMBL1454033 & 688641 & 5.4 & 5.148 & TRN & \\
\hline CHEMBL1531837 & 688641 & 6.6 & $6.4620 e$ & 0000000001 & TRN \\
\hline CHEMBL1357164 & 688641 & 5.0 & 5.1911 & TRN & \\
\hline CHEMBL1476511 & 688641 & 5.1 & 5.0212 & TRN & \\
\hline CHEMBL1512909 & 688641 & 5.5 & 5.1403 & TST & \\
\hline CHEMBL1533680 & 688641 & 4.8 & 4.9157 & TRN & \\
\hline CHEMBL1316953 & 688641 & 6.0 & 5.3163 & TRN & \\
\hline CHEMBL1865649 & 688641 & 6.0 & 6.0319 & TRN & \\
\hline
\end{tabular}


Supplemental Table S2.txt

\begin{tabular}{|c|c|c|c|c|c|}
\hline CHEMBL490749 & 688641 & 6.7001 & 6.8041 & TRN & \\
\hline CHEMBL1476480 & 688641 & 4.9 & 5.1311 & TRN & \\
\hline CHEMBL181633 & 688641 & 5.3 & 5.2127 & TRN & \\
\hline CHEMBL1374335 & 688641 & 5.5 & 5.3474 & TRN & \\
\hline CHEMBL1479470 & 688641 & 4.8 & 4.8126 & TRN & \\
\hline CHEMBL12252 & 688641 & 5.2 & 5.3018 & TRN & \\
\hline CHEMBL1360799 & 688641 & 5.4 & 5.3703 & TRN & \\
\hline CHEMBL1320820 & 688641 & 4.9 & 4.8449 & TRN & \\
\hline CHEMBL1526240 & 688641 & 4.7 & 5.1569 & TRN & \\
\hline CHEMBL1402313 & 688641 & 4.5 & 5.0922 & TRN & \\
\hline CHEMBL1359267 & 688641 & 5.0 & 5.1725 & TST & \\
\hline CHEMBL1342932 & 688641 & 5.5 & 5.5058 & TRN & \\
\hline CHEMBL1523104 & 688641 & 4.5 & 5.0678 & TRN & \\
\hline CHEMBL1444862 & 688641 & 4.9 & 5.2079 & TST & \\
\hline CHEMBL1603264 & 688641 & 5.6 & 5.0273 & TST & \\
\hline CHEMBL1474211 & 688641 & 4.7 & 4.746 & TRN & \\
\hline CHEMBL1554411 & 688641 & 5.5 & 5.4253 & TRN & \\
\hline CHEMBL1256735 & 688641 & 4.8 & 5.0028 & TRN & \\
\hline CHEMBL1476526 & 688641 & 4.8 & 4.8507 & TRN & \\
\hline CHEMBL115121 & 688641 & 5.2 & 5.1955 & TST & \\
\hline CHEMBL92708 & 688641 & 4.8 & 4.9157 & TRN & \\
\hline CHEMBL1530613 & 688641 & 6.1 & 5.9394 & TST & \\
\hline CHEMBL1408259 & 688641 & 6.0 & 5.9542 & TRN & \\
\hline CHEMBL1477081 & 688641 & 4.4 & 5.237 & TRN & \\
\hline CHEMBL1439689 & 688641 & 5.3 & 5.189 & TST & \\
\hline CHEMBL1593663 & 688641 & 5.2 & 5.1618 & TRN & \\
\hline CHEMBL1528820 & 688641 & 4.5 & 4.9207 & TRN & \\
\hline CHEMBL1437011 & 688641 & 5.1 & 5.1213 & TRN & \\
\hline CHEMBL1489568 & 688641 & 4.8 & 4.9511 & TRN & \\
\hline CHEMBL405357 & 688641 & 5.5 & 5.2473 & TRN & \\
\hline CHEMBL1472845 & 688641 & 5.3 & 4.8108 & TRN & \\
\hline CHEMBL450493 & 688641 & 6.5 & \multicolumn{2}{|c|}{6.582999999999999} & TRN \\
\hline CHEMBL1558843 & 688641 & 6.0 & 5.9926 & TRN & \\
\hline CHEMBL1374710 & 688641 & 4.9 & 4.9153 & TRN & \\
\hline CHEMBL239439 & 688641 & 5.8 & 5.5396 & TST & \\
\hline CHEMBL1327619 & 688641 & 5.1 & 5.2309 & TRN & \\
\hline CHEMBL471728 & 688641 & 5.5 & 5.4666 & TST & \\
\hline CHEMBL1370215 & 688641 & 4.8 & 5.1818 & TRN & \\
\hline CHEMBL1355710 & 688641 & 5.0 & 4.9282 & TRN & \\
\hline CHEMBL1411389 & 688641 & 5.2 & 5.3843 & TRN & \\
\hline CHEMBL1596847 & 688641 & 5.1 & 4.9596 & TST & \\
\hline CHEMBL1369406 & 688641 & 5.1 & 5.1366 & TST & \\
\hline CHEMBL1316897 & 688641 & 5.0 & 4.9685 & TRN & \\
\hline CHEMBL1362852 & 688641 & 6.0 & 5.9996 & TRN & \\
\hline CHEMBL1535372 & 688641 & 5.3 & 5.2663 & TRN & \\
\hline CHEMBL1590962 & 688641 & 4.4 & 4.4859 & TRN & \\
\hline CHEMBL1591140 & 688641 & 4.5 & 4.6418 & TRN & \\
\hline CHEMBL244743 & 688641 & 4.9 & 4.9337 & TRN & \\
\hline
\end{tabular}




\begin{tabular}{|c|c|c|c|c|c|}
\hline \multicolumn{6}{|c|}{ Supplemental Table S2.txt } \\
\hline CHEMBL1554099 & 688641 & 5.4 & 5.4801 & TRN & \\
\hline CHEMBL1331045 & 688641 & 5.6 & 5.1711 & TST & \\
\hline CHEMBL1515874 & 688641 & 4.9 & 5.0089 & TRN & \\
\hline CHEMBL1357781 & 688641 & 5.4 & 5.4884 & TRN & \\
\hline CHEMBL1495077 & 688641 & 4.9 & 4.8666 & TRN & \\
\hline CHEMBL1397050 & 688641 & 4.4 & 4.9627 & TRN & \\
\hline CHEMBL1474468 & 688641 & 5.7 & 5.6879 & TRN & \\
\hline CHEMBL1443323 & 688641 & 4.9 & 4.8764 & TRN & \\
\hline CHEMBL1316528 & 688641 & 5.5 & 5.3791 & TRN & \\
\hline CHEMBL406834 & 688641 & 5.4 & 5.1073 & TRN & \\
\hline CHEMBL1332361 & 688641 & 4.5 & 4.7338 & TRN & \\
\hline CHEMBL182461 & 688641 & 7.4001 & 5.0444 & TST & \\
\hline CHEMBL1554577 & 688641 & 6.5 & 6.5926 & TRN & \\
\hline CHEMBL1435118 & 688641 & 4.4 & 5.2272 & TRN & \\
\hline CHEMBL1256663 & 688641 & 4.8 & 4.8521 & TRN & \\
\hline CHEMBL1433687 & 688641 & 5.1 & 5.1473 & TRN & \\
\hline CHEMBL1321459 & 688641 & 5.4 & 5.5476 & TRN & \\
\hline CHEMBL1493117 & 688641 & 5.4 & 5.3638 & TST & \\
\hline CHEMBL29898 & 688641 & 5.2 & 5.0429 & TRN & \\
\hline CHEMBL1603371 & 688641 & 5.0 & 5.1981 & TRN & \\
\hline CHEMBL1593019 & 688641 & 4.9 & 4.8583 & TRN & \\
\hline CHEMBL1514465 & 688641 & 5.0 & 4.91 & TRN & \\
\hline CHEMBL1450455 & 688641 & 4.6 & 4.6434 & TRN & \\
\hline CHEMBL1445946 & 688641 & 5.5 & 5.0712 & TRN & \\
\hline CHEMBL1360610 & 688641 & 4.9 & 5.1806 & TRN & \\
\hline CHEMBL1403041 & 688641 & 5.6 & 5.4848 & TRN & \\
\hline CHEMBL1320518 & 688641 & 5.4 & 5.3478 & TRN & \\
\hline CHEMBL1551066 & 688641 & 4.6 & 4.68199 & 99999999995 & TRN \\
\hline CHEMBL1452946 & 688641 & 5.9 & 5.2303 & TST & \\
\hline CHEMBL3207394 & 688641 & 5.4 & 5.4389 & TRN & \\
\hline CHEMBL1373204 & 688641 & 5.4 & 5.4957 & TRN & \\
\hline CHEMBL1365427 & 688641 & 5.5 & 5.3098 & TRN & \\
\hline CHEMBL1522486 & 688641 & 5.3 & 4.973 & TST & \\
\hline CHEMBL1437166 & 688641 & 4.5 & 5.1944 & TRN & \\
\hline CHEMBL1356041 & 688641 & 5.6 & 5.6433 & TRN & \\
\hline CHEMBL1256686 & 688641 & 5.3 & 5.28299 & 99999999995 & TST \\
\hline CHEMBL1374913 & 688641 & 4.8 & 4.8828 & TRN & \\
\hline CHEMBL1436726 & 688641 & 5.7 & 5.0891 & TRN & \\
\hline CHEMBL1413371 & 688641 & 5.0 & 5.0927 & TRN & \\
\hline CHEMBL1407271 & 688641 & 5.5 & 5.1358 & TRN & \\
\hline CHEMBL1355651 & 688641 & 4.7 & 4.8099 & TRN & \\
\hline CHEMBL1256749 & 688641 & 6.0 & 5.7041 & TST & \\
\hline CHEMBL1356318 & 688641 & 5.5 & 5.1773 & TST & \\
\hline CHEMBL443462 & 688641 & 4.5 & 5.0459 & TST & \\
\hline CHEMBL 9843 & 688641 & 5.1 & 5.1034 & TST & \\
\hline CHEMBL1490998 & 688641 & 5.1 & 5.153 & TRN & \\
\hline CHEMBL1475257 & 688641 & 4.4 & 4.5023 & TRN & \\
\hline CHEMBL1569001 & 688641 & 4.7 & 5.1166 & TRN & \\
\hline
\end{tabular}




\begin{tabular}{|c|c|c|c|c|c|}
\hline \multicolumn{6}{|c|}{ Supplemental Table S2.txt } \\
\hline CHEMBL1319452 & 688641 & 4.6 & 4.9662 & TRN & \\
\hline CHEMBL1591107 & 688641 & 5.2 & 5.2225 & TRN & \\
\hline CHEMBL1333368 & 688641 & 4.7 & 5.1016 & TRN & \\
\hline CHEMBL1358724 & 688641 & 4.9 & 5.119 & TST & \\
\hline CHEMBL1452722 & 688641 & 5.4 & 5.2282 & TST & \\
\hline CHEMBL1611192 & 688641 & 4.8 & 4.9133 & TST & \\
\hline CHEMBL1562612 & 688641 & 5.3 & 5.2301 & TST & \\
\hline CHEMBL1078384 & 688641 & 4.8 & 5.1489 & TRN & \\
\hline CHEMBL1256911 & 688641 & 4.9 & 4.9507 & TRN & \\
\hline CHEMBL467085 & 688641 & 4.5 & 4.6499 & TST & \\
\hline CHEMBL1590259 & 688641 & 4.9 & 4.9472 & TRN & \\
\hline CHEMBL18701 & 688641 & 4.8 & 4.9083 & TRN & \\
\hline CHEMBL1453244 & 688641 & 5.3 & 5.3384 & TRN & \\
\hline CHEMBL1595709 & 688641 & 6.0 & 5.78299 & 99999999995 & TST \\
\hline CHEMBL510275 & 688641 & 4.7 & 5.1165 & TST & \\
\hline CHEMBL1555320 & 688641 & 5.0 & 4.9239 & TRN & \\
\hline CHEMBL1440715 & 688641 & 4.7 & 4.7038 & TRN & \\
\hline CHEMBL1435033 & 688641 & 5.5 & 5.5426 & TST & \\
\hline CHEMBL303579 & 688641 & 5.9 & 5.6202 & TRN & \\
\hline CHEMBL1397009 & 688641 & 5.0 & 4.8472 & TRN & \\
\hline CHEMBL1512250 & 688641 & 4.7 & 4.7348 & TRN & \\
\hline CHEMBL285932 & 688641 & 5.0 & 5.0239 & TST & \\
\hline CHEMBL1222498 & 688641 & 4.8 & 4.8731 & TST & \\
\hline CHEMBL3208495 & 688641 & 5.0 & 5.2781 & TST & \\
\hline CHEMBL1513578 & 688641 & 5.4 & 5.1812 & TRN & \\
\hline CHEMBL275809 & 688641 & 5.1 & 5.1004 & TRN & \\
\hline CHEMBL1599163 & 688641 & 4.6 & 4.6481 & TRN & \\
\hline CHEMBL1511042 & 688641 & 5.7 & 5.4978 & TRN & \\
\hline CHEMBL259140 & 688641 & 5.3 & 5.5623 & TRN & \\
\hline CHEMBL76589 & 688641 & 4.4 & 4.6968 & TRN & \\
\hline CHEMBL1395038 & 688641 & 4.7 & 5.083 & TRN & \\
\hline CHEMBL1557053 & 688641 & 5.7 & 5.4414 & TRN & \\
\hline CHEMBL1572770 & 688641 & 5.5 & 5.3616 & TST & \\
\hline CHEMBL1256797 & 688641 & 6.0 & 5.7904 & TRN & \\
\hline CHEMBL1370770 & 688641 & 6.0 & 5.7465 & TRN & \\
\hline CHEMBL1356721 & 688641 & 5.4 & 5.3451 & TRN & \\
\hline CHEMBL1375229 & 688641 & 5.2 & 5.1338 & TRN & \\
\hline CHEMBL1531294 & 688641 & 6.0 & 6.0242 & TRN & \\
\hline CHEMBL242171 & 688641 & 4.7 & 5.1097 & TRN & \\
\hline CHEMBL1527324 & 688641 & 4.6 & 5.261 & TST & \\
\hline CHEMBL1322233 & 688641 & 4.7 & 4.8 & TRN & \\
\hline CHEMBL1332182 & 688641 & 6.2 & 5.8951 & TST & \\
\hline CHEMBL1318447 & 688641 & 4.6 & 4.67399 & 99999999995 & TRN \\
\hline CHEMBL1378132 & 688641 & 4.6 & 4.6745 & TRN & \\
\hline CHEMBL1589942 & 688641 & 5.9 & 5.7733 & TST & \\
\hline CHEMBL1476271 & 688641 & 4.4 & 5.2114 & TST & \\
\hline CHEMBL1412390 & 688641 & 5.5 & 5.5841 & TRN & \\
\hline CHEMBL1592589 & 688641 & 5.9 & 5.3218 & TST & \\
\hline
\end{tabular}




\begin{tabular}{|c|c|c|c|c|c|}
\hline \multicolumn{6}{|c|}{ Supplemental Table S2.txt } \\
\hline CHEMBL370761 & 688641 & 4.8 & 5.2816 & TST & \\
\hline CHEMBL1409109 & 688641 & 5.0 & 5.02800 & 00000000005 & TST \\
\hline CHEMBL1592376 & 688641 & 5.2 & 5.3003 & TRN & \\
\hline CHEMBL454802 & 688641 & 6.6 & 6.2344 & TRN & \\
\hline CHEMBL1322137 & 688641 & 6.1 & 5.7462 & TST & \\
\hline CHEMBL1595282 & 688641 & 4.8 & 4.9916 & TRN & \\
\hline CHEMBL1361513 & 688641 & 4.9 & 4.917 & TRN & \\
\hline CHEMBL3391702 & 688641 & 6.4 & 5.7337 & TST & \\
\hline CHEMBL1532186 & 688641 & 4.6 & 5.1081 & TRN & \\
\hline CHEMBL447876 & 688641 & 5.1 & 5.4028 & TST & \\
\hline CHEMBL1445522 & 688641 & 4.8 & 4.8939 & TRN & \\
\hline CHEMBL1496569 & 688641 & 4.5 & 4.544 & TRN & \\
\hline CHEMBL95606 & 688641 & 4.5 & 4.6346 & TRN & \\
\hline CHEMBL1516346 & 688641 & 5.2 & 5.2939 & TST & \\
\hline CHEMBL1561579 & 688641 & 5.5 & 5.4845 & TRN & \\
\hline CHEMBL1473754 & 688641 & 4.7 & 4.7894 & TRN & \\
\hline CHEMBL1256913 & 688641 & 5.0 & 5.0043 & TRN & \\
\hline CHEMBL1370675 & 688641 & 4.8 & 5.1756 & TRN & \\
\hline CHEMBL102740 & 688641 & 4.4 & 5.1388 & TST & \\
\hline CHEMBL1474523 & 688641 & 4.4 & 5.3774 & TRN & \\
\hline CHEMBL1491313 & 688641 & 4.5 & 5.2688 & TRN & \\
\hline CHEMBL1320943 & 688641 & 5.4 & 4.9863 & TRN & \\
\hline CHEMBL1475142 & 688641 & 5.5 & 5.1075 & TRN & \\
\hline CHEMBL1359843 & 688641 & 4.9 & 4.8898 & TRN & \\
\hline CHEMBL1513121 & 688641 & 5.1 & 5.09399 & 9999999999 & TRN \\
\hline CHEMBL1370136 & 688641 & 5.4 & 5.5256 & TRN & \\
\hline CHEMBL1375431 & 688641 & 4.8 & 4.8696 & TRN & \\
\hline CHEMBL1479088 & 688641 & 5.6 & 5.8277 & TRN & \\
\hline CHEMBL1318278 & 688641 & 4.6 & 4.6247 & TRN & \\
\hline CHEMBL1553635 & 688641 & 5.3 & 5.3506 & TST & \\
\hline CHEMBL1365994 & 688641 & 5.9 & 5.9686 & TRN & \\
\hline CHEMBL1325335 & 688641 & 4.6 & 4.5927 & TRN & \\
\hline CHEMBL269521 & 688641 & 4.8 & 4.8944 & TST & \\
\hline CHEMBL41092 & 688641 & 4.6 & 4.9661 & TRN & \\
\hline CHEMBL567175 & 688641 & 6.0 & 5.7609 & TST & \\
\hline CHEMBL1611218 & 688641 & 5.0 & 5.0091 & TST & \\
\hline CHEMBL1450169 & 688641 & 5.5 & 5.2214 & TRN & \\
\hline CHEMBL1727680 & 688641 & 5.4 & 5.4364 & TRN & \\
\hline CHEMBL1314844 & 688641 & 5.4 & 5.4571 & TRN & \\
\hline CHEMBL1533413 & 688641 & 5.4 & 5.3552 & TST & \\
\hline CHEMBL83552 & 688641 & 5.3 & 4.9895 & TRN & \\
\hline CHEMBL1475381 & 688641 & 5.0 & 4.9861 & TRN & \\
\hline CHEMBL125569 & 688641 & 4.6 & 4.7037 & TST & \\
\hline CHEMBL1376070 & 688641 & 5.5 & 5.3294 & TST & \\
\hline CHEMBL1445792 & 688641 & 6.0 & 5.1617 & TRN & \\
\hline CHEMBL502242 & 688641 & 5.1 & 5.2011 & TRN & \\
\hline CHEMBL1433776 & 688641 & 4.9 & 4.9318 & TRN & \\
\hline CHEMBL1318518 & 688641 & 4.9 & 4.8284 & TRN & \\
\hline
\end{tabular}




\begin{tabular}{|c|c|c|c|c|c|}
\hline \multicolumn{6}{|c|}{ Supplemental Table S2.txt } \\
\hline CHEMBL14690 & 688641 & 5.8 & 5.6455 & TRN & \\
\hline CHEMBL1256737 & 688641 & 6.0 & 5.6762 & TST & \\
\hline CHEMBL88402 & 688641 & 5.1 & 5.1535 & TST & \\
\hline CHEMBL272682 & 688641 & 4.9 & 5.1635 & TRN & \\
\hline CHEMBL3212160 & 688641 & 5.4 & 5.4397 & TRN & \\
\hline CHEMBL21260 & 688641 & 6.0 & 5.8065 & TST & \\
\hline CHEMBL112816 & 688641 & 4.9 & 4.8254 & TST & \\
\hline CHEMBL1600436 & 688641 & 4.4 & 5.3031 & TST & \\
\hline CHEMBL1403134 & 688641 & 5.0 & 5.117 & TRN & \\
\hline CHEMBL175858 & 688641 & 4.9 & 5.16100 & 00000000005 & TRN \\
\hline CHEMBL1324889 & 688641 & 5.9 & 6.0355 & TRN & \\
\hline CHEMBL1473834 & 688641 & 5.2 & 5.2109 & TRN & \\
\hline CHEMBL1397888 & 688641 & 4.5 & 5.2124 & TRN & \\
\hline CHEMBL1354693 & 688641 & 4.7 & 4.7318 & TRN & \\
\hline CHEMBL1479036 & 688641 & 5.4 & 5.244 & TST & \\
\hline CHEMBL1341097 & 688641 & 5.0 & 5.0428 & TST & \\
\hline CHEMBL1369318 & 688641 & 5.8 & 5.8878 & TRN & \\
\hline CHEMBL1372330 & 688641 & 6.0 & 6.0551 & TRN & \\
\hline CHEMBL1369515 & 688641 & 4.7 & 4.7297 & TRN & \\
\hline CHEMBL1498 & 688641 & 5.8 & 5.3258 & TRN & \\
\hline CHEMBL1445913 & 688641 & 5.6 & 5.4567 & TST & \\
\hline CHEMBL1450525 & 688641 & 5.5 & 5.4123 & TST & \\
\hline CHEMBL1366068 & 688641 & 4.5 & 4.6658 & TRN & \\
\hline CHEMBL1355335 & 688641 & 4.8 & 5.0397 & TRN & \\
\hline CHEMBL1358664 & 688641 & 5.4 & 5.4427 & TRN & \\
\hline CHEMBL3392051 & 688641 & 5.4 & 5.2929 & TRN & \\
\hline CHEMBL474415 & 688641 & 5.1 & 5.2559 & TRN & \\
\hline CHEMBL1401642 & 688641 & 4.8 & 5.4873 & TRN & \\
\hline CHEMBL1564927 & 688641 & 5.4 & 5.2803 & TST & \\
\hline CHEMBL6640 & 688641 & 4.4 & 4.9743 & TRN & \\
\hline CHEMBL1454949 & 688641 & 5.6 & 5.4378 & TST & \\
\hline CHEMBL1357360 & 688641 & 5.4 & 5.3783 & TRN & \\
\hline CHEMBL1454920 & 688641 & 5.0 & 5.0971 & TRN & \\
\hline CHEMBL1565965 & 688641 & 4.8 & 4.7545 & TRN & \\
\hline CHEMBL1374334 & 688641 & 6.2 & 5.9878 & TST & \\
\hline CHEMBL129795 & 688641 & 6.0 & 5.4529 & TRN & \\
\hline CHEMBL1594648 & 688641 & 5.2 & 5.0882 & TRN & \\
\hline CHEMBL1437119 & 688641 & 4.7 & 4.7171 & TRN & \\
\hline CHEMBL492132 & 688641 & 6.4 & 6.5071 & TRN & \\
\hline CHEMBL1491853 & 688641 & 5.5 & 5.4955 & TST & \\
\hline CHEMBL1442987 & 688641 & 6.0 & 6.1043 & TRN & \\
\hline CHEMBL1496590 & 688641 & 4.8 & 5.001 & TRN & \\
\hline CHEMBL1591908 & 688641 & 5.1 & 5.1091 & TRN & \\
\hline CHEMBL1370705 & 688641 & 5.4 & 5.1176 & TRN & \\
\hline CHEMBL429023 & 688641 & 6.0 & 4.7315 & TRN & \\
\hline CHEMBL1257078 & 688641 & 6.0 & 4.9891 & TST & \\
\hline CHEMBL1490869 & 688641 & 5.4 & 5.4988 & TRN & \\
\hline CHEMBL1397490 & 688641 & 4.8 & 4.9631 & TRN & \\
\hline
\end{tabular}




\begin{tabular}{|c|c|c|c|c|c|}
\hline \multicolumn{6}{|c|}{ plemental } \\
\hline CHEMBL137498 & 688641 & 5.4 & 5.0386 & TRN & \\
\hline CHEMBL1604925 & 688641 & 6.0 & 5.09399 & 9999999999 & TST \\
\hline CHEMBL242172 & 688641 & 4.8 & 5.1901 & TRN & \\
\hline CHEMBL1604095 & 688641 & 4.8 & 4.8687 & TRN & \\
\hline CHEMBL1590432 & 688641 & 4.8 & 5.1626 & TST & \\
\hline CHEMBL1534734 & 688641 & 4.6 & 4.933 & TRN & \\
\hline CHEMBL1514375 & 688641 & 4.8 & 4.9995 & TST & \\
\hline CHEMBL68534 & 688641 & 5.1 & 5.0537 & TRN & \\
\hline CHEMBL1086446 & 688641 & 4.8 & 5.0067 & TRN & \\
\hline CHEMBL1314225 & 688641 & 4.8 & 4.8514 & TRN & \\
\hline CHEMBL1398683 & 688641 & 4.8 & 4.9543 & TST & \\
\hline CHEMBL1373160 & 688641 & 4.9 & 4.9135 & TRN & \\
\hline CHEMBL1317885 & 688641 & 4.8 & 4.9068 & TRN & \\
\hline CHEMBL1526852 & 688641 & 4.4 & 4.6217 & TRN & \\
\hline CHEMBL1603418 & 688641 & 4.8 & 4.8433 & TRN & \\
\hline CHEMBL1355408 & 688641 & 6.2 & 6.2046 & TRN & \\
\hline CHEMBL 252722 & 688641 & 4.6 & 5.505 & TRN & \\
\hline CHEMBL1475358 & 688641 & 5.6 & 5.7562 & TRN & \\
\hline CHEMBL175296 & 688641 & 4.7 & 5.1134 & TRN & \\
\hline CHEMBL1317135 & 688641 & 6.4 & 6.1509 & TST & \\
\hline CHEMBL1338708 & 688641 & 6.2 & 5.3857 & TRN & \\
\hline CHEMBL1531163 & 688641 & 5.4 & 5.2524 & TRN & \\
\hline CHEMBL1415521 & 688641 & 6.0 & 6.0894 & TRN & \\
\hline CHEMBL1355051 & 688641 & 4.4 & 5.2331 & TRN & \\
\hline CHEMBL1477870 & 688641 & 5.4 & 4.9815 & TRN & \\
\hline CHEMBL1436532 & 688641 & 5.5 & 5.5807 & TRN & \\
\hline CHEMBL1490919 & 688641 & 4.8 & 5.1409 & TST & \\
\hline CHEMBL35482 & 688641 & 5.1 & 5.1005 & TRN & \\
\hline CHEMBL 261237 & 688641 & 5.9 & 5.1662 & TST & \\
\hline CHEMBL66105 & 688641 & 6.0 & 5.7332 & TST & \\
\hline CHEMBL1457390 & 688641 & 4.6 & 4.6833 & TRN & \\
\hline CHEMBL1255737 & 688641 & 5.9 & 5.1004 & TRN & \\
\hline CHEMBL1369874 & 688641 & 6.0 & 1.2054 & TRN & \\
\hline CHEMBL1235001 & 688641 & 5.0 & 5.0394 & TST & \\
\hline CHEMBL30432 & 688641 & 5.3 & 5.24799 & 9999999999 & TST \\
\hline CHEMBL1322026 & 688641 & 5.4 & 5.3219 & TST & \\
\hline CHEMBL1399103 & 688641 & 5.3 & 5.1391 & TST & \\
\hline CHEMBL1991126 & 688641 & 4.6 & 5.0309 & TRN & \\
\hline CHEMBL1395899 & 688641 & 5.3 & 5.2464 & TRN & \\
\hline CHEMBL1324667 & 688641 & 5.7 & 5.9535 & TRN & \\
\hline CHEMBL1433559 & 688641 & 5.1 & 5.1856 & TRN & \\
\hline CHEMBL1451057 & 688641 & 6.0 & 5.8529 & TRN & \\
\hline CHEMBL131921 & 688641 & 4.7 & 5.1283 & TRN & \\
\hline CHEMBL15192 & 688641 & 4.8 & 4.8791 & TST & \\
\hline CHEMBL192627 & 688641 & 5.7 & 4.8969 & TST & \\
\hline CHEMBL1556218 & 688641 & 4.9 & 4.9347 & TRN & \\
\hline CHEMBL286136 & 688641 & 4.8 & 4.7882 & TRN & \\
\hline CHEMBL1599014 & 688641 & 6.1 & 6.0466 & TRN & \\
\hline
\end{tabular}




\begin{tabular}{|c|c|c|c|c|c|}
\hline & & \multicolumn{4}{|c|}{ Supplemental Table S2.txt } \\
\hline CHEMBL1554937 & 688641 & 4.8 & 4.7613 & TRN & \\
\hline CHEMBL1411424 & 688641 & 5.3 & 5.159 & TRN & \\
\hline CHEMBL1574786 & 688641 & 5.7 & 5.3977 & TRN & \\
\hline CHEMBL1551584 & 688641 & 6.0 & 5.9937 & TRN & \\
\hline CHEMBL1551336 & 688641 & 6.1 & 5.6733 & TST & \\
\hline CHEMBL1471289 & 688641 & 4.6 & 5.0133 & TST & \\
\hline CHEMBL1606727 & 688641 & 5.6 & 5.7125 & TRN & \\
\hline CHEMBL261617 & 688641 & 5.7 & 5.2322 & TRN & \\
\hline CHEMBL1554791 & 688641 & 4.8 & 4.8271 & TRN & \\
\hline CHEMBL1552405 & 688641 & 5.0 & 4.8983 & TRN & \\
\hline CHEMBL1398392 & 688641 & 5.4 & 5.1916 & TST & \\
\hline CHEMBL1485361 & 688641 & 5.5 & 5.6091 & TRN & \\
\hline CHEMBL1370622 & 688641 & 5.7 & 5.6792 & TRN & \\
\hline CHEMBL1329059 & 688641 & 6.0 & 5.0901 & TRN & \\
\hline CHEMBL3351080 & 688641 & 5.5 & 5.3574 & TST & \\
\hline CHEMBL1339029 & 688641 & 5.3 & 5.2759 & TRN & \\
\hline CHEMBL1442458 & 688641 & 4.6 & 4.6667 & TRN & \\
\hline CHEMBL1437990 & 688641 & 5.6 & 5.5427 & TRN & \\
\hline CHEMBL1320662 & 688641 & 4.9 & 4.9314 & TRN & \\
\hline CHEMBL1324418 & 688641 & 4.7 & 4.7394 & TRN & \\
\hline CHEMBL1397860 & 688641 & 6.3 & 6.2509 & TRN & \\
\hline CHEMBL1567944 & 688641 & 6.0 & 6.1161 & TRN & \\
\hline CHEMBL1450026 & 688641 & 4.7 & 4.7574 & TRN & \\
\hline CHEMBL1361285 & 688641 & 5.4 & 5.2761 & TRN & \\
\hline CHEMBL1336166 & 688641 & 4.9 & 5.0285 & TST & \\
\hline CHEMBL1377106 & 688641 & 4.9 & 4.9691 & TRN & \\
\hline CHEMBL1600408 & 688641 & 5.5 & 5.6603 & TRN & \\
\hline CHEMBL1405913 & 688641 & 5.4 & 5.4342 & TRN & \\
\hline CHEMBL416657 & 688641 & 4.7 & 4.8032 & TRN & \\
\hline CHEMBL58033 & 688641 & 6.0 & 5.7775 & TRN & \\
\hline CHEMBL1374524 & 688641 & 5.4 & 5.3195 & TST & \\
\hline CHEMBL1317962 & 688641 & 5.4 & 4.8995 & TST & \\
\hline CHEMBL1410367 & 688641 & 6.0 & 5.7055 & TRN & \\
\hline CHEMBL1597209 & 688641 & 4.6 & 4.7346 & TRN & \\
\hline CHEMBL1513740 & 688641 & 4.8 & 4.8911 & TRN & \\
\hline CHEMBL1407011 & 688641 & 4.9 & 5.1415 & TRN & \\
\hline CHEMBL73711 & 688641 & 5.5 & 5.176 & TRN & \\
\hline CHEMBL1359713 & 688641 & 6.7001 & 6.6863 & TRN & \\
\hline CHEMBL1518947 & 688641 & 4.8 & 4.8271 & TRN & \\
\hline CHEMBL1417140 & 688641 & 5.7 & 5.5343 & TRN & \\
\hline CHEMBL1601662 & 688641 & 4.8 & 4.9636 & TRN & \\
\hline CHEMBL1356713 & 688641 & 4.4 & 5.3516 & TST & \\
\hline CHEMBL1395472 & 688641 & 5.5 & 5.3234 & TRN & \\
\hline CHEMBL1314906 & 688641 & 4.9 & 4.9281 & TRN & \\
\hline CHEMBL1591429 & 688641 & 4.8 & $5.0360 e$ & 00000000005 & TRN \\
\hline CHEMBL1358252 & 688641 & 4.8 & 4.8677 & TRN & \\
\hline CHEMBL1512756 & 688641 & 4.8 & 4.6625 & TRN & \\
\hline CHEMBL1600187 & 688641 & 5.4 & 5.2468 & TRN & \\
\hline
\end{tabular}




\begin{tabular}{|c|c|c|c|c|}
\hline \multicolumn{5}{|c|}{ Supplemental Table s2.txt } \\
\hline CHEMBL2374096 & 688641 & 5.1 & 5.2407 & TST \\
\hline CHEMBL1323438 & 688641 & 4.9 & 4.9827 & TRN \\
\hline CHEMBL1560567 & 688641 & 6.0 & 5.3847 & TRN \\
\hline CHEMBL1314446 & 688641 & 5.1 & 5.0361 & TRN \\
\hline CHEMBL1728023 & 688641 & 6.0 & 5.2367 & TRN \\
\hline CHEMBL1412232 & 688641 & 5.1 & 5.0167 & TRN \\
\hline CHEMBL15060 & 688641 & 4.9 & 4.9954 & TRN \\
\hline CHEMBL1355720 & 688641 & 5.8 & 5.6214 & TRN \\
\hline CHEMBL1316808 & 688641 & 4.9 & 4.8344 & TRN \\
\hline CHEMBL1439893 & 688641 & 5.3 & 5.3818 & TRN \\
\hline CHEMBL1518415 & 688641 & 6.5 & 6.4508 & TRN \\
\hline CHEMBL1256910 & 688641 & 6.0 & 4.9703 & TST \\
\hline CHEMBL1315609 & 688641 & 5.4 & 5.3884 & TRN \\
\hline CHEMBL1332964 & 688641 & 5.6 & 5.8883 & TRN \\
\hline CHEMBL1362225 & 688641 & 4.9 & 4.9863 & TRN \\
\hline CHEMBL1475657 & 688641 & 5.0 & 5.0006 & TRN \\
\hline CHEMBL1356115 & 688641 & 4.5 & 5.2654 & TST \\
\hline CHEMBL1256325 & 688641 & 4.5 & 4.7005 & TRN \\
\hline CHEMBL1319251 & 688641 & 5.4 & 5.16700 & 0000000001 \\
\hline CHEMBL1594421 & 688641 & 5.0 & 4.9664 & TRN \\
\hline CHEMBL1402088 & 688641 & 5.4 & 5.1599 & TRN \\
\hline CHEMBL1314486 & 688641 & 6.1 & 6.2648 & TRN \\
\hline CHEMBL1603788 & 688641 & 4.5 & 5.0793 & TRN \\
\hline CHEMBL1452850 & 688641 & 5.4 & 5.5119 & TRN \\
\hline CHEMBL1570788 & 688641 & 4.9 & 5.0213 & TST \\
\hline CHEMBL1477492 & 688641 & 4.6 & 4.6638 & TRN \\
\hline CHEMBL1590598 & 688641 & 5.2 & 5.0977 & TRN \\
\hline CHEMBL1476892 & 688641 & 6.0 & 6.0425 & TRN \\
\hline CHEMBL476135 & 688641 & 6.0 & 5.7838 & TST \\
\hline CHEMBL1400612 & 688641 & 4.8 & 5.0315 & TST \\
\hline CHEMBL1552150 & 688641 & 5.1 & 5.0742 & TRN \\
\hline CHEMBL1515945 & 688641 & 7.3002 & 6.5487 & TRN \\
\hline CHEMBL1371944 & 688641 & 5.5 & 5.7384 & TRN \\
\hline CHEMBL1317096 & 688641 & 5.5 & 5.0851 & TST \\
\hline CHEMBL1590360 & 688641 & 4.8 & 5.1065 & TRN \\
\hline CHEMBL1611302 & 688641 & 5.9 & 5.3604 & TST \\
\hline CHEMBL3207752 & 688641 & 5.1 & 5.274 & TST \\
\hline CHEMBL1493644 & 688641 & 5.5 & 4.6141 & TRN \\
\hline CHEMBL1494529 & 688641 & 4.8 & 4.879 & TRN \\
\hline CHEMBL1414269 & 688641 & 4.8 & 4.7916 & TRN \\
\hline CHEMBL1318495 & 688641 & 5.9 & 6.0258 & TRN \\
\hline CHEMBL1320469 & 688641 & 5.4 & 5.5322 & TRN \\
\hline CHEMBL1480558 & 688641 & 6.7001 & 5.1486 & TST \\
\hline CHEMBL1327204 & 688641 & 4.8 & 4.8315 & TRN \\
\hline CHEMBL1514486 & 688641 & 5.1 & 5.1175 & TST \\
\hline CHEMBL 258465 & 688641 & 5.5 & 5.3928 & TST \\
\hline CHEMBL1320730 & 688641 & 4.8 & 4.9056 & TRN \\
\hline CHEMBL1395839 & 688641 & 5.4 & 5.1722 & TRN \\
\hline
\end{tabular}




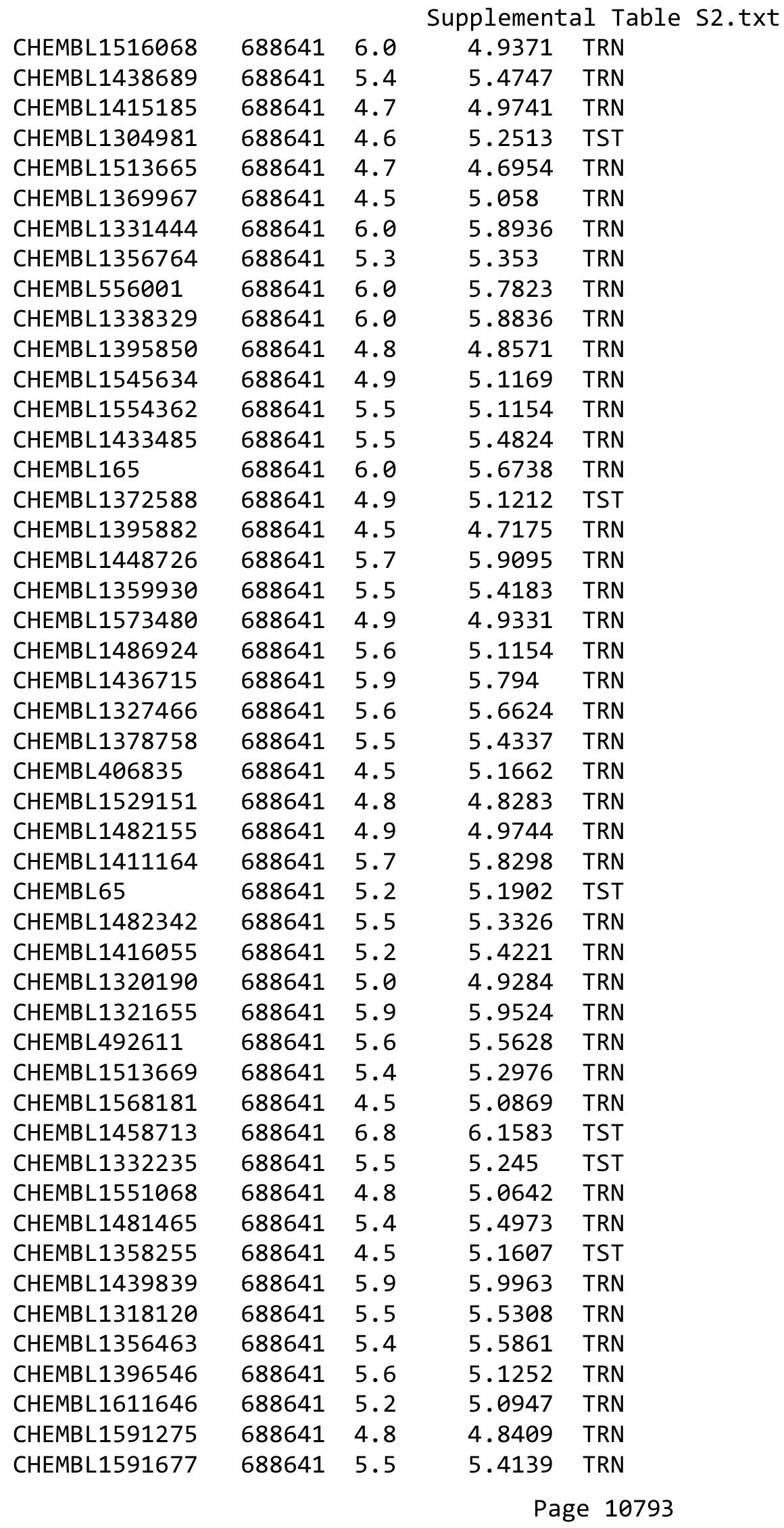




\begin{tabular}{|c|c|c|c|c|c|}
\hline \multicolumn{6}{|c|}{ Supplemental Table S2.txt } \\
\hline CHEMBL1356879 & 688641 & 5.7 & 5.5525 & TST & \\
\hline CHEMBL230056 & 688641 & 4.9 & 5.0168 & TST & \\
\hline CHEMBL1598717 & 688641 & 5.6 & 5.7978 & TRN & \\
\hline CHEMBL1562589 & 688641 & 5.8 & 5.6926 & TST & \\
\hline CHEMBL1564985 & 688641 & 5.9 & 5.4008 & TRN & \\
\hline CHEMBL1574196 & 688641 & 4.9 & 4.9801 & TRN & \\
\hline CHEMBL1590590 & 688641 & 5.4 & 4.88 & TRN & \\
\hline CHEMBL1551518 & 688641 & 4.9 & 5.0198 & TRN & \\
\hline CHEMBL1552747 & 688641 & 5.1 & 5.0558 & TRN & \\
\hline CHEMBL1560685 & 688641 & 5.1 & 5.147 & TRN & \\
\hline CHEMBL210868 & 688641 & 4.7 & 5.1633 & TST & \\
\hline CHEMBL1486902 & 688641 & 5.4 & 5.5661 & TRN & \\
\hline CHEMBL23832 & 688641 & 4.5 & 4.7687 & TRN & \\
\hline CHEMBL19439 & 688641 & 6.0 & 5.7568 & TRN & \\
\hline CHEMBL1302739 & 688641 & 7.8996 & 5.1468 & TST & \\
\hline CHEMBL1374427 & 688641 & 4.6 & 5.1678 & TRN & \\
\hline CHEMBL362223 & 688641 & 4.6 & 4.6688 & TRN & \\
\hline CHEMBL1435254 & 688641 & 5.8 & 5.7779 & TRN & \\
\hline CHEMBL1256573 & 688641 & 6.0 & 5.7222 & TST & \\
\hline CHEMBL307893 & 688641 & 4.4 & 5.0809 & TRN & \\
\hline CHEMBL1315417 & 688641 & 4.9 & 4.9565 & TST & \\
\hline CHEMBL1488467 & 688641 & 4.9 & 5.0397 & TRN & \\
\hline CHEMBL1317294 & 688641 & 4.9 & 5.0494 & TRN & \\
\hline CHEMBL1613725 & 688641 & 4.9 & 4.9392 & TRN & \\
\hline CHEMBL15594 & 688641 & 6.0 & 4.7286 & TRN & \\
\hline CHEMBL405081 & 688641 & 5.6 & 5.1745 & TRN & \\
\hline CHEMBL1409261 & 688641 & 5.0 & 5.1567 & TRN & \\
\hline CHEMBL236789 & 688641 & 6.0 & 5.7799 & TRN & \\
\hline CHEMBL1366812 & 688641 & 4.4 & 5.1951 & TST & \\
\hline CHEMBL481049 & 688641 & 4.5 & 5.0847 & TRN & \\
\hline CHEMBL1335140 & 688641 & 5.4 & 5.1741 & TRN & \\
\hline CHEMBL1316731 & 688641 & 5.1 & 4.9645 & TRN & \\
\hline CHEMBL1526697 & 688641 & 5.5 & $5.4670 e$ & 00000000005 & TRN \\
\hline CHEMBL1357247 & 688641 & 4.8 & 4.9069 & TST & \\
\hline CHEMBL1555396 & 688641 & 5.8 & 5.5164 & TRN & \\
\hline CHEMBL1395098 & 688641 & 4.5 & 4.6474 & TRN & \\
\hline CHEMBL512908 & 688641 & 6.3 & 5.9721 & TRN & \\
\hline CHEMBL1593743 & 688641 & 4.9 & 5.034 & TST & \\
\hline CHEMBL1358092 & 688641 & 5.7 & 5.5734 & TRN & \\
\hline CHEMBL1590545 & 688641 & 5.0 & 5.2461 & TST & \\
\hline CHEMBL1357151 & 688641 & 4.4 & 5.2086 & TST & \\
\hline CHEMBL1558303 & 688641 & 5.0 & 4.9034 & TRN & \\
\hline CHEMBL1409518 & 688641 & 4.9 & 5.2924 & TST & \\
\hline CHEMBL1456688 & 688641 & 4.6 & 4.7112 & TRN & \\
\hline CHEMBL411492 & 688641 & 5.1 & 5.0589 & TRN & \\
\hline CHEMBL1256959 & 688641 & 5.4 & 5.0863 & TST & \\
\hline CHEMBL1361149 & 688641 & 4.9 & 4.9271 & TRN & \\
\hline CHEMBL471226 & 688641 & 5.4 & 5.3873 & TRN & \\
\hline
\end{tabular}




\begin{tabular}{|c|c|c|c|c|c|}
\hline \multicolumn{6}{|c|}{ Supplemental Table S2.txt } \\
\hline CHEMBL294009 & 688641 & 4.6 & 5.0679 & TRN & \\
\hline CHEMBL1333056 & 688641 & 6.0 & 5.6581 & TST & \\
\hline CHEMBL187460 & 688641 & 4.8 & 5.2085 & TST & \\
\hline CHEMBL1385840 & 688641 & 5.9 & 5.5861 & TST & \\
\hline CHEMBL1444973 & 688641 & 4.9 & 5.1888 & TRN & \\
\hline CHEMBL1569585 & 688641 & 5.1 & 5.2009 & TRN & \\
\hline CHEMBL1357293 & 688641 & 5.9 & 5.67299 & 9999999999 & TRN \\
\hline CHEMBL1513614 & 688641 & 6.2 & 5.7076 & TRN & \\
\hline CHEMBL1561500 & 688641 & 4.5 & 4.57 & TRN & \\
\hline CHEMBL1335967 & 688641 & 5.0 & 4.8094 & TRN & \\
\hline CHEMBL1441415 & 688641 & 5.1 & 5.2816 & TRN & \\
\hline CHEMBL1473317 & 688641 & 5.4 & 5.2543 & TRN & \\
\hline CHEMBL1564802 & 688641 & 5.0 & 5.1414 & TRN & \\
\hline CHEMBL1610082 & 688641 & 4.9 & 4.8568 & TRN & \\
\hline CHEMBL1356624 & 688641 & 4.8 & 4.9266 & TRN & \\
\hline CHEMBL1453358 & 688641 & 5.0 & 5.5443 & TRN & \\
\hline CHEMBL1394964 & 688641 & 4.7 & 4.7408 & TRN & \\
\hline CHEMBL1434833 & 688641 & 5.0 & 5.0505 & TRN & \\
\hline CHEMBL1592212 & 688641 & 4.5 & 4.6246 & TRN & \\
\hline CHEMBL 94734 & 688641 & 4.9 & 4.9377 & TRN & \\
\hline CHEMBL1374585 & 688641 & 4.4 & 4.5297 & TRN & \\
\hline CHEMBL1256709 & 688641 & 4.7 & 4.8174 & TRN & \\
\hline CHEMBL490742 & 688641 & 5.9 & 6.115 & TRN & \\
\hline CHEMBL1598334 & 688641 & 5.4 & 5.50899 & 99999999995 & TRN \\
\hline CHEMBL1517425 & 688641 & 4.8 & 5.0993 & TST & \\
\hline CHEMBL1567150 & 688641 & 4.8 & 5.0001 & TRN & \\
\hline CHEMBL587849 & 688641 & 5.8 & 5.5692 & TRN & \\
\hline CHEMBL1412305 & 688641 & 6.0 & 5.8303 & TRN & \\
\hline CHEMBL1522525 & 688641 & 4.5 & 5.1222 & TST & \\
\hline CHEMBL1510786 & 688641 & 5.7 & 5.42299 & 9999999999 & TRN \\
\hline CHEMBL1395792 & 688641 & 5.2 & 5.4071 & TRN & \\
\hline CHEMBL1495634 & 688641 & 5.5 & 5.4947 & TRN & \\
\hline CHEMBL1398467 & 688641 & 4.6 & 4.6739 & TRN & \\
\hline CHEMBL1354529 & 688641 & 4.4 & 5.0427 & TRN & \\
\hline CHEMBL1533575 & 688641 & 4.5 & 4.5561 & TRN & \\
\hline CHEMBL1520411 & 688641 & 4.7 & 5.1763 & TRN & \\
\hline CHEMBL1474817 & 688641 & 5.4 & 5.0294 & TRN & \\
\hline CHEMBL1434085 & 688641 & 4.9 & 4.9187 & TRN & \\
\hline CHEMBL1358735 & 688641 & 4.6 & 5.1259 & TST & \\
\hline CHEMBL1321975 & 688641 & 4.6 & 5.244 & TRN & \\
\hline CHEMBL1609896 & 688641 & 5.5 & 5.335 & TRN & \\
\hline CHEMBL1333531 & 688641 & 4.6 & 4.6917 & TRN & \\
\hline CHEMBL1512478 & 688641 & 5.4 & 5.1265 & TRN & \\
\hline CHEMBL1406782 & 688641 & 4.6 & 4.6584 & TRN & \\
\hline CHEMBL1495665 & 688641 & 5.2 & 5.1799 & TRN & \\
\hline CHEMBL462576 & 688641 & 6.0 & 5.0359 & TST & \\
\hline CHEMBL536950 & 688641 & 4.5 & 4.5728 & TST & \\
\hline CHEMBL1491966 & 688641 & 5.6 & 5.6224 & TRN & \\
\hline
\end{tabular}




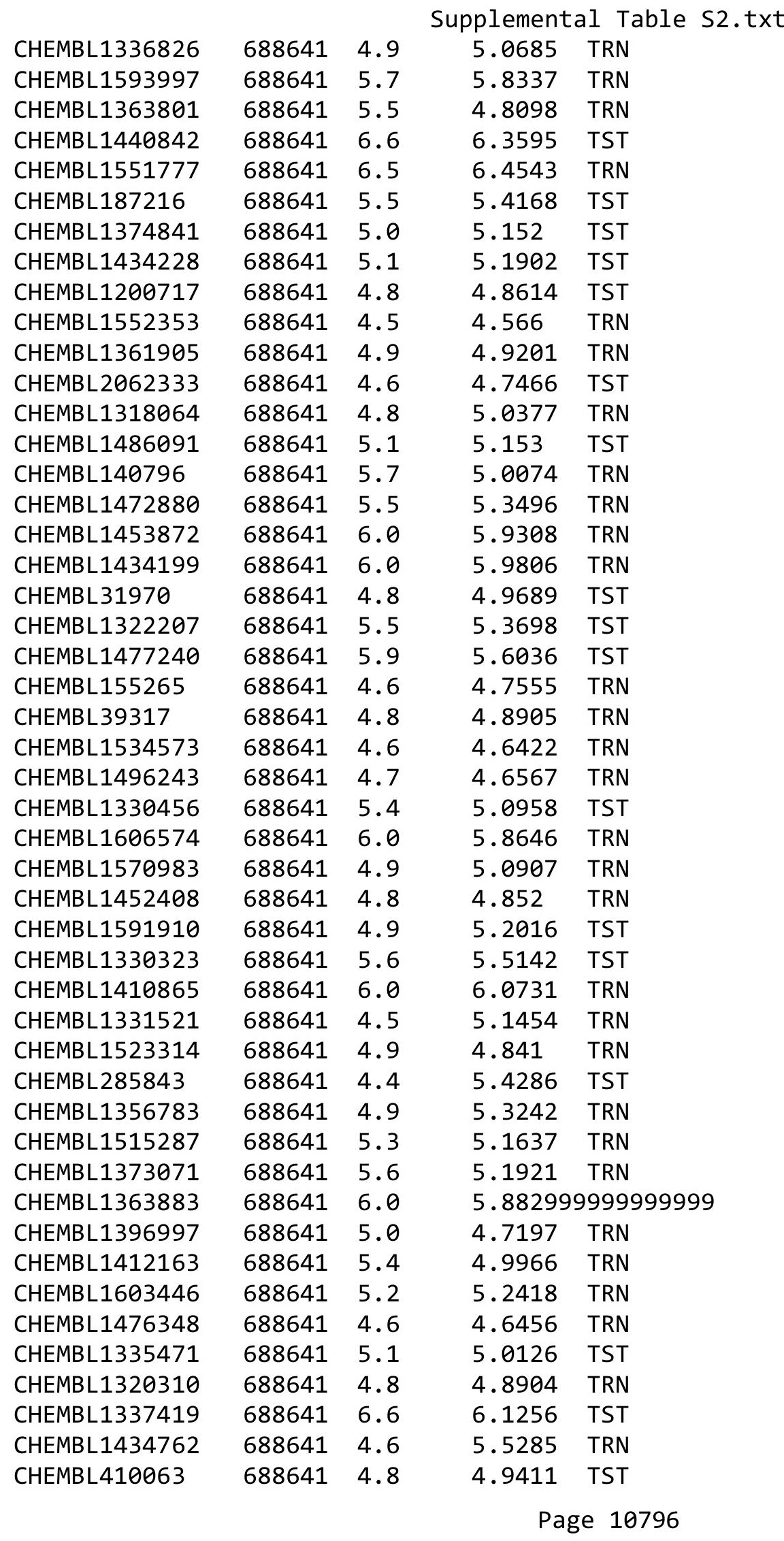




\begin{tabular}{|c|c|c|c|c|c|}
\hline \multicolumn{6}{|c|}{ Supplemental Table S2.txt } \\
\hline CHEMBL299683 & 688641 & 6.0 & 4.9337 & TRN & \\
\hline CHEMBL1608678 & 688641 & 5.5 & 5.4829 & TRN & \\
\hline CHEMBL1355349 & 688641 & 5.4 & 5.2616 & TST & \\
\hline CHEMBL1455570 & 688641 & 4.9 & 4.9525 & TRN & \\
\hline CHEMBL1563507 & 688641 & 5.6 & 5.6427 & TRN & \\
\hline CHEMBL1525438 & 688641 & 5.4 & 5.0215 & TST & \\
\hline CHEMBL1401859 & 688641 & 5.1 & 5.075 & TRN & \\
\hline CHEMBL1516530 & 688641 & 4.8 & 4.8476 & TRN & \\
\hline CHEMBL1398335 & 688641 & 5.5 & 5.4348 & TST & \\
\hline CHEMBL1355010 & 688641 & 4.7 & 4.6942 & TRN & \\
\hline CHEMBL1417135 & 688641 & 4.8 & 4.859 & TRN & \\
\hline CHEMBL294264 & 688641 & 6.0 & 4.9955 & TRN & \\
\hline CHEMBL1405461 & 688641 & 6.0 & 5.9854 & TRN & \\
\hline CHEMBL1337128 & 688641 & 6.0 & 6.0014 & TRN & \\
\hline CHEMBL1397671 & 688641 & 5.1 & 5.1716 & TRN & \\
\hline CHEMBL1530965 & 688641 & 5.1 & 5.1338 & TRN & \\
\hline CHEMBL15193 & 688641 & 4.6 & 4.9952 & TST & \\
\hline CHEMBL 280074 & 688641 & 4.8 & 4.9128 & TRN & \\
\hline CHEMBL1396298 & 688641 & 4.7 & 4.8238 & TST & \\
\hline CHEMBL458765 & 688641 & 5.5 & 5.3197 & TST & \\
\hline CHEMBL1476729 & 688641 & 4.8 & 4.93199 & 99999999995 & TRN \\
\hline CHEMBL1551090 & 688641 & 4.8 & 4.8563 & TRN & \\
\hline CHEMBL1397752 & 688641 & 5.5 & 5.4875 & TRN & \\
\hline CHEMBL1322584 & 688641 & 4.8 & 4.8621 & TRN & \\
\hline CHEMBL1513431 & 688641 & 5.3 & 5.4412 & TRN & \\
\hline CHEMBL1554070 & 688641 & 5.5 & 5.5744 & TRN & \\
\hline CHEMBL8260 & 688641 & 4.5 & 4.7835 & TRN & \\
\hline CHEMBL1317900 & 688641 & 5.1 & 5.4217 & TRN & \\
\hline CHEMBL554311 & 688641 & 4.4 & 5.0855 & TST & \\
\hline CHEMBL1314582 & 688641 & 5.1 & 5.2349 & TST & \\
\hline CHEMBL1366925 & 688641 & 5.0 & 5.5595 & TRN & \\
\hline CHEMBL1553070 & 688641 & 6.4 & 6.4206 & TRN & \\
\hline CHEMBL1377408 & 688641 & 5.8 & 5.7562 & TRN & \\
\hline CHEMBL1358560 & 688641 & 5.4 & 5.563 & TRN & \\
\hline CHEMBL1376212 & 688641 & 5.5 & 5.5356 & TRN & \\
\hline CHEMBL1512199 & 688641 & 4.5 & 4.6849 & TST & \\
\hline CHEMBL1322959 & 688641 & 6.0 & 5.7271 & TST & \\
\hline CHEMBL1358090 & 688641 & 5.3 & 5.3067 & TRN & \\
\hline CHEMBL1356485 & 688641 & 5.1 & 5.1594 & TRN & \\
\hline CHEMBL1557272 & 688641 & 5.3 & 5.1294 & TRN & \\
\hline CHEMBL1357512 & 688641 & 4.9 & 5.231 & TST & \\
\hline CHEMBL1552814 & 688641 & 4.6 & 4.5984 & TRN & \\
\hline CHEMBL1358208 & 688641 & 5.6 & 5.5202 & TST & \\
\hline CHEMBL1396211 & 688641 & 4.9 & 4.9487 & TRN & \\
\hline CHEMBL 244948 & 688641 & 4.9 & 4.9292 & TRN & \\
\hline CHEMBL168461 & 688641 & 6.7001 & 6.1846 & TST & \\
\hline CHEMBL1494592 & 688641 & 4.8 & 4.8155 & TRN & \\
\hline CHEMBL1481127 & 688641 & 5.0 & 4.9742 & TRN & \\
\hline
\end{tabular}




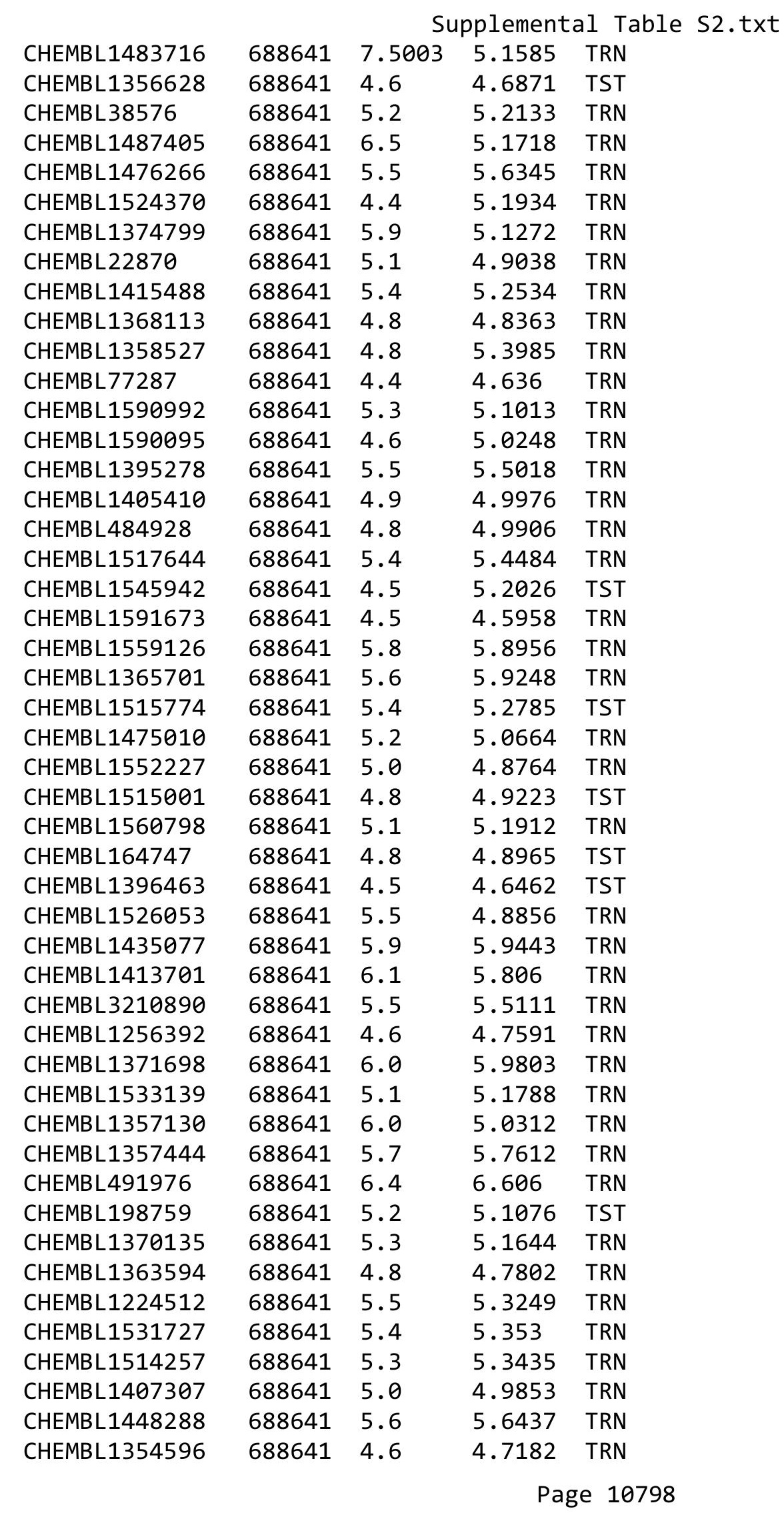




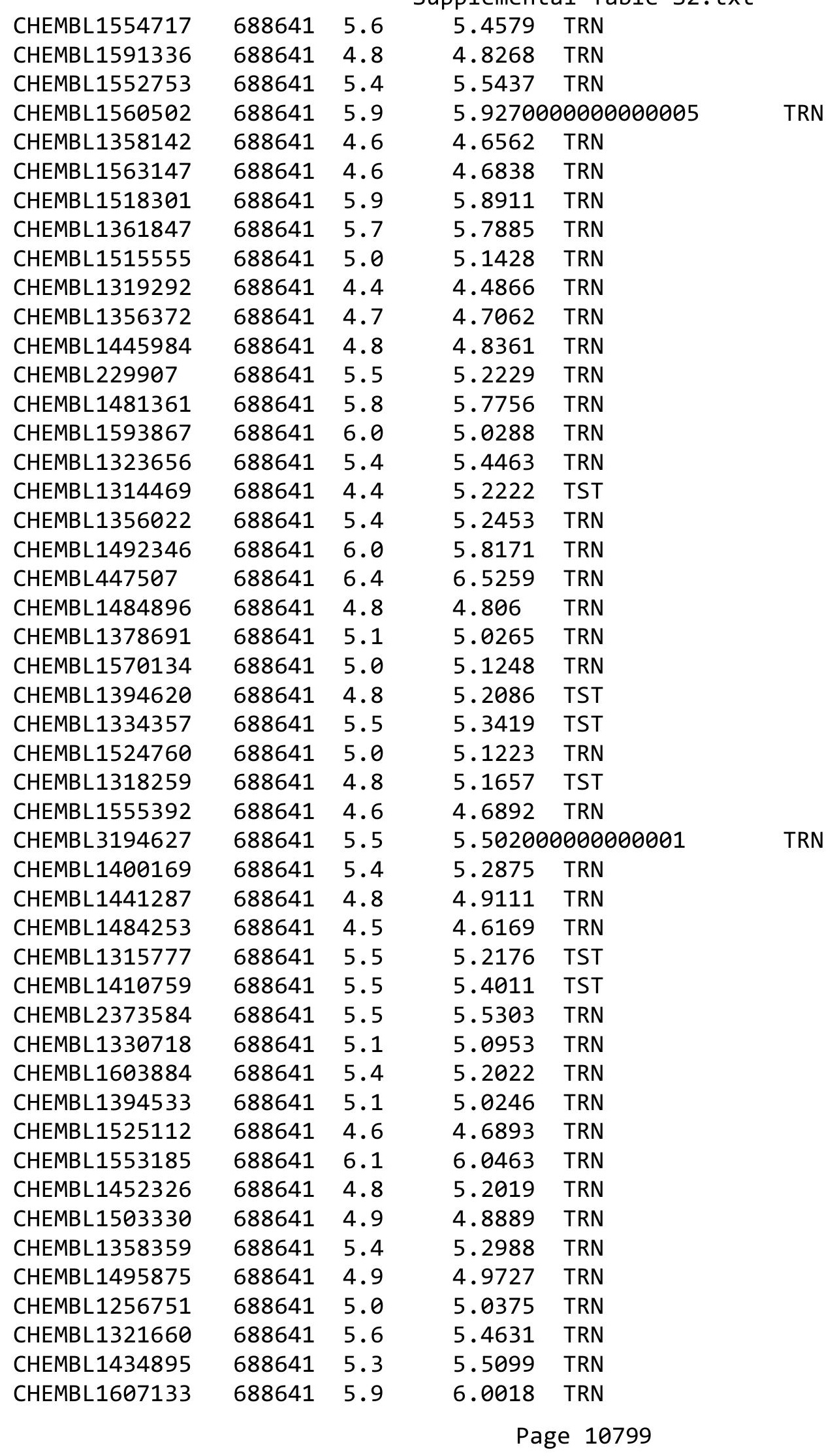




\begin{tabular}{|c|c|c|c|c|c|}
\hline \multicolumn{6}{|c|}{ Supplemental Table S2.txt } \\
\hline CHEMBL1613623 & 688641 & 4.9 & 5.4798 & TST & \\
\hline CHEMBL1590230 & 688641 & 5.0 & 5.0225 & TRN & \\
\hline CHEMBL1316491 & 688641 & 4.8 & 4.8369 & TRN & \\
\hline CHEMBL45176 & 688641 & 5.5 & 5.1197 & TRN & \\
\hline CHEMBL1445572 & 688641 & 4.7 & 4.8066 & TRN & \\
\hline CHEMBL1213139 & 688641 & 5.2 & 5.0318 & TRN & \\
\hline CHEMBL1515559 & 688641 & 4.8 & 4.82100 & 0000000001 & TRN \\
\hline CHEMBL1475015 & 688641 & 5.0 & 5.1464 & TST & \\
\hline CHEMBL1496560 & 688641 & 4.9 & 4.9287 & TRN & \\
\hline CHEMBL1612252 & 688641 & 4.9 & 4.962 & TRN & \\
\hline CHEMBL1373259 & 688641 & 5.6 & 5.4225 & TRN & \\
\hline CHEMBL1416429 & 688641 & 5.5 & 5.3861 & TRN & \\
\hline CHEMBL1568970 & 688641 & 4.8 & 4.8189 & TRN & \\
\hline CHEMBL1408856 & 688641 & 5.3 & 5.2254 & TRN & \\
\hline CHEMBL1592186 & 688641 & 5.0 & 4.9788 & TRN & \\
\hline CHEMBL1530654 & 688641 & 5.1 & 4.8663 & TRN & \\
\hline CHEMBL1552752 & 688641 & 5.6 & 5.6208 & TRN & \\
\hline CHEMBL11458 & 688641 & 5.3 & 5.3062 & TST & \\
\hline CHEMBL1414841 & 688641 & 5.4 & 5.3973 & TRN & \\
\hline CHEMBL1317950 & 688641 & 7.0 & 6.7282 & TRN & \\
\hline CHEMBL1435702 & 688641 & 5.0 & 4.9626 & TRN & \\
\hline CHEMBL1324494 & 688641 & 5.5 & 5.4063 & TRN & \\
\hline CHEMBL88961 & 688641 & 6.1 & 5.1647 & TRN & \\
\hline CHEMBL1591860 & 688641 & 5.8 & 5.5972 & TRN & \\
\hline CHEMBL1394048 & 688641 & 5.5 & 4.9842 & TRN & \\
\hline CHEMBL1414698 & 688641 & 4.8 & 4.9993 & TRN & \\
\hline CHEMBL1436237 & 688641 & 5.4 & 5.4443 & TRN & \\
\hline CHEMBL1373610 & 688641 & 5.7 & 5.715 & TRN & \\
\hline CHEMBL1370043 & 688641 & 4.7 & 4.8428 & TRN & \\
\hline CHEMBL1553804 & 688641 & 4.8 & 4.9032 & TRN & \\
\hline CHEMBL1354372 & 688641 & 4.9 & 4.8714 & TRN & \\
\hline CHEMBL1568111 & 688641 & 5.9 & 6.0426 & TRN & \\
\hline CHEMBL1527029 & 688641 & 4.6 & 4.6865 & TRN & \\
\hline CHEMBL1435907 & 688641 & 5.6 & 5.4714 & TRN & \\
\hline CHEMBL1317458 & 688641 & 4.6 & 5.0371 & TRN & \\
\hline CHEMBL1318421 & 688641 & 5.5 & 5.2986 & TRN & \\
\hline CHEMBL1362892 & 688641 & 4.8 & 4.8313 & TRN & \\
\hline CHEMBL1551295 & 688641 & 4.4 & 4.5415 & TRN & \\
\hline CHEMBL1314273 & 688641 & 5.5 & 5.5272 & TRN & \\
\hline CHEMBL1476159 & 688641 & 5.5 & 5.5014 & TRN & \\
\hline CHEMBL1516468 & 688641 & 6.0 & 6.0059 & TRN & \\
\hline CHEMBL1561888 & 688641 & 4.9 & 4.8681 & TRN & \\
\hline CHEMBL58353 & 688641 & 4.4 & 4.6287 & TST & \\
\hline CHEMBL1609614 & 688641 & 6.1 & 5.1884 & TRN & \\
\hline CHEMBL 30024 & 688641 & 4.8 & 4.8745 & TST & \\
\hline CHEMBL1235966 & 688641 & 4.9 & 5.0079 & TRN & \\
\hline CHEMBL47940 & 688641 & 5.5 & 5.3285 & TRN & \\
\hline CHEMBL1357084 & 688641 & 4.6 & 4.9159 & TRN & \\
\hline
\end{tabular}




\begin{tabular}{|c|c|c|c|c|}
\hline \multicolumn{5}{|c|}{ Supplemental Table S2.txt } \\
\hline CHEMBL85194 & 688641 & 5.0 & 5.1099 & TST \\
\hline CHEMBL1366766 & 688641 & 5.3 & 5.3877 & TRN \\
\hline CHEMBL1318340 & 688641 & 4.9 & 4.9206 & TRN \\
\hline CHEMBL1476274 & 688641 & 5.3 & 5.2392 & TRN \\
\hline CHEMBL1594350 & 688641 & 5.2 & 5.285 & TRN \\
\hline CHEMBL1396949 & 688641 & 4.9 & 4.9538 & TRN \\
\hline CHEMBL1334959 & 688641 & 5.2 & 5.3028 & TRN \\
\hline CHEMBL1596172 & 688641 & 4.8 & 5.1209 & TRN \\
\hline CHEMBL1180 & 688641 & 4.5 & 5.016 & TST \\
\hline CHEMBL1553741 & 688641 & 4.9 & 5.0085 & TRN \\
\hline CHEMBL1488112 & 688641 & 4.5 & 5.0337 & TRN \\
\hline CHEMBL1208903 & 688641 & 5.4 & 5.4582 & TRN \\
\hline CHEMBL1361839 & 688641 & 4.8 & 4.8487 & TRN \\
\hline CHEMBL1355186 & 688641 & 5.1 & 5.1455 & TRN \\
\hline CHEMBL1365712 & 688641 & 5.4 & 5.3278 & TRN \\
\hline CHEMBL1435404 & 688641 & 7.6003 & 6.7047 & TRN \\
\hline CHEMBL1256020 & 688641 & 5.0 & 5.0478 & TRN \\
\hline CHEMBL1406408 & 688641 & 5.4 & 5.2348 & TRN \\
\hline CHEMBL 74913 & 688641 & 4.9 & 5.0667 & TRN \\
\hline CHEMBL1495954 & 688641 & 4.6 & 5.2344 & TRN \\
\hline CHEMBL1358562 & 688641 & 5.6 & 4.8601 & TRN \\
\hline CHEMBL1611800 & 688641 & 4.4 & 5.2889 & TRN \\
\hline CHEMBL1477506 & 688641 & 5.5 & 5.4439 & TST \\
\hline CHEMBL1450004 & 688641 & 6.0 & 5.0446 & TST \\
\hline CHEMBL1399489 & 688641 & 4.9 & 4.9193 & TRN \\
\hline CHEMBL1354841 & 688641 & 5.5 & 5.4185 & TRN \\
\hline CHEMBL1357857 & 688641 & 4.7 & 4.7691 & TRN \\
\hline CHEMBL1435934 & 688641 & 4.9 & 5.1798 & TRN \\
\hline CHEMBL1515691 & 688641 & 4.8 & 4.8572 & TST \\
\hline CHEMBL1551445 & 688641 & 4.7 & 4.7401 & TRN \\
\hline CHEMBL1553694 & 688641 & 5.8 & 5.8764 & TRN \\
\hline CHEMBL1592819 & 688641 & 4.9 & 5.1138 & TRN \\
\hline CHEMBL188 & 688641 & 5.9 & 5.7251 & TRN \\
\hline CHEMBL1435032 & 688641 & 5.9 & 5.8886 & TRN \\
\hline CHEMBL 286722 & 688641 & 5.2 & 5.1431 & TRN \\
\hline CHEMBL272005 & 688641 & 4.9 & 5.114 & TRN \\
\hline CHEMBL1513928 & 688641 & 5.0 & 5.2981 & TRN \\
\hline CHEMBL1354725 & 688641 & 5.6 & 5.3414 & TRN \\
\hline CHEMBL1593438 & 688641 & 4.7 & 4.7222 & TRN \\
\hline CHEMBL1600780 & 688641 & 6.0 & 5.8004 & TRN \\
\hline CHEMBL1514765 & 688641 & 5.5 & 5.4469 & TST \\
\hline CHEMBL1605942 & 688641 & 4.9 & 5.0865 & TRN \\
\hline CHEMBL1561474 & 688641 & 5.9 & 5.6231 & TST \\
\hline CHEMBL1482968 & 688641 & 5.5 & 4.7135 & TRN \\
\hline CHEMBL1611145 & 688641 & 6.0 & 5.6984 & TRN \\
\hline CHEMBL1486821 & 688641 & 6.0 & 5.984 & TRN \\
\hline CHEMBL1360650 & 688641 & 5.6 & 5.7917 & TRN \\
\hline CHEMBL1475685 & 688641 & 5.0 & 4.9086 & TRN \\
\hline
\end{tabular}




\begin{tabular}{|c|c|c|c|c|}
\hline \multicolumn{5}{|c|}{ Supplemental Table S2.txt } \\
\hline CHEMBL1592975 & 688641 & 5.1 & 5.1912 & TST \\
\hline CHEMBL1444396 & 688641 & 5.5 & 5.2995 & TRN \\
\hline CHEMBL1357381 & 688641 & 5.9 & 4.829 & TRN \\
\hline CHEMBL 294878 & 688641 & 5.1 & 5.19600 & 0000000001 \\
\hline CHEMBL1609142 & 688641 & 5.5 & 5.5327 & TRN \\
\hline CHEMBL1398137 & 688641 & 5.1 & 5.1393 & TRN \\
\hline CHEMBL1566556 & 688641 & 4.8 & 4.867 & TRN \\
\hline CHEMBL1562786 & 688641 & 5.3 & 5.3802 & TRN \\
\hline CHEMBL1316265 & 688641 & 5.0 & 5.0111 & TRN \\
\hline CHEMBL1513870 & 688641 & 5.3 & 5.0331 & TRN \\
\hline CHEMBL543767 & 688641 & 4.9 & 5.2911 & TRN \\
\hline CHEMBL273094 & 688641 & 5.6 & 5.6316 & TST \\
\hline CHEMBL1566442 & 688641 & 5.3 & 5.1583 & TRN \\
\hline CHEMBL521970 & 688641 & 5.7 & 5.5948 & TRN \\
\hline CHEMBL270299 & 688641 & 4.6 & 4.6568 & TST \\
\hline CHEMBL1516028 & 688641 & 5.5 & 5.5721 & TRN \\
\hline CHEMBL1516015 & 688641 & 4.6 & 4.7452 & TST \\
\hline CHEMBL453066 & 688641 & 4.8 & 5.0536 & TST \\
\hline CHEMBL1403464 & 688641 & 5.4 & 5.2028 & TRN \\
\hline CHEMBL1447528 & 688641 & 5.4 & 5.3689 & TRN \\
\hline CHEMBL261919 & 688641 & 6.0 & 5.0309 & TST \\
\hline CHEMBL 253786 & 688641 & 4.9 & 5.101 & TRN \\
\hline CHEMBL174588 & 688641 & 5.3 & 5.1606 & TST \\
\hline CHEMBL1324882 & 688641 & 6.0 & 6.0526 & TRN \\
\hline CHEMBL1530168 & 688641 & 4.9 & 4.8159 & TRN \\
\hline CHEMBL491943 & 688641 & 6.6 & 6.6816 & TRN \\
\hline CHEMBL1319813 & 688641 & 4.6 & 5.074 & TRN \\
\hline CHEMBL1449782 & 688641 & 5.5 & 5.2723 & TST \\
\hline CHEMBL1356623 & 688641 & 5.7 & 5.1916 & TRN \\
\hline CHEMBL1523108 & 688641 & 5.1 & 5.0916 & TRN \\
\hline CHEMBL1316647 & 688641 & 4.7 & 4.7179 & TRN \\
\hline CHEMBL1395297 & 688641 & 5.5 & 5.3187 & TRN \\
\hline CHEMBL1358614 & 688641 & 6.0 & 6.1434 & TRN \\
\hline CHEMBL1357294 & 688641 & 4.8 & 4.9261 & TRN \\
\hline CHEMBL267458 & 688641 & 4.7 & 4.8552 & TST \\
\hline CHEMBL265177 & 688641 & 5.4 & 5.4053 & TRN \\
\hline CHEMBL1436195 & 688641 & 5.1 & 5.0781 & TRN \\
\hline CHEMBL1565360 & 688641 & 4.7 & 4.7382 & TRN \\
\hline CHEMBL1400190 & 688641 & 5.5 & 5.1552 & TRN \\
\hline CHEMBL3209702 & 688641 & 6.0 & 6.0097 & TRN \\
\hline CHEMBL446315 & 688641 & 6.0 & 5.6618 & TST \\
\hline CHEMBL1357222 & 688641 & 4.9 & 5.0532 & TRN \\
\hline CHEMBL27403 & 688641 & 4.6 & 4.6635 & TRN \\
\hline CHEMBL1533932 & 688641 & 5.1 & 5.3312 & TRN \\
\hline CHEMBL1606337 & 688641 & 5.2 & 5.0958 & TST \\
\hline CHEMBL1476640 & 688641 & 5.1 & 4.7919 & TRN \\
\hline CHEMBL1475787 & 688641 & 4.6 & 5.1363 & TRN \\
\hline CHEMBL1404501 & 688641 & 4.8 & 4.8082 & TRN \\
\hline
\end{tabular}

TRN 


\begin{tabular}{|c|c|c|c|c|c|}
\hline \multicolumn{6}{|c|}{ Supplemental Table S2.txt } \\
\hline CHEMBL1477964 & 688641 & 4.8 & 4.7599 & TRN & \\
\hline CHEMBL541847 & 688641 & 5.7 & 5.7681 & TRN & \\
\hline CHEMBL1527466 & 688641 & 6.0 & 6.0884 & TRN & \\
\hline CHEMBL423081 & 688641 & 4.5 & 5.1303 & TST & \\
\hline CHEMBL1437690 & 688641 & 5.7 & 5.7169 & TRN & \\
\hline CHEMBL1357195 & 688641 & 6.0 & 5.0461 & TST & \\
\hline CHEMBL399491 & 688641 & 4.5 & 4.6321 & TST & \\
\hline CHEMBL1602926 & 688641 & 5.6 & 5.5576 & TRN & \\
\hline CHEMBL1448974 & 688641 & 5.4 & 5.3309 & TRN & \\
\hline CHEMBL1355088 & 688641 & 5.7 & 5.3604 & TRN & \\
\hline CHEMBL1321008 & 688641 & 4.8 & 5.1496 & TST & \\
\hline CHEMBL1610945 & 688641 & 5.4 & 5.3209 & TST & \\
\hline CHEMBL1436976 & 688641 & 4.8 & 4.7964 & TRN & \\
\hline CHEMBL1601895 & 688641 & 5.4 & 5.2345 & TRN & \\
\hline CHEMBL1514390 & 688641 & 4.8 & 4.8972 & TRN & \\
\hline CHEMBL1474509 & 688641 & 5.1 & 4.9996 & TRN & \\
\hline CHEMBL1357289 & 688641 & 5.0 & 4.9182 & TRN & \\
\hline CHEMBL1566283 & 688641 & 4.8 & 5.0847 & TRN & \\
\hline CHEMBL1435227 & 688641 & 4.6 & 4.598 & TRN & \\
\hline CHEMBL1396661 & 688641 & 5.6 & 5.4099 & TRN & \\
\hline CHEMBL1513278 & 688641 & 4.7 & 5.0944 & TRN & \\
\hline CHEMBL1439334 & 688641 & 6.0 & 6.0598 & TRN & \\
\hline CHEMBL1513478 & 688641 & 4.7 & 4.6955 & TRN & \\
\hline CHEMBL1357199 & 688641 & 4.7 & 4.8077 & TRN & \\
\hline CHEMBL1369822 & 688641 & 6.0 & 6.0032 & TRN & \\
\hline CHEMBL1524001 & 688641 & 5.1 & 4.9407 & TRN & \\
\hline CHEMBL1330692 & 688641 & 5.4 & 5.48799 & 99999999995 & TRN \\
\hline CHEMBL1314505 & 688641 & 5.0 & 4.9986 & TRN & \\
\hline CHEMBL1592556 & 688641 & 5.6 & 5.5163 & TRN & \\
\hline CHEMBL1593096 & 688641 & 5.4 & 5.3291 & TRN & \\
\hline CHEMBL1443741 & 688641 & 4.6 & 4.6905 & TRN & \\
\hline CHEMBL1626274 & 688641 & 6.0 & 5.7924 & TST & \\
\hline CHEMBL 145 & 688641 & 4.6 & 4.9991 & TRN & \\
\hline CHEMBL1314465 & 688641 & 4.8 & 4.8107 & TRN & \\
\hline CHEMBL1513812 & 688641 & 4.8 & 4.8427 & TRN & \\
\hline CHEMBL1552970 & 688641 & 5.0 & 5.0609 & TRN & \\
\hline CHEMBL1318056 & 688641 & 5.5 & 5.5887 & TRN & \\
\hline CHEMBL1561402 & 688641 & 4.9 & 4.9065 & TRN & \\
\hline CHEMBL1369374 & 688641 & 5.5 & 5.3857 & TST & \\
\hline CHEMBL62 & 688641 & 5.0 & 5.0213 & TRN & \\
\hline CHEMBL1580759 & 688641 & 4.7 & 5.1121 & TST & \\
\hline CHEMBL1513684 & 688641 & 4.4 & 4.5536 & TRN & \\
\hline CHEMBL1413962 & 688641 & 6.1 & 6.11100 & 0000000001 & TRN \\
\hline CHEMBL1551841 & 688641 & 5.5 & 5.4509 & TRN & \\
\hline CHEMBL1472523 & 688641 & 5.5 & 5.3144 & TRN & \\
\hline CHEMBL1590484 & 688641 & 4.6 & 4.7585 & TRN & \\
\hline CHEMBL491578 & 688641 & 6.9 & 6.9328 & TRN & \\
\hline CHEMBL1402435 & 688641 & 4.8 & 4.9185 & TST & \\
\hline
\end{tabular}




\begin{tabular}{|c|c|c|c|c|}
\hline \multicolumn{5}{|c|}{ Supplemental Table s2.txt } \\
\hline CHEMBL1591533 & 688641 & 4.4 & 4.5142 & TRN \\
\hline CHEMBL1408445 & 688641 & 4.8 & 5.2062 & TRN \\
\hline CHEMBL1443923 & 688641 & 4.8 & 5.197 & TST \\
\hline CHEMBL1439882 & 688641 & 6.1 & 5.8697 & TRN \\
\hline CHEMBL1418144 & 688641 & 5.4 & 5.1538 & TST \\
\hline CHEMBL 296586 & 688641 & 4.9 & 4.9829 & TST \\
\hline CHEMBL1475945 & 688641 & 5.4 & 5.4538 & TRN \\
\hline CHEMBL491939 & 688641 & 5.8 & 5.8035 & TRN \\
\hline CHEMBL1394596 & 688641 & 4.9 & 4.7596 & TRN \\
\hline CHEMBL1433464 & 688641 & 5.2 & 5.2568 & TRN \\
\hline CHEMBL1556045 & 688641 & 6.7001 & 6.5534 & TRN \\
\hline CHEMBL1473965 & 688641 & 6.7001 & 6.1247 & TRN \\
\hline CHEMBL 305195 & 688641 & 5.0 & 5.1656 & TRN \\
\hline CHEMBL1358666 & 688641 & 5.4 & 5.3889 & TRN \\
\hline CHEMBL1451071 & 688641 & 5.4 & 5.4625 & TRN \\
\hline CHEMBL1480880 & 688641 & 5.4 & 5.431 & TRN \\
\hline CHEMBL1513966 & 688641 & 5.4 & 5.4106 & TRN \\
\hline CHEMBL1376005 & 688641 & 5.3 & 5.2818 & TST \\
\hline CHEMBL1514634 & 688641 & 4.6 & 5.0968 & TST \\
\hline CHEMBL 225230 & 688641 & 4.9 & 4.9838 & TRN \\
\hline CHEMBL1493037 & 688641 & 4.5 & 4.6555 & TST \\
\hline CHEMBL508494 & 688641 & 6.3 & 4.9937 & TRN \\
\hline CHEMBL1565190 & 688641 & 5.5 & 4.8967 & TRN \\
\hline CHEMBL1569592 & 688641 & 6.6 & 6.4444 & TRN \\
\hline CHEMBL1377686 & 688641 & 5.4 & 5.2392 & TRN \\
\hline CHEMBL1474440 & 688641 & 4.9 & 5.1204 & TRN \\
\hline CHEMBL1335397 & 688641 & 5.4 & 5.2166 & TST \\
\hline CHEMBL1552201 & 688641 & 5.8 & 4.9033 & TRN \\
\hline CHEMBL1591009 & 688641 & 6.0 & 4.9695 & TST \\
\hline CHEMBL1590081 & 688641 & 6.1 & 6.2476 & TRN \\
\hline CHEMBL1395620 & 688641 & 5.5 & 5.4177 & TRN \\
\hline CHEMBL1476230 & 688641 & 4.6 & 4.68 & TRN \\
\hline CHEMBL1357796 & 688641 & 5.0 & 5.4901 & TST \\
\hline CHEMBL 276727 & 688641 & 7.2 & 6.5113 & TST \\
\hline CHEMBL1398528 & 688641 & 4.7 & 4.9958 & TRN \\
\hline CHEMBL398673 & 688641 & 4.5 & 4.7199 & TST \\
\hline CHEMBL1520940 & 688641 & 7.8996 & 7.1369 & TRN \\
\hline CHEMBL1473620 & 688641 & 4.6 & 4.6865 & TRN \\
\hline CHEMBL1590857 & 688641 & 5.2 & 5.16799 & 9999999999 \\
\hline CHEMBL1438224 & 688641 & 4.6 & 5.2578 & TRN \\
\hline CHEMBL1600612 & 688641 & 4.4 & 4.5144 & TRN \\
\hline CHEMBL1555011 & 688641 & 5.0 & 4.7876 & TRN \\
\hline CHEMBL1338229 & 688641 & 5.8 & 5.1631 & TST \\
\hline CHEMBL1589856 & 688641 & 5.8 & 5.4804 & TRN \\
\hline CHEMBL1256940 & 688641 & 5.7 & 5.7865 & TRN \\
\hline CHEMBL25236 & 688641 & 5.1 & 5.0836 & TRN \\
\hline CHEMBL1455880 & 688641 & 6.2 & 5.1573 & TRN \\
\hline CHEMBL363332 & 688641 & 5.8 & 5.8298 & TST \\
\hline
\end{tabular}




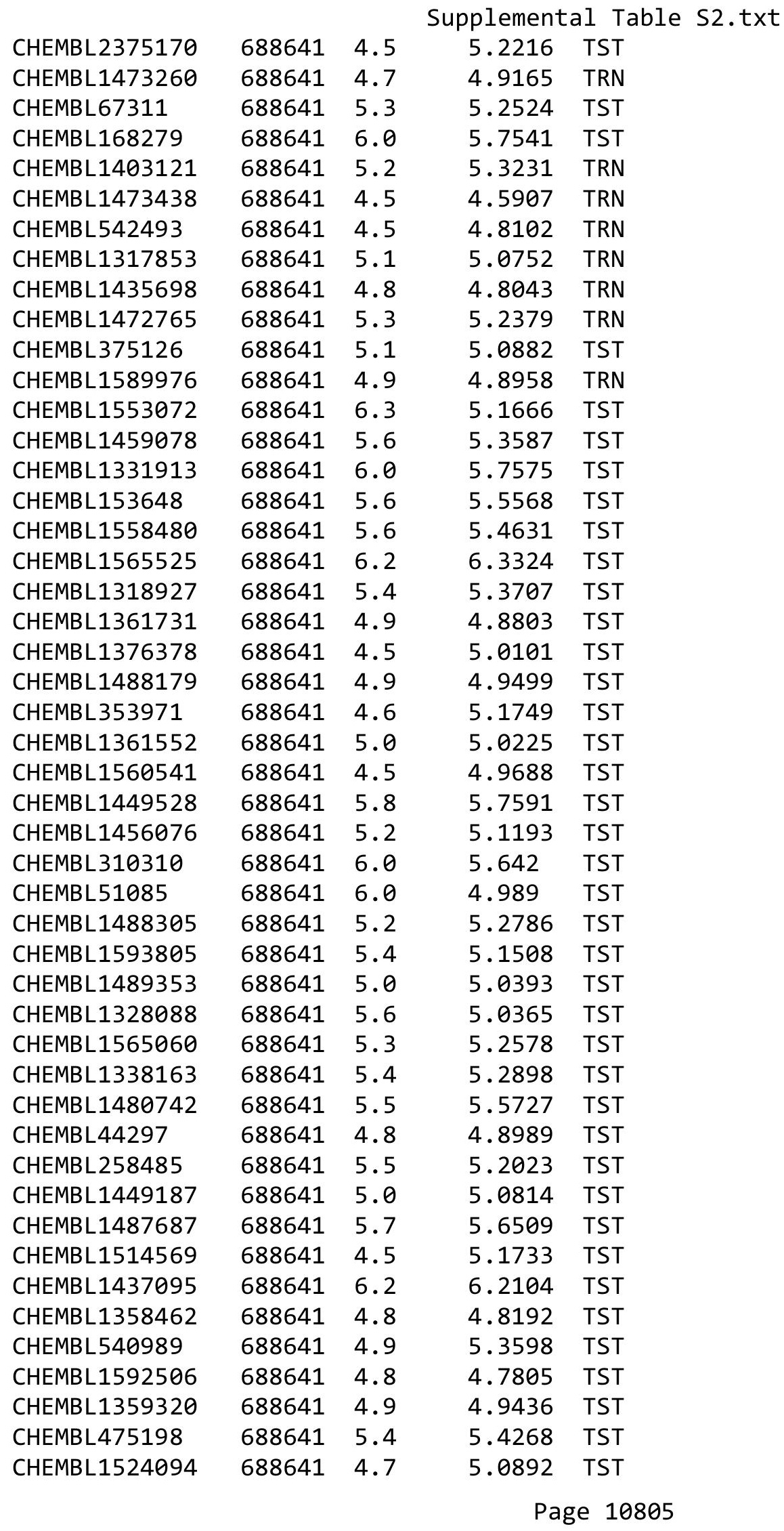




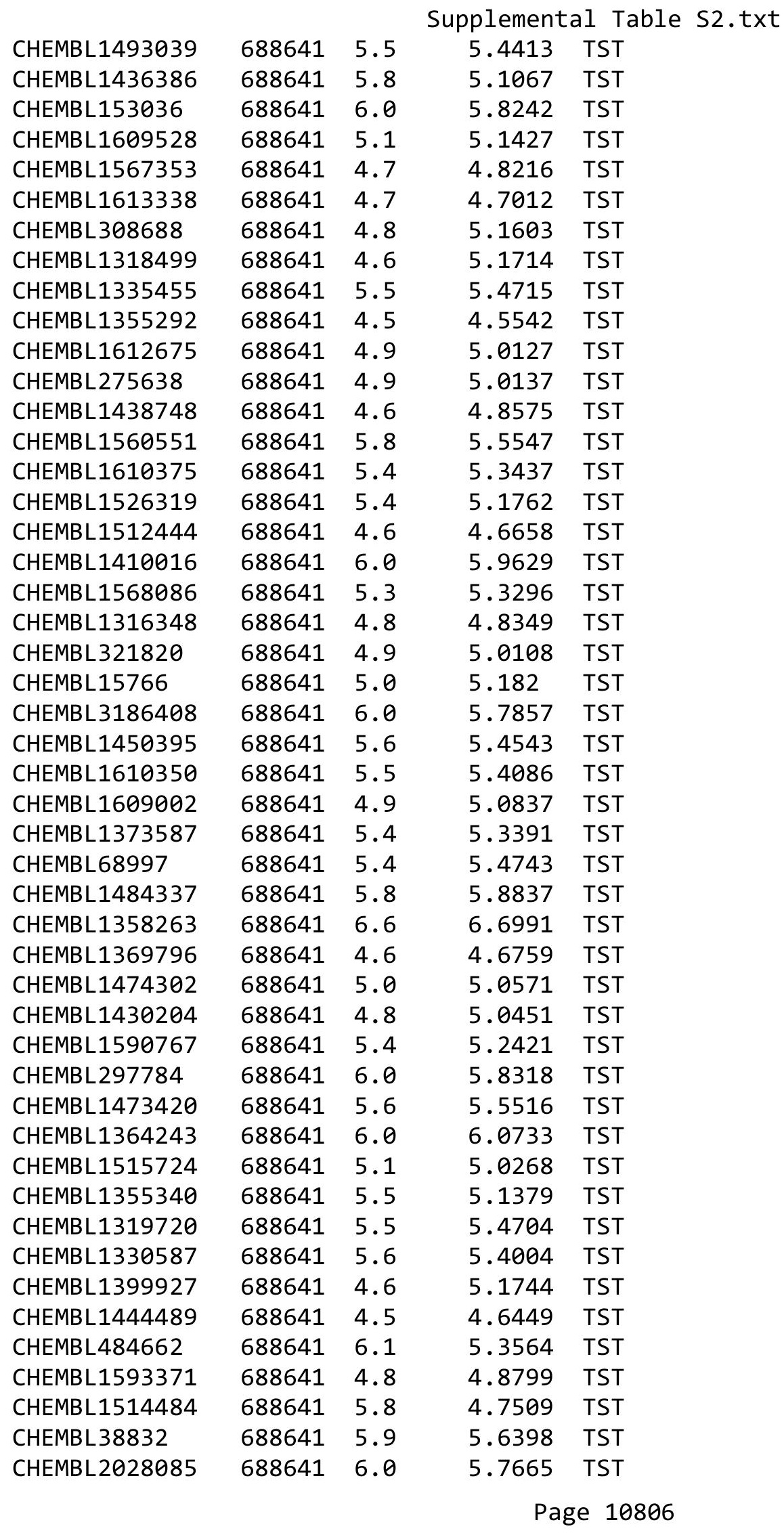




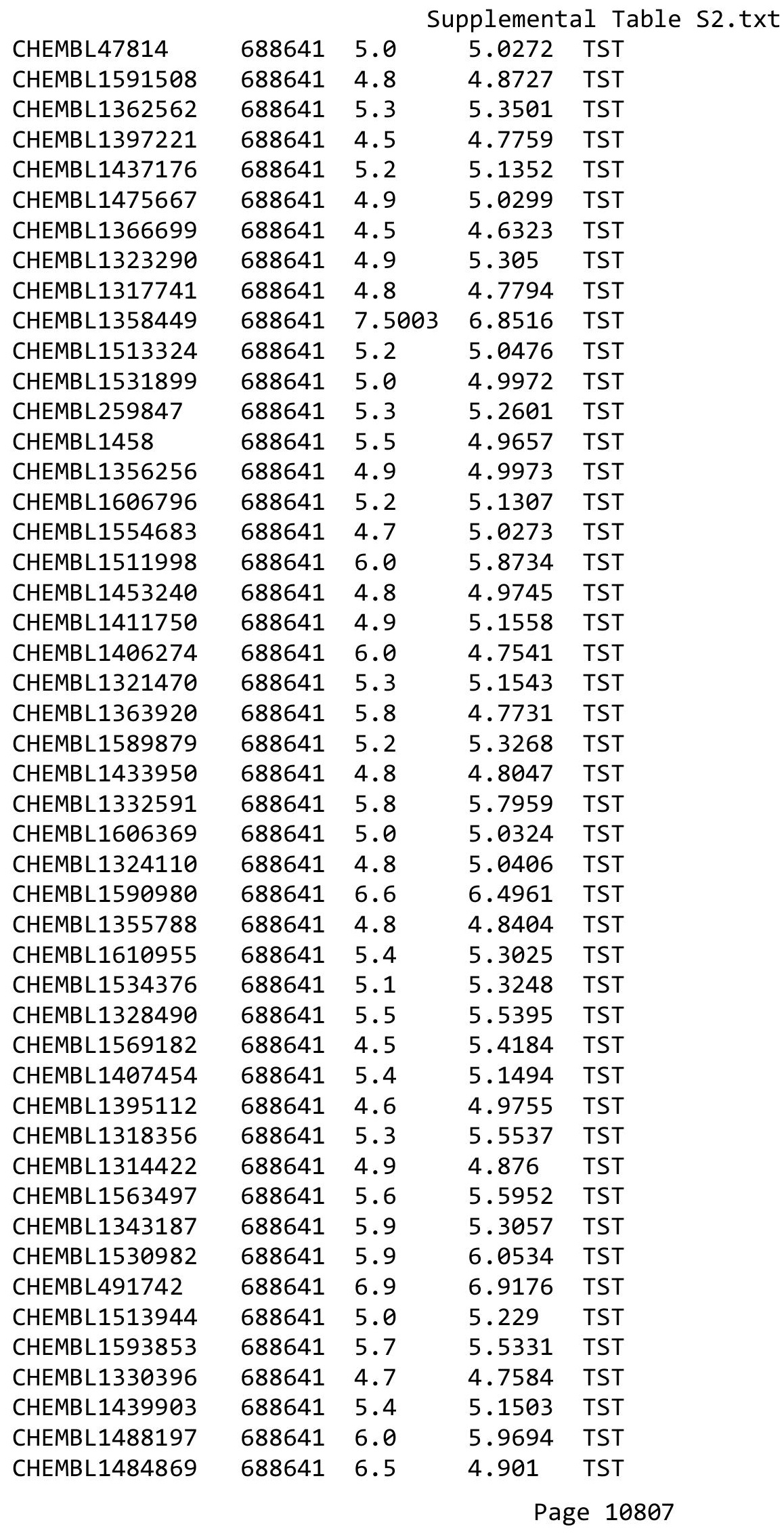




\begin{tabular}{|c|c|c|c|c|}
\hline & & & & L Tabl \\
\hline CHEMBL1594086 & 688641 & 5.0 & 5.0298 & TST \\
\hline CHEMBL1485777 & 688641 & 5.2 & 5.1198 & TST \\
\hline CHEMBL1323355 & 688641 & 5.1 & 5.164 & TST \\
\hline CHEMBL1483427 & 688641 & 4.7 & 4.7287 & TST \\
\hline CHEMBL 288174 & 688641 & 5.5 & 5.4551 & TST \\
\hline CHEMBL1486399 & 688641 & 4.7 & 4.7541 & TST \\
\hline CHEMBL1451697 & 688641 & 5.5 & 5.3443 & TST \\
\hline CHEMBL1527413 & 688641 & 5.3 & 5.3389 & TST \\
\hline CHEMBL192566 & 688641 & 5.4 & 5.2803 & TST \\
\hline CHEMBL1362880 & 688641 & 5.2 & 4.707 & TST \\
\hline CHEMBL1712082 & 688641 & 4.6 & 5.1595 & TST \\
\hline CHEMBL1394887 & 688641 & 5.9 & 5.5977 & TST \\
\hline CHEMBL1316945 & 688641 & 4.8 & 5.1845 & TST \\
\hline CHEMBL1368572 & 688641 & 5.6 & 5.5356 & TST \\
\hline CHEMBL1514910 & 688641 & 4.6 & 5.2521 & TST \\
\hline CHEMBL1395402 & 688641 & 5.1 & 5.0967 & TST \\
\hline CHEMBL1433551 & 688641 & 5.5 & 5.5094 & TST \\
\hline CHEMBL177809 & 688641 & 5.5 & 5.4125 & TST \\
\hline CHEMBL1357085 & 688641 & 5.5 & 5.5169 & TST \\
\hline CHEMBL 2374040 & 688641 & 5.4 & 5.2701 & TST \\
\hline CHEMBL1476831 & 688641 & 4.8 & 4.8147 & TST \\
\hline CHEMBL 269550 & 688641 & 4.8 & 4.8529 & TST \\
\hline CHEMBL 278041 & 688641 & 6.0 & 6.1659 & TST \\
\hline CHEMBL1356652 & 688641 & 6.2 & 6.2226 & TST \\
\hline CHEMBL 1257075 & 688641 & 6.0 & 5.7103 & TST \\
\hline CHEMBL1513078 & 688641 & 4.4 & 4.9939 & TST \\
\hline CHEMBL1355896 & 688641 & 6.5 & 6.3949 & TST \\
\hline CHEMBL1528605 & 688641 & 4.4 & 5.0079 & TST \\
\hline CHEMBL1592982 & 688641 & 5.7 & 5.7476 & TST \\
\hline CHEMBL1474261 & 688641 & 4.5 & 4.6656 & TST \\
\hline CHEMBL1596235 & 688641 & 5.2 & 5.0453 & TST \\
\hline CHEMBL1436816 & 688641 & 5.4 & 5.54700 & 0000000001 \\
\hline CHEMBL1317172 & 688641 & 4.8 & 4.8056 & TST \\
\hline CHEMBL1335654 & 688641 & 4.6 & 4.654 & TST \\
\hline CHEMBL1520489 & 688641 & 4.7 & 5.1 & TST \\
\hline CHEMBL1315328 & 688641 & 5.2 & 5.0038 & TST \\
\hline CHEMBL1326360 & 688641 & 5.8 & 5.9771 & TST \\
\hline CHEMBL1445706 & 688641 & 5.4 & 5.1636 & TST \\
\hline CHEMBL1591080 & 688641 & 4.9 & 5.1633 & TST \\
\hline CHEMBL 39947 & 688641 & 6.0 & 5.0327 & TST \\
\hline CHEMBL1555480 & 688641 & 4.8 & 4.8401 & TST \\
\hline CHEMBL1356262 & 688641 & 5.0 & 5.0219 & TST \\
\hline CHEMBL1375214 & 688641 & 5.4 & 5.1475 & TST \\
\hline CHEMBL1435917 & 688641 & 4.9 & 4.8981 & TST \\
\hline CHEMBL1317148 & 688641 & 5.0 & 5.1047 & TST \\
\hline CHEMBL1592584 & 688641 & 5.4 & 5.3542 & TST \\
\hline CHEMBL91153 & 688641 & 5.1 & 5.0965 & TST \\
\hline CHEMBL1314935 & 688641 & 5.6 & 5.4722 & TST \\
\hline
\end{tabular}




\begin{tabular}{|c|c|c|c|c|}
\hline \multicolumn{5}{|c|}{ Supplemental Table S2.txt } \\
\hline CHEMBL1364366 & 688641 & 5.1 & 5.2405 & TST \\
\hline CHEMBL1434513 & 688641 & 4.5 & 5.1323 & TST \\
\hline CHEMBL1375723 & 688641 & 5.5 & 5.5074 & TST \\
\hline CHEMBL1360011 & 688641 & 5.9 & 5.1835 & TST \\
\hline CHEMBL1434789 & 688641 & 4.4 & 4.5557 & TST \\
\hline CHEMBL1607905 & 688641 & 4.8 & 5.03 & TST \\
\hline CHEMBL1515802 & 688641 & 5.3 & 5.3251 & TST \\
\hline CHEMBL2373602 & 688641 & 6.0 & 5.8242 & TST \\
\hline CHEMBL1449018 & 688641 & 4.6 & 4.9479 & TST \\
\hline CHEMBL1475338 & 688641 & 6.0 & 5.9311 & TST \\
\hline CHEMBL68423 & 688641 & 6.5 & 6.2153 & TST \\
\hline CHEMBL1331476 & 688641 & 4.6 & 4.8299 & TST \\
\hline CHEMBL1405538 & 688641 & 5.8 & 5.7999 & TST \\
\hline CHEMBL1412900 & 688641 & 6.1 & 6.0869 & TST \\
\hline CHEMBL1551534 & 688641 & 4.8 & 4.8372 & TST \\
\hline CHEMBL 240963 & 688641 & 4.6 & 4.9451 & TST \\
\hline CHEMBL1563075 & 688641 & 5.1 & 5.4439 & TST \\
\hline CHEMBL1318261 & 688641 & 5.0 & 4.9984 & TST \\
\hline CHEMBL1316754 & 688641 & 5.5 & 5.2983 & TST \\
\hline CHEMBL1407576 & 688641 & 5.4 & 5.3019 & TST \\
\hline CHEMBL 2373632 & 688641 & 5.6 & 5.1654 & TST \\
\hline CHEMBL 293749 & 688641 & 5.4 & 5.4225 & TST \\
\hline CHEMBL60718 & 688641 & 5.5 & 5.3571 & TST \\
\hline CHEMBL1330614 & 688641 & 5.5 & 5.3401 & TST \\
\hline CHEMBL1551578 & 688641 & 5.6 & 5.3268 & TST \\
\hline CHEMBL571087 & 688641 & 5.2 & 5.0999 & TST \\
\hline CHEMBL484406 & 501800 & 7.3468 & 7.5221 & TRN \\
\hline CHEMBL484787 & 501800 & 6.7986 & 6.879 & TRN \\
\hline CHEMBL521492 & 501800 & 7.3979 & 7.2933 & TRN \\
\hline CHEMBL484002 & 501800 & 7.3665 & 7.3342 & TRN \\
\hline CHEMBL509277 & 501800 & 7.6198 & 7.5195 & TRN \\
\hline CHEMBL451324 & 501800 & 7.8861 & 7.8249 & TRN \\
\hline CHEMBL490465 & 501800 & 6.8633 & 6.9526 & TRN \\
\hline CHEMBL513233 & 501800 & 6.9872 & 7.1274 & TST \\
\hline CHEMBL511313 & 501800 & 7.7447 & 7.5214 & TRN \\
\hline CHEMBL446227 & 501800 & 7.4089 & 7.4406 & TRN \\
\hline CHEMBL484157 & 501800 & 7.4318 & 7.3784 & TRN \\
\hline CHEMBL491073 & 501800 & 6.7852 & 7.0301 & TRN \\
\hline CHEMBL484159 & 501800 & 7.1367 & 7.0816 & TRN \\
\hline CHEMBL484788 & 501800 & 7.2366 & 7.2427 & TRN \\
\hline CHEMBL483740 & 501800 & 7.4202 & 7.1902 & TST \\
\hline CHEMBL499471 & 501800 & 7.284 & 7.3548 & TRN \\
\hline CHEMBL483553 & 501800 & 5.0 & 6.4166 & TST \\
\hline CHEMBL471470 & 501800 & 7.1739 & 7.2221 & TST \\
\hline CHEMBL451371 & 501800 & 7.7696 & 7.6764 & TRN \\
\hline CHEMBL522449 & 501800 & 7.8239 & 7.6095 & TRN \\
\hline CHEMBL500031 & 501800 & 7.6576 & 7.8358 & TRN \\
\hline CHEMBL490466 & 501800 & 6.7399 & 6.6341 & TRN \\
\hline
\end{tabular}




\begin{tabular}{|c|c|c|c|c|c|}
\hline \multicolumn{6}{|c|}{ Supplemental Table s2.txt } \\
\hline CHEMBL501903 & 501800 & 8.1024 & 8.0162 & TRN & \\
\hline CHEMBL491463 & 501800 & 7.4559 & 6.4166 & TST & \\
\hline CHEMBL445540 & 501800 & 8.0655 & 7.9528 & TRN & \\
\hline CHEMBL483739 & 501800 & 7.9208 & 7.8861 & TRN & \\
\hline CHEMBL471674 & 501800 & 7.4815 & 7.63200 & 0000000001 & TRN \\
\hline CHEMBL484004 & 501800 & 8.2676 & 8.2177 & TRN & \\
\hline CHEMBL484156 & 501800 & 7.6576 & 7.5166 & TRN & \\
\hline CHEMBL507109 & 501800 & 6.7235 & 6.8554 & TRN & \\
\hline CHEMBL484921 & 501800 & 6.8665 & 6.735 & TST & \\
\hline CHEMBL489864 & 501800 & 8.3665 & 8.5492 & TRN & \\
\hline CHEMBL508076 & 501800 & 7.4559 & 7.3848 & TRN & \\
\hline CHEMBL490066 & 501800 & 5.0 & 5.0279 & TRN & \\
\hline CHEMBL483360 & 501800 & 7.7696 & 7.9251 & TRN & \\
\hline CHEMBL449550 & 501800 & 7.3468 & 7.4217 & TRN & \\
\hline CHEMBL482560 & 501800 & 7.6021 & 7.5349 & TRN & \\
\hline CHEMBL482574 & 501800 & 7.2676 & 7.2447 & TRN & \\
\hline CHEMBL521174 & 501800 & 7.0362 & 6.9681 & TRN & \\
\hline CHEMBL489263 & 501800 & 7.5528 & 7.5142 & TRN & \\
\hline CHEMBL505395 & 501800 & 7.9586 & 8.0017 & TRN & \\
\hline CHEMBL483340 & 501800 & 7.6021 & 7.0691 & TST & \\
\hline CHEMBL489658 & 501800 & 7.6383 & 7.7 & TRN & \\
\hline CHEMBL521448 & 501800 & 6.6778 & 6.6588 & TRN & \\
\hline CHEMBL484920 & 501800 & 6.9626 & 6.9765 & TRN & \\
\hline CHEMBL504618 & 501800 & 8.0605 & 8.0966 & TRN & \\
\hline CHEMBL521913 & 501800 & 7.2007 & 7.5307 & TST & \\
\hline CHEMBL484596 & 501800 & 7.4685 & 7.2328 & TST & \\
\hline CHEMBL484003 & 501800 & 7.7696 & 7.4585 & TST & \\
\hline CHEMBL484591 & 501800 & 7.5528 & 7.454 & TST & \\
\hline CHEMBL483738 & 501800 & 7.9208 & 7.99 & TST & \\
\hline CHEMBL483361 & 501800 & 7.2441 & 7.2639 & TST & \\
\hline CHEMBL485150 & 501800 & 7.5376 & 7.6492 & TST & \\
\hline CHEMBL 344001 & 44853 & 6.9031 & 6.8808 & TRN & \\
\hline CHEMBL139649 & 44853 & 5.0969 & 5.0575 & TRN & \\
\hline CHEMBL 337328 & 44853 & 7.4318 & 7.4775 & TRN & \\
\hline CHEMBL 335337 & 44853 & 5.2218 & 5.1044 & TRN & \\
\hline CHEMBL142132 & 44853 & 7.6021 & 7.6524 & TRN & \\
\hline CHEMBL141410 & 44853 & 5.3468 & 5.5379 & TRN & \\
\hline CHEMBL141130 & 44853 & 6.0 & 5.7625 & TRN & \\
\hline CHEMBL 344889 & 44853 & 5.6198 & 5.6736 & TRN & \\
\hline CHEMBL 344181 & 44853 & 4.6925 & 4.9773 & TRN & \\
\hline CHEMBL141624 & 44853 & 7.7447 & 7.755 & TRN & \\
\hline CHEMBL140975 & 44853 & 3.8083 & 3.6135 & TRN & \\
\hline CHEMBL138847 & 44853 & 6.0458 & 6.0961 & TRN & \\
\hline CHEMBL 336247 & 44853 & 3.6778 & 3.845 & TRN & \\
\hline CHEMBL422825 & 44853 & 6.8239 & 6.7922 & TRN & \\
\hline CHEMBL140544 & 44853 & 5.9666 & 5.494 & TST & \\
\hline CHEMBL141478 & 44853 & 4.6308 & 4.8713 & TRN & \\
\hline CHEMBL141408 & 44853 & 5.8239 & 6.1034 & TST & \\
\hline
\end{tabular}




\begin{tabular}{|c|c|c|c|c|c|}
\hline \multicolumn{6}{|c|}{ Supplemental Table S2.txt } \\
\hline CHEMBL436573 & 44853 & 6.1192 & 6.0473 & TST & \\
\hline CHEMBL140221 & 44853 & 4.8861 & 5.2285 & TRN & \\
\hline CHEMBL140643 & 44853 & 5.5935 & 5.0915 & TRN & \\
\hline CHEMBL262561 & 44853 & 6.0 & 6.0356 & TRN & \\
\hline CHEMBL139700 & 44853 & 5.6055 & 5.1622 & TRN & \\
\hline CHEMBL140252 & 44853 & 6.2596 & 5.8565 & TRN & \\
\hline CHEMBL138603 & 44853 & 7.6778 & 7.3514 & TRN & \\
\hline CHEMBL141898 & 44853 & 6.4202 & 6.6012 & TST & \\
\hline CHEMBL140696 & 44853 & 5.1135 & 5.0793 & TRN & \\
\hline CHEMBL343332 & 44853 & 4.9031 & 5.4231 & TRN & \\
\hline CHEMBL140370 & 44853 & 7.301 & 7.4402 & TRN & \\
\hline CHEMBL141899 & 44853 & 7.5376 & 7.2594 & TRN & \\
\hline CHEMBL141756 & 44853 & 5.9586 & 6.2098 & TRN & \\
\hline CHEMBL344034 & 44853 & 6.0458 & 5.9399 & TRN & \\
\hline CHEMBL433685 & 44853 & 5.8239 & 5.7138 & TST & \\
\hline CHEMBL140007 & 44853 & 5.1805 & 5.3097 & TRN & \\
\hline CHEMBL264879 & 44853 & 7.5528 & 7.7078 & TRN & \\
\hline CHEMBL140481 & 44853 & 7.7212 & 7.4281 & TRN & \\
\hline CHEMBL 344888 & 44853 & 6.0506 & 6.5282 & TRN & \\
\hline CHEMBL344941 & 44853 & 6.0088 & 5.8394 & TST & \\
\hline CHEMBL343916 & 44853 & 6.9208 & 6.9026 & TRN & \\
\hline CHEMBL141757 & 44853 & 5.3565 & 5.2715 & TRN & \\
\hline CHEMBL344709 & 44853 & 5.9031 & 5.1558 & TST & \\
\hline CHEMBL337136 & 44853 & 5.8239 & 5.6713 & TST & \\
\hline CHEMBL336483 & 44853 & 5.2924 & 5.3091 & TRN & \\
\hline CHEMBL 344055 & 44853 & 5.3979 & 5.2111 & TRN & \\
\hline CHEMBL140389 & 44853 & 5.8539 & 5.765 & TRN & \\
\hline CHEMBL140306 & 44853 & 5.8239 & 5.7862 & TRN & \\
\hline CHEMBL342146 & 44853 & 5.9706 & 5.6524 & TRN & \\
\hline CHEMBL344887 & 44853 & 5.1549 & 5.0882 & TRN & \\
\hline CHEMBL343590 & 44853 & 5.8239 & 6.2663 & TST & \\
\hline CHEMBL140554 & 44853 & 5.7212 & 5.3706 & TST & \\
\hline CHEMBL140616 & 44853 & 7.1871 & 7.1987 & TRN & \\
\hline CHEMBL335353 & 44853 & 5.4685 & 5.0114 & TRN & \\
\hline CHEMBL342407 & 44853 & 6.3979 & 6.2913 & TRN & \\
\hline CHEMBL96361 & 44853 & 6.1192 & 5.8186 & TST & \\
\hline CHEMBL141168 & 44853 & 7.3468 & 7.3307 & TRN & \\
\hline CHEMBL138115 & 44853 & 3.699 & 3.97300 & 00000000003 & TRN \\
\hline CHEMBL139668 & 44853 & 6.0 & 5.9042 & TRN & \\
\hline CHEMBL344237 & 44853 & 4.6108 & 4.3347 & TST & \\
\hline CHEMBL140942 & 44853 & 4.2233 & 4.7604 & TRN & \\
\hline CHEMBL140428 & 44853 & 6.1487 & 6.391 & TST & \\
\hline CHEMBL140933 & 44853 & 5.6021 & 5.7031 & TRN & \\
\hline CHEMBL342485 & 44853 & 5.301 & 5.2459 & TRN & \\
\hline CHEMBL140095 & 44853 & 6.9788 & 6.9288 & TRN & \\
\hline CHEMBL139940 & 44853 & 5.0969 & 5.08 & TRN & \\
\hline CHEMBL336455 & 44853 & 6.1024 & 6.2045 & TST & \\
\hline CHEMBL138920 & 44853 & 6.699 & 6.6826 & TRN & \\
\hline
\end{tabular}




\begin{tabular}{|c|c|c|c|c|c|c|}
\hline & & \multicolumn{5}{|c|}{ Supplemental Table S2.txt } \\
\hline CHEMBL342668 & 44853 & 4.7352 & 5.0238 & TRN & & \\
\hline CHEMBL141526 & 44853 & 5.7959 & 5.9379 & TRN & & \\
\hline CHEMBL341760 & 44853 & 6.6021 & 6.7151 & TRN & & \\
\hline CHEMBL139939 & 44853 & 6.5229 & 6.4831 & TRN & & \\
\hline CHEMBL141965 & 44853 & 6.0 & 5.6309 & TRN & & \\
\hline CHEMBL344861 & 44853 & 6.0155 & 5.8768 & TRN & & \\
\hline CHEMBL141618 & 44853 & 4.699 & 4.6055 & TRN & & \\
\hline CHEMBL141049 & 44853 & 4.9914 & 5.0375 & TRN & & \\
\hline CHEMBL140446 & 44853 & 4.6576 & 5.2259 & TST & & \\
\hline CHEMBL138178 & 44853 & 5.7447 & 5.6981 & TRN & & \\
\hline CHEMBL281794 & 44853 & 5.8539 & 5.6146 & TRN & & \\
\hline CHEMBL142067 & 44853 & 5.2596 & 4.9197 & TRN & & \\
\hline CHEMBL337771 & 44853 & 5.5229 & 5.8836 & TRN & & \\
\hline CHEMBL140805 & 44853 & 7.6198 & 7.4642 & TRN & & \\
\hline CHEMBL342622 & 44853 & 6.0506 & 6.3293 & TRN & & \\
\hline CHEMBL141351 & 44853 & 7.1549 & 7.0791 & TRN & & \\
\hline CHEMBL139549 & 44853 & 4.8239 & 4.867 & TRN & & \\
\hline CHEMBL139946 & 44853 & 7.6198 & 7.7289 & TRN & & \\
\hline CHEMBL141753 & 44853 & 7.2676 & 7.0347 & TRN & & \\
\hline CHEMBL138009 & 44853 & 5.7328 & 5.8542 & TRN & & \\
\hline CHEMBL140879 & 44853 & 6.4559 & 6.2127 & TST & & \\
\hline CHEMBL141309 & 44853 & 5.7557 & 5.9579 & TST & & \\
\hline CHEMBL141255 & 44853 & 6.1249 & 6.0671 & TST & & \\
\hline CHEMBL140391 & 44853 & 5.5229 & 5.5112 & TRN & & \\
\hline CHEMBL342610 & 44853 & 6.5229 & 6.5498 & TRN & & \\
\hline CHEMBL343268 & 44853 & 5.8386 & 6.1865 & TST & & \\
\hline CHEMBL342679 & 44853 & 5.9586 & 5.8369 & TRN & & \\
\hline CHEMBL138253 & 44853 & 6.6021 & 6.6805 & TRN & & \\
\hline CHEMBL344056 & 44853 & 6.0 & 5.9343 & TRN & & \\
\hline CHEMBL341600 & 44853 & 4.6576 & 4.6928 & TST & & \\
\hline CHEMBL138812 & 44853 & 6.5229 & 6.331 & TRN & & \\
\hline CHEMBL140973 & 44853 & 3.75699 & 99999999 & 997 & 3.911 & TST \\
\hline CHEMBL343098 & 44853 & 6.5229 & 7.0624 & TST & & \\
\hline CHEMBL336691 & 44853 & 3.7447 & 4.0368 & TRN & & \\
\hline CHEMBL69149 & 44853 & 6.5686 & 6.6231 & TST & & \\
\hline CHEMBL342026 & 44853 & 7.7696 & 7.9064 & TRN & & \\
\hline CHEMBL343048 & 44853 & 6.2218 & 6.0852 & TRN & & \\
\hline CHEMBL139539 & 44853 & 5.3979 & 5.3486 & TRN & & \\
\hline CHEMBL341548 & 44853 & 5.5229 & 5.6112 & TRN & & \\
\hline CHEMBL140110 & 44853 & 7.3872 & 7.7103 & TRN & & \\
\hline CHEMBL343047 & 44853 & 6.0915 & 5.9363 & TRN & & \\
\hline CHEMBL337369 & 44853 & 6.4437 & 5.8489 & TRN & & \\
\hline CHEMBL139023 & 44853 & 4.0899 & 3.9361 & TRN & & \\
\hline CHEMBL141028 & 44853 & 3.7812 & 3.9545 & TRN & & \\
\hline CHEMBL343944 & 44853 & 6.4881 & 6.3329 & TRN & & \\
\hline CHEMBL140452 & 44853 & 5.857 & 6.1307 & TST & & \\
\hline CHEMBL140791 & 44853 & 6.3979 & 6.2638 & TRN & & \\
\hline CHEMBL344382 & 44853 & 6.5229 & 6.4996 & TRN & & \\
\hline
\end{tabular}




\begin{tabular}{|c|c|c|c|c|c|}
\hline \multicolumn{6}{|c|}{ Supplemental Table S2.txt } \\
\hline CHEMBL138309 & 44853 & 4.8239 & 4.7042 & TRN & \\
\hline CHEMBL344156 & 44853 & 7.2596 & 7.2798 & TRN & \\
\hline CHEMBL343046 & 44853 & 6.0969 & 6.343 & TRN & \\
\hline CHEMBL342038 & 44853 & 5.5918 & 5.3831 & TST & \\
\hline CHEMBL141052 & 44853 & 5.6383 & 5.6805 & TRN & \\
\hline CHEMBL140169 & 44853 & 5.9208 & 5.1587 & TST & \\
\hline CHEMBL139763 & 44853 & 6.5376 & 6.2355 & TST & \\
\hline CHEMBL140938 & 44853 & 3.7249 & 3.6152 & TRN & \\
\hline CHEMBL140379 & 44853 & 4.8182 & 5.1702 & TRN & \\
\hline CHEMBL141562 & 44853 & 6.0 & 5.9762 & TRN & \\
\hline CHEMBL142078 & 44853 & 3.8697 & 4.1044 & TST & \\
\hline CHEMBL443483 & 44853 & 5.8539 & 5.5074 & TRN & \\
\hline CHEMBL140486 & 44853 & 4.0 & 4.0841 & TRN & \\
\hline CHEMBL140820 & 44853 & 4.0969 & 4.0174 & TST & \\
\hline CHEMBL139563 & 44853 & 5.7282 & 5.4403 & TST & \\
\hline CHEMBL138972 & 44853 & 3.8608 & 3.7478 & TST & \\
\hline CHEMBL143294 & 44853 & 5.4437 & 5.3861 & TRN & \\
\hline CHEMBL140692 & 44853 & 6.5229 & 6.1865 & TST & \\
\hline CHEMBL140792 & 44853 & 7.3098 & 7.4603 & TRN & \\
\hline CHEMBL436400 & 44853 & 4.6799 & 4.2253 & TST & \\
\hline CHEMBL141108 & 44853 & 5.7959 & 5.7772 & TRN & \\
\hline CHEMBL342390 & 44853 & 4.8239 & 4.8179 & TST & \\
\hline CHEMBL422639 & 44853 & 5.8386 & 5.9882 & TRN & \\
\hline CHEMBL141425 & 44853 & 6.4815 & 6.4004 & TST & \\
\hline CHEMBL 344030 & 44853 & 5.9431 & 5.6823 & TRN & \\
\hline CHEMBL141346 & 44853 & 5.5229 & 5.7397 & TRN & \\
\hline CHEMBL 265112 & 44853 & 5.0969 & 5.5059 & TRN & \\
\hline CHEMBL140941 & 44853 & 5.699 & 5.9406 & TST & \\
\hline CHEMBL142541 & 44853 & 6.0458 & 6.0344 & TST & \\
\hline CHEMBL141868 & 44853 & 6.5229 & 6.8209 & TRN & \\
\hline CHEMBL141363 & 44853 & 5.4437 & 5.8392 & TRN & \\
\hline CHEMBL142142 & 44853 & 6.0223 & 6.0181 & TRN & \\
\hline CHEMBL94836 & 44853 & 6.6778 & 6.7181 & TRN & \\
\hline CHEMBL1720257 & 812915 & 5.5901 & 5.4945 & TRN & \\
\hline CHEMBL1321508 & 812915 & 5.6576 & 4.6149 & TST & \\
\hline CHEMBL1433326 & 812915 & 3.699 & 3.7877 & TST & \\
\hline CHEMBL1538784 & 812915 & 4.9889 & 4.7516 & TRN & \\
\hline CHEMBL1718692 & 812915 & 3.699 & 3.64399 & 99999999997 & TRN \\
\hline CHEMBL1519988 & 812915 & 5.2007 & 4.3901 & TST & \\
\hline CHEMBL1730320 & 812915 & 3.699 & 3.6652 & TRN & \\
\hline CHEMBL1732337 & 812915 & 6.585 & 6.2896 & TRN & \\
\hline CHEMBL1716673 & 812915 & 3.699 & 3.4971 & TRN & \\
\hline CHEMBL1731582 & 812915 & 3.699 & 3.8553 & TRN & \\
\hline CHEMBL1612423 & 812915 & 6.0809 & 5.0073 & TRN & \\
\hline CHEMBL1351584 & 812915 & 5.2518 & 5.2034 & TRN & \\
\hline CHEMBL1708215 & 812915 & 3.699 & 3.8042 & TRN & \\
\hline CHEMBL 1721360 & 812915 & 3.699 & 3.6523 & TRN & \\
\hline CHEMBL1706268 & 812915 & 5.2314 & 4.9118 & TRN & \\
\hline
\end{tabular}




\begin{tabular}{|c|c|c|c|c|c|}
\hline & & \multicolumn{4}{|c|}{ Supplemental Table S2.txt } \\
\hline CHEMBL1706542 & 812915 & 3.699 & 3.6963 & TRN & \\
\hline CHEMBL1316316 & 812915 & 5.5686 & 4.4889 & TST & \\
\hline CHEMBL1363341 & 812915 & 3.699 & 3.8258 & TST & \\
\hline CHEMBL1721926 & 812915 & 5.699 & 5.7654 & TRN & \\
\hline CHEMBL1704728 & 812915 & 6.6198 & 6.5298 & TRN & \\
\hline CHEMBL1706382 & 812915 & 3.699 & 3.741 & TRN & \\
\hline CHEMBL1699379 & 812915 & 3.699 & 3.4744 & TRN & \\
\hline CHEMBL1719579 & 812915 & 3.699 & 5.0073 & TRN & \\
\hline CHEMBL 1710228 & 812915 & 3.699 & 3.8997 & TRN & \\
\hline CHEMBL1735926 & 812915 & 5.7696 & 5.75200 & 0000000001 & TRN \\
\hline CHEMBL1450407 & 812915 & 6.2924 & 5.7481 & TRN & \\
\hline CHEMBL1314048 & 812915 & 5.1135 & 4.4977 & TST & \\
\hline CHEMBL1532328 & 812915 & 5.5072 & 5.6668 & TRN & \\
\hline CHEMBL1716972 & 812915 & 3.699 & 3.7816 & TRN & \\
\hline CHEMBL1728652 & 812915 & 4.9747 & 5.0486 & TRN & \\
\hline CHEMBL1420187 & 812915 & 5.3546 & 5.2874 & TRN & \\
\hline CHEMBL1364793 & 812915 & 5.7282 & 5.9485 & TRN & \\
\hline CHEMBL1710033 & 812915 & 5.9872 & 6.086 & TRN & \\
\hline CHEMBL1412853 & 812915 & 6.2518 & 4.5551 & TST & \\
\hline CHEMBL 2018276 & 812915 & 4.7878 & 4.2756 & TST & \\
\hline CHEMBL1731586 & 812915 & 3.699 & 3.772 & TRN & \\
\hline CHEMBL1700405 & 812915 & 6.2924 & 6.4365 & TRN & \\
\hline CHEMBL1720861 & 812915 & 3.699 & 3.8492 & TRN & \\
\hline CHEMBL1719980 & 812915 & 4.7595 & 4.1239 & TRN & \\
\hline CHEMBL1535050 & 812915 & 4.7447 & 4.32600 & 00000000005 & TST \\
\hline CHEMBL1733280 & 812915 & 5.2396 & 5.1249 & TRN & \\
\hline CHEMBL1728008 & 812915 & 3.699 & 4.9491 & TRN & \\
\hline CHEMBL1717116 & 812915 & 5.4401 & 5.4944 & TRN & \\
\hline CHEMBL 1726725 & 812915 & 3.699 & 3.6596 & TRN & \\
\hline CHEMBL1700889 & 812915 & 4.9527 & 4.9407 & TRN & \\
\hline CHEMBL1569954 & 812915 & 5.9469 & 4.9491 & TRN & \\
\hline CHEMBL1700026 & 812915 & 3.699 & 3.4951 & TRN & \\
\hline CHEMBL1554526 & 812915 & 5.5528 & 5.4503 & TST & \\
\hline CHEMBL1725712 & 812915 & 3.699 & 3.8693 & TRN & \\
\hline CHEMBL1732890 & 812915 & 3.699 & 4.5291 & TRN & \\
\hline CHEMBL1521474 & 812915 & 7.0458 & 4.734 & TST & \\
\hline CHEMBL1411903 & 812915 & 3.699 & 3.9786 & TST & \\
\hline CHEMBL1734509 & 812915 & 5.7932 & 5.8773 & TRN & \\
\hline CHEMBL1727158 & 812915 & 3.699 & 3.923 & TRN & \\
\hline CHEMBL1700826 & 812915 & 3.699 & 3.5204 & TRN & \\
\hline CHEMBL1729949 & 812915 & 3.699 & 3.6598 & TRN & \\
\hline CHEMBL1709705 & 812915 & 5.9957 & 6.0976 & TRN & \\
\hline CHEMBL1736791 & 812915 & 3.699 & 4.3214 & TRN & \\
\hline CHEMBL1715638 & 812915 & 3.699 & 3.6429 & TRN & \\
\hline CHEMBL 2018275 & 812915 & 3.699 & 4.4851 & TST & \\
\hline CHEMBL1407805 & 812915 & 4.8539 & 4.3194 & TST & \\
\hline CHEMBL1342760 & 812915 & 5.4634 & 4.9535 & TRN & \\
\hline CHEMBL1729147 & 812915 & 3.699 & 4.0291 & TST & \\
\hline
\end{tabular}


Supplemental Table S2.txt

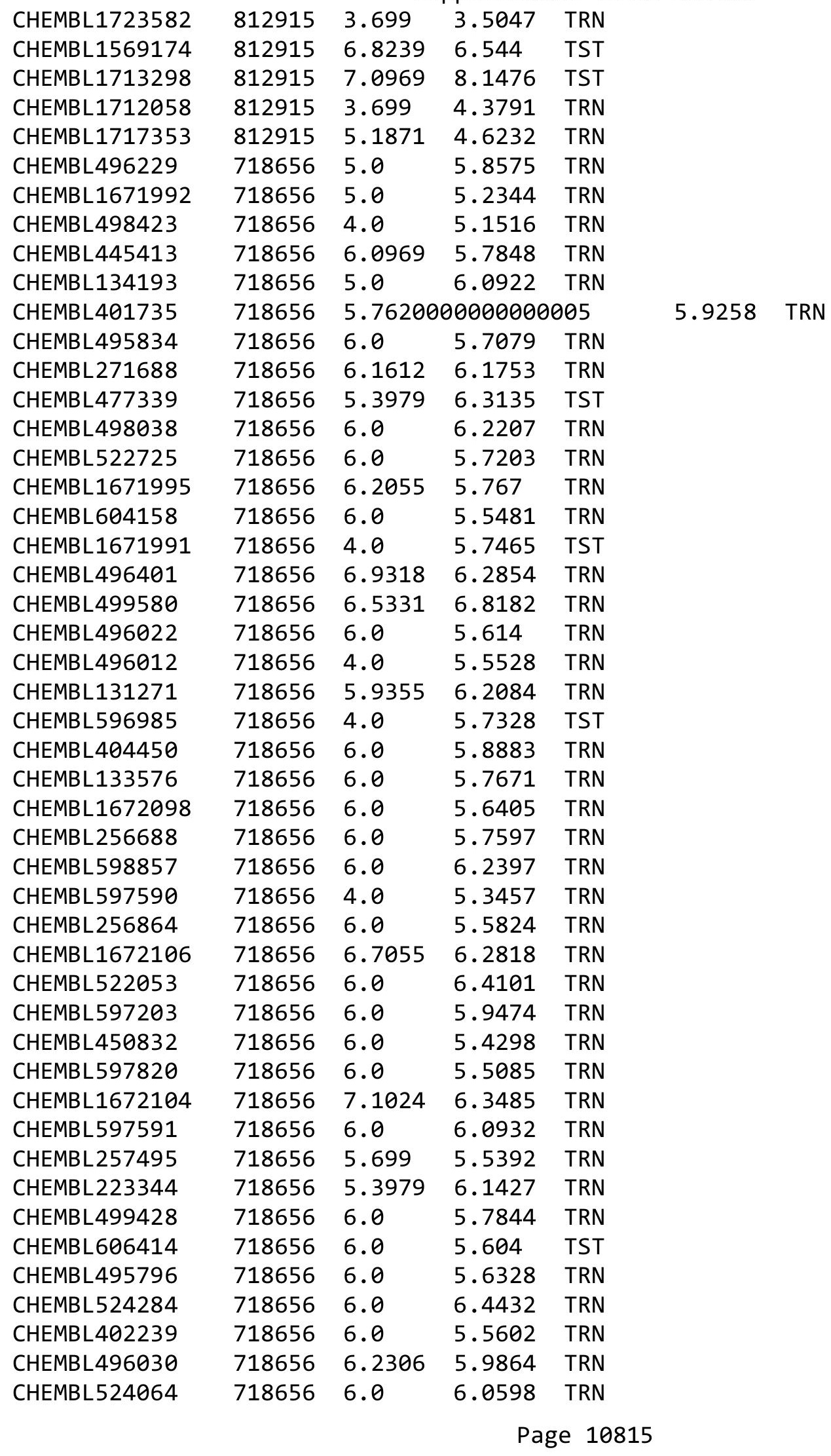




\begin{tabular}{|c|c|c|c|c|c|}
\hline \multirow{3}{*}{$\begin{array}{l}\text { CHEMBL1671997 } \\
\text { CHEMBL1672103 }\end{array}$} & \multirow{3}{*}{$\begin{array}{l}718656 \\
718656\end{array}$} & \multicolumn{4}{|c|}{ Supplemental Table S2.txt } \\
\hline & & 5.0 & 5.4229 & 9999999999 & TRN \\
\hline & & 6.0 & 5.5155 & TRN & \\
\hline CHEMBL1672107 & 718656 & 6.5229 & 6.3457 & TRN & \\
\hline CHEMBL256057 & 718656 & 6.0 & 5.6375 & TRN & \\
\hline CHEMBL403051 & 718656 & 6.0 & 5.5722 & TRN & \\
\hline CHEMBL521709 & 718656 & 6.0 & 5.7342 & TRN & \\
\hline CHEMBL509572 & 718656 & 6.2351 & 6.2802 & TST & \\
\hline CHEMBL1671993 & 718656 & 5.0 & 5.6063 & TST & \\
\hline CHEMBL1672105 & 718656 & 7.0655 & 6.1773 & TST & \\
\hline CHEMBL1672108 & 718656 & 5.3979 & 6.1547 & TST & \\
\hline CHEMBL604300 & 718656 & 6.0 & 6.2679 & TST & \\
\hline CHEMBL1672099 & 718656 & 5.0 & 5.4939 & TST & \\
\hline CHEMBL1672102 & 718656 & 6.0 & 6.4077 & TST & \\
\hline CHEMBL1671996 & 718656 & 5.0 & 5.7825 & TST & \\
\hline CHEMBL596982 & 718656 & 6.0 & 5.8585 & TST & \\
\hline CHEMBL404659 & 718656 & 5.0 & 5.5768 & TST & \\
\hline CHEMBL271672 & 718656 & 7.0 & 5.8183 & TST & \\
\hline CHEMBL1393325 & 688843 & 4.3 & 4.4859 & TRN & \\
\hline CHEMBL242080 & 688843 & 4.3 & 4.3683 & TRN & \\
\hline CHEMBL220845 & 688843 & 4.3 & 4.3052 & TRN & \\
\hline CHEMBL388676 & 688843 & 4.9 & 4.768 & TST & \\
\hline CHEMBL235672 & 688843 & 4.1 & 4.2623 & TRN & \\
\hline CHEMBL1414154 & 688843 & 4.1 & 4.0928 & TRN & \\
\hline CHEMBL334255 & 688843 & 4.5 & 4.4511 & TRN & \\
\hline CHEMBL1566504 & 688843 & 4.3 & 4.5784 & TST & \\
\hline CHEMBL1499545 & 688843 & 5.0 & 5.0485 & TRN & \\
\hline CHEMBL509531 & 688843 & 4.7 & 4.7874 & TST & \\
\hline CHEMBL1506537 & 688843 & 4.1 & 4.3665 & TRN & \\
\hline CHEMBL1408847 & 688843 & 5.2 & 5.4342 & TRN & \\
\hline CHEMBL8739 & 688843 & 4.4 & 4.1748 & TRN & \\
\hline CHEMBL1303139 & 688843 & 5.3 & 5.1316 & TRN & \\
\hline CHEMBL194400 & 688843 & 4.4 & 4.3031 & TST & \\
\hline CHEMBL1579130 & 688843 & 6.0 & 5.9326 & TRN & \\
\hline CHEMBL1517425 & 688843 & 4.3 & 4.0852 & TRN & \\
\hline CHEMBL1430204 & 688843 & 4.3 & 4.3677 & TRN & \\
\hline CHEMBL1527567 & 688843 & 4.5 & 4.5269 & TRN & \\
\hline CHEMBL1609459 & 688843 & 4.8 & 4.9386 & TRN & \\
\hline CHEMBL44072 & 688843 & 4.6 & 4.4327 & TST & \\
\hline CHEMBL1612246 & 688843 & 4.5 & 4.6031 & TRN & \\
\hline CHEMBL194399 & 688843 & 4.3 & 4.2905 & TST & \\
\hline CHEMBL1545634 & 688843 & 6.3 & 6.0564 & TRN & \\
\hline CHEMBL1451833 & 688843 & 4.7 & 4.7379 & TST & \\
\hline CHEMBL1514512 & 688843 & 4.4 & 4.2743 & TRN & \\
\hline CHEMBL1331245 & 688843 & 4.3 & 4.3323 & TRN & \\
\hline CHEMBL1450607 & 688843 & 4.8 & 4.8939 & TST & \\
\hline CHEMBL1200471 & 688843 & 6.6 & 6.5749 & TRN & \\
\hline CHEMBL1558796 & 688843 & 4.4 & 4.4002 & TRN & \\
\hline CHEMBL140 & 688843 & 4.5 & 4.4254 & TRN & \\
\hline
\end{tabular}




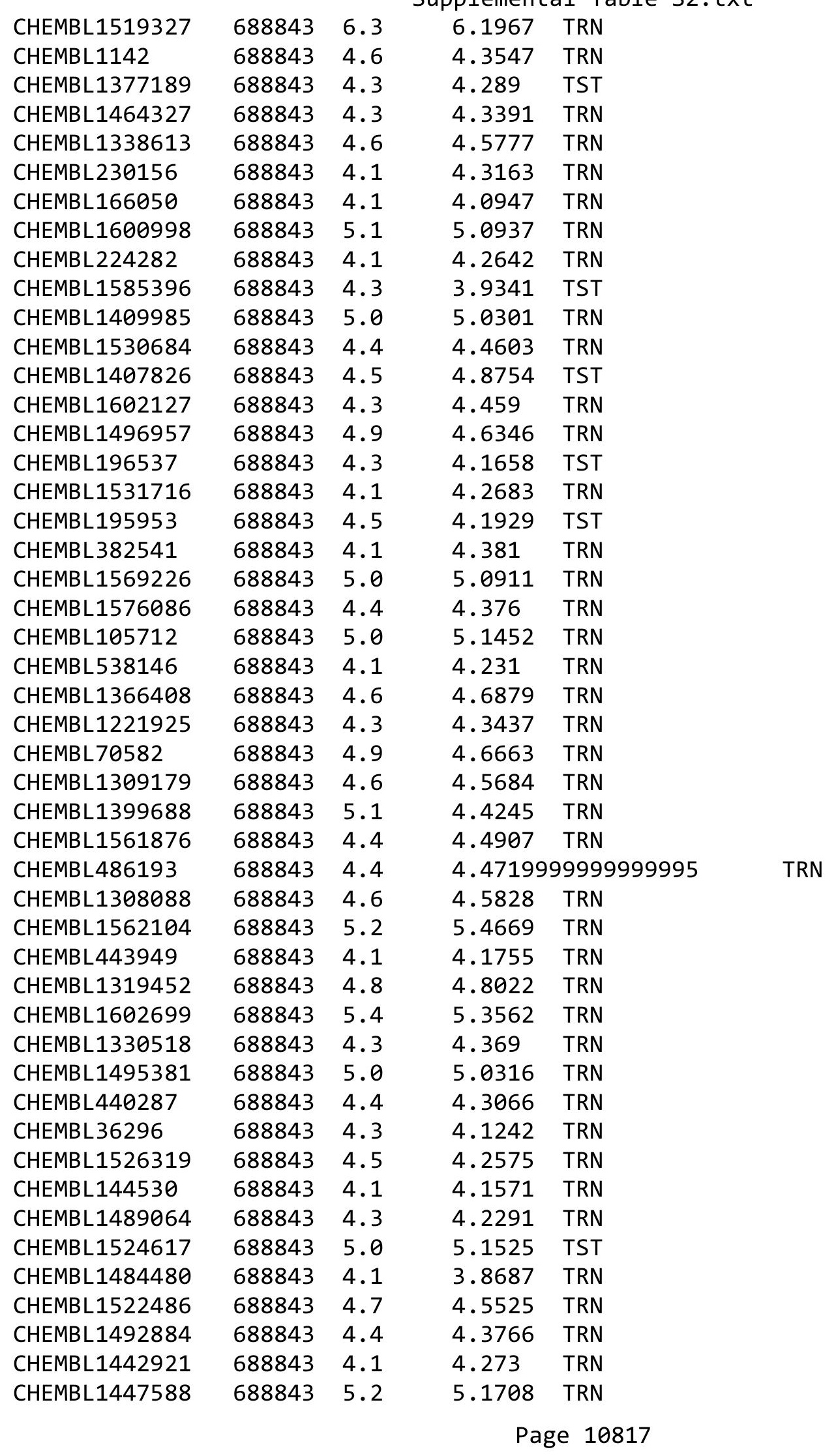




\begin{tabular}{|c|c|c|c|c|}
\hline \multicolumn{5}{|c|}{ Supplemental Table S2.txt } \\
\hline CHEMBL1304981 & 688843 & 4.3 & 4.1597 & TRN \\
\hline CHEMBL1448387 & 688843 & 4.5 & 4.4632 & TRN \\
\hline CHEMBL192627 & 688843 & 4.7 & 4.9099 & TST \\
\hline CHEMBL 38934 & 688843 & 4.1 & 4.2965 & TRN \\
\hline CHEMBL117311 & 688843 & 4.1 & 4.1741 & TRN \\
\hline CHEMBL 1487138 & 688843 & 4.1 & 4.3235 & TST \\
\hline CHEMBL85811 & 688843 & 4.3 & 4.2428 & TST \\
\hline CHEMBL1569493 & 688843 & 5.9 & 5.8887 & TST \\
\hline CHEMBL1452158 & 688843 & 4.4 & 4.1702 & TST \\
\hline CHEMBL1413786 & 688843 & 4.1 & 4.7335 & TST \\
\hline CHEMBL1518369 & 688843 & 4.3 & 3.8288 & TST \\
\hline CHEMBL1549844 & 688843 & 4.6 & 4.4936 & TST \\
\hline CHEMBL1449018 & 688843 & 4.4 & 4.2907 & TST \\
\hline CHEMBL1535689 & 688843 & 4.5 & 4.2829 & TST \\
\hline CHEMBL1082447 & 634306 & 5.301 & 5.3026 & TRN \\
\hline CHEMBL442242 & 634306 & 5.2076 & 5.2109 & TRN \\
\hline CHEMBL1084582 & 634306 & 5.0 & 5.0021 & TRN \\
\hline CHEMBL1084616 & 634306 & 5.284 & 5.2742 & TRN \\
\hline CHEMBL1085592 & 634306 & 5.1024 & 5.1226 & TRN \\
\hline CHEMBL237394 & 634306 & 5.585 & 5.584 & TRN \\
\hline CHEMBL1086072 & 634306 & 5.5086 & 5.5114 & TRN \\
\hline CHEMBL1085866 & 634306 & 5.5528 & 5.5314 & TRN \\
\hline CHEMBL1086074 & 634306 & 5.0 & 5.0083 & TRN \\
\hline CHEMBL1082781 & 634306 & 5.1805 & 5.1843 & TRN \\
\hline CHEMBL1084581 & 634306 & 5.0 & 5.0029 & TRN \\
\hline CHEMBL1085828 & 634306 & 5.0 & 5.0075 & TRN \\
\hline CHEMBL1085325 & 634306 & 5.7696 & 5.771 & TRN \\
\hline CHEMBL1084385 & 634306 & 5.699 & 6.12299 & 9999999999 \\
\hline CHEMBL1083562 & 634306 & 6.3188 & 6.3241 & TRN \\
\hline CHEMBL1082496 & 634306 & 5.3468 & 5.376 & TRN \\
\hline CHEMBL1084826 & 634306 & 5.0 & 5.0021 & TRN \\
\hline CHEMBL1085572 & 634306 & 5.9208 & 5.9192 & TRN \\
\hline CHEMBL1084560 & 634306 & 5.5229 & 5.5173 & TRN \\
\hline CHEMBL1085800 & 634306 & 6.1079 & 6.1059 & TRN \\
\hline CHEMBL1084879 & 634306 & 6.4202 & 6.4183 & TRN \\
\hline CHEMBL1085142 & 634306 & 6.3665 & 6.0553 & TST \\
\hline CHEMBL1086534 & 634306 & 5.9208 & 5.9191 & TRN \\
\hline CHEMBL1085124 & 634306 & 6.301 & 6.31 & TRN \\
\hline CHEMBL1083448 & 634306 & 6.041 & 6.0457 & TRN \\
\hline CHEMBL1084583 & 634306 & 5.3768 & 4.9544 & TST \\
\hline CHEMBL1085782 & 634306 & 5.0 & 4.9996 & TRN \\
\hline CHEMBL1084878 & 634306 & 6.3979 & 6.3886 & TRN \\
\hline CHEMBL237191 & 634306 & 5.585 & 5.5791 & TRN \\
\hline CHEMBL1085783 & 634306 & 5.0 & 4.6679 & TST \\
\hline CHEMBL 1085560 & 634306 & 5.6778 & 5.6718 & TRN \\
\hline CHEMBL1086033 & 634306 & 4.2676 & 4.2612 & TRN \\
\hline CHEMBL1085398 & 634306 & 5.7959 & 5.796 & TRN \\
\hline CHEMBL1083407 & 634306 & 6.0605 & 6.0614 & TRN \\
\hline
\end{tabular}




\begin{tabular}{|c|c|c|c|c|c|}
\hline & & & & & \\
\hline CHEMBL1084827 & 634306 & 5.0 & 5.0017 & TRN & \\
\hline CHEMBL1082489 & 634306 & 5.2518 & 5.2417 & TRN & \\
\hline CHEMBL1084584 & 634306 & 5.8239 & 4.588 & TST & \\
\hline CHEMBL1085337 & 634306 & 5.2518 & 5.2602 & TRN & \\
\hline CHEMBL1086032 & 634306 & 5.0 & 5.0012 & TRN & \\
\hline CHEMBL1085397 & 634306 & 5.8239 & 5.8197 & TRN & \\
\hline CHEMBL1084383 & 634306 & 6.1487 & 5.3359 & TST & \\
\hline CHEMBL1086561 & 634306 & 5.2924 & 5.2891 & TRN & \\
\hline CHEMBL1084877 & 634306 & 5.3768 & 5.3834 & TRN & \\
\hline CHEMBL1085396 & 634306 & 6.3979 & 6.4052 & TRN & \\
\hline CHEMBL1084314 & 634306 & 5.3565 & 5.3448 & TRN & \\
\hline CHEMBL1083274 & 634306 & 5.0 & 5.00899 & 99999999995 & TRN \\
\hline CHEMBL1086514 & 634306 & 5.301 & 5.2955 & TRN & \\
\hline CHEMBL1083447 & 634306 & 5.6778 & 5.6756 & TRN & \\
\hline CHEMBL1085964 & 634306 & 5.2076 & 5.1914 & TRN & \\
\hline CHEMBL1086521 & 634306 & 5.5376 & 5.5414 & TRN & \\
\hline CHEMBL1086520 & 634306 & 6.6576 & 5.808 & TST & \\
\hline CHEMBL1085641 & 634306 & 6.3565 & 6.3542 & TRN & \\
\hline CHEMBL1086513 & 634306 & 6.4685 & 6.4702 & TRN & \\
\hline CHEMBL1086073 & 634306 & 6.1487 & 6.1464 & TRN & \\
\hline CHEMBL263101 & 634306 & 5.0 & 4.998 & TRN & \\
\hline CHEMBL1086034 & 634306 & 4.9586 & 4.9549 & TRN & \\
\hline CHEMBL1086292 & 634306 & 6.0315 & 6.0284 & TRN & \\
\hline CHEMBL1085591 & 634306 & 5.2007 & 5.8859 & TST & \\
\hline CHEMBL1083462 & 634306 & 5.3468 & 5.343 & TRN & \\
\hline CHEMBL392573 & 634306 & 5.6576 & 5.6552 & TRN & \\
\hline CHEMBL1084559 & 634306 & 5.2924 & 5.2925 & TRN & \\
\hline CHEMBL1085336 & 634306 & 6.1612 & 6.1583 & TRN & \\
\hline CHEMBL1082488 & 634306 & 7.5229 & 7.5287 & TRN & \\
\hline CHEMBL1083463 & 634306 & 6.8239 & 6.8218 & TRN & \\
\hline CHEMBL1085326 & 634306 & 5.6778 & 5.4504 & TST & \\
\hline CHEMBL1085841 & 634306 & 5.9208 & 5.4532 & TST & \\
\hline CHEMBL1083406 & 634306 & 5.1612 & 5.3584 & TST & \\
\hline CHEMBL351231 & 634306 & 6.3979 & 6.3942 & TST & \\
\hline CHEMBL393581 & 634306 & 5.301 & 5.5647 & TST & \\
\hline CHEMBL1084294 & 634306 & 5.2924 & 6.4761 & TST & \\
\hline CHEMBL1085829 & 634306 & 6.2076 & 5.7905 & TST & \\
\hline CHEMBL1086315 & 634306 & 6.3188 & 6.1082 & TST & \\
\hline CHEMBL1086098 & 634306 & 6.1427 & 5.2985 & TST & \\
\hline CHEMBL1084384 & 634306 & 5.0 & 5.6042 & TST & \\
\hline CHEMBL1082606 & 634306 & 5.8239 & 5.7603 & TST & \\
\hline CHEMBL3251536 & 1342911 & 4.3904 & 4.3453 & TRN & \\
\hline CHEMBL164489 & 1342911 & 4.752 & 4.9267 & TRN & \\
\hline CHEMBL3251531 & 1342911 & 3.0 & 3.3176 & TST & \\
\hline CHEMBL3244501 & 1342911 & 5.2676 & 4.843 & TRN & \\
\hline CHEMBL484621 & 1342911 & 3.699 & 4.296 & TRN & \\
\hline CHEMBL352923 & 1342911 & 5.1146 & 5.411006 & 20000000005 & TRN \\
\hline CHEMBL500330 & 1342911 & 4.2716 & 4.8193 & TRN & \\
\hline & & & & 1081 & \\
\hline
\end{tabular}


Supplemental Table S2.txt

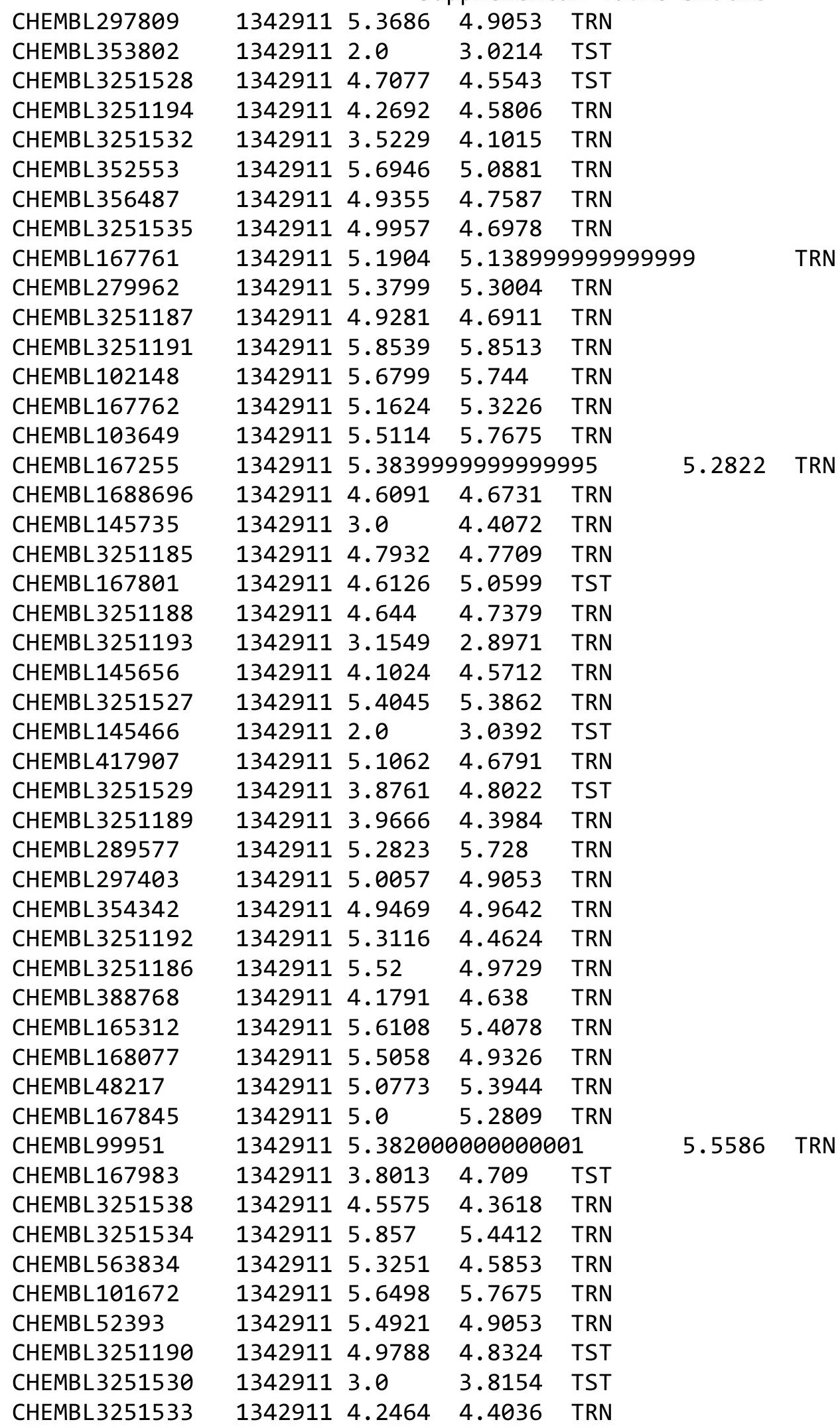

Page 10820 
Supplemental Table S2.txt

\begin{tabular}{|c|c|c|c|c|c|c|}
\hline CHEMBL101261 & 1342911 & 5.5638 & 5.5393 & TST & & \\
\hline CHEMBL1233459 & 1342911 & 5.1759 & 5.3199 & TST & & \\
\hline CHEMBL3251537 & 1342911 & 4.6216 & 4.5042 & TST & & \\
\hline CHEMBL166236 & 1342911 & 4.5513 & 4.7685 & TST & & \\
\hline CHEMBL164947 & 1342911 & 4.8477 & 5.0182 & TST & & \\
\hline CHEMBL 352718 & 1342911 & \multicolumn{3}{|c|}{4.9830000000000005} & 4.6019 & TST \\
\hline CHEMBL168138 & 1342911 & 4.3497 & 4.5223 & TST & & \\
\hline CHEMBL1357247 & 954947 & 3.2904 & 3.4163 & TRN & & \\
\hline CHEMBL1970879 & 954947 & 4.859 & 4.4214 & TRN & & \\
\hline CHEMBL189584 & 954947 & 4.512 & 4.394 & TRN & & \\
\hline CHEMBL 300389 & 954947 & 7.7249 & 7.8747 & TRN & & \\
\hline CHEMBL558642 & 954947 & 4.0628 & 3.9262 & TRN & & \\
\hline CHEMBL240954 & 954947 & 3.237 & 3.2331 & TST & & \\
\hline CHEMBL255342 & 954947 & 3.5988 & 3.677 & TRN & & \\
\hline CHEMBL1190711 & 954947 & \multicolumn{3}{|c|}{5.5329999999999995} & 5.1369 & TRN \\
\hline CHEMBL449158 & 954947 & 6.3613 & 6.9243 & TST & & \\
\hline CHEMBL1242367 & 954947 & 3.7182 & 3.9488 & TRN & & \\
\hline CHEMBL210618 & 954947 & 3.0394 & 2.8575 & TRN & & \\
\hline CHEMBL220241 & 954947 & 4.4738 & 4.3676 & TRN & & \\
\hline CHEMBL3186408 & 954947 & 4.239 & 3.8357 & TST & & \\
\hline CHEMBL1788116 & 954947 & 4.9795 & 5.0538 & TRN & & \\
\hline CHEMBL3199475 & 954947 & 4.9296 & 4.2621 & TRN & & \\
\hline CHEMBL9470 & 954947 & 6.1341 & 5.7422 & TST & & \\
\hline CHEMBL1256459 & 954947 & 7.1936 & 7.1749 & TRN & & \\
\hline CHEMBL192566 & 954947 & 6.19 & 8.0655 & TST & & \\
\hline CHEMBL 379300 & 954947 & 6.3689 & 6.6682 & TRN & & \\
\hline CHEMBL393929 & 954947 & 4.0494 & 4.112 & TRN & & \\
\hline CHEMBL483849 & 954947 & 1.6317 & 1.6218 & TRN & & \\
\hline CHEMBL373751 & 954947 & 3.3125 & 3.3955 & TRN & & \\
\hline CHEMBL577784 & 954947 & 4.9543 & 4.9236 & TRN & & \\
\hline CHEMBL1404918 & 954947 & 2.7376 & 2.7404 & TRN & & \\
\hline CHEMBL512504 & 954947 & 4.337 & 4.3321 & TRN & & \\
\hline CHEMBL65 & 954947 & 8.4947 & 8.349 & TRN & & \\
\hline CHEMBL258844 & 954947 & 3.9414 & 3.9795 & TRN & & \\
\hline CHEMBL 217354 & 954947 & \multicolumn{3}{|c|}{5.752999999999999} & 6.2775 & TRN \\
\hline CHEMBL 2137530 & 954947 & 5.6955 & 5.5654 & TRN & & \\
\hline CHEMBL392695 & 954947 & 5.9838 & 5.5482 & TRN & & \\
\hline CHEMBL379975 & 954947 & 5.5158 & 5.6341 & TRN & & \\
\hline CHEMBL483847 & 954947 & 3.8666 & 4.588 & TRN & & \\
\hline CHEMBL 213100 & 954947 & 3.9903 & 4.2908 & TRN & & \\
\hline CHEMBL3392440 & 954947 & 3.6481 & 3.9717 & TRN & & \\
\hline CHEMBL573107 & 954947 & 5.1038 & 5.0669 & TRN & & \\
\hline CHEMBL221137 & 954947 & 3.926 & 4.7116 & TST & & \\
\hline CHEMBL585951 & 954947 & 6.0811 & 5.9951 & TRN & & \\
\hline CHEMBL515416 & 954947 & 4.9176 & 5.0183 & TRN & & \\
\hline CHEMBL92309 & 954947 & 3.7952 & 2.6636 & TST & & \\
\hline CHEMBL412142 & 954947 & 4.628 & 5.3646 & TRN & & \\
\hline CHEMBL514499 & 954947 & 7.1386 & 7.059 & TRN & & \\
\hline
\end{tabular}




\begin{tabular}{|c|c|c|c|c|c|}
\hline \multicolumn{6}{|c|}{ Supplemental Table S2.txt } \\
\hline CHEMBL259181 & 954947 & 4.1287 & 3.8228 & TRN & \\
\hline CHEMBL1643959 & 954947 & 3.1211 & 2.9691 & TRN & \\
\hline CHEMBL 2144069 & 954947 & 6.8722 & 6.9895 & TRN & \\
\hline CHEMBL1230020 & 954947 & 6.1183 & 5.9492 & TRN & \\
\hline CHEMBL 209148 & 954947 & 3.4826 & 3.8896 & TRN & \\
\hline CHEMBL135561 & 954947 & 5.2315 & 4.7974 & TRN & \\
\hline CHEMBL399530 & 954947 & 4.4792 & 4.301 & TRN & \\
\hline CHEMBL102714 & 954947 & 5.8133 & 5.5179 & TRN & \\
\hline CHEMBL1673039 & 954947 & 4.285 & 4.3851 & TRN & \\
\hline CHEMBL1590308 & 954947 & 2.6547 & 3.2863 & TST & \\
\hline CHEMBL472940 & 954947 & 2.3603 & 2.7734 & TRN & \\
\hline CHEMBL1186585 & 954947 & 4.4131 & 4.1011 & TRN & \\
\hline CHEMBL202721 & 954947 & 3.9953 & 4.2038 & TRN & \\
\hline CHEMBL1516890 & 954947 & 5.6984 & 5.351 & TRN & \\
\hline CHEMBL 2363137 & 954947 & 5.1918 & 6.1017 & TST & \\
\hline CHEMBL191334 & 954947 & 5.8475 & 4.6912 & TST & \\
\hline CHEMBL 2005886 & 954947 & 5.749 & 5.5987 & TST & \\
\hline CHEMBL 2134202 & 954947 & 4.3833 & 4.3569 & TST & \\
\hline CHEMBL188678 & 954947 & 4.9623 & 4.3809 & TST & \\
\hline CHEMBL180127 & 954947 & 4.1456 & 4.6695 & TST & \\
\hline CHEMBL509032 & 954947 & 5.9736 & 5.2778 & TST & \\
\hline CHEMBL 222102 & 954947 & 3.4852 & 3.7001 & TST & \\
\hline CHEMBL1439847 & 688364 & 3.2245 & 3.862 & TST & \\
\hline CHEMBL1415476 & 688364 & 3.2245 & 4.0571 & TRN & \\
\hline CHEMBL1310325 & 688364 & 3.2245 & 3.2405 & TRN & \\
\hline CHEMBL1606773 & 688364 & 3.2245 & 3.10699 & 99999999998 & TRN \\
\hline CHEMBL1410659 & 688364 & 4.8645 & 4.798 & TRN & \\
\hline CHEMBL1583960 & 688364 & 4.2377 & 4.1947 & TRN & \\
\hline CHEMBL1990694 & 688364 & 4.8438 & 4.8263 & TRN & \\
\hline CHEMBL1373849 & 688364 & 3.2245 & 3.5975 & TRN & \\
\hline CHEMBL1495079 & 688364 & 3.2245 & 3.8003 & TRN & \\
\hline CHEMBL1362746 & 688364 & 5.479 & 5.0556 & TST & \\
\hline CHEMBL598477 & 688364 & 3.2245 & 3.0555 & TRN & \\
\hline CHEMBL1379677 & 688364 & 5.2688 & 4.8939 & TRN & \\
\hline CHEMBL1432003 & 688364 & 3.2245 & 3.0393 & TRN & \\
\hline CHEMBL 3198439 & 688364 & 3.2245 & 3.2256 & TRN & \\
\hline CHEMBL1557268 & 688364 & 3.2245 & 4.2709 & TRN & \\
\hline CHEMBL1399400 & 688364 & 4.8369 & 4.3604 & TRN & \\
\hline CHEMBL1500251 & 688364 & 4.508 & 4.6346 & TRN & \\
\hline CHEMBL1412067 & 688364 & 4.9807 & 5.0062 & TRN & \\
\hline CHEMBL1604510 & 688364 & 3.2245 & 3.1538 & TRN & \\
\hline CHEMBL1556007 & 688364 & 4.3233 & 3.8646 & TRN & \\
\hline CHEMBL1333292 & 688364 & 4.6288 & 4.2298 & TRN & \\
\hline CHEMBL1446754 & 688364 & 4.6445 & 3.3912 & TST & \\
\hline CHEMBL1416351 & 688364 & 3.2245 & 3.1399 & TRN & \\
\hline CHEMBL1611002 & 688364 & 3.2245 & 3.6567 & TRN & \\
\hline CHEMBL1518886 & 688364 & 5.5564 & 4.9929 & TST & \\
\hline CHEMBL1522563 & 688364 & 4.7943 & 5.5669 & TST & \\
\hline
\end{tabular}




\begin{tabular}{|c|c|c|c|c|c|}
\hline & & & oplement & & \\
\hline CHEMBL1409608 & 688364 & 4.2748 & 4.0302 & TRN & \\
\hline CHEMBL1523652 & 688364 & 4.3299 & 4.15300 & 00000000005 & TST \\
\hline CHEMBL1372920 & 688364 & 4.7041 & 4.7259 & TRN & \\
\hline CHEMBL1547938 & 688364 & 4.8506 & 5.0847 & TRN & \\
\hline CHEMBL1724937 & 688364 & 5.7899 & 5.5092 & TRN & \\
\hline CHEMBL1542877 & 688364 & 4.4387 & 3.7809 & TST & \\
\hline CHEMBL1502002 & 688364 & 4.4311 & 4.0133 & TRN & \\
\hline CHEMBL1607380 & 688364 & 3.2245 & 4.0089 & TRN & \\
\hline CHEMBL1430184 & 688364 & 3.2245 & 3.6413 & TRN & \\
\hline CHEMBL1463795 & 688364 & 5.4562 & 4.7549 & TST & \\
\hline CHEMBL1604962 & 688364 & 5.1635 & 5.2493 & TST & \\
\hline CHEMBL1605743 & 688364 & 6.3993 & 5.9894 & TRN & \\
\hline CHEMBL1977499 & 688364 & 3.2245 & 3.4325 & TRN & \\
\hline CHEMBL1502551 & 688364 & 3.2245 & 3.5166 & TRN & \\
\hline CHEMBL1458472 & 688364 & 4.6485 & 4.7553 & TRN & \\
\hline CHEMBL533293 & 688364 & 3.2245 & 3.6264 & TST & \\
\hline CHEMBL3190111 & 688364 & 3.2245 & 3.0228 & TRN & \\
\hline CHEMBL1320566 & 688364 & 3.2245 & 3.8664 & TRN & \\
\hline CHEMBL1571034 & 688364 & 5.2503 & 5.0961 & TRN & \\
\hline CHEMBL374632 & 688364 & 5.4893 & 4.8592 & TRN & \\
\hline CHEMBL1396129 & 688364 & 3.2245 & 3.5682 & TRN & \\
\hline CHEMBL1322893 & 688364 & 3.2245 & 3.4087 & TRN & \\
\hline CHEMBL1315955 & 688364 & 3.2245 & 3.42199 & 99999999997 & TRN \\
\hline CHEMBL1966700 & 688364 & 4.9611 & 3.7927 & TRN & \\
\hline CHEMBL1392848 & 688364 & 5.0645 & 5.5512 & TRN & \\
\hline CHEMBL1985696 & 688364 & 3.2245 & 3.3023 & TRN & \\
\hline CHEMBL1372738 & 688364 & 3.2245 & 2.7584 & TRN & \\
\hline CHEMBL1524257 & 688364 & 4.67 & 4.3903 & TRN & \\
\hline CHEMBL1565458 & 688364 & 4.9375 & 4.3642 & TRN & \\
\hline CHEMBL 1431610 & 688364 & 4.1067 & 3.71 & TRN & \\
\hline CHEMBL1331195 & 688364 & 5.9897 & 6.1771 & TRN & \\
\hline CHEMBL1398812 & 688364 & 3.2245 & 4.0199 & TRN & \\
\hline CHEMBL1398345 & 688364 & 4.9478 & 4.915 & TRN & \\
\hline CHEMBL1557243 & 688364 & 4.3783 & 4.0456 & TRN & \\
\hline CHEMBL1527994 & 688364 & 4.9592 & 4.5979 & TRN & \\
\hline CHEMBL1510658 & 688364 & 4.512 & 3.7769 & TRN & \\
\hline CHEMBL1576762 & 688364 & 3.2245 & 3.7168 & TRN & \\
\hline CHEMBL1501987 & 688364 & 4.6851 & 4.2916 & TRN & \\
\hline CHEMBL1498210 & 688364 & 5.3742 & 4.7658 & TST & \\
\hline CHEMBL1966746 & 688364 & 3.2245 & 3.4151 & TST & \\
\hline CHEMBL1304024 & 688364 & 4.4871 & 4.395 & TRN & \\
\hline CHEMBL1991136 & 688364 & 4.8739 & 4.8707 & TRN & \\
\hline CHEMBL1597682 & 688364 & 3.2245 & 3.157 & TRN & \\
\hline CHEMBL1413533 & 688364 & 3.2245 & 3.1405 & TRN & \\
\hline CHEMBL1420142 & 688364 & 4.3544 & 4.3662 & TRN & \\
\hline CHEMBL1538987 & 688364 & 4.4543 & 4.4995 & TRN & \\
\hline CHEMBL1985601 & 688364 & 5.0493 & 4.9911 & TRN & \\
\hline CHEMBL1491016 & 688364 & 3.2245 & 3.0109 & TRN & \\
\hline
\end{tabular}




\begin{tabular}{|c|c|c|c|c|c|}
\hline & & \multicolumn{4}{|c|}{ Supplemental Table S2.txt } \\
\hline CHEMBL1713905 & 688364 & 4.9399 & 4.7911 & TRN & \\
\hline CHEMBL1306565 & 688364 & 3.2245 & 3.6815 & TRN & \\
\hline CHEMBL1492044 & 688364 & 3.2245 & 4.6155 & TRN & \\
\hline CHEMBL1390971 & 688364 & 5.0313 & 4.9708 & TRN & \\
\hline CHEMBL1453652 & 688364 & 4.5196 & 3.91606 & 30000000004 & TRN \\
\hline CHEMBL1510317 & 688364 & 4.9299 & 5.0437 & TRN & \\
\hline CHEMBL3207378 & 688364 & 3.2245 & 3.7007 & TST & \\
\hline CHEMBL1387366 & 688364 & 5.4063 & 5.3594 & TRN & \\
\hline CHEMBL1332522 & 688364 & 5.2948 & 4.7853 & TST & \\
\hline CHEMBL1513792 & 688364 & 3.2245 & 3.4299 & TST & \\
\hline CHEMBL1419637 & 688364 & 3.2245 & 4.1957 & TST & \\
\hline CHEMBL1490312 & 688364 & 3.2245 & 4.0724 & TST & \\
\hline CHEMBL1472131 & 688364 & 4.43 & 4.3661 & TST & \\
\hline CHEMBL1582196 & 688364 & 4.4338 & 4.4317 & TST & \\
\hline CHEMBL1583872 & 688364 & 5.6003 & 4.9929 & TST & \\
\hline CHEMBL1413510 & 688364 & 4.8954 & 4.729 & TST & \\
\hline CHEMBL1303641 & 688364 & 5.6747 & 5.1799 & TST & \\
\hline CHEMBL 2003304 & 688364 & 5.0965 & 5.0588 & TST & \\
\hline CHEMBL581251 & 688364 & 3.2245 & 3.52399 & 99999999996 & TST \\
\hline CHEMBL213505 & 809193 & 7.0 & 6.704 & TRN & \\
\hline CHEMBL1987034 & 809193 & 7.0 & 7.5189 & TRN & \\
\hline CHEMBL1993941 & 809193 & 8.1 & 8.2165 & TRN & \\
\hline CHEMBL 377383 & 809193 & 4.8 & 4.6698 & TRN & \\
\hline CHEMBL578061 & 809193 & 6.2 & 5.8379 & TRN & \\
\hline CHEMBL 2005886 & 809193 & 7.6 & 7.2358 & TST & \\
\hline CHEMBL481491 & 809193 & 4.8 & 5.1586 & TST & \\
\hline CHEMBL1682345 & 809193 & 4.8 & 4.7199 & TRN & \\
\hline CHEMBL1973142 & 809193 & 4.8 & 5.0484 & TST & \\
\hline CHEMBL1973145 & 809193 & 4.8 & 4.8853 & TRN & \\
\hline CHEMBL1982924 & 809193 & 4.8 & 5.7922 & TRN & \\
\hline CHEMBL 2005936 & 809193 & 4.8 & 4.7611 & TRN & \\
\hline CHEMBL1971141 & 809193 & 4.8 & 4.7827 & TRN & \\
\hline CHEMBL1979718 & 809193 & 4.8 & 5.033 & TRN & \\
\hline CHEMBL 206236 & 809193 & 4.8 & 4.6992 & TRN & \\
\hline CHEMBL523823 & 809193 & 4.8 & 4.734 & TST & \\
\hline CHEMBL1973178 & 809193 & 7.2 & 7.4011 & TRN & \\
\hline CHEMBL1988778 & 809193 & 6.5 & 6.5181 & TRN & \\
\hline CHEMBL 2001957 & 809193 & 4.8 & 4.998 & TRN & \\
\hline CHEMBL1969372 & 809193 & 4.8 & 5.0243 & TRN & \\
\hline CHEMBL1990583 & 809193 & 6.9 & 6.2563 & TRN & \\
\hline CHEMBL1986943 & 809193 & 6.1 & 5.7099 & TRN & \\
\hline CHEMBL 2006263 & 809193 & 4.8 & 4.9729 & TST & \\
\hline CHEMBL1993584 & 809193 & 4.8 & 4.7171 & TRN & \\
\hline CHEMBL1986263 & 809193 & 4.8 & 5.4193 & TRN & \\
\hline CHEMBL 2000114 & 809193 & 4.8 & 4.9917 & TRN & \\
\hline CHEMBL210618 & 809193 & 4.8 & 4.6621 & TRN & \\
\hline CHEMBL1975647 & 809193 & 4.8 & 4.916 & TRN & \\
\hline CHEMBL1968380 & 809193 & 4.8 & 4.7897 & TRN & \\
\hline
\end{tabular}




\begin{tabular}{|c|c|c|c|c|}
\hline \multicolumn{5}{|c|}{ ipplemental T } \\
\hline CHEMBL1964644 & 809193 & 4.8 & 4.7581 & TRN \\
\hline CHEMBL1981782 & 809193 & 4.8 & 4.6255 & TRN \\
\hline CHEMBL1977681 & 809193 & 4.8 & 4.8799 & TRN \\
\hline CHEMBL1970142 & 809193 & 8.5 & 8.478 & TRN \\
\hline CHEMBL1990912 & 809193 & 4.8 & 4.7481 & TRN \\
\hline CHEMBL1988163 & 809193 & 7.6 & 7.1248 & TRN \\
\hline CHEMBL1995592 & 809193 & 5.8 & 5.4162 & TST \\
\hline CHEMBL 2006493 & 809193 & 4.8 & 4.7189 & TST \\
\hline CHEMBL1983449 & 809193 & 4.8 & 4.7224 & TRN \\
\hline CHEMBL1992323 & 809193 & 4.8 & 4.7592 & TST \\
\hline CHEMBL1969735 & 809193 & 4.8 & 4.9669 & TRN \\
\hline CHEMBL 2003524 & 809193 & 4.8 & 4.8902 & TST \\
\hline CHEMBL 2002649 & 809193 & 4.8 & 5.6889 & TRN \\
\hline CHEMBL437747 & 809193 & 5.8 & 4.8816 & TRN \\
\hline CHEMBL507936 & 809193 & 4.8 & 5.4725 & TRN \\
\hline CHEMBL104264 & 809193 & 4.8 & 4.9388 & TST \\
\hline CHEMBL1994321 & 809193 & 7.2 & 7.1027 & TRN \\
\hline CHEMBL1997129 & 809193 & 4.8 & 5.5242 & TST \\
\hline CHEMBL451964 & 809193 & 4.8 & 4.8633 & TRN \\
\hline CHEMBL1964307 & 809193 & 4.8 & 5.1954 & TRN \\
\hline CHEMBL 2000508 & 809193 & 4.8 & 4.9888 & TRN \\
\hline CHEMBL 2001547 & 809193 & 4.8 & 4.7731 & TRN \\
\hline CHEMBL 210928 & 809193 & 4.8 & 4.699 & TRN \\
\hline CHEMBL1994361 & 809193 & 4.8 & 4.6427 & TRN \\
\hline CHEMBL1972840 & 809193 & 4.8 & 4.7028 & TRN \\
\hline CHEMBL1977148 & 809193 & 8.8 & 8.4603 & TRN \\
\hline CHEMBL 2003286 & 809193 & 4.8 & 4.6686 & TRN \\
\hline CHEMBL1992306 & 809193 & 7.2 & 6.5872 & TRN \\
\hline CHEMBL 2002165 & 809193 & 8.0 & 8.1185 & TRN \\
\hline CHEMBL 206382 & 809193 & 4.8 & 4.6838 & TRN \\
\hline CHEMBL1998585 & 809193 & 7.2 & 6.9673 & TRN \\
\hline CHEMBL127898 & 809193 & 6.5 & 4.9926 & TST \\
\hline CHEMBL519697 & 809193 & 4.8 & 4.9193 & TST \\
\hline CHEMBL 2004934 & 809193 & 4.8 & 4.7479 & TRN \\
\hline CHEMBL 2000652 & 809193 & 6.8 & 6.6154 & TRN \\
\hline CHEMBL1975128 & 809193 & 4.8 & 4.8666 & TRN \\
\hline CHEMBL1996048 & 809193 & 6.1 & 5.0048 & TST \\
\hline CHEMBL461876 & 809193 & 4.8 & 4.6837 & TST \\
\hline CHEMBL 2001485 & 809193 & 7.6 & 7.9878 & TRN \\
\hline CHEMBL504950 & 809193 & 4.8 & 5.1839 & TRN \\
\hline CHEMBL1966425 & 809193 & 5.8 & 5.3937 & TRN \\
\hline CHEMBL1984363 & 809193 & 4.8 & 5.3183 & TRN \\
\hline CHEMBL1978099 & 809193 & 6.5 & 6.3613 & TRN \\
\hline CHEMBL1977041 & 809193 & 7.2 & 7.05 & TRN \\
\hline CHEMBL1968070 & 809193 & 4.8 & 4.852 & TRN \\
\hline CHEMBL1988608 & 809193 & 4.8 & 4.6409 & TRN \\
\hline CHEMBL184847 & 809193 & 4.8 & 5.5021 & TRN \\
\hline CHEMBL1984367 & 809193 & 4.8 & 4.9018 & TRN \\
\hline
\end{tabular}




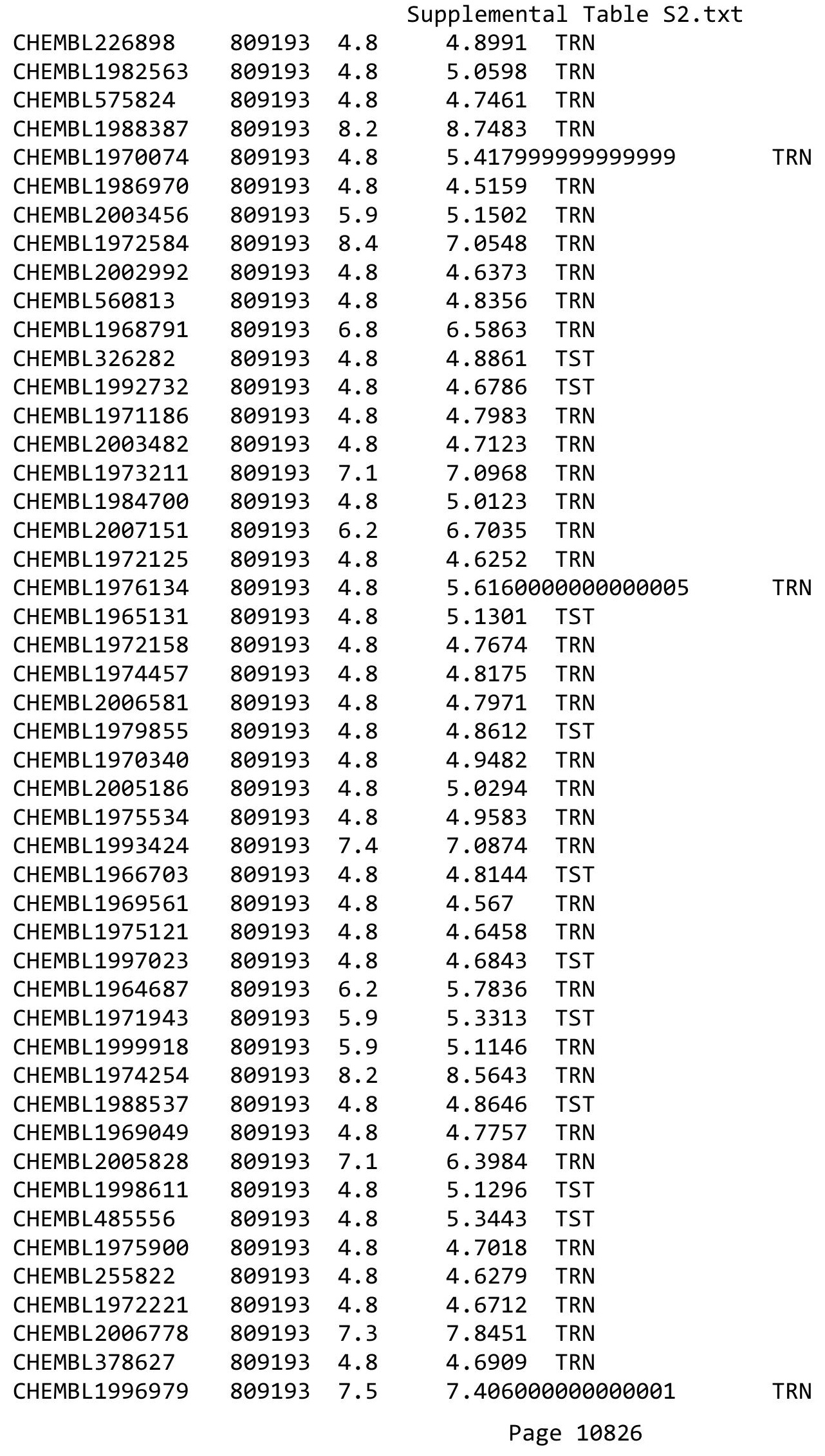




\begin{tabular}{|c|c|c|c|c|}
\hline \multicolumn{5}{|c|}{ Supplemental Table S2.txt } \\
\hline CHEMBL1968406 & 809193 & 6.9 & 6.555 & TRN \\
\hline CHEMBL1982476 & 809193 & 8.6 & 8.4087 & TRN \\
\hline CHEMBL1998545 & 809193 & 4.8 & 4.7165 & TRN \\
\hline CHEMBL1986869 & 809193 & 4.8 & 4.8448 & TST \\
\hline CHEMBL1682558 & 809193 & 4.8 & 4.8013 & TRN \\
\hline CHEMBL1990496 & 809193 & 6.5 & 4.9046 & TRN \\
\hline CHEMBL1997623 & 809193 & 6.4 & 6.4846 & TRN \\
\hline CHEMBL 2002479 & 809193 & 4.8 & 5.4519 & TRN \\
\hline CHEMBL1967094 & 809193 & 4.8 & 4.9529 & TRN \\
\hline CHEMBL2003341 & 809193 & 4.8 & 4.7072 & TRN \\
\hline CHEMBL1992644 & 809193 & 5.7 & 4.9113 & TRN \\
\hline CHEMBL1982992 & 809193 & 4.8 & 5.051 & TRN \\
\hline CHEMBL1999590 & 809193 & 6.4 & 5.8547 & TST \\
\hline CHEMBL1980489 & 809193 & 4.8 & 4.6806 & TRN \\
\hline CHEMBL1967116 & 809193 & 8.6 & 8.6968 & TRN \\
\hline CHEMBL 2000832 & 809193 & 4.8 & 4.8549 & TRN \\
\hline CHEMBL1970709 & 809193 & 4.8 & 4.6021 & TRN \\
\hline CHEMBL1998112 & 809193 & 6.7 & 6.3076 & TRN \\
\hline CHEMBL1993996 & 809193 & 6.8 & 6.5127 & TRN \\
\hline CHEMBL1969126 & 809193 & 4.8 & 4.8281 & TRN \\
\hline CHEMBL1980896 & 809193 & 6.2 & 6.2539 & TRN \\
\hline CHEMBL1970104 & 809193 & 6.6 & 6.3381 & TRN \\
\hline CHEMBL1991429 & 809193 & 7.9 & 8.1706 & TRN \\
\hline CHEMBL1971149 & 809193 & 4.8 & 4.758 & TRN \\
\hline CHEMBL1999714 & 809193 & 4.8 & 4.8886 & TRN \\
\hline CHEMBL1994040 & 809193 & 4.8 & 4.7757 & TRN \\
\hline CHEMBL388978 & 809193 & 8.2 & 7.0994 & TST \\
\hline CHEMBL579246 & 809193 & 4.8 & 4.7178 & TRN \\
\hline CHEMBL398951 & 809193 & 4.8 & 4.7624 & TST \\
\hline CHEMBL1982506 & 809193 & 4.8 & 4.9491 & TST \\
\hline CHEMBL 2004716 & 809193 & 8.2 & 7.8759 & TRN \\
\hline CHEMBL1968127 & 809193 & 4.8 & 4.7596 & TRN \\
\hline CHEMBL1975233 & 809193 & 4.8 & 4.7655 & TRN \\
\hline CHEMBL1985406 & 809193 & 4.8 & 4.7323 & TRN \\
\hline CHEMBL 207400 & 809193 & 4.8 & 4.6611 & TST \\
\hline CHEMBL2000894 & 809193 & 4.8 & 4.9573 & TST \\
\hline CHEMBL1982135 & 809193 & 4.8 & 5.8978 & TRN \\
\hline CHEMBL1976090 & 809193 & 4.8 & 5.018 & TRN \\
\hline CHEMBL1993243 & 809193 & 7.0 & 7.9335 & TRN \\
\hline CHEMBL1992922 & 809193 & 6.1 & 5.7773 & TRN \\
\hline CHEMBL2004771 & 809193 & 4.8 & 5.1181 & TRN \\
\hline CHEMBL399021 & 809193 & 6.5 & 6.6084 & TRN \\
\hline CHEMBL1997597 & 809193 & 4.8 & 4.5964 & TRN \\
\hline CHEMBL1969537 & 809193 & 4.8 & 5.4047 & TST \\
\hline CHEMBL1976093 & 809193 & 4.8 & 4.8033 & TRN \\
\hline CHEMBL1975256 & 809193 & 4.8 & 4.7649 & TST \\
\hline CHEMBL508928 & 809193 & 8.9 & 8.2233 & TRN \\
\hline CHEMBL 2004892 & 809193 & 4.8 & 4.5274 & TRN \\
\hline
\end{tabular}




\begin{tabular}{|c|c|c|c|c|}
\hline & & & plem & \\
\hline CHEMBL116070 & 809193 & 4.8 & 4.9283 & TRN \\
\hline CHEMBL1970314 & 809193 & 4.8 & 4.7438 & TRN \\
\hline CHEMBL 2004871 & 809193 & 4.8 & 4.7999 & TRN \\
\hline CHEMBL1969879 & 809193 & 4.8 & 4.7927 & TRN \\
\hline CHEMBL1981720 & 809193 & 4.8 & 4.882 & TRN \\
\hline CHEMBL419932 & 809193 & 4.8 & 4.6562 & TRN \\
\hline CHEMBL262433 & 809193 & 6.9 & 6.6252 & TRN \\
\hline CHEMBL373798 & 809193 & 6.4 & 6.6539 & TRN \\
\hline CHEMBL306380 & 809193 & 7.7 & 7.5091 & TRN \\
\hline CHEMBL1966722 & 809193 & 4.8 & 4.8181 & TST \\
\hline CHEMBL1976328 & 809193 & 4.8 & 5.3974 & TRN \\
\hline CHEMBL1975500 & 809193 & 4.8 & 5.0233 & TRN \\
\hline CHEMBL394619 & 809193 & 6.3 & 5.8147 & TRN \\
\hline CHEMBL1964399 & 809193 & 4.8 & 5.0796 & TRN \\
\hline CHEMBL1996831 & 809193 & 4.8 & 4.8999 & TST \\
\hline CHEMBL411903 & 809193 & 6.0 & 6.3985 & TRN \\
\hline CHEMBL1965988 & 809193 & 7.1 & 6.9956 & TRN \\
\hline CHEMBL418203 & 809193 & 4.8 & 4.8652 & TST \\
\hline CHEMBL1682357 & 809193 & 4.8 & 4.9158 & TRN \\
\hline CHEMBL 225519 & 809193 & 4.8 & 4.6348 & TST \\
\hline CHEMBL209534 & 809193 & 4.8 & 4.7415 & TRN \\
\hline CHEMBL1978200 & 809193 & 4.8 & 4.888 & TRN \\
\hline CHEMBL1970522 & 809193 & 5.8 & 4.625 & TRN \\
\hline CHEMBL402846 & 809193 & 6.3 & 6.2573 & TRN \\
\hline CHEMBL1964692 & 809193 & 7.2 & 7.4417 & TRN \\
\hline CHEMBL1996931 & 809193 & 4.8 & 4.6883 & TRN \\
\hline CHEMBL1964413 & 809193 & 4.8 & 4.7325 & TRN \\
\hline CHEMBL1973483 & 809193 & 4.8 & 4.8132 & TRN \\
\hline CHEMBL1984432 & 809193 & 4.8 & 4.7824 & TRN \\
\hline CHEMBL 219722 & 809193 & 6.1 & 6.2628 & TRN \\
\hline CHEMBL1997340 & 809193 & 4.8 & 4.7349 & TRN \\
\hline CHEMBL1522508 & 809193 & 4.8 & 4.887 & TRN \\
\hline CHEMBL1989474 & 809193 & 4.8 & 4.8285 & TRN \\
\hline CHEMBL1090360 & 809193 & 8.4 & 8.1036 & TRN \\
\hline CHEMBL 210887 & 809193 & 4.8 & 4.7792 & TST \\
\hline CHEMBL1971021 & 809193 & 4.8 & 5.3262 & TRN \\
\hline CHEMBL227271 & 809193 & 4.8 & 4.7678 & TRN \\
\hline CHEMBL583144 & 809193 & 4.8 & 5.0089 & TST \\
\hline CHEMBL1974310 & 809193 & 4.8 & 4.8858 & TRN \\
\hline CHEMBL1982660 & 809193 & 4.8 & 4.9553 & TRN \\
\hline CHEMBL1994693 & 809193 & 6.3 & 6.2273 & TRN \\
\hline CHEMBL1982957 & 809193 & 6.3 & 6.0516 & TRN \\
\hline CHEMBL1725279 & 809193 & 6.0 & 5.9343 & TST \\
\hline CHEMBL1975138 & 809193 & 4.8 & 4.8654 & TST \\
\hline CHEMBL424872 & 809193 & 4.8 & 4.6138 & TRN \\
\hline CHEMBL1971947 & 809193 & 7.8 & 7.1928 & TRN \\
\hline CHEMBL412142 & 809193 & 4.8 & 4.9034 & TST \\
\hline CHEMBL1980704 & 809193 & 4.8 & 4.8481 & TST \\
\hline
\end{tabular}




\begin{tabular}{|c|c|c|c|c|}
\hline & & & Supplement & \\
\hline CHEMBL2003271 & 809193 & 4.8 & 5.0479 & TST \\
\hline CHEMBL1966808 & 809193 & 4.8 & 4.8055 & TST \\
\hline CHEMBL1996255 & 809193 & 6.4 & 6.3587 & TRN \\
\hline CHEMBL 2004447 & 809193 & 4.8 & 4.794 & TST \\
\hline CHEMBL1973860 & 809193 & 4.8 & 4.7605 & TRN \\
\hline CHEMBL260135 & 809193 & 4.8 & 5.0106 & TRN \\
\hline CHEMBL220241 & 809193 & 4.8 & 5.1603 & TST \\
\hline CHEMBL1982610 & 809193 & 4.8 & 5.3037 & TST \\
\hline CHEMBL1999496 & 809193 & 4.8 & 4.8862 & TRN \\
\hline CHEMBL2006933 & 809193 & 4.8 & 4.9062 & TST \\
\hline CHEMBL1988300 & 809193 & 6.8 & 6.8456 & TRN \\
\hline CHEMBL1991078 & 809193 & 6.3 & 6.1115 & TRN \\
\hline CHEMBL1987359 & 809193 & 4.8 & 4.907 & TST \\
\hline CHEMBL2000685 & 809193 & 4.8 & 4.9506 & TRN \\
\hline CHEMBL1985311 & 809193 & 6.0 & 5.5366 & TRN \\
\hline CHEMBL1969502 & 809193 & 4.8 & 6.8124 & TST \\
\hline CHEMBL1965910 & 809193 & 6.1 & 6.5541 & TRN \\
\hline CHEMBL1682553 & 809193 & 4.8 & 5.0309 & TRN \\
\hline CHEMBL1997764 & 809193 & 4.8 & 5.4597 & TRN \\
\hline CHEMBL1983963 & 809193 & 6.8 & 6.7296 & TRN \\
\hline CHEMBL 2000271 & 809193 & 4.8 & 5.4949 & TRN \\
\hline CHEMBL1985092 & 809193 & 4.8 & 4.8924 & TRN \\
\hline CHEMBL1981410 & 809193 & 4.8 & 5.2334 & TRN \\
\hline CHEMBL1996234 & 809193 & 6.2 & 6.0653 & TRN \\
\hline CHEMBL1991434 & 809193 & 4.8 & 4.8682 & TST \\
\hline CHEMBL1967544 & 809193 & 4.8 & 4.8003 & TRN \\
\hline CHEMBL223367 & 809193 & 4.8 & 4.8002 & TST \\
\hline CHEMBL340384 & 809193 & 5.8 & 5.0598 & TST \\
\hline CHEMBL1996587 & 809193 & 4.8 & 4.747 & TRN \\
\hline CHEMBL1964804 & 809193 & 4.8 & 4.7137 & TRN \\
\hline CHEMBL443962 & 809193 & 4.8 & 5.0592 & TST \\
\hline CHEMBL 2000354 & 809193 & 5.8 & 4.7627 & TRN \\
\hline CHEMBL1965507 & 809193 & 4.9 & 4.9208 & TRN \\
\hline CHEMBL274064 & 809193 & 6.5 & 5.4006 & TRN \\
\hline CHEMBL1967564 & 809193 & 4.8 & 4.7134 & TRN \\
\hline CHEMBL592030 & 809193 & 4.8 & 4.8054 & TST \\
\hline CHEMBL 2000071 & 809193 & 4.9 & 5.5839 & TRN \\
\hline CHEMBL1979176 & 809193 & 4.8 & 4.7907 & TRN \\
\hline CHEMBL1985491 & 809193 & 4.8 & 5.8476 & TRN \\
\hline CHEMBL1970317 & 809193 & 8.2 & 8.4356 & TRN \\
\hline CHEMBL 2000408 & 809193 & 4.8 & 4.9377 & TRN \\
\hline CHEMBL 248757 & 809193 & 4.8 & 4.8208 & TST \\
\hline CHEMBL1978014 & 809193 & 4.8 & 4.8986 & TRN \\
\hline CHEMBL1994538 & 809193 & 4.8 & 4.7766 & TRN \\
\hline CHEMBL1975490 & 809193 & 4.8 & 5.5499 & TRN \\
\hline CHEMBL2006567 & 809193 & 4.8 & 4.7199 & TRN \\
\hline CHEMBL1986139 & 809193 & 4.8 & 4.8609 & TRN \\
\hline CHEMBL383527 & 809193 & 4.8 & 4.7695 & TRN \\
\hline
\end{tabular}




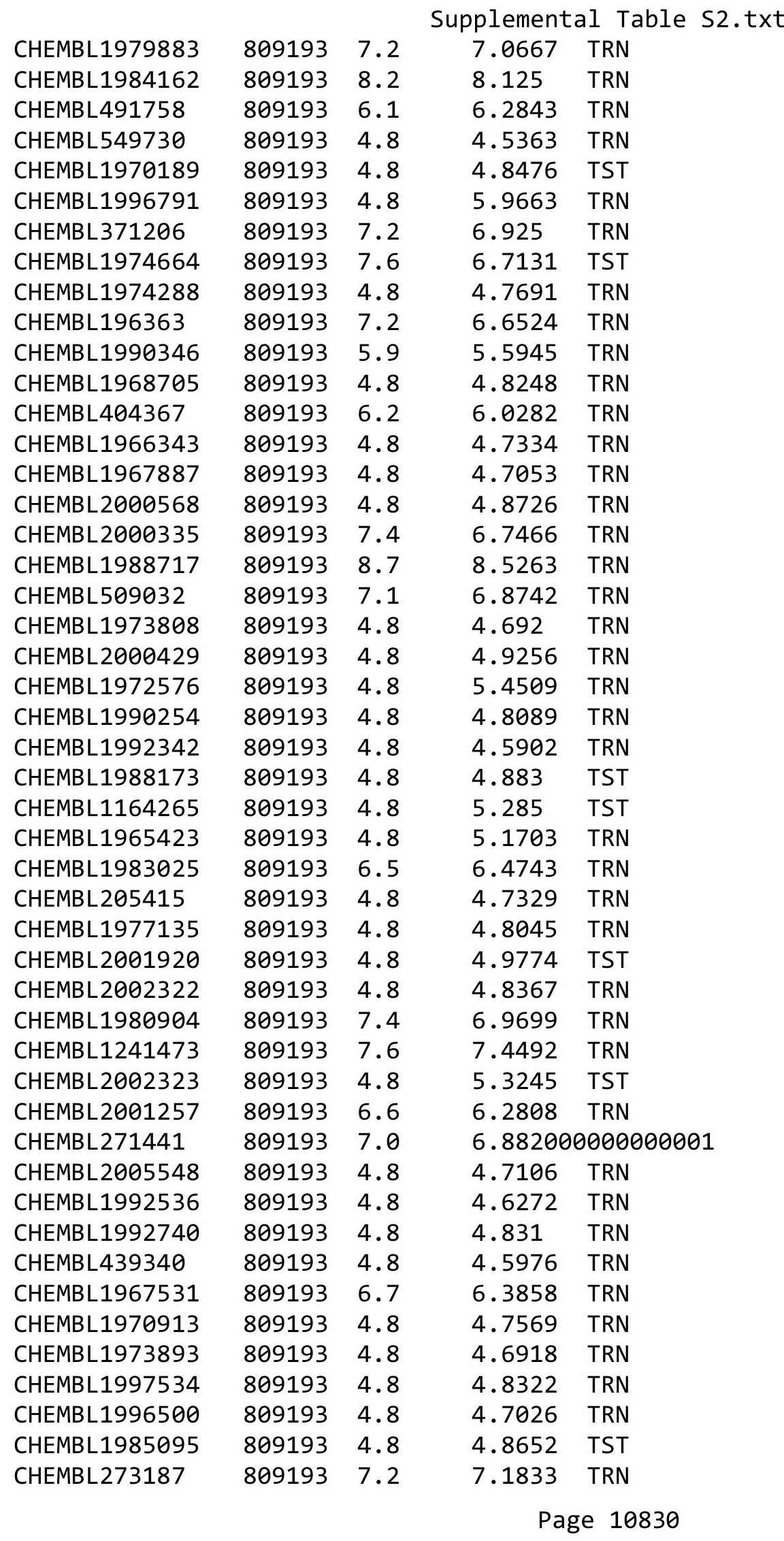




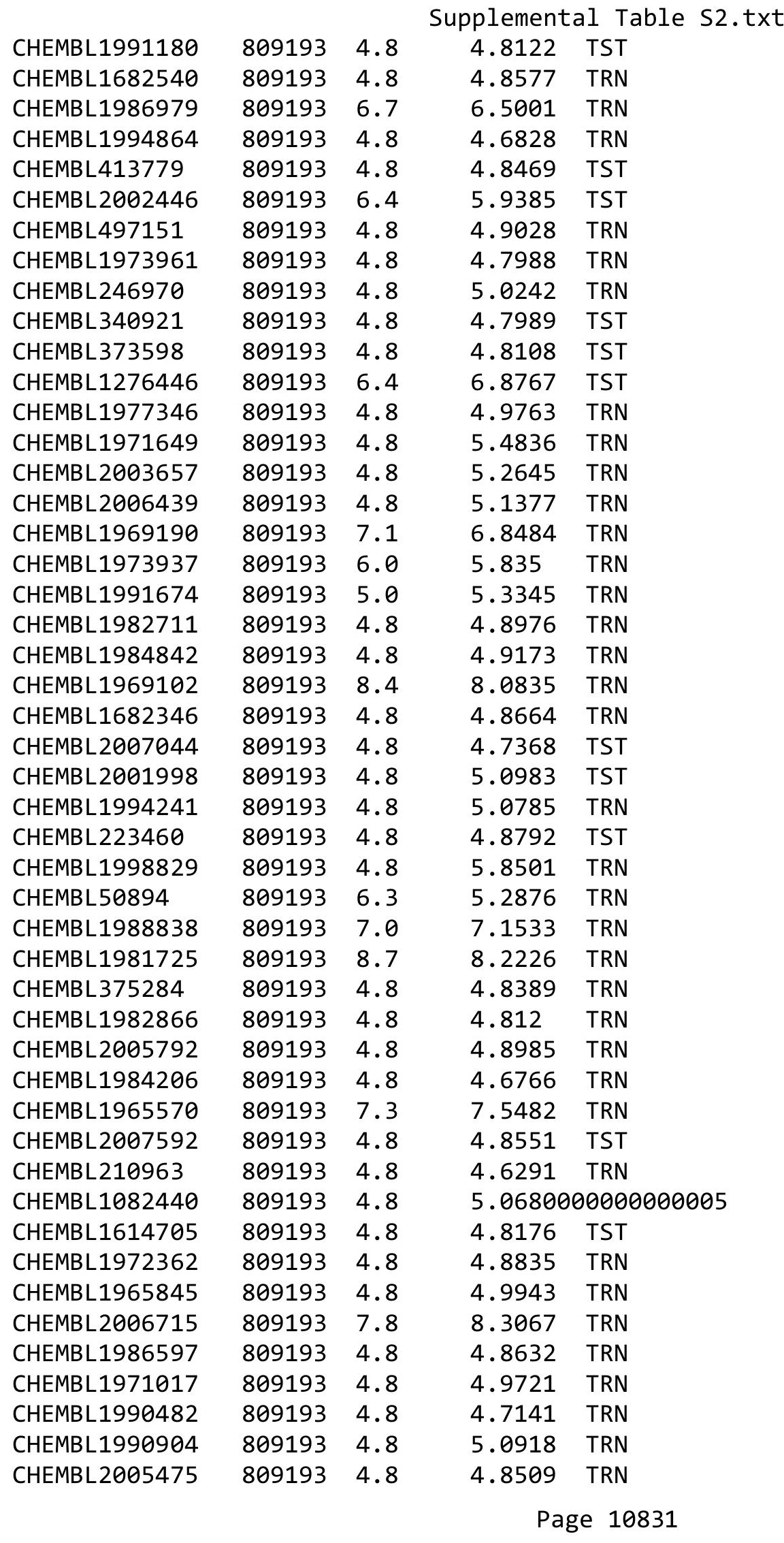




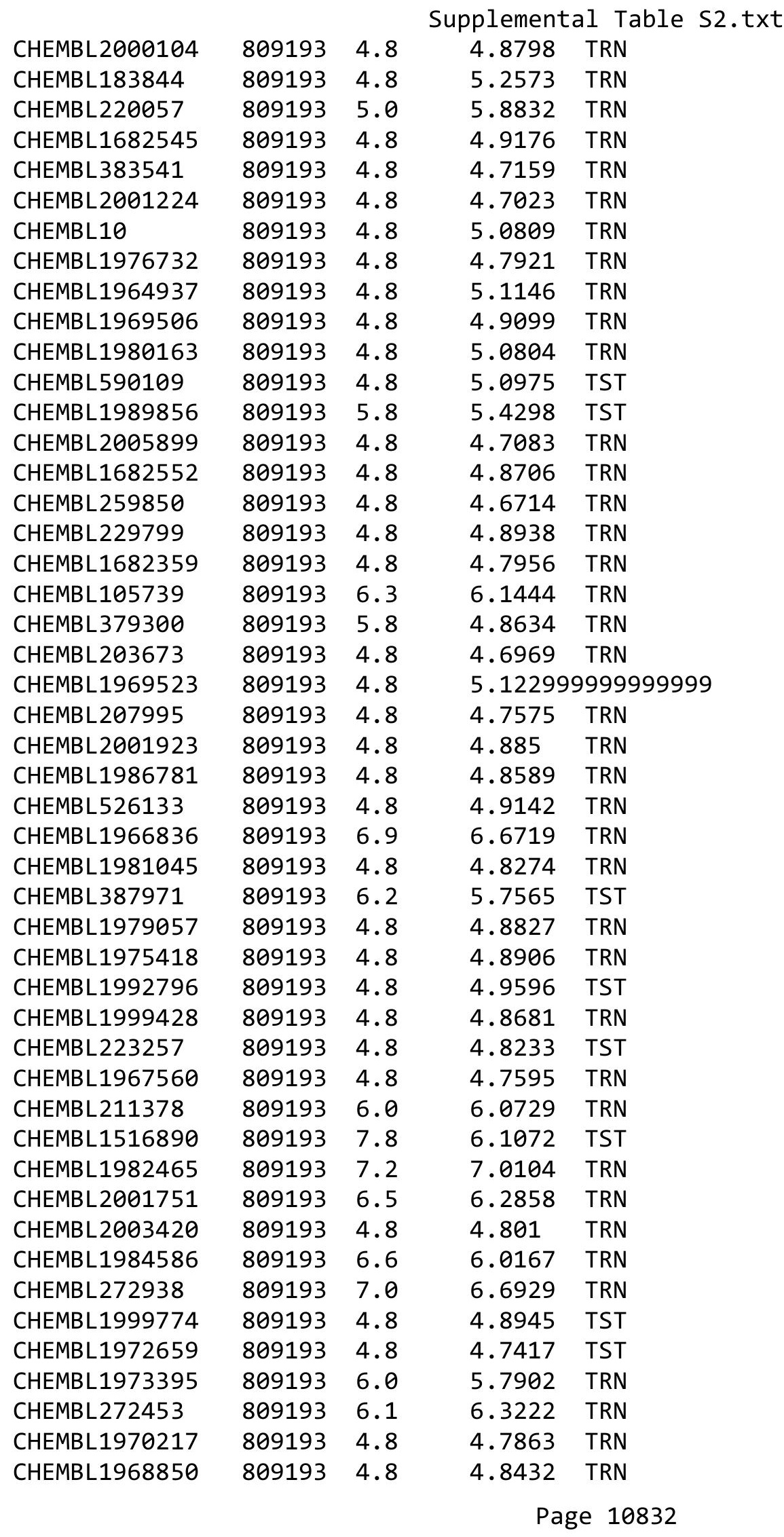




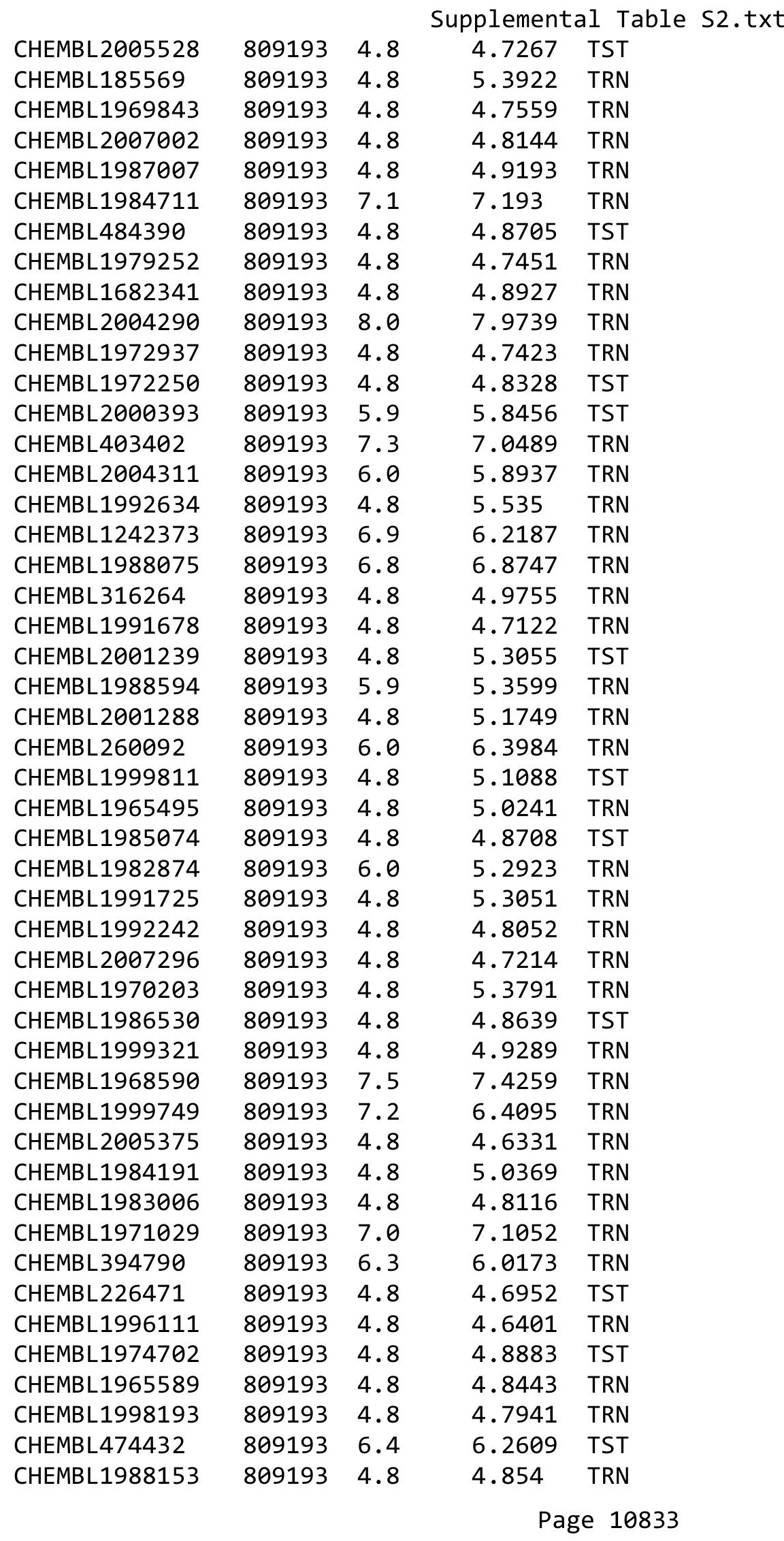




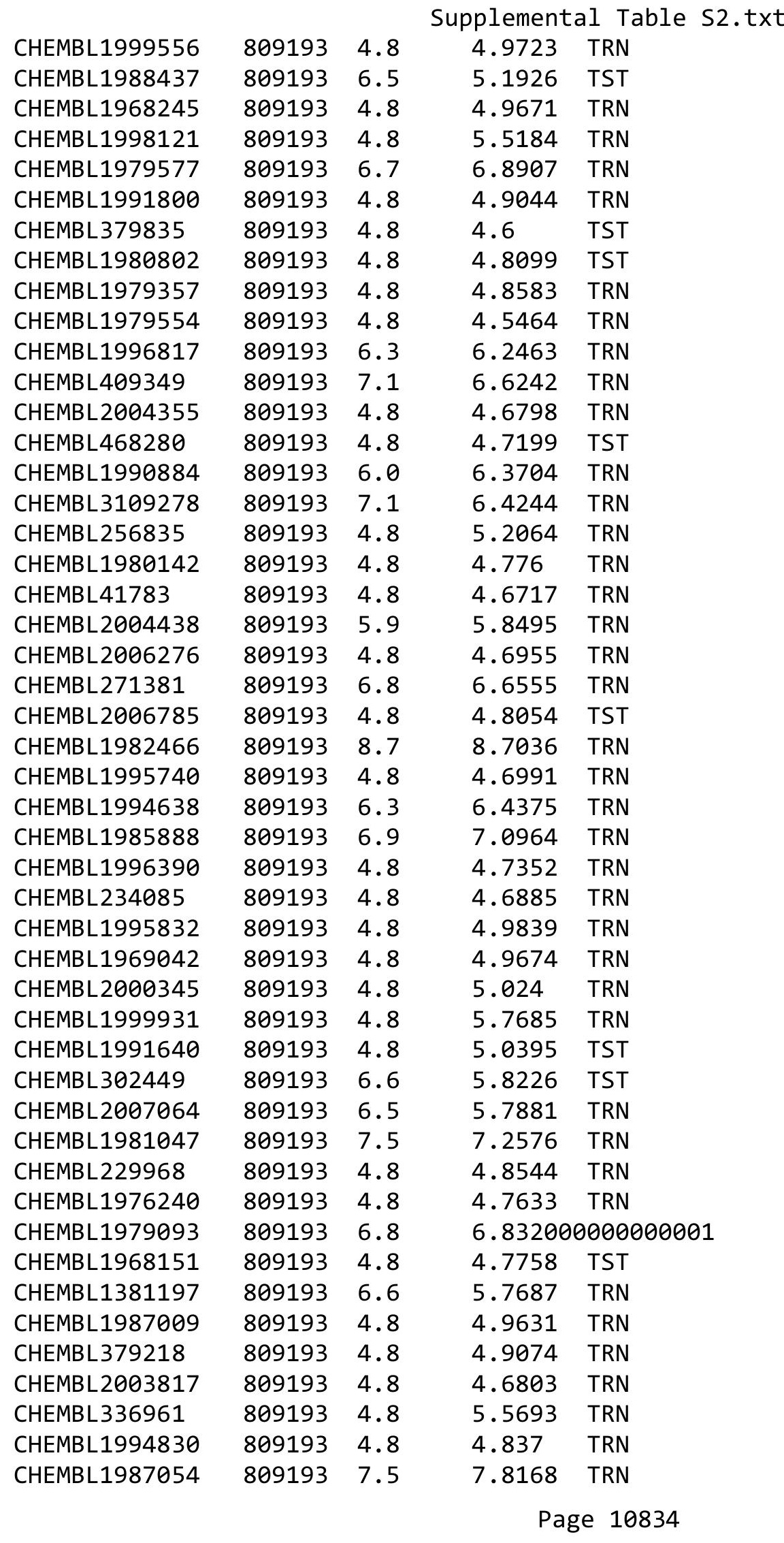




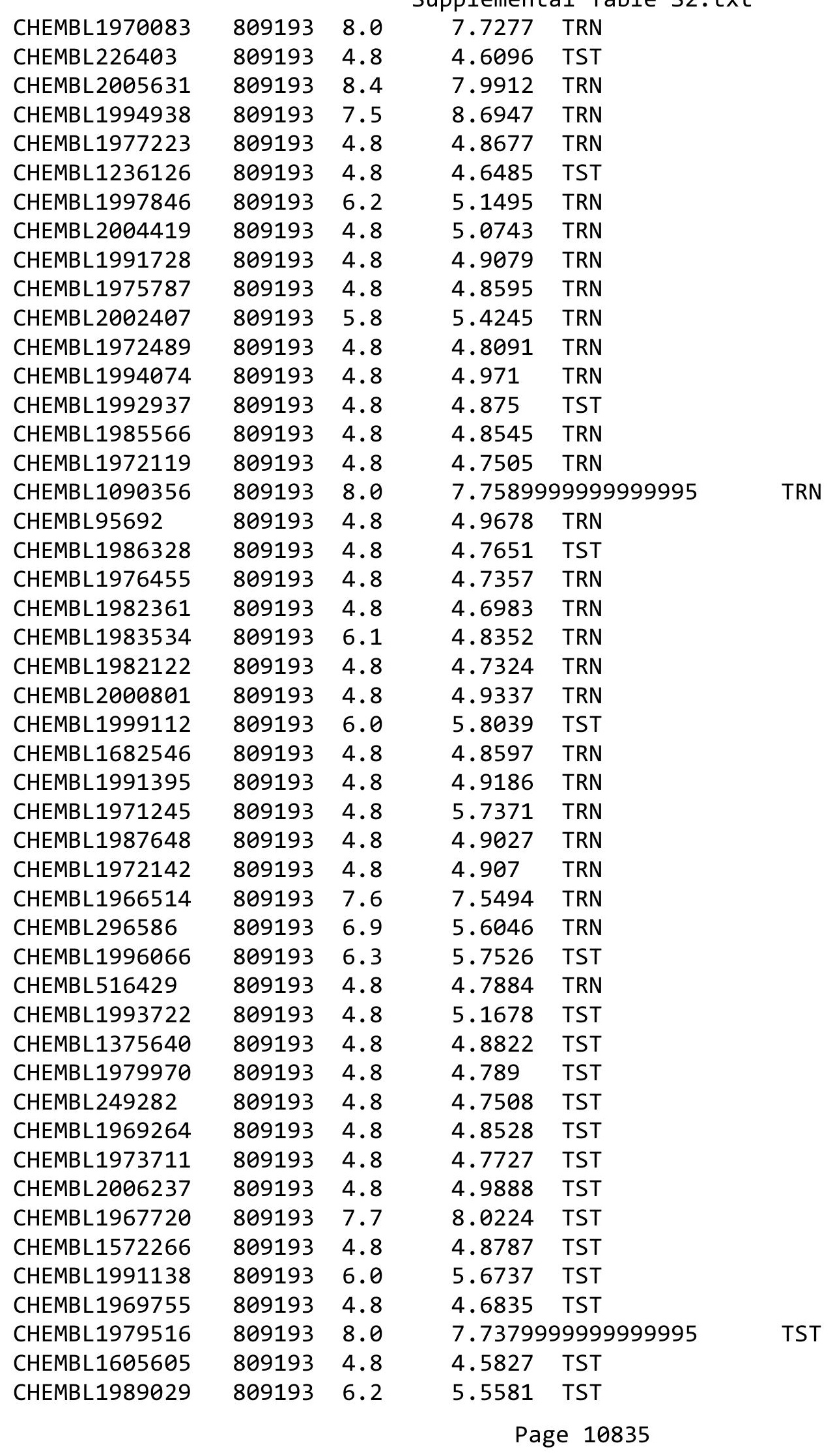




\begin{tabular}{|c|c|c|c|c|}
\hline \multicolumn{5}{|c|}{ Supplemental Table S2.txt } \\
\hline CHEMBL392642 & 809193 & 4.8 & 4.8807 & TST \\
\hline CHEMBL514499 & 809193 & 4.8 & 5.7205 & TST \\
\hline CHEMBL1965631 & 809193 & 4.8 & 4.9759 & TST \\
\hline CHEMBL1980144 & 809193 & 4.8 & 5.2616 & TST \\
\hline CHEMBL1972849 & 809193 & 4.8 & 4.7037 & TST \\
\hline CHEMBL377408 & 809193 & 4.8 & 4.8895 & TST \\
\hline CHEMBL 215152 & 809193 & 6.0 & 5.5093 & TST \\
\hline CHEMBL231209 & 809193 & 6.0 & 5.9303 & TST \\
\hline CHEMBL1976220 & 809193 & 6.5 & 6.1465 & TST \\
\hline CHEMBL 259922 & 809193 & 8.2 & 5.6108 & TST \\
\hline CHEMBL1982383 & 809193 & 4.8 & 5.1434 & TST \\
\hline CHEMBL1969301 & 809193 & 4.8 & 4.7765 & TST \\
\hline CHEMBL17370 & 809193 & 4.8 & 5.2511 & TST \\
\hline CHEMBL1987910 & 809193 & 4.8 & 5.3432 & TST \\
\hline CHEMBL 374044 & 809193 & 6.9 & 6.6279 & TST \\
\hline CHEMBL1983932 & 809193 & 4.8 & 5.0453 & TST \\
\hline CHEMBL404366 & 809193 & 7.0 & 6.6823 & TST \\
\hline CHEMBL1966069 & 809193 & 4.8 & 4.8911 & TST \\
\hline CHEMBL1997822 & 809193 & 6.3 & 6.4551 & TST \\
\hline CHEMBL1991285 & 809193 & 4.8 & 4.7891 & TST \\
\hline CHEMBL1974416 & 809193 & 7.0 & 6.5567 & TST \\
\hline CHEMBL3260630 & 1349289 & 5.3872 & 5.5298 & TST \\
\hline CHEMBL 3260600 & 1349289 & 4.0 & 4.3691 & TRN \\
\hline CHEMBL 3260589 & 1349289 & 6.1549 & 6.0442 & TRN \\
\hline CHEMBL3260611 & 1349289 & 4.0 & 3.8372 & TRN \\
\hline CHEMBL3260904 & 1349289 & 6.8477 & 6.1353 & TST \\
\hline CHEMBL3260897 & 1349289 & 6.1555 & 5.7929 & TRN \\
\hline CHEMBL 3260604 & 1349289 & 4.0 & 4.0658 & TRN \\
\hline CHEMBL3260574 & 1349289 & 5.5918 & 5.3046 & TRN \\
\hline CHEMBL3260591 & 1349289 & 5.8239 & 5.9177 & TRN \\
\hline CHEMBL3260621 & 1349289 & 4.0 & 4.8932 & TRN \\
\hline CHEMBL3260605 & 1349289 & 4.0 & 4.4032 & TRN \\
\hline CHEMBL 3260564 & 1349289 & 5.3107 & 5.432 & TST \\
\hline CHEMBL3260899 & 1349289 & 5.6517 & 5.3249 & TST \\
\hline CHEMBL3260566 & 1349289 & 5.6402 & 5.0829 & TRN \\
\hline CHEMBL3260626 & 1349289 & 5.5452 & 5.1374 & TRN \\
\hline CHEMBL3260586 & 1349289 & 5.9172 & 5.8868 & TRN \\
\hline CHEMBL 3260578 & 1349289 & 5.4045 & 5.2875 & TRN \\
\hline CHEMBL3260629 & 1349289 & 5.3862 & 5.8423 & TRN \\
\hline CHEMBL 3260572 & 1349289 & 5.9586 & 5.5351 & TRN \\
\hline CHEMBL3260570 & 1349289 & 5.7122 & 5.3574 & TRN \\
\hline CHEMBL3260583 & 1349289 & 6.0605 & 5.9881 & TRN \\
\hline CHEMBL3260575 & 1349289 & 5.8861 & 5.6526 & TRN \\
\hline CHEMBL3260579 & 1349289 & 5.7878 & 5.43 & TRN \\
\hline CHEMBL 226838 & 1349289 & 6.2291 & 5.57799 & 9999999999 \\
\hline CHEMBL 3260568 & 1349289 & 4.0 & 5.4413 & TRN \\
\hline CHEMBL3260608 & 1349289 & 4.0 & 4.2999 & TRN \\
\hline CHEMBL3260618 & 1349289 & 4.0 & 5.4072 & TRN \\
\hline
\end{tabular}


Supplemental Table S2.txt

\begin{tabular}{|c|c|c|c|c|}
\hline CHEMBL3260607 & 1349289 & 5.1073 & 4.3706 & TRN \\
\hline CHEMBL3260905 & 1349289 & 6.5867 & 6.0559 & TST \\
\hline CHEMBL3260573 & 1349289 & 5.4342 & 4.7966 & TRN \\
\hline CHEMBL3260625 & 1349289 & 5.5229 & 5.6515 & TRN \\
\hline CHEMBL3260590 & 1349289 & 5.8356 & 5.7417 & TRN \\
\hline CHEMBL3260588 & 1349289 & 5.7305 & 5.7216 & TRN \\
\hline CHEMBL3260585 & 1349289 & 5.9281 & 5.9896 & TRN \\
\hline CHEMBL3260569 & 1349289 & 5.7033 & 5.5723 & TRN \\
\hline CHEMBL3260581 & 1349289 & 6.0862 & 6.325 & TRN \\
\hline CHEMBL3260623 & 1349289 & 6.301 & 6.0124 & TRN \\
\hline CHEMBL3260593 & 1349289 & 5.8508 & 5.9995 & TRN \\
\hline CHEMBL3260617 & 1349289 & 4.0 & 4.5322 & TRN \\
\hline CHEMBL3260901 & 1349289 & 6.0737 & 5.9904 & TRN \\
\hline CHEMBL3260622 & 1349289 & 4.0 & 4.2698 & TRN \\
\hline CHEMBL 3260580 & 1349289 & 5.5482 & 5.199 & TRN \\
\hline CHEMBL3260576 & 1349289 & 5.6882 & 5.4014 & TRN \\
\hline CHEMBL3260906 & 1349289 & 6.2733 & 5.7527 & TST \\
\hline CHEMBL3260587 & 1349289 & 5.6144 & 5.4643 & TRN \\
\hline CHEMBL3260613 & 1349289 & 4.0 & 3.8272 & TRN \\
\hline CHEMBL3260907 & 1349289 & 6.3747 & 5.7009 & TST \\
\hline CHEMBL3260619 & 1349289 & 5.9031 & 5.5692 & TRN \\
\hline CHEMBL3260609 & 1349289 & 4.0 & 4.2244 & TRN \\
\hline CHEMBL3260599 & 1349289 & 5.0315 & 4.5634 & TRN \\
\hline CHEMBL3260612 & 1349289 & 4.0 & 4.212 & TRN \\
\hline CHEMBL3260565 & 1349289 & 5.2048 & 5.5069 & TST \\
\hline CHEMBL3260596 & 1349289 & 5.644 & 5.7354 & TRN \\
\hline CHEMBL3260594 & 1349289 & 5.8928 & 5.8534 & TRN \\
\hline CHEMBL3260597 & 1349289 & 5.4001 & 5.6893 & TRN \\
\hline CHEMBL492634 & 1349289 & 6.3188 & 6.1054 & TST \\
\hline CHEMBL3260601 & 1349289 & 4.0 & 4.2401 & TRN \\
\hline CHEMBL3260606 & 1349289 & 4.0 & 4.1527 & TRN \\
\hline CHEMBL3260571 & 1349289 & 5.8153 & 5.3895 & TRN \\
\hline CHEMBL3260903 & 1349289 & 6.4157 & 5.57600 & 00000000005 \\
\hline CHEMBL 3260624 & 1349289 & 5.9706 & 5.8225 & TRN \\
\hline CHEMBL3260567 & 1349289 & 5.7645 & 5.8783 & TRN \\
\hline CHEMBL3260628 & 1349289 & 5.6055 & 6.2593 & TRN \\
\hline CHEMBL3260631 & 1349289 & 5.767 & 5.5288 & TST \\
\hline CHEMBL3260627 & 1349289 & 6.7496 & 6.5362 & TRN \\
\hline CHEMBL3260615 & 1349289 & 5.0635 & 5.3179 & TRN \\
\hline CHEMBL3260616 & 1349289 & 5.4572 & 5.3242 & TRN \\
\hline CHEMBL3260592 & 1349289 & 5.8125 & 5.8461 & TRN \\
\hline CHEMBL 3260620 & 1349289 & 5.4101 & 5.245 & TRN \\
\hline CHEMBL3260595 & 1349289 & 5.857 & 5.4609 & TRN \\
\hline CHEMBL3260603 & 1349289 & 4.0 & 3.6706 & TRN \\
\hline CHEMBL3260582 & 1349289 & 6.1367 & 6.1308 & TRN \\
\hline CHEMBL3260602 & 1349289 & 4.0 & 4.3227 & TST \\
\hline CHEMBL3260584 & 1349289 & 5.8827 & 5.9261 & TST \\
\hline CHEMBL3260898 & 1349289 & 5.6162 & 5.4145 & TST \\
\hline
\end{tabular}


Supplemental Table S2.txt

\begin{tabular}{|c|c|c|c|c|}
\hline & & 556 & 1 & \\
\hline СНСМРI 2269611 & 349289 & 55952 & & \\
\hline IEMBL & 9289 & & & \\
\hline IEMBL: & 289 & 389 & 024 & \\
\hline AEMBL3260900 & 49289 & 6.4056 & 508 & \\
\hline AEMBL3 & 289 & 89 & 82 & \\
\hline rMa & & & & \\
\hline 53634 & 264 & 28 & 3184 & \\
\hline IEMBL 3959090 & 641264 & 5086 & 0665 & \\
\hline 16198 & 264 & 9.4976 & 9.2477 & \\
\hline 906 & 264 & 6.0 & 292 & \\
\hline 23 & & & & \\
\hline 12621 & 264 & & 639 & \\
\hline 49869 & 641264 & & 402 & \\
\hline 25693 & 64 & 6.0 & & \\
\hline 877 & 64 & & 25 & \\
\hline & & & & \\
\hline 39544 & 264 & 6. & 898 & \\
\hline 76823 & & & 95 & \\
\hline 57514 & 44 & 6. & 58 & \\
\hline & & & 41 & \\
\hline & & & & \\
\hline 5945 & 64 & 15 & 74 & \\
\hline & & 177 & & \\
\hline 961 & 44 & 9 . & 29 & \\
\hline & 54 & & 83 & \\
\hline & & & 17 & \\
\hline & & & 307 & \\
\hline & & & & \\
\hline 2448 & 64 & 6. & 12 & \\
\hline & & & & \\
\hline & & & & \\
\hline & & & 335 & \\
\hline & & & & \\
\hline 247 & 64 & 10 & 96 & \\
\hline & 4 & & 152 & \\
\hline & & & & \\
\hline & & 6. & & \\
\hline 31471 & 64 & 10.2518 & 1221 & TR \\
\hline & & 6. & 84 & \\
\hline & & & & \\
\hline & & & 1492 & \\
\hline 99727 & & 9.5528 & 145 & TS \\
\hline 13910 & 64 & 6. & 45 & - \\
\hline & & 6 . & & \\
\hline (6) & & 6.0 & 6.5181 & \\
\hline & & 9.98 & 9.6985 & \\
\hline CHEMBL3948539 & 1641264 & 10.026 & 11.0489 & \\
\hline
\end{tabular}

Page 10838 
Supplemental Table S2.txt

\begin{tabular}{|c|c|c|c|c|}
\hline 51 & 541264 & & & \\
\hline & 641264 & 6.0 & & \\
\hline & 264 & 60 & & \\
\hline 951197 & 264 & 9.6 & & \\
\hline IEMBL 3930307 & 641264 & 6.0 & 49 & \\
\hline AEMBL & 264 & 11.7 & 279 & \\
\hline & 264 & 10. & & \\
\hline 54 & 64 & 6.0 & & \\
\hline 39529 & 264 & 6.0 & & \\
\hline AEMBL3910940 & 264 & 6.0 & & \\
\hline AEMBL & 64 & 10.4 & & \\
\hline 42 & 64 & 6.0 & & \\
\hline 22 & & 10.3 & & \\
\hline 90372 & 264 & 10.4 & 396 & \\
\hline 30726 & 264 & 9.81 & & \\
\hline 1 & 162 & 6.0 & & \\
\hline 3 & & 9.91 & & \\
\hline 51 & 64 & 10. & & \\
\hline 55 & 264 & 10. & & \\
\hline 9 & & 10. & & \\
\hline$\theta$ & 44 & 9.9 & 39 & \\
\hline & & 11.7 & 07 & \\
\hline 6 & 64 & 6.0 & & \\
\hline 0800 & & 10.2 & & \\
\hline 24 & & 9.0 & & \\
\hline 8 & 64 & 11. & 549 & \\
\hline & & 10. & & \\
\hline & 64 & 11. & 17 & \\
\hline & & 9.9066 & 975 & TR \\
\hline 95 & & 9.2233 & & \\
\hline & 64 & 6.0 & & \\
\hline & & 9.17 & & \\
\hline & 54 & 6.0 & & \\
\hline & & 6.0 & & 0 \\
\hline 14744 & & 9.21 & & \\
\hline & & 7.4 & & \\
\hline & & 9.5 & & \\
\hline & & 6.0 & & T \\
\hline AEMBL & 264 & 9.78 & & $\Gamma R$ \\
\hline & 64 & 6.0 & & \\
\hline & & 10. & & $\mathbf{n}$ \\
\hline CHEME & & 9.16 & & \\
\hline CHEMB & 264 & 10.5229 & & T \\
\hline 94024 & 1641264 & 6.0 & & TR \\
\hline 2 & 64 & 9.51 & & \\
\hline & & 11.7 & 808 & \\
\hline & & 10.6 & 8.9495 & \\
\hline CHEMBL3928304 & 1641264 & 8.8199 & 8.6052 & \\
\hline
\end{tabular}

Page 10839 
Supplemental Table S2.txt

CHEMBL3892442 CHEMBL3966977 CHEMBL 3950602 CHEMBL 3971600 CHEMBL 3913698

CHEMBL 3963659 CHEMBL 3967807 CHEMBL3906043 CHEMBL 3906027 CHEMBL3958425 CHEMBL 3946471 CHEMBL 3980933 CHEMBL3928414 CHEMBL 3925697 CHEMBL3952034 CHEMBL3938876 CHEMBL3934431 CHEMBL 3972849 CHEMBL3956807 CHEMBL 3953022 CHEMBL 3978203 CHEMBL 3900546 CHEMBL 3984970 CHEMBL 3963588 CHEMBL 3937669 CHEMBL 3971031 CHEMBL3947473 CHEMBL 3925097 CHEMBL3918556 CHEMBL 3945068 CHEMBL3922898 CHEMBL3907509 CHEMBL3951773 CHEMBL3920651 CHEMBL3952279 CHEMBL 3907090 CHEMBL3938695 CHEMBL 3899386 CHEMBL3964673 CHEMBL 3934583 CHEMBL 3918294 CHEMBL 3967124 CHEMBL3946149 CHEMBL 3925371 CHEMBL 3896083 CHEMBL 3918354 CHEMBL 3982701 CHEMBL3892883
164126411.744712 .0686 TRN

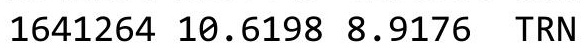
$\begin{array}{lll}1641264 & 11.7447 & 10.7195 \\ \text { TRN }\end{array}$ $\begin{array}{llll}1641264 & 11.7447 & 11.3337 & \text { TRN }\end{array}$ $\begin{array}{lll}1641264 & 10.1739 & 10.0289\end{array}$ $16412646.0 \quad 8.5876$ TRN $16412646.0 \quad 8.7673$ TST $16412646.0 \quad 6.1989$ TRN $\begin{array}{lll}1641264 & 9.762 & 10.2996\end{array}$ $\begin{array}{llll}1641264 & 9.9031 & 9.2862 & \text { TRN }\end{array}$ $\begin{array}{llll}1641264 & 9.4935 & 9.1988 & \text { TRN }\end{array}$ $\begin{array}{lll}1641264 & 9.7282 & 10.6236\end{array}$ $\begin{array}{llll}1641264 & 8.6124 & 7.0623 & \text { TRN }\end{array}$ $\begin{array}{lll}1641264 & 11.7447 & 10.5708 \text { TRN }\end{array}$ $\begin{array}{llll}1641264 & 11.7447 & 11.1488 \text { TRN }\end{array}$ $\begin{array}{lll}1641264 & 6.0 & 7.251\end{array}$ $\begin{array}{lll}1641264 & 9.9626 & 10.4241 \text { TRN }\end{array}$ 164126411.744711 .6571 TRN $\begin{array}{llll}1641264 & 9.8041 & 9.5746 & \text { TST }\end{array}$ $\begin{array}{llll}1641264 & 9.7773 & 9.4737 & \text { TRN }\end{array}$ 164126410.397911 .2205 TRN $\begin{array}{llll}1641264 & 9.1051 & 8.4229 & \text { TRN }\end{array}$ $\begin{array}{llll}1641264 & 11.7447 & 11.2301 & \text { TRN }\end{array}$ $\begin{array}{lll}16412646.0 & 11.9987 & \text { TST }\end{array}$

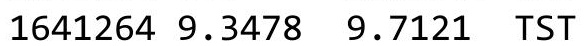
$\begin{array}{lll}16412646.0 & 7.7952 & \text { TRN }\end{array}$ $\begin{array}{llll}1641264 & 9.8996 & 9.2772 & \text { TRN }\end{array}$ $\begin{array}{llll}1641264 & 8.9842 & 9.2425 & \text { TRN }\end{array}$ $\begin{array}{llll}1641264 & 9.6946 & 9.7675 & \text { TRN }\end{array}$ $\begin{array}{lll}1641264 & 10.2757 & 11.1725 \\ \text { TRN }\end{array}$ $\begin{array}{lll}16412646.0 & 7.0061 & \text { TRN }\end{array}$ $16412646.0 \quad 8.3363$ TST $\begin{array}{lll}1641264 & 10.4437 & 10.0139 \\ \text { TRN }\end{array}$ $\begin{array}{lll}1641264 & 11.7447 & 10.5623 \text { TRN }\end{array}$ $\begin{array}{llll}1641264 & 9.4609 & 8.5145 & \text { TRN }\end{array}$ $\begin{array}{llll}1641264 & 6.0 & 8.0991 & \text { TRN }\end{array}$ $\begin{array}{llll}1641264 & 10.4318 & 8.8097 & \text { TRN }\end{array}$ $\begin{array}{llll}1641264 & 6.0 & 5.8198 & \text { TRN }\end{array}$ $\begin{array}{llll}1641264 & 8.9303 & 9.1364 & \text { TRN }\end{array}$ $\begin{array}{lll}16412646.0 & 7.3329 & \text { TRN }\end{array}$ $\begin{array}{llll}1641264 & 8.3755 & 9.094 & \text { TRN }\end{array}$ $16412649.055 \quad 10.5421$ TST

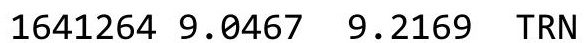
$\begin{array}{lll}1641264 & 10.3979 & 11.3194 \text { TRN }\end{array}$ $\begin{array}{llll}1641264 & 9.3354 & 9.372 & \text { TST }\end{array}$ $\begin{array}{lll}16412646.0 & 6.3455 & \text { TRN }\end{array}$ $\begin{array}{lll}1641264 & 11.7447 & 11.238\end{array}$

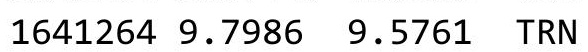


Supplemental Table S2.txt

CHEMBL 3966793

CHEMBL3926126

CHEMBL 3934353

CHEMBL 3903847

CHEMBL3911992

CHEMBL 3964422

CHEMBL3910639

CHEMBL 3933148

CHEMBL 3895252

CHEMBL3916382

CHEMBL 3965848

CHEMBL 3953046

CHEMBL3945448

CHEMBL 3984086

CHEMBL3940853

CHEMBL 3901702

CHEMBL3905755

CHEMBL 3986953

CHEMBL3964976

CHEMBL3986319

CHEMBL3919768

CHEMBL3925423

CHEMBL 3891972

CHEMBL 3909372

CHEMBL 3981905

CHEMBL 3900577

CHEMBL 3899357

CHEMBL3923363

CHEMBL3950733

CHEMBL3945736

CHEMBL3982838

CHEMBL 3978190

CHEMBL 3928850

CHEMBL3977827

CHEMBL3894367

CHEMBL3967954

CHEMBL 3939820

CHEMBL3948496

CHEMBL 3891312

CHEMBL3916399

CHEMBL3898044

CHEMBL3982652

CHEMBL3914164

CHEMBL 3954043

CHEMBL3956025

CHEMBL3956174

CHEMBL3907317

CHEMBL 3932887 $\begin{array}{lll}1641264 & 11.7447 & 10.9119 \\ \text { TRN }\end{array}$

$\begin{array}{lll}1641264 & 10.6198 & 10.3525 \\ \text { TRN }\end{array}$

$\begin{array}{llll}1641264 & 9.9957 & 9.9033 & \text { TRN }\end{array}$

$\begin{array}{llll}1641264 & 8.1276 & 7.7491 & \text { TST }\end{array}$

$\begin{array}{lll}1641264 & 10.0862 & 9.4635 \\ \text { TRN }\end{array}$

$\begin{array}{lll}1641264 & 10.7212 & 11.1854 \text { TRN }\end{array}$

$\begin{array}{llll}1641264 & 9.821 & 9.4728 & \text { TRN }\end{array}$

$\begin{array}{lll}1641264 & 10.6778 & 10.16\end{array}$

164126410.20769 .7773 TRN

$\begin{array}{llll}1641264 & 9.7721 & 9.3882 & \text { TRN }\end{array}$

$\begin{array}{lll}1641264 & 10.4685 & 10.4293 \\ \text { TRN }\end{array}$

$\begin{array}{lll}1641264 & 10.3279 & 10.7008 \text { TRN }\end{array}$

$\begin{array}{llll}1641264 & 9.699 & 8.9605 & \text { TST }\end{array}$

$16412646.0 \quad 6.0673$ TRN

$\begin{array}{llll}1641264 & 9.9208 & 9.4978 & \text { TRN }\end{array}$

164126410.35658 .6036 TRN

$16412646.0 \quad 9.0457$ TST

$164126410.0 \quad 10.0231$ TRN

$\begin{array}{llll}1641264 & 9.7399 & 9.5064 & \text { TRN }\end{array}$

$\begin{array}{lll}16412646.0 & 7.8112 & \text { TRN }\end{array}$

$\begin{array}{llll}1641264 & 9.9066 & 9.706 & \text { TRN }\end{array}$

$\begin{array}{llll}1641264 & 6.0 & 8.5575 & \text { TRN }\end{array}$

$\begin{array}{lll}1641264 & 10.2518 & 10.5339 \\ \text { TRN }\end{array}$

$\begin{array}{llll}1641264 & 8.782 & 8.9749 & \text { TRN }\end{array}$

$\begin{array}{lll}1641264 & 10.585 & 10.9598 \text { TRN }\end{array}$

$16412646.0 \quad 5.8983$ TRN

$\begin{array}{llll}1641264 & 10.2366 & 9.5137 & \text { TRN }\end{array}$

$16412646.0 \quad 5.4336$ TST

$\begin{array}{lll}16412649.6556 & 10.1259 \text { TRN }\end{array}$

$\begin{array}{lll}16412649.9788 & 10.0285 \text { TRN }\end{array}$

$\begin{array}{lll}1641264 & 11.7447 & 10.4269 \\ \text { TRN }\end{array}$

164126410.431810 .8043 TRN

$\begin{array}{llll}1641264 & 10.0315 & 8.951 \quad \text { TRN }\end{array}$

$\begin{array}{lll}1641264 & 11.7447 & 12.2672 \text { TRN }\end{array}$

$\begin{array}{llll}16412646.0 & 6.3824 & \text { TRN }\end{array}$

$\begin{array}{llll}16412649.9136 & 7.595 & \text { TST }\end{array}$

$\begin{array}{lll}16412649.719 & 11.3734 \text { TST }\end{array}$

$\begin{array}{llll}1641264 & 9.6737 & 9.0163 & \text { TRN }\end{array}$

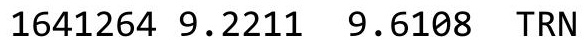

164126410.657610 .5444 TRN

164126410.397910 .0298 TRN

$\begin{array}{llll}16412646.0 & 6.582999999999999 & \text { TRN }\end{array}$

$16412646.0 \quad 6.3501$ TRN

$\begin{array}{llll}1641264 & 11.7447 & 12.2263 & \text { TRN }\end{array}$

$\begin{array}{lll}1641264 & 9.9788 & 10.1346\end{array}$

$\begin{array}{lll}1641264 & 9.9355 & 10.5566 \\ \text { TRN }\end{array}$

$\begin{array}{lll}1641264 & 9.4123 & 9.5625\end{array}$ TRN

$\begin{array}{lll}1641264 & 10.3468 & 10.9984 \text { TRN }\end{array}$ 
Supplemental Table S2.txt

CHEMBL3901733

CHEMBL3963311

CHEMBL 3925835

CHEMBL3929855

CHEMBL 3939448

CHEMBL3969346

CHEMBL 3954652

CHEMBL 3948476

CHEMBL 3933029

CHEMBL3962818

CHEMBL3957451

CHEMBL3903149

CHEMBL3910021

CHEMBL3934316

CHEMBL 3895035

CHEMBL3940507

CHEMBL3951551

CHEMBL 3958843

CHEMBL3981149

CHEMBL 3889577

CHEMBL 3940176

CHEMBL3973252

CHEMBL 3973567

CHEMBL 3913087

CHEMBL 3930435

CHEMBL 3945841

CHEMBL3975649

CHEMBL3983914

CHEMBL3922403

CHEMBL3940617

CHEMBL3930784

CHEMBL 3898297

CHEMBL3986867

CHEMBL3961554

CHEMBL 3942892

CHEMBL3957091

CHEMBL 3905870

CHEMBL3931818

CHEMBL3906529

CHEMBL3969964

CHEMBL 3977802

CHEMBL3906132

CHEMBL3911966

CHEMBL 3938298

CHEMBL 3891540

CHEMBL3911814

CHEMBL3935486

CHEMBL 3903031
16412649.7144

16412646.0

16412646.0

16412649.327

164126410.3098

164126410.5528

164126410.5229

16412648.8891

16412649.9281

16412646.0

16412646.0

16412646.0

16412649.6757

164126410.4089

16412649.6289

164126410.1612

16412649.6576

16412646.0

16412649.5817

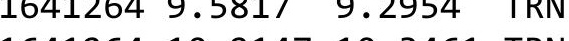

$\begin{array}{lll}1641264 & 10.2147 & 10.3461 \text { TRN }\end{array}$

$\begin{array}{llll}1641264 & 9.7696 & 9.4799 & \text { TRN }\end{array}$

$\begin{array}{lll}16412649.1925 & 10.1606 & \text { TST }\end{array}$

$\begin{array}{lll}16412649.5436 & 9.1968 \text { TRN }\end{array}$

164126410.01329 .5433 TRN

164126410.522910 .0012 TRN

$16412649.7471 \quad 10.3086$ TRN

$\begin{array}{lll}16412646.0 & 6.1524 & \text { TRN }\end{array}$

$16412646.0 \quad 6.5934$ TST

$16412646.0 \quad 5.325$ TRN

$\begin{array}{lll}16412646.0 \quad 7.6517 & \text { TRN }\end{array}$

$\begin{array}{ll}164126410.2596 & 10.5809 \\ \text { TRN }\end{array}$

$\begin{array}{lll}164126410.2007 & 10.7462 \text { TRN }\end{array}$

164126410.494910 .8792 TRN

164126410.14878 .6663 TRN

$\begin{array}{llll}1641264 & 9.7986 & 9.1068 & \text { TRN }\end{array}$

$\begin{array}{llll}1641264 & 6.0 & 9.3197 & \text { TST }\end{array}$

$16412646.0 \quad 6.0905$ TRN

$16412646.0 \quad 8.2577$ TRN

$16412646.0 \quad 6.3699$ TRN

$\begin{array}{llll}16412649.9914 & 9.5199 & \text { TRN }\end{array}$

$\begin{array}{llll}1641264 & 8.6447 & 9.2039 & \text { TRN }\end{array}$

$\begin{array}{llll}1641264 & 9.9957 & 10.350999999999999 & \text { TRN }\end{array}$

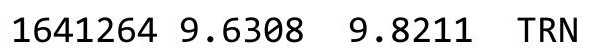

$\begin{array}{lll}16412649.8894 & 9.2042 & \text { TRN }\end{array}$

$16412646.0 \quad 4.8095$ TST

$\begin{array}{lll}1641264 & 10.0044 & 9.9869 \\ \text { TRN }\end{array}$

$\begin{array}{lll}1641264 & 9.8013 & 10.343\end{array}$ TRN

$16412646.0 \quad 6.2506$ TRN
TRN

Page 10842 
Supplemental Table S2.txt

CHEMBL3984823

CHEMBL3985347

CHEMBL 3920745

CHEMBL 3930628

CHEMBL3938468

CHEMBL 3954878

CHEMBL 3979852

CHEMBL3965152

CHEMBL 3907741

CHEMBL 3894737

CHEMBL3910082

CHEMBL 3895769

CHEMBL 3897025

CHEMBL3982587

CHEMBL3922819

CHEMBL 3984556

CHEMBL3924367

CHEMBL 3948853

CHEMBL3954541

CHEMBL3953749

CHEMBL3959410

CHEMBL3941022

CHEMBL 3978664

CHEMBL 3905079

CHEMBL 3899861

CHEMBL 3890333

CHEMBL 3931555

CHEMBL 3889885

CHEMBL3934236

CHEMBL 3914245

CHEMBL 3891693

CHEMBL3891719

CHEMBL3926460

CHEMBL3922206

CHEMBL 3895858

CHEMBL3959759

CHEMBL 3892933

CHEMBL 3959894

CHEMBL 3917700

CHEMBL 3895358

CHEMBL 3966298

CHEMBL 3977483

CHEMBL 3304291

CHEMBL364284

CHEMBL196492

CHEMBL3942651

CHEMBL3979386

CHEMBL3907419 $\begin{array}{lll}164126410.0555 & 10.7667 \text { TRN }\end{array}$

$\begin{array}{lll}16412646.0 \quad 7.1456 \text { TRN } & 6.0\end{array}$

164126410.193810 .5866 TRN

$\begin{array}{llll}1641264 & 10.6021 & 10.919 & \text { TRN }\end{array}$

$\begin{array}{llll}1641264 & 9.4056 & 9.5959 & \text { TST }\end{array}$

$\begin{array}{lll}1641264 & 10.2218 & 10.5087\end{array}$

$\begin{array}{llll}1641264 & 11.7447 & 11.2482 & \text { TRN }\end{array}$

$\begin{array}{llll}1641264 & 9.4976 & 7.5767 & \text { TST }\end{array}$

164126410.619811 .0007 TRN

164126411.744711 .9607 TRN

$16412646.0 \quad 6.7193$ TRN

$\begin{array}{lll}16412646.0 & 6.3202 & \text { TST }\end{array}$

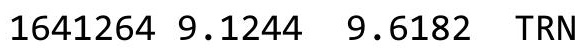

$16412649.3516 \quad 8.2403$ TST

$\begin{array}{lll}1641264 & 11.7447 & 10.8994 \\ \text { TST }\end{array}$

$\begin{array}{llll}1641264 & 9.8794 & 8.2802 & \text { TST }\end{array}$

164126410.72127 .5351 TST

$16412646.0 \quad 7.9515$ TST

$\begin{array}{llll}1641264 & 10.2291 & 10.062000000000001 & \text { TST }\end{array}$

164126411.744711 .5689 TST

164126410.04589 .1509 TST

164126410.11929 .9362 TST

$\begin{array}{llll}1641264 & 9.2255 & 8.0324 & \text { TST }\end{array}$

$\begin{array}{lll}1641264 & 9.0414 & 10.8199\end{array}$

$\begin{array}{llll}1641264 & 11.7447 & 6.7795 & \text { TST }\end{array}$

$\begin{array}{llll}1641264 & 9.0119 & 8.9162 & \text { TST }\end{array}$

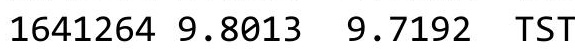

$\begin{array}{llll}1641264 & 6.0 & 9.7876 & \text { TST }\end{array}$

$\begin{array}{llll}1641264 & 9.7258 & 9.2839 & \text { TST }\end{array}$

$\begin{array}{lll}16412646.0 \quad 9.4298 & \text { TST }\end{array}$

$\begin{array}{lll}1641264 & 10.3768 & 9.3311 \\ \text { TST }\end{array}$

$\begin{array}{lll}1641264 & 10.0 & 9.1361\end{array}$

$\begin{array}{llll}1641264 & 9.2725 & 9.8397 & \text { TST }\end{array}$

$\begin{array}{llll}1641264 & 8.9348 & 8.9309 & \text { TST }\end{array}$

$\begin{array}{lll}16412646.0 & 10.3286 & \text { TST }\end{array}$

$164126411.7447 \quad 9.2798$ TST

$\begin{array}{llll}16412646.0 & 9.9781 & \text { TST }\end{array}$

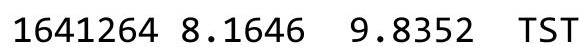

$\begin{array}{llll}1641264 & 9.8894 & 8.8354 & \text { TST }\end{array}$

$\begin{array}{lll}1641264 & 8.982999999999999 & 10.7831 \text { TST }\end{array}$

$\begin{array}{llll}16412649.4634 & 8.966000000000001 & \text { TST }\end{array}$

$16412646.0 \quad 8.9187$ TST

$\begin{array}{llll}1640189 & 8.5591 & 8.396 & \text { TRN }\end{array}$

$\begin{array}{llll}1640189 & 9.757 & 9.717 & \text { TRN }\end{array}$

$\begin{array}{llll}1640189 & 8.4461 & 8.2238 & \text { TRN }\end{array}$

$\begin{array}{llll}1640189 & 5.5171 & 5.6092 & \text { TST }\end{array}$

$\begin{array}{llll}1640189 & 8.9747 & 8.9794 & \text { TRN }\end{array}$

$\begin{array}{llll}16401898.5935 & 8.6507 & \text { TRN }\end{array}$ 
Supplemental Table S2.txt

\begin{tabular}{|c|c|c|c|c|}
\hline CHEMBL197547 & 1640189 & 7.5031 & 7.3488 & TRN \\
\hline CHEMBL196551 & 1640189 & 8.1397 & 8.0352 & TRN \\
\hline CHEMBL120413 & 1640189 & 7.3063 & 7.2098 & TST \\
\hline CHEMBL 3986101 & 1640189 & 8.9957 & 9.3166 & TRN \\
\hline CHEMBL371106 & 1640189 & 7.5114 & 7.7523 & TRN \\
\hline CHEMBL 3961484 & 1640189 & 9.1129 & 9.0786 & TRN \\
\hline CHEMBL550453 & 1640189 & 8.0799 & 8.296 & TRN \\
\hline CHEMBL197377 & 1640189 & 9.1979 & 9.1433 & TRN \\
\hline CHEMBL 3959350 & 1640189 & 7.5735 & 7.3454 & TRN \\
\hline CHEMBL372568 & 1640189 & 6.4881 & 6.5637 & TRN \\
\hline CHEMBL 3968842 & 1640189 & 8.6038 & 8.6817 & TRN \\
\hline CHEMBL1235423 & 1640189 & 7.7144 & 7.2788 & TST \\
\hline CHEMBL564248 & 1640189 & 8.8508 & 8.8248 & TRN \\
\hline CHEMBL372956 & 1640189 & 8.6615 & 8.4882 & TRN \\
\hline CHEMBL197624 & 1640189 & 7.5513 & 7.5039 & TRN \\
\hline CHEMBL370614 & 1640189 & 9.0031 & 8.9832 & TRN \\
\hline CHEMBL196539 & 1640189 & 9.1701 & 9.1786 & TRN \\
\hline CHEMBL557915 & 1640189 & 8.7545 & 8.7117 & TRN \\
\hline CHEMBL 3928201 & 1640189 & 7.6925 & 7.5345 & TST \\
\hline CHEMBL 3957468 & 1640189 & 8.0467 & 8.0896 & TRN \\
\hline CHEMBL383361 & 1640189 & 8.9914 & 9.1815 & TRN \\
\hline CHEMBL196669 & 1640189 & 5.3536 & 5.3656 & TRN \\
\hline CHEMBL194889 & 1640189 & 6.38200 & 000000000 & 6.3223 \\
\hline CHEMBL3955803 & 1640189 & 9.0362 & 8.764 & TRN \\
\hline CHEMBL 316053 & 1640189 & 7.5017 & 7.4139 & TST \\
\hline CHEMBL 3910588 & 1640189 & 9.1713 & 9.2156 & TRN \\
\hline CHEMBL190142 & 1640189 & 8.85700 & 000000000 & 8.6181 \\
\hline CHEMBL381866 & 1640189 & 8.4101 & 8.4953 & TRN \\
\hline CHEMBL 3305961 & 1640189 & 7.6655 & 7.939 & TRN \\
\hline CHEMBL 3958789 & 1640189 & 8.4935 & 8.4388 & TRN \\
\hline CHEMBL 3912108 & 1640189 & 8.9469 & 8.7159 & TRN \\
\hline CHEMBL194810 & 1640189 & 7.8894 & 7.9344 & TRN \\
\hline CHEMBL3974641 & 1640189 & 7.6038 & 7.5322 & TST \\
\hline CHEMBL 3966335 & 1640189 & 6.1512 & 6.2758 & TST \\
\hline CHEMBL 3960154 & 1640189 & 9.2306 & 9.0596 & TST \\
\hline CHEMBL93087 & 1640189 & 7.1397 & 7.4693 & TST \\
\hline CHEMBL3972799 & 1640189 & 9.2048 & 9.2526 & TRN \\
\hline CHEMBL3904655 & 1640189 & 8.6925 & 8.7463 & TRN \\
\hline CHEMBL 3972969 & 1640189 & 8.1733 & 8.3057 & TRN \\
\hline CHEMBL436293 & 1640189 & 7.2541 & 6.957999 & 9999999999 \\
\hline CHEMBL198421 & 1640189 & 6.6326 & 6.7873 & TRN \\
\hline CHEMBL196589 & 1640189 & 7.1451 & 7.2966 & TRN \\
\hline CHEMBL370176 & 1640189 & 6.7305 & 6.9586 & TRN \\
\hline CHEMBL194186 & 1640189 & 9.2441 & 9.2451 & TST \\
\hline CHEMBL196162 & 1640189 & 8.4425 & 7.6944 & TST \\
\hline CHEMBL198654 & 1640189 & 8.4112 & 8.38 & TST \\
\hline CHEMBL 3956658 & 1640189 & 8.2403 & 8.4221 & TST \\
\hline CHEMBL48813 & 1640189 & 8.821 & 8.8189 & TST \\
\hline
\end{tabular}




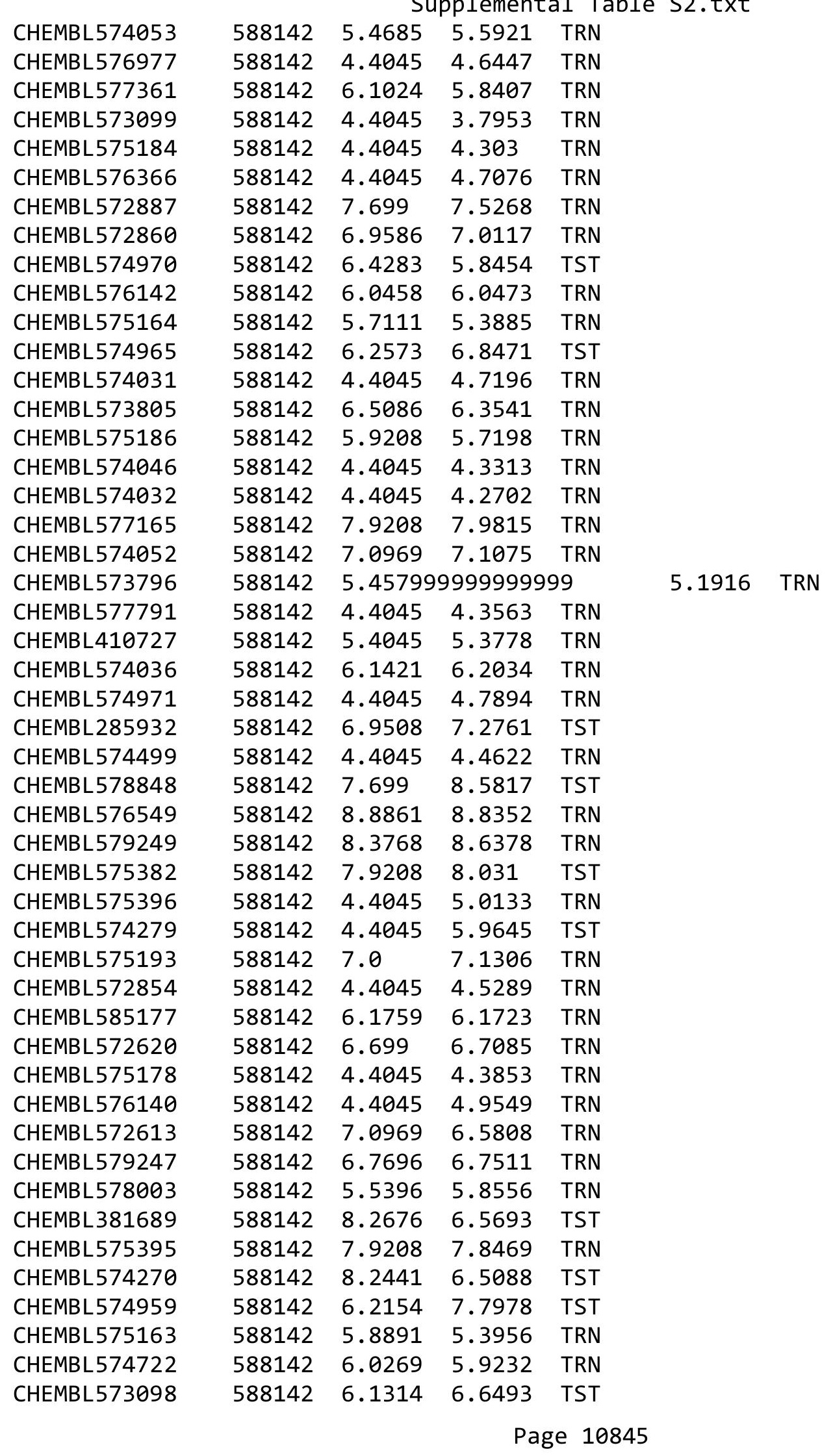



Supplemental Table S2.txt

\begin{tabular}{|c|c|c|c|c|c|}
\hline CHEMBL3753479 & 1548095 & 7.301 & 6.394 & TST & \\
\hline CHEMBL3754277 & 1548095 & 6.2262 & 6.3257 & TST & \\
\hline CHEMBL3754799 & 1548095 & 6.2518 & \multicolumn{2}{|c|}{6.4910000000000005} & TST \\
\hline CHEMBL3753049 & 1548095 & 6.9788 & 6.4315 & TST & \\
\hline CHEMBL 3754270 & 1548095 & 9.0969 & 7.1045 & TST & \\
\hline CHEMBL3751895 & 1548095 & 7.8861 & 7.6526 & TST & \\
\hline CHEMBL3754163 & 1548095 & 9.301 & 8.6739 & TST & \\
\hline CHEMBL3752726 & 1548095 & 7.8861 & 8.9879 & TST & \\
\hline CHEMBL3914767 & 1641331 & 11.0 & 10.2206 & TRN & \\
\hline CHEMBL 3949706 & 1641331 & 6.9393 & 7.2615 & TRN & \\
\hline CHEMBL 3937478 & 1641331 & 11.0 & \multicolumn{2}{|c|}{10.709000000000001} & TRN \\
\hline CHEMBL3926315 & 1641331 & 9.0458 & 9.0195 & TRN & \\
\hline CHEMBL3897213 & 1641331 & 8.2218 & 8.2519 & TRN & \\
\hline CHEMBL3923784 & 1641331 & 9.5229 & 8.7687 & TRN & \\
\hline CHEMBL 3937724 & 1641331 & 7.6778 & 7.5668 & TRN & \\
\hline CHEMBL3985366 & 1641331 & 11.0 & 10.2302 & TST & \\
\hline CHEMBL3971522 & 1641331 & 11.0 & 9.6514 & TST & \\
\hline CHEMBL3977617 & 1641331 & 9.301 & 8.689 & TRN & \\
\hline CHEMBL3930331 & 1641331 & 7.7212 & 8.6853 & TRN & \\
\hline CHEMBL3908218 & 1641331 & 6.5544 & 7.2184 & TRN & \\
\hline CHEMBL3894225 & 1641331 & 8.5229 & 8.1988 & TRN & \\
\hline CHEMBL 3928574 & 1641331 & 11.0 & 9.8778 & TRN & \\
\hline CHEMBL3982752 & 1641331 & 6.3726 & 6.8772 & TRN & \\
\hline CHEMBL 3952822 & 1641331 & 9.3979 & 10.283 & TRN & \\
\hline CHEMBL3913717 & 1641331 & 11.0 & 10.093 & TST & \\
\hline CHEMBL 3974222 & 1641331 & 8.301 & 7.6539 & TRN & \\
\hline CHEMBL3949482 & 1641331 & 11.0 & 9.7253 & TRN & \\
\hline CHEMBL3926978 & 1641331 & 8.301 & 8.3674 & TRN & \\
\hline CHEMBL3951516 & 1641331 & 7.3098 & 7.4878 & TRN & \\
\hline CHEMBL3899394 & 1641331 & 9.1549 & 9.7615 & TRN & \\
\hline CHEMBL3901546 & 1641331 & 9.0 & 7.4381 & TST & \\
\hline CHEMBL 3894010 & 1641331 & 11.0 & 9.6171 & TST & \\
\hline CHEMBL3960340 & 1641331 & 11.0 & 8.2056 & TST & \\
\hline CHEMBL3935841 & 1641331 & 6.7773 & 7.1934 & TRN & \\
\hline CHEMBL3942501 & 1641331 & 7.9208 & 7.6349 & TRN & \\
\hline CHEMBL3945287 & 1641331 & 11.0 & 11.4146 & TRN & \\
\hline CHEMBL3951698 & 1641331 & 6.4214 & 6.1127 & TRN & \\
\hline CHEMBL3924846 & 1641331 & 11.0 & 10.5759 & TST & \\
\hline CHEMBL3954448 & 1641331 & 9.0458 & 9.0324 & TST & \\
\hline CHEMBL3941926 & 1641331 & 11.0 & 10.9455 & TRN & \\
\hline CHEMBL3980575 & 1641331 & 8.1549 & 7.6266 & TRN & \\
\hline CHEMBL3891330 & 1641331 & 8.0969 & 8.4208 & TRN & \\
\hline CHEMBL3929557 & 1641331 & 7.3188 & 7.00700 & 0000000001 & TRN \\
\hline CHEMBL3941341 & 1641331 & 9.2218 & 9.5213 & TRN & \\
\hline CHEMBL3902618 & 1641331 & 8.1549 & 8.3522 & TRN & \\
\hline CHEMBL 3972984 & 1641331 & 7.9208 & 7.3272 & TRN & \\
\hline CHEMBL3977941 & 1641331 & 6.5884 & 7.0634 & TRN & \\
\hline CHEMBL3956947 & 1641331 & 7.7959 & 8.2426 & TRN & \\
\hline
\end{tabular}

Page 10847 
Supplemental Table S2.txt

\begin{tabular}{|c|c|c|c|c|}
\hline - & 541331 & 6.6882 & & TF \\
\hline & & & & \\
\hline & & 16 & & \\
\hline HEMBL 393 & 331 & 9586 & 09 & \\
\hline AEMBL3930937 & 351 & & 867 & \\
\hline HEMBL3932865 & 331 & 9.699 & .4183 & \\
\hline 26 & & & & \\
\hline IEMBL3 & & & & RN \\
\hline HEMBL3903275 & & 9.699 & 0.2106 & \\
\hline HEMBL3937063 & 331 & 9.0458 & .9731 & \\
\hline HEMBL3953848 & 31 & 7.7696 & .4039 & \\
\hline IEMBL 38 & 31 & 9.301 & 442 & \\
\hline IEMBL3 & & & 242 & \\
\hline HEMBL3928464 & 331 & 11.0 & 10.5584 & \\
\hline AEMBL39 & 31 & 4815 & .3162 & \\
\hline IEMBL 392 & 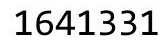 & 8239 & . 3955 & \\
\hline AEMBL3 & & 079 & 29 & \\
\hline HEMBL3S & & 586 & 309 & \\
\hline HEMBL3\& & & 7.0088 & 7.6102 & \\
\hline AEMBL3S & & & & \\
\hline HEMBLS & 6 & & 27 & KIV \\
\hline AEMBL: & & (5) & 72 & RN \\
\hline HEMBL; & & 136 & 05 & \\
\hline AFMB 30 & & 8.8239 & 647 & \\
\hline AEMBL3S & & & & $\Gamma \mathrm{RN}$ \\
\hline HEMBL3S & 6 & 34 & 7 . & SI \\
\hline AEMBL & & & & RN \\
\hline $\mathrm{AFMBI}=$ & & 147 & 06 & \\
\hline HEMBL3S & & 7.7447 & & TRN \\
\hline HEMBL3978558 & & & 886 & $\mathrm{TR}$ \\
\hline HEMBL38 & & & 156 & TRN \\
\hline HEMBL; & & 51 & 73 & ST \\
\hline HEMBL & & 99 & 26 & 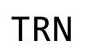 \\
\hline HEMBL3977347 & & 8.0458 & 8.8055 & IRN \\
\hline HEMBL3945285 & 31 & 11.0 & 1.3778 & TRN \\
\hline HEMBL3 & & 01 & 87 & RN \\
\hline HFMRI & & 49 & & RIV \\
\hline HEMBL3 & & 69 & 32 & RN \\
\hline HEMBL3911838 & 31 & 6.4056 & 911 & TRN \\
\hline AEMBL39 & & 318 & 57 & RN \\
\hline HEMBL3S & 6 & .9208 & 849 & DA \\
\hline HEMBL 39 & & 7.6198 & & RIV \\
\hline HEMBL3896818 & & 7.7447 & 8.0562 & RN \\
\hline HEMBL3930283 & 331 & 11.0 & 1.1289 & TR \\
\hline $\mathrm{MRI}=$ & & & & TST \\
\hline HEMBL3S & & .2218 & .4422 & \\
\hline CHEMBL 392 & & 9. 301 & 9.5675 & \\
\hline HEMBL3893422 & 1641331 & 7.7447 & 7.7867 & RN \\
\hline
\end{tabular}

Page 10848 


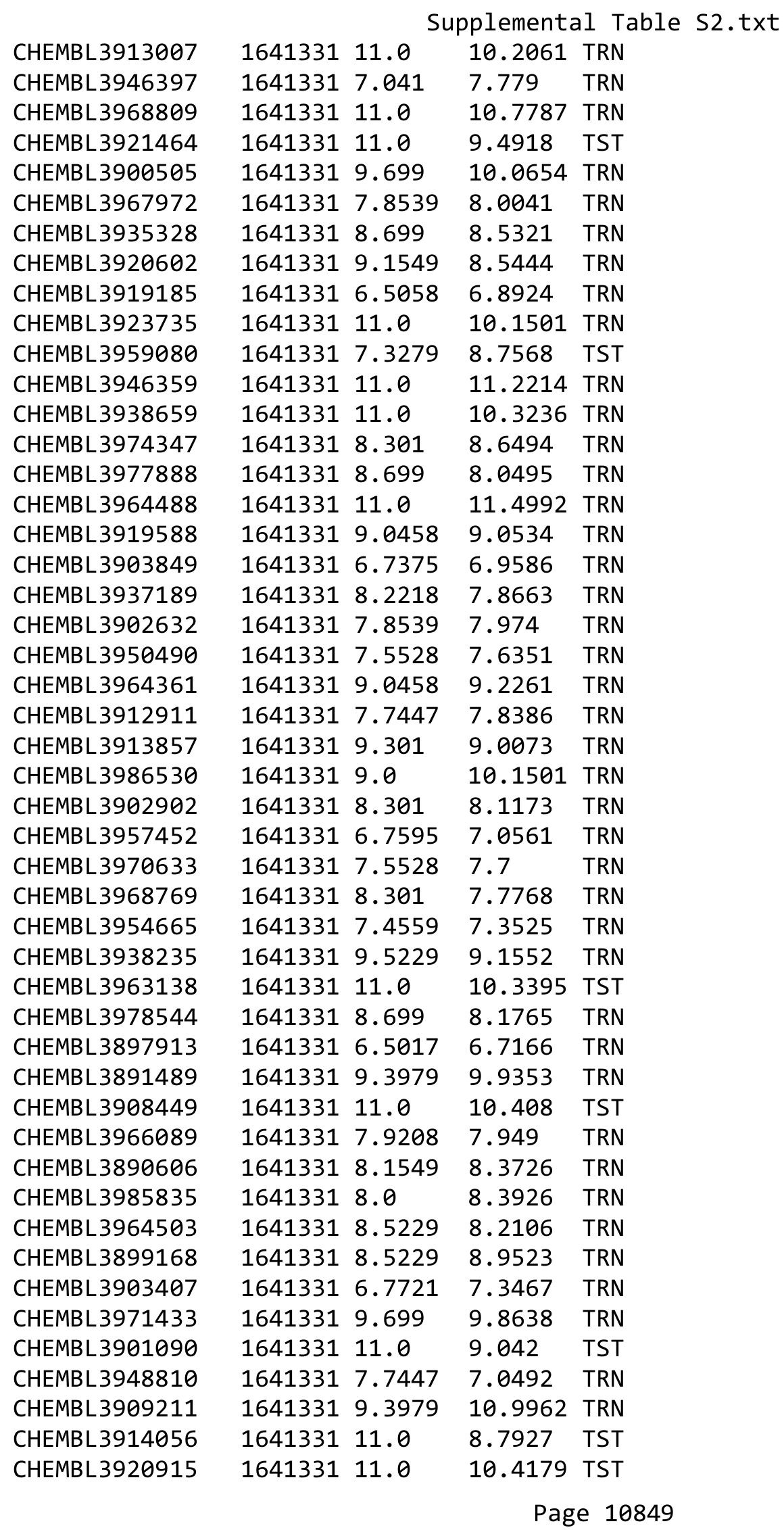


Supplemental Table S2.txt

\begin{tabular}{|c|c|c|c|c|}
\hline CHEMBL3918488 & 1641331 & 9.3979 & 8.5142 & TST \\
\hline CHEMBL3950423 & 1641331 & 11.0 & 10.9501 & TRN \\
\hline CHEMBL3981796 & 1641331 & 7.2147 & 7.5308 & TRN \\
\hline CHEMBL 3894741 & 1641331 & 8.699 & 10.2206 & TRN \\
\hline CHEMBL3905518 & 1641331 & 7.1675 & 7.6428 & TRN \\
\hline CHEMBL 3898365 & 1641331 & 6.7399 & 7.4283 & TRN \\
\hline CHEMBL3899959 & 1641331 & 7.6383 & 7.7395 & TRN \\
\hline CHEMBL3926206 & 1641331 & 7.7212 & 7.5575 & TRN \\
\hline CHEMBL 3964142 & 1641331 & 11.0 & 10.7264 & TRN \\
\hline CHEMBL3940857 & 1641331 & 7.4202 & 7.7065 & TRN \\
\hline CHEMBL 3906104 & 1641331 & 8.3979 & 8.193 & TRN \\
\hline CHEMBL 3940367 & 1641331 & 11.0 & 10.77799 & 99999999999 \\
\hline CHEMBL 3893665 & 1641331 & 11.0 & 9.0673 & TRN \\
\hline CHEMBL 3949624 & 1641331 & 6.7986 & 7.0268 & TRN \\
\hline CHEMBL3907071 & 1641331 & 9.0 & 8.9433 & TRN \\
\hline CHEMBL 3895034 & 1641331 & 11.0 & 10.6401 & TRN \\
\hline CHEMBL3916278 & 1641331 & 7.1938 & 7.2786 & TRN \\
\hline CHEMBL3931310 & 1641331 & 8.699 & 8.5674 & TRN \\
\hline CHEMBL 3901241 & 1641331 & 9.699 & 7.9094 & TST \\
\hline CHEMBL3952597 & 1641331 & 9.5229 & 9.1161 & TRN \\
\hline CHEMBL3972650 & 1641331 & 8.6383 & 9.2143 & TRN \\
\hline CHEMBL3892521 & 1641331 & 8.0969 & 7.6891 & TRN \\
\hline CHEMBL3937433 & 1641331 & 11.0 & 10.8144 & TRN \\
\hline CHEMBL 3949188 & 1641331 & 7.7959 & 7.7259 & TRN \\
\hline CHEMBL 3918145 & 1641331 & 9.2218 & 8.3379 & TRN \\
\hline CHEMBL3929193 & 1641331 & 11.0 & 10.9962 & TRN \\
\hline CHEMBL3934794 & 1641331 & 7.7696 & 8.152999 & \\
\hline CHEMBL3922702 & 1641331 & 11.0 & 10.2009 & TRN \\
\hline CHEMBL3916115 & 1641331 & 8.8539 & 9.0223 & TRN \\
\hline CHEMBL3979454 & 1641331 & 8.5229 & 9.5814 & TST \\
\hline CHEMBL 3945230 & 1641331 & 7.8539 & 7.4665 & TST \\
\hline CHEMBL3912857 & 1641331 & 7.5528 & 7.4372 & TST \\
\hline CHEMBL3910441 & 1641331 & 7.041 & 7.2353 & TST \\
\hline CHEMBL 3964893 & 1641331 & 7.5376 & 7.4231 & TST \\
\hline CHEMBL 3928078 & 1641331 & 8.2218 & 7.7449 & TST \\
\hline CHEMBL3901568 & 1641331 & 9.5229 & 7.9918 & TST \\
\hline CHEMBL3923925 & 1641331 & 11.0 & 10.1436 & TST \\
\hline CHEMBL3933526 & 1641331 & 6.7447 & 6.5668 & TST \\
\hline CHEMBL 3891111 & 1641331 & 5.0 & 7.6163 & TST \\
\hline CHEMBL3921932 & 1641331 & 7.7212 & 7.7591 & TST \\
\hline CHEMBL3984574 & 1641331 & 11.0 & 10.2527 & TST \\
\hline CHEMBL3936294 & 1641331 & 11.0 & 10.2078 & TST \\
\hline CHEMBL3935029 & 1641331 & 7.7959 & 8.2205 & TST \\
\hline CHEMBL3955657 & 1641331 & 11.0 & 10.3186 & TST \\
\hline CHEMBL3977349 & 1641331 & 8.3979 & 8.0879 & TST \\
\hline CHEMBL3965661 & 1641331 & 9.301 & 8.9999 & TST \\
\hline CHEMBL3925353 & 1641331 & 7.5086 & 7.0222 & TST \\
\hline CHEMBL3975564 & 1641331 & 9.3979 & 8.5637 & TST \\
\hline
\end{tabular}





\begin{tabular}{|c|c|c|c|c|c|c|}
\hline & & \multicolumn{5}{|c|}{ Supplemental Table S2.txt } \\
\hline CHEMBL1214986 & 649999 & 6.5086 & 6.4634 & TRN & & \\
\hline CHEMBL1214696 & 649999 & 5.8268 & 6.6403 & TST & & \\
\hline CHEMBL1215501 & 649999 & 8.699 & 8.5342 & TRN & & \\
\hline CHEMBL1214772 & 649999 & $6.7520 e$ & 300000006 & & 6.6247 & TRN \\
\hline CHEMBL1215765 & 649999 & 6.3969 & 5.9732 & TRN & & \\
\hline CHEMBL1215500 & 649999 & 9.0 & 8.7331 & TRN & & \\
\hline CHEMBL1215707 & 649999 & 6.5969 & 6.6273 & TRN & & \\
\hline CHEMBL1215638 & 649999 & 7.3872 & 7.49100 & 0000000006 & 305 & TRN \\
\hline CHEMBL1215775 & 649999 & 6.4609 & 6.761 & TST & & \\
\hline CHEMBL1215342 & 649999 & 6.0605 & 6.9326 & TST & & \\
\hline CHEMBL1215705 & 649999 & 6.0937 & 6.8561 & TST & & \\
\hline CHEMBL1214847 & 649999 & 7.5686 & 7.3037 & TRN & & \\
\hline CHEMBL1214773 & 649999 & 5.6253 & 6.0451 & TRN & & \\
\hline CHEMBL1215767 & 649999 & 5.9666 & 6.5465 & TST & & \\
\hline CHEMBL1215637 & 649999 & 7.7447 & 7.7282 & TST & & \\
\hline CHEMBL1215568 & 649999 & 6.3947 & 7.4326 & TST & & \\
\hline CHEMBL3917158 & 1642463 & 8.9626 & 8.877 & TST & & \\
\hline CHEMBL3923381 & 1642463 & 6.5935 & 7.2468 & TRN & & \\
\hline CHEMBL3915741 & 1642463 & $6.3820 e$ & 30000000 & & 5.6007 & TST \\
\hline CHEMBL3943121 & 1642463 & 7.0635 & 6.9202 & TRN & & \\
\hline CHEMBL3895453 & 1642463 & 7.7144 & 7.9506 & TRN & & \\
\hline CHEMBL 3987001 & 1642463 & 7.3036 & 7.7723 & TRN & & \\
\hline CHEMBL3973697 & 1642463 & 7.6655 & 7.1938 & TST & & \\
\hline CHEMBL3951004 & 1642463 & 7.7773 & 7.9261 & TRN & & \\
\hline CHEMBL3919291 & 1642463 & 6.9872 & 6.7639 & TRN & & \\
\hline CHEMBL3973474 & 1642463 & 8.1158 & 8.0252 & TRN & & \\
\hline CHEMBL3892048 & 1642463 & 7.8069 & 7.7371 & TRN & & \\
\hline CHEMBL3979159 & 1642463 & 9.1427 & 8.8902 & TRN & & \\
\hline CHEMBL 3894625 & 1642463 & 8.5654 & 7.9848 & TRN & & \\
\hline CHEMBL3902479 & 1642463 & 7.6696 & 7.7204 & TRN & & \\
\hline CHEMBL3953311 & 1642463 & 7.0835 & 6.9752 & TRN & & \\
\hline CHEMBL 3958747 & 1642463 & 8.5391 & 8.4414 & TRN & & \\
\hline CHEMBL3921882 & 1642463 & 8.9208 & 8.6847 & TRN & & \\
\hline CHEMBL3974586 & 1642463 & 6.8861 & 6.7051 & TRN & & \\
\hline CHEMBL3936240 & 1642463 & 8.0975 & 7.8892 & TRN & & \\
\hline CHEMBL3965594 & 1642463 & 6.0 & 6.1993 & TRN & & \\
\hline CHEMBL 3902471 & 1642463 & 9.6383 & 10.2606 & TST & & \\
\hline CHEMBL3950612 & 1642463 & 7.9626 & 7.0598 & TRN & & \\
\hline CHEMBL3939581 & 1642463 & 9.0655 & 9.1817 & TST & & \\
\hline CHEMBL3969934 & 1642463 & 8.5952 & 8.933 & TRN & & \\
\hline CHEMBL3931254 & 1642463 & 7.585 & 7.1662 & TST & & \\
\hline CHEMBL3943648 & 1642463 & 8.4045 & 8.1456 & TRN & & \\
\hline CHEMBL3960608 & 1642463 & 8.4449 & 8.5157 & TRN & & \\
\hline CHEMBL 3947868 & 1642463 & 6.3242 & 5.9753 & TRN & & \\
\hline CHEMBL3904054 & 1642463 & 8.757 & 9.2312 & TST & & \\
\hline CHEMBL3969951 & 1642463 & 8.6345 & 8.4922 & TRN & & \\
\hline CHEMBL3967606 & 1642463 & 8.6421 & 8.5181 & TST & & \\
\hline CHEMBL3975539 & 1642463 & 7.3307 & 7.6542 & TST & & \\
\hline
\end{tabular}


Supplemental Table S2.txt

\begin{tabular}{|c|c|c|c|c|c|}
\hline CHEMBL3960736 & 1642463 & 8.6421 & 8.6712 & TRN & \\
\hline CHEMBL3965615 & 1642463 & 5.1864 & 6.4278 & TST & \\
\hline CHEMBL3980726 & 1642463 & 7.1129 & 7.0888 & TRN & \\
\hline CHEMBL3947236 & 1642463 & 7.0711 & 6.8128 & TRN & \\
\hline CHEMBL3907466 & 1642463 & 6.7212 & 6.5475 & TST & \\
\hline CHEMBL3901566 & 1642463 & 8.5702 & 8.1917 & TRN & \\
\hline CHEMBL3958305 & 1642463 & 9.0706 & 9.2285 & TRN & \\
\hline CHEMBL3916624 & 1642463 & 6.8894 & 6.8826 & TST & \\
\hline CHEMBL3893355 & 1642463 & 7.5654 & 7.1988 & TRN & \\
\hline CHEMBL3910152 & 1642463 & 9.4318 & 9.4844 & TRN & \\
\hline CHEMBL 3890248 & 1642463 & 6.0 & 5.8281 & TRN & \\
\hline CHEMBL3910168 & 1642463 & 8.585 & 8.1426 & TRN & \\
\hline CHEMBL3977577 & 1642463 & 9.301 & 9.1702 & TST & \\
\hline CHEMBL3981704 & 1642463 & 7.9393 & 7.1343 & TRN & \\
\hline CHEMBL3906029 & 1642463 & 6.3585 & 6.6688 & TST & \\
\hline CHEMBL3965260 & 1642463 & 8.8894 & 8.9795 & TRN & \\
\hline CHEMBL3939992 & 1642463 & 7.3615 & 7.74700 & 0000000001 & TRN \\
\hline CHEMBL3982811 & 1642463 & 7.8539 & 7.7091 & TRN & \\
\hline CHEMBL3956238 & 1642463 & 9.3979 & 9.4298 & TRN & \\
\hline CHEMBL3898965 & 1642463 & 6.0 & 6.4209 & TRN & \\
\hline CHEMBL3928973 & 1642463 & 7.7235 & 7.9948 & TRN & \\
\hline CHEMBL3913767 & 1642463 & 6.2495 & 6.0651 & TRN & \\
\hline CHEMBL3932327 & 1642463 & 8.0283 & 7.9127 & TRN & \\
\hline CHEMBL3943471 & 1642463 & 8.5272 & 8.4543 & TRN & \\
\hline CHEMBL3928424 & 1642463 & 6.0 & 5.99299 & 7999999999 & TRN \\
\hline CHEMBL3960225 & 1642463 & 6.0 & 6.5033 & TRN & \\
\hline CHEMBL3968698 & 1642463 & 8.3979 & 7.9954 & TRN & \\
\hline CHEMBL3961538 & 1642463 & 9.4815 & 10.066 & TST & \\
\hline CHEMBL3914478 & 1642463 & 8.0841 & 7.8092 & TRN & \\
\hline CHEMBL3919941 & 1642463 & 5.87 & 7.1408 & TRN & \\
\hline CHEMBL3984075 & 1642463 & 6.0 & 6.4485 & TRN & \\
\hline CHEMBL3976301 & 1642463 & 7.3883 & 6.7503 & TRN & \\
\hline CHEMBL3922088 & 1642463 & 8.6576 & 8.5525 & TRN & \\
\hline CHEMBL3896967 & 1642463 & 7.8894 & 8.6093 & TST & \\
\hline CHEMBL3893554 & 1642463 & 6.0 & 5.9868 & TRN & \\
\hline CHEMBL3942539 & 1642463 & 6.6904 & 7.0221 & TST & \\
\hline CHEMBL3969325 & 1642463 & 9.1487 & 9.2106 & TST & \\
\hline CHEMBL3957730 & 1642463 & 7.5686 & 7.4811 & TRN & \\
\hline CHEMBL3982579 & 1642463 & 7.6308 & 7.515 & TRN & \\
\hline CHEMBL3982461 & 1642463 & 7.9355 & 8.4179 & TST & \\
\hline CHEMBL3965912 & 1642463 & 7.2248 & 7.6621 & TRN & \\
\hline CHEMBL3907530 & 1642463 & 6.6882 & 7.0195 & TRN & \\
\hline CHEMBL3892122 & 1642463 & 8.6073 & 8.3651 & TRN & \\
\hline CHEMBL3983535 & 1642463 & 6.983 & 6.8936 & TRN & \\
\hline CHEMBL3964418 & 1642463 & 9.4437 & 8.9595 & TRN & \\
\hline CHEMBL3949659 & 1642463 & 6.0737 & 5.9951 & TRN & \\
\hline CHEMBL3923391 & 1642463 & 8.3251 & 7.9056 & TST & \\
\hline CHEMBL3956525 & 1642463 & 6.9586 & 6.9393 & TST & \\
\hline
\end{tabular}


Supplemental Table S2.txt

\begin{tabular}{|c|c|c|c|c|c|}
\hline CHEMBL3953574 & 1642463 & 5.8268 & 5.3614 & TST & \\
\hline CHEMBL3934418 & 1642463 & 8.5834 & 8.673 & TST & \\
\hline CHEMBL3913336 & 1642463 & 9.0706 & 9.1654 & TRN & \\
\hline CHEMBL3947211 & 1642463 & 6.0 & 6.5263 & TRN & \\
\hline CHEMBL3957651 & 1642463 & 9.0706 & 9.3162 & TRN & \\
\hline CHEMBL3912670 & 1642463 & 6.0 & 6.3024 & TRN & \\
\hline CHEMBL3936330 & 1642463 & 6.0 & 6.1666 & TRN & \\
\hline CHEMBL3928809 & 1642463 & 9.0706 & 9.1432 & TRN & \\
\hline CHEMBL3959827 & 1642463 & 8.4622 & 8.4863 & TRN & \\
\hline CHEMBL3937334 & 1642463 & 8.1713 & 7.7497 & TRN & \\
\hline CHEMBL3985681 & 1642463 & 8.7305 & 8.7012 & TST & \\
\hline CHEMBL3900611 & 1642463 & 6.8894 & 7.2553 & TRN & \\
\hline CHEMBL3945324 & 1642463 & 7.426 & 7.2089 & TRN & \\
\hline CHEMBL3912625 & 1642463 & 7.1979 & 7.4786 & TRN & \\
\hline CHEMBL3930519 & 1642463 & 6.0 & 6.4802 & TRN & \\
\hline CHEMBL3965554 & 1642463 & 8.6091 & 8.2475 & TRN & \\
\hline CHEMBL3911197 & 1642463 & 6.3969 & 6.6481 & TST & \\
\hline CHEMBL3965274 & 1642463 & 6.0 & 6.104 & TRN & \\
\hline CHEMBL3890038 & 1642463 & 5.7222 & 4.9812 & TST & \\
\hline CHEMBL3902850 & 1642463 & 6.1759 & 6.1506 & TST & \\
\hline CHEMBL3905628 & 1642463 & 7.7721 & 7.6381 & TRN & \\
\hline CHEMBL3947008 & 1642463 & 9.4949 & 9.5861 & TRN & \\
\hline CHEMBL3954919 & 1642463 & 8.3439 & 8.6354 & TRN & \\
\hline CHEMBL3938539 & 1642463 & 8.4045 & 8.1982 & TRN & \\
\hline CHEMBL3964822 & 1642463 & 8.55600 & 200000000 & $\partial 1$ & 8.6129 \\
\hline CHEMBL3918529 & 1642463 & 6.1129 & 8.8181 & TST & \\
\hline CHEMBL3911734 & 1642463 & 7.9101 & 7.6525 & TRN & \\
\hline CHEMBL3914458 & 1642463 & 7.5591 & 7.75 & TRN & \\
\hline CHEMBL3966859 & 1642463 & 8.5768 & 8.3138 & TRN & \\
\hline CHEMBL3950431 & 1642463 & 6.6968 & 7.0692 & TST & \\
\hline CHEMBL3952342 & 1642463 & 8.6716 & 8.4719 & TRN & \\
\hline CHEMBL3912545 & 1642463 & 7.4724 & 7.6641 & TST & \\
\hline CHEMBL3907133 & 1642463 & 8.9469 & 8.9219 & TRN & \\
\hline CHEMBL3948586 & 1642463 & 8.399 & 8.7952 & TRN & \\
\hline CHEMBL3919521 & 1642463 & 6.0 & 6.07 & TRN & \\
\hline CHEMBL3896978 & 1642463 & 8.5302 & 8.368 & TRN & \\
\hline CHEMBL3892417 & 1642463 & 7.1249 & 6.3074 & TRN & \\
\hline CHEMBL3899127 & 1642463 & 6.8539 & 6.6485 & TRN & \\
\hline CHEMBL3967402 & 1642463 & 7.2541 & 7.2826 & TRN & \\
\hline CHEMBL3986100 & 1642463 & 7.1273 & 7.315 & TRN & \\
\hline CHEMBL3901295 & 1642463 & 6.0 & 6.1815 & TRN & \\
\hline CHEMBL3950542 & 1642463 & 7.7959 & 7.5581 & TRN & \\
\hline CHEMBL3951573 & 1642463 & 7.1811 & 7.171 & TRN & \\
\hline CHEMBL3967386 & 1642463 & 8.3969 & 8.6104 & TRN & \\
\hline CHEMBL3942625 & 1642463 & 7.1537 & 6.9972 & TST & \\
\hline CHEMBL3949136 & 1642463 & 9.7212 & 9.9585 & TRN & \\
\hline CHEMBL3934001 & 1642463 & 8.032 & 8.0145 & TRN & \\
\hline CHEMBL3900158 & 1642463 & 8.4045 & 8.1416 & TST & \\
\hline
\end{tabular}


Supplemental Table S2.txt

\begin{tabular}{|c|c|c|c|c|}
\hline CHEMBL3920062 & 1642463 & 8.9431 & 9.287 & TRN \\
\hline CHEMBL3957117 & 1642463 & 7.3224 & 6.6073 & TRN \\
\hline CHEMBL 3897427 & 1642463 & 7.6108 & 7.3915 & TRN \\
\hline CHEMBL3965403 & 1642463 & 8.1986 & 8.2008 & TRN \\
\hline CHEMBL 3985775 & 1642463 & 8.618 & 8.1646 & TRN \\
\hline CHEMBL3896915 & 1642463 & 6.0 & 6.2383 & TRN \\
\hline CHEMBL3928475 & 1642463 & 7.9586 & 7.8983 & TRN \\
\hline CHEMBL3915532 & 1642463 & 8.5969 & 8.8305 & TRN \\
\hline CHEMBL 3899661 & 1642463 & 6.0 & 6.478 & TRN \\
\hline CHEMBL3972689 & 1642463 & \multicolumn{2}{|c|}{7.218999999999999} & 7.2284 \\
\hline CHEMBL 3964208 & 1642463 & 8.025 & 7.9076 & TST \\
\hline CHEMBL3963293 & 1642463 & 7.1073 & 7.1605 & TRN \\
\hline CHEMBL 3961024 & 1642463 & 9.3372 & 9.0339 & TRN \\
\hline CHEMBL3927282 & 1642463 & 8.4547 & 8.1753 & TST \\
\hline CHEMBL 3936832 & 1642463 & 7.5482 & 7.3741 & TRN \\
\hline CHEMBL 3957110 & 1642463 & 7.7235 & 8.4718 & TST \\
\hline CHEMBL3987039 & 1642463 & 7.6799 & 8.1539 & TRN \\
\hline CHEMBL 3898415 & 1642463 & 6.0 & 6.5561 & TRN \\
\hline CHEMBL 3928122 & 1642463 & 7.284 & 7.4056 & TRN \\
\hline CHEMBL 3929051 & 1642463 & 6.1046 & 6.1544 & TRN \\
\hline CHEMBL 3983453 & 1642463 & 8.7033 & 8.6552 & TRN \\
\hline CHEMBL3903819 & 1642463 & 7.5575 & 7.4234 & TRN \\
\hline CHEMBL3916429 & 1642463 & 6.6819 & 4.7888 & TST \\
\hline CHEMBL 3981137 & 1642463 & 7.2204 & 7.2822 & TRN \\
\hline CHEMBL 3896691 & 1642463 & 6.0 & 7.0236 & TRN \\
\hline CHEMBL3928583 & 1642463 & 7.6234 & 7.6775 & TRN \\
\hline CHEMBL 3932451 & 1642463 & 7.8153 & 7.78299 & 99999999995 \\
\hline CHEMBL3979701 & 1642463 & 8.9872 & 8.8782 & TRN \\
\hline CHEMBL 3946401 & 1642463 & 7.7773 & 7.3395 & TST \\
\hline CHEMBL3906535 & 1642463 & 8.3288 & 8.3587 & TRN \\
\hline CHEMBL3938075 & 1642463 & 6.2125 & 4.9552 & TST \\
\hline CHEMBL3962377 & 1642463 & 6.0 & 6.0282 & TRN \\
\hline CHEMBL3971299 & 1642463 & 7.4437 & 8.0544 & TRN \\
\hline CHEMBL 3975905 & 1642463 & 7.8182 & 7.053 & TST \\
\hline CHEMBL 3982864 & 1642463 & 7.1574 & 7.5566 & TRN \\
\hline CHEMBL3970956 & 1642463 & 7.4585 & 7.8804 & TRN \\
\hline CHEMBL 3951271 & 1642463 & 8.9245 & 8.6193 & TRN \\
\hline CHEMBL 3925445 & 1642463 & 7.4437 & 7.4043 & TRN \\
\hline CHEMBL 3928198 & 1642463 & 9.0862 & 8.5847 & TRN \\
\hline CHEMBL 3944777 & 1642463 & 7.2774 & 7.3586 & TRN \\
\hline CHEMBL 3890180 & 1642463 & 7.8601 & 7.7404 & TRN \\
\hline CHEMBL 3950642 & 1642463 & 6.0 & 6.129 & TRN \\
\hline CHEMBL 3894920 & 1642463 & 5.8794 & 5.2839 & TRN \\
\hline CHEMBL 3986384 & 1642463 & 8.2503 & 8.4878 & TRN \\
\hline CHEMBL 3890689 & 1642463 & 8.2503 & 6.9083 & TRN \\
\hline CHEMBL 3952741 & 1642463 & 7.9393 & 7.9451 & TRN \\
\hline CHEMBL 3908339 & 1642463 & 6.2857 & 5.9993 & TRN \\
\hline CHEMBL 3969281 & 1642463 & 7.6737 & 7.7572 & TRN \\
\hline
\end{tabular}

Page 10855 
Supplemental Table S2.txt

\begin{tabular}{|c|c|c|c|c|c|}
\hline CHEMBL3985772 & 1642463 & 9.1427 & 8.9675 & TRN & \\
\hline CHEMBL 3985261 & 1642463 & 7.9393 & 8.0679 & TST & \\
\hline CHEMBL3956456 & 1642463 & 7.3516 & 7.2594 & TRN & \\
\hline CHEMBL3905905 & 1642463 & 7.6308 & 8.0036 & TST & \\
\hline CHEMBL 3900840 & 1642463 & 7.2083 & 7.0822 & TRN & \\
\hline CHEMBL 3986802 & 1642463 & 9.0706 & 9.3456 & TRN & \\
\hline CHEMBL 3952575 & 1642463 & 8.1255 & 8.2345 & TRN & \\
\hline CHEMBL 3930451 & 1642463 & 6.0 & 6.6691 & TRN & \\
\hline CHEMBL3918029 & 1642463 & 8.0521 & 7.9777 & TRN & \\
\hline CHEMBL 3889653 & 1642463 & 8.5575 & 8.5419 & TRN & \\
\hline CHEMBL3953239 & 1642463 & 8.083 & 7.91799 & 9999999999 & TRN \\
\hline CHEMBL3963276 & 1642463 & 6.1707 & 6.2717 & TST & \\
\hline CHEMBL3976502 & 1642463 & 6.7328 & 7.0525 & TST & \\
\hline CHEMBL3933653 & 1642463 & 8.8665 & 8.7854 & TRN & \\
\hline CHEMBL 3950030 & 1642463 & 9.1739 & 8.6026 & TRN & \\
\hline CHEMBL3979165 & 1642463 & 8.7959 & 8.615 & TRN & \\
\hline CHEMBL 3974675 & 1642463 & 7.9431 & 7.8612 & TRN & \\
\hline CHEMBL3931902 & 1642463 & 8.7212 & 8.6096 & TRN & \\
\hline CHEMBL 3914530 & 1642463 & 8.2076 & 8.5386 & TST & \\
\hline CHEMBL 3903654 & 1642463 & 5.9957 & 6.0466 & TRN & \\
\hline CHEMBL3946874 & 1642463 & 8.1146 & 8.412 & TRN & \\
\hline CHEMBL 3975031 & 1642463 & 8.7235 & 8.5743 & TST & \\
\hline CHEMBL 3956875 & 1642463 & 8.5969 & 9.1337 & TST & \\
\hline CHEMBL 3926244 & 1642463 & 8.4647 & 7.7881 & TRN & \\
\hline CHEMBL3935094 & 1642463 & 7.6289 & 7.8727 & TRN & \\
\hline CHEMBL3939661 & 1642463 & 7.9788 & 7.811 & TRN & \\
\hline CHEMBL 3980770 & 1642463 & 7.0283 & 6.7753 & TRN & \\
\hline CHEMBL 3968042 & 1642463 & 6.5243 & 5.7958 & TRN & \\
\hline CHEMBL3980727 & 1642463 & 7.8477 & 7.7125 & TST & \\
\hline CHEMBL 3921203 & 1642463 & 8.0074 & 8.3423 & TST & \\
\hline CHEMBL3926252 & 1642463 & 5.8514 & 6.0563 & TRN & \\
\hline CHEMBL 3922917 & 1642463 & 7.2907 & 7.7898 & TST & \\
\hline CHEMBL 3986370 & 1642463 & 8.5834 & 8.6936 & TST & \\
\hline CHEMBL 3893663 & 1642463 & 6.4815 & 6.8829 & TRN & \\
\hline CHEMBL 3946084 & 1642463 & 6.0 & 6.5405 & TRN & \\
\hline CHEMBL3908876 & 1642463 & 8.3575 & 8.65 & TRN & \\
\hline CHEMBL 3895792 & 1642463 & 8.1586 & 8.4059 & TRN & \\
\hline CHEMBL3965421 & 1642463 & 8.3072 & 8.0466 & TRN & \\
\hline CHEMBL 3945260 & 1642463 & 6.5391 & 6.3737 & TRN & \\
\hline CHEMBL 3899293 & 1642463 & 6.0 & 5.8372 & TRN & \\
\hline CHEMBL3959242 & 1642463 & 7.7545 & 7.8558 & TST & \\
\hline CHEMBL3915928 & 1642463 & 9.0044 & 8.5345 & TRN & \\
\hline CHEMBL 3965294 & 1642463 & 8.0696 & 7.8129 & TST & \\
\hline CHEMBL 3930850 & 1642463 & 6.9957 & 8.0339 & TST & \\
\hline CHEMBL 3955270 & 1642463 & 6.0 & 7.1142 & TRN & \\
\hline CHEMBL3964562 & 1642463 & 6.8416 & 7.4404 & TRN & \\
\hline CHEMBL 3978005 & 1642463 & 8.1884 & 8.471 & TST & \\
\hline CHEMBL 3917947 & 1642463 & 7.9626 & 7.5231 & TST & \\
\hline
\end{tabular}


Supplemental Table S2.txt

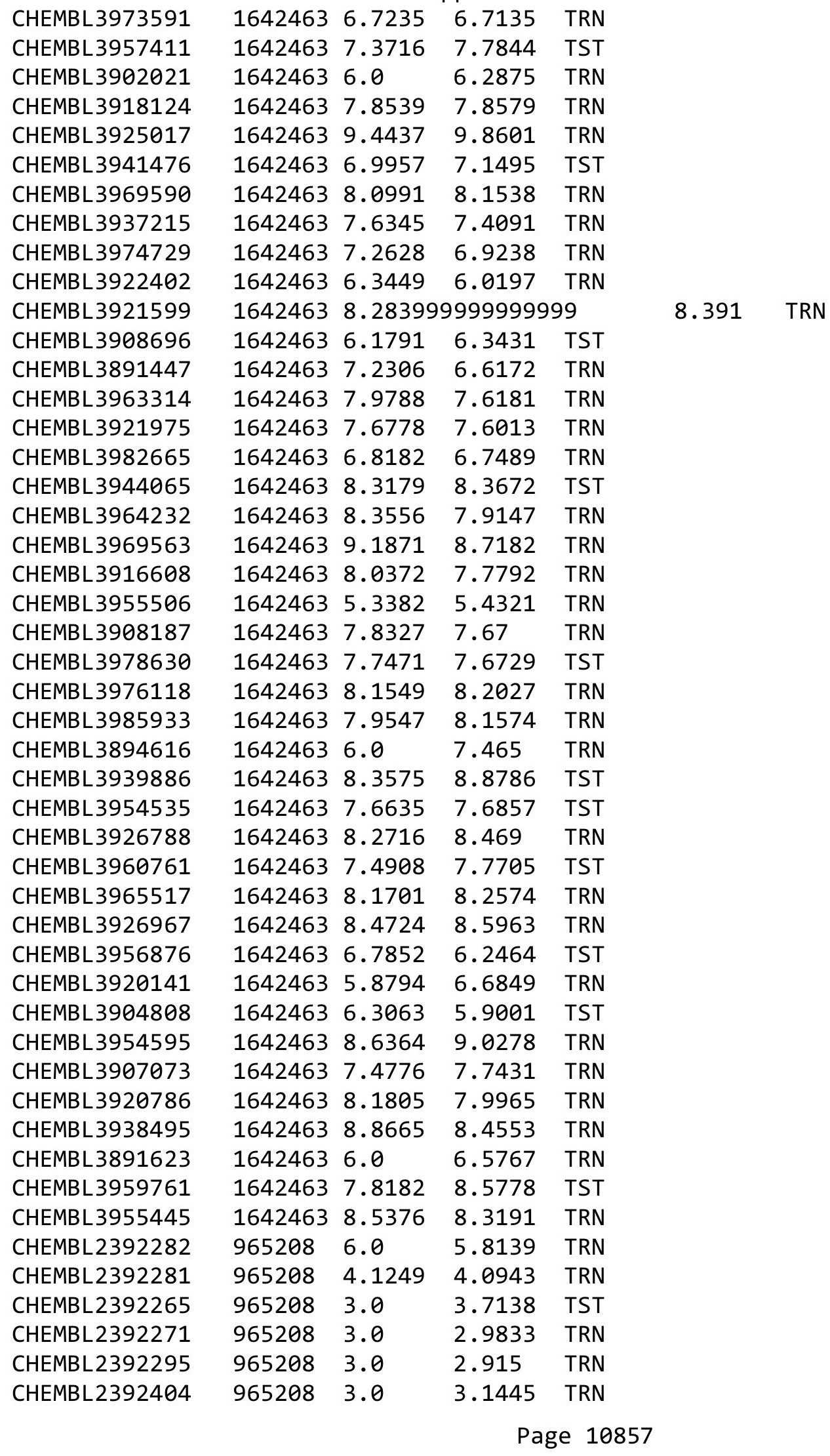




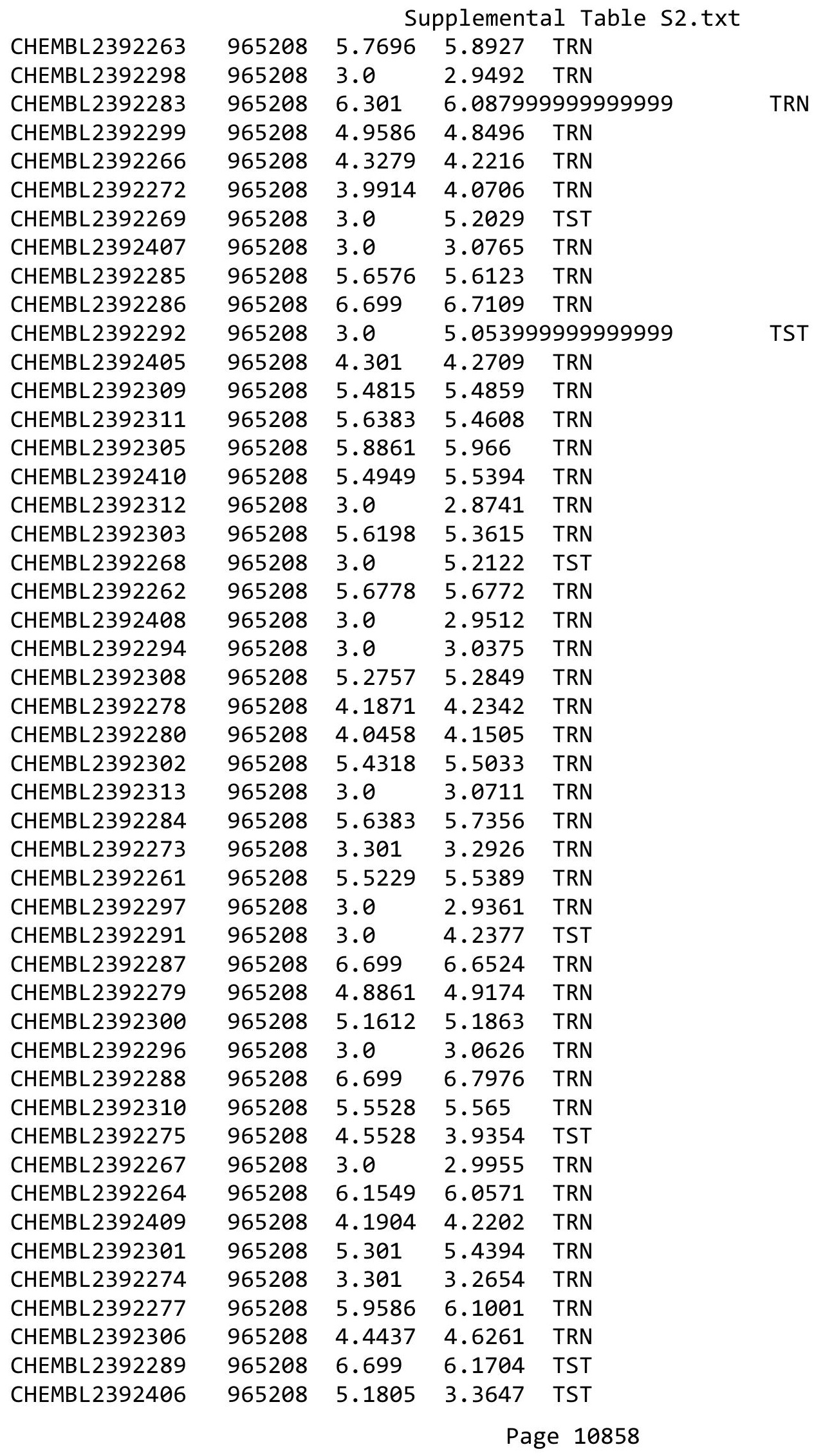




\begin{tabular}{|c|c|c|c|c|c|}
\hline & & \multicolumn{4}{|c|}{ Supplemental Table S2.txt } \\
\hline CHEMBL1585860 & 965208 & 5.1192 & 4.9291 & TST & \\
\hline CHEMBL 2392270 & 965208 & 3.301 & 3.2 & TST & \\
\hline CHEMBL1565236 & 965208 & 4.0458 & 3.4596 & TST & \\
\hline CHEMBL2392290 & 965208 & 6.699 & 6.4605 & TST & \\
\hline CHEMBL2392293 & 965208 & 5.301 & 6.1227 & TST & \\
\hline CHEMBL2392307 & 965208 & 4.9031 & 5.1794 & TST & \\
\hline CHEMBL 2392276 & 965208 & 6.301 & 5.8338 & TST & \\
\hline CHEMBL2392304 & 965208 & 5.6576 & 4.5572 & TST & \\
\hline CHEMBL558855 & 583010 & 7.3 & 7.5604 & TRN & \\
\hline CHEMBL539713 & 583010 & 8.7 & 8.4239 & TRN & \\
\hline CHEMBL540980 & 583010 & 7.4 & 7.5054 & TRN & \\
\hline CHEMBL538956 & 583010 & 8.1 & 8.0452 & TRN & \\
\hline CHEMBL549449 & 583010 & 7.4 & 7.4525 & TRN & \\
\hline CHEMBL555693 & 583010 & 8.0 & 7.9501 & TRN & \\
\hline CHEMBL549650 & 583010 & 7.4 & 7.8297 & TRN & \\
\hline CHEMBL559322 & 583010 & 8.7 & 8.40299 & 9999999999 & TRN \\
\hline CHEMBL559050 & 583010 & 6.7 & 6.9041 & TRN & \\
\hline CHEMBL553404 & 583010 & 8.3 & 8.0694 & TRN & \\
\hline CHEMBL555222 & 583010 & 8.1 & 8.0983 & TRN & \\
\hline CHEMBL539651 & 583010 & 8.4 & 8.4069 & TRN & \\
\hline CHEMBL561398 & 583010 & 8.2 & 7.8195 & TRN & \\
\hline CHEMBL551013 & 583010 & 8.6 & 8.5354 & TRN & \\
\hline CHEMBL555223 & 583010 & 8.3 & 8.1949 & TRN & \\
\hline CHEMBL540981 & 583010 & 8.6 & 8.7725 & TRN & \\
\hline CHEMBL556438 & 583010 & 6.8 & 6.7731 & TRN & \\
\hline CHEMBL539652 & 583010 & 6.5 & 6.4702 & TRN & \\
\hline CHEMBL541969 & 583010 & 5.8 & 5.8843 & TRN & \\
\hline CHEMBL539212 & 583010 & 5.9 & 5.8177 & TST & \\
\hline CHEMBL556235 & 583010 & 6.6 & 6.6938 & TRN & \\
\hline CHEMBL551535 & 583010 & 6.1 & 6.1753 & TRN & \\
\hline CHEMBL551614 & 583010 & 5.5 & 5.5005 & TRN & \\
\hline CHEMBL550064 & 583010 & 7.2 & 6.2445 & TST & \\
\hline CHEMBL552796 & 583010 & 8.1 & 3.9263 & TST & \\
\hline CHEMBL61130 & 583010 & 6.4 & 5.0145 & TST & \\
\hline CHEMBL551820 & 583010 & 6.5 & 6.7369 & TST & \\
\hline CHEMBL560940 & 583010 & 7.4 & 6.695 & TST & \\
\hline CHEMBL553658 & 583010 & 5.8 & 5.5491 & TST & \\
\hline CHEMBL550459 & 583010 & 6.9 & 6.5 & TST & \\
\hline CHEMBL551743 & 583010 & 5.5 & 6.0504 & TST & \\
\hline CHEMBL570780 & 583010 & 5.4 & 5.6495 & TST & \\
\hline CHEMBL558757 & 583010 & 5.5 & 3.74399 & 99999999998 & TST \\
\hline CHEMBL553688 & 583010 & 6.5 & 3.9677 & TST & \\
\hline CHEMBL570074 & 583010 & 6.0 & 5.9288 & TRN & \\
\hline CHEMBL557053 & 583010 & 7.0 & 6.9275 & TRN & \\
\hline CHEMBL551940 & 583010 & 7.1 & 7.1499 & TRN & \\
\hline CHEMBL552218 & 583010 & 6.9 & 6.8167 & TRN & \\
\hline CHEMBL551941 & 583010 & 7.2 & 6.983 & TRN & \\
\hline CHEMBL562400 & 583010 & 7.2 & 7.3136 & TRN & \\
\hline
\end{tabular}




\begin{tabular}{|c|c|c|c|c|}
\hline & & & ipplement & al Table S \\
\hline CHEMBL562477 & 583010 & 6.7 & 6.7614 & TRN \\
\hline CHEMBL552693 & 583010 & 7.2 & 7.1398 & TRN \\
\hline CHEMBL555447 & 583010 & 7.1 & 7.1398 & TRN \\
\hline CHEMBL552420 & 583010 & 6.9 & 6.8816 & TRN \\
\hline CHEMBL563261 & 583010 & 7.2 & 7.1491 & TRN \\
\hline CHEMBL560876 & 583010 & 7.3 & 7.1491 & TRN \\
\hline CHEMBL563276 & 583010 & 5.1 & 5.1461 & TRN \\
\hline CHEMBL557867 & 583010 & 7.7 & 7.5886 & TRN \\
\hline CHEMBL559548 & 583010 & 7.4 & 7.5886 & TRN \\
\hline CHEMBL563799 & 583010 & 6.0 & 6.0523 & TRN \\
\hline CHEMBL559317 & 583010 & 7.8 & 7.6301 & TRN \\
\hline CHEMBL556279 & 583010 & 7.5 & 7.6301 & TRN \\
\hline CHEMBL560597 & 583010 & 4.6 & 4.5326 & TRN \\
\hline CHEMBL551678 & 583010 & 5.2 & 4.9708 & TRN \\
\hline CHEMBL549998 & 583010 & 4.8 & 4.9708 & TRN \\
\hline CHEMBL552075 & 583010 & 6.0 & 6.1133 & TRN \\
\hline CHEMBL559746 & 583010 & 5.8 & 6.4811 & TRN \\
\hline CHEMBL550122 & 583010 & 7.2 & 6.4811 & TRN \\
\hline CHEMBL563445 & 583010 & 6.6 & 6.6086 & TRN \\
\hline CHEMBL562902 & 583010 & 8.0 & 8.0112 & TRN \\
\hline CHEMBL562636 & 583010 & 8.5 & 8.0112 & TST \\
\hline CHEMBL558259 & 583010 & 7.1 & 7.1747 & TRN \\
\hline CHEMBL558719 & 583010 & 8.3 & 8.5354 & TRN \\
\hline CHEMBL538706 & 583010 & 8.5 & 8.5354 & TRN \\
\hline CHEMBL550530 & 583010 & 6.9 & 6.11100 & 0000000001 \\
\hline CHEMBL558924 & 583010 & 7.4 & 6.9396 & TST \\
\hline CHEMBL558261 & 583010 & 7.8 & 6.9396 & TST \\
\hline CHEMBL565146 & 583010 & 7.2 & 6.9117 & TRN \\
\hline CHEMBL553685 & 583010 & 7.8 & 7.9501 & TRN \\
\hline CHEMBL556326 & 583010 & 7.8 & 7.9501 & TRN \\
\hline CHEMBL556595 & 583010 & 7.4 & 6.4844 & TST \\
\hline CHEMBL561278 & 583010 & 8.8 & 7.909 & TST \\
\hline CHEMBL552484 & 583010 & 8.9 & 7.909 & TST \\
\hline CHEMBL541223 & 583010 & 7.4 & 7.3916 & TRN \\
\hline CHEMBL558163 & 583010 & 8.5 & 8.5186 & TRN \\
\hline CHEMBL555210 & 583010 & 8.5 & 8.5186 & TRN \\
\hline CHEMBL1964290 & 809171 & 6.3 & 6.2698 & TRN \\
\hline CHEMBL2003768 & 809171 & 4.1 & 4.0228 & TRN \\
\hline CHEMBL213505 & 809171 & 4.1 & 3.9252 & TRN \\
\hline CHEMBL1982880 & 809171 & 5.3 & 4.6439 & TRN \\
\hline CHEMBL1987034 & 809171 & 8.1 & 7.8122 & TRN \\
\hline CHEMBL1993941 & 809171 & 4.1 & 4.2819 & TRN \\
\hline CHEMBL1980435 & 809171 & 7.4 & 7.3561 & TRN \\
\hline CHEMBL1989293 & 809171 & 6.4 & 6.2024 & TRN \\
\hline CHEMBL377383 & 809171 & 4.1 & 3.655 & TRN \\
\hline CHEMBL578061 & 809171 & 5.3 & 5.7297 & TRN \\
\hline CHEMBL2005886 & 809171 & 5.5 & 5.113 & TST \\
\hline CHEMBL481491 & 809171 & 4.1 & 4.4967 & TST \\
\hline
\end{tabular}




\begin{tabular}{|c|c|c|c|c|c|}
\hline & & & & & \\
\hline CHEMBL1682345 & 809171 & 6.6 & 6.4409 & TRN & \\
\hline CHEMBL1973142 & 809171 & 5.7 & 6.1856 & TST & \\
\hline CHEMBL1973145 & 809171 & 4.1 & 4.1291 & TRN & \\
\hline CHEMBL1982924 & 809171 & 4.1 & 5.0114 & TRN & \\
\hline CHEMBL 2005936 & 809171 & 7.0 & 7.8318 & TRN & \\
\hline CHEMBL1971141 & 809171 & 4.1 & 4.3037 & TRN & \\
\hline CHEMBL1995813 & 809171 & 7.9 & 8.0251 & TRN & \\
\hline CHEMBL1979718 & 809171 & 4.1 & 4.5034 & TRN & \\
\hline CHEMBL206236 & 809171 & 4.1 & 3.8336 & TRN & \\
\hline CHEMBL1964288 & 809171 & 8.3 & 6.9838 & TRN & \\
\hline CHEMBL523823 & 809171 & 4.1 & 4.3904 & TST & \\
\hline CHEMBL1562756 & 809171 & 5.2 & 5.1008 & TST & \\
\hline CHEMBL 244378 & 809171 & 7.3 & 7.2932 & TRN & \\
\hline CHEMBL 2001957 & 809171 & 4.1 & 4.0408 & TRN & \\
\hline CHEMBL1969372 & 809171 & 4.1 & $4.6610 e$ & 00000000005 & TRN \\
\hline CHEMBL1993413 & 809171 & 4.5 & 4.3645 & TRN & \\
\hline CHEMBL1990583 & 809171 & 4.1 & 4.7692 & TRN & \\
\hline CHEMBL1986943 & 809171 & 7.9 & 7.8978 & TRN & \\
\hline CHEMBL 2006263 & 809171 & 5.3 & 4.6344 & TST & \\
\hline CHEMBL1988662 & 809171 & 5.5 & 5.841 & TRN & \\
\hline CHEMBL1993584 & 809171 & 4.1 & 3.9838 & TRN & \\
\hline CHEMBL1986263 & 809171 & 7.7 & 7.3647 & TRN & \\
\hline CHEMBL 2000114 & 809171 & 5.5 & 5.6343 & TRN & \\
\hline CHEMBL 210618 & 809171 & 6.1 & 4.7494 & TRN & \\
\hline CHEMBL1971172 & 809171 & 6.7 & 6.4018 & TRN & \\
\hline CHEMBL1975647 & 809171 & 6.6 & 7.079 & TRN & \\
\hline CHEMBL1968380 & 809171 & 4.1 & 4.0333 & TRN & \\
\hline CHEMBL1997643 & 809171 & 6.6 & 7.2149 & TRN & \\
\hline CHEMBL1964644 & 809171 & 5.6 & 4.9512 & TRN & \\
\hline CHEMBL1981782 & 809171 & 4.1 & 4.5386 & TRN & \\
\hline CHEMBL1977681 & 809171 & 5.3 & 5.1325 & TRN & \\
\hline CHEMBL1970142 & 809171 & 4.1 & 3.905 & TRN & \\
\hline CHEMBL1990912 & 809171 & 6.9 & 5.8494 & TRN & \\
\hline CHEMBL1988163 & 809171 & 7.6 & 7.5399 & TRN & \\
\hline CHEMBL1995592 & 809171 & 6.1 & 5.8813 & TRN & \\
\hline CHEMBL 2006493 & 809171 & 4.1 & 3.8932 & TST & \\
\hline CHEMBL1982541 & 809171 & 4.1 & 4.5202 & TRN & \\
\hline CHEMBL1996923 & 809171 & 4.1 & 4.7956 & TST & \\
\hline CHEMBL1983449 & 809171 & 4.1 & 3.9797 & TRN & \\
\hline CHEMBL1992323 & 809171 & 4.1 & 4.667 & TST & \\
\hline CHEMBL1969735 & 809171 & 4.1 & 4.1356 & TRN & \\
\hline CHEMBL 2003524 & 809171 & 6.4 & 5.9619 & TST & \\
\hline CHEMBL 2002649 & 809171 & 7.3 & 7.0355 & TRN & \\
\hline CHEMBL1983589 & 809171 & 6.4 & 6.6777 & TRN & \\
\hline CHEMBL437747 & 809171 & 6.2 & 6.5125 & TRN & \\
\hline CHEMBL 2005718 & 809171 & 6.6 & 6.7259 & TRN & \\
\hline CHEMBL1995172 & 809171 & 4.1 & 4.7984 & TST & \\
\hline CHEMBL507936 & 809171 & 4.1 & 4.1387 & TRN & \\
\hline & & & & 10861 & \\
\hline
\end{tabular}




\begin{tabular}{|c|c|c|c|c|}
\hline & & & Supplement & al \\
\hline CHEMBL104264 & 809171 & 4.1 & 5.1455 & TST \\
\hline CHEMBL1994321 & 809171 & 4.1 & 4.2823 & TRN \\
\hline CHEMBL1997129 & 809171 & 5.8 & 5.2768 & TRN \\
\hline CHEMBL 229799 & 809171 & 7.6 & 7.926 & TRN \\
\hline CHEMBL1984788 & 809171 & 4.1 & 4.2294 & TRN \\
\hline CHEMBL451964 & 809171 & 4.1 & 4.1218 & TRN \\
\hline CHEMBL1964307 & 809171 & 5.6 & 5.4889 & TRN \\
\hline CHEMBL 2000508 & 809171 & 4.1 & 3.9741 & TRN \\
\hline CHEMBL1971694 & 809171 & 4.1 & 4.5367 & TST \\
\hline CHEMBL 2001547 & 809171 & 4.1 & 4.2036 & TRN \\
\hline CHEMBL210928 & 809171 & 4.1 & 4.0923 & TRN \\
\hline CHEMBL1994361 & 809171 & 4.1 & 3.9114 & TRN \\
\hline CHEMBL1986603 & 809171 & 4.1 & 4.7668 & TST \\
\hline CHEMBL1972840 & 809171 & 5.4 & 5.8622 & TRN \\
\hline CHEMBL1977148 & 809171 & 4.1 & 4.2012 & TRN \\
\hline CHEMBL 2004443 & 809171 & 4.1 & 4.8788 & TRN \\
\hline CHEMBL2003286 & 809171 & 4.1 & 3.9295 & TRN \\
\hline CHEMBL1992306 & 809171 & 4.1 & 3.7986 & TRN \\
\hline CHEMBL2002165 & 809171 & 4.1 & 3.9559 & TRN \\
\hline CHEMBL 2001668 & 809171 & 4.1 & 4.2886 & TRN \\
\hline CHEMBL1979318 & 809171 & 4.1 & 4.9894 & TST \\
\hline CHEMBL 206382 & 809171 & 4.1 & 3.8876 & TRN \\
\hline CHEMBL1998585 & 809171 & 4.1 & 4.1563 & TRN \\
\hline CHEMBL127898 & 809171 & 4.1 & 4.3476 & TST \\
\hline CHEMBL519697 & 809171 & 4.1 & 4.3263 & TST \\
\hline CHEMBL 2004934 & 809171 & 5.7 & 5.3711 & TRN \\
\hline CHEMBL1987261 & 809171 & 6.5 & 6.6414 & TRN \\
\hline CHEMBL1968459 & 809171 & 6.7 & 7.2034 & TRN \\
\hline CHEMBL1975128 & 809171 & 7.6 & 7.2695 & TRN \\
\hline CHEMBL1970369 & 809171 & 4.1 & 4.2282 & TRN \\
\hline CHEMBL 2001485 & 809171 & 4.1 & 3.9651 & TRN \\
\hline CHEMBL504950 & 809171 & 5.1 & 5.1672 & TRN \\
\hline CHEMBL1966425 & 809171 & 5.9 & 5.2574 & TRN \\
\hline CHEMBL1984363 & 809171 & 5.4 & 5.5264 & TRN \\
\hline CHEMBL1978099 & 809171 & 7.0 & 6.5234 & TRN \\
\hline CHEMBL1977041 & 809171 & 5.2 & 4.6057 & TRN \\
\hline CHEMBL1968070 & 809171 & 6.2 & 6.0876 & TRN \\
\hline CHEMBL1988608 & 809171 & 5.9 & 5.5488 & TRN \\
\hline CHEMBL184847 & 809171 & 4.1 & 4.525 & TRN \\
\hline CHEMBL1984367 & 809171 & 4.1 & 3.8959 & TRN \\
\hline CHEMBL1985723 & 809171 & 6.3 & 6.3911 & TRN \\
\hline CHEMBL178737 & 809171 & 6.5 & 4.9408 & TST \\
\hline CHEMBL226898 & 809171 & 8.0 & 6.8847 & TRN \\
\hline CHEMBL1982563 & 809171 & 4.1 & 4.1829 & TRN \\
\hline CHEMBL539474 & 809171 & 4.1 & 4.7957 & TST \\
\hline CHEMBL575824 & 809171 & 5.6 & 5.2341 & TRN \\
\hline CHEMBL1988387 & 809171 & 4.1 & 4.6119 & TRN \\
\hline CHEMBL1977128 & 809171 & 7.5 & 7.4434 & TRN \\
\hline
\end{tabular}




\begin{tabular}{|c|c|c|c|c|c|}
\hline \multicolumn{6}{|c|}{ Supplemental Table S2.txt } \\
\hline CHEMBL1997759 & 809171 & 4.1 & 4.0707 & TRN & \\
\hline CHEMBL1990288 & 809171 & 4.1 & 4.332 & TRN & \\
\hline CHEMBL1989708 & 809171 & 4.1 & 4.0491 & TRN & \\
\hline CHEMBL1974803 & 809171 & 5.3 & 4.9562 & TST & \\
\hline CHEMBL1970074 & 809171 & 5.1 & 4.4461 & TRN & \\
\hline CHEMBL1965702 & 809171 & 5.9 & 6.6506 & TRN & \\
\hline CHEMBL1986970 & 809171 & 6.2 & 6.1341 & TRN & \\
\hline CHEMBL 2002456 & 809171 & 6.9 & 5.88899 & 9999999999 & TRN \\
\hline CHEMBL 2005112 & 809171 & 4.1 & 4.3159 & TST & \\
\hline CHEMBL1958401 & 809171 & 6.6 & 6.0723 & TRN & \\
\hline CHEMBL1984044 & 809171 & 4.1 & 4.3919 & TRN & \\
\hline CHEMBL 2003456 & 809171 & 5.1 & 5.1814 & TRN & \\
\hline CHEMBL1966816 & 809171 & 7.3 & 6.7255 & TRN & \\
\hline CHEMBL1972584 & 809171 & 4.1 & 3.9747 & TRN & \\
\hline CHEMBL 2002992 & 809171 & 6.0 & 5.5672 & TRN & \\
\hline CHEMBL560813 & 809171 & 4.1 & 4.2829 & TRN & \\
\hline CHEMBL207253 & 809171 & 4.1 & 4.7743 & TRN & \\
\hline CHEMBL1890036 & 809171 & 4.1 & 4.5808 & TST & \\
\hline CHEMBL1968791 & 809171 & 4.1 & 4.0997 & TRN & \\
\hline CHEMBL326282 & 809171 & 4.1 & 4.5862 & TST & \\
\hline CHEMBL 2002682 & 809171 & 4.1 & 4.1479 & TST & \\
\hline CHEMBL1992732 & 809171 & 4.1 & 4.7505 & TST & \\
\hline CHEMBL1971186 & 809171 & 4.1 & 4.4953 & TRN & \\
\hline CHEMBL 2003482 & 809171 & 6.4 & 5.41799 & 7999999999 & TRN \\
\hline CHEMBL 2006456 & 809171 & 6.6 & 7.2865 & TRN & \\
\hline CHEMBL1973211 & 809171 & 4.1 & 4.4333 & TRN & \\
\hline CHEMBL1984700 & 809171 & 4.1 & 4.2231 & TRN & \\
\hline CHEMBL 2007151 & 809171 & 4.1 & 4.0767 & TRN & \\
\hline CHEMBL1964340 & 809171 & 6.6 & 6.5756 & TRN & \\
\hline CHEMBL1972125 & 809171 & 4.1 & 3.5777 & TRN & \\
\hline CHEMBL1461728 & 809171 & 4.1 & 3.9876 & TRN & \\
\hline CHEMBL1976134 & 809171 & 5.9 & 5.4836 & TRN & \\
\hline CHEMBL1965131 & 809171 & 5.7 & 5.7377 & TST & \\
\hline CHEMBL1995448 & 809171 & 4.1 & 4.6759 & TRN & \\
\hline CHEMBL1972158 & 809171 & 7.3 & 7.2396 & TRN & \\
\hline CHEMBL1974457 & 809171 & 5.5 & 4.6489 & TRN & \\
\hline CHEMBL1967662 & 809171 & 7.0 & 6.651 & TRN & \\
\hline CHEMBL 2006580 & 809171 & 4.1 & 4.4629 & TRN & \\
\hline CHEMBL1999414 & 809171 & 4.5 & 4.4988 & TRN & \\
\hline CHEMBL 280074 & 809171 & 5.4 & 5.2925 & TST & \\
\hline CHEMBL 2006581 & 809171 & 4.1 & 3.8953 & TRN & \\
\hline CHEMBL 2006481 & 809171 & 4.1 & 4.1734 & TRN & \\
\hline CHEMBL1979855 & 809171 & 4.1 & 3.844 & TST & \\
\hline CHEMBL1970340 & 809171 & 4.1 & 4.3541 & TRN & \\
\hline CHEMBL 2005186 & 809171 & 4.1 & 4.7817 & TRN & \\
\hline CHEMBL1995927 & 809171 & 4.1 & 4.7503 & TST & \\
\hline CHEMBL 2006450 & 809171 & 4.5 & 5.7741 & TRN & \\
\hline CHEMBL1975534 & 809171 & 4.1 & 4.4147 & TRN & \\
\hline
\end{tabular}




\begin{tabular}{|c|c|c|c|c|c|}
\hline & & & & & \\
\hline CHEMBL1993424 & 809171 & 7.0 & 7.22 & TRN & \\
\hline CHEMBL1966703 & 809171 & 5.7 & 5.851 & TST & \\
\hline CHEMBL243518 & 809171 & 6.4 & 6.3734 & TRN & \\
\hline CHEMBL1969561 & 809171 & 7.0 & 6.49799 & 9999999999 & TRN \\
\hline CHEMBL1997023 & 809171 & 4.1 & 4.5103 & TST & \\
\hline CHEMBL1964687 & 809171 & 5.4 & 4.197 & TRN & \\
\hline CHEMBL1971943 & 809171 & 6.4 & 5.25299 & 9999999999 & TRN \\
\hline CHEMBL1999918 & 809171 & 6.5 & 7.0353 & TRN & \\
\hline CHEMBL1974254 & 809171 & 4.1 & 4.1111 & TRN & \\
\hline CHEMBL1988537 & 809171 & 5.7 & 5.8043 & TST & \\
\hline CHEMBL1969049 & 809171 & 5.4 & 4.9905 & TRN & \\
\hline CHEMBL 2005828 & 809171 & 5.1 & 4.2395 & TRN & \\
\hline CHEMBL 2002240 & 809171 & 4.1 & 4.7325 & TRN & \\
\hline CHEMBL1991143 & 809171 & 4.1 & 4.3383 & TRN & \\
\hline CHEMBL1980178 & 809171 & 6.3 & 6.7286 & TRN & \\
\hline CHEMBL1998611 & 809171 & 6.3 & 6.1348 & TST & \\
\hline CHEMBL485556 & 809171 & 4.1 & 4.341 & TST & \\
\hline CHEMBL1975900 & 809171 & 4.1 & 3.9286 & TRN & \\
\hline CHEMBL255822 & 809171 & 4.1 & 4.1287 & TRN & \\
\hline CHEMBL1972221 & 809171 & 7.2 & 6.7042 & TRN & \\
\hline CHEMBL2006778 & 809171 & 4.1 & 4.5625 & TRN & \\
\hline CHEMBL1981511 & 809171 & 6.3 & 5.6644 & TRN & \\
\hline CHEMBL378627 & 809171 & 4.1 & 4.0916 & TRN & \\
\hline CHEMBL1996979 & 809171 & 5.4 & 4.7291 & TRN & \\
\hline CHEMBL1997025 & 809171 & 4.1 & 4.0692 & TRN & \\
\hline CHEMBL1968406 & 809171 & 5.1 & 4.4048 & TRN & \\
\hline CHEMBL1982476 & 809171 & 5.1 & 4.3098 & TRN & \\
\hline CHEMBL1984274 & 809171 & 6.0 & 4.2039 & TST & \\
\hline CHEMBL1998545 & 809171 & 4.1 & 4.2178 & TRN & \\
\hline CHEMBL1986869 & 809171 & 4.1 & 4.2001 & TST & \\
\hline CHEMBL2006010 & 809171 & 5.5 & 5.1912 & TRN & \\
\hline CHEMBL1682558 & 809171 & 4.1 & 4.2188 & TRN & \\
\hline CHEMBL1990496 & 809171 & 4.1 & 4.062 & TST & \\
\hline CHEMBL1975937 & 809171 & 5.2 & 5.124 & TRN & \\
\hline CHEMBL1998068 & 809171 & 6.8 & 6.5483 & TRN & \\
\hline CHEMBL1997623 & 809171 & 4.1 & 3.9618 & TRN & \\
\hline CHEMBL 2002479 & 809171 & 4.1 & 4.9248 & TRN & \\
\hline CHEMBL1980371 & 809171 & 5.1 & 5.193 & TST & \\
\hline CHEMBL1993166 & 809171 & 6.0 & 6.2179 & TRN & \\
\hline CHEMBL1967094 & 809171 & 4.1 & 3.9064 & TRN & \\
\hline CHEMBL1966035 & 809171 & 4.1 & 4.0129 & TRN & \\
\hline CHEMBL 2003341 & 809171 & 4.1 & 4.6304 & TRN & \\
\hline CHEMBL1992644 & 809171 & 4.9 & 4.9641 & TRN & \\
\hline CHEMBL1992645 & 809171 & 4.1 & 4.2737 & TST & \\
\hline CHEMBL1990708 & 809171 & 4.1 & 4.9528 & TRN & \\
\hline CHEMBL1982992 & 809171 & 4.1 & 5.0896 & TRN & \\
\hline CHEMBL1999590 & 809171 & 4.1 & 4.5973 & TST & \\
\hline CHEMBL1981079 & 809171 & 6.4 & 6.7277 & TRN & \\
\hline
\end{tabular}




\begin{tabular}{|c|c|c|c|c|c|}
\hline \multicolumn{6}{|c|}{ Supplemental Table S2.txt } \\
\hline CHEMBL1972276 & 809171 & 4.1 & 4.2147 & TRN & \\
\hline CHEMBL1980489 & 809171 & 4.1 & 3.9713 & TRN & \\
\hline CHEMBL 2000832 & 809171 & 6.3 & 6.7438 & TRN & \\
\hline CHEMBL1967116 & 809171 & 4.1 & 4.1953 & TRN & \\
\hline CHEMBL1977814 & 809171 & 6.0 & 4.5685 & TRN & \\
\hline CHEMBL513846 & 809171 & 6.1 & 5.1884 & TRN & \\
\hline CHEMBL1970709 & 809171 & 4.1 & 4.3921 & TRN & \\
\hline CHEMBL1965660 & 809171 & 7.2 & 7.2463 & TRN & \\
\hline CHEMBL1998112 & 809171 & 4.1 & 4.579 & TRN & \\
\hline CHEMBL1972290 & 809171 & 6.4 & 6.9712 & TRN & \\
\hline CHEMBL1969126 & 809171 & 4.1 & 4.5332 & TRN & \\
\hline CHEMBL1980896 & 809171 & 4.1 & 4.258 & TRN & \\
\hline CHEMBL1975208 & 809171 & 4.1 & 3.4351 & TST & \\
\hline CHEMBL1970104 & 809171 & 6.1 & 5.6581 & TRN & \\
\hline CHEMBL1991429 & 809171 & 4.1 & 4.7545 & TRN & \\
\hline CHEMBL1964777 & 809171 & 6.0 & 5.79299 & 9999999999 & TRN \\
\hline CHEMBL1971149 & 809171 & 4.1 & 4.1282 & TRN & \\
\hline CHEMBL1999714 & 809171 & 4.1 & 4.3348 & TRN & \\
\hline CHEMBL1987533 & 809171 & 4.1 & 4.6491 & TRN & \\
\hline CHEMBL1994040 & 809171 & 4.1 & 4.1768 & TRN & \\
\hline CHEMBL1984548 & 809171 & 8.9 & 8.2538 & TRN & \\
\hline CHEMBL579246 & 809171 & 5.5 & 5.9792 & TRN & \\
\hline CHEMBL398951 & 809171 & 5.2 & 4.4974 & TST & \\
\hline CHEMBL1982506 & 809171 & 6.4 & 5.8142 & TST & \\
\hline CHEMBL 2004716 & 809171 & 4.3 & 4.2649 & TRN & \\
\hline CHEMBL1968127 & 809171 & 4.1 & 4.0863 & TRN & \\
\hline CHEMBL1975233 & 809171 & 5.2 & 5.0508 & TRN & \\
\hline CHEMBL1985406 & 809171 & 7.8 & 7.7717 & TRN & \\
\hline CHEMBL207400 & 809171 & 4.1 & 4.3833 & TRN & \\
\hline CHEMBL 2000894 & 809171 & 6.2 & 5.7493 & TRN & \\
\hline CHEMBL 2002553 & 809171 & 4.1 & 3.8736 & TST & \\
\hline CHEMBL1982135 & 809171 & 4.1 & 4.1829 & TRN & \\
\hline CHEMBL1976090 & 809171 & 5.8 & 5.4133 & TRN & \\
\hline CHEMBL1993243 & 809171 & 4.1 & 4.2458 & TRN & \\
\hline CHEMBL 2004771 & 809171 & 5.3 & 5.0765 & TRN & \\
\hline CHEMBL1992922 & 809171 & 6.6 & 6.8076 & TRN & \\
\hline CHEMBL399021 & 809171 & 4.1 & 4.0186 & TRN & \\
\hline CHEMBL1997597 & 809171 & 5.4 & 5.3289 & TRN & \\
\hline CHEMBL1969537 & 809171 & 4.1 & 4.9627 & TST & \\
\hline CHEMBL1976093 & 809171 & 5.3 & 4.3145 & TRN & \\
\hline CHEMBL210032 & 809171 & 5.9 & 4.7424 & TRN & \\
\hline CHEMBL1996543 & 809171 & 4.1 & 4.445 & TRN & \\
\hline CHEMBL1975256 & 809171 & 5.8 & 4.8237 & TST & \\
\hline CHEMBL508928 & 809171 & 4.1 & 4.2683 & TRN & \\
\hline CHEMBL1991356 & 809171 & 4.1 & 4.7426 & TST & \\
\hline CHEMBL1983309 & 809171 & 5.5 & 4.8771 & TRN & \\
\hline CHEMBL 2004892 & 809171 & 5.5 & 5.3924 & TRN & \\
\hline CHEMBL1999126 & 809171 & 4.1 & 4.2203 & TST & \\
\hline
\end{tabular}




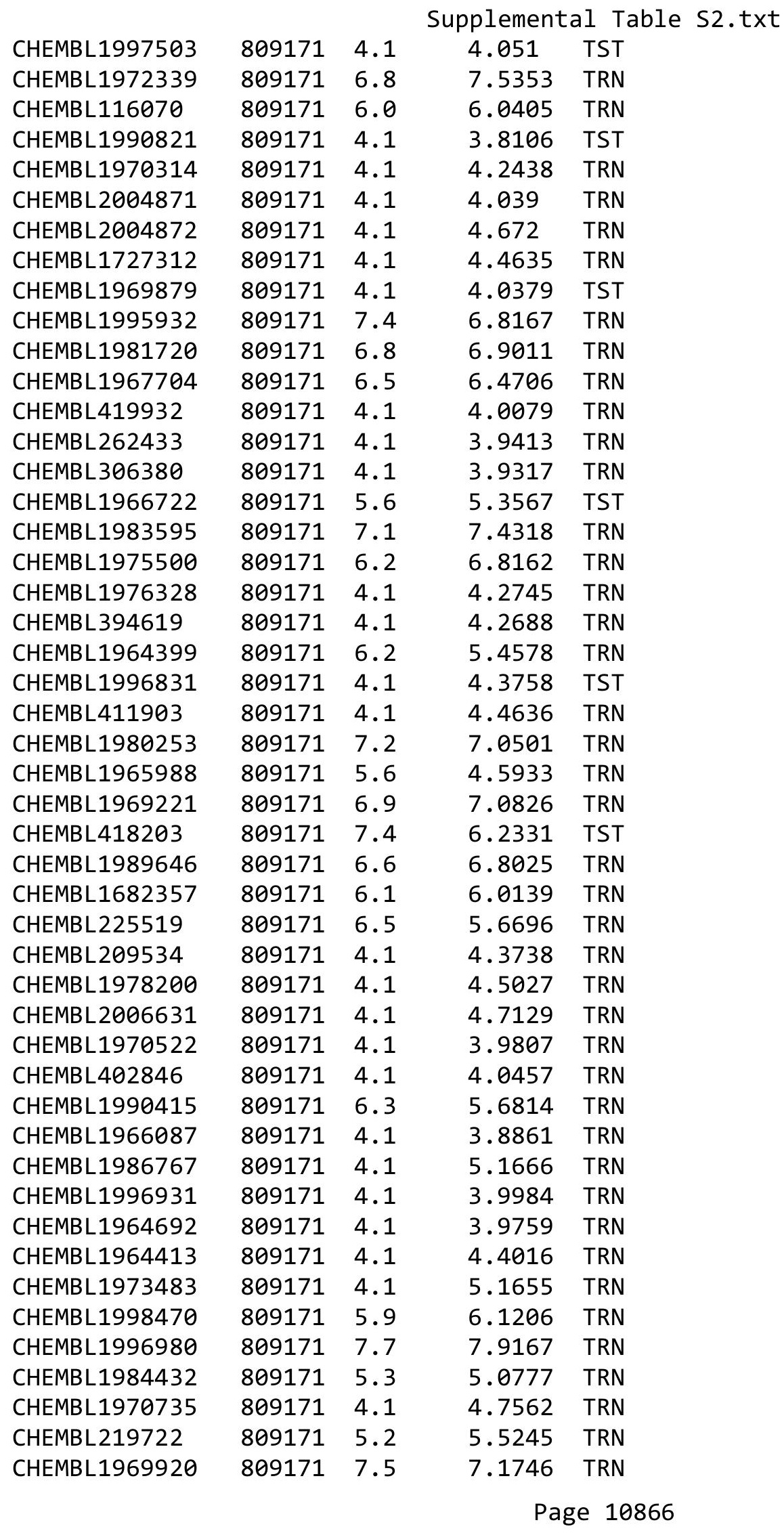




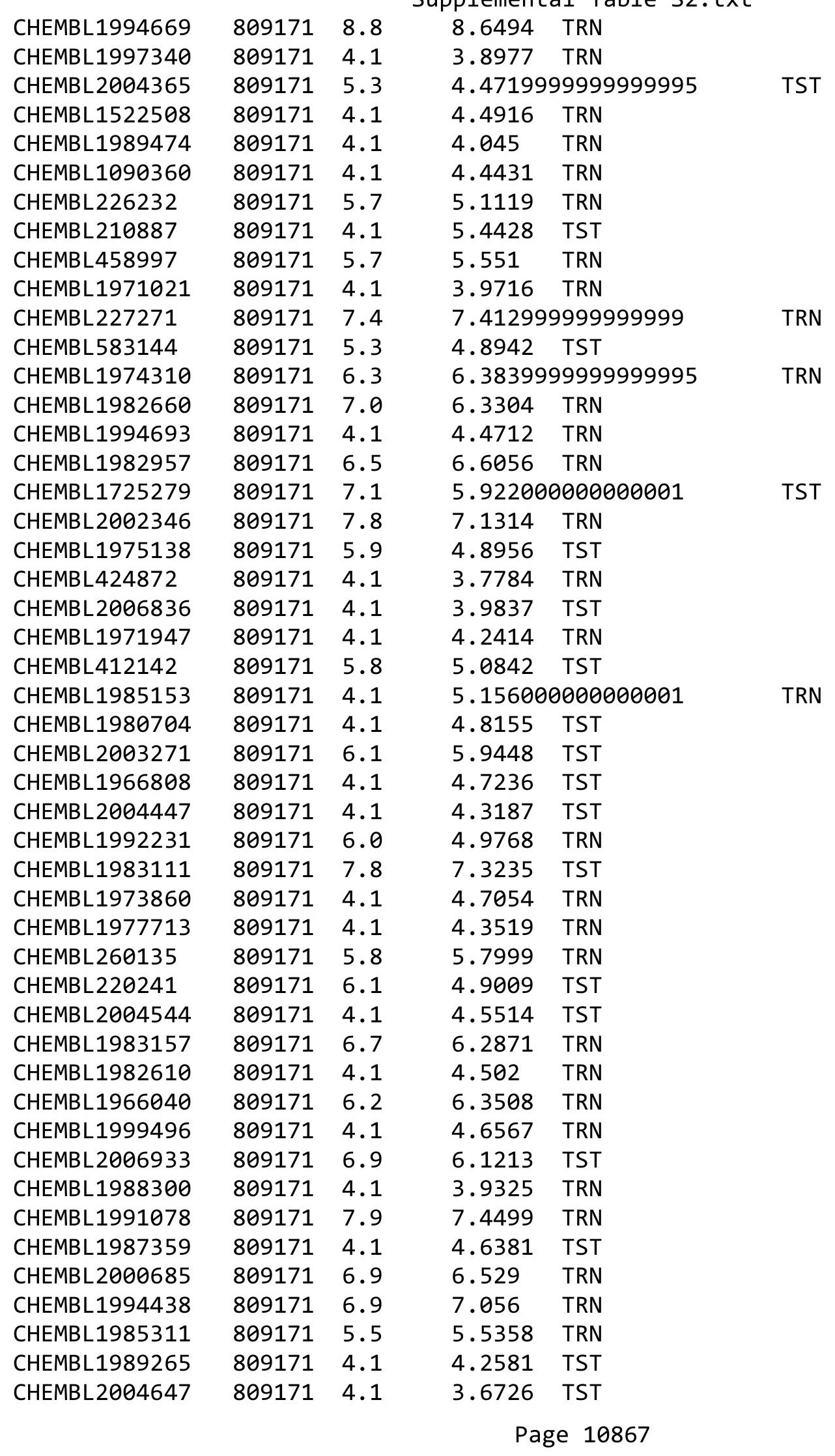




\begin{tabular}{|c|c|c|c|c|}
\hline & & & & \\
\hline CHEMBL1969502 & 809171 & 6.2 & 5.6527 & TRN \\
\hline CHEMBL1965910 & 809171 & 4.1 & 4.1094 & TRN \\
\hline CHEMBL1996447 & 809171 & 6.0 & 6.3641 & TRN \\
\hline CHEMBL1682553 & 809171 & 6.6 & 6.0783 & TRN \\
\hline CHEMBL1971430 & 809171 & 4.1 & 3.8754 & TST \\
\hline CHEMBL1983963 & 809171 & 4.1 & 4.0692 & TRN \\
\hline CHEMBL1997764 & 809171 & 4.1 & 4.8033 & TRN \\
\hline CHEMBL2000271 & 809171 & 6.8 & 6.9585 & TRN \\
\hline CHEMBL1985092 & 809171 & 5.5 & 5.13 & TST \\
\hline CHEMBL2004692 & 809171 & 5.4 & 4.17399 & 99999999995 \\
\hline CHEMBL1981410 & 809171 & 4.1 & 4.1375 & TRN \\
\hline CHEMBL1996234 & 809171 & 4.1 & 4.313 & TRN \\
\hline CHEMBL1967544 & 809171 & 5.1 & 4.9368 & TRN \\
\hline CHEMBL223367 & 809171 & 5.2 & 5.1553 & TST \\
\hline CHEMBL340384 & 809171 & 6.6 & 6.3373 & TRN \\
\hline CHEMBL1969151 & 809171 & 7.6 & 7.5501 & TRN \\
\hline CHEMBL1996587 & 809171 & 4.1 & 4.2121 & TRN \\
\hline CHEMBL1964804 & 809171 & 6.4 & 5.7819 & TRN \\
\hline CHEMBL443962 & 809171 & 6.6 & 5.4967 & TST \\
\hline CHEMBL2000354 & 809171 & 4.1 & 4.3371 & TRN \\
\hline CHEMBL1965507 & 809171 & 4.1 & 4.2355 & TRN \\
\hline CHEMBL1981107 & 809171 & 3.7 & 4.7871 & TST \\
\hline CHEMBL 274064 & 809171 & 4.1 & 4.2057 & TRN \\
\hline CHEMBL1967564 & 809171 & 6.2 & 6.6713 & TRN \\
\hline CHEMBL592030 & 809171 & 7.9 & 6.5617 & TST \\
\hline CHEMBL 2000071 & 809171 & 6.2 & $6.7420 e$ & 0000000001 \\
\hline CHEMBL1979176 & 809171 & 4.1 & 4.973 & TRN \\
\hline CHEMBL1970317 & 809171 & 4.1 & 4.0257 & TRN \\
\hline CHEMBL2002613 & 809171 & 6.6 & 6.9075 & TRN \\
\hline CHEMBL2000408 & 809171 & 4.1 & 4.4319 & TRN \\
\hline CHEMBL248757 & 809171 & 5.5 & 4.5645 & TST \\
\hline CHEMBL1978014 & 809171 & 4.1 & 4.8888 & TRN \\
\hline CHEMBL1974250 & 809171 & 6.8 & 5.1931 & TRN \\
\hline CHEMBL1994538 & 809171 & 6.0 & 6.2977 & TRN \\
\hline CHEMBL1983195 & 809171 & 4.1 & 4.7397 & TST \\
\hline CHEMBL1975490 & 809171 & 5.7 & 5.2088 & TRN \\
\hline CHEMBL1964444 & 809171 & 7.1 & 6.0644 & TRN \\
\hline CHEMBL1989957 & 809171 & 4.1 & 4.4853 & TRN \\
\hline CHEMBL1986139 & 809171 & 4.1 & 3.9972 & TRN \\
\hline CHEMBL383527 & 809171 & 4.1 & 4.1999 & TRN \\
\hline CHEMBL1980540 & 809171 & 4.1 & 5.067 & TRN \\
\hline CHEMBL2003229 & 809171 & 6.2 & 5.7453 & TRN \\
\hline CHEMBL1979883 & 809171 & 4.3 & 4.2558 & TRN \\
\hline CHEMBL1984162 & 809171 & 4.1 & 4.7966 & TRN \\
\hline CHEMBL1988331 & 809171 & 6.7 & 6.6853 & TRN \\
\hline CHEMBL1998432 & 809171 & 6.8 & 6.9416 & TRN \\
\hline CHEMBL491758 & 809171 & 6.4 & 6.266 & TRN \\
\hline CHEMBL86066 & 809171 & 5.8 & 5.3165 & TST \\
\hline
\end{tabular}




\begin{tabular}{|c|c|c|c|c|}
\hline & & & ipplemen & \\
\hline CHEMBL549730 & 809171 & 4.1 & 3.5852 & TRN \\
\hline CHEMBL1998826 & 809171 & 6.3 & 6.3525 & TRN \\
\hline CHEMBL1682360 & 809171 & 6.0 & 5.4973 & TRN \\
\hline CHEMBL1970189 & 809171 & 4.1 & 5.0743 & TST \\
\hline CHEMBL1996791 & 809171 & 6.0 & 4.9381 & TRN \\
\hline CHEMBL371206 & 809171 & 4.1 & 4.1291 & TRN \\
\hline CHEMBL1974664 & 809171 & 4.1 & 5.4758 & TST \\
\hline CHEMBL1974288 & 809171 & 5.5 & 5.2658 & TRN \\
\hline CHEMBL 213207 & 809171 & 8.4 & 7.511 & TRN \\
\hline CHEMBL196363 & 809171 & 4.1 & 4.1289 & TRN \\
\hline CHEMBL1190711 & 809171 & 6.5 & 6.4088 & TRN \\
\hline CHEMBL1990346 & 809171 & 5.4 & 5.3037 & TRN \\
\hline CHEMBL1968705 & 809171 & 5.9 & 5.2229 & TRN \\
\hline CHEMBL1991410 & 809171 & 4.5 & 4.6548 & TRN \\
\hline CHEMBL404367 & 809171 & 4.1 & 4.3052 & TRN \\
\hline CHEMBL1966343 & 809171 & 6.6 & 6.1376 & TRN \\
\hline CHEMBL1967887 & 809171 & 6.6 & 6.5571 & TRN \\
\hline CHEMBL 2000568 & 809171 & 5.3 & 4.7734 & TRN \\
\hline CHEMBL 2000335 & 809171 & 5.1 & 4.8951 & TRN \\
\hline CHEMBL1977604 & 809171 & 4.1 & 4.0014 & TST \\
\hline CHEMBL1993648 & 809171 & 5.9 & 6.0807 & TRN \\
\hline CHEMBL1988717 & 809171 & 4.1 & 3.8266 & TRN \\
\hline CHEMBL1974328 & 809171 & 7.0 & 6.6236 & TRN \\
\hline CHEMBL509032 & 809171 & 6.9 & 6.8014 & TRN \\
\hline CHEMBL243298 & 809171 & 6.5 & 6.2638 & TRN \\
\hline CHEMBL573339 & 809171 & 4.1 & 4.8472 & TST \\
\hline CHEMBL1971951 & 809171 & 5.9 & 5.41 & TRN \\
\hline CHEMBL1973808 & 809171 & 4.1 & 4.4184 & TRN \\
\hline CHEMBL 2000429 & 809171 & 4.1 & 4.1577 & TRN \\
\hline CHEMBL1972576 & 809171 & 4.1 & 4.0252 & TRN \\
\hline CHEMBL1992555 & 809171 & 4.1 & 4.1737 & TST \\
\hline CHEMBL1989069 & 809171 & 4.7 & 4.6804 & TST \\
\hline CHEMBL1992342 & 809171 & 5.5 & 5.6136 & TRN \\
\hline CHEMBL 2003682 & 809171 & 6.1 & 5.3066 & TRN \\
\hline CHEMBL1988173 & 809171 & 6.5 & 5.3715 & TST \\
\hline CHEMBL535331 & 809171 & 4.1 & 4.2042 & TRN \\
\hline CHEMBL1989805 & 809171 & 5.1 & 4.8342 & TST \\
\hline CHEMBL1966204 & 809171 & 7.9 & 7.6576 & TRN \\
\hline CHEMBL1982980 & 809171 & 4.1 & 3.9652 & TST \\
\hline CHEMBL1965423 & 809171 & 4.1 & 3.9996 & TRN \\
\hline CHEMBL1983025 & 809171 & 6.1 & 4.5475 & TRN \\
\hline CHEMBL205415 & 809171 & 5.4 & 4.3456 & TRN \\
\hline CHEMBL1999153 & 809171 & 8.3 & 7.4844 & TRN \\
\hline CHEMBL1969473 & 809171 & 7.2 & 7.0841 & TRN \\
\hline CHEMBL1977135 & 809171 & 4.1 & 4.3745 & TRN \\
\hline CHEMBL 2001920 & 809171 & 4.1 & 5.3544 & TST \\
\hline CHEMBL 2002322 & 809171 & 5.5 & 5.7555 & TRN \\
\hline CHEMBL1985654 & 809171 & 5.7 & 6.4703 & TRN \\
\hline
\end{tabular}




\begin{tabular}{|c|c|c|c|c|c|}
\hline \multicolumn{6}{|c|}{ Supplemental Table S2.txt } \\
\hline CHEMBL 2002323 & 809171 & 4.1 & 4.6725 & TST & \\
\hline CHEMBL1241473 & 809171 & 7.8 & 8.3512 & TRN & \\
\hline CHEMBL1978448 & 809171 & 4.1 & 4.2408 & TST & \\
\hline CHEMBL 2004513 & 809171 & 4.1 & 4.7717 & TRN & \\
\hline CHEMBL1972258 & 809171 & 4.1 & 3.8158 & TRN & \\
\hline CHEMBL1983855 & 809171 & 6.3 & 6.5085 & TRN & \\
\hline CHEMBL 2001257 & 809171 & 4.2 & 4.0705 & TRN & \\
\hline CHEMBL 2005548 & 809171 & 4.1 & 4.1852 & TRN & \\
\hline CHEMBL1987793 & 809171 & 4.1 & 4.3415 & TST & \\
\hline CHEMBL1992536 & 809171 & 4.1 & 4.7627 & TRN & \\
\hline CHEMBL1992740 & 809171 & 6.0 & 6.8296 & TRN & \\
\hline CHEMBL 2002373 & 809171 & 4.1 & 4.504 & TRN & \\
\hline CHEMBL439340 & 809171 & 4.1 & 3.38100 & 30000000002 & TRN \\
\hline CHEMBL 2006188 & 809171 & 5.2 & 4.8213 & TRN & \\
\hline CHEMBL1967531 & 809171 & 4.1 & 4.317 & TRN & \\
\hline CHEMBL1970913 & 809171 & 6.5 & 6.396 & TRN & \\
\hline CHEMBL1973893 & 809171 & 7.0 & 6.4444 & TRN & \\
\hline CHEMBL 2004631 & 809171 & 7.1 & 7.1124 & TRN & \\
\hline CHEMBL1995736 & 809171 & 4.1 & 4.11 & TRN & \\
\hline CHEMBL1997534 & 809171 & 7.3 & 6.5828 & TRN & \\
\hline CHEMBL1996500 & 809171 & 4.1 & 4.3134 & TRN & \\
\hline CHEMBL1985095 & 809171 & 6.4 & 6.3468 & TST & \\
\hline CHEMBL1998551 & 809171 & 4.1 & 4.0398 & TRN & \\
\hline CHEMBL1977374 & 809171 & 4.1 & 4.0995 & TRN & \\
\hline CHEMBL1991180 & 809171 & 5.7 & 5.1875 & TST & \\
\hline CHEMBL1682540 & 809171 & 5.9 & 5.8621 & TRN & \\
\hline CHEMBL1983315 & 809171 & 8.4 & 7.7623 & TRN & \\
\hline CHEMBL1978656 & 809171 & 4.1 & 3.83600 & 00000000003 & TRN \\
\hline CHEMBL1976420 & 809171 & 6.6 & 5.4183 & TST & \\
\hline CHEMBL413779 & 809171 & 5.7 & 5.2584 & TST & \\
\hline CHEMBL1994864 & 809171 & 4.1 & 3.7296 & TRN & \\
\hline CHEMBL 2002446 & 809171 & 5.4 & 4.4931 & TST & \\
\hline CHEMBL497151 & 809171 & 4.1 & 4.8568 & TRN & \\
\hline CHEMBL1973961 & 809171 & 4.5 & 4.9535 & TRN & \\
\hline CHEMBL 246970 & 809171 & 6.2 & 6.443 & TRN & \\
\hline CHEMBL1980497 & 809171 & 5.7 & 5.2833 & TRN & \\
\hline CHEMBL340921 & 809171 & 5.7 & 5.8442 & TRN & \\
\hline CHEMBL373598 & 809171 & 4.1 & 5.1592 & TST & \\
\hline CHEMBL1999718 & 809171 & 4.1 & 4.7246 & TRN & \\
\hline CHEMBL1987073 & 809171 & 7.7 & 7.4788 & TRN & \\
\hline CHEMBL1995712 & 809171 & 5.7 & 6.5684 & TRN & \\
\hline CHEMBL1977346 & 809171 & 6.5 & 6.45200 & 0000000001 & TRN \\
\hline CHEMBL 2003657 & 809171 & 4.1 & 3.8451 & TRN & \\
\hline CHEMBL1971649 & 809171 & 4.1 & 4.3667 & TRN & \\
\hline CHEMBL1975440 & 809171 & 6.3 & 6.5958 & TRN & \\
\hline CHEMBL1998435 & 809171 & 4.1 & 4.5031 & TRN & \\
\hline CHEMBL 2006439 & 809171 & 6.7 & 6.2793 & TRN & \\
\hline CHEMBL2006156 & 809171 & 5.5 & 4.2642 & TST & \\
\hline
\end{tabular}




\begin{tabular}{|c|c|c|c|c|c|}
\hline \multicolumn{6}{|c|}{ Supplemental Table S2.txt } \\
\hline CHEMBL1969190 & 809171 & 4.1 & 4.2512 & TRN & \\
\hline CHEMBL1973937 & 809171 & 4.2 & 4.8474 & TRN & \\
\hline CHEMBL1991674 & 809171 & 6.6 & 6.6252 & TRN & \\
\hline CHEMBL1982711 & 809171 & 6.3 & 6.7386 & TRN & \\
\hline CHEMBL1987982 & 809171 & 4.1 & 4.1887 & TST & \\
\hline CHEMBL1984842 & 809171 & 4.1 & 4.052 & TRN & \\
\hline CHEMBL1969102 & 809171 & 4.1 & 4.1826 & TRN & \\
\hline CHEMBL1682346 & 809171 & 6.3 & 6.871 & TRN & \\
\hline CHEMBL2007044 & 809171 & 5.2 & 4.7095 & TST & \\
\hline CHEMBL2001998 & 809171 & 4.1 & 4.4834 & TST & \\
\hline CHEMBL1994241 & 809171 & 6.0 & 5.4627 & TRN & \\
\hline CHEMBL223460 & 809171 & 4.1 & 4.8526 & TST & \\
\hline CHEMBL1998829 & 809171 & 4.1 & 4.1962 & TRN & \\
\hline CHEMBL50894 & 809171 & 7.5 & $7.3820 e$ & 0000000001 & TRN \\
\hline CHEMBL1988838 & 809171 & 6.7 & 6.9249 & TRN & \\
\hline CHEMBL1981725 & 809171 & 4.1 & 4.5326 & TRN & \\
\hline CHEMBL375284 & 809171 & 4.1 & 4.4531 & TRN & \\
\hline CHEMBL1980562 & 809171 & 7.0 & 7.4203 & TRN & \\
\hline CHEMBL1982866 & 809171 & 4.1 & 4.0963 & TRN & \\
\hline CHEMBL2004156 & 809171 & 4.1 & 4.7739 & TRN & \\
\hline CHEMBL2005792 & 809171 & 4.1 & 4.2128 & TRN & \\
\hline CHEMBL1968926 & 809171 & 4.1 & 4.6285 & TRN & \\
\hline CHEMBL365617 & 809171 & 5.2 & 5.3726 & TST & \\
\hline CHEMBL1984206 & 809171 & 4.1 & 3.9326 & TRN & \\
\hline CHEMBL462120 & 809171 & 5.3 & 4.9428 & TST & \\
\hline CHEMBL1991577 & 809171 & 4.1 & 3.8279 & TRN & \\
\hline CHEMBL1979933 & 809171 & 6.2 & 5.6773 & TRN & \\
\hline CHEMBL1965570 & 809171 & 4.1 & 4.2826 & TRN & \\
\hline CHEMBL2007592 & 809171 & 4.1 & 4.3687 & TST & \\
\hline CHEMBL1976936 & 809171 & 6.2 & 6.2528 & TRN & \\
\hline CHEMBL210963 & 809171 & 4.1 & 4.1187 & TRN & \\
\hline CHEMBL 2005387 & 809171 & 6.6 & 6.5255 & TRN & \\
\hline CHEMBL1082440 & 809171 & 5.6 & 5.2715 & TST & \\
\hline CHEMBL1614705 & 809171 & 4.1 & 4.2828 & TRN & \\
\hline CHEMBL1972362 & 809171 & 6.0 & 6.0963 & TRN & \\
\hline CHEMBL1982400 & 809171 & 7.0 & 6.9511 & TRN & \\
\hline CHEMBL1984633 & 809171 & 4.1 & 4.7472 & TRN & \\
\hline CHEMBL1972988 & 809171 & 4.5 & 6.1033 & TRN & \\
\hline CHEMBL1965845 & 809171 & 6.5 & 6.5014 & TRN & \\
\hline CHEMBL2007372 & 809171 & 4.1 & 4.0314 & TRN & \\
\hline CHEMBL1982167 & 809171 & 4.1 & 4.0624 & TRN & \\
\hline CHEMBL1971017 & 809171 & 6.8 & $6.7010 e$ & 00000000005 & TRN \\
\hline CHEMBL2006715 & 809171 & 4.1 & 4.6098 & TRN & \\
\hline CHEMBL1986597 & 809171 & 5.1 & 4.13899 & 9999999999 & TRN \\
\hline CHEMBL1990482 & 809171 & 4.1 & 4.1491 & TRN & \\
\hline CHEMBL1990904 & 809171 & 4.1 & 4.8474 & TRN & \\
\hline CHEMBL 2000104 & 809171 & 5.8 & 6.3029 & TRN & \\
\hline CHEMBL2005475 & 809171 & 4.1 & 4.3626 & TRN & \\
\hline
\end{tabular}




\begin{tabular}{|c|c|c|c|c|c|}
\hline \multirow{2}{*}{ CHEMBL1987448 } & \multirow{2}{*}{809171} & \\
\hline & & 7.4 & 7.3956 & TRN & \\
\hline CHEMBL1997349 & 809171 & 5.8 & 4.6534 & TST & \\
\hline CHEMBL183844 & 809171 & 4.1 & 4.1968 & TRN & \\
\hline CHEMBL220057 & 809171 & 4.1 & 5.2373 & TRN & \\
\hline CHEMBL1682545 & 809171 & 5.2 & 5.185 & TRN & \\
\hline CHEMBL383541 & 809171 & 4.1 & 4.2227 & TRN & \\
\hline CHEMBL 2001224 & 809171 & 4.1 & 4.6398 & TRN & \\
\hline CHEMBL10 & 809171 & 4.1 & 4.1989 & TRN & \\
\hline CHEMBL1976732 & 809171 & 4.1 & 4.4251 & TRN & \\
\hline CHEMBL1982982 & 809171 & 5.5 & 4.9118 & TRN & \\
\hline CHEMBL 2005216 & 809171 & 6.4 & 6.4437 & TRN & \\
\hline CHEMBL1969506 & 809171 & 4.1 & 4.1104 & TRN & \\
\hline CHEMBL1964937 & 809171 & 5.8 & 5.9705 & TRN & \\
\hline CHEMBL1980163 & 809171 & 4.1 & 4.1107 & TRN & \\
\hline CHEMBL590109 & 809171 & 6.9 & 6.4986 & TST & \\
\hline CHEMBL1970879 & 809171 & 4.1 & 3.8398 & TRN & \\
\hline CHEMBL1989856 & 809171 & 4.1 & 4.7928 & TST & \\
\hline CHEMBL2005899 & 809171 & 4.1 & 3.8288 & TRN & \\
\hline CHEMBL1682552 & 809171 & 5.9 & 6.1081 & TRN & \\
\hline CHEMBL259850 & 809171 & 5.3 & 5.2349 & TRN & \\
\hline CHEMBL1972568 & 809171 & 4.1 & 3.8682 & TRN & \\
\hline CHEMBL1996155 & 809171 & 4.1 & 4.2458 & TST & \\
\hline CHEMBL1986851 & 809171 & 4.5 & 4.5572 & TRN & \\
\hline CHEMBL1987745 & 809171 & 6.3 & 5.9886 & TRN & \\
\hline CHEMBL105739 & 809171 & 4.1 & 4.3922 & TRN & \\
\hline CHEMBL1682359 & 809171 & 6.2 & 5.8709 & TRN & \\
\hline CHEMBL379300 & 809171 & 7.3 & 7.1982 & TRN & \\
\hline CHEMBL203673 & 809171 & 4.1 & 3.8399 & TRN & \\
\hline CHEMBL1973720 & 809171 & 7.5 & 7.9141 & TRN & \\
\hline CHEMBL1969523 & 809171 & 6.5 & $5.4860 €$ & 0000000001 & TRN \\
\hline CHEMBL1988995 & 809171 & 4.1 & 4.2475 & TRN & \\
\hline CHEMBL207995 & 809171 & 5.5 & 5.2916 & TRN & \\
\hline CHEMBL 2001923 & 809171 & 4.1 & 4.6899 & TRN & \\
\hline CHEMBL1986781 & 809171 & 5.1 & 4.4723 & TRN & \\
\hline CHEMBL526133 & 809171 & 6.4 & 5.8559 & TRN & \\
\hline CHEMBL 2002470 & 809171 & 5.1 & 4.9097 & TST & \\
\hline CHEMBL1979057 & 809171 & 4.1 & 4.56 & TRN & \\
\hline CHEMBL1981045 & 809171 & 4.1 & 4.855 & TRN & \\
\hline CHEMBL387971 & 809171 & 4.1 & 4.0625 & TST & \\
\hline CHEMBL1975418 & 809171 & 7.5 & 7.2104 & TRN & \\
\hline CHEMBL1992796 & 809171 & 4.1 & 4.8936 & TST & \\
\hline CHEMBL1164180 & 809171 & 4.5 & 5.5169 & TST & \\
\hline CHEMBL223257 & 809171 & 4.1 & 4.7964 & TST & \\
\hline CHEMBL1999428 & 809171 & 5.4 & 4.8762 & TRN & \\
\hline CHEMBL1967560 & 809171 & 4.1 & 3.9689 & TRN & \\
\hline CHEMBL1516890 & 809171 & 5.1 & 5.2426 & TRN & \\
\hline CHEMBL211378 & 809171 & 4.1 & 3.9908 & TRN & \\
\hline CHEMBL1682358 & 809171 & 6.7 & 6.4125 & TRN & \\
\hline & & & & 10872 & \\
\hline
\end{tabular}




\begin{tabular}{|c|c|c|c|c|}
\hline & & & $p l \epsilon$ & \\
\hline CHEMBL1982465 & 809171 & 4.1 & 3.9836 & TRN \\
\hline CHEMBL 2001751 & 809171 & 6.9 & 6.4808 & TRN \\
\hline CHEMBL 2003420 & 809171 & 4.1 & 4.5046 & TRN \\
\hline CHEMBL1984586 & 809171 & 4.1 & 4.1595 & TRN \\
\hline CHEMBL1999774 & 809171 & 5.1 & 3.9579 & TST \\
\hline CHEMBL1972659 & 809171 & 4.1 & 4.2196 & TST \\
\hline CHEMBL1973395 & 809171 & 6.6 & 6.5864 & TRN \\
\hline CHEMBL272453 & 809171 & 4.1 & 4.2466 & TRN \\
\hline CHEMBL1970217 & 809171 & 5.7 & 5.4455 & TRN \\
\hline CHEMBL1971801 & 809171 & 5.6 & 5.4921 & TRN \\
\hline CHEMBL1968850 & 809171 & 6.5 & 6.2865 & TRN \\
\hline CHEMBL 2005528 & 809171 & 5.3 & 4.8742 & TST \\
\hline CHEMBL185569 & 809171 & 4.1 & 4.3962 & TRN \\
\hline CHEMBL1969843 & 809171 & 5.7 & 5.0507 & TRN \\
\hline CHEMBL 2007002 & 809171 & 6.1 & 5.6979 & TRN \\
\hline CHEMBL1987007 & 809171 & 4.1 & 4.1406 & TRN \\
\hline CHEMBL1969588 & 809171 & 7.7 & 7.3663 & TRN \\
\hline CHEMBL1984711 & 809171 & 4.1 & 5.0706 & TRN \\
\hline CHEMBL1990212 & 809171 & 5.2 & 4.4779 & TRN \\
\hline CHEMBL484390 & 809171 & 4.1 & 4.6333 & TST \\
\hline CHEMBL1979252 & 809171 & 4.1 & 3.785 & TRN \\
\hline CHEMBL1682341 & 809171 & 6.2 & 6.2966 & TRN \\
\hline CHEMBL 2004290 & 809171 & 5.1 & 3.9695 & TRN \\
\hline CHEMBL1986499 & 809171 & 6.9 & 7.0187 & TRN \\
\hline CHEMBL1972937 & 809171 & 4.1 & 3.8887 & TRN \\
\hline CHEMBL1972250 & 809171 & 4.1 & 4.8438 & TST \\
\hline CHEMBL 2000393 & 809171 & 6.8 & 5.6767 & TST \\
\hline CHEMBL 2004072 & 809171 & 4.1 & 4.5073 & TRN \\
\hline CHEMBL2001477 & 809171 & 4.1 & 4.8588 & TRN \\
\hline CHEMBL 2004311 & 809171 & 4.1 & 4.3004 & TRN \\
\hline CHEMBL1992634 & 809171 & 6.6 & 6.3638 & TRN \\
\hline CHEMBL1242373 & 809171 & 4.1 & 4.2694 & TRN \\
\hline CHEMBL 2000433 & 809171 & 4.1 & 4.7716 & TST \\
\hline CHEMBL56543 & 809171 & 4.1 & 4.1249 & TST \\
\hline CHEMBL316264 & 809171 & 4.1 & 4.0594 & TRN \\
\hline CHEMBL1988075 & 809171 & 4.1 & 4.1176 & TRN \\
\hline CHEMBL1991678 & 809171 & 4.1 & 4.3117 & TRN \\
\hline CHEMBL 2001239 & 809171 & 5.5 & 5.0799 & TST \\
\hline CHEMBL1988594 & 809171 & 4.1 & 4.3979 & TRN \\
\hline CHEMBL 2001288 & 809171 & 5.5 & 4.7237 & TRN \\
\hline CHEMBL1992363 & 809171 & 7.3 & 7.6882 & TRN \\
\hline CHEMBL260092 & 809171 & 4.1 & 4.1365 & TRN \\
\hline CHEMBL1999811 & 809171 & 4.1 & 5.0097 & TST \\
\hline CHEMBL1965495 & 809171 & 5.8 & 5.9592 & TRN \\
\hline CHEMBL1985074 & 809171 & 5.1 & 4.7392 & TST \\
\hline CHEMBL 2000481 & 809171 & 5.6 & 5.0677 & TRN \\
\hline CHEMBL1982874 & 809171 & 4.1 & 4.1073 & TRN \\
\hline CHEMBL1991725 & 809171 & 5.3 & 4.8834 & TRN \\
\hline
\end{tabular}




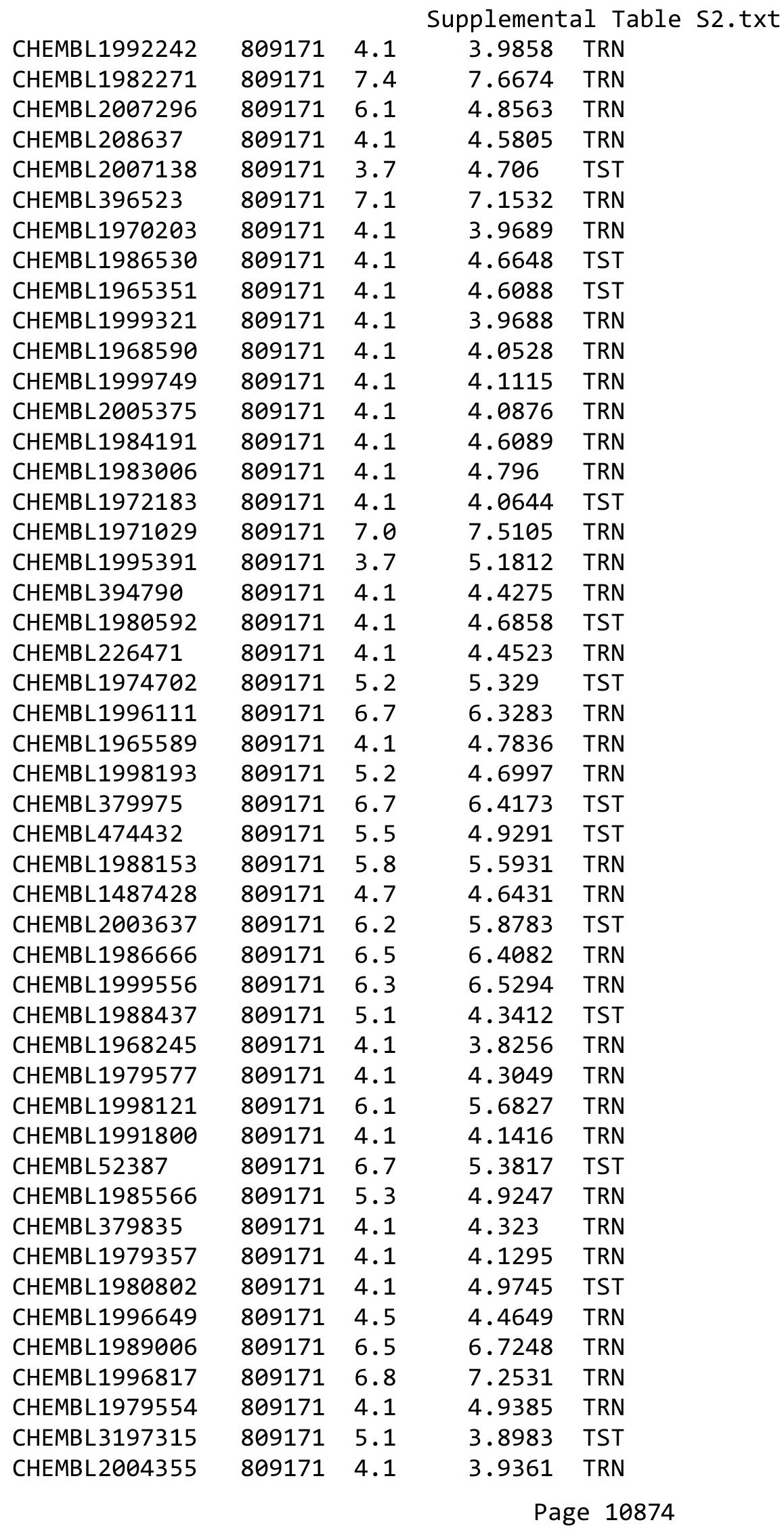




\begin{tabular}{|c|c|c|c|c|}
\hline & & & Supplement & al $\mathrm{T}$ \\
\hline CHEMBL468280 & 809171 & 4.1 & 4.2791 & TST \\
\hline CHEMBL1990884 & 809171 & 4.1 & 4.2858 & TRN \\
\hline CHEMBL1996339 & 809171 & 7.0 & 6.7806 & TRN \\
\hline CHEMBL3109278 & 809171 & 4.1 & 4.2409 & TRN \\
\hline CHEMBL 256835 & 809171 & 4.1 & 4.1342 & TRN \\
\hline CHEMBL1980142 & 809171 & 4.1 & 5.1078 & TRN \\
\hline CHEMBL41783 & 809171 & 5.9 & 6.6932 & TRN \\
\hline CHEMBL 2004438 & 809171 & 4.1 & 3.6872 & TRN \\
\hline CHEMBL2006276 & 809171 & 6.0 & 4.8799 & TRN \\
\hline CHEMBL271381 & 809171 & 4.1 & 4.5517 & TRN \\
\hline CHEMBL 2006785 & 809171 & 4.1 & 3.9532 & TST \\
\hline CHEMBL1982466 & 809171 & 4.1 & 4.0713 & TRN \\
\hline CHEMBL249697 & 809171 & 5.7 & 5.2916 & TST \\
\hline CHEMBL1995740 & 809171 & 7.2 & 7.0093 & TRN \\
\hline CHEMBL1996390 & 809171 & 5.1 & 4.8009 & TRN \\
\hline CHEMBL1990162 & 809171 & 7.9 & 7.5525 & TRN \\
\hline CHEMBL1992220 & 809171 & 8.0 & 7.9971 & TRN \\
\hline CHEMBL234085 & 809171 & 4.1 & 4.3582 & TST \\
\hline CHEMBL1998414 & 809171 & 4.1 & 4.3281 & TRN \\
\hline CHEMBL1995832 & 809171 & 4.1 & 4.1924 & TRN \\
\hline CHEMBL1969042 & 809171 & 5.9 & 5.239 & TST \\
\hline CHEMBL 2000345 & 809171 & 4.1 & 5.1559 & TRN \\
\hline CHEMBL1991640 & 809171 & 5.4 & 4.8597 & TST \\
\hline CHEMBL1375418 & 809171 & 4.1 & 4.082 & TRN \\
\hline CHEMBL 302449 & 809171 & 7.8 & 7.4738 & TST \\
\hline CHEMBL 2007064 & 809171 & 4.1 & 4.713 & TRN \\
\hline CHEMBL1981047 & 809171 & 6.3 & 5.579 & TRN \\
\hline CHEMBL229968 & 809171 & 7.6 & 7.5777 & TRN \\
\hline CHEMBL1976240 & 809171 & 5.6 & 5.4476 & TRN \\
\hline CHEMBL1987948 & 809171 & 6.9 & 6.7404 & TRN \\
\hline CHEMBL1979093 & 809171 & 4.1 & 4.485 & TRN \\
\hline CHEMBL1968151 & 809171 & 4.1 & 4.6177 & TST \\
\hline CHEMBL1381197 & 809171 & 4.1 & 4.1263 & TRN \\
\hline CHEMBL1987009 & 809171 & 5.1 & 4.5554 & TRN \\
\hline CHEMBL379218 & 809171 & 7.1 & 7.335 & TRN \\
\hline CHEMBL 2003817 & 809171 & 5.7 & 5.5913 & TRN \\
\hline CHEMBL336961 & 809171 & 6.3 & 5.8187 & TRN \\
\hline CHEMBL1994830 & 809171 & 6.2 & 6.1137 & TRN \\
\hline CHEMBL1987054 & 809171 & 4.1 & 4.7386 & TRN \\
\hline CHEMBL1970083 & 809171 & 4.1 & 4.0467 & TRN \\
\hline CHEMBL226403 & 809171 & 4.1 & 4.1032 & TRN \\
\hline CHEMBL 2005631 & 809171 & 4.1 & 3.9485 & TRN \\
\hline CHEMBL1994938 & 809171 & 4.1 & 4.2051 & TRN \\
\hline CHEMBL1977223 & 809171 & 8.5 & 8.2422 & TRN \\
\hline CHEMBL1966279 & 809171 & 4.1 & 4.6907 & TRN \\
\hline CHEMBL1236126 & 809171 & 4.1 & 4.8455 & TST \\
\hline CHEMBL1997846 & 809171 & 4.8 & 5.4024 & TRN \\
\hline CHEMBL2004419 & 809171 & 4.1 & 4.0854 & TRN \\
\hline
\end{tabular}




\begin{tabular}{|c|c|c|c|c|}
\hline & & & pplement & al $\mathrm{Ta}$ \\
\hline CHEMBL1991728 & 809171 & 6.3 & 6.2117 & TRN \\
\hline CHEMBL1995811 & 809171 & 7.6 & 7.3459 & TRN \\
\hline CHEMBL1975787 & 809171 & 6.6 & 6.6947 & TRN \\
\hline CHEMBL 2002407 & 809171 & 5.9 & 5.3511 & TRN \\
\hline CHEMBL1972489 & 809171 & 4.1 & 4.2935 & TRN \\
\hline CHEMBL1994074 & 809171 & 5.2 & 4.8633 & TRN \\
\hline CHEMBL1992937 & 809171 & 5.9 & 5.7269 & TST \\
\hline CHEMBL1990541 & 809171 & 6.0 & 5.1046 & TST \\
\hline CHEMBL1968930 & 809171 & 7.4 & 7.5456 & TRN \\
\hline CHEMBL1972119 & 809171 & 4.1 & 4.6867 & TRN \\
\hline CHEMBL1986328 & 809171 & 4.1 & 4.6628 & TST \\
\hline CHEMBL95692 & 809171 & 4.1 & 4.0295 & TRN \\
\hline CHEMBL1090356 & 809171 & 4.1 & 4.3851 & TRN \\
\hline CHEMBL1976455 & 809171 & 7.2 & 6.3861 & TRN \\
\hline CHEMBL1983923 & 809171 & 4.1 & 5.1229 & TST \\
\hline CHEMBL1983534 & 809171 & 4.1 & 4.5238 & TRN \\
\hline CHEMBL1970950 & 809171 & 4.1 & 5.0915 & TRN \\
\hline CHEMBL1982361 & 809171 & 4.1 & 4.2061 & TRN \\
\hline CHEMBL1999112 & 809171 & 4.1 & 4.3481 & TST \\
\hline CHEMBL 2000801 & 809171 & 4.1 & 3.9024 & TRN \\
\hline CHEMBL1982122 & 809171 & 5.7 & 4.7234 & TRN \\
\hline CHEMBL1682546 & 809171 & 5.2 & 4.9102 & TRN \\
\hline CHEMBL1991395 & 809171 & 4.1 & 4.2822 & TRN \\
\hline CHEMBL1971245 & 809171 & 5.1 & 5.3462 & TRN \\
\hline CHEMBL1987648 & 809171 & 4.1 & 4.1513 & TRN \\
\hline CHEMBL1996780 & 809171 & 5.4 & 5.1942 & TRN \\
\hline CHEMBL1972142 & 809171 & 4.1 & 3.9267 & TRN \\
\hline CHEMBL1966514 & 809171 & 4.1 & 3.9427 & TRN \\
\hline CHEMBL 2003638 & 809171 & 6.6 & 7.647 & TRN \\
\hline CHEMBL296586 & 809171 & 7.0 & 6.4546 & TRN \\
\hline CHEMBL1996066 & 809171 & 4.1 & 4.2825 & TST \\
\hline CHEMBL516429 & 809171 & 6.8 & 6.5098 & TRN \\
\hline CHEMBL1972152 & 809171 & 4.1 & 4.5865 & TST \\
\hline CHEMBL1993722 & 809171 & 5.7 & 5.6886 & TRN \\
\hline CHEMBL1970806 & 809171 & 4.1 & 4.4504 & TST \\
\hline CHEMBL202635 & 809171 & 4.1 & 4.8865 & TRN \\
\hline CHEMBL1375640 & 809171 & 4.1 & 4.7433 & TST \\
\hline CHEMBL1979970 & 809171 & 7.6 & 7.3658 & TRN \\
\hline CHEMBL 249282 & 809171 & 4.1 & 4.4164 & TST \\
\hline CHEMBL1970821 & 809171 & 6.9 & 6.8093 & TRN \\
\hline CHEMBL1969264 & 809171 & 4.1 & 4.3779 & TRN \\
\hline CHEMBL1973711 & 809171 & 4.1 & 5.1257 & TST \\
\hline CHEMBL 2006237 & 809171 & 4.1 & 4.3517 & TST \\
\hline CHEMBL1967720 & 809171 & 4.1 & 4.1913 & TST \\
\hline CHEMBL 2005509 & 809171 & 7.8 & 7.8207 & TST \\
\hline CHEMBL1572266 & 809171 & 4.1 & 4.5478 & TST \\
\hline CHEMBL1991138 & 809171 & 4.1 & 4.355 & TST \\
\hline CHEMBL1979516 & 809171 & 4.1 & 4.1403 & TST \\
\hline
\end{tabular}




\begin{tabular}{|c|c|c|c|c|}
\hline \multicolumn{5}{|c|}{ Supplemental Table S2.txt } \\
\hline CHEMBL1969755 & 809171 & 4.1 & 4.2293 & TST \\
\hline CHEMBL1972820 & 809171 & 4.1 & 3.8429 & TST \\
\hline CHEMBL1605605 & 809171 & 5.1 & 5.0667 & TST \\
\hline CHEMBL1996208 & 809171 & 4.1 & 4.4855 & TST \\
\hline CHEMBL1989029 & 809171 & 4.1 & 4.2081 & TST \\
\hline CHEMBL392642 & 809171 & 6.5 & 6.4116 & TST \\
\hline CHEMBL514499 & 809171 & 4.1 & 4.7535 & TST \\
\hline CHEMBL1965631 & 809171 & 7.6 & 7.2529 & TST \\
\hline CHEMBL1980144 & 809171 & 4.1 & 4.3556 & TST \\
\hline CHEMBL1991188 & 809171 & 6.7 & 5.9384 & TST \\
\hline CHEMBL1682554 & 809171 & 6.4 & 6.7217 & TST \\
\hline CHEMBL1972849 & 809171 & 4.1 & 4.107 & TST \\
\hline CHEMBL377408 & 809171 & 4.1 & 4.0306 & TST \\
\hline CHEMBL1986855 & 809171 & 8.1 & 7.1332 & TST \\
\hline CHEMBL 215152 & 809171 & 4.1 & 4.6485 & TST \\
\hline CHEMBL231209 & 809171 & 4.1 & 4.2596 & TST \\
\hline CHEMBL1975357 & 809171 & 4.1 & 4.2242 & TST \\
\hline CHEMBL1976220 & 809171 & 4.1 & 4.4783 & TST \\
\hline CHEMBL1989136 & 809171 & 6.0 & 5.7986 & TST \\
\hline CHEMBL 259922 & 809171 & 4.1 & 3.6551 & TST \\
\hline CHEMBL1997617 & 809171 & 4.1 & 4.4917 & TST \\
\hline CHEMBL1969301 & 809171 & 4.1 & 4.9358 & TST \\
\hline CHEMBL1982383 & 809171 & 4.1 & 3.9092 & TST \\
\hline CHEMBL17370 & 809171 & 4.1 & 4.1566 & TST \\
\hline CHEMBL1987910 & 809171 & 4.1 & 4.0986 & TST \\
\hline CHEMBL1983932 & 809171 & 6.1 & 5.9323 & TST \\
\hline CHEMBL1966069 & 809171 & 6.0 & 6.1798 & TST \\
\hline CHEMBL1991285 & 809171 & 4.1 & 5.0084 & TST \\
\hline CHEMBL1997822 & 809171 & 4.1 & 4.3546 & TST \\
\hline CHEMBL 243088 & 809171 & 6.5 & 6.6149 & TST \\
\hline CHEMBL1984038 & 809171 & 5.4 & 5.0065 & TST \\
\hline CHEMBL1974416 & 809171 & 4.1 & 4.7967 & TST \\
\hline CHEMBL 2004615 & 809171 & 4.1 & 4.708 & TST \\
\hline CHEMBL1984039 & 809171 & 4.1 & 4.1304 & TST \\
\hline CHEMBL1997872 & 809171 & 4.1 & 3.8476 & TST \\
\hline CHEMBL 2402650 & 971799 & 3.301 & 3.7331 & TRN \\
\hline CHEMBL 2402627 & 971799 & 3.301 & 3.6223 & TRN \\
\hline CHEMBL518707 & 971799 & 3.301 & 3.2267 & TRN \\
\hline CHEMBL 2402626 & 971799 & 3.301 & 3.2282 & TRN \\
\hline CHEMBL 2402801 & 971799 & 3.301 & 3.2143 & TRN \\
\hline CHEMBL 2402657 & 971799 & 4.8196 & 4.2847 & TRN \\
\hline CHEMBL 2402673 & 971799 & 4.4643 & 4.2402 & TRN \\
\hline CHEMBL 2402651 & 971799 & 4.4603 & 4.1573 & TRN \\
\hline CHEMBL 2402656 & 971799 & 3.301 & 3.8229 & TRN \\
\hline CHEMBL2402636 & 971799 & 3.301 & 3.3396 & TST \\
\hline CHEMBL 2402643 & 971799 & 4.5183 & 3.734 & TST \\
\hline CHEMBL 2402797 & 971799 & 3.301 & 3.0972 & TRN \\
\hline \multirow[t]{2}{*}{ CHEMBL1590966 } & 971799 & 3.301 & 3.64899 & 99999999996 \\
\hline & & \multicolumn{3}{|c|}{ Page 10877} \\
\hline
\end{tabular}




\begin{tabular}{|c|c|c|c|c|c|}
\hline & & \multicolumn{4}{|c|}{ Supplemental Table S2.txt } \\
\hline CHEMBL2402663 & 971799 & 3.301 & 3.8689 & TRN & \\
\hline CHEMBL 2402644 & 971799 & 4.5411 & 3.9963 & TST & \\
\hline CHEMBL 2402795 & 971799 & 3.301 & 3.5509 & TRN & \\
\hline CHEMBL 2402794 & 971799 & 3.301 & 3.4875 & TRN & \\
\hline CHEMBL 2402634 & 971799 & 3.301 & 3.4347 & TST & \\
\hline CHEMBL2402638 & 971799 & 3.301 & 3.7213 & TST & \\
\hline CHEMBL 2402647 & 971799 & 4.3721 & 4.0328 & TRN & \\
\hline CHEMBL 2402664 & 971799 & 3.301 & 3.5135 & TRN & \\
\hline CHEMBL 2402662 & 971799 & 3.301 & 3.4162 & TRN & \\
\hline CHEMBL2402796 & 971799 & 3.301 & 3.7026 & TST & \\
\hline CHEMBL2402659 & 971799 & 3.301 & 3.9409 & TRN & \\
\hline CHEMBL2402671 & 971799 & 4.4265 & 4.2833 & TRN & \\
\hline CHEMBL 2402661 & 971799 & 3.301 & 3.3709 & TRN & \\
\hline CHEMBL2402669 & 971799 & 3.301 & 3.4317 & TRN & \\
\hline CHEMBL2402629 & 971799 & 4.5355 & 3.7278 & TRN & \\
\hline CHEMBL 2402645 & 971799 & 3.301 & 3.5088 & TRN & \\
\hline CHEMBL 2402640 & 971799 & 4.6099 & 3.2133 & TRN & \\
\hline CHEMBL 2402635 & 971799 & 3.301 & 3.4134 & TST & \\
\hline CHEMBL2402666 & 971799 & 4.869 & 4.2496 & TRN & \\
\hline CHEMBL 2402802 & 971799 & 3.301 & 3.1748 & TRN & \\
\hline CHEMBL 2402670 & 971799 & 3.301 & 3.4208 & TRN & \\
\hline CHEMBL2402799 & 971799 & 3.301 & 3.4681 & TST & \\
\hline CHEMBL 2402630 & 971799 & 4.5057 & 3.8846 & TRN & \\
\hline CHEMBL 2402631 & 971799 & 3.301 & 3.1508 & TRN & \\
\hline CHEMBL 2402800 & 971799 & 3.301 & 3.09 & TRN & \\
\hline CHEMBL 2402665 & 971799 & 3.301 & 3.7089 & TRN & \\
\hline CHEMBL2402649 & 971799 & 3.301 & 3.7356 & TRN & \\
\hline CHEMBL 2402637 & 971799 & 3.301 & 3.2987 & TST & \\
\hline CHEMBL 2338066 & 971799 & 4.8567 & 4.1946 & TST & \\
\hline CHEMBL 2402648 & 971799 & 3.301 & 4.0042 & TRN & \\
\hline CHEMBL 2402646 & 971799 & 3.301 & 3.2764 & TRN & \\
\hline CHEMBL2402655 & 971799 & 3.301 & 3.8283 & TRN & \\
\hline CHEMBL2402633 & 971799 & 3.301 & 3.2887 & TST & \\
\hline CHEMBL 2402628 & 971799 & 3.301 & 3.2433 & TRN & \\
\hline CHEMBL 2402660 & 971799 & 3.301 & 4.0157 & TST & \\
\hline CHEMBL 2402654 & 971799 & 4.3862 & 4.2062 & TRN & \\
\hline CHEMBL 2402632 & 971799 & 3.301 & 3.0722 & TST & \\
\hline CHEMBL 2402641 & 971799 & 3.301 & 3.7243 & TST & \\
\hline CHEMBL 2402668 & 971799 & 4.4568 & 4.0744 & TRN & \\
\hline CHEMBL 2402674 & 971799 & 4.6916 & 4.313 & TRN & \\
\hline CHEMBL 2402642 & 971799 & 3.301 & 3.7286 & TST & \\
\hline CHEMBL 2402653 & 971799 & 3.301 & 3.80899 & 99999999997 & TRN \\
\hline CHEMBL2402675 & 971799 & 4.4183 & 3.9408 & TRN & \\
\hline CHEMBL 2402672 & 971799 & 4.3636 & 4.2763 & TRN & \\
\hline CHEMBL 2402798 & 971799 & 3.301 & 3.1585 & TRN & \\
\hline CHEMBL 2402667 & 971799 & 3.301 & 3.622 & TRN & \\
\hline CHEMBL 2402639 & 971799 & 3.301 & 3.2035 & TRN & \\
\hline CHEMBL 2402652 & 971799 & 3.301 & 3.718 & TRN & \\
\hline
\end{tabular}




\begin{tabular}{|c|c|c|c|c|c|}
\hline & & \multicolumn{4}{|c|}{ Supplemental Table S2.txt } \\
\hline CHEMBL2402658 & 971799 & 3.301 & 3.9502 & TRN & \\
\hline CHEMBL1428964 & 688625 & 4.1 & 4.3603 & TRN & \\
\hline CHEMBL1496957 & 688625 & 4.6 & 4.6676 & TRN & \\
\hline CHEMBL1527567 & 688625 & 4.4 & 4.2393 & TRN & \\
\hline CHEMBL334255 & 688625 & 4.7 & 4.9725 & TRN & \\
\hline CHEMBL1585396 & 688625 & 4.3 & 4.3196 & TRN & \\
\hline CHEMBL1529759 & 688625 & 4.3 & 4.399 & TST & \\
\hline CHEMBL1518369 & 688625 & 4.1 & 4.3878 & TRN & \\
\hline CHEMBL1408847 & 688625 & 5.3 & 5.2256 & TRN & \\
\hline CHEMBL1450607 & 688625 & 4.6 & 4.5717 & TRN & \\
\hline CHEMBL1331245 & 688625 & 4.4 & 4.1927 & TRN & \\
\hline CHEMBL1221925 & 688625 & 4.3 & 4.3191 & TRN & \\
\hline CHEMBL1409985 & 688625 & 5.3 & 5.1931 & TRN & \\
\hline CHEMBL39763 & 688625 & 4.1 & 4.3632 & TRN & \\
\hline CHEMBL1407826 & 688625 & 4.5 & 4.6914 & TST & \\
\hline CHEMBL1545634 & 688625 & 6.3 & 6.5169 & TRN & \\
\hline CHEMBL1549844 & 688625 & 4.8 & 4.5636 & TST & \\
\hline CHEMBL144530 & 688625 & 4.5 & 4.2724 & TRN & \\
\hline CHEMBL1516868 & 688625 & 4.1 & 4.3688 & TRN & \\
\hline CHEMBL1393325 & 688625 & 4.3 & 4.3262 & TRN & \\
\hline CHEMBL1580759 & 688625 & 4.3 & 4.4442 & TRN & \\
\hline CHEMBL1519327 & 688625 & 6.5 & 6.2995 & TRN & \\
\hline CHEMBL1371285 & 688625 & 4.1 & 4.4587 & TRN & \\
\hline CHEMBL1489568 & 688625 & 4.3 & 4.2802 & TRN & \\
\hline CHEMBL1338613 & 688625 & 4.4 & 4.3158 & TST & \\
\hline CHEMBL1576086 & 688625 & 4.4 & 4.381 & TRN & \\
\hline CHEMBL1535689 & 688625 & 4.4 & 4.3146 & TRN & \\
\hline CHEMBL462576 & 688625 & 4.3 & 4.4508 & TRN & \\
\hline CHEMBL1304981 & 688625 & 4.3 & 4.2007 & TST & \\
\hline CHEMBL1303139 & 688625 & 5.4 & 5.0886 & TRN & \\
\hline CHEMBL 242080 & 688625 & 4.3 & 4.5295 & TRN & \\
\hline CHEMBL1330518 & 688625 & 4.3 & 4.2946 & TRN & \\
\hline CHEMBL1499545 & 688625 & 5.1 & 5.2848 & TRN & \\
\hline CHEMBL1492884 & 688625 & 4.6 & 4.3383 & TRN & \\
\hline CHEMBL1344952 & 688625 & 4.3 & 4.2932 & TRN & \\
\hline CHEMBL85811 & 688625 & 4.3 & 4.1806 & TRN & \\
\hline CHEMBL1579130 & 688625 & 6.0 & 5.6272 & TRN & \\
\hline CHEMBL1142 & 688625 & 4.4 & 4.3164 & TRN & \\
\hline CHEMBL1566504 & 688625 & 4.4 & 4.3139 & TST & \\
\hline CHEMBL1524617 & 688625 & 5.3 & 5.10800 & 00000000005 & TST \\
\hline CHEMBL1366408 & 688625 & 4.7 & 4.5788 & TRN & \\
\hline CHEMBL3391990 & 688625 & 4.3 & 4.44300 & 00000000005 & TST \\
\hline CHEMBL1448387 & 688625 & 4.4 & 4.5553 & TRN & \\
\hline CHEMBL445957 & 688625 & 4.4 & 4.4287 & TRN & \\
\hline CHEMBL1517425 & 688625 & 4.3 & 4.1208 & TRN & \\
\hline CHEMBL1522486 & 688625 & 4.6 & 4.5794 & TRN & \\
\hline CHEMBL1613534 & 688625 & 4.1 & 4.3471 & TRN & \\
\hline CHEMBL220845 & 688625 & 4.4 & 4.2259 & TRN & \\
\hline
\end{tabular}




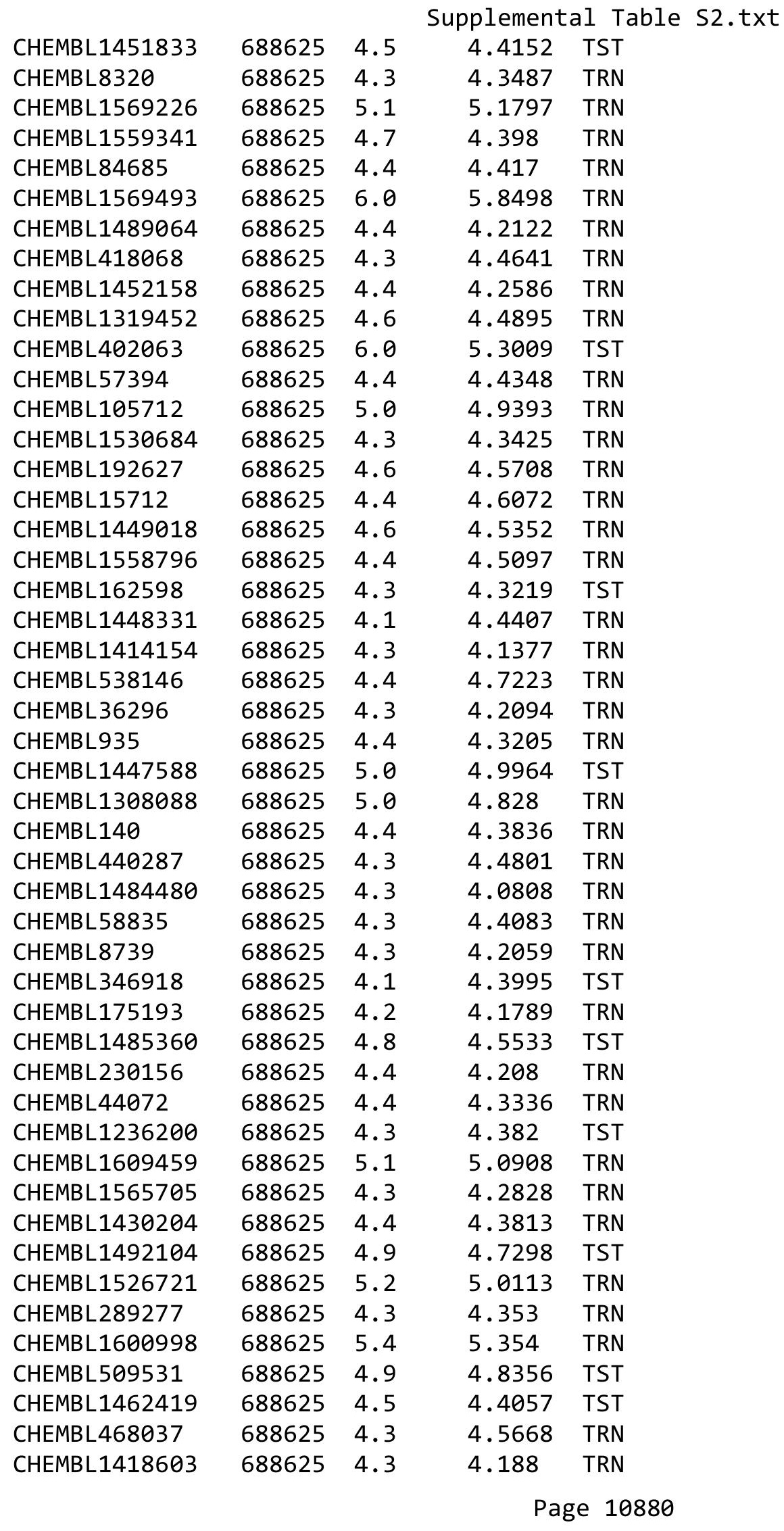




\begin{tabular}{|c|c|c|c|c|c|}
\hline & & \\
\hline CHEMBL1561876 & 688625 & 4.4 & 4.4683 & TRN & \\
\hline CHEMBL1526319 & 688625 & 4.4 & 4.3387 & TRN & \\
\hline CHEMBL1200471 & 688625 & 6.6 & 6.6332 & TRN & \\
\hline CHEMBL443949 & 688625 & 4.3 & 4.4219 & TRN & \\
\hline CHEMBL468582 & 688625 & 4.1 & 4.3283 & TST & \\
\hline CHEMBL1562104 & 688625 & 5.4 & 5.3729 & TST & \\
\hline CHEMBL1309179 & 688625 & 5.0 & 4.7418 & TST & \\
\hline CHEMBL486193 & 688625 & 4.4 & 4.7279 & TST & \\
\hline CHEMBL1495381 & 688625 & 4.7 & 5.0921 & TST & \\
\hline CHEMBL 224282 & 688625 & 4.4 & 4.2182 & TST & \\
\hline CHEMBL1602699 & 688625 & 5.4 & 5.2559 & TST & \\
\hline CHEMBL31425 & 688625 & 4.1 & 4.3686 & TST & \\
\hline CHEMBL1612246 & 688625 & 4.4 & 4.4694 & TST & \\
\hline CHEMBL195953 & 688625 & 4.4 & 4.1933 & TST & \\
\hline CHEMBL1190711 & 954989 & 6.13 & 5.8641 & TRN & \\
\hline CHEMBL300389 & 954989 & 7.5468 & 7.8414 & TRN & \\
\hline CHEMBL191334 & 954989 & 3.1282 & 3.3402 & TRN & \\
\hline CHEMBL3392440 & 954989 & 3.8909 & 4.2659 & TRN & \\
\hline CHEMBL189584 & 954989 & 5.0695 & 4.9565 & TRN & \\
\hline CHEMBL102714 & 954989 & 3.5328 & 3.8021 & TRN & \\
\hline CHEMBL1256459 & 954989 & 7.6041 & 7.4552 & TRN & \\
\hline CHEMBL1970879 & 954989 & 6.8433 & 6.6424 & TRN & \\
\hline CHEMBL220241 & 954989 & 4.5469 & 4.5874 & TRN & \\
\hline CHEMBL1590308 & 954989 & 3.5739 & 3.6807 & TST & \\
\hline CHEMBL483849 & 954989 & 2.0178 & 1.9442 & TRN & \\
\hline CHEMBL412142 & 954989 & 5.0001 & 4.9807 & TRN & \\
\hline CHEMBL188678 & 954989 & 5.2093 & 4.93199 & 99999999995 & TRN \\
\hline CHEMBL222102 & 954989 & 4.6461 & 4.4332 & TRN & \\
\hline CHEMBL 373751 & 954989 & 3.3579 & 4.0849 & TRN & \\
\hline CHEMBL509032 & 954989 & 6.2632 & 6.42200 & 0000000001 & TRN \\
\hline CHEMBL558642 & 954989 & 5.2074 & 5.0377 & TRN & \\
\hline CHEMBL9470 & 954989 & 6.5194 & 6.2221 & TST & \\
\hline CHEMBL259181 & 954989 & 4.4223 & 4.6575 & TRN & \\
\hline CHEMBL 379300 & 954989 & 7.0595 & 7.0653 & TRN & \\
\hline CHEMBL1516890 & 954989 & 5.3857 & 4.6738 & TRN & \\
\hline CHEMBL217354 & 954989 & 6.4957 & 6.9953 & TRN & \\
\hline CHEMBL 209148 & 954989 & 4.7056 & 4.6656 & TRN & \\
\hline CHEMBL1404918 & 954989 & 3.1512 & 3.0859 & TRN & \\
\hline CHEMBL392695 & 954989 & 5.5853 & 5.0548 & TRN & \\
\hline CHEMBL 2005886 & 954989 & 6.1928 & 5.9796 & TRN & \\
\hline CHEMBL 210618 & 954989 & 4.2832 & 4.1552 & TRN & \\
\hline CHEMBL472940 & 954989 & 3.327 & 3.3848 & TRN & \\
\hline CHEMBL1643959 & 954989 & 4.788 & 4.8386 & TRN & \\
\hline CHEMBL577784 & 954989 & 5.8885 & 5.935 & TRN & \\
\hline CHEMBL180127 & 954989 & 4.0656 & 4.3161 & TRN & \\
\hline CHEMBL65 & 954989 & 8.1025 & 8.1248 & TRN & \\
\hline CHEMBL399530 & 954989 & 4.8328 & 4.9162 & TRN & \\
\hline CHEMBL258844 & 954989 & 4.8495 & 5.0092 & TRN & \\
\hline
\end{tabular}




\begin{tabular}{|c|c|c|c|c|c|c|}
\hline & & \multicolumn{5}{|c|}{ Supplemental Table s2.txt } \\
\hline CHEMBL92309 & 954989 & 4.3009 & 3.2883 & TST & & \\
\hline CHEMBL 240954 & 954989 & 3.1697 & 3.8668 & TST & & \\
\hline CHEMBL573107 & 954989 & 5.3867 & 5.5672 & TRN & & \\
\hline CHEMBL449158 & 954989 & 6.1417 & 7.4412 & TST & & \\
\hline CHEMBL192566 & 954989 & \multicolumn{3}{|c|}{8.152000000000001} & 9.1966 & TST \\
\hline CHEMBL135561 & 954989 & 4.5739 & 5.1092 & TRN & & \\
\hline CHEMBL1186585 & 954989 & 3.2954 & 3.6872 & TRN & & \\
\hline CHEMBL3349342 & 954989 & 5.9617 & 5.2897 & TRN & & \\
\hline CHEMBL1242367 & 954989 & 4.7505 & 4.8166 & TRN & & \\
\hline CHEMBL 202721 & 954989 & 5.002 & 4.9413 & TRN & & \\
\hline CHEMBL1357247 & 954989 & 4.1031 & 3.9636 & TRN & & \\
\hline CHEMBL 2144069 & 954989 & 4.9765 & 4.3412 & TRN & & \\
\hline CHEMBL512504 & 954989 & 4.3332 & 4.6992 & TST & & \\
\hline CHEMBL483847 & 954989 & 5.2774 & 5.2716 & TRN & & \\
\hline CHEMBL 213100 & 954989 & 7.1196 & 7.4242 & TRN & & \\
\hline CHEMBL 2137530 & 954989 & 5.3808 & 5.3838 & TRN & & \\
\hline CHEMBL393929 & 954989 & 5.4901 & 5.0503 & TRN & & \\
\hline CHEMBL1909414 & 954989 & 3.2738 & 3.4955 & TRN & & \\
\hline CHEMBL1788116 & 954989 & 5.7753 & 5.6759 & TRN & & \\
\hline CHEMBL1230020 & 954989 & 4.3468 & 4.1448 & TRN & & \\
\hline CHEMBL 255342 & 954989 & 3.1962 & 3.4298 & TRN & & \\
\hline CHEMBL221137 & 954989 & 5.2363 & 5.1447 & TST & & \\
\hline CHEMBL585951 & 954989 & 6.3955 & 6.7799 & TST & & \\
\hline CHEMBL2363137 & 954989 & 5.1711 & 5.2772 & TST & & \\
\hline CHEMBL3186408 & 954989 & \multicolumn{3}{|c|}{3.4560000000000004} & 3.8564 & TST \\
\hline CHEMBL 2134202 & 954989 & 4.1149 & 3.8312 & TST & & \\
\hline CHEMBL1673039 & 954989 & 4.4695 & 5.1621 & TST & & \\
\hline CHEMBL514499 & 954989 & 7.5943 & 7.2573 & TST & & \\
\hline CHEMBL515416 & 954989 & 4.8148 & 5.1686 & TST & & \\
\hline CHEMBL3199475 & 954989 & 5.399 & 4.5962 & TST & & \\
\hline CHEMBL2355203 & 1301469 & 4.3721 & 4.4704 & TRN & & \\
\hline CHEMBL2355758 & 1301469 & 4.3084 & 5.3286 & TRN & & \\
\hline CHEMBL2362033 & 1301469 & 4.6607 & 4.4455 & TRN & & \\
\hline CHEMBL1420472 & 1301469 & 4.8827 & 4.6404 & TST & & \\
\hline CHEMBL2359934 & 1301469 & 4.4574 & 4.4927 & TRN & & \\
\hline CHEMBL2360428 & 1301469 & 4.3404 & 4.6716 & TRN & & \\
\hline CHEMBL585827 & 1301469 & \multicolumn{3}{|c|}{5.2620000000000005} & 5.0275 & TST \\
\hline CHEMBL2359131 & 1301469 & 6.0 & 5.3593 & TRN & & \\
\hline CHEMBL2360282 & 1301469 & 4.2414 & 4.7749 & TRN & & \\
\hline CHEMBL2361346 & 1301469 & 4.5063 & 4.4591 & TRN & & \\
\hline CHEMBL1396619 & 1301469 & 4.6849 & 4.6259 & TST & & \\
\hline CHEMBL2356186 & 1301469 & 5.3251 & 4.7583 & TRN & & \\
\hline CHEMBL2356879 & 1301469 & 4.3823 & 4.6526 & TRN & & \\
\hline CHEMBL1489779 & 1301469 & 4.8871 & 5.0146 & TST & & \\
\hline CHEMBL1625031 & 1301469 & 4.3557 & 4.4442 & TST & & \\
\hline CHEMBL 3183012 & 1301469 & 4.2563 & 4.5272 & TRN & & \\
\hline CHEMBL2359710 & 1301469 & 4.6507 & 4.566 & TRN & & \\
\hline CHEMBL3186044 & 1301469 & 4.5575 & 4.4733 & TRN & & \\
\hline
\end{tabular}




\begin{tabular}{|c|c|c|c|c|c|c|}
\hline \multicolumn{7}{|c|}{ Supplemental Table S2.txt } \\
\hline CHEMBL2359785 & 1301469 & 6.0 & 5.1964 & TRN & & \\
\hline CHEMBL 2355103 & 1301469 & 4.4086 & 4.698 & TRN & & \\
\hline CHEMBL2355817 & 1301469 & 4.3702 & 4.7236 & TRN & & \\
\hline CHEMBL2362538 & 1301469 & 6.0 & 4.9932 & TRN & & \\
\hline CHEMBL1551808 & 1301469 & 5.0255 & 4.6837 & TST & & \\
\hline CHEMBL1864597 & 1301469 & 6.0 & 5.2286 & TRN & & \\
\hline CHEMBL 2358490 & 1301469 & 6.0 & 5.365 & TRN & & \\
\hline CHEMBL2361503 & 1301469 & 4.5229 & 4.5233 & TRN & & \\
\hline CHEMBL 2357924 & 1301469 & 4.8827 & 4.6752 & TRN & & \\
\hline CHEMBL 2357087 & 1301469 & 4.215 & 4.9504 & TRN & & \\
\hline CHEMBL 3183001 & 1301469 & 4.3491 & 4.7915 & TRN & & \\
\hline CHEMBL2362298 & 1301469 & 4.36600 & 30000000 & 205 & 4.7442 & TRN \\
\hline CHEMBL2361127 & 1301469 & 4.1957 & 4.5227 & TRN & & \\
\hline CHEMBL2361002 & 1301469 & 4.545 & 5.2003 & TRN & & \\
\hline CHEMBL2355890 & 1301469 & 4.7986 & 5.1414 & TRN & & \\
\hline CHEMBL1866791 & 1301469 & 5.0301 & 4.5138 & TST & & \\
\hline CHEMBL2356860 & 1301469 & 4.7162 & 4.7913 & TRN & & \\
\hline CHEMBL2359466 & 1301469 & 6.0 & 5.3981 & TRN & & \\
\hline CHEMBL2358729 & 1301469 & 4.7873 & 4.7606 & TRN & & \\
\hline CHEMBL2354689 & 1301469 & 4.7251 & 4.9895 & TRN & & \\
\hline CHEMBL3187821 & 1301469 & 4.3252 & 4.5048 & TRN & & \\
\hline CHEMBL591363 & 1301469 & 5.1475 & 4.9033 & TST & & \\
\hline CHEMBL3182522 & 1301469 & 4.4765 & 4.5833 & TRN & & \\
\hline CHEMBL 2362650 & 1301469 & 5.2132 & 4.9188 & TRN & & \\
\hline CHEMBL 2354348 & 1301469 & 4.3319 & 4.3962 & TRN & & \\
\hline CHEMBL 2362010 & 1301469 & 4.3884 & 5.2024 & TRN & & \\
\hline CHEMBL 2356543 & 1301469 & 4.3353 & 5.2003 & TRN & & \\
\hline CHEMBL 2361216 & 1301469 & 4.3023 & 4.7299 & TRN & & \\
\hline CHEMBL1378851 & 1301469 & 4.4489 & 4.649 & TST & & \\
\hline CHEMBL 2360357 & 1301469 & 4.9 & 4.4732 & TRN & & \\
\hline CHEMBL 2354757 & 1301469 & 4.178 & 5.1535 & TRN & & \\
\hline CHEMBL2355771 & 1301469 & 4.4781 & 4.5728 & TRN & & \\
\hline CHEMBL 2138714 & 1301469 & 5.38200 & 00000000 & & 4.8891 & TRN \\
\hline CHEMBL2360483 & 1301469 & 4.7268 & 4.5697 & TRN & & \\
\hline CHEMBL1711200 & 1301469 & 4.5701 & 4.5864 & TST & & \\
\hline CHEMBL 2356820 & 1301469 & 4.4176 & 5.2505 & TRN & & \\
\hline CHEMBL 2362273 & 1301469 & 4.3228 & 5.3446 & TRN & & \\
\hline CHEMBL2361921 & 1301469 & 4.4303 & 4.6301 & TRN & & \\
\hline CHEMBL2360228 & 1301469 & 4.1956 & 4.532 & TRN & & \\
\hline CHEMBL1622981 & 1301469 & 4.4648 & 4.5066 & TST & & \\
\hline CHEMBL2358546 & 1301469 & 4.3919 & 4.9826 & TRN & & \\
\hline CHEMBL 2358870 & 1301469 & 4.5727 & 4.5278 & TRN & & \\
\hline CHEMBL2356052 & 1301469 & 4.5439 & 4.7493 & TRN & & \\
\hline CHEMBL 2361755 & 1301469 & 6.0 & 5.1119 & TRN & & \\
\hline CHEMBL2354815 & 1301469 & 6.0 & 5.0594 & TRN & & \\
\hline CHEMBL3182148 & 1301469 & 5.0386 & 4.598 & TST & & \\
\hline CHEMBL2361605 & 1301469 & 4.688 & 4.5271 & TRN & & \\
\hline CHEMBL2358824 & 1301469 & 4.184 & 5.3065 & TRN & & \\
\hline
\end{tabular}


Supplemental Table S2.txt

\begin{tabular}{|c|c|c|c|c|}
\hline 026 & & & 5801 & \\
\hline & 301469 & 4.8483 & & \\
\hline FMRI & 01469 & 6.0 & & \\
\hline HEMBL1 & 59 & 133 & & \\
\hline AEMBL2359989 & 301469 & 935 & 8188 & \\
\hline HEMBL 2359612 & 301469 & 6.0 & 3521 & \\
\hline HEMBL2 & 301 & & 746 & \\
\hline AEMBL23 & 59 & & 193 & \\
\hline HEMBL2142401 & 301469 & 4.6312 & 6494 & \\
\hline HEMBL2355845 & 301469 & 4.5438 & 6723 & \\
\hline HEMBL2358899 & 3014 & 6.0 & 5139 & \\
\hline AEMBL 2 & 301 & 741 & 477 & \\
\hline HEMBL3 & 59 & & & \\
\hline HEMBL2358640 & 301469 & 4.2545 & 6345 & \\
\hline HEMBL 235 & 301469 & 271 & & \\
\hline HEMBL 2 & 301 & 6 . & 605 & \\
\hline HEMBL: & 36 & & & ונס \\
\hline HEMBL 2 & 301 & 6. & 65 & \\
\hline HEMBL2 & 301469 & & & \\
\hline HEMBL 235 & 59 & & & I KIV \\
\hline HEMBL3 & 36 & 4. & & ГRN \\
\hline HEM & 30 & & & ונס \\
\hline AEMBL & 59 & 4.31 & 96 & ST \\
\hline HEMBL1 & 59 & 5 . & & IST \\
\hline AEMBL1. & & & 03 & ISI \\
\hline HEMBL1 & 30 & & 01 & ST \\
\hline HEMBL & 301 & & & RN \\
\hline 9 & 9 & 03 & & RN \\
\hline AEMBL2 & & 985 & & IK \\
\hline HEMBL 213 & 301 & 4.2831 & 892 & TRN \\
\hline AEMBL: & 30 & 6 & 29 & RN \\
\hline HFN & $y$ & 6 & & 「RN \\
\hline ? & & 4. & & RN \\
\hline HEMBL1 & 301 & & & TST \\
\hline HEMBL 235 & 301 & 4. & & RN \\
\hline AFMRI & 30 & 4. & 04 & TRN \\
\hline 1 & 0 & 6 . & & ГRN \\
\hline HEMBL2 & & 6 . & & TRN \\
\hline HEMBL 2 & 301 & 5.24 & & $\Gamma R$ \\
\hline 9 & 30 & 6 & & RN \\
\hline HEMBL1 & 30 & & 11 & ГST \\
\hline HEMBL 2 & 59 & 6.6 & 981 & TRN \\
\hline HEMBL2. & 3014 & 4.28 & & {$\left[R_{2}\right.$} \\
\hline HEMBL 2 & 301 & 4. & & TR \\
\hline תL & & & & \\
\hline HEMBL 2354788 & 3014 & 4.4088 & 5162 & \\
\hline CHEMBL1617452 & 3014 & 4.5935 & 7916 & \\
\hline CHEMBL2356397 & 1301469 & 6.0 & 5.2518 & ГRN \\
\hline
\end{tabular}

Page 10884 
Supplemental Table S2.txt

\begin{tabular}{|c|c|c|c|c|}
\hline 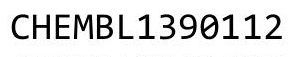 & & & & \\
\hline HEMBL2360426 & 301469 & 6.0 & 603 & \\
\hline HEMBL2355418 & 301469 & 4.2369 & & \\
\hline 22 & 59 & 2052 & 047 & \\
\hline EMBL 2359515 & 301469 & 6.0 & 134 & \\
\hline HEMBL2360127 & 301469 & 4.2756 & 4865 & \\
\hline HEMBL 2357597 & 301469 & 4.4249 & 5693 & \\
\hline HEMBL2132942 & 301469 & 495 & 666 & \\
\hline IEMBL2 & 301 & 943 & 611 & \\
\hline IEMBL1: & 301 & 4.2952 & 068 & \\
\hline HEMBL2360439 & 301469 & 4.5669 & 5401 & \\
\hline HEMBL 2359969 & 301469 & 4.3787 & 5799 & \\
\hline HEMBL1544797 & 301469 & 4.6657 & 139 & \\
\hline HEMBL 236 & 59 & 66 & 923 & \\
\hline HEMBL 235 & 301 & 33 & & \\
\hline HEMBL1379675 & 301469 & 248 & 669 & \\
\hline HEMBL1350915 & 59 & 4.7706 & 1059 & \\
\hline HEMBL23 & 36 & 39 & 293 & \\
\hline HEMBL14 & & 34 & 352 & \\
\hline HEMBL 235 & 301 & 4. & 788 & \\
\hline HEMBL 235 & 59 & 681 & 311 & \\
\hline AEMBL1392 & 59 & 5.3206 & 624 & 1 \\
\hline HEMBL 236 & 301 & 355 & 699 & RN \\
\hline HEMBL31 & & & 18 & RIV \\
\hline HEM & 59 & 556 & 577 & \\
\hline HEMBL 235 & 291 & 912 & 978 & IST \\
\hline AEMBL 235 & 99 & 4.5032 & 586 & $\mathrm{R}$ \\
\hline HEMBL23 & 30 & & 756 & RN \\
\hline HEM & 30 & & 24 & RN \\
\hline HEMBL2 & 59 & 6. & 762 & $\mathrm{RN}$ \\
\hline HEMBL 1488 & רou & & & is \\
\hline HEMBL 2355430 & 301 & 4.3602 & 645 & ГRN \\
\hline HEMBL 2362 & 30 & 755 & 734 & RN \\
\hline 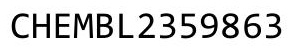 & 0 & 6 & 65 & \\
\hline HEMBL 236 & & & 7578 & RN \\
\hline HEMBL1578386 & 301 & & 059 & TST \\
\hline HEMBL 2359406 & $301<$ & 43 & 838 & ГRN \\
\hline HEMBL137 & 30 & 17 & 433 & IST \\
\hline 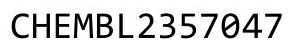 & מר & & 996 & TRN \\
\hline HEMBL $235 \angle$ & 301 & & 5032 & TRN \\
\hline HEMBL1898843 & 301469 & 4. & 903 & RN \\
\hline HEMBL147: & 301 & 331 & 003 & IST \\
\hline HEMBL2357 & 3014 & & 913 & 「RN \\
\hline HEMBL 3188 & 301 & 619 & 7275 & TRN \\
\hline HEMBL2355165 & 301469 & & 3709 & TRN \\
\hline HEMBL 2358 & 301469 & & 028 & $\mathrm{~N}$ \\
\hline CHEMBL 23588 & 10 & & & \\
\hline & 3 & & & \\
\hline
\end{tabular}

Page 10885 


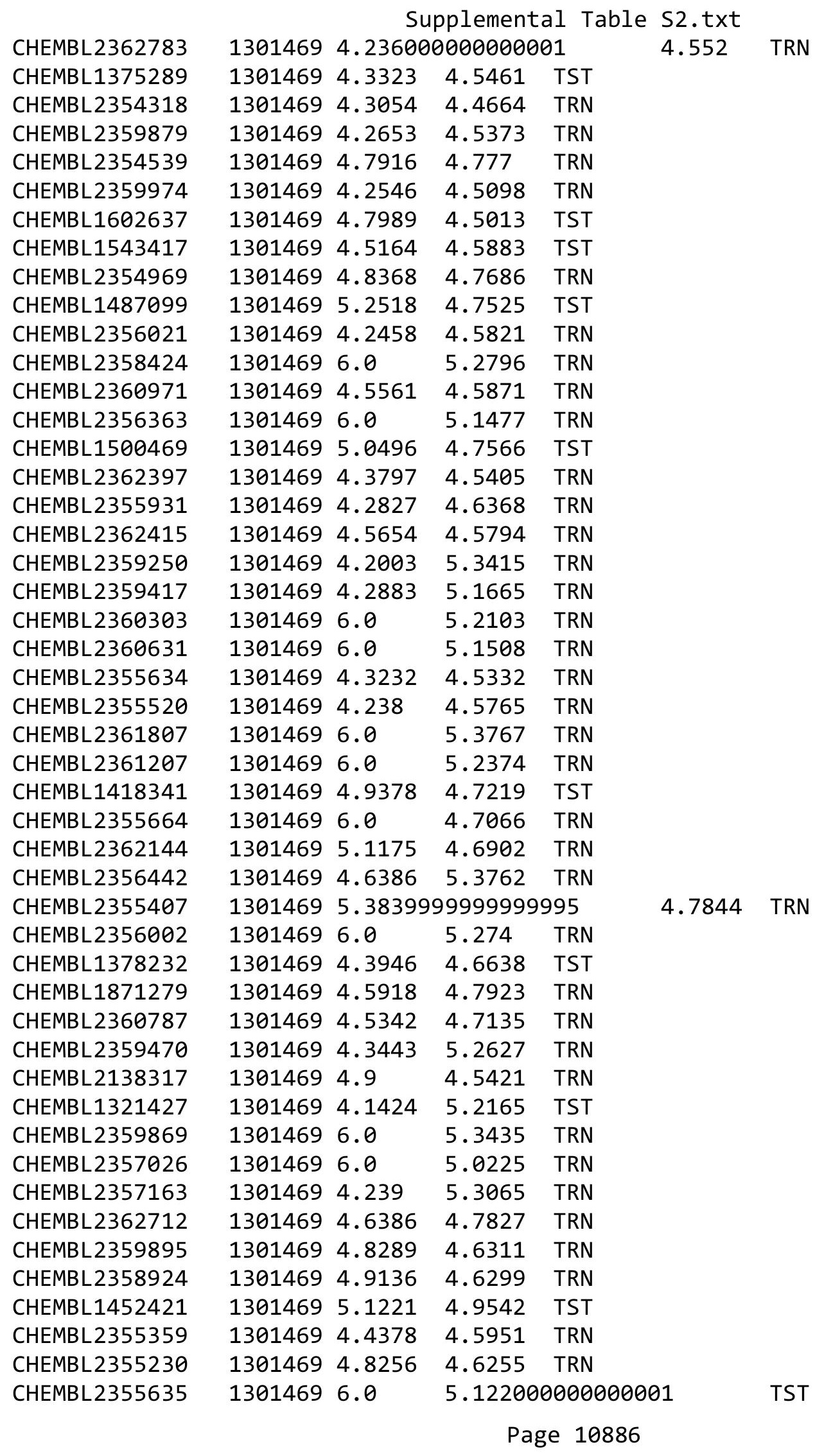


Supplemental Table S2.txt

\begin{tabular}{|c|c|c|c|c|}
\hline IEMBL 2362353 & & & & \\
\hline & 301469 & 4.5805 & & \\
\hline IFMRI 23 & 01469 & & & \\
\hline IEMBL2361210 & 301469 & 4034 & & \\
\hline AEMBL 2360506 & 301469 & 4.346 & 7652 & \\
\hline HEMBL236 & 301 & 4.9855 & 4.9833 & \\
\hline IEMBL15 & 59 & 865 & & \\
\hline IEMBL132 & 59 & 3542 & & \\
\hline AEMBL 2359438 & 301469 & 4.3532 & & \\
\hline HEMBL3188924 & 301469 & 4.7421 & & \\
\hline AEMBL2357765 & 301 & 4.2431 & & \\
\hline IEMBL 318 & 301 & 306 & & \\
\hline HEMBL 235 & 301 & & & \\
\hline IEMBL 2354467 & 301 & 4.6008 & 39 & \\
\hline HEMBL2361591 & 301 & 366 & & \\
\hline AEMBL 236 & 301 & 545 & 31 & \\
\hline IEMBL2 & 301 & 739 & & RN \\
\hline AEMBL 23 & 301 & 4.5753 & & \\
\hline IEMBL: & 301 & 4686 & & \\
\hline AEMBL 2356688 & 301 & & & \\
\hline IEMBL2 & 301 & & & \\
\hline IEMBL & 9 & & & RN \\
\hline IEMBL236 & 301 & 753 & & \\
\hline IEMBL2 & 015 & 559 & & \\
\hline IEMBL3 & 5 & & & RN \\
\hline EMBL: & 15 & 39 & & RI \\
\hline 96 & 31 & 69 & & $\cdots$ \\
\hline 7 & 5 & 586 & & \\
\hline IEMBL & 75 & & & Rा \\
\hline IEMBL155 & 315 & & & ГRI \\
\hline$\Gamma M O$ & & & & $\Gamma R$ \\
\hline 5 & 5 & & & \\
\hline & & 7.6778 & & 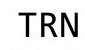 \\
\hline IEMBL2 & ז & 28 & & $\Gamma \mathrm{R}$ \\
\hline IEMBL 345 & $\partial 15$ & 696 & & $S$ \\
\hline 9 & 1 & 12 & & $\Gamma \mathrm{R}$ \\
\hline 1 & 75 & 72 & & \\
\hline IEMBL: & & & & ST \\
\hline IEMBL: & $\partial 15$ & 229 & & $\Gamma$ \\
\hline EMB & 01 & & & $\mathrm{RI}$ \\
\hline IEMBL & 21 & 37 & & 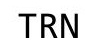 \\
\hline HEMBL; & 015 & 12 & 246 & \\
\hline EMBL2 & 5 & & 6.5247 & $R$ \\
\hline AEMBL: & 21 & 78 & & $\mathrm{~s}$ \\
\hline 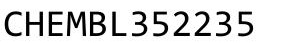 & & & & N \\
\hline CHEMBL 2237877 & & & & \\
\hline CHEMBL 2237583 & 1575 & 506 & 6.3623 & R \\
\hline CHEMBL156449 & 901575 & 5.7959 & 5.8768 & TS \\
\hline
\end{tabular}

Page 10887 


\begin{tabular}{|c|c|c|c|c|c|}
\hline & & \multicolumn{4}{|c|}{ Supplemental Table S2.txt } \\
\hline CHEMBL 2237585 & 901575 & 7.1427 & 7.2419 & TRN & \\
\hline CHEMBL 2237612 & 901575 & 6.1079 & 6.5007 & TRN & \\
\hline CHEMBL2237587 & 901575 & 7.0 & 7.3043 & TRN & \\
\hline CHEMBL345696 & 901575 & 7.1249 & 7.2061 & TRN & \\
\hline CHEMBL423418 & 901575 & 6.0 & 5.9221 & TST & \\
\hline CHEMBL 345570 & 901575 & 8.4815 & 8.7583 & TRN & \\
\hline CHEMBL348568 & 901575 & 7.3098 & 7.1238 & TRN & \\
\hline CHEMBL345459 & 901575 & 8.5229 & 8.3903 & TRN & \\
\hline CHEMBL154708 & 901575 & 6.0315 & 6.1271 & TST & \\
\hline CHEMBL157185 & 901575 & 7.3768 & 7.4614 & TRN & \\
\hline CHEMBL154640 & 901575 & 7.1549 & 7.0438 & TRN & \\
\hline CHEMBL2237597 & 901575 & 6.9208 & 7.06 & TRN & \\
\hline CHEMBL153968 & 901575 & 7.2218 & 7.3019 & TRN & \\
\hline CHEMBL347513 & 901575 & 6.4949 & 6.5003 & TRN & \\
\hline CHEMBL423233 & 901575 & 7.5229 & 7.46399 & 99999999995 & TRN \\
\hline CHEMBL155554 & 901575 & 7.301 & 8.0316 & TST & \\
\hline CHEMBL 2237592 & 901575 & 7.0088 & 7.0997 & TRN & \\
\hline CHEMBL345139 & 901575 & 8.1192 & 8.1291 & TRN & \\
\hline CHEMBL 2237611 & 901575 & 6.8539 & 6.8887 & TRN & \\
\hline CHEMBL2237609 & 901575 & 7.2007 & 6.9664 & TRN & \\
\hline CHEMBL155877 & 901575 & 8.1675 & 8.2923 & TRN & \\
\hline CHEMBL2237599 & 901575 & 7.0458 & 7.2888 & TRN & \\
\hline CHEMBL155948 & 901575 & 7.8539 & 7.7396 & TRN & \\
\hline CHEMBL 2237606 & 901575 & 7.3979 & 7.5779 & TST & \\
\hline CHEMBL156084 & 901575 & 7.8539 & 8.0534 & TRN & \\
\hline CHEMBL157878 & 901575 & 7.5229 & 7.3238 & TRN & \\
\hline CHEMBL347234 & 901575 & 6.3188 & 6.1459 & TRN & \\
\hline CHEMBL156181 & 901575 & 6.1427 & 5.9156 & TRN & \\
\hline CHEMBL157597 & 901575 & 5.3188 & 5.4149 & TST & \\
\hline CHEMBL346742 & 901575 & 5.284 & 5.2272 & TRN & \\
\hline CHEMBL 2237595 & 901575 & 8.1805 & 7.9099 & TRN & \\
\hline CHEMBL155984 & 901575 & 7.4949 & 7.5165 & TRN & \\
\hline CHEMBL2237603 & 901575 & 6.3979 & 6.522 & TST & \\
\hline CHEMBL 2237604 & 901575 & 7.3188 & 6.6902 & TST & \\
\hline CHEMBL157620 & 901575 & 7.585 & 7.7011 & TRN & \\
\hline CHEMBL 2237584 & 901575 & 6.5086 & 6.5052 & TRN & \\
\hline CHEMBL 2237586 & 901575 & 7.4437 & 7.4454 & TRN & \\
\hline CHEMBL2237602 & 901575 & 8.8539 & 7.9245 & TRN & \\
\hline CHEMBL2237607 & 901575 & 8.0 & 8.6531 & TST & \\
\hline CHEMBL 2237588 & 901575 & 8.1487 & 8.0723 & TRN & \\
\hline CHEMBL157690 & 901575 & 7.699 & 8.2962 & TST & \\
\hline CHEMBL 2237580 & 901575 & 7.2441 & 7.1282 & TRN & \\
\hline CHEMBL2237590 & 901575 & 7.7696 & 7.7757 & TRN & \\
\hline CHEMBL347050 & 901575 & 5.8539 & 6.0562 & TST & \\
\hline CHEMBL346745 & 901575 & 6.0 & 6.1871 & TRN & \\
\hline CHEMBL158133 & 901575 & 8.1308 & 8.46600 & 3000000001 & TST \\
\hline CHEMBL 2237594 & 901575 & 6.8861 & 7.1806 & TRN & \\
\hline CHEMBL154772 & 901575 & 7.2218 & 7.1376 & TRN & \\
\hline
\end{tabular}


Supplemental Table S2.txt

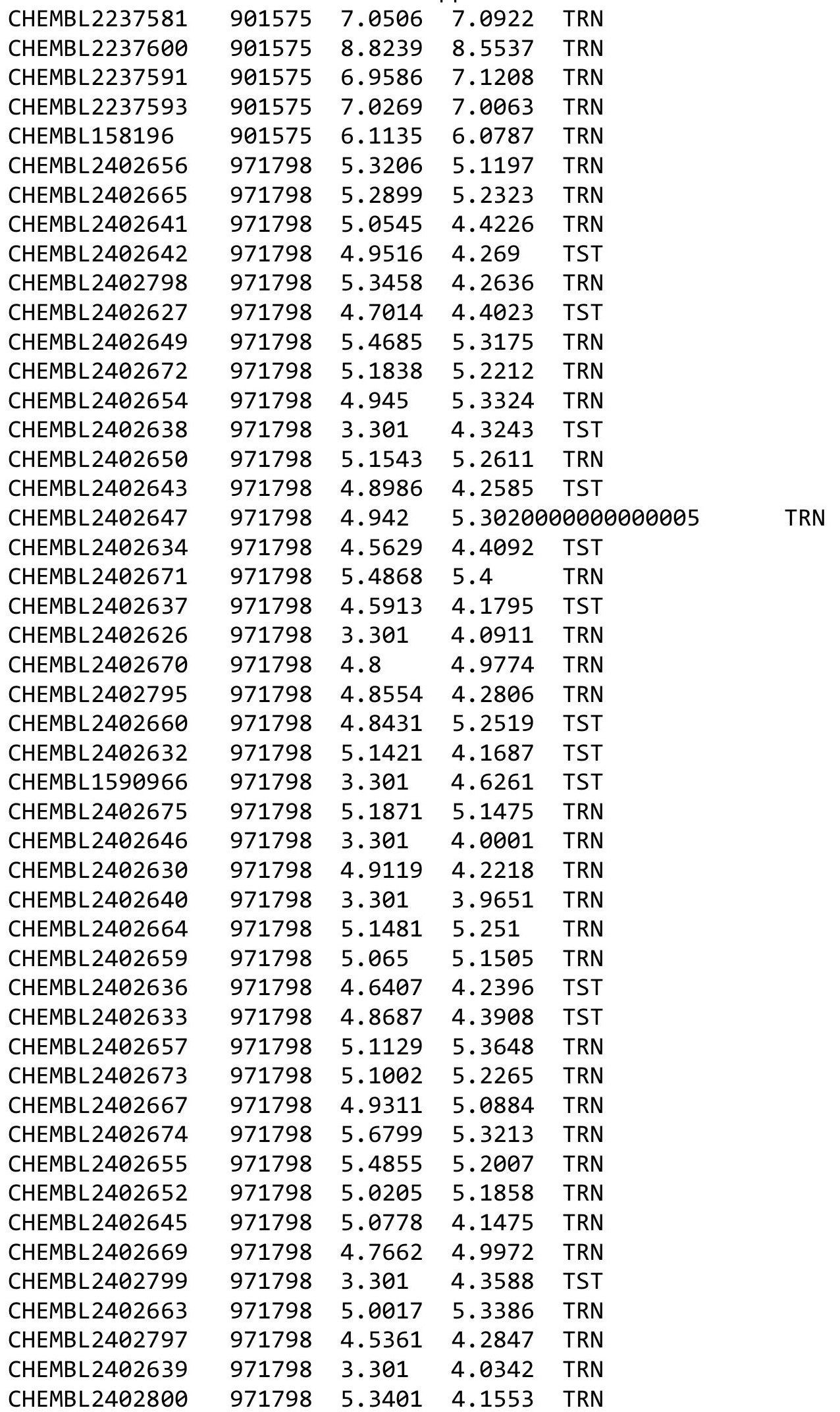

Page 10889 


\begin{tabular}{|c|c|c|c|c|c|c|}
\hline & & \multicolumn{5}{|c|}{ Supplemental Table S2.txt } \\
\hline CHEMBL 2402668 & 971798 & 5.2441 & 5.2414 & TRN & & \\
\hline CHEMBL 2402662 & 971798 & 4.9935 & 4.9336 & TRN & & \\
\hline CHEMBL 2402631 & 971798 & 3.301 & 4.0737 & TRN & & \\
\hline CHEMBL 2402661 & 971798 & 5.1308 & 5.0155 & TRN & & \\
\hline CHEMBL 2402653 & 971798 & 4.8595 & 5.0958 & TRN & & \\
\hline CHEMBL 2402801 & 971798 & 3.301 & 4.0741 & TRN & & \\
\hline CHEMBL 2338066 & 971798 & 5.1864 & 4.9031 & TST & & \\
\hline CHEMBL 2402635 & 971798 & 4.6548 & 4.3358 & TST & & \\
\hline CHEMBL 2402658 & 971798 & 5.3152 & 5.2042 & TRN & & \\
\hline CHEMBL 2402644 & 971798 & 5.2495 & 4.3729 & TST & & \\
\hline CHEMBL 2402629 & 971798 & 5.4078 & 4.1971 & TRN & & \\
\hline CHEMBL 2402666 & 971798 & 5.9626 & 5.2457 & TRN & & \\
\hline CHEMBL 2402651 & 971798 & 4.9952 & 5.3172 & TRN & & \\
\hline CHEMBL 2402628 & 971798 & 3.301 & 4.1417 & TRN & & \\
\hline CHEMBL518707 & 971798 & 3.301 & 4.0113 & TRN & & \\
\hline CHEMBL 2402802 & 971798 & 4.6012 & 4.1548 & TRN & & \\
\hline CHEMBL 2402648 & 971798 & $5.3820 e$ & 00000000 & 01 & 5.4237 & TRN \\
\hline CHEMBL 2402794 & 971798 & 4.9034 & 4.9819 & TRN & & \\
\hline CHEMBL 2402796 & 971798 & 4.7637 & 4.508 & TST & & \\
\hline CHEMBL3958893 & 1637320 & 9.0 & 7.7349 & TRN & & \\
\hline CHEMBL3944722 & 1637320 & 7.0 & 7.7933 & TRN & & \\
\hline CHEMBL3958836 & 1637320 & 6.301 & 6.7695 & TRN & & \\
\hline CHEMBL3969679 & 1637320 & 9.0 & 7.7531 & TRN & & \\
\hline CHEMBL3899050 & 1637320 & 7.0 & 7.6699 & TRN & & \\
\hline CHEMBL3932590 & 1637320 & 7.0 & 7.6932 & TRN & & \\
\hline CHEMBL3981748 & 1637320 & 7.0 & 6.5949 & TRN & & \\
\hline CHEMBL 3898273 & 1637320 & 9.0 & 7.7254 & TRN & & \\
\hline CHEMBL 3898620 & 1637320 & 7.0 & 7.4572 & TRN & & \\
\hline CHEMBL 3892108 & 1637320 & 7.0 & 7.6465 & TRN & & \\
\hline CHEMBL3918195 & 1637320 & 7.0 & 7.6539 & TRN & & \\
\hline CHEMBL3961888 & 1637320 & 6.301 & 6.8372 & TRN & & \\
\hline CHEMBL3966546 & 1637320 & 7.0 & 7.7018 & TRN & & \\
\hline CHEMBL3974668 & 1637320 & 7.0 & 6.6822 & TRN & & \\
\hline CHEMBL3935274 & 1637320 & 6.301 & 7.6377 & TRN & & \\
\hline CHEMBL3933284 & 1637320 & 9.0 & 7.8175 & TRN & & \\
\hline CHEMBL3948390 & 1637320 & 7.0 & 7.7005 & TRN & & \\
\hline CHEMBL3939938 & 1637320 & 7.0 & 7.7641 & TRN & & \\
\hline CHEMBL3937622 & 1637320 & 6.0 & 7.6252 & TRN & & \\
\hline CHEMBL3973035 & 1637320 & 6.301 & 6.62200 & 0000000001 & & $\mathrm{TR}$ \\
\hline CHEMBL3915198 & 1637320 & 7.0 & 6.3807 & TRN & & \\
\hline CHEMBL3938515 & 1637320 & 9.0 & 7.5039 & TST & & \\
\hline CHEMBL3938103 & 1637320 & 7.0 & 6.5652 & TST & & \\
\hline CHEMBL3986300 & 1637320 & 7.0 & 7.6618 & TRN & & \\
\hline CHEMBL3943415 & 1637320 & 7.0 & 6.6364 & TRN & & \\
\hline CHEMBL3984673 & 1637320 & 7.0 & 7.7517 & TRN & & \\
\hline CHEMBL3974722 & 1637320 & 7.0 & 6.6544 & TST & & \\
\hline CHEMBL3932489 & 1637320 & 6.301 & 6.8918 & TRN & & \\
\hline CHEMBL3928999 & 1637320 & 9.0 & 7.7785 & TRN & & \\
\hline
\end{tabular}


Supplemental Table S2.txt

\begin{tabular}{|c|c|c|c|c|c|}
\hline CHEMBL3894266 & 1637320 & 6.301 & 6.5751 & TST & \\
\hline CHEMBL3927679 & 1637320 & 9.0 & 7.6477 & TRN & \\
\hline CHEMBL3916632 & 1637320 & 7.0 & 6.8002 & TRN & \\
\hline CHEMBL3948991 & 1637320 & 7.0 & 7.6257 & TST & \\
\hline CHEMBL3903620 & 1637320 & 6.301 & 6.5832 & TRN & \\
\hline CHEMBL3945802 & 1637320 & 9.0 & 7.7246 & TST & \\
\hline CHEMBL3940789 & 1637320 & 7.0 & 6.7337 & TST & \\
\hline CHEMBL 3897688 & 1637320 & 7.0 & 6.7571 & TST & \\
\hline CHEMBL3912772 & 1637320 & 6.0 & 6.3807 & TRN & \\
\hline CHEMBL3970431 & 1637320 & 7.0 & 6.6565 & TRN & \\
\hline CHEMBL3935448 & 1637320 & 9.0 & 7.5115 & TRN & \\
\hline CHEMBL3948435 & 1637320 & 7.0 & 6.6006 & TRN & \\
\hline CHEMBL3977459 & 1637320 & 7.0 & 6.9296 & TRN & \\
\hline CHEMBL3908619 & 1637320 & 9.0 & 7.7079 & TST & \\
\hline CHEMBL3945214 & 1637320 & 7.0 & 7.5814 & TRN & \\
\hline CHEMBL3967417 & 1637320 & 7.0 & 7.8029 & TRN & \\
\hline CHEMBL3952353 & 1637320 & 7.0 & 7.7809 & TRN & \\
\hline CHEMBL3896322 & 1637320 & 9.0 & 7.8029 & TRN & \\
\hline CHEMBL3904053 & 1637320 & 9.0 & 7.7566 & TRN & \\
\hline CHEMBL3907920 & 1637320 & 7.0 & 6.5973 & TRN & \\
\hline CHEMBL3907633 & 1637320 & 7.0 & 7.5585 & TRN & \\
\hline CHEMBL3951065 & 1637320 & 7.0 & 6.3344 & TRN & \\
\hline CHEMBL3985038 & 1637320 & 6.301 & 6.9016 & TRN & \\
\hline CHEMBL 3889651 & 1637320 & 7.0 & 6.6482 & TRN & \\
\hline CHEMBL3952338 & 1637320 & 9.0 & 7.7176 & TRN & \\
\hline CHEMBL3983598 & 1637320 & 7.0 & 7.5284 & TRN & \\
\hline CHEMBL3962003 & 1637320 & 7.0 & 7.5427 & TST & \\
\hline CHEMBL3929672 & 1637320 & 7.0 & \multicolumn{2}{|c|}{7.6739999999999995} & TRN \\
\hline CHEMBL3907878 & 1637320 & 7.0 & 7.7787 & TRN & \\
\hline CHEMBL3967511 & 1637320 & 7.0 & 7.7378 & TRN & \\
\hline CHEMBL 3892282 & 1637320 & 6.301 & 6.4083 & TST & \\
\hline CHEMBL3897634 & 1637320 & 9.0 & 7.4923 & TRN & \\
\hline CHEMBL3977313 & 1637320 & 9.0 & \multicolumn{2}{|c|}{ 7.747999999999999 } & TRN \\
\hline CHEMBL3906010 & 1637320 & 7.0 & 6.6701 & TRN & \\
\hline CHEMBL3896874 & 1637320 & 6.301 & 7.8102 & TRN & \\
\hline CHEMBL3912101 & 1637320 & 6.301 & 6.4818 & TRN & \\
\hline CHEMBL3976063 & 1637320 & 9.0 & 7.4396 & TRN & \\
\hline CHEMBL3938863 & 1637320 & 7.0 & 7.6426 & TRN & \\
\hline CHEMBL3931216 & 1637320 & 7.0 & 6.7135 & TRN & \\
\hline CHEMBL3976508 & 1637320 & 7.0 & 7.5829 & TRN & \\
\hline CHEMBL3925297 & 1637320 & 6.301 & 6.5194 & TRN & \\
\hline CHEMBL3908945 & 1637320 & 9.0 & 7.7955 & TRN & \\
\hline CHEMBL3955708 & 1637320 & 6.301 & 7.6823 & TRN & \\
\hline CHEMBL3944955 & 1637320 & 7.0 & 7.4952 & TRN & \\
\hline CHEMBL3983330 & 1637320 & 7.0 & 7.8226 & TRN & \\
\hline CHEMBL3911659 & 1637320 & 7.0 & 6.5941 & TRN & \\
\hline CHEMBL 3913887 & 1637320 & 6.301 & 6.3454 & TST & \\
\hline CHEMBL3965794 & 1637320 & 6.0 & 6.2475 & TRN & \\
\hline
\end{tabular}


Supplemental Table S2.txt

\begin{tabular}{|c|c|c|c|c|}
\hline CHEMBL3973843 & 1637320 & 6.301 & 6.7622 & TRN \\
\hline CHEMBL3908490 & 1637320 & 7.0 & 6.7375 & TST \\
\hline CHEMBL3949598 & 1637320 & 6.0 & 6.4948 & TRN \\
\hline CHEMBL3981766 & 1637320 & 9.0 & 7.8102 & TRN \\
\hline CHEMBL3915507 & 1637320 & 7.0 & 6.6336 & TST \\
\hline CHEMBL3958002 & 1637320 & 9.0 & 7.7842 & TRN \\
\hline CHEMBL3965587 & 1637320 & 7.0 & 7.7047 & TRN \\
\hline CHEMBL3983501 & 1637320 & 9.0 & 7.4493 & TRN \\
\hline CHEMBL3938051 & 1637320 & 9.0 & 7.7371 & TST \\
\hline CHEMBL3978536 & 1637320 & 9.0 & 7.5397 & TRN \\
\hline CHEMBL3940108 & 1637320 & 7.0 & 7.6903 & TRN \\
\hline CHEMBL3979671 & 1637320 & 7.0 & 7.6301 & TRN \\
\hline CHEMBL3898123 & 1637320 & 9.0 & 7.7809 & TRN \\
\hline CHEMBL3953383 & 1637320 & 9.0 & 7.5692 & TST \\
\hline CHEMBL3946142 & 1637320 & 6.301 & 6.6446 & TST \\
\hline CHEMBL3967743 & 1637320 & 7.0 & 7.5787 & TRN \\
\hline CHEMBL3933201 & 1637320 & 9.0 & 7.7714 & TRN \\
\hline CHEMBL3941336 & 1637320 & 6.301 & 7.5788 & TRN \\
\hline CHEMBL3922040 & 1637320 & 9.0 & 7.4725 & TRN \\
\hline CHEMBL3972221 & 1637320 & 6.0 & 6.1331 & TST \\
\hline CHEMBL3958382 & 1637320 & 7.0 & 7.596 & TST \\
\hline CHEMBL 3984184 & 1637320 & 9.0 & 7.669 & TST \\
\hline CHEMBL 3892276 & 1637320 & 7.0 & 7.6939 & TRN \\
\hline CHEMBL3958933 & 1637320 & 7.0 & 6.6987 & TST \\
\hline CHEMBL3910630 & 1637320 & 7.0 & 6.8535 & TST \\
\hline CHEMBL3921362 & 1637320 & 9.0 & 6.5363 & TST \\
\hline CHEMBL3908773 & 1637320 & 9.0 & 7.7838 & TRN \\
\hline CHEMBL3971619 & 1637320 & 7.0 & 7.5238 & TRN \\
\hline CHEMBL3917446 & 1637320 & 7.0 & 7.6932 & TRN \\
\hline CHEMBL3947572 & 1637320 & 7.0 & 7.3312 & TRN \\
\hline CHEMBL3983841 & 1637320 & 6.301 & 6.4889 & TST \\
\hline CHEMBL3931739 & 1637320 & 9.0 & 7.8102 & TRN \\
\hline CHEMBL3984158 & 1637320 & 7.0 & 6.5188 & TST \\
\hline CHEMBL3915423 & 1637320 & 6.301 & 6.8869 & TRN \\
\hline CHEMBL3965049 & 1637320 & 9.0 & 7.7517 & TRN \\
\hline CHEMBL3982495 & 1637320 & 7.0 & 7.7028 & TRN \\
\hline CHEMBL 3898820 & 1637320 & 7.0 & 7.7836 & TRN \\
\hline CHEMBL3986198 & 1637320 & 9.0 & 7.0903 & TRN \\
\hline CHEMBL3922382 & 1637320 & 9.0 & 7.7522 & TRN \\
\hline CHEMBL3922657 & 1637320 & 9.0 & 7.6499 & TST \\
\hline CHEMBL3910628 & 1637320 & 6.301 & 6.4009 & TST \\
\hline CHEMBL3975089 & 1637320 & 6.0 & 6.4815 & TST \\
\hline CHEMBL3917324 & 1637320 & 6.301 & 6.5714 & TST \\
\hline CHEMBL 3980275 & 1637320 & 7.0 & 6.6606 & TRN \\
\hline CHEMBL3981886 & 1637320 & 7.0 & 7.6917 & TRN \\
\hline CHEMBL3961564 & 1637320 & 6.301 & 6.3053 & TST \\
\hline CHEMBL 3924081 & 1637320 & 6.301 & 6.5452 & TST \\
\hline \multirow[t]{2}{*}{ CHEMBL3913286 } & 1637320 & 6.301 & 7.67200 & 3000000001 \\
\hline & & \multicolumn{3}{|c|}{ Page 10892} \\
\hline
\end{tabular}




\begin{tabular}{|c|c|c|c|c|c|}
\hline & & & oplement & & \\
\hline CHEMBL 3936415 & 1637320 & 7.0 & 7.7371 & TRN & \\
\hline CHEMBL3961498 & 1637320 & 7.0 & 7.50799 & 9999999999 & TRN \\
\hline CHEMBL3913246 & 1637320 & 7.0 & 7.7225 & TRN & \\
\hline CHEMBL 3947131 & 1637320 & 6.301 & 7.7968 & TRN & \\
\hline CHEMBL3975689 & 1637320 & 7.0 & 7.7809 & TRN & \\
\hline CHEMBL3905971 & 1637320 & 7.0 & 6.6224 & TRN & \\
\hline CHEMBL 3943023 & 1637320 & 7.0 & 6.7585 & TRN & \\
\hline CHEMBL3939666 & 1637320 & 7.0 & 7.5819 & TRN & \\
\hline CHEMBL 3949147 & 1637320 & 7.0 & 7.7882 & TRN & \\
\hline CHEMBL3901336 & 1637320 & 9.0 & 7.7517 & TRN & \\
\hline CHEMBL 3962987 & 1637320 & 9.0 & 7.7273 & TRN & \\
\hline CHEMBL 3934829 & 1637320 & 6.301 & 7.8248 & TRN & \\
\hline CHEMBL3938282 & 1637320 & 6.301 & 6.7773 & TRN & \\
\hline CHEMBL 3977847 & 1637320 & 9.0 & 7.8102 & TRN & \\
\hline CHEMBL 3893843 & 1637320 & 6.0 & 6.1855 & TRN & \\
\hline CHEMBL 3927704 & 1637320 & 7.0 & 7.7144 & TRN & \\
\hline CHEMBL 3926507 & 1637320 & 9.0 & 7.7334 & TRN & \\
\hline CHEMBL3898382 & 1637320 & 7.0 & 6.5802 & TST & \\
\hline CHEMBL3982699 & 1637320 & 7.0 & 7.5398 & TRN & \\
\hline CHEMBL 3941400 & 1637320 & 6.301 & 6.6271 & TRN & \\
\hline CHEMBL 3974147 & 1637320 & 6.301 & 6.4552 & TRN & \\
\hline CHEMBL 3898766 & 1637320 & 6.301 & 6.6783 & TRN & \\
\hline CHEMBL3924512 & 1637320 & 7.0 & 6.5692 & TST & \\
\hline CHEMBL3980116 & 1637320 & 6.301 & 6.3819 & TRN & \\
\hline CHEMBL 3895021 & 1637320 & 6.301 & 7.7057 & TRN & \\
\hline CHEMBL 3924980 & 1637320 & 9.0 & 7.7933 & TRN & \\
\hline CHEMBL 3970607 & 1637320 & 9.0 & 7.796 & TRN & \\
\hline CHEMBL3948999 & 1637320 & 7.0 & 7.8175 & TRN & \\
\hline CHEMBL 3927538 & 1637320 & 9.0 & 7.7347 & TRN & \\
\hline CHEMBL 3913298 & 1637320 & 7.0 & 6.8087 & TRN & \\
\hline CHEMBL 3898930 & 1637320 & 9.0 & 7.62299 & 9999999999 & TST \\
\hline CHEMBL 3958043 & 1637320 & 7.0 & 7.7057 & TRN & \\
\hline CHEMBL 3978627 & 1637320 & 6.301 & 7.4977 & TRN & \\
\hline CHEMBL3929735 & 1637320 & 6.301 & 6.5325 & TST & \\
\hline CHEMBL 3914756 & 1637320 & 6.301 & 7.4713 & TRN & \\
\hline CHEMBL3947349 & 1637320 & 6.301 & 7.8102 & TRN & \\
\hline CHEMBL 3941898 & 1637320 & 6.301 & 6.7767 & TRN & \\
\hline CHEMBL 3945039 & 1637320 & 7.0 & 7.7298 & TST & \\
\hline CHEMBL 3950173 & 1637320 & 7.0 & 6.4005 & TRN & \\
\hline CHEMBL 3920805 & 1637320 & 7.0 & 7.7495 & TRN & \\
\hline CHEMBL 3930452 & 1637320 & 7.0 & 7.7619 & TRN & \\
\hline CHEMBL 3928990 & 1637320 & 9.0 & 7.7882 & TRN & \\
\hline CHEMBL3906336 & 1637320 & 7.0 & 7.7641 & TRN & \\
\hline CHEMBL 3976504 & 1637320 & 7.0 & 6.7688 & TST & \\
\hline CHEMBL 3912827 & 1637320 & 6.301 & 6.4529 & TST & \\
\hline CHEMBL 3908824 & 1637320 & 7.0 & 7.8102 & TRN & \\
\hline CHEMBL 3935288 & 1637320 & 9.0 & 7.7809 & TRN & \\
\hline CHEMBL3981971 & 1637320 & 9.0 & 7.7663 & TRN & \\
\hline
\end{tabular}




\begin{tabular}{|c|c|c|c|c|c|}
\hline & & & & & \\
\hline CHEMBL 3921384 & 1637320 & 7.0 & 7.7568 & TRN & \\
\hline CHEMBL3943852 & 1637320 & 9.0 & 7.75899 & 99999999995 & TRN \\
\hline CHEMBL3979504 & 1637320 & 7.0 & 7.7809 & TRN & \\
\hline CHEMBL3945897 & 1637320 & 9.0 & 7.7495 & TRN & \\
\hline CHEMBL3954991 & 1637320 & 9.0 & 7.8175 & TRN & \\
\hline CHEMBL3955045 & 1637320 & 7.0 & 7.7546 & TRN & \\
\hline CHEMBL3937156 & 1637320 & 7.0 & 7.7785 & TRN & \\
\hline CHEMBL 3960627 & 1637320 & 7.0 & 7.7955 & TRN & \\
\hline CHEMBL3939733 & 1637320 & 6.0 & 7.6888 & TRN & \\
\hline CHEMBL3914549 & 1637320 & 9.0 & 7.8297 & TRN & \\
\hline CHEMBL3984476 & 1637320 & 9.0 & 7.7349 & TRN & \\
\hline CHEMBL3967338 & 1637320 & 7.0 & 7.607 & TST & \\
\hline CHEMBL3979530 & 1637320 & 7.0 & 6.8164 & TST & \\
\hline CHEMBL3902928 & 1637320 & 7.0 & 7.4351 & TRN & \\
\hline CHEMBL3949720 & 1637320 & 9.0 & 7.7225 & TRN & \\
\hline CHEMBL3973234 & 1637320 & 7.0 & 7.7327 & TRN & \\
\hline CHEMBL3908463 & 1637320 & 9.0 & 7.7349 & TRN & \\
\hline CHEMBL3934393 & 1637320 & 9.0 & 7.8007 & TRN & \\
\hline CHEMBL3920989 & 1637320 & 6.0 & 6.2359 & TRN & \\
\hline CHEMBL3984668 & 1637320 & 6.0 & 6.5403 & TRN & \\
\hline CHEMBL3927670 & 1637320 & 7.0 & 6.8126 & TST & \\
\hline CHEMBL3946123 & 1637320 & 7.0 & 6.699 & TRN & \\
\hline CHEMBL3890434 & 1637320 & 6.301 & 6.6979 & TRN & \\
\hline CHEMBL3897382 & 1637320 & 7.0 & 6.5934 & TRN & \\
\hline CHEMBL 3951028 & 1637320 & 7.0 & 7.6908 & TRN & \\
\hline CHEMBL3979825 & 1637320 & 7.0 & 7.6986 & TRN & \\
\hline CHEMBL3907726 & 1637320 & 9.0 & $7.6560 e$ & 0000000001 & TRN \\
\hline CHEMBL 3930325 & 1637320 & 6.301 & 6.6367 & TRN & \\
\hline CHEMBL3893627 & 1637320 & 6.301 & 6.6079 & TST & \\
\hline CHEMBL 3985568 & 1637320 & 6.0 & 6.7512 & TRN & \\
\hline CHEMBL3976626 & 1637320 & 7.0 & 7.8102 & TRN & \\
\hline CHEMBL3971101 & 1637320 & 7.0 & 6.5524 & TST & \\
\hline CHEMBL3915499 & 1637320 & 9.0 & 7.7361 & TST & \\
\hline CHEMBL3986743 & 1637320 & 7.0 & 6.7597 & TRN & \\
\hline CHEMBL 3970498 & 1637320 & 6.301 & 6.7032 & TRN & \\
\hline CHEMBL3959944 & 1637320 & 7.0 & 6.20799 & 9999999999 & TRN \\
\hline CHEMBL3914532 & 1637320 & 7.0 & 6.5766 & TST & \\
\hline CHEMBL3964438 & 1637320 & 7.0 & 6.6016 & TRN & \\
\hline CHEMBL3918595 & 1637320 & 7.0 & 7.6947 & TRN & \\
\hline CHEMBL 3895868 & 1637320 & 6.0 & 6.6062 & TRN & \\
\hline CHEMBL3952213 & 1637320 & 7.0 & 6.3844 & TRN & \\
\hline CHEMBL3947205 & 1637320 & 7.0 & 7.403 & TRN & \\
\hline CHEMBL3941334 & 1637320 & 9.0 & 7.7451 & TRN & \\
\hline CHEMBL3954565 & 1637320 & 7.0 & 7.1741 & TST & \\
\hline CHEMBL 3896630 & 1637320 & 7.0 & 7.7566 & TRN & \\
\hline CHEMBL3917371 & 1637320 & 6.301 & 7.8175 & TRN & \\
\hline CHEMBL3955753 & 1637320 & 9.0 & 7.5851 & TST & \\
\hline CHEMBL3908780 & 1637320 & 7.0 & 6.5765 & TRN & \\
\hline
\end{tabular}


Supplemental Table S2.txt

\begin{tabular}{|c|c|c|c|c|c|}
\hline CHEMBL3978964 & 1637320 & 6.301 & 7.6367 & TRN & \\
\hline CHEMBL3904301 & 1637320 & 9.0 & 7.7755 & TRN & \\
\hline CHEMBL3968973 & 1637320 & 7.0 & 7.596 & TRN & \\
\hline CHEMBL3948793 & 1637320 & 7.0 & 6.5349 & TST & \\
\hline CHEMBL3936342 & 1637320 & 7.0 & 6.7922 & TRN & \\
\hline CHEMBL3914084 & 1637320 & 9.0 & 7.7645 & TRN & \\
\hline CHEMBL3961956 & 1637320 & 6.301 & 6.3811 & TRN & \\
\hline CHEMBL3934511 & 1637320 & 7.0 & 7.4177 & TRN & \\
\hline CHEMBL3895594 & 1637320 & 9.0 & 7.7035 & TRN & \\
\hline CHEMBL3915630 & 1637320 & 6.0 & 6.5904 & TRN & \\
\hline CHEMBL3934692 & 1637320 & 7.0 & 6.5396 & TST & \\
\hline CHEMBL3968632 & 1637320 & 9.0 & 7.7737 & TRN & \\
\hline CHEMBL3907279 & 1637320 & 9.0 & 7.6764 & TST & \\
\hline CHEMBL3953617 & 1637320 & 9.0 & 7.7901 & TRN & \\
\hline CHEMBL 3973675 & 1637320 & 9.0 & 7.5763 & TST & \\
\hline CHEMBL3923848 & 1637320 & 6.301 & 6.5017 & TRN & \\
\hline CHEMBL3890137 & 1637320 & 9.0 & 7.6758 & TRN & \\
\hline CHEMBL3933071 & 1637320 & 7.0 & 7.4742 & TRN & \\
\hline CHEMBL3974704 & 1637320 & 6.301 & 6.1454 & TRN & \\
\hline CHEMBL 3944041 & 1637320 & 6.301 & 6.7474 & TRN & \\
\hline CHEMBL3935680 & 1637320 & 6.301 & 6.6884 & TRN & \\
\hline CHEMBL3907665 & 1637320 & 9.0 & 7.7378 & TRN & \\
\hline CHEMBL3965032 & 1637320 & 9.0 & 7.7144 & TST & \\
\hline CHEMBL3924659 & 1637320 & 9.0 & 7.5989 & TRN & \\
\hline CHEMBL3914575 & 1637320 & 7.0 & 7.4855 & TRN & \\
\hline CHEMBL3890938 & 1637320 & 7.0 & 7.6238 & TRN & \\
\hline CHEMBL3926544 & 1637320 & 6.0 & 6.688 & TRN & \\
\hline CHEMBL3926335 & 1637320 & 6.301 & 6.3807 & TRN & \\
\hline CHEMBL3936845 & 1637320 & 6.301 & 6.4925 & TRN & \\
\hline CHEMBL 3970818 & 1637320 & 7.0 & 6.77 & TRN & \\
\hline CHEMBL3918254 & 1637320 & 6.301 & 6.5677 & TRN & \\
\hline CHEMBL3925174 & 1637320 & 6.301 & 6.5165 & TRN & \\
\hline CHEMBL3928484 & 1637320 & 6.301 & 7.7838 & TRN & \\
\hline CHEMBL 3932380 & 1637320 & 9.0 & 7.4709 & TST & \\
\hline CHEMBL3936441 & 1637320 & 7.0 & \multicolumn{2}{|c|}{6.792999999999999} & TRN \\
\hline CHEMBL3984246 & 1637320 & 9.0 & 7.7349 & TRN & \\
\hline CHEMBL3915302 & 1637320 & 7.0 & 7.6885 & TST & \\
\hline CHEMBL3946326 & 1637320 & 7.0 & 7.4385 & TRN & \\
\hline CHEMBL3907114 & 1637320 & 7.0 & 6.5302 & TST & \\
\hline CHEMBL3917339 & 1637320 & 9.0 & 7.7955 & TRN & \\
\hline CHEMBL3981082 & 1637320 & 6.0 & 6.5253 & TRN & \\
\hline CHEMBL3952589 & 1637320 & 7.0 & 7.7347 & TRN & \\
\hline CHEMBL3890357 & 1637320 & 6.0 & 6.4471 & TRN & \\
\hline CHEMBL3928974 & 1637320 & 7.0 & 6.5224 & TST & \\
\hline CHEMBL3970916 & 1637320 & 6.0 & 6.3587 & TST & \\
\hline CHEMBL 3934142 & 1637320 & 7.0 & 7.3767 & TST & \\
\hline CHEMBL3911880 & 1637320 & 6.301 & 7.4747 & TRN & \\
\hline CHEMBL3931371 & 1637320 & 7.0 & 6.4772 & TST & \\
\hline
\end{tabular}




\begin{tabular}{|c|c|c|c|c|}
\hline \multicolumn{5}{|c|}{ Supplemental Table S2.txt } \\
\hline CHEMBL3928482 & 1637320 & 7.0 & 7.6896 & TRN \\
\hline CHEMBL3953337 & 1637320 & 9.0 & 6.8068 & TRN \\
\hline CHEMBL 3894187 & 1637320 & 7.0 & 7.8007 & TRN \\
\hline CHEMBL 3947866 & 1637320 & 7.0 & 6.8291 & TRN \\
\hline CHEMBL3931280 & 1637320 & 7.0 & 7.5997 & TST \\
\hline CHEMBL3930823 & 1637320 & 9.0 & 7.5546 & TRN \\
\hline CHEMBL3921074 & 1637320 & 6.301 & 6.2819 & TRN \\
\hline CHEMBL3959533 & 1637320 & 7.0 & 7.4258 & TRN \\
\hline CHEMBL 3938758 & 1637320 & 6.301 & 6.3491 & TST \\
\hline CHEMBL3967883 & 1637320 & 9.0 & 7.6055 & TRN \\
\hline CHEMBL3941550 & 1637320 & 7.0 & 6.5297 & TRN \\
\hline CHEMBL 3924438 & 1637320 & 7.0 & 6.6433 & TST \\
\hline CHEMBL3943519 & 1637320 & 9.0 & 7.6129 & TRN \\
\hline CHEMBL 3954206 & 1637320 & 6.301 & 6.5576 & TRN \\
\hline CHEMBL3968145 & 1637320 & 7.0 & 7.6856 & TRN \\
\hline CHEMBL3928285 & 1637320 & 7.0 & 6.2708 & TRN \\
\hline CHEMBL3913894 & 1637320 & 7.0 & 7.4871 & TRN \\
\hline CHEMBL 3980875 & 1637320 & 7.0 & 7.8175 & TRN \\
\hline CHEMBL 3925144 & 1637320 & 7.0 & 7.563 & TRN \\
\hline CHEMBL3982556 & 1637320 & 6.301 & 6.6538 & TST \\
\hline CHEMBL3939867 & 1637320 & 7.0 & 7.6255 & TST \\
\hline CHEMBL3948879 & 1637320 & 6.301 & 7.7968 & TRN \\
\hline CHEMBL3916000 & 1637320 & 7.0 & 7.8226 & TRN \\
\hline CHEMBL 3914490 & 1637320 & 9.0 & 7.7495 & TRN \\
\hline CHEMBL3900135 & 1637320 & 7.0 & 7.6713 & TRN \\
\hline CHEMBL3930370 & 1637320 & 7.0 & $7.7020 e$ & 0000000001 \\
\hline CHEMBL3981303 & 1637320 & 7.0 & 7.7955 & TRN \\
\hline CHEMBL3927154 & 1637320 & 7.0 & 6.4355 & TST \\
\hline CHEMBL 3984226 & 1637320 & 9.0 & 7.7183 & TRN \\
\hline CHEMBL 3932892 & 1637320 & 7.0 & 7.5061 & TRN \\
\hline CHEMBL3972573 & 1637320 & 7.0 & 6.8577 & TRN \\
\hline CHEMBL3900462 & 1637320 & 7.0 & 7.4711 & TST \\
\hline CHEMBL3920589 & 1637320 & 7.0 & 7.5382 & TST \\
\hline CHEMBL 3978490 & 1637320 & 7.0 & 7.7568 & TRN \\
\hline CHEMBL3941704 & 1637320 & 9.0 & 7.7836 & TRN \\
\hline CHEMBL3945016 & 1637320 & 7.0 & 6.8126 & TRN \\
\hline CHEMBL3977176 & 1637320 & 7.0 & 7.5324 & TST \\
\hline CHEMBL3980119 & 1637320 & 7.0 & 6.8316 & TRN \\
\hline CHEMBL 3956837 & 1637320 & 9.0 & 7.7517 & TRN \\
\hline CHEMBL3904877 & 1637320 & 9.0 & 7.5248 & TRN \\
\hline CHEMBL3904170 & 1637320 & 7.0 & 6.5941 & TST \\
\hline CHEMBL3961075 & 1637320 & 9.0 & 7.7079 & TRN \\
\hline CHEMBL3898099 & 1637320 & 7.0 & 6.4432 & TRN \\
\hline CHEMBL 3933570 & 1637320 & 7.0 & 6.5616 & TRN \\
\hline CHEMBL3973731 & 1637320 & 7.0 & 6.513 & TST \\
\hline CHEMBL3963339 & 1637320 & 9.0 & 7.7955 & TRN \\
\hline CHEMBL3917271 & 1637320 & 9.0 & 7.7057 & TST \\
\hline CHEMBL3900894 & 1637320 & 7.0 & 7.7663 & TRN \\
\hline
\end{tabular}




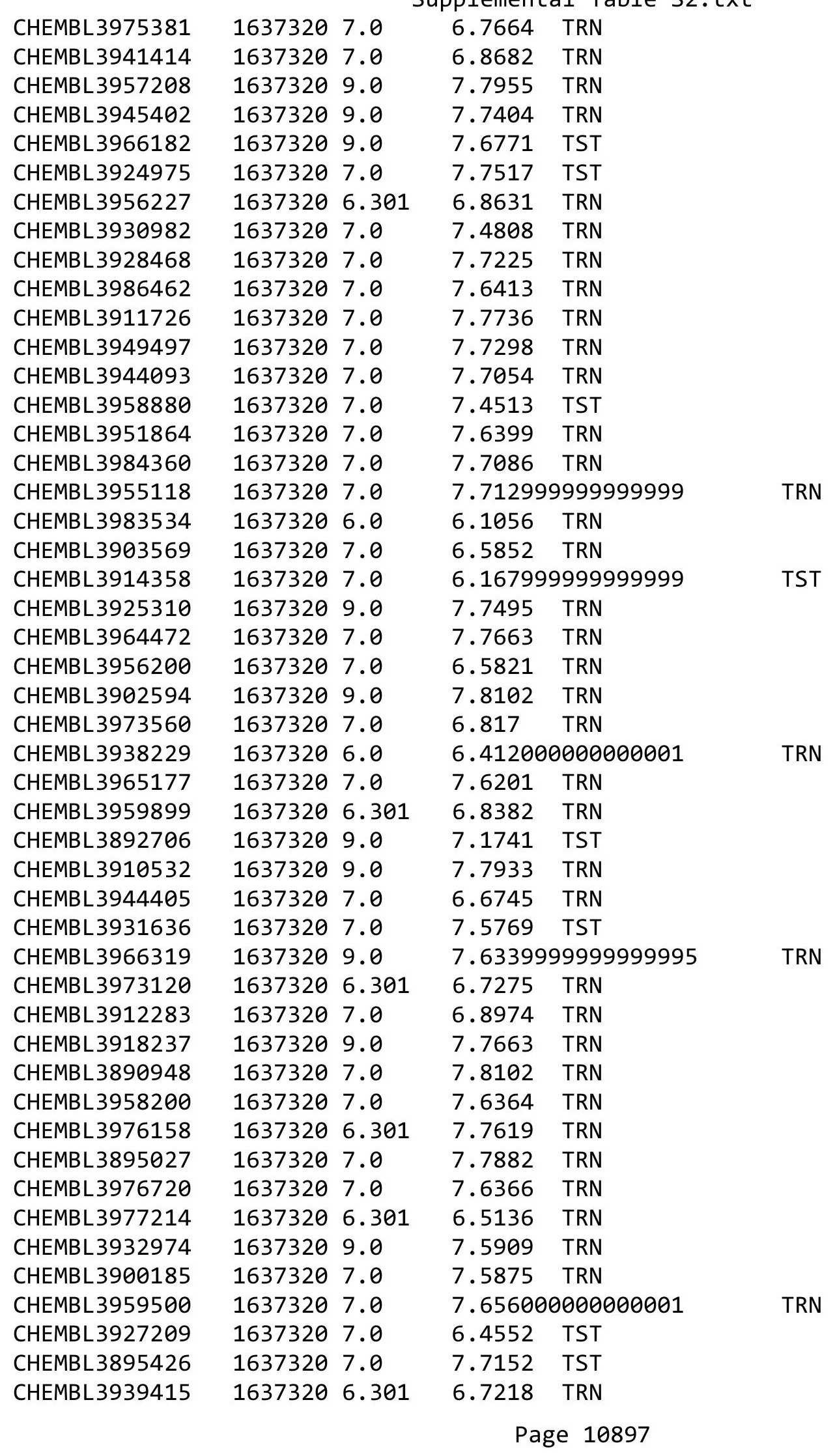


Supplemental Table S2.txt

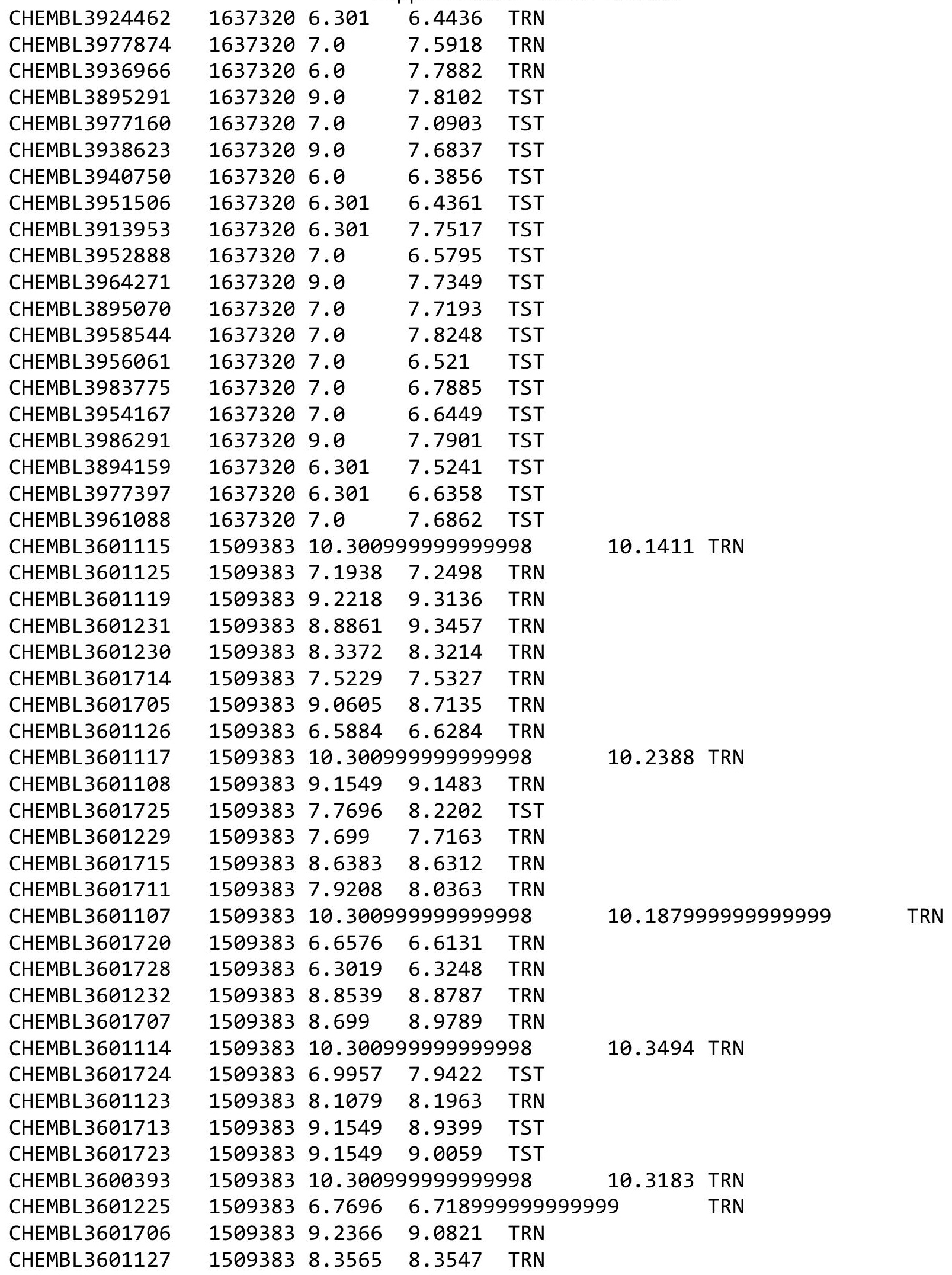

Page 10898 
Supplemental Table S2.txt

\begin{tabular}{|c|c|c|c|c|c|c|}
\hline CHEMBL 3601710 & 1509383 & 8.7959 & 8.7927 & TRN & & \\
\hline CHEMBL 3601861 & 1509383 & 5.5654 & 5.6515 & TRN & & \\
\hline CHEMBL 3601124 & 1509383 & 6.6108 & 6.7906 & TRN & & \\
\hline CHEMBL 3601726 & 1509383 & 9.0458 & 7.7663 & TST & & \\
\hline CHEMBL 3601224 & 1509383 & 7.3372 & 7.2383 & TRN & & \\
\hline CHEMBL 3601110 & 1509383 & 9.301 & 9.2799 & TRN & & \\
\hline CHEMBL 3601243 & 1509383 & 8.7696 & 8.7941 & TRN & & \\
\hline CHEMBL3601106 & 1509383 & 8.8539 & 8.8408 & TRN & & \\
\hline CHEMBL 3601719 & 1509383 & 7.5086 & 7.5048 & TRN & & \\
\hline CHEMBL3601236 & 1509383 & 8.4437 & 8.4877 & TRN & & \\
\hline CHEMBL 3601227 & 1509383 & 9.0458 & 9.0291 & TRN & & \\
\hline CHEMBL 3601121 & 1509383 & 9.2218 & 9.277000 & 0000000001 & & TRN \\
\hline CHEMBL 3601111 & 1509383 & 8.9586 & 8.9335 & TRN & & \\
\hline CHEMBL 3601233 & 1509383 & 9.0458 & 9.0263 & TRN & & \\
\hline CHEMBL3601116 & 1509383 & 10.30099 & 999999999 & 998 & 10.2963 & TRN \\
\hline CHEMBL 3601704 & 1509383 & 7.0809 & 7.031000 & 0000000001 & & TRN \\
\hline CHEMBL 3601118 & 1509383 & 9.1549 & 9.2256 & TRN & & \\
\hline CHEMBL 3601235 & 1509383 & 7.699 & 7.6933 & TRN & & \\
\hline CHEMBL 3601708 & 1509383 & 8.8861 & 9.0344 & TRN & & \\
\hline CHEMBL 3601237 & 1509383 & 8.1308 & 8.1357 & TRN & & \\
\hline CHEMBL 3601244 & 1509383 & 8.5376 & 8.7162 & TST & & \\
\hline CHEMBL 3601239 & 1509383 & 7.6198 & 7.7735 & TST & & \\
\hline CHEMBL 3601717 & 1509383 & 5.5901 & 5.5829 & TRN & & \\
\hline CHEMBL 3601122 & 1509383 & 6.4089 & 6.3807 & TRN & & \\
\hline CHEMBL 3601109 & 1509383 & 10.30099 & 999999999 & 998 & 9.9044 & TRN \\
\hline CHEMBL 3601862 & 1509383 & 8.6383 & 9.2894 & TST & & \\
\hline CHEMBL 3601120 & 1509383 & 10.30099 & э99999999 & 998 & 10.4479 & T TRT \\
\hline CHEMBL 3601716 & 1509383 & 7.7447 & 7.6744 & TRN & & \\
\hline CHEMBL 3601234 & 1509383 & 8.283999 & 999999999 & & 8.2311 & TRN \\
\hline CHEMBL 3601113 & 1509383 & 10.30099 & 999999999 & 998 & 10.3354 & TRN \\
\hline CHEMBL 3601721 & 1509383 & 6.6536 & 6.4351 & TRN & & \\
\hline CHEMBL 3601112 & 1509383 & 9.2218 & 9.1538 & TRN & & \\
\hline CHEMBL 3601722 & 1509383 & 8.0044 & 6.7362 & TST & & \\
\hline CHEMBL 3601242 & 1509383 & 9.2218 & 10.0712 & TST & & \\
\hline CHEMBL 3601727 & 1509383 & 8.1549 & 8.1155 & TST & & \\
\hline CHEMBL 3601226 & 1509383 & 8.9208 & 9.0426 & TST & & \\
\hline CHEMBL 3601238 & 1509383 & 8.2076 & 8.5755 & TST & & \\
\hline CHEMBL 3601223 & 1509383 & 8.3188 & 7.9114 & TST & & \\
\hline CHEMBL 3601712 & 1509383 & 8.9208 & 10.0164 & TST & & \\
\hline CHEMBL 3601228 & 1509383 & 8.699 & 8.8536 & TST & & \\
\hline CHEMBL 3601718 & 1509383 & 7.5086 & 7.0874 & TST & & \\
\hline CHEMBL 3601709 & 1509383 & 8.1805 & 6.653 & TST & & \\
\hline CHEMBL1407203 & 736852 & 3.0044 & 3.1511 & TRN & & \\
\hline CHEMBL1736022 & 736852 & 3.0 & 3.9697 & TRN & & \\
\hline CHEMBL1447397 & 736852 & 3.0044 & 2.4614 & TRN & & \\
\hline CHEMBL 3193786 & 736852 & 5.1135 & 5.2171 & TRN & & \\
\hline CHEMBL1385949 & 736852 & 3.0044 & 4.5073 & TST & & \\
\hline CHEMBL1717981 & 736852 & 3.0 & 2.9383 & TRN & & \\
\hline
\end{tabular}




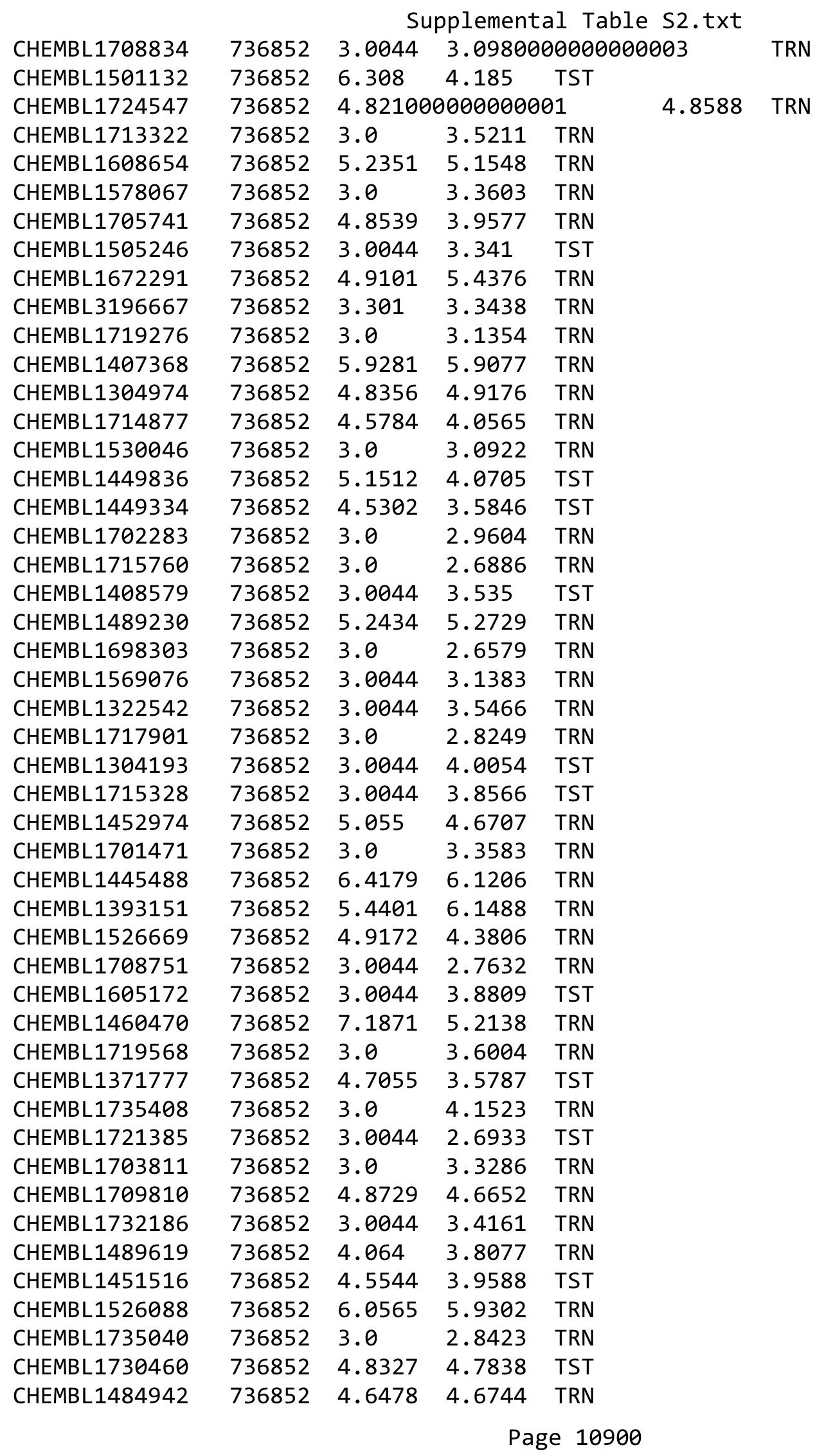




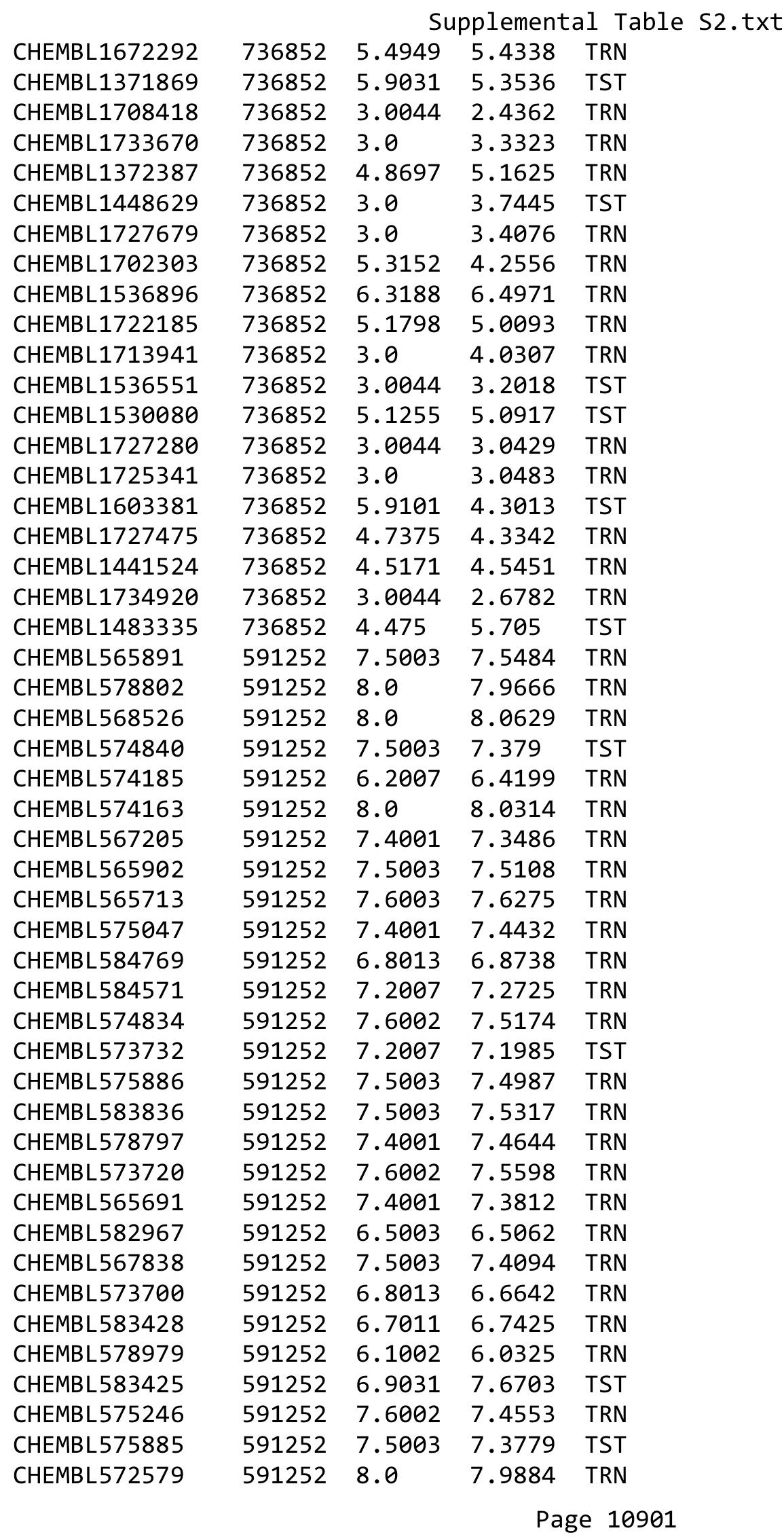


Supplemental Table S2.txt

\begin{tabular}{|c|c|c|c|c|}
\hline CHEMBL578376 & 591252 & 7.5003 & 7.4207 & TRN \\
\hline CHEMBL583934 & 591252 & 8.1002 & 8.0632 & TRN \\
\hline CHEMBL574164 & 591252 & 7.5003 & 7.5856 & TRN \\
\hline CHEMBL576627 & 591252 & 7.2007 & 7.2139 & TRN \\
\hline CHEMBL575464 & 591252 & 8.0 & 8.0323 & TRN \\
\hline CHEMBL578558 & 591252 & 7.4001 & 7.1363 & TRN \\
\hline CHEMBL583493 & 591252 & 6.1002 & 6.3389 & TRN \\
\hline CHEMBL584137 & 591252 & 7.5003 & 7.4841 & TRN \\
\hline CHEMBL583839 & 591252 & 7.5003 & 7.33299 & э999999999 \\
\hline CHEMBL573021 & 591252 & 7.3002 & 7.2763 & TRN \\
\hline CHEMBL566761 & 591252 & 7.7011 & 7.9245 & TRN \\
\hline CHEMBL577277 & 591252 & 7.7011 & 7.7505 & TRN \\
\hline CHEMBL366692 & 591252 & 7.2 & 7.3563 & TST \\
\hline CHEMBL575458 & 591252 & 7.5003 & 7.399 & TRN \\
\hline CHEMBL574374 & 591252 & 7.5003 & 7.6108 & TRN \\
\hline CHEMBL573185 & 591252 & 7.8013 & 7.8258 & TRN \\
\hline CHEMBL575884 & 591252 & 7.4001 & 7.4987 & TRN \\
\hline CHEMBL576184 & 591252 & 7.6002 & 7.5935 & TRN \\
\hline CHEMBL565890 & 591252 & 7.3002 & 7.2108 & TRN \\
\hline CHEMBL572509 & 591252 & 7.4001 & 7.1089 & TRN \\
\hline CHEMBL584409 & 591252 & 8.1024 & 8.1572 & TRN \\
\hline CHEMBL565477 & 591252 & 8.2007 & 8.2421 & TRN \\
\hline CHEMBL568278 & 591252 & 7.5003 & 7.5087 & TRN \\
\hline CHEMBL566750 & 591252 & 8.2007 & 7.9873 & TRN \\
\hline CHEMBL567623 & 591252 & 8.2007 & 8.2478 & TRN \\
\hline CHEMBL566751 & 591252 & 8.0 & 7.9502 & TRN \\
\hline CHEMBL583614 & 591252 & 7.5003 & 7.4668 & TRN \\
\hline CHEMBL576592 & 591252 & 7.4001 & 7.4279 & TRN \\
\hline CHEMBL578764 & 591252 & 7.8013 & 7.8715 & TRN \\
\hline CHEMBL575040 & 591252 & 5.9003 & 6.8321 & TST \\
\hline CHEMBL572798 & 591252 & 7.4001 & 7.3717 & TRN \\
\hline CHEMBL574592 & 591252 & 6.2007 & 6.3301 & TRN \\
\hline CHEMBL567214 & 591252 & 7.4001 & 7.2234 & TRN \\
\hline CHEMBL573467 & 591252 & 7.4001 & 7.3383 & TRN \\
\hline CHEMBL573699 & 591252 & 7.5003 & 7.4608 & TRN \\
\hline CHEMBL575683 & 591252 & 6.7011 & 6.7641 & TRN \\
\hline CHEMBL566547 & 591252 & 7.5003 & 7.5946 & TRN \\
\hline CHEMBL233664 & 591252 & 7.7011 & 7.7801 & TRN \\
\hline CHEMBL568496 & 591252 & 7.4001 & 7.2915 & TRN \\
\hline CHEMBL565690 & 591252 & 7.5003 & 7.7181 & TRN \\
\hline CHEMBL573960 & 591252 & 6.7011 & 6.7485 & TRN \\
\hline CHEMBL568065 & 591252 & 7.6003 & 7.5586 & TRN \\
\hline CHEMBL565903 & 591252 & 7.6003 & 7.6672 & TRN \\
\hline CHEMBL566556 & 591252 & 7.5003 & 7.5194 & TRN \\
\hline CHEMBL567204 & 591252 & 8.301 & 8.2772 & TRN \\
\hline CHEMBL572507 & 591252 & 8.1024 & 8.0752 & TRN \\
\hline CHEMBL576961 & 591252 & 7.2007 & 7.3437 & TST \\
\hline CHEMBL567215 & 591252 & 7.0 & 6.9671 & TRN \\
\hline
\end{tabular}




\begin{tabular}{|c|c|c|c|c|c|}
\hline \multirow[b]{2}{*}{ CHEMBL573489 } & \multicolumn{5}{|c|}{ Supplemental Table s2.txt } \\
\hline & 591252 & 7.4001 & 7.2557 & TRN & \\
\hline CHEMBL565680 & 591252 & 7.8013 & 7.9221 & TST & \\
\hline CHEMBL566555 & 591252 & 7.6003 & 7.7819 & TST & \\
\hline CHEMBL566546 & 591252 & 6.8013 & 7.3002 & TST & \\
\hline CHEMBL338047 & 591252 & 7.0 & 6.8747 & TST & \\
\hline CHEMBL577276 & 591252 & 7.5003 & 7.6436 & TST & \\
\hline CHEMBL584160 & 591252 & 8.0 & 7.6971 & TST & \\
\hline CHEMBL573020 & 591252 & 6.7011 & 6.7563 & TST & \\
\hline CHEMBL565703 & 591252 & 7.5003 & 7.7545 & TST & \\
\hline CHEMBL565689 & 591252 & 7.4001 & 7.5115 & TST & \\
\hline CHEMBL565702 & 591252 & 7.3002 & 7.46200 & 0000000001 & TST \\
\hline CHEMBL578367 & 591252 & 8.2007 & 8.1243 & TST & \\
\hline CHEMBL574141 & 591252 & 7.5003 & 7.5569 & TST & \\
\hline CHEMBL577247 & 591252 & 8.2291 & 8.1093 & TST & \\
\hline CHEMBL567837 & 591252 & 8.1002 & 8.3702 & TST & \\
\hline CHEMBL565712 & 591252 & 6.8013 & 6.9014 & TST & \\
\hline CHEMBL1334710 & 737353 & 5.3645 & 4.8795 & TRN & \\
\hline CHEMBL1546307 & 737353 & 3.0 & 3.19199 & 99999999997 & TST \\
\hline CHEMBL1699194 & 737353 & 5.6253 & 5.274 & TRN & \\
\hline CHEMBL587759 & 737353 & 4.7258 & 4.837 & TRN & \\
\hline CHEMBL1736975 & 737353 & 4.4056 & 5.1621 & TRN & \\
\hline CHEMBL1702405 & 737353 & 5.3125 & 5.3029 & TRN & \\
\hline CHEMBL1325487 & 737353 & 4.8962 & 3.6313 & TST & \\
\hline CHEMBL1326265 & 737353 & 3.0 & 2.7833 & TRN & \\
\hline CHEMBL1709944 & 737353 & 5.3045 & 5.0561 & TRN & \\
\hline CHEMBL1487722 & 737353 & 5.2526 & 4.9779 & TRN & \\
\hline CHEMBL599359 & 737353 & 3.0 & 3.0158 & TRN & \\
\hline CHEMBL148645 & 737353 & 5.5143 & 5.2292 & TRN & \\
\hline CHEMBL1527436 & 737353 & 3.0 & 2.7573 & TRN & \\
\hline CHEMBL1718270 & 737353 & 3.0 & 3.1836 & TST & \\
\hline CHEMBL1733841 & 737353 & 3.0 & 3.1912 & TRN & \\
\hline CHEMBL1570045 & 737353 & 3.0 & 3.1899 & TST & \\
\hline CHEMBL1722831 & 737353 & 3.0 & 3.1615 & TST & \\
\hline CHEMBL1409617 & 737353 & 3.0 & 3.4796 & TST & \\
\hline CHEMBL1410922 & 737353 & 3.0 & 3.2103 & TRN & \\
\hline CHEMBL599678 & 737353 & 3.0 & $3.9530 e$ & 00000000003 & TRN \\
\hline CHEMBL1705410 & 737353 & 4.3526 & 4.3153 & TRN & \\
\hline CHEMBL1524082 & 737353 & 3.0 & 3.1025 & TRN & \\
\hline CHEMBL1725074 & 737353 & 4.8239 & 4.5401 & TRN & \\
\hline CHEMBL358546 & 737353 & 4.9431 & 5.0529 & TRN & \\
\hline CHEMBL1497466 & 737353 & 3.0 & 3.2765 & TST & \\
\hline CHEMBL596813 & 737353 & 4.2907 & 4.1485 & TRN & \\
\hline CHEMBL1420033 & 737353 & 4.0 & 3.5949 & TRN & \\
\hline CHEMBL1703867 & 737353 & 3.0 & 3.0597 & TRN & \\
\hline CHEMBL1732820 & 737353 & 5.0675 & 5.2448 & TRN & \\
\hline CHEMBL1718174 & 737353 & 5.0575 & 4.8397 & TRN & \\
\hline CHEMBL467853 & 737353 & 3.0 & 2.9492 & TRN & \\
\hline CHEMBL445965 & 737353 & 3.0 & 3.0934 & TRN & \\
\hline
\end{tabular}




\begin{tabular}{|c|c|c|c|c|c|}
\hline \multicolumn{6}{|c|}{ Supplemental Table S2.txt } \\
\hline CHEMBL1723614 & 737353 & 3.0 & 4.6368 & TRN & \\
\hline CHEMBL1490165 & 737353 & 3.0 & 3.2875 & TRN & \\
\hline CHEMBL1451022 & 737353 & 3.0 & 3.245 & TRN & \\
\hline CHEMBL1609596 & 737353 & 3.0 & 3.1377 & TRN & \\
\hline CHEMBL1562738 & 737353 & 3.0 & 2.9126 & TRN & \\
\hline CHEMBL1591163 & 737353 & 4.8665 & 4.9621 & TRN & \\
\hline CHEMBL1452776 & 737353 & 3.0 & 3.3008 & TRN & \\
\hline CHEMBL1414254 & 737353 & 3.0 & 3.6486 & TST & \\
\hline CHEMBL1324863 & 737353 & 3.0 & 3.3036 & TRN & \\
\hline CHEMBL254255 & 737353 & 5.8477 & 5.2778 & TRN & \\
\hline CHEMBL585591 & 737353 & 3.0 & 3.4639 & TST & \\
\hline CHEMBL1699317 & 737353 & 5.4283 & 5.2796 & TRN & \\
\hline CHEMBL1523213 & 737353 & 3.0 & 3.1976 & TRN & \\
\hline CHEMBL1359140 & 737353 & 3.0 & 2.887 & TRN & \\
\hline CHEMBL1717050 & 737353 & 5.0205 & 4.8311 & TRN & \\
\hline CHEMBL1371339 & 737353 & 5.5452 & 3.4814 & TST & \\
\hline CHEMBL1703256 & 737353 & 3.0 & 3.3795 & TST & \\
\hline CHEMBL468676 & 737353 & 3.0 & 2.7933 & TRN & \\
\hline CHEMBL1521009 & 737353 & 3.0 & \multicolumn{2}{|c|}{3.2539999999999996} & TRN \\
\hline CHEMBL 610508 & 737353 & 5.5302 & 5.4285 & TRN & \\
\hline CHEMBL455023 & 737353 & 3.0 & 2.8574 & TRN & \\
\hline CHEMBL1714675 & 737353 & 5.2741 & 4.8009 & TRN & \\
\hline CHEMBL1529865 & 737353 & 3.0 & 3.3159 & TRN & \\
\hline CHEMBL1718162 & 737353 & 4.0348 & 3.446 & TST & \\
\hline CHEMBL1709345 & 737353 & 3.0 & 3.5511 & TST & \\
\hline CHEMBL1338906 & 737353 & 3.0 & \multicolumn{2}{|c|}{3.1180000000000003} & TRN \\
\hline CHEMBL502169 & 737353 & 3.0 & 2.7774 & TRN & \\
\hline CHEMBL1723324 & 737353 & 3.0 & 3.9161 & TRN & \\
\hline CHEMBL556847 & 737353 & 5.1415 & 4.8202 & TRN & \\
\hline CHEMBL1459896 & 737353 & 4.0921 & 3.2985 & TST & \\
\hline CHEMBL1334421 & 737353 & 3.0 & 3.3083 & TRN & \\
\hline CHEMBL509575 & 737353 & 3.0 & 3.1334 & TRN & \\
\hline CHEMBL1713061 & 737353 & 4.7645 & 5.1972 & TRN & \\
\hline CHEMBL1709736 & 737353 & 4.9318 & 4.8414 & TRN & \\
\hline CHEMBL1704727 & 737353 & 4.6021 & 4.8211 & TRN & \\
\hline CHEMBL1718423 & 737353 & 3.0 & \multicolumn{2}{|c|}{3.7030000000000003} & TST \\
\hline CHEMBL1450091 & 737353 & 3.0 & 2.4175 & TRN & \\
\hline CHEMBL1438508 & 737353 & 3.0 & 2.84 & TST & \\
\hline CHEMBL1319346 & 737353 & 3.0 & 3.0304 & TRN & \\
\hline CHEMBL346451 & 737353 & 5.3197 & 5.2259 & TRN & \\
\hline CHEMBL1735198 & 737353 & 4.056 & 3.3615 & TST & \\
\hline CHEMBL1705728 & 737353 & 3.0 & 4.1147 & TRN & \\
\hline CHEMBL1408338 & 737353 & 3.0 & 2.8317 & TRN & \\
\hline CHEMBL1529466 & 737353 & 3.0 & 2.9892 & TRN & \\
\hline CHEMBL1526624 & 737353 & 5.4123 & 5.4634 & TRN & \\
\hline CHEMBL1523405 & 737353 & 3.0 & 2.85699 & 99999999998 & TRN \\
\hline CHEMBL599967 & 737353 & 3.0 & $3.2560 e$ & 20000000002 & TRN \\
\hline CHEMBL1530380 & 737353 & 3.0 & 3.2427 & TRN & \\
\hline
\end{tabular}




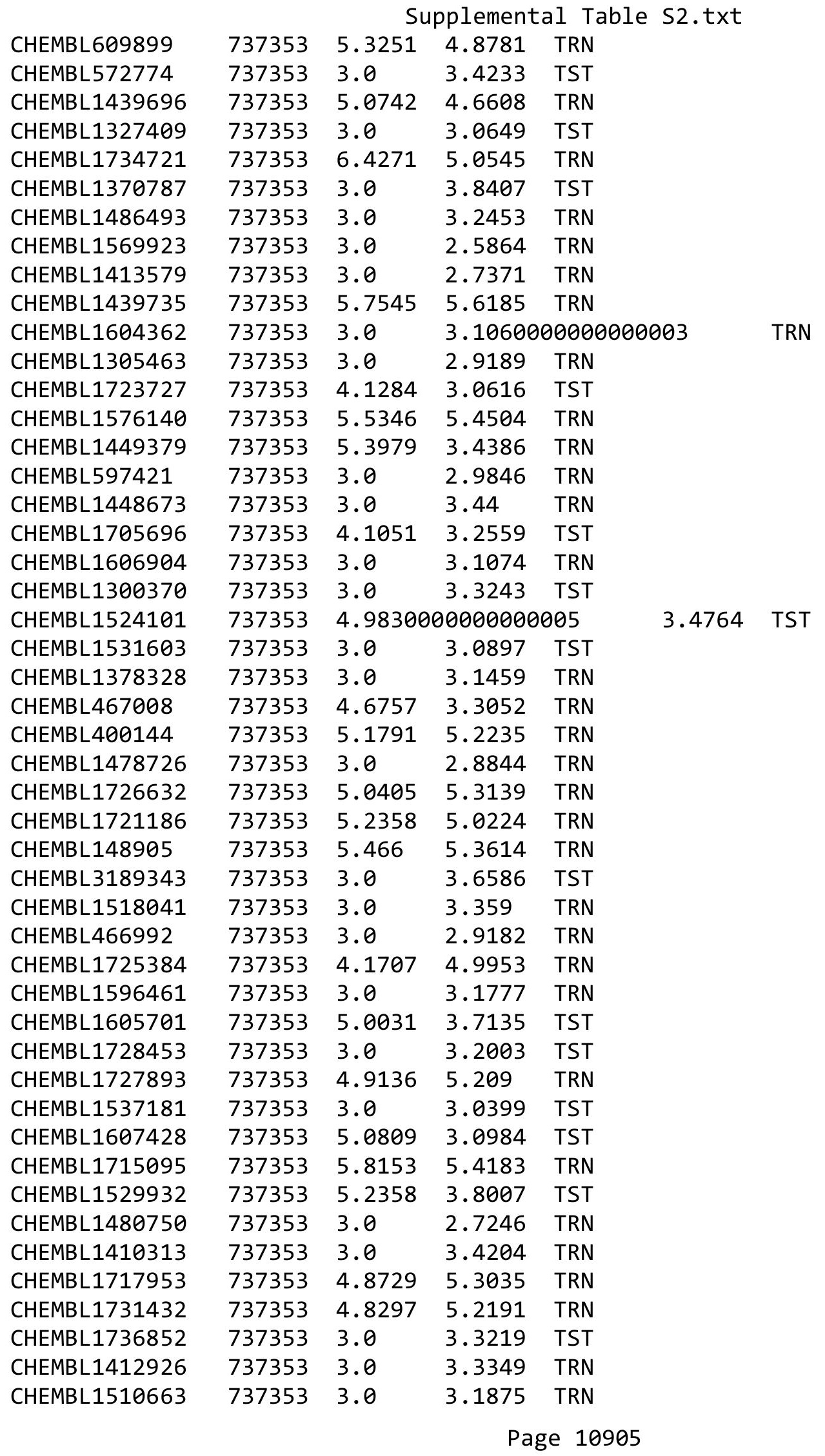




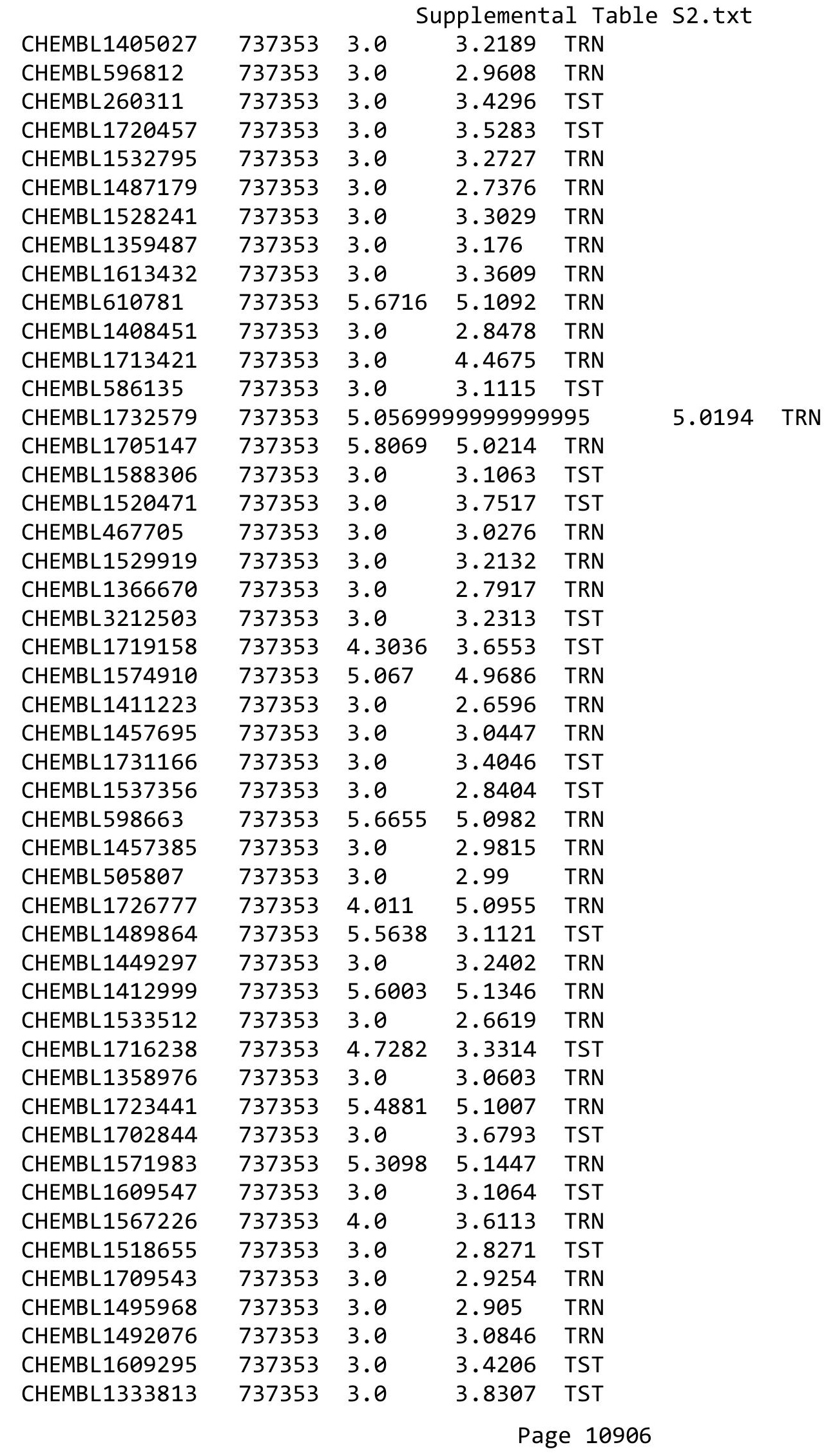




\begin{tabular}{|c|c|c|c|c|c|}
\hline & & \multicolumn{4}{|c|}{ Supplemental Table S2.txt } \\
\hline CHEMBL501296 & 737353 & 3.6021 & 3.1695 & TRN & \\
\hline CHEMBL594957 & 737353 & 3.0 & 2.8903 & TRN & \\
\hline CHEMBL1608135 & 737353 & 3.0 & 3.2674 & TRN & \\
\hline CHEMBL1711577 & 737353 & 3.0 & 3.343 & TST & \\
\hline CHEMBL1450666 & 737353 & 3.0 & 3.4822 & TRN & \\
\hline CHEMBL1720160 & 737353 & 4.8013 & 5.2867 & TRN & \\
\hline CHEMBL1532702 & 737353 & 3.0 & 3.04600 & 00000000003 & TRN \\
\hline CHEMBL1531945 & 737353 & 3.0 & 3.043 & TRN & \\
\hline CHEMBL1544838 & 737353 & 3.0 & 2.7472 & TRN & \\
\hline CHEMBL1486827 & 737353 & 3.0 & 4.2545 & TST & \\
\hline CHEMBL1407614 & 737353 & 4.9393 & 3.6386 & TRN & \\
\hline CHEMBL1737011 & 737353 & 4.2557 & 3.2626 & TST & \\
\hline CHEMBL1450066 & 737353 & 3.0 & 3.0988 & TRN & \\
\hline CHEMBL1730628 & 737353 & 4.0381 & 3.1748 & TST & \\
\hline CHEMBL1470219 & 737353 & 3.0 & 2.8338 & TRN & \\
\hline CHEMBL1707715 & 737353 & 5.2434 & 5.0856 & TRN & \\
\hline CHEMBL1362833 & 737353 & 3.0 & 2.9507 & TRN & \\
\hline CHEMBL1727550 & 737353 & 5.5969 & 5.1036 & TRN & \\
\hline CHEMBL1732263 & 737353 & 5.983 & 4.8319 & TST & \\
\hline CHEMBL468685 & 737353 & 3.0 & 2.8358 & TRN & \\
\hline CHEMBL1400401 & 737353 & 3.0 & 3.0411 & TRN & \\
\hline CHEMBL1735993 & 737353 & 3.0 & 3.6744 & TRN & \\
\hline CHEMBL1527423 & 737353 & 3.0 & 2.7618 & TRN & \\
\hline CHEMBL549785 & 737353 & 5.2336 & 4.7677 & TRN & \\
\hline CHEMBL1717729 & 737353 & 4.9281 & 5.0444 & TRN & \\
\hline CHEMBL592869 & 737353 & 6.0 & 4.9427 & TRN & \\
\hline CHEMBL1320284 & 737353 & 3.0 & 3.1103 & TRN & \\
\hline CHEMBL599476 & 737353 & 4.2782 & 3.9743 & TRN & \\
\hline CHEMBL467854 & 737353 & 3.0 & 3.1629 & TRN & \\
\hline CHEMBL1531645 & 737353 & 3.0 & 2.6632 & TRN & \\
\hline CHEMBL1706513 & 737353 & 5.8013 & 5.13299 & 9999999999 & TRN \\
\hline CHEMBL1546037 & 737353 & 3.0 & 3.0 & TRN & \\
\hline CHEMBL349641 & 737353 & 6.0 & 5.6413 & TRN & \\
\hline CHEMBL1407064 & 737353 & 3.0 & 3.1689 & TST & \\
\hline CHEMBL1730259 & 737353 & 4.7852 & 5.4721 & TRN & \\
\hline CHEMBL1606954 & 737353 & 3.0 & 2.9817 & TST & \\
\hline CHEMBL1479664 & 737353 & 3.0 & 3.542 & TST & \\
\hline CHEMBL468686 & 737353 & 3.0 & 2.8717 & TRN & \\
\hline CHEMBL1708865 & 737353 & 3.0 & 3.464 & TST & \\
\hline CHEMBL1413142 & 737353 & 3.0 & 3.1435 & TST & \\
\hline CHEMBL1609125 & 737353 & 3.0 & 2.8586 & TRN & \\
\hline CHEMBL1405576 & 737353 & 3.0 & 2.707 & TRN & \\
\hline CHEMBL1566209 & 737353 & 3.0 & 3.0096 & TRN & \\
\hline CHEMBL1374971 & 737353 & 3.0 & 3.2537 & TRN & \\
\hline CHEMBL1582381 & 737353 & 3.0 & 2.8261 & TRN & \\
\hline CHEMBL1330574 & 737353 & 5.0888 & 5.2608 & TRN & \\
\hline CHEMBL1730470 & 737353 & 5.2343 & 5.1341 & TRN & \\
\hline CHEMBL459929 & 737353 & 4.8153 & 4.7828 & TRN & \\
\hline
\end{tabular}




\begin{tabular}{|c|c|c|c|c|c|c|}
\hline \multicolumn{7}{|c|}{ Supplemental Table S2.txt } \\
\hline CHEMBL1363961 & 737353 & 3.0 & 2.7869 & TRN & & \\
\hline CHEMBL1335905 & 737353 & 3.0 & 3.2725 & TST & & \\
\hline CHEMBL560074 & 737353 & 3.0 & 4.802 & TRN & & \\
\hline CHEMBL1338487 & 737353 & 5.0685 & 3.9884 & TST & & \\
\hline CHEMBL1725748 & 737353 & 3.0 & 3.0243 & TRN & & \\
\hline CHEMBL1452278 & 737353 & 3.0 & 3.1152 & TRN & & \\
\hline CHEMBL1377001 & 737353 & 3.0 & 3.2066 & TRN & & \\
\hline CHEMBL1712030 & 737353 & 3.0 & 3.3127 & TRN & & \\
\hline CHEMBL1708559 & 737353 & 3.0 & 3.0514 & TST & & \\
\hline CHEMBL1710344 & 737353 & 3.0 & 3.6787 & TRN & & \\
\hline CHEMBL359176 & 737353 & 5.2097 & 5.1569 & TRN & & \\
\hline CHEMBL1369256 & 737353 & 3.0 & 2.9173 & TRN & & \\
\hline CHEMBL1624209 & 737353 & 3.0 & 3.2537 & TST & & \\
\hline CHEMBL 1350596 & 737353 & 4.9281 & 4.835 & TRN & & \\
\hline CHEMBL1375393 & 737353 & 5.7235 & 5.4388 & TRN & & \\
\hline CHEMBL1480882 & 737353 & 3.0 & 3.2265 & TRN & & \\
\hline CHEMBL1736776 & 737353 & 5.1785 & 5.2147 & TRN & & \\
\hline CHEMBL1449951 & 737353 & 3.0 & 2.9014 & TRN & & \\
\hline CHEMBL1369494 & 737353 & 3.0 & 3.3112 & TRN & & \\
\hline CHEMBL1734946 & 737353 & 5.1024 & 5.2414 & TRN & & \\
\hline CHEMBL1707106 & 737353 & 3.0 & 2.7286 & TRN & & \\
\hline CHEMBL445266 & 737353 & 3.0 & 3.1315 & TRN & & \\
\hline CHEMBL1523111 & 737353 & 5.2557 & 5.1139 & TRN & & \\
\hline CHEMBL1716509 & 737353 & 5.15799 & 99999999 & 995 & 5.3417 & TRN \\
\hline CHEMBL1726265 & 737353 & 3.0 & 2.8511 & TRN & & \\
\hline CHEMBL1531156 & 737353 & 5.1707 & 3.5917 & TST & & \\
\hline CHEMBL1608620 & 737353 & 3.0 & 3.1106 & TRN & & \\
\hline CHEMBL1404998 & 737353 & 3.0 & 3.0901 & TRN & & \\
\hline CHEMBL1706140 & 737353 & 5.0804 & 4.8423 & TRN & & \\
\hline CHEMBL1442092 & 737353 & 3.0 & 3.2514 & TRN & & \\
\hline CHEMBL1529827 & 737353 & 3.0 & 3.0467 & TST & & \\
\hline CHEMBL1319254 & 737353 & 3.0 & 3.7233 & TRN & & \\
\hline CHEMBL567850 & 737353 & 3.0 & 3.4525 & TST & & \\
\hline CHEMBL246893 & 456580 & 3.699 & 3.8101 & TRN & & \\
\hline CHEMBL246695 & 456580 & 4.0 & 4.1731 & TRN & & \\
\hline CHEMBL396160 & 456580 & 7.7696 & 7.4655 & TRN & & \\
\hline CHEMBL246088 & 456580 & 7.4559 & 7.0547 & TRN & & \\
\hline CHEMBL 245680 & 456580 & 6.1135 & 6.0778 & TRN & & \\
\hline CHEMBL246699 & 456580 & 5.5686 & 5.3658 & TRN & & \\
\hline CHEMBL247905 & 456580 & 3.3979 & 2.6834 & TST & & \\
\hline CHEMBL246481 & 456580 & 3.699 & 4.827 & TRN & & \\
\hline CHEMBL395592 & 456580 & 5.8861 & 5.7018 & TRN & & \\
\hline CHEMBL394493 & 456580 & 3.3979 & 3.5119 & TRN & & \\
\hline CHEMBL245485 & 456580 & 6.1249 & 7.1238 & TRN & & \\
\hline CHEMBL247305 & 456580 & 3.699 & 3.2966 & TRN & & \\
\hline CHEMBL437943 & 456580 & 6.284 & 6.0843 & TRN & & \\
\hline CHEMBL 246300 & 456580 & 7.3565 & 6.8873 & TRN & & \\
\hline CHEMBL246301 & 456580 & 8.0 & 7.2722 & TRN & & \\
\hline
\end{tabular}




\begin{tabular}{|c|}
\hline CHEMBL246299 \\
\hline CHEMBL247907 \\
\hline CHEMBL394494 \\
\hline CHEMBL397388 \\
\hline CHEMBL246894 \\
\hline CHEMBL395593 \\
\hline CHEMBL429474 \\
\hline CHEMBL396919 \\
\hline CHEMBL394926 \\
\hline CHEMBL245682 \\
\hline CHEMBL246090 \\
\hline CHEMBL248365 \\
\hline CHEMBL396159 \\
\hline CHEMBL 246891 \\
\hline CHEMBL247095 \\
\hline CHEMBL245883 \\
\hline CHEMBL248532 \\
\hline CHEMBL 248333 \\
\hline CHEMBL246906 \\
\hline CHEMBL247904 \\
\hline CHEMBL393057 \\
\hline CHEMBL395194 \\
\hline CHEMBL 245473 \\
\hline CHEMBL 246508 \\
\hline CHEMBL245474 \\
\hline CHEMBL397642 \\
\hline CHEMBL 246910 \\
\hline CHEMBL 248335 \\
\hline CHEMBL246696 \\
\hline CHEMBL248331 \\
\hline CHEMBL393056 \\
\hline CHEMBL 248366 \\
\hline CHEMBL392596 \\
\hline CHEMBL 248364 \\
\hline CHEMBL 247509 \\
\hline CHEMBL246892 \\
\hline CHEMBL442419 \\
\hline CHEMBL391983 \\
\hline CHEMBL394735 \\
\hline CHEMBL246526 \\
\hline CHEMBL246907 \\
\hline CHEMBL 248533 \\
\hline CHEMBL247333 \\
\hline CHEMBL 245884 \\
\hline CHEMBL392597 \\
\hline CHEMBL246507 \\
\hline CHEMBL248104 \\
\hline CHEMBL246089 \\
\hline
\end{tabular}

Supplemental Table S2.txt

$\begin{array}{lllll}456580 & 7.3468 & 7.1076 & \text { TRN } & \\ 456580 & 3.3979 & 3.6101 & \text { TRN } \\ 456580 & 4.8239 & 3.8507 & \text { TRN } & \\ 456580 & 5.7447 & 5.5987 & \text { TRN } & \\ 456580 & 3.699 & 4.2703 & \text { TRN } & \\ 456580 & 5.5229 & 5.8712 & \text { TRN } & \\ 456580 & 4.0 & 4.3141 & \text { TRN } & \\ 456580 & 3.3979 & 4.6437 & \text { TST } & \text { TRN } \\ 456580 & 6.1192 & 6.388999999999999 & \\ 456580 & 6.9208 & 6.4635 & \text { TRN } & \\ 456580 & 7.6778 & 7.5209 & \text { TRN } & \\ 456580 & 3.3979 & 4.5962 & \text { TST } & \\ 456580 & 7.1427 & 7.1904 & \text { TRN } & \\ 456580 & 3.3979 & 4.3551 & \text { TRN } & \\ 456580 & 3.699 & 3.7369 & \text { TRN } & \\ 456580 & 6.4776 & 6.7798 & \text { TRN } & \\ 456580 & 5.5686 & 5.8248 & \text { TRN } & \\ 456580 & 5.3565 & 5.1061 & \text { TRN } & \\ 456580 & 5.4685 & 5.1762 & \text { TRN } & \\ 456580 & 3.3979 & 4.7948 & \text { TST } & \\ 456580 & 5.5376 & 4.5538 & \text { TRN } & \\ 456580 & 3.3979 & 4.2410000000000005 & \text { TST }\end{array}$

$\begin{array}{llll}456580 & 5.7696 & 6.204 & \text { TRN }\end{array}$

$\begin{array}{llll}456580 & 6.3188 & 6.0675 & \text { TRN }\end{array}$

$\begin{array}{llll}456580 & 5.1549 & 5.7538 & \text { TRN }\end{array}$

$\begin{array}{llll}456580 & 6.6021 & 6.7971 & \text { TRN }\end{array}$

$\begin{array}{llll}456580 & 6.1135 & 5.5867 & \text { TRN }\end{array}$

$\begin{array}{llll}456580 & 5.1135 & 5.3179 & \text { TRN }\end{array}$

$\begin{array}{llll}456580 & 3.699 & 4.7006 & \text { TRN }\end{array}$

$\begin{array}{llll}456580 & 5.1308 & 5.3523 & \text { TRN }\end{array}$

$\begin{array}{llll}456580 & 4.9208 & 4.6191 & \text { TRN }\end{array}$

$\begin{array}{llll}456580 & 5.9586 & 4.4355 & \text { TST }\end{array}$

$\begin{array}{llll}456580 & 6.3565 & 5.9887 & \text { TRN }\end{array}$

$\begin{array}{llll}456580 & 5.5686 & 4.3539 & \text { TST }\end{array}$

$\begin{array}{llll}456580 & 6.1192 & 6.2621 & \text { TRN }\end{array}$

$\begin{array}{llll}456580 & 5.2676 & 4.6635 & \text { TRN }\end{array}$

$\begin{array}{lllll}456580 & 6.2076 & 6.2766 & \text { TRN }\end{array}$

$\begin{array}{llll}456580 & 5.5229 & 4.6599 & \text { TRN }\end{array}$

$\begin{array}{llll}456580 & 5.8239 & 5.8035 & \text { TRN }\end{array}$

$\begin{array}{lllll}456580 & 5.3468 & 4.5666 & \text { TRN }\end{array}$

$\begin{array}{llll}456580 & 3.699 & 4.5893 & \text { TRN }\end{array}$

$\begin{array}{llll}456580 & 5.5229 & 5.6454 & \text { TRN }\end{array}$

$\begin{array}{llll}456580 & 6.2076 & 6.6866 & \text { TRN }\end{array}$

$\begin{array}{llll}456580 & 7.4685 & 7.0007 & \text { TRN }\end{array}$

$\begin{array}{llll}456580 & 5.8239 & 5.6198 & \text { TST }\end{array}$

$\begin{array}{lllll}456580 & 5.8861 & 5.9437 & \text { TRN }\end{array}$

$\begin{array}{llll}456580 & 3.3979 & 3.1854 & \text { TST }\end{array}$

$\begin{array}{llll}456580 & 6.9066 & 7.3777 & \text { TRN }\end{array}$ 


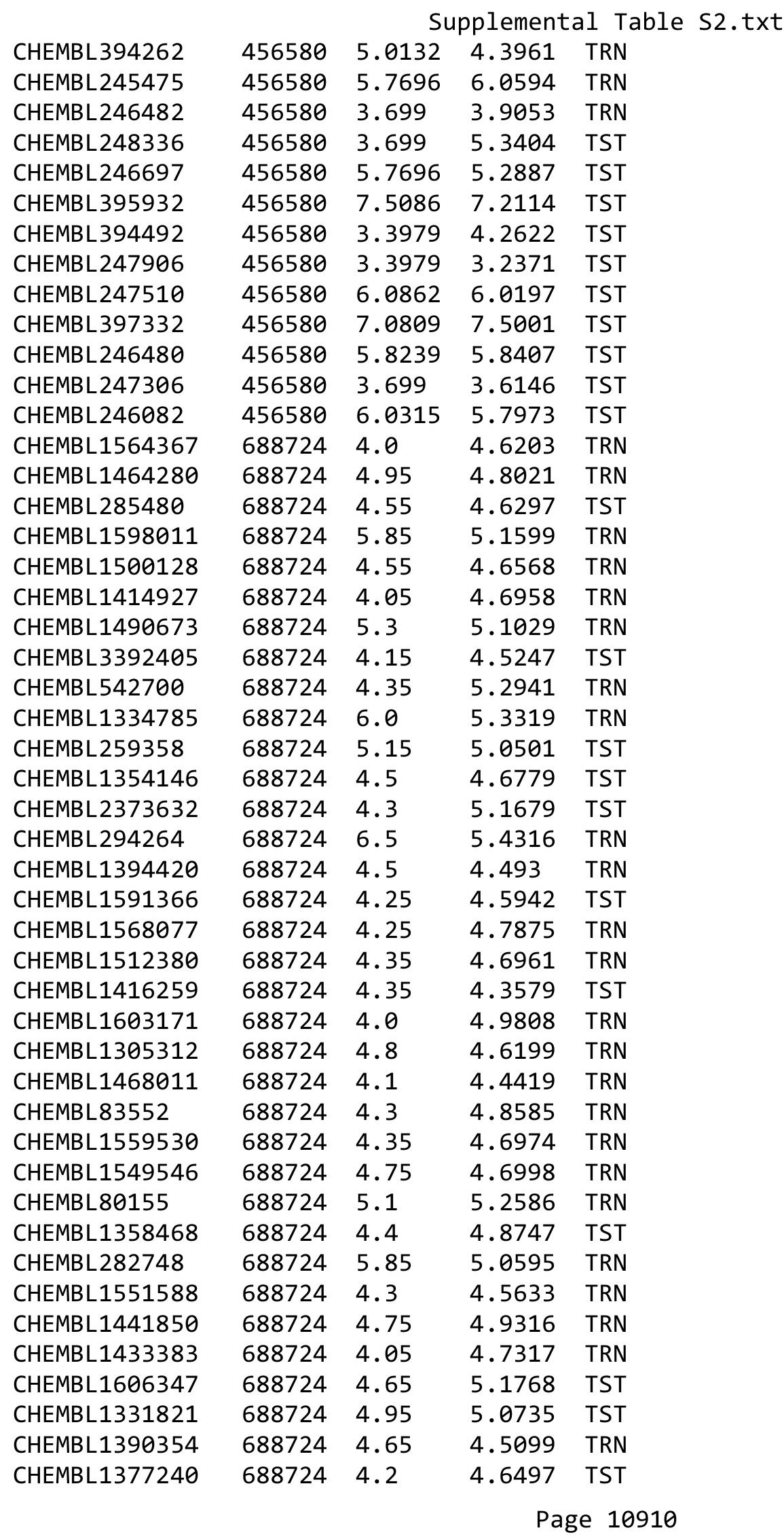




\begin{tabular}{|c|c|c|c|c|}
\hline \multicolumn{5}{|c|}{ Supplemental Table S2.txt } \\
\hline CHEMBL1503923 & 688724 & 4.45 & 4.7317 & TRN \\
\hline CHEMBL1381676 & 688724 & 4.4 & 5.0247 & TRN \\
\hline CHEMBL1583011 & 688724 & 5.0 & 4.7192 & TST \\
\hline CHEMBL1393248 & 688724 & 4.1 & 4.6792 & TRN \\
\hline CHEMBL1432618 & 688724 & 4.6 & 4.992 & TRN \\
\hline CHEMBL1516015 & 688724 & 5.6 & 5.1393 & TST \\
\hline CHEMBL3193655 & 688724 & 5.05 & 4.8223 & TRN \\
\hline CHEMBL3196930 & 688724 & 6.0 & 4.9998 & TRN \\
\hline CHEMBL1300497 & 688724 & 5.8 & 5.4498 & TRN \\
\hline CHEMBL1418430 & 688724 & 5.5 & 4.9855 & TRN \\
\hline CHEMBL1330464 & 688724 & 4.1 & 4.6277 & TRN \\
\hline CHEMBL267476 & 688724 & 4.25 & 5.4409 & TRN \\
\hline CHEMBL2006569 & 688724 & 4.75 & 4.832 & TRN \\
\hline CHEMBL1520729 & 688724 & 4.55 & 5.0307 & TST \\
\hline CHEMBL1361498 & 688724 & 4.05 & 4.7706 & TRN \\
\hline CHEMBL1354361 & 688724 & 4.4 & 4.3238 & TRN \\
\hline CHEMBL1489250 & 688724 & 5.0 & 4.8874 & TST \\
\hline CHEMBL1555385 & 688724 & 4.2 & 4.9455 & TRN \\
\hline CHEMBL1603622 & 688724 & 5.0 & 4.9311 & TRN \\
\hline CHEMBL164968 & 688724 & 5.3 & 5.3165 & TRN \\
\hline CHEMBL1446643 & 688724 & 4.3 & 5.0225 & TRN \\
\hline CHEMBL1584579 & 688724 & 4.65 & 5.0893 & TRN \\
\hline CHEMBL1596318 & 688724 & 4.85 & 4.8314 & TST \\
\hline CHEMBL1450918 & 688724 & 6.5 & 5.3173 & TST \\
\hline CHEMBL1567285 & 688724 & 4.25 & 4.7856 & TST \\
\hline CHEMBL1487509 & 688724 & 4.75 & 4.7069 & TRN \\
\hline CHEMBL1432851 & 688724 & 4.05 & 4.7262 & TRN \\
\hline CHEMBL1369032 & 688724 & 5.2 & 4.7663 & TRN \\
\hline CHEMBL1502851 & 688724 & 4.95 & 5.1712 & TST \\
\hline CHEMBL3195314 & 688724 & 4.9 & 4.7057 & TRN \\
\hline CHEMBL1353253 & 688724 & 4.35 & 4.7166 & TRN \\
\hline CHEMBL1487298 & 688724 & 4.4 & 4.9709 & TRN \\
\hline CHEMBL3210366 & 688724 & 4.5 & 4.6613 & TST \\
\hline CHEMBL1307081 & 688724 & 4.8 & 4.6598 & TRN \\
\hline CHEMBL1531976 & 688724 & 5.0 & 4.7036 & TST \\
\hline CHEMBL1604701 & 688724 & 4.0 & 4.7758 & TRN \\
\hline CHEMBL1469827 & 688724 & 6.7501 & 5.4981 & TRN \\
\hline CHEMBL243216 & 688724 & 5.7 & 4.6744 & TRN \\
\hline CHEMBL1497282 & 688724 & 5.15 & 5.2017 & TRN \\
\hline CHEMBL1576281 & 688724 & 5.8 & 4.893 & TRN \\
\hline CHEMBL1559716 & 688724 & 4.6 & 4.7619 & TRN \\
\hline CHEMBL 252419 & 688724 & 4.5 & 4.6572 & TRN \\
\hline CHEMBL1530125 & 688724 & 4.5 & 4.6721 & TRN \\
\hline CHEMBL1304974 & 688724 & 4.05 & 4.8086 & TRN \\
\hline CHEMBL201289 & 688724 & 6.2 & 5.5378 & TRN \\
\hline CHEMBL1426818 & 688724 & 4.55 & 4.7992 & TRN \\
\hline CHEMBL1592219 & 688724 & 4.4 & 4.6755 & TRN \\
\hline CHEMBL1386973 & 688724 & 4.5 & 4.6127 & TRN \\
\hline
\end{tabular}




\begin{tabular}{|c|c|c|c|c|}
\hline \multicolumn{5}{|c|}{ Supplemental Table S2.txt } \\
\hline CHEMBL1569635 & 688724 & 4.15 & 4.7302 & TRN \\
\hline CHEMBL3209102 & 688724 & 5.0 & 4.9896 & TRN \\
\hline CHEMBL1545040 & 688724 & 4.3 & 4.555 & TRN \\
\hline CHEMBL 3214218 & 688724 & 4.35 & 4.4776 & TRN \\
\hline CHEMBL1363898 & 688724 & 4.6 & 4.949 & TST \\
\hline CHEMBL1445370 & 688724 & 5.15 & 5.064 & TRN \\
\hline CHEMBL 3144948 & 688724 & 4.75 & 4.9108 & TRN \\
\hline CHEMBL1471730 & 688724 & 5.05 & 4.7826 & TST \\
\hline CHEMBL1578785 & 688724 & 4.55 & 4.8452 & TRN \\
\hline CHEMBL1550359 & 688724 & 4.7 & 4.7137 & TRN \\
\hline CHEMBL1410321 & 688724 & 4.8 & 4.8792 & TRN \\
\hline CHEMBL1324556 & 688724 & 5.45 & 4.6552 & TST \\
\hline CHEMBL3195987 & 688724 & 4.9 & 4.8247 & TRN \\
\hline CHEMBL1553083 & 688724 & 6.15 & 4.7894 & TST \\
\hline CHEMBL1554178 & 688724 & 4.7 & 4.7958 & TST \\
\hline CHEMBL1442699 & 688724 & 4.0 & 4.7844 & TST \\
\hline CHEMBL1299477 & 688724 & 4.45 & 4.8721 & TRN \\
\hline CHEMBL1366939 & 688724 & 4.2 & 4.5888 & TRN \\
\hline CHEMBL1337420 & 688724 & 4.55 & 4.7669 & TRN \\
\hline CHEMBL1382019 & 688724 & 4.3 & 4.5208 & TRN \\
\hline CHEMBL1540581 & 688724 & 4.35 & 4.3715 & TRN \\
\hline CHEMBL1573186 & 688724 & 4.1 & 5.0312 & TRN \\
\hline CHEMBL1344560 & 688724 & 4.05 & 4.4557 & TRN \\
\hline CHEMBL1426965 & 688724 & 4.0 & 4.6697 & TST \\
\hline CHEMBL1392972 & 688724 & 4.4 & 4.8997 & TST \\
\hline CHEMBL1478815 & 688724 & 4.8 & 4.5272 & TRN \\
\hline CHEMBL1554772 & 688724 & 4.25 & 4.4448 & TRN \\
\hline CHEMBL1334307 & 688724 & 4.8 & 4.8692 & TST \\
\hline CHEMBL1563198 & 688724 & 4.0 & 4.8621 & TRN \\
\hline CHEMBL1390571 & 688724 & 4.4 & 4.6723 & TRN \\
\hline CHEMBL 258405 & 688724 & 7.3002 & 5.1289 & TST \\
\hline CHEMBL1568870 & 688724 & 4.45 & 4.7706 & TRN \\
\hline CHEMBL1584719 & 688724 & 4.1 & 4.9372 & TST \\
\hline CHEMBL1518820 & 688724 & 6.2 & 5.2018 & TST \\
\hline CHEMBL1318535 & 688724 & 5.4 & 4.5093 & TST \\
\hline CHEMBL1317398 & 688724 & 4.7 & 4.7183 & TST \\
\hline CHEMBL1530741 & 688724 & 4.35 & 4.5872 & TRN \\
\hline CHEMBL1509161 & 688724 & 5.1 & 5.1807 & TST \\
\hline CHEMBL1563219 & 688724 & 6.15 & 5.0469 & TRN \\
\hline CHEMBL1558482 & 688724 & 4.05 & 5.2416 & TST \\
\hline CHEMBL1308393 & 688724 & 4.4 & 4.9326 & TRN \\
\hline CHEMBL408430 & 688724 & 4.5 & 4.8832 & TST \\
\hline CHEMBL1321168 & 688724 & 4.6 & 4.8016 & TRN \\
\hline CHEMBL1420147 & 688724 & 6.35 & 4.9007 & TRN \\
\hline CHEMBL1576497 & 688724 & 4.5 & 4.4659 & TST \\
\hline CHEMBL1432446 & 688724 & 4.35 & 4.515 & TRN \\
\hline CHEMBL1522622 & 688724 & 4.3 & 4.6935 & TRN \\
\hline CHEMBL1588896 & 688724 & 4.4 & 4.6678 & TRN \\
\hline
\end{tabular}




\begin{tabular}{|c|c|c|c|c|}
\hline \multicolumn{5}{|c|}{ Supplemental Table S2.txt } \\
\hline CHEMBL1343743 & 688724 & 5.2 & 5.1695 & TRN \\
\hline CHEMBL1324667 & 688724 & 4.7 & 4.7125 & TRN \\
\hline CHEMBL1431710 & 688724 & 6.4 & 5.4249 & TRN \\
\hline CHEMBL1386003 & 688724 & 4.25 & 4.6461 & TRN \\
\hline CHEMBL3197916 & 688724 & 4.1 & 5.1526 & TRN \\
\hline CHEMBL1453309 & 688724 & 4.95 & 5.1307 & TST \\
\hline CHEMBL3191800 & 688724 & 4.5 & 4.8429 & TST \\
\hline CHEMBL1550779 & 688724 & 4.45 & 4.9806 & TST \\
\hline CHEMBL 3210488 & 688724 & 5.45 & 4.9917 & TRN \\
\hline CHEMBL3189325 & 688724 & 7.2 & 5.4359 & TRN \\
\hline CHEMBL1542086 & 688724 & 4.7 & 4.9245 & TRN \\
\hline CHEMBL3196099 & 688724 & 5.45 & 4.4813 & TRN \\
\hline CHEMBL1571442 & 688724 & 5.55 & 4.7666 & TRN \\
\hline CHEMBL3195803 & 688724 & 4.65 & 5.1311 & TRN \\
\hline CHEMBL1605320 & 688724 & 7.5498 & 5.2723 & TST \\
\hline CHEMBL1559937 & 688724 & 4.6 & 4.6796 & TST \\
\hline CHEMBL1440656 & 688724 & 4.8 & 4.8281 & TRN \\
\hline CHEMBL1444829 & 688724 & 4.65 & 4.9948 & TRN \\
\hline CHEMBL1309949 & 688724 & 5.0 & 5.2146 & TRN \\
\hline CHEMBL1366427 & 688724 & 4.9 & 4.7398 & TRN \\
\hline CHEMBL1585127 & 688724 & 6.0 & 4.8165 & TRN \\
\hline CHEMBL1611306 & 688724 & 5.1 & 5.1014 & TRN \\
\hline CHEMBL1459161 & 688724 & 4.75 & 4.665 & TRN \\
\hline CHEMBL3196628 & 688724 & 4.35 & 4.6748 & TRN \\
\hline CHEMBL1379479 & 688724 & 4.85 & 4.2836 & TRN \\
\hline CHEMBL1966952 & 688724 & 4.6 & 4.7911 & TRN \\
\hline CHEMBL1407081 & 688724 & 5.6 & 5.0982 & TST \\
\hline CHEMBL1449968 & 688724 & 4.6 & 5.0149 & TRN \\
\hline CHEMBL1314890 & 688724 & 4.35 & 5.0236 & TRN \\
\hline CHEMBL3145149 & 688724 & 5.35 & 4.9438 & TRN \\
\hline CHEMBL1589402 & 688724 & 4.95 & 5.0073 & TST \\
\hline CHEMBL1476465 & 688724 & 3.95 & 4.7983 & TST \\
\hline CHEMBL 2002008 & 688724 & 4.55 & 5.0212 & TRN \\
\hline CHEMBL1548422 & 688724 & 4.35 & 4.5421 & TRN \\
\hline CHEMBL1327249 & 688724 & 4.7 & 4.8355 & TRN \\
\hline CHEMBL1558599 & 688724 & 5.5 & 5.1966 & TST \\
\hline CHEMBL1493962 & 688724 & 4.2 & 4.9535 & TRN \\
\hline CHEMBL1301868 & 688724 & 5.2 & 4.6977 & TRN \\
\hline CHEMBL1328546 & 688724 & 4.3 & 4.5946 & TRN \\
\hline CHEMBL1376173 & 688724 & 4.7 & 4.5905 & TRN \\
\hline CHEMBL1563084 & 688724 & 4.25 & 5.0863 & TRN \\
\hline CHEMBL1455481 & 688724 & 4.7 & 4.8316 & TST \\
\hline CHEMBL77030 & 688724 & 6.05 & 5.7895 & TRN \\
\hline CHEMBL 3194878 & 688724 & 4.45 & 4.9707 & TRN \\
\hline CHEMBL3194447 & 688724 & 4.4 & 4.9357 & TRN \\
\hline CHEMBL1377466 & 688724 & 4.1 & 4.9213 & TRN \\
\hline CHEMBL1311588 & 688724 & 4.85 & 4.5235 & TRN \\
\hline CHEMBL371523 & 688724 & 4.65 & 4.5922 & TRN \\
\hline
\end{tabular}




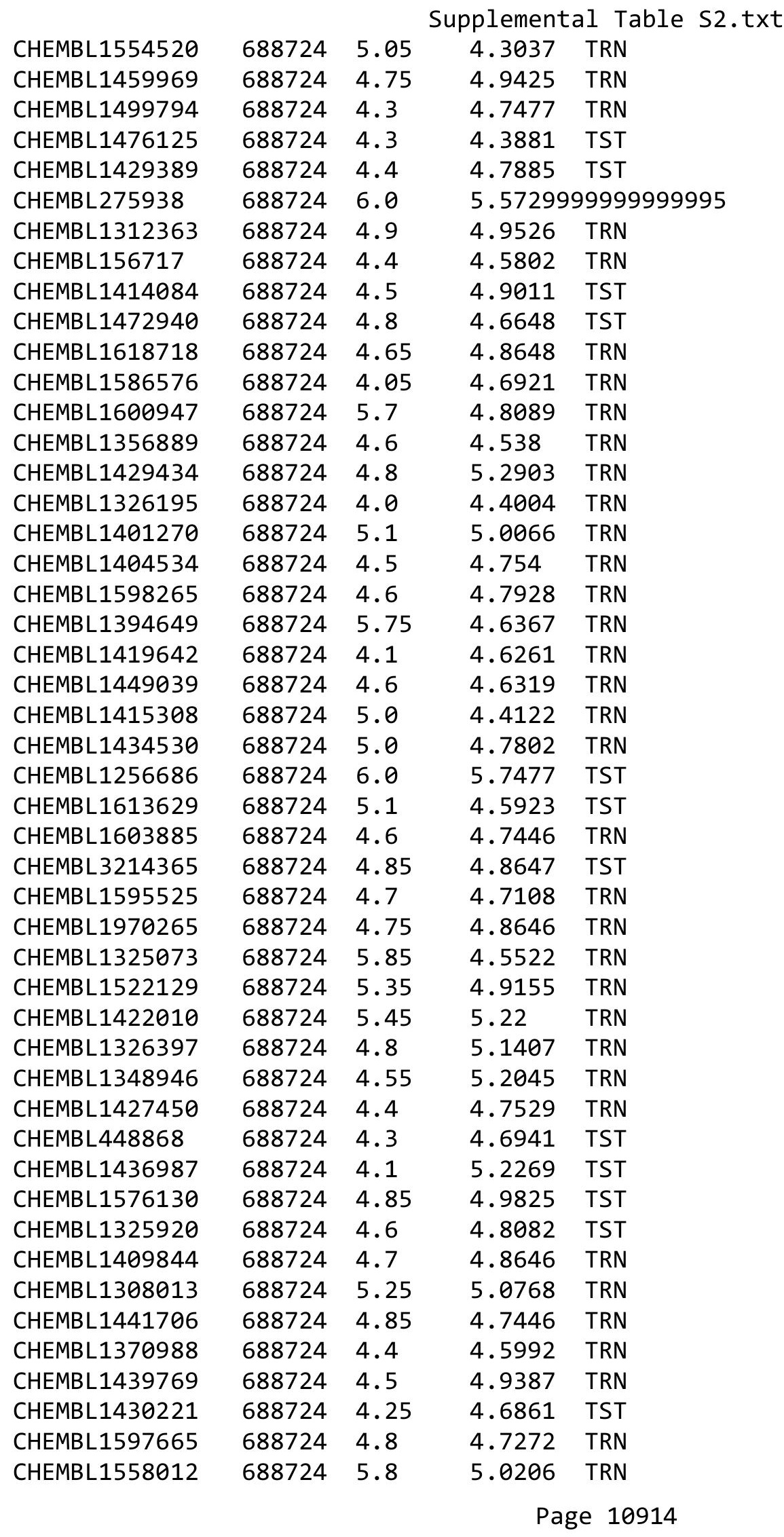




\begin{tabular}{|c|c|c|c|c|}
\hline \multicolumn{5}{|c|}{ Supplemental Table S2.txt } \\
\hline CHEMBL1419334 & 688724 & 4.8 & 4.7098 & TST \\
\hline CHEMBL1372997 & 688724 & 5.45 & 5.1482 & TST \\
\hline CHEMBL228281 & 688724 & 5.1 & 5.3148 & TRN \\
\hline CHEMBL1597248 & 688724 & 4.35 & 4.3481 & TRN \\
\hline CHEMBL1300509 & 688724 & 4.35 & 4.9599 & TRN \\
\hline CHEMBL 3196921 & 688724 & 6.2 & 5.1031 & TRN \\
\hline CHEMBL1425885 & 688724 & 5.45 & 4.9497 & TRN \\
\hline CHEMBL 547483 & 688724 & 4.6 & 4.7306 & TRN \\
\hline CHEMBL584074 & 688724 & 4.75 & 5.1492 & TRN \\
\hline CHEMBL1456747 & 688724 & 6.0 & 5.1403 & TST \\
\hline CHEMBL1371285 & 688724 & 5.45 & 4.9918 & TST \\
\hline CHEMBL1310022 & 688724 & 4.3 & 4.3458 & TRN \\
\hline CHEMBL1207889 & 688724 & 4.1 & 5.2995 & TST \\
\hline CHEMBL274438 & 688724 & 4.55 & 4.4632 & TRN \\
\hline CHEMBL1437787 & 688724 & 6.0 & 5.0274 & TRN \\
\hline CHEMBL1527567 & 688724 & 4.8 & 5.1426 & TRN \\
\hline CHEMBL1569730 & 688724 & 4.55 & 4.3996 & TRN \\
\hline CHEMBL 3211875 & 688724 & 4.95 & 5.0328 & TST \\
\hline CHEMBL1444266 & 688724 & 4.5 & 4.5667 & TRN \\
\hline CHEMBL1301388 & 688724 & 4.6 & 4.4391 & TRN \\
\hline CHEMBL1332139 & 688724 & 5.15 & 5.3479 & TRN \\
\hline CHEMBL1368771 & 688724 & 4.65 & 5.1895 & TRN \\
\hline CHEMBL1256687 & 688724 & 4.85 & 4.8833 & TST \\
\hline CHEMBL1543031 & 688724 & 4.9 & 4.7286 & TRN \\
\hline CHEMBL1456111 & 688724 & 5.3 & 5.1872 & TRN \\
\hline CHEMBL1530775 & 688724 & 4.55 & 4.8778 & TST \\
\hline CHEMBL 363535 & 688724 & 4.95 & 5.1398 & TRN \\
\hline CHEMBL1328990 & 688724 & 5.2 & 4.808 & TRN \\
\hline CHEMBL1510420 & 688724 & 4.05 & 4.6987 & TST \\
\hline CHEMBL319244 & 688724 & 5.3 & 5.3199 & TRN \\
\hline CHEMBL1422767 & 688724 & 4.85 & 4.8103 & TRN \\
\hline CHEMBL1328604 & 688724 & 4.4 & 5.2613 & TRN \\
\hline CHEMBL1975516 & 688724 & 4.9 & 4.7882 & TRN \\
\hline CHEMBL1581782 & 688724 & 5.1 & 4.8796 & TRN \\
\hline CHEMBL1587286 & 688724 & 4.95 & 4.9107 & TST \\
\hline CHEMBL1474564 & 688724 & 6.1 & 5.4956 & TRN \\
\hline CHEMBL187845 & 688724 & 4.65 & 4.3965 & TST \\
\hline CHEMBL1994838 & 688724 & 4.5 & 4.8721 & TRN \\
\hline CHEMBL1401820 & 688724 & 4.35 & 4.6617 & TRN \\
\hline CHEMBL1333847 & 688724 & 4.6 & 5.0037 & TRN \\
\hline CHEMBL1345892 & 688724 & 4.0 & 4.8521 & TST \\
\hline CHEMBL1588222 & 688724 & 4.6 & 4.7408 & TRN \\
\hline CHEMBL1449284 & 688724 & 4.55 & 4.5483 & TRN \\
\hline CHEMBL1395860 & 688724 & 4.05 & 4.8361 & TST \\
\hline CHEMBL1501773 & 688724 & 5.05 & 4.609 & TST \\
\hline CHEMBL3198440 & 688724 & 4.7 & 4.9613 & TRN \\
\hline CHEMBL1525659 & 688724 & 4.6 & 4.8525 & TRN \\
\hline CHEMBL3207456 & 688724 & 4.6 & $4.8180 €$ & 00000000005 \\
\hline & & & & 10915 \\
\hline
\end{tabular}




\begin{tabular}{|c|c|c|c|c|}
\hline & & & pplement & $d t$ \\
\hline CHEMBL3198005 & 688724 & 4.85 & 4.7861 & TST \\
\hline CHEMBL1494194 & 688724 & 4.3 & 4.883 & TST \\
\hline CHEMBL1531716 & 688724 & 7.0 & 5.4108 & TST \\
\hline CHEMBL1498783 & 688724 & 4.8 & 5.081 & TST \\
\hline CHEMBL499968 & 688724 & 4.15 & 4.9971 & TST \\
\hline CHEMBL1442519 & 688724 & 6.15 & 4.5717 & TST \\
\hline CHEMBL1380498 & 688724 & 4.45 & 4.7056 & TRN \\
\hline CHEMBL1467892 & 688724 & 4.7 & 5.121 & TRN \\
\hline CHEMBL1517799 & 688724 & 4.4 & 4.7871 & TRN \\
\hline CHEMBL3199037 & 688724 & 6.5501 & 5.2352 & TRN \\
\hline CHEMBL1564871 & 688724 & 4.7 & 4.6944 & TRN \\
\hline CHEMBL3199379 & 688724 & 4.85 & 4.8931 & TST \\
\hline CHEMBL2000877 & 688724 & 5.2 & 4.8751 & TRN \\
\hline CHEMBL1435732 & 688724 & 4.7 & 4.7776 & TST \\
\hline CHEMBL1396978 & 688724 & 4.25 & 4.5083 & TRN \\
\hline CHEMBL1511067 & 688724 & 4.4 & 4.7087 & TRN \\
\hline CHEMBL1587813 & 688724 & 4.05 & 5.1581 & TRN \\
\hline CHEMBL1407906 & 688724 & 5.05 & 4.6464 & TRN \\
\hline CHEMBL1502229 & 688724 & 4.85 & 4.7433 & TST \\
\hline CHEMBL1514583 & 688724 & 4.8 & 4.7993 & TRN \\
\hline CHEMBL1311959 & 688724 & 4.95 & 4.7387 & TRN \\
\hline CHEMBL1548384 & 688724 & 4.25 & 4.5749 & TRN \\
\hline CHEMBL1538096 & 688724 & 4.75 & 4.7085 & TRN \\
\hline CHEMBL1482715 & 688724 & 4.75 & 5.1636 & TST \\
\hline CHEMBL1467236 & 688724 & 4.4 & 4.6445 & TRN \\
\hline CHEMBL3190142 & 688724 & 5.6 & 4.6101 & TRN \\
\hline CHEMBL1380287 & 688724 & 4.8 & 4.6108 & TRN \\
\hline CHEMBL 3144898 & 688724 & 5.1 & 5.0978 & TRN \\
\hline CHEMBL1494980 & 688724 & 4.85 & 5.2261 & TST \\
\hline CHEMBL1368326 & 688724 & 4.75 & 4.5672 & TST \\
\hline CHEMBL1365118 & 688724 & 4.4 & 4.9396 & TRN \\
\hline CHEMBL1490549 & 688724 & 4.1 & 4.9215 & TRN \\
\hline CHEMBL1340628 & 688724 & 4.85 & 4.8086 & TST \\
\hline CHEMBL 3144922 & 688724 & 4.9 & 5.1705 & TST \\
\hline CHEMBL1392525 & 688724 & 4.95 & 4.6935 & TRN \\
\hline CHEMBL1354063 & 688724 & 4.8 & 5.1502 & TST \\
\hline CHEMBL3213842 & 688724 & 4.65 & 5.0683 & TST \\
\hline CHEMBL1534725 & 688724 & 4.45 & 4.6129 & TST \\
\hline CHEMBL1369767 & 688724 & 4.9 & 4.9396 & TRN \\
\hline CHEMBL1557847 & 688724 & 5.4 & 4.7598 & TRN \\
\hline CHEMBL1313691 & 688724 & 4.7 & 4.7375 & TRN \\
\hline CHEMBL3192054 & 688724 & 4.5 & 5.0901 & TRN \\
\hline CHEMBL3209105 & 688724 & 4.4 & 4.8949 & TRN \\
\hline CHEMBL1605733 & 688724 & 5.7 & 4.8935 & TST \\
\hline CHEMBL1439507 & 688724 & 5.2 & 4.8049 & TRN \\
\hline CHEMBL1410176 & 688724 & 4.05 & 4.7539 & TST \\
\hline CHEMBL1606935 & 688724 & 4.45 & 4.5088 & TST \\
\hline CHEMBL1559039 & 688724 & 4.35 & 5.006 & TRN \\
\hline
\end{tabular}




\begin{tabular}{|c|c|c|c|c|c|}
\hline \multirow[b]{2}{*}{ CHEMBL1377463 } & \multicolumn{5}{|c|}{ Supplemental Table S2.txt } \\
\hline & 688724 & 4.25 & 4.4447 & TRN & \\
\hline CHEMBL1438435 & 688724 & 4.5 & 4.9723 & TRN & \\
\hline CHEMBL1313635 & 688724 & 4.25 & 4.67899 & 9999999999 & TRN \\
\hline CHEMBL1463629 & 688724 & 4.5 & 4.7613 & TRN & \\
\hline CHEMBL1566856 & 688724 & 4.55 & 4.6192 & TRN & \\
\hline CHEMBL3212202 & 688724 & 4.8 & 5.0336 & TST & \\
\hline CHEMBL405912 & 688724 & 4.55 & 4.6092 & TRN & \\
\hline CHEMBL1346941 & 688724 & 4.3 & 4.3871 & TRN & \\
\hline CHEMBL3212459 & 688724 & 4.5 & 4.7658 & TRN & \\
\hline CHEMBL 1477826 & 688724 & 4.25 & 4.6995 & TRN & \\
\hline CHEMBL1534310 & 688724 & 5.65 & 4.7555 & TRN & \\
\hline CHEMBL1489910 & 688724 & 4.7 & 4.6476 & TST & \\
\hline CHEMBL66953 & 688724 & 6.0 & 5.5885 & TST & \\
\hline CHEMBL1606596 & 688724 & 5.05 & 5.0471 & TRN & \\
\hline CHEMBL327035 & 688724 & 4.45 & 4.7867 & TRN & \\
\hline CHEMBL1565192 & 688724 & 4.15 & 5.2606 & TST & \\
\hline CHEMBL1431490 & 688724 & 5.95 & 4.7285 & TRN & \\
\hline CHEMBL1539720 & 688724 & 5.45 & 4.8984 & TST & \\
\hline CHEMBL1592011 & 688724 & 4.4 & 4.8096 & TRN & \\
\hline CHEMBL1552782 & 688724 & 4.25 & 4.8876 & TRN & \\
\hline CHEMBL1431126 & 688724 & 4.55 & 5.1329 & TST & \\
\hline CHEMBL1478319 & 688724 & 4.4 & 4.8475 & TST & \\
\hline CHEMBL1546440 & 688724 & 4.45 & 5.2318 & TST & \\
\hline CHEMBL1398474 & 688724 & 4.5 & 5.1226 & TST & \\
\hline CHEMBL3208485 & 688724 & 4.65 & 4.2616 & TRN & \\
\hline CHEMBL1553873 & 688724 & 5.65 & 5.1147 & TST & \\
\hline CHEMBL1481117 & 688724 & 6.45 & 4.831 & TST & \\
\hline CHEMBL1565236 & 688724 & 4.1 & 4.6647 & TRN & \\
\hline CHEMBL1544175 & 688724 & 4.05 & 4.3772 & TST & \\
\hline CHEMBL1608529 & 688724 & 7.0501 & 5.1985 & TRN & \\
\hline CHEMBL1973504 & 688724 & 5.9 & 4.8719 & TRN & \\
\hline CHEMBL1343244 & 688724 & 4.65 & 4.7668 & TST & \\
\hline CHEMBL1426071 & 688724 & 4.3 & 4.433 & TRN & \\
\hline CHEMBL1473397 & 688724 & 4.3 & 4.5842 & TRN & \\
\hline CHEMBL1327691 & 688724 & 4.2 & 5.064 & TST & \\
\hline CHEMBL1393705 & 688724 & 4.05 & 4.4584 & TRN & \\
\hline CHEMBL3212273 & 688724 & 4.7 & 4.9258 & TRN & \\
\hline CHEMBL1502313 & 688724 & 4.35 & 4.8257 & TST & \\
\hline CHEMBL1970627 & 688724 & 4.75 & 4.8542 & TRN & \\
\hline CHEMBL1542511 & 688724 & 4.35 & 4.7257 & TRN & \\
\hline CHEMBL1478023 & 688724 & 4.25 & 5.3602 & TST & \\
\hline CHEMBL1512168 & 688724 & 4.3 & 4.4422 & TRN & \\
\hline CHEMBL3191500 & 688724 & 4.8 & 4.5999 & TST & \\
\hline CHEMBL1460669 & 688724 & 4.95 & 5.1054 & TRN & \\
\hline CHEMBL1391582 & 688724 & 4.65 & 4.8116 & TST & \\
\hline CHEMBL1509515 & 688724 & 4.65 & 4.6785 & TRN & \\
\hline CHEMBL3195505 & 688724 & 5.4 & 4.9468 & TRN & \\
\hline CHEMBL1559308 & 688724 & 6.05 & 5.2792 & TRN & \\
\hline
\end{tabular}




\begin{tabular}{|c|c|c|c|c|c|}
\hline \multicolumn{6}{|c|}{ Supplemental Table S2.txt } \\
\hline CHEMBL 3184468 & 688724 & 6.1 & 5.2154 & TRN & \\
\hline CHEMBL1589712 & 688724 & 4.3 & 4.8543 & TRN & \\
\hline CHEMBL1567135 & 688724 & 4.55 & 4.6295 & TST & \\
\hline CHEMBL1552249 & 688724 & 9.5229 & 5.2472 & TST & \\
\hline CHEMBL1976446 & 688724 & 4.45 & 4.9705 & TST & \\
\hline CHEMBL3145039 & 688724 & 5.85 & 5.0619 & TRN & \\
\hline CHEMBL1389034 & 688724 & 4.3 & 4.3904 & TRN & \\
\hline CHEMBL13662 & 688724 & 6.1 & 4.6643 & TST & \\
\hline CHEMBL1579498 & 688724 & 5.0 & \multicolumn{2}{|c|}{4.7860000000000005} & TRN \\
\hline CHEMBL1424161 & 688724 & 4.15 & 4.6018 & TRN & \\
\hline CHEMBL1555751 & 688724 & 5.85 & 5.4719 & TRN & \\
\hline CHEMBL1578491 & 688724 & 4.1 & 4.5429 & TRN & \\
\hline CHEMBL1312788 & 688724 & 4.35 & 4.7712 & TRN & \\
\hline CHEMBL1320181 & 688724 & 4.85 & 4.7293 & TRN & \\
\hline CHEMBL1966773 & 688724 & 4.35 & 4.519 & TRN & \\
\hline CHEMBL1448067 & 688724 & 4.8 & 4.9814 & TST & \\
\hline CHEMBL1458633 & 688724 & 4.05 & 4.7962 & TST & \\
\hline CHEMBL1405895 & 688724 & 5.05 & 4.8519 & TRN & \\
\hline CHEMBL1430659 & 688724 & 5.15 & \multicolumn{2}{|c|}{4.9110000000000005} & TRN \\
\hline CHEMBL1435929 & 688724 & 4.0 & 4.4791 & TST & \\
\hline CHEMBL1350917 & 688724 & 6.95 & 4.6194 & TST & \\
\hline CHEMBL3195481 & 688724 & 4.95 & 4.9497 & TRN & \\
\hline CHEMBL1546677 & 688724 & 4.35 & 4.6576 & TST & \\
\hline CHEMBL1514910 & 688724 & 4.15 & 5.0358 & TRN & \\
\hline CHEMBL1513771 & 688724 & 5.55 & 4.8943 & TST & \\
\hline CHEMBL1567764 & 688724 & 4.9 & 4.874 & TST & \\
\hline CHEMBL1609564 & 688724 & 5.45 & 5.0117 & TRN & \\
\hline CHEMBL1540929 & 688724 & 5.2 & 4.9341 & TRN & \\
\hline CHEMBL376426 & 688724 & 4.65 & 4.8345 & TST & \\
\hline CHEMBL1534097 & 688724 & 4.2 & 4.5336 & TRN & \\
\hline CHEMBL1466712 & 688724 & 5.0 & 5.1303 & TRN & \\
\hline CHEMBL1588455 & 688724 & 5.2 & \multicolumn{2}{|c|}{4.9639999999999995} & TRN \\
\hline CHEMBL1367182 & 688724 & 4.4 & 5.3343 & TST & \\
\hline CHEMBL1352445 & 688724 & 5.15 & 4.7334 & TRN & \\
\hline CHEMBL1357450 & 688724 & 4.45 & 4.9796 & TST & \\
\hline CHEMBL520107 & 688724 & 4.4 & 4.6526 & TST & \\
\hline CHEMBL1340288 & 688724 & 4.65 & 4.5851 & TRN & \\
\hline CHEMBL1482965 & 688724 & 4.05 & 4.4215 & TST & \\
\hline CHEMBL1449018 & 688724 & 5.25 & 4.6482 & TRN & \\
\hline CHEMBL398363 & 688724 & 4.4 & 4.8158 & TRN & \\
\hline CHEMBL1536472 & 688724 & 4.8 & 4.9255 & TST & \\
\hline CHEMBL1340962 & 688724 & 4.1 & 5.0428 & TST & \\
\hline CHEMBL3192046 & 688724 & 7.2503 & 4.5269 & TRN & \\
\hline CHEMBL1486585 & 688724 & 4.7 & 5.0402 & TRN & \\
\hline CHEMBL1413468 & 688724 & 4.1 & 4.3807 & TRN & \\
\hline CHEMBL1474341 & 688724 & 4.6 & 4.9066 & TRN & \\
\hline CHEMBL1433969 & 688724 & 4.45 & 4.8113 & TRN & \\
\hline CHEMBL3198983 & 688724 & 4.55 & 4.7633 & TRN & \\
\hline
\end{tabular}




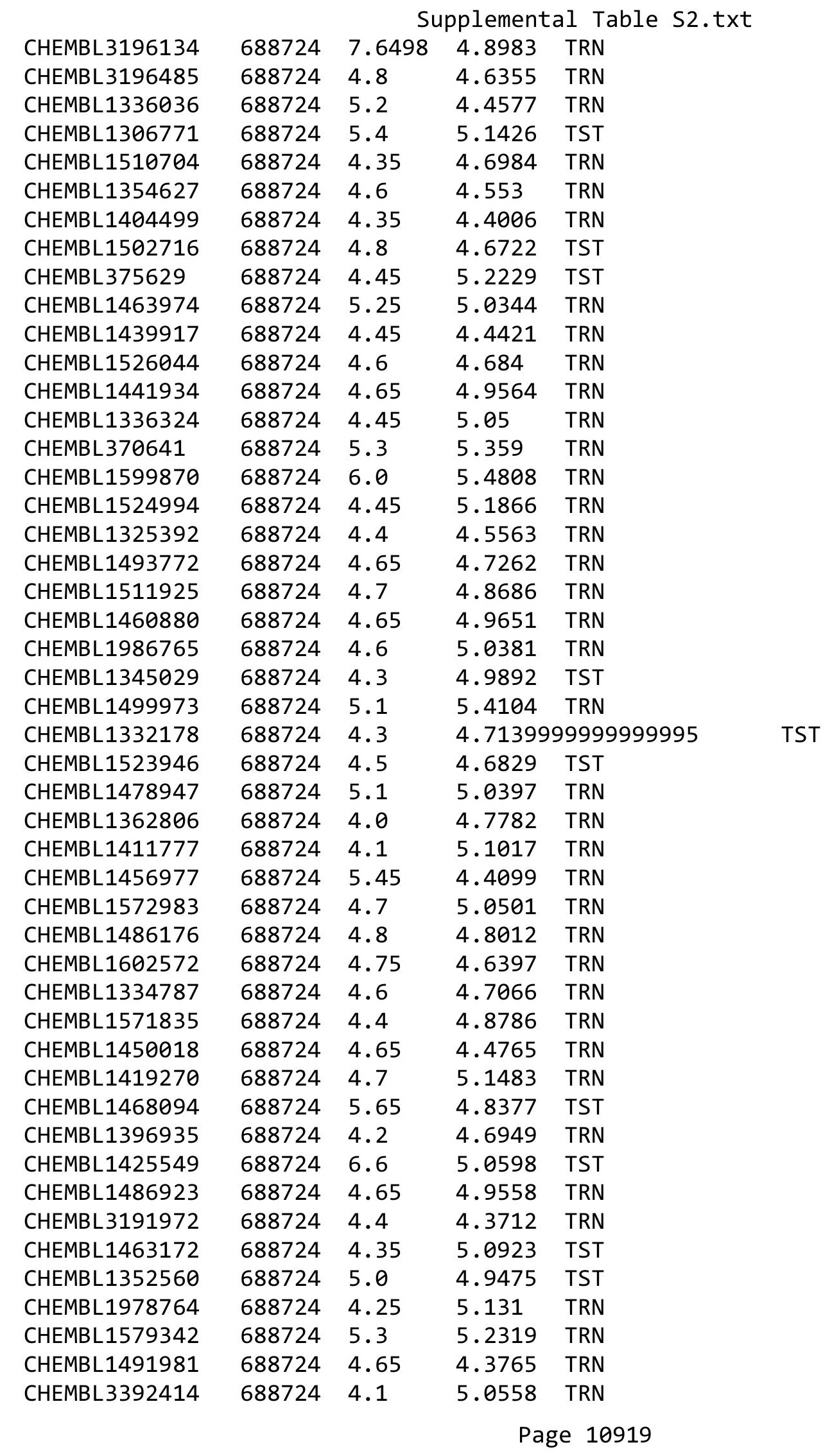




\begin{tabular}{|c|c|c|c|c|c|}
\hline \multicolumn{6}{|c|}{ Supplemental Table S2.txt } \\
\hline CHEMBL521970 & 688724 & 4.9 & 4.8545 & TRN & \\
\hline CHEMBL1558007 & 688724 & 5.25 & 4.7494 & TRN & \\
\hline CHEMBL1389047 & 688724 & 5.7 & 5.3647 & TRN & \\
\hline CHEMBL1353027 & 688724 & 6.95 & 4.8284 & TRN & \\
\hline CHEMBL1517631 & 688724 & 6.45 & 5.0074 & TRN & \\
\hline CHEMBL1382202 & 688724 & 4.5 & 4.9141 & TRN & \\
\hline CHEMBL1322000 & 688724 & 4.3 & 4.217 & TRN & \\
\hline CHEMBL1998759 & 688724 & 4.9 & 5.1087 & TRN & \\
\hline CHEMBL1468369 & 688724 & 5.1242 & 4.8213 & TRN & \\
\hline CHEMBL3144988 & 688724 & 6.15 & 5.2611 & TRN & \\
\hline CHEMBL1543152 & 688724 & 4.7 & 4.7645 & TRN & \\
\hline CHEMBL504936 & 688724 & 4.45 & 5.2201 & TRN & \\
\hline CHEMBL1445044 & 688724 & 4.2 & 4.8034 & TRN & \\
\hline CHEMBL1447322 & 688724 & 4.3 & 4.4926 & TRN & \\
\hline CHEMBL1581399 & 688724 & 4.0 & 4.9151 & TST & \\
\hline CHEMBL1585558 & 688724 & 4.35 & 4.567 & TRN & \\
\hline CHEMBL1509478 & 688724 & 4.5 & 4.9756 & TRN & \\
\hline CHEMBL3210072 & 688724 & 4.95 & 5.0789 & TRN & \\
\hline CHEMBL1528925 & 688724 & 4.05 & 5.1811 & TST & \\
\hline CHEMBL199387 & 688724 & 4.6 & 5.0091 & TRN & \\
\hline CHEMBL1604976 & 688724 & 4.55 & 4.7156 & TST & \\
\hline CHEMBL1515663 & 688724 & 4.1 & 4.8971 & TRN & \\
\hline CHEMBL1435293 & 688724 & 4.65 & 4.6848 & TRN & \\
\hline CHEMBL1405764 & 688724 & 5.6 & 4.4631 & TRN & \\
\hline CHEMBL1431705 & 688724 & 5.3 & 5.2312 & TRN & \\
\hline CHEMBL1356680 & 688724 & 6.0 & 5.2818 & TST & \\
\hline CHEMBL1458486 & 688724 & 4.65 & 4.5643 & TRN & \\
\hline CHEMBL1517045 & 688724 & 5.45 & 4.7305 & TRN & \\
\hline CHEMBL1560258 & 688724 & 4.45 & 4.5136 & TRN & \\
\hline CHEMBL187266 & 688724 & 6.0 & 5.0394 & TRN & \\
\hline CHEMBL1360725 & 688724 & 7.2503 & 5.1535 & TST & \\
\hline CHEMBL1445650 & 688724 & 6.0 & 5.2969 & TRN & \\
\hline CHEMBL184450 & 688724 & 4.55 & 5.12 & TRN & \\
\hline CHEMBL1454198 & 688724 & 6.0 & 5.2387 & TST & \\
\hline CHEMBL1440432 & 688724 & 4.6 & 4.8782 & TST & \\
\hline CHEMBL3391990 & 688724 & 4.05 & 5.0755 & TST & \\
\hline CHEMBL1330862 & 688724 & 5.0 & 4.7112 & TRN & \\
\hline CHEMBL1364182 & 688724 & 4.75 & 4.5885 & TRN & \\
\hline CHEMBL1410878 & 688724 & 5.15 & 4.9335 & TRN & \\
\hline CHEMBL1528570 & 688724 & 4.75 & 5.2398 & TRN & \\
\hline CHEMBL1504580 & 688724 & 4.25 & 4.4855 & TRN & \\
\hline CHEMBL3197065 & 688724 & 5.45 & 5.2562 & TRN & \\
\hline CHEMBL1611726 & 688724 & 5.0 & $5.0680 e$ & 00000000005 & TRN \\
\hline CHEMBL1511149 & 688724 & 4.35 & 4.838 & TRN & \\
\hline CHEMBL1555810 & 688724 & 4.6 & 5.17899 & 9999999999 & TRN \\
\hline CHEMBL1377629 & 688724 & 5.0 & 4.8298 & TRN & \\
\hline CHEMBL1353223 & 688724 & 4.7 & 4.6307 & TRN & \\
\hline CHEMBL1480207 & 688724 & 4.2 & 4.7848 & TST & \\
\hline
\end{tabular}




\begin{tabular}{|c|c|c|c|c|}
\hline \multicolumn{5}{|c|}{ Supplemental Table S2.txt } \\
\hline CHEMBL1556531 & 688724 & 4.85 & 5.1873 & TRN \\
\hline CHEMBL1465211 & 688724 & 4.2 & 4.8533 & TRN \\
\hline CHEMBL1404913 & 688724 & 4.5 & 4.6119 & TRN \\
\hline CHEMBL1442830 & 688724 & 6.0 & 4.7749 & TRN \\
\hline CHEMBL1495460 & 688724 & 4.6 & 4.7308 & TRN \\
\hline CHEMBL1483407 & 688724 & 5.35 & 5.0719 & TRN \\
\hline CHEMBL1397747 & 688724 & 4.8 & 4.5505 & TRN \\
\hline CHEMBL1556123 & 688724 & 4.4 & 4.7658 & TRN \\
\hline CHEMBL1314453 & 688724 & 4.6 & 4.5855 & TRN \\
\hline CHEMBL1428499 & 688724 & 4.7 & 4.6362 & TRN \\
\hline CHEMBL1375274 & 688724 & 4.55 & 4.9758 & TRN \\
\hline CHEMBL1542936 & 688724 & 4.45 & 4.8773 & TRN \\
\hline CHEMBL1391203 & 688724 & 4.85 & 4.596 & TRN \\
\hline CHEMBL 3197045 & 688724 & 4.4 & 4.6836 & TRN \\
\hline CHEMBL1473233 & 688724 & 4.35 & 4.8542 & TST \\
\hline CHEMBL3191691 & 688724 & 5.05 & 4.9369 & TRN \\
\hline CHEMBL1470408 & 688724 & 4.05 & 4.8925 & TRN \\
\hline CHEMBL1392702 & 688724 & 6.05 & 5.3388 & TRN \\
\hline CHEMBL3190051 & 688724 & 5.5 & 4.796 & TRN \\
\hline CHEMBL1579284 & 688724 & 4.4 & 4.3025 & TRN \\
\hline CHEMBL1389086 & 688724 & 4.25 & 4.8932 & TST \\
\hline CHEMBL1478864 & 688724 & 4.0 & 4.6337 & TRN \\
\hline CHEMBL85194 & 688724 & 4.85 & 4.5857 & TRN \\
\hline CHEMBL1531761 & 688724 & 4.9 & 4.82 & TRN \\
\hline CHEMBL1602842 & 688724 & 4.15 & 4.7369 & TRN \\
\hline CHEMBL1394845 & 688724 & 4.25 & 4.6154 & TRN \\
\hline CHEMBL1341590 & 688724 & 4.35 & 4.6452 & TRN \\
\hline CHEMBL1448410 & 688724 & 5.2 & 5.1493 & TRN \\
\hline CHEMBL1493558 & 688724 & 4.4 & 4.5173 & TRN \\
\hline CHEMBL1334293 & 688724 & 4.3 & 4.4283 & TRN \\
\hline CHEMBL1606497 & 688724 & 4.85 & 4.8603 & TRN \\
\hline CHEMBL1440698 & 688724 & 4.4 & 4.7423 & TRN \\
\hline CHEMBL1375802 & 688724 & 4.05 & 4.4991 & TRN \\
\hline CHEMBL1539086 & 688724 & 4.75 & 4.8164 & TRN \\
\hline CHEMBL1364316 & 688724 & 4.4 & 4.4707 & TRN \\
\hline CHEMBL1380847 & 688724 & 4.1 & 4.4268 & TRN \\
\hline CHEMBL1533117 & 688724 & 4.9 & 4.6804 & TRN \\
\hline CHEMBL1544915 & 688724 & 4.4 & 4.9282 & TRN \\
\hline CHEMBL1400606 & 688724 & 5.45 & 5.1222 & TRN \\
\hline CHEMBL1385899 & 688724 & 4.85 & 4.7953 & TRN \\
\hline CHEMBL1347860 & 688724 & 4.4 & 4.7841 & TRN \\
\hline CHEMBL1326229 & 688724 & 4.7 & 4.8219 & TRN \\
\hline CHEMBL1347514 & 688724 & 4.45 & 5.2872 & TRN \\
\hline CHEMBL1440906 & 688724 & 4.65 & 4.9604 & TST \\
\hline CHEMBL1467815 & 688724 & 4.55 & 4.6377 & TRN \\
\hline CHEMBL1592156 & 688724 & 4.3 & 4.5753 & TRN \\
\hline CHEMBL1361049 & 688724 & 5.0 & 4.4594 & TRN \\
\hline CHEMBL1449518 & 688724 & 4.55 & 5.0493 & TRN \\
\hline
\end{tabular}




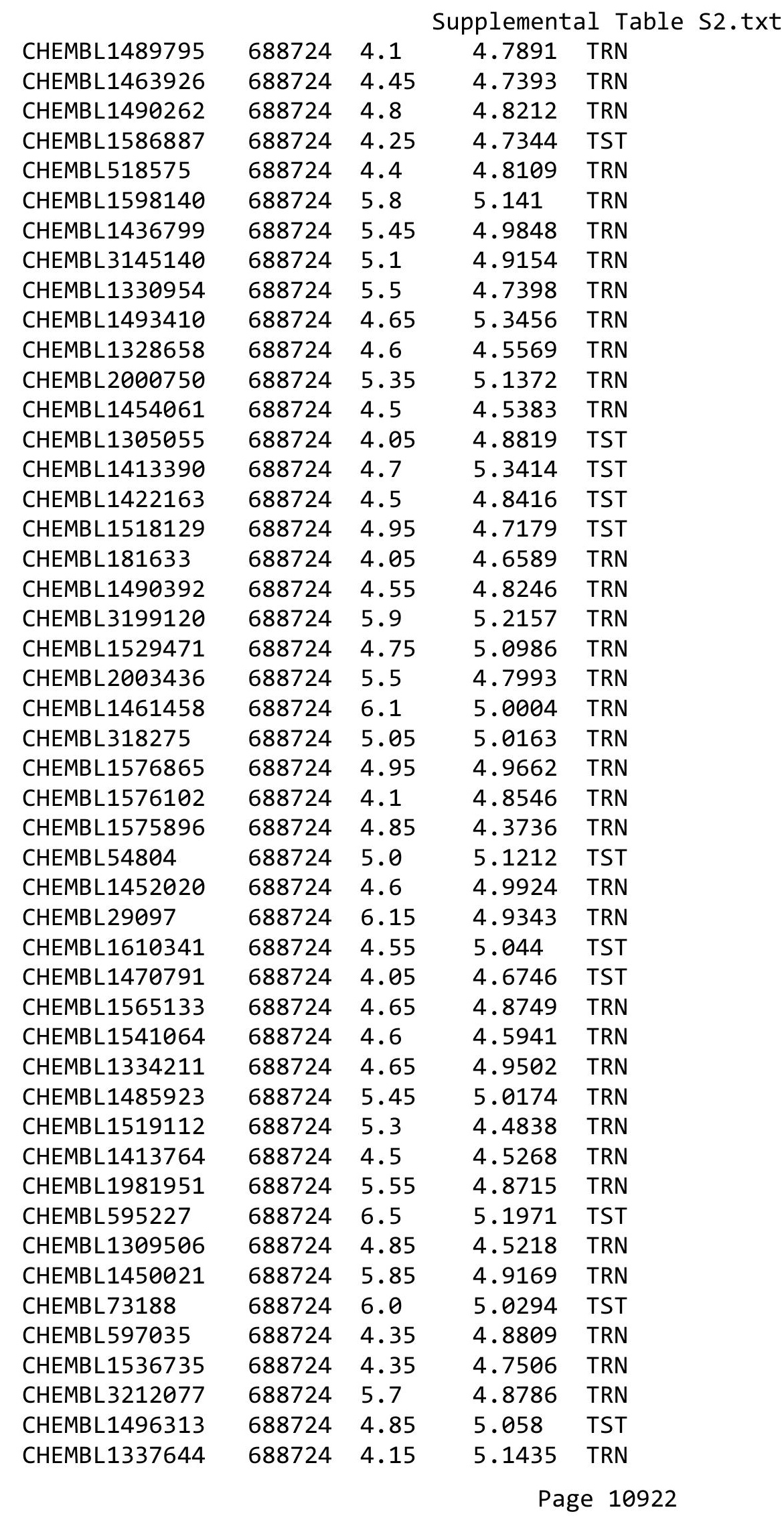




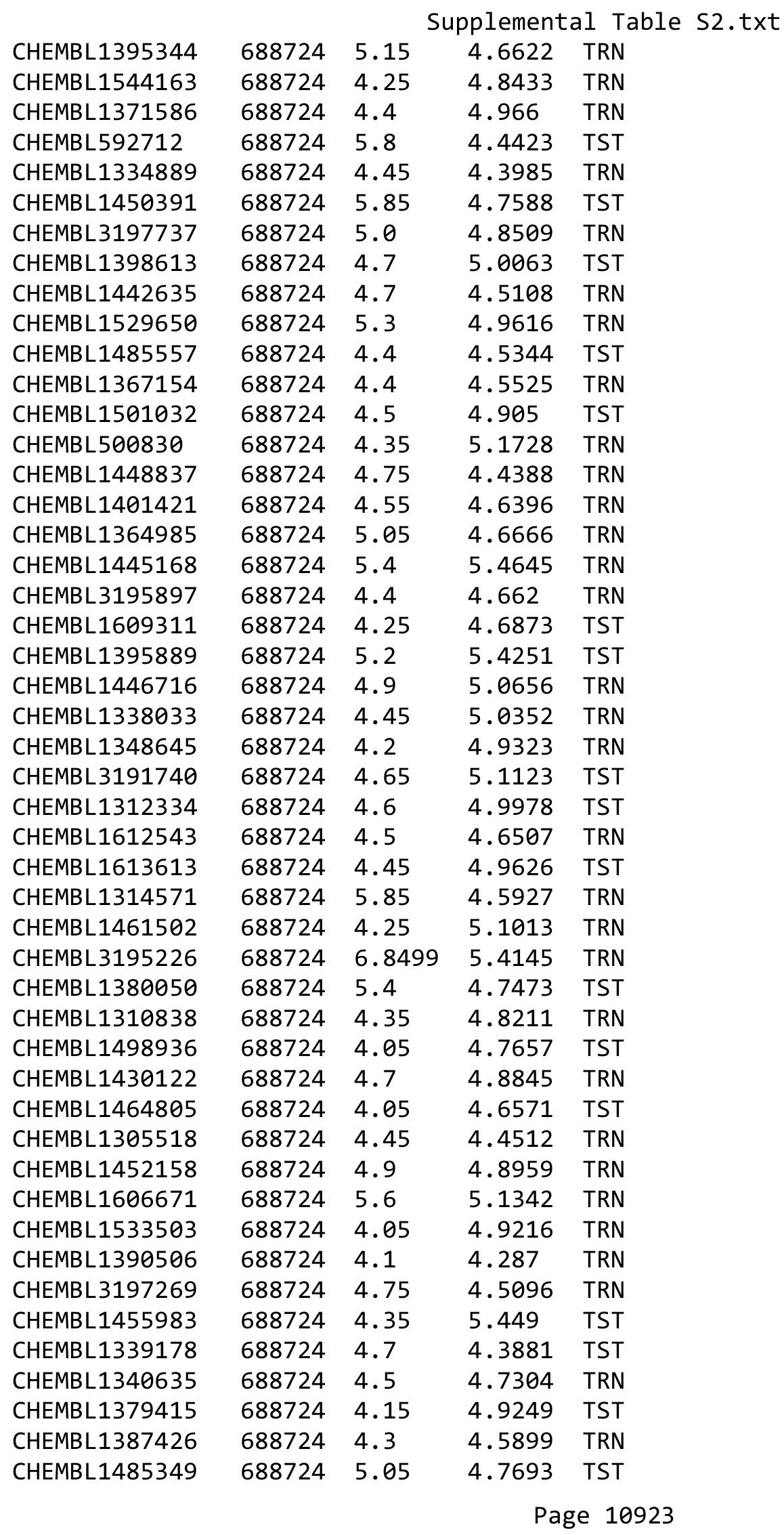




\begin{tabular}{|c|c|c|c|c|}
\hline \multicolumn{5}{|c|}{ Supplemental Table S2.txt } \\
\hline CHEMBL1471337 & 688724 & 4.95 & 4.9928 & TRN \\
\hline CHEMBL1482457 & 688724 & 4.55 & 5.0326 & TRN \\
\hline CHEMBL1437443 & 688724 & 4.7 & 4.8668 & TRN \\
\hline CHEMBL1409195 & 688724 & 4.7 & 4.7762 & TRN \\
\hline CHEMBL1549292 & 688724 & 4.6 & 4.8901 & TST \\
\hline CHEMBL312487 & 688724 & 6.0 & 5.0602 & TRN \\
\hline CHEMBL1531814 & 688724 & 4.5 & 4.9118 & TRN \\
\hline CHEMBL1377521 & 688724 & 4.35 & 4.7146 & TST \\
\hline CHEMBL1332390 & 688724 & 4.75 & 4.859 & TST \\
\hline CHEMBL1418782 & 688724 & 4.8 & 4.8462 & TRN \\
\hline CHEMBL1537884 & 688724 & 4.4 & 4.5824 & TRN \\
\hline CHEMBL1352415 & 688724 & 3.95 & 4.7504 & TRN \\
\hline CHEMBL406819 & 688724 & 4.1 & 5.008 & TST \\
\hline CHEMBL1336866 & 688724 & 4.85 & 4.7735 & TST \\
\hline CHEMBL1345129 & 688724 & 4.7 & 4.6785 & TRN \\
\hline CHEMBL1360572 & 688724 & 4.5 & 4.9421 & TRN \\
\hline CHEMBL1502860 & 688724 & 5.0 & 4.9414 & TRN \\
\hline CHEMBL1336742 & 688724 & 4.4 & 4.7597 & TRN \\
\hline CHEMBL1573121 & 688724 & 4.7 & 4.7703 & TRN \\
\hline CHEMBL1476774 & 688724 & 4.25 & 4.8691 & TRN \\
\hline CHEMBL1395520 & 688724 & 4.7 & 4.6634 & TRN \\
\hline CHEMBL1573697 & 688724 & 5.4 & 5.6662 & TRN \\
\hline CHEMBL1303739 & 688724 & 4.0 & 4.9025 & TST \\
\hline CHEMBL1361582 & 688724 & 5.0 & 5.0927 & TRN \\
\hline CHEMBL1419324 & 688724 & 4.8 & 4.7449 & TRN \\
\hline CHEMBL1478628 & 688724 & 4.75 & 4.7219 & TRN \\
\hline CHEMBL1514721 & 688724 & 4.65 & 5.657 & TRN \\
\hline CHEMBL1591077 & 688724 & 4.55 & 4.3523 & TRN \\
\hline CHEMBL1595820 & 688724 & 5.9 & 5.7626 & TRN \\
\hline CHEMBL1411951 & 688724 & 4.8 & 4.9492 & TST \\
\hline CHEMBL1544946 & 688724 & 5.0 & 5.1777 & TRN \\
\hline CHEMBL1406255 & 688724 & 5.1 & 4.6107 & TRN \\
\hline CHEMBL1430796 & 688724 & 6.05 & 4.6162 & TST \\
\hline CHEMBL1575081 & 688724 & 4.25 & 4.9675 & TRN \\
\hline CHEMBL1546531 & 688724 & 4.65 & 4.5917 & TST \\
\hline CHEMBL1498541 & 688724 & 4.5 & 5.2834 & TRN \\
\hline CHEMBL1506603 & 688724 & 4.1 & 4.79899 & 99999999995 \\
\hline CHEMBL225230 & 688724 & 4.8 & 5.6878 & TRN \\
\hline CHEMBL1578456 & 688724 & 4.4 & 4.6573 & TRN \\
\hline CHEMBL1506729 & 688724 & 4.35 & 4.2744 & TRN \\
\hline CHEMBL1482998 & 688724 & 6.5 & 4.8957 & TRN \\
\hline CHEMBL1332919 & 688724 & 4.0 & 4.4813 & TRN \\
\hline CHEMBL1305422 & 688724 & 4.6 & 4.5355 & TST \\
\hline CHEMBL1490169 & 688724 & 4.2 & 4.8925 & TRN \\
\hline CHEMBL1559220 & 688724 & 4.3 & 4.7283 & TST \\
\hline CHEMBL1509833 & 688724 & 4.05 & 4.6141 & TRN \\
\hline CHEMBL1528235 & 688724 & 6.15 & 4.4072 & TST \\
\hline CHEMBL1492565 & 688724 & 6.0 & 5.0268 & TRN \\
\hline
\end{tabular}




\begin{tabular}{|c|c|c|c|c|}
\hline \multicolumn{5}{|c|}{ Supplemental Table S2.txt } \\
\hline CHEMBL1305500 & 688724 & 4.85 & 4.6414 & TRN \\
\hline CHEMBL1344828 & 688724 & 4.05 & 4.4942 & TRN \\
\hline CHEMBL1554633 & 688724 & 4.7 & 4.7124 & TRN \\
\hline CHEMBL1482509 & 688724 & 4.35 & 4.6155 & TRN \\
\hline CHEMBL1566050 & 688724 & 4.9 & 4.6657 & TRN \\
\hline CHEMBL1399553 & 688724 & 6.0 & 5.1757 & TST \\
\hline CHEMBL1517543 & 688724 & 5.25 & 4.8834 & TST \\
\hline CHEMBL1549629 & 688724 & 5.3 & 4.6372 & TRN \\
\hline CHEMBL1559263 & 688724 & 4.6 & 4.7691 & TST \\
\hline CHEMBL399350 & 688724 & 4.8 & 4.5875 & TRN \\
\hline CHEMBL1501481 & 688724 & 4.65 & 4.7375 & TRN \\
\hline CHEMBL 3190724 & 688724 & 4.8 & 5.1393 & TST \\
\hline CHEMBL1577341 & 688724 & 5.2 & 4.8009 & TRN \\
\hline CHEMBL1507723 & 688724 & 4.6 & 4.6441 & TRN \\
\hline CHEMBL1479045 & 688724 & 4.45 & 5.0784 & TRN \\
\hline CHEMBL1611378 & 688724 & 4.95 & 4.8607 & TRN \\
\hline CHEMBL1479557 & 688724 & 5.8 & 5.1381 & TRN \\
\hline CHEMBL44201 & 688724 & 4.55 & 4.6679 & TRN \\
\hline CHEMBL1361563 & 688724 & 5.0 & 4.8714 & TRN \\
\hline CHEMBL1499783 & 688724 & 5.25 & 4.547 & TRN \\
\hline CHEMBL1566898 & 688724 & 4.6 & 4.2738 & TRN \\
\hline CHEMBL1604472 & 688724 & 4.45 & 4.6727 & TRN \\
\hline CHEMBL1306923 & 688724 & 5.45 & 5.0053 & TRN \\
\hline CHEMBL1517192 & 688724 & 4.5 & 4.6117 & TST \\
\hline CHEMBL1609614 & 688724 & 4.1 & 4.7924 & TST \\
\hline CHEMBL1505120 & 688724 & 4.9 & 4.9913 & TRN \\
\hline CHEMBL1567754 & 688724 & 4.4 & 4.4056 & TRN \\
\hline CHEMBL1374450 & 688724 & 4.4 & 4.9384 & TST \\
\hline CHEMBL1565350 & 688724 & 4.8 & 4.5525 & TST \\
\hline CHEMBL1518374 & 688724 & 4.9 & 5.0857 & TRN \\
\hline CHEMBL1562030 & 688724 & 4.85 & 5.1631 & TRN \\
\hline CHEMBL1464338 & 688724 & 4.8 & 4.7061 & TRN \\
\hline CHEMBL1562713 & 688724 & 4.5 & 4.8678 & TRN \\
\hline CHEMBL1338046 & 688724 & 4.8 & 4.7453 & TST \\
\hline CHEMBL1488189 & 688724 & 4.3 & 4.6314 & TRN \\
\hline CHEMBL1474528 & 688724 & 4.25 & 4.7324 & TRN \\
\hline CHEMBL1361818 & 688724 & 4.85 & 4.4927 & TRN \\
\hline CHEMBL1524482 & 688724 & 4.65 & 4.8008 & TRN \\
\hline CHEMBL1460394 & 688724 & 5.6 & 5.0339 & TRN \\
\hline CHEMBL1422670 & 688724 & 4.9 & 5.0112 & TST \\
\hline CHEMBL1460107 & 688724 & 4.85 & 4.9495 & TRN \\
\hline CHEMBL3195049 & 688724 & 4.35 & 4.8098 & TST \\
\hline CHEMBL1489240 & 688724 & 4.4 & 5.0982 & TRN \\
\hline CHEMBL1603269 & 688724 & 4.05 & 4.958 & TRN \\
\hline CHEMBL1412068 & 688724 & 4.1 & 4.6968 & TRN \\
\hline CHEMBL1476704 & 688724 & 4.05 & 4.7826 & TST \\
\hline CHEMBL1426638 & 688724 & 4.6 & 4.978 & TRN \\
\hline CHEMBL1329911 & 688724 & 5.0 & 4.8695 & TRN \\
\hline
\end{tabular}




\begin{tabular}{|c|c|c|c|c|c|}
\hline \multirow{2}{*}{ CHEMBL1992447 } & \multirow[b]{2}{*}{688724} & \\
\hline & & 4.4 & 4.5767 & TRN & \\
\hline CHEMBL1500614 & 688724 & 4.6 & 5.0691 & TRN & \\
\hline CHEMBL1427649 & 688724 & 4.7 & 4.7795 & TST & \\
\hline CHEMBL1348119 & 688724 & 6.15 & 5.3299 & TRN & \\
\hline CHEMBL1451277 & 688724 & 8.6021 & 4.9505 & TST & \\
\hline CHEMBL1433078 & 688724 & 4.1 & 4.7349 & TST & \\
\hline CHEMBL1569094 & 688724 & 4.65 & 4.6802 & TRN & \\
\hline CHEMBL196590 & 688724 & 4.45 & 4.8956 & TRN & \\
\hline CHEMBL1386252 & 688724 & 4.5 & \multicolumn{2}{|c|}{4.8389999999999995} & TRN \\
\hline CHEMBL 289277 & 688724 & 6.0 & 5.4678 & TRN & \\
\hline CHEMBL1256360 & 688724 & 6.0 & 5.7049 & TRN & \\
\hline CHEMBL1363707 & 688724 & 4.15 & 4.636 & TRN & \\
\hline CHEMBL1600954 & 688724 & 4.45 & 4.6273 & TRN & \\
\hline CHEMBL3392355 & 688724 & 5.35 & 5.1896 & TRN & \\
\hline CHEMBL3191785 & 688724 & 4.3 & 4.585 & TRN & \\
\hline CHEMBL3199440 & 688724 & 4.25 & 4.5492 & TRN & \\
\hline CHEMBL1533052 & 688724 & 4.55 & 4.4784 & TST & \\
\hline CHEMBL1467911 & 688724 & 4.2 & 5.0311 & TRN & \\
\hline CHEMBL1312576 & 688724 & 5.5 & 4.6943 & TRN & \\
\hline CHEMBL354330 & 688724 & 4.5 & 4.7022 & TRN & \\
\hline CHEMBL1361656 & 688724 & 5.15 & 4.5654 & TRN & \\
\hline CHEMBL1302872 & 688724 & 4.55 & 4.3915 & TRN & \\
\hline CHEMBL1418100 & 688724 & 4.0 & 4.5926 & TRN & \\
\hline CHEMBL1408872 & 688724 & 5.15 & 4.8278 & TRN & \\
\hline CHEMBL1610779 & 688724 & 4.55 & 4.803 & TRN & \\
\hline CHEMBL1579917 & 688724 & 4.35 & 4.4758 & TRN & \\
\hline CHEMBL1341410 & 688724 & 5.35 & 4.7982 & TST & \\
\hline CHEMBL370611 & 688724 & 4.7 & 4.7279 & TRN & \\
\hline CHEMBL1348066 & 688724 & 4.4 & 4.7489 & TRN & \\
\hline CHEMBL1410931 & 688724 & 4.4 & 4.4649 & TRN & \\
\hline CHEMBL1500751 & 688724 & 4.55 & 4.8333 & TST & \\
\hline CHEMBL168276 & 688724 & 6.05 & 5.4873 & TRN & \\
\hline CHEMBL1510332 & 688724 & 5.05 & 5.2939 & TRN & \\
\hline CHEMBL1532324 & 688724 & 4.5 & 4.7931 & TRN & \\
\hline CHEMBL1409610 & 688724 & 5.55 & 4.8107 & TRN & \\
\hline CHEMBL1556609 & 688724 & 5.45 & 4.61600 & 00000000005 & TST \\
\hline CHEMBL1313342 & 688724 & 4.85 & 4.5029 & TRN & \\
\hline CHEMBL1415156 & 688724 & 4.85 & 4.6366 & TRN & \\
\hline CHEMBL1535060 & 688724 & 4.3 & 4.8491 & TST & \\
\hline CHEMBL1325508 & 688724 & 5.4 & 4.7945 & TST & \\
\hline CHEMBL1351226 & 688724 & 4.9 & 4.6665 & TST & \\
\hline CHEMBL406652 & 688724 & 4.3 & 4.8929 & TST & \\
\hline CHEMBL3189184 & 688724 & 4.0 & 4.5378 & TRN & \\
\hline CHEMBL1459273 & 688724 & 5.25 & 4.5606 & TRN & \\
\hline CHEMBL1571493 & 688724 & 4.0 & 4.2534 & TST & \\
\hline CHEMBL1424381 & 688724 & 4.5 & 4.7394 & TRN & \\
\hline CHEMBL1597733 & 688724 & 4.7 & 4.6228 & TRN & \\
\hline \multirow[t]{2}{*}{ CHEMBL1484189 } & 688724 & 4.5 & 4.5927 & TRN & \\
\hline & & \multicolumn{4}{|c|}{ Page 10926} \\
\hline
\end{tabular}




\begin{tabular}{|c|c|c|c|c|c|}
\hline \multicolumn{6}{|c|}{ Supplemental Table S2.txt } \\
\hline CHEMBL1332598 & 688724 & 4.6 & 4.7004 & TST & \\
\hline CHEMBL1560833 & 688724 & 5.5 & 4.7761 & TRN & \\
\hline CHEMBL1580066 & 688724 & 4.4 & 4.8843 & TRN & \\
\hline CHEMBL3192212 & 688724 & 4.7 & 4.7016 & TRN & \\
\hline CHEMBL2359911 & 688724 & 4.75 & 5.4246 & TRN & \\
\hline CHEMBL1486302 & 688724 & 4.4 & 4.7517 & TRN & \\
\hline CHEMBL1611709 & 688724 & 5.4 & 4.838 & TRN & \\
\hline CHEMBL1307776 & 688724 & 6.3 & 5.0472 & TRN & \\
\hline CHEMBL1390565 & 688724 & 4.65 & 4.7793 & TRN & \\
\hline CHEMBL1575932 & 688724 & 4.4 & 4.5269 & TST & \\
\hline CHEMBL1371049 & 688724 & 6.25 & 5.1848 & TRN & \\
\hline CHEMBL1611542 & 688724 & 5.2 & 4.7267 & TRN & \\
\hline CHEMBL1344027 & 688724 & 4.8 & 4.6263 & TST & \\
\hline CHEMBL1426947 & 688724 & 5.05 & 4.865 & TRN & \\
\hline CHEMBL1472878 & 688724 & 4.25 & 4.5118 & TRN & \\
\hline CHEMBL1488983 & 688724 & 4.4 & 5.0447 & TRN & \\
\hline CHEMBL1321952 & 688724 & 5.3 & 4.7354 & TRN & \\
\hline CHEMBL35479 & 688724 & 5.2 & 4.8722 & TRN & \\
\hline CHEMBL1353420 & 688724 & 4.55 & 4.5683 & TRN & \\
\hline CHEMBL1330558 & 688724 & 4.8 & 5.3857 & TRN & \\
\hline CHEMBL1478 & 688724 & 6.0 & 5.2332 & TRN & \\
\hline CHEMBL1581201 & 688724 & 5.7 & 4.6051 & TRN & \\
\hline CHEMBL1494301 & 688724 & 4.55 & 4.79899 & 99999999995 & TRN \\
\hline CHEMBL1544326 & 688724 & 4.4 & 4.8776 & TRN & \\
\hline CHEMBL1398290 & 688724 & 4.6 & 4.7744 & TST & \\
\hline CHEMBL1532919 & 688724 & 4.95 & 4.7444 & TST & \\
\hline CHEMBL321691 & 688724 & 5.45 & 5.4549 & TRN & \\
\hline CHEMBL501680 & 688724 & 4.5 & 5.0391 & TST & \\
\hline CHEMBL1586975 & 688724 & 4.75 & 4.842 & TRN & \\
\hline CHEMBL1342597 & 688724 & 4.35 & 5.0276 & TRN & \\
\hline CHEMBL1466735 & 688724 & 4.75 & 4.9077 & TRN & \\
\hline CHEMBL1425108 & 688724 & 4.85 & 5.1043 & TRN & \\
\hline CHEMBL1974916 & 688724 & 4.8 & 4.8549 & TRN & \\
\hline CHEMBL1364081 & 688724 & 4.15 & 4.9509 & TST & \\
\hline CHEMBL1419714 & 688724 & 4.95 & 4.8442 & TRN & \\
\hline CHEMBL1392200 & 688724 & 4.3242 & 5.6216 & TRN & \\
\hline CHEMBL1420365 & 688724 & 4.65 & 5.3032 & TRN & \\
\hline CHEMBL1331013 & 688724 & 4.95 & 4.8559 & TRN & \\
\hline CHEMBL1302631 & 688724 & 4.45 & 4.6966 & TRN & \\
\hline CHEMBL1409519 & 688724 & 4.45 & 5.0618 & TRN & \\
\hline CHEMBL1509377 & 688724 & 4.95 & 4.5208 & TRN & \\
\hline CHEMBL3189770 & 688724 & 4.4 & 4.9082 & TRN & \\
\hline CHEMBL1466856 & 688724 & 4.4 & 4.7708 & TRN & \\
\hline CHEMBL1345143 & 688724 & 4.6 & 4.8417 & TRN & \\
\hline CHEMBL1368108 & 688724 & 4.25 & 4.6446 & TRN & \\
\hline CHEMBL1468953 & 688724 & 4.95 & 4.965 & TRN & \\
\hline CHEMBL1426096 & 688724 & 4.75 & 4.4926 & TRN & \\
\hline CHEMBL1334895 & 688724 & 5.05 & 4.8293 & TST & \\
\hline
\end{tabular}




\begin{tabular}{|c|c|c|c|c|c|}
\hline \multicolumn{6}{|c|}{ Supplemental Table S2.txt } \\
\hline CHEMBL1430983 & 688724 & 5.7 & 4.9913 & TRN & \\
\hline CHEMBL1491340 & 688724 & 4.1 & 5.619 & TST & \\
\hline CHEMBL1580247 & 688724 & 6.95 & 4.4016 & TRN & \\
\hline CHEMBL1519152 & 688724 & 4.1 & 4.8487 & TRN & \\
\hline CHEMBL1484494 & 688724 & 4.75 & 4.3434 & TRN & \\
\hline CHEMBL3195286 & 688724 & 4.95 & 4.877 & TRN & \\
\hline CHEMBL1601864 & 688724 & 4.5 & 4.4812 & TST & \\
\hline CHEMBL3210119 & 688724 & 4.35 & 4.445 & TRN & \\
\hline CHEMBL1469526 & 688724 & 4.1 & 4.9887 & TST & \\
\hline CHEMBL1425586 & 688724 & 5.1 & 5.0719 & TRN & \\
\hline CHEMBL1514634 & 688724 & 5.15 & 4.8057 & TST & \\
\hline CHEMBL1517551 & 688724 & 4.75 & 5.1315 & TRN & \\
\hline CHEMBL604119 & 688724 & 4.85 & 5.1478 & TST & \\
\hline CHEMBL 3145108 & 688724 & 4.65 & 4.9896 & TRN & \\
\hline CHEMBL1430660 & 688724 & 4.85 & 4.7816 & TRN & \\
\hline CHEMBL3191643 & 688724 & 4.85 & 4.8801 & TRN & \\
\hline CHEMBL1487062 & 688724 & 4.95 & 4.5503 & TST & \\
\hline CHEMBL1464898 & 688724 & 4.95 & 4.687 & TRN & \\
\hline CHEMBL1570078 & 688724 & 4.4 & 5.2558 & TRN & \\
\hline CHEMBL1597042 & 688724 & 6.4 & 5.1437 & TRN & \\
\hline CHEMBL1541205 & 688724 & 4.35 & 4.9488 & TRN & \\
\hline CHEMBL1536053 & 688724 & 6.4 & 5.0527 & TRN & \\
\hline CHEMBL1506191 & 688724 & 4.65 & 4.7226 & TRN & \\
\hline CHEMBL1367573 & 688724 & 5.0 & 5.1721 & TST & \\
\hline CHEMBL3199005 & 688724 & 4.9 & 5.0807 & TRN & \\
\hline CHEMBL 2000172 & 688724 & 4.75 & 4.8533 & TRN & \\
\hline CHEMBL1594553 & 688724 & 4.9 & 5.3309 & TRN & \\
\hline CHEMBL1414110 & 688724 & 4.7 & 4.7425 & TRN & \\
\hline CHEMBL1452952 & 688724 & 4.9 & 4.6958 & TRN & \\
\hline CHEMBL1333996 & 688724 & 4.9 & 5.1591 & TRN & \\
\hline CHEMBL1376239 & 688724 & 5.25 & 5.15799 & 99999999995 & TST \\
\hline CHEMBL1465935 & 688724 & 4.3 & 4.5886 & TRN & \\
\hline CHEMBL1508433 & 688724 & 4.75 & 5.2018 & TRN & \\
\hline CHEMBL3190112 & 688724 & 4.4 & 4.9959 & TRN & \\
\hline CHEMBL1345041 & 688724 & 4.6 & 4.5352 & TRN & \\
\hline CHEMBL1496441 & 688724 & 5.1 & 4.6969 & TRN & \\
\hline CHEMBL585628 & 688724 & 4.85 & 5.2131 & TRN & \\
\hline CHEMBL1312262 & 688724 & 4.65 & 4.3613 & TRN & \\
\hline CHEMBL3392494 & 688724 & 5.25 & 5.2845 & TRN & \\
\hline CHEMBL1490060 & 688724 & 6.0 & 5.1003 & TST & \\
\hline CHEMBL3210411 & 688724 & 5.35 & 4.4827 & TRN & \\
\hline CHEMBL3193905 & 688724 & 5.7 & 5.0583 & TRN & \\
\hline CHEMBL3192484 & 688724 & 4.9 & 4.9573 & TRN & \\
\hline CHEMBL 3189382 & 688724 & 4.05 & 5.1482 & TRN & \\
\hline CHEMBL1432564 & 688724 & 4.4 & 4.6574 & TRN & \\
\hline CHEMBL1540373 & 688724 & 4.35 & 4.4228 & TRN & \\
\hline CHEMBL1403497 & 688724 & 5.0 & 4.9879 & TRN & \\
\hline CHEMBL1546069 & 688724 & 4.4 & 4.6388 & TRN & \\
\hline
\end{tabular}




\begin{tabular}{|c|c|c|c|c|}
\hline \multicolumn{5}{|c|}{ Supplemental Table S2.txt } \\
\hline CHEMBL1324882 & 688724 & 4.15 & 4.4692 & TRN \\
\hline CHEMBL3193947 & 688724 & 4.95 & 4.8119 & TRN \\
\hline CHEMBL 3198782 & 688724 & 5.9 & 4.7015 & TRN \\
\hline CHEMBL1546299 & 688724 & 4.25 & 5.1908 & TRN \\
\hline CHEMBL1342281 & 688724 & 4.8 & 4.5935 & TRN \\
\hline CHEMBL1313077 & 688724 & 4.75 & 4.5679 & TRN \\
\hline CHEMBL1568269 & 688724 & 4.45 & 4.8938 & TST \\
\hline CHEMBL1400056 & 688724 & 4.75 & 4.6955 & TRN \\
\hline CHEMBL3198659 & 688724 & 4.55 & 4.8714 & TRN \\
\hline CHEMBL1379554 & 688724 & 4.2 & 4.6353 & TST \\
\hline CHEMBL1399136 & 688724 & 4.55 & 4.7149 & TRN \\
\hline CHEMBL1407746 & 688724 & 4.7 & 4.6905 & TST \\
\hline CHEMBL1380171 & 688724 & 4.45 & 4.8721 & TRN \\
\hline CHEMBL1340299 & 688724 & 4.75 & 5.25 & TRN \\
\hline CHEMBL1521049 & 688724 & 4.6 & 4.6839 & TST \\
\hline CHEMBL1361920 & 688724 & 5.35 & 4.9865 & TRN \\
\hline CHEMBL1388981 & 688724 & 4.05 & 4.7128 & TRN \\
\hline CHEMBL1406193 & 688724 & 4.55 & 4.6903 & TRN \\
\hline CHEMBL1485449 & 688724 & 4.1 & 4.5303 & TST \\
\hline CHEMBL1331771 & 688724 & 4.6 & 5.0513 & TRN \\
\hline CHEMBL1309315 & 688724 & 4.7 & 5.1353 & TST \\
\hline CHEMBL1561148 & 688724 & 4.25 & 5.5134 & TST \\
\hline CHEMBL1485119 & 688724 & 4.25 & 5.1207 & TRN \\
\hline CHEMBL1529310 & 688724 & 4.05 & 4.9447 & TRN \\
\hline CHEMBL1318310 & 688724 & 4.45 & 4.9137 & TRN \\
\hline CHEMBL1537421 & 688724 & 4.3 & 4.65 & TRN \\
\hline CHEMBL1470925 & 688724 & 4.5 & 5.296 & TRN \\
\hline CHEMBL1448942 & 688724 & 4.7 & 4.5519 & TRN \\
\hline CHEMBL1415045 & 688724 & 4.85 & 5.0513 & TST \\
\hline CHEMBL1999911 & 688724 & 4.7 & 5.1448 & TRN \\
\hline CHEMBL1503208 & 688724 & 5.95 & 4.9097 & TST \\
\hline CHEMBL3189503 & 688724 & 6.2 & 4.8514 & TST \\
\hline CHEMBL1419472 & 688724 & 4.85 & 4.7443 & TRN \\
\hline CHEMBL3190410 & 688724 & 5.7 & 4.7182 & TRN \\
\hline CHEMBL1413250 & 688724 & 4.45 & 5.052 & TRN \\
\hline CHEMBL1564933 & 688724 & 4.3 & 4.5886 & TRN \\
\hline CHEMBL1315784 & 688724 & 5.9 & 5.2327 & TST \\
\hline CHEMBL1415426 & 688724 & 4.75 & 4.9569 & TRN \\
\hline CHEMBL1533313 & 688724 & 4.1 & 4.5857 & TST \\
\hline CHEMBL1484000 & 688724 & 4.0 & 4.6424 & TRN \\
\hline CHEMBL1475749 & 688724 & 6.0 & 4.9835 & TRN \\
\hline CHEMBL3189410 & 688724 & 5.6 & 4.7693 & TRN \\
\hline CHEMBL1461829 & 688724 & 4.5 & 4.7177 & TRN \\
\hline CHEMBL3196884 & 688724 & 4.5 & 4.8516 & TRN \\
\hline CHEMBL1549627 & 688724 & 4.6 & 4.8231 & TRN \\
\hline CHEMBL1427969 & 688724 & 5.25 & 4.8018 & TRN \\
\hline CHEMBL1611096 & 688724 & 4.1 & 4.7398 & TRN \\
\hline CHEMBL462314 & 688724 & 6.5 & 4.9769 & TST \\
\hline
\end{tabular}




\begin{tabular}{|c|c|c|c|c|c|}
\hline \multicolumn{6}{|c|}{ Supplemental Table S2.txt } \\
\hline CHEMBL1506329 & 688724 & 6.0 & 4.7512 & TRN & \\
\hline CHEMBL1309573 & 688724 & 4.35 & 5.2525 & TRN & \\
\hline CHEMBL1462348 & 688724 & 4.05 & 4.6597 & TST & \\
\hline CHEMBL1609794 & 688724 & 4.9 & 5.0045 & TST & \\
\hline CHEMBL1302457 & 688724 & 4.35 & 4.7586 & TST & \\
\hline CHEMBL1377973 & 688724 & 4.65 & 4.7387 & TRN & \\
\hline CHEMBL3199475 & 688724 & 4.45 & 5.0147 & TRN & \\
\hline CHEMBL1162110 & 688724 & 4.3 & 4.5844 & TRN & \\
\hline CHEMBL1433908 & 688724 & 4.05 & 4.7082 & TRN & \\
\hline CHEMBL1535651 & 688724 & 4.3 & 4.6304 & TST & \\
\hline CHEMBL1455014 & 688724 & 5.05 & 5.1318 & TRN & \\
\hline CHEMBL1313449 & 688724 & 5.1 & 4.9334 & TST & \\
\hline CHEMBL1328515 & 688724 & 4.4 & 4.5903 & TRN & \\
\hline CHEMBL1458840 & 688724 & 5.05 & 5.3606 & TST & \\
\hline CHEMBL1507719 & 688724 & 4.25 & 4.7566 & TRN & \\
\hline CHEMBL1343068 & 688724 & 4.4 & 5.0372 & TRN & \\
\hline CHEMBL1408143 & 688724 & 4.55 & 4.7641 & TST & \\
\hline CHEMBL3189923 & 688724 & 4.5 & 4.5047 & TRN & \\
\hline CHEMBL1426330 & 688724 & 4.05 & 4.4813 & TRN & \\
\hline CHEMBL1442492 & 688724 & 4.55 & 4.9637 & TST & \\
\hline CHEMBL1463968 & 688724 & 4.45 & 4.9927 & TRN & \\
\hline CHEMBL1526861 & 688724 & 4.25 & 4.4751 & TRN & \\
\hline CHEMBL1990292 & 688724 & 4.85 & 5.2824 & TRN & \\
\hline CHEMBL1393635 & 688724 & 4.75 & 4.8614 & TRN & \\
\hline CHEMBL3210191 & 688724 & 4.75 & 4.5149 & TRN & \\
\hline CHEMBL1514003 & 688724 & 4.45 & 4.8622 & TRN & \\
\hline CHEMBL1348572 & 688724 & 5.9 & 5.0747 & TST & \\
\hline CHEMBL1301067 & 688724 & 4.7 & 4.9447 & TRN & \\
\hline CHEMBL1442915 & 688724 & 4.5 & 4.6488 & TRN & \\
\hline CHEMBL1468601 & 688724 & 4.0 & 4.6642 & TST & \\
\hline CHEMBL1407636 & 688724 & 4.05 & 4.9526 & TRN & \\
\hline CHEMBL1489659 & 688724 & 4.3 & 4.4388 & TRN & \\
\hline CHEMBL1451216 & 688724 & 4.9 & 5.607 & TST & \\
\hline CHEMBL1603474 & 688724 & 4.75 & 5.0009 & TRN & \\
\hline CHEMBL1478759 & 688724 & 4.9 & 5.0187 & TST & \\
\hline CHEMBL1397123 & 688724 & 6.0 & 5.05699 & 99999999995 & TRN \\
\hline CHEMBL1397367 & 688724 & 4.75 & 5.2358 & TRN & \\
\hline CHEMBL1571751 & 688724 & 4.35 & 4.7358 & TST & \\
\hline CHEMBL1411060 & 688724 & 5.65 & 4.7024 & TST & \\
\hline CHEMBL1526322 & 688724 & 4.7 & 4.7303 & TRN & \\
\hline CHEMBL1424208 & 688724 & 4.4 & 4.7818 & TRN & \\
\hline CHEMBL1609206 & 688724 & 4.45 & 4.8236 & TRN & \\
\hline CHEMBL1969543 & 688724 & 4.7 & 4.5845 & TRN & \\
\hline CHEMBL 3212217 & 688724 & 4.9 & 4.8527 & TST & \\
\hline CHEMBL3392462 & 688724 & 4.35 & 4.9758 & TRN & \\
\hline CHEMBL1441920 & 688724 & 7.5498 & 4.7771 & TST & \\
\hline CHEMBL1334007 & 688724 & 4.35 & 4.7931 & TRN & \\
\hline CHEMBL1348723 & 688724 & 4.6 & 4.9411 & TRN & \\
\hline
\end{tabular}




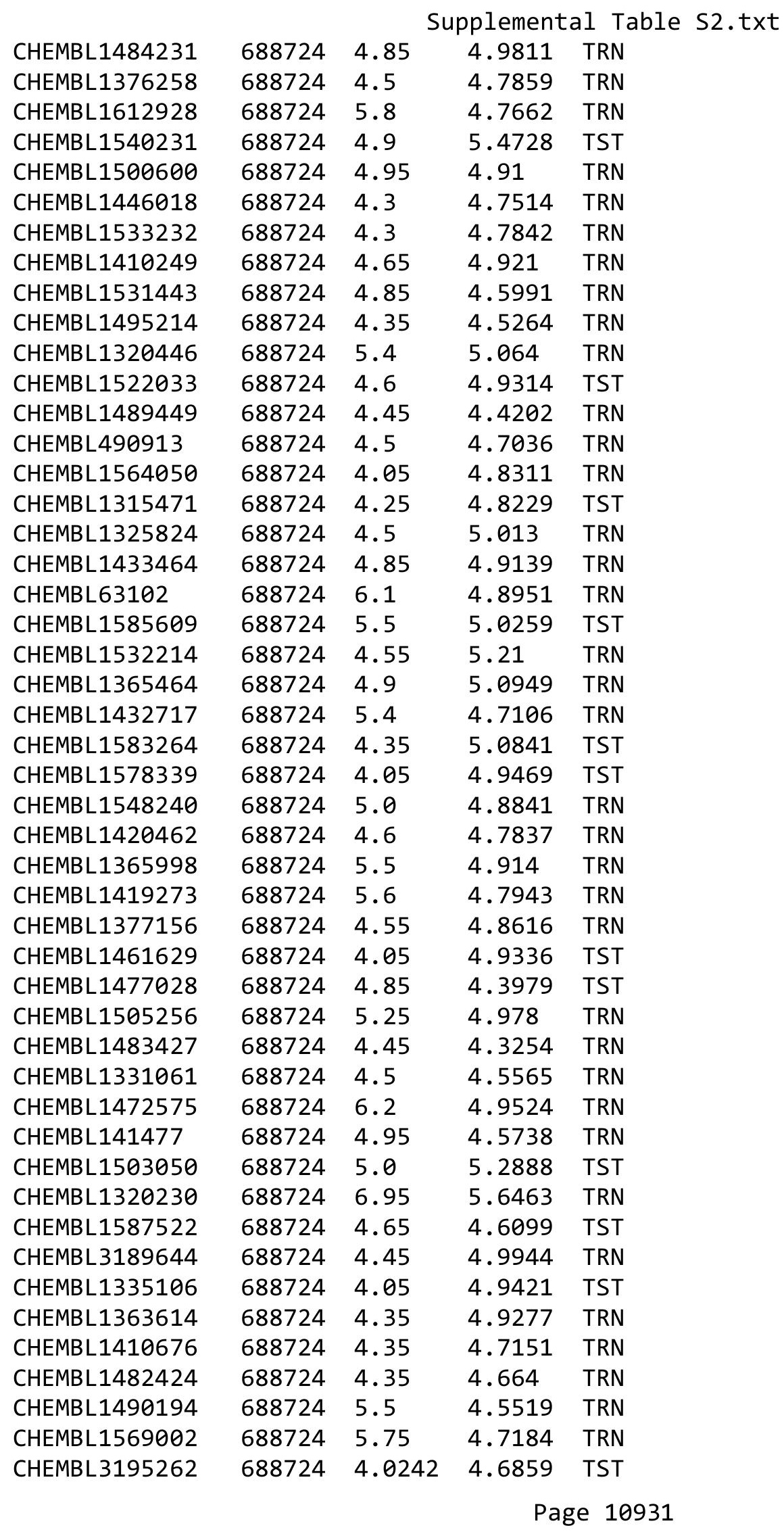




\begin{tabular}{|c|c|c|c|c|c|}
\hline \multicolumn{6}{|c|}{ Supplemental Table S2.txt } \\
\hline CHEMBL229760 & 688724 & 4.7 & 4.8467 & TST & \\
\hline CHEMBL1542869 & 688724 & 4.5 & 4.4662 & TRN & \\
\hline CHEMBL1501588 & 688724 & 6.0 & 5.4299 & TRN & \\
\hline CHEMBL1311416 & 688724 & 5.05 & 4.9762 & TRN & \\
\hline CHEMBL 3199302 & 688724 & 5.85 & 4.607 & TST & \\
\hline CHEMBL1414240 & 688724 & 4.8 & 4.8676 & TRN & \\
\hline CHEMBL1583365 & 688724 & 5.35 & 5.0002 & TRN & \\
\hline CHEMBL1587941 & 688724 & 4.7 & 4.8019 & TRN & \\
\hline CHEMBL3210521 & 688724 & 4.05 & 4.8135 & TRN & \\
\hline CHEMBL1597622 & 688724 & 4.75 & 4.5358 & TRN & \\
\hline CHEMBL1429479 & 688724 & 5.5 & 4.9749 & TRN & \\
\hline CHEMBL1459918 & 688724 & 4.5 & 5.3111 & TRN & \\
\hline CHEMBL1377300 & 688724 & 5.3 & 4.7127 & TRN & \\
\hline CHEMBL1440056 & 688724 & 6.05 & 5.3413 & TRN & \\
\hline CHEMBL200027 & 688724 & 4.1 & 4.537 & TST & \\
\hline CHEMBL1388553 & 688724 & 4.95 & 4.5739 & TST & \\
\hline CHEMBL1427000 & 688724 & 4.25 & 4.7747 & TRN & \\
\hline CHEMBL1546767 & 688724 & 6.05 & 5.6643 & TRN & \\
\hline CHEMBL461349 & 688724 & 4.35 & 4.8924 & TST & \\
\hline CHEMBL1461446 & 688724 & 4.15 & 5.1993 & TST & \\
\hline CHEMBL1443570 & 688724 & 4.8 & 4.7697 & TRN & \\
\hline CHEMBL1472282 & 688724 & 4.4 & 4.9342 & TST & \\
\hline CHEMBL1319104 & 688724 & 4.4 & 4.7408 & TRN & \\
\hline CHEMBL1513423 & 688724 & 4.4 & 4.6565 & TRN & \\
\hline CHEMBL 3189808 & 688724 & 4.9 & 5.1351 & TRN & \\
\hline CHEMBL3190402 & 688724 & 5.0 & 4.6844 & TRN & \\
\hline CHEMBL1357519 & 688724 & 4.6 & 4.8636 & TRN & \\
\hline CHEMBL1509888 & 688724 & 4.25 & 4.5893 & TRN & \\
\hline CHEMBL1491867 & 688724 & 4.65 & 5.1777 & TRN & \\
\hline CHEMBL1447203 & 688724 & 5.0 & 4.80399 & 9999999999 & TRN \\
\hline CHEMBL1350420 & 688724 & 5.05 & 4.7472 & TRN & \\
\hline CHEMBL 77387 & 688724 & 6.0 & 5.2333 & TST & \\
\hline CHEMBL1302300 & 688724 & 4.8 & 4.8938 & TRN & \\
\hline CHEMBL1574716 & 688724 & 4.25 & 5.3311 & TST & \\
\hline CHEMBL1605384 & 688724 & 4.9 & 4.7935 & TRN & \\
\hline CHEMBL1455522 & 688724 & 4.3 & 4.4844 & TRN & \\
\hline CHEMBL1454109 & 688724 & 4.55 & 5.0854 & TRN & \\
\hline CHEMBL1327732 & 688724 & 4.85 & 4.4117 & TRN & \\
\hline CHEMBL1513522 & 688724 & 5.3 & 5.246 & TST & \\
\hline CHEMBL1384817 & 688724 & 4.0 & 4.5098 & TRN & \\
\hline CHEMBL1422046 & 688724 & 4.35 & 5.0684 & TRN & \\
\hline CHEMBL 3194584 & 688724 & 5.15 & 5.0791 & TRN & \\
\hline CHEMBL1491822 & 688724 & 4.35 & 4.9475 & TRN & \\
\hline CHEMBL1344567 & 688724 & 4.9 & 4.6224 & TST & \\
\hline CHEMBL1592598 & 688724 & 6.0 & 4.4386 & TRN & \\
\hline CHEMBL1528240 & 688724 & 5.4 & 4.6903 & TRN & \\
\hline CHEMBL1516232 & 688724 & 4.35 & 4.7609 & TRN & \\
\hline CHEMBL1612331 & 688724 & 4.4 & 4.8726 & TRN & \\
\hline
\end{tabular}




\begin{tabular}{|c|c|c|c|c|}
\hline \multicolumn{5}{|c|}{ Supplemental Table S2.txt } \\
\hline CHEMBL1607180 & 688724 & 4.05 & 4.6077 & TRN \\
\hline CHEMBL355496 & 688724 & 5.45 & 5.3624 & TRN \\
\hline CHEMBL3392427 & 688724 & 5.35 & 5.0397 & TRN \\
\hline CHEMBL1968978 & 688724 & 5.1 & 4.7319 & TRN \\
\hline CHEMBL 3197847 & 688724 & 4.75 & 5.2372 & TRN \\
\hline CHEMBL1551810 & 688724 & 4.25 & 4.7913 & TRN \\
\hline CHEMBL3196412 & 688724 & 4.65 & 4.9165 & TRN \\
\hline CHEMBL1606828 & 688724 & 4.35 & 4.5859 & TRN \\
\hline CHEMBL1416127 & 688724 & 4.55 & 4.9911 & TRN \\
\hline CHEMBL1461577 & 688724 & 5.5 & 5.0541 & TRN \\
\hline CHEMBL1519432 & 688724 & 4.05 & 4.2928 & TRN \\
\hline CHEMBL1459686 & 688724 & 5.35 & 5.1369 & TRN \\
\hline CHEMBL1600324 & 688724 & 5.15 & 4.7247 & TRN \\
\hline CHEMBL1538360 & 688724 & 4.9 & 4.6574 & TST \\
\hline CHEMBL1369516 & 688724 & 4.7 & 4.7154 & TST \\
\hline CHEMBL 2007329 & 688724 & 4.9 & 4.7561 & TST \\
\hline CHEMBL1508727 & 688724 & 4.4 & 4.4385 & TRN \\
\hline CHEMBL1613480 & 688724 & 4.9 & 4.4812 & TRN \\
\hline CHEMBL1381511 & 688724 & 5.0 & 4.6221 & TRN \\
\hline CHEMBL1441827 & 688724 & 4.35 & 4.7052 & TRN \\
\hline CHEMBL1362316 & 688724 & 4.35 & 4.6276 & TRN \\
\hline CHEMBL3193878 & 688724 & 4.5 & 4.9497 & TRN \\
\hline CHEMBL1306461 & 688724 & 4.5 & 4.622 & TRN \\
\hline CHEMBL1376248 & 688724 & 5.05 & 5.4464 & TRN \\
\hline CHEMBL1375502 & 688724 & 4.35 & 4.9605 & TST \\
\hline CHEMBL 2094532 & 688724 & 5.6 & 5.1563 & TRN \\
\hline CHEMBL1550947 & 688724 & 4.65 & 4.7492 & TRN \\
\hline CHEMBL1612018 & 688724 & 4.3 & 4.4513 & TRN \\
\hline CHEMBL1365741 & 688724 & 5.05 & 4.87 & TRN \\
\hline CHEMBL1384217 & 688724 & 5.0 & 4.6534 & TST \\
\hline CHEMBL1511720 & 688724 & 5.0 & 4.814 & TRN \\
\hline CHEMBL1430147 & 688724 & 4.8 & 4.6287 & TST \\
\hline CHEMBL1502646 & 688724 & 4.65 & 5.5956 & TRN \\
\hline CHEMBL1402539 & 688724 & 4.6 & 5.0272 & TST \\
\hline CHEMBL1323621 & 688724 & 4.25 & 5.0367 & TRN \\
\hline CHEMBL1552341 & 688724 & 4.65 & 4.74 & TST \\
\hline CHEMBL1462675 & 688724 & 4.45 & 4.52 & TRN \\
\hline CHEMBL1489693 & 688724 & 4.35 & 4.9541 & TRN \\
\hline CHEMBL1382718 & 688724 & 5.0 & 4.6277 & TRN \\
\hline CHEMBL1561123 & 688724 & 4.9 & 4.8657 & TST \\
\hline CHEMBL1330780 & 688724 & 4.65 & 4.6299 & TRN \\
\hline CHEMBL1422443 & 688724 & 5.45 & 4.8712 & TRN \\
\hline CHEMBL1368810 & 688724 & 4.05 & 4.3057 & TRN \\
\hline CHEMBL1474286 & 688724 & 5.3 & 5.5579 & TRN \\
\hline CHEMBL1497173 & 688724 & 4.7 & 4.8537 & TRN \\
\hline CHEMBL1544407 & 688724 & 4.7 & 4.8428 & TRN \\
\hline CHEMBL1981937 & 688724 & 4.9 & 4.7254 & TRN \\
\hline CHEMBL3199107 & 688724 & 4.9 & 5.16 & TRN \\
\hline
\end{tabular}




\begin{tabular}{|c|c|c|c|c|}
\hline \multirow[b]{2}{*}{ CHEMBL1981008 } & \multicolumn{4}{|c|}{ Supplemental Table s2.txt } \\
\hline & 688724 & 4.15 & 5.0068 & TRN \\
\hline CHEMBL1451525 & 688724 & 4.75 & 4.7428 & TRN \\
\hline CHEMBL 3194765 & 688724 & 5.0 & 4.7238 & TRN \\
\hline CHEMBL 1460068 & 688724 & 4.55 & 4.5866 & TST \\
\hline CHEMBL1453664 & 688724 & 4.05 & 4.7367 & TRN \\
\hline CHEMBL1499286 & 688724 & 4.35 & 5.0667 & TRN \\
\hline CHEMBL 3195168 & 688724 & 4.55 & 4.4949 & TRN \\
\hline CHEMBL1460127 & 688724 & 4.1 & 4.7542 & TST \\
\hline CHEMBL1362829 & 688724 & 4.9 & 4.8001 & TRN \\
\hline CHEMBL239478 & 688724 & 5.6 & 5.0931 & TRN \\
\hline CHEMBL1308336 & 688724 & 4.1 & 4.5467 & TRN \\
\hline CHEMBL 3195707 & 688724 & 4.1 & 4.4298 & TRN \\
\hline CHEMBL1367305 & 688724 & 4.3 & 4.2141 & TRN \\
\hline CHEMBL1474140 & 688724 & 4.2 & 4.6096 & TRN \\
\hline CHEMBL1504866 & 688724 & 4.4 & 4.9233 & TST \\
\hline CHEMBL 244707 & 688724 & 5.3 & 5.3309 & TRN \\
\hline CHEMBL1302787 & 688724 & 4.9 & 4.7005 & TRN \\
\hline CHEMBL1434555 & 688724 & 6.0 & 4.7815 & TRN \\
\hline CHEMBL1312932 & 688724 & 4.6 & 4.9698 & TST \\
\hline CHEMBL1498161 & 688724 & 5.25 & 4.9067 & TRN \\
\hline CHEMBL1462508 & 688724 & 4.25 & 4.4143 & TRN \\
\hline CHEMBL1980197 & 688724 & 5.8 & 4.8834 & TRN \\
\hline CHEMBL1601253 & 688724 & 4.6 & 4.9321 & TRN \\
\hline CHEMBL1491536 & 688724 & 4.8 & 4.6929 & TRN \\
\hline CHEMBL 3212487 & 688724 & 4.1 & 4.5062 & TRN \\
\hline CHEMBL1299283 & 688724 & 4.35 & 4.8216 & TRN \\
\hline CHEMBL1536781 & 688724 & 4.25 & 4.6468 & TRN \\
\hline CHEMBL1388881 & 688724 & 4.25 & 4.8216 & TRN \\
\hline CHEMBL1496473 & 688724 & 5.4 & 4.9345 & TST \\
\hline CHEMBL1593132 & 688724 & 4.25 & 4.8928 & TRN \\
\hline CHEMBL1408801 & 688724 & 4.85 & 4.9727 & TRN \\
\hline CHEMBL1976677 & 688724 & 5.25 & 5.2983 & TRN \\
\hline CHEMBL1446592 & 688724 & 4.05 & 4.68 & TRN \\
\hline CHEMBL118902 & 688724 & 8.699 & 5.3806 & TST \\
\hline CHEMBL1418786 & 688724 & 4.45 & 4.6318 & TRN \\
\hline CHEMBL1470061 & 688724 & 5.05 & 4.9485 & TRN \\
\hline CHEMBL1543191 & 688724 & 4.8 & 5.2706 & TST \\
\hline CHEMBL1365618 & 688724 & 4.5 & 4.8095 & TRN \\
\hline CHEMBL1401188 & 688724 & 5.15 & 5.2537 & TRN \\
\hline CHEMBL1562761 & 688724 & 4.1 & 4.7217 & TRN \\
\hline CHEMBL1414236 & 688724 & 6.0 & 5.1837 & TRN \\
\hline CHEMBL1584917 & 688724 & 4.35 & 5.0071 & TST \\
\hline CHEMBL1506131 & 688724 & 4.0 & 5.3561 & TRN \\
\hline CHEMBL1574527 & 688724 & 4.5 & 4.7719 & TRN \\
\hline CHEMBL3189717 & 688724 & 6.8499 & 5.1947 & TRN \\
\hline CHEMBL1384567 & 688724 & 4.35 & 4.9517 & TRN \\
\hline CHEMBL1370269 & 688724 & 4.35 & 4.8472 & TRN \\
\hline CHEMBL1488758 & 688724 & 4.6 & 4.6609 & TRN \\
\hline
\end{tabular}




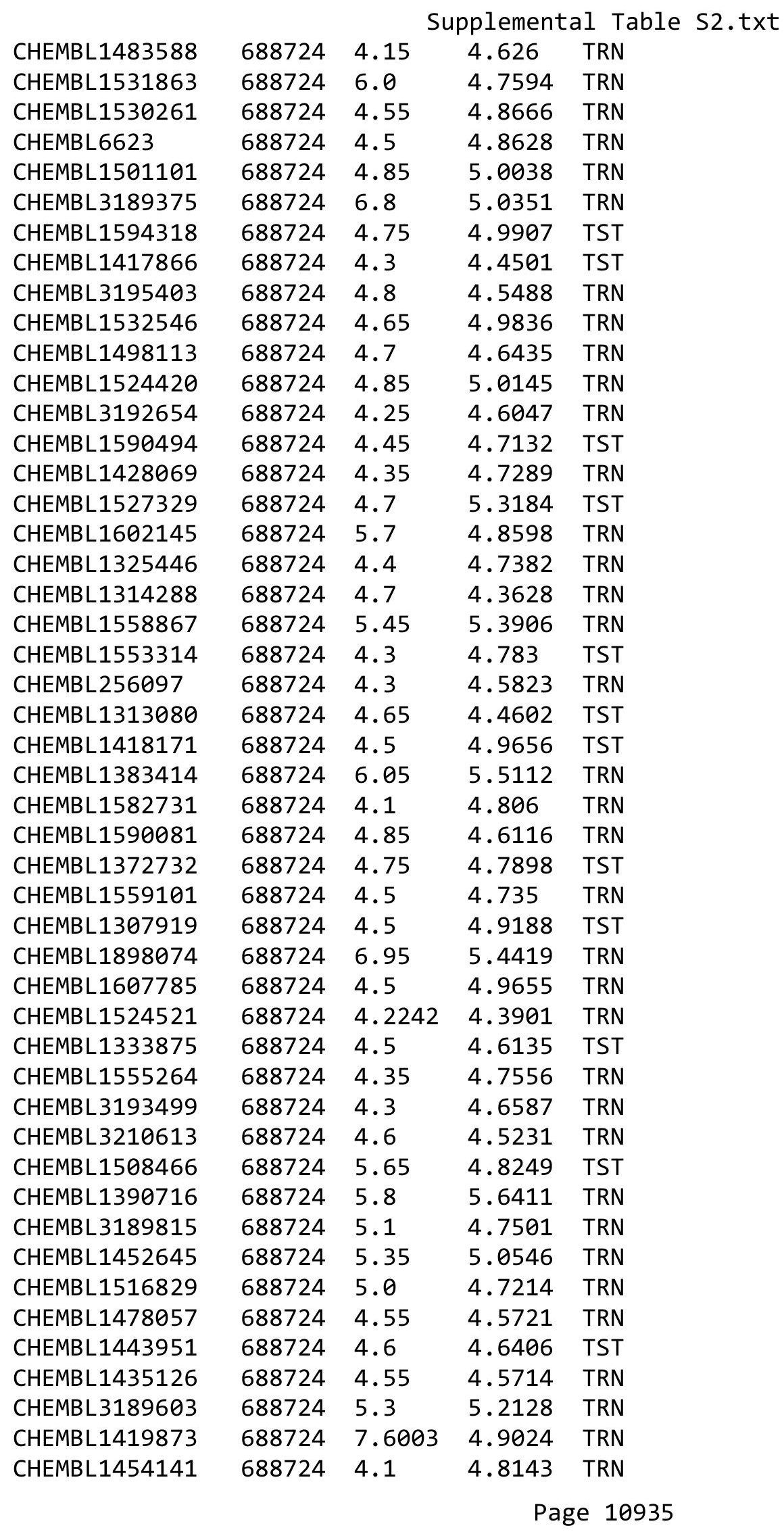




\begin{tabular}{|c|c|c|c|c|c|}
\hline \multicolumn{6}{|c|}{ Supplemental Table S2.txt } \\
\hline CHEMBL1413696 & 688724 & 5.05 & 5.0247 & TRN & \\
\hline CHEMBL236614 & 688724 & 4.15 & 5.0791 & TRN & \\
\hline CHEMBL1974450 & 688724 & 6.15 & 5.0867 & TRN & \\
\hline CHEMBL1505060 & 688724 & 4.9 & 5.4051 & TRN & \\
\hline CHEMBL1524976 & 688724 & 4.75 & 4.5692 & TRN & \\
\hline CHEMBL1522016 & 688724 & 4.4 & 4.7085 & TRN & \\
\hline CHEMBL1596647 & 688724 & 4.6 & 4.3707 & TRN & \\
\hline CHEMBL591006 & 688724 & 4.6 & 4.7827 & TRN & \\
\hline CHEMBL1308090 & 688724 & 4.4 & 4.5609 & TRN & \\
\hline CHEMBL1355889 & 688724 & 5.05 & 5.1699 & TST & \\
\hline CHEMBL1498291 & 688724 & 4.05 & 4.5764 & TST & \\
\hline CHEMBL1395982 & 688724 & 7.6003 & 5.3707 & TRN & \\
\hline CHEMBL1492174 & 688724 & 4.95 & 4.80699 & 99999999995 & TRN \\
\hline CHEMBL1470401 & 688724 & 4.95 & 4.8466 & TRN & \\
\hline CHEMBL1345357 & 688724 & 6.45 & 4.671 & TRN & \\
\hline CHEMBL1423416 & 688724 & 4.95 & 4.7937 & TRN & \\
\hline CHEMBL1596016 & 688724 & 5.3 & 4.8884 & TRN & \\
\hline CHEMBL1451731 & 688724 & 4.8 & 5.1022 & TST & \\
\hline CHEMBL1327240 & 688724 & 4.0 & 4.9172 & TST & \\
\hline CHEMBL1521307 & 688724 & 4.5 & 4.7117 & TST & \\
\hline CHEMBL1397956 & 688724 & 4.25 & 4.5415 & TST & \\
\hline CHEMBL1338476 & 688724 & 5.0 & 4.5131 & TST & \\
\hline CHEMBL1436980 & 688724 & 4.1 & 4.621 & TRN & \\
\hline CHEMBL1402476 & 688724 & 4.9 & 4.6255 & TRN & \\
\hline CHEMBL149518 & 688724 & 4.15 & 4.7668 & TST & \\
\hline CHEMBL1347387 & 688724 & 4.75 & 4.5669 & TRN & \\
\hline CHEMBL1520032 & 688724 & 4.05 & 4.6694 & TRN & \\
\hline CHEMBL1440741 & 688724 & 4.95 & 4.9403 & TRN & \\
\hline CHEMBL1385074 & 688724 & 4.1 & 4.6235 & TRN & \\
\hline CHEMBL1612919 & 688724 & 4.05 & 4.6427 & TST & \\
\hline CHEMBL1336537 & 688724 & 5.8 & 5.2561 & TRN & \\
\hline CHEMBL1983104 & 688724 & 4.55 & 4.9659 & TRN & \\
\hline CHEMBL1409053 & 688724 & 4.4 & 4.7086 & TST & \\
\hline CHEMBL1319693 & 688724 & 4.4 & 4.9387 & TST & \\
\hline CHEMBL3196294 & 688724 & 4.6 & 4.7154 & TRN & \\
\hline CHEMBL1400218 & 688724 & 4.95 & 4.9289 & TST & \\
\hline CHEMBL1318228 & 688724 & 4.65 & 4.4986 & TRN & \\
\hline CHEMBL1584438 & 688724 & 4.3 & 4.9064 & TRN & \\
\hline CHEMBL1971767 & 688724 & 8.1024 & 4.7131 & TRN & \\
\hline CHEMBL1422806 & 688724 & 6.1 & 4.6481 & TST & \\
\hline CHEMBL1375500 & 688724 & 5.1 & 4.829 & TRN & \\
\hline CHEMBL3190868 & 688724 & 5.65 & 5.58799 & 7999999999 & TRN \\
\hline CHEMBL1507207 & 688724 & 4.25 & 4.425 & TRN & \\
\hline CHEMBL1969647 & 688724 & 5.05 & 5.3236 & TRN & \\
\hline CHEMBL1357456 & 688724 & 4.0 & 4.4149 & TRN & \\
\hline CHEMBL1365745 & 688724 & 4.05 & 4.7169 & TRN & \\
\hline CHEMBL1334827 & 688724 & 4.4 & 4.5217 & TRN & \\
\hline CHEMBL1335083 & 688724 & 4.05 & 4.6496 & TRN & \\
\hline
\end{tabular}




\begin{tabular}{|c|c|c|c|c|}
\hline \multicolumn{5}{|c|}{ Supplemental Table S2.txt } \\
\hline CHEMBL1469489 & 688724 & 4.3 & 4.7336 & TRN \\
\hline CHEMBL1338723 & 688724 & 4.55 & 4.9222 & TRN \\
\hline CHEMBL1432184 & 688724 & 5.5 & 4.8148 & TRN \\
\hline CHEMBL1536708 & 688724 & 4.4 & 4.6302 & TRN \\
\hline CHEMBL1562954 & 688724 & 4.35 & 5.0109 & TST \\
\hline CHEMBL1395973 & 688724 & 5.65 & 4.526 & TRN \\
\hline CHEMBL1451521 & 688724 & 4.05 & 4.8204 & TRN \\
\hline CHEMBL1375620 & 688724 & 4.05 & 4.4918 & TST \\
\hline CHEMBL1519327 & 688724 & 4.5 & 5.8121 & TST \\
\hline CHEMBL1351111 & 688724 & 6.25 & 5.1616 & TRN \\
\hline CHEMBL1397721 & 688724 & 4.7 & 5.0668 & TST \\
\hline CHEMBL1397687 & 688724 & 4.7 & 4.7151 & TRN \\
\hline CHEMBL549640 & 688724 & 5.05 & 4.9819 & TRN \\
\hline CHEMBL1320643 & 688724 & 4.3 & 4.8082 & TRN \\
\hline CHEMBL1562225 & 688724 & 4.1 & 4.7993 & TST \\
\hline CHEMBL3190426 & 688724 & 4.4 & 4.7829 & TRN \\
\hline CHEMBL1596835 & 688724 & 4.65 & 4.6643 & TRN \\
\hline CHEMBL422942 & 688724 & 5.5 & 4.956 & TST \\
\hline CHEMBL1324935 & 688724 & 4.35 & 5.0195 & TRN \\
\hline CHEMBL1542747 & 688724 & 4.75 & 4.9349 & TRN \\
\hline CHEMBL 207881 & 688724 & 4.25 & 4.7751 & TRN \\
\hline CHEMBL482642 & 688724 & 4.25 & 4.852 & TRN \\
\hline CHEMBL1387152 & 688724 & 4.4 & 4.9569 & TST \\
\hline CHEMBL1396003 & 688724 & 4.4 & 4.5091 & TRN \\
\hline CHEMBL1965162 & 688724 & 4.1 & 4.5825 & TRN \\
\hline CHEMBL483091 & 688724 & 9.1549 & 5.2733 & TST \\
\hline CHEMBL1428947 & 688724 & 4.95 & 4.7231 & TRN \\
\hline CHEMBL1562373 & 688724 & 4.0 & 4.7039 & TRN \\
\hline CHEMBL1400211 & 688724 & 4.4 & 4.9084 & TRN \\
\hline CHEMBL34241 & 688724 & 6.0 & 4.9375 & TST \\
\hline CHEMBL1401767 & 688724 & 4.7 & 4.9152 & TST \\
\hline CHEMBL1610916 & 688724 & 4.5 & 4.7292 & TRN \\
\hline CHEMBL1458412 & 688724 & 4.7 & 5.1912 & TST \\
\hline CHEMBL3145107 & 688724 & 6.05 & 4.9396 & TRN \\
\hline CHEMBL1406731 & 688724 & 4.3 & 4.7357 & TRN \\
\hline CHEMBL1484679 & 688724 & 4.9 & 4.6542 & TRN \\
\hline CHEMBL1357564 & 688724 & 4.25 & 4.5149 & TST \\
\hline CHEMBL1518855 & 688724 & 4.95 & 4.8987 & TRN \\
\hline CHEMBL1507167 & 688724 & 4.7 & 4.8414 & TRN \\
\hline CHEMBL1433461 & 688724 & 4.25 & 4.6716 & TRN \\
\hline CHEMBL1590690 & 688724 & 6.1 & 4.5652 & TST \\
\hline CHEMBL1318943 & 688724 & 4.75 & 4.9555 & TST \\
\hline CHEMBL1310221 & 688724 & 4.7 & 4.9459 & TRN \\
\hline CHEMBL1390554 & 688724 & 4.45 & 4.6141 & TST \\
\hline CHEMBL1375468 & 688724 & 6.35 & 5.0975 & TST \\
\hline CHEMBL1394290 & 688724 & 4.1 & 4.8075 & TST \\
\hline CHEMBL2028179 & 688724 & 5.05 & 4.878 & TST \\
\hline CHEMBL1387357 & 688724 & 4.5 & 4.4673 & TRN \\
\hline
\end{tabular}




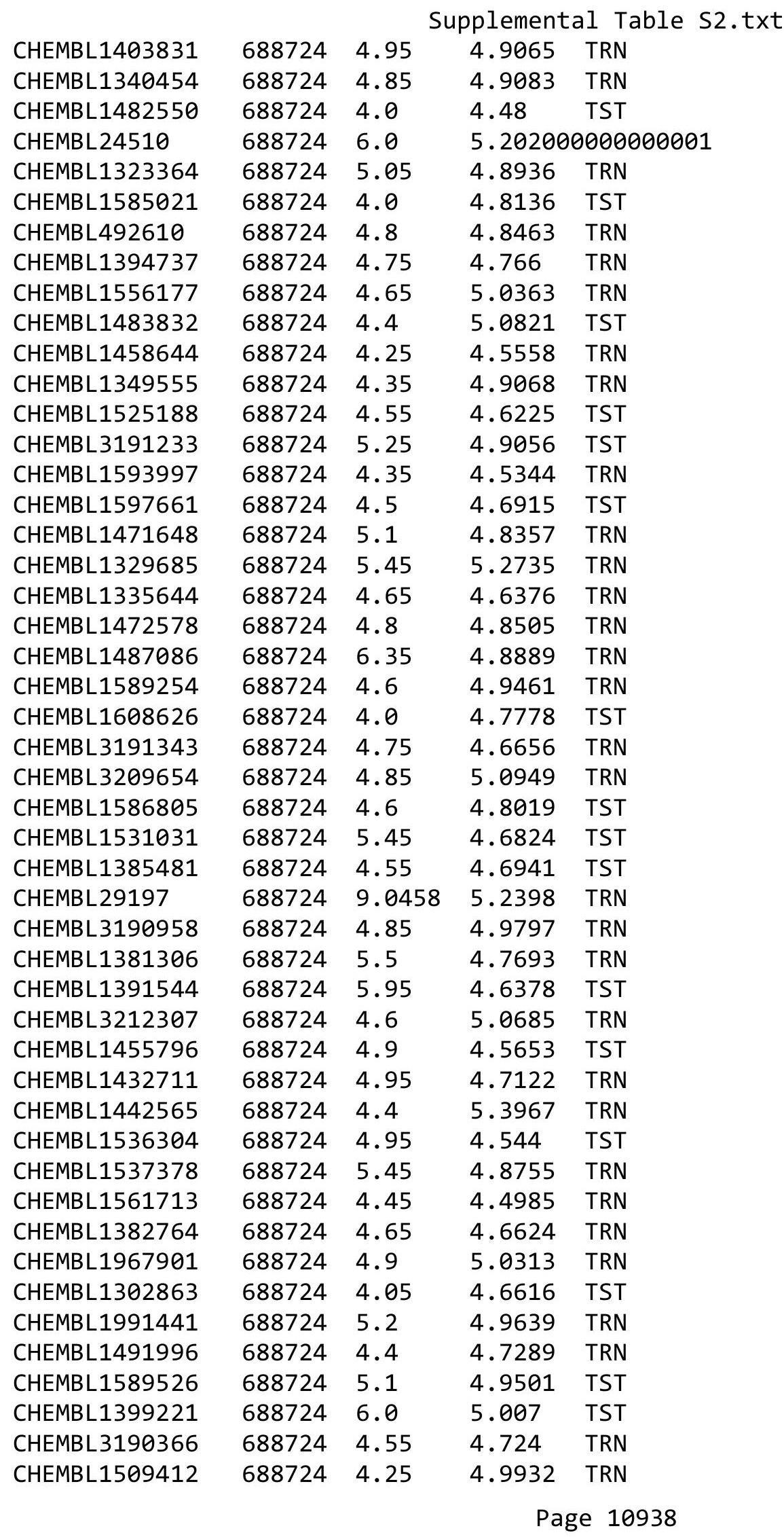




\begin{tabular}{|c|c|c|c|c|}
\hline & & & pplemen & al $\mathrm{T}$ \\
\hline CHEMBL1581149 & 688724 & 5.6 & 4.5667 & TRN \\
\hline CHEMBL1359240 & 688724 & 4.35 & 4.9732 & TRN \\
\hline CHEMBL1971613 & 688724 & 4.05 & 4.6849 & TST \\
\hline CHEMBL1981856 & 688724 & 5.4 & 5.3144 & TRN \\
\hline CHEMBL1422964 & 688724 & 4.55 & 4.7168 & TRN \\
\hline CHEMBL1517120 & 688724 & 4.4 & 5.2684 & TRN \\
\hline CHEMBL1966316 & 688724 & 4.9 & 4.6366 & TRN \\
\hline CHEMBL1304345 & 688724 & 5.5 & 4.7448 & TRN \\
\hline CHEMBL1479183 & 688724 & 5.4 & 4.6737 & TRN \\
\hline CHEMBL1468796 & 688724 & 4.45 & 5.3083 & TRN \\
\hline CHEMBL1608005 & 688724 & 4.5 & 4.7885 & TRN \\
\hline CHEMBL3198199 & 688724 & 4.4 & 4.779 & TST \\
\hline CHEMBL3196501 & 688724 & 4.9 & 4.8832 & TRN \\
\hline CHEMBL1424337 & 688724 & 4.4 & 4.6953 & TRN \\
\hline CHEMBL3197197 & 688724 & 4.4 & 4.9468 & TRN \\
\hline CHEMBL3195742 & 688724 & 5.95 & 5.2921 & TRN \\
\hline CHEMBL1577232 & 688724 & 5.35 & 4.4871 & TRN \\
\hline CHEMBL1967019 & 688724 & 4.15 & 5.0143 & TRN \\
\hline CHEMBL1503251 & 688724 & 4.75 & 4.5646 & TRN \\
\hline CHEMBL1399362 & 688724 & 4.75 & 4.9174 & TRN \\
\hline CHEMBL1496954 & 688724 & 4.85 & 4.4826 & TRN \\
\hline CHEMBL1478189 & 688724 & 4.5 & 4.7456 & TST \\
\hline CHEMBL1399472 & 688724 & 4.6 & 4.5911 & TST \\
\hline CHEMBL1353426 & 688724 & 5.1 & 5.0809 & TRN \\
\hline CHEMBL1437248 & 688724 & 4.25 & 4.6763 & TRN \\
\hline CHEMBL1530797 & 688724 & 5.5 & 5.0074 & TRN \\
\hline CHEMBL1395030 & 688724 & 4.2 & 5.0456 & TRN \\
\hline CHEMBL1477102 & 688724 & 4.15 & 4.9367 & TRN \\
\hline CHEMBL1580668 & 688724 & 4.55 & 5.0057 & TRN \\
\hline CHEMBL1332444 & 688724 & 4.65 & 5.0796 & TRN \\
\hline CHEMBL1453372 & 688724 & 4.35 & 4.8837 & TRN \\
\hline CHEMBL1334390 & 688724 & 5.1 & 5.0302 & TRN \\
\hline CHEMBL 72365 & 688724 & 6.0 & 4.9477 & TST \\
\hline CHEMBL264141 & 688724 & 4.6 & 4.6043 & TRN \\
\hline CHEMBL3192482 & 688724 & 6.0 & 5.0592 & TRN \\
\hline CHEMBL1591904 & 688724 & 4.5 & 4.7642 & TRN \\
\hline CHEMBL 296407 & 688724 & 5.25 & 5.4653 & TRN \\
\hline CHEMBL1402308 & 688724 & 4.6 & 4.4995 & TRN \\
\hline CHEMBL1393310 & 688724 & 5.3 & 4.7842 & TST \\
\hline CHEMBL1410863 & 688724 & 4.75 & 4.9222 & TRN \\
\hline CHEMBL1491855 & 688724 & 5.1 & 4.9127 & TST \\
\hline CHEMBL1512786 & 688724 & 4.85 & 4.697 & TRN \\
\hline CHEMBL1333189 & 688724 & 4.55 & 4.8387 & TST \\
\hline CHEMBL1467352 & 688724 & 5.45 & 4.379 & TST \\
\hline CHEMBL1501259 & 688724 & 5.0 & 4.7725 & TRN \\
\hline CHEMBL1375373 & 688724 & 5.35 & 6.0311 & TRN \\
\hline CHEMBL1576000 & 688724 & 5.05 & 5.1799 & TRN \\
\hline CHEMBL1412580 & 688724 & 4.1 & 5.1492 & TRN \\
\hline
\end{tabular}




\begin{tabular}{|c|c|c|c|c|c|}
\hline & & \multicolumn{4}{|c|}{ Supplemental Table S2.txt } \\
\hline CHEMBL1470781 & 688724 & 7.0 & 4.748 & TRN & \\
\hline CHEMBL1437869 & 688724 & 4.75 & 4.8147 & TRN & \\
\hline CHEMBL1577952 & 688724 & 4.6 & 4.8841 & TRN & \\
\hline CHEMBL1480203 & 688724 & 6.9 & 5.0024 & TRN & \\
\hline CHEMBL 1474044 & 688724 & 4.25 & 4.7434 & TRN & \\
\hline CHEMBL1351397 & 688724 & 4.6 & 4.9505 & TRN & \\
\hline CHEMBL1965132 & 688724 & 5.0 & 4.8056 & TRN & \\
\hline CHEMBL3197462 & 688724 & 5.05 & 4.723 & TRN & \\
\hline CHEMBL1555108 & 688724 & 4.25 & 4.7904 & TRN & \\
\hline CHEMBL1600573 & 688724 & 4.0 & 4.6877 & TRN & \\
\hline CHEMBL1445661 & 688724 & 4.95 & 4.926 & TST & \\
\hline CHEMBL1469246 & 688724 & 4.85 & 4.9072 & TRN & \\
\hline CHEMBL1528309 & 688724 & 5.15 & 4.9837 & TRN & \\
\hline CHEMBL1321616 & 688724 & 5.8 & 4.7169 & TST & \\
\hline CHEMBL1416177 & 688724 & 4.3 & 5.12799 & 9999999999 & TST \\
\hline CHEMBL1331107 & 688724 & 4.65 & 5.4496 & TRN & \\
\hline CHEMBL1355712 & 688724 & 4.55 & 4.772 & TRN & \\
\hline CHEMBL1528089 & 688724 & 4.6 & 4.7298 & TST & \\
\hline CHEMBL3190125 & 688724 & 5.05 & 5.0463 & TRN & \\
\hline CHEMBL1359367 & 688724 & 5.6 & 4.97 & TRN & \\
\hline CHEMBL1545697 & 688724 & 4.8 & 4.9374 & TRN & \\
\hline CHEMBL1501452 & 688724 & 4.95 & 4.6736 & TST & \\
\hline CHEMBL1305918 & 688724 & 6.05 & 5.1649 & TRN & \\
\hline CHEMBL1429429 & 688724 & 5.2 & 5.2934 & TRN & \\
\hline CHEMBL1326546 & 688724 & 4.85 & 4.8845 & TRN & \\
\hline CHEMBL3191169 & 688724 & 4.6 & 4.7167 & TRN & \\
\hline CHEMBL1537730 & 688724 & 4.65 & 4.6411 & TRN & \\
\hline CHEMBL1584508 & 688724 & 4.6 & 4.6246 & TRN & \\
\hline CHEMBL1567683 & 688724 & 4.3 & 4.3872 & TRN & \\
\hline CHEMBL1601703 & 688724 & 4.1 & 4.8479 & TRN & \\
\hline CHEMBL1474548 & 688724 & 4.4 & 4.3789 & TRN & \\
\hline CHEMBL1522581 & 688724 & 4.75 & 4.867 & TRN & \\
\hline CHEMBL1349204 & 688724 & 5.2 & 4.6406 & TRN & \\
\hline CHEMBL1486180 & 688724 & 4.55 & 4.5355 & TRN & \\
\hline CHEMBL1339069 & 688724 & 4.8 & 4.6519 & TRN & \\
\hline CHEMBL1369512 & 688724 & 6.35 & 5.0508 & TRN & \\
\hline CHEMBL1312404 & 688724 & 4.35 & 5.0628 & TST & \\
\hline CHEMBL1531217 & 688724 & 4.3 & 4.6856 & TRN & \\
\hline CHEMBL1356258 & 688724 & 4.4 & 4.6685 & TRN & \\
\hline CHEMBL1256865 & 688724 & 4.95 & 4.7411 & TST & \\
\hline CHEMBL322970 & 688724 & 4.6 & 5.1621 & TST & \\
\hline CHEMBL1320010 & 688724 & 4.0 & 4.8924 & TRN & \\
\hline CHEMBL1323644 & 688724 & 4.0 & 4.1387 & TRN & \\
\hline CHEMBL1376643 & 688724 & 4.4 & 4.8789 & TRN & \\
\hline CHEMBL 299683 & 688724 & 4.4 & 4.7347 & TRN & \\
\hline CHEMBL1995177 & 688724 & 4.3 & 5.0433 & TST & \\
\hline CHEMBL1375011 & 688724 & 4.25 & 4.6972 & TRN & \\
\hline CHEMBL1554185 & 688724 & 4.55 & 4.535 & TST & \\
\hline
\end{tabular}




\begin{tabular}{|c|c|c|c|c|}
\hline & & & pplement & al $\mathrm{Ta}$ \\
\hline CHEMBL1980657 & 688724 & 4.3 & 5.5671 & TST \\
\hline CHEMBL1599706 & 688724 & 4.3 & 4.9031 & TRN \\
\hline CHEMBL119264 & 688724 & 4.05 & 4.9726 & TST \\
\hline CHEMBL1336395 & 688724 & 4.3 & 4.9161 & TST \\
\hline CHEMBL1789996 & 688724 & 4.65 & 5.0777 & TST \\
\hline CHEMBL1498511 & 688724 & 5.95 & 4.9668 & TRN \\
\hline CHEMBL 2068684 & 688724 & 5.1 & 5.1141 & TST \\
\hline CHEMBL1488541 & 688724 & 4.4 & 4.8482 & TRN \\
\hline CHEMBL1422034 & 688724 & 5.95 & 4.5954 & TST \\
\hline CHEMBL1566555 & 688724 & 4.2 & 4.8234 & TRN \\
\hline CHEMBL1863606 & 688724 & 4.9 & 5.2406 & TRN \\
\hline CHEMBL1515875 & 688724 & 4.9 & 4.7883 & TRN \\
\hline CHEMBL1609513 & 688724 & 4.4 & 4.6922 & TRN \\
\hline CHEMBL1600273 & 688724 & 4.85 & 4.8825 & TRN \\
\hline CHEMBL1431332 & 688724 & 5.45 & 4.9759 & TRN \\
\hline CHEMBL1447010 & 688724 & 4.85 & 4.686 & TRN \\
\hline CHEMBL1613170 & 688724 & 4.4 & 4.4238 & TRN \\
\hline CHEMBL1555117 & 688724 & 4.5 & 4.9852 & TST \\
\hline CHEMBL1491815 & 688724 & 5.3 & 4.8436 & TRN \\
\hline CHEMBL1572216 & 688724 & 4.55 & 4.8198 & TRN \\
\hline CHEMBL3191602 & 688724 & 4.65 & 4.817 & TRN \\
\hline CHEMBL1583101 & 688724 & 4.65 & 4.896 & TRN \\
\hline CHEMBL1502088 & 688724 & 4.75 & 4.5007 & TRN \\
\hline CHEMBL1421887 & 688724 & 4.3 & 4.5328 & TRN \\
\hline CHEMBL1326655 & 688724 & 4.25 & 5.079 & TRN \\
\hline CHEMBL1391963 & 688724 & 4.65 & 4.6814 & TST \\
\hline CHEMBL1418634 & 688724 & 4.6 & 4.6031 & TRN \\
\hline CHEMBL1365615 & 688724 & 5.5 & 4.8875 & TRN \\
\hline CHEMBL1567054 & 688724 & 4.95 & 4.5156 & TRN \\
\hline CHEMBL1573994 & 688724 & 4.45 & 4.8271 & TRN \\
\hline CHEMBL3199324 & 688724 & 4.6 & 5.3777 & TRN \\
\hline CHEMBL1354256 & 688724 & 5.5 & 5.6697 & TRN \\
\hline CHEMBL1424412 & 688724 & 5.1 & 4.6231 & TRN \\
\hline CHEMBL1596060 & 688724 & 4.75 & 4.9841 & TST \\
\hline CHEMBL1361812 & 688724 & 4.3 & 4.4233 & TRN \\
\hline CHEMBL1538479 & 688724 & 4.9 & 5.1165 & TST \\
\hline CHEMBL1300161 & 688724 & 5.3 & 5.0188 & TST \\
\hline CHEMBL1546783 & 688724 & 5.35 & 4.8932 & TRN \\
\hline CHEMBL1421172 & 688724 & 4.5 & 5.437 & TRN \\
\hline CHEMBL1304438 & 688724 & 5.55 & 5.6971 & TRN \\
\hline CHEMBL1597273 & 688724 & 4.75 & 5.2487 & TST \\
\hline CHEMBL1398517 & 688724 & 4.65 & 4.5821 & TRN \\
\hline CHEMBL1328508 & 688724 & 5.0 & 4.7034 & TRN \\
\hline CHEMBL1331359 & 688724 & 4.3 & 4.9419 & TRN \\
\hline CHEMBL1321310 & 688724 & 4.65 & 4.7471 & TRN \\
\hline CHEMBL3195326 & 688724 & 4.6 & 4.7431 & TST \\
\hline CHEMBL1364119 & 688724 & 4.8 & 5.086 & TRN \\
\hline CHEMBL585656 & 688724 & 4.65 & 5.1937 & TST \\
\hline
\end{tabular}




\begin{tabular}{|c|c|c|c|c|c|}
\hline \multicolumn{6}{|c|}{ Supplemental Table S2.txt } \\
\hline CHEMBL1372692 & 688724 & 4.0 & 4.5194 & TRN & \\
\hline CHEMBL1392273 & 688724 & 4.6 & 5.0165 & TST & \\
\hline CHEMBL3194139 & 688724 & 4.9 & 4.7054 & TRN & \\
\hline CHEMBL1533166 & 688724 & 4.7 & 4.5584 & TRN & \\
\hline CHEMBL440464 & 688724 & 6.8499 & 4.7744 & TRN & \\
\hline CHEMBL1439735 & 688724 & 4.35 & 4.7575 & TRN & \\
\hline CHEMBL1565114 & 688724 & 4.75 & 4.4833 & TRN & \\
\hline CHEMBL1321794 & 688724 & 4.25 & 4.7486 & TRN & \\
\hline CHEMBL3198907 & 688724 & 4.55 & 4.5835 & TRN & \\
\hline CHEMBL1354173 & 688724 & 6.0 & 4.9597 & TRN & \\
\hline CHEMBL1581942 & 688724 & 4.6 & 4.8978 & TRN & \\
\hline CHEMBL1423932 & 688724 & 4.85 & 4.7226 & TST & \\
\hline CHEMBL1209491 & 688724 & 4.6 & 4.9796 & TRN & \\
\hline CHEMBL1515568 & 688724 & 5.0 & 4.8193 & TST & \\
\hline CHEMBL1357930 & 688724 & 4.85 & 5.1969 & TST & \\
\hline CHEMBL1419762 & 688724 & 4.8 & 4.9445 & TRN & \\
\hline CHEMBL1360529 & 688724 & 4.6 & 5.0697 & TRN & \\
\hline CHEMBL1400197 & 688724 & 4.75 & 4.8748 & TRN & \\
\hline CHEMBL1565040 & 688724 & 4.1 & 4.5946 & TST & \\
\hline CHEMBL1373029 & 688724 & 4.35 & 4.5878 & TRN & \\
\hline CHEMBL1601730 & 688724 & 4.45 & 4.9653 & TST & \\
\hline CHEMBL1988657 & 688724 & 4.85 & 5.3166 & TRN & \\
\hline CHEMBL1450108 & 688724 & 4.75 & 4.8977 & TRN & \\
\hline CHEMBL1445756 & 688724 & 4.65 & 5.1993 & TRN & \\
\hline CHEMBL1464457 & 688724 & 4.3 & 4.7648 & TRN & \\
\hline CHEMBL1597269 & 688724 & 5.0 & 4.9376 & TRN & \\
\hline CHEMBL3199293 & 688724 & 4.1 & 4.7151 & TRN & \\
\hline CHEMBL1447055 & 688724 & 4.6 & 4.7934 & TRN & \\
\hline CHEMBL1411430 & 688724 & 4.95 & 5.1503 & TRN & \\
\hline CHEMBL1380396 & 688724 & 4.9 & 4.5416 & TRN & \\
\hline CHEMBL1478760 & 688724 & 4.4 & 4.4782 & TRN & \\
\hline CHEMBL1419369 & 688724 & 4.35 & 5.0407 & TST & \\
\hline CHEMBL1346567 & 688724 & 4.7 & 4.6193 & TRN & \\
\hline CHEMBL1311269 & 688724 & 5.45 & 4.5282 & TST & \\
\hline CHEMBL1332823 & 688724 & 4.45 & 5.1119 & TST & \\
\hline CHEMBL1543400 & 688724 & 5.15 & 4.67399 & 99999999995 & TRN \\
\hline CHEMBL1495138 & 688724 & 6.3242 & 5.1508 & TRN & \\
\hline CHEMBL1400696 & 688724 & 4.4 & 4.5852 & TRN & \\
\hline CHEMBL3195630 & 688724 & 4.4 & 5.1365 & TRN & \\
\hline CHEMBL1458900 & 688724 & 4.4 & 4.5264 & TRN & \\
\hline CHEMBL1987510 & 688724 & 4.3 & 5.0172 & TRN & \\
\hline CHEMBL58033 & 688724 & 7.0 & 5.0701 & TRN & \\
\hline CHEMBL1393066 & 688724 & 4.9 & 4.7157 & TRN & \\
\hline CHEMBL1501577 & 688724 & 5.5 & 4.7639 & TRN & \\
\hline CHEMBL1337397 & 688724 & 5.45 & 4.7313 & TST & \\
\hline CHEMBL1338256 & 688724 & 4.1 & 4.7582 & TRN & \\
\hline CHEMBL1377872 & 688724 & 4.85 & 4.4939 & TRN & \\
\hline CHEMBL1539136 & 688724 & 4.7 & 4.6825 & TRN & \\
\hline
\end{tabular}




\begin{tabular}{|c|c|c|c|c|c|}
\hline \multicolumn{6}{|c|}{ Supplemental Table S2.txt } \\
\hline CHEMBL1313956 & 688724 & 4.4 & 4.5701 & TRN & \\
\hline CHEMBL1332913 & 688724 & 4.5 & 5.003 & TRN & \\
\hline CHEMBL1609946 & 688724 & 6.25 & 5.9924 & TRN & \\
\hline CHEMBL482116 & 688724 & 4.2 & 4.8089 & TRN & \\
\hline CHEMBL3199887 & 688724 & 4.45 & 4.9823 & TST & \\
\hline CHEMBL1608530 & 688724 & 4.45 & 4.6178 & TRN & \\
\hline CHEMBL3189342 & 688724 & 7.3002 & 5.3407 & TRN & \\
\hline CHEMBL 3213566 & 688724 & 4.85 & 5.1187 & TRN & \\
\hline CHEMBL1608355 & 688724 & 5.15 & 4.7695 & TRN & \\
\hline CHEMBL1535291 & 688724 & 4.5 & 4.5774 & TRN & \\
\hline CHEMBL1503918 & 688724 & 5.1 & 5.6651 & TRN & \\
\hline CHEMBL1603776 & 688724 & 4.65 & 4.9844 & TST & \\
\hline CHEMBL1566780 & 688724 & 5.75 & 4.732 & TRN & \\
\hline CHEMBL1517264 & 688724 & 4.05 & 4.593 & TRN & \\
\hline CHEMBL1609026 & 688724 & 4.3 & 4.55399 & 9999999999 & TRN \\
\hline CHEMBL1471926 & 688724 & 4.35 & 4.9101 & TRN & \\
\hline CHEMBL3145285 & 688724 & 6.7001 & 5.3257 & TRN & \\
\hline CHEMBL1370529 & 688724 & 5.65 & 4.9389 & TRN & \\
\hline CHEMBL1540103 & 688724 & 5.0 & 4.3443 & TRN & \\
\hline CHEMBL1457016 & 688724 & 4.7 & 4.6055 & TRN & \\
\hline CHEMBL1345365 & 688724 & 4.45 & 5.1508 & TST & \\
\hline CHEMBL3195342 & 688724 & 4.4 & 4.6012 & TRN & \\
\hline CHEMBL1369612 & 688724 & 6.0 & 4.94600 & 0000000001 & TST \\
\hline CHEMBL1399250 & 688724 & 4.8 & 4.6881 & TRN & \\
\hline CHEMBL1610944 & 688724 & 4.5 & 4.5748 & TST & \\
\hline CHEMBL1362734 & 688724 & 5.3 & 4.7832 & TRN & \\
\hline CHEMBL1484779 & 688724 & 4.7 & 4.6584 & TRN & \\
\hline CHEMBL1453909 & 688724 & 4.45 & 4.936 & TRN & \\
\hline CHEMBL1331521 & 688724 & 4.45 & 4.7718 & TRN & \\
\hline CHEMBL140425 & 688724 & 5.5 & 5.4566 & TRN & \\
\hline CHEMBL1304482 & 688724 & 4.35 & 4.5874 & TRN & \\
\hline CHEMBL1365552 & 688724 & 4.35 & 4.9488 & TST & \\
\hline CHEMBL3190029 & 688724 & 6.35 & 5.0964 & TRN & \\
\hline CHEMBL1542128 & 688724 & 5.55 & 5.0652 & TRN & \\
\hline CHEMBL415248 & 688724 & 5.25 & 5.2519 & TRN & \\
\hline CHEMBL1417203 & 688724 & 5.05 & 4.8933 & TRN & \\
\hline CHEMBL7463 & 688724 & 6.0 & 5.2026 & TRN & \\
\hline CHEMBL3191474 & 688724 & 4.4 & 4.6245 & TRN & \\
\hline CHEMBL 3189814 & 688724 & 4.05 & 4.4081 & TST & \\
\hline CHEMBL1485016 & 688724 & 4.35 & 4.7877 & TST & \\
\hline CHEMBL1299583 & 688724 & 4.3 & 4.5695 & TRN & \\
\hline CHEMBL1363965 & 688724 & 4.6 & 5.1168 & TST & \\
\hline CHEMBL1386032 & 688724 & 5.45 & 4.9558 & TRN & \\
\hline CHEMBL1481924 & 688724 & 4.8 & 4.6244 & TRN & \\
\hline CHEMBL1328213 & 688724 & 5.05 & 4.8041 & TST & \\
\hline CHEMBL1515567 & 688724 & 4.2 & 4.9561 & TRN & \\
\hline CHEMBL109037 & 688724 & 6.7501 & 5.5181 & TRN & \\
\hline CHEMBL1480213 & 688724 & 4.4 & 4.6573 & TRN & \\
\hline
\end{tabular}




\begin{tabular}{|c|c|c|c|c|}
\hline \multicolumn{5}{|c|}{ Supplemental Table S2.txt } \\
\hline CHEMBL1970117 & 688724 & 5.45 & 4.8445 & TRN \\
\hline CHEMBL1379618 & 688724 & 4.45 & 4.5974 & TRN \\
\hline CHEMBL1465793 & 688724 & 4.4 & 5.1873 & TST \\
\hline CHEMBL1540389 & 688724 & 4.6 & 4.915 & TRN \\
\hline CHEMBL1404003 & 688724 & 6.15 & 4.4901 & TST \\
\hline CHEMBL1439605 & 688724 & 4.4 & 4.5358 & TST \\
\hline CHEMBL1306239 & 688724 & 4.4 & 4.3725 & TRN \\
\hline CHEMBL1556159 & 688724 & 4.7 & 4.9984 & TRN \\
\hline CHEMBL1462784 & 688724 & 4.8 & 4.6179 & TRN \\
\hline CHEMBL1583782 & 688724 & 4.4 & 4.6657 & TST \\
\hline CHEMBL1545699 & 688724 & 6.0 & 5.1413 & TRN \\
\hline CHEMBL1581745 & 688724 & 4.8 & 4.9581 & TRN \\
\hline CHEMBL1446504 & 688724 & 4.75 & 4.9091 & TRN \\
\hline CHEMBL1541889 & 688724 & 4.35 & 4.9896 & TRN \\
\hline CHEMBL1310632 & 688724 & 4.1 & 5.0885 & TRN \\
\hline CHEMBL1583198 & 688724 & 4.6 & 4.6803 & TRN \\
\hline CHEMBL3212133 & 688724 & 5.4 & 5.1117 & TRN \\
\hline CHEMBL3191734 & 688724 & 4.85 & 5.2065 & TRN \\
\hline CHEMBL1606192 & 688724 & 4.0 & 4.6209 & TRN \\
\hline CHEMBL1352340 & 688724 & 4.85 & 5.1622 & TST \\
\hline CHEMBL1476478 & 688724 & 4.1 & 4.4893 & TST \\
\hline CHEMBL1616787 & 688724 & 4.05 & 4.7208 & TRN \\
\hline CHEMBL1391063 & 688724 & 7.5003 & 6.1791 & TRN \\
\hline CHEMBL1361279 & 688724 & 4.9 & 4.6694 & TRN \\
\hline CHEMBL1433257 & 688724 & 5.1 & 4.669 & TRN \\
\hline CHEMBL1346771 & 688724 & 5.85 & 5.6873 & TRN \\
\hline CHEMBL3210553 & 688724 & 5.9 & 5.0567 & TRN \\
\hline CHEMBL1326812 & 688724 & 5.25 & 4.425 & TST \\
\hline CHEMBL1464098 & 688724 & 4.35 & 5.2416 & TRN \\
\hline CHEMBL1531715 & 688724 & 4.4 & 4.9834 & TRN \\
\hline CHEMBL1528931 & 688724 & 4.05 & 4.5843 & TRN \\
\hline CHEMBL1531788 & 688724 & 4.1 & 4.6174 & TRN \\
\hline CHEMBL1256660 & 688724 & 4.45 & 5.015 & TRN \\
\hline CHEMBL1341609 & 688724 & 4.9 & 4.9337 & TRN \\
\hline CHEMBL1433532 & 688724 & 4.25 & 4.6027 & TRN \\
\hline CHEMBL1438970 & 688724 & 5.05 & 5.0783 & TRN \\
\hline CHEMBL1500225 & 688724 & 4.75 & 4.9902 & TRN \\
\hline CHEMBL1574029 & 688724 & 4.5 & 4.6667 & TST \\
\hline CHEMBL275626 & 688724 & 4.65 & 5.2812 & TST \\
\hline CHEMBL1536328 & 688724 & 6.4 & 4.6419 & TRN \\
\hline CHEMBL1595674 & 688724 & 4.0 & 4.8104 & TRN \\
\hline CHEMBL1401818 & 688724 & 4.5 & 4.5242 & TRN \\
\hline CHEMBL1329286 & 688724 & 6.45 & 5.0358 & TRN \\
\hline CHEMBL1574612 & 688724 & 4.3 & 5.2073 & TST \\
\hline CHEMBL1404149 & 688724 & 4.65 & 4.5757 & TRN \\
\hline CHEMBL1079460 & 688724 & 5.0 & 5.1783 & TST \\
\hline CHEMBL1581590 & 688724 & 4.7 & 4.5961 & TRN \\
\hline CHEMBL1365825 & 688724 & 4.1 & 4.8889 & TRN \\
\hline
\end{tabular}




\begin{tabular}{|c|c|c|c|c|c|}
\hline \multicolumn{6}{|c|}{ Supplemental Table S2.txt } \\
\hline CHEMBL1329336 & 688724 & 4.35 & 5.2421 & TRN & \\
\hline CHEMBL3198974 & 688724 & 4.9 & 4.8139 & TRN & \\
\hline CHEMBL3199135 & 688724 & 5.5 & 5.0007 & TRN & \\
\hline CHEMBL1370976 & 688724 & 4.3 & 4.7987 & TRN & \\
\hline CHEMBL1560211 & 688724 & 5.3 & 4.7995 & TRN & \\
\hline CHEMBL1535175 & 688724 & 4.1 & 4.5366 & TRN & \\
\hline CHEMBL1343740 & 688724 & 7.4001 & 4.7371 & TRN & \\
\hline CHEMBL1495651 & 688724 & 5.55 & 4.9527 & TRN & \\
\hline CHEMBL1557335 & 688724 & 4.0 & 5.2126 & TRN & \\
\hline CHEMBL1480005 & 688724 & 4.5 & 4.9747 & TRN & \\
\hline CHEMBL1370199 & 688724 & 4.7 & 4.391 & TRN & \\
\hline CHEMBL1462461 & 688724 & 4.8 & 5.0941 & TRN & \\
\hline CHEMBL1531474 & 688724 & 4.65 & 4.4837 & TRN & \\
\hline CHEMBL1330895 & 688724 & 4.9 & 4.8879 & TRN & \\
\hline CHEMBL1422573 & 688724 & 4.1 & 4.65300 & 00000000005 & TRN \\
\hline CHEMBL1441736 & 688724 & 4.8 & 4.4851 & TRN & \\
\hline CHEMBL1610842 & 688724 & 4.4 & 5.08 & TST & \\
\hline CHEMBL1380191 & 688724 & 4.4 & 4.7699 & TRN & \\
\hline CHEMBL1341561 & 688724 & 4.75 & 4.9251 & TRN & \\
\hline CHEMBL1471888 & 688724 & 4.55 & 4.67 & TRN & \\
\hline CHEMBL1570785 & 688724 & 4.65 & 4.7127 & TRN & \\
\hline CHEMBL1428437 & 688724 & 6.5 & 5.03 & TRN & \\
\hline CHEMBL455571 & 688724 & 4.8 & 4.7738 & TRN & \\
\hline CHEMBL485636 & 688724 & 4.35 & 4.8408 & TRN & \\
\hline CHEMBL1537339 & 688724 & 4.4 & 4.7373 & TRN & \\
\hline CHEMBL1300389 & 688724 & 4.65 & 4.9007 & TRN & \\
\hline CHEMBL1391066 & 688724 & 6.25 & 5.165 & TRN & \\
\hline CHEMBL1505799 & 688724 & 4.85 & 4.85800 & 00000000005 & TRN \\
\hline CHEMBL1541230 & 688724 & 4.8 & 4.4735 & TRN & \\
\hline CHEMBL1369406 & 688724 & 5.3 & 5.0829 & TST & \\
\hline CHEMBL1507413 & 688724 & 4.05 & 5.1128 & TST & \\
\hline CHEMBL1377249 & 688724 & 4.4 & 4.494 & TRN & \\
\hline CHEMBL1347686 & 688724 & 5.1 & 4.9917 & TRN & \\
\hline CHEMBL562334 & 688724 & 4.7 & 4.9007 & TRN & \\
\hline CHEMBL126077 & 688724 & 6.0 & 5.2277 & TRN & \\
\hline CHEMBL1427844 & 688724 & 6.1 & 5.2866 & TRN & \\
\hline CHEMBL1473059 & 688724 & 5.6 & 4.7862 & TRN & \\
\hline CHEMBL310578 & 688724 & 5.65 & 5.1752 & TRN & \\
\hline CHEMBL1599280 & 688724 & 4.5 & 4.8006 & TRN & \\
\hline CHEMBL1606751 & 688724 & 5.85 & 5.2282 & TST & \\
\hline CHEMBL1378418 & 688724 & 4.95 & 4.8952 & TRN & \\
\hline CHEMBL1469432 & 688724 & 4.4 & 5.1625 & TRN & \\
\hline CHEMBL1449331 & 688724 & 4.7 & 4.63399 & 99999999995 & TRN \\
\hline CHEMBL1333618 & 688724 & 4.1 & 4.3299 & TRN & \\
\hline CHEMBL1421715 & 688724 & 4.55 & 4.5893 & TRN & \\
\hline CHEMBL1528349 & 688724 & 4.3 & 4.7148 & TRN & \\
\hline CHEMBL1451913 & 688724 & 4.4 & 4.4521 & TRN & \\
\hline CHEMBL1498750 & 688724 & 5.35 & 5.0084 & TRN & \\
\hline
\end{tabular}




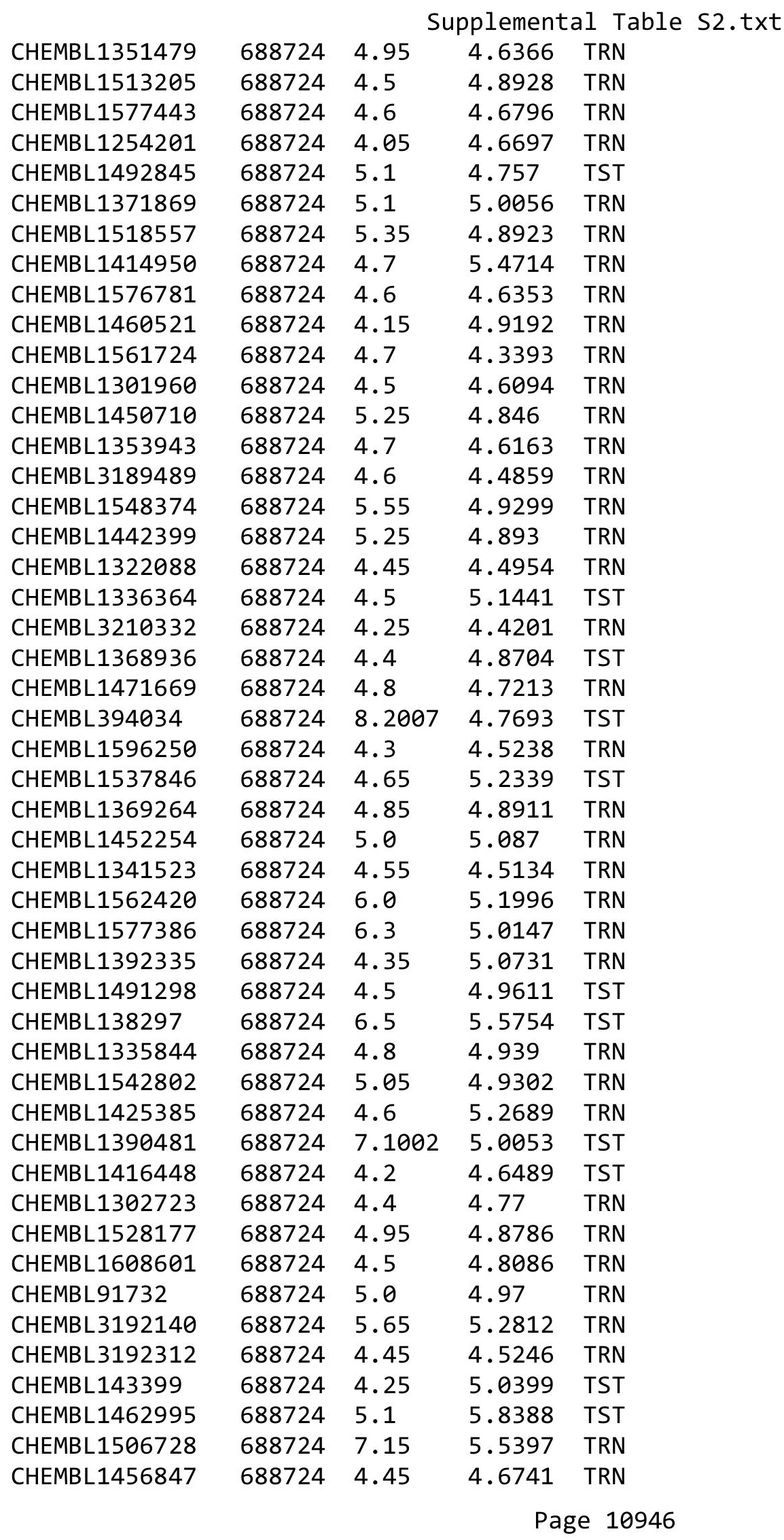




\begin{tabular}{|c|c|c|c|c|}
\hline & & & upplement & al $\mathrm{T}$ \\
\hline CHEMBL1558278 & 688724 & 4.4 & 4.9697 & TRN \\
\hline CHEMBL3189304 & 688724 & 4.55 & 4.8919 & TRN \\
\hline CHEMBL1601997 & 688724 & 4.9 & 4.9092 & TST \\
\hline CHEMBL542493 & 688724 & 6.6 & 5.4382 & TRN \\
\hline CHEMBL73639 & 688724 & 4.7 & 4.6707 & TRN \\
\hline CHEMBL3194798 & 688724 & 4.55 & 4.952 & TRN \\
\hline CHEMBL1573612 & 688724 & 5.45 & 4.7596 & TST \\
\hline CHEMBL1452421 & 688724 & 5.0 & 5.7415 & TRN \\
\hline CHEMBL1445007 & 688724 & 4.0 & 4.4417 & TRN \\
\hline CHEMBL3189218 & 688724 & 4.9 & 4.6758 & TST \\
\hline CHEMBL1393630 & 688724 & 4.8 & 4.5239 & TRN \\
\hline CHEMBL1354892 & 688724 & 4.05 & 4.783 & TST \\
\hline CHEMBL1349942 & 688724 & 4.9 & 4.7695 & TRN \\
\hline CHEMBL1518235 & 688724 & 4.05 & 4.6831 & TRN \\
\hline CHEMBL1359806 & 688724 & 4.05 & 4.857 & TRN \\
\hline CHEMBL50267 & 688724 & 6.05 & 5.2186 & TST \\
\hline CHEMBL1507294 & 688724 & 4.1 & 5.2398 & TRN \\
\hline CHEMBL1369226 & 688724 & 6.0 & 5.1618 & TRN \\
\hline CHEMBL1481935 & 688724 & 4.45 & 4.598 & TRN \\
\hline CHEMBL1427024 & 688724 & 4.1 & 4.3821 & TRN \\
\hline CHEMBL1511665 & 688724 & 4.5 & 4.7028 & TRN \\
\hline CHEMBL1362971 & 688724 & 4.3 & 4.8493 & TST \\
\hline CHEMBL1446904 & 688724 & 4.8 & 4.9103 & TRN \\
\hline CHEMBL3198034 & 688724 & 5.2 & 4.5359 & TRN \\
\hline CHEMBL1424638 & 688724 & 4.95 & 4.7255 & TRN \\
\hline CHEMBL1301937 & 688724 & 4.9 & 4.7368 & TRN \\
\hline CHEMBL1428142 & 688724 & 5.55 & 4.7727 & TST \\
\hline CHEMBL1509790 & 688724 & 4.7 & 5.0054 & TRN \\
\hline CHEMBL517186 & 688724 & 5.15 & 5.1739 & TST \\
\hline CHEMBL1485137 & 688724 & 4.4 & 4.9624 & TRN \\
\hline CHEMBL1527664 & 688724 & 4.85 & 4.9108 & TRN \\
\hline CHEMBL1401669 & 688724 & 4.9 & 4.9888 & TRN \\
\hline CHEMBL3193728 & 688724 & 5.55 & 4.9359 & TRN \\
\hline CHEMBL1362512 & 688724 & 4.3 & 4.5257 & TRN \\
\hline CHEMBL1605162 & 688724 & 5.7 & 5.2956 & TRN \\
\hline CHEMBL1379102 & 688724 & 4.55 & 4.8767 & TST \\
\hline CHEMBL1355686 & 688724 & 4.35 & 4.5073 & TRN \\
\hline CHEMBL1348347 & 688724 & 4.7 & 5.2243 & TST \\
\hline CHEMBL1532692 & 688724 & 5.55 & 4.7277 & TRN \\
\hline CHEMBL1329033 & 688724 & 5.7 & 5.1981 & TST \\
\hline CHEMBL154580 & 688724 & 5.45 & 4.6036 & TST \\
\hline CHEMBL1335364 & 688724 & 4.6 & 4.9579 & TRN \\
\hline CHEMBL1337961 & 688724 & 4.4 & 4.6996 & TRN \\
\hline CHEMBL1489113 & 688724 & 6.0 & 5.1518 & TRN \\
\hline CHEMBL1512965 & 688724 & 4.4 & 4.5962 & TRN \\
\hline CHEMBL1570032 & 688724 & 5.8 & 4.9506 & TRN \\
\hline CHEMBL1356898 & 688724 & 5.4 & 4.544 & TST \\
\hline CHEMBL1334097 & 688724 & 4.2 & 5.1568 & TRN \\
\hline
\end{tabular}




\begin{tabular}{|c|c|c|c|c|}
\hline \multirow[b]{2}{*}{ CHEMBL1476879 } & \multicolumn{4}{|c|}{ Supplemental Table S2.txt } \\
\hline & 688724 & 4.5 & 4.7404 & TRN \\
\hline CHEMBL1406485 & 688724 & 4.75 & 4.8683 & TST \\
\hline CHEMBL1551371 & 688724 & 4.65 & 4.7034 & TRN \\
\hline CHEMBL1490685 & 688724 & 5.75 & 5.1856 & TRN \\
\hline CHEMBL1338096 & 688724 & 4.65 & 4.6179 & TRN \\
\hline CHEMBL1598676 & 688724 & 5.2 & 5.1376 & TRN \\
\hline CHEMBL1437118 & 688724 & 4.85 & 4.9666 & TRN \\
\hline CHEMBL1449245 & 688724 & 4.2 & 5.0872 & TST \\
\hline CHEMBL3209181 & 688724 & 4.7 & 5.0379 & TRN \\
\hline CHEMBL1327256 & 688724 & 5.3 & 5.0641 & TRN \\
\hline CHEMBL1385186 & 688724 & 4.1 & 4.6073 & TRN \\
\hline CHEMBL1416372 & 688724 & 4.65 & 4.7351 & TST \\
\hline CHEMBL1569215 & 688724 & 5.5 & 4.7987 & TRN \\
\hline CHEMBL1537907 & 688724 & 4.9 & 4.6995 & TRN \\
\hline CHEMBL3856090 & 688724 & 4.15 & 5.0364 & TST \\
\hline CHEMBL1327203 & 688724 & 4.95 & 4.9516 & TRN \\
\hline CHEMBL3195194 & 688724 & 4.9 & 5.0922 & TRN \\
\hline CHEMBL1424665 & 688724 & 5.35 & 5.8648 & TRN \\
\hline CHEMBL1348382 & 688724 & 4.45 & 4.7097 & TRN \\
\hline CHEMBL1569439 & 688724 & 4.1 & 5.3033 & TST \\
\hline CHEMBL1346181 & 688724 & 4.05 & 4.7762 & TRN \\
\hline CHEMBL1508349 & 688724 & 4.3 & 4.5503 & TST \\
\hline CHEMBL1437109 & 688724 & 5.45 & 4.5053 & TRN \\
\hline CHEMBL1586042 & 688724 & 4.0 & 4.9984 & TST \\
\hline CHEMBL1375485 & 688724 & 4.5 & 4.6843 & TRN \\
\hline CHEMBL1506466 & 688724 & 4.9 & 4.5659 & TRN \\
\hline CHEMBL1594914 & 688724 & 4.75 & 5.0131 & TRN \\
\hline CHEMBL1580511 & 688724 & 5.05 & 4.9229 & TRN \\
\hline CHEMBL1491015 & 688724 & 4.7 & 5.138 & TRN \\
\hline CHEMBL1399113 & 688724 & 6.5501 & 5.218 & TRN \\
\hline CHEMBL1477399 & 688724 & 4.8 & 4.7412 & TRN \\
\hline CHEMBL1530786 & 688724 & 4.7 & 4.907 & TST \\
\hline CHEMBL1454194 & 688724 & 5.0 & 4.8948 & TST \\
\hline CHEMBL3189394 & 688724 & 4.4 & 5.1945 & TRN \\
\hline CHEMBL1414095 & 688724 & 4.3 & 4.8915 & TST \\
\hline CHEMBL1417349 & 688724 & 4.55 & 4.6488 & TRN \\
\hline CHEMBL1588912 & 688724 & 4.55 & 4.7278 & TRN \\
\hline CHEMBL1418612 & 688724 & 5.5 & 4.2 & TRN \\
\hline CHEMBL1540526 & 688724 & 4.35 & 4.4809 & TRN \\
\hline CHEMBL1543663 & 688724 & 4.45 & 4.5418 & TRN \\
\hline CHEMBL 270605 & 688724 & 4.9 & 5.2703 & TRN \\
\hline CHEMBL1307604 & 688724 & 4.3 & 4.5487 & TRN \\
\hline CHEMBL1553733 & 688724 & 4.85 & 4.785 & TRN \\
\hline CHEMBL1382268 & 688724 & 5.55 & 5.0708 & TST \\
\hline CHEMBL1390896 & 688724 & 4.5 & 5.013 & TST \\
\hline CHEMBL352949 & 688724 & 4.3 & 4.8713 & TST \\
\hline CHEMBL1343668 & 688724 & 4.7 & 4.7763 & TRN \\
\hline CHEMBL1555389 & 688724 & 4.45 & 4.8612 & TRN \\
\hline
\end{tabular}




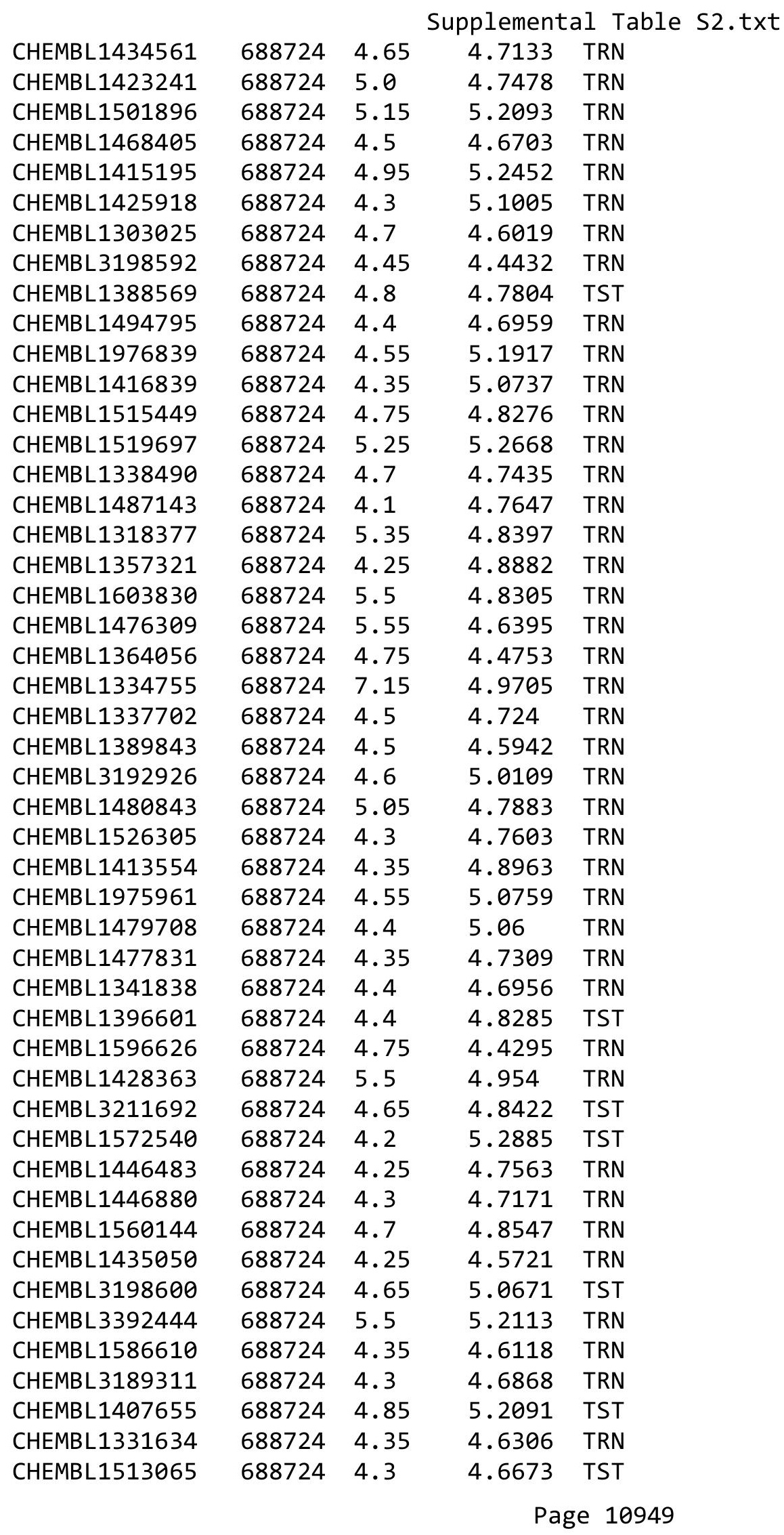




\begin{tabular}{|c|c|c|c|c|}
\hline \multicolumn{5}{|c|}{ Supplemental Table S2.txt } \\
\hline CHEMBL1549745 & 688724 & 4.55 & 5.1488 & TRN \\
\hline CHEMBL1587863 & 688724 & 4.9 & 4.883 & TRN \\
\hline CHEMBL253642 & 688724 & 4.9 & 4.7172 & TRN \\
\hline CHEMBL1342429 & 688724 & 5.05 & 4.9332 & TRN \\
\hline CHEMBL3193113 & 688724 & 4.9 & 4.8499 & TRN \\
\hline CHEMBL1572197 & 688724 & 5.7 & 5.1197 & TRN \\
\hline CHEMBL3192802 & 688724 & 5.1 & 4.8856 & TRN \\
\hline CHEMBL3198159 & 688724 & 4.4 & 4.7942 & TRN \\
\hline CHEMBL1332745 & 688724 & 4.35 & 4.631 & TRN \\
\hline CHEMBL1301562 & 688724 & 4.45 & 4.5905 & TRN \\
\hline CHEMBL1605227 & 688724 & 4.1 & 4.4675 & TRN \\
\hline CHEMBL1331399 & 688724 & 4.6 & 5.0368 & TRN \\
\hline CHEMBL1508680 & 688724 & 4.45 & 4.6102 & TST \\
\hline CHEMBL1587433 & 688724 & 4.7 & 5.002 & TRN \\
\hline CHEMBL1582179 & 688724 & 4.95 & 4.8084 & TRN \\
\hline CHEMBL1607021 & 688724 & 4.65 & 4.2608 & TRN \\
\hline CHEMBL3194647 & 688724 & 4.5 & 5.1046 & TRN \\
\hline CHEMBL1206126 & 688724 & 6.0 & 4.9247 & TRN \\
\hline CHEMBL1321033 & 688724 & 4.5 & 4.7392 & TST \\
\hline CHEMBL140 & 688724 & 6.0 & 5.1598 & TRN \\
\hline CHEMBL1346438 & 688724 & 4.45 & 4.8806 & TRN \\
\hline CHEMBL1522288 & 688724 & 5.15 & 5.1943 & TRN \\
\hline CHEMBL1493609 & 688724 & 4.4 & 4.7964 & TRN \\
\hline CHEMBL3194097 & 688724 & 4.75 & 5.3436 & TRN \\
\hline CHEMBL1992547 & 688724 & 4.4 & 4.8747 & TRN \\
\hline CHEMBL1568333 & 688724 & 4.25 & 4.7434 & TRN \\
\hline CHEMBL1519397 & 688724 & 5.15 & 4.883 & TST \\
\hline CHEMBL1322068 & 688724 & 4.3 & 4.7289 & TRN \\
\hline CHEMBL456807 & 688724 & 5.1 & 4.8 & TRN \\
\hline CHEMBL1448744 & 688724 & 4.7 & 4.5046 & TRN \\
\hline CHEMBL1566488 & 688724 & 4.3 & 4.8501 & TRN \\
\hline CHEMBL1532861 & 688724 & 4.05 & 4.8337 & TRN \\
\hline CHEMBL1495448 & 688724 & 4.3 & 4.7595 & TRN \\
\hline CHEMBL1390703 & 688724 & 4.65 & 4.5294 & TRN \\
\hline CHEMBL1580441 & 688724 & 5.55 & 4.796 & TRN \\
\hline CHEMBL1409602 & 688724 & 4.95 & 5.0354 & TRN \\
\hline CHEMBL1467061 & 688724 & 5.0 & 4.8376 & TRN \\
\hline CHEMBL3193015 & 688724 & 4.6 & 5.2672 & TST \\
\hline CHEMBL3193295 & 688724 & 4.7 & 4.663 & TRN \\
\hline CHEMBL1461196 & 688724 & 6.0 & 5.7984 & TRN \\
\hline CHEMBL1558336 & 688724 & 4.75 & 4.9371 & TRN \\
\hline CHEMBL1467643 & 688724 & 4.2 & 4.5649 & TST \\
\hline CHEMBL1312239 & 688724 & 4.8 & 4.9034 & TST \\
\hline CHEMBL351042 & 688724 & 6.0 & 5.421 & TRN \\
\hline CHEMBL1596040 & 688724 & 4.7 & 4.7624 & TRN \\
\hline CHEMBL1496321 & 688724 & 5.2 & 5.1973 & TRN \\
\hline CHEMBL 1448448 & 688724 & 4.4 & 5.0313 & TST \\
\hline CHEMBL1971015 & 688724 & 4.7 & 4.8621 & TRN \\
\hline
\end{tabular}




\begin{tabular}{|c|c|c|c|c|c|}
\hline \multicolumn{6}{|c|}{ Supplemental Table S2.txt } \\
\hline CHEMBL1393622 & 688724 & 4.25 & 5.1495 & TST & \\
\hline CHEMBL1602804 & 688724 & 4.7 & 4.1401 & TRN & \\
\hline CHEMBL1484500 & 688724 & 5.1 & 4.8528 & TRN & \\
\hline CHEMBL1347457 & 688724 & 4.75 & 4.5478 & TST & \\
\hline CHEMBL1555120 & 688724 & 6.6499 & 4.855 & TST & \\
\hline CHEMBL1585192 & 688724 & 5.35 & 5.1514 & TST & \\
\hline CHEMBL1317872 & 688724 & 4.3 & 4.9947 & TRN & \\
\hline CHEMBL1337614 & 688724 & 4.3 & 5.0808 & TRN & \\
\hline CHEMBL1510731 & 688724 & 4.8 & 4.6321 & TST & \\
\hline CHEMBL1448854 & 688724 & 5.15 & 4.8932 & TRN & \\
\hline CHEMBL1547640 & 688724 & 4.9 & 4.6975 & TRN & \\
\hline CHEMBL1605099 & 688724 & 4.35 & 4.9989 & TRN & \\
\hline CHEMBL1380103 & 688724 & 7.15 & 4.2708 & TST & \\
\hline CHEMBL1566418 & 688724 & 6.15 & 4.9436 & TRN & \\
\hline CHEMBL 3145244 & 688724 & 6.35 & 5.1642 & TRN & \\
\hline CHEMBL3191163 & 688724 & 4.75 & 4.5164 & TRN & \\
\hline CHEMBL1386300 & 688724 & 5.25 & 4.8506 & TRN & \\
\hline CHEMBL1550629 & 688724 & 4.35 & 4.5626 & TRN & \\
\hline CHEMBL1604231 & 688724 & 4.35 & 4.3632 & TRN & \\
\hline CHEMBL1348273 & 688724 & 4.95 & 4.6566 & TRN & \\
\hline CHEMBL1308500 & 688724 & 4.3 & 5.03600 & 00000000005 & TRN \\
\hline CHEMBL1558809 & 688724 & 4.65 & 4.7752 & TRN & \\
\hline CHEMBL573524 & 688724 & 4.15 & 4.9125 & TRN & \\
\hline CHEMBL1351610 & 688724 & 4.95 & 4.7057 & TRN & \\
\hline CHEMBL1309224 & 688724 & 4.05 & 4.5133 & TRN & \\
\hline CHEMBL1388922 & 688724 & 4.6 & 5.1359 & TRN & \\
\hline CHEMBL1410774 & 688724 & 5.05 & 4.8405 & TRN & \\
\hline CHEMBL1562439 & 688724 & 4.8 & 4.6414 & TRN & \\
\hline CHEMBL1299705 & 688724 & 4.8 & 4.8901 & TST & \\
\hline CHEMBL 1447750 & 688724 & 4.45 & 4.6353 & TRN & \\
\hline CHEMBL1403586 & 688724 & 4.4 & 5.0959 & TRN & \\
\hline CHEMBL1319257 & 688724 & 4.3 & 5.5728 & TST & \\
\hline CHEMBL1573944 & 688724 & 4.6 & 4.5076 & TRN & \\
\hline CHEMBL1446171 & 688724 & 4.7 & 5.0403 & TST & \\
\hline CHEMBL1545911 & 688724 & 5.75 & 5.4871 & TRN & \\
\hline CHEMBL1569755 & 688724 & 5.15 & 5.0236 & TST & \\
\hline CHEMBL1374586 & 688724 & 4.1 & 4.3821 & TRN & \\
\hline CHEMBL1386802 & 688724 & 5.55 & 5.2303 & TRN & \\
\hline CHEMBL1412488 & 688724 & 4.9 & 4.7048 & TRN & \\
\hline CHEMBL1549103 & 688724 & 4.85 & 4.9871 & TRN & \\
\hline CHEMBL1461098 & 688724 & 4.65 & 4.6839 & TST & \\
\hline CHEMBL1413112 & 688724 & 4.45 & 4.4486 & TRN & \\
\hline CHEMBL1446754 & 688724 & 4.35 & 4.5546 & TRN & \\
\hline CHEMBL1519298 & 688724 & 4.9 & 5.1022 & TRN & \\
\hline CHEMBL74852 & 688724 & 4.25 & 5.1892 & TRN & \\
\hline CHEMBL1599593 & 688724 & 4.5 & 4.949 & TRN & \\
\hline CHEMBL1558072 & 688724 & 5.1 & 4.651 & TRN & \\
\hline CHEMBL1609842 & 688724 & 4.1 & 4.4695 & TST & \\
\hline
\end{tabular}




\begin{tabular}{|c|c|c|c|c|}
\hline \multicolumn{5}{|c|}{ Supplemental Table S2.txt } \\
\hline CHEMBL1319865 & 688724 & 4.95 & 4.5448 & TRN \\
\hline CHEMBL1426118 & 688724 & 4.0 & 4.5786 & TST \\
\hline CHEMBL1417672 & 688724 & 4.75 & 4.962 & TRN \\
\hline CHEMBL1519313 & 688724 & 4.75 & 4.9607 & TST \\
\hline CHEMBL1350611 & 688724 & 4.85 & 5.2114 & TST \\
\hline CHEMBL1372815 & 688724 & 4.4 & 4.6556 & TRN \\
\hline CHEMBL1444270 & 688724 & 4.65 & 4.6163 & TRN \\
\hline CHEMBL1516461 & 688724 & 4.5 & 4.7085 & TRN \\
\hline CHEMBL1488354 & 688724 & 5.45 & 4.9014 & TST \\
\hline CHEMBL1395983 & 688724 & 4.35 & 4.9258 & TRN \\
\hline CHEMBL1530054 & 688724 & 4.3 & 4.8627 & TRN \\
\hline CHEMBL1980967 & 688724 & 4.8 & 4.5834 & TRN \\
\hline CHEMBL1502833 & 688724 & 8.301 & 4.5198 & TST \\
\hline CHEMBL1555402 & 688724 & 4.3 & 4.637 & TRN \\
\hline CHEMBL1414718 & 688724 & 4.7 & 4.6424 & TST \\
\hline CHEMBL1321017 & 688724 & 4.3 & 4.8364 & TST \\
\hline CHEMBL1453602 & 688724 & 4.35 & 4.707 & TRN \\
\hline CHEMBL513116 & 688724 & 6.4 & 4.8594 & TRN \\
\hline CHEMBL3190837 & 688724 & 5.05 & 4.8144 & TRN \\
\hline CHEMBL1540693 & 688724 & 4.15 & 4.7976 & TST \\
\hline CHEMBL 252418 & 688724 & 4.1 & 4.7397 & TRN \\
\hline CHEMBL1539079 & 688724 & 4.0 & 4.775 & TRN \\
\hline CHEMBL1442731 & 688724 & 4.15 & 4.6458 & TST \\
\hline CHEMBL1506805 & 688724 & 4.75 & 5.1182 & TRN \\
\hline CHEMBL1384854 & 688724 & 4.65 & 5.0911 & TRN \\
\hline CHEMBL3195649 & 688724 & 5.6 & 5.5216 & TST \\
\hline CHEMBL1394428 & 688724 & 4.3 & 4.6551 & TRN \\
\hline CHEMBL1443784 & 688724 & 4.4 & 5.0878 & TST \\
\hline CHEMBL3191778 & 688724 & 4.55 & 4.919 & TRN \\
\hline CHEMBL1453579 & 688724 & 4.0 & 4.7603 & TRN \\
\hline CHEMBL1443157 & 688724 & 6.5 & 5.2532 & TST \\
\hline CHEMBL1580769 & 688724 & 4.95 & 5.2293 & TST \\
\hline CHEMBL1353022 & 688724 & 5.05 & 4.7705 & TRN \\
\hline CHEMBL1302599 & 688724 & 4.5 & 4.8599 & TRN \\
\hline CHEMBL1313762 & 688724 & 6.6499 & 4.9679 & TST \\
\hline CHEMBL1358512 & 688724 & 5.2 & 4.7103 & TRN \\
\hline CHEMBL1368229 & 688724 & 4.8 & 4.5482 & TRN \\
\hline CHEMBL116569 & 688724 & 4.35 & 4.988 & TRN \\
\hline CHEMBL1601857 & 688724 & 4.7 & 4.6159 & TRN \\
\hline CHEMBL1507508 & 688724 & 5.75 & 4.9765 & TRN \\
\hline CHEMBL1981243 & 688724 & 5.4 & 4.7262 & TRN \\
\hline CHEMBL1611776 & 688724 & 4.5 & 4.8837 & TRN \\
\hline CHEMBL1481519 & 688724 & 4.15 & 4.7311 & TRN \\
\hline CHEMBL1405257 & 688724 & 4.25 & 4.6456 & TRN \\
\hline CHEMBL1500644 & 688724 & 4.05 & 4.9943 & TRN \\
\hline CHEMBL1558414 & 688724 & 4.05 & 4.2616 & TRN \\
\hline CHEMBL1394046 & 688724 & 5.4 & 5.2 & TRN \\
\hline CHEMBL1997659 & 688724 & 4.25 & 4.5928 & TRN \\
\hline
\end{tabular}




\begin{tabular}{|c|c|c|c|c|}
\hline \multicolumn{5}{|c|}{ Supplemental Table S2.txt } \\
\hline CHEMBL1373731 & 688724 & 4.95 & 4.9792 & TRN \\
\hline CHEMBL1545634 & 688724 & 6.0 & 5.2548 & TRN \\
\hline CHEMBL1460726 & 688724 & 5.1 & 4.9057 & TRN \\
\hline CHEMBL1342496 & 688724 & 5.4 & 4.7425 & TRN \\
\hline CHEMBL1390188 & 688724 & 4.35 & 4.7766 & TRN \\
\hline CHEMBL1442142 & 688724 & 4.85 & 4.7155 & TRN \\
\hline CHEMBL1569333 & 688724 & 4.35 & 5.0617 & TRN \\
\hline CHEMBL1538285 & 688724 & 4.5 & 4.8487 & TRN \\
\hline CHEMBL1448065 & 688724 & 4.35 & 4.5077 & TST \\
\hline CHEMBL1584162 & 688724 & 4.3 & 4.5506 & TRN \\
\hline CHEMBL1428842 & 688724 & 4.7 & 4.7308 & TRN \\
\hline CHEMBL1510245 & 688724 & 4.05 & 5.0163 & TST \\
\hline CHEMBL1429713 & 688724 & 4.4 & 5.3391 & TRN \\
\hline CHEMBL3199359 & 688724 & 6.25 & 4.8949 & TRN \\
\hline CHEMBL1506232 & 688724 & 4.55 & 4.9212 & TRN \\
\hline CHEMBL198468 & 688724 & 6.35 & 5.7529 & TRN \\
\hline CHEMBL1577286 & 688724 & 4.55 & 4.9328 & TRN \\
\hline CHEMBL1349382 & 688724 & 4.45 & 4.7012 & TRN \\
\hline CHEMBL1502201 & 688724 & 5.0 & 5.0231 & TST \\
\hline CHEMBL1499598 & 688724 & 4.6 & 4.5774 & TRN \\
\hline CHEMBL1520312 & 688724 & 5.9 & 5.6477 & TRN \\
\hline CHEMBL1350032 & 688724 & 4.6 & 5.1728 & TRN \\
\hline CHEMBL1535055 & 688724 & 5.5 & 4.8874 & TRN \\
\hline CHEMBL1491354 & 688724 & 4.0 & 4.9817 & TST \\
\hline CHEMBL1547874 & 688724 & 5.25 & 5.2047 & TRN \\
\hline CHEMBL1565093 & 688724 & 4.65 & 5.0508 & TRN \\
\hline CHEMBL1342581 & 688724 & 7.7496 & 4.8964 & TRN \\
\hline CHEMBL1334507 & 688724 & 4.25 & 4.5202 & TRN \\
\hline CHEMBL1482040 & 688724 & 4.65 & 4.6196 & TRN \\
\hline CHEMBL1590113 & 688724 & 4.6 & 4.4752 & TRN \\
\hline CHEMBL1572928 & 688724 & 4.35 & 4.6962 & TRN \\
\hline CHEMBL1520213 & 688724 & 4.15 & 4.9432 & TRN \\
\hline CHEMBL1391264 & 688724 & 5.4 & 5.2551 & TRN \\
\hline CHEMBL1328652 & 688724 & 4.4 & 4.8606 & TRN \\
\hline CHEMBL1523127 & 688724 & 4.4 & 4.5143 & TST \\
\hline CHEMBL1377445 & 688724 & 5.45 & 5.3881 & TRN \\
\hline CHEMBL1565890 & 688724 & 4.65 & 5.1976 & TRN \\
\hline CHEMBL1347561 & 688724 & 4.45 & 4.9929 & TRN \\
\hline CHEMBL193646 & 688724 & 4.15 & 4.9829 & TST \\
\hline CHEMBL1384497 & 688724 & 5.35 & 4.5498 & TRN \\
\hline CHEMBL1434882 & 688724 & 4.35 & 4.6258 & TRN \\
\hline CHEMBL3199678 & 688724 & 6.0 & 4.805 & TST \\
\hline CHEMBL1309254 & 688724 & 4.75 & 4.8027 & TST \\
\hline CHEMBL1302533 & 688724 & 4.9 & 4.7322 & TRN \\
\hline CHEMBL1430235 & 688724 & 5.35 & 5.2838 & TST \\
\hline CHEMBL1399411 & 688724 & 5.3 & 5.3619 & TRN \\
\hline CHEMBL1459398 & 688724 & 4.3 & 5.3241 & TST \\
\hline CHEMBL592124 & 688724 & 5.2 & 5.1667 & TRN \\
\hline
\end{tabular}




\begin{tabular}{|c|c|c|c|c|c|}
\hline \\
\hline CHEMBL1570302 & 688724 & 6.0 & 4.8748 & TRN & \\
\hline CHEMBL1375942 & 688724 & 4.55 & 4.9336 & TRN & \\
\hline CHEMBL1313094 & 688724 & 6.6499 & 5.0011 & TRN & \\
\hline CHEMBL3199376 & 688724 & 4.35 & 4.69300 & 00000000005 & TRN \\
\hline CHEMBL3195766 & 688724 & 4.55 & 4.7179 & TRN & \\
\hline CHEMBL533226 & 688724 & 4.95 & 5.013 & TST & \\
\hline CHEMBL1413032 & 688724 & 4.7 & 4.3101 & TRN & \\
\hline CHEMBL1584329 & 688724 & 4.55 & 4.6326 & TRN & \\
\hline CHEMBL3197914 & 688724 & 4.25 & 4.9356 & TRN & \\
\hline CHEMBL1479772 & 688724 & 5.8 & 5.0605 & TRN & \\
\hline CHEMBL1349845 & 688724 & 4.5 & 4.9609 & TRN & \\
\hline CHEMBL1375378 & 688724 & 4.5 & 4.7323 & TST & \\
\hline CHEMBL1599728 & 688724 & 5.85 & 5.0462 & TRN & \\
\hline CHEMBL3198641 & 688724 & 4.1 & 4.5733 & TRN & \\
\hline CHEMBL1588976 & 688724 & 5.55 & 4.7033 & TRN & \\
\hline CHEMBL1474865 & 688724 & 4.05 & 4.8144 & TST & \\
\hline CHEMBL1597481 & 688724 & 4.7 & 4.6112 & TRN & \\
\hline CHEMBL1382573 & 688724 & 6.6 & 5.63200 & 0000000001 & TRN \\
\hline CHEMBL1354914 & 688724 & 4.6 & 4.9264 & TST & \\
\hline CHEMBL1433975 & 688724 & 4.25 & 4.6872 & TRN & \\
\hline CHEMBL1525485 & 688724 & 4.3 & 4.5754 & TRN & \\
\hline CHEMBL3392440 & 688724 & 4.35 & 4.93 & TRN & \\
\hline CHEMBL1601959 & 688724 & 4.65 & 4.8307 & TST & \\
\hline CHEMBL3214501 & 688724 & 4.75 & 4.6894 & TST & \\
\hline CHEMBL1539920 & 688724 & 5.05 & 4.6012 & TRN & \\
\hline CHEMBL3192514 & 688724 & 4.55 & 4.8286 & TRN & \\
\hline CHEMBL1410400 & 688724 & 4.4 & 5.0097 & TST & \\
\hline CHEMBL1349353 & 688724 & 4.35 & 5.0196 & TRN & \\
\hline CHEMBL1459482 & 688724 & 4.4 & 4.5412 & TRN & \\
\hline CHEMBL1331206 & 688724 & 5.65 & 4.8019 & TRN & \\
\hline CHEMBL1488398 & 688724 & 4.45 & 4.7861 & TRN & \\
\hline CHEMBL1354076 & 688724 & 4.3 & 4.6299 & TRN & \\
\hline CHEMBL1342528 & 688724 & 4.35 & 4.6118 & TRN & \\
\hline CHEMBL1383473 & 688724 & 4.3 & 4.6151 & TRN & \\
\hline CHEMBL1394247 & 688724 & 4.55 & 4.3035 & TST & \\
\hline CHEMBL1256573 & 688724 & 7.8013 & 5.0737 & TST & \\
\hline CHEMBL1574432 & 688724 & 5.45 & 5.0616 & TST & \\
\hline CHEMBL 258465 & 688724 & 4.65 & 4.8284 & TST & \\
\hline CHEMBL1327128 & 688724 & 4.15 & 4.5661 & TRN & \\
\hline CHEMBL448741 & 688724 & 9.2218 & 5.4697 & TRN & \\
\hline CHEMBL1310655 & 688724 & 4.9 & 4.72199 & 99999999995 & TRN \\
\hline CHEMBL1502271 & 688724 & 6.5 & 4.8167 & TST & \\
\hline CHEMBL1469043 & 688724 & 4.6 & 4.7342 & TRN & \\
\hline CHEMBL1579866 & 688724 & 4.9 & 5.0638 & TST & \\
\hline CHEMBL1518638 & 688724 & 4.45 & 4.8973 & TRN & \\
\hline CHEMBL1232474 & 688724 & 5.0 & 4.9342 & TRN & \\
\hline CHEMBL1301650 & 688724 & 5.8 & 5.4583 & TRN & \\
\hline CHEMBL1353542 & 688724 & 4.4 & 4.2366 & TST & \\
\hline
\end{tabular}




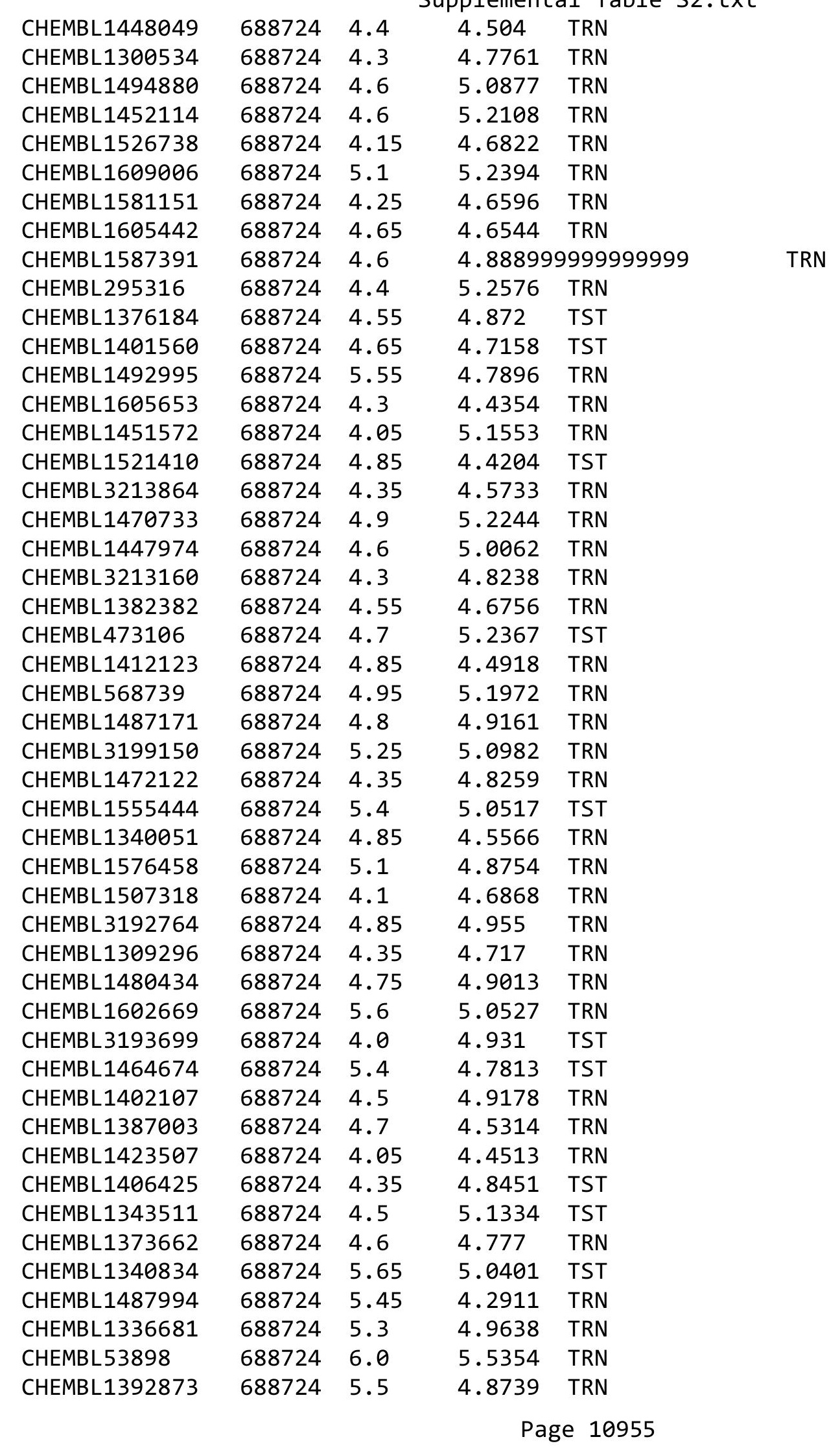




\begin{tabular}{|c|c|c|c|c|c|}
\hline \multicolumn{6}{|c|}{ Supplemental Table S2.txt } \\
\hline CHEMBL1610431 & 688724 & 4.0 & 4.8867 & TST & \\
\hline CHEMBL1421862 & 688724 & 4.8 & 4.9361 & TST & \\
\hline CHEMBL1357061 & 688724 & 4.35 & 4.293 & TRN & \\
\hline CHEMBL 3208287 & 688724 & 4.65 & \multicolumn{2}{|c|}{4.803999999999999} & TST \\
\hline CHEMBL1331884 & 688724 & 4.7 & 4.7464 & TRN & \\
\hline CHEMBL1333796 & 688724 & 5.85 & 5.0658 & TST & \\
\hline CHEMBL1377031 & 688724 & 4.35 & 4.9764 & TST & \\
\hline CHEMBL1607846 & 688724 & 4.95 & 4.9404 & TST & \\
\hline CHEMBL1351223 & 688724 & 4.6 & 5.0469 & TRN & \\
\hline CHEMBL1312514 & 688724 & 5.6 & 4.8789 & TRN & \\
\hline CHEMBL1256910 & 688724 & 6.0 & 5.0045 & TST & \\
\hline CHEMBL1586700 & 688724 & 4.25 & 4.5203 & TRN & \\
\hline CHEMBL1428244 & 688724 & 5.5 & 5.3876 & TRN & \\
\hline CHEMBL3193794 & 688724 & 4.4 & 4.5968 & TRN & \\
\hline CHEMBL1377799 & 688724 & 4.9 & 4.7692 & TRN & \\
\hline CHEMBL1414135 & 688724 & 5.5 & 4.8676 & TRN & \\
\hline CHEMBL1391916 & 688724 & 4.35 & 4.4693 & TRN & \\
\hline CHEMBL1566634 & 688724 & 4.15 & 4.8613 & TST & \\
\hline CHEMBL1303288 & 688724 & 5.0 & 4.7648 & TST & \\
\hline CHEMBL1314676 & 688724 & 5.1 & 4.4882 & TRN & \\
\hline CHEMBL1456471 & 688724 & 6.0 & 4.6814 & TST & \\
\hline CHEMBL1502633 & 688724 & 4.55 & \multicolumn{2}{|c|}{4.5360000000000005} & TRN \\
\hline CHEMBL1381495 & 688724 & 4.6 & 4.7628 & TRN & \\
\hline CHEMBL29878 & 688724 & 4.6 & 5.2525 & TST & \\
\hline CHEMBL1483169 & 688724 & 5.1 & 4.9364 & TRN & \\
\hline CHEMBL1466087 & 688724 & 5.5 & 4.8231 & TRN & \\
\hline CHEMBL1413473 & 688724 & 4.4 & 4.8975 & TST & \\
\hline CHEMBL3194964 & 688724 & 5.95 & 5.4261 & TRN & \\
\hline CHEMBL1462692 & 688724 & 4.85 & 4.869 & TST & \\
\hline CHEMBL1972962 & 688724 & 5.0 & 4.9999 & TRN & \\
\hline CHEMBL1431071 & 688724 & 4.95 & 4.8388 & TST & \\
\hline CHEMBL1572968 & 688724 & 4.45 & 5.2032 & TRN & \\
\hline CHEMBL1439591 & 688724 & 4.8 & 4.9333 & TRN & \\
\hline CHEMBL124706 & 688724 & 5.65 & 4.9226 & TST & \\
\hline CHEMBL1356916 & 688724 & 4.35 & 5.0248 & TRN & \\
\hline CHEMBL1541914 & 688724 & 4.1 & 4.5415 & TRN & \\
\hline CHEMBL1445590 & 688724 & 6.3 & 5.483 & TRN & \\
\hline CHEMBL1431975 & 688724 & 4.85 & 4.6052 & TST & \\
\hline CHEMBL3192406 & 688724 & 4.95 & \multicolumn{2}{|c|}{4.781000000000001} & TST \\
\hline CHEMBL1310832 & 688724 & 5.05 & 4.6141 & TRN & \\
\hline CHEMBL 2000517 & 688724 & 5.35 & 5.3348 & TRN & \\
\hline CHEMBL1500766 & 688724 & 4.3 & \multicolumn{2}{|c|}{4.781000000000001} & TRN \\
\hline CHEMBL1427185 & 688724 & 4.4 & 4.9426 & TRN & \\
\hline CHEMBL1387834 & 688724 & 4.1 & 4.9005 & TRN & \\
\hline CHEMBL1336187 & 688724 & 6.1 & 4.7035 & TRN & \\
\hline CHEMBL1599781 & 688724 & 4.25 & 4.5018 & TRN & \\
\hline CHEMBL3190412 & 688724 & 4.65 & 5.3214 & TRN & \\
\hline CHEMBL1448573 & 688724 & 4.4 & 5.1776 & TST & \\
\hline
\end{tabular}




\begin{tabular}{|c|c|c|c|c|c|}
\hline \multicolumn{6}{|c|}{ Supplemental Table S2.txt } \\
\hline CHEMBL1320542 & 688724 & 7.0 & 5.5464 & TRN & \\
\hline CHEMBL1446004 & 688724 & 4.3 & 4.7806 & TST & \\
\hline CHEMBL1450322 & 688724 & 5.05 & 4.5321 & TRN & \\
\hline CHEMBL 2005973 & 688724 & 4.4 & 4.7053 & TRN & \\
\hline CHEMBL1540954 & 688724 & 4.65 & 5.1261 & TRN & \\
\hline CHEMBL1442051 & 688724 & 4.05 & 4.765 & TST & \\
\hline CHEMBL1413566 & 688724 & 4.55 & 4.6687 & TRN & \\
\hline CHEMBL1545105 & 688724 & 5.5 & 5.3462 & TRN & \\
\hline CHEMBL1602187 & 688724 & 4.3 & 4.437 & TRN & \\
\hline CHEMBL1364980 & 688724 & 4.45 & 5.095 & TST & \\
\hline CHEMBL1361153 & 688724 & 6.05 & 5.1114 & TRN & \\
\hline CHEMBL517444 & 688724 & 4.9 & 4.9467 & TRN & \\
\hline CHEMBL1357554 & 688724 & 4.5 & 4.4227 & TRN & \\
\hline CHEMBL1441170 & 688724 & 4.35 & 5.0863 & TST & \\
\hline CHEMBL1366342 & 688724 & 4.75 & 5.1299 & TRN & \\
\hline CHEMBL3198107 & 688724 & 4.9 & 5.1986 & TRN & \\
\hline CHEMBL1416702 & 688724 & 4.75 & 4.9503 & TST & \\
\hline CHEMBL1391768 & 688724 & 5.45 & 5.1925 & TRN & \\
\hline CHEMBL3192690 & 688724 & 5.6 & 5.223 & TRN & \\
\hline CHEMBL1463399 & 688724 & 4.15 & 4.4034 & TRN & \\
\hline CHEMBL1452062 & 688724 & 5.1 & 5.1025 & TRN & \\
\hline CHEMBL1569018 & 688724 & 4.8 & 4.7188 & TST & \\
\hline CHEMBL1375019 & 688724 & 4.8 & 5.05699 & 99999999995 & TST \\
\hline CHEMBL1520005 & 688724 & 4.4 & 4.5133 & TRN & \\
\hline CHEMBL1588557 & 688724 & 5.15 & 5.2676 & TRN & \\
\hline CHEMBL1490258 & 688724 & 4.4 & 5.2232 & TST & \\
\hline CHEMBL1432700 & 688724 & 4.4 & 5.0815 & TRN & \\
\hline CHEMBL1442776 & 688724 & 4.3 & 4.5604 & TRN & \\
\hline CHEMBL1396469 & 688724 & 4.45 & 4.7641 & TRN & \\
\hline CHEMBL1585209 & 688724 & 5.1 & 5.0071 & TRN & \\
\hline CHEMBL1502381 & 688724 & 6.2 & 5.1153 & TST & \\
\hline CHEMBL1523212 & 688724 & 6.15 & 4.3904 & TRN & \\
\hline CHEMBL1576602 & 688724 & 4.55 & 4.8269 & TST & \\
\hline CHEMBL1588873 & 688724 & 4.8 & 5.4275 & TRN & \\
\hline CHEMBL1302857 & 688724 & 4.65 & 4.8727 & TRN & \\
\hline CHEMBL1411172 & 688724 & 4.5 & 5.1203 & TRN & \\
\hline CHEMBL581868 & 688724 & 4.35 & 5.1052 & TST & \\
\hline CHEMBL1420618 & 688724 & 5.85 & 4.8792 & TRN & \\
\hline CHEMBL1407479 & 688724 & 4.45 & 4.8326 & TRN & \\
\hline CHEMBL19439 & 688724 & 5.85 & 5.1168 & TST & \\
\hline CHEMBL490510 & 688724 & 5.4 & 5.449 & TST & \\
\hline CHEMBL1256737 & 688724 & 6.0 & 5.1222 & TRN & \\
\hline CHEMBL1374830 & 688724 & 4.05 & 4.6559 & TRN & \\
\hline CHEMBL1172912 & 688724 & 5.5 & 4.7091 & TRN & \\
\hline CHEMBL1360916 & 688724 & 4.5 & 5.1086 & TRN & \\
\hline CHEMBL1606232 & 688724 & 4.75 & 5.1275 & TRN & \\
\hline CHEMBL1521517 & 688724 & 4.5 & 5.06800 & 00000000005 & TST \\
\hline CHEMBL1562926 & 688724 & 6.7501 & 5.3103 & TRN & \\
\hline
\end{tabular}




\begin{tabular}{|c|c|c|c|c|c|}
\hline \multicolumn{6}{|c|}{ Supplemental Table S2.txt } \\
\hline CHEMBL1342063 & 688724 & 4.25 & 4.4747 & TRN & \\
\hline CHEMBL1306440 & 688724 & 4.55 & 4.3884 & TST & \\
\hline CHEMBL1347741 & 688724 & 4.75 & 4.8954 & TRN & \\
\hline CHEMBL1465684 & 688724 & 5.05 & 4.7588 & TRN & \\
\hline CHEMBL1381466 & 688724 & 5.25 & 5.2664 & TRN & \\
\hline CHEMBL3210663 & 688724 & 4.1 & 4.4819 & TRN & \\
\hline CHEMBL1370038 & 688724 & 4.7 & 4.457 & TRN & \\
\hline CHEMBL1519992 & 688724 & 4.65 & 4.8448 & TRN & \\
\hline CHEMBL1369945 & 688724 & 5.3 & 5.0683 & TRN & \\
\hline CHEMBL1558905 & 688724 & 4.3 & 4.7706 & TRN & \\
\hline CHEMBL1299738 & 688724 & 6.7001 & 4.4594 & TRN & \\
\hline CHEMBL1367464 & 688724 & 4.7 & 4.6594 & TST & \\
\hline CHEMBL1530299 & 688724 & 4.8 & 5.0847 & TRN & \\
\hline CHEMBL1302147 & 688724 & 4.45 & 4.5347 & TRN & \\
\hline CHEMBL1608931 & 688724 & 4.85 & 4.7101 & TRN & \\
\hline CHEMBL1528124 & 688724 & 4.45 & 4.8338 & TRN & \\
\hline CHEMBL1490424 & 688724 & 4.9 & 5.3167 & TRN & \\
\hline CHEMBL1528378 & 688724 & 5.6 & 4.9838 & TST & \\
\hline CHEMBL1500094 & 688724 & 4.0 & 4.5677 & TRN & \\
\hline CHEMBL1436878 & 688724 & 4.4 & 4.6147 & TRN & \\
\hline CHEMBL1416153 & 688724 & 6.35 & 5.4267 & TRN & \\
\hline CHEMBL1462885 & 688724 & 4.6 & 4.9739 & TST & \\
\hline CHEMBL1531172 & 688724 & 5.0 & 4.8729 & TRN & \\
\hline CHEMBL473314 & 688724 & 6.35 & 5.6116 & TRN & \\
\hline CHEMBL1310961 & 688724 & 4.6 & 5.1409 & TRN & \\
\hline CHEMBL1360315 & 688724 & 4.5 & 4.2913 & TRN & \\
\hline CHEMBL1567129 & 688724 & 4.05 & 4.4746 & TRN & \\
\hline CHEMBL1332996 & 688724 & 6.0 & 5.1289 & TRN & \\
\hline CHEMBL1352215 & 688724 & 5.3 & 5.0203 & TRN & \\
\hline CHEMBL1404509 & 688724 & 4.45 & 4.6244 & TST & \\
\hline CHEMBL3194329 & 688724 & 5.1 & 4.9357 & TST & \\
\hline CHEMBL1460857 & 688724 & 6.0 & 4.5893 & TRN & \\
\hline CHEMBL1359297 & 688724 & 4.25 & 5.3811 & TST & \\
\hline CHEMBL45152 & 688724 & 6.4 & 5.3825 & TRN & \\
\hline CHEMBL3192701 & 688724 & 4.75 & 4.6341 & TRN & \\
\hline CHEMBL1532435 & 688724 & 4.0 & 4.448 & TST & \\
\hline CHEMBL1394239 & 688724 & 4.1 & 5.3946 & TRN & \\
\hline CHEMBL1574715 & 688724 & 4.45 & 4.8006 & TRN & \\
\hline CHEMBL1335892 & 688724 & 5.0 & 4.98300 & 00000000005 & TRN \\
\hline CHEMBL1512878 & 688724 & 5.45 & 4.7228 & TRN & \\
\hline CHEMBL1449333 & 688724 & 4.4 & 4.814 & TRN & \\
\hline CHEMBL353971 & 688724 & 4.7 & 4.6841 & TRN & \\
\hline CHEMBL1514608 & 688724 & 4.25 & 4.3668 & TRN & \\
\hline CHEMBL1526953 & 688724 & 4.1 & 4.6439 & TRN & \\
\hline CHEMBL1503778 & 688724 & 5.05 & 4.6814 & TST & \\
\hline CHEMBL1522160 & 688724 & 4.8 & 5.0036 & TST & \\
\hline CHEMBL1470573 & 688724 & 4.35 & 4.6985 & TRN & \\
\hline CHEMBL1416629 & 688724 & 4.55 & 4.4854 & TRN & \\
\hline
\end{tabular}




\begin{tabular}{|c|c|c|c|c|}
\hline \multicolumn{5}{|c|}{ Supplemental Table S2.txt } \\
\hline CHEMBL1506123 & 688724 & 4.35 & 4.4752 & TRN \\
\hline CHEMBL3199404 & 688724 & 4.35 & 4.5715 & TRN \\
\hline CHEMBL1605033 & 688724 & 5.5 & 4.8649 & TRN \\
\hline CHEMBL1452716 & 688724 & 6.0 & 5.1746 & TRN \\
\hline CHEMBL3197450 & 688724 & 5.5 & 4.7739 & TRN \\
\hline CHEMBL1571554 & 688724 & 4.95 & 4.9157 & TST \\
\hline CHEMBL1357627 & 688724 & 4.7 & 4.342 & TRN \\
\hline CHEMBL1348681 & 688724 & 4.9 & 4.797 & TRN \\
\hline CHEMBL1556157 & 688724 & 4.85 & 4.7076 & TRN \\
\hline CHEMBL1464830 & 688724 & 4.6 & 4.8141 & TRN \\
\hline CHEMBL3196713 & 688724 & 4.45 & 4.6834 & TRN \\
\hline CHEMBL1357558 & 688724 & 4.9 & 5.079 & TST \\
\hline CHEMBL1570277 & 688724 & 5.4 & 4.6972 & TRN \\
\hline CHEMBL1429145 & 688724 & 4.4 & 4.6305 & TRN \\
\hline CHEMBL1598264 & 688724 & 4.35 & 4.9706 & TRN \\
\hline CHEMBL1376441 & 688724 & 4.95 & 4.8276 & TRN \\
\hline CHEMBL1594376 & 688724 & 6.25 & 4.5642 & TST \\
\hline CHEMBL1595644 & 688724 & 5.2 & 5.2741 & TRN \\
\hline CHEMBL1348729 & 688724 & 5.75 & 5.4819 & TRN \\
\hline CHEMBL1493687 & 688724 & 4.6 & 4.9065 & TRN \\
\hline CHEMBL1986380 & 688724 & 4.95 & 4.973 & TRN \\
\hline CHEMBL540851 & 688724 & 6.0 & 5.0513 & TRN \\
\hline CHEMBL1501582 & 688724 & 5.15 & 5.0837 & TRN \\
\hline CHEMBL1379713 & 688724 & 4.75 & 5.4683 & TRN \\
\hline CHEMBL1403262 & 688724 & 7.4001 & 5.5165 & TRN \\
\hline CHEMBL1441044 & 688724 & 4.1 & 4.5138 & TRN \\
\hline CHEMBL1504738 & 688724 & 4.55 & 4.6362 & TRN \\
\hline CHEMBL399759 & 688724 & 4.55 & 4.6977 & TRN \\
\hline CHEMBL3199861 & 688724 & 4.75 & 4.8366 & TRN \\
\hline CHEMBL1342516 & 688724 & 4.0 & 4.7888 & TST \\
\hline CHEMBL1389449 & 688724 & 4.6 & 4.5161 & TRN \\
\hline CHEMBL1341906 & 688724 & 5.7 & 5.2861 & TRN \\
\hline CHEMBL1359924 & 688724 & 4.25 & 4.6159 & TRN \\
\hline CHEMBL1553871 & 688724 & 5.5 & 4.9071 & TST \\
\hline CHEMBL1557130 & 688724 & 5.2 & 4.6753 & TRN \\
\hline CHEMBL1711538 & 688724 & 4.25 & 4.3664 & TRN \\
\hline CHEMBL1420189 & 688724 & 5.05 & 4.5108 & TRN \\
\hline CHEMBL3197374 & 688724 & 4.8 & 4.765 & TRN \\
\hline CHEMBL1440277 & 688724 & 4.35 & 4.6864 & TRN \\
\hline CHEMBL1325897 & 688724 & 4.5 & 4.4952 & TRN \\
\hline CHEMBL1523344 & 688724 & 4.7 & 4.9468 & TRN \\
\hline CHEMBL1507020 & 688724 & 7.8013 & 5.2581 & TST \\
\hline CHEMBL1518440 & 688724 & 4.35 & 5.1668 & TRN \\
\hline CHEMBL1341064 & 688724 & 4.6 & 4.6055 & TRN \\
\hline CHEMBL1601400 & 688724 & 4.8 & 4.9003 & TRN \\
\hline CHEMBL1429980 & 688724 & 4.7 & 5.2172 & TRN \\
\hline CHEMBL1433214 & 688724 & 4.45 & 4.7123 & TRN \\
\hline CHEMBL1327110 & 688724 & 4.3 & 4.5512 & TST \\
\hline
\end{tabular}




\begin{tabular}{|c|c|c|c|c|}
\hline \multicolumn{5}{|c|}{ Supplemental Table S2.txt } \\
\hline CHEMBL1460705 & 688724 & 5.55 & 5.1645 & TRN \\
\hline CHEMBL1378764 & 688724 & 4.6 & 4.598 & TRN \\
\hline CHEMBL1562837 & 688724 & 4.6 & 4.525 & TRN \\
\hline CHEMBL1531022 & 688724 & 4.7 & 4.6024 & TRN \\
\hline CHEMBL1367603 & 688724 & 4.1 & 4.6569 & TRN \\
\hline CHEMBL1413557 & 688724 & 4.55 & 4.6671 & TRN \\
\hline CHEMBL1380394 & 688724 & 4.4 & 4.8269 & TRN \\
\hline CHEMBL 3196808 & 688724 & 4.35 & 4.8106 & TRN \\
\hline CHEMBL1505665 & 688724 & 4.6 & 4.6793 & TRN \\
\hline CHEMBL602363 & 688724 & 4.9 & 5.2051 & TST \\
\hline CHEMBL1519276 & 688724 & 4.4 & 4.8016 & TRN \\
\hline CHEMBL1510676 & 688724 & 4.35 & 5.2999 & TST \\
\hline CHEMBL 3145303 & 688724 & 5.4 & 5.5783 & TRN \\
\hline CHEMBL1455555 & 688724 & 4.35 & 4.8409 & TRN \\
\hline CHEMBL467987 & 688724 & 6.35 & 5.8761 & TRN \\
\hline CHEMBL1477870 & 688724 & 4.65 & 4.9398 & TRN \\
\hline CHEMBL1524439 & 688724 & 4.35 & 4.6258 & TST \\
\hline CHEMBL1446335 & 688724 & 4.75 & 4.2501 & TRN \\
\hline CHEMBL1540926 & 688724 & 5.0 & 4.6798 & TRN \\
\hline CHEMBL1420111 & 688724 & 4.9 & 4.5795 & TRN \\
\hline CHEMBL1300717 & 688724 & 4.9 & 4.6035 & TRN \\
\hline CHEMBL1567236 & 688724 & 4.75 & 4.7106 & TRN \\
\hline CHEMBL1591254 & 688724 & 4.5 & 4.5442 & TRN \\
\hline CHEMBL3197661 & 688724 & 4.3 & 4.74 & TRN \\
\hline CHEMBL1555782 & 688724 & 5.5 & 4.7485 & TRN \\
\hline CHEMBL1386703 & 688724 & 5.65 & 5.1575 & TRN \\
\hline CHEMBL1529095 & 688724 & 4.65 & 4.6381 & TST \\
\hline CHEMBL3198993 & 688724 & 4.8 & 5.0155 & TRN \\
\hline CHEMBL1556103 & 688724 & 4.1 & 4.8336 & TRN \\
\hline CHEMBL1556263 & 688724 & 4.5 & 4.3507 & TST \\
\hline CHEMBL1503862 & 688724 & 5.1 & 4.2606 & TRN \\
\hline CHEMBL1360393 & 688724 & 4.45 & 4.4801 & TST \\
\hline CHEMBL1510581 & 688724 & 4.75 & 4.3777 & TRN \\
\hline CHEMBL1319213 & 688724 & 4.2 & 4.6863 & TRN \\
\hline CHEMBL1417859 & 688724 & 4.8 & 4.7266 & TRN \\
\hline CHEMBL1600399 & 688724 & 4.6 & 5.0739 & TST \\
\hline CHEMBL1579130 & 688724 & 5.0 & 5.3347 & TRN \\
\hline CHEMBL1481939 & 688724 & 4.45 & 4.6417 & TRN \\
\hline CHEMBL1443925 & 688724 & 4.9 & 4.5496 & TST \\
\hline CHEMBL1332023 & 688724 & 4.6 & 4.6804 & TST \\
\hline CHEMBL1324988 & 688724 & 4.45 & 4.6738 & TST \\
\hline CHEMBL3192596 & 688724 & 4.75 & 4.7117 & TRN \\
\hline CHEMBL1601163 & 688724 & 4.5 & 4.5387 & TRN \\
\hline CHEMBL1510727 & 688724 & 4.85 & 4.6775 & TRN \\
\hline CHEMBL1498623 & 688724 & 4.95 & 5.216 & TRN \\
\hline CHEMBL592414 & 688724 & 4.15 & 4.6172 & TST \\
\hline CHEMBL1321285 & 688724 & 4.4 & 4.8952 & TRN \\
\hline CHEMBL1420116 & 688724 & 4.65 & 4.9 & TRN \\
\hline
\end{tabular}




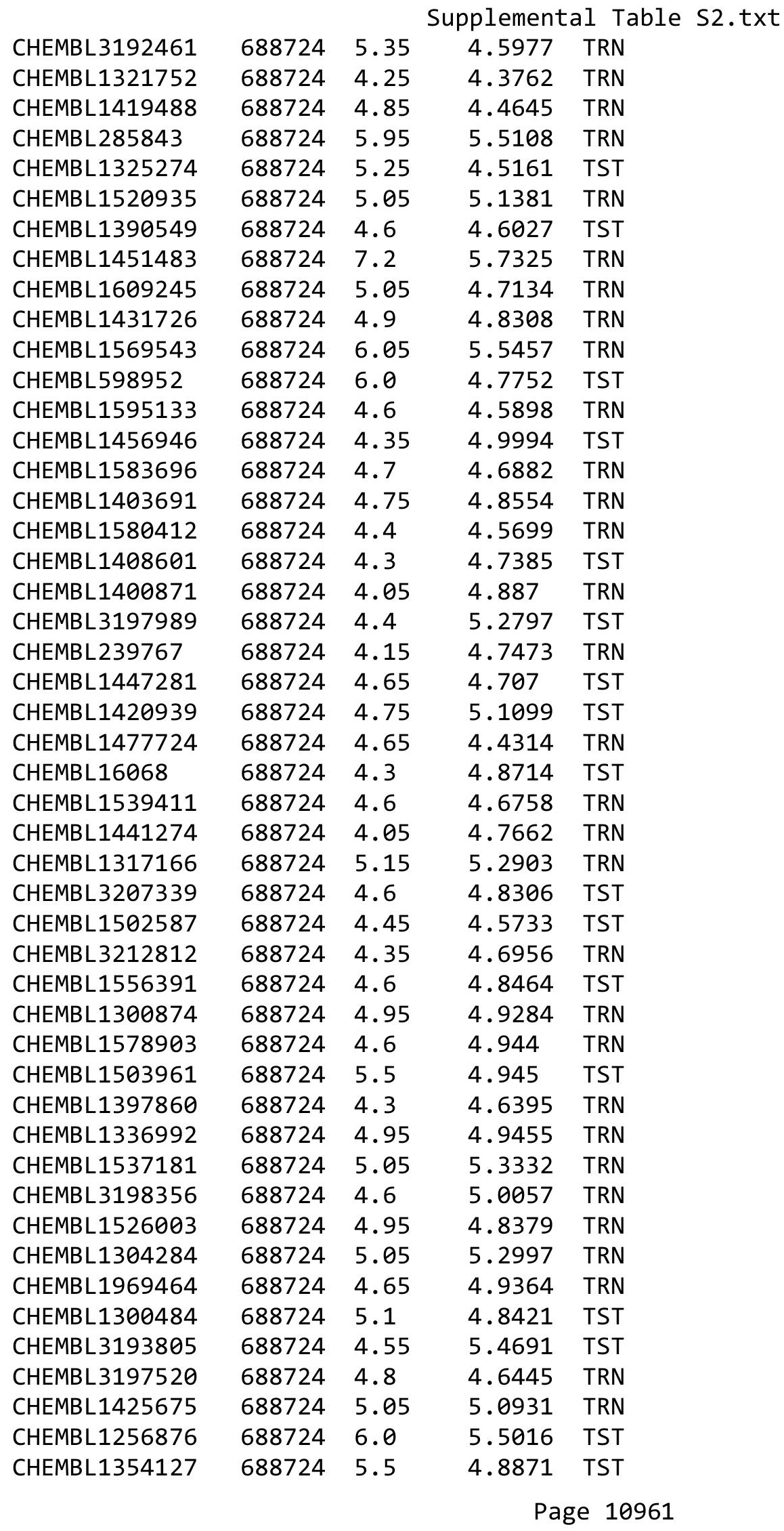




\begin{tabular}{|c|c|c|c|c|}
\hline \multicolumn{5}{|c|}{ Supplemental Table S2.txt } \\
\hline CHEMBL1434876 & 688724 & 4.25 & 4.8856 & TRN \\
\hline CHEMBL454761 & 688724 & 6.0 & 5.5791 & TRN \\
\hline CHEMBL1610181 & 688724 & 4.4 & 5.0767 & TRN \\
\hline CHEMBL1347443 & 688724 & 4.4 & 4.5528 & TRN \\
\hline CHEMBL1581915 & 688724 & 4.7 & 4.8506 & TRN \\
\hline CHEMBL1410986 & 688724 & 5.15 & 4.7124 & TST \\
\hline CHEMBL1333923 & 688724 & 4.1 & 4.748 & TST \\
\hline CHEMBL1467422 & 688724 & 4.55 & 5.5384 & TRN \\
\hline CHEMBL1493936 & 688724 & 5.4 & 5.8713 & TRN \\
\hline CHEMBL1567070 & 688724 & 4.55 & 4.9903 & TRN \\
\hline CHEMBL1384014 & 688724 & 4.5 & 4.4711 & TRN \\
\hline CHEMBL1315134 & 688724 & 4.35 & 4.5294 & TRN \\
\hline CHEMBL579919 & 688724 & 4.85 & 4.7353 & TRN \\
\hline CHEMBL1309429 & 688724 & 6.2 & 4.9096 & TRN \\
\hline CHEMBL507122 & 688724 & 4.7 & 5.0923 & TST \\
\hline CHEMBL3192879 & 688724 & 4.15 & 4.9936 & TRN \\
\hline CHEMBL1310236 & 688724 & 5.95 & 5.0388 & TRN \\
\hline CHEMBL399530 & 688724 & 5.15 & 4.82 & TRN \\
\hline CHEMBL1364515 & 688724 & 4.35 & 5.1338 & TST \\
\hline CHEMBL1515832 & 688724 & 4.4 & 4.8836 & TRN \\
\hline CHEMBL1389810 & 688724 & 4.7 & 4.6069 & TRN \\
\hline CHEMBL1451232 & 688724 & 4.8 & 5.0218 & TRN \\
\hline CHEMBL1582353 & 688724 & 4.95 & 4.6085 & TRN \\
\hline CHEMBL1347009 & 688724 & 4.1 & 5.0949 & TST \\
\hline CHEMBL1299550 & 688724 & 5.85 & 4.7929 & TST \\
\hline CHEMBL1331828 & 688724 & 4.7 & 4.9485 & TRN \\
\hline CHEMBL3212695 & 688724 & 7.3497 & 4.6928 & TST \\
\hline CHEMBL321585 & 688724 & 4.4 & 5.2899 & TRN \\
\hline CHEMBL1377329 & 688724 & 5.1 & 4.751 & TRN \\
\hline CHEMBL1551939 & 688724 & 4.15 & 5.1926 & TST \\
\hline CHEMBL1541859 & 688724 & 4.8 & 4.9657 & TRN \\
\hline CHEMBL1441295 & 688724 & 4.9 & 4.9835 & TRN \\
\hline CHEMBL1597035 & 688724 & 4.75 & 4.8988 & TRN \\
\hline CHEMBL1344355 & 688724 & 4.25 & 4.6484 & TRN \\
\hline CHEMBL1401989 & 688724 & 5.95 & 5.4821 & TRN \\
\hline CHEMBL1598242 & 688724 & 4.15 & 4.6956 & TRN \\
\hline CHEMBL3213945 & 688724 & 4.4 & 4.7925 & TRN \\
\hline CHEMBL1601605 & 688724 & 4.55 & 4.8857 & TRN \\
\hline CHEMBL6291 & 688724 & 6.0 & 5.1113 & TRN \\
\hline CHEMBL1578867 & 688724 & 4.4 & 4.6712 & TST \\
\hline CHEMBL3191015 & 688724 & 6.35 & 5.4722 & TRN \\
\hline CHEMBL1446182 & 688724 & 3.9 & 4.857 & TST \\
\hline CHEMBL1997827 & 688724 & 4.8 & 5.0038 & TRN \\
\hline CHEMBL1446740 & 688724 & 4.05 & 4.6642 & TST \\
\hline CHEMBL1452879 & 688724 & 5.5 & 4.9224 & TRN \\
\hline CHEMBL3189780 & 688724 & 4.85 & 4.9564 & TST \\
\hline CHEMBL 327588 & 688724 & 4.5 & 4.8409 & TRN \\
\hline CHEMBL1335492 & 688724 & 4.55 & 4.7487 & TST \\
\hline
\end{tabular}




\begin{tabular}{|c|c|c|c|c|c|}
\hline \multicolumn{6}{|c|}{ Supplemental Table S2.txt } \\
\hline CHEMBL1487236 & 688724 & 4.1 & 4.5495 & TRN & \\
\hline CHEMBL1565221 & 688724 & 4.85 & 4.7661 & TST & \\
\hline CHEMBL1462808 & 688724 & 4.9 & 4.7303 & TST & \\
\hline CHEMBL1387671 & 688724 & 4.4 & 4.6529 & TRN & \\
\hline CHEMBL1574104 & 688724 & 4.05 & 4.5011 & TRN & \\
\hline CHEMBL1531316 & 688724 & 4.45 & 4.6201 & TST & \\
\hline CHEMBL3214594 & 688724 & 4.9 & 5.0798 & TRN & \\
\hline CHEMBL 286494 & 688724 & 4.55 & 5.2226 & TST & \\
\hline CHEMBL1375961 & 688724 & 6.35 & 4.9743 & TRN & \\
\hline CHEMBL1444798 & 688724 & 4.8 & 4.9034 & TST & \\
\hline CHEMBL1453858 & 688724 & 5.8 & 5.1389 & TST & \\
\hline CHEMBL1399249 & 688724 & 4.2 & $4.8580 e$ & 00000000005 & TST \\
\hline CHEMBL1368051 & 688724 & 4.95 & 5.0181 & TRN & \\
\hline CHEMBL3208696 & 688724 & 4.8 & 5.0102 & TRN & \\
\hline CHEMBL1312248 & 688724 & 4.55 & 4.5361 & TRN & \\
\hline CHEMBL1310907 & 688724 & 5.95 & 4.9351 & TRN & \\
\hline CHEMBL1303350 & 688724 & 4.3 & 4.3154 & TRN & \\
\hline CHEMBL1495763 & 688724 & 4.9 & 4.8982 & TRN & \\
\hline CHEMBL3195682 & 688724 & 4.3 & 4.5017 & TRN & \\
\hline CHEMBL3195426 & 688724 & 4.4 & 4.3744 & TRN & \\
\hline CHEMBL1443500 & 688724 & 5.15 & 5.0556 & TRN & \\
\hline CHEMBL1543701 & 688724 & 5.45 & 4.855 & TRN & \\
\hline CHEMBL1501392 & 688724 & 5.15 & 5.0478 & TRN & \\
\hline CHEMBL1463903 & 688724 & 4.3 & 4.9163 & TRN & \\
\hline CHEMBL1488244 & 688724 & 4.5 & 4.8229 & TRN & \\
\hline CHEMBL1509631 & 688724 & 4.05 & 4.8572 & TST & \\
\hline CHEMBL1432762 & 688724 & 4.65 & 4.8643 & TRN & \\
\hline CHEMBL1510257 & 688724 & 4.8 & 4.703 & TRN & \\
\hline CHEMBL1546664 & 688724 & 4.35 & 4.8644 & TST & \\
\hline CHEMBL1595515 & 688724 & 4.85 & 4.5272 & TRN & \\
\hline CHEMBL1431098 & 688724 & 4.55 & 4.7805 & TRN & \\
\hline CHEMBL1328930 & 688724 & 4.5 & 4.6373 & TRN & \\
\hline CHEMBL1587748 & 688724 & 4.55 & 4.6047 & TRN & \\
\hline CHEMBL1451076 & 688724 & 4.05 & 5.0063 & TRN & \\
\hline CHEMBL1481864 & 688724 & 4.15 & 4.5269 & TRN & \\
\hline CHEMBL1425606 & 688724 & 4.4 & 5.1158 & TRN & \\
\hline CHEMBL1352627 & 688724 & 4.05 & 4.8872 & TST & \\
\hline CHEMBL1390139 & 688724 & 4.6 & 5.0003 & TRN & \\
\hline CHEMBL1437854 & 688724 & 4.15 & 4.7742 & TRN & \\
\hline CHEMBL1452565 & 688724 & 5.85 & 4.5381 & TRN & \\
\hline CHEMBL1523828 & 688724 & 4.8 & 4.6971 & TST & \\
\hline CHEMBL1600212 & 688724 & 4.05 & 4.8029 & TRN & \\
\hline CHEMBL1565710 & 688724 & 4.55 & 4.6588 & TRN & \\
\hline CHEMBL1348816 & 688724 & 4.05 & 5.1435 & TRN & \\
\hline CHEMBL1356876 & 688724 & 5.05 & 5.1545 & TRN & \\
\hline CHEMBL3191846 & 688724 & 5.25 & 5.5263 & TRN & \\
\hline CHEMBL1478384 & 688724 & 4.0 & 4.8093 & TST & \\
\hline CHEMBL1340528 & 688724 & 5.15 & 4.6771 & TST & \\
\hline
\end{tabular}




\begin{tabular}{|c|c|c|c|c|c|}
\hline \multicolumn{6}{|c|}{ Supplemental Table S2.txt } \\
\hline CHEMBL1407173 & 688724 & 4.25 & 5.4579 & TST & \\
\hline CHEMBL1506241 & 688724 & 4.8 & 4.7025 & TRN & \\
\hline CHEMBL1547457 & 688724 & 4.7 & 4.547 & TRN & \\
\hline CHEMBL1422022 & 688724 & 4.35 & 4.5902 & TRN & \\
\hline CHEMBL1463106 & 688724 & 5.35 & 4.4838 & TRN & \\
\hline CHEMBL1505677 & 688724 & 7.0 & 5.0127 & TRN & \\
\hline CHEMBL 3194087 & 688724 & 5.1 & 5.2092 & TRN & \\
\hline CHEMBL 3198155 & 688724 & 4.35 & 4.7389 & TRN & \\
\hline CHEMBL1357148 & 688724 & 4.35 & 4.8809 & TRN & \\
\hline CHEMBL1311676 & 688724 & 5.3 & 4.7692 & TRN & \\
\hline CHEMBL 2005518 & 688724 & 4.4 & 5.0207 & TRN & \\
\hline CHEMBL1371896 & 688724 & 4.7 & 4.9705 & TRN & \\
\hline CHEMBL1331734 & 688724 & 5.45 & 5.2774 & TST & \\
\hline CHEMBL1404086 & 688724 & 4.75 & 5.1652 & TRN & \\
\hline CHEMBL1335512 & 688724 & 4.55 & 4.5543 & TRN & \\
\hline CHEMBL1593851 & 688724 & 7.4001 & 5.4792 & TRN & \\
\hline CHEMBL1529952 & 688724 & 4.05 & 4.7541 & TRN & \\
\hline CHEMBL1585105 & 688724 & 4.8 & 4.8094 & TRN & \\
\hline CHEMBL1497709 & 688724 & 4.05 & 4.7899 & TST & \\
\hline CHEMBL3194666 & 688724 & 4.7 & 4.6391 & TRN & \\
\hline CHEMBL1554797 & 688724 & 4.5 & 4.6429 & TRN & \\
\hline CHEMBL1335491 & 688724 & 5.7 & 5.5735 & TRN & \\
\hline CHEMBL1538977 & 688724 & 4.35 & 4.8352 & TRN & \\
\hline CHEMBL1520016 & 688724 & 4.5 & 4.7545 & TRN & \\
\hline CHEMBL1328362 & 688724 & 4.6 & 4.3205 & TRN & \\
\hline CHEMBL3392448 & 688724 & 4.9 & 4.9851 & TRN & \\
\hline CHEMBL1473216 & 688724 & 4.55 & 5.3817 & TRN & \\
\hline CHEMBL1493478 & 688724 & 4.7 & 4.67899 & 9999999999 & TRN \\
\hline CHEMBL1538963 & 688724 & 4.8 & 4.846 & TRN & \\
\hline CHEMBL1512264 & 688724 & 4.4 & 4.9755 & TRN & \\
\hline CHEMBL1334876 & 688724 & 6.0 & 4.8497 & TRN & \\
\hline CHEMBL 29898 & 688724 & 6.0 & 5.5499 & TRN & \\
\hline CHEMBL1489064 & 688724 & 6.5501 & 4.9898 & TST & \\
\hline CHEMBL1580065 & 688724 & 4.7 & 4.3414 & TRN & \\
\hline CHEMBL144686 & 688724 & 4.1 & 4.9645 & TRN & \\
\hline CHEMBL1529959 & 688724 & 4.4 & 4.4357 & TST & \\
\hline CHEMBL1594959 & 688724 & 4.1 & 4.9503 & TST & \\
\hline CHEMBL1458691 & 688724 & 4.2 & 4.8119 & TRN & \\
\hline CHEMBL 2005302 & 688724 & 4.8 & 4.8665 & TRN & \\
\hline CHEMBL1443609 & 688724 & 5.5 & 4.7103 & TRN & \\
\hline CHEMBL1437343 & 688724 & 4.25 & 4.4981 & TRN & \\
\hline CHEMBL1524956 & 688724 & 4.55 & 5.0232 & TST & \\
\hline CHEMBL1377900 & 688724 & 5.0 & 4.6498 & TRN & \\
\hline CHEMBL1474427 & 688724 & 4.5 & 4.6509 & TRN & \\
\hline CHEMBL1312657 & 688724 & 4.6 & 4.6895 & TRN & \\
\hline CHEMBL1583001 & 688724 & 4.35 & 4.6947 & TST & \\
\hline CHEMBL1333805 & 688724 & 4.3 & 4.744 & TRN & \\
\hline CHEMBL1396573 & 688724 & 4.15 & 4.8482 & TRN & \\
\hline
\end{tabular}




\begin{tabular}{|c|c|c|c|c|c|}
\hline \multicolumn{6}{|c|}{ Supplemental Table S2.txt } \\
\hline CHEMBL1511824 & 688724 & 6.15 & 4.8407 & TRN & \\
\hline CHEMBL1535048 & 688724 & 5.4 & 5.425 & TRN & \\
\hline CHEMBL1522018 & 688724 & 4.95 & 5.1131 & TRN & \\
\hline CHEMBL1547595 & 688724 & 4.05 & 4.6787 & TRN & \\
\hline CHEMBL1585024 & 688724 & 4.6 & 5.0549 & TRN & \\
\hline CHEMBL373839 & 688724 & 4.3 & 5.0054 & TRN & \\
\hline CHEMBL1555454 & 688724 & 7.6498 & 4.9435 & TRN & \\
\hline CHEMBL1972638 & 688724 & 5.3 & 4.989 & TRN & \\
\hline CHEMBL1332296 & 688724 & 4.1 & 4.8371 & TRN & \\
\hline CHEMBL1313926 & 688724 & 5.55 & 4.8423 & TRN & \\
\hline CHEMBL1991936 & 688724 & 4.4 & 4.79899 & 99999999995 & TRN \\
\hline CHEMBL1339791 & 688724 & 4.6 & 4.7725 & TRN & \\
\hline CHEMBL1329408 & 688724 & 4.0 & 4.8925 & TST & \\
\hline CHEMBL3199190 & 688724 & 4.1 & 4.8479 & TRN & \\
\hline CHEMBL1495714 & 688724 & 5.05 & 4.9589 & TRN & \\
\hline CHEMBL3213263 & 688724 & 4.35 & 4.6704 & TST & \\
\hline CHEMBL1484777 & 688724 & 5.45 & 5.5014 & TRN & \\
\hline CHEMBL1510543 & 688724 & 4.85 & 4.955 & TST & \\
\hline CHEMBL1505198 & 688724 & 4.55 & 4.7876 & TRN & \\
\hline CHEMBL1256878 & 688724 & 4.15 & 4.8107 & TST & \\
\hline CHEMBL1467919 & 688724 & 4.3 & 4.6697 & TST & \\
\hline CHEMBL1307086 & 688724 & 5.6 & 5.1422 & TRN & \\
\hline CHEMBL1326978 & 688724 & 4.65 & 4.7863 & TRN & \\
\hline CHEMBL 253240 & 688724 & 4.5 & 4.6012 & TRN & \\
\hline CHEMBL1379540 & 688724 & 4.95 & 5.4804 & TRN & \\
\hline CHEMBL1461843 & 688724 & 4.7 & 4.7871 & TRN & \\
\hline CHEMBL1416424 & 688724 & 4.65 & 4.9519 & TRN & \\
\hline CHEMBL305469 & 688724 & 5.5 & 4.6644 & TRN & \\
\hline CHEMBL1530454 & 688724 & 4.1 & 4.5913 & TRN & \\
\hline CHEMBL1514113 & 688724 & 5.4 & 4.6537 & TRN & \\
\hline CHEMBL1599161 & 688724 & 5.65 & 4.4756 & TRN & \\
\hline CHEMBL1481602 & 688724 & 4.65 & 4.7303 & TRN & \\
\hline CHEMBL3189613 & 688724 & 4.6 & 4.9379 & TRN & \\
\hline CHEMBL1402957 & 688724 & 6.35 & 5.0937 & TRN & \\
\hline CHEMBL1460037 & 688724 & 5.5 & 4.8318 & TRN & \\
\hline CHEMBL3197958 & 688724 & 4.25 & 4.6857 & TRN & \\
\hline CHEMBL 2000167 & 688724 & 4.65 & 4.6299 & TST & \\
\hline CHEMBL1380131 & 688724 & 4.55 & 4.7662 & TST & \\
\hline CHEMBL1304028 & 688724 & 4.75 & 4.6775 & TRN & \\
\hline CHEMBL1306262 & 688724 & 6.15 & 4.6881 & TRN & \\
\hline CHEMBL1566950 & 688724 & 4.85 & 4.8369 & TRN & \\
\hline CHEMBL170405 & 688724 & 6.5501 & 5.4247 & TRN & \\
\hline CHEMBL1583448 & 688724 & 4.25 & 4.7094 & TST & \\
\hline CHEMBL 2005944 & 688724 & 5.35 & 5.2068 & TRN & \\
\hline CHEMBL1304401 & 688724 & 5.4 & 4.9281 & TRN & \\
\hline CHEMBL1441508 & 688724 & 4.9 & 5.0435 & TRN & \\
\hline CHEMBL3208555 & 688724 & 4.35 & 4.705 & TRN & \\
\hline CHEMBL1410701 & 688724 & 4.4 & 5.0704 & TRN & \\
\hline
\end{tabular}




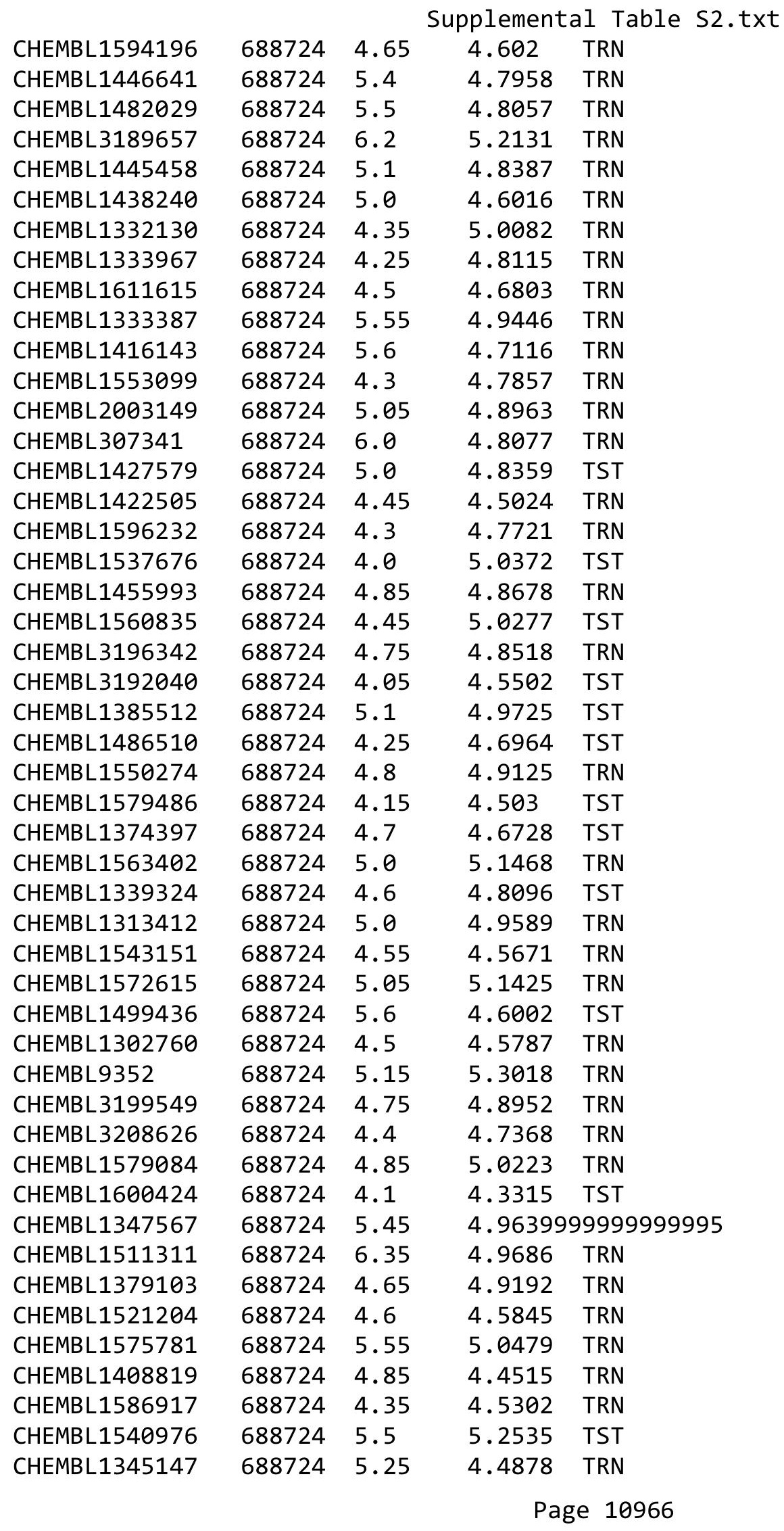




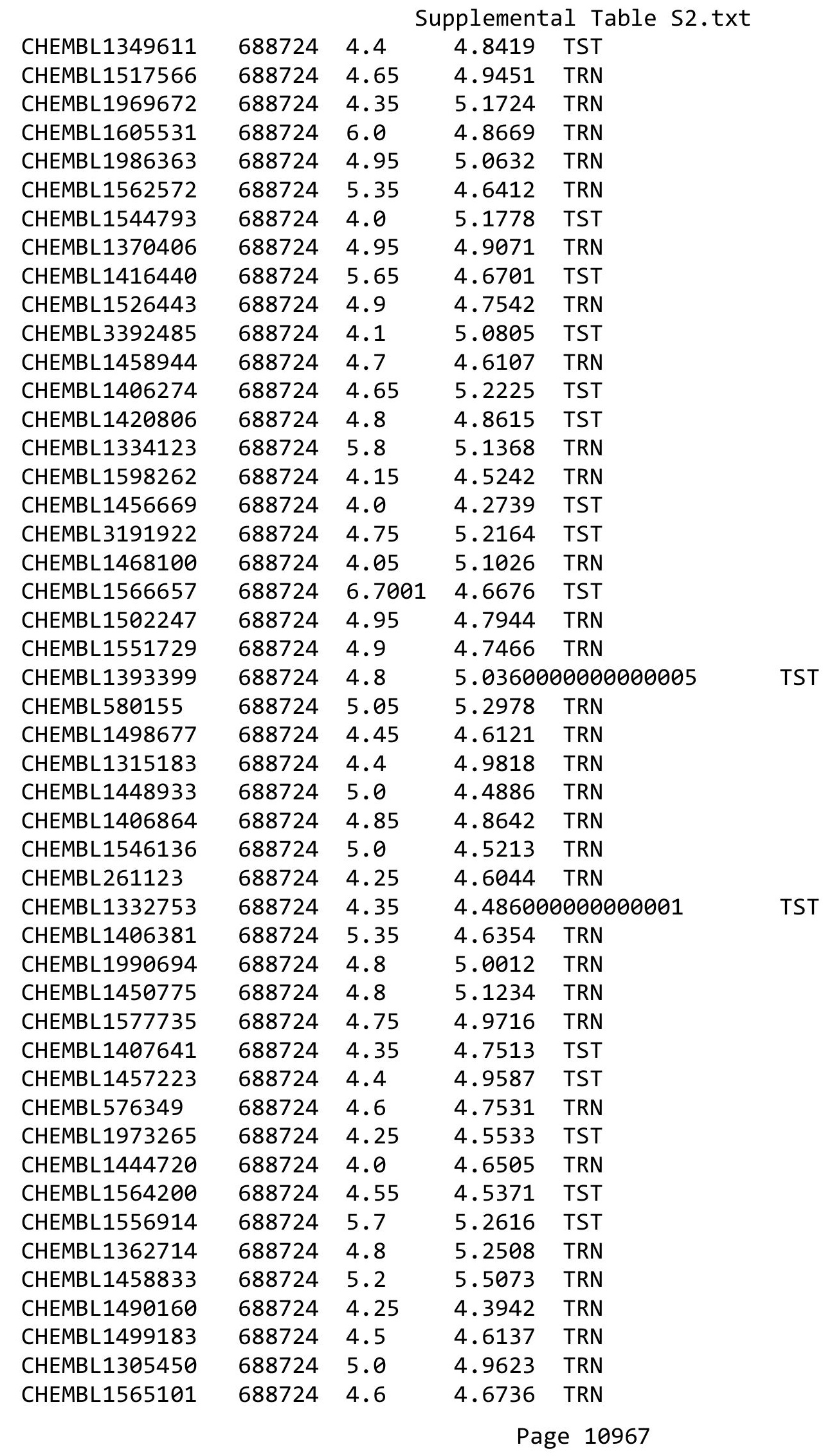




\begin{tabular}{|c|c|c|c|c|c|}
\hline \multicolumn{6}{|c|}{ Supplemental Table S2.txt } \\
\hline CHEMBL1574351 & 688724 & 5.0 & 4.8476 & TST & \\
\hline CHEMBL1519388 & 688724 & 4.95 & 5.2256 & TRN & \\
\hline CHEMBL1500850 & 688724 & 5.4 & 4.57100 & 0000000001 & TRN \\
\hline CHEMBL1443546 & 688724 & 4.7 & 4.9823 & TST & \\
\hline CHEMBL446452 & 688724 & 4.45 & 4.9899 & TRN & \\
\hline CHEMBL261641 & 688724 & 4.9 & 5.0953 & TRN & \\
\hline CHEMBL1344854 & 688724 & 4.5 & 4.4733 & TRN & \\
\hline CHEMBL3192495 & 688724 & 4.7 & 5.0252 & TRN & \\
\hline CHEMBL1604058 & 688724 & 5.35 & 4.9437 & TST & \\
\hline CHEMBL1380585 & 688724 & 4.7 & 4.8391 & TRN & \\
\hline CHEMBL1420259 & 688724 & 5.55 & 4.9278 & TST & \\
\hline CHEMBL1516170 & 688724 & 4.55 & 4.6095 & TRN & \\
\hline CHEMBL1424982 & 688724 & 4.8 & 4.6194 & TRN & \\
\hline CHEMBL1540325 & 688724 & 4.25 & 4.5343 & TRN & \\
\hline CHEMBL1573681 & 688724 & 4.85 & 4.7339 & TST & \\
\hline CHEMBL1590703 & 688724 & 4.35 & 4.6599 & TRN & \\
\hline CHEMBL1526171 & 688724 & 4.45 & 5.4 & TRN & \\
\hline CHEMBL1548870 & 688724 & 4.4 & 4.4418 & TRN & \\
\hline CHEMBL1545826 & 688724 & 4.45 & 4.7294 & TST & \\
\hline CHEMBL1326032 & 688724 & 5.05 & 5.1037 & TRN & \\
\hline CHEMBL1988010 & 688724 & 4.55 & 4.9861 & TRN & \\
\hline CHEMBL3193555 & 688724 & 4.9 & 4.6982 & TRN & \\
\hline CHEMBL1570161 & 688724 & 4.35 & 4.9027 & TRN & \\
\hline CHEMBL1492385 & 688724 & 4.6 & 4.9097 & TRN & \\
\hline CHEMBL1409603 & 688724 & 6.0 & 4.6962 & TRN & \\
\hline CHEMBL1970918 & 688724 & 4.8 & 4.9073 & TRN & \\
\hline CHEMBL1485064 & 688724 & 5.0 & 4.96 & TRN & \\
\hline CHEMBL489738 & 688724 & 4.45 & 4.779 & TRN & \\
\hline CHEMBL1589704 & 688724 & 5.2 & 4.997 & TRN & \\
\hline CHEMBL1411673 & 688724 & 4.3 & 4.8012 & TRN & \\
\hline CHEMBL3213220 & 688724 & 5.3 & 5.0264 & TRN & \\
\hline CHEMBL1535261 & 688724 & 4.7 & 4.7018 & TST & \\
\hline CHEMBL1541733 & 688724 & 4.75 & 4.827 & TRN & \\
\hline CHEMBL1476264 & 688724 & 7.3002 & 5.82100 & 2000000001 & TRN \\
\hline CHEMBL1540525 & 688724 & 5.15 & 5.4153 & TRN & \\
\hline CHEMBL258893 & 688724 & 4.2 & 4.9093 & TRN & \\
\hline CHEMBL1497129 & 688724 & 4.55 & 4.8356 & TRN & \\
\hline CHEMBL1302024 & 688724 & 4.55 & 4.3512 & TRN & \\
\hline CHEMBL3392071 & 688724 & 4.45 & 4.93 & TRN & \\
\hline CHEMBL1327247 & 688724 & 4.0 & 4.8581 & TRN & \\
\hline CHEMBL1341135 & 688724 & 6.5501 & 4.5955 & TRN & \\
\hline CHEMBL7939 & 688724 & 4.25 & 4.8291 & TRN & \\
\hline CHEMBL1378478 & 688724 & 5.05 & 4.742 & TRN & \\
\hline CHEMBL1579199 & 688724 & 4.65 & 4.5494 & TRN & \\
\hline CHEMBL3190747 & 688724 & 5.05 & 5.2259 & TST & \\
\hline CHEMBL1347385 & 688724 & 4.45 & 4.654 & TRN & \\
\hline CHEMBL1422087 & 688724 & 4.6 & 4.9456 & TST & \\
\hline CHEMBL1596241 & 688724 & 4.35 & 4.6153 & TRN & \\
\hline
\end{tabular}




\begin{tabular}{|c|c|c|c|c|}
\hline & & & pplemen & al $\mathrm{T}$ \\
\hline CHEMBL1486366 & 688724 & 4.6 & 5.3734 & TRN \\
\hline CHEMBL1588895 & 688724 & 4.9 & 4.7057 & TST \\
\hline CHEMBL1413958 & 688724 & 5.05 & 4.8071 & TST \\
\hline CHEMBL1577993 & 688724 & 4.95 & 5.0588 & TRN \\
\hline CHEMBL1972217 & 688724 & 5.35 & 5.4034 & TRN \\
\hline CHEMBL3189255 & 688724 & 4.3 & 4.7579 & TRN \\
\hline CHEMBL1373829 & 688724 & 5.5 & 5.1773 & TRN \\
\hline CHEMBL 312163 & 688724 & 4.5 & 5.5464 & TRN \\
\hline CHEMBL1474278 & 688724 & 4.5 & 5.0151 & TRN \\
\hline CHEMBL334707 & 688724 & 4.6 & 5.397 & TRN \\
\hline CHEMBL1416218 & 688724 & 5.4 & 5.1393 & TRN \\
\hline CHEMBL1577501 & 688724 & 6.0 & 4.9022 & TRN \\
\hline CHEMBL1376894 & 688724 & 4.5 & 4.5965 & TRN \\
\hline CHEMBL1480313 & 688724 & 6.05 & 4.8573 & TRN \\
\hline CHEMBL1453942 & 688724 & 4.65 & 4.8001 & TRN \\
\hline CHEMBL 1458710 & 688724 & 4.15 & 4.8282 & TRN \\
\hline CHEMBL1598306 & 688724 & 4.55 & 4.7623 & TST \\
\hline CHEMBL1447147 & 688724 & 4.45 & 4.6965 & TRN \\
\hline CHEMBL1349524 & 688724 & 4.0 & 4.4286 & TRN \\
\hline CHEMBL1436064 & 688724 & 4.55 & 4.5825 & TST \\
\hline CHEMBL1507743 & 688724 & 4.8 & 4.7937 & TST \\
\hline CHEMBL1469643 & 688724 & 5.15 & 4.9182 & TRN \\
\hline CHEMBL1412410 & 688724 & 5.55 & 4.5741 & TRN \\
\hline CHEMBL1469921 & 688724 & 5.25 & 4.7007 & TST \\
\hline CHEMBL1510117 & 688724 & 4.85 & 4.8018 & TRN \\
\hline CHEMBL1439473 & 688724 & 4.0 & 4.9673 & TST \\
\hline CHEMBL1441583 & 688724 & 4.4 & 4.8847 & TRN \\
\hline CHEMBL1439414 & 688724 & 4.1 & 5.131 & TST \\
\hline CHEMBL 2094422 & 688724 & 5.4 & 4.9389 & TRN \\
\hline CHEMBL1598455 & 688724 & 4.8 & 4.8183 & TRN \\
\hline CHEMBL324774 & 688724 & 4.25 & 5.3542 & TST \\
\hline CHEMBL 3190881 & 688724 & 4.95 & 4.4724 & TRN \\
\hline CHEMBL1388860 & 688724 & 4.7 & 4.681 & TRN \\
\hline CHEMBL1507934 & 688724 & 4.85 & 4.8378 & TST \\
\hline CHEMBL1547404 & 688724 & 5.45 & 5.2705 & TRN \\
\hline CHEMBL327002 & 688724 & 5.0 & 4.5843 & TRN \\
\hline CHEMBL3191206 & 688724 & 4.35 & 4.9025 & TRN \\
\hline CHEMBL546257 & 688724 & 4.2 & 4.9804 & TRN \\
\hline CHEMBL1543396 & 688724 & 4.75 & 4.4063 & TRN \\
\hline CHEMBL1498473 & 688724 & 4.5 & 4.7422 & TST \\
\hline CHEMBL 266158 & 688724 & 5.1 & 5.0584 & TST \\
\hline CHEMBL1534359 & 688724 & 4.8 & 4.9987 & TST \\
\hline CHEMBL1432740 & 688724 & 5.65 & 4.7697 & TST \\
\hline CHEMBL1528671 & 688724 & 4.4 & 4.7004 & TRN \\
\hline CHEMBL1497538 & 688724 & 4.4 & 4.8837 & TST \\
\hline CHEMBL1329282 & 688724 & 4.8 & 5.2222 & TRN \\
\hline CHEMBL1404838 & 688724 & 4.1 & 4.7458 & TST \\
\hline CHEMBL1421651 & 688724 & 4.0 & 4.7923 & TST \\
\hline
\end{tabular}




\begin{tabular}{|c|c|c|c|c|}
\hline \multicolumn{5}{|c|}{ Supplemental Table S2.txt } \\
\hline CHEMBL1597655 & 688724 & 5.55 & 5.4921 & TRN \\
\hline CHEMBL1598122 & 688724 & 4.45 & 4.6096 & TRN \\
\hline CHEMBL1515978 & 688724 & 6.2 & 4.5228 & TST \\
\hline CHEMBL1554980 & 688724 & 5.65 & 5.2084 & TRN \\
\hline CHEMBL3187596 & 688724 & 4.9 & 4.8995 & TST \\
\hline CHEMBL1987344 & 688724 & 5.1 & 4.7954 & TRN \\
\hline CHEMBL1328143 & 688724 & 4.5 & 5.3084 & TRN \\
\hline CHEMBL1488345 & 688724 & 5.35 & 4.9687 & TRN \\
\hline CHEMBL1433231 & 688724 & 4.4242 & 4.9677 & TRN \\
\hline CHEMBL1350274 & 688724 & 4.4 & 4.9999 & TRN \\
\hline CHEMBL1304408 & 688724 & 4.7 & 4.3873 & TRN \\
\hline CHEMBL1457888 & 688724 & 6.25 & 4.8744 & TRN \\
\hline CHEMBL1321458 & 688724 & 5.0 & 4.7806 & TST \\
\hline CHEMBL1445507 & 688724 & 4.95 & 4.4881 & TRN \\
\hline CHEMBL1351361 & 688724 & 4.6 & 5.0549 & TRN \\
\hline CHEMBL1338286 & 688724 & 6.5 & 4.5804 & TST \\
\hline CHEMBL1378974 & 688724 & 4.25 & 5.3145 & TST \\
\hline CHEMBL1604687 & 688724 & 4.05 & 4.5325 & TRN \\
\hline CHEMBL1341945 & 688724 & 4.9 & 4.8388 & TST \\
\hline CHEMBL1533277 & 688724 & 4.35 & 5.077 & TRN \\
\hline CHEMBL1315943 & 688724 & 5.2 & 4.8687 & TRN \\
\hline CHEMBL1307513 & 688724 & 5.6 & 5.0163 & TRN \\
\hline CHEMBL1370154 & 688724 & 4.0 & 4.7657 & TRN \\
\hline CHEMBL1472137 & 688724 & 4.05 & 4.9651 & TST \\
\hline CHEMBL507 & 688724 & 8.1487 & 4.937 & TST \\
\hline CHEMBL1573198 & 688724 & 4.45 & 4.5963 & TRN \\
\hline CHEMBL1315559 & 688724 & 5.15 & 5.1592 & TRN \\
\hline CHEMBL 3145085 & 688724 & 4.8 & 4.7575 & TRN \\
\hline CHEMBL1605229 & 688724 & 5.05 & 4.9194 & TRN \\
\hline CHEMBL1363684 & 688724 & 6.15 & 4.8999 & TRN \\
\hline CHEMBL1599125 & 688724 & 4.3 & 4.2986 & TRN \\
\hline CHEMBL1432427 & 688724 & 5.35 & 5.7382 & TRN \\
\hline CHEMBL1409474 & 688724 & 4.35 & 4.8206 & TST \\
\hline CHEMBL1496995 & 688724 & 5.1 & 4.6604 & TRN \\
\hline CHEMBL1612623 & 688724 & 4.8 & 5.0513 & TRN \\
\hline CHEMBL1402628 & 688724 & 4.7 & 4.7799 & TRN \\
\hline CHEMBL1501687 & 688724 & 5.1 & 5.0721 & TST \\
\hline CHEMBL1434806 & 688724 & 4.5 & 4.8999 & TRN \\
\hline CHEMBL1418168 & 688724 & 4.85 & 5.0936 & TRN \\
\hline CHEMBL1524495 & 688724 & 4.4 & 5.2579 & TST \\
\hline CHEMBL1378295 & 688724 & 5.35 & 5.043 & TRN \\
\hline CHEMBL1307743 & 688724 & 4.55 & 4.9161 & TRN \\
\hline CHEMBL1312153 & 688724 & 4.5 & 4.9478 & TRN \\
\hline CHEMBL1385681 & 688724 & 5.55 & 5.1871 & TST \\
\hline CHEMBL1506055 & 688724 & 4.45 & 4.5643 & TST \\
\hline CHEMBL3199634 & 688724 & 5.7 & 5.119 & TRN \\
\hline CHEMBL1607202 & 688724 & 4.25 & 4.8991 & TRN \\
\hline CHEMBL1306002 & 688724 & 4.9 & 4.6521 & TRN \\
\hline
\end{tabular}




\begin{tabular}{|c|c|c|c|c|}
\hline & & & oplement & al $\mathrm{T}$ \\
\hline CHEMBL1418403 & 688724 & 4.55 & 4.7796 & TST \\
\hline CHEMBL3208876 & 688724 & 4.25 & 4.5427 & TRN \\
\hline CHEMBL48310 & 688724 & 4.55 & 5.1121 & TST \\
\hline CHEMBL1480135 & 688724 & 5.9 & 5.2896 & TRN \\
\hline CHEMBL3214061 & 688724 & 5.85 & 4.5181 & TRN \\
\hline CHEMBL1613606 & 688724 & 4.65 & 5.0402 & TRN \\
\hline CHEMBL257167 & 688724 & 4.6 & 4.7931 & TST \\
\hline CHEMBL1373601 & 688724 & 4.75 & 4.7599 & TST \\
\hline CHEMBL1516561 & 688724 & 4.75 & 5.2843 & TRN \\
\hline CHEMBL1605184 & 688724 & 4.05 & 4.6267 & TST \\
\hline CHEMBL1330381 & 688724 & 5.05 & 4.8298 & TRN \\
\hline CHEMBL400585 & 688724 & 4.6 & 4.9061 & TRN \\
\hline CHEMBL1411743 & 688724 & 5.0 & 4.7458 & TRN \\
\hline CHEMBL3193888 & 688724 & 4.4 & 4.8242 & TRN \\
\hline CHEMBL1550955 & 688724 & 4.05 & 4.9377 & TST \\
\hline CHEMBL1340165 & 688724 & 4.5 & 4.7231 & TST \\
\hline CHEMBL1449110 & 688724 & 4.5 & 4.7963 & TRN \\
\hline CHEMBL37312 & 688724 & 6.1 & 4.8288 & TST \\
\hline CHEMBL571296 & 688724 & 4.8 & 4.5624 & TRN \\
\hline CHEMBL1417231 & 688724 & 4.05 & 4.5964 & TRN \\
\hline CHEMBL1332066 & 688724 & 4.85 & 4.6068 & TRN \\
\hline CHEMBL1500271 & 688724 & 5.35 & 4.6841 & TRN \\
\hline CHEMBL1536089 & 688724 & 4.45 & 4.9487 & TRN \\
\hline CHEMBL1360322 & 688724 & 5.5 & 4.8782 & TRN \\
\hline CHEMBL1396835 & 688724 & 4.6 & 4.7484 & TST \\
\hline CHEMBL1306388 & 688724 & 5.3 & 4.7412 & TRN \\
\hline CHEMBL1451347 & 688724 & 4.3 & 4.5881 & TRN \\
\hline CHEMBL1490676 & 688724 & 4.35 & 4.8657 & TRN \\
\hline CHEMBL 3195475 & 688724 & 5.15 & 5.1189 & TRN \\
\hline CHEMBL1416955 & 688724 & 5.15 & 4.7024 & TRN \\
\hline CHEMBL1486606 & 688724 & 4.95 & 4.7369 & TRN \\
\hline CHEMBL242946 & 688724 & 4.7 & 5.0215 & TRN \\
\hline CHEMBL1544464 & 688724 & 4.65 & 4.4669 & TST \\
\hline CHEMBL1404757 & 688724 & 4.1 & 4.4638 & TRN \\
\hline CHEMBL 295652 & 688724 & 6.0 & 4.7577 & TRN \\
\hline CHEMBL1558378 & 688724 & 4.6 & 4.7656 & TRN \\
\hline CHEMBL1517788 & 688724 & 4.35 & 4.5616 & TRN \\
\hline CHEMBL1489223 & 688724 & 8.0506 & 5.0401 & TRN \\
\hline CHEMBL1382418 & 688724 & 4.3 & 4.7795 & TRN \\
\hline CHEMBL1441918 & 688724 & 4.6 & 4.9916 & TST \\
\hline CHEMBL 2373648 & 688724 & 6.15 & 5.1955 & TST \\
\hline CHEMBL1528722 & 688724 & 4.55 & 4.541 & TST \\
\hline CHEMBL1438907 & 688724 & 4.75 & 4.941 & TRN \\
\hline CHEMBL1379448 & 688724 & 5.55 & 5.0729 & TST \\
\hline CHEMBL1520373 & 688724 & 4.85 & 4.7313 & TRN \\
\hline CHEMBL1301534 & 688724 & 4.75 & 4.7762 & TRN \\
\hline CHEMBL3198496 & 688724 & 4.35 & 5.3376 & TRN \\
\hline CHEMBL1545225 & 688724 & 5.45 & 5.1472 & TRN \\
\hline
\end{tabular}




\begin{tabular}{|c|c|c|c|c|c|}
\hline \multicolumn{6}{|c|}{ Supplemental Table S2.txt } \\
\hline CHEMBL1473987 & 688724 & 4.25 & 4.7894 & TRN & \\
\hline CHEMBL1608159 & 688724 & 5.35 & 5.1345 & TST & \\
\hline CHEMBL1337147 & 688724 & 4.1 & 4.3479 & TRN & \\
\hline CHEMBL1601202 & 688724 & 4.75 & 4.8905 & TRN & \\
\hline CHEMBL1602663 & 688724 & 4.9 & 4.9757 & TST & \\
\hline CHEMBL3199718 & 688724 & 4.45 & 5.1631 & TST & \\
\hline CHEMBL1411384 & 688724 & 4.05 & 4.84399 & 9999999999 & TRN \\
\hline CHEMBL1573336 & 688724 & 4.6 & 4.9306 & TST & \\
\hline CHEMBL172064 & 688724 & 6.0 & 5.149 & TRN & \\
\hline CHEMBL1419188 & 688724 & 5.05 & 5.0102 & TRN & \\
\hline CHEMBL1987145 & 688724 & 5.1 & 5.0538 & TRN & \\
\hline CHEMBL304291 & 688724 & 6.0 & 5.0538 & TST & \\
\hline CHEMBL1348784 & 688724 & 5.05 & 4.6633 & TRN & \\
\hline CHEMBL1301673 & 688724 & 4.45 & 4.7263 & TRN & \\
\hline CHEMBL 340807 & 688724 & 5.2 & 5.0046 & TRN & \\
\hline CHEMBL1342518 & 688724 & 4.6 & 5.0269 & TST & \\
\hline CHEMBL1327418 & 688724 & 4.8 & 4.9238 & TRN & \\
\hline CHEMBL1576093 & 688724 & 5.05 & 4.896 & TST & \\
\hline CHEMBL1348418 & 688724 & 6.0 & 4.9351 & TRN & \\
\hline CHEMBL1572510 & 688724 & 5.15 & 5.1696 & TRN & \\
\hline CHEMBL1300195 & 688724 & 4.35 & 4.7544 & TRN & \\
\hline CHEMBL1413941 & 688724 & 4.25 & 4.8442 & TRN & \\
\hline CHEMBL1419809 & 688724 & 4.1 & 4.5908 & TRN & \\
\hline CHEMBL1369081 & 688724 & 5.35 & 5.2869 & TRN & \\
\hline CHEMBL1324778 & 688724 & 4.25 & 4.6955 & TRN & \\
\hline CHEMBL1712981 & 688724 & 4.6 & 4.7152 & TST & \\
\hline CHEMBL1581920 & 688724 & 6.35 & 5.1999 & TRN & \\
\hline CHEMBL1531320 & 688724 & 4.6 & 4.6235 & TRN & \\
\hline CHEMBL1528787 & 688724 & 4.35 & 4.77 & TRN & \\
\hline CHEMBL1360735 & 688724 & 4.75 & 4.8388 & TST & \\
\hline CHEMBL1606179 & 688724 & 4.45 & 4.8466 & TRN & \\
\hline CHEMBL1987579 & 688724 & 5.9 & 5.2611 & TRN & \\
\hline CHEMBL 3195955 & 688724 & 4.15 & 4.7374 & TRN & \\
\hline CHEMBL1420246 & 688724 & 4.8 & 4.6469 & TRN & \\
\hline CHEMBL1367642 & 688724 & 4.6 & 4.6455 & TST & \\
\hline CHEMBL1573291 & 688724 & 4.65 & 5.1482 & TST & \\
\hline CHEMBL3199050 & 688724 & 4.4 & 4.9673 & TRN & \\
\hline CHEMBL1333095 & 688724 & 4.4 & 4.7937 & TRN & \\
\hline CHEMBL1508696 & 688724 & 4.4 & 4.8656 & TRN & \\
\hline CHEMBL1312418 & 688724 & 4.9 & 4.7702 & TRN & \\
\hline CHEMBL3198804 & 688724 & 4.45 & 4.5381 & TST & \\
\hline CHEMBL1408728 & 688724 & 4.15 & 4.5075 & TST & \\
\hline CHEMBL1603832 & 688724 & 4.0 & 4.9571 & TRN & \\
\hline CHEMBL1611913 & 688724 & 5.25 & 4.7787 & TRN & \\
\hline CHEMBL1493011 & 688724 & 5.2 & 5.42299 & 9999999999 & TST \\
\hline CHEMBL3193923 & 688724 & 6.1 & 5.2276 & TRN & \\
\hline CHEMBL1512390 & 688724 & 4.55 & 5.0225 & TRN & \\
\hline CHEMBL1340979 & 688724 & 4.0 & 4.68 & TST & \\
\hline
\end{tabular}




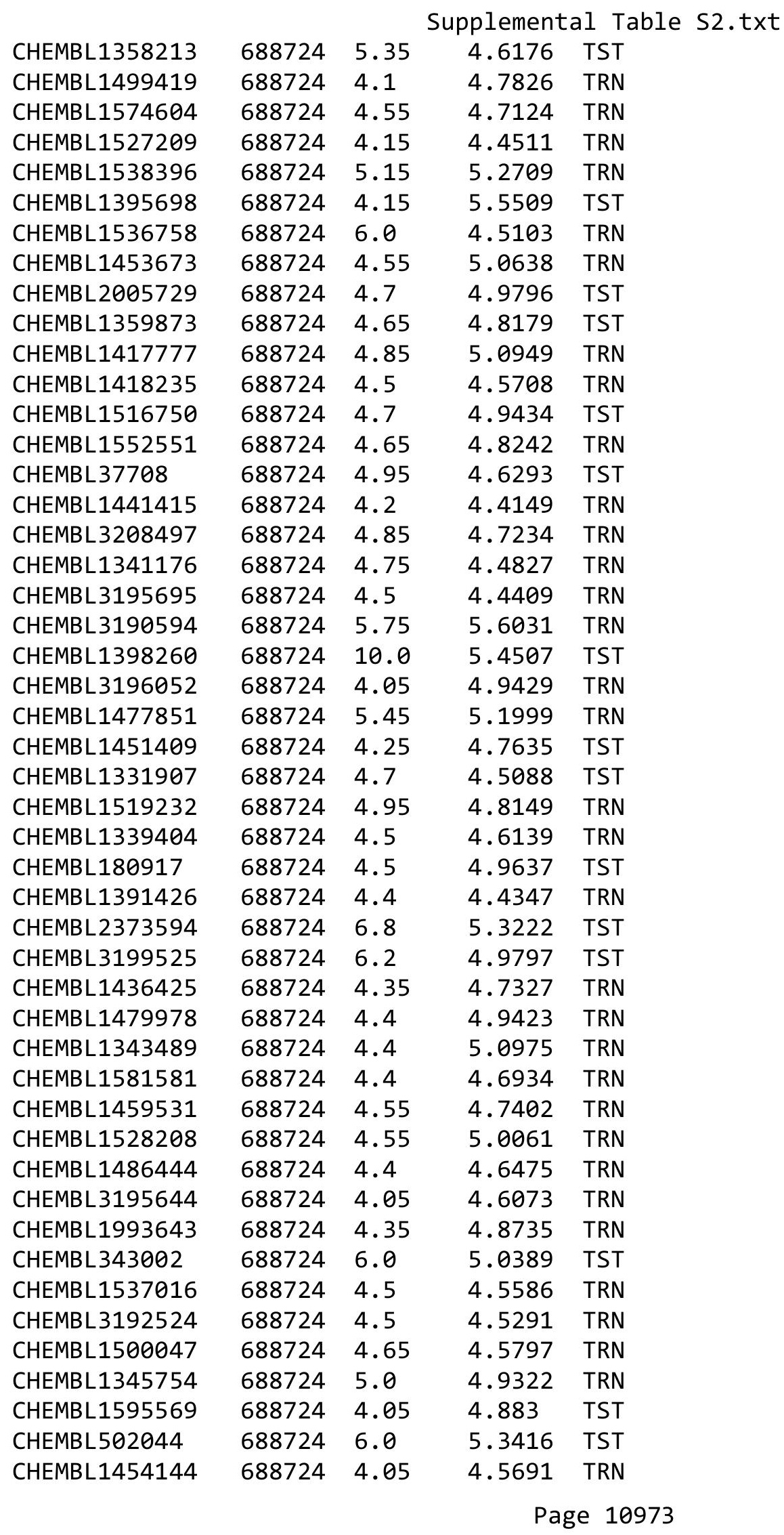




\begin{tabular}{|c|c|c|c|c|c|}
\hline \multicolumn{6}{|c|}{ plemental labıe s2.tx } \\
\hline CHEMBL1332082 & 688724 & 4.1 & 4.6554 & TRN & \\
\hline CHEMBL1380046 & 688724 & 5.2 & 4.90300 & 20000000005 & TRN \\
\hline CHEMBL1557048 & 688724 & 5.45 & 4.6686 & TRN & \\
\hline CHEMBL1485442 & 688724 & 6.25 & 5.077 & TRN & \\
\hline CHEMBL1442097 & 688724 & 4.9 & 4.9234 & TST & \\
\hline CHEMBL1467504 & 688724 & 4.85 & 4.6737 & TST & \\
\hline CHEMBL1411565 & 688724 & 4.35 & 4.5182 & TRN & \\
\hline CHEMBL3191896 & 688724 & 4.05 & 4.6089 & TRN & \\
\hline CHEMBL1551915 & 688724 & 4.9 & 4.8922 & TRN & \\
\hline CHEMBL1416176 & 688724 & 4.3 & 4.7942 & TST & \\
\hline CHEMBL1523483 & 688724 & 4.6 & 4.4901 & TRN & \\
\hline CHEMBL1604674 & 688724 & 4.45 & 4.912 & TRN & \\
\hline CHEMBL1338267 & 688724 & 5.45 & 4.5981 & TRN & \\
\hline CHEMBL1439102 & 688724 & 4.45 & 5.4093 & TRN & \\
\hline CHEMBL3189395 & 688724 & 4.35 & 4.6326 & TRN & \\
\hline CHEMBL1433074 & 688724 & 4.35 & 4.7124 & TRN & \\
\hline CHEMBL1972346 & 688724 & 5.55 & 5.5606 & TRN & \\
\hline CHEMBL3193997 & 688724 & 4.3 & 4.8777 & TRN & \\
\hline CHEMBL1200958 & 688724 & 4.6 & 5.4714 & TST & \\
\hline CHEMBL1448364 & 688724 & 4.45 & 4.6781 & TRN & \\
\hline CHEMBL1334376 & 688724 & 4.95 & 5.2257 & TRN & \\
\hline CHEMBL1468277 & 688724 & 4.4 & 4.7601 & TRN & \\
\hline CHEMBL1479949 & 688724 & 4.5 & 4.8385 & TRN & \\
\hline CHEMBL1556925 & 688724 & 4.3 & 4.6754 & TST & \\
\hline CHEMBL1455824 & 688724 & 4.9 & 4.7761 & TRN & \\
\hline CHEMBL1541005 & 688724 & 6.3 & 5.034 & TRN & \\
\hline CHEMBL1361335 & 688724 & 4.35 & 4.9145 & TST & \\
\hline CHEMBL1420891 & 688724 & 5.45 & 4.8508 & TRN & \\
\hline CHEMBL3197554 & 688724 & 4.85 & 4.3804 & TRN & \\
\hline CHEMBL1420473 & 688724 & 5.45 & 4.8473 & TRN & \\
\hline CHEMBL1421702 & 688724 & 4.55 & 5.1096 & TRN & \\
\hline CHEMBL1421565 & 688724 & 5.75 & 4.7336 & TRN & \\
\hline CHEMBL1548878 & 688724 & 4.45 & 4.7861 & TST & \\
\hline CHEMBL1984604 & 688724 & 5.5 & 5.1123 & TRN & \\
\hline CHEMBL1990990 & 688724 & 5.6 & 4.729 & TRN & \\
\hline CHEMBL1368496 & 688724 & 4.5 & 4.873 & TRN & \\
\hline CHEMBL1519539 & 688724 & 4.55 & 4.918 & TRN & \\
\hline CHEMBL3208691 & 688724 & 5.8 & 4.9461 & TST & \\
\hline CHEMBL1515044 & 688724 & 5.0 & 4.9274 & TRN & \\
\hline CHEMBL 271673 & 688724 & 5.0 & 4.9179 & TRN & \\
\hline CHEMBL1460029 & 688724 & 4.55 & 4.6773 & TST & \\
\hline CHEMBL1433440 & 688724 & 4.15 & 4.6946 & TRN & \\
\hline CHEMBL1583348 & 688724 & 4.55 & 4.4316 & TRN & \\
\hline CHEMBL1413280 & 688724 & 5.3 & 4.8179 & TST & \\
\hline CHEMBL1436459 & 688724 & 4.1 & 4.8368 & TRN & \\
\hline CHEMBL 3190370 & 688724 & 5.45 & 4.7553 & TRN & \\
\hline CHEMBL1514685 & 688724 & 4.5 & 4.7886 & TRN & \\
\hline CHEMBL1431206 & 688724 & 4.7 & 4.6418 & TRN & \\
\hline
\end{tabular}




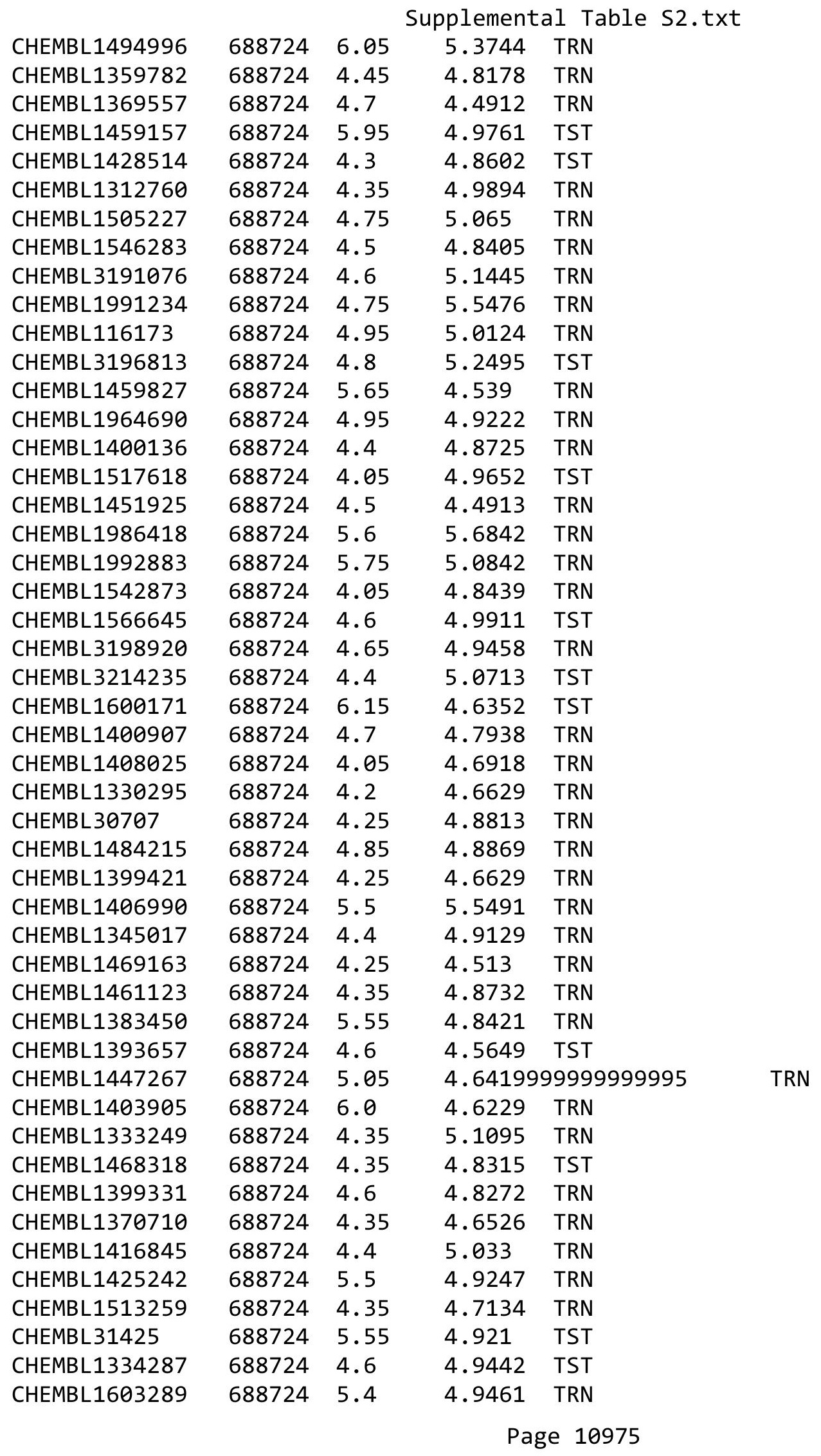




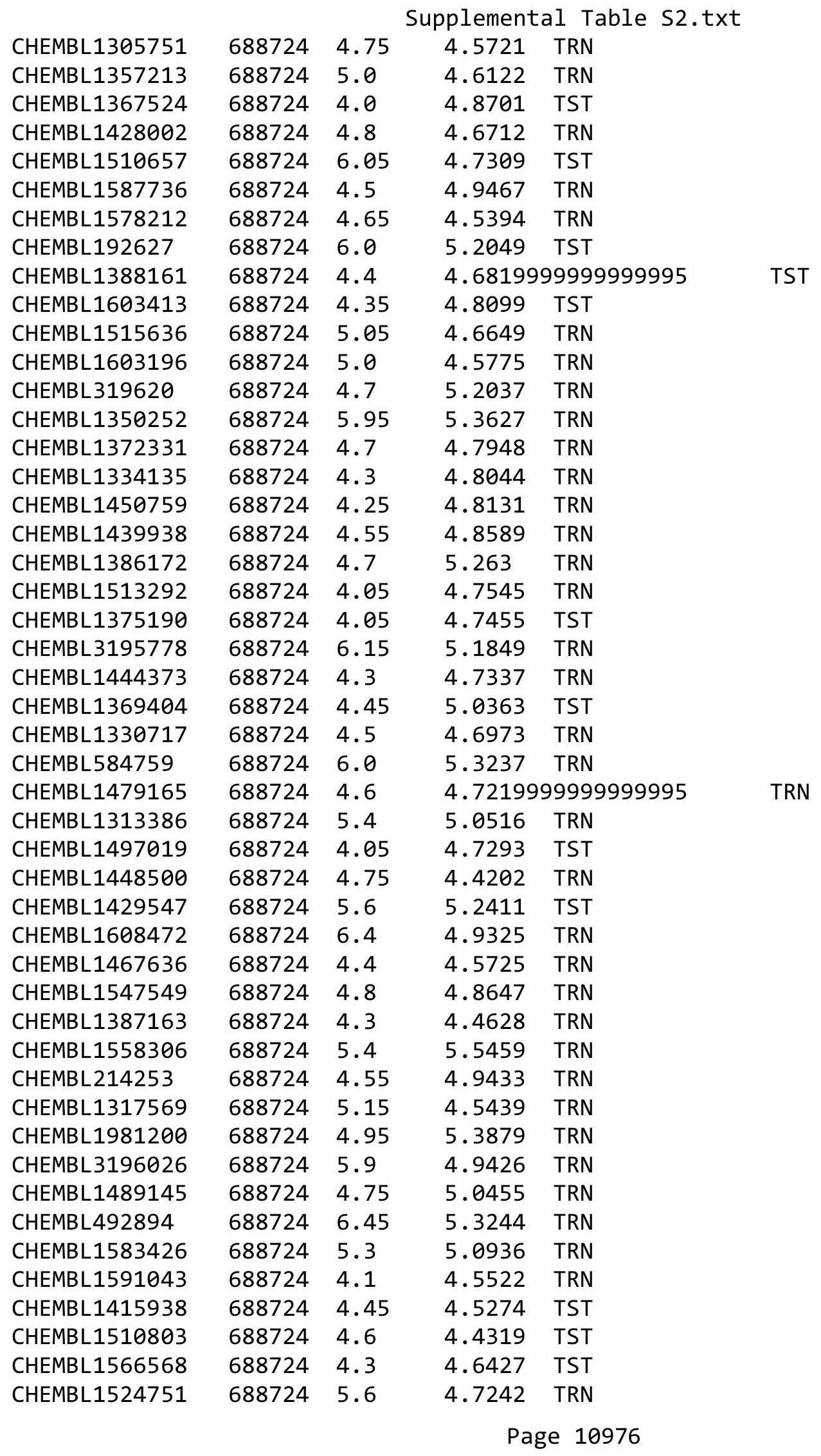




\begin{tabular}{|c|c|c|c|c|c|}
\hline & & \multicolumn{4}{|c|}{ Supplemental Table S2.txt } \\
\hline CHEMBL1368602 & 688724 & 4.35 & 4.885 & TST & \\
\hline CHEMBL1446458 & 688724 & 4.8 & 4.6684 & TRN & \\
\hline CHEMBL1422078 & 688724 & 5.15 & 5.8974 & TRN & \\
\hline CHEMBL1327091 & 688724 & 5.15 & 4.6933 & TRN & \\
\hline CHEMBL1556971 & 688724 & 4.25 & 4.6637 & TRN & \\
\hline CHEMBL1566512 & 688724 & 4.35 & 5.1497 & TRN & \\
\hline CHEMBL1565972 & 688724 & 4.7 & 4.5453 & TRN & \\
\hline CHEMBL1548136 & 688724 & 4.05 & 4.7468 & TRN & \\
\hline CHEMBL1569088 & 688724 & 5.0 & 4.8543 & TST & \\
\hline CHEMBL1584523 & 688724 & 4.75 & 4.8267 & TRN & \\
\hline CHEMBL3209579 & 688724 & 4.7 & 4.4746 & TRN & \\
\hline CHEMBL1530810 & 688724 & 5.1 & 4.9739 & TRN & \\
\hline CHEMBL1531487 & 688724 & 4.05 & 5.027 & TRN & \\
\hline CHEMBL1491726 & 688724 & 4.35 & 4.6186 & TST & \\
\hline CHEMBL1574271 & 688724 & 5.2 & 4.8573 & TRN & \\
\hline CHEMBL1384964 & 688724 & 4.4 & 4.4132 & TST & \\
\hline CHEMBL1408111 & 688724 & 4.9 & 5.002 & TRN & \\
\hline CHEMBL1371683 & 688724 & 4.9 & 4.8669 & TST & \\
\hline CHEMBL1515123 & 688724 & 4.55 & 4.5251 & TST & \\
\hline CHEMBL1460722 & 688724 & 4.45 & 4.7602 & TRN & \\
\hline CHEMBL1567423 & 688724 & 4.0 & 4.4463 & TST & \\
\hline CHEMBL189438 & 688724 & 8.699 & 5.1407 & TRN & \\
\hline CHEMBL1309890 & 688724 & 6.0 & 5.5986 & TRN & \\
\hline CHEMBL1561952 & 688724 & 6.25 & 5.0296 & TRN & \\
\hline CHEMBL3192053 & 688724 & 5.6 & 4.7338 & TST & \\
\hline CHEMBL3193808 & 688724 & 4.65 & 4.6414 & TST & \\
\hline CHEMBL1506730 & 688724 & 4.7 & 4.8888 & TRN & \\
\hline CHEMBL1565328 & 688724 & 4.85 & 4.9323 & TRN & \\
\hline CHEMBL1411001 & 688724 & 4.85 & 4.6203 & TST & \\
\hline CHEMBL1539050 & 688724 & 4.55 & 5.0295 & TRN & \\
\hline CHEMBL1991815 & 688724 & 4.85 & 5.0075 & TRN & \\
\hline CHEMBL1435542 & 688724 & 4.25 & 4.9436 & TST & \\
\hline CHEMBL1388399 & 688724 & 5.05 & 4.7588 & TRN & \\
\hline CHEMBL1413988 & 688724 & 4.4 & 4.5856 & TRN & \\
\hline CHEMBL1327717 & 688724 & 4.85 & 4.5757 & TRN & \\
\hline CHEMBL3191714 & 688724 & 5.55 & 5.4762 & TRN & \\
\hline CHEMBL 3213083 & 688724 & 4.2 & 4.6610 & 00000000005 & TRN \\
\hline CHEMBL3199571 & 688724 & 4.75 & 4.6252 & TST & \\
\hline CHEMBL1437954 & 688724 & 4.75 & 4.6034 & TRN & \\
\hline CHEMBL1505180 & 688724 & 4.15 & 4.8221 & TST & \\
\hline CHEMBL1420945 & 688724 & 4.85 & 4.9359 & TRN & \\
\hline CHEMBL1412039 & 688724 & 4.8 & 4.6976 & TST & \\
\hline CHEMBL1609880 & 688724 & 4.2 & 4.5577 & TRN & \\
\hline CHEMBL1540616 & 688724 & 4.4 & 4.9460 & 0000000001 & TST \\
\hline CHEMBL1531919 & 688724 & 5.3 & 4.2583 & TRN & \\
\hline CHEMBL1371132 & 688724 & 4.75 & 4.2735 & TRN & \\
\hline CHEMBL3199733 & 688724 & 4.8 & 4.8874 & TRN & \\
\hline CHEMBL1576118 & 688724 & 4.6 & 5.0083 & TST & \\
\hline
\end{tabular}




\begin{tabular}{|c|c|c|c|c|c|}
\hline \\
\hline CHEMBL1314077 & 688724 & 6.0 & 4.9645 & TRN & \\
\hline CHEMBL1406513 & 688724 & 4.2 & 5.0734 & TRN & \\
\hline CHEMBL1606122 & 688724 & 4.75 & 4.8935 & TRN & \\
\hline CHEMBL1896972 & 688724 & 4.8 & 4.8051 & TRN & \\
\hline CHEMBL1366263 & 688724 & 4.65 & 4.7318 & TRN & \\
\hline CHEMBL1501642 & 688724 & 5.7 & 4.7138 & TST & \\
\hline CHEMBL1327596 & 688724 & 5.0 & 5.1515 & TRN & \\
\hline CHEMBL1413069 & 688724 & 4.4 & 4.6698 & TRN & \\
\hline CHEMBL1581032 & 688724 & 4.2 & 4.7217 & TST & \\
\hline CHEMBL1414766 & 688724 & 4.7 & 4.942 & TRN & \\
\hline CHEMBL1322012 & 688724 & 4.0 & 4.8061 & TST & \\
\hline CHEMBL1439480 & 688724 & 4.75 & 4.7625 & TRN & \\
\hline CHEMBL1300675 & 688724 & 4.8 & 4.948 & TST & \\
\hline CHEMBL1456550 & 688724 & 4.3 & 4.7707 & TRN & \\
\hline CHEMBL1348165 & 688724 & 6.05 & 4.4679 & TRN & \\
\hline CHEMBL1530826 & 688724 & 4.35 & 4.8122 & TRN & \\
\hline CHEMBL1577764 & 688724 & 4.4 & 4.3994 & TRN & \\
\hline CHEMBL336296 & 688724 & 4.4 & 4.9819 & TST & \\
\hline CHEMBL1360011 & 688724 & 5.4 & 5.0196 & TRN & \\
\hline CHEMBL1377547 & 688724 & 5.4 & 4.5682 & TST & \\
\hline CHEMBL1310290 & 688724 & 4.75 & 4.6149 & TRN & \\
\hline CHEMBL1300042 & 688724 & 4.45 & 4.3823 & TRN & \\
\hline CHEMBL1325137 & 688724 & 5.45 & 4.6625 & TRN & \\
\hline CHEMBL1337277 & 688724 & 4.7 & 4.2975 & TRN & \\
\hline CHEMBL1371528 & 688724 & 5.3 & 5.4049 & TRN & \\
\hline CHEMBL3197024 & 688724 & 5.45 & 5.3938 & TRN & \\
\hline CHEMBL1391810 & 688724 & 4.95 & 5.2736 & TRN & \\
\hline CHEMBL1482023 & 688724 & 4.75 & 4.6265 & TRN & \\
\hline CHEMBL1448700 & 688724 & 4.5 & 4.4992 & TST & \\
\hline CHEMBL602150 & 688724 & 4.85 & 4.8914 & TRN & \\
\hline CHEMBL1520323 & 688724 & 4.45 & 4.8771 & TRN & \\
\hline CHEMBL1376492 & 688724 & 5.0 & 4.7097 & TST & \\
\hline CHEMBL1555946 & 688724 & 4.55 & 4.1052 & TRN & \\
\hline CHEMBL 3194816 & 688724 & 4.45 & 5.00899 & 99999999995 & TRN \\
\hline CHEMBL1385027 & 688724 & 4.65 & 4.6531 & TRN & \\
\hline CHEMBL1359561 & 688724 & 4.35 & 5.0592 & TST & \\
\hline CHEMBL1352751 & 688724 & 4.0 & 4.9211 & TST & \\
\hline CHEMBL1511025 & 688724 & 4.6 & 4.8988 & TRN & \\
\hline CHEMBL1569878 & 688724 & 4.3 & 4.3794 & TRN & \\
\hline CHEMBL1457241 & 688724 & 4.65 & 4.4719 & TRN & \\
\hline CHEMBL1361054 & 688724 & 6.35 & 5.9753 & TRN & \\
\hline CHEMBL1431536 & 688724 & 4.85 & 4.5846 & TRN & \\
\hline CHEMBL3208389 & 688724 & 5.25 & 4.7548 & TRN & \\
\hline CHEMBL1492376 & 688724 & 4.65 & 5.0529 & TRN & \\
\hline CHEMBL1611155 & 688724 & 4.45 & 4.4075 & TRN & \\
\hline CHEMBL1366319 & 688724 & 4.05 & 5.1161 & TRN & \\
\hline CHEMBL1516787 & 688724 & 4.45 & 4.72199 & 99999999995 & TRN \\
\hline CHEMBL1533888 & 688724 & 4.7 & 4.4497 & TRN & \\
\hline
\end{tabular}




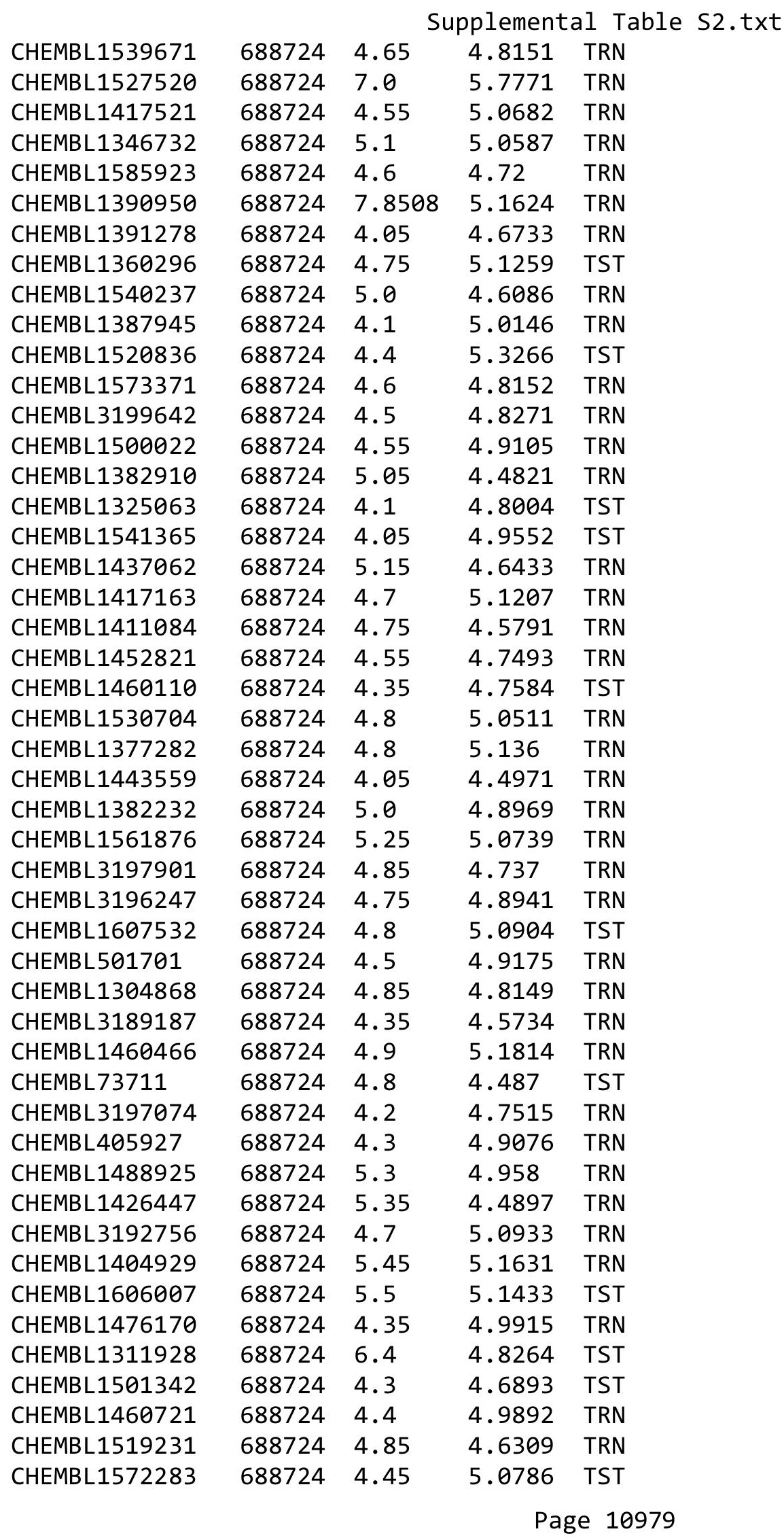




\begin{tabular}{|c|c|c|c|c|c|c|}
\hline & & \multicolumn{5}{|c|}{ Supplemental Table s2.txt } \\
\hline CHEMBL1559826 & 688724 & 4.15 & 5.27 & TST & & \\
\hline CHEMBL1562 & 688724 & 8.0506 & 5.1674 & TRN & & \\
\hline CHEMBL1552259 & 688724 & 4.05 & 4.5462 & TRN & & \\
\hline CHEMBL1377266 & 688724 & 4.6 & 5.0078 & TST & & \\
\hline CHEMBL280074 & 688724 & 7.0501 & 4.8387 & TRN & & \\
\hline CHEMBL1347712 & 688724 & 4.4 & 4.6639 & TRN & & \\
\hline CHEMBL1525888 & 688724 & 5.7 & 5.0573 & TRN & & \\
\hline CHEMBL1370873 & 688724 & 5.35 & 4.5441 & TRN & & \\
\hline CHEMBL1544873 & 688724 & 5.35 & 4.7012 & TRN & & \\
\hline CHEMBL3209799 & 688724 & 5.0 & 4.7906 & TST & & \\
\hline CHEMBL1559476 & 688724 & 4.5 & 4.5091 & TRN & & \\
\hline CHEMBL3209451 & 688724 & 5.7 & 5.1011 & TRN & & \\
\hline CHEMBL1493210 & 688724 & 4.15 & 4.5704 & TRN & & \\
\hline CHEMBL1547450 & 688724 & 5.45 & 4.8851 & TRN & & \\
\hline CHEMBL3196386 & 688724 & 4.9 & 4.8938 & TST & & \\
\hline CHEMBL3198485 & 688724 & 7.0501 & 5.1784 & TRN & & \\
\hline CHEMBL1969851 & 688724 & 4.4 & 4.8143 & TRN & & \\
\hline CHEMBL1585845 & 688724 & 4.35 & 4.4695 & TRN & & \\
\hline CHEMBL67378 & 688724 & 5.35 & 4.8196 & TST & & \\
\hline CHEMBL1430854 & 688724 & 6.7501 & 5.2772 & TST & & \\
\hline CHEMBL1533889 & 688724 & 5.1 & 4.9931 & TRN & & \\
\hline CHEMBL1485503 & 688724 & 4.6 & 5.118 & TRN & & \\
\hline CHEMBL1333512 & 688724 & \multicolumn{3}{|c|}{5.462999999999999} & 4.7509 & TRN \\
\hline CHEMBL1501026 & 688724 & 4.6 & 4.705 & TRN & & \\
\hline CHEMBL1517910 & 688724 & 5.0 & 4.5509 & TRN & & \\
\hline CHEMBL1511693 & 688724 & 4.65 & 4.6824 & TRN & & \\
\hline CHEMBL1579746 & 688724 & 4.05 & 4.3868 & TRN & & \\
\hline CHEMBL572994 & 688724 & 5.75 & 5.0529 & TST & & \\
\hline CHEMBL 1976046 & 688724 & 4.45 & 4.5596 & TST & & \\
\hline CHEMBL1493700 & 688724 & 4.7 & 4.7004 & TRN & & \\
\hline CHEMBL1447002 & 688724 & 6.0 & 5.0379 & TRN & & \\
\hline CHEMBL1482621 & 688724 & 5.05 & 4.7168 & TRN & & \\
\hline CHEMBL1568277 & 688724 & 5.2 & 5.2004 & TRN & & \\
\hline CHEMBL1423284 & 688724 & 4.3 & 4.7064 & TRN & & \\
\hline CHEMBL1440636 & 688724 & 6.3 & 5.3933 & TRN & & \\
\hline CHEMBL1256693 & 688724 & 4.25 & 5.0066 & TRN & & \\
\hline CHEMBL1407935 & 688724 & 4.9 & 4.8793 & TST & & \\
\hline CHEMBL428495 & 688724 & 5.0 & 4.7238 & TRN & & \\
\hline CHEMBL1987173 & 688724 & 4.65 & 5.0698 & TRN & & \\
\hline CHEMBL1422591 & 688724 & 4.2 & 4.8087 & TST & & \\
\hline CHEMBL1376201 & 688724 & 6.4 & 4.7982 & TRN & & \\
\hline CHEMBL1575588 & 688724 & 4.75 & 5.0596 & TST & & \\
\hline CHEMBL1424300 & 688724 & 4.4 & 4.8011 & TST & & \\
\hline CHEMBL1426340 & 688724 & 6.4 & 5.9248 & TRN & & \\
\hline CHEMBL1332013 & 688724 & 4.75 & 5.2379 & TRN & & \\
\hline CHEMBL1394518 & 688724 & 5.55 & 4.7366 & TRN & & \\
\hline CHEMBL1339026 & 688724 & 4.6 & 4.9816 & TRN & & \\
\hline CHEMBL1516565 & 688724 & 4.1 & 4.4287 & TRN & & \\
\hline
\end{tabular}




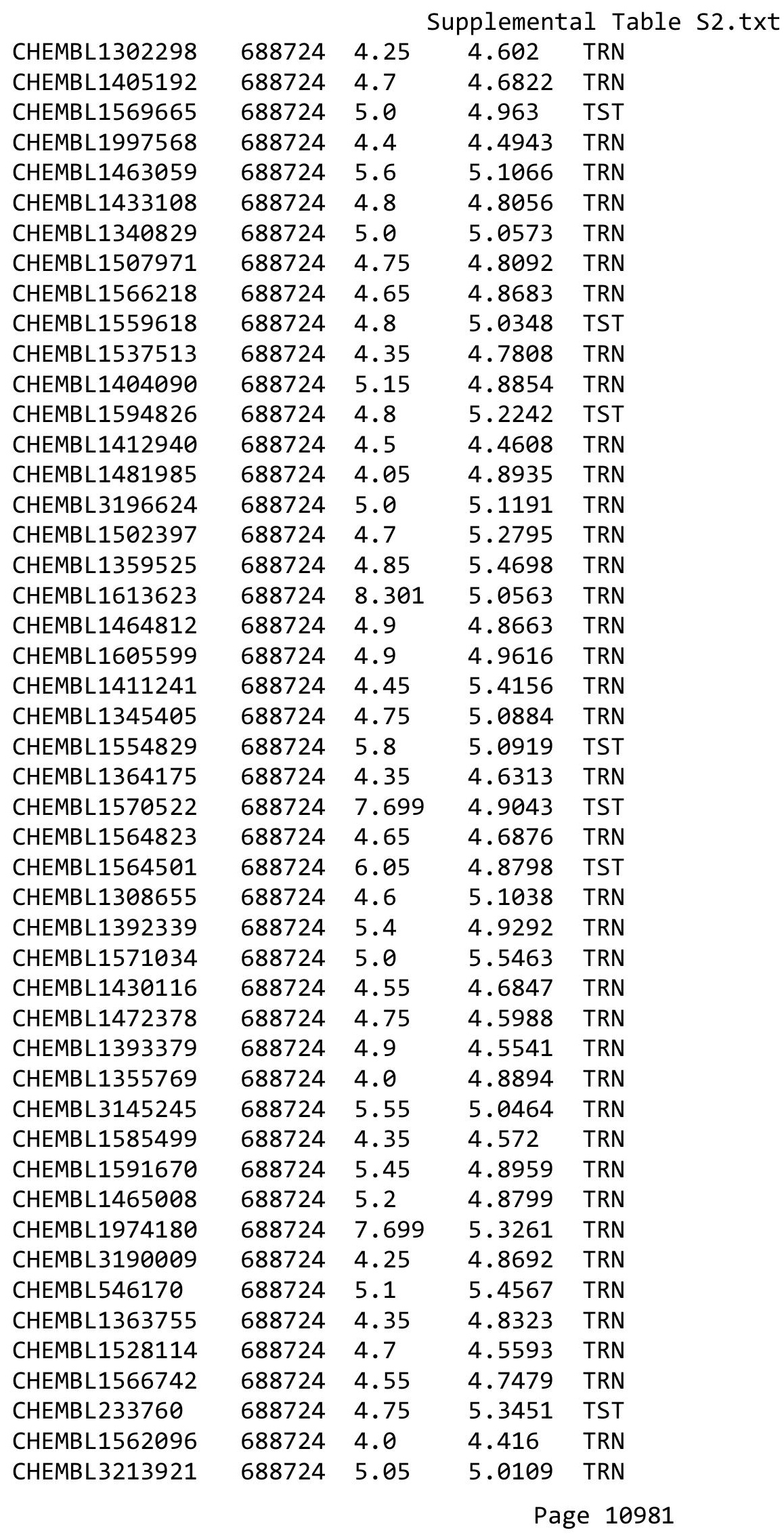




\begin{tabular}{|c|c|c|c|c|c|}
\hline & & \multicolumn{4}{|c|}{ Supplemental Table S2.txt } \\
\hline CHEMBL1413246 & 688724 & 4.65 & 4.6799 & TRN & \\
\hline CHEMBL1429107 & 688724 & 4.05 & 4.5698 & TRN & \\
\hline CHEMBL1513890 & 688724 & 4.6 & 4.7668 & TRN & \\
\hline CHEMBL1504887 & 688724 & 4.25 & 4.47199 & 99999999995 & TST \\
\hline CHEMBL1518604 & 688724 & 4.75 & 4.5389 & TRN & \\
\hline CHEMBL1374174 & 688724 & 4.25 & 4.7521 & TRN & \\
\hline CHEMBL1397794 & 688724 & 4.4 & 4.8636 & TRN & \\
\hline CHEMBL1476362 & 688724 & 6.25 & 5.0312 & TST & \\
\hline CHEMBL1427078 & 688724 & 5.95 & 5.1128 & TRN & \\
\hline CHEMBL1596507 & 688724 & 4.7 & 5.3508 & TRN & \\
\hline CHEMBL1465461 & 688724 & 4.5 & 4.6116 & TRN & \\
\hline CHEMBL1586807 & 688724 & 4.6 & 4.6616 & TRN & \\
\hline CHEMBL1255659 & 688724 & 4.75 & 4.7981 & TRN & \\
\hline CHEMBL1329881 & 688724 & 4.4 & 5.2569 & TST & \\
\hline CHEMBL3211859 & 688724 & 5.15 & 5.2826 & TRN & \\
\hline CHEMBL1338491 & 688724 & 5.6 & 5.0217 & TRN & \\
\hline CHEMBL1527725 & 688724 & 5.45 & 4.9071 & TST & \\
\hline CHEMBL1439593 & 688724 & 4.7 & 4.494 & TST & \\
\hline CHEMBL1519634 & 688724 & 4.8 & 4.9605 & TRN & \\
\hline CHEMBL1554507 & 688724 & 4.8 & 5.4105 & TRN & \\
\hline CHEMBL1341078 & 688724 & 4.95 & 4.4274 & TRN & \\
\hline CHEMBL3208992 & 688724 & 4.95 & 4.9433 & TST & \\
\hline CHEMBL1346289 & 688724 & 6.4 & 4.5401 & TST & \\
\hline CHEMBL1565977 & 688724 & 5.3 & 4.8107 & TRN & \\
\hline CHEMBL490577 & 688724 & 6.25 & 5.5195 & TRN & \\
\hline CHEMBL1590450 & 688724 & 5.25 & 4.6164 & TRN & \\
\hline CHEMBL1356271 & 688724 & 4.45 & 4.9292 & TRN & \\
\hline CHEMBL1409597 & 688724 & 4.4 & 4.4772 & TST & \\
\hline CHEMBL1518926 & 688724 & 4.0 & 4.7319 & TST & \\
\hline CHEMBL1384345 & 688724 & 4.05 & 4.8999 & TRN & \\
\hline CHEMBL1342158 & 688724 & 4.8 & 4.5806 & TRN & \\
\hline CHEMBL3196767 & 688724 & 4.35 & 5.0754 & TRN & \\
\hline CHEMBL1404841 & 688724 & 4.8 & 4.8726 & TRN & \\
\hline CHEMBL1349987 & 688724 & 4.8 & 4.5415 & TRN & \\
\hline CHEMBL455284 & 688724 & 6.3 & 5.5616 & TRN & \\
\hline CHEMBL1372470 & 688724 & 4.9 & 4.816 & TRN & \\
\hline CHEMBL2001337 & 688724 & 4.8 & 4.4047 & TRN & \\
\hline CHEMBL1452949 & 688724 & 4.4 & 4.7087 & TRN & \\
\hline CHEMBL1495485 & 688724 & 4.35 & 5.0267 & TST & \\
\hline CHEMBL1521453 & 688724 & 4.55 & 5.1668 & TST & \\
\hline CHEMBL 3190433 & 688724 & 4.9 & 5.2899 & TRN & \\
\hline CHEMBL1299763 & 688724 & 4.7 & 5.3248 & TRN & \\
\hline CHEMBL3191141 & 688724 & 4.45 & 5.357 & TRN & \\
\hline CHEMBL1411009 & 688724 & 4.4 & 4.8175 & TRN & \\
\hline CHEMBL1416130 & 688724 & 4.0 & 4.917 & TRN & \\
\hline CHEMBL1506332 & 688724 & 4.55 & 4.7739 & TST & \\
\hline CHEMBL1595582 & 688724 & 4.0 & 4.9497 & TRN & \\
\hline CHEMBL1518920 & 688724 & 4.35 & 4.7677 & TRN & \\
\hline
\end{tabular}




\begin{tabular}{|c|c|c|c|c|c|}
\hline & & & & & \\
\hline CHEMBL150 & 688724 & 5.7 & 5.5375 & TRN & \\
\hline CHEMBL1553879 & 688724 & 5.4 & 4.7337 & TRN & \\
\hline CHEMBL1299528 & 688724 & 6.0 & 4.9241 & TST & \\
\hline CHEMBL1307683 & 688724 & 4.1 & 4.8403 & TST & \\
\hline CHEMBL 2007403 & 688724 & 4.55 & 5.0484 & TRN & \\
\hline CHEMBL1981570 & 688724 & 4.9 & 5.2067 & TRN & \\
\hline CHEMBL1544683 & 688724 & 5.1 & 4.7897 & TST & \\
\hline CHEMBL445332 & 688724 & 6.0 & $5.1770 e$ & 00000000005 & TRN \\
\hline CHEMBL1597561 & 688724 & 5.25 & 4.3933 & TRN & \\
\hline CHEMBL1331705 & 688724 & 4.0 & 4.7253 & TRN & \\
\hline CHEMBL1496698 & 688724 & 4.2 & 4.5602 & TRN & \\
\hline CHEMBL1552731 & 688724 & 5.25 & 4.8719 & TST & \\
\hline CHEMBL1572884 & 688724 & 5.15 & 4.8628 & TRN & \\
\hline CHEMBL1576224 & 688724 & 5.05 & 4.7393 & TRN & \\
\hline CHEMBL1572952 & 688724 & 4.55 & 5.1654 & TST & \\
\hline CHEMBL1486877 & 688724 & 4.5 & 4.6343 & TRN & \\
\hline CHEMBL1387194 & 688724 & 4.3 & 4.8329 & TRN & \\
\hline CHEMBL1609454 & 688724 & 4.85 & 5.0141 & TRN & \\
\hline CHEMBL160145 & 688724 & 4.4 & 4.6706 & TST & \\
\hline CHEMBL1563317 & 688724 & 5.3 & 5.0286 & TRN & \\
\hline CHEMBL1455547 & 688724 & 4.5 & 4.8503 & TST & \\
\hline CHEMBL1373461 & 688724 & 4.7 & 4.9163 & TRN & \\
\hline CHEMBL167316 & 688724 & 5.5 & 4.8478 & TRN & \\
\hline CHEMBL 3190508 & 688724 & 4.6 & 4.6784 & TRN & \\
\hline CHEMBL1569472 & 688724 & 4.25 & 4.8553 & TST & \\
\hline CHEMBL1303429 & 688724 & 5.55 & 5.034 & TST & \\
\hline CHEMBL1524862 & 688724 & 4.05 & 4.572 & TRN & \\
\hline CHEMBL1413655 & 688724 & 4.85 & 4.7931 & TST & \\
\hline CHEMBL1550554 & 688724 & 4.35 & 4.6533 & TRN & \\
\hline CHEMBL1374867 & 688724 & 4.55 & 4.7832 & TST & \\
\hline CHEMBL1585844 & 688724 & 4.4 & 5.0742 & TST & \\
\hline CHEMBL164 & 688724 & 6.0 & 5.9329 & TRN & \\
\hline CHEMBL1438182 & 688724 & 5.15 & 4.8674 & TRN & \\
\hline CHEMBL1381478 & 688724 & 5.05 & 5.315 & TRN & \\
\hline CHEMBL403419 & 688724 & 4.55 & 4.9235 & TRN & \\
\hline CHEMBL1382827 & 688724 & 5.75 & 5.2857 & TRN & \\
\hline CHEMBL1522852 & 688724 & 4.3 & 4.6743 & TRN & \\
\hline CHEMBL1402110 & 688724 & 4.4 & 5.0356 & TRN & \\
\hline CHEMBL1550336 & 688724 & 4.75 & 4.7193 & TRN & \\
\hline CHEMBL1367518 & 688724 & 4.45 & 4.8688 & TRN & \\
\hline CHEMBL1530375 & 688724 & 4.25 & 4.5887 & TRN & \\
\hline CHEMBL1362961 & 688724 & 4.8 & 4.4657 & TRN & \\
\hline CHEMBL1585318 & 688724 & 4.5 & 4.7378 & TST & \\
\hline CHEMBL1366888 & 688724 & 6.2 & 4.6932 & TST & \\
\hline CHEMBL1613149 & 688724 & 4.5 & 4.2691 & TRN & \\
\hline CHEMBL1346883 & 688724 & 4.85 & 4.5509 & TRN & \\
\hline CHEMBL1529749 & 688724 & 4.65 & 4.8425 & TRN & \\
\hline CHEMBL1558760 & 688724 & 5.5 & 5.0055 & TRN & \\
\hline & & & & 10983 & \\
\hline
\end{tabular}




\begin{tabular}{|c|c|c|c|c|}
\hline \multicolumn{5}{|c|}{ Supplemental Table S2.txt } \\
\hline CHEMBL1516859 & 688724 & 4.9 & 5.151 & TST \\
\hline CHEMBL1449526 & 688724 & 5.15 & 5.225 & TRN \\
\hline CHEMBL1596785 & 688724 & 4.05 & 4.9612 & TRN \\
\hline CHEMBL2311908 & 688724 & 5.5 & 4.9287 & TRN \\
\hline CHEMBL1403127 & 688724 & 4.35 & 5.1544 & TRN \\
\hline CHEMBL1304189 & 688724 & 4.65 & 4.6885 & TRN \\
\hline CHEMBL1495849 & 688724 & 5.6 & 5.0425 & TRN \\
\hline CHEMBL1270169 & 688724 & 4.8 & 4.8977 & TST \\
\hline CHEMBL1610409 & 688724 & 4.35 & 4.4335 & TST \\
\hline CHEMBL1541852 & 688724 & 5.7 & 5.0909 & TRN \\
\hline CHEMBL1405482 & 688724 & 4.45 & 5.1164 & TST \\
\hline CHEMBL1982539 & 688724 & 6.4 & 4.9717 & TRN \\
\hline CHEMBL1560906 & 688724 & 4.6 & 4.6014 & TRN \\
\hline CHEMBL3196823 & 688724 & 4.75 & 5.1649 & TRN \\
\hline CHEMBL333298 & 688724 & 4.7 & 5.3043 & TST \\
\hline CHEMBL1400412 & 688724 & 5.2 & 4.819 & TRN \\
\hline CHEMBL1506125 & 688724 & 4.05 & 4.6968 & TST \\
\hline CHEMBL3195375 & 688724 & 4.85 & 4.8695 & TRN \\
\hline CHEMBL1556907 & 688724 & 4.5 & 5.3036 & TRN \\
\hline CHEMBL1353554 & 688724 & 4.35 & 5.1717 & TST \\
\hline CHEMBL1358599 & 688724 & 4.05 & 4.7211 & TST \\
\hline CHEMBL1410381 & 688724 & 5.45 & 5.5974 & TRN \\
\hline CHEMBL1284 & 688724 & 4.65 & 5.5281 & TRN \\
\hline CHEMBL1588544 & 688724 & 4.6 & 4.8326 & TRN \\
\hline CHEMBL1564110 & 688724 & 4.5 & 4.4179 & TRN \\
\hline CHEMBL3216654 & 688724 & 4.4 & 5.0325 & TRN \\
\hline CHEMBL1479621 & 688724 & 4.7 & 4.3915 & TST \\
\hline CHEMBL1391750 & 688724 & 4.3 & 4.6117 & TRN \\
\hline CHEMBL1438684 & 688724 & 6.2 & 4.7573 & TRN \\
\hline CHEMBL1583133 & 688724 & 4.0 & 4.5215 & TRN \\
\hline CHEMBL1606763 & 688724 & 4.85 & 4.6522 & TST \\
\hline CHEMBL1344618 & 688724 & 4.7 & 5.2226 & TRN \\
\hline CHEMBL1548928 & 688724 & 4.4 & 4.9635 & TRN \\
\hline CHEMBL1502254 & 688724 & 4.9 & 4.4792 & TRN \\
\hline CHEMBL1536850 & 688724 & 4.45 & 4.8504 & TRN \\
\hline CHEMBL1393460 & 688724 & 4.25 & 4.668 & TRN \\
\hline CHEMBL3195749 & 688724 & 6.2 & 5.2359 & TRN \\
\hline CHEMBL1388851 & 688724 & 6.1 & 4.9091 & TST \\
\hline CHEMBL1465659 & 688724 & 4.3 & 4.5935 & TRN \\
\hline CHEMBL1407952 & 688724 & 5.65 & 5.6767 & TRN \\
\hline CHEMBL1409337 & 688724 & 4.65 & 4.6443 & TST \\
\hline CHEMBL1436357 & 688724 & 5.5 & 4.6036 & TRN \\
\hline CHEMBL1591342 & 688724 & 4.85 & 4.3874 & TRN \\
\hline CHEMBL1432160 & 688724 & 4.8 & 4.7805 & TRN \\
\hline CHEMBL1338313 & 688724 & 4.1 & 4.573 & TRN \\
\hline CHEMBL1325813 & 688724 & 4.55 & 4.5978 & TRN \\
\hline CHEMBL 3193785 & 688724 & 4.35 & 4.9354 & TST \\
\hline CHEMBL1359874 & 688724 & 4.55 & 4.7753 & TRN \\
\hline
\end{tabular}




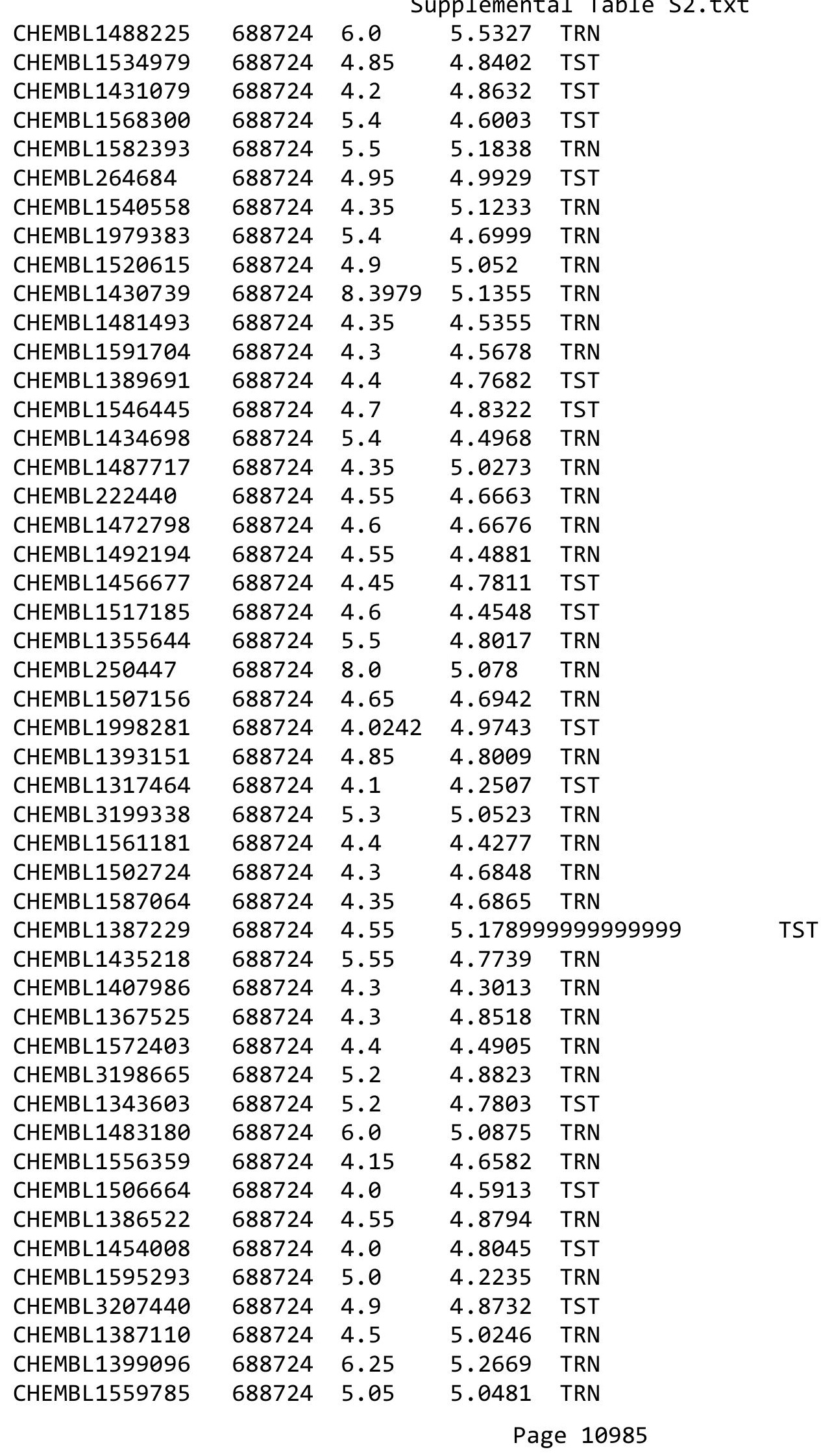




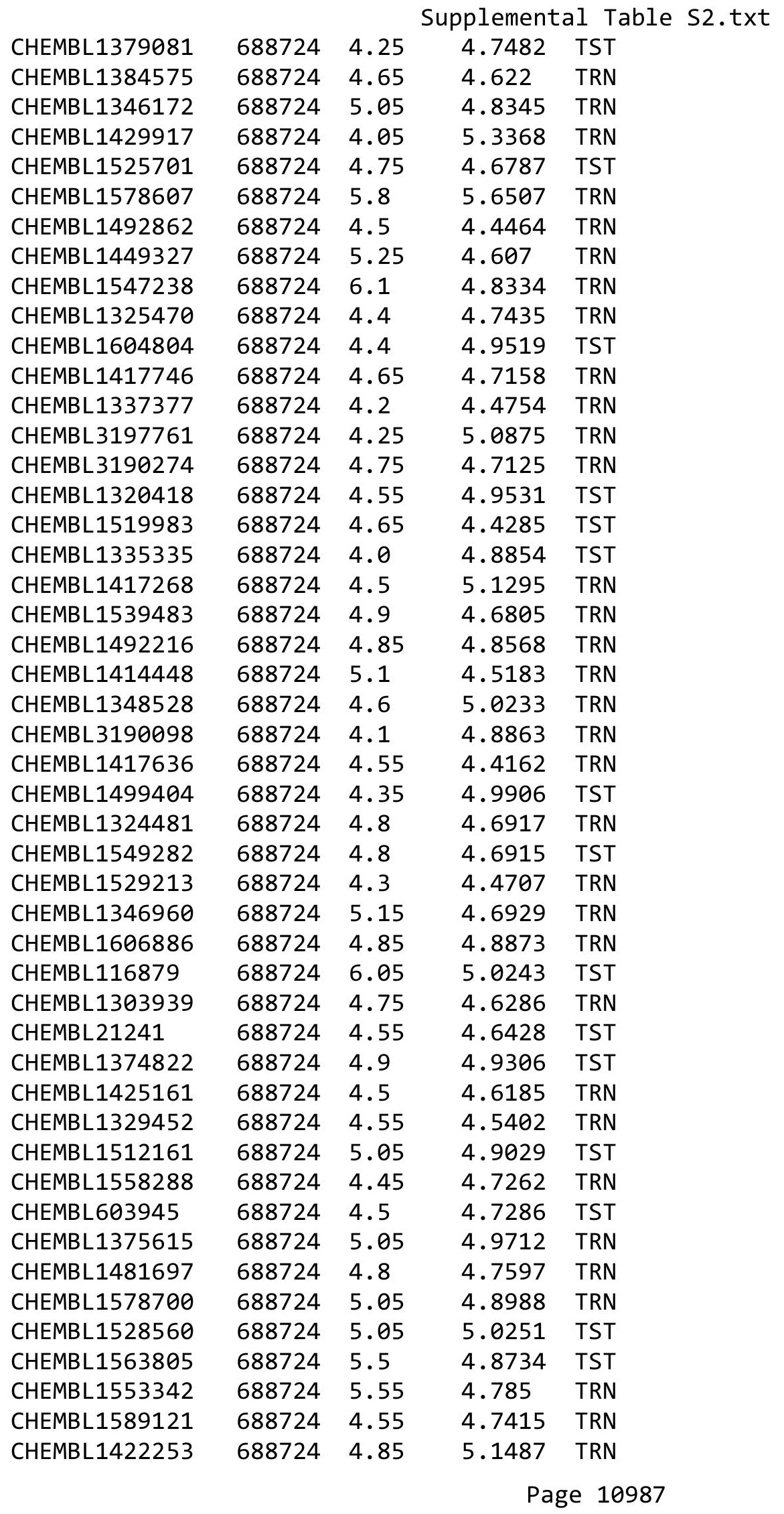




\begin{tabular}{|c|c|c|c|c|c|}
\hline \multicolumn{6}{|c|}{ Supplemental Table S2.txt } \\
\hline CHEMBL1537405 & 688724 & 5.25 & 5.1468 & TRN & \\
\hline CHEMBL1607866 & 688724 & 4.65 & 4.644 & TRN & \\
\hline CHEMBL1500636 & 688724 & 4.2 & 4.5806 & TRN & \\
\hline CHEMBL1439733 & 688724 & 6.7001 & 4.6746 & TRN & \\
\hline CHEMBL1410741 & 688724 & 4.75 & 4.6182 & TRN & \\
\hline CHEMBL54909 & 688724 & 4.85 & 5.081 & TRN & \\
\hline CHEMBL1360184 & 688724 & 5.15 & 5.3764 & TRN & \\
\hline CHEMBL1611440 & 688724 & 4.6 & 4.8567 & TRN & \\
\hline CHEMBL539947 & 688724 & 6.0 & 5.2406 & TRN & \\
\hline CHEMBL1592185 & 688724 & 5.0 & 4.6044 & TRN & \\
\hline CHEMBL3193098 & 688724 & 7.0 & 5.2708 & TRN & \\
\hline CHEMBL1505061 & 688724 & 4.05 & 5.0183 & TRN & \\
\hline CHEMBL1453572 & 688724 & 5.6 & 5.50799 & 9999999999 & TRN \\
\hline CHEMBL3199469 & 688724 & 4.35 & 5.0941 & TRN & \\
\hline CHEMBL1608598 & 688724 & 4.0 & 4.8719 & TST & \\
\hline CHEMBL1500840 & 688724 & 5.0 & 4.6697 & TRN & \\
\hline CHEMBL1599946 & 688724 & 5.15 & 4.7292 & TRN & \\
\hline CHEMBL 3211140 & 688724 & 4.6 & 4.9898 & TRN & \\
\hline CHEMBL1456811 & 688724 & 5.25 & 4.9079 & TRN & \\
\hline CHEMBL1400070 & 688724 & 4.0 & 4.776 & TST & \\
\hline CHEMBL1487744 & 688724 & 4.25 & 4.6549 & TRN & \\
\hline CHEMBL1436498 & 688724 & 4.3 & 4.7756 & TRN & \\
\hline CHEMBL3194327 & 688724 & 4.6 & 5.3388 & TST & \\
\hline CHEMBL1978364 & 688724 & 5.45 & 4.8899 & TRN & \\
\hline CHEMBL1320746 & 688724 & 4.65 & 4.5388 & TRN & \\
\hline CHEMBL1407197 & 688724 & 5.45 & 4.8324 & TRN & \\
\hline CHEMBL1531750 & 688724 & 5.2 & 5.0979 & TRN & \\
\hline CHEMBL531322 & 688724 & 4.6 & 4.8055 & TRN & \\
\hline CHEMBL1430463 & 688724 & 4.1 & 4.7459 & TRN & \\
\hline CHEMBL1545287 & 688724 & 4.45 & 4.8532 & TRN & \\
\hline CHEMBL1333659 & 688724 & 4.7 & 5.0079 & TRN & \\
\hline CHEMBL3145049 & 688724 & 4.95 & 4.6609 & TRN & \\
\hline CHEMBL1981657 & 688724 & 5.55 & 4.9771 & TST & \\
\hline CHEMBL1311419 & 688724 & 4.45 & 4.496 & TRN & \\
\hline CHEMBL1423049 & 688724 & 5.65 & 4.6378 & TRN & \\
\hline CHEMBL1484061 & 688724 & 5.5 & 4.2634 & TRN & \\
\hline CHEMBL1572853 & 688724 & 5.5 & 5.0026 & TST & \\
\hline CHEMBL87791 & 688724 & 6.0 & 5.067 & TRN & \\
\hline CHEMBL1388036 & 688724 & 4.35 & 4.913 & TST & \\
\hline CHEMBL3210153 & 688724 & 4.5 & 4.8003 & TST & \\
\hline CHEMBL1475032 & 688724 & 4.35 & 4.6996 & TRN & \\
\hline CHEMBL 277525 & 688724 & 7.2503 & 4.5762 & TRN & \\
\hline CHEMBL1305431 & 688724 & 4.1 & 5.0052 & TRN & \\
\hline CHEMBL1348074 & 688724 & 5.45 & 5.0371 & TST & \\
\hline CHEMBL1407551 & 688724 & 5.05 & 4.5577 & TST & \\
\hline CHEMBL1322518 & 688724 & 4.55 & 5.1177 & TST & \\
\hline CHEMBL1486198 & 688724 & 4.7 & 4.8299 & TRN & \\
\hline CHEMBL1358403 & 688724 & 4.75 & 4.7477 & TRN & \\
\hline
\end{tabular}




\begin{tabular}{|c|c|c|c|c|c|}
\hline \multicolumn{6}{|c|}{ Supplemental Table S2.txt } \\
\hline CHEMBL212827 & 688724 & 5.1 & 4.7201 & TRN & \\
\hline CHEMBL1358848 & 688724 & 4.35 & 4.6015 & TRN & \\
\hline CHEMBL1598817 & 688724 & 4.15 & 4.9181 & TRN & \\
\hline CHEMBL1324221 & 688724 & 4.35 & 4.1938 & TRN & \\
\hline CHEMBL1556602 & 688724 & 4.5 & 5.0361 & TST & \\
\hline CHEMBL1533502 & 688724 & 4.6 & 5.0203 & TRN & \\
\hline CHEMBL1607133 & 688724 & 4.35 & 4.6973 & TRN & \\
\hline CHEMBL1085215 & 688724 & 4.45 & 4.7563 & TRN & \\
\hline CHEMBL1383287 & 688724 & 4.4 & 4.6383 & TRN & \\
\hline CHEMBL1612915 & 688724 & 4.05 & 4.1687 & TRN & \\
\hline CHEMBL1607500 & 688724 & 4.5 & 4.5228 & TRN & \\
\hline CHEMBL1973802 & 688724 & 4.75 & $4.6080 e$ & 00000000005 & TRN \\
\hline CHEMBL1501622 & 688724 & 7.0 & 4.7602 & TST & \\
\hline CHEMBL1445039 & 688724 & 4.0 & 5.1704 & TRN & \\
\hline CHEMBL1349474 & 688724 & 4.75 & 4.6424 & TRN & \\
\hline CHEMBL1592592 & 688724 & 4.3 & $4.4910 e$ & 30000000005 & TRN \\
\hline CHEMBL1503386 & 688724 & 4.3 & 5.2032 & TRN & \\
\hline CHEMBL1330656 & 688724 & 4.05 & 4.7121 & TST & \\
\hline CHEMBL1443651 & 688724 & 4.5 & 4.8327 & TRN & \\
\hline CHEMBL1437464 & 688724 & 5.5 & 5.0129 & TRN & \\
\hline CHEMBL1517686 & 688724 & 5.9 & 4.8843 & TST & \\
\hline CHEMBL1375845 & 688724 & 5.7 & 4.7411 & TST & \\
\hline CHEMBL1548062 & 688724 & 4.25 & 4.2903 & TRN & \\
\hline CHEMBL1573799 & 688724 & 5.55 & 5.5274 & TRN & \\
\hline CHEMBL1490692 & 688724 & 5.7 & 5.2112 & TRN & \\
\hline CHEMBL 252994 & 688724 & 4.15 & 4.5594 & TRN & \\
\hline CHEMBL1492760 & 688724 & 4.4 & 5.0785 & TST & \\
\hline CHEMBL1241452 & 688724 & 4.6 & 4.9124 & TRN & \\
\hline CHEMBL1471689 & 688724 & 4.25 & 4.9613 & TST & \\
\hline CHEMBL3191954 & 688724 & 4.45 & 4.8608 & TRN & \\
\hline CHEMBL1314600 & 688724 & 4.25 & 4.7965 & TRN & \\
\hline CHEMBL1384669 & 688724 & 4.25 & 4.7941 & TRN & \\
\hline CHEMBL 7634 & 688724 & 9.0458 & 5.0914 & TST & \\
\hline CHEMBL1401424 & 688724 & 4.65 & 4.9096 & TRN & \\
\hline CHEMBL1300082 & 688724 & 4.0 & 4.9243 & TST & \\
\hline CHEMBL1376754 & 688724 & 5.4 & 4.9999 & TRN & \\
\hline CHEMBL1410367 & 688724 & 6.0 & 4.7681 & TST & \\
\hline CHEMBL1308502 & 688724 & 4.65 & 4.4586 & TST & \\
\hline CHEMBL 275177 & 688724 & 5.55 & 4.931 & TST & \\
\hline CHEMBL1374040 & 688724 & 4.45 & 4.7531 & TRN & \\
\hline CHEMBL1433565 & 688724 & 4.0 & 4.7425 & TRN & \\
\hline CHEMBL1304445 & 688724 & 5.25 & 5.3366 & TRN & \\
\hline CHEMBL1366538 & 688724 & 4.35 & 4.4746 & TST & \\
\hline CHEMBL1413629 & 688724 & 4.3 & 4.6915 & TRN & \\
\hline CHEMBL1502019 & 688724 & 5.4 & 5.064 & TRN & \\
\hline CHEMBL1392551 & 688724 & 6.0 & 5.5721 & TRN & \\
\hline CHEMBL1566067 & 688724 & 5.45 & 5.2938 & TST & \\
\hline CHEMBL1971033 & 688724 & 5.8 & 5.3763 & TRN & \\
\hline
\end{tabular}




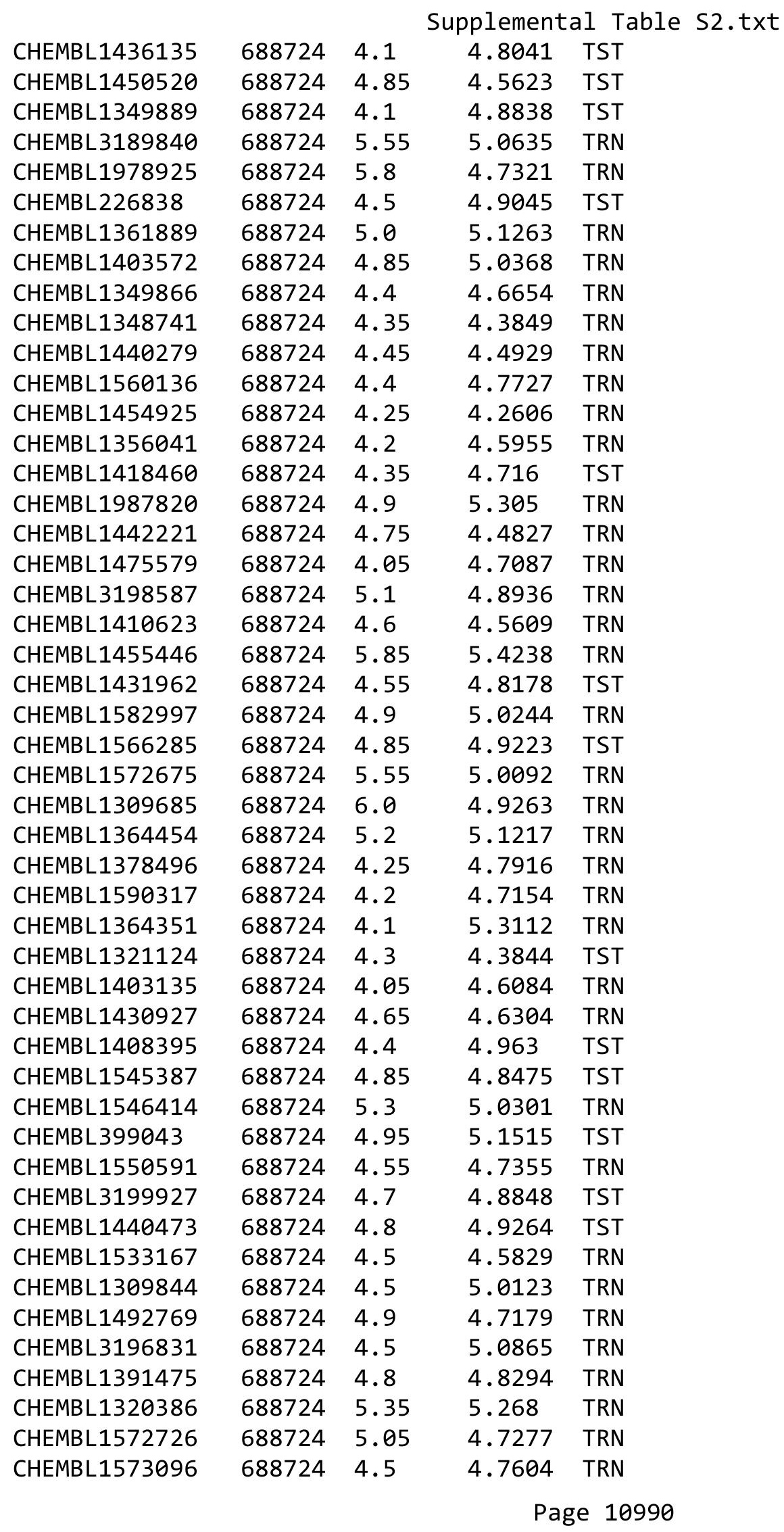




\begin{tabular}{|c|c|c|c|c|}
\hline \multicolumn{5}{|c|}{ Supplemental Table S2.txt } \\
\hline CHEMBL1369517 & 688724 & 4.2 & 4.6688 & TRN \\
\hline CHEMBL 3210363 & 688724 & 4.95 & 4.4968 & TRN \\
\hline CHEMBL 3195202 & 688724 & 4.45 & 4.7393 & TRN \\
\hline CHEMBL1606819 & 688724 & 4.15 & 5.1953 & TST \\
\hline CHEMBL1500982 & 688724 & 4.85 & 5.0168 & TRN \\
\hline CHEMBL1492143 & 688724 & 5.45 & 4.5863 & TRN \\
\hline CHEMBL1572988 & 688724 & 4.05 & 4.3823 & TRN \\
\hline CHEMBL1399767 & 688724 & 4.8 & 4.4192 & TRN \\
\hline CHEMBL1545691 & 688724 & 4.5 & 4.7626 & TST \\
\hline CHEMBL1445219 & 688724 & 4.35 & 4.925 & TST \\
\hline CHEMBL 3145314 & 688724 & 4.75 & 5.1883 & TRN \\
\hline CHEMBL1338655 & 688724 & 4.8 & 4.9156 & TRN \\
\hline CHEMBL1991439 & 688724 & 4.8 & 4.8323 & TRN \\
\hline CHEMBL1496143 & 688724 & 4.95 & 5.2565 & TRN \\
\hline CHEMBL1431346 & 688724 & 5.65 & 4.7551 & TST \\
\hline CHEMBL1329169 & 688724 & 4.4 & 4.9676 & TRN \\
\hline CHEMBL1446166 & 688724 & 4.8 & 4.6021 & TRN \\
\hline CHEMBL1389510 & 688724 & 4.8 & 4.5794 & TST \\
\hline CHEMBL 267373 & 688724 & 6.0 & 4.8197 & TRN \\
\hline CHEMBL1424283 & 688724 & 5.4 & 4.6175 & TST \\
\hline CHEMBL1455437 & 688724 & 4.85 & 4.7646 & TRN \\
\hline CHEMBL1423551 & 688724 & 4.7 & 4.8857 & TRN \\
\hline CHEMBL1377743 & 688724 & 4.7 & 4.5543 & TST \\
\hline CHEMBL1516186 & 688724 & 4.25 & 4.6497 & TRN \\
\hline CHEMBL1553438 & 688724 & 4.3 & 4.8957 & TRN \\
\hline CHEMBL1341804 & 688724 & 6.15 & 4.3685 & TST \\
\hline CHEMBL1526069 & 688724 & 4.55 & 5.164 & TRN \\
\hline CHEMBL1449481 & 688724 & 4.75 & 4.6608 & TRN \\
\hline CHEMBL1507186 & 688724 & 4.5 & 4.8353 & TRN \\
\hline CHEMBL1303261 & 688724 & 5.0 & 4.8734 & TRN \\
\hline CHEMBL1477647 & 688724 & 4.85 & 4.6531 & TST \\
\hline CHEMBL1407040 & 688724 & 5.45 & 5.1287 & TRN \\
\hline CHEMBL1365568 & 688724 & 4.65 & 5.0952 & TRN \\
\hline CHEMBL1423216 & 688724 & 4.75 & 4.7579 & TRN \\
\hline CHEMBL1560181 & 688724 & 4.25 & 5.1166 & TRN \\
\hline CHEMBL1481077 & 688724 & 5.8 & 4.9112 & TRN \\
\hline CHEMBL1332784 & 688724 & 4.5 & 4.9012 & TRN \\
\hline CHEMBL1335738 & 688724 & 5.45 & 5.1412 & TRN \\
\hline CHEMBL1349813 & 688724 & 4.75 & 4.7868 & TRN \\
\hline CHEMBL1426979 & 688724 & 4.05 & 4.4667 & TST \\
\hline CHEMBL1301285 & 688724 & 4.0 & 5.2837 & TST \\
\hline CHEMBL1382785 & 688724 & 5.5 & 4.851 & TRN \\
\hline CHEMBL1514251 & 688724 & 5.55 & 4.5791 & TRN \\
\hline CHEMBL1470721 & 688724 & 5.15 & 4.8261 & TRN \\
\hline CHEMBL1371119 & 688724 & 4.5 & 4.5507 & TRN \\
\hline CHEMBL1443347 & 688724 & 4.95 & 4.8915 & TRN \\
\hline CHEMBL1506499 & 688724 & 4.55 & 4.8979 & TRN \\
\hline CHEMBL1518767 & 688724 & 5.65 & 5.211 & TRN \\
\hline
\end{tabular}




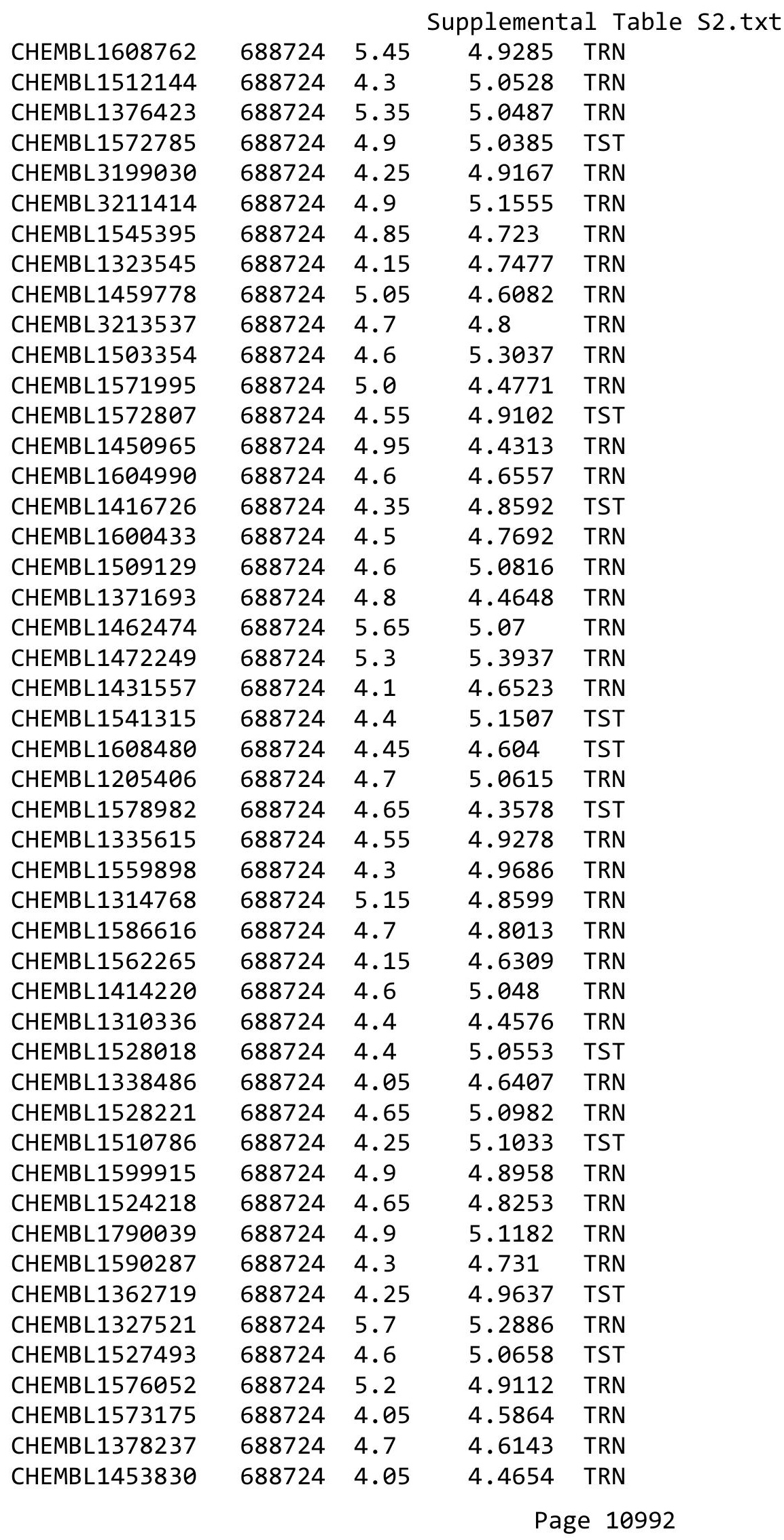




\begin{tabular}{|c|c|c|c|c|c|}
\hline \multicolumn{6}{|c|}{ Supplemental Table S2.txt } \\
\hline CHEMBL1302139 & 688724 & 5.9 & 5.3406 & TRN & \\
\hline CHEMBL1338960 & 688724 & 4.8 & 4.9065 & TRN & \\
\hline CHEMBL1329413 & 688724 & 4.7 & 4.5804 & TRN & \\
\hline CHEMBL1530999 & 688724 & 4.4 & 4.5728 & TST & \\
\hline CHEMBL1330585 & 688724 & 4.8 & 4.5217 & TRN & \\
\hline CHEMBL1457448 & 688724 & 4.45 & 4.9794 & TRN & \\
\hline CHEMBL1591163 & 688724 & 4.45 & 4.5009 & TRN & \\
\hline CHEMBL3392484 & 688724 & 5.3 & 5.0819 & TRN & \\
\hline CHEMBL1310412 & 688724 & 4.35 & 4.8045 & TST & \\
\hline CHEMBL1478852 & 688724 & 4.55 & 5.0063 & TRN & \\
\hline CHEMBL1333619 & 688724 & 4.1 & 4.8074 & TRN & \\
\hline CHEMBL1323873 & 688724 & 4.65 & 4.3217 & TST & \\
\hline CHEMBL1546070 & 688724 & 4.85 & 4.6274 & TST & \\
\hline CHEMBL1392241 & 688724 & 5.55 & 5.0495 & TRN & \\
\hline CHEMBL1323042 & 688724 & 4.85 & 4.8965 & TRN & \\
\hline CHEMBL3193326 & 688724 & 5.05 & 5.3969 & TRN & \\
\hline CHEMBL3392426 & 688724 & 5.45 & 5.0653 & TRN & \\
\hline CHEMBL1434517 & 688724 & 5.05 & 4.7699 & TRN & \\
\hline CHEMBL1351135 & 688724 & 4.25 & 4.8773 & TST & \\
\hline CHEMBL1323335 & 688724 & 4.1 & 4.7457 & TST & \\
\hline CHEMBL1606249 & 688724 & 4.35 & 4.4563 & TST & \\
\hline CHEMBL1468147 & 688724 & 4.9 & 5.0906 & TRN & \\
\hline CHEMBL1373723 & 688724 & 4.45 & 4.8213 & TRN & \\
\hline CHEMBL1317359 & 688724 & 4.5 & 4.4418 & TRN & \\
\hline CHEMBL1390521 & 688724 & 6.3 & $5.5760 e$ & 00000000005 & TRN \\
\hline CHEMBL1555814 & 688724 & 4.6 & 4.7451 & TRN & \\
\hline CHEMBL1571627 & 688724 & 4.1 & 4.7107 & TRN & \\
\hline CHEMBL1571287 & 688724 & 4.55 & 4.6734 & TRN & \\
\hline CHEMBL1595865 & 688724 & 4.2 & 4.7156 & TST & \\
\hline CHEMBL1314545 & 688724 & 4.85 & 4.7347 & TRN & \\
\hline CHEMBL1448770 & 688724 & 4.5 & 4.5505 & TST & \\
\hline CHEMBL1362002 & 688724 & 4.25 & 4.4683 & TRN & \\
\hline CHEMBL1558826 & 688724 & 5.0 & 5.3183 & TRN & \\
\hline CHEMBL1460737 & 688724 & 4.35 & 5.0406 & TRN & \\
\hline CHEMBL1453654 & 688724 & 4.35 & 4.8973 & TRN & \\
\hline CHEMBL1424878 & 688724 & 5.9 & 4.8639 & TRN & \\
\hline CHEMBL1473519 & 688724 & 4.4 & 5.1551 & TRN & \\
\hline CHEMBL1558896 & 688724 & 4.75 & 4.9255 & TRN & \\
\hline CHEMBL1558621 & 688724 & 6.0 & 5.2335 & TST & \\
\hline CHEMBL1302815 & 688724 & 5.85 & 5.4312 & TRN & \\
\hline CHEMBL1352517 & 688724 & 4.05 & 4.499 & TRN & \\
\hline CHEMBL22183 & 688724 & 4.2 & 4.9162 & TST & \\
\hline CHEMBL1411575 & 688724 & 4.95 & 4.9937 & TRN & \\
\hline CHEMBL1558301 & 688724 & 4.65 & 5.096 & TRN & \\
\hline CHEMBL3197135 & 688724 & 4.85 & 5.105 & TST & \\
\hline CHEMBL1527588 & 688724 & 6.05 & 4.8854 & TST & \\
\hline CHEMBL3198193 & 688724 & 4.65 & 4.8335 & TRN & \\
\hline CHEMBL1317441 & 688724 & 7.0 & 4.8812 & TST & \\
\hline
\end{tabular}




\begin{tabular}{|c|c|c|c|c|}
\hline \multicolumn{5}{|c|}{ Supplemental Table S2.txt } \\
\hline CHEMBL1413866 & 688724 & 4.05 & 5.1595 & TRN \\
\hline CHEMBL1462292 & 688724 & 4.05 & 4.6363 & TRN \\
\hline CHEMBL3199716 & 688724 & 4.35 & 4.8717 & TRN \\
\hline CHEMBL1567916 & 688724 & 4.65 & 4.7892 & TRN \\
\hline CHEMBL1597435 & 688724 & 5.35 & 5.2198 & TRN \\
\hline CHEMBL1571320 & 688724 & 4.95 & 4.7856 & TST \\
\hline CHEMBL1375012 & 688724 & 4.3 & 4.6297 & TST \\
\hline CHEMBL1496585 & 688724 & 4.5 & 4.4191 & TST \\
\hline CHEMBL1435267 & 688724 & 4.2 & 4.5875 & TRN \\
\hline CHEMBL1392005 & 688724 & 4.85 & 4.5118 & TRN \\
\hline CHEMBL1521123 & 688724 & 4.2 & 4.4199 & TRN \\
\hline CHEMBL1410477 & 688724 & 4.0 & 4.9164 & TST \\
\hline CHEMBL1503165 & 688724 & 4.5 & 4.4784 & TRN \\
\hline CHEMBL1376309 & 688724 & 4.4 & 4.8851 & TRN \\
\hline CHEMBL1413775 & 688724 & 4.65 & 4.7485 & TRN \\
\hline CHEMBL1437629 & 688724 & 4.05 & 4.9404 & TST \\
\hline CHEMBL3193966 & 688724 & 5.0 & 5.0226 & TST \\
\hline CHEMBL1442354 & 688724 & 4.85 & 4.8854 & TRN \\
\hline CHEMBL1344739 & 688724 & 4.95 & 4.6091 & TRN \\
\hline CHEMBL3199285 & 688724 & 5.15 & 4.4781 & TRN \\
\hline CHEMBL1509526 & 688724 & 4.7 & 5.0103 & TST \\
\hline CHEMBL1583689 & 688724 & 5.3 & 4.7073 & TRN \\
\hline CHEMBL1433062 & 688724 & 5.05 & 4.8991 & TST \\
\hline CHEMBL1314096 & 688724 & 5.25 & 4.9891 & TRN \\
\hline CHEMBL1521137 & 688724 & 4.6 & 4.4707 & TRN \\
\hline CHEMBL1458873 & 688724 & 4.75 & 4.6116 & TRN \\
\hline CHEMBL1551243 & 688724 & 4.65 & 4.4545 & TRN \\
\hline CHEMBL120526 & 688724 & 4.55 & 5.2632 & TRN \\
\hline CHEMBL1517791 & 688724 & 4.4 & 4.8765 & TST \\
\hline CHEMBL3198694 & 688724 & 4.7 & 4.7306 & TST \\
\hline CHEMBL1462667 & 688724 & 5.3 & 4.9154 & TRN \\
\hline CHEMBL1388533 & 688724 & 4.15 & 4.868 & TST \\
\hline CHEMBL1355990 & 688724 & 4.7 & 4.8501 & TRN \\
\hline CHEMBL1979455 & 688724 & 4.25 & 5.1311 & TRN \\
\hline CHEMBL1550984 & 688724 & 4.5 & 4.6943 & TRN \\
\hline CHEMBL3213928 & 688724 & 5.0 & 4.6987 & TRN \\
\hline CHEMBL 1317439 & 688724 & 4.5 & 4.6534 & TRN \\
\hline CHEMBL1462003 & 688724 & 5.15 & 4.4804 & TST \\
\hline CHEMBL3213088 & 688724 & 4.7 & 5.1629 & TRN \\
\hline CHEMBL1562384 & 688724 & 4.8 & 4.5499 & TRN \\
\hline CHEMBL1524519 & 688724 & 4.4 & 4.5764 & TST \\
\hline CHEMBL1308104 & 688724 & 5.55 & 5.025 & TST \\
\hline CHEMBL1319089 & 688724 & 4.2 & 4.5653 & TRN \\
\hline CHEMBL1413305 & 688724 & 5.25 & 4.9213 & TST \\
\hline CHEMBL1514861 & 688724 & 4.5 & 4.9554 & TRN \\
\hline CHEMBL1416780 & 688724 & 4.55 & 4.4157 & TRN \\
\hline CHEMBL1483800 & 688724 & 6.1 & 4.7532 & TRN \\
\hline CHEMBL1436475 & 688724 & 4.35 & 4.4373 & TRN \\
\hline
\end{tabular}




\begin{tabular}{|c|c|c|c|c|}
\hline \multicolumn{5}{|c|}{ Supplemental Table s2.txt } \\
\hline CHEMBL1451814 & 688724 & 5.15 & 4.7723 & TRN \\
\hline CHEMBL1557331 & 688724 & 4.5 & 4.6636 & TRN \\
\hline CHEMBL1492000 & 688724 & 4.7 & 5.3017 & TST \\
\hline CHEMBL1526505 & 688724 & 4.75 & 4.8382 & TRN \\
\hline CHEMBL1607485 & 688724 & 5.65 & 4.9788 & TRN \\
\hline CHEMBL1335810 & 688724 & 4.95 & 4.8281 & TST \\
\hline CHEMBL1332861 & 688724 & 5.0 & 4.7594 & TRN \\
\hline CHEMBL1471698 & 688724 & 5.95 & 5.2747 & TST \\
\hline CHEMBL522983 & 688724 & 6.05 & 5.6434 & TRN \\
\hline CHEMBL1565057 & 688724 & 5.0 & 4.6945 & TRN \\
\hline CHEMBL1484234 & 688724 & 4.45 & 4.8666 & TST \\
\hline CHEMBL1551610 & 688724 & 4.25 & 5.5466 & TST \\
\hline CHEMBL1539508 & 688724 & 4.55 & 4.7078 & TRN \\
\hline CHEMBL 3190866 & 688724 & 5.65 & 5.3188 & TST \\
\hline CHEMBL1537604 & 688724 & 4.75 & 5.0818 & TRN \\
\hline CHEMBL1574844 & 688724 & 4.25 & 4.5883 & TRN \\
\hline CHEMBL1408125 & 688724 & 4.05 & 5.0482 & TST \\
\hline CHEMBL1390568 & 688724 & 4.4 & 4.7893 & TRN \\
\hline CHEMBL3191212 & 688724 & 6.0 & 4.937 & TRN \\
\hline CHEMBL1303545 & 688724 & 4.45 & 4.5288 & TRN \\
\hline CHEMBL1568009 & 688724 & 4.8 & 4.8583 & TRN \\
\hline CHEMBL1490473 & 688724 & 4.75 & 4.7355 & TRN \\
\hline CHEMBL1484327 & 688724 & 4.1 & 4.8392 & TRN \\
\hline CHEMBL3194831 & 688724 & 4.85 & 4.6198 & TRN \\
\hline CHEMBL1507307 & 688724 & 4.35 & 4.8815 & TST \\
\hline CHEMBL1410441 & 688724 & 4.55 & 5.1745 & TRN \\
\hline CHEMBL1356094 & 688724 & 7.8996 & 5.0208 & TST \\
\hline CHEMBL1305807 & 688724 & 4.8 & 4.4718 & TRN \\
\hline CHEMBL1326851 & 688724 & 5.05 & 4.7923 & TRN \\
\hline CHEMBL1505467 & 688724 & 5.75 & 4.7295 & TRN \\
\hline CHEMBL1303198 & 688724 & 4.9 & 4.7794 & TRN \\
\hline CHEMBL1307553 & 688724 & 4.8 & 4.5718 & TRN \\
\hline CHEMBL1528512 & 688724 & 4.7 & 4.3501 & TRN \\
\hline CHEMBL1470366 & 688724 & 4.3 & 4.2917 & TRN \\
\hline CHEMBL1414348 & 688724 & 4.6 & 4.3672 & TRN \\
\hline CHEMBL1473822 & 688724 & 4.25 & 4.5739 & TRN \\
\hline CHEMBL405070 & 688724 & 4.05 & 5.0086 & TST \\
\hline CHEMBL157026 & 688724 & 4.05 & 5.1270 & 0000000001 \\
\hline CHEMBL1544660 & 688724 & 4.75 & 4.808 & TRN \\
\hline CHEMBL1482720 & 688724 & 5.05 & 5.3101 & TRN \\
\hline CHEMBL1299750 & 688724 & 4.8 & 4.8704 & TST \\
\hline CHEMBL1548055 & 688724 & 4.5 & 4.5825 & TST \\
\hline CHEMBL1302804 & 688724 & 4.8 & 4.784 & TRN \\
\hline CHEMBL1442379 & 688724 & 4.35 & 4.3358 & TRN \\
\hline CHEMBL1257080 & 688724 & 4.85 & 4.8308 & TRN \\
\hline CHEMBL1485078 & 688724 & 5.55 & 5.6488 & TRN \\
\hline CHEMBL1413724 & 688724 & 5.8 & 5.1456 & TST \\
\hline CHEMBL1362986 & 688724 & 5.35 & 4.8505 & TRN \\
\hline
\end{tabular}




\begin{tabular}{|c|c|c|c|c|c|}
\hline & & \multicolumn{4}{|c|}{ Supplemental Table S2.txt } \\
\hline CHEMBL1308854 & 688724 & 4.05 & 4.7088 & TRN & \\
\hline CHEMBL1525340 & 688724 & 4.9 & 4.7722 & TRN & \\
\hline CHEMBL529939 & 688724 & 4.35 & 4.8206 & TST & \\
\hline CHEMBL1341913 & 688724 & 4.5 & 4.8545 & TRN & \\
\hline CHEMBL1321022 & 688724 & 4.7 & 4.5141 & TST & \\
\hline CHEMBL1608830 & 688724 & 8.0 & 4.7564 & TST & \\
\hline CHEMBL1582536 & 688724 & 4.6 & 4.7451 & TRN & \\
\hline CHEMBL169233 & 688724 & 6.0 & 5.1279 & TST & \\
\hline CHEMBL 2001408 & 688724 & 4.55 & 4.9685 & TST & \\
\hline CHEMBL1325859 & 688724 & 6.0 & 5.3454 & TRN & \\
\hline CHEMBL1424181 & 688724 & 4.8 & 4.9142 & TRN & \\
\hline CHEMBL1612569 & 688724 & 4.45 & 4.7106 & TRN & \\
\hline CHEMBL1430977 & 688724 & 4.7 & 4.6641 & TRN & \\
\hline CHEMBL3198259 & 688724 & 5.0 & 4.9837 & TRN & \\
\hline CHEMBL1524527 & 688724 & 4.95 & 4.6484 & TST & \\
\hline CHEMBL1323320 & 688724 & 5.0 & 4.7131 & TRN & \\
\hline CHEMBL1448568 & 688724 & 4.35 & 4.4957 & TST & \\
\hline CHEMBL1459082 & 688724 & 4.0 & 5.3202 & TST & \\
\hline CHEMBL1304363 & 688724 & 6.45 & 5.343 & TRN & \\
\hline CHEMBL1490919 & 688724 & 6.3 & 5.1259 & TRN & \\
\hline CHEMBL1968986 & 688724 & 4.4 & 4.6798 & TRN & \\
\hline CHEMBL1564294 & 688724 & 4.75 & 4.9828 & TST & \\
\hline CHEMBL1357604 & 688724 & 4.4 & 4.4179 & TRN & \\
\hline CHEMBL1459826 & 688724 & 4.85 & 4.8202 & TRN & \\
\hline CHEMBL1516975 & 688724 & 5.0 & 4.4539 & TRN & \\
\hline CHEMBL3191434 & 688724 & 4.5 & 4.9662 & TRN & \\
\hline CHEMBL1525189 & 688724 & 5.0 & 4.4889 & TRN & \\
\hline CHEMBL1306782 & 688724 & 4.55 & 5.02800 & 00000000005 & TRN \\
\hline CHEMBL1509152 & 688724 & 4.85 & 4.8554 & TRN & \\
\hline CHEMBL3144976 & 688724 & 5.9 & 5.5479 & TRN & \\
\hline CHEMBL3197063 & 688724 & 4.85 & 4.6394 & TRN & \\
\hline CHEMBL1394438 & 688724 & 4.25 & 4.7974 & TRN & \\
\hline CHEMBL3198488 & 688724 & 5.45 & 4.8785 & TST & \\
\hline CHEMBL1423153 & 688724 & 4.4 & 4.5684 & TRN & \\
\hline CHEMBL3193734 & 688724 & 4.95 & 4.9603 & TRN & \\
\hline CHEMBL1705092 & 688724 & 4.7 & 4.8 & TST & \\
\hline CHEMBL1554192 & 688724 & 4.4 & 4.5402 & TRN & \\
\hline CHEMBL1343458 & 688724 & 4.15 & 4.3507 & TRN & \\
\hline CHEMBL1591192 & 688724 & 4.65 & 4.7254 & TRN & \\
\hline CHEMBL1400831 & 688724 & 4.55 & 4.688 & TST & \\
\hline CHEMBL1334316 & 688724 & 4.25 & 4.5716 & TRN & \\
\hline CHEMBL1332459 & 688724 & 4.05 & 4.9388 & TST & \\
\hline CHEMBL1448322 & 688724 & 4.85 & 4.7525 & TRN & \\
\hline CHEMBL1373124 & 688724 & 4.65 & 4.6851 & TRN & \\
\hline CHEMBL1402230 & 688724 & 4.3 & 4.6851 & TST & \\
\hline CHEMBL1383895 & 688724 & 5.55 & 5.4215 & TRN & \\
\hline CHEMBL1391385 & 688724 & 6.6 & 4.9394 & TRN & \\
\hline CHEMBL1990598 & 688724 & 5.25 & 4.7196 & TST & \\
\hline
\end{tabular}




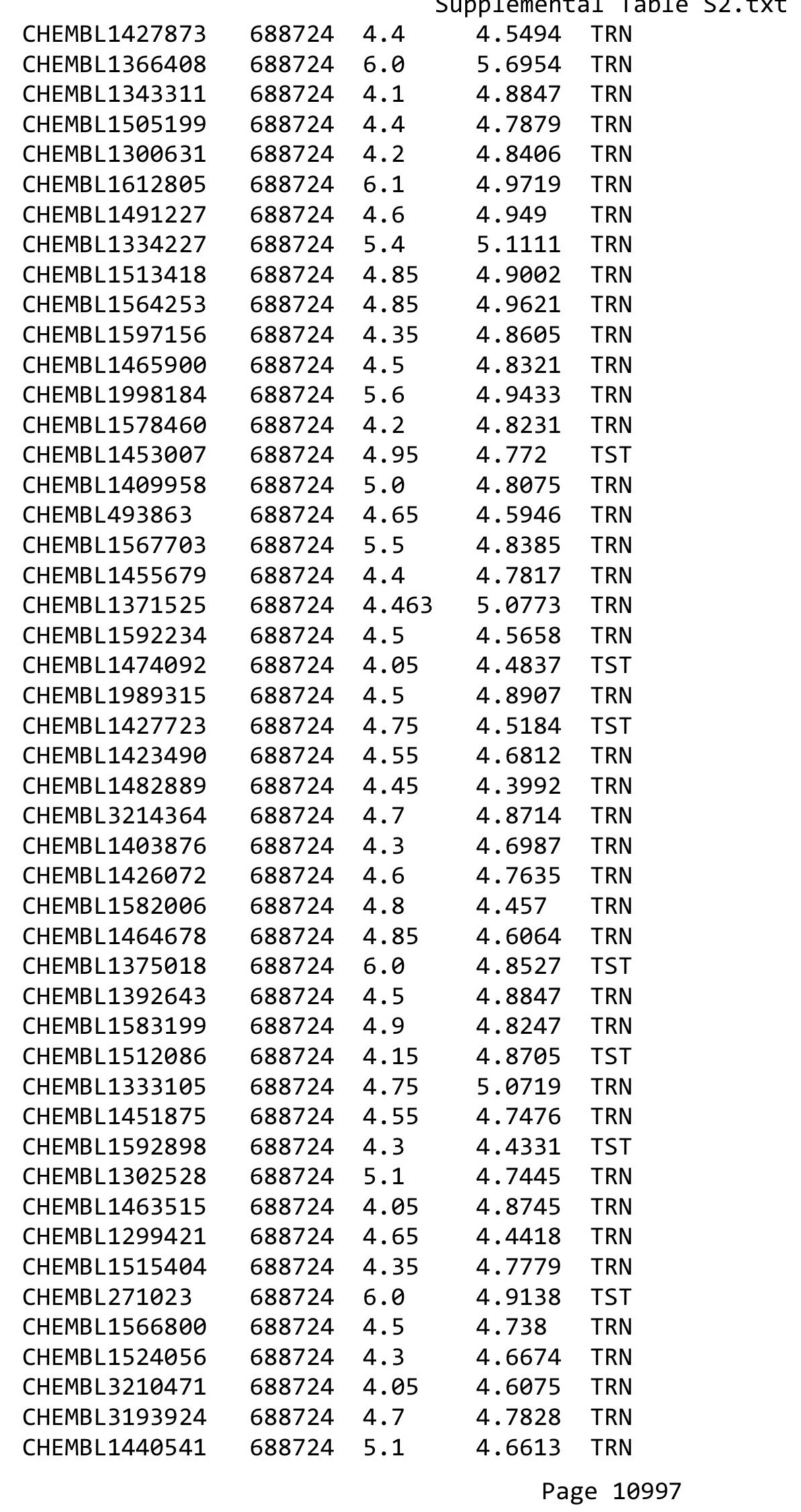




\begin{tabular}{|c|c|c|c|c|c|}
\hline \multicolumn{6}{|c|}{ Supplemental Table S2.txt } \\
\hline CHEMBL1349895 & 688724 & 7.2 & 4.8948 & TRN & \\
\hline CHEMBL1370186 & 688724 & 5.75 & 4.7753 & TRN & \\
\hline CHEMBL1585979 & 688724 & 4.65 & 4.9878 & TST & \\
\hline CHEMBL1310341 & 688724 & 6.35 & 5.0031 & TRN & \\
\hline CHEMBL1312995 & 688724 & 4.65 & 4.9023 & TST & \\
\hline CHEMBL3195883 & 688724 & 4.55 & 4.7562 & TRN & \\
\hline CHEMBL1358005 & 688724 & 4.5 & 4.887 & TRN & \\
\hline CHEMBL 212414 & 688724 & 5.55 & 5.0076 & TRN & \\
\hline CHEMBL1358631 & 688724 & 5.0 & 4.4353 & TRN & \\
\hline CHEMBL1578635 & 688724 & 4.45 & 4.7326 & TRN & \\
\hline CHEMBL2006168 & 688724 & 5.75 & 5.3214 & TST & \\
\hline CHEMBL1308990 & 688724 & 5.4 & 5.06 & TST & \\
\hline CHEMBL1533523 & 688724 & 4.65 & 4.96399 & 99999999995 & TRN \\
\hline CHEMBL1317823 & 688724 & 9.0969 & 4.4543 & TST & \\
\hline CHEMBL1485368 & 688724 & 5.35 & 4.9645 & TRN & \\
\hline CHEMBL401504 & 688724 & 5.4 & 5.1273 & TRN & \\
\hline CHEMBL1410745 & 688724 & 5.5 & 4.8693 & TST & \\
\hline CHEMBL1329490 & 688724 & 4.35 & 4.7132 & TRN & \\
\hline CHEMBL1504777 & 688724 & 4.1 & 5.2748 & TRN & \\
\hline CHEMBL1472413 & 688724 & 4.35 & 5.1057 & TRN & \\
\hline CHEMBL3193990 & 688724 & 4.8 & 4.8941 & TRN & \\
\hline CHEMBL1524323 & 688724 & 5.05 & 4.6197 & TRN & \\
\hline CHEMBL1559372 & 688724 & 4.4 & 4.6745 & TRN & \\
\hline CHEMBL1430846 & 688724 & 4.35 & 4.5015 & TRN & \\
\hline CHEMBL1403279 & 688724 & 4.45 & 4.6356 & TRN & \\
\hline CHEMBL1360940 & 688724 & 4.35 & 4.8569 & TRN & \\
\hline CHEMBL1349839 & 688724 & 4.55 & 4.4075 & TST & \\
\hline CHEMBL57997 & 688724 & 4.25 & 4.8516 & TST & \\
\hline CHEMBL1593399 & 688724 & 4.5 & 4.888 & TRN & \\
\hline CHEMBL1470448 & 688724 & 5.85 & 5.6597 & TRN & \\
\hline CHEMBL1478587 & 688724 & 4.15 & 4.9317 & TST & \\
\hline CHEMBL1578056 & 688724 & 4.95 & 4.8276 & TST & \\
\hline CHEMBL1989750 & 688724 & 7.4001 & 5.2121 & TRN & \\
\hline CHEMBL1613501 & 688724 & 4.55 & 4.2773 & TRN & \\
\hline CHEMBL1593408 & 688724 & 4.3 & 4.6375 & TRN & \\
\hline CHEMBL1384056 & 688724 & 7.1002 & 4.6844 & TRN & \\
\hline CHEMBL3193389 & 688724 & 4.6 & 5.05699 & 99999999995 & TRN \\
\hline CHEMBL1491871 & 688724 & 5.05 & 4.8875 & TRN & \\
\hline CHEMBL1356373 & 688724 & 4.75 & 4.6396 & TST & \\
\hline CHEMBL1306084 & 688724 & 4.05 & 4.7346 & TST & \\
\hline CHEMBL1489812 & 688724 & 4.25 & 4.8925 & TST & \\
\hline CHEMBL1404357 & 688724 & 5.0 & 5.052 & TRN & \\
\hline CHEMBL1399036 & 688724 & 4.15 & 4.9395 & TRN & \\
\hline CHEMBL1430175 & 688724 & 5.75 & 4.8998 & TRN & \\
\hline CHEMBL1490300 & 688724 & 4.4 & 4.6881 & TST & \\
\hline CHEMBL1536665 & 688724 & 4.9 & 5.4635 & TST & \\
\hline CHEMBL1593754 & 688724 & 6.0 & 5.3866 & TST & \\
\hline CHEMBL1357618 & 688724 & 4.6 & 4.6445 & TRN & \\
\hline
\end{tabular}




\begin{tabular}{|c|c|c|c|c|c|}
\hline \multicolumn{6}{|c|}{ Supplemental Table S2.txt } \\
\hline CHEMBL1601214 & 688724 & 6.0 & 5.0926 & TST & \\
\hline CHEMBL1376331 & 688724 & 4.3 & 4.4331 & TRN & \\
\hline CHEMBL1356230 & 688724 & 5.05 & 4.7164 & TRN & \\
\hline CHEMBL1609749 & 688724 & 4.3 & 4.9567 & TST & \\
\hline CHEMBL1578537 & 688724 & 5.5 & 4.6335 & TRN & \\
\hline CHEMBL1449253 & 688724 & 4.85 & 4.8903 & TRN & \\
\hline CHEMBL1513108 & 688724 & 4.7 & 4.9001 & TRN & \\
\hline CHEMBL592184 & 688724 & 4.75 & 4.9836 & TST & \\
\hline CHEMBL1313418 & 688724 & 5.0 & 5.2692 & TRN & \\
\hline CHEMBL1445427 & 688724 & 5.3 & 5.0631 & TST & \\
\hline CHEMBL1454572 & 688724 & 4.25 & 4.6704 & TRN & \\
\hline CHEMBL1337470 & 688724 & 4.35 & 4.7765 & TST & \\
\hline CHEMBL1608950 & 688724 & 4.2 & 4.3522 & TRN & \\
\hline CHEMBL3197031 & 688724 & 5.25 & 5.1894 & TRN & \\
\hline CHEMBL1357976 & 688724 & 4.45 & 4.7893 & TRN & \\
\hline CHEMBL1444100 & 688724 & 4.7 & 4.6436 & TRN & \\
\hline CHEMBL1332764 & 688724 & 7.4001 & 5.0702 & TRN & \\
\hline CHEMBL1454986 & 688724 & 4.8 & 4.7211 & TRN & \\
\hline CHEMBL252621 & 688724 & 4.05 & 4.7441 & TRN & \\
\hline CHEMBL1378138 & 688724 & 4.8 & 4.6843 & TRN & \\
\hline CHEMBL1351543 & 688724 & 4.35 & 4.3265 & TRN & \\
\hline CHEMBL1453409 & 688724 & 5.5 & 4.4439 & TRN & \\
\hline CHEMBL1556174 & 688724 & 4.55 & 4.646 & TRN & \\
\hline CHEMBL1608424 & 688724 & 4.55 & 4.7491 & TRN & \\
\hline CHEMBL1439051 & 688724 & 4.55 & 4.414 & TRN & \\
\hline CHEMBL3197210 & 688724 & 4.1 & 5.1095 & TST & \\
\hline CHEMBL1379278 & 688724 & 4.9 & 4.7784 & TRN & \\
\hline CHEMBL 70783 & 688724 & 4.55 & 5.0264 & TRN & \\
\hline CHEMBL1440934 & 688724 & 4.65 & 4.7775 & TST & \\
\hline CHEMBL1511724 & 688724 & 4.1 & 4.7597 & TST & \\
\hline CHEMBL163970 & 688724 & 4.35 & 4.8487 & TRN & \\
\hline CHEMBL1570769 & 688724 & 4.95 & 4.9071 & TRN & \\
\hline CHEMBL1450772 & 688724 & 6.5 & 4.9802 & TRN & \\
\hline CHEMBL1468835 & 688724 & 4.85 & 4.9365 & TRN & \\
\hline CHEMBL1423705 & 688724 & 4.95 & 4.831 & TST & \\
\hline CHEMBL1299757 & 688724 & 5.25 & 5.3041 & TRN & \\
\hline CHEMBL1300776 & 688724 & 5.0 & 5.1326 & TST & \\
\hline CHEMBL1495905 & 688724 & 4.4 & 4.5157 & TST & \\
\hline CHEMBL1510832 & 688724 & 4.9 & 4.5085 & TRN & \\
\hline CHEMBL1491331 & 688724 & 4.05 & 4.71899 & 9999999999 & TRN \\
\hline CHEMBL1365664 & 688724 & 4.6 & 4.8022 & TRN & \\
\hline CHEMBL1607452 & 688724 & 4.55 & 4.6122 & TRN & \\
\hline CHEMBL3199237 & 688724 & 4.85 & 4.6151 & TRN & \\
\hline CHEMBL1478353 & 688724 & 4.75 & 4.7097 & TRN & \\
\hline CHEMBL1609652 & 688724 & 5.15 & 4.7263 & TRN & \\
\hline CHEMBL3192181 & 688724 & 5.45 & 5.7558 & TRN & \\
\hline CHEMBL3207725 & 688724 & 8.7447 & 5.3473 & TRN & \\
\hline CHEMBL1338474 & 688724 & 4.45 & 4.9632 & TRN & \\
\hline
\end{tabular}




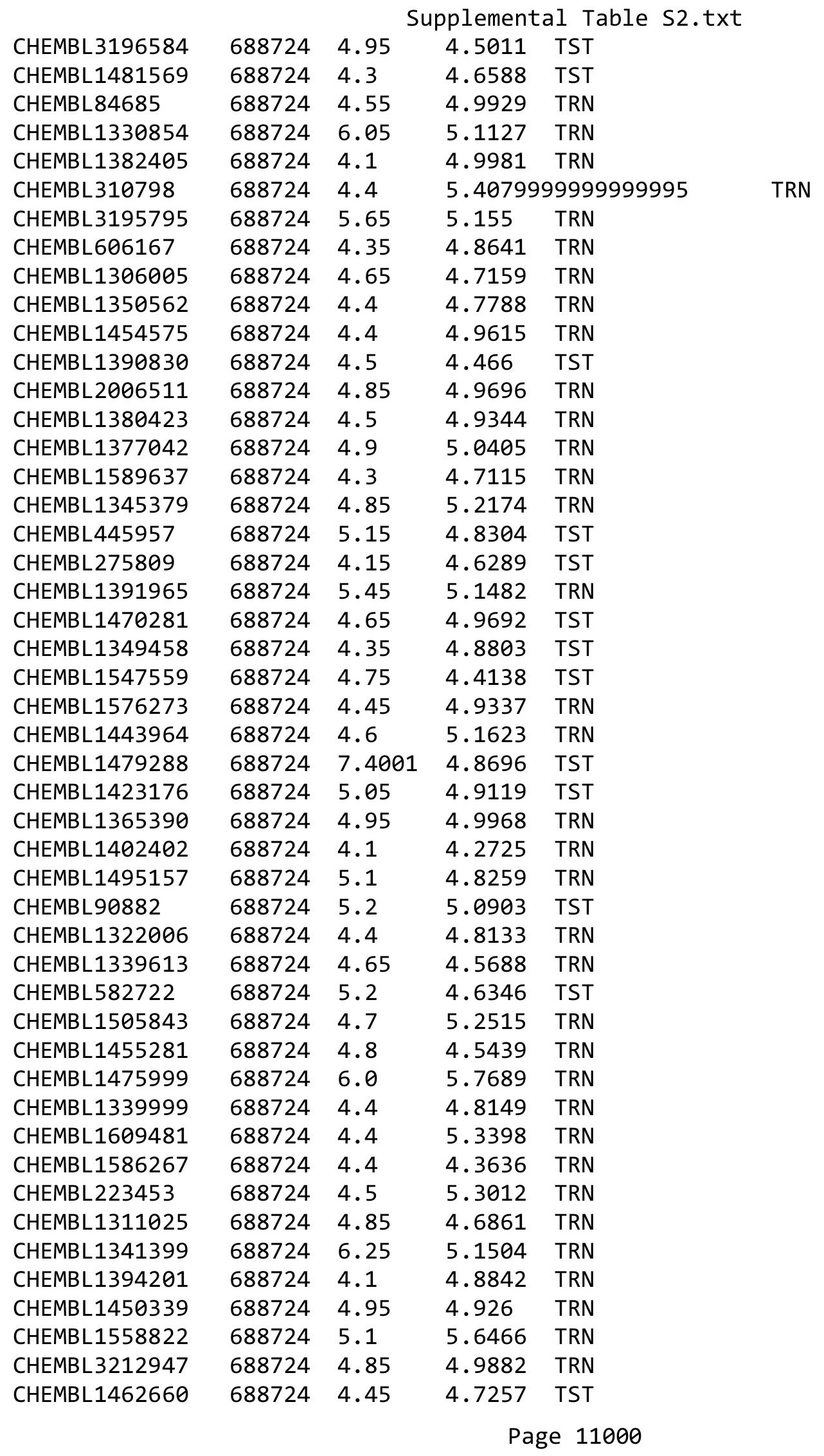




\begin{tabular}{|c|c|c|c|c|c|}
\hline & & \multicolumn{4}{|c|}{ Supplemental Table S2.txt } \\
\hline CHEMBL1479248 & 688724 & 5.45 & 4.5476 & TRN & \\
\hline CHEMBL1364673 & 688724 & 4.1 & 5.0105 & TRN & \\
\hline CHEMBL1344600 & 688724 & 4.45 & 5.05699 & 99999999995 & TRN \\
\hline CHEMBL3192165 & 688724 & 4.55 & 5.2015 & TRN & \\
\hline CHEMBL1507165 & 688724 & 6.45 & 4.7945 & TST & \\
\hline CHEMBL3210465 & 688724 & 5.35 & 4.8022 & TRN & \\
\hline CHEMBL18879 & 688724 & 5.35 & 5.1156 & TST & \\
\hline CHEMBL3145305 & 688724 & 4.3 & 5.1443 & TRN & \\
\hline CHEMBL1507474 & 688724 & 4.85 & 4.4165 & TST & \\
\hline CHEMBL1560522 & 688724 & 4.4 & 4.9386 & TRN & \\
\hline CHEMBL578585 & 688724 & 4.75 & 4.6006 & TRN & \\
\hline CHEMBL1582520 & 688724 & 4.15 & 4.8882 & TRN & \\
\hline CHEMBL1326833 & 688724 & 4.6 & 5.2276 & TRN & \\
\hline CHEMBL1541497 & 688724 & 4.55 & 5.2582 & TST & \\
\hline CHEMBL1381419 & 688724 & 4.25 & 5.1544 & TRN & \\
\hline CHEMBL1874620 & 688724 & 5.9 & 5.5451 & TRN & \\
\hline CHEMBL1583805 & 688724 & 4.35 & 4.2945 & TRN & \\
\hline CHEMBL1564021 & 688724 & 5.2 & 4.3603 & TRN & \\
\hline CHEMBL1533860 & 688724 & 5.0 & 4.6094 & TRN & \\
\hline CHEMBL1584674 & 688724 & 4.85 & 4.3863 & TRN & \\
\hline CHEMBL1395509 & 688724 & 4.55 & 4.4996 & TRN & \\
\hline CHEMBL1369162 & 688724 & 4.25 & 4.7462 & TRN & \\
\hline CHEMBL1521781 & 688724 & 5.0 & 5.1045 & TST & \\
\hline CHEMBL3192868 & 688724 & 6.35 & 5.2765 & TRN & \\
\hline CHEMBL1399873 & 688724 & 4.4 & 5.0799 & TRN & \\
\hline CHEMBL1390775 & 688724 & 5.45 & 5.0394 & TRN & \\
\hline CHEMBL1310972 & 688724 & 4.85 & 4.7829 & TRN & \\
\hline CHEMBL1301500 & 688724 & 4.5 & 4.7803 & TRN & \\
\hline CHEMBL1554884 & 688724 & 4.1 & 4.9841 & TST & \\
\hline CHEMBL1568644 & 688724 & 4.6 & 4.5417 & TRN & \\
\hline CHEMBL1301082 & 688724 & 6.2 & 5.4237 & TRN & \\
\hline CHEMBL2005947 & 688724 & 4.65 & 4.745 & TST & \\
\hline CHEMBL1369742 & 688724 & 4.95 & 4.9819 & TRN & \\
\hline CHEMBL1476616 & 688724 & 5.15 & 5.1829 & TRN & \\
\hline CHEMBL1507012 & 688724 & 4.35 & 4.6671 & TRN & \\
\hline CHEMBL1487454 & 688724 & 4.75 & 5.0373 & TRN & \\
\hline CHEMBL3189545 & 688724 & 4.3 & 4.4001 & TRN & \\
\hline CHEMBL1510020 & 688724 & 4.75 & 4.9451 & TRN & \\
\hline CHEMBL1393917 & 688724 & 4.25 & 4.8018 & TST & \\
\hline CHEMBL1450386 & 688724 & 4.7 & 4.4601 & TRN & \\
\hline CHEMBL1589737 & 688724 & 4.8 & 4.9669 & TRN & \\
\hline CHEMBL1352004 & 688724 & 7.5003 & 5.0077 & TRN & \\
\hline CHEMBL1384534 & 688724 & 4.65 & 4.8332 & TRN & \\
\hline CHEMBL1314309 & 688724 & 4.2 & 4.4983 & TRN & \\
\hline CHEMBL3191960 & 688724 & 4.85 & 4.4151 & TRN & \\
\hline CHEMBL1602538 & 688724 & 4.9 & 4.8846 & TRN & \\
\hline CHEMBL1471883 & 688724 & 4.1 & 4.6472 & TRN & \\
\hline CHEMBL1449644 & 688724 & 4.6 & 4.8335 & TRN & \\
\hline
\end{tabular}




\begin{tabular}{|c|c|c|c|c|c|}
\hline \multicolumn{6}{|c|}{ Supplemental Table S2.txt } \\
\hline CHEMBL1993491 & 688724 & 4.45 & 4.7177 & TST & \\
\hline CHEMBL1514021 & 688724 & 3.95 & 4.624 & TRN & \\
\hline CHEMBL1587413 & 688724 & 4.8 & 4.7424 & TST & \\
\hline CHEMBL1493630 & 688724 & 5.05 & 4.3488 & TRN & \\
\hline CHEMBL1586252 & 688724 & 5.7 & 4.8872 & TST & \\
\hline CHEMBL1476722 & 688724 & 4.35 & 4.6503 & TRN & \\
\hline CHEMBL1322221 & 688724 & 4.65 & 4.9778 & TST & \\
\hline CHEMBL 3193417 & 688724 & 5.45 & 4.77800 & 00000000005 & TRN \\
\hline CHEMBL3198603 & 688724 & 7.9508 & 5.4061 & TRN & \\
\hline CHEMBL1591870 & 688724 & 4.25 & 5.0774 & TRN & \\
\hline CHEMBL1538023 & 688724 & 4.75 & 4.8157 & TRN & \\
\hline CHEMBL1529910 & 688724 & 5.05 & 4.5917 & TRN & \\
\hline CHEMBL1364909 & 688724 & 4.4 & 4.6401 & TRN & \\
\hline CHEMBL1402603 & 688724 & 4.2 & 4.7944 & TRN & \\
\hline CHEMBL1571433 & 688724 & 4.95 & 4.8372 & TRN & \\
\hline CHEMBL3196591 & 688724 & 5.6 & 5.1747 & TST & \\
\hline CHEMBL1440119 & 688724 & 6.4 & 5.1166 & TRN & \\
\hline CHEMBL3199583 & 688724 & 5.0 & 4.7622 & TRN & \\
\hline CHEMBL1441163 & 688724 & 4.75 & 5.0958 & TRN & \\
\hline CHEMBL1442207 & 688724 & 4.9 & 5.0811 & TRN & \\
\hline CHEMBL1457328 & 688724 & 4.15 & 4.4536 & TRN & \\
\hline CHEMBL1436125 & 688724 & 4.6 & 4.8301 & TRN & \\
\hline CHEMBL1468908 & 688724 & 5.6 & 5.2792 & TST & \\
\hline CHEMBL1594230 & 688724 & 4.95 & 4.6926 & TRN & \\
\hline CHEMBL1349795 & 688724 & 4.25 & 4.9335 & TRN & \\
\hline CHEMBL1449393 & 688724 & 4.6 & 4.9867 & TRN & \\
\hline CHEMBL1224512 & 688724 & 5.55 & 5.5833 & TRN & \\
\hline CHEMBL1347829 & 688724 & 4.4 & 4.5519 & TST & \\
\hline CHEMBL1390343 & 688724 & 4.4 & 4.7172 & TRN & \\
\hline CHEMBL1335299 & 688724 & 4.45 & 4.9129 & TRN & \\
\hline CHEMBL1369967 & 688724 & 5.9 & 5.1587 & TST & \\
\hline CHEMBL1560642 & 688724 & 4.4 & 4.539 & TRN & \\
\hline CHEMBL1365899 & 688724 & 4.4 & 5.073 & TRN & \\
\hline CHEMBL1440002 & 688724 & 4.85 & 5.0421 & TRN & \\
\hline CHEMBL1350393 & 688724 & 4.95 & 4.7048 & TRN & \\
\hline CHEMBL1485402 & 688724 & 4.35 & 4.6392 & TST & \\
\hline CHEMBL1584553 & 688724 & 4.7 & 4.887 & TRN & \\
\hline CHEMBL1331851 & 688724 & 4.8 & 5.3812 & TRN & \\
\hline CHEMBL1458130 & 688724 & 5.05 & 4.5744 & TRN & \\
\hline CHEMBL3192616 & 688724 & 4.95 & 5.4796 & TRN & \\
\hline CHEMBL1562566 & 688724 & 4.75 & 5.0034 & TST & \\
\hline CHEMBL1413956 & 688724 & 4.9 & 5.0838 & TRN & \\
\hline CHEMBL1467582 & 688724 & 4.5 & 4.7326 & TRN & \\
\hline CHEMBL1450191 & 688724 & 5.25 & 5.2762 & TRN & \\
\hline CHEMBL1417750 & 688724 & 4.25 & 4.5612 & TRN & \\
\hline CHEMBL1602501 & 688724 & 5.2 & 4.8901 & TRN & \\
\hline CHEMBL1319534 & 688724 & 4.1 & 4.7777 & TRN & \\
\hline CHEMBL1522738 & 688724 & 4.8 & 4.731 & TRN & \\
\hline
\end{tabular}




\begin{tabular}{|c|c|c|c|c|}
\hline \multicolumn{5}{|c|}{ Supplemental Table S2.txt } \\
\hline CHEMBL1300008 & 688724 & 5.5 & 4.5741 & TRN \\
\hline CHEMBL1485818 & 688724 & 6.25 & 5.7706 & TRN \\
\hline CHEMBL1348135 & 688724 & 4.4 & 5.0864 & TRN \\
\hline CHEMBL1596985 & 688724 & 5.55 & 5.6087 & TRN \\
\hline CHEMBL1301096 & 688724 & 4.55 & 5.023 & TST \\
\hline CHEMBL3193224 & 688724 & 4.3 & 4.7184 & TRN \\
\hline CHEMBL1550518 & 688724 & 5.65 & 5.6576 & TRN \\
\hline CHEMBL3190558 & 688724 & 4.5 & 4.8987 & TRN \\
\hline CHEMBL3189712 & 688724 & 7.1002 & 4.9564 & TRN \\
\hline CHEMBL1572466 & 688724 & 4.25 & 4.7647 & TRN \\
\hline CHEMBL1601166 & 688724 & 6.0 & 5.1616 & TRN \\
\hline CHEMBL1554052 & 688724 & 5.05 & 5.3476 & TRN \\
\hline CHEMBL1392573 & 688724 & 4.45 & 5.0816 & TRN \\
\hline CHEMBL494891 & 688724 & 4.65 & 5.1901 & TST \\
\hline CHEMBL1564810 & 688724 & 5.45 & 4.7351 & TRN \\
\hline CHEMBL1547804 & 688724 & 5.05 & 4.8903 & TRN \\
\hline CHEMBL1541391 & 688724 & 4.9 & 5.0394 & TRN \\
\hline CHEMBL1531174 & 688724 & 5.35 & 4.6545 & TRN \\
\hline CHEMBL1506274 & 688724 & 4.3 & 4.7533 & TRN \\
\hline CHEMBL1605375 & 688724 & 4.8 & 5.3461 & TRN \\
\hline CHEMBL1316395 & 688724 & 4.6 & 4.4468 & TRN \\
\hline CHEMBL1370646 & 688724 & 4.15 & 5.0006 & TST \\
\hline CHEMBL1553974 & 688724 & 4.75 & 4.9985 & TRN \\
\hline CHEMBL1453208 & 688724 & 9.0458 & 5.5181 & TRN \\
\hline CHEMBL1428964 & 688724 & 5.1 & 5.1268 & TRN \\
\hline CHEMBL111654 & 688724 & 4.55 & 5.1085 & TRN \\
\hline CHEMBL1410048 & 688724 & 4.15 & 4.4147 & TRN \\
\hline CHEMBL1535604 & 688724 & 4.65 & 4.7854 & TRN \\
\hline CHEMBL1523894 & 688724 & 5.6 & 5.1905 & TST \\
\hline CHEMBL1599937 & 688724 & 4.95 & 5.4411 & TST \\
\hline CHEMBL1364084 & 688724 & 4.4 & 4.8207 & TST \\
\hline CHEMBL1461459 & 688724 & 4.9 & 5.3762 & TST \\
\hline CHEMBL1534634 & 688724 & 4.8 & 5.3086 & TST \\
\hline CHEMBL1388059 & 688724 & 7.2 & 4.7665 & TST \\
\hline CHEMBL1448346 & 688724 & 4.45 & 5.1795 & TRN \\
\hline CHEMBL1573230 & 688724 & 4.8 & 4.8443 & TRN \\
\hline CHEMBL1716742 & 688724 & 4.4 & 5.0536 & TST \\
\hline CHEMBL1467261 & 688724 & 4.55 & 4.5645 & TRN \\
\hline CHEMBL591412 & 688724 & 4.6 & 5.6791 & TRN \\
\hline CHEMBL1988202 & 688724 & 5.0 & 4.9147 & TRN \\
\hline CHEMBL1531289 & 688724 & 5.3 & 4.9783 & TRN \\
\hline CHEMBL1609015 & 688724 & 4.95 & 5.1669 & TST \\
\hline CHEMBL1362588 & 688724 & 4.55 & 4.6443 & TRN \\
\hline CHEMBL260311 & 688724 & 6.8499 & 5.4158 & TRN \\
\hline CHEMBL1326554 & 688724 & 4.9 & 5.8416 & TRN \\
\hline CHEMBL1489368 & 688724 & 5.6 & 5.0307 & TRN \\
\hline CHEMBL1346995 & 688724 & 5.95 & 4.7765 & TRN \\
\hline CHEMBL1479627 & 688724 & 4.45 & 4.9003 & TRN \\
\hline
\end{tabular}




\begin{tabular}{|c|c|c|c|c|c|}
\hline \multicolumn{6}{|c|}{ Supplemental Table S2.txt } \\
\hline CHEMBL1469493 & 688724 & 4.65 & 5.1285 & TRN & \\
\hline CHEMBL1354721 & 688724 & 4.5 & 4.5406 & TRN & \\
\hline CHEMBL1422472 & 688724 & 4.0 & 5.0803 & TST & \\
\hline CHEMBL1448258 & 688724 & 4.7 & 4.5714 & TRN & \\
\hline CHEMBL1556308 & 688724 & 4.9 & 4.5353 & TRN & \\
\hline CHEMBL1313410 & 688724 & 5.0 & 5.2107 & TST & \\
\hline CHEMBL1518895 & 688724 & 5.15 & 4.816 & TRN & \\
\hline CHEMBL1357126 & 688724 & 4.65 & 5.1065 & TST & \\
\hline CHEMBL1968628 & 688724 & 5.2 & 5.1847 & TRN & \\
\hline CHEMBL3193225 & 688724 & 5.3 & 4.8713 & TRN & \\
\hline CHEMBL1580706 & 688724 & 4.55 & 4.6354 & TRN & \\
\hline CHEMBL1325575 & 688724 & 4.35 & 4.8003 & TRN & \\
\hline CHEMBL1414136 & 688724 & 4.1 & 4.5388 & TST & \\
\hline CHEMBL1381590 & 688724 & 4.95 & 4.8276 & TRN & \\
\hline CHEMBL1473534 & 688724 & 4.4 & 4.6805 & TST & \\
\hline CHEMBL116438 & 688724 & 5.25 & 5.1438 & TRN & \\
\hline CHEMBL1487453 & 688724 & 4.05 & 4.8448 & TRN & \\
\hline CHEMBL1569509 & 688724 & 4.75 & 4.8795 & TRN & \\
\hline CHEMBL1562463 & 688724 & 4.65 & 4.7817 & TRN & \\
\hline CHEMBL1508375 & 688724 & 5.25 & 4.8821 & TRN & \\
\hline CHEMBL1481546 & 688724 & 5.5 & 5.1997 & TRN & \\
\hline CHEMBL1332318 & 688724 & 4.45 & 4.8082 & TRN & \\
\hline CHEMBL15901 & 688724 & 4.3 & 4.6061 & TRN & \\
\hline CHEMBL1323965 & 688724 & 4.3 & 4.7377 & TRN & \\
\hline CHEMBL1525996 & 688724 & 4.55 & 4.8191 & TRN & \\
\hline CHEMBL1580960 & 688724 & 4.85 & 4.6132 & TRN & \\
\hline CHEMBL1361703 & 688724 & 6.5501 & 4.9107 & TRN & \\
\hline CHEMBL1472593 & 688724 & 4.4 & 5.04899 & 99999999995 & TRN \\
\hline CHEMBL1400868 & 688724 & 5.25 & 4.582 & TRN & \\
\hline CHEMBL1422686 & 688724 & 4.25 & 4.8823 & TST & \\
\hline CHEMBL1505207 & 688724 & 4.7 & 4.9165 & TST & \\
\hline CHEMBL1499301 & 688724 & 4.3 & 4.7895 & TST & \\
\hline CHEMBL1410260 & 688724 & 4.8 & 4.973 & TRN & \\
\hline CHEMBL1612945 & 688724 & 4.75 & 4.8472 & TRN & \\
\hline CHEMBL1241371 & 688724 & 4.6 & 5.0462 & TRN & \\
\hline CHEMBL1592379 & 688724 & 6.0 & 4.8368 & TRN & \\
\hline CHEMBL94990 & 688724 & 4.35 & 4.7103 & TRN & \\
\hline CHEMBL1561749 & 688724 & 4.05 & 4.5323 & TRN & \\
\hline CHEMBL1461797 & 688724 & 4.1 & 4.4079 & TRN & \\
\hline CHEMBL1525215 & 688724 & 5.05 & 4.8876 & TRN & \\
\hline CHEMBL1446108 & 688724 & 4.2 & 4.3075 & TRN & \\
\hline CHEMBL1492075 & 688724 & 5.1 & 4.8243 & TST & \\
\hline CHEMBL1311045 & 688724 & 5.5 & 4.8332 & TRN & \\
\hline CHEMBL1574133 & 688724 & 5.5 & 4.3295 & TRN & \\
\hline CHEMBL1490149 & 688724 & 4.55 & 4.6524 & TRN & \\
\hline CHEMBL45068 & 688724 & 4.65 & 5.3451 & TST & \\
\hline CHEMBL1565861 & 688724 & 6.0 & 4.893 & TRN & \\
\hline CHEMBL1560884 & 688724 & 6.0 & 5.5854 & TRN & \\
\hline
\end{tabular}




\begin{tabular}{|c|c|c|c|c|}
\hline \multicolumn{5}{|c|}{ Supplemental Table S2.txt } \\
\hline CHEMBL1397344 & 688724 & 5.0 & 5.1795 & TRN \\
\hline CHEMBL1425069 & 688724 & 6.0 & 5.2783 & TRN \\
\hline CHEMBL1553517 & 688724 & 4.3 & 4.8552 & TST \\
\hline CHEMBL1995947 & 688724 & 4.4 & 4.4131 & TRN \\
\hline CHEMBL 3193228 & 688724 & 4.75 & 5.4484 & TRN \\
\hline CHEMBL3189172 & 688724 & 5.1 & 4.912 & TST \\
\hline CHEMBL1603870 & 688724 & 5.15 & 4.8135 & TRN \\
\hline CHEMBL1595203 & 688724 & 5.25 & 5.1163 & TRN \\
\hline CHEMBL1330442 & 688724 & 4.7 & 4.657 & TRN \\
\hline CHEMBL1505278 & 688724 & 5.75 & 4.765 & TST \\
\hline CHEMBL1366128 & 688724 & 7.4498 & 5.1326 & TRN \\
\hline CHEMBL1514090 & 688724 & 6.0 & 5.683 & TRN \\
\hline CHEMBL1444684 & 688724 & 5.2 & 4.6363 & TRN \\
\hline CHEMBL1481204 & 688724 & 6.0 & 5.2614 & TRN \\
\hline CHEMBL428064 & 688724 & 5.45 & 5.1291 & TRN \\
\hline CHEMBL1373297 & 688724 & 4.0 & 5.044 & TRN \\
\hline CHEMBL1333386 & 688724 & 6.1 & 5.6353 & TRN \\
\hline CHEMBL1559468 & 688724 & 4.4 & 4.4657 & TRN \\
\hline CHEMBL1570716 & 688724 & 6.0 & 5.024 & TRN \\
\hline CHEMBL3199837 & 688724 & 4.95 & 4.6795 & TRN \\
\hline CHEMBL429023 & 688724 & 8.301 & 5.215 & TRN \\
\hline CHEMBL1323006 & 688724 & 4.65 & 4.5536 & TRN \\
\hline CHEMBL1475690 & 688724 & 4.3 & 4.7245 & TRN \\
\hline CHEMBL1473141 & 688724 & 4.35 & 4.5833 & TRN \\
\hline CHEMBL1516738 & 688724 & 5.55 & 5.1514 & TRN \\
\hline CHEMBL1409076 & 688724 & 6.0 & 4.9793 & TRN \\
\hline CHEMBL1336680 & 688724 & 5.35 & 4.6268 & TRN \\
\hline CHEMBL1416847 & 688724 & 5.0 & 4.9215 & TRN \\
\hline CHEMBL1322200 & 688724 & 4.25 & 4.7447 & TRN \\
\hline CHEMBL1344207 & 688724 & 4.35 & 4.8467 & TST \\
\hline CHEMBL3197259 & 688724 & 5.15 & 5.1591 & TRN \\
\hline CHEMBL1347349 & 688724 & 4.35 & 4.3835 & TRN \\
\hline CHEMBL1578064 & 688724 & 5.2 & 5.1089 & TRN \\
\hline CHEMBL1463849 & 688724 & 4.05 & 4.7614 & TRN \\
\hline CHEMBL1562146 & 688724 & 4.35 & 4.9707 & TST \\
\hline CHEMBL1408293 & 688724 & 4.25 & 4.6294 & TRN \\
\hline CHEMBL1388044 & 688724 & 4.6 & 4.8261 & TST \\
\hline CHEMBL1422097 & 688724 & 4.0 & 4.7584 & TRN \\
\hline CHEMBL1455279 & 688724 & 4.95 & 5.2037 & TRN \\
\hline CHEMBL1443205 & 688724 & 5.35 & 5.2951 & TRN \\
\hline CHEMBL1335833 & 688724 & 4.5 & 4.9531 & TRN \\
\hline CHEMBL1458369 & 688724 & 4.45 & 4.4727 & TRN \\
\hline CHEMBL1573813 & 688724 & 5.55 & 5.0489 & TRN \\
\hline CHEMBL1332843 & 688724 & 4.65 & 4.8532 & TRN \\
\hline CHEMBL1585997 & 688724 & 4.7 & 4.857 & TRN \\
\hline CHEMBL1541282 & 688724 & 4.4 & 4.5938 & TST \\
\hline CHEMBL1476133 & 688724 & 5.15 & 5.0206 & TST \\
\hline CHEMBL1589921 & 688724 & 6.8499 & 5.2351 & TRN \\
\hline
\end{tabular}




\begin{tabular}{|c|c|c|c|c|}
\hline \multicolumn{5}{|c|}{ Supplemental Table S2.txt } \\
\hline CHEMBL1567802 & 688724 & 4.95 & 4.6723 & TST \\
\hline CHEMBL1376745 & 688724 & 5.55 & 5.1295 & TRN \\
\hline CHEMBL1409748 & 688724 & 4.85 & 4.7978 & TRN \\
\hline CHEMBL1318718 & 688724 & 4.75 & 4.6554 & TST \\
\hline CHEMBL1414388 & 688724 & 4.85 & 5.0033 & TST \\
\hline CHEMBL1566699 & 688724 & 5.1 & 4.805 & TRN \\
\hline CHEMBL1369283 & 688724 & 4.4 & 4.4516 & TRN \\
\hline CHEMBL1450353 & 688724 & 4.4 & 4.356 & TRN \\
\hline CHEMBL1494850 & 688724 & 5.0 & 4.6625 & TST \\
\hline CHEMBL1541863 & 688724 & 5.55 & 4.7823 & TRN \\
\hline CHEMBL1403218 & 688724 & 4.25 & 4.7493 & TRN \\
\hline CHEMBL1490298 & 688724 & 4.05 & 5.1236 & TST \\
\hline CHEMBL1340616 & 688724 & 4.4 & 4.5581 & TST \\
\hline CHEMBL1338809 & 688724 & 4.8 & 4.646 & TRN \\
\hline CHEMBL1589300 & 688724 & 5.6 & 5.2625 & TRN \\
\hline CHEMBL1383610 & 688724 & 4.2 & 4.7766 & TRN \\
\hline CHEMBL1435178 & 688724 & 4.7 & 4.7619 & TRN \\
\hline CHEMBL1546048 & 688724 & 4.4 & 5.2435 & TST \\
\hline CHEMBL1542061 & 688724 & 4.65 & 5.0919 & TRN \\
\hline CHEMBL1568611 & 688724 & 4.05 & 4.6799 & TRN \\
\hline CHEMBL1346664 & 688724 & 4.1 & 4.6779 & TRN \\
\hline CHEMBL3194805 & 688724 & 4.55 & 4.6159 & TRN \\
\hline CHEMBL1369410 & 688724 & 4.4 & 4.7782 & TST \\
\hline CHEMBL1599215 & 688724 & 4.35 & 5.1296 & TST \\
\hline CHEMBL1541738 & 688724 & 4.75 & 4.7437 & TRN \\
\hline CHEMBL1334452 & 688724 & 5.05 & 4.8176 & TRN \\
\hline CHEMBL1348630 & 688724 & 4.9 & 4.7784 & TRN \\
\hline CHEMBL1309198 & 688724 & 4.35 & 4.7968 & TRN \\
\hline CHEMBL1598391 & 688724 & 4.8 & 4.562 & TST \\
\hline CHEMBL1321445 & 688724 & 5.4 & 4.5531 & TRN \\
\hline CHEMBL1489025 & 688724 & 4.75 & 4.6912 & TRN \\
\hline CHEMBL1341445 & 688724 & 4.1 & 4.5083 & TRN \\
\hline CHEMBL1579823 & 688724 & 4.55 & 4.8416 & TST \\
\hline CHEMBL1480364 & 688724 & 4.5 & 4.8351 & TST \\
\hline CHEMBL3192557 & 688724 & 6.6499 & 5.1118 & TRN \\
\hline CHEMBL1604304 & 688724 & 4.8 & 4.7047 & TRN \\
\hline CHEMBL1420935 & 688724 & 4.0 & 4.5041 & TST \\
\hline CHEMBL1308991 & 688724 & 7.2 & 5.0104 & TRN \\
\hline CHEMBL1575649 & 688724 & 4.8 & 5.2477 & TRN \\
\hline CHEMBL1467047 & 688724 & 4.7 & 5.0489 & TST \\
\hline CHEMBL1485600 & 688724 & 5.65 & 5.1129 & TRN \\
\hline CHEMBL1529759 & 688724 & 5.45 & 5.2875 & TST \\
\hline CHEMBL1391966 & 688724 & 4.65 & 4.757 & TRN \\
\hline CHEMBL1505300 & 688724 & 5.4 & 4.9369 & TRN \\
\hline CHEMBL1460008 & 688724 & 5.2 & 4.9276 & TRN \\
\hline CHEMBL3144956 & 688724 & 5.45 & 4.7309 & TST \\
\hline CHEMBL1457011 & 688724 & 4.25 & 4.5361 & TRN \\
\hline CHEMBL1301238 & 688724 & 4.35 & 4.6422 & TRN \\
\hline
\end{tabular}




\begin{tabular}{|c|c|c|c|c|c|}
\hline & & \multicolumn{4}{|c|}{ Supplemental Table S2.txt } \\
\hline CHEMBL1530352 & 688724 & 4.35 & 4.6664 & TST & \\
\hline CHEMBL1523516 & 688724 & 4.25 & 4.5648 & TRN & \\
\hline CHEMBL1318751 & 688724 & 4.35 & 4.6928 & TRN & \\
\hline CHEMBL1380368 & 688724 & 4.05 & 4.6041 & TRN & \\
\hline CHEMBL 3196754 & 688724 & 5.45 & 5.3721 & TRN & \\
\hline CHEMBL1547030 & 688724 & 4.45 & 4.4206 & TRN & \\
\hline CHEMBL1347236 & 688724 & 4.6 & 4.9396 & TST & \\
\hline CHEMBL1407683 & 688724 & 4.35 & 4.7544 & TRN & \\
\hline CHEMBL 3191503 & 688724 & 4.75 & 4.9725 & TRN & \\
\hline CHEMBL1547642 & 688724 & 4.05 & 4.7757 & TRN & \\
\hline CHEMBL1362708 & 688724 & 4.6 & 4.48600 & 0000000001 & TRN \\
\hline CHEMBL1464101 & 688724 & 4.65 & 4.9444 & TST & \\
\hline CHEMBL 3194704 & 688724 & 6.8 & 5.2551 & TRN & \\
\hline CHEMBL1380986 & 688724 & 5.3 & 5.0873 & TRN & \\
\hline CHEMBL1421845 & 688724 & 4.35 & 4.6041 & TST & \\
\hline CHEMBL1603253 & 688724 & 4.45 & 4.9369 & TST & \\
\hline CHEMBL1391678 & 688724 & 5.0 & 4.7569 & TRN & \\
\hline CHEMBL1995948 & 688724 & 5.4 & 4.6196 & TRN & \\
\hline CHEMBL 3212292 & 688724 & 4.4 & 4.6283 & TST & \\
\hline CHEMBL1424694 & 688724 & 7.4001 & 5.2727 & TRN & \\
\hline CHEMBL1449105 & 688724 & 4.35 & 4.9612 & TRN & \\
\hline CHEMBL1534730 & 688724 & 5.9 & 4.537 & TST & \\
\hline CHEMBL1368261 & 688724 & 6.5501 & 5.2418 & TRN & \\
\hline CHEMBL1376354 & 688724 & 4.1 & 5.2107 & TST & \\
\hline CHEMBL1528847 & 688724 & 4.85 & 4.5699 & TRN & \\
\hline CHEMBL1309765 & 688724 & 4.45 & 4.5127 & TRN & \\
\hline CHEMBL1521086 & 688724 & 4.75 & 4.5462 & TST & \\
\hline CHEMBL1472886 & 688724 & 5.1 & 5.0611 & TRN & \\
\hline CHEMBL 3192010 & 688724 & 5.35 & 5.2423 & TRN & \\
\hline CHEMBL 3210982 & 688724 & 4.9 & 4.6976 & TRN & \\
\hline CHEMBL1439630 & 688724 & 4.4 & 4.7488 & TST & \\
\hline CHEMBL1334926 & 688724 & 6.6 & 4.6727 & TST & \\
\hline CHEMBL1536704 & 688724 & 6.6 & 4.4156 & TST & \\
\hline CHEMBL1603572 & 688724 & 4.35 & 4.8588 & TRN & \\
\hline CHEMBL1510336 & 688724 & 4.6 & 4.7943 & TRN & \\
\hline CHEMBL1582919 & 688724 & 4.4 & 5.4524 & TRN & \\
\hline CHEMBL1300154 & 688724 & 4.7 & 4.9632 & TRN & \\
\hline CHEMBL1411971 & 688724 & 4.4 & 4.6688 & TRN & \\
\hline CHEMBL3196296 & 688724 & 4.4 & 5.05 & TRN & \\
\hline CHEMBL1365809 & 688724 & 4.55 & 4.7582 & TRN & \\
\hline CHEMBL1508617 & 688724 & 4.3 & 4.5856 & TST & \\
\hline CHEMBL1421850 & 688724 & 5.35 & 4.8394 & TRN & \\
\hline CHEMBL3198438 & 688724 & 5.4 & 4.7603 & TRN & \\
\hline CHEMBL1450898 & 688724 & 4.1 & 4.5714 & TRN & \\
\hline CHEMBL 1487050 & 688724 & 5.6 & 4.5516 & TST & \\
\hline CHEMBL3193504 & 688724 & 4.35 & 4.7928 & TRN & \\
\hline CHEMBL3190104 & 688724 & 4.85 & 4.7758 & TRN & \\
\hline CHEMBL1080648 & 688724 & 5.4 & 4.6544 & TRN & \\
\hline
\end{tabular}




\begin{tabular}{|c|c|c|c|c|c|}
\hline \multicolumn{6}{|c|}{ Supplemental Table S2.txt } \\
\hline CHEMBL1369913 & 688724 & 5.6 & 5.2455 & TRN & \\
\hline CHEMBL3199832 & 688724 & 5.3 & 5.0026 & TST & \\
\hline CHEMBL3192824 & 688724 & 4.75 & 5.1365 & TST & \\
\hline CHEMBL1426121 & 688724 & 4.75 & 4.664 & TST & \\
\hline CHEMBL1463958 & 688724 & 4.05 & 4.574 & TST & \\
\hline CHEMBL1409269 & 688724 & 4.95 & 5.3078 & TRN & \\
\hline CHEMBL1529525 & 688724 & 4.1 & 4.5449 & TST & \\
\hline CHEMBL1568537 & 688724 & 4.5 & 4.6569 & TRN & \\
\hline CHEMBL1300211 & 688724 & 4.5 & 5.0172 & TST & \\
\hline CHEMBL1560053 & 688724 & 4.3 & 4.5893 & TRN & \\
\hline CHEMBL1378968 & 688724 & 4.75 & 4.9097 & TRN & \\
\hline CHEMBL1555132 & 688724 & 4.75 & 4.8953 & TST & \\
\hline CHEMBL1470520 & 688724 & 4.95 & 5.1177 & TRN & \\
\hline CHEMBL1372610 & 688724 & 5.0 & 4.9662 & TRN & \\
\hline CHEMBL293776 & 688724 & 6.0 & 4.9441 & TRN & \\
\hline CHEMBL80941 & 688724 & 5.5 & 5.4668 & TRN & \\
\hline CHEMBL1554742 & 688724 & 4.6 & 5.2226 & TRN & \\
\hline CHEMBL1342664 & 688724 & 4.3 & 4.4591 & TRN & \\
\hline CHEMBL1484544 & 688724 & 4.25 & 4.5699 & TRN & \\
\hline CHEMBL1490988 & 688724 & 5.6 & 4.8547 & TST & \\
\hline CHEMBL1596516 & 688724 & 4.55 & 4.4665 & TRN & \\
\hline CHEMBL1590897 & 688724 & 4.15 & 4.399 & TRN & \\
\hline CHEMBL1376436 & 688724 & 4.1 & 4.6438 & TRN & \\
\hline CHEMBL1529809 & 688724 & 4.7 & 4.9471 & TRN & \\
\hline CHEMBL1539579 & 688724 & 6.25 & 5.6432 & TRN & \\
\hline CHEMBL1551909 & 688724 & 4.3 & 5.0067 & TRN & \\
\hline CHEMBL1383746 & 688724 & 5.0 & 5.0481 & TRN & \\
\hline CHEMBL1495778 & 688724 & 5.6 & 4.9011 & TRN & \\
\hline CHEMBL1402664 & 688724 & 5.85 & 5.1654 & TRN & \\
\hline CHEMBL1469110 & 688724 & 5.45 & 4.9014 & TRN & \\
\hline CHEMBL1589109 & 688724 & 4.75 & 4.75899 & 99999999995 & TRN \\
\hline CHEMBL1420032 & 688724 & 4.75 & 4.8592 & TRN & \\
\hline CHEMBL1721226 & 688724 & 4.6 & 5.0502 & TRN & \\
\hline CHEMBL1516650 & 688724 & 4.0 & 4.867 & TST & \\
\hline CHEMBL1491598 & 688724 & 5.35 & 4.9382 & TRN & \\
\hline CHEMBL1510868 & 688724 & 4.95 & 4.9448 & TST & \\
\hline CHEMBL1402044 & 688724 & 4.75 & 4.9702 & TRN & \\
\hline CHEMBL1312929 & 688724 & 4.3 & 4.7108 & TST & \\
\hline CHEMBL1392781 & 688724 & 4.0 & 4.3966 & TST & \\
\hline CHEMBL1553466 & 688724 & 4.5 & 4.2852 & TST & \\
\hline CHEMBL 209102 & 688724 & 4.05 & 4.7956 & TRN & \\
\hline CHEMBL1392052 & 688724 & 4.7 & 5.0796 & TRN & \\
\hline CHEMBL1544400 & 688724 & 4.4 & 5.0062 & TST & \\
\hline CHEMBL1335961 & 688724 & 4.9 & 4.8634 & TRN & \\
\hline CHEMBL3189743 & 688724 & 5.0 & 5.278 & TRN & \\
\hline CHEMBL402468 & 688724 & 6.9 & 4.8437 & TRN & \\
\hline CHEMBL1386091 & 688724 & 4.2 & 4.8701 & TST & \\
\hline CHEMBL1451715 & 688724 & 4.45 & 4.8861 & TST & \\
\hline
\end{tabular}




\begin{tabular}{|c|c|c|c|c|}
\hline \multicolumn{5}{|c|}{ Supplemental Table } \\
\hline CHEMBL1549682 & 688724 & 5.35 & 4.7603 & TST \\
\hline CHEMBL1539368 & 688724 & 5.0 & 4.7266 & TRN \\
\hline CHEMBL1371889 & 688724 & 4.75 & 4.5631 & TST \\
\hline CHEMBL1362244 & 688724 & 4.65 & 4.7025 & TRN \\
\hline CHEMBL3197525 & 688724 & 5.05 & 4.6481 & TST \\
\hline CHEMBL1235717 & 688724 & 4.75 & 5.0942 & TST \\
\hline CHEMBL1387693 & 688724 & 4.25 & 5.1388 & TRN \\
\hline CHEMBL1577554 & 688724 & 4.05 & 4.6314 & TRN \\
\hline CHEMBL1458941 & 688724 & 4.5 & 4.9093 & TST \\
\hline CHEMBL1532597 & 688724 & 4.1 & 4.8028 & TRN \\
\hline CHEMBL1404205 & 688724 & 4.65 & 5.4111 & TRN \\
\hline CHEMBL3192096 & 688724 & 4.85 & 4.8203 & TRN \\
\hline CHEMBL1503929 & 688724 & 4.55 & 4.4638 & TRN \\
\hline CHEMBL1354424 & 688724 & 7.2 & 5.1163 & TST \\
\hline CHEMBL1424588 & 688724 & 4.75 & 5.0355 & TRN \\
\hline CHEMBL1447828 & 688724 & 5.05 & 4.6765 & TRN \\
\hline CHEMBL1337734 & 688724 & 5.95 & 5.0234 & TST \\
\hline CHEMBL1458629 & 688724 & 4.35 & 4.6293 & TST \\
\hline CHEMBL1999480 & 688724 & 4.9 & 4.901 & TRN \\
\hline CHEMBL1491470 & 688724 & 4.4 & 4.6377 & TRN \\
\hline CHEMBL1557171 & 688724 & 4.3 & 4.2795 & TST \\
\hline CHEMBL1492802 & 688724 & 4.4 & 4.3986 & TRN \\
\hline CHEMBL1528968 & 688724 & 4.75 & 4.8042 & TST \\
\hline CHEMBL1359760 & 688724 & 6.95 & 4.647 & TST \\
\hline CHEMBL1384007 & 688724 & 4.5 & 4.8219 & TRN \\
\hline CHEMBL1367691 & 688724 & 5.1 & 4.6437 & TRN \\
\hline CHEMBL1330433 & 688724 & 4.2 & 4.9992 & TRN \\
\hline CHEMBL1331150 & 688724 & 4.0 & 4.4886 & TRN \\
\hline CHEMBL1509421 & 688724 & 4.35 & 4.6167 & TST \\
\hline CHEMBL1562311 & 688724 & 4.45 & 4.3481 & TST \\
\hline CHEMBL1389185 & 688724 & 4.55 & 4.6985 & TRN \\
\hline CHEMBL1512375 & 688724 & 4.85 & 4.5375 & TRN \\
\hline CHEMBL3198222 & 688724 & 4.35 & 4.5479 & TRN \\
\hline CHEMBL1546947 & 688724 & 5.7 & 4.879 & TRN \\
\hline CHEMBL1333319 & 688724 & 4.5 & 4.728 & TRN \\
\hline CHEMBL1491773 & 688724 & 5.05 & 4.5484 & TRN \\
\hline CHEMBL1304416 & 688724 & 4.25 & 4.258 & TRN \\
\hline CHEMBL1504708 & 688724 & 4.1 & 4.811 & TRN \\
\hline CHEMBL1302915 & 688724 & 4.4 & 4.4778 & TST \\
\hline CHEMBL1374976 & 688724 & 4.7 & 5.2167 & TRN \\
\hline CHEMBL1430795 & 688724 & 4.4 & 4.5203 & TRN \\
\hline CHEMBL3189416 & 688724 & 5.9 & 5.3002 & TRN \\
\hline CHEMBL1300506 & 688724 & 6.45 & 4.9766 & TST \\
\hline CHEMBL 278980 & 688724 & 4.55 & 5.3092 & TST \\
\hline CHEMBL1552409 & 688724 & 4.75 & 5.0959 & TST \\
\hline CHEMBL1558950 & 688724 & 4.25 & 4.7006 & TRN \\
\hline CHEMBL1564166 & 688724 & 4.45 & 4.306 & TRN \\
\hline CHEMBL1537741 & 688724 & 4.55 & 4.8623 & TST \\
\hline
\end{tabular}




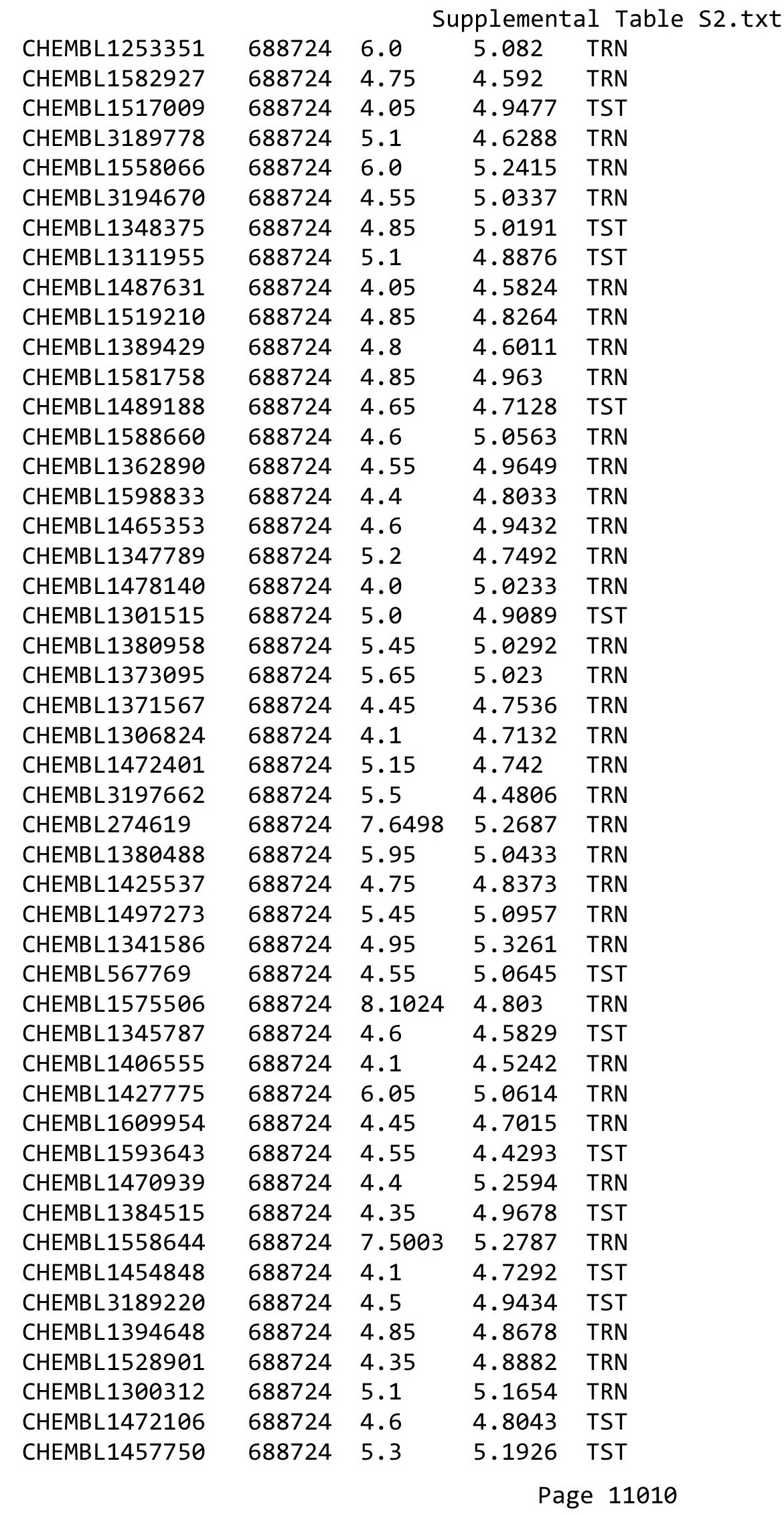




\begin{tabular}{|c|c|c|c|c|c|}
\hline \multicolumn{6}{|c|}{ plemental } \\
\hline CHEMBL1578960 & 688724 & 4.9 & 4.9429 & TST & \\
\hline CHEMBL1464823 & 688724 & 4.0 & 4.6662 & TST & \\
\hline CHEMBL1564195 & 688724 & 5.3 & 4.5323 & TRN & \\
\hline CHEMBL1503307 & 688724 & 5.3 & 4.7528 & TRN & \\
\hline CHEMBL1587667 & 688724 & 4.25 & 4.4222 & TRN & \\
\hline CHEMBL1467866 & 688724 & 5.05 & 4.8218 & TRN & \\
\hline CHEMBL1562110 & 688724 & 4.8 & 4.8409 & TRN & \\
\hline CHEMBL1555535 & 688724 & 6.7001 & 5.5218 & TRN & \\
\hline CHEMBL1366048 & 688724 & 4.85 & 4.6137 & TRN & \\
\hline CHEMBL1520034 & 688724 & 4.3 & 4.8979 & TST & \\
\hline CHEMBL3212518 & 688724 & 4.4 & 4.4376 & TRN & \\
\hline CHEMBL1493910 & 688724 & 4.25 & 4.3458 & TRN & \\
\hline CHEMBL1491222 & 688724 & 5.3 & 5.7255 & TRN & \\
\hline CHEMBL1439815 & 688724 & 4.95 & 4.5106 & TRN & \\
\hline CHEMBL1503071 & 688724 & 4.7 & 4.5188 & TST & \\
\hline CHEMBL1327973 & 688724 & 7.5498 & 5.0777 & TRN & \\
\hline CHEMBL1522037 & 688724 & 4.8 & 4.883 & TRN & \\
\hline CHEMBL1322848 & 688724 & 5.5 & 4.8317 & TRN & \\
\hline CHEMBL1985165 & 688724 & 4.5 & 4.5166 & TRN & \\
\hline CHEMBL1576254 & 688724 & 5.15 & 5.0291 & TST & \\
\hline CHEMBL1322710 & 688724 & 4.6 & 4.774 & TRN & \\
\hline CHEMBL1523477 & 688724 & 5.6 & 5.0115 & TST & \\
\hline CHEMBL17331 & 688724 & 6.0 & 4.7929 & TRN & \\
\hline CHEMBL1552869 & 688724 & 4.5 & 4.7764 & TST & \\
\hline CHEMBL1342488 & 688724 & 4.75 & 4.6979 & TST & \\
\hline CHEMBL1582071 & 688724 & 4.95 & 4.478 & TRN & \\
\hline CHEMBL1372039 & 688724 & 4.3 & 4.449 & TRN & \\
\hline CHEMBL1585753 & 688724 & 4.6 & 4.5314 & TST & \\
\hline CHEMBL1492704 & 688724 & 4.0 & 4.6276 & TST & \\
\hline CHEMBL1374886 & 688724 & 4.8 & 4.9561 & TRN & \\
\hline CHEMBL1530141 & 688724 & 4.35 & 5.04899 & 99999999995 & TST \\
\hline CHEMBL1326340 & 688724 & 4.35 & 4.8944 & TRN & \\
\hline CHEMBL1338220 & 688724 & 4.05 & 4.6879 & TRN & \\
\hline CHEMBL1467347 & 688724 & 4.05 & 4.4 & TRN & \\
\hline CHEMBL1516858 & 688724 & 4.95 & 5.0657 & TST & \\
\hline CHEMBL1357592 & 688724 & 4.4 & 4.7118 & TST & \\
\hline CHEMBL1460173 & 688724 & 4.0 & 4.6284 & TRN & \\
\hline CHEMBL1324508 & 688724 & 4.75 & 4.6057 & TST & \\
\hline CHEMBL1318708 & 688724 & 5.45 & 5.2141 & TRN & \\
\hline CHEMBL1349969 & 688724 & 4.0 & 4.3216 & TRN & \\
\hline CHEMBL1566611 & 688724 & 4.7 & 4.525 & TST & \\
\hline CHEMBL1499444 & 688724 & 4.95 & 4.8037 & TST & \\
\hline CHEMBL1440349 & 688724 & 5.45 & 5.1477 & TST & \\
\hline CHEMBL1324568 & 688724 & 4.05 & 4.688 & TRN & \\
\hline CHEMBL1256813 & 688724 & 4.55 & 4.878 & TST & \\
\hline CHEMBL1387558 & 688724 & 4.25 & 4.5125 & TRN & \\
\hline CHEMBL1409522 & 688724 & 4.55 & 4.5949 & TRN & \\
\hline CHEMBL1480813 & 688724 & 4.8 & 4.5597 & TST & \\
\hline
\end{tabular}




\begin{tabular}{|c|c|c|c|c|c|}
\hline \multicolumn{6}{|c|}{ Supplemental Table S2.txt } \\
\hline CHEMBL1510406 & 688724 & 4.6 & 4.8602 & TST & \\
\hline CHEMBL1532515 & 688724 & 4.95 & 4.9673 & TRN & \\
\hline CHEMBL1533497 & 688724 & 6.25 & 5.1531 & TRN & \\
\hline CHEMBL1564056 & 688724 & 5.2 & 4.721 & TST & \\
\hline CHEMBL1391976 & 688724 & 4.55 & 4.6285 & TRN & \\
\hline CHEMBL1460052 & 688724 & 4.7 & 5.1947 & TST & \\
\hline CHEMBL1418214 & 688724 & 4.6 & 5.1404 & TST & \\
\hline CHEMBL1507261 & 688724 & 4.55 & 4.5977 & TRN & \\
\hline CHEMBL1469047 & 688724 & 4.4 & 4.859 & TRN & \\
\hline CHEMBL1365562 & 688724 & 6.1 & 5.0818 & TST & \\
\hline CHEMBL1571648 & 688724 & 5.3 & 5.1509 & TST & \\
\hline CHEMBL1525494 & 688724 & 4.55 & 5.0791 & TST & \\
\hline CHEMBL1498939 & 688724 & 4.75 & 4.9815 & TRN & \\
\hline CHEMBL1311853 & 688724 & 4.45 & 4.9273 & TRN & \\
\hline CHEMBL1424109 & 688724 & 5.05 & 4.5938 & TST & \\
\hline CHEMBL1554531 & 688724 & 4.35 & 4.7029 & TRN & \\
\hline CHEMBL1393087 & 688724 & 4.7 & 4.5741 & TRN & \\
\hline CHEMBL1475784 & 688724 & 5.65 & 4.7374 & TRN & \\
\hline CHEMBL1368760 & 688724 & 4.4 & 4.9918 & TST & \\
\hline CHEMBL1602112 & 688724 & 4.9 & 4.5505 & TRN & \\
\hline CHEMBL 29726 & 688724 & 6.2 & 5.2135 & TRN & \\
\hline CHEMBL1419923 & 688724 & 4.1 & 4.5821 & TST & \\
\hline CHEMBL1551991 & 688724 & 6.25 & 4.9272 & TST & \\
\hline CHEMBL1341022 & 688724 & 4.9 & 4.9932 & TRN & \\
\hline CHEMBL559934 & 688724 & 5.1 & 5.1855 & TRN & \\
\hline CHEMBL1519030 & 688724 & 4.3 & 5.45100 & 00000000005 & TST \\
\hline CHEMBL1401426 & 688724 & 4.6 & 4.0986 & TRN & \\
\hline CHEMBL1442974 & 688724 & 3.9 & 4.3294 & TRN & \\
\hline CHEMBL1425897 & 688724 & 4.8 & 5.0893 & TRN & \\
\hline CHEMBL1374646 & 688724 & 4.35 & 4.8371 & TST & \\
\hline CHEMBL1426603 & 688724 & 4.75 & 4.7492 & TST & \\
\hline CHEMBL1427642 & 688724 & 4.5 & 4.5901 & TRN & \\
\hline CHEMBL1584192 & 688724 & 4.4 & 4.6478 & TRN & \\
\hline CHEMBL1360615 & 688724 & 4.4 & 4.9881 & TRN & \\
\hline CHEMBL1566068 & 688724 & 4.9 & 4.6396 & TRN & \\
\hline CHEMBL1489071 & 688724 & 5.85 & 5.1984 & TRN & \\
\hline CHEMBL1327756 & 688724 & 4.05 & 4.7012 & TST & \\
\hline CHEMBL3197709 & 688724 & 4.1 & 4.4752 & TRN & \\
\hline CHEMBL355280 & 688724 & 4.05 & 4.8706 & TRN & \\
\hline CHEMBL1556316 & 688724 & 4.3 & 4.3757 & TRN & \\
\hline CHEMBL1304194 & 688724 & 5.2 & 4.9984 & TST & \\
\hline CHEMBL1548022 & 688724 & 4.55 & 5.0562 & TST & \\
\hline CHEMBL1594374 & 688724 & 6.1 & 5.1956 & TST & \\
\hline CHEMBL1551764 & 688724 & 4.45 & 4.3694 & TRN & \\
\hline CHEMBL 362223 & 688724 & 4.25 & 4.7947 & TRN & \\
\hline CHEMBL1481246 & 688724 & 4.25 & 5.2826 & TST & \\
\hline CHEMBL1536068 & 688724 & 5.05 & 4.8492 & TST & \\
\hline CHEMBL1456872 & 688724 & 5.2 & 4.6269 & TRN & \\
\hline
\end{tabular}




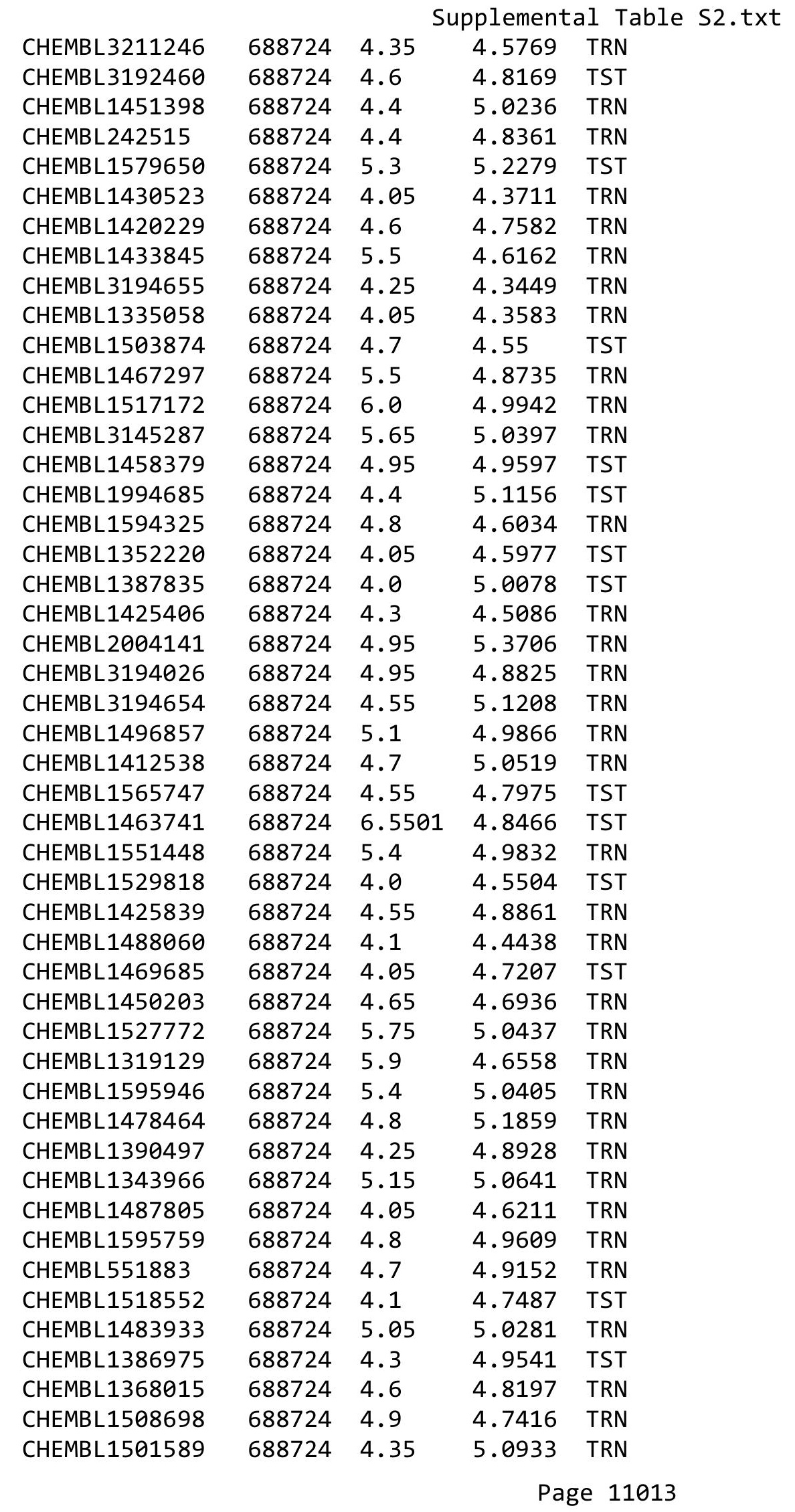




\begin{tabular}{|c|c|c|c|c|c|}
\hline \multicolumn{6}{|c|}{ Supplemental Table S2.txt } \\
\hline CHEMBL558569 & 688724 & 4.95 & 4.2827 & TRN & \\
\hline CHEMBL1494226 & 688724 & 4.0 & 4.9513 & TST & \\
\hline CHEMBL1358777 & 688724 & 5.3 & 4.8837 & TRN & \\
\hline CHEMBL1601234 & 688724 & 4.45 & 4.2737 & TST & \\
\hline CHEMBL1447034 & 688724 & 5.6 & 5.4842 & TRN & \\
\hline CHEMBL1551188 & 688724 & 4.1 & 4.5812 & TST & \\
\hline CHEMBL1587791 & 688724 & 4.75 & 4.6531 & TRN & \\
\hline CHEMBL 2374058 & 688724 & 4.2 & 5.2701 & TST & \\
\hline CHEMBL578741 & 688724 & 6.0 & 4.9689 & TRN & \\
\hline CHEMBL1577918 & 688724 & 4.45 & 4.5008 & TRN & \\
\hline CHEMBL1360618 & 688724 & 4.0 & 4.6965 & TRN & \\
\hline CHEMBL1518871 & 688724 & 4.35 & 5.1367 & TRN & \\
\hline CHEMBL1585527 & 688724 & 5.4 & 5.4921 & TRN & \\
\hline CHEMBL1417352 & 688724 & 4.15 & 4.7831 & TST & \\
\hline CHEMBL1388131 & 688724 & 4.7 & 4.6754 & TRN & \\
\hline CHEMBL1561618 & 688724 & 4.45 & 4.6566 & TRN & \\
\hline CHEMBL1300803 & 688724 & 6.0 & 4.8166 & TRN & \\
\hline CHEMBL1602379 & 688724 & 4.8 & 4.8633 & TST & \\
\hline CHEMBL1459828 & 688724 & 4.7 & 4.8759 & TRN & \\
\hline CHEMBL1970824 & 688724 & 4.95 & 4.6425 & TRN & \\
\hline CHEMBL1592322 & 688724 & 4.75 & 4.6296 & TRN & \\
\hline CHEMBL1612004 & 688724 & 4.25 & 4.9306 & TST & \\
\hline CHEMBL1473102 & 688724 & 4.45 & 4.4519 & TST & \\
\hline CHEMBL1467058 & 688724 & 5.0 & 5.5392 & TRN & \\
\hline CHEMBL1389163 & 688724 & 4.9 & 4.7752 & TRN & \\
\hline CHEMBL 2007390 & 688724 & 4.8 & 5.3753 & TST & \\
\hline CHEMBL1493245 & 688724 & 4.0 & 4.7134 & TRN & \\
\hline CHEMBL 3145010 & 688724 & 4.35 & 4.956 & TRN & \\
\hline CHEMBL1406634 & 688724 & 4.75 & 4.4734 & TST & \\
\hline CHEMBL1381375 & 688724 & 4.0 & 4.4147 & TRN & \\
\hline CHEMBL1377552 & 688724 & 4.75 & 4.7202 & TST & \\
\hline CHEMBL1451087 & 688724 & 4.05 & 5.0197 & TRN & \\
\hline CHEMBL1479078 & 688724 & 6.0 & 5.2219 & TRN & \\
\hline CHEMBL1583021 & 688724 & 4.85 & 4.78600 & 00000000005 & TRN \\
\hline CHEMBL1462323 & 688724 & 7.9508 & 4.89 & TRN & \\
\hline CHEMBL1305946 & 688724 & 4.95 & 4.5884 & TST & \\
\hline CHEMBL1526342 & 688724 & 4.55 & 4.6953 & TRN & \\
\hline CHEMBL1560433 & 688724 & 4.7 & 4.9803 & TST & \\
\hline CHEMBL195895 & 688724 & 4.15 & 4.7028 & TST & \\
\hline CHEMBL18797 & 688724 & 4.35 & 4.91100 & 00000000005 & TST \\
\hline CHEMBL1497944 & 688724 & 4.35 & 5.1273 & TRN & \\
\hline CHEMBL1487635 & 688724 & 6.0 & 5.0656 & TRN & \\
\hline CHEMBL1539811 & 688724 & 4.45 & 4.7136 & TST & \\
\hline CHEMBL1362915 & 688724 & 4.95 & 4.6678 & TRN & \\
\hline CHEMBL1407676 & 688724 & 4.7 & 5.2158 & TRN & \\
\hline CHEMBL66693 & 688724 & 5.6 & 5.1603 & TST & \\
\hline CHEMBL1477225 & 688724 & 4.35 & 4.667 & TRN & \\
\hline CHEMBL1602892 & 688724 & 4.5 & 4.8359 & TRN & \\
\hline
\end{tabular}




\begin{tabular}{|c|c|c|c|c|}
\hline \multicolumn{5}{|c|}{ Supplemental Table s2.txt } \\
\hline CHEMBL 3192648 & 688724 & 6.8 & 5.1834 & TRN \\
\hline CHEMBL1370162 & 688724 & 5.75 & 4.7972 & TST \\
\hline CHEMBL1485048 & 688724 & 4.75 & 5.1132 & TRN \\
\hline CHEMBL1387831 & 688724 & 4.05 & 4.8431 & TRN \\
\hline CHEMBL1392104 & 688724 & 5.0 & 4.5811 & TRN \\
\hline CHEMBL1508964 & 688724 & 4.05 & 4.7945 & TRN \\
\hline CHEMBL1379365 & 688724 & 6.7501 & 5.3655 & TRN \\
\hline CHEMBL1460032 & 688724 & 5.05 & 5.121 & TRN \\
\hline CHEMBL1373115 & 688724 & 7.0 & 4.7114 & TRN \\
\hline CHEMBL1483277 & 688724 & 4.55 & 4.9429 & TST \\
\hline CHEMBL1603385 & 688724 & 5.35 & 4.7325 & TRN \\
\hline CHEMBL3194157 & 688724 & 4.3 & 4.782 & TRN \\
\hline CHEMBL1400120 & 688724 & 5.1 & 4.7313 & TRN \\
\hline CHEMBL1556041 & 688724 & 4.6 & 4.6647 & TRN \\
\hline CHEMBL1422842 & 688724 & 6.15 & 4.8817 & TRN \\
\hline CHEMBL3190381 & 688724 & 4.8 & 4.9348 & TRN \\
\hline CHEMBL1391539 & 688724 & 4.95 & 4.7098 & TRN \\
\hline CHEMBL3190697 & 688724 & 6.0 & 4.9477 & TRN \\
\hline CHEMBL1566795 & 688724 & 4.9 & 4.5729 & TRN \\
\hline CHEMBL1318970 & 688724 & 4.35 & 4.9519 & TRN \\
\hline CHEMBL1533561 & 688724 & 4.4 & 4.6249 & TRN \\
\hline CHEMBL1354502 & 688724 & 6.0 & 5.2079 & TRN \\
\hline CHEMBL1356036 & 688724 & 4.2 & 4.8133 & TST \\
\hline CHEMBL1354789 & 688724 & 4.1 & 4.4677 & TST \\
\hline CHEMBL1406197 & 688724 & 4.45 & 4.8083 & TST \\
\hline CHEMBL3196430 & 688724 & 5.15 & 4.893 & TST \\
\hline CHEMBL1399121 & 688724 & 4.6 & 4.8258 & TRN \\
\hline CHEMBL276727 & 688724 & 4.4 & 5.1182 & TST \\
\hline CHEMBL1569629 & 688724 & 4.5 & 4.6472 & TRN \\
\hline CHEMBL1608377 & 688724 & 4.7 & 4.4672 & TRN \\
\hline CHEMBL1361080 & 688724 & 4.65 & 4.7309 & TRN \\
\hline CHEMBL1438745 & 688724 & 4.3 & 4.3972 & TRN \\
\hline CHEMBL1342012 & 688724 & 4.3 & 4.8617 & TST \\
\hline CHEMBL1410512 & 688724 & 4.75 & 4.7497 & TRN \\
\hline CHEMBL1462044 & 688724 & 4.9 & 4.9356 & TRN \\
\hline CHEMBL 235891 & 688724 & 5.25 & 5.318 & TRN \\
\hline CHEMBL1336912 & 688724 & 4.0 & 4.4028 & TST \\
\hline CHEMBL1414224 & 688724 & 4.5 & 4.8873 & TRN \\
\hline CHEMBL1609769 & 688724 & 4.4 & 5.4424 & TST \\
\hline CHEMBL440084 & 688724 & 6.0 & 4.8892 & TST \\
\hline CHEMBL1488172 & 688724 & 5.35 & 5.6992 & TRN \\
\hline CHEMBL1505247 & 688724 & 4.85 & 4.8651 & TST \\
\hline CHEMBL1371955 & 688724 & 4.6 & 5.008 & TST \\
\hline CHEMBL1613004 & 688724 & 6.3 & 5.3289 & TST \\
\hline CHEMBL1573446 & 688724 & 4.4 & 4.8344 & TRN \\
\hline CHEMBL1436294 & 688724 & 6.7501 & 5.0188 & TST \\
\hline CHEMBL63829 & 688724 & 4.2 & 5.1991 & TST \\
\hline CHEMBL3198220 & 688724 & 4.35 & 4.3766 & TRN \\
\hline
\end{tabular}




\begin{tabular}{|c|c|c|c|c|}
\hline & & & ipplement & al Table S2. \\
\hline CHEMBL1561907 & 688724 & 4.85 & 4.8932 & TST \\
\hline CHEMBL1602303 & 688724 & 4.8 & 4.6388 & TRN \\
\hline CHEMBL1476669 & 688724 & 4.6 & 4.36 & TRN \\
\hline CHEMBL3197494 & 688724 & 5.05 & 5.1994 & TRN \\
\hline CHEMBL1523171 & 688724 & 4.05 & 4.4576 & TST \\
\hline CHEMBL1331760 & 688724 & 4.5 & 4.6293 & TST \\
\hline CHEMBL1580209 & 688724 & 5.0 & 5.1917 & TRN \\
\hline CHEMBL1420591 & 688724 & 4.4 & 4.662 & TST \\
\hline CHEMBL1339277 & 688724 & 4.4 & 4.8781 & TRN \\
\hline CHEMBL3235884 & 688724 & 5.2 & 4.6499 & TRN \\
\hline CHEMBL 2374044 & 688724 & 5.15 & 5.3247 & TST \\
\hline CHEMBL1593607 & 688724 & 4.75 & 4.5663 & TRN \\
\hline CHEMBL1978997 & 688724 & 4.85 & 5.0185 & TRN \\
\hline CHEMBL1993746 & 688724 & 4.65 & 5.2158 & TRN \\
\hline CHEMBL1498236 & 688724 & 4.1 & 4.9376 & TST \\
\hline CHEMBL1500960 & 688724 & 5.75 & 5.3776 & TRN \\
\hline CHEMBL1314247 & 688724 & 4.7 & 4.6049 & TRN \\
\hline CHEMBL1328571 & 688724 & 4.25 & 4.7549 & TRN \\
\hline CHEMBL1974389 & 688724 & 4.75 & 4.9177 & TRN \\
\hline CHEMBL 2107391 & 688724 & 5.5 & 5.3487 & TST \\
\hline CHEMBL3196046 & 688724 & 5.0 & 4.5022 & TRN \\
\hline CHEMBL3197595 & 688724 & 4.55 & 4.5539 & TRN \\
\hline CHEMBL1406895 & 688724 & 4.65 & 5.0466 & TRN \\
\hline CHEMBL1564305 & 688724 & 4.85 & 4.6327 & TST \\
\hline CHEMBL3189180 & 688724 & 4.9 & 4.6977 & TRN \\
\hline CHEMBL1578546 & 688724 & 4.8 & 4.4649 & TRN \\
\hline CHEMBL1432715 & 688724 & 5.0 & 5.0603 & TRN \\
\hline CHEMBL3145382 & 688724 & 4.55 & 5.126 & TRN \\
\hline CHEMBL 3196540 & 688724 & 6.0 & 4.66100 & 00000000005 \\
\hline CHEMBL1423627 & 688724 & 4.0 & 4.6223 & TST \\
\hline CHEMBL1329045 & 688724 & 4.15 & 4.8387 & TST \\
\hline CHEMBL69234 & 688724 & 6.0 & 5.1198 & TRN \\
\hline CHEMBL 3213021 & 688724 & 5.15 & 4.6831 & TRN \\
\hline CHEMBL1499346 & 688724 & 5.05 & 4.4617 & TRN \\
\hline CHEMBL1479083 & 688724 & 4.95 & 5.1536 & TRN \\
\hline CHEMBL3196343 & 688724 & 5.2 & 4.6041 & TRN \\
\hline CHEMBL1331729 & 688724 & 4.55 & 4.845 & TRN \\
\hline CHEMBL1311607 & 688724 & 4.35 & 4.6914 & TST \\
\hline CHEMBL1329771 & 688724 & 4.05 & 4.7294 & TST \\
\hline CHEMBL1422448 & 688724 & 4.6 & 4.7508 & TRN \\
\hline CHEMBL1547235 & 688724 & 4.4 & 4.8162 & TST \\
\hline CHEMBL1529687 & 688724 & 5.5 & 5.0729 & TRN \\
\hline CHEMBL1368038 & 688724 & 5.5 & 5.1996 & TRN \\
\hline CHEMBL1386272 & 688724 & 4.75 & 4.7634 & TRN \\
\hline CHEMBL2001211 & 688724 & 6.95 & 5.2209 & TRN \\
\hline CHEMBL1975523 & 688724 & 4.6 & 5.3147 & TRN \\
\hline CHEMBL1414316 & 688724 & 4.55 & 5.032 & TST \\
\hline CHEMBL1538232 & 688724 & 4.35 & 4.6531 & TRN \\
\hline
\end{tabular}




\begin{tabular}{|c|c|c|c|c|}
\hline \multicolumn{5}{|c|}{ Supplemental Table S2.txt } \\
\hline CHEMBL1322976 & 688724 & 6.0 & 5.2095 & TRN \\
\hline CHEMBL1506938 & 688724 & 4.95 & 4.8591 & TRN \\
\hline CHEMBL1559708 & 688724 & 4.65 & 4.7428 & TST \\
\hline CHEMBL1532112 & 688724 & 4.05 & 5.2008 & TRN \\
\hline CHEMBL1967814 & 688724 & 4.25 & 4.6723 & TRN \\
\hline CHEMBL1544909 & 688724 & 4.8 & 5.0113 & TRN \\
\hline CHEMBL3194218 & 688724 & 4.5 & 4.8931 & TRN \\
\hline CHEMBL1427643 & 688724 & 4.75 & 4.9096 & TRN \\
\hline CHEMBL3198576 & 688724 & 5.25 & 5.1769 & TRN \\
\hline CHEMBL1520215 & 688724 & 4.4 & 4.8958 & TRN \\
\hline CHEMBL 3211198 & 688724 & 4.5 & 5.1114 & TRN \\
\hline CHEMBL1571661 & 688724 & 4.15 & 4.8821 & TRN \\
\hline CHEMBL1495589 & 688724 & 4.5 & 4.7139 & TRN \\
\hline CHEMBL1386352 & 688724 & 4.8 & 4.6059 & TRN \\
\hline CHEMBL1315876 & 688724 & 4.3 & 4.5732 & TRN \\
\hline CHEMBL1323795 & 688724 & 4.95 & 5.0682 & TST \\
\hline CHEMBL1432336 & 688724 & 4.8 & 4.7991 & TRN \\
\hline CHEMBL1548498 & 688724 & 5.5 & 4.9605 & TST \\
\hline CHEMBL1511858 & 688724 & 4.45 & 4.6296 & TRN \\
\hline CHEMBL1321218 & 688724 & 4.85 & 4.9047 & TRN \\
\hline CHEMBL1509111 & 688724 & 6.6 & 4.9875 & TRN \\
\hline CHEMBL1965687 & 688724 & 5.0 & 5.1953 & TRN \\
\hline CHEMBL1318103 & 688724 & 4.7 & 4.957 & TRN \\
\hline CHEMBL1334484 & 688724 & 5.7 & 5.1047 & TRN \\
\hline CHEMBL1443884 & 688724 & 4.35 & 4.6545 & TRN \\
\hline CHEMBL1357611 & 688724 & 4.4 & 4.4116 & TRN \\
\hline CHEMBL1558015 & 688724 & 4.3 & 4.6329 & TRN \\
\hline CHEMBL1613089 & 688724 & 4.8 & 5.018 & TRN \\
\hline CHEMBL1419788 & 688724 & 4.55 & 4.7235 & TST \\
\hline CHEMBL1461980 & 688724 & 4.35 & 4.9763 & TRN \\
\hline CHEMBL1393762 & 688724 & 4.35 & 4.6989 & TRN \\
\hline CHEMBL3193886 & 688724 & 4.95 & 4.9949 & TST \\
\hline CHEMBL1462513 & 688724 & 5.6 & 4.9192 & TRN \\
\hline CHEMBL1407268 & 688724 & 5.0 & 4.8277 & TRN \\
\hline CHEMBL1356645 & 688724 & 4.7 & 4.4886 & TRN \\
\hline CHEMBL1318529 & 688724 & 4.75 & 4.9293 & TST \\
\hline CHEMBL1560553 & 688724 & 4.85 & 4.7539 & TST \\
\hline CHEMBL1573347 & 688724 & 4.45 & 4.7185 & TRN \\
\hline CHEMBL1505539 & 688724 & 4.35 & 5.0733 & TST \\
\hline CHEMBL1426578 & 688724 & 4.55 & 4.8155 & TST \\
\hline CHEMBL1445617 & 688724 & 5.3 & 4.683 & TRN \\
\hline CHEMBL1492303 & 688724 & 4.95 & 5.1571 & TRN \\
\hline CHEMBL1381308 & 688724 & 4.8 & 4.8516 & TST \\
\hline CHEMBL1326836 & 688724 & 5.15 & 5.4014 & TST \\
\hline CHEMBL1417543 & 688724 & 4.65 & 5.2346 & TRN \\
\hline CHEMBL1568118 & 688724 & 5.8 & 4.712 & TRN \\
\hline CHEMBL1424235 & 688724 & 4.15 & 4.5526 & TST \\
\hline CHEMBL1303683 & 688724 & 4.9 & 4.6683 & TRN \\
\hline
\end{tabular}




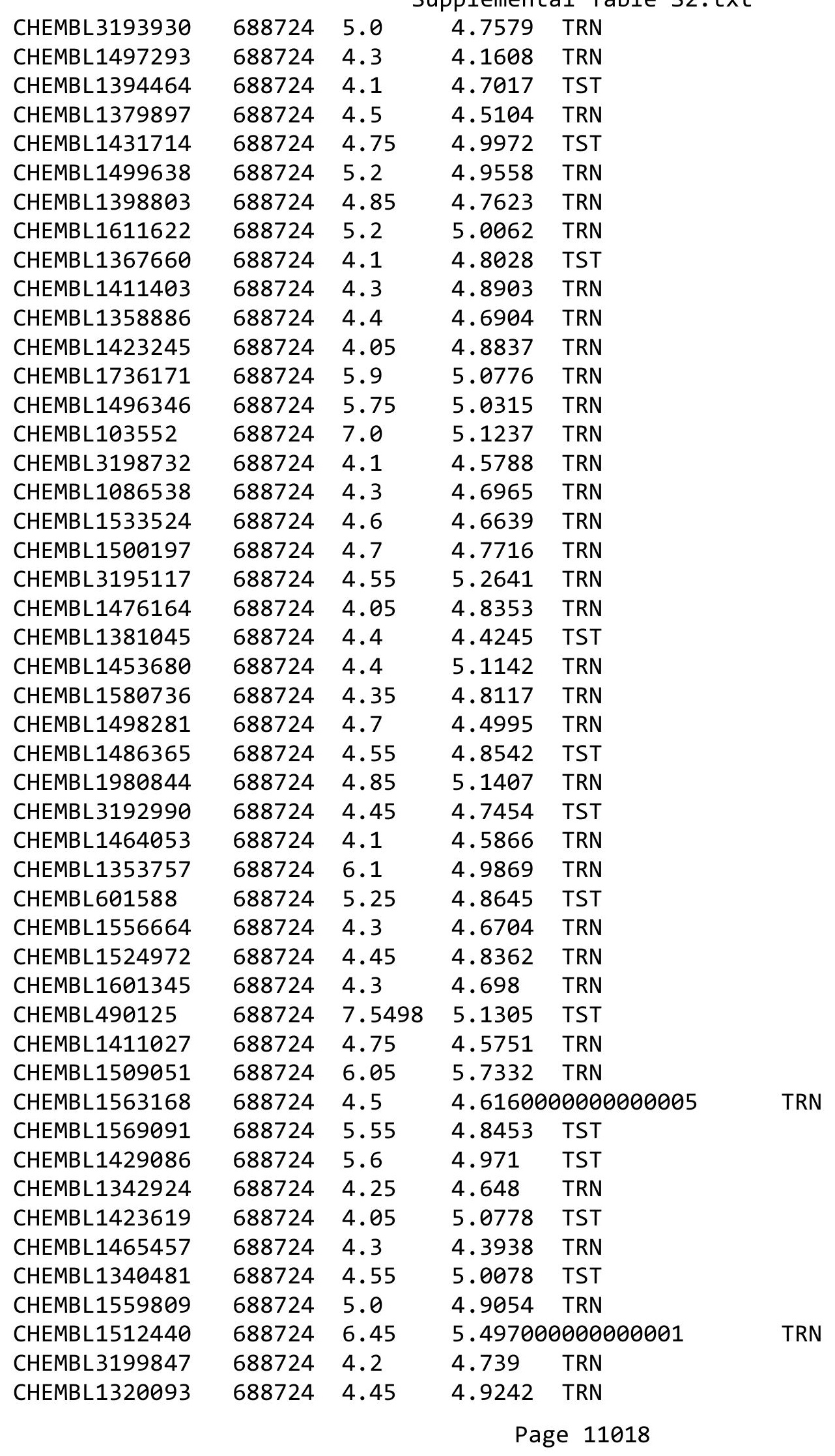




\begin{tabular}{|c|c|c|c|c|c|}
\hline \multicolumn{6}{|c|}{ Supplemental Table S2.txt } \\
\hline CHEMBL1338426 & 688724 & 4.3 & 4.7075 & TRN & \\
\hline CHEMBL1453074 & 688724 & 4.05 & 4.6036 & TST & \\
\hline CHEMBL1454761 & 688724 & 4.65 & 5.1889 & TST & \\
\hline CHEMBL1445330 & 688724 & 4.25 & 4.8582 & TRN & \\
\hline CHEMBL1516388 & 688724 & 6.0 & 5.3107 & TST & \\
\hline CHEMBL1319933 & 688724 & 4.5 & 4.8062 & TRN & \\
\hline CHEMBL1344248 & 688724 & 4.25 & 4.6871 & TRN & \\
\hline CHEMBL1536469 & 688724 & 5.2 & 4.8143 & TRN & \\
\hline CHEMBL1522314 & 688724 & 4.3 & 4.731 & TRN & \\
\hline CHEMBL1465044 & 688724 & 4.1 & 4.4749 & TRN & \\
\hline CHEMBL1527900 & 688724 & 4.8 & 4.5853 & TRN & \\
\hline CHEMBL1600506 & 688724 & 5.05 & 5.3918 & TRN & \\
\hline CHEMBL1964702 & 688724 & 5.1 & 5.0703 & TRN & \\
\hline CHEMBL161343 & 688724 & 4.5 & 5.2246 & TRN & \\
\hline CHEMBL1406702 & 688724 & 5.55 & 5.9965 & TRN & \\
\hline CHEMBL1316178 & 688724 & 4.4 & 5.2527 & TRN & \\
\hline CHEMBL1598047 & 688724 & 4.85 & 4.8383 & TRN & \\
\hline CHEMBL1313816 & 688724 & 4.55 & 4.7518 & TRN & \\
\hline CHEMBL1300087 & 688724 & 5.0 & 4.7358 & TST & \\
\hline CHEMBL1355747 & 688724 & 4.05 & 4.6132 & TRN & \\
\hline CHEMBL3392455 & 688724 & 4.75 & 4.9411 & TRN & \\
\hline CHEMBL1498695 & 688724 & 5.6 & 5.3314 & TRN & \\
\hline CHEMBL1361699 & 688724 & 6.0 & 5.2005 & TRN & \\
\hline CHEMBL1402827 & 688724 & 4.4 & 4.7688 & TRN & \\
\hline CHEMBL1454430 & 688724 & 5.55 & 5.2754 & TRN & \\
\hline CHEMBL1489519 & 688724 & 8.3468 & 4.85800 & 00000000005 & TRN \\
\hline CHEMBL1609807 & 688724 & 4.7 & 4.9375 & TRN & \\
\hline CHEMBL1349915 & 688724 & 4.95 & 5.131 & TRN & \\
\hline CHEMBL1398748 & 688724 & 4.1 & 4.8744 & TRN & \\
\hline CHEMBL1325301 & 688724 & 4.3 & 4.2684 & TRN & \\
\hline CHEMBL1407819 & 688724 & 4.65 & 4.9672 & TRN & \\
\hline CHEMBL1556917 & 688724 & 5.7 & 5.0948 & TRN & \\
\hline CHEMBL1362893 & 688724 & 4.6 & 4.7159 & TRN & \\
\hline CHEMBL1422456 & 688724 & 4.5 & 5.0188 & TST & \\
\hline CHEMBL1559655 & 688724 & 4.55 & 4.7964 & TRN & \\
\hline CHEMBL1452195 & 688724 & 4.6 & 5.3161 & TRN & \\
\hline CHEMBL 271663 & 688724 & 5.55 & 4.7965 & TRN & \\
\hline CHEMBL1441099 & 688724 & 4.8 & 4.8998 & TST & \\
\hline CHEMBL1564446 & 688724 & 4.35 & 4.7591 & TRN & \\
\hline CHEMBL3209349 & 688724 & 4.9 & 4.8153 & TRN & \\
\hline CHEMBL1592095 & 688724 & 6.0 & 5.5978 & TRN & \\
\hline CHEMBL1320902 & 688724 & 6.0 & 5.4622 & TRN & \\
\hline CHEMBL1301125 & 688724 & 5.45 & 4.901 & TST & \\
\hline CHEMBL1321058 & 688724 & 4.35 & 4.6129 & TRN & \\
\hline CHEMBL1300772 & 688724 & 4.4 & 4.2948 & TRN & \\
\hline CHEMBL452370 & 688724 & 5.55 & 5.29899 & 99999999995 & TST \\
\hline CHEMBL1446559 & 688724 & 5.1 & 4.8331 & TRN & \\
\hline CHEMBL1584128 & 688724 & 4.65 & 5.154 & TRN & \\
\hline
\end{tabular}




\begin{tabular}{|c|c|c|c|c|c|}
\hline \multicolumn{6}{|c|}{ Supplemental Table S2.txt } \\
\hline CHEMBL1497472 & 688724 & 4.7 & 4.6674 & TRN & \\
\hline CHEMBL1495376 & 688724 & 4.4 & 4.3966 & TRN & \\
\hline CHEMBL1476849 & 688724 & 4.1 & 5.2286 & TRN & \\
\hline CHEMBL1570982 & 688724 & 4.95 & 4.8104 & TRN & \\
\hline CHEMBL1373819 & 688724 & 4.05 & 4.6063 & TRN & \\
\hline CHEMBL1548872 & 688724 & 5.45 & 5.1137 & TST & \\
\hline CHEMBL1459133 & 688724 & 4.75 & 4.6631 & TST & \\
\hline CHEMBL1592721 & 688724 & 4.95 & 4.791 & TST & \\
\hline CHEMBL1365988 & 688724 & 5.9 & 5.596 & TRN & \\
\hline CHEMBL1461619 & 688724 & 4.95 & 5.149 & TRN & \\
\hline CHEMBL1387421 & 688724 & 5.35 & 4.8727 & TRN & \\
\hline CHEMBL1603005 & 688724 & 4.85 & 4.6264 & TRN & \\
\hline CHEMBL1368345 & 688724 & 4.75 & 4.5474 & TRN & \\
\hline CHEMBL1502769 & 688724 & 4.35 & 4.6747 & TRN & \\
\hline CHEMBL1348401 & 688724 & 5.0 & 4.5514 & TST & \\
\hline CHEMBL1471372 & 688724 & 4.25 & 5.0411 & TRN & \\
\hline CHEMBL1400376 & 688724 & 4.65 & 4.8004 & TRN & \\
\hline CHEMBL1582076 & 688724 & 4.35 & 4.8466 & TRN & \\
\hline CHEMBL41092 & 688724 & 4.7 & 5.2541 & TRN & \\
\hline CHEMBL1610107 & 688724 & 4.2 & 4.5511 & TRN & \\
\hline CHEMBL1540301 & 688724 & 4.6 & 4.6288 & TRN & \\
\hline CHEMBL1583832 & 688724 & 4.45 & 4.52800 & 00000000005 & TRN \\
\hline CHEMBL1608604 & 688724 & 4.45 & 4.9878 & TRN & \\
\hline CHEMBL1303399 & 688724 & 4.7 & 4.7333 & TRN & \\
\hline CHEMBL1482041 & 688724 & 4.85 & 4.9295 & TRN & \\
\hline CHEMBL3208708 & 688724 & 4.1 & 4.5741 & TRN & \\
\hline CHEMBL1387298 & 688724 & 4.75 & 4.6947 & TST & \\
\hline CHEMBL1589723 & 688724 & 4.3 & 5.0239 & TRN & \\
\hline CHEMBL1503006 & 688724 & 6.1 & 5.7048 & TRN & \\
\hline CHEMBL1511052 & 688724 & 4.7 & 4.5177 & TST & \\
\hline CHEMBL1536290 & 688724 & 5.3 & 4.5195 & TRN & \\
\hline CHEMBL1531294 & 688724 & 4.35 & 4.6243 & TRN & \\
\hline CHEMBL1433315 & 688724 & 4.35 & 4.716 & TST & \\
\hline CHEMBL1575710 & 688724 & 4.95 & 4.4602 & TRN & \\
\hline CHEMBL1600677 & 688724 & 4.05 & 4.8177 & TRN & \\
\hline CHEMBL1336911 & 688724 & 4.85 & 4.6735 & TRN & \\
\hline CHEMBL3199594 & 688724 & 4.1 & 4.6212 & TRN & \\
\hline CHEMBL1587947 & 688724 & 7.15 & 4.9914 & TST & \\
\hline CHEMBL375126 & 688724 & 7.15 & 4.6991 & TST & \\
\hline CHEMBL1472476 & 688724 & 4.2 & 4.6533 & TRN & \\
\hline CHEMBL1511226 & 688724 & 4.55 & 4.822 & TRN & \\
\hline CHEMBL1549021 & 688724 & 5.2 & 4.987 & TRN & \\
\hline CHEMBL1449147 & 688724 & 4.7 & 4.7783 & TRN & \\
\hline CHEMBL1580295 & 688724 & 5.2 & 4.8067 & TRN & \\
\hline CHEMBL1533517 & 688724 & 5.7 & 5.2756 & TST & \\
\hline CHEMBL1394302 & 688724 & 6.0 & 4.7657 & TRN & \\
\hline CHEMBL1485666 & 688724 & 4.3 & 4.6974 & TST & \\
\hline CHEMBL1384410 & 688724 & 4.25 & 4.4311 & TRN & \\
\hline
\end{tabular}




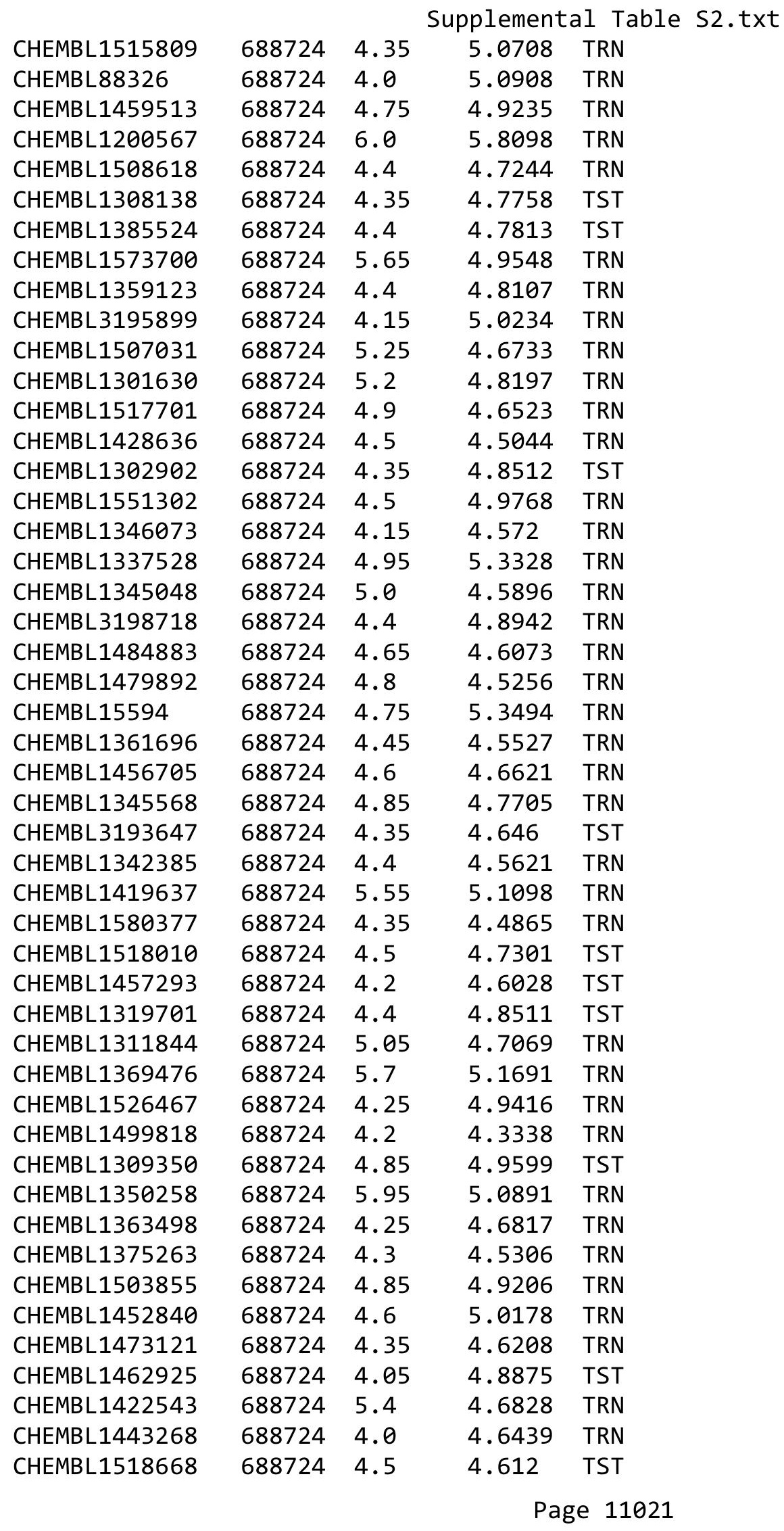




\begin{tabular}{|c|c|c|c|c|c|}
\hline \multicolumn{6}{|c|}{ Supplemental Table S2.txt } \\
\hline CHEMBL1334962 & 688724 & 4.9 & 4.7556 & TRN & \\
\hline CHEMBL1375576 & 688724 & 4.65 & 5.0926 & TST & \\
\hline CHEMBL1410109 & 688724 & 4.45 & 5.0183 & TST & \\
\hline CHEMBL1405171 & 688724 & 4.05 & 4.5608 & TRN & \\
\hline CHEMBL1527869 & 688724 & 5.5 & 5.2293 & TRN & \\
\hline CHEMBL1453216 & 688724 & 4.25 & 4.8169 & TST & \\
\hline CHEMBL3194682 & 688724 & 4.6 & 5.0802 & TRN & \\
\hline CHEMBL151167 & 688724 & 4.6 & 5.2339 & TRN & \\
\hline CHEMBL1521960 & 688724 & 5.4 & 5.0692 & TRN & \\
\hline CHEMBL1392477 & 688724 & 5.0 & 4.5827 & TRN & \\
\hline CHEMBL108851 & 688724 & 5.05 & 5.16299 & 9999999999 & TRN \\
\hline CHEMBL1343906 & 688724 & 4.85 & 4.8764 & TRN & \\
\hline CHEMBL1412371 & 688724 & 4.35 & 4.2869 & TRN & \\
\hline CHEMBL1432190 & 688724 & 6.0 & 4.7952 & TRN & \\
\hline CHEMBL1613658 & 688724 & 4.75 & 4.9179 & TRN & \\
\hline CHEMBL1418389 & 688724 & 6.4 & 5.5121 & TRN & \\
\hline CHEMBL8145 & 688724 & 6.45 & 5.3315 & TRN & \\
\hline CHEMBL1517284 & 688724 & 4.45 & 5.33 & TRN & \\
\hline CHEMBL1319773 & 688724 & 5.25 & 4.8135 & TRN & \\
\hline CHEMBL434778 & 688724 & 4.15 & 4.8594 & TRN & \\
\hline CHEMBL1446742 & 688724 & 4.55 & 4.4902 & TRN & \\
\hline CHEMBL1612383 & 688724 & 5.3 & 5.51200 & 00000000005 & TRN \\
\hline CHEMBL1430209 & 688724 & 4.8 & 4.6596 & TRN & \\
\hline CHEMBL1373773 & 688724 & 4.25 & 4.6003 & TRN & \\
\hline CHEMBL3192822 & 688724 & 4.65 & 4.84399 & 9999999999 & TRN \\
\hline CHEMBL1601336 & 688724 & 4.35 & 4.7571 & TRN & \\
\hline CHEMBL 2374063 & 688724 & 5.0 & 5.3484 & TRN & \\
\hline CHEMBL1983939 & 688724 & 4.7 & 5.0582 & TRN & \\
\hline CHEMBL1404089 & 688724 & 4.6 & 4.3934 & TRN & \\
\hline CHEMBL1968739 & 688724 & 4.85 & 5.3172 & TRN & \\
\hline CHEMBL1321406 & 688724 & 4.4 & 4.5731 & TRN & \\
\hline CHEMBL1606239 & 688724 & 4.4 & 5.0689 & TST & \\
\hline CHEMBL3191647 & 688724 & 4.65 & 4.8703 & TRN & \\
\hline CHEMBL1396458 & 688724 & 4.75 & 4.5059 & TRN & \\
\hline CHEMBL1539923 & 688724 & 4.8 & 4.7999 & TST & \\
\hline CHEMBL1558957 & 688724 & 4.6 & 4.6513 & TRN & \\
\hline CHEMBL3190592 & 688724 & 4.9 & 5.1253 & TRN & \\
\hline CHEMBL1503563 & 688724 & 4.65 & 4.8513 & TRN & \\
\hline CHEMBL1410739 & 688724 & 4.75 & 5.0357 & TRN & \\
\hline CHEMBL1384873 & 688724 & 4.7 & 4.4114 & TRN & \\
\hline CHEMBL1367718 & 688724 & 5.05 & 4.6887 & TRN & \\
\hline CHEMBL1473133 & 688724 & 4.45 & 4.4099 & TRN & \\
\hline CHEMBL349641 & 688724 & 4.45 & 4.9566 & TRN & \\
\hline CHEMBL1299333 & 688724 & 4.35 & 4.728 & TRN & \\
\hline CHEMBL1594861 & 688724 & 4.3 & 4.5321 & TRN & \\
\hline CHEMBL 2000888 & 688724 & 4.9 & 4.5046 & TRN & \\
\hline CHEMBL1479161 & 688724 & 4.75 & 4.7124 & TST & \\
\hline CHEMBL259388 & 688724 & 4.5 & 4.6268 & TST & \\
\hline
\end{tabular}




\begin{tabular}{|c|c|c|c|c|c|}
\hline \multicolumn{6}{|c|}{ Supplemental Table S2.txt } \\
\hline CHEMBL135561 & 688724 & 5.7 & 5.3147 & TRN & \\
\hline CHEMBL3209974 & 688724 & 4.5 & 4.6862 & TRN & \\
\hline CHEMBL1432784 & 688724 & 4.6 & 5.58299 & 9999999999 & TRN \\
\hline CHEMBL1456232 & 688724 & 4.4 & 5.0992 & TRN & \\
\hline CHEMBL3190195 & 688724 & 4.4 & 4.73300 & 00000000005 & TRN \\
\hline CHEMBL1331443 & 688724 & 4.4 & 4.9733 & TRN & \\
\hline CHEMBL1555503 & 688724 & 4.65 & 4.8261 & TRN & \\
\hline CHEMBL1468195 & 688724 & 4.85 & 4.7691 & TRN & \\
\hline CHEMBL1310120 & 688724 & 5.05 & 4.8111 & TRN & \\
\hline CHEMBL3195767 & 688724 & 5.95 & 5.5744 & TST & \\
\hline CHEMBL1468130 & 688724 & 5.35 & 5.1085 & TRN & \\
\hline CHEMBL1597329 & 688724 & 4.25 & 5.1002 & TRN & \\
\hline CHEMBL1513033 & 688724 & 4.1 & 4.6996 & TRN & \\
\hline CHEMBL1334980 & 688724 & 4.95 & 4.6402 & TRN & \\
\hline CHEMBL3194058 & 688724 & 4.05 & 4.8228 & TRN & \\
\hline CHEMBL3195592 & 688724 & 5.35 & 4.8459 & TRN & \\
\hline CHEMBL1967829 & 688724 & 4.3 & 4.8136 & TRN & \\
\hline CHEMBL1321361 & 688724 & 4.6 & 4.6928 & TRN & \\
\hline CHEMBL1544056 & 688724 & 4.35 & 5.0507 & TRN & \\
\hline CHEMBL1422992 & 688724 & 4.7 & 5.07600 & 00000000005 & TST \\
\hline CHEMBL1458217 & 688724 & 5.5 & 5.2451 & TRN & \\
\hline CHEMBL1469505 & 688724 & 4.45 & 4.8817 & TRN & \\
\hline CHEMBL1423715 & 688724 & 4.1 & 4.655 & TRN & \\
\hline CHEMBL1503274 & 688724 & 4.9 & 4.6688 & TST & \\
\hline CHEMBL1331835 & 688724 & 4.85 & 4.9967 & TRN & \\
\hline CHEMBL1398059 & 688724 & 4.55 & 4.9821 & TRN & \\
\hline CHEMBL3189193 & 688724 & 4.65 & 5.1799 & TRN & \\
\hline CHEMBL1555326 & 688724 & 4.9 & 4.6403 & TST & \\
\hline CHEMBL1307707 & 688724 & 4.8 & 4.85 & TRN & \\
\hline CHEMBL1472478 & 688724 & 4.7 & 4.5251 & TRN & \\
\hline CHEMBL1525545 & 688724 & 4.5 & 5.0936 & TRN & \\
\hline CHEMBL1343211 & 688724 & 4.25 & 4.6685 & TRN & \\
\hline CHEMBL1383713 & 688724 & 5.5 & 5.1212 & TRN & \\
\hline CHEMBL1448202 & 688724 & 5.0 & 4.7403 & TRN & \\
\hline CHEMBL1378198 & 688724 & 4.2 & 4.3378 & TRN & \\
\hline CHEMBL1562537 & 688724 & 4.7 & 4.4951 & TRN & \\
\hline CHEMBL1301536 & 688724 & 5.0 & 5.1959 & TRN & \\
\hline CHEMBL1534914 & 688724 & 4.0 & 4.8457 & TST & \\
\hline CHEMBL1335363 & 688724 & 4.9 & 4.7747 & TRN & \\
\hline CHEMBL 3199841 & 688724 & 5.0 & 4.6638 & TRN & \\
\hline CHEMBL1160028 & 688724 & 4.35 & 5.1533 & TST & \\
\hline CHEMBL1898790 & 688724 & 4.75 & 4.6906 & TST & \\
\hline CHEMBL1484128 & 688724 & 4.85 & 4.699 & TRN & \\
\hline CHEMBL1393926 & 688724 & 5.1 & 4.4314 & TST & \\
\hline CHEMBL1314778 & 688724 & 6.0 & 4.7039 & TRN & \\
\hline CHEMBL1533262 & 688724 & 4.4 & 4.6485 & TST & \\
\hline CHEMBL1372000 & 688724 & 5.4 & 5.1159 & TRN & \\
\hline CHEMBL1414213 & 688724 & 4.25 & 4.5959 & TRN & \\
\hline
\end{tabular}




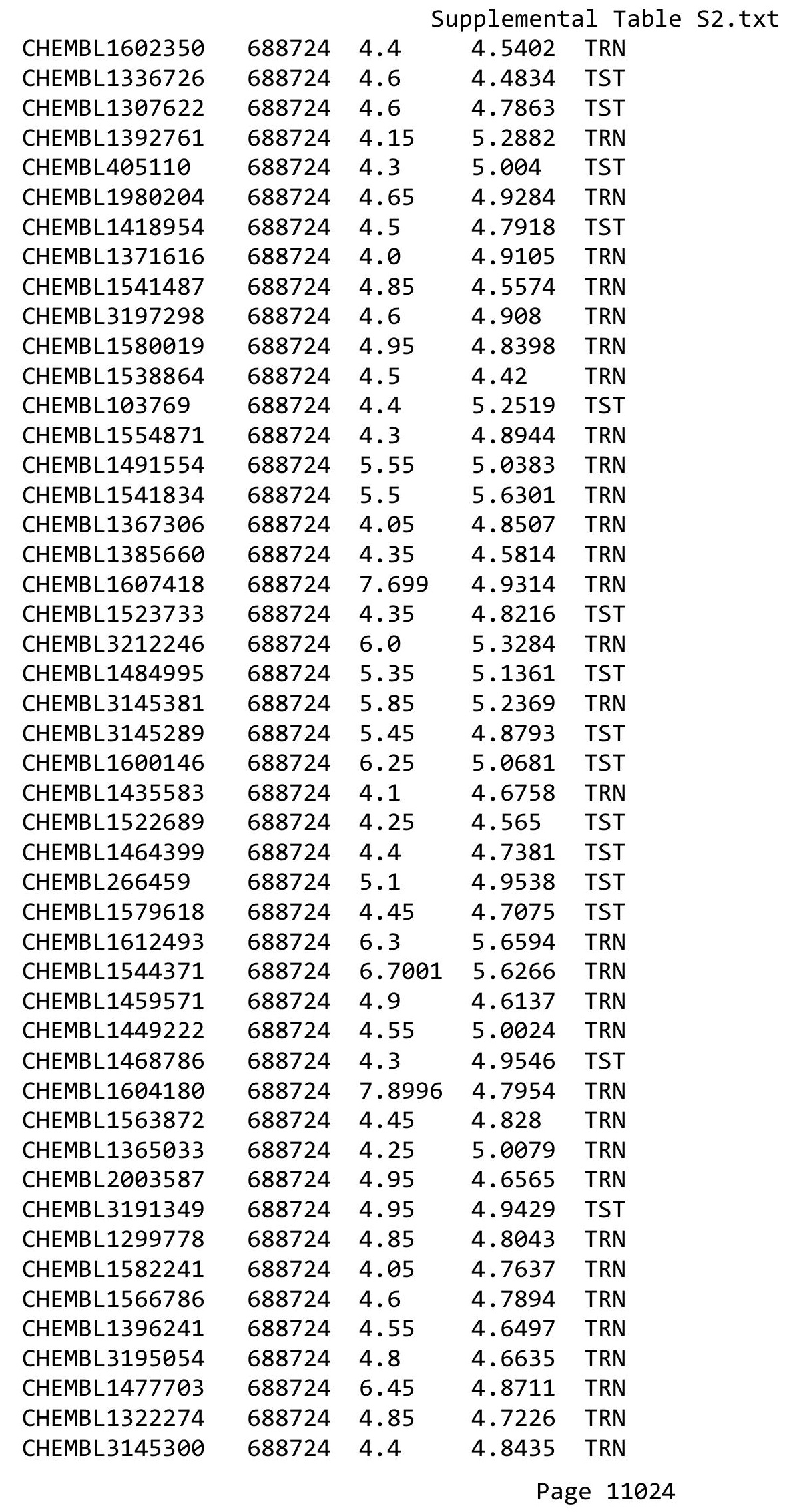




\begin{tabular}{|c|c|c|c|c|c|}
\hline \\
\hline CHEMBL1456284 & 688724 & 4.7 & 4.6557 & TRN & \\
\hline CHEMBL1559126 & 688724 & 4.65 & 4.6502 & TST & \\
\hline CHEMBL1522440 & 688724 & 4.6 & 4.5366 & TST & \\
\hline CHEMBL1419337 & 688724 & 4.4 & 4.6529 & TRN & \\
\hline CHEMBL1325670 & 688724 & 5.45 & 4.979 & TST & \\
\hline CHEMBL1423690 & 688724 & 5.65 & 5.1576 & TRN & \\
\hline CHEMBL1345343 & 688724 & 4.0 & 4.6135 & TRN & \\
\hline CHEMBL1563217 & 688724 & 4.35 & 4.6086 & TRN & \\
\hline CHEMBL3211648 & 688724 & 4.0 & 4.6445 & TRN & \\
\hline CHEMBL1356542 & 688724 & 4.6 & 5.0965 & TST & \\
\hline CHEMBL1335745 & 688724 & 6.7001 & 4.566 & TRN & \\
\hline CHEMBL1421613 & 688724 & 5.9 & 5.3321 & TST & \\
\hline CHEMBL1349595 & 688724 & 6.0 & 4.9205 & TRN & \\
\hline CHEMBL1431478 & 688724 & 4.0 & 4.9926 & TST & \\
\hline CHEMBL1392500 & 688724 & 5.3 & 5.1474 & TRN & \\
\hline CHEMBL1560556 & 688724 & 4.95 & 5.0764 & TRN & \\
\hline CHEMBL1404169 & 688724 & 6.0 & 4.5586 & TRN & \\
\hline CHEMBL1320213 & 688724 & 4.75 & 4.8705 & TRN & \\
\hline CHEMBL1381433 & 688724 & 4.4 & 4.9598 & TRN & \\
\hline CHEMBL1364708 & 688724 & 4.3 & 4.7604 & TRN & \\
\hline CHEMBL1576346 & 688724 & 5.0 & 5.1422 & TRN & \\
\hline CHEMBL1407610 & 688724 & 4.85 & 4.9884 & TST & \\
\hline CHEMBL1348263 & 688724 & 5.1 & 5.2519 & TRN & \\
\hline CHEMBL3716478 & 688724 & 6.0 & 5.4755 & TRN & \\
\hline CHEMBL1423797 & 688724 & 4.95 & 4.4541 & TRN & \\
\hline CHEMBL1336319 & 688724 & 5.15 & 5.1978 & TRN & \\
\hline CHEMBL3189667 & 688724 & 4.75 & 4.9583 & TRN & \\
\hline CHEMBL552741 & 688724 & 4.7 & 4.8461 & TRN & \\
\hline CHEMBL1525950 & 688724 & 4.35 & 4.9409 & TRN & \\
\hline CHEMBL1412785 & 688724 & 5.1 & 4.9625 & TRN & \\
\hline CHEMBL1332923 & 688724 & 4.75 & 4.8568 & TRN & \\
\hline CHEMBL1421043 & 688724 & 4.1 & 4.4314 & TRN & \\
\hline CHEMBL1326809 & 688724 & 4.5 & 4.4631 & TST & \\
\hline CHEMBL1349908 & 688724 & 4.6 & 4.9104 & TRN & \\
\hline CHEMBL1561804 & 688724 & 4.35 & 5.0377 & TRN & \\
\hline CHEMBL1478563 & 688724 & 4.75 & 4.96399 & 99999999995 & TRN \\
\hline CHEMBL 282731 & 688724 & 6.1 & 5.5821 & TRN & \\
\hline CHEMBL1320393 & 688724 & 4.35 & 4.5994 & TRN & \\
\hline CHEMBL1610792 & 688724 & 4.4 & 4.65600 & 0000000001 & TRN \\
\hline CHEMBL1311754 & 688724 & 4.4 & 4.7494 & TRN & \\
\hline CHEMBL1398734 & 688724 & 4.4 & 4.6912 & TST & \\
\hline CHEMBL1531458 & 688724 & 4.05 & 4.8162 & TRN & \\
\hline CHEMBL1598418 & 688724 & 6.45 & 4.8159 & TRN & \\
\hline CHEMBL1604009 & 688724 & 5.2 & 4.756 & TRN & \\
\hline CHEMBL1366339 & 688724 & 4.25 & 4.4243 & TRN & \\
\hline CHEMBL1471865 & 688724 & 4.3 & 4.4086 & TRN & \\
\hline CHEMBL1315505 & 688724 & 4.4 & 5.1514 & TST & \\
\hline CHEMBL1449094 & 688724 & 4.8 & 4.8009 & TRN & \\
\hline
\end{tabular}




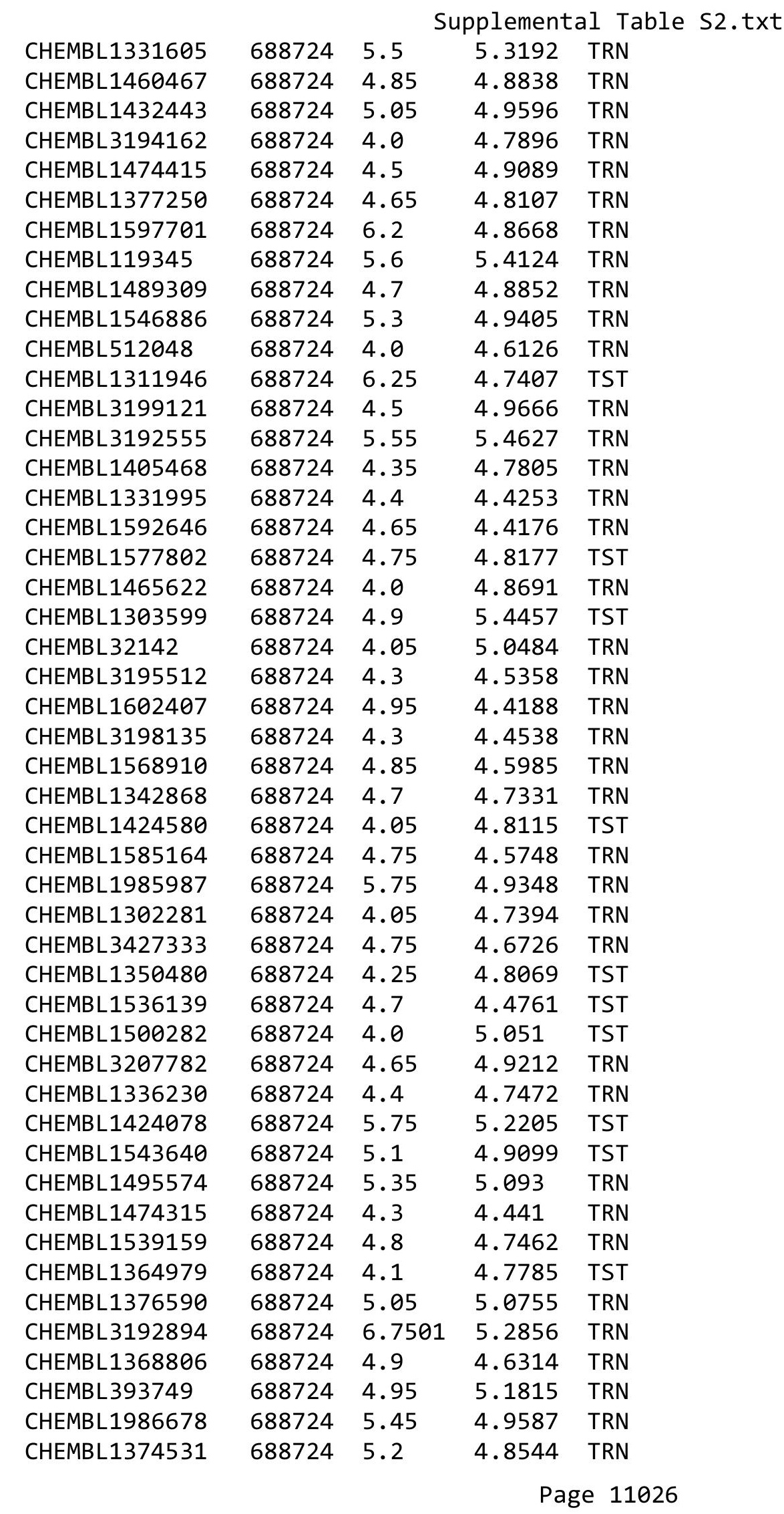




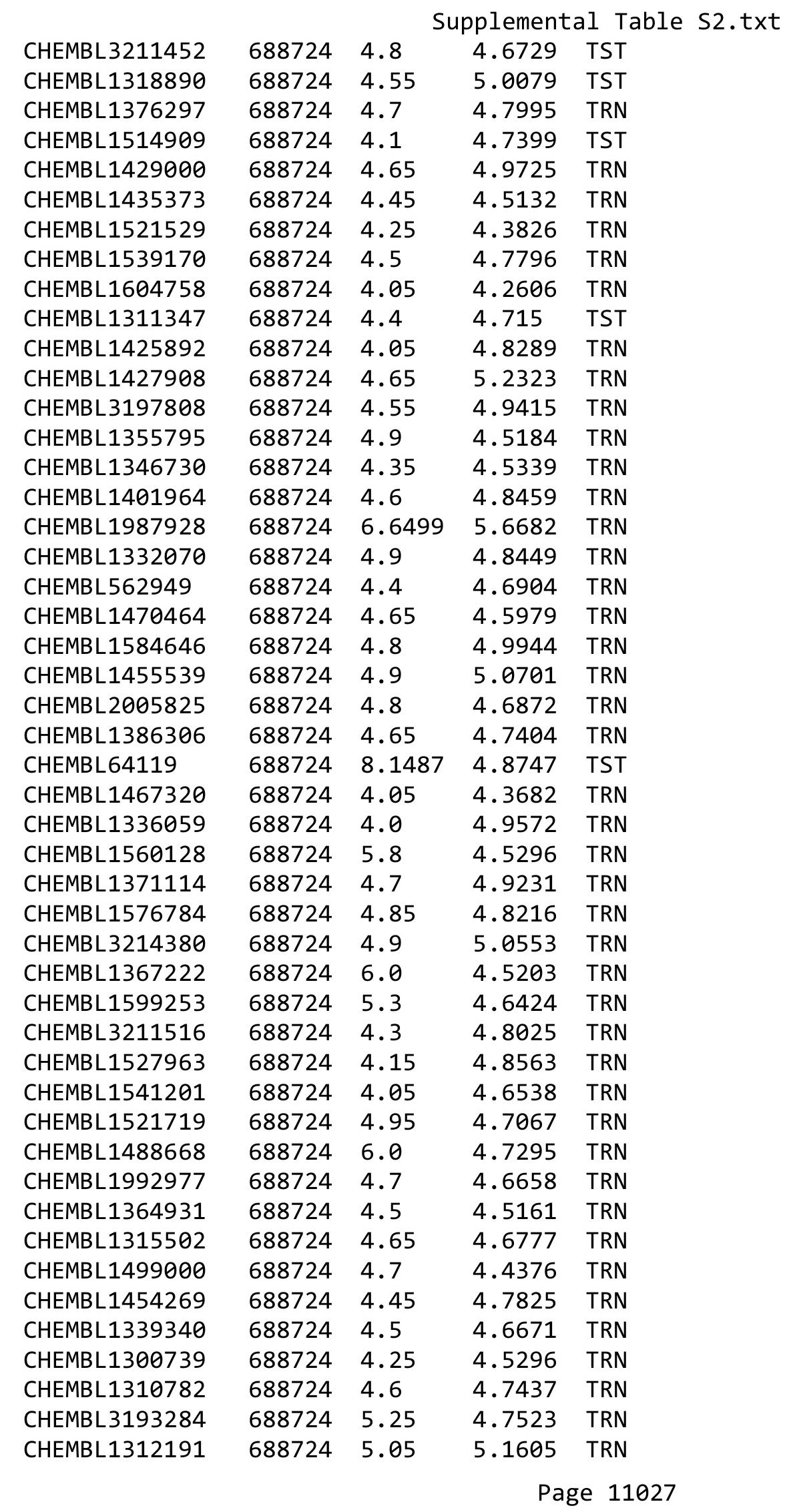




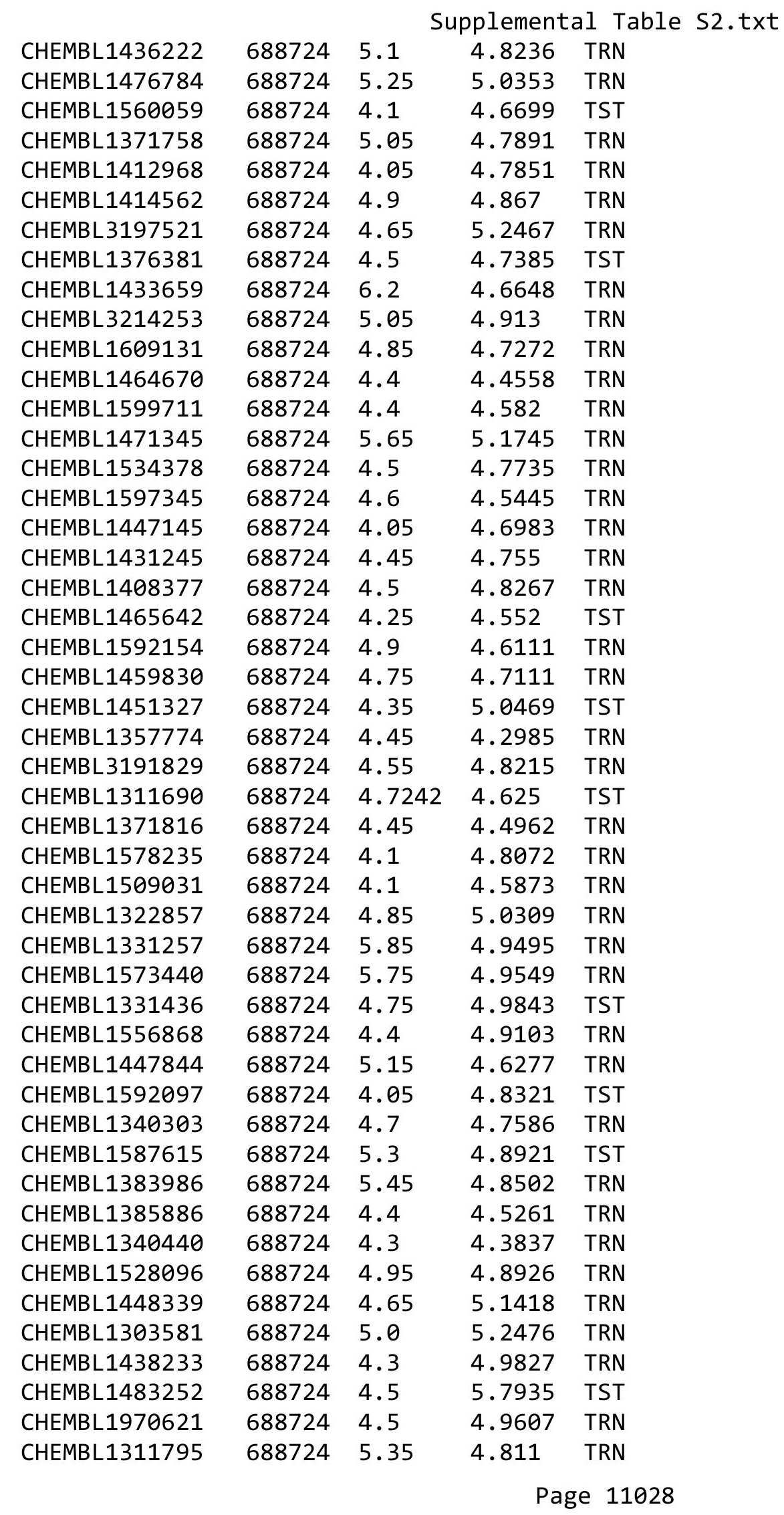




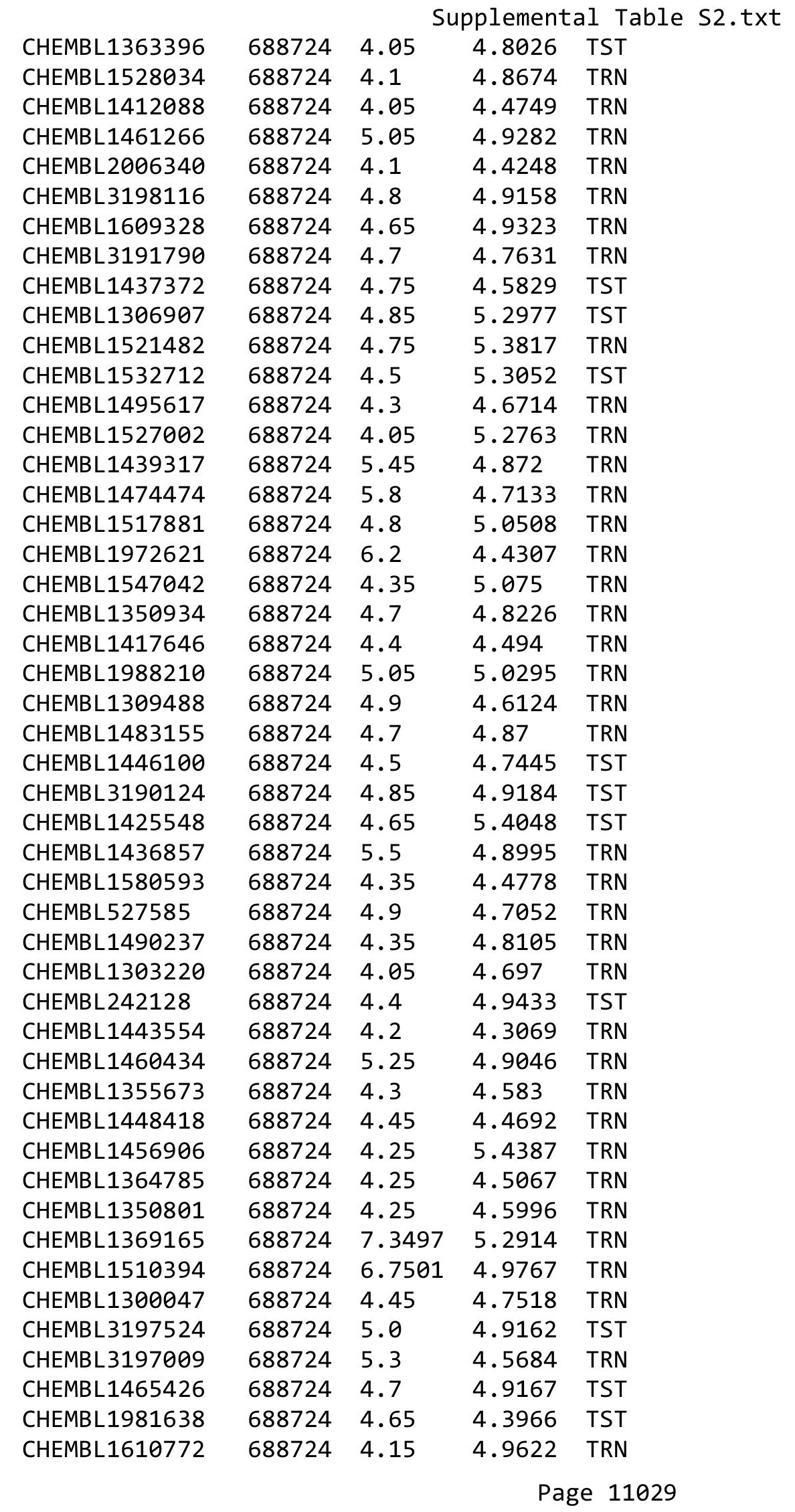




\begin{tabular}{|c|c|c|c|c|c|}
\hline \multicolumn{6}{|c|}{ Supplemental Table S2.txt } \\
\hline CHEMBL1548991 & 688724 & 4.25 & 4.6196 & TST & \\
\hline CHEMBL1323967 & 688724 & 4.45 & 4.7953 & TRN & \\
\hline CHEMBL1324388 & 688724 & 5.55 & 5.2245 & TRN & \\
\hline CHEMBL1382433 & 688724 & 4.5 & 5.1486 & TRN & \\
\hline CHEMBL1440725 & 688724 & 4.8 & 4.7786 & TRN & \\
\hline CHEMBL1519374 & 688724 & 5.0 & 4.9065 & TRN & \\
\hline CHEMBL1409552 & 688724 & 4.25 & 4.4481 & TRN & \\
\hline CHEMBL1574368 & 688724 & 4.7 & 4.9517 & TRN & \\
\hline CHEMBL1319209 & 688724 & 7.8013 & 5.1139 & TRN & \\
\hline CHEMBL1496385 & 688724 & 4.4 & 4.5435 & TRN & \\
\hline CHEMBL1563387 & 688724 & 5.05 & 4.9732 & TRN & \\
\hline CHEMBL1432364 & 688724 & 5.15 & 4.5856 & TRN & \\
\hline CHEMBL1581527 & 688724 & 5.0 & 4.8753 & TST & \\
\hline CHEMBL 3195238 & 688724 & 4.5 & 4.9962 & TRN & \\
\hline CHEMBL1570673 & 688724 & 4.75 & 4.7949 & TRN & \\
\hline CHEMBL1472406 & 688724 & 4.6 & 4.6572 & TRN & \\
\hline CHEMBL1428198 & 688724 & 4.8 & 5.1955 & TRN & \\
\hline CHEMBL1331128 & 688724 & 4.75 & 4.7043 & TST & \\
\hline CHEMBL1436724 & 688724 & 4.65 & 4.6881 & TST & \\
\hline CHEMBL1498493 & 688724 & 5.45 & 4.8065 & TRN & \\
\hline CHEMBL1494603 & 688724 & 5.0 & 4.8028 & TST & \\
\hline CHEMBL3192121 & 688724 & 4.75 & 4.9839 & TRN & \\
\hline CHEMBL1504315 & 688724 & 4.05 & 4.456 & TRN & \\
\hline CHEMBL1377441 & 688724 & 5.0 & 5.0153 & TRN & \\
\hline CHEMBL1319558 & 688724 & 5.05 & 4.4793 & TST & \\
\hline CHEMBL208926 & 688724 & 4.95 & 4.9392 & TRN & \\
\hline CHEMBL1543776 & 688724 & 4.95 & 5.1075 & TRN & \\
\hline CHEMBL1516515 & 688724 & 5.3 & 4.7685 & TST & \\
\hline CHEMBL1589770 & 688724 & 4.35 & 4.8344 & TRN & \\
\hline CHEMBL1328526 & 688724 & 4.65 & 4.8073 & TRN & \\
\hline CHEMBL1302843 & 688724 & 4.55 & 4.6917 & TST & \\
\hline CHEMBL1313171 & 688724 & 4.6 & 4.7972 & TST & \\
\hline CHEMBL1722566 & 688724 & 4.85 & 5.04899 & 99999999995 & TRN \\
\hline CHEMBL1543245 & 688724 & 5.55 & 4.8446 & TST & \\
\hline CHEMBL1315627 & 688724 & 4.7 & 4.9937 & TRN & \\
\hline CHEMBL1525711 & 688724 & 5.0 & 5.0782 & TRN & \\
\hline CHEMBL1461389 & 688724 & 4.95 & 4.5637 & TRN & \\
\hline CHEMBL1532816 & 688724 & 4.35 & 4.4449 & TRN & \\
\hline CHEMBL1557307 & 688724 & 4.75 & 4.8786 & TRN & \\
\hline CHEMBL1609459 & 688724 & 5.1 & 4.9528 & TST & \\
\hline CHEMBL1424950 & 688724 & 5.45 & 4.5196 & TRN & \\
\hline CHEMBL1588644 & 688724 & 4.7 & 4.8646 & TRN & \\
\hline CHEMBL1997797 & 688724 & 6.0 & 4.8241 & TRN & \\
\hline CHEMBL1553382 & 688724 & 4.35 & 4.662 & TST & \\
\hline CHEMBL1373583 & 688724 & 4.55 & 4.4651 & TRN & \\
\hline CHEMBL1505042 & 688724 & 4.6 & 4.8579 & TRN & \\
\hline CHEMBL1503492 & 688724 & 4.4 & 4.8052 & TRN & \\
\hline CHEMBL1487646 & 688724 & 4.75 & 4.8281 & TRN & \\
\hline
\end{tabular}




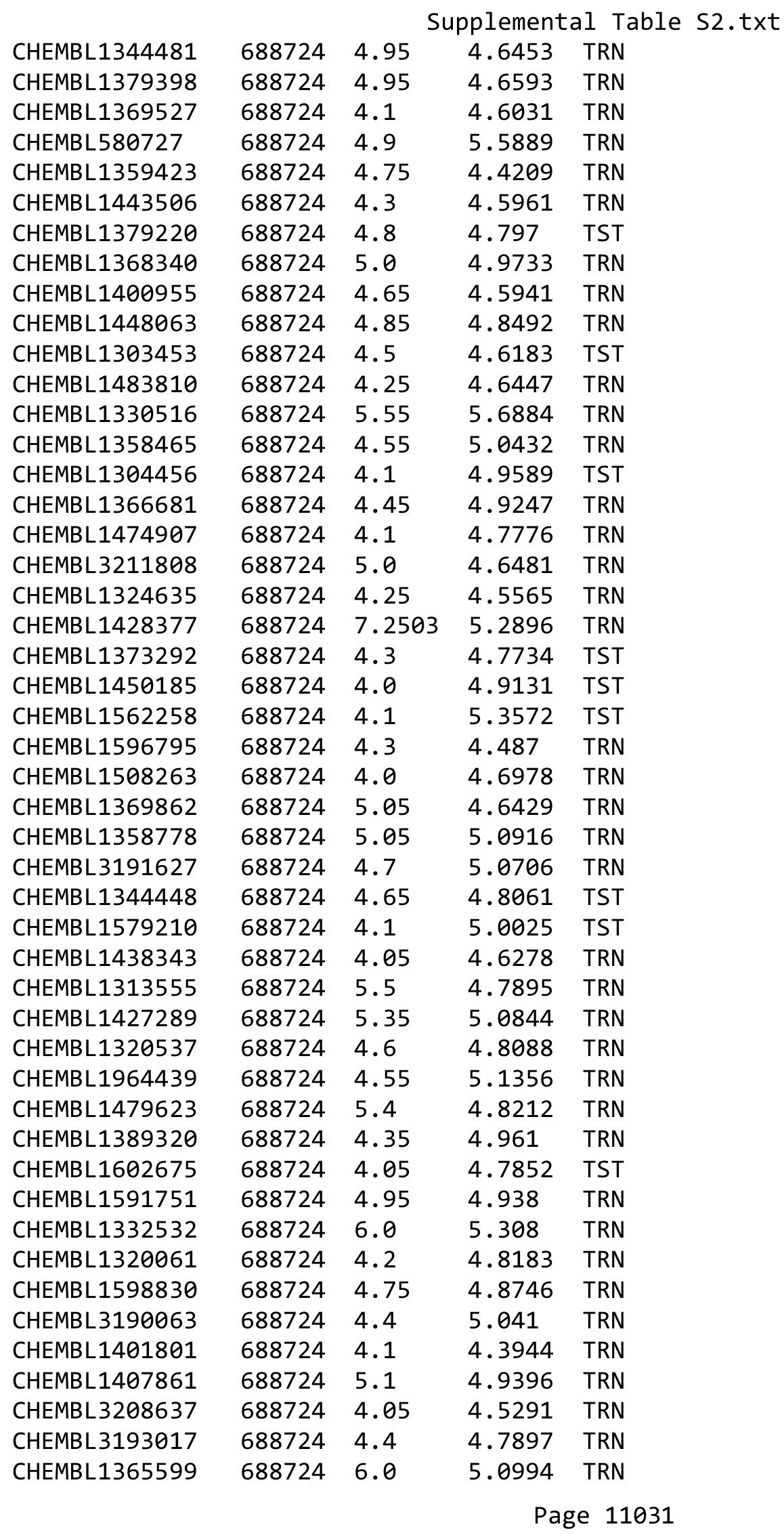




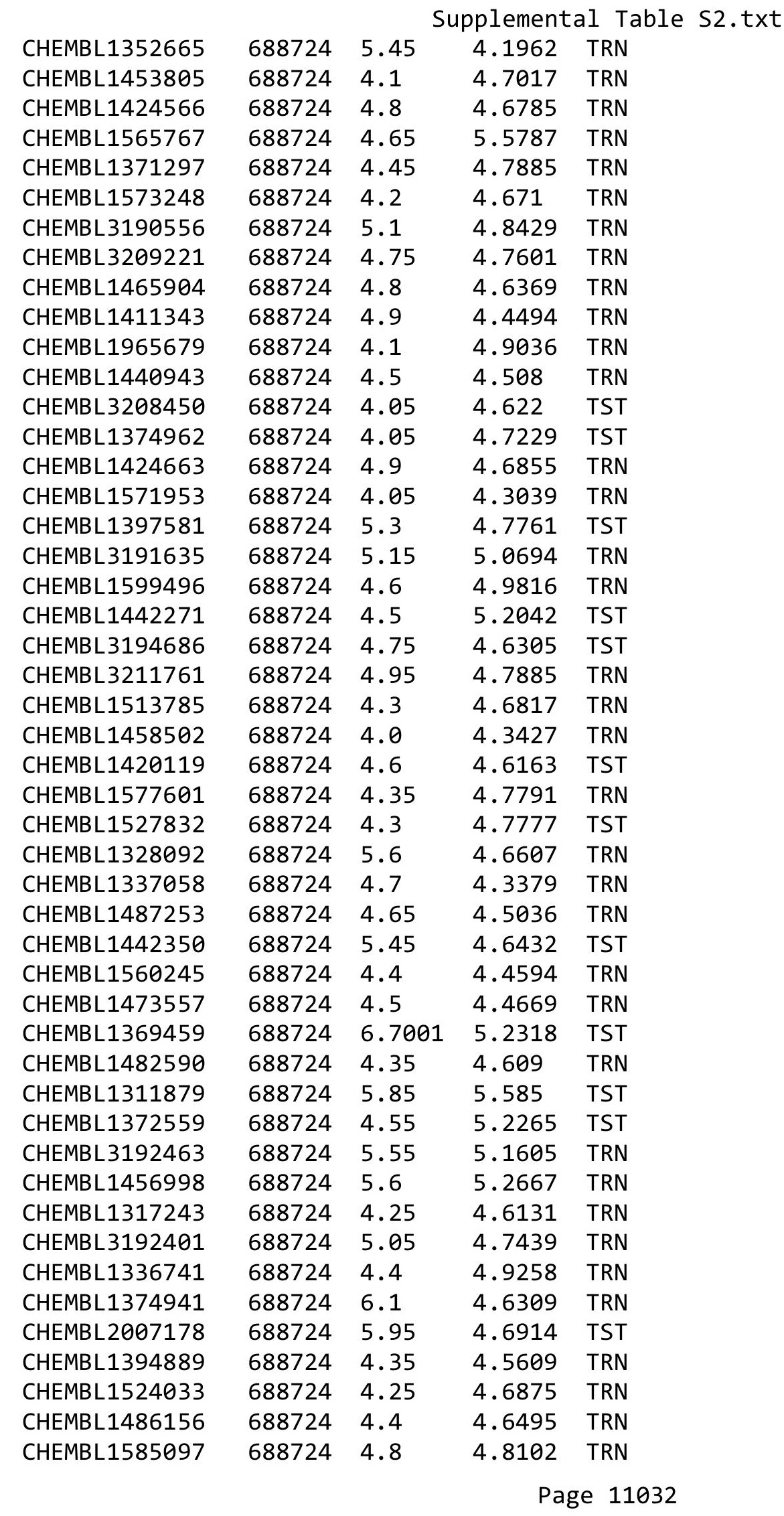




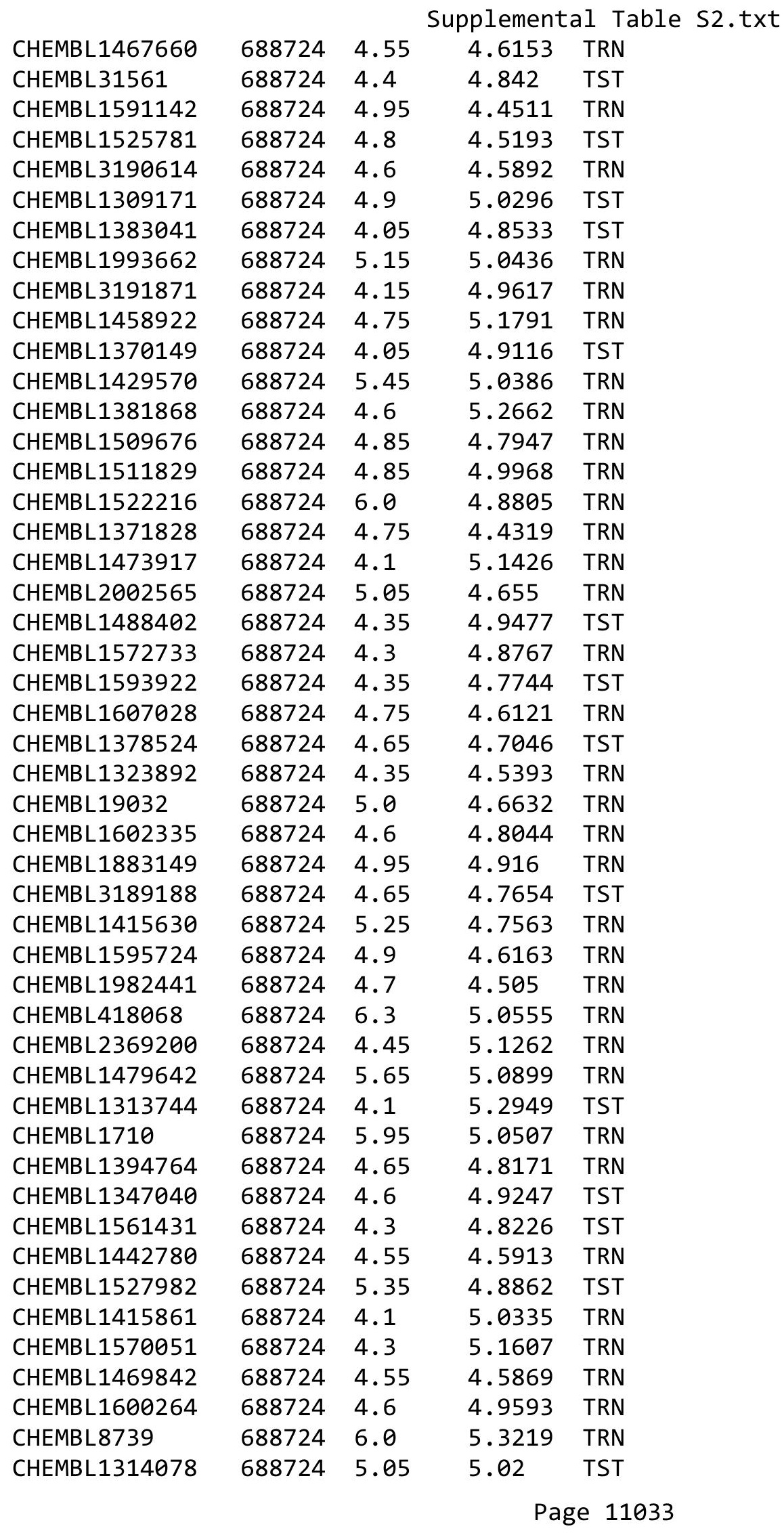




\begin{tabular}{|c|c|c|c|c|c|}
\hline \multicolumn{6}{|c|}{ Supplemental Table S2.txt } \\
\hline CHEMBL1410824 & 688724 & 4.65 & 4.4539 & TRN & \\
\hline CHEMBL1558070 & 688724 & 5.55 & 5.7782 & TRN & \\
\hline CHEMBL1892270 & 688724 & 5.15 & 4.7486 & TRN & \\
\hline CHEMBL1322180 & 688724 & 5.0 & 5.005 & TST & \\
\hline CHEMBL3191875 & 688724 & 4.45 & 4.7433 & TRN & \\
\hline CHEMBL1350396 & 688724 & 5.05 & 4.8323 & TRN & \\
\hline CHEMBL3212478 & 688724 & 4.6 & 4.7042 & TRN & \\
\hline CHEMBL1327690 & 688724 & 5.85 & 4.8295 & TRN & \\
\hline CHEMBL1603069 & 688724 & 4.7 & 4.7535 & TRN & \\
\hline CHEMBL599552 & 688724 & 5.45 & 4.8646 & TRN & \\
\hline CHEMBL1537222 & 688724 & 4.25 & 4.8694 & TRN & \\
\hline CHEMBL1319332 & 688724 & 4.4 & 4.638 & TRN & \\
\hline CHEMBL1606716 & 688724 & 5.35 & 5.1758 & TRN & \\
\hline CHEMBL1356637 & 688724 & 4.25 & 4.8566 & TST & \\
\hline CHEMBL1504781 & 688724 & 4.25 & 5.01699 & 99999999995 & TST \\
\hline CHEMBL1591932 & 688724 & 5.05 & 4.7808 & TRN & \\
\hline CHEMBL1379875 & 688724 & 4.75 & 4.9538 & TST & \\
\hline CHEMBL1446804 & 688724 & 6.5501 & 5.1526 & TRN & \\
\hline CHEMBL1310604 & 688724 & 4.7 & 4.7789 & TRN & \\
\hline CHEMBL1444241 & 688724 & 4.6 & 4.8998 & TST & \\
\hline CHEMBL1308689 & 688724 & 4.6 & 4.8342 & TRN & \\
\hline CHEMBL1256835 & 688724 & 6.1 & 4.8759 & TRN & \\
\hline CHEMBL1400620 & 688724 & 4.95 & 4.6738 & TRN & \\
\hline CHEMBL571087 & 688724 & 4.55 & 4.9126 & TRN & \\
\hline CHEMBL1562246 & 688724 & 4.5 & 4.6233 & TRN & \\
\hline CHEMBL3197718 & 688724 & 4.5 & 4.607 & TRN & \\
\hline CHEMBL1398855 & 688724 & 4.25 & 4.8602 & TRN & \\
\hline CHEMBL1336948 & 688724 & 4.65 & 4.6979 & TRN & \\
\hline CHEMBL1420257 & 688724 & 5.4 & 4.9707 & TST & \\
\hline CHEMBL1437312 & 688724 & 4.3 & 4.5295 & TRN & \\
\hline CHEMBL1975504 & 688724 & 4.45 & 4.9762 & TRN & \\
\hline CHEMBL1596275 & 688724 & 4.05 & 4.9072 & TRN & \\
\hline CHEMBL1307059 & 688724 & 4.7 & 5.112 & TRN & \\
\hline CHEMBL1328098 & 688724 & 4.2 & 4.9169 & TRN & \\
\hline CHEMBL1611567 & 688724 & 4.25 & 4.5611 & TRN & \\
\hline CHEMBL1320170 & 688724 & 4.4 & 4.783 & TRN & \\
\hline CHEMBL1471169 & 688724 & 4.4 & 4.8052 & TST & \\
\hline CHEMBL3212204 & 688724 & 4.7 & 4.6527 & TRN & \\
\hline CHEMBL1427266 & 688724 & 4.35 & 4.944 & TST & \\
\hline CHEMBL1335824 & 688724 & 5.45 & 4.8769 & TRN & \\
\hline CHEMBL1471715 & 688724 & 5.0 & 4.6201 & TRN & \\
\hline CHEMBL1096638 & 688724 & 4.9 & 4.8219 & TRN & \\
\hline CHEMBL1993788 & 688724 & 5.45 & 5.0807 & TRN & \\
\hline CHEMBL134074 & 688724 & 4.05 & 5.1381 & TST & \\
\hline CHEMBL1384398 & 688724 & 6.4 & 4.9089 & TRN & \\
\hline CHEMBL3190310 & 688724 & 4.85 & 4.3274 & TRN & \\
\hline CHEMBL1573365 & 688724 & 4.6 & 5.1251 & TST & \\
\hline CHEMBL1579683 & 688724 & 4.35 & 4.5859 & TRN & \\
\hline
\end{tabular}




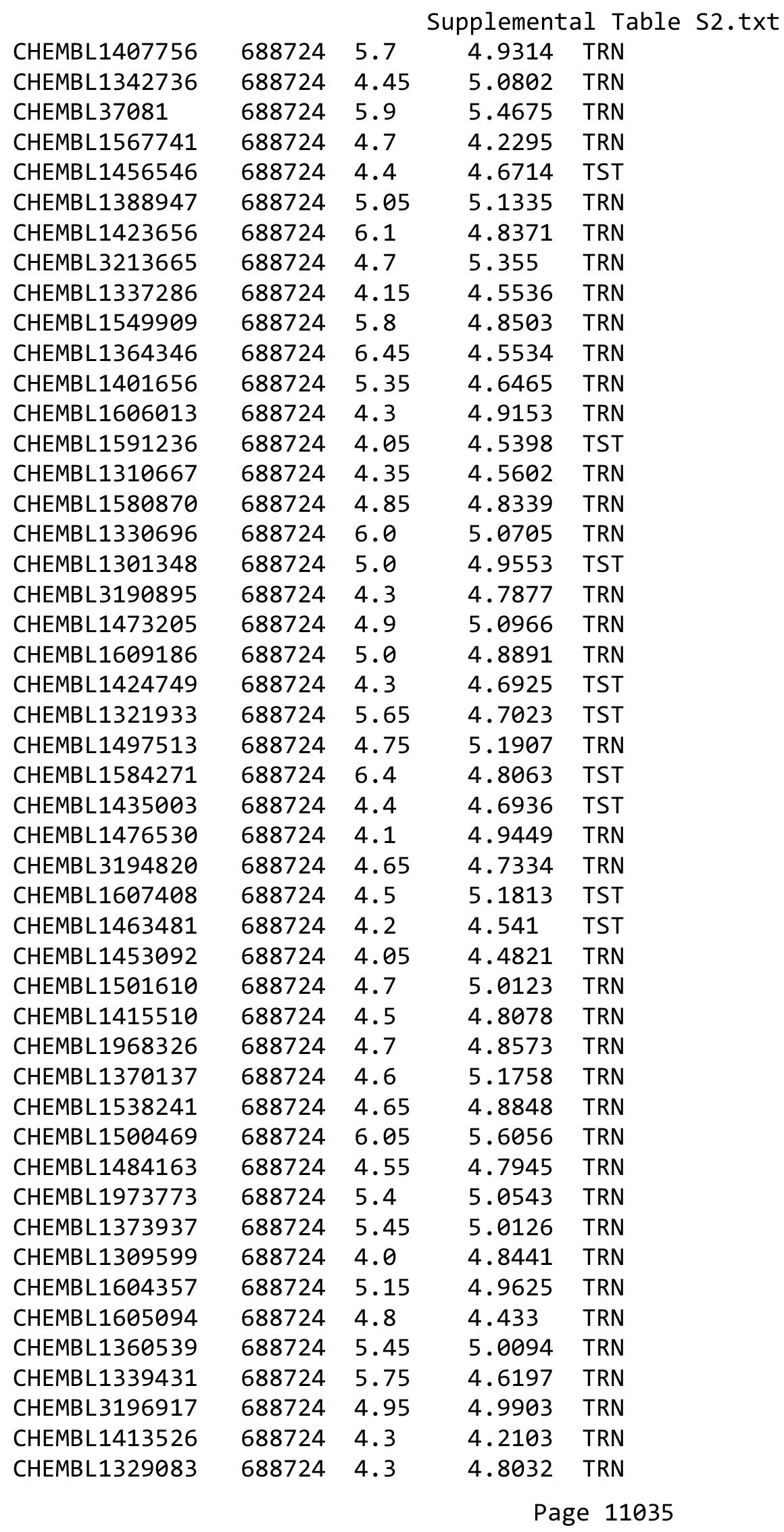




\begin{tabular}{|c|c|c|c|c|c|}
\hline & & \multicolumn{4}{|c|}{ Supplemental Table S2.txt } \\
\hline CHEMBL 2003794 & 688724 & 4.75 & 4.6573 & TRN & \\
\hline CHEMBL1579771 & 688724 & 5.2 & 4.6667 & TST & \\
\hline CHEMBL1331415 & 688724 & 4.65 & 5.0085 & TRN & \\
\hline CHEMBL1579368 & 688724 & 4.0 & 4.7399 & TST & \\
\hline CHEMBL1573069 & 688724 & 4.35 & 4.9332 & TRN & \\
\hline CHEMBL1559734 & 688724 & 5.0 & 4.5818 & TRN & \\
\hline CHEMBL1503034 & 688724 & 5.3 & 5.0024 & TRN & \\
\hline CHEMBL1395253 & 688724 & 4.35 & 4.6729 & TST & \\
\hline CHEMBL1356869 & 688724 & 4.25 & 4.9164 & TRN & \\
\hline CHEMBL1416554 & 688724 & 4.35 & 4.7007 & TRN & \\
\hline CHEMBL1407478 & 688724 & 4.55 & 4.9963 & TST & \\
\hline CHEMBL1409437 & 688724 & 4.45 & 5.353 & TST & \\
\hline CHEMBL1481669 & 688724 & 4.35 & 4.5453 & TRN & \\
\hline CHEMBL3351065 & 688724 & 5.15 & 5.24799 & 9999999999 & TRN \\
\hline CHEMBL1993711 & 688724 & 4.1 & 4.5847 & TRN & \\
\hline CHEMBL3208140 & 688724 & 4.35 & 4.5752 & TRN & \\
\hline CHEMBL1601133 & 688724 & 5.8 & 5.5152 & TRN & \\
\hline CHEMBL1522236 & 688724 & 5.5 & 4.7045 & TST & \\
\hline CHEMBL1552452 & 688724 & 4.45 & 4.5432 & TRN & \\
\hline CHEMBL1342904 & 688724 & 5.45 & 4.6025 & TRN & \\
\hline CHEMBL1562777 & 688724 & 4.5 & 5.1333 & TRN & \\
\hline CHEMBL1521020 & 688724 & 4.25 & 4.6783 & TRN & \\
\hline CHEMBL1541221 & 688724 & 4.75 & 5.0477 & TRN & \\
\hline CHEMBL1332111 & 688724 & 5.5 & 5.2286 & TRN & \\
\hline CHEMBL1383104 & 688724 & 6.6 & 4.7013 & TST & \\
\hline CHEMBL1458698 & 688724 & 4.75 & 4.3971 & TRN & \\
\hline CHEMBL1365694 & 688724 & 4.05 & 4.467 & TRN & \\
\hline CHEMBL1505437 & 688724 & 4.8 & 5.2931 & TRN & \\
\hline CHEMBL1334970 & 688724 & 5.0 & 4.7097 & TRN & \\
\hline CHEMBL1528903 & 688724 & 4.55 & 4.7339 & TRN & \\
\hline CHEMBL3194299 & 688724 & 4.5 & 4.4002 & TRN & \\
\hline CHEMBL1736377 & 688724 & 4.8 & 4.4018 & TRN & \\
\hline CHEMBL 2369261 & 688724 & 5.35 & 5.0674 & TRN & \\
\hline CHEMBL1461833 & 688724 & 5.1 & 4.6819 & TRN & \\
\hline CHEMBL1411140 & 688724 & 4.4 & 4.9106 & TST & \\
\hline CHEMBL1462798 & 688724 & 4.9 & 4.9161 & TRN & \\
\hline CHEMBL1433429 & 688724 & 4.35 & 4.5771 & TRN & \\
\hline CHEMBL 2000619 & 688724 & 6.1 & 5.1761 & TRN & \\
\hline CHEMBL233119 & 688724 & 4.3 & 4.811 & TRN & \\
\hline CHEMBL1317136 & 688724 & 5.05 & 5.3759 & TRN & \\
\hline CHEMBL1480522 & 688724 & 4.45 & 4.6816 & TRN & \\
\hline CHEMBL548540 & 688724 & 5.85 & 5.7259 & TRN & \\
\hline CHEMBL1378180 & 688724 & 4.05 & 4.5885 & TRN & \\
\hline CHEMBL1333426 & 688724 & 4.5 & 4.6077 & TRN & \\
\hline CHEMBL1338375 & 688724 & 4.45 & 4.3856 & TRN & \\
\hline CHEMBL1379421 & 688724 & 4.3 & 4.5632 & TST & \\
\hline CHEMBL1524475 & 688724 & 4.3 & 4.4908 & TRN & \\
\hline CHEMBL1492622 & 688724 & 4.25 & 4.6163 & TRN & \\
\hline
\end{tabular}




\begin{tabular}{|c|c|c|c|c|c|}
\hline \\
\hline CHEMBL1491435 & 688724 & 6.0 & 5.2539 & TRN & \\
\hline CHEMBL1309624 & 688724 & 4.5 & 4.8565 & TRN & \\
\hline CHEMBL1472193 & 688724 & 4.6 & 4.8515 & TRN & \\
\hline CHEMBL1516686 & 688724 & 4.0 & 4.7456 & TRN & \\
\hline CHEMBL1427661 & 688724 & 5.8 & 5.4814 & TRN & \\
\hline CHEMBL1599867 & 688724 & 4.4 & 4.8053 & TST & \\
\hline CHEMBL 3211884 & 688724 & 5.45 & 4.5043 & TRN & \\
\hline CHEMBL1387264 & 688724 & 4.6 & 4.6478 & TRN & \\
\hline CHEMBL1494870 & 688724 & 4.35 & 4.9815 & TST & \\
\hline CHEMBL1473413 & 688724 & 4.65 & 4.6999 & TRN & \\
\hline CHEMBL1604529 & 688724 & 4.6 & 4.5827 & TRN & \\
\hline CHEMBL 3190250 & 688724 & 4.65 & 4.9582 & TRN & \\
\hline CHEMBL1541632 & 688724 & 4.55 & 4.7353 & TST & \\
\hline CHEMBL1439255 & 688724 & 4.5 & 4.8089 & TRN & \\
\hline CHEMBL1344663 & 688724 & 4.4 & 4.8093 & TST & \\
\hline CHEMBL1537822 & 688724 & 4.35 & 4.2637 & TRN & \\
\hline CHEMBL1538599 & 688724 & 4.8 & 4.80399 & 9999999999 & TRN \\
\hline CHEMBL1519528 & 688724 & 5.2 & 5.1323 & TRN & \\
\hline CHEMBL1586645 & 688724 & 4.25 & 4.79899 & 99999999995 & TRN \\
\hline CHEMBL1529422 & 688724 & 4.25 & 5.1063 & TST & \\
\hline CHEMBL384808 & 688724 & 4.65 & 4.7501 & TST & \\
\hline CHEMBL1465049 & 688724 & 4.55 & 4.7314 & TRN & \\
\hline CHEMBL3199438 & 688724 & 4.8 & 4.7283 & TRN & \\
\hline CHEMBL3190259 & 688724 & 4.85 & 5.2711 & TRN & \\
\hline CHEMBL1332402 & 688724 & 5.5 & 4.8045 & TRN & \\
\hline CHEMBL1426649 & 688724 & 5.5 & 4.586 & TRN & \\
\hline CHEMBL1561353 & 688724 & 5.4 & 4.9186 & TRN & \\
\hline CHEMBL1537212 & 688724 & 4.6 & 5.1223 & TST & \\
\hline CHEMBL1493257 & 688724 & 4.15 & 4.465 & TRN & \\
\hline CHEMBL1471037 & 688724 & 4.45 & 4.8046 & TRN & \\
\hline CHEMBL1461116 & 688724 & 4.2 & 5.2618 & TST & \\
\hline CHEMBL1334246 & 688724 & 4.95 & 4.75899 & 99999999995 & TRN \\
\hline CHEMBL1608696 & 688724 & 4.35 & 4.5517 & TST & \\
\hline CHEMBL1469192 & 688724 & 5.15 & 5.0832 & TRN & \\
\hline CHEMBL1164316 & 688724 & 5.05 & 5.0806 & TST & \\
\hline CHEMBL3197927 & 688724 & 6.05 & 4.9107 & TST & \\
\hline CHEMBL1323744 & 688724 & 6.35 & 5.4847 & TRN & \\
\hline CHEMBL1403524 & 688724 & 4.75 & 4.6008 & TRN & \\
\hline CHEMBL1302308 & 688724 & 4.1 & 5.4624 & TRN & \\
\hline CHEMBL1433770 & 688724 & 4.3 & 4.6551 & TRN & \\
\hline CHEMBL1514534 & 688724 & 4.3 & 4.9944 & TRN & \\
\hline CHEMBL1306211 & 688724 & 4.1 & 4.5615 & TST & \\
\hline CHEMBL41040 & 688724 & 6.0 & 4.8825 & TST & \\
\hline CHEMBL596674 & 688724 & 6.0 & 4.6641 & TST & \\
\hline CHEMBL1414153 & 688724 & 4.05 & 4.6555 & TST & \\
\hline CHEMBL1467888 & 688724 & 4.35 & 4.6837 & TST & \\
\hline CHEMBL1349063 & 688724 & 4.0 & 5.0336 & TRN & \\
\hline CHEMBL1415370 & 688724 & 4.05 & 4.7747 & TST & \\
\hline
\end{tabular}




\begin{tabular}{|c|c|c|c|c|c|}
\hline & & \multicolumn{4}{|c|}{ Supplemental Table S2.txt } \\
\hline CHEMBL1495592 & 688724 & 4.85 & 4.982 & TRN & \\
\hline CHEMBL1423621 & 688724 & 4.0 & 4.9849 & TST & \\
\hline CHEMBL1488072 & 688724 & 4.3 & 4.7131 & TRN & \\
\hline CHEMBL 3193534 & 688724 & 5.75 & 4.8577 & TRN & \\
\hline CHEMBL1459167 & 688724 & 5.2 & 4.7346 & TRN & \\
\hline CHEMBL1388760 & 688724 & 4.65 & 4.7777 & TRN & \\
\hline CHEMBL 3189177 & 688724 & 4.55 & 4.7453 & TRN & \\
\hline CHEMBL522990 & 688724 & 4.7 & 5.0088 & TRN & \\
\hline CHEMBL1303785 & 688724 & 4.75 & 4.6316 & TST & \\
\hline CHEMBL1556707 & 688724 & 4.35 & 4.8017 & TRN & \\
\hline CHEMBL1576822 & 688724 & 4.85 & 4.8903 & TST & \\
\hline CHEMBL1576165 & 688724 & 4.0 & 4.6083 & TRN & \\
\hline CHEMBL1322163 & 688724 & 4.4 & 4.7339 & TRN & \\
\hline CHEMBL 3195734 & 688724 & 4.3 & 4.7037 & TST & \\
\hline CHEMBL105310 & 688724 & 4.4 & 4.9198 & TRN & \\
\hline CHEMBL1379000 & 688724 & 4.9 & 4.8859 & TRN & \\
\hline CHEMBL1420493 & 688724 & 4.6 & 4.9932 & TRN & \\
\hline CHEMBL1426837 & 688724 & 4.35 & 4.7851 & TRN & \\
\hline CHEMBL1458561 & 688724 & 7.0501 & 4.7585 & TRN & \\
\hline CHEMBL1328277 & 688724 & 4.45 & 4.4654 & TST & \\
\hline CHEMBL1523501 & 688724 & 4.85 & 4.6776 & TST & \\
\hline CHEMBL3392435 & 688724 & 4.3 & 4.9393 & TRN & \\
\hline CHEMBL1311848 & 688724 & 4.75 & 4.4879 & TRN & \\
\hline CHEMBL1532818 & 688724 & 4.1 & 4.456 & TRN & \\
\hline CHEMBL1301688 & 688724 & 4.35 & 4.8497 & TRN & \\
\hline CHEMBL1406151 & 688724 & 4.75 & 4.7358 & TRN & \\
\hline CHEMBL1606183 & 688724 & 5.35 & 4.5277 & TST & \\
\hline CHEMBL1493178 & 688724 & 4.0 & 4.65300 & 00000000005 & TRN \\
\hline CHEMBL446240 & 688724 & 4.1 & 4.8168 & TRN & \\
\hline CHEMBL1398523 & 688724 & 5.1 & 5.1947 & TRN & \\
\hline CHEMBL1499996 & 688724 & 6.05 & 5.1014 & TRN & \\
\hline CHEMBL1522544 & 688724 & 5.1 & 4.7927 & TRN & \\
\hline CHEMBL1427182 & 688724 & 4.35 & 4.8121 & TRN & \\
\hline CHEMBL1496284 & 688724 & 4.75 & 4.912 & TST & \\
\hline CHEMBL1517362 & 688724 & 5.45 & 5.6356 & TRN & \\
\hline CHEMBL1427833 & 688724 & 4.25 & 4.9906 & TST & \\
\hline CHEMBL1372817 & 688724 & 5.6 & 5.1991 & TRN & \\
\hline CHEMBL546649 & 688724 & 4.05 & 4.7388 & TRN & \\
\hline CHEMBL1533401 & 688724 & 4.8 & 5.2484 & TRN & \\
\hline CHEMBL3198366 & 688724 & 5.05 & 4.7582 & TRN & \\
\hline CHEMBL1606731 & 688724 & 5.95 & 5.0474 & TRN & \\
\hline CHEMBL3191708 & 688724 & 5.5 & 5.0655 & TRN & \\
\hline CHEMBL1544948 & 688724 & 4.6 & 5.1115 & TRN & \\
\hline CHEMBL1408156 & 688724 & 5.35 & 5.0845 & TRN & \\
\hline CHEMBL468037 & 688724 & 4.9 & 4.8855 & TRN & \\
\hline CHEMBL3209187 & 688724 & 4.35 & 4.8932 & TRN & \\
\hline CHEMBL1454686 & 688724 & 5.35 & 4.7332 & TST & \\
\hline CHEMBL1441228 & 688724 & 4.3 & 4.4919 & TRN & \\
\hline
\end{tabular}




\begin{tabular}{|c|c|c|c|c|}
\hline \multicolumn{5}{|c|}{ Supplemental Table S2.txt } \\
\hline CHEMBL1499207 & 688724 & 4.55 & 4.5166 & TRN \\
\hline CHEMBL1539706 & 688724 & 4.35 & 4.952 & TST \\
\hline CHEMBL1517299 & 688724 & 4.7 & 5.2436 & TRN \\
\hline CHEMBL19980 & 688724 & 5.65 & 5.5943 & TST \\
\hline CHEMBL1412710 & 688724 & 4.7 & 4.9655 & TRN \\
\hline CHEMBL1346062 & 688724 & 4.65 & 4.8333 & TRN \\
\hline CHEMBL1461089 & 688724 & 4.4 & 4.6844 & TRN \\
\hline CHEMBL1489920 & 688724 & 4.1 & 4.7945 & TST \\
\hline CHEMBL1308764 & 688724 & 4.75 & 4.8149 & TRN \\
\hline CHEMBL466 & 688724 & 4.35 & 4.8336 & TRN \\
\hline CHEMBL1576713 & 688724 & 6.3 & 5.2668 & TST \\
\hline CHEMBL 274070 & 688724 & 4.4 & 4.944 & TRN \\
\hline CHEMBL15849 & 688724 & 4.25 & 5.2173 & TRN \\
\hline CHEMBL1334206 & 688724 & 4.45 & 4.6324 & TRN \\
\hline CHEMBL1506817 & 688724 & 4.7 & 5.1046 & TRN \\
\hline CHEMBL3192936 & 688724 & 4.45 & 4.974 & TRN \\
\hline CHEMBL1551945 & 688724 & 4.35 & 4.6345 & TRN \\
\hline CHEMBL1511193 & 688724 & 7.8508 & 5.0498 & TRN \\
\hline CHEMBL3190073 & 688724 & 4.65 & 5.0016 & TRN \\
\hline CHEMBL3197892 & 688724 & 4.25 & 4.4641 & TRN \\
\hline CHEMBL1492819 & 688724 & 4.6 & 4.9961 & TST \\
\hline CHEMBL1310171 & 688724 & 4.65 & 4.3969 & TRN \\
\hline CHEMBL 3145101 & 688724 & 5.65 & 4.8531 & TRN \\
\hline CHEMBL1454948 & 688724 & 4.65 & 4.391 & TRN \\
\hline CHEMBL1589975 & 688724 & 4.35 & 4.4081 & TRN \\
\hline CHEMBL1349206 & 688724 & 4.9 & 4.7666 & TST \\
\hline CHEMBL68096 & 688724 & 4.25 & 5.0416 & TST \\
\hline CHEMBL1555793 & 688724 & 4.35 & 5.1142 & TRN \\
\hline CHEMBL1342299 & 688724 & 5.5 & 4.5912 & TST \\
\hline CHEMBL1447676 & 688724 & 4.1 & 4.8416 & TRN \\
\hline CHEMBL1604520 & 688724 & 4.15 & 4.7011 & TRN \\
\hline CHEMBL1522449 & 688724 & 5.1 & 4.8036 & TRN \\
\hline CHEMBL1371284 & 688724 & 4.05 & 4.6938 & TRN \\
\hline CHEMBL1579780 & 688724 & 4.95 & 4.7642 & TRN \\
\hline CHEMBL 3145330 & 688724 & 5.05 & 5.1902 & TRN \\
\hline CHEMBL1413790 & 688724 & 4.55 & 4.4059 & TST \\
\hline CHEMBL1370530 & 688724 & 4.05 & 4.8157 & TRN \\
\hline CHEMBL1330225 & 688724 & 4.0 & 4.82600 & 20000000005 \\
\hline CHEMBL1566005 & 688724 & 4.85 & 4.5131 & TRN \\
\hline CHEMBL1575099 & 688724 & 4.1 & 4.7393 & TST \\
\hline CHEMBL1583798 & 688724 & 4.65 & 4.6413 & TRN \\
\hline CHEMBL1331363 & 688724 & 5.55 & 4.5748 & TRN \\
\hline CHEMBL1384702 & 688724 & 5.6 & 4.9581 & TRN \\
\hline CHEMBL1552194 & 688724 & 4.7 & 4.9929 & TRN \\
\hline CHEMBL1508258 & 688724 & 5.3 & 4.8302 & TST \\
\hline CHEMBL1475325 & 688724 & 4.9 & 5.0691 & TRN \\
\hline CHEMBL3191174 & 688724 & 4.0 & 4.5702 & TRN \\
\hline CHEMBL1600149 & 688724 & 6.2 & 4.8282 & TST \\
\hline
\end{tabular}




\begin{tabular}{|c|c|c|c|c|c|}
\hline & & \multicolumn{4}{|c|}{ Supplemental Table S2.txt } \\
\hline CHEMBL1577815 & 688724 & 5.1 & 4.9949 & TST & \\
\hline CHEMBL1372392 & 688724 & 4.55 & 4.5172 & TRN & \\
\hline CHEMBL1428972 & 688724 & 4.95 & 4.9679 & TST & \\
\hline CHEMBL1308312 & 688724 & 4.9 & 4.895 & TRN & \\
\hline CHEMBL1256869 & 688724 & 6.0 & 4.9983 & TRN & \\
\hline CHEMBL1497849 & 688724 & 4.6 & 5.0142 & TRN & \\
\hline CHEMBL1545676 & 688724 & 4.85 & 4.7915 & TRN & \\
\hline CHEMBL1399698 & 688724 & 4.7 & 5.4013 & TRN & \\
\hline CHEMBL1371776 & 688724 & 5.3 & 5.0129 & TRN & \\
\hline CHEMBL1319984 & 688724 & 6.3 & 5.3756 & TRN & \\
\hline CHEMBL1519796 & 688724 & 5.15 & 4.7409 & TST & \\
\hline CHEMBL1335471 & 688724 & 5.1 & 4.8067 & TRN & \\
\hline CHEMBL1527955 & 688724 & 5.0 & 5.0817 & TST & \\
\hline CHEMBL1526871 & 688724 & 4.55 & 4.9715 & TST & \\
\hline CHEMBL3189405 & 688724 & 6.0 & 5.0122 & TRN & \\
\hline CHEMBL1381963 & 688724 & 5.0 & 5.376 & TRN & \\
\hline CHEMBL1448069 & 688724 & 4.6 & $4.4510 e$ & 00000000005 & TRN \\
\hline CHEMBL1554733 & 688724 & 4.35 & 4.5472 & TRN & \\
\hline CHEMBL1563476 & 688724 & 4.85 & 4.7725 & TRN & \\
\hline CHEMBL1339505 & 688724 & 5.95 & 5.2129 & TRN & \\
\hline CHEMBL1570659 & 688724 & 5.35 & 5.1403 & TRN & \\
\hline CHEMBL1590171 & 688724 & 5.25 & 4.5458 & TRN & \\
\hline CHEMBL1453696 & 688724 & 5.55 & 4.9044 & TST & \\
\hline CHEMBL3198836 & 688724 & 4.8 & 4.9737 & TRN & \\
\hline CHEMBL72410 & 688724 & 4.45 & 4.7217 & TRN & \\
\hline CHEMBL1606292 & 688724 & 4.9 & 4.6725 & TRN & \\
\hline CHEMBL1386620 & 688724 & 4.6 & 4.7611 & TRN & \\
\hline CHEMBL1491801 & 688724 & 4.75 & 4.7223 & TST & \\
\hline CHEMBL591137 & 688724 & 5.5 & 5.6412 & TRN & \\
\hline CHEMBL1574108 & 688724 & 4.6 & 4.6521 & TRN & \\
\hline CHEMBL1416244 & 688724 & 4.7 & 4.6077 & TRN & \\
\hline CHEMBL1491589 & 688724 & 6.0 & 5.0364 & TRN & \\
\hline CHEMBL3191009 & 688724 & 4.05 & 4.7382 & TRN & \\
\hline CHEMBL1394997 & 688724 & 4.55 & 4.631 & TST & \\
\hline CHEMBL1579585 & 688724 & 4.8 & 4.8043 & TRN & \\
\hline CHEMBL1420739 & 688724 & 4.35 & 4.9394 & TST & \\
\hline CHEMBL1450097 & 688724 & 4.35 & 4.6374 & TRN & \\
\hline CHEMBL1307323 & 688724 & 4.35 & 4.9666 & TST & \\
\hline CHEMBL1409320 & 688724 & 4.8 & 4.7807 & TRN & \\
\hline CHEMBL1602127 & 688724 & 5.55 & 5.0469 & TRN & \\
\hline CHEMBL1317053 & 688724 & 4.0 & 4.6946 & TST & \\
\hline CHEMBL1173823 & 688724 & 4.65 & 4.8276 & TRN & \\
\hline CHEMBL3196500 & 688724 & 4.55 & 4.6405 & TRN & \\
\hline CHEMBL1976392 & 688724 & 4.75 & 4.7699 & TST & \\
\hline CHEMBL1976312 & 688724 & 5.1 & 5.426 & TRN & \\
\hline CHEMBL1324207 & 688724 & 4.55 & 4.935 & TST & \\
\hline CHEMBL1704267 & 688724 & 5.85 & 5.2048 & TRN & \\
\hline CHEMBL1575945 & 688724 & 4.25 & 4.3665 & TST & \\
\hline
\end{tabular}




\begin{tabular}{|c|c|c|c|c|}
\hline \multicolumn{5}{|c|}{ Supplemental Table S2.txt } \\
\hline CHEMBL1324939 & 688724 & 4.55 & 4.8785 & TRN \\
\hline CHEMBL1310425 & 688724 & 4.35 & 4.6787 & TRN \\
\hline CHEMBL1431724 & 688724 & 4.7 & 4.5897 & TRN \\
\hline CHEMBL1160160 & 688724 & 6.2 & 5.2943 & TRN \\
\hline CHEMBL1299589 & 688724 & 4.55 & 4.8967 & TRN \\
\hline CHEMBL1601496 & 688724 & 4.25 & 4.6969 & TRN \\
\hline CHEMBL1303996 & 688724 & 4.5 & 4.5804 & TRN \\
\hline CHEMBL1575783 & 688724 & 4.95 & 4.7608 & TRN \\
\hline CHEMBL1441413 & 688724 & 4.3 & 4.7759 & TRN \\
\hline CHEMBL1396827 & 688724 & 4.9 & 4.7273 & TST \\
\hline CHEMBL1470395 & 688724 & 5.1 & 4.8219 & TRN \\
\hline CHEMBL 3145026 & 688724 & 4.4 & 4.7609 & TRN \\
\hline CHEMBL1507881 & 688724 & 5.55 & 5.0534 & TRN \\
\hline CHEMBL1558442 & 688724 & 5.15 & 4.6932 & TRN \\
\hline CHEMBL1524461 & 688724 & 4.4 & 4.7171 & TRN \\
\hline CHEMBL1531693 & 688724 & 4.9 & 4.5828 & TRN \\
\hline CHEMBL1328576 & 688724 & 4.4 & 5.8354 & TST \\
\hline CHEMBL3192580 & 688724 & 4.75 & 4.6495 & TRN \\
\hline CHEMBL1532631 & 688724 & 7.15 & 4.6747 & TRN \\
\hline CHEMBL3197561 & 688724 & 4.65 & 4.8876 & TRN \\
\hline CHEMBL1523711 & 688724 & 4.45 & 4.3331 & TST \\
\hline CHEMBL1417045 & 688724 & 4.75 & 5.0029 & TRN \\
\hline CHEMBL1304325 & 688724 & 4.3 & 4.4427 & TRN \\
\hline CHEMBL1592061 & 688724 & 4.1 & 4.2687 & TRN \\
\hline CHEMBL1356799 & 688724 & 4.3 & 4.5164 & TRN \\
\hline CHEMBL1392657 & 688724 & 4.7 & 4.9617 & TST \\
\hline CHEMBL1422986 & 688724 & 4.95 & 4.8955 & TRN \\
\hline CHEMBL1417329 & 688724 & 4.55 & 4.7146 & TRN \\
\hline CHEMBL1499739 & 688724 & 4.55 & 4.959 & TRN \\
\hline CHEMBL1332093 & 688724 & 4.1 & 4.8054 & TRN \\
\hline CHEMBL1369634 & 688724 & 4.3 & 4.6427 & TRN \\
\hline CHEMBL1513255 & 688724 & 6.2 & 4.4378 & TRN \\
\hline CHEMBL1503392 & 688724 & 4.7 & 4.7315 & TRN \\
\hline CHEMBL1443464 & 688724 & 4.4 & 5.0943 & TRN \\
\hline CHEMBL1595076 & 688724 & 4.75 & 4.7237 & TRN \\
\hline CHEMBL1510712 & 688724 & 4.4 & 4.6856 & TRN \\
\hline CHEMBL3207417 & 688724 & 4.1 & 4.8204 & TRN \\
\hline CHEMBL1440117 & 688724 & 4.0 & 4.4843 & TRN \\
\hline CHEMBL1363142 & 688724 & 4.1 & 4.556 & TRN \\
\hline CHEMBL1369105 & 688724 & 5.05 & 4.6156 & TRN \\
\hline CHEMBL1510711 & 688724 & 5.05 & 4.859 & TST \\
\hline CHEMBL 1445030 & 688724 & 4.95 & 4.7046 & TRN \\
\hline CHEMBL1305104 & 688724 & 5.3 & 4.8711 & TST \\
\hline CHEMBL1367674 & 688724 & 7.6003 & 4.6084 & TST \\
\hline CHEMBL1346195 & 688724 & 5.2 & 4.8901 & TRN \\
\hline CHEMBL1484407 & 688724 & 4.9 & 4.7694 & TRN \\
\hline CHEMBL1544423 & 688724 & 4.85 & 4.9032 & TRN \\
\hline CHEMBL1325489 & 688724 & 4.1 & 4.8125 & TST \\
\hline
\end{tabular}




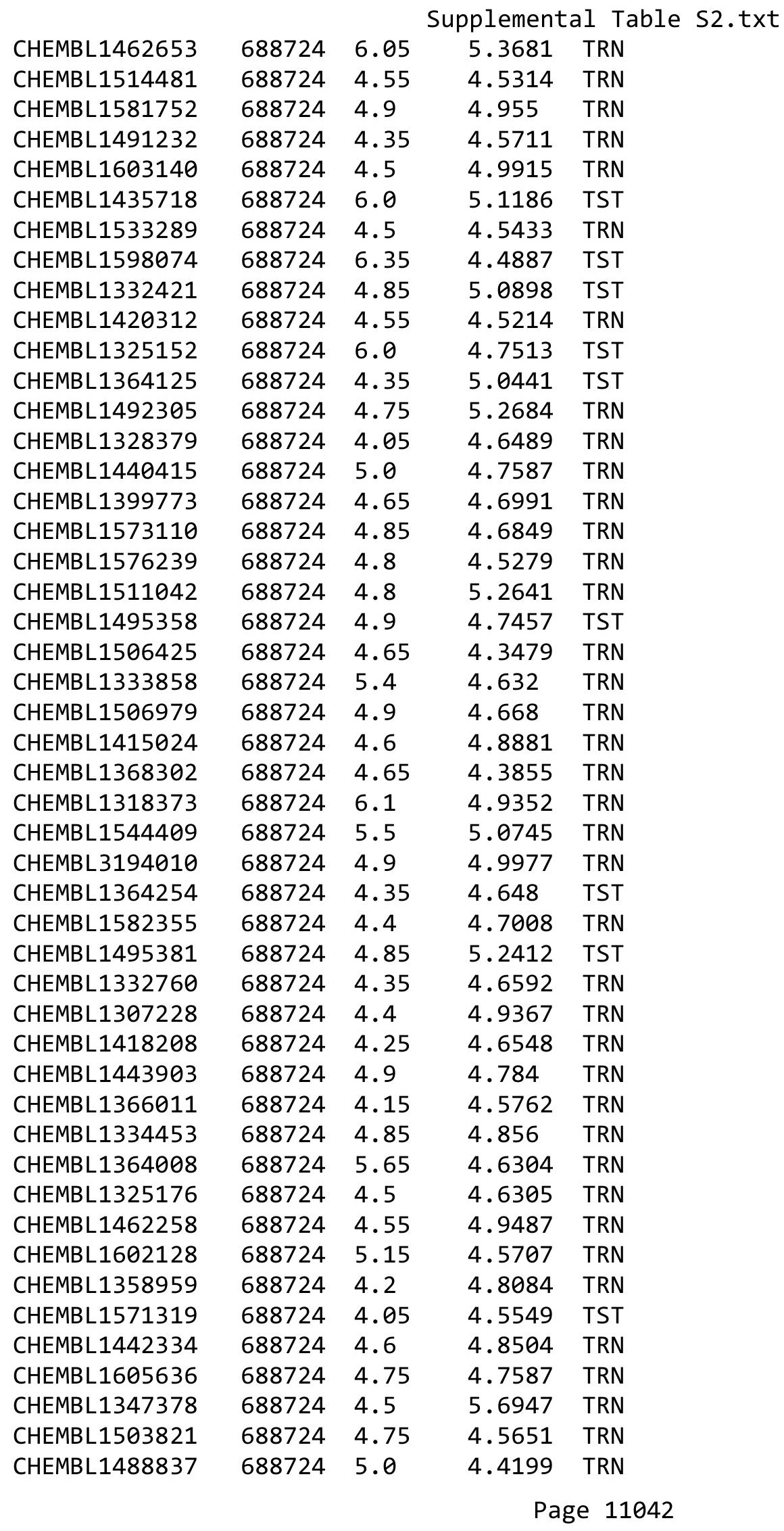




\begin{tabular}{|c|c|c|c|c|c|}
\hline \multicolumn{6}{|c|}{ Supplemental Table S2.txt } \\
\hline CHEMBL1978830 & 688724 & 4.55 & 5.1153 & TRN & \\
\hline CHEMBL1561877 & 688724 & 4.55 & 4.7309 & TRN & \\
\hline CHEMBL1487657 & 688724 & 5.55 & 5.1751 & TRN & \\
\hline CHEMBL1597468 & 688724 & 4.45 & 4.7057 & TST & \\
\hline CHEMBL1308388 & 688724 & 4.55 & 4.7389 & TST & \\
\hline CHEMBL1546002 & 688724 & 4.3 & 4.9658 & TST & \\
\hline CHEMBL1339417 & 688724 & 4.35 & 5.0446 & TST & \\
\hline CHEMBL1358638 & 688724 & 5.15 & 5.1612 & TST & \\
\hline CHEMBL1386928 & 688724 & 4.95 & 4.7055 & TRN & \\
\hline CHEMBL1510852 & 688724 & 5.7 & 5.1742 & TRN & \\
\hline CHEMBL1325966 & 688724 & 4.05 & 4.3598 & TRN & \\
\hline CHEMBL1323312 & 688724 & 4.1 & 4.6572 & TRN & \\
\hline CHEMBL1535919 & 688724 & 4.95 & 5.1824 & TRN & \\
\hline CHEMBL1562691 & 688724 & 4.35 & 4.5426 & TRN & \\
\hline CHEMBL1988708 & 688724 & 5.45 & 5.44799 & 99999999995 & TRN \\
\hline CHEMBL1909453 & 688724 & 4.8 & 4.9918 & TRN & \\
\hline CHEMBL3194760 & 688724 & 4.6 & 4.6624 & TST & \\
\hline CHEMBL1493269 & 688724 & 5.1 & 4.8223 & TRN & \\
\hline CHEMBL1580973 & 688724 & 4.45 & 5.0627 & TRN & \\
\hline CHEMBL1200608 & 688724 & 4.9 & 4.9696 & TRN & \\
\hline CHEMBL1377148 & 688724 & 4.2 & 4.96 & TST & \\
\hline CHEMBL1493481 & 688724 & 5.25 & 5.1546 & TST & \\
\hline CHEMBL1492926 & 688724 & 4.1 & 4.5475 & TRN & \\
\hline CHEMBL1388356 & 688724 & 5.15 & 4.9931 & TST & \\
\hline CHEMBL1394337 & 688724 & 6.5 & 5.7656 & TRN & \\
\hline CHEMBL1341390 & 688724 & 4.4 & 4.6864 & TRN & \\
\hline CHEMBL1553123 & 688724 & 4.3 & 4.6875 & TRN & \\
\hline CHEMBL1315692 & 688724 & 4.7 & 4.7714 & TRN & \\
\hline CHEMBL1468225 & 688724 & 4.75 & 4.5609 & TRN & \\
\hline CHEMBL1386797 & 688724 & 4.0 & 4.3478 & TRN & \\
\hline CHEMBL1480339 & 688724 & 4.85 & 5.1276 & TRN & \\
\hline CHEMBL1441975 & 688724 & 4.55 & 5.0249 & TST & \\
\hline CHEMBL1442300 & 688724 & 4.55 & 4.6678 & TRN & \\
\hline CHEMBL1400409 & 688724 & 4.8 & 4.9933 & TRN & \\
\hline CHEMBL3197008 & 688724 & 4.35 & 4.9036 & TRN & \\
\hline CHEMBL1581613 & 688724 & 4.95 & 4.6829 & TRN & \\
\hline CHEMBL1586590 & 688724 & 5.3 & 5.5084 & TRN & \\
\hline CHEMBL1364869 & 688724 & 4.7 & 4.5635 & TST & \\
\hline CHEMBL3191023 & 688724 & 4.6 & 4.9089 & TRN & \\
\hline CHEMBL1404959 & 688724 & 4.65 & 4.765 & TRN & \\
\hline CHEMBL137803 & 688724 & 4.8 & 5.2794 & TST & \\
\hline CHEMBL1559341 & 688724 & 5.6 & 5.2008 & TST & \\
\hline CHEMBL3196328 & 688724 & 4.4 & 4.6331 & TRN & \\
\hline CHEMBL1602906 & 688724 & 4.45 & 5.3281 & TRN & \\
\hline CHEMBL1331744 & 688724 & 4.25 & 4.992 & TRN & \\
\hline CHEMBL1469117 & 688724 & 4.4 & 4.8529 & TRN & \\
\hline CHEMBL1299668 & 688724 & 4.5 & 4.7888 & TRN & \\
\hline CHEMBL1580452 & 688724 & 6.35 & 5.0153 & TST & \\
\hline
\end{tabular}




\begin{tabular}{|c|c|c|c|c|}
\hline \multicolumn{5}{|c|}{ Supplemental Table S2.txt } \\
\hline CHEMBL1379832 & 688724 & 4.75 & 4.6772 & TRN \\
\hline CHEMBL1379362 & 688724 & 4.8 & 4.5034 & TRN \\
\hline CHEMBL1411044 & 688724 & 4.95 & 4.7303 & TRN \\
\hline CHEMBL1361858 & 688724 & 4.55 & 4.8209 & TRN \\
\hline CHEMBL1577064 & 688724 & 4.5 & 5.1492 & TST \\
\hline CHEMBL1388300 & 688724 & 4.9 & 4.7654 & TRN \\
\hline CHEMBL3392035 & 688724 & 4.8 & 5.0965 & TRN \\
\hline CHEMBL 3194807 & 688724 & 4.7 & 5.3191 & TRN \\
\hline CHEMBL1591288 & 688724 & 6.15 & 4.8553 & TRN \\
\hline CHEMBL1440968 & 688724 & 5.05 & 4.5733 & TRN \\
\hline CHEMBL1461947 & 688724 & 4.9 & 4.5584 & TST \\
\hline CHEMBL1373110 & 688724 & 4.5 & 4.883 & TRN \\
\hline CHEMBL1304495 & 688724 & 4.7 & 4.7504 & TRN \\
\hline CHEMBL1986785 & 688724 & 4.55 & 4.7746 & TRN \\
\hline CHEMBL1478537 & 688724 & 4.25 & 4.5485 & TST \\
\hline CHEMBL1351505 & 688724 & 6.0 & 5.1456 & TRN \\
\hline CHEMBL1469863 & 688724 & 4.8 & 4.7162 & TRN \\
\hline CHEMBL1449354 & 688724 & 4.85 & 4.5977 & TRN \\
\hline CHEMBL1528567 & 688724 & 4.65 & 4.6575 & TRN \\
\hline CHEMBL1323907 & 688724 & 4.3 & 4.7657 & TRN \\
\hline CHEMBL1364424 & 688724 & 4.95 & 5.0936 & TST \\
\hline CHEMBL1345751 & 688724 & 5.45 & 4.4987 & TRN \\
\hline CHEMBL1371735 & 688724 & 4.95 & 5.2824 & TST \\
\hline CHEMBL1553561 & 688724 & 4.7 & 4.622 & TRN \\
\hline CHEMBL1410021 & 688724 & 7.3002 & 4.7658 & TRN \\
\hline CHEMBL1350656 & 688724 & 5.05 & 5.2588 & TRN \\
\hline CHEMBL1585661 & 688724 & 4.85 & 4.5537 & TST \\
\hline CHEMBL1582032 & 688724 & 4.55 & 4.6103 & TRN \\
\hline CHEMBL1444690 & 688724 & 4.45 & 4.8197 & TRN \\
\hline CHEMBL1428924 & 688724 & 4.45 & 4.8146 & TRN \\
\hline CHEMBL1403414 & 688724 & 6.0 & 5.0907 & TRN \\
\hline CHEMBL1321449 & 688724 & 4.65 & 4.7313 & TST \\
\hline CHEMBL1535507 & 688724 & 4.4 & 4.5168 & TST \\
\hline CHEMBL1317982 & 688724 & 4.5 & 4.7097 & TRN \\
\hline CHEMBL1430321 & 688724 & 5.2 & 4.8468 & TRN \\
\hline CHEMBL1571785 & 688724 & 6.0 & 4.9207 & TRN \\
\hline CHEMBL1452706 & 688724 & 5.0 & 5.1791 & TRN \\
\hline CHEMBL1573719 & 688724 & 4.4 & 4.897 & TST \\
\hline CHEMBL104468 & 688724 & 4.35 & 4.6395 & TRN \\
\hline CHEMBL1557342 & 688724 & 5.6 & 4.7918 & TRN \\
\hline CHEMBL1380526 & 688724 & 4.9 & 4.7029 & TRN \\
\hline CHEMBL 1553070 & 688724 & 4.6 & 4.5713 & TRN \\
\hline CHEMBL1509453 & 688724 & 5.85 & 4.925 & TRN \\
\hline CHEMBL1441922 & 688724 & 4.85 & 4.5812 & TST \\
\hline CHEMBL269733 & 688724 & 6.3 & 5.5731 & TRN \\
\hline CHEMBL1372492 & 688724 & 5.5 & 5.3802 & TRN \\
\hline CHEMBL3189870 & 688724 & 4.75 & 5.0598 & TRN \\
\hline CHEMBL1565265 & 688724 & 4.4 & 4.8293 & TST \\
\hline
\end{tabular}




\begin{tabular}{|c|c|c|c|c|c|}
\hline \\
\hline CHEMBL1601302 & 688724 & 4.3 & 4.6402 & TRN & \\
\hline CHEMBL1450838 & 688724 & 4.6 & 4.8389 & TRN & \\
\hline CHEMBL2369280 & 688724 & 4.95 & 4.9029 & TRN & \\
\hline CHEMBL1335321 & 688724 & 5.5 & 4.9931 & TRN & \\
\hline CHEMBL1497777 & 688724 & 5.0 & 4.768 & TRN & \\
\hline CHEMBL508112 & 688724 & 6.0 & 4.9222 & TRN & \\
\hline CHEMBL1305385 & 688724 & 4.95 & 4.7386 & TRN & \\
\hline CHEMBL1528814 & 688724 & 6.25 & 5.5966 & TRN & \\
\hline CHEMBL1361202 & 688724 & 5.1 & 5.435 & TRN & \\
\hline CHEMBL1529350 & 688724 & 4.4 & 4.8262 & TRN & \\
\hline CHEMBL528694 & 688724 & 5.55 & 5.3745 & TRN & \\
\hline CHEMBL1554557 & 688724 & 4.15 & 4.445 & TRN & \\
\hline CHEMBL1433075 & 688724 & 4.8 & 4.7804 & TRN & \\
\hline CHEMBL1299540 & 688724 & 4.7 & 4.6491 & TRN & \\
\hline CHEMBL1459124 & 688724 & 4.6 & 4.72199 & 99999999995 & TRN \\
\hline CHEMBL1405147 & 688724 & 6.0 & 4.9868 & TRN & \\
\hline CHEMBL1459486 & 688724 & 4.4 & 4.825 & TRN & \\
\hline CHEMBL297784 & 688724 & 4.3 & 4.737 & TRN & \\
\hline CHEMBL1982202 & 688724 & 4.1 & 4.851 & TRN & \\
\hline CHEMBL193872 & 688724 & 4.4 & 5.4388 & TRN & \\
\hline CHEMBL1379408 & 688724 & 4.7 & 5.1889 & TST & \\
\hline CHEMBL1553125 & 688724 & 5.15 & 5.1775 & TRN & \\
\hline CHEMBL1589193 & 688724 & 4.25 & 4.2566 & TRN & \\
\hline CHEMBL1428250 & 688724 & 5.75 & 5.09699 & 99999999995 & TST \\
\hline CHEMBL1322987 & 688724 & 4.3 & 4.503 & TRN & \\
\hline CHEMBL1540089 & 688724 & 4.45 & 4.6944 & TRN & \\
\hline CHEMBL1988133 & 688724 & 5.2 & 4.7374 & TST & \\
\hline CHEMBL1973328 & 688724 & 4.0 & 4.5648 & TRN & \\
\hline CHEMBL1592335 & 688724 & 4.35 & 4.5674 & TRN & \\
\hline CHEMBL3197703 & 688724 & 6.2 & 5.4521 & TRN & \\
\hline CHEMBL1596455 & 688724 & 4.05 & 4.6026 & TRN & \\
\hline CHEMBL3194622 & 688724 & 4.25 & 4.8806 & TRN & \\
\hline CHEMBL1568084 & 688724 & 4.5 & 4.8175 & TRN & \\
\hline CHEMBL1436698 & 688724 & 5.1 & 4.3849 & TRN & \\
\hline CHEMBL1312716 & 688724 & 4.85 & 4.9288 & TRN & \\
\hline CHEMBL1527443 & 688724 & 4.5 & 4.7104 & TRN & \\
\hline CHEMBL1392153 & 688724 & 5.6 & 5.3576 & TST & \\
\hline CHEMBL1580116 & 688724 & 4.6 & 4.55 & TRN & \\
\hline CHEMBL1493103 & 688724 & 4.75 & 5.1345 & TRN & \\
\hline CHEMBL1596692 & 688724 & 5.4 & 5.16299 & 9999999999 & TRN \\
\hline CHEMBL1496380 & 688724 & 4.35 & 4.8085 & TRN & \\
\hline CHEMBL1970082 & 688724 & 5.55 & 4.8299 & TRN & \\
\hline CHEMBL1255936 & 688724 & 4.65 & 4.7682 & TST & \\
\hline CHEMBL1426634 & 688724 & 4.75 & 4.5017 & TRN & \\
\hline CHEMBL1518085 & 688724 & 5.05 & 5.5282 & TRN & \\
\hline CHEMBL1492786 & 688724 & 4.8 & 4.8425 & TST & \\
\hline CHEMBL1997130 & 688724 & 5.05 & 5.0351 & TRN & \\
\hline CHEMBL1365324 & 688724 & 4.2 & 4.6943 & TRN & \\
\hline
\end{tabular}




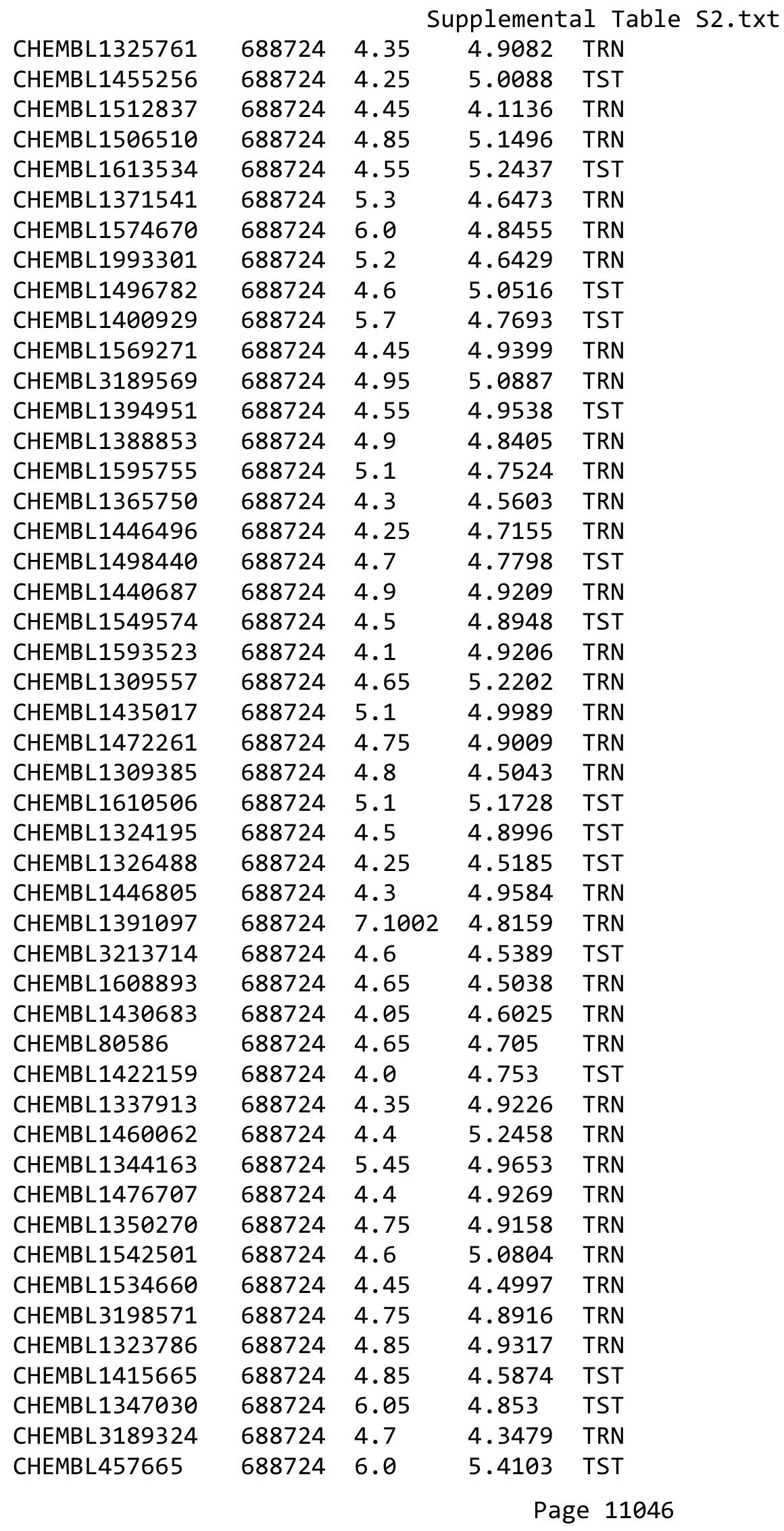




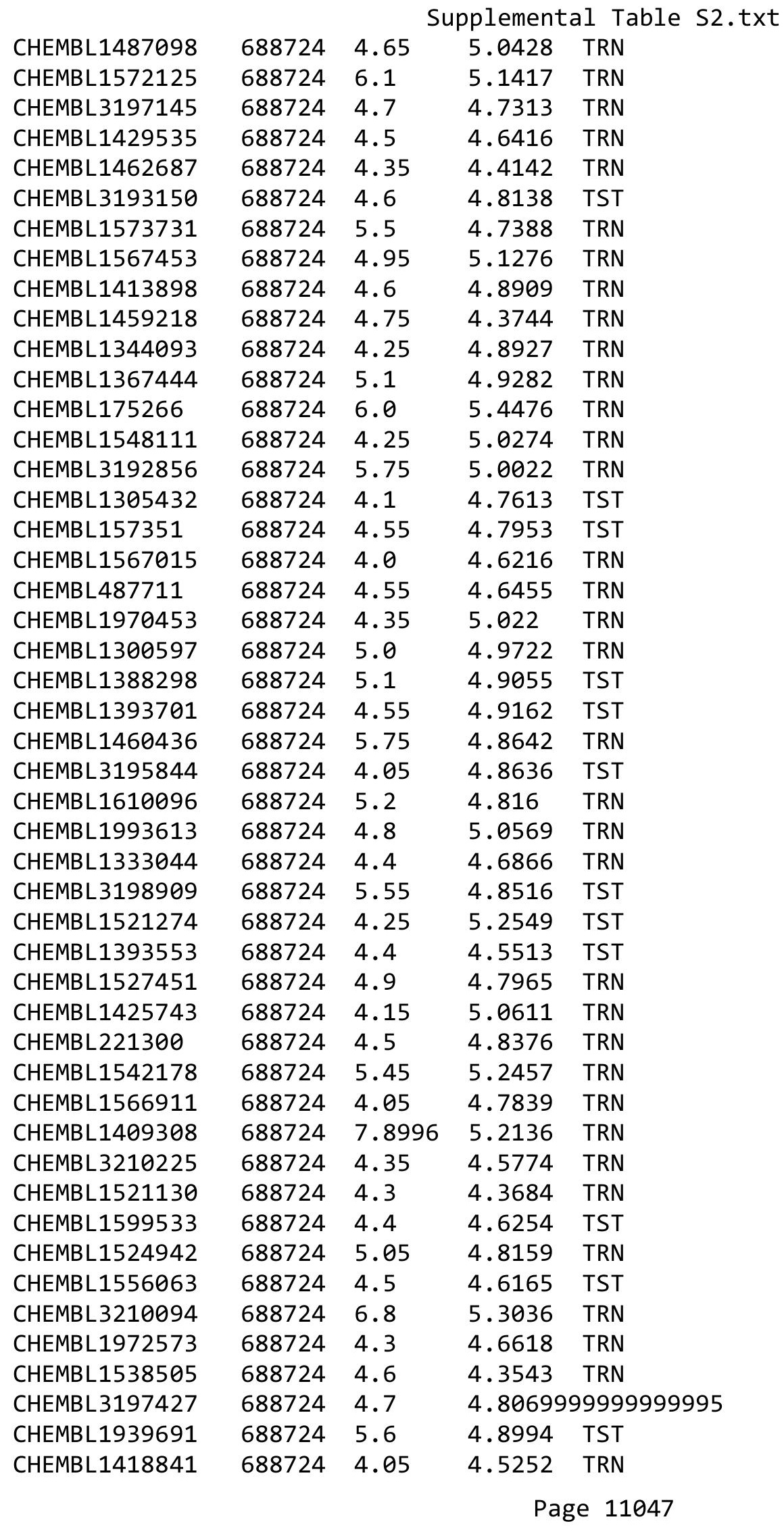




\begin{tabular}{|c|c|c|c|c|}
\hline & & & upplement & al $\mathrm{T}$ \\
\hline CHEMBL1533772 & 688724 & 4.65 & 4.9784 & TRN \\
\hline CHEMBL3191242 & 688724 & 5.05 & 5.2004 & TRN \\
\hline CHEMBL3191182 & 688724 & 4.9 & 5.0959 & TRN \\
\hline CHEMBL1568497 & 688724 & 5.45 & 4.757 & TRN \\
\hline CHEMBL565486 & 688724 & 4.7 & 4.6775 & TRN \\
\hline CHEMBL1428930 & 688724 & 4.7 & 4.9213 & TST \\
\hline CHEMBL533602 & 688724 & 4.9 & 4.9873 & TRN \\
\hline CHEMBL1997212 & 688724 & 4.3 & 4.5524 & TRN \\
\hline CHEMBL1482637 & 688724 & 4.95 & 5.1272 & TST \\
\hline CHEMBL1557783 & 688724 & 4.8 & 4.7119 & TRN \\
\hline CHEMBL3198912 & 688724 & 4.8 & 5.216 & TST \\
\hline CHEMBL1579532 & 688724 & 4.05 & 4.654 & TST \\
\hline CHEMBL1533737 & 688724 & 4.7 & 4.5582 & TRN \\
\hline CHEMBL1550145 & 688724 & 4.95 & 4.7581 & TRN \\
\hline CHEMBL1488063 & 688724 & 5.05 & 4.7968 & TST \\
\hline CHEMBL 2004640 & 688724 & 5.15 & 4.6344 & TRN \\
\hline CHEMBL1342666 & 688724 & 4.75 & 4.86 & TST \\
\hline CHEMBL1514615 & 688724 & 4.85 & 4.5498 & TRN \\
\hline CHEMBL1437158 & 688724 & 5.45 & 4.8054 & TST \\
\hline CHEMBL1416961 & 688724 & 4.75 & 4.7772 & TRN \\
\hline CHEMBL1504623 & 688724 & 4.9 & 5.0164 & TST \\
\hline CHEMBL1379535 & 688724 & 4.85 & 4.9833 & TRN \\
\hline CHEMBL1542151 & 688724 & 4.5 & 4.6507 & TRN \\
\hline CHEMBL1591950 & 688724 & 4.15 & 4.6674 & TRN \\
\hline CHEMBL1539708 & 688724 & 4.4 & 4.5105 & TRN \\
\hline CHEMBL1474941 & 688724 & 4.7 & 4.6312 & TST \\
\hline CHEMBL1407392 & 688724 & 4.6 & 5.0495 & TRN \\
\hline CHEMBL1406746 & 688724 & 4.25 & 5.1458 & TST \\
\hline CHEMBL1456124 & 688724 & 4.95 & 4.9113 & TRN \\
\hline CHEMBL1483311 & 688724 & 6.3 & 4.9429 & TST \\
\hline CHEMBL1375251 & 688724 & 5.35 & 5.4276 & TRN \\
\hline CHEMBL1412731 & 688724 & 4.95 & 4.9728 & TST \\
\hline CHEMBL1491916 & 688724 & 4.5 & 4.8856 & TRN \\
\hline CHEMBL1373726 & 688724 & 4.6 & 4.669 & TRN \\
\hline CHEMBL1395497 & 688724 & 4.9 & 4.7833 & TRN \\
\hline CHEMBL1352624 & 688724 & 4.4 & 4.775 & TRN \\
\hline CHEMBL1416030 & 688724 & 4.65 & 4.7288 & TRN \\
\hline CHEMBL1523348 & 688724 & 4.05 & 4.7795 & TRN \\
\hline CHEMBL1584339 & 688724 & 4.0 & 4.9121 & TRN \\
\hline CHEMBL1312320 & 688724 & 4.8 & 4.8782 & TRN \\
\hline CHEMBL3392069 & 688724 & 4.4 & 4.82 & TST \\
\hline CHEMBL1319267 & 688724 & 4.3 & 4.6889 & TRN \\
\hline CHEMBL1307301 & 688724 & 4.65 & 4.6146 & TRN \\
\hline CHEMBL1516211 & 688724 & 4.75 & 4.8786 & TRN \\
\hline CHEMBL1370828 & 688724 & 5.5 & 5.0565 & TRN \\
\hline CHEMBL1381540 & 688724 & 4.3 & 4.6959 & TST \\
\hline CHEMBL1452003 & 688724 & 4.8 & 5.1381 & TRN \\
\hline CHEMBL3208674 & 688724 & 6.15 & 5.1561 & TRN \\
\hline
\end{tabular}




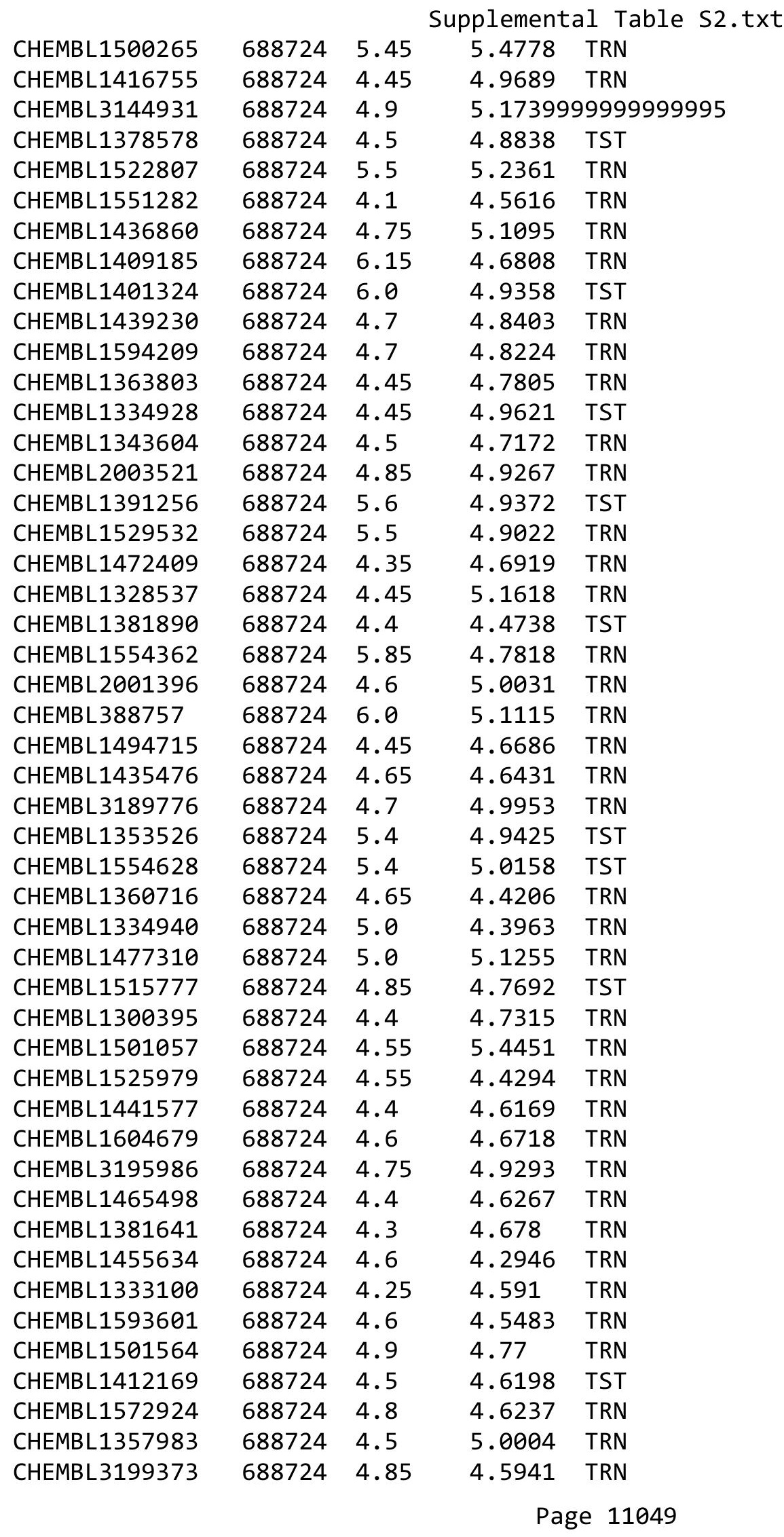




\begin{tabular}{|c|c|c|c|c|}
\hline \multicolumn{5}{|c|}{ Supplemental Tabl } \\
\hline CHEMBL1492088 & 688724 & 4.25 & 4.6602 & TRN \\
\hline CHEMBL1989662 & 688724 & 5.3 & 4.8053 & TST \\
\hline CHEMBL1350986 & 688724 & 5.1 & 4.7831 & TRN \\
\hline CHEMBL558459 & 688724 & 4.15 & 4.9228 & TRN \\
\hline CHEMBL1337483 & 688724 & 4.0 & 4.877 & TRN \\
\hline CHEMBL18840 & 688724 & 6.0 & 4.9338 & TRN \\
\hline CHEMBL3193631 & 688724 & 4.35 & 4.8401 & TRN \\
\hline CHEMBL1565369 & 688724 & 4.9 & 5.5563 & TRN \\
\hline CHEMBL1510314 & 688724 & 5.35 & 4.7842 & TRN \\
\hline CHEMBL1968859 & 688724 & 5.55 & 5.1609 & TRN \\
\hline CHEMBL1313927 & 688724 & 4.35 & 4.6448 & TRN \\
\hline CHEMBL1503325 & 688724 & 5.8 & 5.3136 & TRN \\
\hline CHEMBL1319452 & 688724 & 4.3 & 4.8978 & TRN \\
\hline CHEMBL3191895 & 688724 & 4.7 & 4.7559 & TRN \\
\hline CHEMBL1565585 & 688724 & 4.25 & 4.7623 & TST \\
\hline CHEMBL1543354 & 688724 & 6.2 & 5.3376 & TRN \\
\hline CHEMBL400881 & 688724 & 4.1 & 4.6045 & TRN \\
\hline CHEMBL1599723 & 688724 & 4.55 & 4.9471 & TRN \\
\hline CHEMBL1406040 & 688724 & 4.6 & 4.7668 & TRN \\
\hline CHEMBL1515732 & 688724 & 4.15 & 4.8947 & TRN \\
\hline CHEMBL1436528 & 688724 & 4.55 & 4.5625 & TRN \\
\hline CHEMBL1597793 & 688724 & 4.55 & 4.684 & TRN \\
\hline CHEMBL1602644 & 688724 & 4.35 & 4.5053 & TRN \\
\hline CHEMBL1529589 & 688724 & 4.65 & 4.5843 & TRN \\
\hline CHEMBL1430792 & 688724 & 4.95 & 4.4842 & TRN \\
\hline CHEMBL1509035 & 688724 & 4.4 & 4.4583 & TRN \\
\hline CHEMBL1408091 & 688724 & 4.35 & 5.0264 & TST \\
\hline CHEMBL1418175 & 688724 & 4.6 & 4.9535 & TRN \\
\hline CHEMBL1379197 & 688724 & 4.5 & 5.0158 & TRN \\
\hline CHEMBL94631 & 688724 & 4.4 & 4.7129 & TST \\
\hline CHEMBL1598544 & 688724 & 4.4 & 4.5894 & TST \\
\hline CHEMBL1343147 & 688724 & 4.35 & 5.2412 & TST \\
\hline CHEMBL1524723 & 688724 & 6.15 & 4.6284 & TRN \\
\hline CHEMBL3198342 & 688724 & 6.0 & 4.6235 & TRN \\
\hline CHEMBL1361744 & 688724 & 5.1 & 4.6244 & TRN \\
\hline CHEMBL1548576 & 688724 & 5.45 & 5.0247 & TRN \\
\hline CHEMBL1473939 & 688724 & 4.1 & 4.6117 & TRN \\
\hline CHEMBL1417935 & 688724 & 4.1 & 4.4747 & TST \\
\hline CHEMBL1473612 & 688724 & 4.7 & 5.1171 & TRN \\
\hline CHEMBL1395449 & 688724 & 5.2 & 5.0721 & TRN \\
\hline CHEMBL1598791 & 688724 & 4.6 & 5.0277 & TST \\
\hline CHEMBL1535216 & 688724 & 4.8 & 4.738 & TST \\
\hline CHEMBL1408923 & 688724 & 4.45 & 4.5601 & TRN \\
\hline CHEMBL3210839 & 688724 & 5.65 & 4.8335 & TRN \\
\hline CHEMBL3191626 & 688724 & 4.95 & 4.9712 & TRN \\
\hline CHEMBL1439208 & 688724 & 4.65 & 4.6762 & TRN \\
\hline CHEMBL 220845 & 688724 & 5.35 & 5.5057 & TST \\
\hline CHEMBL3196703 & 688724 & 5.05 & 5.2396 & TRN \\
\hline
\end{tabular}




\begin{tabular}{|c|c|c|c|c|c|}
\hline & & \multicolumn{4}{|c|}{ Supplemental Table S2.txt } \\
\hline CHEMBL1561968 & 688724 & 5.85 & 4.7894 & TRN & \\
\hline CHEMBL1381098 & 688724 & 4.15 & 4.9683 & TST & \\
\hline CHEMBL1455380 & 688724 & 5.45 & 5.2039 & TRN & \\
\hline CHEMBL91722 & 688724 & 6.0 & 5.1253 & TRN & \\
\hline CHEMBL3195859 & 688724 & 4.2 & 4.5043 & TRN & \\
\hline CHEMBL1318426 & 688724 & 4.45 & 4.8458 & TRN & \\
\hline CHEMBL1320404 & 688724 & 4.4 & 4.63899 & 9999999999 & TRN \\
\hline CHEMBL1597055 & 688724 & 4.25 & 4.7219 & TRN & \\
\hline CHEMBL1467202 & 688724 & 5.1 & 4.8943 & TRN & \\
\hline CHEMBL1400811 & 688724 & 4.5 & 4.5492 & TRN & \\
\hline CHEMBL1301661 & 688724 & 4.55 & 4.8303 & TST & \\
\hline CHEMBL1447764 & 688724 & 4.3 & 4.3845 & TRN & \\
\hline CHEMBL1428940 & 688724 & 4.55 & 4.7519 & TRN & \\
\hline CHEMBL1985932 & 688724 & 4.15 & 4.8202 & TRN & \\
\hline CHEMBL1381690 & 688724 & 4.3 & 4.9677 & TRN & \\
\hline CHEMBL1605135 & 688724 & 4.5 & 4.3101 & TST & \\
\hline CHEMBL1429988 & 688724 & 4.3 & 4.46399 & 99999999995 & TRN \\
\hline CHEMBL 273481 & 688724 & 6.8 & 5.1318 & TST & \\
\hline CHEMBL1413045 & 688724 & 4.45 & 4.5304 & TRN & \\
\hline CHEMBL1349535 & 688724 & 5.35 & 4.9058 & TRN & \\
\hline CHEMBL1558816 & 688724 & 4.05 & 5.0693 & TRN & \\
\hline CHEMBL1395598 & 688724 & 5.05 & 4.9997 & TRN & \\
\hline CHEMBL1581251 & 688724 & 5.5 & 4.8386 & TRN & \\
\hline CHEMBL1434431 & 688724 & 4.45 & 4.6604 & TRN & \\
\hline CHEMBL1541681 & 688724 & 4.85 & 4.626 & TRN & \\
\hline CHEMBL1323007 & 688724 & 4.45 & 4.7029 & TRN & \\
\hline CHEMBL1393131 & 688724 & 5.45 & 5.2369 & TRN & \\
\hline CHEMBL408994 & 688724 & 5.45 & 4.5845 & TRN & \\
\hline CHEMBL1497012 & 688724 & 4.8 & 4.6485 & TRN & \\
\hline CHEMBL3194082 & 688724 & 5.95 & 5.0736 & TRN & \\
\hline CHEMBL1455691 & 688724 & 4.3 & 4.6077 & TRN & \\
\hline CHEMBL1489748 & 688724 & 4.6 & 4.873 & TRN & \\
\hline CHEMBL1563508 & 688724 & 5.5 & 5.0485 & TRN & \\
\hline CHEMBL1431591 & 688724 & 4.85 & 5.0773 & TST & \\
\hline CHEMBL1406862 & 688724 & 4.8 & 4.5719 & TRN & \\
\hline CHEMBL1999900 & 688724 & 4.5 & 5.0858 & TRN & \\
\hline CHEMBL1612230 & 688724 & 4.9 & 5.0507 & TRN & \\
\hline CHEMBL1494409 & 688724 & 4.25 & 4.4723 & TRN & \\
\hline CHEMBL492010 & 688724 & 4.05 & 4.7583 & TRN & \\
\hline CHEMBL1490656 & 688724 & 6.1 & 5.3394 & TRN & \\
\hline CHEMBL1310516 & 688724 & 5.05 & 4.6502 & TRN & \\
\hline CHEMBL1377130 & 688724 & 5.35 & 4.5136 & TRN & \\
\hline CHEMBL1486391 & 688724 & 4.05 & 4.5593 & TRN & \\
\hline CHEMBL1330835 & 688724 & 4.4 & 4.7533 & TST & \\
\hline CHEMBL 2000120 & 688724 & 4.2 & 4.7176 & TRN & \\
\hline CHEMBL3392397 & 688724 & 5.45 & 5.0753 & TRN & \\
\hline CHEMBL1465663 & 688724 & 5.4 & 5.12 & TRN & \\
\hline CHEMBL1379070 & 688724 & 4.05 & 4.9614 & TST & \\
\hline
\end{tabular}




\begin{tabular}{|c|c|c|c|c|c|}
\hline & & & & & \\
\hline CHEMBL3194904 & 688724 & 4.4 & 4.9545 & TST & \\
\hline CHEMBL1485164 & 688724 & 4.75 & 4.8402 & TRN & \\
\hline CHEMBL1538584 & 688724 & 4.65 & 5.4418 & TST & \\
\hline CHEMBL10009 & 688724 & 4.35 & 4.5828 & TRN & \\
\hline CHEMBL1428809 & 688724 & 4.4 & 4.8694 & TRN & \\
\hline CHEMBL243664 & 688724 & 4.6 & 4.8624 & TRN & \\
\hline CHEMBL1477340 & 688724 & 4.05 & 4.6722 & TRN & \\
\hline CHEMBL1439833 & 688724 & 5.7 & 5.82700 & 0000000001 & TRN \\
\hline CHEMBL1550704 & 688724 & 4.1 & 4.4601 & TRN & \\
\hline CHEMBL1302840 & 688724 & 4.25 & 4.4543 & TRN & \\
\hline CHEMBL1325871 & 688724 & 4.05 & 4.9043 & TST & \\
\hline CHEMBL1213637 & 688724 & 4.1 & 4.7137 & TST & \\
\hline CHEMBL1348800 & 688724 & 5.05 & 5.0363 & TST & \\
\hline CHEMBL3208432 & 688724 & 4.4 & 4.996 & TRN & \\
\hline CHEMBL1565382 & 688724 & 5.2 & 5.1819 & TRN & \\
\hline CHEMBL1599163 & 688724 & 4.5 & 4.5356 & TRN & \\
\hline CHEMBL1462346 & 688724 & 4.4 & 4.8526 & TST & \\
\hline CHEMBL1548862 & 688724 & 4.5 & 4.8641 & TRN & \\
\hline CHEMBL3210654 & 688724 & 4.9 & 4.8629 & TRN & \\
\hline CHEMBL1423059 & 688724 & 5.05 & 5.0204 & TRN & \\
\hline CHEMBL1571110 & 688724 & 4.4 & 4.9964 & TRN & \\
\hline CHEMBL1501558 & 688724 & 5.55 & 5.6199 & TRN & \\
\hline CHEMBL1548331 & 688724 & 4.7 & 5.1874 & TST & \\
\hline CHEMBL1302966 & 688724 & 4.6 & 4.9947 & TRN & \\
\hline CHEMBL1612802 & 688724 & 4.85 & 4.5515 & TST & \\
\hline CHEMBL1351451 & 688724 & 6.5 & 5.0186 & TRN & \\
\hline CHEMBL1317522 & 688724 & 4.25 & 4.7381 & TRN & \\
\hline CHEMBL1543008 & 688724 & 4.05 & 4.9097 & TST & \\
\hline CHEMBL1468873 & 688724 & 4.05 & 4.6162 & TRN & \\
\hline CHEMBL1586806 & 688724 & 4.85 & 5.1275 & TRN & \\
\hline CHEMBL3212364 & 688724 & 6.5 & 5.1837 & TRN & \\
\hline CHEMBL2002162 & 688724 & 4.4 & 5.1525 & TST & \\
\hline CHEMBL328710 & 688724 & 6.0 & 4.7912 & TRN & \\
\hline CHEMBL1329848 & 688724 & 4.7 & 4.7337 & TRN & \\
\hline CHEMBL294590 & 688724 & 7.7496 & 4.9769 & TST & \\
\hline CHEMBL1573667 & 688724 & 4.65 & 4.6924 & TRN & \\
\hline CHEMBL1478395 & 688724 & 5.5 & 5.2069 & TST & \\
\hline CHEMBL1461279 & 688724 & 4.55 & 4.6241 & TRN & \\
\hline CHEMBL1556035 & 688724 & 4.65 & 5.6087 & TRN & \\
\hline CHEMBL1478589 & 688724 & 5.35 & 4.8147 & TRN & \\
\hline CHEMBL1460108 & 688724 & 4.55 & 4.8513 & TRN & \\
\hline CHEMBL1999908 & 688724 & 5.15 & 4.5045 & TRN & \\
\hline CHEMBL1560502 & 688724 & 4.35 & 4.7263 & TRN & \\
\hline CHEMBL1544557 & 688724 & 4.45 & 4.5568 & TRN & \\
\hline CHEMBL1489596 & 688724 & 4.9 & 4.9268 & TRN & \\
\hline CHEMBL1326167 & 688724 & 4.4 & 4.9913 & TRN & \\
\hline CHEMBL1431923 & 688724 & 4.55 & 5.1035 & TRN & \\
\hline CHEMBL1361145 & 688724 & 4.85 & 4.3196 & TRN & \\
\hline & & & & 11052 & \\
\hline
\end{tabular}




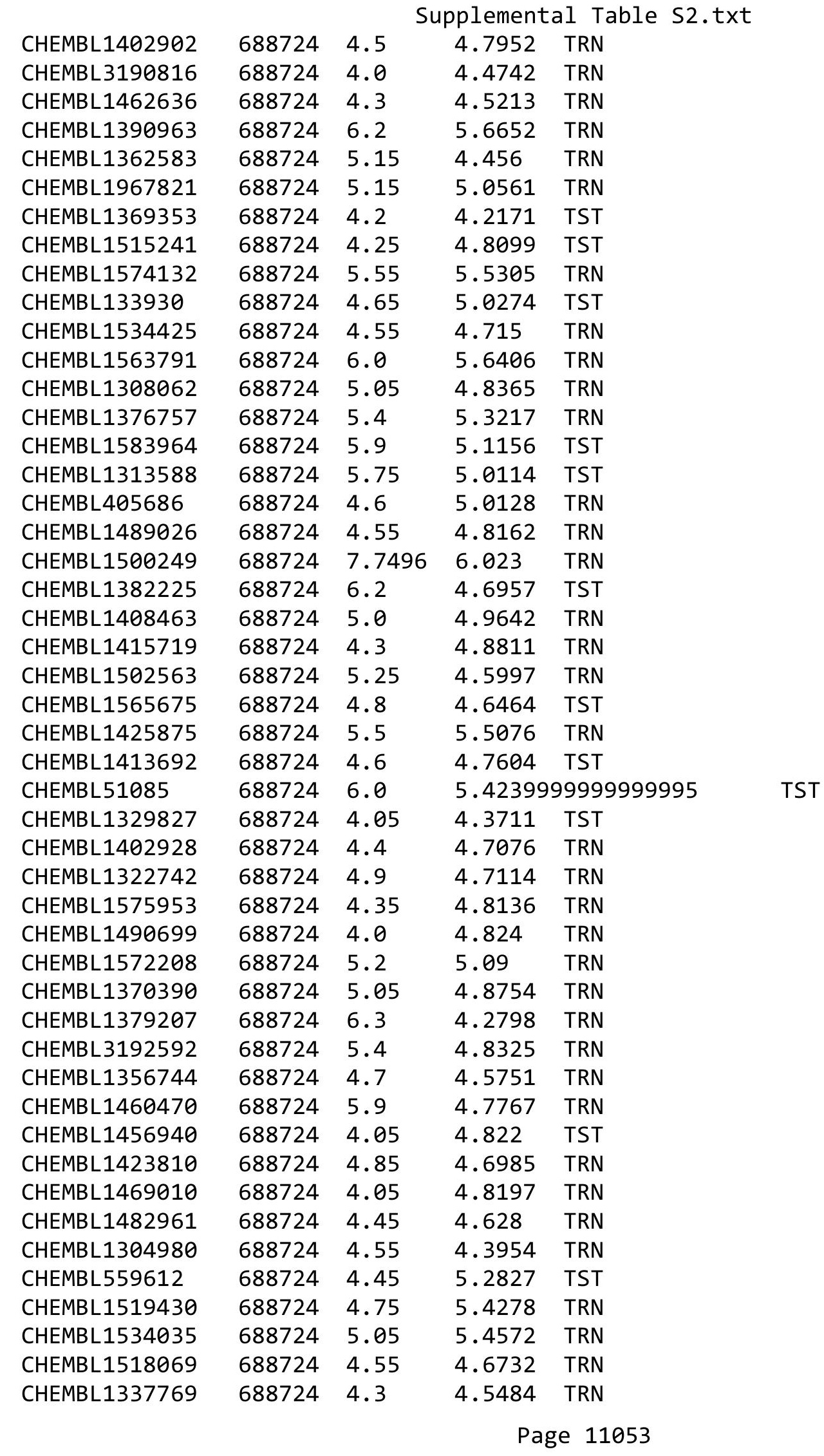




\begin{tabular}{|c|c|c|c|c|}
\hline \multicolumn{5}{|c|}{ Supplemental Table S2.txt } \\
\hline CHEMBL1408695 & 688724 & 4.5 & 5.1307 & TRN \\
\hline CHEMBL1319648 & 688724 & 4.8 & 5.1264 & TRN \\
\hline CHEMBL565893 & 688724 & 4.4 & 5.2134 & TRN \\
\hline CHEMBL1330711 & 688724 & 4.15 & 4.5919 & TRN \\
\hline CHEMBL1548363 & 688724 & 4.0 & 5.1723 & TST \\
\hline CHEMBL1964873 & 688724 & 5.9 & 4.7167 & TRN \\
\hline CHEMBL139935 & 688724 & 4.65 & 5.5553 & TRN \\
\hline CHEMBL1467349 & 688724 & 4.05 & 4.4509 & TRN \\
\hline CHEMBL1348354 & 688724 & 4.8 & 4.6971 & TRN \\
\hline CHEMBL1526774 & 688724 & 4.3 & 4.3078 & TRN \\
\hline CHEMBL1993380 & 688724 & 4.65 & 4.8415 & TRN \\
\hline CHEMBL1438591 & 688724 & 4.6 & 4.8324 & TRN \\
\hline CHEMBL1579663 & 688724 & 4.4 & 4.5041 & TRN \\
\hline CHEMBL17551 & 688724 & 5.0 & 4.848 & TST \\
\hline CHEMBL1316784 & 688724 & 4.0 & 4.5629 & TRN \\
\hline CHEMBL1580272 & 688724 & 6.8499 & 5.1511 & TRN \\
\hline CHEMBL1594490 & 688724 & 4.85 & 5.1346 & TST \\
\hline CHEMBL1461470 & 688724 & 4.9 & 4.771 & TST \\
\hline CHEMBL1388072 & 688724 & 4.95 & 4.5924 & TRN \\
\hline CHEMBL1569541 & 688724 & 4.35 & 4.6409 & TST \\
\hline CHEMBL3195145 & 688724 & 4.55 & 4.8531 & TRN \\
\hline CHEMBL1526030 & 688724 & 4.35 & 4.6538 & TRN \\
\hline CHEMBL3207586 & 688724 & 4.35 & 4.7903 & TST \\
\hline CHEMBL1570548 & 688724 & 4.35 & 4.6874 & TST \\
\hline CHEMBL 3199211 & 688724 & 4.1242 & 4.9268 & TRN \\
\hline CHEMBL1414452 & 688724 & 6.0 & 5.6646 & TRN \\
\hline CHEMBL1605081 & 688724 & 4.35 & 4.5505 & TRN \\
\hline CHEMBL1387028 & 688724 & 6.7001 & 4.8677 & TST \\
\hline CHEMBL1581277 & 688724 & 5.35 & 5.2031 & TRN \\
\hline CHEMBL1549120 & 688724 & 5.4 & 5.0915 & TRN \\
\hline CHEMBL1563240 & 688724 & 4.0 & 4.793 & TRN \\
\hline CHEMBL448620 & 688724 & 4.25 & 4.7569 & TRN \\
\hline CHEMBL1434503 & 688724 & 4.35 & 4.5098 & TST \\
\hline CHEMBL1520464 & 688724 & 4.4 & 4.6183 & TRN \\
\hline CHEMBL1461131 & 688724 & 4.85 & 5.1001 & TRN \\
\hline CHEMBL1568932 & 688724 & 4.35 & 4.684 & TRN \\
\hline CHEMBL1610697 & 688724 & 5.1 & 4.8752 & TRN \\
\hline CHEMBL1462450 & 688724 & 4.65 & 4.745 & TRN \\
\hline CHEMBL1576495 & 688724 & 4.7 & 5.184 & TRN \\
\hline CHEMBL1987136 & 688724 & 4.35 & 4.9035 & TRN \\
\hline CHEMBL1351406 & 688724 & 4.35 & 5.0586 & TRN \\
\hline CHEMBL1508178 & 688724 & 4.35 & 5.0705 & TRN \\
\hline CHEMBL1256914 & 688724 & 8.301 & 4.5324 & TST \\
\hline CHEMBL1526998 & 688724 & 4.5 & 4.8808 & TRN \\
\hline CHEMBL1401885 & 688724 & 4.65 & 5.016 & TRN \\
\hline CHEMBL1437008 & 688724 & 4.0 & 4.7038 & TRN \\
\hline CHEMBL1991779 & 688724 & 4.6 & 5.053 & TRN \\
\hline CHEMBL1472904 & 688724 & 4.6 & 4.7053 & TST \\
\hline
\end{tabular}




\begin{tabular}{|c|c|c|c|c|c|}
\hline & & & & & \\
\hline CHEMBL1501132 & 688724 & 4.9 & 4.9745 & TRN & \\
\hline CHEMBL1502079 & 688724 & 4.3 & 4.462 & TRN & \\
\hline CHEMBL1565087 & 688724 & 4.0 & 4.6854 & TRN & \\
\hline CHEMBL1521869 & 688724 & 4.35 & 4.5621 & TRN & \\
\hline CHEMBL1552441 & 688724 & 5.35 & 4.9062 & TRN & \\
\hline CHEMBL1307534 & 688724 & 4.8 & 4.7704 & TRN & \\
\hline CHEMBL1411578 & 688724 & 5.25 & 5.1007 & TST & \\
\hline CHEMBL126804 & 688724 & 4.35 & 4.9042 & TRN & \\
\hline CHEMBL1561884 & 688724 & 6.0 & 5.5201 & TRN & \\
\hline CHEMBL1517327 & 688724 & 4.75 & 4.5999 & TRN & \\
\hline CHEMBL1302756 & 688724 & 5.45 & 5.0449 & TRN & \\
\hline CHEMBL1427232 & 688724 & 4.05 & 4.64199 & 99999999995 & TRN \\
\hline CHEMBL3145187 & 688724 & 4.55 & 5.0661 & TST & \\
\hline CHEMBL1459316 & 688724 & 4.65 & 4.8432 & TRN & \\
\hline CHEMBL1574943 & 688724 & 5.0 & 4.9811 & TRN & \\
\hline CHEMBL1419884 & 688724 & 4.6 & 4.7591 & TRN & \\
\hline CHEMBL1523510 & 688724 & 4.5 & 4.9222 & TRN & \\
\hline CHEMBL1332097 & 688724 & 4.2 & 4.5798 & TRN & \\
\hline CHEMBL1593445 & 688724 & 6.1 & 4.6972 & TRN & \\
\hline CHEMBL1520787 & 688724 & 4.5 & 4.5366 & TST & \\
\hline CHEMBL1355340 & 688724 & 4.75 & 4.9774 & TRN & \\
\hline CHEMBL1546102 & 688724 & 4.55 & 4.7218 & TRN & \\
\hline CHEMBL1384773 & 688724 & 4.6 & 4.6939 & TRN & \\
\hline CHEMBL1596131 & 688724 & 5.6 & 4.6621 & TRN & \\
\hline CHEMBL1402385 & 688724 & 4.6 & 4.7591 & TRN & \\
\hline CHEMBL1313024 & 688724 & 4.5 & 4.846 & TRN & \\
\hline CHEMBL3211962 & 688724 & 4.5 & 4.9242 & TRN & \\
\hline CHEMBL1509284 & 688724 & 4.75 & 4.8312 & TST & \\
\hline CHEMBL1373197 & 688724 & 4.35 & 4.787 & TRN & \\
\hline CHEMBL1534533 & 688724 & 4.75 & 4.3615 & TST & \\
\hline CHEMBL1521693 & 688724 & 4.75 & 4.2554 & TRN & \\
\hline CHEMBL1582178 & 688724 & 4.4 & 5.0608 & TST & \\
\hline CHEMBL3198994 & 688724 & 4.6 & 5.088 & TRN & \\
\hline CHEMBL1333867 & 688724 & 4.8 & 5.4197 & TRN & \\
\hline CHEMBL1356505 & 688724 & 4.9 & 4.5732 & TRN & \\
\hline CHEMBL1460846 & 688724 & 4.3 & 4.7753 & TRN & \\
\hline CHEMBL1559405 & 688724 & 5.0 & 5.1128 & TST & \\
\hline CHEMBL3194613 & 688724 & 4.8 & 4.6942 & TRN & \\
\hline CHEMBL410396 & 688724 & 4.8 & 5.1052 & TRN & \\
\hline CHEMBL3212890 & 688724 & 4.35 & 4.8751 & TRN & \\
\hline CHEMBL3145073 & 688724 & 6.4 & 5.0151 & TRN & \\
\hline CHEMBL1499431 & 688724 & 5.4 & 4.875 & TST & \\
\hline CHEMBL1444164 & 688724 & 4.7 & 4.7459 & TRN & \\
\hline CHEMBL192966 & 688724 & 4.6 & 4.8124 & TST & \\
\hline CHEMBL1346123 & 688724 & 4.7 & 4.4393 & TST & \\
\hline CHEMBL1538959 & 688724 & 4.3 & 4.4917 & TRN & \\
\hline CHEMBL1552639 & 688724 & 5.4 & 4.7978 & TRN & \\
\hline CHEMBL1330307 & 688724 & 5.2 & 5.8407 & TRN & \\
\hline & & & & 11055 & \\
\hline
\end{tabular}




\begin{tabular}{|c|c|c|c|c|c|}
\hline \multicolumn{6}{|c|}{ Supplemental Table S2.txt } \\
\hline CHEMBL1580348 & 688724 & 6.25 & 4.833 & TRN & \\
\hline CHEMBL1328707 & 688724 & 4.55 & 4.9714 & TRN & \\
\hline CHEMBL1543944 & 688724 & 4.75 & 4.8511 & TRN & \\
\hline CHEMBL1418619 & 688724 & 4.65 & 4.5317 & TRN & \\
\hline CHEMBL1302117 & 688724 & 4.6 & 4.7522 & TST & \\
\hline CHEMBL1522599 & 688724 & 4.3 & 4.9317 & TRN & \\
\hline CHEMBL1486861 & 688724 & 5.25 & 4.745 & TRN & \\
\hline CHEMBL1511708 & 688724 & 4.05 & 4.9702 & TST & \\
\hline CHEMBL 3198743 & 688724 & 4.85 & 5.1861 & TRN & \\
\hline CHEMBL1498207 & 688724 & 5.3 & 4.9253 & TRN & \\
\hline CHEMBL1991885 & 688724 & 4.75 & 4.8684 & TRN & \\
\hline CHEMBL1404488 & 688724 & 4.6 & 4.8931 & TST & \\
\hline CHEMBL1337900 & 688724 & 4.35 & 4.3653 & TRN & \\
\hline CHEMBL1976940 & 688724 & 4.1 & 4.5004 & TRN & \\
\hline CHEMBL1527646 & 688724 & 4.65 & 4.5141 & TRN & \\
\hline CHEMBL1379313 & 688724 & 4.5 & 4.5596 & TRN & \\
\hline CHEMBL1423610 & 688724 & 4.8 & 4.7132 & TST & \\
\hline CHEMBL1449293 & 688724 & 4.05 & 4.5739 & TST & \\
\hline CHEMBL1459984 & 688724 & 4.25 & 4.7708 & TRN & \\
\hline CHEMBL1489633 & 688724 & 5.15 & 5.0048 & TRN & \\
\hline CHEMBL1452766 & 688724 & 4.5 & 4.4553 & TRN & \\
\hline CHEMBL1482180 & 688724 & 4.55 & 4.8453 & TRN & \\
\hline CHEMBL1492041 & 688724 & 4.25 & 4.7157 & TRN & \\
\hline CHEMBL1469227 & 688724 & 5.85 & 4.8912 & TRN & \\
\hline CHEMBL1332591 & 688724 & 4.6 & 4.525 & TRN & \\
\hline CHEMBL1336312 & 688724 & 4.65 & 4.9555 & TRN & \\
\hline CHEMBL3197620 & 688724 & 4.05 & 4.5379 & TRN & \\
\hline CHEMBL1333542 & 688724 & 4.8 & 5.0508 & TRN & \\
\hline CHEMBL1573520 & 688724 & 4.85 & 4.5045 & TRN & \\
\hline CHEMBL1453064 & 688724 & 4.3 & 4.853 & TST & \\
\hline CHEMBL1814509 & 688724 & 5.3 & 5.29299 & 9999999999 & TRN \\
\hline CHEMBL1383606 & 688724 & 6.35 & 5.0032 & TRN & \\
\hline CHEMBL1494308 & 688724 & 4.1 & 4.6136 & TST & \\
\hline CHEMBL3196704 & 688724 & 4.8 & 4.8578 & TST & \\
\hline CHEMBL1364192 & 688724 & 4.85 & 4.7879 & TRN & \\
\hline CHEMBL1323674 & 688724 & 5.65 & 4.4997 & TRN & \\
\hline CHEMBL1484214 & 688724 & 4.9 & 4.6293 & TRN & \\
\hline CHEMBL1415058 & 688724 & 4.85 & 4.6377 & TRN & \\
\hline CHEMBL1580269 & 688724 & 6.0 & 5.3373 & TRN & \\
\hline CHEMBL1583292 & 688724 & 6.6 & 5.94799 & 99999999995 & TRN \\
\hline CHEMBL3197968 & 688724 & 4.45 & 4.773 & TRN & \\
\hline CHEMBL1403684 & 688724 & 4.4 & 5.1353 & TST & \\
\hline CHEMBL1422221 & 688724 & 5.25 & 5.0575 & TRN & \\
\hline CHEMBL1588229 & 688724 & 4.5 & 4.9849 & TRN & \\
\hline CHEMBL1478754 & 688724 & 4.7 & 5.147 & TRN & \\
\hline CHEMBL1546375 & 688724 & 4.5 & 4.9687 & TRN & \\
\hline CHEMBL1555833 & 688724 & 5.5 & 5.0641 & TST & \\
\hline CHEMBL1611140 & 688724 & 5.15 & 4.9611 & TST & \\
\hline
\end{tabular}




\begin{tabular}{|c|c|c|c|c|c|}
\hline & & & & & \\
\hline CHEMBL1341682 & 688724 & 6.2 & 4.9424 & TST & \\
\hline CHEMBL1603825 & 688724 & 4.65 & 5.0178 & TST & \\
\hline CHEMBL1542725 & 688724 & 4.05 & 4.7356 & TRN & \\
\hline CHEMBL1500196 & 688724 & 4.6 & 4.75899 & 99999999995 & TRN \\
\hline CHEMBL1347204 & 688724 & 6.15 & 5.5262 & TRN & \\
\hline CHEMBL1432274 & 688724 & 4.8 & 4.7565 & TRN & \\
\hline CHEMBL591370 & 688724 & 5.15 & 5.0007 & TRN & \\
\hline CHEMBL1423708 & 688724 & 4.9 & 5.3218 & TST & \\
\hline CHEMBL1464647 & 688724 & 5.25 & 5.5632 & TRN & \\
\hline CHEMBL1345939 & 688724 & 5.75 & 5.6108 & TRN & \\
\hline CHEMBL1551180 & 688724 & 5.45 & 4.8858 & TST & \\
\hline CHEMBL1505707 & 688724 & 6.9 & 4.5454 & TST & \\
\hline CHEMBL1573268 & 688724 & 4.4 & 4.8878 & TST & \\
\hline CHEMBL1326704 & 688724 & 4.95 & 4.4863 & TRN & \\
\hline CHEMBL1472835 & 688724 & 4.6 & 5.0595 & TRN & \\
\hline CHEMBL1604857 & 688724 & 4.35 & 4.6506 & TRN & \\
\hline CHEMBL1517986 & 688724 & 5.7 & 4.7816 & TRN & \\
\hline CHEMBL1515795 & 688724 & 5.5 & 5.0006 & TRN & \\
\hline CHEMBL1481257 & 688724 & 4.35 & 4.7389 & TRN & \\
\hline CHEMBL1534057 & 688724 & 4.45 & 4.4532 & TRN & \\
\hline CHEMBL1591074 & 688724 & 4.4 & 4.8277 & TST & \\
\hline CHEMBL1482228 & 688724 & 6.4 & 4.8854 & TST & \\
\hline CHEMBL1366992 & 688724 & 5.0 & 5.2575 & TRN & \\
\hline CHEMBL1474317 & 688724 & 4.15 & 4.723 & TRN & \\
\hline CHEMBL1424819 & 688724 & 4.45 & 4.562 & TRN & \\
\hline CHEMBL31212 & 688724 & 4.45 & 4.8528 & TRN & \\
\hline CHEMBL3194745 & 688724 & 4.15 & 4.9043 & TRN & \\
\hline CHEMBL3207686 & 688724 & 5.0 & 4.8385 & TST & \\
\hline CHEMBL1439579 & 688724 & 4.55 & 4.7682 & TRN & \\
\hline CHEMBL1403589 & 688724 & 4.3 & 4.9614 & TRN & \\
\hline CHEMBL1316524 & 688724 & 4.75 & 4.6936 & TRN & \\
\hline CHEMBL1438587 & 688724 & 5.7 & 5.1236 & TRN & \\
\hline CHEMBL1444459 & 688724 & 4.8 & 5.1926 & TRN & \\
\hline CHEMBL1365994 & 688724 & 4.95 & 4.6722 & TRN & \\
\hline CHEMBL1452392 & 688724 & 7.0 & 5.5946 & TRN & \\
\hline CHEMBL1406889 & 688724 & 4.8 & 5.0327 & TRN & \\
\hline CHEMBL1386676 & 688724 & 4.35 & 4.2177 & TRN & \\
\hline CHEMBL3196983 & 688724 & 4.85 & 5.0881 & TRN & \\
\hline CHEMBL1358284 & 688724 & 4.5 & 5.0213 & TST & \\
\hline CHEMBL3209866 & 688724 & 5.55 & 5.1753 & TRN & \\
\hline CHEMBL1460678 & 688724 & 4.5 & 4.7421 & TST & \\
\hline CHEMBL1308058 & 688724 & 4.45 & 4.7763 & TRN & \\
\hline CHEMBL1487246 & 688724 & 4.4 & 4.7875 & TRN & \\
\hline CHEMBL447111 & 688724 & 4.3 & 4.8863 & TRN & \\
\hline CHEMBL3199822 & 688724 & 4.4 & 4.9737 & TRN & \\
\hline CHEMBL1350056 & 688724 & 5.2 & 4.7549 & TRN & \\
\hline CHEMBL1468371 & 688724 & 4.8 & 5.1113 & TRN & \\
\hline CHEMBL1358338 & 688724 & 5.45 & 4.59399 & 9999999999 & TRN \\
\hline & & & & 11057 & \\
\hline
\end{tabular}




\begin{tabular}{|c|c|c|c|c|c|}
\hline \multicolumn{6}{|c|}{ Supplemental Table S2.txt } \\
\hline CHEMBL1575584 & 688724 & 4.2 & 4.9238 & TRN & \\
\hline CHEMBL1468852 & 688724 & 6.35 & 4.9038 & TST & \\
\hline CHEMBL1334382 & 688724 & 4.1 & 4.7114 & TRN & \\
\hline CHEMBL30432 & 688724 & 4.35 & 5.1195 & TST & \\
\hline CHEMBL1476866 & 688724 & 5.5 & 4.7306 & TRN & \\
\hline CHEMBL1991599 & 688724 & 5.05 & 5.227 & TRN & \\
\hline CHEMBL1408962 & 688724 & 4.7 & 4.9525 & TST & \\
\hline CHEMBL1470016 & 688724 & 5.05 & 4.7011 & TRN & \\
\hline CHEMBL3211145 & 688724 & 4.75 & 4.7717 & TRN & \\
\hline CHEMBL1494881 & 688724 & 4.25 & 5.2109 & TST & \\
\hline CHEMBL1606795 & 688724 & 4.05 & 4.9582 & TST & \\
\hline CHEMBL1537047 & 688724 & 4.85 & 5.2241 & TRN & \\
\hline CHEMBL1606514 & 688724 & 4.05 & 5.1324 & TRN & \\
\hline CHEMBL1422133 & 688724 & 4.55 & 4.8928 & TRN & \\
\hline CHEMBL1577965 & 688724 & 4.8 & 4.7358 & TRN & \\
\hline CHEMBL1577440 & 688724 & 4.5 & 4.6044 & TRN & \\
\hline CHEMBL1087751 & 688724 & 4.25 & 4.8476 & TRN & \\
\hline CHEMBL1302388 & 688724 & 5.25 & 4.9694 & TRN & \\
\hline CHEMBL1438593 & 688724 & 4.45 & 5.0942 & TRN & \\
\hline CHEMBL1420379 & 688724 & 5.95 & 5.4996 & TRN & \\
\hline CHEMBL1431153 & 688724 & 5.7 & 5.4333 & TST & \\
\hline CHEMBL1539336 & 688724 & 4.65 & 4.9344 & TRN & \\
\hline CHEMBL1374565 & 688724 & 4.3 & 5.3483 & TST & \\
\hline CHEMBL3191374 & 688724 & 4.65 & 4.8693 & TRN & \\
\hline CHEMBL1302090 & 688724 & 4.95 & 4.6989 & TRN & \\
\hline CHEMBL1307564 & 688724 & 4.45 & 4.8524 & TRN & \\
\hline CHEMBL3189281 & 688724 & 4.6 & 4.7675 & TRN & \\
\hline CHEMBL269362 & 688724 & 8.6576 & 4.9905 & TST & \\
\hline CHEMBL1318447 & 688724 & 4.85 & 4.9261 & TRN & \\
\hline CHEMBL1518719 & 688724 & 4.45 & 4.6791 & TST & \\
\hline CHEMBL1490887 & 688724 & 4.85 & 5.1588 & TRN & \\
\hline CHEMBL1301862 & 688724 & 4.65 & 4.7545 & TRN & \\
\hline CHEMBL1521260 & 688724 & 4.35 & 4.7423 & TST & \\
\hline CHEMBL1977376 & 688724 & 4.35 & 4.7904 & TRN & \\
\hline CHEMBL1983451 & 688724 & 4.55 & 5.0169 & TRN & \\
\hline CHEMBL3198489 & 688724 & 4.7 & 4.67399 & 99999999995 & TRN \\
\hline CHEMBL1374319 & 688724 & 6.35 & 5.2975 & TRN & \\
\hline CHEMBL446315 & 688724 & 5.5 & 4.9792 & TRN & \\
\hline CHEMBL1601581 & 688724 & 4.1 & 4.6295 & TRN & \\
\hline CHEMBL1500677 & 688724 & 4.5 & 4.5139 & TRN & \\
\hline CHEMBL1503729 & 688724 & 5.15 & 5.5162 & TRN & \\
\hline CHEMBL1348277 & 688724 & 5.8 & 4.7945 & TRN & \\
\hline CHEMBL1410821 & 688724 & 4.8 & 5.0562 & TRN & \\
\hline CHEMBL1392817 & 688724 & 4.8 & 4.6252 & TRN & \\
\hline CHEMBL1567471 & 688724 & 4.1 & 4.7891 & TRN & \\
\hline CHEMBL1409173 & 688724 & 4.3 & 4.738 & TRN & \\
\hline CHEMBL131091 & 688724 & 6.0 & 5.1604 & TRN & \\
\hline CHEMBL1548350 & 688724 & 5.55 & 4.8441 & TRN & \\
\hline
\end{tabular}




\begin{tabular}{|c|c|c|c|c|}
\hline \multicolumn{5}{|c|}{ Supplemental Table S2.txt } \\
\hline CHEMBL1413572 & 688724 & 4.2 & 4.9011 & TST \\
\hline CHEMBL1497504 & 688724 & 4.8 & 4.3849 & TST \\
\hline CHEMBL199405 & 688724 & 4.45 & 5.0967 & TRN \\
\hline CHEMBL1302935 & 688724 & 4.0 & 4.918 & TST \\
\hline CHEMBL1524564 & 688724 & 4.85 & 4.9297 & TST \\
\hline CHEMBL1580784 & 688724 & 4.3 & 4.7747 & TRN \\
\hline CHEMBL1341735 & 688724 & 4.8 & 4.8671 & TRN \\
\hline CHEMBL1528316 & 688724 & 4.5 & 4.6328 & TRN \\
\hline CHEMBL1305391 & 688724 & 4.95 & 4.6599 & TRN \\
\hline CHEMBL1563596 & 688724 & 5.05 & 4.6745 & TST \\
\hline CHEMBL1530085 & 688724 & 4.5 & 4.9271 & TRN \\
\hline CHEMBL1372426 & 688724 & 4.4 & 4.4753 & TRN \\
\hline CHEMBL1606729 & 688724 & 4.8 & 4.721 & TST \\
\hline CHEMBL1334991 & 688724 & 4.1 & 4.7617 & TRN \\
\hline CHEMBL1981446 & 688724 & 6.2 & 5.1123 & TRN \\
\hline CHEMBL1362566 & 688724 & 4.85 & 4.8935 & TRN \\
\hline CHEMBL38832 & 688724 & 6.0 & 4.8817 & TST \\
\hline CHEMBL1574121 & 688724 & 5.75 & 5.4185 & TRN \\
\hline CHEMBL1319992 & 688724 & 6.0 & 5.1738 & TRN \\
\hline CHEMBL1481530 & 688724 & 4.05 & 4.8492 & TST \\
\hline CHEMBL 2146131 & 688724 & 5.6 & 4.8851 & TRN \\
\hline CHEMBL1449334 & 688724 & 5.45 & 5.1503 & TRN \\
\hline CHEMBL1352368 & 688724 & 4.85 & 5.3875 & TRN \\
\hline CHEMBL1308170 & 688724 & 6.45 & 4.87 & TRN \\
\hline CHEMBL1546796 & 688724 & 5.25 & 4.8528 & TRN \\
\hline CHEMBL65675 & 688724 & 5.45 & 5.399 & TRN \\
\hline CHEMBL1598975 & 688724 & 4.65 & 4.695 & TST \\
\hline CHEMBL1345601 & 688724 & 4.4 & 4.8129 & TST \\
\hline CHEMBL1332057 & 688724 & 4.35 & 4.4311 & TRN \\
\hline CHEMBL490743 & 688724 & 4.6242 & 4.6924 & TRN \\
\hline CHEMBL1347628 & 688724 & 4.55 & 5.395 & TRN \\
\hline CHEMBL1299388 & 688724 & 4.65 & 4.9686 & TST \\
\hline CHEMBL367741 & 688724 & 4.65 & 5.0848 & TRN \\
\hline CHEMBL1979800 & 688724 & 4.1 & 5.501 & TRN \\
\hline CHEMBL3196256 & 688724 & 5.55 & 5.1256 & TRN \\
\hline CHEMBL3211998 & 688724 & 5.55 & 5.2229 & TRN \\
\hline CHEMBL1560954 & 688724 & 6.4 & 4.8632 & TST \\
\hline CHEMBL1340519 & 688724 & 5.6 & 5.5494 & TRN \\
\hline CHEMBL1311789 & 688724 & 6.0 & 5.1552 & TRN \\
\hline CHEMBL1536776 & 688724 & 5.35 & 5.1196 & TRN \\
\hline CHEMBL1342665 & 688724 & 4.9 & 4.754 & TRN \\
\hline CHEMBL 1441782 & 688724 & 4.6 & 5.2853 & TRN \\
\hline CHEMBL1359230 & 688724 & 4.4 & 4.8579 & TRN \\
\hline CHEMBL1398145 & 688724 & 5.35 & 5.073 & TRN \\
\hline CHEMBL1613725 & 688724 & 5.05 & 4.7323 & TRN \\
\hline CHEMBL 247378 & 688724 & 5.9 & 4.9441 & TST \\
\hline CHEMBL1484071 & 688724 & 4.75 & 4.9432 & TST \\
\hline CHEMBL1594807 & 688724 & 4.45 & 4.4727 & TRN \\
\hline
\end{tabular}




\begin{tabular}{|c|c|c|c|c|c|}
\hline \multicolumn{6}{|c|}{ Supplemental Table S2.txt } \\
\hline CHEMBL1300015 & 688724 & 5.0 & 4.7992 & TRN & \\
\hline CHEMBL1415453 & 688724 & 6.0 & 5.2711 & TRN & \\
\hline CHEMBL1588351 & 688724 & 4.25 & 4.7673 & TRN & \\
\hline CHEMBL1364903 & 688724 & 4.95 & 4.766 & TRN & \\
\hline CHEMBL1565526 & 688724 & 4.25 & 5.1571 & TST & \\
\hline CHEMBL1538088 & 688724 & 4.6 & 4.7432 & TRN & \\
\hline CHEMBL1490689 & 688724 & 4.65 & 4.8194 & TST & \\
\hline CHEMBL1889837 & 688724 & 4.7 & 4.8684 & TRN & \\
\hline CHEMBL1432848 & 688724 & 5.1 & 4.6689 & TRN & \\
\hline CHEMBL1602108 & 688724 & 4.05 & 4.7297 & TRN & \\
\hline CHEMBL1394847 & 688724 & 4.15 & 4.3522 & TRN & \\
\hline CHEMBL1548606 & 688724 & 5.85 & 4.8889 & TRN & \\
\hline CHEMBL1611748 & 688724 & 4.1 & 4.828 & TRN & \\
\hline CHEMBL1593765 & 688724 & 4.25 & 5.24200 & 0000000001 & TRN \\
\hline CHEMBL1438222 & 688724 & 4.45 & 4.745 & TRN & \\
\hline CHEMBL1403321 & 688724 & 6.7501 & 4.55399 & 9999999999 & TRN \\
\hline CHEMBL1363277 & 688724 & 4.3 & 4.2541 & TRN & \\
\hline CHEMBL1526319 & 688724 & 4.15 & 5.0116 & TST & \\
\hline CHEMBL1076555 & 688724 & 6.0 & 4.987 & TRN & \\
\hline CHEMBL1401208 & 688724 & 4.8 & 4.8957 & TST & \\
\hline CHEMBL1366361 & 688724 & 4.7 & 4.8241 & TRN & \\
\hline CHEMBL1440375 & 688724 & 6.15 & 5.0622 & TST & \\
\hline CHEMBL1439149 & 688724 & 4.85 & 4.8846 & TST & \\
\hline CHEMBL1453675 & 688724 & 4.4 & 4.5707 & TRN & \\
\hline CHEMBL1316929 & 688724 & 4.1 & 4.7997 & TST & \\
\hline CHEMBL575239 & 688724 & 6.1 & 5.0121 & TST & \\
\hline CHEMBL1391552 & 688724 & 5.9 & 5.2223 & TRN & \\
\hline CHEMBL1443966 & 688724 & 4.35 & 4.5042 & TRN & \\
\hline CHEMBL1491469 & 688724 & 4.4 & 5.2678 & TST & \\
\hline CHEMBL1334 & 688724 & 4.5 & 5.5191 & TST & \\
\hline CHEMBL1986557 & 688724 & 5.35 & 5.2644 & TRN & \\
\hline CHEMBL1333583 & 688724 & 4.45 & 4.5836 & TST & \\
\hline CHEMBL1329314 & 688724 & 4.5 & 4.7549 & TST & \\
\hline CHEMBL571295 & 688724 & 4.05 & 5.0707 & TST & \\
\hline CHEMBL3196873 & 688724 & 7.0501 & 4.827 & TST & \\
\hline CHEMBL1474325 & 688724 & 4.25 & 4.5001 & TRN & \\
\hline CHEMBL1565860 & 688724 & 5.45 & 4.7256 & TST & \\
\hline CHEMBL1531851 & 688724 & 4.7 & 4.6836 & TRN & \\
\hline CHEMBL1540245 & 688724 & 4.4 & 4.6247 & TRN & \\
\hline CHEMBL1480797 & 688724 & 5.3 & 5.0813 & TRN & \\
\hline CHEMBL1579118 & 688724 & 4.7 & 5.1421 & TST & \\
\hline CHEMBL1303235 & 688724 & 4.15 & 4.7857 & TRN & \\
\hline CHEMBL600347 & 688724 & 4.35 & 4.5456 & TST & \\
\hline CHEMBL1476838 & 688724 & 4.8 & 4.7089 & TRN & \\
\hline CHEMBL1606823 & 688724 & 5.6 & 5.1528 & TRN & \\
\hline CHEMBL1499041 & 688724 & 4.35 & 5.1296 & TST & \\
\hline CHEMBL1426842 & 688724 & 5.6 & 4.7355 & TRN & \\
\hline CHEMBL1568835 & 688724 & 4.45 & 4.3548 & TRN & \\
\hline
\end{tabular}




\begin{tabular}{|c|c|c|c|c|}
\hline \multicolumn{5}{|c|}{ Supplemental Table S2.txt } \\
\hline CHEMBL1329661 & 688724 & 5.3 & 4.442 & TRN \\
\hline CHEMBL1538120 & 688724 & 7.3002 & 4.868 & TRN \\
\hline CHEMBL1410895 & 688724 & 4.35 & 5.0486 & TST \\
\hline CHEMBL456881 & 688724 & 4.4 & 4.7195 & TRN \\
\hline CHEMBL1403438 & 688724 & 4.35 & 5.0769 & TRN \\
\hline CHEMBL1539333 & 688724 & 4.4 & 5.0475 & TRN \\
\hline CHEMBL1493247 & 688724 & 4.5 & 4.6715 & TST \\
\hline CHEMBL1223397 & 688724 & 4.6 & 4.4114 & TRN \\
\hline CHEMBL 3198417 & 688724 & 4.3 & 4.9812 & TRN \\
\hline CHEMBL581044 & 688724 & 4.6 & 4.6346 & TRN \\
\hline CHEMBL1570267 & 688724 & 5.3 & 5.0657 & TST \\
\hline CHEMBL345635 & 688724 & 4.65 & 5.2518 & TST \\
\hline CHEMBL1312975 & 688724 & 4.7 & 4.8941 & TRN \\
\hline CHEMBL1571808 & 688724 & 4.25 & 4.8502 & TST \\
\hline CHEMBL1532453 & 688724 & 4.3 & 5.1603 & TRN \\
\hline CHEMBL1565438 & 688724 & 4.75 & 4.7452 & TRN \\
\hline CHEMBL3193092 & 688724 & 5.5 & 4.9263 & TRN \\
\hline CHEMBL1464608 & 688724 & 4.05 & 4.5905 & TRN \\
\hline CHEMBL3213249 & 688724 & 4.8 & 4.5737 & TRN \\
\hline CHEMBL1423983 & 688724 & 4.45 & 5.0305 & TRN \\
\hline CHEMBL1534168 & 688724 & 4.8 & 4.5773 & TRN \\
\hline CHEMBL1455949 & 688724 & 5.0 & 4.7221 & TRN \\
\hline CHEMBL1354219 & 688724 & 4.4 & 4.8586 & TST \\
\hline CHEMBL1971872 & 688724 & 4.55 & 4.7322 & TRN \\
\hline CHEMBL1498079 & 688724 & 5.15 & 5.1501 & TRN \\
\hline CHEMBL1528826 & 688724 & 4.8 & 5.0597 & TRN \\
\hline CHEMBL1517425 & 688724 & 4.55 & 4.8407 & TRN \\
\hline CHEMBL1488576 & 688724 & 4.8 & 4.8632 & TRN \\
\hline CHEMBL1496919 & 688724 & 4.25 & 4.6439 & TST \\
\hline CHEMBL1299740 & 688724 & 4.05 & 4.8685 & TST \\
\hline CHEMBL1530492 & 688724 & 5.15 & 4.7946 & TRN \\
\hline CHEMBL1481464 & 688724 & 5.05 & 5.15 & TST \\
\hline CHEMBL3392041 & 688724 & 5.5 & 5.033 & TRN \\
\hline CHEMBL1456910 & 688724 & 4.05 & 4.5816 & TRN \\
\hline CHEMBL 1447845 & 688724 & 3.85 & 4.9015 & TRN \\
\hline CHEMBL1299420 & 688724 & 4.5 & 4.8449 & TRN \\
\hline CHEMBL1519818 & 688724 & 6.0 & 4.9596 & TRN \\
\hline CHEMBL3195609 & 688724 & 4.45 & 4.8547 & TRN \\
\hline CHEMBL1305050 & 688724 & 5.3 & 4.6302 & TRN \\
\hline CHEMBL1316908 & 688724 & 5.2 & 4.7967 & TRN \\
\hline CHEMBL1612836 & 688724 & 4.35 & 5.1093 & TRN \\
\hline CHEMBL1454400 & 688724 & 4.4 & 5.0366 & TST \\
\hline CHEMBL1534901 & 688724 & 4.35 & 4.6941 & TRN \\
\hline CHEMBL3190371 & 688724 & 4.35 & 5.0185 & TRN \\
\hline CHEMBL1508816 & 688724 & 4.3 & 5.0218 & TST \\
\hline CHEMBL1509368 & 688724 & 4.7 & 4.6204 & TRN \\
\hline CHEMBL 213432 & 688724 & 5.7 & 4.7161 & TRN \\
\hline CHEMBL1586603 & 688724 & 5.45 & 4.5497 & TRN \\
\hline
\end{tabular}




\begin{tabular}{|c|c|c|c|c|}
\hline & & & pplement & $d \perp$ \\
\hline CHEMBL1356870 & 688724 & 4.9 & 5.1095 & TST \\
\hline CHEMBL1601417 & 688724 & 4.2 & 4.6478 & TRN \\
\hline CHEMBL1965471 & 688724 & 4.35 & 4.6471 & TRN \\
\hline CHEMBL1457139 & 688724 & 6.0 & 5.8807 & TRN \\
\hline CHEMBL133576 & 688724 & 5.15 & 4.8877 & TRN \\
\hline CHEMBL51628 & 688724 & 4.3 & 4.8904 & TRN \\
\hline CHEMBL1468682 & 688724 & 6.0 & 4.7773 & TRN \\
\hline CHEMBL1552623 & 688724 & 4.65 & 4.8523 & TRN \\
\hline CHEMBL3209346 & 688724 & 4.3 & 4.9279 & TRN \\
\hline CHEMBL1592943 & 688724 & 4.55 & 4.6908 & TRN \\
\hline CHEMBL1379550 & 688724 & 4.75 & 5.0838 & TST \\
\hline CHEMBL1461915 & 688724 & 4.75 & 4.6342 & TRN \\
\hline CHEMBL606166 & 688724 & 4.9 & 5.1078 & TST \\
\hline CHEMBL1594074 & 688724 & 4.2 & 4.8821 & TRN \\
\hline CHEMBL1564891 & 688724 & 4.8 & 4.5479 & TRN \\
\hline CHEMBL1541448 & 688724 & 4.55 & 4.6456 & TRN \\
\hline CHEMBL1322290 & 688724 & 4.75 & 4.7485 & TST \\
\hline CHEMBL1371238 & 688724 & 4.55 & 4.7964 & TRN \\
\hline CHEMBL1514157 & 688724 & 4.3 & 4.6468 & TRN \\
\hline CHEMBL1456052 & 688724 & 4.95 & 4.9129 & TRN \\
\hline CHEMBL1201074 & 688724 & 4.7 & 4.9797 & TRN \\
\hline CHEMBL1338836 & 688724 & 5.45 & 4.7543 & TST \\
\hline CHEMBL1579673 & 688724 & 5.05 & 5.1099 & TRN \\
\hline CHEMBL3193415 & 688724 & 5.3 & 5.1658 & TRN \\
\hline CHEMBL1399655 & 688724 & 4.55 & 4.8311 & TRN \\
\hline CHEMBL3196505 & 688724 & 4.45 & 5.0423 & TRN \\
\hline CHEMBL1508792 & 688724 & 4.3 & 5.192 & TST \\
\hline CHEMBL1357648 & 688724 & 5.9 & 5.1163 & TRN \\
\hline CHEMBL1373950 & 688724 & 6.05 & 4.9377 & TST \\
\hline CHEMBL1998863 & 688724 & 5.4 & 5.228 & TRN \\
\hline CHEMBL1457102 & 688724 & 4.0 & 4.9848 & TST \\
\hline CHEMBL3191273 & 688724 & 5.15 & 4.8884 & TRN \\
\hline CHEMBL1451772 & 688724 & 4.95 & 4.8634 & TRN \\
\hline CHEMBL3209537 & 688724 & 4.65 & 4.7179 & TRN \\
\hline CHEMBL1443798 & 688724 & 4.6 & 4.7729 & TST \\
\hline CHEMBL1479316 & 688724 & 4.7 & 5.5726 & TRN \\
\hline CHEMBL1361949 & 688724 & 4.8 & 5.0188 & TRN \\
\hline CHEMBL1302593 & 688724 & 4.05 & 4.7015 & TST \\
\hline CHEMBL1308797 & 688724 & 4.0 & 4.5713 & TST \\
\hline CHEMBL1256885 & 688724 & 5.05 & 5.1765 & TRN \\
\hline CHEMBL3195511 & 688724 & 5.1 & 4.6599 & TRN \\
\hline CHEMBL1428443 & 688724 & 5.15 & 5.0292 & TRN \\
\hline CHEMBL1500905 & 688724 & 4.3 & 4.762 & TRN \\
\hline CHEMBL1397913 & 688724 & 4.45 & 4.8785 & TRN \\
\hline CHEMBL1570624 & 688724 & 4.7 & 4.72 & TST \\
\hline CHEMBL1526988 & 688724 & 4.15 & 4.5719 & TRN \\
\hline CHEMBL3196020 & 688724 & 6.05 & 5.0814 & TRN \\
\hline CHEMBL1315642 & 688724 & 4.1 & 4.425 & TRN \\
\hline
\end{tabular}




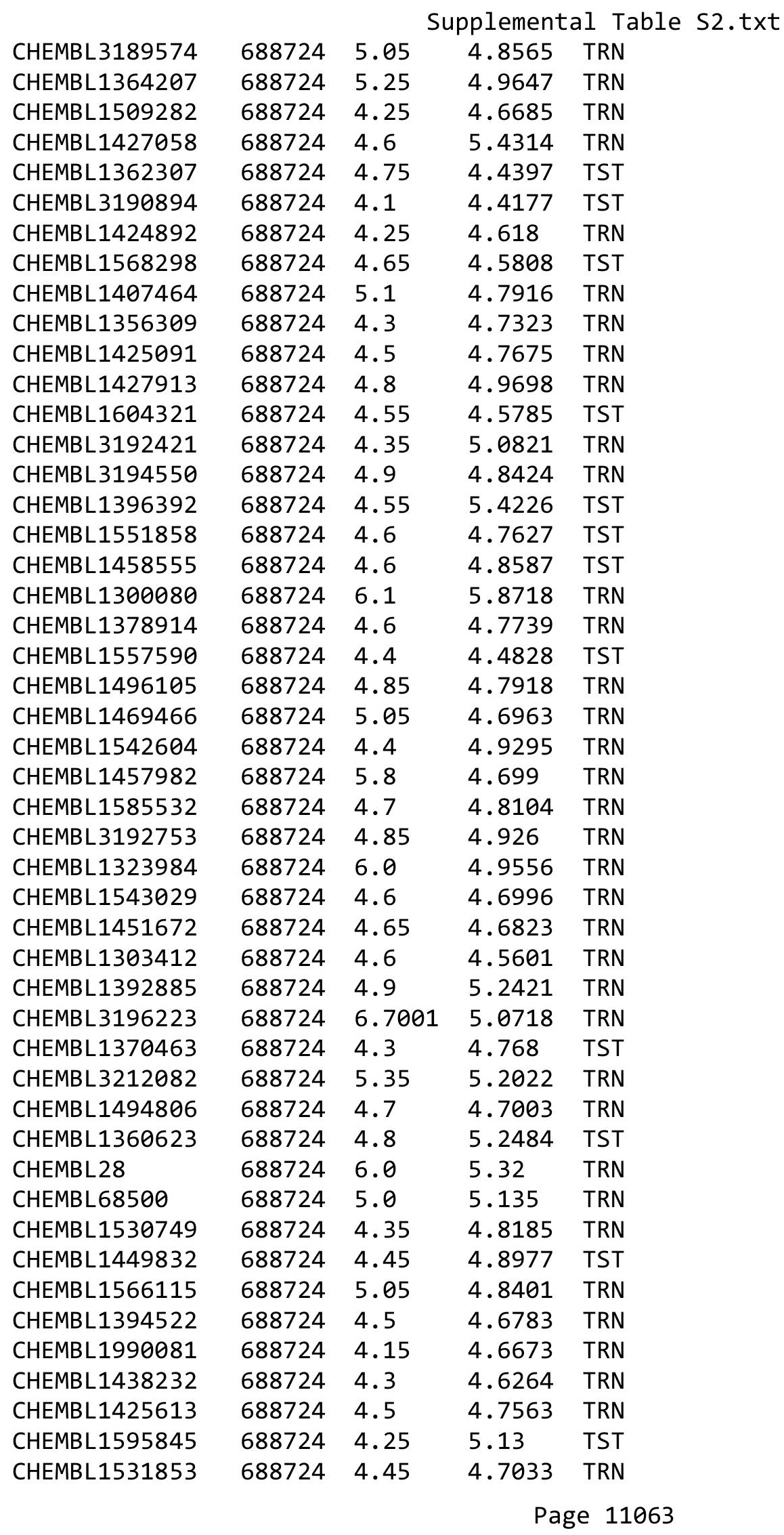




\begin{tabular}{|c|c|c|c|c|}
\hline \multicolumn{5}{|c|}{ Supplemental Table S2.txt } \\
\hline CHEMBL1454624 & 688724 & 4.15 & 5.1795 & TRN \\
\hline CHEMBL1539860 & 688724 & 5.4 & 5.3927 & TRN \\
\hline CHEMBL3196147 & 688724 & 4.05 & 4.3728 & TRN \\
\hline CHEMBL1482199 & 688724 & 5.1 & 5.0166 & TRN \\
\hline CHEMBL1508037 & 688724 & 5.0 & 4.7048 & TRN \\
\hline CHEMBL 242171 & 688724 & 4.5 & 5.2111 & TRN \\
\hline CHEMBL1459043 & 688724 & 4.3 & 4.6138 & TRN \\
\hline CHEMBL1478652 & 688724 & 5.35 & 5.0937 & TRN \\
\hline CHEMBL3197368 & 688724 & 4.25 & 4.5673 & TRN \\
\hline CHEMBL1422476 & 688724 & 4.8 & 4.992 & TRN \\
\hline CHEMBL3191389 & 688724 & 5.1 & 4.6501 & TRN \\
\hline CHEMBL1563809 & 688724 & 5.1 & 4.7372 & TRN \\
\hline CHEMBL1594200 & 688724 & 4.55 & 4.5852 & TRN \\
\hline CHEMBL1542370 & 688724 & 4.15 & 4.4688 & TRN \\
\hline CHEMBL1511328 & 688724 & 4.85 & 4.626 & TST \\
\hline CHEMBL1564471 & 688724 & 4.7 & 4.4756 & TST \\
\hline CHEMBL1584150 & 688724 & 4.3 & 4.9464 & TRN \\
\hline CHEMBL1490080 & 688724 & 4.35 & 4.7871 & TRN \\
\hline CHEMBL1588368 & 688724 & 5.6 & 5.4451 & TRN \\
\hline CHEMBL1456767 & 688724 & 5.0 & 4.9282 & TRN \\
\hline CHEMBL1452924 & 688724 & 5.15 & 4.5517 & TRN \\
\hline CHEMBL453388 & 688724 & 6.0 & 5.2153 & TRN \\
\hline CHEMBL1385999 & 688724 & 6.35 & 4.7888 & TRN \\
\hline CHEMBL1568222 & 688724 & 4.65 & 4.6744 & TST \\
\hline CHEMBL1332656 & 688724 & 4.8 & 4.8328 & TRN \\
\hline CHEMBL1567921 & 688724 & 4.7 & 5.0469 & TST \\
\hline CHEMBL1453160 & 688724 & 4.8 & 4.8562 & TST \\
\hline CHEMBL1389124 & 688724 & 4.6 & 4.8774 & TRN \\
\hline CHEMBL1430635 & 688724 & 5.1 & 4.7713 & TRN \\
\hline CHEMBL1586339 & 688724 & 4.75 & 4.8076 & TRN \\
\hline CHEMBL 221137 & 688724 & 5.3 & 5.3628 & TST \\
\hline CHEMBL1403112 & 688724 & 5.05 & 5.4489 & TRN \\
\hline CHEMBL1551512 & 688724 & 6.6 & 4.581 & TST \\
\hline CHEMBL567529 & 688724 & 5.35 & 4.8069 & TST \\
\hline CHEMBL1586439 & 688724 & 4.15 & 4.9055 & TRN \\
\hline CHEMBL1530302 & 688724 & 4.85 & 4.7336 & TRN \\
\hline CHEMBL1601846 & 688724 & 6.5 & 5.6684 & TRN \\
\hline CHEMBL1389445 & 688724 & 5.45 & 4.7913 & TRN \\
\hline CHEMBL1598394 & 688724 & 4.85 & 4.4577 & TRN \\
\hline CHEMBL1487501 & 688724 & 4.55 & 4.5002 & TST \\
\hline CHEMBL1530039 & 688724 & 5.5 & 4.6413 & TRN \\
\hline CHEMBL1506930 & 688724 & 4.05 & 4.6895 & TRN \\
\hline CHEMBL1585679 & 688724 & 4.8 & 5.1653 & TRN \\
\hline CHEMBL1256995 & 688724 & 7.5498 & 5.2131 & TRN \\
\hline CHEMBL1501931 & 688724 & 4.05 & 5.0027 & TST \\
\hline CHEMBL1345121 & 688724 & 4.6 & 4.9852 & TST \\
\hline CHEMBL1553393 & 688724 & 4.3 & 4.6879 & TRN \\
\hline CHEMBL1487971 & 688724 & 4.0 & 4.868 & TST \\
\hline
\end{tabular}




\begin{tabular}{|c|c|c|c|c|}
\hline \multicolumn{5}{|c|}{ Supplemental Table S2.txt } \\
\hline CHEMBL1399952 & 688724 & 4.25 & 4.5926 & TRN \\
\hline CHEMBL1330287 & 688724 & 4.7 & 4.7596 & TRN \\
\hline CHEMBL1606940 & 688724 & 5.2 & 4.8633 & TRN \\
\hline CHEMBL1350512 & 688724 & 4.4 & 4.6122 & TST \\
\hline CHEMBL1437244 & 688724 & 6.0 & 5.0077 & TRN \\
\hline CHEMBL1444280 & 688724 & 4.4 & 4.9183 & TRN \\
\hline CHEMBL1487349 & 688724 & 4.1 & 4.5488 & TRN \\
\hline CHEMBL1352712 & 688724 & 4.6 & 4.8018 & TRN \\
\hline CHEMBL1313968 & 688724 & 4.85 & 4.7426 & TRN \\
\hline CHEMBL3196616 & 688724 & 5.0 & 4.6722 & TRN \\
\hline CHEMBL1489760 & 688724 & 4.25 & 4.5856 & TRN \\
\hline CHEMBL1367954 & 688724 & 4.65 & 5.1976 & TRN \\
\hline CHEMBL1458569 & 688724 & 5.05 & 4.7207 & TST \\
\hline CHEMBL1607586 & 688724 & 4.1 & 4.6419 & TST \\
\hline CHEMBL1436026 & 688724 & 4.35 & 4.58 & TRN \\
\hline CHEMBL 2003741 & 688724 & 5.4 & 4.7523 & TRN \\
\hline CHEMBL1389737 & 688724 & 4.8 & 4.4663 & TRN \\
\hline CHEMBL1349546 & 688724 & 5.1 & 4.8363 & TRN \\
\hline CHEMBL1464659 & 688724 & 4.45 & 4.5731 & TRN \\
\hline CHEMBL1353221 & 688724 & 4.7 & 4.8064 & TST \\
\hline CHEMBL1569232 & 688724 & 4.1 & 4.8733 & TRN \\
\hline CHEMBL1415008 & 688724 & 4.5 & 4.3734 & TRN \\
\hline CHEMBL1600366 & 688724 & 6.5 & 4.8522 & TST \\
\hline CHEMBL1544901 & 688724 & 4.35 & 4.8373 & TRN \\
\hline CHEMBL1530127 & 688724 & 4.95 & 4.6 & TRN \\
\hline CHEMBL1483566 & 688724 & 4.05 & 4.6387 & TRN \\
\hline CHEMBL1531118 & 688724 & 4.4 & 5.1382 & TST \\
\hline CHEMBL 216504 & 688724 & 5.05 & 4.9111 & TRN \\
\hline CHEMBL1560141 & 688724 & 4.95 & 4.7958 & TRN \\
\hline CHEMBL222519 & 688724 & 6.0 & 5.1818 & TST \\
\hline CHEMBL1411556 & 688724 & 6.0 & 5.2643 & TRN \\
\hline CHEMBL1456728 & 688724 & 4.25 & 4.6617 & TRN \\
\hline CHEMBL3209206 & 688724 & 4.55 & 4.7745 & TST \\
\hline CHEMBL1522438 & 688724 & 4.8 & 4.5963 & TST \\
\hline CHEMBL1312641 & 688724 & 5.15 & 4.7345 & TRN \\
\hline CHEMBL1309997 & 688724 & 5.8 & 5.3406 & TRN \\
\hline CHEMBL1466100 & 688724 & 4.3 & 5.2415 & TRN \\
\hline CHEMBL1363824 & 688724 & 5.75 & 5.2808 & TRN \\
\hline CHEMBL 3193178 & 688724 & 5.15 & 4.9761 & TRN \\
\hline CHEMBL1439023 & 688724 & 4.25 & 4.5464 & TRN \\
\hline CHEMBL1575272 & 688724 & 6.4 & 5.0764 & TRN \\
\hline CHEMBL1453782 & 688724 & 4.8 & 4.8236 & TST \\
\hline CHEMBL1367036 & 688724 & 5.45 & 4.8144 & TST \\
\hline CHEMBL1469790 & 688724 & 4.7 & 4.6356 & TST \\
\hline CHEMBL1344790 & 688724 & 4.4 & 4.6435 & TST \\
\hline CHEMBL1495539 & 688724 & 5.6 & 4.9171 & TRN \\
\hline CHEMBL1462274 & 688724 & 4.15 & 4.5981 & TRN \\
\hline CHEMBL1506195 & 688724 & 4.35 & 4.317 & TRN \\
\hline
\end{tabular}




\begin{tabular}{|c|c|c|c|c|}
\hline \multicolumn{5}{|c|}{ Supplemental Table S2.txt } \\
\hline CHEMBL 3191810 & 688724 & 4.35 & 4.9968 & TRN \\
\hline CHEMBL1560544 & 688724 & 4.55 & 4.7014 & TST \\
\hline CHEMBL1317461 & 688724 & 5.3 & 4.6818 & TRN \\
\hline CHEMBL548615 & 688724 & 7.6003 & 5.3626 & TRN \\
\hline CHEMBL1540993 & 688724 & 5.0 & 4.5646 & TRN \\
\hline CHEMBL 3189708 & 688724 & 4.35 & 4.4604 & TRN \\
\hline CHEMBL1573534 & 688724 & 4.1 & 4.9378 & TST \\
\hline CHEMBL1330508 & 688724 & 4.7 & 4.5317 & TRN \\
\hline CHEMBL1557626 & 688724 & 4.85 & 4.806 & TST \\
\hline CHEMBL1312214 & 688724 & 4.45 & 4.5325 & TRN \\
\hline CHEMBL1474799 & 688724 & 4.45 & 4.8075 & TRN \\
\hline CHEMBL1995078 & 688724 & 4.65 & 5.0659 & TST \\
\hline CHEMBL1362054 & 688724 & 5.45 & 4.8299 & TRN \\
\hline CHEMBL1609557 & 688724 & 4.25 & 4.4102 & TRN \\
\hline CHEMBL3197991 & 688724 & 4.85 & 5.3054 & TRN \\
\hline CHEMBL 1460085 & 688724 & 5.4 & 5.4395 & TRN \\
\hline CHEMBL1328811 & 688724 & 4.15 & 4.9441 & TST \\
\hline CHEMBL1412496 & 688724 & 4.1 & 4.55 & TRN \\
\hline CHEMBL1510246 & 688724 & 4.35 & 5.1987 & TRN \\
\hline CHEMBL1526648 & 688724 & 5.55 & 4.7018 & TRN \\
\hline CHEMBL1541779 & 688724 & 5.0 & 4.4972 & TRN \\
\hline CHEMBL3211950 & 688724 & 4.6 & 4.4095 & TRN \\
\hline CHEMBL1447350 & 688724 & 5.0 & 4.8541 & TRN \\
\hline CHEMBL 3207313 & 688724 & 4.3 & 4.871 & TST \\
\hline CHEMBL1308615 & 688724 & 5.25 & 5.2121 & TRN \\
\hline CHEMBL1329465 & 688724 & 4.9 & 4.5106 & TRN \\
\hline CHEMBL1348007 & 688724 & 4.65 & 4.6103 & TST \\
\hline CHEMBL1556385 & 688724 & 4.2 & 4.2397 & TRN \\
\hline CHEMBL1328116 & 688724 & 4.35 & 4.8313 & TRN \\
\hline CHEMBL1322052 & 688724 & 4.45 & 5.3082 & TRN \\
\hline CHEMBL1415040 & 688724 & 5.15 & 4.9692 & TRN \\
\hline CHEMBL1327581 & 688724 & 4.7 & 4.6158 & TRN \\
\hline CHEMBL1571978 & 688724 & 4.4 & 4.6239 & TRN \\
\hline CHEMBL1562779 & 688724 & 4.4 & 4.9066 & TST \\
\hline CHEMBL1363479 & 688724 & 4.2 & 4.7616 & TRN \\
\hline CHEMBL1978315 & 688724 & 5.15 & 4.8612 & TRN \\
\hline CHEMBL1348235 & 688724 & 4.95 & 4.8517 & TST \\
\hline CHEMBL1496297 & 688724 & 4.75 & 4.7663 & TRN \\
\hline CHEMBL1507335 & 688724 & 4.65 & 4.8396 & TRN \\
\hline CHEMBL1545527 & 688724 & 4.75 & 4.6461 & TST \\
\hline CHEMBL3198989 & 688724 & 5.0 & 4.9934 & TST \\
\hline CHEMBL1995800 & 688724 & 5.0 & 4.8683 & TRN \\
\hline CHEMBL1303179 & 688724 & 6.0 & 5.0249 & TRN \\
\hline CHEMBL1376870 & 688724 & 6.1 & 5.4574 & TRN \\
\hline CHEMBL1553317 & 688724 & 4.3 & 4.8267 & TRN \\
\hline CHEMBL1364028 & 688724 & 4.7 & 5.0007 & TRN \\
\hline CHEMBL1527752 & 688724 & 4.75 & 4.6372 & TST \\
\hline CHEMBL3193536 & 688724 & 4.75 & 5.082 & TRN \\
\hline
\end{tabular}




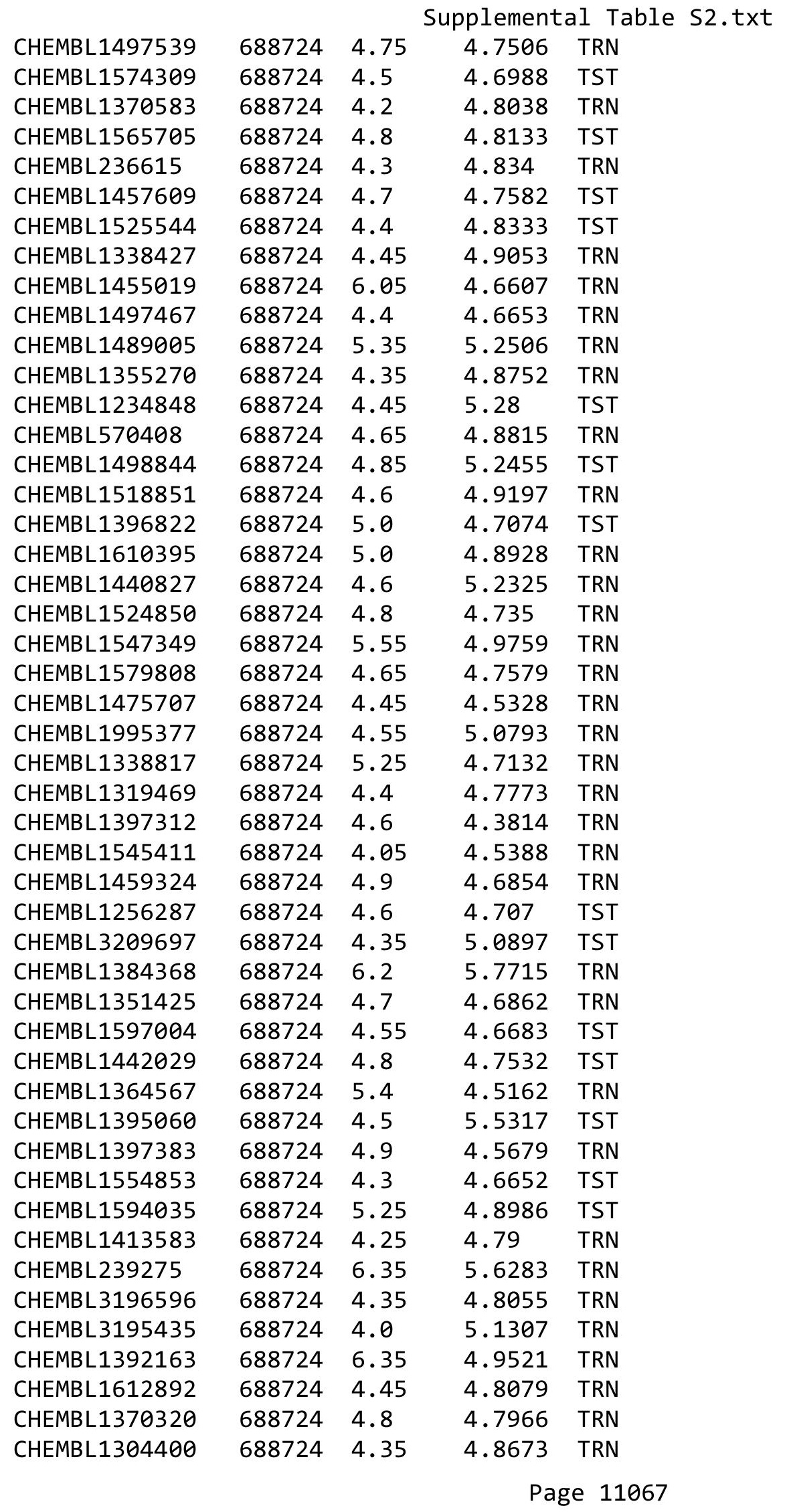




\begin{tabular}{|c|c|c|c|c|c|}
\hline & & \multicolumn{4}{|c|}{ Supplemental Table S2.txt } \\
\hline CHEMBL1435543 & 688724 & 5.05 & 4.755 & TRN & \\
\hline CHEMBL1559946 & 688724 & 4.75 & 4.7351 & TRN & \\
\hline CHEMBL1553908 & 688724 & 4.3 & 4.7889 & TRN & \\
\hline CHEMBL1394259 & 688724 & 4.45 & 4.8753 & TRN & \\
\hline CHEMBL3195241 & 688724 & 4.8 & 5.0823 & TRN & \\
\hline CHEMBL1490536 & 688724 & 5.15 & 5.0716 & TRN & \\
\hline CHEMBL1448038 & 688724 & 4.25 & 4.7934 & TST & \\
\hline CHEMBL1436077 & 688724 & 5.05 & 4.742 & TRN & \\
\hline CHEMBL1497374 & 688724 & 4.4 & 4.5477 & TRN & \\
\hline CHEMBL3190389 & 688724 & 4.4 & 4.4964 & TRN & \\
\hline CHEMBL1583997 & 688724 & 4.65 & 4.7495 & TRN & \\
\hline CHEMBL1463482 & 688724 & 4.05 & 5.0556 & TST & \\
\hline CHEMBL156127 & 688724 & 4.35 & 4.8237 & TRN & \\
\hline CHEMBL1328629 & 688724 & 4.85 & 4.9314 & TST & \\
\hline CHEMBL3196408 & 688724 & 6.05 & 5.16299 & 9999999999 & TRN \\
\hline CHEMBL474933 & 688724 & 5.75 & 5.1761 & TRN & \\
\hline CHEMBL1472780 & 688724 & 4.15 & 4.8379 & TRN & \\
\hline CHEMBL1532659 & 688724 & 4.3 & 4.4563 & TRN & \\
\hline CHEMBL1387836 & 688724 & 4.45 & 4.3224 & TRN & \\
\hline CHEMBL1465115 & 688724 & 5.25 & 4.7088 & TST & \\
\hline CHEMBL1390938 & 688724 & 4.65 & 4.7329 & TRN & \\
\hline CHEMBL1480173 & 688724 & 5.5 & 4.8097 & TRN & \\
\hline CHEMBL1301350 & 688724 & 5.2 & 4.6927 & TRN & \\
\hline CHEMBL1596591 & 688724 & 4.0 & 4.6076 & TST & \\
\hline CHEMBL1417159 & 688724 & 4.45 & 5.1472 & TST & \\
\hline CHEMBL1381017 & 688724 & 5.6 & 5.0952 & TST & \\
\hline CHEMBL1415888 & 688724 & 6.0 & 4.862 & TRN & \\
\hline CHEMBL1570045 & 688724 & 4.7 & 4.9031 & TST & \\
\hline CHEMBL1409985 & 688724 & 4.35 & 4.8085 & TST & \\
\hline CHEMBL1303831 & 688724 & 4.45 & 4.4509 & TRN & \\
\hline CHEMBL1541434 & 688724 & 4.1 & 4.8252 & TST & \\
\hline CHEMBL1348796 & 688724 & 4.45 & 4.8315 & TRN & \\
\hline CHEMBL1533357 & 688724 & 4.6 & 4.6284 & TRN & \\
\hline CHEMBL1353516 & 688724 & 4.5 & 4.6324 & TST & \\
\hline CHEMBL1468500 & 688724 & 4.75 & 4.9614 & TRN & \\
\hline CHEMBL1494408 & 688724 & 4.9 & 4.5064 & TRN & \\
\hline CHEMBL1385692 & 688724 & 4.65 & 4.7391 & TST & \\
\hline CHEMBL3145067 & 688724 & 4.65 & 5.1567 & TRN & \\
\hline CHEMBL1474921 & 688724 & 5.1 & 4.8036 & TST & \\
\hline CHEMBL1397984 & 688724 & 4.5 & 4.8962 & TRN & \\
\hline CHEMBL1385479 & 688724 & 5.05 & 4.6281 & TRN & \\
\hline CHEMBL1328617 & 688724 & 4.25 & 4.3821 & TRN & \\
\hline CHEMBL1525314 & 688724 & 4.3 & 4.8744 & TRN & \\
\hline CHEMBL1304770 & 688724 & 4.7 & 5.2531 & TRN & \\
\hline CHEMBL1334412 & 688724 & 5.0 & 5.3452 & TRN & \\
\hline CHEMBL338790 & 688724 & 6.0 & 4.9143 & TST & \\
\hline CHEMBL1457068 & 688724 & 4.55 & 4.851 & TRN & \\
\hline CHEMBL1610067 & 688724 & 4.85 & 4.8955 & TRN & \\
\hline
\end{tabular}




\begin{tabular}{|c|c|c|c|c|}
\hline \multicolumn{5}{|c|}{ Supplemental Table S2.txt } \\
\hline CHEMBL1537492 & 688724 & 4.25 & 4.7363 & TST \\
\hline CHEMBL1539624 & 688724 & 5.95 & 5.9009 & TRN \\
\hline CHEMBL1328988 & 688724 & 4.65 & 4.4846 & TRN \\
\hline CHEMBL1563029 & 688724 & 4.35 & 4.6057 & TRN \\
\hline CHEMBL1584754 & 688724 & 4.85 & 5.197 & TST \\
\hline CHEMBL1571202 & 688724 & 4.1 & 5.1401 & TRN \\
\hline CHEMBL1304684 & 688724 & 4.3 & 4.9692 & TRN \\
\hline CHEMBL1542804 & 688724 & 4.95 & 5.0722 & TRN \\
\hline CHEMBL3209399 & 688724 & 4.05 & 4.4574 & TST \\
\hline CHEMBL1410436 & 688724 & 4.75 & 4.7801 & TRN \\
\hline CHEMBL1361079 & 688724 & 4.8 & 4.5177 & TRN \\
\hline CHEMBL1431647 & 688724 & 5.7 & 5.1224 & TRN \\
\hline CHEMBL1318829 & 688724 & 4.7 & 4.7265 & TRN \\
\hline CHEMBL1443726 & 688724 & 6.35 & 4.8938 & TRN \\
\hline CHEMBL1590980 & 688724 & 4.7 & 4.7286 & TRN \\
\hline CHEMBL1574295 & 688724 & 4.15 & 4.6143 & TRN \\
\hline CHEMBL1578798 & 688724 & 4.1 & 4.8331 & TRN \\
\hline CHEMBL1467667 & 688724 & 5.05 & 4.747 & TRN \\
\hline CHEMBL1557362 & 688724 & 5.35 & 4.7505 & TRN \\
\hline CHEMBL1340060 & 688724 & 4.4 & 5.265 & TST \\
\hline CHEMBL1553859 & 688724 & 6.3 & 5.5925 & TRN \\
\hline CHEMBL1985295 & 688724 & 4.9 & 4.806 & TRN \\
\hline CHEMBL1416439 & 688724 & 6.15 & 5.2945 & TRN \\
\hline CHEMBL1567171 & 688724 & 5.55 & 4.9806 & TST \\
\hline CHEMBL1484570 & 688724 & 5.55 & 4.7381 & TRN \\
\hline CHEMBL1470701 & 688724 & 4.75 & 5.0007 & TRN \\
\hline CHEMBL1468708 & 688724 & 4.65 & 4.6042 & TRN \\
\hline CHEMBL1456760 & 688724 & 4.95 & 4.8677 & TRN \\
\hline CHEMBL1505858 & 688724 & 4.1 & 4.423 & TRN \\
\hline CHEMBL1461575 & 688724 & 4.95 & 4.6672 & TRN \\
\hline CHEMBL1984703 & 688724 & 5.1 & 4.854 & TRN \\
\hline CHEMBL1442173 & 688724 & 4.45 & 4.5917 & TRN \\
\hline CHEMBL1329311 & 688724 & 7.7496 & 4.9869 & TRN \\
\hline CHEMBL1493551 & 688724 & 4.75 & 4.7817 & TST \\
\hline CHEMBL1410054 & 688724 & 4.25 & 4.5981 & TRN \\
\hline CHEMBL1561308 & 688724 & 5.0 & 4.6096 & TST \\
\hline CHEMBL3195461 & 688724 & 4.85 & 4.8627 & TRN \\
\hline CHEMBL1557267 & 688724 & 5.0 & 5.2259 & TRN \\
\hline CHEMBL3195101 & 688724 & 4.4 & 5.166 & TRN \\
\hline CHEMBL1464984 & 688724 & 4.35 & 4.4589 & TRN \\
\hline CHEMBL1442235 & 688724 & 4.85 & 4.6599 & TRN \\
\hline CHEMBL1552708 & 688724 & 4.3 & 5.1189 & TST \\
\hline CHEMBL1374054 & 688724 & 4.5 & 5.0555 & TST \\
\hline CHEMBL3209608 & 688724 & 4.8 & 4.8851 & TST \\
\hline CHEMBL1377632 & 688724 & 4.45 & 4.9779 & TRN \\
\hline CHEMBL1568362 & 688724 & 5.55 & 4.8503 & TRN \\
\hline CHEMBL1320799 & 688724 & 4.35 & 4.9906 & TST \\
\hline CHEMBL1390729 & 688724 & 4.9 & 4.6636 & TRN \\
\hline
\end{tabular}




\begin{tabular}{|c|c|c|c|c|}
\hline \multicolumn{5}{|c|}{ Supplemental Table S2.txt } \\
\hline CHEMBL1495785 & 688724 & 4.4 & 5.1575 & TRN \\
\hline CHEMBL1443031 & 688724 & 4.6 & 4.6957 & TRN \\
\hline CHEMBL1575531 & 688724 & 4.95 & 4.7303 & TST \\
\hline CHEMBL1341597 & 688724 & 5.2 & 5.0886 & TRN \\
\hline CHEMBL1560541 & 688724 & 5.1 & 4.8917 & TST \\
\hline CHEMBL1487875 & 688724 & 4.0 & 4.6201 & TRN \\
\hline CHEMBL1593846 & 688724 & 4.3 & 4.4262 & TRN \\
\hline CHEMBL1530824 & 688724 & 4.4 & 4.6894 & TRN \\
\hline CHEMBL1495622 & 688724 & 4.4 & 4.7299 & TRN \\
\hline CHEMBL1324674 & 688724 & 4.5 & 4.6082 & TST \\
\hline CHEMBL1547881 & 688724 & 4.75 & 5.0355 & TRN \\
\hline CHEMBL1999959 & 688724 & 4.45 & 4.6571 & TRN \\
\hline CHEMBL1544974 & 688724 & 4.3 & 4.3089 & TRN \\
\hline CHEMBL1458276 & 688724 & 4.35 & 4.4422 & TRN \\
\hline CHEMBL1406350 & 688724 & 4.55 & 4.905 & TRN \\
\hline CHEMBL1543022 & 688724 & 5.7 & 5.489 & TRN \\
\hline CHEMBL1999551 & 688724 & 4.2 & 4.7891 & TRN \\
\hline CHEMBL1500520 & 688724 & 4.05 & 4.4687 & TRN \\
\hline CHEMBL3196606 & 688724 & 6.8499 & 5.1324 & TST \\
\hline CHEMBL1361704 & 688724 & 4.1 & 4.617 & TRN \\
\hline CHEMBL1337773 & 688724 & 4.65 & 5.091 & TRN \\
\hline CHEMBL1554137 & 688724 & 4.7 & 4.9729 & TRN \\
\hline CHEMBL1367408 & 688724 & 4.9 & 4.3482 & TRN \\
\hline CHEMBL1353716 & 688724 & 4.05 & 4.5919 & TST \\
\hline CHEMBL1471700 & 688724 & 5.05 & 4.7721 & TRN \\
\hline CHEMBL1971051 & 688724 & 5.5 & 4.7973 & TRN \\
\hline CHEMBL1566928 & 688724 & 4.9 & 4.7726 & TRN \\
\hline CHEMBL1366770 & 688724 & 4.6 & 4.619 & TRN \\
\hline CHEMBL1312307 & 688724 & 5.3 & 5.0126 & TST \\
\hline CHEMBL1301488 & 688724 & 4.7 & 4.4865 & TRN \\
\hline CHEMBL1525426 & 688724 & 4.85 & 5.098 & TST \\
\hline CHEMBL1976638 & 688724 & 5.55 & 5.3013 & TST \\
\hline CHEMBL1522044 & 688724 & 4.3 & 4.8236 & TRN \\
\hline CHEMBL1346067 & 688724 & 4.0 & 4.6367 & TST \\
\hline CHEMBL32307 & 688724 & 4.1 & 5.2671 & TST \\
\hline CHEMBL1526008 & 688724 & 4.95 & 4.6092 & TRN \\
\hline CHEMBL1557027 & 688724 & 4.55 & 4.9675 & TRN \\
\hline CHEMBL3190989 & 688724 & 5.25 & 5.1549 & TRN \\
\hline CHEMBL1386287 & 688724 & 6.5501 & 5.1667 & TRN \\
\hline CHEMBL1509338 & 688724 & 6.05 & 5.2687 & TST \\
\hline CHEMBL1335032 & 688724 & 4.25 & 4.6364 & TST \\
\hline CHEMBL1333328 & 688724 & 5.0 & 4.9498 & TRN \\
\hline CHEMBL1437123 & 688724 & 4.5 & 5.1117 & TRN \\
\hline CHEMBL1348169 & 688724 & 5.5 & 4.8948 & TST \\
\hline CHEMBL1611611 & 688724 & 4.5 & 4.4267 & TST \\
\hline CHEMBL530499 & 688724 & 6.4 & 5.8003 & TRN \\
\hline CHEMBL1423626 & 688724 & 6.3 & 4.6924 & TST \\
\hline CHEMBL3199505 & 688724 & 4.45 & 4.7027 & TRN \\
\hline
\end{tabular}




\begin{tabular}{|c|c|c|c|c|c|}
\hline \\
\hline CHEMBL1384794 & 688724 & 5.9 & 4.7232 & TRN & \\
\hline CHEMBL1519486 & 688724 & 4.45 & 4.6027 & TST & \\
\hline CHEMBL1457747 & 688724 & 4.6 & 4.4009 & TRN & \\
\hline CHEMBL1327133 & 688724 & 9.699 & 5.2782 & TST & \\
\hline CHEMBL3194122 & 688724 & 5.0 & 4.8421 & TRN & \\
\hline CHEMBL1577041 & 688724 & 5.1 & 4.5902 & TRN & \\
\hline CHEMBL123 & 688724 & 6.0 & 5.4008 & TST & \\
\hline CHEMBL1581244 & 688724 & 4.5 & 4.827 & TST & \\
\hline CHEMBL1312969 & 688724 & 5.0 & 5.4467 & TRN & \\
\hline CHEMBL1467925 & 688724 & 3.95 & 4.8816 & TST & \\
\hline CHEMBL3210516 & 688724 & 4.25 & 4.4227 & TRN & \\
\hline CHEMBL1521285 & 688724 & 4.9 & 4.67899 & 9999999999 & TRN \\
\hline CHEMBL1602290 & 688724 & 4.9 & 4.9689 & TST & \\
\hline CHEMBL1978908 & 688724 & 6.6 & 5.1959 & TRN & \\
\hline CHEMBL1460445 & 688724 & 4.25 & 4.6237 & TST & \\
\hline CHEMBL1366388 & 688724 & 4.4 & 4.9003 & TRN & \\
\hline CHEMBL3214310 & 688724 & 7.4001 & 5.1865 & TRN & \\
\hline CHEMBL1503277 & 688724 & 4.25 & 4.7814 & TRN & \\
\hline CHEMBL1408749 & 688724 & 6.5 & 4.8331 & TRN & \\
\hline CHEMBL1538976 & 688724 & 4.55 & 4.6676 & TRN & \\
\hline CHEMBL1350960 & 688724 & 4.3 & 4.3046 & TRN & \\
\hline CHEMBL1551449 & 688724 & 4.1 & 4.6378 & TST & \\
\hline CHEMBL1439458 & 688724 & 4.0 & 4.3198 & TRN & \\
\hline CHEMBL1474636 & 688724 & 4.1 & 4.7007 & TRN & \\
\hline CHEMBL1365476 & 688724 & 4.5 & 4.4571 & TST & \\
\hline CHEMBL1454142 & 688724 & 4.35 & 4.8025 & TRN & \\
\hline CHEMBL1465693 & 688724 & 4.95 & 5.0586 & TST & \\
\hline CHEMBL3391890 & 688724 & 4.3 & 4.684 & TRN & \\
\hline CHEMBL3191145 & 688724 & 5.05 & 4.8774 & TRN & \\
\hline CHEMBL1412709 & 688724 & 4.75 & 4.6059 & TRN & \\
\hline CHEMBL1422900 & 688724 & 4.35 & 4.843 & TST & \\
\hline CHEMBL1451681 & 688724 & 5.1 & 4.7028 & TRN & \\
\hline CHEMBL1524050 & 688724 & 4.85 & 4.8531 & TRN & \\
\hline CHEMBL1447755 & 688724 & 5.55 & 4.9229 & TRN & \\
\hline CHEMBL1384927 & 688724 & 4.55 & 4.8206 & TRN & \\
\hline CHEMBL1323352 & 688724 & 4.0 & 4.4971 & TRN & \\
\hline CHEMBL1382698 & 688724 & 4.05 & 4.9271 & TST & \\
\hline CHEMBL1582756 & 688724 & 4.4 & 4.8276 & TRN & \\
\hline CHEMBL1412545 & 688724 & 4.55 & 4.8391 & TRN & \\
\hline CHEMBL1588733 & 688724 & 4.9 & 5.0979 & TST & \\
\hline CHEMBL1594313 & 688724 & 4.05 & 4.4696 & TRN & \\
\hline CHEMBL1590761 & 688724 & 4.1 & 4.7038 & TRN & \\
\hline CHEMBL1423492 & 688724 & 4.65 & 5.0039 & TST & \\
\hline CHEMBL1333395 & 688724 & 4.05 & 4.8619 & TRN & \\
\hline CHEMBL1510977 & 688724 & 4.85 & 5.2147 & TRN & \\
\hline CHEMBL1305384 & 688724 & 4.05 & 4.77 & TST & \\
\hline CHEMBL1487903 & 688724 & 4.45 & 4.8845 & TRN & \\
\hline CHEMBL1557093 & 688724 & 4.4 & 4.7927 & TRN & \\
\hline
\end{tabular}




\begin{tabular}{|c|c|c|c|c|}
\hline \multicolumn{5}{|c|}{ Supplemental Table S2.txt } \\
\hline CHEMBL1554900 & 688724 & 4.1 & 4.4637 & TRN \\
\hline CHEMBL1355384 & 688724 & 4.1 & 4.5921 & TRN \\
\hline CHEMBL 3211664 & 688724 & 4.6 & 5.0154 & TST \\
\hline CHEMBL1365920 & 688724 & 4.55 & 4.7607 & TRN \\
\hline CHEMBL1583391 & 688724 & 4.55 & 4.7121 & TST \\
\hline CHEMBL1430626 & 688724 & 4.4 & 4.4567 & TRN \\
\hline CHEMBL1438137 & 688724 & 4.25 & 4.913 & TST \\
\hline CHEMBL1583475 & 688724 & 4.8 & 4.8475 & TRN \\
\hline CHEMBL1514805 & 688724 & 4.15 & 4.4273 & TRN \\
\hline CHEMBL 3197360 & 688724 & 4.9 & 4.8995 & TRN \\
\hline CHEMBL1315457 & 688724 & 4.8 & 5.0696 & TST \\
\hline CHEMBL119171 & 688724 & 5.45 & 5.2977 & TRN \\
\hline CHEMBL1438860 & 688724 & 4.55 & 5.5236 & TRN \\
\hline CHEMBL 3193428 & 688724 & 4.9 & 5.1836 & TST \\
\hline CHEMBL1613634 & 688724 & 4.1 & 4.5524 & TRN \\
\hline CHEMBL1982868 & 688724 & 5.5 & 4.8889 & TRN \\
\hline CHEMBL1361026 & 688724 & 6.8499 & 5.1678 & TST \\
\hline CHEMBL1365523 & 688724 & 6.0 & 5.1909 & TRN \\
\hline CHEMBL1398443 & 688724 & 8.7447 & 5.1014 & TST \\
\hline CHEMBL1469792 & 688724 & 4.05 & 4.2803 & TRN \\
\hline CHEMBL1431971 & 688724 & 4.45 & 4.5692 & TRN \\
\hline CHEMBL1581440 & 688724 & 4.9 & 4.7293 & TRN \\
\hline CHEMBL1414269 & 688724 & 4.85 & 4.567 & TRN \\
\hline CHEMBL1337583 & 688724 & 4.0242 & 4.3564 & TST \\
\hline CHEMBL404845 & 688724 & 4.8 & 5.4963 & TRN \\
\hline CHEMBL3199763 & 688724 & 4.8 & 4.9754 & TRN \\
\hline CHEMBL1605352 & 688724 & 5.45 & 4.7089 & TRN \\
\hline CHEMBL1557199 & 688724 & 4.3 & 4.7456 & TRN \\
\hline CHEMBL1365596 & 688724 & 4.9 & 4.957 & TST \\
\hline CHEMBL580819 & 688724 & 4.6 & 4.8504 & TRN \\
\hline CHEMBL1533391 & 688724 & 4.65 & 4.9612 & TRN \\
\hline CHEMBL1307971 & 688724 & 4.8 & 4.9424 & TST \\
\hline CHEMBL1477178 & 688724 & 4.3 & 4.5341 & TRN \\
\hline CHEMBL1611535 & 688724 & 4.65 & 4.695 & TRN \\
\hline CHEMBL 1403920 & 688724 & 4.95 & 4.7508 & TRN \\
\hline CHEMBL1587004 & 688724 & 4.45 & 4.7354 & TST \\
\hline CHEMBL1576649 & 688724 & 5.65 & 5.1842 & TRN \\
\hline CHEMBL3193311 & 688724 & 5.45 & 4.7202 & TRN \\
\hline CHEMBL1354288 & 688724 & 4.4 & 4.8336 & TRN \\
\hline CHEMBL1314486 & 688724 & 4.1 & 4.7012 & TRN \\
\hline CHEMBL1487776 & 688724 & 4.95 & 4.8408 & TRN \\
\hline CHEMBL1599287 & 688724 & 4.35 & 4.7073 & TST \\
\hline CHEMBL1584916 & 688724 & 4.75 & 4.6189 & TRN \\
\hline CHEMBL1364349 & 688724 & 4.95 & 5.1164 & TRN \\
\hline CHEMBL187460 & 688724 & 6.0 & 5.1609 & TRN \\
\hline CHEMBL1510238 & 688724 & 4.8 & 4.8461 & TST \\
\hline CHEMBL1401860 & 688724 & 4.8 & 4.993 & TST \\
\hline CHEMBL1306316 & 688724 & 4.7 & 4.9181 & TRN \\
\hline
\end{tabular}




\begin{tabular}{|c|c|c|c|c|}
\hline \multicolumn{5}{|c|}{ Supplemental Table S2.txt } \\
\hline CHEMBL1491798 & 688724 & 5.0 & 4.515 & TRN \\
\hline CHEMBL1599272 & 688724 & 5.8 & 4.6113 & TRN \\
\hline CHEMBL1362333 & 688724 & 4.75 & 4.5073 & TRN \\
\hline CHEMBL1510930 & 688724 & 4.3 & 4.6722 & TRN \\
\hline CHEMBL1410179 & 688724 & 4.7 & 4.8567 & TRN \\
\hline CHEMBL1406759 & 688724 & 5.2 & 4.3933 & TST \\
\hline CHEMBL1451846 & 688724 & 4.1 & 4.644 & TRN \\
\hline CHEMBL1327534 & 688724 & 4.65 & 4.5431 & TRN \\
\hline CHEMBL1419484 & 688724 & 4.95 & 5.2472 & TRN \\
\hline CHEMBL1578118 & 688724 & 4.05 & 5.3276 & TST \\
\hline CHEMBL1301497 & 688724 & 4.5 & 5.1915 & TRN \\
\hline CHEMBL1504311 & 688724 & 4.8 & 4.5073 & TRN \\
\hline CHEMBL3191342 & 688724 & 4.85 & 4.7861 & TST \\
\hline CHEMBL3199275 & 688724 & 4.0 & 4.414 & TRN \\
\hline CHEMBL1313211 & 688724 & 4.05 & 4.8253 & TRN \\
\hline CHEMBL1356700 & 688724 & 4.6 & 4.5106 & TRN \\
\hline CHEMBL43612 & 688724 & 6.45 & 5.3155 & TST \\
\hline CHEMBL3192838 & 688724 & 4.3 & 4.6326 & TRN \\
\hline CHEMBL1368750 & 688724 & 5.45 & 5.3405 & TRN \\
\hline CHEMBL3199691 & 688724 & 4.5 & 5.0789 & TRN \\
\hline CHEMBL3198921 & 688724 & 4.65 & 4.5732 & TST \\
\hline CHEMBL3190766 & 688724 & 4.1 & 4.9959 & TRN \\
\hline CHEMBL1310332 & 688724 & 4.55 & 4.5063 & TRN \\
\hline CHEMBL3195769 & 688724 & 4.45 & 4.9201 & TRN \\
\hline CHEMBL1479050 & 688724 & 4.5 & 4.5788 & TRN \\
\hline CHEMBL1594610 & 688724 & 5.0 & 4.7616 & TST \\
\hline CHEMBL1448466 & 688724 & 4.75 & 4.5395 & TRN \\
\hline CHEMBL1387263 & 688724 & 4.35 & 4.7367 & TRN \\
\hline CHEMBL1519400 & 688724 & 5.15 & 5.151 & TRN \\
\hline CHEMBL1345334 & 688724 & 4.55 & 4.6234 & TRN \\
\hline CHEMBL1539800 & 688724 & 4.75 & 4.6907 & TST \\
\hline CHEMBL1611696 & 688724 & 5.4 & 4.2024 & TRN \\
\hline CHEMBL 267160 & 688724 & 4.25 & 4.6598 & TRN \\
\hline CHEMBL257359 & 688724 & 6.1 & 5.4719 & TRN \\
\hline CHEMBL1566994 & 688724 & 4.65 & 5.1092 & TRN \\
\hline CHEMBL1498077 & 688724 & 4.65 & 4.6866 & TST \\
\hline CHEMBL543467 & 688724 & 6.2 & 4.905 & TRN \\
\hline CHEMBL1327184 & 688724 & 4.9 & 4.5686 & TRN \\
\hline CHEMBL1437690 & 688724 & 4.3 & 4.9007 & TRN \\
\hline CHEMBL1510352 & 688724 & 5.05 & 4.8872 & TRN \\
\hline CHEMBL3197466 & 688724 & 5.0 & 4.7982 & TRN \\
\hline CHEMBL1510511 & 688724 & 5.5 & 4.9467 & TRN \\
\hline CHEMBL2373606 & 688724 & 4.15 & 5.1308 & TST \\
\hline CHEMBL1256019 & 688724 & 5.4 & 4.9019 & TST \\
\hline CHEMBL1401417 & 688724 & 4.45 & 4.8983 & TRN \\
\hline CHEMBL1581385 & 688724 & 4.4 & 4.7038 & TST \\
\hline CHEMBL1483975 & 688724 & 5.5 & 5.2876 & TRN \\
\hline CHEMBL1449385 & 688724 & 4.5 & 4.8268 & TST \\
\hline
\end{tabular}




\begin{tabular}{|c|c|c|c|c|c|}
\hline \multicolumn{6}{|c|}{ Supplemental Table S2.txt } \\
\hline CHEMBL1269862 & 688724 & 4.3 & 4.8639 & TRN & \\
\hline CHEMBL1492017 & 688724 & 5.45 & 5.5344 & TRN & \\
\hline CHEMBL1319918 & 688724 & 5.2 & 5.2197 & TRN & \\
\hline CHEMBL 3190443 & 688724 & 5.05 & 4.7872 & TRN & \\
\hline CHEMBL1416342 & 688724 & 5.5 & 4.8769 & TST & \\
\hline CHEMBL 272005 & 688724 & 6.25 & 5.1137 & TRN & \\
\hline CHEMBL1340698 & 688724 & 5.5 & 5.064 & TRN & \\
\hline CHEMBL15192 & 688724 & 4.4 & 5.2507 & TST & \\
\hline CHEMBL1467321 & 688724 & 4.3 & 4.502 & TRN & \\
\hline CHEMBL1462800 & 688724 & 5.55 & 4.936 & TRN & \\
\hline CHEMBL1302033 & 688724 & 5.5 & 5.0458 & TRN & \\
\hline CHEMBL1590084 & 688724 & 4.65 & 4.8901 & TRN & \\
\hline CHEMBL1600581 & 688724 & 4.85 & 4.84399 & 9999999999 & TRN \\
\hline CHEMBL1417464 & 688724 & 4.4 & 4.9322 & TRN & \\
\hline CHEMBL1377615 & 688724 & 4.5 & 4.5689 & TST & \\
\hline CHEMBL1447487 & 688724 & 4.85 & 4.8168 & TRN & \\
\hline CHEMBL1369820 & 688724 & 6.0 & 4.8481 & TRN & \\
\hline CHEMBL3195783 & 688724 & 4.75 & 5.3835 & TRN & \\
\hline CHEMBL1480895 & 688724 & 4.75 & 4.8129 & TST & \\
\hline CHEMBL1455709 & 688724 & 4.25 & 4.621 & TST & \\
\hline CHEMBL1974348 & 688724 & 4.8 & 4.9713 & TRN & \\
\hline CHEMBL1521213 & 688724 & 5.65 & 4.4945 & TRN & \\
\hline CHEMBL1533229 & 688724 & 4.85 & 4.6615 & TRN & \\
\hline CHEMBL1421034 & 688724 & 4.3 & 4.5499 & TRN & \\
\hline CHEMBL1402838 & 688724 & 4.1 & 4.9076 & TRN & \\
\hline CHEMBL1457236 & 688724 & 4.6 & 4.8594 & TRN & \\
\hline CHEMBL1580825 & 688724 & 4.45 & 4.962 & TRN & \\
\hline CHEMBL1389193 & 688724 & 4.4 & 5.0074 & TST & \\
\hline CHEMBL1607300 & 688724 & 4.9 & 4.5527 & TRN & \\
\hline CHEMBL1310052 & 688724 & 4.7 & 4.9734 & TRN & \\
\hline CHEMBL 257286 & 688724 & 5.1 & 5.0153 & TRN & \\
\hline CHEMBL3196124 & 688724 & 4.5 & 5.2845 & TRN & \\
\hline CHEMBL1478742 & 688724 & 4.6 & 4.6981 & TRN & \\
\hline CHEMBL1323268 & 688724 & 4.3 & 4.5468 & TRN & \\
\hline CHEMBL3195582 & 688724 & 4.95 & 4.6762 & TRN & \\
\hline CHEMBL1430890 & 688724 & 4.45 & 5.1915 & TRN & \\
\hline CHEMBL1493496 & 688724 & 4.25 & 4.6748 & TRN & \\
\hline CHEMBL1340172 & 688724 & 4.3 & 4.2005 & TRN & \\
\hline CHEMBL3199651 & 688724 & 4.35 & 5.0477 & TRN & \\
\hline CHEMBL1484057 & 688724 & 4.4 & 5.1207 & TRN & \\
\hline CHEMBL1591065 & 688724 & 4.4 & 4.5861 & TRN & \\
\hline CHEMBL1494973 & 688724 & 5.5 & 4.9067 & TRN & \\
\hline CHEMBL1451628 & 688724 & 6.6499 & 5.08899 & 99999999995 & TRN \\
\hline CHEMBL1560250 & 688724 & 6.0 & 4.7294 & TRN & \\
\hline CHEMBL1452561 & 688724 & 6.0 & 5.3114 & TRN & \\
\hline CHEMBL1485895 & 688724 & 4.75 & 4.9749 & TRN & \\
\hline CHEMBL1455485 & 688724 & 5.7 & 5.6951 & TRN & \\
\hline CHEMBL1384046 & 688724 & 4.45 & 4.6182 & TRN & \\
\hline
\end{tabular}




\begin{tabular}{|c|c|c|c|c|c|}
\hline \multicolumn{6}{|c|}{ Supplemental Table S2.txt } \\
\hline CHEMBL1549738 & 688724 & 4.45 & 4.7897 & TST & \\
\hline CHEMBL1450385 & 688724 & 7.2 & 5.0948 & TRN & \\
\hline CHEMBL1358042 & 688724 & 4.1 & 4.4198 & TRN & \\
\hline CHEMBL1477093 & 688724 & 4.35 & 4.9266 & TRN & \\
\hline CHEMBL1389542 & 688724 & 5.25 & 5.5718 & TRN & \\
\hline CHEMBL1468730 & 688724 & 4.85 & 4.8042 & TRN & \\
\hline CHEMBL3190368 & 688724 & 4.75 & 4.7409 & TRN & \\
\hline CHEMBL1606907 & 688724 & 4.85 & 5.087 & TRN & \\
\hline CHEMBL1370993 & 688724 & 4.8 & 4.963 & TRN & \\
\hline CHEMBL1349631 & 688724 & 5.8 & 5.9035 & TRN & \\
\hline CHEMBL1560226 & 688724 & 4.35 & 4.6456 & TRN & \\
\hline CHEMBL1312918 & 688724 & 4.7 & 4.2691 & TRN & \\
\hline CHEMBL1590855 & 688724 & 4.8 & 4.8853 & TRN & \\
\hline CHEMBL1312263 & 688724 & 4.9 & 4.6166 & TST & \\
\hline CHEMBL1352868 & 688724 & 4.3 & 4.4764 & TRN & \\
\hline CHEMBL1318851 & 688724 & 4.45 & 5.0275 & TRN & \\
\hline CHEMBL1503134 & 688724 & 4.4 & 5.32700 & 0000000001 & TRN \\
\hline CHEMBL1517260 & 688724 & 5.8 & 4.5362 & TRN & \\
\hline CHEMBL1452185 & 688724 & 5.45 & 4.5625 & TST & \\
\hline CHEMBL1473875 & 688724 & 8.3468 & 4.9963 & TRN & \\
\hline CHEMBL1447349 & 688724 & 6.0 & 5.1603 & TRN & \\
\hline CHEMBL1236200 & 688724 & 5.55 & 5.0443 & TST & \\
\hline CHEMBL3207504 & 688724 & 4.45 & 4.688 & TRN & \\
\hline CHEMBL1428303 & 688724 & 4.75 & 4.7364 & TST & \\
\hline CHEMBL1256291 & 688724 & 4.45 & 5.0776 & TST & \\
\hline CHEMBL1327789 & 688724 & 5.45 & 5.2387 & TRN & \\
\hline CHEMBL1213050 & 688724 & 4.35 & 4.585 & TST & \\
\hline CHEMBL1408477 & 688724 & 5.45 & 4.7836 & TRN & \\
\hline CHEMBL1605074 & 688724 & 4.35 & 4.8353 & TRN & \\
\hline CHEMBL1582246 & 688724 & 4.7 & 4.8936 & TRN & \\
\hline CHEMBL1612820 & 688724 & 5.45 & 5.2101 & TRN & \\
\hline CHEMBL3199590 & 688724 & 4.4 & 5.1288 & TRN & \\
\hline CHEMBL1511442 & 688724 & 4.45 & 4.50899 & 99999999995 & TRN \\
\hline CHEMBL1311826 & 688724 & 5.6 & 5.9389 & TRN & \\
\hline CHEMBL3197693 & 688724 & 4.6 & 5.0207 & TST & \\
\hline CHEMBL1549202 & 688724 & 4.65 & 5.5018 & TRN & \\
\hline CHEMBL608699 & 688724 & 6.2 & 5.2088 & TRN & \\
\hline CHEMBL1555931 & 688724 & 4.35 & 4.7443 & TST & \\
\hline CHEMBL1422393 & 688724 & 4.0 & 4.6685 & TST & \\
\hline CHEMBL1399928 & 688724 & 6.95 & 4.8833 & TST & \\
\hline CHEMBL1494393 & 688724 & 6.6 & 5.1473 & TRN & \\
\hline CHEMBL1611972 & 688724 & 4.4 & 4.2849 & TRN & \\
\hline CHEMBL3192738 & 688724 & 4.6 & 4.8194 & TRN & \\
\hline CHEMBL1352543 & 688724 & 4.9 & 4.8044 & TRN & \\
\hline CHEMBL1519554 & 688724 & 4.1 & 5.0333 & TRN & \\
\hline CHEMBL1505438 & 688724 & 4.85 & 4.5486 & TRN & \\
\hline CHEMBL1384090 & 688724 & 4.35 & 4.4654 & TRN & \\
\hline CHEMBL1501822 & 688724 & 4.35 & 4.881 & TRN & \\
\hline
\end{tabular}




\begin{tabular}{|c|c|c|c|c|c|}
\hline & & \multicolumn{4}{|c|}{ Supplemental Table S2.txt } \\
\hline CHEMBL1437856 & 688724 & 4.8 & 4.6434 & TRN & \\
\hline CHEMBL1500166 & 688724 & 4.5 & 4.4931 & TRN & \\
\hline CHEMBL47940 & 688724 & 6.0 & 4.7649 & TST & \\
\hline CHEMBL1541336 & 688724 & 4.85 & 5.05399 & 9999999999 & TRN \\
\hline CHEMBL1582168 & 688724 & 4.7 & 4.6962 & TRN & \\
\hline CHEMBL1412392 & 688724 & 4.55 & 4.9481 & TST & \\
\hline CHEMBL1397419 & 688724 & 4.6 & 5.1557 & TST & \\
\hline CHEMBL1539002 & 688724 & 4.35 & 4.6216 & TRN & \\
\hline CHEMBL1347633 & 688724 & 5.25 & 5.0569 & TRN & \\
\hline CHEMBL3207539 & 688724 & 4.25 & 4.9399 & TRN & \\
\hline CHEMBL1425143 & 688724 & 4.55 & 4.4411 & TST & \\
\hline CHEMBL1471702 & 688724 & 4.1 & 4.6633 & TRN & \\
\hline CHEMBL1368963 & 688724 & 4.65 & 4.9216 & TRN & \\
\hline CHEMBL1565528 & 688724 & 5.05 & 4.9665 & TRN & \\
\hline CHEMBL1300572 & 688724 & 4.9 & 4.3702 & TST & \\
\hline CHEMBL1374385 & 688724 & 4.75 & 4.5667 & TRN & \\
\hline CHEMBL1575047 & 688724 & 4.75 & 4.8274 & TST & \\
\hline CHEMBL1573389 & 688724 & 4.7 & 4.5883 & TRN & \\
\hline CHEMBL1548037 & 688724 & 4.1 & 4.7089 & TRN & \\
\hline CHEMBL1477672 & 688724 & 4.85 & 4.6741 & TRN & \\
\hline CHEMBL1437120 & 688724 & 4.35 & 4.8926 & TST & \\
\hline CHEMBL1361854 & 688724 & 4.65 & 5.0547 & TST & \\
\hline CHEMBL1515544 & 688724 & 5.0 & 4.8688 & TRN & \\
\hline CHEMBL1500419 & 688724 & 4.75 & 4.8558 & TST & \\
\hline CHEMBL3192629 & 688724 & 4.45 & 5.1013 & TST & \\
\hline CHEMBL1552334 & 688724 & 4.05 & 4.9479 & TRN & \\
\hline CHEMBL1346180 & 688724 & 4.4 & 4.9464 & TST & \\
\hline CHEMBL1598460 & 688724 & 4.65 & 4.7414 & TRN & \\
\hline CHEMBL1558607 & 688724 & 4.3 & 4.8994 & TRN & \\
\hline CHEMBL1568178 & 688724 & 4.55 & 4.4407 & TRN & \\
\hline CHEMBL1474222 & 688724 & 4.8 & 4.8639 & TST & \\
\hline CHEMBL1417584 & 688724 & 4.15 & 4.9612 & TST & \\
\hline CHEMBL1315592 & 688724 & 5.1 & 5.1587 & TRN & \\
\hline CHEMBL1974818 & 688724 & 4.55 & 4.8558 & TRN & \\
\hline CHEMBL1466926 & 688724 & 4.85 & 4.5794 & TRN & \\
\hline CHEMBL1547701 & 688724 & 4.15 & 4.4814 & TRN & \\
\hline CHEMBL 28862 & 688724 & 6.15 & 5.6314 & TRN & \\
\hline CHEMBL1359796 & 688724 & 4.8 & 4.8338 & TRN & \\
\hline CHEMBL1481025 & 688724 & 4.35 & 4.8036 & TRN & \\
\hline CHEMBL1434966 & 688724 & 4.95 & 4.5974 & TRN & \\
\hline CHEMBL1340766 & 688724 & 4.85 & 4.7129 & TRN & \\
\hline CHEMBL1732967 & 688724 & 5.3 & 5.1159 & TRN & \\
\hline CHEMBL104264 & 688724 & 4.8 & 4.8072 & TST & \\
\hline CHEMBL1475417 & 688724 & 4.55 & 4.7476 & TRN & \\
\hline CHEMBL1446243 & 688724 & 4.75 & 4.6447 & TRN & \\
\hline CHEMBL3195057 & 688724 & 4.4 & 4.7811 & TRN & \\
\hline CHEMBL1599180 & 688724 & 4.95 & 5.1845 & TRN & \\
\hline CHEMBL1306666 & 688724 & 6.3 & 5.7771 & TRN & \\
\hline
\end{tabular}




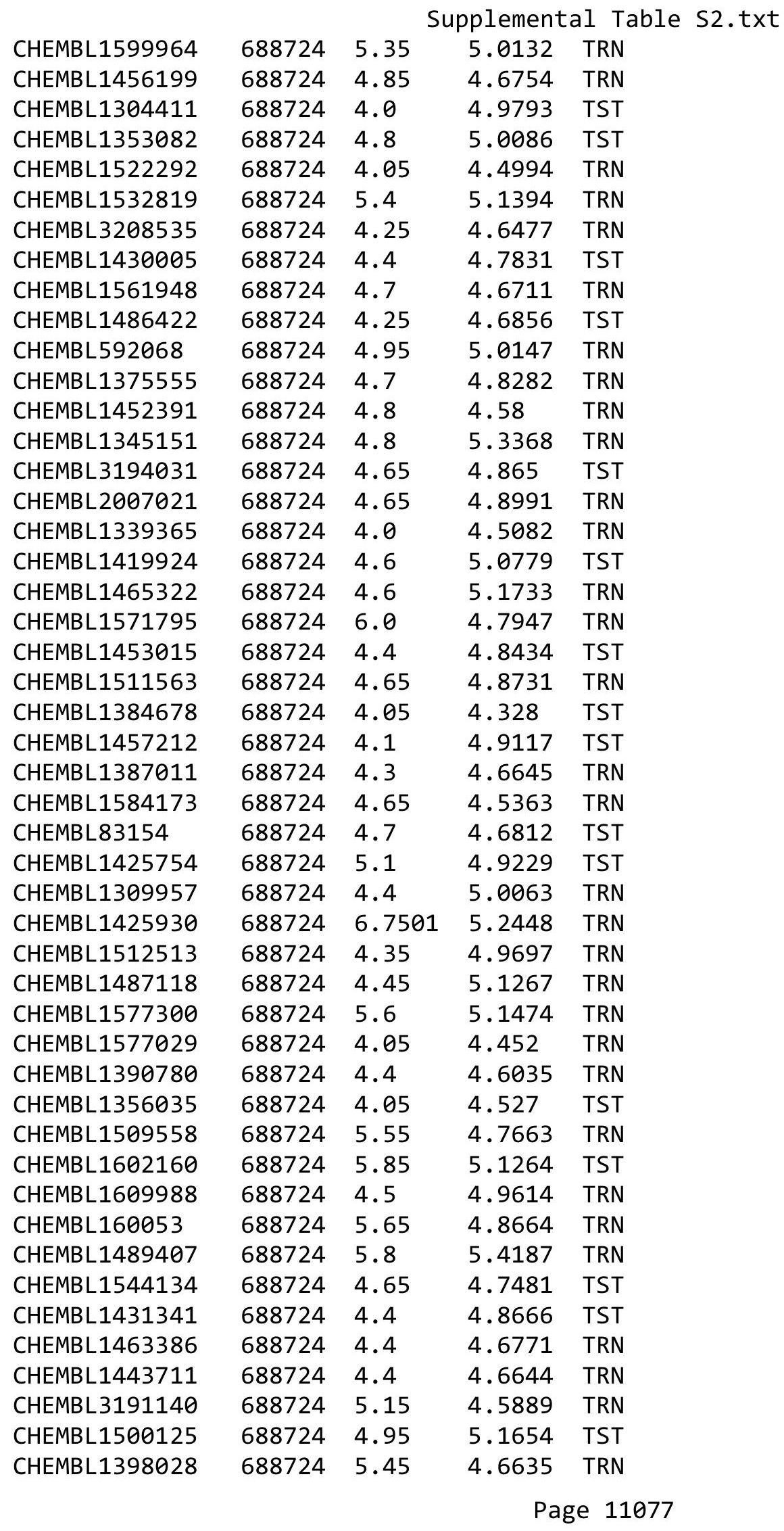




\begin{tabular}{|c|c|c|c|c|}
\hline \multicolumn{5}{|c|}{ Supplemental Table S2.txt } \\
\hline CHEMBL1467089 & 688724 & 4.1 & 4.5431 & TRN \\
\hline CHEMBL1486321 & 688724 & 4.15 & 5.3493 & TRN \\
\hline CHEMBL1488706 & 688724 & 4.9 & 5.0299 & TRN \\
\hline CHEMBL1587487 & 688724 & 4.4 & 5.0196 & TST \\
\hline CHEMBL3197885 & 688724 & 4.35 & 5.1127 & TST \\
\hline CHEMBL1396106 & 688724 & 4.3 & 4.9822 & TST \\
\hline CHEMBL1393004 & 688724 & 4.9 & 4.8175 & TRN \\
\hline CHEMBL602718 & 688724 & 5.45 & 5.5982 & TRN \\
\hline CHEMBL1529203 & 688724 & 5.75 & 5.4297 & TRN \\
\hline CHEMBL1424740 & 688724 & 5.45 & 4.5732 & TRN \\
\hline CHEMBL1588275 & 688724 & 4.6 & 5.1869 & TRN \\
\hline CHEMBL1604952 & 688724 & 4.85 & 4.9543 & TST \\
\hline CHEMBL3193897 & 688724 & 4.35 & 4.7081 & TRN \\
\hline CHEMBL1446313 & 688724 & 5.4 & 5.0467 & TST \\
\hline CHEMBL1329732 & 688724 & 5.0 & 5.1884 & TRN \\
\hline CHEMBL1417934 & 688724 & 4.4 & 4.6713 & TRN \\
\hline CHEMBL1465465 & 688724 & 4.65 & 4.8077 & TRN \\
\hline CHEMBL1467931 & 688724 & 4.6 & 5.0656 & TST \\
\hline CHEMBL1539068 & 688724 & 7.6498 & 4.8948 & TST \\
\hline CHEMBL1317229 & 688724 & 4.55 & 4.9084 & TRN \\
\hline CHEMBL1581799 & 688724 & 5.7 & 4.7416 & TRN \\
\hline CHEMBL1517774 & 688724 & 4.85 & 5.0227 & TRN \\
\hline CHEMBL1490664 & 688724 & 4.45 & 5.0821 & TST \\
\hline CHEMBL1433248 & 688724 & 5.95 & 5.1199 & TST \\
\hline CHEMBL1469612 & 688724 & 4.75 & 4.9325 & TST \\
\hline CHEMBL1300881 & 688724 & 4.95 & 4.7367 & TRN \\
\hline CHEMBL1388369 & 688724 & 5.0 & 4.9727 & TRN \\
\hline CHEMBL1404599 & 688724 & 4.45 & 4.6778 & TST \\
\hline CHEMBL1356672 & 688724 & 4.25 & 4.9069 & TRN \\
\hline CHEMBL1310108 & 688724 & 5.45 & 5.0392 & TRN \\
\hline CHEMBL1469828 & 688724 & 4.45 & 4.7856 & TRN \\
\hline CHEMBL1505411 & 688724 & 5.65 & 4.9533 & TRN \\
\hline CHEMBL1459961 & 688724 & 4.35 & 4.7671 & TRN \\
\hline CHEMBL1342906 & 688724 & 4.95 & 4.9949 & TRN \\
\hline CHEMBL1594556 & 688724 & 7.3002 & 5.0402 & TRN \\
\hline CHEMBL1418918 & 688724 & 4.7 & 4.6771 & TRN \\
\hline CHEMBL3195981 & 688724 & 4.75 & 4.8507 & TRN \\
\hline CHEMBL1520896 & 688724 & 5.35 & 5.3518 & TRN \\
\hline CHEMBL1599498 & 688724 & 4.6 & 4.7735 & TST \\
\hline CHEMBL 3196277 & 688724 & 5.35 & 4.6621 & TRN \\
\hline CHEMBL1473569 & 688724 & 4.0 & 4.666 & TRN \\
\hline CHEMBL1610718 & 688724 & 4.75 & 4.547 & TRN \\
\hline CHEMBL1325748 & 688724 & 4.15 & 4.6528 & TRN \\
\hline CHEMBL1523910 & 688724 & 4.8 & 4.6575 & TRN \\
\hline CHEMBL1556530 & 688724 & 4.9 & 4.7989 & TRN \\
\hline CHEMBL1550393 & 688724 & 4.35 & 4.5148 & TST \\
\hline CHEMBL1362015 & 688724 & 5.4 & 4.4374 & TST \\
\hline CHEMBL1555995 & 688724 & 4.65 & 4.8929 & TST \\
\hline
\end{tabular}




\begin{tabular}{|c|c|c|c|c|}
\hline \multicolumn{5}{|c|}{ Supplemental Table S2.txt } \\
\hline CHEMBL1312717 & 688724 & 4.05 & 4.4334 & TRN \\
\hline CHEMBL1463813 & 688724 & 4.3 & 4.6202 & TRN \\
\hline CHEMBL1493037 & 688724 & 4.45 & 5.0172 & TRN \\
\hline CHEMBL1432536 & 688724 & 4.65 & 4.6817 & TRN \\
\hline CHEMBL 1407260 & 688724 & 5.0 & 4.7402 & TRN \\
\hline CHEMBL1456701 & 688724 & 4.65 & 5.0602 & TRN \\
\hline CHEMBL1350028 & 688724 & 4.9 & 4.5854 & TRN \\
\hline CHEMBL216276 & 688724 & 4.65 & 4.9998 & TRN \\
\hline CHEMBL1481771 & 688724 & 4.7 & 4.843 & TST \\
\hline CHEMBL1338179 & 688724 & 4.7 & 4.8797 & TRN \\
\hline CHEMBL1521514 & 688724 & 4.2 & 5.0098 & TRN \\
\hline CHEMBL1416346 & 688724 & 4.5 & 4.5764 & TST \\
\hline CHEMBL1444407 & 688724 & 4.8 & 4.9457 & TRN \\
\hline CHEMBL394197 & 688724 & 4.1 & 4.6348 & TRN \\
\hline CHEMBL1391939 & 688724 & 4.2 & 4.4766 & TST \\
\hline CHEMBL1354511 & 688724 & 4.25 & 4.7002 & TRN \\
\hline CHEMBL1584739 & 688724 & 4.55 & 4.6944 & TRN \\
\hline CHEMBL1507147 & 688724 & 4.6 & 4.9079 & TRN \\
\hline CHEMBL 78257 & 688724 & 6.35 & 5.4501 & TRN \\
\hline CHEMBL1607276 & 688724 & 4.8 & 4.8411 & TRN \\
\hline CHEMBL3198896 & 688724 & 4.95 & 4.8346 & TST \\
\hline CHEMBL1609270 & 688724 & 4.05 & 4.7067 & TRN \\
\hline CHEMBL 3145114 & 688724 & 4.55 & 5.0156 & TRN \\
\hline CHEMBL1449694 & 688724 & 4.8 & 4.9599 & TRN \\
\hline CHEMBL39372 & 688724 & 4.05 & 5.3162 & TRN \\
\hline CHEMBL3196320 & 688724 & 4.65 & 4.6897 & TST \\
\hline CHEMBL1360482 & 688724 & 4.3 & 4.8752 & TRN \\
\hline CHEMBL1607306 & 688724 & 4.3 & 4.7024 & TRN \\
\hline CHEMBL1411232 & 688724 & 6.0 & 5.0111 & TRN \\
\hline CHEMBL3190387 & 688724 & 4.8 & 4.7614 & TRN \\
\hline CHEMBL1420033 & 688724 & 4.4 & 4.7468 & TRN \\
\hline CHEMBL1382153 & 688724 & 4.5 & 4.9914 & TRN \\
\hline CHEMBL1518781 & 688724 & 4.35 & 4.7278 & TRN \\
\hline CHEMBL1572586 & 688724 & 4.25 & 4.53 & TRN \\
\hline CHEMBL1414480 & 688724 & 4.35 & 4.8809 & TRN \\
\hline CHEMBL1556267 & 688724 & 4.4 & 4.5454 & TRN \\
\hline CHEMBL1562794 & 688724 & 4.55 & 4.8228 & TRN \\
\hline CHEMBL1324402 & 688724 & 4.85 & 4.7025 & TRN \\
\hline CHEMBL3193726 & 688724 & 4.85 & 4.2616 & TRN \\
\hline CHEMBL1546967 & 688724 & 4.7 & 5.062 & TRN \\
\hline CHEMBL1562033 & 688724 & 5.05 & 5.3608 & TRN \\
\hline CHEMBL1991908 & 688724 & 4.5 & 4.8979 & TRN \\
\hline CHEMBL259355 & 688724 & 4.8 & 4.9152 & TST \\
\hline CHEMBL1363505 & 688724 & 4.9 & 4.5401 & TRN \\
\hline CHEMBL56543 & 688724 & 6.0 & 5.3083 & TRN \\
\hline CHEMBL31970 & 688724 & 6.0 & 5.0874 & TRN \\
\hline CHEMBL1390814 & 688724 & 4.05 & 5.3334 & TST \\
\hline CHEMBL1535577 & 688724 & 6.15 & 4.785 & TRN \\
\hline
\end{tabular}




\begin{tabular}{|c|c|c|c|c|c|}
\hline & & \multicolumn{4}{|c|}{ Supplemental Table s2.txt } \\
\hline CHEMBL1430372 & 688724 & 5.85 & 5.0217 & TRN & \\
\hline CHEMBL1331499 & 688724 & 4.6 & 4.9276 & TST & \\
\hline CHEMBL1433732 & 688724 & 5.15 & 4.4926 & TRN & \\
\hline CHEMBL1319120 & 688724 & 4.4 & 4.5963 & TRN & \\
\hline CHEMBL1384172 & 688724 & 6.0 & 5.1903 & TRN & \\
\hline CHEMBL1605701 & 688724 & 4.8 & 5.2089 & TRN & \\
\hline CHEMBL3195898 & 688724 & 5.3 & 5.3011 & TRN & \\
\hline CHEMBL1363452 & 688724 & 4.45 & 4.5068 & TRN & \\
\hline CHEMBL1594268 & 688724 & 4.4 & 4.77800 & 00000000005 & TRN \\
\hline CHEMBL1520264 & 688724 & 4.15 & 4.6837 & TRN & \\
\hline CHEMBL1372534 & 688724 & 5.25 & 5.0123 & TST & \\
\hline CHEMBL1547311 & 688724 & 4.9 & 4.9144 & TRN & \\
\hline CHEMBL3212379 & 688724 & 4.1 & 4.7216 & TST & \\
\hline CHEMBL1525766 & 688724 & 4.6 & 4.7417 & TST & \\
\hline CHEMBL3210557 & 688724 & 4.55 & 4.7031 & TRN & \\
\hline CHEMBL1432679 & 688724 & 4.75 & 4.6481 & TRN & \\
\hline CHEMBL3195011 & 688724 & 4.7 & 4.5213 & TRN & \\
\hline CHEMBL1560574 & 688724 & 4.15 & 4.7026 & TRN & \\
\hline CHEMBL1609090 & 688724 & 5.0 & 4.9515 & TRN & \\
\hline CHEMBL1549687 & 688724 & 4.75 & 5.1 & TST & \\
\hline CHEMBL1384524 & 688724 & 5.15 & 5.6079 & TRN & \\
\hline CHEMBL101263 & 688724 & 4.15 & 4.4699 & TRN & \\
\hline CHEMBL1345171 & 688724 & 4.05 & 4.5707 & TST & \\
\hline CHEMBL1486390 & 688724 & 4.05 & 4.7954 & TRN & \\
\hline CHEMBL210868 & 688724 & 4.9 & 4.9562 & TST & \\
\hline CHEMBL3192780 & 688724 & 5.8 & 4.6816 & TST & \\
\hline CHEMBL1486016 & 688724 & 4.65 & 4.7961 & TRN & \\
\hline CHEMBL1306460 & 688724 & 4.75 & 4.7123 & TRN & \\
\hline CHEMBL1499260 & 688724 & 4.45 & 5.0887 & TST & \\
\hline CHEMBL1706577 & 688724 & 5.9 & 5.1486 & TRN & \\
\hline CHEMBL1465739 & 688724 & 4.95 & 4.65 & TRN & \\
\hline CHEMBL144530 & 688724 & 4.5 & 4.8048 & TRN & \\
\hline CHEMBL1355580 & 688724 & 4.2 & 4.5517 & TRN & \\
\hline CHEMBL1451439 & 688724 & 4.6 & 4.5082 & TRN & \\
\hline CHEMBL3198275 & 688724 & 4.55 & 4.7079 & TRN & \\
\hline CHEMBL1590868 & 688724 & 5.7 & 4.9241 & TRN & \\
\hline CHEMBL1966168 & 688724 & 4.65 & 4.8596 & TRN & \\
\hline CHEMBL166812 & 688724 & 4.3 & 4.9121 & TST & \\
\hline CHEMBL1303064 & 688724 & 4.85 & 4.8626 & TRN & \\
\hline CHEMBL1411246 & 688724 & 4.85 & 5.5246 & TST & \\
\hline CHEMBL3193935 & 688724 & 5.25 & 4.9435 & TRN & \\
\hline CHEMBL1541353 & 688724 & 4.4 & 4.4843 & TRN & \\
\hline CHEMBL1344827 & 688724 & 5.1 & 4.6986 & TRN & \\
\hline CHEMBL1472369 & 688724 & 4.2 & 4.6664 & TST & \\
\hline CHEMBL1344064 & 688724 & 4.3 & 5.2451 & TST & \\
\hline CHEMBL1471965 & 688724 & 5.85 & 5.3491 & TRN & \\
\hline CHEMBL1497565 & 688724 & 5.55 & 5.0658 & TST & \\
\hline CHEMBL1455791 & 688724 & 4.65 & 5.2018 & TRN & \\
\hline
\end{tabular}




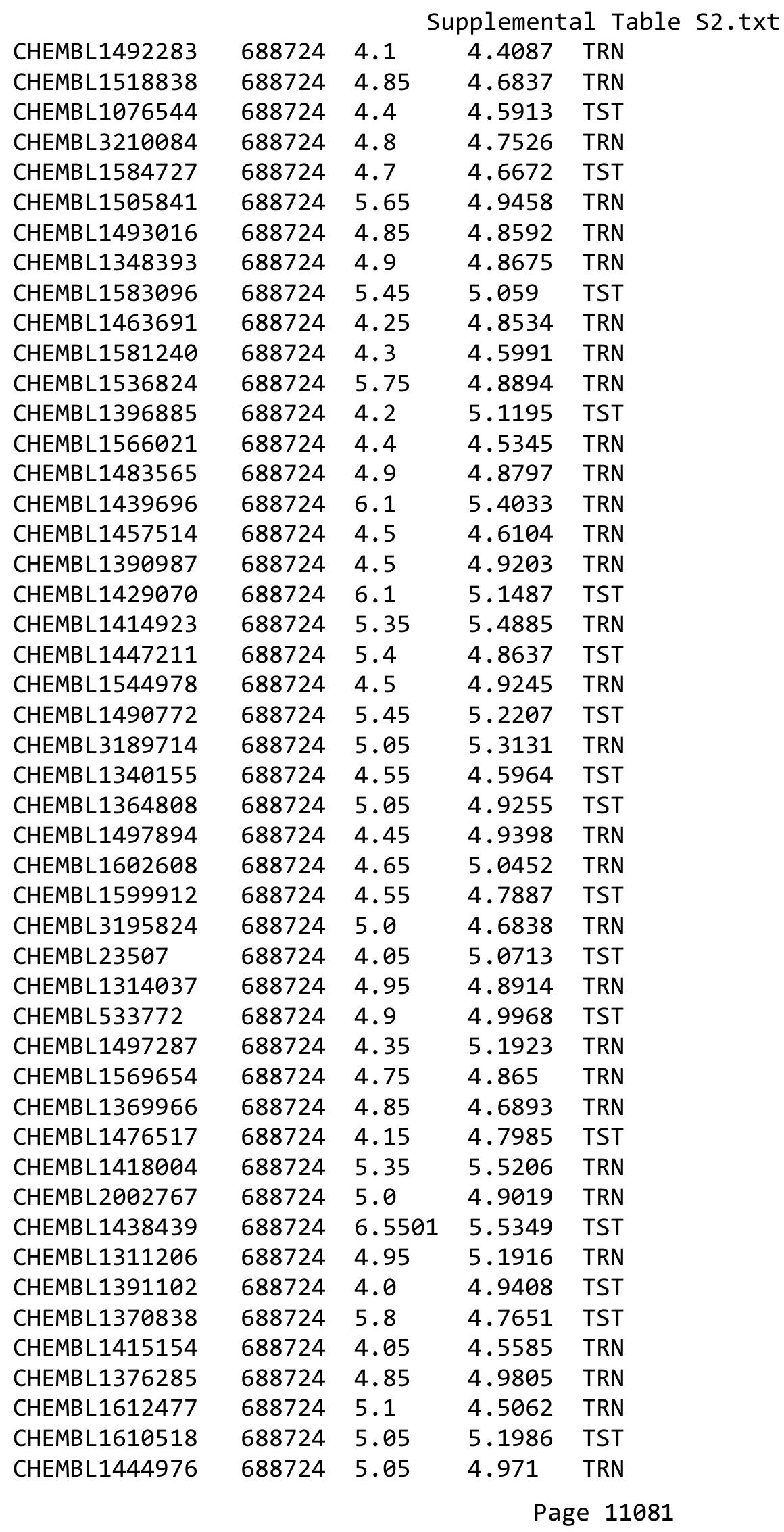




\begin{tabular}{|c|c|c|c|c|}
\hline \multicolumn{5}{|c|}{ Supplemental Table S2.txt } \\
\hline CHEMBL1331280 & 688724 & 6.0 & 4.5171 & TST \\
\hline CHEMBL1496973 & 688724 & 5.35 & 5.0644 & TRN \\
\hline CHEMBL597366 & 688724 & 4.75 & 4.9614 & TRN \\
\hline CHEMBL1556892 & 688724 & 4.75 & 4.9028 & TRN \\
\hline CHEMBL253446 & 688724 & 4.1 & 4.5766 & TRN \\
\hline CHEMBL3193163 & 688724 & 4.05 & 4.9597 & TST \\
\hline CHEMBL1408033 & 688724 & 4.25 & 4.5331 & TRN \\
\hline CHEMBL1359426 & 688724 & 4.3 & 4.6976 & TRN \\
\hline CHEMBL 3189145 & 688724 & 4.7 & 5.2335 & TRN \\
\hline CHEMBL1331134 & 688724 & 5.6 & 5.1902 & TRN \\
\hline CHEMBL1462918 & 688724 & 4.3 & 5.1705 & TRN \\
\hline CHEMBL1433813 & 688724 & 4.55 & 4.4832 & TRN \\
\hline CHEMBL1391621 & 688724 & 5.35 & 5.4795 & TRN \\
\hline CHEMBL536950 & 688724 & 5.3 & 5.1768 & TST \\
\hline CHEMBL1509384 & 688724 & 4.3 & 4.9099 & TRN \\
\hline CHEMBL399982 & 688724 & 5.55 & 5.109 & TRN \\
\hline CHEMBL1513683 & 688724 & 4.5 & 4.7838 & TST \\
\hline CHEMBL1348104 & 688724 & 4.65 & 4.9896 & TST \\
\hline CHEMBL1526016 & 688724 & 4.65 & 4.7093 & TRN \\
\hline CHEMBL1472872 & 688724 & 4.55 & 4.8077 & TRN \\
\hline CHEMBL1364180 & 688724 & 4.75 & 4.676 & TRN \\
\hline CHEMBL56393 & 688724 & 6.6499 & 5.5966 & TRN \\
\hline CHEMBL1513962 & 688724 & 4.9 & 4.7836 & TST \\
\hline CHEMBL1580429 & 688724 & 4.0 & 4.6699 & TST \\
\hline CHEMBL1369893 & 688724 & 5.45 & 5.6206 & TRN \\
\hline CHEMBL1305713 & 688724 & 4.55 & 4.4174 & TRN \\
\hline CHEMBL1560379 & 688724 & 4.75 & 4.8572 & TRN \\
\hline CHEMBL1494114 & 688724 & 4.05 & 4.7794 & TST \\
\hline CHEMBL1508990 & 688724 & 4.0 & 5.1391 & TRN \\
\hline CHEMBL1428857 & 688724 & 5.1 & 5.1896 & TRN \\
\hline CHEMBL1313050 & 688724 & 4.3 & 4.5272 & TRN \\
\hline CHEMBL3191178 & 688724 & 5.85 & 4.95 & TST \\
\hline CHEMBL1485472 & 688724 & 4.85 & 4.3729 & TST \\
\hline CHEMBL476833 & 688724 & 4.15 & 4.6839 & TRN \\
\hline CHEMBL3198961 & 688724 & 5.55 & 5.3368 & TRN \\
\hline CHEMBL1448387 & 688724 & 6.0 & 5.7458 & TST \\
\hline CHEMBL1432468 & 688724 & 4.5 & 4.6434 & TRN \\
\hline CHEMBL1587225 & 688724 & 4.1 & 4.4818 & TRN \\
\hline CHEMBL1577036 & 688724 & 4.8 & 4.6813 & TRN \\
\hline CHEMBL1329271 & 688724 & 4.9 & 4.5737 & TRN \\
\hline CHEMBL1333250 & 688724 & 4.05 & 4.8443 & TRN \\
\hline CHEMBL1315150 & 688724 & 4.8 & 4.6816 & TRN \\
\hline CHEMBL1428343 & 688724 & 4.7 & 4.3852 & TRN \\
\hline CHEMBL1526721 & 688724 & 4.35 & 5.1769 & TST \\
\hline CHEMBL92547 & 688724 & 4.15 & 5.0358 & TRN \\
\hline CHEMBL1562688 & 688724 & 4.6 & 4.8123 & TST \\
\hline CHEMBL1331178 & 688724 & 4.9 & 4.3855 & TRN \\
\hline CHEMBL1386913 & 688724 & 4.95 & 4.9154 & TRN \\
\hline
\end{tabular}




\begin{tabular}{|c|c|c|c|c|c|}
\hline & & \multicolumn{4}{|c|}{ Supplemental Table S2.txt } \\
\hline CHEMBL1372217 & 688724 & 4.25 & 4.97 & TRN & \\
\hline CHEMBL1348846 & 688724 & 4.4 & 4.7563 & TST & \\
\hline CHEMBL1604217 & 688724 & 5.5 & 5.5196 & TRN & \\
\hline CHEMBL1461453 & 688724 & 4.7 & 5.0571 & TRN & \\
\hline CHEMBL1360512 & 688724 & 5.05 & 4.3782 & TRN & \\
\hline CHEMBL1985061 & 688724 & 4.9 & 4.7939 & TST & \\
\hline CHEMBL1585438 & 688724 & 4.05 & 4.5769 & TRN & \\
\hline CHEMBL1451156 & 688724 & 4.5 & 4.5847 & TRN & \\
\hline CHEMBL1347710 & 688724 & 4.75 & 4.8859 & TRN & \\
\hline CHEMBL573540 & 688724 & 4.7 & 4.7605 & TST & \\
\hline CHEMBL1531669 & 688724 & 4.75 & 4.743 & TRN & \\
\hline CHEMBL1389438 & 688724 & 4.65 & 4.8127 & TRN & \\
\hline CHEMBL1565302 & 688724 & 5.1 & 4.4496 & TRN & \\
\hline CHEMBL1598682 & 688724 & 4.35 & 4.8272 & TRN & \\
\hline CHEMBL1327720 & 688724 & 4.7 & 4.935 & TRN & \\
\hline CHEMBL1735892 & 688724 & 4.65 & 4.9663 & TRN & \\
\hline CHEMBL1449886 & 688724 & 5.8 & 5.5678 & TRN & \\
\hline CHEMBL1309341 & 688724 & 4.35 & 4.5729 & TRN & \\
\hline CHEMBL1608690 & 688724 & 4.85 & 4.6211 & TRN & \\
\hline CHEMBL1405834 & 688724 & 6.2 & 5.0998 & TRN & \\
\hline CHEMBL1301947 & 688724 & 4.25 & 4.5454 & TRN & \\
\hline CHEMBL1574671 & 688724 & 4.9 & 4.9335 & TST & \\
\hline CHEMBL1432508 & 688724 & 4.8 & 4.8058 & TST & \\
\hline CHEMBL1505636 & 688724 & 4.5 & 4.8541 & TRN & \\
\hline CHEMBL1606521 & 688724 & 4.85 & 4.9327 & TRN & \\
\hline CHEMBL1397046 & 688724 & 4.35 & 4.5518 & TRN & \\
\hline CHEMBL1368942 & 688724 & 4.9 & 4.4910 & 00000000005 & TRN \\
\hline CHEMBL1486191 & 688724 & 7.0 & 5.6043 & TRN & \\
\hline CHEMBL527586 & 688724 & 4.3 & 4.9431 & TST & \\
\hline CHEMBL1512770 & 688724 & 4.15 & 5.0769 & TRN & \\
\hline CHEMBL1583598 & 688724 & 4.65 & 4.5964 & TRN & \\
\hline CHEMBL1308455 & 688724 & 4.55 & 5.227 & TST & \\
\hline CHEMBL1565377 & 688724 & 4.35 & 4.6789 & TRN & \\
\hline CHEMBL1448824 & 688724 & 4.8 & 4.8352 & TRN & \\
\hline CHEMBL1445437 & 688724 & 5.45 & 5.0524 & TST & \\
\hline CHEMBL1426571 & 688724 & 4.4 & 4.9381 & TST & \\
\hline CHEMBL1612869 & 688724 & 4.7 & 4.5474 & TRN & \\
\hline CHEMBL1402662 & 688724 & 4.55 & 4.489 & TRN & \\
\hline CHEMBL1997970 & 688724 & 4.9 & 5.3161 & TRN & \\
\hline CHEMBL1395391 & 688724 & 4.25 & 4.6530 & 00000000005 & TRN \\
\hline CHEMBL1459351 & 688724 & 4.75 & 4.5525 & TRN & \\
\hline CHEMBL1349170 & 688724 & 4.3 & 4.3878 & TRN & \\
\hline CHEMBL1469553 & 688724 & 4.05 & 4.4202 & TRN & \\
\hline CHEMBL1316439 & 688724 & 5.0 & 5.0395 & TRN & \\
\hline CHEMBL3189801 & 688724 & 4.05 & 4.7605 & TST & \\
\hline CHEMBL1527018 & 688724 & 4.25 & 4.4346 & TRN & \\
\hline CHEMBL1493204 & 688724 & 4.05 & 4.795 & TST & \\
\hline CHEMBL1447781 & 688724 & 4.25 & 4.6046 & TRN & \\
\hline
\end{tabular}




\begin{tabular}{|c|c|c|c|c|}
\hline \multicolumn{5}{|c|}{ Supplemental Table S2.txt } \\
\hline CHEMBL1515454 & 688724 & 5.2 & 5.3412 & TRN \\
\hline CHEMBL1490386 & 688724 & 4.55 & 4.5151 & TRN \\
\hline CHEMBL1561653 & 688724 & 5.25 & 4.9036 & TRN \\
\hline CHEMBL1418230 & 688724 & 4.95 & 5.0085 & TRN \\
\hline CHEMBL1441401 & 688724 & 4.75 & 4.5885 & TRN \\
\hline CHEMBL1470588 & 688724 & 4.6 & 4.636 & TRN \\
\hline CHEMBL1602146 & 688724 & 4.4 & 4.6565 & TRN \\
\hline CHEMBL1610000 & 688724 & 4.45 & 4.4383 & TRN \\
\hline CHEMBL 362919 & 688724 & 4.65 & 4.7222 & TST \\
\hline CHEMBL482477 & 688724 & 6.0 & 5.4052 & TRN \\
\hline CHEMBL1409787 & 688724 & 4.45 & 5.1478 & TST \\
\hline CHEMBL1308724 & 688724 & 4.65 & 5.1976 & TST \\
\hline CHEMBL 2003901 & 688724 & 4.8 & 4.7927 & TRN \\
\hline CHEMBL1320927 & 688724 & 4.85 & 4.5731 & TRN \\
\hline CHEMBL3196429 & 688724 & 5.15 & 4.6693 & TRN \\
\hline CHEMBL3189553 & 688724 & 6.0 & 5.0038 & TRN \\
\hline CHEMBL1533994 & 688724 & 5.3 & 4.9695 & TST \\
\hline CHEMBL1464106 & 688724 & 5.35 & 5.2747 & TRN \\
\hline CHEMBL1313464 & 688724 & 4.3 & 4.9231 & TST \\
\hline CHEMBL1423716 & 688724 & 4.05 & 4.6487 & TRN \\
\hline CHEMBL1563532 & 688724 & 4.55 & 4.7329 & TST \\
\hline CHEMBL1378205 & 688724 & 4.8 & 4.6893 & TRN \\
\hline CHEMBL1303745 & 688724 & 4.95 & 5.0325 & TST \\
\hline CHEMBL1517252 & 688724 & 4.05 & 4.2875 & TRN \\
\hline CHEMBL 239732 & 688724 & 4.55 & 5.0545 & TST \\
\hline CHEMBL1522300 & 688724 & 4.95 & 4.6986 & TRN \\
\hline CHEMBL1509369 & 688724 & 4.35 & 4.9901 & TRN \\
\hline CHEMBL1504742 & 688724 & 4.05 & 4.5006 & TRN \\
\hline CHEMBL1545873 & 688724 & 5.5 & 5.0769 & TRN \\
\hline CHEMBL1429158 & 688724 & 5.45 & 4.7971 & TRN \\
\hline CHEMBL 3211130 & 688724 & 4.35 & 4.5842 & TRN \\
\hline CHEMBL1386060 & 688724 & 4.35 & 4.6053 & TRN \\
\hline CHEMBL1431314 & 688724 & 5.4 & 5.4841 & TRN \\
\hline CHEMBL1471775 & 688724 & 7.2 & 4.8638 & TRN \\
\hline CHEMBL1561575 & 688724 & 5.0 & 4.5841 & TRN \\
\hline CHEMBL1575453 & 688724 & 4.5 & 4.5761 & TRN \\
\hline CHEMBL1554731 & 688724 & 4.85 & 4.8136 & TRN \\
\hline CHEMBL3196822 & 688724 & 6.8499 & 4.739 & TRN \\
\hline CHEMBL1572439 & 688724 & 4.35 & 4.4471 & TRN \\
\hline CHEMBL1556341 & 688724 & 4.3 & 4.7592 & TRN \\
\hline CHEMBL1606248 & 688724 & 4.7 & 5.3005 & TST \\
\hline CHEMBL1309148 & 688724 & 4.3 & 4.578 & TRN \\
\hline CHEMBL1357929 & 688724 & 4.35 & 4.6384 & TRN \\
\hline CHEMBL1531779 & 688724 & 4.95 & 4.8325 & TRN \\
\hline CHEMBL1369918 & 688724 & 4.7 & 4.4939 & TRN \\
\hline CHEMBL1335522 & 688724 & 4.9 & 4.732 & TST \\
\hline CHEMBL1569683 & 688724 & 4.25 & 4.8458 & TRN \\
\hline CHEMBL1301950 & 688724 & 6.4 & 4.6456 & TST \\
\hline
\end{tabular}




\begin{tabular}{|c|c|c|c|c|}
\hline \multicolumn{5}{|c|}{ Supplemental Table S2.txt } \\
\hline CHEMBL3189493 & 688724 & 4.55 & 5.0682 & TRN \\
\hline CHEMBL1331476 & 688724 & 4.6 & 5.1481 & TST \\
\hline CHEMBL319398 & 688724 & 4.35 & 4.8814 & TRN \\
\hline CHEMBL 2003806 & 688724 & 4.45 & 5.1972 & TRN \\
\hline CHEMBL1428054 & 688724 & 4.45 & 4.7302 & TRN \\
\hline CHEMBL354318 & 688724 & 4.3 & 4.8139 & TRN \\
\hline CHEMBL3210967 & 688724 & 4.25 & 4.691 & TRN \\
\hline CHEMBL1374338 & 688724 & 4.3 & 4.7226 & TRN \\
\hline CHEMBL1489372 & 688724 & 4.55 & 4.6476 & TRN \\
\hline CHEMBL1588434 & 688724 & 5.45 & 5.0562 & TRN \\
\hline CHEMBL1528531 & 688724 & 4.55 & 5.1403 & TRN \\
\hline CHEMBL1992764 & 688724 & 4.95 & 4.7918 & TRN \\
\hline CHEMBL1332897 & 688724 & 6.0 & 5.1856 & TST \\
\hline CHEMBL1513100 & 688724 & 4.4 & 4.3641 & TRN \\
\hline CHEMBL1401800 & 688724 & 4.6 & 5.4577 & TRN \\
\hline CHEMBL1462597 & 688724 & 4.55 & 4.7356 & TRN \\
\hline CHEMBL1483081 & 688724 & 4.25 & 4.7085 & TST \\
\hline CHEMBL1445850 & 688724 & 4.05 & 4.795 & TRN \\
\hline CHEMBL1320184 & 688724 & 5.55 & 4.512 & TST \\
\hline CHEMBL1305075 & 688724 & 4.8 & 4.8911 & TRN \\
\hline CHEMBL1409255 & 688724 & 4.35 & 4.6679 & TRN \\
\hline CHEMBL1505148 & 688724 & 4.05 & 4.5077 & TRN \\
\hline CHEMBL1440446 & 688724 & 4.15 & 4.6061 & TRN \\
\hline CHEMBL1424231 & 688724 & 4.5 & 4.994 & TRN \\
\hline CHEMBL1971324 & 688724 & 5.05 & 4.7414 & TRN \\
\hline CHEMBL1590421 & 688724 & 4.3 & 4.6626 & TST \\
\hline CHEMBL1535811 & 688724 & 4.6 & 4.8427 & TRN \\
\hline CHEMBL1370073 & 688724 & 5.05 & 4.6287 & TST \\
\hline CHEMBL1345838 & 688724 & 4.5 & 4.9251 & TST \\
\hline CHEMBL509579 & 688724 & 5.3 & 4.8419 & TST \\
\hline CHEMBL473107 & 688724 & 4.4 & 4.8188 & TST \\
\hline CHEMBL1467229 & 688724 & 4.35 & 4.6829 & TRN \\
\hline CHEMBL1965814 & 688724 & 4.8 & 4.9326 & TRN \\
\hline CHEMBL1476153 & 688724 & 4.3 & 4.6176 & TRN \\
\hline CHEMBL1480963 & 688724 & 4.9 & 5.1609 & TRN \\
\hline CHEMBL1351637 & 688724 & 4.85 & 4.3988 & TST \\
\hline CHEMBL1975069 & 688724 & 4.35 & 5.0889 & TRN \\
\hline CHEMBL1388287 & 688724 & 4.85 & 4.7585 & TRN \\
\hline CHEMBL1585999 & 688724 & 4.95 & 5.1324 & TRN \\
\hline CHEMBL1362396 & 688724 & 4.3 & 4.5765 & TRN \\
\hline CHEMBL1474709 & 688724 & 4.9 & 5.1004 & TRN \\
\hline CHEMBL1477837 & 688724 & 5.5 & 5.0682 & TRN \\
\hline CHEMBL1257002 & 688724 & 7.6498 & 4.9271 & TST \\
\hline CHEMBL1568767 & 688724 & 4.35 & 4.6853 & TRN \\
\hline CHEMBL1537149 & 688724 & 4.55 & 4.6039 & TRN \\
\hline CHEMBL1513633 & 688724 & 4.55 & 4.6933 & TRN \\
\hline CHEMBL1533147 & 688724 & 4.45 & 4.7546 & TRN \\
\hline CHEMBL1968402 & 688724 & 4.6 & 4.9778 & TRN \\
\hline
\end{tabular}




\begin{tabular}{|c|c|c|c|c|c|}
\hline \multicolumn{6}{|c|}{ Supplemental Table S2.txt } \\
\hline CHEMBL1523475 & 688724 & 4.45 & 4.9676 & TST & \\
\hline CHEMBL277362 & 688724 & 5.55 & 5.1361 & TST & \\
\hline CHEMBL561114 & 688724 & 4.75 & 4.7598 & TST & \\
\hline CHEMBL1549969 & 688724 & 4.35 & 4.3529 & TRN & \\
\hline CHEMBL1417269 & 688724 & 4.45 & 4.9696 & TRN & \\
\hline CHEMBL1526580 & 688724 & 4.55 & 4.7358 & TRN & \\
\hline CHEMBL1519862 & 688724 & 4.45 & 4.5227 & TRN & \\
\hline CHEMBL1427421 & 688724 & 4.5 & 4.4535 & TRN & \\
\hline CHEMBL1563980 & 688724 & 4.35 & 4.3497 & TST & \\
\hline CHEMBL151 & 688724 & 6.0 & 5.5272 & TRN & \\
\hline CHEMBL1373957 & 688724 & 4.8 & 5.1635 & TRN & \\
\hline CHEMBL3195053 & 688724 & 5.15 & 4.7884 & TRN & \\
\hline CHEMBL1444092 & 688724 & 4.35 & 4.7542 & TRN & \\
\hline CHEMBL1365978 & 688724 & 4.65 & 5.4226 & TRN & \\
\hline CHEMBL1324182 & 688724 & 4.4 & 4.5989 & TST & \\
\hline CHEMBL1412795 & 688724 & 4.25 & 4.74100 & 00000000005 & TST \\
\hline CHEMBL1339576 & 688724 & 4.35 & 4.5467 & TRN & \\
\hline CHEMBL1237212 & 688724 & 6.0 & 5.1903 & TST & \\
\hline CHEMBL1613685 & 688724 & 4.35 & 4.7607 & TRN & \\
\hline CHEMBL1461203 & 688724 & 4.35 & 4.612 & TRN & \\
\hline CHEMBL1481914 & 688724 & 5.7 & 4.7532 & TRN & \\
\hline CHEMBL1500318 & 688724 & 4.65 & 4.9367 & TRN & \\
\hline CHEMBL1565966 & 688724 & 5.85 & 4.4543 & TRN & \\
\hline CHEMBL1583148 & 688724 & 6.15 & 5.25799 & 9999999999 & TST \\
\hline CHEMBL1459825 & 688724 & 3.95 & 4.4419 & TRN & \\
\hline CHEMBL1371424 & 688724 & 5.9 & 5.0841 & TRN & \\
\hline CHEMBL1601604 & 688724 & 4.05 & 4.8018 & TRN & \\
\hline CHEMBL19117 & 688724 & 4.6 & 4.7196 & TRN & \\
\hline CHEMBL1483609 & 688724 & 4.05 & 4.4696 & TRN & \\
\hline CHEMBL1600998 & 688724 & 4.25 & 4.7764 & TRN & \\
\hline CHEMBL1393059 & 688724 & 4.35 & 4.8422 & TST & \\
\hline CHEMBL1327013 & 688724 & 4.65 & 4.683 & TRN & \\
\hline CHEMBL1577005 & 688724 & 4.35 & 4.9246 & TRN & \\
\hline CHEMBL1599847 & 688724 & 4.8 & 4.2932 & TRN & \\
\hline CHEMBL1524617 & 688724 & 4.5 & 5.3956 & TST & \\
\hline CHEMBL1502211 & 688724 & 4.4 & 4.5548 & TRN & \\
\hline CHEMBL1379124 & 688724 & 4.65 & 4.9898 & TST & \\
\hline CHEMBL1361913 & 688724 & 4.35 & 5.0713 & TST & \\
\hline CHEMBL1994510 & 688724 & 4.35 & 4.5218 & TRN & \\
\hline CHEMBL 2003564 & 688724 & 5.95 & 4.4694 & TRN & \\
\hline CHEMBL1607815 & 688724 & 5.5 & 4.7317 & TRN & \\
\hline CHEMBL1522027 & 688724 & 5.25 & 4.9737 & TRN & \\
\hline CHEMBL1484059 & 688724 & 4.8 & 4.5257 & TRN & \\
\hline CHEMBL1503182 & 688724 & 4.85 & 4.546 & TST & \\
\hline CHEMBL1509165 & 688724 & 5.4 & 4.7453 & TRN & \\
\hline CHEMBL1383301 & 688724 & 8.1487 & 4.7997 & TST & \\
\hline CHEMBL1490573 & 688724 & 4.55 & 4.8059 & TRN & \\
\hline CHEMBL1557172 & 688724 & 5.05 & 4.6274 & TRN & \\
\hline
\end{tabular}




\begin{tabular}{|c|c|c|c|c|c|}
\hline \multicolumn{6}{|c|}{ Supplemental Table S2.txt } \\
\hline CHEMBL1412158 & 688724 & 4.8 & 4.7547 & TRN & \\
\hline CHEMBL1565196 & 688724 & 4.3 & 4.6529 & TRN & \\
\hline CHEMBL1340647 & 688724 & 4.15 & 4.7789 & TRN & \\
\hline CHEMBL1486073 & 688724 & 4.55 & 4.4231 & TRN & \\
\hline CHEMBL1483249 & 688724 & 4.8 & 4.8007 & TRN & \\
\hline CHEMBL1363000 & 688724 & 6.95 & 4.8264 & TST & \\
\hline CHEMBL1302321 & 688724 & 4.8 & 4.6032 & TRN & \\
\hline CHEMBL1540272 & 688724 & 5.15 & 4.6885 & TRN & \\
\hline CHEMBL3192506 & 688724 & 4.3 & $4.7010 e$ & 00000000005 & TRN \\
\hline CHEMBL1447470 & 688724 & 5.2 & 4.9086 & TRN & \\
\hline CHEMBL1417701 & 688724 & 4.95 & 4.9212 & TRN & \\
\hline CHEMBL1310877 & 688724 & 4.45 & 4.7269 & TRN & \\
\hline CHEMBL3196898 & 688724 & 4.4 & 5.0083 & TRN & \\
\hline CHEMBL172439 & 688724 & 5.25 & 5.475 & TRN & \\
\hline CHEMBL1515332 & 688724 & 4.4 & 4.7141 & TRN & \\
\hline CHEMBL1510493 & 688724 & 5.45 & 4.8461 & TRN & \\
\hline CHEMBL1348086 & 688724 & 4.4 & 4.6731 & TRN & \\
\hline CHEMBL1561234 & 688724 & 5.05 & 4.5321 & TRN & \\
\hline CHEMBL1314174 & 688724 & 6.6499 & 5.0839 & TST & \\
\hline CHEMBL1461106 & 688724 & 4.55 & 4.6624 & TST & \\
\hline CHEMBL3199586 & 688724 & 5.3 & 4.5701 & TRN & \\
\hline CHEMBL1439202 & 688724 & 4.35 & 4.7839 & TST & \\
\hline CHEMBL1385033 & 688724 & 6.5501 & 5.2126 & TRN & \\
\hline CHEMBL1347832 & 688724 & 4.8 & 4.8033 & TRN & \\
\hline CHEMBL1579642 & 688724 & 4.35 & 4.8016 & TST & \\
\hline CHEMBL1327627 & 688724 & 4.75 & 4.9425 & TRN & \\
\hline CHEMBL1343866 & 688724 & 5.65 & 4.6592 & TRN & \\
\hline CHEMBL1426514 & 688724 & 4.5 & 4.6854 & TST & \\
\hline CHEMBL1440240 & 688724 & 5.05 & 5.1051 & TRN & \\
\hline CHEMBL1402720 & 688724 & 5.2 & $5.4120 e$ & 2000000001 & TRN \\
\hline CHEMBL1418216 & 688724 & 4.45 & 4.9245 & TRN & \\
\hline CHEMBL1588546 & 688724 & 4.0 & 4.5647 & TRN & \\
\hline CHEMBL1375105 & 688724 & 4.05 & 4.7843 & TRN & \\
\hline CHEMBL1391013 & 688724 & 4.95 & 5.0817 & TRN & \\
\hline CHEMBL1439864 & 688724 & 5.1 & 4.7709 & TRN & \\
\hline CHEMBL1531574 & 688724 & 4.4 & 4.7693 & TRN & \\
\hline CHEMBL1390731 & 688724 & 4.85 & 5.3 & TRN & \\
\hline CHEMBL1613340 & 688724 & 4.25 & 4.8683 & TST & \\
\hline CHEMBL2006390 & 688724 & 4.6 & 5.2645 & TRN & \\
\hline CHEMBL1502806 & 688724 & 4.0 & 4.9942 & TST & \\
\hline CHEMBL1398825 & 688724 & 6.0 & 5.1337 & TRN & \\
\hline CHEMBL1535796 & 688724 & 4.35 & 4.5099 & TRN & \\
\hline CHEMBL1545847 & 688724 & 4.4 & 4.6444 & TST & \\
\hline CHEMBL1477599 & 688724 & 4.35 & 4.6336 & TRN & \\
\hline CHEMBL1466134 & 688724 & 5.0 & 4.6292 & TST & \\
\hline CHEMBL1520528 & 688724 & 4.75 & 4.8402 & TRN & \\
\hline CHEMBL1336326 & 688724 & 4.65 & 4.9086 & TST & \\
\hline CHEMBL1581683 & 688724 & 4.45 & 4.9294 & TST & \\
\hline
\end{tabular}




\begin{tabular}{|c|c|c|c|c|}
\hline \multicolumn{5}{|c|}{ Supplemental Table S2.txt } \\
\hline CHEMBL1592448 & 688724 & 4.1 & 4.492 & TRN \\
\hline CHEMBL1550600 & 688724 & 7.2 & 5.28 & TRN \\
\hline CHEMBL1603092 & 688724 & 5.2 & 5.3139 & TRN \\
\hline CHEMBL1492608 & 688724 & 4.05 & 4.4703 & TST \\
\hline CHEMBL1365367 & 688724 & 4.6 & 4.7794 & TRN \\
\hline CHEMBL1365456 & 688724 & 4.3 & 5.066 & TRN \\
\hline CHEMBL1405235 & 688724 & 4.45 & 4.5438 & TRN \\
\hline CHEMBL1424288 & 688724 & 4.05 & 4.4713 & TRN \\
\hline CHEMBL1414251 & 688724 & 5.4 & 4.8836 & TRN \\
\hline CHEMBL1611955 & 688724 & 5.05 & 5.006 & TST \\
\hline CHEMBL1587109 & 688724 & 4.85 & 4.8757 & TRN \\
\hline CHEMBL1302988 & 688724 & 4.0 & 4.578 & TST \\
\hline CHEMBL1536155 & 688724 & 4.35 & $4.9510 e$ & 20000000005 \\
\hline CHEMBL1364266 & 688724 & 4.1 & 4.9881 & TST \\
\hline CHEMBL1331360 & 688724 & 4.1 & 4.4827 & TRN \\
\hline CHEMBL1423596 & 688724 & 4.6 & 4.7152 & TRN \\
\hline CHEMBL3195139 & 688724 & 5.7 & 4.9389 & TST \\
\hline CHEMBL1330161 & 688724 & 5.5 & 4.9922 & TRN \\
\hline CHEMBL1332200 & 688724 & 4.3 & 4.5004 & TRN \\
\hline CHEMBL3208919 & 688724 & 4.05 & 4.8913 & TST \\
\hline CHEMBL268868 & 688724 & 4.15 & 4.742 & TRN \\
\hline CHEMBL1603264 & 688724 & 4.6 & 4.7304 & TST \\
\hline CHEMBL1558685 & 688724 & 4.0 & 4.6703 & TRN \\
\hline CHEMBL1552976 & 688724 & 4.1 & 4.7209 & TST \\
\hline CHEMBL1423524 & 688724 & 4.85 & 4.7462 & TRN \\
\hline CHEMBL1611758 & 688724 & 4.5 & 4.6807 & TRN \\
\hline CHEMBL1512382 & 688724 & 4.45 & 4.5704 & TRN \\
\hline CHEMBL1326087 & 688724 & 4.2 & 5.2395 & TST \\
\hline CHEMBL166415 & 688724 & 4.05 & 4.8657 & TRN \\
\hline CHEMBL1504113 & 688724 & 6.15 & 5.6113 & TRN \\
\hline CHEMBL1586948 & 688724 & 5.3 & 4.7849 & TRN \\
\hline CHEMBL1469723 & 688724 & 4.35 & 4.7736 & TST \\
\hline CHEMBL1581916 & 688724 & 5.65 & 5.2018 & TRN \\
\hline CHEMBL1446662 & 688724 & 4.95 & 5.1916 & TRN \\
\hline CHEMBL1324710 & 688724 & 4.7 & 4.5394 & TRN \\
\hline CHEMBL1462379 & 688724 & 4.7 & 4.8812 & TRN \\
\hline CHEMBL1595140 & 688724 & 4.05 & 4.7888 & TRN \\
\hline CHEMBL1312509 & 688724 & 4.75 & 4.2953 & TST \\
\hline CHEMBL1501047 & 688724 & 5.4 & 5.3607 & TRN \\
\hline CHEMBL1558216 & 688724 & 4.6 & 4.9685 & TRN \\
\hline CHEMBL1346386 & 688724 & 4.2 & 4.9616 & TST \\
\hline CHEMBL3209938 & 688724 & 4.55 & 4.8295 & TRN \\
\hline CHEMBL1369157 & 688724 & 4.55 & 4.7069 & TRN \\
\hline CHEMBL1984721 & 688724 & 4.05 & 4.4852 & TRN \\
\hline CHEMBL3196840 & 688724 & 4.5 & 4.5581 & TRN \\
\hline CHEMBL1415489 & 688724 & 4.4 & 4.7893 & TRN \\
\hline CHEMBL12998 & 688724 & 4.65 & 4.868 & TST \\
\hline CHEMBL1571480 & 688724 & 4.9 & 4.9015 & TRN \\
\hline
\end{tabular}




\begin{tabular}{|c|c|c|c|c|}
\hline \multicolumn{5}{|c|}{ Supplemental Table S2.txt } \\
\hline CHEMBL1370921 & 688724 & 4.35 & 4.6274 & TRN \\
\hline CHEMBL1561127 & 688724 & 4.5 & 4.6797 & TST \\
\hline CHEMBL1399239 & 688724 & 4.85 & 4.8201 & TRN \\
\hline CHEMBL1338736 & 688724 & 4.9 & 5.0937 & TRN \\
\hline CHEMBL1305289 & 688724 & 5.0 & 4.8248 & TST \\
\hline CHEMBL1433421 & 688724 & 4.75 & 4.4756 & TRN \\
\hline CHEMBL 2000264 & 688724 & 4.4 & 4.5666 & TRN \\
\hline CHEMBL1541963 & 688724 & 4.4 & 4.8219 & TRN \\
\hline CHEMBL1392584 & 688724 & 5.6 & 5.0617 & TRN \\
\hline CHEMBL1524395 & 688724 & 4.45 & 4.7279 & TST \\
\hline CHEMBL1561408 & 688724 & 4.75 & 5.0891 & TRN \\
\hline CHEMBL393287 & 688724 & 6.35 & 4.8389 & TRN \\
\hline CHEMBL1567572 & 688724 & 4.85 & 5.0669 & TST \\
\hline CHEMBL1511661 & 688724 & 4.25 & 4.7306 & TRN \\
\hline CHEMBL1442023 & 688724 & 5.55 & 4.5542 & TRN \\
\hline CHEMBL449690 & 688724 & 6.0 & 5.296 & TRN \\
\hline CHEMBL1467372 & 688724 & 6.6 & 5.0714 & TRN \\
\hline CHEMBL1526928 & 688724 & 4.45 & 4.5086 & TST \\
\hline CHEMBL1579217 & 688724 & 4.55 & 5.0123 & TRN \\
\hline CHEMBL1400905 & 688724 & 4.65 & 4.9254 & TRN \\
\hline CHEMBL1439573 & 688724 & 4.8 & 4.5891 & TRN \\
\hline CHEMBL468582 & 688724 & 4.75 & 5.2255 & TST \\
\hline CHEMBL1537118 & 688724 & 5.15 & 4.7183 & TST \\
\hline CHEMBL1461581 & 688724 & 5.45 & 4.9444 & TRN \\
\hline CHEMBL1488201 & 688724 & 4.4 & 4.3493 & TRN \\
\hline CHEMBL1548395 & 688724 & 4.3 & 4.6415 & TRN \\
\hline CHEMBL1422766 & 688724 & 5.1 & 4.7735 & TRN \\
\hline CHEMBL586000 & 688724 & 4.7 & 4.8426 & TRN \\
\hline CHEMBL1437819 & 688724 & 4.55 & 4.2657 & TRN \\
\hline CHEMBL1339523 & 688724 & 5.4 & 5.0224 & TST \\
\hline CHEMBL1581911 & 688724 & 4.8 & 4.9035 & TRN \\
\hline CHEMBL1337283 & 688724 & 4.45 & 4.6176 & TRN \\
\hline CHEMBL 2369288 & 688724 & 4.75 & 4.6138 & TRN \\
\hline CHEMBL1325641 & 688724 & 4.6 & 5.1674 & TST \\
\hline CHEMBL1495072 & 688724 & 6.0 & 5.9576 & TRN \\
\hline CHEMBL1576310 & 688724 & 4.95 & 4.8518 & TST \\
\hline CHEMBL1491635 & 688724 & 5.85 & 5.1926 & TRN \\
\hline CHEMBL1318586 & 688724 & 4.7 & 4.6209 & TRN \\
\hline CHEMBL1569416 & 688724 & 4.6 & 4.9469 & TRN \\
\hline CHEMBL1365491 & 688724 & 4.2 & 4.5899 & TRN \\
\hline CHEMBL1567034 & 688724 & 4.7 & 4.9344 & TST \\
\hline CHEMBL1548326 & 688724 & 4.85 & 4.87 & TRN \\
\hline CHEMBL1544657 & 688724 & 5.1 & 4.9718 & TRN \\
\hline CHEMBL3144970 & 688724 & 4.95 & 4.7239 & TRN \\
\hline CHEMBL1579503 & 688724 & 4.3 & 4.4474 & TRN \\
\hline CHEMBL1612081 & 688724 & 5.2 & 4.8576 & TST \\
\hline CHEMBL1336927 & 688724 & 4.6 & 4.5458 & TRN \\
\hline CHEMBL1556045 & 688724 & 4.4 & 4.7307 & TRN \\
\hline
\end{tabular}




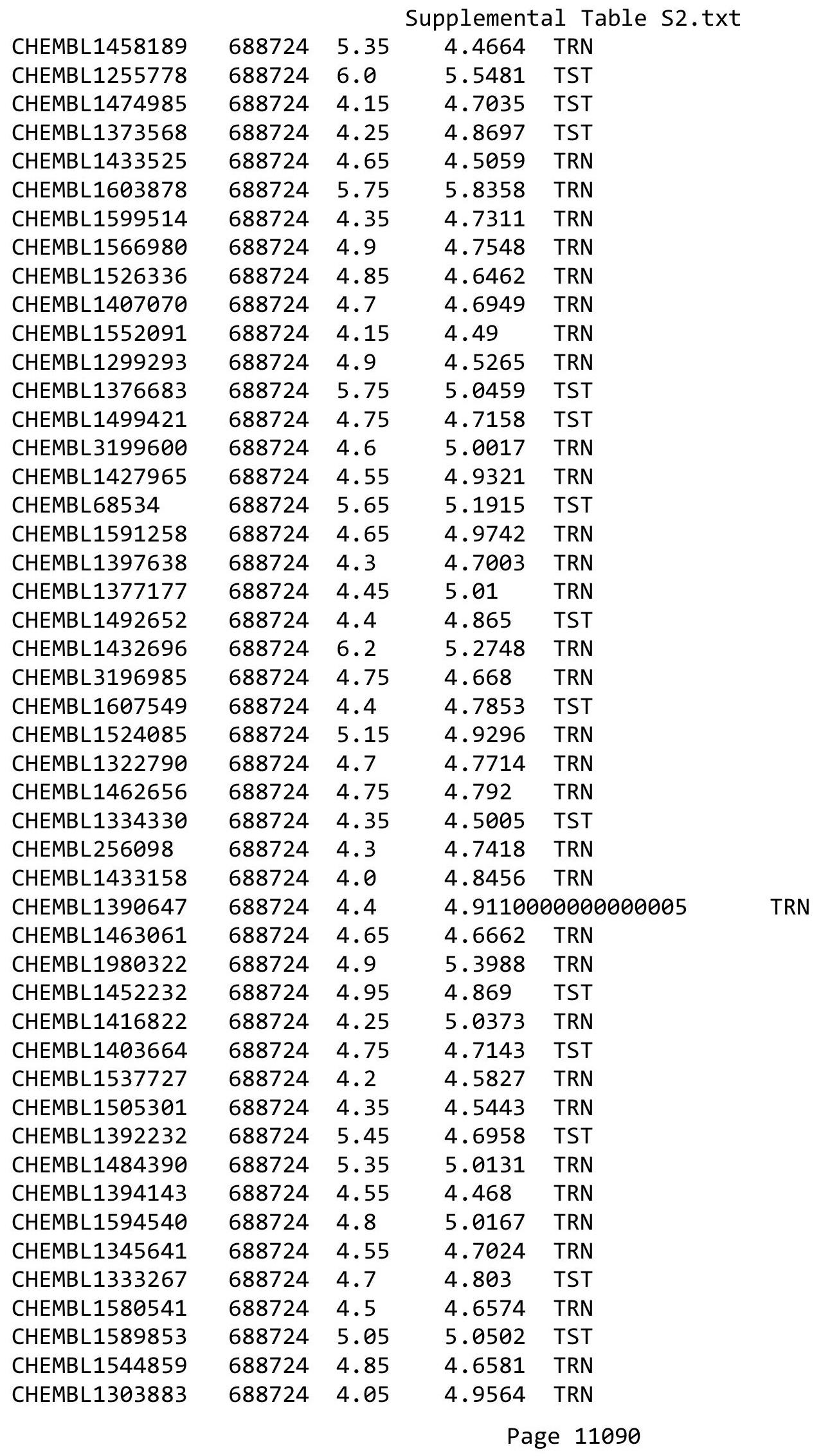




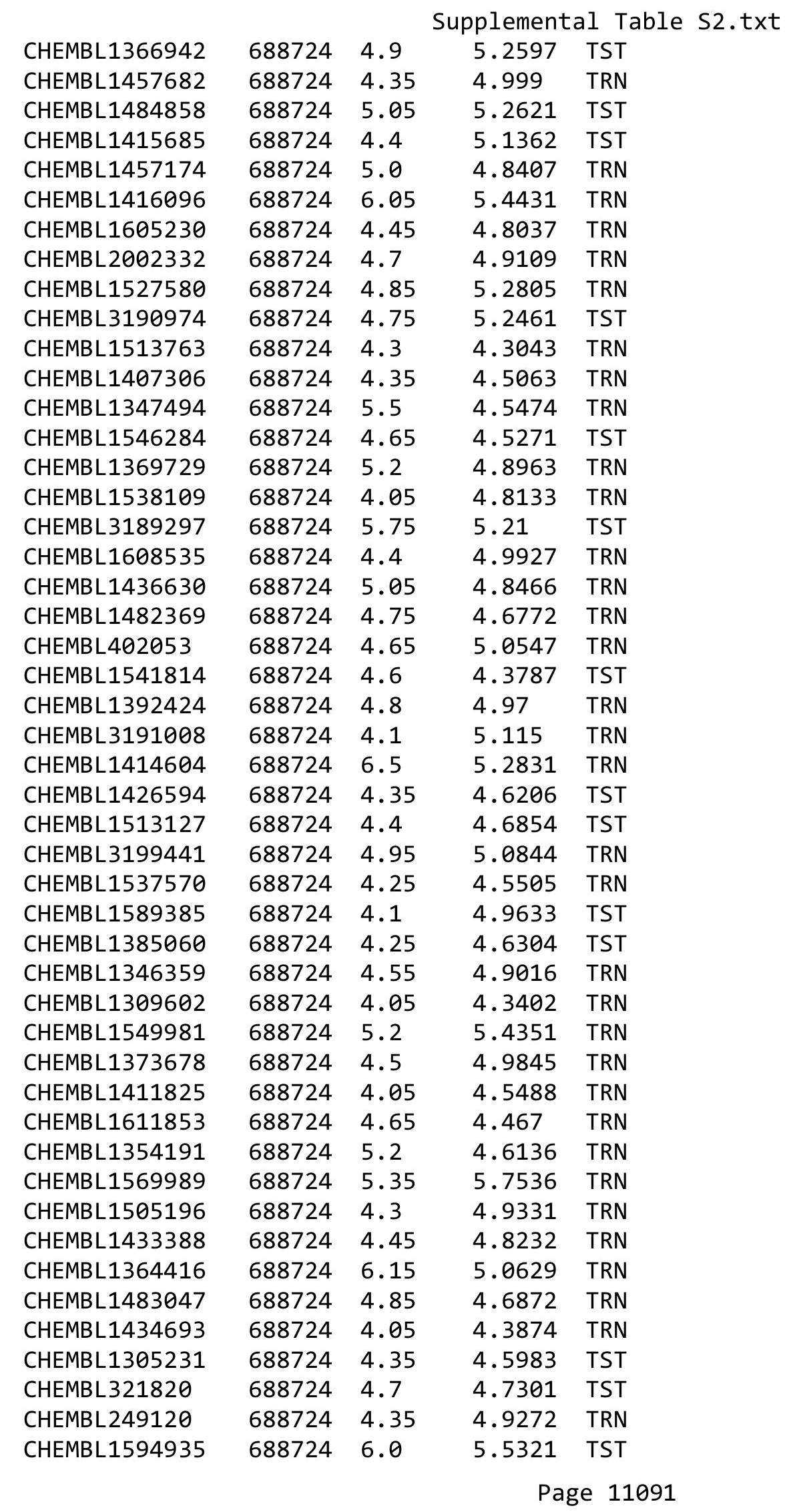




\begin{tabular}{|c|c|c|c|c|}
\hline \multicolumn{5}{|c|}{ Supplemental Table S2.txt } \\
\hline CHEMBL1400512 & 688724 & 4.65 & 4.6025 & TRN \\
\hline CHEMBL1482975 & 688724 & 4.95 & 4.7785 & TRN \\
\hline CHEMBL1300063 & 688724 & 4.8 & 4.6266 & TRN \\
\hline CHEMBL1523566 & 688724 & 4.85 & 5.0166 & TRN \\
\hline CHEMBL1428067 & 688724 & 5.1 & 4.7492 & TRN \\
\hline CHEMBL1364811 & 688724 & 4.65 & 4.7005 & TRN \\
\hline CHEMBL1572269 & 688724 & 5.55 & 5.1493 & TRN \\
\hline CHEMBL1535723 & 688724 & 4.1 & 4.9786 & TRN \\
\hline CHEMBL 295960 & 688724 & 4.55 & 4.9519 & TRN \\
\hline CHEMBL1495847 & 688724 & 5.85 & 5.5453 & TRN \\
\hline CHEMBL1391607 & 688724 & 5.15 & 4.7396 & TST \\
\hline CHEMBL1445375 & 688724 & 7.7496 & 5.3779 & TRN \\
\hline CHEMBL1530835 & 688724 & 4.75 & 4.8181 & TST \\
\hline CHEMBL1571390 & 688724 & 4.25 & 4.8396 & TST \\
\hline CHEMBL1517893 & 688724 & 6.0 & 5.276 & TRN \\
\hline CHEMBL1593717 & 688724 & 4.45 & 4.7272 & TST \\
\hline CHEMBL1444729 & 688724 & 4.55 & 4.9043 & TRN \\
\hline CHEMBL1404843 & 688724 & 4.0 & 4.7268 & TRN \\
\hline CHEMBL3194209 & 688724 & 5.9 & 4.8213 & TRN \\
\hline CHEMBL1391890 & 688724 & 4.05 & 4.9119 & TRN \\
\hline CHEMBL1329366 & 688724 & 5.0 & 5.1768 & TRN \\
\hline CHEMBL1320000 & 688724 & 4.6 & 4.9063 & TST \\
\hline CHEMBL1311273 & 688724 & 4.7 & 4.9359 & TRN \\
\hline CHEMBL 3209400 & 688724 & 4.85 & 4.6104 & TST \\
\hline CHEMBL1448331 & 688724 & 4.3 & 4.8457 & TST \\
\hline CHEMBL1382672 & 688724 & 4.35 & 4.7111 & TRN \\
\hline CHEMBL1397432 & 688724 & 4.5 & 4.385 & TRN \\
\hline CHEMBL1480066 & 688724 & 4.25 & 4.7543 & TRN \\
\hline CHEMBL1512946 & 688724 & 5.3 & 5.2109 & TRN \\
\hline CHEMBL1327742 & 688724 & 4.5 & 4.956 & TRN \\
\hline CHEMBL1391099 & 688724 & 4.5 & 4.5703 & TRN \\
\hline CHEMBL1383142 & 688724 & 5.2 & 4.5468 & TRN \\
\hline CHEMBL1576510 & 688724 & 4.05 & 4.8908 & TST \\
\hline CHEMBL1435227 & 688724 & 4.55 & 4.5522 & TRN \\
\hline CHEMBL1432149 & 688724 & 4.6 & 4.8066 & TRN \\
\hline CHEMBL3198232 & 688724 & 6.5 & 4.5794 & TRN \\
\hline CHEMBL1447467 & 688724 & 5.45 & 5.1599 & TST \\
\hline CHEMBL1566165 & 688724 & 5.85 & 5.0654 & TRN \\
\hline CHEMBL1600238 & 688724 & 5.4 & 4.5506 & TST \\
\hline CHEMBL1363920 & 688724 & 4.4 & 4.4846 & TRN \\
\hline CHEMBL523052 & 688724 & 5.5 & 4.4704 & TRN \\
\hline CHEMBL1418322 & 688724 & 4.6 & 4.9111 & TRN \\
\hline CHEMBL1485259 & 688724 & 4.3 & 5.1774 & TRN \\
\hline CHEMBL3191677 & 688724 & 4.85 & 5.1132 & TRN \\
\hline CHEMBL1405244 & 688724 & 4.5 & 5.0326 & TST \\
\hline CHEMBL1505760 & 688724 & 6.2 & 5.4969 & TRN \\
\hline CHEMBL1458356 & 688724 & 5.15 & 5.1633 & TST \\
\hline CHEMBL1544564 & 688724 & 4.3 & 4.7548 & TRN \\
\hline
\end{tabular}




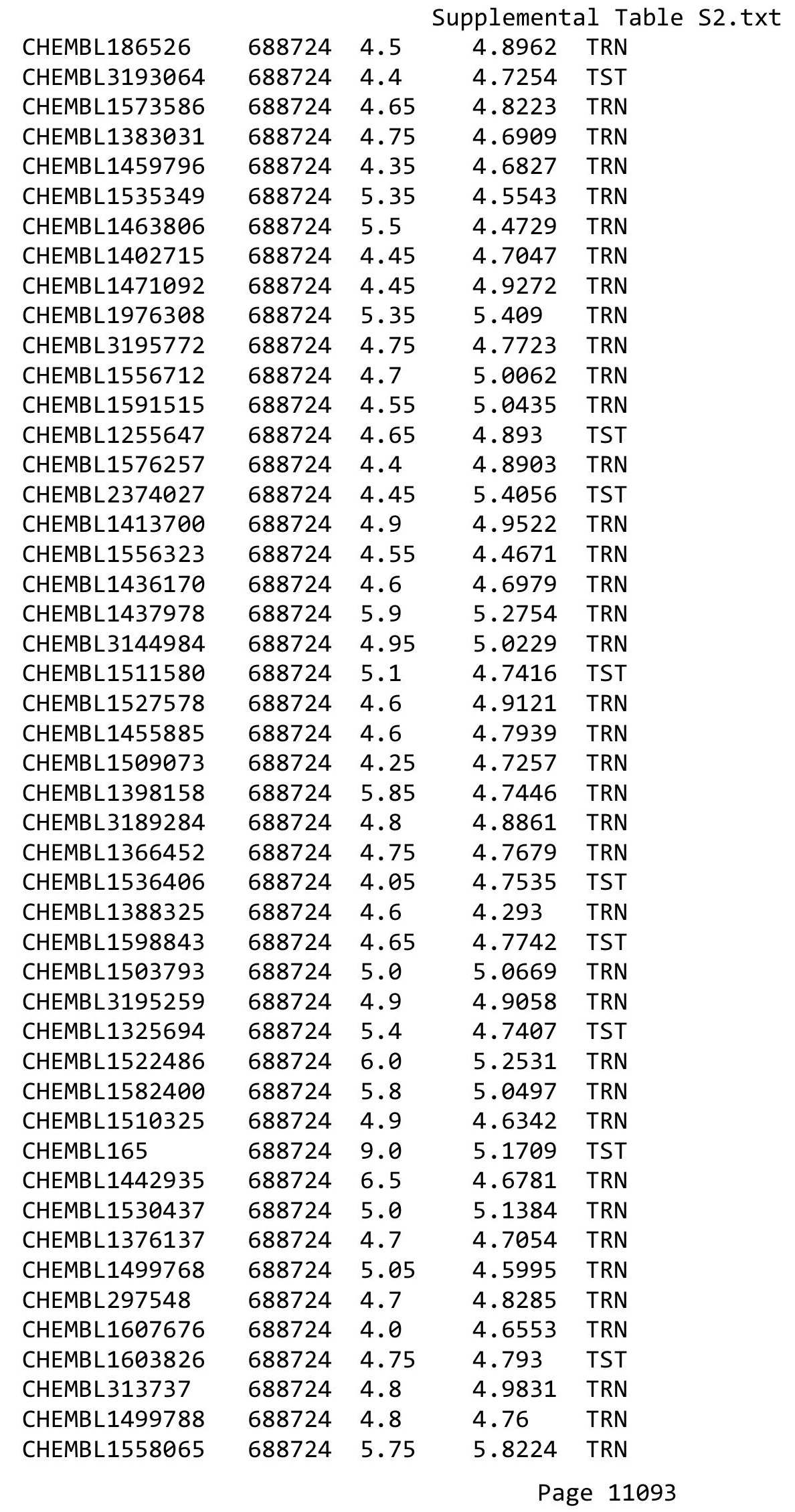




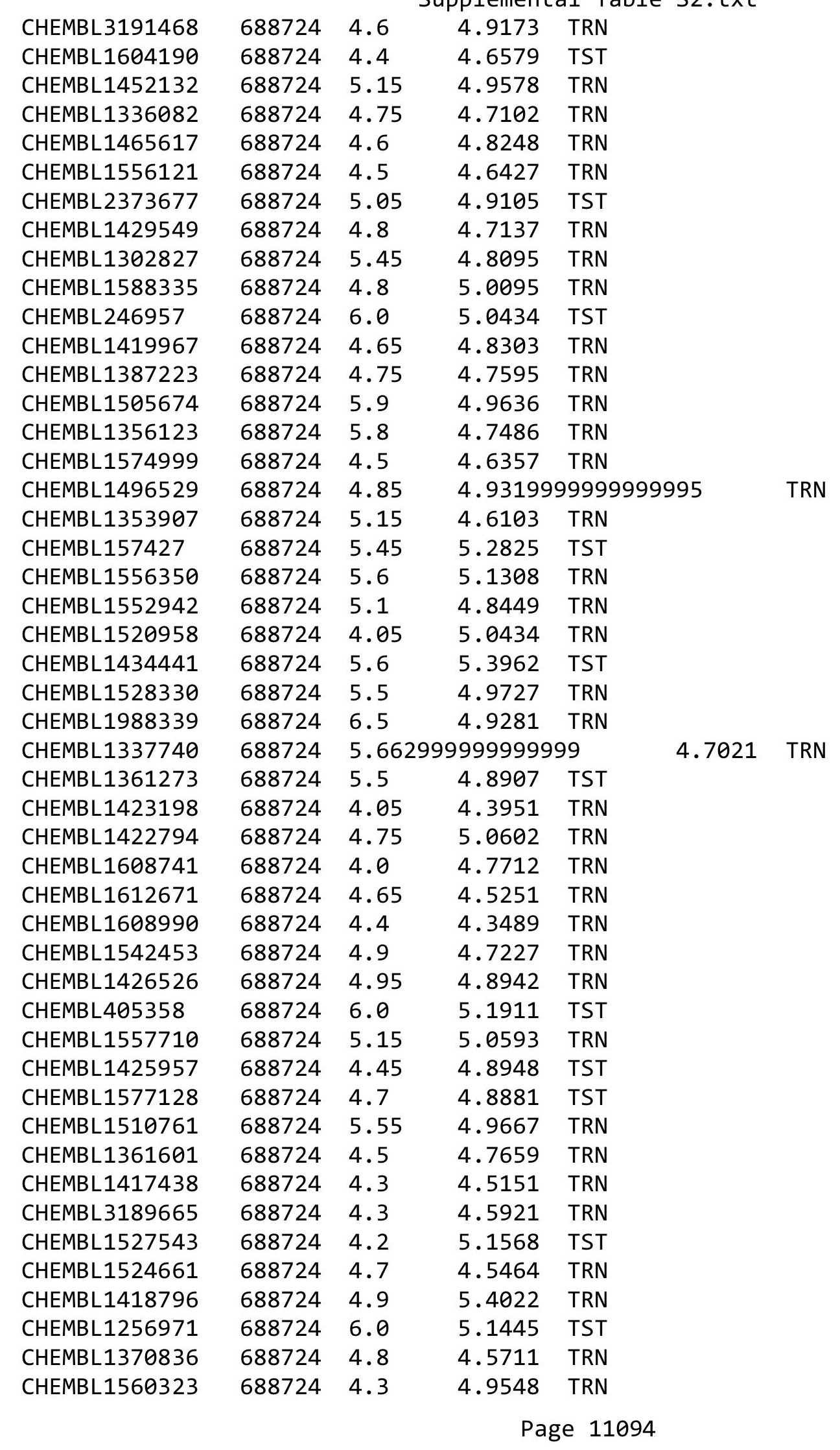




\begin{tabular}{|c|c|c|c|c|c|}
\hline \multirow{3}{*}{$\begin{array}{l}\text { CHEMBL1572356 } \\
\text { CHEMBL1989625 }\end{array}$} & \multirow{3}{*}{$\begin{array}{l}688724 \\
688724\end{array}$} & \multicolumn{4}{|c|}{ Supplemental Table S2.txt } \\
\hline & & 4.85 & \multicolumn{2}{|c|}{5.287999999999999} & TRN \\
\hline & & 4.35 & 4.7728 & TRN & \\
\hline CHEMBL1323512 & 688724 & 4.1 & 5.3122 & TST & \\
\hline CHEMBL1389248 & 688724 & 4.7 & 4.7951 & TST & \\
\hline CHEMBL1566078 & 688724 & 4.1 & 4.6162 & TRN & \\
\hline CHEMBL1359181 & 688724 & 6.0 & 5.2045 & TRN & \\
\hline CHEMBL240524 & 688724 & 6.25 & 5.3315 & TRN & \\
\hline CHEMBL1579269 & 688724 & 4.4 & 4.7674 & TRN & \\
\hline CHEMBL1527898 & 688724 & 5.65 & 4.8614 & TRN & \\
\hline CHEMBL1353481 & 688724 & 5.65 & 5.0653 & TST & \\
\hline CHEMBL1406510 & 688724 & 4.25 & 4.2856 & TRN & \\
\hline CHEMBL1604218 & 688724 & 4.65 & 4.8758 & TRN & \\
\hline CHEMBL1580036 & 688724 & 4.4 & 4.7256 & TRN & \\
\hline CHEMBL1395183 & 688724 & 4.25 & 4.9851 & TRN & \\
\hline CHEMBL1606429 & 688724 & 5.0 & 5.0547 & TRN & \\
\hline CHEMBL1570920 & 688724 & 4.7 & 4.6688 & TST & \\
\hline CHEMBL1425058 & 688724 & 5.8 & 4.6903 & TST & \\
\hline CHEMBL1496055 & 688724 & 4.4 & 4.6246 & TRN & \\
\hline CHEMBL1384036 & 688724 & 6.05 & 4.71 & TRN & \\
\hline CHEMBL1507544 & 688724 & 4.45 & 4.8705 & TST & \\
\hline CHEMBL1556726 & 688724 & 4.05 & 4.887 & TRN & \\
\hline CHEMBL1580276 & 688724 & 4.45 & 4.4372 & TRN & \\
\hline CHEMBL532412 & 688724 & 5.0 & 5.3243 & TST & \\
\hline CHEMBL1463400 & 688724 & 5.05 & 4.9474 & TRN & \\
\hline CHEMBL1602142 & 688724 & 4.55 & 4.8601 & TST & \\
\hline CHEMBL162783 & 688724 & 5.0 & 5.6507 & TST & \\
\hline CHEMBL1331525 & 688724 & 4.35 & 4.7728 & TRN & \\
\hline CHEMBL3211356 & 688724 & 4.25 & 5.0679 & TRN & \\
\hline CHEMBL1494599 & 688724 & 5.6 & 4.8195 & TRN & \\
\hline CHEMBL1305998 & 688724 & 4.25 & 4.6479 & TST & \\
\hline CHEMBL1415795 & 688724 & 4.4 & 4.6379 & TRN & \\
\hline CHEMBL1411396 & 688724 & 4.6 & 4.8625 & TRN & \\
\hline CHEMBL87706 & 688724 & 4.6 & 4.9004 & TRN & \\
\hline CHEMBL1504297 & 688724 & 6.35 & 4.8802 & TRN & \\
\hline CHEMBL1437864 & 688724 & 4.0 & 4.4111 & TRN & \\
\hline CHEMBL1488945 & 688724 & 4.25 & 4.7139 & TST & \\
\hline CHEMBL3190455 & 688724 & 5.05 & 5.025 & TRN & \\
\hline CHEMBL47986 & 688724 & 5.1 & 5.2408 & TST & \\
\hline CHEMBL1312547 & 688724 & 4.7 & 4.8079 & TST & \\
\hline CHEMBL1304044 & 688724 & 4.35 & 4.755 & TRN & \\
\hline CHEMBL3191045 & 688724 & 4.55 & 4.72 & TST & \\
\hline CHEMBL1361845 & 688724 & 5.0 & 4.5625 & TRN & \\
\hline CHEMBL3208987 & 688724 & 4.35 & 4.4198 & TRN & \\
\hline CHEMBL1472457 & 688724 & 4.1 & 4.9525 & TRN & \\
\hline CHEMBL1469698 & 688724 & 4.8 & 5.0594 & TRN & \\
\hline CHEMBL 3194407 & 688724 & 4.6 & 5.1745 & TRN & \\
\hline CHEMBL3196910 & 688724 & 4.4 & 4.4894 & TRN & \\
\hline CHEMBL1486522 & 688724 & 4.85 & 5.1737 & TRN & \\
\hline
\end{tabular}




\begin{tabular}{|c|c|c|c|c|c|}
\hline \multicolumn{6}{|c|}{ Supplemental Table S2.txt } \\
\hline CHEMBL1551368 & 688724 & 5.75 & 4.7653 & TRN & \\
\hline CHEMBL1476383 & 688724 & 4.45 & 5.29899 & 99999999995 & TST \\
\hline CHEMBL1493684 & 688724 & 4.35 & 4.4291 & TST & \\
\hline CHEMBL1491588 & 688724 & 5.1 & 4.6942 & TRN & \\
\hline CHEMBL1341295 & 688724 & 4.7 & 4.5949 & TRN & \\
\hline CHEMBL1977867 & 688724 & 4.5 & 5.3091 & TST & \\
\hline CHEMBL1491309 & 688724 & 4.75 & 4.6941 & TRN & \\
\hline CHEMBL1994935 & 688724 & 4.45 & 4.9277 & TRN & \\
\hline CHEMBL1479236 & 688724 & 4.7 & 4.7931 & TRN & \\
\hline CHEMBL3197679 & 688724 & 4.4 & 5.2689 & TRN & \\
\hline CHEMBL1332492 & 688724 & 5.05 & 5.1493 & TRN & \\
\hline CHEMBL1317770 & 688724 & 4.3 & 4.5217 & TRN & \\
\hline CHEMBL1991573 & 688724 & 5.55 & 4.9413 & TRN & \\
\hline CHEMBL1576212 & 688724 & 5.0 & 5.0603 & TST & \\
\hline CHEMBL1464003 & 688724 & 4.35 & 4.8413 & TRN & \\
\hline CHEMBL1418110 & 688724 & 4.7 & 5.1014 & TRN & \\
\hline CHEMBL1590048 & 688724 & 5.3 & 4.8715 & TST & \\
\hline CHEMBL1336692 & 688724 & 4.3 & 4.7526 & TST & \\
\hline CHEMBL1539727 & 688724 & 5.6 & 5.2696 & TRN & \\
\hline CHEMBL1400534 & 688724 & 4.45 & 4.6168 & TST & \\
\hline CHEMBL1540097 & 688724 & 4.75 & 5.003 & TST & \\
\hline CHEMBL3192842 & 688724 & 5.65 & 4.6624 & TRN & \\
\hline CHEMBL1493656 & 688724 & 4.35 & 4.891 & TRN & \\
\hline CHEMBL11608 & 688724 & 4.3 & 5.2419 & TST & \\
\hline CHEMBL1328886 & 688724 & 4.4 & 5.1196 & TRN & \\
\hline CHEMBL1430335 & 688724 & 4.7 & 4.7769 & TRN & \\
\hline CHEMBL1307141 & 688724 & 4.05 & 4.8221 & TRN & \\
\hline CHEMBL1403337 & 688724 & 4.0 & 4.6946 & TRN & \\
\hline CHEMBL1342766 & 688724 & 4.5 & 5.0961 & TST & \\
\hline CHEMBL3195208 & 688724 & 4.45 & 4.6503 & TRN & \\
\hline CHEMBL44 & 688724 & 5.05 & 5.4166 & TRN & \\
\hline CHEMBL313938 & 688724 & 6.0 & 4.875 & TST & \\
\hline CHEMBL1305810 & 688724 & 4.9 & 5.0761 & TST & \\
\hline CHEMBL1478187 & 688724 & 4.75 & 4.7826 & TST & \\
\hline CHEMBL1546392 & 688724 & 5.3 & 5.0804 & TRN & \\
\hline CHEMBL3191730 & 688724 & 4.3 & 5.527 & TRN & \\
\hline CHEMBL1604283 & 688724 & 6.0 & 5.4061 & TRN & \\
\hline CHEMBL1556273 & 688724 & 7.6003 & 4.82600 & 00000000005 & TST \\
\hline CHEMBL1352659 & 688724 & 4.55 & 4.6812 & TST & \\
\hline CHEMBL3189673 & 688724 & 4.05 & 4.7535 & TRN & \\
\hline CHEMBL1374860 & 688724 & 4.95 & 4.6418 & TRN & \\
\hline CHEMBL1380352 & 688724 & 4.55 & 4.1985 & TRN & \\
\hline CHEMBL1878162 & 688724 & 5.45 & 4.7767 & TST & \\
\hline CHEMBL1581216 & 688724 & 4.8 & 4.9615 & TST & \\
\hline CHEMBL1305100 & 688724 & 4.4 & 4.4344 & TRN & \\
\hline CHEMBL1342263 & 688724 & 5.0 & 4.5119 & TST & \\
\hline CHEMBL1369276 & 688724 & 4.45 & 4.8134 & TST & \\
\hline CHEMBL1513511 & 688724 & 4.4 & 4.4585 & TRN & \\
\hline
\end{tabular}




\begin{tabular}{|c|c|c|c|c|}
\hline \multicolumn{5}{|c|}{ Supplemental Table S2.txt } \\
\hline CHEMBL1411701 & 688724 & 4.8 & 4.9527 & TST \\
\hline CHEMBL1306181 & 688724 & 5.0 & 4.6095 & TRN \\
\hline CHEMBL1540637 & 688724 & 6.15 & 5.0458 & TRN \\
\hline CHEMBL1303711 & 688724 & 4.75 & 4.4814 & TRN \\
\hline CHEMBL1382394 & 688724 & 4.65 & 4.7838 & TST \\
\hline CHEMBL1432957 & 688724 & 4.75 & 5.0001 & TST \\
\hline CHEMBL1609799 & 688724 & 4.3 & 4.6251 & TRN \\
\hline CHEMBL137498 & 688724 & 6.15 & 4.752 & TST \\
\hline CHEMBL1698283 & 688724 & 4.6 & 4.7532 & TRN \\
\hline CHEMBL1544553 & 688724 & 4.7 & 5.1855 & TST \\
\hline CHEMBL3193342 & 688724 & 4.6 & 4.6241 & TRN \\
\hline CHEMBL1471190 & 688724 & 4.95 & 4.4738 & TRN \\
\hline CHEMBL1501061 & 688724 & 4.75 & 5.3437 & TRN \\
\hline CHEMBL1299767 & 688724 & 4.8 & 4.8298 & TST \\
\hline CHEMBL1549719 & 688724 & 4.05 & 4.8107 & TST \\
\hline CHEMBL3191402 & 688724 & 4.4 & 4.7914 & TRN \\
\hline CHEMBL1590698 & 688724 & 4.25 & 4.4901 & TRN \\
\hline CHEMBL1412266 & 688724 & 4.0 & 4.4998 & TRN \\
\hline CHEMBL1389597 & 688724 & 4.3 & 4.4209 & TRN \\
\hline CHEMBL1404013 & 688724 & 4.3 & 4.8283 & TRN \\
\hline CHEMBL1340342 & 688724 & 5.5 & 4.9535 & TRN \\
\hline CHEMBL3199467 & 688724 & 5.65 & 5.4059 & TRN \\
\hline CHEMBL1313191 & 688724 & 4.6 & 4.9987 & TST \\
\hline CHEMBL1380326 & 688724 & 4.35 & 5.0288 & TRN \\
\hline CHEMBL1532448 & 688724 & 4.35 & 5.1424 & TST \\
\hline CHEMBL403317 & 688724 & 4.75 & 4.8511 & TST \\
\hline CHEMBL1536896 & 688724 & 5.45 & 5.0115 & TRN \\
\hline CHEMBL1976049 & 688724 & 5.5 & 5.0522 & TRN \\
\hline CHEMBL426123 & 688724 & 4.8 & 4.8111 & TST \\
\hline CHEMBL1546502 & 688724 & 4.8 & 4.7249 & TRN \\
\hline CHEMBL1343705 & 688724 & 4.85 & 4.9101 & TST \\
\hline CHEMBL1549453 & 688724 & 4.65 & 4.908 & TRN \\
\hline CHEMBL1434377 & 688724 & 5.0 & 4.3115 & TRN \\
\hline CHEMBL1341315 & 688724 & 4.5 & 4.5717 & TRN \\
\hline CHEMBL1585364 & 688724 & 4.6 & 5.3009 & TST \\
\hline CHEMBL1521553 & 688724 & 5.1 & 5.2754 & TRN \\
\hline CHEMBL1456574 & 688724 & 5.65 & 4.8202 & TRN \\
\hline CHEMBL1404512 & 688724 & 4.15 & 4.8531 & TRN \\
\hline CHEMBL3196561 & 688724 & 6.0 & 5.2129 & TRN \\
\hline CHEMBL3190720 & 688724 & 6.15 & 5.3274 & TRN \\
\hline CHEMBL1314114 & 688724 & 4.4 & 4.8176 & TRN \\
\hline CHEMBL1390226 & 688724 & 7.8013 & 5.0706 & TRN \\
\hline CHEMBL1478406 & 688724 & 4.45 & 4.5879 & TRN \\
\hline CHEMBL1488019 & 688724 & 4.3 & 4.5358 & TRN \\
\hline CHEMBL1369691 & 688724 & 4.9 & 5.0383 & TRN \\
\hline CHEMBL1405111 & 688724 & 5.0 & 4.6277 & TRN \\
\hline CHEMBL1448726 & 688724 & 4.1 & 4.4186 & TRN \\
\hline CHEMBL 85728 & 688724 & 4.45 & 4.7101 & TST \\
\hline
\end{tabular}




\begin{tabular}{|c|c|c|c|c|c|}
\hline \multicolumn{6}{|c|}{ Supplemental Table S2.txt } \\
\hline CHEMBL1408115 & 688724 & 6.05 & 5.5386 & TRN & \\
\hline CHEMBL1443822 & 688724 & 4.35 & 4.9851 & TRN & \\
\hline CHEMBL1585488 & 688724 & 6.1 & 5.0612 & TRN & \\
\hline CHEMBL1434547 & 688724 & 4.55 & 4.8242 & TRN & \\
\hline CHEMBL1517793 & 688724 & 4.7 & 5.1616 & TST & \\
\hline CHEMBL1458899 & 688724 & 4.9 & 4.5121 & TRN & \\
\hline CHEMBL 28626 & 688724 & 6.7001 & 5.5978 & TRN & \\
\hline CHEMBL1488492 & 688724 & 4.45 & 4.4954 & TRN & \\
\hline CHEMBL1430336 & 688724 & 4.3 & 4.9407 & TRN & \\
\hline CHEMBL1540491 & 688724 & 4.7 & 4.5391 & TRN & \\
\hline CHEMBL 3207880 & 688724 & 5.0 & 4.7081 & TRN & \\
\hline CHEMBL1577509 & 688724 & 4.8 & 4.9079 & TRN & \\
\hline CHEMBL3191380 & 688724 & 4.4 & 4.9593 & TST & \\
\hline CHEMBL1410089 & 688724 & 4.7 & 4.8034 & TRN & \\
\hline CHEMBL1415521 & 688724 & 4.8 & 4.4926 & TRN & \\
\hline CHEMBL1979432 & 688724 & 4.6 & 4.7454 & TRN & \\
\hline CHEMBL1465850 & 688724 & 4.75 & 4.5591 & TRN & \\
\hline CHEMBL1164301 & 688724 & 4.65 & 4.942 & TST & \\
\hline CHEMBL1310720 & 688724 & 4.65 & 4.5508 & TRN & \\
\hline CHEMBL48449 & 688724 & 4.65 & 5.4589 & TST & \\
\hline CHEMBL1299600 & 688724 & 4.95 & 4.7346 & TST & \\
\hline CHEMBL1605787 & 688724 & 4.45 & 4.9062 & TRN & \\
\hline CHEMBL491909 & 688724 & 4.55 & 4.5627 & TRN & \\
\hline CHEMBL1586432 & 688724 & 5.35 & 5.3591 & TRN & \\
\hline CHEMBL1328384 & 688724 & 4.9 & 5.1915 & TST & \\
\hline CHEMBL1325311 & 688724 & 4.4 & 4.7658 & TST & \\
\hline CHEMBL1492898 & 688724 & 4.85 & 4.8433 & TRN & \\
\hline CHEMBL1270504 & 688724 & 4.85 & 4.8273 & TRN & \\
\hline CHEMBL1428441 & 688724 & 4.15 & 4.6562 & TRN & \\
\hline CHEMBL1359749 & 688724 & 4.5 & 4.6625 & TST & \\
\hline CHEMBL1417117 & 688724 & 4.3 & 4.6851 & TRN & \\
\hline CHEMBL1965786 & 688724 & 4.9 & 4.8581 & TRN & \\
\hline CHEMBL1446450 & 688724 & 4.95 & 4.9564 & TRN & \\
\hline CHEMBL1334528 & 688724 & 4.8 & 4.8034 & TRN & \\
\hline CHEMBL1439600 & 688724 & 4.6 & 4.5466 & TRN & \\
\hline CHEMBL1497697 & 688724 & 5.65 & 4.8345 & TST & \\
\hline CHEMBL1382305 & 688724 & 5.05 & 4.8447 & TRN & \\
\hline CHEMBL1421728 & 688724 & 4.7 & 4.8785 & TRN & \\
\hline CHEMBL3213606 & 688724 & 4.75 & 5.1225 & TRN & \\
\hline CHEMBL1588023 & 688724 & 4.05 & 4.7921 & TRN & \\
\hline CHEMBL1330663 & 688724 & 4.45 & 4.4063 & TRN & \\
\hline CHEMBL1431650 & 688724 & 4.05 & 4.3861 & TRN & \\
\hline CHEMBL1513413 & 688724 & 4.95 & 4.5502 & TRN & \\
\hline CHEMBL1370221 & 688724 & 4.65 & 5.2564 & TRN & \\
\hline CHEMBL1468634 & 688724 & 5.1 & 4.7687 & TRN & \\
\hline CHEMBL1563714 & 688724 & 5.0 & 5.0705 & TRN & \\
\hline CHEMBL1453441 & 688724 & 4.25 & 4.57600 & 00000000005 & TRN \\
\hline CHEMBL1597993 & 688724 & 4.65 & 5.24299 & 9999999999 & TST \\
\hline & & & & 1109 & \\
\hline
\end{tabular}




\begin{tabular}{|c|c|c|c|c|}
\hline & & & pplemen & $n^{2}$ \\
\hline CHEMBL1603147 & 688724 & 4.85 & 4.7862 & TRN \\
\hline CHEMBL1394038 & 688724 & 4.4 & 5.0002 & TST \\
\hline CHEMBL1496325 & 688724 & 4.5 & 4.6869 & TST \\
\hline CHEMBL1581471 & 688724 & 4.65 & 4.9083 & TRN \\
\hline CHEMBL1408612 & 688724 & 4.05 & 4.4581 & TRN \\
\hline CHEMBL1470675 & 688724 & 4.8 & 4.7294 & TST \\
\hline CHEMBL3191593 & 688724 & 4.65 & 4.8006 & TRN \\
\hline CHEMBL1509671 & 688724 & 4.85 & 4.891 & TRN \\
\hline CHEMBL 3209497 & 688724 & 4.65 & 4.7577 & TST \\
\hline CHEMBL1581350 & 688724 & 5.05 & 4.5173 & TRN \\
\hline CHEMBL3193203 & 688724 & 5.0 & 4.6048 & TRN \\
\hline CHEMBL1448160 & 688724 & 4.1 & 4.6374 & TRN \\
\hline CHEMBL1372738 & 688724 & 4.3 & 4.6129 & TRN \\
\hline CHEMBL3197431 & 688724 & 5.5 & 4.8056 & TRN \\
\hline CHEMBL1498582 & 688724 & 5.8 & 4.7098 & TST \\
\hline CHEMBL1395311 & 688724 & 5.45 & 4.9077 & TRN \\
\hline CHEMBL1364831 & 688724 & 4.7 & 4.4094 & TRN \\
\hline CHEMBL1471492 & 688724 & 4.6 & 4.7572 & TRN \\
\hline CHEMBL1410696 & 688724 & 4.85 & 4.7267 & TRN \\
\hline CHEMBL1589093 & 688724 & 5.2 & 4.503 & TST \\
\hline CHEMBL1569592 & 688724 & 6.0 & 4.6553 & TRN \\
\hline CHEMBL1365263 & 688724 & 4.9 & 5.3863 & TRN \\
\hline CHEMBL1497196 & 688724 & 4.65 & 5.1858 & TRN \\
\hline CHEMBL1592542 & 688724 & 6.0 & 5.1618 & TST \\
\hline CHEMBL1348173 & 688724 & 4.1 & 4.8425 & TRN \\
\hline CHEMBL3199148 & 688724 & 4.5 & 4.66 & TST \\
\hline CHEMBL1545332 & 688724 & 4.5 & 4.6737 & TRN \\
\hline CHEMBL1312308 & 688724 & 5.6 & 5.2426 & TRN \\
\hline CHEMBL1448168 & 688724 & 4.4 & 4.7808 & TST \\
\hline CHEMBL1522554 & 688724 & 4.75 & 4.7214 & TRN \\
\hline CHEMBL366861 & 688724 & 4.4 & 5.0846 & TRN \\
\hline CHEMBL1494334 & 688724 & 4.75 & 4.6084 & TRN \\
\hline CHEMBL1557648 & 688724 & 5.75 & 5.5221 & TRN \\
\hline CHEMBL1513845 & 688724 & 6.0 & 5.3841 & TRN \\
\hline CHEMBL1718398 & 688724 & 6.6 & 5.647 & TST \\
\hline CHEMBL1510319 & 688724 & 5.0 & 4.8841 & TRN \\
\hline CHEMBL1474304 & 688724 & 4.3 & 4.5747 & TRN \\
\hline CHEMBL1605187 & 688724 & 4.75 & 4.7506 & TRN \\
\hline CHEMBL1394603 & 688724 & 4.45 & 4.5705 & TRN \\
\hline CHEMBL1553721 & 688724 & 5.5 & 5.5139 & TRN \\
\hline CHEMBL1461960 & 688724 & 5.35 & 5.3604 & TRN \\
\hline CHEMBL1424913 & 688724 & 6.0 & 5.1015 & TRN \\
\hline CHEMBL1486702 & 688724 & 6.4 & 4.8105 & TRN \\
\hline CHEMBL1542263 & 688724 & 4.65 & 5.1216 & TRN \\
\hline CHEMBL1529276 & 688724 & 4.85 & 5.0886 & TRN \\
\hline CHEMBL1497492 & 688724 & 4.95 & 4.9777 & TRN \\
\hline CHEMBL1386550 & 688724 & 4.3 & 5.0376 & TST \\
\hline CHEMBL 261491 & 688724 & 4.8 & 5.1481 & TRN \\
\hline
\end{tabular}




\begin{tabular}{|c|c|c|c|c|}
\hline \multicolumn{5}{|c|}{ Supplemental Table } \\
\hline CHEMBL1364573 & 688724 & 5.05 & 4.5614 & TST \\
\hline CHEMBL1339157 & 688724 & 5.55 & 4.9909 & TRN \\
\hline CHEMBL1594138 & 688724 & 4.55 & 4.9175 & TRN \\
\hline CHEMBL1576814 & 688724 & 4.55 & 4.8857 & TRN \\
\hline CHEMBL1503173 & 688724 & 4.95 & 4.7883 & TRN \\
\hline CHEMBL1463665 & 688724 & 5.35 & 4.6916 & TRN \\
\hline CHEMBL1581048 & 688724 & 4.45 & 5.2606 & TRN \\
\hline CHEMBL3197089 & 688724 & 4.25 & 4.5963 & TRN \\
\hline CHEMBL1561903 & 688724 & 4.4 & 4.6844 & TRN \\
\hline CHEMBL1493199 & 688724 & 4.45 & 4.6409 & TST \\
\hline CHEMBL1967105 & 688724 & 4.5 & 5.2255 & TRN \\
\hline CHEMBL1302102 & 688724 & 4.45 & 5.3271 & TRN \\
\hline CHEMBL1602895 & 688724 & 4.65 & 4.485 & TRN \\
\hline CHEMBL1339394 & 688724 & 4.05 & 4.7767 & TRN \\
\hline CHEMBL1565252 & 688724 & 4.4 & 4.5698 & TST \\
\hline CHEMBL1576749 & 688724 & 5.0 & 5.1334 & TRN \\
\hline CHEMBL1504590 & 688724 & 4.4 & 5.1288 & TRN \\
\hline CHEMBL1601394 & 688724 & 4.7 & 5.2142 & TRN \\
\hline CHEMBL312535 & 688724 & 4.9 & 5.1792 & TRN \\
\hline CHEMBL1364176 & 688724 & 4.35 & 4.8408 & TRN \\
\hline CHEMBL1362864 & 688724 & 5.5 & 4.6195 & TST \\
\hline CHEMBL1510349 & 688724 & 4.9 & 4.6409 & TRN \\
\hline CHEMBL93655 & 688724 & 4.55 & 4.726 & TST \\
\hline CHEMBL1386056 & 688724 & 4.55 & 4.9588 & TRN \\
\hline CHEMBL 227937 & 688724 & 4.6 & 5.3728 & TST \\
\hline CHEMBL3195307 & 688724 & 4.85 & 4.6047 & TRN \\
\hline CHEMBL1434082 & 688724 & 4.4 & 4.669 & TRN \\
\hline CHEMBL1602854 & 688724 & 6.0 & 5.2368 & TST \\
\hline CHEMBL1548829 & 688724 & 5.5 & 5.5956 & TRN \\
\hline CHEMBL1507698 & 688724 & 4.05 & 4.5744 & TST \\
\hline CHEMBL1522538 & 688724 & 4.75 & 4.9337 & TST \\
\hline CHEMBL1598977 & 688724 & 4.4 & 4.5823 & TRN \\
\hline CHEMBL34450 & 688724 & 4.8 & 4.8355 & TST \\
\hline CHEMBL1321557 & 688724 & 6.15 & 4.4982 & TST \\
\hline CHEMBL1392552 & 688724 & 4.85 & 4.9476 & TRN \\
\hline CHEMBL1408574 & 688724 & 4.35 & 4.4428 & TST \\
\hline CHEMBL1570463 & 688724 & 4.75 & 4.865 & TRN \\
\hline CHEMBL3144936 & 688724 & 5.0 & 5.1417 & TRN \\
\hline CHEMBL1479394 & 688724 & 4.55 & 4.6795 & TRN \\
\hline CHEMBL118175 & 688724 & 5.1 & 4.9011 & TRN \\
\hline CHEMBL1093074 & 688724 & 4.95 & 4.8345 & TRN \\
\hline CHEMBL3192758 & 688724 & 4.5 & 5.1544 & TRN \\
\hline CHEMBL1518301 & 688724 & 4.9 & 4.6093 & TRN \\
\hline CHEMBL1335536 & 688724 & 5.0 & 4.7726 & TRN \\
\hline CHEMBL69612 & 688724 & 6.15 & 5.4002 & TST \\
\hline CHEMBL1484194 & 688724 & 5.0 & 5.1822 & TST \\
\hline CHEMBL1369562 & 688724 & 4.6 & 4.726 & TRN \\
\hline CHEMBL1375934 & 688724 & 4.85 & 4.3708 & TRN \\
\hline
\end{tabular}




\begin{tabular}{|c|c|c|c|c|c|}
\hline \multicolumn{6}{|c|}{ Supplemental Table s2.txt } \\
\hline CHEMBL1493193 & 688724 & 5.55 & 4.8406 & TRN & \\
\hline CHEMBL1528576 & 688724 & 4.25 & 4.4105 & TRN & \\
\hline CHEMBL1528450 & 688724 & 4.45 & 4.343 & TST & \\
\hline CHEMBL1597074 & 688724 & 5.35 & 5.087 & TRN & \\
\hline CHEMBL1510416 & 688724 & 4.3 & 4.867 & TRN & \\
\hline CHEMBL1306657 & 688724 & 4.05 & 4.5224 & TRN & \\
\hline CHEMBL1475563 & 688724 & 4.4 & 4.6488 & TRN & \\
\hline CHEMBL1575370 & 688724 & 4.9 & 4.5504 & TRN & \\
\hline CHEMBL487203 & 688724 & 6.25 & 5.2205 & TRN & \\
\hline CHEMBL1301115 & 688724 & 4.4 & 4.6386 & TRN & \\
\hline CHEMBL1439385 & 688724 & 4.5 & 4.9511 & TRN & \\
\hline CHEMBL1424468 & 688724 & 4.85 & 4.7101 & TRN & \\
\hline CHEMBL1567646 & 688724 & 5.85 & 4.6486 & TST & \\
\hline CHEMBL1563761 & 688724 & 4.1 & 4.5784 & TRN & \\
\hline CHEMBL1485984 & 688724 & 6.0 & 5.8934 & TRN & \\
\hline CHEMBL1611102 & 688724 & 5.6 & 5.5439 & TRN & \\
\hline CHEMBL1430317 & 688724 & 4.95 & 4.57600 & 00000000005 & TRN \\
\hline CHEMBL1480651 & 688724 & 4.3 & 4.823 & TRN & \\
\hline CHEMBL3191432 & 688724 & 4.9 & 5.1265 & TRN & \\
\hline CHEMBL1452939 & 688724 & 4.9 & 4.8986 & TRN & \\
\hline CHEMBL1528630 & 688724 & 7.2 & 4.9705 & TST & \\
\hline CHEMBL1322039 & 688724 & 4.4 & 4.7947 & TST & \\
\hline CHEMBL3198098 & 688724 & 4.4 & 4.59 & TRN & \\
\hline CHEMBL1357982 & 688724 & 4.55 & 4.5401 & TRN & \\
\hline CHEMBL1561587 & 688724 & 4.45 & 4.7224 & TRN & \\
\hline CHEMBL1533560 & 688724 & 5.55 & 5.0889 & TRN & \\
\hline CHEMBL3197824 & 688724 & 4.35 & 4.5597 & TRN & \\
\hline CHEMBL1601358 & 688724 & 4.4 & 4.8784 & TST & \\
\hline CHEMBL1305537 & 688724 & 5.35 & 4.5669 & TST & \\
\hline CHEMBL1333677 & 688724 & 5.05 & 4.9449 & TRN & \\
\hline CHEMBL1347535 & 688724 & 4.1 & 5.28100 & 0000000001 & TST \\
\hline CHEMBL1425964 & 688724 & 4.7 & 4.8471 & TRN & \\
\hline CHEMBL3191622 & 688724 & 4.6 & 4.6632 & TRN & \\
\hline CHEMBL1598805 & 688724 & 4.25 & 5.1211 & TST & \\
\hline CHEMBL1350168 & 688724 & 4.3 & 5.2255 & TST & \\
\hline CHEMBL1347493 & 688724 & 4.65 & 4.69 & TRN & \\
\hline CHEMBL1373135 & 688724 & 4.25 & 4.7269 & TRN & \\
\hline CHEMBL1306955 & 688724 & 4.25 & 4.8781 & TRN & \\
\hline CHEMBL1456501 & 688724 & 4.15 & 4.7326 & TRN & \\
\hline CHEMBL1603442 & 688724 & 4.4 & 5.2386 & TST & \\
\hline CHEMBL1382939 & 688724 & 5.0 & 4.8397 & TRN & \\
\hline CHEMBL8682 & 688724 & 4.15 & 4.4982 & TRN & \\
\hline CHEMBL1476174 & 688724 & 4.45 & 4.7562 & TST & \\
\hline CHEMBL45891 & 688724 & 4.4 & 5.3135 & TRN & \\
\hline CHEMBL1503513 & 688724 & 5.0 & 5.2752 & TRN & \\
\hline CHEMBL1331957 & 688724 & 4.2 & 5.1929 & TRN & \\
\hline CHEMBL1460155 & 688724 & 5.15 & 5.71200 & 0000000001 & TRN \\
\hline CHEMBL1368727 & 688724 & 4.8 & 4.7589 & TRN & \\
\hline & & & & 11101 & \\
\hline
\end{tabular}




\begin{tabular}{|c|c|c|c|c|c|}
\hline \multicolumn{6}{|c|}{ Supplemental Table S2.txt } \\
\hline CHEMBL1583534 & 688724 & 4.7 & 4.8947 & TRN & \\
\hline CHEMBL1382483 & 688724 & 4.55 & 4.4286 & TRN & \\
\hline CHEMBL1401748 & 688724 & 4.35 & 4.5123 & TRN & \\
\hline CHEMBL1314256 & 688724 & 4.8 & 4.6349 & TRN & \\
\hline CHEMBL1380146 & 688724 & 4.65 & 4.4688 & TST & \\
\hline CHEMBL3197987 & 688724 & 4.35 & 4.4169 & TST & \\
\hline CHEMBL1473982 & 688724 & 5.6 & 4.6876 & TRN & \\
\hline CHEMBL1470056 & 688724 & 4.25 & 4.6648 & TST & \\
\hline CHEMBL1484885 & 688724 & 4.65 & 4.7048 & TRN & \\
\hline CHEMBL1452241 & 688724 & 4.3 & 4.4241 & TRN & \\
\hline CHEMBL3195713 & 688724 & 4.55 & 5.1062 & TRN & \\
\hline CHEMBL1388121 & 688724 & 4.85 & 4.7918 & TRN & \\
\hline CHEMBL1353227 & 688724 & 4.45 & 5.0186 & TRN & \\
\hline CHEMBL1345724 & 688724 & 4.3 & 4.9083 & TRN & \\
\hline CHEMBL1352200 & 688724 & 5.45 & 5.1603 & TRN & \\
\hline CHEMBL1505964 & 688724 & 4.6 & 4.9381 & TRN & \\
\hline CHEMBL1442537 & 688724 & 4.25 & 4.436 & TRN & \\
\hline CHEMBL3192796 & 688724 & 4.55 & 4.7403 & TRN & \\
\hline CHEMBL1459809 & 688724 & 4.75 & 4.9034 & TRN & \\
\hline CHEMBL1553064 & 688724 & 4.7 & 5.1138 & TRN & \\
\hline CHEMBL1384106 & 688724 & 4.4 & 5.0608 & TST & \\
\hline CHEMBL3144978 & 688724 & 4.8 & 5.2344 & TRN & \\
\hline CHEMBL1466165 & 688724 & 4.35 & $4.6160 e$ & 00000000005 & TRN \\
\hline CHEMBL1549267 & 688724 & 5.4 & 5.1804 & TST & \\
\hline CHEMBL1473893 & 688724 & 7.3002 & 5.501 & TRN & \\
\hline CHEMBL1583337 & 688724 & 4.9 & 5.0819 & TST & \\
\hline CHEMBL1463047 & 688724 & 4.0 & 5.0196 & TST & \\
\hline CHEMBL1543210 & 688724 & 4.2 & 4.7969 & TRN & \\
\hline CHEMBL3197887 & 688724 & 4.7 & 4.9529 & TRN & \\
\hline CHEMBL1448671 & 688724 & 4.85 & 4.6639 & TRN & \\
\hline CHEMBL1606104 & 688724 & 5.05 & 5.12799 & 9999999999 & TRN \\
\hline CHEMBL1998302 & 688724 & 5.45 & 5.0132 & TRN & \\
\hline CHEMBL1370230 & 688724 & 5.65 & 5.3349 & TRN & \\
\hline CHEMBL1348582 & 688724 & 6.25 & 5.5333 & TRN & \\
\hline CHEMBL1611199 & 688724 & 4.4 & 4.6051 & TRN & \\
\hline CHEMBL1372232 & 688724 & 4.4 & 4.831 & TRN & \\
\hline CHEMBL1538387 & 688724 & 4.1 & 4.5217 & TRN & \\
\hline CHEMBL1509367 & 688724 & 4.05 & 4.7436 & TRN & \\
\hline CHEMBL1600148 & 688724 & 4.45 & 4.6518 & TRN & \\
\hline CHEMBL1338419 & 688724 & 4.8 & 4.6691 & TRN & \\
\hline CHEMBL1494506 & 688724 & 5.4 & 5.0261 & TRN & \\
\hline CHEMBL1473062 & 688724 & 4.5 & 4.9222 & TRN & \\
\hline CHEMBL1605606 & 688724 & 4.2 & 4.6632 & TRN & \\
\hline CHEMBL1402031 & 688724 & 4.85 & 4.7682 & TRN & \\
\hline CHEMBL1965873 & 688724 & 4.95 & $4.7010 e$ & 00000000005 & TRN \\
\hline CHEMBL1495901 & 688724 & 6.9 & 5.1424 & TRN & \\
\hline CHEMBL1511333 & 688724 & 4.45 & 5.106 & TST & \\
\hline CHEMBL1457001 & 688724 & 5.3 & 4.9785 & TRN & \\
\hline
\end{tabular}




\begin{tabular}{|c|c|c|c|c|c|}
\hline \multicolumn{6}{|c|}{ Supplemental Table S2.txt } \\
\hline CHEMBL1594531 & 688724 & 4.5 & 4.4618 & TRN & \\
\hline CHEMBL1519665 & 688724 & 4.35 & 4.6257 & TRN & \\
\hline CHEMBL1401108 & 688724 & 4.55 & 4.4743 & TRN & \\
\hline CHEMBL 3194947 & 688724 & 4.3 & 4.5494 & TRN & \\
\hline CHEMBL1533459 & 688724 & 5.5 & 5.5299 & TRN & \\
\hline CHEMBL1316156 & 688724 & 4.4 & 4.6743 & TRN & \\
\hline CHEMBL1548109 & 688724 & 5.65 & 5.0351 & TST & \\
\hline CHEMBL1414318 & 688724 & 5.35 & 4.8171 & TRN & \\
\hline CHEMBL1601096 & 688724 & 5.5 & 4.5357 & TRN & \\
\hline CHEMBL1551543 & 688724 & 4.35 & 4.9302 & TST & \\
\hline CHEMBL1449391 & 688724 & 5.2 & 4.5407 & TRN & \\
\hline CHEMBL1322656 & 688724 & 4.8 & 4.7372 & TST & \\
\hline CHEMBL1531710 & 688724 & 4.25 & 4.6571 & TST & \\
\hline CHEMBL1492970 & 688724 & 4.25 & 4.8783 & TRN & \\
\hline CHEMBL1465197 & 688724 & 5.55 & 4.9944 & TRN & \\
\hline CHEMBL1602964 & 688724 & 5.2 & 5.1429 & TST & \\
\hline CHEMBL530049 & 688724 & 6.95 & 5.6074 & TST & \\
\hline CHEMBL1317098 & 688724 & 4.95 & 4.7536 & TRN & \\
\hline CHEMBL1320202 & 688724 & 4.25 & 4.6258 & TRN & \\
\hline CHEMBL1415724 & 688724 & 5.2 & 4.7962 & TRN & \\
\hline CHEMBL 3144995 & 688724 & 4.6 & 4.8805 & TRN & \\
\hline CHEMBL1537444 & 688724 & 5.15 & 5.026 & TRN & \\
\hline CHEMBL1318230 & 688724 & 4.8 & 4.4292 & TST & \\
\hline CHEMBL3199850 & 688724 & 6.25 & 4.8115 & TRN & \\
\hline CHEMBL1389870 & 688724 & 4.45 & 4.8911 & TST & \\
\hline CHEMBL1595409 & 688724 & 5.5 & 5.0471 & TRN & \\
\hline CHEMBL1602682 & 688724 & 4.8 & 4.7881 & TRN & \\
\hline CHEMBL1590181 & 688724 & 4.4 & 5.3121 & TRN & \\
\hline CHEMBL1310314 & 688724 & 4.75 & 4.7174 & TRN & \\
\hline CHEMBL1513119 & 688724 & 7.7496 & 5.3209 & TST & \\
\hline CHEMBL1401965 & 688724 & 4.1 & 4.3776 & TRN & \\
\hline CHEMBL1452858 & 688724 & 5.6 & 5.0919 & TRN & \\
\hline CHEMBL1396955 & 688724 & 4.8 & 4.6959 & TRN & \\
\hline CHEMBL171281 & 688724 & 4.45 & 5.5766 & TST & \\
\hline CHEMBL1371259 & 688724 & 4.0 & 4.8267 & TRN & \\
\hline CHEMBL1412388 & 688724 & 4.95 & 4.6278 & TRN & \\
\hline CHEMBL1524022 & 688724 & 4.8 & 4.86600 & 00000000005 & TST \\
\hline CHEMBL1606218 & 688724 & 5.3 & 4.8596 & TST & \\
\hline CHEMBL1526332 & 688724 & 4.65 & 4.6408 & TRN & \\
\hline CHEMBL1384956 & 688724 & 4.85 & 4.4311 & TRN & \\
\hline CHEMBL1423275 & 688724 & 4.55 & 4.9312 & TST & \\
\hline CHEMBL1432358 & 688724 & 7.8996 & 5.3967 & TRN & \\
\hline CHEMBL1566010 & 688724 & 4.5 & 4.7919 & TRN & \\
\hline CHEMBL1395025 & 688724 & 4.45 & 4.9273 & TRN & \\
\hline CHEMBL1307754 & 688724 & 4.95 & 4.8649 & TRN & \\
\hline CHEMBL1375115 & 688724 & 4.5 & 4.8873 & TST & \\
\hline CHEMBL1355537 & 688724 & 4.95 & 4.9713 & TRN & \\
\hline CHEMBL1606583 & 688724 & 5.4 & 5.7229 & TRN & \\
\hline
\end{tabular}




\begin{tabular}{|c|c|c|c|c|}
\hline & & & pplement & $\mathrm{a} \perp \mathrm{Ta}$ \\
\hline CHEMBL3392240 & 688724 & 5.0 & 5.0075 & TST \\
\hline CHEMBL1547392 & 688724 & 4.05 & 4.5596 & TST \\
\hline CHEMBL1528842 & 688724 & 5.1 & 5.0927 & TRN \\
\hline CHEMBL1386588 & 688724 & 4.9 & 4.8133 & TRN \\
\hline CHEMBL1334569 & 688724 & 4.0 & 4.9611 & TRN \\
\hline CHEMBL1381184 & 688724 & 4.65 & 4.7404 & TRN \\
\hline CHEMBL3190886 & 688724 & 4.85 & 4.8292 & TRN \\
\hline CHEMBL 3190748 & 688724 & 4.4 & 4.8112 & TRN \\
\hline CHEMBL1510956 & 688724 & 4.4 & 4.8394 & TRN \\
\hline CHEMBL3145185 & 688724 & 5.3 & 5.0802 & TRN \\
\hline CHEMBL1386955 & 688724 & 4.05 & 4.5548 & TRN \\
\hline CHEMBL1366461 & 688724 & 5.35 & 5.4194 & TRN \\
\hline CHEMBL1490212 & 688724 & 4.55 & 4.5766 & TRN \\
\hline CHEMBL1502153 & 688724 & 5.35 & 4.9884 & TRN \\
\hline CHEMBL1515918 & 688724 & 4.4 & 4.7148 & TRN \\
\hline CHEMBL1558234 & 688724 & 5.0 & 5.291 & TRN \\
\hline CHEMBL3190507 & 688724 & 4.6 & 5.0138 & TRN \\
\hline CHEMBL1305193 & 688724 & 4.05 & 4.4822 & TRN \\
\hline CHEMBL1452028 & 688724 & 5.55 & 4.4836 & TST \\
\hline CHEMBL1371277 & 688724 & 4.85 & 4.6858 & TST \\
\hline CHEMBL1348635 & 688724 & 5.05 & 4.5543 & TRN \\
\hline CHEMBL1471220 & 688724 & 4.45 & 4.8708 & TRN \\
\hline CHEMBL1598629 & 688724 & 4.1 & 4.8949 & TST \\
\hline CHEMBL1559841 & 688724 & 5.65 & 4.897 & TST \\
\hline CHEMBL1900654 & 688724 & 5.7 & 4.7278 & TRN \\
\hline CHEMBL1416049 & 688724 & 5.05 & 5.3176 & TST \\
\hline CHEMBL1459738 & 688724 & 4.25 & 4.3465 & TRN \\
\hline CHEMBL1510118 & 688724 & 5.0 & 4.6337 & TST \\
\hline CHEMBL3197408 & 688724 & 4.05 & 4.4373 & TRN \\
\hline CHEMBL1386380 & 688724 & 4.4 & 4.7242 & TST \\
\hline CHEMBL1434103 & 688724 & 4.0 & 4.6934 & TST \\
\hline CHEMBL1172911 & 688724 & 4.2 & 4.8509 & TRN \\
\hline CHEMBL1500598 & 688724 & 4.6 & 4.7089 & TRN \\
\hline CHEMBL1375264 & 688724 & 4.4 & 4.6358 & TRN \\
\hline CHEMBL1415494 & 688724 & 4.65 & 4.54 & TRN \\
\hline CHEMBL1592991 & 688724 & 4.25 & 4.3075 & TRN \\
\hline CHEMBL3193602 & 688724 & 4.9 & 5.0163 & TST \\
\hline CHEMBL1558034 & 688724 & 4.6 & 4.6314 & TRN \\
\hline CHEMBL1553129 & 688724 & 4.35 & 5.0784 & TST \\
\hline CHEMBL1333320 & 688724 & 4.35 & 4.9894 & TST \\
\hline CHEMBL1408747 & 688724 & 4.3 & 4.6952 & TRN \\
\hline CHEMBL1565799 & 688724 & 5.2 & 4.5413 & TRN \\
\hline CHEMBL1430961 & 688724 & 4.95 & 4.8882 & TRN \\
\hline CHEMBL1424801 & 688724 & 4.65 & 4.9066 & TRN \\
\hline CHEMBL1545553 & 688724 & 5.15 & 5.1855 & TRN \\
\hline CHEMBL1434655 & 688724 & 4.4 & 4.442 & TRN \\
\hline CHEMBL1320432 & 688724 & 4.8 & 4.9579 & TST \\
\hline CHEMBL1549345 & 688724 & 4.5 & 4.677 & TST \\
\hline
\end{tabular}




\begin{tabular}{|c|c|c|c|c|}
\hline \multicolumn{5}{|c|}{ Supplemental Table S2.txt } \\
\hline CHEMBL1552990 & 688724 & 4.05 & 4.9293 & TRN \\
\hline CHEMBL1355667 & 688724 & 4.4 & 4.6779 & TRN \\
\hline CHEMBL1864436 & 688724 & 5.45 & 4.9503 & TST \\
\hline CHEMBL1585588 & 688724 & 5.45 & 4.9327 & TRN \\
\hline CHEMBL1400958 & 688724 & 6.25 & 5.1901 & TST \\
\hline CHEMBL1600756 & 688724 & 4.6 & 4.913 & TRN \\
\hline CHEMBL1555840 & 688724 & 5.3 & 4.8076 & TRN \\
\hline CHEMBL1432438 & 688724 & 4.5 & 4.5571 & TRN \\
\hline CHEMBL1578446 & 688724 & 4.5 & 4.8927 & TRN \\
\hline CHEMBL1305581 & 688724 & 4.8 & 4.6569 & TRN \\
\hline CHEMBL1457287 & 688724 & 4.85 & 4.7512 & TRN \\
\hline CHEMBL1456555 & 688724 & 5.0 & 4.5574 & TRN \\
\hline CHEMBL1321359 & 688724 & 4.65 & 4.5115 & TRN \\
\hline CHEMBL1299534 & 688724 & 4.5 & 4.968 & TRN \\
\hline CHEMBL1326444 & 688724 & 4.35 & 4.8583 & TST \\
\hline CHEMBL1585855 & 688724 & 4.35 & 4.935 & TRN \\
\hline CHEMBL1354473 & 688724 & 4.05 & 4.4048 & TRN \\
\hline CHEMBL1305666 & 688724 & 4.4 & 4.2825 & TRN \\
\hline CHEMBL1596132 & 688724 & 5.45 & 4.5045 & TRN \\
\hline CHEMBL1349885 & 688724 & 5.4 & 5.1494 & TRN \\
\hline CHEMBL1369825 & 688724 & 6.4 & 5.1056 & TST \\
\hline CHEMBL 3193592 & 688724 & 5.0 & 4.4919 & TRN \\
\hline CHEMBL1582111 & 688724 & 4.8 & 5.1706 & TST \\
\hline CHEMBL 3207643 & 688724 & 4.65 & 4.8924 & TRN \\
\hline CHEMBL1565280 & 688724 & 4.85 & 4.4837 & TRN \\
\hline CHEMBL1577184 & 688724 & 4.65 & 4.6088 & TRN \\
\hline CHEMBL416615 & 688724 & 6.8499 & 5.6193 & TST \\
\hline CHEMBL1444094 & 688724 & 4.4 & 4.9444 & TRN \\
\hline CHEMBL1491816 & 688724 & 5.05 & 5.16 & TST \\
\hline CHEMBL1549644 & 688724 & 4.0 & 4.785 & TST \\
\hline CHEMBL1412089 & 688724 & 4.65 & 4.4386 & TRN \\
\hline CHEMBL1467360 & 688724 & 4.55 & 4.8144 & TRN \\
\hline CHEMBL528734 & 688724 & 5.05 & 4.6519 & TST \\
\hline CHEMBL 3235881 & 688724 & 4.7 & 4.631 & TRN \\
\hline CHEMBL1520414 & 688724 & 6.0 & 4.6576 & TRN \\
\hline CHEMBL1427505 & 688724 & 5.6 & 5.1675 & TRN \\
\hline CHEMBL1361258 & 688724 & 4.05 & 4.8385 & TST \\
\hline CHEMBL3195391 & 688724 & 4.55 & 4.6991 & TRN \\
\hline CHEMBL1381723 & 688724 & 4.9 & 4.4858 & TRN \\
\hline CHEMBL106437 & 688724 & 6.05 & 5.0505 & TRN \\
\hline CHEMBL1360886 & 688724 & 4.05 & 4.7504 & TRN \\
\hline CHEMBL1356143 & 688724 & 4.45 & 4.8146 & TRN \\
\hline CHEMBL1587606 & 688724 & 4.8 & 4.8962 & TRN \\
\hline CHEMBL1613508 & 688724 & 6.25 & 5.2233 & TST \\
\hline CHEMBL1592671 & 688724 & 5.45 & 4.7479 & TRN \\
\hline CHEMBL3190149 & 688724 & 4.4 & 5.051 & TRN \\
\hline CHEMBL1430166 & 688724 & 5.55 & 5.0367 & TRN \\
\hline CHEMBL1256957 & 688724 & 6.05 & 4.8419 & TRN \\
\hline
\end{tabular}




\begin{tabular}{|c|c|c|c|c|c|}
\hline \multicolumn{6}{|c|}{ Supplemental Table S2.txt } \\
\hline CHEMBL1449916 & 688724 & 5.2 & 5.2446 & TRN & \\
\hline CHEMBL 2001294 & 688724 & 5.5 & 5.2066 & TST & \\
\hline CHEMBL1568345 & 688724 & 4.5 & 4.5792 & TST & \\
\hline CHEMBL1351287 & 688724 & 4.05 & 4.5624 & TST & \\
\hline CHEMBL1495531 & 688724 & 4.4 & 4.9883 & TST & \\
\hline CHEMBL1366438 & 688724 & 4.55 & 4.902 & TRN & \\
\hline CHEMBL1389051 & 688724 & 4.7 & 4.9413 & TST & \\
\hline CHEMBL1566177 & 688724 & 4.85 & 4.862 & TRN & \\
\hline CHEMBL1546228 & 688724 & 5.0 & 4.9942 & TST & \\
\hline CHEMBL191066 & 688724 & 4.3 & 5.0087 & TST & \\
\hline CHEMBL1382537 & 688724 & 4.65 & 4.89 & TRN & \\
\hline CHEMBL1416886 & 688724 & 4.2 & 5.1619 & TST & \\
\hline CHEMBL3194473 & 688724 & 4.55 & 4.8849 & TRN & \\
\hline CHEMBL1402330 & 688724 & 5.3 & 4.5419 & TRN & \\
\hline CHEMBL1503083 & 688724 & 4.55 & 4.4767 & TRN & \\
\hline CHEMBL1516758 & 688724 & 5.85 & 5.3441 & TST & \\
\hline CHEMBL1587644 & 688724 & 4.05 & 4.6507 & TRN & \\
\hline CHEMBL1406412 & 688724 & 4.05 & 4.8878 & TST & \\
\hline CHEMBL1452056 & 688724 & 4.1 & 4.8733 & TRN & \\
\hline CHEMBL1433052 & 688724 & 5.7 & 4.8487 & TRN & \\
\hline CHEMBL1327977 & 688724 & 4.6 & 4.4983 & TRN & \\
\hline CHEMBL3194340 & 688724 & 4.3 & 4.873 & TRN & \\
\hline CHEMBL1611544 & 688724 & 4.15 & 4.3624 & TRN & \\
\hline CHEMBL1508594 & 688724 & 5.0 & 4.9776 & TRN & \\
\hline CHEMBL1471193 & 688724 & 4.45 & 4.6205 & TRN & \\
\hline CHEMBL1342144 & 688724 & 4.75 & 4.4524 & TRN & \\
\hline CHEMBL2004916 & 688724 & 4.55 & 4.8085 & TRN & \\
\hline CHEMBL1382443 & 688724 & 5.45 & 4.979 & TRN & \\
\hline CHEMBL3196772 & 688724 & 4.85 & 5.1749 & TRN & \\
\hline CHEMBL1975975 & 688724 & 4.3 & 4.3897 & TRN & \\
\hline CHEMBL1474435 & 688724 & 5.85 & 4.8729 & TST & \\
\hline CHEMBL1319655 & 688724 & 5.5 & 4.8081 & TRN & \\
\hline CHEMBL1453720 & 688724 & 5.7 & 4.6861 & TRN & \\
\hline CHEMBL1328641 & 688724 & 4.3 & 4.5798 & TST & \\
\hline CHEMBL1573569 & 688724 & 5.0 & 4.80699 & 99999999995 & TRN \\
\hline CHEMBL1570915 & 688724 & 4.75 & 4.5497 & TRN & \\
\hline CHEMBL1544051 & 688724 & 4.4 & 4.9694 & TST & \\
\hline CHEMBL1417212 & 688724 & 5.5 & 4.8372 & TRN & \\
\hline CHEMBL1415205 & 688724 & 5.0 & 4.9284 & TST & \\
\hline CHEMBL1511638 & 688724 & 4.05 & 4.6726 & TRN & \\
\hline CHEMBL1544136 & 688724 & 4.85 & 4.9031 & TRN & \\
\hline CHEMBL36654 & 688724 & 4.1 & 5.0937 & TST & \\
\hline CHEMBL1372880 & 688724 & 4.75 & 4.6982 & TRN & \\
\hline CHEMBL1533068 & 688724 & 4.25 & 4.8141 & TST & \\
\hline CHEMBL1404572 & 688724 & 4.6 & 5.1468 & TRN & \\
\hline CHEMBL1542886 & 688724 & 6.15 & 5.2371 & TRN & \\
\hline CHEMBL1343349 & 688724 & 4.95 & 4.5576 & TRN & \\
\hline CHEMBL 3145137 & 688724 & 5.55 & 5.1348 & TST & \\
\hline
\end{tabular}




\begin{tabular}{|c|c|c|c|c|}
\hline \multicolumn{5}{|c|}{ Supplemental Table S2.txt } \\
\hline CHEMBL1587781 & 688724 & 6.0 & 5.3887 & TRN \\
\hline CHEMBL1275655 & 688724 & 6.0 & 5.2032 & TRN \\
\hline CHEMBL1606809 & 688724 & 4.45 & 4.7167 & TRN \\
\hline CHEMBL1365553 & 688724 & 4.85 & 4.9166 & TRN \\
\hline CHEMBL1482801 & 688724 & 5.05 & 4.5005 & TRN \\
\hline CHEMBL398233 & 688724 & 6.05 & 4.7914 & TRN \\
\hline CHEMBL1505129 & 688724 & 4.95 & 4.6998 & TRN \\
\hline CHEMBL1345999 & 688724 & 4.95 & 4.6603 & TRN \\
\hline CHEMBL1589029 & 688724 & 5.45 & 5.1537 & TRN \\
\hline CHEMBL1485713 & 688724 & 4.65 & 4.3494 & TRN \\
\hline CHEMBL1353712 & 688724 & 4.45 & 4.6125 & TST \\
\hline CHEMBL3197771 & 688724 & 4.7 & 4.8434 & TRN \\
\hline CHEMBL1398077 & 688724 & 4.45 & 4.7327 & TRN \\
\hline CHEMBL1567571 & 688724 & 4.6 & 4.923 & TRN \\
\hline CHEMBL1486513 & 688724 & 4.25 & 4.8397 & TST \\
\hline CHEMBL1530869 & 688724 & 4.05 & 4.4845 & TRN \\
\hline CHEMBL1478949 & 688724 & 5.0 & 4.8856 & TST \\
\hline CHEMBL1582364 & 688724 & 5.25 & 4.632 & TST \\
\hline CHEMBL1388951 & 688724 & 4.9 & 4.4764 & TRN \\
\hline CHEMBL1373985 & 688724 & 4.65 & 5.1011 & TST \\
\hline CHEMBL1539235 & 688724 & 4.65 & 4.6036 & TRN \\
\hline CHEMBL270299 & 688724 & 6.0 & 5.2162 & TRN \\
\hline CHEMBL1435896 & 688724 & 4.65 & 4.7905 & TRN \\
\hline CHEMBL1234781 & 688724 & 4.5 & 4.7139 & TRN \\
\hline CHEMBL1394741 & 688724 & 4.05 & 4.7817 & TRN \\
\hline CHEMBL1731995 & 688724 & 5.55 & 4.7407 & TRN \\
\hline CHEMBL1383267 & 688724 & 4.85 & 5.6456 & TRN \\
\hline CHEMBL1312356 & 688724 & 4.9 & 5.1712 & TRN \\
\hline CHEMBL1413400 & 688724 & 4.35 & 4.7937 & TRN \\
\hline CHEMBL1338362 & 688724 & 4.7 & 4.7176 & TRN \\
\hline CHEMBL8320 & 688724 & 4.75 & 4.9982 & TST \\
\hline CHEMBL 3207740 & 688724 & 4.8 & 4.9863 & TRN \\
\hline CHEMBL1443680 & 688724 & 4.05 & 4.7087 & TST \\
\hline CHEMBL1498393 & 688724 & 4.6 & 4.5714 & TRN \\
\hline CHEMBL1513050 & 688724 & 5.95 & 5.2487 & TST \\
\hline CHEMBL1597887 & 688724 & 4.05 & 4.3847 & TST \\
\hline CHEMBL1482346 & 688724 & 4.9 & 4.4737 & TRN \\
\hline CHEMBL3195091 & 688724 & 7.0 & 5.1897 & TRN \\
\hline CHEMBL1535285 & 688724 & 4.8 & 4.7382 & TRN \\
\hline CHEMBL1336572 & 688724 & 4.35 & 4.6613 & TRN \\
\hline CHEMBL1526099 & 688724 & 6.1 & 5.1104 & TRN \\
\hline CHEMBL1442760 & 688724 & 5.05 & 4.9313 & TRN \\
\hline CHEMBL1305034 & 688724 & 5.75 & 5.0396 & TRN \\
\hline CHEMBL1967566 & 688724 & 5.6 & 5.0342 & TRN \\
\hline CHEMBL1309493 & 688724 & 4.5 & 4.7418 & TRN \\
\hline CHEMBL3194056 & 688724 & 4.55 & 4.8292 & TST \\
\hline CHEMBL1324853 & 688724 & 4.05 & 5.0843 & TRN \\
\hline CHEMBL1347594 & 688724 & 4.9 & 4.5031 & TRN \\
\hline
\end{tabular}




\begin{tabular}{|c|c|c|c|c|c|}
\hline & & \multicolumn{4}{|c|}{ Supplemental Table s2.txt } \\
\hline CHEMBL1321993 & 688724 & 4.35 & 4.7991 & TRN & \\
\hline CHEMBL1473414 & 688724 & 4.5 & 4.8428 & TST & \\
\hline CHEMBL1299443 & 688724 & 4.5 & 4.6999 & TST & \\
\hline CHEMBL1571824 & 688724 & 5.0 & 5.0423 & TRN & \\
\hline CHEMBL1432276 & 688724 & 5.5 & 4.4473 & TRN & \\
\hline CHEMBL1466600 & 688724 & 4.35 & 4.4529 & TST & \\
\hline CHEMBL1343918 & 688724 & 4.45 & 4.8326 & TST & \\
\hline CHEMBL1307835 & 688724 & 5.0 & 5.1777 & TRN & \\
\hline CHEMBL1501986 & 688724 & 4.05 & 4.3718 & TRN & \\
\hline CHEMBL3195636 & 688724 & 4.85 & 4.6467 & TRN & \\
\hline CHEMBL1389059 & 688724 & 5.4 & 4.8158 & TRN & \\
\hline CHEMBL1594286 & 688724 & 4.3 & 4.6197 & TRN & \\
\hline CHEMBL1339203 & 688724 & 4.55 & 5.0149 & TST & \\
\hline CHEMBL1995204 & 688724 & 4.4 & 4.3734 & TRN & \\
\hline CHEMBL3198185 & 688724 & 4.95 & 5.0652 & TRN & \\
\hline CHEMBL1453985 & 688724 & 5.15 & 4.6359 & TST & \\
\hline CHEMBL1381627 & 688724 & 6.25 & 5.1087 & TRN & \\
\hline CHEMBL1612872 & 688724 & 5.55 & 5.3148 & TRN & \\
\hline CHEMBL1425432 & 688724 & 4.65 & 4.5408 & TST & \\
\hline CHEMBL1322516 & 688724 & 4.75 & 4.5466 & TRN & \\
\hline CHEMBL1325964 & 688724 & 4.4 & 4.4936 & TRN & \\
\hline CHEMBL3213142 & 688724 & 4.4 & 4.9042 & TRN & \\
\hline CHEMBL1518936 & 688724 & 5.9 & 5.0602 & TST & \\
\hline CHEMBL1555897 & 688724 & 4.1 & 4.7694 & TST & \\
\hline CHEMBL1497651 & 688724 & 6.25 & 4.9442 & TST & \\
\hline CHEMBL1373180 & 688724 & 4.15 & 4.6819 & TRN & \\
\hline CHEMBL1580759 & 688724 & 4.4 & 5.1419 & TRN & \\
\hline CHEMBL1605189 & 688724 & 5.75 & 4.73300 & 00000000005 & TST \\
\hline CHEMBL1438613 & 688724 & 4.85 & 4.7853 & TRN & \\
\hline CHEMBL1541341 & 688724 & 5.1 & 4.8413 & TRN & \\
\hline CHEMBL1491545 & 688724 & 4.45 & 4.4893 & TRN & \\
\hline CHEMBL470881 & 688724 & 6.0 & 4.9887 & TST & \\
\hline CHEMBL1531566 & 688724 & 4.9 & 4.655 & TST & \\
\hline CHEMBL3392033 & 688724 & 5.0 & 5.0159 & TRN & \\
\hline CHEMBL1398829 & 688724 & 4.0 & 4.5514 & TRN & \\
\hline CHEMBL1423002 & 688724 & 4.55 & 4.8912 & TRN & \\
\hline CHEMBL1469743 & 688724 & 5.0 & 4.7809 & TST & \\
\hline CHEMBL1533288 & 688724 & 4.6 & 5.0616 & TST & \\
\hline CHEMBL1448043 & 688724 & 4.3 & 4.6796 & TRN & \\
\hline CHEMBL1520309 & 688724 & 4.35 & 4.6148 & TRN & \\
\hline CHEMBL1450499 & 688724 & 4.35 & 5.1843 & TST & \\
\hline CHEMBL1328283 & 688724 & 4.8 & 4.6315 & TRN & \\
\hline CHEMBL1473003 & 688724 & 5.35 & 4.8536 & TST & \\
\hline CHEMBL1514680 & 688724 & 4.55 & 4.5936 & TRN & \\
\hline CHEMBL1552095 & 688724 & 4.45 & 4.8987 & TRN & \\
\hline CHEMBL1307861 & 688724 & 4.55 & 4.7578 & TRN & \\
\hline CHEMBL1407483 & 688724 & 5.4 & 5.0602 & TST & \\
\hline CHEMBL1988121 & 688724 & 6.25 & 5.2635 & TRN & \\
\hline
\end{tabular}




\begin{tabular}{|c|c|c|c|c|c|}
\hline \multicolumn{6}{|c|}{ Supplemental Table S2.txt } \\
\hline CHEMBL1322044 & 688724 & 4.3 & 4.626 & TST & \\
\hline CHEMBL1574019 & 688724 & 4.75 & 4.6957 & TRN & \\
\hline CHEMBL1461018 & 688724 & 5.0 & 5.0781 & TST & \\
\hline CHEMBL1487555 & 688724 & 5.15 & 5.1078 & TRN & \\
\hline CHEMBL1449156 & 688724 & 4.65 & 4.6619 & TRN & \\
\hline CHEMBL1563769 & 688724 & 4.05 & 4.6457 & TST & \\
\hline CHEMBL1419057 & 688724 & 6.25 & 5.26399 & 9999999999 & TRN \\
\hline CHEMBL141689 & 688724 & 4.3 & 4.4204 & TRN & \\
\hline CHEMBL1549883 & 688724 & 5.15 & 4.4891 & TRN & \\
\hline CHEMBL1440487 & 688724 & 5.05 & 4.7903 & TRN & \\
\hline CHEMBL563294 & 688724 & 5.15 & 4.8317 & TRN & \\
\hline CHEMBL1580710 & 688724 & 4.85 & 4.8374 & TST & \\
\hline CHEMBL1554098 & 688724 & 5.95 & 5.04 & TST & \\
\hline CHEMBL1460025 & 688724 & 4.35 & 4.6633 & TRN & \\
\hline CHEMBL1965254 & 688724 & 5.05 & 5.0493 & TST & \\
\hline CHEMBL1482010 & 688724 & 4.75 & 4.614 & TRN & \\
\hline CHEMBL1430882 & 688724 & 4.9 & 4.8279 & TST & \\
\hline CHEMBL1491947 & 688724 & 5.4 & 5.189 & TST & \\
\hline CHEMBL1308694 & 688724 & 4.45 & 4.9445 & TRN & \\
\hline CHEMBL1554815 & 688724 & 4.4 & 4.7674 & TRN & \\
\hline CHEMBL1347423 & 688724 & 4.6 & 4.7177 & TRN & \\
\hline CHEMBL1423342 & 688724 & 4.95 & 4.8466 & TRN & \\
\hline CHEMBL1481140 & 688724 & 4.05 & 4.8266 & TST & \\
\hline CHEMBL1494800 & 688724 & 4.35 & 4.3743 & TST & \\
\hline CHEMBL1969475 & 688724 & 5.7 & 4.9871 & TRN & \\
\hline CHEMBL1609016 & 688724 & 4.45 & 5.0087 & TRN & \\
\hline CHEMBL3196384 & 688724 & 5.8 & 5.4984 & TRN & \\
\hline CHEMBL1362917 & 688724 & 5.95 & 5.1129 & TST & \\
\hline CHEMBL1584120 & 688724 & 5.7 & 4.4997 & TRN & \\
\hline CHEMBL1457743 & 688724 & 4.0 & 4.8492 & TST & \\
\hline CHEMBL1534154 & 688724 & 4.75 & 4.7609 & TRN & \\
\hline CHEMBL1517375 & 688724 & 5.05 & 4.2507 & TST & \\
\hline CHEMBL1997422 & 688724 & 4.85 & 4.6926 & TRN & \\
\hline CHEMBL3194311 & 688724 & 5.4 & 5.1479 & TRN & \\
\hline CHEMBL77675 & 688724 & 4.1 & 4.6225 & TRN & \\
\hline CHEMBL1526167 & 688724 & 4.35 & 5.1621 & TST & \\
\hline CHEMBL3192160 & 688724 & 4.55 & 5.1319 & TRN & \\
\hline CHEMBL1364847 & 688724 & 5.95 & 4.961 & TRN & \\
\hline CHEMBL1315288 & 688724 & 5.2 & 4.9141 & TST & \\
\hline CHEMBL1473171 & 688724 & 4.4 & 5.0448 & TRN & \\
\hline CHEMBL1520137 & 688724 & 5.1 & 4.9549 & TRN & \\
\hline CHEMBL1300593 & 688724 & 4.8 & 4.5174 & TRN & \\
\hline CHEMBL1521711 & 688724 & 5.25 & 5.0865 & TRN & \\
\hline CHEMBL1301072 & 688724 & 4.35 & 4.7204 & TST & \\
\hline CHEMBL1502020 & 688724 & 5.65 & 5.6438 & TRN & \\
\hline CHEMBL1496555 & 688724 & 4.5 & 5.1891 & TRN & \\
\hline CHEMBL1540897 & 688724 & 4.6 & 4.9833 & TRN & \\
\hline CHEMBL1173380 & 688724 & 4.35 & 5.3982 & TRN & \\
\hline
\end{tabular}




\begin{tabular}{|c|c|c|c|c|c|}
\hline & & \multicolumn{4}{|c|}{ Supplemental Table s2.txt } \\
\hline CHEMBL1509755 & 688724 & 4.45 & 4.5842 & TST & \\
\hline CHEMBL1303891 & 688724 & 5.25 & 4.5046 & TRN & \\
\hline CHEMBL1385933 & 688724 & 5.75 & 5.6068 & TRN & \\
\hline CHEMBL1445897 & 688724 & 4.85 & 4.5555 & TRN & \\
\hline CHEMBL1329397 & 688724 & 4.4 & 5.3406 & TRN & \\
\hline CHEMBL1431928 & 688724 & 4.85 & 5.1097 & TRN & \\
\hline CHEMBL1359872 & 688724 & 4.3 & 4.4613 & TRN & \\
\hline CHEMBL1547462 & 688724 & 4.9 & 5.3369 & TST & \\
\hline CHEMBL 3189940 & 688724 & 4.65 & 4.5292 & TRN & \\
\hline CHEMBL1556896 & 688724 & 4.5 & 4.5116 & TRN & \\
\hline CHEMBL1567824 & 688724 & 4.95 & 4.9606 & TRN & \\
\hline CHEMBL1541858 & 688724 & 4.8 & 4.8375 & TST & \\
\hline CHEMBL1320110 & 688724 & 4.55 & 4.8379 & TRN & \\
\hline CHEMBL1508575 & 688724 & 5.6 & 4.5138 & TRN & \\
\hline CHEMBL1443258 & 688724 & 5.3 & 5.146 & TRN & \\
\hline CHEMBL1525936 & 688724 & 4.75 & 4.4524 & TRN & \\
\hline CHEMBL1456604 & 688724 & 4.75 & 4.8873 & TST & \\
\hline CHEMBL1351419 & 688724 & 4.55 & 4.5681 & TRN & \\
\hline CHEMBL3196993 & 688724 & 5.65 & 5.2722 & TST & \\
\hline CHEMBL1529425 & 688724 & 4.7 & 4.5129 & TRN & \\
\hline CHEMBL1438770 & 688724 & 5.25 & 5.1631 & TRN & \\
\hline CHEMBL1581705 & 688724 & 4.6 & 4.8792 & TST & \\
\hline CHEMBL1608593 & 688724 & 4.75 & 4.8333 & TRN & \\
\hline CHEMBL1315606 & 688724 & 4.3 & 4.5898 & TRN & \\
\hline CHEMBL1399743 & 688724 & 4.4 & 4.8891 & TST & \\
\hline CHEMBL1422482 & 688724 & 6.0 & 4.7362 & TST & \\
\hline CHEMBL1599458 & 688724 & 5.4 & 5.21 & TRN & \\
\hline CHEMBL1466256 & 688724 & 4.0 & 4.7208 & TRN & \\
\hline CHEMBL1524220 & 688724 & 4.9 & 4.8013 & TRN & \\
\hline CHEMBL1410102 & 688724 & 4.65 & 4.8358 & TRN & \\
\hline CHEMBL1419416 & 688724 & 4.5 & 4.4004 & TRN & \\
\hline CHEMBL1555364 & 688724 & 5.15 & 4.5553 & TRN & \\
\hline CHEMBL1391179 & 688724 & 4.5 & 4.9827 & TRN & \\
\hline CHEMBL1514581 & 688724 & 4.75 & 4.3946 & TRN & \\
\hline CHEMBL1386531 & 688724 & 4.35 & 4.7394 & TRN & \\
\hline CHEMBL1448677 & 688724 & 4.0 & 4.4835 & TST & \\
\hline CHEMBL1390386 & 688724 & 4.85 & 4.9885 & TST & \\
\hline CHEMBL1410093 & 688724 & 4.85 & 5.03600 & 00000000005 & TRN \\
\hline CHEMBL1465998 & 688724 & 4.65 & 4.612 & TRN & \\
\hline CHEMBL1375210 & 688724 & 4.05 & 5.0048 & TRN & \\
\hline CHEMBL144614 & 688724 & 4.8 & 5.2191 & TST & \\
\hline CHEMBL1316831 & 688724 & 4.85 & 5.1787 & TRN & \\
\hline CHEMBL1586726 & 688724 & 5.05 & 4.891 & TST & \\
\hline CHEMBL1790010 & 688724 & 4.3 & 5.0596 & TST & \\
\hline CHEMBL1402146 & 688724 & 5.15 & 5.0632 & TRN & \\
\hline CHEMBL1983460 & 688724 & 4.05 & 4.3061 & TRN & \\
\hline CHEMBL1611372 & 688724 & 4.95 & 4.7366 & TST & \\
\hline CHEMBL1374919 & 688724 & 4.75 & 4.5195 & TRN & \\
\hline
\end{tabular}




\begin{tabular}{|c|c|c|c|c|c|}
\hline & & \multicolumn{4}{|c|}{ Supplemental Table S2.txt } \\
\hline CHEMBL1506113 & 688724 & 5.15 & 4.776 & TRN & \\
\hline CHEMBL1374970 & 688724 & 5.45 & 4.5993 & TRN & \\
\hline CHEMBL1430606 & 688724 & 5.25 & 4.8886 & TST & \\
\hline CHEMBL1566203 & 688724 & 5.5 & 4.9181 & TRN & \\
\hline CHEMBL1455212 & 688724 & 6.3 & 4.7112 & TRN & \\
\hline CHEMBL498423 & 688724 & 5.4 & 4.7647 & TRN & \\
\hline CHEMBL1302328 & 688724 & 5.4 & 4.7582 & TRN & \\
\hline CHEMBL3193797 & 688724 & 4.75 & 4.6484 & TRN & \\
\hline CHEMBL401743 & 688724 & 4.65 & 4.6838 & TRN & \\
\hline CHEMBL3191763 & 688724 & 5.15 & 4.8796 & TRN & \\
\hline CHEMBL1494999 & 688724 & 4.85 & 4.7813 & TRN & \\
\hline CHEMBL 244090 & 688724 & 4.7 & 4.79899 & 99999999995 & TST \\
\hline CHEMBL1598617 & 688724 & 4.5 & 4.5104 & TRN & \\
\hline CHEMBL142735 & 688724 & 5.25 & 5.3686 & TST & \\
\hline CHEMBL1352170 & 688724 & 5.5 & 4.975 & TRN & \\
\hline CHEMBL1488356 & 688724 & 4.45 & 4.9252 & TRN & \\
\hline CHEMBL1379580 & 688724 & 5.95 & 5.2225 & TRN & \\
\hline CHEMBL1575578 & 688724 & 5.6 & 5.0513 & TRN & \\
\hline CHEMBL1610314 & 688724 & 4.25 & 4.2971 & TRN & \\
\hline CHEMBL3192637 & 688724 & 4.35 & 4.5128 & TRN & \\
\hline CHEMBL1346592 & 688724 & 5.85 & 4.8974 & TRN & \\
\hline CHEMBL1438476 & 688724 & 6.2242 & 4.9639 & TRN & \\
\hline CHEMBL1496413 & 688724 & 6.1 & 4.745 & TRN & \\
\hline CHEMBL209101 & 688724 & 4.1 & 4.9054 & TRN & \\
\hline CHEMBL1447132 & 688724 & 5.15 & 4.8086 & TRN & \\
\hline CHEMBL3213937 & 688724 & 4.6 & 4.5884 & TRN & \\
\hline CHEMBL1429555 & 688724 & 4.05 & 4.6598 & TRN & \\
\hline CHEMBL1544633 & 688724 & 6.25 & 5.6699 & TRN & \\
\hline CHEMBL1490654 & 688724 & 4.95 & 4.7279 & TST & \\
\hline CHEMBL1586235 & 688724 & 5.45 & 4.7031 & TST & \\
\hline CHEMBL1992681 & 688724 & 4.9 & 4.7941 & TRN & \\
\hline CHEMBL3189723 & 688724 & 4.6 & 5.1952 & TRN & \\
\hline CHEMBL1514129 & 688724 & 4.6 & 4.6418 & TRN & \\
\hline CHEMBL1300545 & 688724 & 4.25 & 4.7787 & TST & \\
\hline CHEMBL1492002 & 688724 & 7.2 & 4.9034 & TST & \\
\hline CHEMBL1367035 & 688724 & 4.1 & 4.4315 & TST & \\
\hline CHEMBL1503092 & 688724 & 4.05 & 4.6636 & TRN & \\
\hline CHEMBL1441197 & 688724 & 4.7 & 4.7799 & TRN & \\
\hline CHEMBL1359568 & 688724 & 4.4 & 4.859 & TRN & \\
\hline CHEMBL1388994 & 688724 & 5.5 & 4.6878 & TRN & \\
\hline CHEMBL1322434 & 688724 & 5.15 & 4.6137 & TRN & \\
\hline CHEMBL1470841 & 688724 & 4.7 & 4.3107 & TRN & \\
\hline CHEMBL3209507 & 688724 & 4.45 & 5.0552 & TST & \\
\hline CHEMBL1398187 & 688724 & 4.8 & 4.7337 & TRN & \\
\hline CHEMBL1417928 & 688724 & 4.05 & 4.6815 & TST & \\
\hline CHEMBL1578082 & 688724 & 4.6 & 5.142 & TRN & \\
\hline CHEMBL1572386 & 688724 & 5.8 & 4.7785 & TRN & \\
\hline CHEMBL1365585 & 688724 & 5.75 & 5.4851 & TRN & \\
\hline
\end{tabular}




\begin{tabular}{|c|c|c|c|c|c|}
\hline \multicolumn{6}{|c|}{ Supplemental Table S2.txt } \\
\hline CHEMBL1313465 & 688724 & 5.4 & 5.0637 & TRN & \\
\hline CHEMBL1428775 & 688724 & 4.15 & 4.8463 & TST & \\
\hline CHEMBL1256395 & 688724 & 4.4 & 5.1186 & TST & \\
\hline CHEMBL1432434 & 688724 & 4.7 & 4.7487 & TST & \\
\hline CHEMBL1564215 & 688724 & 4.35 & 4.7795 & TRN & \\
\hline CHEMBL1364068 & 688724 & 4.45 & 4.8371 & TRN & \\
\hline CHEMBL1441885 & 688724 & 5.35 & 5.0719 & TRN & \\
\hline CHEMBL1375276 & 688724 & 4.85 & 4.9695 & TRN & \\
\hline CHEMBL290914 & 688724 & 6.0 & 5.2752 & TRN & \\
\hline CHEMBL1542349 & 688724 & 5.85 & 5.2213 & TRN & \\
\hline CHEMBL1434535 & 688724 & 4.65 & 4.5566 & TRN & \\
\hline CHEMBL1356152 & 688724 & 5.25 & 5.2603 & TRN & \\
\hline CHEMBL1337797 & 688724 & 4.6 & 4.5631 & TRN & \\
\hline CHEMBL1315476 & 688724 & 4.15 & 4.4759 & TRN & \\
\hline CHEMBL1403448 & 688724 & 4.55 & 4.9887 & TST & \\
\hline CHEMBL59451 & 688724 & 6.0 & 5.5349 & TST & \\
\hline CHEMBL1483904 & 688724 & 4.9 & 5.192 & TRN & \\
\hline CHEMBL1400298 & 688724 & 5.9 & 5.5928 & TRN & \\
\hline CHEMBL258844 & 688724 & 4.8 & 5.0495 & TST & \\
\hline CHEMBL1465122 & 688724 & 4.85 & 5.0824 & TST & \\
\hline CHEMBL1395811 & 688724 & 5.4 & 5.1526 & TRN & \\
\hline CHEMBL1599622 & 688724 & 4.4 & 4.6932 & TRN & \\
\hline CHEMBL1420267 & 688724 & 4.55 & 5.4552 & TRN & \\
\hline CHEMBL1319128 & 688724 & 4.65 & 4.7924 & TRN & \\
\hline CHEMBL1562712 & 688724 & 4.3 & 4.3654 & TRN & \\
\hline CHEMBL1478327 & 688724 & 5.05 & 5.0311 & TRN & \\
\hline CHEMBL1543371 & 688724 & 7.2503 & 5.3186 & TRN & \\
\hline CHEMBL 3189290 & 688724 & 4.4 & 4.7771 & TRN & \\
\hline CHEMBL1611858 & 688724 & 4.6 & 5.0587 & TRN & \\
\hline CHEMBL1532218 & 688724 & 4.9 & 5.0594 & TRN & \\
\hline CHEMBL1543612 & 688724 & 4.8 & 4.7492 & TRN & \\
\hline CHEMBL173530 & 688724 & 6.0 & 5.2806 & TRN & \\
\hline CHEMBL1572065 & 688724 & 4.15 & 5.3224 & TST & \\
\hline CHEMBL1349676 & 688724 & 4.4 & 4.9513 & TRN & \\
\hline CHEMBL582005 & 688724 & 6.0 & 4.58899 & 99999999995 & TST \\
\hline CHEMBL1415852 & 688724 & 4.65 & 4.8017 & TST & \\
\hline CHEMBL1503604 & 688724 & 4.45 & 4.9745 & TST & \\
\hline CHEMBL1531332 & 688724 & 4.1 & 4.5055 & TRN & \\
\hline CHEMBL1597650 & 688724 & 4.1 & 4.7643 & TRN & \\
\hline CHEMBL1570159 & 688724 & 6.05 & 5.394 & TRN & \\
\hline CHEMBL1544412 & 688724 & 4.4 & 4.585 & TRN & \\
\hline CHEMBL1338919 & 688724 & 4.8 & 4.7126 & TRN & \\
\hline CHEMBL1543292 & 688724 & 4.1 & 4.3547 & TRN & \\
\hline CHEMBL3191186 & 688724 & 4.5 & 4.1882 & TRN & \\
\hline CHEMBL1528850 & 688724 & 4.65 & 5.0269 & TRN & \\
\hline CHEMBL1461976 & 688724 & 5.4 & 5.1014 & TRN & \\
\hline CHEMBL3192587 & 688724 & 4.2 & 4.583 & TRN & \\
\hline CHEMBL1577574 & 688724 & 4.45 & 4.6699 & TST & \\
\hline
\end{tabular}




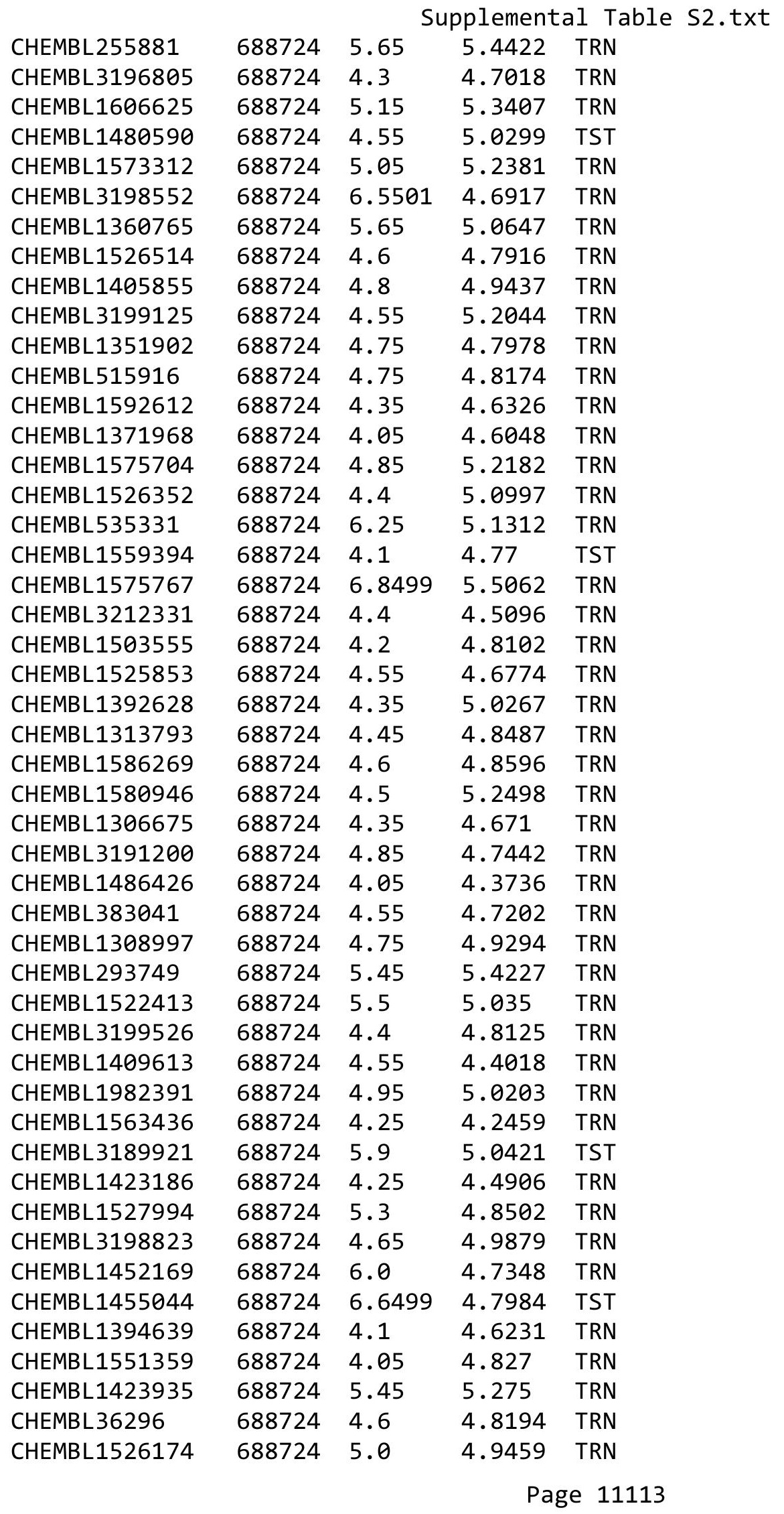




\begin{tabular}{|c|c|c|c|c|}
\hline \multicolumn{5}{|c|}{ Supplemental Table s2.txt } \\
\hline CHEMBL1474932 & 688724 & 5.2 & 4.3352 & TRN \\
\hline CHEMBL 338474 & 688724 & 4.95 & 5.0128 & TST \\
\hline CHEMBL1354665 & 688724 & 4.35 & 4.8495 & TRN \\
\hline CHEMBL1364687 & 688724 & 4.6 & 4.6536 & TRN \\
\hline CHEMBL1477017 & 688724 & 4.25 & 4.9579 & TRN \\
\hline CHEMBL1510757 & 688724 & 4.35 & 4.6703 & TRN \\
\hline CHEMBL1309607 & 688724 & 4.65 & 4.8636 & TRN \\
\hline CHEMBL1306283 & 688724 & 6.6499 & 6.1053 & TRN \\
\hline CHEMBL 3145028 & 688724 & 4.95 & 4.8374 & TRN \\
\hline CHEMBL1388871 & 688724 & 4.85 & 4.8801 & TST \\
\hline CHEMBL1972249 & 688724 & 4.1 & 4.9693 & TST \\
\hline CHEMBL1425723 & 688724 & 4.7 & 4.9298 & TRN \\
\hline CHEMBL1491320 & 688724 & 4.2 & 4.365 & TRN \\
\hline CHEMBL 3194415 & 688724 & 4.75 & 4.4267 & TRN \\
\hline CHEMBL1643542 & 688724 & 4.75 & 4.6472 & TST \\
\hline CHEMBL1468497 & 688724 & 4.8 & 5.1846 & TRN \\
\hline CHEMBL289356 & 688724 & 4.85 & 4.909 & TRN \\
\hline CHEMBL1454215 & 688724 & 4.9 & 4.8605 & TRN \\
\hline CHEMBL1423852 & 688724 & 5.0 & 4.9055 & TRN \\
\hline CHEMBL1353435 & 688724 & 4.55 & 4.8207 & TRN \\
\hline CHEMBL1447877 & 688724 & 4.65 & 4.9798 & TRN \\
\hline CHEMBL1528142 & 688724 & 5.05 & 4.6498 & TRN \\
\hline CHEMBL1334586 & 688724 & 4.65 & 4.6618 & TRN \\
\hline CHEMBL1368514 & 688724 & 5.25 & 5.2734 & TRN \\
\hline CHEMBL1406977 & 688724 & 4.25 & 4.6961 & TST \\
\hline CHEMBL1479475 & 688724 & 4.75 & 4.9056 & TRN \\
\hline CHEMBL1556561 & 688724 & 5.45 & 4.8194 & TRN \\
\hline CHEMBL135703 & 688724 & 4.0 & 4.852 & TRN \\
\hline CHEMBL3348955 & 688724 & 5.9 & 5.3079 & TST \\
\hline CHEMBL1320875 & 688724 & 4.1 & 4.3048 & TRN \\
\hline CHEMBL1612535 & 688724 & 4.65 & 4.7229 & TRN \\
\hline CHEMBL1528958 & 688724 & 4.25 & 4.6023 & TRN \\
\hline CHEMBL 3195685 & 688724 & 4.7 & 5.2838 & TRN \\
\hline CHEMBL1453188 & 688724 & 4.4 & 5.0197 & TST \\
\hline CHEMBL1580892 & 688724 & 5.0 & 4.7513 & TRN \\
\hline CHEMBL1979574 & 688724 & 5.3 & 4.9185 & TRN \\
\hline CHEMBL1359636 & 688724 & 5.45 & 5.1134 & TRN \\
\hline CHEMBL1435948 & 688724 & 5.45 & 4.7455 & TRN \\
\hline CHEMBL1333064 & 688724 & 4.75 & 4.8038 & TRN \\
\hline CHEMBL1571280 & 688724 & 5.35 & 4.7539 & TRN \\
\hline CHEMBL1554479 & 688724 & 4.3 & 5.5326 & TST \\
\hline CHEMBL3194219 & 688724 & 4.85 & 4.9027 & TRN \\
\hline CHEMBL47258 & 688724 & 4.25 & 5.25700 & 0000000001 \\
\hline CHEMBL1412562 & 688724 & 4.25 & 4.6093 & TRN \\
\hline CHEMBL1554148 & 688724 & 4.45 & 4.8171 & TST \\
\hline CHEMBL1536813 & 688724 & 4.35 & 4.7106 & TRN \\
\hline CHEMBL1382329 & 688724 & 4.5 & 4.8368 & TRN \\
\hline CHEMBL1333012 & 688724 & 4.05 & 4.6645 & TST \\
\hline
\end{tabular}




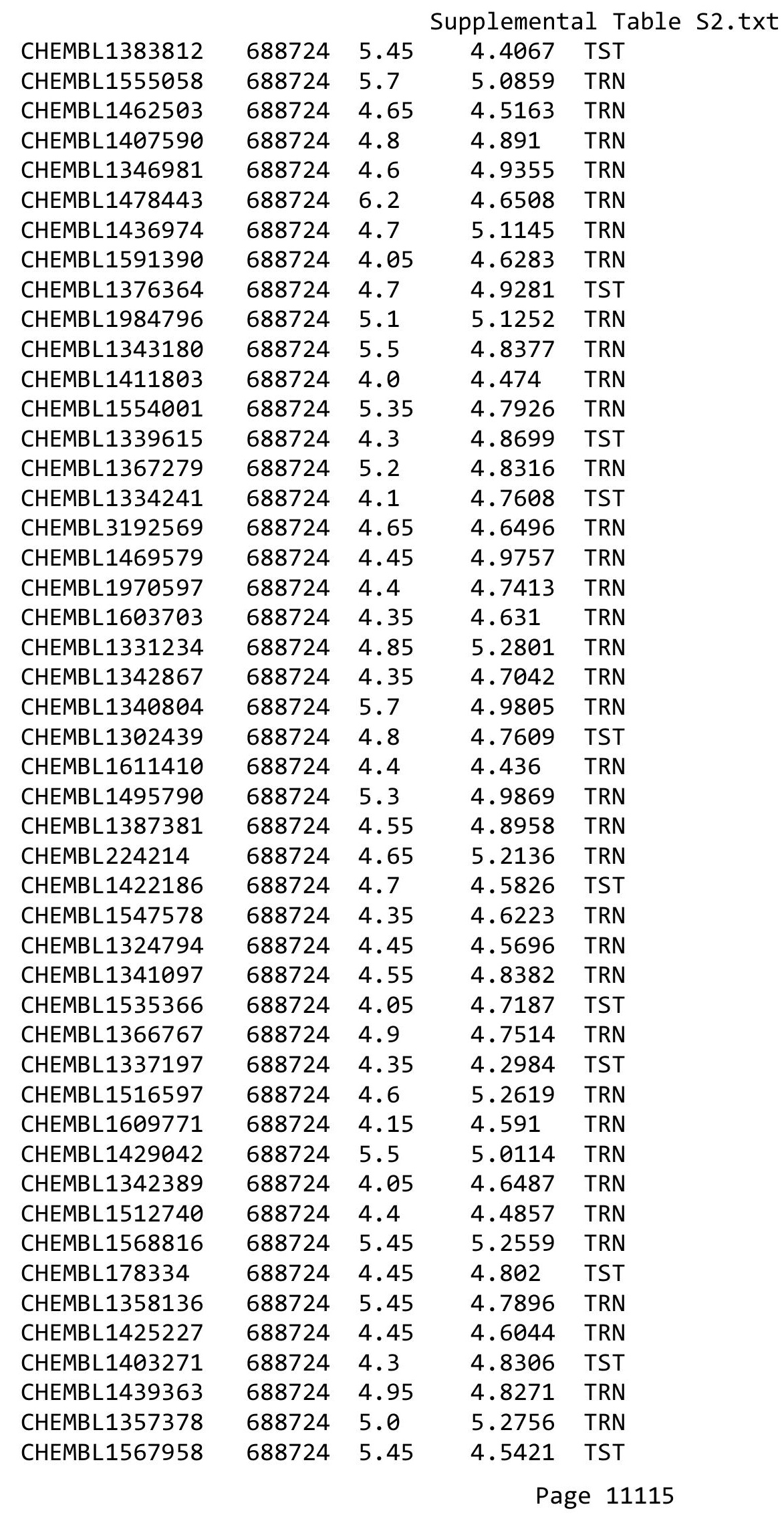




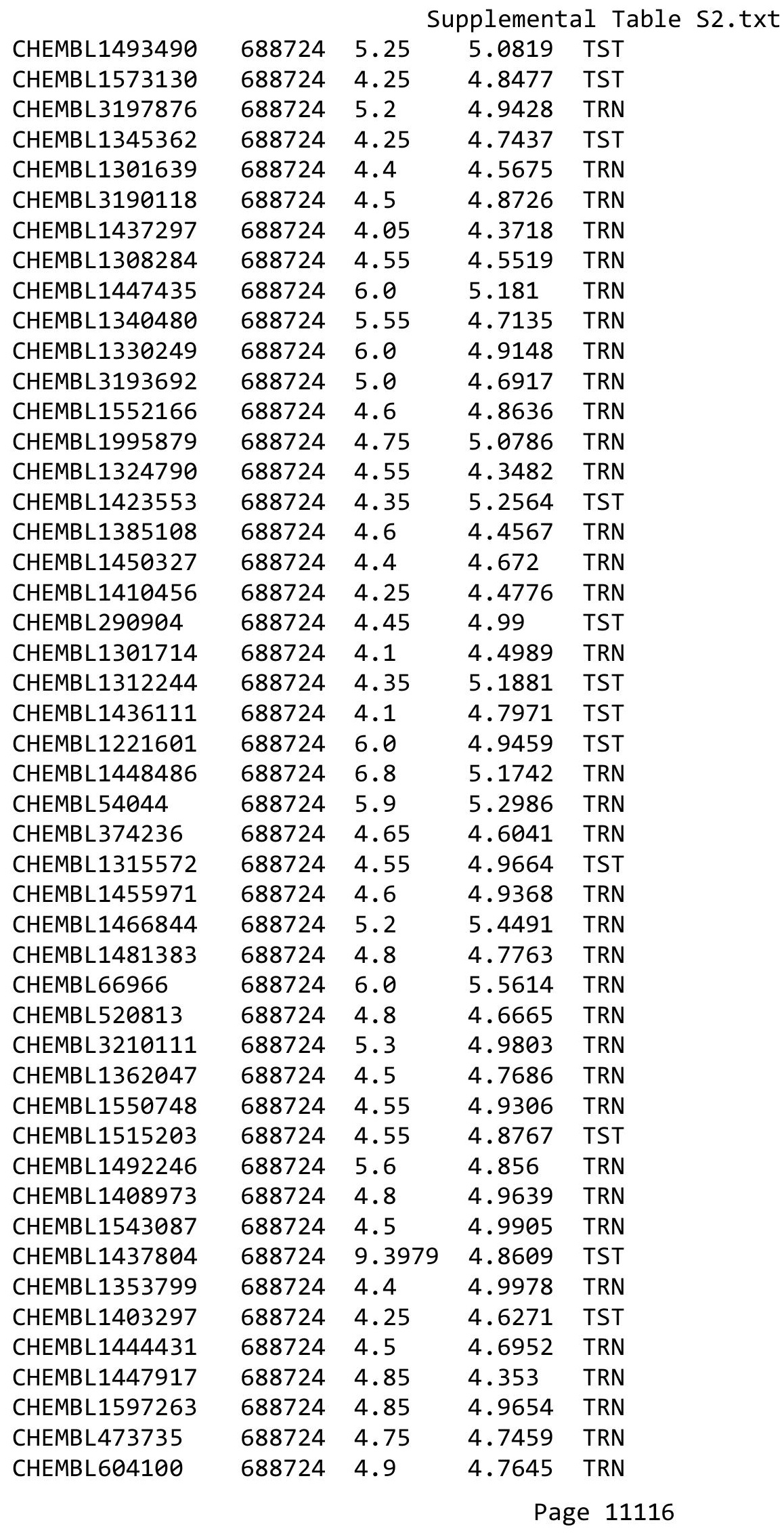




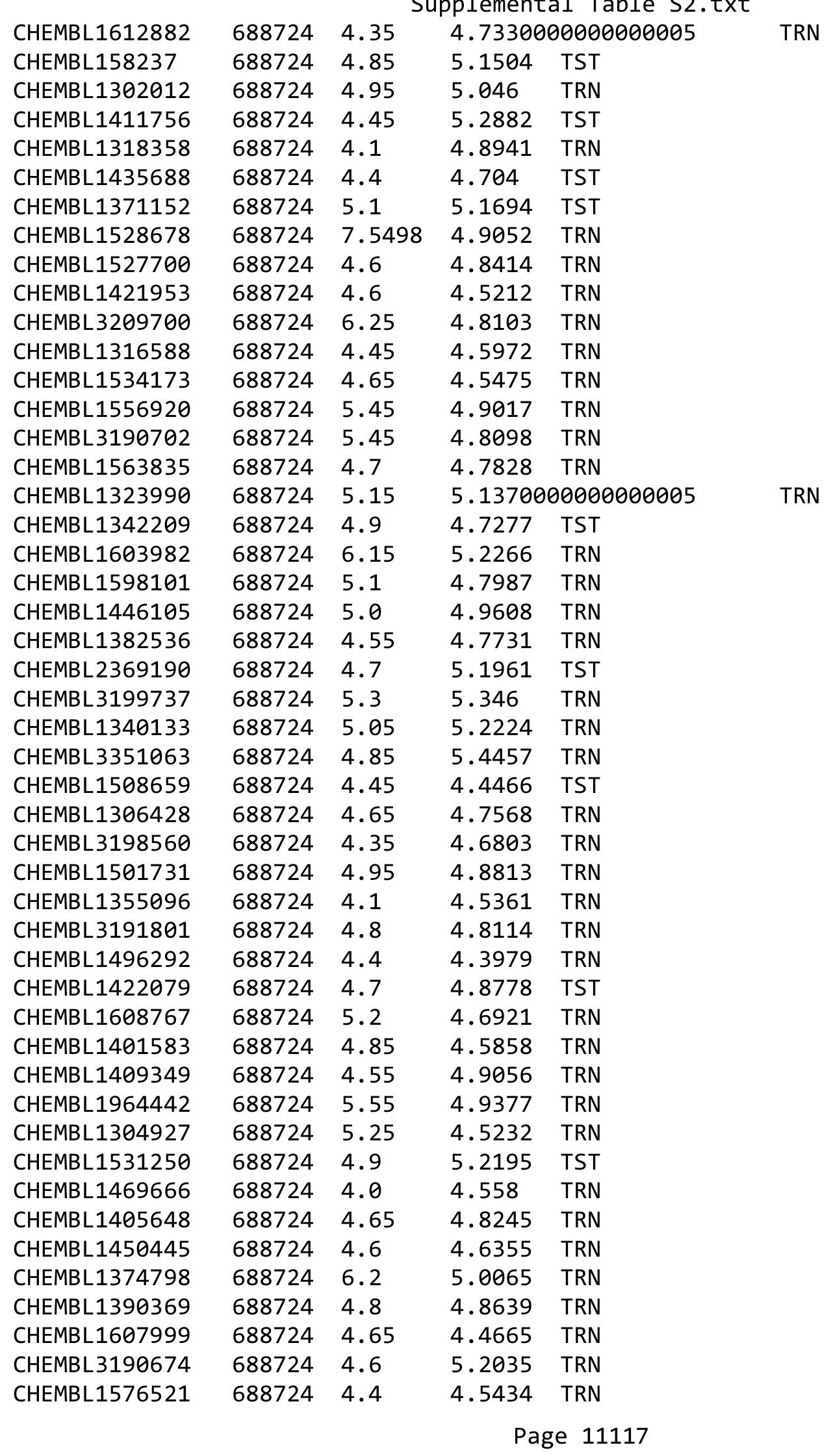




\begin{tabular}{|c|c|c|c|c|c|}
\hline \multicolumn{6}{|c|}{ Supplemental Table S2.txt } \\
\hline CHEMBL198666 & 688724 & 4.35 & 4.553 & TRN & \\
\hline CHEMBL280998 & 688724 & 4.7 & 5.2324 & TRN & \\
\hline CHEMBL1341444 & 688724 & 4.3 & 4.7166 & TRN & \\
\hline CHEMBL1588642 & 688724 & 4.8 & 4.80699 & 99999999995 & TRN \\
\hline CHEMBL1426127 & 688724 & 4.35 & 4.9288 & TST & \\
\hline CHEMBL1391094 & 688724 & 4.7 & 4.7322 & TRN & \\
\hline CHEMBL1351550 & 688724 & 4.8 & 4.613 & TRN & \\
\hline CHEMBL1981928 & 688724 & 4.55 & 4.7462 & TST & \\
\hline CHEMBL3195872 & 688724 & 4.85 & 4.6903 & TST & \\
\hline CHEMBL 98245 & 688724 & 4.5 & 4.6086 & TST & \\
\hline CHEMBL1549313 & 688724 & 4.9 & 4.4722 & TRN & \\
\hline CHEMBL1561248 & 688724 & 4.65 & 4.9031 & TRN & \\
\hline CHEMBL443462 & 688724 & 4.65 & 5.2592 & TST & \\
\hline CHEMBL1388666 & 688724 & 4.35 & 5.0458 & TRN & \\
\hline CHEMBL3192625 & 688724 & 4.75 & 5.3616 & TRN & \\
\hline CHEMBL478 & 688724 & 9.1549 & 4.9394 & TST & \\
\hline CHEMBL1403734 & 688724 & 4.45 & 4.5596 & TRN & \\
\hline CHEMBL1509325 & 688724 & 7.5498 & 4.9599 & TRN & \\
\hline CHEMBL1469132 & 688724 & 4.35 & 4.8902 & TST & \\
\hline CHEMBL1983886 & 688724 & 4.8 & 4.6603 & TST & \\
\hline CHEMBL1350152 & 688724 & 4.75 & 4.6085 & TRN & \\
\hline CHEMBL1494476 & 688724 & 4.5 & 4.9357 & TRN & \\
\hline CHEMBL1475769 & 688724 & 4.55 & 4.4692 & TRN & \\
\hline CHEMBL3195386 & 688724 & 4.05 & 4.7541 & TRN & \\
\hline CHEMBL1565541 & 688724 & 4.8 & 4.7174 & TRN & \\
\hline CHEMBL1589776 & 688724 & 4.4 & 4.8456 & TST & \\
\hline CHEMBL1353369 & 688724 & 4.25 & 4.6203 & TRN & \\
\hline CHEMBL521083 & 688724 & 4.8 & 4.6269 & TST & \\
\hline CHEMBL1317490 & 688724 & 4.7 & 4.6057 & TRN & \\
\hline CHEMBL1382096 & 688724 & 6.8499 & 4.6891 & TST & \\
\hline CHEMBL1369690 & 688724 & 4.55 & 4.6146 & TRN & \\
\hline CHEMBL1976412 & 688724 & 4.55 & 5.0247 & TRN & \\
\hline CHEMBL1322349 & 688724 & 4.1 & 4.7378 & TST & \\
\hline CHEMBL1443898 & 688724 & 4.9 & 4.8556 & TRN & \\
\hline CHEMBL 2002444 & 688724 & 4.85 & 5.1292 & TRN & \\
\hline CHEMBL1312038 & 688724 & 4.85 & 4.5319 & TRN & \\
\hline CHEMBL1580765 & 688724 & 4.1 & 4.4072 & TRN & \\
\hline CHEMBL1440025 & 688724 & 4.8 & 4.8305 & TST & \\
\hline CHEMBL1303079 & 688724 & 4.65 & 4.7893 & TRN & \\
\hline CHEMBL1338882 & 688724 & 4.9 & 5.0484 & TRN & \\
\hline CHEMBL1548122 & 688724 & 4.35 & 5.2186 & TST & \\
\hline CHEMBL1341919 & 688724 & 4.75 & 4.9346 & TRN & \\
\hline CHEMBL1562105 & 688724 & 5.1 & 4.3791 & TRN & \\
\hline CHEMBL3193848 & 688724 & 4.55 & 4.8896 & TRN & \\
\hline CHEMBL 2007212 & 688724 & 4.4 & 4.8317 & TRN & \\
\hline CHEMBL1420112 & 688724 & 4.4 & 4.6287 & TRN & \\
\hline CHEMBL1984772 & 688724 & 5.1 & 4.3857 & TRN & \\
\hline CHEMBL1388509 & 688724 & 4.8 & 4.9295 & TRN & \\
\hline
\end{tabular}




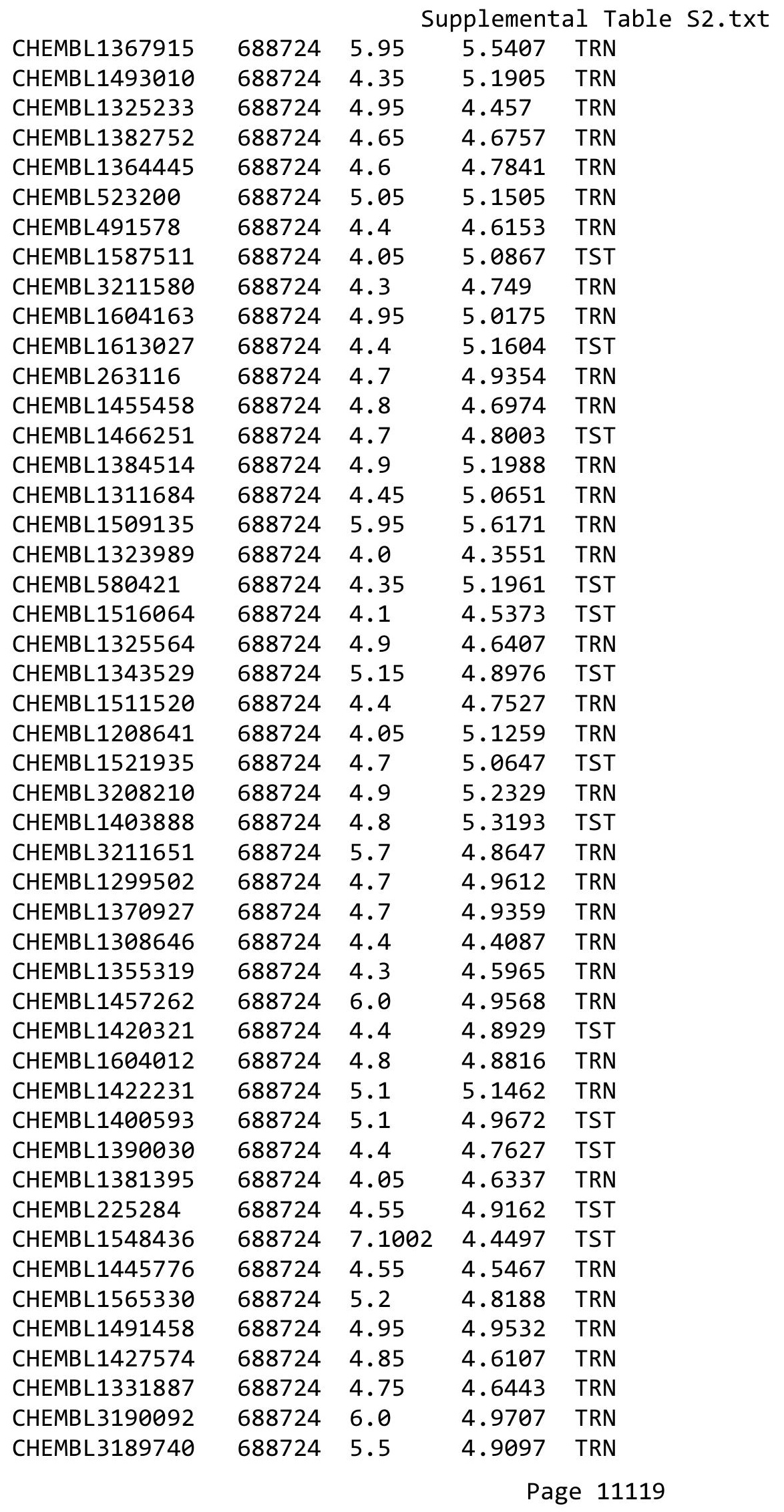




\begin{tabular}{|c|c|c|c|c|c|}
\hline & & \multicolumn{4}{|c|}{ Supplemental Table S2.txt } \\
\hline CHEMBL1349026 & 688724 & 4.25 & 4.501 & TRN & \\
\hline CHEMBL1512775 & 688724 & 4.5 & 4.7753 & TRN & \\
\hline CHEMBL1348265 & 688724 & 4.2 & 4.5845 & TST & \\
\hline CHEMBL3196373 & 688724 & 4.75 & 4.9074 & TST & \\
\hline CHEMBL3213656 & 688724 & 4.85 & 4.7519 & TST & \\
\hline CHEMBL1502173 & 688724 & 4.15 & 4.371 & TRN & \\
\hline CHEMBL 276473 & 688724 & 4.25 & 4.695 & TRN & \\
\hline CHEMBL1585849 & 688724 & 4.75 & 4.9963 & TRN & \\
\hline CHEMBL1413243 & 688724 & 4.7 & 5.2741 & TRN & \\
\hline CHEMBL1317950 & 688724 & 4.75 & 4.8471 & TRN & \\
\hline CHEMBL1306204 & 688724 & 4.7 & 4.5556 & TRN & \\
\hline CHEMBL1504418 & 688724 & 4.45 & 4.4474 & TRN & \\
\hline CHEMBL1613260 & 688724 & 4.65 & 4.8605 & TRN & \\
\hline CHEMBL601822 & 688724 & 4.4 & 4.6192 & TRN & \\
\hline CHEMBL1308730 & 688724 & 4.4 & 4.602 & TRN & \\
\hline CHEMBL1317745 & 688724 & 4.4 & 4.61600 & 00000000005 & TST \\
\hline CHEMBL1567670 & 688724 & 5.0 & 4.5625 & TRN & \\
\hline CHEMBL1355176 & 688724 & 5.05 & 4.9792 & TRN & \\
\hline CHEMBL1511356 & 688724 & 4.3 & 4.6259 & TRN & \\
\hline CHEMBL1441665 & 688724 & 6.05 & 5.1656 & TRN & \\
\hline CHEMBL261663 & 688724 & 4.85 & 5.1261 & TST & \\
\hline CHEMBL1970867 & 688724 & 5.15 & 4.8592 & TRN & \\
\hline CHEMBL1367565 & 688724 & 4.9 & 5.1154 & TRN & \\
\hline CHEMBL1512559 & 688724 & 5.15 & 4.8223 & TST & \\
\hline CHEMBL1362415 & 688724 & 4.25 & 4.43 & TRN & \\
\hline CHEMBL1529835 & 688724 & 4.05 & 4.5589 & TRN & \\
\hline CHEMBL291278 & 688724 & 5.75 & 5.2589 & TST & \\
\hline CHEMBL1352867 & 688724 & 5.3 & 5.2495 & TRN & \\
\hline CHEMBL1451468 & 688724 & 4.4 & 4.7884 & TRN & \\
\hline CHEMBL3192144 & 688724 & 6.2 & 4.7579 & TRN & \\
\hline CHEMBL458328 & 688724 & 6.0 & 5.6903 & TRN & \\
\hline CHEMBL1322780 & 688724 & 4.35 & 4.8291 & TRN & \\
\hline CHEMBL1373934 & 688724 & 4.4 & 4.5215 & TRN & \\
\hline CHEMBL1589012 & 688724 & 4.05 & 4.5998 & TRN & \\
\hline CHEMBL1446511 & 688724 & 4.3 & 4.7921 & TRN & \\
\hline CHEMBL1405039 & 688724 & 4.3 & 4.773 & TRN & \\
\hline CHEMBL1350435 & 688724 & 4.3 & 4.9269 & TRN & \\
\hline CHEMBL1448321 & 688724 & 4.45 & 4.8867 & TRN & \\
\hline CHEMBL1453854 & 688724 & 4.55 & 4.6132 & TRN & \\
\hline CHEMBL1504655 & 688724 & 5.5 & 4.8407 & TRN & \\
\hline CHEMBL1326059 & 688724 & 5.3 & 4.4707 & TRN & \\
\hline CHEMBL1352062 & 688724 & 5.15 & 4.8217 & TRN & \\
\hline CHEMBL1465297 & 688724 & 4.65 & 4.8347 & TRN & \\
\hline CHEMBL1408835 & 688724 & 6.05 & 5.0348 & TRN & \\
\hline CHEMBL1374016 & 688724 & 4.9 & 4.9063 & TRN & \\
\hline CHEMBL1411816 & 688724 & 4.35 & 4.8761 & TRN & \\
\hline CHEMBL1386720 & 688724 & 4.05 & 4.3712 & TRN & \\
\hline CHEMBL3197891 & 688724 & 4.85 & 4.4743 & TRN & \\
\hline
\end{tabular}




\begin{tabular}{|c|c|c|c|c|}
\hline \multicolumn{5}{|c|}{ Supplemental Table S2.txt } \\
\hline CHEMBL1560370 & 688724 & 4.35 & 4.728 & TST \\
\hline CHEMBL1592644 & 688724 & 4.35 & 4.7056 & TRN \\
\hline CHEMBL3198925 & 688724 & 5.0 & 4.919 & TRN \\
\hline CHEMBL1413963 & 688724 & 6.9 & 4.9926 & TRN \\
\hline CHEMBL1256656 & 688724 & 6.0 & 4.8227 & TRN \\
\hline CHEMBL1422657 & 688724 & 4.7 & 4.842 & TRN \\
\hline CHEMBL1348732 & 688724 & 4.85 & 4.8476 & TRN \\
\hline CHEMBL392394 & 688724 & 6.05 & 4.7803 & TST \\
\hline CHEMBL1584083 & 688724 & 7.15 & 5.3048 & TRN \\
\hline CHEMBL1338973 & 688724 & 4.35 & 4.673 & TRN \\
\hline CHEMBL1504850 & 688724 & 7.5003 & 5.3033 & TRN \\
\hline CHEMBL1379164 & 688724 & 5.0 & 5.1901 & TST \\
\hline CHEMBL3195528 & 688724 & 4.8 & 4.5524 & TRN \\
\hline CHEMBL1507904 & 688724 & 5.3 & 4.9682 & TRN \\
\hline CHEMBL1333327 & 688724 & 4.5 & 4.952 & TRN \\
\hline CHEMBL1505704 & 688724 & 4.35 & 4.338 & TRN \\
\hline CHEMBL1501005 & 688724 & 5.0 & 4.5262 & TRN \\
\hline CHEMBL1556956 & 688724 & 4.9 & 4.8152 & TRN \\
\hline CHEMBL1369624 & 688724 & 4.05 & 4.836 & TRN \\
\hline CHEMBL1537781 & 688724 & 4.75 & 4.8389 & TRN \\
\hline CHEMBL3214386 & 688724 & 4.75 & 4.863 & TRN \\
\hline CHEMBL1306159 & 688724 & 4.25 & 4.7425 & TRN \\
\hline CHEMBL1392651 & 688724 & 4.5 & 4.7617 & TST \\
\hline CHEMBL1461928 & 688724 & 5.0 & 4.8458 & TRN \\
\hline CHEMBL1392558 & 688724 & 4.95 & 4.8872 & TRN \\
\hline CHEMBL3199938 & 688724 & 4.4 & 4.9975 & TRN \\
\hline CHEMBL1394846 & 688724 & 4.1 & 4.6659 & TRN \\
\hline CHEMBL1432734 & 688724 & 5.1 & 5.1988 & TRN \\
\hline CHEMBL1543343 & 688724 & 4.4 & 4.6119 & TRN \\
\hline CHEMBL1483478 & 688724 & 5.45 & 5.3492 & TST \\
\hline CHEMBL179024 & 688724 & 4.55 & 4.7624 & TST \\
\hline CHEMBL3193247 & 688724 & 4.1 & 4.6791 & TST \\
\hline CHEMBL1560995 & 688724 & 4.45 & 4.9786 & TRN \\
\hline CHEMBL1377769 & 688724 & 5.5 & 4.6039 & TST \\
\hline CHEMBL1449966 & 688724 & 4.25 & 4.8134 & TRN \\
\hline CHEMBL1529990 & 688724 & 5.05 & 4.8609 & TRN \\
\hline CHEMBL460124 & 688724 & 6.0 & 4.9018 & TRN \\
\hline CHEMBL1342383 & 688724 & 4.8 & 4.5072 & TRN \\
\hline CHEMBL1404190 & 688724 & 4.1 & 5.0306 & TRN \\
\hline CHEMBL3392363 & 688724 & 4.3 & 4.9562 & TRN \\
\hline CHEMBL1577954 & 688724 & 4.25 & 4.4961 & TST \\
\hline CHEMBL1465906 & 688724 & 4.35 & 4.5486 & TRN \\
\hline CHEMBL1417820 & 688724 & 4.1 & 5.1166 & TRN \\
\hline CHEMBL 3194528 & 688724 & 5.5 & 5.0197 & TRN \\
\hline CHEMBL1442223 & 688724 & 4.4 & 4.7053 & TRN \\
\hline CHEMBL1503652 & 688724 & 4.7 & 4.7112 & TRN \\
\hline CHEMBL1405211 & 688724 & 4.4 & 4.5272 & TST \\
\hline CHEMBL1497821 & 688724 & 4.4 & 5.1575 & TRN \\
\hline
\end{tabular}




\begin{tabular}{|c|c|c|c|c|c|}
\hline \multicolumn{6}{|c|}{ Supplemental Table S2 } \\
\hline CHEMBL1580068 & 688724 & 4.25 & 5.0377 & TST & \\
\hline CHEMBL1367893 & 688724 & 4.05 & 4.5626 & TRN & \\
\hline CHEMBL 3392043 & 688724 & 4.9 & 4.8139 & TST & \\
\hline CHEMBL1434513 & 688724 & 6.0 & 5.6046 & TRN & \\
\hline CHEMBL1969699 & 688724 & 4.7 & 4.7874 & TRN & \\
\hline CHEMBL1374495 & 688724 & 4.45 & 4.8139 & TRN & \\
\hline CHEMBL1470741 & 688724 & 4.3 & 4.9211 & TRN & \\
\hline CHEMBL1256623 & 688724 & 6.4 & 5.6118 & TRN & \\
\hline CHEMBL188343 & 688724 & 4.35 & 4.7302 & TST & \\
\hline CHEMBL1531235 & 688724 & 4.3 & 5.01 & TST & \\
\hline CHEMBL1429984 & 688724 & 4.35 & 4.4095 & TRN & \\
\hline CHEMBL1583031 & 688724 & 4.0 & 4.725 & TRN & \\
\hline CHEMBL1369784 & 688724 & 4.25 & 5.0049 & TRN & \\
\hline CHEMBL1579667 & 688724 & 4.4 & 4.4072 & TRN & \\
\hline CHEMBL1502351 & 688724 & 5.65 & 4.9387 & TRN & \\
\hline CHEMBL1471957 & 688724 & 4.7 & 4.785 & TRN & \\
\hline CHEMBL1996730 & 688724 & 5.7 & 5.5471 & TRN & \\
\hline CHEMBL1327279 & 688724 & 4.6 & 4.7818 & TRN & \\
\hline CHEMBL1571536 & 688724 & 4.65 & 4.9514 & TST & \\
\hline CHEMBL1522529 & 688724 & 5.75 & 4.8441 & TRN & \\
\hline CHEMBL1323267 & 688724 & 5.0 & 4.8641 & TRN & \\
\hline CHEMBL1530257 & 688724 & 4.8 & 5.0146 & TRN & \\
\hline CHEMBL1412013 & 688724 & 4.6 & 5.2103 & TRN & \\
\hline CHEMBL1356324 & 688724 & 4.55 & 4.5409 & TRN & \\
\hline CHEMBL1301813 & 688724 & 7.4001 & 5.00899 & 99999999995 & TRN \\
\hline CHEMBL1308978 & 688724 & 4.75 & 4.7684 & TRN & \\
\hline CHEMBL1346481 & 688724 & 4.4 & 4.6858 & TRN & \\
\hline CHEMBL3195471 & 688724 & 5.0 & 4.9204 & TRN & \\
\hline CHEMBL1417932 & 688724 & 4.1 & 4.6851 & TRN & \\
\hline CHEMBL1343856 & 688724 & 4.7 & 4.7686 & TRN & \\
\hline CHEMBL1525811 & 688724 & 4.7 & 4.9239 & TRN & \\
\hline CHEMBL1595977 & 688724 & 4.1 & 4.7902 & TST & \\
\hline CHEMBL1469848 & 688724 & 4.1 & 4.5635 & TRN & \\
\hline CHEMBL1494406 & 688724 & 6.0 & 4.6408 & TRN & \\
\hline CHEMBL1385318 & 688724 & 4.3 & 4.843 & TRN & \\
\hline CHEMBL1526150 & 688724 & 4.6 & 4.8764 & TRN & \\
\hline CHEMBL1529041 & 688724 & 4.85 & 4.8875 & TST & \\
\hline CHEMBL1610567 & 688724 & 4.2 & 4.9718 & TST & \\
\hline CHEMBL1331639 & 688724 & 4.85 & 4.7744 & TRN & \\
\hline CHEMBL1987791 & 688724 & 4.65 & 4.9609 & TRN & \\
\hline CHEMBL1299641 & 688724 & 4.6 & 4.5295 & TST & \\
\hline CHEMBL1514618 & 688724 & 4.05 & 4.5994 & TRN & \\
\hline CHEMBL1378659 & 688724 & 5.5 & 5.7298 & TRN & \\
\hline CHEMBL1500174 & 688724 & 4.35 & 4.6387 & TST & \\
\hline CHEMBL1324332 & 688724 & 4.95 & 5.0343 & TRN & \\
\hline CHEMBL 3192787 & 688724 & 4.3 & 4.782 & TRN & \\
\hline CHEMBL1520907 & 688724 & 4.75 & 5.016 & TST & \\
\hline CHEMBL1408237 & 688724 & 5.25 & 5.1379 & TRN & \\
\hline
\end{tabular}




\begin{tabular}{|c|c|c|c|c|c|}
\hline & & \multicolumn{4}{|c|}{ Supplemental Table s2.txt } \\
\hline CHEMBL1513799 & 688724 & 4.65 & 4.7178 & TRN & \\
\hline CHEMBL1420987 & 688724 & 4.05 & 4.7421 & TST & \\
\hline CHEMBL1487905 & 688724 & 4.35 & 4.9563 & TRN & \\
\hline CHEMBL1421041 & 688724 & 4.45 & 4.5608 & TRN & \\
\hline CHEMBL1359809 & 688724 & 4.5 & 4.4115 & TST & \\
\hline CHEMBL1329448 & 688724 & 5.1 & 4.8054 & TRN & \\
\hline CHEMBL136344 & 688724 & 5.6 & 5.2774 & TRN & \\
\hline CHEMBL1582706 & 688724 & 4.05 & 4.4882 & TRN & \\
\hline CHEMBL1448776 & 688724 & 4.7 & 5.0268 & TST & \\
\hline CHEMBL250969 & 688724 & 4.15 & 4.7601 & TRN & \\
\hline CHEMBL1428205 & 688724 & 4.35 & 4.71399 & 99999999995 & TST \\
\hline CHEMBL1605335 & 688724 & 4.05 & 4.6053 & TRN & \\
\hline CHEMBL1610669 & 688724 & 4.55 & 4.6074 & TRN & \\
\hline CHEMBL1595221 & 688724 & 4.7 & 4.9763 & TRN & \\
\hline CHEMBL1308918 & 688724 & 4.35 & 4.9638 & TRN & \\
\hline CHEMBL1382120 & 688724 & 4.0 & 4.5867 & TRN & \\
\hline CHEMBL1510722 & 688724 & 6.05 & 4.5434 & TRN & \\
\hline CHEMBL1201113 & 688724 & 7.6003 & 5.1047 & TRN & \\
\hline CHEMBL3195494 & 688724 & 4.65 & 4.6226 & TRN & \\
\hline CHEMBL1340285 & 688724 & 4.55 & 4.5566 & TRN & \\
\hline CHEMBL1992872 & 688724 & 5.95 & 4.5888 & TRN & \\
\hline CHEMBL1480742 & 688724 & 4.55 & 4.422 & TRN & \\
\hline CHEMBL1409344 & 688724 & 4.85 & 5.0169 & TST & \\
\hline CHEMBL1567320 & 688724 & 5.05 & 4.8737 & TRN & \\
\hline CHEMBL1557023 & 688724 & 6.6 & 5.5849 & TRN & \\
\hline CHEMBL1968695 & 688724 & 4.75 & 4.79 & TRN & \\
\hline CHEMBL1610726 & 688724 & 4.8 & 5.1072 & TST & \\
\hline CHEMBL1502131 & 688724 & 4.4 & 4.6862 & TRN & \\
\hline CHEMBL1323537 & 688724 & 5.05 & 4.5917 & TST & \\
\hline CHEMBL1372094 & 688724 & 5.45 & 5.2928 & TRN & \\
\hline CHEMBL1528475 & 688724 & 4.5 & 4.4257 & TRN & \\
\hline CHEMBL1584662 & 688724 & 5.0 & 4.6535 & TRN & \\
\hline CHEMBL1552945 & 688724 & 5.0 & 4.6964 & TRN & \\
\hline CHEMBL1446951 & 688724 & 4.45 & 4.7779 & TST & \\
\hline CHEMBL1396780 & 688724 & 4.75 & 4.6649 & TRN & \\
\hline CHEMBL1312765 & 688724 & 4.6 & 4.8264 & TRN & \\
\hline CHEMBL1480793 & 688724 & 4.5 & 5.1219 & TRN & \\
\hline CHEMBL487356 & 688724 & 5.65 & 4.76 & TRN & \\
\hline CHEMBL1606403 & 688724 & 4.4 & 4.4543 & TRN & \\
\hline CHEMBL1440351 & 688724 & 4.8 & 4.5373 & TRN & \\
\hline CHEMBL1526321 & 688724 & 5.25 & 4.9583 & TRN & \\
\hline CHEMBL1552927 & 688724 & 4.55 & 4.8156 & TRN & \\
\hline CHEMBL3214056 & 688724 & 4.0 & 4.35 & TRN & \\
\hline CHEMBL1408422 & 688724 & 4.7 & 4.7576 & TRN & \\
\hline CHEMBL1517266 & 688724 & 4.6 & 4.6344 & TRN & \\
\hline CHEMBL1471716 & 688724 & 4.7 & 4.9152 & TRN & \\
\hline CHEMBL1439439 & 688724 & 5.45 & 4.6663 & TRN & \\
\hline CHEMBL1430204 & 688724 & 4.85 & 4.9897 & TRN & \\
\hline
\end{tabular}




\begin{tabular}{|c|c|c|c|c|c|}
\hline \multicolumn{6}{|c|}{ Supplemental Table S2.txt } \\
\hline CHEMBL1601701 & 688724 & 5.35 & 5.0375 & TRN & \\
\hline CHEMBL1506716 & 688724 & 4.9 & 4.8841 & TST & \\
\hline CHEMBL1315601 & 688724 & 4.55 & 4.8107 & TRN & \\
\hline CHEMBL3198716 & 688724 & 4.3 & 4.7662 & TRN & \\
\hline CHEMBL1474873 & 688724 & 4.5 & 4.7294 & TRN & \\
\hline CHEMBL1492110 & 688724 & 5.1 & 4.9764 & TRN & \\
\hline CHEMBL1545723 & 688724 & 4.4 & 4.4409 & TRN & \\
\hline CHEMBL1472570 & 688724 & 4.75 & 4.9702 & TRN & \\
\hline CHEMBL1426749 & 688724 & 4.3 & 4.8081 & TRN & \\
\hline CHEMBL1578821 & 688724 & 4.85 & 4.8684 & TRN & \\
\hline CHEMBL1442102 & 688724 & 4.2 & 4.4769 & TRN & \\
\hline CHEMBL1545240 & 688724 & 4.5 & 4.6983 & TRN & \\
\hline CHEMBL3196183 & 688724 & 4.45 & 4.9735 & TRN & \\
\hline CHEMBL1324011 & 688724 & 5.4 & 6.1115 & TRN & \\
\hline CHEMBL3190945 & 688724 & 4.4 & 4.535 & TRN & \\
\hline CHEMBL1441861 & 688724 & 4.8 & 4.748 & TRN & \\
\hline CHEMBL1323438 & 688724 & 4.8 & 4.7642 & TRN & \\
\hline CHEMBL1581996 & 688724 & 4.4 & 5.0364 & TST & \\
\hline CHEMBL1386455 & 688724 & 5.1 & 4.8161 & TRN & \\
\hline CHEMBL1604074 & 688724 & 4.15 & 4.9517 & TRN & \\
\hline CHEMBL3195858 & 688724 & 4.4 & 4.6361 & TRN & \\
\hline CHEMBL1552075 & 688724 & 4.95 & 4.9601 & TRN & \\
\hline CHEMBL1366627 & 688724 & 5.75 & 5.061 & TRN & \\
\hline CHEMBL1320310 & 688724 & 6.0 & 5.081 & TRN & \\
\hline CHEMBL1485208 & 688724 & 5.2 & 5.3628 & TRN & \\
\hline CHEMBL1498300 & 688724 & 4.8 & 5.1775 & TRN & \\
\hline CHEMBL1589598 & 688724 & 4.55 & 4.7477 & TST & \\
\hline CHEMBL1374589 & 688724 & 4.0 & 4.8988 & TST & \\
\hline CHEMBL1381 & 688724 & 8.3979 & 4.6384 & TRN & \\
\hline CHEMBL1331895 & 688724 & 4.15 & 4.6759 & TRN & \\
\hline CHEMBL1536994 & 688724 & 4.6 & 4.5625 & TRN & \\
\hline CHEMBL1379924 & 688724 & 4.95 & 5.1119 & TST & \\
\hline CHEMBL1370067 & 688724 & 4.6 & 5.2184 & TRN & \\
\hline CHEMBL1488587 & 688724 & 4.5 & 4.8043 & TST & \\
\hline CHEMBL1556508 & 688724 & 4.65 & 4.4264 & TRN & \\
\hline CHEMBL375107 & 688724 & 4.5 & 5.06800 & 00000000005 & TST \\
\hline CHEMBL1349057 & 688724 & 4.0 & 4.4752 & TRN & \\
\hline CHEMBL1496709 & 688724 & 4.05 & 4.8108 & TRN & \\
\hline CHEMBL1510974 & 688724 & 5.5 & 5.347 & TRN & \\
\hline CHEMBL1480021 & 688724 & 4.1 & 4.756 & TRN & \\
\hline CHEMBL338115 & 688724 & 4.75 & 4.9852 & TRN & \\
\hline CHEMBL1314547 & 688724 & 4.3 & 4.9655 & TST & \\
\hline CHEMBL1449666 & 688724 & 4.5 & 4.5945 & TRN & \\
\hline CHEMBL1554619 & 688724 & 5.35 & 4.6648 & TST & \\
\hline CHEMBL1501204 & 688724 & 4.9 & 4.8901 & TRN & \\
\hline CHEMBL3213920 & 688724 & 5.4 & 4.8727 & TST & \\
\hline CHEMBL1450669 & 688724 & 4.85 & 5.5943 & TRN & \\
\hline CHEMBL 234338 & 688724 & 5.35 & 5.1242 & TRN & \\
\hline
\end{tabular}




\begin{tabular}{|c|c|c|c|c|}
\hline \multicolumn{5}{|c|}{ Supplemental Table S2.txt } \\
\hline CHEMBL1441522 & 688724 & 4.95 & 4.9777 & TRN \\
\hline CHEMBL1465853 & 688724 & 4.6 & 4.7129 & TRN \\
\hline CHEMBL3193510 & 688724 & 6.5501 & 5.3541 & TRN \\
\hline CHEMBL1566601 & 688724 & 4.55 & 4.5394 & TRN \\
\hline CHEMBL1547350 & 688724 & 5.45 & 5.5499 & TRN \\
\hline CHEMBL1480581 & 688724 & 4.8 & 5.1734 & TST \\
\hline CHEMBL1572352 & 688724 & 4.45 & 4.9369 & TRN \\
\hline CHEMBL1532623 & 688724 & 4.7 & 4.537 & TRN \\
\hline CHEMBL1504403 & 688724 & 4.6 & 4.8871 & TRN \\
\hline CHEMBL1586389 & 688724 & 4.7 & 4.5308 & TRN \\
\hline CHEMBL1303264 & 688724 & 4.25 & 4.829 & TRN \\
\hline CHEMBL1485593 & 688724 & 5.5 & 4.6231 & TRN \\
\hline CHEMBL1379329 & 688724 & 4.85 & 5.1417 & TRN \\
\hline CHEMBL45315 & 688724 & 4.85 & 5.2772 & TRN \\
\hline CHEMBL1099177 & 688724 & 4.1 & 4.7481 & TST \\
\hline CHEMBL1501153 & 688724 & 4.75 & 5.0588 & TST \\
\hline CHEMBL1347200 & 688724 & 4.5 & 4.795 & TRN \\
\hline CHEMBL1970221 & 688724 & 4.6 & 5.0083 & TRN \\
\hline CHEMBL1418852 & 688724 & 4.65 & 4.7342 & TRN \\
\hline CHEMBL1607186 & 688724 & 5.0 & 5.1324 & TRN \\
\hline CHEMBL1482347 & 688724 & 4.1 & 4.508 & TRN \\
\hline CHEMBL1491719 & 688724 & 5.5 & 4.8541 & TST \\
\hline CHEMBL1575619 & 688724 & 7.6003 & 4.7755 & TRN \\
\hline CHEMBL1525387 & 688724 & 5.3 & 4.9985 & TST \\
\hline CHEMBL1966792 & 688724 & 4.35 & 4.7633 & TST \\
\hline CHEMBL1995252 & 688724 & 5.1 & 5.2826 & TRN \\
\hline CHEMBL1467712 & 688724 & 6.35 & 4.846 & TST \\
\hline CHEMBL1381318 & 688724 & 4.65 & 5.1413 & TRN \\
\hline CHEMBL1353089 & 688724 & 4.45 & 4.9128 & TRN \\
\hline CHEMBL1536424 & 688724 & 4.0 & 4.8714 & TRN \\
\hline CHEMBL1596728 & 688724 & 4.2 & 4.8348 & TST \\
\hline CHEMBL1508105 & 688724 & 4.4 & 4.5203 & TRN \\
\hline CHEMBL1580205 & 688724 & 4.7 & 4.5572 & TRN \\
\hline CHEMBL3199916 & 688724 & 4.5 & 5.1484 & TST \\
\hline CHEMBL3197433 & 688724 & 5.1 & 5.5016 & TRN \\
\hline CHEMBL3195842 & 688724 & 4.55 & 4.9442 & TRN \\
\hline CHEMBL1394024 & 688724 & 4.6 & 5.0 & TRN \\
\hline CHEMBL1349911 & 688724 & 4.55 & 5.0742 & TST \\
\hline CHEMBL1534751 & 688724 & 5.15 & 5.0431 & TRN \\
\hline CHEMBL3189301 & 688724 & 5.0 & 5.2667 & TRN \\
\hline CHEMBL1503380 & 688724 & 6.4 & 4.9686 & TRN \\
\hline CHEMBL1488344 & 688724 & 5.05 & 5.0078 & TRN \\
\hline CHEMBL1321179 & 688724 & 4.55 & 4.8451 & TRN \\
\hline CHEMBL1347865 & 688724 & 4.65 & 4.5534 & TRN \\
\hline CHEMBL1699206 & 688724 & 5.5 & 4.7572 & TRN \\
\hline CHEMBL1568441 & 688724 & 4.5 & 4.7951 & TRN \\
\hline CHEMBL1577720 & 688724 & 4.05 & 4.3525 & TRN \\
\hline CHEMBL1490716 & 688724 & 4.95 & 5.1399 & TRN \\
\hline
\end{tabular}




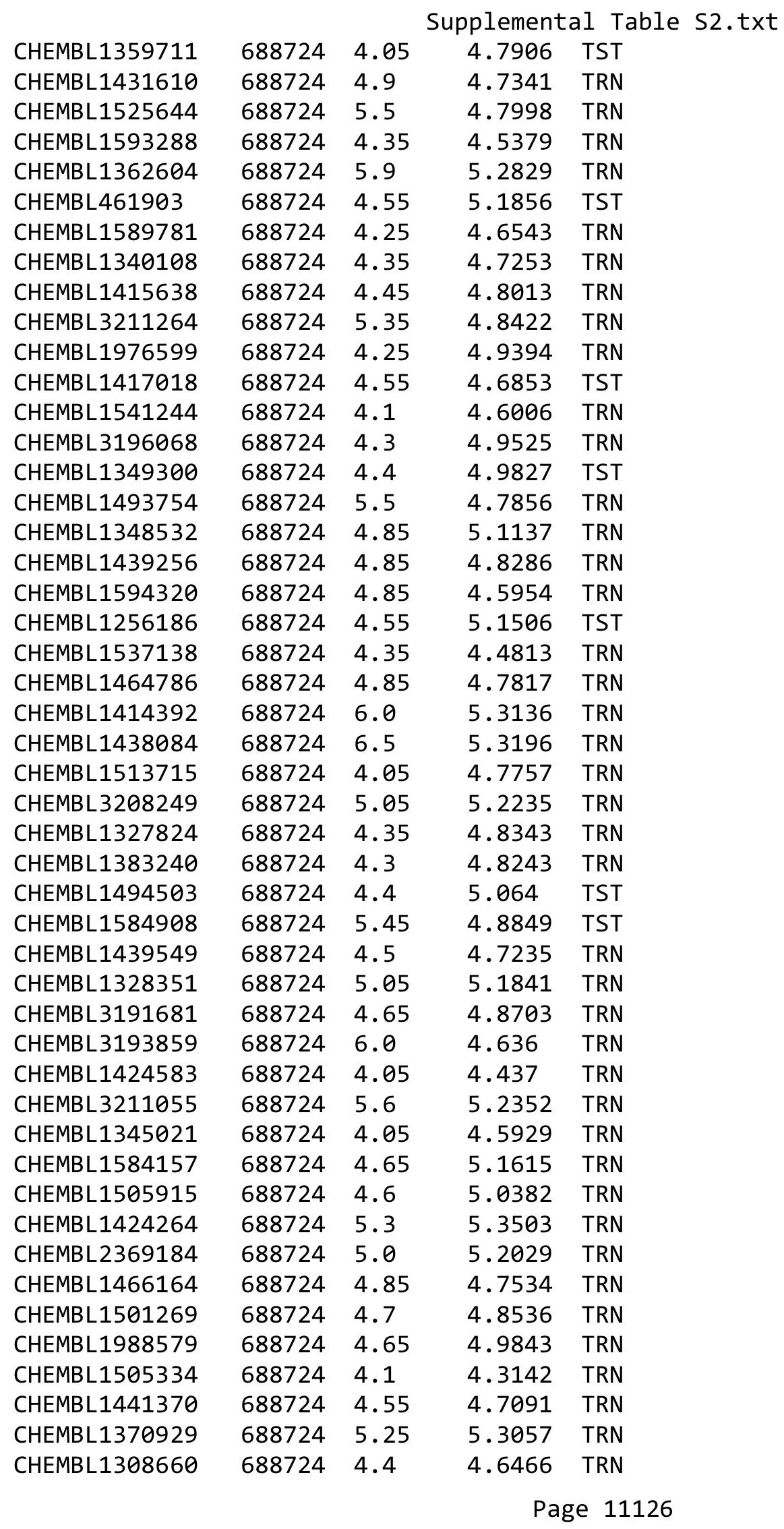




\begin{tabular}{|c|c|c|c|c|}
\hline \multicolumn{5}{|c|}{ Supplemental Table S2.txt } \\
\hline CHEMBL1589817 & 688724 & 4.5 & 4.5146 & TRN \\
\hline CHEMBL1465177 & 688724 & 4.6 & 4.4144 & TRN \\
\hline CHEMBL1562195 & 688724 & 5.85 & 5.3741 & TRN \\
\hline CHEMBL1431754 & 688724 & 5.9 & 5.1173 & TRN \\
\hline CHEMBL78573 & 688724 & 6.5501 & 5.7986 & TRN \\
\hline CHEMBL3190806 & 688724 & 4.55 & 5.3202 & TRN \\
\hline CHEMBL1503140 & 688724 & 4.45 & 4.606 & TRN \\
\hline CHEMBL1410281 & 688724 & 4.45 & 4.7454 & TRN \\
\hline CHEMBL1379268 & 688724 & 5.55 & 4.9354 & TRN \\
\hline CHEMBL533293 & 688724 & 4.0 & 5.3027 & TST \\
\hline CHEMBL1300775 & 688724 & 4.05 & 5.0618 & TST \\
\hline CHEMBL1385808 & 688724 & 5.2 & 5.3422 & TRN \\
\hline CHEMBL1523394 & 688724 & 4.5 & 4.7533 & TST \\
\hline CHEMBL1546163 & 688724 & 4.05 & 4.4812 & TRN \\
\hline CHEMBL1564405 & 688724 & 4.35 & 4.7516 & TRN \\
\hline CHEMBL1595595 & 688724 & 4.3 & 4.8917 & TST \\
\hline CHEMBL1255837 & 688724 & 4.75 & 4.7819 & TRN \\
\hline CHEMBL1528598 & 688724 & 4.9 & 4.7581 & TRN \\
\hline CHEMBL1496237 & 688724 & 6.2 & 5.0306 & TRN \\
\hline CHEMBL1992631 & 688724 & 5.0 & 5.1568 & TRN \\
\hline CHEMBL1442773 & 688724 & 5.0 & 4.9955 & TRN \\
\hline CHEMBL1588513 & 688724 & 5.8 & 5.7796 & TRN \\
\hline CHEMBL1402085 & 688724 & 4.1 & 4.2727 & TRN \\
\hline CHEMBL1576920 & 688724 & 5.05 & 5.4245 & TRN \\
\hline CHEMBL1586238 & 688724 & 4.75 & 4.9125 & TRN \\
\hline CHEMBL1566171 & 688724 & 5.4 & 4.8734 & TRN \\
\hline CHEMBL1438764 & 688724 & 4.75 & 4.8717 & TRN \\
\hline CHEMBL1520631 & 688724 & 5.55 & 5.1224 & TRN \\
\hline CHEMBL1470585 & 688724 & 4.5 & 4.8317 & TRN \\
\hline CHEMBL1441085 & 688724 & 4.7 & 5.2765 & TRN \\
\hline CHEMBL1500909 & 688724 & 4.2 & 4.6251 & TST \\
\hline CHEMBL1510806 & 688724 & 4.05 & 4.5654 & TRN \\
\hline CHEMBL518494 & 688724 & 6.0 & 5.1636 & TST \\
\hline CHEMBL1441984 & 688724 & 4.5 & 5.0894 & TST \\
\hline CHEMBL1424942 & 688724 & 4.45 & 4.7676 & TRN \\
\hline CHEMBL83980 & 688724 & 4.45 & 4.5472 & TRN \\
\hline CHEMBL1519379 & 688724 & 4.5 & 5.0198 & TRN \\
\hline CHEMBL1502551 & 688724 & 4.95 & 4.7482 & TST \\
\hline CHEMBL1588914 & 688724 & 4.35 & 4.7166 & TRN \\
\hline CHEMBL1388709 & 688724 & 5.45 & 4.3867 & TRN \\
\hline CHEMBL3193709 & 688724 & 4.3 & 4.6825 & TRN \\
\hline CHEMBL1451209 & 688724 & 4.8 & 4.7512 & TRN \\
\hline CHEMBL3213802 & 688724 & 4.55 & 4.862 & TRN \\
\hline CHEMBL1460981 & 688724 & 4.65 & 4.8564 & TRN \\
\hline CHEMBL1545614 & 688724 & 4.75 & 4.7374 & TST \\
\hline CHEMBL1399542 & 688724 & 6.45 & 5.2039 & TRN \\
\hline CHEMBL1541195 & 688724 & 4.35 & 5.1973 & TRN \\
\hline CHEMBL1426027 & 688724 & 5.4 & 4.9073 & TST \\
\hline
\end{tabular}




\begin{tabular}{|c|c|c|c|c|}
\hline \\
\hline CHEMBL1487677 & 688724 & 4.4 & 4.8678 & TST \\
\hline CHEMBL1577840 & 688724 & 5.0 & 4.8477 & TST \\
\hline CHEMBL3195662 & 688724 & 5.45 & 5.0449 & TRN \\
\hline CHEMBL3189960 & 688724 & 4.1 & 4.7188 & TRN \\
\hline CHEMBL 372832 & 688724 & 4.3 & 4.6855 & TRN \\
\hline CHEMBL450948 & 688724 & 4.85 & 4.3536 & TRN \\
\hline CHEMBL1504928 & 688724 & 5.95 & 4.7005 & TRN \\
\hline CHEMBL1975746 & 688724 & 4.25 & 4.8604 & TRN \\
\hline CHEMBL1388171 & 688724 & 5.95 & 5.3368 & TST \\
\hline CHEMBL3199340 & 688724 & 4.65 & 5.0756 & TRN \\
\hline CHEMBL1311764 & 688724 & 4.55 & 5.1877 & TST \\
\hline CHEMBL1541462 & 688724 & 4.3 & 4.81 & TRN \\
\hline CHEMBL1401847 & 688724 & 4.75 & 4.9646 & TST \\
\hline CHEMBL1447526 & 688724 & 4.5 & 4.8526 & TST \\
\hline CHEMBL1518513 & 688724 & 4.75 & 4.5281 & TRN \\
\hline CHEMBL106525 & 688724 & 4.1 & 4.8883 & TRN \\
\hline CHEMBL1446491 & 688724 & 4.55 & 4.8579 & TRN \\
\hline CHEMBL1590063 & 688724 & 5.45 & 4.8251 & TRN \\
\hline CHEMBL1349128 & 688724 & 4.1 & 4.5243 & TRN \\
\hline CHEMBL1461513 & 688724 & 4.55 & 4.7706 & TRN \\
\hline CHEMBL1507947 & 688724 & 4.8 & 4.5437 & TST \\
\hline CHEMBL1572087 & 688724 & 4.7 & 4.7512 & TST \\
\hline CHEMBL1986099 & 688724 & 5.0 & 4.8419 & TRN \\
\hline CHEMBL1594606 & 688724 & 5.5 & 5.5888 & TRN \\
\hline CHEMBL1586377 & 688724 & 4.3 & 4.8218 & TRN \\
\hline CHEMBL1515865 & 688724 & 4.35 & 4.6443 & TRN \\
\hline CHEMBL1200471 & 688724 & 5.3 & 5.5917 & TST \\
\hline CHEMBL1593096 & 688724 & 6.7501 & 4.562 & TST \\
\hline CHEMBL1545189 & 688724 & 4.25 & 5.1743 & TRN \\
\hline CHEMBL1384216 & 688724 & 4.25 & 4.3995 & TRN \\
\hline CHEMBL1455944 & 688724 & 4.8 & 4.5413 & TST \\
\hline CHEMBL1528260 & 688724 & 4.05 & 4.7618 & TRN \\
\hline CHEMBL1333760 & 688724 & 4.7 & 4.5255 & TRN \\
\hline CHEMBL1448721 & 688724 & 4.45 & 4.4113 & TRN \\
\hline CHEMBL1433041 & 688724 & 5.5 & 4.953 & TRN \\
\hline CHEMBL1497286 & 688724 & 4.4 & 4.7282 & TRN \\
\hline CHEMBL3195156 & 688724 & 4.4 & 5.0177 & TST \\
\hline CHEMBL 1480782 & 688724 & 4.45 & 4.8018 & TRN \\
\hline CHEMBL1491099 & 688724 & 4.6 & 5.1245 & TST \\
\hline CHEMBL1477979 & 688724 & 5.1 & 4.8645 & TST \\
\hline CHEMBL1308744 & 688724 & 4.35 & 4.5261 & TST \\
\hline CHEMBL1501635 & 688724 & 4.7 & 4.7233 & TRN \\
\hline CHEMBL1496665 & 688724 & 4.75 & 4.9573 & TRN \\
\hline CHEMBL1548882 & 688724 & 5.65 & 4.5851 & TRN \\
\hline CHEMBL1558563 & 688724 & 4.0 & 5.0123 & TST \\
\hline CHEMBL 3198174 & 688724 & 4.6 & 4.8 & TRN \\
\hline CHEMBL1336320 & 688724 & 4.4 & 4.5802 & TST \\
\hline CHEMBL1440298 & 688724 & 6.0 & 5.4232 & TRN \\
\hline
\end{tabular}




\begin{tabular}{|c|c|c|c|c|}
\hline \multicolumn{5}{|c|}{ Supplemental Table S2.txt } \\
\hline CHEMBL1364967 & 688724 & 4.45 & 4.6804 & TRN \\
\hline CHEMBL1511276 & 688724 & 6.0 & 4.9611 & TRN \\
\hline CHEMBL1355023 & 688724 & 4.2 & 4.773 & TRN \\
\hline CHEMBL486193 & 688724 & 5.45 & 5.09399 & 9999999999 \\
\hline CHEMBL1466654 & 688724 & 4.65 & 5.0486 & TRN \\
\hline CHEMBL1577661 & 688724 & 4.9 & 4.7058 & TRN \\
\hline CHEMBL1514312 & 688724 & 4.45 & 4.6851 & TRN \\
\hline CHEMBL3191151 & 688724 & 5.2 & 5.1489 & TST \\
\hline CHEMBL1499508 & 688724 & 5.5 & 4.7871 & TRN \\
\hline CHEMBL1453027 & 688724 & 5.2 & 4.8062 & TRN \\
\hline CHEMBL1570676 & 688724 & 4.45 & 4.5888 & TRN \\
\hline CHEMBL316446 & 688724 & 4.2 & 5.0724 & TST \\
\hline CHEMBL1576939 & 688724 & 4.6 & 4.7947 & TRN \\
\hline CHEMBL1574630 & 688724 & 4.55 & 4.9511 & TST \\
\hline CHEMBL1554894 & 688724 & 4.45 & 4.9471 & TRN \\
\hline CHEMBL 2095095 & 688724 & 5.35 & 5.3441 & TRN \\
\hline CHEMBL1603234 & 688724 & 6.0 & 5.3496 & TRN \\
\hline CHEMBL1382865 & 688724 & 4.8 & 5.0059 & TRN \\
\hline CHEMBL3190693 & 688724 & 7.5003 & 5.1908 & TRN \\
\hline CHEMBL3196707 & 688724 & 4.65 & 4.9987 & TRN \\
\hline CHEMBL1542862 & 688724 & 5.1 & 5.0254 & TRN \\
\hline CHEMBL1256364 & 688724 & 4.1 & 5.223 & TST \\
\hline CHEMBL1566820 & 688724 & 4.3 & 4.4694 & TRN \\
\hline CHEMBL1461249 & 688724 & 4.8 & 4.7108 & TRN \\
\hline CHEMBL1490056 & 688724 & 4.45 & 4.4969 & TST \\
\hline CHEMBL1566722 & 688724 & 4.5 & 4.8915 & TRN \\
\hline CHEMBL1309743 & 688724 & 4.85 & 4.7438 & TST \\
\hline CHEMBL1300716 & 688724 & 4.4 & 4.9441 & TRN \\
\hline CHEMBL1365265 & 688724 & 4.05 & 4.6168 & TRN \\
\hline CHEMBL1474498 & 688724 & 6.0 & 5.194 & TST \\
\hline CHEMBL1390068 & 688724 & 4.75 & 4.7661 & TRN \\
\hline CHEMBL1300236 & 688724 & 4.75 & 4.7543 & TST \\
\hline CHEMBL1446679 & 688724 & 4.85 & 4.5653 & TST \\
\hline CHEMBL1358194 & 688724 & 4.3 & 4.3546 & TRN \\
\hline CHEMBL1430741 & 688724 & 4.7 & 5.2828 & TRN \\
\hline CHEMBL1329230 & 688724 & 4.95 & 4.5775 & TRN \\
\hline CHEMBL1562078 & 688724 & 4.15 & 4.6344 & TRN \\
\hline CHEMBL1310318 & 688724 & 5.55 & 5.0921 & TST \\
\hline CHEMBL1365223 & 688724 & 4.45 & 4.6224 & TRN \\
\hline CHEMBL1509978 & 688724 & 4.45 & 4.4536 & TRN \\
\hline CHEMBL1455028 & 688724 & 4.1 & 4.5476 & TRN \\
\hline CHEMBL1544275 & 688724 & 4.15 & 4.6578 & TRN \\
\hline CHEMBL1453134 & 688724 & 4.9 & 4.9944 & TRN \\
\hline CHEMBL1558195 & 688724 & 6.1 & 4.7275 & TRN \\
\hline CHEMBL1336959 & 688724 & 5.55 & 5.3554 & TRN \\
\hline CHEMBL1550006 & 688724 & 5.25 & 4.9604 & TRN \\
\hline CHEMBL3191252 & 688724 & 4.5 & 4.5476 & TRN \\
\hline CHEMBL1301642 & 688724 & 5.1 & 4.854 & TRN \\
\hline
\end{tabular}

TRN 


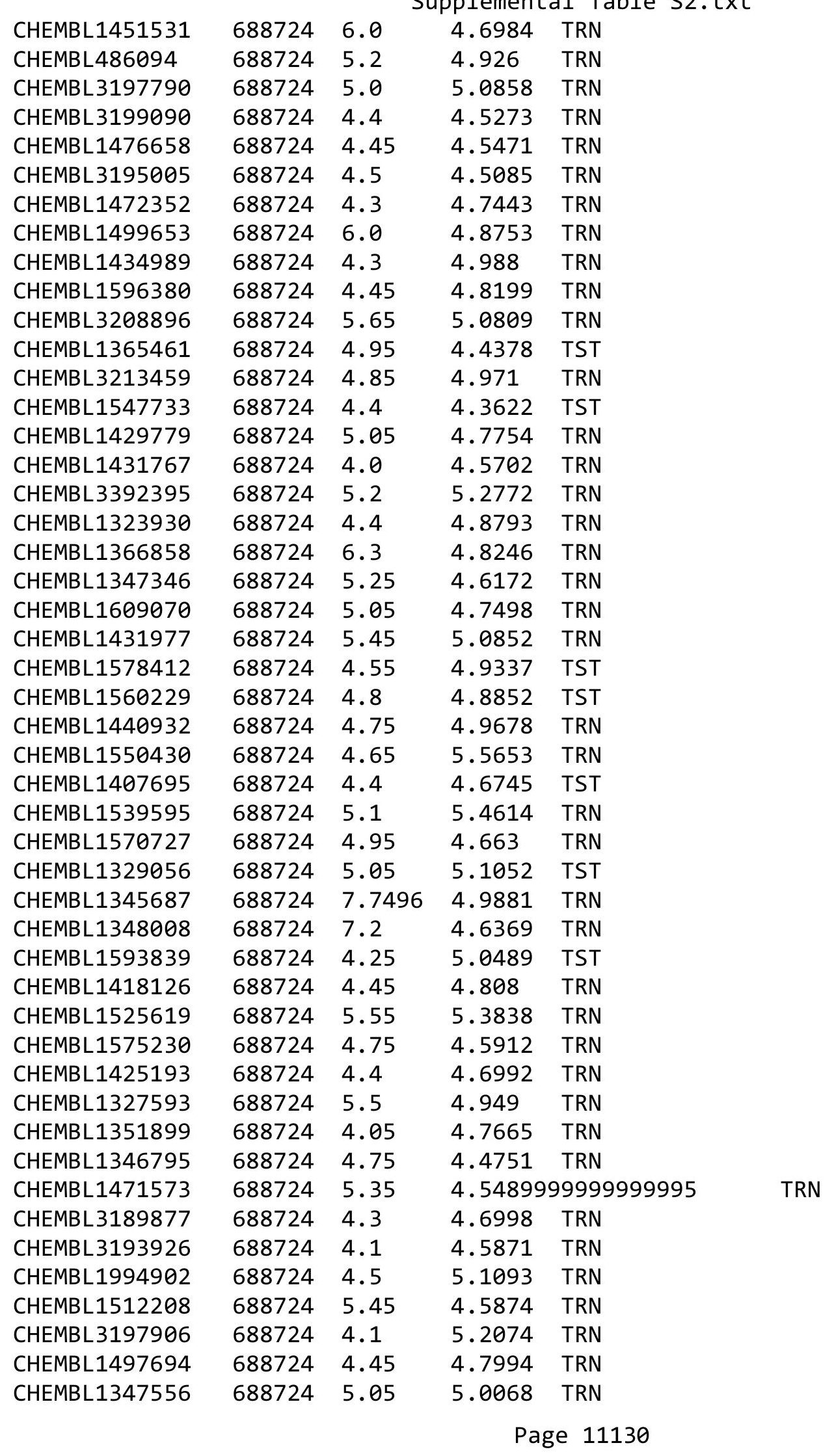




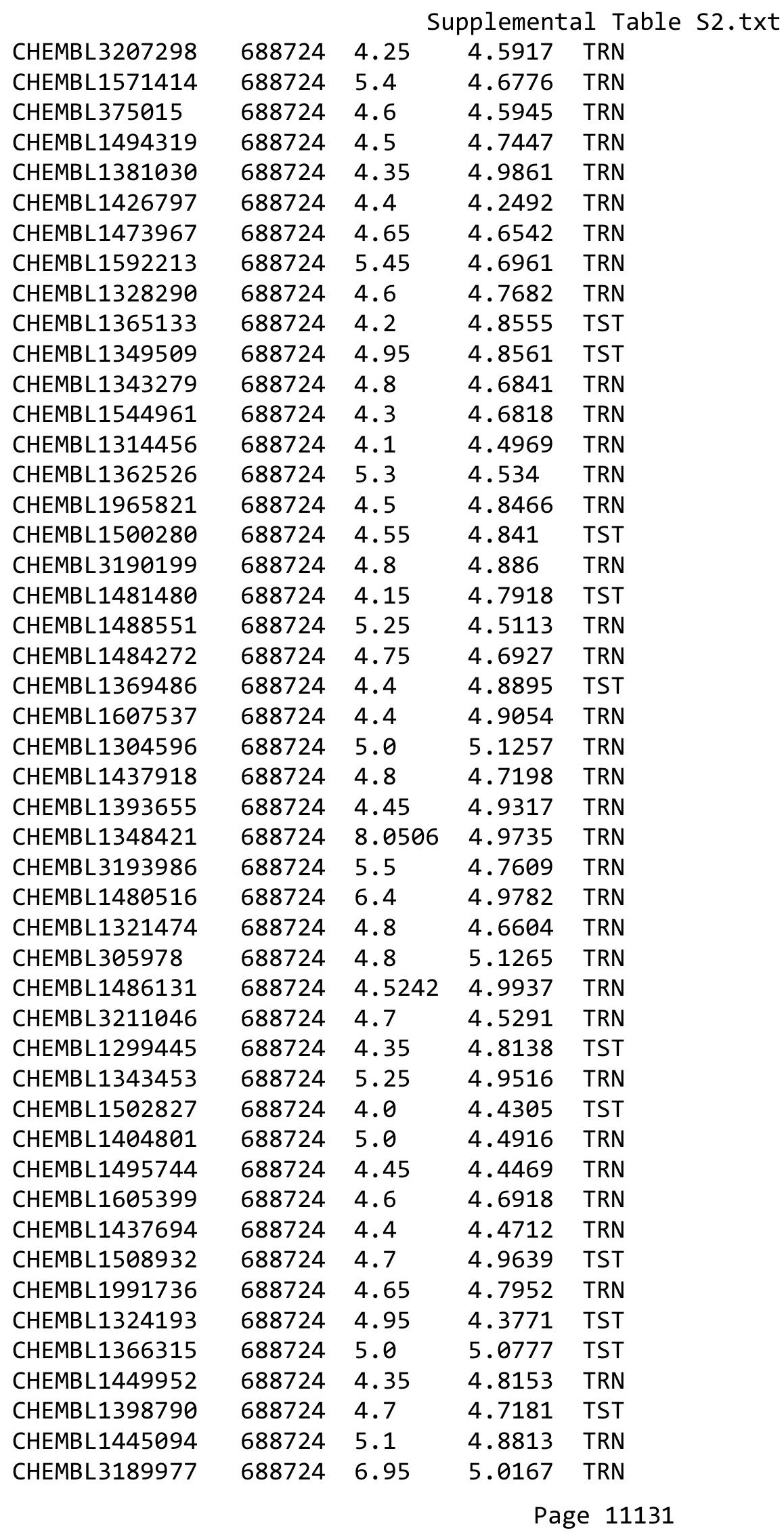




\begin{tabular}{|c|c|c|c|c|c|}
\hline & & \multicolumn{4}{|c|}{ Supplemental Table S2.txt } \\
\hline CHEMBL3193332 & 688724 & 4.85 & 4.9618 & TST & \\
\hline CHEMBL1572145 & 688724 & 4.65 & 4.859 & TRN & \\
\hline CHEMBL1360922 & 688724 & 5.4 & 4.9331 & TRN & \\
\hline CHEMBL1579003 & 688724 & 4.45 & 4.7063 & TRN & \\
\hline CHEMBL1596739 & 688724 & 5.75 & 5.0401 & TRN & \\
\hline CHEMBL1609264 & 688724 & 6.15 & 5.728 & TRN & \\
\hline CHEMBL3189417 & 688724 & 4.6 & 4.9977 & TRN & \\
\hline CHEMBL1406870 & 688724 & 4.7 & 4.4739 & TRN & \\
\hline CHEMBL1441016 & 688724 & 4.9 & 4.8024 & TRN & \\
\hline CHEMBL1458841 & 688724 & 4.65 & 4.3449 & TRN & \\
\hline CHEMBL 3197845 & 688724 & 4.3 & 4.6899 & TRN & \\
\hline CHEMBL434063 & 688724 & 4.85 & 4.8209 & TST & \\
\hline CHEMBL1475596 & 688724 & 5.4 & 4.6856 & TRN & \\
\hline CHEMBL1457060 & 688724 & 5.4 & 4.6434 & TRN & \\
\hline CHEMBL3194752 & 688724 & 4.25 & 4.9377 & TRN & \\
\hline CHEMBL1426692 & 688724 & 4.3 & 4.7758 & TRN & \\
\hline CHEMBL1486090 & 688724 & 5.75 & 4.8181 & TRN & \\
\hline CHEMBL1487834 & 688724 & 4.65 & 4.7664 & TRN & \\
\hline CHEMBL1494428 & 688724 & 4.9 & 4.7557 & TRN & \\
\hline CHEMBL601119 & 688724 & 7.1002 & 5.28799 & 9999999999 & TRN \\
\hline CHEMBL1554216 & 688724 & 4.6 & 4.895 & TRN & \\
\hline CHEMBL1473932 & 688724 & 4.35 & 4.966 & TRN & \\
\hline CHEMBL1483121 & 688724 & 4.8 & 4.7225 & TRN & \\
\hline CHEMBL1546383 & 688724 & 4.65 & 4.9447 & TRN & \\
\hline CHEMBL1303523 & 688724 & 4.25 & 4.735 & TRN & \\
\hline CHEMBL1417633 & 688724 & 4.85 & 5.0817 & TRN & \\
\hline CHEMBL1456904 & 688724 & 5.15 & 4.7696 & TRN & \\
\hline CHEMBL1336801 & 688724 & 4.4 & 4.9807 & TRN & \\
\hline CHEMBL1412163 & 688724 & 4.55 & 4.9791 & TRN & \\
\hline CHEMBL1307827 & 688724 & 5.1 & 4.4803 & TRN & \\
\hline CHEMBL1594161 & 688724 & 4.3 & 4.893 & TRN & \\
\hline CHEMBL1312189 & 688724 & 4.9 & 4.7343 & TRN & \\
\hline CHEMBL1349905 & 688724 & 4.9 & 5.4132 & TRN & \\
\hline CHEMBL1398683 & 688724 & 7.3497 & 4.7342 & TST & \\
\hline CHEMBL1733605 & 688724 & 4.45 & 4.5515 & TRN & \\
\hline CHEMBL1509663 & 688724 & 4.05 & 4.8444 & TRN & \\
\hline CHEMBL1304079 & 688724 & 4.4 & 4.9946 & TRN & \\
\hline CHEMBL3192254 & 688724 & 5.0 & 5.0493 & TST & \\
\hline CHEMBL1605526 & 688724 & 4.55 & 4.6731 & TRN & \\
\hline CHEMBL1413373 & 688724 & 4.9 & 4.8653 & TRN & \\
\hline CHEMBL588804 & 688724 & 6.2 & 5.7877 & TRN & \\
\hline CHEMBL1323553 & 688724 & 5.6 & 5.0546 & TRN & \\
\hline CHEMBL1307271 & 688724 & 6.05 & 5.1952 & TRN & \\
\hline CHEMBL3193507 & 688724 & 4.6 & 4.8359 & TRN & \\
\hline CHEMBL1517431 & 688724 & 4.6 & 4.5256 & TST & \\
\hline CHEMBL1384901 & 688724 & 4.3 & 4.6551 & TRN & \\
\hline CHEMBL3191629 & 688724 & 4.05 & 4.6773 & TRN & \\
\hline CHEMBL1373091 & 688724 & 4.1 & 4.2274 & TRN & \\
\hline
\end{tabular}




\begin{tabular}{|c|c|c|c|c|c|}
\hline \multirow[b]{2}{*}{ CHEMBL1594591 } & & \multicolumn{4}{|c|}{ Supplemental Table S2.txt } \\
\hline & 688724 & 5.3 & 4.5089 & 99999999995 & TRN \\
\hline CHEMBL1462613 & 688724 & 5.55 & 4.4460 & 0000000001 & TRN \\
\hline CHEMBL1333529 & 688724 & 5.0 & 4.5385 & TRN & \\
\hline CHEMBL1593557 & 688724 & 4.4 & 4.872 & TRN & \\
\hline CHEMBL1514259 & 688724 & 4.55 & 4.8568 & TRN & \\
\hline CHEMBL1512831 & 688724 & 4.1 & 4.3947 & TRN & \\
\hline CHEMBL1578953 & 688724 & 4.35 & 4.5501 & TRN & \\
\hline CHEMBL3197107 & 688724 & 4.6 & 5.1002 & TRN & \\
\hline CHEMBL1464772 & 688724 & 4.05 & 4.6715 & TRN & \\
\hline CHEMBL1528008 & 688724 & 4.85 & 4.9192 & TRN & \\
\hline CHEMBL1419900 & 688724 & 4.7 & 4.4154 & TRN & \\
\hline CHEMBL3145316 & 688724 & 4.45 & 4.9636 & TRN & \\
\hline CHEMBL1509032 & 688724 & 4.2 & 4.7318 & TRN & \\
\hline CHEMBL1389574 & 688724 & 4.25 & 4.4508 & TRN & \\
\hline CHEMBL1589644 & 688724 & 4.05 & 4.8597 & TRN & \\
\hline CHEMBL1357199 & 688724 & 4.4 & 4.8825 & TRN & \\
\hline CHEMBL1441059 & 688724 & 4.25 & 5.5325 & TRN & \\
\hline CHEMBL1338567 & 688724 & 5.05 & 4.54 & TRN & \\
\hline CHEMBL1382664 & 688724 & 4.05 & 4.5376 & TRN & \\
\hline CHEMBL1974056 & 688724 & 4.55 & 5.1654 & TRN & \\
\hline CHEMBL1340745 & 688724 & 4.8 & 4.9301 & TST & \\
\hline CHEMBL1529601 & 688724 & 4.95 & 4.5703 & TRN & \\
\hline CHEMBL1318296 & 688724 & 5.3 & 4.9476 & TST & \\
\hline CHEMBL1256180 & 688724 & 4.5 & 4.8545 & TST & \\
\hline CHEMBL1982195 & 688724 & 4.55 & 4.8732 & TST & \\
\hline CHEMBL52 & 688724 & 5.55 & 5.3502 & TRN & \\
\hline CHEMBL3195377 & 688724 & 4.6 & 4.8631 & TRN & \\
\hline CHEMBL1964909 & 688724 & 5.5 & 4.9389 & TRN & \\
\hline CHEMBL1399287 & 688724 & 4.8 & 5.0267 & TRN & \\
\hline CHEMBL1493640 & 688724 & 4.35 & 4.4156 & TRN & \\
\hline CHEMBL1408052 & 688724 & 4.25 & 4.978 & TRN & \\
\hline CHEMBL1299269 & 688724 & 4.05 & 5.0707 & TST & \\
\hline CHEMBL1555738 & 688724 & 5.6 & 4.6977 & TRN & \\
\hline CHEMBL1361502 & 688724 & 4.85 & 4.8442 & TRN & \\
\hline CHEMBL1587135 & 688724 & 4.0 & 4.452 & TRN & \\
\hline CHEMBL56731 & 688724 & 6.0 & 5.2695 & TRN & \\
\hline CHEMBL1451059 & 688724 & 5.1 & 5.4963 & TRN & \\
\hline CHEMBL1604191 & 688724 & 4.95 & 4.6677 & TRN & \\
\hline CHEMBL1586534 & 688724 & 6.15 & 5.4414 & TRN & \\
\hline CHEMBL1582448 & 688724 & 4.95 & 4.8554 & TRN & \\
\hline CHEMBL3392059 & 688724 & 5.45 & 5.4135 & TST & \\
\hline CHEMBL1299622 & 688724 & 4.3 & 4.7722 & TST & \\
\hline CHEMBL1411285 & 688724 & 5.35 & 5.3404 & TRN & \\
\hline CHEMBL1401480 & 688724 & 4.4 & 4.944 & TST & \\
\hline CHEMBL1604284 & 688724 & 4.05 & 4.8133 & TRN & \\
\hline CHEMBL1316789 & 688724 & 5.0 & 4.6937 & TST & \\
\hline CHEMBL1730100 & 688724 & 6.0 & 5.4922 & TST & \\
\hline CHEMBL1322784 & 688724 & 4.6 & 4.8452 & TRN & \\
\hline
\end{tabular}




\begin{tabular}{|c|c|c|c|c|c|}
\hline \multirow[b]{2}{*}{ CHEMBL1591949 } & \multirow[b]{2}{*}{688724} & \multicolumn{4}{|c|}{ olemental Table S2 } \\
\hline & & 4.45 & 4.8771 & TRN & \\
\hline CHEMBL1608144 & 688724 & 6.35 & 4.9756 & TRN & \\
\hline CHEMBL1453429 & 688724 & 4.0 & 4.8754 & TRN & \\
\hline CHEMBL1363848 & 688724 & 4.5 & 5.0314 & TST & \\
\hline CHEMBL1472444 & 688724 & 4.6 & 4.5881 & TRN & \\
\hline CHEMBL1339797 & 688724 & 4.9 & 4.8304 & TRN & \\
\hline CHEMBL1595121 & 688724 & 5.5 & 4.9156 & TRN & \\
\hline CHEMBL1521196 & 688724 & 4.9 & 4.8608 & TST & \\
\hline CHEMBL1551201 & 688724 & 4.05 & 4.7942 & TST & \\
\hline CHEMBL1339859 & 688724 & 4.45 & 4.6761 & TRN & \\
\hline CHEMBL 278041 & 688724 & 4.2 & 4.8649 & TRN & \\
\hline CHEMBL1430390 & 688724 & 4.4 & 4.5425 & TRN & \\
\hline CHEMBL1399232 & 688724 & 4.4 & 4.9795 & TST & \\
\hline CHEMBL1322563 & 688724 & 4.9 & 4.6441 & TRN & \\
\hline CHEMBL1567733 & 688724 & 4.85 & 5.1559 & TRN & \\
\hline CHEMBL 89295 & 688724 & 4.6 & \multicolumn{2}{|c|}{5.2410000000000005} & TST \\
\hline CHEMBL1574521 & 688724 & 4.8 & 4.8223 & TRN & \\
\hline CHEMBL1305441 & 688724 & 4.75 & 4.8972 & TRN & \\
\hline CHEMBL1504970 & 688724 & 4.9 & 4.6654 & TST & \\
\hline CHEMBL1564259 & 688724 & 4.25 & 4.6314 & TRN & \\
\hline CHEMBL1602894 & 688724 & 4.15 & 4.7844 & TRN & \\
\hline CHEMBL1450103 & 688724 & 4.7 & 5.0434 & TST & \\
\hline CHEMBL 2005497 & 688724 & 5.6 & 4.334 & TRN & \\
\hline CHEMBL1398128 & 688724 & 5.25 & 4.9752 & TRN & \\
\hline CHEMBL449928 & 688724 & 4.2 & 4.8942 & TRN & \\
\hline CHEMBL1351103 & 688724 & 4.3 & 4.7735 & TST & \\
\hline CHEMBL1421509 & 688724 & 5.05 & 4.6735 & TRN & \\
\hline CHEMBL1394001 & 688724 & 5.3 & 4.6692 & TRN & \\
\hline CHEMBL1508382 & 688724 & 4.5 & 5.1063 & TST & \\
\hline CHEMBL1367860 & 688724 & 4.65 & 4.9558 & TST & \\
\hline CHEMBL1386852 & 688724 & 4.0 & 4.59 & TST & \\
\hline CHEMBL1498595 & 688724 & 4.7 & 5.0251 & TST & \\
\hline CHEMBL1416575 & 688724 & 4.05 & 4.5128 & TRN & \\
\hline CHEMBL1605713 & 688724 & 5.5 & 4.6353 & TRN & \\
\hline CHEMBL1335502 & 688724 & 4.65 & 4.4162 & TRN & \\
\hline CHEMBL1406195 & 688724 & 6.1 & 5.0991 & TRN & \\
\hline CHEMBL1426386 & 688724 & 4.35 & 4.5555 & TRN & \\
\hline CHEMBL1423806 & 688724 & 4.1 & 4.8705 & TRN & \\
\hline CHEMBL1373142 & 688724 & 5.5 & 5.0112 & TRN & \\
\hline CHEMBL1417598 & 688724 & 4.35 & 4.8271 & TRN & \\
\hline CHEMBL1335286 & 688724 & 4.2 & $4.7360 e$ & 0000000001 & TST \\
\hline CHEMBL 20963 & 688724 & 6.0 & 5.1106 & TRN & \\
\hline CHEMBL1450073 & 688724 & 4.75 & 4.5524 & TRN & \\
\hline CHEMBL1478578 & 688724 & 4.75 & 4.9453 & TST & \\
\hline CHEMBL1324183 & 688724 & 4.65 & 4.8338 & TRN & \\
\hline CHEMBL1543467 & 688724 & 4.05 & 5.1942 & TST & \\
\hline CHEMBL1380490 & 688724 & 4.1 & 4.42899 & 9999999999 & TST \\
\hline \multirow[t]{2}{*}{ CHEMBL1370252 } & 688724 & 4.35 & 5.0215 & TRN & \\
\hline & & \multicolumn{4}{|c|}{ Page 11134} \\
\hline
\end{tabular}




\begin{tabular}{|c|c|c|c|c|c|}
\hline \multicolumn{6}{|c|}{ Supplemental Table S2.txt } \\
\hline CHEMBL1582625 & 688724 & 4.85 & 4.5999 & TRN & \\
\hline CHEMBL1325390 & 688724 & 6.8499 & 5.7932 & TRN & \\
\hline CHEMBL1563559 & 688724 & 4.35 & 4.4567 & TRN & \\
\hline CHEMBL1581638 & 688724 & 4.85 & 4.7141 & TRN & \\
\hline CHEMBL1393016 & 688724 & 4.35 & 4.8502 & TRN & \\
\hline CHEMBL1397564 & 688724 & 4.4 & 4.3697 & TRN & \\
\hline CHEMBL1450356 & 688724 & 4.2 & 5.0845 & TST & \\
\hline CHEMBL1432386 & 688724 & 4.25 & 4.4203 & TRN & \\
\hline CHEMBL1492943 & 688724 & 4.6 & 5.3788 & TRN & \\
\hline CHEMBL1457550 & 688724 & 9.0969 & 4.8803 & TST & \\
\hline CHEMBL1307934 & 688724 & 4.05 & 4.8658 & TRN & \\
\hline CHEMBL1504295 & 688724 & 5.35 & 4.9169 & TRN & \\
\hline CHEMBL1458822 & 688724 & 4.4 & 4.9587 & TRN & \\
\hline CHEMBL3216363 & 688724 & 6.0 & 5.0627 & TRN & \\
\hline CHEMBL 296641 & 688724 & 4.05 & 5.0655 & TRN & \\
\hline CHEMBL244948 & 688724 & 4.45 & 5.0645 & TRN & \\
\hline CHEMBL1377602 & 688724 & 5.05 & 4.6533 & TRN & \\
\hline CHEMBL1486928 & 688724 & 4.75 & 4.6705 & TRN & \\
\hline CHEMBL1301086 & 688724 & 4.05 & 4.8338 & TRN & \\
\hline CHEMBL1525683 & 688724 & 4.75 & 5.3686 & TRN & \\
\hline CHEMBL1332191 & 688724 & 4.8 & 4.6766 & TST & \\
\hline CHEMBL3189169 & 688724 & 4.5 & 4.88399 & 99999999995 & TRN \\
\hline CHEMBL1476488 & 688724 & 4.15 & 4.8443 & TST & \\
\hline CHEMBL3193915 & 688724 & 4.6 & 4.4467 & TRN & \\
\hline CHEMBL1340907 & 688724 & 4.3 & 4.7157 & TRN & \\
\hline CHEMBL1544589 & 688724 & 4.6 & 4.7299 & TST & \\
\hline CHEMBL1468959 & 688724 & 4.35 & 4.9857 & TRN & \\
\hline CHEMBL1538711 & 688724 & 5.65 & 5.3332 & TST & \\
\hline CHEMBL1562310 & 688724 & 4.75 & 4.8919 & TRN & \\
\hline CHEMBL1580164 & 688724 & 4.8 & 4.5021 & TST & \\
\hline CHEMBL1307247 & 688724 & 4.35 & 4.5983 & TRN & \\
\hline CHEMBL1357522 & 688724 & 5.2 & 5.21899 & & TRN \\
\hline CHEMBL157368 & 688724 & 5.5 & 5.4421 & TST & \\
\hline CHEMBL1329688 & 688724 & 4.05 & 4.5188 & TRN & \\
\hline CHEMBL1360585 & 688724 & 4.3 & 4.6777 & TRN & \\
\hline CHEMBL1386365 & 688724 & 4.5 & 4.6456 & TRN & \\
\hline CHEMBL269550 & 688724 & 5.8 & 5.0098 & TST & \\
\hline CHEMBL1432377 & 688724 & 4.05 & 4.7106 & TST & \\
\hline CHEMBL1605065 & 688724 & 4.45 & 4.6758 & TRN & \\
\hline CHEMBL1331457 & 688724 & 4.7 & 4.9761 & TRN & \\
\hline CHEMBL1552723 & 688724 & 5.0 & 4.8716 & TRN & \\
\hline CHEMBL1362157 & 688724 & 4.75 & 4.6568 & TRN & \\
\hline CHEMBL3191201 & 688724 & 4.5 & 4.8951 & TRN & \\
\hline CHEMBL1477450 & 688724 & 4.75 & 4.5576 & TRN & \\
\hline CHEMBL1565849 & 688724 & 5.3 & 4.7581 & TRN & \\
\hline CHEMBL1558533 & 688724 & 4.35 & 4.508 & TRN & \\
\hline CHEMBL34704 & 688724 & 6.0 & 4.9138 & TST & \\
\hline CHEMBL1481622 & 688724 & 5.55 & 5.5308 & TRN & \\
\hline
\end{tabular}




\begin{tabular}{|c|c|c|c|c|}
\hline & & & & al Table \\
\hline CHEMBL1574887 & 688724 & 5.0 & 5.0805 & TRN \\
\hline CHEMBL1993778 & 688724 & 4.35 & 5.053 & TST \\
\hline CHEMBL1443778 & 688724 & 4.7 & 4.8035 & TRN \\
\hline CHEMBL1505245 & 688724 & 4.15 & 4.6755 & TRN \\
\hline CHEMBL1486520 & 688724 & 4.25 & 4.9176 & TRN \\
\hline CHEMBL1508373 & 688724 & 4.4 & 4.4677 & TRN \\
\hline CHEMBL1370986 & 688724 & 4.8 & 4.524 & TRN \\
\hline CHEMBL1468919 & 688724 & 4.4 & 4.4531 & TST \\
\hline CHEMBL1323774 & 688724 & 4.8 & 4.8154 & TRN \\
\hline CHEMBL1440213 & 688724 & 4.3 & 4.5226 & TRN \\
\hline CHEMBL1383312 & 688724 & 5.1 & 5.2606 & TRN \\
\hline CHEMBL1580703 & 688724 & 4.35 & 4.7234 & TRN \\
\hline CHEMBL1532262 & 688724 & 4.3 & 4.5955 & TST \\
\hline CHEMBL1305011 & 688724 & 4.55 & 5.2313 & TRN \\
\hline CHEMBL1562896 & 688724 & 4.35 & 4.7265 & TRN \\
\hline CHEMBL1510817 & 688724 & 5.15 & 4.8706 & TST \\
\hline CHEMBL1491258 & 688724 & 4.45 & 5.1575 & TST \\
\hline CHEMBL1411962 & 688724 & 5.5 & 5.0747 & TRN \\
\hline CHEMBL522311 & 688724 & 4.45 & 4.6668 & TRN \\
\hline CHEMBL1360493 & 688724 & 4.9 & 4.9637 & TRN \\
\hline CHEMBL3196041 & 688724 & 4.5 & 4.813 & TRN \\
\hline CHEMBL1322667 & 688724 & 6.0 & 5.2629 & TRN \\
\hline CHEMBL1322821 & 688724 & 4.3 & 4.5647 & TRN \\
\hline CHEMBL500996 & 688724 & 4.5 & 5.12200 & 0000000001 \\
\hline CHEMBL1325440 & 688724 & 5.45 & 4.6689 & TRN \\
\hline CHEMBL1387010 & 688724 & 4.95 & 5.2896 & TRN \\
\hline CHEMBL1300319 & 688724 & 4.65 & 5.2565 & TRN \\
\hline CHEMBL 3194477 & 688724 & 5.35 & 5.3049 & TRN \\
\hline CHEMBL1363485 & 688724 & 3.9 & 4.8029 & TRN \\
\hline CHEMBL1495402 & 688724 & 4.45 & 4.4835 & TST \\
\hline CHEMBL1418332 & 688724 & 4.75 & 5.3969 & TST \\
\hline CHEMBL1311614 & 688724 & 4.65 & 4.8587 & TRN \\
\hline CHEMBL1407011 & 688724 & 6.95 & 5.2214 & TRN \\
\hline CHEMBL1586445 & 688724 & 6.0 & 5.0581 & TRN \\
\hline CHEMBL1555092 & 688724 & 4.3 & 4.7535 & TRN \\
\hline CHEMBL1460059 & 688724 & 4.8 & 5.1564 & TRN \\
\hline CHEMBL1445410 & 688724 & 4.3 & 5.016 & TRN \\
\hline CHEMBL1399481 & 688724 & 5.05 & 4.6223 & TRN \\
\hline CHEMBL1404242 & 688724 & 5.45 & 4.7747 & TST \\
\hline CHEMBL1604761 & 688724 & 4.45 & 4.7165 & TRN \\
\hline CHEMBL1584877 & 688724 & 4.55 & 4.9803 & TRN \\
\hline CHEMBL1514631 & 688724 & 4.8 & 5.2932 & TST \\
\hline CHEMBL258767 & 688724 & 6.0 & 5.5624 & TRN \\
\hline CHEMBL1979580 & 688724 & 4.95 & 4.9867 & TRN \\
\hline CHEMBL3192961 & 688724 & 4.55 & 5.0559 & TRN \\
\hline CHEMBL3194133 & 688724 & 5.0 & 4.8224 & TST \\
\hline CHEMBL 3199451 & 688724 & 5.5 & 5.0929 & TRN \\
\hline CHEMBL1501854 & 688724 & 4.4 & 4.6504 & TRN \\
\hline
\end{tabular}




\begin{tabular}{|c|c|c|c|c|c|}
\hline & & \multicolumn{4}{|c|}{ Supplemental Table s2.txt } \\
\hline CHEMBL1299405 & 688724 & 4.75 & 4.4077 & TRN & \\
\hline CHEMBL1353953 & 688724 & 7.0 & 5.1626 & TST & \\
\hline CHEMBL89445 & 688724 & 6.95 & 5.3672 & TRN & \\
\hline CHEMBL1530645 & 688724 & 4.6 & 4.6684 & TRN & \\
\hline CHEMBL1467244 & 688724 & 4.8 & 4.6556 & TRN & \\
\hline CHEMBL1416493 & 688724 & 4.75 & 4.8788 & TRN & \\
\hline CHEMBL 269755 & 688724 & 4.2 & 5.0311 & TRN & \\
\hline CHEMBL1574262 & 688724 & 4.6 & 5.2255 & TRN & \\
\hline CHEMBL1419810 & 688724 & 4.55 & 4.7115 & TRN & \\
\hline CHEMBL1420826 & 688724 & 4.9 & 4.9679 & TRN & \\
\hline CHEMBL1558857 & 688724 & 4.05 & 4.7647 & TRN & \\
\hline CHEMBL220087 & 688724 & 4.1 & 5.0939 & TRN & \\
\hline CHEMBL1516495 & 688724 & 4.55 & 4.8647 & TRN & \\
\hline CHEMBL1326366 & 688724 & 4.0 & 4.58 & TST & \\
\hline CHEMBL1427508 & 688724 & 4.55 & 4.82600 & 00000000005 & TRN \\
\hline CHEMBL1521334 & 688724 & 4.5 & 4.7424 & TRN & \\
\hline CHEMBL1339808 & 688724 & 4.65 & 4.7572 & TRN & \\
\hline CHEMBL3197978 & 688724 & 6.3 & 5.5277 & TRN & \\
\hline CHEMBL1589019 & 688724 & 4.85 & 4.3786 & TRN & \\
\hline CHEMBL1561854 & 688724 & 6.1 & 4.6787 & TRN & \\
\hline CHEMBL3208376 & 688724 & 4.0 & 4.3767 & TRN & \\
\hline CHEMBL1522821 & 688724 & 4.85 & 4.5929 & TRN & \\
\hline CHEMBL1537291 & 688724 & 4.65 & 5.0903 & TRN & \\
\hline CHEMBL1383519 & 688724 & 4.3 & 5.0485 & TRN & \\
\hline CHEMBL1491665 & 688724 & 4.0 & 4.9256 & TRN & \\
\hline CHEMBL1968732 & 688724 & 4.95 & 5.2303 & TRN & \\
\hline CHEMBL1522066 & 688724 & 4.8 & 5.0963 & TRN & \\
\hline CHEMBL1423665 & 688724 & 4.05 & 4.7084 & TST & \\
\hline CHEMBL1374242 & 688724 & 4.8 & 5.005 & TRN & \\
\hline CHEMBL1453243 & 688724 & 4.25 & 4.4444 & TST & \\
\hline CHEMBL1512195 & 688724 & 4.6 & 4.89199 & 99999999995 & TRN \\
\hline CHEMBL1498690 & 688724 & 4.25 & 4.6481 & TRN & \\
\hline CHEMBL1170688 & 688724 & 4.6 & 5.0823 & TRN & \\
\hline CHEMBL1449344 & 688724 & 4.4 & 5.7027 & TRN & \\
\hline CHEMBL1448619 & 688724 & 4.4 & 4.5698 & TRN & \\
\hline CHEMBL1509804 & 688724 & 4.95 & 4.8215 & TRN & \\
\hline CHEMBL1331245 & 688724 & 6.25 & 5.3464 & TST & \\
\hline CHEMBL1498788 & 688724 & 4.3 & 4.5725 & TRN & \\
\hline CHEMBL1500256 & 688724 & 5.2 & 4.8612 & TRN & \\
\hline CHEMBL46730 & 688724 & 5.7 & 4.7591 & TST & \\
\hline CHEMBL1366112 & 688724 & 4.1 & 4.7089 & TRN & \\
\hline CHEMBL1446799 & 688724 & 4.4 & 4.7073 & TST & \\
\hline CHEMBL3192957 & 688724 & 4.75 & 4.9971 & TRN & \\
\hline CHEMBL1385841 & 688724 & 4.65 & 5.0254 & TST & \\
\hline CHEMBL1470038 & 688724 & 4.55 & 4.636 & TRN & \\
\hline CHEMBL1983418 & 688724 & 4.4 & 5.2792 & TRN & \\
\hline CHEMBL1397349 & 688724 & 4.55 & 4.8174 & TRN & \\
\hline CHEMBL1517987 & 688724 & 4.65 & 4.5654 & TRN & \\
\hline
\end{tabular}




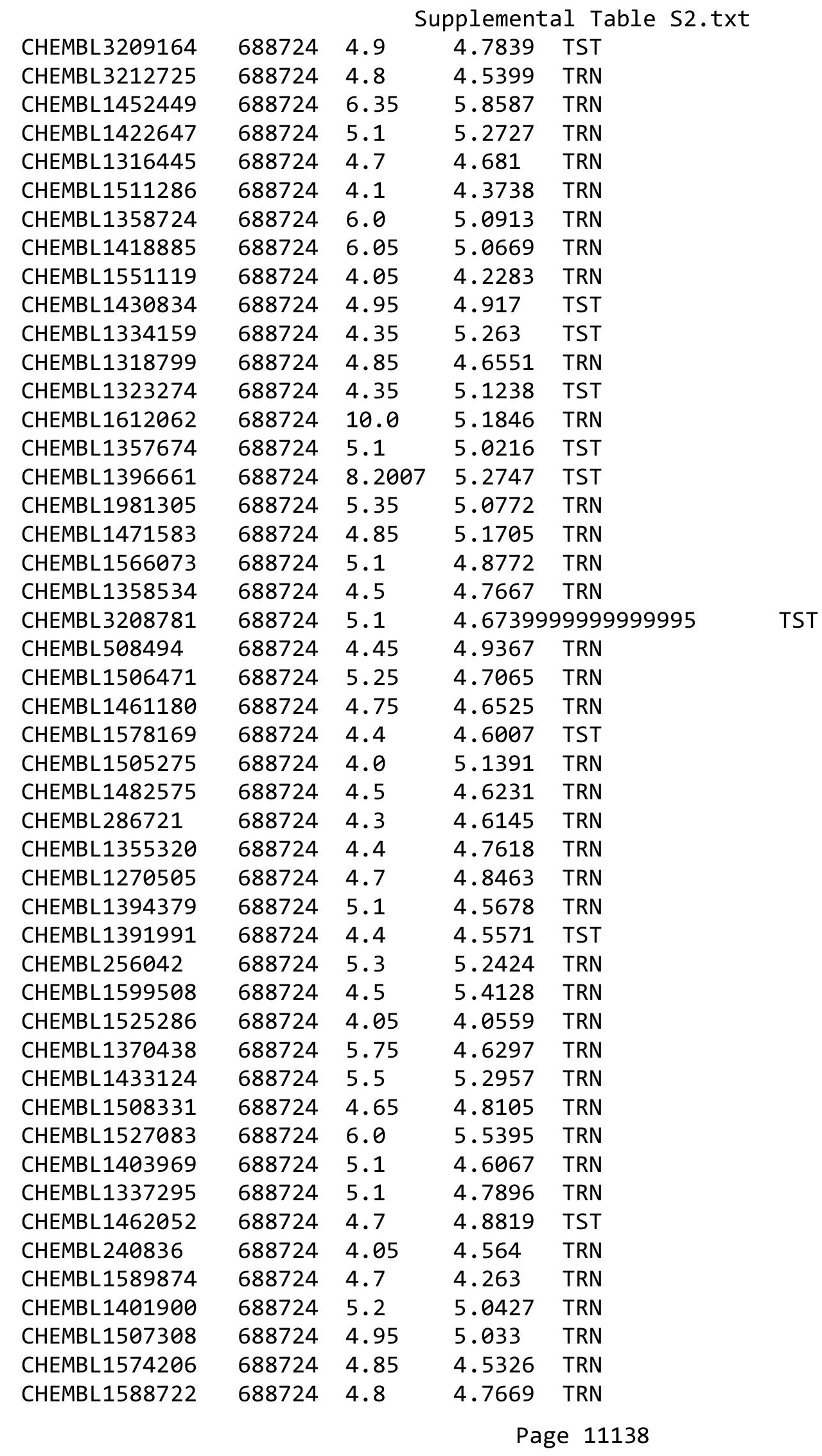




\begin{tabular}{|c|c|c|c|c|c|}
\hline & & \multicolumn{4}{|c|}{ Supplemental Table S2.txt } \\
\hline CHEMBL1611255 & 688724 & 5.05 & 4.4262 & TST & \\
\hline CHEMBL1331974 & 688724 & 4.35 & 5.1316 & TRN & \\
\hline CHEMBL1415842 & 688724 & 4.3 & 4.5944 & TRN & \\
\hline CHEMBL1520217 & 688724 & 4.65 & 4.5815 & TRN & \\
\hline CHEMBL1594875 & 688724 & 4.35 & 4.7564 & TST & \\
\hline CHEMBL1411304 & 688724 & 5.15 & 4.8483 & TRN & \\
\hline CHEMBL1530474 & 688724 & 5.9 & 4.4476 & TST & \\
\hline CHEMBL1559063 & 688724 & 4.4 & 4.6082 & TST & \\
\hline CHEMBL3196920 & 688724 & 4.9 & 4.7693 & TST & \\
\hline CHEMBL1528149 & 688724 & 4.4 & 5.2028 & TRN & \\
\hline CHEMBL1302894 & 688724 & 5.45 & 4.7612 & TRN & \\
\hline CHEMBL1410497 & 688724 & 4.6 & 4.8932 & TST & \\
\hline CHEMBL1403722 & 688724 & 4.35 & 4.5364 & TRN & \\
\hline CHEMBL1375027 & 688724 & 5.25 & 5.3008 & TRN & \\
\hline CHEMBL1495303 & 688724 & 4.05 & 5.1625 & TST & \\
\hline CHEMBL1359190 & 688724 & 4.6 & 4.8093 & TRN & \\
\hline CHEMBL1456197 & 688724 & 4.5 & 4.8206 & TST & \\
\hline CHEMBL1513616 & 688724 & 4.55 & 4.62 & TRN & \\
\hline CHEMBL1507004 & 688724 & 4.7 & 4.6869 & TRN & \\
\hline CHEMBL1559303 & 688724 & 5.3 & 5.1437 & TST & \\
\hline CHEMBL1494520 & 688724 & 4.9 & 4.9739 & TRN & \\
\hline CHEMBL1449743 & 688724 & 4.75 & 4.8337 & TRN & \\
\hline CHEMBL1390340 & 688724 & 4.65 & 4.6217 & TST & \\
\hline CHEMBL1520273 & 688724 & 4.75 & 4.8194 & TRN & \\
\hline CHEMBL1393186 & 688724 & 4.8 & 4.8289 & TST & \\
\hline CHEMBL3193740 & 688724 & 4.25 & 4.5667 & TRN & \\
\hline CHEMBL1506985 & 688724 & 4.5 & 4.698 & TRN & \\
\hline CHEMBL1326314 & 688724 & 4.7 & 4.8261 & TST & \\
\hline CHEMBL1396552 & 688724 & 4.3 & 4.4462 & TST & \\
\hline CHEMBL1604303 & 688724 & 5.75 & 4.4593 & TRN & \\
\hline CHEMBL1543134 & 688724 & 4.4 & 5.0006 & TRN & \\
\hline CHEMBL1508282 & 688724 & 5.5 & 4.6436 & TRN & \\
\hline CHEMBL1522796 & 688724 & 6.2 & 5.2381 & TRN & \\
\hline CHEMBL335231 & 688724 & 4.7 & 5.0591 & TST & \\
\hline CHEMBL1424835 & 688724 & 5.4 & 4.7199 & TRN & \\
\hline CHEMBL3192779 & 688724 & 4.35 & 4.8802 & TRN & \\
\hline CHEMBL1577268 & 688724 & 4.9 & 4.6122 & TRN & \\
\hline CHEMBL1307255 & 688724 & 4.45 & 4.9201 & TRN & \\
\hline CHEMBL1427901 & 688724 & 4.35 & 5.1095 & TST & \\
\hline CHEMBL1326482 & 688724 & 4.65 & 4.8442 & TST & \\
\hline CHEMBL1499696 & 688724 & 5.45 & 4.9548 & TST & \\
\hline CHEMBL1323724 & 688724 & 5.8 & 4.7455 & TST & \\
\hline CHEMBL1323518 & 688724 & 5.9 & 5.09399 & 9999999999 & TRN \\
\hline CHEMBL14276 & 688724 & 4.5 & 4.7036 & TRN & \\
\hline CHEMBL451432 & 688724 & 4.6 & 4.9118 & TST & \\
\hline CHEMBL1549070 & 688724 & 4.05 & 4.5044 & TRN & \\
\hline CHEMBL1594966 & 688724 & 4.55 & 4.9136 & TRN & \\
\hline CHEMBL1542981 & 688724 & 4.05 & 4.881 & TRN & \\
\hline
\end{tabular}




\begin{tabular}{|c|c|c|c|c|c|}
\hline \multicolumn{6}{|c|}{ Supplemental Table S2.txt } \\
\hline CHEMBL1572732 & 688724 & 4.65 & 4.6247 & TRN & \\
\hline CHEMBL1412774 & 688724 & 6.0 & 4.9473 & TRN & \\
\hline CHEMBL1483402 & 688724 & 5.15 & 4.8432 & TRN & \\
\hline CHEMBL1313065 & 688724 & 5.45 & 4.9697 & TRN & \\
\hline CHEMBL1487309 & 688724 & 4.5 & 4.5688 & TST & \\
\hline CHEMBL1531820 & 688724 & 4.55 & 4.6206 & TRN & \\
\hline CHEMBL1463969 & 688724 & 4.05 & 4.7441 & TRN & \\
\hline CHEMBL 8867 & 688724 & 6.0 & 5.1401 & TRN & \\
\hline CHEMBL1554018 & 688724 & 4.5 & 4.5341 & TRN & \\
\hline CHEMBL1430473 & 688724 & 4.8242 & 5.5669 & TRN & \\
\hline CHEMBL1456425 & 688724 & 4.75 & 4.7633 & TRN & \\
\hline CHEMBL1490513 & 688724 & 4.35 & 4.9459 & TRN & \\
\hline CHEMBL1544707 & 688724 & 4.5 & 4.6847 & TRN & \\
\hline CHEMBL1527657 & 688724 & 4.5 & 4.6802 & TRN & \\
\hline CHEMBL1474625 & 688724 & 5.45 & 4.9235 & TRN & \\
\hline CHEMBL1334100 & 688724 & 6.9 & 4.8272 & TRN & \\
\hline CHEMBL1486834 & 688724 & 4.4 & 4.5811 & TRN & \\
\hline CHEMBL1332468 & 688724 & 4.4 & 4.5551 & TRN & \\
\hline CHEMBL1417122 & 688724 & 4.35 & 4.3318 & TRN & \\
\hline CHEMBL1492531 & 688724 & 5.1 & 5.1074 & TRN & \\
\hline CHEMBL1596940 & 688724 & 5.0 & 4.8574 & TRN & \\
\hline CHEMBL3197127 & 688724 & 6.6 & 5.11600 & 00000000005 & TRN \\
\hline CHEMBL1324061 & 688724 & 4.5 & 4.7509 & TRN & \\
\hline CHEMBL1561729 & 688724 & 5.8 & 5.0464 & TRN & \\
\hline CHEMBL 3208560 & 688724 & 5.35 & 5.0235 & TRN & \\
\hline CHEMBL1439329 & 688724 & 5.45 & 4.9996 & TRN & \\
\hline CHEMBL192600 & 688724 & 5.4 & 4.6328 & TST & \\
\hline CHEMBL1550456 & 688724 & 5.1 & 4.757 & TRN & \\
\hline CHEMBL1601646 & 688724 & 4.6 & 5.0229 & TRN & \\
\hline CHEMBL1397359 & 688724 & 5.3 & 4.7546 & TRN & \\
\hline CHEMBL1463091 & 688724 & 4.75 & 4.9292 & TRN & \\
\hline CHEMBL291057 & 688724 & 6.0 & 5.2617 & TST & \\
\hline CHEMBL1569643 & 688724 & 4.4 & 4.6402 & TRN & \\
\hline CHEMBL1607341 & 688724 & 4.65 & 4.9157 & TST & \\
\hline CHEMBL 289431 & 688724 & 4.05 & 5.1082 & TST & \\
\hline CHEMBL1517129 & 688724 & 5.2 & 5.1651 & TRN & \\
\hline CHEMBL1608929 & 688724 & 5.15 & 5.0259 & TRN & \\
\hline CHEMBL1414814 & 688724 & 5.6 & 5.1571 & TRN & \\
\hline CHEMBL1500835 & 688724 & 4.35 & 4.8071 & TRN & \\
\hline CHEMBL3190468 & 688724 & 6.15 & 5.3717 & TRN & \\
\hline CHEMBL 284104 & 688724 & 5.85 & 4.8902 & TRN & \\
\hline CHEMBL3191030 & 688724 & 4.8 & 5.3731 & TRN & \\
\hline CHEMBL1343773 & 688724 & 4.45 & 4.6201 & TRN & \\
\hline CHEMBL1396171 & 688724 & 4.7 & 4.7046 & TRN & \\
\hline CHEMBL1395202 & 688724 & 4.05 & 4.6918 & TRN & \\
\hline CHEMBL1490606 & 688724 & 4.7 & 4.564 & TRN & \\
\hline CHEMBL1372143 & 688724 & 5.1 & 4.8545 & TST & \\
\hline CHEMBL 286615 & 688724 & 8.2518 & 4.7922 & TRN & \\
\hline
\end{tabular}

Page 11140 


\begin{tabular}{|c|c|c|c|c|c|}
\hline \multicolumn{6}{|c|}{ Supplemental Table S2.txt } \\
\hline CHEMBL1391649 & 688724 & 5.05 & 4.4079 & TRN & \\
\hline CHEMBL1313195 & 688724 & 4.75 & 4.9648 & TRN & \\
\hline CHEMBL1451023 & 688724 & 5.05 & 4.9508 & TST & \\
\hline CHEMBL1569972 & 688724 & 4.75 & 4.7817 & TRN & \\
\hline CHEMBL1325782 & 688724 & 6.2 & 4.9598 & TRN & \\
\hline CHEMBL1440953 & 688724 & 5.7 & 4.55699 & 99999999995 & TRN \\
\hline CHEMBL3212290 & 688724 & 4.4 & 4.9627 & TST & \\
\hline CHEMBL3214589 & 688724 & 5.6 & 4.9459 & TRN & \\
\hline CHEMBL1422312 & 688724 & 5.25 & 4.8845 & TRN & \\
\hline CHEMBL1440336 & 688724 & 4.35 & 4.7453 & TRN & \\
\hline CHEMBL1473063 & 688724 & 4.6 & 4.5289 & TRN & \\
\hline CHEMBL3195237 & 688724 & 4.7 & 5.1402 & TRN & \\
\hline CHEMBL1411897 & 688724 & 4.35 & 5.1432 & TST & \\
\hline CHEMBL1337347 & 688724 & 4.0 & 4.9166 & TRN & \\
\hline CHEMBL1521058 & 688724 & 4.1 & 5.4185 & TST & \\
\hline CHEMBL1452090 & 688724 & 5.1 & 5.6075 & TRN & \\
\hline CHEMBL1994803 & 688724 & 4.55 & 4.7813 & TRN & \\
\hline CHEMBL1382264 & 688724 & 4.4 & 4.6823 & TRN & \\
\hline CHEMBL1348114 & 688724 & 4.05 & 4.5621 & TRN & \\
\hline CHEMBL1348969 & 688724 & 4.55 & 4.7626 & TRN & \\
\hline CHEMBL1549371 & 688724 & 4.45 & 4.7576 & TST & \\
\hline CHEMBL1541068 & 688724 & 4.45 & 4.7385 & TST & \\
\hline CHEMBL1353498 & 688724 & 4.1 & 4.4805 & TRN & \\
\hline CHEMBL1426704 & 688724 & 4.0 & 4.7954 & TST & \\
\hline CHEMBL1569660 & 688724 & 5.4 & 5.0616 & TRN & \\
\hline CHEMBL1537542 & 688724 & 4.55 & 5.165 & TRN & \\
\hline CHEMBL1439411 & 688724 & 4.4 & 4.69600 & 0000000001 & TRN \\
\hline CHEMBL1510979 & 688724 & 4.65 & 4.7935 & TRN & \\
\hline CHEMBL1572085 & 688724 & 4.65 & 4.863 & TST & \\
\hline CHEMBL354663 & 688724 & 4.35 & 4.6739 & TRN & \\
\hline CHEMBL3039775 & 688724 & 4.7 & 4.8973 & TRN & \\
\hline CHEMBL1571375 & 688724 & 4.65 & 4.8801 & TST & \\
\hline CHEMBL1412087 & 688724 & 5.35 & 5.0081 & TRN & \\
\hline CHEMBL1594833 & 688724 & 5.55 & 4.9557 & TRN & \\
\hline CHEMBL1528965 & 688724 & 6.2 & 5.3808 & TRN & \\
\hline CHEMBL1511179 & 688724 & 6.1 & 5.4538 & TRN & \\
\hline CHEMBL3199899 & 688724 & 4.95 & 5.1139 & TRN & \\
\hline CHEMBL1490461 & 688724 & 4.8 & 5.1026 & TST & \\
\hline CHEMBL1460015 & 688724 & 4.3 & 4.2896 & TRN & \\
\hline CHEMBL1575701 & 688724 & 4.4 & 4.9006 & TST & \\
\hline CHEMBL3392364 & 688724 & 5.25 & 5.2375 & TRN & \\
\hline CHEMBL1465733 & 688724 & 4.4 & 4.8504 & TST & \\
\hline CHEMBL1586973 & 688724 & 5.0 & 4.5341 & TRN & \\
\hline CHEMBL3195027 & 688724 & 4.8 & 4.8859 & TRN & \\
\hline CHEMBL1412999 & 688724 & 4.3 & 4.9779 & TRN & \\
\hline CHEMBL1333216 & 688724 & 5.5 & 5.2396 & TRN & \\
\hline CHEMBL1411253 & 688724 & 4.1 & 4.6684 & TRN & \\
\hline CHEMBL1427314 & 688724 & 6.1 & 4.8884 & TRN & \\
\hline
\end{tabular}




\begin{tabular}{|c|c|c|c|c|}
\hline \multicolumn{5}{|c|}{ Supplemental Table S2.txt } \\
\hline CHEMBL1490750 & 688724 & 5.5 & 5.5047 & TRN \\
\hline CHEMBL1327817 & 688724 & 4.95 & 4.595 & TST \\
\hline CHEMBL1358863 & 688724 & 5.0 & 4.6984 & TRN \\
\hline CHEMBL1608853 & 688724 & 5.15 & 4.8716 & TRN \\
\hline CHEMBL1366310 & 688724 & 4.85 & 4.789 & TST \\
\hline CHEMBL590927 & 688724 & 5.55 & 5.7192 & TRN \\
\hline CHEMBL1535409 & 688724 & 4.4 & 4.6978 & TST \\
\hline CHEMBL1500035 & 688724 & 5.2 & 4.9361 & TST \\
\hline CHEMBL1586906 & 688724 & 4.05 & 4.6743 & TRN \\
\hline CHEMBL3199206 & 688724 & 6.0 & 5.0264 & TRN \\
\hline CHEMBL1530296 & 688724 & 4.3 & 4.8934 & TRN \\
\hline CHEMBL3211365 & 688724 & 4.9 & 4.4877 & TRN \\
\hline CHEMBL1469910 & 688724 & 4.25 & 4.6864 & TRN \\
\hline CHEMBL1392870 & 688724 & 4.5 & 4.5339 & TRN \\
\hline CHEMBL1439839 & 688724 & 5.15 & 4.4524 & TRN \\
\hline CHEMBL1598766 & 688724 & 5.8 & 5.0507 & TRN \\
\hline CHEMBL3195732 & 688724 & 4.85 & 4.9429 & TRN \\
\hline CHEMBL1489782 & 688724 & 4.4 & 4.6321 & TST \\
\hline CHEMBL1473665 & 688724 & 4.95 & 4.8446 & TST \\
\hline CHEMBL1469099 & 688724 & 4.95 & 5.157 & TST \\
\hline CHEMBL468590 & 688724 & 4.7 & 4.7025 & TRN \\
\hline CHEMBL3197836 & 688724 & 4.6 & 5.0557 & TRN \\
\hline CHEMBL1536196 & 688724 & 5.7 & 5.1757 & TST \\
\hline CHEMBL1533766 & 688724 & 4.1 & 4.4929 & TRN \\
\hline CHEMBL1411307 & 688724 & 4.8 & 5.0054 & TRN \\
\hline CHEMBL1332140 & 688724 & 4.65 & 4.2442 & TRN \\
\hline CHEMBL1472067 & 688724 & 4.75 & 4.6092 & TRN \\
\hline CHEMBL1471841 & 688724 & 5.75 & 5.0125 & TRN \\
\hline CHEMBL 70141 & 688724 & 4.55 & 5.2278 & TRN \\
\hline CHEMBL 275006 & 688724 & 5.8 & 4.9157 & TST \\
\hline CHEMBL1316860 & 688724 & 4.1 & 4.4488 & TRN \\
\hline CHEMBL1587620 & 688724 & 4.65 & 4.502 & TRN \\
\hline CHEMBL1373294 & 688724 & 4.2 & 4.6309 & TRN \\
\hline CHEMBL150924 & 688724 & 6.0 & 5.1225 & TRN \\
\hline CHEMBL1363099 & 688724 & 4.55 & 4.728 & TRN \\
\hline CHEMBL1609717 & 688724 & 4.3 & 4.5083 & TRN \\
\hline CHEMBL1501199 & 688724 & 4.35 & 4.8903 & TST \\
\hline CHEMBL1580684 & 688724 & 6.0 & 5.0488 & TRN \\
\hline CHEMBL3192697 & 688724 & 4.45 & 4.8285 & TRN \\
\hline CHEMBL1584828 & 688724 & 4.9 & 4.7687 & TRN \\
\hline CHEMBL1584895 & 688724 & 5.1 & 4.6545 & TST \\
\hline CHEMBL168279 & 688724 & 8.4559 & 5.1507 & TST \\
\hline CHEMBL3392458 & 688724 & 5.45 & 5.1485 & TRN \\
\hline CHEMBL577635 & 688724 & 4.5 & 5.4713 & TST \\
\hline CHEMBL1469647 & 688724 & 4.95 & 4.3135 & TRN \\
\hline CHEMBL1560052 & 688724 & 4.45 & 4.3859 & TRN \\
\hline CHEMBL1393339 & 688724 & 4.85 & 4.6048 & TRN \\
\hline CHEMBL1304238 & 688724 & 7.8013 & 4.3507 & TST \\
\hline
\end{tabular}




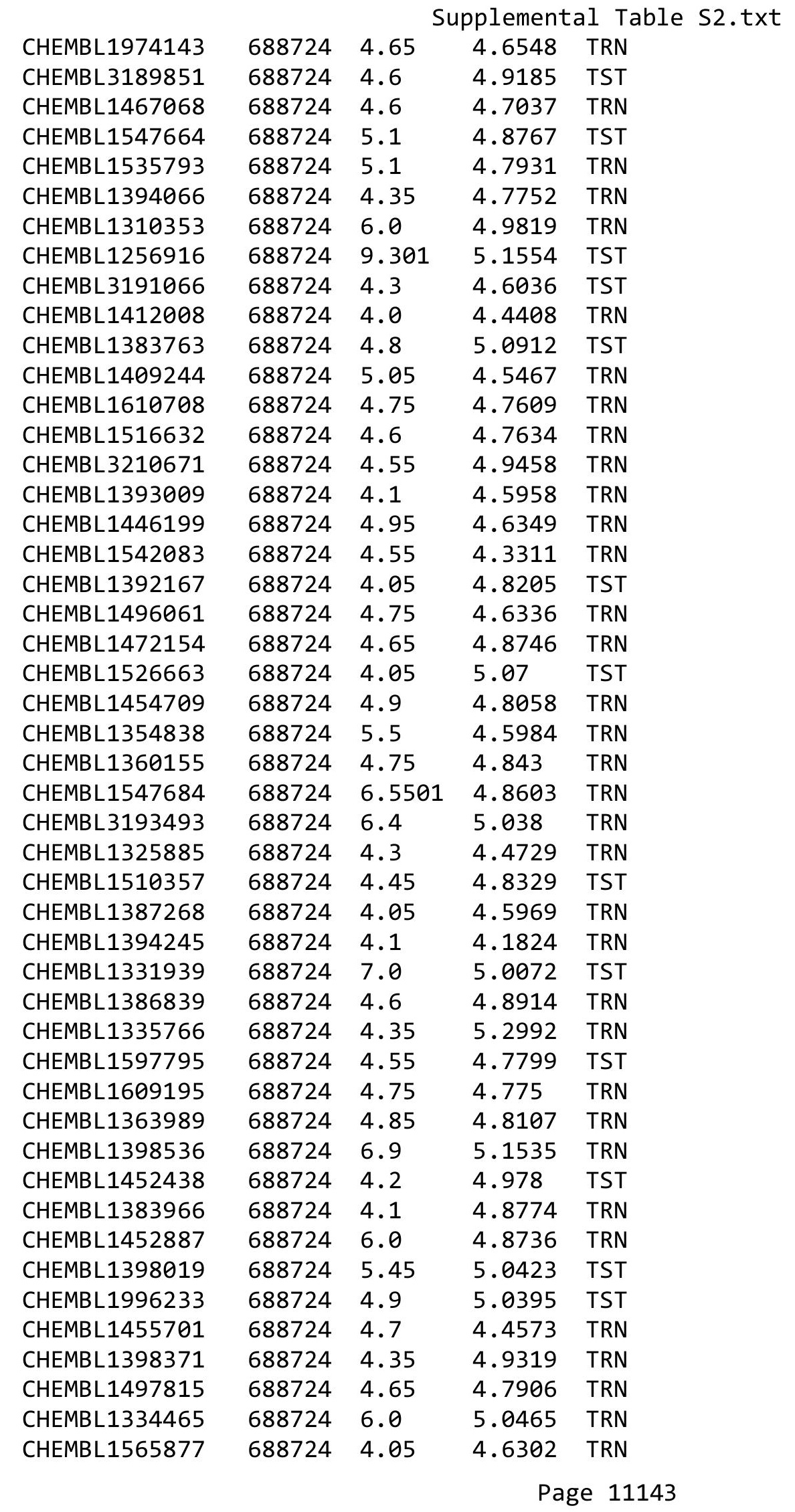




\begin{tabular}{|c|c|c|c|c|}
\hline \multicolumn{5}{|c|}{ Supplemental Table S2.txt } \\
\hline CHEMBL3208729 & 688724 & 4.9 & 5.0448 & TRN \\
\hline CHEMBL3190303 & 688724 & 5.95 & 4.7182 & TRN \\
\hline CHEMBL1323356 & 688724 & 4.4 & 4.7025 & TRN \\
\hline CHEMBL1444536 & 688724 & 4.8 & 4.6976 & TST \\
\hline CHEMBL1607707 & 688724 & 4.95 & 4.8412 & TRN \\
\hline CHEMBL1980308 & 688724 & 4.05 & 4.6426 & TRN \\
\hline CHEMBL3197471 & 688724 & 5.25 & 4.894 & TRN \\
\hline CHEMBL1370528 & 688724 & 4.4 & 4.9134 & TST \\
\hline CHEMBL1362935 & 688724 & 6.0 & 5.3059 & TRN \\
\hline CHEMBL1366479 & 688724 & 4.65 & 4.9268 & TRN \\
\hline CHEMBL1436069 & 688724 & 4.45 & 4.5623 & TRN \\
\hline CHEMBL1346673 & 688724 & 4.65 & 5.1337 & TRN \\
\hline CHEMBL1399266 & 688724 & 4.05 & 4.8112 & TRN \\
\hline CHEMBL1481866 & 688724 & 4.35 & 4.8014 & TST \\
\hline CHEMBL1369006 & 688724 & 5.0 & 4.9597 & TRN \\
\hline CHEMBL3199539 & 688724 & 4.65 & 5.2842 & TRN \\
\hline CHEMBL1584299 & 688724 & 4.4 & 4.7826 & TRN \\
\hline CHEMBL512366 & 688724 & 5.7 & 5.2386 & TRN \\
\hline CHEMBL1573754 & 688724 & 4.8 & 5.3532 & TST \\
\hline CHEMBL1393820 & 688724 & 4.75 & 4.3954 & TRN \\
\hline CHEMBL1983116 & 688724 & 5.0 & 4.9424 & TST \\
\hline CHEMBL1598056 & 688724 & 4.7 & 4.6792 & TRN \\
\hline CHEMBL3196572 & 688724 & 4.9 & 4.7838 & TRN \\
\hline CHEMBL1582494 & 688724 & 4.4 & 4.6891 & TRN \\
\hline CHEMBL1345821 & 688724 & 5.45 & 4.5165 & TRN \\
\hline CHEMBL1496701 & 688724 & 4.4 & 4.7079 & TRN \\
\hline CHEMBL327209 & 688724 & 4.55 & 4.8713 & TRN \\
\hline CHEMBL1527092 & 688724 & 4.65 & 4.971 & TRN \\
\hline CHEMBL1445252 & 688724 & 4.3 & 4.8114 & TRN \\
\hline CHEMBL1335406 & 688724 & 8.4949 & 4.9836 & TST \\
\hline CHEMBL3199796 & 688724 & 4.65 & 4.73 & TRN \\
\hline CHEMBL1467287 & 688724 & 5.1 & 4.9449 & TRN \\
\hline CHEMBL1364166 & 688724 & 4.5 & 4.6956 & TRN \\
\hline CHEMBL3191227 & 688724 & 5.05 & 4.5448 & TST \\
\hline CHEMBL1501185 & 688724 & 4.6 & 4.7826 & TRN \\
\hline CHEMBL606532 & 688724 & 5.95 & 5.5153 & TRN \\
\hline CHEMBL3197688 & 688724 & 4.65 & 4.4628 & TRN \\
\hline CHEMBL1535661 & 688724 & 5.15 & 4.5248 & TRN \\
\hline CHEMBL1322456 & 688724 & 4.25 & 4.4077 & TRN \\
\hline CHEMBL1431875 & 688724 & 4.6 & 5.0275 & TRN \\
\hline CHEMBL1309258 & 688724 & 5.5 & 4.7498 & TRN \\
\hline CHEMBL1315238 & 688724 & 5.65 & 4.6449 & TRN \\
\hline CHEMBL1333129 & 688724 & 4.6 & 4.7965 & TRN \\
\hline CHEMBL1476136 & 688724 & 4.35 & 4.7828 & TRN \\
\hline CHEMBL1315088 & 688724 & 4.3 & 4.6058 & TRN \\
\hline CHEMBL1970753 & 688724 & 5.05 & 4.9244 & TRN \\
\hline CHEMBL1328054 & 688724 & 4.85 & 4.9862 & TRN \\
\hline CHEMBL1547278 & 688724 & 5.5 & 4.6293 & TRN \\
\hline
\end{tabular}




\begin{tabular}{|c|c|c|c|c|c|}
\hline \multicolumn{6}{|c|}{ pplemental Table S2. } \\
\hline CHEMBL145 & 688724 & 6.0 & 5.3294 & TRN & \\
\hline CHEMBL1589964 & 688724 & 4.3 & 5.2109 & TRN & \\
\hline CHEMBL1359848 & 688724 & 4.95 & 4.92399 & 99999999995 & TRN \\
\hline CHEMBL1526487 & 688724 & 4.4 & 4.5024 & TRN & \\
\hline CHEMBL1339983 & 688724 & 4.15 & 4.574 & TST & \\
\hline CHEMBL1362974 & 688724 & 4.05 & 4.5839 & TRN & \\
\hline CHEMBL1337575 & 688724 & 4.95 & 4.694 & TRN & \\
\hline CHEMBL1306931 & 688724 & 4.95 & 5.0844 & TRN & \\
\hline CHEMBL1489269 & 688724 & 5.1 & 5.2244 & TRN & \\
\hline CHEMBL1559927 & 688724 & 5.45 & 4.8019 & TRN & \\
\hline CHEMBL1527289 & 688724 & 4.0 & 4.7434 & TRN & \\
\hline CHEMBL1309004 & 688724 & 5.75 & 4.663 & TRN & \\
\hline CHEMBL1319552 & 688724 & 4.05 & 4.7666 & TST & \\
\hline CHEMBL1539325 & 688724 & 5.2 & 4.9358 & TRN & \\
\hline CHEMBL1578948 & 688724 & 4.8 & 4.6745 & TRN & \\
\hline CHEMBL538965 & 688724 & 4.3 & 4.8471 & TRN & \\
\hline CHEMBL1309710 & 688724 & 4.8 & 5.2831 & TRN & \\
\hline CHEMBL1371395 & 688724 & 4.4 & 4.8334 & TST & \\
\hline CHEMBL 3209142 & 688724 & 5.0 & 4.9431 & TRN & \\
\hline CHEMBL1431676 & 688724 & 4.85 & 4.9212 & TRN & \\
\hline CHEMBL1606329 & 688724 & 4.35 & 4.6052 & TRN & \\
\hline CHEMBL3145109 & 688724 & 5.1 & 4.9232 & TST & \\
\hline CHEMBL1335224 & 688724 & 5.1 & 4.7479 & TST & \\
\hline CHEMBL3193993 & 688724 & 4.25 & 4.8702 & TRN & \\
\hline CHEMBL1393348 & 688724 & 4.35 & 4.583 & TRN & \\
\hline CHEMBL1444337 & 688724 & 4.9 & 5.37 & TRN & \\
\hline CHEMBL1601549 & 688724 & 4.65 & 5.2172 & TRN & \\
\hline CHEMBL1535453 & 688724 & 5.45 & 4.6967 & TRN & \\
\hline CHEMBL1325604 & 688724 & 4.35 & 4.7918 & TRN & \\
\hline CHEMBL1566153 & 688724 & 5.95 & 5.1755 & TRN & \\
\hline CHEMBL1487849 & 688724 & 4.75 & 5.1668 & TRN & \\
\hline CHEMBL1568609 & 688724 & 4.05 & 4.7897 & TST & \\
\hline CHEMBL 256062 & 688724 & 6.0 & 5.0457 & TRN & \\
\hline CHEMBL1452124 & 688724 & 4.15 & 4.5974 & TRN & \\
\hline CHEMBL1565329 & 688724 & 4.55 & 4.9369 & TST & \\
\hline CHEMBL1368835 & 688724 & 6.0 & 4.9963 & TRN & \\
\hline CHEMBL1540041 & 688724 & 4.0 & 4.66 & TRN & \\
\hline CHEMBL1422306 & 688724 & 4.8 & 5.30200 & 00000000005 & TRN \\
\hline CHEMBL1522226 & 688724 & 4.6 & 4.9567 & TRN & \\
\hline CHEMBL1555353 & 688724 & 5.7 & 4.9255 & TST & \\
\hline CHEMBL3189736 & 688724 & 4.7 & 4.8372 & TST & \\
\hline CHEMBL1335589 & 688724 & 6.0 & 5.2907 & TRN & \\
\hline CHEMBL1413219 & 688724 & 4.7 & 5.0487 & TRN & \\
\hline CHEMBL1341109 & 688724 & 4.35 & 4.8879 & TRN & \\
\hline CHEMBL599013 & 688724 & 4.95 & 5.1354 & TRN & \\
\hline CHEMBL1582133 & 688724 & 4.6 & 4.7699 & TRN & \\
\hline CHEMBL1408056 & 688724 & 4.8 & 5.2149 & TRN & \\
\hline CHEMBL1300732 & 688724 & 4.8 & 4.7755 & TRN & \\
\hline
\end{tabular}




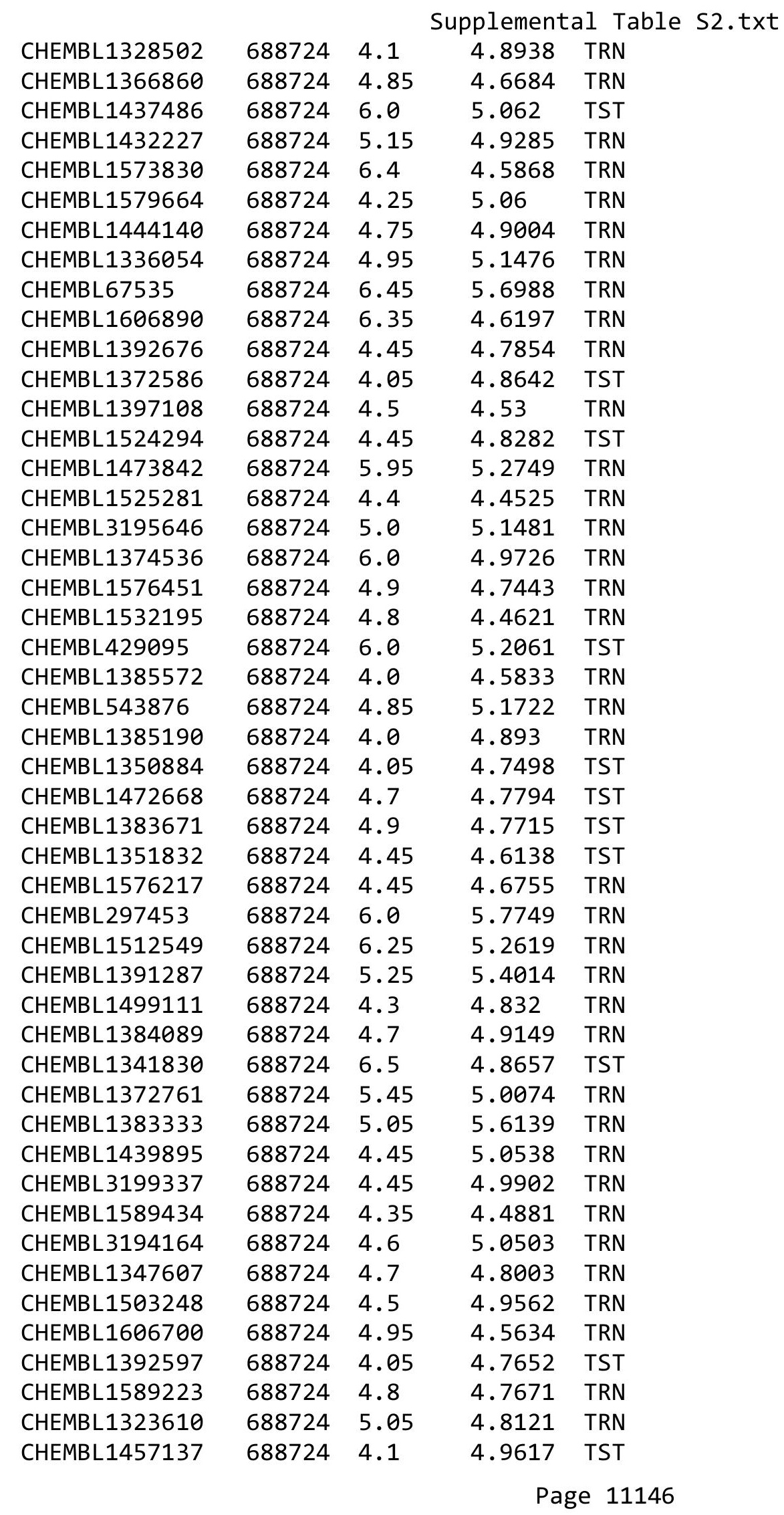




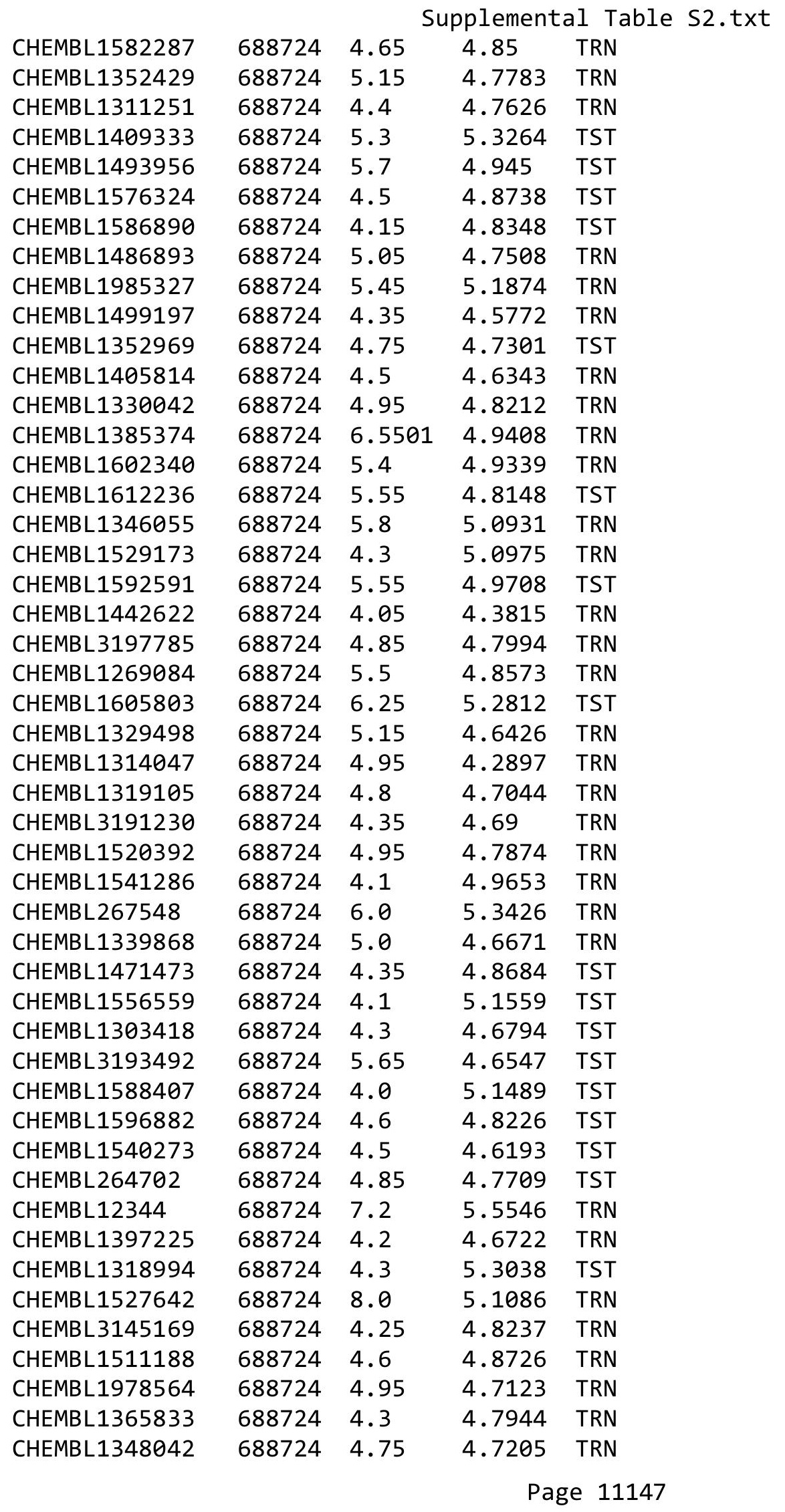




\begin{tabular}{|c|c|c|c|c|}
\hline \multicolumn{5}{|c|}{ Supplemental Table s2.txt } \\
\hline CHEMBL1613708 & 688724 & 4.35 & 4.4065 & TRN \\
\hline CHEMBL217894 & 688724 & 6.0 & 5.2438 & TST \\
\hline CHEMBL1505057 & 688724 & 4.9 & 5.0712 & TRN \\
\hline CHEMBL10347 & 688724 & 7.8996 & 5.2643 & TRN \\
\hline CHEMBL1563507 & 688724 & 4.75 & 4.7388 & TRN \\
\hline CHEMBL1547893 & 688724 & 4.05 & 5.0149 & TST \\
\hline CHEMBL1567624 & 688724 & 6.6 & 4.7048 & TRN \\
\hline CHEMBL1362627 & 688724 & 4.8 & 5.3831 & TRN \\
\hline CHEMBL1271047 & 688724 & 4.6 & 4.6173 & TST \\
\hline CHEMBL1555494 & 688724 & 4.7 & 5.0859 & TRN \\
\hline CHEMBL1580357 & 688724 & 5.4 & 4.9241 & TRN \\
\hline CHEMBL1343539 & 688724 & 7.2503 & 5.1368 & TRN \\
\hline CHEMBL3194979 & 688724 & 5.45 & 4.6964 & TST \\
\hline CHEMBL1418986 & 688724 & 4.35 & 4.5033 & TRN \\
\hline CHEMBL1422021 & 688724 & 4.55 & 4.9336 & TRN \\
\hline CHEMBL1586116 & 688724 & 4.8 & 4.7004 & TRN \\
\hline CHEMBL1442714 & 688724 & 4.6 & 5.4009 & TRN \\
\hline CHEMBL1408838 & 688724 & 4.5 & 5.2806 & TRN \\
\hline CHEMBL3214090 & 688724 & 5.65 & 5.0387 & TRN \\
\hline CHEMBL1381662 & 688724 & 4.4 & 4.6883 & TST \\
\hline CHEMBL1442665 & 688724 & 4.75 & 5.0104 & TST \\
\hline CHEMBL1494805 & 688724 & 4.85 & 4.5015 & TST \\
\hline CHEMBL3198025 & 688724 & 4.9 & 4.7763 & TRN \\
\hline CHEMBL1362979 & 688724 & 5.0 & 4.8157 & TST \\
\hline CHEMBL1441033 & 688724 & 5.85 & 5.1376 & TST \\
\hline CHEMBL1315981 & 688724 & 6.2 & 5.274 & TRN \\
\hline CHEMBL1512871 & 688724 & 5.0 & 4.7426 & TRN \\
\hline CHEMBL1610680 & 688724 & 4.7 & 4.8731 & TRN \\
\hline CHEMBL1336571 & 688724 & 4.05 & 4.832 & TST \\
\hline CHEMBL1173475 & 688724 & 6.0 & 5.8157 & TRN \\
\hline CHEMBL1315298 & 688724 & 4.7 & 4.8253 & TRN \\
\hline CHEMBL1503962 & 688724 & 4.35 & 5.0385 & TST \\
\hline CHEMBL1610981 & 688724 & 4.25 & 4.7392 & TRN \\
\hline CHEMBL1341123 & 688724 & 4.45 & 4.7751 & TST \\
\hline CHEMBL1498164 & 688724 & 5.15 & 4.7774 & TRN \\
\hline CHEMBL1456894 & 688724 & 4.5 & 4.4792 & TRN \\
\hline CHEMBL1452684 & 688724 & 4.9 & 4.4517 & TRN \\
\hline CHEMBL1574720 & 688724 & 4.25 & 4.9021 & TRN \\
\hline CHEMBL3192892 & 688724 & 4.35 & 4.5645 & TRN \\
\hline CHEMBL1471439 & 688724 & 4.8 & 4.4122 & TST \\
\hline CHEMBL1535781 & 688724 & 4.05 & 4.4626 & TRN \\
\hline CHEMBL1471170 & 688724 & 6.4 & 5.3999 & TRN \\
\hline CHEMBL1417696 & 688724 & 4.35 & 4.6049 & TST \\
\hline CHEMBL1611990 & 688724 & 5.0 & 4.7052 & TRN \\
\hline CHEMBL1519958 & 688724 & 5.85 & 5.2205 & TRN \\
\hline CHEMBL1449186 & 688724 & 4.0 & 4.8756 & TRN \\
\hline CHEMBL410063 & 688724 & 6.0 & 5.01399 & 9999999999 \\
\hline CHEMBL1520007 & 688724 & 4.85 & 4.9324 & TRN \\
\hline
\end{tabular}




\begin{tabular}{|c|c|c|c|c|c|c|}
\hline \multicolumn{7}{|c|}{ Supplemental Table S2.txt } \\
\hline CHEMBL1338779 & 688724 & 4.25 & 5.1988 & TST & & \\
\hline CHEMBL3212259 & 688724 & 7.0 & 4.569 & TRN & & \\
\hline CHEMBL3213715 & 688724 & 4.45 & 5.2601 & TRN & & \\
\hline CHEMBL1600760 & 688724 & 4.55 & 5.1855 & TRN & & \\
\hline CHEMBL1327201 & 688724 & 4.55 & 4.9466 & TST & & \\
\hline CHEMBL1346550 & 688724 & 4.3 & 4.8882 & TST & & \\
\hline CHEMBL3212606 & 688724 & 4.75 & 4.9382 & TRN & & \\
\hline CHEMBL1577165 & 688724 & 4.8 & 4.8075 & TRN & & \\
\hline CHEMBL3195522 & 688724 & 4.5 & 4.7867 & TRN & & \\
\hline CHEMBL1426748 & 688326 & 4.6868 & 4.3063 & TRN & & \\
\hline CHEMBL1313883 & 688326 & 4.6236 & 4.1981 & TRN & & \\
\hline CHEMBL3198383 & 688326 & 3.2308 & 3.9628 & TRN & & \\
\hline CHEMBL1472263 & 688326 & 5.8601 & 5.2112 & TRN & & \\
\hline CHEMBL1304420 & 688326 & 4.6139 & 4.1965 & TRN & & \\
\hline CHEMBL1976586 & 688326 & 5.2175 & 4.7306 & TRN & & \\
\hline CHEMBL3195875 & 688326 & 4.4675 & 4.0643 & TRN & & \\
\hline CHEMBL1528635 & 688326 & 4.2901 & 3.9533 & TRN & & \\
\hline CHEMBL1327844 & 688326 & $3.3960 e$ & 00000000 & 204 & 4.4015 & TRN \\
\hline CHEMBL1341308 & 688326 & 4.9237 & 4.3298 & TRN & & \\
\hline CHEMBL1403209 & 688326 & 5.3344 & 4.9575 & TRN & & \\
\hline CHEMBL1495281 & 688326 & $4.6560 e$ & 00000000 & & 4.1818 & TRN \\
\hline CHEMBL1353226 & 688326 & 3.4517 & 4.2492 & TRN & & \\
\hline CHEMBL1401034 & 688326 & 4.9508 & 4.3898 & TRN & & \\
\hline CHEMBL1965068 & 688326 & 4.6198 & 4.9175 & TRN & & \\
\hline CHEMBL1346860 & 688326 & 4.3667 & 4.5789 & TRN & & \\
\hline CHEMBL1516860 & 688326 & 4.7349 & 4.1919 & TRN & & \\
\hline CHEMBL1585589 & 688326 & 4.0984 & 3.9406 & TST & & \\
\hline CHEMBL1471200 & 688326 & 4.6923 & 4.7364 & TRN & & \\
\hline CHEMBL1558462 & 688326 & 3.8677 & 4.6002 & TRN & & \\
\hline CHEMBL1443834 & 688326 & 4.4234 & 3.9236 & TRN & & \\
\hline CHEMBL3196069 & 688326 & 4.4345 & 4.3889 & TRN & & \\
\hline CHEMBL1420638 & 688326 & 4.6421 & 4.1785 & TRN & & \\
\hline CHEMBL1549103 & 688326 & 3.2835 & 4.1133 & TRN & & \\
\hline CHEMBL1452235 & 688326 & 4.9255 & 4.6093 & TRN & & \\
\hline CHEMBL3195975 & 688326 & 4.6447 & 4.1659 & TST & & \\
\hline CHEMBL1303443 & 688326 & 4.7233 & 4.294 & TRN & & \\
\hline CHEMBL1472008 & 688326 & 4.5709 & 4.1259 & TRN & & \\
\hline CHEMBL1488597 & 688326 & 3.4435 & 4.7389 & TRN & & \\
\hline CHEMBL1350543 & 688326 & 4.7147 & 4.6227 & TRN & & \\
\hline CHEMBL1423003 & 688326 & 4.945 & 4.6248 & TRN & & \\
\hline CHEMBL1365517 & 688326 & 3.0467 & 3.6782 & TRN & & \\
\hline CHEMBL1612260 & 688326 & 4.697 & 4.4957 & TRN & & \\
\hline CHEMBL1483112 & 688326 & 4.648 & 4.4756 & TRN & & \\
\hline CHEMBL1497867 & 688326 & 3.3606 & 3.9836 & TRN & & \\
\hline CHEMBL1611026 & 688326 & 4.6334 & 4.1252 & TRN & & \\
\hline CHEMBL1372085 & 688326 & 4.9136 & 4.4045 & TRN & & \\
\hline CHEMBL602969 & 688326 & 5.063 & 4.6281 & TST & & \\
\hline CHEMBL1576837 & 688326 & 4.6123 & 4.2968 & TST & & \\
\hline
\end{tabular}




\begin{tabular}{|c|c|c|c|c|c|c|}
\hline & & \multicolumn{5}{|c|}{ Supplemental Table s2.txt } \\
\hline CHEMBL1990598 & 688326 & 4.63 & 4.332 & TRN & & \\
\hline CHEMBL1550591 & 688326 & 4.9344 & 4.4253 & TST & & \\
\hline CHEMBL1517153 & 688326 & 4.3656 & 3.9962 & TRN & & \\
\hline CHEMBL1562079 & 688326 & 5.0141 & 4.9392 & TRN & & \\
\hline CHEMBL1537770 & 688326 & 3.0032 & 4.1571 & TRN & & \\
\hline CHEMBL3212193 & 688326 & 5.0376 & 5.0228 & TRN & & \\
\hline CHEMBL1585527 & 688326 & 4.5064 & 4.3721 & TRN & & \\
\hline CHEMBL1437516 & 688326 & 4.5441 & 4.1219 & TRN & & \\
\hline CHEMBL1302576 & 688326 & 3.1895 & 4.1122 & TST & & \\
\hline CHEMBL1512306 & 688326 & 3.1483 & 3.8466 & TRN & & \\
\hline CHEMBL 3208118 & 688326 & 4.8645 & 4.4725 & TRN & & \\
\hline CHEMBL1479550 & 688326 & 5.1574 & 4.6188 & TRN & & \\
\hline CHEMBL585656 & 688326 & 4.9923 & 4.6174 & TRN & & \\
\hline CHEMBL429095 & 688326 & 4.9477 & 4.6821 & TRN & & \\
\hline CHEMBL1514881 & 688326 & 3.0106 & 4.1696 & TRN & & \\
\hline CHEMBL1313887 & 688326 & 4.3333 & 4.2405 & TRN & & \\
\hline CHEMBL1461822 & 688326 & 3.1075 & 3.8268 & TRN & & \\
\hline CHEMBL1325558 & 688326 & 3.012 & 4.1863 & TRN & & \\
\hline CHEMBL1315069 & 688326 & 4.9292 & 4.6032 & TRN & & \\
\hline CHEMBL3199305 & 688326 & 4.34399 & 99999999 & 99 & 4.2406 & TRN \\
\hline CHEMBL1562304 & 688326 & 4.6592 & 4.7705 & TST & & \\
\hline CHEMBL1581244 & 688326 & 4.4448 & 4.44600 & 0000000001 & & TRN \\
\hline CHEMBL1398080 & 688326 & 4.2061 & 4.1364 & TRN & & \\
\hline CHEMBL1470679 & 688326 & 5.3125 & 5.3593 & TRN & & \\
\hline CHEMBL1542899 & 688326 & 3.0 & 5.6421 & TRN & & \\
\hline CHEMBL1463750 & 688326 & 4.5403 & 4.7656 & TRN & & \\
\hline CHEMBL1544423 & 688326 & 5.5935 & 5.0978 & TRN & & \\
\hline CHEMBL1444767 & 688326 & 4.9634 & 4.4041 & TRN & & \\
\hline CHEMBL1453809 & 688326 & 4.6419 & 4.1637 & TRN & & \\
\hline CHEMBL443510 & 688326 & 4.5065 & 4.1606 & TRN & & \\
\hline CHEMBL1528781 & 688326 & 4.325 & 4.0192 & TRN & & \\
\hline CHEMBL1461563 & 688326 & 4.9223 & 4.4786 & TRN & & \\
\hline CHEMBL1344675 & 688326 & 4.2685 & 3.9151 & TRN & & \\
\hline CHEMBL1597655 & 688326 & 3.1384 & 3.9007 & TRN & & \\
\hline CHEMBL1535055 & 688326 & 3.4798 & 4.1385 & TRN & & \\
\hline CHEMBL1579424 & 688326 & 3.3458 & 4.0191 & TRN & & \\
\hline CHEMBL1405602 & 688326 & 4.7203 & 4.4925 & TRN & & \\
\hline CHEMBL1305307 & 688326 & 3.0428 & 4.2099 & TRN & & \\
\hline CHEMBL1509379 & 688326 & 5.556 & 5.3198 & TRN & & \\
\hline CHEMBL1987274 & 688326 & 3.3393 & 4.2052 & TRN & & \\
\hline CHEMBL1470941 & 688326 & 4.8918 & 4.5291 & TRN & & \\
\hline CHEMBL1334809 & 688326 & 4.6312 & 4.1758 & TRN & & \\
\hline CHEMBL1538353 & 688326 & 4.6225 & 4.2205 & TRN & & \\
\hline CHEMBL1368816 & 688326 & 3.3007 & 3.9884 & TRN & & \\
\hline CHEMBL582444 & 688326 & 4.6019 & 4.1849 & TST & & \\
\hline CHEMBL1499682 & 688326 & 3.74300 & 000000006 & 203 & 4.7982 & TRN \\
\hline CHEMBL1411355 & 688326 & 4.3851 & 4.2047 & TRN & & \\
\hline CHEMBL1380775 & 688326 & 4.618 & 4.247 & TRN & & \\
\hline
\end{tabular}




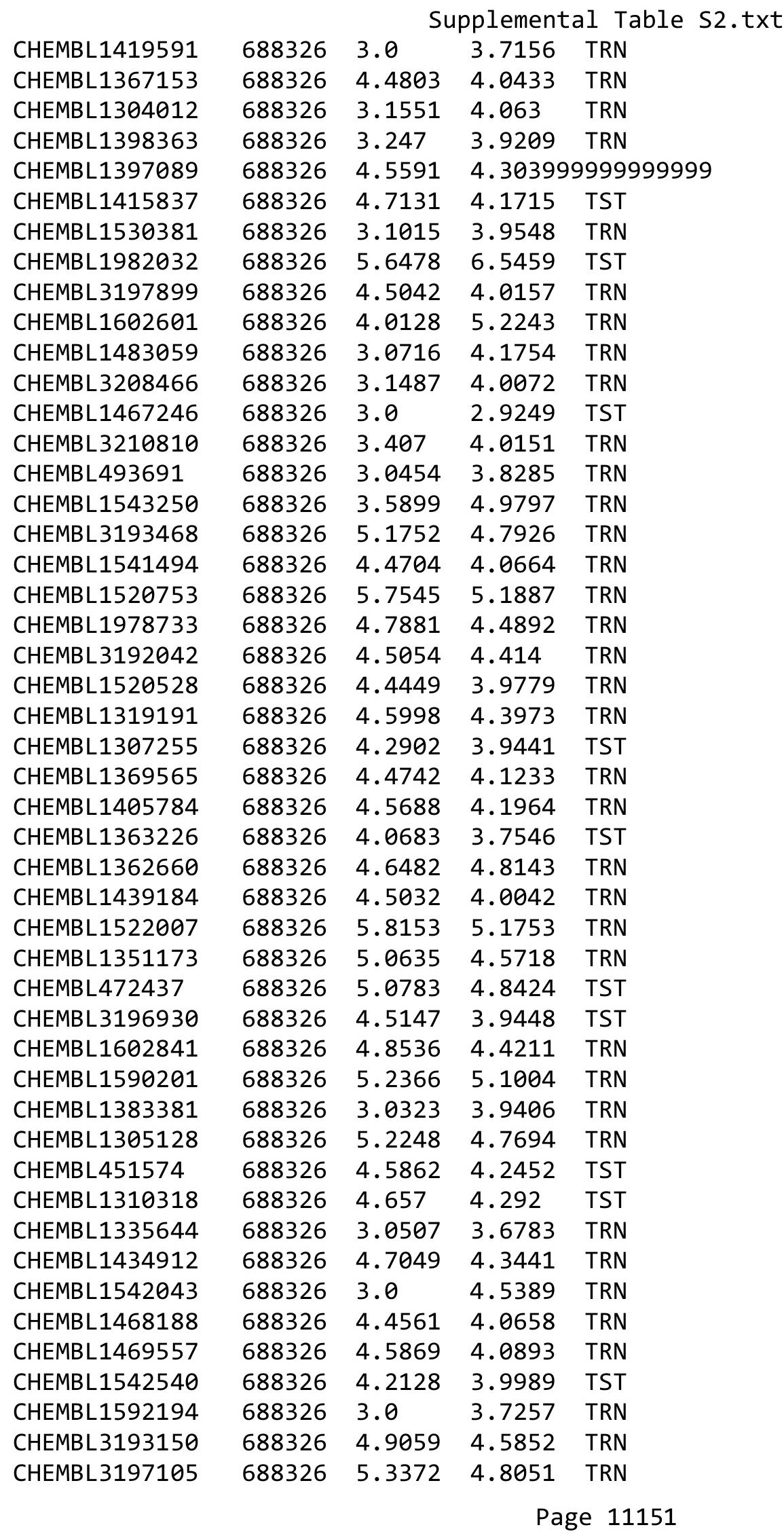




\begin{tabular}{|c|c|c|c|c|c|c|}
\hline & & & & & & \\
\hline CHEMBL1607882 & 688326 & 5.2147 & 5.2742 & TRN & & \\
\hline CHEMBL1520844 & 688326 & 4.6724 & 4.327 & TRN & & \\
\hline CHEMBL1364999 & 688326 & 5.062 & 4.7179 & TRN & & \\
\hline CHEMBL1354632 & 688326 & 4.4319 & 4.827 & TRN & & \\
\hline CHEMBL1594567 & 688326 & 4.1782 & 4.0625 & TRN & & \\
\hline CHEMBL1417614 & 688326 & 4.1938 & 4.1391 & TRN & & \\
\hline CHEMBL1381257 & 688326 & 4.8761 & 4.3897 & TRN & & \\
\hline CHEMBL604321 & 688326 & 4.9151 & 4.3378 & TRN & & \\
\hline CHEMBL1310527 & 688326 & 4.5479 & 4.1189 & TRN & & \\
\hline CHEMBL1490799 & 688326 & 4.2001 & 3.9803 & TRN & & \\
\hline CHEMBL1440530 & 688326 & 3.0916 & 4.3917 & TRN & & \\
\hline CHEMBL1503165 & 688326 & 4.6214 & 4.2333 & TRN & & \\
\hline CHEMBL1515513 & 688326 & 4.5933 & 4.1501 & TRN & & \\
\hline CHEMBL1573291 & 688326 & 4.4996 & 4.1846 & TST & & \\
\hline CHEMBL1461279 & 688326 & 4.3541 & 3.9807 & TRN & & \\
\hline CHEMBL1370239 & 688326 & 5.2741 & 4.7535 & TRN & & \\
\hline CHEMBL 300389 & 688326 & 4.1347 & 4.2238 & TRN & & \\
\hline CHEMBL1532238 & 688326 & 4.7194 & 4.3997 & TRN & & \\
\hline CHEMBL1485168 & 688326 & 5.4711 & 6.3865 & TRN & & \\
\hline CHEMBL1440810 & 688326 & 4.716 & 4.9422 & TRN & & \\
\hline CHEMBL1885024 & 688326 & 5.2557 & 4.8488 & TRN & & \\
\hline CHEMBL1600169 & 688326 & 4.4376 & 4.0887 & TRN & & \\
\hline CHEMBL1365482 & 688326 & 4.4593 & 4.2385 & TRN & & \\
\hline CHEMBL1535546 & 688326 & 5.1694 & 4.8138 & TRN & & \\
\hline CHEMBL1593107 & 688326 & 4.4717 & 4.1061 & TRN & & \\
\hline CHEMBL1574647 & 688326 & 4.6096 & 4.4448 & TRN & & \\
\hline CHEMBL1329027 & 688326 & 3.0378 & 3.9921 & TRN & & \\
\hline CHEMBL1580735 & 688326 & 4.6668 & 4.2923 & TST & & \\
\hline CHEMBL1383777 & 688326 & 5.2351 & 4.6464 & TST & & \\
\hline CHEMBL1396951 & 688326 & 4.7476 & 5.0447 & TRN & & \\
\hline CHEMBL1345421 & 688326 & 4.2612 & 4.4151 & TRN & & \\
\hline CHEMBL1375555 & 688326 & 4.8265 & 4.7619 & TRN & & \\
\hline CHEMBL1409954 & 688326 & 4.419 & 3.9251 & TRN & & \\
\hline CHEMBL1519414 & 688326 & 3.13199 & 99999999 & 997 & 3.8193 & TS \\
\hline CHEMBL1593484 & 688326 & 4.1767 & 4.0048 & TRN & & \\
\hline CHEMBL1575156 & 688326 & 4.6315 & 4.2451 & TST & & \\
\hline CHEMBL1558865 & 688326 & 4.6866 & 4.1755 & TRN & & \\
\hline CHEMBL3195591 & 688326 & 4.3418 & 5.4075 & TRN & & \\
\hline CHEMBL1390303 & 688326 & 4.1085 & 4.3404 & TRN & & \\
\hline CHEMBL1519411 & 688326 & 4.8941 & 4.3439 & TRN & & \\
\hline CHEMBL 2004193 & 688326 & 4.7075 & 4.5018 & TRN & & \\
\hline CHEMBL1982308 & 688326 & 5.5171 & 5.1748 & TRN & & \\
\hline CHEMBL1311792 & 688326 & 3.5511 & 4.3535 & TRN & & \\
\hline CHEMBL1581309 & 688326 & 4.6574 & 4.3412 & TST & & \\
\hline CHEMBL1556481 & 688326 & 5.8447 & 5.2803 & TRN & & \\
\hline CHEMBL1534019 & 688326 & 5.3778 & 4.4353 & TRN & & \\
\hline CHEMBL1485349 & 688326 & 4.6212 & 4.2465 & TRN & & \\
\hline CHEMBL1423404 & 688326 & 5.0164 & 4.729 & TRN & & \\
\hline
\end{tabular}




\begin{tabular}{|c|c|c|c|c|c|c|}
\hline \multirow[b]{2}{*}{ CHEMBL1550143 } & \multirow[b]{2}{*}{688326} & \multicolumn{5}{|c|}{ Supplemental Table S2.txt } \\
\hline & & 4.5267 & 4.129 & TRN & & \\
\hline CHEMBL1538647 & 688326 & 4.3479 & 4.3864 & TRN & & \\
\hline CHEMBL1320111 & 688326 & 4.7347 & 4.3296 & TRN & & \\
\hline CHEMBL1546797 & 688326 & 3.0 & 4.3755 & TRN & & \\
\hline CHEMBL1351495 & 688326 & 4.5511 & 4.1114 & TRN & & \\
\hline CHEMBL579318 & 688326 & 4.9112 & 4.4367 & TRN & & \\
\hline CHEMBL1441270 & 688326 & 4.7053 & 4.1743 & TRN & & \\
\hline CHEMBL 1256686 & 688326 & 5.5498 & 5.0892 & TST & & \\
\hline CHEMBL1446547 & 688326 & 3.301 & 2.9914 & TRN & & \\
\hline CHEMBL1371896 & 688326 & 4.6434 & 4.1425 & TRN & & \\
\hline CHEMBL1313588 & 688326 & 4.4295 & 5.6982 & TRN & & \\
\hline CHEMBL1484411 & 688326 & 4.6726 & 4.2787 & TST & & \\
\hline CHEMBL1579339 & 688326 & 3.8713 & 4.3694 & TRN & & \\
\hline CHEMBL1524180 & 688326 & 5.5528 & 5.3002 & TRN & & \\
\hline CHEMBL494668 & 688326 & 4.9531 & 4.6193 & TRN & & \\
\hline CHEMBL263972 & 688326 & 5.4389 & 4.9381 & TRN & & \\
\hline CHEMBL1403112 & 688326 & 4.5782 & 5.0741 & TRN & & \\
\hline CHEMBL1443601 & 688326 & 4.0777 & 3.9385 & TRN & & \\
\hline CHEMBL1541360 & 688326 & 3.0688 & 3.9347 & TRN & & \\
\hline CHEMBL1334065 & 688326 & 4.6033 & 4.2321 & TRN & & \\
\hline CHEMBL1309597 & 688326 & 3.2977 & 4.024 & TRN & & \\
\hline CHEMBL1611561 & 688326 & 3.0845 & 3.6602 & TRN & & \\
\hline CHEMBL1509812 & 688326 & 4.5137 & 4.1714 & TRN & & \\
\hline CHEMBL1322532 & 688326 & 4.2743 & 3.9399 & TRN & & \\
\hline CHEMBL1525781 & 688326 & 3.0079 & 3.7355 & TRN & & \\
\hline CHEMBL1506442 & 688326 & 5.5302 & 4.6729 & TRN & & \\
\hline CHEMBL1594055 & 688326 & 5.3449 & 5.2216 & TST & & \\
\hline CHEMBL 3198678 & 688326 & 4.4402 & 4.2879 & TRN & & \\
\hline CHEMBL1386094 & 688326 & 4.0521 & 4.351 & TRN & & \\
\hline CHEMBL1500855 & 688326 & 5.3161 & 5.3032 & TRN & & \\
\hline CHEMBL1560366 & 688326 & 4.9404 & 4.6685 & TRN & & \\
\hline CHEMBL1431312 & 688326 & 3.2357 & 4.1527 & TRN & & \\
\hline CHEMBL1989760 & 688326 & 4.914 & 4.3945 & TRN & & \\
\hline CHEMBL1543133 & 688326 & 4.1767 & 3.7542 & TST & & \\
\hline CHEMBL 3197008 & 688326 & 3.3814 & 4.0336 & TRN & & \\
\hline CHEMBL1471344 & 688326 & 4.8831 & 4.6489 & TRN & & \\
\hline CHEMBL1592636 & 688326 & 4.8116 & 4.312 & TRN & & \\
\hline CHEMBL536375 & 688326 & 4.6133 & 4.1587 & TRN & & \\
\hline CHEMBL1446971 & 688326 & 4.5256 & 4.5717 & TRN & & \\
\hline CHEMBL 1353710 & 688326 & 4.6404 & 4.4237 & TRN & & \\
\hline CHEMBL1498022 & 688326 & 4.9205 & 4.4508 & TRN & & \\
\hline CHEMBL1384503 & 688326 & 3.0 & 4.1301 & TRN & & \\
\hline CHEMBL1306243 & 688326 & 3.0 & 3.7394 & TRN & & \\
\hline CHEMBL1586301 & 688326 & 4.2603 & 3.8596 & TRN & & \\
\hline CHEMBL1515261 & 688326 & 3.1166 & 3.9538 & TRN & & \\
\hline CHEMBL1999437 & 688326 & 3.00699 & 99999999 & 997 & 4.0415 & TRN \\
\hline CHEMBL1410618 & 688326 & 6.699 & 6.3869 & TRN & & \\
\hline CHEMBL 1434681 & 688326 & 4.5147 & 4.2758 & TRN & & \\
\hline
\end{tabular}

Page 11153 


\begin{tabular}{|c|c|c|c|c|c|c|}
\hline \multirow{3}{*}{$\begin{array}{l}\text { CHEMBL1457697 } \\
\text { CHEMBL1481135 }\end{array}$} & \multirow{3}{*}{$\begin{array}{l}688326 \\
688326\end{array}$} & \multicolumn{5}{|c|}{ supplemental Table s2.txt } \\
\hline & & 4.7165 & \multicolumn{3}{|c|}{4.1930000000000005} & TRN \\
\hline & & 5.4647 & 4.8727 & TRN & & \\
\hline CHEMBL1463329 & 688326 & 3.1029 & 4.0571 & TRN & & \\
\hline CHEMBL1334138 & 688326 & 5.0937 & 4.3051 & TRN & & \\
\hline CHEMBL1333386 & 688326 & 4.4694 & 4.1112 & TRN & & \\
\hline CHEMBL1460823 & 688326 & 3.0161 & 4.0026 & TRN & & \\
\hline CHEMBL1444345 & 688326 & 4.4666 & 4.3104 & TRN & & \\
\hline CHEMBL1559098 & 688326 & 3.0 & 4.3732 & TRN & & \\
\hline CHEMBL1430266 & 688326 & 3.0 & 4.1223 & TST & & \\
\hline CHEMBL1375823 & 688326 & 3.5239 & 4.2522 & TRN & & \\
\hline CHEMBL1425195 & 688326 & 5.7033 & 6.4735 & TRN & & \\
\hline CHEMBL 3190934 & 688326 & 5.3372 & 4.708 & TRN & & \\
\hline CHEMBL1334719 & 688326 & \multicolumn{3}{|c|}{4.821000000000001} & 4.6918 & TRN \\
\hline CHEMBL3196108 & 688326 & 4.731 & 4.2985 & TRN & & \\
\hline CHEMBL1413130 & 688326 & 4.3945 & 4.1916 & TRN & & \\
\hline CHEMBL1972500 & 688326 & 4.4176 & 4.1896 & TRN & & \\
\hline CHEMBL1564038 & 688326 & 4.4489 & 4.0349 & TRN & & \\
\hline CHEMBL1969246 & 688326 & 5.5287 & 4.879 & TRN & & \\
\hline CHEMBL1418039 & 688326 & 4.6112 & 4.1854 & TRN & & \\
\hline CHEMBL1402664 & 688326 & 5.2366 & 4.6703 & TRN & & \\
\hline CHEMBL1429052 & 688326 & 3.4295 & 4.4044 & TST & & \\
\hline CHEMBL1506321 & 688326 & 4.7943 & 4.4166 & TRN & & \\
\hline CHEMBL1445710 & 688326 & 4.567 & 4.0697 & TRN & & \\
\hline CHEMBL1582440 & 688326 & 4.4522 & 4.0725 & TRN & & \\
\hline CHEMBL1454790 & 688326 & 3.0626 & 4.1262 & TRN & & \\
\hline CHEMBL1442523 & 688326 & 4.5979 & 4.1158 & TRN & & \\
\hline CHEMBL1526479 & 688326 & 4.8798 & 4.5377 & TRN & & \\
\hline CHEMBL1566401 & 688326 & 4.3247 & 3.9467 & TRN & & \\
\hline CHEMBL1337704 & 688326 & 4.4642 & 4.0503 & TRN & & \\
\hline CHEMBL1576407 & 688326 & 6.0915 & 5.3593 & TRN & & \\
\hline CHEMBL1561576 & 688326 & \multicolumn{3}{|c|}{4.9830000000000005} & 4.9012 & TRN \\
\hline CHEMBL1330459 & 688326 & 5.4034 & 4.8306 & TST & & \\
\hline CHEMBL1564543 & 688326 & 5.6162 & 6.4915 & TRN & & \\
\hline CHEMBL1076559 & 688326 & 3.0842 & 3.9565 & TRN & & \\
\hline CHEMBL1510647 & 688326 & 3.0417 & 4.0487 & TRN & & \\
\hline CHEMBL1482988 & 688326 & 5.6655 & 6.3752 & TRN & & \\
\hline CHEMBL1608333 & 688326 & 5.3063 & 4.8118 & TRN & & \\
\hline CHEMBL1416483 & 688326 & 3.1223 & 3.7679 & TRN & & \\
\hline CHEMBL1422929 & 688326 & 4.6149 & 4.1764 & TRN & & \\
\hline CHEMBL 1491010 & 688326 & 4.3641 & 3.8846 & TRN & & \\
\hline CHEMBL1574219 & 688326 & 4.7404 & 4.7345 & TRN & & \\
\hline CHEMBL3211910 & 688326 & 3.9237 & 4.2302 & TRN & & \\
\hline CHEMBL1515190 & 688326 & 4.3056 & 3.9472 & TRN & & \\
\hline CHEMBL1427913 & 688326 & 6.699 & 6.5681 & TRN & & \\
\hline CHEMBL 1497838 & 688326 & 5.9355 & 5.1724 & TRN & & \\
\hline CHEMBL1352171 & 688326 & 3.1438 & 3.8969 & TRN & & \\
\hline CHEMBL1327677 & 688326 & 3.0842 & 3.9253 & TRN & & \\
\hline CHEMBL1373625 & 688326 & 3.3218 & 4.1051 & TRN & & \\
\hline
\end{tabular}




\begin{tabular}{|c|c|c|c|c|c|c|}
\hline & & \multicolumn{5}{|c|}{ Supplemental Table S2.txt } \\
\hline CHEMBL1495462 & 688326 & 3.3112 & 3.9586 & TRN & & \\
\hline CHEMBL1577829 & 688326 & 4.9112 & 4.4451 & TRN & & \\
\hline CHEMBL1495124 & 688326 & \multicolumn{3}{|c|}{ 4. 2669999999999995} & 3.8372 & TST \\
\hline CHEMBL1548060 & 688326 & 3.0321 & 3.9651 & TRN & & \\
\hline CHEMBL1460591 & 688326 & 4.7716 & 4.5132 & TRN & & \\
\hline CHEMBL1383998 & 688326 & 4.6068 & 4.1702 & TRN & & \\
\hline CHEMBL1412012 & 688326 & 4.5445 & 4.5627 & TRN & & \\
\hline CHEMBL1399805 & 688326 & 4.5967 & 4.099 & TRN & & \\
\hline CHEMBL1358582 & 688326 & 3.4142 & 3.9181 & TRN & & \\
\hline CHEMBL1408517 & 688326 & 5.0353 & 4.9082 & TRN & & \\
\hline CHEMBL1469493 & 688326 & 3.9586 & 4.4863 & TRN & & \\
\hline CHEMBL1422182 & 688326 & 5.6308 & 4.9732 & TRN & & \\
\hline CHEMBL1995862 & 688326 & 4.4909 & 4.4148 & TRN & & \\
\hline CHEMBL1570468 & 688326 & \multicolumn{3}{|c|}{3.2910000000000004} & 4.1951 & TRN \\
\hline CHEMBL1407492 & 688326 & 3.9788 & 5.5924 & TRN & & \\
\hline CHEMBL1505221 & 688326 & 5.0814 & 4.6411 & TST & & \\
\hline CHEMBL1556766 & 688326 & 4.0281 & 3.8602 & TST & & \\
\hline CHEMBL1411860 & 688326 & 4.3582 & 3.9813 & TRN & & \\
\hline CHEMBL1978479 & 688326 & 7.699 & 6.5232 & TRN & & \\
\hline CHEMBL1470131 & 688326 & 3.5638 & 4.1328 & TRN & & \\
\hline CHEMBL1586982 & 688326 & 5.2644 & 6.3609 & TRN & & \\
\hline CHEMBL1304898 & 688326 & 3.2242 & 4.4223 & TRN & & \\
\hline CHEMBL1383506 & 688326 & 5.2924 & 5.0301 & TRN & & \\
\hline CHEMBL1521861 & 688326 & 4.5605 & 4.2566 & TRN & & \\
\hline CHEMBL1368213 & 688326 & 6.699 & 6.2719 & TRN & & \\
\hline CHEMBL1373197 & 688326 & 4.8841 & 4.4659 & TRN & & \\
\hline CHEMBL455284 & 688326 & 4.6304 & 4.5605 & TRN & & \\
\hline CHEMBL1374077 & 688326 & 4.4532 & 4.0223 & TRN & & \\
\hline CHEMBL1507180 & 688326 & 3.2997 & 4.0587 & TRN & & \\
\hline CHEMBL1422395 & 688326 & 4.3675 & 4.4044 & TST & & \\
\hline CHEMBL 373481 & 688326 & 4.2961 & 4.1227 & TRN & & \\
\hline CHEMBL1341756 & 688326 & 5.8477 & 5.57299 & 99999 & 995 & TRN \\
\hline CHEMBL1539376 & 688326 & 4.7402 & 4.2809 & TST & & \\
\hline CHEMBL1307124 & 688326 & 5.1068 & 4.5371 & TRN & & \\
\hline CHEMBL1374668 & 688326 & 3.8748 & 4.3798 & TRN & & \\
\hline CHEMBL1423611 & 688326 & \multicolumn{3}{|c|}{4.6339999999999995} & 4.227 & TRN \\
\hline CHEMBL1607086 & 688326 & 4.5824 & 4.6106 & TRN & & \\
\hline CHEMBL1342025 & 688326 & 3.616 & 3.0039 & TRN & & \\
\hline CHEMBL1594915 & 688326 & 4.6404 & 4.2553 & TRN & & \\
\hline CHEMBL1483215 & 688326 & 4.5148 & 4.2205 & TRN & & \\
\hline CHEMBL1344838 & 688326 & 3.4417 & 4.4041 & TRN & & \\
\hline CHEMBL1559953 & 688326 & 4.506 & 4.1626 & TRN & & \\
\hline CHEMBL1332327 & 688326 & 4.7873 & 4.4189 & TRN & & \\
\hline CHEMBL1339324 & 688326 & 6.1367 & 5.4635 & TRN & & \\
\hline CHEMBL1300529 & 688326 & 4.3182 & 3.9531 & TRN & & \\
\hline CHEMBL1586531 & 688326 & 4.4593 & 4.135 & TRN & & \\
\hline CHEMBL1500199 & 688326 & 3.6142 & 4.2676 & TRN & & \\
\hline CHEMBL1608143 & 688326 & 4.9767 & 4.6374 & TST & & \\
\hline
\end{tabular}




\begin{tabular}{|c|c|c|c|c|c|}
\hline & & \multicolumn{4}{|c|}{ Supplemental Table S2.txt } \\
\hline CHEMBL1333248 & 688326 & 5.1152 & 4.6346 & TRN & \\
\hline CHEMBL1399463 & 688326 & 4.3394 & 3.9852 & TRN & \\
\hline CHEMBL1574603 & 688326 & 4.335 & 4.1946 & TRN & \\
\hline CHEMBL1392478 & 688326 & 5.6055 & 4.8256 & TRN & \\
\hline CHEMBL1542015 & 688326 & 5.5287 & 4.6822 & TST & \\
\hline CHEMBL1467427 & 688326 & 4.3309 & 3.9433 & TRN & \\
\hline CHEMBL1468929 & 688326 & 5.0565 & 4.9461 & TRN & \\
\hline CHEMBL1512568 & 688326 & 3.1803 & 3.9477 & TRN & \\
\hline CHEMBL1586404 & 688326 & 4.6232 & 4.1566 & TRN & \\
\hline CHEMBL1496578 & 688326 & 3.4388 & \multicolumn{2}{|c|}{4.2860000000000005} & TRN \\
\hline CHEMBL1385350 & 688326 & 4.6861 & 4.7967 & TRN & \\
\hline CHEMBL1423668 & 688326 & 5.6126 & 4.9706 & TRN & \\
\hline CHEMBL1463698 & 688326 & 4.6444 & 4.3294 & TRN & \\
\hline CHEMBL1396258 & 688326 & 4.3869 & 4.2882 & TRN & \\
\hline CHEMBL1372738 & 688326 & 4.6033 & 4.1241 & TRN & \\
\hline CHEMBL1477770 & 688326 & 4.7433 & 4.5486 & TRN & \\
\hline CHEMBL1444373 & 688326 & 4.6809 & 4.2804 & TRN & \\
\hline CHEMBL1420768 & 688326 & 5.4168 & 5.2662 & TRN & \\
\hline CHEMBL3198213 & 688326 & 4.7156 & 4.3512 & TST & \\
\hline CHEMBL1471601 & 688326 & 4.9996 & 5.2732 & TRN & \\
\hline CHEMBL1309506 & 688326 & 3.4572 & 4.1253 & TRN & \\
\hline CHEMBL106562 & 688326 & 4.6417 & 4.3301 & TRN & \\
\hline CHEMBL1510574 & 688326 & 4.7349 & 4.5867 & TRN & \\
\hline CHEMBL1570656 & 688326 & 3.3604 & 3.802 & TRN & \\
\hline CHEMBL1558955 & 688326 & 3.3341 & 3.8932 & TRN & \\
\hline CHEMBL1463808 & 688326 & 4.4556 & 4.431 & TRN & \\
\hline CHEMBL1371706 & 688326 & 4.272 & 3.6797 & TRN & \\
\hline CHEMBL1502273 & 688326 & 5.8794 & 5.17700 & 00000000005 & TST \\
\hline CHEMBL1416410 & 688326 & 4.7757 & 4.4431 & TRN & \\
\hline CHEMBL1482184 & 688326 & 4.753 & 4.2649 & TST & \\
\hline CHEMBL1518976 & 688326 & 4.945 & 4.6465 & TRN & \\
\hline CHEMBL1391340 & 688326 & 5.3872 & 5.3866 & TRN & \\
\hline CHEMBL1467194 & 688326 & \multicolumn{3}{|c|}{3.2569999999999997} & TST \\
\hline CHEMBL1303785 & 688326 & 3.6254 & 5.4705 & TST & \\
\hline CHEMBL1445858 & 688326 & 4.404 & 4.0672 & TRN & \\
\hline CHEMBL1980982 & 688326 & 5.5436 & 5.5206 & TRN & \\
\hline CHEMBL1351106 & 688326 & 4.4363 & 3.9608 & TRN & \\
\hline CHEMBL1547797 & 688326 & 4.6381 & 4.4132 & TRN & \\
\hline CHEMBL1558826 & 688326 & 5.7144 & 5.1348 & TST & \\
\hline CHEMBL1452821 & 688326 & 4.3512 & 4.1843 & TST & \\
\hline CHEMBL1412700 & 688326 & 3.0161 & 5.1861 & TRN & \\
\hline CHEMBL1459271 & 688326 & 3.123 & 3.9612 & TRN & \\
\hline CHEMBL 2139687 & 688326 & 4.9266 & 4.4183 & TRN & \\
\hline CHEMBL1389416 & 688326 & 4.556 & 4.2531 & TRN & \\
\hline CHEMBL1595476 & 688326 & 4.393 & 4.4306 & TRN & \\
\hline CHEMBL1300410 & 688326 & 5.2262 & 4.6948 & TRN & \\
\hline CHEMBL1428094 & 688326 & 4.5027 & 4.2649 & TST & \\
\hline CHEMBL1374615 & 688326 & 4.4729 & 4.1304 & TRN & \\
\hline
\end{tabular}




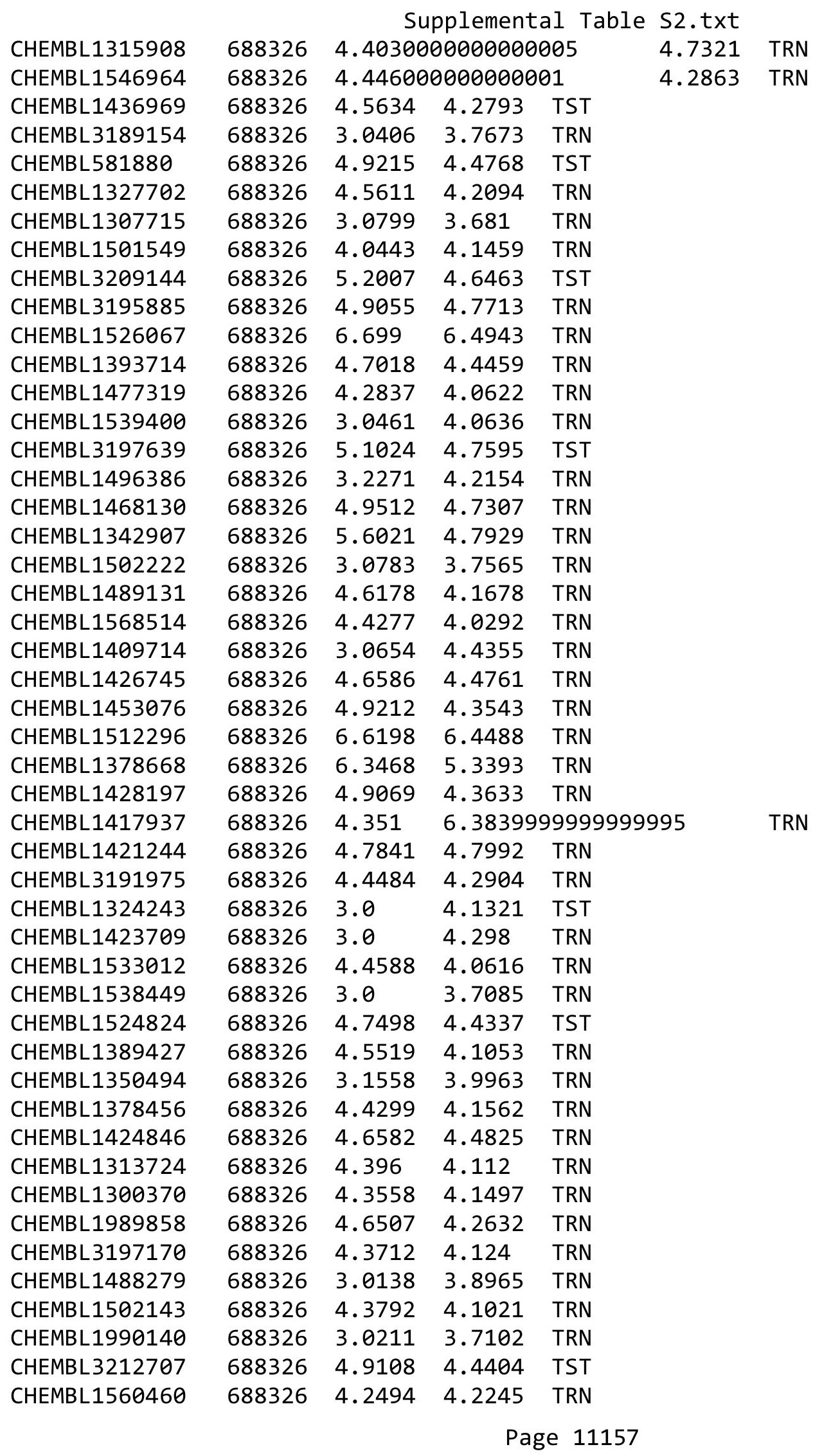




\begin{tabular}{|c|c|c|c|c|c|}
\hline \multicolumn{6}{|c|}{ Supplemental Table S2.txt } \\
\hline CHEMBL3209956 & 688326 & 4.5931 & 4.2244 & TRN & \\
\hline CHEMBL1421502 & 688326 & 3.6415 & 4.3156 & TRN & \\
\hline CHEMBL1374306 & 688326 & 4.5792 & 4.4036 & TRN & \\
\hline CHEMBL1467383 & 688326 & 4.8094 & 4.5114 & TRN & \\
\hline CHEMBL 1445886 & 688326 & 3.0424 & 4.0518 & TRN & \\
\hline CHEMBL1439119 & 688326 & 5.5086 & 5.1445 & TRN & \\
\hline CHEMBL1550359 & 688326 & 3.0 & 3.8936 & TRN & \\
\hline CHEMBL1489353 & 688326 & 3.0165 & 3.812 & TRN & \\
\hline CHEMBL1600717 & 688326 & 4.6578 & 4.1529 & TRN & \\
\hline CHEMBL 1488576 & 688326 & 3.1451 & 3.82 & TRN & \\
\hline CHEMBL1241420 & 688326 & 4.2047 & 3.9528 & TRN & \\
\hline CHEMBL1455633 & 688326 & 4.9784 & 4.5085 & TST & \\
\hline CHEMBL1455542 & 688326 & 3.7775 & 4.414 & TRN & \\
\hline CHEMBL1557632 & 688326 & 6.0223 & 6.7254 & TRN & \\
\hline CHEMBL1608392 & 688326 & 4.823 & 4.5563 & TRN & \\
\hline CHEMBL1502199 & 688326 & 5.0306 & 4.73600 & 0000000001 & TRN \\
\hline CHEMBL3196538 & 688326 & 4.1949 & 4.1552 & TRN & \\
\hline CHEMBL3199737 & 688326 & 4.8428 & 4.3935 & TRN & \\
\hline CHEMBL1582695 & 688326 & 4.4573 & 4.4115 & TST & \\
\hline CHEMBL1588463 & 688326 & 3.1322 & 3.7487 & TRN & \\
\hline CHEMBL1605089 & 688326 & 6.699 & 6.3693 & TRN & \\
\hline CHEMBL1477154 & 688326 & 5.4711 & 4.9036 & TRN & \\
\hline CHEMBL1387887 & 688326 & 4.4658 & 4.3219 & TRN & \\
\hline CHEMBL1338792 & 688326 & 4.856 & 4.6629 & TRN & \\
\hline CHEMBL1512603 & 688326 & 4.3702 & 4.2582 & TRN & \\
\hline CHEMBL1375577 & 688326 & 4.3492 & 3.8754 & TRN & \\
\hline CHEMBL1503243 & 688326 & 4.5382 & 4.3029 & TRN & \\
\hline CHEMBL1310481 & 688326 & 3.5337 & 4.283 & TRN & \\
\hline CHEMBL1323425 & 688326 & 4.9245 & 4.4701 & TRN & \\
\hline CHEMBL1307827 & 688326 & 3.0 & 4.2682 & TRN & \\
\hline CHEMBL1458512 & 688326 & 5.5171 & 4.9482 & TRN & \\
\hline CHEMBL1551228 & 688326 & 4.9062 & 4.3137 & TRN & \\
\hline CHEMBL1611662 & 688326 & 3.3629 & 4.1574 & TRN & \\
\hline CHEMBL1400809 & 688326 & 5.3565 & 6.4113 & TRN & \\
\hline CHEMBL1451713 & 688326 & 4.6826 & 4.8747 & TRN & \\
\hline CHEMBL1551682 & 688326 & 3.0 & 4.375 & TRN & \\
\hline CHEMBL1498517 & 688326 & 5.0645 & 5.1338 & TRN & \\
\hline CHEMBL1188078 & 688326 & 4.6319 & 4.2966 & TRN & \\
\hline CHEMBL1476797 & 688326 & 3.3772 & 4.3648 & TRN & \\
\hline CHEMBL 3214555 & 688326 & 6.699 & 5.1296 & TRN & \\
\hline CHEMBL1564658 & 688326 & 3.3998 & 4.3644 & TST & \\
\hline CHEMBL1334260 & 688326 & 4.9551 & 4.6677 & TRN & \\
\hline CHEMBL1377490 & 688326 & 4.2224 & 4.3167 & TRN & \\
\hline CHEMBL1406021 & 688326 & 3.117 & 4.2543 & TRN & \\
\hline CHEMBL1306598 & 688326 & 4.3345 & 3.9743 & TRN & \\
\hline CHEMBL1453960 & 688326 & 3.6751 & 5.1791 & TRN & \\
\hline CHEMBL3191592 & 688326 & 4.9772 & 4.4206 & TRN & \\
\hline CHEMBL1408463 & 688326 & 4.064 & 3.8096 & TST & \\
\hline
\end{tabular}




\begin{tabular}{|c|c|c|c|c|c|}
\hline \multicolumn{6}{|c|}{ Supplemental Table S2.txt } \\
\hline CHEMBL388823 & 688326 & 3.0104 & 4.0304 & TRN & \\
\hline CHEMBL3211808 & 688326 & 4.4334 & 4.5389 & TRN & \\
\hline CHEMBL1995097 & 688326 & 4.9234 & 4.4469 & TRN & \\
\hline CHEMBL1468359 & 688326 & 4.3707 & 4.1503 & TST & \\
\hline CHEMBL1587075 & 688326 & 4.6312 & 4.4289 & TST & \\
\hline CHEMBL1370865 & 688326 & 5.063 & 4.6438 & TRN & \\
\hline CHEMBL1573635 & 688326 & 4.7607 & 4.6412 & TRN & \\
\hline CHEMBL1599666 & 688326 & 4.3413 & 4.008 & TRN & \\
\hline CHEMBL1515360 & 688326 & 5.2381 & 4.5025 & TRN & \\
\hline CHEMBL1558285 & 688326 & 5.4908 & 4.9782 & TRN & \\
\hline CHEMBL1408258 & 688326 & 4.3435 & 3.9789 & TST & \\
\hline CHEMBL1495602 & 688326 & 4.5805 & 4.0882 & TST & \\
\hline CHEMBL1458597 & 688326 & 4.0501 & 3.7192 & TRN & \\
\hline CHEMBL1550076 & 688326 & 6.699 & 6.6595 & TRN & \\
\hline CHEMBL1421427 & 688326 & 4.6619 & 4.7177 & TRN & \\
\hline CHEMBL1527783 & 688326 & 3.5474 & 4.2842 & TRN & \\
\hline CHEMBL1494654 & 688326 & 4.3373 & 4.0155 & TRN & \\
\hline CHEMBL1516044 & 688326 & 4.9867 & 4.3878 & TRN & \\
\hline CHEMBL1570293 & 688326 & 4.7508 & 4.6939 & TRN & \\
\hline CHEMBL1361116 & 688326 & 3.0266 & 4.0677 & TRN & \\
\hline CHEMBL518923 & 688326 & 6.699 & 4.66100 & 00000000005 & TRN \\
\hline CHEMBL1532265 & 688326 & 4.3758 & 3.9382 & TRN & \\
\hline CHEMBL1472327 & 688326 & 4.9523 & 4.4978 & TST & \\
\hline CHEMBL1580940 & 688326 & 4.4378 & 4.2493 & TRN & \\
\hline CHEMBL1577085 & 688326 & 4.9404 & 4.754 & TRN & \\
\hline CHEMBL1535702 & 688326 & 5.6402 & 5.3144 & TRN & \\
\hline CHEMBL1479020 & 688326 & 3.16 & 3.8577 & TRN & \\
\hline CHEMBL1573869 & 688326 & 4.4638 & 4.1069 & TRN & \\
\hline CHEMBL530038 & 688326 & 6.0132 & 6.303 & TRN & \\
\hline CHEMBL1521687 & 688326 & 3.0923 & 3.7546 & TRN & \\
\hline CHEMBL3197818 & 688326 & 3.3655 & 5.0099 & TRN & \\
\hline CHEMBL1585633 & 688326 & 4.5566 & 4.4947 & TRN & \\
\hline CHEMBL1323274 & 688326 & 4.1538 & 3.9019 & TRN & \\
\hline CHEMBL1256132 & 688326 & 4.4512 & 4.3213 & TST & \\
\hline CHEMBL1353346 & 688326 & 4.9031 & 4.387 & TRN & \\
\hline CHEMBL1333929 & 688326 & 4.3519 & 4.20100 & 00000000005 & TRN \\
\hline CHEMBL1343697 & 688326 & 4.5086 & 4.149 & TRN & \\
\hline CHEMBL1537149 & 688326 & 3.0855 & 3.8607 & TST & \\
\hline CHEMBL1434073 & 688326 & 5.3439 & 5.05 & TRN & \\
\hline CHEMBL1410066 & 688326 & 5.2336 & 4.6996 & TRN & \\
\hline CHEMBL1402229 & 688326 & 4.9179 & 4.3582 & TRN & \\
\hline CHEMBL1580584 & 688326 & 4.7411 & 4.6264 & TRN & \\
\hline CHEMBL3196936 & 688326 & 4.5379 & 4.3001 & TRN & \\
\hline CHEMBL1575594 & 688326 & 4.9809 & 4.8164 & TST & \\
\hline CHEMBL1386080 & 688326 & 4.3408 & 4.0011 & TRN & \\
\hline CHEMBL1467396 & 688326 & 4.6735 & 4.2864 & TST & \\
\hline CHEMBL1559422 & 688326 & 3.6607 & 4.2222 & TRN & \\
\hline CHEMBL1389509 & 688326 & 4.6847 & 4.1851 & TRN & \\
\hline
\end{tabular}




\begin{tabular}{|c|c|c|c|c|c|c|}
\hline \multirow[b]{2}{*}{ CHEMBL1547007 } & \multirow[b]{2}{*}{688326} & \multicolumn{5}{|c|}{ Supplemental Table S2.txt } \\
\hline & & \multicolumn{2}{|c|}{3.01113 .7914} & TRN & & \\
\hline CHEMBL1421481 & 688326 & 4.3715 & 4.0824 & TRN & & \\
\hline CHEMBL578487 & 688326 & 4.99100 & 30000000 & 205 & 4.7268 & TST \\
\hline CHEMBL1555739 & 688326 & 4.6916 & 4.3676 & TRN & & \\
\hline CHEMBL1507759 & 688326 & 3.0 & 3.8414 & TRN & & \\
\hline CHEMBL1363861 & 688326 & 4.5789 & 4.3016 & TRN & & \\
\hline CHEMBL1543836 & 688326 & 5.699 & 6.8254 & TRN & & \\
\hline CHEMBL1489026 & 688326 & 3.0 & 2.9472 & TRN & & \\
\hline CHEMBL1550943 & 688326 & 3.1848 & 4.4985 & TRN & & \\
\hline CHEMBL3196272 & 688326 & 3.0812 & 4.294 & TRN & & \\
\hline CHEMBL1330556 & 688326 & 4.754 & 4.5431 & TRN & & \\
\hline CHEMBL1345018 & 688326 & 6.699 & 6.8086 & TRN & & \\
\hline CHEMBL1345801 & 688326 & 4.8474 & 4.4075 & TRN & & \\
\hline CHEMBL1521681 & 688326 & 5.567 & 4.7696 & TST & & \\
\hline CHEMBL1344130 & 688326 & 4.3665 & 3.9568 & TRN & & \\
\hline CHEMBL1510023 & 688326 & 5.5391 & 4.8738 & TRN & & \\
\hline CHEMBL1463825 & 688326 & 3.4153 & 4.2555 & TRN & & \\
\hline CHEMBL1332275 & 688326 & 3.1544 & 3.9238 & TRN & & \\
\hline CHEMBL1507990 & 688326 & 4.6449 & 4.2816 & TRN & & \\
\hline CHEMBL1431776 & 688326 & 4.586 & 4.1639 & TST & & \\
\hline CHEMBL1470350 & 688326 & 4.63 & 4.2245 & TRN & & \\
\hline CHEMBL578512 & 688326 & 5.5467 & 5.0268 & TRN & & \\
\hline CHEMBL1392811 & 688326 & 4.9481 & 4.3798 & TRN & & \\
\hline CHEMBL1581065 & 688326 & 5.5243 & 6.3696 & TRN & & \\
\hline CHEMBL1387950 & 688326 & 5.0241 & 4.8429 & TRN & & \\
\hline CHEMBL1407017 & 688326 & 4.8732 & 4.4832 & TRN & & \\
\hline CHEMBL1353090 & 688326 & 3.5574 & 4.0696 & TRN & & \\
\hline CHEMBL1451125 & 688326 & 4.755 & 4.4212 & TRN & & \\
\hline CHEMBL1360206 & 688326 & 3.0367 & 4.4857 & TRN & & \\
\hline CHEMBL1391269 & 688326 & 3.5309 & 4.4482 & TRN & & \\
\hline CHEMBL1609538 & 688326 & 3.4162 & 4.0913 & TRN & & \\
\hline CHEMBL1306240 & 688326 & 3.32899 & 99999999 & 997 & 3.9901 & TRN \\
\hline CHEMBL1433503 & 688326 & 3.3476 & 4.4492 & TRN & & \\
\hline CHEMBL1315061 & 688326 & 5.0119 & 4.7372 & TST & & \\
\hline CHEMBL1559898 & 688326 & 4.4584 & 3.9372 & TST & & \\
\hline CHEMBL1385868 & 688326 & 4.7562 & 4.4611 & TRN & & \\
\hline CHEMBL3213352 & 688326 & 4.9245 & 4.6497 & TRN & & \\
\hline CHEMBL1433263 & 688326 & 5.3316 & 5.3197 & TRN & & \\
\hline CHEMBL1550406 & 688326 & 5.17200 & 30000000 & & 4.9101 & TST \\
\hline CHEMBL1301556 & 688326 & 5.3002 & 4.7927 & TRN & & \\
\hline CHEMBL1469642 & 688326 & 3.0234 & 3.7849 & TRN & & \\
\hline CHEMBL1469539 & 688326 & 4.9307 & 4.3289 & TRN & & \\
\hline CHEMBL1487397 & 688326 & 3.4104 & 4.1721 & TRN & & \\
\hline CHEMBL1349034 & 688326 & 4.6538 & 4.6872 & TRN & & \\
\hline CHEMBL3187596 & 688326 & 4.7572 & 4.4217 & TST & & \\
\hline CHEMBL1422155 & 688326 & 4.9205 & 4.3707 & TRN & & \\
\hline CHEMBL1563204 & 688326 & 4.3766 & 4.0411 & TRN & & \\
\hline CHEMBL1346437 & 688326 & 4.6453 & 4.5127 & TRN & & \\
\hline
\end{tabular}


Supplemental Table S2.txt

\begin{tabular}{|c|c|c|c|c|c|}
\hline CHEMBL1505574 & 688326 & 4.649 & 4.3825 & TRN & \\
\hline CHEMBL1501186 & 688326 & 4.9359 & 4.3561 & TST & \\
\hline CHEMBL1399212 & 688326 & 4.7572 & 4.7645 & TRN & \\
\hline CHEMBL1583807 & 688326 & 4.6024 & 4.1448 & TRN & \\
\hline CHEMBL1385784 & 688326 & 5.4318 & 5.1474 & TRN & \\
\hline CHEMBL1453396 & 688326 & 3.9796 & 5.6189 & TST & \\
\hline CHEMBL1301536 & 688326 & 4.9311 & 4.8799 & TRN & \\
\hline CHEMBL1463614 & 688326 & 4.6315 & 4.3157 & TRN & \\
\hline CHEMBL1420354 & 688326 & 4.4703 & 4.0415 & TRN & \\
\hline CHEMBL 3196266 & 688326 & 4.6326 & 4.1759 & TRN & \\
\hline CHEMBL51931 & 688326 & 5.1062 & 4.6441 & TRN & \\
\hline CHEMBL1390888 & 688326 & 3.1089 & 4.5781 & TRN & \\
\hline CHEMBL1483154 & 688326 & 5.2204 & 4.8117 & TRN & \\
\hline CHEMBL1421212 & 688326 & 4.3429 & 4.1508 & TST & \\
\hline CHEMBL 1524488 & 688326 & 3.1331 & 4.0893 & TRN & \\
\hline CHEMBL1306490 & 688326 & 3.3317 & 4.048 & TRN & \\
\hline CHEMBL1469676 & 688326 & 5.5686 & 5.4489 & TRN & \\
\hline CHEMBL1481343 & 688326 & 3.2446 & 4.4064 & TRN & \\
\hline CHEMBL1586590 & 688326 & 4.49 & 4.1609 & TRN & \\
\hline CHEMBL1581549 & 688326 & 4.4885 & 4.0403 & TRN & \\
\hline CHEMBL1423275 & 688326 & 3.2695 & 4.1928 & TRN & \\
\hline CHEMBL1300881 & 688326 & 4.439 & 3.8912 & TRN & \\
\hline CHEMBL1456419 & 688326 & 3.1067 & 4.4293 & TRN & \\
\hline CHEMBL1562104 & 688326 & 5.6861 & 5.0737 & TRN & \\
\hline CHEMBL1563766 & 688326 & 4.6615 & 4.3971 & TRN & \\
\hline CHEMBL1607550 & 688326 & 4.6668 & 4.2084 & TRN & \\
\hline CHEMBL1502035 & 688326 & 5.2007 & 6.5276 & TRN & \\
\hline CHEMBL 1427516 & 688326 & 4.9931 & 4.6543 & TRN & \\
\hline CHEMBL1600447 & 688326 & 4.6625 & 4.3921 & TRN & \\
\hline CHEMBL1344348 & 688326 & 4.9322 & 4.9157 & TRN & \\
\hline CHEMBL 3193608 & 688326 & 4.6171 & 4.4915 & TRN & \\
\hline CHEMBL 3195331 & 688326 & 4.0911 & 3.9569 & TRN & \\
\hline CHEMBL1532668 & 688326 & 5.0405 & 4.6602 & TRN & \\
\hline CHEMBL1993627 & 688326 & 3.1266 & 3.8699 & TRN & \\
\hline CHEMBL1542861 & 688326 & 5.2426 & 4.8269 & TRN & \\
\hline CHEMBL1600257 & 688326 & 4.449 & 4.015 & TRN & \\
\hline CHEMBL 1322008 & 688326 & 4.6424 & 4.2083 & TRN & \\
\hline CHEMBL 3214119 & 688326 & 4.9201 & 4.8456 & TST & \\
\hline CHEMBL 3196616 & 688326 & 4.5148 & 4.2117 & TRN & \\
\hline CHEMBL 3190909 & 688326 & 3.0 & 4.2642 & TRN & \\
\hline CHEMBL1330101 & 688326 & 3.0678 & 3.7988 & TRN & \\
\hline CHEMBL1416648 & 688326 & 4.4523 & 4.154 & TRN & \\
\hline CHEMBL1610008 & 688326 & 3.3029 & 4.4105 & TRN & \\
\hline CHEMBL1574691 & 688326 & 4.442 & 4.2497 & TRN & \\
\hline CHEMBL 3197521 & 688326 & 4.0673 & 3.8944 & TRN & \\
\hline CHEMBL1501178 & 688326 & 3.0 & 3.7358 & TRN & \\
\hline CHEMBL1389339 & 688326 & 5.0278 & 4.6464 & TRN & \\
\hline CHEMBL1341524 & 688326 & \multicolumn{3}{|c|}{5.0680000000000005} & 5.1162 \\
\hline
\end{tabular}




\begin{tabular}{|c|c|c|c|c|}
\hline & & & pplement & al $\mathrm{T}$ \\
\hline CHEMBL1572129 & 688326 & 5.2984 & 5.2344 & TRN \\
\hline CHEMBL1573650 & 688326 & 3.9838 & 4.7328 & TRN \\
\hline CHEMBL1348119 & 688326 & 5.7545 & 5.0624 & TRN \\
\hline CHEMBL1391810 & 688326 & 5.1986 & 4.6272 & TRN \\
\hline CHEMBL1333422 & 688326 & 4.4289 & 3.908 & TRN \\
\hline CHEMBL1580960 & 688326 & 4.1991 & 3.9192 & TRN \\
\hline CHEMBL579837 & 688326 & 4.7196 & 4.2897 & TRN \\
\hline CHEMBL1337525 & 688326 & 5.2104 & 4.7976 & TRN \\
\hline CHEMBL1600533 & 688326 & 4.3322 & 4.1112 & TRN \\
\hline CHEMBL579082 & 688326 & 4.9562 & 4.4043 & TRN \\
\hline CHEMBL1598340 & 688326 & 4.5955 & 4.7355 & TST \\
\hline CHEMBL1448732 & 688326 & 5.8861 & 5.6143 & TRN \\
\hline CHEMBL1432642 & 688326 & 4.6094 & 4.2605 & TRN \\
\hline CHEMBL 1457787 & 688326 & 5.3546 & 4.7479 & TRN \\
\hline CHEMBL1562280 & 688326 & 4.3417 & 4.1601 & TRN \\
\hline CHEMBL1476029 & 688326 & 4.7849 & 4.6328 & TST \\
\hline CHEMBL1315950 & 688326 & 4.9578 & 4.6121 & TRN \\
\hline CHEMBL1347533 & 688326 & 4.0487 & 4.221 & TRN \\
\hline CHEMBL1510149 & 688326 & 4.4618 & 4.0042 & TRN \\
\hline CHEMBL1302885 & 688326 & 4.2169 & 3.9285 & TRN \\
\hline CHEMBL1467038 & 688326 & 4.6211 & 4.5428 & TRN \\
\hline CHEMBL1372467 & 688326 & 4.6467 & 4.1651 & TRN \\
\hline CHEMBL1997112 & 688326 & 4.4627 & 4.1571 & TRN \\
\hline CHEMBL1348980 & 688326 & 3.1029 & 4.0222 & TRN \\
\hline CHEMBL1378445 & 688326 & 4.4683 & 4.2314 & TRN \\
\hline CHEMBL1430882 & 688326 & 5.0799 & 4.5383 & TRN \\
\hline CHEMBL1459822 & 688326 & 4.4594 & 4.5471 & TRN \\
\hline CHEMBL1500119 & 688326 & 4.63 & 4.3409 & TRN \\
\hline CHEMBL1492103 & 688326 & 4.1166 & 4.1288 & TRN \\
\hline CHEMBL1612019 & 688326 & 4.5252 & 4.5273 & TST \\
\hline CHEMBL1484681 & 688326 & 3.6249 & 4.1489 & TST \\
\hline CHEMBL1408593 & 688326 & 4.3879 & 4.2957 & TST \\
\hline CHEMBL1495265 & 688326 & 3.7033 & 4.4775 & TRN \\
\hline CHEMBL1389318 & 688326 & 4.631 & 4.1881 & TST \\
\hline CHEMBL1366648 & 688326 & 5.3372 & 6.4745 & TRN \\
\hline CHEMBL3193568 & 688326 & 4.2994 & 4.1924 & TRN \\
\hline CHEMBL1362314 & 688326 & 3.0 & 4.2253 & TRN \\
\hline CHEMBL1496464 & 688326 & 3.6066 & 4.5415 & TRN \\
\hline CHEMBL1372112 & 688326 & 4.9197 & 4.6189 & TRN \\
\hline CHEMBL1339273 & 688326 & 5.0516 & 4.7358 & TRN \\
\hline CHEMBL1494461 & 688326 & 4.4618 & 4.1566 & TRN \\
\hline CHEMBL1997543 & 688326 & 4.6546 & 4.2323 & TRN \\
\hline CHEMBL1481318 & 688326 & 4.6144 & 4.1852 & TRN \\
\hline CHEMBL1342473 & 688326 & 4.9618 & 5.0827 & TRN \\
\hline CHEMBL1459487 & 688326 & 4.3991 & 4.1748 & TRN \\
\hline CHEMBL1466340 & 688326 & 5.3925 & 5.4305 & TRN \\
\hline CHEMBL1488795 & 688326 & 3.0425 & 3.8873 & TRN \\
\hline CHEMBL1396156 & 688326 & 3.052 & 5.5592 & TRN \\
\hline
\end{tabular}


Supplemental Table S2.txt

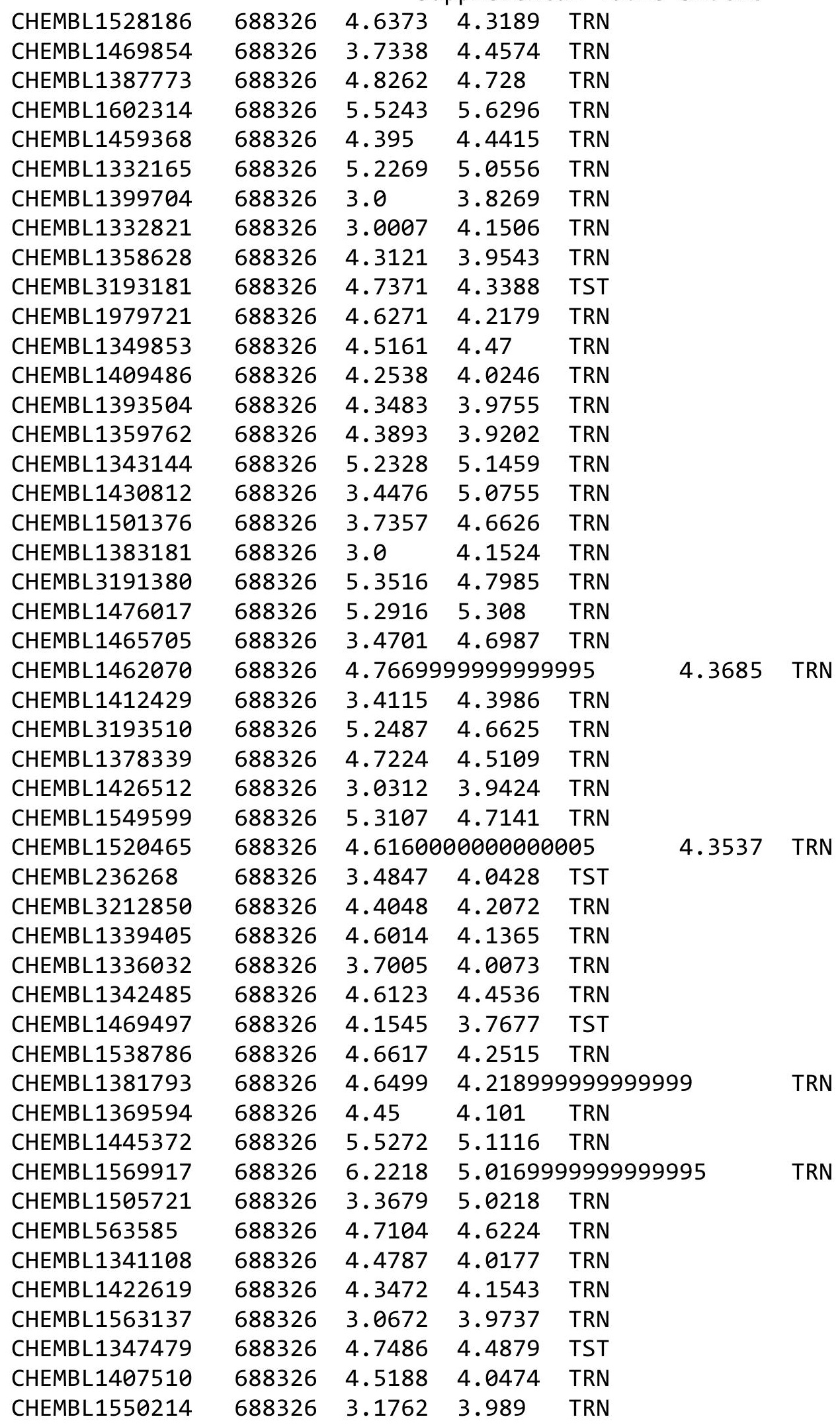

Page 11163 


\begin{tabular}{|c|c|c|c|c|}
\hline \multicolumn{5}{|c|}{ Supplemental Table s2.txt } \\
\hline CHEMBL1555004 & 688326 & 4.5694 & 4.1328 & TRN \\
\hline CHEMBL1552591 & 688326 & 4.8444 & 4.3559 & TRN \\
\hline CHEMBL1564599 & 688326 & 3.6156 & 4.613 & TRN \\
\hline CHEMBL1428063 & 688326 & 3.0263 & 3.827 & TRN \\
\hline CHEMBL1399822 & 688326 & 4.2698 & 3.8872 & TRN \\
\hline CHEMBL1522198 & 688326 & 4.4402 & 4.481 & TRN \\
\hline CHEMBL1460723 & 688326 & 3.0 & 3.636 & TRN \\
\hline CHEMBL1429160 & 688326 & 5.2541 & 5.0579 & TRN \\
\hline CHEMBL1507949 & 688326 & 3.0 & 3.9447 & TRN \\
\hline CHEMBL1365507 & 688326 & 4.4124 & 4.3121 & TRN \\
\hline CHEMBL3198919 & 688326 & 3.0 & 3.7346 & TRN \\
\hline CHEMBL1476262 & 688326 & 4.4144 & 4.0352 & TST \\
\hline CHEMBL1336036 & 688326 & 4.4254 & 4.0537 & TRN \\
\hline CHEMBL1594650 & 688326 & 3.3179 & 4.0914 & TRN \\
\hline CHEMBL1412226 & 688326 & 4.02 & 4.6918 & TRN \\
\hline CHEMBL1331995 & 688326 & 4.6444 & 4.477 & TST \\
\hline CHEMBL1585597 & 688326 & 3.0899 & 4.152 & TRN \\
\hline CHEMBL1448940 & 688326 & 4.5528 & 4.1943 & TRN \\
\hline CHEMBL1378019 & 688326 & 4.7496 & 4.2692 & TRN \\
\hline CHEMBL1315169 & 688326 & 5.0625 & 4.9051 & TRN \\
\hline CHEMBL1964793 & 688326 & 4.9678 & 5.6469 & TRN \\
\hline CHEMBL1606685 & 688326 & 5.8928 & 5.1611 & TRN \\
\hline CHEMBL1500712 & 688326 & 4.4915 & 4.7243 & TST \\
\hline CHEMBL1304913 & 688326 & 4.9329 & 4.3571 & TRN \\
\hline CHEMBL1303293 & 688326 & 3.2573 & 4.3256 & TRN \\
\hline CHEMBL1306816 & 688326 & 4.6972 & 4.4413 & TRN \\
\hline CHEMBL1481132 & 688326 & 4.7027 & 4.7055 & TRN \\
\hline CHEMBL1473706 & 688326 & 3.5482 & 4.23 & TRN \\
\hline CHEMBL1423559 & 688326 & 3.301 & 3.2363 & TRN \\
\hline CHEMBL1581700 & 688326 & 4.667 & 4.4096 & TRN \\
\hline CHEMBL1509380 & 688326 & 4.8011 & 4.5668 & TRN \\
\hline CHEMBL1543899 & 688326 & 6.1367 & 5.6994 & TST \\
\hline CHEMBL1586725 & 688326 & 4.6962 & 4.5466 & TRN \\
\hline CHEMBL1201074 & 688326 & 4.6364 & 4.1564 & TST \\
\hline CHEMBL1592492 & 688326 & 6.3468 & 6.8455 & TRN \\
\hline CHEMBL1312315 & 688326 & 4.3602 & 4.5616 & TRN \\
\hline CHEMBL1359579 & 688326 & 5.2457 & 4.9168 & TRN \\
\hline CHEMBL1424042 & 688326 & 4.8114 & 4.2443 & TRN \\
\hline CHEMBL1495859 & 688326 & 3.301 & 4.1984 & TRN \\
\hline CHEMBL1583579 & 688326 & 4.3763 & 4.0252 & TRN \\
\hline CHEMBL1433269 & 688326 & 5.0052 & 4.58 & TST \\
\hline CHEMBL3199926 & 688326 & 4.0927 & 4.0007 & TRN \\
\hline CHEMBL1344941 & 688326 & 4.9266 & 4.2901 & TRN \\
\hline CHEMBL1400481 & 688326 & 4.4807 & 4.4489 & TST \\
\hline CHEMBL1483678 & 688326 & 4.415 & 4.3506 & TRN \\
\hline CHEMBL1520551 & 688326 & 4.8649 & 4.5857 & TRN \\
\hline CHEMBL1554074 & 688326 & 4.4211 & 4.1737 & TRN \\
\hline CHEMBL1592705 & 688326 & 4.5549 & 4.3857 & TRN \\
\hline
\end{tabular}




\begin{tabular}{|c|c|c|c|c|c|}
\hline \multirow[b]{2}{*}{ CHEMBL445311 } & \multicolumn{5}{|c|}{ Supplemental Table S2.txt } \\
\hline & 688326 & 4.426 & 4.1599 & TRN & \\
\hline CHEMBL3190369 & 688326 & 7.699 & 6.4396 & TST & \\
\hline CHEMBL1400824 & 688326 & 4.3395 & 4.14199 & 99999999995 & TRN \\
\hline CHEMBL1371089 & 688326 & 4.5369 & 4.1897 & TRN & \\
\hline CHEMBL1256916 & 688326 & 4.914 & 4.4079 & TRN & \\
\hline CHEMBL1430904 & 688326 & 3.7174 & 4.3067 & TRN & \\
\hline CHEMBL1401767 & 688326 & 4.5113 & 4.1576 & TRN & \\
\hline CHEMBL3193986 & 688326 & 3.4372 & 4.0465 & TRN & \\
\hline CHEMBL1470502 & 688326 & 4.2029 & 3.8932 & TRN & \\
\hline CHEMBL1492432 & 688326 & 5.2351 & 4.913 & TRN & \\
\hline CHEMBL1559156 & 688326 & 7.699 & 6.6643 & TRN & \\
\hline CHEMBL1475085 & 688326 & 3.6142 & 4.4374 & TRN & \\
\hline CHEMBL1432466 & 688326 & 4.3774 & 4.5434 & TRN & \\
\hline CHEMBL1311547 & 688326 & 3.6398 & 4.2373 & TRN & \\
\hline CHEMBL1329396 & 688326 & 4.4442 & 4.0365 & TRN & \\
\hline CHEMBL1465165 & 688326 & 4.4532 & 4.1513 & TRN & \\
\hline CHEMBL1599021 & 688326 & 3.7533 & 4.4786 & TST & \\
\hline CHEMBL1360385 & 688326 & 4.6216 & 4.3116 & TRN & \\
\hline CHEMBL1531536 & 688326 & 4.724 & 4.8445 & TRN & \\
\hline CHEMBL1572280 & 688326 & 5.4868 & 5.0797 & TST & \\
\hline CHEMBL1398613 & 688326 & 4.5669 & 4.3186 & TST & \\
\hline CHEMBL288174 & 688326 & 4.5124 & 4.2024 & TST & \\
\hline CHEMBL1405439 & 688326 & 3.9935 & 4.6684 & TRN & \\
\hline CHEMBL1454557 & 688326 & 4.8422 & 4.8792 & TRN & \\
\hline CHEMBL1591102 & 688326 & 4.6908 & 4.2641 & TRN & \\
\hline CHEMBL1477118 & 688326 & 4.3548 & 3.98199 & 99999999998 & TRN \\
\hline CHEMBL1527324 & 688326 & 4.6249 & 4.0601 & TRN & \\
\hline CHEMBL1586054 & 688326 & 4.4476 & 4.2715 & TRN & \\
\hline CHEMBL1415447 & 688326 & 4.0439 & 3.7532 & TST & \\
\hline CHEMBL1467036 & 688326 & 4.5979 & 4.2092 & TST & \\
\hline CHEMBL1437560 & 688326 & 4.8483 & 4.3959 & TST & \\
\hline CHEMBL1463626 & 688326 & 5.2874 & 4.8047 & TRN & \\
\hline CHEMBL1581275 & 688326 & 3.7471 & 4.5165 & TRN & \\
\hline CHEMBL1510371 & 688326 & 4.6849 & 4.308 & TRN & \\
\hline CHEMBL1491696 & 688326 & 3.0475 & 4.2991 & TRN & \\
\hline CHEMBL1561474 & 688326 & 4.0487 & 4.0853 & TST & \\
\hline CHEMBL1566321 & 688326 & 5.1385 & 4.919 & TRN & \\
\hline CHEMBL1994401 & 688326 & 5.3019 & 4.6961 & TRN & \\
\hline CHEMBL585591 & 688326 & 5.2358 & 4.8371 & TST & \\
\hline CHEMBL1492648 & 688326 & 4.745 & 4.55399 & 9999999999 & TRN \\
\hline CHEMBL3199825 & 688326 & 3.083 & 3.6834 & TRN & \\
\hline CHEMBL1522050 & 688326 & 5.1506 & 5.2789 & TRN & \\
\hline CHEMBL1604551 & 688326 & 3.3738 & 4.3969 & TRN & \\
\hline CHEMBL1539177 & 688326 & 4.4575 & 4.4452 & TRN & \\
\hline CHEMBL1360870 & 688326 & 4.6101 & 4.1857 & TST & \\
\hline CHEMBL1978623 & 688326 & 4.3582 & 4.0915 & TRN & \\
\hline CHEMBL3190259 & 688326 & 4.6345 & 4.3674 & TST & \\
\hline CHEMBL1463659 & 688326 & 4.9027 & 4.6184 & TRN & \\
\hline
\end{tabular}




\begin{tabular}{|c|c|c|c|c|c|c|}
\hline & & \multicolumn{5}{|c|}{ Supplemental Table S2.txt } \\
\hline CHEMBL1389982 & 688326 & 4.4891 & 4.5167 & TST & & \\
\hline CHEMBL3192475 & 688326 & 4.7716 & 4.4019 & TRN & & \\
\hline CHEMBL1556582 & 688326 & 4.9654 & 4.7613 & TRN & & \\
\hline CHEMBL1373411 & 688326 & 6.1308 & 5.3892 & TRN & & \\
\hline CHEMBL1309134 & 688326 & 4.6507 & 4.5995 & TST & & \\
\hline CHEMBL1399213 & 688326 & 3.7433 & 4.6027 & TRN & & \\
\hline CHEMBL1527476 & 688326 & 3.1742 & 3.9817 & TRN & & \\
\hline CHEMBL1340684 & 688326 & 4.6173 & 4.3847 & TRN & & \\
\hline CHEMBL1576999 & 688326 & 5.3737 & 5.2976 & TRN & & \\
\hline CHEMBL1307125 & 688326 & 4.6189 & 4.2192 & TRN & & \\
\hline CHEMBL1320267 & 688326 & 4.1089 & 3.8747 & TRN & & \\
\hline CHEMBL1550840 & 688326 & 3.0521 & 3.9627 & TST & & \\
\hline CHEMBL1510456 & 688326 & 4.6379 & 4.2352 & TRN & & \\
\hline CHEMBL1789993 & 688326 & 5.3958 & 4.8159 & TST & & \\
\hline CHEMBL1497430 & 688326 & 4.8318 & 4.5252 & TRN & & \\
\hline CHEMBL1232805 & 688326 & \multicolumn{3}{|c|}{5.2620000000000005} & 4.6238 & TST \\
\hline CHEMBL1431684 & 688326 & 4.9512 & 4.958 & TRN & & \\
\hline CHEMBL1523542 & 688326 & 5.4078 & 4.9628 & TRN & & \\
\hline CHEMBL1320707 & 688326 & 3.1641 & 3.841 & TRN & & \\
\hline CHEMBL1521841 & 688326 & 4.4915 & 4.1841 & TST & & \\
\hline CHEMBL1523762 & 688326 & 4.7338 & 4.6254 & TRN & & \\
\hline CHEMBL3189770 & 688326 & 4.727 & 4.2653 & TRN & & \\
\hline CHEMBL1429343 & 688326 & 4.4686 & 4.1395 & TRN & & \\
\hline CHEMBL1526567 & 688326 & 4.5553 & 4.3241 & TRN & & \\
\hline CHEMBL1452158 & 688326 & 5.0477 & 4.4521 & TRN & & \\
\hline CHEMBL1502870 & 688326 & 5.8996 & 5.3352 & TRN & & \\
\hline CHEMBL1572538 & 688326 & 5.5867 & 4.7811 & TRN & & \\
\hline CHEMBL1401091 & 688326 & 4.4614 & 4.269 & TRN & & \\
\hline CHEMBL1320592 & 688326 & 3.1695 & 3.9078 & TRN & & \\
\hline CHEMBL1570139 & 688326 & 4.7683 & 4.5211 & TRN & & \\
\hline CHEMBL1387328 & 688326 & 4.6821 & 4.5652 & TRN & & \\
\hline CHEMBL1382443 & 688326 & 3.0356 & 3.9215 & TRN & & \\
\hline CHEMBL3190261 & 688326 & 3.5296 & 4.5595 & TRN & & \\
\hline CHEMBL1459918 & 688326 & 3.9923 & 5.0393 & TRN & & \\
\hline CHEMBL1334456 & 688326 & 5.5317 & 5.1216 & TST & & \\
\hline CHEMBL1539910 & 688326 & 5.5058 & 4.6138 & TRN & & \\
\hline CHEMBL1419184 & 688326 & 4.3518 & 4.0475 & TRN & & \\
\hline CHEMBL1502109 & 688326 & 4.4176 & 4.0473 & TRN & & \\
\hline CHEMBL1574179 & 688326 & 5.2976 & 4.7588 & TST & & \\
\hline CHEMBL1565135 & 688326 & 5.0044 & 4.5171 & TRN & & \\
\hline CHEMBL1580037 & 688326 & 3.123 & 4.0836 & TRN & & \\
\hline CHEMBL1311886 & 688326 & 3.1127 & 3.9189 & TRN & & \\
\hline CHEMBL2001577 & 688326 & 4.373 & 4.0049 & TRN & & \\
\hline CHEMBL1573586 & 688326 & 4.9412 & 4.3794 & TST & & \\
\hline CHEMBL1541672 & 688326 & 4.2954 & 4.2137 & TRN & & \\
\hline CHEMBL1554131 & 688326 & 5.4012 & 4.8936 & TST & & \\
\hline CHEMBL1409835 & 688326 & 4.4115 & 4.3527 & TRN & & \\
\hline CHEMBL1459140 & 688326 & 5.5229 & 5.3212 & TRN & & \\
\hline
\end{tabular}




\begin{tabular}{|c|c|c|c|c|c|}
\hline \multicolumn{6}{|c|}{ Supplemental Table S2.txt } \\
\hline CHEMBL1575502 & 688326 & 5.5638 & 5.1804 & TRN & \\
\hline CHEMBL1992105 & 688326 & 4.3631 & 4.0881 & TRN & \\
\hline CHEMBL1565344 & 688326 & 4.3652 & 4.0581 & TRN & \\
\hline CHEMBL1452948 & 688326 & 4.3651 & 4.066 & TRN & \\
\hline CHEMBL1330256 & 688326 & 4.1256 & 3.8823 & TRN & \\
\hline CHEMBL1403554 & 688326 & 3.9439 & 4.6062 & TRN & \\
\hline CHEMBL3191202 & 688326 & 5.0241 & 4.7794 & TST & \\
\hline CHEMBL1528260 & 688326 & 4.658 & 4.317 & TRN & \\
\hline CHEMBL1973360 & 688326 & 5.2 & 4.618 & TRN & \\
\hline CHEMBL1533589 & 688326 & 3.716 & 4.4331 & TRN & \\
\hline CHEMBL1414769 & 688326 & 4.4056 & 4.22199 & 99999999995 & TRN \\
\hline CHEMBL1358604 & 688326 & 4.5627 & 4.2366 & TRN & \\
\hline CHEMBL1488012 & 688326 & 3.0892 & 4.2025 & TRN & \\
\hline CHEMBL1459485 & 688326 & 4.671 & 4.1438 & TRN & \\
\hline CHEMBL1561085 & 688326 & 4.4169 & 4.1748 & TST & \\
\hline CHEMBL1476975 & 688326 & 4.1955 & 3.89600 & 00000000004 & TRN \\
\hline CHEMBL1531502 & 688326 & 4.9813 & 4.8531 & TRN & \\
\hline CHEMBL1595755 & 688326 & 4.6631 & 4.313 & TRN & \\
\hline CHEMBL1319341 & 688326 & 3.2707 & 4.0998 & TRN & \\
\hline CHEMBL1385443 & 688326 & 4.2694 & 3.7771 & TRN & \\
\hline CHEMBL1545088 & 688326 & 4.3778 & 5.3167 & TRN & \\
\hline CHEMBL1353690 & 688326 & 3.0852 & 3.9647 & TRN & \\
\hline CHEMBL1554037 & 688326 & 3.1383 & 3.8974 & TRN & \\
\hline CHEMBL1441992 & 688326 & 4.2916 & 3.8225 & TRN & \\
\hline CHEMBL1535532 & 688326 & 5.1752 & 5.1672 & TRN & \\
\hline CHEMBL1460865 & 688326 & 5.399 & 4.9289 & TRN & \\
\hline CHEMBL503363 & 688326 & 5.2565 & 4.6153 & TRN & \\
\hline CHEMBL1430795 & 688326 & 5.27 & 4.909 & TRN & \\
\hline CHEMBL1339131 & 688326 & 5.5272 & 4.84399 & 9999999999 & TRN \\
\hline CHEMBL1373992 & 688326 & 5.8125 & 5.482 & TST & \\
\hline CHEMBL1412497 & 688326 & 4.8755 & 4.4793 & TRN & \\
\hline CHEMBL1256186 & 688326 & 4.4145 & 4.2702 & TST & \\
\hline CHEMBL3213855 & 688326 & 4.3605 & 4.0283 & TRN & \\
\hline CHEMBL1491929 & 688326 & 4.4438 & 4.1366 & TRN & \\
\hline CHEMBL 994 & 688326 & 5.0448 & 4.551 & TST & \\
\hline CHEMBL1373255 & 688326 & 3.0373 & 4.3126 & TRN & \\
\hline CHEMBL1521247 & 688326 & 4.6182 & 4.373 & TRN & \\
\hline CHEMBL1395534 & 688326 & 3.1039 & 3.6963 & TRN & \\
\hline CHEMBL1544580 & 688326 & 3.6167 & 4.2538 & TRN & \\
\hline CHEMBL1499389 & 688326 & 5.2306 & 4.7736 & TRN & \\
\hline CHEMBL1530139 & 688326 & 4.1577 & 3.9244 & TRN & \\
\hline CHEMBL19954 & 688326 & 5.8761 & 5.1722 & TST & \\
\hline CHEMBL 2138014 & 688326 & 4.6525 & 4.6706 & TST & \\
\hline CHEMBL1557212 & 688326 & 3.2527 & 3.9421 & TRN & \\
\hline CHEMBL600060 & 688326 & 5.644 & 5.5292 & TRN & \\
\hline CHEMBL1608593 & 688326 & 4.515 & 4.2166 & TRN & \\
\hline CHEMBL1475498 & 688326 & 4.0265 & 4.3989 & TRN & \\
\hline CHEMBL1378798 & 688326 & 4.9492 & 4.4524 & TRN & \\
\hline
\end{tabular}




\begin{tabular}{|c|c|c|c|c|c|}
\hline \multicolumn{6}{|c|}{ lemental } \\
\hline CHEMBL1594275 & 688326 & 4.3451 & 4.1085 & TRN & \\
\hline CHEMBL1425701 & 688326 & 4.5862 & 4.0954 & TRN & \\
\hline CHEMBL1995800 & 688326 & 5.9245 & 4.9318 & TRN & \\
\hline CHEMBL1585147 & 688326 & 4.4093 & 3.96 & TRN & \\
\hline CHEMBL1537101 & 688326 & 5.7799 & 5.2212 & TRN & \\
\hline CHEMBL1598934 & 688326 & 3.0758 & 4.4905 & TRN & \\
\hline CHEMBL1303331 & 688326 & 3.1361 & 4.1353 & TRN & \\
\hline CHEMBL1481814 & 688326 & 4.42899 & 99999999 & 3. & TRN \\
\hline CHEMBL1986741 & 688326 & 4.4014 & 4.0004 & TRN & \\
\hline CHEMBL1441974 & 688326 & 5.0137 & 4.6722 & TST & \\
\hline CHEMBL1494293 & 688326 & 3.3745 & 5.5633 & TRN & \\
\hline CHEMBL1398511 & 688326 & 4.7383 & 4.6505 & TRN & \\
\hline CHEMBL3199642 & 688326 & 3.0478 & 3.8739 & TRN & \\
\hline CHEMBL3192977 & 688326 & 4.3334 & 4.2736 & TRN & \\
\hline CHEMBL1454414 & 688326 & 3.7455 & 4.5208 & TRN & \\
\hline CHEMBL1576940 & 688326 & 5.065 & 4.6877 & TST & \\
\hline CHEMBL1970597 & 688326 & 5.2449 & 5.2081 & TRN & \\
\hline CHEMBL1607286 & 688326 & 4.6836 & 4.0964 & TRN & \\
\hline CHEMBL3211062 & 688326 & 5.4698 & 4.9368 & TST & \\
\hline CHEMBL1299475 & 688326 & 3.0 & 4.1982 & TST & \\
\hline CHEMBL1365552 & 688326 & 5.3556 & 5.3061 & TRN & \\
\hline CHEMBL1400960 & 688326 & 4.4746 & 4.2479 & TRN & \\
\hline CHEMBL489 & 688326 & 4.5764 & 4.1508 & TRN & \\
\hline CHEMBL172 & 688326 & 4.6436 & 4.2178 & TST & \\
\hline CHEMBL3213912 & 688326 & 3.0 & 3.6954 & TRN & \\
\hline CHEMBL1462548 & 688326 & 4.1131 & 3.7939 & TRN & \\
\hline CHEMBL1613064 & 688326 & 4.4602 & 3.7808 & TRN & \\
\hline CHEMBL1555532 & 688326 & 4.6459 & 4.4114 & TRN & \\
\hline CHEMBL1360199 & 688326 & 4.6609 & 4.1222 & TRN & \\
\hline CHEMBL1319850 & 688326 & 4.9416 & 4.7452 & TRN & \\
\hline CHEMBL1520030 & 688326 & 4.9172 & 4.6183 & TRN & \\
\hline CHEMBL1418007 & 688326 & 5.153 & 4.6263 & TRN & \\
\hline CHEMBL1465648 & 688326 & 3.1999 & 4.1279 & TRN & \\
\hline CHEMBL1488976 & 688326 & 4.828 & 4.2511 & TRN & \\
\hline CHEMBL598270 & 688326 & 4.4309 & 4.1277 & TRN & \\
\hline CHEMBL1424151 & 688326 & 3.0752 & 3.6111 & TRN & \\
\hline CHEMBL1270217 & 688326 & 3.3253 & 4.1095 & TRN & \\
\hline CHEMBL1501809 & 688326 & 4.6234 & 4.2482 & TRN & \\
\hline CHEMBL3191542 & 688326 & 4.4227 & 3.9151 & TRN & \\
\hline CHEMBL1319374 & 688326 & 4.7231 & 4.3326 & TRN & \\
\hline CHEMBL1360823 & 688326 & 4.4542 & 4.2006 & TRN & \\
\hline CHEMBL1485363 & 688326 & 4.567 & 4.2648 & TRN & \\
\hline CHEMBL1995152 & 688326 & 5.0061 & 4.4003 & TRN & \\
\hline CHEMBL1467326 & 688326 & 4.63 & 4.23600 & 0000000001 & TRN \\
\hline CHEMBL1333312 & 688326 & 4.2978 & 3.9669 & TRN & \\
\hline CHEMBL1367989 & 688326 & 4.4478 & 3.996006 & 20000000004 & TRN \\
\hline CHEMBL3195309 & 688326 & 4.4309 & 4.3343 & TRN & \\
\hline CHEMBL1348465 & 688326 & 4.6413 & 4.4875 & TRN & \\
\hline
\end{tabular}




\begin{tabular}{|c|c|c|c|c|c|}
\hline & & \multicolumn{4}{|c|}{ Supplemental Table S2.txt } \\
\hline CHEMBL1483224 & 688326 & 4.4185 & 4.095 & TRN & \\
\hline CHEMBL1992432 & 688326 & 4.8811 & 4.7221 & TST & \\
\hline CHEMBL1533220 & 688326 & 4.6535 & 4.3028 & TRN & \\
\hline CHEMBL1526703 & 688326 & 3.0339 & 3.8225 & TRN & \\
\hline CHEMBL1550330 & 688326 & 3.3285 & 4.3611 & TRN & \\
\hline CHEMBL3196585 & 688326 & 4.7303 & 4.7637 & TRN & \\
\hline CHEMBL3145174 & 688326 & 4.63 & 4.6386 & TRN & \\
\hline CHEMBL1384554 & 688326 & 4.6185 & 4.4167 & TST & \\
\hline CHEMBL1584066 & 688326 & 4.9834 & 4.5008 & TRN & \\
\hline CHEMBL117447 & 688326 & 4.7486 & 4.4791 & TRN & \\
\hline CHEMBL1421265 & 688326 & 5.5331 & 4.9682 & TRN & \\
\hline CHEMBL1512724 & 688326 & 4.1996 & 3.9097 & TRN & \\
\hline CHEMBL1383584 & 688326 & 4.7953 & 4.6006 & TRN & \\
\hline CHEMBL1538748 & 688326 & 4.1953 & 3.8461 & TST & \\
\hline CHEMBL1332956 & 688326 & 4.6946 & 4.2092 & TST & \\
\hline CHEMBL1502358 & 688326 & 4.9073 & 4.5482 & TST & \\
\hline CHEMBL1325250 & 688326 & 3.2488 & 4.6956 & TRN & \\
\hline CHEMBL1567951 & 688326 & 4.5147 & 4.0296 & TRN & \\
\hline CHEMBL1518440 & 688326 & 3.9488 & 5.0539 & TRN & \\
\hline CHEMBL1589428 & 688326 & 5.5834 & 5.1775 & TRN & \\
\hline CHEMBL1342495 & 688326 & 4.7498 & 4.57 & TRN & \\
\hline CHEMBL1597705 & 688326 & 5.2262 & 5.3282 & TRN & \\
\hline CHEMBL1607137 & 688326 & 4.3292 & 4.086 & TRN & \\
\hline CHEMBL1383664 & 688326 & 5.0575 & 4.9263 & TRN & \\
\hline CHEMBL1598561 & 688326 & 4.8 & 4.7601 & TRN & \\
\hline CHEMBL1381450 & 688326 & 4.2398 & 4.0186 & TRN & \\
\hline CHEMBL3197927 & 688326 & 5.0762 & 4.6122 & TRN & \\
\hline CHEMBL1511793 & 688326 & 4.3482 & 3.9587 & TRN & \\
\hline CHEMBL1424729 & 688326 & 4.8063 & 4.5498 & TRN & \\
\hline CHEMBL1611370 & 688326 & 3.1031 & 3.8862 & TRN & \\
\hline CHEMBL1613096 & 688326 & 4.8554 & 4.2912 & TST & \\
\hline CHEMBL1387564 & 688326 & 4.3153 & 4.3223 & TRN & \\
\hline CHEMBL1462257 & 688326 & 4.6419 & 4.7555 & TRN & \\
\hline CHEMBL3192106 & 688326 & 3.6906 & 4.7151 & TST & \\
\hline CHEMBL1513654 & 688326 & 4.5396 & 4.1193 & TST & \\
\hline CHEMBL1417731 & 688326 & 6.3768 & 5.3292 & TRN & \\
\hline CHEMBL1459318 & 688326 & 5.0904 & 4.9815 & TRN & \\
\hline CHEMBL1369287 & 688326 & 4.9504 & 4.5199 & TRN & \\
\hline CHEMBL1521646 & 688326 & 3.6064 & 3.9956 & TRN & \\
\hline CHEMBL1464854 & 688326 & 4.6453 & 4.50899 & 99999999995 & TRN \\
\hline CHEMBL1529827 & 688326 & 4.3502 & 4.0778 & TRN & \\
\hline CHEMBL581152 & 688326 & 4.8156 & 4.2382 & TRN & \\
\hline CHEMBL1386048 & 688326 & 5.3161 & 4.7345 & TRN & \\
\hline CHEMBL1340794 & 688326 & 4.633 & 4.6015 & TST & \\
\hline CHEMBL1400856 & 688326 & 4.6951 & 4.582 & TST & \\
\hline CHEMBL1312803 & 688326 & 4.333 & 4.1314 & TST & \\
\hline CHEMBL1340221 & 688326 & 5.1325 & 5.2634 & TRN & \\
\hline CHEMBL1545900 & 688326 & 3.1451 & 3.8181 & TST & \\
\hline
\end{tabular}




\begin{tabular}{|c|c|c|c|c|c|}
\hline & & \multicolumn{4}{|c|}{ Supplemental Table S2.txt } \\
\hline CHEMBL1563483 & 688326 & 5.6498 & 5.1588 & TST & \\
\hline CHEMBL1507666 & 688326 & 3.1249 & 4.4023 & TRN & \\
\hline CHEMBL1415208 & 688326 & 4.4604 & 4.0449 & TRN & \\
\hline CHEMBL1488075 & 688326 & 5.6253 & 5.1716 & TRN & \\
\hline CHEMBL3199620 & 688326 & 5.8861 & 5.4009 & TRN & \\
\hline CHEMBL1980813 & 688326 & 5.5702 & 5.0547 & TRN & \\
\hline CHEMBL1361820 & 688326 & 4.8047 & 4.3749 & TRN & \\
\hline CHEMBL1509758 & 688326 & 4.1302 & 3.9043 & TRN & \\
\hline CHEMBL1472773 & 688326 & 4.7841 & 4.5498 & TRN & \\
\hline CHEMBL1378570 & 688326 & 4.4808 & 4.0039 & TRN & \\
\hline CHEMBL1463156 & 688326 & 4.6098 & 4.5525 & TRN & \\
\hline CHEMBL1600969 & 688326 & 3.0662 & 3.8527 & TRN & \\
\hline CHEMBL1550600 & 688326 & 3.0481 & 4.3562 & TRN & \\
\hline CHEMBL1428194 & 688326 & 5.04 & 4.5905 & TRN & \\
\hline CHEMBL462576 & 688326 & 4.3524 & 4.0768 & TST & \\
\hline CHEMBL1566928 & 688326 & 4.6455 & 4.4838 & TRN & \\
\hline CHEMBL1322923 & 688326 & 4.3403 & 4.3208 & TST & \\
\hline CHEMBL1426274 & 688326 & 4.3959 & 3.897 & TRN & \\
\hline CHEMBL1393095 & 688326 & 5.0223 & 4.7202 & TRN & \\
\hline CHEMBL1584509 & 688326 & 4.919 & 4.6055 & TRN & \\
\hline CHEMBL1509484 & 688326 & 3.452 & 3.957 & TRN & \\
\hline CHEMBL1414059 & 688326 & 4.5047 & 4.2408 & TRN & \\
\hline CHEMBL117966 & 688326 & 5.0458 & 4.9138 & TRN & \\
\hline CHEMBL1601176 & 688326 & 3.2776 & 4.1919 & TRN & \\
\hline CHEMBL1598251 & 688326 & 3.4222 & 4.0584 & TST & \\
\hline CHEMBL1333088 & 688326 & 4.5366 & 4.3909 & TST & \\
\hline CHEMBL1522758 & 688326 & 4.7438 & 4.4966 & TRN & \\
\hline CHEMBL1478525 & 688326 & 4.3445 & 4.2656 & TRN & \\
\hline CHEMBL1314342 & 688326 & 5.8069 & $5.4920 e$ & 0000000001 & TRN \\
\hline CHEMBL1514917 & 688326 & 4.5268 & 4.1607 & TRN & \\
\hline CHEMBL1421881 & 688326 & 4.3649 & 4.1401 & TST & \\
\hline CHEMBL1579342 & 688326 & 4.5727 & $4.3260 e$ & 00000000005 & TRN \\
\hline CHEMBL1417988 & 688326 & 4.4066 & 4.3125 & TRN & \\
\hline CHEMBL3193188 & 688326 & 4.6245 & 4.47 & TRN & \\
\hline CHEMBL1558070 & 688326 & 4.6404 & 4.3402 & TRN & \\
\hline CHEMBL1453114 & 688326 & 4.6774 & 4.3983 & TRN & \\
\hline CHEMBL1415720 & 688326 & 4.2831 & 4.0293 & TRN & \\
\hline CHEMBL1554047 & 688326 & 3.9101 & 4.6633 & TRN & \\
\hline CHEMBL1571761 & 688326 & 4.9161 & 4.9022 & TRN & \\
\hline CHEMBL1468518 & 688326 & 4.6273 & 4.38399 & 99999999995 & TRN \\
\hline CHEMBL1459535 & 688326 & 5.0443 & 4.5763 & TRN & \\
\hline CHEMBL1484389 & 688326 & 4.9792 & 4.65 & TRN & \\
\hline CHEMBL1376799 & 688326 & 4.4557 & 4.0417 & TRN & \\
\hline CHEMBL1431146 & 688326 & 3.0 & 4.202 & TRN & \\
\hline CHEMBL1375966 & 688326 & 4.7031 & 4.7058 & TRN & \\
\hline CHEMBL1434353 & 688326 & 4.1776 & 3.9442 & TRN & \\
\hline CHEMBL1359675 & 688326 & 3.4075 & 4.0061 & TRN & \\
\hline CHEMBL1516047 & 688326 & 3.301 & 3.9362 & TRN & \\
\hline
\end{tabular}




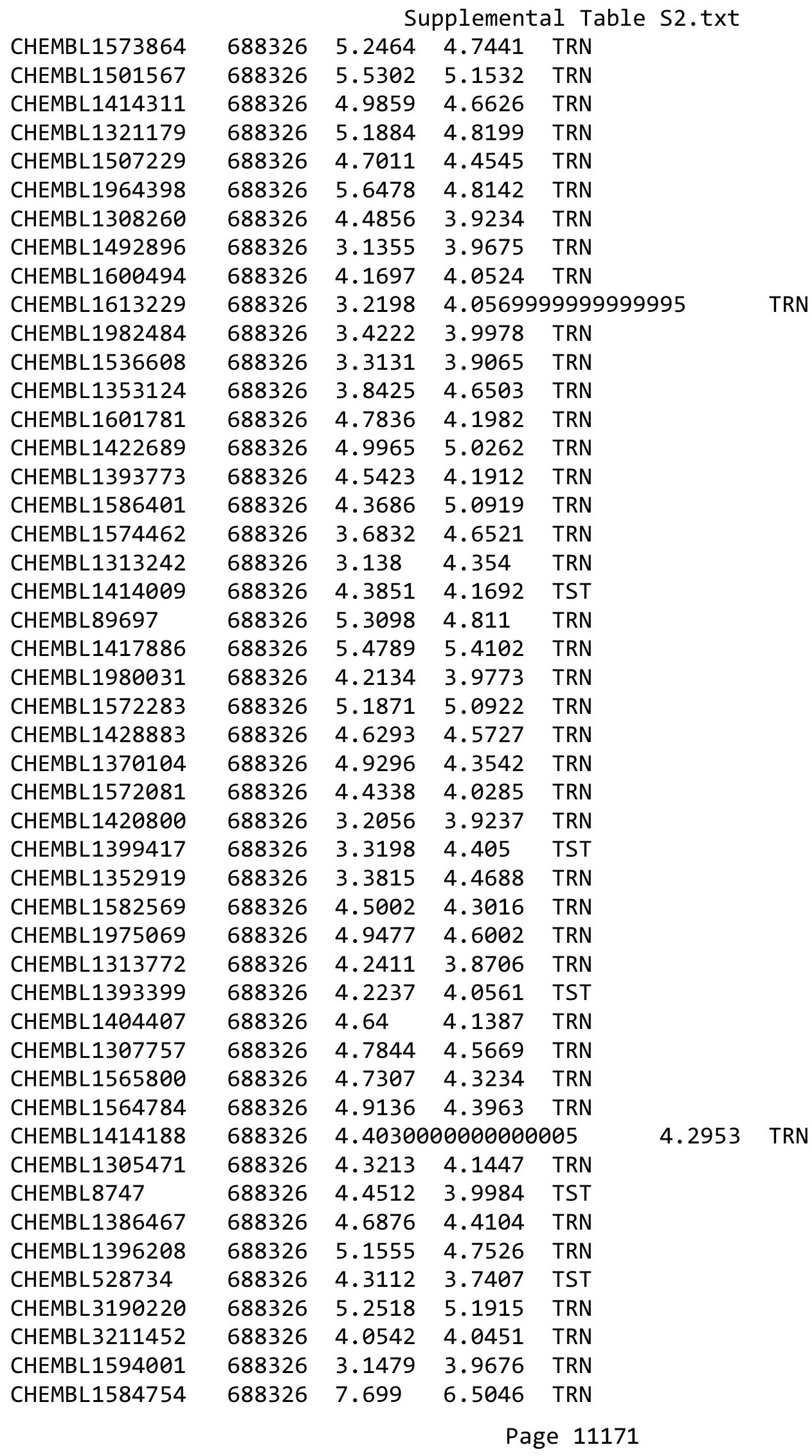




\begin{tabular}{|c|c|c|c|c|c|c|}
\hline & & \multicolumn{5}{|c|}{ Supplemental Table s2.txt } \\
\hline CHEMBL1405645 & 688326 & 4.9626 & 4.3992 & TRN & & \\
\hline CHEMBL1379929 & 688326 & 3.5594 & 4.3021 & TRN & & \\
\hline CHEMBL1586241 & 688326 & 4.4187 & 4.0797 & TRN & & \\
\hline CHEMBL1386605 & 688326 & 4.6349 & 4.2277 & TRN & & \\
\hline CHEMBL1471737 & 688326 & 4.5201 & 4.1082 & TRN & & \\
\hline CHEMBL1328824 & 688326 & 5.0301 & 4.7487 & TST & & \\
\hline CHEMBL1544291 & 688326 & 3.2548 & 4.3302 & TRN & & \\
\hline CHEMBL1487183 & 688326 & 5.27 & 4.8395 & TST & & \\
\hline CHEMBL1333275 & 688326 & 4.9397 & 4.6108 & TRN & & \\
\hline CHEMBL1307988 & 688326 & 4.6419 & 4.0866 & TRN & & \\
\hline CHEMBL1441408 & 688326 & 4.6117 & 4.0165 & TST & & \\
\hline CHEMBL1520182 & 688326 & 3.4418 & 4.1477 & TST & & \\
\hline CHEMBL1594452 & 688326 & 4.841 & 4.6937 & TRN & & \\
\hline CHEMBL1586047 & 688326 & 4.5013 & 4.046 & TRN & & \\
\hline CHEMBL1516161 & 688326 & 4.4624 & 4.1916 & TRN & & \\
\hline CHEMBL1497995 & 688326 & 4.6304 & 4.2094 & TRN & & \\
\hline CHEMBL1321578 & 688326 & 4.1508 & 3.8987 & TRN & & \\
\hline CHEMBL1606918 & 688326 & 3.0 & 3.7958 & TST & & \\
\hline CHEMBL1340792 & 688326 & 3.0205 & 3.8148 & TRN & & \\
\hline CHEMBL1574748 & 688326 & 3.133 & 4.0565 & TRN & & \\
\hline CHEMBL1340213 & 688326 & 5.0477 & 4.7967 & TRN & & \\
\hline CHEMBL1568431 & 688326 & 3.3152 & 4.0873 & TRN & & \\
\hline CHEMBL1562086 & 688326 & 5.6198 & 5.541 & TRN & & \\
\hline CHEMBL3197433 & 688326 & 6.699 & 6.3563 & TRN & & \\
\hline CHEMBL1600917 & 688326 & 4.6064 & 4.2072 & TRN & & \\
\hline CHEMBL 236267 & 688326 & 4.6666 & 4.1203 & TRN & & \\
\hline CHEMBL1365734 & 688326 & 4.4981 & 4.1872 & TST & & \\
\hline CHEMBL1371385 & 688326 & 4.63899 & 99999999 & 99 & 4.3714 & TRN \\
\hline CHEMBL1334115 & 688326 & 4.6521 & 4.4797 & TRN & & \\
\hline CHEMBL1988120 & 688326 & 5.2565 & 4.5782 & TRN & & \\
\hline CHEMBL1598829 & 688326 & 5.2132 & 4.8032 & TRN & & \\
\hline CHEMBL1442080 & 688326 & 5.2125 & 5.3262 & TRN & & \\
\hline CHEMBL1335734 & 688326 & 3.38 & 4.3184 & TRN & & \\
\hline CHEMBL1561446 & 688326 & 4.7875 & 4.5735 & TRN & & \\
\hline CHEMBL1522550 & 688326 & 4.5286 & 4.1542 & TST & & \\
\hline CHEMBL1565290 & 688326 & 4.3921 & 4.0377 & TRN & & \\
\hline CHEMBL1543127 & 688326 & 5.8665 & 5.4687 & TRN & & \\
\hline CHEMBL1550490 & 688326 & 4.4232 & 4.0007 & TRN & & \\
\hline CHEMBL1375142 & 688326 & 4.4103 & 4.1641 & TRN & & \\
\hline CHEMBL1302894 & 688326 & 4.32 & 3.92199 & 99999 & 997 & TRN \\
\hline CHEMBL1376606 & 688326 & 5.066 & 4.6517 & TRN & & \\
\hline CHEMBL1305678 & 688326 & 3.22 & 4.1376 & TRN & & \\
\hline CHEMBL1446181 & 688326 & 3.0 & 4.1276 & TST & & \\
\hline CHEMBL1333095 & 688326 & 4.1966 & 4.0214 & TRN & & \\
\hline CHEMBL1472103 & 688326 & 5.4559 & 6.7523 & TRN & & \\
\hline CHEMBL1603862 & 688326 & 3.0699 & 4.1649 & TRN & & \\
\hline CHEMBL1436062 & 688326 & $3.0380 e$ & 30000000 & 203 & 3.8854 & TRN \\
\hline CHEMBL1512404 & 688326 & 3.9208 & 4.5944 & TRN & & \\
\hline
\end{tabular}




\begin{tabular}{|c|c|c|c|c|c|c|}
\hline & & \multicolumn{5}{|c|}{ Supplemental Table S2.txt } \\
\hline CHEMBL1597716 & 688326 & 5.5331 & 5.564 & TRN & & \\
\hline CHEMBL1432784 & 688326 & 4.7491 & 4.5082 & TRN & & \\
\hline CHEMBL1374480 & 688326 & 4.9374 & 4.413 & TRN & & \\
\hline CHEMBL1428563 & 688326 & 4.7617 & 4.4156 & TRN & & \\
\hline CHEMBL1526910 & 688326 & 4.6625 & 4.5112 & TRN & & \\
\hline CHEMBL1523817 & 688326 & 4.5467 & 4.1914 & TST & & \\
\hline CHEMBL1522777 & 688326 & 4.6527 & 4.2521 & TRN & & \\
\hline CHEMBL1375216 & 688326 & 3.1007 & 3.8164 & TRN & & \\
\hline CHEMBL533388 & 688326 & 4.9427 & 4.8317 & TRN & & \\
\hline CHEMBL3196754 & 688326 & 5.24799 & 99999999 & 99 & 5.1169 & TRN \\
\hline CHEMBL1482808 & 688326 & 4.4874 & 4.4484 & TRN & & \\
\hline CHEMBL1539471 & 688326 & 3.1223 & 3.7417 & TST & & \\
\hline CHEMBL1528618 & 688326 & 4.4631 & 4.2522 & TRN & & \\
\hline CHEMBL1539959 & 688326 & 3.3394 & 4.011 & TRN & & \\
\hline CHEMBL1338801 & 688326 & 4.4676 & 4.1805 & TRN & & \\
\hline CHEMBL1321725 & 688326 & 4.7924 & 4.8854 & TRN & & \\
\hline CHEMBL1504710 & 688326 & 5.2495 & 4.6369 & TRN & & \\
\hline CHEMBL1549067 & 688326 & 3.0 & 4.317 & TRN & & \\
\hline CHEMBL3193196 & 688326 & 4.3863 & 3.8661 & TST & & \\
\hline CHEMBL1556891 & 688326 & 4.6415 & 4.1329 & TST & & \\
\hline CHEMBL1433728 & 688326 & 4.6472 & 4.1253 & TRN & & \\
\hline CHEMBL1523417 & 688326 & 4.2177 & 3.9399 & TRN & & \\
\hline CHEMBL1342293 & 688326 & 4.8674 & 4.4585 & TRN & & \\
\hline CHEMBL1559601 & 688326 & 4.738 & 4.2258 & TRN & & \\
\hline CHEMBL1409985 & 688326 & 5.6364 & 5.0985 & TST & & \\
\hline CHEMBL1389533 & 688326 & 6.0862 & 6.5259 & TST & & \\
\hline CHEMBL3192820 & 688326 & 3.4224 & 4.0774 & TST & & \\
\hline CHEMBL3193873 & 688326 & 5.2984 & 4.8456 & TRN & & \\
\hline CHEMBL1362206 & 688326 & 3.0 & 3.9644 & TST & & \\
\hline CHEMBL1379656 & 688326 & 3.1106 & 3.9289 & TST & & \\
\hline CHEMBL1609009 & 688326 & 5.2916 & 5.4004 & TRN & & \\
\hline CHEMBL1331206 & 688326 & 4.3417 & 3.9838 & TRN & & \\
\hline CHEMBL1570159 & 688326 & 4.9034 & 4.3798 & TST & & \\
\hline CHEMBL1429042 & 688326 & 4.8136 & 4.1828 & TRN & & \\
\hline CHEMBL1338747 & 688326 & 4.9237 & 4.3884 & TRN & & \\
\hline CHEMBL1613402 & 688326 & 4.7518 & 4.4304 & TRN & & \\
\hline CHEMBL1547916 & 688326 & 4.9519 & 4.8266 & TRN & & \\
\hline CHEMBL1452379 & 688326 & 4.3446 & 4.1638 & TRN & & \\
\hline CHEMBL1489173 & 688326 & 4.9208 & 4.7621 & TRN & & \\
\hline CHEMBL1408567 & 688326 & 4.2927 & 4.2182 & TRN & & \\
\hline CHEMBL1592917 & 688326 & 5.0975 & 4.4931 & TRN & & \\
\hline CHEMBL1563257 & 688326 & 4.9658 & 5.0696 & TRN & & \\
\hline CHEMBL1472423 & 688326 & 3.1475 & 3.7843 & TRN & & \\
\hline CHEMBL478501 & 688326 & 5.58 & 5.1407 & TST & & \\
\hline CHEMBL1593516 & 688326 & 4.9527 & 4.4122 & TRN & & \\
\hline CHEMBL1462313 & 688326 & 4.9801 & 4.6306 & TRN & & \\
\hline CHEMBL1546758 & 688326 & 4.4755 & 4.1682 & TRN & & \\
\hline CHEMBL1502053 & 688326 & 4.5521 & 4.4505 & TRN & & \\
\hline
\end{tabular}




\begin{tabular}{|c|c|c|c|c|}
\hline \multicolumn{5}{|c|}{ Supplemental Tab. } \\
\hline CHEMBL1356472 & 688326 & 4.4839 & 4.0715 & TRN \\
\hline CHEMBL1342553 & 688326 & 4.3164 & 4.0357 & TRN \\
\hline CHEMBL1319750 & 688326 & 5.5436 & 4.8369 & TRN \\
\hline CHEMBL 3195226 & 688326 & 5.466 & 5.3419 & TRN \\
\hline CHEMBL1337445 & 688326 & 3.2134 & 3.9163 & TRN \\
\hline CHEMBL1524101 & 688326 & 4.6276 & 4.4263 & TST \\
\hline CHEMBL1320256 & 688326 & 4.6676 & 4.1016 & TRN \\
\hline CHEMBL1606709 & 688326 & 5.7645 & 5.1885 & TRN \\
\hline CHEMBL1566772 & 688326 & 4.3739 & 4.0532 & TRN \\
\hline CHEMBL1376350 & 688326 & 4.4504 & 4.0116 & TRN \\
\hline CHEMBL1336626 & 688326 & 3.2715 & 4.099 & TRN \\
\hline CHEMBL1457690 & 688326 & 4.712 & 4.2866 & TST \\
\hline CHEMBL1590743 & 688326 & 4.6347 & 4.265 & TRN \\
\hline CHEMBL36654 & 688326 & 5.6289 & 4.9879 & TRN \\
\hline CHEMBL1461508 & 688326 & 4.6221 & 4.3467 & TST \\
\hline CHEMBL1327172 & 688326 & 5.6615 & 5.0942 & TRN \\
\hline CHEMBL1471431 & 688326 & 4.6592 & 4.2384 & TRN \\
\hline CHEMBL1606097 & 688326 & 3.3576 & 4.2402 & TRN \\
\hline CHEMBL1586169 & 688326 & 5.064 & 4.5862 & TRN \\
\hline CHEMBL1452303 & 688326 & 5.4078 & 5.1307 & TST \\
\hline CHEMBL1406804 & 688326 & 4.6434 & 4.3857 & TRN \\
\hline CHEMBL1401660 & 688326 & 4.2001 & 4.341 & TRN \\
\hline CHEMBL1544987 & 688326 & 5.4921 & 5.1171 & TRN \\
\hline CHEMBL1497387 & 688326 & 4.3858 & 3.9882 & TRN \\
\hline CHEMBL3193118 & 688326 & 4.9735 & 4.7117 & TRN \\
\hline CHEMBL1379702 & 688326 & 3.3072 & 3.9424 & TST \\
\hline CHEMBL1563920 & 688326 & 3.6191 & 4.607 & TRN \\
\hline CHEMBL3189714 & 688326 & 4.9477 & 4.5641 & TST \\
\hline CHEMBL1337598 & 688326 & 3.0 & 3.7926 & TST \\
\hline CHEMBL1353340 & 688326 & 4.5139 & 4.127 & TRN \\
\hline CHEMBL1343853 & 688326 & 3.2063 & 4.0616 & TRN \\
\hline CHEMBL1581808 & 688326 & 4.4325 & 4.0785 & TRN \\
\hline CHEMBL1458022 & 688326 & 4.7867 & 4.7123 & TRN \\
\hline CHEMBL1431906 & 688326 & 4.5977 & 4.3118 & TRN \\
\hline CHEMBL393287 & 688326 & 4.1848 & 3.7741 & TRN \\
\hline CHEMBL1428009 & 688326 & 4.828 & 4.4135 & TRN \\
\hline CHEMBL1557139 & 688326 & 5.1192 & 4.8761 & TRN \\
\hline CHEMBL1407488 & 688326 & 4.7442 & 4.2159 & TRN \\
\hline CHEMBL1438983 & 688326 & 4.6409 & 4.2278 & TST \\
\hline CHEMBL1440761 & 688326 & 3.0433 & 4.2143 & TRN \\
\hline CHEMBL1560649 & 688326 & 3.5308 & 4.5886 & TRN \\
\hline CHEMBL1449278 & 688326 & 5.1494 & 4.4943 & TRN \\
\hline CHEMBL1305987 & 688326 & 3.3479 & 4.2006 & TRN \\
\hline CHEMBL1427106 & 688326 & 4.3452 & 4.041 & TRN \\
\hline CHEMBL1330578 & 688326 & 4.6021 & 4.025 & TRN \\
\hline CHEMBL1580790 & 688326 & 4.1921 & 4.1427 & TRN \\
\hline CHEMBL 3196253 & 688326 & 6.1249 & 5.2537 & TRN \\
\hline CHEMBL1345665 & 688326 & 4.1016 & 3.8363 & TRN \\
\hline
\end{tabular}




\begin{tabular}{|c|c|c|c|c|c|c|}
\hline \multirow{2}{*}{ CHEMBL1970707 } & \multirow{2}{*}{688326} & \\
\hline & & 5.2343 & 4.8992 & TRN & & \\
\hline CHEMBL1506397 & 688326 & 4.9618 & 4.5249 & TRN & & \\
\hline CHEMBL1338422 & 688326 & 4.7073 & 4.6349 & TRN & & \\
\hline CHEMBL1588559 & 688326 & 4.5977 & 4.4343 & TRN & & \\
\hline CHEMBL1982010 & 688326 & 3.5924 & 4.4727 & TRN & & \\
\hline CHEMBL1461370 & 688326 & 3.2101 & 4.1346 & TRN & & \\
\hline CHEMBL1534285 & 688326 & 3.1008 & \multicolumn{3}{|c|}{ 4.013999999999999 } & TRN \\
\hline CHEMBL1493761 & 688326 & \multicolumn{3}{|c|}{ 3.3539999999999996 } & 4.0899 & TRN \\
\hline CHEMBL1492849 & 688326 & 5.0511 & 4.898 & TRN & & \\
\hline CHEMBL1602160 & 688326 & 5.5421 & 5.2084 & TST & & \\
\hline CHEMBL1313206 & 688326 & 5.5751 & 6.885 & TRN & & \\
\hline CHEMBL1581146 & 688326 & 3.0 & 3.6909 & TRN & & \\
\hline CHEMBL1491019 & 688326 & 4.7768 & 4.428 & TRN & & \\
\hline CHEMBL1489358 & 688326 & 3.4638 & 4.3477 & TRN & & \\
\hline CHEMBL1428897 & 688326 & 4.7029 & 4.4141 & TRN & & \\
\hline CHEMBL1551631 & 688326 & 5.0878 & 4.9425 & TST & & \\
\hline CHEMBL1602754 & 688326 & 3.7357 & 4.3559 & TRN & & \\
\hline CHEMBL1427476 & 688326 & 5.8794 & 5.4429 & TRN & & \\
\hline CHEMBL1552867 & 688326 & 4.1807 & 3.9751 & TRN & & \\
\hline CHEMBL1464421 & 688326 & 4.3931 & 4.0169 & TRN & & \\
\hline CHEMBL1559881 & 688326 & 3.1172 & 3.992 & TRN & & \\
\hline CHEMBL1445200 & 688326 & 4.1163 & 4.8716 & TRN & & \\
\hline CHEMBL1584684 & 688326 & 3.0949 & 3.8375 & TRN & & \\
\hline CHEMBL1343565 & 688326 & 3.2415 & 4.3009 & TRN & & \\
\hline CHEMBL1973332 & 688326 & 4.3547 & 4.0029 & TRN & & \\
\hline CHEMBL1307515 & 688326 & 4.3279 & 4.6671 & TRN & & \\
\hline CHEMBL1460249 & 688326 & 5.0752 & 4.8192 & TRN & & \\
\hline CHEMBL1381804 & 688326 & 4.4585 & 3.9947 & TRN & & \\
\hline CHEMBL1409511 & 688326 & 4.6578 & 4.4308 & TRN & & \\
\hline CHEMBL1587160 & 688326 & 4.6379 & 4.2646 & TRN & & \\
\hline CHEMBL1521502 & 688326 & 4.4901 & 4.8658 & TRN & & \\
\hline CHEMBL1308461 & 688326 & 4.6465 & 4.093 & TRN & & \\
\hline CHEMBL1582091 & 688326 & 4.6503 & 4.4139 & TRN & & \\
\hline CHEMBL1420009 & 688326 & 5.7825 & 5.3882 & TRN & & \\
\hline CHEMBL1981797 & 688326 & 5.3686 & 5.1403 & TRN & & \\
\hline CHEMBL1560105 & 688326 & 3.3586 & 4.0834 & TRN & & \\
\hline CHEMBL1605435 & 688326 & 4.5491 & 4.2963 & TRN & & \\
\hline CHEMBL1564523 & 688326 & 4.6605 & 4.1111 & TRN & & \\
\hline CHEMBL1391463 & 688326 & 4.6315 & 4.3626 & TRN & & \\
\hline CHEMBL1388722 & 688326 & 4.6688 & 4.3997 & TRN & & \\
\hline CHEMBL3145205 & 688326 & 3.4047 & 4.6581 & TRN & & \\
\hline CHEMBL1379181 & 688326 & 3.8697 & 5.143 & TRN & & \\
\hline CHEMBL1452546 & 688326 & 4.4437 & 3.8451 & TST & & \\
\hline CHEMBL1348933 & 688326 & 3.4413 & 4.1096 & TRN & & \\
\hline CHEMBL1300700 & 688326 & 4.7062 & 4.2616 & TRN & & \\
\hline CHEMBL1570920 & 688326 & 4.1676 & 4.1763 & TRN & & \\
\hline CHEMBL1309280 & 688326 & 4.78600 & 30000000 & 205 & 4.4599 & TRN \\
\hline CHEMBL27811 & 688326 & 4.2477 & 4.0166 & TRN & & \\
\hline
\end{tabular}


Supplemental Table S2.txt

\begin{tabular}{|c|c|c|c|c|c|}
\hline CHEMBL1357228 & 688326 & 4.3955 & 4.2803 & TST & \\
\hline CHEMBL1543733 & 688326 & 4.7854 & 4.3249 & TRN & \\
\hline CHEMBL1586416 & 688326 & 5.6882 & 5.0934 & TRN & \\
\hline CHEMBL11475 & 688326 & 5.2487 & 4.602 & TST & \\
\hline CHEMBL1522544 & 688326 & 4.7595 & 4.3008 & TRN & \\
\hline CHEMBL1301368 & 688326 & 3.217 & 4.1571 & TRN & \\
\hline CHEMBL1311416 & 688326 & 4.6801 & 5.3261 & TRN & \\
\hline CHEMBL1585327 & 688326 & 3.3887 & 4.23600 & 0000000001 & TRN \\
\hline CHEMBL90181 & 688326 & 4.9281 & 4.4078 & TST & \\
\hline CHEMBL1600649 & 688326 & 4.5114 & 4.20100 & 00000000005 & TST \\
\hline CHEMBL1405220 & 688326 & 4.7474 & 4.5221 & TRN & \\
\hline CHEMBL1513242 & 688326 & 4.4014 & 4.1617 & TRN & \\
\hline CHEMBL1385701 & 688326 & 4.7635 & 4.1702 & TRN & \\
\hline CHEMBL1422381 & 688326 & 3.029 & 4.8414 & TRN & \\
\hline CHEMBL1394557 & 688326 & 4.5967 & 4.1163 & TRN & \\
\hline CHEMBL1389671 & 688326 & 5.0168 & 4.6637 & TST & \\
\hline CHEMBL1316573 & 688326 & 4.6912 & 4.2216 & TRN & \\
\hline CHEMBL 203108 & 688326 & 3.5525 & 4.607 & TRN & \\
\hline CHEMBL461579 & 688326 & 5.9469 & 5.2467 & TST & \\
\hline CHEMBL1478222 & 688326 & 4.6507 & 4.2128 & TRN & \\
\hline CHEMBL1352373 & 688326 & 3.7416 & 4.6031 & TRN & \\
\hline CHEMBL1347156 & 688326 & 4.6472 & 4.2438 & TRN & \\
\hline CHEMBL1325258 & 688326 & 4.4127 & 4.1587 & TRN & \\
\hline CHEMBL1533651 & 688326 & 4.5375 & 4.2472 & TRN & \\
\hline CHEMBL1300956 & 688326 & 4.8765 & 4.5726 & TRN & \\
\hline CHEMBL1390546 & 688326 & 4.4332 & 4.1655 & TRN & \\
\hline CHEMBL 2002849 & 688326 & 4.6552 & 4.1526 & TRN & \\
\hline CHEMBL1497052 & 688326 & 4.6842 & 4.5826 & TRN & \\
\hline CHEMBL1403980 & 688326 & 4.7799 & 5.0349 & TRN & \\
\hline CHEMBL599943 & 688326 & 4.6211 & 4.2371 & TRN & \\
\hline CHEMBL3198950 & 688326 & 3.0 & 3.8823 & TRN & \\
\hline CHEMBL1966865 & 688326 & 4.0665 & 6.6341 & TRN & \\
\hline CHEMBL1548703 & 688326 & 4.7788 & 4.4761 & TRN & \\
\hline CHEMBL1340965 & 688326 & 4.6417 & 4.1585 & TST & \\
\hline CHEMBL1521164 & 688326 & 4.0767 & \multicolumn{2}{|c|}{4.178999999999999} & TRN \\
\hline CHEMBL1516976 & 688326 & 4.727 & 4.1604 & TRN & \\
\hline CHEMBL1584595 & 688326 & 5.0022 & 4.8068 & TRN & \\
\hline CHEMBL3209974 & 688326 & 4.0593 & 3.8507 & TRN & \\
\hline CHEMBL1455662 & 688326 & 3.657 & 4.5049 & TRN & \\
\hline CHEMBL1390784 & 688326 & 4.353 & 4.2326 & TRN & \\
\hline CHEMBL1573166 & 688326 & 3.6243 & 4.3575 & TRN & \\
\hline CHEMBL 2000807 & 688326 & 4.3781 & 4.0474 & TRN & \\
\hline CHEMBL1449173 & 688326 & 4.5031 & 4.6301 & TRN & \\
\hline CHEMBL1571658 & 688326 & 4.6824 & 4.255 & TRN & \\
\hline CHEMBL1560530 & 688326 & 4.9508 & 4.3922 & TRN & \\
\hline CHEMBL1457570 & 688326 & 4.8928 & 4.7358 & TRN & \\
\hline CHEMBL1571378 & 688326 & 3.687 & 4.6476 & TRN & \\
\hline CHEMBL1430667 & 688326 & 3.3639 & 3.9926 & TRN & \\
\hline
\end{tabular}

Page 11176 


\begin{tabular}{|c|c|c|c|c|c|c|}
\hline & & & pplement & al Tabl & S2.txt & \\
\hline CHEMBL1429838 & 688326 & 3.0634 & 3.9549 & TRN & & \\
\hline CHEMBL3198095 & 688326 & 3.3158 & 4.0449 & TRN & & \\
\hline CHEMBL3192324 & 688326 & 4.5964 & 4.30699 & 99999999 & 995 & TST \\
\hline CHEMBL1493982 & 688326 & 4.6192 & 4.1644 & TRN & & \\
\hline CHEMBL1434649 & 688326 & 4.3983 & 4.0587 & TRN & & \\
\hline CHEMBL1450957 & 688326 & 4.5281 & 4.2995 & TRN & & \\
\hline CHEMBL3193291 & 688326 & 4.5213 & 4.1188 & TRN & & \\
\hline CHEMBL1999908 & 688326 & 3.0 & 3.8642 & TRN & & \\
\hline CHEMBL1556750 & 688326 & 5.8794 & 5.6448 & TRN & & \\
\hline CHEMBL1409148 & 688326 & 4.4076 & 4.2106 & TST & & \\
\hline CHEMBL 2094456 & 688326 & 4.203 & 3.9843 & TRN & & \\
\hline CHEMBL1969867 & 688326 & 4.6438 & 4.3865 & TRN & & \\
\hline CHEMBL1530087 & 688326 & 4.6472 & 4.3418 & TRN & & \\
\hline CHEMBL1565391 & 688326 & 4.1726 & 3.8408 & TRN & & \\
\hline CHEMBL1375045 & 688326 & 4.44300 & 00000000 & 005 & 4.1287 & TRN \\
\hline CHEMBL1445640 & 688326 & 4.3594 & 4.086 & TRN & & \\
\hline CHEMBL1495058 & 688326 & 3.0 & 3.8989 & TRN & & \\
\hline CHEMBL1383937 & 688326 & 4.63899 & 99999999 & 99 & 4.4726 & TRN \\
\hline CHEMBL1418496 & 688326 & 3.0 & 3.8458 & TRN & & \\
\hline CHEMBL1351922 & 688326 & 3.3839 & 4.0006 & TST & & \\
\hline CHEMBL1342388 & 688326 & 4.98300 & 00000000 & 005 & 4.6372 & TST \\
\hline CHEMBL1331851 & 688326 & 4.1275 & 4.2995 & TRN & & \\
\hline CHEMBL1538399 & 688326 & 4.5781 & 4.1258 & TRN & & \\
\hline CHEMBL1993662 & 688326 & 4.2092 & 3.9864 & TRN & & \\
\hline CHEMBL1548295 & 688326 & 4.6494 & 4.5745 & TRN & & \\
\hline CHEMBL1561043 & 688326 & 4.328 & 3.9665 & TRN & & \\
\hline CHEMBL3211304 & 688326 & 5.1911 & 5.0365 & TST & & \\
\hline CHEMBL1527803 & 688326 & 4.3701 & 4.1079 & TRN & & \\
\hline CHEMBL1407137 & 688326 & 3.0003 & 3.7954 & TRN & & \\
\hline CHEMBL3191867 & 688326 & 5.2255 & 4.5947 & TRN & & \\
\hline CHEMBL1439088 & 688326 & 4.1186 & 3.9681 & TRN & & \\
\hline CHEMBL1323880 & 688326 & 4.6068 & 4.2673 & TRN & & \\
\hline CHEMBL233896 & 688326 & 4.71899 & 99999999 & 99 & 4.4135 & TRN \\
\hline CHEMBL1479780 & 688326 & 4.3823 & 3.9405 & TRN & & \\
\hline CHEMBL1545480 & 688326 & 5.58 & 5.4204 & TRN & & \\
\hline CHEMBL1460452 & 688326 & 3.0782 & 3.8237 & TRN & & \\
\hline CHEMBL1526649 & 688326 & 3.1862 & 4.2259 & TRN & & \\
\hline CHEMBL1487609 & 688326 & 4.4577 & 3.9706 & TRN & & \\
\hline CHEMBL1519146 & 688326 & 5.2168 & 4.8535 & TRN & & \\
\hline CHEMBL1592562 & 688326 & 4.4298 & 4.1812 & TRN & & \\
\hline CHEMBL1459696 & 688326 & 4.3529 & 3.9564 & TRN & & \\
\hline CHEMBL1585923 & 688326 & 4.6463 & 4.2673 & TRN & & \\
\hline CHEMBL1399232 & 688326 & 4.5984 & 4.0542 & TRN & & \\
\hline CHEMBL1509860 & 688326 & 3.0263 & 3.9423 & TRN & & \\
\hline CHEMBL1355039 & 688326 & 4.1672 & 4.003 & TRN & & \\
\hline CHEMBL1970527 & 688326 & 3.2725 & 4.2523 & TRN & & \\
\hline CHEMBL1559358 & 688326 & 5.567 & 5.0538 & TRN & & \\
\hline CHEMBL1378118 & 688326 & 4.7249 & 4.5434 & TRN & & \\
\hline
\end{tabular}




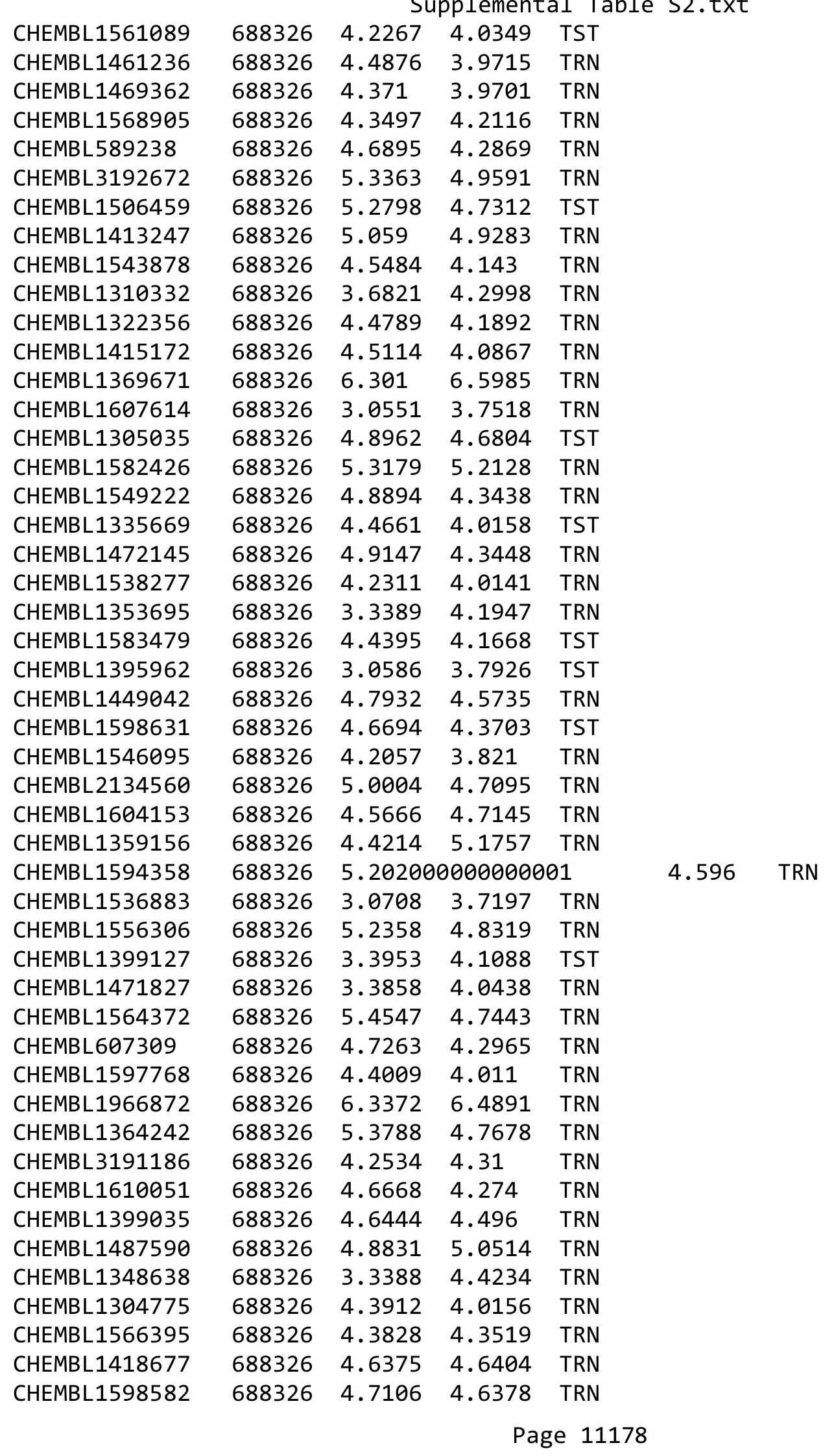




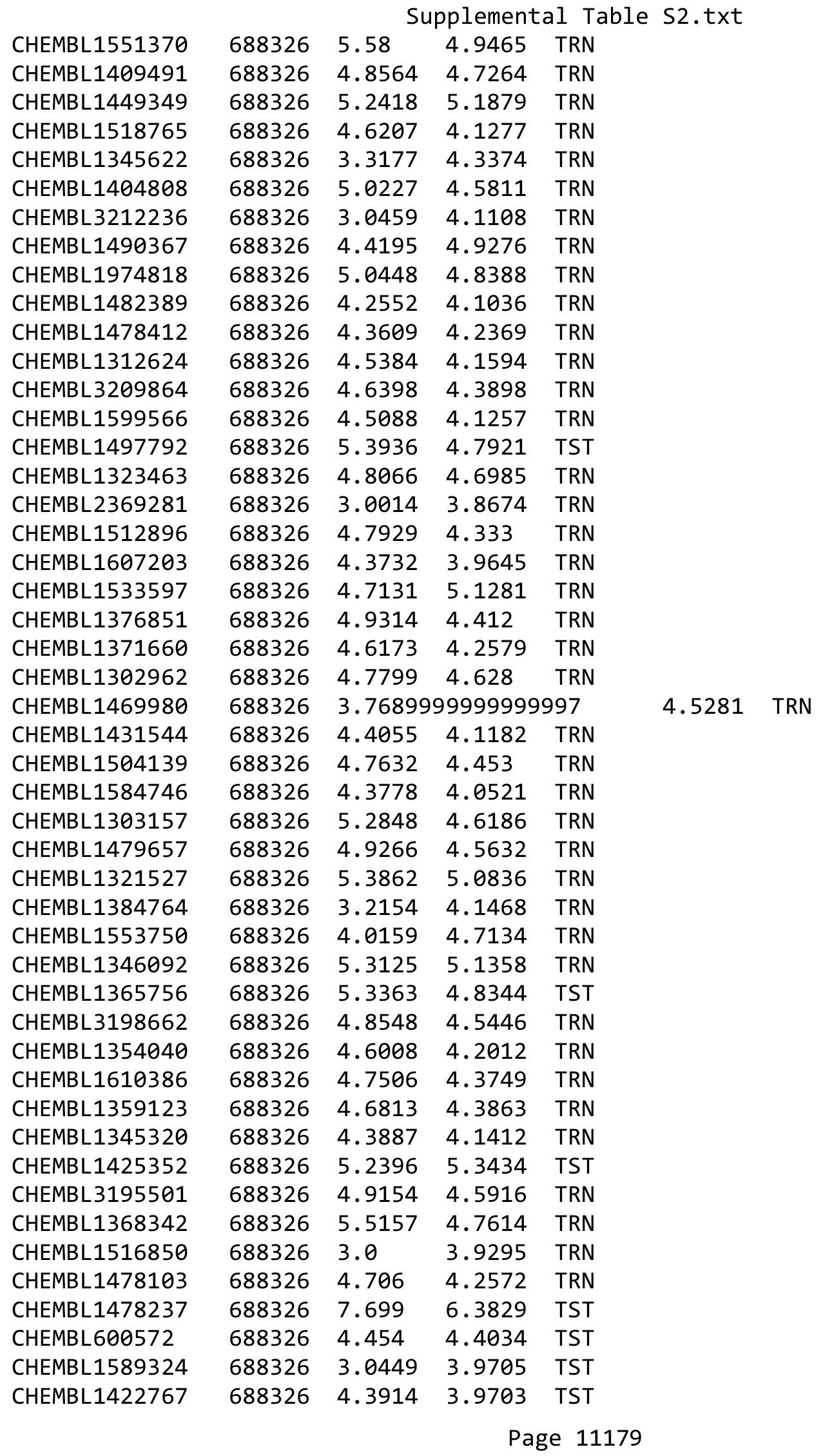


Supplemental Table S2.txt

\begin{tabular}{|c|c|c|c|c|}
\hline CHEMBL1501964 & 688326 & 3.2374 & 3.8001 & TST \\
\hline CHEMBL1560784 & 688326 & 4.7484 & 4.3312 & TST \\
\hline CHEMBL1300181 & 688326 & 4.0259 & 4.44600 & \\
\hline CHEMBL1428714 & 688326 & 4.9126 & 4.3419 & TST \\
\hline CHEMBL1490887 & 688326 & 4.745 & 4.197 & TST \\
\hline CHEMBL1595536 & 688326 & 3.5931 & 4.5415 & TST \\
\hline CHEMBL1355437 & 688326 & 4.7147 & 4.1717 & TST \\
\hline CHEMBL1358375 & 688326 & 4.8788 & 4.3898 & TST \\
\hline CHEMBL1348830 & 688326 & 4.2538 & 3.8912 & TST \\
\hline CHEMBL1304134 & 688326 & 5.0155 & 4.7062 & TST \\
\hline CHEMBL1375731 & 688326 & 4.8626 & 6.691 & TST \\
\hline CHEMBL1299470 & 688326 & 4.6005 & 4.1241 & TST \\
\hline CHEMBL1505727 & 688326 & 4.8027 & 4.8848 & TST \\
\hline CHEMBL1531820 & 688326 & 4.6402 & 4.1959 & TST \\
\hline CHEMBL1510905 & 688326 & 5.5452 & 4.8803 & TST \\
\hline CHEMBL1552626 & 688326 & 5.4522 & 5.1726 & TST \\
\hline CHEMBL1431303 & 688326 & 3.5995 & 4.5053 & TST \\
\hline CHEMBL3210529 & 688326 & 4.2377 & 4.0108 & TST \\
\hline CHEMBL1371353 & 688326 & 4.9535 & 5.0298 & TST \\
\hline CHEMBL1326813 & 688326 & 5.1469 & 4.6305 & TST \\
\hline CHEMBL1420417 & 688326 & 4.5394 & 4.0205 & TST \\
\hline CHEMBL1451716 & 688326 & 5.2411 & 6.3645 & TST \\
\hline CHEMBL1537065 & 688326 & 4.6627 & 3.9747 & TST \\
\hline CHEMBL1605956 & 688326 & 6.699 & 6.4494 & TST \\
\hline CHEMBL1420466 & 688326 & 4.694 & 4.5888 & TST \\
\hline CHEMBL1412150 & 688326 & 5.699 & 6.4723 & TST \\
\hline CHEMBL1454334 & 688326 & 4.6202 & 4.1004 & TST \\
\hline CHEMBL1383015 & 688326 & 4.622 & 4.1856 & TST \\
\hline CHEMBL1371841 & 688326 & 4.6615 & 4.1826 & TST \\
\hline CHEMBL1485010 & 688326 & 5.5376 & 5.2581 & TST \\
\hline CHEMBL1391530 & 688326 & 3.4195 & 4.2037 & TST \\
\hline CHEMBL1492922 & 688326 & 3.5847 & 4.5898 & TST \\
\hline CHEMBL1584696 & 688326 & 4.9555 & 4.6085 & TST \\
\hline CHEMBL1484537 & 688326 & 4.5542 & 4.309 & TST \\
\hline CHEMBL1548086 & 688326 & 5.0953 & 4.5398 & TST \\
\hline CHEMBL1517264 & 688326 & 3.1696 & 4.1233 & TST \\
\hline CHEMBL1438956 & 688326 & 4.655 & 4.4203 & TST \\
\hline CHEMBL213896 & 688326 & 4.688 & 4.5602 & TST \\
\hline CHEMBL1427147 & 688326 & 3.9322 & 5.003 & TST \\
\hline CHEMBL3183714 & 688326 & 4.6643 & 4.2079 & TST \\
\hline CHEMBL1322886 & 688326 & 4.7349 & 4.7526 & TST \\
\hline CHEMBL1353891 & 688326 & 5.1824 & 4.7452 & TST \\
\hline CHEMBL1319018 & 688326 & 4.4573 & 4.1241 & TST \\
\hline CHEMBL1570557 & 688326 & 4.7258 & 6.5229 & TST \\
\hline CHEMBL1421862 & 688326 & 4.6203 & 4.2675 & TST \\
\hline CHEMBL1463015 & 688326 & 5.3325 & 4.9208 & TST \\
\hline CHEMBL1403774 & 688326 & 5.1367 & 4.5502 & TST \\
\hline CHEMBL1302100 & 688326 & 4.5164 & 4.2359 & TST \\
\hline
\end{tabular}




\begin{tabular}{|c|c|c|c|c|}
\hline \multicolumn{5}{|c|}{ Supplemental Table s2.txt } \\
\hline CHEMBL1331670 & 688326 & 4.3532 & 4.1546 & TST \\
\hline CHEMBL1465113 & 688326 & 4.3604 & 3.9823 & TST \\
\hline CHEMBL1431850 & 688326 & 3.1894 & 4.0643 & TST \\
\hline CHEMBL1376992 & 688326 & 3.0 & 3.801 & TST \\
\hline CHEMBL1381113 & 688326 & 4.794 & 4.5026 & TST \\
\hline CHEMBL1405092 & 688326 & 4.7235 & 4.2986 & TST \\
\hline CHEMBL1413395 & 688326 & 4.4835 & 4.1653 & TST \\
\hline CHEMBL1508058 & 688326 & 4.4913 & 4.3095 & TST \\
\hline CHEMBL1456111 & 688326 & 4.6488 & 4.6373 & TST \\
\hline CHEMBL1079460 & 688326 & 4.95 & 4.3779 & TST \\
\hline CHEMBL1307483 & 688326 & 3.096 & 4.2987 & TST \\
\hline CHEMBL3144979 & 688326 & 4.7373 & 4.7454 & TST \\
\hline CHEMBL1385593 & 688326 & 4.4514 & 4.0211 & TST \\
\hline CHEMBL1609437 & 688326 & 4.6284 & 4.1931 & TST \\
\hline CHEMBL1567159 & 688326 & 4.1284 & 4.2925 & TST \\
\hline CHEMBL1318742 & 688326 & 5.1599 & 4.907 & TST \\
\hline CHEMBL1335492 & 688326 & 3.0952 & 4.3696 & TST \\
\hline CHEMBL1586285 & 688326 & 4.9512 & 4.2872 & TST \\
\hline CHEMBL1978069 & 688326 & 4.7989 & 4.3228 & TST \\
\hline CHEMBL1340776 & 688326 & 3.301 & 5.4174 & TST \\
\hline CHEMBL1365183 & 688326 & 4.6386 & 4.2636 & TST \\
\hline CHEMBL1449706 & 688326 & 5.251 & 4.8438 & TST \\
\hline CHEMBL530682 & 688326 & 5.1733 & 4.9353 & TST \\
\hline CHEMBL 259388 & 688326 & 4.4455 & 3.9405 & TST \\
\hline CHEMBL1470728 & 688326 & 5.0044 & 4.5328 & TST \\
\hline CHEMBL1485601 & 688326 & 4.7632 & 4.5287 & TST \\
\hline CHEMBL3196221 & 688326 & 3.6319 & 4.4253 & TST \\
\hline CHEMBL1390496 & 688326 & 4.6417 & 4.4294 & TST \\
\hline CHEMBL 3199272 & 688326 & 4.9458 & 4.8849 & TST \\
\hline CHEMBL 1256740 & 688326 & 4.5624 & 4.1238 & TST \\
\hline CHEMBL1503586 & 688326 & 4.6562 & 4.4103 & TST \\
\hline CHEMBL1567119 & 688326 & 3.0328 & 3.8988 & TST \\
\hline CHEMBL388959 & 688326 & 4.3384 & 4.2855 & TST \\
\hline CHEMBL1359688 & 688326 & 5.9872 & 5.4062 & TST \\
\hline CHEMBL580918 & 688326 & 4.6455 & 4.1638 & TST \\
\hline CHEMBL1476094 & 688326 & 4.6103 & 4.164 & TST \\
\hline CHEMBL410063 & 688326 & 3.3124 & 3.9963 & TST \\
\hline CHEMBL1542076 & 688326 & 4.3906 & 4.0469 & TST \\
\hline CHEMBL1299328 & 688326 & 5.0857 & 4.8362 & TST \\
\hline CHEMBL1383025 & 688326 & 4.9278 & 4.7269 & TST \\
\hline CHEMBL590949 & 688326 & 4.7652 & 4.2411 & TST \\
\hline CHEMBL1327387 & 688326 & 5.2644 & 4.8775 & TST \\
\hline CHEMBL1537171 & 688326 & 3.0 & 3.8107 & TST \\
\hline CHEMBL3195813 & 688326 & 5.0119 & 4.3993 & TST \\
\hline CHEMBL1480783 & 688326 & 5.065 & 5.6139 & TST \\
\hline CHEMBL 2007227 & 688326 & 3.0326 & 4.3583 & TST \\
\hline CHEMBL1430757 & 688326 & 4.9654 & 4.5122 & TST \\
\hline CHEMBL1490037 & 688326 & 4.0599 & 3.8811 & TST \\
\hline
\end{tabular}


Supplemental Table S2.txt

\begin{tabular}{|c|c|c|c|c|}
\hline HEM & & 033 & & 15 \\
\hline & & 7324 & 4.7951 & \\
\hline AEMRI 12 & & & & \\
\hline IEMBL1996343 & 8326 & & & \\
\hline HEMBL1508591 & 88326 & 2968 & 2168 & \\
\hline HEMBL1313500 & 88326 & .1632 & 582 & \\
\hline HEMBL152 & & & & \\
\hline HEMBL143 & & & & \\
\hline HEMBL1312788 & 88326 & 3625 & 9665 & \\
\hline HEMBL142€ & 88326 & 91 & 913 & \\
\hline HEMBL155 & & & 1826 & \\
\hline AEMBL1 & & & & \\
\hline AEMBL2 & & & & \\
\hline HEMBL1472513 & 8326 & 5253 & 3255 & \\
\hline HEMBL137C & & & & \\
\hline HEMBL1: & & & & \\
\hline HEMBL1 & & & & \\
\hline HEMBL1: & & & & \\
\hline HFMBI 56 & & 44 & & \\
\hline AEMBL133 & & 22 & 777 & \\
\hline HEMBL1 & & & 53 & SI \\
\hline HEMBL & & & & \\
\hline HEMBL1 & & & & \\
\hline HEMBL 52 & & & & \\
\hline AEMBL31C & & & & ISI \\
\hline HEMBL4 & & & & ST \\
\hline HFMBI 1 & & & & \\
\hline 1 & & & & \\
\hline HEMBL14 & & & & \\
\hline HEMBL133 & & & & TST \\
\hline HEMBL1C & & & & ST \\
\hline HEM & & & & \\
\hline 9 & & & & \\
\hline HEMBL14 & & & & IST \\
\hline HEMBL1336 & & & & IST \\
\hline AEMR 1 & & 2 & & \\
\hline 10 & & & & \\
\hline HEMBL16 & & & & - \\
\hline HEMBL14 & & & & $\Gamma S$ \\
\hline TIL & & & & TST \\
\hline HEMBL3: & & & & \\
\hline & & & & ST \\
\hline HEMBL153 & & & 3331 & TS \\
\hline HEMBL13 & & & & TS \\
\hline CHFMRI 131 & & & & \\
\hline HEMBL132 & & & & \\
\hline CHEMBL153 & & & 5433 & \\
\hline IHEMBL 289277 & 688326 & 3.0509 & 3.7044 & \\
\hline
\end{tabular}

Page 11182 
Supplemental Table S2.txt

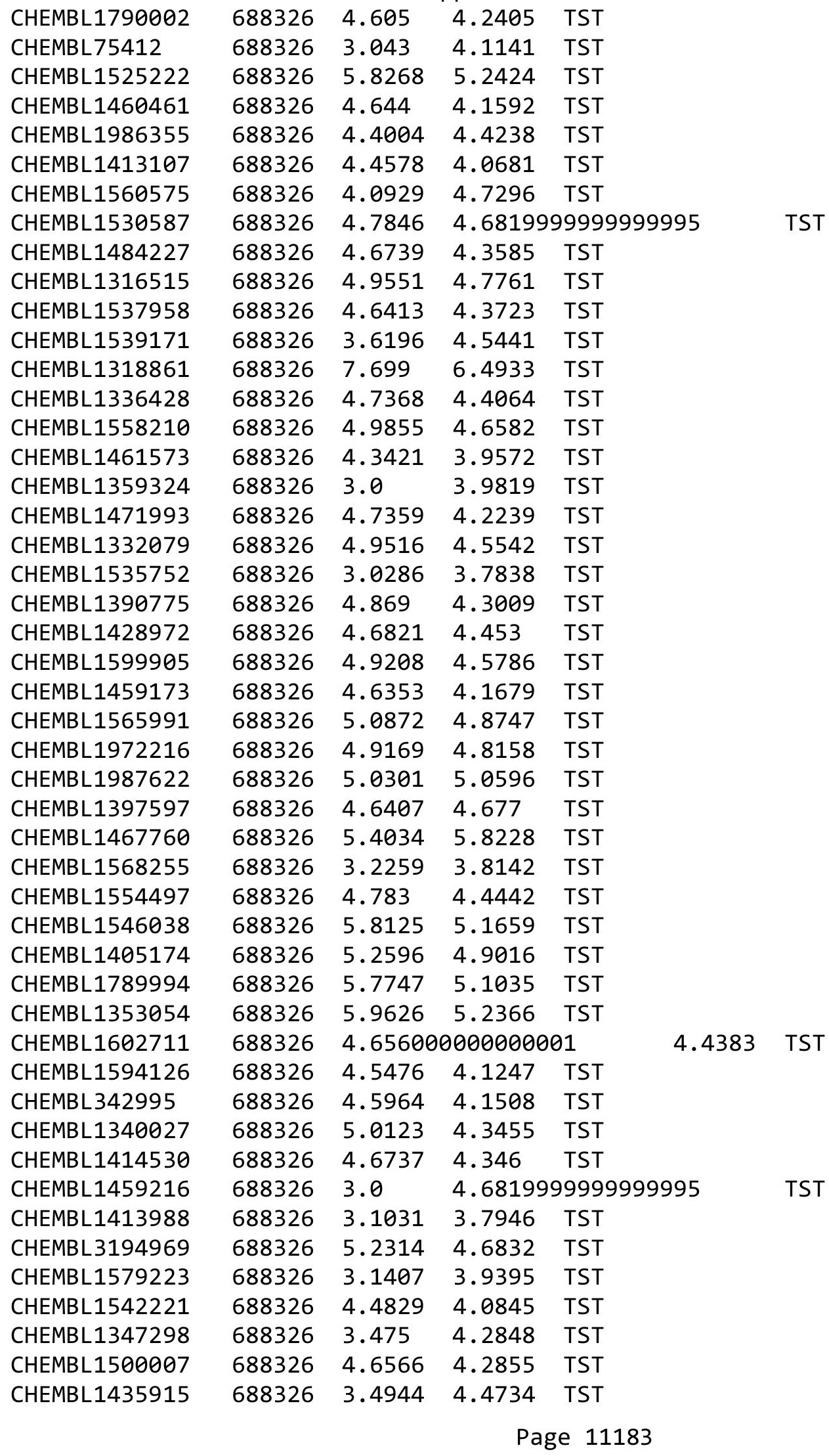




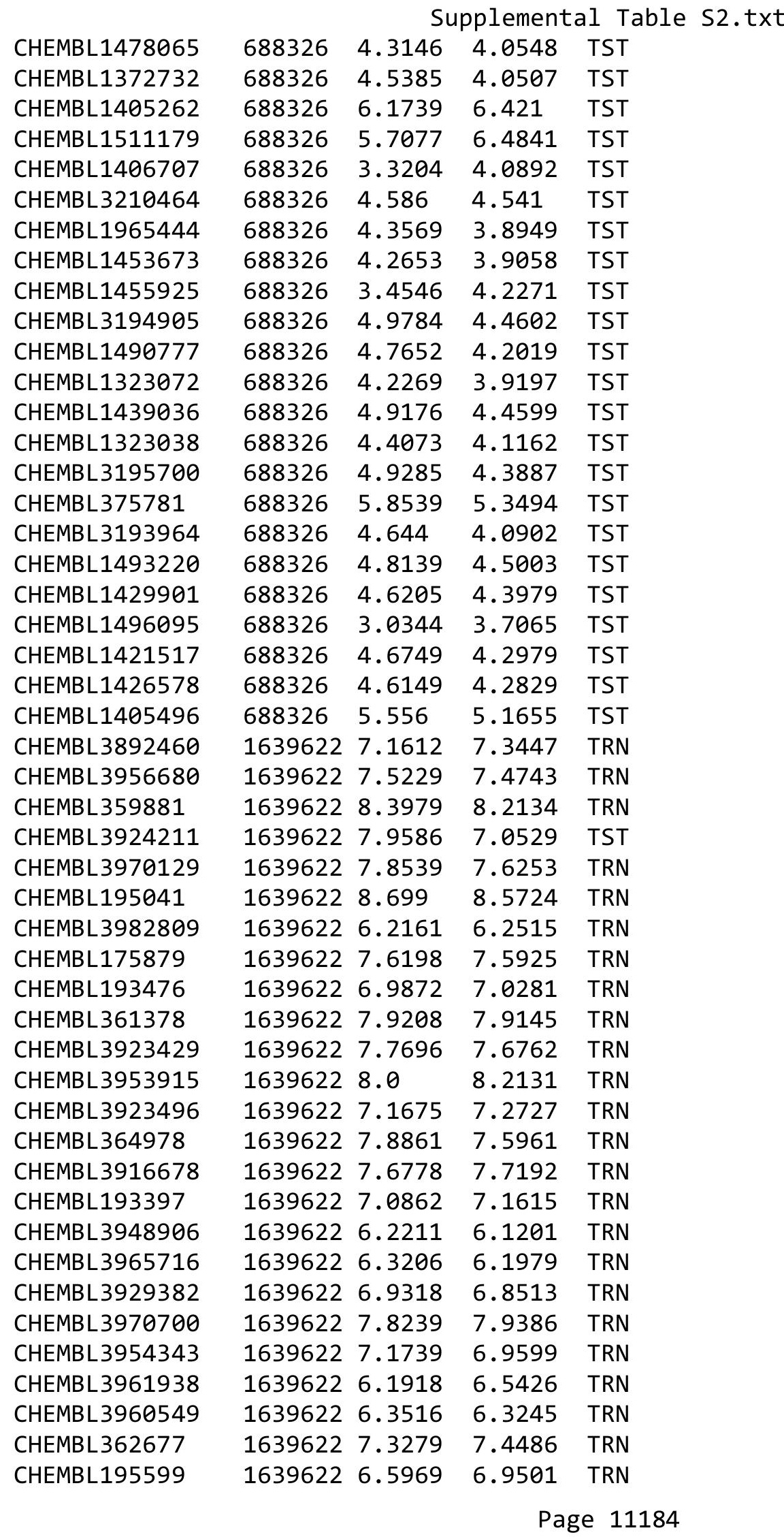


Supplemental Table S2.txt

\begin{tabular}{|c|c|c|c|c|c|}
\hline CHEMBL363339 & 1639622 & 7.3372 & 7.3348 & TRN & \\
\hline CHEMBL3933192 & 1639622 & 7.8239 & 7.9553 & TRN & \\
\hline CHEMBL3964555 & 1639622 & 7.7212 & 7.6481 & TRN & \\
\hline CHEMBL175472 & 1639622 & 8.0 & 8.2606 & TRN & \\
\hline CHEMBL3889622 & 1639622 & 7.5086 & 7.584 & TRN & \\
\hline CHEMBL195846 & 1639622 & 8.0 & 7.9339 & TRN & \\
\hline CHEMBL179267 & 1639622 & 7.5086 & 7.7086 & TRN & \\
\hline CHEMBL3929268 & 1639622 & 7.4685 & \multicolumn{2}{|c|}{7.361000000000001} & TRN \\
\hline CHEMBL3961387 & 1639622 & 6.71899 & Э9999999 & 6.7252 & TRN \\
\hline CHEMBL3951780 & 1639622 & 7.5528 & 7.4809 & TRN & \\
\hline CHEMBL381436 & 1639622 & 6.1457 & 6.1334 & TRN & \\
\hline CHEMBL195678 & 1639622 & 6.0862 & 6.0418 & TRN & \\
\hline CHEMBL3909679 & 1639622 & 8.2218 & 8.302 & TRN & \\
\hline CHEMBL369254 & 1639622 & 7.9208 & 7.8012 & TRN & \\
\hline CHEMBL3894138 & 1639622 & 7.8539 & 7.7734 & TRN & \\
\hline CHEMBL3956375 & 1639622 & 6.5686 & 6.2228 & TRN & \\
\hline CHEMBL3958697 & 1639622 & 8.3979 & 8.4698 & TRN & \\
\hline CHEMBL195598 & 1639622 & 6.1681 & 6.0792 & TRN & \\
\hline CHEMBL193394 & 1639622 & 6.3872 & 6.3195 & TRN & \\
\hline CHEMBL3952374 & 1639622 & 7.4815 & 8.7439 & TST & \\
\hline CHEMBL3971843 & 1639622 & 7.7959 & 7.8066 & TRN & \\
\hline CHEMBL3949385 & 1639622 & 6.6799 & 6.7466 & TRN & \\
\hline CHEMBL3906161 & 1639622 & 6.9666 & 6.9544 & TRN & \\
\hline CHEMBL3980237 & 1639622 & 6.4584 & 6.7823 & TRN & \\
\hline CHEMBL3932401 & 1639622 & 6.1986 & 6.2947 & TRN & \\
\hline CHEMBL3979896 & 1639622 & 6.0477 & 5.9936 & TRN & \\
\hline CHEMBL3894750 & 1639622 & 7.8539 & 7.7097 & TRN & \\
\hline CHEMBL179717 & 1639622 & 8.5229 & 8.5325 & TRN & \\
\hline CHEMBL3923712 & 1639622 & 7.5376 & 7.6 & TRN & \\
\hline CHEMBL178972 & 1639622 & 7.7696 & 7.7954 & TRN & \\
\hline CHEMBL3982788 & 1639622 & 7.1427 & 6.07799 & 9999999999 & TST \\
\hline CHEMBL176015 & 1639622 & 6.5391 & 7.6406 & TST & \\
\hline CHEMBL3897490 & 1639622 & 6.7878 & 6.8804 & TRN & \\
\hline CHEMBL3924947 & 1639622 & 7.4559 & 8.3369 & TST & \\
\hline CHEMBL179583 & 1639622 & 7.7959 & 7.6477 & TRN & \\
\hline CHEMBL3909532 & 1639622 & 8.0 & 7.9711 & TRN & \\
\hline CHEMBL3904466 & 1639622 & 7.7959 & 7.8309 & TRN & \\
\hline CHEMBL206609 & 1639622 & 7.1135 & 7.6877 & TST & \\
\hline CHEMBL3906984 & 1639622 & 7.7447 & 7.8322 & TRN & \\
\hline CHEMBL3904289 & 1639622 & 6.4547 & 6.6762 & TRN & \\
\hline CHEMBL3942502 & 1639622 & 7.8539 & 7.864 & TRN & \\
\hline CHEMBL362255 & 1639622 & 7.9208 & 8.0104 & TRN & \\
\hline CHEMBL3894962 & 1639622 & 8.3979 & 8.2547 & TRN & \\
\hline CHEMBL3956950 & 1639622 & 7.585 & 7.5603 & TRN & \\
\hline CHEMBL 367390 & 1639622 & 6.0737 & 6.2223 & TRN & \\
\hline CHEMBL3961522 & 1639622 & 6.1858 & 6.2081 & TRN & \\
\hline CHEMBL3981163 & 1639622 & 7.3372 & 7.1819 & TRN & \\
\hline CHEMBL3921179 & 1639622 & 7.1487 & 7.421 & TRN & \\
\hline
\end{tabular}


Supplemental Table S2.txt

\begin{tabular}{|c|c|c|c|c|c|}
\hline CHEMBL3932142 & 1639622 & 6.8327 & 6.7581 & TRN & \\
\hline CHEMBL3921492 & 1639622 & 6.8327 & 6.8235 & TRN & \\
\hline CHEMBL208463 & 1639622 & 6.8761 & 6.7566 & TRN & \\
\hline CHEMBL3893157 & 1639622 & 7.3872 & 8.7492 & TST & \\
\hline CHEMBL195177 & 1639622 & 8.5229 & 8.3669 & TRN & \\
\hline CHEMBL3949750 & 1639622 & 7.3372 & 8.0397 & TST & \\
\hline CHEMBL3931376 & 1639622 & 8.2218 & 8.2304 & TRN & \\
\hline CHEMBL3942083 & 1639622 & 7.3372 & 7.2524 & TRN & \\
\hline CHEMBL175553 & 1639622 & 8.301 & 8.3107 & TRN & \\
\hline CHEMBL3942698 & 1639622 & 8.0458 & 7.8749 & TRN & \\
\hline CHEMBL3918849 & 1639622 & 7.2596 & 8.1448 & TST & \\
\hline CHEMBL3912368 & 1639622 & 5.8239 & 8.6503 & TST & \\
\hline CHEMBL3897063 & 1639622 & 7.2757 & 7.1977 & TRN & \\
\hline CHEMBL3961695 & 1639622 & 6.5591 & 6.5408 & TRN & \\
\hline CHEMBL3919738 & 1639622 & 7.8861 & 7.1578 & TST & \\
\hline CHEMBL3956891 & 1639622 & 8.301 & 7.5807 & TST & \\
\hline CHEMBL3924197 & 1639622 & 6.5575 & 7.2763 & TST & \\
\hline CHEMBL3923907 & 1639622 & 7.1675 & 7.0886 & TST & \\
\hline CHEMBL3973311 & 1639622 & 6.3883 & 7.6738 & TST & \\
\hline CHEMBL191969 & 1639622 & 8.1549 & 8.0017 & TST & \\
\hline CHEMBL193990 & 1639622 & 8.1549 & 7.53 & TST & \\
\hline CHEMBL3917001 & 1639622 & 8.301 & 7.5893 & TST & \\
\hline CHEMBL3971136 & 1639622 & 7.2218 & 7.2091 & TST & \\
\hline CHEMBL3907976 & 1639622 & 7.585 & 7.6464 & TST & \\
\hline CHEMBL176164 & 1639622 & 7.6383 & 7.41299 & 9999999999 & TST \\
\hline CHEMBL3939390 & 1639622 & 7.5086 & 7.2559 & TST & \\
\hline CHEMBL3891573 & 1639622 & 7.585 & 7.4403 & TST & \\
\hline CHEMBL3916197 & 1639622 & 8.2218 & 8.0338 & TST & \\
\hline CHEMBL3942275 & 1639622 & 7.5376 & 7.6907 & TST & \\
\hline CHEMBL 3935552 & 1639622 & 7.8861 & 8.1966 & TST & \\
\hline CHEMBL1865393 & 1301511 & 2.9141 & 3.2411 & TST & \\
\hline CHEMBL1611463 & 1301511 & 2.9145 & 3.2156 & TRN & \\
\hline CHEMBL1506580 & 1301511 & 2.9142 & 3.2303 & TRN & \\
\hline CHEMBL1334972 & 1301511 & 2.91399 & 79999999 & 3.5477 & TRN \\
\hline CHEMBL1577606 & 1301511 & 4.609 & 4.9843 & TRN & \\
\hline CHEMBL1577443 & 1301511 & 2.9142 & 3.0451 & TRN & \\
\hline CHEMBL1973532 & 1301511 & 4.4884 & 3.6605 & TRN & \\
\hline CHEMBL1604932 & 1301511 & 2.9142 & 2.7272 & TRN & \\
\hline CHEMBL 2005545 & 1301511 & 2.9143 & 2.9727 & TRN & \\
\hline CHEMBL3195133 & 1301511 & 4.4972 & 3.3298 & TRN & \\
\hline CHEMBL1549272 & 1301511 & 2.9142 & 3.0213 & TRN & \\
\hline CHEMBL1417479 & 1301511 & 2.9142 & 3.6338 & TRN & \\
\hline CHEMBL1303276 & 1301511 & 2.9142 & 2.9472 & TRN & \\
\hline CHEMBL1333387 & 1301511 & 4.1682 & 3.5441 & TRN & \\
\hline CHEMBL1558561 & 1301511 & 2.9142 & 3.017 & TST & \\
\hline CHEMBL1371946 & 1301511 & 2.9142 & 3.1048 & TST & \\
\hline CHEMBL1345515 & 1301511 & 2.9142 & 2.9135 & TRN & \\
\hline CHEMBL1287980 & 1301511 & 5.2123 & 3.7942 & TST & \\
\hline
\end{tabular}


Supplemental Table S2.txt

\begin{tabular}{|c|c|c|c|c|c|c|}
\hline CHEMBL1537279 & 1301511 & 2.9144 & 3.0306 & TRN & & \\
\hline CHEMBL1365585 & 1301511 & 2.9142 & 3.3881 & TRN & & \\
\hline CHEMBL1425911 & 1301511 & 2.9142 & 3.1908 & TRN & & \\
\hline CHEMBL1713380 & 1301511 & 2.9141 & 2.8727 & TRN & & \\
\hline CHEMBL1346604 & 1301511 & 2.9141 & 2.9971 & TRN & & \\
\hline CHEMBL1466426 & 1301511 & 2.9142 & 2.9418 & TRN & & \\
\hline CHEMBL1550565 & 1301511 & 2.9144 & 3.187 & TRN & & \\
\hline CHEMBL1602240 & 1301511 & \multicolumn{3}{|c|}{2.9139999999999997} & 2.9889 & TRN \\
\hline CHEMBL1301082 & 1301511 & 4.175 & 3.55 & TRN & & \\
\hline CHEMBL1477452 & 1301511 & 2.9142 & 3.1074 & TST & & \\
\hline CHEMBL1478726 & 1301511 & 2.9142 & 2.9036 & TRN & & \\
\hline CHEMBL1367791 & 1301511 & 2.9139 & 3.2082 & TRN & & \\
\hline CHEMBL1449718 & 1301511 & 2.9142 & 2.6349 & TRN & & \\
\hline CHEMBL1399543 & 1301511 & 2.9142 & 2.5218 & TST & & \\
\hline CHEMBL1256364 & 1301511 & 2.9137 & 2.9296 & TRN & & \\
\hline CHEMBL1310327 & 1301511 & \multicolumn{3}{|c|}{2.9139999999999997} & 2.7916 & TRN \\
\hline CHEMBL1519755 & 1301511 & 3.3911 & 3.3652 & TRN & & \\
\hline CHEMBL1427689 & 1301511 & 4.2875 & 3.3517 & TRN & & \\
\hline CHEMBL1534203 & 1301511 & 4.5192 & 2.8586 & TST & & \\
\hline CHEMBL1336537 & 1301511 & 4.587 & 4.9697 & TRN & & \\
\hline CHEMBL1568830 & 1301511 & 2.9146 & 2.6407 & TRN & & \\
\hline CHEMBL1409674 & 1301511 & 2.9142 & 3.0647 & TRN & & \\
\hline CHEMBL1559564 & 1301511 & 2.9143 & 3.3271 & TRN & & \\
\hline CHEMBL1406348 & 1301511 & 2.9141 & 3.0373 & TRN & & \\
\hline CHEMBL1401571 & 1301511 & 4.582 & 3.9423 & TRN & & \\
\hline CHEMBL1413615 & 1301511 & 2.9144 & 2.9869 & TRN & & \\
\hline CHEMBL1419769 & 1301511 & 2.9139 & 2.9824 & TRN & & \\
\hline CHEMBL1348874 & 1301511 & 4.6157 & 3.8141 & TRN & & \\
\hline CHEMBL1433246 & 1301511 & 4.6514 & 3.7487 & TRN & & \\
\hline CHEMBL1506134 & 1301511 & 2.9143 & 2.9588 & TRN & & \\
\hline CHEMBL1381466 & 1301511 & 2.9143 & 3.2568 & TRN & & \\
\hline CHEMBL1417143 & 1301511 & 2.9139 & 2.7249 & TRN & & \\
\hline CHEMBL1528965 & 1301511 & 4.4322 & 3.5995 & TRN & & \\
\hline CHEMBL1530420 & 1301511 & 2.91399 & 999999999 & 997 & 3.4057 & TRN \\
\hline CHEMBL1451888 & 1301511 & 4.3562 & 3.7156 & TRN & & \\
\hline CHEMBL1714971 & 1301511 & 3.3912 & 3.6582 & TST & & \\
\hline CHEMBL1609564 & 1301511 & 4.3646 & 4.0341 & TRN & & \\
\hline CHEMBL1311844 & 1301511 & 4.3974 & 3.0961 & TRN & & \\
\hline CHEMBL1301650 & 1301511 & 4.7203 & 4.8667 & TRN & & \\
\hline CHEMBL1988666 & 1301511 & 2.9146 & 3.0923 & TRN & & \\
\hline CHEMBL1435878 & 1301511 & 4.1207 & 3.7734 & TRN & & \\
\hline CHEMBL1987622 & 1301511 & 2.9144 & 2.9603 & TRN & & \\
\hline CHEMBL1342993 & 1301511 & 2.9143 & 2.9776 & TRN & & \\
\hline CHEMBL1324251 & 1301511 & 2.9144 & 2.9924 & TRN & & \\
\hline CHEMBL1499914 & 1301511 & 2.9142 & 3.2141 & TRN & & \\
\hline CHEMBL1727678 & 1301511 & 4.7168 & 3.4545 & TST & & \\
\hline CHEMBL1577157 & 1301511 & 2.9139 & 3.196 & TRN & & \\
\hline CHEMBL1372606 & 1301511 & 4.2847 & 3.4747 & TRN & & \\
\hline
\end{tabular}


Supplemental Table S2.txt

\begin{tabular}{|c|c|c|c|c|c|c|c|}
\hline CHEMBL1582919 & 1301511 & 2.9142 & 3.4822 & TRN & & & \\
\hline CHEMBL1447430 & 1301511 & 2.9143 & 3.7499 & TST & & & \\
\hline CHEMBL1448234 & 1301511 & 2.9142 & 3.0599 & TRN & & & \\
\hline CHEMBL1469656 & 1301511 & 4.1787 & 3.7707 & TRN & & & \\
\hline CHEMBL1380502 & 1301511 & 2.9142 & 3.3686 & TRN & & & \\
\hline CHEMBL1517325 & 1301511 & 4.3806 & 3.6697 & TST & & & \\
\hline CHEMBL1596969 & 1301511 & 4.681 & 3.6394 & TRN & & & \\
\hline CHEMBL1327674 & 1301511 & 2.9141 & 3.603 & TRN & & & \\
\hline CHEMBL1366088 & 1301511 & 2.9142 & 2.9011 & TRN & & & \\
\hline CHEMBL1335018 & 1301511 & 2.9143 & 3.3771 & TRN & & & \\
\hline CHEMBL1299869 & 1301511 & 2.9142 & 2.6846 & TRN & & & \\
\hline CHEMBL1387581 & 1301511 & 4.3186 & 3.5725 & TRN & & & \\
\hline CHEMBL1420895 & 1301511 & 2.9145 & 3.1304 & TRN & & & \\
\hline CHEMBL1454087 & 1301511 & 2.91399 & 99999999 & 997 & 3.056 & TRN & \\
\hline CHEMBL1359359 & 1301511 & 2.9143 & 2.7433 & TRN & & & \\
\hline CHEMBL1561775 & 1301511 & 2.9143 & 2.5681 & TRN & & & \\
\hline CHEMBL1573786 & 1301511 & 2.9143 & 2.8381 & TRN & & & \\
\hline CHEMBL 3192194 & 1301511 & 2.9142 & 3.3273 & TRN & & & \\
\hline CHEMBL1416153 & 1301511 & 4.2473 & 3.6411 & TRN & & & \\
\hline CHEMBL1408451 & 1301511 & 2.915 & 2.593 & TRN & & & \\
\hline CHEMBL1503803 & 1301511 & 2.9143 & 3.1674 & TRN & & & \\
\hline CHEMBL1350252 & 1301511 & 3.3914 & 3.3697 & TRN & & & \\
\hline CHEMBL 2141747 & 1301511 & 2.9138 & 3.2267 & TST & & & \\
\hline CHEMBL1360461 & 1301511 & 2.9141 & 3.865 & TRN & & & \\
\hline CHEMBL1734036 & 1301511 & 2.9139 & 2.8266 & TRN & & & \\
\hline CHEMBL1569180 & 1301511 & 2.9142 & 3.0765 & TRN & & & \\
\hline CHEMBL1324944 & 1301511 & 4.6711 & 4.9058 & TRN & & & \\
\hline CHEMBL1528395 & 1301511 & 2.9135 & 2.8021 & TRN & & & \\
\hline CHEMBL1565980 & 1301511 & 2.9147 & 3.1953 & TRN & & & \\
\hline CHEMBL3191203 & 1301511 & \multicolumn{3}{|c|}{2.9139999999999997} & \multicolumn{2}{|c|}{3.4419999999999997} & TST \\
\hline CHEMBL1509338 & 1301511 & 2.9146 & 3.1039 & TST & & & \\
\hline CHEMBL603445 & 1301511 & 4.5936 & 3.6197 & TST & & & \\
\hline CHEMBL1415305 & 1301511 & 4.291 & 3.1439 & TST & & & \\
\hline CHEMBL 3184468 & 1301511 & 4.1387 & 3.6856 & TST & & & \\
\hline CHEMBL1379329 & 1301511 & 2.9143 & 3.5053 & TRN & & & \\
\hline CHEMBL1708194 & 1301511 & 2.9143 & 3.0445 & TRN & & & \\
\hline CHEMBL1339505 & 1301511 & 3.9521 & 3.1219 & TRN & & & \\
\hline CHEMBL 2005572 & 1301511 & 2.9143 & 2.8337 & TRN & & & \\
\hline CHEMBL1425675 & 1301511 & 4.3356 & 4.203 & TRN & & & \\
\hline CHEMBL1520137 & 1301511 & \multicolumn{3}{|c|}{2.9139999999999997} & 3.1255 & TRN & \\
\hline CHEMBL1466182 & 1301511 & 2.9146 & 3.2347 & TRN & & & \\
\hline CHEMBL1506358 & 1301511 & 2.9143 & 3.9363 & TRN & & & \\
\hline CHEMBL1438241 & 1301511 & 2.9142 & 2.6983 & TRN & & & \\
\hline CHEMBL1471170 & 1301511 & 4.4573 & 3.9146 & TRN & & & \\
\hline CHEMBL1531834 & 1301511 & 2.9143 & 3.2715 & TRN & & & \\
\hline CHEMBL1609245 & 1301511 & 2.9143 & 3.7098 & TST & & & \\
\hline CHEMBL1521003 & 1301511 & 2.9142 & 2.8508 & TRN & & & \\
\hline CHEMBL1374616 & 1301511 & 2.9141 & 2.8889 & TRN & & & \\
\hline
\end{tabular}

Page 11188 
Supplemental Table S2.txt

\begin{tabular}{|c|c|c|c|c|c|c|}
\hline CHEMBL1970940 & 1301511 & 2.915 & 3.2273 & TST & & \\
\hline CHEMBL1522915 & 1301511 & 3.3914 & 3.2211 & TRN & & \\
\hline CHEMBL1564446 & 1301511 & 2.9144 & 2.7955 & TRN & & \\
\hline CHEMBL1501588 & 1301511 & 4.0263 & 3.4268 & TST & & \\
\hline CHEMBL1968789 & 1301511 & 4.3048 & 3.5569 & TST & & \\
\hline CHEMBL1427820 & 1301511 & 2.9143 & 3.2146 & TRN & & \\
\hline CHEMBL1441430 & 1301511 & 2.9143 & 2.7752 & TRN & & \\
\hline CHEMBL1382221 & 1301511 & 2.9142 & 3.1057 & TST & & \\
\hline CHEMBL1314342 & 1301511 & 2.9145 & 3.3407 & TRN & & \\
\hline CHEMBL1443660 & 1301511 & 4.4571 & 3.4297 & TRN & & \\
\hline CHEMBL1300154 & 1301511 & 4.136 & 3.3614 & TST & & \\
\hline CHEMBL1468130 & 1301511 & 2.9142 & 3.1446 & TRN & & \\
\hline CHEMBL1411272 & 1301511 & 4.0803 & 3.3288 & TRN & & \\
\hline CHEMBL1705208 & 1301511 & 2.9135 & 2.9464 & TST & & \\
\hline CHEMBL1309598 & 1301511 & 2.9143 & 3.5773 & TRN & & \\
\hline CHEMBL1605805 & 1301511 & 2.9142 & 3.145 & TRN & & \\
\hline CHEMBL1441999 & 1301511 & 3.9988 & 3.8974 & TRN & & \\
\hline CHEMBL548540 & 1301511 & 2.9143 & 3.2623 & TRN & & \\
\hline CHEMBL1318817 & 1301511 & 4.0355 & 3.0014 & TST & & \\
\hline CHEMBL1712981 & 1301511 & 4.3202 & 3.7057 & TRN & & \\
\hline CHEMBL1564033 & 1301511 & 2.9142 & 3.2908 & TRN & & \\
\hline CHEMBL1890387 & 1301511 & 2.9142 & 3.3418 & TST & & \\
\hline CHEMBL1525546 & 1301511 & 2.9141 & 2.7079 & TRN & & \\
\hline CHEMBL1727775 & 1301511 & 2.9134 & 3.3118 & TRN & & \\
\hline CHEMBL1364363 & 1301511 & 2.9143 & 3.1291 & TRN & & \\
\hline CHEMBL1426383 & 1301511 & 2.9141 & 3.3875 & TRN & & \\
\hline CHEMBL1341173 & 1301511 & 2.9142 & 2.8731 & TRN & & \\
\hline CHEMBL1405165 & 1301511 & 2.9139 & 2.9624 & TRN & & \\
\hline CHEMBL1368265 & 1301511 & 4.6027 & 3.6826 & TST & & \\
\hline CHEMBL3182269 & 1301511 & 2.9142 & 3.6724 & TST & & \\
\hline CHEMBL1595936 & 1301511 & 2.9139 & 3.3186 & TRN & & \\
\hline CHEMBL1976433 & 1301511 & 2.9143 & 3.1676 & TRN & & \\
\hline CHEMBL1610846 & 1301511 & 2.9143 & 2.9175 & TRN & & \\
\hline CHEMBL1311796 & 1301511 & 2.9143 & 2.8963 & TRN & & \\
\hline CHEMBL1351463 & 1301511 & 2.91399 & 99999999 & 997 & 4.247 & TST \\
\hline CHEMBL1377415 & 1301511 & 2.9142 & 2.7967 & TRN & & \\
\hline CHEMBL1497459 & 1301511 & 2.9143 & 3.6993 & TST & & \\
\hline CHEMBL 3199820 & 1301511 & 4.372 & 3.5049 & TRN & & \\
\hline CHEMBL335782 & 1301511 & 2.9137 & 3.4932 & TST & & \\
\hline CHEMBL1360416 & 1301511 & 2.9139 & 3.3614 & TRN & & \\
\hline CHEMBL1996749 & 1301511 & 2.9143 & 3.2093 & TRN & & \\
\hline CHEMBL1996281 & 1301511 & 2.9142 & 3.1874 & TRN & & \\
\hline CHEMBL1613238 & 1301511 & 4.6092 & 3.3097 & TST & & \\
\hline CHEMBL1400434 & 1301511 & 2.9142 & 3.2003 & TRN & & \\
\hline CHEMBL1491028 & 1301511 & 2.9143 & 2.9528 & TRN & & \\
\hline CHEMBL1977333 & 1301511 & 2.9145 & 3.3229 & TRN & & \\
\hline CHEMBL1303524 & 1301511 & 4.2683 & 3.7914 & TRN & & \\
\hline CHEMBL1596353 & 1301511 & 2.9139 & 3.5981 & TRN & & \\
\hline
\end{tabular}

Page 11189 
Supplemental Table S2.txt

\begin{tabular}{|c|c|c|c|c|c|c|}
\hline CHEMBL593506 & 1301511 & 4.4953 & 3.5429 & TST & & \\
\hline CHEMBL1563746 & 1301511 & 2.9142 & 3.3249 & TRN & & \\
\hline CHEMBL3183423 & 1301511 & 4.2197 & 3.4145 & TRN & & \\
\hline CHEMBL1409965 & 1301511 & 2.91399 & 999999999 & 997 & 3.395 & TRN \\
\hline CHEMBL1563219 & 1301511 & 2.9143 & 3.2048 & TRN & & \\
\hline CHEMBL1596948 & 1301511 & 2.91399 & 999999999 & 997 & 3.2112 & TST \\
\hline CHEMBL1523064 & 1301511 & 2.9143 & 2.7825 & TRN & & \\
\hline CHEMBL1406051 & 1301511 & 4.3504 & 3.9324 & TRN & & \\
\hline CHEMBL1516672 & 1301511 & 2.9142 & 3.0955 & TRN & & \\
\hline CHEMBL1404485 & 1301511 & 4.1815 & 3.7253 & TRN & & \\
\hline CHEMBL1348263 & 1301511 & 2.9143 & 2.8939 & TRN & & \\
\hline CHEMBL1527358 & 1301511 & 2.9139 & 3.5721 & TRN & & \\
\hline CHEMBL1492585 & 1301511 & 4.4686 & 3.418 & TST & & \\
\hline CHEMBL1373171 & 1301511 & 4.7268 & 3.4364 & TRN & & \\
\hline CHEMBL1435749 & 1301511 & 3.9994 & 3.4804 & TRN & & \\
\hline CHEMBL1392912 & 1301511 & 2.9143 & 2.8856 & TRN & & \\
\hline CHEMBL1727228 & 1301511 & 4.4421 & 3.4749 & TST & & \\
\hline CHEMBL1339003 & 1301511 & 2.9142 & 2.9338 & TRN & & \\
\hline CHEMBL1986557 & 1301511 & 4.3838 & 3.2547 & TST & & \\
\hline CHEMBL1565762 & 1301511 & 2.9142 & 3.4725 & TST & & \\
\hline CHEMBL1307849 & 1301511 & 2.9143 & 3.1712 & TRN & & \\
\hline CHEMBL1602141 & 1301511 & 4.6873 & 3.8955 & TRN & & \\
\hline CHEMBL1501307 & 1301511 & 2.9143 & 3.1543 & TST & & \\
\hline CHEMBL 3188830 & 1301511 & 3.3914 & 3.4745 & TRN & & \\
\hline CHEMBL1492244 & 1301511 & 2.9142 & 3.0163 & TRN & & \\
\hline CHEMBL1504920 & 1301511 & 2.9142 & 3.1091 & TRN & & \\
\hline CHEMBL1374827 & 1301511 & 2.9143 & 3.3565 & TRN & & \\
\hline CHEMBL1415195 & 1301511 & 4.1879 & 3.6698 & TRN & & \\
\hline CHEMBL1330702 & 1301511 & 2.9145 & 3.0572 & TRN & & \\
\hline CHEMBL1383259 & 1301511 & 2.9143 & 3.0004 & TRN & & \\
\hline CHEMBL1452421 & 1301511 & 2.9142 & 3.1298 & TRN & & \\
\hline CHEMBL1451507 & 1301511 & 2.9139 & 2.957 & TRN & & \\
\hline CHEMBL1698845 & 1301511 & 3.3916 & 3.1845 & TRN & & \\
\hline CHEMBL1883210 & 1301511 & 4.4957 & 3.3792 & TST & & \\
\hline CHEMBL1404200 & 1301511 & 3.9389 & 3.5256 & TRN & & \\
\hline CHEMBL1713992 & 1301511 & 2.91399 & 999999999 & 997 & 3.3922 & TST \\
\hline CHEMBL1386049 & 1301511 & 2.9143 & 3.4334 & TRN & & \\
\hline CHEMBL1197872 & 1301511 & 2.9142 & 3.3065 & TST & & \\
\hline CHEMBL1456400 & 1301511 & 2.9145 & 2.9694 & TRN & & \\
\hline CHEMBL1467718 & 1301511 & 2.9139 & 3.6066 & TRN & & \\
\hline CHEMBL1374818 & 1301511 & 2.9144 & 2.9015 & TRN & & \\
\hline CHEMBL1383036 & 1301511 & 2.9147 & 2.9701 & TRN & & \\
\hline CHEMBL1974063 & 1301511 & 2.9138 & 3.3979 & TRN & & \\
\hline CHEMBL1971760 & 1301511 & 4.2957 & 3.1597 & TST & & \\
\hline CHEMBL1405862 & 1301511 & 2.91399 & 999999999 & 997 & 2.9716 & TRN \\
\hline CHEMBL3189736 & 1301511 & 4.325 & 3.555 & TRN & & \\
\hline CHEMBL3186316 & 1301511 & 2.9142 & 3.3223 & TRN & & \\
\hline CHEMBL1387173 & 1301511 & 2.9139 & 2.8722 & TRN & & \\
\hline
\end{tabular}


Supplemental Table S2.txt

\begin{tabular}{|c|c|c|c|c|c|}
\hline CHEMBL1327303 & 1301511 & 4.1974 & 3.468 & TRN & \\
\hline CHEMBL1609596 & 1301511 & 2.9142 & 3.0163 & TRN & \\
\hline CHEMBL1564853 & 1301511 & 2.9142 & 3.1506 & TST & \\
\hline CHEMBL1522807 & 1301511 & 2.9142 & 3.8594 & TRN & \\
\hline CHEMBL3198396 & 1301511 & 3.3914 & 3.5949 & TRN & \\
\hline CHEMBL1509671 & 1301511 & 2.9142 & 3.4199 & TRN & \\
\hline CHEMBL1583166 & 1301511 & 2.9143 & 3.6842 & TRN & \\
\hline CHEMBL1533229 & 1301511 & 2.9142 & 3.3424 & TST & \\
\hline CHEMBL 3182042 & 1301511 & 2.9139 & 3.2632 & TRN & \\
\hline CHEMBL1424109 & 1301511 & 2.9143 & 3.1969 & TST & \\
\hline CHEMBL1721330 & 1301511 & 4.1481 & 3.505 & TST & \\
\hline CHEMBL1575634 & 1301511 & 4.6602 & 3.321 & TRN & \\
\hline CHEMBL1419472 & 1301511 & 2.9142 & 3.2092 & TST & \\
\hline CHEMBL1458922 & 1301511 & 2.9142 & 3.388 & TRN & \\
\hline CHEMBL3191975 & 1301511 & 2.91399 & 99999999 & 3.2396 & TST \\
\hline CHEMBL 2369333 & 1301511 & 2.9147 & 2.9506 & TST & \\
\hline CHEMBL1312716 & 1301511 & 2.9142 & 3.341 & TST & \\
\hline CHEMBL1452391 & 1301511 & 2.9142 & 3.0183 & TST & \\
\hline CHEMBL1287983 & 1301511 & 4.1751 & 3.308006 & 00000000003 & TST \\
\hline CHEMBL1409333 & 1301511 & 2.9143 & 3.4168 & TST & \\
\hline CHEMBL1386299 & 1301511 & 2.9139 & 3.1741 & TST & \\
\hline CHEMBL1537378 & 1301511 & 2.9142 & 3.283 & TST & \\
\hline CHEMBL 3196548 & 1301511 & 2.9142 & 3.0129 & TST & \\
\hline CHEMBL1363669 & 1301511 & 2.9142 & 2.9089 & TST & \\
\hline CHEMBL1880794 & 1301511 & 2.91399 & 99999999 & 2.7796 & TST \\
\hline CHEMBL 3212453 & 688186 & 3.301 & 3.9686 & TRN & \\
\hline CHEMBL1501968 & 688186 & 3.301 & 4.158 & TRN & \\
\hline CHEMBL1426993 & 688186 & 3.301 & 3.4998 & TST & \\
\hline CHEMBL1578233 & 688186 & 4.8091 & 3.8194 & TRN & \\
\hline CHEMBL1421891 & 688186 & 4.9066 & 4.4769 & TRN & \\
\hline CHEMBL1556273 & 688186 & 4.9296 & 4.4999 & TRN & \\
\hline CHEMBL 3189743 & 688186 & 4.7086 & 4.7384 & TRN & \\
\hline CHEMBL1480241 & 688186 & 4.9197 & 3.5134 & TRN & \\
\hline CHEMBL1704267 & 688186 & 4.4218 & 4.4111 & TRN & \\
\hline CHEMBL1414382 & 688186 & 4.3723 & 3.8416 & TRN & \\
\hline CHEMBL1387843 & 688186 & 5.1284 & 4.2255 & TST & \\
\hline CHEMBL1491222 & 688186 & 5.1965 & 5.7609 & TRN & \\
\hline CHEMBL1478659 & 688186 & 3.301 & 3.3926 & TRN & \\
\hline CHEMBL1487684 & 688186 & 3.301 & 3.7184 & TRN & \\
\hline CHEMBL1319036 & 688186 & 3.301 & 4.0401 & TRN & \\
\hline CHEMBL1438881 & 688186 & 6.5686 & 6.4055 & TRN & \\
\hline CHEMBL1526540 & 688186 & 3.301 & 3.4263 & TRN & \\
\hline CHEMBL1577983 & 688186 & 5.7282 & 4.6501 & TRN & \\
\hline CHEMBL1349230 & 688186 & 3.301 & 4.1861 & TRN & \\
\hline CHEMBL1342455 & 688186 & 3.301 & 3.7857 & TRN & \\
\hline CHEMBL1361988 & 688186 & 3.301 & 3.8101 & TRN & \\
\hline CHEMBL1390645 & 688186 & 4.4316 & 3.4802 & TRN & \\
\hline CHEMBL475335 & 688186 & 3.301 & 4.2395 & TST & \\
\hline
\end{tabular}




\begin{tabular}{|c|c|c|c|c|c|}
\hline \multicolumn{6}{|c|}{ Supplemental Table S2.txt } \\
\hline CHEMBL1424833 & 688186 & 3.301 & 3.9732 & TRN & \\
\hline CHEMBL3199263 & 688186 & 3.301 & 3.9098 & TRN & \\
\hline CHEMBL1405776 & 688186 & 5.1152 & 4.0602 & TST & \\
\hline CHEMBL1375073 & 688186 & 4.5394 & 3.9446 & TST & \\
\hline CHEMBL1528127 & 688186 & 4.3262 & 3.7582 & TRN & \\
\hline CHEMBL1319488 & 688186 & 5.5498 & 5.0597 & TRN & \\
\hline CHEMBL1411646 & 688186 & 5.6716 & 5.338999 & 99999999995 & TRN \\
\hline CHEMBL1423833 & 688186 & 3.301 & 4.2424 & TST & \\
\hline CHEMBL1479316 & 688186 & $5.7520 e$ & 000000006 & 5.6703 & TRN \\
\hline CHEMBL1445327 & 688186 & 4.9884 & 3.836006 & 00000000003 & TRN \\
\hline CHEMBL1399190 & 688186 & 4.8844 & 4.1897 & TRN & \\
\hline CHEMBL1387247 & 688186 & 3.301 & 3.8365 & TST & \\
\hline CHEMBL1585003 & 688186 & 5.2233 & 3.8235 & TST & \\
\hline CHEMBL1583398 & 688186 & 3.301 & 4.0457 & TST & \\
\hline CHEMBL1610525 & 688186 & 4.8941 & 3.888 & TRN & \\
\hline CHEMBL1406607 & 688186 & 3.301 & 4.2045 & TST & \\
\hline CHEMBL1345507 & 688186 & 3.301 & 3.2965 & TRN & \\
\hline CHEMBL1312766 & 688186 & 4.5911 & 3.7912 & TRN & \\
\hline CHEMBL1426233 & 688186 & 4.5824 & 4.0715 & TRN & \\
\hline CHEMBL 2373661 & 688186 & 4.9245 & 4.9764 & TST & \\
\hline CHEMBL1431433 & 688186 & 4.6463 & 4.1178 & TRN & \\
\hline CHEMBL1583127 & 688186 & 4.8359 & 4.2883 & TRN & \\
\hline CHEMBL3198301 & 688186 & 3.301 & 4.7721 & TRN & \\
\hline CHEMBL1378260 & 688186 & 3.301 & 3.7932 & TRN & \\
\hline CHEMBL1541657 & 688186 & 5.1979 & 4.9865 & TST & \\
\hline CHEMBL1360697 & 688186 & 3.301 & 3.4467 & TRN & \\
\hline CHEMBL1378383 & 688186 & 3.301 & 3.9126 & TRN & \\
\hline CHEMBL1572134 & 688186 & 4.848 & 4.1572 & TRN & \\
\hline CHEMBL1495504 & 688186 & 4.697 & 3.873 & TRN & \\
\hline CHEMBL1362838 & 688186 & 3.301 & 3.844 & TRN & \\
\hline CHEMBL1569917 & 688186 & 3.301 & 3.2748 & TRN & \\
\hline CHEMBL1442682 & 688186 & 3.301 & 3.3537 & TRN & \\
\hline CHEMBL1500132 & 688186 & 3.301 & 3.5793 & TRN & \\
\hline CHEMBL1492021 & 688186 & 4.9539 & 3.7425 & TRN & \\
\hline CHEMBL544752 & 688186 & 4.823 & 4.2002 & TRN & \\
\hline CHEMBL1600422 & 688186 & 3.301 & 3.6929 & TST & \\
\hline CHEMBL1390602 & 688186 & 4.3506 & 3.9872 & TRN & \\
\hline CHEMBL1408802 & 688186 & 3.301 & 4.0765 & TRN & \\
\hline CHEMBL1555425 & 688186 & 3.301 & 3.8277 & TRN & \\
\hline CHEMBL1604104 & 688186 & 3.301 & 3.4303 & TRN & \\
\hline CHEMBL530609 & 688186 & 5.1518 & 4.8535 & TRN & \\
\hline CHEMBL1562020 & 688186 & 3.301 & 3.8453 & TRN & \\
\hline CHEMBL1497597 & 688186 & 5.5361 & 4.5346 & TRN & \\
\hline CHEMBL1301477 & 688186 & 3.301 & 3.2611 & TRN & \\
\hline CHEMBL1310576 & 688186 & 3.301 & 3.467 & TRN & \\
\hline CHEMBL1569490 & 688186 & 3.301 & 4.0581 & TRN & \\
\hline CHEMBL1500500 & 688186 & 4.7506 & 4.421 & TRN & \\
\hline CHEMBL3212192 & 688186 & 4.3563 & 4.3023 & TRN & \\
\hline
\end{tabular}




\begin{tabular}{|c|c|c|c|c|c|}
\hline & & \multicolumn{4}{|c|}{ Supplemental Table S2.txt } \\
\hline CHEMBL1583254 & 688186 & 3.301 & 3.9519 & TRN & \\
\hline CHEMBL1427808 & 688186 & 5.1772 & 4.1873 & TRN & \\
\hline CHEMBL1305478 & 688186 & 5.0501 & 4.7695 & TRN & \\
\hline CHEMBL1498545 & 688186 & 3.301 & 3.6734 & TRN & \\
\hline CHEMBL1514790 & 688186 & 5.1549 & 4.7414 & TRN & \\
\hline CHEMBL586000 & 688186 & 5.0482 & 4.3672 & TST & \\
\hline CHEMBL1321620 & 688186 & 4.7256 & 4.4364 & TRN & \\
\hline CHEMBL 3190369 & 688186 & 3.301 & 6.13899 & 9999999999 & TST \\
\hline CHEMBL1602963 & 688186 & 3.301 & 3.576 & TRN & \\
\hline CHEMBL3190941 & 688186 & 5.433 & 4.6285 & TST & \\
\hline CHEMBL1968085 & 688186 & 6.1805 & 5.1981 & TRN & \\
\hline CHEMBL1492241 & 688186 & 4.3156 & 3.861 & TRN & \\
\hline CHEMBL1364411 & 688186 & 4.3334 & 4.3018 & TST & \\
\hline CHEMBL3191362 & 688186 & 3.301 & 4.548 & TRN & \\
\hline CHEMBL1320446 & 688186 & 4.6174 & 4.1585 & TRN & \\
\hline CHEMBL3192021 & 688186 & 4.961 & 4.3976 & TRN & \\
\hline CHEMBL1387125 & 688186 & 3.301 & 3.9262 & TRN & \\
\hline CHEMBL1404086 & 688186 & 5.0186 & 4.6155 & TRN & \\
\hline CHEMBL 3212972 & 688186 & 5.2588 & 4.7955 & TRN & \\
\hline CHEMBL1409001 & 688186 & 4.6979 & 4.231 & TRN & \\
\hline CHEMBL1600822 & 688186 & 3.301 & 3.8237 & TRN & \\
\hline CHEMBL1576690 & 688186 & 3.301 & 3.72 & TRN & \\
\hline CHEMBL1405797 & 688186 & 3.301 & 3.83699 & 99999999997 & TRN \\
\hline CHEMBL1379286 & 688186 & 3.301 & 4.5028 & TRN & \\
\hline CHEMBL1364803 & 688186 & 4.8784 & 3.7067 & TRN & \\
\hline CHEMBL3198111 & 688186 & 4.7109 & 4.6615 & TRN & \\
\hline CHEMBL1518625 & 688186 & 6.0088 & 6.2195 & TRN & \\
\hline CHEMBL1312026 & 688186 & 3.301 & 4.1998 & TST & \\
\hline CHEMBL1468700 & 688186 & 3.301 & 3.6302 & TRN & \\
\hline CHEMBL1464129 & 688186 & 3.301 & 4.7131 & TRN & \\
\hline CHEMBL1493402 & 688186 & 3.301 & 3.5404 & TRN & \\
\hline CHEMBL1340050 & 688186 & 3.301 & 3.3988 & TRN & \\
\hline CHEMBL1529849 & 688186 & 3.301 & 4.1161 & TRN & \\
\hline CHEMBL1470712 & 688186 & 5.4868 & 5.437 & TRN & \\
\hline CHEMBL1508477 & 688186 & 3.301 & 3.8202 & TRN & \\
\hline CHEMBL1566068 & 688186 & 4.93 & 3.6413 & TRN & \\
\hline CHEMBL1405411 & 688186 & 3.301 & 3.5653 & TRN & \\
\hline CHEMBL1375045 & 688186 & 6.1549 & 6.1128 & TST & \\
\hline CHEMBL580340 & 688186 & 5.2765 & 5.0941 & TRN & \\
\hline CHEMBL1995879 & 688186 & 4.4869 & 4.7935 & TRN & \\
\hline CHEMBL1577793 & 688186 & 3.301 & 3.6544 & TRN & \\
\hline CHEMBL1454614 & 688186 & 5.1624 & 4.1402 & TRN & \\
\hline CHEMBL1608118 & 688186 & 4.6128 & 4.4083 & TRN & \\
\hline CHEMBL1352979 & 688186 & 3.301 & 3.7968 & TRN & \\
\hline CHEMBL1493824 & 688186 & 3.301 & 3.285 & TRN & \\
\hline CHEMBL1547780 & 688186 & 3.301 & 4.3875 & TRN & \\
\hline CHEMBL1390665 & 688186 & 3.301 & 3.8004 & TRN & \\
\hline CHEMBL1481963 & 688186 & 4.3985 & 3.7945 & TST & \\
\hline
\end{tabular}




\begin{tabular}{|c|c|c|c|c|}
\hline & & & pplement & al $\mathrm{T}$ \\
\hline CHEMBL1304592 & 688186 & 3.301 & 3.3626 & TRN \\
\hline CHEMBL1413726 & 688186 & 4.9348 & 4.3444 & TRN \\
\hline CHEMBL1454183 & 688186 & 5.8539 & 3.7117 & TST \\
\hline CHEMBL1407634 & 688186 & 3.301 & 3.9342 & TST \\
\hline CHEMBL3197141 & 688186 & 5.3487 & 4.96 & TRN \\
\hline CHEMBL1383151 & 688186 & 3.301 & 3.8184 & TST \\
\hline CHEMBL3211756 & 688186 & 3.301 & 4.2951 & TST \\
\hline CHEMBL1360037 & 688186 & 4.8901 & 5.1971 & TRN \\
\hline CHEMBL1527015 & 688186 & 3.301 & 3.6192 & TRN \\
\hline CHEMBL1519404 & 688186 & 3.301 & 4.0833 & TRN \\
\hline CHEMBL1432707 & 688186 & 5.5272 & 4.3087 & TRN \\
\hline CHEMBL1533511 & 688186 & 4.515 & 4.2403 & TST \\
\hline CHEMBL1501932 & 688186 & 3.301 & 4.4333 & TRN \\
\hline CHEMBL3207440 & 688186 & 3.301 & 3.9823 & TST \\
\hline CHEMBL1452298 & 688186 & 3.301 & 3.4735 & TRN \\
\hline CHEMBL1967566 & 688186 & 4.8099 & 4.7105 & TRN \\
\hline CHEMBL1613611 & 688186 & 3.301 & 3.8181 & TRN \\
\hline CHEMBL1336829 & 688186 & 3.301 & 3.7467 & TRN \\
\hline CHEMBL1446900 & 688186 & 4.4551 & 4.2935 & TRN \\
\hline CHEMBL1370331 & 688186 & 3.301 & 4.055 & TRN \\
\hline CHEMBL1425847 & 688186 & 3.301 & 3.8285 & TRN \\
\hline CHEMBL1312889 & 688186 & 3.301 & 3.7413 & TRN \\
\hline CHEMBL1455894 & 688186 & 3.301 & 4.2103 & TRN \\
\hline CHEMBL3193102 & 688186 & 4.5781 & 3.9779 & TRN \\
\hline CHEMBL1465706 & 688186 & 4.5766 & 3.7472 & TRN \\
\hline CHEMBL1986342 & 688186 & 3.301 & 4.5194 & TST \\
\hline CHEMBL460018 & 688186 & 3.301 & 4.098 & TRN \\
\hline CHEMBL1526655 & 688186 & 4.6645 & 3.7106 & TRN \\
\hline CHEMBL1549646 & 688186 & 4.7891 & 4.11 & TST \\
\hline CHEMBL549321 & 688186 & 3.301 & 4.2599 & TRN \\
\hline CHEMBL3189460 & 688186 & 4.8941 & 4.9072 & TRN \\
\hline CHEMBL1493695 & 688186 & 3.301 & 3.5164 & TRN \\
\hline CHEMBL1327548 & 688186 & 3.301 & 3.3424 & TRN \\
\hline CHEMBL3210450 & 688186 & 3.301 & 4.1678 & TRN \\
\hline CHEMBL1370694 & 688186 & 4.6492 & 4.631 & TRN \\
\hline CHEMBL935 & 688186 & 4.8187 & 4.6018 & TRN \\
\hline CHEMBL1594055 & 688186 & 4.8854 & 4.8767 & TST \\
\hline CHEMBL1347831 & 688186 & 3.301 & 3.3285 & TRN \\
\hline CHEMBL1351542 & 688186 & 5.5287 & 5.2746 & TRN \\
\hline CHEMBL1422161 & 688186 & 5.9208 & 4.6445 & TST \\
\hline CHEMBL1462417 & 688186 & 3.301 & 3.6499 & TRN \\
\hline CHEMBL1301390 & 688186 & 3.301 & 3.6216 & TRN \\
\hline CHEMBL1497301 & 688186 & 4.7077 & 3.6352 & TRN \\
\hline CHEMBL3212307 & 688186 & 4.314 & 4.936 & TRN \\
\hline CHEMBL1494087 & 688186 & 4.3044 & 4.3546 & TRN \\
\hline CHEMBL1573774 & 688186 & 3.301 & 3.7847 & TRN \\
\hline CHEMBL1565059 & 688186 & 4.8114 & 3.9767 & TRN \\
\hline CHEMBL1570835 & 688186 & 4.9136 & 4.8107 & TRN \\
\hline
\end{tabular}




\begin{tabular}{|c|c|c|c|c|c|}
\hline \multicolumn{6}{|c|}{ Supplemental Table S2.txt } \\
\hline CHEMBL1478024 & 688186 & 4.7399 & 4.5483 & TRN & \\
\hline CHEMBL1373159 & 688186 & 3.301 & 3.5922 & TRN & \\
\hline CHEMBL3192837 & 688186 & 4.6291 & 4.7747 & TRN & \\
\hline CHEMBL1416858 & 688186 & 3.301 & 3.775 & TST & \\
\hline CHEMBL1424162 & 688186 & 4.4781 & 3.842 & TRN & \\
\hline CHEMBL1504086 & 688186 & 3.301 & 4.0544 & TRN & \\
\hline CHEMBL1339934 & 688186 & 3.301 & 3.7098 & TRN & \\
\hline CHEMBL1463980 & 688186 & 3.301 & 3.4789 & TRN & \\
\hline CHEMBL1542642 & 688186 & 4.3177 & 2.7812 & TRN & \\
\hline CHEMBL66953 & 688186 & 3.301 & 4.3964 & TRN & \\
\hline CHEMBL1569232 & 688186 & 4.7459 & 4.3217 & TRN & \\
\hline CHEMBL1534666 & 688186 & 5.2449 & 4.6911 & TRN & \\
\hline CHEMBL1562824 & 688186 & 3.301 & 4.8858 & TRN & \\
\hline CHEMBL1304363 & 688186 & 6.0969 & 6.0344 & TRN & \\
\hline CHEMBL3199539 & 688186 & 5.5086 & 5.2646 & TRN & \\
\hline CHEMBL1526539 & 688186 & 5.7305 & 4.8401 & TRN & \\
\hline CHEMBL1520465 & 688186 & 4.9296 & 4.6979 & TRN & \\
\hline CHEMBL1093246 & 688186 & 5.1169 & 4.664 & TRN & \\
\hline CHEMBL1361821 & 688186 & 5.5452 & 4.3439 & TRN & \\
\hline CHEMBL1447650 & 688186 & 3.301 & 3.4652 & TRN & \\
\hline CHEMBL 2007091 & 688186 & 5.2118 & 4.7094 & TRN & \\
\hline CHEMBL1487098 & 688186 & 4.3193 & 3.6739 & TRN & \\
\hline CHEMBL590186 & 688186 & 4.7228 & 4.7402 & TRN & \\
\hline CHEMBL1303626 & 688186 & 4.4169 & 4.4716 & TST & \\
\hline CHEMBL1309381 & 688186 & 3.301 & 4.2089 & TRN & \\
\hline CHEMBL1999480 & 688186 & 5.6271 & 4.7451 & TRN & \\
\hline CHEMBL1460981 & 688186 & 3.301 & 3.8337 & TRN & \\
\hline CHEMBL1572237 & 688186 & 3.301 & 3.156 & TRN & \\
\hline CHEMBL1353363 & 688186 & 3.301 & 3.1948 & TRN & \\
\hline CHEMBL1987685 & 688186 & 4.8614 & 4.9386 & TRN & \\
\hline CHEMBL1558725 & 688186 & 5.0155 & 4.1022 & TRN & \\
\hline CHEMBL1338083 & 688186 & 3.301 & 3.8675 & TRN & \\
\hline CHEMBL1453970 & 688186 & 4.5891 & 4.078 & TRN & \\
\hline CHEMBL1524292 & 688186 & 3.301 & 4.2887 & TRN & \\
\hline CHEMBL3199504 & 688186 & 4.4299 & 4.704 & TRN & \\
\hline CHEMBL1589036 & 688186 & 4.6421 & 4.0311 & TRN & \\
\hline CHEMBL1336722 & 688186 & 4.9144 & 4.1212 & TRN & \\
\hline CHEMBL1566877 & 688186 & 3.301 & 4.4591 & TRN & \\
\hline CHEMBL341910 & 688186 & 3.301 & 4.3803 & TRN & \\
\hline CHEMBL1496705 & 688186 & 5.4724 & 5.7765 & TRN & \\
\hline CHEMBL1351349 & 688186 & 4.3326 & 3.9283 & TRN & \\
\hline CHEMBL123 & 688186 & 5.5969 & 5.15600 & 0000000001 & TST \\
\hline CHEMBL3192181 & 688186 & 5.5686 & 5.8522 & TRN & \\
\hline CHEMBL1473670 & 688186 & 3.301 & 4.0639 & TRN & \\
\hline CHEMBL 2006909 & 688186 & 5.5986 & 4.6708 & TRN & \\
\hline CHEMBL1530234 & 688186 & 3.301 & 4.4629 & TRN & \\
\hline CHEMBL1352023 & 688186 & 3.301 & 3.6515 & TRN & \\
\hline CHEMBL1468909 & 688186 & 3.301 & 3.39 & TST & \\
\hline
\end{tabular}




\begin{tabular}{|c|c|c|c|c|}
\hline \multicolumn{5}{|c|}{ Supplemental Table S2.txt } \\
\hline CHEMBL1562835 & 688186 & 3.301 & 4.2717 & TRN \\
\hline CHEMBL 3198672 & 688186 & 3.301 & 3.8945 & TRN \\
\hline CHEMBL1392922 & 688186 & 4.359 & 3.9032 & TRN \\
\hline CHEMBL1594717 & 688186 & 4.323 & 3.8997 & TRN \\
\hline CHEMBL199387 & 688186 & 4.8225 & 5.1208 & TRN \\
\hline CHEMBL1600045 & 688186 & 4.4806 & 4.0122 & TST \\
\hline CHEMBL1321398 & 688186 & 5.7932 & 5.0785 & TRN \\
\hline CHEMBL1448122 & 688186 & 3.301 & 3.9179 & TRN \\
\hline CHEMBL1419329 & 688186 & 4.648 & 3.6355 & TST \\
\hline CHEMBL1382312 & 688186 & 4.5799 & 4.0183 & TRN \\
\hline CHEMBL 3190268 & 688186 & 5.1612 & 5.16 & TRN \\
\hline CHEMBL1389657 & 688186 & 3.301 & 3.1869 & TRN \\
\hline CHEMBL3192554 & 688186 & 4.5658 & 5.235 & TRN \\
\hline CHEMBL1568184 & 688186 & 4.6761 & 4.2761 & TRN \\
\hline CHEMBL582444 & 688186 & 4.9706 & 5.2885 & TRN \\
\hline CHEMBL1472135 & 688186 & 4.5658 & 3.6736 & TRN \\
\hline CHEMBL1393828 & 688186 & 3.301 & 4.0066 & TRN \\
\hline CHEMBL1524904 & 688186 & 3.301 & 4.2396 & TRN \\
\hline CHEMBL1313669 & 688186 & 3.301 & 3.6789 & TRN \\
\hline CHEMBL1608375 & 688186 & 5.3224 & 3.7711 & TST \\
\hline CHEMBL1380497 & 688186 & 4.9205 & 4.9601 & TRN \\
\hline CHEMBL3192690 & 688186 & 3.301 & 4.506 & TRN \\
\hline CHEMBL1310862 & 688186 & 4.3313 & 3.8425 & TRN \\
\hline CHEMBL1329235 & 688186 & 5.2218 & 6.0747 & TRN \\
\hline CHEMBL1974180 & 688186 & 5.3925 & 5.3687 & TRN \\
\hline CHEMBL81782 & 688186 & 6.3665 & 6.0633 & TRN \\
\hline CHEMBL1521960 & 688186 & 6.8239 & 5.5871 & TST \\
\hline CHEMBL1572266 & 688186 & 4.522 & 3.8606 & TRN \\
\hline CHEMBL1968095 & 688186 & 4.3581 & 4.6974 & TRN \\
\hline CHEMBL1443881 & 688186 & 3.301 & 4.2339 & TRN \\
\hline CHEMBL1971410 & 688186 & 3.301 & 4.3417 & TRN \\
\hline CHEMBL1567682 & 688186 & 5.1244 & 3.7721 & TRN \\
\hline CHEMBL3197372 & 688186 & 4.791 & 5.0234 & TRN \\
\hline CHEMBL1503512 & 688186 & 3.301 & 3.4673 & TRN \\
\hline CHEMBL1360730 & 688186 & 3.301 & 3.9956 & TRN \\
\hline CHEMBL1401989 & 688186 & 5.6946 & 5.141 & TRN \\
\hline CHEMBL 1407147 & 688186 & 3.301 & 3.6587 & TST \\
\hline CHEMBL1586158 & 688186 & 3.301 & 4.3396 & TRN \\
\hline CHEMBL1343101 & 688186 & 4.9473 & 4.1252 & TST \\
\hline CHEMBL1213834 & 688186 & 3.301 & 3.4203 & TRN \\
\hline CHEMBL1495238 & 688186 & 3.301 & 3.8961 & TRN \\
\hline CHEMBL1500249 & 688186 & 4.8551 & 4.1788 & TST \\
\hline CHEMBL1359616 & 688186 & 3.301 & 3.9225 & TRN \\
\hline CHEMBL1321342 & 688186 & 3.301 & 4.4029 & TST \\
\hline CHEMBL1361685 & 688186 & 4.3363 & 4.1679 & TRN \\
\hline CHEMBL1612634 & 688186 & 4.9961 & 3.9993 & TRN \\
\hline CHEMBL1309993 & 688186 & 3.301 & 3.9285 & TRN \\
\hline CHEMBL 2018847 & 688186 & 4.4511 & 4.8433 & TRN \\
\hline
\end{tabular}




\begin{tabular}{|c|c|c|c|c|}
\hline \multicolumn{5}{|c|}{ Supplemental Tabl } \\
\hline CHEMBL1519379 & 688186 & 4.6853 & 4.5453 & TRN \\
\hline CHEMBL1558625 & 688186 & 4.4014 & 3.8564 & TST \\
\hline CHEMBL1549891 & 688186 & 3.301 & 3.9163 & TRN \\
\hline CHEMBL3191726 & 688186 & 4.5577 & 4.4809 & TRN \\
\hline CHEMBL1462938 & 688186 & 8.0 & 4.7951 & TRN \\
\hline CHEMBL1422579 & 688186 & 3.301 & 4.0809 & TST \\
\hline CHEMBL1390787 & 688186 & 3.301 & 3.825 & TRN \\
\hline CHEMBL1456311 & 688186 & 3.301 & 4.5308 & TRN \\
\hline CHEMBL1576087 & 688186 & 4.3617 & 4.4582 & TRN \\
\hline CHEMBL1456371 & 688186 & 4.7203 & 3.5665 & TRN \\
\hline CHEMBL1600246 & 688186 & 3.301 & 4.6496 & TRN \\
\hline CHEMBL1598791 & 688186 & 5.3893 & 4.2345 & TRN \\
\hline CHEMBL1325945 & 688186 & 5.6271 & 4.7704 & TST \\
\hline CHEMBL3191149 & 688186 & 5.1397 & 4.7971 & TRN \\
\hline CHEMBL1568414 & 688186 & 5.2218 & 4.5095 & TRN \\
\hline CHEMBL1998606 & 688186 & 6.0132 & 4.9892 & TRN \\
\hline CHEMBL1467304 & 688186 & 5.3487 & 4.1253 & TST \\
\hline CHEMBL1410101 & 688186 & 3.301 & 3.6772 & TRN \\
\hline CHEMBL1367187 & 688186 & 3.301 & 3.8666 & TST \\
\hline CHEMBL1437516 & 688186 & 6.0223 & 5.8569 & TRN \\
\hline CHEMBL1322031 & 688186 & 3.301 & 3.9896 & TST \\
\hline CHEMBL1330558 & 688186 & 5.1884 & 5.1887 & TRN \\
\hline CHEMBL1327137 & 688186 & 5.0273 & 4.2519 & TRN \\
\hline CHEMBL1304388 & 688186 & 3.301 & 3.7751 & TRN \\
\hline CHEMBL592124 & 688186 & 5.3686 & 4.7423 & TRN \\
\hline CHEMBL1444838 & 688186 & 3.301 & 3.5191 & TRN \\
\hline CHEMBL1455650 & 688186 & 4.5321 & 3.7247 & TST \\
\hline CHEMBL1441479 & 688186 & 3.301 & 4.1591 & TRN \\
\hline CHEMBL1389618 & 688186 & 3.301 & 3.6663 & TRN \\
\hline CHEMBL1430804 & 688186 & 3.301 & 4.1327 & TRN \\
\hline CHEMBL1613649 & 688186 & 4.5114 & 3.6559 & TRN \\
\hline CHEMBL1543731 & 688186 & 4.93 & 4.99 & TRN \\
\hline CHEMBL1537039 & 688186 & 3.301 & 3.7937 & TRN \\
\hline CHEMBL1569525 & 688186 & 4.3931 & 4.0879 & TST \\
\hline CHEMBL1597827 & 688186 & 3.301 & 4.5736 & TRN \\
\hline CHEMBL1518765 & 688186 & 4.8242 & 4.0341 & TRN \\
\hline CHEMBL1587339 & 688186 & 3.301 & 3.852 & TRN \\
\hline CHEMBL1981464 & 688186 & 4.5864 & 4.4685 & TRN \\
\hline CHEMBL1407234 & 688186 & 4.4994 & 4.1853 & TST \\
\hline CHEMBL1303446 & 688186 & 4.7708 & 3.7796 & TRN \\
\hline CHEMBL 3197628 & 688186 & 4.702 & 4.4752 & TRN \\
\hline CHEMBL1460315 & 688186 & 5.4112 & 4.6078 & TRN \\
\hline CHEMBL530049 & 688186 & 5.6655 & 6.1964 & TRN \\
\hline CHEMBL1588107 & 688186 & 3.301 & 3.6668 & TRN \\
\hline CHEMBL1353170 & 688186 & 3.301 & 4.6199 & TRN \\
\hline CHEMBL1589298 & 688186 & 4.5661 & 3.5228 & TRN \\
\hline CHEMBL1311740 & 688186 & 4.8948 & 3.9129 & TRN \\
\hline CHEMBL1369578 & 688186 & 4.7135 & 3.9256 & TST \\
\hline
\end{tabular}




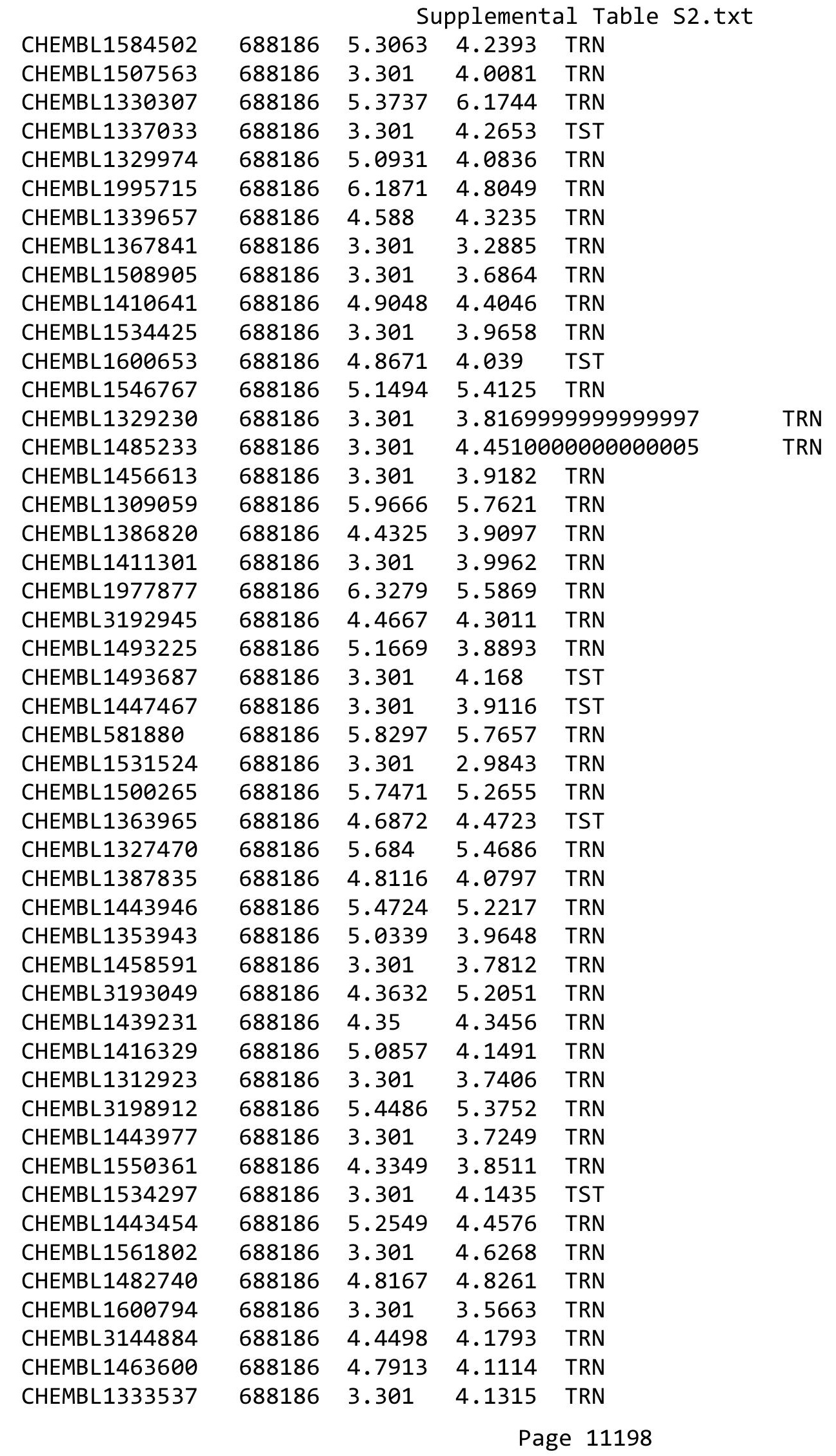




\begin{tabular}{|c|c|c|c|c|c|c|}
\hline \multicolumn{7}{|c|}{. } \\
\hline CHEMBL1585764 & 688186 & 4.8438 & 4.2226 & TRN & & \\
\hline CHEMBL1998521 & 688186 & 8.0 & 5.8837 & TRN & & \\
\hline CHEMBL578294 & 688186 & 4.9952 & 5.0782 & TRN & & \\
\hline CHEMBL1386783 & 688186 & 4.6572 & 3.641 & TRN & & \\
\hline CHEMBL1303416 & 688186 & 4.3063 & 3.9584 & TST & & \\
\hline CHEMBL1460030 & 688186 & 3.301 & 3.2173 & TRN & & \\
\hline CHEMBL1303653 & 688186 & 5.1599 & 4.13899 & 9999999999 & TRN & \\
\hline CHEMBL1420930 & 688186 & 4.4487 & 3.6485 & TST & & \\
\hline CHEMBL1322646 & 688186 & 3.301 & 3.2123 & TRN & & \\
\hline CHEMBL1428407 & 688186 & 5.3161 & 4.1778 & TRN & & \\
\hline CHEMBL1439088 & 688186 & 3.301 & 3.9144 & TST & & \\
\hline CHEMBL1588513 & 688186 & 6.1871 & 5.9287 & TRN & & \\
\hline CHEMBL1198307 & 688186 & 5.9066 & 5.1008 & TRN & & \\
\hline CHEMBL1382202 & 688186 & 3.301 & 3.7503 & TRN & & \\
\hline CHEMBL1559391 & 688186 & 4.67899 & 79999999 & 3.8 & 00000000003 & TST \\
\hline CHEMBL1308075 & 688186 & 4.5897 & 4.1901 & TRN & & \\
\hline CHEMBL1577829 & 688186 & 5.1113 & 4.1968 & TRN & & \\
\hline CHEMBL1530274 & 688186 & 3.301 & 3.3072 & TRN & & \\
\hline CHEMBL1319643 & 688186 & 3.301 & 3.9354 & TRN & & \\
\hline CHEMBL1458249 & 688186 & 3.301 & 3.9707 & TST & & \\
\hline CHEMBL1308971 & 688186 & 4.5484 & 4.6114 & TRN & & \\
\hline CHEMBL1492092 & 688186 & 3.301 & 3.2685 & TRN & & \\
\hline CHEMBL3198852 & 688186 & 3.301 & 4.4695 & TRN & & \\
\hline CHEMBL3189342 & 688186 & 5.5058 & 5.6296 & TRN & & \\
\hline CHEMBL1604546 & 688186 & 5.2708 & 4.3216 & TST & & \\
\hline CHEMBL1450615 & 688186 & 5.699 & 5.407 & TRN & & \\
\hline CHEMBL1549557 & 688186 & 3.301 & 3.5377 & TST & & \\
\hline CHEMBL1382884 & 688186 & 6.1938 & 5.6001 & TRN & & \\
\hline CHEMBL1426762 & 688186 & 3.301 & 3.7861 & TRN & & \\
\hline CHEMBL1546738 & 688186 & 3.301 & 2.8056 & TRN & & \\
\hline CHEMBL1583898 & 688186 & 4.4598 & 4.1626 & TRN & & \\
\hline CHEMBL3208179 & 688186 & 5.2848 & 4.5418 & TRN & & \\
\hline CHEMBL1562029 & 688186 & 4.5613 & 4.3513 & TRN & & \\
\hline CHEMBL1566280 & 688186 & 4.8804 & 4.2154 & TST & & \\
\hline CHEMBL1599856 & 688186 & 3.301 & 3.8106 & TRN & & \\
\hline CHEMBL1503034 & 688186 & 4.9007 & 4.8274 & TRN & & \\
\hline CHEMBL1523690 & 688186 & 3.301 & 3.8282 & TRN & & \\
\hline CHEMBL1569989 & 688186 & 5.5086 & 5.9945 & TRN & & \\
\hline CHEMBL1607938 & 688186 & 4.4536 & 4.2301 & TRN & & \\
\hline CHEMBL1522247 & 688186 & 3.301 & 3.1883 & TRN & & \\
\hline CHEMBL1610834 & 688186 & 3.301 & 3.4549 & TRN & & \\
\hline CHEMBL1556805 & 688186 & 5.8239 & 5.7419 & TRN & & \\
\hline CHEMBL1323744 & 688186 & 4.9212 & 5.3257 & TRN & & \\
\hline CHEMBL1550957 & 688186 & 3.301 & 4.5908 & TRN & & \\
\hline CHEMBL1470019 & 688186 & 4.5018 & 3.601006 & 00000000004 & TRN & \\
\hline CHEMBL1993199 & 688186 & 3.301 & 3.9703 & TRN & & \\
\hline CHEMBL1312054 & 688186 & 3.301 & 3.6903 & TRN & & \\
\hline CHEMBL1593697 & 688186 & 3.301 & 4.503 & TST & & \\
\hline
\end{tabular}


Supplemental Table S2.txt

\begin{tabular}{|c|c|c|c|c|c|}
\hline CHEMBL1989852 & 688186 & 4.5222 & 4.3905 & TRN & \\
\hline CHEMBL1304356 & 688186 & 4.8216 & 4.5779 & TRN & \\
\hline CHEMBL1521671 & 688186 & 3.301 & 3.3038 & TRN & \\
\hline CHEMBL1453673 & 688186 & 4.7001 & 4.1498 & TRN & \\
\hline CHEMBL1391744 & 688186 & 3.301 & 4.4255 & TRN & \\
\hline CHEMBL533226 & 688186 & 5.8633 & 4.8277 & TRN & \\
\hline CHEMBL603024 & 688186 & 4.9539 & 4.5893 & TRN & \\
\hline CHEMBL3197991 & 688186 & 4.5781 & 4.69 & TRN & \\
\hline CHEMBL1427508 & 688186 & 5.0278 & 3.7504 & TRN & \\
\hline CHEMBL1384903 & 688186 & 3.301 & 3.7947 & TRN & \\
\hline CHEMBL 3144874 & 688186 & 3.301 & 4.2698 & TRN & \\
\hline CHEMBL1597489 & 688186 & 4.6302 & 3.8727 & TRN & \\
\hline CHEMBL1420396 & 688186 & 3.301 & 3.7945 & TRN & \\
\hline CHEMBL1256737 & 688186 & 4.9739 & 4.4894 & TST & \\
\hline CHEMBL1588020 & 688186 & 3.301 & 3.4271 & TRN & \\
\hline CHEMBL 3194133 & 688186 & 5.0937 & 4.3587 & TRN & \\
\hline CHEMBL1370927 & 688186 & 4.9248 & 4.2103 & TRN & \\
\hline CHEMBL1508296 & 688186 & 3.301 & 3.9289 & TRN & \\
\hline CHEMBL1555739 & 688186 & 4.8938 & 3.7023 & TRN & \\
\hline CHEMBL1305375 & 688186 & 4.6286 & 4.175 & TRN & \\
\hline CHEMBL1568173 & 688186 & 5.0794 & 3.2724 & TRN & \\
\hline CHEMBL1330925 & 688186 & 3.301 & 4.5563 & TST & \\
\hline CHEMBL1490707 & 688186 & 4.4901 & 4.5488 & TRN & \\
\hline CHEMBL1312320 & 688186 & 4.6098 & 4.0813 & TRN & \\
\hline CHEMBL1612714 & 688186 & 3.301 & 3.497 & TRN & \\
\hline CHEMBL1392145 & 688186 & 3.301 & 3.8834 & TRN & \\
\hline CHEMBL1427189 & 688186 & 4.3193 & 3.5536 & TRN & \\
\hline CHEMBL1306512 & 688186 & 3.301 & 3.7285 & TRN & \\
\hline CHEMBL1391118 & 688186 & 3.301 & 4.2197 & TST & \\
\hline CHEMBL1463614 & 688186 & 4.3633 & 4.2143 & TRN & \\
\hline CHEMBL1388953 & 688186 & 3.301 & 3.8753 & TRN & \\
\hline CHEMBL1509530 & 688186 & 3.301 & 3.6384 & TRN & \\
\hline CHEMBL 3210629 & 688186 & 3.301 & 4.5794 & TST & \\
\hline CHEMBL1581201 & 688186 & 3.301 & 4.4954 & TRN & \\
\hline CHEMBL1509559 & 688186 & 3.301 & 3.7854 & TST & \\
\hline CHEMBL 3190482 & 688186 & 4.4223 & 4.7325 & TRN & \\
\hline CHEMBL1989897 & 688186 & 6.4559 & 5.3308 & TRN & \\
\hline CHEMBL 3195240 & 688186 & 4.8674 & 4.5665 & TRN & \\
\hline CHEMBL 3211130 & 688186 & 3.301 & 4.316 & TRN & \\
\hline CHEMBL1608061 & 688186 & 3.301 & 4.0903 & TRN & \\
\hline CHEMBL1385616 & 688186 & 5.0675 & 4.7427 & TRN & \\
\hline CHEMBL1348018 & 688186 & 4.3371 & 4.1595 & TRN & \\
\hline CHEMBL1418974 & 688186 & 4.5619 & 4.5085 & TRN & \\
\hline CHEMBL1415720 & 688186 & 5.38399 & 99999999 & 995 & 4.9139 \\
\hline CHEMBL1566903 & 688186 & 4.4725 & 3.9079 & TST & \\
\hline CHEMBL1508538 & 688186 & 3.301 & 4.1078 & TRN & \\
\hline CHEMBL1300436 & 688186 & 3.301 & 3.5287 & TRN & \\
\hline CHEMBL1337416 & 688186 & 6.2218 & 6.6563 & TRN & \\
\hline
\end{tabular}

Page 11200 


\begin{tabular}{|c|c|c|c|c|}
\hline \multicolumn{5}{|c|}{ Supplemental Table S2.txt } \\
\hline CHEMBL1472126 & 688186 & 5.4609 & 5.3778 & TRN \\
\hline CHEMBL1418057 & 688186 & 3.301 & 3.6546 & TST \\
\hline CHEMBL3193964 & 688186 & 4.8404 & 4.6581 & TST \\
\hline CHEMBL1533590 & 688186 & 4.6101 & 4.462 & TRN \\
\hline CHEMBL1602059 & 688186 & 3.301 & 4.1366 & TRN \\
\hline CHEMBL3196191 & 688186 & 5.4828 & 5.2915 & TRN \\
\hline CHEMBL1299474 & 688186 & 3.301 & 3.4653 & TRN \\
\hline CHEMBL1542959 & 688186 & 3.301 & 4.2274 & TRN \\
\hline CHEMBL1517637 & 688186 & 4.6895 & 3.965 & TRN \\
\hline CHEMBL139935 & 688186 & 4.5163 & 4.9263 & TRN \\
\hline CHEMBL1365456 & 688186 & 4.5913 & 4.5389 & TRN \\
\hline CHEMBL1491847 & 688186 & 5.4841 & 4.9829 & TRN \\
\hline CHEMBL3195334 & 688186 & 4.9492 & 3.8269 & TST \\
\hline CHEMBL1528425 & 688186 & 4.9404 & 4.4138 & TRN \\
\hline CHEMBL1498430 & 688186 & 4.863 & 4.0375 & TST \\
\hline CHEMBL1462270 & 688186 & 3.301 & 3.6888 & TRN \\
\hline CHEMBL 2004776 & 688186 & 3.301 & 4.2874 & TRN \\
\hline CHEMBL1577165 & 688186 & 4.8074 & 4.5917 & TRN \\
\hline CHEMBL1439925 & 688186 & 4.3975 & 3.7327 & TRN \\
\hline CHEMBL1581833 & 688186 & 3.301 & 3.8473 & TRN \\
\hline CHEMBL1381238 & 688186 & 3.301 & 3.912 & TRN \\
\hline CHEMBL3196837 & 688186 & 3.301 & 4.9598 & TRN \\
\hline CHEMBL1563042 & 688186 & 3.301 & 4.3721 & TST \\
\hline CHEMBL1599520 & 688186 & 5.1481 & 4.1873 & TRN \\
\hline CHEMBL1594618 & 688186 & 3.301 & 4.1571 & TRN \\
\hline CHEMBL1388870 & 688186 & 3.301 & 3.6609 & TRN \\
\hline CHEMBL1306095 & 688186 & 3.301 & 3.6007 & TRN \\
\hline CHEMBL309016 & 688186 & 4.8993 & 4.6549 & TRN \\
\hline CHEMBL1454171 & 688186 & 4.4284 & 3.9284 & TST \\
\hline CHEMBL68997 & 688186 & 3.301 & 4.2869 & TRN \\
\hline CHEMBL1305411 & 688186 & 3.301 & 4.1507 & TRN \\
\hline CHEMBL1534924 & 688186 & 3.301 & 3.7742 & TRN \\
\hline CHEMBL1459734 & 688186 & 5.5528 & 4.5587 & TRN \\
\hline CHEMBL1443834 & 688186 & 4.7192 & 4.4604 & TRN \\
\hline CHEMBL1600351 & 688186 & 3.301 & 3.5964 & TRN \\
\hline CHEMBL1399035 & 688186 & 5.0768 & 4.89 & TRN \\
\hline CHEMBL1594926 & 688186 & 4.6694 & 4.5978 & TRN \\
\hline CHEMBL1302097 & 688186 & 3.301 & 3.8983 & TRN \\
\hline CHEMBL1342436 & 688186 & 4.9957 & 4.7603 & TST \\
\hline CHEMBL589715 & 688186 & 5.0872 & 4.1253 & TRN \\
\hline CHEMBL1350225 & 688186 & 4.7836 & 3.5384 & TRN \\
\hline CHEMBL3196813 & 688186 & 5.4271 & 5.0462 & TRN \\
\hline CHEMBL1386522 & 688186 & 3.301 & 4.5817 & TRN \\
\hline CHEMBL3213876 & 688186 & 4.9176 & 4.8921 & TRN \\
\hline CHEMBL1597103 & 688186 & 4.3345 & 3.5573 & TRN \\
\hline CHEMBL1595936 & 688186 & 4.6265 & 4.6925 & TRN \\
\hline CHEMBL1545064 & 688186 & 4.6368 & 4.1171 & TRN \\
\hline CHEMBL410533 & 688186 & 3.301 & 3.7809 & TRN \\
\hline
\end{tabular}




\begin{tabular}{|c|c|c|c|c|c|}
\hline & & \multicolumn{4}{|c|}{ Supplemental Table S2.txt } \\
\hline CHEMBL1374594 & 688186 & 3.301 & 3.82 & TRN & \\
\hline CHEMBL1607366 & 688186 & 3.301 & 3.8265 & TRN & \\
\hline CHEMBL1506505 & 688186 & 5.1046 & 4.2566 & TRN & \\
\hline CHEMBL1608736 & 688186 & 3.301 & 3.2843 & TRN & \\
\hline CHEMBL1302383 & 688186 & 3.301 & 4.3856 & TRN & \\
\hline CHEMBL1454566 & 688186 & 3.301 & 3.9058 & TST & \\
\hline CHEMBL146525 & 688186 & 5.3716 & 4.5295 & TRN & \\
\hline CHEMBL1443478 & 688186 & 4.8914 & 3.9855 & TRN & \\
\hline CHEMBL1989760 & 688186 & 3.301 & 4.3966 & TRN & \\
\hline CHEMBL1387744 & 688186 & 3.301 & 3.7479 & TRN & \\
\hline CHEMBL1460004 & 688186 & 5.7959 & 5.4299 & TRN & \\
\hline CHEMBL1463624 & 688186 & 4.9017 & 3.6373 & TRN & \\
\hline CHEMBL1338237 & 688186 & 3.301 & 4.2745 & TRN & \\
\hline CHEMBL1344363 & 688186 & 3.301 & 3.5565 & TST & \\
\hline CHEMBL1487183 & 688186 & 5.7212 & 5.2461 & TST & \\
\hline CHEMBL1503390 & 688186 & 3.301 & 4.5456 & TST & \\
\hline CHEMBL1530726 & 688186 & 3.301 & 3.6949 & TRN & \\
\hline CHEMBL1610747 & 688186 & 3.301 & 3.1967 & TST & \\
\hline CHEMBL1548109 & 688186 & 5.0467 & 4.8116 & TRN & \\
\hline CHEMBL1605220 & 688186 & 3.301 & 4.0505 & TST & \\
\hline CHEMBL1492585 & 688186 & 6.1938 & 6.1016 & TRN & \\
\hline CHEMBL1588151 & 688186 & 3.301 & 3.7338 & TST & \\
\hline CHEMBL1337078 & 688186 & 3.301 & 3.7606 & TRN & \\
\hline CHEMBL1242180 & 688186 & 6.5229 & 6.2194 & TRN & \\
\hline CHEMBL3198517 & 688186 & 4.3223 & 3.85100 & 00000000004 & TRN \\
\hline CHEMBL1505615 & 688186 & 3.301 & 3.6131 & TRN & \\
\hline CHEMBL1332241 & 688186 & 4.7809 & 4.1129 & TST & \\
\hline CHEMBL1330068 & 688186 & 4.6724 & 4.3774 & TRN & \\
\hline CHEMBL1496073 & 688186 & 3.301 & 4.2478 & TRN & \\
\hline CHEMBL1373678 & 688186 & 4.6003 & 3.8608 & TRN & \\
\hline CHEMBL1428763 & 688186 & 3.301 & 3.4692 & TRN & \\
\hline CHEMBL1363558 & 688186 & 3.301 & 3.6032 & TRN & \\
\hline CHEMBL2359911 & 688186 & 5.8125 & 5.7919 & TRN & \\
\hline CHEMBL1387155 & 688186 & 4.5146 & 3.6771 & TRN & \\
\hline CHEMBL3192402 & 688186 & 4.6254 & 4.8138 & TRN & \\
\hline CHEMBL1345584 & 688186 & 3.301 & 4.0312 & TRN & \\
\hline CHEMBL1321972 & 688186 & 4.5857 & 3.6401 & TRN & \\
\hline CHEMBL1490728 & 688186 & 4.6415 & 4.6022 & TRN & \\
\hline CHEMBL3194704 & 688186 & 4.76699 & 99999999 & 4.8125 & TRN \\
\hline CHEMBL123810 & 688186 & 3.301 & 4.5231 & TRN & \\
\hline CHEMBL3195409 & 688186 & 5.3862 & 4.3278 & TRN & \\
\hline CHEMBL3191653 & 688186 & 3.301 & 4.3445 & TRN & \\
\hline CHEMBL1428566 & 688186 & 5.1959 & 4.5929 & TRN & \\
\hline CHEMBL600778 & 688186 & 6.5528 & 6.5368 & TRN & \\
\hline CHEMBL1563323 & 688186 & 5.1512 & 4.2498 & TRN & \\
\hline CHEMBL1542886 & 688186 & 4.7077 & 4.1913 & TRN & \\
\hline CHEMBL1429132 & 688186 & 3.301 & 3.9173 & TRN & \\
\hline CHEMBL1577606 & 688186 & 5.4841 & 4.1093 & TRN & \\
\hline
\end{tabular}

Page 11202 


\begin{tabular}{|c|c|c|c|c|}
\hline \multicolumn{5}{|c|}{ Supplemental Tab. } \\
\hline CHEMBL1378959 & 688186 & 4.3656 & 3.7542 & TRN \\
\hline CHEMBL417727 & 688186 & 5.6517 & 5.0682 & TRN \\
\hline CHEMBL1456132 & 688186 & 3.301 & 3.8271 & TRN \\
\hline CHEMBL1522556 & 688186 & 3.301 & 4.0934 & TRN \\
\hline CHEMBL348267 & 688186 & 3.301 & 4.0288 & TRN \\
\hline CHEMBL1996730 & 688186 & 6.3768 & 5.9845 & TRN \\
\hline CHEMBL494325 & 688186 & 3.301 & 4.3227 & TRN \\
\hline CHEMBL1469579 & 688186 & 4.765 & 4.6192 & TRN \\
\hline CHEMBL1499432 & 688186 & 3.301 & 4.1242 & TST \\
\hline CHEMBL1480843 & 688186 & 4.4729 & 3.7533 & TST \\
\hline CHEMBL1597655 & 688186 & 5.4698 & 5.7681 & TRN \\
\hline CHEMBL1492219 & 688186 & 3.301 & 3.5909 & TRN \\
\hline CHEMBL1503513 & 688186 & 4.471 & 3.9181 & TST \\
\hline CHEMBL1974112 & 688186 & 3.301 & 3.7098 & TST \\
\hline CHEMBL1587572 & 688186 & 3.301 & 3.846 & TRN \\
\hline CHEMBL1324885 & 688186 & 4.5887 & 4.4081 & TRN \\
\hline CHEMBL1416618 & 688186 & 4.6289 & 4.3218 & TRN \\
\hline CHEMBL1527341 & 688186 & 5.6576 & 5.6609 & TRN \\
\hline CHEMBL1483585 & 688186 & 3.301 & 3.8474 & TRN \\
\hline CHEMBL1464731 & 688186 & 3.301 & 4.5217 & TRN \\
\hline CHEMBL1339554 & 688186 & 4.9248 & 4.2077 & TRN \\
\hline CHEMBL1346640 & 688186 & 4.5698 & 4.4808 & TRN \\
\hline CHEMBL1346518 & 688186 & 3.301 & 3.9067 & TRN \\
\hline CHEMBL3214119 & 688186 & 3.301 & 3.9761 & TST \\
\hline CHEMBL3196069 & 688186 & 3.301 & 3.7584 & TRN \\
\hline CHEMBL1538246 & 688186 & 4.9698 & 4.3919 & TRN \\
\hline CHEMBL1328328 & 688186 & 3.301 & 3.7676 & TRN \\
\hline CHEMBL1301299 & 688186 & 3.301 & 3.1851 & TRN \\
\hline CHEMBL1463692 & 688186 & 3.301 & 4.2757 & TRN \\
\hline CHEMBL1571161 & 688186 & 4.7523 & 4.6291 & TRN \\
\hline CHEMBL1457008 & 688186 & 4.9801 & 3.9843 & TRN \\
\hline CHEMBL1413610 & 688186 & 4.5124 & 3.7588 & TRN \\
\hline CHEMBL1084441 & 688186 & 4.7022 & 4.0896 & TRN \\
\hline CHEMBL1384157 & 688186 & 4.4227 & 3.5436 & TST \\
\hline CHEMBL1454812 & 688186 & 3.301 & 3.2055 & TRN \\
\hline CHEMBL1413155 & 688186 & 3.301 & 3.5845 & TRN \\
\hline CHEMBL1422849 & 688186 & 5.7496 & 5.3258 & TRN \\
\hline CHEMBL 3189889 & 688186 & 3.301 & 4.0464 & TRN \\
\hline CHEMBL1562041 & 688186 & 3.301 & 3.7899 & TRN \\
\hline CHEMBL1422928 & 688186 & 3.301 & 4.2748 & TRN \\
\hline CHEMBL1519664 & 688186 & 3.301 & 4.1697 & TRN \\
\hline CHEMBL1980018 & 688186 & 5.3851 & 4.4064 & TRN \\
\hline CHEMBL1490843 & 688186 & 3.301 & 4.1713 & TRN \\
\hline CHEMBL1300831 & 688186 & 5.2958 & 4.5375 & TST \\
\hline CHEMBL1325192 & 688186 & 5.585 & 5.4653 & TRN \\
\hline CHEMBL1483986 & 688186 & 3.301 & 3.758 & TRN \\
\hline CHEMBL1486366 & 688186 & 5.3072 & 4.7549 & TRN \\
\hline CHEMBL1340843 & 688186 & 3.301 & 3.9481 & TRN \\
\hline
\end{tabular}




\begin{tabular}{|c|c|c|c|c|c|c|}
\hline \multirow[b]{2}{*}{ CHEMBL1340724 } & & \multicolumn{5}{|c|}{ Supplemental Table S2.txt } \\
\hline & 688186 & 4.6647 & 3.8048 & TRN & & \\
\hline CHEMBL1470835 & 688186 & 4.7027 & 4.4011 & TST & & \\
\hline CHEMBL1410381 & 688186 & 4.3855 & 5.021 & TRN & & \\
\hline CHEMBL1541391 & 688186 & 4.3463 & 4.459 & TRN & & \\
\hline CHEMBL1301334 & 688186 & 3.301 & 3.2212 & TRN & & \\
\hline CHEMBL1326404 & 688186 & 4.60800 & 00000000 & 905 & 3.7228 & TRN \\
\hline CHEMBL601768 & 688186 & 6.4202 & 6.515 & TRN & & \\
\hline CHEMBL1348582 & 688186 & 4.9965 & 5.3431 & TRN & & \\
\hline CHEMBL587892 & 688186 & 4.7878 & 4.8289 & TRN & & \\
\hline CHEMBL1329197 & 688186 & 3.301 & 4.1531 & TRN & & \\
\hline CHEMBL1578886 & 688186 & 3.301 & 3.6725 & TRN & & \\
\hline CHEMBL1413203 & 688186 & 3.301 & 3.8999 & TRN & & \\
\hline CHEMBL 209101 & 688186 & 3.301 & 3.5799 & TRN & & \\
\hline CHEMBL1338743 & 688186 & 4.3984 & 4.1793 & TRN & & \\
\hline CHEMBL1390145 & 688186 & 4.5161 & 3.6679 & TRN & & \\
\hline CHEMBL1580989 & 688186 & 4.3922 & 4.0311 & TRN & & \\
\hline CHEMBL1335804 & 688186 & 4.5166 & 3.8384 & TRN & & \\
\hline CHEMBL1200567 & 688186 & 4.5605 & 4.7842 & TST & & \\
\hline CHEMBL1594766 & 688186 & 5.2411 & 4.3076 & TRN & & \\
\hline CHEMBL1528900 & 688186 & 3.301 & 3.878 & TRN & & \\
\hline CHEMBL1449995 & 688186 & 4.4991 & 3.9006 & TRN & & \\
\hline CHEMBL1468601 & 688186 & 3.301 & 3.9148 & TRN & & \\
\hline CHEMBL1438751 & 688186 & 3.301 & 3.8205 & TRN & & \\
\hline CHEMBL1411502 & 688186 & 3.301 & 3.5546 & TRN & & \\
\hline CHEMBL1461413 & 688186 & 4.6718 & 4.7299 & TST & & \\
\hline CHEMBL1556842 & 688186 & 3.301 & 3.7034 & TST & & \\
\hline CHEMBL1375174 & 688186 & 3.301 & 3.2888 & TRN & & \\
\hline CHEMBL1465833 & 688186 & 3.301 & 3.7518 & TRN & & \\
\hline CHEMBL1307716 & 688186 & 3.301 & 3.7647 & TST & & \\
\hline CHEMBL1383765 & 688186 & 3.301 & 3.9651 & TRN & & \\
\hline CHEMBL1971144 & 688186 & 5.6819 & 5.2942 & TRN & & \\
\hline CHEMBL1322516 & 688186 & 4.3618 & 3.8188 & TRN & & \\
\hline CHEMBL1505338 & 688186 & 3.301 & 3.9068 & TRN & & \\
\hline CHEMBL1501167 & 688186 & 5.8729 & 4.2236 & TRN & & \\
\hline CHEMBL1386656 & 688186 & 3.301 & 4.3248 & TRN & & \\
\hline CHEMBL1308322 & 688186 & 3.301 & 3.6724 & TRN & & \\
\hline CHEMBL1537440 & 688186 & 3.301 & 3.7612 & TRN & & \\
\hline CHEMBL1503699 & 688186 & 3.301 & 4.372 & TRN & & \\
\hline CHEMBL3192557 & 688186 & 4.6668 & 4.7874 & TRN & & \\
\hline CHEMBL1497284 & 688186 & 3.301 & 3.2848 & TRN & & \\
\hline CHEMBL241657 & 688186 & 4.5127 & 3.5615 & TST & & \\
\hline CHEMBL1309806 & 688186 & 3.301 & 3.8077 & TRN & & \\
\hline CHEMBL1322002 & 688186 & 4.3566 & 3.6658 & TRN & & \\
\hline CHEMBL586135 & 688186 & 6.2076 & 6.4829 & TRN & & \\
\hline CHEMBL584269 & 688186 & 5.1844 & 5.105 & TRN & & \\
\hline CHEMBL1543939 & 688186 & 3.301 & 4.1211 & TST & & \\
\hline CHEMBL1527459 & 688186 & 3.301 & 3.4829 & TRN & & \\
\hline CHEMBL1310721 & 688186 & 3.301 & 4.0325 & TRN & & \\
\hline
\end{tabular}




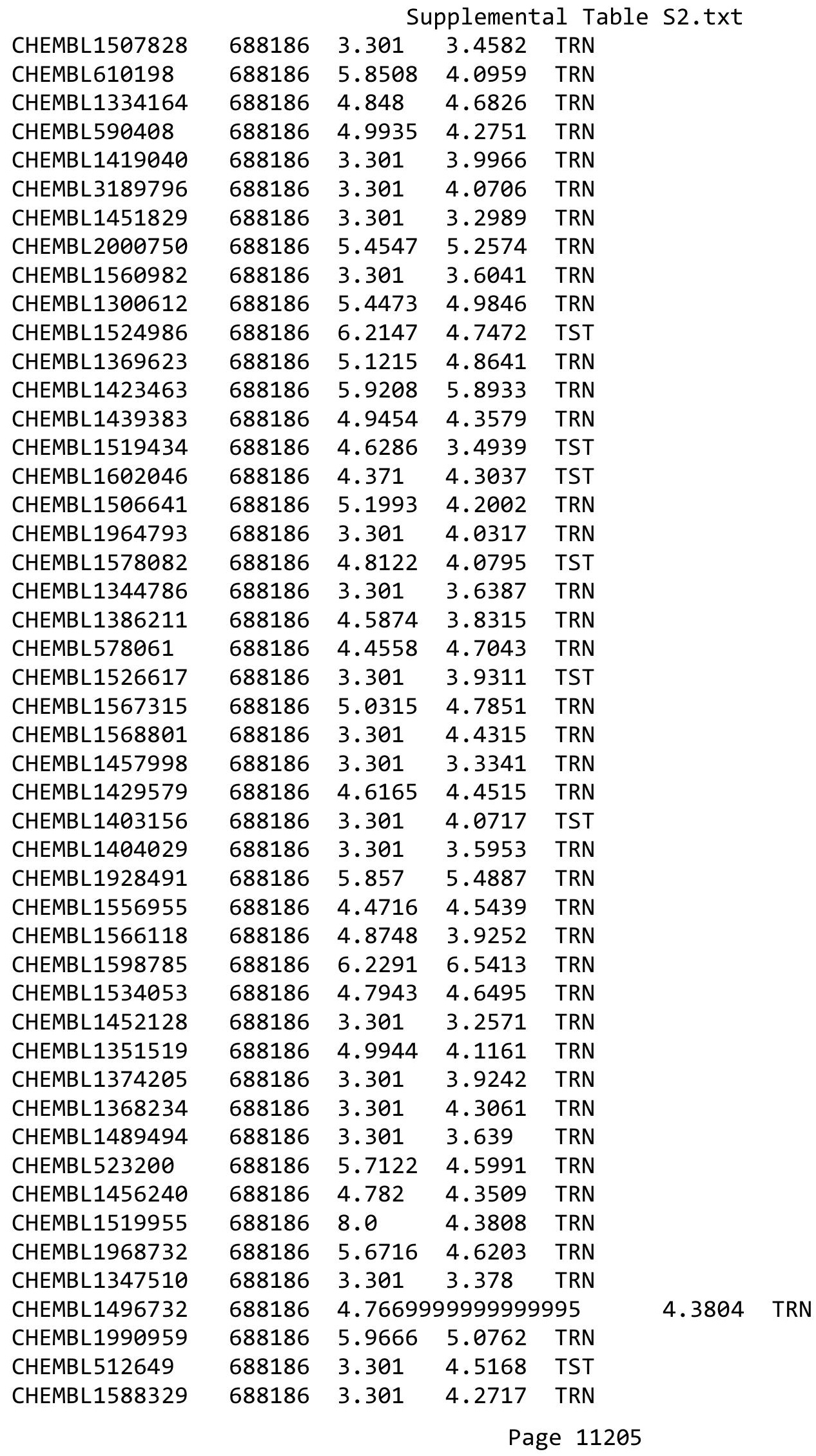




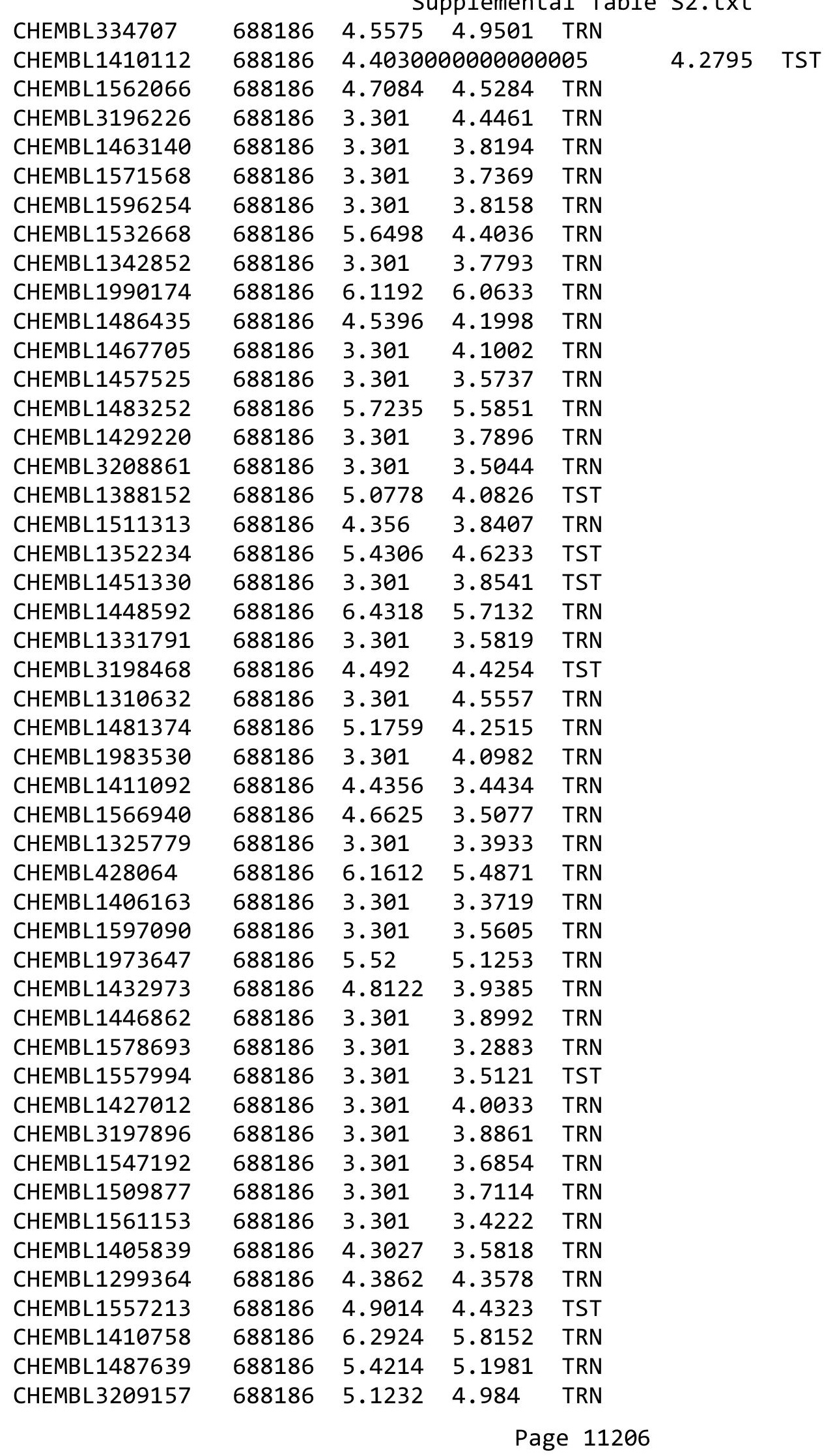





\begin{tabular}{|c|c|c|c|c|c|}
\hline & & & & & \\
\hline CHEMBL67311 & 688186 & 4.4414 & 4.0166 & TST & \\
\hline CHEMBL1335844 & 688186 & 5.2716 & 4.5323 & TRN & \\
\hline CHEMBL1351638 & 688186 & 3.301 & 4.0713 & TRN & \\
\hline CHEMBL1365431 & 688186 & 3.301 & 3.9101 & TRN & \\
\hline CHEMBL1346468 & 688186 & 5.2596 & 5.7554 & TRN & \\
\hline CHEMBL1425646 & 688186 & 3.301 & 4.0472 & TRN & \\
\hline CHEMBL1318099 & 688186 & 3.301 & 4.1589 & TST & \\
\hline CHEMBL1431928 & 688186 & 5.3507 & 4.2434 & TRN & \\
\hline CHEMBL1492073 & 688186 & 3.301 & 3.4012 & TRN & \\
\hline CHEMBL1304103 & 688186 & 3.301 & 4.0371 & TRN & \\
\hline CHEMBL1559713 & 688186 & 4.8147 & 3.786 & TST & \\
\hline CHEMBL1391455 & 688186 & 3.301 & 3.9142 & TRN & \\
\hline CHEMBL1367363 & 688186 & 3.301 & 3.5723 & TRN & \\
\hline CHEMBL1337851 & 688186 & 3.301 & 3.64600 & 30000000004 & TRN \\
\hline CHEMBL1399453 & 688186 & 3.301 & 3.1695 & TRN & \\
\hline CHEMBL1360478 & 688186 & 3.301 & 4.0807 & TRN & \\
\hline CHEMBL1503359 & 688186 & 5.3161 & 4.57100 & $\partial 000000001$ & TRN \\
\hline CHEMBL1325688 & 688186 & 3.301 & 3.8079 & TRN & \\
\hline CHEMBL1522100 & 688186 & 4.4911 & 3.7256 & TST & \\
\hline CHEMBL1503446 & 688186 & 3.301 & 4.439 & TRN & \\
\hline CHEMBL3191443 & 688186 & 5.4647 & 4.9744 & TRN & \\
\hline CHEMBL89445 & 688186 & 6.3468 & 5.9714 & TRN & \\
\hline CHEMBL1493816 & 688186 & 3.301 & 3.536 & TRN & \\
\hline CHEMBL1501311 & 688186 & 3.301 & 4.2479 & TRN & \\
\hline CHEMBL1528893 & 688186 & 3.301 & 3.8736 & TRN & \\
\hline CHEMBL1418937 & 688186 & 4.3985 & 3.8887 & TRN & \\
\hline CHEMBL1556917 & 688186 & 3.301 & 4.0885 & TRN & \\
\hline CHEMBL1330913 & 688186 & 3.301 & 3.6762 & TST & \\
\hline CHEMBL1600947 & 688186 & 3.301 & 4.1081 & TRN & \\
\hline CHEMBL1557948 & 688186 & 3.301 & 4.0779 & TRN & \\
\hline CHEMBL327035 & 688186 & 4.7921 & 3.8712 & TRN & \\
\hline CHEMBL1537189 & 688186 & 3.301 & 3.7812 & TRN & \\
\hline CHEMBL1409733 & 688186 & 3.301 & 3.6168 & TRN & \\
\hline CHEMBL3193515 & 688186 & 4.8742 & 4.7759 & TRN & \\
\hline CHEMBL1522007 & 688186 & 5.5784 & 4.6884 & TRN & \\
\hline CHEMBL1337086 & 688186 & 3.301 & 3.5484 & TRN & \\
\hline CHEMBL531322 & 688186 & 4.8791 & 4.65300 & 00000000005 & TRN \\
\hline CHEMBL3145049 & 688186 & 4.34699 & 99999999 & 4.103 & TRN \\
\hline CHEMBL1469091 & 688186 & 4.9212 & 4.0831 & TRN & \\
\hline CHEMBL1485442 & 688186 & 4.8353 & 4.2331 & TRN & \\
\hline CHEMBL1386050 & 688186 & 3.301 & 3.9759 & TRN & \\
\hline CHEMBL1509380 & 688186 & 5.6882 & 5.9507 & TRN & \\
\hline CHEMBL1483235 & 688186 & 5.3565 & 5.7321 & TRN & \\
\hline CHEMBL3197750 & 688186 & 3.301 & 4.878 & TRN & \\
\hline CHEMBL1484885 & 688186 & 3.301 & 3.8201 & TRN & \\
\hline CHEMBL1454726 & 688186 & 4.3942 & 3.37399 & 99999999997 & TRN \\
\hline CHEMBL1609279 & 688186 & 3.301 & 3.8782 & TRN & \\
\hline CHEMBL1482009 & 688186 & 4.4726 & 3.7402 & TST & \\
\hline
\end{tabular}




\begin{tabular}{|c|c|c|c|c|c|}
\hline & & \multicolumn{4}{|c|}{ Supplemental Table s2.txt } \\
\hline CHEMBL1342576 & 688186 & 3.301 & 3.9929 & TRN & \\
\hline CHEMBL601547 & 688186 & 5.5406 & 4.9545 & TRN & \\
\hline CHEMBL1303508 & 688186 & 4.585 & 4.2457 & TRN & \\
\hline CHEMBL1459534 & 688186 & 3.301 & 3.76800 & 00000000002 & TST \\
\hline CHEMBL1568848 & 688186 & 5.5528 & 5.4686 & TRN & \\
\hline CHEMBL1342468 & 688186 & 3.301 & 3.7803 & TRN & \\
\hline CHEMBL1332756 & 688186 & 6.3098 & 6.1569 & TRN & \\
\hline CHEMBL1338862 & 688186 & 3.301 & 3.7319 & TRN & \\
\hline CHEMBL1505584 & 688186 & 3.301 & 3.6746 & TRN & \\
\hline CHEMBL582980 & 688186 & 5.1198 & 4.8293 & TRN & \\
\hline CHEMBL3191273 & 688186 & 4.6409 & 5.1686 & TRN & \\
\hline CHEMBL1566545 & 688186 & 3.301 & 4.0964 & TST & \\
\hline CHEMBL1500801 & 688186 & 4.431 & 3.3212 & TRN & \\
\hline CHEMBL1519239 & 688186 & 5.8097 & 4.7851 & TRN & \\
\hline CHEMBL1535919 & 688186 & 4.8768 & 3.9529 & TRN & \\
\hline CHEMBL1351148 & 688186 & 3.301 & 3.4647 & TRN & \\
\hline CHEMBL1579433 & 688186 & 3.301 & 3.2536 & TRN & \\
\hline CHEMBL1461481 & 688186 & 3.301 & 3.9011 & TRN & \\
\hline CHEMBL1484972 & 688186 & 5.3089 & 4.2334 & TRN & \\
\hline CHEMBL1392636 & 688186 & 3.301 & 4.1104 & TRN & \\
\hline CHEMBL1470996 & 688186 & 4.3385 & 3.9986 & TRN & \\
\hline CHEMBL1595759 & 688186 & 5.0182 & 4.188 & TRN & \\
\hline CHEMBL512366 & 688186 & 4.8239 & 4.058 & TRN & \\
\hline CHEMBL1470080 & 688186 & 3.301 & 3.7094 & TRN & \\
\hline CHEMBL1557585 & 688186 & 4.5022 & 3.5571 & TRN & \\
\hline CHEMBL1534598 & 688186 & 4.4342 & 3.4386 & TRN & \\
\hline CHEMBL1388711 & 688186 & 3.301 & 4.1284 & TRN & \\
\hline CHEMBL1582448 & 688186 & 4.3285 & 4.7123 & TRN & \\
\hline CHEMBL19954 & 688186 & 5.8962 & 5.1542 & TST & \\
\hline CHEMBL1467637 & 688186 & 3.301 & 4.0091 & TRN & \\
\hline CHEMBL1419082 & 688186 & 5.5834 & 3.9578 & TRN & \\
\hline CHEMBL1537795 & 688186 & 3.301 & 3.7438 & TRN & \\
\hline CHEMBL1509804 & 688186 & 5.3143 & 4.4325 & TRN & \\
\hline CHEMBL1375583 & 688186 & 3.301 & 3.9891 & TST & \\
\hline CHEMBL1502014 & 688186 & 5.8928 & 5.1313 & TST & \\
\hline CHEMBL1586466 & 688186 & 3.301 & 3.7306 & TRN & \\
\hline CHEMBL1319848 & 688186 & 4.5168 & 4.0273 & TRN & \\
\hline CHEMBL1972844 & 688186 & 3.301 & 4.1182 & TST & \\
\hline CHEMBL355159 & 688186 & 3.301 & 4.0802 & TRN & \\
\hline CHEMBL1325384 & 688186 & 3.301 & 3.4587 & TRN & \\
\hline CHEMBL261692 & 688186 & 3.301 & 4.0217 & TST & \\
\hline CHEMBL1556766 & 688186 & 3.301 & 4.133 & TST & \\
\hline CHEMBL1611743 & 688186 & 3.301 & 3.7007 & TRN & \\
\hline CHEMBL1582674 & 688186 & 4.3313 & 3.8441 & TST & \\
\hline CHEMBL1402267 & 688186 & 4.6584 & 4.6127 & TRN & \\
\hline CHEMBL3209857 & 688186 & 3.301 & 4.5096 & TRN & \\
\hline CHEMBL1993401 & 688186 & 4.9674 & 4.0913 & TRN & \\
\hline CHEMBL1520233 & 688186 & 3.301 & 3.755 & TRN & \\
\hline
\end{tabular}




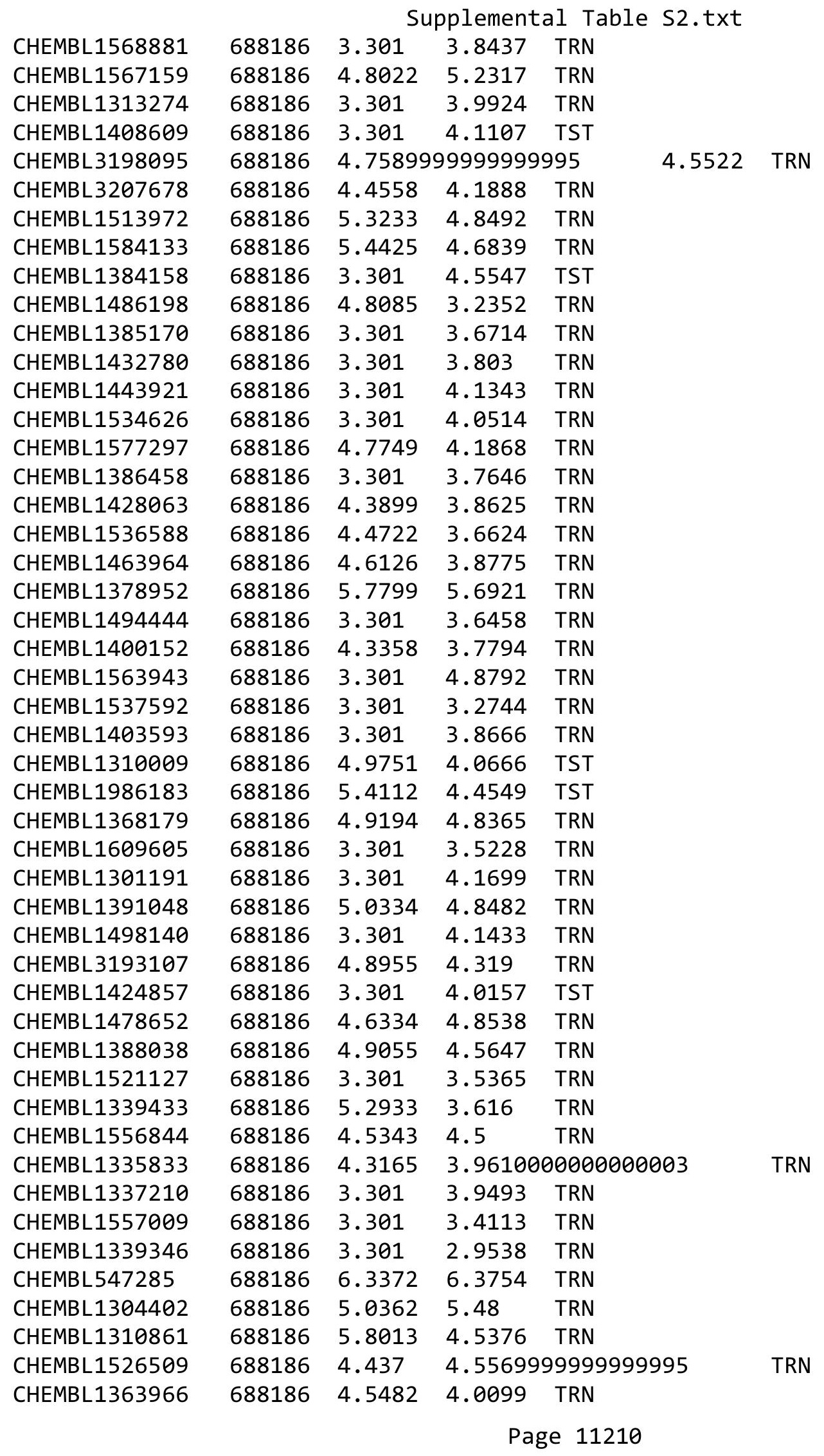




\begin{tabular}{|c|c|c|c|c|c|}
\hline \multicolumn{6}{|c|}{ Supplemental Table S2.txt } \\
\hline CHEMBL1495290 & 688186 & 3.301 & 4.2748 & TRN & \\
\hline CHEMBL1345528 & 688186 & 3.301 & 3.6918 & TRN & \\
\hline CHEMBL 3190974 & 688186 & 5.5591 & 4.8807 & TRN & \\
\hline CHEMBL1382247 & 688186 & 3.301 & 3.2654 & TRN & \\
\hline CHEMBL1309890 & 688186 & 5.1931 & 5.4007 & TRN & \\
\hline CHEMBL1527520 & 688186 & 4.6457 & 4.2984 & TST & \\
\hline CHEMBL1499792 & 688186 & 6.4318 & 6.5814 & TRN & \\
\hline CHEMBL1870697 & 688186 & 4.4141 & 4.1135 & TRN & \\
\hline CHEMBL1569755 & 688186 & 3.301 & 4.4721 & TRN & \\
\hline CHEMBL3189832 & 688186 & 4.6615 & 4.5447 & TST & \\
\hline CHEMBL1360352 & 688186 & 3.301 & 3.4534 & TST & \\
\hline CHEMBL1599463 & 688186 & 3.301 & 3.9069 & TRN & \\
\hline CHEMBL1432427 & 688186 & 4.9194 & 5.3534 & TRN & \\
\hline CHEMBL1379951 & 688186 & 3.301 & 4.2617 & TRN & \\
\hline CHEMBL 1507560 & 688186 & 3.301 & 4.0312 & TRN & \\
\hline CHEMBL1537583 & 688186 & 3.301 & 3.6936 & TRN & \\
\hline CHEMBL1492374 & 688186 & 3.301 & 3.486 & TRN & \\
\hline CHEMBL 32793 & 688186 & 4.3822 & 4.1807 & TRN & \\
\hline CHEMBL1432186 & 688186 & 4.7047 & 4.0057 & TRN & \\
\hline CHEMBL1465040 & 688186 & 5.8962 & 4.41100 & 00000000005 & TRN \\
\hline CHEMBL3209342 & 688186 & 4.3314 & 4.3525 & TRN & \\
\hline CHEMBL 3199549 & 688186 & 5.1555 & 4.3938 & TRN & \\
\hline CHEMBL1490845 & 688186 & 4.4261 & 4.3268 & TRN & \\
\hline CHEMBL1467519 & 688186 & 3.301 & 4.1146 & TRN & \\
\hline CHEMBL1490757 & 688186 & 3.301 & 3.4567 & TST & \\
\hline CHEMBL1499652 & 688186 & 3.301 & 3.6809 & TRN & \\
\hline CHEMBL1581682 & 688186 & 4.4653 & 4.1514 & TRN & \\
\hline CHEMBL1556209 & 688186 & 3.301 & 3.5865 & TST & \\
\hline CHEMBL1339327 & 688186 & 3.301 & 3.8062 & TRN & \\
\hline CHEMBL601757 & 688186 & 5.9136 & 5.7873 & TST & \\
\hline CHEMBL1560562 & 688186 & 3.301 & 3.3488 & TRN & \\
\hline CHEMBL1606386 & 688186 & 4.7673 & 4.3641 & TRN & \\
\hline CHEMBL1488177 & 688186 & 3.301 & 3.9991 & TRN & \\
\hline CHEMBL1989372 & 688186 & 3.301 & 4.5305 & TRN & \\
\hline CHEMBL1341865 & 688186 & 4.7438 & 4.3575 & TRN & \\
\hline CHEMBL1520777 & 688186 & 5.8697 & 5.5981 & TRN & \\
\hline CHEMBL1338677 & 688186 & 5.7721 & 4.7212 & TRN & \\
\hline CHEMBL1461972 & 688186 & 4.8024 & 4.3148 & TRN & \\
\hline CHEMBL1366942 & 688186 & 6.585 & 5.3987 & TRN & \\
\hline CHEMBL1578474 & 688186 & 8.0 & 3.8278 & TRN & \\
\hline CHEMBL1544407 & 688186 & 4.5913 & 3.9536 & TRN & \\
\hline CHEMBL1459764 & 688186 & 5.0685 & 4.4625 & TRN & \\
\hline CHEMBL3191200 & 688186 & 3.301 & 4.0149 & TRN & \\
\hline CHEMBL1524163 & 688186 & 3.301 & 3.7757 & TRN & \\
\hline CHEMBL1530420 & 688186 & 3.301 & 3.8969 & TRN & \\
\hline CHEMBL1432848 & 688186 & 4.3283 & 3.8079 & TRN & \\
\hline CHEMBL 1441738 & 688186 & 5.2269 & 4.0188 & TST & \\
\hline CHEMBL1404984 & 688186 & 3.301 & 3.8407 & TRN & \\
\hline
\end{tabular}




\begin{tabular}{|c|c|c|c|c|c|c|}
\hline & & \multicolumn{5}{|c|}{ Supplemental Table S2.txt } \\
\hline CHEMBL1525861 & 688186 & 3.301 & 3.5774 & TRN & & \\
\hline CHEMBL 3199870 & 688186 & 3.301 & 4.2287 & TST & & \\
\hline CHEMBL1524757 & 688186 & 3.301 & 3.3583 & TRN & & \\
\hline CHEMBL1367788 & 688186 & 3.301 & 3.4997 & TRN & & \\
\hline CHEMBL1600855 & 688186 & 6.1024 & 5.7753 & TST & & \\
\hline CHEMBL1543640 & 688186 & 3.301 & 4.3751 & TRN & & \\
\hline CHEMBL1482112 & 688186 & 3.301 & 3.353 & TRN & & \\
\hline CHEMBL1424729 & 688186 & 5.3344 & 4.6145 & TST & & \\
\hline CHEMBL1379561 & 688186 & 4.769 & 4.4833 & TRN & & \\
\hline CHEMBL3209306 & 688186 & 6.0915 & 5.5558 & TRN & & \\
\hline CHEMBL1569370 & 688186 & 3.301 & 3.8662 & TRN & & \\
\hline CHEMBL1419557 & 688186 & 4.5738 & 4.0606 & TRN & & \\
\hline CHEMBL1330096 & 688186 & 3.301 & 3.3751 & TRN & & \\
\hline CHEMBL1608783 & 688186 & 3.301 & 3.7379 & TRN & & \\
\hline CHEMBL1548492 & 688186 & 6.2147 & 6.2937 & TRN & & \\
\hline CHEMBL1541655 & 688186 & 3.301 & 3.0366 & TRN & & \\
\hline CHEMBL580918 & 688186 & 6.1079 & 7.0766 & TRN & & \\
\hline CHEMBL1508113 & 688186 & 4.3539 & 3.6362 & TRN & & \\
\hline CHEMBL1540231 & 688186 & 4.852 & 4.8647 & TST & & \\
\hline CHEMBL1442216 & 688186 & 3.301 & 3.0586 & TRN & & \\
\hline CHEMBL1601022 & 688186 & 3.301 & 3.8944 & TRN & & \\
\hline CHEMBL140425 & 688186 & 4.8242 & 4.9957 & TRN & & \\
\hline CHEMBL1535518 & 688186 & 3.301 & 3.3026 & TRN & & \\
\hline CHEMBL1391137 & 688186 & 3.301 & 3.877 & TRN & & \\
\hline CHEMBL1983839 & 688186 & 5.6478 & 5.0384 & TRN & & \\
\hline CHEMBL1589425 & 688186 & 5.7773 & 5.949 & TST & & \\
\hline CHEMBL1457915 & 688186 & 4.3947 & 4.3677 & TRN & & \\
\hline CHEMBL1373503 & 688186 & 4.3707 & 4.2724 & TRN & & \\
\hline CHEMBL1990646 & 688186 & 5.05399 & 79999999 & 99 & 4.0382 & TRN \\
\hline CHEMBL1479637 & 688186 & 4.6662 & 4.1021 & TRN & & \\
\hline CHEMBL3190186 & 688186 & 3.301 & 3.8355 & TRN & & \\
\hline CHEMBL1487309 & 688186 & 3.301 & 3.9183 & TRN & & \\
\hline CHEMBL1302321 & 688186 & 3.301 & 4.4671 & TRN & & \\
\hline CHEMBL1303038 & 688186 & 3.301 & 3.1358 & TRN & & \\
\hline CHEMBL1573504 & 688186 & 4.9296 & 4.3436 & TRN & & \\
\hline CHEMBL1522486 & 688186 & 5.4202 & 5.6507 & TRN & & \\
\hline CHEMBL1494925 & 688186 & 3.301 & 3.9708 & TRN & & \\
\hline CHEMBL1450635 & 688186 & 3.301 & 4.2246 & TST & & \\
\hline CHEMBL1466774 & 688186 & 3.301 & 3.9926 & TRN & & \\
\hline CHEMBL1574403 & 688186 & 3.301 & 3.5102 & TRN & & \\
\hline CHEMBL1585390 & 688186 & 5.4377 & 4.4115 & TRN & & \\
\hline CHEMBL1556349 & 688186 & 3.301 & 3.852 & TRN & & \\
\hline CHEMBL1528768 & 688186 & 4.4559 & 4.6873 & TRN & & \\
\hline CHEMBL1524381 & 688186 & 4.901 & 4.7735 & TRN & & \\
\hline CHEMBL482116 & 688186 & 4.9115 & 5.0995 & TRN & & \\
\hline CHEMBL1382827 & 688186 & 5.5406 & 4.1071 & TRN & & \\
\hline CHEMBL1489205 & 688186 & 3.301 & 4.1994 & TRN & & \\
\hline CHEMBL 206483 & 688186 & 3.301 & 3.6061 & TRN & & \\
\hline
\end{tabular}




\begin{tabular}{|c|c|c|c|c|c|c|}
\hline & & \multicolumn{5}{|c|}{ Supplemental Table S2.txt } \\
\hline CHEMBL1481601 & 688186 & 3.301 & 3.8829 & TST & & \\
\hline CHEMBL532641 & 688186 & 5.6459 & 5.0206 & TRN & & \\
\hline CHEMBL3207336 & 688186 & 4.6169 & 4.2351 & TRN & & \\
\hline CHEMBL1981840 & 688186 & 4.5006 & 4.3812 & TRN & & \\
\hline CHEMBL69612 & 688186 & 5.0424 & 4.6473 & TRN & & \\
\hline CHEMBL1511879 & 688186 & 5.1798 & 3.8778 & TRN & & \\
\hline CHEMBL1422726 & 688186 & 4.5979 & 4.5573 & TRN & & \\
\hline CHEMBL586602 & 688186 & 6.4318 & 7.0766 & TRN & & \\
\hline CHEMBL1499658 & 688186 & 4.8207 & 3.5274 & TRN & & \\
\hline CHEMBL3192605 & 688186 & 4.8486 & 5.0856 & TRN & & \\
\hline CHEMBL1429841 & 688186 & 4.5137 & 4.8821 & TRN & & \\
\hline CHEMBL1523670 & 688186 & 3.301 & 3.4605 & TRN & & \\
\hline CHEMBL1575285 & 688186 & 3.301 & 3.7792 & TRN & & \\
\hline CHEMBL1570760 & 688186 & 5.5302 & 4.4511 & TRN & & \\
\hline CHEMBL1565648 & 688186 & 3.301 & 3.8776 & TRN & & \\
\hline CHEMBL1549911 & 688186 & 4.6637 & 4.3645 & TST & & \\
\hline CHEMBL1532828 & 688186 & 5.7423 & 5.8569 & TRN & & \\
\hline CHEMBL1489995 & 688186 & 3.301 & 4.0722 & TRN & & \\
\hline CHEMBL1391333 & 688186 & 3.301 & 4.0989 & TRN & & \\
\hline CHEMBL1339544 & 688186 & 3.301 & 4.133 & TRN & & \\
\hline CHEMBL1363249 & 688186 & 5.0788 & 4.9385 & TRN & & \\
\hline CHEMBL 3145303 & 688186 & 6.2441 & 5.0488 & TRN & & \\
\hline CHEMBL1353889 & 688186 & 3.301 & 3.7375 & TST & & \\
\hline CHEMBL1486635 & 688186 & 3.301 & 4.1753 & TRN & & \\
\hline CHEMBL 2369277 & 688186 & 5.5361 & 4.6048 & TRN & & \\
\hline CHEMBL1974450 & 688186 & \multicolumn{3}{|c|}{5.327000000000001} & 4.7093 & TRN \\
\hline CHEMBL1323015 & 688186 & 3.301 & 3.7591 & TRN & & \\
\hline CHEMBL1471457 & 688186 & 3.301 & 4.0753 & TST & & \\
\hline CHEMBL1305982 & 688186 & 3.301 & 4.1685 & TRN & & \\
\hline CHEMBL1345969 & 688186 & 4.5207 & 3.8182 & TRN & & \\
\hline CHEMBL1485216 & 688186 & 4.6392 & 4.4361 & TRN & & \\
\hline CHEMBL51931 & 688186 & 5.0953 & 5.2402 & TRN & & \\
\hline CHEMBL 1403380 & 688186 & 4.9322 & 4.3078 & TRN & & \\
\hline CHEMBL461579 & 688186 & 6.3372 & \multicolumn{3}{|c|}{5.5760000000000005} & TRN \\
\hline CHEMBL1352062 & 688186 & 4.6979 & 3.6414 & TRN & & \\
\hline CHEMBL1391077 & 688186 & 4.4387 & 4.5071 & TRN & & \\
\hline CHEMBL3194943 & 688186 & 3.301 & 3.8436 & TRN & & \\
\hline CHEMBL3189712 & 688186 & 6.2924 & 5.3318 & TRN & & \\
\hline CHEMBL1447750 & 688186 & 4.4144 & 3.9943 & TRN & & \\
\hline CHEMBL1531670 & 688186 & 3.301 & 4.0767 & TRN & & \\
\hline CHEMBL1346707 & 688186 & 3.301 & 3.8804 & TRN & & \\
\hline CHEMBL1516420 & 688186 & 3.301 & 3.9116 & TRN & & \\
\hline CHEMBL429095 & 688186 & 5.0899 & 4.4321 & TRN & & \\
\hline CHEMBL3213353 & 688186 & 3.301 & 5.1389 & TRN & & \\
\hline CHEMBL1325908 & 688186 & 4.856 & 3.5876 & TRN & & \\
\hline CHEMBL1425701 & 688186 & 3.301 & 3.5539 & TRN & & \\
\hline CHEMBL1503204 & 688186 & 3.301 & 3.6211 & TST & & \\
\hline CHEMBL1344611 & 688186 & 4.521 & 4.1794 & TRN & & \\
\hline
\end{tabular}




\begin{tabular}{|c|c|c|c|c|}
\hline \multicolumn{5}{|c|}{ Supplemental Table s2.txt } \\
\hline CHEMBL1502185 & 688186 & 4.9965 & 4.3659 & TRN \\
\hline CHEMBL1327844 & 688186 & 4.5837 & 3.963 & TRN \\
\hline CHEMBL1516833 & 688186 & 3.301 & 3.6037 & TST \\
\hline CHEMBL1472406 & 688186 & 3.301 & 3.7319 & TRN \\
\hline CHEMBL1420730 & 688186 & 3.301 & 4.0839 & TRN \\
\hline CHEMBL1574145 & 688186 & 3.301 & 4.2552 & TRN \\
\hline CHEMBL1606572 & 688186 & 4.7513 & 3.7215 & TRN \\
\hline CHEMBL1492696 & 688186 & 5.0419 & 4.8355 & TRN \\
\hline CHEMBL 3197284 & 688186 & 4.4624 & 4.0827 & TST \\
\hline CHEMBL1596681 & 688186 & 6.3768 & 6.9544 & TRN \\
\hline CHEMBL1422113 & 688186 & 3.301 & 3.9608 & TRN \\
\hline CHEMBL1478496 & 688186 & 4.3106 & 4.0529 & TST \\
\hline CHEMBL1544694 & 688186 & 4.4083 & 4.6806 & TST \\
\hline CHEMBL1303741 & 688186 & 3.301 & 4.0655 & TRN \\
\hline CHEMBL1421737 & 688186 & 3.301 & 3.6824 & TRN \\
\hline CHEMBL1388892 & 688186 & 3.301 & 3.9754 & TRN \\
\hline CHEMBL1547409 & 688186 & 3.301 & 3.6239 & TRN \\
\hline CHEMBL1428562 & 688186 & 4.5574 & 3.8156 & TRN \\
\hline CHEMBL1452963 & 688186 & 5.2464 & 3.7352 & TRN \\
\hline CHEMBL1425521 & 688186 & 5.2381 & 4.5854 & TRN \\
\hline CHEMBL1604283 & 688186 & 4.4811 & 5.205 & TST \\
\hline CHEMBL3196606 & 688186 & 5.4935 & 4.8132 & TRN \\
\hline CHEMBL1338624 & 688186 & 3.301 & 4.093 & TST \\
\hline CHEMBL1385128 & 688186 & 4.5303 & 3.9142 & TRN \\
\hline CHEMBL1322183 & 688186 & 3.301 & 3.8021 & TRN \\
\hline CHEMBL1301650 & 688186 & 5.3288 & 4.3082 & TRN \\
\hline CHEMBL1518745 & 688186 & 3.301 & 3.8493 & TST \\
\hline CHEMBL1400397 & 688186 & 3.301 & 3.6124 & TRN \\
\hline CHEMBL1427448 & 688186 & 4.9594 & 4.2942 & TST \\
\hline CHEMBL3190793 & 688186 & 3.301 & 4.1472 & TRN \\
\hline CHEMBL1608574 & 688186 & 3.301 & 3.6361 & TRN \\
\hline CHEMBL1541834 & 688186 & 5.06 & 5.8361 & TRN \\
\hline CHEMBL1400272 & 688186 & 3.301 & 3.844 & TRN \\
\hline CHEMBL1496004 & 688186 & 5.1643 & 3.6998 & TRN \\
\hline CHEMBL1401044 & 688186 & 3.301 & 3.7509 & TRN \\
\hline CHEMBL3193474 & 688186 & 4.743 & 4.2764 & TRN \\
\hline CHEMBL1427476 & 688186 & 4.323 & 4.2721 & TRN \\
\hline CHEMBL1578958 & 688186 & 3.301 & 4.3668 & TRN \\
\hline CHEMBL1308687 & 688186 & 5.0788 & 5.9964 & TRN \\
\hline CHEMBL1444584 & 688186 & 3.301 & 3.4507 & TRN \\
\hline CHEMBL1563201 & 688186 & 6.585 & 3.9293 & TRN \\
\hline CHEMBL1606984 & 688186 & 4.7642 & 3.8612 & TRN \\
\hline CHEMBL1594575 & 688186 & 3.301 & 3.1285 & TRN \\
\hline CHEMBL1988657 & 688186 & 5.1226 & 5.1047 & TRN \\
\hline CHEMBL3209349 & 688186 & 3.301 & 4.7368 & TST \\
\hline CHEMBL1560366 & 688186 & 4.553 & 4.1956 & TST \\
\hline CHEMBL1542191 & 688186 & 3.301 & 3.6719 & TST \\
\hline CHEMBL1533602 & 688186 & 3.301 & 3.9628 & TST \\
\hline
\end{tabular}




\begin{tabular}{|c|c|c|c|c|c|}
\hline \multirow[b]{2}{*}{ CHEMBL3197599 } & & \multicolumn{4}{|c|}{ Supplemental Table S2.txt } \\
\hline & 688186 & 4.6895 & 4.42899 & 9999999999 & TST \\
\hline CHEMBL1369571 & 688186 & 5.0297 & 4.2775 & TST & \\
\hline CHEMBL1547271 & 688186 & 3.301 & 3.822 & TST & \\
\hline CHEMBL1388691 & 688186 & 4.7823 & 3.8837 & TST & \\
\hline CHEMBL 3210347 & 688186 & 4.3579 & 4.3745 & TST & \\
\hline CHEMBL1310248 & 688186 & 4.325 & 3.8457 & TST & \\
\hline CHEMBL570345 & 688186 & 5.5834 & 4.3881 & TST & \\
\hline CHEMBL1326083 & 688186 & 5.4123 & 5.8252 & TST & \\
\hline CHEMBL1986678 & 688186 & 5.5045 & 5.20799 & 9999999999 & TST \\
\hline CHEMBL1606504 & 688186 & 4.9382 & 4.4268 & TST & \\
\hline CHEMBL1470322 & 688186 & 3.301 & 3.6633 & TST & \\
\hline CHEMBL1521723 & 688186 & 3.301 & 3.2726 & TST & \\
\hline CHEMBL1569284 & 688186 & 3.301 & 4.5812 & TST & \\
\hline CHEMBL 290077 & 688186 & 6.5229 & 6.0138 & TST & \\
\hline CHEMBL1487570 & 688186 & 3.301 & 4.713 & TST & \\
\hline CHEMBL1417305 & 688186 & 3.301 & 3.6954 & TST & \\
\hline CHEMBL 2095095 & 688186 & 5.8239 & 6.2744 & TST & \\
\hline CHEMBL1467166 & 688186 & 3.301 & 3.8505 & TST & \\
\hline CHEMBL1528775 & 688186 & 3.301 & 4.1085 & TST & \\
\hline CHEMBL1430918 & 688186 & 3.301 & 5.0022 & TST & \\
\hline CHEMBL1562494 & 688186 & 4.7716 & 4.0431 & TST & \\
\hline CHEMBL 3210087 & 688186 & 3.301 & 4.1422 & TST & \\
\hline CHEMBL1399977 & 688186 & 3.301 & 3.6999 & TST & \\
\hline CHEMBL1312087 & 688186 & 4.7233 & 4.22 & TST & \\
\hline CHEMBL1507898 & 688186 & 3.301 & 3.8825 & TST & \\
\hline CHEMBL1346815 & 688186 & 3.301 & 3.2429 & TST & \\
\hline CHEMBL1576361 & 688186 & 4.5604 & 4.1288 & TST & \\
\hline CHEMBL1609529 & 688186 & 4.8242 & 4.6257 & TST & \\
\hline CHEMBL 1467857 & 688186 & 4.4547 & 4.1192 & TST & \\
\hline CHEMBL193872 & 688186 & 4.8677 & 6.2426 & TST & \\
\hline CHEMBL1309484 & 688186 & 6.0969 & 5.8807 & TST & \\
\hline CHEMBL1342637 & 688186 & 3.301 & 3.2894 & TST & \\
\hline CHEMBL1417955 & 688186 & 3.301 & 3.4339 & TST & \\
\hline CHEMBL1563898 & 688186 & 4.9788 & 4.1594 & TST & \\
\hline CHEMBL1505902 & 688186 & 5.1261 & 4.1506 & TST & \\
\hline CHEMBL1401534 & 688186 & 3.301 & 4.1989 & TST & \\
\hline CHEMBL 3210727 & 688186 & 3.301 & 4.5909 & TST & \\
\hline CHEMBL1454021 & 688186 & 3.301 & 4.4515 & TST & \\
\hline CHEMBL1351342 & 688186 & 4.6345 & 4.6338 & TST & \\
\hline CHEMBL1369680 & 688186 & 3.301 & 3.862 & TST & \\
\hline CHEMBL1306079 & 688186 & 5.2749 & 4.4849 & TST & \\
\hline CHEMBL1385808 & 688186 & 6.0 & 5.2245 & TST & \\
\hline CHEMBL1388379 & 688186 & 3.301 & 3.1779 & TST & \\
\hline CHEMBL1392820 & 688186 & 3.301 & 3.4626 & TST & \\
\hline CHEMBL1448849 & 688186 & 4.3658 & 3.7337 & TST & \\
\hline CHEMBL1407708 & 688186 & 4.8745 & 3.8747 & TST & \\
\hline CHEMBL 2001792 & 688186 & 4.3436 & 4.7149 & TST & \\
\hline CHEMBL1589754 & 688186 & 3.301 & 3.3946 & TST & \\
\hline
\end{tabular}




\begin{tabular}{|c|c|c|c|c|c|}
\hline & & \multicolumn{4}{|c|}{ Supplemental Table S2.txt } \\
\hline CHEMBL473107 & 688186 & 3.301 & 4.0079 & TST & \\
\hline CHEMBL1519149 & 688186 & 3.301 & 3.6949 & TST & \\
\hline CHEMBL520667 & 688186 & 4.6119 & 3.8199 & TST & \\
\hline CHEMBL1427637 & 688186 & 5.3382 & 4.6361 & TST & \\
\hline CHEMBL1573630 & 688186 & 4.4764 & 4.2253 & TST & \\
\hline CHEMBL1345709 & 688186 & 4.3465 & 3.7468 & TST & \\
\hline CHEMBL3189791 & 688186 & 5.7496 & 5.5729 & TST & \\
\hline CHEMBL1438153 & 688186 & 3.301 & 3.758 & TST & \\
\hline CHEMBL142816 & 688186 & 5.1945 & 4.4417 & TST & \\
\hline CHEMBL1398826 & 688186 & 4.9492 & 3.9431 & TST & \\
\hline CHEMBL1545187 & 688186 & 3.301 & 3.9581 & TST & \\
\hline CHEMBL3191413 & 688186 & 3.301 & 4.3664 & TST & \\
\hline CHEMBL1423690 & 688186 & 5.5607 & 3.82899 & 99999999997 & TST \\
\hline CHEMBL1349832 & 688186 & 5.6383 & 4.9183 & TST & \\
\hline CHEMBL1542915 & 688186 & 3.301 & 3.7846 & TST & \\
\hline CHEMBL1588476 & 688186 & 4.7967 & 4.5144 & TST & \\
\hline CHEMBL3198208 & 688186 & 3.301 & 4.6278 & TST & \\
\hline CHEMBL1463234 & 688186 & 4.5862 & 4.3091 & TST & \\
\hline CHEMBL1373096 & 688186 & 6.6198 & 6.7439 & TST & \\
\hline CHEMBL1505070 & 688186 & 3.301 & 3.8397 & TST & \\
\hline CHEMBL1379952 & 688186 & 3.301 & 3.5672 & TST & \\
\hline CHEMBL1381860 & 688186 & 4.3695 & 4.1201 & TST & \\
\hline CHEMBL1328510 & 688186 & 6.0 & 6.2633 & TST & \\
\hline CHEMBL1511404 & 688186 & 3.301 & 3.1783 & TST & \\
\hline CHEMBL1511034 & 688186 & 4.755 & 3.9541 & TST & \\
\hline CHEMBL1414291 & 688186 & 3.301 & 3.9233 & TST & \\
\hline CHEMBL1313386 & 688186 & 3.301 & 4.8592 & TST & \\
\hline CHEMBL1532337 & 688186 & 3.301 & 3.6411 & TST & \\
\hline CHEMBL1611580 & 688186 & 3.301 & 3.8719 & TST & \\
\hline CHEMBL1468397 & 688186 & 3.301 & 3.1194 & TST & \\
\hline CHEMBL1428928 & 688186 & 4.9788 & 3.656 & TST & \\
\hline CHEMBL601737 & 688186 & 3.301 & 3.9673 & TST & \\
\hline CHEMBL1883149 & 688186 & 4.9821 & 4.2635 & TST & \\
\hline CHEMBL1598769 & 688186 & 5.1759 & 4.324 & TST & \\
\hline CHEMBL3199748 & 688186 & 3.301 & 4.3206 & TST & \\
\hline CHEMBL1301480 & 688186 & 5.3625 & 5.0556 & TST & \\
\hline CHEMBL1304268 & 688186 & 3.301 & 3.93600 & 00000000004 & TST \\
\hline CHEMBL3190878 & 688186 & 4.5538 & 4.0579 & TST & \\
\hline CHEMBL1423986 & 688186 & 4.4946 & 4.1753 & TST & \\
\hline CHEMBL1565537 & 688186 & 4.4978 & 4.0819 & TST & \\
\hline CHEMBL1489944 & 688186 & 3.301 & 3.7312 & TST & \\
\hline CHEMBL1172192 & 688186 & 3.301 & 4.7051 & TST & \\
\hline CHEMBL1375849 & 688186 & 4.7075 & 3.7356 & TST & \\
\hline CHEMBL1313890 & 688186 & 3.301 & 3.6231 & TST & \\
\hline CHEMBL1567013 & 688186 & 3.301 & 3.2474 & TST & \\
\hline CHEMBL1495848 & 688186 & 3.301 & 3.9456 & TST & \\
\hline CHEMBL3192400 & 688186 & 5.1752 & 4.8329 & TST & \\
\hline CHEMBL1462899 & 688186 & 3.301 & 4.0572 & TST & \\
\hline
\end{tabular}




\begin{tabular}{|c|c|c|c|c|c|}
\hline & & \multicolumn{4}{|c|}{ Supplemental Table S2.txt } \\
\hline CHEMBL1576090 & 688186 & 4.365 & 3.3164 & TST & \\
\hline CHEMBL1370773 & 688186 & 4.6227 & 3.795 & TST & \\
\hline CHEMBL1608143 & 688186 & 5.4056 & 4.1439 & TST & \\
\hline CHEMBL602377 & 688186 & 3.301 & 4.3645 & TST & \\
\hline CHEMBL1583979 & 688186 & 3.301 & 3.951 & TST & \\
\hline CHEMBL1579686 & 688186 & 3.301 & 3.4758 & TST & \\
\hline CHEMBL1969475 & 688186 & 4.9788 & 4.101 & TST & \\
\hline CHEMBL1312656 & 688186 & 3.301 & 4.7649 & TST & \\
\hline CHEMBL 2004417 & 688186 & 5.9172 & 5.8073 & TST & \\
\hline CHEMBL3190468 & 688186 & 4.6386 & 5.4169 & TST & \\
\hline CHEMBL1402883 & 688186 & 4.5594 & 3.5331 & TST & \\
\hline CHEMBL1489924 & 688186 & 3.301 & 3.502 & TST & \\
\hline CHEMBL1426787 & 688186 & 3.301 & 3.6082 & TST & \\
\hline CHEMBL1426059 & 688186 & 4.5844 & 3.8965 & TST & \\
\hline CHEMBL1430921 & 688186 & 3.301 & 3.927 & TST & \\
\hline CHEMBL1587519 & 688186 & 4.3128 & 3.4282 & TST & \\
\hline CHEMBL1488579 & 688186 & 3.301 & 3.1266 & TST & \\
\hline CHEMBL1401089 & 688186 & 4.9996 & 4.4143 & TST & \\
\hline CHEMBL1975888 & 688186 & 4.9352 & 4.2585 & TST & \\
\hline CHEMBL1459239 & 688186 & 3.301 & 4.0452 & TST & \\
\hline CHEMBL1405263 & 688186 & 3.301 & 3.93899 & 99999999996 & TST \\
\hline CHEMBL1488723 & 688186 & 4.7011 & 4.4673 & TST & \\
\hline CHEMBL3191713 & 688186 & 6.0362 & 5.9312 & TST & \\
\hline CHEMBL1335106 & 688186 & 3.301 & 3.9425 & TST & \\
\hline CHEMBL3191363 & 688186 & 4.4949 & 4.6648 & TST & \\
\hline CHEMBL1421048 & 688186 & 4.4764 & 4.4155 & TST & \\
\hline CHEMBL1570277 & 688186 & 3.301 & 4.45100 & 00000000005 & TST \\
\hline CHEMBL1572723 & 688186 & 3.301 & 3.626006 & 00000000003 & TST \\
\hline CHEMBL1426411 & 688186 & 4.7934 & 3.661 & TST & \\
\hline CHEMBL1587205 & 688186 & 5.1215 & 4.6553 & TST & \\
\hline CHEMBL1390112 & 688186 & 5.7375 & 4.5151 & TST & \\
\hline CHEMBL1463272 & 688186 & 3.301 & 4.0631 & TST & \\
\hline CHEMBL591834 & 688186 & 5.5361 & 4.1166 & TST & \\
\hline CHEMBL1530097 & 688186 & 4.8614 & 5.2065 & TST & \\
\hline CHEMBL1366194 & 688186 & 3.301 & 3.6641 & TST & \\
\hline CHEMBL1489407 & 688186 & 5.1163 & 5.0418 & TST & \\
\hline CHEMBL1365773 & 688186 & 3.301 & 4.2669 & TST & \\
\hline CHEMBL1336774 & 688186 & 4.3119 & 3.76 & TST & \\
\hline CHEMBL1337537 & 688186 & 3.301 & 3.5505 & TST & \\
\hline CHEMBL3189193 & 688186 & 5.5072 & 5.0225 & TST & \\
\hline CHEMBL73451 & 688186 & 5.1007 & 3.9926 & TST & \\
\hline CHEMBL1390836 & 688186 & 4.7645 & 4.2687 & TST & \\
\hline CHEMBL1359775 & 688186 & 3.301 & 4.2523 & TST & \\
\hline CHEMBL1454903 & 688186 & 4.3226 & 3.6419 & TST & \\
\hline CHEMBL3190774 & 688186 & 3.301 & 4.0095 & TST & \\
\hline CHEMBL3191137 & 688186 & 4.5879 & 4.7763 & TST & \\
\hline CHEMBL3191293 & 688186 & 4.5845 & 4.6249 & TST & \\
\hline CHEMBL1958251 & 688186 & 5.2907 & 5.1946 & TST & \\
\hline
\end{tabular}




\begin{tabular}{|c|c|c|c|c|c|}
\hline & & \multicolumn{4}{|c|}{ Supplemental Table s2.txt } \\
\hline CHEMBL1270410 & 688186 & 3.301 & 3.5455 & TST & \\
\hline CHEMBL1318861 & 688186 & 3.301 & 4.6027 & TST & \\
\hline CHEMBL1271726 & 674308 & 3.4089 & 3.1081 & TRN & \\
\hline CHEMBL1271901 & 674308 & 3.5901 & 3.3402 & TRN & \\
\hline CHEMBL1271462 & 674308 & 3.7878 & 3.6435 & TRN & \\
\hline CHEMBL1271566 & 674308 & 3.8508 & 3.9157 & TRN & \\
\hline CHEMBL1271845 & 674308 & 3.6576 & 3.5965 & TRN & \\
\hline CHEMBL1269629 & 674308 & 2.301 & 1.9574 & TRN & \\
\hline CHEMBL1269627 & 674308 & 3.9031 & 3.4561 & TRN & \\
\hline CHEMBL1272282 & 674308 & 3.5482 & 3.6581 & TRN & \\
\hline CHEMBL1271517 & 674308 & 3.3635 & 3.3635 & TRN & \\
\hline CHEMBL1272173 & 674308 & 3.4776 & 3.917 & TRN & \\
\hline CHEMBL1269515 & 674308 & 4.0458 & 3.9157 & TRN & \\
\hline CHEMBL1272013 & 674308 & 3.6882 & 3.72899 & 99999999996 & TRN \\
\hline CHEMBL1269657 & 674308 & 2.301 & 2.6324 & TST & \\
\hline CHEMBL1272119 & 674308 & 2.301 & 3.2724 & TRN & \\
\hline CHEMBL1271786 & 674308 & 2.301 & 1.7795 & TRN & \\
\hline CHEMBL1272067 & 674308 & 3.7122 & 3.5323 & TRN & \\
\hline CHEMBL1272172 & 674308 & 2.301 & 2.8318 & TRN & \\
\hline CHEMBL1271568 & 674308 & 3.5229 & 3.3937 & TRN & \\
\hline CHEMBL1271728 & 674308 & 2.301 & 2.2929 & TRN & \\
\hline CHEMBL1271625 & 674308 & 4.6021 & 3.6021 & TST & \\
\hline CHEMBL1271900 & 674308 & 2.301 & 3.19100 & 00000000003 & TRN \\
\hline CHEMBL1272281 & 674308 & 3.6055 & 3.44100 & 00000000003 & TRN \\
\hline CHEMBL1269712 & 674308 & 5.5229 & 4.4315 & TRN & \\
\hline CHEMBL1271623 & 674308 & 2.301 & 2.7211 & TST & \\
\hline CHEMBL1271463 & 674308 & 3.4089 & 3.6459 & TRN & \\
\hline CHEMBL1271674 & 674308 & 2.301 & 2.8504 & TST & \\
\hline CHEMBL1271567 & 674308 & 2.301 & 2.10699 & 99999999998 & TST \\
\hline CHEMBL1272069 & 674308 & 3.4776 & 3.3599 & TRN & \\
\hline CHEMBL1269655 & 674308 & 2.301 & 2.6858 & TST & \\
\hline CHEMBL1271785 & 674308 & 2.301 & 3.0288 & TRN & \\
\hline CHEMBL48449 & 674308 & 5.0458 & 4.7481 & TST & \\
\hline CHEMBL1271518 & 674308 & 2.301 & 2.2734 & TRN & \\
\hline CHEMBL1269512 & 674308 & 2.301 & 2.7378 & TST & \\
\hline CHEMBL1271727 & 674308 & 3.9747 & 3.1081 & TRN & \\
\hline CHEMBL1237212 & 674308 & 4.301 & 3.7195 & TST & \\
\hline CHEMBL1271673 & 674308 & 3.3979 & 3.5857 & TRN & \\
\hline CHEMBL1272068 & 674308 & 3.3979 & 2.6523 & TRN & \\
\hline CHEMBL1271672 & 674308 & 2.301 & 2.8585 & TRN & \\
\hline CHEMBL1271569 & 674308 & 3.6383 & 3.2509 & TRN & \\
\hline CHEMBL1269730 & 674308 & 2.301 & 2.58699 & 99999999997 & TRN \\
\hline CHEMBL1269628 & 674308 & 4.2596 & 3.4529 & TST & \\
\hline CHEMBL1269711 & 674308 & 2.301 & 2.3669 & TRN & \\
\hline CHEMBL1271464 & 674308 & 3.4776 & 3.5533 & TRN & \\
\hline CHEMBL1269514 & 674308 & 4.9031 & 4.4409 & TST & \\
\hline CHEMBL1272117 & 674308 & 3.4202 & 3.3992 & TRN & \\
\hline CHEMBL1269513 & 674308 & 2.301 & 3.0561 & TST & \\
\hline
\end{tabular}




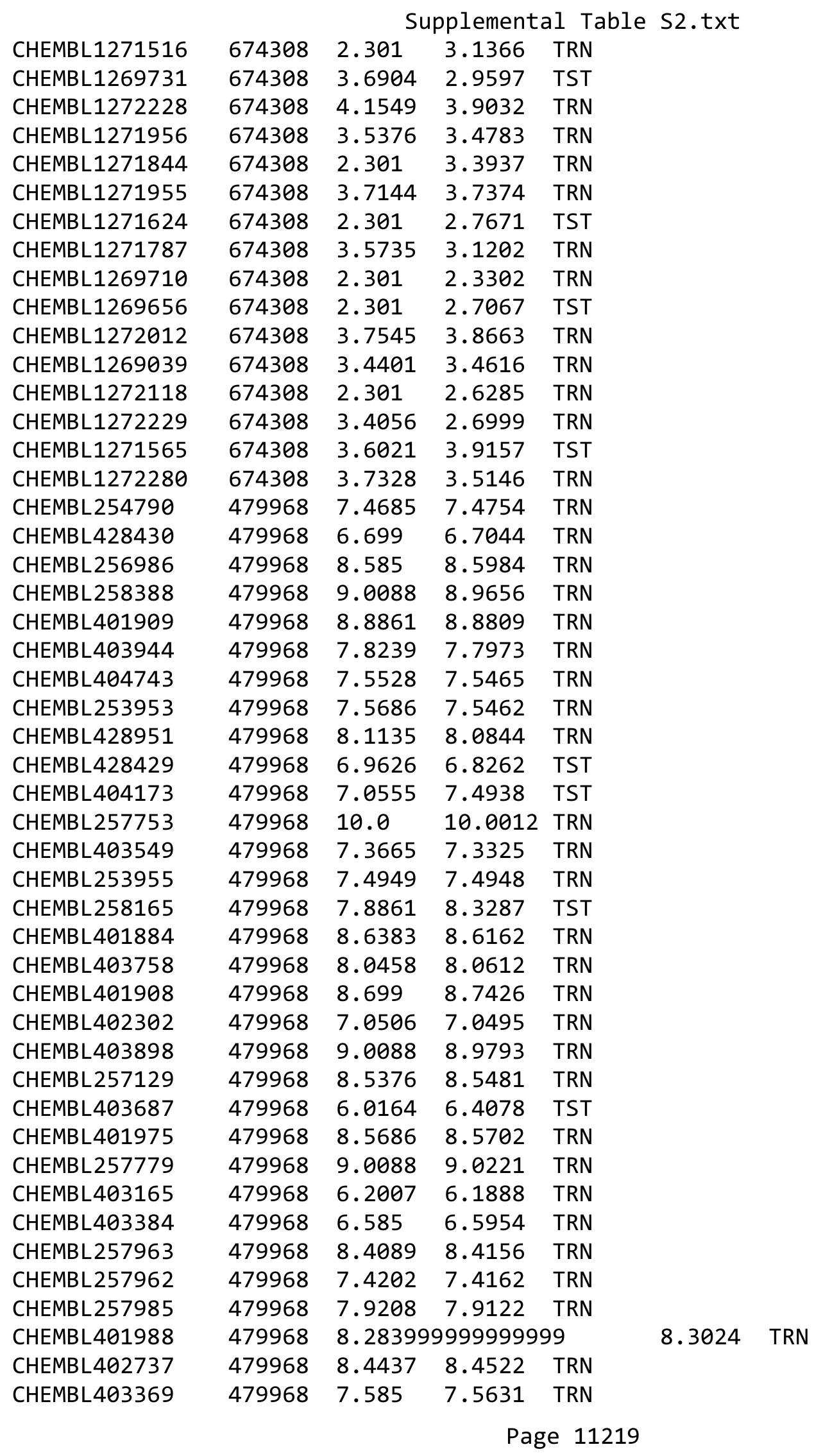




\begin{tabular}{|c|c|c|c|c|c|}
\hline & & & oplement & al lable & \\
\hline CHEMBL 257752 & 479968 & 8.3665 & 8.3968 & TRN & \\
\hline CHEMBL403811 & 479968 & 8.8861 & 8.85700 & 0000000001 & TRN \\
\hline CHEMBL257601 & 479968 & 8.8539 & 8.8595 & TRN & \\
\hline CHEMBL 256158 & 479968 & 8.5086 & 8.5475 & TRN & \\
\hline CHEMBL 254993 & 479968 & 7.5528 & 7.5493 & TRN & \\
\hline CHEMBL429318 & 479968 & 7.0458 & 7.0973 & TRN & \\
\hline CHEMBL 256298 & 479968 & 9.0 & 9.0056 & TRN & \\
\hline CHEMBL401883 & 479968 & 8.7212 & 8.9261 & TST & \\
\hline CHEMBL404880 & 479968 & 7.0506 & 7.0604 & TRN & \\
\hline CHEMBL403589 & 479968 & 7.301 & 7.3026 & TRN & \\
\hline CHEMBL 257364 & 479968 & 7.699 & 7.9852 & TST & \\
\hline CHEMBL404564 & 479968 & 7.6778 & 7.5821 & TST & \\
\hline CHEMBL401830 & 479968 & 8.3372 & 8.186 & TST & \\
\hline CHEMBL404638 & 479968 & 8.2366 & 8.411 & TST & \\
\hline CHEMBL 257754 & 479968 & 10.0 & 10.3661 & TST & \\
\hline CHEMBL 254789 & 479968 & 10.0 & 8.5075 & TST & \\
\hline CHEMBL 258389 & 479968 & 8.5376 & 8.6296 & TST & \\
\hline CHEMBL 258217 & 479968 & 6.6021 & 7.0634 & TST & \\
\hline CHEMBL1784062 & 749914 & 7.2076 & 7.1861 & TRN & \\
\hline CHEMBL1784052 & 749914 & 7.5686 & 7.6494 & TRN & \\
\hline CHEMBL1784059 & 749914 & 7.6021 & 7.4544 & TRN & \\
\hline CHEMBL1783866 & 749914 & 8.4949 & 8.3851 & TRN & \\
\hline CHEMBL1784063 & 749914 & 7.3665 & 7.6789 & TST & \\
\hline CHEMBL1784077 & 749914 & 7.2007 & 7.4093 & TST & \\
\hline CHEMBL1783867 & 749914 & 8.9208 & 9.2216 & TRN & \\
\hline CHEMBL1783868 & 749914 & 9.699 & 9.2731 & TRN & \\
\hline CHEMBL1784053 & 749914 & 8.0969 & 7.9153 & TRN & \\
\hline CHEMBL1783872 & 749914 & 7.8861 & 7.9832 & TST & \\
\hline CHEMBL1784049 & 749914 & 9.1549 & 8.9004 & TRN & \\
\hline CHEMBL428909 & 749914 & 8.1024 & 8.14 & TRN & \\
\hline CHEMBL1784051 & 749914 & 7.7447 & 7.9151 & TRN & \\
\hline CHEMBL1783858 & 749914 & 8.9586 & 8.7958 & TRN & \\
\hline CHEMBL1784078 & 749914 & 7.1612 & 7.287006 & 0000000001 & TST \\
\hline CHEMBL1784050 & 749914 & 7.5528 & 7.6634 & TRN & \\
\hline CHEMBL1784070 & 749914 & 7.5376 & 7.9862 & TRN & \\
\hline CHEMBL1784060 & 749914 & 6.0 & 5.9423 & TRN & \\
\hline CHEMBL1783859 & 749914 & 8.5686 & 8.9961 & TRN & \\
\hline CHEMBL1784067 & 749914 & 8.3565 & 8.09799 & 9999999999 & TRN \\
\hline CHEMBL1784056 & 749914 & 8.1249 & 8.23299 & 9999999999 & TRN \\
\hline CHEMBL1784055 & 749914 & 8.5376 & 8.4935 & TRN & \\
\hline CHEMBL1783862 & 749914 & 7.8539 & 7.9117 & TRN & \\
\hline CHEMBL1784061 & 749914 & 7.4202 & 7.6436 & TRN & \\
\hline CHEMBL1784066 & 749914 & 7.1938 & 7.278 & TST & \\
\hline CHEMBL1784071 & 749914 & 7.1135 & 6.8289 & TRN & \\
\hline CHEMBL1783871 & 749914 & 7.8861 & 7.9973 & TRN & \\
\hline CHEMBL1783876 & 749914 & 8.4559 & 8.6729 & TRN & \\
\hline CHEMBL1784057 & 749914 & 8.4202 & 8.3394 & TRN & \\
\hline CHEMBL1783875 & 749914 & 8.7959 & 8.9551 & TRN & \\
\hline
\end{tabular}


Supplemental Table S2.txt

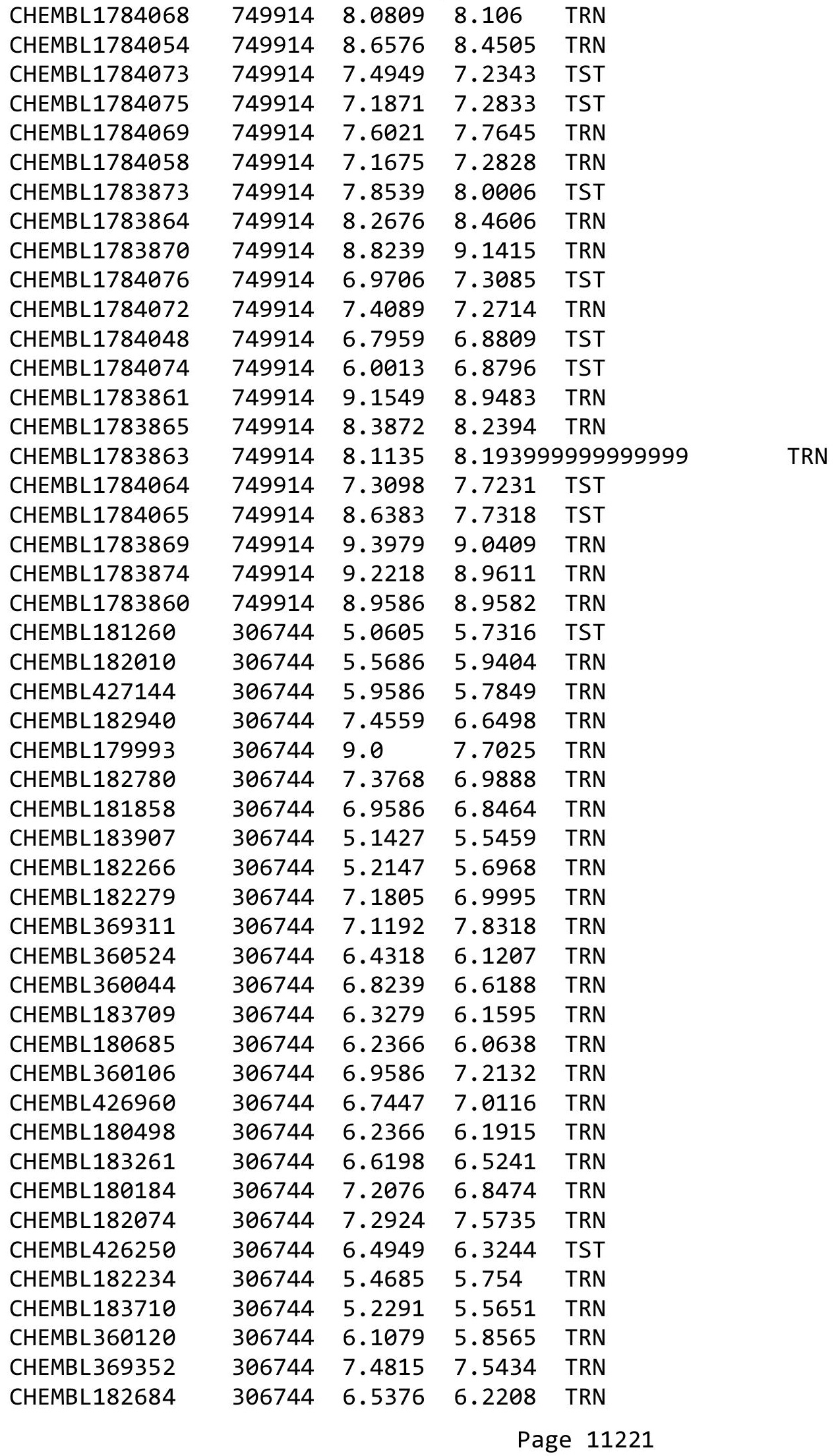




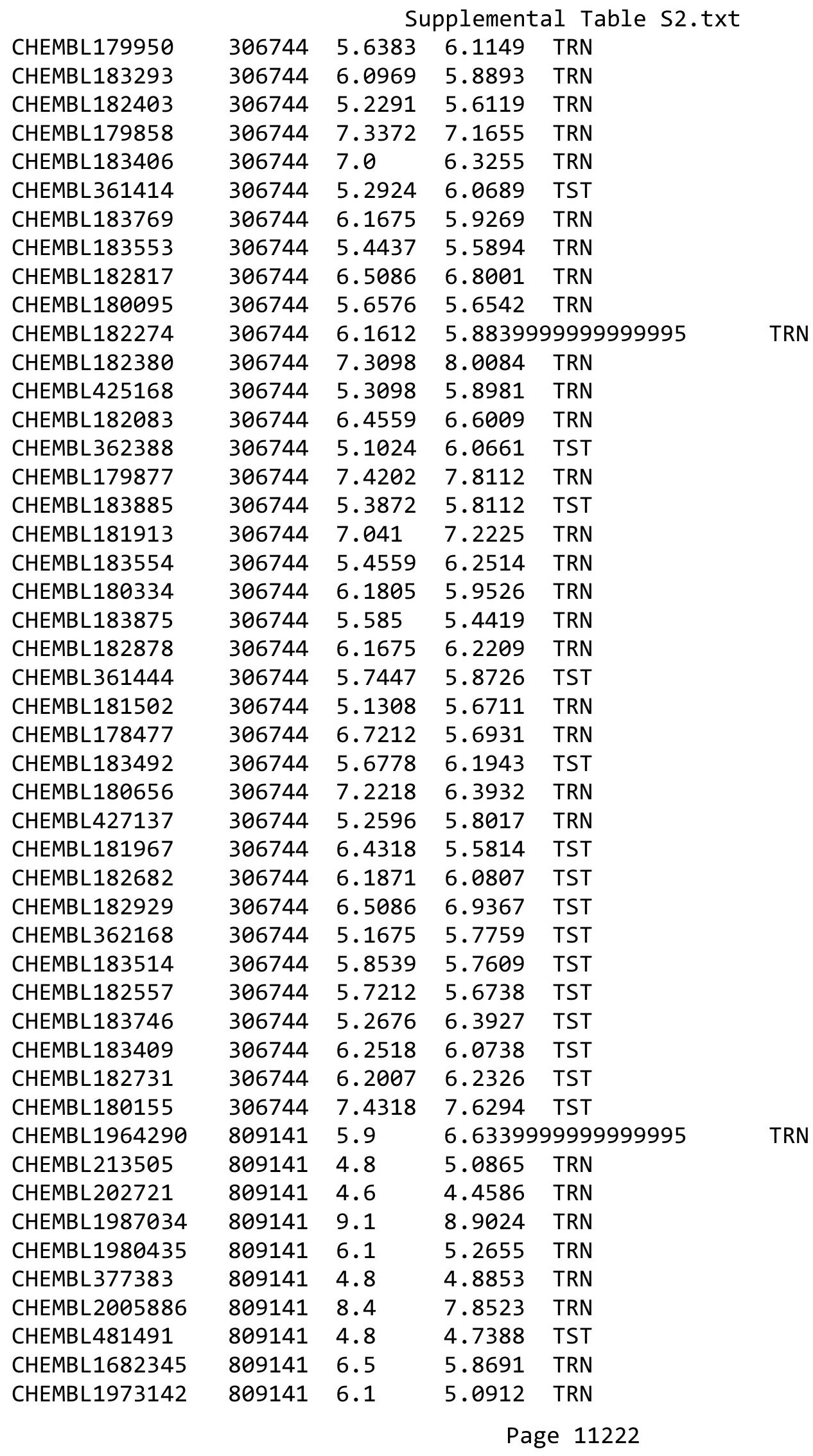




\begin{tabular}{|c|c|c|c|c|c|}
\hline \multicolumn{6}{|c|}{ Supplemental Table S2.txt } \\
\hline CHEMBL388311 & 809141 & 7.2 & 7.3583 & TRN & \\
\hline CHEMBL1973145 & 809141 & 4.8 & 5.3176 & TRN & \\
\hline CHEMBL1982924 & 809141 & 4.8 & 4.7455 & TRN & \\
\hline CHEMBL 2005936 & 809141 & 4.8 & 6.0932 & TRN & \\
\hline CHEMBL1807515 & 809141 & 6.6 & 6.0817 & TRN & \\
\hline CHEMBL1964948 & 809141 & 4.6 & 4.2911 & TRN & \\
\hline CHEMBL1971141 & 809141 & 4.8 & 5.0923 & TRN & \\
\hline CHEMBL1995813 & 809141 & 6.1 & 5.9696 & TRN & \\
\hline CHEMBL1979718 & 809141 & 4.8 & 5.1474 & TRN & \\
\hline CHEMBL206236 & 809141 & 4.8 & 4.8017 & TRN & \\
\hline CHEMBL1989834 & 809141 & 3.7 & 3.4103 & TRN & \\
\hline CHEMBL523823 & 809141 & 4.8 & 5.1714 & TST & \\
\hline CHEMBL1987430 & 809141 & 4.6 & 4.4886 & TRN & \\
\hline CHEMBL244378 & 809141 & 7.5 & 8.0703 & TRN & \\
\hline CHEMBL1969372 & 809141 & 4.8 & 4.7015 & TRN & \\
\hline CHEMBL1993413 & 809141 & 4.6 & 4.2604 & TRN & \\
\hline CHEMBL1990583 & 809141 & 4.8 & 5.5919 & TRN & \\
\hline CHEMBL1986943 & 809141 & 6.7 & 6.6115 & TRN & \\
\hline CHEMBL289959 & 809141 & 3.8 & 3.9528 & TRN & \\
\hline CHEMBL 2006263 & 809141 & 4.8 & 5.194 & TST & \\
\hline CHEMBL1993584 & 809141 & 4.8 & 4.7787 & TRN & \\
\hline CHEMBL1986263 & 809141 & 7.1 & 6.0998 & TRN & \\
\hline CHEMBL 2000114 & 809141 & 4.8 & 4.9738 & TRN & \\
\hline CHEMBL210618 & 809141 & 4.8 & 4.9935 & TRN & \\
\hline CHEMBL1986265 & 809141 & 4.6 & 4.34699 & 99999999995 & TRN \\
\hline CHEMBL1971172 & 809141 & 5.6 & 6.189 & TRN & \\
\hline CHEMBL1975647 & 809141 & 4.8 & 4.9625 & TRN & \\
\hline CHEMBL1968380 & 809141 & 4.8 & 4.5223 & TRN & \\
\hline CHEMBL1967211 & 809141 & 4.0 & 4.452 & TRN & \\
\hline CHEMBL1964644 & 809141 & 4.8 & 4.9122 & TRN & \\
\hline CHEMBL1991734 & 809141 & 6.0 & 5.9484 & TST & \\
\hline CHEMBL1981782 & 809141 & 4.8 & 4.9205 & TRN & \\
\hline CHEMBL1977681 & 809141 & 4.8 & 4.6189 & TRN & \\
\hline CHEMBL1970142 & 809141 & 4.8 & 5.285 & TRN & \\
\hline CHEMBL1990912 & 809141 & 5.9 & 4.9619 & TRN & \\
\hline CHEMBL1991782 & 809141 & 3.3 & 3.4508 & TRN & \\
\hline CHEMBL 2002105 & 809141 & 5.0 & 4.8584 & TRN & \\
\hline CHEMBL1983348 & 809141 & 7.0 & 6.3529 & TRN & \\
\hline CHEMBL1988163 & 809141 & 7.9 & 8.3449 & TRN & \\
\hline CHEMBL1995592 & 809141 & 4.8 & 5.8388 & TST & \\
\hline CHEMBL1974480 & 809141 & 5.6 & 5.7141 & TRN & \\
\hline CHEMBL 2000934 & 809141 & 4.6 & 4.4561 & TRN & \\
\hline CHEMBL 2006493 & 809141 & 4.8 & 4.8086 & TST & \\
\hline CHEMBL1986177 & 809141 & 4.6 & 4.5771 & TRN & \\
\hline CHEMBL1992323 & 809141 & 4.8 & 4.9863 & TRN & \\
\hline CHEMBL 2003524 & 809141 & 4.8 & 4.9536 & TST & \\
\hline CHEMBL 2002649 & 809141 & 6.3 & 6.2283 & TRN & \\
\hline CHEMBL1989423 & 809141 & 3.8 & 3.7829 & TRN & \\
\hline
\end{tabular}




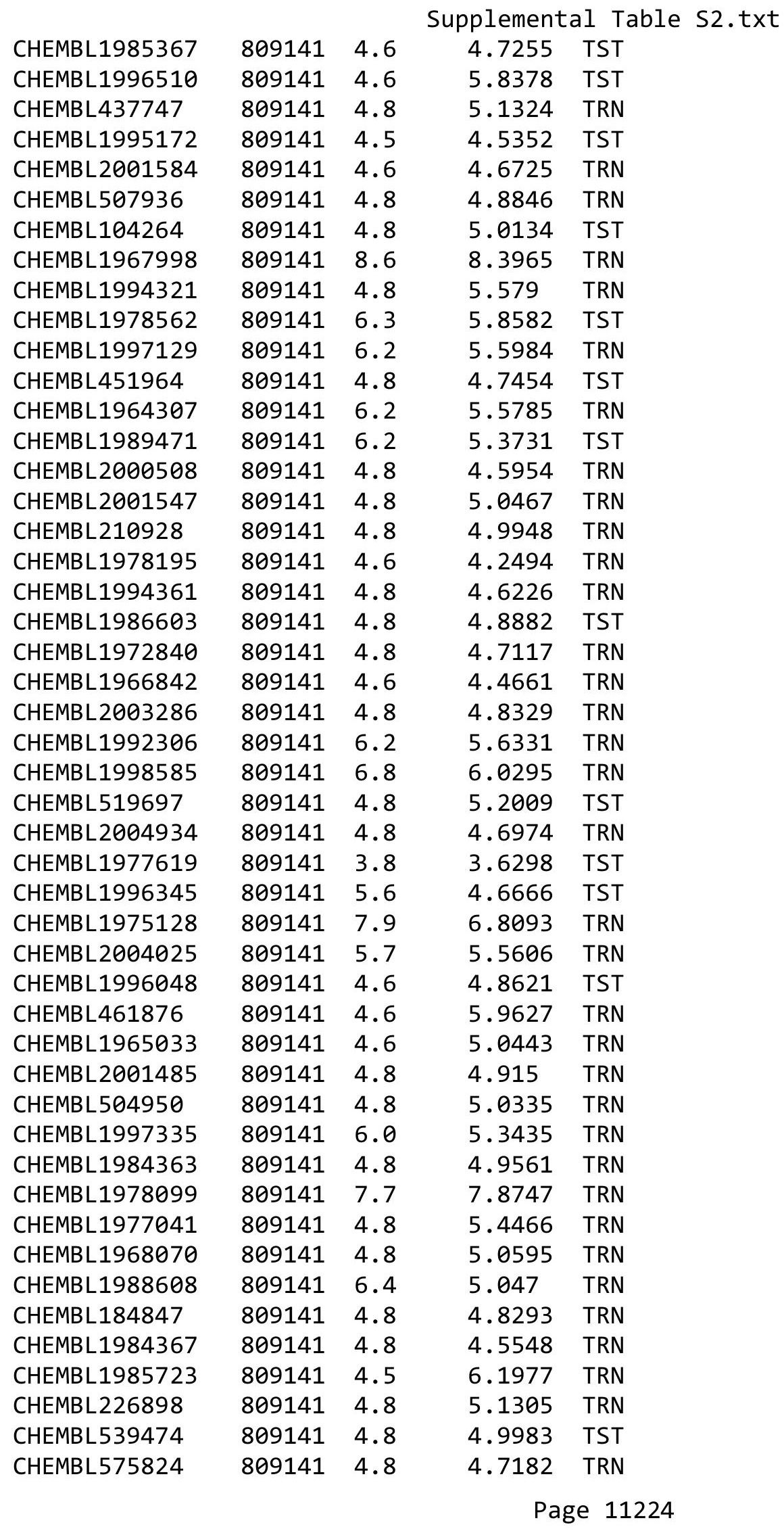




\begin{tabular}{|c|c|c|c|c|c|}
\hline \\
\hline CHEMBL1988387 & 809141 & 6.2 & 6.2255 & TRN & \\
\hline CHEMBL1973868 & 809141 & 4.6 & 4.329 & TRN & \\
\hline CHEMBL1990288 & 809141 & 4.8 & 4.8144 & TRN & \\
\hline CHEMBL1970074 & 809141 & 5.8 & 5.71 & TRN & \\
\hline CHEMBL1986970 & 809141 & 4.8 & 5.2278 & TRN & \\
\hline CHEMBL1958401 & 809141 & 4.8 & 5.0693 & TRN & \\
\hline CHEMBL 2003456 & 809141 & 4.8 & 4.6001 & TRN & \\
\hline CHEMBL1966816 & 809141 & 4.8 & 4.8281 & TRN & \\
\hline CHEMBL1972584 & 809141 & 4.8 & 5.0429 & TRN & \\
\hline CHEMBL 2002992 & 809141 & 4.8 & 5.1782 & TRN & \\
\hline CHEMBL560813 & 809141 & 4.8 & 5.0636 & TRN & \\
\hline CHEMBL1982700 & 809141 & 4.6 & 4.4973 & TST & \\
\hline CHEMBL1990635 & 809141 & 6.0 & 5.2726 & TST & \\
\hline CHEMBL1968791 & 809141 & 4.8 & 4.3305 & TRN & \\
\hline CHEMBL326282 & 809141 & 4.8 & 4.8781 & TST & \\
\hline CHEMBL1977634 & 809141 & 4.6 & 4.6248 & TRN & \\
\hline CHEMBL1992732 & 809141 & 4.8 & 4.9576 & TST & \\
\hline CHEMBL1971186 & 809141 & 4.8 & 4.9966 & TRN & \\
\hline CHEMBL 2003482 & 809141 & 4.8 & 5.021 & TRN & \\
\hline CHEMBL1976872 & 809141 & 3.8 & 3.8169 & TRN & \\
\hline CHEMBL1969156 & 809141 & 3.8 & 3.7897 & TST & \\
\hline CHEMBL1973211 & 809141 & 5.0 & 5.0731 & TRN & \\
\hline CHEMBL 2007151 & 809141 & 4.8 & 4.6063 & TRN & \\
\hline CHEMBL1998953 & 809141 & 4.6 & 5.0687 & TRN & \\
\hline CHEMBL1971606 & 809141 & 4.6 & 4.5623 & TRN & \\
\hline CHEMBL1972125 & 809141 & 4.8 & 4.6585 & TRN & \\
\hline CHEMBL1976134 & 809141 & 6.8 & 6.3624 & TRN & \\
\hline CHEMBL1965131 & 809141 & 4.8 & 4.99 & TRN & \\
\hline CHEMBL1972158 & 809141 & 4.9 & 6.4656 & TRN & \\
\hline CHEMBL1981215 & 809141 & 4.6 & 4.7947 & TRN & \\
\hline CHEMBL1999414 & 809141 & 5.8 & 5.4749 & TRN & \\
\hline CHEMBL1967336 & 809141 & 4.6 & 4.7341 & TRN & \\
\hline CHEMBL 2001228 & 809141 & 4.6 & 4.7513 & TRN & \\
\hline CHEMBL1994056 & 809141 & 4.0 & 4.80699 & 99999999995 & TST \\
\hline CHEMBL 2006581 & 809141 & 4.8 & 4.6187 & TRN & \\
\hline CHEMBL1970340 & 809141 & 4.8 & 4.2233 & TRN & \\
\hline CHEMBL1967992 & 809141 & 4.6 & 4.5235 & TRN & \\
\hline CHEMBL 2005186 & 809141 & 4.8 & 5.0028 & TRN & \\
\hline CHEMBL 2006450 & 809141 & 4.6 & 4.1954 & TRN & \\
\hline CHEMBL1975534 & 809141 & 4.8 & 4.3638 & TRN & \\
\hline CHEMBL1993424 & 809141 & 8.3 & 8.9091 & TRN & \\
\hline CHEMBL1966703 & 809141 & 4.8 & 5.0897 & TST & \\
\hline CHEMBL 2001987 & 809141 & 4.6 & 4.5037 & TRN & \\
\hline CHEMBL1969561 & 809141 & 4.8 & 5.8774 & TRN & \\
\hline CHEMBL1994555 & 809141 & 4.6 & 5.4557 & TST & \\
\hline CHEMBL1975121 & 809141 & 4.6 & 4.4653 & TRN & \\
\hline CHEMBL1983640 & 809141 & 4.6 & 5.0198 & TRN & \\
\hline CHEMBL1997023 & 809141 & 4.8 & 5.1819 & TST & \\
\hline
\end{tabular}




\begin{tabular}{|c|c|c|c|c|c|}
\hline \multicolumn{6}{|c|}{ Supplemental Table s2.txt } \\
\hline CHEMBL1964687 & 809141 & 4.8 & 5.336 & TRN & \\
\hline CHEMBL1971943 & 809141 & 4.6 & 4.9268 & TRN & \\
\hline CHEMBL1999918 & 809141 & 4.8 & 5.1805 & TRN & \\
\hline CHEMBL1997924 & 809141 & 8.7 & 7.4245 & TRN & \\
\hline CHEMBL1988537 & 809141 & 4.8 & 4.7149 & TST & \\
\hline CHEMBL1969049 & 809141 & 4.8 & 4.7807 & TRN & \\
\hline CHEMBL 2005828 & 809141 & 4.8 & 4.2529 & TRN & \\
\hline CHEMBL1978267 & 809141 & 4.6 & 4.1542 & TRN & \\
\hline CHEMBL1998611 & 809141 & 4.8 & 4.8461 & TRN & \\
\hline CHEMBL485556 & 809141 & 4.8 & 5.4173 & TST & \\
\hline CHEMBL1975900 & 809141 & 4.8 & 4.6255 & TRN & \\
\hline CHEMBL255822 & 809141 & 4.8 & 4.9398 & TRN & \\
\hline CHEMBL1972221 & 809141 & 7.4 & 7.01200 & 00000000005 & TRN \\
\hline CHEMBL 2006778 & 809141 & 6.6 & 6.3419 & TRN & \\
\hline CHEMBL378627 & 809141 & 4.8 & 4.7939 & TRN & \\
\hline CHEMBL1996979 & 809141 & 4.8 & 5.1882 & TRN & \\
\hline CHEMBL1968406 & 809141 & 4.8 & 5.0937 & TRN & \\
\hline CHEMBL1975921 & 809141 & 4.1 & 4.5906 & TRN & \\
\hline CHEMBL1982476 & 809141 & 8.0 & 7.1881 & TRN & \\
\hline CHEMBL1998545 & 809141 & 4.8 & 4.801 & TRN & \\
\hline CHEMBL1986869 & 809141 & 4.8 & 4.6477 & TRN & \\
\hline CHEMBL1975923 & 809141 & 4.9 & 5.5045 & TST & \\
\hline CHEMBL 2005449 & 809141 & 7.9 & 7.3337 & TRN & \\
\hline CHEMBL1987998 & 809141 & 4.6 & 4.1279 & TRN & \\
\hline CHEMBL1682558 & 809141 & 4.8 & 4.8179 & TRN & \\
\hline CHEMBL1990496 & 809141 & 4.7 & 4.4056 & TRN & \\
\hline CHEMBL242865 & 809141 & 6.2 & 6.4948 & TRN & \\
\hline CHEMBL1997623 & 809141 & 4.8 & 6.5594 & TRN & \\
\hline CHEMBL1472492 & 809141 & 6.1 & 5.0965 & TST & \\
\hline CHEMBL1967094 & 809141 & 4.8 & 4.6405 & TRN & \\
\hline CHEMBL1982992 & 809141 & 4.8 & 4.8553 & TRN & \\
\hline CHEMBL1998110 & 809141 & 4.6 & 4.2492 & TRN & \\
\hline CHEMBL1999590 & 809141 & 4.8 & 4.6515 & TST & \\
\hline CHEMBL1981079 & 809141 & 7.0 & 5.6235 & TRN & \\
\hline CHEMBL1978166 & 809141 & 5.8 & 5.5254 & TRN & \\
\hline CHEMBL1980489 & 809141 & 4.8 & 4.5118 & TRN & \\
\hline CHEMBL 2000832 & 809141 & 4.8 & 5.53299 & 99999999995 & TRN \\
\hline CHEMBL1967116 & 809141 & 7.2 & 6.5813 & TRN & \\
\hline CHEMBL1990590 & 809141 & 4.6 & 4.6742 & TRN & \\
\hline CHEMBL86755 & 809141 & 4.6 & 6.1908 & TRN & \\
\hline CHEMBL1970709 & 809141 & 4.8 & 4.8358 & TRN & \\
\hline CHEMBL1974617 & 809141 & 4.6 & 4.5422 & TRN & \\
\hline CHEMBL1965660 & 809141 & 7.7 & 6.2703 & TRN & \\
\hline CHEMBL1992125 & 809141 & 5.6 & 6.2626 & TRN & \\
\hline CHEMBL1998112 & 809141 & 6.1 & 5.103 & TRN & \\
\hline CHEMBL1969126 & 809141 & 4.8 & 4.87 & TRN & \\
\hline CHEMBL1980896 & 809141 & 4.8 & 4.8428 & TRN & \\
\hline CHEMBL1970104 & 809141 & 7.3 & 6.7153 & TRN & \\
\hline
\end{tabular}




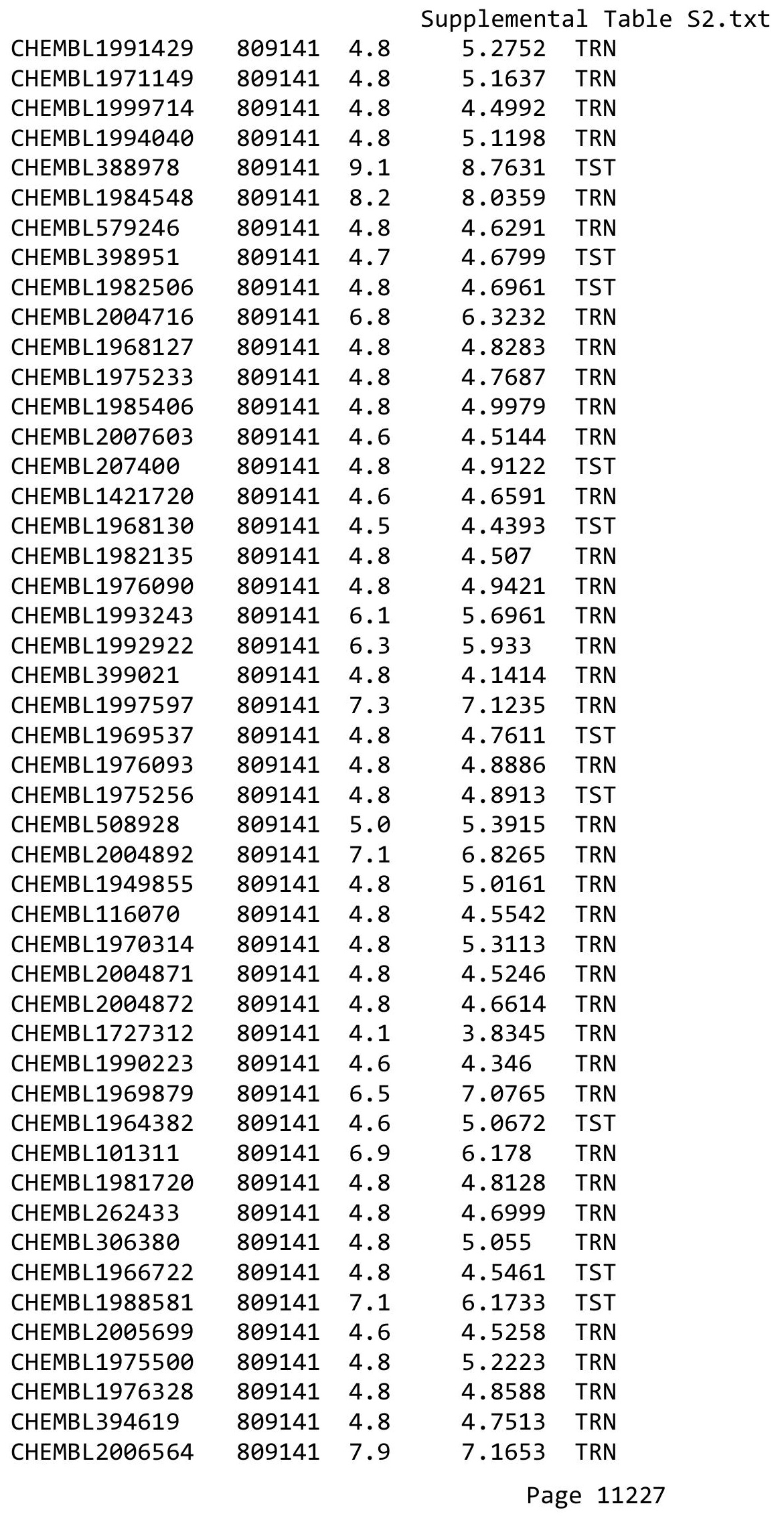




\begin{tabular}{|c|c|c|c|c|c|}
\hline \multicolumn{6}{|c|}{ Supplemental Table S2.txt } \\
\hline CHEMBL1964399 & 809141 & 4.8 & 5.4493 & TRN & \\
\hline CHEMBL1996831 & 809141 & 4.8 & 4.6279 & TST & \\
\hline CHEMBL411903 & 809141 & 6.3 & 6.4804 & TRN & \\
\hline CHEMBL1980253 & 809141 & 6.5 & 6.2618 & TRN & \\
\hline CHEMBL1978167 & 809141 & 5.9 & 4.9902 & TST & \\
\hline CHEMBL1965988 & 809141 & 6.5 & 5.7273 & TRN & \\
\hline CHEMBL418203 & 809141 & 4.7 & 5.0274 & TST & \\
\hline CHEMBL1989646 & 809141 & 6.8 & 6.3718 & TRN & \\
\hline CHEMBL1682357 & 809141 & 6.5 & 5.1406 & TRN & \\
\hline CHEMBL225519 & 809141 & 4.7 & 5.4482 & TRN & \\
\hline CHEMBL209534 & 809141 & 4.8 & 4.7838 & TRN & \\
\hline CHEMBL1978200 & 809141 & 4.8 & 5.2281 & TRN & \\
\hline CHEMBL1994159 & 809141 & 4.5 & 4.48600 & 0000000001 & TRN \\
\hline CHEMBL1970522 & 809141 & 4.8 & 4.6887 & TRN & \\
\hline CHEMBL402846 & 809141 & 4.8 & 4.6467 & TRN & \\
\hline CHEMBL1964692 & 809141 & 7.1 & 5.7028 & TRN & \\
\hline CHEMBL1996931 & 809141 & 4.8 & 4.8644 & TRN & \\
\hline CHEMBL1964413 & 809141 & 4.8 & 4.8669 & TRN & \\
\hline CHEMBL1973483 & 809141 & 4.8 & 4.9475 & TRN & \\
\hline CHEMBL1998470 & 809141 & 4.6 & 4.5082 & TRN & \\
\hline CHEMBL1984432 & 809141 & 4.8 & 4.9037 & TRN & \\
\hline CHEMBL219722 & 809141 & 6.2 & 5.8509 & TRN & \\
\hline CHEMBL1975903 & 809141 & 4.6 & 5.5163 & TRN & \\
\hline CHEMBL1994669 & 809141 & 8.4 & 8.5236 & TRN & \\
\hline CHEMBL1997340 & 809141 & 4.8 & 5.0534 & TRN & \\
\hline CHEMBL1522508 & 809141 & 4.8 & 4.6248 & TRN & \\
\hline CHEMBL1989474 & 809141 & 4.8 & 4.6186 & TRN & \\
\hline CHEMBL1090360 & 809141 & 4.8 & 4.4685 & TRN & \\
\hline CHEMBL210887 & 809141 & 4.8 & 5.4112 & TST & \\
\hline CHEMBL1988805 & 809141 & 4.6 & 4.7666 & TST & \\
\hline CHEMBL458997 & 809141 & 6.1 & 6.176 & TRN & \\
\hline CHEMBL1971021 & 809141 & 4.8 & 5.7624 & TRN & \\
\hline CHEMBL227271 & 809141 & 4.8 & 4.8129 & TRN & \\
\hline CHEMBL583144 & 809141 & 4.8 & 5.2355 & TRN & \\
\hline CHEMBL1974310 & 809141 & 4.8 & 4.5585 & TRN & \\
\hline CHEMBL1969942 & 809141 & 4.6 & 4.3855 & TRN & \\
\hline CHEMBL1978567 & 809141 & 4.6 & 4.2492 & TRN & \\
\hline CHEMBL1982660 & 809141 & 4.8 & 5.4886 & TRN & \\
\hline CHEMBL1994693 & 809141 & 4.8 & 4.5076 & TRN & \\
\hline CHEMBL1982957 & 809141 & 4.8 & 6.2213 & TRN & \\
\hline CHEMBL 2002346 & 809141 & 7.2 & 7.0992 & TRN & \\
\hline CHEMBL1975138 & 809141 & 4.8 & 4.5241 & TST & \\
\hline CHEMBL424872 & 809141 & 4.7 & 4.7677 & TRN & \\
\hline CHEMBL1971947 & 809141 & 6.3 & 5.3402 & TRN & \\
\hline CHEMBL412142 & 809141 & 4.8 & 5.4709 & TST & \\
\hline CHEMBL1980704 & 809141 & 4.8 & 4.7832 & TST & \\
\hline CHEMBL 2003271 & 809141 & 4.8 & 4.9514 & TRN & \\
\hline CHEMBL1972365 & 809141 & 4.9 & 4.3315 & TST & \\
\hline
\end{tabular}




\begin{tabular}{|c|c|c|c|c|c|}
\hline \multicolumn{6}{|c|}{ Supplemental Table S2.txt } \\
\hline CHEMBL1966808 & 809141 & 4.8 & 4.6059 & TRN & \\
\hline CHEMBL 2004447 & 809141 & 4.8 & 5.0774 & TRN & \\
\hline CHEMBL1983111 & 809141 & 8.4 & 8.4419 & TRN & \\
\hline CHEMBL1973860 & 809141 & 6.1 & 5.0783 & TRN & \\
\hline CHEMBL260135 & 809141 & 4.8 & 4.8608 & TRN & \\
\hline CHEMBL220241 & 809141 & 4.8 & 5.138 & TRN & \\
\hline CHEMBL1988141 & 809141 & 6.3 & 6.2742 & TST & \\
\hline CHEMBL1982610 & 809141 & 4.8 & 5.2924 & TST & \\
\hline CHEMBL1977134 & 809141 & 4.6 & 5.3212 & TRN & \\
\hline CHEMBL2006933 & 809141 & 5.9 & 4.9783 & TST & \\
\hline CHEMBL1985206 & 809141 & 4.6 & 4.3676 & TST & \\
\hline CHEMBL1988300 & 809141 & 4.8 & 5.4178 & TRN & \\
\hline CHEMBL1991078 & 809141 & 6.9 & 6.1261 & TRN & \\
\hline CHEMBL1977749 & 809141 & 4.6 & 4.9672 & TST & \\
\hline CHEMBL 2000685 & 809141 & 6.7 & 6.0535 & TRN & \\
\hline CHEMBL 2001613 & 809141 & 4.6 & 4.5291 & TRN & \\
\hline CHEMBL1997275 & 809141 & 4.6 & 4.902 & TRN & \\
\hline CHEMBL1993904 & 809141 & 4.6 & 5.0419 & TRN & \\
\hline CHEMBL1967513 & 809141 & 4.6 & 4.6486 & TRN & \\
\hline CHEMBL 2000724 & 809141 & 4.6 & 4.9781 & TRN & \\
\hline CHEMBL1985311 & 809141 & 4.8 & 5.6572 & TRN & \\
\hline CHEMBL1982413 & 809141 & 4.6 & 5.4609 & TST & \\
\hline CHEMBL1969502 & 809141 & 7.8 & 6.5455 & TST & \\
\hline CHEMBL1965910 & 809141 & 4.8 & 4.4229 & TRN & \\
\hline CHEMBL1682553 & 809141 & 4.8 & 4.9574 & TRN & \\
\hline CHEMBL1983963 & 809141 & 5.9 & 5.0361 & TRN & \\
\hline CHEMBL1997764 & 809141 & 4.8 & 4.6673 & TRN & \\
\hline CHEMBL 2000271 & 809141 & 4.8 & 5.0002 & TRN & \\
\hline CHEMBL1981792 & 809141 & 5.6 & 5.3309 & TRN & \\
\hline CHEMBL1987535 & 809141 & 4.6 & 4.5059 & TRN & \\
\hline CHEMBL1985092 & 809141 & 4.8 & 5.1627 & TRN & \\
\hline CHEMBL1981410 & 809141 & 4.8 & 5.3232 & TRN & \\
\hline CHEMBL 2002586 & 809141 & 5.9 & 5.5818 & TRN & \\
\hline CHEMBL1987815 & 809141 & 4.1 & 3.841 & TST & \\
\hline CHEMBL1996234 & 809141 & 4.8 & 4.5723 & TRN & \\
\hline CHEMBL383264 & 809141 & 4.6 & 4.4257 & TRN & \\
\hline CHEMBL 2007421 & 809141 & 7.0 & 7.1034 & TST & \\
\hline CHEMBL1967544 & 809141 & 4.8 & 4.8869 & TRN & \\
\hline CHEMBL1973138 & 809141 & 4.6 & 4.59399 & 9999999999 & TRN \\
\hline CHEMBL223367 & 809141 & 4.8 & 4.5597 & TST & \\
\hline CHEMBL1992673 & 809141 & 4.0 & 4.6793 & TRN & \\
\hline CHEMBL1969151 & 809141 & 5.9 & 5.7618 & TRN & \\
\hline CHEMBL1996587 & 809141 & 4.8 & 4.9159 & TRN & \\
\hline CHEMBL1981492 & 809141 & 4.1 & 4.6049 & TRN & \\
\hline CHEMBL1993335 & 809141 & 6.1 & 5.8445 & TST & \\
\hline CHEMBL1988692 & 809141 & 4.6 & 5.21899 & 9999999999 & TRN \\
\hline CHEMBL 2007574 & 809141 & 4.6 & 4.7859 & TRN & \\
\hline CHEMBL1964804 & 809141 & 4.8 & 5.1882 & TRN & \\
\hline
\end{tabular}




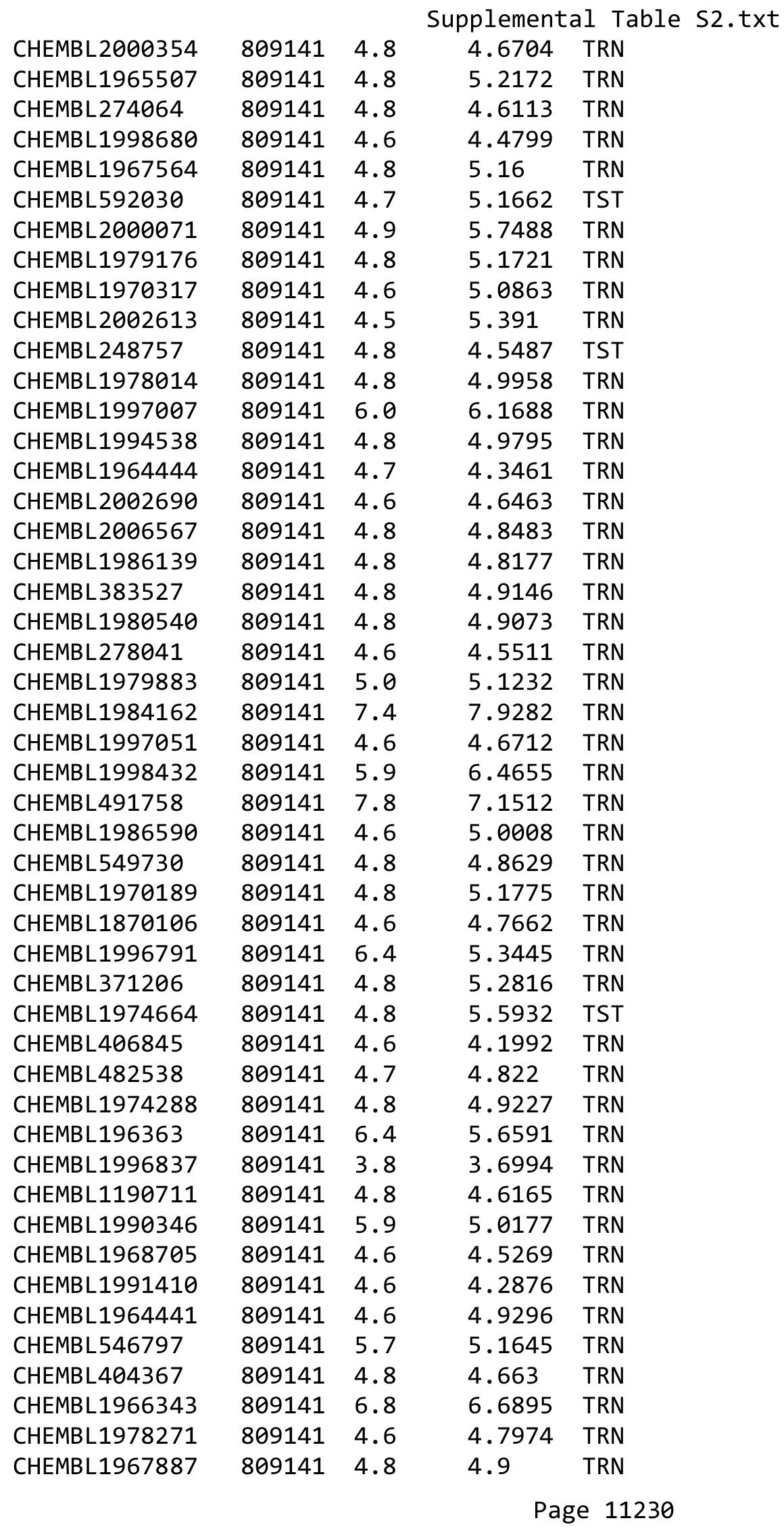




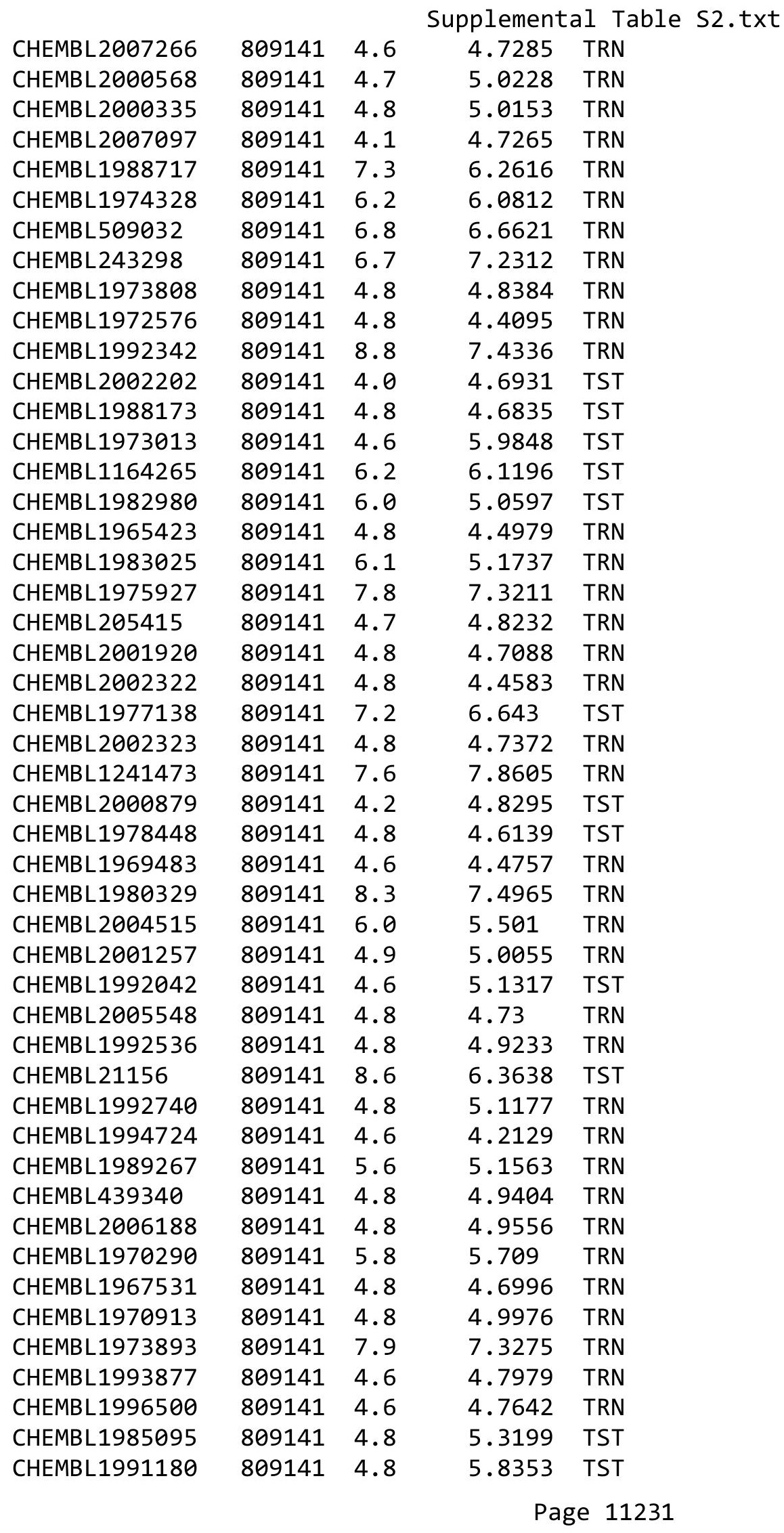




\begin{tabular}{|c|c|c|c|c|}
\hline & & & & $a \perp 1$ \\
\hline CHEMBL1989708 & 809141 & 5.0 & 5.2061 & TRN \\
\hline CHEMBL1682540 & 809141 & 4.8 & 5.1404 & TRN \\
\hline CHEMBL1976420 & 809141 & 6.2 & 5.8984 & TST \\
\hline CHEMBL413779 & 809141 & 4.8 & 4.8612 & TST \\
\hline CHEMBL1981744 & 809141 & 5.6 & 5.2748 & TRN \\
\hline CHEMBL1994864 & 809141 & 4.8 & 4.6375 & TRN \\
\hline CHEMBL2002446 & 809141 & 4.8 & 4.8229 & TST \\
\hline CHEMBL497151 & 809141 & 4.8 & 5.118 & TRN \\
\hline CHEMBL 2000029 & 809141 & 6.0 & 6.3991 & TRN \\
\hline CHEMBL1973961 & 809141 & 4.6 & 5.1569 & TRN \\
\hline CHEMBL246970 & 809141 & 4.8 & 4.8776 & TRN \\
\hline CHEMBL340921 & 809141 & 4.8 & 4.6392 & TST \\
\hline CHEMBL1994977 & 809141 & 4.6 & 4.7552 & TRN \\
\hline CHEMBL373598 & 809141 & 4.8 & 4.6801 & TST \\
\hline CHEMBL1999718 & 809141 & 4.8 & 4.8884 & TRN \\
\hline CHEMBL 2000078 & 809141 & 4.6 & 4.6937 & TRN \\
\hline CHEMBL 2005478 & 809141 & 4.6 & 5.5057 & TST \\
\hline CHEMBL1276446 & 809141 & 6.8 & 7.5395 & TST \\
\hline CHEMBL1996646 & 809141 & 5.9 & 6.5814 & TRN \\
\hline CHEMBL1979773 & 809141 & 4.6 & 4.2405 & TRN \\
\hline CHEMBL1977346 & 809141 & 4.8 & 4.9848 & TRN \\
\hline CHEMBL2003657 & 809141 & 4.8 & 4.8726 & TRN \\
\hline CHEMBL1971649 & 809141 & 4.8 & 4.6682 & TRN \\
\hline CHEMBL 2005482 & 809141 & 4.6 & 4.9886 & TRN \\
\hline CHEMBL1996702 & 809141 & 4.6 & 5.4375 & TRN \\
\hline CHEMBL1997909 & 809141 & 4.6 & 4.4184 & TRN \\
\hline CHEMBL 2007124 & 809141 & 7.3 & 5.0911 & TRN \\
\hline CHEMBL1998435 & 809141 & 5.9 & 4.8736 & TRN \\
\hline CHEMBL 2006439 & 809141 & 4.6 & 5.5147 & TRN \\
\hline CHEMBL1985681 & 809141 & 4.6 & 5.037 & TST \\
\hline CHEMBL1969190 & 809141 & 4.8 & 4.7944 & TRN \\
\hline CHEMBL1973937 & 809141 & 4.9 & 5.6554 & TRN \\
\hline CHEMBL1991674 & 809141 & 6.8 & 6.175 & TRN \\
\hline CHEMBL1982711 & 809141 & 4.7 & 4.7974 & TRN \\
\hline CHEMBL262623 & 809141 & 4.0 & 4.8004 & TRN \\
\hline CHEMBL1987982 & 809141 & 6.0 & 5.5221 & TST \\
\hline CHEMBL1984842 & 809141 & 4.7 & 4.7504 & TRN \\
\hline CHEMBL1969102 & 809141 & 7.1 & 6.5871 & TRN \\
\hline CHEMBL 2004118 & 809141 & 6.4 & 6.3583 & TRN \\
\hline CHEMBL1682346 & 809141 & 7.3 & 6.0527 & TRN \\
\hline CHEMBL 2007044 & 809141 & 4.8 & 4.7409 & TST \\
\hline CHEMBL 2001998 & 809141 & 4.8 & $5.1220 e$ & 0000000001 \\
\hline CHEMBL1994241 & 809141 & 5.1 & 5.7846 & TRN \\
\hline CHEMBL 223460 & 809141 & 4.8 & 4.757 & TST \\
\hline CHEMBL50894 & 809141 & 4.8 & 4.6321 & TRN \\
\hline CHEMBL1995211 & 809141 & 4.6 & 5.0 & TRN \\
\hline CHEMBL1988838 & 809141 & 8.4 & 8.1494 & TRN \\
\hline CHEMBL1981725 & 809141 & 4.8 & 5.4474 & TRN \\
\hline
\end{tabular}




\begin{tabular}{|c|c|c|c|c|}
\hline \multicolumn{5}{|c|}{ plement } \\
\hline CHEMBL1982753 & 809141 & 5.6 & 5.0509 & TRN \\
\hline CHEMBL375284 & 809141 & 4.8 & 4.6056 & TRN \\
\hline CHEMBL 2006299 & 809141 & 4.6 & 4.2839 & TRN \\
\hline CHEMBL1972346 & 809141 & 6.1 & 5.7916 & TST \\
\hline CHEMBL1965169 & 809141 & 4.6 & 4.6515 & TST \\
\hline CHEMBL1081312 & 809141 & 6.0 & 5.3909 & TRN \\
\hline CHEMBL1965170 & 809141 & 4.6 & 4.4942 & TRN \\
\hline CHEMBL1982866 & 809141 & 4.8 & 4.5859 & TRN \\
\hline CHEMBL 2005792 & 809141 & 4.7 & 4.6478 & TRN \\
\hline CHEMBL1984206 & 809141 & 4.8 & 4.8452 & TRN \\
\hline CHEMBL1965570 & 809141 & 4.8 & 5.0445 & TRN \\
\hline CHEMBL 2007592 & 809141 & 4.8 & 4.6686 & TRN \\
\hline CHEMBL1972355 & 809141 & 5.7 & 5.484 & TRN \\
\hline CHEMBL1997892 & 809141 & 4.6 & 5.4822 & TRN \\
\hline CHEMBL 2001641 & 809141 & 4.5 & 4.9983 & TRN \\
\hline CHEMBL1997193 & 809141 & 6.1 & 5.3321 & TST \\
\hline CHEMBL210963 & 809141 & 4.8 & 4.9221 & TRN \\
\hline CHEMBL1964902 & 809141 & 4.6 & 4.5482 & TRN \\
\hline CHEMBL1082440 & 809141 & 5.0 & 5.4807 & TST \\
\hline CHEMBL1614705 & 809141 & 4.8 & 5.1439 & TRN \\
\hline CHEMBL1972362 & 809141 & 4.8 & 4.5249 & TRN \\
\hline CHEMBL1984633 & 809141 & 4.8 & 4.6439 & TRN \\
\hline CHEMBL1965845 & 809141 & 4.8 & 4.9516 & TRN \\
\hline CHEMBL1983715 & 809141 & 7.5 & 6.6835 & TRN \\
\hline CHEMBL 2006715 & 809141 & 4.8 & 5.2931 & TRN \\
\hline CHEMBL1971017 & 809141 & 4.8 & 5.0598 & TRN \\
\hline CHEMBL1990482 & 809141 & 4.8 & 4.6671 & TRN \\
\hline CHEMBL1990904 & 809141 & 4.8 & 4.6725 & TRN \\
\hline CHEMBL 2005475 & 809141 & 4.8 & 4.8508 & TRN \\
\hline CHEMBL 2000104 & 809141 & 4.8 & 4.4471 & TRN \\
\hline CHEMBL183844 & 809141 & 4.8 & 5.3017 & TRN \\
\hline CHEMBL220057 & 809141 & 5.0 & 5.5532 & TRN \\
\hline CHEMBL1682545 & 809141 & 4.8 & 5.0615 & TRN \\
\hline CHEMBL383541 & 809141 & 4.8 & 4.6471 & TRN \\
\hline CHEMBL 2001224 & 809141 & 4.8 & 4.8929 & TRN \\
\hline CHEMBL10 & 809141 & 4.6 & 4.4036 & TRN \\
\hline CHEMBL1969506 & 809141 & 4.8 & 5.2257 & TRN \\
\hline CHEMBL1964937 & 809141 & 4.8 & 5.3054 & TRN \\
\hline CHEMBL1980763 & 809141 & 6.4 & 6.4623 & TRN \\
\hline CHEMBL1980163 & 809141 & 4.8 & 4.6133 & TRN \\
\hline CHEMBL590109 & 809141 & 4.8 & 5.5792 & TST \\
\hline CHEMBL1977931 & 809141 & 4.3 & 4.4698 & TRN \\
\hline CHEMBL1970879 & 809141 & 4.8 & 4.7745 & TRN \\
\hline CHEMBL1989856 & 809141 & 4.8 & 5.6692 & TST \\
\hline CHEMBL 2005899 & 809141 & 4.8 & 4.7272 & TRN \\
\hline CHEMBL1682552 & 809141 & 4.8 & 4.9983 & TRN \\
\hline CHEMBL259850 & 809141 & 4.8 & 4.8969 & TRN \\
\hline CHEMBL 2007479 & 809141 & 4.6 & 4.5786 & TRN \\
\hline
\end{tabular}




\begin{tabular}{|c|c|c|c|c|}
\hline & & & Supplement & \\
\hline CHEMBL229799 & 809141 & 5.9 & 5.5003 & TRN \\
\hline CHEMBL105739 & 809141 & 6.7 & 6.0208 & TRN \\
\hline CHEMBL1682359 & 809141 & 4.8 & 5.0759 & TRN \\
\hline CHEMBL1972220 & 809141 & 4.6 & 5.1237 & TRN \\
\hline CHEMBL 379300 & 809141 & 4.8 & 5.6247 & TRN \\
\hline CHEMBL203673 & 809141 & 4.8 & 4.8229 & TRN \\
\hline CHEMBL 2003785 & 809141 & 4.5 & 5.0398 & TST \\
\hline CHEMBL1973720 & 809141 & 6.1 & 6.1176 & TRN \\
\hline CHEMBL1969523 & 809141 & 4.8 & 5.2588 & TRN \\
\hline CHEMBL207995 & 809141 & 4.8 & 4.478 & TRN \\
\hline CHEMBL2001923 & 809141 & 4.7 & 4.7275 & TRN \\
\hline CHEMBL1986781 & 809141 & 4.8 & 4.9801 & TRN \\
\hline CHEMBL1983070 & 809141 & 4.6 & 4.9418 & TRN \\
\hline CHEMBL526133 & 809141 & 4.8 & 5.0456 & TRN \\
\hline CHEMBL 2003514 & 809141 & 4.6 & 4.2507 & TRN \\
\hline CHEMBL1989043 & 809141 & 4.6 & 5.1902 & TRN \\
\hline CHEMBL1979057 & 809141 & 4.8 & 4.6135 & TRN \\
\hline CHEMBL1981045 & 809141 & 5.9 & 5.0891 & TRN \\
\hline CHEMBL387971 & 809141 & 4.8 & 4.9708 & TST \\
\hline CHEMBL1975418 & 809141 & 6.2 & 5.5106 & TRN \\
\hline CHEMBL1992796 & 809141 & 4.8 & 4.8755 & TRN \\
\hline CHEMBL1164180 & 809141 & 7.4 & 6.2851 & TST \\
\hline CHEMBL223257 & 809141 & 4.8 & 4.7329 & TST \\
\hline CHEMBL1967560 & 809141 & 4.8 & 5.0866 & TRN \\
\hline CHEMBL1516890 & 809141 & 4.8 & 5.3553 & TRN \\
\hline CHEMBL 211378 & 809141 & 4.8 & 4.5298 & TRN \\
\hline CHEMBL1982465 & 809141 & 6.3 & 5.666 & TRN \\
\hline CHEMBL 2001751 & 809141 & 6.5 & 6.3878 & TRN \\
\hline CHEMBL1984586 & 809141 & 4.8 & 4.1748 & TRN \\
\hline CHEMBL1999774 & 809141 & 4.8 & 4.9483 & TST \\
\hline CHEMBL1972659 & 809141 & 4.8 & 5.1981 & TST \\
\hline CHEMBL 2002723 & 809141 & 5.7 & 5.4971 & TST \\
\hline CHEMBL1973395 & 809141 & 6.4 & 6.4473 & TRN \\
\hline CHEMBL272453 & 809141 & 4.8 & 4.6674 & TRN \\
\hline CHEMBL1970217 & 809141 & 4.8 & 4.822 & TRN \\
\hline CHEMBL1968850 & 809141 & 4.8 & 4.7712 & TRN \\
\hline CHEMBL 2005528 & 809141 & 6.4 & 5.2534 & TRN \\
\hline CHEMBL1984686 & 809141 & 4.6 & 4.721 & TRN \\
\hline CHEMBL185569 & 809141 & 4.8 & 5.3393 & TRN \\
\hline CHEMBL1969843 & 809141 & 4.8 & 5.2289 & TRN \\
\hline CHEMBL 2007002 & 809141 & 4.8 & 5.0092 & TRN \\
\hline CHEMBL1987007 & 809141 & 4.8 & 4.5022 & TRN \\
\hline CHEMBL1973793 & 809141 & 4.6 & 5.0889 & TST \\
\hline CHEMBL1969588 & 809141 & 7.5 & 7.8109 & TRN \\
\hline CHEMBL1984711 & 809141 & 6.4 & 6.5122 & TRN \\
\hline CHEMBL1992073 & 809141 & 9.9 & 7.8993 & TRN \\
\hline CHEMBL1990212 & 809141 & 5.9 & 4.9066 & TST \\
\hline CHEMBL484390 & 809141 & 4.8 & 5.1544 & TST \\
\hline
\end{tabular}




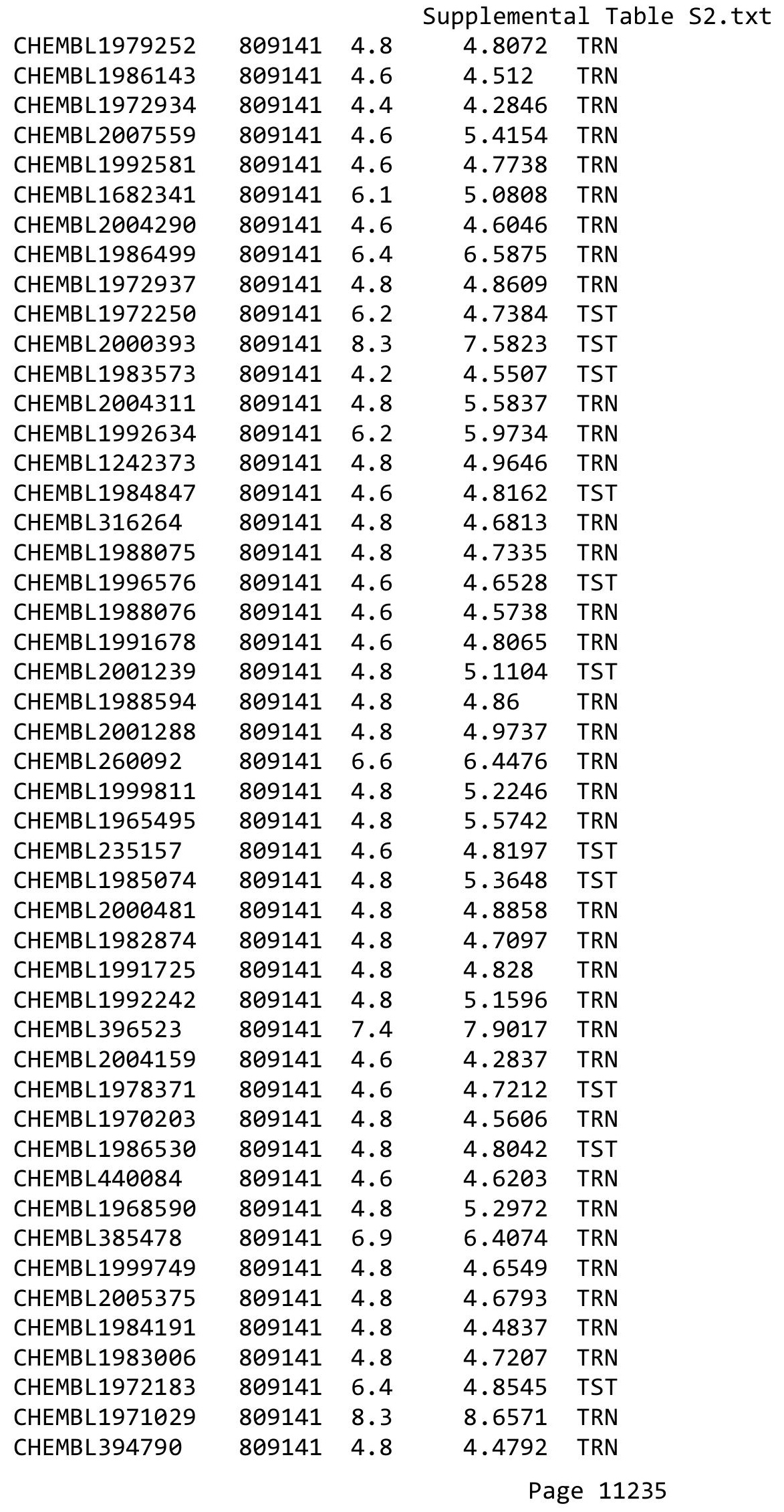




\begin{tabular}{|c|c|c|c|c|}
\hline \multicolumn{5}{|c|}{ Supplemental Table S2.txt } \\
\hline CHEMBL226471 & 809141 & 4.8 & 4.7596 & TRN \\
\hline CHEMBL1974702 & 809141 & 4.8 & 5.1636 & TRN \\
\hline CHEMBL1996111 & 809141 & 4.8 & 5.5923 & TRN \\
\hline CHEMBL1966175 & 809141 & 9.1 & 7.4562 & TRN \\
\hline CHEMBL1965589 & 809141 & 4.8 & 5.1803 & TRN \\
\hline CHEMBL 2007375 & 809141 & 4.6 & 4.5812 & TRN \\
\hline CHEMBL379975 & 809141 & 6.4 & 5.6282 & TST \\
\hline CHEMBL474432 & 809141 & 6.1 & 6.2777 & TST \\
\hline CHEMBL1965387 & 809141 & 4.6 & 4.5686 & TRN \\
\hline CHEMBL 2001539 & 809141 & 3.3 & 4.0791 & TST \\
\hline CHEMBL1997041 & 809141 & 5.6 & 5.54 & TRN \\
\hline CHEMBL1988153 & 809141 & 4.8 & 4.6101 & TRN \\
\hline CHEMBL550418 & 809141 & 4.6 & 4.717 & TRN \\
\hline CHEMBL1971289 & 809141 & 4.6 & 4.6628 & TRN \\
\hline CHEMBL1999556 & 809141 & 4.8 & 5.0579 & TRN \\
\hline CHEMBL1988437 & 809141 & 4.9 & 5.9508 & TST \\
\hline CHEMBL1968245 & 809141 & 4.8 & 4.7358 & TRN \\
\hline CHEMBL1979577 & 809141 & 4.8 & 5.2044 & TRN \\
\hline CHEMBL1998121 & 809141 & 4.8 & 5.075 & TRN \\
\hline CHEMBL1233887 & 809141 & 5.9 & 4.9527 & TST \\
\hline CHEMBL1991800 & 809141 & 4.8 & 4.9397 & TRN \\
\hline CHEMBL1985566 & 809141 & 5.9 & 4.9681 & TRN \\
\hline CHEMBL1979357 & 809141 & 4.8 & 5.0155 & TRN \\
\hline CHEMBL1980802 & 809141 & 4.8 & 4.6037 & TST \\
\hline CHEMBL1996649 & 809141 & 4.6 & 6.0181 & TRN \\
\hline CHEMBL1996817 & 809141 & 5.2 & 5.4668 & TRN \\
\hline CHEMBL1979554 & 809141 & 6.4 & 4.8469 & TRN \\
\hline CHEMBL1986756 & 809141 & 4.6 & 4.433 & TRN \\
\hline CHEMBL2004355 & 809141 & 4.8 & 4.8727 & TRN \\
\hline CHEMBL468280 & 809141 & 4.8 & 5.0082 & TST \\
\hline CHEMBL1990884 & 809141 & 4.8 & 5.3436 & TRN \\
\hline CHEMBL3109278 & 809141 & 4.7 & 5.0071 & TRN \\
\hline CHEMBL256835 & 809141 & 4.8 & 4.8018 & TRN \\
\hline CHEMBL1980142 & 809141 & 4.8 & 4.8546 & TRN \\
\hline CHEMBL41783 & 809141 & 4.8 & 5.0105 & TRN \\
\hline CHEMBL 2004438 & 809141 & 4.8 & 5.223 & TRN \\
\hline CHEMBL 2006276 & 809141 & 4.8 & 4.9522 & TRN \\
\hline CHEMBL191003 & 809141 & 7.0 & 6.7553 & TRN \\
\hline CHEMBL271381 & 809141 & 6.6 & 6.06 & TRN \\
\hline CHEMBL 2006785 & 809141 & 4.8 & 4.8978 & TRN \\
\hline CHEMBL1982466 & 809141 & 4.8 & 5.2199 & TRN \\
\hline CHEMBL1973359 & 809141 & 5.9 & 5.5634 & TST \\
\hline CHEMBL1995740 & 809141 & 4.8 & 4.8296 & TRN \\
\hline CHEMBL1996390 & 809141 & 4.8 & 4.6984 & TRN \\
\hline CHEMBL1979690 & 809141 & 8.6 & 8.5867 & TRN \\
\hline CHEMBL 234085 & 809141 & 8.4 & 7.2854 & TRN \\
\hline CHEMBL1969042 & 809141 & 4.8 & 5.2429 & TRN \\
\hline CHEMBL 2000345 & 809141 & 5.0 & 5.6775 & TRN \\
\hline
\end{tabular}




\begin{tabular}{|c|c|c|c|c|c|}
\hline \multicolumn{6}{|c|}{ Supplemental Table S2.txt } \\
\hline CHEMBL1999931 & 809141 & 6.8 & 6.3658 & TRN & \\
\hline CHEMBL1976376 & 809141 & 4.6 & 4.151 & TRN & \\
\hline CHEMBL1991640 & 809141 & 4.8 & 5.1925 & TST & \\
\hline CHEMBL1983575 & 809141 & 5.6 & 6.1491 & TRN & \\
\hline CHEMBL1968868 & 809141 & 4.6 & 4.6118 & TRN & \\
\hline CHEMBL 2007064 & 809141 & 6.7 & 6.7404 & TRN & \\
\hline CHEMBL1981047 & 809141 & 6.7 & 7.1691 & TRN & \\
\hline CHEMBL229968 & 809141 & 4.8 & 5.2191 & TRN & \\
\hline CHEMBL1976196 & 809141 & 4.6 & 4.7192 & TST & \\
\hline CHEMBL1976240 & 809141 & 4.8 & 4.7742 & TRN & \\
\hline CHEMBL1997197 & 809141 & 4.6 & 4.4853 & TRN & \\
\hline CHEMBL1979093 & 809141 & 4.8 & 4.92899 & 9999999999 & TRN \\
\hline CHEMBL1968151 & 809141 & 4.8 & 4.7519 & TRN & \\
\hline CHEMBL1987009 & 809141 & 4.8 & 4.7592 & TRN & \\
\hline CHEMBL379218 & 809141 & 5.9 & 4.6684 & TRN & \\
\hline CHEMBL 2003817 & 809141 & 4.8 & 4.9741 & TRN & \\
\hline CHEMBL336961 & 809141 & 4.8 & 4.9422 & TRN & \\
\hline CHEMBL1994830 & 809141 & 4.8 & 4.7478 & TRN & \\
\hline CHEMBL1987054 & 809141 & 7.5 & 7.6619 & TRN & \\
\hline CHEMBL1970083 & 809141 & 7.7 & 6.8316 & TRN & \\
\hline CHEMBL226403 & 809141 & 4.8 & 4.9299 & TRN & \\
\hline CHEMBL 2005631 & 809141 & 7.4 & 6.7657 & TRN & \\
\hline CHEMBL1994938 & 809141 & 4.8 & 5.9622 & TRN & \\
\hline CHEMBL1977223 & 809141 & 6.2 & 5.3217 & TRN & \\
\hline CHEMBL1995765 & 809141 & 4.4 & 4.8524 & TST & \\
\hline CHEMBL1966279 & 809141 & 4.8 & 4.7811 & TRN & \\
\hline CHEMBL1236126 & 809141 & 4.8 & 5.2859 & TST & \\
\hline CHEMBL1997846 & 809141 & 4.6 & 5.0654 & TRN & \\
\hline CHEMBL1984760 & 809141 & 6.3 & 6.3784 & TRN & \\
\hline CHEMBL 2004419 & 809141 & 4.8 & 4.5552 & TRN & \\
\hline CHEMBL1991728 & 809141 & 6.0 & 5.5775 & TRN & \\
\hline CHEMBL360847 & 809141 & 4.6 & 5.265 & TST & \\
\hline CHEMBL1995811 & 809141 & 4.6 & 4.8638 & TRN & \\
\hline CHEMBL1975787 & 809141 & 4.8 & 4.9969 & TRN & \\
\hline CHEMBL 2002407 & 809141 & 4.8 & 5.5597 & TRN & \\
\hline CHEMBL1994074 & 809141 & 4.8 & 4.6582 & TRN & \\
\hline CHEMBL1992937 & 809141 & 4.7 & 5.11600 & 00000000005 & TST \\
\hline CHEMBL451401 & 809141 & 3.5 & 4.3917 & TRN & \\
\hline CHEMBL1972119 & 809141 & 4.8 & 5.0105 & TRN & \\
\hline CHEMBL 95692 & 809141 & 4.8 & 4.7614 & TRN & \\
\hline CHEMBL1090356 & 809141 & 4.8 & 4.1831 & TRN & \\
\hline CHEMBL 2002450 & 809141 & 4.1 & 4.473 & TRN & \\
\hline CHEMBL1976455 & 809141 & 4.8 & 5.1614 & TRN & \\
\hline CHEMBL261849 & 809141 & 4.6 & 5.1362 & TST & \\
\hline CHEMBL1983923 & 809141 & 7.6 & 7.4567 & TRN & \\
\hline CHEMBL1983534 & 809141 & 4.8 & 4.9349 & TRN & \\
\hline CHEMBL1982361 & 809141 & 4.8 & 4.7669 & TST & \\
\hline CHEMBL1999112 & 809141 & 4.8 & 4.9465 & TST & \\
\hline
\end{tabular}




\begin{tabular}{|c|c|c|c|c|c|}
\hline \multicolumn{6}{|c|}{ Supplemental Table S2.txt } \\
\hline CHEMBL1982122 & 809141 & 4.8 & 4.7868 & TST & \\
\hline CHEMBL 2000801 & 809141 & 4.8 & 5.1194 & TST & \\
\hline CHEMBL1682546 & 809141 & 4.8 & 5.3149 & TST & \\
\hline CHEMBL1991395 & 809141 & 4.8 & 4.8332 & TST & \\
\hline CHEMBL1971245 & 809141 & 4.8 & 5.7064 & TST & \\
\hline CHEMBL1987648 & 809141 & 4.8 & 4.97199 & 99999999995 & TST \\
\hline CHEMBL1996780 & 809141 & 4.8 & 4.6793 & TST & \\
\hline CHEMBL1972142 & 809141 & 6.3 & 5.1157 & TST & \\
\hline CHEMBL1966514 & 809141 & 6.3 & 5.5721 & TST & \\
\hline CHEMBL 2003638 & 809141 & 6.7 & 5.5452 & TST & \\
\hline CHEMBL296586 & 809141 & 4.8 & 4.7301 & TST & \\
\hline CHEMBL1996066 & 809141 & 5.8 & 5.414 & TST & \\
\hline CHEMBL1983393 & 809141 & 4.6 & 4.6664 & TST & \\
\hline CHEMBL516429 & 809141 & 6.0 & 4.8198 & TST & \\
\hline CHEMBL1993722 & 809141 & 6.2 & 5.8188 & TST & \\
\hline CHEMBL 2006674 & 809141 & 4.6 & 4.6946 & TST & \\
\hline CHEMBL1984236 & 809141 & 4.6 & 4.5838 & TST & \\
\hline CHEMBL1992371 & 809141 & 4.6 & 4.8179 & TST & \\
\hline CHEMBL1375640 & 809141 & 4.8 & 5.222 & TST & \\
\hline CHEMBL1979970 & 809141 & 4.8 & 4.9377 & TST & \\
\hline CHEMBL 2002599 & 809141 & 4.6 & 5.085 & TST & \\
\hline CHEMBL249282 & 809141 & 5.1 & 4.8937 & TST & \\
\hline CHEMBL1967252 & 809141 & 5.1 & 4.4357 & TST & \\
\hline CHEMBL 2004637 & 809141 & 5.6 & 5.1395 & TST & \\
\hline CHEMBL1993374 & 809141 & 4.6 & 5.4198 & TST & \\
\hline CHEMBL1969264 & 809141 & 4.8 & 5.482 & TST & \\
\hline CHEMBL1973711 & 809141 & 5.9 & 4.7311 & TST & \\
\hline CHEMBL 2006237 & 809141 & 4.8 & 5.129 & TST & \\
\hline CHEMBL1965604 & 809141 & 5.6 & 5.0926 & TST & \\
\hline CHEMBL1991138 & 809141 & 4.8 & 4.3104 & TST & \\
\hline CHEMBL1969755 & 809141 & 4.8 & 4.7889 & TST & \\
\hline CHEMBL1979516 & 809141 & 5.8 & 6.0065 & TST & \\
\hline CHEMBL1605605 & 809141 & 4.6 & 4.4141 & TST & \\
\hline CHEMBL1989029 & 809141 & 4.8 & 4.9304 & TST & \\
\hline CHEMBL 392642 & 809141 & 4.8 & 4.71399 & 99999999995 & TST \\
\hline CHEMBL514499 & 809141 & 5.9 & 5.50899 & 99999999995 & TST \\
\hline CHEMBL1970352 & 809141 & 4.6 & 5.4392 & TST & \\
\hline CHEMBL1965631 & 809141 & 4.8 & 5.1776 & TST & \\
\hline CHEMBL1980144 & 809141 & 4.8 & 4.3366 & TST & \\
\hline CHEMBL1991188 & 809141 & 4.8 & 4.894 & TST & \\
\hline CHEMBL1980167 & 809141 & 5.6 & 5.12 & TST & \\
\hline CHEMBL 377408 & 809141 & 4.6 & 4.2975 & TST & \\
\hline CHEMBL 215152 & 809141 & 4.7 & 4.3938 & TST & \\
\hline CHEMBL231209 & 809141 & 4.8 & 4.2531 & TST & \\
\hline CHEMBL1976220 & 809141 & 4.8 & 4.68199 & 99999999995 & TST \\
\hline CHEMBL 2006765 & 809141 & 7.6 & 6.9056 & TST & \\
\hline CHEMBL259922 & 809141 & 4.8 & 4.7543 & TST & \\
\hline CHEMBL1997617 & 809141 & 4.8 & 4.9689 & TST & \\
\hline
\end{tabular}




\begin{tabular}{|c|c|c|c|c|}
\hline \multicolumn{5}{|c|}{ Supplemental Table S2.txt } \\
\hline CHEMBL1969301 & 809141 & 4.8 & 5.4551 & TST \\
\hline CHEMBL17370 & 809141 & 4.8 & 4.6127 & TST \\
\hline CHEMBL1980246 & 809141 & 4.6 & 4.842 & TST \\
\hline CHEMBL1987910 & 809141 & 4.8 & 4.7556 & TST \\
\hline CHEMBL1983932 & 809141 & 4.8 & 5.2658 & TST \\
\hline CHEMBL1983980 & 809141 & 5.7 & 5.3777 & TST \\
\hline CHEMBL1999484 & 809141 & 7.5 & 6.6644 & TST \\
\hline CHEMBL1966069 & 809141 & 4.8 & 5.1246 & TST \\
\hline CHEMBL1986899 & 809141 & 4.6 & 4.8112 & TST \\
\hline CHEMBL1991285 & 809141 & 4.8 & 4.8808 & TST \\
\hline CHEMBL1997822 & 809141 & 4.8 & 5.1405 & TST \\
\hline CHEMBL243088 & 809141 & 7.5 & 7.5158 & TST \\
\hline CHEMBL1984038 & 809141 & 4.7 & 4.9774 & TST \\
\hline CHEMBL1993661 & 809141 & 9.1 & 9.0975 & TST \\
\hline CHEMBL1974416 & 809141 & 4.8 & 4.5719 & TST \\
\hline CHEMBL1997872 & 809141 & 6.0 & 5.0513 & TST \\
\hline CHEMBL3945930 & 1641552 & 8.3188 & 8.5087 & TST \\
\hline CHEMBL3924258 & 1641552 & 8.3468 & 8.3026 & TRN \\
\hline CHEMBL3967059 & 1641552 & 8.0655 & 7.9042 & TRN \\
\hline CHEMBL3893712 & 1641552 & 8.699 & 8.6482 & TRN \\
\hline CHEMBL3955944 & 1641552 & 7.9208 & 7.9263 & TST \\
\hline CHEMBL 3918770 & 1641552 & 8.6778 & 8.9636 & TRN \\
\hline CHEMBL3959521 & 1641552 & 8.5086 & 8.3669 & TRN \\
\hline CHEMBL 3943341 & 1641552 & 8.5376 & 8.6788 & TRN \\
\hline CHEMBL3965300 & 1641552 & 8.3468 & 8.9646 & TST \\
\hline CHEMBL3919355 & 1641552 & 8.0809 & 8.0675 & TRN \\
\hline CHEMBL3979626 & 1641552 & 8.1739 & 8.0241 & TST \\
\hline CHEMBL3946724 & 1641552 & 8.2676 & 8.2622 & TST \\
\hline CHEMBL 3890697 & 1641552 & 8.4559 & 8.4056 & TRN \\
\hline CHEMBL 3915914 & 1641552 & 7.585 & 7.75 & TRN \\
\hline CHEMBL 3942745 & 1641552 & 7.8861 & 7.9427 & TRN \\
\hline CHEMBL 3951927 & 1641552 & 8.6778 & 8.9148 & TRN \\
\hline CHEMBL3942239 & 1641552 & 8.4089 & 8.3537 & TST \\
\hline CHEMBL 3935788 & 1641552 & 7.6778 & 7.7278 & TRN \\
\hline CHEMBL3938297 & 1641552 & 8.2366 & 8.2867 & TRN \\
\hline CHEMBL 3978087 & 1641552 & 8.3768 & 8.499 & TRN \\
\hline CHEMBL 3920064 & 1641552 & 8.4559 & 8.5792 & TRN \\
\hline CHEMBL3982370 & 1641552 & 7.6383 & 7.6713 & TRN \\
\hline CHEMBL 3894006 & 1641552 & 7.7959 & 7.8418 & TRN \\
\hline CHEMBL3935204 & 1641552 & 8.2757 & 7.9944 & TST \\
\hline CHEMBL3969207 & 1641552 & 9.2007 & 8.9223 & TRN \\
\hline CHEMBL 3981264 & 1641552 & 8.699 & 8.6218 & TRN \\
\hline CHEMBL3936748 & 1641552 & 8.4202 & 8.3657 & TST \\
\hline CHEMBL 3905268 & 1641552 & 8.6576 & 8.7334 & TRN \\
\hline CHEMBL3935513 & 1641552 & 8.1192 & 8.418 & TRN \\
\hline CHEMBL3914327 & 1641552 & 9.0605 & 8.753 & TRN \\
\hline CHEMBL 3964857 & 1641552 & 7.699 & 7.7973 & TRN \\
\hline CHEMBL3947669 & 1641552 & 7.3279 & 7.3618 & TRN \\
\hline
\end{tabular}


Supplemental Table S2.txt

\begin{tabular}{|c|c|c|c|c|}
\hline HEMBL3 & 641552 & 8.4437 & 8.8892 & \\
\hline HEMBL3946671 & 641552 & 8.4685 & 8.7122 & \\
\hline HEMBL3920659 & 552 & & 3614 & \\
\hline HEMBL3942302 & 552 & 7959 & 253 & \\
\hline HEMBL3949411 & 552 & 7.4437 & 6827 & \\
\hline HEMBL3937856 & 641552 & 8.7447 & 8.7501 & \\
\hline JEMBL395 & 52 & 7.5229 & 5646 & \\
\hline AEMBL3934471 & & & 8836 & \\
\hline HEMBL3890288 & 552 & 7.5528 & 8.1785 & \\
\hline HEMBL3911336 & 552 & 8.8239 & 9237 & \\
\hline HEMBL3929034 & 552 & 8.8539 & 8117 & \\
\hline HEMBL390 & 52 & 9.0177 & 9998 & \\
\hline HEMBL39 & 52 & & & \\
\hline AEMBL3913687 & 552 & 9.1249 & 9.088 & \\
\hline AEMBL3951565 & 52 & 39 & 6534 & \\
\hline HEMBL3986757 & 164 & 8. & 8.1764 & \\
\hline AEMBL3964018 & 02 & 7. & 014 & \\
\hline JEMBL 39 & 52 & & 823 & \\
\hline HEMBL3969728 & & 08 & 8.7826 & \\
\hline AEMBL3926015 & 52 & & & \\
\hline HEMBL3S & 16 & 8 . & 8 & \\
\hline AEMBL3S & 2 & 8. & 892 & \\
\hline HEMBL39 & 52 & 86 & & \\
\hline HEMBL3926823 & & & 038 & \\
\hline HEMBL3923952 & & & 376 & \\
\hline HEMBL39 & 16 & 7. & 062 & \\
\hline AEMBL3S & 16 & & 718 & \\
\hline AEMBL 38 & 52 & 86 & 841 & \\
\hline HEMBL3915120 & & & 8.5827 & \\
\hline HEMBL3953308 & 64 & & 8531 & \\
\hline HEMBL3963423 & 6 & & 5536 & \\
\hline HEMBL3 & 52 & & 53 & \\
\hline HEMBL 394 & 52 & 8 . & 659 & \\
\hline HEMBL3985953 & 52 & & 5937 & \\
\hline HEMBL3895784 & 52 & 8.5086 & 8.8394 & \\
\hline HEMBL3960273 & 64 & 8 . & 209 & \\
\hline HEMBL 3 & 2 & 8 . & 243 & \\
\hline HEMBL3893124 & 16 & 8. & 664 & \\
\hline HEMBL3943448 & 552 & 8.2596 & 8.5453 & \\
\hline AEMBL3916523 & 52 & 7. & 204 & \\
\hline HEMBL3962002 & 164 & 596 & 3136 & \\
\hline CHEMBL3959186 & & & 8.3112 & \\
\hline CHEMBL3967461 & 164 & 7.7212 & 7.73 & \\
\hline HEMBL3976421 & 552 & 7.9586 & 8.0121 & \\
\hline MBL39 & 52 & & 8.6494 & \\
\hline CHEMBL3899741 & 164 & 7.699 & 7.5979 & \\
\hline CHEMBL3906452 & 164 & 8.4202 & 7.0197 & \\
\hline CHEMBL3939904 & 1641552 & 8.0 & 7.8369 & \\
\hline
\end{tabular}

Page 11240 
Supplemental Table S2.txt

\begin{tabular}{|c|c|c|c|c|c|}
\hline CHEMBL3922835 & 1641552 & 9.1192 & 8.5635 & TRN & \\
\hline CHEMBL3936969 & 1641552 & 7.8539 & 7.7869 & TRN & \\
\hline CHEMBL3917489 & 1641552 & 8.8239 & 8.9376 & TRN & \\
\hline CHEMBL3960945 & 1641552 & 7.1249 & 7.3729 & TRN & \\
\hline CHEMBL 3907566 & 1641552 & 8.5086 & 8.3568 & TRN & \\
\hline CHEMBL3900283 & 1641552 & 7.9586 & 7.9033 & TRN & \\
\hline CHEMBL3914659 & 1641552 & 7.3279 & 7.4959 & TRN & \\
\hline CHEMBL3940438 & 1641552 & 7.9586 & 7.7987 & TRN & \\
\hline CHEMBL3930069 & 1641552 & 7.4089 & 7.4406 & TRN & \\
\hline CHEMBL3932855 & 1641552 & 8.0809 & 8.1293 & TST & \\
\hline CHEMBL3909308 & 1641552 & 8.6198 & 8.4605 & TRN & \\
\hline CHEMBL 3929252 & 1641552 & 9.1079 & 8.5969 & TRN & \\
\hline CHEMBL 3899840 & 1641552 & 8.041 & 8.1611 & TRN & \\
\hline CHEMBL3939069 & 1641552 & 7.9586 & 8.0323 & TRN & \\
\hline CHEMBL 3963843 & 1641552 & 6.0 & 6.3723 & TRN & \\
\hline CHEMBL3950644 & 1641552 & 8.4815 & 8.4692 & TST & \\
\hline CHEMBL3966083 & 1641552 & 8.9208 & 8.293 & TST & \\
\hline CHEMBL 3923853 & 1641552 & 8.6576 & 8.6695 & TRN & \\
\hline CHEMBL3941585 & 1641552 & 7.1938 & 7.2735 & TRN & \\
\hline CHEMBL 3919047 & 1641552 & 8.8861 & 8.9156 & TRN & \\
\hline CHEMBL3926765 & 1641552 & 7.9586 & 7.9664 & TRN & \\
\hline CHEMBL3951118 & 1641552 & 7.6778 & 7.6446 & TRN & \\
\hline CHEMBL3906507 & 1641552 & 7.7212 & 8.0537 & TRN & \\
\hline CHEMBL3921131 & 1641552 & 8.7696 & 8.7901 & TRN & \\
\hline CHEMBL3959701 & 1641552 & 8.6198 & 8.5562 & TRN & \\
\hline CHEMBL 3938083 & 1641552 & 8.7212 & \multicolumn{2}{|c|}{8.511000000000001} & TRN \\
\hline CHEMBL3981667 & 1641552 & 8.7696 & 8.72 & TRN & \\
\hline CHEMBL3917865 & 1641552 & 7.9586 & 7.99 & TRN & \\
\hline CHEMBL3985288 & 1641552 & 8.585 & 8.5773 & TRN & \\
\hline CHEMBL3984478 & 1641552 & 8.7447 & 8.6727 & TRN & \\
\hline CHEMBL3914531 & 1641552 & 7.0809 & 7.0609 & TRN & \\
\hline CHEMBL 3898176 & 1641552 & 7.6021 & 7.9263 & TST & \\
\hline CHEMBL 3903422 & 1641552 & 8.4202 & 8.4071 & TRN & \\
\hline CHEMBL3907035 & 1641552 & 8.2441 & 8.2258 & TRN & \\
\hline CHEMBL3975974 & 1641552 & 7.8239 & 7.7958 & TRN & \\
\hline CHEMBL3959840 & 1641552 & 7.9586 & 8.0324 & TRN & \\
\hline CHEMBL 3974443 & 1641552 & 8.585 & 8.6375 & TRN & \\
\hline CHEMBL 3947594 & 1641552 & 8.6383 & 8.7695 & TRN & \\
\hline CHEMBL3951974 & 1641552 & 8.4559 & 8.3635 & TRN & \\
\hline CHEMBL3929798 & 1641552 & 8.0506 & 7.7807 & TST & \\
\hline CHEMBL3898541 & 1641552 & 9.0 & 8.9583 & TRN & \\
\hline CHEMBL 3977515 & 1641552 & 8.3279 & 8.6477 & TST & \\
\hline CHEMBL 3957934 & 1641552 & 8.5376 & 8.5102 & TRN & \\
\hline CHEMBL3925154 & 1641552 & 8.3565 & 8.5075 & TRN & \\
\hline CHEMBL3921484 & 1641552 & 9.0862 & 8.8004 & TRN & \\
\hline CHEMBL3971012 & 1641552 & 8.28399 & 999999999 & 8.0517 & TRN \\
\hline CHEMBL3971415 & 1641552 & 7.8539 & 7.567 & TRN & \\
\hline CHEMBL 3934416 & 1641552 & 7.9586 & 8.066 & TRN & \\
\hline
\end{tabular}


Supplemental Table S2.txt

\begin{tabular}{|c|c|c|c|c|c|}
\hline CHEMBL3949283 & 1641552 & 7.1308 & 6.5318 & TRN & \\
\hline CHEMBL3922011 & 1641552 & 7.7696 & 7.8065 & TRN & \\
\hline CHEMBL3912533 & 1641552 & 8.2676 & 8.3009 & TRN & \\
\hline CHEMBL3982450 & 1641552 & 7.0985 & 7.6107 & TST & \\
\hline CHEMBL3908968 & 1641552 & 7.6383 & 7.6151 & TRN & \\
\hline CHEMBL3890764 & 1641552 & 7.6778 & 7.6829 & TRN & \\
\hline CHEMBL3941053 & 1641552 & 8.4318 & 8.2706 & TRN & \\
\hline CHEMBL3914389 & 1641552 & 7.6198 & 7.697999 & 99999999995 & TST \\
\hline CHEMBL 3948342 & 1641552 & 7.3188 & 7.388999 & э999999999 & TRN \\
\hline CHEMBL3931399 & 1641552 & 8.699 & 7.8431 & TST & \\
\hline CHEMBL3919429 & 1641552 & 8.5086 & 8.5733 & TRN & \\
\hline CHEMBL3908438 & 1641552 & 8.3979 & 8.4077 & TRN & \\
\hline CHEMBL3923689 & 1641552 & 7.5086 & 7.8323 & TRN & \\
\hline CHEMBL3954462 & 1641552 & 7.8539 & 7.3895 & TST & \\
\hline CHEMBL3923337 & 1641552 & 8.2366 & 7.8045 & TST & \\
\hline CHEMBL1372082 & 688192 & 6.2834 & 6.2219 & TRN & \\
\hline CHEMBL1405453 & 688192 & 7.2533 & 6.0902 & TRN & \\
\hline CHEMBL1497549 & 688192 & 5.7852 & 6.4631 & TRN & \\
\hline CHEMBL 2359072 & 688192 & 6.5288 & 6.1544 & TRN & \\
\hline CHEMBL1990598 & 688192 & 5.7545 & 5.8094 & TRN & \\
\hline CHEMBL1486214 & 688192 & 6.2891 & 5.9076 & TRN & \\
\hline CHEMBL89445 & 688192 & 6.3159 & 6.735 & TRN & \\
\hline CHEMBL257286 & 688192 & 5.6815 & 5.9038 & TRN & \\
\hline CHEMBL1544633 & 688192 & 6.0524 & 6.0224 & TRN & \\
\hline CHEMBL1567944 & 688192 & 7.4613 & 6.7346 & TST & \\
\hline CHEMBL1580075 & 688192 & 6.7517 & 6.1153 & TRN & \\
\hline CHEMBL1572157 & 688192 & 6.3712 & 5.7109 & TRN & \\
\hline CHEMBL1603890 & 688192 & 5.4543 & 6.0004 & TST & \\
\hline CHEMBL3198812 & 688192 & 5.7442 & 5.7836 & TRN & \\
\hline CHEMBL1332756 & 688192 & 5.869 & 5.9812 & TRN & \\
\hline CHEMBL1366838 & 688192 & 5.8262 & 5.8151 & TRN & \\
\hline CHEMBL1584985 & 688192 & 6.4098 & 6.4328 & TRN & \\
\hline CHEMBL3197177 & 688192 & 6.6119 & 5.9438 & TRN & \\
\hline CHEMBL3191874 & 688192 & 6.7373 & 6.0284 & TRN & \\
\hline CHEMBL1536981 & 688192 & 7.0483 & 6.7475 & TRN & \\
\hline CHEMBL1555271 & 688192 & 5.8419 & 6.0126 & TRN & \\
\hline CHEMBL1593815 & 688192 & 5.7467 & 6.1188 & TST & \\
\hline CHEMBL1594475 & 688192 & 5.8286 & 6.0194 & TRN & \\
\hline CHEMBL1504701 & 688192 & 5.9855 & 6.3959 & TRN & \\
\hline CHEMBL 3194760 & 688192 & 5.8407 & 5.9501 & TRN & \\
\hline CHEMBL1455468 & 688192 & 7.3269 & 6.6132 & TST & \\
\hline CHEMBL1487099 & 688192 & 5.8256 & 6.3928 & TRN & \\
\hline CHEMBL1377737 & 688192 & 5.78299 & 999999999 & 6.0759 & $|\mathrm{R}|$ \\
\hline CHEMBL1462938 & 688192 & 7.6946 & 6.6646 & TST & \\
\hline CHEMBL1890899 & 688192 & 5.9642 & 6.0049 & TRN & \\
\hline CHEMBL547285 & 688192 & 5.8324 & 5.9904 & TRN & \\
\hline CHEMBL3189873 & 688192 & 6.9868 & 5.9489 & TRN & \\
\hline CHEMBL460601 & 688192 & 6.8364 & 6.6831 & TRN & \\
\hline
\end{tabular}





\begin{tabular}{|c|c|c|c|c|c|c|}
\hline & & \multicolumn{5}{|c|}{ Supplemental Table S2.txt } \\
\hline CHEMBL1987938 & 688192 & 6.0284 & 6.0536 & TRN & & \\
\hline CHEMBL1523841 & 688192 & 6.7242 & 5.7318 & TST & & \\
\hline CHEMBL1574879 & 688192 & 5.8945 & 6.0635 & TRN & & \\
\hline CHEMBL1300144 & 688192 & 5.2722 & 5.8195 & TRN & & \\
\hline CHEMBL1457201 & 688192 & 5.6038 & 5.9796 & TRN & & \\
\hline CHEMBL1492585 & 688192 & 5.6647 & 6.0756 & TRN & & \\
\hline CHEMBL1597839 & 688192 & 5.1863 & 5.7484 & TRN & & \\
\hline CHEMBL323668 & 688192 & 6.9177 & 6.5498 & TRN & & \\
\hline CHEMBL1406251 & 688192 & 5.7528 & 5.9474 & TST & & \\
\hline CHEMBL1445650 & 688192 & 5.8008 & 6.0159 & TRN & & \\
\hline CHEMBL1473676 & 688192 & $6.9970 e$ & 0000000 & $\partial 1$ & 6.8319 & TST \\
\hline CHEMBL56897 & 688192 & 6.3727 & 6.1213 & TST & & \\
\hline CHEMBL 2006628 & 688192 & 6.1599 & 5.9182 & TRN & & \\
\hline CHEMBL1486176 & 688192 & 5.3773 & 5.8341 & TRN & & \\
\hline CHEMBL1341270 & 688192 & 5.565 & 6.1937 & TST & & \\
\hline CHEMBL 3193468 & 688192 & 6.3173 & 6.0125 & TRN & & \\
\hline CHEMBL1514283 & 688192 & 5.1848 & 5.7499 & TRN & & \\
\hline CHEMBL1354927 & 688192 & 6.4021 & 6.8156 & TST & & \\
\hline CHEMBL546170 & 688192 & 5.8551 & 6.0883 & TRN & & \\
\hline CHEMBL1996749 & 688192 & 5.9245 & 5.9847 & TRN & & \\
\hline CHEMBL1541771 & 688192 & 6.1876 & 6.0738 & TRN & & \\
\hline CHEMBL 3192432 & 688192 & 6.2629 & 6.1704 & TRN & & \\
\hline CHEMBL600778 & 688192 & 6.4131 & 6.0472 & TRN & & \\
\hline CHEMBL1489294 & 688192 & 6.4277 & 6.0855 & TRN & & \\
\hline CHEMBL1540099 & 688192 & 6.9976 & 6.5989 & TRN & & \\
\hline CHEMBL1596326 & 688192 & 5.2229 & 6.0253 & TRN & & \\
\hline CHEMBL1366942 & 688192 & 5.6173 & 6.0219 & TRN & & \\
\hline CHEMBL1440300 & 688192 & 5.5983 & 5.9221 & TRN & & \\
\hline CHEMBL1321568 & 688192 & 5.2674 & 5.905 & TST & & \\
\hline CHEMBL1613238 & 688192 & 5.9144 & 6.0592 & TST & & \\
\hline CHEMBL1367034 & 688192 & 6.6453 & 6.0202 & TST & & \\
\hline CHEMBL587801 & 688192 & 5.2813 & 5.7869 & TST & & \\
\hline CHEMBL 3199403 & 688192 & 6.1267 & 5.9338 & TST & & \\
\hline CHEMBL1595169 & 688192 & 6.8541 & 6.74 & TST & & \\
\hline CHEMBL525826 & 954340 & 4.8548 & 5.6713 & TRN & & \\
\hline CHEMBL2145204 & 954340 & 5.0254 & 4.9639 & TRN & & \\
\hline CHEMBL2359853 & 954340 & 5.184 & 4.954 & TRN & & \\
\hline CHEMBL1728552 & 954340 & 5.1803 & 5.0372 & TRN & & \\
\hline CHEMBL1597672 & 954340 & 5.0879 & 5.1558 & TRN & & \\
\hline CHEMBL3208746 & 954340 & 4.7339 & 4.0188 & TRN & & \\
\hline CHEMBL1506119 & 954340 & 4.7719 & 4.9214 & TST & & \\
\hline CHEMBL406341 & 954340 & 6.3342 & 5.9016 & TST & & \\
\hline CHEMBL1183425 & 954340 & 5.7768 & 4.7233 & TRN & & \\
\hline CHEMBL1320254 & 954340 & 6.0301 & 5.5396 & TRN & & \\
\hline CHEMBL345735 & 954340 & 3.5242 & 4.253 & TRN & & \\
\hline CHEMBL1473677 & 954340 & 5.147 & 5.2009 & TRN & & \\
\hline CHEMBL2360290 & 954340 & 5.1123 & 5.159 & TRN & & \\
\hline CHEMBL2355271 & 954340 & 5.2878 & 5.2276 & TRN & & \\
\hline
\end{tabular}


Supplemental Table S2.txt

\begin{tabular}{|c|c|c|c|c|c|}
\hline CHEMBL1886930 & 954340 & 5.4752 & 5.3677 & TRN & \\
\hline CHEMBL1449262 & 954340 & 4.9478 & 4.7175 & TRN & \\
\hline CHEMBL 2355229 & 954340 & 5.0031 & 5.3742 & TRN & \\
\hline CHEMBL 2357051 & 954340 & 3.5237 & 5.2262 & TST & \\
\hline CHEMBL1383417 & 954340 & 3.5246 & 4.3876 & TRN & \\
\hline CHEMBL1576416 & 954340 & 6.2187 & 5.6059 & TRN & \\
\hline CHEMBL1469426 & 954340 & 4.9108 & 4.9418 & TRN & \\
\hline CHEMBL1708460 & 954340 & 5.1414 & 4.5862 & TRN & \\
\hline CHEMBL1477268 & 954340 & 5.1081 & 5.1676 & TRN & \\
\hline CHEMBL1623028 & 954340 & 5.7833 & 5.8248 & TRN & \\
\hline CHEMBL1421450 & 954340 & 3.5245 & 4.4303 & TRN & \\
\hline CHEMBL1476474 & 954340 & 4.9564 & 4.8559 & TRN & \\
\hline CHEMBL11608 & 954340 & 6.0546 & 5.0825 & TRN & \\
\hline CHEMBL 2356408 & 954340 & 5.2228 & 5.1325 & TRN & \\
\hline CHEMBL1340446 & 954340 & 4.8321 & 5.4143 & TRN & \\
\hline CHEMBL1379597 & 954340 & 5.0482 & 5.1626 & TRN & \\
\hline CHEMBL1533231 & 954340 & 4.4783 & 5.269 & TRN & \\
\hline CHEMBL1569653 & 954340 & 5.9755 & 5.5679 & TRN & \\
\hline CHEMBL1873269 & 954340 & 5.4742 & 5.3305 & TST & \\
\hline CHEMBL3191063 & 954340 & 5.1424 & 5.0412 & TRN & \\
\hline CHEMBL39947 & 954340 & 5.3394 & 5.1239 & TST & \\
\hline CHEMBL589061 & 954340 & 3.5242 & 4.6509 & TRN & \\
\hline CHEMBL 2361355 & 954340 & 5.1766 & 5.1296 & TRN & \\
\hline CHEMBL1566565 & 954340 & 5.3293 & 5.0021 & TRN & \\
\hline CHEMBL1370193 & 954340 & 5.1507 & 5.33799 & 9999999999 & TRN \\
\hline CHEMBL1458675 & 954340 & 4.9607 & 5.303 & TRN & \\
\hline CHEMBL1610758 & 954340 & 4.6647 & 4.715 & TST & \\
\hline CHEMBL 1407270 & 954340 & 5.2583 & 5.2792 & TRN & \\
\hline CHEMBL1490416 & 954340 & 5.1273 & 5.0192 & TRN & \\
\hline CHEMBL1597959 & 954340 & 4.7627 & 4.3799 & TRN & \\
\hline CHEMBL3211097 & 954340 & \multicolumn{3}{|c|}{5.547000000000001} & TRN \\
\hline CHEMBL 2360698 & 954340 & 5.0685 & 5.0834 & TRN & \\
\hline CHEMBL3193382 & 954340 & 4.8117 & 4.0459 & TRN & \\
\hline CHEMBL 2356557 & 954340 & 5.1825 & 5.2633 & TRN & \\
\hline CHEMBL1531312 & 954340 & 5.0372 & 5.3166 & TRN & \\
\hline CHEMBL 2356880 & 954340 & 5.3975 & 5.2647 & TRN & \\
\hline CHEMBL1540947 & 954340 & 5.6807 & 4.4452 & TST & \\
\hline CHEMBL3213795 & 954340 & \multicolumn{2}{|c|}{5.486000000000001} & 5.3089 & TRN \\
\hline CHEMBL591598 & 954340 & 5.0789 & 5.3481 & TRN & \\
\hline CHEMBL1378576 & 954340 & 5.1953 & 4.886 & TRN & \\
\hline CHEMBL1531127 & 954340 & 5.3744 & 5.2572 & TRN & \\
\hline CHEMBL1878125 & 954340 & 3.5242 & 4.4741 & TRN & \\
\hline CHEMBL1537381 & 954340 & 5.7862 & 5.8687 & TRN & \\
\hline CHEMBL1378332 & 954340 & 4.8409 & 5.0268 & TRN & \\
\hline CHEMBL1725501 & 954340 & 5.1791 & 4.7654 & TRN & \\
\hline CHEMBL 2361315 & 954340 & 5.4973 & 5.2151 & TRN & \\
\hline CHEMBL1557071 & 954340 & 4.9135 & 5.2057 & TRN & \\
\hline CHEMBL1492904 & 954340 & 5.365 & 5.2978 & TRN & \\
\hline
\end{tabular}




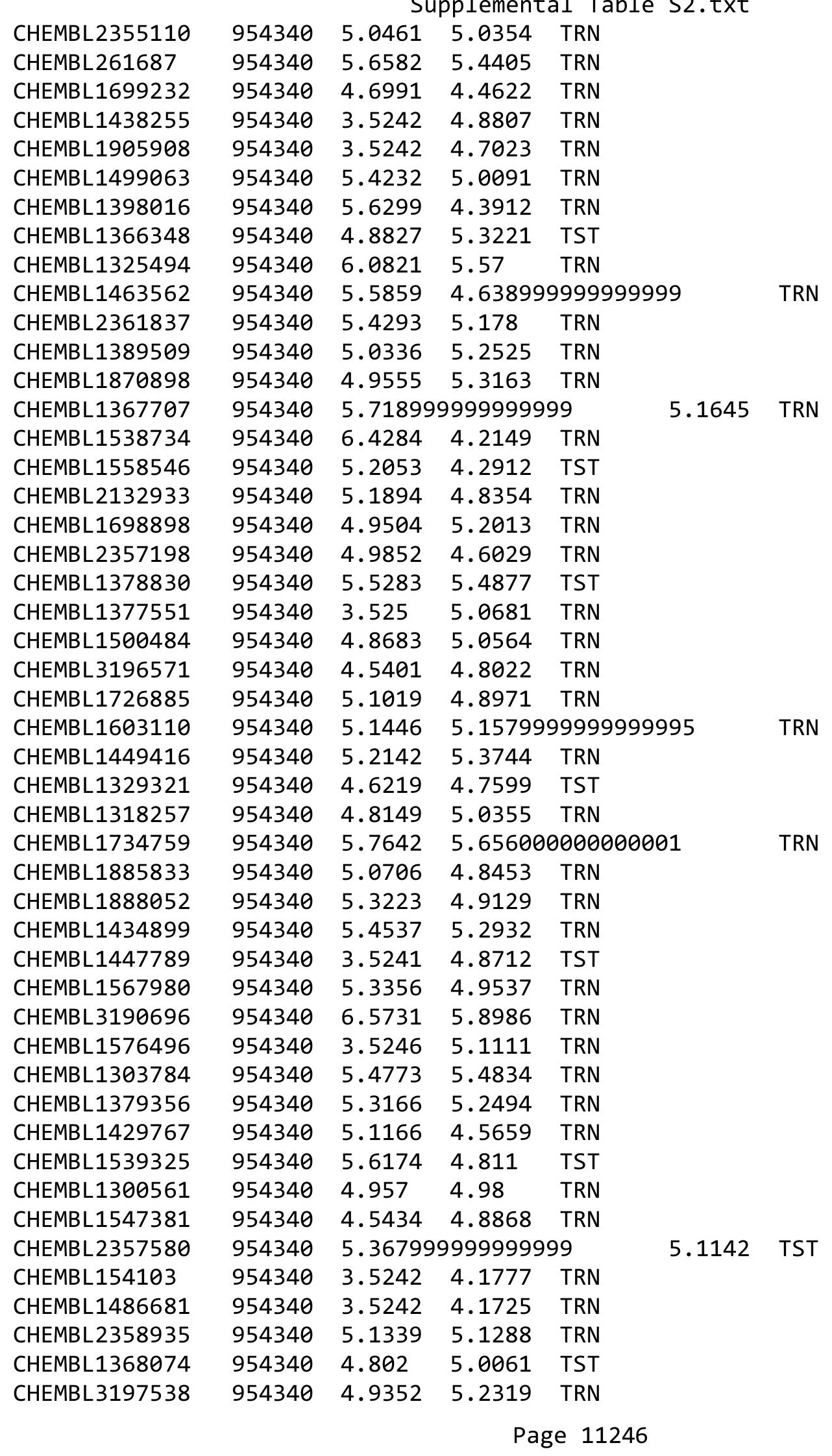


Supplemental Table S2.txt

\begin{tabular}{|c|c|c|c|c|c|c|}
\hline CHEMBL 2136532 & 954340 & 5.2279 & 4.9275 & TRN & & \\
\hline CHEMBL1534795 & 954340 & 5.4265 & 5.4833 & TRN & & \\
\hline CHEMBL1882407 & 954340 & 3.5243 & 4.6831 & TST & & \\
\hline CHEMBL1460607 & 954340 & 5.1425 & 5.0354 & TRN & & \\
\hline CHEMBL 2143258 & 954340 & 5.6299 & 5.4409 & TRN & & \\
\hline CHEMBL1417050 & 954340 & 4.7097 & 4.8317 & TRN & & \\
\hline CHEMBL1599156 & 954340 & 4.6985 & 4.7357 & TRN & & \\
\hline CHEMBL1404077 & 954340 & 5.1117 & 4.825 & TRN & & \\
\hline CHEMBL 3194231 & 954340 & 4.9426 & 4.2289 & TRN & & \\
\hline CHEMBL1463068 & 954340 & 5.9884 & 5.5912 & TRN & & \\
\hline CHEMBL1467587 & 954340 & 4.9833 & 5.2387 & TRN & & \\
\hline CHEMBL1428644 & 954340 & 3.5241 & 3.9503 & TRN & & \\
\hline CHEMBL1541237 & 954340 & 5.0951 & 5.1598 & TRN & & \\
\hline CHEMBL3210912 & 954340 & 3.5243 & 4.4584 & TRN & & \\
\hline CHEMBL1348375 & 954340 & 4.8703 & 5.2107 & TST & & \\
\hline CHEMBL1542557 & 954340 & 4.5574 & 4.5432 & TRN & & \\
\hline CHEMBL1469275 & 954340 & 5.3299 & 5.315 & TRN & & \\
\hline CHEMBL1605900 & 954340 & 5.7345 & 4.9913 & TST & & \\
\hline CHEMBL1722523 & 954340 & 5.1585 & 5.1089 & TRN & & \\
\hline CHEMBL1501805 & 954340 & 5.901 & 5.5521 & TRN & & \\
\hline CHEMBL1411785 & 954340 & 5.8256 & 5.5284 & TRN & & \\
\hline CHEMBL2358939 & 954340 & 5.159 & 5.0187 & TRN & & \\
\hline CHEMBL1508576 & 954340 & 5.1112 & 5.3522 & TRN & & \\
\hline CHEMBL1438321 & 954340 & 5.4476 & 5.5963 & TRN & & \\
\hline CHEMBL1542890 & 954340 & 5.461 & 5.3332 & TRN & & \\
\hline CHEMBL1256191 & 954340 & 5.3634 & 5.0434 & TST & & \\
\hline CHEMBL1557646 & 954340 & 5.0848 & 4.8721 & TST & & \\
\hline CHEMBL 2354481 & 954340 & 5.3395 & 5.2561 & TRN & & \\
\hline CHEMBL524376 & 954340 & 6.6989 & 6.2107 & TRN & & \\
\hline CHEMBL1603785 & 954340 & 4.7732 & 4.4952 & TRN & & \\
\hline CHEMBL1479715 & 954340 & $5.1720 e$ & 00000006 & 31 & 5.2105 & TRN \\
\hline CHEMBL2131436 & 954340 & 5.3158 & 5.1215 & TRN & & \\
\hline CHEMBL1735835 & 954340 & 4.6931 & 4.9652 & TRN & & \\
\hline CHEMBL2360906 & 954340 & 4.867 & 4.8724 & TRN & & \\
\hline CHEMBL1879995 & 954340 & 6.1134 & 5.8464 & TST & & \\
\hline CHEMBL1423790 & 954340 & 4.9837 & 5.3498 & TRN & & \\
\hline CHEMBL 2362944 & 954340 & 5.0253 & 4.9387 & TRN & & \\
\hline CHEMBL1512974 & 954340 & 4.863 & 4.8501 & TRN & & \\
\hline CHEMBL 3193114 & 954340 & 4.6711 & 4.1342 & TRN & & \\
\hline CHEMBL1541872 & 954340 & 5.2607 & 5.1434 & TRN & & \\
\hline CHEMBL 2135019 & 954340 & 5.2325 & 4.8909 & TRN & & \\
\hline CHEMBL1715558 & 954340 & 5.9252 & 5.1495 & TRN & & \\
\hline CHEMBL3212150 & 954340 & 5.0642 & 5.2008 & TRN & & \\
\hline CHEMBL1562679 & 954340 & 4.7519 & 5.2363 & TRN & & \\
\hline CHEMBL1700180 & 954340 & 5.2446 & 4.9228 & TRN & & \\
\hline CHEMBL2359610 & 954340 & 5.6328 & 5.2724 & TRN & & \\
\hline CHEMBL1887682 & 954340 & 3.5245 & 4.8553 & TRN & & \\
\hline CHEMBL1589687 & 954340 & 4.9864 & 5.083 & TRN & & \\
\hline
\end{tabular}

Page 11247 


\begin{tabular}{|c|c|c|c|c|c|}
\hline \multicolumn{6}{|c|}{ Supplemental Table S2.txt } \\
\hline CHEMBL1401155 & 954340 & 5.1693 & 4.8822 & TST & \\
\hline CHEMBL1313560 & 954340 & 5.237 & 5.3153 & TRN & \\
\hline CHEMBL3195509 & 954340 & 6.2911 & 5.8442 & TRN & \\
\hline CHEMBL1609529 & 954340 & 4.9948 & 4.6189 & TRN & \\
\hline CHEMBL2356177 & 954340 & 4.8764 & 4.8877 & TRN & \\
\hline CHEMBL1446878 & 954340 & 5.0281 & 5.0964 & TRN & \\
\hline CHEMBL1724146 & 954340 & 5.6162 & 5.3753 & TRN & \\
\hline CHEMBL1304117 & 954340 & 5.0059 & 5.6017 & TRN & \\
\hline CHEMBL1449587 & 954340 & 5.0271 & 5.2186 & TST & \\
\hline CHEMBL579919 & 954340 & 5.1432 & 5.0012 & TRN & \\
\hline CHEMBL 3213883 & 954340 & 4.6877 & 5.4426 & TRN & \\
\hline CHEMBL 3799844 & 954340 & 3.5247 & 5.1253 & TST & \\
\hline CHEMBL1382433 & 954340 & 5.5769 & 5.1635 & TST & \\
\hline CHEMBL2355777 & 954340 & 5.2574 & 5.2021 & TRN & \\
\hline CHEMBL1342198 & 954340 & 4.6254 & 5.2381 & TRN & \\
\hline CHEMBL1604713 & 954340 & 5.0527 & 5.2922 & TST & \\
\hline CHEMBL1305696 & 954340 & 5.0622 & 4.7215 & TST & \\
\hline CHEMBL 2357233 & 954340 & 5.5309 & 5.17399 & 99999999995 & TRN \\
\hline CHEMBL1608597 & 954340 & 4.7808 & 4.96 & TRN & \\
\hline CHEMBL 2362576 & 954340 & 5.5854 & 5.2412 & TRN & \\
\hline CHEMBL1398607 & 954340 & 6.1264 & 5.9812 & TRN & \\
\hline CHEMBL3190051 & 954340 & 6.0339 & 5.5475 & TST & \\
\hline CHEMBL 2359354 & 954340 & 3.5241 & 4.7022 & TRN & \\
\hline CHEMBL530698 & 954340 & 6.5833 & 6.25899 & 99999999995 & TRN \\
\hline CHEMBL1468992 & 954340 & 4.6597 & 4.8675 & TST & \\
\hline CHEMBL1305977 & 954340 & 5.0725 & 4.973 & TRN & \\
\hline CHEMBL1418373 & 954340 & 5.3329 & 5.0195 & TRN & \\
\hline CHEMBL1319219 & 954340 & 5.2816 & 5.0868 & TRN & \\
\hline CHEMBL1421659 & 954340 & 5.379 & 5.355 & TRN & \\
\hline CHEMBL2358598 & 954340 & 5.245 & 5.1136 & TRN & \\
\hline CHEMBL 2360891 & 954340 & 5.9208 & 5.3899 & TRN & \\
\hline CHEMBL2369275 & 954340 & 4.7531 & 4.7934 & TRN & \\
\hline CHEMBL483956 & 954340 & 5.0494 & 5.3438 & TRN & \\
\hline CHEMBL1728498 & 954340 & 4.8735 & 5.096 & TRN & \\
\hline CHEMBL1491982 & 954340 & 4.9793 & 5.276 & TRN & \\
\hline CHEMBL1391510 & 954340 & 5.0237 & 4.9788 & TRN & \\
\hline CHEMBL 2356944 & 954340 & 5.4238 & 5.2803 & TRN & \\
\hline CHEMBL1432152 & 954340 & 4.9087 & 4.7551 & TRN & \\
\hline CHEMBL1335190 & 954340 & 6.7945 & 5.8507 & TRN & \\
\hline CHEMBL1873950 & 954340 & 4.9061 & 5.1017 & TRN & \\
\hline CHEMBL1899596 & 954340 & 5.1194 & 4.6856 & TST & \\
\hline CHEMBL1882311 & 954340 & 4.8062 & 5.0986 & TRN & \\
\hline CHEMBL1525315 & 954340 & 5.0427 & 5.2165 & TRN & \\
\hline CHEMBL1704437 & 954340 & 3.5242 & 4.6906 & TST & \\
\hline CHEMBL1536693 & 954340 & 5.0876 & 5.3716 & TRN & \\
\hline CHEMBL3211702 & 954340 & 3.5244 & 4.2178 & TRN & \\
\hline CHEMBL2354809 & 954340 & 4.8405 & 4.9928 & TRN & \\
\hline CHEMBL546344 & 954340 & 5.001 & 5.1967 & TRN & \\
\hline
\end{tabular}


Supplemental Table S2.txt

\begin{tabular}{|c|c|c|c|c|c|c|}
\hline CHEMBL1363380 & 954340 & 4.9807 & 4.7868 & TST & & \\
\hline CHEMBL1313769 & 954340 & 3.5243 & 3.826 & TST & & \\
\hline CHEMBL2355180 & 954340 & 5.1498 & 5.0282 & TRN & & \\
\hline CHEMBL 2358672 & 954340 & 4.9393 & 4.9991 & TRN & & \\
\hline CHEMBL 2356494 & 954340 & 5.8153 & 5.3298 & TRN & & \\
\hline CHEMBL1556845 & 954340 & 5.6366 & 5.1927 & TRN & & \\
\hline CHEMBL168337 & 954340 & 5.3086 & 4.7589 & TRN & & \\
\hline CHEMBL1732597 & 954340 & 6.5838 & 6.0437 & TRN & & \\
\hline CHEMBL1898588 & 954340 & 6.876 & 5.7693 & TST & & \\
\hline CHEMBL1436462 & 954340 & 5.0866 & 5.0709 & TRN & & \\
\hline CHEMBL1429444 & 954340 & 5.45299 & 99999999 & 99 & 5.4137 & TRN \\
\hline CHEMBL 2354450 & 954340 & 5.6542 & 5.3418 & TRN & & \\
\hline CHEMBL1720591 & 954340 & 5.074 & 4.9731 & TRN & & \\
\hline CHEMBL1532210 & 954340 & 3.5242 & 4.8824 & TRN & & \\
\hline CHEMBL3193006 & 954340 & 5.3309 & 5.2206 & TRN & & \\
\hline CHEMBL3197611 & 954340 & 5.0192 & 5.1941 & TRN & & \\
\hline CHEMBL1718535 & 954340 & 3.5239 & 5.2255 & TRN & & \\
\hline CHEMBL1429050 & 954340 & 5.9352 & 4.0585 & TRN & & \\
\hline CHEMBL 2357704 & 954340 & 5.2979 & 5.1777 & TRN & & \\
\hline CHEMBL 3197282 & 954340 & 5.7747 & 4.6874 & TST & & \\
\hline CHEMBL3198735 & 954340 & 5.0816 & 4.6088 & TRN & & \\
\hline CHEMBL1511312 & 954340 & 4.8264 & 5.0114 & TRN & & \\
\hline CHEMBL1420390 & 954340 & 5.5084 & 5.2425 & TRN & & \\
\hline CHEMBL1602864 & 954340 & 4.902 & 4.7557 & TST & & \\
\hline CHEMBL1377675 & 954340 & 4.94 & 5.0126 & TRN & & \\
\hline CHEMBL1453263 & 954340 & 5.6588 & 5.5036 & TRN & & \\
\hline CHEMBL1880660 & 954340 & 3.5244 & 4.5762 & TST & & \\
\hline CHEMBL 2356751 & 954340 & 4.8587 & 4.978 & TRN & & \\
\hline CHEMBL1341865 & 954340 & 5.0326 & 5.2921 & TRN & & \\
\hline CHEMBL1391385 & 954340 & 5.1963 & 5.3842 & TRN & & \\
\hline CHEMBL1376491 & 954340 & 4.625 & 4.9409 & TRN & & \\
\hline CHEMBL1359255 & 954340 & 5.0574 & 5.3161 & TRN & & \\
\hline CHEMBL1462723 & 954340 & 4.8047 & 4.7621 & TST & & \\
\hline CHEMBL1612278 & 954340 & 5.2019 & 5.1379 & TRN & & \\
\hline CHEMBL1582580 & 954340 & 4.9226 & 5.2564 & TRN & & \\
\hline CHEMBL1305907 & 954340 & 4.9711 & 4.9751 & TRN & & \\
\hline CHEMBL1518866 & 954340 & 6.3528 & 5.8678 & TRN & & \\
\hline CHEMBL1487478 & 954340 & 5.0666 & 5.0656 & TRN & & \\
\hline CHEMBL 2355518 & 954340 & 4.8932 & 4.9562 & TRN & & \\
\hline CHEMBL 2357734 & 954340 & 5.1332 & 5.1055 & TRN & & \\
\hline CHEMBL1389476 & 954340 & 5.2559 & 4.539 & TRN & & \\
\hline CHEMBL1589612 & 954340 & \multicolumn{3}{|c|}{3.5239999999999996} & 4.2657 & TST \\
\hline CHEMBL1364849 & 954340 & 4.8849 & 4.9334 & TRN & & \\
\hline CHEMBL 2356254 & 954340 & 4.9794 & 5.0167 & TRN & & \\
\hline CHEMBL43459 & 954340 & 5.2972 & 4.8293 & TRN & & \\
\hline CHEMBL 2357195 & 954340 & 5.3112 & 4.9767 & TRN & & \\
\hline CHEMBL1582087 & 954340 & 5.0905 & 5.0942 & TRN & & \\
\hline CHEMBL1558163 & 954340 & 4.4783 & 4.8823 & TRN & & \\
\hline
\end{tabular}

Page 11249 
Supplemental Table S2.txt

\begin{tabular}{|c|c|c|c|c|c|}
\hline CHEMBL1895912 & 954340 & 5.0178 & 4.8763 & TRN & \\
\hline CHEMBL1350323 & 954340 & 5.0028 & 4.937 & TRN & \\
\hline CHEMBL1595537 & 954340 & 5.046 & 4.7422 & TRN & \\
\hline CHEMBL3190656 & 954340 & 4.8439 & 5.3253 & TRN & \\
\hline CHEMBL1213139 & 954340 & 5.1299 & 5.1269 & TST & \\
\hline CHEMBL3193664 & 954340 & 5.607 & 5.0761 & TRN & \\
\hline CHEMBL1871423 & 954340 & 4.9156 & 5.0753 & TRN & \\
\hline CHEMBL1490462 & 954340 & 5.2378 & 5.0047 & TRN & \\
\hline CHEMBL560832 & 954340 & 3.5242 & 4.215 & TST & \\
\hline CHEMBL2354461 & 954340 & 4.817 & 5.2413 & TRN & \\
\hline CHEMBL1510163 & 954340 & 4.9851 & 5.1707 & TRN & \\
\hline CHEMBL3191460 & 954340 & 5.019 & 3.9991 & TRN & \\
\hline CHEMBL1703181 & 954340 & 5.0468 & 5.0848 & TRN & \\
\hline CHEMBL1547425 & 954340 & 4.9077 & 5.3585 & TRN & \\
\hline CHEMBL1561460 & 954340 & 5.2056 & 5.1953 & TRN & \\
\hline CHEMBL2359412 & 954340 & 3.5242 & 5.0071 & TRN & \\
\hline CHEMBL1886420 & 954340 & 5.282 & 5.7076 & TST & \\
\hline CHEMBL1904433 & 954340 & 5.056 & 5.1907 & TRN & \\
\hline CHEMBL3208826 & 954340 & 6.2088 & 5.7611 & TRN & \\
\hline CHEMBL1410154 & 954340 & 4.9769 & $5.07600 t$ & 00000000005 & TRN \\
\hline CHEMBL1542918 & 954340 & 5.5468 & 5.615 & TRN & \\
\hline CHEMBL1479941 & 954340 & 5.4508 & 5.3192 & TRN & \\
\hline CHEMBL2359184 & 954340 & 5.4595 & 5.2743 & TRN & \\
\hline CHEMBL1621012 & 954340 & 5.1486 & 5.2257 & TST & \\
\hline CHEMBL1536976 & 954340 & 5.4511 & 5.1256 & TST & \\
\hline CHEMBL1592934 & 954340 & 5.4532 & 5.3578 & TST & \\
\hline CHEMBL1454429 & 954340 & 5.0999 & 5.4908 & TRN & \\
\hline CHEMBL1511717 & 954340 & 5.7515 & 5.8332 & TRN & \\
\hline CHEMBL1703117 & 954340 & 3.5246 & 4.8768 & TRN & \\
\hline CHEMBL1323911 & 954340 & 4.9706 & 4.9786 & TRN & \\
\hline CHEMBL1886030 & 954340 & 4.8354 & 5.0736 & TRN & \\
\hline CHEMBL1500127 & 954340 & 5.1695 & 5.2934 & TRN & \\
\hline CHEMBL1346716 & 954340 & 3.5241 & 4.7622 & TST & \\
\hline CHEMBL1511007 & 954340 & 4.7303 & 4.8017 & TRN & \\
\hline CHEMBL1540878 & 954340 & 3.5241 & 3.9445 & TRN & \\
\hline CHEMBL 2359304 & 954340 & 5.4174 & 5.0331 & TRN & \\
\hline CHEMBL1997990 & 954340 & 4.0015 & 4.6767 & TRN & \\
\hline CHEMBL1343298 & 954340 & 6.1104 & 5.5664 & TRN & \\
\hline CHEMBL3190925 & 954340 & \multicolumn{3}{|c|}{4.611000000000001} & TRN \\
\hline CHEMBL2356536 & 954340 & 5.3322 & 5.2206 & TRN & \\
\hline CHEMBL1333983 & 954340 & 6.2411 & 6.0801 & TRN & \\
\hline CHEMBL1595732 & 954340 & \multicolumn{3}{|c|}{5.6579999999999995} & TRN \\
\hline CHEMBL553503 & 954340 & 3.5241 & 5.1229 & TST & \\
\hline CHEMBL1725080 & 954340 & 5.6182 & 5.395 & TRN & \\
\hline CHEMBL1479974 & 954340 & 5.1353 & 4.8842 & TRN & \\
\hline CHEMBL1735124 & 954340 & 6.5638 & 5.6443 & TRN & \\
\hline CHEMBL1466608 & 954340 & 5.2409 & 5.4926 & TRN & \\
\hline CHEMBL1722433 & 954340 & 4.5841 & 4.7876 & TRN & \\
\hline
\end{tabular}


Supplemental Table S2.txt

\begin{tabular}{|c|c|c|c|c|c|c|}
\hline CHEMBL1393484 & 954340 & 6.1812 & 5.6463 & TRN & & \\
\hline CHEMBL1602445 & 954340 & 4.9859 & 5.2879 & TRN & & \\
\hline CHEMBL1887240 & 954340 & 5.0331 & 4.9142 & TRN & & \\
\hline CHEMBL1472129 & 954340 & 4.7071 & 5.0743 & TRN & & \\
\hline CHEMBL1888416 & 954340 & 5.0888 & 4.6245 & TRN & & \\
\hline CHEMBL 3212402 & 954340 & 6.0083 & 5.3365 & TRN & & \\
\hline CHEMBL3195298 & 954340 & 4.7633 & 4.7092 & TRN & & \\
\hline CHEMBL1423730 & 954340 & 5.2829 & 5.2881 & TRN & & \\
\hline CHEMBL 3194978 & 954340 & 4.7654 & 4.6985 & TST & & \\
\hline CHEMBL1878997 & 954340 & 3.5242 & 4.4605 & TRN & & \\
\hline CHEMBL1526328 & 954340 & 3.5242 & 4.9275 & TRN & & \\
\hline CHEMBL1416014 & 954340 & 5.1937 & 5.4555 & TRN & & \\
\hline CHEMBL1718277 & 954340 & 4.8711 & 5.1136 & TRN & & \\
\hline CHEMBL1345740 & 954340 & 4.4863 & 4.7053 & TRN & & \\
\hline CHEMBL1371471 & 954340 & 5.2967 & 4.9188 & TRN & & \\
\hline CHEMBL 3197751 & 954340 & 6.4672 & 6.1043 & TRN & & \\
\hline CHEMBL1549077 & 954340 & 5.1084 & 4.82 & TST & & \\
\hline CHEMBL1332279 & 954340 & 4.9396 & 4.8561 & TST & & \\
\hline CHEMBL 2141406 & 954340 & 5.4861 & 5.2925 & TRN & & \\
\hline CHEMBL1312140 & 954340 & 5.6467 & 5.4711 & TRN & & \\
\hline CHEMBL1364248 & 954340 & 5.0542 & 5.3171 & TRN & & \\
\hline CHEMBL1423849 & 954340 & 5.2674 & 5.1017 & TRN & & \\
\hline CHEMBL1579150 & 954340 & 4.2393 & 5.3566 & TRN & & \\
\hline CHEMBL2360359 & 954340 & 5.04899 & 99999999 & 95 & 5.2484 & TRN \\
\hline CHEMBL1466922 & 954340 & 5.4542 & 5.4768 & TRN & & \\
\hline CHEMBL1302888 & 954340 & 5.12 & 4.971 & TRN & & \\
\hline CHEMBL1380028 & 954340 & 5.4199 & 5.5591 & TRN & & \\
\hline CHEMBL1403250 & 954340 & 5.4579 & 4.603 & TRN & & \\
\hline CHEMBL1705485 & 954340 & 5.3345 & 4.9757 & TRN & & \\
\hline CHEMBL 2354920 & 954340 & 5.5017 & 5.3337 & TRN & & \\
\hline CHEMBL1415470 & 954340 & 6.1064 & 4.6445 & TRN & & \\
\hline CHEMBL1541755 & 954340 & 3.52399 & 99999999 & 96 & 4.48 & 17 \\
\hline CHEMBL152670 & 954340 & 5.9252 & 5.2829 & TRN & & \\
\hline CHEMBL1331469 & 954340 & 5.0428 & 4.6707 & TRN & & \\
\hline CHEMBL 2357494 & 954340 & 5.3855 & 5.1146 & TST & & \\
\hline CHEMBL1870655 & 954340 & 4.8426 & 4.7681 & TRN & & \\
\hline CHEMBL1732067 & 954340 & 3.5243 & 4.7633 & TRN & & \\
\hline CHEMBL1589671 & 954340 & 5.0534 & 5.3931 & TST & & \\
\hline CHEMBL1162428 & 954340 & 4.8345 & 5.2306 & TRN & & \\
\hline CHEMBL 3195378 & 954340 & 5.1348 & 4.8765 & TRN & & \\
\hline CHEMBL1589413 & 954340 & 4.7416 & 5.2587 & TST & & \\
\hline CHEMBL1451121 & 954340 & 4.6506 & 5.4713 & TRN & & \\
\hline CHEMBL1375754 & 954340 & 5.4482 & 5.064 & TRN & & \\
\hline CHEMBL 3213620 & 954340 & 5.63 & 5.4769 & TRN & & \\
\hline CHEMBL1304172 & 954340 & 5.1653 & 5.6438 & TRN & & \\
\hline CHEMBL441948 & 954340 & 5.4377 & 5.6348 & TST & & \\
\hline CHEMBL1736439 & 954340 & 4.8436 & 5.013 & TRN & & \\
\hline CHEMBL1872433 & 954340 & 5.6876 & 5.5817 & TRN & & \\
\hline
\end{tabular}

Page 11251 
Supplemental Table S2.txt

\begin{tabular}{|c|c|c|c|c|}
\hline CHEMBL1602148 & 954340 & 5.1425 & 5.2522 & TRN \\
\hline CHEMBL1602292 & 954340 & 5.279 & 5.3961 & TRN \\
\hline CHEMBL3191793 & 954340 & 5.0548 & 4.8244 & TRN \\
\hline CHEMBL 2138994 & 954340 & 5.1592 & 5.0711 & TRN \\
\hline CHEMBL1332912 & 954340 & 5.2556 & 5.2027 & TRN \\
\hline CHEMBL1715965 & 954340 & 5.3053 & 5.2128 & TST \\
\hline CHEMBL1420608 & 954340 & 3.5244 & 4.9944 & TST \\
\hline CHEMBL1608286 & 954340 & 5.0413 & 5.4389 & TST \\
\hline CHEMBL1463960 & 954340 & 3.5242 & 4.5768 & TST \\
\hline CHEMBL3191126 & 954340 & 5.5988 & 4.3772 & TST \\
\hline CHEMBL1501007 & 954340 & 4.7012 & 5.0856 & TST \\
\hline CHEMBL 2361028 & 954340 & 4.7673 & 5.1293 & TST \\
\hline CHEMBL3212757 & 954340 & 6.6453 & 5.8471 & TST \\
\hline CHEMBL598204 & 954340 & 5.0721 & 5.2997 & TST \\
\hline CHEMBL1451277 & 954340 & 5.2205 & 5.2546 & TST \\
\hline CHEMBL1606897 & 954340 & 4.9295 & 5.0284 & TST \\
\hline CHEMBL1605615 & 954340 & 5.7788 & 4.8941 & TST \\
\hline CHEMBL358290 & 954340 & 5.1514 & 5.0882 & TST \\
\hline CHEMBL 2361506 & 954340 & 5.1973 & 5.2064 & TST \\
\hline CHEMBL313833 & 954340 & 5.6784 & 5.4831 & TST \\
\hline CHEMBL1435619 & 954340 & 4.6551 & 5.4388 & TST \\
\hline CHEMBL1448326 & 954340 & 4.6653 & 4.7357 & TST \\
\hline CHEMBL1408579 & 954340 & 5.3858 & 5.3551 & TST \\
\hline CHEMBL 2134712 & 954340 & 5.3634 & 5.1415 & TST \\
\hline CHEMBL 2355781 & 954340 & 5.4203 & 5.3716 & TST \\
\hline CHEMBL1379139 & 954340 & 4.0013 & 5.606 & TST \\
\hline CHEMBL1526161 & 954340 & 5.4844 & 5.332999 & 7999999999 \\
\hline CHEMBL1508812 & 954340 & 4.587 & 4.9661 & TST \\
\hline CHEMBL1487563 & 954340 & 5.2267 & 5.2458 & TST \\
\hline CHEMBL1891198 & 954340 & 4.9567 & 5.0325 & TST \\
\hline CHEMBL1529081 & 954340 & 4.8803 & 5.6207 & TST \\
\hline CHEMBL1300980 & 954340 & 5.6287 & 5.6365 & TST \\
\hline CHEMBL1353406 & 954340 & 4.7566 & 4.9731 & TST \\
\hline CHEMBL1733489 & 954340 & 5.0181 & 5.0944 & TST \\
\hline CHEMBL1345189 & 954340 & 3.5239 & 4.9308 & TST \\
\hline CHEMBL1337758 & 954340 & 5.144 & 5.027 & TST \\
\hline CHEMBL1519667 & 954340 & 5.6236 & 5.1618 & TST \\
\hline CHEMBL3214461 & 954340 & 5.2361 & 4.4214 & TST \\
\hline CHEMBL1224310 & 954340 & 5.2835 & $5.26200 t$ & 00000000005 \\
\hline CHEMBL1333283 & 954340 & 5.8758 & 5.6328 & TST \\
\hline CHEMBL1545571 & 954340 & 5.5535 & 5.667006 & 0000000001 \\
\hline CHEMBL1729231 & 954340 & 5.151 & 5.2633 & TST \\
\hline CHEMBL1528135 & 954340 & 4.6979 & 4.9383 & TST \\
\hline CHEMBL 2138173 & 954340 & 5.0344 & 5.0534 & TST \\
\hline CHEMBL170012 & 954340 & 5.1516 & 5.1757 & TST \\
\hline CHEMBL1873712 & 954340 & 5.0067 & 5.2419 & TST \\
\hline CHEMBL3195694 & 954340 & 4.7224 & 5.4475 & TST \\
\hline CHEMBL3211970 & 954340 & 4.9686 & 4.2184 & TST \\
\hline
\end{tabular}




\begin{tabular}{|c|c|c|c|c|c|}
\hline \multicolumn{6}{|c|}{ Supplemental Table S2.txt } \\
\hline CHEMBL 2356479 & 954340 & 5.1619 & 5.2358 & TST & \\
\hline CHEMBL1995645 & 954340 & 5.1784 & 4.3831 & TST & \\
\hline CHEMBL1560683 & 954340 & 5.2541 & 4.8238 & TST & \\
\hline CHEMBL590666 & 954340 & 5.3102 & 4.7237 & TST & \\
\hline CHEMBL3116407 & 1289425 & 4.8861 & 4.9223 & TRN & \\
\hline CHEMBL3116400 & 1289425 & 5.2147 & 4.3038 & TRN & \\
\hline CHEMBL3116424 & 1289425 & 5.8239 & 4.4173 & TST & \\
\hline CHEMBL3116426 & 1289425 & 5.4685 & 5.2737 & TRN & \\
\hline CHEMBL 3116420 & 1289425 & 7.7212 & 7.9554 & TRN & \\
\hline CHEMBL3116425 & 1289425 & 5.041 & 5.1424 & TRN & \\
\hline CHEMBL3112705 & 1289425 & 6.0 & 5.6993 & TRN & \\
\hline CHEMBL1412250 & 1289425 & 6.0 & 6.0771 & TRN & \\
\hline CHEMBL3116433 & 1289425 & 3.0 & 2.7585 & TRN & \\
\hline CHEMBL1412046 & 1289425 & 4.4202 & 4.5881 & TST & \\
\hline CHEMBL3116398 & 1289425 & 5.4318 & 6.5991 & TRN & \\
\hline CHEMBL3112701 & 1289425 & 3.0 & 2.745 & TRN & \\
\hline CHEMBL3116411 & 1289425 & 4.6021 & 4.4022 & TRN & \\
\hline CHEMBL3116419 & 1289425 & 4.2076 & 4.0985 & TRN & \\
\hline CHEMBL3116410 & 1289425 & 6.2147 & 5.7018 & TRN & \\
\hline CHEMBL3116415 & 1289425 & 4.0809 & 3.7556 & TRN & \\
\hline CHEMBL3116423 & 1289425 & 4.4437 & 4.0816 & TRN & \\
\hline CHEMBL3112704 & 1289425 & 3.0 & 2.6444 & TST & \\
\hline CHEMBL3116428 & 1289425 & 5.3872 & 4.4355 & TST & \\
\hline CHEMBL3112696 & 1289425 & 3.0 & 3.2511 & TRN & \\
\hline CHEMBL3112703 & 1289425 & 3.0 & 3.1726 & TST & \\
\hline CHEMBL3116399 & 1289425 & 7.8239 & 7.142 & TRN & \\
\hline CHEMBL3116432 & 1289425 & 3.0 & 3.2974 & TRN & \\
\hline CHEMBL3116408 & 1289425 & 5.4815 & 4.9503 & TRN & \\
\hline CHEMBL 3112700 & 1289425 & 3.0 & 4.0938 & TST & \\
\hline CHEMBL3116417 & 1289425 & 6.1938 & 6.0727 & TRN & \\
\hline CHEMBL3112692 & 1289425 & 4.4685 & 4.6717 & TRN & \\
\hline CHEMBL3116402 & 1289425 & 3.0 & 2.95899 & 99999999996 & TRN \\
\hline CHEMBL3116414 & 1289425 & 4.3979 & 4.5908 & TRN & \\
\hline CHEMBL3116406 & 1289425 & 3.0 & 3.0634 & TRN & \\
\hline CHEMBL3112694 & 1289425 & 3.0 & 4.5091 & TST & \\
\hline CHEMBL3112695 & 1289425 & 4.301 & 4.0484 & TRN & \\
\hline CHEMBL3116421 & 1289425 & 6.5376 & 6.2648 & TRN & \\
\hline CHEMBL3112706 & 1289425 & 3.0 & 3.3293 & TRN & \\
\hline CHEMBL3116430 & 1289425 & 4.6778 & 4.5743 & TST & \\
\hline CHEMBL3116403 & 1289425 & 3.0 & 3.8233 & TRN & \\
\hline CHEMBL3105156 & 1289425 & 7.7212 & 7.7252 & TRN & \\
\hline CHEMBL259398 & 1289425 & 4.8861 & 5.2449 & TRN & \\
\hline CHEMBL3116397 & 1289425 & 5.8539 & 4.8512 & TRN & \\
\hline CHEMBL3112691 & 1289425 & 3.0 & 2.8516 & TST & \\
\hline CHEMBL3116404 & 1289425 & 6.3768 & 6.3194 & TRN & \\
\hline CHEMBL3116429 & 1289425 & 4.6778 & 4.7461 & TRN & \\
\hline CHEMBL3116412 & 1289425 & 6.6778 & 7.1059 & TRN & \\
\hline CHEMBL3112628 & 1289425 & 3.0 & 3.487 & TRN & \\
\hline
\end{tabular}


Supplemental Table S2.txt

\begin{tabular}{|c|c|c|c|c|c|}
\hline CHEMBL3116409 & 1289425 & 5.301 & 6.0389 & TRN & \\
\hline CHEMBL 3116431 & 1289425 & 3.0 & 3.583 & TRN & \\
\hline CHEMBL 3112697 & 1289425 & 3.0 & 4.0674 & TST & \\
\hline CHEMBL3112693 & 1289425 & 3.0 & 3.5192 & TRN & \\
\hline CHEMBL 3112698 & 1289425 & 3.0 & 2.86800 & 00000000003 & TST \\
\hline CHEMBL 3116401 & 1289425 & 4.8539 & 5.249 & TRN & \\
\hline CHEMBL3116416 & 1289425 & 7.8539 & 7.4874 & TRN & \\
\hline CHEMBL3112699 & 1289425 & 3.0 & 3.2369 & TST & \\
\hline CHEMBL 3116405 & 1289425 & 4.9872 & 4.0138 & TRN & \\
\hline CHEMBL 3112702 & 1289425 & 3.0 & 3.2955 & TST & \\
\hline CHEMBL 3116413 & 1289425 & 5.8239 & 5.9081 & TRN & \\
\hline CHEMBL1494030 & 1289425 & 4.041 & 3.25100 & 00000000003 & ות \\
\hline CHEMBL 3116422 & 1289425 & 4.0969 & 4.8473 & TRN & \\
\hline CHEMBL 3116418 & 1289425 & 5.5086 & 5.0392 & TRN & \\
\hline CHEMBL 3116427 & 1289425 & 4.585 & 4.07 & TST & \\
\hline CHEMBL1645406 & 1289425 & 4.8861 & 4.8754 & TRN & \\
\hline CHEMBL226073 & 435551 & 6.8069 & 6.8538 & TRN & \\
\hline CHEMBL226497 & 435551 & 7.20200 & 00000000 & 7.1486 & \\
\hline CHEMBL389957 & 435551 & 5.9031 & 6.1716 & TST & \\
\hline CHEMBL 225799 & 435551 & 6.1851 & 6.5249 & TRN & \\
\hline CHEMBL 226177 & 435551 & 7.567 & 7.74 & TRN & \\
\hline CHEMBL226124 & 435551 & 7.4815 & 7.5409 & TRN & \\
\hline CHEMBL 226228 & 435551 & 7.8182 & 7.9833 & TRN & \\
\hline CHEMBL427270 & 435551 & 7.3706 & 7.1064 & TRN & \\
\hline CHEMBL225909 & 435551 & 6.6459 & 6.3932 & TRN & \\
\hline CHEMBL 225691 & 435551 & 5.9245 & 6.3136 & TST & \\
\hline CHEMBL226280 & 435551 & 7.6271 & 7.6013 & TRN & \\
\hline CHEMBL 226227 & 435551 & 7.6144 & 7.7565 & TRN & \\
\hline CHEMBL225692 & 435551 & 6.5186 & 6.4692 & TRN & \\
\hline CHEMBL226281 & 435551 & 7.9788 & 7.2756 & TRN & \\
\hline CHEMBL 225967 & 435551 & \multicolumn{3}{|c|}{7.082000000000001} & $T$ \\
\hline CHEMBL225749 & 435551 & 6.8327 & 6.6312 & TRN & \\
\hline CHEMBL 226341 & 435551 & 7.2741 & 7.3977 & TRN & \\
\hline CHEMBL 220092 & 435551 & 6.6421 & 7.0611 & TRN & \\
\hline CHEMBL 226176 & 435551 & 7.9318 & 7.9354 & TRN & \\
\hline CHEMBL389733 & 435551 & 6.2464 & 6.3134 & TRN & \\
\hline CHEMBL 226442 & 435551 & 6.6819 & 6.6321 & TRN & \\
\hline CHEMBL225911 & 435551 & 5.4449 & 5.6829 & TRN & \\
\hline CHEMBL376609 & 435551 & 7.4342 & 7.5514 & TST & \\
\hline CHEMBL 225855 & 435551 & 6.5287 & 6.4559 & TRN & \\
\hline CHEMBL 226496 & 435551 & 6.6615 & 6.5743 & TRN & \\
\hline CHEMBL 226125 & 435551 & 7.567 & 7.5641 & TRN & \\
\hline CHEMBL 226074 & 435551 & 6.6144 & 6.775 & TRN & \\
\hline CHEMBL 226025 & 435551 & 7.9508 & 7.3056 & TRN & \\
\hline CHEMBL 225968 & 435551 & 7.3261 & 7.5652 & TST & \\
\hline CHEMBL375251 & 435551 & 7.1409 & 7.0838 & TRN & \\
\hline CHEMBL226443 & 435551 & 6.9281 & 6.6288 & TRN & \\
\hline CHEMBL 389073 & 435551 & 7.0339 & 7.1216 & TRN & \\
\hline
\end{tabular}




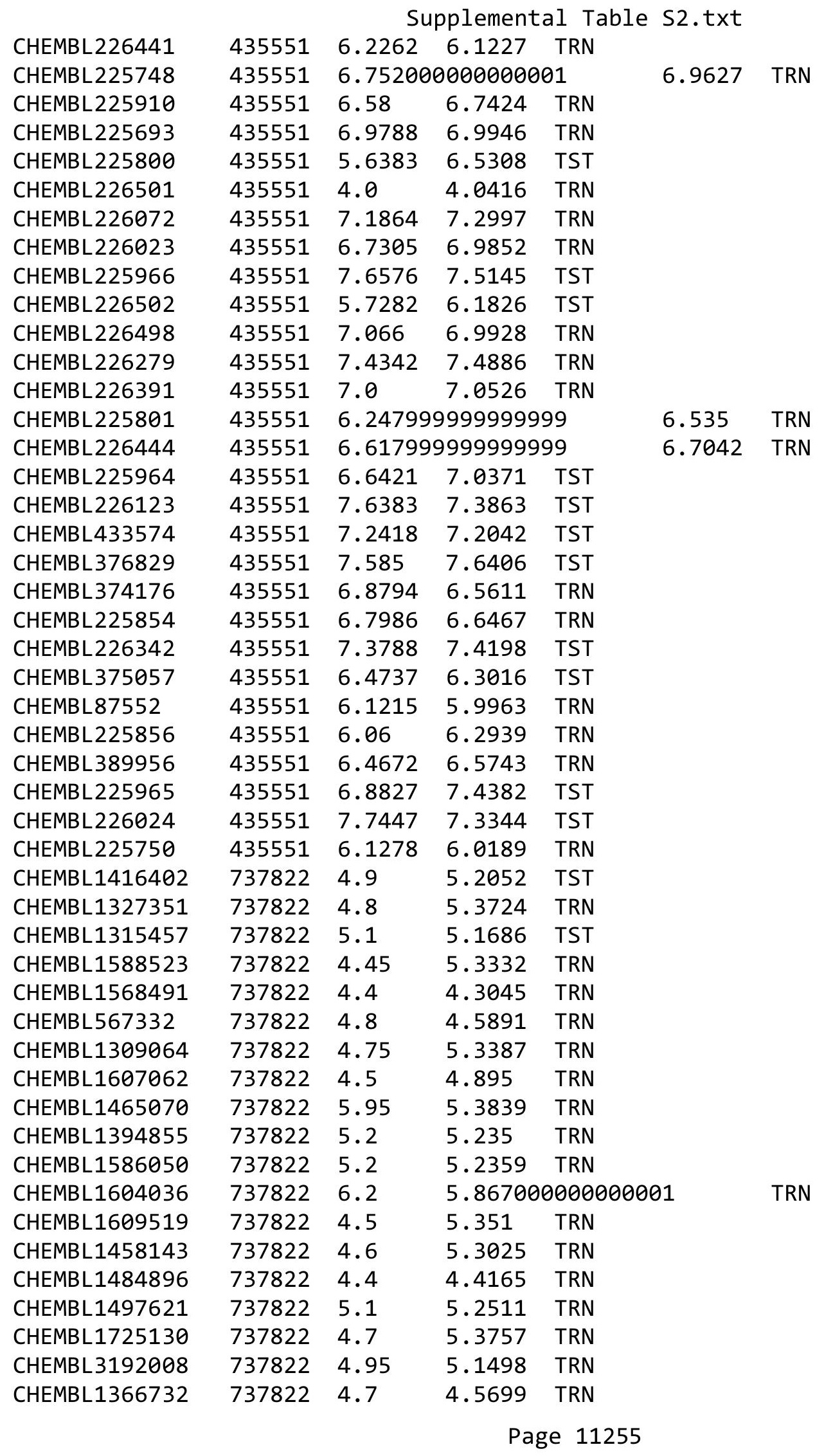




\begin{tabular}{|c|c|c|c|c|c|}
\hline & & & & & \\
\hline CHEMBL1505752 & 737822 & 4.4 & 5.1339 & TRN & \\
\hline CHEMBL1564545 & 737822 & 4.6 & 4.5962 & TRN & \\
\hline CHEMBL1590378 & 737822 & 6.0 & 5.6329 & TRN & \\
\hline CHEMBL1573957 & 737822 & 7.8 & 6.934 & TRN & \\
\hline CHEMBL1445984 & 737822 & 4.9 & 4.8617 & TRN & \\
\hline CHEMBL1256364 & 737822 & 4.5 & 4.635 & TRN & \\
\hline CHEMBL1741451 & 737822 & 6.15 & 5.3683 & TRN & \\
\hline CHEMBL1573862 & 737822 & 5.0 & 4.8487 & TRN & \\
\hline CHEMBL402468 & 737822 & 4.4 & 4.6027 & TST & \\
\hline CHEMBL1339762 & 737822 & 4.4 & 5.2891 & TST & \\
\hline CHEMBL1401960 & 737822 & 4.95 & 5.2835 & TRN & \\
\hline CHEMBL1395850 & 737822 & 4.8 & 4.6371 & TRN & \\
\hline CHEMBL1433551 & 737822 & 5.5 & 5.4629 & TRN & \\
\hline CHEMBL90769 & 737822 & 5.9 & 5.5775 & TRN & \\
\hline CHEMBL1742231 & 737822 & 5.3 & 5.3641 & TRN & \\
\hline CHEMBL495068 & 737822 & 4.7 & 4.6721 & TRN & \\
\hline CHEMBL419815 & 737822 & 5.7 & 5.4224 & TRN & \\
\hline CHEMBL1306278 & 737822 & 4.45 & 5.5823 & TRN & \\
\hline CHEMBL1337408 & 737822 & 5.65 & 5.2241 & TRN & \\
\hline CHEMBL1516154 & 737822 & 5.2 & 5.1897 & TRN & \\
\hline CHEMBL1481741 & 737822 & 4.7 & 4.6218 & TRN & \\
\hline CHEMBL1529330 & 737822 & 5.4 & 5.0522 & TRN & \\
\hline CHEMBL3212789 & 737822 & 4.65 & 5.3112 & TRN & \\
\hline CHEMBL1527851 & 737822 & 5.15 & $5.2170 e$ & 00000000005 & TRN \\
\hline CHEMBL1564907 & 737822 & 4.6 & 5.209 & TRN & \\
\hline CHEMBL1987784 & 737822 & 6.5 & 5.077 & TST & \\
\hline CHEMBL1452272 & 737822 & 7.4 & 6.8234 & TRN & \\
\hline CHEMBL1527221 & 737822 & 4.8 & 4.5847 & TRN & \\
\hline CHEMBL1320190 & 737822 & 5.7 & 5.3626 & TRN & \\
\hline CHEMBL1558574 & 737822 & 5.15 & 5.329 & TRN & \\
\hline CHEMBL1458583 & 737822 & 5.1 & 5.3841 & TRN & \\
\hline CHEMBL1367030 & 737822 & 6.2 & 6.0224 & TRN & \\
\hline CHEMBL1444632 & 737822 & 5.55 & 5.2751 & TST & \\
\hline CHEMBL1586264 & 737822 & 4.75 & 5.3792 & TRN & \\
\hline CHEMBL1496596 & 737822 & 4.7 & 4.654 & TRN & \\
\hline CHEMBL1319381 & 737822 & 5.0 & 5.2253 & TST & \\
\hline CHEMBL1312169 & 737822 & 7.5 & 5.0137 & TRN & \\
\hline CHEMBL1492339 & 737822 & 4.55 & 5.1045 & TRN & \\
\hline CHEMBL1500518 & 737822 & 5.45 & 5.1141 & TRN & \\
\hline CHEMBL1369242 & 737822 & 5.6 & 5.4898 & TRN & \\
\hline CHEMBL1378764 & 737822 & 4.9 & 4.6554 & TRN & \\
\hline CHEMBL1401822 & 737822 & 5.1 & 5.2412 & TRN & \\
\hline CHEMBL1315991 & 737822 & 4.4 & 4.4018 & TRN & \\
\hline CHEMBL1598680 & 737822 & 6.0 & 5.8056 & TRN & \\
\hline CHEMBL1433724 & 737822 & 5.9 & 5.6057 & TRN & \\
\hline CHEMBL 3207544 & 737822 & 4.8 & 5.2997 & TRN & \\
\hline CHEMBL 310310 & 737822 & 6.0 & 5.91799 & 9999999999 & TRN \\
\hline CHEMBL1433687 & 737822 & 4.5 & 4.4464 & TRN & \\
\hline & & & & 11256 & \\
\hline
\end{tabular}




\begin{tabular}{|c|c|c|c|c|c|}
\hline CHEMBL491771 & 737822 & 4.9 & \multicolumn{2}{|c|}{4.6739999999999995} & TRN \\
\hline CHEMBL1327355 & 737822 & 4.8 & 4.7305 & TRN & \\
\hline CHEMBL1477982 & 737822 & 4.6 & 4.7117 & TRN & \\
\hline CHEMBL1591712 & 737822 & 4.9 & 4.8647 & TRN & \\
\hline CHEMBL1725279 & 737822 & 6.4 & 6.0488 & TST & \\
\hline CHEMBL1572430 & 737822 & 5.15 & 5.3285 & TST & \\
\hline CHEMBL1436664 & 737822 & 4.7 & 5.0924 & TRN & \\
\hline CHEMBL1452750 & 737822 & 4.4 & 5.4048 & TRN & \\
\hline CHEMBL3213443 & 737822 & 4.45 & \multicolumn{2}{|c|}{5.428999999999999} & TRN \\
\hline CHEMBL1392374 & 737822 & 4.85 & 5.3774 & TRN & \\
\hline CHEMBL1446244 & 737822 & 8.25 & 5.1669 & TRN & \\
\hline CHEMBL1365932 & 737822 & 6.5 & 5.3559 & TRN & \\
\hline CHEMBL1482184 & 737822 & 5.9 & 5.8009 & TST & \\
\hline CHEMBL56 & 737822 & 6.0 & 5.8792 & TRN & \\
\hline CHEMBL1463140 & 737822 & 4.7 & 5.5021 & TRN & \\
\hline CHEMBL51697 & 737822 & 6.0 & 5.7078 & TRN & \\
\hline CHEMBL1592760 & 737822 & 4.8 & 4.6665 & TRN & \\
\hline CHEMBL1401073 & 737822 & 4.9 & 5.16 & TRN & \\
\hline CHEMBL1346226 & 737822 & 5.45 & \multicolumn{2}{|c|}{5.247000000000001} & TRN \\
\hline CHEMBL1339544 & 737822 & 6.1 & 5.4313 & TRN & \\
\hline CHEMBL1430037 & 737822 & 4.4 & 4.5472 & TRN & \\
\hline CHEMBL90472 & 737822 & 6.0 & \multicolumn{2}{|c|}{5.6339999999999995} & TST \\
\hline CHEMBL1566044 & 737822 & 5.5 & \multicolumn{2}{|c|}{5.367000000000001} & TRN \\
\hline CHEMBL3191765 & 737822 & 6.0 & 5.2938 & TST & \\
\hline CHEMBL1741658 & 737822 & 4.8 & 5.3965 & TRN & \\
\hline CHEMBL1742363 & 737822 & 4.8 & 5.4053 & TRN & \\
\hline CHEMBL1409078 & 737822 & 5.4 & 5.2405 & TRN & \\
\hline CHEMBL1552172 & 737822 & 4.4 & 4.4204 & TRN & \\
\hline CHEMBL1483874 & 737822 & 4.8 & 5.3008 & TRN & \\
\hline CHEMBL1354319 & 737822 & 5.0 & 4.7353 & TRN & \\
\hline CHEMBL411502 & 737822 & 4.4 & 4.4796 & TRN & \\
\hline CHEMBL474415 & 737822 & 5.9 & 5.5909 & TRN & \\
\hline CHEMBL1329940 & 737822 & 5.3 & 5.3344 & TST & \\
\hline CHEMBL1473123 & 737822 & 4.7 & 4.7282 & TRN & \\
\hline CHEMBL1471920 & 737822 & 5.1 & 5.2003 & TRN & \\
\hline CHEMBL1589282 & 737822 & 5.65 & 5.3536 & TST & \\
\hline CHEMBL1533214 & 737822 & 4.6 & 4.773 & TRN & \\
\hline CHEMBL1354596 & 737822 & 4.8 & 4.6088 & TRN & \\
\hline CHEMBL1564927 & 737822 & 5.4 & 5.2978 & TST & \\
\hline CHEMBL1741748 & 737822 & 4.65 & 5.3407 & TRN & \\
\hline CHEMBL1421390 & 737822 & 5.2 & 5.4156 & TRN & \\
\hline CHEMBL1200938 & 737822 & 6.0 & 5.7816 & TRN & \\
\hline CHEMBL1467717 & 737822 & 4.95 & 6.476 & TRN & \\
\hline CHEMBL1407769 & 737822 & 5.7 & 5.6053 & TRN & \\
\hline CHEMBL1741473 & 737822 & 4.8 & 5.4952 & TRN & \\
\hline CHEMBL1491271 & 737822 & 5.05 & 5.3621 & TRN & \\
\hline CHEMBL1554411 & 737822 & 5.5 & 5.3691 & TST & \\
\hline \multirow[t]{2}{*}{ CHEMBL1562730 } & 737822 & 5.9 & 5.0856 & TRN & \\
\hline & & & \multicolumn{2}{|c|}{ Page 11257} & \\
\hline
\end{tabular}




\begin{tabular}{|c|c|c|c|c|}
\hline \multicolumn{5}{|c|}{ Supplemental Table S2.txt } \\
\hline CHEMBL1374524 & 737822 & 5.5 & 5.388 & TRN \\
\hline CHEMBL1554023 & 737822 & 5.2 & 5.1839 & TST \\
\hline CHEMBL1342813 & 737822 & 4.85 & 5.6295 & TRN \\
\hline CHEMBL1357157 & 737822 & 4.6 & 4.4626 & TRN \\
\hline CHEMBL1397169 & 737822 & 7.1 & 6.5949 & TST \\
\hline CHEMBL1391282 & 737822 & 5.05 & 5.4605 & TST \\
\hline CHEMBL1395412 & 737822 & 4.5 & 4.8173 & TST \\
\hline CHEMBL1554579 & 737822 & 5.3 & 5.1817 & TRN \\
\hline CHEMBL1516103 & 737822 & 5.8 & 5.4818 & TRN \\
\hline CHEMBL1515324 & 737822 & 5.3 & 5.3239 & TRN \\
\hline CHEMBL3197172 & 737822 & 4.4 & 5.3683 & TRN \\
\hline CHEMBL338115 & 737822 & 6.2 & 5.9052 & TRN \\
\hline CHEMBL1323215 & 737822 & 5.1 & 5.1564 & TRN \\
\hline CHEMBL1528076 & 737822 & 4.95 & 5.5956 & TRN \\
\hline CHEMBL67378 & 737822 & 6.0 & 5.6933 & TST \\
\hline CHEMBL1566936 & 737822 & 4.6 & 4.4341 & TRN \\
\hline CHEMBL1358297 & 737822 & 4.4 & 4.5345 & TST \\
\hline CHEMBL1596387 & 737822 & 5.95 & 5.1238 & TRN \\
\hline CHEMBL1551066 & 737822 & 5.1 & 4.8938 & TRN \\
\hline CHEMBL1601805 & 737822 & 5.4 & 5.2669 & TRN \\
\hline CHEMBL1420531 & 737822 & 4.95 & 4.9628 & TRN \\
\hline CHEMBL1602710 & 737822 & 4.6 & 4.461 & TRN \\
\hline CHEMBL1579328 & 737822 & 4.6 & 5.4876 & TST \\
\hline CHEMBL1374544 & 737822 & 5.8 & 5.569 & TRN \\
\hline CHEMBL1442542 & 737822 & 4.55 & 5.4124 & TST \\
\hline CHEMBL1368632 & 737822 & 6.2 & 5.9431 & TST \\
\hline CHEMBL250447 & 737822 & 4.4 & 4.8115 & TRN \\
\hline CHEMBL1452436 & 737822 & 4.9 & 5.4318 & TRN \\
\hline CHEMBL1324194 & 737822 & 5.0 & 5.6043 & TRN \\
\hline CHEMBL1395029 & 737822 & 4.4 & 4.3485 & TRN \\
\hline CHEMBL1446523 & 737822 & 5.5 & 5.4555 & TRN \\
\hline CHEMBL1413701 & 737822 & 4.4 & 4.6292 & TRN \\
\hline CHEMBL1413161 & 737822 & 5.0 & 4.7401 & TRN \\
\hline CHEMBL1439808 & 737822 & 4.85 & 5.2378 & TRN \\
\hline CHEMBL1505568 & 737822 & 4.7 & 5.1366 & TRN \\
\hline CHEMBL3189243 & 737822 & 4.4 & 5.2682 & TST \\
\hline CHEMBL1725270 & 737822 & 5.4 & 5.2649 & TRN \\
\hline CHEMBL1525073 & 737822 & 4.7 & 5.4581 & TRN \\
\hline CHEMBL1372282 & 737822 & 6.1 & 5.666 & TST \\
\hline CHEMBL1528648 & 737822 & 4.5 & 4.7565 & TRN \\
\hline CHEMBL1473868 & 737822 & 5.4 & 5.3252 & TRN \\
\hline CHEMBL1414633 & 737822 & 5.35 & 5.2994 & TRN \\
\hline CHEMBL1595037 & 737822 & 5.8 & 5.2407 & TST \\
\hline CHEMBL1515410 & 737822 & 4.4 & 4.4374 & TRN \\
\hline CHEMBL1354901 & 737822 & 6.2 & 6.2218 & TRN \\
\hline CHEMBL1448161 & 737822 & 5.15 & 5.4022 & TST \\
\hline CHEMBL510009 & 737822 & 5.4 & 5.0965 & TRN \\
\hline CHEMBL1311749 & 737822 & 4.75 & 5.1889 & TST \\
\hline
\end{tabular}




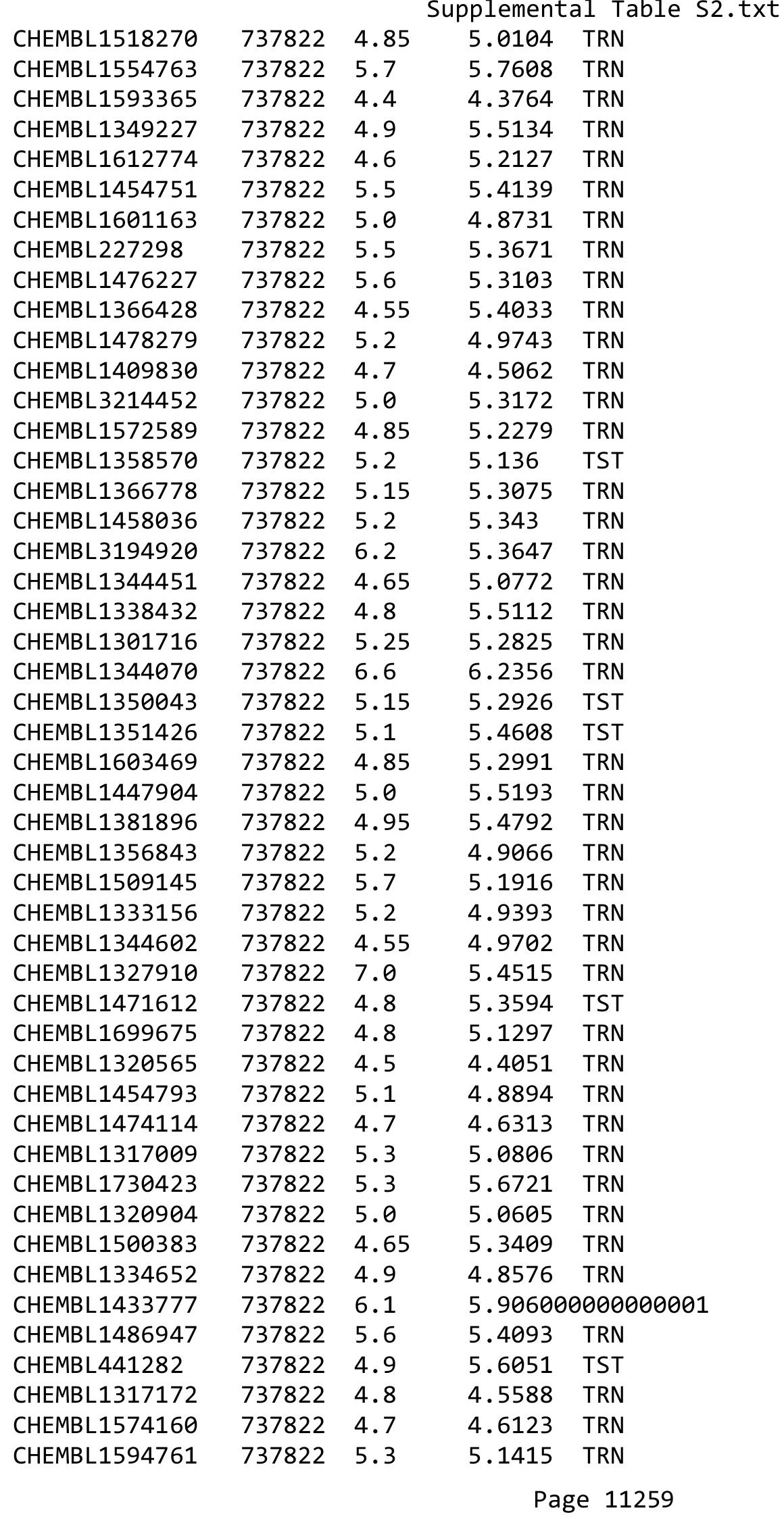

TRN 


\begin{tabular}{|c|c|c|c|c|c|}
\hline & & & & & \\
\hline CHEMBL1535022 & 737822 & 4.5 & 5.1046 & TRN & \\
\hline CHEMBL73824 & 737822 & 4.9 & 5.0969 & TRN & \\
\hline CHEMBL1476729 & 737822 & 5.0 & 4.8904 & TRN & \\
\hline CHEMBL1721191 & 737822 & 4.9 & 5.1139 & TRN & \\
\hline CHEMBL1592364 & 737822 & 4.9 & 4.9202 & TRN & \\
\hline CHEMBL1510930 & 737822 & 5.05 & 5.2677 & TRN & \\
\hline CHEMBL1459527 & 737822 & 4.85 & 5.1782 & TRN & \\
\hline CHEMBL1603534 & 737822 & 5.1 & 5.1249 & TRN & \\
\hline CHEMBL3214196 & 737822 & 4.4 & 5.1903 & TST & \\
\hline CHEMBL1439866 & 737822 & 4.8 & 4.8999 & TST & \\
\hline CHEMBL1312936 & 737822 & 4.7 & 4.99 & TRN & \\
\hline CHEMBL1500945 & 737822 & 5.15 & 5.7035 & TRN & \\
\hline CHEMBL1371756 & 737822 & 5.8 & 5.5469 & TRN & \\
\hline CHEMBL492122 & 737822 & 4.5 & 4.4137 & TRN & \\
\hline CHEMBL1517241 & 737822 & 4.9 & 4.7847 & TRN & \\
\hline CHEMBL1214274 & 737822 & 5.5 & 5.29299 & 9999999999 & TRN \\
\hline CHEMBL1480984 & 737822 & 5.7 & 5.4265 & TRN & \\
\hline CHEMBL50112 & 737822 & 4.9 & 5.0149 & TRN & \\
\hline CHEMBL1590245 & 737822 & 5.4 & 5.3393 & TRN & \\
\hline CHEMBL1742246 & 737822 & 4.9 & 5.4257 & TRN & \\
\hline CHEMBL1357018 & 737822 & 5.0 & 5.0094 & TRN & \\
\hline CHEMBL1356783 & 737822 & -0.0 & 5.2335 & TST & \\
\hline CHEMBL1577056 & 737822 & 5.0 & 5.3845 & TRN & \\
\hline CHEMBL1456076 & 737822 & 5.1 & 4.9124 & TRN & \\
\hline CHEMBL1357199 & 737822 & 4.6 & 4.5449 & TRN & \\
\hline CHEMBL1494218 & 737822 & 5.5 & 5.4367 & TRN & \\
\hline CHEMBL1368186 & 737822 & 4.6 & 5.2241 & TRN & \\
\hline CHEMBL1484398 & 737822 & 5.35 & 5.1701 & TRN & \\
\hline CHEMBL1401324 & 737822 & 6.9 & 6.42899 & 9999999999 & TRN \\
\hline CHEMBL1570769 & 737822 & 4.8 & 5.3361 & TRN & \\
\hline CHEMBL1610387 & 737822 & 5.2 & 5.0312 & TRN & \\
\hline CHEMBL1320662 & 737822 & 4.9 & 4.6457 & TRN & \\
\hline CHEMBL275097 & 737822 & 7.2 & 6.9159 & TRN & \\
\hline CHEMBL1494979 & 737822 & 4.9 & 5.2832 & TRN & \\
\hline CHEMBL1401859 & 737822 & 5.0 & 4.7524 & TRN & \\
\hline CHEMBL1379481 & 737822 & 4.85 & 5.3002 & TRN & \\
\hline CHEMBL1548902 & 737822 & 4.85 & 5.4299 & TRN & \\
\hline CHEMBL1334357 & 737822 & 5.4 & 5.2495 & TST & \\
\hline CHEMBL1374043 & 737822 & 4.8 & 5.2261 & TRN & \\
\hline CHEMBL1592803 & 737822 & 5.6 & 5.5667 & TRN & \\
\hline CHEMBL1608811 & 737822 & 5.45 & 5.392 & TRN & \\
\hline CHEMBL16857 & 737822 & 6.0 & 5.6935 & TRN & \\
\hline CHEMBL1256974 & 737822 & 4.6 & 4.6405 & TRN & \\
\hline CHEMBL1385652 & 737822 & 5.5 & 5.3938 & TRN & \\
\hline CHEMBL1358738 & 737822 & 5.6 & 5.4787 & TRN & \\
\hline CHEMBL1301722 & 737822 & 4.85 & 5.1544 & TST & \\
\hline CHEMBL1462833 & 737822 & 4.85 & 5.2738 & TRN & \\
\hline CHEMBL1534919 & 737822 & 4.65 & 5.3673 & TRN & \\
\hline & & & & 11260 & \\
\hline
\end{tabular}




\begin{tabular}{|c|c|c|c|c|c|}
\hline \multicolumn{6}{|c|}{ Supplemental Table S2.txt } \\
\hline CHEMBL1438000 & 737822 & 5.7 & 5.5903 & TRN & \\
\hline CHEMBL1356060 & 737822 & 5.6 & 5.3456 & TRN & \\
\hline CHEMBL1549831 & 737822 & 4.85 & 5.3987 & TRN & \\
\hline CHEMBL1591380 & 737822 & 4.7 & 4.5138 & TRN & \\
\hline CHEMBL1353502 & 737822 & 4.5 & 5.3867 & TRN & \\
\hline CHEMBL1502536 & 737822 & 4.7 & 5.303 & TST & \\
\hline CHEMBL1529694 & 737822 & 5.05 & 5.2889 & TRN & \\
\hline CHEMBL1597169 & 737822 & 5.6 & 5.3822 & TRN & \\
\hline CHEMBL1317998 & 737822 & 5.0 & 4.9646 & TRN & \\
\hline CHEMBL1514149 & 737822 & 5.0 & 4.7637 & TRN & \\
\hline CHEMBL1420370 & 737822 & 5.0 & 4.7014 & TRN & \\
\hline CHEMBL1317928 & 737822 & 5.5 & 5.381 & TRN & \\
\hline CHEMBL1500686 & 737822 & 5.9 & 5.3876 & TRN & \\
\hline CHEMBL1497610 & 737822 & 5.45 & 5.2528 & TRN & \\
\hline CHEMBL1434789 & 737822 & 4.5 & 4.412 & TRN & \\
\hline CHEMBL1453216 & 737822 & 5.3 & 5.0606 & TRN & \\
\hline CHEMBL1700937 & 737822 & 4.75 & 5.2905 & TRN & \\
\hline CHEMBL1395088 & 737822 & 4.8 & 4.7541 & TRN & \\
\hline CHEMBL1530189 & 737822 & 5.2 & 5.3415 & TST & \\
\hline CHEMBL1489085 & 737822 & 5.4 & 5.3224 & TRN & \\
\hline CHEMBL1424582 & 737822 & 5.6 & 5.19 & TRN & \\
\hline CHEMBL1437783 & 737822 & 6.6 & 6.3733 & TRN & \\
\hline CHEMBL1536766 & 737822 & 5.05 & 5.4275 & TRN & \\
\hline CHEMBL1351212 & 737822 & 4.6 & 5.3306 & TRN & \\
\hline CHEMBL1351579 & 737822 & 7.5501 & 5.1568 & TRN & \\
\hline CHEMBL1556283 & 737822 & 4.6 & 4.5615 & TRN & \\
\hline CHEMBL1589133 & 737822 & 4.5 & 5.1631 & TRN & \\
\hline CHEMBL1474977 & 737822 & 5.8 & 5.5764 & TRN & \\
\hline CHEMBL1343240 & 737822 & 4.6 & 5.4654 & TRN & \\
\hline CHEMBL1381498 & 737822 & 4.8 & 5.3674 & TST & \\
\hline CHEMBL1414948 & 737822 & 4.8 & 4.7759 & TRN & \\
\hline CHEMBL1554612 & 737822 & 5.5 & $5.3660 e$ & 00000000005 & TRN \\
\hline CHEMBL1313506 & 737822 & 5.8 & 5.2487 & TRN & \\
\hline CHEMBL1450317 & 737822 & 5.5 & 5.4747 & TRN & \\
\hline CHEMBL1397833 & 737822 & 4.9 & 5.6699 & TST & \\
\hline CHEMBL1403034 & 737822 & 4.85 & 5.1822 & TRN & \\
\hline CHEMBL534084 & 737822 & 4.9 & 4.988 & TRN & \\
\hline CHEMBL1594020 & 737822 & 6.4 & 6.1718 & TRN & \\
\hline CHEMBL1374763 & 737822 & 5.6 & 5.3492 & TRN & \\
\hline CHEMBL1370726 & 737822 & 5.7 & 5.5282 & TRN & \\
\hline CHEMBL1428554 & 737822 & 4.85 & 5.4043 & TRN & \\
\hline CHEMBL1399141 & 737822 & 5.85 & 5.3222 & TRN & \\
\hline CHEMBL3189288 & 737822 & 4.6 & 5.2133 & TRN & \\
\hline CHEMBL1317458 & 737822 & 7.1 & $6.4060 e$ & $\partial 000000001$ & TRN \\
\hline CHEMBL1516500 & 737822 & 6.7 & 5.3108 & TRN & \\
\hline CHEMBL1519178 & 737822 & 5.65 & 5.4807 & TRN & \\
\hline CHEMBL1545141 & 737822 & 5.5 & 5.2011 & TST & \\
\hline CHEMBL1543808 & 737822 & 5.85 & 5.4629 & TRN & \\
\hline
\end{tabular}




\begin{tabular}{|c|c|c|c|c|c|}
\hline \\
\hline CHEMBL1479203 & 737822 & 6.9 & 6.6526 & TRN & \\
\hline CHEMBL1598394 & 737822 & 4.4 & 4.2848 & TRN & \\
\hline CHEMBL1450934 & 737822 & 4.8 & 5.3263 & TRN & \\
\hline CHEMBL1418881 & 737822 & 4.8 & 5.2834 & TST & \\
\hline CHEMBL1475945 & 737822 & 5.5 & 5.3859 & TRN & \\
\hline CHEMBL1394353 & 737822 & 4.4 & 4.3326 & TRN & \\
\hline CHEMBL1454711 & 737822 & 4.55 & 5.4289 & TST & \\
\hline CHEMBL1357231 & 737822 & 4.8 & 4.6585 & TRN & \\
\hline CHEMBL1404907 & 737822 & 4.5 & 4.5142 & TRN & \\
\hline CHEMBL1367845 & 737822 & 5.7 & 5.1294 & TRN & \\
\hline CHEMBL1551618 & 737822 & 4.4 & 4.8214 & TRN & \\
\hline CHEMBL1473030 & 737822 & 6.0 & 5.8412 & TRN & \\
\hline CHEMBL1574956 & 737822 & 5.1 & 5.1817 & TRN & \\
\hline CHEMBL1592388 & 737822 & 4.8 & 4.5809 & TRN & \\
\hline CHEMBL1411519 & 737822 & 4.7 & 4.6672 & TRN & \\
\hline CHEMBL543467 & 737822 & 6.0 & 5.7277 & TRN & \\
\hline CHEMBL1605510 & 737822 & 6.8 & 6.71899 & 9999999999 & TRN \\
\hline CHEMBL1475562 & 737822 & 5.1 & 4.9286 & TRN & \\
\hline CHEMBL1354713 & 737822 & 5.0 & 4.8951 & TRN & \\
\hline CHEMBL1256754 & 737822 & 6.3 & 6.1221 & TRN & \\
\hline CHEMBL1358541 & 737822 & 4.8 & 5.1018 & TRN & \\
\hline CHEMBL1495854 & 737822 & 4.7 & 4.5863 & TRN & \\
\hline CHEMBL362863 & 737822 & 5.1 & 5.05 & TST & \\
\hline CHEMBL1499501 & 737822 & 5.5 & 5.2573 & TRN & \\
\hline CHEMBL1717575 & 737822 & 5.2 & 5.4554 & TRN & \\
\hline CHEMBL1324697 & 737822 & 4.6 & 4.5864 & TST & \\
\hline CHEMBL1462421 & 737822 & 5.35 & 5.2469 & TST & \\
\hline CHEMBL1973729 & 737822 & 6.75 & 5.1735 & TRN & \\
\hline CHEMBL448741 & 737822 & 6.0 & 5.7827 & TRN & \\
\hline CHEMBL1359713 & 737822 & 5.3 & 5.4792 & TRN & \\
\hline CHEMBL1578674 & 737822 & 4.5 & 5.2036 & TST & \\
\hline CHEMBL1504955 & 737822 & 5.5 & 5.2355 & TRN & \\
\hline CHEMBL7162 & 737822 & 7.3 & 6.4847 & TRN & \\
\hline CHEMBL1331122 & 737822 & 6.0 & 5.7552 & TST & \\
\hline CHEMBL1454052 & 737822 & 5.4 & 5.1806 & TRN & \\
\hline CHEMBL1395252 & 737822 & 4.7 & 4.8973 & TRN & \\
\hline CHEMBL1256727 & 737822 & 5.4 & 5.3747 & TRN & \\
\hline CHEMBL1490786 & 737822 & 4.8 & 4.6319 & TRN & \\
\hline CHEMBL1575899 & 737822 & 4.5 & 5.244 & TRN & \\
\hline CHEMBL1315424 & 737822 & 5.3 & 5.1399 & TRN & \\
\hline CHEMBL1596952 & 737822 & 4.4 & 4.39 & TRN & \\
\hline CHEMBL1564740 & 737822 & 6.3 & 5.2055 & TRN & \\
\hline CHEMBL1408303 & 737822 & 5.4 & 5.2547 & TRN & \\
\hline CHEMBL11684 & 737822 & 6.9 & 6.2918 & TST & \\
\hline CHEMBL1347660 & 737822 & 5.2 & 5.1156 & TST & \\
\hline CHEMBL1399058 & 737822 & 6.3 & 5.8466 & TRN & \\
\hline CHEMBL3209359 & 737822 & 4.7 & 5.3074 & TRN & \\
\hline CHEMBL87418 & 737822 & 5.6 & 5.4985 & TRN & \\
\hline & & & & 11262 & \\
\hline
\end{tabular}




\begin{tabular}{|c|c|c|c|c|c|}
\hline \multicolumn{6}{|c|}{ Supplemental Table S2.txt } \\
\hline CHEMBL1412557 & 737822 & 4.85 & 5.6901 & TRN & \\
\hline CHEMBL1568111 & 737822 & 4.4 & 4.333 & TRN & \\
\hline CHEMBL1558609 & 737822 & 4.6 & 5.1063 & TRN & \\
\hline CHEMBL1256678 & 737822 & 5.0 & 5.1652 & TST & \\
\hline CHEMBL1467931 & 737822 & 6.15 & 5.4728 & TRN & \\
\hline CHEMBL1447410 & 737822 & 4.6 & 5.2214 & TRN & \\
\hline CHEMBL1356280 & 737822 & 6.2 & 5.8141 & TRN & \\
\hline CHEMBL1303868 & 737822 & 4.9 & 5.2341 & TST & \\
\hline CHEMBL1333282 & 737822 & 4.75 & 5.2548 & TRN & \\
\hline CHEMBL1359620 & 737822 & 4.6 & 5.2278 & TRN & \\
\hline CHEMBL1568870 & 737822 & 4.85 & 5.2621 & TRN & \\
\hline CHEMBL1396822 & 737822 & 4.7 & 4.7322 & TRN & \\
\hline CHEMBL1729979 & 737822 & 5.1 & 5.5426 & TRN & \\
\hline CHEMBL3193293 & 737822 & 4.9 & 5.4085 & TST & \\
\hline CHEMBL1399619 & 737822 & 5.1 & 5.0625 & TST & \\
\hline CHEMBL1516232 & 737822 & 4.4 & 4.3713 & TRN & \\
\hline CHEMBL1374363 & 737822 & 5.5 & 5.4752 & TRN & \\
\hline CHEMBL1269022 & 737822 & 5.7 & 5.4677 & TST & \\
\hline CHEMBL 3194740 & 737822 & 5.25 & 5.3872 & TRN & \\
\hline CHEMBL1396792 & 737822 & 4.6 & 4.5276 & TRN & \\
\hline CHEMBL1576078 & 737822 & 4.85 & 5.3679 & TST & \\
\hline CHEMBL1304686 & 737822 & 5.2 & 5.3707 & TRN & \\
\hline CHEMBL1552314 & 737822 & 4.9 & 5.0917 & TRN & \\
\hline CHEMBL1559248 & 737822 & 6.2 & 5.4451 & TRN & \\
\hline CHEMBL1343012 & 737822 & 4.7 & 5.4533 & TRN & \\
\hline CHEMBL1595002 & 737822 & 4.7 & 4.4761 & TRN & \\
\hline CHEMBL129795 & 737822 & 4.8 & 4.8517 & TRN & \\
\hline CHEMBL1312105 & 737822 & 5.0 & 5.7795 & TRN & \\
\hline CHEMBL1334477 & 737822 & 4.7 & 4.6132 & TRN & \\
\hline CHEMBL1372528 & 737822 & 5.5 & 5.3047 & TRN & \\
\hline CHEMBL1359691 & 737822 & 5.1 & 4.8547 & TRN & \\
\hline CHEMBL1456454 & 737822 & 4.7 & 4.6292 & TRN & \\
\hline CHEMBL1474989 & 737822 & 4.4 & 4.3688 & TRN & \\
\hline CHEMBL1364135 & 737822 & 4.7 & 5.1536 & TRN & \\
\hline CHEMBL1529948 & 737822 & 4.45 & 5.0809 & TRN & \\
\hline CHEMBL1552066 & 737822 & 5.1 & 5.0131 & TRN & \\
\hline CHEMBL1505375 & 737822 & 5.85 & 4.9674 & TRN & \\
\hline CHEMBL1400043 & 737822 & 4.4 & 4.2598 & TRN & \\
\hline CHEMBL1552098 & 737822 & 5.7 & 5.6104 & TRN & \\
\hline CHEMBL1591879 & 737822 & 5.5 & 5.3525 & TST & \\
\hline CHEMBL1347768 & 737822 & 5.5 & 5.7531 & TRN & \\
\hline CHEMBL 250053 & 737822 & 4.8 & 5.5795 & TST & \\
\hline CHEMBL1536129 & 737822 & 4.6 & 5.3464 & TRN & \\
\hline CHEMBL1591573 & 737822 & 4.7 & 4.5965 & TRN & \\
\hline CHEMBL1565751 & 737822 & 5.8 & 5.61299 & 99999999995 & TRN \\
\hline CHEMBL1573306 & 737822 & 4.85 & 5.3047 & TRN & \\
\hline CHEMBL3198835 & 737822 & 5.35 & 5.3878 & TRN & \\
\hline CHEMBL1255758 & 737822 & 5.4 & 5.3955 & TST & \\
\hline
\end{tabular}




\begin{tabular}{|c|c|c|c|c|c|}
\hline & & \multicolumn{4}{|c|}{ Supplemental Table S2.txt } \\
\hline CHEMBL1439839 & 737822 & 4.4 & 4.3114 & TRN & \\
\hline CHEMBL1352225 & 737822 & 4.45 & 5.4219 & TRN & \\
\hline CHEMBL1564361 & 737822 & 5.9 & 5.5409 & TRN & \\
\hline CHEMBL1512708 & 737822 & 5.8 & 5.5124 & TRN & \\
\hline CHEMBL1551970 & 737822 & 5.6 & 5.4715 & TRN & \\
\hline CHEMBL1742372 & 737822 & 6.65 & 5.1922 & TRN & \\
\hline CHEMBL1363110 & 737822 & 4.85 & 5.2146 & TRN & \\
\hline CHEMBL1592966 & 737822 & 6.3 & 6.2538 & TRN & \\
\hline CHEMBL1567229 & 737822 & 4.65 & 5.41799 & 9999999999 & TRN \\
\hline CHEMBL1741907 & 737822 & 6.0 & 5.1652 & TST & \\
\hline CHEMBL1501400 & 737822 & 4.75 & 4.956 & TRN & \\
\hline CHEMBL1311432 & 737822 & 4.6 & 5.3447 & TRN & \\
\hline CHEMBL1352808 & 737822 & 4.55 & 5.0903 & TRN & \\
\hline CHEMBL1319120 & 737822 & 5.6 & 5.4465 & TRN & \\
\hline CHEMBL1330614 & 737822 & 8.6 & 7.7163 & TRN & \\
\hline CHEMBL1436222 & 737822 & 4.5 & 4.394 & TRN & \\
\hline CHEMBL1421173 & 737822 & 4.8 & 5.4481 & TRN & \\
\hline CHEMBL1521453 & 737822 & 6.0 & 5.6985 & TST & \\
\hline CHEMBL1741721 & 737822 & 4.85 & 5.5437 & TST & \\
\hline CHEMBL544115 & 737822 & 4.6 & 4.677 & TRN & \\
\hline CHEMBL1315504 & 737822 & 4.8 & 4.5957 & TRN & \\
\hline CHEMBL1454463 & 737822 & 4.85 & 5.4208 & TRN & \\
\hline CHEMBL1399207 & 737822 & 4.65 & 5.5116 & TRN & \\
\hline CHEMBL1085765 & 737822 & 5.5 & 5.5384 & TRN & \\
\hline CHEMBL1568250 & 737822 & 4.7 & 4.8118 & TRN & \\
\hline CHEMBL1368892 & 737822 & 4.7 & 4.6076 & TRN & \\
\hline CHEMBL1384628 & 737822 & 4.4 & 5.1233 & TRN & \\
\hline CHEMBL1514821 & 737822 & 6.0 & 5.7835 & TRN & \\
\hline CHEMBL1578011 & 737822 & 5.0 & 5.0694 & TRN & \\
\hline CHEMBL1577187 & 737822 & 4.6 & 5.042 & TRN & \\
\hline CHEMBL1591964 & 737822 & 4.7 & 4.523 & TRN & \\
\hline CHEMBL1431953 & 737822 & 4.9 & 5.305 & TST & \\
\hline CHEMBL1396907 & 737822 & 4.5 & 4.4107 & TRN & \\
\hline CHEMBL1412305 & 737822 & 7.8 & 7.2216 & TRN & \\
\hline CHEMBL1256844 & 737822 & 6.0 & 5.7895 & TRN & \\
\hline CHEMBL1407089 & 737822 & 5.35 & 5.4782 & TRN & \\
\hline CHEMBL1327187 & 737822 & 5.5 & 5.3932 & TRN & \\
\hline CHEMBL1555164 & 737822 & 5.5 & 5.3698 & TRN & \\
\hline CHEMBL345124 & 737822 & 5.2 & 5.1366 & TST & \\
\hline CHEMBL1486304 & 737822 & 6.0 & 5.7013 & TRN & \\
\hline CHEMBL1573813 & 737822 & 4.55 & 5.1438 & TST & \\
\hline CHEMBL1494182 & 737822 & 4.7 & 4.8707 & TST & \\
\hline CHEMBL3194051 & 737822 & 5.3 & 5.2262 & TST & \\
\hline CHEMBL1355665 & 737822 & 5.1 & 5.0986 & TRN & \\
\hline CHEMBL1584003 & 737822 & 4.75 & 5.3681 & TRN & \\
\hline CHEMBL1377111 & 737822 & 6.0 & 5.6168 & TST & \\
\hline CHEMBL1593765 & 737822 & 6.0 & 5.6742 & TRN & \\
\hline CHEMBL1079460 & 737822 & 6.7 & 6.2053 & TST & \\
\hline
\end{tabular}




\begin{tabular}{|c|c|c|c|c|c|}
\hline \multirow{2}{*}{\multicolumn{3}{|c|}{ CHEMBL1613562 }} & \\
\hline & & 5.2 & 5.2068 & TRN & \\
\hline CHEMBL1503178 & 737822 & 5.5 & 5.6133 & TST & \\
\hline CHEMBL1464956 & 737822 & 4.7 & 5.2932 & TRN & \\
\hline CHEMBL265177 & 737822 & 5.5 & 5.3139 & TST & \\
\hline CHEMBL1570851 & 737822 & 5.5 & 5.4181 & TST & \\
\hline CHEMBL1405627 & 737822 & 4.8 & 4.5835 & TRN & \\
\hline CHEMBL1481347 & 737822 & 5.45 & 5.2196 & TST & \\
\hline CHEMBL3194967 & 737822 & 4.55 & 5.2164 & TRN & \\
\hline CHEMBL1717521 & 737822 & 4.65 & 5.4285 & TRN & \\
\hline CHEMBL1323183 & 737822 & 5.1 & 5.4073 & TRN & \\
\hline CHEMBL1612127 & 737822 & 4.8 & 5.2109 & TRN & \\
\hline CHEMBL1555067 & 737822 & 5.1 & 5.1119 & TST & \\
\hline CHEMBL1374260 & 737822 & 4.55 & 5.0564 & TST & \\
\hline CHEMBL1473752 & 737822 & 4.7 & 4.5559 & TRN & \\
\hline CHEMBL1356834 & 737822 & 4.5 & 4.3736 & TRN & \\
\hline CHEMBL1530613 & 737822 & 5.8 & 5.5728 & TST & \\
\hline CHEMBL1317786 & 737822 & 4.9 & 4.9478 & TRN & \\
\hline CHEMBL3212631 & 737822 & 5.5 & 5.29799 & 9999999999 & TRN \\
\hline CHEMBL1613702 & 737822 & 5.1 & 5.3016 & TRN & \\
\hline CHEMBL1560551 & 737822 & 5.7 & 5.2645 & TST & \\
\hline CHEMBL1446922 & 737822 & 8.0 & 7.5886 & TRN & \\
\hline CHEMBL93403 & 737822 & 4.5 & 4.7124 & TRN & \\
\hline CHEMBL1368337 & 737822 & 4.45 & 5.2828 & TRN & \\
\hline CHEMBL1300309 & 737822 & 6.05 & 5.1623 & TRN & \\
\hline CHEMBL1312813 & 737822 & 5.3 & 5.4915 & TRN & \\
\hline CHEMBL1466372 & 737822 & 4.8 & 5.3859 & TRN & \\
\hline CHEMBL1609160 & 737822 & 5.6 & 5.5468 & TST & \\
\hline CHEMBL1574576 & 737822 & 4.6 & 5.2771 & TRN & \\
\hline CHEMBL1532597 & 737822 & 4.7 & 4.475 & TRN & \\
\hline CHEMBL1256878 & 737822 & 6.0 & 5.6324 & TRN & \\
\hline CHEMBL1347641 & 737822 & 4.65 & 5.2486 & TST & \\
\hline CHEMBL1374334 & 737822 & 5.5 & 5.41100 & 00000000005 & TRN \\
\hline CHEMBL1741458 & 737822 & 4.55 & 5.3594 & TRN & \\
\hline CHEMBL1353317 & 737822 & 6.8 & 5.404 & TRN & \\
\hline CHEMBL1553804 & 737822 & 4.6 & 4.6463 & TRN & \\
\hline CHEMBL1334512 & 737822 & 5.6 & 5.3837 & TST & \\
\hline CHEMBL1334543 & 737822 & 4.8 & 4.7058 & TRN & \\
\hline CHEMBL1517195 & 737822 & 4.5 & 4.8168 & TRN & \\
\hline CHEMBL1460553 & 737822 & 4.85 & 5.5911 & TRN & \\
\hline CHEMBL1501406 & 737822 & 4.85 & 5.3172 & TRN & \\
\hline CHEMBL1553114 & 737822 & 4.8 & 4.6264 & TRN & \\
\hline CHEMBL1200462 & 737822 & 6.0 & 5.7526 & TRN & \\
\hline CHEMBL1602812 & 737822 & 4.8 & 4.7166 & TRN & \\
\hline CHEMBL1502201 & 737822 & 5.0 & 5.261 & TST & \\
\hline CHEMBL3194463 & 737822 & 4.6 & 5.3206 & TST & \\
\hline CHEMBL1529571 & 737822 & 4.8 & 5.4016 & TRN & \\
\hline CHEMBL1489359 & 737822 & 5.4 & 5.3505 & TST & \\
\hline CHEMBL1571410 & 737822 & 5.5 & 5.3858 & TRN & \\
\hline & & & & 11265 & \\
\hline
\end{tabular}




\begin{tabular}{|c|c|c|c|c|c|}
\hline \\
\hline CHEMBL1536844 & 737822 & 4.85 & 5.2242 & TST & \\
\hline CHEMBL1516476 & 737822 & 6.0 & 5.5591 & TRN & \\
\hline CHEMBL1394923 & 737822 & 6.9 & 6.3456 & TRN & \\
\hline CHEMBL1396230 & 737822 & 4.4 & 4.4224 & TRN & \\
\hline CHEMBL1400520 & 737822 & 5.0 & 5.5295 & TRN & \\
\hline CHEMBL1395661 & 737822 & 6.0 & 5.6803 & TRN & \\
\hline CHEMBL1314211 & 737822 & 4.7 & 4.6485 & TRN & \\
\hline CHEMBL1491545 & 737822 & 5.1 & 4.9557 & TRN & \\
\hline CHEMBL1376212 & 737822 & 5.5 & 5.3336 & TRN & \\
\hline CHEMBL1551139 & 737822 & 5.0 & 4.7169 & TRN & \\
\hline CHEMBL1392865 & 737822 & 4.55 & 5.2886 & TRN & \\
\hline CHEMBL1399750 & 737822 & 5.9 & 5.4604 & TRN & \\
\hline CHEMBL1540034 & 737822 & 5.3 & 5.1184 & TRN & \\
\hline CHEMBL3208639 & 737822 & 4.55 & $5.4570 e$ & 0000000001 & TST \\
\hline CHEMBL1411651 & 737822 & 4.65 & 5.2409 & TRN & \\
\hline CHEMBL288174 & 737822 & 4.8 & 4.9361 & TST & \\
\hline CHEMBL3190254 & 737822 & 4.8 & 5.2961 & TRN & \\
\hline CHEMBL574189 & 737822 & 4.4 & 5.1986 & TST & \\
\hline CHEMBL1538552 & 737822 & 5.1 & 5.3069 & TRN & \\
\hline CHEMBL1477727 & 737822 & 5.6 & 5.4036 & TRN & \\
\hline CHEMBL1606137 & 737822 & 5.05 & 5.3071 & TRN & \\
\hline CHEMBL1497504 & 737822 & 5.3 & 5.4109 & TRN & \\
\hline CHEMBL1473405 & 737822 & 4.9 & 4.8037 & TRN & \\
\hline CHEMBL1552165 & 737822 & 4.4 & 4.6655 & TRN & \\
\hline CHEMBL1437648 & 737822 & 5.9 & 5.7315 & TRN & \\
\hline CHEMBL1441359 & 737822 & 7.9 & 5.355 & TRN & \\
\hline CHEMBL1365994 & 737822 & 4.4 & 4.3112 & TRN & \\
\hline CHEMBL1435477 & 737822 & 6.0 & 5.97 & TRN & \\
\hline CHEMBL1495875 & 737822 & 4.7 & 4.6055 & TRN & \\
\hline CHEMBL1314022 & 737822 & 5.4 & $5.2870 e$ & $\partial 000000001$ & TST \\
\hline CHEMBL1424307 & 737822 & 6.6 & 5.6792 & TRN & \\
\hline CHEMBL1375753 & 737822 & 5.4 & 5.0731 & TRN & \\
\hline CHEMBL1327232 & 737822 & 4.7 & 4.6164 & TRN & \\
\hline CHEMBL 2004183 & 737822 & 6.55 & 5.3128 & TST & \\
\hline CHEMBL1401981 & 737822 & 4.65 & 5.3927 & TRN & \\
\hline CHEMBL1396326 & 737822 & 4.4 & 4.4061 & TRN & \\
\hline CHEMBL1435053 & 737822 & 5.6 & 5.4062 & TST & \\
\hline CHEMBL3190499 & 737822 & 4.85 & 5.2697 & TST & \\
\hline CHEMBL1973886 & 737822 & 4.65 & 5.2319 & TRN & \\
\hline CHEMBL1440329 & 737822 & 4.6 & 5.4517 & TRN & \\
\hline CHEMBL1610581 & 737822 & 5.6 & 5.314 & TRN & \\
\hline CHEMBL356688 & 737822 & 6.9 & 6.4267 & TRN & \\
\hline CHEMBL464157 & 737822 & 4.75 & 5.0913 & TRN & \\
\hline CHEMBL1371824 & 737822 & 5.15 & 5.0952 & TRN & \\
\hline CHEMBL1494099 & 737822 & 6.3 & 6.1487 & TRN & \\
\hline CHEMBL1339627 & 737822 & 4.85 & 5.0517 & TRN & \\
\hline CHEMBL1376952 & 737822 & 5.5 & 5.407 & TRN & \\
\hline CHEMBL1389090 & 737822 & 4.85 & 5.2639 & TRN & \\
\hline
\end{tabular}




\begin{tabular}{|c|c|c|c|c|}
\hline \multicolumn{5}{|c|}{ pplemental $\mathrm{T}$} \\
\hline CHEMBL1334959 & 737822 & 4.5 & 4.4168 & TRN \\
\hline CHEMBL1374373 & 737822 & 4.6 & 5.2725 & TST \\
\hline CHEMBL1435934 & 737822 & 5.5 & 5.4096 & TRN \\
\hline CHEMBL1568370 & 737822 & 4.6 & 5.3767 & TRN \\
\hline CHEMBL1362931 & 737822 & 4.7 & 4.5492 & TRN \\
\hline CHEMBL1368572 & 737822 & 5.4 & 5.3698 & TRN \\
\hline CHEMBL1355089 & 737822 & 6.4 & 5.9387 & TRN \\
\hline CHEMBL1579981 & 737822 & 4.55 & 5.7414 & TRN \\
\hline CHEMBL1595826 & 737822 & 5.65 & 5.2205 & TRN \\
\hline CHEMBL1466869 & 737822 & 5.1 & 5.3033 & TRN \\
\hline CHEMBL1494878 & 737822 & 6.5 & 6.2626 & TRN \\
\hline CHEMBL264702 & 737822 & 8.0 & 5.3498 & TST \\
\hline CHEMBL1557213 & 737822 & 5.5 & 5.4455 & TRN \\
\hline CHEMBL1473996 & 737822 & 6.2 & 5.8524 & TRN \\
\hline CHEMBL1392634 & 737822 & 6.7 & 5.4772 & TRN \\
\hline CHEMBL1553941 & 737822 & 4.4 & 4.2814 & TRN \\
\hline CHEMBL1580159 & 737822 & 5.0 & 5.0941 & TRN \\
\hline CHEMBL1594350 & 737822 & 5.5 & 5.3693 & TRN \\
\hline CHEMBL1446112 & 737822 & 4.5 & 4.4078 & TRN \\
\hline CHEMBL14690 & 737822 & 4.9 & 5.075 & TRN \\
\hline CHEMBL1351562 & 737822 & 4.65 & 5.0341 & TRN \\
\hline CHEMBL1488305 & 737822 & 4.4 & 4.4099 & TRN \\
\hline CHEMBL 85194 & 737822 & 4.9 & 4.7818 & TRN \\
\hline CHEMBL1332636 & 737822 & 5.4 & 5.3378 & TRN \\
\hline CHEMBL1554306 & 737822 & 5.8 & 5.7476 & TRN \\
\hline CHEMBL1333248 & 737822 & 6.1 & 5.4742 & TRN \\
\hline CHEMBL1361984 & 737822 & 5.0 & 5.1443 & TRN \\
\hline CHEMBL1335319 & 737822 & 5.85 & 5.2528 & TRN \\
\hline CHEMBL371811 & 737822 & 4.6 & 4.7342 & TST \\
\hline CHEMBL1365785 & 737822 & 4.7 & 5.2086 & TRN \\
\hline CHEMBL1487318 & 737822 & 5.4 & 5.2686 & TRN \\
\hline CHEMBL1592212 & 737822 & 6.1 & 5.8304 & TRN \\
\hline CHEMBL3192219 & 737822 & 4.5 & 5.2724 & TRN \\
\hline CHEMBL1387431 & 737822 & 4.8 & 5.4576 & TRN \\
\hline CHEMBL1409720 & 737822 & 5.5 & 5.3887 & TRN \\
\hline CHEMBL1552677 & 737822 & 4.6 & 4.4499 & TRN \\
\hline CHEMBL1582268 & 737822 & 4.85 & 5.4142 & TRN \\
\hline CHEMBL1307887 & 737822 & 4.6 & 5.3664 & TRN \\
\hline CHEMBL1355788 & 737822 & 5.4 & 5.1913 & TRN \\
\hline CHEMBL1554465 & 737822 & 5.1 & 4.9628 & TRN \\
\hline CHEMBL1394956 & 737822 & 4.4 & 4.4039 & TRN \\
\hline CHEMBL1385802 & 737822 & 5.1 & 5.5393 & TRN \\
\hline CHEMBL1516211 & 737822 & 5.0 & 4.9457 & TRN \\
\hline CHEMBL1377637 & 737822 & 5.1 & 5.4649 & TRN \\
\hline CHEMBL1354626 & 737822 & 5.6 & 5.4776 & TRN \\
\hline CHEMBL608828 & 737822 & 4.8 & 4.925 & TRN \\
\hline CHEMBL88147 & 737822 & 5.0 & 4.9288 & TRN \\
\hline CHEMBL1418916 & 737822 & 5.55 & 5.3657 & TRN \\
\hline
\end{tabular}




\begin{tabular}{|c|c|c|c|c|}
\hline \multicolumn{5}{|c|}{ Supplemental Table s2.txt } \\
\hline CHEMBL1325335 & 737822 & 4.4 & 4.3527 & TRN \\
\hline CHEMBL1471091 & 737822 & 5.0 & 5.4466 & TRN \\
\hline CHEMBL1396898 & 737822 & 4.7 & 4.5414 & TRN \\
\hline CHEMBL1503678 & 737822 & 5.45 & 5.3172 & TRN \\
\hline CHEMBL1982520 & 737822 & 5.1 & 5.3756 & TST \\
\hline CHEMBL1444983 & 737822 & 4.7 & 5.5348 & TRN \\
\hline CHEMBL1512562 & 737822 & 4.9 & 4.7977 & TRN \\
\hline CHEMBL1408703 & 737822 & 4.4 & 4.3367 & TRN \\
\hline CHEMBL 29811 & 737822 & 5.5 & 5.3647 & TST \\
\hline CHEMBL1741944 & 737822 & 4.75 & 5.0813 & TRN \\
\hline CHEMBL1524363 & 737822 & 7.0 & 5.1937 & TST \\
\hline CHEMBL1586390 & 737822 & 4.8 & 5.2649 & TST \\
\hline CHEMBL517986 & 737822 & 4.5 & 4.5614 & TRN \\
\hline CHEMBL1605426 & 737822 & 4.6 & 4.6148 & TST \\
\hline CHEMBL1519603 & 737822 & 4.65 & 5.541 & TRN \\
\hline CHEMBL1481402 & 737822 & 5.4 & 5.2757 & TST \\
\hline CHEMBL1501395 & 737822 & 5.05 & 5.2838 & TST \\
\hline CHEMBL1582789 & 737822 & 4.8 & 5.2045 & TRN \\
\hline CHEMBL1594883 & 737822 & 5.5 & 5.3714 & TRN \\
\hline CHEMBL1416812 & 737822 & 6.2 & 5.8367 & TRN \\
\hline CHEMBL1551200 & 737822 & 4.6 & 4.7231 & TRN \\
\hline CHEMBL1515449 & 737822 & 5.1 & 4.9267 & TRN \\
\hline CHEMBL1741578 & 737822 & 4.9 & 5.0011 & TRN \\
\hline CHEMBL1380424 & 737822 & 5.25 & 5.2881 & TRN \\
\hline CHEMBL1414754 & 737822 & 5.35 & 5.1167 & TRN \\
\hline CHEMBL1461511 & 737822 & 5.65 & 5.2259 & TRN \\
\hline CHEMBL1514280 & 737822 & 5.9 & 5.7842 & TRN \\
\hline CHEMBL1308821 & 737822 & 4.6 & 5.4611 & TRN \\
\hline CHEMBL1449103 & 737822 & 5.45 & 5.4252 & TRN \\
\hline CHEMBL1523314 & 737822 & 5.9 & 5.9401 & TRN \\
\hline CHEMBL1304114 & 737822 & 4.85 & 5.4423 & TRN \\
\hline CHEMBL1448849 & 737822 & 6.45 & 5.38 & TRN \\
\hline CHEMBL1522803 & 737822 & 4.6 & 5.1189 & TST \\
\hline CHEMBL1466350 & 737822 & 4.85 & 5.501 & TRN \\
\hline CHEMBL1534248 & 737822 & 5.4 & 5.3084 & TRN \\
\hline CHEMBL1426500 & 737822 & 5.15 & 5.1492 & TRN \\
\hline CHEMBL586946 & 737822 & 6.1 & 5.7425 & TRN \\
\hline CHEMBL1256924 & 737822 & 4.5 & 4.6964 & TRN \\
\hline CHEMBL1456034 & 737822 & 5.05 & 5.1187 & TRN \\
\hline CHEMBL1612346 & 737822 & 6.2 & 5.86700 & 0000000001 \\
\hline CHEMBL1517187 & 737822 & 4.4 & 4.3202 & TST \\
\hline CHEMBL1343639 & 737822 & 4.8 & 5.3791 & TRN \\
\hline CHEMBL1435947 & 737822 & 4.9 & 4.7936 & TRN \\
\hline CHEMBL1542467 & 737822 & 5.5 & 5.2956 & TRN \\
\hline CHEMBL1593432 & 737822 & 5.0 & 4.9088 & TRN \\
\hline CHEMBL1601633 & 737822 & 4.8 & 4.8572 & TRN \\
\hline CHEMBL1607885 & 737822 & 4.9 & 4.8042 & TRN \\
\hline CHEMBL1559279 & 737822 & 4.7 & 4.5152 & TRN \\
\hline
\end{tabular}




\begin{tabular}{|c|c|c|c|c|}
\hline & & & upplemen & at \\
\hline CHEMBL3212919 & 737822 & 5.6 & 5.4377 & TRN \\
\hline CHEMBL1590261 & 737822 & 4.4 & 4.2922 & TRN \\
\hline CHEMBL1552752 & 737822 & 4.9 & 4.7118 & TRN \\
\hline CHEMBL 76897 & 737822 & 4.4 & 4.6231 & TRN \\
\hline CHEMBL1478530 & 737822 & 4.5 & 4.7061 & TST \\
\hline CHEMBL1741361 & 737822 & 5.15 & 5.2103 & TRN \\
\hline CHEMBL1555238 & 737822 & 4.8 & 4.7164 & TRN \\
\hline CHEMBL1599844 & 737822 & 4.85 & 5.2767 & TRN \\
\hline CHEMBL 275311 & 737822 & 7.9 & 7.0552 & TST \\
\hline CHEMBL1555396 & 737822 & 4.7 & 4.5249 & TRN \\
\hline CHEMBL1742187 & 737822 & 4.8 & 5.6157 & TRN \\
\hline CHEMBL1457808 & 737822 & 6.4 & 5.5585 & TST \\
\hline CHEMBL1449293 & 737822 & 4.95 & 5.1848 & TRN \\
\hline CHEMBL192566 & 737822 & 4.4 & 4.6452 & TST \\
\hline CHEMBL1433486 & 737822 & 6.0 & 5.8478 & TRN \\
\hline CHEMBL1507611 & 737822 & 5.0 & 5.2989 & TRN \\
\hline CHEMBL1457049 & 737822 & 4.5 & 5.3602 & TRN \\
\hline CHEMBL1322743 & 737822 & 6.0 & 5.7679 & TRN \\
\hline CHEMBL1513740 & 737822 & 4.7 & 4.6381 & TRN \\
\hline CHEMBL1562420 & 737822 & 7.8 & 6.89 & TRN \\
\hline CHEMBL1404955 & 737822 & 6.15 & 5.3924 & TRN \\
\hline CHEMBL1440145 & 737822 & 5.1 & 5.083 & TRN \\
\hline CHEMBL1331525 & 737822 & 4.8 & 4.7102 & TRN \\
\hline CHEMBL1593682 & 737822 & 5.5 & 5.4142 & TST \\
\hline CHEMBL1582432 & 737822 & 6.2 & 5.2055 & TRN \\
\hline CHEMBL1575007 & 737822 & 6.45 & 5.3373 & TRN \\
\hline CHEMBL1335865 & 737822 & 4.8 & 5.5263 & TRN \\
\hline CHEMBL1485629 & 737822 & 4.5 & 4.5829 & TST \\
\hline CHEMBL1564816 & 737822 & 5.7 & 5.3127 & TRN \\
\hline CHEMBL1452722 & 737822 & 5.3 & 5.3211 & TST \\
\hline CHEMBL1575726 & 737822 & 5.0 & 5.3945 & TRN \\
\hline CHEMBL1592117 & 737822 & 6.5 & 5.9615 & TRN \\
\hline CHEMBL1398669 & 737822 & 4.7 & 5.4219 & TRN \\
\hline CHEMBL1361905 & 737822 & 4.7 & 4.6128 & TRN \\
\hline CHEMBL1532949 & 737822 & 6.65 & 5.2768 & TRN \\
\hline CHEMBL1483773 & 737822 & 4.85 & 5.1658 & TRN \\
\hline CHEMBL1591847 & 737822 & 4.6 & 4.6304 & TRN \\
\hline CHEMBL349384 & 737822 & 4.4 & 4.6154 & TST \\
\hline CHEMBL1552277 & 737822 & 4.9 & 4.8946 & TRN \\
\hline CHEMBL1475487 & 737822 & 4.4 & 4.4366 & TRN \\
\hline CHEMBL1436237 & 737822 & 5.5 & 5.4185 & TRN \\
\hline CHEMBL1453410 & 737822 & 4.6 & 5.1455 & TRN \\
\hline CHEMBL1558777 & 737822 & 4.8 & 4.6742 & TRN \\
\hline CHEMBL3194219 & 737822 & 5.1 & 5.5862 & TRN \\
\hline CHEMBL1480575 & 737822 & 5.9 & 5.1525 & TRN \\
\hline CHEMBL3211113 & 737822 & 5.1 & 5.3259 & TRN \\
\hline CHEMBL1399489 & 737822 & 4.7 & 4.5703 & TRN \\
\hline CHEMBL1323465 & 737822 & 4.7 & 5.5698 & TRN \\
\hline
\end{tabular}




\begin{tabular}{|c|c|c|c|c|}
\hline \multicolumn{5}{|c|}{ Supplemental Table S2.txt } \\
\hline CHEMBL293349 & 737822 & 4.5 & 4.7668 & TRN \\
\hline CHEMBL1437159 & 737822 & 4.4 & 4.4225 & TRN \\
\hline CHEMBL34704 & 737822 & 6.0 & 5.6081 & TST \\
\hline CHEMBL1369990 & 737822 & 5.4 & 5.3864 & TRN \\
\hline CHEMBL1555348 & 737822 & 5.5 & 5.3636 & TRN \\
\hline CHEMBL1475311 & 737822 & 5.6 & 5.1778 & TRN \\
\hline CHEMBL1357444 & 737822 & 5.0 & 4.9828 & TRN \\
\hline CHEMBL475198 & 737822 & 5.5 & 5.2313 & TRN \\
\hline CHEMBL1333531 & 737822 & 4.9 & 4.8756 & TRN \\
\hline CHEMBL899 & 737822 & 6.4 & 5.3371 & TRN \\
\hline CHEMBL1361468 & 737822 & 4.6 & 4.5252 & TRN \\
\hline CHEMBL1571138 & 737822 & 5.5 & 5.3638 & TRN \\
\hline CHEMBL1485397 & 737822 & 5.0 & 5.5505 & TRN \\
\hline CHEMBL1711658 & 737822 & 5.15 & 5.2783 & TST \\
\hline CHEMBL1317932 & 737822 & 5.5 & 5.4219 & TRN \\
\hline CHEMBL1329046 & 737822 & 5.7 & 5.0996 & TRN \\
\hline CHEMBL1493861 & 737822 & 4.85 & 5.2456 & TRN \\
\hline CHEMBL1331120 & 737822 & 5.55 & 5.1878 & TST \\
\hline CHEMBL1512850 & 737822 & 5.6 & 5.4548 & TRN \\
\hline CHEMBL1742034 & 737822 & 8.25 & 5.2374 & TRN \\
\hline CHEMBL1741807 & 737822 & 5.05 & 5.3994 & TRN \\
\hline CHEMBL1371311 & 737822 & 5.4 & 5.3493 & TRN \\
\hline CHEMBL1354112 & 737822 & 5.4 & 5.2792 & TRN \\
\hline CHEMBL1613332 & 737822 & 4.4 & 5.3419 & TRN \\
\hline CHEMBL64569 & 737822 & 5.5 & 5.4198 & TRN \\
\hline CHEMBL1404737 & 737822 & 5.1 & 5.1983 & TRN \\
\hline CHEMBL1493039 & 737822 & 5.6 & 5.3808 & TST \\
\hline CHEMBL1356794 & 737822 & 5.4 & 5.1495 & TRN \\
\hline CHEMBL1578474 & 737822 & 4.8 & 5.2968 & TRN \\
\hline CHEMBL1499721 & 737822 & 4.5 & 5.3176 & TST \\
\hline CHEMBL1742296 & 737822 & 4.85 & 5.3174 & TRN \\
\hline CHEMBL1308023 & 737822 & 4.9 & 5.2897 & TRN \\
\hline CHEMBL1741625 & 737822 & 5.1 & 5.0982 & TST \\
\hline CHEMBL1511690 & 737822 & 4.95 & 5.3264 & TST \\
\hline CHEMBL1569019 & 737822 & 5.05 & 5.1729 & TRN \\
\hline CHEMBL1324667 & 737822 & 4.5 & 4.3819 & TRN \\
\hline CHEMBL1997220 & 737822 & 5.0 & 5.1698 & TRN \\
\hline CHEMBL1527579 & 737822 & 5.5 & 5.3555 & TST \\
\hline CHEMBL1562333 & 737822 & 5.2 & 5.2348 & TRN \\
\hline CHEMBL1352255 & 737822 & 5.35 & 5.3313 & TRN \\
\hline CHEMBL 279556 & 737822 & 6.0 & 5.8417 & TST \\
\hline CHEMBL1413306 & 737822 & 4.8 & 5.1727 & TRN \\
\hline CHEMBL1473191 & 737822 & 5.4 & 5.2442 & TST \\
\hline CHEMBL1407160 & 737822 & 4.8 & 5.1964 & TRN \\
\hline CHEMBL1554622 & 737822 & 4.7 & 4.6104 & TRN \\
\hline CHEMBL1541564 & 737822 & 4.85 & 5.2828 & TRN \\
\hline CHEMBL1562987 & 737822 & 5.2 & 5.3272 & TST \\
\hline CHEMBL1338249 & 737822 & 5.7 & 5.388 & TRN \\
\hline
\end{tabular}




\begin{tabular}{|c|c|c|c|c|}
\hline \multicolumn{5}{|c|}{ Supplemental Table S2.txt } \\
\hline CHEMBL1724116 & 737822 & 5.15 & 5.5779 & TRN \\
\hline CHEMBL1515788 & 737822 & 6.0 & 5.7521 & TRN \\
\hline CHEMBL177809 & 737822 & 5.1 & 4.9926 & TRN \\
\hline CHEMBL1309557 & 737822 & 5.2 & 4.9784 & TST \\
\hline CHEMBL1549510 & 737822 & 5.15 & 5.0931 & TRN \\
\hline CHEMBL1314674 & 737822 & 4.6 & 4.4951 & TRN \\
\hline CHEMBL489943 & 737822 & 6.4 & 5.9536 & TRN \\
\hline CHEMBL1352745 & 737822 & 4.75 & 5.1079 & TST \\
\hline CHEMBL1516005 & 737822 & 4.7 & 4.5769 & TRN \\
\hline CHEMBL491943 & 737822 & 4.9 & 4.7615 & TRN \\
\hline CHEMBL1431981 & 737822 & 4.7 & 5.2842 & TRN \\
\hline CHEMBL1424920 & 737822 & 4.6 & 5.3596 & TRN \\
\hline CHEMBL1338311 & 737822 & 6.1 & 5.6917 & TRN \\
\hline CHEMBL1543168 & 737822 & 4.8 & 5.3213 & TRN \\
\hline CHEMBL1356348 & 737822 & 5.3 & 5.218 & TST \\
\hline CHEMBL3190938 & 737822 & 4.95 & 5.1652 & TST \\
\hline CHEMBL1424097 & 737822 & 4.6 & 5.1009 & TST \\
\hline CHEMBL1397406 & 737822 & 4.7 & 4.5932 & TRN \\
\hline CHEMBL1367733 & 737822 & 5.7 & 5.3284 & TRN \\
\hline CHEMBL1443163 & 737822 & 5.2 & 5.2236 & TRN \\
\hline CHEMBL1437056 & 737822 & 4.8 & 4.6437 & TRN \\
\hline CHEMBL1445094 & 737822 & 4.9 & 4.7694 & TRN \\
\hline CHEMBL1553977 & 737822 & 5.4 & 5.3157 & TRN \\
\hline CHEMBL1471680 & 737822 & 4.9 & 5.2666 & TRN \\
\hline CHEMBL1395899 & 737822 & 4.4 & 4.27 & TRN \\
\hline CHEMBL1488990 & 737822 & 4.7 & 4.52 & TRN \\
\hline CHEMBL1612048 & 737822 & 4.9 & 5.4103 & TRN \\
\hline CHEMBL83954 & 737822 & 6.9 & 6.3772 & TRN \\
\hline CHEMBL1376143 & 737822 & 4.9 & 4.7058 & TRN \\
\hline CHEMBL1592213 & 737822 & 4.5 & 4.4051 & TRN \\
\hline CHEMBL1390586 & 737822 & 4.75 & 5.3592 & TRN \\
\hline CHEMBL1415728 & 737822 & 4.6 & 4.4823 & TRN \\
\hline CHEMBL1554960 & 737822 & 5.5 & 5.2933 & TRN \\
\hline CHEMBL1335617 & 737822 & 5.2 & 5.2028 & TST \\
\hline CHEMBL1305322 & 737822 & 5.35 & 5.4275 & TRN \\
\hline CHEMBL1546374 & 737822 & 5.85 & 5.3315 & TST \\
\hline CHEMBL1474402 & 737822 & 5.0 & 4.9853 & TRN \\
\hline CHEMBL1556619 & 737822 & 6.4 & 5.394 & TRN \\
\hline CHEMBL1566105 & 737822 & 5.4 & 5.3976 & TST \\
\hline CHEMBL146855 & 737822 & 6.0 & 5.5998 & TRN \\
\hline CHEMBL434119 & 737822 & 5.6 & 5.3828 & TST \\
\hline CHEMBL1436925 & 737822 & 5.0 & 4.9824 & TRN \\
\hline CHEMBL1300494 & 737822 & 5.75 & 5.3922 & TRN \\
\hline CHEMBL1396975 & 737822 & 4.9 & 4.6855 & TRN \\
\hline CHEMBL1417980 & 737822 & 4.8 & 5.2638 & TRN \\
\hline CHEMBL1552329 & 737822 & 4.4 & 4.3187 & TRN \\
\hline CHEMBL3192647 & 737822 & 6.2 & 5.4605 & TRN \\
\hline CHEMBL1741327 & 737822 & 4.6 & 5.1514 & TST \\
\hline
\end{tabular}




\begin{tabular}{|c|c|c|c|c|c|}
\hline \multicolumn{6}{|c|}{ Supplemental Table S2.txt } \\
\hline CHEMBL1457785 & 737822 & 4.85 & 5.3563 & TST & \\
\hline CHEMBL1705167 & 737822 & 4.85 & 5.4377 & TRN & \\
\hline CHEMBL1337873 & 737822 & 6.0 & 5.4112 & TRN & \\
\hline CHEMBL1330396 & 737822 & 5.7 & 5.3603 & TRN & \\
\hline CHEMBL601135 & 737822 & 7.05 & 5.1817 & TRN & \\
\hline CHEMBL1590992 & 737822 & 5.7 & 5.3731 & TRN & \\
\hline CHEMBL1560555 & 737822 & 5.45 & 5.3779 & TRN & \\
\hline CHEMBL1975888 & 737822 & 4.95 & 5.2039 & TRN & \\
\hline CHEMBL1409258 & 737822 & 5.65 & 5.2669 & TRN & \\
\hline CHEMBL1256661 & 737822 & 5.7 & 5.7646 & TRN & \\
\hline CHEMBL1374050 & 737822 & 5.0 & 5.4588 & TRN & \\
\hline CHEMBL375672 & 737822 & 5.4 & 5.1875 & TRN & \\
\hline CHEMBL1518571 & 737822 & 5.2 & 5.17399 & 99999999995 & TST \\
\hline CHEMBL41040 & 737822 & 4.5 & 4.6997 & TRN & \\
\hline CHEMBL3210667 & 737822 & 4.9 & 5.2032 & TRN & \\
\hline CHEMBL1354644 & 737822 & 7.7001 & 7.0166 & TRN & \\
\hline CHEMBL1358796 & 737822 & 6.3 & 5.9563 & TRN & \\
\hline CHEMBL1603700 & 737822 & 4.75 & 5.28299 & 99999999995 & TRN \\
\hline CHEMBL1381739 & 737822 & 6.25 & 5.6407 & TRN & \\
\hline CHEMBL1489528 & 737822 & 4.6 & 4.5417 & TRN & \\
\hline CHEMBL1444367 & 737822 & 5.5 & 5.2704 & TRN & \\
\hline CHEMBL1419702 & 737822 & 4.8 & 5.336 & TRN & \\
\hline CHEMBL1471962 & 737822 & 5.0 & 5.1934 & TRN & \\
\hline CHEMBL1314545 & 737822 & 4.9 & 4.9531 & TST & \\
\hline CHEMBL1992293 & 737822 & 5.85 & 5.2385 & TST & \\
\hline CHEMBL1411912 & 737822 & 6.75 & 5.5712 & TRN & \\
\hline CHEMBL1571840 & 737822 & 4.75 & 5.227 & TRN & \\
\hline CHEMBL1353815 & 737822 & 4.8 & 5.1696 & TRN & \\
\hline CHEMBL1396829 & 737822 & 5.4 & 5.3248 & TRN & \\
\hline CHEMBL1592876 & 737822 & 5.4 & 5.2752 & TRN & \\
\hline CHEMBL1514604 & 737822 & 5.8 & 5.6165 & TRN & \\
\hline CHEMBL1526515 & 737822 & 4.85 & 5.2366 & TRN & \\
\hline CHEMBL61605 & 737822 & 7.0 & 6.3248 & TST & \\
\hline CHEMBL1330758 & 737822 & 5.1 & 4.9821 & TRN & \\
\hline CHEMBL1489981 & 737822 & 4.55 & 5.2628 & TRN & \\
\hline CHEMBL1544265 & 737822 & 4.7 & 5.2413 & TRN & \\
\hline CHEMBL1719583 & 737822 & 6.05 & 5.2245 & TST & \\
\hline CHEMBL1474468 & 737822 & 5.1 & 4.8374 & TRN & \\
\hline CHEMBL1371572 & 737822 & 4.4 & 4.4584 & TRN & \\
\hline CHEMBL1314273 & 737822 & 5.5 & 5.5376 & TRN & \\
\hline CHEMBL1999906 & 737822 & 5.7 & 5.309 & TST & \\
\hline CHEMBL1413605 & 737822 & 5.4 & 4.9355 & TRN & \\
\hline CHEMBL1256775 & 737822 & 4.5 & 4.6138 & TRN & \\
\hline CHEMBL1526262 & 737822 & 5.3 & 5.4771 & TRN & \\
\hline CHEMBL 3212521 & 737822 & 6.75 & 5.3092 & TRN & \\
\hline CHEMBL1590354 & 737822 & 4.4 & 4.3386 & TRN & \\
\hline CHEMBL3199688 & 737822 & 4.7 & 5.3247 & TST & \\
\hline CHEMBL1440157 & 737822 & 5.6 & 5.4458 & TRN & \\
\hline
\end{tabular}




\begin{tabular}{|c|c|c|c|c|c|}
\hline \\
\hline CHEMBL1554789 & 737822 & 6.0 & 5.8307 & TRN & \\
\hline CHEMBL1581951 & 737822 & 4.85 & 5.5977 & TRN & \\
\hline CHEMBL293749 & 737822 & 4.4 & 4.5961 & TRN & \\
\hline CHEMBL1514729 & 737822 & 6.4 & 5.7844 & TRN & \\
\hline CHEMBL1570869 & 737822 & 5.3 & 5.0309 & TRN & \\
\hline CHEMBL1356113 & 737822 & 5.4 & 5.2616 & TRN & \\
\hline CHEMBL1328943 & 737822 & 5.5 & 5.435 & TRN & \\
\hline CHEMBL1531899 & 737822 & 4.4 & 4.2971 & TRN & \\
\hline CHEMBL1303328 & 737822 & 4.7 & 5.5468 & TRN & \\
\hline CHEMBL1555713 & 737822 & 4.6 & 4.4354 & TRN & \\
\hline CHEMBL1601957 & 737822 & 6.2 & 5.8835 & TRN & \\
\hline CHEMBL1607646 & 737822 & 6.0 & 5.1586 & TRN & \\
\hline CHEMBL552439 & 737822 & 5.4 & 5.2351 & TST & \\
\hline CHEMBL1595500 & 737822 & 5.1 & 5.1831 & TRN & \\
\hline CHEMBL1457381 & 737822 & 6.4 & 5.2861 & TRN & \\
\hline CHEMBL1594149 & 737822 & 5.0 & 4.9939 & TST & \\
\hline CHEMBL1330926 & 737822 & 7.9 & 5.2157 & TRN & \\
\hline CHEMBL1320471 & 737822 & 4.4 & 5.6969 & TRN & \\
\hline CHEMBL1334321 & 737822 & 5.7 & 5.1837 & TRN & \\
\hline CHEMBL1576649 & 737822 & 4.45 & 5.119 & TRN & \\
\hline CHEMBL1436957 & 737822 & 4.6 & 4.6031 & TRN & \\
\hline CHEMBL1213137 & 737822 & 5.3 & 5.2428 & TRN & \\
\hline CHEMBL1512978 & 737822 & 6.9 & 6.3265 & TST & \\
\hline CHEMBL1496344 & 737822 & 4.75 & 4.9217 & TRN & \\
\hline CHEMBL1374605 & 737822 & 4.8 & 5.3068 & TRN & \\
\hline CHEMBL1256656 & 737822 & 6.0 & 5.579 & TRN & \\
\hline CHEMBL1496663 & 737822 & 6.8 & 5.4281 & TST & \\
\hline CHEMBL1410311 & 737822 & 4.95 & 4.9919 & TRN & \\
\hline CHEMBL1329761 & 737822 & 4.85 & 5.2969 & TRN & \\
\hline CHEMBL1317741 & 737822 & 5.4 & 5.3245 & TRN & \\
\hline CHEMBL1568588 & 737822 & 4.95 & 5.3223 & TRN & \\
\hline CHEMBL1415331 & 737822 & 6.45 & 5.3875 & TRN & \\
\hline CHEMBL1345724 & 737822 & 4.75 & 5.2213 & TRN & \\
\hline CHEMBL587714 & 737822 & 4.9 & 5.0754 & TRN & \\
\hline CHEMBL1378030 & 737822 & 6.65 & 5.3054 & TRN & \\
\hline CHEMBL1428217 & 737822 & 4.85 & 5.0261 & TRN & \\
\hline CHEMBL1473055 & 737822 & 4.4 & 4.3693 & TRN & \\
\hline CHEMBL1376879 & 737822 & 4.65 & 5.32299 & 99999999995 & TRN \\
\hline CHEMBL1356395 & 737822 & 5.5 & 5.4098 & TRN & \\
\hline CHEMBL1395278 & 737822 & 5.6 & 5.4498 & TRN & \\
\hline CHEMBL1411360 & 737822 & 5.5 & 5.3295 & TST & \\
\hline CHEMBL1548428 & 737822 & 4.9 & 5.0311 & TRN & \\
\hline CHEMBL1418280 & 737822 & 4.85 & 5.4737 & TRN & \\
\hline CHEMBL1495251 & 737822 & 4.9 & 4.816 & TRN & \\
\hline CHEMBL1256916 & 737822 & 6.6 & 6.8798 & TRN & \\
\hline CHEMBL1531688 & 737822 & 4.85 & 5.2919 & TRN & \\
\hline CHEMBL1456872 & 737822 & 4.9 & 4.6412 & TRN & \\
\hline CHEMBL1397322 & 737822 & 5.0 & 4.8283 & TRN & \\
\hline
\end{tabular}




\begin{tabular}{|c|c|c|c|c|c|}
\hline \multirow[b]{2}{*}{ CHEMBL1538177 } & \multirow[b]{2}{*}{737822} & \\
\hline & & 5.0 & 5.7383 & TRN & \\
\hline CHEMBL187216 & 737822 & 5.4 & 5.3057 & TRN & \\
\hline CHEMBL1380717 & 737822 & 4.8 & 5.3875 & TRN & \\
\hline CHEMBL1599861 & 737822 & 4.6 & 5.4385 & TST & \\
\hline CHEMBL 258465 & 737822 & 5.7 & 5.5277 & TRN & \\
\hline CHEMBL1412209 & 737822 & 4.75 & 5.5508 & TRN & \\
\hline CHEMBL1596221 & 737822 & 5.6 & 5.1515 & TRN & \\
\hline CHEMBL1441066 & 737822 & 4.85 & 5.3123 & TST & \\
\hline CHEMBL1389262 & 737822 & 5.35 & 5.2026 & TRN & \\
\hline CHEMBL1516028 & 737822 & 4.9 & 4.9235 & TRN & \\
\hline CHEMBL1492178 & 737822 & 4.4 & 5.2176 & TRN & \\
\hline CHEMBL3189190 & 737822 & 5.4 & 5.3315 & TRN & \\
\hline CHEMBL1593796 & 737822 & 5.6 & 5.5107 & TRN & \\
\hline CHEMBL1579424 & 737822 & 6.65 & 5.4479 & TRN & \\
\hline CHEMBL518430 & 737822 & 5.15 & 5.0889 & TRN & \\
\hline CHEMBL1580538 & 737822 & 5.3 & 5.1493 & TRN & \\
\hline CHEMBL1411081 & 737822 & 6.0 & 5.8048 & TRN & \\
\hline CHEMBL24909 & 737822 & 4.4 & 4.6419 & TRN & \\
\hline CHEMBL1489213 & 737822 & 4.65 & 5.3192 & TRN & \\
\hline CHEMBL275006 & 737822 & 6.0 & 5.6786 & TST & \\
\hline CHEMBL1557657 & 737822 & 4.8 & 4.7869 & TRN & \\
\hline CHEMBL1592507 & 737822 & 5.4 & 5.3409 & TRN & \\
\hline CHEMBL1343857 & 737822 & 5.4 & 5.4244 & TRN & \\
\hline CHEMBL1733652 & 737822 & 5.5 & 5.78600 & 00000000005 & TST \\
\hline CHEMBL1596698 & 737822 & 5.3 & 5.2306 & TRN & \\
\hline CHEMBL1733013 & 737822 & 4.55 & 5.40799 & 99999999995 & TRN \\
\hline CHEMBL1433762 & 737822 & 5.7 & 5.4886 & TRN & \\
\hline CHEMBL1533852 & 737822 & 5.55 & 4.9888 & TRN & \\
\hline CHEMBL1483214 & 737822 & 5.0 & 5.4269 & TRN & \\
\hline CHEMBL1512742 & 737822 & 5.9 & 5.8048 & TRN & \\
\hline CHEMBL1353342 & 737822 & 5.6 & 5.2707 & TRN & \\
\hline CHEMBL1742325 & 737822 & 5.9 & 5.2602 & TRN & \\
\hline CHEMBL358326 & 737822 & 4.85 & 5.3871 & TRN & \\
\hline CHEMBL1514639 & 737822 & 8.2 & 7.3516 & TST & \\
\hline CHEMBL1515221 & 737822 & 4.9 & 4.8222 & TRN & \\
\hline CHEMBL63426 & 737822 & 6.0 & 5.8065 & TST & \\
\hline CHEMBL32503 & 737822 & 5.4 & 5.2715 & TRN & \\
\hline CHEMBL1473849 & 737822 & 7.5 & 6.6666 & TRN & \\
\hline CHEMBL1414668 & 737822 & 4.6 & 5.3851 & TRN & \\
\hline CHEMBL1456464 & 737822 & 5.9 & 5.4435 & TRN & \\
\hline CHEMBL1551729 & 737822 & 5.2 & 5.1361 & TRN & \\
\hline CHEMBL1522155 & 737822 & 5.3 & 5.228 & TST & \\
\hline CHEMBL1331363 & 737822 & 5.1 & 4.8965 & TRN & \\
\hline CHEMBL1604264 & 737822 & 4.7 & 5.5473 & TRN & \\
\hline CHEMBL1557234 & 737822 & 4.6 & 4.4436 & TRN & \\
\hline CHEMBL1374028 & 737822 & 5.8 & 5.6485 & TST & \\
\hline CHEMBL1417999 & 737822 & 4.65 & 5.0398 & TRN & \\
\hline CHEMBL1092376 & 737822 & 4.9 & 5.1755 & TRN & \\
\hline & & & & 1127 & \\
\hline
\end{tabular}




\begin{tabular}{|c|c|c|c|c|c|}
\hline \multicolumn{6}{|c|}{ Supplemental Table S2.txt } \\
\hline CHEMBL1402495 & 737822 & 5.5 & 5.3641 & TRN & \\
\hline CHEMBL3209319 & 737822 & 4.65 & 5.2259 & TRN & \\
\hline CHEMBL15060 & 737822 & 4.6 & 4.6893 & TRN & \\
\hline CHEMBL1308155 & 737822 & 5.6 & 5.4753 & TST & \\
\hline CHEMBL1603595 & 737822 & 4.5 & 4.5359 & TRN & \\
\hline CHEMBL1559126 & 737822 & 4.7 & 4.5733 & TRN & \\
\hline CHEMBL1317748 & 737822 & 7.0 & 6.8435 & TRN & \\
\hline CHEMBL574181 & 737822 & 4.4 & 4.4741 & TST & \\
\hline CHEMBL1483302 & 737822 & 4.9 & 5.1175 & TRN & \\
\hline CHEMBL1467940 & 737822 & 5.15 & 5.2142 & TRN & \\
\hline CHEMBL1342399 & 737822 & 5.0 & 5.3872 & TRN & \\
\hline CHEMBL1603871 & 737822 & 6.35 & 5.2924 & TRN & \\
\hline CHEMBL1392360 & 737822 & 4.85 & 5.6222 & TST & \\
\hline CHEMBL1712760 & 737822 & 4.85 & 5.4017 & TRN & \\
\hline CHEMBL1589856 & 737822 & 6.1 & 5.8024 & TRN & \\
\hline CHEMBL1571264 & 737822 & 4.6 & 4.4201 & TRN & \\
\hline CHEMBL1308401 & 737822 & 6.25 & 5.4045 & TST & \\
\hline CHEMBL1357221 & 737822 & 6.0 & 5.789 & TRN & \\
\hline CHEMBL1523040 & 737822 & 5.05 & 5.2186 & TRN & \\
\hline CHEMBL1361675 & 737822 & 5.05 & 5.4267 & TRN & \\
\hline CHEMBL1448291 & 737822 & 4.6 & 5.2164 & TRN & \\
\hline CHEMBL1523936 & 737822 & 4.95 & 5.5532 & TRN & \\
\hline CHEMBL216973 & 737822 & 4.65 & 5.2007 & TRN & \\
\hline CHEMBL1708288 & 737822 & 4.55 & 5.1789 & TRN & \\
\hline CHEMBL1592227 & 737822 & 5.3 & 5.078 & TRN & \\
\hline CHEMBL1433559 & 737822 & 4.5 & 4.3861 & TRN & \\
\hline CHEMBL1400385 & 737822 & 4.8 & 5.2636 & TRN & \\
\hline CHEMBL3195193 & 737822 & 4.8 & 5.3553 & TRN & \\
\hline CHEMBL1256735 & 737822 & 4.5 & 4.5704 & TRN & \\
\hline CHEMBL471226 & 737822 & 5.4 & 5.2467 & TST & \\
\hline CHEMBL1591170 & 737822 & 7.2 & 6.8535 & TRN & \\
\hline CHEMBL1522566 & 737822 & 5.35 & 5.3801 & TRN & \\
\hline CHEMBL15192 & 737822 & 4.8 & 4.868 & TST & \\
\hline CHEMBL491548 & 737822 & 4.6 & 4.504 & TRN & \\
\hline CHEMBL1388771 & 737822 & 4.65 & 5.2236 & TRN & \\
\hline CHEMBL56393 & 737822 & -0.0 & 4.7129 & TRN & \\
\hline CHEMBL1518035 & 737822 & 4.7 & 4.5443 & TRN & \\
\hline CHEMBL1316408 & 737822 & 5.6 & 5.2768 & TRN & \\
\hline CHEMBL20730 & 737822 & 6.0 & 5.71899 & 9999999999 & TRN \\
\hline CHEMBL 188 & 737822 & 4.8 & 4.8325 & TRN & \\
\hline CHEMBL316611 & 737822 & 5.7 & 5.4707 & TRN & \\
\hline CHEMBL1474890 & 737822 & 5.2 & 5.0152 & TRN & \\
\hline CHEMBL1460531 & 737822 & 4.9 & 5.1604 & TST & \\
\hline CHEMBL1724517 & 737822 & 4.8 & 5.3835 & TRN & \\
\hline CHEMBL1393461 & 737822 & 6.6 & 5.4611 & TRN & \\
\hline CHEMBL1364220 & 737822 & 4.75 & 5.3646 & TRN & \\
\hline CHEMBL1512391 & 737822 & 6.0 & 5.5977 & TRN & \\
\hline CHEMBL1316055 & 737822 & 5.0 & 4.9338 & TRN & \\
\hline
\end{tabular}




\begin{tabular}{|c|c|c|c|c|c|}
\hline \multicolumn{6}{|c|}{ Supplemental Table S2.txt } \\
\hline CHEMBL136906 & 737822 & 5.4 & 5.2927 & TRN & \\
\hline CHEMBL544713 & 737822 & 6.9 & 6.5843 & TRN & \\
\hline CHEMBL1335466 & 737822 & 5.4 & 5.3933 & TRN & \\
\hline CHEMBL1366635 & 737822 & 6.55 & 5.2843 & TRN & \\
\hline CHEMBL1404656 & 737822 & 5.0 & 5.0978 & TST & \\
\hline CHEMBL1549336 & 737822 & 5.7 & 5.4941 & TRN & \\
\hline CHEMBL1311305 & 737822 & 5.0 & 5.0315 & TRN & \\
\hline CHEMBL1335471 & 737822 & 4.9 & 4.7447 & TST & \\
\hline CHEMBL1601506 & 737822 & 5.5 & 5.4242 & TRN & \\
\hline CHEMBL3199708 & 737822 & 5.7 & 5.3908 & TRN & \\
\hline CHEMBL1553399 & 737822 & 5.7 & 5.4875 & TST & \\
\hline CHEMBL1605255 & 737822 & 4.7 & 4.5431 & TRN & \\
\hline CHEMBL274189 & 737822 & 4.9 & 5.0172 & TST & \\
\hline CHEMBL1335890 & 737822 & 6.0 & 5.95799 & 7999999999 & TRN \\
\hline CHEMBL1479506 & 737822 & 5.0 & 4.9267 & TRN & \\
\hline CHEMBL1591381 & 737822 & 5.0 & 4.9261 & TRN & \\
\hline CHEMBL1404792 & 737822 & 7.15 & 5.9942 & TST & \\
\hline CHEMBL1418864 & 737822 & 7.35 & 5.4221 & TRN & \\
\hline CHEMBL1467857 & 737822 & 4.55 & 5.4169 & TRN & \\
\hline CHEMBL1732963 & 737822 & 4.8 & 5.356 & TRN & \\
\hline CHEMBL1435908 & 737822 & 6.0 & 5.3506 & TRN & \\
\hline CHEMBL3207571 & 737822 & 4.5 & 5.2425 & TRN & \\
\hline CHEMBL3191343 & 737822 & 5.45 & 5.2467 & TRN & \\
\hline CHEMBL1612486 & 737822 & 5.0 & 5.3663 & TRN & \\
\hline CHEMBL1415406 & 737822 & 4.9 & 4.7971 & TRN & \\
\hline CHEMBL1493910 & 737822 & 5.0 & 5.1625 & TRN & \\
\hline CHEMBL1370480 & 737822 & 5.8 & 5.7511 & TRN & \\
\hline CHEMBL1396407 & 737822 & 5.0 & 4.8089 & TRN & \\
\hline CHEMBL1603471 & 737822 & 4.9 & 5.3966 & TRN & \\
\hline CHEMBL1316348 & 737822 & 4.7 & 4.5827 & TRN & \\
\hline CHEMBL1573171 & 737822 & 6.75 & 4.9888 & TRN & \\
\hline CHEMBL1317373 & 737822 & 4.5 & 4.3907 & TRN & \\
\hline CHEMBL1476280 & 737822 & 5.2 & 5.3585 & TRN & \\
\hline CHEMBL1550052 & 737822 & 4.85 & 5.5552 & TRN & \\
\hline CHEMBL491953 & 737822 & 4.9 & 4.8005 & TRN & \\
\hline CHEMBL1416184 & 737822 & 4.85 & 5.2764 & TRN & \\
\hline CHEMBL1363398 & 737822 & 4.4 & 4.3547 & TRN & \\
\hline CHEMBL1607197 & 737822 & 4.9 & 5.5712 & TRN & \\
\hline CHEMBL1308013 & 737822 & 5.3 & 5.3119 & TST & \\
\hline CHEMBL542493 & 737822 & 4.5 & 4.5881 & TRN & \\
\hline CHEMBL250428 & 737822 & 5.3 & 5.1944 & TRN & \\
\hline CHEMBL1367944 & 737822 & 8.0 & 7.2542 & TRN & \\
\hline CHEMBL576997 & 737822 & 6.0 & 5.8411 & TST & \\
\hline CHEMBL1335777 & 737822 & 5.0 & 5.3542 & TRN & \\
\hline CHEMBL1356023 & 737822 & 5.6 & 5.3794 & TRN & \\
\hline CHEMBL1543356 & 737822 & 5.0 & 5.296 & TRN & \\
\hline CHEMBL1539107 & 737822 & 7.2 & 5.3848 & TRN & \\
\hline CHEMBL17002 & 737822 & 7.0 & 6.224 & TST & \\
\hline
\end{tabular}




\begin{tabular}{|c|c|c|c|c|c|}
\hline CHEMBL1551557 & 737822 & 4.7 & \multicolumn{2}{|c|}{4.5969999999999995} & TRN \\
\hline CHEMBL3214406 & 737822 & 5.45 & 5.3783 & TST & \\
\hline CHEMBL1334283 & 737822 & 4.9 & 5.6184 & TRN & \\
\hline CHEMBL598270 & 737822 & 6.5 & 6.1095 & TST & \\
\hline CHEMBL1360026 & 737822 & 4.65 & 5.2726 & TRN & \\
\hline CHEMBL1556700 & 737822 & 4.4 & 4.3853 & TRN & \\
\hline CHEMBL1451315 & 737822 & 4.6 & 4.4496 & TRN & \\
\hline CHEMBL1414698 & 737822 & 4.9 & 4.7778 & TRN & \\
\hline CHEMBL3197456 & 737822 & 4.7 & 5.1731 & TRN & \\
\hline CHEMBL1742071 & 737822 & 4.7 & 5.4219 & TRN & \\
\hline CHEMBL1434817 & 737822 & 5.5 & 5.2726 & TRN & \\
\hline CHEMBL1590106 & 737822 & 4.6 & 4.8139 & TRN & \\
\hline CHEMBL1397466 & 737822 & 4.9 & 4.8479 & TST & \\
\hline CHEMBL1525169 & 737822 & 5.5 & 5.1124 & TRN & \\
\hline CHEMBL13790 & 737822 & 6.0 & 5.6593 & TRN & \\
\hline CHEMBL1300755 & 737822 & 5.25 & 5.215 & TRN & \\
\hline CHEMBL1562277 & 737822 & 4.9 & 5.5883 & TRN & \\
\hline CHEMBL1255747 & 737822 & 4.5 & 4.7349 & TRN & \\
\hline CHEMBL1316265 & 737822 & 6.9 & 6.1638 & TRN & \\
\hline CHEMBL1489424 & 737822 & 5.6 & 5.4846 & TRN & \\
\hline CHEMBL1526170 & 737822 & 4.6 & 4.4531 & TRN & \\
\hline CHEMBL1523400 & 737822 & 4.45 & 5.2655 & TRN & \\
\hline CHEMBL1522909 & 737822 & 6.25 & 5.2236 & TRN & \\
\hline CHEMBL1515774 & 737822 & 5.6 & 5.4646 & TRN & \\
\hline CHEMBL1323270 & 737822 & 4.6 & 5.4021 & TRN & \\
\hline CHEMBL1612158 & 737822 & 4.8 & 4.5972 & TRN & \\
\hline CHEMBL1490143 & 737822 & 4.95 & 5.2209 & TRN & \\
\hline CHEMBL1553218 & 737822 & 6.2 & 6.0826 & TRN & \\
\hline CHEMBL1402894 & 737822 & 5.2 & 5.2477 & TRN & \\
\hline CHEMBL1446009 & 737822 & 4.4 & \multicolumn{2}{|c|}{4.4830000000000005} & TRN \\
\hline CHEMBL1439945 & 737822 & 4.8 & 4.6376 & TRN & \\
\hline CHEMBL1573964 & 737822 & 5.1 & 4.9306 & TRN & \\
\hline CHEMBL464433 & 737822 & 7.45 & 4.7019 & TRN & \\
\hline CHEMBL1517999 & 737822 & 6.8 & 6.6309 & TRN & \\
\hline CHEMBL3208086 & 737822 & 5.15 & 5.1617 & TRN & \\
\hline CHEMBL1605237 & 737822 & 4.85 & 5.5353 & TRN & \\
\hline CHEMBL1472036 & 737822 & 4.6 & 5.5261 & TRN & \\
\hline CHEMBL1587168 & 737822 & 5.5 & 5.3643 & TRN & \\
\hline CHEMBL1443952 & 737822 & 4.75 & 5.3512 & TRN & \\
\hline CHEMBL1496934 & 737822 & 4.4 & 4.3024 & TRN & \\
\hline CHEMBL1590397 & 737822 & 4.4 & 4.3667 & TRN & \\
\hline CHEMBL1447909 & 737822 & 4.9 & 4.6927 & TRN & \\
\hline CHEMBL1549118 & 737822 & 4.8 & 5.5197 & TRN & \\
\hline CHEMBL1351829 & 737822 & 4.9 & 5.2002 & TRN & \\
\hline CHEMBL375126 & 737822 & 5.4 & 5.2875 & TRN & \\
\hline CHEMBL1414251 & 737822 & 5.3 & 4.9818 & TRN & \\
\hline CHEMBL1330954 & 737822 & 5.1 & 5.2886 & TRN & \\
\hline CHEMBL1351254 & 737822 & 4.55 & 5.296 & TRN & \\
\hline
\end{tabular}




\begin{tabular}{|c|c|c|c|c|}
\hline & & & pplement & al $\mathrm{Ta}$ \\
\hline CHEMBL28140 & 737822 & 6.0 & 5.7502 & TRN \\
\hline CHEMBL3304020 & 737822 & 5.5 & 5.3613 & TST \\
\hline CHEMBL1488197 & 737822 & 7.0 & 6.6422 & TRN \\
\hline CHEMBL1393667 & 737822 & 4.65 & 5.1602 & TRN \\
\hline CHEMBL1443798 & 737822 & 4.65 & 5.2815 & TST \\
\hline CHEMBL1526697 & 737822 & 5.0 & 4.8465 & TRN \\
\hline CHEMBL1314222 & 737822 & 4.7 & 4.5614 & TRN \\
\hline CHEMBL1344002 & 737822 & 4.6 & 5.2186 & TST \\
\hline CHEMBL1441667 & 737822 & 4.95 & 5.3466 & TRN \\
\hline CHEMBL1306988 & 737822 & 4.65 & 5.3845 & TRN \\
\hline CHEMBL 2000120 & 737822 & 4.95 & 5.3414 & TST \\
\hline CHEMBL1450805 & 737822 & 6.5 & 6.2122 & TRN \\
\hline CHEMBL1515717 & 737822 & 5.0 & 4.8436 & TRN \\
\hline CHEMBL1480008 & 737822 & 4.7 & 4.6739 & TRN \\
\hline CHEMBL1337078 & 737822 & 5.3 & 5.4021 & TRN \\
\hline CHEMBL1538256 & 737822 & 5.7 & 5.4974 & TRN \\
\hline CHEMBL1408334 & 737822 & 5.6 & 5.6942 & TRN \\
\hline CHEMBL1379083 & 737822 & 5.7 & 5.2214 & TRN \\
\hline CHEMBL1471369 & 737822 & 5.05 & 5.1282 & TRN \\
\hline CHEMBL1493168 & 737822 & 6.8 & 6.4648 & TRN \\
\hline CHEMBL1554723 & 737822 & 5.1 & 4.8988 & TRN \\
\hline CHEMBL3196704 & 737822 & 4.8 & 5.1773 & TST \\
\hline CHEMBL1578326 & 737822 & 6.9 & 5.3666 & TRN \\
\hline CHEMBL1320947 & 737822 & 5.5 & 5.4203 & TRN \\
\hline CHEMBL1379480 & 737822 & 5.5 & 5.1168 & TRN \\
\hline CHEMBL1394765 & 737822 & 4.4 & 4.2774 & TRN \\
\hline CHEMBL1349158 & 737822 & 4.85 & 5.1751 & TST \\
\hline CHEMBL1570515 & 737822 & 5.25 & 5.1319 & TRN \\
\hline CHEMBL1388711 & 737822 & 5.4 & 5.5706 & TRN \\
\hline CHEMBL1741781 & 737822 & 4.6 & 5.3159 & TRN \\
\hline CHEMBL3207783 & 737822 & 5.1 & 5.1138 & TRN \\
\hline CHEMBL1450096 & 737822 & 7.3 & 5.2026 & TRN \\
\hline CHEMBL1406406 & 737822 & 6.3 & 5.1503 & TRN \\
\hline CHEMBL1572173 & 737822 & 4.6 & 4.6339 & TRN \\
\hline CHEMBL1341642 & 737822 & 5.15 & 5.1568 & TRN \\
\hline CHEMBL1564194 & 737822 & 4.9 & 4.8651 & TRN \\
\hline CHEMBL3189663 & 737822 & 4.75 & 5.4903 & TRN \\
\hline CHEMBL1438041 & 737822 & 4.7 & 4.5831 & TRN \\
\hline CHEMBL1396595 & 737822 & 4.7 & 4.5674 & TRN \\
\hline CHEMBL1386058 & 737822 & 5.5 & 5.1289 & TRN \\
\hline CHEMBL1589842 & 737822 & 5.5 & 5.4717 & TRN \\
\hline CHEMBL1305982 & 737822 & 6.55 & 5.6335 & TRN \\
\hline CHEMBL1726157 & 737822 & 5.3 & 5.1481 & TRN \\
\hline CHEMBL1395344 & 737822 & 4.7 & 4.582 & TRN \\
\hline CHEMBL1498144 & 737822 & 4.8 & 5.5434 & TRN \\
\hline CHEMBL1378878 & 737822 & 4.6 & 5.4071 & TRN \\
\hline CHEMBL1321655 & 737822 & 4.4 & 4.7343 & TRN \\
\hline CHEMBL1372883 & 737822 & 4.9 & 5.3795 & TRN \\
\hline
\end{tabular}




\begin{tabular}{|c|c|c|c|c|c|}
\hline \multicolumn{6}{|c|}{ dole } \\
\hline CHEMBL1323759 & 737822 & 4.6 & 4.4244 & TRN & \\
\hline CHEMBL1720911 & 737822 & 4.8 & 5.2688 & TRN & \\
\hline CHEMBL1332450 & 737822 & 5.4 & 5.2919 & TRN & \\
\hline CHEMBL1535796 & 737822 & 4.6 & 4.4718 & TRN & \\
\hline CHEMBL1389326 & 737822 & 4.85 & 5.1657 & TRN & \\
\hline CHEMBL1303557 & 737822 & 5.85 & 5.3052 & TST & \\
\hline CHEMBL1359184 & 737822 & 4.65 & 5.2071 & TRN & \\
\hline CHEMBL1376629 & 737822 & 4.75 & 5.4119 & TRN & \\
\hline CHEMBL1741700 & 737822 & 6.25 & 5.4065 & TST & \\
\hline CHEMBL346898 & 737822 & 6.1 & 5.8077 & TRN & \\
\hline CHEMBL1551274 & 737822 & 5.5 & 5.3872 & TRN & \\
\hline CHEMBL1610945 & 737822 & 6.0 & 5.6814 & TST & \\
\hline CHEMBL1409074 & 737822 & 5.4 & 5.2518 & TRN & \\
\hline CHEMBL1395337 & 737822 & 4.4 & 4.4358 & TRN & \\
\hline CHEMBL 30432 & 737822 & 4.5 & 4.5229 & TRN & \\
\hline CHEMBL1441608 & 737822 & 4.7 & 4.6231 & TRN & \\
\hline CHEMBL1420206 & 737822 & 4.85 & 5.3528 & TRN & \\
\hline CHEMBL1576777 & 737822 & 4.9 & 5.2964 & TRN & \\
\hline CHEMBL1483789 & 737822 & 5.4 & 5.4220 & 0000000001 & TRN \\
\hline CHEMBL1448542 & 737822 & 6.6 & 5.9667 & TRN & \\
\hline CHEMBL1542082 & 737822 & 6.05 & 5.3059 & TRN & \\
\hline CHEMBL1347631 & 737822 & 4.95 & 5.4225 & TRN & \\
\hline CHEMBL1563992 & 737822 & 4.9 & 4.9903 & TRN & \\
\hline CHEMBL1201074 & 737822 & 5.6 & 5.8457 & TRN & \\
\hline CHEMBL1396100 & 737822 & 4.9 & 4.8574 & TRN & \\
\hline CHEMBL1479727 & 737822 & 4.9 & 5.0533 & TRN & \\
\hline CHEMBL1408427 & 737822 & 4.6 & 4.5877 & TRN & \\
\hline CHEMBL1407398 & 737822 & 8.25 & 5.1687 & TRN & \\
\hline CHEMBL1444778 & 737822 & 4.45 & 5.3188 & TRN & \\
\hline CHEMBL1592542 & 737822 & 5.5 & 5.3425 & TST & \\
\hline CHEMBL1322216 & 737822 & 4.6 & 4.4852 & TRN & \\
\hline CHEMBL1436832 & 737822 & 4.7 & 4.4807 & TRN & \\
\hline CHEMBL1447149 & 737822 & 5.5 & 5.1676 & TRN & \\
\hline CHEMBL1368282 & 737822 & 5.5 & 5.3519 & TRN & \\
\hline CHEMBL1363275 & 737822 & 4.85 & 5.1355 & TRN & \\
\hline CHEMBL1428519 & 737822 & 4.75 & 5.3608 & TST & \\
\hline CHEMBL1487092 & 737822 & 4.95 & 5.3873 & TRN & \\
\hline CHEMBL1592982 & 737822 & 5.6 & 5.4791 & TRN & \\
\hline CHEMBL1519978 & 737822 & 4.4 & 4.5421 & TRN & \\
\hline CHEMBL1387271 & 737822 & 4.6 & 5.461 & TRN & \\
\hline CHEMBL523283 & 737822 & 5.4 & 5.1166 & TRN & \\
\hline CHEMBL1434149 & 737822 & 4.8 & 4.7184 & TRN & \\
\hline CHEMBL1441920 & 737822 & 6.0 & 5.7816 & TRN & \\
\hline CHEMBL1590508 & 737822 & 5.8 & 5.5779 & TRN & \\
\hline CHEMBL1554888 & 737822 & 4.7 & 4.5968 & TRN & \\
\hline CHEMBL1595142 & 737822 & 7.0 & 6.8086 & TRN & \\
\hline CHEMBL1595944 & 737822 & 5.8 & 5.4306 & TRN & \\
\hline CHEMBL1360310 & 737822 & 4.6 & 4.4712 & TRN & \\
\hline & & & & 11279 & \\
\hline
\end{tabular}




\begin{tabular}{|c|c|c|c|c|c|}
\hline \\
\hline CHEMBL1572383 & 737822 & 4.55 & 5.3274 & TRN & \\
\hline CHEMBL1741617 & 737822 & 4.85 & 5.0924 & TRN & \\
\hline CHEMBL1594704 & 737822 & 4.5 & 4.5028 & TRN & \\
\hline CHEMBL1585944 & 737822 & 6.0 & 5.7211 & TRN & \\
\hline CHEMBL1352269 & 737822 & 6.3 & 5.1426 & TRN & \\
\hline CHEMBL1554717 & 737822 & 4.8 & 4.8964 & TRN & \\
\hline CHEMBL1571995 & 737822 & 5.5 & 5.4007 & TRN & \\
\hline CHEMBL1390207 & 737822 & 4.4 & 5.1566 & TST & \\
\hline CHEMBL1551616 & 737822 & 6.8 & 6.3416 & TRN & \\
\hline CHEMBL1411396 & 737822 & 4.5 & 5.1824 & TST & \\
\hline CHEMBL1362517 & 737822 & 6.7 & 6.2823 & TRN & \\
\hline CHEMBL1543887 & 737822 & 5.3 & 5.3397 & TRN & \\
\hline CHEMBL1437075 & 737822 & 4.7 & 4.5147 & TRN & \\
\hline CHEMBL1414493 & 737822 & 6.5 & 5.4642 & TRN & \\
\hline CHEMBL1486009 & 737822 & 5.0 & 4.7312 & TRN & \\
\hline CHEMBL1456334 & 737822 & 5.55 & 5.4865 & TRN & \\
\hline CHEMBL1358758 & 737822 & 6.1 & 5.58299 & 9999999999 & TRN \\
\hline CHEMBL1602394 & 737822 & 4.5 & 4.4225 & TRN & \\
\hline CHEMBL1256995 & 737822 & 6.0 & 5.6753 & TRN & \\
\hline CHEMBL1377552 & 737822 & 4.75 & 5.6385 & TRN & \\
\hline CHEMBL1512744 & 737822 & 6.0 & 5.4059 & TRN & \\
\hline CHEMBL1327915 & 737822 & 4.7 & 4.5145 & TRN & \\
\hline CHEMBL1571807 & 737822 & 4.8 & 5.1102 & TRN & \\
\hline CHEMBL1427403 & 737822 & 4.5 & 5.1601 & TRN & \\
\hline CHEMBL24983 & 737822 & 4.5 & 4.6508 & TST & \\
\hline CHEMBL3199929 & 737822 & 5.8 & 5.5609 & TST & \\
\hline CHEMBL1398456 & 737822 & 4.6 & 4.7828 & TST & \\
\hline CHEMBL1429762 & 737822 & 5.2 & 5.2802 & TST & \\
\hline CHEMBL1522136 & 737822 & 4.9 & 5.4928 & TRN & \\
\hline CHEMBL1467491 & 737822 & 4.95 & 5.289 & TRN & \\
\hline CHEMBL 2003072 & 737822 & 5.9 & 5.2214 & TRN & \\
\hline CHEMBL1395415 & 737822 & 4.5 & 4.3798 & TRN & \\
\hline CHEMBL1452675 & 737822 & 5.25 & 5.3187 & TRN & \\
\hline CHEMBL1462374 & 737822 & 5.1 & 5.1862 & TRN & \\
\hline CHEMBL1414438 & 737822 & 4.6 & 5.1857 & TST & \\
\hline CHEMBL1312833 & 737822 & 5.3 & 5.5574 & TRN & \\
\hline CHEMBL1354403 & 737822 & 4.9 & 4.9947 & TRN & \\
\hline CHEMBL1461491 & 737822 & 6.0 & 5.7128 & TST & \\
\hline CHEMBL1513121 & 737822 & 4.4 & 4.3419 & TRN & \\
\hline CHEMBL1572893 & 737822 & 4.4 & 5.2582 & TRN & \\
\hline CHEMBL393417 & 737822 & 7.2 & 6.7077 & TST & \\
\hline CHEMBL1356628 & 737822 & 4.7 & 4.5405 & TST & \\
\hline CHEMBL1333556 & 737822 & 4.8 & 4.8056 & TST & \\
\hline CHEMBL1355146 & 737822 & 4.8 & 4.7763 & TRN & \\
\hline CHEMBL389390 & 737822 & 6.0 & 5.8295 & TRN & \\
\hline CHEMBL1463453 & 737822 & 6.3 & 5.2009 & TRN & \\
\hline CHEMBL1386594 & 737822 & 4.6 & 5.1737 & TRN & \\
\hline CHEMBL83899 & 737822 & 4.9 & 4.9741 & TRN & \\
\hline
\end{tabular}




\begin{tabular}{|c|c|c|c|c|c|}
\hline \\
\hline CHEMBL1405546 & 737822 & 7.2 & 6.7143 & TRN & \\
\hline CHEMBL1475079 & 737822 & 4.7 & 4.5687 & TRN & \\
\hline CHEMBL1611066 & 737822 & 8.5 & 5.1052 & TRN & \\
\hline CHEMBL1303741 & 737822 & 7.1 & 5.2062 & TRN & \\
\hline CHEMBL1725383 & 737822 & 6.9 & 5.3523 & TRN & \\
\hline CHEMBL1405581 & 737822 & 4.85 & 4.9915 & TST & \\
\hline CHEMBL1395054 & 737822 & 4.4 & 4.3297 & TRN & \\
\hline CHEMBL1423999 & 737822 & 4.8 & 5.1771 & TRN & \\
\hline CHEMBL1554664 & 737822 & 5.0 & 4.8193 & TRN & \\
\hline CHEMBL492130 & 737822 & 5.1 & 4.9991 & TRN & \\
\hline CHEMBL1435080 & 737822 & 4.7 & 4.5897 & TRN & \\
\hline CHEMBL1568744 & 737822 & 6.0 & 5.5432 & TRN & \\
\hline CHEMBL1340140 & 737822 & 6.95 & 5.1876 & TRN & \\
\hline CHEMBL1413443 & 737822 & 5.85 & 5.4378 & TRN & \\
\hline CHEMBL11458 & 737822 & 4.4 & 4.5476 & TST & \\
\hline CHEMBL1436979 & 737822 & 5.4 & 5.4502 & TRN & \\
\hline CHEMBL1332990 & 737822 & 4.65 & 5.3295 & TRN & \\
\hline CHEMBL1393658 & 737822 & 4.85 & 5.3227 & TRN & \\
\hline CHEMBL1359378 & 737822 & 6.3 & 5.0605 & TRN & \\
\hline CHEMBL1318041 & 737822 & 5.1 & 4.9997 & TRN & \\
\hline CHEMBL1395226 & 737822 & 4.7 & 4.466 & TRN & \\
\hline CHEMBL1420699 & 737822 & 5.9 & 5.25899 & 99999999995 & TRN \\
\hline CHEMBL441948 & 737822 & 4.4 & 4.5956 & TST & \\
\hline CHEMBL2373602 & 737822 & 6.0 & 5.7959 & TRN & \\
\hline CHEMBL1437095 & 737822 & 5.0 & 4.9114 & TRN & \\
\hline CHEMBL1394118 & 737822 & 5.9 & 5.9351 & TRN & \\
\hline CHEMBL567175 & 737822 & 6.0 & 5.8703 & TRN & \\
\hline CHEMBL1318262 & 737822 & 5.0 & 4.819 & TRN & \\
\hline CHEMBL1410859 & 737822 & 4.8 & 4.7111 & TRN & \\
\hline CHEMBL3197340 & 737822 & 7.6 & 5.29200 & 0000000001 & TRN \\
\hline CHEMBL1588068 & 737822 & 5.55 & 5.2216 & TST & \\
\hline CHEMBL3436365 & 737822 & 5.5 & 5.4365 & TRN & \\
\hline CHEMBL1430113 & 737822 & 4.8 & 5.0897 & TRN & \\
\hline CHEMBL581929 & 737822 & 4.8 & 5.3545 & TRN & \\
\hline CHEMBL105739 & 737822 & 6.4 & 5.9497 & TST & \\
\hline CHEMBL1574831 & 737822 & 5.0 & 5.3212 & TRN & \\
\hline CHEMBL565856 & 737822 & 6.3 & 6.0003 & TRN & \\
\hline CHEMBL1461759 & 737822 & 4.85 & 5.4683 & TRN & \\
\hline CHEMBL1404660 & 737822 & 5.0 & 4.9591 & TRN & \\
\hline CHEMBL1451037 & 737822 & 4.85 & 5.2055 & TST & \\
\hline CHEMBL1543685 & 737822 & 5.3 & 4.9301 & TST & \\
\hline CHEMBL1470566 & 737822 & 5.15 & 5.1661 & TRN & \\
\hline CHEMBL1587467 & 737822 & 5.05 & 5.3014 & TRN & \\
\hline CHEMBL1525571 & 737822 & 5.95 & 5.4319 & TRN & \\
\hline CHEMBL1527955 & 737822 & 6.45 & 5.3054 & TST & \\
\hline CHEMBL1413524 & 737822 & 5.05 & 5.3082 & TRN & \\
\hline CHEMBL1516622 & 737822 & 5.6 & 5.5751 & TRN & \\
\hline CHEMBL1600871 & 737822 & 4.9 & 5.4169 & TRN & \\
\hline & & & & 1128 & \\
\hline
\end{tabular}




\begin{tabular}{|c|c|c|c|c|c|}
\hline & & & & & \\
\hline CHEMBL1474613 & 737822 & 4.4 & 4.4342 & TRN & \\
\hline CHEMBL1458544 & 737822 & 8.0 & 5.2567 & TRN & \\
\hline CHEMBL1499919 & 737822 & 4.85 & 5.1026 & TRN & \\
\hline CHEMBL1472523 & 737822 & 7.1 & 6.4958 & TRN & \\
\hline CHEMBL1742378 & 737822 & 5.35 & 5.0232 & TRN & \\
\hline CHEMBL 2006154 & 737822 & 4.75 & $5.2920 e$ & 0000000001 & TRN \\
\hline CHEMBL1357724 & 737822 & 5.0 & 4.8681 & TRN & \\
\hline CHEMBL1576725 & 737822 & 4.9 & 5.0917 & TST & \\
\hline CHEMBL1399844 & 737822 & 4.55 & 5.3317 & TRN & \\
\hline CHEMBL1515374 & 737822 & 5.4 & 5.5949 & TRN & \\
\hline CHEMBL1256392 & 737822 & 4.5 & 4.5853 & TRN & \\
\hline CHEMBL1741639 & 737822 & 4.75 & 5.567 & TRN & \\
\hline CHEMBL1532736 & 737822 & 4.9 & 5.1416 & TRN & \\
\hline CHEMBL1718033 & 737822 & 8.0 & 5.3044 & TRN & \\
\hline CHEMBL1413343 & 737822 & 4.9 & 4.6326 & TRN & \\
\hline CHEMBL19439 & 737822 & 6.0 & 5.624 & TRN & \\
\hline CHEMBL317757 & 737822 & 6.2 & 5.9389 & TRN & \\
\hline CHEMBL1576355 & 737822 & 4.95 & 5.3305 & TST & \\
\hline CHEMBL 2002680 & 737822 & 4.55 & 5.2501 & TRN & \\
\hline CHEMBL1379086 & 737822 & 5.4 & 5.3479 & TRN & \\
\hline CHEMBL1555014 & 737822 & 4.4 & 4.3669 & TRN & \\
\hline CHEMBL48278 & 737822 & 4.7 & 4.7518 & TST & \\
\hline CHEMBL1454368 & 737822 & 4.6 & 5.2238 & TRN & \\
\hline CHEMBL1439210 & 737822 & 4.75 & 5.0837 & TRN & \\
\hline CHEMBL1608942 & 737822 & 5.1 & 5.5068 & TRN & \\
\hline CHEMBL1343101 & 737822 & 4.8 & 5.2958 & TST & \\
\hline CHEMBL1395027 & 737822 & 4.4 & 4.6049 & TRN & \\
\hline CHEMBL1497805 & 737822 & 4.85 & 5.3386 & TRN & \\
\hline CHEMBL104264 & 737822 & 4.6 & 4.7547 & TRN & \\
\hline CHEMBL1329197 & 737822 & 6.4 & 5.4913 & TRN & \\
\hline CHEMBL1560758 & 737822 & 4.9 & 4.7 & TRN & \\
\hline CHEMBL1706994 & 737822 & 4.8 & 5.3839 & TST & \\
\hline CHEMBL3212941 & 737822 & 4.45 & 5.2958 & TRN & \\
\hline CHEMBL1471600 & 737822 & 6.65 & 5.8065 & TRN & \\
\hline CHEMBL1553428 & 737822 & 4.6 & 4.7046 & TRN & \\
\hline CHEMBL1323684 & 737822 & 5.5 & 5.4996 & TRN & \\
\hline CHEMBL1461827 & 737822 & 4.8 & 5.3409 & TRN & \\
\hline CHEMBL1314906 & 737822 & 4.7 & 4.4669 & TRN & \\
\hline CHEMBL1741754 & 737822 & 4.95 & 5.521 & TRN & \\
\hline CHEMBL1595576 & 737822 & 5.0 & 4.8294 & TRN & \\
\hline CHEMBL1388234 & 737822 & 5.4 & 5.2953 & TRN & \\
\hline CHEMBL1406851 & 737822 & 5.5 & 5.2541 & TRN & \\
\hline CHEMBL1562047 & 737822 & 4.85 & 5.2754 & TRN & \\
\hline CHEMBL1380062 & 737822 & 4.55 & 5.1602 & TST & \\
\hline CHEMBL1605811 & 737822 & 5.0 & 5.2278 & TST & \\
\hline CHEMBL3197565 & 737822 & 4.95 & 5.1658 & TRN & \\
\hline CHEMBL1720282 & 737822 & 5.3 & 5.2619 & TRN & \\
\hline CHEMBL1601482 & 737822 & 4.55 & 5.28299 & 99999999995 & TRN \\
\hline & & & & 11282 & \\
\hline
\end{tabular}




\begin{tabular}{|c|c|c|c|c|}
\hline \multicolumn{5}{|c|}{ Supplemental Table S2.txt } \\
\hline CHEMBL1438371 & 737822 & 5.4 & 5.1303 & TRN \\
\hline CHEMBL1301946 & 737822 & 8.25 & 5.2412 & TRN \\
\hline CHEMBL1322864 & 737822 & 6.5 & 6.1276 & TRN \\
\hline CHEMBL1551122 & 737822 & 4.4 & 4.2753 & TRN \\
\hline CHEMBL189438 & 737822 & 6.4 & 5.8092 & TRN \\
\hline CHEMBL1331572 & 737822 & 4.85 & 5.4273 & TRN \\
\hline CHEMBL1362918 & 737822 & 4.85 & 5.3871 & TST \\
\hline CHEMBL1376723 & 737822 & 4.5 & 4.6352 & TST \\
\hline CHEMBL1404940 & 737822 & 5.1 & 5.5722 & TRN \\
\hline CHEMBL3208849 & 737822 & 6.0 & 5.2864 & TRN \\
\hline CHEMBL1452391 & 737822 & 4.95 & 5.4313 & TRN \\
\hline CHEMBL1310248 & 737822 & 4.9 & 5.3155 & TRN \\
\hline CHEMBL1329402 & 737822 & 4.8 & 5.2147 & TRN \\
\hline CHEMBL1413654 & 737822 & 4.9 & 5.2599 & TRN \\
\hline CHEMBL1522972 & 737822 & 5.7 & 5.2922 & TRN \\
\hline CHEMBL1315637 & 737822 & 5.0 & 4.8438 & TRN \\
\hline CHEMBL1321535 & 737822 & 5.3 & 5.1669 & TRN \\
\hline CHEMBL1476407 & 737822 & 5.1 & 4.9781 & TRN \\
\hline CHEMBL1363467 & 737822 & 4.7 & 4.5066 & TRN \\
\hline CHEMBL1358122 & 737822 & 4.8 & 4.5853 & TRN \\
\hline CHEMBL1532991 & 737822 & 5.3 & 5.1872 & TRN \\
\hline CHEMBL1475284 & 737822 & 4.9 & 4.7766 & TRN \\
\hline CHEMBL1726069 & 737822 & 5.4 & 5.3553 & TST \\
\hline CHEMBL1519829 & 737822 & 4.9 & 5.1139 & TRN \\
\hline CHEMBL107528 & 737822 & 5.1 & 5.0524 & TST \\
\hline CHEMBL1440108 & 737822 & 4.85 & 5.3723 & TST \\
\hline CHEMBL1317461 & 737822 & 6.2 & 5.6635 & TRN \\
\hline CHEMBL1441404 & 737822 & 5.7 & 5.5252 & TRN \\
\hline CHEMBL1315716 & 737822 & 5.0 & 4.8375 & TRN \\
\hline CHEMBL1377507 & 737822 & 6.8 & 6.2543 & TST \\
\hline CHEMBL1314647 & 737822 & 5.6 & 5.4709 & TRN \\
\hline CHEMBL1506550 & 737822 & 5.2 & 5.4539 & TRN \\
\hline CHEMBL 22075 & 737822 & 6.6 & 6.2868 & TRN \\
\hline CHEMBL1572174 & 737822 & 4.9 & 5.1413 & TRN \\
\hline CHEMBL1520442 & 737822 & 4.4 & 4.4254 & TRN \\
\hline CHEMBL1425640 & 737822 & 4.85 & 5.4581 & TST \\
\hline CHEMBL1501374 & 737822 & 4.85 & 5.5051 & TRN \\
\hline CHEMBL1593867 & 737822 & 5.1 & 5.0142 & TRN \\
\hline CHEMBL1985310 & 737822 & 4.85 & 5.4534 & TST \\
\hline CHEMBL1595145 & 737822 & 4.95 & 5.3139 & TST \\
\hline CHEMBL522600 & 737822 & 5.7 & 5.4326 & TRN \\
\hline CHEMBL1358583 & 737822 & 5.7 & 5.3797 & TRN \\
\hline CHEMBL1704069 & 737822 & 5.1 & 5.5702 & TRN \\
\hline CHEMBL1494100 & 737822 & 4.7 & 5.1446 & TRN \\
\hline CHEMBL1388180 & 737822 & 4.6 & 5.3471 & TST \\
\hline CHEMBL1566015 & 737822 & 5.65 & 5.0974 & TRN \\
\hline CHEMBL1445840 & 737822 & 4.65 & 5.343 & TRN \\
\hline CHEMBL1398351 & 737822 & 6.5 & 6.0425 & TST \\
\hline
\end{tabular}




\begin{tabular}{|c|c|c|c|c|}
\hline & & & pplement & al $\mathrm{Ta}$ \\
\hline CHEMBL1255649 & 737822 & 6.0 & 5.6545 & TST \\
\hline CHEMBL1321719 & 737822 & 5.45 & 5.082 & TRN \\
\hline CHEMBL1555308 & 737822 & 5.1 & 5.3003 & TRN \\
\hline CHEMBL1331148 & 737822 & 5.9 & 5.6898 & TRN \\
\hline CHEMBL1469460 & 737822 & 4.65 & 5.4963 & TRN \\
\hline CHEMBL1353611 & 737822 & 4.85 & 5.3792 & TRN \\
\hline CHEMBL47940 & 737822 & 4.5 & 4.5584 & TST \\
\hline CHEMBL1741829 & 737822 & 4.85 & 5.2946 & TRN \\
\hline CHEMBL1568129 & 737822 & 5.1 & 4.8882 & TRN \\
\hline CHEMBL1431724 & 737822 & 5.0 & 5.218 & TST \\
\hline CHEMBL1358628 & 737822 & 6.0 & 5.7122 & TRN \\
\hline CHEMBL1437905 & 737822 & 4.75 & 5.1334 & TRN \\
\hline CHEMBL1336469 & 737822 & 5.0 & 5.1856 & TRN \\
\hline CHEMBL1474016 & 737822 & 6.2 & 5.9762 & TRN \\
\hline CHEMBL1741405 & 737822 & 4.6 & 5.3849 & TST \\
\hline CHEMBL3190830 & 737822 & 4.9 & 5.3272 & TST \\
\hline CHEMBL1596499 & 737822 & 4.6 & 4.4811 & TRN \\
\hline CHEMBL1476139 & 737822 & 4.9 & 5.0893 & TRN \\
\hline CHEMBL1383364 & 737822 & 4.8 & 5.3999 & TRN \\
\hline CHEMBL1476871 & 737822 & 6.6 & 6.2708 & TRN \\
\hline CHEMBL1471546 & 737822 & 4.8 & 5.2858 & TST \\
\hline CHEMBL1484253 & 737822 & 4.7 & 4.5236 & TRN \\
\hline CHEMBL1515802 & 737822 & 5.3 & 5.4245 & TRN \\
\hline CHEMBL1319432 & 737822 & 4.8 & 4.8353 & TST \\
\hline CHEMBL1493037 & 737822 & 4.9 & 5.1007 & TST \\
\hline CHEMBL1603803 & 737822 & 5.0 & 5.2213 & TRN \\
\hline CHEMBL1495091 & 737822 & 4.6 & 5.3182 & TRN \\
\hline CHEMBL1485500 & 737822 & 5.5 & 5.3382 & TRN \\
\hline CHEMBL1319789 & 737822 & 5.7 & 5.5149 & TRN \\
\hline CHEMBL1316893 & 737822 & 4.7 & 4.5073 & TRN \\
\hline CHEMBL3209784 & 737822 & 4.8 & 5.3706 & TST \\
\hline CHEMBL1451794 & 737822 & 5.6 & 5.6709 & TRN \\
\hline CHEMBL1359930 & 737822 & 5.5 & 5.3641 & TRN \\
\hline CHEMBL1332471 & 737822 & 4.9 & 4.5822 & TRN \\
\hline CHEMBL1335889 & 737822 & 5.5 & 5.1575 & TRN \\
\hline CHEMBL1306752 & 737822 & 4.8 & 5.2316 & TRN \\
\hline CHEMBL1472837 & 737822 & 5.4 & 5.3826 & TRN \\
\hline CHEMBL1447682 & 737822 & 5.2 & 5.2716 & TRN \\
\hline CHEMBL1591543 & 737822 & 5.0 & 4.7671 & TRN \\
\hline CHEMBL15134 & 737822 & 6.0 & 5.7871 & TST \\
\hline CHEMBL1562791 & 737822 & 4.7 & 4.5832 & TRN \\
\hline CHEMBL1472129 & 737822 & 7.2 & 5.4302 & TRN \\
\hline CHEMBL1996020 & 737822 & 5.15 & 5.2627 & TRN \\
\hline CHEMBL1473205 & 737822 & 5.1 & 5.8551 & TRN \\
\hline CHEMBL1592500 & 737822 & 5.5 & 5.8058 & TST \\
\hline CHEMBL1554459 & 737822 & 5.5 & 5.3766 & TRN \\
\hline CHEMBL491555 & 737822 & 5.1 & 4.9192 & TRN \\
\hline CHEMBL1358342 & 737822 & 4.4 & 4.3523 & TRN \\
\hline
\end{tabular}




\begin{tabular}{|c|c|c|c|c|c|}
\hline \multicolumn{6}{|c|}{ Supplemental Table S2.txt } \\
\hline CHEMBL1383753 & 737822 & 4.7 & 5.325 & TRN & \\
\hline CHEMBL1380396 & 737822 & 6.95 & 5.3021 & TRN & \\
\hline CHEMBL1556377 & 737822 & 5.5 & 5.2005 & TRN & \\
\hline CHEMBL1555122 & 737822 & 4.9 & 4.6583 & TRN & \\
\hline CHEMBL1525916 & 737822 & 4.6 & 5.3288 & TRN & \\
\hline CHEMBL1307198 & 737822 & 4.6 & 5.5771 & TRN & \\
\hline CHEMBL1527195 & 737822 & 4.9 & 5.4522 & TRN & \\
\hline CHEMBL1472779 & 737822 & 4.8 & 4.7439 & TRN & \\
\hline CHEMBL1391723 & 737822 & 5.4 & 5.2008 & TRN & \\
\hline CHEMBL1590458 & 737822 & 4.4 & 4.4028 & TRN & \\
\hline CHEMBL1514572 & 737822 & 6.0 & 5.8224 & TRN & \\
\hline CHEMBL1447946 & 737822 & 4.9 & 4.776 & TRN & \\
\hline CHEMBL1455802 & 737822 & 4.75 & 5.2875 & TRN & \\
\hline CHEMBL1484127 & 737822 & 6.1 & 5.8179 & TRN & \\
\hline CHEMBL1408879 & 737822 & 5.5 & 5.3168 & TRN & \\
\hline CHEMBL450493 & 737822 & 4.9 & 4.7047 & TRN & \\
\hline CHEMBL1363481 & 737822 & 4.7 & 4.6806 & TRN & \\
\hline CHEMBL1454841 & 737822 & 4.85 & 4.962 & TRN & \\
\hline CHEMBL1584779 & 737822 & 4.65 & 5.1934 & TST & \\
\hline CHEMBL1313693 & 737822 & 4.8 & 5.3582 & TST & \\
\hline CHEMBL1597203 & 737822 & 6.4 & 5.222 & TRN & \\
\hline CHEMBL1334145 & 737822 & 5.25 & 5.2357 & TRN & \\
\hline CHEMBL1722408 & 737822 & 5.5 & 5.0416 & TRN & \\
\hline CHEMBL1510151 & 737822 & 4.6 & 5.0803 & TRN & \\
\hline CHEMBL1603124 & 737822 & 5.1 & 5.4029 & TST & \\
\hline CHEMBL1525558 & 737822 & 4.85 & 5.3817 & TST & \\
\hline CHEMBL1387144 & 737822 & 4.9 & 5.3069 & TRN & \\
\hline CHEMBL491940 & 737822 & 5.1 & 4.9565 & TRN & \\
\hline CHEMBL1496125 & 737822 & 5.5 & 5.32100 & 0000000001 & TRN \\
\hline CHEMBL1319093 & 737822 & 4.9 & 4.7256 & TRN & \\
\hline CHEMBL1373998 & 737822 & 5.5 & 5.3651 & TRN & \\
\hline CHEMBL1299856 & 737822 & 5.25 & 5.2785 & TRN & \\
\hline CHEMBL1606199 & 737822 & 4.4 & 4.3656 & TRN & \\
\hline CHEMBL1742228 & 737822 & 5.85 & 5.1876 & TRN & \\
\hline CHEMBL1322757 & 737822 & 4.4 & 4.4075 & TRN & \\
\hline CHEMBL1311780 & 737822 & 4.45 & 5.331 & TRN & \\
\hline CHEMBL1719114 & 737822 & 4.8 & 5.3009 & TRN & \\
\hline CHEMBL1338083 & 737822 & 5.9 & 5.42299 & 9999999999 & TRN \\
\hline CHEMBL1533658 & 737822 & 5.0 & 5.4649 & TRN & \\
\hline CHEMBL1467219 & 737822 & 6.55 & 5.0005 & TRN & \\
\hline CHEMBL1550134 & 737822 & 4.7 & 5.5708 & TRN & \\
\hline CHEMBL434063 & 737822 & 7.5 & 6.6864 & TST & \\
\hline CHEMBL1373907 & 737822 & 4.4 & 4.2939 & TRN & \\
\hline CHEMBL 9225 & 737822 & 4.8 & 4.9194 & TRN & \\
\hline CHEMBL1370189 & 737822 & 5.6 & 5.3517 & TRN & \\
\hline CHEMBL3199540 & 737822 & 4.75 & 5.442 & TRN & \\
\hline CHEMBL258405 & 737822 & 4.7 & 4.7742 & TST & \\
\hline CHEMBL1367220 & 737822 & 4.6 & 5.0023 & TRN & \\
\hline
\end{tabular}




\begin{tabular}{|c|c|c|c|c|}
\hline \multicolumn{5}{|c|}{ Supplemental Table S2.txt } \\
\hline CHEMBL1416795 & 737822 & 5.4 & 5.3337 & TRN \\
\hline CHEMBL1586835 & 737822 & 4.7 & 5.0293 & TRN \\
\hline CHEMBL1419738 & 737822 & 6.15 & 5.2236 & TRN \\
\hline CHEMBL1437990 & 737822 & 5.4 & 5.3697 & TRN \\
\hline CHEMBL489737 & 737822 & 5.0 & 4.8757 & TRN \\
\hline CHEMBL1404928 & 737822 & 8.0 & 5.4635 & TRN \\
\hline CHEMBL1561910 & 737822 & 5.35 & 5.3795 & TRN \\
\hline CHEMBL1400275 & 737822 & 5.0 & 5.0676 & TRN \\
\hline CHEMBL1256836 & 737822 & 4.8 & 5.0082 & TRN \\
\hline CHEMBL1734782 & 737822 & 4.55 & 5.2126 & TST \\
\hline CHEMBL1442987 & 737822 & 6.0 & 5.9288 & TRN \\
\hline CHEMBL3211462 & 737822 & 4.6 & 5.3316 & TST \\
\hline CHEMBL1432676 & 737822 & 6.05 & 5.331 & TST \\
\hline CHEMBL1256866 & 737822 & 4.5 & 4.7459 & TRN \\
\hline CHEMBL1319286 & 737822 & 4.7 & 4.5273 & TRN \\
\hline CHEMBL1489182 & 737822 & 5.0 & 4.8623 & TRN \\
\hline CHEMBL1441737 & 737822 & 4.7 & 4.5599 & TRN \\
\hline CHEMBL1479296 & 737822 & 5.5 & 5.1824 & TRN \\
\hline CHEMBL1333742 & 737822 & 6.3 & 5.1663 & TRN \\
\hline CHEMBL1304293 & 737822 & 7.15 & 5.6037 & TRN \\
\hline CHEMBL1570350 & 737822 & 6.3 & 5.8604 & TRN \\
\hline CHEMBL137648 & 737822 & 5.5 & 5.3712 & TRN \\
\hline CHEMBL1527958 & 737822 & 6.4 & 6.1645 & TRN \\
\hline CHEMBL1564113 & 737822 & 4.9 & 4.9523 & TRN \\
\hline CHEMBL1547490 & 737822 & 5.0 & 5.6631 & TRN \\
\hline CHEMBL1567805 & 737822 & 7.35 & 5.2188 & TRN \\
\hline CHEMBL1535207 & 737822 & 5.2 & 5.109 & TST \\
\hline CHEMBL492121 & 737822 & 5.6 & 5.3715 & TRN \\
\hline CHEMBL1369062 & 737822 & 4.7 & 4.7619 & TRN \\
\hline CHEMBL1519576 & 737822 & 4.8 & 5.2039 & TRN \\
\hline CHEMBL1357401 & 737822 & 4.5 & 4.5867 & TRN \\
\hline CHEMBL1315459 & 737822 & 5.9 & 5.6952 & TST \\
\hline CHEMBL1359298 & 737822 & 5.85 & 5.5784 & TRN \\
\hline CHEMBL1591189 & 737822 & 5.4 & 5.4104 & TST \\
\hline CHEMBL1384802 & 737822 & 4.75 & 4.9719 & TRN \\
\hline CHEMBL1592289 & 737822 & 4.9 & 4.8025 & TRN \\
\hline CHEMBL1408140 & 737822 & 7.5 & 5.2694 & TRN \\
\hline CHEMBL1308726 & 737822 & 5.05 & 5.3955 & TRN \\
\hline CHEMBL1450275 & 737822 & 4.9 & 5.2537 & TRN \\
\hline CHEMBL1355963 & 737822 & 5.0 & 5.0423 & TST \\
\hline CHEMBL1323549 & 737822 & 4.4 & 4.4181 & TRN \\
\hline CHEMBL1593096 & 737822 & 6.2 & 5.9332 & TRN \\
\hline CHEMBL1520292 & 737822 & 4.4 & 4.3178 & TRN \\
\hline CHEMBL1533962 & 737822 & 4.65 & 5.4172 & TRN \\
\hline CHEMBL1474568 & 737822 & 4.9 & 4.8135 & TRN \\
\hline CHEMBL1397596 & 737822 & 5.3 & 5.1855 & TRN \\
\hline CHEMBL3211454 & 737822 & 4.9 & 5.4054 & TRN \\
\hline CHEMBL1473188 & 737822 & 5.2 & 5.1306 & TRN \\
\hline
\end{tabular}




\begin{tabular}{|c|c|c|c|c|}
\hline & & & ent & al Ta \\
\hline CHEMBL1437876 & 737822 & 5.0 & 5.0159 & TRN \\
\hline CHEMBL1356029 & 737822 & 5.1 & 4.8039 & TRN \\
\hline CHEMBL1596743 & 737822 & 5.6 & 5.3439 & TRN \\
\hline CHEMBL1513654 & 737822 & 7.2 & 6.7573 & TST \\
\hline CHEMBL1353886 & 737822 & 4.6 & 5.3008 & TRN \\
\hline CHEMBL1561366 & 737822 & 5.2 & 5.026 & TRN \\
\hline CHEMBL3213877 & 737822 & 4.6 & 5.3663 & TRN \\
\hline CHEMBL1534897 & 737822 & 4.9 & 5.2053 & TRN \\
\hline CHEMBL609628 & 737822 & 5.15 & 5.4859 & TST \\
\hline CHEMBL1605922 & 737822 & 5.75 & 5.4385 & TRN \\
\hline CHEMBL1613349 & 737822 & 5.35 & 5.3322 & TRN \\
\hline CHEMBL1437007 & 737822 & 4.5 & 4.4539 & TRN \\
\hline CHEMBL1500867 & 737822 & 4.55 & 4.9613 & TRN \\
\hline CHEMBL1357180 & 737822 & 4.7 & 4.5945 & TRN \\
\hline CHEMBL1529327 & 737822 & 4.85 & 5.2608 & TRN \\
\hline CHEMBL1355896 & 737822 & 5.5 & 5.3781 & TRN \\
\hline CHEMBL 602314 & 737822 & 4.7 & 5.395 & TRN \\
\hline CHEMBL1487191 & 737822 & 5.1 & 4.8561 & TRN \\
\hline CHEMBL490717 & 737822 & 4.9 & 4.8597 & TRN \\
\hline CHEMBL3195732 & 737822 & 5.45 & 5.1943 & TST \\
\hline CHEMBL 1565852 & 737822 & 4.7 & 5.4938 & TRN \\
\hline CHEMBL1988621 & 737822 & 4.6 & 5.2459 & TRN \\
\hline CHEMBL27441 & 737822 & 6.6 & 6.2323 & TST \\
\hline CHEMBL1611715 & 737822 & 5.3 & 5.2804 & TRN \\
\hline CHEMBL425403 & 737822 & 5.8 & 5.725 & TST \\
\hline CHEMBL1310477 & 737822 & 4.85 & 5.1949 & TRN \\
\hline CHEMBL1363587 & 737822 & 5.55 & 5.471 & TRN \\
\hline CHEMBL1415310 & 737822 & 5.05 & 5.1102 & TRN \\
\hline CHEMBL1255655 & 737822 & 4.9 & 4.9587 & TST \\
\hline CHEMBL1457494 & 737822 & 5.3 & 5.1508 & TRN \\
\hline CHEMBL1473379 & 737822 & 4.7 & 4.7208 & TRN \\
\hline CHEMBL1317869 & 737822 & 4.9 & 4.8672 & TRN \\
\hline CHEMBL1529665 & 737822 & 7.0 & 6.3904 & TST \\
\hline CHEMBL1422230 & 737822 & 6.2 & 5.3185 & TRN \\
\hline CHEMBL1451768 & 737822 & 4.8 & 4.5955 & TRN \\
\hline CHEMBL1445702 & 737822 & 4.9 & 5.0227 & TRN \\
\hline CHEMBL1600497 & 737822 & 6.3 & 6.0426 & TRN \\
\hline CHEMBL1592209 & 737822 & 4.7 & 4.5865 & TRN \\
\hline CHEMBL1355701 & 737822 & 4.4 & 4.3853 & TRN \\
\hline CHEMBL1460192 & 737822 & 5.4 & 5.8505 & TST \\
\hline CHEMBL1592663 & 737822 & 5.9 & 5.7304 & TST \\
\hline CHEMBL1443376 & 737822 & 4.8 & 4.7873 & TRN \\
\hline CHEMBL56731 & 737822 & 4.4 & 4.4899 & TRN \\
\hline CHEMBL1547626 & 737822 & 4.65 & 5.1035 & TRN \\
\hline CHEMBL 3214477 & 737822 & 4.6 & 5.2413 & TRN \\
\hline CHEMBL1437171 & 737822 & 5.5 & 5.3784 & TST \\
\hline CHEMBL1336727 & 737822 & 4.5 & 4.6859 & TRN \\
\hline CHEMBL 7257 & 737822 & 4.7 & 4.7407 & TRN \\
\hline
\end{tabular}




\begin{tabular}{|c|c|c|c|c|}
\hline & & & pplement & al $\mathrm{Ta}$ \\
\hline CHEMBL1601970 & 737822 & 4.5 & 5.2137 & TRN \\
\hline CHEMBL1405203 & 737822 & 6.0 & 5.2564 & TRN \\
\hline CHEMBL1420945 & 737822 & 4.55 & 5.0236 & TRN \\
\hline CHEMBL1538763 & 737822 & 4.6 & 5.0969 & TRN \\
\hline CHEMBL1478520 & 737822 & 4.45 & 5.1532 & TRN \\
\hline CHEMBL1489961 & 737822 & 8.0 & 5.1694 & TRN \\
\hline CHEMBL1341789 & 737822 & 4.5 & 5.2273 & TRN \\
\hline CHEMBL1473755 & 737822 & 5.1 & 4.8974 & TRN \\
\hline CHEMBL1356808 & 737822 & 4.8 & 4.7136 & TRN \\
\hline CHEMBL1393468 & 737822 & 4.9 & 5.5109 & TRN \\
\hline CHEMBL1520177 & 737822 & 4.6 & 5.3035 & TRN \\
\hline CHEMBL440084 & 737822 & 4.9 & 4.9691 & TRN \\
\hline CHEMBL287327 & 737822 & 4.9 & 4.8975 & TST \\
\hline CHEMBL1466432 & 737822 & 4.8 & 4.8467 & TRN \\
\hline CHEMBL1416476 & 737822 & 5.4 & 5.0976 & TRN \\
\hline CHEMBL159096 & 737822 & 5.0 & 5.0743 & TST \\
\hline CHEMBL1404882 & 737822 & 4.9 & 4.8028 & TRN \\
\hline CHEMBL1403982 & 737822 & 5.8 & 5.5172 & TRN \\
\hline CHEMBL1337991 & 737822 & 4.55 & 5.1526 & TST \\
\hline CHEMBL1409320 & 737822 & 7.3 & 6.3244 & TRN \\
\hline CHEMBL1355387 & 737822 & 6.0 & 5.6448 & TRN \\
\hline CHEMBL3191940 & 737822 & 4.85 & 5.2688 & TST \\
\hline CHEMBL1356336 & 737822 & 5.8 & 5.444 & TRN \\
\hline CHEMBL1470690 & 737822 & 4.85 & 5.2608 & TRN \\
\hline CHEMBL1593438 & 737822 & 4.7 & 4.6657 & TRN \\
\hline CHEMBL1585534 & 737822 & 5.45 & 5.3384 & TRN \\
\hline CHEMBL1446649 & 737822 & 4.6 & 4.4712 & TRN \\
\hline CHEMBL1603186 & 737822 & 5.0 & 4.8309 & TRN \\
\hline CHEMBL1490998 & 737822 & 4.8 & 4.8181 & TRN \\
\hline CHEMBL1369212 & 737822 & 6.0 & 5.8996 & TRN \\
\hline CHEMBL1329194 & 737822 & 4.65 & 5.2241 & TST \\
\hline CHEMBL1525180 & 737822 & 5.0 & 4.9729 & TRN \\
\hline CHEMBL1417581 & 737822 & 6.0 & 5.4165 & TRN \\
\hline CHEMBL1529384 & 737822 & 5.5 & 5.3192 & TRN \\
\hline CHEMBL1357558 & 737822 & 6.0 & 6.2053 & TRN \\
\hline CHEMBL1601015 & 737822 & 4.8 & 5.2301 & TRN \\
\hline CHEMBL1603852 & 737822 & 4.7 & 4.5752 & TRN \\
\hline CHEMBL1476741 & 737822 & 4.55 & 5.3251 & TRN \\
\hline CHEMBL1330114 & 737822 & 6.0 & 5.7421 & TRN \\
\hline CHEMBL44297 & 737822 & 4.5 & 4.7277 & TST \\
\hline CHEMBL1587070 & 737822 & 4.6 & 5.3109 & TRN \\
\hline CHEMBL1436882 & 737822 & 4.8 & 4.7041 & TST \\
\hline CHEMBL1331410 & 737822 & 4.9 & 4.687 & TRN \\
\hline CHEMBL1510194 & 737822 & 4.85 & 5.6081 & TRN \\
\hline CHEMBL1473099 & 737822 & 4.8 & 4.6409 & TRN \\
\hline CHEMBL1493496 & 737822 & 4.5 & 4.4281 & TRN \\
\hline CHEMBL1981840 & 737822 & 5.3 & 5.3575 & TST \\
\hline CHEMBL1590980 & 737822 & 6.7 & 6.1728 & TRN \\
\hline
\end{tabular}




\begin{tabular}{|c|c|c|c|c|c|}
\hline & & & & & \\
\hline CHEMBL1256998 & 737822 & 5.9 & 5.6239 & TRN & \\
\hline CHEMBL1450157 & 737822 & 8.5 & 5.3558 & TRN & \\
\hline CHEMBL1716016 & 737822 & 4.6 & 5.1872 & TRN & \\
\hline CHEMBL1441287 & 737822 & 4.6 & 4.5491 & TRN & \\
\hline CHEMBL1311630 & 737822 & 5.35 & 5.169 & TRN & \\
\hline CHEMBL547101 & 737822 & 4.85 & 5.32 & TRN & \\
\hline CHEMBL1481747 & 737822 & 4.6 & 4.5945 & TRN & \\
\hline CHEMBL1426826 & 737822 & 4.95 & 5.3562 & TRN & \\
\hline CHEMBL16687 & 737822 & 4.9 & 4.7778 & TRN & \\
\hline CHEMBL1419308 & 737822 & 4.7 & 5.2974 & TRN & \\
\hline CHEMBL18686 & 737822 & -0.0 & 5.5543 & TST & \\
\hline CHEMBL1551732 & 737822 & 5.4 & 5.3944 & TRN & \\
\hline CHEMBL472994 & 737822 & 5.5 & 5.2794 & TST & \\
\hline CHEMBL1601908 & 737822 & 4.8 & 4.6127 & TRN & \\
\hline CHEMBL87285 & 737822 & 4.9 & 4.9525 & TST & \\
\hline CHEMBL3198933 & 737822 & 4.6 & 5.2232 & TRN & \\
\hline CHEMBL1599163 & 737822 & 4.4 & 4.2876 & TRN & \\
\hline CHEMBL1600243 & 737822 & 5.15 & 5.4241 & TRN & \\
\hline CHEMBL1524127 & 737822 & 4.85 & 5.26 & TRN & \\
\hline CHEMBL1491744 & 737822 & 5.0 & 4.7726 & TRN & \\
\hline CHEMBL1585833 & 737822 & 5.45 & 5.3481 & TST & \\
\hline CHEMBL1364980 & 737822 & 5.0 & 5.0262 & TRN & \\
\hline CHEMBL1506638 & 737822 & 5.05 & 5.216 & TRN & \\
\hline CHEMBL1336166 & 737822 & 4.6 & 4.6864 & TRN & \\
\hline CHEMBL1344743 & 737822 & 4.85 & 5.474 & TRN & \\
\hline CHEMBL1492087 & 737822 & 5.6 & 5.3432 & TRN & \\
\hline CHEMBL1358263 & 737822 & 4.8 & 4.614 & TRN & \\
\hline CHEMBL1546161 & 737822 & 5.45 & 5.0929 & TRN & \\
\hline CHEMBL1354190 & 737822 & 5.3 & 5.2357 & TST & \\
\hline CHEMBL1364243 & 737822 & 6.0 & 5.8875 & TRN & \\
\hline CHEMBL1435450 & 737822 & 4.6 & 4.4726 & TRN & \\
\hline CHEMBL1517643 & 737822 & 5.6 & 5.4155 & TRN & \\
\hline CHEMBL1516262 & 737822 & 4.4 & 4.5052 & TRN & \\
\hline CHEMBL1319038 & 737822 & 4.95 & 5.3154 & TRN & \\
\hline CHEMBL1317986 & 737822 & 5.4 & 5.2661 & TRN & \\
\hline CHEMBL1409689 & 737822 & 4.9 & 4.6808 & TRN & \\
\hline CHEMBL1568684 & 737822 & 5.0 & 5.5305 & TST & \\
\hline CHEMBL1991234 & 737822 & 4.85 & 5.4872 & TST & \\
\hline CHEMBL1513669 & 737822 & 5.3 & 5.045 & TRN & \\
\hline CHEMBL1601416 & 737822 & 4.9 & 4.8187 & TRN & \\
\hline CHEMBL1520216 & 737822 & 4.8 & 4.6166 & TRN & \\
\hline CHEMBL18879 & 737822 & 8.2 & 7.0139 & TST & \\
\hline CHEMBL1514110 & 737822 & 4.7 & 4.711 & TRN & \\
\hline CHEMBL3195611 & 737822 & 5.0 & 5.3191 & TRN & \\
\hline CHEMBL1466490 & 737822 & 4.85 & 5.3492 & TRN & \\
\hline CHEMBL1330957 & 737822 & 6.5 & 6.1595 & TRN & \\
\hline CHEMBL1586735 & 737822 & 4.85 & 5.1784 & TRN & \\
\hline CHEMBL1403831 & 737822 & 5.45 & 5.29299 & 9999999999 & TRN \\
\hline & & & & 11289 & \\
\hline
\end{tabular}




\begin{tabular}{|c|c|c|c|c|c|}
\hline \multicolumn{6}{|c|}{ Supplemental Table S2.txt } \\
\hline CHEMBL3210111 & 737822 & 4.95 & 5.4859 & TRN & \\
\hline CHEMBL1375321 & 737822 & 4.85 & 5.1977 & TRN & \\
\hline CHEMBL1399394 & 737822 & 4.7 & 4.484 & TRN & \\
\hline CHEMBL1359761 & 737822 & 4.9 & 5.3227 & TRN & \\
\hline CHEMBL1446467 & 737822 & 5.4 & 5.2804 & TRN & \\
\hline CHEMBL1565888 & 737822 & 5.05 & 5.3018 & TRN & \\
\hline CHEMBL1591508 & 737822 & 5.3 & 5.315 & TRN & \\
\hline CHEMBL1340514 & 737822 & 5.05 & 5.4092 & TRN & \\
\hline CHEMBL1486506 & 737822 & 5.15 & 5.2456 & TRN & \\
\hline CHEMBL1570633 & 737822 & 4.6 & 4.4954 & TRN & \\
\hline CHEMBL1349471 & 737822 & 5.5 & 5.2522 & TRN & \\
\hline CHEMBL1570413 & 737822 & 4.7 & 4.5451 & TRN & \\
\hline CHEMBL1572371 & 737822 & 4.6 & 5.1575 & TRN & \\
\hline CHEMBL1522579 & 737822 & 6.25 & 5.2437 & TRN & \\
\hline CHEMBL1318495 & 737822 & 5.3 & 5.0997 & TRN & \\
\hline CHEMBL1413058 & 737822 & 4.85 & 5.4132 & TRN & \\
\hline CHEMBL1436049 & 737822 & 5.8 & 5.4328 & TRN & \\
\hline CHEMBL1437700 & 737822 & 5.5 & 5.3743 & TRN & \\
\hline CHEMBL1544332 & 737822 & 5.5 & 5.1455 & TRN & \\
\hline CHEMBL 1483700 & 737822 & -0.0 & 4.6973 & TRN & \\
\hline CHEMBL1341070 & 737822 & 4.75 & 5.3454 & TRN & \\
\hline CHEMBL1534143 & 737822 & 4.6 & 5.435 & TRN & \\
\hline CHEMBL1561570 & 737822 & 7.05 & 5.5075 & TRN & \\
\hline CHEMBL1390555 & 737822 & 4.95 & 5.4571 & TRN & \\
\hline CHEMBL1448411 & 737822 & 5.1 & 5.4917 & TRN & \\
\hline CHEMBL1373464 & 737822 & 4.5 & 4.7113 & TRN & \\
\hline CHEMBL1498788 & 737822 & 4.95 & 5.2724 & TRN & \\
\hline CHEMBL1467110 & 737822 & 4.8 & 5.3527 & TST & \\
\hline CHEMBL1457332 & 737822 & 5.7 & 5.9725 & TRN & \\
\hline CHEMBL1727631 & 737822 & 4.85 & 5.6253 & TRN & \\
\hline CHEMBL1369948 & 737822 & 5.4 & 5.4356 & TRN & \\
\hline CHEMBL1405538 & 737822 & 5.0 & 4.9473 & TRN & \\
\hline CHEMBL1742011 & 737822 & 5.55 & 5.2981 & TRN & \\
\hline CHEMBL1472753 & 737822 & 4.4 & 4.44600 & 0000000001 & TRN \\
\hline CHEMBL1435698 & 737822 & 5.0 & 4.7149 & TRN & \\
\hline CHEMBL1427943 & 737822 & 4.6 & 5.3668 & TRN & \\
\hline CHEMBL1562663 & 737822 & 5.0 & 4.882 & TRN & \\
\hline CHEMBL 25236 & 737822 & 6.0 & 5.7376 & TRN & \\
\hline CHEMBL1336796 & 737822 & 5.5 & 5.2622 & TRN & \\
\hline CHEMBL1501148 & 737822 & 4.85 & 5.1403 & TRN & \\
\hline CHEMBL 74121 & 737822 & 6.0 & 5.7299 & TST & \\
\hline CHEMBL1626013 & 737822 & 6.35 & 5.6149 & TRN & \\
\hline CHEMBL12129 & 737822 & 5.3 & 5.5833 & TRN & \\
\hline CHEMBL1357674 & 737822 & 4.6 & 4.7845 & TST & \\
\hline CHEMBL1530955 & 737822 & 4.85 & 5.4309 & TRN & \\
\hline CHEMBL1741558 & 737822 & 4.9 & 5.3474 & TRN & \\
\hline CHEMBL 1406703 & 737822 & 4.5 & 5.4872 & TRN & \\
\hline CHEMBL1364298 & 737822 & 5.85 & 5.2793 & TRN & \\
\hline
\end{tabular}




\begin{tabular}{|c|c|c|c|c|}
\hline \multicolumn{5}{|c|}{ Supplemental Table S2.txt } \\
\hline CHEMBL1554937 & 737822 & 4.8 & 4.6734 & TRN \\
\hline CHEMBL1503232 & 737822 & 4.95 & 5.7226 & TRN \\
\hline CHEMBL404505 & 737822 & 4.4 & 4.4874 & TST \\
\hline CHEMBL1741364 & 737822 & 4.9 & 5.4023 & TRN \\
\hline CHEMBL1514779 & 737822 & 5.0 & 4.8799 & TRN \\
\hline CHEMBL1406644 & 737822 & 4.95 & 5.5409 & TRN \\
\hline CHEMBL1547788 & 737822 & 6.3 & 5.5621 & TRN \\
\hline CHEMBL1333030 & 737822 & 5.95 & 5.4009 & TST \\
\hline CHEMBL1423034 & 737822 & 4.9 & 5.4594 & TRN \\
\hline CHEMBL1599748 & 737822 & 5.6 & 5.4231 & TRN \\
\hline CHEMBL1437011 & 737822 & 5.5 & 5.2594 & TRN \\
\hline CHEMBL1465487 & 737822 & 5.05 & 5.4352 & TRN \\
\hline CHEMBL1314465 & 737822 & 5.7 & 5.5143 & TRN \\
\hline CHEMBL1475860 & 737822 & 5.5 & 5.4403 & TRN \\
\hline CHEMBL1610132 & 737822 & 4.55 & 5.5204 & TRN \\
\hline CHEMBL1323732 & 737822 & 5.95 & 5.4489 & TRN \\
\hline CHEMBL1256957 & 737822 & 6.0 & 5.7447 & TRN \\
\hline CHEMBL1571975 & 737822 & 5.8 & 5.7872 & TRN \\
\hline CHEMBL1322818 & 737822 & 4.9 & 4.6766 & TRN \\
\hline CHEMBL1450617 & 737822 & 5.85 & 5.1762 & TRN \\
\hline CHEMBL1558939 & 737822 & 7.0 & 5.1757 & TRN \\
\hline CHEMBL1410399 & 737822 & 5.5 & 5.4849 & TRN \\
\hline CHEMBL1374796 & 737822 & 6.45 & 5.2276 & TRN \\
\hline CHEMBL1462299 & 737822 & 5.65 & 5.3074 & TRN \\
\hline CHEMBL3214385 & 737822 & 4.75 & 5.2284 & TRN \\
\hline CHEMBL1581055 & 737822 & 5.5 & 5.2098 & TRN \\
\hline CHEMBL1459485 & 737822 & 4.6 & 5.1816 & TRN \\
\hline CHEMBL1587783 & 737822 & 6.5 & 5.3794 & TRN \\
\hline CHEMBL1561927 & 737822 & 5.4 & 5.2937 & TRN \\
\hline CHEMBL1741725 & 737822 & 4.85 & 5.2975 & TRN \\
\hline CHEMBL1331702 & 737822 & 4.7 & 5.1697 & TRN \\
\hline CHEMBL 79140 & 737822 & 5.1 & 5.0799 & TRN \\
\hline CHEMBL1553662 & 737822 & 6.0 & 5.8621 & TRN \\
\hline CHEMBL1492558 & 737822 & 5.1 & 4.9389 & TRN \\
\hline CHEMBL1547410 & 737822 & 4.75 & 5.0225 & TRN \\
\hline CHEMBL1398707 & 737822 & 4.5 & 5.396 & TRN \\
\hline CHEMBL172064 & 737822 & 5.6 & 5.4721 & TRN \\
\hline CHEMBL1451526 & 737822 & 5.5 & 5.3889 & TRN \\
\hline CHEMBL1402049 & 737822 & 5.4 & 5.3355 & TRN \\
\hline CHEMBL1565311 & 737822 & 6.5 & 6.1183 & TRN \\
\hline CHEMBL1308361 & 737822 & 4.65 & 5.2035 & TST \\
\hline CHEMBL1256914 & 737822 & 5.5 & 5.3911 & TRN \\
\hline CHEMBL1452905 & 737822 & 4.3 & 5.2217 & TRN \\
\hline CHEMBL1256148 & 737822 & 6.0 & 5.8116 & TRN \\
\hline CHEMBL1611902 & 737822 & 5.4 & 5.4808 & TST \\
\hline CHEMBL1502064 & 737822 & 4.85 & 5.4396 & TRN \\
\hline CHEMBL1443307 & 737822 & 4.95 & 5.5955 & TRN \\
\hline CHEMBL1304054 & 737822 & 5.1 & 5.4233 & TRN \\
\hline
\end{tabular}




\begin{tabular}{|c|c|c|c|c|}
\hline & & & ipplement & al $\mathrm{T}$ \\
\hline CHEMBL1510139 & 737822 & 4.7 & 5.3238 & TRN \\
\hline CHEMBL1479074 & 737822 & 4.85 & 5.27 & TRN \\
\hline CHEMBL3196162 & 737822 & 4.85 & 5.2025 & TST \\
\hline CHEMBL1355703 & 737822 & 5.4 & 5.2734 & TRN \\
\hline CHEMBL1400637 & 737822 & 4.6 & 4.8326 & TRN \\
\hline CHEMBL1417583 & 737822 & 4.8 & 5.2433 & TST \\
\hline CHEMBL1500226 & 737822 & 4.85 & 5.1503 & TST \\
\hline CHEMBL1440487 & 737822 & 4.8 & 4.7486 & TRN \\
\hline CHEMBL1339319 & 737822 & 4.6 & 5.3447 & TRN \\
\hline CHEMBL3189225 & 737822 & 4.55 & 5.1661 & TST \\
\hline CHEMBL1521414 & 737822 & 4.85 & 5.205 & TRN \\
\hline CHEMBL1557951 & 737822 & 4.95 & 5.2378 & TST \\
\hline CHEMBL1333783 & 737822 & 4.7 & 4.5257 & TRN \\
\hline CHEMBL1501526 & 737822 & 5.7 & 5.4005 & TRN \\
\hline CHEMBL1519953 & 737822 & 5.4 & 5.2528 & TRN \\
\hline CHEMBL1609324 & 737822 & 4.9 & 4.7538 & TRN \\
\hline CHEMBL1404209 & 737822 & 4.85 & 5.1525 & TRN \\
\hline CHEMBL1333401 & 737822 & 5.2 & 5.0892 & TRN \\
\hline CHEMBL471728 & 737822 & 5.9 & 5.6346 & TST \\
\hline CHEMBL1409292 & 737822 & 5.2 & 5.2669 & TRN \\
\hline CHEMBL1606038 & 737822 & 5.4 & 5.2797 & TRN \\
\hline CHEMBL1355693 & 737822 & 5.5 & 5.4792 & TRN \\
\hline CHEMBL1511408 & 737822 & 4.5 & 5.2302 & TRN \\
\hline CHEMBL1584704 & 737822 & 4.85 & 5.2074 & TRN \\
\hline CHEMBL490744 & 737822 & 4.4 & 4.4277 & TRN \\
\hline CHEMBL1354841 & 737822 & 4.6 & 4.6585 & TRN \\
\hline CHEMBL3196672 & 737822 & 4.6 & 5.1607 & TST \\
\hline CHEMBL1464940 & 737822 & 4.9 & 5.4741 & TST \\
\hline CHEMBL1256646 & 737822 & 5.5 & 5.3023 & TRN \\
\hline CHEMBL1329855 & 737822 & 4.9 & 5.2168 & TRN \\
\hline CHEMBL1713992 & 737822 & 6.0 & 5.7194 & TST \\
\hline CHEMBL476513 & 737822 & 4.8 & 5.1472 & TRN \\
\hline CHEMBL1590223 & 737822 & 5.4 & 5.395 & TRN \\
\hline CHEMBL31741 & 737822 & 5.2 & 5.005 & TRN \\
\hline CHEMBL1591956 & 737822 & 4.7 & 4.5868 & TRN \\
\hline CHEMBL375270 & 737822 & 5.0 & 4.9377 & TRN \\
\hline CHEMBL1340002 & 737822 & 4.55 & 5.2762 & TRN \\
\hline CHEMBL1362079 & 737822 & 4.4 & 4.3584 & TRN \\
\hline CHEMBL1496811 & 737822 & 4.5 & 5.2368 & TRN \\
\hline CHEMBL1514455 & 737822 & 4.9 & 4.6866 & TRN \\
\hline CHEMBL1437138 & 737822 & 7.6 & 7.1675 & TRN \\
\hline CHEMBL1598896 & 737822 & 4.8 & 5.261 & TRN \\
\hline CHEMBL1404422 & 737822 & 4.9 & 5.4789 & TRN \\
\hline CHEMBL1389059 & 737822 & 5.0 & 5.1926 & TRN \\
\hline CHEMBL1551090 & 737822 & 4.6 & 4.4958 & TRN \\
\hline CHEMBL1894909 & 737822 & 5.6 & 5.568 & TRN \\
\hline CHEMBL1571692 & 737822 & 4.8 & 4.8788 & TST \\
\hline CHEMBL1256359 & 737822 & 4.9 & 5.0021 & TST \\
\hline
\end{tabular}




\begin{tabular}{|c|c|c|c|c|c|}
\hline \multicolumn{6}{|c|}{ Supplemental Table S2.txt } \\
\hline CHEMBL1384330 & 737822 & 5.05 & 5.3997 & TRN & \\
\hline CHEMBL1492177 & 737822 & 4.9 & 5.3395 & TRN & \\
\hline CHEMBL1443979 & 737822 & 4.7 & 5.3476 & TRN & \\
\hline CHEMBL3195211 & 737822 & 4.6 & 5.5586 & TRN & \\
\hline CHEMBL1411164 & 737822 & 6.1 & 5.9801 & TRN & \\
\hline CHEMBL1305594 & 737822 & 4.8 & 5.3779 & TRN & \\
\hline CHEMBL1303042 & 737822 & 4.8 & 5.3856 & TRN & \\
\hline CHEMBL1496370 & 737822 & 4.75 & 5.3515 & TST & \\
\hline CHEMBL1357168 & 737822 & 4.6 & 4.4962 & TRN & \\
\hline CHEMBL1400976 & 737822 & 5.2 & 5.1875 & TRN & \\
\hline CHEMBL1363568 & 737822 & 4.7 & 4.6793 & TRN & \\
\hline CHEMBL1405464 & 737822 & 5.2 & 5.1463 & TRN & \\
\hline CHEMBL1342908 & 737822 & 7.3 & 5.2516 & TRN & \\
\hline CHEMBL1372102 & 737822 & 4.85 & 5.5536 & TRN & \\
\hline CHEMBL1417610 & 737822 & 4.85 & 5.3156 & TRN & \\
\hline CHEMBL1565610 & 737822 & 4.85 & 5.3768 & TRN & \\
\hline CHEMBL1452057 & 737822 & 4.7 & 4.6485 & TRN & \\
\hline CHEMBL1611691 & 737822 & 4.7 & 5.2335 & TRN & \\
\hline CHEMBL3189154 & 737822 & 5.9 & 5.0985 & TRN & \\
\hline CHEMBL1446731 & 737822 & 6.1 & 5.8847 & TRN & \\
\hline CHEMBL1525112 & 737822 & 4.7 & 4.7488 & TRN & \\
\hline CHEMBL1314388 & 737822 & 5.0 & 4.8762 & TRN & \\
\hline CHEMBL1591876 & 737822 & 5.2 & 4.8707 & TRN & \\
\hline CHEMBL1384429 & 737822 & 6.1 & 5.2563 & TRN & \\
\hline CHEMBL1544494 & 737822 & 4.55 & 5.3955 & TRN & \\
\hline CHEMBL1495077 & 737822 & 5.1 & 4.9659 & TRN & \\
\hline CHEMBL1300098 & 737822 & 6.25 & 5.2758 & TRN & \\
\hline CHEMBL1330087 & 737822 & 6.0 & 5.87700 & 0000000001 & TRN \\
\hline CHEMBL1705400 & 737822 & 4.7 & 5.3017 & TRN & \\
\hline CHEMBL1524183 & 737822 & 7.25 & 4.9815 & TRN & \\
\hline CHEMBL1394774 & 737822 & 4.8 & 4.5757 & TRN & \\
\hline CHEMBL1613623 & 737822 & 5.1 & 5.8566 & TRN & \\
\hline CHEMBL1565139 & 737822 & 4.75 & 5.1454 & TRN & \\
\hline CHEMBL10009 & 737822 & 4.4 & 4.3504 & TRN & \\
\hline CHEMBL1589049 & 737822 & 5.55 & 5.4147 & TRN & \\
\hline CHEMBL1419997 & 737822 & 4.7 & 5.0708 & TRN & \\
\hline CHEMBL1416426 & 737822 & 5.1 & 5.0468 & TRN & \\
\hline CHEMBL1552623 & 737822 & 5.0 & 4.9936 & TRN & \\
\hline CHEMBL1487126 & 737822 & 5.5 & 5.3141 & TRN & \\
\hline CHEMBL1512722 & 737822 & 6.1 & 5.8103 & TRN & \\
\hline CHEMBL1338060 & 737822 & 4.65 & 5.2753 & TRN & \\
\hline CHEMBL1378505 & 737822 & 4.45 & 5.2706 & TST & \\
\hline CHEMBL1542112 & 737822 & 4.55 & 5.2842 & TRN & \\
\hline CHEMBL1336793 & 737822 & 4.9 & 4.7741 & TRN & \\
\hline CHEMBL1984764 & 737822 & 6.1 & 5.1838 & TST & \\
\hline CHEMBL1509477 & 737822 & 4.4 & 5.41 & TST & \\
\hline CHEMBL1398586 & 737822 & 5.5 & 5.4152 & TRN & \\
\hline CHEMBL1451031 & 737822 & 4.8 & 5.1888 & TRN & \\
\hline
\end{tabular}




\begin{tabular}{|c|c|c|c|c|c|}
\hline & & & & & \\
\hline CHEMBL1545452 & 737822 & 4.9 & 5.0997 & TRN & \\
\hline CHEMBL1516187 & 737822 & 6.1 & 5.8891 & TRN & \\
\hline CHEMBL1586326 & 737822 & 4.65 & 5.3885 & TRN & \\
\hline CHEMBL1315965 & 737822 & 4.4 & 4.2915 & TRN & \\
\hline CHEMBL1485060 & 737822 & 5.3 & 5.0622 & TRN & \\
\hline CHEMBL1397766 & 737822 & 4.5 & 4.7498 & TRN & \\
\hline CHEMBL53206 & 737822 & 6.3 & 6.2024 & TRN & \\
\hline CHEMBL1402965 & 737822 & 4.75 & 5.1922 & TRN & \\
\hline CHEMBL1533572 & 737822 & 4.6 & 4.505 & TRN & \\
\hline CHEMBL1546037 & 737822 & 4.75 & 4.9176 & TRN & \\
\hline CHEMBL1412847 & 737822 & 4.6 & 4.4798 & TRN & \\
\hline CHEMBL1735424 & 737822 & 7.9 & 5.1081 & TRN & \\
\hline CHEMBL1434098 & 737822 & 4.8 & 4.6934 & TRN & \\
\hline CHEMBL1410367 & 737822 & 4.9 & 4.7878 & TRN & \\
\hline CHEMBL1310142 & 737822 & 4.95 & $5.2870 e$ & 0000000001 & TRN \\
\hline CHEMBL1343900 & 737822 & 4.75 & 5.3603 & TRN & \\
\hline CHEMBL1491009 & 737822 & 5.3 & 5.4312 & TRN & \\
\hline CHEMBL1314255 & 737822 & 4.4 & 4.4379 & TRN & \\
\hline CHEMBL1596235 & 737822 & 5.7 & 5.3615 & TRN & \\
\hline CHEMBL1520238 & 737822 & 4.85 & 5.5281 & TRN & \\
\hline CHEMBL1573532 & 737822 & 5.5 & 5.415 & TRN & \\
\hline CHEMBL325238 & 737822 & 7.4 & 6.7634 & TRN & \\
\hline CHEMBL1442106 & 737822 & 4.8 & 4.8545 & TRN & \\
\hline CHEMBL1433950 & 737822 & 5.7 & 5.2927 & TRN & \\
\hline CHEMBL1567887 & 737822 & 4.95 & 5.2619 & TRN & \\
\hline CHEMBL1588356 & 737822 & 5.1 & 5.3178 & TRN & \\
\hline CHEMBL1182777 & 737822 & 4.8 & 4.7791 & TST & \\
\hline CHEMBL1460362 & 737822 & 4.4 & 5.0917 & TRN & \\
\hline CHEMBL448966 & 737822 & 4.8 & 4.5775 & TRN & \\
\hline CHEMBL3195516 & 737822 & 5.1 & 5.3328 & TRN & \\
\hline CHEMBL27403 & 737822 & 4.6 & 4.683 & TRN & \\
\hline CHEMBL1334327 & 737822 & 5.5 & 5.3856 & TRN & \\
\hline CHEMBL1555314 & 737822 & 4.6 & 4.495 & TRN & \\
\hline CHEMBL1399898 & 737822 & 5.35 & 5.2598 & TRN & \\
\hline CHEMBL1524866 & 737822 & 4.8 & 5.164 & TST & \\
\hline CHEMBL1462816 & 737822 & 4.85 & 5.16799 & 9999999999 & TRN \\
\hline CHEMBL1319049 & 737822 & 6.0 & 5.8996 & TRN & \\
\hline CHEMBL1561692 & 737822 & 4.65 & 5.3746 & TST & \\
\hline CHEMBL1350410 & 737822 & 4.9 & 5.3642 & TRN & \\
\hline CHEMBL1316463 & 737822 & 4.8 & 5.2434 & TRN & \\
\hline CHEMBL1523038 & 737822 & 5.55 & 5.1746 & TRN & \\
\hline CHEMBL1474317 & 737822 & 5.2 & 4.867 & TRN & \\
\hline CHEMBL491910 & 737822 & 5.7 & 5.3767 & TRN & \\
\hline CHEMBL1382389 & 737822 & 4.75 & 5.1327 & TRN & \\
\hline CHEMBL280074 & 737822 & 5.9 & 5.5619 & TRN & \\
\hline CHEMBL1596756 & 737822 & 5.6 & 5.2512 & TRN & \\
\hline CHEMBL1398315 & 737822 & 5.1 & 5.0853 & TRN & \\
\hline CHEMBL1352069 & 737822 & 4.6 & 5.4543 & TST & \\
\hline & & & & 11294 & \\
\hline
\end{tabular}




\begin{tabular}{|c|c|c|c|c|}
\hline \multicolumn{5}{|c|}{ Supplemental Table S2.txt } \\
\hline CHEMBL1395165 & 737822 & -0.0 & 5.5773 & TRN \\
\hline CHEMBL1576417 & 737822 & 5.9 & 4.9966 & TRN \\
\hline CHEMBL491978 & 737822 & 4.7 & 4.631 & TRN \\
\hline CHEMBL1324528 & 737822 & 4.95 & 5.3428 & TRN \\
\hline CHEMBL1561341 & 737822 & 5.2 & 5.1485 & TRN \\
\hline CHEMBL1544357 & 737822 & 4.8 & 5.0921 & TST \\
\hline CHEMBL1417604 & 737822 & 5.1 & 5.3067 & TST \\
\hline CHEMBL1301305 & 737822 & 4.65 & 4.9848 & TRN \\
\hline CHEMBL1554976 & 737822 & 4.6 & 4.4163 & TRN \\
\hline CHEMBL1531672 & 737822 & 4.9 & 5.2658 & TRN \\
\hline CHEMBL1302141 & 737822 & 4.85 & 5.3372 & TRN \\
\hline CHEMBL1423810 & 737822 & 4.9 & 5.3338 & TST \\
\hline CHEMBL1462730 & 737822 & 4.9 & 5.4979 & TST \\
\hline CHEMBL1404788 & 737822 & 4.65 & 4.9403 & TRN \\
\hline CHEMBL1408315 & 737822 & 4.65 & 5.2908 & TST \\
\hline CHEMBL1423348 & 737822 & 4.9 & 5.3277 & TRN \\
\hline CHEMBL1323529 & 737822 & 4.4 & 4.5487 & TST \\
\hline CHEMBL1487898 & 737822 & 4.8 & 4.6594 & TRN \\
\hline CHEMBL1256873 & 737822 & 4.5 & 4.5471 & TRN \\
\hline CHEMBL1355855 & 737822 & 7.9 & 7.152 & TRN \\
\hline CHEMBL1365665 & 737822 & 5.2 & 5.2098 & TRN \\
\hline CHEMBL1553034 & 737822 & 5.7 & 5.6983 & TRN \\
\hline CHEMBL1302643 & 737822 & 4.8 & 5.4682 & TRN \\
\hline CHEMBL1572006 & 737822 & 4.9 & 5.2842 & TRN \\
\hline CHEMBL1450689 & 737822 & 4.8 & 5.3457 & TRN \\
\hline CHEMBL1478570 & 737822 & 4.5 & 5.1504 & TRN \\
\hline CHEMBL1568086 & 737822 & 4.9 & 4.7192 & TRN \\
\hline CHEMBL1611388 & 737822 & 6.55 & 5.1404 & TRN \\
\hline CHEMBL1368895 & 737822 & 5.3 & 4.9607 & TST \\
\hline CHEMBL1416705 & 737822 & 4.4 & 4.4151 & TRN \\
\hline CHEMBL1257076 & 737822 & 5.5 & 5.3612 & TRN \\
\hline CHEMBL1355712 & 737822 & 6.1 & 5.705 & TRN \\
\hline CHEMBL1330569 & 737822 & 4.65 & 5.4996 & TST \\
\hline CHEMBL1442011 & 737822 & 5.0 & 4.9542 & TRN \\
\hline CHEMBL1475990 & 737822 & 5.5 & 5.4363 & TRN \\
\hline CHEMBL1468324 & 737822 & 5.55 & 5.2484 & TRN \\
\hline CHEMBL1356505 & 737822 & 4.8 & 4.6189 & TRN \\
\hline CHEMBL1328688 & 737822 & 4.65 & 5.2327 & TRN \\
\hline CHEMBL490577 & 737822 & 4.5 & 4.8385 & TRN \\
\hline CHEMBL1544498 & 737822 & 6.1 & 5.2901 & TRN \\
\hline CHEMBL1554803 & 737822 & 5.6 & 5.5157 & TRN \\
\hline CHEMBL1722019 & 737822 & 6.7 & 5.3565 & TRN \\
\hline CHEMBL1472456 & 737822 & 6.25 & 5.2859 & TRN \\
\hline CHEMBL1573949 & 737822 & 4.85 & 5.1894 & TRN \\
\hline CHEMBL1604883 & 737822 & 5.5 & 5.4025 & TST \\
\hline CHEMBL1579870 & 737822 & 4.8 & 5.2418 & TRN \\
\hline CHEMBL1316056 & 737822 & 4.9 & 4.8662 & TRN \\
\hline CHEMBL1333076 & 737822 & 4.95 & 5.4668 & TRN \\
\hline
\end{tabular}




\begin{tabular}{|c|c|c|c|c|}
\hline \multicolumn{5}{|c|}{ Supplemental Table S2.txt } \\
\hline CHEMBL1396936 & 737822 & 4.7 & 4.5445 & TRN \\
\hline CHEMBL1593589 & 737822 & 4.8 & 4.751 & TRN \\
\hline CHEMBL1302393 & 737822 & 5.45 & 5.2021 & TRN \\
\hline CHEMBL1564828 & 737822 & 6.75 & 5.3294 & TRN \\
\hline CHEMBL1453244 & 737822 & 4.9 & 4.7955 & TRN \\
\hline CHEMBL1441508 & 737822 & 6.0 & 5.324 & TST \\
\hline CHEMBL1366926 & 737822 & 5.1 & 4.8648 & TRN \\
\hline CHEMBL87385 & 737822 & 5.0 & 5.1602 & TRN \\
\hline CHEMBL1318285 & 737822 & 5.5 & 5.3832 & TRN \\
\hline CHEMBL1305416 & 737822 & 5.15 & 5.3795 & TST \\
\hline CHEMBL115225 & 737822 & 7.0 & 6.5006 & TST \\
\hline CHEMBL1611220 & 737822 & 7.6 & 6.8639 & TST \\
\hline CHEMBL1447520 & 737822 & 5.15 & 5.2681 & TST \\
\hline CHEMBL1200450 & 737822 & 6.0 & 5.7676 & TST \\
\hline CHEMBL1448228 & 737822 & 5.5 & 5.3288 & TST \\
\hline CHEMBL1567238 & 737822 & 5.6 & 5.4638 & TRN \\
\hline CHEMBL1396583 & 737822 & 5.5 & 5.2434 & TRN \\
\hline CHEMBL1453208 & 737822 & 4.8 & 5.8502 & TRN \\
\hline CHEMBL1393435 & 737822 & 4.95 & 5.3459 & TST \\
\hline CHEMBL39 & 737822 & 5.0 & 4.8389 & TRN \\
\hline CHEMBL1548421 & 737822 & 4.75 & 5.4159 & TRN \\
\hline CHEMBL1437281 & 737822 & 5.2 & 5.1988 & TRN \\
\hline CHEMBL1578958 & 737822 & 5.85 & 5.6523 & TRN \\
\hline CHEMBL1332463 & 737822 & 4.9 & 4.7937 & TRN \\
\hline CHEMBL1595376 & 737822 & 4.9 & 5.2185 & TST \\
\hline CHEMBL1484196 & 737822 & 4.4 & 4.2771 & TRN \\
\hline CHEMBL1523816 & 737822 & 4.9 & 4.8495 & TRN \\
\hline CHEMBL1440867 & 737822 & 4.6 & 5.2952 & TRN \\
\hline CHEMBL1593775 & 737822 & 4.9 & 4.8378 & TST \\
\hline CHEMBL1606892 & 737822 & 4.4 & 4.5091 & TRN \\
\hline CHEMBL1559333 & 737822 & 4.65 & 5.2016 & TRN \\
\hline CHEMBL1586684 & 737822 & 5.7 & 5.0212 & TRN \\
\hline CHEMBL1723995 & 737822 & 5.35 & 5.2464 & TRN \\
\hline CHEMBL 234978 & 737822 & 5.0 & 5.6748 & TRN \\
\hline CHEMBL1314505 & 737822 & 4.6 & 4.752 & TRN \\
\hline CHEMBL1549980 & 737822 & 4.8 & 5.1991 & TRN \\
\hline CHEMBL1453519 & 737822 & 5.3 & 5.3426 & TRN \\
\hline CHEMBL566899 & 737822 & 5.0 & 4.8622 & TRN \\
\hline CHEMBL1402562 & 737822 & 4.8 & 5.436 & TRN \\
\hline CHEMBL1537500 & 737822 & 5.0 & 5.3616 & TRN \\
\hline CHEMBL3192627 & 737822 & 6.25 & 5.4054 & TRN \\
\hline CHEMBL1568012 & 737822 & 5.05 & 5.2457 & TRN \\
\hline CHEMBL1524904 & 737822 & 5.4 & 5.6193 & TRN \\
\hline CHEMBL1387681 & 737822 & 4.65 & 5.2518 & TRN \\
\hline CHEMBL1300301 & 737822 & 4.55 & 5.1133 & TST \\
\hline CHEMBL1407257 & 737822 & 6.3 & 5.815 & TRN \\
\hline CHEMBL1318480 & 737822 & 4.8 & 4.984 & TRN \\
\hline CHEMBL1429297 & 737822 & 4.9 & 5.2041 & TST \\
\hline
\end{tabular}




\begin{tabular}{|c|c|c|c|c|}
\hline & & & pplement & al $\mathrm{Ta}$ \\
\hline CHEMBL581886 & 737822 & 5.0 & 5.0941 & TRN \\
\hline CHEMBL1299384 & 737822 & 4.9 & 5.1404 & TST \\
\hline CHEMBL1480779 & 737822 & 7.6 & 7.1614 & TRN \\
\hline CHEMBL1416912 & 737822 & 4.6 & 4.4891 & TRN \\
\hline CHEMBL1729717 & 737822 & 5.6 & 5.3359 & TRN \\
\hline CHEMBL1479862 & 737822 & 4.65 & 5.1978 & TST \\
\hline CHEMBL1515829 & 737822 & 4.6 & 4.4639 & TRN \\
\hline CHEMBL1488264 & 737822 & 4.65 & 5.1565 & TRN \\
\hline CHEMBL1498694 & 737822 & 5.95 & 5.3958 & TRN \\
\hline CHEMBL1505600 & 737822 & 6.75 & 5.3464 & TRN \\
\hline CHEMBL1592679 & 737822 & 4.5 & 4.8269 & TRN \\
\hline CHEMBL1310444 & 737822 & 4.8 & 5.5832 & TRN \\
\hline CHEMBL 3214295 & 737822 & 5.45 & 5.4197 & TRN \\
\hline CHEMBL1340272 & 737822 & 4.85 & 5.2748 & TRN \\
\hline CHEMBL1475484 & 737822 & 4.9 & 4.8387 & TRN \\
\hline CHEMBL1379839 & 737822 & 4.7 & 5.3795 & TST \\
\hline CHEMBL1338163 & 737822 & 5.3 & 4.974 & TRN \\
\hline CHEMBL 3210367 & 737822 & 5.7 & 5.4436 & TRN \\
\hline CHEMBL1604396 & 737822 & 4.8 & 5.1735 & TST \\
\hline CHEMBL1560365 & 737822 & 6.45 & 5.3493 & TST \\
\hline CHEMBL1578122 & 737822 & 5.4 & 5.1192 & TRN \\
\hline CHEMBL1741648 & 737822 & 8.1 & 5.2659 & TRN \\
\hline CHEMBL463783 & 737822 & 5.4 & 5.3183 & TRN \\
\hline CHEMBL1530672 & 737822 & 4.65 & 5.2839 & TRN \\
\hline CHEMBL 3191740 & 737822 & 5.1 & 5.335 & TRN \\
\hline CHEMBL1362504 & 737822 & 5.55 & 5.2516 & TST \\
\hline CHEMBL1413296 & 737822 & 4.6 & 5.3572 & TRN \\
\hline CHEMBL1339404 & 737822 & 4.85 & 5.5156 & TRN \\
\hline CHEMBL1588603 & 737822 & 5.2 & 4.926 & TRN \\
\hline CHEMBL1398537 & 737822 & 4.5 & 4.4645 & TST \\
\hline CHEMBL1481781 & 737822 & 4.5 & 4.7328 & TRN \\
\hline CHEMBL1510947 & 737822 & 5.05 & 5.3391 & TRN \\
\hline CHEMBL1462483 & 737822 & 4.85 & 5.4504 & TRN \\
\hline CHEMBL1330317 & 737822 & 5.1 & 4.9124 & TRN \\
\hline CHEMBL1552635 & 737822 & 4.9 & 4.7767 & TRN \\
\hline CHEMBL1505191 & 737822 & 5.1 & 5.0363 & TRN \\
\hline CHEMBL1301521 & 737822 & 5.8 & 5.4188 & TRN \\
\hline CHEMBL1479340 & 737822 & 4.85 & 5.4863 & TRN \\
\hline CHEMBL188641 & 737822 & 5.8 & 5.6153 & TRN \\
\hline CHEMBL1412225 & 737822 & 5.7 & 5.5988 & TRN \\
\hline CHEMBL3211591 & 737822 & 4.6 & 5.4054 & TST \\
\hline CHEMBL1415465 & 737822 & 5.0 & 4.6344 & TRN \\
\hline CHEMBL3211761 & 737822 & 6.2 & 5.1597 & TST \\
\hline CHEMBL1356657 & 737822 & 4.6 & 4.4071 & TRN \\
\hline CHEMBL1479817 & 737822 & 4.7 & 4.566 & TRN \\
\hline CHEMBL1547186 & 737822 & 5.3 & 5.4795 & TST \\
\hline CHEMBL1410759 & 737822 & 5.5 & 5.3477 & TRN \\
\hline CHEMBL 3196691 & 737822 & 4.5 & 5.3032 & TRN \\
\hline
\end{tabular}




\begin{tabular}{|c|c|c|c|c|}
\hline CHEMBL1519435 & 737822 & 5.1 & 4.8721 & TRN \\
\hline CHEMBL1451363 & 737822 & 5.7 & 5.2682 & TRN \\
\hline CHEMBL157351 & 737822 & 4.4 & 4.3939 & TST \\
\hline CHEMBL1417552 & 737822 & 5.1 & 4.9916 & TRN \\
\hline CHEMBL1474241 & 737822 & 5.6 & 5.6946 & TRN \\
\hline CHEMBL1485727 & 737822 & 6.5 & 5.4876 & TST \\
\hline CHEMBL1573058 & 737822 & 4.9 & 4.7017 & TRN \\
\hline CHEMBL1333144 & 737822 & 5.5 & 5.1696 & TST \\
\hline CHEMBL1356346 & 737822 & 4.5 & 4.6683 & TRN \\
\hline CHEMBL1394854 & 737822 & 4.6 & 4.4631 & TRN \\
\hline CHEMBL1574693 & 737822 & 5.4 & \multicolumn{2}{|c|}{5.3839999999999995} \\
\hline CHEMBL1597037 & 737822 & 5.1 & 4.8313 & TRN \\
\hline CHEMBL1370053 & 737822 & 4.8 & 5.3057 & TRN \\
\hline CHEMBL1369125 & 737822 & 5.0 & 5.4902 & TRN \\
\hline CHEMBL1303935 & 737822 & 6.0 & 5.5509 & TRN \\
\hline CHEMBL1434882 & 737822 & 4.6 & 4.5006 & TRN \\
\hline CHEMBL1368773 & 737822 & 6.1 & 5.8907 & TRN \\
\hline CHEMBL1598062 & 737822 & 6.9 & 6.4884 & TRN \\
\hline CHEMBL1557947 & 737822 & 5.05 & 5.2617 & TRN \\
\hline CHEMBL1471244 & 737822 & 4.7 & 4.9691 & TRN \\
\hline CHEMBL1436715 & 737822 & 5.0 & 4.8107 & TRN \\
\hline CHEMBL1322414 & 737822 & 5.4 & 5.2884 & TRN \\
\hline CHEMBL1553491 & 737822 & 5.2 & 4.9295 & TRN \\
\hline CHEMBL1441222 & 737822 & 5.5 & 5.4109 & TRN \\
\hline CHEMBL1524520 & 737822 & 4.9 & 4.7006 & TRN \\
\hline CHEMBL1542047 & 737822 & 4.55 & 5.5454 & TRN \\
\hline CHEMBL1479792 & 737822 & 4.9 & 4.7502 & TRN \\
\hline CHEMBL1434643 & 737822 & -0.0 & 4.6793 & TRN \\
\hline CHEMBL1409547 & 737822 & 4.8 & 4.7865 & TRN \\
\hline CHEMBL1528578 & 737822 & 5.7 & 5.2733 & TRN \\
\hline CHEMBL1558834 & 737822 & 5.0 & 4.8589 & TRN \\
\hline CHEMBL3194142 & 737822 & 5.5 & 5.3496 & TRN \\
\hline CHEMBL482116 & 737822 & 4.8 & 5.2624 & TRN \\
\hline CHEMBL1495395 & 737822 & 5.4 & 5.2566 & TRN \\
\hline CHEMBL153036 & 737822 & 6.0 & 5.7685 & TRN \\
\hline CHEMBL1330067 & 737822 & 5.1 & 5.2792 & TRN \\
\hline CHEMBL1316285 & 737822 & 4.4 & 4.3626 & TRN \\
\hline CHEMBL1330781 & 737822 & 4.8 & 5.2522 & TST \\
\hline CHEMBL1592571 & 737822 & 4.7 & 4.5554 & TRN \\
\hline CHEMBL399705 & 737822 & 5.0 & 5.0083 & TST \\
\hline CHEMBL1590556 & 737822 & 4.9 & 4.8562 & TRN \\
\hline CHEMBL1446323 & 737822 & 4.6 & 4.4243 & TRN \\
\hline CHEMBL1395620 & 737822 & 5.4 & 5.1841 & TRN \\
\hline CHEMBL1330587 & 737822 & 5.1 & 4.8238 & TRN \\
\hline CHEMBL1355408 & 737822 & 5.5 & 5.3112 & TRN \\
\hline CHEMBL1362959 & 737822 & 5.05 & 5.2175 & TST \\
\hline CHEMBL1471064 & 737822 & 4.85 & 5.4552 & TRN \\
\hline CHEMBL1730483 & 737822 & 4.65 & 5.2632 & TRN \\
\hline
\end{tabular}




\begin{tabular}{|c|c|c|c|c|c|}
\hline \multicolumn{6}{|c|}{ Supplemental Table S2.txt } \\
\hline CHEMBL1523995 & 737822 & 6.1 & 5.2385 & TST & \\
\hline CHEMBL1529729 & 737822 & 4.85 & 5.52 & TRN & \\
\hline CHEMBL1539897 & 737822 & 4.7 & 5.4787 & TST & \\
\hline CHEMBL1509329 & 737822 & 4.6 & 5.1862 & TRN & \\
\hline CHEMBL1603582 & 737822 & 5.0 & 5.1348 & TST & \\
\hline CHEMBL1303722 & 737822 & 6.0 & 5.3411 & TRN & \\
\hline CHEMBL1324494 & 737822 & 4.5 & 4.4056 & TRN & \\
\hline CHEMBL1536299 & 737822 & 5.5 & 5.225 & TRN & \\
\hline CHEMBL1445817 & 737822 & 5.3 & 5.2411 & TST & \\
\hline CHEMBL1481185 & 737822 & 4.95 & 5.5056 & TRN & \\
\hline CHEMBL1356439 & 737822 & 4.9 & 4.7395 & TRN & \\
\hline CHEMBL1414910 & 737822 & 5.5 & 5.3853 & TRN & \\
\hline CHEMBL1467911 & 737822 & 6.45 & 5.3586 & TRN & \\
\hline CHEMBL1454735 & 737822 & 4.85 & 5.2547 & TRN & \\
\hline CHEMBL1608337 & 737822 & 5.1 & 5.1652 & TRN & \\
\hline CHEMBL1351838 & 737822 & 4.6 & 5.0437 & TST & \\
\hline CHEMBL1316979 & 737822 & 5.0 & 4.8857 & TRN & \\
\hline CHEMBL1435235 & 737822 & 5.3 & 5.1342 & TRN & \\
\hline CHEMBL1464821 & 737822 & 4.55 & 5.1706 & TST & \\
\hline CHEMBL1437776 & 737822 & 4.7 & 4.6317 & TRN & \\
\hline CHEMBL1373723 & 737822 & 5.1 & 4.90300 & 00000000005 & TRN \\
\hline CHEMBL1463543 & 737822 & 5.0 & 5.1272 & TRN & \\
\hline CHEMBL1518970 & 737822 & 4.85 & 5.3816 & TRN & \\
\hline CHEMBL1394640 & 737822 & 6.6 & 6.5182 & TRN & \\
\hline CHEMBL1395241 & 737822 & 4.9 & 4.6184 & TRN & \\
\hline CHEMBL540294 & 737822 & 4.5 & 4.569 & TST & \\
\hline CHEMBL1395219 & 737822 & 4.6 & 4.3885 & TRN & \\
\hline CHEMBL58033 & 737822 & 6.0 & 6.0511 & TRN & \\
\hline CHEMBL1531620 & 737822 & 4.4 & 5.2323 & TST & \\
\hline CHEMBL1352766 & 737822 & 5.0 & 5.1238 & TRN & \\
\hline CHEMBL1558135 & 737822 & 4.5 & 4.7504 & TRN & \\
\hline CHEMBL1313179 & 737822 & 5.3 & 5.7915 & TRN & \\
\hline CHEMBL1358009 & 737822 & 5.8 & 5.5492 & TRN & \\
\hline CHEMBL1383867 & 737822 & 4.6 & 5.2061 & TRN & \\
\hline CHEMBL1465342 & 737822 & 6.45 & 5.515 & TRN & \\
\hline CHEMBL1552607 & 737822 & 6.1 & 5.8607 & TRN & \\
\hline CHEMBL 278041 & 737822 & 5.3 & 5.5244 & TST & \\
\hline CHEMBL1316897 & 737822 & 5.1 & 4.9927 & TRN & \\
\hline CHEMBL1486638 & 737822 & 5.6 & 5.3529 & TST & \\
\hline CHEMBL1610944 & 737822 & 4.8 & 5.0688 & TRN & \\
\hline CHEMBL1446110 & 737822 & 5.4 & 5.3111 & TRN & \\
\hline CHEMBL1340482 & 737822 & 6.7 & 5.4318 & TRN & \\
\hline CHEMBL1556436 & 737822 & 4.5 & 5.4032 & TRN & \\
\hline CHEMBL1559387 & 737822 & 4.85 & 5.2291 & TST & \\
\hline CHEMBL1563190 & 737822 & 5.05 & 5.1466 & TRN & \\
\hline CHEMBL1574567 & 737822 & 4.65 & 5.1922 & TST & \\
\hline CHEMBL1256959 & 737822 & 6.0 & 5.6555 & TRN & \\
\hline CHEMBL2062333 & 737822 & 4.5 & 4.6628 & TRN & \\
\hline
\end{tabular}




\begin{tabular}{|c|c|c|c|c|c|}
\hline \multicolumn{6}{|c|}{ Supplemental Table S2.txt } \\
\hline CHEMBL1450860 & 737822 & 5.65 & 5.1945 & TRN & \\
\hline CHEMBL1357872 & 737822 & 4.4 & 4.5278 & TRN & \\
\hline CHEMBL1481746 & 737822 & 5.0 & 5.1844 & TST & \\
\hline CHEMBL1612107 & 737822 & 4.8 & 5.3106 & TRN & \\
\hline CHEMBL1484866 & 737822 & 5.6 & 5.0137 & TRN & \\
\hline CHEMBL3197350 & 737822 & 5.05 & 5.0974 & TST & \\
\hline CHEMBL1348845 & 737822 & 4.85 & 5.4595 & TRN & \\
\hline CHEMBL1597843 & 737822 & 4.75 & 5.0946 & TST & \\
\hline CHEMBL1440032 & 737822 & 4.9 & 5.3841 & TRN & \\
\hline CHEMBL1442173 & 737822 & 4.4 & 4.3699 & TRN & \\
\hline CHEMBL1591368 & 737822 & 5.2 & 5.228 & TRN & \\
\hline CHEMBL1511412 & 737822 & 8.1 & 5.1342 & TRN & \\
\hline CHEMBL1525261 & 737822 & 4.85 & 5.191 & TRN & \\
\hline CHEMBL1509804 & 737822 & 4.85 & 5.3543 & TST & \\
\hline CHEMBL1465231 & 737822 & 5.5 & 4.8765 & TRN & \\
\hline CHEMBL1374335 & 737822 & 5.6 & 5.4417 & TRN & \\
\hline CHEMBL1306342 & 737822 & 5.6 & 5.3066 & TST & \\
\hline CHEMBL513116 & 737822 & 6.0 & 5.6898 & TRN & \\
\hline CHEMBL3211338 & 737822 & 5.4 & 5.3 & TRN & \\
\hline CHEMBL1585050 & 737822 & 6.0 & 5.1925 & TRN & \\
\hline CHEMBL1597209 & 737822 & 4.8 & 4.5778 & TRN & \\
\hline CHEMBL1423533 & 737822 & 6.5 & 5.2899 & TRN & \\
\hline CHEMBL1414083 & 737822 & 4.4 & 5.2378 & TRN & \\
\hline CHEMBL1478545 & 737822 & 5.45 & 5.6915 & TRN & \\
\hline CHEMBL1357551 & 737822 & 4.6 & 4.4821 & TRN & \\
\hline CHEMBL1606796 & 737822 & 5.0 & 4.97 & TRN & \\
\hline CHEMBL1315609 & 737822 & 5.7 & 5.2905 & TRN & \\
\hline CHEMBL909 & 737822 & 6.9 & 6.5547 & TRN & \\
\hline CHEMBL1318340 & 737822 & 4.8 & 4.6218 & TRN & \\
\hline CHEMBL3192681 & 737822 & 5.8 & 5.2198 & TRN & \\
\hline CHEMBL1498258 & 737822 & 6.35 & 5.3994 & TRN & \\
\hline CHEMBL1397206 & 737822 & 5.4 & 5.1452 & TRN & \\
\hline CHEMBL1442060 & 737822 & 4.85 & 5.1827 & TRN & \\
\hline CHEMBL1513511 & 737822 & 4.7 & 4.6288 & TRN & \\
\hline CHEMBL1579956 & 737822 & 4.6 & 5.40600 & 0000000001 & TRN \\
\hline CHEMBL1363367 & 737822 & 5.5 & 5.3717 & TST & \\
\hline CHEMBL1356138 & 737822 & 4.4 & 4.3052 & TRN & \\
\hline CHEMBL1332929 & 737822 & 4.6 & 4.5007 & TRN & \\
\hline CHEMBL1464417 & 737822 & 5.0 & 5.1999 & TRN & \\
\hline CHEMBL1256869 & 737822 & 4.5 & 4.6914 & TRN & \\
\hline CHEMBL1430379 & 737822 & 5.6 & 5.2864 & TRN & \\
\hline CHEMBL3192246 & 737822 & 4.65 & 5.4801 & TRN & \\
\hline CHEMBL1534734 & 737822 & 5.1 & 4.9881 & TRN & \\
\hline CHEMBL1573739 & 737822 & 4.65 & 5.3021 & TRN & \\
\hline CHEMBL164 & 737822 & 4.7 & 4.8297 & TRN & \\
\hline CHEMBL1340458 & 737822 & 5.1 & 5.1455 & TRN & \\
\hline CHEMBL1338985 & 737822 & 4.6 & 4.4452 & TRN & \\
\hline CHEMBL3213163 & 737822 & 5.5 & 5.3928 & TRN & \\
\hline
\end{tabular}




\begin{tabular}{|c|c|c|c|c|c|}
\hline \\
\hline CHEMBL1396202 & 737822 & 5.1 & 4.8457 & TRN & \\
\hline CHEMBL1356652 & 737822 & 4.4 & 4.3232 & TRN & \\
\hline CHEMBL3194166 & 737822 & 4.4 & 5.3561 & TST & \\
\hline CHEMBL1601111 & 737822 & 5.05 & 5.4333 & TST & \\
\hline CHEMBL3209973 & 737822 & 7.25 & 5.4051 & TRN & \\
\hline CHEMBL1369874 & 737822 & 5.1 & 5.7409 & TST & \\
\hline CHEMBL1705804 & 737822 & 5.95 & 5.2283 & TST & \\
\hline CHEMBL1593353 & 737822 & 4.7 & 4.5011 & TRN & \\
\hline CHEMBL545050 & 737822 & 8.2 & 7.4423 & TST & \\
\hline CHEMBL1591908 & 737822 & 5.2 & 5.0283 & TRN & \\
\hline CHEMBL1468272 & 737822 & 4.85 & 5.4362 & TRN & \\
\hline CHEMBL1552270 & 737822 & 6.9 & 6.1832 & TRN & \\
\hline CHEMBL1719399 & 737822 & 4.85 & 5.4289 & 9999999999 & TRN \\
\hline CHEMBL3208184 & 737822 & 5.8 & 4.9295 & TRN & \\
\hline CHEMBL1409758 & 737822 & 5.0 & 4.7367 & TRN & \\
\hline CHEMBL1413668 & 737822 & 4.75 & 5.2247 & TRN & \\
\hline CHEMBL1741439 & 737822 & 5.15 & 5.6247 & TRN & \\
\hline CHEMBL1609857 & 737822 & 4.75 & 5.3013 & TRN & \\
\hline CHEMBL1590048 & 737822 & 4.6 & 4.887 & TRN & \\
\hline CHEMBL1357857 & 737822 & 4.7 & 4.5484 & TRN & \\
\hline CHEMBL1482582 & 737822 & 5.0 & 4.8233 & TRN & \\
\hline CHEMBL994 & 737822 & 5.1 & 5.1418 & TRN & \\
\hline CHEMBL1327850 & 737822 & 4.55 & 5.4278 & TRN & \\
\hline CHEMBL1570435 & 737822 & 6.5 & 5.3783 & TRN & \\
\hline CHEMBL1437442 & 737822 & 5.4 & 5.3399 & TRN & \\
\hline CHEMBL1413637 & 737822 & 5.0 & 4.9048 & TRN & \\
\hline CHEMBL1537962 & 737822 & 5.95 & 5.3892 & TRN & \\
\hline CHEMBL1558526 & 737822 & 5.0 & 4.7192 & TRN & \\
\hline CHEMBL1587623 & 737822 & 5.0 & 5.0586 & TRN & \\
\hline CHEMBL1593663 & 737822 & 6.6 & 6.4536 & TRN & \\
\hline CHEMBL1539590 & 737822 & 6.0 & 5.414 & TRN & \\
\hline CHEMBL1417002 & 737822 & 4.65 & 5.2926 & TRN & \\
\hline CHEMBL1484261 & 737822 & 5.6 & 5.3708 & TRN & \\
\hline CHEMBL165 & 737822 & 5.0 & 5.7281 & TRN & \\
\hline CHEMBL1411148 & 737822 & 4.7 & 4.9609 & TST & \\
\hline CHEMBL1724554 & 737822 & 5.0 & 5.3174 & TRN & \\
\hline CHEMBL1529151 & 737822 & 5.4 & 5.1402 & TRN & \\
\hline CHEMBL1361847 & 737822 & 5.1 & 5.0207 & TRN & \\
\hline CHEMBL1741628 & 737822 & 4.85 & 5.303 & TRN & \\
\hline CHEMBL1597865 & 737822 & 4.45 & 5.3328 & TRN & \\
\hline CHEMBL1728635 & 737822 & 4.95 & 5.5898 & TRN & \\
\hline CHEMBL1509513 & 737822 & 5.45 & 5.5915 & TRN & \\
\hline CHEMBL1600685 & 737822 & 6.65 & 5.3892 & TRN & \\
\hline CHEMBL1342562 & 737822 & 4.8 & 5.3217 & TRN & \\
\hline CHEMBL1612976 & 737822 & 4.6 & 5.3299 & TRN & \\
\hline CHEMBL475375 & 737822 & 4.6 & 4.566 & TRN & \\
\hline CHEMBL585861 & 737822 & 4.9 & 4.7407 & TRN & \\
\hline CHEMBL1360337 & 737822 & 4.9 & 5.4186 & TRN & \\
\hline & & & & 1301 & \\
\hline
\end{tabular}




\begin{tabular}{|c|c|c|c|c|c|}
\hline \multicolumn{6}{|c|}{ Supplemental Table s2.txt } \\
\hline CHEMBL1381863 & 737822 & 4.55 & 5.3183 & TRN & \\
\hline CHEMBL1596762 & 737822 & 4.95 & 5.336 & TRN & \\
\hline CHEMBL1358614 & 737822 & 4.9 & 4.6096 & TRN & \\
\hline CHEMBL600287 & 737822 & 4.75 & 5.4148 & TST & \\
\hline CHEMBL1598334 & 737822 & 7.6 & 7.0729 & TRN & \\
\hline CHEMBL1431111 & 737822 & 4.9 & 5.4104 & TST & \\
\hline CHEMBL1389235 & 737822 & 5.3 & 5.2898 & TRN & \\
\hline CHEMBL1492063 & 737822 & 5.5 & 5.4352 & TRN & \\
\hline CHEMBL1255578 & 737822 & 5.4 & 5.2911 & TST & \\
\hline CHEMBL1474876 & 737822 & 5.5 & 5.4278 & TRN & \\
\hline CHEMBL1461462 & 737822 & 5.7 & 5.4704 & TRN & \\
\hline CHEMBL1384971 & 737822 & 4.95 & 5.5194 & TRN & \\
\hline CHEMBL1406631 & 737822 & 4.85 & 5.3839 & TRN & \\
\hline CHEMBL1588072 & 737822 & 4.8 & 5.2272 & TST & \\
\hline CHEMBL1510347 & 737822 & 6.0 & 5.2843 & TST & \\
\hline CHEMBL1325530 & 737822 & 4.5 & 5.1054 & TRN & \\
\hline CHEMBL1558538 & 737822 & 5.25 & 5.5535 & TRN & \\
\hline CHEMBL1340013 & 737822 & 5.7 & 5.273 & TRN & \\
\hline CHEMBL1384720 & 737822 & 5.1 & 5.2584 & TST & \\
\hline CHEMBL1582419 & 737822 & 4.8 & 5.1746 & TRN & \\
\hline CHEMBL1451815 & 737822 & 5.9 & 5.17899 & 9999999999 & TRN \\
\hline CHEMBL1555537 & 737822 & 5.7 & 5.5431 & TST & \\
\hline CHEMBL1528170 & 737822 & 4.6 & 4.4344 & TRN & \\
\hline CHEMBL1373007 & 737822 & 4.6 & 4.7254 & TST & \\
\hline CHEMBL1327247 & 737822 & 4.4 & 4.5023 & TRN & \\
\hline CHEMBL1362892 & 737822 & 4.9 & 4.6827 & TRN & \\
\hline CHEMBL1370622 & 737822 & 4.7 & 4.677 & TRN & \\
\hline CHEMBL3197465 & 737822 & 5.05 & 5.2604 & TRN & \\
\hline CHEMBL1476334 & 737822 & 4.5 & 4.5096 & TRN & \\
\hline CHEMBL1460951 & 737822 & 5.3 & 5.4967 & TRN & \\
\hline CHEMBL1742280 & 737822 & 4.6 & 5.1183 & TRN & \\
\hline CHEMBL1309131 & 737822 & 4.6 & 5.3688 & TRN & \\
\hline CHEMBL1388133 & 737822 & 4.7 & 5.4441 & TRN & \\
\hline CHEMBL1563819 & 737822 & 4.55 & 5.3445 & TST & \\
\hline CHEMBL1564011 & 737822 & 5.4 & 5.3209 & TRN & \\
\hline CHEMBL1316623 & 737822 & 5.0 & 4.9228 & TST & \\
\hline CHEMBL1511986 & 737822 & 4.6 & 4.57600 & 00000000005 & TRN \\
\hline CHEMBL1536058 & 737822 & 5.4 & 5.4516 & TST & \\
\hline CHEMBL1531681 & 737822 & 4.95 & 5.6392 & TRN & \\
\hline CHEMBL1331786 & 737822 & 6.0 & 5.7023 & TRN & \\
\hline CHEMBL1592202 & 737822 & 4.4 & 4.5415 & TRN & \\
\hline CHEMBL1533335 & 737822 & 4.7 & 4.5898 & TRN & \\
\hline CHEMBL1490198 & 737822 & 4.75 & 5.2831 & TRN & \\
\hline CHEMBL1256666 & 737822 & 4.5 & 4.77800 & 00000000005 & TRN \\
\hline CHEMBL1449726 & 737822 & 5.6 & 5.4647 & TRN & \\
\hline CHEMBL1366433 & 737822 & 4.4 & 4.2876 & TRN & \\
\hline CHEMBL1302492 & 737822 & 4.55 & 5.2195 & TRN & \\
\hline CHEMBL1591548 & 737822 & 5.0 & 5.20200 & 0000000001 & TRN \\
\hline & & & & 11302 & \\
\hline
\end{tabular}




\begin{tabular}{|c|c|c|c|c|c|}
\hline & & & & & \\
\hline CHEMBL1315373 & 737822 & 4.9 & 4.9146 & TRN & \\
\hline CHEMBL1485865 & 737822 & 4.55 & 5.1937 & TST & \\
\hline CHEMBL1594405 & 737822 & 4.7 & 4.5434 & TRN & \\
\hline CHEMBL1474461 & 737822 & 4.9 & 4.9646 & TRN & \\
\hline CHEMBL1316956 & 737822 & 5.9 & 5.6713 & TRN & \\
\hline CHEMBL1509815 & 737822 & 5.4 & 5.61799 & 9999999999 & TRN \\
\hline CHEMBL1434747 & 737822 & 4.5 & 4.4668 & TRN & \\
\hline CHEMBL1463577 & 737822 & 6.2 & 5.147 & TRN & \\
\hline CHEMBL1400491 & 737822 & 4.4 & 4.3026 & TRN & \\
\hline CHEMBL1318758 & 737822 & 4.8 & 5.0575 & TST & \\
\hline CHEMBL1372363 & 737822 & 4.6 & 4.5347 & TRN & \\
\hline CHEMBL1410016 & 737822 & 6.0 & 5.7348 & TRN & \\
\hline CHEMBL1396010 & 737822 & 4.6 & 4.4926 & TRN & \\
\hline CHEMBL1546319 & 737822 & 4.65 & 5.3319 & TRN & \\
\hline CHEMBL1567725 & 737822 & 4.9 & 4.7159 & TRN & \\
\hline CHEMBL1446539 & 737822 & 4.5 & 4.4088 & TRN & \\
\hline CHEMBL1389497 & 737822 & 4.9 & 5.1859 & TST & \\
\hline CHEMBL1318066 & 737822 & 6.1 & 5.8059 & TRN & \\
\hline CHEMBL1583276 & 737822 & 4.8 & 5.2384 & TRN & \\
\hline CHEMBL1353190 & 737822 & 5.05 & 5.1634 & TRN & \\
\hline CHEMBL1440943 & 737822 & 4.4 & 4.2476 & TRN & \\
\hline CHEMBL1588553 & 737822 & 4.95 & 5.0954 & TRN & \\
\hline CHEMBL 1348252 & 737822 & 5.5 & 5.487 & TRN & \\
\hline CHEMBL1451747 & 737822 & 6.1 & 5.4627 & TST & \\
\hline CHEMBL1433464 & 737822 & 5.0 & 4.8163 & TRN & \\
\hline CHEMBL1553530 & 737822 & 5.2 & 5.0229 & TRN & \\
\hline CHEMBL1400667 & 737822 & 6.4 & 6.0009 & TRN & \\
\hline CHEMBL452861 & 737822 & 5.6 & 5.5133 & TRN & \\
\hline CHEMBL1400921 & 737822 & 4.85 & 5.4688 & TRN & \\
\hline CHEMBL1544132 & 737822 & 4.65 & 5.4582 & TRN & \\
\hline CHEMBL1564066 & 737822 & 5.0 & 5.4125 & TRN & \\
\hline CHEMBL1363867 & 737822 & 4.6 & 5.1758 & TRN & \\
\hline CHEMBL1540708 & 737822 & 6.9 & 5.4954 & TRN & \\
\hline CHEMBL3197876 & 737822 & 5.6 & 5.2915 & TRN & \\
\hline CHEMBL1321846 & 737822 & 5.0 & 4.7672 & TRN & \\
\hline CHEMBL1360821 & 737822 & 4.6 & 5.4579 & TST & \\
\hline CHEMBL1513160 & 737822 & 4.4 & 4.3978 & TRN & \\
\hline CHEMBL1349241 & 737822 & 4.8 & 5.3539 & TRN & \\
\hline CHEMBL1256851 & 737822 & 7.3 & 6.8015 & TST & \\
\hline CHEMBL1446815 & 737822 & 5.0 & 5.0649 & TRN & \\
\hline CHEMBL1409938 & 737822 & 4.65 & 5.352 & TRN & \\
\hline CHEMBL1386709 & 737822 & 5.65 & 5.3542 & TRN & \\
\hline CHEMBL1475541 & 737822 & 4.6 & 4.5206 & TRN & \\
\hline CHEMBL429095 & 737822 & 4.5 & 5.7644 & TST & \\
\hline CHEMBL1446990 & 737822 & 5.9 & 5.9194 & TRN & \\
\hline CHEMBL1355292 & 737822 & 5.3 & 5.3437 & TRN & \\
\hline CHEMBL1440663 & 737822 & 5.9 & 5.3073 & TRN & \\
\hline CHEMBL1575193 & 737822 & 4.6 & 5.29799 & 9999999999 & TRN \\
\hline & & & & 11303 & \\
\hline
\end{tabular}




\begin{tabular}{|c|c|c|c|c|c|}
\hline \multicolumn{6}{|c|}{ Supplemental Table S2.txt } \\
\hline CHEMBL1537609 & 737822 & 5.05 & 5.3692 & TRN & \\
\hline CHEMBL1559877 & 737822 & 5.1 & 5.433 & TRN & \\
\hline CHEMBL1476791 & 737822 & 4.4 & 4.3494 & TRN & \\
\hline CHEMBL1562101 & 737822 & 4.65 & 5.5017 & TRN & \\
\hline CHEMBL1600292 & 737822 & 5.4 & 5.1959 & TRN & \\
\hline CHEMBL1483427 & 737822 & 4.6 & 4.437 & TRN & \\
\hline CHEMBL282489 & 737822 & 4.4 & 4.6319 & TRN & \\
\hline CHEMBL1324405 & 737822 & 6.0 & 5.8259 & TRN & \\
\hline CHEMBL1330296 & 737822 & 4.8 & 4.7798 & TRN & \\
\hline CHEMBL1472765 & 737822 & 4.4 & 4.33899 & 99999999995 & TRN \\
\hline CHEMBL1559654 & 737822 & 4.9 & 4.734 & TRN & \\
\hline CHEMBL1529853 & 737822 & 5.3 & 5.4533 & TST & \\
\hline CHEMBL1551913 & 737822 & 4.4 & 4.3349 & TRN & \\
\hline CHEMBL1536604 & 737822 & 4.9 & 5.2118 & TRN & \\
\hline CHEMBL1366667 & 737822 & 5.4 & 5.3514 & TRN & \\
\hline CHEMBL1600552 & 737822 & 4.85 & 5.3448 & TRN & \\
\hline CHEMBL1465834 & 737822 & 4.55 & 5.3107 & TRN & \\
\hline CHEMBL1607650 & 737822 & 4.9 & 5.3619 & TRN & \\
\hline CHEMBL1300710 & 737822 & 4.85 & 5.5515 & TRN & \\
\hline CHEMBL1492229 & 737822 & 4.8 & 4.6209 & TRN & \\
\hline CHEMBL1329312 & 737822 & 5.5 & 5.3507 & TRN & \\
\hline CHEMBL1465191 & 737822 & 4.85 & 5.3799 & TRN & \\
\hline CHEMBL1513643 & 737822 & 6.2 & 5.9508 & TST & \\
\hline CHEMBL1564579 & 737822 & 4.85 & 5.2968 & TRN & \\
\hline CHEMBL1341999 & 737822 & 5.05 & 5.4135 & TRN & \\
\hline CHEMBL1310543 & 737822 & 4.7 & 5.3422 & TRN & \\
\hline CHEMBL1364182 & 737822 & 4.7 & 4.5016 & TRN & \\
\hline CHEMBL1560068 & 737822 & 6.0 & 5.2379 & TRN & \\
\hline CHEMBL1450936 & 737822 & 4.8 & 4.8191 & TRN & \\
\hline CHEMBL1450573 & 737822 & 6.2 & 5.9335 & TRN & \\
\hline CHEMBL1351101 & 737822 & 4.55 & 5.3194 & TST & \\
\hline CHEMBL1567854 & 737822 & 5.4 & 5.3985 & TRN & \\
\hline CHEMBL1306134 & 737822 & 5.95 & 5.285 & TRN & \\
\hline CHEMBL1581905 & 737822 & 4.85 & 5.3657 & TRN & \\
\hline CHEMBL1536139 & 737822 & 7.9 & 5.3355 & TRN & \\
\hline CHEMBL1613513 & 737822 & 4.6 & 4.4404 & TRN & \\
\hline CHEMBL1377727 & 737822 & 5.3 & 4.948 & TRN & \\
\hline CHEMBL1396577 & 737822 & 4.8 & 4.7082 & TRN & \\
\hline CHEMBL1718851 & 737822 & 6.35 & 5.704 & TRN & \\
\hline CHEMBL1510646 & 737822 & 4.8 & 4.9618 & TRN & \\
\hline CHEMBL1352421 & 737822 & 4.75 & 5.231 & TRN & \\
\hline CHEMBL 1425063 & 737822 & 4.95 & 5.4037 & TST & \\
\hline CHEMBL1360980 & 737822 & 4.85 & 5.0379 & TST & \\
\hline CHEMBL1490079 & 737822 & 4.85 & 5.3904 & TRN & \\
\hline CHEMBL1491036 & 737822 & 5.5 & 5.4764 & TRN & \\
\hline CHEMBL1389687 & 737822 & 4.5 & 5.4927 & TRN & \\
\hline CHEMBL1566684 & 737822 & 4.6 & 5.1842 & TST & \\
\hline CHEMBL1526526 & 737822 & 4.9 & 4.9949 & TRN & \\
\hline
\end{tabular}




\begin{tabular}{|c|c|c|c|c|c|}
\hline \\
\hline CHEMBL1565366 & 737822 & 4.8 & 5.3478 & TRN & \\
\hline CHEMBL1304386 & 737822 & 4.9 & 5.2317 & TRN & \\
\hline CHEMBL1336102 & 737822 & 5.5 & 5.2181 & TRN & \\
\hline CHEMBL1490078 & 737822 & 5.7 & 5.2223 & TRN & \\
\hline CHEMBL1329562 & 737822 & 4.9 & 5.5345 & TRN & \\
\hline CHEMBL1490820 & 737822 & 4.8 & 5.0275 & TRN & \\
\hline CHEMBL1516503 & 737822 & 4.75 & 5.3723 & TRN & \\
\hline CHEMBL1574504 & 737822 & 5.05 & 5.3826 & TRN & \\
\hline CHEMBL1551979 & 737822 & 5.4 & 4.9953 & TRN & \\
\hline CHEMBL1591190 & 737822 & 4.9 & 4.7179 & TRN & \\
\hline CHEMBL1394137 & 737822 & 4.4 & 4.3876 & TRN & \\
\hline CHEMBL1496056 & 737822 & 5.25 & 5.4655 & TRN & \\
\hline CHEMBL1338917 & 737822 & 4.55 & 5.0816 & TRN & \\
\hline CHEMBL1560798 & 737822 & 5.5 & 5.2997 & TRN & \\
\hline CHEMBL1360401 & 737822 & 4.9 & 4.6921 & TRN & \\
\hline CHEMBL1336782 & 737822 & 5.4 & 5.3103 & TRN & \\
\hline CHEMBL1340538 & 737822 & 4.8 & 5.4035 & TRN & \\
\hline CHEMBL1192187 & 737822 & 6.0 & 5.7755 & TRN & \\
\hline CHEMBL1357968 & 737822 & 4.7 & 4.7142 & TRN & \\
\hline CHEMBL1474244 & 737822 & 6.3 & 5.943 & TRN & \\
\hline CHEMBL1501813 & 737822 & 4.9 & 5.6071 & TRN & \\
\hline CHEMBL1570480 & 737822 & 5.4 & 5.2735 & TST & \\
\hline CHEMBL1337584 & 737822 & 4.9 & 5.1498 & TRN & \\
\hline CHEMBL1523900 & 737822 & 6.5 & 6.4155 & TRN & \\
\hline CHEMBL1582787 & 737822 & 6.7 & 5.6724 & TRN & \\
\hline CHEMBL1626274 & 737822 & 6.0 & 5.6187 & TRN & \\
\hline CHEMBL1470084 & 737822 & 4.85 & 5.1426 & TRN & \\
\hline CHEMBL1387098 & 737822 & 5.8 & 5.0026 & TRN & \\
\hline CHEMBL1301140 & 737822 & 4.85 & 5.3865 & TRN & \\
\hline CHEMBL1490782 & 737822 & 5.05 & 5.1595 & TRN & \\
\hline CHEMBL1553325 & 737822 & 6.0 & 5.7734 & TRN & \\
\hline CHEMBL1459103 & 737822 & 4.8 & 5.3294 & TRN & \\
\hline CHEMBL1474445 & 737822 & 5.4 & 5.2336 & TST & \\
\hline CHEMBL1560567 & 737822 & 6.2 & 6.01399 & 9999999999 & TRN \\
\hline CHEMBL1554577 & 737822 & 5.9 & 5.6315 & TRN & \\
\hline CHEMBL1490634 & 737822 & 5.05 & 5.4818 & TRN & \\
\hline CHEMBL1611549 & 737822 & 4.7 & 5.3316 & TRN & \\
\hline CHEMBL1527611 & 737822 & 4.65 & 5.2566 & TRN & \\
\hline CHEMBL1595862 & 737822 & 4.5 & 5.1019 & TST & \\
\hline CHEMBL1357982 & 737822 & 5.2 & 4.8551 & TRN & \\
\hline CHEMBL1500174 & 737822 & 4.45 & 4.8852 & TRN & \\
\hline CHEMBL1461234 & 737822 & 4.85 & 5.1141 & TRN & \\
\hline CHEMBL1435823 & 737822 & 4.4 & 4.2836 & TRN & \\
\hline CHEMBL1426905 & 737822 & 4.8 & 5.4752 & TRN & \\
\hline CHEMBL1496986 & 737822 & 5.3 & 5.5095 & TRN & \\
\hline CHEMBL1361455 & 737822 & 5.0 & 5.2335 & TRN & \\
\hline CHEMBL1580701 & 737822 & 4.9 & 5.2872 & TRN & \\
\hline CHEMBL1374931 & 737822 & 5.05 & 5.0342 & TRN & \\
\hline & & & & 13 & \\
\hline
\end{tabular}




\begin{tabular}{|c|c|c|c|c|}
\hline \multicolumn{5}{|c|}{ plemental T } \\
\hline CHEMBL1524305 & 737822 & 4.6 & 4.6563 & TRN \\
\hline CHEMBL1358568 & 737822 & 6.0 & 5.8428 & TRN \\
\hline CHEMBL1453970 & 737822 & 4.9 & 5.2705 & TST \\
\hline CHEMBL491976 & 737822 & 4.9 & 4.8942 & TRN \\
\hline CHEMBL1377201 & 737822 & 4.85 & 5.1718 & TRN \\
\hline CHEMBL3195867 & 737822 & 5.7 & 5.2582 & TRN \\
\hline CHEMBL1417448 & 737822 & 4.7 & 4.6209 & TRN \\
\hline CHEMBL1338077 & 737822 & 4.8 & 5.1326 & TRN \\
\hline CHEMBL1318042 & 737822 & 4.7 & 4.6361 & TRN \\
\hline CHEMBL73451 & 737822 & 6.4 & 6.3034 & TRN \\
\hline CHEMBL 1372952 & 737822 & 4.85 & 5.1821 & TRN \\
\hline CHEMBL1553047 & 737822 & 6.8 & 6.8073 & TRN \\
\hline CHEMBL1454533 & 737822 & 4.95 & 5.3187 & TST \\
\hline CHEMBL1406274 & 737822 & 5.6 & 5.3811 & TRN \\
\hline CHEMBL1565927 & 737822 & 5.5 & 5.2221 & TRN \\
\hline CHEMBL 1455816 & 737822 & 4.8 & 5.1301 & TST \\
\hline CHEMBL1592211 & 737822 & 4.4 & 4.3439 & TRN \\
\hline CHEMBL1335644 & 737822 & 5.95 & 5.1333 & TRN \\
\hline CHEMBL1409682 & 737822 & 5.5 & 5.5385 & TRN \\
\hline CHEMBL1332803 & 737822 & 5.4 & 5.3893 & TST \\
\hline CHEMBL 1485598 & 737822 & 5.45 & 5.3215 & TRN \\
\hline CHEMBL1483855 & 737822 & 5.2 & 4.9676 & TRN \\
\hline CHEMBL1552747 & 737822 & 5.1 & 4.9551 & TRN \\
\hline CHEMBL1487735 & 737822 & 4.6 & 4.4924 & TRN \\
\hline CHEMBL1570894 & 737822 & 5.3 & 5.2933 & TRN \\
\hline CHEMBL1313170 & 737822 & 6.55 & 5.438 & TRN \\
\hline CHEMBL1256737 & 737822 & 6.0 & 5.8971 & TRN \\
\hline CHEMBL1571290 & 737822 & 4.6 & 5.2815 & TRN \\
\hline CHEMBL1563753 & 737822 & 4.7 & 5.2889 & TST \\
\hline CHEMBL491909 & 737822 & 4.9 & 4.7563 & TRN \\
\hline CHEMBL1553766 & 737822 & 4.6 & 4.6512 & TRN \\
\hline CHEMBL1449870 & 737822 & 5.45 & 5.4161 & TRN \\
\hline CHEMBL1417349 & 737822 & 4.4 & 4.4506 & TRN \\
\hline CHEMBL3196953 & 737822 & 5.4 & 5.3895 & TRN \\
\hline CHEMBL1378710 & 737822 & 4.55 & 5.1849 & TRN \\
\hline CHEMBL1406920 & 737822 & 4.45 & 5.3986 & TST \\
\hline CHEMBL1256876 & 737822 & 4.5 & 4.588 & TST \\
\hline CHEMBL1604492 & 737822 & 4.7 & 5.3937 & TRN \\
\hline CHEMBL1515287 & 737822 & 4.6 & 4.562 & TRN \\
\hline CHEMBL1604077 & 737822 & 4.7 & 5.0287 & TST \\
\hline CHEMBL1570465 & 737822 & 5.65 & 5.3845 & TRN \\
\hline CHEMBL1326533 & 737822 & 4.6 & 5.0857 & TRN \\
\hline CHEMBL1512683 & 737822 & 4.6 & 4.6748 & TST \\
\hline CHEMBL1590321 & 737822 & 6.8 & 6.6716 & TRN \\
\hline CHEMBL1486399 & 737822 & 4.4 & 4.3057 & TRN \\
\hline CHEMBL1441572 & 737822 & 7.5 & 5.5607 & TRN \\
\hline CHEMBL1548943 & 737822 & 4.75 & 5.4841 & TRN \\
\hline CHEMBL1435381 & 737822 & 4.5 & 4.3202 & TST \\
\hline
\end{tabular}




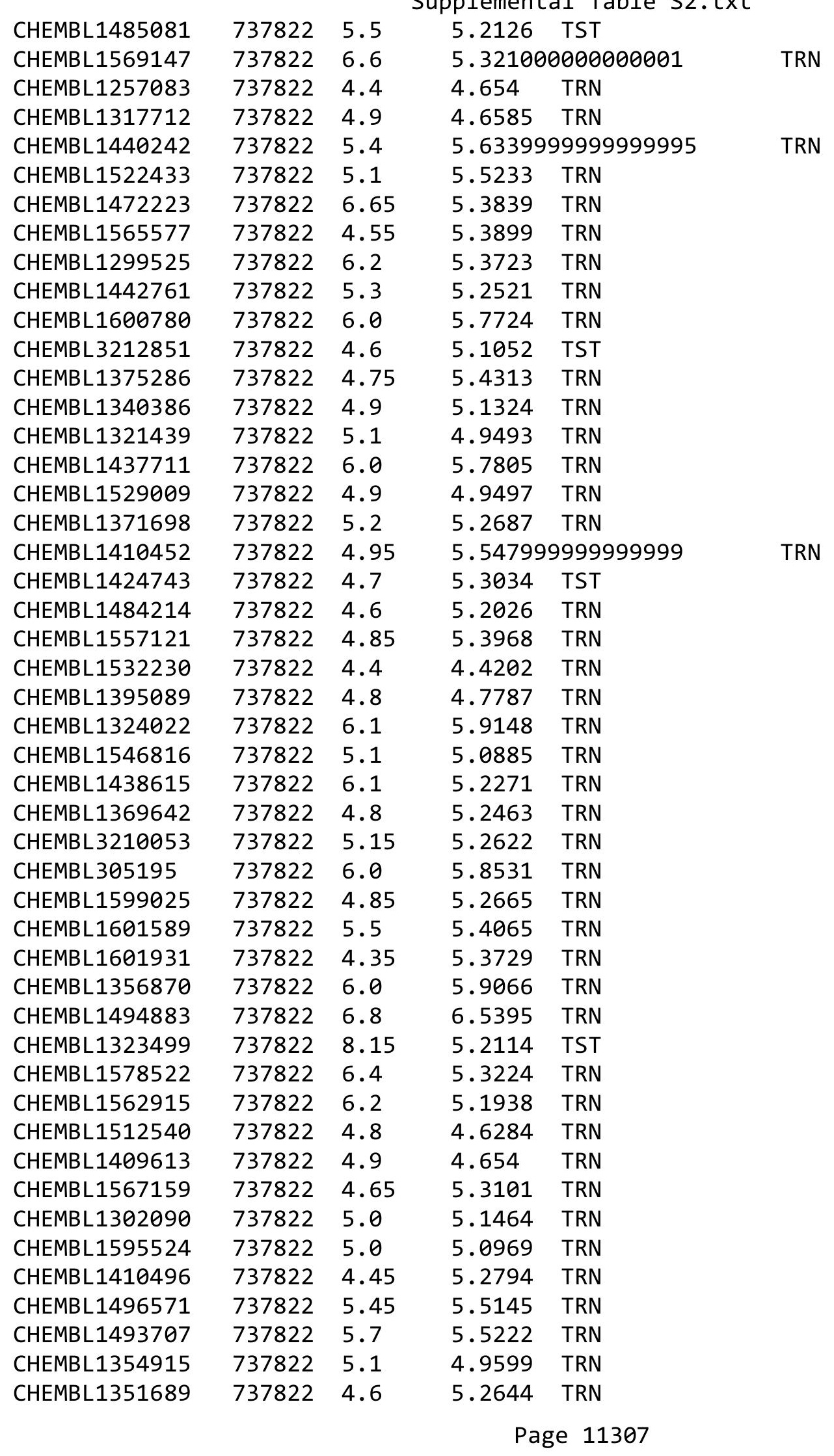




\begin{tabular}{|c|c|c|c|c|}
\hline \multicolumn{5}{|c|}{ Supplemental Table S2.txt } \\
\hline CHEMBL1403333 & 737822 & 4.7 & 4.5472 & TRN \\
\hline CHEMBL1484231 & 737822 & 4.7 & 5.3327 & TRN \\
\hline CHEMBL1582074 & 737822 & 4.95 & 5.2919 & TRN \\
\hline CHEMBL1529478 & 737822 & 4.6 & 4.5449 & TRN \\
\hline CHEMBL1483608 & 737822 & 4.65 & 5.1932 & TRN \\
\hline CHEMBL1310938 & 737822 & 5.5 & 5.2622 & TRN \\
\hline CHEMBL1502523 & 737822 & 5.4 & 4.9834 & TRN \\
\hline CHEMBL1355111 & 737822 & 5.0 & 5.2093 & TRN \\
\hline CHEMBL1474625 & 737822 & 4.5 & 4.481 & TRN \\
\hline CHEMBL1606727 & 737822 & 5.5 & 5.3191 & TRN \\
\hline CHEMBL1377767 & 737822 & 4.6 & 5.4165 & TRN \\
\hline CHEMBL1438331 & 737822 & 4.75 & 5.3133 & TRN \\
\hline CHEMBL1969457 & 737822 & 4.55 & 5.3079 & TST \\
\hline CHEMBL1407910 & 737822 & 6.4 & 5.1697 & TST \\
\hline CHEMBL1580790 & 737822 & 5.1 & 5.1023 & TRN \\
\hline CHEMBL1483672 & 737822 & 5.5 & 5.7671 & TST \\
\hline CHEMBL1436174 & 737822 & 5.3 & 5.2537 & TRN \\
\hline CHEMBL1422891 & 737822 & 6.6 & 5.5447 & TRN \\
\hline CHEMBL3208809 & 737822 & 4.45 & 5.1793 & TRN \\
\hline CHEMBL1515194 & 737822 & 4.4 & 4.3047 & TRN \\
\hline CHEMBL1321094 & 737822 & 4.6 & 4.4499 & TRN \\
\hline CHEMBL1328118 & 737822 & 6.05 & 5.7265 & TRN \\
\hline CHEMBL1533024 & 737822 & 5.15 & 5.3146 & TRN \\
\hline CHEMBL1530645 & 737822 & 4.4 & 4.3563 & TRN \\
\hline CHEMBL1331980 & 737822 & 5.5 & 5.5078 & TST \\
\hline CHEMBL491977 & 737822 & 5.4 & 5.1537 & TRN \\
\hline CHEMBL1376258 & 737822 & 5.05 & 5.0821 & TRN \\
\hline CHEMBL1534566 & 737822 & 5.0 & 4.9434 & TRN \\
\hline CHEMBL1322942 & 737822 & 4.85 & 5.2563 & TRN \\
\hline CHEMBL1482510 & 737822 & 6.05 & 5.2291 & TRN \\
\hline CHEMBL1436992 & 737822 & 4.8 & 4.6832 & TST \\
\hline CHEMBL1569491 & 737822 & 4.65 & 5.551 & TRN \\
\hline CHEMBL1356135 & 737822 & 6.9 & 6.2111 & TRN \\
\hline CHEMBL1563772 & 737822 & 4.8 & 5.4062 & TRN \\
\hline CHEMBL1563066 & 737822 & 5.6 & 5.4351 & TRN \\
\hline CHEMBL1394113 & 737822 & 4.9 & 4.8112 & TRN \\
\hline CHEMBL1492493 & 737822 & 4.75 & 5.2399 & TRN \\
\hline CHEMBL1598049 & 737822 & 4.75 & 5.1598 & TRN \\
\hline CHEMBL1505836 & 737822 & 4.55 & 5.1384 & TRN \\
\hline CHEMBL1553422 & 737822 & 4.5 & 4.6903 & TRN \\
\hline CHEMBL490913 & 737822 & 4.7 & 4.5417 & TRN \\
\hline CHEMBL3208106 & 737822 & 4.85 & 5.4517 & TRN \\
\hline CHEMBL1530982 & 737822 & 4.7 & 4.5184 & TRN \\
\hline CHEMBL1525767 & 737822 & 4.8 & 4.8009 & TRN \\
\hline CHEMBL1553939 & 737822 & 5.0 & 5.0971 & TRN \\
\hline CHEMBL3212657 & 737822 & 5.15 & 5.2613 & TRN \\
\hline CHEMBL1552897 & 737822 & 5.6 & 5.3839 & TRN \\
\hline CHEMBL1343620 & 737822 & 4.85 & 5.2388 & TRN \\
\hline
\end{tabular}




\begin{tabular}{|c|c|c|c|c|}
\hline \multicolumn{5}{|c|}{ Supplemental Table S2.txt } \\
\hline CHEMBL1489512 & 737822 & 4.75 & 5.093 & TRN \\
\hline CHEMBL1428605 & 737822 & 7.15 & 5.2611 & TRN \\
\hline CHEMBL1314011 & 737822 & 5.45 & 5.3597 & TRN \\
\hline CHEMBL1362669 & 737822 & 4.5 & 5.1011 & TRN \\
\hline CHEMBL1567435 & 737822 & 5.5 & 5.2402 & TRN \\
\hline CHEMBL491748 & 737822 & 5.6 & 5.2524 & TRN \\
\hline CHEMBL421215 & 737822 & 5.3 & 5.2311 & TST \\
\hline CHEMBL1331778 & 737822 & 5.5 & 5.3755 & TRN \\
\hline CHEMBL1301881 & 737822 & 4.6 & 5.2922 & TRN \\
\hline CHEMBL1367399 & 737822 & 7.0 & 5.2153 & TST \\
\hline CHEMBL1590857 & 737822 & 4.6 & 4.5608 & TRN \\
\hline CHEMBL1439893 & 737822 & 4.6 & 4.5481 & TRN \\
\hline CHEMBL1597539 & 737822 & 5.6 & 5.1746 & TRN \\
\hline CHEMBL1724748 & 737822 & 6.3 & 5.2087 & TRN \\
\hline CHEMBL1347390 & 737822 & 4.8 & 5.2748 & TST \\
\hline CHEMBL1497099 & 737822 & 4.8 & 5.352 & TRN \\
\hline CHEMBL1371238 & 737822 & 4.6 & 5.3103 & TRN \\
\hline CHEMBL1354864 & 737822 & 4.6 & 4.4297 & TRN \\
\hline CHEMBL1533537 & 737822 & 4.9 & 4.6776 & TRN \\
\hline CHEMBL1515540 & 737822 & 5.0 & 4.9135 & TRN \\
\hline CHEMBL1395935 & 737822 & 5.5 & 5.4379 & TRN \\
\hline CHEMBL 2062344 & 737822 & 5.3 & 5.1468 & TST \\
\hline CHEMBL1314971 & 737822 & 4.4 & 4.3134 & TRN \\
\hline CHEMBL1437226 & 737822 & 4.6 & 4.5927 & TRN \\
\hline CHEMBL 3199344 & 737822 & 5.3 & 5.1227 & TRN \\
\hline CHEMBL1366390 & 737822 & 5.0 & 5.3634 & TRN \\
\hline CHEMBL1426948 & 737822 & 4.5 & 4.7169 & TRN \\
\hline CHEMBL1472649 & 737822 & 6.3 & 5.9774 & TRN \\
\hline CHEMBL1562974 & 737822 & 5.25 & 5.3474 & TRN \\
\hline CHEMBL1311531 & 737822 & 4.9 & 5.5696 & TRN \\
\hline CHEMBL1328341 & 737822 & 6.6 & 5.1927 & TRN \\
\hline CHEMBL1256647 & 737822 & 6.3 & 6.044 & TRN \\
\hline CHEMBL1516787 & 737822 & 5.0 & 4.9741 & TRN \\
\hline CHEMBL1477169 & 737822 & 5.9 & 5.6319 & TRN \\
\hline CHEMBL1429119 & 737822 & 4.65 & 4.9606 & TRN \\
\hline CHEMBL 3213666 & 737822 & 4.8 & 5.4316 & TRN \\
\hline CHEMBL1410865 & 737822 & 6.0 & 6.0032 & TRN \\
\hline CHEMBL1529490 & 737822 & 6.7 & 5.8389 & TRN \\
\hline CHEMBL1451224 & 737822 & 5.8 & 5.819 & TRN \\
\hline CHEMBL1450977 & 737822 & 4.85 & 5.3958 & TST \\
\hline CHEMBL1363474 & 737822 & 4.45 & 5.2475 & TRN \\
\hline CHEMBL1591107 & 737822 & 4.9 & 4.725 & TRN \\
\hline CHEMBL1453817 & 737822 & 7.1 & 5.0236 & TRN \\
\hline CHEMBL1316461 & 737822 & 5.6 & 5.8192 & TRN \\
\hline CHEMBL1439144 & 737822 & 4.75 & 5.1982 & TST \\
\hline CHEMBL495069 & 737822 & 5.1 & 5.0327 & TRN \\
\hline CHEMBL1590909 & 737822 & 4.9 & 4.7636 & TRN \\
\hline CHEMBL1582198 & 737822 & 4.75 & 4.9707 & TRN \\
\hline
\end{tabular}




\begin{tabular}{|c|c|c|c|c|}
\hline \multicolumn{5}{|c|}{ plemental } \\
\hline CHEMBL1331288 & 737822 & 4.4 & 4.4948 & TRN \\
\hline CHEMBL1733088 & 737822 & 5.65 & 5.1622 & TRN \\
\hline CHEMBL1505285 & 737822 & 5.35 & 5.4919 & TRN \\
\hline CHEMBL1605940 & 737822 & 4.7 & 5.2641 & TRN \\
\hline CHEMBL479014 & 737822 & 6.6 & 6.013 & TST \\
\hline CHEMBL1319672 & 737822 & 6.2 & 5.8345 & TRN \\
\hline CHEMBL472656 & 737822 & 5.4 & 5.3657 & TST \\
\hline CHEMBL1391936 & 737822 & 5.75 & 5.33 & TRN \\
\hline CHEMBL446774 & 737822 & 5.2 & \multicolumn{2}{|c|}{5.196000000000001} \\
\hline CHEMBL1326322 & 737822 & 4.4 & 4.2988 & TRN \\
\hline CHEMBL288096 & 737822 & 4.8 & 4.8452 & TRN \\
\hline CHEMBL1718423 & 737822 & 4.8 & 5.6241 & TRN \\
\hline CHEMBL1317494 & 737822 & 4.8 & 4.6262 & TRN \\
\hline CHEMBL 221137 & 737822 & 5.7 & 5.6621 & TST \\
\hline CHEMBL 3213624 & 737822 & 4.6 & 5.2528 & TRN \\
\hline CHEMBL1318461 & 737822 & 5.4 & 5.2958 & TRN \\
\hline CHEMBL1596831 & 737822 & 6.9 & 5.5806 & TST \\
\hline CHEMBL1522673 & 737822 & 7.5 & 5.1636 & TRN \\
\hline CHEMBL1604887 & 737822 & 7.1 & 5.2969 & TRN \\
\hline CHEMBL1449111 & 737822 & 5.0 & 5.2033 & TRN \\
\hline CHEMBL1329327 & 737822 & 5.3 & 5.2539 & TRN \\
\hline CHEMBL 2001481 & 737822 & 5.15 & 5.1393 & TST \\
\hline CHEMBL81977 & 737822 & 4.7 & 4.7421 & TRN \\
\hline CHEMBL1584987 & 737822 & 4.85 & 5.3556 & TRN \\
\hline CHEMBL1504920 & 737822 & 5.05 & 5.2788 & TRN \\
\hline CHEMBL1352396 & 737822 & 6.5 & 5.2143 & TRN \\
\hline CHEMBL1367995 & 737822 & 4.8 & 4.8891 & TRN \\
\hline CHEMBL1590038 & 737822 & 4.4 & 4.3912 & TRN \\
\hline CHEMBL1323434 & 737822 & 5.4 & 5.1393 & TRN \\
\hline CHEMBL1345410 & 737822 & 4.95 & 5.3787 & TRN \\
\hline CHEMBL1516249 & 737822 & 4.8 & 4.5964 & TRN \\
\hline CHEMBL1436324 & 737822 & 6.0 & 5.7395 & TRN \\
\hline CHEMBL 277120 & 737822 & 4.8 & 4.865 & TRN \\
\hline CHEMBL1503387 & 737822 & 4.95 & 5.2782 & TRN \\
\hline CHEMBL3198283 & 737822 & 4.6 & 5.28 & TST \\
\hline CHEMBL1489549 & 737822 & 4.95 & 5.26 & TRN \\
\hline CHEMBL1490656 & 737822 & 4.4 & 5.1489 & TRN \\
\hline CHEMBL37081 & 737822 & 4.9 & 4.8223 & TRN \\
\hline CHEMBL266084 & 737822 & 4.9 & 4.9393 & TRN \\
\hline CHEMBL1741855 & 737822 & 4.4 & 5.5694 & TRN \\
\hline CHEMBL1609808 & 737822 & 4.9 & 5.2663 & TRN \\
\hline CHEMBL1330422 & 737822 & 4.6 & 4.5344 & TRN \\
\hline CHEMBL1429320 & 737822 & 4.6 & 5.3469 & TST \\
\hline CHEMBL1324882 & 737822 & 4.4 & 4.3093 & TRN \\
\hline CHEMBL1427738 & 737822 & 4.75 & 5.5862 & TRN \\
\hline CHEMBL1560095 & 737822 & 4.7 & 4.768 & TRN \\
\hline CHEMBL1319783 & 737822 & 4.4 & 4.3889 & TRN \\
\hline CHEMBL1321892 & 737822 & 5.3 & 5.2808 & TRN \\
\hline
\end{tabular}

TRN 


\begin{tabular}{|c|c|c|c|c|c|}
\hline \\
\hline CHEMBL1688558 & 737822 & 6.5 & 6.1365 & TRN & \\
\hline CHEMBL3208526 & 737822 & 5.95 & 5.2357 & TST & \\
\hline CHEMBL1598818 & 737822 & 4.6 & 5.3102 & TST & \\
\hline CHEMBL1732557 & 737822 & 4.9 & 5.3289 & TRN & \\
\hline CHEMBL1449669 & 737822 & 4.85 & 5.30399 & 9999999999 & TRN \\
\hline CHEMBL1517121 & 737822 & 4.6 & 5.2747 & TST & \\
\hline CHEMBL1384399 & 737822 & 4.65 & 5.2136 & TRN & \\
\hline CHEMBL1369318 & 737822 & 4.8 & 4.5571 & TRN & \\
\hline CHEMBL1461873 & 737822 & 5.75 & 5.1547 & TRN & \\
\hline CHEMBL452153 & 737822 & 4.8 & 5.1102 & TST & \\
\hline CHEMBL1593592 & 737822 & 4.4 & 4.4398 & TRN & \\
\hline CHEMBL1419356 & 737822 & 5.9 & 5.2632 & TRN & \\
\hline CHEMBL1568413 & 737822 & 5.85 & 5.2918 & TRN & \\
\hline CHEMBL1728158 & 737822 & 6.4 & 5.4621 & TRN & \\
\hline CHEMBL1448896 & 737822 & 5.5 & 5.3503 & TRN & \\
\hline CHEMBL1328480 & 737822 & 6.1 & 5.8312 & TRN & \\
\hline CHEMBL1256996 & 737822 & 6.0 & 5.8219 & TRN & \\
\hline CHEMBL1388315 & 737822 & 5.1 & 5.3811 & TRN & \\
\hline CHEMBL1426147 & 737822 & 5.35 & 5.4508 & TRN & \\
\hline CHEMBL1448668 & 737822 & 6.3 & 6.0703 & TRN & \\
\hline CHEMBL1321511 & 737822 & 5.5 & 5.4396 & TRN & \\
\hline CHEMBL1300602 & 737822 & 4.8 & 5.1809 & TRN & \\
\hline CHEMBL1453591 & 737822 & 4.95 & $5.4570 e$ & 0000000001 & TRN \\
\hline CHEMBL1256885 & 737822 & 6.0 & 5.688 & TRN & \\
\hline CHEMBL1348828 & 737822 & 4.7 & 5.2923 & TRN & \\
\hline CHEMBL1590968 & 737822 & 5.1 & 5.047 & TRN & \\
\hline CHEMBL1419672 & 737822 & 6.4 & 5.6904 & TRN & \\
\hline CHEMBL1306717 & 737822 & 6.7 & 5.239 & TRN & \\
\hline CHEMBL1563722 & 737822 & 4.95 & 5.3442 & TST & \\
\hline CHEMBL1452408 & 737822 & 5.0 & 4.7306 & TRN & \\
\hline CHEMBL1392154 & 737822 & 5.5 & 5.0619 & TRN & \\
\hline CHEMBL1443332 & 737822 & 4.65 & 5.4201 & TRN & \\
\hline CHEMBL1346893 & 737822 & 4.9 & 5.13399 & 99999999995 & TRN \\
\hline CHEMBL1527466 & 737822 & 6.0 & 5.9133 & TRN & \\
\hline CHEMBL1443681 & 737822 & 5.0 & 5.1081 & TRN & \\
\hline CHEMBL1468521 & 737822 & 5.35 & 5.2825 & TST & \\
\hline CHEMBL1447248 & 737822 & 6.2 & 5.4813 & TRN & \\
\hline CHEMBL1517652 & 737822 & 5.65 & 5.4378 & TRN & \\
\hline CHEMBL 3084891 & 737822 & 4.6 & 4.8594 & TRN & \\
\hline CHEMBL1383532 & 737822 & 6.4 & 5.1597 & TST & \\
\hline CHEMBL1366699 & 737822 & 4.8 & 4.6676 & TRN & \\
\hline CHEMBL1549392 & 737822 & 4.85 & 5.2254 & TST & \\
\hline CHEMBL1588802 & 737822 & 4.6 & 5.3334 & TRN & \\
\hline CHEMBL1383146 & 737822 & 4.75 & 5.3525 & TRN & \\
\hline CHEMBL1576264 & 737822 & 5.0 & 5.147 & TST & \\
\hline CHEMBL1568277 & 737822 & 4.95 & 5.1037 & TRN & \\
\hline CHEMBL1339570 & 737822 & 4.65 & 5.4098 & TRN & \\
\hline CHEMBL1396374 & 737822 & 4.7 & 4.6366 & TRN & \\
\hline
\end{tabular}




\begin{tabular}{|c|c|c|c|c|}
\hline \multicolumn{5}{|c|}{ Supplemental T } \\
\hline CHEMBL1362264 & 737822 & 5.1 & 5.3734 & TRN \\
\hline CHEMBL1603322 & 737822 & 4.8 & 4.7942 & TRN \\
\hline CHEMBL 1600210 & 737822 & 4.5 & 4.3552 & TRN \\
\hline CHEMBL1512121 & 737822 & 4.4 & 4.3634 & TRN \\
\hline CHEMBL1340722 & 737822 & 5.5 & 5.4374 & TRN \\
\hline CHEMBL1494294 & 737822 & 4.4 & 4.5399 & TRN \\
\hline CHEMBL1358234 & 737822 & 4.4 & 4.4428 & TRN \\
\hline CHEMBL565654 & 737822 & 5.0 & 4.8039 & TRN \\
\hline CHEMBL492127 & 737822 & 4.9 & 4.9002 & TRN \\
\hline CHEMBL1589879 & 737822 & 5.2 & 5.1732 & TRN \\
\hline CHEMBL1560487 & 737822 & 4.9 & 5.0932 & TRN \\
\hline CHEMBL1397353 & 737822 & 4.4 & 4.3972 & TRN \\
\hline CHEMBL 285932 & 737822 & 5.4 & 5.2203 & TRN \\
\hline CHEMBL1396615 & 737822 & 4.7 & 4.5878 & TRN \\
\hline CHEMBL1590763 & 737822 & 5.0 & 4.7525 & TRN \\
\hline CHEMBL1568854 & 737822 & 4.4 & 4.4283 & TRN \\
\hline CHEMBL1741390 & 737822 & 5.1 & 5.2102 & TRN \\
\hline CHEMBL1448726 & 737822 & 4.4 & 4.2541 & TRN \\
\hline CHEMBL1540313 & 737822 & 6.9 & 5.4412 & TRN \\
\hline CHEMBL 280822 & 737822 & 5.6 & 5.4216 & TRN \\
\hline CHEMBL1529089 & 737822 & 5.0 & 5.1625 & TST \\
\hline CHEMBL1370296 & 737822 & 5.0 & 4.7962 & TRN \\
\hline CHEMBL 1350038 & 737822 & 4.9 & 5.3454 & TRN \\
\hline CHEMBL1324418 & 737822 & 4.9 & 4.6884 & TRN \\
\hline CHEMBL150 & 737822 & 5.0 & 5.5905 & TRN \\
\hline CHEMBL3210945 & 737822 & 5.0 & 5.4313 & TRN \\
\hline CHEMBL26320 & 737822 & 6.0 & 5.9775 & TRN \\
\hline CHEMBL1385067 & 737822 & 4.85 & 5.3002 & TRN \\
\hline CHEMBL1508906 & 737822 & 4.9 & 5.0116 & TRN \\
\hline CHEMBL1363569 & 737822 & 5.4 & 5.1152 & TRN \\
\hline CHEMBL117405 & 737822 & 6.0 & 5.7766 & TRN \\
\hline CHEMBL 8618 & 737822 & 6.0 & 5.65 & TRN \\
\hline CHEMBL1330357 & 737822 & 4.5 & 4.8017 & TST \\
\hline CHEMBL123433 & 737822 & 4.4 & 4.5901 & TST \\
\hline CHEMBL1516856 & 737822 & 4.8 & 4.8319 & TRN \\
\hline CHEMBL1314956 & 737822 & 7.1 & 6.4888 & TRN \\
\hline CHEMBL1317579 & 737822 & 4.8 & 4.6913 & TRN \\
\hline CHEMBL1441415 & 737822 & 4.6 & 4.4813 & TRN \\
\hline CHEMBL1358012 & 737822 & 7.2 & 5.7839 & TRN \\
\hline CHEMBL3196561 & 737822 & 5.65 & 5.5421 & TST \\
\hline CHEMBL1461188 & 737822 & 5.0 & 5.2259 & TRN \\
\hline CHEMBL1519261 & 737822 & 4.7 & 4.5664 & TRN \\
\hline CHEMBL1427243 & 737822 & 5.5 & 5.2473 & TRN \\
\hline CHEMBL1342714 & 737822 & 4.8 & 5.3416 & TRN \\
\hline CHEMBL1438748 & 737822 & 4.7 & 4.7412 & TRN \\
\hline CHEMBL522311 & 737822 & 4.7 & 4.6736 & TRN \\
\hline CHEMBL1467157 & 737822 & 5.45 & 5.0968 & TRN \\
\hline CHEMBL1354398 & 737822 & 6.0 & 5.8426 & TRN \\
\hline
\end{tabular}




\begin{tabular}{|c|c|c|c|c|c|}
\hline \multirow[b]{2}{*}{ CHEMBL1331674 } & \multicolumn{5}{|c|}{ splemental Table S } \\
\hline & 737822 & 4.65 & 5.2911 & TRN & \\
\hline CHEMBL1725148 & 737822 & 4.85 & 5.4854 & TRN & \\
\hline CHEMBL1371726 & 737822 & 6.0 & 5.67200 & 0000000001 & TRN \\
\hline CHEMBL1382909 & 737822 & 4.45 & 5.2166 & TRN & \\
\hline CHEMBL1454229 & 737822 & 5.4 & 5.2757 & TST & \\
\hline CHEMBL1453542 & 737822 & 4.9 & 4.809 & TST & \\
\hline CHEMBL1425720 & 737822 & 5.0 & 5.0978 & TST & \\
\hline CHEMBL1411049 & 737822 & 4.7 & 4.5615 & TRN & \\
\hline CHEMBL1529925 & 737822 & 4.8 & 5.4184 & TRN & \\
\hline CHEMBL1364946 & 737822 & 4.85 & 5.5365 & TRN & \\
\hline CHEMBL3213185 & 737822 & 4.85 & 5.2889 & TRN & \\
\hline CHEMBL1741618 & 737822 & 5.25 & 5.6379 & TRN & \\
\hline CHEMBL1257002 & 737822 & 6.0 & 5.6753 & TST & \\
\hline CHEMBL 254348 & 737822 & 6.8 & 5.7712 & TRN & \\
\hline CHEMBL1525931 & 737822 & 4.8 & 5.2709 & TRN & \\
\hline CHEMBL1385649 & 737822 & 5.0 & 5.4098 & TST & \\
\hline CHEMBL1471858 & 737822 & 5.05 & 5.4059 & TRN & \\
\hline CHEMBL 372797 & 737822 & 4.7 & 4.8627 & TST & \\
\hline CHEMBL1571211 & 737822 & 6.7 & 5.42899 & 9999999999 & TRN \\
\hline CHEMBL1519798 & 737822 & 4.75 & 4.9842 & TRN & \\
\hline CHEMBL1509531 & 737822 & 4.8 & 5.2701 & TRN & \\
\hline CHEMBL1712981 & 737822 & 4.75 & 5.1917 & TRN & \\
\hline CHEMBL1310415 & 737822 & 7.45 & 5.0829 & TRN & \\
\hline CHEMBL1718952 & 737822 & 5.6 & 5.7943 & TRN & \\
\hline CHEMBL1403270 & 737822 & 5.1 & 5.3288 & TST & \\
\hline CHEMBL1383786 & 737822 & 4.95 & 4.9871 & TRN & \\
\hline CHEMBL1467630 & 737822 & 4.8 & 5.5299 & TRN & \\
\hline CHEMBL1547372 & 737822 & 4.65 & 5.1301 & TRN & \\
\hline CHEMBL1480219 & 737822 & 4.4 & 4.3546 & TRN & \\
\hline CHEMBL1521352 & 737822 & 5.0 & 5.0503 & TRN & \\
\hline CHEMBL1565525 & 737822 & 4.9 & 4.6429 & TRN & \\
\hline CHEMBL1574148 & 737822 & 4.95 & 5.3355 & TRN & \\
\hline CHEMBL1540475 & 737822 & 4.85 & 5.3519 & TRN & \\
\hline CHEMBL1547205 & 737822 & 4.45 & 5.2903 & TRN & \\
\hline CHEMBL1382870 & 737822 & 4.6 & 5.3757 & TRN & \\
\hline CHEMBL1365367 & 737822 & 4.9 & 4.6301 & TRN & \\
\hline CHEMBL1313459 & 737822 & 5.0 & 5.4423 & TRN & \\
\hline CHEMBL1331618 & 737822 & 6.7 & 6.4769 & TRN & \\
\hline CHEMBL1613081 & 737822 & 5.15 & 5.3972 & TRN & \\
\hline CHEMBL1486844 & 737822 & 5.6 & 5.4604 & TRN & \\
\hline CHEMBL112816 & 737822 & 5.2 & 5.8169 & TRN & \\
\hline CHEMBL1600620 & 737822 & 7.0 & 6.653 & TRN & \\
\hline CHEMBL1507026 & 737822 & 4.65 & 5.2306 & TRN & \\
\hline CHEMBL1310284 & 737822 & 4.6 & 5.3409 & TRN & \\
\hline CHEMBL1551387 & 737822 & 4.6 & 4.5796 & TRN & \\
\hline CHEMBL1495397 & 737822 & 7.7501 & 5.6357 & TRN & \\
\hline CHEMBL1443491 & 737822 & 5.3 & 5.3757 & TRN & \\
\hline CHEMBL1320019 & 737822 & 5.75 & 5.4462 & TRN & \\
\hline
\end{tabular}




\begin{tabular}{|c|c|c|c|c|}
\hline \multicolumn{5}{|c|}{ Supplemental Ta } \\
\hline CHEMBL1413371 & 737822 & 4.6 & 4.6997 & TRN \\
\hline CHEMBL3193508 & 737822 & 4.8 & 5.5402 & TST \\
\hline CHEMBL1444844 & 737822 & 7.6 & 6.8214 & TRN \\
\hline CHEMBL1592470 & 737822 & 4.9 & 5.3007 & TRN \\
\hline CHEMBL1391974 & 737822 & 4.4 & 5.4273 & TST \\
\hline CHEMBL1545055 & 737822 & 4.8 & 5.2511 & TRN \\
\hline CHEMBL1715023 & 737822 & 4.8 & 5.4302 & TRN \\
\hline CHEMBL1434975 & 737822 & 5.9 & 5.6065 & TST \\
\hline CHEMBL98350 & 737822 & 4.6 & 4.5923 & TST \\
\hline CHEMBL1308052 & 737822 & 5.05 & 5.0579 & TST \\
\hline CHEMBL101168 & 737822 & 4.5 & 4.6986 & TST \\
\hline CHEMBL1572167 & 737822 & 4.9 & 4.9018 & TRN \\
\hline CHEMBL1436031 & 737822 & 5.0 & 5.0204 & TRN \\
\hline CHEMBL 228862 & 737822 & 4.9 & 4.8255 & TRN \\
\hline CHEMBL1589893 & 737822 & 4.9 & 4.7024 & TRN \\
\hline CHEMBL 1608397 & 737822 & 5.15 & 5.2504 & TRN \\
\hline CHEMBL1330299 & 737822 & 6.45 & 5.2366 & TRN \\
\hline CHEMBL3191489 & 737822 & 4.75 & 5.3547 & TRN \\
\hline CHEMBL1339209 & 737822 & 4.9 & 4.7436 & TRN \\
\hline CHEMBL1967062 & 737822 & 7.3 & 5.2445 & TRN \\
\hline CHEMBL1310057 & 737822 & 4.95 & 5.3708 & TRN \\
\hline CHEMBL1607187 & 737822 & 6.6 & 5.6539 & TRN \\
\hline CHEMBL1410009 & 737822 & 5.45 & 5.1763 & TRN \\
\hline CHEMBL1530805 & 737822 & 6.4 & 5.2655 & TRN \\
\hline CHEMBL1450716 & 737822 & 4.4 & 4.3484 & TRN \\
\hline CHEMBL1362021 & 737822 & 5.5 & 5.2915 & TRN \\
\hline CHEMBL1553768 & 737822 & 6.0 & 5.8186 & TRN \\
\hline CHEMBL1394472 & 737822 & 5.5 & 5.4455 & TRN \\
\hline CHEMBL1365455 & 737822 & 8.1 & 5.9596 & TRN \\
\hline CHEMBL1371959 & 737822 & 7.95 & 5.1846 & TRN \\
\hline CHEMBL1308218 & 737822 & 5.8 & 5.5322 & TRN \\
\hline CHEMBL1741463 & 737822 & 5.4 & 5.3944 & TRN \\
\hline CHEMBL1358939 & 737822 & 4.95 & 5.4737 & TRN \\
\hline CHEMBL1357016 & 737822 & 4.4 & 4.6171 & TRN \\
\hline CHEMBL1330385 & 737822 & 4.9 & 4.6817 & TRN \\
\hline CHEMBL1456015 & 737822 & 4.4 & 4.3047 & TRN \\
\hline CHEMBL1394371 & 737822 & 4.8 & 4.6625 & TRN \\
\hline CHEMBL1394187 & 737822 & 5.4 & 5.274 & TRN \\
\hline CHEMBL1584775 & 737822 & 4.8 & 5.6962 & TRN \\
\hline CHEMBL1451149 & 737822 & 4.7 & 5.2843 & TRN \\
\hline CHEMBL1458869 & 737822 & 6.4 & 5.4474 & TRN \\
\hline CHEMBL3207645 & 737822 & 5.15 & 5.1271 & TRN \\
\hline CHEMBL545523 & 737822 & 4.7 & 4.5791 & TRN \\
\hline CHEMBL1408013 & 737822 & 7.0 & 6.6647 & TRN \\
\hline CHEMBL1430657 & 737822 & 4.6 & 5.4205 & TRN \\
\hline CHEMBL1492953 & 737822 & 5.0 & 4.9784 & TRN \\
\hline CHEMBL1243269 & 737822 & 6.0 & 5.7028 & TRN \\
\hline CHEMBL1433886 & 737822 & 5.5 & 5.3796 & TRN \\
\hline
\end{tabular}




\begin{tabular}{|c|c|c|c|c|c|}
\hline \\
\hline CHEMBL1355227 & 737822 & 4.8 & 4.5775 & TRN & \\
\hline CHEMBL1365537 & 737822 & 6.1 & 5.8428 & TRN & \\
\hline CHEMBL1362464 & 737822 & 4.65 & 5.2831 & TRN & \\
\hline CHEMBL1256770 & 737822 & 5.1 & 5.1416 & TRN & \\
\hline CHEMBL1531607 & 737822 & 4.6 & 5.391 & TRN & \\
\hline CHEMBL1526390 & 737822 & 4.7 & 5.5247 & TRN & \\
\hline CHEMBL1508220 & 737822 & 4.5 & 5.126 & TRN & \\
\hline CHEMBL1360942 & 737822 & 5.2 & 5.1454 & TRN & \\
\hline CHEMBL1608425 & 737822 & 6.85 & 5.1478 & TRN & \\
\hline CHEMBL 845 & 737822 & 5.2 & 5.1806 & TRN & \\
\hline CHEMBL1372850 & 737822 & 6.1 & 5.7271 & TRN & \\
\hline CHEMBL1572747 & 737822 & 4.9 & 4.7263 & TRN & \\
\hline CHEMBL1359320 & 737822 & 5.1 & 4.9499 & TRN & \\
\hline CHEMBL1330718 & 737822 & 4.7 & 4.5768 & TRN & \\
\hline CHEMBL1581512 & 737822 & 6.1 & 5.3006 & TRN & \\
\hline CHEMBL1531779 & 737822 & 4.85 & 5.186 & TST & \\
\hline CHEMBL1605688 & 737822 & 4.6 & 4.6091 & TRN & \\
\hline CHEMBL1551518 & 737822 & 4.7 & 4.6244 & TRN & \\
\hline CHEMBL1352779 & 737822 & 4.8 & 5.5709 & TRN & \\
\hline CHEMBL1457554 & 737822 & 4.6 & 5.5971 & TRN & \\
\hline CHEMBL1377140 & 737822 & 5.4 & 5.2087 & TRN & \\
\hline CHEMBL568379 & 737822 & 4.7 & 4.5518 & TRN & \\
\hline CHEMBL1594612 & 737822 & 4.9 & 4.7564 & TRN & \\
\hline CHEMBL1565258 & 737822 & 4.8 & 5.2367 & TRN & \\
\hline CHEMBL1307320 & 737822 & 5.0 & 5.4213 & TRN & \\
\hline CHEMBL1363801 & 737822 & 4.7 & 4.5613 & TRN & \\
\hline CHEMBL1393076 & 737822 & 5.2 & 5.1915 & TST & \\
\hline CHEMBL1493644 & 737822 & 4.6 & 4.4395 & TRN & \\
\hline CHEMBL1516015 & 737822 & 4.6 & 4.817 & TRN & \\
\hline CHEMBL10 & 737822 & 4.4 & 4.6898 & TST & \\
\hline CHEMBL1421262 & 737822 & 5.15 & 5.5054 & TRN & \\
\hline CHEMBL1512190 & 737822 & 4.4 & 4.3117 & TRN & \\
\hline CHEMBL1366020 & 737822 & 4.8 & 4.7631 & TRN & \\
\hline CHEMBL1594217 & 737822 & 5.1 & 5.3024 & TRN & \\
\hline CHEMBL1594421 & 737822 & 4.4 & 4.34399 & 9999999999 & TRN \\
\hline CHEMBL3350578 & 737822 & 5.5 & 5.3833 & TST & \\
\hline CHEMBL1594329 & 737822 & 4.4 & 4.2539 & TRN & \\
\hline CHEMBL1444856 & 737822 & 4.4 & 4.3156 & TRN & \\
\hline CHEMBL1400535 & 737822 & 4.8 & 5.4089 & TRN & \\
\hline CHEMBL1525473 & 737822 & 4.8 & 5.4792 & TST & \\
\hline CHEMBL1568178 & 737822 & 4.7 & 4.6175 & TRN & \\
\hline CHEMBL336467 & 737822 & 4.4 & 4.5433 & TST & \\
\hline CHEMBL275938 & 737822 & 4.4 & 4.5966 & TST & \\
\hline CHEMBL388342 & 737822 & 6.0 & 5.6675 & TRN & \\
\hline CHEMBL1320619 & 737822 & 5.9 & 5.6268 & TRN & \\
\hline CHEMBL1445647 & 737822 & 4.95 & 5.4862 & TRN & \\
\hline CHEMBL 2009961 & 737822 & 5.8 & 5.7024 & TST & \\
\hline CHEMBL1602780 & 737822 & 5.45 & 5.2173 & TRN & \\
\hline
\end{tabular}




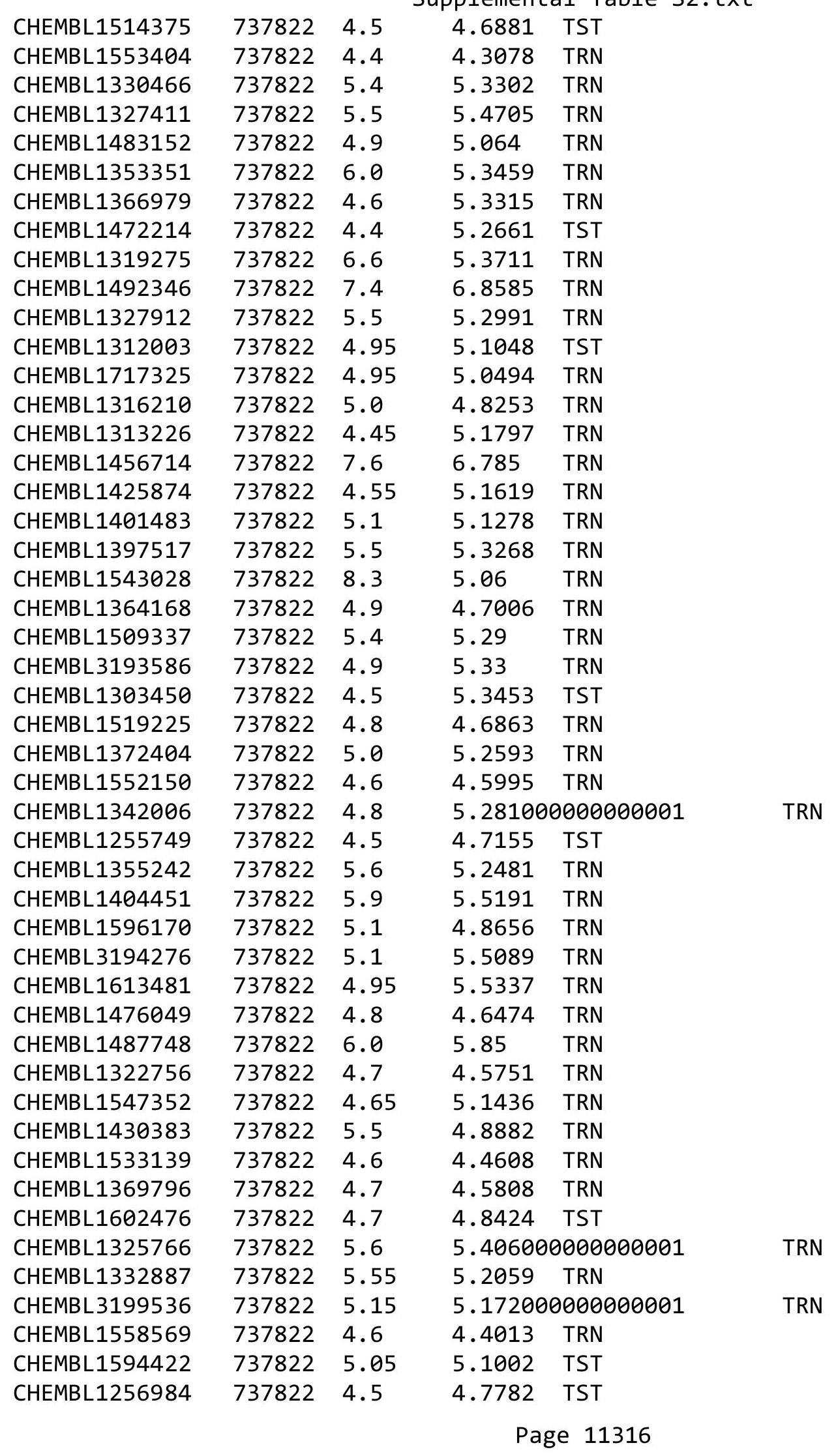




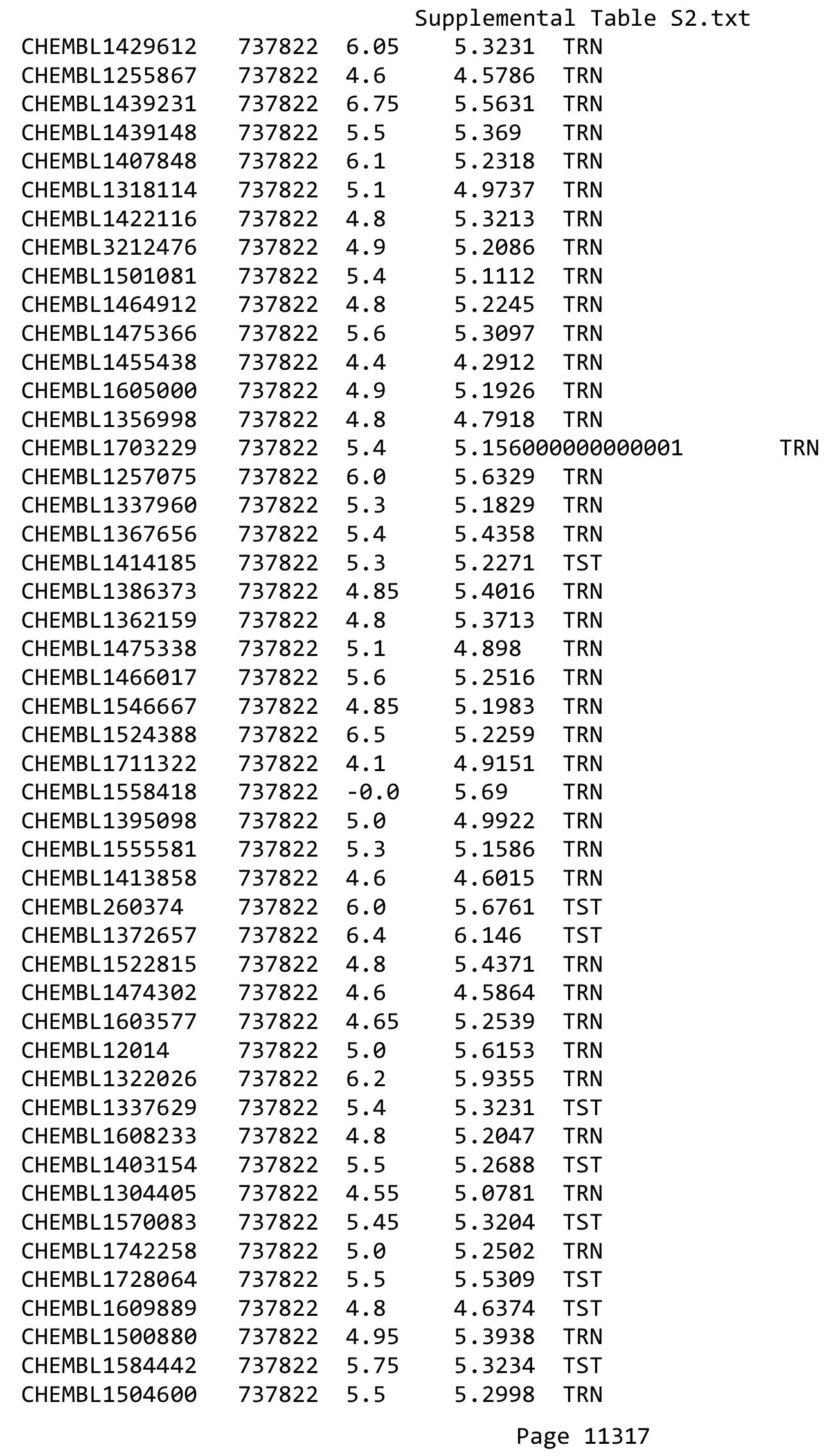




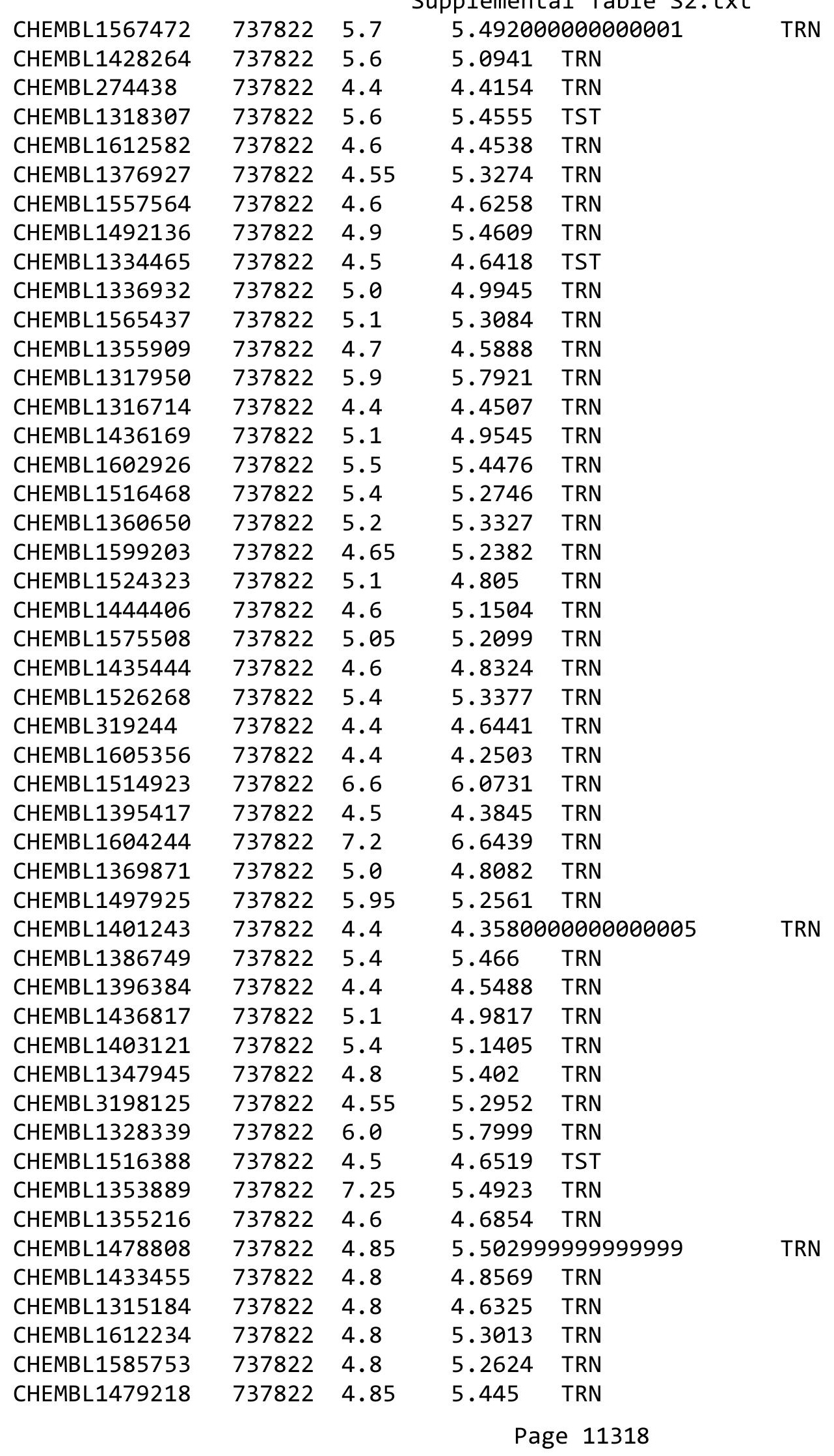




\begin{tabular}{|c|c|c|c|c|c|}
\hline \multicolumn{6}{|c|}{ oplemental Table } \\
\hline CHEMBL1482011 & 737822 & 5.3 & 5.2706 & TRN & \\
\hline CHEMBL3195224 & 737822 & 4.65 & 5.5005 & TRN & \\
\hline CHEMBL1457262 & 737822 & 5.3 & 5.5177 & TRN & \\
\hline CHEMBL1433785 & 737822 & 4.8 & 4.6693 & TRN & \\
\hline CHEMBL1350293 & 737822 & 5.3 & 5.1489 & TRN & \\
\hline CHEMBL1312774 & 737822 & 5.0 & 5.1444 & TST & \\
\hline CHEMBL1511739 & 737822 & 4.7 & 4.9707 & TRN & \\
\hline CHEMBL1479106 & 737822 & 4.95 & 5.2614 & TRN & \\
\hline CHEMBL577635 & 737822 & 5.4 & 5.3835 & TRN & \\
\hline CHEMBL1580804 & 737822 & 4.65 & 5.294 & TRN & \\
\hline CHEMBL1321899 & 737822 & 4.7 & 4.5898 & TRN & \\
\hline CHEMBL1479131 & 737822 & 4.8 & 5.084 & TRN & \\
\hline CHEMBL1741489 & 737822 & 4.9 & 5.4726 & TRN & \\
\hline CHEMBL1459503 & 737822 & 5.0 & 5.3586 & TRN & \\
\hline CHEMBL1566780 & 737822 & 4.7 & 4.6883 & TRN & \\
\hline CHEMBL1256835 & 737822 & 6.0 & 5.8806 & TRN & \\
\hline CHEMBL67212 & 737822 & 5.05 & 5.2341 & TRN & \\
\hline CHEMBL1255832 & 737822 & 6.0 & 4.7136 & TST & \\
\hline CHEMBL1531070 & 737822 & 4.7 & 4.6666 & TRN & \\
\hline CHEMBL1404529 & 737822 & 4.85 & 5.5634 & TRN & \\
\hline CHEMBL1443961 & 737822 & 4.6 & 5.4473 & TRN & \\
\hline CHEMBL527271 & 737822 & 5.55 & 5.4139 & TST & \\
\hline CHEMBL1732403 & 737822 & 4.9 & 5.4996 & TRN & \\
\hline CHEMBL1600131 & 737822 & 4.95 & 5.181 & TRN & \\
\hline CHEMBL1409815 & 737822 & 4.7 & 5.0148 & TRN & \\
\hline CHEMBL1490740 & 737822 & 4.7 & 4.7121 & TRN & \\
\hline CHEMBL1524907 & 737822 & 4.7 & 5.2887 & TRN & \\
\hline CHEMBL1701448 & 737822 & 5.5 & 5.42899 & 9999999999 & TRN \\
\hline CHEMBL1525716 & 737822 & 6.3 & 5.5043 & TRN & \\
\hline CHEMBL332898 & 737822 & 5.7 & 5.4358 & TRN & \\
\hline CHEMBL1594372 & 737822 & 5.0 & 4.915 & TRN & \\
\hline CHEMBL490742 & 737822 & 4.7 & 4.5014 & TRN & \\
\hline CHEMBL1397548 & 737822 & 4.6 & 4.4041 & TRN & \\
\hline CHEMBL1381224 & 737822 & 5.3 & 5.2015 & TRN & \\
\hline CHEMBL1373818 & 737822 & 4.6 & 4.7717 & TST & \\
\hline CHEMBL1529652 & 737822 & 4.6 & 5.2859 & TRN & \\
\hline CHEMBL1322959 & 737822 & 5.2 & 5.2109 & TST & \\
\hline CHEMBL1327673 & 737822 & 6.2 & 5.7526 & TRN & \\
\hline CHEMBL1419019 & 737822 & 7.6 & 5.3682 & TRN & \\
\hline CHEMBL1564977 & 737822 & 5.0 & 5.1986 & TRN & \\
\hline CHEMBL1442105 & 737822 & 5.0 & 5.3764 & TRN & \\
\hline CHEMBL536950 & 737822 & 4.5 & 4.615 & TST & \\
\hline CHEMBL1440842 & 737822 & 5.5 & 5.39 & TRN & \\
\hline CHEMBL1452065 & 737822 & 4.5 & 4.4072 & TRN & \\
\hline CHEMBL1433039 & 737822 & 4.7 & 5.5548 & TST & \\
\hline CHEMBL1520792 & 737822 & 4.8 & 5.3009 & TRN & \\
\hline CHEMBL1482566 & 737822 & 4.95 & 5.1735 & TRN & \\
\hline CHEMBL1436355 & 737822 & 6.5 & 6.0303 & TRN & \\
\hline
\end{tabular}




\begin{tabular}{|c|c|c|c|c|c|}
\hline \multicolumn{6}{|c|}{ oplementa1 } \\
\hline CHEMBL1581282 & 737822 & 4.8 & 5.2592 & TRN & \\
\hline CHEMBL1412044 & 737822 & 5.5 & 5.4188 & TST & \\
\hline CHEMBL1613268 & 737822 & 5.65 & 5.20200 & 0000000001 & TRN \\
\hline CHEMBL1591903 & 737822 & 5.4 & 5.3357 & TRN & \\
\hline CHEMBL1560276 & 737822 & 6.65 & 5.227 & TRN & \\
\hline CHEMBL1255837 & 737822 & 4.8 & 5.91 & TRN & \\
\hline CHEMBL1588990 & 737822 & 5.65 & 5.3112 & TRN & \\
\hline CHEMBL1599378 & 737822 & 4.9 & 4.8555 & TRN & \\
\hline CHEMBL157754 & 737822 & 5.5 & 5.3536 & TRN & \\
\hline CHEMBL366489 & 737822 & 5.4 & 5.2275 & TST & \\
\hline CHEMBL1548218 & 737822 & 4.65 & 5.3173 & TRN & \\
\hline CHEMBL1520603 & 737822 & 5.4 & 5.4255 & TRN & \\
\hline CHEMBL1498884 & 737822 & 6.05 & 5.1965 & TRN & \\
\hline CHEMBL490749 & 737822 & 5.7 & 5.352 & TRN & \\
\hline CHEMBL1567416 & 737822 & 5.2 & 5.4109 & TRN & \\
\hline CHEMBL1544155 & 737822 & 5.6 & 5.4372 & TST & \\
\hline CHEMBL1402633 & 737822 & 5.9 & 5.3737 & TRN & \\
\hline CHEMBL1347463 & 737822 & 4.8 & 5.2789 & TRN & \\
\hline CHEMBL1318553 & 737822 & 6.0 & 5.8487 & TST & \\
\hline CHEMBL1317805 & 737822 & 5.1 & 4.9488 & TRN & \\
\hline CHEMBL1485069 & 737822 & 5.4 & 5.2793 & TST & \\
\hline CHEMBL1605449 & 737822 & 4.65 & 5.3103 & TRN & \\
\hline CHEMBL1559187 & 737822 & 5.45 & 5.34 & TRN & \\
\hline CHEMBL1398608 & 737822 & 5.5 & 5.4471 & TRN & \\
\hline CHEMBL1741606 & 737822 & 5.75 & 5.7297 & TRN & \\
\hline CHEMBL1575698 & 737822 & 6.6 & 5.5784 & TRN & \\
\hline CHEMBL1256709 & 737822 & 6.0 & 5.8429 & TRN & \\
\hline CHEMBL476833 & 737822 & 4.9 & 4.9669 & TRN & \\
\hline CHEMBL1303347 & 737822 & 4.95 & 5.5103 & TRN & \\
\hline CHEMBL391997 & 737822 & 4.9 & 5.7067 & TRN & \\
\hline CHEMBL1321275 & 737822 & 5.5 & 5.1313 & TRN & \\
\hline CHEMBL1404071 & 737822 & 5.85 & 5.4647 & TRN & \\
\hline CHEMBL1389823 & 737822 & 4.9 & 5.1849 & TST & \\
\hline CHEMBL3196775 & 737822 & 5.1 & 5.4995 & TRN & \\
\hline CHEMBL1381161 & 737822 & 5.5 & 5.5075 & TRN & \\
\hline CHEMBL1423713 & 737822 & 4.95 & 5.2798 & TRN & \\
\hline CHEMBL1407677 & 737822 & 4.55 & 5.3393 & TRN & \\
\hline CHEMBL1531584 & 737822 & 6.5 & 6.0731 & TRN & \\
\hline CHEMBL1322311 & 737822 & 4.9 & 5.4742 & TRN & \\
\hline CHEMBL1476711 & 737822 & 4.9 & 4.7396 & TRN & \\
\hline CHEMBL1415790 & 737822 & 4.6 & 4.5029 & TRN & \\
\hline CHEMBL1434085 & 737822 & 4.9 & 4.8634 & TRN & \\
\hline CHEMBL1527029 & 737822 & 5.1 & 5.1159 & TRN & \\
\hline CHEMBL3145119 & 737822 & 6.8 & 5.28700 & 0000000001 & TST \\
\hline CHEMBL1573063 & 737822 & 4.5 & 4.3863 & TRN & \\
\hline CHEMBL1423337 & 737822 & 5.0 & 5.3701 & TRN & \\
\hline CHEMBL1473875 & 737822 & 5.7 & 5.855 & TRN & \\
\hline CHEMBL1399528 & 737822 & 5.0 & 4.8314 & TRN & \\
\hline
\end{tabular}




\begin{tabular}{|c|c|c|c|c|c|}
\hline \\
\hline CHEMBL1403931 & 737822 & 5.2 & 5.2296 & TST & \\
\hline CHEMBL1435917 & 737822 & 5.3 & 5.0897 & TRN & \\
\hline CHEMBL88272 & 737822 & 7.0 & 6.4383 & TST & \\
\hline CHEMBL1572029 & 737822 & 4.8 & 5.2732 & TRN & \\
\hline CHEMBL1602849 & 737822 & 5.4 & 5.3431 & TRN & \\
\hline CHEMBL1331710 & 737822 & 5.8 & 5.5487 & TST & \\
\hline CHEMBL1537075 & 737822 & 4.85 & 5.2103 & TST & \\
\hline CHEMBL3193279 & 737822 & 4.55 & 5.1878 & TRN & \\
\hline CHEMBL1567295 & 737822 & 4.7 & 4.5266 & TRN & \\
\hline CHEMBL1393189 & 737822 & 5.05 & 5.1788 & TRN & \\
\hline CHEMBL1502413 & 737822 & 4.85 & 5.3128 & TRN & \\
\hline CHEMBL1343750 & 737822 & 4.9 & 5.1341 & TRN & \\
\hline CHEMBL1442380 & 737822 & 4.75 & 5.2004 & TRN & \\
\hline CHEMBL1566552 & 737822 & 6.3 & 5.7363 & TRN & \\
\hline CHEMBL1741438 & 737822 & 5.75 & 5.6307 & TRN & \\
\hline CHEMBL1435032 & 737822 & 4.8 & 4.6521 & TRN & \\
\hline CHEMBL1321005 & 737822 & 6.0 & 5.8742 & TRN & \\
\hline CHEMBL1445893 & 737822 & 5.4 & 5.0594 & TRN & \\
\hline CHEMBL1391286 & 737822 & 4.85 & 5.3662 & TRN & \\
\hline CHEMBL1413132 & 737822 & 6.1 & 6.0722 & TRN & \\
\hline CHEMBL1441218 & 737822 & 4.85 & 5.2164 & TRN & \\
\hline CHEMBL1324352 & 737822 & 4.85 & 5.30399 & 9999999999 & TRN \\
\hline CHEMBL1389078 & 737822 & 4.85 & 5.6095 & TRN & \\
\hline CHEMBL1594078 & 737822 & 4.9 & 4.7979 & TRN & \\
\hline CHEMBL1597474 & 737822 & 4.6 & 4.5257 & TRN & \\
\hline CHEMBL1392169 & 737822 & 4.8 & 5.0811 & TRN & \\
\hline CHEMBL1594054 & 737822 & 5.5 & 5.3802 & TRN & \\
\hline CHEMBL1373326 & 737822 & 4.7 & 4.6833 & TRN & \\
\hline CHEMBL1369973 & 737822 & 4.5 & 4.43199 & 99999999995 & TRN \\
\hline CHEMBL1545002 & 737822 & 5.7 & 5.3112 & TRN & \\
\hline CHEMBL1397558 & 737822 & 5.2 & 5.0895 & TRN & \\
\hline CHEMBL1395137 & 737822 & 4.4 & 4.3107 & TRN & \\
\hline CHEMBL1453980 & 737822 & 4.4 & 4.4826 & TRN & \\
\hline CHEMBL1451875 & 737822 & 4.85 & 5.21 & TRN & \\
\hline CHEMBL546597 & 737822 & 4.9 & 4.9754 & TRN & \\
\hline CHEMBL1316219 & 737822 & 4.9 & 4.9283 & TRN & \\
\hline CHEMBL521970 & 737822 & 5.0 & 4.869 & TRN & \\
\hline CHEMBL3193784 & 737822 & 4.85 & 5.3056 & TRN & \\
\hline CHEMBL1314625 & 737822 & 4.9 & 4.7396 & TRN & \\
\hline CHEMBL 247129 & 737822 & 4.8 & 5.0966 & TST & \\
\hline CHEMBL1354137 & 737822 & 4.65 & 5.20200 & $\partial 000000001$ & TRN \\
\hline CHEMBL1394258 & 737822 & 4.4 & 4.2821 & TRN & \\
\hline CHEMBL1392935 & 737822 & 4.85 & 5.5425 & TRN & \\
\hline CHEMBL1459858 & 737822 & 4.45 & 5.2301 & TRN & \\
\hline CHEMBL1567584 & 737822 & 6.7 & 5.4184 & TRN & \\
\hline CHEMBL1344331 & 737822 & 5.7 & 5.4413 & TRN & \\
\hline CHEMBL1420885 & 737822 & 4.55 & 5.1241 & TST & \\
\hline CHEMBL1479741 & 737822 & 6.0 & 5.5786 & TRN & \\
\hline
\end{tabular}




\begin{tabular}{|c|c|c|c|c|c|}
\hline \\
\hline CHEMBL1368395 & 737822 & 6.0 & 5.8802 & TRN & \\
\hline CHEMBL432527 & 737822 & 5.4 & 5.8212 & TRN & \\
\hline CHEMBL1557279 & 737822 & 4.9 & 5.2032 & TST & \\
\hline CHEMBL1540150 & 737822 & 4.8 & 5.1778 & TRN & \\
\hline CHEMBL1568465 & 737822 & 4.4 & 5.0142 & TRN & \\
\hline CHEMBL1330404 & 737822 & 4.4 & 4.7462 & TRN & \\
\hline CHEMBL1600612 & 737822 & 5.0 & 4.9015 & TRN & \\
\hline CHEMBL1404598 & 737822 & 4.9 & 4.7775 & TRN & \\
\hline CHEMBL1600973 & 737822 & 5.4 & 5.2926 & TRN & \\
\hline CHEMBL447507 & 737822 & 4.9 & 4.6664 & TRN & \\
\hline CHEMBL1551981 & 737822 & 6.4 & 6.1723 & TRN & \\
\hline CHEMBL1492669 & 737822 & 5.5 & 5.456 & TST & \\
\hline CHEMBL20377 & 737822 & 6.1 & 6.0603 & TRN & \\
\hline CHEMBL269733 & 737822 & 4.5 & 4.7033 & TST & \\
\hline CHEMBL1256687 & 737822 & 6.2 & 5.9065 & TRN & \\
\hline CHEMBL1328292 & 737822 & 5.4 & 5.3063 & TST & \\
\hline CHEMBL3212934 & 737822 & 4.65 & 5.2296 & TST & \\
\hline CHEMBL1401786 & 737822 & 5.15 & 5.1138 & TRN & \\
\hline CHEMBL1398250 & 737822 & 5.4 & 5.3655 & TRN & \\
\hline CHEMBL1491858 & 737822 & 5.0 & 5.3285 & TRN & \\
\hline CHEMBL 2374062 & 737822 & 4.7 & 4.8545 & TST & \\
\hline CHEMBL1357422 & 737822 & 5.2 & 5.1211 & TRN & \\
\hline CHEMBL1373610 & 737822 & 4.4 & 4.3844 & TRN & \\
\hline CHEMBL1585838 & 737822 & 5.15 & 5.706 & TST & \\
\hline CHEMBL 1256740 & 737822 & 6.0 & 5.7228 & TST & \\
\hline CHEMBL1433883 & 737822 & 4.7 & 4.7325 & TRN & \\
\hline CHEMBL1361149 & 737822 & 5.5 & 5.2579 & TRN & \\
\hline CHEMBL1397225 & 737822 & 5.0 & 4.9615 & TRN & \\
\hline CHEMBL1426036 & 737822 & 4.6 & 5.1057 & TRN & \\
\hline CHEMBL1358115 & 737822 & 5.5 & 5.4192 & TRN & \\
\hline CHEMBL1577686 & 737822 & 5.7 & 5.3438 & TRN & \\
\hline CHEMBL 3208361 & 737822 & 4.55 & 5.5855 & TST & \\
\hline CHEMBL1594030 & 737822 & 4.5 & 4.493 & TRN & \\
\hline CHEMBL1256667 & 737822 & 4.5 & 4.622 & TST & \\
\hline CHEMBL1579705 & 737822 & 4.8 & 5.28799 & 9999999999 & TRN \\
\hline CHEMBL582507 & 737822 & 5.1 & 5.1541 & TST & \\
\hline CHEMBL1448803 & 737822 & 5.45 & 5.1365 & TRN & \\
\hline CHEMBL1551051 & 737822 & 5.6 & 5.2892 & TRN & \\
\hline CHEMBL1565564 & 737822 & 4.7 & 4.6065 & TRN & \\
\hline CHEMBL1703300 & 737822 & 4.6 & 5.2084 & TRN & \\
\hline CHEMBL1512878 & 737822 & 5.2 & 4.9619 & TRN & \\
\hline CHEMBL3194547 & 737822 & 4.85 & 5.3246 & TRN & \\
\hline CHEMBL1454660 & 737822 & 6.15 & 5.39 & TRN & \\
\hline CHEMBL1480516 & 737822 & 6.0 & 5.8279 & TRN & \\
\hline CHEMBL1403307 & 737822 & 4.9 & 5.5635 & TRN & \\
\hline CHEMBL1443695 & 737822 & 4.4 & 4.5088 & TRN & \\
\hline CHEMBL1434006 & 737822 & 4.7 & 4.5042 & TRN & \\
\hline CHEMBL1304918 & 737822 & 5.5 & 5.4054 & TRN & \\
\hline & & & & 1322 & \\
\hline
\end{tabular}




\begin{tabular}{|c|c|c|c|c|c|}
\hline \\
\hline CHEMBL1332346 & 737822 & 4.7 & 4.4671 & TRN & \\
\hline CHEMBL1552194 & 737822 & 4.4 & 4.2647 & TRN & \\
\hline CHEMBL1741952 & 737822 & 6.1 & 5.4109 & TRN & \\
\hline CHEMBL1469597 & 737822 & 4.8 & 5.3173 & TRN & \\
\hline CHEMBL1417636 & 737822 & 5.1 & 4.9116 & TRN & \\
\hline CHEMBL1554141 & 737822 & 5.5 & 5.3838 & TRN & \\
\hline CHEMBL1578210 & 737822 & 4.8 & 5.3599 & TRN & \\
\hline CHEMBL1395009 & 737822 & 5.6 & 5.4506 & TST & \\
\hline CHEMBL1402381 & 737822 & 5.9 & 6.0091 & TRN & \\
\hline CHEMBL3392050 & 737822 & 4.6 & 4.467 & TST & \\
\hline CHEMBL1448819 & 737822 & 5.05 & 5.1536 & TRN & \\
\hline CHEMBL1551777 & 737822 & 4.9 & 4.6288 & TRN & \\
\hline CHEMBL1438867 & 737822 & 7.4 & 6.7432 & TST & \\
\hline CHEMBL1403793 & 737822 & 6.6 & 6.0962 & TRN & \\
\hline CHEMBL1493592 & 737822 & 4.9 & 5.2408 & TRN & \\
\hline CHEMBL1434111 & 737822 & 5.0 & 4.7584 & TRN & \\
\hline CHEMBL1593889 & 737822 & 5.5 & 5.4347 & TRN & \\
\hline CHEMBL1590060 & 737822 & 4.8 & 4.6393 & TRN & \\
\hline CHEMBL1256186 & 737822 & 4.6 & 4.7284 & TST & \\
\hline CHEMBL1476939 & 737822 & 5.5 & 5.3873 & TST & \\
\hline CHEMBL1233960 & 737822 & 5.7 & 5.54799 & 9999999999 & TRN \\
\hline CHEMBL 3145176 & 737822 & 4.55 & 5.1828 & TST & \\
\hline CHEMBL1306540 & 737822 & 5.1 & 5.4254 & TRN & \\
\hline CHEMBL1555028 & 737822 & 4.4 & 4.3689 & TRN & \\
\hline CHEMBL1318638 & 737822 & 5.8 & 5.8586 & TRN & \\
\hline CHEMBL1255966 & 737822 & 6.1 & 6.0435 & TRN & \\
\hline CHEMBL 35482 & 737822 & 5.1 & 4.912 & TST & \\
\hline CHEMBL1790009 & 737822 & 5.2 & 5.1418 & TRN & \\
\hline CHEMBL1353420 & 737822 & 4.8 & 5.6176 & TRN & \\
\hline CHEMBL1331657 & 737822 & 5.1 & 5.0677 & TRN & \\
\hline CHEMBL1572599 & 737822 & 4.9 & 5.4358 & TRN & \\
\hline CHEMBL1357553 & 737822 & 4.4 & 4.3298 & TRN & \\
\hline CHEMBL1320141 & 737822 & 5.5 & 5.3087 & TRN & \\
\hline CHEMBL1306864 & 737822 & 5.45 & 5.4469 & TRN & \\
\hline CHEMBL1594134 & 737822 & 4.9 & 4.8095 & TRN & \\
\hline CHEMBL 28992 & 737822 & 4.4 & 4.6754 & TRN & \\
\hline CHEMBL1493118 & 737822 & 5.45 & 4.9733 & TST & \\
\hline CHEMBL292477 & 737822 & 8.2 & 7.5935 & TRN & \\
\hline CHEMBL 2374027 & 737822 & 4.6 & 4.8181 & TRN & \\
\hline CHEMBL1613725 & 737822 & 4.4 & 4.3495 & TRN & \\
\hline CHEMBL1429733 & 737822 & 5.3 & 5.42299 & 9999999999 & TRN \\
\hline CHEMBL1559062 & 737822 & 8.05 & 5.2894 & TST & \\
\hline CHEMBL1448562 & 737822 & 8.1 & 7.5706 & TRN & \\
\hline CHEMBL1331745 & 737822 & 4.65 & 5.348 & TRN & \\
\hline CHEMBL1603926 & 737822 & 5.0 & 4.9701 & TST & \\
\hline CHEMBL1317358 & 737822 & 4.8 & 4.7081 & TRN & \\
\hline CHEMBL1517172 & 737822 & 5.1 & 5.2813 & TRN & \\
\hline CHEMBL1322050 & 737822 & 5.8 & 5.7079 & TRN & \\
\hline
\end{tabular}




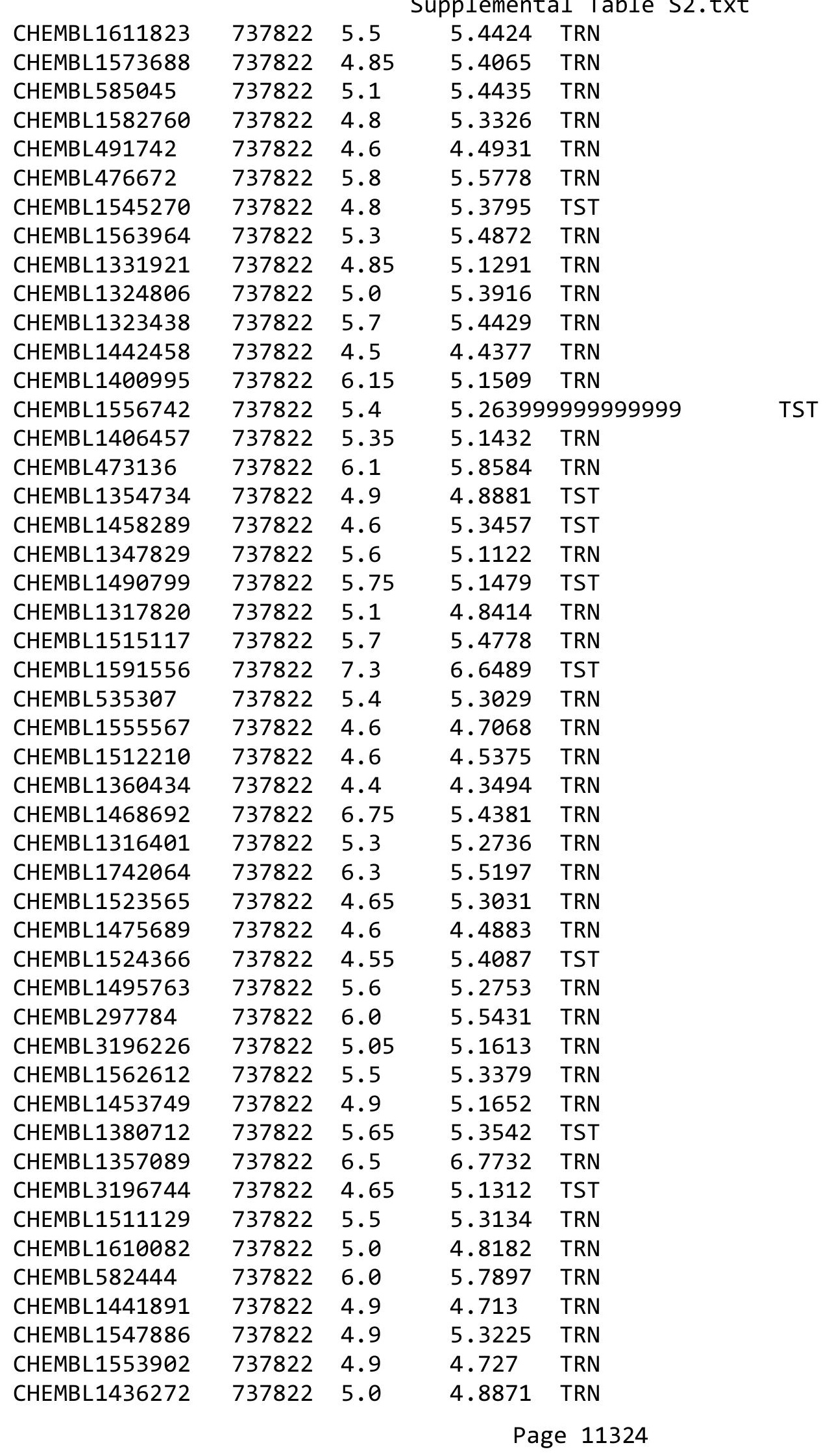




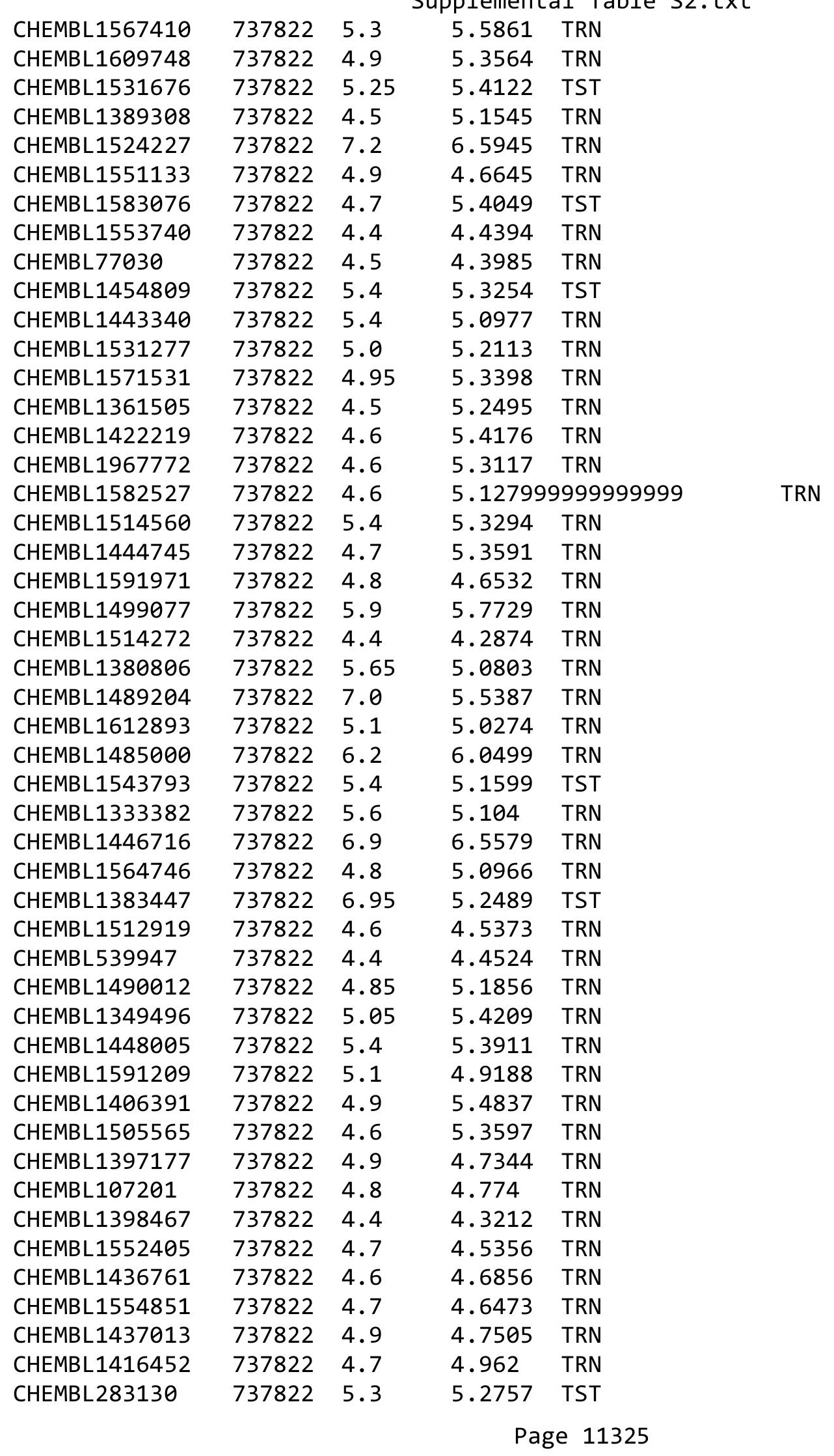




\begin{tabular}{|c|c|c|c|c|}
\hline & & & pplement & al Ta \\
\hline CHEMBL1591730 & 737822 & 4.9 & 5.0199 & TRN \\
\hline CHEMBL1527332 & 737822 & 4.8 & 4.5906 & TRN \\
\hline CHEMBL1555896 & 737822 & 5.1 & 5.1264 & TRN \\
\hline CHEMBL1422980 & 737822 & 4.7 & 5.3943 & TRN \\
\hline CHEMBL1491674 & 737822 & 4.75 & 5.2522 & TRN \\
\hline CHEMBL1699997 & 737822 & 4.4 & 5.2582 & TRN \\
\hline CHEMBL1392932 & 737822 & 4.65 & 5.2572 & TST \\
\hline CHEMBL1591451 & 737822 & 5.9 & 5.5999 & TRN \\
\hline CHEMBL407874 & 737822 & 6.3 & 5.9502 & TRN \\
\hline CHEMBL1435276 & 737822 & 5.0 & 5.0376 & TRN \\
\hline CHEMBL1474927 & 737822 & 4.8 & 4.7091 & TRN \\
\hline CHEMBL1515918 & 737822 & 4.7 & 4.6029 & TRN \\
\hline CHEMBL1704847 & 737822 & 4.9 & 5.3663 & TST \\
\hline CHEMBL1335465 & 737822 & 4.9 & 4.9969 & TRN \\
\hline CHEMBL1312233 & 737822 & 5.4 & 5.4136 & TST \\
\hline CHEMBL1416389 & 737822 & 6.0 & 5.6941 & TST \\
\hline CHEMBL1579455 & 737822 & 4.8 & 5.1332 & TST \\
\hline CHEMBL1372037 & 737822 & 4.9 & 4.9377 & TRN \\
\hline CHEMBL1487159 & 737822 & 4.85 & 5.0981 & TST \\
\hline CHEMBL1591673 & 737822 & 4.8 & 4.612 & TRN \\
\hline CHEMBL3192856 & 737822 & 5.1 & 5.3395 & TRN \\
\hline CHEMBL1414232 & 737822 & 5.5 & 5.4279 & TRN \\
\hline CHEMBL1395431 & 737822 & 4.7 & 4.7267 & TRN \\
\hline CHEMBL1513247 & 737822 & 4.4 & 4.3686 & TRN \\
\hline CHEMBL122270 & 737822 & 6.0 & 5.8631 & TRN \\
\hline CHEMBL1488997 & 737822 & 5.45 & 5.3004 & TRN \\
\hline CHEMBL3190590 & 737822 & 4.55 & 5.4022 & TST \\
\hline CHEMBL1558245 & 737822 & 5.5 & 5.3942 & TRN \\
\hline CHEMBL1453620 & 737822 & 5.1 & 5.2454 & TRN \\
\hline CHEMBL1370314 & 737822 & 4.6 & 5.3161 & TRN \\
\hline CHEMBL538430 & 737822 & 4.6 & 5.4192 & TRN \\
\hline CHEMBL1473430 & 737822 & 4.6 & 4.5968 & TRN \\
\hline CHEMBL1507282 & 737822 & 4.6 & 5.2686 & TRN \\
\hline CHEMBL1414317 & 737822 & 4.65 & 5.1093 & TRN \\
\hline CHEMBL1481017 & 737822 & 4.8 & 4.7232 & TRN \\
\hline CHEMBL1360725 & 737822 & 5.2 & 5.8103 & TST \\
\hline CHEMBL1315129 & 737822 & 7.2 & 7.0071 & TRN \\
\hline CHEMBL1518718 & 737822 & 4.5 & 4.3151 & TRN \\
\hline CHEMBL1374913 & 737822 & 4.7 & 4.6655 & TRN \\
\hline CHEMBL1441981 & 737822 & 5.7 & 5.3284 & TRN \\
\hline CHEMBL1730707 & 737822 & 5.65 & 5.3493 & TST \\
\hline CHEMBL1521167 & 737822 & 5.4 & 5.2858 & TST \\
\hline CHEMBL1437325 & 737822 & 4.9 & 4.6579 & TRN \\
\hline CHEMBL1502952 & 737822 & 5.75 & 5.2874 & TRN \\
\hline CHEMBL591613 & 737822 & 5.8 & 5.1813 & TRN \\
\hline CHEMBL1384711 & 737822 & 4.8 & 5.6939 & TRN \\
\hline CHEMBL1435447 & 737822 & 4.6 & 4.4199 & TRN \\
\hline CHEMBL1339210 & 737822 & 8.25 & 5.334 & TRN \\
\hline
\end{tabular}




\begin{tabular}{|c|c|c|c|c|}
\hline \multicolumn{5}{|c|}{ lemental T } \\
\hline CHEMBL1507076 & 737822 & 6.5 & 5.2445 & TRN \\
\hline CHEMBL3214238 & 737822 & 4.9 & 5.2115 & TRN \\
\hline CHEMBL1445795 & 737822 & 6.45 & 5.4664 & TRN \\
\hline CHEMBL1389184 & 737822 & 4.8 & 5.4142 & TST \\
\hline CHEMBL1390531 & 737822 & 4.5 & 5.0115 & TRN \\
\hline CHEMBL1506687 & 737822 & 4.75 & 5.2717 & TRN \\
\hline CHEMBL1469557 & 737822 & 4.9 & 5.2265 & TRN \\
\hline CHEMBL1595551 & 737822 & 4.75 & 5.154 & TRN \\
\hline CHEMBL1302342 & 737822 & 4.6 & 5.1827 & TRN \\
\hline CHEMBL1533853 & 737822 & 4.6 & 4.4551 & TRN \\
\hline CHEMBL 1406082 & 737822 & 5.0 & 4.7951 & TRN \\
\hline CHEMBL1420257 & 737822 & 5.05 & 5.5092 & TRN \\
\hline CHEMBL1354273 & 737822 & 4.7 & 4.7482 & TRN \\
\hline CHEMBL1574966 & 737822 & 6.0 & 5.7613 & TRN \\
\hline CHEMBL1313588 & 737822 & 4.9 & 5.1209 & TRN \\
\hline CHEMBL1425971 & 737822 & 4.8 & 5.6208 & TRN \\
\hline CHEMBL1454544 & 737822 & 5.1 & 4.8323 & TRN \\
\hline CHEMBL1611348 & 737822 & 5.0 & 4.9163 & TRN \\
\hline CHEMBL1556561 & 737822 & 5.25 & 5.5184 & TRN \\
\hline CHEMBL1422148 & 737822 & 5.6 & 5.6507 & TRN \\
\hline CHEMBL1398714 & 737822 & 5.7 & 5.5387 & TRN \\
\hline CHEMBL1706387 & 737822 & 4.75 & 5.4263 & TRN \\
\hline CHEMBL580421 & 737822 & 5.6 & 5.4202 & TST \\
\hline CHEMBL1591140 & 737822 & 4.9 & 4.6954 & TRN \\
\hline CHEMBL1516629 & 737822 & 4.6 & 5.0963 & TRN \\
\hline CHEMBL 7634 & 737822 & 5.1 & 5.0616 & TST \\
\hline CHEMBL38288 & 737822 & 4.7 & 4.8033 & TRN \\
\hline CHEMBL1514027 & 737822 & 4.6 & 4.5841 & TRN \\
\hline CHEMBL1313894 & 737822 & 4.75 & 4.9571 & TRN \\
\hline CHEMBL 39947 & 737822 & 6.9 & 5.7282 & TRN \\
\hline CHEMBL1402827 & 737822 & 4.7 & 4.7153 & TRN \\
\hline CHEMBL1355256 & 737822 & 4.7 & 4.5098 & TRN \\
\hline CHEMBL1599118 & 737822 & 5.0 & 4.6694 & TRN \\
\hline CHEMBL1441823 & 737822 & 5.6 & 5.2807 & TRN \\
\hline CHEMBL1352082 & 737822 & 4.6 & 5.2027 & TRN \\
\hline CHEMBL1356262 & 737822 & 4.9 & 4.6878 & TRN \\
\hline CHEMBL1592481 & 737822 & 6.3 & 5.975 & TRN \\
\hline CHEMBL1364859 & 737822 & 5.1 & 4.8974 & TRN \\
\hline CHEMBL3210860 & 737822 & 5.45 & 5.2595 & TRN \\
\hline CHEMBL1607010 & 737822 & 4.7 & 4.5386 & TRN \\
\hline CHEMBL 2062345 & 737822 & 5.0 & 4.9882 & TST \\
\hline CHEMBL1443703 & 737822 & 5.4 & 5.3176 & TRN \\
\hline CHEMBL1319426 & 737822 & 7.45 & 5.0504 & TRN \\
\hline CHEMBL1323563 & 737822 & 4.9 & 4.7782 & TRN \\
\hline CHEMBL1368942 & 737822 & 4.4 & 4.2508 & TRN \\
\hline CHEMBL1565125 & 737822 & 4.8 & 4.7868 & TST \\
\hline CHEMBL1408856 & 737822 & 4.9 & 4.7254 & TRN \\
\hline CHEMBL1528351 & 737822 & 5.45 & 5.4766 & TRN \\
\hline
\end{tabular}




\begin{tabular}{|c|c|c|c|c|c|}
\hline \\
\hline CHEMBL1593213 & 737822 & 5.0 & 5.1162 & TST & \\
\hline CHEMBL1358197 & 737822 & 4.9 & 4.6495 & TRN & \\
\hline CHEMBL1370377 & 737822 & 4.4 & 5.2018 & TRN & \\
\hline CHEMBL1396109 & 737822 & 4.6 & 4.4867 & TRN & \\
\hline CHEMBL1369693 & 737822 & 4.55 & 5.3295 & TRN & \\
\hline CHEMBL1416351 & 737822 & 6.2 & 5.471 & TRN & \\
\hline CHEMBL1457603 & 737822 & 4.75 & 5.2747 & TRN & \\
\hline CHEMBL3209977 & 737822 & 4.85 & 5.4964 & TRN & \\
\hline CHEMBL1328324 & 737822 & 4.4 & 4.6293 & TST & \\
\hline CHEMBL40998 & 737822 & 4.4 & 4.6127 & TRN & \\
\hline CHEMBL1397902 & 737822 & 5.4 & 5.3486 & TRN & \\
\hline CHEMBL1326546 & 737822 & 4.8 & 5.3685 & TRN & \\
\hline CHEMBL1397752 & 737822 & 6.2 & 5.9777 & TRN & \\
\hline CHEMBL1593827 & 737822 & 5.4 & 5.1707 & TRN & \\
\hline CHEMBL1393947 & 737822 & 5.3 & 5.2313 & TRN & \\
\hline CHEMBL1349366 & 737822 & 5.55 & 5.1939 & TRN & \\
\hline CHEMBL1491684 & 737822 & 7.3 & 6.7091 & TST & \\
\hline CHEMBL1371944 & 737822 & 4.6 & 4.4561 & TRN & \\
\hline CHEMBL1735211 & 737822 & 5.4 & 5.2677 & TRN & \\
\hline CHEMBL1346358 & 737822 & 4.9 & 5.5844 & TRN & \\
\hline CHEMBL1438674 & 737822 & 4.9 & 4.7722 & TRN & \\
\hline CHEMBL1314799 & 737822 & 4.9 & 4.6708 & TRN & \\
\hline CHEMBL1565342 & 737822 & 6.0 & 5.8693 & TRN & \\
\hline CHEMBL1515985 & 737822 & 5.1 & 4.8811 & TRN & \\
\hline CHEMBL1576560 & 737822 & 5.55 & 4.8059 & TRN & \\
\hline CHEMBL45281 & 737822 & 5.8 & 5.5762 & TST & \\
\hline CHEMBL1587369 & 737822 & 5.65 & 5.2348 & TRN & \\
\hline CHEMBL500996 & 737822 & 4.5 & 4.8134 & TRN & \\
\hline CHEMBL1454049 & 737822 & 5.0 & 4.7755 & TRN & \\
\hline CHEMBL1408874 & 737822 & 6.75 & 5.3783 & TRN & \\
\hline CHEMBL1335579 & 737822 & 5.05 & 5.3877 & TRN & \\
\hline CHEMBL1311417 & 737822 & 4.65 & 5.2549 & TRN & \\
\hline CHEMBL1322702 & 737822 & 4.5 & 4.68199 & 99999999995 & TRN \\
\hline CHEMBL1351231 & 737822 & 4.55 & 5.4682 & TST & \\
\hline CHEMBL1599388 & 737822 & 5.05 & 5.4499 & TRN & \\
\hline CHEMBL1335862 & 737822 & 5.4 & 5.3244 & TST & \\
\hline CHEMBL1554910 & 737822 & 6.3 & 6.1055 & TRN & \\
\hline CHEMBL276140 & 737822 & 4.5 & 4.833 & TRN & \\
\hline CHEMBL1568643 & 737822 & 4.85 & 5.2697 & TST & \\
\hline CHEMBL1433752 & 737822 & 5.3 & 5.1671 & TRN & \\
\hline CHEMBL1505026 & 737822 & 4.7 & 5.4181 & TRN & \\
\hline CHEMBL1436160 & 737822 & 4.7 & 4.5515 & TRN & \\
\hline CHEMBL1789988 & 737822 & 5.5 & 5.3958 & TRN & \\
\hline CHEMBL1394499 & 737822 & 5.8 & 5.4833 & TRN & \\
\hline CHEMBL1374710 & 737822 & 4.7 & 4.458 & TRN & \\
\hline CHEMBL1526964 & 737822 & 5.8 & 5.5355 & TST & \\
\hline CHEMBL1421758 & 737822 & 4.85 & 5.2027 & TRN & \\
\hline CHEMBL1476511 & 737822 & 4.8 & 4.6873 & TRN & \\
\hline & & & & 1328 & \\
\hline
\end{tabular}




\begin{tabular}{|c|c|c|c|c|}
\hline & & & & al Table s \\
\hline CHEMBL1491258 & 737822 & 6.0 & 5.6995 & TRN \\
\hline CHEMBL 305881 & 737822 & 6.0 & 5.7518 & TRN \\
\hline CHEMBL3199657 & 737822 & 4.8 & 5.3431 & TST \\
\hline CHEMBL1611463 & 737822 & 4.85 & 5.0462 & TRN \\
\hline CHEMBL1490330 & 737822 & 4.9 & 5.2099 & TRN \\
\hline CHEMBL1427548 & 737822 & 5.6 & 5.3035 & TRN \\
\hline CHEMBL1741802 & 737822 & 4.7 & 5.1576 & TRN \\
\hline CHEMBL1591896 & 737822 & 5.0 & 5.0686 & TRN \\
\hline CHEMBL1378704 & 737822 & 4.6 & 4.6032 & TRN \\
\hline CHEMBL1458255 & 737822 & 4.6 & 5.3631 & TRN \\
\hline CHEMBL1512701 & 737822 & 4.9 & 4.8208 & TRN \\
\hline CHEMBL1256910 & 737822 & 4.5 & 4.579 & TST \\
\hline CHEMBL1474151 & 737822 & 4.4 & 4.4454 & TRN \\
\hline CHEMBL1488931 & 737822 & 4.65 & 5.3194 & TST \\
\hline CHEMBL1162107 & 737822 & 5.5 & 5.25700 & 0000000001 \\
\hline CHEMBL1437491 & 737822 & 4.9 & 4.8492 & TRN \\
\hline CHEMBL1558916 & 737822 & 5.1 & 5.4032 & TRN \\
\hline CHEMBL1352133 & 737822 & 5.3 & 5.1228 & TRN \\
\hline CHEMBL1327945 & 737822 & 4.8 & 4.6966 & TRN \\
\hline CHEMBL1256751 & 737822 & 4.5 & 4.7129 & TRN \\
\hline CHEMBL1545514 & 737822 & 4.85 & 5.2864 & TRN \\
\hline CHEMBL1257123 & 737822 & 5.3 & 5.8791 & TRN \\
\hline CHEMBL304008 & 737822 & 5.6 & 5.4456 & TST \\
\hline CHEMBL1542591 & 737822 & 4.8 & 5.2959 & TST \\
\hline CHEMBL1399313 & 737822 & 4.9 & 4.6877 & TRN \\
\hline CHEMBL3211211 & 737822 & 5.05 & 5.2356 & TST \\
\hline CHEMBL3189655 & 737822 & 6.75 & 5.5861 & TST \\
\hline CHEMBL3198312 & 737822 & 4.6 & 5.2054 & TRN \\
\hline CHEMBL1437804 & 737822 & 5.0 & 4.9697 & TST \\
\hline CHEMBL1447719 & 737822 & 5.1 & 5.1758 & TRN \\
\hline CHEMBL1313043 & 737822 & 5.95 & 5.2598 & TRN \\
\hline CHEMBL1362630 & 737822 & 5.1 & 5.0661 & TST \\
\hline CHEMBL1329218 & 737822 & 6.5 & 6.1199 & TST \\
\hline CHEMBL1594359 & 737822 & 5.7 & 5.0649 & TRN \\
\hline CHEMBL1405461 & 737822 & 5.0 & 5.0106 & TRN \\
\hline CHEMBL1473480 & 737822 & 6.3 & 6.2211 & TRN \\
\hline CHEMBL1396358 & 737822 & 4.4 & 4.4622 & TRN \\
\hline CHEMBL1486915 & 737822 & 4.7 & 4.5364 & TRN \\
\hline CHEMBL1604925 & 737822 & 6.6 & 5.8263 & TST \\
\hline CHEMBL1424426 & 737822 & 4.4 & 5.3949 & TRN \\
\hline CHEMBL1522087 & 737822 & 5.9 & 5.1902 & TST \\
\hline CHEMBL539027 & 737822 & 6.0 & 5.7998 & TRN \\
\hline CHEMBL1607115 & 737822 & 5.65 & 5.4505 & TRN \\
\hline CHEMBL1327243 & 737822 & 4.4 & 4.54 & TST \\
\hline CHEMBL523167 & 737822 & 4.6 & 4.7719 & TRN \\
\hline CHEMBL1490544 & 737822 & 5.1 & 5.277 & TRN \\
\hline CHEMBL1529705 & 737822 & 4.6 & 5.3261 & TST \\
\hline CHEMBL1538975 & 737822 & 4.8 & 5.2955 & TRN \\
\hline
\end{tabular}




\begin{tabular}{|c|c|c|c|c|}
\hline \multicolumn{5}{|c|}{ Supplemental Table S2.txt } \\
\hline CHEMBL1406879 & 737822 & 4.7 & 4.499 & TRN \\
\hline CHEMBL1390028 & 737822 & 6.35 & 5.0182 & TRN \\
\hline CHEMBL1405257 & 737822 & 4.75 & 5.4676 & TRN \\
\hline CHEMBL1337419 & 737822 & 5.5 & 5.4885 & TST \\
\hline CHEMBL1569352 & 737822 & 5.3 & 5.4912 & TRN \\
\hline CHEMBL1741791 & 737822 & 4.75 & 5.2946 & TRN \\
\hline CHEMBL1472933 & 737822 & 6.0 & 5.807 & TRN \\
\hline CHEMBL1471206 & 737822 & 4.8 & 5.2744 & TRN \\
\hline CHEMBL1576372 & 737822 & 4.85 & 5.3529 & TRN \\
\hline CHEMBL1317232 & 737822 & 4.9 & 4.8386 & TRN \\
\hline CHEMBL1607407 & 737822 & 5.3 & 5.5046 & TRN \\
\hline CHEMBL3194238 & 737822 & 4.8 & 5.3209 & TRN \\
\hline CHEMBL512908 & 737822 & 5.5 & 5.3981 & TST \\
\hline CHEMBL1596241 & 737822 & 4.4 & 4.4101 & TRN \\
\hline CHEMBL1391308 & 737822 & 5.2 & 5.1916 & TST \\
\hline CHEMBL1511845 & 737822 & 7.7001 & 7.0097 & TRN \\
\hline CHEMBL1481160 & 737822 & 6.7 & 6.2588 & TST \\
\hline CHEMBL1313321 & 737822 & 4.55 & 5.4735 & TRN \\
\hline CHEMBL52 & 737822 & 4.4 & 5.7513 & TRN \\
\hline CHEMBL1473925 & 737822 & 5.5 & 5.4434 & TRN \\
\hline CHEMBL1552227 & 737822 & 4.8 & 4.6656 & TRN \\
\hline CHEMBL3349050 & 737822 & 7.2 & 6.9165 & TRN \\
\hline CHEMBL1339696 & 737822 & 6.55 & 5.3806 & TRN \\
\hline CHEMBL1505006 & 737822 & 5.1 & 5.1965 & TRN \\
\hline CHEMBL1514634 & 737822 & 5.5 & 5.5333 & TST \\
\hline CHEMBL1438164 & 737822 & 4.9 & 4.6837 & TRN \\
\hline CHEMBL1980198 & 737822 & 4.45 & 5.034 & TRN \\
\hline CHEMBL1567447 & 737822 & 4.7 & 5.2798 & TRN \\
\hline CHEMBL123904 & 737822 & 4.9 & 4.912 & TST \\
\hline CHEMBL1361757 & 737822 & 4.6 & 5.4653 & TST \\
\hline CHEMBL1536326 & 737822 & 4.9 & 5.3083 & TRN \\
\hline CHEMBL1311026 & 737822 & 5.5 & 5.2737 & TST \\
\hline CHEMBL3193159 & 737822 & 4.55 & 5.4445 & TRN \\
\hline CHEMBL1368474 & 737822 & 5.0 & 4.8974 & TRN \\
\hline CHEMBL1333236 & 737822 & 4.65 & 5.3529 & TRN \\
\hline CHEMBL1437690 & 737822 & 4.5 & 4.5292 & TRN \\
\hline CHEMBL1332033 & 737822 & 5.3 & 4.9801 & TRN \\
\hline CHEMBL1512833 & 737822 & 4.7 & 4.6793 & TRN \\
\hline CHEMBL3195693 & 737822 & 5.55 & 5.3868 & TRN \\
\hline CHEMBL1318045 & 737822 & 4.7 & 4.5561 & TRN \\
\hline CHEMBL1494296 & 737822 & 5.9 & 5.3553 & TRN \\
\hline CHEMBL1472052 & 737822 & 5.55 & 5.3536 & TRN \\
\hline CHEMBL1356094 & 737822 & 6.8 & 6.2802 & TRN \\
\hline CHEMBL1517696 & 737822 & 5.5 & 5.2952 & TRN \\
\hline CHEMBL1610687 & 737822 & 4.85 & 5.4299 & TRN \\
\hline CHEMBL1381730 & 737822 & 5.15 & 5.3674 & TST \\
\hline CHEMBL1366453 & 737822 & 4.8 & 5.1471 & TST \\
\hline CHEMBL1512802 & 737822 & 4.5 & 4.4259 & TRN \\
\hline
\end{tabular}




\begin{tabular}{|c|c|c|c|c|c|}
\hline \multicolumn{6}{|c|}{ plemental } \\
\hline CHEMBL1606547 & 737822 & 5.05 & 5.3239 & TST & \\
\hline CHEMBL1515982 & 737822 & 5.3 & 5.2213 & TRN & \\
\hline CHEMBL1496514 & 737822 & 6.0 & 5.7458 & TST & \\
\hline CHEMBL1484738 & 737822 & 7.4 & 6.5723 & TST & \\
\hline CHEMBL1512250 & 737822 & 4.5 & 4.3552 & TRN & \\
\hline CHEMBL1256660 & 737822 & 6.4 & 6.1296 & TRN & \\
\hline CHEMBL3207808 & 737822 & 4.8 & 5.3927 & TRN & \\
\hline CHEMBL1611225 & 737822 & 7.9 & 7.2645 & TRN & \\
\hline CHEMBL1544250 & 737822 & 4.4 & 5.3351 & TRN & \\
\hline CHEMBL3211748 & 737822 & 8.0 & 5.2115 & TRN & \\
\hline CHEMBL1418178 & 737822 & 5.65 & 5.2077 & TRN & \\
\hline CHEMBL1393350 & 737822 & 4.4 & 5.5398 & TRN & \\
\hline CHEMBL1493369 & 737822 & 4.9 & 4.9349 & TRN & \\
\hline CHEMBL1584461 & 737822 & 4.9 & 5.7315 & TRN & \\
\hline CHEMBL1475789 & 737822 & 4.4 & 4.28100 & 2000000001 & TRN \\
\hline CHEMBL45068 & 737822 & 4.4 & 5.7756 & TRN & \\
\hline CHEMBL1554982 & 737822 & 4.4 & 4.2627 & TRN & \\
\hline CHEMBL1544694 & 737822 & 4.85 & 5.1569 & TST & \\
\hline CHEMBL1376224 & 737822 & 4.85 & 5.482 & TRN & \\
\hline CHEMBL1331634 & 737822 & 6.0 & 5.8632 & TRN & \\
\hline CHEMBL1546034 & 737822 & 5.9 & 5.42899 & 9999999999 & TRN \\
\hline CHEMBL1603906 & 737822 & 6.05 & 5.2787 & TRN & \\
\hline CHEMBL1552332 & 737822 & 4.7 & 4.542 & TRN & \\
\hline CHEMBL1724983 & 737822 & 5.35 & 5.3735 & TRN & \\
\hline CHEMBL1320315 & 737822 & 5.4 & 5.3321 & TST & \\
\hline CHEMBL1358085 & 737822 & 5.3 & 5.3128 & TRN & \\
\hline CHEMBL340807 & 737822 & 5.4 & 5.9228 & TRN & \\
\hline CHEMBL1353921 & 737822 & 4.9 & 5.3733 & TRN & \\
\hline CHEMBL1544918 & 737822 & 5.5 & 5.5939 & TRN & \\
\hline CHEMBL1311840 & 737822 & 4.4 & 5.3256 & TRN & \\
\hline CHEMBL1704641 & 737822 & 5.3 & 5.5872 & TRN & \\
\hline CHEMBL1326406 & 737822 & 6.2 & 5.4524 & TRN & \\
\hline CHEMBL1312265 & 737822 & 6.1 & 5.3948 & TRN & \\
\hline CHEMBL1422001 & 737822 & 6.05 & 5.2137 & TRN & \\
\hline CHEMBL1741914 & 737822 & 4.4 & 5.3553 & TRN & \\
\hline CHEMBL1590191 & 737822 & 4.4 & 4.8223 & TRN & \\
\hline CHEMBL1451119 & 737822 & 5.4 & 5.1679 & TRN & \\
\hline CHEMBL1301725 & 737822 & 4.9 & 5.1952 & TRN & \\
\hline CHEMBL1467364 & 737822 & 4.4 & 5.2817 & TRN & \\
\hline CHEMBL1507862 & 737822 & 4.85 & 5.41200 & 0000000001 & TST \\
\hline CHEMBL1255662 & 737822 & 4.7 & 4.9397 & TRN & \\
\hline CHEMBL1438688 & 737822 & 4.8 & 4.5702 & TRN & \\
\hline CHEMBL509150 & 737822 & 4.5 & 4.4525 & TRN & \\
\hline CHEMBL 3195524 & 737822 & 5.8 & 5.2509 & TST & \\
\hline CHEMBL33103 & 737822 & 4.8 & 4.664 & TRN & \\
\hline CHEMBL1488727 & 737822 & 7.15 & 5.1586 & TRN & \\
\hline CHEMBL1414592 & 737822 & 5.5 & 5.4474 & TRN & \\
\hline CHEMBL1519291 & 737822 & 4.6 & 5.595 & TRN & \\
\hline
\end{tabular}




\begin{tabular}{|c|c|c|c|c|c|}
\hline \\
\hline CHEMBL291536 & 737822 & 5.0 & 4.9284 & TST & \\
\hline CHEMBL1358272 & 737822 & 5.1 & 5.0323 & TRN & \\
\hline CHEMBL1447663 & 737822 & 4.9 & 4.6872 & TRN & \\
\hline CHEMBL1987514 & 737822 & 4.85 & 5.1465 & TRN & \\
\hline CHEMBL1378959 & 737822 & 5.6 & 5.7224 & TRN & \\
\hline CHEMBL1579123 & 737822 & 4.55 & 5.4535 & TRN & \\
\hline CHEMBL1489663 & 737822 & 5.4 & 5.3887 & TRN & \\
\hline CHEMBL1555519 & 737822 & 4.8 & 5.4578 & TRN & \\
\hline CHEMBL1447089 & 737822 & 6.4 & 5.24 & TST & \\
\hline CHEMBL1498977 & 737822 & 5.0 & 4.9763 & TRN & \\
\hline CHEMBL1301385 & 737822 & 4.9 & 5.189 & TRN & \\
\hline CHEMBL1514517 & 737822 & 5.0 & 4.827 & TRN & \\
\hline CHEMBL1480136 & 737822 & 4.8 & 4.9487 & TRN & \\
\hline CHEMBL1590601 & 737822 & 5.1 & 5.2176 & TRN & \\
\hline CHEMBL1542604 & 737822 & 4.55 & 5.0654 & TRN & \\
\hline CHEMBL1491853 & 737822 & 5.5 & 5.5422 & TRN & \\
\hline CHEMBL1556027 & 737822 & 5.1 & 5.0831 & TRN & \\
\hline CHEMBL1322914 & 737822 & 5.6 & 5.2076 & TRN & \\
\hline CHEMBL127421 & 737822 & 4.4 & 4.4282 & TRN & \\
\hline CHEMBL1330483 & 737822 & 5.3 & 5.4584 & TRN & \\
\hline CHEMBL1396211 & 737822 & 4.4 & 4.3439 & 9999999999 & TRN \\
\hline CHEMBL1511553 & 737822 & 4.55 & 5.2784 & TRN & \\
\hline CHEMBL1385495 & 737822 & 4.95 & 5.3067 & TRN & \\
\hline CHEMBL1789995 & 737822 & 6.3 & 5.9596 & TRN & \\
\hline CHEMBL1568575 & 737822 & 4.4 & 4.3695 & TRN & \\
\hline CHEMBL 1454249 & 737822 & 6.15 & 5.2392 & TRN & \\
\hline CHEMBL1348993 & 737822 & 4.8 & 5.2256 & TRN & \\
\hline CHEMBL1473760 & 737822 & 4.4 & 4.3691 & TRN & \\
\hline CHEMBL536480 & 737822 & 5.7 & 5.4874 & TRN & \\
\hline CHEMBL1317620 & 737822 & 6.3 & 6.0019 & TRN & \\
\hline CHEMBL492193 & 737822 & 5.0 & 5.7678 & TST & \\
\hline CHEMBL1255866 & 737822 & 4.6 & 4.7482 & TST & \\
\hline CHEMBL1532443 & 737822 & 4.6 & 5.615 & TRN & \\
\hline CHEMBL1603884 & 737822 & 5.4 & 5.2954 & TST & \\
\hline CHEMBL1257012 & 737822 & 5.9 & 5.6748 & TRN & \\
\hline CHEMBL1516054 & 737822 & 6.1 & 5.9018 & TRN & \\
\hline CHEMBL1372997 & 737822 & 4.9 & 5.0349 & TST & \\
\hline CHEMBL1482426 & 737822 & 4.4 & 4.2942 & TRN & \\
\hline CHEMBL1717253 & 737822 & 4.8 & 5.2048 & TRN & \\
\hline CHEMBL1313121 & 737822 & 5.35 & 5.6858 & TRN & \\
\hline CHEMBL1315318 & 737822 & 5.1 & 4.9288 & TRN & \\
\hline CHEMBL1330032 & 737822 & 5.15 & 5.2776 & TRN & \\
\hline CHEMBL1374205 & 737822 & 4.7 & 5.4672 & TRN & \\
\hline CHEMBL1375867 & 737822 & 5.2 & 5.4194 & TRN & \\
\hline CHEMBL1384157 & 737822 & 4.6 & 5.1422 & TRN & \\
\hline CHEMBL1591238 & 737822 & 4.7 & 4.5652 & TRN & \\
\hline CHEMBL1437054 & 737822 & 5.8 & 5.4184 & TST & \\
\hline CHEMBL1410635 & 737822 & 4.5 & 4.4408 & TRN & \\
\hline & & & & 32 & \\
\hline
\end{tabular}




\begin{tabular}{|c|c|c|c|c|c|}
\hline & & \multicolumn{4}{|c|}{ Supplemental Table S2.txt } \\
\hline CHEMBL1964690 & 737822 & 5.35 & 5.2209 & TST & \\
\hline CHEMBL1553694 & 737822 & 5.2 & 4.9522 & TRN & \\
\hline CHEMBL1526543 & 737822 & 5.0 & 5.6884 & TST & \\
\hline CHEMBL1513324 & 737822 & 4.7 & 4.595 & TRN & \\
\hline CHEMBL117 & 737822 & 4.9 & 4.7329 & TRN & \\
\hline CHEMBL1500523 & 737822 & 5.0 & 5.3426 & TRN & \\
\hline CHEMBL1489354 & 737822 & 4.55 & 5.1485 & TRN & \\
\hline CHEMBL1315725 & 737822 & 5.8 & 5.5965 & TST & \\
\hline CHEMBL1508532 & 737822 & 4.9 & 5.2335 & TRN & \\
\hline CHEMBL1526032 & 737822 & 5.0 & 4.8967 & TRN & \\
\hline CHEMBL1256750 & 737822 & 4.4 & 5.0197 & TRN & \\
\hline CHEMBL1590550 & 737822 & 4.4 & 4.2464 & TRN & \\
\hline CHEMBL1593371 & 737822 & 5.1 & 4.8916 & TRN & \\
\hline CHEMBL1505211 & 737822 & 4.85 & 5.4318 & TRN & \\
\hline CHEMBL1319517 & 737822 & 5.3 & 5.4037 & TRN & \\
\hline CHEMBL53898 & 737822 & 4.5 & 5.5288 & TRN & \\
\hline CHEMBL492610 & 737822 & 4.9 & 4.7274 & TRN & \\
\hline CHEMBL1350860 & 737822 & 4.55 & 5.0633 & TRN & \\
\hline CHEMBL1408878 & 737822 & 4.6 & 4.5149 & TRN & \\
\hline CHEMBL554041 & 737822 & 5.5 & 5.348 & TST & \\
\hline CHEMBL1554194 & 737822 & 4.8 & 4.7097 & TRN & \\
\hline CHEMBL1496311 & 737822 & 4.85 & 5.1812 & TRN & \\
\hline CHEMBL1414719 & 737822 & 5.95 & 5.1202 & TRN & \\
\hline CHEMBL1428990 & 737822 & 4.8 & 5.1153 & TRN & \\
\hline CHEMBL455185 & 737822 & 7.3 & 6.6564 & TST & \\
\hline CHEMBL1358380 & 737822 & 5.7 & 5.561 & TRN & \\
\hline CHEMBL1397877 & 737822 & 4.4 & 4.3414 & TRN & \\
\hline CHEMBL1610228 & 737822 & 5.2 & 4.9746 & TRN & \\
\hline CHEMBL1574476 & 737822 & 4.4 & 4.3773 & TRN & \\
\hline CHEMBL1522232 & 737822 & 4.6 & 5.1514 & TRN & \\
\hline CHEMBL16410 & 737822 & 4.6 & 4.8971 & TRN & \\
\hline CHEMBL1395634 & 737822 & 5.5 & 5.4291 & TRN & \\
\hline CHEMBL540848 & 737822 & 6.0 & 5.6087 & TRN & \\
\hline CHEMBL1493064 & 737822 & 4.85 & 5.1043 & TRN & \\
\hline CHEMBL1318316 & 737822 & 5.8 & 5.7657 & TRN & \\
\hline CHEMBL1424256 & 737822 & 4.75 & 5.2335 & TRN & \\
\hline CHEMBL591126 & 737822 & 5.1 & 5.3734 & TRN & \\
\hline CHEMBL1591992 & 737822 & 6.2 & 6.0399 & TRN & \\
\hline CHEMBL1314486 & 737822 & 4.4 & 4.3695 & TRN & \\
\hline CHEMBL1603100 & 737822 & 5.5 & 5.4896 & TST & \\
\hline CHEMBL1433052 & 737822 & 4.6 & 5.3361 & TST & \\
\hline CHEMBL1388707 & 737822 & 4.8 & 5.04899 & 99999999995 & TRN \\
\hline CHEMBL1606990 & 737822 & 6.4 & 5.9329 & TRN & \\
\hline CHEMBL85251 & 737822 & 4.9 & 4.968 & TRN & \\
\hline CHEMBL1466551 & 737822 & 4.9 & 5.5646 & TRN & \\
\hline CHEMBL1314897 & 737822 & 5.4 & 5.2139 & TRN & \\
\hline CHEMBL1515001 & 737822 & 5.2 & 5.1965 & TRN & \\
\hline CHEMBL1741671 & 737822 & 4.75 & 5.4731 & TRN & \\
\hline
\end{tabular}




\begin{tabular}{|c|c|c|c|c|c|}
\hline \\
\hline CHEMBL1517550 & 737822 & 4.6 & 5.0324 & TRN & \\
\hline CHEMBL1435540 & 737822 & 6.7 & 6.2185 & TRN & \\
\hline CHEMBL1503171 & 737822 & 5.45 & 5.4997 & TRN & \\
\hline CHEMBL1416235 & 737822 & 5.6 & 5.274 & TRN & \\
\hline CHEMBL1601285 & 737822 & 4.8 & 5.2438 & TRN & \\
\hline CHEMBL1357722 & 737822 & 4.8 & 4.9642 & TRN & \\
\hline CHEMBL1432053 & 737822 & 8.0 & 5.466 & TRN & \\
\hline CHEMBL1339054 & 737822 & 4.85 & 5.1893 & TRN & \\
\hline CHEMBL1409802 & 737822 & 5.45 & 4.9984 & TRN & \\
\hline CHEMBL1318509 & 737822 & 5.1 & 4.8799 & TRN & \\
\hline CHEMBL1732035 & 737822 & 4.4 & 5.0808 & TRN & \\
\hline CHEMBL605003 & 737822 & 4.5 & 4.6237 & TST & \\
\hline CHEMBL1450942 & 737822 & 5.95 & 5.7004 & TRN & \\
\hline CHEMBL1486821 & 737822 & 5.2 & 5.1778 & TRN & \\
\hline CHEMBL38832 & 737822 & 5.9 & 5.699 & TST & \\
\hline CHEMBL1400309 & 737822 & 5.2 & 4.9748 & TRN & \\
\hline CHEMBL3209999 & 737822 & 5.4 & 5.3144 & TRN & \\
\hline CHEMBL1419252 & 737822 & 7.1 & 5.3107 & TST & \\
\hline CHEMBL1456312 & 737822 & 6.4 & 6.00700 & 0000000001 & TRN \\
\hline CHEMBL1372330 & 737822 & 6.0 & 5.9051 & TRN & \\
\hline CHEMBL1460723 & 737822 & 5.15 & 5.1543 & TRN & \\
\hline CHEMBL1408954 & 737822 & 5.4 & 5.3077 & TRN & \\
\hline CHEMBL1411555 & 737822 & 5.0 & 5.0848 & TRN & \\
\hline CHEMBL1480806 & 737822 & 5.2 & 5.0602 & TRN & \\
\hline CHEMBL1437012 & 737822 & 6.1 & 5.7089 & TRN & \\
\hline CHEMBL1742086 & 737822 & 4.75 & 5.2566 & TRN & \\
\hline CHEMBL601616 & 737822 & 4.55 & 5.2648 & TRN & \\
\hline CHEMBL1288013 & 737822 & 5.5 & 5.4522 & TRN & \\
\hline CHEMBL1558934 & 737822 & 4.7 & 5.2743 & TRN & \\
\hline CHEMBL1387625 & 737822 & 4.5 & 5.5134 & TRN & \\
\hline CHEMBL1398637 & 737822 & 4.9 & 5.0306 & TRN & \\
\hline CHEMBL1476430 & 737822 & 4.9 & 4.7068 & TRN & \\
\hline CHEMBL1534773 & 737822 & 5.85 & 5.115 & TRN & \\
\hline CHEMBL1411457 & 737822 & 4.75 & 5.0757 & TRN & \\
\hline CHEMBL1350339 & 737822 & 4.95 & 5.39 & TRN & \\
\hline CHEMBL1589340 & 737822 & 7.45 & 5.019 & TRN & \\
\hline CHEMBL90882 & 737822 & 7.4 & 6.6791 & TRN & \\
\hline CHEMBL1610312 & 737822 & 5.1 & 5.17399 & 99999999995 & TST \\
\hline CHEMBL321691 & 737822 & 5.4 & 5.305 & TRN & \\
\hline CHEMBL1317066 & 737822 & 7.1 & 6.4526 & TRN & \\
\hline CHEMBL475376 & 737822 & 4.9 & 4.8615 & TRN & \\
\hline CHEMBL269550 & 737822 & 4.5 & 4.6909 & TRN & \\
\hline CHEMBL1352043 & 737822 & 4.6 & 5.0147 & TRN & \\
\hline CHEMBL1579133 & 737822 & 4.95 & 5.2577 & TRN & \\
\hline CHEMBL1316656 & 737822 & 5.2 & 5.025 & TRN & \\
\hline CHEMBL1256971 & 737822 & 5.0 & 5.7883 & TST & \\
\hline CHEMBL1480840 & 737822 & 4.85 & 5.2753 & TRN & \\
\hline CHEMBL1383487 & 737822 & 5.05 & 5.2609 & TST & \\
\hline & & & & 1133 & \\
\hline
\end{tabular}




\begin{tabular}{|c|c|c|c|c|c|}
\hline \multirow[b]{2}{*}{ CHEMBL587849 } & \multicolumn{5}{|c|}{ Iable sz } \\
\hline & 737822 & 5.4 & 5.2341 & TST & \multirow{3}{*}{ TRN } \\
\hline CHEMBL1397636 & 737822 & 4.6 & \multicolumn{2}{|c|}{4.468999999999999} & \\
\hline CHEMBL1534082 & 737822 & 4.7 & 4.5455 & TRN & \\
\hline CHEMBL1476051 & 737822 & 4.5 & 4.3845 & TRN & \\
\hline CHEMBL321820 & 737822 & 4.4 & 4.6529 & TST & \\
\hline CHEMBL1361731 & 737822 & 4.7 & 4.6815 & TRN & \\
\hline CHEMBL1544037 & 737822 & 4.4 & 5.0798 & TRN & \\
\hline CHEMBL1557015 & 737822 & 4.6 & 5.2704 & TST & \\
\hline CHEMBL1421764 & 737822 & 5.1 & 5.1327 & TRN & \\
\hline CHEMBL1606737 & 737822 & 5.0 & 5.3047 & TRN & \\
\hline CHEMBL1598492 & 737822 & 6.5 & 5.2519 & TRN & \\
\hline CHEMBL 259073 & 737822 & 4.4 & 4.4437 & TRN & \\
\hline CHEMBL1607228 & 737822 & 5.0 & 4.8985 & TRN & \\
\hline CHEMBL1485384 & 737822 & 5.3 & 5.2698 & TRN & \\
\hline CHEMBL1413311 & 737822 & 5.05 & 5.3158 & TRN & \\
\hline CHEMBL1373587 & 737822 & 6.1 & 5.7459 & TST & \\
\hline CHEMBL1377566 & 737822 & 5.0 & 5.3673 & TST & \\
\hline CHEMBL1526369 & 737822 & 4.75 & 5.3011 & TRN & \\
\hline CHEMBL1309130 & 737822 & 4.85 & 5.2683 & TRN & \\
\hline CHEMBL1374355 & 737822 & 5.0 & 4.7508 & TRN & \\
\hline CHEMBL1342791 & 737822 & 4.85 & 5.0079 & TRN & \\
\hline CHEMBL1315700 & 737822 & 4.5 & 4.4178 & TRN & \\
\hline CHEMBL1581594 & 737822 & 6.05 & 5.1851 & TRN & \\
\hline CHEMBL1497812 & 737822 & 6.0 & 5.4445 & TRN & \\
\hline CHEMBL166161 & 737822 & 4.8 & 4.8601 & TST & \\
\hline CHEMBL1445233 & 737822 & 5.2 & 5.331 & TRN & \\
\hline CHEMBL1600239 & 737822 & 6.0 & 5.3424 & TRN & \\
\hline CHEMBL1526229 & 737822 & 5.1 & 5.678 & TST & \\
\hline CHEMBL1555118 & 737822 & 4.6 & $4.4860 e$ & 0000000001 & TRN \\
\hline CHEMBL1392457 & 737822 & 4.7 & 5.2625 & TRN & \\
\hline CHEMBL1593162 & 737822 & 5.3 & 5.1214 & TRN & \\
\hline CHEMBL1433783 & 737822 & 4.7 & 4.5961 & TRN & \\
\hline CHEMBL1488420 & 737822 & 5.9 & 5.6726 & TRN & \\
\hline CHEMBL445102 & 737822 & 6.5 & 5.7101 & TRN & \\
\hline CHEMBL1556828 & 737822 & 5.5 & 5.3822 & TRN & \\
\hline CHEMBL251904 & 737822 & 6.0 & 6.2453 & TRN & \\
\hline CHEMBL1355831 & 737822 & 4.8 & 4.7404 & TRN & \\
\hline CHEMBL1707095 & 737822 & 4.65 & 5.2999 & TRN & \\
\hline CHEMBL1399249 & 737822 & 4.6 & 4.7708 & TST & \\
\hline CHEMBL1507984 & 737822 & 4.95 & 5.3776 & TST & \\
\hline CHEMBL1574158 & 737822 & 5.5 & 5.1841 & TRN & \\
\hline CHEMBL1610955 & 737822 & 4.9 & 4.9136 & TRN & \\
\hline CHEMBL1393064 & 737822 & 4.85 & 5.2206 & TRN & \\
\hline CHEMBL1337108 & 737822 & 4.8 & 4.644 & TRN & \\
\hline CHEMBL1409446 & 737822 & 4.9 & 5.3138 & TRN & \\
\hline CHEMBL1383348 & 737822 & 4.7 & 5.4343 & TRN & \\
\hline CHEMBL3209702 & 737822 & 5.2 & 5.2206 & TRN & \\
\hline CHEMBL1437902 & 737822 & 5.4 & 5.3938 & TST & \\
\hline & & & & 1133 & \\
\hline
\end{tabular}




\begin{tabular}{|c|c|c|c|c|c|}
\hline \\
\hline CHEMBL1464982 & 737822 & 8.25 & 5.1636 & TRN & \\
\hline CHEMBL1406712 & 737822 & 5.2 & 5.1941 & TRN & \\
\hline CHEMBL1256693 & 737822 & 4.9 & 5.0253 & TRN & \\
\hline CHEMBL1463479 & 737822 & 4.75 & 5.431 & TRN & \\
\hline CHEMBL1329846 & 737822 & 4.85 & 5.2676 & TRN & \\
\hline CHEMBL1470721 & 737822 & 4.8 & 5.1368 & TRN & \\
\hline CHEMBL1397914 & 737822 & 4.6 & 4.4962 & TRN & \\
\hline CHEMBL1452398 & 737822 & 5.1 & 5.4676 & TRN & \\
\hline CHEMBL1595371 & 737822 & 6.2 & 5.7103 & TRN & \\
\hline CHEMBL1455783 & 737822 & 5.6 & 5.2358 & TRN & \\
\hline CHEMBL1552707 & 737822 & 5.1 & 4.8254 & TRN & \\
\hline CHEMBL1607106 & 737822 & 5.5 & 5.3805 & TRN & \\
\hline CHEMBL113142 & 737822 & 5.0 & 4.9553 & TRN & \\
\hline CHEMBL3193466 & 737822 & 5.6 & 5.1883 & TRN & \\
\hline CHEMBL1450926 & 737822 & 5.0 & 4.8661 & TRN & \\
\hline CHEMBL1497087 & 737822 & 6.35 & 5.6288 & TRN & \\
\hline CHEMBL1256839 & 737822 & 6.0 & 5.75799 & 9999999999 & TRN \\
\hline CHEMBL1426718 & 737822 & 5.65 & 5.0908 & TRN & \\
\hline CHEMBL1550597 & 737822 & 7.0 & 5.3328 & TRN & \\
\hline CHEMBL1382013 & 737822 & 5.2 & 5.3289 & TRN & \\
\hline CHEMBL1314434 & 737822 & 4.6 & 4.5365 & TRN & \\
\hline CHEMBL1255583 & 737822 & 6.0 & 5.6642 & TRN & \\
\hline CHEMBL1401672 & 737822 & 4.7 & 4.4848 & TRN & \\
\hline CHEMBL1451824 & 737822 & 6.1 & 5.5498 & TRN & \\
\hline CHEMBL1590270 & 737822 & 6.8 & 6.5727 & TRN & \\
\hline CHEMBL1437488 & 737822 & 4.9 & 5.6432 & TRN & \\
\hline CHEMBL1319506 & 737822 & 4.4 & 4.4667 & TRN & \\
\hline CHEMBL1366393 & 737822 & 4.7 & 4.6296 & TRN & \\
\hline CHEMBL1569058 & 737822 & 6.2 & 5.2115 & TRN & \\
\hline CHEMBL119264 & 737822 & 5.3 & 5.2578 & TRN & \\
\hline CHEMBL1551310 & 737822 & 5.6 & 5.3113 & TRN & \\
\hline CHEMBL 1487561 & 737822 & 4.7 & 4.784 & TRN & \\
\hline CHEMBL1543489 & 737822 & 4.85 & 5.2962 & TRN & \\
\hline CHEMBL1606673 & 737822 & 4.75 & 5.2571 & TRN & \\
\hline CHEMBL1531699 & 737822 & 5.0 & 4.8603 & TRN & \\
\hline CHEMBL3211795 & 737822 & 4.8 & 5.2129 & TRN & \\
\hline CHEMBL 1607443 & 737822 & 6.1 & 5.6759 & TRN & \\
\hline CHEMBL1543285 & 737822 & 4.7 & 5.0781 & TRN & \\
\hline CHEMBL491578 & 737822 & 6.3 & 5.8172 & TRN & \\
\hline CHEMBL1348021 & 737822 & 4.65 & 5.3552 & TRN & \\
\hline CHEMBL1474471 & 737822 & 5.0 & 5.0179 & TRN & \\
\hline CHEMBL1451057 & 737822 & 5.4 & 5.3267 & TRN & \\
\hline CHEMBL1436054 & 737822 & 6.2 & 5.7158 & TRN & \\
\hline CHEMBL1399438 & 737822 & 4.55 & 4.995 & TRN & \\
\hline CHEMBL3194695 & 737822 & 4.85 & 5.2253 & TRN & \\
\hline CHEMBL1314286 & 737822 & 6.0 & 5.7228 & TST & \\
\hline CHEMBL1318447 & 737822 & 4.4 & 4.4214 & TRN & \\
\hline CHEMBL1363551 & 737822 & 5.7 & 5.5762 & TST & \\
\hline
\end{tabular}




\begin{tabular}{|c|c|c|c|c|c|}
\hline \multicolumn{6}{|c|}{ oplemental Table S2 } \\
\hline CHEMBL1349875 & 737822 & 4.95 & 4.9539 & TRN & \\
\hline CHEMBL420539 & 737822 & 4.75 & 4.6184 & TRN & \\
\hline CHEMBL1530352 & 737822 & 4.55 & 5.1934 & TST & \\
\hline CHEMBL1596872 & 737822 & 4.8 & 4.6527 & TRN & \\
\hline CHEMBL1480161 & 737822 & 4.6 & 4.648 & TRN & \\
\hline CHEMBL1480742 & 737822 & 4.4 & 4.387 & TRN & \\
\hline CHEMBL1408323 & 737822 & 4.85 & 5.1567 & TRN & \\
\hline CHEMBL1538008 & 737822 & 5.25 & 5.2822 & TRN & \\
\hline CHEMBL1415957 & 737822 & 4.6 & 4.436 & TRN & \\
\hline CHEMBL1378755 & 737822 & 5.0 & 4.7589 & TRN & \\
\hline CHEMBL1370244 & 737822 & 5.45 & 5.4511 & TRN & \\
\hline CHEMBL1356733 & 737822 & 4.6 & 4.4917 & TRN & \\
\hline CHEMBL1160730 & 737822 & 5.5 & 5.4917 & TRN & \\
\hline CHEMBL171064 & 737822 & 4.5 & 4.6642 & TRN & \\
\hline CHEMBL1364372 & 737822 & 5.4 & 5.2803 & TRN & \\
\hline CHEMBL1613233 & 737822 & 5.0 & 4.9787 & TRN & \\
\hline CHEMBL1383537 & 737822 & 4.95 & 5.1458 & TRN & \\
\hline CHEMBL1359917 & 737822 & 7.5 & 6.9757 & TRN & \\
\hline CHEMBL 273386 & 737822 & 5.4 & 5.2886 & TRN & \\
\hline CHEMBL 296586 & 737822 & 6.4 & 5.9365 & TST & \\
\hline CHEMBL1512740 & 737822 & 4.9 & 4.6721 & TRN & \\
\hline CHEMBL1419469 & 737822 & 2.05 & 5.2915 & TRN & \\
\hline CHEMBL1514390 & 737822 & 4.9 & 4.7382 & TRN & \\
\hline CHEMBL1496576 & 737822 & 5.0 & 4.7518 & TRN & \\
\hline CHEMBL68534 & 737822 & 4.6 & 4.6793 & TRN & \\
\hline CHEMBL1257125 & 737822 & 6.0 & 5.7598 & TRN & \\
\hline CHEMBL 243664 & 737822 & 4.9 & 4.824 & TRN & \\
\hline CHEMBL1412390 & 737822 & 4.5 & 4.4967 & TRN & \\
\hline CHEMBL1399922 & 737822 & 4.8 & 4.865 & TST & \\
\hline CHEMBL1255936 & 737822 & 5.0 & 5.0008 & TRN & \\
\hline CHEMBL1597695 & 737822 & 4.6 & 5.12799 & 9999999999 & TST \\
\hline CHEMBL1551503 & 737822 & 4.7 & 4.6703 & TRN & \\
\hline CHEMBL1473753 & 737822 & 5.1 & 4.9217 & TRN & \\
\hline CHEMBL3212319 & 737822 & 4.65 & 5.2398 & TRN & \\
\hline CHEMBL1315292 & 737822 & 4.4 & 4.3055 & TRN & \\
\hline CHEMBL1319717 & 737822 & 7.5 & 4.9859 & TRN & \\
\hline CHEMBL1550370 & 737822 & 5.95 & 5.5552 & TRN & \\
\hline CHEMBL 261011 & 737822 & 4.7 & 4.5705 & TRN & \\
\hline CHEMBL64119 & 737822 & 5.1 & 5.1288 & TRN & \\
\hline CHEMBL1575531 & 737822 & 4.6 & 5.32299 & 99999999995 & TST \\
\hline CHEMBL1361552 & 737822 & 4.7 & 4.615 & TRN & \\
\hline CHEMBL1536942 & 737822 & 6.6 & 5.3967 & TRN & \\
\hline CHEMBL1316222 & 737822 & 5.5 & 5.454 & TST & \\
\hline CHEMBL1335332 & 737822 & 5.7 & 5.3806 & TRN & \\
\hline CHEMBL1594473 & 737822 & 5.2 & 5.4093 & TRN & \\
\hline CHEMBL1514045 & 737822 & 4.4 & 4.3725 & TRN & \\
\hline CHEMBL1594150 & 737822 & 5.9 & 5.6307 & TST & \\
\hline CHEMBL1408760 & 737822 & 4.4 & 4.3607 & TRN & \\
\hline & & & & e 11337 & \\
\hline
\end{tabular}




\begin{tabular}{|c|c|c|c|c|}
\hline \multicolumn{5}{|c|}{ Supplemental Table S2.txt } \\
\hline CHEMBL1455353 & 737822 & 5.45 & 5.0738 & TRN \\
\hline CHEMBL476135 & 737822 & 5.5 & 5.5074 & TRN \\
\hline CHEMBL1741471 & 737822 & 5.05 & 5.4014 & TRN \\
\hline CHEMBL363332 & 737822 & 5.4 & 5.2882 & TRN \\
\hline CHEMBL 1377215 & 737822 & 4.9 & 5.0707 & TRN \\
\hline CHEMBL1568735 & 737822 & 6.4 & 5.9612 & TRN \\
\hline CHEMBL1440067 & 737822 & 4.8 & 5.1713 & TRN \\
\hline CHEMBL1200766 & 737822 & 5.4 & 5.2737 & TRN \\
\hline CHEMBL1329326 & 737822 & 6.1 & 5.7943 & TRN \\
\hline CHEMBL1592464 & 737822 & 6.2 & 5.9004 & TRN \\
\hline CHEMBL1357491 & 737822 & 4.4 & 4.3757 & TRN \\
\hline CHEMBL1437448 & 737822 & 4.9 & 4.765 & TST \\
\hline CHEMBL1605496 & 737822 & 5.5 & 5.1408 & TRN \\
\hline CHEMBL1492641 & 737822 & 5.45 & 5.4221 & TRN \\
\hline CHEMBL1543760 & 737822 & 5.65 & 4.8959 & TRN \\
\hline CHEMBL1355651 & 737822 & 4.9 & 4.717 & TRN \\
\hline CHEMBL1528993 & 737822 & 4.85 & 5.3318 & TRN \\
\hline CHEMBL1603418 & 737822 & 4.8 & 4.5942 & TRN \\
\hline CHEMBL1513392 & 737822 & 4.9 & 5.0647 & TRN \\
\hline CHEMBL1366573 & 737822 & 4.8 & 5.3045 & TRN \\
\hline CHEMBL1317451 & 737822 & 4.4 & 4.3219 & TRN \\
\hline CHEMBL1495634 & 737822 & 5.4 & 5.5635 & TRN \\
\hline CHEMBL1588349 & 737822 & 5.05 & 5.1906 & TRN \\
\hline CHEMBL1468406 & 737822 & 4.6 & 5.3442 & TRN \\
\hline CHEMBL103469 & 737822 & 5.0 & 4.9905 & TRN \\
\hline CHEMBL3198146 & 737822 & 4.85 & 5.1991 & TRN \\
\hline CHEMBL1418437 & 737822 & 5.75 & 5.5338 & TRN \\
\hline CHEMBL1480903 & 737822 & 4.5 & 4.6099 & TST \\
\hline CHEMBL1358416 & 737822 & 5.5 & 5.3624 & TRN \\
\hline CHEMBL1450602 & 737822 & 5.35 & 5.2357 & TRN \\
\hline CHEMBL1556431 & 737822 & 4.4 & 4.2842 & TRN \\
\hline CHEMBL189724 & 737822 & 5.6 & 5.4648 & TRN \\
\hline CHEMBL1430918 & 737822 & 5.7 & 5.4516 & TRN \\
\hline CHEMBL1504465 & 737822 & 5.8 & 5.1934 & TRN \\
\hline CHEMBL3199351 & 737822 & 5.3 & 5.3971 & TRN \\
\hline CHEMBL287689 & 737822 & 5.6 & 5.4474 & TST \\
\hline CHEMBL 256835 & 737822 & 4.9 & 4.9055 & TRN \\
\hline CHEMBL1551834 & 737822 & 4.7 & 4.5888 & TRN \\
\hline CHEMBL1742283 & 737822 & 5.7 & 5.1999 & TRN \\
\hline CHEMBL1409461 & 737822 & 5.3 & 5.2468 & TRN \\
\hline CHEMBL1343392 & 737822 & 4.8 & 5.3025 & TST \\
\hline CHEMBL1611646 & 737822 & 5.9 & 5.8511 & TRN \\
\hline CHEMBL1516068 & 737822 & 7.8 & 7.2619 & TRN \\
\hline CHEMBL1598281 & 737822 & 8.3 & 5.0197 & TST \\
\hline CHEMBL1439183 & 737822 & 4.4 & 4.4381 & TRN \\
\hline CHEMBL1435544 & 737822 & 4.9 & 4.9821 & TRN \\
\hline CHEMBL1581696 & 737822 & 5.85 & 5.4527 & TRN \\
\hline CHEMBL1396693 & 737822 & 4.9 & 4.6708 & TRN \\
\hline
\end{tabular}




\begin{tabular}{|c|c|c|c|c|c|}
\hline & & \multicolumn{4}{|c|}{ Supplemental Table S2.txt } \\
\hline CHEMBL1317943 & 737822 & -0.0 & 5.5135 & TRN & \\
\hline CHEMBL1742244 & 737822 & 4.95 & 5.3569 & TRN & \\
\hline CHEMBL1485948 & 737822 & 4.65 & 5.1482 & TRN & \\
\hline CHEMBL1417771 & 737822 & 5.9 & 5.6872 & TRN & \\
\hline CHEMBL1312953 & 737822 & 7.95 & 5.5886 & TST & \\
\hline CHEMBL1480350 & 737822 & 4.4 & 4.3559 & TRN & \\
\hline CHEMBL1399994 & 737822 & 6.3 & 6.0592 & TRN & \\
\hline CHEMBL1508815 & 737822 & 4.5 & 5.2771 & TRN & \\
\hline CHEMBL1405922 & 737822 & 6.8 & 6.5569 & TRN & \\
\hline CHEMBL1305452 & 737822 & 5.25 & 5.2123 & TRN & \\
\hline CHEMBL1392075 & 737822 & 5.0 & 5.40600 & 0000000001 & TRN \\
\hline CHEMBL1361656 & 737822 & 4.8 & 4.6859 & TRN & \\
\hline CHEMBL1478761 & 737822 & 4.6 & 4.5797 & TRN & \\
\hline CHEMBL489935 & 737822 & 5.3 & 5.0446 & TRN & \\
\hline CHEMBL1465985 & 737822 & 5.55 & 5.3735 & TRN & \\
\hline CHEMBL52387 & 737822 & 4.5 & 4.6336 & TRN & \\
\hline CHEMBL1573244 & 737822 & 5.9 & 5.7359 & TRN & \\
\hline CHEMBL1564665 & 737822 & 4.85 & 5.4168 & TRN & \\
\hline CHEMBL1559362 & 737822 & 4.5 & 5.0603 & TRN & \\
\hline CHEMBL1326093 & 737822 & 7.35 & 5.2837 & TRN & \\
\hline CHEMBL1553070 & 737822 & 5.1 & 4.8505 & TRN & \\
\hline CHEMBL1476078 & 737822 & 5.1 & 4.9506 & TRN & \\
\hline CHEMBL1543433 & 737822 & 4.9 & 5.2215 & TRN & \\
\hline CHEMBL1428282 & 737822 & 4.55 & 5.3222 & TRN & \\
\hline CHEMBL1380096 & 737822 & 6.75 & 5.0996 & TRN & \\
\hline CHEMBL1603589 & 737822 & 4.95 & 5.4682 & TRN & \\
\hline CHEMBL 274844 & 737822 & 5.1 & 5.2228 & TRN & \\
\hline CHEMBL1341400 & 737822 & 4.95 & 4.8153 & TRN & \\
\hline CHEMBL489738 & 737822 & 5.3 & 5.0159 & TRN & \\
\hline CHEMBL311158 & 737822 & 4.4 & 5.5456 & TRN & \\
\hline CHEMBL1519567 & 737822 & 5.5 & 5.2178 & TRN & \\
\hline CHEMBL1363622 & 737822 & 4.6 & 4.4433 & TRN & \\
\hline CHEMBL1337781 & 737822 & 5.1 & 5.1101 & TRN & \\
\hline CHEMBL1528906 & 737822 & 5.35 & 5.3934 & TRN & \\
\hline CHEMBL1396559 & 737822 & 4.7 & 4.6068 & TRN & \\
\hline CHEMBL1356941 & 737822 & 4.6 & 4.5415 & TRN & \\
\hline CHEMBL1558843 & 737822 & 6.3 & 6.0836 & TRN & \\
\hline CHEMBL1478772 & 737822 & 4.9 & 4.7811 & TRN & \\
\hline CHEMBL1320485 & 737822 & 5.7 & 5.6101 & TRN & \\
\hline CHEMBL1458309 & 737822 & 5.15 & 5.2419 & TST & \\
\hline CHEMBL1376755 & 737822 & 5.1 & 5.4665 & TRN & \\
\hline CHEMBL1488504 & 737822 & 4.9 & 5.4194 & TRN & \\
\hline CHEMBL38576 & 737822 & 7.9 & 7.1066 & TRN & \\
\hline CHEMBL 275854 & 737822 & 6.0 & 5.7712 & TRN & \\
\hline CHEMBL1536842 & 737822 & 4.95 & 4.8183 & TRN & \\
\hline CHEMBL1478425 & 737822 & 7.35 & 5.2532 & TRN & \\
\hline CHEMBL1493877 & 737822 & 4.85 & 5.3806 & TST & \\
\hline CHEMBL1318067 & 737822 & 4.9 & 4.7231 & TRN & \\
\hline
\end{tabular}




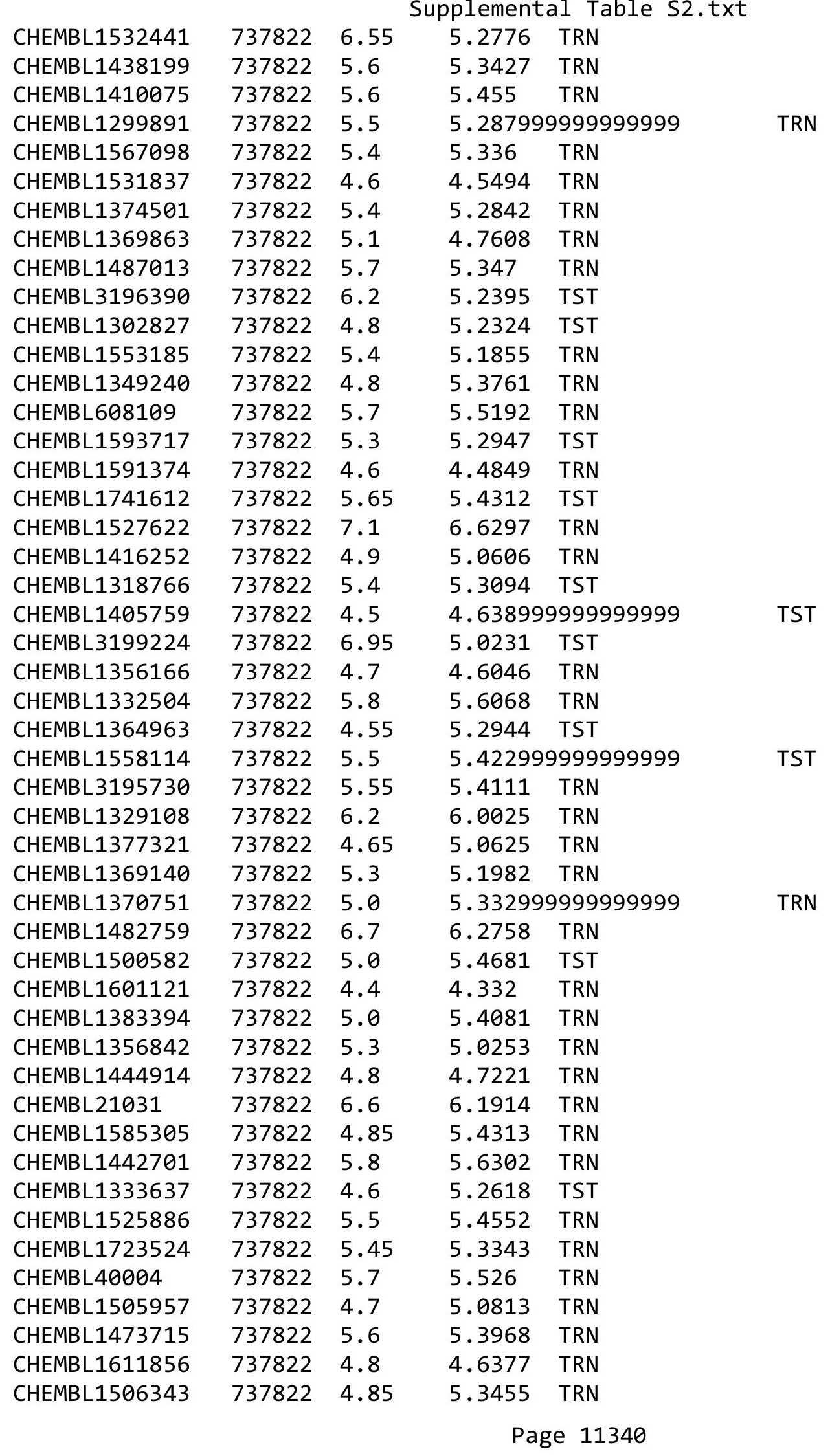




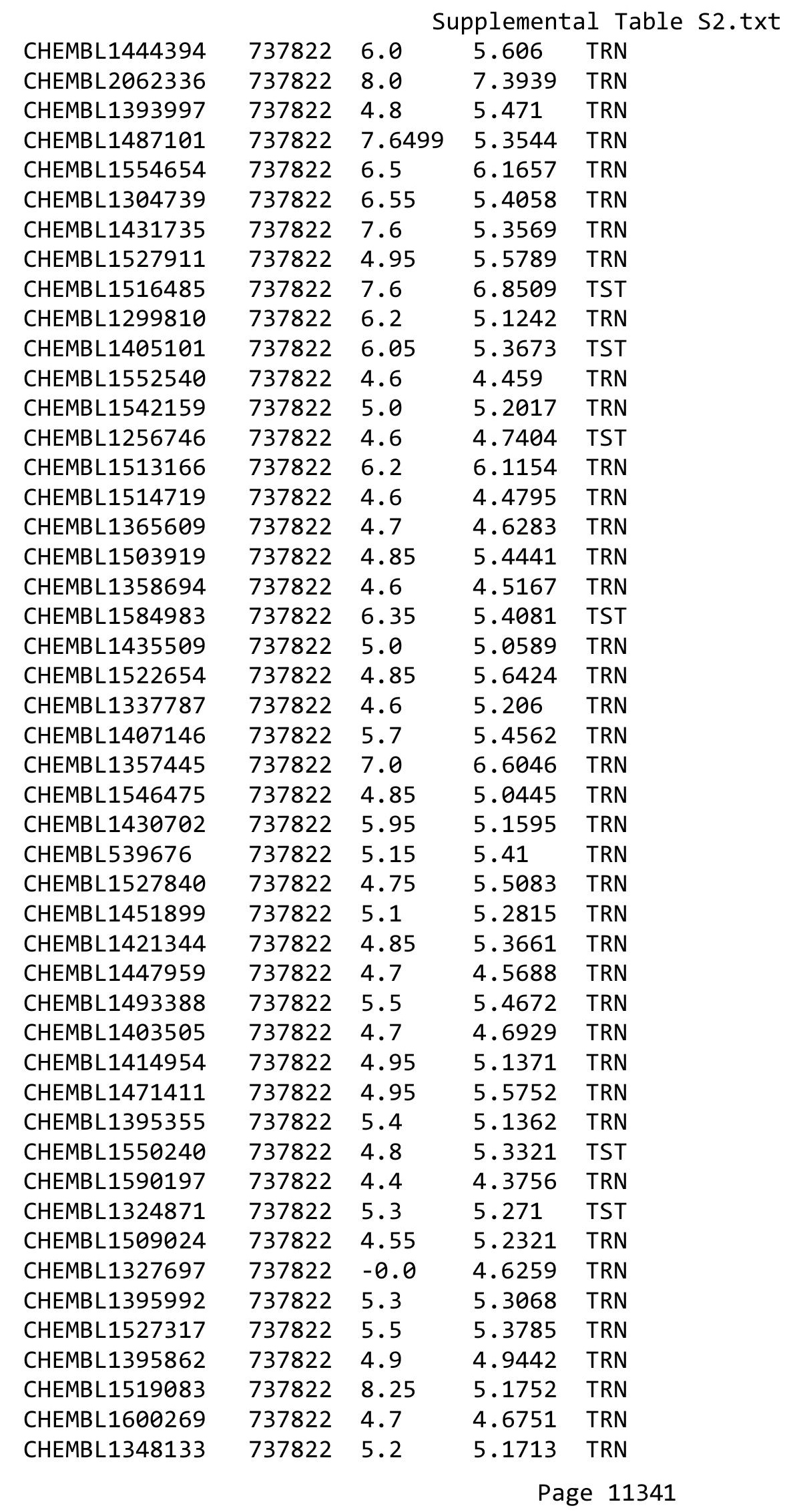




\begin{tabular}{|c|c|c|c|c|}
\hline \multicolumn{5}{|c|}{ Supplemental Table S2.txt } \\
\hline CHEMBL1480371 & 737822 & 4.75 & 5.1028 & TRN \\
\hline CHEMBL1593443 & 737822 & 7.3 & 7.0677 & TRN \\
\hline CHEMBL533542 & 737822 & 6.1 & 5.1147 & TRN \\
\hline CHEMBL1567251 & 737822 & 4.7 & 4.4903 & TRN \\
\hline CHEMBL1414780 & 737822 & 5.1 & 5.0578 & TRN \\
\hline CHEMBL1079374 & 737822 & 4.5 & 4.8541 & TRN \\
\hline CHEMBL1405762 & 737822 & 5.6 & 5.5342 & TST \\
\hline CHEMBL41680 & 737822 & 4.4 & 5.6299 & TST \\
\hline CHEMBL1601104 & 737822 & 4.85 & 5.4919 & TRN \\
\hline CHEMBL 21823 & 737822 & 5.1 & 5.1562 & TRN \\
\hline CHEMBL 3189451 & 737822 & 8.1 & 5.0444 & TRN \\
\hline CHEMBL1345104 & 737822 & 4.55 & 5.4054 & TRN \\
\hline CHEMBL1309266 & 737822 & 4.95 & 5.3654 & TRN \\
\hline CHEMBL1446905 & 737822 & 6.5 & 5.8776 & TRN \\
\hline CHEMBL1361725 & 737822 & 6.2 & 6.2962 & TRN \\
\hline CHEMBL1377394 & 737822 & 4.7 & 5.3442 & TRN \\
\hline CHEMBL 28 & 737822 & 4.9 & 5.4509 & TRN \\
\hline CHEMBL1608975 & 737822 & 5.5 & 5.3253 & TRN \\
\hline CHEMBL1515706 & 737822 & 5.5 & 5.3535 & TRN \\
\hline CHEMBL1536296 & 737822 & 4.75 & 5.3686 & TRN \\
\hline CHEMBL1467643 & 737822 & 4.95 & 5.4676 & TRN \\
\hline CHEMBL1397782 & 737822 & 4.6 & 4.4947 & TST \\
\hline CHEMBL1499076 & 737822 & 5.65 & 5.3601 & TRN \\
\hline CHEMBL1482880 & 737822 & 5.1 & 4.9414 & TRN \\
\hline CHEMBL3190451 & 737822 & 4.8 & 5.5266 & TRN \\
\hline CHEMBL1485450 & 737822 & 6.95 & 5.2375 & TRN \\
\hline CHEMBL1398528 & 737822 & 5.6 & 5.3742 & TRN \\
\hline CHEMBL1408908 & 737822 & 5.5 & 5.3591 & TRN \\
\hline CHEMBL45244 & 737822 & 5.0 & 5.0166 & TRN \\
\hline CHEMBL1339029 & 737822 & 5.0 & 4.9411 & TRN \\
\hline CHEMBL1418721 & 737822 & 4.65 & 5.2798 & TRN \\
\hline CHEMBL1541518 & 737822 & 5.5 & 5.2794 & TRN \\
\hline CHEMBL1717360 & 737822 & 4.6 & 5.5764 & TRN \\
\hline CHEMBL 303516 & 737822 & 5.3 & 5.2737 & TST \\
\hline CHEMBL1485654 & 737822 & 4.4 & 4.6168 & TRN \\
\hline CHEMBL1550866 & 737822 & 5.5 & 5.4638 & TRN \\
\hline CHEMBL 3197893 & 737822 & 4.75 & 5.2186 & TRN \\
\hline CHEMBL1518559 & 737822 & 5.0 & 5.1586 & TRN \\
\hline CHEMBL1327466 & 737822 & 5.7 & 5.5349 & TRN \\
\hline CHEMBL1491976 & 737822 & 4.85 & 5.0138 & TRN \\
\hline CHEMBL1561718 & 737822 & 4.55 & 5.3007 & TRN \\
\hline CHEMBL1729853 & 737822 & 7.05 & 5.3156 & TRN \\
\hline CHEMBL3199347 & 737822 & 4.55 & 5.3353 & TRN \\
\hline CHEMBL1460770 & 737822 & 4.55 & 5.2351 & TRN \\
\hline CHEMBL1304794 & 737822 & 4.75 & 5.3921 & TRN \\
\hline CHEMBL1358983 & 737822 & 5.0 & 4.8049 & TRN \\
\hline CHEMBL1557821 & 737822 & 5.0 & 4.7552 & TRN \\
\hline CHEMBL1395974 & 737822 & 5.5 & 5.5065 & TRN \\
\hline
\end{tabular}




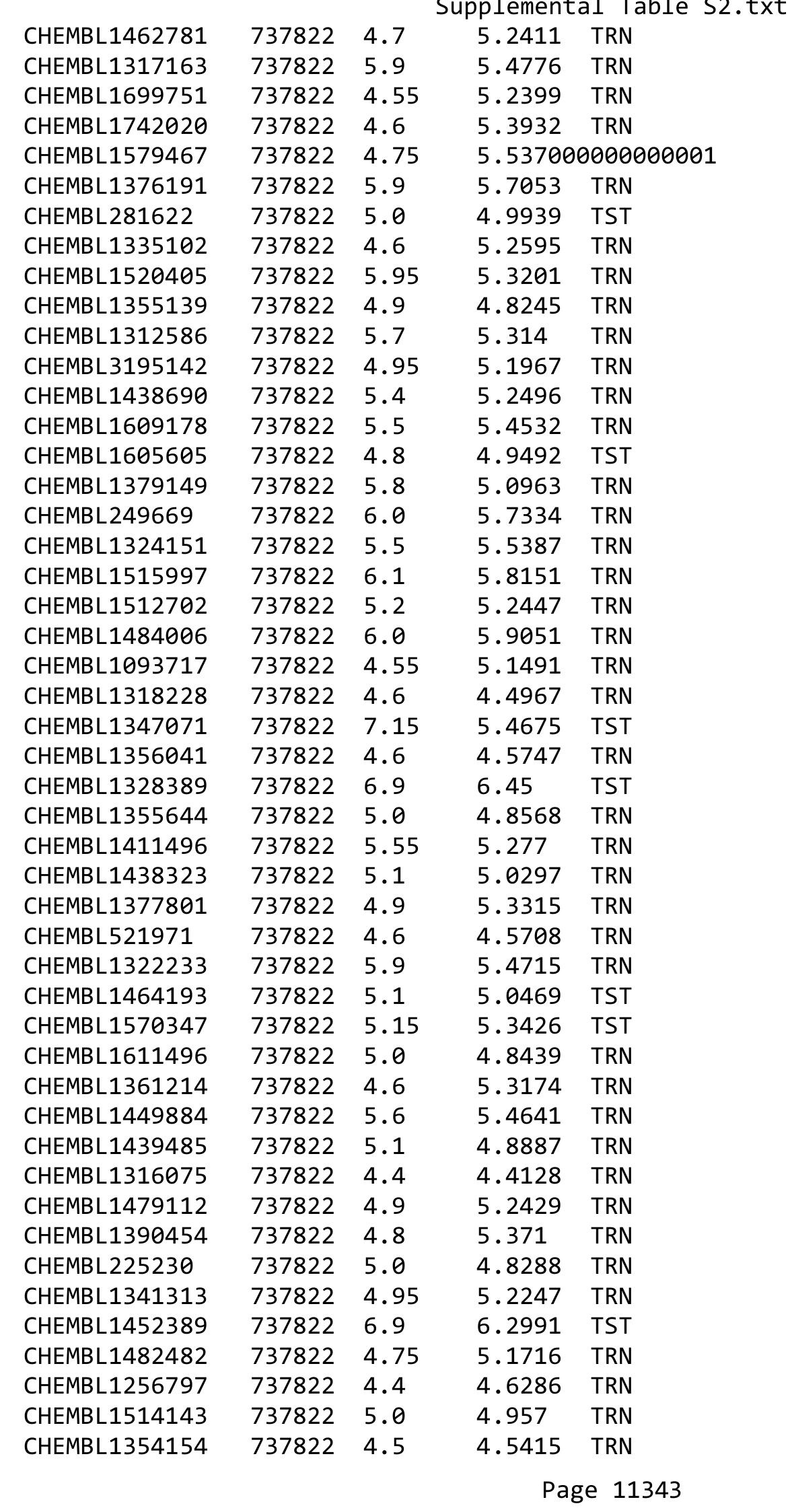




\begin{tabular}{|c|c|c|c|c|c|}
\hline \\
\hline CHEMBL1317761 & 737822 & 5.1 & 4.9326 & TRN & \\
\hline CHEMBL 20963 & 737822 & 4.9 & 4.9386 & TRN & \\
\hline CHEMBL1587851 & 737822 & 7.0 & 5.2649 & TRN & \\
\hline CHEMBL1559163 & 737822 & 5.5 & 5.3707 & TRN & \\
\hline CHEMBL1420680 & 737822 & 4.8 & 5.2826 & TST & \\
\hline CHEMBL1473498 & 737822 & 5.9 & 5.4961 & TRN & \\
\hline CHEMBL1486583 & 737822 & 4.9 & 5.2377 & TRN & \\
\hline CHEMBL1575920 & 737822 & 5.4 & 5.4026 & TRN & \\
\hline CHEMBL1379308 & 737822 & 5.95 & 5.4788 & TST & \\
\hline CHEMBL1470330 & 737822 & 4.75 & 5.2141 & TRN & \\
\hline CHEMBL1190214 & 737822 & 5.3 & 5.1836 & TST & \\
\hline CHEMBL1382819 & 737822 & 4.9 & 5.0602 & TST & \\
\hline CHEMBL1554745 & 737822 & 5.1 & 5.0671 & TRN & \\
\hline CHEMBL1300933 & 737822 & 4.7 & 5.1496 & TRN & \\
\hline CHEMBL1435079 & 737822 & 5.4 & 5.3211 & TRN & \\
\hline CHEMBL1395058 & 737822 & 5.3 & 5.1458 & TRN & \\
\hline CHEMBL1573507 & 737822 & 4.95 & 5.3524 & TST & \\
\hline CHEMBL1477299 & 737822 & 6.0 & 5.2225 & TRN & \\
\hline CHEMBL1365701 & 737822 & 6.0 & 5.7701 & TRN & \\
\hline CHEMBL1517099 & 737822 & 4.4 & 4.5033 & TRN & \\
\hline CHEMBL331372 & 737822 & 4.9 & 4.9068 & TST & \\
\hline CHEMBL1461573 & 737822 & 4.55 & 5.1107 & TST & \\
\hline CHEMBL1398790 & 737822 & 4.65 & 5.449 & TRN & \\
\hline CHEMBL1567020 & 737822 & 7.3 & 6.5662 & TST & \\
\hline CHEMBL3212049 & 737822 & 4.6 & 5.3239 & TRN & \\
\hline CHEMBL30024 & 737822 & 4.7 & 4.8462 & TST & \\
\hline CHEMBL1355634 & 737822 & 5.0 & 4.9674 & TRN & \\
\hline CHEMBL1459535 & 737822 & 4.85 & 5.4083 & TRN & \\
\hline CHEMBL1392455 & 737822 & 5.0 & 5.2258 & TST & \\
\hline CHEMBL1611895 & 737822 & 5.1 & 5.4112 & TRN & \\
\hline CHEMBL3207962 & 737822 & 4.75 & 5.0177 & TRN & \\
\hline CHEMBL1377868 & 737822 & 4.8 & 5.1632 & TRN & \\
\hline CHEMBL1482437 & 737822 & 5.7 & 5.41299 & 9999999999 & TRN \\
\hline CHEMBL1334323 & 737822 & 4.95 & 5.3763 & TRN & \\
\hline CHEMBL1308386 & 737822 & 4.9 & 5.2617 & TST & \\
\hline CHEMBL1358816 & 737822 & 5.8 & 5.6104 & TST & \\
\hline CHEMBL1358161 & 737822 & 5.0 & 4.9621 & TRN & \\
\hline CHEMBL1454748 & 737822 & 5.45 & 5.3603 & TRN & \\
\hline CHEMBL1605713 & 737822 & 5.45 & 5.1774 & TRN & \\
\hline CHEMBL1256865 & 737822 & 6.0 & 5.7462 & TRN & \\
\hline CHEMBL1406944 & 737822 & 4.7 & 5.9489 & TRN & \\
\hline CHEMBL1558076 & 737822 & 4.95 & 5.2406 & TST & \\
\hline CHEMBL1456417 & 737822 & 4.5 & 4.6414 & TRN & \\
\hline CHEMBL1513077 & 737822 & 4.7 & 4.5149 & TRN & \\
\hline CHEMBL1329418 & 737822 & 6.15 & 5.4542 & TRN & \\
\hline CHEMBL1410004 & 737822 & 5.6 & 5.4649 & TRN & \\
\hline CHEMBL1489211 & 737822 & 4.8 & 4.618 & TRN & \\
\hline CHEMBL1337617 & 737822 & 4.4 & 5.3194 & TRN & \\
\hline & & & & 113 & \\
\hline
\end{tabular}




\begin{tabular}{|c|c|c|c|c|}
\hline \multicolumn{5}{|c|}{ Supplemental Table S2.txt } \\
\hline CHEMBL 3210057 & 737822 & 4.85 & 5.2519 & TRN \\
\hline CHEMBL1398137 & 737822 & 4.6 & 4.5014 & TRN \\
\hline CHEMBL1496004 & 737822 & 5.8 & 5.2995 & TRN \\
\hline CHEMBL467085 & 737822 & 5.7 & 5.6993 & TRN \\
\hline CHEMBL1483257 & 737822 & 5.45 & 5.4629 & TRN \\
\hline CHEMBL1522582 & 737822 & 5.05 & 5.2718 & TRN \\
\hline CHEMBL1472481 & 737822 & 4.75 & 5.4593 & TRN \\
\hline CHEMBL1345528 & 737822 & 4.85 & 5.5408 & TST \\
\hline CHEMBL1318310 & 737822 & 5.0 & 5.0144 & TRN \\
\hline CHEMBL1367377 & 737822 & 4.8 & 5.0882 & TRN \\
\hline CHEMBL1327681 & 737822 & 5.0 & 4.8239 & TRN \\
\hline CHEMBL1379350 & 737822 & 5.1 & 5.1474 & TST \\
\hline CHEMBL1497138 & 737822 & 4.4 & 5.4285 & TST \\
\hline CHEMBL1429076 & 737822 & 4.55 & 5.2998 & TRN \\
\hline CHEMBL1523894 & 737822 & 5.9 & 5.6726 & TST \\
\hline CHEMBL1525292 & 737822 & 4.85 & 5.2538 & TRN \\
\hline CHEMBL1428167 & 737822 & 4.65 & 5.4792 & TRN \\
\hline CHEMBL118109 & 737822 & 7.6 & 6.7537 & TRN \\
\hline CHEMBL1468264 & 737822 & 5.5 & 5.2433 & TST \\
\hline CHEMBL1460429 & 737822 & 4.85 & 5.0792 & TRN \\
\hline CHEMBL1742381 & 737822 & 4.8 & 5.2915 & TRN \\
\hline CHEMBL1388665 & 737822 & 5.5 & 5.2865 & TRN \\
\hline CHEMBL1502052 & 737822 & 5.55 & 5.21 & TRN \\
\hline CHEMBL1441290 & 737822 & 5.05 & 5.3323 & TRN \\
\hline CHEMBL1463609 & 737822 & 5.2 & 5.189 & TRN \\
\hline CHEMBL1609440 & 737822 & 5.0 & 4.8959 & TRN \\
\hline CHEMBL1590156 & 737822 & 4.9 & 4.8006 & TRN \\
\hline CHEMBL1572239 & 737822 & 5.2 & 5.2088 & TRN \\
\hline CHEMBL1388353 & 737822 & 4.65 & 5.1433 & TRN \\
\hline CHEMBL1468477 & 737822 & 4.8 & 5.1921 & TRN \\
\hline CHEMBL1373954 & 737822 & 5.6 & 5.5855 & TRN \\
\hline CHEMBL541847 & 737822 & 5.2 & 5.0047 & TRN \\
\hline CHEMBL1448403 & 737822 & 4.7 & 5.1859 & TRN \\
\hline CHEMBL1566202 & 737822 & 6.2 & 5.3851 & TRN \\
\hline CHEMBL1455018 & 737822 & 5.0 & 4.7382 & TRN \\
\hline CHEMBL1491888 & 737822 & 5.7 & 5.1623 & TST \\
\hline CHEMBL1317504 & 737822 & 4.7 & 4.5464 & TRN \\
\hline CHEMBL1446774 & 737822 & 4.6 & 4.5887 & TRN \\
\hline CHEMBL1538161 & 737822 & 4.85 & 5.4247 & TRN \\
\hline CHEMBL1495694 & 737822 & 4.6 & 4.8386 & TRN \\
\hline CHEMBL1349246 & 737822 & 5.4 & 5.0611 & TST \\
\hline CHEMBL1325408 & 737822 & 5.4 & 5.2519 & TRN \\
\hline CHEMBL1472926 & 737822 & 4.6 & 4.5022 & TRN \\
\hline CHEMBL1336175 & 737822 & 5.8 & 5.7909 & TRN \\
\hline CHEMBL1375759 & 737822 & 5.0 & 5.3949 & TRN \\
\hline CHEMBL1347469 & 737822 & 6.15 & 5.1133 & TST \\
\hline CHEMBL1491104 & 737822 & 4.4 & 4.3013 & TRN \\
\hline CHEMBL1505628 & 737822 & 5.1 & 5.3914 & TST \\
\hline
\end{tabular}




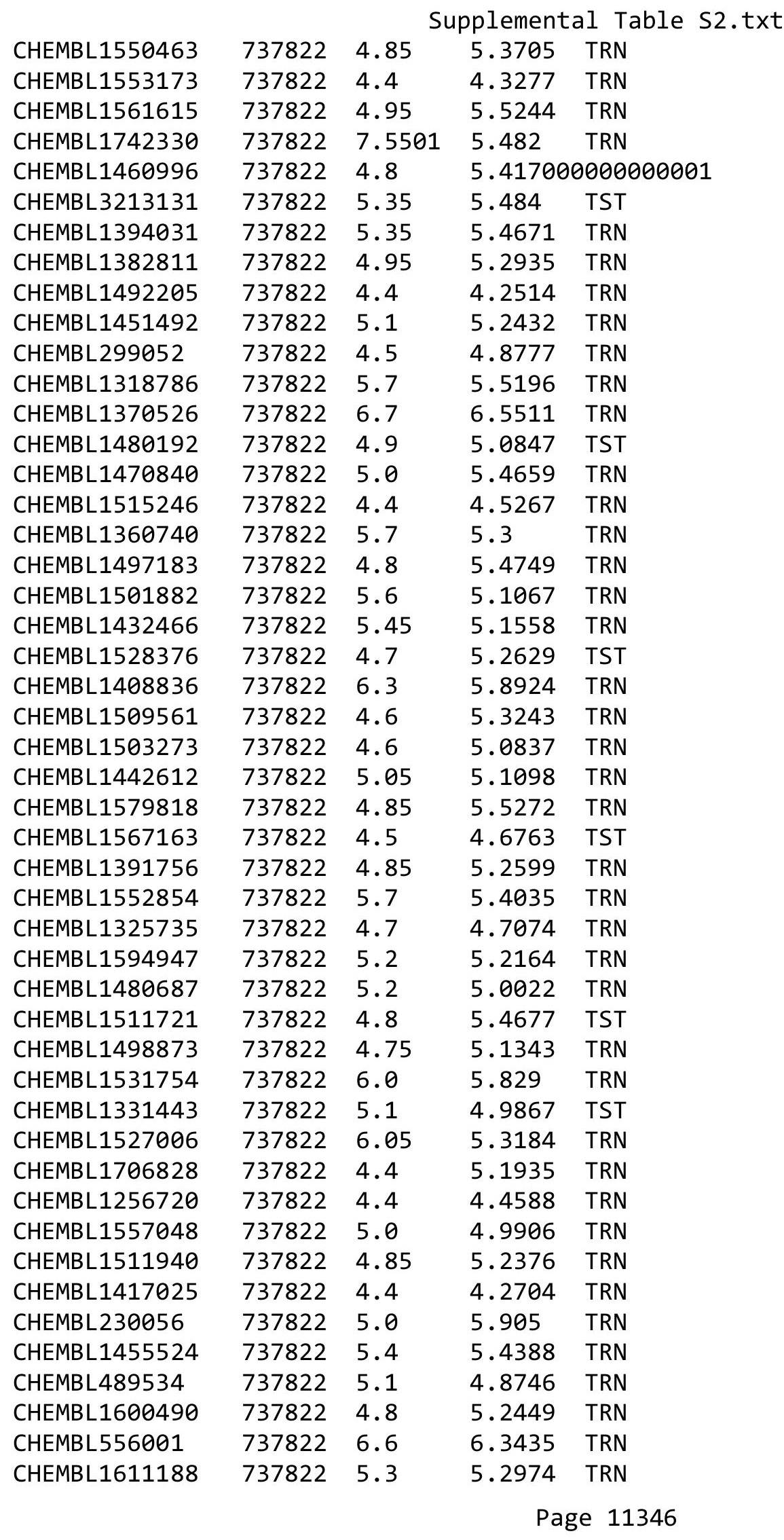




\begin{tabular}{|c|c|c|c|c|c|}
\hline \\
\hline CHEMBL1437088 & 737822 & 5.0 & 4.8583 & TRN & \\
\hline CHEMBL1475151 & 737822 & 5.5 & 5.3997 & TRN & \\
\hline CHEMBL1980031 & 737822 & 4.75 & 5.1812 & TRN & \\
\hline CHEMBL1378208 & 737822 & 4.5 & 4.3372 & TRN & \\
\hline CHEMBL1312952 & 737822 & 5.45 & 5.1212 & TRN & \\
\hline CHEMBL1435216 & 737822 & 5.6 & 5.4764 & TRN & \\
\hline CHEMBL1597410 & 737822 & 4.7 & 4.4872 & TRN & \\
\hline CHEMBL1317626 & 737822 & 4.9 & 4.7253 & TRN & \\
\hline CHEMBL1341335 & 737822 & 4.65 & 5.4406 & TRN & \\
\hline CHEMBL1310193 & 737822 & 4.65 & 5.7524 & TRN & \\
\hline CHEMBL1522198 & 737822 & 5.05 & 5.2615 & TST & \\
\hline CHEMBL1484337 & 737822 & 4.7 & 4.605 & TRN & \\
\hline CHEMBL1308019 & 737822 & 4.8 & 5.3139 & TRN & \\
\hline CHEMBL125569 & 737822 & 5.1 & 5.1018 & TRN & \\
\hline CHEMBL1742171 & 737822 & 5.5 & 5.4432 & TRN & \\
\hline CHEMBL3210042 & 737822 & 4.65 & 5.3031 & TRN & \\
\hline CHEMBL1741391 & 737822 & 5.6 & 5.2462 & TRN & \\
\hline CHEMBL1569583 & 737822 & 5.5 & 5.3861 & TRN & \\
\hline CHEMBL1256911 & 737822 & 4.6 & 4.7058 & TST & \\
\hline CHEMBL1409148 & 737822 & 6.0 & 5.9609 & TRN & \\
\hline CHEMBL1363967 & 737822 & 7.5 & 6.5743 & TRN & \\
\hline CHEMBL1591635 & 737822 & 6.4 & 6.1888 & TRN & \\
\hline CHEMBL 1456743 & 737822 & 4.8 & 5.3173 & TST & \\
\hline CHEMBL3194935 & 737822 & 5.65 & 5.431 & TRN & \\
\hline CHEMBL1376097 & 737822 & 4.85 & 5.5901 & TRN & \\
\hline CHEMBL1255935 & 737822 & 4.5 & 4.6391 & TST & \\
\hline CHEMBL1360952 & 737822 & 5.15 & 5.3861 & TST & \\
\hline CHEMBL1316749 & 737822 & 5.1 & 5.0252 & TRN & \\
\hline CHEMBL1335760 & 737822 & 5.45 & 5.07 & TRN & \\
\hline CHEMBL1535905 & 737822 & 4.55 & 5.2864 & TRN & \\
\hline CHEMBL501701 & 737822 & 4.4 & 4.494 & TRN & \\
\hline CHEMBL1472955 & 737822 & 4.7 & 4.5627 & TRN & \\
\hline CHEMBL1232474 & 737822 & 6.7 & 6.3866 & TRN & \\
\hline CHEMBL1433798 & 737822 & 4.6 & 4.4026 & TRN & \\
\hline CHEMBL1602661 & 737822 & 5.5 & 5.2577 & TRN & \\
\hline CHEMBL1433601 & 737822 & 5.4 & 5.2121 & TRN & \\
\hline CHEMBL1425511 & 737822 & 4.75 & 5.1751 & TST & \\
\hline CHEMBL1407215 & 737822 & 4.65 & 5.2273 & TRN & \\
\hline CHEMBL1506622 & 737822 & 4.65 & 5.2898 & TRN & \\
\hline CHEMBL1370553 & 737822 & 5.9 & 5.369 & TRN & \\
\hline CHEMBL1496013 & 737822 & 6.0 & 5.7259 & TRN & \\
\hline CHEMBL1603113 & 737822 & 5.0 & 4.9565 & TRN & \\
\hline CHEMBL1464306 & 737822 & 4.85 & 5.3316 & TRN & \\
\hline CHEMBL1590818 & 737822 & 5.1 & 4.9029 & TRN & \\
\hline CHEMBL1447313 & 737822 & 6.4 & 5.2686 & TRN & \\
\hline CHEMBL1723673 & 737822 & 4.9 & 5.5822 & TRN & \\
\hline CHEMBL1554721 & 737822 & 5.2 & 4.98306 & 00000000005 & TRN \\
\hline CHEMBL1325282 & 737822 & 6.2 & 5.8617 & TRN & \\
\hline
\end{tabular}




\begin{tabular}{|c|c|c|c|c|c|}
\hline & & \\
\hline CHEMBL1357293 & 737822 & 5.1 & 4.8652 & TRN & \\
\hline CHEMBL1314367 & 737822 & 5.4 & 5.2084 & TRN & \\
\hline CHEMBL1557167 & 737822 & 5.3 & 5.3258 & TST & \\
\hline CHEMBL1360890 & 737822 & 4.9 & 4.7343 & TRN & \\
\hline CHEMBL444309 & 737822 & 5.8 & 5.6693 & TRN & \\
\hline CHEMBL1514748 & 737822 & 4.9 & 4.8559 & TRN & \\
\hline CHEMBL 2373666 & 737822 & 5.3 & 5.4152 & TRN & \\
\hline CHEMBL3194665 & 737822 & 4.6 & 5.26200 & 00000000005 & TST \\
\hline CHEMBL1589124 & 737822 & 5.05 & 5.2741 & TST & \\
\hline CHEMBL1491037 & 737822 & 5.05 & 5.3806 & TST & \\
\hline CHEMBL1482035 & 737822 & 4.9 & 5.3179 & TRN & \\
\hline CHEMBL1514161 & 737822 & 5.6 & 5.3746 & TRN & \\
\hline CHEMBL1503527 & 737822 & 4.8 & 5.2346 & TRN & \\
\hline CHEMBL365739 & 737822 & 6.0 & 5.6769 & TST & \\
\hline CHEMBL1550048 & 737822 & 5.35 & 4.9471 & TRN & \\
\hline CHEMBL1514836 & 737822 & 4.6 & 4.6105 & TRN & \\
\hline CHEMBL1719582 & 737822 & 4.9 & 5.1383 & TRN & \\
\hline CHEMBL1437486 & 737822 & 5.2 & 5.1727 & TST & \\
\hline CHEMBL1414240 & 737822 & 5.8 & 5.6332 & TST & \\
\hline CHEMBL1590821 & 737822 & 4.5 & 4.373 & TRN & \\
\hline CHEMBL444422 & 737822 & 4.5 & 4.6774 & TRN & \\
\hline CHEMBL400598 & 737822 & 5.8 & 5.9066 & TRN & \\
\hline CHEMBL597047 & 737822 & 4.75 & 5.358 & TRN & \\
\hline CHEMBL1594227 & 737822 & 4.6 & 4.5961 & TRN & \\
\hline CHEMBL1424953 & 737822 & 4.55 & 4.7981 & TRN & \\
\hline CHEMBL 329872 & 737822 & 5.15 & 5.2434 & TRN & \\
\hline CHEMBL1323124 & 737822 & 4.5 & 4.3941 & TRN & \\
\hline CHEMBL1484422 & 737822 & 4.4 & 4.4746 & TRN & \\
\hline CHEMBL1446743 & 737822 & 4.8 & 4.9834 & TST & \\
\hline CHEMBL1416438 & 737822 & 7.7501 & 5.2558 & TRN & \\
\hline CHEMBL1354272 & 737822 & 4.9 & 4.715 & TRN & \\
\hline CHEMBL1507494 & 737822 & 4.95 & 5.2358 & TST & \\
\hline CHEMBL1554637 & 737822 & 4.7 & 4.7368 & TRN & \\
\hline CHEMBL1604087 & 737822 & 4.8 & 5.1927 & TRN & \\
\hline CHEMBL1506831 & 737822 & 4.35 & 5.3876 & TRN & \\
\hline CHEMBL1404408 & 737822 & 4.8 & 4.7911 & TRN & \\
\hline CHEMBL1573783 & 737822 & 4.75 & 5.0584 & TRN & \\
\hline CHEMBL1593923 & 737822 & 5.5 & 5.4168 & TRN & \\
\hline CHEMBL1372951 & 737822 & 5.5 & 5.41299 & 9999999999 & TST \\
\hline CHEMBL1326132 & 737822 & 5.4 & 5.0919 & TRN & \\
\hline CHEMBL1536220 & 737822 & 4.8 & 5.2448 & TRN & \\
\hline CHEMBL1354693 & 737822 & 4.8 & 4.5685 & TRN & \\
\hline CHEMBL1522864 & 737822 & 4.6 & 5.2143 & TST & \\
\hline CHEMBL1377809 & 737822 & 5.0 & 5.2232 & TRN & \\
\hline CHEMBL1306897 & 737822 & 4.5 & 5.2806 & TRN & \\
\hline CHEMBL1360601 & 737822 & 4.85 & 5.1549 & TRN & \\
\hline CHEMBL1574393 & 737822 & 5.0 & 5.6881 & TRN & \\
\hline CHEMBL1414269 & 737822 & 4.9 & 4.6328 & TRN & \\
\hline & & & & 11348 & \\
\hline
\end{tabular}




\begin{tabular}{|c|c|c|c|c|c|}
\hline \\
\hline CHEMBL1346628 & 737822 & 5.0 & 5.2236 & TRN & \\
\hline CHEMBL1316709 & 737822 & 4.8 & 4.623 & TRN & \\
\hline CHEMBL1514071 & 737822 & 4.9 & 4.7892 & TRN & \\
\hline CHEMBL1559246 & 737822 & 4.4 & 4.3327 & TRN & \\
\hline CHEMBL1736254 & 737822 & 5.8 & 5.5144 & TST & \\
\hline CHEMBL1548799 & 737822 & 5.55 & 5.2533 & TRN & \\
\hline CHEMBL1317537 & 737822 & 6.0 & 5.626 & TRN & \\
\hline CHEMBL1514683 & 737822 & 5.1 & 5.2087 & TRN & \\
\hline CHEMBL1383143 & 737822 & 7.45 & 5.1855 & TST & \\
\hline CHEMBL1407572 & 737822 & 4.9 & 5.2259 & TRN & \\
\hline CHEMBL1483307 & 737822 & 5.85 & 5.261 & TRN & \\
\hline CHEMBL3197859 & 737822 & 4.95 & 5.12200 & 0000000001 & TST \\
\hline CHEMBL1483978 & 737822 & 5.0 & 5.2093 & TRN & \\
\hline CHEMBL1565409 & 737822 & 4.75 & 5.3917 & TST & \\
\hline CHEMBL1408604 & 737822 & 5.4 & 5.3046 & TRN & \\
\hline CHEMBL1565215 & 737822 & 5.4 & 5.2749 & TRN & \\
\hline CHEMBL1425367 & 737822 & 4.85 & 5.3446 & TRN & \\
\hline CHEMBL1547741 & 737822 & 4.65 & 5.2435 & TRN & \\
\hline CHEMBL1479470 & 737822 & 4.9 & 4.7944 & TRN & \\
\hline CHEMBL10347 & 737822 & 6.0 & 5.9139 & TRN & \\
\hline CHEMBL1415521 & 737822 & 5.0 & 4.8361 & TRN & \\
\hline CHEMBL1597569 & 737822 & 5.45 & 5.2043 & TRN & \\
\hline CHEMBL405912 & 737822 & 5.1 & 4.9242 & TRN & \\
\hline CHEMBL1422614 & 737822 & 4.8 & 5.4393 & TRN & \\
\hline CHEMBL1418135 & 737822 & 5.85 & 5.3092 & TRN & \\
\hline CHEMBL1586504 & 737822 & 4.5 & 5.3382 & TRN & \\
\hline CHEMBL1440715 & 737822 & 4.7 & 4.5138 & TRN & \\
\hline CHEMBL1532985 & 737822 & 5.45 & 5.2386 & TRN & \\
\hline CHEMBL75913 & 737822 & 5.5 & 5.2275 & TST & \\
\hline CHEMBL1742007 & 737822 & 5.8 & 5.1568 & TST & \\
\hline CHEMBL1385365 & 737822 & 4.9 & 5.1898 & TRN & \\
\hline CHEMBL1483550 & 737822 & 4.8 & 5.33700 & $\partial 000000001$ & TRN \\
\hline CHEMBL1503191 & 737822 & 4.75 & 4.9584 & TST & \\
\hline CHEMBL1449268 & 737822 & 4.5 & 4.8224 & TRN & \\
\hline CHEMBL1490181 & 737822 & 5.0 & 5.2946 & TRN & \\
\hline CHEMBL516075 & 737822 & 5.5 & 5.143 & TRN & \\
\hline CHEMBL1380069 & 737822 & 4.85 & 5.4128 & TRN & \\
\hline CHEMBL267014 & 737822 & 6.0 & 5.6026 & TRN & \\
\hline CHEMBL1448646 & 737822 & 4.6 & 4.8716 & TRN & \\
\hline CHEMBL3197073 & 737822 & 4.8 & 5.3575 & TST & \\
\hline CHEMBL1399301 & 737822 & 4.9 & 4.7994 & TRN & \\
\hline CHEMBL1519453 & 737822 & 6.0 & 5.4003 & TRN & \\
\hline CHEMBL1454920 & 737822 & 4.9 & 4.7645 & TRN & \\
\hline CHEMBL1607623 & 737822 & 6.0 & 5.7977 & TRN & \\
\hline CHEMBL1256776 & 737822 & 4.8 & 5.0478 & TRN & \\
\hline CHEMBL1603802 & 737822 & 5.4 & 5.3187 & TST & \\
\hline CHEMBL1366737 & 737822 & 4.9 & 4.8274 & TRN & \\
\hline CHEMBL1711464 & 737822 & 5.05 & 5.2549 & TRN & \\
\hline
\end{tabular}




\begin{tabular}{|c|c|c|c|c|c|}
\hline \\
\hline CHEMBL587259 & 737822 & 4.6 & 5.2805 & TRN & \\
\hline CHEMBL1390261 & 737822 & 6.0 & 5.1865 & TRN & \\
\hline CHEMBL1496611 & 737822 & 6.0 & 5.1558 & TRN & \\
\hline CHEMBL1357850 & 737822 & 4.9 & 4.7627 & TRN & \\
\hline CHEMBL1436540 & 737822 & 4.4 & 4.3476 & TRN & \\
\hline CHEMBL 267548 & 737822 & 4.6 & 4.7157 & TST & \\
\hline CHEMBL1485494 & 737822 & 5.5 & 5.0239 & TRN & \\
\hline CHEMBL1538611 & 737822 & 6.0 & 5.1471 & TRN & \\
\hline CHEMBL1578591 & 737822 & 6.95 & 5.3618 & TRN & \\
\hline CHEMBL1326501 & 737822 & 4.9 & 5.4588 & TRN & \\
\hline CHEMBL398673 & 737822 & 6.0 & 5.7663 & TRN & \\
\hline CHEMBL1435787 & 737822 & 5.0 & 4.9596 & TRN & \\
\hline CHEMBL1455203 & 737822 & 5.1 & 5.1671 & TRN & \\
\hline CHEMBL1435077 & 737822 & 4.6 & 4.6893 & TRN & \\
\hline CHEMBL1467618 & 737822 & 4.95 & 5.7789 & TRN & \\
\hline CHEMBL1583320 & 737822 & 4.65 & 5.29299 & 9999999999 & TRN \\
\hline CHEMBL1485152 & 737822 & 4.8 & 5.5586 & TRN & \\
\hline CHEMBL1352096 & 737822 & 4.45 & 5.3954 & TRN & \\
\hline CHEMBL1342700 & 737822 & 4.7 & 5.2087 & TRN & \\
\hline CHEMBL1530213 & 737822 & 4.85 & 5.2473 & TRN & \\
\hline CHEMBL1540956 & 737822 & 5.5 & 5.1278 & TRN & \\
\hline CHEMBL39317 & 737822 & 6.9 & 6.3578 & TRN & \\
\hline CHEMBL1372371 & 737822 & 4.7 & 4.5356 & TRN & \\
\hline CHEMBL1574626 & 737822 & 4.9 & 4.8267 & TRN & \\
\hline CHEMBL1575560 & 737822 & 5.2 & 5.3426 & TRN & \\
\hline CHEMBL1434801 & 737822 & 4.4 & 4.4009 & TRN & \\
\hline CHEMBL1515366 & 737822 & 5.3 & 5.0217 & TRN & \\
\hline CHEMBL489934 & 737822 & 4.4 & 4.3558 & TRN & \\
\hline CHEMBL1335690 & 737822 & 5.4 & 5.3922 & TRN & \\
\hline CHEMBL1326359 & 737822 & 5.05 & 5.0542 & TRN & \\
\hline CHEMBL1371696 & 737822 & 5.9 & 5.6864 & TRN & \\
\hline CHEMBL1317913 & 737822 & 4.7 & 4.5557 & TRN & \\
\hline CHEMBL1381005 & 737822 & 6.35 & 5.2969 & TST & \\
\hline CHEMBL 277362 & 737822 & 4.4 & 4.4837 & TRN & \\
\hline CHEMBL1392275 & 737822 & 4.85 & 5.2947 & TRN & \\
\hline CHEMBL1402241 & 737822 & 5.5 & 5.4119 & TRN & \\
\hline CHEMBL471397 & 737822 & 5.5 & 5.4114 & TRN & \\
\hline CHEMBL3210437 & 737822 & 4.4 & 5.3294 & TST & \\
\hline CHEMBL1256180 & 737822 & 4.4 & 4.5944 & TRN & \\
\hline CHEMBL1569585 & 737822 & 4.4 & 4.4232 & TRN & \\
\hline CHEMBL1741548 & 737822 & 6.6 & 5.2958 & TRN & \\
\hline CHEMBL333985 & 737822 & 4.4 & 4.7603 & TRN & \\
\hline CHEMBL1447160 & 737822 & 6.2 & 5.985 & TRN & \\
\hline CHEMBL1311978 & 737822 & 4.65 & 5.3068 & TRN & \\
\hline CHEMBL76904 & 737822 & 4.7 & 4.6121 & TRN & \\
\hline CHEMBL1534951 & 737822 & 4.4 & 4.4339 & TRN & \\
\hline CHEMBL1354119 & 737822 & 4.9 & 4.6802 & TRN & \\
\hline CHEMBL1367772 & 737822 & 4.9 & 5.2533 & TRN & \\
\hline & & & & 11350 & \\
\hline
\end{tabular}




\begin{tabular}{|c|c|c|c|c|c|}
\hline \\
\hline CHEMBL1602940 & 737822 & 4.75 & 5.0932 & TRN & \\
\hline CHEMBL1572834 & 737822 & 4.4 & 4.3035 & TRN & \\
\hline CHEMBL1546136 & 737822 & 4.9 & 5.3167 & TRN & \\
\hline CHEMBL1409866 & 737822 & 4.5 & 5.2415 & TRN & \\
\hline CHEMBL1566670 & 737822 & 4.4 & 4.6117 & TRN & \\
\hline CHEMBL1452250 & 737822 & 5.9 & 5.4979 & TRN & \\
\hline CHEMBL1463576 & 737822 & 4.8 & 5.1644 & TRN & \\
\hline CHEMBL491952 & 737822 & 4.4 & 4.351 & TRN & \\
\hline CHEMBL1523520 & 737822 & 4.4 & 5.4539 & TST & \\
\hline CHEMBL1330951 & 737822 & 6.8 & 6.6322 & TRN & \\
\hline CHEMBL1396561 & 737822 & 4.9 & 4.7094 & TRN & \\
\hline CHEMBL1422472 & 737822 & 5.05 & 5.2622 & TRN & \\
\hline CHEMBL3194842 & 737822 & 4.9 & 5.3986 & TRN & \\
\hline CHEMBL1475255 & 737822 & 5.1 & 4.8571 & TRN & \\
\hline CHEMBL1439665 & 737822 & 4.5 & 4.3595 & TRN & \\
\hline CHEMBL1523773 & 737822 & 5.4 & 5.2949 & TRN & \\
\hline CHEMBL1485338 & 737822 & 4.85 & 5.1685 & TST & \\
\hline CHEMBL1571716 & 737822 & 4.7 & 5.1171 & TST & \\
\hline CHEMBL1570658 & 737822 & 5.55 & 5.16799 & 9999999999 & TST \\
\hline CHEMBL1465250 & 737822 & 4.5 & 5.2451 & TST & \\
\hline CHEMBL1589925 & 737822 & 4.9 & 4.7774 & TST & \\
\hline CHEMBL1529777 & 737822 & 5.25 & 5.0226 & TST & \\
\hline CHEMBL1559023 & 737822 & 6.5 & 5.95200 & 0000000001 & TST \\
\hline CHEMBL1400132 & 737822 & 4.8 & 5.1687 & TST & \\
\hline CHEMBL1255865 & 737822 & 7.0 & 6.5683 & TST & \\
\hline CHEMBL1448044 & 737822 & 5.2 & 5.0925 & TST & \\
\hline CHEMBL1586480 & 737822 & 5.15 & 5.3556 & TST & \\
\hline CHEMBL1386134 & 737822 & 4.85 & 5.1454 & TST & \\
\hline CHEMBL1411146 & 737822 & 4.4 & 4.4737 & TST & \\
\hline CHEMBL1307909 & 737822 & 6.1 & 5.2363 & TST & \\
\hline CHEMBL1480063 & 737822 & 6.75 & 5.1465 & TST & \\
\hline CHEMBL1432651 & 737822 & 4.9 & 5.3851 & TST & \\
\hline CHEMBL1425402 & 737822 & 4.85 & 5.3702 & TST & \\
\hline CHEMBL1577515 & 737822 & 5.7 & 5.5095 & TST & \\
\hline CHEMBL1324530 & 737822 & 4.4 & 4.4125 & TST & \\
\hline CHEMBL1478504 & 737822 & 5.9 & 5.6974 & TST & \\
\hline CHEMBL1435009 & 737822 & 5.8 & 5.7513 & TST & \\
\hline CHEMBL1356744 & 737822 & 4.9 & 4.67899 & 9999999999 & TST \\
\hline CHEMBL1497338 & 737822 & 4.95 & 5.5056 & TST & \\
\hline CHEMBL1591677 & 737822 & 5.0 & 4.7301 & TST & \\
\hline CHEMBL1442538 & 737822 & 4.5 & 4.5125 & TST & \\
\hline CHEMBL1374527 & 737822 & 4.9 & 5.0502 & TST & \\
\hline CHEMBL1364808 & 737822 & 4.7 & 4.7622 & TST & \\
\hline CHEMBL1482575 & 737822 & 4.7 & 4.5322 & TST & \\
\hline CHEMBL428814 & 737822 & 4.7 & 4.6348 & TST & \\
\hline CHEMBL1478703 & 737822 & 5.3 & 5.3054 & TST & \\
\hline CHEMBL1484079 & 737822 & 5.35 & 5.1807 & TST & \\
\hline CHEMBL1335882 & 737822 & 4.8 & 5.1201 & TST & \\
\hline
\end{tabular}




\begin{tabular}{|c|c|c|c|c|c|}
\hline \multirow[b]{2}{*}{ CHEMBL1358462 } & \multirow[b]{2}{*}{737822} & \\
\hline & & 4.9 & 4.7568 & TST & \\
\hline CHEMBL1318400 & 737822 & 6.0 & 5.9024 & TST & \\
\hline CHEMBL1370525 & 737822 & 5.5 & 5.42399 & 99999999995 & TST \\
\hline CHEMBL1256659 & 737822 & 4.9 & 4.9746 & TST & \\
\hline CHEMBL1735134 & 737822 & 5.6 & 5.4908 & TST & \\
\hline CHEMBL1588312 & 737822 & 5.15 & 5.3802 & TST & \\
\hline CHEMBL1302930 & 737822 & 5.0 & 5.4543 & TST & \\
\hline CHEMBL1301326 & 737822 & 4.9 & 5.2213 & TST & \\
\hline CHEMBL1582666 & 737822 & 5.35 & 5.3046 & TST & \\
\hline CHEMBL 287045 & 737822 & 4.8 & 4.9112 & TST & \\
\hline CHEMBL1365235 & 737822 & 4.9 & 5.3943 & TST & \\
\hline CHEMBL611207 & 737822 & 7.0 & 6.8146 & TST & \\
\hline CHEMBL1516170 & 737822 & 4.4 & 4.2986 & TST & \\
\hline CHEMBL60518 & 737822 & 4.9 & 5.0593 & TST & \\
\hline CHEMBL1338596 & 737822 & 5.3 & 5.3251 & TST & \\
\hline CHEMBL3214169 & 737822 & 5.0 & 5.33 & TST & \\
\hline CHEMBL1488574 & 737822 & 4.5 & 4.4275 & TST & \\
\hline CHEMBL1369822 & 737822 & 4.4 & 4.2287 & TST & \\
\hline CHEMBL1307715 & 737822 & 4.9 & 5.6096 & TST & \\
\hline CHEMBL491547 & 737822 & 5.0 & 4.7468 & TST & \\
\hline CHEMBL1400543 & 737822 & 6.0 & 5.9001 & TST & \\
\hline CHEMBL1611048 & 737822 & 4.9 & 5.3613 & TST & \\
\hline CHEMBL1393664 & 737822 & 6.2 & 5.9111 & TST & \\
\hline CHEMBL1581408 & 737822 & 5.1 & 5.2966 & TST & \\
\hline CHEMBL1331489 & 737822 & 5.8 & 5.473 & TST & \\
\hline CHEMBL1371127 & 737822 & 6.8 & 6.2653 & TST & \\
\hline CHEMBL1327793 & 737822 & 5.6 & 5.50799 & 9999999999 & TST \\
\hline CHEMBL1560839 & 737822 & 4.75 & 5.1685 & TST & \\
\hline CHEMBL1475620 & 737822 & 5.0 & 5.0857 & TST & \\
\hline CHEMBL1574071 & 737822 & 4.6 & 5.5426 & TST & \\
\hline CHEMBL1518285 & 737822 & 4.6 & 5.4091 & TST & \\
\hline CHEMBL1605152 & 737822 & 5.4 & 5.3252 & TST & \\
\hline CHEMBL182310 & 737822 & 4.7 & 4.7485 & TST & \\
\hline CHEMBL1483545 & 737822 & 5.35 & 5.3716 & TST & \\
\hline CHEMBL1347066 & 737822 & 4.8 & 5.3579 & TST & \\
\hline CHEMBL1379187 & 737822 & 4.65 & 5.3899 & TST & \\
\hline CHEMBL1358384 & 737822 & 5.2 & 5.1624 & TST & \\
\hline CHEMBL1452894 & 737822 & 4.4 & 4.3182 & TST & \\
\hline CHEMBL1741716 & 737822 & 4.85 & 5.4798 & TST & \\
\hline CHEMBL94734 & 737822 & 5.5 & 5.7528 & TST & \\
\hline CHEMBL1476303 & 737822 & 4.9 & 4.7975 & TST & \\
\hline CHEMBL1589942 & 737822 & 5.5 & 5.5361 & TST & \\
\hline CHEMBL6640 & 737822 & 4.5 & 4.6951 & TST & \\
\hline CHEMBL1492580 & 737822 & 5.25 & 5.3777 & TST & \\
\hline CHEMBL1307201 & 737822 & 4.95 & 5.3778 & TST & \\
\hline CHEMBL1437778 & 737822 & 5.3 & 5.2434 & TST & \\
\hline CHEMBL3210631 & 737822 & 4.85 & 5.3126 & TST & \\
\hline CHEMBL1581244 & 737822 & 5.05 & 5.0903 & TST & \\
\hline & & & & 11352 & \\
\hline
\end{tabular}




\begin{tabular}{|c|c|c|c|c|}
\hline \multicolumn{5}{|c|}{ Supplemental Table S2.txt } \\
\hline CHEMBL 258893 & 737822 & 4.6 & 4.8082 & TST \\
\hline CHEMBL1365347 & 737822 & 4.7 & 5.3299 & TST \\
\hline CHEMBL1402277 & 737822 & 6.1 & 6.4895 & TST \\
\hline CHEMBL1388465 & 737822 & 4.95 & 5.2252 & TST \\
\hline CHEMBL1508837 & 737822 & 4.55 & 5.2854 & TST \\
\hline CHEMBL1305916 & 737822 & 4.8 & 5.3482 & TST \\
\hline CHEMBL1421334 & 737822 & 4.8 & 5.3603 & TST \\
\hline CHEMBL1356485 & 737822 & 4.4 & 4.4646 & TST \\
\hline CHEMBL520992 & 737822 & 4.6 & 4.5343 & TST \\
\hline CHEMBL1305215 & 737822 & 5.1 & 5.3264 & TST \\
\hline CHEMBL1397009 & 737822 & 5.0 & 4.7831 & TST \\
\hline CHEMBL1415482 & 737822 & 4.85 & 5.1984 & TST \\
\hline CHEMBL1593930 & 737822 & 5.4 & 5.4231 & TST \\
\hline CHEMBL1372133 & 737822 & 4.7 & 4.5265 & TST \\
\hline CHEMBL1518920 & 737822 & 4.8 & 5.2558 & TST \\
\hline CHEMBL113180 & 737822 & 5.8 & 5.5684 & TST \\
\hline CHEMBL1493838 & 737822 & 5.5 & 5.2919 & TST \\
\hline CHEMBL32142 & 737822 & 4.6 & 4.6794 & TST \\
\hline CHEMBL608555 & 737822 & 4.8 & 4.9988 & TST \\
\hline CHEMBL86676 & 737822 & 5.0 & 5.6709 & TST \\
\hline CHEMBL1591460 & 737822 & 4.9 & 4.7312 & TST \\
\hline CHEMBL1445522 & 737822 & 4.8 & 4.694 & TST \\
\hline CHEMBL1586705 & 737822 & 6.4 & 5.6721 & TST \\
\hline CHEMBL1605085 & 737822 & 5.9 & 5.68 & TST \\
\hline CHEMBL1320042 & 737822 & 4.8 & 5.2116 & TST \\
\hline CHEMBL1597692 & 737822 & 6.0 & 5.7734 & TST \\
\hline CHEMBL1393933 & 737822 & 4.75 & 5.2314 & TST \\
\hline CHEMBL1424808 & 737822 & 5.6 & 5.2774 & TST \\
\hline CHEMBL1322901 & 737822 & 5.2 & 5.2314 & TST \\
\hline CHEMBL1374696 & 737822 & 6.0 & 5.689 & TST \\
\hline CHEMBL1474272 & 737822 & 4.8 & 4.673 & TST \\
\hline CHEMBL1465393 & 737822 & 6.1 & 5.4588 & TST \\
\hline CHEMBL1542526 & 737822 & 5.4 & 5.282 & TST \\
\hline CHEMBL1558413 & 737822 & 5.05 & 5.4547 & TST \\
\hline CHEMBL1329094 & 737822 & 5.3 & 5.1605 & TST \\
\hline CHEMBL1398800 & 737822 & 5.4 & 5.0396 & TST \\
\hline CHEMBL1410676 & 737822 & 6.1 & 5.7171 & TST \\
\hline CHEMBL1466951 & 737822 & 4.55 & 5.2578 & TST \\
\hline CHEMBL1533467 & 737822 & 7.3 & 7.01 & TST \\
\hline CHEMBL1742326 & 737822 & 7.6499 & 5.364 & TST \\
\hline CHEMBL1425169 & 737822 & 4.75 & 5.4445 & TST \\
\hline CHEMBL1602549 & 737822 & 4.6 & 5.2655 & TST \\
\hline CHEMBL1569009 & 737822 & 5.6 & 5.5722 & TST \\
\hline CHEMBL1385137 & 737822 & 4.8 & 5.3296 & TST \\
\hline CHEMBL268609 & 737822 & 4.6 & 5.7062 & TST \\
\hline CHEMBL1601300 & 737822 & 4.8 & 5.0792 & TST \\
\hline CHEMBL1393431 & 737822 & 5.3 & 5.3509 & TST \\
\hline CHEMBL1522796 & 737822 & 5.5 & 5.3387 & TST \\
\hline
\end{tabular}




\begin{tabular}{|c|c|c|c|c|c|}
\hline \\
\hline CHEMBL1542458 & 737822 & 5.75 & 5.5778 & TST & \\
\hline CHEMBL1701206 & 737822 & 4.9 & 5.2997 & TST & \\
\hline CHEMBL1399055 & 737822 & 4.6 & 4.5032 & TST & \\
\hline CHEMBL1611820 & 737822 & 4.8 & 4.6462 & TST & \\
\hline CHEMBL1329927 & 737822 & 6.0 & 5.8115 & TST & \\
\hline CHEMBL1315417 & 737822 & 5.0 & 5.0633 & TST & \\
\hline CHEMBL1593019 & 737822 & 5.0 & 4.7845 & TST & \\
\hline CHEMBL1388158 & 737822 & 5.2 & 5.1674 & TST & \\
\hline CHEMBL1592438 & 737822 & 4.9 & 4.7329 & TST & \\
\hline CHEMBL1450373 & 737822 & 4.8 & 5.3369 & TST & \\
\hline CHEMBL1422254 & 737822 & 5.1 & 5.2916 & TST & \\
\hline CHEMBL1538481 & 737822 & 4.55 & 5.0929 & TST & \\
\hline CHEMBL1407 & 737822 & 5.2 & 5.7657 & TST & \\
\hline CHEMBL1315083 & 737822 & 4.9 & 4.7314 & TST & \\
\hline CHEMBL1420830 & 737822 & 4.5 & 5.1185 & TST & \\
\hline CHEMBL3190647 & 737822 & 4.9 & 5.4599 & TST & \\
\hline CHEMBL1741745 & 737822 & 4.8 & 5.1098 & TST & \\
\hline CHEMBL1407012 & 737822 & 5.0 & 5.0346 & TST & \\
\hline CHEMBL1379991 & 737822 & 6.2 & 5.09699 & 99999999995 & TST \\
\hline CHEMBL1534755 & 737822 & 4.9 & 5.4319 & TST & \\
\hline CHEMBL1409825 & 737822 & 5.3 & 5.3135 & TST & \\
\hline CHEMBL1530789 & 737822 & 5.6 & 5.3075 & TST & \\
\hline CHEMBL1354325 & 737822 & 4.8 & 4.895 & TST & \\
\hline CHEMBL1318120 & 737822 & 5.5 & 5.3584 & TST & \\
\hline CHEMBL1545653 & 737822 & 5.2 & 5.2419 & TST & \\
\hline CHEMBL3190602 & 737822 & 4.8 & 5.1389 & TST & \\
\hline CHEMBL1255659 & 737822 & 4.8 & 4.8378 & TST & \\
\hline CHEMBL1331351 & 737822 & 4.7 & 4.654 & TST & \\
\hline CHEMBL1530558 & 737822 & 5.7 & 5.6207 & TST & \\
\hline CHEMBL1396282 & 737822 & 5.6 & 5.4775 & TST & \\
\hline CHEMBL1321338 & 737822 & 5.4 & 5.1491 & TST & \\
\hline CHEMBL1331881 & 737822 & 4.95 & 5.1702 & TST & \\
\hline CHEMBL1490333 & 737822 & 4.55 & 5.3991 & TST & \\
\hline CHEMBL1433939 & 737822 & 5.1 & 5.0902 & TST & \\
\hline CHEMBL1477964 & 737822 & 4.7 & 4.5412 & TST & \\
\hline CHEMBL1435086 & 737822 & 4.6 & 4.548 & TST & \\
\hline CHEMBL478 & 737822 & 6.0 & 5.6522 & TST & \\
\hline CHEMBL1565360 & 737822 & 4.6 & 4.615 & TST & \\
\hline CHEMBL1562937 & 737822 & 4.8 & 5.2489 & TST & \\
\hline CHEMBL294649 & 737822 & 7.2 & 6.4913 & TST & \\
\hline CHEMBL1365033 & 737822 & 5.2 & 5.2444 & TST & \\
\hline CHEMBL1389531 & 737822 & 5.45 & 5.2219 & TST & \\
\hline CHEMBL119841 & 737822 & 4.8 & 4.6215 & TST & \\
\hline CHEMBL1378306 & 737822 & 4.55 & 5.2451 & TST & \\
\hline CHEMBL1450521 & 737822 & 5.7 & 5.5956 & TST & \\
\hline CHEMBL596674 & 737822 & 5.7 & 5.6682 & TST & \\
\hline CHEMBL1601095 & 737822 & 5.0 & 5.1294 & TST & \\
\hline CHEMBL1317244 & 737822 & 5.6 & 5.1685 & TST & \\
\hline
\end{tabular}




\begin{tabular}{|c|c|c|c|c|}
\hline \\
\hline CHEMBL1477492 & 737822 & 4.4 & 4.3619 & TST \\
\hline CHEMBL1398138 & 737822 & 6.7 & 6.3475 & TST \\
\hline CHEMBL1556218 & 737822 & 5.1 & 5.1215 & TST \\
\hline CHEMBL1742056 & 737822 & 4.5 & 5.1764 & TST \\
\hline CHEMBL1351822 & 737822 & 4.6 & 5.2406 & TST \\
\hline CHEMBL1550537 & 737822 & 5.35 & 5.4556 & TST \\
\hline CHEMBL3191520 & 737822 & 5.15 & 5.4985 & TST \\
\hline CHEMBL1235966 & 737822 & 7.5 & 6.8501 & TST \\
\hline CHEMBL1431605 & 737822 & 4.75 & 5.2974 & TST \\
\hline CHEMBL1432016 & 737822 & 4.9 & 5.2336 & TST \\
\hline CHEMBL1355010 & 737822 & 4.7 & 4.4983 & TST \\
\hline CHEMBL1337725 & 737822 & 5.65 & 5.2182 & TST \\
\hline CHEMBL1490894 & 737822 & 4.6 & 5.2036 & TST \\
\hline CHEMBL1365427 & 737822 & 4.4 & 4.297 & TST \\
\hline CHEMBL546257 & 737822 & 6.0 & 5.7635 & TST \\
\hline CHEMBL1336557 & 737822 & 4.9 & 5.3772 & TST \\
\hline CHEMBL1508951 & 737822 & 4.95 & 5.569 & TST \\
\hline CHEMBL1466677 & 737822 & 5.15 & 5.4792 & TST \\
\hline CHEMBL1473472 & 737822 & 4.9 & 4.6344 & TST \\
\hline CHEMBL1580660 & 737822 & 4.55 & 5.2004 & TST \\
\hline CHEMBL1415305 & 737822 & 5.5 & 5.1599 & TST \\
\hline CHEMBL1288014 & 737822 & 5.6 & 5.4833 & TST \\
\hline CHEMBL1523323 & 737822 & 4.85 & 5.2898 & TST \\
\hline CHEMBL1358560 & 737822 & 4.7 & 4.5571 & TST \\
\hline CHEMBL 29197 & 737822 & 5.0 & 4.806 & TST \\
\hline CHEMBL1436024 & 737822 & 4.9 & 4.6697 & TST \\
\hline CHEMBL1396862 & 737822 & 6.0 & 5.7904 & TST \\
\hline CHEMBL1568982 & 737822 & 6.45 & 5.0408 & TST \\
\hline CHEMBL1457798 & 737822 & 4.8 & 5.4226 & TST \\
\hline CHEMBL601110 & 737822 & 5.5 & 4.93199 & 99999999995 \\
\hline CHEMBL1592327 & 737822 & 4.7 & 4.6192 & TST \\
\hline CHEMBL1328562 & 737822 & 5.4 & 5.8934 & TST \\
\hline CHEMBL1427238 & 737822 & 4.5 & 5.276 & TST \\
\hline CHEMBL1359181 & 737822 & 4.6 & 4.8564 & TST \\
\hline CHEMBL1601662 & 737822 & 4.4 & 4.3027 & TST \\
\hline CHEMBL1552519 & 737822 & 4.8 & 4.7066 & TST \\
\hline CHEMBL1570854 & 737822 & 5.35 & 5.102 & TST \\
\hline CHEMBL3199340 & 737822 & 5.05 & 5.45 & TST \\
\hline CHEMBL1545539 & 737822 & 4.55 & 5.1906 & TST \\
\hline CHEMBL 1598878 & 737822 & 6.05 & 5.3118 & TST \\
\hline CHEMBL1481127 & 737822 & 5.0 & 4.9401 & TST \\
\hline CHEMBL1507704 & 737822 & 4.85 & 5.1506 & TST \\
\hline CHEMBL1437713 & 737822 & 4.6 & 4.6186 & TST \\
\hline CHEMBL1320469 & 737822 & 4.4 & 4.2894 & TST \\
\hline CHEMBL 3193687 & 737822 & 4.4 & 5.3762 & TST \\
\hline CHEMBL 3198587 & 737822 & 6.8 & 5.2247 & TST \\
\hline CHEMBL1334334 & 737822 & 4.7 & 5.3326 & TST \\
\hline CHEMBL123 & 737822 & 5.2 & 5.6539 & TST \\
\hline
\end{tabular}




\begin{tabular}{|c|c|c|c|c|}
\hline \multicolumn{5}{|c|}{ Supplemental Table S2.tx } \\
\hline CHEMBL1554936 & 737822 & 5.4 & 5.3141 & TST \\
\hline CHEMBL1985350 & 737822 & 5.5 & 5.1036 & TST \\
\hline CHEMBL1299692 & 737822 & 4.85 & 5.2182 & TST \\
\hline CHEMBL1421523 & 737822 & 4.55 & 5.3593 & TST \\
\hline CHEMBL1305846 & 737822 & 4.6 & 5.5025 & TST \\
\hline CHEMBL1492898 & 737822 & 4.95 & 5.0946 & TST \\
\hline CHEMBL3212912 & 737822 & 4.85 & 5.2396 & TST \\
\hline CHEMBL490743 & 737822 & 4.9 & 4.7873 & TST \\
\hline CHEMBL1414899 & 737822 & 5.3 & 5.092 & TST \\
\hline CHEMBL1592936 & 737822 & 6.6 & 6.0101 & TST \\
\hline CHEMBL1408138 & 737822 & 5.5 & 5.2776 & TST \\
\hline CHEMBL 259389 & 737822 & -0.0 & 5.25200 & 0000000001 \\
\hline CHEMBL1552953 & 737822 & 5.5 & 5.401 & TST \\
\hline CHEMBL1425311 & 737822 & 4.9 & 5.4188 & TST \\
\hline CHEMBL1359473 & 737822 & 4.85 & 5.2027 & TST \\
\hline CHEMBL19259 & 737822 & 7.9 & 7.2143 & TST \\
\hline CHEMBL1491874 & 737822 & 5.3 & 5.1355 & TST \\
\hline CHEMBL1440302 & 737822 & 5.8 & 5.6484 & TST \\
\hline CHEMBL1513041 & 737822 & 5.2 & 5.3321 & TST \\
\hline CHEMBL1542442 & 737822 & 5.9 & 5.3734 & TST \\
\hline CHEMBL313833 & 737822 & 6.0 & 5.7652 & TST \\
\hline CHEMBL1514397 & 737822 & 6.0 & 5.9012 & TST \\
\hline CHEMBL1399481 & 737822 & 4.7 & 4.5196 & TST \\
\hline CHEMBL1466628 & 737822 & 5.2 & 5.5618 & TST \\
\hline CHEMBL1316314 & 737822 & 6.2 & 5.9538 & TST \\
\hline CHEMBL3192068 & 737822 & 4.55 & 5.2451 & TST \\
\hline CHEMBL1561206 & 737822 & 4.9 & 5.2961 & TST \\
\hline CHEMBL1354563 & 737822 & 4.9 & 4.7514 & TST \\
\hline CHEMBL1302877 & 737822 & 4.85 & 5.3157 & TST \\
\hline CHEMBL1408735 & 737822 & 4.9 & 4.6713 & TST \\
\hline CHEMBL303579 & 737822 & 4.4 & 4.5378 & TST \\
\hline CHEMBL1727976 & 737822 & 4.8 & 5.2368 & TST \\
\hline CHEMBL3196565 & 737822 & 5.3 & 5.3283 & TST \\
\hline CHEMBL1504481 & 737822 & 4.7 & 5.1354 & TST \\
\hline CHEMBL1517085 & 737822 & 5.15 & 5.3762 & TST \\
\hline CHEMBL1486380 & 737822 & 4.75 & 5.2958 & TST \\
\hline CHEMBL1441039 & 737822 & 4.85 & 5.5701 & TST \\
\hline CHEMBL1544930 & 737822 & 5.8 & 5.4913 & TST \\
\hline CHEMBL1408484 & 737822 & 4.5 & 5.3805 & TST \\
\hline CHEMBL1431523 & 737822 & 4.85 & 5.2468 & TST \\
\hline CHEMBL1436125 & 737822 & 5.8 & 5.5427 & TST \\
\hline CHEMBL1741947 & 737822 & 4.9 & 5.0635 & TST \\
\hline CHEMBL1320765 & 737822 & 4.9 & 4.8563 & TST \\
\hline CHEMBL3212051 & 737822 & 4.8 & 5.4361 & TST \\
\hline CHEMBL1208858 & 737822 & 7.4 & 6.8918 & TST \\
\hline CHEMBL1488127 & 737822 & 4.75 & 5.6033 & TST \\
\hline CHEMBL1350707 & 737822 & 4.85 & 5.4612 & TST \\
\hline CHEMBL1490268 & 737822 & 4.4 & 4.3477 & TST \\
\hline
\end{tabular}




\begin{tabular}{|c|c|c|c|c|c|}
\hline \multirow{2}{*}{ CHEMBL1515334 } & \multirow[b]{2}{*}{737822} & \\
\hline & & 6.0 & 5.58 & TST & \\
\hline CHEMBL1256695 & 737822 & 6.0 & 5.7239 & TST & \\
\hline CHEMBL1354408 & 737822 & 4.6 & 4.4523 & TST & \\
\hline CHEMBL1435702 & 737822 & 5.8 & 5.4819 & TST & \\
\hline CHEMBL1437408 & 737822 & 5.3 & 5.1514 & TST & \\
\hline CHEMBL1525602 & 737822 & 5.1 & 4.8601 & TST & \\
\hline CHEMBL1558771 & 737822 & 4.8 & 5.428 & TST & \\
\hline CHEMBL1448354 & 737822 & 5.35 & 5.2666 & TST & \\
\hline CHEMBL1358806 & 737822 & 5.5 & \multicolumn{2}{|c|}{5.382999999999999} & TST \\
\hline CHEMBL1324640 & 737822 & 4.95 & 5.2318 & TST & \\
\hline CHEMBL1518415 & 737822 & 4.9 & 4.7407 & TST & \\
\hline CHEMBL1310810 & 737822 & 4.9 & 5.2946 & TST & \\
\hline CHEMBL1496569 & 737822 & 5.3 & 5.1212 & TST & \\
\hline CHEMBL1593486 & 737822 & 5.4 & 5.354 & TST & \\
\hline CHEMBL1544437 & 737822 & 4.85 & 5.3838 & TST & \\
\hline CHEMBL1448979 & 737822 & 6.1 & 5.7635 & TST & \\
\hline CHEMBL1526455 & 737822 & 4.4 & 4.7101 & TST & \\
\hline CHEMBL1589809 & 737822 & 4.75 & 5.4986 & TST & \\
\hline CHEMBL1733680 & 737822 & 4.9 & 5.3678 & TST & \\
\hline CHEMBL1559860 & 737822 & 7.0 & 6.6003 & TST & \\
\hline CHEMBL1569277 & 737822 & 5.95 & 4.9966 & TST & \\
\hline CHEMBL1601305 & 737822 & 4.4 & 4.3223 & TST & \\
\hline CHEMBL1441088 & 737822 & 5.2 & 5.2688 & TST & \\
\hline CHEMBL1473116 & 737822 & 6.2 & 6.0063 & TST & \\
\hline CHEMBL1552095 & 737822 & 6.0 & 5.8092 & TST & \\
\hline CHEMBL1448655 & 737822 & 5.5 & 5.2046 & TST & \\
\hline CHEMBL1534376 & 737822 & 4.9 & 4.7169 & TST & \\
\hline CHEMBL1530692 & 737822 & 5.35 & 5.2436 & TST & \\
\hline CHEMBL3392072 & 737822 & 4.5 & 4.467 & TST & \\
\hline CHEMBL478501 & 737822 & 4.55 & 5.435 & TST & \\
\hline CHEMBL1552249 & 737822 & 7.8 & \multicolumn{2}{|c|}{7.0489999999999995} & TST \\
\hline CHEMBL543557 & 737822 & 4.7 & 4.8396 & TST & \\
\hline CHEMBL1371631 & 737822 & 6.5 & 6.1095 & TST & \\
\hline CHEMBL1585650 & 737822 & 4.55 & 5.3227 & TST & \\
\hline CHEMBL1399561 & 737822 & 5.6 & \multicolumn{2}{|c|}{5.617999999999999} & TST \\
\hline CHEMBL1356107 & 737822 & 7.0 & 6.3597 & TST & \\
\hline CHEMBL428768 & 737822 & 4.5 & 4.5867 & TST & \\
\hline CHEMBL1742042 & 737822 & 4.75 & 5.3906 & TST & \\
\hline CHEMBL1742357 & 737822 & 4.55 & 5.2123 & TST & \\
\hline CHEMBL1435638 & 737822 & 4.7 & 4.6399 & TST & \\
\hline CHEMBL 8145 & 737822 & 4.8 & 4.7217 & TST & \\
\hline CHEMBL1496722 & 737822 & 5.25 & 5.2272 & TST & \\
\hline CHEMBL1439338 & 737822 & 5.75 & 5.0832 & TST & \\
\hline CHEMBL1361427 & 737822 & 4.4 & 5.1823 & TST & \\
\hline CHEMBL1317306 & 737822 & 7.0 & 6.8155 & TST & \\
\hline CHEMBL1384477 & 737822 & 6.1 & 5.3563 & TST & \\
\hline CHEMBL1435409 & 737822 & 4.6 & 4.4686 & TST & \\
\hline \multirow[t]{2}{*}{ CHEMBL1445889 } & 737822 & 4.85 & 5.3639 & TST & \\
\hline & & \multicolumn{4}{|c|}{ Page 11357} \\
\hline
\end{tabular}




\begin{tabular}{|c|c|c|c|c|c|}
\hline & & & & & \\
\hline CHEMBL1371510 & 737822 & 6.9 & 6.4692 & TST & \\
\hline CHEMBL1392464 & 737822 & 4.6 & 5.3304 & TST & \\
\hline CHEMBL1992166 & 737822 & 5.25 & 5.4163 & TST & \\
\hline CHEMBL1256178 & 737822 & 4.4 & 4.7573 & TST & \\
\hline CHEMBL1552985 & 737822 & 5.1 & 4.9107 & TST & \\
\hline CHEMBL1343091 & 737822 & 4.65 & 5.3261 & TST & \\
\hline CHEMBL1554826 & 737822 & 4.6 & 4.5337 & TST & \\
\hline CHEMBL1604074 & 737822 & 6.0 & 5.8367 & TST & \\
\hline CHEMBL1445737 & 737822 & 4.85 & 5.066 & TST & \\
\hline CHEMBL1488466 & 737822 & 5.05 & 5.1909 & TST & \\
\hline CHEMBL3193992 & 737822 & 4.6 & 5.19 & TST & \\
\hline CHEMBL1395429 & 737822 & 5.0 & 5.0772 & TST & \\
\hline CHEMBL1395997 & 737822 & 5.3 & 5.1398 & TST & \\
\hline CHEMBL1415080 & 737822 & 6.5 & 6.4311 & TST & \\
\hline CHEMBL3210605 & 737822 & 4.65 & 5.29799 & 9999999999 & TST \\
\hline CHEMBL598263 & 737822 & 6.0 & 5.6594 & TST & \\
\hline CHEMBL1467355 & 737822 & 5.75 & 5.348 & TST & \\
\hline CHEMBL1555255 & 737822 & 5.5 & 5.4004 & TST & \\
\hline CHEMBL1789998 & 737822 & 5.1 & 5.0764 & TST & \\
\hline CHEMBL1600813 & 737822 & 4.55 & 5.5363 & TST & \\
\hline CHEMBL1560912 & 737822 & 4.65 & 5.3536 & TST & \\
\hline CHEMBL1357429 & 737822 & 4.7 & 4.7147 & TST & \\
\hline CHEMBL1444545 & 737822 & 4.6 & 5.3722 & TST & \\
\hline CHEMBL106437 & 737822 & 8.2 & 7.3516 & TST & \\
\hline CHEMBL1437667 & 737822 & 4.7 & 4.5726 & TST & \\
\hline CHEMBL1345777 & 737822 & 5.45 & 5.3803 & TST & \\
\hline CHEMBL1343385 & 737822 & 4.55 & 4.9096 & TST & \\
\hline CHEMBL1476712 & 737822 & 4.4 & 4.3394 & TST & \\
\hline CHEMBL1314247 & 737822 & 4.4 & 4.3946 & TST & \\
\hline CHEMBL1364611 & 737822 & 4.8 & 4.5502 & TST & \\
\hline CHEMBL1391888 & 737822 & 4.8 & 5.0682 & TST & \\
\hline CHEMBL399491 & 737822 & 5.1 & 5.1024 & TST & \\
\hline CHEMBL1572789 & 737822 & 4.85 & 5.1552 & TST & \\
\hline CHEMBL1507850 & 737822 & 5.0 & 5.3321 & TST & \\
\hline CHEMBL1429628 & 737822 & 4.95 & 5.3608 & TST & \\
\hline CHEMBL1374585 & 737822 & 4.9 & 4.6694 & TST & \\
\hline CHEMBL1543205 & 737822 & 5.95 & 5.3526 & TST & \\
\hline CHEMBL1317885 & 737822 & 5.0 & 4.9667 & TST & \\
\hline CHEMBL1437831 & 737822 & 4.5 & 4.7268 & TST & \\
\hline CHEMBL1318824 & 737822 & 5.5 & 5.5187 & TST & \\
\hline CHEMBL1454931 & 737822 & 4.7 & 5.1767 & TST & \\
\hline CHEMBL1528565 & 737822 & 7.3 & 6.6704 & TST & \\
\hline CHEMBL1374962 & 737822 & 7.4 & 5.2423 & TST & \\
\hline CHEMBL1519391 & 737822 & 8.25 & 4.8875 & TST & \\
\hline CHEMBL492611 & 737822 & 4.7 & 4.4975 & TST & \\
\hline CHEMBL1473990 & 737822 & 6.2 & 5.8881 & TST & \\
\hline CHEMBL1435227 & 737822 & 4.5 & 4.4376 & TST & \\
\hline CHEMBL1726083 & 737822 & 5.45 & $5.2810 e$ & 2000000001 & TST \\
\hline & & & & 11358 & \\
\hline
\end{tabular}




\begin{tabular}{|c|c|c|c|c|}
\hline & & & & al lable s \\
\hline CHEMBL1443628 & 737822 & 5.8 & 5.4991 & TST \\
\hline CHEMBL1407527 & 737822 & 4.6 & 4.556 & TST \\
\hline CHEMBL1499204 & 737822 & 4.85 & 5.1574 & TST \\
\hline CHEMBL1515295 & 737822 & 4.7 & 4.705 & TST \\
\hline CHEMBL1338229 & 737822 & 6.0 & 5.8494 & TST \\
\hline CHEMBL148124 & 737822 & 6.1 & 5.4557 & TST \\
\hline CHEMBL1445026 & 737822 & 5.5 & 5.3431 & TST \\
\hline CHEMBL1392232 & 737822 & 4.9 & 5.5015 & TST \\
\hline CHEMBL1522778 & 737822 & 6.0 & 5.7332 & TST \\
\hline CHEMBL1396737 & 737822 & 5.5 & 5.392 & TST \\
\hline CHEMBL1473754 & 737822 & 4.8 & 4.6126 & TST \\
\hline CHEMBL1316760 & 737822 & 4.9 & 4.6742 & TST \\
\hline CHEMBL1328533 & 737822 & 4.6 & 4.4859 & TST \\
\hline CHEMBL1742323 & 737822 & 5.0 & 5.2619 & TST \\
\hline CHEMBL1422909 & 737822 & 4.65 & 5.1128 & TST \\
\hline CHEMBL1611893 & 737822 & 7.4 & 6.6787 & TST \\
\hline CHEMBL3213468 & 737822 & 4.8 & 5.3742 & TST \\
\hline CHEMBL180966 & 737822 & 4.5 & 4.6882 & TST \\
\hline CHEMBL1447538 & 737822 & 5.5 & 5.42 & TST \\
\hline CHEMBL1478249 & 737822 & 5.5 & 5.4461 & TST \\
\hline CHEMBL1552764 & 737822 & 4.8 & 4.8465 & TST \\
\hline CHEMBL1424384 & 737822 & 6.1 & 5.3437 & TST \\
\hline CHEMBL1378731 & 737822 & 5.4 & 5.3249 & TST \\
\hline CHEMBL1424596 & 737822 & 4.85 & 5.2374 & TST \\
\hline CHEMBL1380969 & 737822 & 6.15 & 5.3856 & TST \\
\hline CHEMBL1376736 & 737822 & 5.0 & 4.7385 & TST \\
\hline CHEMBL23957 & 737822 & 5.4 & 5.2368 & TST \\
\hline CHEMBL1439401 & 737822 & 4.6 & 4.4747 & TST \\
\hline CHEMBL490718 & 737822 & 4.7 & 4.4842 & TST \\
\hline CHEMBL1892270 & 737822 & 4.7 & 5.3586 & TST \\
\hline CHEMBL1742383 & 737822 & 5.05 & 5.1636 & TST \\
\hline CHEMBL1449575 & 737822 & 5.0 & 5.0027 & TST \\
\hline CHEMBL1436045 & 737822 & 4.9 & 4.8637 & TST \\
\hline CHEMBL1336412 & 737822 & 4.9 & 5.2627 & TST \\
\hline CHEMBL1476526 & 737822 & 5.4 & 5.2118 & TST \\
\hline CHEMBL1328247 & 737822 & 4.6 & 5.38899 & 9999999999 \\
\hline CHEMBL1427884 & 737822 & 5.0 & 5.4038 & TST \\
\hline CHEMBL1355224 & 737822 & 4.5 & 4.8644 & TST \\
\hline CHEMBL1255650 & 737822 & 4.9 & 5.0303 & TST \\
\hline CHEMBL1379079 & 737822 & 4.6 & 5.0798 & TST \\
\hline CHEMBL1568061 & 737822 & 5.65 & 5.3641 & TST \\
\hline CHEMBL1323355 & 737822 & 7.2 & 7.0859 & TST \\
\hline CHEMBL1320051 & 737822 & 4.4 & 5.1795 & TST \\
\hline CHEMBL1418094 & 737822 & 5.6 & 5.3878 & TST \\
\hline CHEMBL1439063 & 737822 & 5.0 & 5.1492 & TST \\
\hline CHEMBL1418420 & 737822 & 4.7 & 4.5857 & TST \\
\hline CHEMBL1536459 & 737822 & 4.4 & 5.359 & TST \\
\hline CHEMBL1322686 & 737822 & 5.0 & 4.8029 & TST \\
\hline
\end{tabular}




\begin{tabular}{|c|c|c|c|c|}
\hline & & & & al Table S \\
\hline CHEMBL1096400 & 737822 & 5.3 & 5.1305 & TST \\
\hline CHEMBL1359661 & 737822 & 4.7 & 5.228 & TST \\
\hline CHEMBL1445572 & 737822 & 5.3 & 5.2217 & TST \\
\hline CHEMBL1742255 & 737822 & 5.45 & 5.2655 & TST \\
\hline CHEMBL1314288 & 737822 & 4.4 & 4.3338 & TST \\
\hline CHEMBL1499633 & 737822 & 4.7 & 5.2334 & TST \\
\hline CHEMBL73310 & 737822 & 4.8 & 4.9135 & TST \\
\hline CHEMBL1355835 & 737822 & 4.4 & 4.3606 & TST \\
\hline CHEMBL1461321 & 737822 & 5.45 & 5.1327 & TST \\
\hline CHEMBL1396203 & 737822 & 5.0 & 4.8541 & TST \\
\hline CHEMBL1256749 & 737822 & 6.9 & 6.3166 & TST \\
\hline CHEMBL536803 & 737822 & 4.5 & 4.7294 & TST \\
\hline CHEMBL 2094549 & 737822 & 4.8 & 5.2853 & TST \\
\hline CHEMBL1485991 & 737822 & 5.1 & 5.5227 & TST \\
\hline CHEMBL 3214277 & 737822 & 4.6 & 5.3252 & TST \\
\hline CHEMBL1540663 & 737822 & 4.8 & 5.2501 & TST \\
\hline CHEMBL1478946 & 737822 & 4.7 & 4.6827 & TST \\
\hline CHEMBL1496418 & 737822 & 4.8 & 5.2462 & TST \\
\hline CHEMBL1487371 & 737822 & 5.3 & 5.2348 & TST \\
\hline CHEMBL1396261 & 737822 & 5.0 & 4.9052 & TST \\
\hline CHEMBL1318411 & 737822 & 5.5 & 5.8536 & TST \\
\hline CHEMBL1575145 & 737822 & 4.6 & 5.1424 & TST \\
\hline CHEMBL1358137 & 737822 & 5.4 & 5.4505 & TST \\
\hline CHEMBL1366260 & 737822 & 5.05 & 5.1683 & TST \\
\hline CHEMBL86931 & 737822 & 4.5 & 4.5843 & TST \\
\hline CHEMBL16671 & 737822 & 5.0 & 5.065 & TST \\
\hline CHEMBL1562832 & 737822 & 5.3 & 5.2986 & TST \\
\hline CHEMBL399121 & 737822 & 5.0 & 5.6164 & TST \\
\hline CHEMBL1410725 & 737822 & 4.55 & 5.46700 & 00000000005 \\
\hline CHEMBL1303933 & 737822 & 4.75 & 5.2209 & TST \\
\hline CHEMBL1433173 & 737822 & 5.45 & 5.4435 & TST \\
\hline CHEMBL1403482 & 737822 & 5.1 & 5.3557 & TST \\
\hline CHEMBL62 & 737822 & 6.0 & 5.7111 & TST \\
\hline CHEMBL1440964 & 737822 & 5.35 & 5.186 & TST \\
\hline CHEMBL1482196 & 737822 & 5.0 & 5.3787 & TST \\
\hline CHEMBL1290409 & 737822 & 5.4 & 5.1965 & TST \\
\hline CHEMBL1319195 & 737822 & 4.9 & 5.1496 & TST \\
\hline CHEMBL1455926 & 737822 & 4.6 & 4.4104 & TST \\
\hline CHEMBL1340893 & 737822 & 4.55 & 5.4376 & TST \\
\hline CHEMBL3191557 & 737822 & 4.85 & 5.2953 & TST \\
\hline CHEMBL 203722 & 737822 & 5.9 & 5.6603 & TST \\
\hline CHEMBL1514953 & 737822 & 4.4 & 4.3916 & TST \\
\hline CHEMBL1314808 & 737822 & 4.9 & 5.3933 & TST \\
\hline CHEMBL1484447 & 737822 & 4.4 & 4.4 & TST \\
\hline CHEMBL1355840 & 737822 & 4.7 & 4.4852 & TST \\
\hline CHEMBL1493411 & 737822 & 4.55 & 5.4049 & TST \\
\hline CHEMBL1563147 & 737822 & 5.4 & 5.1395 & TST \\
\hline CHEMBL1360125 & 737822 & 4.45 & 5.3255 & TST \\
\hline
\end{tabular}




\begin{tabular}{|c|c|c|c|c|}
\hline & & & pplement & al $\mathrm{Ta}$ \\
\hline CHEMBL1417861 & 737822 & 5.2 & 5.0985 & TST \\
\hline CHEMBL1611026 & 737822 & 4.85 & 5.4668 & TST \\
\hline CHEMBL1411264 & 737822 & 6.0 & 5.9062 & TST \\
\hline CHEMBL1446407 & 737822 & 4.85 & 5.5038 & TST \\
\hline CHEMBL 3208488 & 737822 & 5.4 & 5.3292 & TST \\
\hline CHEMBL1513078 & 737822 & 4.6 & 5.0495 & TST \\
\hline CHEMBL1553498 & 737822 & 8.2 & 6.9979 & TST \\
\hline CHEMBL1741345 & 737822 & 4.55 & 5.2595 & TST \\
\hline CHEMBL1340207 & 737822 & 6.5 & 5.4494 & TST \\
\hline CHEMBL1741795 & 737822 & 4.55 & 5.3927 & TST \\
\hline CHEMBL1591336 & 737822 & 4.6 & 4.4461 & TST \\
\hline CHEMBL1356630 & 737822 & 4.7 & 4.7925 & TST \\
\hline CHEMBL1515355 & 737822 & 4.7 & 4.4925 & TST \\
\hline CHEMBL1349047 & 737822 & 4.95 & 5.3302 & TST \\
\hline CHEMBL1309244 & 737822 & 4.75 & 5.2506 & TST \\
\hline CHEMBL1711461 & 737822 & 4.85 & 5.4213 & TST \\
\hline CHEMBL1563513 & 737822 & 4.7 & 5.0971 & TST \\
\hline CHEMBL1468265 & 737822 & 4.8 & 5.2164 & TST \\
\hline CHEMBL1402656 & 737822 & 4.4 & 4.3758 & TST \\
\hline CHEMBL1528011 & 737822 & 5.3 & 5.3485 & TST \\
\hline CHEMBL1592804 & 737822 & 7.5 & 6.909 & TST \\
\hline CHEMBL1525376 & 737822 & 4.9 & 5.1107 & TST \\
\hline CHEMBL1337087 & 737822 & 4.6 & 5.1432 & TST \\
\hline CHEMBL1371898 & 737822 & 5.8 & 5.4981 & TST \\
\hline CHEMBL2002517 & 737822 & 4.5 & 5.3751 & TST \\
\hline CHEMBL467706 & 737822 & 6.0 & 5.7778 & TST \\
\hline CHEMBL1335409 & 737822 & 5.3 & 5.239 & TST \\
\hline CHEMBL1515815 & 737822 & 5.9 & 5.8077 & TST \\
\hline CHEMBL1517335 & 737822 & 5.9 & 5.1878 & TST \\
\hline CHEMBL1552864 & 737822 & 4.6 & 4.4881 & TST \\
\hline CHEMBL1461802 & 737822 & 5.95 & 5.4505 & TST \\
\hline CHEMBL1352020 & 737822 & 4.75 & 5.4377 & TST \\
\hline CHEMBL1320820 & 737822 & 5.0 & 4.7613 & TST \\
\hline CHEMBL1518709 & 737822 & 6.0 & 5.4658 & TST \\
\hline CHEMBL1382247 & 737822 & 4.6 & 5.3299 & TST \\
\hline CHEMBL1505689 & 737822 & 5.35 & 5.2635 & TST \\
\hline CHEMBL1385992 & 737822 & 4.8 & 5.2238 & TST \\
\hline CHEMBL1475951 & 737822 & 4.7 & 4.5142 & TST \\
\hline CHEMBL1434082 & 737822 & 4.8 & 4.5611 & TST \\
\hline CHEMBL1433021 & 737822 & 5.3 & 5.4411 & TST \\
\hline CHEMBL1435254 & 737822 & 4.4 & 4.2587 & TST \\
\hline CHEMBL1256654 & 737822 & 6.0 & 5.7359 & TST \\
\hline CHEMBL1384353 & 737822 & 5.05 & 5.195 & TST \\
\hline CHEMBL1392359 & 737822 & 5.95 & 5.3719 & TST \\
\hline CHEMBL1332759 & 737822 & 4.4 & 4.3671 & TST \\
\hline CHEMBL1613194 & 737822 & 5.1 & 5.2198 & TST \\
\hline CHEMBL326967 & 737822 & 4.5 & 4.6126 & TST \\
\hline CHEMBL1475191 & 737822 & 5.0 & 5.104 & TST \\
\hline
\end{tabular}




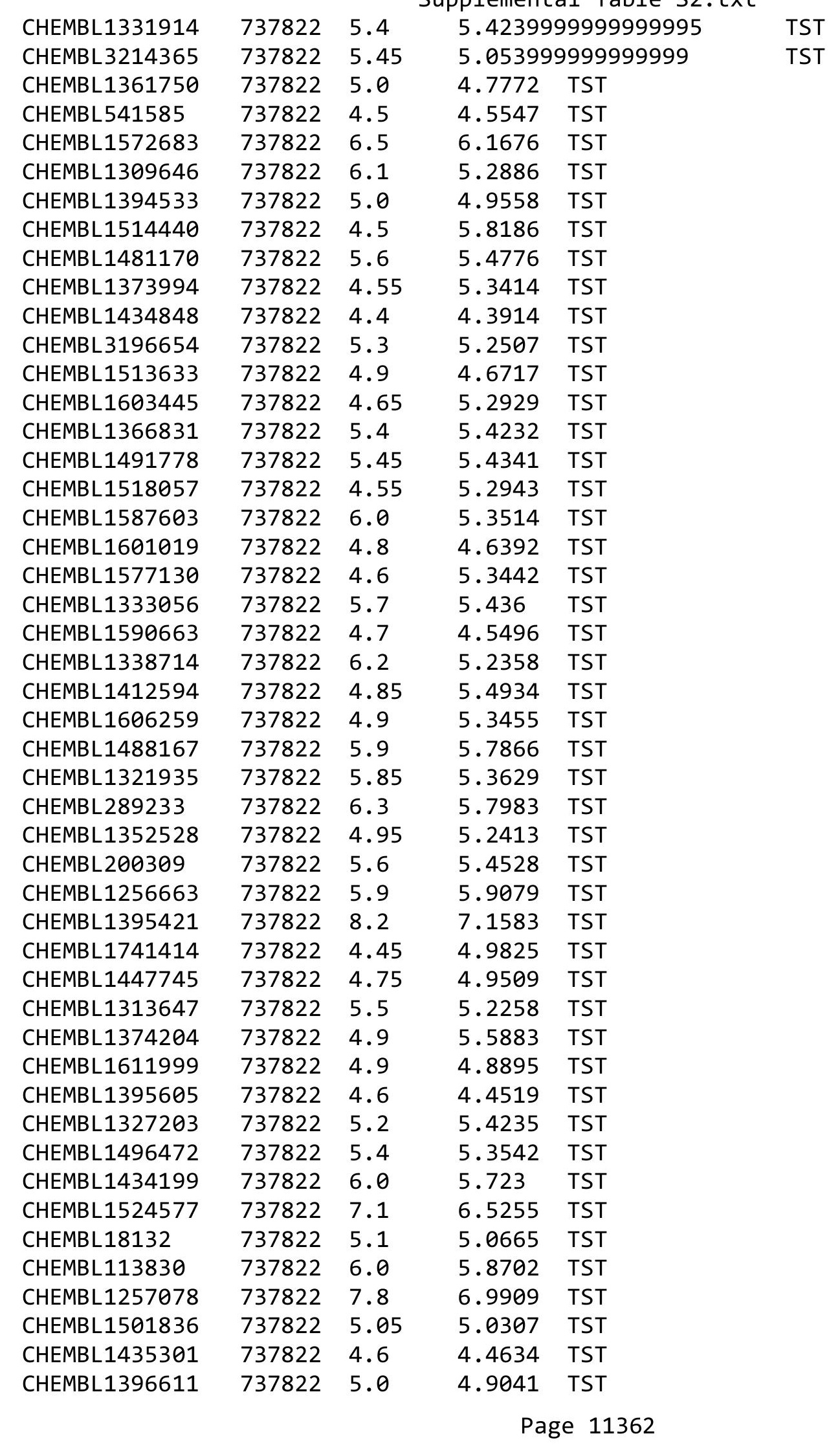




\begin{tabular}{|c|c|c|c|c|}
\hline \multicolumn{5}{|c|}{ Supplemental Table S2.txt } \\
\hline CHEMBL1485319 & 737822 & 5.3 & 5.1719 & TST \\
\hline CHEMBL541543 & 737822 & 6.2 & 5.7524 & TST \\
\hline CHEMBL1400835 & 737822 & 4.9 & 5.3234 & TST \\
\hline CHEMBL1376290 & 737822 & 5.4 & 5.3861 & TST \\
\hline CHEMBL1337127 & 737822 & 5.4 & 5.4737 & TST \\
\hline CHEMBL1474681 & 737822 & 5.0 & 4.8748 & TST \\
\hline CHEMBL1369886 & 737822 & 4.6 & 5.1494 & TST \\
\hline CHEMBL492132 & 737822 & 5.6 & 5.3412 & TST \\
\hline CHEMBL1472899 & 737822 & 4.9 & 4.9835 & TST \\
\hline CHEMBL1397257 & 737822 & 5.6 & 5.1572 & TST \\
\hline CHEMBL2369256 & 737822 & 4.8 & 5.5282 & TST \\
\hline CHEMBL1392699 & 737822 & 4.55 & 5.125 & TST \\
\hline CHEMBL1541487 & 737822 & 4.75 & 5.1286 & TST \\
\hline CHEMBL1386361 & 737822 & 6.85 & 5.6241 & TST \\
\hline CHEMBL1556022 & 737822 & 4.4 & 5.4421 & TST \\
\hline CHEMBL1717461 & 737822 & 6.05 & 5.1272 & TST \\
\hline CHEMBL1516890 & 954546 & 4.9403 & 4.9403 & TRN \\
\hline CHEMBL 202721 & 954546 & 4.5445 & 4.5444 & TRN \\
\hline CHEMBL 255342 & 954546 & 3.2572 & 3.2573 & TRN \\
\hline CHEMBL1230020 & 954546 & 3.2918 & 3.2918 & TRN \\
\hline CHEMBL 221137 & 954546 & 5.3699 & 5.1119 & TST \\
\hline CHEMBL135561 & 954546 & 5.5724 & 5.5724 & TRN \\
\hline CHEMBL1590308 & 954546 & 3.2921 & 2.7715 & TST \\
\hline CHEMBL 3186408 & 954546 & 4.2522 & 4.6915 & TST \\
\hline CHEMBL191334 & 954546 & 5.5489 & 5.5489 & TRN \\
\hline CHEMBL585951 & 954546 & 6.6003 & 6.6004 & TRN \\
\hline CHEMBL 217354 & 954546 & 6.4859 & 6.4859 & TRN \\
\hline CHEMBL 373751 & 954546 & 4.175 & 4.175 & TRN \\
\hline CHEMBL412142 & 954546 & 3.4426 & 3.4426 & TRN \\
\hline CHEMBL189584 & 954546 & 3.989 & 3.989 & TRN \\
\hline CHEMBL180127 & 954546 & 3.6719 & 3.6719 & TRN \\
\hline CHEMBL65 & 954546 & 7.7447 & 7.7448 & TRN \\
\hline CHEMBL1909414 & 954546 & 4.659 & 4.659 & TRN \\
\hline CHEMBL 3199475 & 954546 & 5.6346 & 5.6346 & TRN \\
\hline CHEMBL379975 & 954546 & 5.0134 & 5.0134 & TRN \\
\hline CHEMBL1357247 & 954546 & 3.0443 & 3.0443 & TRN \\
\hline CHEMBL512504 & 954546 & 4.2253 & 4.2253 & TRN \\
\hline CHEMBL 2134202 & 954546 & 3.512 & 3.5119 & TRN \\
\hline CHEMBL 2137530 & 954546 & 4.4933 & 4.4934 & TRN \\
\hline CHEMBL1186585 & 954546 & 3.5217 & 3.5217 & TRN \\
\hline CHEMBL 222102 & 954546 & 3.6987 & 3.6986 & TRN \\
\hline CHEMBL220241 & 954546 & 5.9808 & 5.9808 & TRN \\
\hline CHEMBL472940 & 954546 & 4.1425 & 4.1425 & TRN \\
\hline CHEMBL192566 & 954546 & 8.5222 & 9.2117 & TST \\
\hline CHEMBL1673039 & 954546 & 4.541 & 4.541 & TRN \\
\hline CHEMBL449158 & 954546 & 6.4931 & 6.7962 & TST \\
\hline CHEMBL102714 & 954546 & 4.1039 & 4.1039 & TRN \\
\hline CHEMBL393929 & 954546 & 4.1836 & 4.1835 & TRN \\
\hline
\end{tabular}




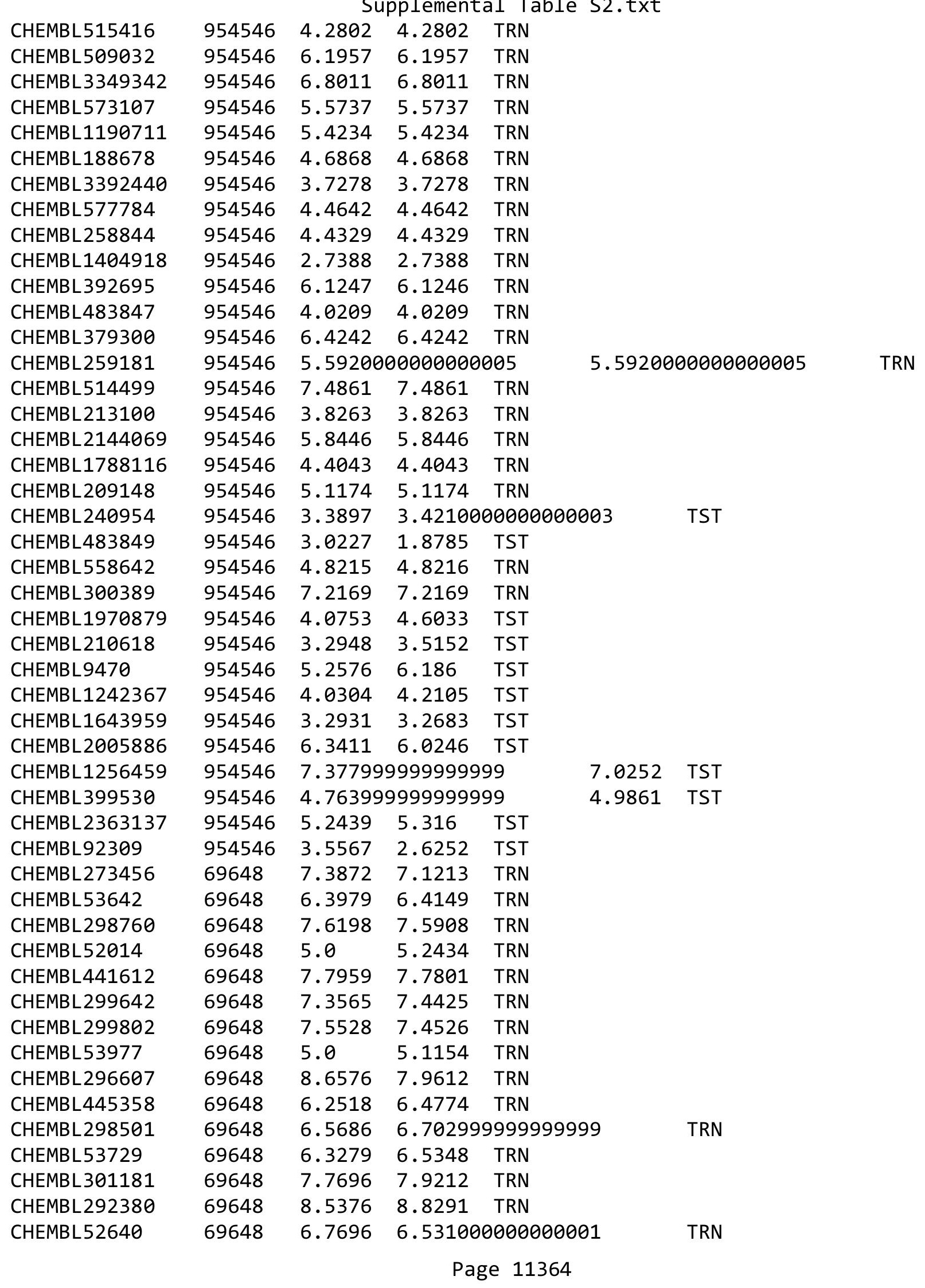




\begin{tabular}{|c|c|c|c|c|c|}
\hline \multicolumn{6}{|c|}{ Supplemental Table S2.txt } \\
\hline CHEMBL55081 & 69648 & 6.2366 & 5.8864 & TRN & \\
\hline CHEMBL292462 & 69648 & 8.4318 & 8.3066 & TRN & \\
\hline CHEMBL297958 & 69648 & 5.0 & 5.6421 & TST & \\
\hline CHEMBL273680 & 69648 & 5.0 & 4.8878 & TRN & \\
\hline CHEMBL54211 & 69648 & 5.0 & 5.4037 & TRN & \\
\hline CHEMBL52818 & 69648 & 6.284 & 6.3464 & TRN & \\
\hline CHEMBL301063 & 69648 & 8.2366 & 8.1601 & TRN & \\
\hline CHEMBL299995 & 69648 & 5.0 & 5.0751 & TST & \\
\hline CHEMBL299736 & 69648 & 6.8861 & 6.7772 & TRN & \\
\hline CHEMBL297717 & 69648 & 6.0706 & 6.6149 & TRN & \\
\hline CHEMBL301336 & 69648 & 6.4685 & 6.6499 & TRN & \\
\hline CHEMBL300018 & 69648 & 6.7959 & 6.82700 & 0000000001 & TRN \\
\hline CHEMBL299882 & 69648 & 5.0 & 5.2276 & TRN & \\
\hline CHEMBL53238 & 69648 & 8.7212 & 8.5861 & TRN & \\
\hline CHEMBL13662 & 69648 & 5.699 & 5.8605 & TST & \\
\hline CHEMBL300951 & 69648 & 8.7447 & 8.6177 & TRN & \\
\hline CHEMBL298386 & 69648 & 8.6383 & 8.6588 & TRN & \\
\hline CHEMBL441978 & 69648 & 6.9208 & 6.69 & TRN & \\
\hline CHEMBL52962 & 69648 & 5.0 & 4.7595 & TST & \\
\hline CHEMBL55450 & 69648 & 7.3979 & 6.7426 & TRN & \\
\hline CHEMBL52672 & 69648 & 8.7696 & 8.5001 & TRN & \\
\hline CHEMBL51911 & 69648 & 6.2076 & 6.0262 & TRN & \\
\hline CHEMBL50581 & 69648 & 7.7959 & 7.0024 & TRN & \\
\hline CHEMBL54859 & 69648 & 5.7447 & 5.1951 & TST & \\
\hline CHEMBL50320 & 69648 & 7.6021 & 7.4007 & TRN & \\
\hline CHEMBL416659 & 69648 & 8.0969 & 8.7121 & TRN & \\
\hline CHEMBL 298730 & 69648 & 5.0 & 5.0408 & TRN & \\
\hline CHEMBL301104 & 69648 & 5.0 & 5.0285 & TRN & \\
\hline CHEMBL300497 & 69648 & 8.4437 & 8.6698 & TRN & \\
\hline CHEMBL299210 & 69648 & 9.1549 & 9.3586 & TRN & \\
\hline CHEMBL53529 & 69648 & 7.2518 & 6.9595 & TRN & \\
\hline CHEMBL 296383 & 69648 & 8.0132 & 8.5621 & TRN & \\
\hline CHEMBL300862 & 69648 & 8.7959 & 8.8845 & TRN & \\
\hline CHEMBL 297481 & 69648 & 5.0 & 5.3105 & TRN & \\
\hline CHEMBL53528 & 69648 & 5.0 & 4.6072 & TST & \\
\hline CHEMBL300867 & 69648 & 6.6576 & 6.7331 & TST & \\
\hline CHEMBL53587 & 69648 & 7.585 & 8.0693 & TST & \\
\hline CHEMBL299437 & 69648 & 7.7959 & 7.3625 & TST & \\
\hline CHEMBL52030 & 69648 & 7.6576 & 7.8249 & TST & \\
\hline CHEMBL52310 & 69648 & 7.4202 & 7.5612 & TST & \\
\hline CHEMBL299611 & 69648 & 8.7696 & 8.8749 & TST & \\
\hline CHEMBL52696 & 69648 & 6.4202 & 6.5548 & TST & \\
\hline CHEMBL300690 & 69648 & 6.2924 & 6.2404 & TST & \\
\hline CHEMBL50402 & 69648 & 7.9586 & 8.0835 & TST & \\
\hline CHEMBL 2179174 & 934066 & 5.2147 & 5.1581 & TRN & \\
\hline CHEMBL 2312821 & 934066 & 3.2218 & 3.5515 & TRN & \\
\hline CHEMBL 2313080 & 934066 & 5.585 & 5.3715 & TRN & \\
\hline CHEMBL 2313133 & 934066 & 4.6383 & 4.7574 & TST & \\
\hline
\end{tabular}




\begin{tabular}{|c|c|c|c|c|}
\hline \multicolumn{5}{|c|}{ Supplemental Tab. } \\
\hline CHEMBL2313099 & 934066 & 5.3665 & 5.2389 & TRN \\
\hline CHEMBL 2088014 & 934066 & 5.5528 & 5.032 & TRN \\
\hline CHEMBL2313119 & 934066 & 5.1135 & 4.6671 & TRN \\
\hline CHEMBL 2313087 & 934066 & 5.2757 & 5.3334 & TRN \\
\hline CHEMBL2313118 & 934066 & 5.2518 & 5.3037 & TRN \\
\hline CHEMBL584646 & 934066 & 4.9586 & 4.9182 & TRN \\
\hline CHEMBL2313130 & 934066 & 3.2218 & 4.9562 & TST \\
\hline CHEMBL2313107 & 934066 & 5.2147 & 5.4763 & TRN \\
\hline CHEMBL2313109 & 934066 & 5.2676 & 5.3345 & TRN \\
\hline CHEMBL2313115 & 934066 & 5.2676 & 5.1609 & TRN \\
\hline CHEMBL2313137 & 934066 & 5.0915 & 5.0828 & TRN \\
\hline CHEMBL2313102 & 934066 & 5.2076 & 5.2885 & TRN \\
\hline CHEMBL2313126 & 934066 & 3.2218 & 4.1594 & TRN \\
\hline CHEMBL2313116 & 934066 & 5.6021 & 5.4196 & TRN \\
\hline CHEMBL 2313090 & 934066 & 5.2366 & 5.1442 & TRN \\
\hline CHEMBL 2313098 & 934066 & 5.4949 & 5.3284 & TRN \\
\hline CHEMBL1892375 & 934066 & 4.6576 & 3.9002 & TRN \\
\hline CHEMBL2313095 & 934066 & 4.7447 & 4.6455 & TRN \\
\hline CHEMBL2313129 & 934066 & 4.8861 & 5.0363 & TST \\
\hline CHEMBL 2313125 & 934066 & 3.2218 & 2.9372 & TRN \\
\hline CHEMBL 2313134 & 934066 & 4.5686 & 4.9408 & TRN \\
\hline CHEMBL2312831 & 934066 & 5.0969 & 5.1244 & TRN \\
\hline CHEMBL 2312828 & 934066 & 3.2218 & 4.2115 & TRN \\
\hline CHEMBL2179164 & 934066 & 5.2441 & 4.7968 & TRN \\
\hline CHEMBL 2313124 & 934066 & 3.2218 & 3.574 & TRN \\
\hline CHEMBL 2313084 & 934066 & 5.0706 & 5.2186 & TRN \\
\hline CHEMBL589733 & 934066 & 5.2291 & 4.8955 & TRN \\
\hline CHEMBL2313136 & 934066 & 5.3098 & 5.2118 & TRN \\
\hline CHEMBL2313122 & 934066 & 3.2218 & 5.2361 & TST \\
\hline CHEMBL2313079 & 934066 & 5.4559 & 5.2981 & TRN \\
\hline CHEMBL2313139 & 934066 & 3.2218 & 4.0283 & TST \\
\hline CHEMBL2313127 & 934066 & 4.7696 & 3.7761 & TRN \\
\hline CHEMBL2313106 & 934066 & 5.3279 & 5.615 & TRN \\
\hline CHEMBL2313114 & 934066 & 5.5086 & 5.0128 & TST \\
\hline CHEMBL2179173 & 934066 & 5.5086 & 4.967 & TRN \\
\hline CHEMBL2313135 & 934066 & 4.7212 & 4.7574 & TRN \\
\hline CHEMBL 2313138 & 934066 & 5.1805 & 5.2982 & TRN \\
\hline CHEMBL2313094 & 934066 & 5.2366 & 5.4797 & TRN \\
\hline CHEMBL2312830 & 934066 & 3.2218 & 3.6102 & TRN \\
\hline CHEMBL2313083 & 934066 & 5.4949 & 5.3196 & TRN \\
\hline CHEMBL 2313120 & 934066 & 3.2218 & 4.4528 & TRN \\
\hline CHEMBL2313076 & 934066 & 4.9586 & 5.4295 & TRN \\
\hline CHEMBL2312826 & 934066 & 3.2218 & 4.2138 & TRN \\
\hline CHEMBL2313082 & 934066 & 5.3188 & 4.7393 & TRN \\
\hline CHEMBL2313092 & 934066 & 5.1135 & 5.1226 & TRN \\
\hline CHEMBL2313128 & 934066 & 5.1079 & 4.9845 & TST \\
\hline CHEMBL 2179168 & 934066 & 5.0 & 4.7622 & TRN \\
\hline CHEMBL2313111 & 934066 & 5.2147 & 5.1768 & TRN \\
\hline
\end{tabular}




\begin{tabular}{|c|c|c|c|c|c|}
\hline \multicolumn{6}{|c|}{ Supplemental Table S2.txt } \\
\hline CHEMBL 2313075 & 934066 & 4.8861 & 5.3788 & TRN & \\
\hline CHEMBL 2313085 & 934066 & 4.6383 & 4.9506 & TRN & \\
\hline CHEMBL 2313081 & 934066 & 5.5376 & 5.4714 & TRN & \\
\hline CHEMBL 2313103 & 934066 & 5.1739 & 5.2963 & TRN & \\
\hline CHEMBL 2312824 & 934066 & 4.3665 & 3.7345 & TRN & \\
\hline CHEMBL536151 & 934066 & 5.284 & 5.1269 & TRN & \\
\hline CHEMBL 2313089 & 934066 & 5.3468 & 5.4003 & TRN & \\
\hline CHEMBL 2312825 & 934066 & 4.7212 & 4.9451 & TRN & \\
\hline CHEMBL 2313110 & 934066 & 5.2924 & 5.5627 & TRN & \\
\hline CHEMBL 2313108 & 934066 & 5.0177 & 5.336 & TRN & \\
\hline CHEMBL 2313117 & 934066 & 5.3098 & 5.473 & TRN & \\
\hline CHEMBL 2312822 & 934066 & 4.7696 & 5.0296 & TRN & \\
\hline CHEMBL2313096 & 934066 & 5.3872 & 5.0714 & TRN & \\
\hline CHEMBL 2312829 & 934066 & 3.2218 & 3.4976 & TRN & \\
\hline CHEMBL 2313097 & 934066 & 6.7212 & 5.3741 & TRN & \\
\hline CHEMBL 2313121 & 934066 & 5.7696 & 4.7314 & TRN & \\
\hline CHEMBL1956577 & 934066 & 3.2218 & 4.4235 & TST & \\
\hline CHEMBL 2312823 & 934066 & 5.1367 & 4.8921 & TRN & \\
\hline CHEMBL 2313074 & 934066 & 4.8861 & 5.0284 & TRN & \\
\hline CHEMBL461542 & 934066 & 4.9208 & 4.5338 & TRN & \\
\hline CHEMBL 2179169 & 934066 & 4.8239 & 4.843 & TRN & \\
\hline CHEMBL 2313086 & 934066 & 3.2218 & 4.8555 & TRN & \\
\hline CHEMBL 2313112 & 934066 & 3.2218 & 3.6289 & TST & \\
\hline CHEMBL 2312819 & 934066 & 4.7696 & 4.2223 & TRN & \\
\hline CHEMBL2313101 & 934066 & 5.2676 & 4.97 & TRN & \\
\hline CHEMBL 2313077 & 934066 & 5.6198 & 5.1454 & TST & \\
\hline CHEMBL 2178702 & 934066 & 4.6778 & 4.93 & TST & \\
\hline CHEMBL 2313131 & 934066 & 4.9208 & 4.752 & TST & \\
\hline CHEMBL 2313123 & 934066 & 3.2218 & 3.9716 & TST & \\
\hline CHEMBL 2313093 & 934066 & 5.2007 & 4.9575 & TST & \\
\hline CHEMBL 2313091 & 934066 & 5.3565 & 5.1098 & TST & \\
\hline CHEMBL 2312818 & 934066 & 3.2218 & 4.0519 & TST & \\
\hline CHEMBL 2313105 & 934066 & 4.4949 & 5.0307 & TST & \\
\hline CHEMBL 2313088 & 934066 & 5.3468 & 5.2565 & TST & \\
\hline CHEMBL 2313104 & 934066 & 5.0969 & 4.4345 & TST & \\
\hline CHEMBL 2313078 & 934066 & 5.0706 & 5.29899 & 99999999995 & TST \\
\hline CHEMBL 2312820 & 934066 & 3.2218 & 4.1026 & TST & \\
\hline CHEMBL 2313100 & 934066 & 5.3279 & 5.1309 & TST & \\
\hline CHEMBL 2312832 & 934066 & 5.2757 & 5.1891 & TST & \\
\hline CHEMBL1528032 & 688300 & 2.9499 & 2.2856 & TRN & \\
\hline CHEMBL1390836 & 688300 & 2.9499 & 4.5156 & TST & \\
\hline CHEMBL1321091 & 688300 & 2.9499 & 3.5284 & TRN & \\
\hline CHEMBL1971142 & 688300 & 8.0555 & 6.7781 & TRN & \\
\hline CHEMBL1330076 & 688300 & 2.9499 & 4.2122 & TRN & \\
\hline CHEMBL1430755 & 688300 & 2.9499 & 3.201 & TRN & \\
\hline CHEMBL589351 & 688300 & 5.9446 & 6.5902 & TRN & \\
\hline CHEMBL1559414 & 688300 & 6.3883 & 5.3542 & TRN & \\
\hline CHEMBL1581794 & 688300 & 2.9499 & 2.6729 & TST & \\
\hline
\end{tabular}




\begin{tabular}{|c|c|c|c|c|c|c|}
\hline & & \multicolumn{5}{|c|}{ Supplemental Table S2.txt } \\
\hline CHEMBL1349301 & 688300 & 2.9499 & 3.0009 & TST & & \\
\hline CHEMBL1316069 & 688300 & 2.9499 & 2.6039 & TRN & & \\
\hline CHEMBL3208355 & 688300 & 2.9499 & 2.7333 & TRN & & \\
\hline CHEMBL1381307 & 688300 & 2.9499 & 2.7179 & TRN & & \\
\hline CHEMBL1543209 & 688300 & 2.9499 & 4.0846 & TRN & & \\
\hline CHEMBL1517275 & 688300 & 2.9499 & 2.8276 & TRN & & \\
\hline CHEMBL1352154 & 688300 & 6.0315 & 5.6828 & TRN & & \\
\hline CHEMBL1985575 & 688300 & $6.8210 e$ & 00000000 & & 6.6863 & TRN \\
\hline CHEMBL1556937 & 688300 & 2.9499 & 3.4028 & TRN & & \\
\hline CHEMBL1391688 & 688300 & 2.9499 & 3.5952 & TRN & & \\
\hline CHEMBL530609 & 688300 & 6.1163 & 5.1203 & TRN & & \\
\hline CHEMBL405317 & 688300 & 6.9136 & 6.9881 & TRN & & \\
\hline CHEMBL1575124 & 688300 & 5.994 & 6.4527 & TRN & & \\
\hline CHEMBL1363200 & 688300 & 2.9499 & 2.4957 & TST & & \\
\hline CHEMBL1424442 & 688300 & 2.9499 & 3.1737 & TRN & & \\
\hline CHEMBL1500807 & 688300 & 2.9499 & 3.0541 & TRN & & \\
\hline CHEMBL1492209 & 688300 & 5.1924 & 4.5064 & TRN & & \\
\hline CHEMBL1488020 & 688300 & 5.9234 & 5.2824 & TRN & & \\
\hline CHEMBL1551203 & 688300 & 2.9499 & 2.7092 & TRN & & \\
\hline CHEMBL1365952 & 688300 & 2.9499 & 2.9609 & TRN & & \\
\hline CHEMBL1427265 & 688300 & 5.1965 & 4.8728 & TRN & & \\
\hline CHEMBL1445157 & 688300 & 2.9499 & 2.5362 & TRN & & \\
\hline CHEMBL1604503 & 688300 & 2.9499 & 2.99 & TRN & & \\
\hline CHEMBL1365815 & 688300 & 2.9499 & 3.3545 & TRN & & \\
\hline CHEMBL1353184 & 688300 & 5.7698 & 5.5596 & TRN & & \\
\hline CHEMBL1529787 & 688300 & 2.9499 & 2.4103 & TRN & & \\
\hline CHEMBL1350152 & 688300 & 6.1844 & 6.7036 & TRN & & \\
\hline CHEMBL1416364 & 688300 & 2.9499 & 3.2848 & TRN & & \\
\hline CHEMBL1443750 & 688300 & 2.9499 & 3.8248 & TRN & & \\
\hline CHEMBL260342 & 688300 & 8.0555 & 7.3696 & TRN & & \\
\hline CHEMBL1518778 & 688300 & 4.7657 & 4.8476 & TRN & & \\
\hline CHEMBL1580554 & 688300 & 2.9499 & 2.7031 & TRN & & \\
\hline CHEMBL1474711 & 688300 & 2.9499 & 3.4222 & TRN & & \\
\hline CHEMBL1471899 & 688300 & 4.8569 & 4.5354 & TST & & \\
\hline CHEMBL1477386 & 688300 & 2.9499 & 3.5062 & TRN & & \\
\hline CHEMBL1575708 & 688300 & 6.0904 & 6.0358 & TRN & & \\
\hline CHEMBL1588099 & 688300 & 2.9499 & 2.6278 & TRN & & \\
\hline CHEMBL1516626 & 688300 & 2.9499 & 2.8244 & TRN & & \\
\hline CHEMBL1449264 & 688300 & 2.9499 & 3.5484 & TRN & & \\
\hline CHEMBL1359246 & 688300 & 2.9499 & 3.5196 & TST & & \\
\hline CHEMBL1524355 & 688300 & 2.9499 & 2.8462 & TRN & & \\
\hline CHEMBL1461365 & 688300 & 2.9499 & 2.5398 & TRN & & \\
\hline CHEMBL 2005141 & 688300 & 2.9499 & 3.3234 & TST & & \\
\hline CHEMBL3210276 & 688300 & 2.9499 & 3.2177 & TRN & & \\
\hline CHEMBL1401302 & 688300 & 6.0545 & 5.7306 & TRN & & \\
\hline CHEMBL1490427 & 688300 & 5.23 & 5.7563 & TRN & & \\
\hline CHEMBL1601930 & 688300 & 2.9499 & 3.3016 & TRN & & \\
\hline CHEMBL1548731 & 688300 & 2.9499 & 3.4665 & TST & & \\
\hline
\end{tabular}




\begin{tabular}{|c|c|c|c|c|c|}
\hline \multicolumn{6}{|c|}{ Supplemental Table S2.txt } \\
\hline CHEMBL1427156 & 688300 & 2.9499 & 2.7921 & TRN & \\
\hline CHEMBL1438962 & 688300 & 2.9499 & 2.7023 & TRN & \\
\hline CHEMBL1493085 & 688300 & 2.9499 & 3.2126 & TRN & \\
\hline CHEMBL1371339 & 688300 & 6.2848 & 6.0921 & TRN & \\
\hline CHEMBL1344160 & 688300 & 2.9499 & 3.2745 & TRN & \\
\hline CHEMBL1564595 & 688300 & 2.9499 & 2.8313 & TRN & \\
\hline CHEMBL1553597 & 688300 & 2.9499 & 2.7618 & TRN & \\
\hline CHEMBL1359762 & 688300 & 2.9499 & 3.1215 & TRN & \\
\hline CHEMBL1441042 & 688300 & 4.457 & 4.619 & TRN & \\
\hline CHEMBL1462301 & 688300 & 4.8558 & 4.7088 & TRN & \\
\hline CHEMBL1323089 & 688300 & 2.9499 & 2.6864 & TRN & \\
\hline CHEMBL1502654 & 688300 & 2.9499 & 3.0989 & TRN & \\
\hline CHEMBL1307776 & 688300 & 5.6379 & 5.0635 & TRN & \\
\hline CHEMBL1314349 & 688300 & 2.9499 & 2.8139 & TRN & \\
\hline CHEMBL1478415 & 688300 & 2.9499 & 2.9874 & TST & \\
\hline CHEMBL1557987 & 688300 & 2.9499 & 3.23100 & 00000000003 & TRN \\
\hline CHEMBL1329224 & 688300 & 2.9499 & 3.0709 & TRN & \\
\hline CHEMBL290077 & 688300 & 2.9499 & 3.4276 & TRN & \\
\hline CHEMBL1339683 & 688300 & 2.9499 & 2.9675 & TRN & \\
\hline CHEMBL1497510 & 688300 & 2.9499 & 2.7772 & TRN & \\
\hline CHEMBL1409610 & 688300 & 2.9499 & 3.1699 & TRN & \\
\hline CHEMBL1610324 & 688300 & 2.9499 & 2.7598 & TRN & \\
\hline CHEMBL1445579 & 688300 & 2.9499 & 2.7145 & TRN & \\
\hline CHEMBL1575897 & 688300 & 2.9499 & 2.2897 & TRN & \\
\hline CHEMBL1456224 & 688300 & 2.9499 & 2.57800 & 00000000003 & TRN \\
\hline CHEMBL3196827 & 688300 & 6.0237 & 6.28 & TRN & \\
\hline CHEMBL1990529 & 688300 & 2.9499 & 2.8058 & TRN & \\
\hline CHEMBL1416658 & 688300 & 2.9499 & 3.5913 & TRN & \\
\hline CHEMBL3198496 & 688300 & 6.1965 & 5.6274 & TST & \\
\hline CHEMBL1444056 & 688300 & 2.9499 & 3.437 & TRN & \\
\hline CHEMBL1575068 & 688300 & 2.9499 & 3.0435 & TRN & \\
\hline CHEMBL1581280 & 688300 & 2.9499 & 3.0109 & TRN & \\
\hline CHEMBL34137 & 688300 & 2.9499 & 3.3671 & TRN & \\
\hline CHEMBL1407766 & 688300 & 4.1318 & 2.8773 & TRN & \\
\hline CHEMBL1604790 & 688300 & 5.9792 & 5.8967 & TRN & \\
\hline CHEMBL1528570 & 688300 & 4.6439 & 2.8827 & TST & \\
\hline CHEMBL1404803 & 688300 & 2.9499 & 3.1879 & TRN & \\
\hline CHEMBL1383991 & 688300 & 5.7291 & 5.1789 & TRN & \\
\hline CHEMBL1459024 & 688300 & 2.9499 & 2.9236 & TRN & \\
\hline CHEMBL1463492 & 688300 & 2.9499 & 3.4752 & TST & \\
\hline CHEMBL1383162 & 688300 & 2.9499 & 2.9323 & TST & \\
\hline CHEMBL1509068 & 688300 & 2.9499 & 3.0167 & TRN & \\
\hline CHEMBL1567199 & 688300 & 2.9499 & 2.8981 & TRN & \\
\hline CHEMBL1466375 & 688300 & 2.9499 & 3.4353 & TST & \\
\hline CHEMBL1558162 & 688300 & 2.9499 & 2.8262 & TRN & \\
\hline CHEMBL1346239 & 688300 & 2.9499 & 3.6242 & TRN & \\
\hline CHEMBL1574393 & 688300 & 2.9499 & 2.9811 & TST & \\
\hline CHEMBL1976507 & 688300 & 5.4651 & 5.6425 & TRN & \\
\hline
\end{tabular}




\begin{tabular}{|c|c|c|c|c|c|}
\hline \multicolumn{6}{|c|}{ Supplemental Table S2.txt } \\
\hline CHEMBL1519619 & 688300 & 2.9499 & 3.8508 & TST & \\
\hline CHEMBL1395528 & 688300 & 4.4954 & 3.045 & TRN & \\
\hline CHEMBL1400773 & 688300 & 2.9499 & 3.4702 & TRN & \\
\hline CHEMBL1584076 & 688300 & 2.9499 & 3.102 & TRN & \\
\hline CHEMBL1390012 & 688300 & 2.9499 & 2.5628 & TST & \\
\hline CHEMBL1439683 & 688300 & 2.9499 & 3.47300 & 20000000003 & TRN \\
\hline CHEMBL1605424 & 688300 & 2.9499 & 2.8913 & TRN & \\
\hline CHEMBL1387610 & 688300 & 6.9788 & 6.0785 & TRN & \\
\hline CHEMBL1420372 & 688300 & 2.9499 & 2.7967 & TST & \\
\hline CHEMBL1431510 & 688300 & 2.9499 & 2.3981 & TRN & \\
\hline CHEMBL1461383 & 688300 & 2.9499 & 2.9308 & TRN & \\
\hline CHEMBL1368422 & 688300 & 2.9499 & 3.1203 & TRN & \\
\hline CHEMBL 2002776 & 688300 & 5.9404 & 5.6795 & TRN & \\
\hline CHEMBL1367229 & 688300 & 2.9499 & 3.7247 & TRN & \\
\hline CHEMBL1600679 & 688300 & 2.9499 & 3.6204 & TRN & \\
\hline CHEMBL1345739 & 688300 & 2.9499 & 3.301 & TRN & \\
\hline CHEMBL1380879 & 688300 & 2.9499 & 2.7688 & TRN & \\
\hline CHEMBL1556623 & 688300 & 2.9499 & 3.0398 & TRN & \\
\hline CHEMBL1604379 & 688300 & 2.9499 & 2.8948 & TRN & \\
\hline CHEMBL1395672 & 688300 & 2.9499 & 3.012 & TRN & \\
\hline CHEMBL1399039 & 688300 & 2.9499 & 2.5747 & TRN & \\
\hline CHEMBL1338042 & 688300 & 2.9499 & 3.3179 & TRN & \\
\hline CHEMBL1602702 & 688300 & 2.9499 & 3.0247 & TRN & \\
\hline CHEMBL1462373 & 688300 & 6.2899 & 6.2176 & TRN & \\
\hline CHEMBL1560740 & 688300 & 2.9499 & 3.3371 & TRN & \\
\hline CHEMBL1375202 & 688300 & 2.9499 & 3.38100 & 00000000002 & TRN \\
\hline CHEMBL1444088 & 688300 & 2.9499 & 2.758 & TRN & \\
\hline CHEMBL1465301 & 688300 & 2.9499 & 2.9549 & TRN & \\
\hline CHEMBL1511023 & 688300 & 2.9499 & 2.8993 & TST & \\
\hline CHEMBL1405526 & 688300 & 2.9499 & 2.4412 & TRN & \\
\hline CHEMBL1989440 & 688300 & 6.1959 & 5.5951 & TRN & \\
\hline CHEMBL1378867 & 688300 & 2.9499 & 3.0884 & TRN & \\
\hline CHEMBL1495187 & 688300 & 2.9499 & 2.5897 & TRN & \\
\hline CHEMBL1546066 & 688300 & 2.9499 & 4.2595 & TRN & \\
\hline CHEMBL1423495 & 688300 & 2.9499 & 2.7237 & TRN & \\
\hline CHEMBL1578636 & 688300 & 2.9499 & 3.37 & TRN & \\
\hline CHEMBL191015 & 688300 & 5.4004 & 4.2254 & TRN & \\
\hline CHEMBL1429218 & 688300 & 5.6751 & 6.2773 & TRN & \\
\hline CHEMBL149322 & 688300 & 5.7383 & 5.6835 & TRN & \\
\hline CHEMBL1539359 & 688300 & 5.8636 & 6.2078 & TRN & \\
\hline CHEMBL1468230 & 688300 & 2.9499 & 3.4873 & TRN & \\
\hline CHEMBL1346222 & 688300 & 2.9499 & 3.0265 & TRN & \\
\hline CHEMBL1378443 & 688300 & 2.9499 & 2.9037 & TRN & \\
\hline CHEMBL1371529 & 688300 & 2.9499 & 2.6121 & TRN & \\
\hline CHEMBL1446954 & 688300 & 2.9499 & 2.3521 & TST & \\
\hline CHEMBL1541658 & 688300 & 2.9499 & 2.3998 & TRN & \\
\hline CHEMBL3210376 & 688300 & 2.9499 & 2.9925 & TRN & \\
\hline CHEMBL1580851 & 688300 & 2.9499 & 2.6791 & TRN & \\
\hline
\end{tabular}




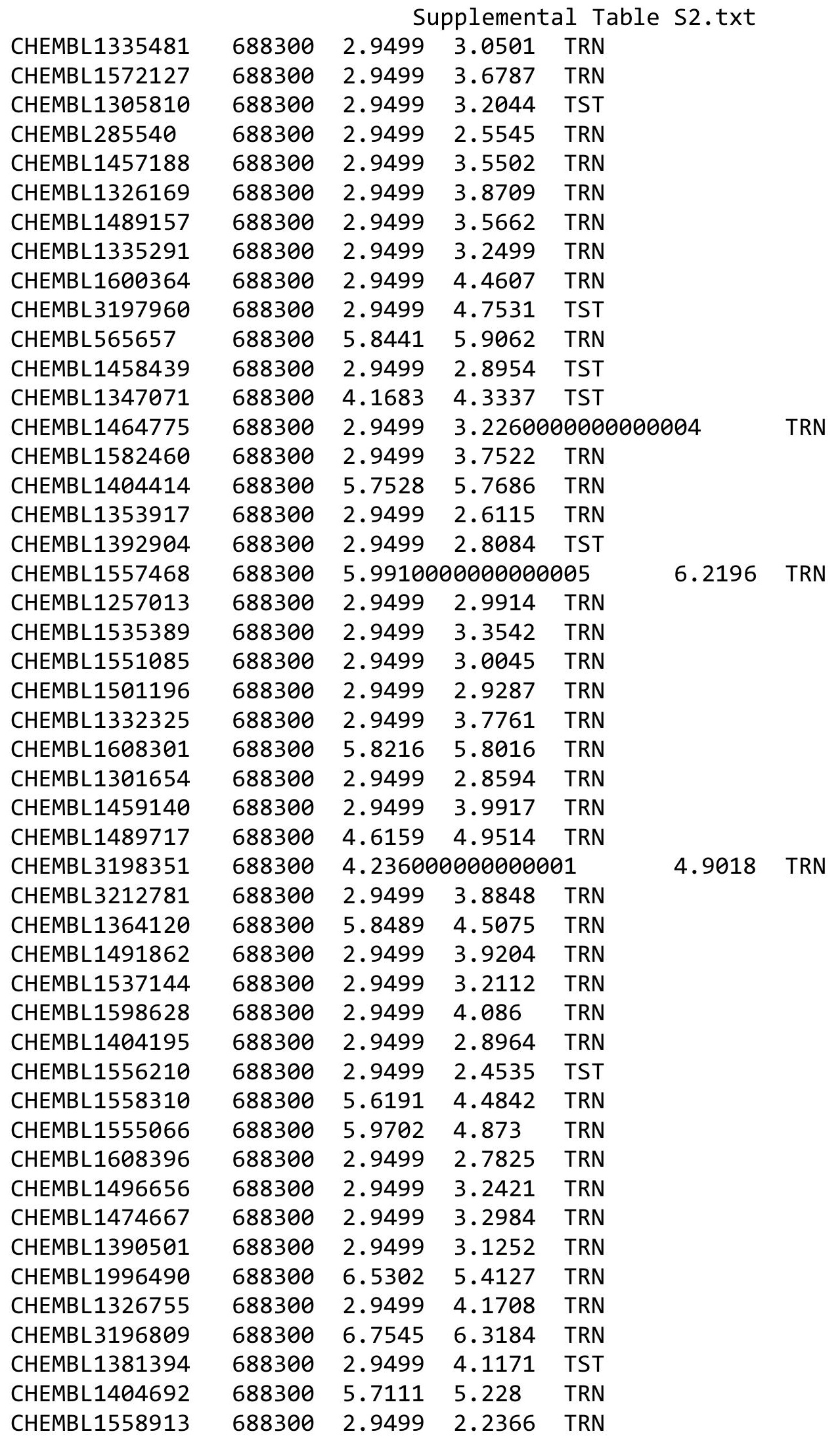

Page 11371 


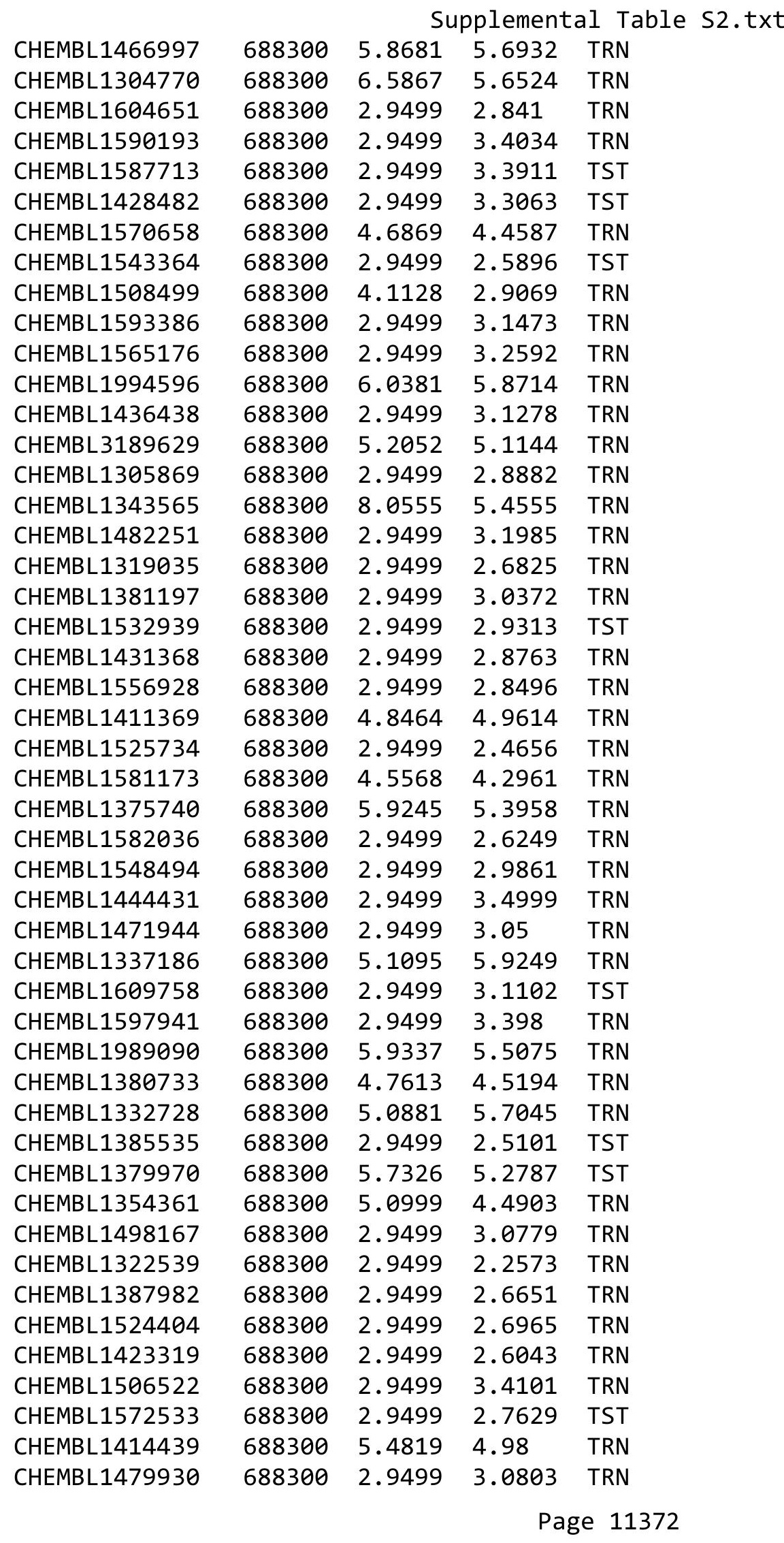




\begin{tabular}{|c|c|c|c|c|c|}
\hline & & \multicolumn{4}{|c|}{ Supplemental Table S2.txt } \\
\hline CHEMBL1405269 & 688300 & 2.9499 & 2.8751 & TRN & \\
\hline CHEMBL1423000 & 688300 & 2.9499 & 3.3507 & TRN & \\
\hline CHEMBL1423924 & 688300 & 4.6708 & 3.7326 & TRN & \\
\hline CHEMBL1375370 & 688300 & 2.9499 & 3.4137 & TST & \\
\hline CHEMBL1490104 & 688300 & 2.9499 & 4.1888 & TRN & \\
\hline CHEMBL1587915 & 688300 & 2.9499 & 2.2398 & TRN & \\
\hline CHEMBL1339206 & 688300 & 2.9499 & 3.5472 & TRN & \\
\hline CHEMBL3194013 & 688300 & 6.1739 & 5.8492 & TRN & \\
\hline CHEMBL1532512 & 688300 & 4.4233 & 5.0882 & TRN & \\
\hline CHEMBL1573994 & 688300 & 5.2987 & 4.7351 & TST & \\
\hline CHEMBL1508268 & 688300 & 2.9499 & 2.784 & TRN & \\
\hline CHEMBL1533919 & 688300 & 2.9499 & 3.4999 & TRN & \\
\hline CHEMBL1322500 & 688300 & 2.9499 & 3.0054 & TRN & \\
\hline CHEMBL1497635 & 688300 & 5.6328 & 5.2775 & TRN & \\
\hline CHEMBL1452854 & 688300 & 2.9499 & 3.1023 & TRN & \\
\hline CHEMBL1493607 & 688300 & 2.9499 & 2.46599 & 99999999997 & TST \\
\hline CHEMBL1367227 & 688300 & 2.9499 & 3.0824 & TST & \\
\hline CHEMBL1374873 & 688300 & 2.9499 & 2.6959 & TST & \\
\hline CHEMBL1470619 & 688300 & 4.6021 & 3.7713 & TRN & \\
\hline CHEMBL1399001 & 688300 & 2.9499 & 3.0075 & TRN & \\
\hline CHEMBL1451815 & 688300 & 2.9499 & 3.5587 & TRN & \\
\hline CHEMBL1458038 & 688300 & 6.4168 & 6.4681 & TRN & \\
\hline CHEMBL1311937 & 688300 & 2.9499 & 2.9259 & TRN & \\
\hline CHEMBL1366712 & 688300 & 5.9876 & 5.5252 & TRN & \\
\hline CHEMBL1465261 & 688300 & 2.9499 & 2.7454 & TRN & \\
\hline CHEMBL1459767 & 688300 & 4.8025 & 4.7478 & TRN & \\
\hline CHEMBL1337356 & 688300 & 2.9499 & 3.2851 & TRN & \\
\hline CHEMBL1360822 & 688300 & 2.9499 & 3.7395 & TRN & \\
\hline CHEMBL1531806 & 688300 & 5.8136 & 4.7803 & TRN & \\
\hline CHEMBL1388041 & 688300 & 2.9499 & 2.6133 & TRN & \\
\hline CHEMBL1500900 & 688300 & 2.9499 & 2.7989 & TRN & \\
\hline CHEMBL1321728 & 688300 & 2.9499 & 2.9147 & TRN & \\
\hline CHEMBL1608077 & 688300 & 4.5452 & 3.2213 & TRN & \\
\hline CHEMBL1392877 & 688300 & 2.9499 & 2.495 & TRN & \\
\hline CHEMBL1426973 & 688300 & 2.9499 & 3.0742 & TST & \\
\hline CHEMBL1347016 & 688300 & 2.9499 & 2.5547 & TST & \\
\hline CHEMBL1589029 & 688300 & 5.4044 & 4.6404 & TRN & \\
\hline CHEMBL1361529 & 688300 & 2.9499 & 3.0425 & TRN & \\
\hline CHEMBL3199632 & 688300 & 2.9499 & 3.3654 & TRN & \\
\hline CHEMBL171279 & 688300 & 2.9499 & 2.8711 & TRN & \\
\hline CHEMBL1599219 & 688300 & 2.9499 & 3.1841 & TRN & \\
\hline CHEMBL1471294 & 688300 & 2.9499 & 3.1648 & TRN & \\
\hline CHEMBL3192027 & 688300 & 4.7015 & 4.6772 & TRN & \\
\hline CHEMBL3207589 & 688300 & 2.9499 & 4.2291 & TST & \\
\hline CHEMBL1414273 & 688300 & 5.9485 & 6.1369 & TRN & \\
\hline CHEMBL3196977 & 688300 & 2.9499 & 3.2999 & TRN & \\
\hline CHEMBL1385635 & 688300 & 2.9499 & 2.3053 & TRN & \\
\hline CHEMBL1528618 & 688300 & 2.9499 & 3.5176 & TST & \\
\hline
\end{tabular}




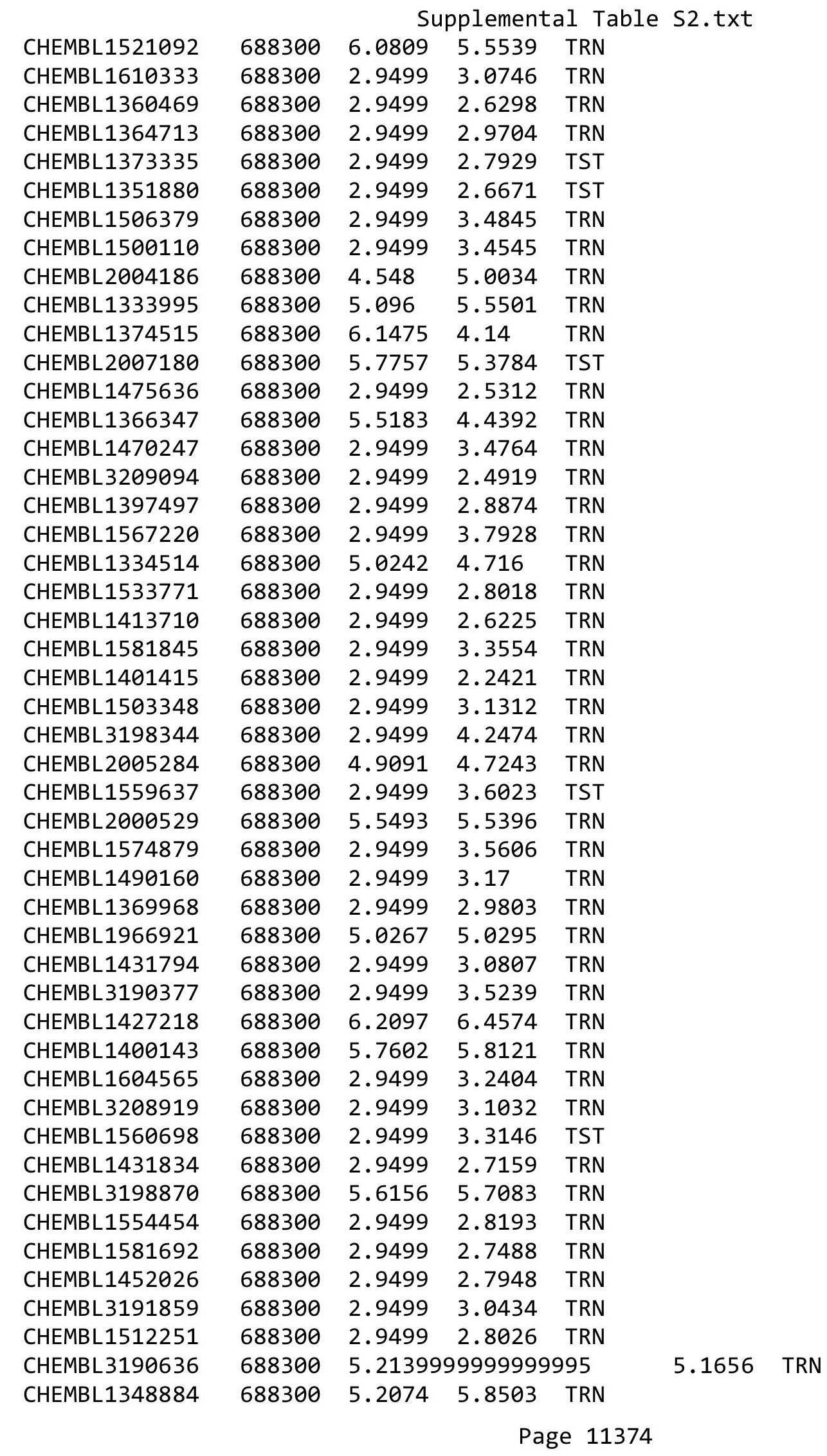




\begin{tabular}{|c|c|c|c|c|c|}
\hline \multicolumn{6}{|c|}{ Supplemental Table S2.txt } \\
\hline CHEMBL1428826 & 688300 & 2.9499 & 3.0974 & TST & \\
\hline CHEMBL3209179 & 688300 & 2.9499 & 4.4751 & TRN & \\
\hline CHEMBL473721 & 688300 & 6.0227 & 6.7689 & TRN & \\
\hline CHEMBL1573789 & 688300 & 2.9499 & 2.7787 & TST & \\
\hline CHEMBL1515601 & 688300 & 2.9499 & 2.9425 & TRN & \\
\hline CHEMBL1390311 & 688300 & 2.9499 & 3.0247 & TST & \\
\hline CHEMBL1479862 & 688300 & 2.9499 & 2.9934 & TRN & \\
\hline CHEMBL1388707 & 688300 & 2.9499 & 3.1482 & TRN & \\
\hline CHEMBL1505074 & 688300 & 2.9499 & 2.8885 & TRN & \\
\hline CHEMBL1331020 & 688300 & 2.9499 & 3.1141 & TRN & \\
\hline CHEMBL1311780 & 688300 & 2.9499 & 2.3676 & TRN & \\
\hline CHEMBL1353358 & 688300 & 2.9499 & 3.6928 & TRN & \\
\hline CHEMBL1521649 & 688300 & 2.9499 & 4.1677 & TRN & \\
\hline CHEMBL1349543 & 688300 & 2.9499 & 2.9698 & TRN & \\
\hline CHEMBL1576148 & 688300 & 2.9499 & 3.3794 & TRN & \\
\hline CHEMBL1452733 & 688300 & 2.9499 & 2.66399 & 99999999997 & TRN \\
\hline CHEMBL1214519 & 688300 & 4.7942 & 5.5406 & TRN & \\
\hline CHEMBL1595734 & 688300 & 2.9499 & 3.1603 & TRN & \\
\hline CHEMBL1423749 & 688300 & 2.9499 & 3.1665 & TST & \\
\hline CHEMBL1380941 & 688300 & 2.9499 & 3.8906 & TRN & \\
\hline CHEMBL1526174 & 688300 & 6.8633 & 5.6903 & TRN & \\
\hline CHEMBL1333831 & 688300 & 6.1186 & 6.4853 & TRN & \\
\hline CHEMBL1445973 & 688300 & 2.9499 & 3.123 & TRN & \\
\hline CHEMBL1392444 & 688300 & 2.9499 & 3.2051 & TRN & \\
\hline CHEMBL1447914 & 688300 & 2.9499 & 3.2313 & TRN & \\
\hline CHEMBL1390088 & 688300 & 2.9499 & 2.5595 & TRN & \\
\hline CHEMBL1332181 & 688300 & 2.9499 & 2.6287 & TRN & \\
\hline CHEMBL1454010 & 688300 & 2.9499 & 3.2945 & TRN & \\
\hline CHEMBL1376303 & 688300 & 2.9499 & 2.82899 & 99999999997 & TRN \\
\hline CHEMBL1524929 & 688300 & 6.5287 & 6.081 & TRN & \\
\hline CHEMBL1326128 & 688300 & 2.9499 & 2.6358 & TRN & \\
\hline CHEMBL1380888 & 688300 & 2.9499 & 2.7455 & TRN & \\
\hline CHEMBL1477957 & 688300 & 4.757 & 4.9313 & TRN & \\
\hline CHEMBL1574165 & 688300 & 2.9499 & 3.0826 & TRN & \\
\hline CHEMBL1335066 & 688300 & 2.9499 & 2.8042 & TRN & \\
\hline CHEMBL1415440 & 688300 & 2.9499 & 2.7631 & TRN & \\
\hline CHEMBL1481506 & 688300 & 2.9499 & 2.3603 & TRN & \\
\hline CHEMBL1428421 & 688300 & 2.9499 & 3.1044 & TST & \\
\hline CHEMBL1310341 & 688300 & 6.2874 & 6.6865 & TRN & \\
\hline CHEMBL1463879 & 688300 & 2.9499 & 3.5936 & TRN & \\
\hline CHEMBL1477100 & 688300 & 5.4519 & 5.2014 & TRN & \\
\hline CHEMBL1524484 & 688300 & 6.5072 & 5.1961 & TST & \\
\hline CHEMBL1564790 & 688300 & 2.9499 & 2.9499 & TRN & \\
\hline CHEMBL1332742 & 688300 & 2.9499 & 4.2219 & TRN & \\
\hline CHEMBL1572634 & 688300 & 5.4976 & 4.9052 & TRN & \\
\hline CHEMBL1580616 & 688300 & 4.1599 & 3.1297 & TRN & \\
\hline CHEMBL1544877 & 688300 & 6.2248 & 5.4863 & TRN & \\
\hline CHEMBL1582941 & 688300 & 2.9499 & 2.6891 & TRN & \\
\hline
\end{tabular}




\begin{tabular}{|c|c|c|c|c|}
\hline \multicolumn{5}{|c|}{ Supplemental Tab. } \\
\hline CHEMBL1347197 & 688300 & 2.9499 & 3.1323 & TRN \\
\hline CHEMBL1547714 & 688300 & 5.7575 & 4.6087 & TRN \\
\hline CHEMBL1503002 & 688300 & 4.7884 & 4.5055 & TRN \\
\hline CHEMBL1519698 & 688300 & 2.9499 & 4.0049 & TST \\
\hline CHEMBL1564425 & 688300 & 2.9499 & 3.1262 & TRN \\
\hline CHEMBL1535293 & 688300 & 2.9499 & 3.2337 & TST \\
\hline CHEMBL1561343 & 688300 & 2.9499 & 2.824 & TRN \\
\hline CHEMBL3209223 & 688300 & 2.9499 & 3.1549 & TST \\
\hline CHEMBL1539053 & 688300 & 2.9499 & 2.8165 & TRN \\
\hline CHEMBL1571574 & 688300 & 5.9259 & 5.3051 & TRN \\
\hline CHEMBL1423110 & 688300 & 2.9499 & 2.7467 & TRN \\
\hline CHEMBL1401584 & 688300 & 2.9499 & 2.7847 & TRN \\
\hline CHEMBL1305898 & 688300 & 2.9499 & 3.1558 & TRN \\
\hline CHEMBL1417398 & 688300 & 2.9499 & 2.4518 & TST \\
\hline CHEMBL1566932 & 688300 & 2.9499 & 4.2448 & TST \\
\hline CHEMBL1368187 & 688300 & 2.9499 & 3.9534 & TRN \\
\hline CHEMBL1325478 & 688300 & 4.6468 & 3.8056 & TRN \\
\hline CHEMBL1579322 & 688300 & 2.9499 & 3.3539 & TRN \\
\hline CHEMBL1482341 & 688300 & 2.9499 & 3.0089 & TRN \\
\hline CHEMBL1486109 & 688300 & 6.2612 & 6.4563 & TRN \\
\hline CHEMBL1313073 & 688300 & 2.9499 & 2.3599 & TRN \\
\hline CHEMBL1501238 & 688300 & 5.1828 & 4.5363 & TRN \\
\hline CHEMBL1466388 & 688300 & 2.9499 & 2.9847 & TRN \\
\hline CHEMBL1585865 & 688300 & 2.9499 & 3.7554 & TRN \\
\hline CHEMBL1304456 & 688300 & 2.9499 & 3.4941 & TRN \\
\hline CHEMBL3195189 & 688300 & 5.9598 & 5.0709 & TRN \\
\hline CHEMBL1521226 & 688300 & 2.9499 & 3.0753 & TRN \\
\hline CHEMBL1468581 & 688300 & 2.9499 & 2.8344 & TRN \\
\hline CHEMBL1388611 & 688300 & 5.0935 & 4.7171 & TRN \\
\hline CHEMBL1478970 & 688300 & 2.9499 & 3.0638 & TST \\
\hline CHEMBL1465831 & 688300 & 2.9499 & 2.8242 & TRN \\
\hline CHEMBL1307286 & 688300 & 2.9499 & 3.1881 & TRN \\
\hline CHEMBL 3211074 & 688300 & 2.9499 & 2.9856 & TRN \\
\hline CHEMBL1595743 & 688300 & 2.9499 & 2.8114 & TRN \\
\hline CHEMBL1584140 & 688300 & 2.9499 & 2.5299 & TRN \\
\hline CHEMBL1424324 & 688300 & 2.9499 & 2.8967 & TRN \\
\hline CHEMBL1385296 & 688300 & 2.9499 & 2.8002 & TRN \\
\hline CHEMBL1451245 & 688300 & 6.04 & 5.3942 & TRN \\
\hline CHEMBL1528232 & 688300 & 2.9499 & 2.6321 & TRN \\
\hline CHEMBL1454289 & 688300 & 2.9499 & 3.2656 & TRN \\
\hline CHEMBL1401891 & 688300 & 2.9499 & 4.3908 & TST \\
\hline CHEMBL1448184 & 688300 & 2.9499 & 2.9875 & TRN \\
\hline CHEMBL1378527 & 688300 & 2.9499 & 3.653 & TRN \\
\hline CHEMBL3193650 & 688300 & 4.4406 & 4.7244 & TRN \\
\hline CHEMBL3198603 & 688300 & 6.1175 & 5.7534 & TST \\
\hline CHEMBL1369683 & 688300 & 2.9499 & 3.3706 & TRN \\
\hline CHEMBL1379683 & 688300 & 4.6895 & 3.6292 & TRN \\
\hline CHEMBL1411333 & 688300 & 2.9499 & 3.8199 & TRN \\
\hline
\end{tabular}




\begin{tabular}{|c|c|c|c|c|c|}
\hline & & \multicolumn{4}{|c|}{ Supplemental Table S2.txt } \\
\hline CHEMBL1346564 & 688300 & 2.9499 & 2.7109 & TRN & \\
\hline CHEMBL1355540 & 688300 & 2.9499 & 2.6847 & TRN & \\
\hline CHEMBL1337402 & 688300 & 4.7986 & 3.5192 & TST & \\
\hline CHEMBL1471315 & 688300 & 2.9499 & 3.0028 & TRN & \\
\hline CHEMBL1558747 & 688300 & 2.9499 & 2.4475 & TRN & \\
\hline CHEMBL1458626 & 688300 & 2.9499 & 2.9788 & TRN & \\
\hline CHEMBL1344582 & 688300 & 5.9642 & 6.3434 & TRN & \\
\hline CHEMBL1459448 & 688300 & 2.9499 & 2.892 & TRN & \\
\hline CHEMBL1379363 & 688300 & 2.9499 & 3.335 & TRN & \\
\hline CHEMBL1399363 & 688300 & 2.9499 & 3.4419 & TST & \\
\hline CHEMBL1964891 & 688300 & 2.9499 & 3.2053 & TRN & \\
\hline CHEMBL1588813 & 688300 & 2.9499 & 4.5458 & TST & \\
\hline CHEMBL1308461 & 688300 & 3.9621 & 3.4294 & TRN & \\
\hline CHEMBL1476189 & 688300 & 6.2503 & 5.8769 & TRN & \\
\hline CHEMBL3195360 & 688300 & 6.2716 & 4.7344 & TRN & \\
\hline CHEMBL1349416 & 688300 & 2.9499 & 2.461 & TRN & \\
\hline CHEMBL3210725 & 688300 & 2.9499 & 4.1754 & TST & \\
\hline CHEMBL1463050 & 688300 & 2.9499 & 3.335 & TRN & \\
\hline CHEMBL1489863 & 688300 & 2.9499 & 2.8388 & TST & \\
\hline CHEMBL1457108 & 688300 & 2.9499 & 2.80899 & 99999999997 & TRN \\
\hline CHEMBL1300067 & 688300 & 2.9499 & 2.8962 & TRN & \\
\hline CHEMBL1402404 & 688300 & 2.9499 & 3.8152 & TST & \\
\hline CHEMBL1330417 & 688300 & 5.3517 & 5.3562 & TRN & \\
\hline CHEMBL1339911 & 688300 & 2.9499 & 3.2969 & TRN & \\
\hline CHEMBL1558550 & 688300 & 2.9499 & 3.585 & TRN & \\
\hline CHEMBL1509287 & 688300 & 5.3919 & 4.6178 & TRN & \\
\hline CHEMBL1584490 & 688300 & 2.9499 & 3.0586 & TRN & \\
\hline CHEMBL1564893 & 688300 & 2.9499 & 2.6465 & TRN & \\
\hline CHEMBL1581327 & 688300 & 2.9499 & 3.3017 & TRN & \\
\hline CHEMBL1305526 & 688300 & 2.9499 & 3.4596 & TRN & \\
\hline CHEMBL1328296 & 688300 & 2.9499 & 2.7454 & TST & \\
\hline CHEMBL1441315 & 688300 & 2.9499 & 2.9871 & TST & \\
\hline CHEMBL1400661 & 688300 & 2.9499 & 2.9399 & TST & \\
\hline CHEMBL1441481 & 688300 & 2.9499 & 3.2018 & TST & \\
\hline CHEMBL1446415 & 688300 & 2.9499 & 3.4524 & TRN & \\
\hline CHEMBL1460540 & 688300 & 2.9499 & 2.9608 & TRN & \\
\hline CHEMBL3198883 & 688300 & 4.2776 & 4.5627 & TRN & \\
\hline CHEMBL1562684 & 688300 & 5.4045 & 5.0052 & TRN & \\
\hline CHEMBL1928491 & 688300 & 5.9801 & 6.1806 & TRN & \\
\hline CHEMBL1536112 & 688300 & 2.9499 & 3.3053 & TST & \\
\hline CHEMBL1589612 & 688300 & 6.0 & 4.5926 & TST & \\
\hline CHEMBL1580081 & 688300 & 2.9499 & 2.2221 & TRN & \\
\hline CHEMBL3190606 & 688300 & 6.098 & 5.99299 & 9999999999 & TRN \\
\hline CHEMBL1323405 & 688300 & 4.0967 & 3.3408 & TRN & \\
\hline CHEMBL1464574 & 688300 & 2.9499 & 3.3608 & TRN & \\
\hline CHEMBL1545660 & 688300 & 6.5591 & 6.3333 & TRN & \\
\hline CHEMBL1429659 & 688300 & 2.9499 & 2.6928 & TRN & \\
\hline CHEMBL1409752 & 688300 & 2.9499 & 3.4065 & TRN & \\
\hline
\end{tabular}




\begin{tabular}{|c|c|c|c|c|c|}
\hline & & & & & \\
\hline CHEMBL1353602 & 688300 & 2.9499 & 2.7783 & TRN & \\
\hline CHEMBL1531320 & 688300 & 6.5406 & 5.3677 & TRN & \\
\hline CHEMBL1522839 & 688300 & 2.9499 & 2.6062 & TRN & \\
\hline CHEMBL1405180 & 688300 & 2.9499 & 2.8001 & TRN & \\
\hline CHEMBL3208326 & 688300 & 2.9499 & 3.7704 & TRN & \\
\hline CHEMBL1424054 & 688300 & 2.9499 & 3.0914 & TRN & \\
\hline CHEMBL1565070 & 688300 & 2.9499 & 2.8477 & TRN & \\
\hline CHEMBL1585837 & 688300 & 2.9499 & 3.4904 & TRN & \\
\hline CHEMBL3210689 & 688300 & 2.9499 & 4.2284 & TST & \\
\hline CHEMBL1385660 & 688300 & 2.9499 & 2.7114 & TRN & \\
\hline CHEMBL1509175 & 688300 & 2.9499 & 2.5766 & TRN & \\
\hline CHEMBL1403141 & 688300 & 2.9499 & 2.8065 & TRN & \\
\hline CHEMBL1517888 & 688300 & 2.9499 & 2.2236 & TRN & \\
\hline CHEMBL1539172 & 688300 & 2.9499 & 3.34800 & 00000000003 & TRN \\
\hline CHEMBL1432946 & 688300 & 2.9499 & 2.5479 & TRN & \\
\hline CHEMBL1372420 & 688300 & 2.9499 & 2.9254 & TRN & \\
\hline CHEMBL1501197 & 688300 & 6.3969 & 5.8883 & TRN & \\
\hline CHEMBL1472690 & 688300 & 2.9499 & 3.1595 & TST & \\
\hline CHEMBL1300964 & 688300 & 2.9499 & 3.0861 & TST & \\
\hline CHEMBL1516719 & 688300 & 2.9499 & 2.8521 & TST & \\
\hline CHEMBL1319969 & 688300 & 4.5805 & 4.6615 & TRN & \\
\hline CHEMBL1342654 & 688300 & 4.5447 & 4.6225 & TRN & \\
\hline CHEMBL1373766 & 688300 & 2.9499 & 2.3083 & TST & \\
\hline CHEMBL1497226 & 688300 & 4.4686 & 3.6264 & TRN & \\
\hline CHEMBL1392228 & 688300 & 5.8016 & 5.7848 & TRN & \\
\hline CHEMBL1374660 & 688300 & 2.9499 & 2.9341 & TRN & \\
\hline CHEMBL1452409 & 688300 & 6.2636 & 6.6851 & TRN & \\
\hline CHEMBL3211930 & 688300 & 6.2154 & 5.782 & TRN & \\
\hline CHEMBL1397979 & 688300 & 2.9499 & 2.4946 & TRN & \\
\hline CHEMBL1568259 & 688300 & 2.9499 & 3.4116 & TRN & \\
\hline CHEMBL1548167 & 688300 & 4.1526 & 4.921 & TRN & \\
\hline CHEMBL1392673 & 688300 & 6.1475 & 6.8235 & TRN & \\
\hline CHEMBL1534065 & 688300 & 2.9499 & 2.5144 & TST & \\
\hline CHEMBL1337574 & 688300 & 2.9499 & 2.6337 & TRN & \\
\hline CHEMBL3199254 & 688300 & 5.9147 & 5.25799 & 9999999999 & TRN \\
\hline CHEMBL1612409 & 688300 & 2.9499 & 2.5041 & TRN & \\
\hline CHEMBL1464533 & 688300 & 2.9499 & 2.7548 & TRN & \\
\hline CHEMBL1397255 & 688300 & 2.9499 & 2.8382 & TRN & \\
\hline CHEMBL1480613 & 688300 & 6.762006 & 30000000 & 6.2639 & TRN \\
\hline CHEMBL1381870 & 688300 & 2.9499 & 3.23199 & 99999999998 & TRN \\
\hline CHEMBL1594961 & 688300 & 6.3098 & 5.985 & TRN & \\
\hline CHEMBL1331561 & 688300 & 2.9499 & 3.0193 & TST & \\
\hline CHEMBL1613662 & 688300 & 2.9499 & 3.0213 & TRN & \\
\hline CHEMBL1536627 & 688300 & 2.9499 & 2.5526 & TRN & \\
\hline CHEMBL1550756 & 688300 & 2.9499 & 2.9461 & TRN & \\
\hline CHEMBL1494476 & 688300 & 2.9499 & 2.6255 & TRN & \\
\hline CHEMBL1586325 & 688300 & 2.9499 & 3.429 & TRN & \\
\hline CHEMBL1525300 & 688300 & 5.3278 & 5.8512 & TRN & \\
\hline
\end{tabular}




\begin{tabular}{|c|c|c|c|c|c|}
\hline \multirow[b]{2}{*}{ CHEMBL1376224 } & & \multicolumn{4}{|c|}{ Supplemental Table S2.txt } \\
\hline & 688300 & 4.5478 & 3.7925 & TRN & \\
\hline CHEMBL1564396 & 688300 & 6.2716 & 5.8018 & TRN & \\
\hline CHEMBL1527992 & 688300 & 6.8268 & 5.2861 & TST & \\
\hline CHEMBL1491701 & 688300 & 2.9499 & 3.1326 & TRN & \\
\hline CHEMBL1466311 & 688300 & 2.9499 & 3.0007 & TRN & \\
\hline CHEMBL1380496 & 688300 & 2.9499 & 2.8382 & TRN & \\
\hline CHEMBL1381194 & 688300 & 2.9499 & 3.241 & TRN & \\
\hline CHEMBL 3194523 & 688300 & \multicolumn{3}{|c|}{5.9879999999999995} & TRN \\
\hline CHEMBL1450797 & 688300 & 6.0721 & 5.9375 & TRN & \\
\hline CHEMBL1566445 & 688300 & 2.9499 & 2.4773 & TRN & \\
\hline CHEMBL339587 & 688300 & 6.3595 & 5.8566 & TRN & \\
\hline CHEMBL1497939 & 688300 & 6.2269 & 6.3623 & TRN & \\
\hline CHEMBL1312103 & 688300 & 2.9499 & 2.3046 & TST & \\
\hline CHEMBL1445047 & 688300 & 2.9499 & 2.5242 & TST & \\
\hline CHEMBL3190253 & 688300 & 2.9499 & 3.4799 & TST & \\
\hline CHEMBL1587764 & 688300 & 2.9499 & 3.0857 & TRN & \\
\hline CHEMBL1476816 & 688300 & 4.3369 & 4.2401 & TRN & \\
\hline CHEMBL1432374 & 688300 & 2.9499 & 4.2749 & TST & \\
\hline CHEMBL1562496 & 688300 & 5.5847 & 5.7306 & TRN & \\
\hline CHEMBL1345944 & 688300 & 2.9499 & 2.5739 & TST & \\
\hline CHEMBL1344470 & 688300 & 4.5387 & 3.6113 & TRN & \\
\hline CHEMBL1468817 & 688300 & 2.9499 & 3.5104 & TRN & \\
\hline CHEMBL1595793 & 688300 & 2.9499 & 3.1305 & TRN & \\
\hline CHEMBL3189921 & 688300 & 2.9499 & 3.5551 & TRN & \\
\hline CHEMBL1591294 & 688300 & 2.9499 & 4.7968 & TST & \\
\hline CHEMBL1419082 & 688300 & 5.4289 & 4.3698 & TRN & \\
\hline CHEMBL1401297 & 688300 & 2.9499 & 3.431 & TRN & \\
\hline CHEMBL1403900 & 688300 & 2.9499 & 2.8486 & TRN & \\
\hline CHEMBL 3208736 & 688300 & 5.4484 & 5.4634 & TRN & \\
\hline CHEMBL 2003508 & 688300 & 6.4828 & 5.8711 & TRN & \\
\hline CHEMBL3192393 & 688300 & 6.6055 & 5.8943 & TRN & \\
\hline CHEMBL1607613 & 688300 & 2.9499 & 2.7139 & TRN & \\
\hline CHEMBL1382566 & 688300 & 2.9499 & 2.5666 & TST & \\
\hline CHEMBL1390308 & 688300 & 2.9499 & 2.9147 & TRN & \\
\hline CHEMBL1566293 & 688300 & 2.9499 & 3.3233 & TRN & \\
\hline CHEMBL1544272 & 688300 & 4.3907 & 3.3364 & TRN & \\
\hline CHEMBL1519965 & 688300 & 6.58 & 6.3267 & TRN & \\
\hline CHEMBL1556732 & 688300 & 2.9499 & 3.8872 & TRN & \\
\hline CHEMBL584074 & 688300 & 4.346 & 4.1414 & TRN & \\
\hline CHEMBL 2007190 & 688300 & 5.4595 & 5.5009 & TRN & \\
\hline CHEMBL1460951 & 688300 & 2.9499 & 3.7035 & TRN & \\
\hline CHEMBL1452243 & 688300 & 2.9499 & 3.01800 & 00000000002 & TRN \\
\hline CHEMBL1547895 & 688300 & 2.9499 & 2.7626 & TRN & \\
\hline CHEMBL1563743 & 688300 & 2.9499 & 2.6498 & TRN & \\
\hline CHEMBL1441586 & 688300 & 2.9499 & 2.8084 & TRN & \\
\hline CHEMBL1974563 & 688300 & 5.9905 & 5.79700 & 0000000001 & TRN \\
\hline CHEMBL1353788 & 688300 & 2.9499 & 3.4355 & TRN & \\
\hline CHEMBL1484327 & 688300 & 5.9094 & 5.2477 & TRN & \\
\hline
\end{tabular}

Page 11379 


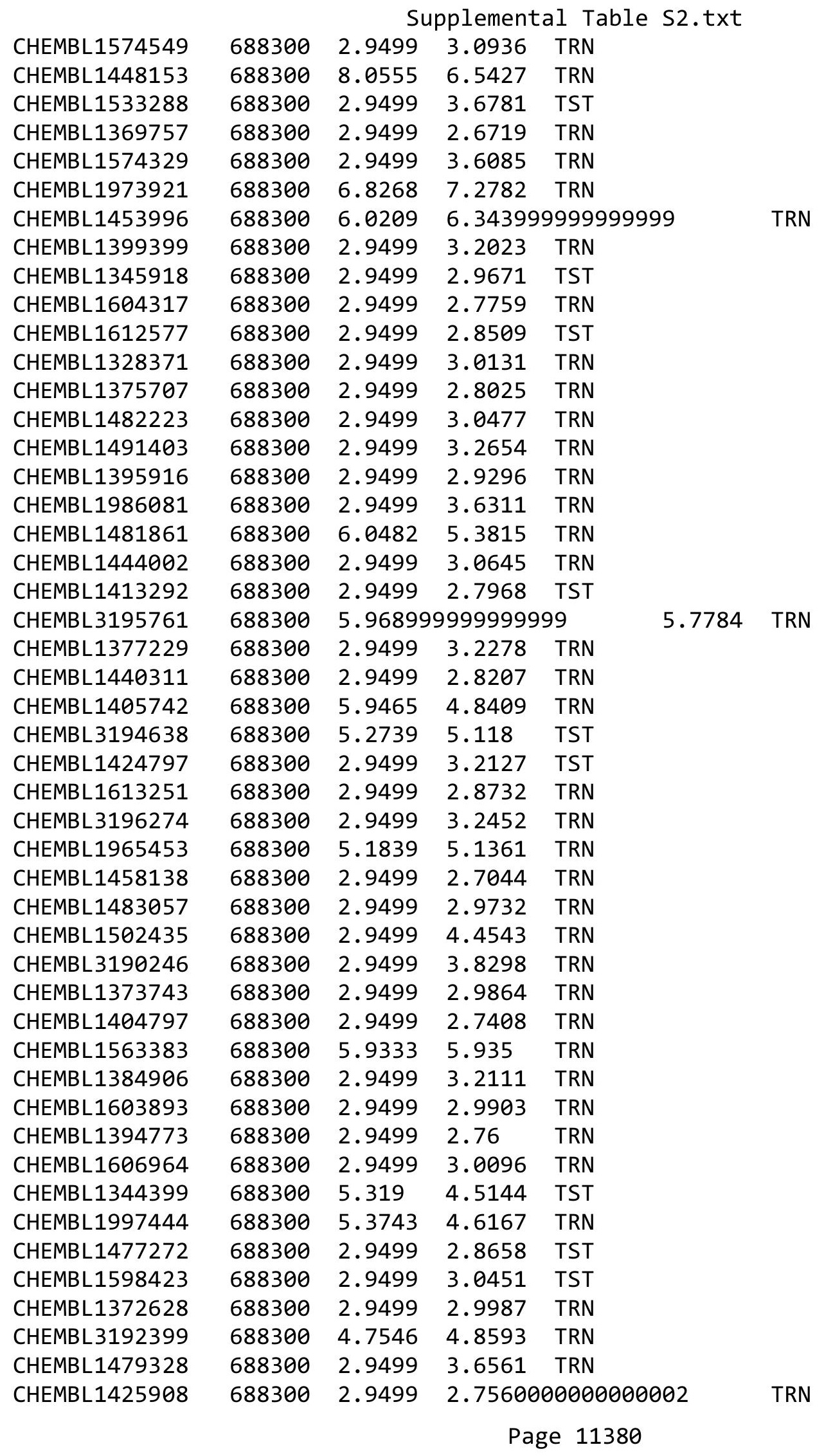




\begin{tabular}{|c|c|c|c|c|c|}
\hline \multirow[b]{2}{*}{ CHEMBL1301241 } & \multicolumn{5}{|c|}{ Supplemental Table S2.txt } \\
\hline & 688300 & 2.9499 & 2.7462 & TRN & \\
\hline CHEMBL1512774 & 688300 & 2.9499 & 2.8662 & TRN & \\
\hline CHEMBL1321177 & 688300 & 2.9499 & 2.85100 & 00000000004 & TST \\
\hline CHEMBL1582337 & 688300 & 5.4572 & 3.6525 & TRN & \\
\hline CHEMBL3192335 & 688300 & 5.8693 & 6.1566 & TRN & \\
\hline CHEMBL1598222 & 688300 & 5.4395 & 5.3455 & TRN & \\
\hline CHEMBL1530966 & 688300 & 2.9499 & 2.8285 & TST & \\
\hline CHEMBL1528779 & 688300 & 2.9499 & 2.898 & TRN & \\
\hline CHEMBL1534513 & 688300 & 2.9499 & 2.7704 & TRN & \\
\hline CHEMBL1430094 & 688300 & 6.61799 & 99999999 & 6.4378 & TRN \\
\hline CHEMBL1497097 & 688300 & 2.9499 & 5.2582 & TST & \\
\hline CHEMBL1579491 & 688300 & 2.9499 & 2.7575 & TST & \\
\hline CHEMBL1325612 & 688300 & 2.9499 & 3.0572 & TRN & \\
\hline CHEMBL1535927 & 688300 & 2.9499 & 2.9059 & TRN & \\
\hline CHEMBL1304385 & 688300 & 2.9499 & 2.8476 & TRN & \\
\hline CHEMBL1303384 & 688300 & 5.8821 & 5.4947 & TRN & \\
\hline CHEMBL1559801 & 688300 & 2.9499 & 2.9548 & TRN & \\
\hline CHEMBL1571642 & 688300 & 2.9499 & 2.8416 & TRN & \\
\hline CHEMBL1300624 & 688300 & 2.9499 & 2.8175 & TRN & \\
\hline CHEMBL3196355 & 688300 & 2.9499 & 3.1319 & TRN & \\
\hline CHEMBL1390799 & 688300 & 2.9499 & 3.8113 & TRN & \\
\hline CHEMBL1308946 & 688300 & 2.9499 & 2.4459 & TRN & \\
\hline CHEMBL1364277 & 688300 & 2.9499 & 3.0112 & TRN & \\
\hline CHEMBL1467334 & 688300 & 2.9499 & 3.0498 & TRN & \\
\hline CHEMBL1269779 & 688300 & 2.9499 & 3.5623 & TRN & \\
\hline CHEMBL1306132 & 688300 & 6.2 & 6.1014 & TRN & \\
\hline CHEMBL1543238 & 688300 & 6.1979 & 5.2987 & TRN & \\
\hline CHEMBL1486516 & 688300 & 2.9499 & 3.4107 & TRN & \\
\hline CHEMBL1982744 & 688300 & 2.9499 & 3.16899 & 99999999996 & TST \\
\hline CHEMBL3194985 & 688300 & 5.0732 & 5.6279 & TRN & \\
\hline CHEMBL1381932 & 688300 & 2.9499 & 3.3258 & TST & \\
\hline CHEMBL1427301 & 688300 & 2.9499 & 3.6251 & TRN & \\
\hline CHEMBL3213198 & 688300 & 2.9499 & 3.8029 & TST & \\
\hline CHEMBL1326342 & 688300 & 2.9499 & 3.0397 & TST & \\
\hline CHEMBL15063 & 688300 & 2.9499 & 2.83 & TST & \\
\hline CHEMBL1495271 & 688300 & 2.9499 & 2.6283 & TRN & \\
\hline CHEMBL1320389 & 688300 & 2.9499 & 2.7843 & TRN & \\
\hline CHEMBL1596719 & 688300 & 6.1931 & 5.9956 & TRN & \\
\hline CHEMBL1305099 & 688300 & 2.9499 & 2.4338 & TRN & \\
\hline CHEMBL1519788 & 688300 & 2.9499 & 4.8582 & TRN & \\
\hline CHEMBL1304544 & 688300 & 2.9499 & 3.1211 & TRN & \\
\hline CHEMBL1329761 & 688300 & 2.9499 & 2.6647 & TRN & \\
\hline CHEMBL1579034 & 688300 & 2.9499 & 2.8469 & TRN & \\
\hline CHEMBL1503930 & 688300 & 6.2434 & 6.0391 & TRN & \\
\hline CHEMBL1336068 & 688300 & 2.9499 & 2.8646 & TRN & \\
\hline CHEMBL1383312 & 688300 & 6.6716 & 6.6854 & TRN & \\
\hline CHEMBL1558033 & 688300 & 2.9499 & 3.556 & TRN & \\
\hline CHEMBL1302512 & 688300 & 2.9499 & 2.9163 & TRN & \\
\hline
\end{tabular}




\begin{tabular}{|c|c|c|c|c|c|}
\hline & & \multicolumn{4}{|c|}{ Supplemental Table S2.txt } \\
\hline CHEMBL1327598 & 688300 & 2.9499 & 3.3437 & TRN & \\
\hline CHEMBL1560552 & 688300 & 2.9499 & 2.7982 & TRN & \\
\hline CHEMBL1330633 & 688300 & 2.9499 & 3.1343 & TRN & \\
\hline CHEMBL1374595 & 688300 & 2.9499 & 2.2617 & TRN & \\
\hline CHEMBL1372889 & 688300 & 6.1433 & 5.4177 & TST & \\
\hline CHEMBL1577306 & 688300 & 2.9499 & 3.1321 & TRN & \\
\hline CHEMBL1496592 & 688300 & 6.1238 & 5.4929 & TRN & \\
\hline CHEMBL1419488 & 688300 & 4.7457 & 3.4482 & TRN & \\
\hline CHEMBL1323963 & 688300 & 2.9499 & 3.0629 & TRN & \\
\hline CHEMBL1421712 & 688300 & 2.9499 & 2.9965 & TST & \\
\hline CHEMBL 7747 & 688300 & 8.0555 & 6.6574 & TRN & \\
\hline CHEMBL1570402 & 688300 & 2.9499 & 3.4874 & TRN & \\
\hline CHEMBL1327226 & 688300 & 2.9499 & 2.6686 & TRN & \\
\hline CHEMBL1495092 & 688300 & 2.9499 & 4.0411 & TRN & \\
\hline CHEMBL1344378 & 688300 & 2.9499 & 2.9288 & TRN & \\
\hline CHEMBL1460336 & 688300 & 2.9499 & 3.3783 & TRN & \\
\hline CHEMBL1477354 & 688300 & 2.9499 & 3.8422 & TRN & \\
\hline CHEMBL1365813 & 688300 & 2.9499 & 3.3592 & TRN & \\
\hline CHEMBL1573221 & 688300 & 2.9499 & 3.2772 & TST & \\
\hline CHEMBL1359989 & 688300 & 2.9499 & 3.5983 & TRN & \\
\hline CHEMBL1311732 & 688300 & 2.9499 & 2.9659 & TRN & \\
\hline CHEMBL1597777 & 688300 & 2.9499 & 3.5421 & TRN & \\
\hline CHEMBL1302990 & 688300 & 2.9499 & 2.844 & TRN & \\
\hline CHEMBL1584812 & 688300 & 2.9499 & 2.7568 & TRN & \\
\hline CHEMBL1341067 & 688300 & 2.9499 & 3.5414 & TRN & \\
\hline CHEMBL1553470 & 688300 & 2.9499 & 2.8821 & TRN & \\
\hline CHEMBL 3192773 & 688300 & 5.777 & 5.5573 & TRN & \\
\hline CHEMBL1371479 & 688300 & 6.1373 & 5.6943 & TRN & \\
\hline CHEMBL1521187 & 688300 & 5.7981 & 5.2289 & TRN & \\
\hline CHEMBL1525501 & 688300 & 4.508 & 3.54100 & 00000000004 & TRN \\
\hline CHEMBL1560954 & 688300 & 2.9499 & 4.3048 & TST & \\
\hline CHEMBL1445248 & 688300 & 2.9499 & 2.9058 & TRN & \\
\hline CHEMBL1408307 & 688300 & 6.1494 & 5.7807 & TRN & \\
\hline CHEMBL1569988 & 688300 & 5.2498 & 5.9138 & TRN & \\
\hline CHEMBL1986907 & 688300 & 6.5436 & 6.0085 & TRN & \\
\hline CHEMBL1508973 & 688300 & 2.9499 & 2.7482 & TRN & \\
\hline CHEMBL1512743 & 688300 & 2.9499 & 2.8719 & TRN & \\
\hline CHEMBL1334410 & 688300 & 2.9499 & 4.3079 & TRN & \\
\hline CHEMBL1522362 & 688300 & 2.9499 & 2.7641 & TRN & \\
\hline CHEMBL3208997 & 688300 & 2.9499 & 3.9759 & TRN & \\
\hline CHEMBL1373740 & 688300 & 2.9499 & 3.3402 & TRN & \\
\hline CHEMBL1399447 & 688300 & 4.7242 & 3.5331 & TRN & \\
\hline CHEMBL1542014 & 688300 & 2.9499 & 4.0077 & TRN & \\
\hline CHEMBL1424396 & 688300 & 2.9499 & 3.7936 & TRN & \\
\hline CHEMBL1564677 & 688300 & 2.9499 & 3.4447 & TRN & \\
\hline CHEMBL1360618 & 688300 & 6.6536 & 5.9903 & TST & \\
\hline CHEMBL1327368 & 688300 & 2.9499 & 2.5309 & TRN & \\
\hline CHEMBL1449173 & 688300 & 5.3751 & 5.1054 & TRN & \\
\hline
\end{tabular}




\begin{tabular}{|c|c|c|c|c|c|}
\hline \multicolumn{6}{|c|}{ Supplemental Table S2.txt } \\
\hline CHEMBL1518866 & 688300 & 5.9038 & 5.6095 & TRN & \\
\hline CHEMBL1424110 & 688300 & 2.9499 & 3.109 & TST & \\
\hline CHEMBL1388194 & 688300 & 4.7865 & 5.4022 & TRN & \\
\hline CHEMBL1309377 & 688300 & 5.487 & 4.94600 & 0000000001 & TRN \\
\hline CHEMBL125044 & 688300 & 6.4157 & 5.5502 & TRN & \\
\hline CHEMBL1386836 & 688300 & 2.9499 & 3.2782 & TRN & \\
\hline CHEMBL1365502 & 688300 & 2.9499 & 2.9369 & TRN & \\
\hline CHEMBL1482896 & 688300 & 2.9499 & 2.144 & TRN & \\
\hline CHEMBL1586559 & 688300 & 2.9499 & 3.1801 & TRN & \\
\hline CHEMBL1308404 & 688300 & 2.9499 & 3.8831 & TRN & \\
\hline CHEMBL1527176 & 688300 & 5.815 & 5.5348 & TRN & \\
\hline CHEMBL1557678 & 688300 & 4.7517 & 5.1475 & TRN & \\
\hline CHEMBL1975118 & 688300 & 6.1759 & 6.0948 & TRN & \\
\hline CHEMBL1601298 & 688300 & 2.9499 & 3.4399 & TST & \\
\hline CHEMBL1402831 & 688300 & 2.9499 & 2.9383 & TRN & \\
\hline CHEMBL1568578 & 688300 & 2.9499 & 2.9549 & TRN & \\
\hline CHEMBL1383281 & 688300 & 6.4461 & 5.9463 & TRN & \\
\hline CHEMBL1986514 & 688300 & 5.2784 & 5.2035 & TRN & \\
\hline CHEMBL 3193741 & 688300 & 2.9499 & 2.7656 & TST & \\
\hline CHEMBL1336277 & 688300 & 5.8742 & 5.1022 & TRN & \\
\hline CHEMBL1526576 & 688300 & 2.9499 & 2.815 & TRN & \\
\hline CHEMBL1545489 & 688300 & 2.9499 & 3.2705 & TRN & \\
\hline CHEMBL1612693 & 688300 & 2.9499 & 2.9637 & TRN & \\
\hline CHEMBL1534616 & 688300 & 2.9499 & 3.1124 & TRN & \\
\hline CHEMBL 2007273 & 688300 & 6.5003 & 5.7834 & TRN & \\
\hline CHEMBL202965 & 688300 & 2.9499 & 2.5025 & TRN & \\
\hline CHEMBL1537594 & 688300 & 2.9499 & 3.3373 & TRN & \\
\hline CHEMBL1333774 & 688300 & 2.9499 & 2.4826 & TRN & \\
\hline CHEMBL1406284 & 688300 & 2.9499 & 2.8279 & TRN & \\
\hline CHEMBL1522390 & 688300 & 2.9499 & 2.9048 & TST & \\
\hline CHEMBL1471786 & 688300 & 2.9499 & 2.9551 & TRN & \\
\hline CHEMBL1342574 & 688300 & 2.9499 & 4.3463 & TST & \\
\hline CHEMBL1349397 & 688300 & 2.9499 & 3.2939 & TST & \\
\hline CHEMBL1376424 & 688300 & 2.9499 & 2.9613 & TRN & \\
\hline CHEMBL1362496 & 688300 & 2.9499 & 2.9825 & TRN & \\
\hline CHEMBL1723238 & 688300 & 2.9499 & 2.6346 & TST & \\
\hline CHEMBL 1308506 & 688300 & 2.9499 & 3.0419 & TST & \\
\hline CHEMBL1543836 & 688300 & 2.9499 & 2.3201 & TST & \\
\hline CHEMBL1601294 & 688300 & 2.9499 & 2.3467 & TRN & \\
\hline CHEMBL3194093 & 688300 & 6.7352 & 5.9853 & TRN & \\
\hline CHEMBL1429902 & 688300 & 2.9499 & 2.2269 & TST & \\
\hline CHEMBL1569489 & 688300 & 2.9499 & 3.889 & TRN & \\
\hline CHEMBL1416853 & 688300 & 5.1986 & 3.8669 & TST & \\
\hline CHEMBL1409939 & 688300 & 4.3525 & 4.731 & TRN & \\
\hline CHEMBL1354330 & 688300 & 2.9499 & 3.179 & TRN & \\
\hline CHEMBL1585258 & 688300 & 2.9499 & 2.8973 & TRN & \\
\hline CHEMBL1405897 & 688300 & 2.9499 & 2.9135 & TRN & \\
\hline CHEMBL3197372 & 688300 & 2.9499 & 3.1881 & TRN & \\
\hline
\end{tabular}




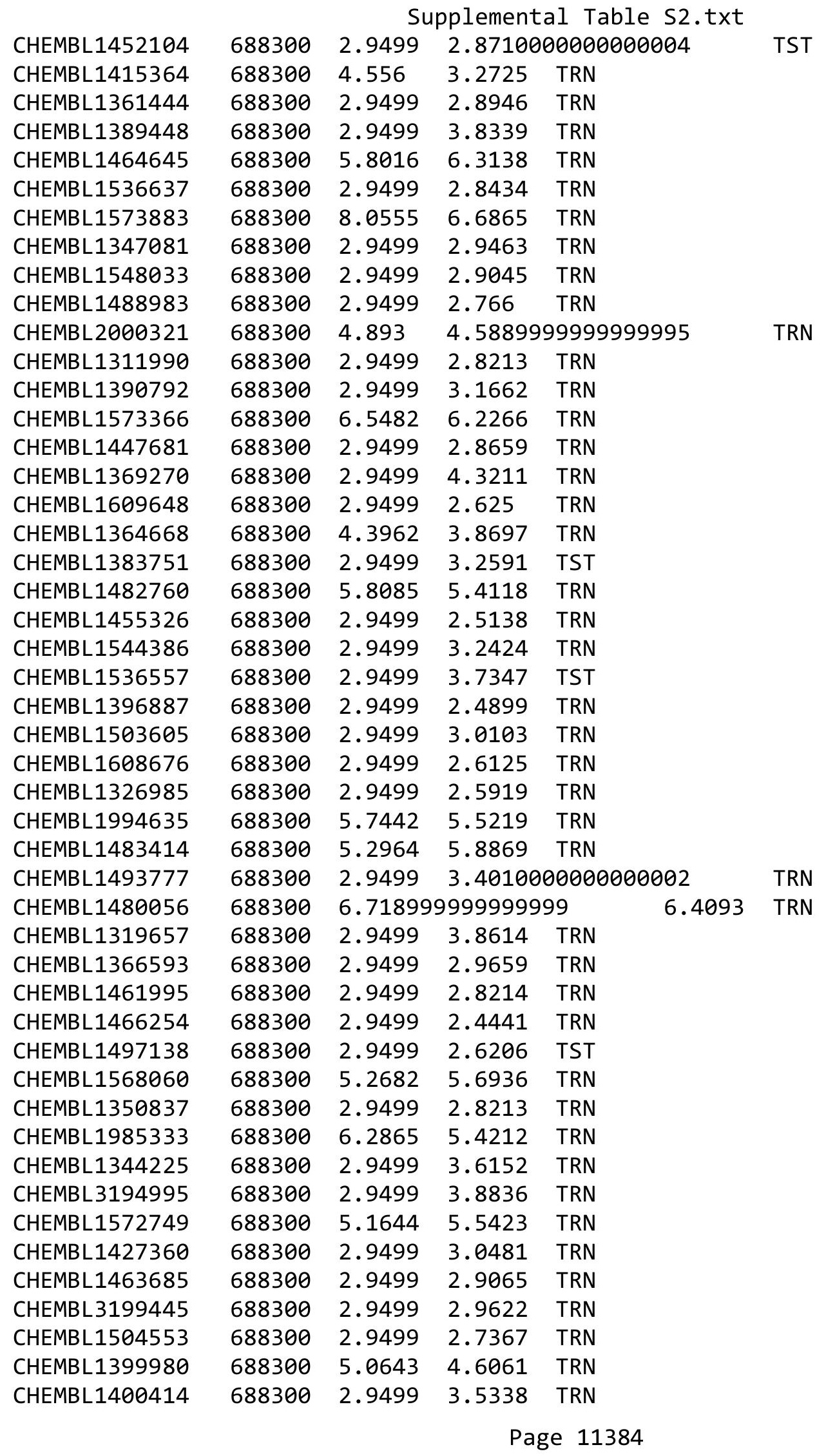




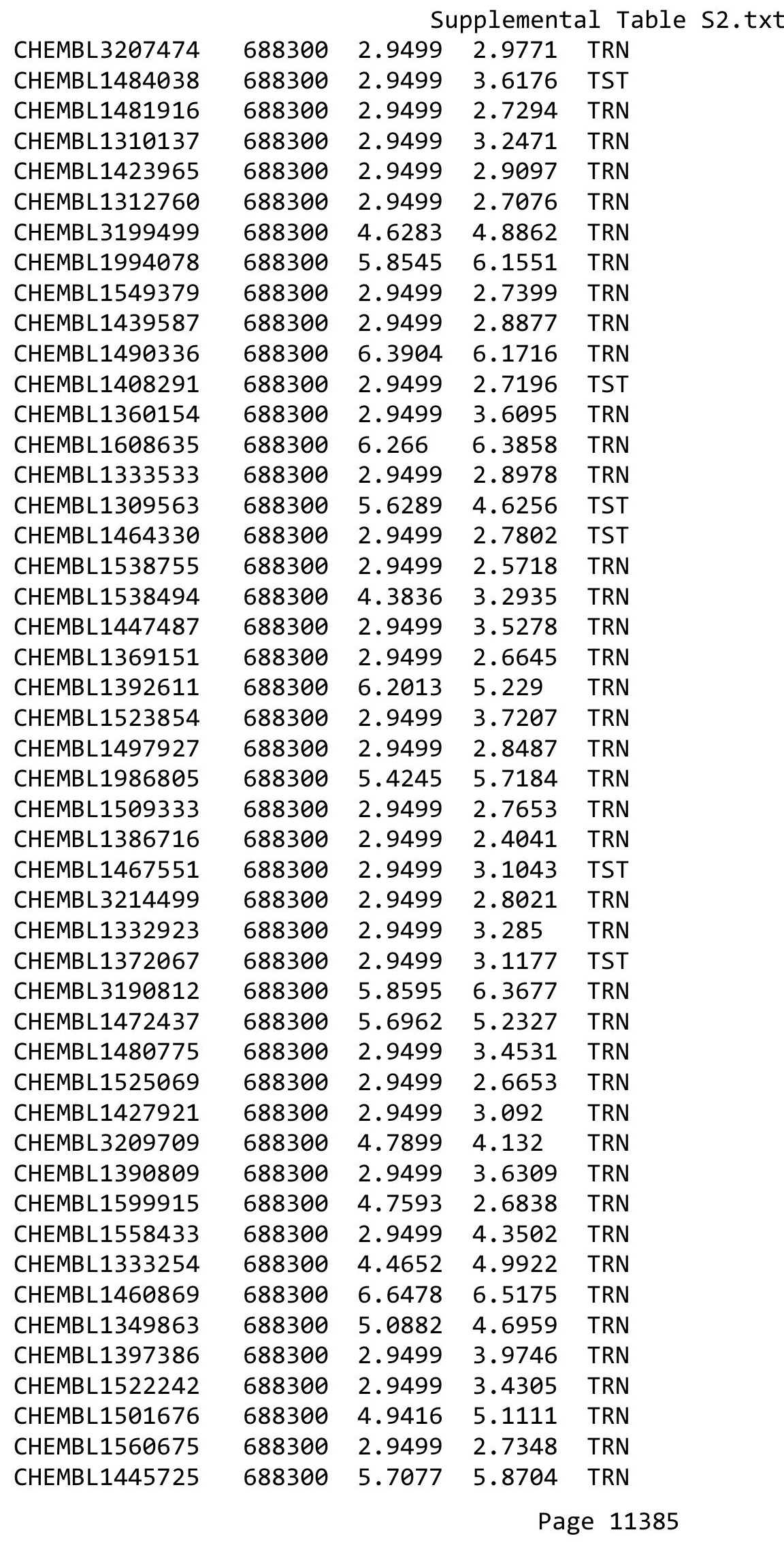




\begin{tabular}{|c|c|c|c|c|c|}
\hline & & \multicolumn{4}{|c|}{ Supplemental Table s2.txt } \\
\hline CHEMBL1349226 & 688300 & 2.9499 & 3.1353 & TRN & \\
\hline CHEMBL1585869 & 688300 & 2.9499 & 2.8395 & TRN & \\
\hline CHEMBL1486981 & 688300 & 2.9499 & 3.1586 & TRN & \\
\hline CHEMBL3198361 & 688300 & 2.9499 & 2.9113 & TST & \\
\hline CHEMBL1353266 & 688300 & 4.9127 & 4.9529 & TRN & \\
\hline CHEMBL1362488 & 688300 & 2.9499 & 3.0592 & TST & \\
\hline CHEMBL1410321 & 688300 & 2.9499 & 2.3808 & TST & \\
\hline CHEMBL1536990 & 688300 & 2.9499 & 2.6737 & TRN & \\
\hline CHEMBL1392557 & 688300 & 2.9499 & 2.8514 & TRN & \\
\hline CHEMBL1313232 & 688300 & 2.9499 & 4.1215 & TRN & \\
\hline CHEMBL1588563 & 688300 & 2.9499 & 3.0732 & TRN & \\
\hline CHEMBL1523396 & 688300 & 2.9499 & 3.0022 & TRN & \\
\hline CHEMBL1528665 & 688300 & 2.9499 & 2.9408 & TRN & \\
\hline CHEMBL1406276 & 688300 & 2.9499 & 2.5236 & TRN & \\
\hline CHEMBL1343626 & 688300 & 2.9499 & 3.66399 & 99999999997 & TRN \\
\hline CHEMBL1497686 & 688300 & 2.9499 & 2.7222 & TRN & \\
\hline CHEMBL1501191 & 688300 & 5.83799 & 99999999 & 5.5238 & TRN \\
\hline CHEMBL1451032 & 688300 & 2.9499 & 2.531 & TST & \\
\hline CHEMBL3197013 & 688300 & 2.9499 & 3.4096 & TRN & \\
\hline CHEMBL1584473 & 688300 & 2.9499 & 2.2535 & TRN & \\
\hline CHEMBL1570099 & 688300 & 2.9499 & 3.14899 & 99999999996 & TRN \\
\hline CHEMBL1611714 & 688300 & 2.9499 & 3.4817 & TRN & \\
\hline CHEMBL1426977 & 688300 & 2.9499 & 3.1174 & TRN & \\
\hline CHEMBL1468807 & 688300 & 2.9499 & 3.3821 & TRN & \\
\hline CHEMBL1574452 & 688300 & 2.9499 & 2.9733 & TRN & \\
\hline CHEMBL1345927 & 688300 & 2.9499 & 3.0741 & TST & \\
\hline CHEMBL1429929 & 688300 & 2.9499 & 3.6301 & TRN & \\
\hline CHEMBL1460048 & 688300 & 2.9499 & 2.7201 & TRN & \\
\hline CHEMBL1521415 & 688300 & 2.9499 & 3.4465 & TRN & \\
\hline CHEMBL1566692 & 688300 & 2.9499 & 3.0137 & TRN & \\
\hline CHEMBL584015 & 688300 & 2.9499 & 3.4121 & TRN & \\
\hline CHEMBL1387309 & 688300 & 2.9499 & 2.8723 & TRN & \\
\hline CHEMBL1545487 & 688300 & 2.9499 & 3.0 & TRN & \\
\hline CHEMBL3196469 & 688300 & 6.8013 & 6.7093 & TRN & \\
\hline CHEMBL3210373 & 688300 & 2.9499 & 3.00699 & 99999999997 & TRN \\
\hline CHEMBL1513114 & 688300 & 5.7178 & 4.5022 & TRN & \\
\hline CHEMBL1408083 & 688300 & 2.9499 & 3.2524 & TRN & \\
\hline CHEMBL1388254 & 688300 & 2.9499 & 3.2715 & TRN & \\
\hline CHEMBL1608667 & 688300 & 2.9499 & 3.7011 & TRN & \\
\hline CHEMBL1414953 & 688300 & 2.9499 & 2.98100 & 00000000003 & TRN \\
\hline CHEMBL1574903 & 688300 & 2.9499 & 2.9878 & TRN & \\
\hline CHEMBL3193424 & 688300 & 6.4271 & 5.3964 & TRN & \\
\hline CHEMBL1458858 & 688300 & 2.9499 & 3.3829 & TRN & \\
\hline CHEMBL1506762 & 688300 & 2.9499 & 3.5361 & TST & \\
\hline CHEMBL1596372 & 688300 & 2.9499 & 3.2149 & TRN & \\
\hline CHEMBL1408570 & 688300 & 2.9499 & 3.9567 & TRN & \\
\hline CHEMBL1311416 & 688300 & 2.9499 & 3.0938 & TST & \\
\hline CHEMBL1458931 & 688300 & 2.9499 & 3.2973 & TST & \\
\hline
\end{tabular}




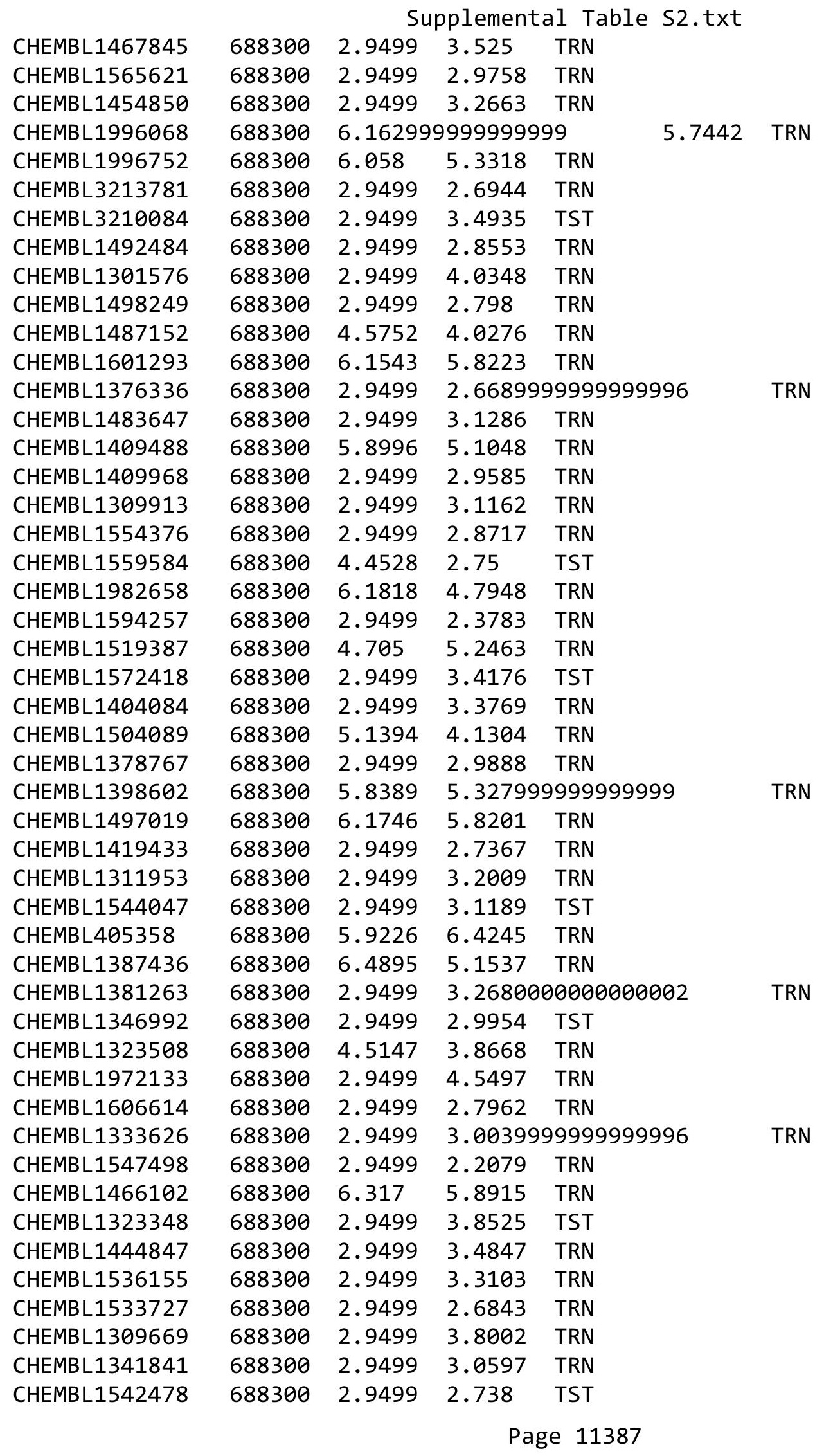




\begin{tabular}{|c|c|c|c|c|c|}
\hline & & \multicolumn{4}{|c|}{ Supplemental Table s2.txt } \\
\hline CHEMBL1965132 & 688300 & 5.8864 & 6.2066 & TRN & \\
\hline CHEMBL1339678 & 688300 & 5.9743 & 5.2568 & TRN & \\
\hline CHEMBL1387417 & 688300 & 2.9499 & 3.0299 & TST & \\
\hline CHEMBL1408438 & 688300 & 5.9731 & 6.2068 & TRN & \\
\hline CHEMBL1502328 & 688300 & 2.9499 & 3.1569 & TRN & \\
\hline CHEMBL1549091 & 688300 & 2.9499 & 2.8014 & TRN & \\
\hline CHEMBL1537779 & 688300 & 2.9499 & 3.2158 & TRN & \\
\hline CHEMBL1303835 & 688300 & 5.5427 & 5.6453 & TRN & \\
\hline CHEMBL1606392 & 688300 & 2.9499 & 2.3181 & TRN & \\
\hline CHEMBL1301855 & 688300 & 2.9499 & 3.0956 & TRN & \\
\hline CHEMBL1585453 & 688300 & 2.9499 & 2.7344 & TRN & \\
\hline CHEMBL1567031 & 688300 & 2.9499 & 2.9609 & TST & \\
\hline CHEMBL1469916 & 688300 & 2.9499 & 3.8307 & TRN & \\
\hline CHEMBL1598863 & 688300 & 2.9499 & 2.7735 & TRN & \\
\hline CHEMBL2006611 & 688300 & 5.3703 & 5.6269 & TRN & \\
\hline CHEMBL1380801 & 688300 & 2.9499 & 3.4047 & TRN & \\
\hline CHEMBL1623028 & 688300 & 6.0691 & 5.0392 & TRN & \\
\hline CHEMBL1324979 & 688300 & 2.9499 & 2.4812 & TRN & \\
\hline CHEMBL1429789 & 688300 & 6.9706 & 6.3854 & TRN & \\
\hline CHEMBL1541966 & 688300 & 2.9499 & 3.4087 & TRN & \\
\hline CHEMBL1444802 & 688300 & 2.9499 & 3.36899 & 99999999998 & TRN \\
\hline CHEMBL1338057 & 688300 & 2.9499 & 4.2854 & TRN & \\
\hline CHEMBL1543818 & 688300 & 6.15799 & 79999999 & 6.0831 & TRN \\
\hline CHEMBL1556766 & 688300 & 2.9499 & 2.5015 & TST & \\
\hline CHEMBL1503809 & 688300 & 2.9499 & 2.826 & TRN & \\
\hline CHEMBL1528998 & 688300 & 2.9499 & 2.7238 & TST & \\
\hline CHEMBL1353398 & 688300 & 2.9499 & 2.3851 & TST & \\
\hline CHEMBL1467416 & 688300 & 2.9499 & 2.6713 & TRN & \\
\hline CHEMBL1581957 & 688300 & 2.9499 & 3.0899 & TRN & \\
\hline CHEMBL587892 & 688300 & 6.2774 & 5.63899 & 9999999999 & TRN \\
\hline CHEMBL1537961 & 688300 & 2.9499 & 2.8903 & TRN & \\
\hline CHEMBL1300772 & 688300 & 5.7926 & 4.8126 & TRN & \\
\hline CHEMBL1583460 & 688300 & 5.6278 & 5.3474 & TRN & \\
\hline CHEMBL1519137 & 688300 & 2.9499 & 2.2813 & TRN & \\
\hline CHEMBL1236872 & 688300 & 2.9499 & 2.4128 & TRN & \\
\hline CHEMBL1989500 & 688300 & 5.9136 & 5.2617 & TRN & \\
\hline CHEMBL1542915 & 688300 & 2.9499 & 3.0491 & TRN & \\
\hline CHEMBL339304 & 688300 & 6.7932 & 6.8651 & TRN & \\
\hline CHEMBL1509670 & 688300 & 2.9499 & 4.1376 & TRN & \\
\hline CHEMBL3199298 & 688300 & 6.1007 & 6.4747 & TRN & \\
\hline CHEMBL1462710 & 688300 & 5.4376 & 5.8603 & TRN & \\
\hline CHEMBL1328395 & 688300 & 2.9499 & 3.5238 & TRN & \\
\hline CHEMBL1368846 & 688300 & 2.9499 & 2.4296 & TRN & \\
\hline CHEMBL1532736 & 688300 & 2.9499 & 2.9117 & TRN & \\
\hline CHEMBL3198412 & 688300 & 5.5376 & 5.42299 & 9999999999 & TRN \\
\hline CHEMBL1493470 & 688300 & 2.9499 & 2.8199 & TRN & \\
\hline CHEMBL1534556 & 688300 & 2.9499 & 3.1217 & TRN & \\
\hline CHEMBL1504793 & 688300 & 2.9499 & 2.6862 & TRN & \\
\hline
\end{tabular}




\begin{tabular}{|c|c|c|c|c|c|c|}
\hline & & \multicolumn{5}{|c|}{ Supplemental Table S2.txt } \\
\hline CHEMBL3196633 & 688300 & 2.9499 & 4.3486 & TRN & & \\
\hline CHEMBL1460127 & 688300 & 2.9499 & 3.5341 & TRN & & \\
\hline CHEMBL1471597 & 688300 & 2.9499 & 2.6694 & TRN & & \\
\hline CHEMBL1332533 & 688300 & 6.4572 & 5.5578 & TRN & & \\
\hline CHEMBL 225903 & 688300 & 6.1267 & 5.7342 & TRN & & \\
\hline CHEMBL1384497 & 688300 & 2.9499 & 2.8576 & TRN & & \\
\hline CHEMBL1334528 & 688300 & 2.9499 & 3.24899 & 99999995 & 997 & TRN \\
\hline CHEMBL1544685 & 688300 & 5.0801 & 4.6236 & TRN & & \\
\hline CHEMBL1572907 & 688300 & 2.9499 & 2.7929 & TRN & & \\
\hline CHEMBL1593417 & 688300 & 2.9499 & 2.5883 & TRN & & \\
\hline CHEMBL1504094 & 688300 & 2.9499 & 3.0034 & TRN & & \\
\hline CHEMBL1501708 & 688300 & 4.8283 & 3.0535 & TST & & \\
\hline CHEMBL3199673 & 688300 & 6.1593 & 6.3248 & TRN & & \\
\hline CHEMBL1405699 & 688300 & 2.9499 & 2.6576 & TRN & & \\
\hline CHEMBL1595632 & 688300 & 6.2628 & 6.3165 & TRN & & \\
\hline CHEMBL1337066 & 688300 & 2.9499 & 3.3181 & TRN & & \\
\hline CHEMBL1605090 & 688300 & 2.9499 & 3.6094 & TRN & & \\
\hline CHEMBL1499276 & 688300 & 5.9763 & 5.3394 & TRN & & \\
\hline CHEMBL1423192 & 688300 & \multicolumn{3}{|c|}{6.007000000000001} & 5.605 & TRN \\
\hline CHEMBL1533271 & 688300 & 2.9499 & 2.8478 & TRN & & \\
\hline CHEMBL1455176 & 688300 & 2.9499 & 2.5855 & TRN & & \\
\hline CHEMBL1595861 & 688300 & 2.9499 & 2.9709 & TRN & & \\
\hline CHEMBL1370281 & 688300 & 2.9499 & 3.0761 & TRN & & \\
\hline CHEMBL1310213 & 688300 & 2.9499 & 3.1583 & TRN & & \\
\hline CHEMBL1360977 & 688300 & 5.0208 & 4.7015 & TRN & & \\
\hline CHEMBL1576682 & 688300 & 2.9499 & 3.9058 & TST & & \\
\hline CHEMBL1313659 & 688300 & 2.9499 & 3.8488 & TRN & & \\
\hline CHEMBL1338658 & 688300 & 2.9499 & 4.599 & TRN & & \\
\hline CHEMBL1477473 & 688300 & 5.4208 & 5.1008 & TRN & & \\
\hline CHEMBL1514411 & 688300 & 2.9499 & 2.5935 & TRN & & \\
\hline CHEMBL1599564 & 688300 & 2.9499 & 3.5757 & TRN & & \\
\hline CHEMBL3198235 & 688300 & 5.2961 & 5.6126 & TRN & & \\
\hline CHEMBL331372 & 688300 & 2.9499 & 3.9167 & TRN & & \\
\hline CHEMBL 378887 & 688300 & 5.9367 & 5.5157 & TRN & & \\
\hline CHEMBL1401606 & 688300 & 2.9499 & 2.7336 & TRN & & \\
\hline CHEMBL1464431 & 688300 & 2.9499 & 2.5882 & TRN & & \\
\hline CHEMBL 1378362 & 688300 & 2.9499 & 2.4881 & TRN & & \\
\hline CHEMBL1369108 & 688300 & \multicolumn{3}{|c|}{4.7330000000000005} & 2.1827 & TST \\
\hline CHEMBL3192372 & 688300 & 5.7802 & 5.8668 & TRN & & \\
\hline CHEMBL1404547 & 688300 & 5.9602 & 5.2511 & TRN & & \\
\hline CHEMBL1505952 & 688300 & 2.9499 & 2.929 & TRN & & \\
\hline CHEMBL1542070 & 688300 & 2.9499 & 2.7752 & TRN & & \\
\hline CHEMBL1463108 & 688300 & 2.9499 & 3.1089 & TRN & & \\
\hline CHEMBL1327101 & 688300 & 2.9499 & 3.4192 & TRN & & \\
\hline CHEMBL3392070 & 688300 & 2.9499 & 3.2386 & TRN & & \\
\hline CHEMBL1412725 & 688300 & 2.9499 & 3.3407 & TRN & & \\
\hline CHEMBL1444534 & 688300 & 2.9499 & 2.9232 & TRN & & \\
\hline CHEMBL1313891 & 688300 & 5.7219 & 5.9822 & TRN & & \\
\hline
\end{tabular}




\begin{tabular}{|c|c|c|c|c|c|}
\hline \multirow[b]{2}{*}{ CHEMBL1453673 } & \multicolumn{5}{|c|}{ Supplemental Table S2.txt } \\
\hline & 688300 & 2.9499 & 1.7463 & TST & \\
\hline CHEMBL1302515 & 688300 & 4.5059 & 4.1082 & TRN & \\
\hline CHEMBL1582610 & 688300 & 2.9499 & 3.2299 & TRN & \\
\hline CHEMBL3211413 & 688300 & 2.9499 & 4.1111 & TRN & \\
\hline CHEMBL1572538 & 688300 & 2.9499 & 3.7926 & TRN & \\
\hline CHEMBL1403704 & 688300 & 2.9499 & 2.89 & TRN & \\
\hline CHEMBL3197158 & 688300 & 2.9499 & 3.085 & TRN & \\
\hline CHEMBL1581455 & 688300 & 2.9499 & 3.574 & TRN & \\
\hline CHEMBL1349101 & 688300 & 2.9499 & 3.4814 & TRN & \\
\hline CHEMBL1570806 & 688300 & 2.9499 & 3.4499 & TST & \\
\hline CHEMBL1533399 & 688300 & 2.9499 & 3.3343 & TRN & \\
\hline CHEMBL3199853 & 688300 & 2.9499 & 3.3805 & TRN & \\
\hline CHEMBL1539622 & 688300 & 2.9499 & 2.9663 & TST & \\
\hline CHEMBL1447703 & 688300 & 2.9499 & 2.8075 & TRN & \\
\hline CHEMBL3212455 & 688300 & 2.9499 & 3.2649 & TRN & \\
\hline CHEMBL1586351 & 688300 & 2.9499 & 3.0322 & TRN & \\
\hline CHEMBL1578331 & 688300 & 2.9499 & 2.7112 & TST & \\
\hline CHEMBL3195435 & 688300 & 5.4075 & 4.8849 & TRN & \\
\hline CHEMBL1439909 & 688300 & 5.5741 & 5.9829 & TRN & \\
\hline CHEMBL1364037 & 688300 & 2.9499 & 2.82800 & 00000000003 & TRN \\
\hline CHEMBL1459468 & 688300 & 6.7986 & 5.8599 & TRN & \\
\hline CHEMBL1302225 & 688300 & 2.9499 & 2.4475 & TRN & \\
\hline CHEMBL1581676 & 688300 & 2.9499 & 3.1308 & TRN & \\
\hline CHEMBL1570531 & 688300 & 2.9499 & 2.7527 & TRN & \\
\hline CHEMBL1350148 & 688300 & 2.9499 & 2.8254 & TRN & \\
\hline CHEMBL1540173 & 688300 & 2.9499 & 3.8706 & TRN & \\
\hline CHEMBL1513199 & 688300 & 2.9499 & 2.7395 & TRN & \\
\hline CHEMBL1417083 & 688300 & 5.3479 & 4.3044 & TRN & \\
\hline CHEMBL1995156 & 688300 & 5.7724 & 5.5838 & TRN & \\
\hline CHEMBL1471302 & 688300 & 2.9499 & 2.6077 & TRN & \\
\hline CHEMBL1507124 & 688300 & 2.9499 & 2.843 & TRN & \\
\hline CHEMBL1602449 & 688300 & 2.9499 & 4.3701 & TRN & \\
\hline CHEMBL1347985 & 688300 & 2.9499 & 2.7231 & TRN & \\
\hline CHEMBL1539578 & 688300 & 2.9499 & 2.7242 & TRN & \\
\hline CHEMBL1418721 & 688300 & 2.9499 & 2.7951 & TRN & \\
\hline CHEMBL3193673 & 688300 & 2.9499 & 4.2124 & TRN & \\
\hline CHEMBL1528106 & 688300 & 2.9499 & 3.5668 & TST & \\
\hline CHEMBL1360741 & 688300 & 2.9499 & 2.5544 & TRN & \\
\hline CHEMBL1527239 & 688300 & 2.9499 & 2.8487 & TRN & \\
\hline CHEMBL1372562 & 688300 & 2.9499 & 2.3919 & TRN & \\
\hline CHEMBL1370234 & 688300 & 2.9499 & 3.7122 & TRN & \\
\hline CHEMBL 1488730 & 688300 & 5.6662 & 5.0796 & TRN & \\
\hline CHEMBL1438213 & 688300 & 2.9499 & 2.8451 & TRN & \\
\hline CHEMBL1308965 & 688300 & 2.9499 & 3.0994 & TRN & \\
\hline CHEMBL1340312 & 688300 & 2.9499 & 3.0662 & TRN & \\
\hline CHEMBL1534344 & 688300 & 2.9499 & 2.445 & TRN & \\
\hline CHEMBL1408777 & 688300 & 2.9499 & 2.9104 & TRN & \\
\hline CHEMBL1445241 & 688300 & 2.9499 & 2.9813 & TRN & \\
\hline
\end{tabular}

Page 11390 


\begin{tabular}{|c|c|c|c|c|c|}
\hline & & \multicolumn{4}{|c|}{ Supplemental Table S2.txt } \\
\hline CHEMBL 3210692 & 688300 & 2.9499 & 3.4 & TST & \\
\hline CHEMBL1469084 & 688300 & 2.9499 & 3.9996 & TRN & \\
\hline CHEMBL1337091 & 688300 & 2.9499 & 3.0594 & TRN & \\
\hline CHEMBL1328504 & 688300 & 6.8894 & 5.6512 & TRN & \\
\hline CHEMBL1431049 & 688300 & 2.9499 & 2.826 & TRN & \\
\hline CHEMBL1566988 & 688300 & 2.9499 & 2.5147 & TST & \\
\hline CHEMBL 3193227 & 688300 & 5.8857 & 4.2971 & TRN & \\
\hline CHEMBL1450116 & 688300 & 4.2424 & 3.39899 & 99999999996 & TRN \\
\hline CHEMBL1544466 & 688300 & 2.9499 & 3.5373 & TRN & \\
\hline CHEMBL1452227 & 688300 & 5.4662 & 5.5078 & TRN & \\
\hline CHEMBL1532657 & 688300 & 2.9499 & 2.7045 & TRN & \\
\hline CHEMBL1596568 & 688300 & 2.9499 & 2.8611 & TST & \\
\hline CHEMBL1602976 & 688300 & 2.9499 & 3.6764 & TRN & \\
\hline CHEMBL1327169 & 688300 & 5.1377 & 4.7774 & TRN & \\
\hline CHEMBL1523955 & 688300 & 6.5935 & 6.2253 & TRN & \\
\hline CHEMBL1547350 & 688300 & 2.9499 & 3.3961 & TRN & \\
\hline CHEMBL1497122 & 688300 & 2.9499 & 3.2972 & TRN & \\
\hline CHEMBL1501902 & 688300 & 2.9499 & 2.8659 & TRN & \\
\hline CHEMBL37400 & 688300 & 2.9499 & 2.8734 & TRN & \\
\hline CHEMBL1453723 & 688300 & 6.2916 & 5.1399 & TRN & \\
\hline CHEMBL1573499 & 688300 & 2.9499 & 2.9097 & TRN & \\
\hline CHEMBL1595627 & 688300 & 2.9499 & 3.1358 & TRN & \\
\hline CHEMBL1428920 & 688300 & 2.9499 & 2.5514 & TST & \\
\hline CHEMBL1442280 & 688300 & 2.9499 & 3.5179 & TST & \\
\hline CHEMBL1605437 & 688300 & 2.9499 & 3.8009 & TRN & \\
\hline CHEMBL1391738 & 688300 & 2.9499 & 3.3972 & TRN & \\
\hline CHEMBL1417128 & 688300 & 2.9499 & 3.4666 & TRN & \\
\hline CHEMBL1542638 & 688300 & 2.9499 & 3.0696 & TRN & \\
\hline CHEMBL1524978 & 688300 & 2.9499 & 2.9271 & TRN & \\
\hline CHEMBL1790005 & 688300 & 2.9499 & 4.0428 & TST & \\
\hline CHEMBL 3213574 & 688300 & 5.7841 & 5.2979 & TRN & \\
\hline CHEMBL1459174 & 688300 & 2.9499 & 3.0327 & TRN & \\
\hline CHEMBL1541684 & 688300 & 2.9499 & 3.4071 & TRN & \\
\hline CHEMBL 3194273 & 688300 & 5.9527 & 6.4432 & TRN & \\
\hline CHEMBL1377440 & 688300 & 2.9499 & 2.6552 & TRN & \\
\hline CHEMBL1502192 & 688300 & 5.0655 & 5.4158 & TRN & \\
\hline CHEMBL1343675 & 688300 & 2.9499 & 2.3623 & TST & \\
\hline CHEMBL1304314 & 688300 & 2.9499 & 3.2836 & TRN & \\
\hline CHEMBL1379740 & 688300 & 6.0348 & 4.9664 & TRN & \\
\hline CHEMBL1611182 & 688300 & 2.9499 & 4.0548 & TRN & \\
\hline CHEMBL1527433 & 688300 & 5.5556 & 5.9556 & TRN & \\
\hline CHEMBL1469581 & 688300 & 2.9499 & 2.8338 & TRN & \\
\hline CHEMBL1436882 & 688300 & 2.9499 & 2.8562 & TRN & \\
\hline CHEMBL1566877 & 688300 & 5.6375 & 6.0416 & TRN & \\
\hline CHEMBL1439985 & 688300 & 5.3801 & 4.9651 & TRN & \\
\hline CHEMBL1539236 & 688300 & 2.9499 & 3.0986 & TRN & \\
\hline CHEMBL1401676 & 688300 & 6.4377 & 6.539 & TRN & \\
\hline CHEMBL1444779 & 688300 & 2.9499 & 2.7065 & TRN & \\
\hline
\end{tabular}




\begin{tabular}{|c|c|c|c|c|}
\hline \multicolumn{5}{|c|}{ Supplemental Tabl } \\
\hline CHEMBL1366510 & 688300 & 2.9499 & 2.6062 & TST \\
\hline CHEMBL1483824 & 688300 & 2.9499 & 3.6249 & TST \\
\hline CHEMBL1403233 & 688300 & 2.9499 & 2.1336 & TRN \\
\hline CHEMBL1515296 & 688300 & 2.9499 & 2.7678 & TRN \\
\hline CHEMBL1612413 & 688300 & 2.9499 & 3.2893 & TRN \\
\hline CHEMBL1609763 & 688300 & 2.9499 & 3.0704 & TST \\
\hline CHEMBL1510748 & 688300 & 2.9499 & 2.7353 & TRN \\
\hline CHEMBL1978607 & 688300 & 5.9927 & 5.5291 & TRN \\
\hline CHEMBL3211417 & 688300 & 2.9499 & 2.9106 & TRN \\
\hline CHEMBL1379076 & 688300 & 2.9499 & 2.7543 & TRN \\
\hline CHEMBL1453801 & 688300 & 5.7147 & 4.8698 & TRN \\
\hline CHEMBL1420307 & 688300 & 2.9499 & 3.9633 & TRN \\
\hline CHEMBL1345908 & 688300 & 4.3055 & 3.6321 & TRN \\
\hline CHEMBL1977570 & 688300 & 5.4188 & 5.3444 & TRN \\
\hline CHEMBL572346 & 688300 & 2.9499 & 3.7914 & TRN \\
\hline CHEMBL1530917 & 688300 & 2.9499 & 3.8941 & TST \\
\hline CHEMBL1488176 & 688300 & 2.9499 & 3.3719 & TRN \\
\hline CHEMBL1352955 & 688300 & 4.5034 & 4.2253 & TRN \\
\hline CHEMBL1336637 & 688300 & 2.9499 & 3.0135 & TRN \\
\hline CHEMBL1419515 & 688300 & 2.9499 & 3.5656 & TRN \\
\hline CHEMBL47875 & 688300 & 5.9014 & 5.6325 & TRN \\
\hline CHEMBL1531368 & 688300 & 2.9499 & 3.1129 & TRN \\
\hline CHEMBL1604163 & 688300 & 5.3712 & 5.6683 & TRN \\
\hline CHEMBL1305341 & 688300 & 4.729 & 4.0171 & TRN \\
\hline CHEMBL1340492 & 688300 & 6.1002 & 5.2404 & TRN \\
\hline CHEMBL1561592 & 688300 & 2.9499 & 3.6893 & TRN \\
\hline CHEMBL1554779 & 688300 & 2.9499 & 2.8276 & TRN \\
\hline CHEMBL1557637 & 688300 & 2.9499 & 4.4307 & TRN \\
\hline CHEMBL1352981 & 688300 & 2.9499 & 3.3539 & TRN \\
\hline CHEMBL1587018 & 688300 & 6.2434 & 5.6626 & TRN \\
\hline CHEMBL1550657 & 688300 & 4.7394 & 5.1241 & TRN \\
\hline CHEMBL1545290 & 688300 & 2.9499 & 3.5523 & TRN \\
\hline CHEMBL3209305 & 688300 & 2.9499 & 4.6551 & TRN \\
\hline CHEMBL1610058 & 688300 & 2.9499 & 2.6295 & TRN \\
\hline CHEMBL1477499 & 688300 & 2.9499 & 3.266 & TST \\
\hline CHEMBL3212032 & 688300 & 2.9499 & 4.192 & TST \\
\hline CHEMBL1543337 & 688300 & 6.684 & 5.4606 & TST \\
\hline CHEMBL1304244 & 688300 & 4.1703 & 3.0503 & TST \\
\hline CHEMBL1381279 & 688300 & 2.9499 & 2.7036 & TRN \\
\hline CHEMBL1406458 & 688300 & 2.9499 & 2.9452 & TRN \\
\hline CHEMBL3192141 & 688300 & 4.3816 & 3.9018 & TRN \\
\hline CHEMBL1587391 & 688300 & 2.9499 & 2.5365 & TRN \\
\hline CHEMBL1539252 & 688300 & 2.9499 & 2.3839 & TRN \\
\hline CHEMBL1455183 & 688300 & 2.9499 & 2.9384 & TRN \\
\hline CHEMBL408850 & 688300 & 6.58 & 7.2009 & TRN \\
\hline CHEMBL1386322 & 688300 & 6.2857 & 5.2285 & TST \\
\hline CHEMBL1342565 & 688300 & 2.9499 & 3.3092 & TST \\
\hline CHEMBL1358201 & 688300 & 2.9499 & 3.4213 & TRN \\
\hline
\end{tabular}




\begin{tabular}{|c|c|c|c|c|c|}
\hline & & & & & \\
\hline CHEMBL1993190 & 688300 & 5.3411 & 6.1619 & TRN & \\
\hline CHEMBL1351768 & 688300 & 2.9499 & 3.03800 & 00000000003 & TRN \\
\hline CHEMBL1366631 & 688300 & 2.9499 & 2.67100 & 00000000003 & TRN \\
\hline CHEMBL1546429 & 688300 & 2.9499 & 3.5117 & TST & \\
\hline CHEMBL1978730 & 688300 & 6.2083 & 5.7157 & TRN & \\
\hline CHEMBL1318975 & 688300 & 2.9499 & 2.4444 & TRN & \\
\hline CHEMBL1489879 & 688300 & 2.9499 & 2.1679 & TRN & \\
\hline CHEMBL1309486 & 688300 & 2.9499 & 2.7912 & TST & \\
\hline CHEMBL1362275 & 688300 & 2.9499 & 3.4596 & TRN & \\
\hline CHEMBL1965630 & 688300 & 5.9197 & 4.7316 & TRN & \\
\hline CHEMBL1399855 & 688300 & 2.9499 & 2.4221 & TST & \\
\hline CHEMBL1993627 & 688300 & 6.06 & 5.5833 & TST & \\
\hline CHEMBL1326967 & 688300 & 6.0186 & 6.0491 & TRN & \\
\hline CHEMBL1403065 & 688300 & 5.2521 & 4.2707 & TRN & \\
\hline CHEMBL1412754 & 688300 & 2.9499 & 2.9814 & TRN & \\
\hline CHEMBL1303429 & 688300 & 5.9014 & 5.8896 & TRN & \\
\hline CHEMBL1435852 & 688300 & 2.9499 & 3.1134 & TRN & \\
\hline CHEMBL1417732 & 688300 & 5.2513 & 4.8828 & TRN & \\
\hline CHEMBL1585352 & 688300 & 2.9499 & 2.7648 & TRN & \\
\hline CHEMBL1376218 & 688300 & 2.9499 & 2.7615 & TRN & \\
\hline CHEMBL1581417 & 688300 & 2.9499 & 3.9118 & TRN & \\
\hline CHEMBL1547361 & 688300 & 2.9499 & 2.927 & TRN & \\
\hline CHEMBL1612044 & 688300 & 5.9363 & 6.1065 & TRN & \\
\hline CHEMBL1529461 & 688300 & 2.9499 & 3.0789 & TRN & \\
\hline CHEMBL1480311 & 688300 & 2.9499 & 2.8524 & TRN & \\
\hline CHEMBL1331429 & 688300 & 2.9499 & 2.6234 & TRN & \\
\hline CHEMBL1542081 & 688300 & 2.9499 & 3.0725 & TRN & \\
\hline CHEMBL1416653 & 688300 & 2.9499 & 3.8897 & TRN & \\
\hline CHEMBL1508840 & 688300 & 2.9499 & 3.57800 & 00000000003 & TRN \\
\hline CHEMBL1353666 & 688300 & 4.5631 & 3.9108 & TRN & \\
\hline CHEMBL1368148 & 688300 & 2.9499 & 3.6395 & TRN & \\
\hline CHEMBL1561773 & 688300 & 2.9499 & 2.9613 & TRN & \\
\hline CHEMBL3212557 & 688300 & 2.9499 & 2.8252 & TRN & \\
\hline CHEMBL1340249 & 688300 & 2.9499 & 3.0837 & TRN & \\
\hline CHEMBL1325549 & 688300 & 6.0883 & 5.9178 & TRN & \\
\hline CHEMBL1326195 & 688300 & 2.9499 & 3.8426 & TST & \\
\hline CHEMBL1394799 & 688300 & 2.9499 & 2.6905 & TRN & \\
\hline CHEMBL1489580 & 688300 & 2.9499 & 2.1339 & TST & \\
\hline CHEMBL1610821 & 688300 & 2.9499 & 5.6324 & TST & \\
\hline CHEMBL1413806 & 688300 & 6.1798 & 5.4293 & TRN & \\
\hline CHEMBL1363706 & 688300 & 5.6381 & 5.8083 & TRN & \\
\hline CHEMBL1374047 & 688300 & 2.9499 & 3.0045 & TRN & \\
\hline CHEMBL1450925 & 688300 & 2.9499 & 3.0487 & TRN & \\
\hline CHEMBL1439717 & 688300 & 4.6274 & 4.2647 & TRN & \\
\hline CHEMBL1386131 & 688300 & 2.9499 & 3.3605 & TST & \\
\hline CHEMBL1329548 & 688300 & 4.6363 & 4.2519 & TRN & \\
\hline CHEMBL1571240 & 688300 & 2.9499 & 2.8222 & TRN & \\
\hline CHEMBL1377834 & 688300 & 2.9499 & 2.5996 & TRN & \\
\hline
\end{tabular}

Page 11393 


\begin{tabular}{|c|c|c|c|c|c|}
\hline \multicolumn{6}{|c|}{ Supplemental Table S2.txt } \\
\hline CHEMBL1424060 & 688300 & 4.5027 & 4.5641 & TRN & \\
\hline CHEMBL1438981 & 688300 & 2.9499 & 3.1628 & TRN & \\
\hline CHEMBL1402126 & 688300 & 2.9499 & 3.5263 & TRN & \\
\hline CHEMBL1430096 & 688300 & 5.1186 & 4.6507 & TST & \\
\hline CHEMBL3212828 & 688300 & 2.9499 & 3.4751 & TRN & \\
\hline CHEMBL1343458 & 688300 & 6.3556 & 5.6234 & TRN & \\
\hline CHEMBL1465861 & 688300 & 2.9499 & 3.8245 & TRN & \\
\hline CHEMBL1552612 & 688300 & 2.9499 & 3.0756 & TRN & \\
\hline CHEMBL1489620 & 688300 & 2.9499 & 3.1418 & TST & \\
\hline CHEMBL1975825 & 688300 & 2.9499 & 3.3632 & TRN & \\
\hline CHEMBL1581884 & 688300 & 2.9499 & 3.2552 & TRN & \\
\hline CHEMBL1411861 & 688300 & 2.9499 & 3.4179 & TST & \\
\hline CHEMBL1489087 & 688300 & 6.9208 & 6.1629 & TRN & \\
\hline CHEMBL1421853 & 688300 & 2.9499 & 2.8717 & TRN & \\
\hline CHEMBL1486494 & 688300 & 2.9499 & 2.8376 & TST & \\
\hline CHEMBL1533279 & 688300 & 2.9499 & 4.1793 & TST & \\
\hline CHEMBL1582317 & 688300 & 2.9499 & 2.7195 & TRN & \\
\hline CHEMBL1572014 & 688300 & 2.9499 & 3.5285 & TRN & \\
\hline CHEMBL1388781 & 688300 & 2.9499 & 2.9003 & TRN & \\
\hline CHEMBL1402519 & 688300 & 2.9499 & 4.378 & TST & \\
\hline CHEMBL1330583 & 688300 & 5.98799 & 99999999 & 6.8034 & TRN \\
\hline CHEMBL1490043 & 688300 & 6.3439 & 6.2153 & TRN & \\
\hline CHEMBL1350144 & 688300 & 2.9499 & 3.0601 & TRN & \\
\hline CHEMBL1570561 & 688300 & 2.9499 & 2.5873 & TRN & \\
\hline CHEMBL1450150 & 688300 & 2.9499 & 3.4593 & TRN & \\
\hline CHEMBL1585766 & 688300 & 2.9499 & 3.3239 & TRN & \\
\hline CHEMBL1550431 & 688300 & 2.9499 & 3.20300 & 00000000003 & TST \\
\hline CHEMBL1350091 & 688300 & 2.9499 & 2.9124 & TRN & \\
\hline CHEMBL1575440 & 688300 & 2.9499 & 2.6412 & TRN & \\
\hline CHEMBL1547381 & 688300 & 2.9499 & 3.7076 & TRN & \\
\hline CHEMBL1565445 & 688300 & 2.9499 & 2.0967 & TST & \\
\hline CHEMBL1501767 & 688300 & 2.9499 & 2.9536 & TRN & \\
\hline CHEMBL1495483 & 688300 & 4.7596 & 4.5597 & TRN & \\
\hline CHEMBL1453561 & 688300 & 2.9499 & 2.9923 & TRN & \\
\hline CHEMBL1474147 & 688300 & 2.9499 & 3.2803 & TRN & \\
\hline CHEMBL1336241 & 688300 & 2.9499 & 2.5741 & TRN & \\
\hline CHEMBL1603509 & 688300 & 6.0218 & 6.0447 & TRN & \\
\hline CHEMBL3191048 & 688300 & 5.334 & 4.8056 & TRN & \\
\hline CHEMBL1465438 & 688300 & 2.9499 & 2.9215 & TST & \\
\hline CHEMBL1572731 & 688300 & 2.9499 & 3.4666 & TRN & \\
\hline CHEMBL1366066 & 688300 & 2.9499 & 3.0613 & TST & \\
\hline CHEMBL1558092 & 688300 & 4.7848 & 5.5038 & TRN & \\
\hline CHEMBL1450686 & 688300 & 2.9499 & 2.7537 & TRN & \\
\hline CHEMBL1327321 & 688300 & 2.9499 & 2.7915 & TRN & \\
\hline CHEMBL 3209234 & 688300 & 2.9499 & 3.5311 & TRN & \\
\hline CHEMBL1608430 & 688300 & 5.9914 & 5.3766 & TRN & \\
\hline CHEMBL1412749 & 688300 & 2.9499 & 2.6733 & TRN & \\
\hline CHEMBL1488288 & 688300 & 2.9499 & 3.4632 & TRN & \\
\hline
\end{tabular}




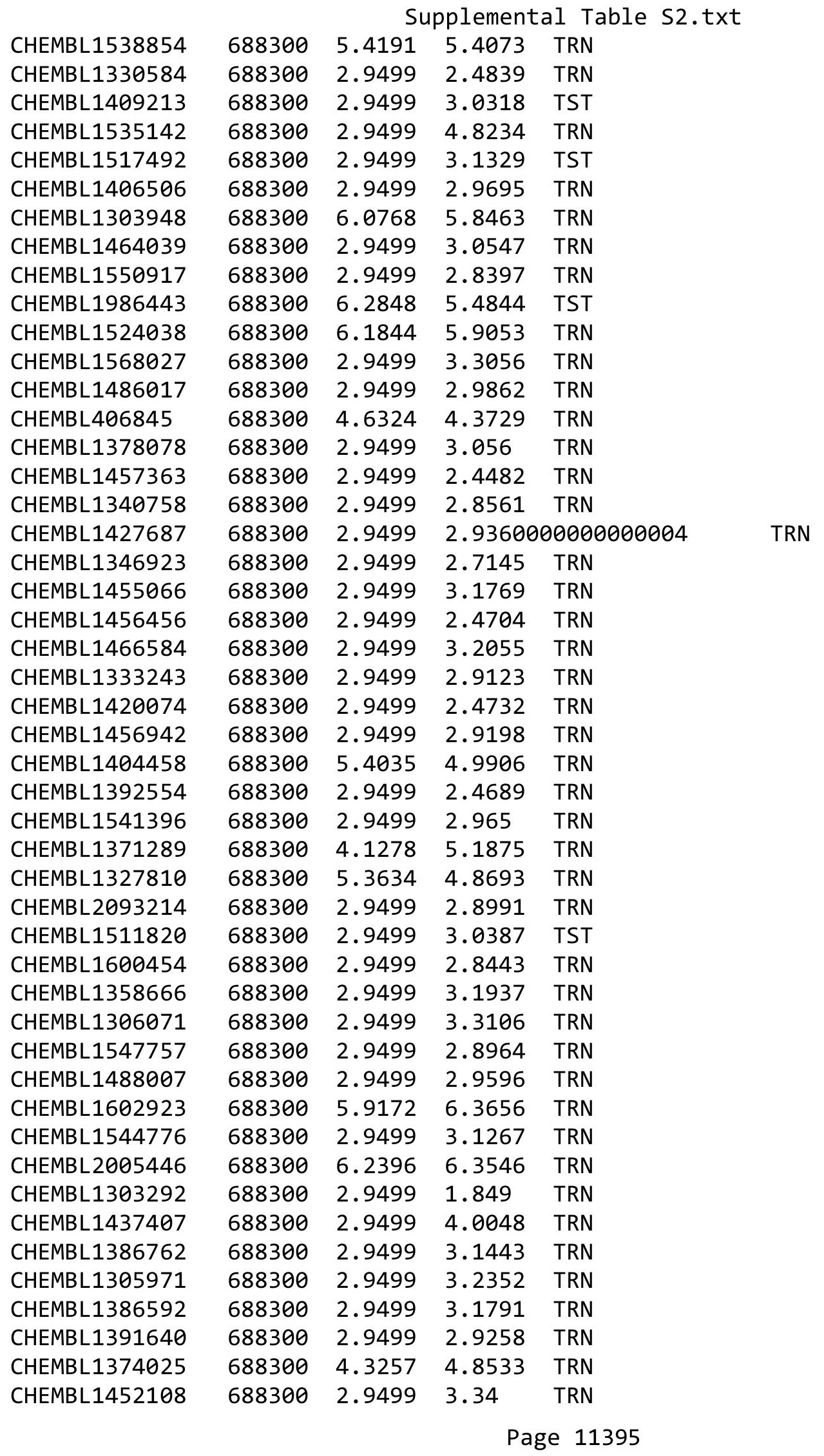


Supplemental Table S2.txt

\begin{tabular}{|c|c|c|c|c|c|}
\hline CHEMBL225951 & 688300 & 5.9622 & 5.3844 & TRN & \\
\hline CHEMBL1335571 & 688300 & 6.9136 & 5.9764 & TRN & \\
\hline CHEMBL1445662 & 688300 & 2.9499 & 3.137 & TRN & \\
\hline CHEMBL1967151 & 688300 & 5.0914 & 5.436 & TRN & \\
\hline CHEMBL1424873 & 688300 & 2.9499 & 2.9433 & TRN & \\
\hline CHEMBL1492504 & 688300 & 2.9499 & 2.9788 & TRN & \\
\hline CHEMBL1309735 & 688300 & 2.9499 & 2.7736 & TRN & \\
\hline CHEMBL1349067 & 688300 & 5.4194 & 5.2539 & TRN & \\
\hline CHEMBL1481516 & 688300 & 2.9499 & 2.4293 & TRN & \\
\hline CHEMBL1403024 & 688300 & 6.0026 & 5.8693 & TRN & \\
\hline CHEMBL1983323 & 688300 & 5.8465 & 6.2317 & TRN & \\
\hline CHEMBL 3209485 & 688300 & 2.9499 & 3.5573 & TST & \\
\hline CHEMBL1595528 & 688300 & 2.9499 & 3.5622 & TRN & \\
\hline CHEMBL1500524 & 688300 & 2.9499 & 2.8755 & TRN & \\
\hline CHEMBL1471391 & 688300 & \multicolumn{3}{|c|}{ 4. 3580000000000005} & 3.51 \\
\hline CHEMBL 2373673 & 688300 & 2.9499 & 2.931 & TST & \\
\hline CHEMBL72135 & 688300 & 2.9499 & 2.7934 & TST & \\
\hline CHEMBL1403257 & 688300 & 2.9499 & 2.8684 & TST & \\
\hline CHEMBL1413193 & 688300 & 2.9499 & 3.1577 & TRN & \\
\hline CHEMBL1435336 & 688300 & 2.9499 & 2.6187 & TST & \\
\hline CHEMBL1361038 & 688300 & 2.9499 & 3.6451 & TRN & \\
\hline CHEMBL1485017 & 688300 & 2.9499 & 2.8312 & TRN & \\
\hline CHEMBL1546367 & 688300 & 2.9499 & 2.7121 & TRN & \\
\hline CHEMBL1392570 & 688300 & 6.0088 & 5.4205 & TRN & \\
\hline CHEMBL1349374 & 688300 & 5.215 & 5.392 & TRN & \\
\hline CHEMBL1470568 & 688300 & 6.1068 & 6.2109 & TRN & \\
\hline CHEMBL1457634 & 688300 & 5.6842 & 5.6134 & TRN & \\
\hline CHEMBL1310785 & 688300 & 2.9499 & 2.8486 & TRN & \\
\hline CHEMBL1344803 & 688300 & 2.9499 & 4.0494 & TRN & \\
\hline CHEMBL1420155 & 688300 & 2.9499 & 3.7751 & TRN & \\
\hline CHEMBL1413557 & 688300 & 4.4347 & 4.2937 & TRN & \\
\hline CHEMBL1497777 & 688300 & 2.9499 & 2.8794 & TST & \\
\hline CHEMBL1980658 & 688300 & 5.9516 & 6.4255 & TST & \\
\hline CHEMBL1526637 & 688300 & 5.4076 & 6.1518 & TST & \\
\hline CHEMBL1496651 & 688300 & 5.1108 & 5.4118 & TST & \\
\hline CHEMBL1458200 & 688300 & 5.6131 & 5.5814 & TST & \\
\hline CHEMBL1467431 & 688300 & 6.4449 & 5.1841 & TST & \\
\hline CHEMBL1565696 & 688300 & 2.9499 & 3.1959 & TST & \\
\hline CHEMBL1373921 & 688300 & 2.9499 & 2.5086 & TST & \\
\hline CHEMBL1349985 & 688300 & 2.9499 & 3.0568 & TST & \\
\hline CHEMBL1562602 & 688300 & 2.9499 & 3.0101 & TST & \\
\hline CHEMBL1382194 & 688300 & 2.9499 & 3.5041 & TST & \\
\hline CHEMBL1340899 & 688300 & 2.9499 & 2.5508 & TST & \\
\hline CHEMBL1341816 & 688300 & 5.8315 & 6.3987 & TST & \\
\hline CHEMBL1342602 & 688300 & 5.3787 & 5.4235 & TST & \\
\hline CHEMBL1457975 & 688300 & 2.9499 & 4.0794 & TST & \\
\hline CHEMBL 3191962 & 688300 & 6.1051 & 6.053 & TST & \\
\hline CHEMBL1612679 & 688300 & 2.9499 & 2.5804 & TST & \\
\hline
\end{tabular}




\begin{tabular}{|c|c|c|c|c|c|}
\hline \multicolumn{6}{|c|}{ Supplemental Table S2.txt } \\
\hline CHEMBL1384798 & 688300 & 2.9499 & 3.7981 & TST & \\
\hline CHEMBL1560223 & 688300 & 5.5558 & 5.2358 & TST & \\
\hline CHEMBL1498862 & 688300 & 2.9499 & 3.0644 & TST & \\
\hline CHEMBL1511385 & 688300 & 2.9499 & 3.9213 & TST & \\
\hline CHEMBL3198494 & 688300 & 5.1218 & 5.3518 & TST & \\
\hline CHEMBL1485175 & 688300 & 2.9499 & 3.1116 & TST & \\
\hline CHEMBL1333973 & 688300 & 2.9499 & 3.1609 & TST & \\
\hline CHEMBL1404395 & 688300 & 2.9499 & 2.9112 & TST & \\
\hline CHEMBL1571355 & 688300 & 2.9499 & 2.5318 & TST & \\
\hline CHEMBL 1354276 & 688300 & 2.9499 & 3.0997 & TST & \\
\hline CHEMBL1594988 & 688300 & 2.9499 & 3.5909 & TST & \\
\hline CHEMBL1450158 & 688300 & 2.9499 & 2.9722 & TST & \\
\hline CHEMBL1456273 & 688300 & 2.9499 & 3.7055 & TST & \\
\hline CHEMBL1540374 & 688300 & 2.9499 & 4.0905 & TST & \\
\hline CHEMBL1443034 & 688300 & 2.9499 & 2.8069 & TST & \\
\hline CHEMBL1414030 & 688300 & 2.9499 & 3.0197 & TST & \\
\hline CHEMBL1330013 & 688300 & 2.9499 & 2.5634 & TST & \\
\hline CHEMBL1604913 & 688300 & 2.9499 & 3.917 & TST & \\
\hline CHEMBL1546621 & 688300 & 2.9499 & 3.2736 & TST & \\
\hline CHEMBL1983871 & 688300 & 4.9707 & 5.181 & TST & \\
\hline CHEMBL1605021 & 688300 & 4.8424 & 4.2367 & TST & \\
\hline CHEMBL1352089 & 688300 & 2.9499 & 2.6627 & TST & \\
\hline CHEMBL1613218 & 688300 & 2.9499 & 3.77100 & 00000000004 & TST \\
\hline CHEMBL1301753 & 688300 & 2.9499 & 3.3107 & TST & \\
\hline CHEMBL1424946 & 688300 & 2.9499 & 4.1664 & TST & \\
\hline CHEMBL1334614 & 688300 & 2.9499 & 3.76800 & 00000000002 & TST \\
\hline CHEMBL1491075 & 688300 & 2.9499 & 3.5788 & TST & \\
\hline CHEMBL3212753 & 688300 & 2.9499 & 2.8255 & TST & \\
\hline CHEMBL1439343 & 688300 & 2.9499 & 2.8085 & TST & \\
\hline CHEMBL1596334 & 688300 & 2.9499 & 3.4279 & TST & \\
\hline CHEMBL1441898 & 688300 & 2.9499 & 2.3444 & TST & \\
\hline CHEMBL1972249 & 688300 & 5.4191 & 5.5336 & TST & \\
\hline CHEMBL1404116 & 688300 & 2.9499 & 3.3528 & TST & \\
\hline CHEMBL1468318 & 688300 & 6.0022 & 5.9507 & TST & \\
\hline CHEMBL1578056 & 688300 & 2.9499 & 3.2193 & TST & \\
\hline CHEMBL1377193 & 688300 & 2.9499 & 4.8489 & TST & \\
\hline CHEMBL1587776 & 688300 & 2.9499 & 2.1788 & TST & \\
\hline CHEMBL1541436 & 688300 & 2.9499 & 2.8311 & TST & \\
\hline CHEMBL1972405 & 688300 & 4.8698 & 5.483 & TST & \\
\hline CHEMBL3191594 & 688300 & 5.9158 & 6.4151 & TST & \\
\hline CHEMBL1456976 & 688300 & 2.9499 & 2.9142 & TST & \\
\hline CHEMBL1488017 & 688300 & 2.9499 & 2.8905 & TST & \\
\hline CHEMBL3191815 & 688300 & 2.9499 & 4.4181 & TST & \\
\hline CHEMBL1313428 & 688300 & 5.9784 & 5.402 & TST & \\
\hline CHEMBL1600851 & 688300 & 5.8911 & 4.2201 & TST & \\
\hline CHEMBL1532980 & 688300 & 2.9499 & 2.926 & TST & \\
\hline CHEMBL1525635 & 688300 & 2.9499 & 2.5299 & TST & \\
\hline CHEMBL1377421 & 688300 & 2.9499 & 2.7952 & TST & \\
\hline
\end{tabular}




\begin{tabular}{|c|c|c|c|c|}
\hline & & & oplement & al $\mathrm{T}$ \\
\hline CHEMBL1403415 & 688300 & 2.9499 & 2.4832 & TST \\
\hline CHEMBL1430286 & 688300 & 2.9499 & 3.2146 & TST \\
\hline CHEMBL1524570 & 688300 & 2.9499 & 2.9374 & TST \\
\hline CHEMBL2004183 & 688300 & 4.3295 & 3.47 & TST \\
\hline CHEMBL1578917 & 688300 & 2.9499 & 3.1969 & TST \\
\hline CHEMBL1457697 & 688300 & 2.9499 & 3.5319 & TST \\
\hline CHEMBL1314567 & 688300 & 2.9499 & 2.35 & TST \\
\hline CHEMBL1455604 & 688300 & 2.9499 & 2.9544 & TST \\
\hline CHEMBL1603034 & 688300 & 4.5284 & 4.9808 & TST \\
\hline CHEMBL1608918 & 688300 & 2.9499 & 2.8316 & TST \\
\hline CHEMBL1480031 & 688300 & 2.9499 & 4.1395 & TST \\
\hline CHEMBL1454313 & 688300 & 2.9499 & 3.2643 & TST \\
\hline CHEMBL1386646 & 688300 & 2.9499 & 4.31 & TST \\
\hline CHEMBL1533835 & 688300 & 6.1361 & 5.9733 & TST \\
\hline CHEMBL1489352 & 688300 & 2.9499 & 3.0665 & TST \\
\hline CHEMBL1607729 & 688300 & 2.9499 & 3.1481 & TST \\
\hline CHEMBL1610081 & 688300 & 2.9499 & 3.1516 & TST \\
\hline CHEMBL1407964 & 688300 & 2.9499 & 3.9938 & TST \\
\hline CHEMBL1471946 & 688300 & 2.9499 & 3.0164 & TST \\
\hline CHEMBL1586230 & 688300 & 2.9499 & 3.1892 & TST \\
\hline CHEMBL1450616 & 688300 & 2.9499 & 4.1828 & TST \\
\hline CHEMBL1511219 & 688300 & 6.8182 & 6.8074 & TST \\
\hline CHEMBL1479010 & 688300 & 6.0975 & 5.4511 & TST \\
\hline CHEMBL1422840 & 688300 & 2.9499 & 2.9171 & TST \\
\hline CHEMBL1477575 & 688300 & 5.6457 & 5.5155 & TST \\
\hline CHEMBL1564969 & 688300 & 2.9499 & 3.2671 & TST \\
\hline CHEMBL131037 & 688300 & 2.9499 & 3.778 & TST \\
\hline CHEMBL1370888 & 688300 & 2.9499 & 2.6072 & TST \\
\hline CHEMBL3207928 & 688300 & 2.9499 & 4.1323 & TST \\
\hline CHEMBL1586391 & 688300 & 2.9499 & 4.673 & TST \\
\hline CHEMBL1485577 & 688300 & 4.6978 & 4.8314 & TST \\
\hline CHEMBL1522591 & 688300 & 2.9499 & 2.9831 & TST \\
\hline CHEMBL1586912 & 688300 & 4.4014 & 2.5297 & TST \\
\hline CHEMBL1501609 & 688300 & 2.9499 & 2.4977 & TST \\
\hline CHEMBL1492671 & 688300 & 6.6003 & 5.7326 & TST \\
\hline CHEMBL1330058 & 688300 & 6.3757 & 7.2284 & TST \\
\hline CHEMBL112115 & 688300 & 4.2881 & 4.7256 & TST \\
\hline CHEMBL1518907 & 688300 & 2.9499 & 3.0789 & TST \\
\hline CHEMBL1461445 & 688300 & 2.9499 & 2.3819 & TST \\
\hline CHEMBL1508121 & 688300 & 2.9499 & 4.0717 & TST \\
\hline CHEMBL1492001 & 688300 & 6.6778 & 5.8835 & TST \\
\hline CHEMBL1535200 & 688300 & 2.9499 & 4.0022 & TST \\
\hline CHEMBL1304945 & 688300 & 2.9499 & 3.4582 & TST \\
\hline CHEMBL3193970 & 688300 & 2.9499 & 3.6056 & TST \\
\hline CHEMBL1435120 & 688300 & 2.9499 & 3.068 & TST \\
\hline CHEMBL1336359 & 688300 & 2.9499 & 2.725 & TST \\
\hline CHEMBL1502358 & 688300 & 2.9499 & 3.9506 & TST \\
\hline CHEMBL1338085 & 688300 & 6.3904 & 5.1655 & TST \\
\hline
\end{tabular}




\begin{tabular}{|c|c|c|c|c|c|}
\hline & & \multicolumn{4}{|c|}{ Supplemental Table S2.txt } \\
\hline CHEMBL1430805 & 688300 & 2.9499 & 2.3378 & TST & \\
\hline CHEMBL1417508 & 688300 & 2.9499 & 4.3717 & TST & \\
\hline CHEMBL1301440 & 688300 & 2.9499 & 2.8087 & TST & \\
\hline CHEMBL1325243 & 688300 & 4.7809 & 5.2686 & TST & \\
\hline CHEMBL1509096 & 688300 & 2.9499 & 3.1664 & TST & \\
\hline CHEMBL1520766 & 688300 & 2.9499 & 3.9081 & TST & \\
\hline CHEMBL1598649 & 688300 & 2.9499 & 3.6617 & TST & \\
\hline CHEMBL3191437 & 688300 & 5.4175 & 5.0912 & TST & \\
\hline CHEMBL1505003 & 688300 & 6.0675 & 5.3741 & TST & \\
\hline CHEMBL1413360 & 688300 & 2.9499 & 3.4718 & TST & \\
\hline CHEMBL3190132 & 688300 & 6.7167 & 5.6795 & TST & \\
\hline CHEMBL 3195878 & 688300 & 5.8033 & 5.557 & TST & \\
\hline CHEMBL1327004 & 688300 & 2.9499 & 3.2348 & TST & \\
\hline CHEMBL1547928 & 688300 & 2.9499 & 2.8624 & TST & \\
\hline CHEMBL1574553 & 688300 & 6.5243 & 6.5838 & TST & \\
\hline CHEMBL1427599 & 688300 & 2.9499 & 3.4806 & TST & \\
\hline CHEMBL1442883 & 688300 & 2.9499 & 3.0794 & TST & \\
\hline CHEMBL285819 & 688300 & 2.9499 & 3.5512 & TST & \\
\hline CHEMBL1576260 & 688300 & 2.9499 & 3.4737 & TST & \\
\hline CHEMBL1604007 & 688300 & 2.9499 & 4.044 & TST & \\
\hline CHEMBL1560434 & 688300 & 5.9559 & 4.3539 & TST & \\
\hline CHEMBL1438419 & 688300 & 2.9499 & 2.5972 & TST & \\
\hline CHEMBL1395404 & 688300 & 5.8526 & 5.098 & TST & \\
\hline CHEMBL1342038 & 688300 & 5.8239 & 5.9712 & TST & \\
\hline CHEMBL1382202 & 688300 & 2.9499 & 3.1324 & TST & \\
\hline CHEMBL546344 & 688300 & 6.4597 & 5.9667 & TST & \\
\hline CHEMBL1332236 & 688300 & 2.9499 & 4.1546 & TST & \\
\hline CHEMBL1339775 & 688300 & 4.5679 & 2.9857 & TST & \\
\hline CHEMBL1558189 & 688300 & 2.9499 & 2.8372 & TST & \\
\hline CHEMBL1584332 & 688300 & 2.9499 & 2.5333 & TST & \\
\hline CHEMBL1348864 & 688300 & 2.9499 & 3.8044 & TST & \\
\hline CHEMBL1312155 & 688300 & 2.9499 & 3.0666 & TST & \\
\hline CHEMBL1530379 & 688300 & 6.064 & 7.0096 & TST & \\
\hline CHEMBL1370147 & 688300 & 2.9499 & 3.7876 & TST & \\
\hline CHEMBL1969298 & 688300 & 8.0555 & 5.6056 & TST & \\
\hline CHEMBL1420035 & 688300 & 2.9499 & 2.6102 & TST & \\
\hline CHEMBL1591222 & 688300 & 5.4848 & 5.186 & TST & \\
\hline CHEMBL1597122 & 688300 & 2.9499 & 2.4466 & TST & \\
\hline CHEMBL1352257 & 688300 & 2.9499 & 2.8487 & TST & \\
\hline CHEMBL1353757 & 688300 & 5.8496 & 4.5564 & TST & \\
\hline CHEMBL1540804 & 688300 & 2.9499 & 3.7239 & TST & \\
\hline CHEMBL1340293 & 688300 & 2.9499 & 3.514 & TST & \\
\hline CHEMBL1307161 & 688300 & 2.9499 & 2.4111 & TST & \\
\hline CHEMBL1987906 & 688300 & 2.9499 & 4.0448 & TST & \\
\hline CHEMBL1443148 & 688300 & 2.9499 & 3.0934 & TST & \\
\hline CHEMBL1545140 & 688300 & 2.9499 & 3.07800 & 00000000003 & TST \\
\hline CHEMBL1302889 & 688300 & 6.1135 & 4.9926 & TST & \\
\hline CHEMBL1545043 & 688300 & 2.9499 & 4.648 & TST & \\
\hline
\end{tabular}




\begin{tabular}{|c|c|}
\hline CHEMBL1403276 & 688300 \\
\hline CHEMBL1510591 & 688300 \\
\hline CHEMBL1357378 & 688300 \\
\hline CHEMBL1543741 & 688300 \\
\hline CHEMBL3196042 & 688300 \\
\hline CHEMBL1501760 & 688300 \\
\hline CHEMBL1375497 & 688300 \\
\hline CHEMBL1465837 & 688300 \\
\hline CHEMBL1581612 & 688300 \\
\hline CHEMBL1432858 & 688300 \\
\hline CHEMBL1510527 & 688300 \\
\hline CHEMBL1367027 & 688300 \\
\hline CHEMBL1377098 & 688300 \\
\hline CHEMBL1463600 & 688300 \\
\hline CHEMBL1994913 & 688300 \\
\hline CHEMBL1380161 & 688300 \\
\hline CHEMBL1349069 & 688300 \\
\hline CHEMBL1498744 & 688300 \\
\hline CHEMBL1504458 & 688300 \\
\hline CHEMBL1483581 & 688300 \\
\hline CHEMBL1299412 & 688300 \\
\hline CHEMBL3197774 & 688300 \\
\hline CHEMBL1432329 & 688300 \\
\hline CHEMBL1579042 & 688300 \\
\hline CHEMBL1417677 & 688300 \\
\hline CHEMBL1487967 & 688300 \\
\hline CHEMBL1800499 & 757250 \\
\hline CHEMBL1800706 & 757250 \\
\hline CHEMBL1800423 & 757250 \\
\hline CHEMBL1800410 & 757250 \\
\hline CHEMBL1800482 & 757250 \\
\hline CHEMBL1800707 & 757250 \\
\hline CHEMBL1800494 & 757250 \\
\hline CHEMBL1800709 & 757250 \\
\hline CHEMBL1800489 & 757250 \\
\hline CHEMBL1800708 & 757250 \\
\hline CHEMBL 1800420 & 757250 \\
\hline CHEMBL1800479 & 757250 \\
\hline CHEMBL1800486 & 757250 \\
\hline CHEMBL1800505 & 757250 \\
\hline CHEMBL1800415 & 757250 \\
\hline CHEMBL1800492 & 757250 \\
\hline CHEMBL1800490 & 757250 \\
\hline CHEMBL1800416 & 757250 \\
\hline CHEMBL1800418 & 757250 \\
\hline CHEMBL1800412 & 757250 \\
\hline CHEMBL1800413 & 757250 \\
\hline CHEMBL1800521 & 757250 \\
\hline
\end{tabular}

Supplemental Table S2.txt

6.10075 .9967 TST

$\begin{array}{lll}2.9499 & 2.5636 & \text { TST }\end{array}$

$\begin{array}{llll}2.9499 & 3.2958 \text { TST }\end{array}$

$\begin{array}{lll}2.9499 & 3.7724 & \text { TST }\end{array}$

$\begin{array}{lll}5.9574 & 5.6495 & \text { TST }\end{array}$

$\begin{array}{lll}2.9499 & 2.5408 \text { TST }\end{array}$

$\begin{array}{lll}2.9499 & 2.883 \quad \text { TST }\end{array}$

$2.9499 \quad 2.2319999999999998$

$\begin{array}{lll}2.9499 & 2.7984 & \text { TST }\end{array}$

$\begin{array}{lll}2.9499 & 1.9537 & \text { TST }\end{array}$

$\begin{array}{lll}2.9499 & 3.1209 & \text { TST }\end{array}$

$\begin{array}{lll}2.9499 & 3.2012 & \text { TST }\end{array}$

$\begin{array}{lll}2.9499 & 2.3298 & \text { TST }\end{array}$

$\begin{array}{lll}2.9499 & 3.2082 & \text { TST }\end{array}$

$\begin{array}{lll}2.9499 & 3.6298 & \text { TST }\end{array}$

$\begin{array}{lll}2.9499 & 4.8827 & \text { TST }\end{array}$

$\begin{array}{lll}2.9499 & 3.1493 & \text { TST }\end{array}$

$\begin{array}{lll}2.9499 & 3.1819 & \text { TST }\end{array}$

$\begin{array}{lll}2.9499 & 2.6793 & \text { TST }\end{array}$

$\begin{array}{llll}2.9499 & 3.2396 & \text { TST }\end{array}$

$\begin{array}{lll}2.9499 & 2.7784 & \text { TST }\end{array}$

$\begin{array}{lll}2.9499 & 4.667 & \text { TST }\end{array}$

$\begin{array}{lll}2.9499 & 3.1418 \text { TST }\end{array}$

$\begin{array}{llll}6.3335 & 5.2107 & \text { TST }\end{array}$

$\begin{array}{lll}2.9499 & 4.1233 & \text { TST }\end{array}$

$\begin{array}{lll}5.325 & 5.8949 & \text { TST }\end{array}$

$\begin{array}{lll}7.4949 & 6.6733 \text { TRN }\end{array}$

$\begin{array}{lll}4.301 & 7.4672 & \text { TST }\end{array}$

$\begin{array}{lll}6.8794 & 6.8548 & \text { TRN }\end{array}$

$\begin{array}{lll}5.0 & 5.1925 & \text { TST }\end{array}$

$\begin{array}{lll}4.301 & 6.261 & \text { TRN }\end{array}$

$\begin{array}{lll}5.0 & 5.6009 & \text { TRN }\end{array}$

$\begin{array}{lll}6.5229 & 6.642 \quad \text { TRN }\end{array}$

$\begin{array}{llll}5.6038 & 5.9243 & \text { TRN }\end{array}$

$\begin{array}{lll}6.5114 & 6.7414 & \text { TRN }\end{array}$

$\begin{array}{llll}6.3768 & 6.4584 & \text { TRN }\end{array}$

$\begin{array}{lll}7.2676 & 6.8297 & \text { TRN }\end{array}$

$\begin{array}{llll}7.0458 & 7.2961 & \text { TRN }\end{array}$

$\begin{array}{lll}6.4437 & 6.7312 & \text { TRN }\end{array}$

5.86975 .4642 TRN

$\begin{array}{lll}6.0 & 6.4222 & \text { TRN }\end{array}$

$\begin{array}{lll}7.284 & 6.596 & \text { TRN }\end{array}$

$\begin{array}{llll}7.3098 & 6.6455 & \text { TRN }\end{array}$

$\begin{array}{llll}5.4437 & 6.2366 & \text { TRN }\end{array}$

$\begin{array}{llll}7.5086 & 6.5623 & \text { TRN }\end{array}$

$\begin{array}{lll}4.0 & 6.9826 & \text { TST }\end{array}$

$\begin{array}{lll}5.0066 & 7.0013 & \text { TST }\end{array}$

6.33725 .2143 TRN

Page 11400 
Supplemental Table S2.txt

\begin{tabular}{|c|c|c|c|c|c|}
\hline CHEMBL1800425 & 757250 & 6.1192 & 6.4512 & TRN & \\
\hline CHEMBL1800705 & 757250 & 9.0 & 7.7113 & TRN & \\
\hline CHEMBL1800488 & 757250 & 6.7423 & 6.9834 & TRN & \\
\hline CHEMBL1800519 & 757250 & 5.4168 & 5.5793 & TRN & \\
\hline CHEMBL1800500 & 757250 & 6.4202 & 6.8601 & TRN & \\
\hline CHEMBL1800503 & 757250 & 4.8827 & 5.6153 & TRN & \\
\hline CHEMBL1800516 & 757250 & 8.4202 & 7.3284 & TRN & \\
\hline CHEMBL1800506 & 757250 & 5.5406 & 5.1661 & TST & \\
\hline CHEMBL1800514 & 757250 & 7.7212 & 7.5065 & TRN & \\
\hline CHEMBL1800419 & 757250 & 7.1612 & 6.7985 & TRN & \\
\hline CHEMBL1800481 & 757250 & 6.8827 & 7.312 & TRN & \\
\hline CHEMBL1800360 & 757250 & 6.5086 & 6.2258 & TST & \\
\hline CHEMBL1800712 & 757250 & 5.0 & 4.7667 & TRN & \\
\hline CHEMBL1800476 & 757250 & 6.5686 & 6.8506 & TRN & \\
\hline CHEMBL1800511 & 757250 & 6.7212 & 7.08799 & 999999999 & TRN \\
\hline CHEMBL1800409 & 757250 & 5.0 & 5.3743 & TST & \\
\hline CHEMBL1800513 & 757250 & 8.0969 & 6.8544 & TRN & \\
\hline CHEMBL1800496 & 757250 & 7.5086 & 7.5878 & TRN & \\
\hline CHEMBL1800495 & 757250 & 6.7959 & 7.3292 & TRN & \\
\hline CHEMBL1800407 & 757250 & 5.0 & 4.3388 & TST & \\
\hline CHEMBL1800408 & 757250 & 5.0 & 4.7516 & TST & \\
\hline CHEMBL1800362 & 757250 & 4.301 & 4.5666 & TST & \\
\hline CHEMBL1800713 & 757250 & 5.0 & 4.8672 & TRN & \\
\hline CHEMBL1484316 & 757250 & 6.9208 & 5.3531 & TST & \\
\hline CHEMBL1800485 & 757250 & 7.6021 & 6.9385 & TRN & \\
\hline CHEMBL1800502 & 757250 & 6.1662 & 5.5431 & TRN & \\
\hline CHEMBL1800477 & 757250 & 7.0458 & 7.61100 & 000000001 & TRN \\
\hline CHEMBL1800414 & 757250 & 5.6308 & 5.2581 & TST & \\
\hline CHEMBL1800484 & 757250 & 6.9101 & 6.4237 & TRN & \\
\hline CHEMBL1800487 & 757250 & 6.7696 & 6.6838 & TRN & \\
\hline CHEMBL1800711 & 757250 & 5.0 & 5.0728 & TRN & \\
\hline CHEMBL1800478 & 757250 & 6.1858 & 7.4323 & TRN & \\
\hline CHEMBL1800515 & 757250 & 6.5686 & 6.975 & TRN & \\
\hline CHEMBL1800417 & 757250 & 7.5086 & 6.6735 & TRN & \\
\hline CHEMBL1800480 & 757250 & 6.7352 & 7.0844 & TRN & \\
\hline CHEMBL1800483 & 757250 & 7.1805 & 6.4582 & TRN & \\
\hline CHEMBL1800421 & 757250 & 7.3979 & 6.8013 & TRN & \\
\hline CHEMBL1800504 & 757250 & 5.4168 & 6.5296 & TST & \\
\hline CHEMBL1800491 & 757250 & 6.2596 & 6.1247 & TRN & \\
\hline CHEMBL1800512 & 757250 & 7.0 & 6.1913 & TRN & \\
\hline CHEMBL1800411 & 757250 & 5.0 & 4.9825 & TST & \\
\hline CHEMBL1800493 & 757250 & 6.7747 & 6.1948 & TRN & \\
\hline CHEMBL1800497 & 757250 & 6.3279 & 7.1048 & TRN & \\
\hline CHEMBL1800509 & 757250 & 4.9031 & 6.3251 & TRN & \\
\hline CHEMBL1800405 & 757250 & 4.301 & 5.1515 & TST & \\
\hline CHEMBL1800508 & 757250 & 5.3778 & 6.5632 & TRN & \\
\hline CHEMBL1800522 & 757250 & 7.8239 & 6.9135 & TRN & \\
\hline CHEMBL1800518 & 757250 & 6.1096 & 6.1802 & TRN & \\
\hline
\end{tabular}

Page 11401 


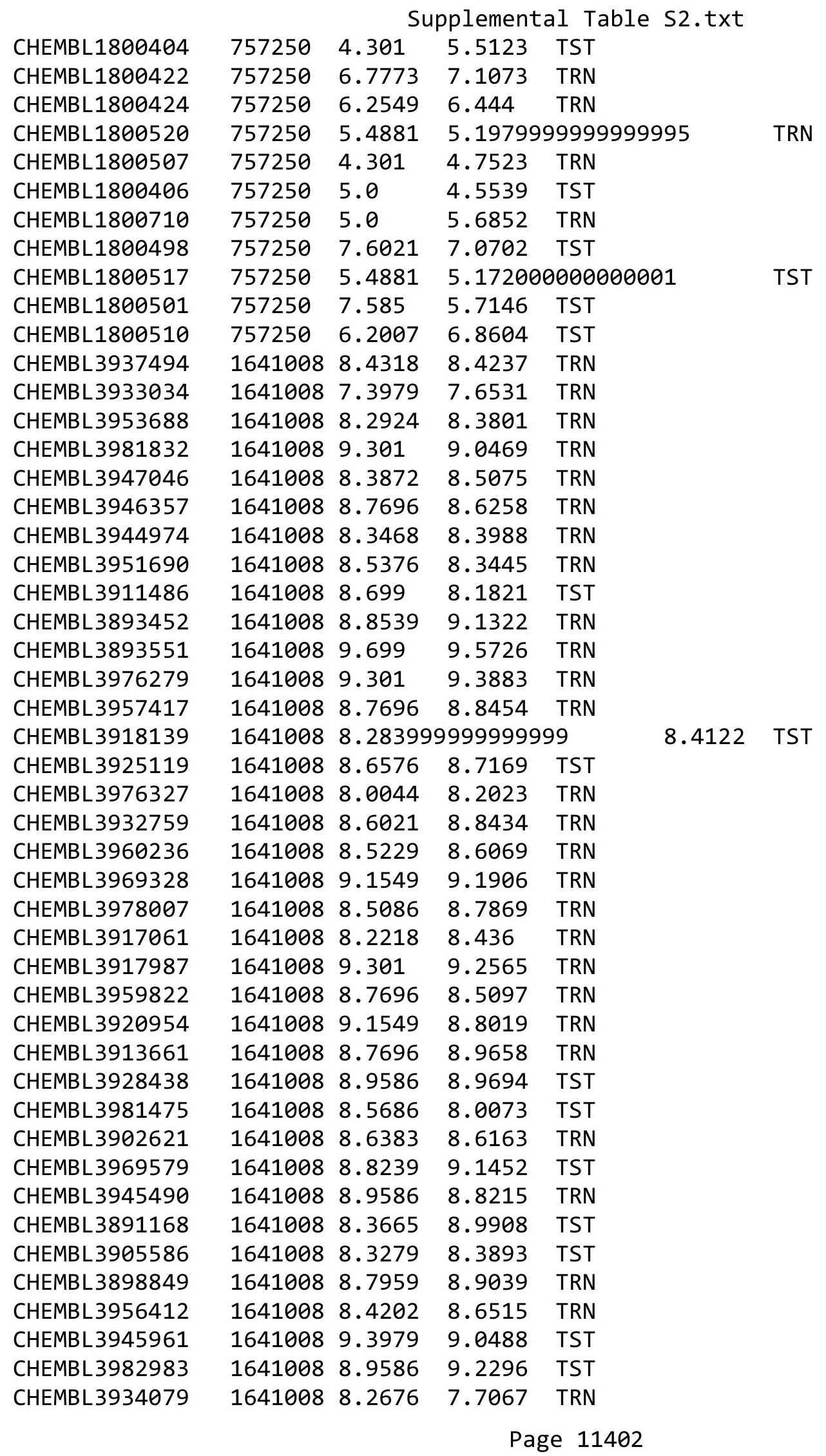


Supplemental Table S2.txt

\begin{tabular}{|c|c|c|c|}
\hline HEMBL3947457 & 1641008 & 8.3098 & 8.7297 \\
\hline CHEMBL 3924895 & 1641008 & 9.699 & 9.6464 \\
\hline HEMBL3918653 & 1641008 & 7.7959 & 7197 \\
\hline HEMBL3964123 & 1641008 & 8.2366 & 5036 \\
\hline HEMBL3984394 & 641008 & 8.7959 & .901 \\
\hline CHEMBL3938258 & 1641008 & 8.3872 & 8.4236 \\
\hline HEMBL3920366 & 1641008 & 9.0 & 8.8997 \\
\hline HEMBL3961918 & L641008 & 8.1367 & 8.7082 \\
\hline HEMBL3966725 & 1641008 & 9.5229 & 9.3803 \\
\hline HEMBL3933601 & 1641008 & 8.5686 & 9.2637 \\
\hline HEMBL 3891143 & 1641008 & 9.2218 & 8.1184 \\
\hline HEMBL3960986 & 1641008 & 9.3979 & 8.9495 \\
\hline HEMBL 396 & 164 & 8.8239 & 9.0598 \\
\hline HEMBL3948760 & 1641008 & 8.7696 & 8.4737 \\
\hline HEMBL3944772 & 1641008 & 9.3979 & 9.4468 \\
\hline HEMBL3940202 & 1641008 & 8.8239 & 8.95 \\
\hline HEMBL397 & 164 & 7.4815 & 8.0361 \\
\hline HEMBL 394 & 164 & 9.5229 & 9.3034 \\
\hline HEMBL3983792 & 1641008 & 8.2076 & 8.6273 \\
\hline HEMBL3933374 & 008 & 8.699 & 8.7012 \\
\hline HEMBL392 & 164 & 7.9208 & 7.6699 \\
\hline HEMBL394 & 164 & 8.9586 & 8.5651 \\
\hline HEMBL 391 & 164 & 6.9172 & 8.1532 \\
\hline HEMBL3897689 & 1641008 & 8.4815 & 8.583 \\
\hline HEMBL3907870 & 164 & 6.7399 & 6.7994 \\
\hline CHEMBL395 & 164 & 8.4437 & 8.5442 \\
\hline HEMBL395 & 164 & 8 & 8.2675 \\
\hline HEMBL 394 & 164 & 79 & 8.878 \\
\hline HEMBL3951735 & 1641008 & 9.699 & 9.5853 \\
\hline HEMBL3975669 & 1641008 & 8.8539 & 8.5823 \\
\hline CHEMBL 3948964 & 164 & 8.4559 & 8.4301 \\
\hline CHEMBL393 & 164 & 8.6778 & 8.7173 \\
\hline CHEMBL 3943428 & 164 & 8.585 & 8.4111 \\
\hline CHEMBL3907639 & 1641008 & 8.0362 & 7.7737 \\
\hline CHEMBL 3974258 & 1641008 & 9.3979 & 9.4166 \\
\hline CHEMBL392 & 164 & 9.3979 & 303 \\
\hline CHEMBL39 & 164 & 8.4202 & 9.0039 \\
\hline CHEMBL3954531 & 164 & 8.9586 & 9.0659 \\
\hline CHEMBL3915636 & 1641008 & 8.7959 & 8.8645 \\
\hline CHEMBL 3971315 & 1641008 & 9.3979 & 9.1663 \\
\hline CHEMBL3903173 & 164 & 8.0458 & 8.2348 \\
\hline CHEMBL3912194 & 1641008 & 8.8239 & 9.0382 \\
\hline CHEMBL3921465 & 1641008 & 9.3979 & 9.3679 \\
\hline CHEMBL 3945404 & 1641008 & 7.0315 & 7.2359 \\
\hline CHEMBL 3962210 & 1641008 & 8.3768 & 8.8401 \\
\hline CHEMBL3925781 & 1641008 & 8.5376 & 8.5296 \\
\hline CHEMBL3961402 & 1641008 & 8.2596 & 8.1038 \\
\hline CHEMBL3896647 & 1641008 & 8.4815 & 8.75 \\
\hline
\end{tabular}

Page 11403 
Supplemental Table S2.txt

\begin{tabular}{|c|c|c|c|c|c|}
\hline CHEMBL3924675 & 1641008 & 8.5376 & 8.3932 & TRN & \\
\hline CHEMBL3930612 & 1641008 & 8.6576 & 8.7331 & TRN & \\
\hline CHEMBL3924827 & 1641008 & 8.7696 & 8.826 & TRN & \\
\hline CHEMBL3928149 & 1641008 & 8.3768 & 8.7671 & TST & \\
\hline CHEMBL 3948385 & 1641008 & 7.4089 & 8.144 & TST & \\
\hline CHEMBL3909204 & 1641008 & 8.7696 & 8.8165 & TST & \\
\hline CHEMBL3891735 & 1641008 & 9.3979 & 9.4012 & TRN & \\
\hline CHEMBL3953801 & 1641008 & 10.0 & 9.805 & TRN & \\
\hline CHEMBL3943600 & 1641008 & 9.1549 & 9.2324 & TRN & \\
\hline CHEMBL 3906340 & 1641008 & 9.5229 & 9.3385 & TRN & \\
\hline CHEMBL3909305 & 1641008 & 7.6021 & 7.733 & TRN & \\
\hline CHEMBL3906085 & 1641008 & 7.8539 & 7.8461 & TRN & \\
\hline CHEMBL3964477 & 1641008 & 8.7696 & 8.7195 & TRN & \\
\hline CHEMBL3935833 & 1641008 & 7.3468 & 7.4245 & TRN & \\
\hline CHEMBL 3937065 & 1641008 & 7.0269 & 6.8933 & TRN & \\
\hline CHEMBL3944771 & 1641008 & 9.0458 & 8.5505 & TST & \\
\hline CHEMBL363632 & 312923 & 7.4089 & 7.0332 & TRN & \\
\hline CHEMBL363841 & 312923 & 6.2441 & 6.369 & TRN & \\
\hline CHEMBL192029 & 312923 & 4.3979 & 4.7635 & TRN & \\
\hline CHEMBL191607 & 312923 & 8.1871 & 7.19799 & 99999999995 & TRN \\
\hline CHEMBL192642 & 312923 & 6.2076 & 6.3065 & TRN & \\
\hline CHEMBL195257 & 312923 & 6.8539 & 6.8496 & TRN & \\
\hline CHEMBL191031 & 312923 & 6.7212 & 6.5893 & TRN & \\
\hline CHEMBL365354 & 312923 & 4.3979 & 4.3601 & TRN & \\
\hline CHEMBL191756 & 312923 & 6.5686 & 7.1091 & TRN & \\
\hline CHEMBL191940 & 312923 & 6.7696 & 6.9549 & TRN & \\
\hline CHEMBL192292 & 312923 & 6.9586 & 6.75 & TRN & \\
\hline CHEMBL195803 & 312923 & 7.4437 & 7.7357 & TRN & \\
\hline CHEMBL192079 & 312923 & 6.6021 & 6.8382 & TRN & \\
\hline CHEMBL 263703 & 312923 & 4.3979 & 5.1322 & TST & \\
\hline CHEMBL191708 & 312923 & 5.5686 & 6.211 & TRN & \\
\hline CHEMBL 370078 & 312923 & 7.3372 & 7.25799 & 9999999999 & TRN \\
\hline CHEMBL192201 & 312923 & 6.8239 & 6.2845 & TST & \\
\hline CHEMBL191247 & 312923 & 8.7212 & 8.8599 & TRN & \\
\hline CHEMBL 236139 & 312923 & 6.5528 & 6.4678 & TRN & \\
\hline CHEMBL192383 & 312923 & 6.1739 & 5.9775 & TST & \\
\hline CHEMBL 363810 & 312923 & 7.5229 & 7.0583 & TRN & \\
\hline CHEMBL 372226 & 312923 & 7.0 & 7.0043 & TRN & \\
\hline CHEMBL427181 & 312923 & 7.2596 & 7.5224 & TRN & \\
\hline CHEMBL195085 & 312923 & 7.6778 & 7.8689 & TRN & \\
\hline CHEMBL195875 & 312923 & 8.6021 & 8.3588 & TRN & \\
\hline CHEMBL 365121 & 312923 & 6.9586 & 6.7286 & TRN & \\
\hline CHEMBL370426 & 312923 & 7.7959 & 7.7514 & TRN & \\
\hline CHEMBL391997 & 312923 & 6.3768 & 6.6956 & TST & \\
\hline CHEMBL195374 & 312923 & 5.7447 & 5.6574 & TRN & \\
\hline CHEMBL195115 & 312923 & 8.9586 & 9.3039 & TST & \\
\hline CHEMBL194443 & 312923 & 6.2596 & 6.7162 & TRN & \\
\hline CHEMBL191628 & 312923 & 4.3979 & 4.1149 & TRN & \\
\hline
\end{tabular}




\begin{tabular}{|c|c|c|c|c|c|}
\hline \multicolumn{6}{|c|}{ Supplemental Table S2 } \\
\hline CHEMBL191782 & 312923 & 5.7447 & 5.444 & TST & \\
\hline CHEMBL195880 & 312923 & 7.8239 & 7.8892 & TRN & \\
\hline CHEMBL194228 & 312923 & 6.6778 & 6.5455 & TRN & \\
\hline CHEMBL194280 & 312923 & 6.301 & 5.9034 & TRN & \\
\hline CHEMBL195546 & 312923 & 7.5686 & 6.9374 & TRN & \\
\hline CHEMBL426634 & 312923 & 6.4815 & 6.6716 & TRN & \\
\hline CHEMBL194871 & 312923 & 5.4089 & 5.3421 & TRN & \\
\hline CHEMBL370977 & 312923 & 7.6021 & 7.7489 & TRN & \\
\hline CHEMBL190818 & 312923 & 7.2147 & 7.3601 & TRN & \\
\hline CHEMBL191939 & 312923 & 6.6778 & 6.673999 & 99999999995 & TRN \\
\hline CHEMBL191657 & 312923 & 6.4437 & 6.4248 & TRN & \\
\hline CHEMBL193135 & 312923 & 7.699 & 7.4646 & TRN & \\
\hline CHEMBL372930 & 312923 & 7.4437 & 7.4781 & TRN & \\
\hline CHEMBL194449 & 312923 & 7.1079 & 7.4216 & TRN & \\
\hline CHEMBL195876 & 312923 & 7.8539 & 7.7304 & TRN & \\
\hline CHEMBL190874 & 312923 & 9.3768 & 9.469 & TRN & \\
\hline CHEMBL195112 & 312923 & 4.3979 & 4.732 & TRN & \\
\hline CHEMBL195877 & 312923 & 6.7696 & 6.9925 & TRN & \\
\hline CHEMBL191768 & 312923 & 7.3565 & 7.1218 & TRN & \\
\hline CHEMBL194924 & 312923 & 6.0605 & 6.0841 & TRN & \\
\hline CHEMBL365128 & 312923 & 7.0 & 6.1008 & TST & \\
\hline CHEMBL362959 & 312923 & 4.3979 & 5.3378 & TST & \\
\hline CHEMBL192984 & 312923 & 4.3979 & 5.0208 & TST & \\
\hline CHEMBL191807 & 312923 & 6.4437 & 6.4614 & TST & \\
\hline CHEMBL439855 & 312923 & 7.8239 & 6.6241 & TST & \\
\hline CHEMBL195870 & 312923 & 7.2218 & 6.8534 & TST & \\
\hline CHEMBL371621 & 312923 & 4.3979 & 5.8513 & TST & \\
\hline CHEMBL192235 & 312923 & 6.0 & 5.5303 & TST & \\
\hline CHEMBL192205 & 312923 & 7.7959 & 7.3504 & TST & \\
\hline CHEMBL191783 & 312923 & 6.4437 & 6.7072 & TST & \\
\hline CHEMBL 2170900 & 865013 & 7.301 & 6.4548 & TST & \\
\hline CHEMBL 2171052 & 865013 & 3.8239 & 3.7555 & TRN & \\
\hline CHEMBL 2170882 & 865013 & 10.0 & 9.325 & TRN & \\
\hline CHEMBL 2170858 & 865013 & 3.8239 & 4.7356 & TST & \\
\hline CHEMBL 2170888 & 865013 & 6.9586 & 7.5914 & TRN & \\
\hline CHEMBL1093370 & 865013 & 10.0 & 7.7338 & TRN & \\
\hline CHEMBL 2170881 & 865013 & 6.9208 & 6.6034 & TST & \\
\hline CHEMBL 2170862 & 865013 & 6.6198 & 6.2072 & TST & \\
\hline CHEMBL 2171084 & 865013 & 10.0 & 10.2698 & TRN & \\
\hline CHEMBL 2171071 & 865013 & 6.3768 & 8.4624 & TRN & \\
\hline CHEMBL 2171068 & 865013 & 10.0 & 8.6015 & TRN & \\
\hline CHEMBL 2171064 & 865013 & 3.8239 & 5.0355 & TRN & \\
\hline CHEMBL2170899 & 865013 & 8.0 & 6.0915 & TST & \\
\hline CHEMBL 2170905 & 865013 & 3.8239 & 4.2213 & TRN & \\
\hline CHEMBL1090974 & 865013 & 3.8239 & 6.6013 & TRN & \\
\hline CHEMBL 2170876 & 865013 & 7.1549 & 7.3458 & TRN & \\
\hline CHEMBL 2170878 & 865013 & 6.8861 & 7.4524 & TRN & \\
\hline CHEMBL2170883 & 865013 & 7.301 & 7.4832 & TRN & \\
\hline
\end{tabular}




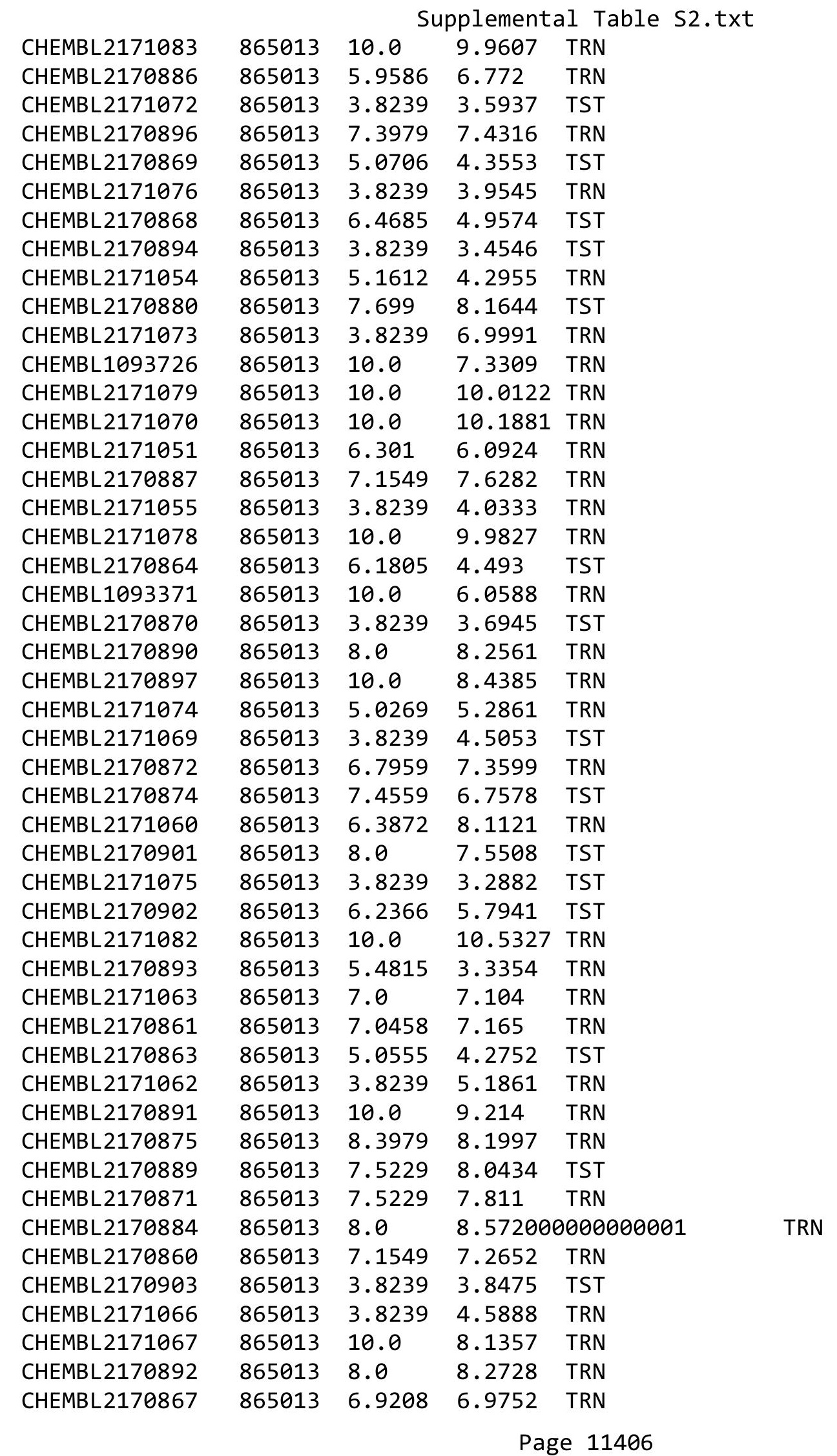




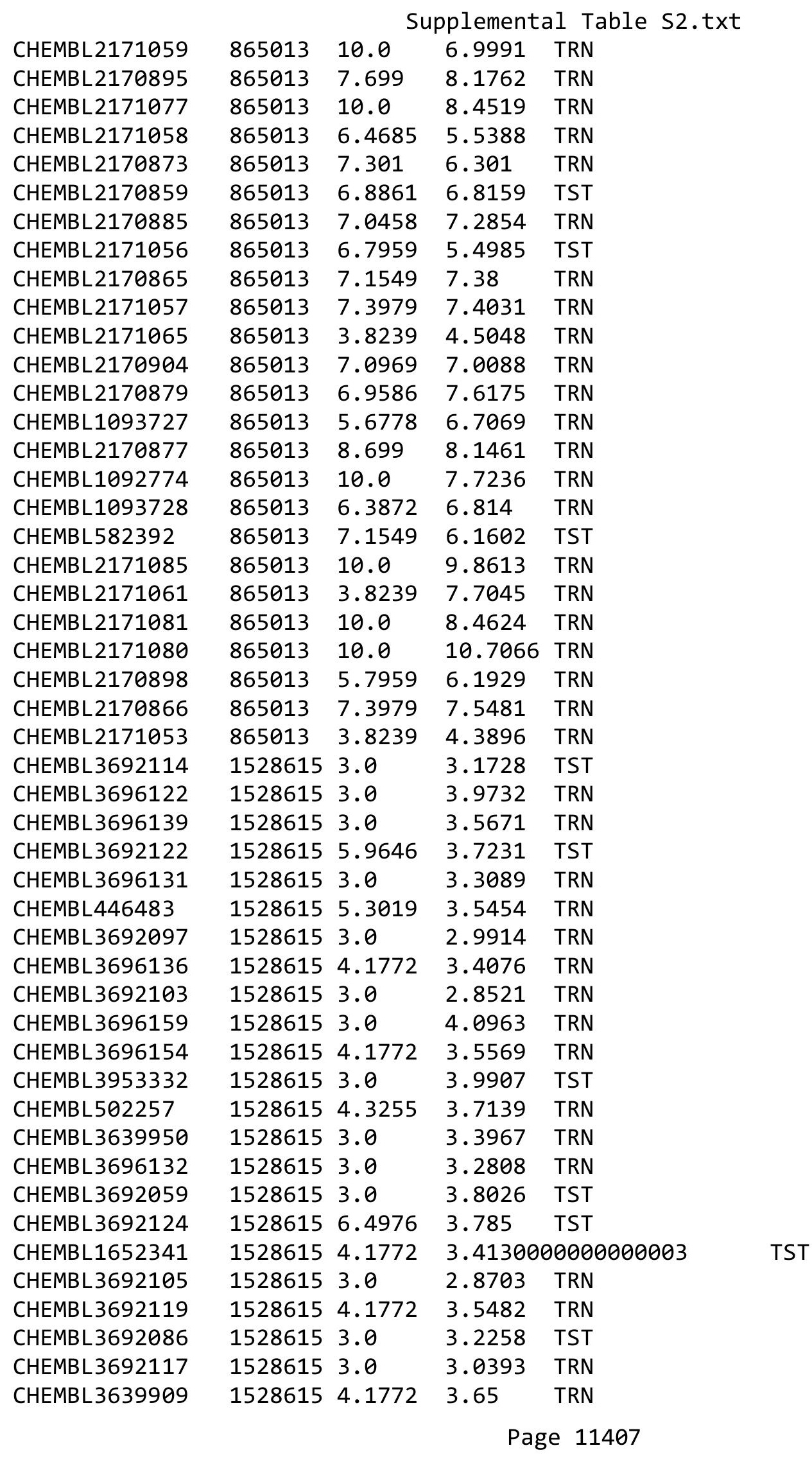


Supplemental Table S2.txt

\begin{tabular}{|c|c|c|c|c|}
\hline CHEMBL3692066 & 1528615 & 3.0 & 4.3055 & TST \\
\hline CHEMBL3696145 & 1528615 & 3.0 & 3.2178 & TRN \\
\hline CHEMBL3696151 & 1528615 & 4.1772 & 3.5751 & TRN \\
\hline CHEMBL3696142 & 1528615 & 4.1772 & 4.1152 & TRN \\
\hline CHEMBL3692101 & 1528615 & 3.0 & 3.2387 & TRN \\
\hline CHEMBL3696143 & 1528615 & 4.1772 & 4.0807 & TRN \\
\hline CHEMBL3692080 & 1528615 & 4.1772 & 3.7542 & TRN \\
\hline CHEMBL3692089 & 1528615 & 3.0 & 3.2129 & TRN \\
\hline CHEMBL3696144 & 1528615 & 3.0 & 3.3655 & TST \\
\hline CHEMBL3696156 & 1528615 & 3.0 & 3.60100 & 00000000004 \\
\hline CHEMBL3696150 & 1528615 & 3.0 & 3.6912 & TRN \\
\hline CHEMBL3692079 & 1528615 & 4.1772 & 3.7252 & TRN \\
\hline CHEMBL3696152 & 1528615 & 4.1772 & 3.6962 & TRN \\
\hline CHEMBL3692077 & 1528615 & 5.1002 & 3.7417 & TRN \\
\hline CHEMBL3692076 & 1528615 & 4.1772 & 3.8737 & TRN \\
\hline CHEMBL3692087 & 1528615 & 3.0 & 3.4601 & TRN \\
\hline CHEMBL3692070 & 1528615 & 3.0 & 3.838 & TRN \\
\hline CHEMBL3696160 & 1528615 & 3.0 & 4.0056 & TST \\
\hline CHEMBL3696130 & 1528615 & 3.0 & 3.6208 & TRN \\
\hline CHEMBL 3692106 & 1528615 & 3.0 & 3.1135 & TRN \\
\hline CHEMBL3696123 & 1528615 & 3.0 & 3.6161 & TRN \\
\hline CHEMBL3692099 & 1528615 & 3.0 & 3.2139 & TRN \\
\hline CHEMBL3692094 & 1528615 & 3.0 & 3.3169 & TRN \\
\hline CHEMBL3696146 & 1528615 & 4.1772 & 3.9314 & TRN \\
\hline CHEMBL3692082 & 1528615 & 4.1772 & 3.4597 & TRN \\
\hline CHEMBL3692098 & 1528615 & 3.0 & 3.1647 & TRN \\
\hline CHEMBL3692123 & 1528615 & 5.6126 & 3.7381 & TST \\
\hline CHEMBL3977616 & 1528615 & 3.0 & 3.7953 & TRN \\
\hline CHEMBL3696155 & 1528615 & 4.1772 & 3.7761 & TRN \\
\hline CHEMBL 3692093 & 1528615 & 3.0 & 3.3239 & TST \\
\hline CHEMBL526644 & 1528615 & 5.4498 & 4.0745 & TRN \\
\hline CHEMBL3696126 & 1528615 & 3.0 & 3.588 & TRN \\
\hline CHEMBL3696135 & 1528615 & 4.1772 & 3.3021 & TRN \\
\hline CHEMBL3696133 & 1528615 & 3.0 & 3.3391 & TRN \\
\hline CHEMBL3692064 & 1528615 & 3.0 & 4.2528 & TST \\
\hline CHEMBL1945663 & 1528615 & 3.0 & 4.1365 & TST \\
\hline CHEMBL3696153 & 1528615 & 3.0 & 3.6173 & TRN \\
\hline CHEMBL3692095 & 1528615 & 3.0 & 3.2736 & TRN \\
\hline CHEMBL3692104 & 1528615 & 3.0 & 3.0804 & TRN \\
\hline CHEMBL3692072 & 1528615 & 4.1772 & 3.5491 & TRN \\
\hline CHEMBL3692096 & 1528615 & 3.0 & 3.005 & TRN \\
\hline CHEMBL3696129 & 1528615 & 3.0 & 3.5564 & TRN \\
\hline CHEMBL3692069 & 1528615 & 3.0 & 4.2326 & TST \\
\hline CHEMBL3692110 & 1528615 & 3.0 & 3.0811 & TRN \\
\hline CHEMBL498650 & 1528615 & 4.1772 & 3.5773 & TRN \\
\hline CHEMBL3692075 & 1528615 & 3.0 & 3.8354 & TRN \\
\hline CHEMBL 3960510 & 1528615 & 4.1772 & 3.9357 & TRN \\
\hline CHEMBL3696140 & 1528615 & 4.1772 & 3.7224 & TRN \\
\hline
\end{tabular}




\begin{tabular}{|c|c|c|c|c|c|}
\hline \multicolumn{6}{|c|}{ Supplemental Table S2.txt } \\
\hline CHEMBL 3696125 & 1528615 & 3.0 & 3.4273 & TRN & \\
\hline CHEMBL 3692065 & 1528615 & 3.0 & 3.7648 & TST & \\
\hline CHEMBL3692081 & 1528615 & 4.1772 & 3.8743 & TRN & \\
\hline CHEMBL3692084 & 1528615 & 3.0 & 3.3697 & TST & \\
\hline CHEMBL3692061 & 1528615 & 4.1772 & 3.9476 & TST & \\
\hline CHEMBL3692071 & 1528615 & 3.0 & 3.6465 & TRN & \\
\hline CHEMBL3692109 & 1528615 & 3.0 & 3.0523 & TRN & \\
\hline CHEMBL3692112 & 1528615 & 3.0 & 2.98199 & 99999999998 & TRN \\
\hline CHEMBL1360563 & 1528615 & 5.1871 & 3.7508 & TST & \\
\hline CHEMBL3692090 & 1528615 & 4.3045 & 3.4462 & TRN & \\
\hline CHEMBL 3692060 & 1528615 & 3.0 & 4.1494 & TST & \\
\hline CHEMBL3692108 & 1528615 & 3.0 & 3.1527 & TRN & \\
\hline CHEMBL3692074 & 1528615 & 4.1772 & 3.7717 & TRN & \\
\hline CHEMBL3696134 & 1528615 & 3.0 & 3.6575 & TRN & \\
\hline CHEMBL3692063 & 1528615 & 3.0 & 4.0436 & TST & \\
\hline CHEMBL3692107 & 1528615 & 3.0 & 3.128 & TRN & \\
\hline CHEMBL3696158 & 1528615 & 3.0 & 3.8174 & TRN & \\
\hline CHEMBL3692091 & 1528615 & 3.0 & 3.1329 & TRN & \\
\hline CHEMBL3692115 & 1528615 & 3.0 & 3.0497 & TRN & \\
\hline CHEMBL497509 & 1528615 & 4.794 & 4.3011 & TRN & \\
\hline CHEMBL3696137 & 1528615 & 3.0 & 3.3407 & TRN & \\
\hline CHEMBL3696162 & 1528615 & 3.0 & 4.1608 & TST & \\
\hline CHEMBL3692100 & 1528615 & 4.1772 & 3.2937 & TRN & \\
\hline CHEMBL3696148 & 1528615 & 3.0 & 3.5638 & TRN & \\
\hline CHEMBL3696124 & 1528615 & 3.0 & 3.9353 & TRN & \\
\hline CHEMBL3692088 & 1528615 & 3.0 & 3.1753 & TRN & \\
\hline CHEMBL3692118 & 1528615 & 3.0 & 3.1988 & TRN & \\
\hline CHEMBL3692092 & 1528615 & 3.0 & 3.3517 & TRN & \\
\hline CHEMBL3696141 & 1528615 & 3.0 & 3.47399 & 99999999998 & TRN \\
\hline CHEMBL3696157 & 1528615 & 4.1772 & 3.8294 & TRN & \\
\hline CHEMBL526866 & 1528615 & 5.1203 & 4.0895 & TRN & \\
\hline CHEMBL3692113 & 1528615 & 3.0 & 3.1926 & TRN & \\
\hline CHEMBL3696161 & 1528615 & 3.0 & 3.6249 & TST & \\
\hline CHEMBL3692078 & 1528615 & 4.1772 & 3.7173 & TRN & \\
\hline CHEMBL3696138 & 1528615 & 3.0 & 3.4903 & TRN & \\
\hline CHEMBL3692102 & 1528615 & 3.0 & 3.3797 & TRN & \\
\hline CHEMBL525812 & 1528615 & 4.9948 & 3.1839 & TRN & \\
\hline CHEMBL3696149 & 1528615 & 3.0 & 3.8597 & TRN & \\
\hline CHEMBL3696163 & 1528615 & 3.0 & 3.7887 & TST & \\
\hline CHEMBL3696127 & 1528615 & 3.0 & 3.78899 & 99999999997 & TRN \\
\hline CHEMBL3692085 & 1528615 & 3.0 & 3.2834 & TST & \\
\hline CHEMBL3696147 & 1528615 & 4.3728 & 3.5727 & TRN & \\
\hline CHEMBL3692067 & 1528615 & 3.0 & 4.2032 & TST & \\
\hline CHEMBL3692083 & 1528615 & 4.1772 & 3.4046 & TRN & \\
\hline CHEMBL3692116 & 1528615 & 3.0 & 3.0124 & TRN & \\
\hline CHEMBL 3692073 & 1528615 & 3.0 & 3.7341 & TRN & \\
\hline CHEMBL3692062 & 1528615 & 4.1772 & 4.2121 & TST & \\
\hline CHEMBL3696128 & 1528615 & 3.0 & 4.1103 & TST & \\
\hline
\end{tabular}




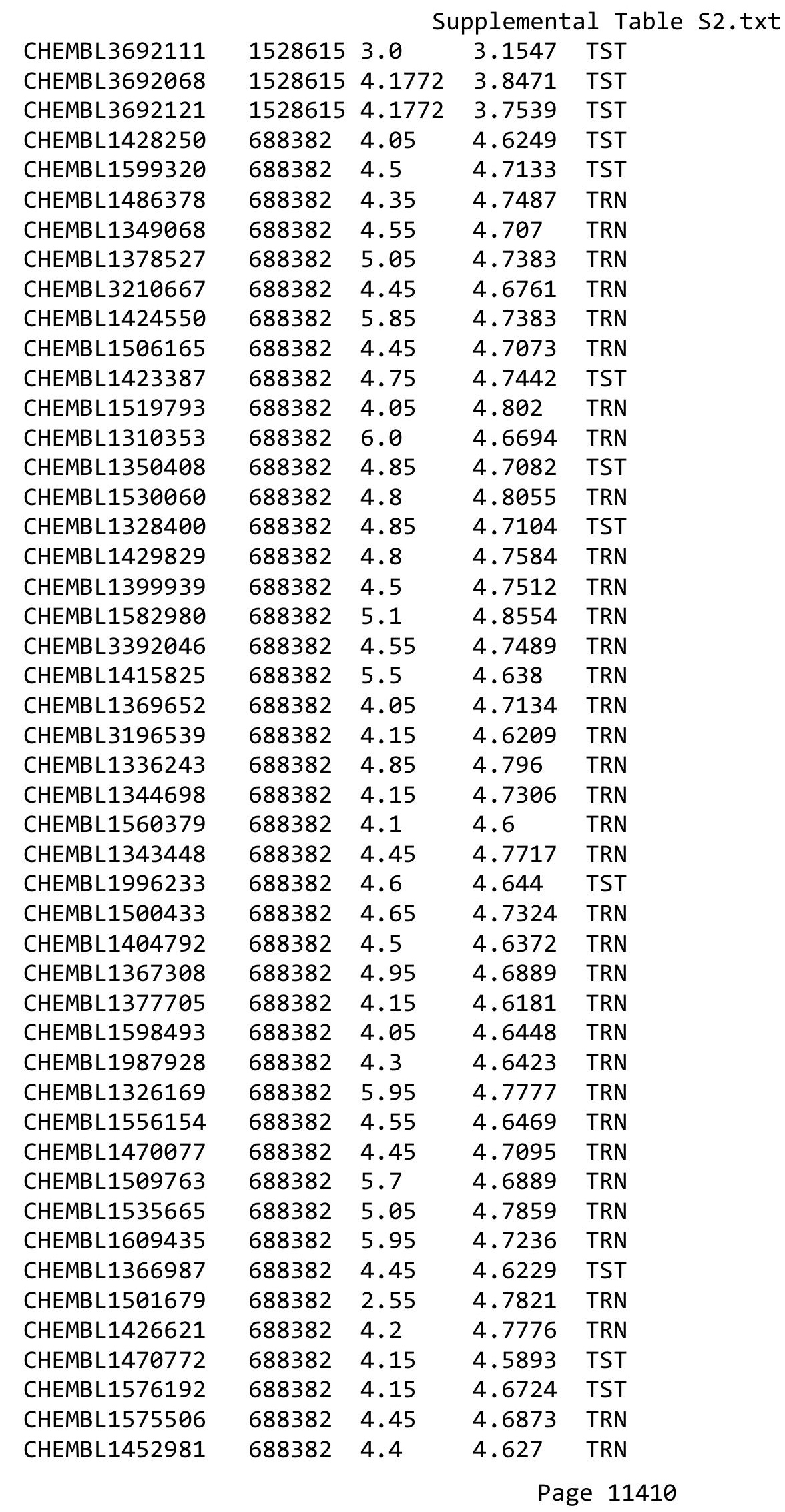




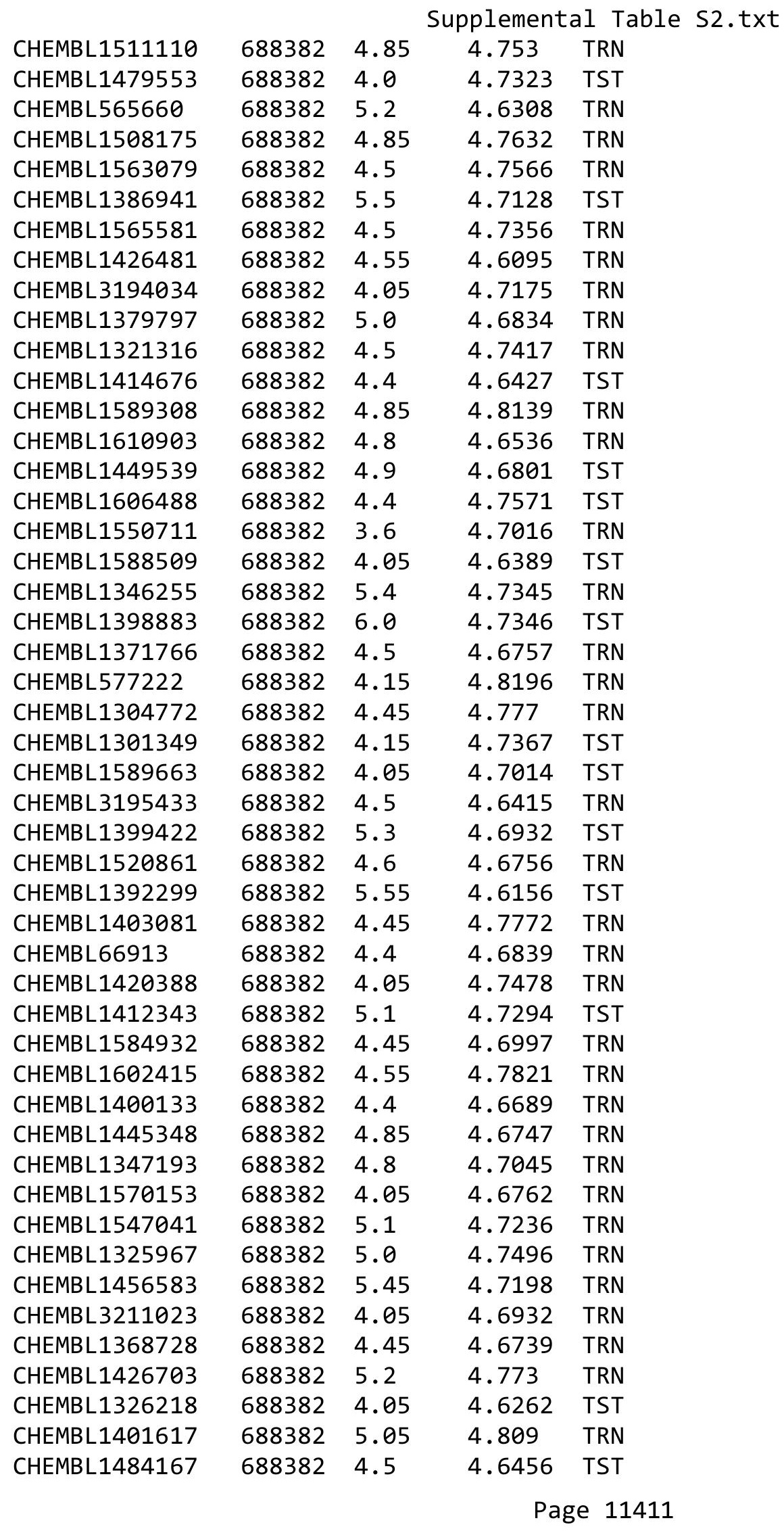




\begin{tabular}{|c|c|c|c|c|}
\hline \multicolumn{5}{|c|}{ Supplemental Table } \\
\hline CHEMBL1464110 & 688382 & 5.45 & 4.6697 & TRN \\
\hline CHEMBL1387533 & 688382 & 4.05 & 4.7809 & TRN \\
\hline CHEMBL1340490 & 688382 & 4.85 & 4.7664 & TRN \\
\hline CHEMBL1342554 & 688382 & 4.85 & 4.8576 & TRN \\
\hline CHEMBL1349187 & 688382 & 4.2 & 4.8008 & TRN \\
\hline CHEMBL1404850 & 688382 & 4.55 & 4.7243 & TRN \\
\hline CHEMBL1376216 & 688382 & 4.0 & 4.7082 & TRN \\
\hline CHEMBL1391644 & 688382 & 4.85 & 4.7699 & TRN \\
\hline CHEMBL1380942 & 688382 & 4.45 & 4.6624 & TST \\
\hline CHEMBL1530009 & 688382 & 4.55 & 4.6933 & TRN \\
\hline CHEMBL1311572 & 688382 & 5.05 & 4.7439 & TRN \\
\hline CHEMBL1520800 & 688382 & 4.3 & 4.7375 & TRN \\
\hline CHEMBL1382848 & 688382 & 4.35 & 4.7742 & TRN \\
\hline CHEMBL1409950 & 688382 & 4.0 & 4.6987 & TRN \\
\hline CHEMBL1441406 & 688382 & 4.5 & 4.6762 & TRN \\
\hline CHEMBL1412754 & 688382 & 4.85 & 4.7795 & TST \\
\hline CHEMBL1546414 & 688382 & 4.55 & 4.6423 & TRN \\
\hline CHEMBL1392016 & 688382 & 5.5 & 4.8186 & TRN \\
\hline CHEMBL1332060 & 688382 & 4.5 & 4.6177 & TST \\
\hline CHEMBL1972347 & 688382 & 5.0 & 4.665 & TRN \\
\hline CHEMBL1343807 & 688382 & 4.6 & 4.7599 & TRN \\
\hline CHEMBL1385605 & 688382 & 5.25 & 4.7924 & TRN \\
\hline CHEMBL1509390 & 688382 & 4.95 & 4.7361 & TRN \\
\hline CHEMBL1429037 & 688382 & 4.85 & 4.5789 & TST \\
\hline CHEMBL1569150 & 688382 & 4.15 & 4.6911 & TST \\
\hline CHEMBL1454207 & 688382 & 5.0 & 4.6802 & TST \\
\hline CHEMBL1612984 & 688382 & 4.45 & 4.6806 & TRN \\
\hline CHEMBL1341853 & 688382 & 4.15 & 4.6628 & TST \\
\hline CHEMBL1332063 & 688382 & 4.55 & 4.6761 & TRN \\
\hline CHEMBL1389365 & 688382 & 5.7 & 4.6955 & TST \\
\hline CHEMBL1583867 & 688382 & 4.85 & 4.6696 & TRN \\
\hline CHEMBL1392259 & 688382 & 4.15 & 4.678 & TST \\
\hline CHEMBL1534062 & 688382 & 4.25 & 4.7552 & TRN \\
\hline CHEMBL1366428 & 688382 & 5.2 & 4.7091 & TRN \\
\hline CHEMBL1504282 & 688382 & 4.4 & 4.6965 & TST \\
\hline CHEMBL1388495 & 688382 & 4.35 & 4.6528 & TRN \\
\hline CHEMBL1460413 & 688382 & 4.5 & 4.7028 & TST \\
\hline CHEMBL1558013 & 688382 & 4.05 & 4.7186 & TRN \\
\hline CHEMBL1581215 & 688382 & 4.55 & 4.6808 & TRN \\
\hline CHEMBL1484404 & 688382 & 4.05 & 4.7807 & TRN \\
\hline CHEMBL1303105 & 688382 & 4.15 & 4.8101 & TRN \\
\hline CHEMBL1484336 & 688382 & 4.95 & 4.7579 & TRN \\
\hline CHEMBL1382177 & 688382 & 4.8 & 4.7123 & TRN \\
\hline CHEMBL1599584 & 688382 & 4.4 & 4.782 & TRN \\
\hline CHEMBL82134 & 688382 & 4.5 & 4.6319 & TRN \\
\hline CHEMBL19954 & 688382 & 5.55 & 4.6238 & TRN \\
\hline CHEMBL1418110 & 688382 & 4.45 & 4.6994 & TST \\
\hline CHEMBL1299284 & 688382 & 4.85 & 4.6756 & TST \\
\hline
\end{tabular}




\begin{tabular}{|c|c|c|c|c|}
\hline \multicolumn{5}{|c|}{ Supplemental Table S2.txt } \\
\hline CHEMBL1573468 & 688382 & 4.9 & 4.76 & TRN \\
\hline CHEMBL1561204 & 688382 & 4.05 & 4.6773 & TRN \\
\hline CHEMBL1321111 & 688382 & 4.65 & 4.8136 & TRN \\
\hline CHEMBL1392256 & 688382 & 4.85 & 4.7426 & TRN \\
\hline CHEMBL1496186 & 688382 & 5.05 & 4.7031 & TST \\
\hline CHEMBL 3213064 & 688382 & 4.45 & 4.6234 & TRN \\
\hline CHEMBL1375216 & 688382 & 5.05 & 4.7005 & TRN \\
\hline CHEMBL1608481 & 688382 & 4.2 & 4.7217 & TST \\
\hline CHEMBL1410019 & 688382 & 4.35 & 4.7801 & TRN \\
\hline CHEMBL1312451 & 688382 & 4.05 & 4.6798 & TRN \\
\hline CHEMBL1500265 & 688382 & 4.45 & 4.6497 & TST \\
\hline CHEMBL1594927 & 688382 & 5.0 & 4.6948 & TST \\
\hline CHEMBL1401286 & 688382 & 5.5 & 4.6624 & TRN \\
\hline CHEMBL1359987 & 688382 & 4.8 & 4.726 & TST \\
\hline CHEMBL1445327 & 688382 & 4.5 & 4.6725 & TRN \\
\hline CHEMBL3191158 & 688382 & 5.2 & 4.6461 & TRN \\
\hline CHEMBL519824 & 688382 & 4.15 & 4.712 & TRN \\
\hline CHEMBL1572183 & 688382 & 4.3 & 4.8809 & TRN \\
\hline CHEMBL1468325 & 688382 & 4.15 & 4.7855 & TST \\
\hline CHEMBL1363287 & 688382 & 5.5 & 4.6831 & TRN \\
\hline CHEMBL1412947 & 688382 & 5.85 & 4.6573 & TST \\
\hline CHEMBL1537220 & 688382 & 4.65 & 4.6341 & TRN \\
\hline CHEMBL1572018 & 688382 & 5.15 & 4.6733 & TRN \\
\hline CHEMBL1595011 & 688382 & 4.7 & 4.6528 & TRN \\
\hline CHEMBL1407253 & 688382 & 4.45 & 4.658 & TRN \\
\hline CHEMBL1565606 & 688382 & 3.95 & 4.7845 & TST \\
\hline CHEMBL1366980 & 688382 & 5.15 & 4.6852 & TRN \\
\hline CHEMBL1577228 & 688382 & 5.0 & 4.7441 & TRN \\
\hline CHEMBL1340595 & 688382 & 4.8 & 4.7571 & TRN \\
\hline CHEMBL1609452 & 688382 & 4.5 & 4.7779 & TRN \\
\hline CHEMBL3207711 & 688382 & 4.05 & 4.6886 & TRN \\
\hline CHEMBL1415612 & 688382 & 4.7 & 4.614 & TRN \\
\hline CHEMBL1446454 & 688382 & 4.5 & 4.6502 & TST \\
\hline CHEMBL1428814 & 688382 & 4.6 & 4.6656 & TRN \\
\hline CHEMBL1481393 & 688382 & 4.45 & 4.7279 & TRN \\
\hline CHEMBL1470626 & 688382 & 4.95 & 4.6953 & TST \\
\hline CHEMBL1302552 & 688382 & 4.0 & 4.7349 & TRN \\
\hline CHEMBL1605008 & 688382 & 6.0 & 4.6905 & TST \\
\hline CHEMBL1456234 & 688382 & 4.45 & 4.7249 & TST \\
\hline CHEMBL1483025 & 688382 & 4.65 & 4.7185 & TRN \\
\hline CHEMBL1382993 & 688382 & 4.4 & 4.6636 & TRN \\
\hline CHEMBL1504835 & 688382 & 4.0 & 4.739 & TRN \\
\hline CHEMBL1467427 & 688382 & 4.85 & 4.8042 & TST \\
\hline CHEMBL1541718 & 688382 & 5.2 & 4.7923 & TRN \\
\hline CHEMBL1444136 & 688382 & 5.95 & 4.6749 & TRN \\
\hline CHEMBL1304252 & 688382 & 4.85 & 4.621 & TRN \\
\hline CHEMBL1564141 & 688382 & 5.0 & 4.6851 & TST \\
\hline CHEMBL3213289 & 688382 & 5.0 & 4.6706 & TRN \\
\hline
\end{tabular}




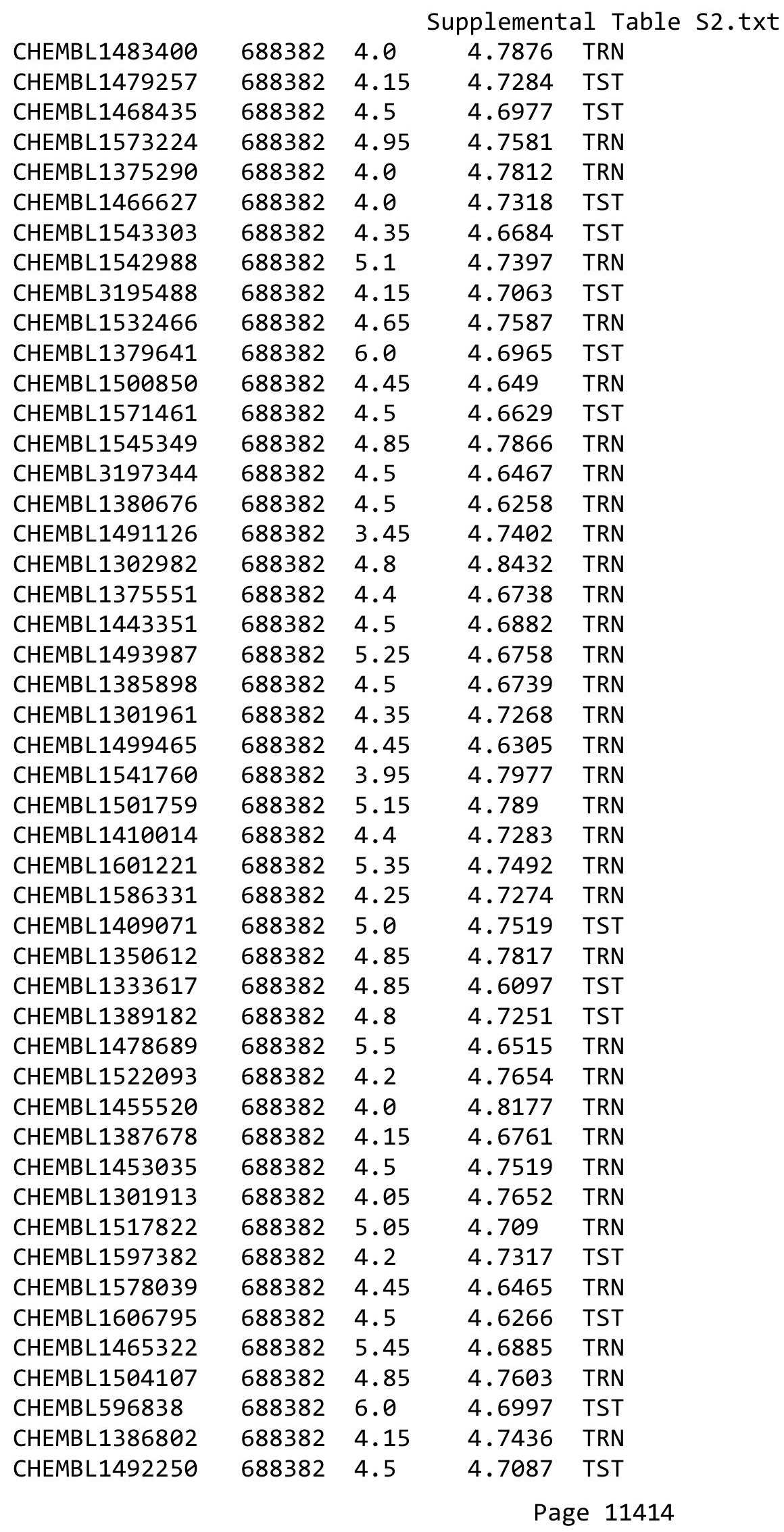




\begin{tabular}{|c|c|c|c|c|}
\hline & & & upplement & $\mathrm{T}$ \\
\hline CHEMBL1458640 & 688382 & 4.95 & 4.6858 & TST \\
\hline CHEMBL3194312 & 688382 & 5.8 & 4.6718 & TRN \\
\hline CHEMBL1477336 & 688382 & 4.8 & 4.7531 & TRN \\
\hline CHEMBL1375314 & 688382 & 5.0 & 4.7661 & TRN \\
\hline CHEMBL1380457 & 688382 & 4.8 & 4.7223 & TST \\
\hline CHEMBL3193057 & 688382 & 4.95 & 4.715 & TRN \\
\hline CHEMBL1403316 & 688382 & 5.2 & 4.6653 & TRN \\
\hline CHEMBL1466455 & 688382 & 4.4 & 4.7319 & TRN \\
\hline CHEMBL1479334 & 688382 & 5.0 & 4.6794 & TRN \\
\hline CHEMBL1566010 & 688382 & 4.5 & 4.6581 & TRN \\
\hline CHEMBL1485432 & 688382 & 4.3 & 4.7667 & TST \\
\hline CHEMBL1562299 & 688382 & 4.6 & 4.675 & TRN \\
\hline CHEMBL1453319 & 688382 & 4.45 & 4.6837 & TRN \\
\hline CHEMBL 299052 & 688382 & 4.4 & 4.6877 & TST \\
\hline CHEMBL1583336 & 688382 & 4.5 & 4.7446 & TRN \\
\hline CHEMBL3199348 & 688382 & 4.85 & 4.6879 & TRN \\
\hline CHEMBL3189855 & 688382 & 4.4 & 4.5577 & TRN \\
\hline CHEMBL1379274 & 688382 & 4.5 & 4.6923 & TST \\
\hline CHEMBL1524439 & 688382 & 5.0 & 4.7388 & TRN \\
\hline CHEMBL1605047 & 688382 & 5.45 & 4.6205 & TRN \\
\hline CHEMBL1300283 & 688382 & 4.5 & 4.6948 & TRN \\
\hline CHEMBL1601069 & 688382 & 4.95 & 4.7418 & TST \\
\hline CHEMBL3209824 & 688382 & 4.8 & 4.6832 & TRN \\
\hline CHEMBL1304413 & 688382 & 4.7 & 4.6656 & TRN \\
\hline CHEMBL 273365 & 688382 & 4.85 & 4.6672 & TRN \\
\hline CHEMBL1344702 & 688382 & 4.35 & 4.6962 & TRN \\
\hline CHEMBL1479538 & 688382 & 4.5 & 4.7709 & TRN \\
\hline CHEMBL1500795 & 688382 & 4.8 & 4.6558 & TST \\
\hline CHEMBL1406370 & 688382 & 4.85 & 4.8248 & TRN \\
\hline CHEMBL1576489 & 688382 & 5.0 & 4.6814 & TRN \\
\hline CHEMBL1446181 & 688382 & 4.5 & 4.6959 & TST \\
\hline CHEMBL3197712 & 688382 & 5.0 & 4.7156 & TRN \\
\hline CHEMBL1586956 & 688382 & 4.8 & 4.7566 & TRN \\
\hline CHEMBL1457926 & 688382 & 6.0 & 4.7233 & TST \\
\hline CHEMBL1576227 & 688382 & 4.8 & 4.7401 & TST \\
\hline CHEMBL1501132 & 688382 & 4.15 & 4.7023 & TRN \\
\hline CHEMBL1404461 & 688382 & 4.45 & 4.6542 & TST \\
\hline CHEMBL1351920 & 688382 & 4.45 & 4.6562 & TRN \\
\hline CHEMBL1310928 & 688382 & 4.15 & 4.7326 & TST \\
\hline CHEMBL1464054 & 688382 & 4.85 & 4.7705 & TRN \\
\hline CHEMBL3195111 & 688382 & 5.05 & 4.6536 & TST \\
\hline CHEMBL1439181 & 688382 & 4.15 & 4.6452 & TST \\
\hline CHEMBL1460407 & 688382 & 5.0 & 4.6956 & TRN \\
\hline CHEMBL 2004304 & 688382 & 4.15 & 4.698 & TRN \\
\hline CHEMBL1986284 & 688382 & 4.5 & 4.6924 & TRN \\
\hline CHEMBL1508214 & 688382 & 4.8 & 4.7406 & TRN \\
\hline CHEMBL1980322 & 688382 & 5.0 & 4.6713 & TRN \\
\hline CHEMBL1579313 & 688382 & 4.4 & 4.8012 & TRN \\
\hline
\end{tabular}




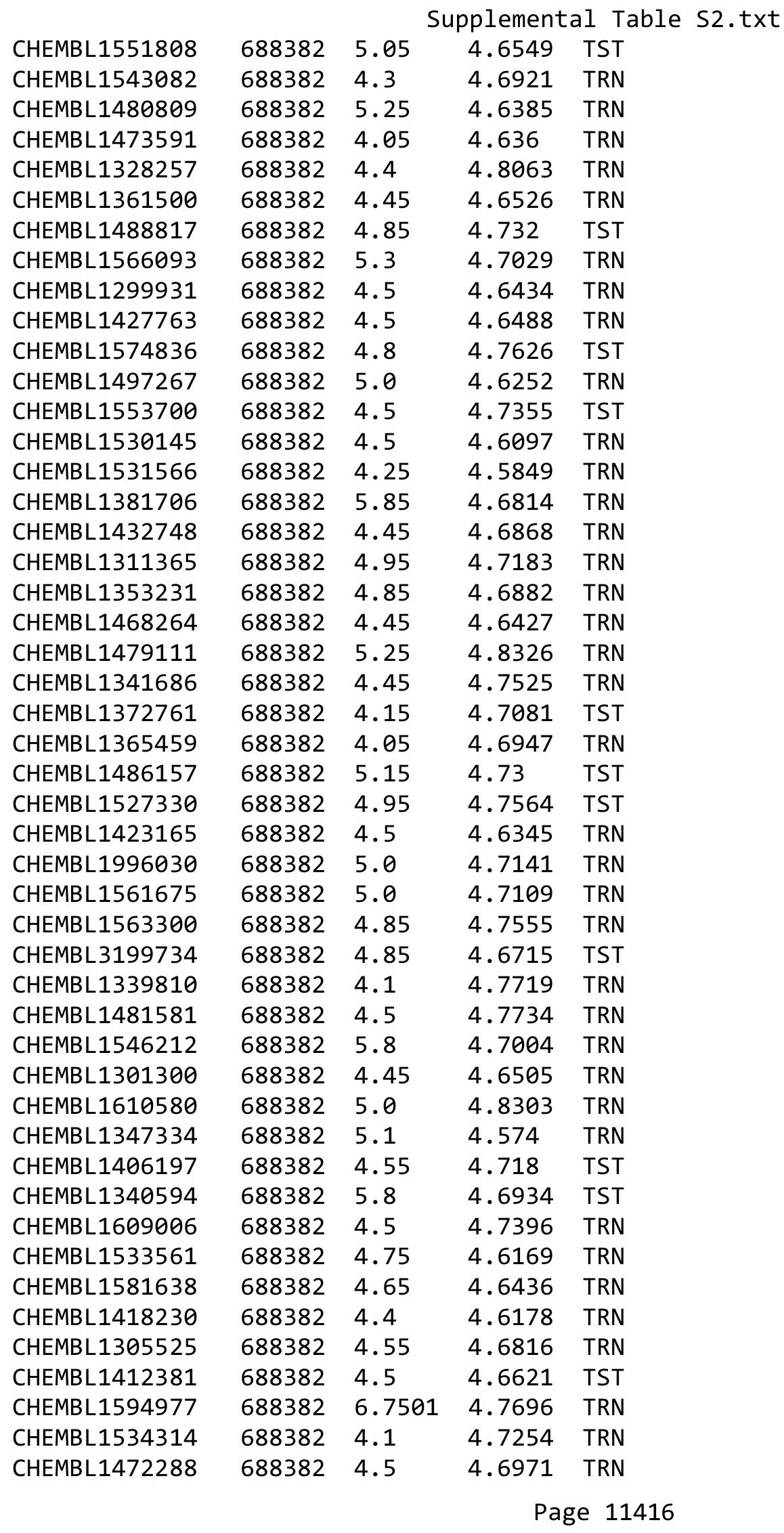




\begin{tabular}{|c|c|c|c|c|}
\hline \multicolumn{5}{|c|}{ Supplemental Table s2.txt } \\
\hline CHEMBL1399297 & 688382 & 4.55 & 4.6292 & TRN \\
\hline CHEMBL1480160 & 688382 & 5.95 & 4.835 & TRN \\
\hline CHEMBL1349199 & 688382 & 4.85 & 4.7729 & TRN \\
\hline CHEMBL1367202 & 688382 & 5.05 & 4.732 & TST \\
\hline CHEMBL1602489 & 688382 & 4.9 & 4.6827 & TRN \\
\hline CHEMBL1310029 & 688382 & 4.5 & 4.7785 & TST \\
\hline CHEMBL1520325 & 688382 & 5.75 & 4.6505 & TRN \\
\hline CHEMBL1309309 & 688382 & 4.45 & 4.6948 & TRN \\
\hline CHEMBL1465635 & 688382 & 5.9 & 4.8043 & TST \\
\hline CHEMBL1580403 & 688382 & 5.8 & 4.7754 & TRN \\
\hline CHEMBL1590596 & 688382 & 6.0 & 4.7812 & TRN \\
\hline CHEMBL1580369 & 688382 & 4.8 & 4.8435 & TRN \\
\hline CHEMBL1425183 & 688382 & 4.75 & 4.6991 & TRN \\
\hline CHEMBL122360 & 688382 & 4.55 & 4.7372 & TRN \\
\hline CHEMBL1543203 & 688382 & 4.85 & 4.6096 & TRN \\
\hline CHEMBL1546008 & 688382 & 4.85 & 4.7021 & TRN \\
\hline CHEMBL1326044 & 688382 & 4.45 & 4.7132 & TRN \\
\hline CHEMBL1543050 & 688382 & 4.5 & 4.6566 & TRN \\
\hline CHEMBL1500712 & 688382 & 4.85 & 4.7005 & TST \\
\hline CHEMBL1425889 & 688382 & 4.9 & 4.6116 & TRN \\
\hline CHEMBL1336906 & 688382 & 4.2 & 4.6744 & TST \\
\hline CHEMBL1443415 & 688382 & 4.25 & 4.5841 & TRN \\
\hline CHEMBL1380299 & 688382 & 4.05 & 4.7426 & TRN \\
\hline CHEMBL1529321 & 688382 & 4.4 & 4.6907 & TRN \\
\hline CHEMBL3194892 & 688382 & 4.45 & 4.6445 & TRN \\
\hline CHEMBL1549883 & 688382 & 5.3 & 4.7515 & TRN \\
\hline CHEMBL1988289 & 688382 & 4.45 & 4.6041 & TRN \\
\hline CHEMBL1601999 & 688382 & 4.4 & 4.8022 & TST \\
\hline CHEMBL1385849 & 688382 & 5.0 & 4.7578 & TST \\
\hline CHEMBL1343501 & 688382 & 4.65 & 4.7792 & TRN \\
\hline CHEMBL1454895 & 688382 & 5.0 & 4.7364 & TRN \\
\hline CHEMBL1492585 & 688382 & 4.5 & 4.6329 & TRN \\
\hline CHEMBL1337552 & 688382 & 5.1 & 4.6308 & TRN \\
\hline CHEMBL1545350 & 688382 & 4.7 & 4.6747 & TRN \\
\hline CHEMBL1483873 & 688382 & 6.05 & 4.7312 & TRN \\
\hline CHEMBL1500876 & 688382 & 4.15 & 4.6355 & TRN \\
\hline CHEMBL1308617 & 688382 & 4.8 & 4.7422 & TRN \\
\hline CHEMBL1313706 & 688382 & 5.25 & 4.665 & TST \\
\hline CHEMBL1364621 & 688382 & 4.8 & 4.6535 & TRN \\
\hline CHEMBL1421884 & 688382 & 6.0 & 4.7672 & TRN \\
\hline CHEMBL1608926 & 688382 & 4.8 & 4.7386 & TRN \\
\hline CHEMBL3196472 & 688382 & 4.35 & 4.6055 & TRN \\
\hline CHEMBL1546540 & 688382 & 4.4 & 4.76 & TRN \\
\hline CHEMBL1456399 & 688382 & 5.0 & 4.7839 & TRN \\
\hline CHEMBL1320341 & 688382 & 4.9 & 4.6743 & TRN \\
\hline CHEMBL1301817 & 688382 & 4.75 & 4.6448 & TRN \\
\hline CHEMBL1572998 & 688382 & 4.5 & 4.7197 & TRN \\
\hline CHEMBL1407601 & 688382 & 4.45 & 4.7269 & TRN \\
\hline
\end{tabular}




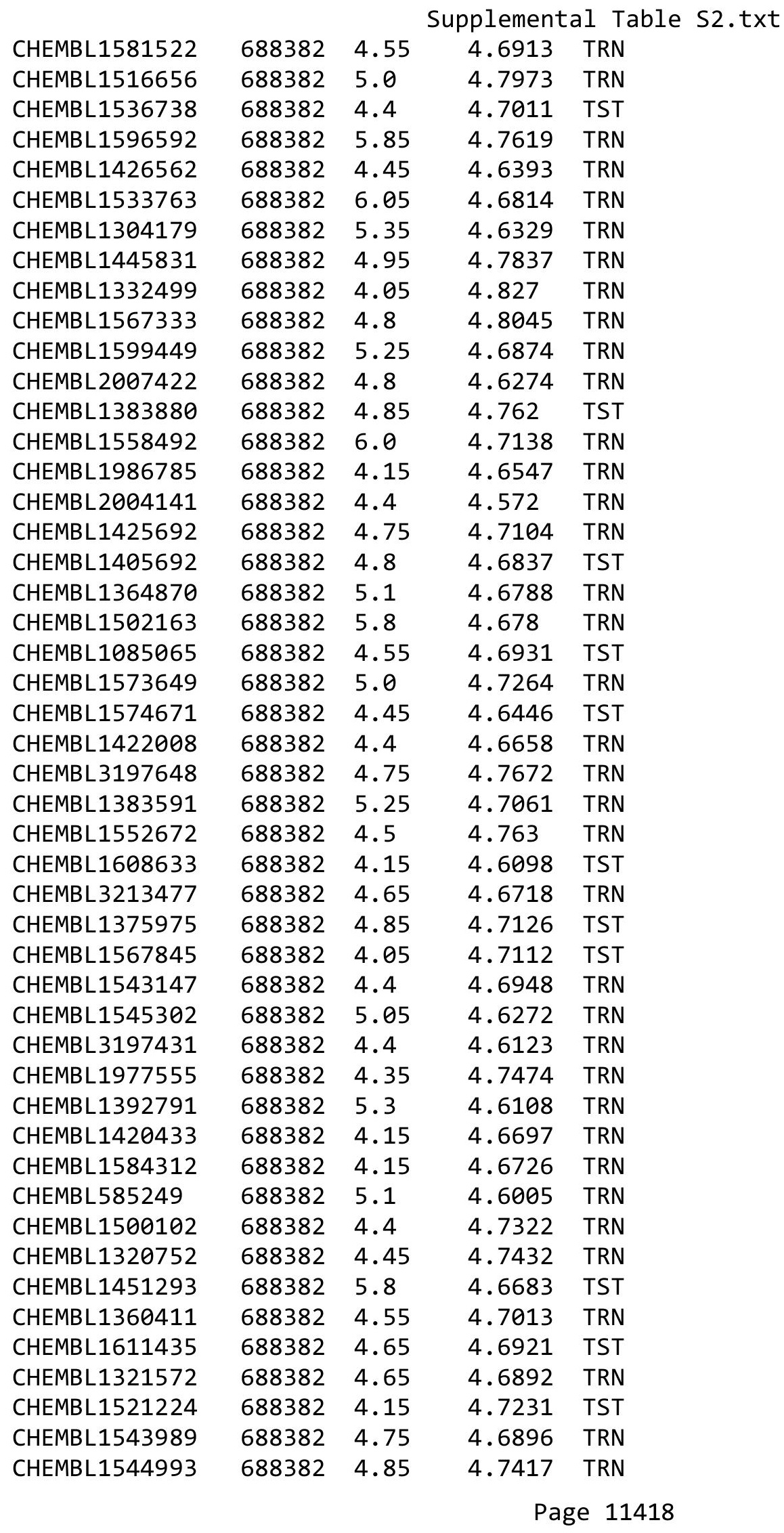




\begin{tabular}{|c|c|c|c|c|c|}
\hline \multicolumn{6}{|c|}{ Supplemental Table S2.txt } \\
\hline CHEMBL1390091 & 688382 & 5.0 & 4.6747 & TRN & \\
\hline CHEMBL1450615 & 688382 & 4.1 & 4.7356 & TRN & \\
\hline CHEMBL3212481 & 688382 & 4.35 & 4.6604 & TST & \\
\hline CHEMBL1470741 & 688382 & 4.05 & 4.7691 & TRN & \\
\hline CHEMBL1413692 & 688382 & 4.85 & 4.72199 & 99999999995 & TRN \\
\hline CHEMBL1445798 & 688382 & 4.5 & 4.6915 & TRN & \\
\hline CHEMBL3194116 & 688382 & 4.8 & 4.6793 & TRN & \\
\hline CHEMBL1312905 & 688382 & 5.0 & 4.7333 & TRN & \\
\hline CHEMBL1588236 & 688382 & 4.9 & 4.6726 & TRN & \\
\hline CHEMBL1487253 & 688382 & 5.0 & 4.7577 & TRN & \\
\hline CHEMBL1466273 & 688382 & 4.45 & 4.8024 & TRN & \\
\hline CHEMBL 3213557 & 688382 & 4.05 & 4.6703 & TST & \\
\hline CHEMBL1390367 & 688382 & 4.15 & 4.6368 & TRN & \\
\hline CHEMBL1606124 & 688382 & 5.0 & 4.7254 & TRN & \\
\hline CHEMBL1583642 & 688382 & 5.0 & 4.8019 & TRN & \\
\hline CHEMBL1521704 & 688382 & 4.45 & 4.6602 & TRN & \\
\hline CHEMBL3212124 & 688382 & 4.45 & 4.5802 & TST & \\
\hline CHEMBL1422232 & 688382 & 4.8 & 4.7638 & TRN & \\
\hline CHEMBL1595967 & 688382 & 4.85 & 4.6707 & TRN & \\
\hline CHEMBL1335321 & 688382 & 4.55 & 4.7147 & TRN & \\
\hline CHEMBL1572734 & 688382 & 4.35 & 4.6079 & TRN & \\
\hline CHEMBL1345523 & 688382 & 4.15 & 4.6935 & TRN & \\
\hline CHEMBL1426970 & 688382 & 5.95 & 4.8031 & TST & \\
\hline CHEMBL1427795 & 688382 & 4.5 & 4.6593 & TRN & \\
\hline CHEMBL1512738 & 688382 & 5.55 & 4.6257 & TST & \\
\hline CHEMBL1605649 & 688382 & 6.0 & 4.85 & TRN & \\
\hline CHEMBL1584101 & 688382 & 4.55 & 4.6612 & TST & \\
\hline CHEMBL1350453 & 688382 & 5.0 & 4.7624 & TRN & \\
\hline CHEMBL1582814 & 688382 & 4.05 & 4.7967 & TRN & \\
\hline CHEMBL1377417 & 688382 & 4.4 & 4.6316 & TRN & \\
\hline CHEMBL1468522 & 688382 & 5.4 & 4.6422 & TRN & \\
\hline CHEMBL1367612 & 688382 & 5.05 & 4.6669 & TRN & \\
\hline CHEMBL1530553 & 688382 & 5.15 & $4.6560 e$ & 3000000001 & TRN \\
\hline CHEMBL1601902 & 688382 & 4.15 & 4.7359 & TST & \\
\hline CHEMBL1332910 & 688382 & 4.35 & 4.6916 & TRN & \\
\hline CHEMBL3189447 & 688382 & 4.95 & 4.6023 & TRN & \\
\hline CHEMBL1558657 & 688382 & 5.55 & 4.7388 & TRN & \\
\hline CHEMBL1438983 & 688382 & 4.15 & 4.6395 & TST & \\
\hline CHEMBL1471948 & 688382 & 5.8 & 4.6422 & TRN & \\
\hline CHEMBL1611530 & 688382 & 4.45 & 4.7796 & TRN & \\
\hline CHEMBL1469291 & 688382 & 4.45 & 4.7508 & TRN & \\
\hline CHEMBL1582609 & 688382 & 4.5 & 4.6349 & TRN & \\
\hline CHEMBL1491847 & 688382 & 5.45 & 4.7191 & TRN & \\
\hline CHEMBL1496250 & 688382 & 5.55 & 4.7532 & TRN & \\
\hline CHEMBL1609232 & 688382 & 4.5 & 4.6892 & TRN & \\
\hline CHEMBL1421060 & 688382 & 4.45 & 4.6701 & TRN & \\
\hline CHEMBL1466756 & 688382 & 4.7 & 4.6444 & TST & \\
\hline CHEMBL1401492 & 688382 & 4.8 & 4.6758 & TRN & \\
\hline
\end{tabular}




\begin{tabular}{|c|c|c|c|c|}
\hline \multicolumn{5}{|c|}{ Supplemental Table S2.txt } \\
\hline CHEMBL1545735 & 688382 & 4.5 & 4.6037 & TST \\
\hline CHEMBL1572741 & 688382 & 4.95 & 4.6514 & TST \\
\hline CHEMBL3145087 & 688382 & 4.45 & 4.607 & TST \\
\hline CHEMBL1544615 & 688382 & 5.5 & 4.7116 & TRN \\
\hline CHEMBL1459502 & 688382 & 4.35 & 4.6582 & TRN \\
\hline CHEMBL1350796 & 688382 & 4.0 & 4.7762 & TST \\
\hline CHEMBL531079 & 688382 & 4.2 & 4.7123 & TST \\
\hline CHEMBL1346927 & 688382 & 5.0 & 4.66 & TRN \\
\hline CHEMBL1331420 & 688382 & 4.85 & 4.7977 & TRN \\
\hline CHEMBL1580572 & 688382 & 4.95 & 4.7755 & TRN \\
\hline CHEMBL1428710 & 688382 & 4.4 & 4.6383 & TRN \\
\hline CHEMBL1569803 & 688382 & 4.05 & 4.7562 & TRN \\
\hline CHEMBL1572394 & 688382 & 5.5 & 4.7495 & TRN \\
\hline CHEMBL1423353 & 688382 & 4.0 & 4.793 & TRN \\
\hline CHEMBL1345159 & 688382 & 4.2 & 4.6307 & TST \\
\hline CHEMBL1457944 & 688382 & 4.8 & 4.673 & TRN \\
\hline CHEMBL1306565 & 688382 & 4.85 & 4.752 & TST \\
\hline CHEMBL1354040 & 688382 & 5.05 & 4.6647 & TRN \\
\hline CHEMBL1532537 & 688382 & 4.95 & 4.7759 & TRN \\
\hline CHEMBL1361850 & 688382 & 4.15 & 4.7842 & TRN \\
\hline CHEMBL1383309 & 688382 & 5.05 & 4.751 & TRN \\
\hline CHEMBL3192568 & 688382 & 4.35 & 4.7211 & TST \\
\hline CHEMBL1573661 & 688382 & 4.3 & 4.6719 & TRN \\
\hline CHEMBL1376542 & 688382 & 4.8 & 4.8202 & TRN \\
\hline CHEMBL1569836 & 688382 & 4.3 & 4.7688 & TRN \\
\hline CHEMBL1481332 & 688382 & 4.45 & 4.6775 & TRN \\
\hline CHEMBL1577608 & 688382 & 4.2 & 4.8249 & TRN \\
\hline CHEMBL1445625 & 688382 & 4.45 & 4.6795 & TRN \\
\hline CHEMBL1498450 & 688382 & 4.45 & 4.6913 & TRN \\
\hline CHEMBL3145082 & 688382 & 4.15 & 4.6493 & TST \\
\hline CHEMBL1459884 & 688382 & 4.05 & 4.5968 & TST \\
\hline CHEMBL3195067 & 688382 & 4.4 & 4.6716 & TST \\
\hline CHEMBL1396782 & 688382 & 6.6 & 4.7026 & TST \\
\hline CHEMBL1548269 & 688382 & 4.95 & 4.6121 & TRN \\
\hline CHEMBL1491004 & 688382 & 4.45 & 4.6548 & TRN \\
\hline CHEMBL1460858 & 688382 & 4.45 & 4.7145 & TRN \\
\hline CHEMBL1416382 & 688382 & 4.2 & 4.6205 & TRN \\
\hline CHEMBL1365909 & 688382 & 4.5 & 4.651 & TST \\
\hline CHEMBL1332507 & 688382 & 4.8 & 4.6706 & TST \\
\hline CHEMBL1544901 & 688382 & 4.55 & 4.6728 & TRN \\
\hline CHEMBL1200488 & 688382 & 4.0 & 4.7319 & TST \\
\hline CHEMBL1429351 & 688382 & 5.0 & 4.6398 & TST \\
\hline CHEMBL1382479 & 688382 & 5.15 & 4.5757 & TRN \\
\hline CHEMBL1605155 & 688382 & 4.8 & 4.7835 & TRN \\
\hline CHEMBL1530809 & 688382 & 3.95 & 4.7747 & TRN \\
\hline CHEMBL1303814 & 688382 & 6.0 & 4.843 & TRN \\
\hline CHEMBL3195671 & 688382 & 4.05 & 4.761 & TRN \\
\hline CHEMBL1448427 & 688382 & 4.05 & 4.6336 & TST \\
\hline
\end{tabular}




\begin{tabular}{|c|c|c|c|c|c|}
\hline & & \multicolumn{4}{|c|}{ Supplemental Table S2.txt } \\
\hline CHEMBL1387245 & 688382 & 4.85 & 4.7141 & TRN & \\
\hline CHEMBL1484701 & 688382 & 5.1 & 4.7061 & TST & \\
\hline CHEMBL1547736 & 688382 & 4.45 & 4.695 & TST & \\
\hline CHEMBL1383351 & 688382 & 6.1 & 4.8537 & TRN & \\
\hline CHEMBL1601721 & 688382 & 4.6 & 4.6376 & TRN & \\
\hline CHEMBL1518557 & 688382 & 4.7 & 4.6896 & TRN & \\
\hline CHEMBL1605554 & 688382 & 4.05 & 4.7519 & TST & \\
\hline CHEMBL1968493 & 688382 & 4.35 & 4.6778 & TRN & \\
\hline CHEMBL1306306 & 688382 & 4.85 & 4.7113 & TST & \\
\hline CHEMBL1342652 & 688382 & 4.45 & 4.7402 & TST & \\
\hline CHEMBL 3192206 & 688382 & 4.85 & 4.6683 & TRN & \\
\hline CHEMBL1433168 & 688382 & 4.5 & 4.6873 & TST & \\
\hline CHEMBL1559105 & 688382 & 4.05 & 4.7455 & TRN & \\
\hline CHEMBL1504848 & 688382 & 5.0 & 4.7804 & TRN & \\
\hline CHEMBL1967857 & 688382 & 4.15 & 4.66 & TRN & \\
\hline CHEMBL1561590 & 688382 & 5.85 & 4.721 & TRN & \\
\hline CHEMBL1540889 & 688382 & 4.5 & 4.7073 & TRN & \\
\hline CHEMBL1372120 & 688382 & 5.6 & 4.7119 & TST & \\
\hline CHEMBL1423523 & 688382 & 4.45 & 4.8551 & TST & \\
\hline CHEMBL1494710 & 688382 & 5.85 & 4.793 & TRN & \\
\hline CHEMBL1477826 & 688382 & 4.5 & 4.6819 & TRN & \\
\hline CHEMBL1486005 & 688382 & 4.85 & 4.7611 & TRN & \\
\hline CHEMBL1379568 & 688382 & 4.8 & 4.7395 & TRN & \\
\hline CHEMBL1582735 & 688382 & 4.5 & 4.6944 & TRN & \\
\hline CHEMBL3190353 & 688382 & 4.4 & 4.6379 & TRN & \\
\hline CHEMBL1328538 & 688382 & 4.15 & 4.5814 & TRN & \\
\hline CHEMBL1573754 & 688382 & 4.45 & 4.6657 & TRN & \\
\hline CHEMBL1496458 & 688382 & 4.15 & 4.6891 & TST & \\
\hline CHEMBL1413089 & 688382 & 4.45 & 4.6765 & TRN & \\
\hline CHEMBL1587205 & 688382 & 4.45 & 4.6717 & TRN & \\
\hline CHEMBL 3199425 & 688382 & 4.5 & 4.63399 & 99999999995 & TRN \\
\hline CHEMBL1301318 & 688382 & 4.95 & 4.7747 & TRN & \\
\hline CHEMBL1573152 & 688382 & 5.8 & 4.8126 & TST & \\
\hline CHEMBL1304587 & 688382 & 4.8 & 4.7267 & TST & \\
\hline CHEMBL1488586 & 688382 & 4.4 & 4.7395 & TRN & \\
\hline CHEMBL1526766 & 688382 & 4.9 & 4.6869 & TST & \\
\hline CHEMBL1361536 & 688382 & 4.85 & 4.7464 & TRN & \\
\hline CHEMBL1366170 & 688382 & 4.15 & 4.7029 & TRN & \\
\hline CHEMBL1405015 & 688382 & 4.8 & 4.7007 & TRN & \\
\hline CHEMBL1461154 & 688382 & 4.6 & 4.7824 & TST & \\
\hline CHEMBL1599815 & 688382 & 5.1 & 4.6327 & TRN & \\
\hline CHEMBL3197472 & 688382 & 4.15 & 4.6613 & TRN & \\
\hline CHEMBL1445300 & 688382 & 5.1 & 4.7072 & TRN & \\
\hline CHEMBL1337288 & 688382 & 5.8 & 4.7564 & TRN & \\
\hline CHEMBL1493991 & 688382 & 4.8 & 4.7173 & TRN & \\
\hline CHEMBL1472203 & 688382 & 4.85 & 4.8089 & TRN & \\
\hline CHEMBL1347570 & 688382 & 4.4 & 4.6896 & TST & \\
\hline CHEMBL1585527 & 688382 & 4.4 & 4.6604 & TST & \\
\hline
\end{tabular}




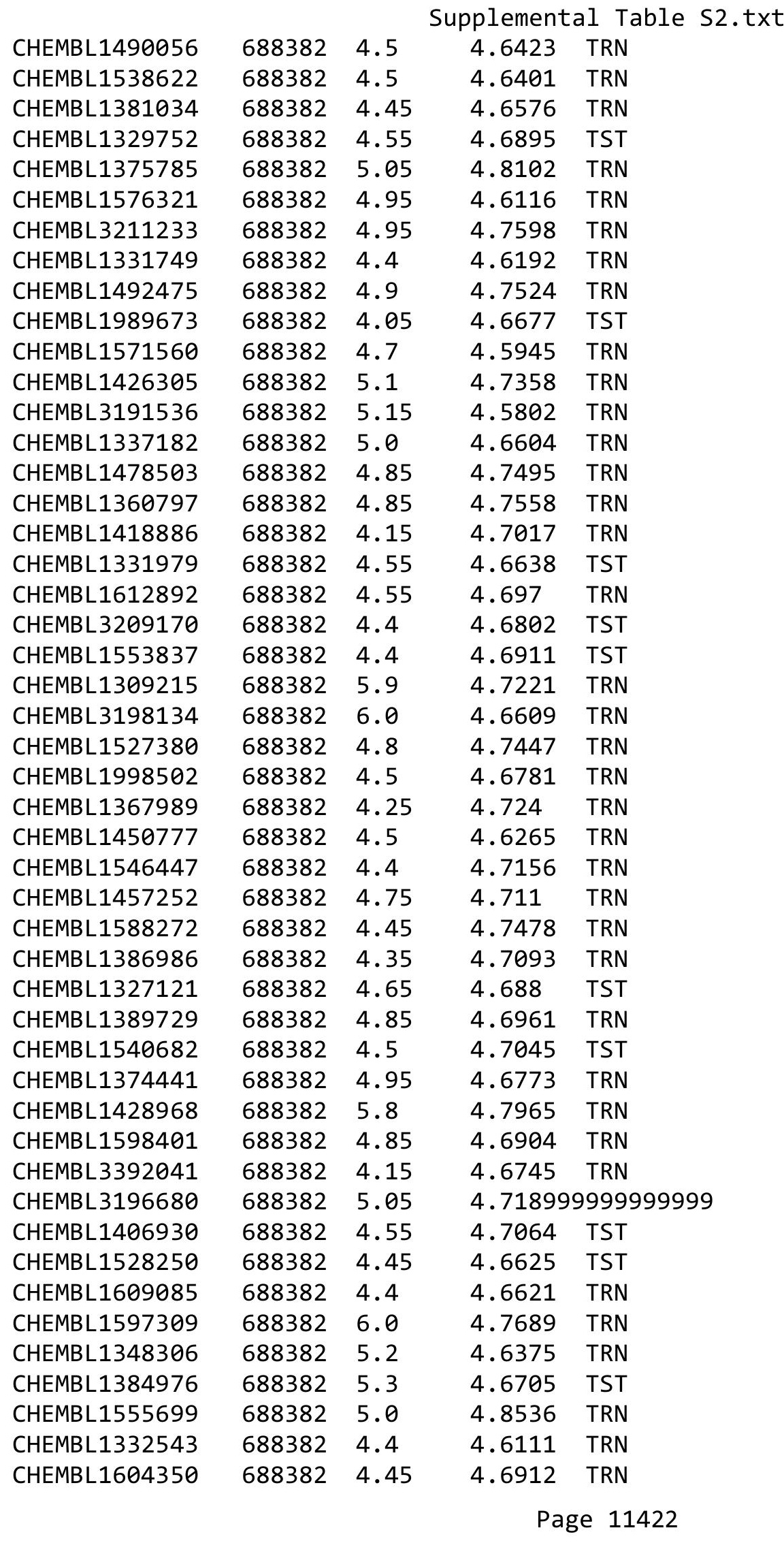




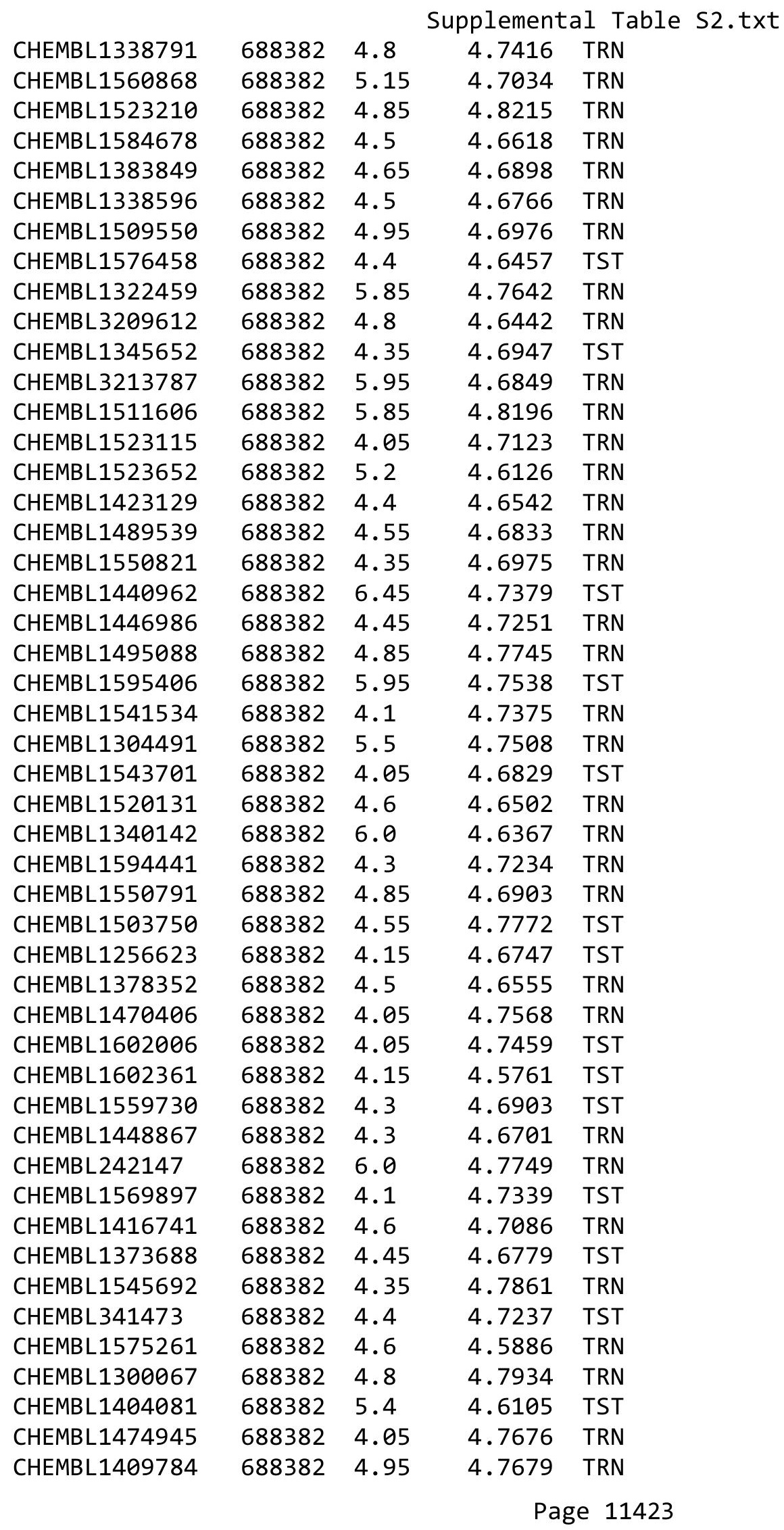




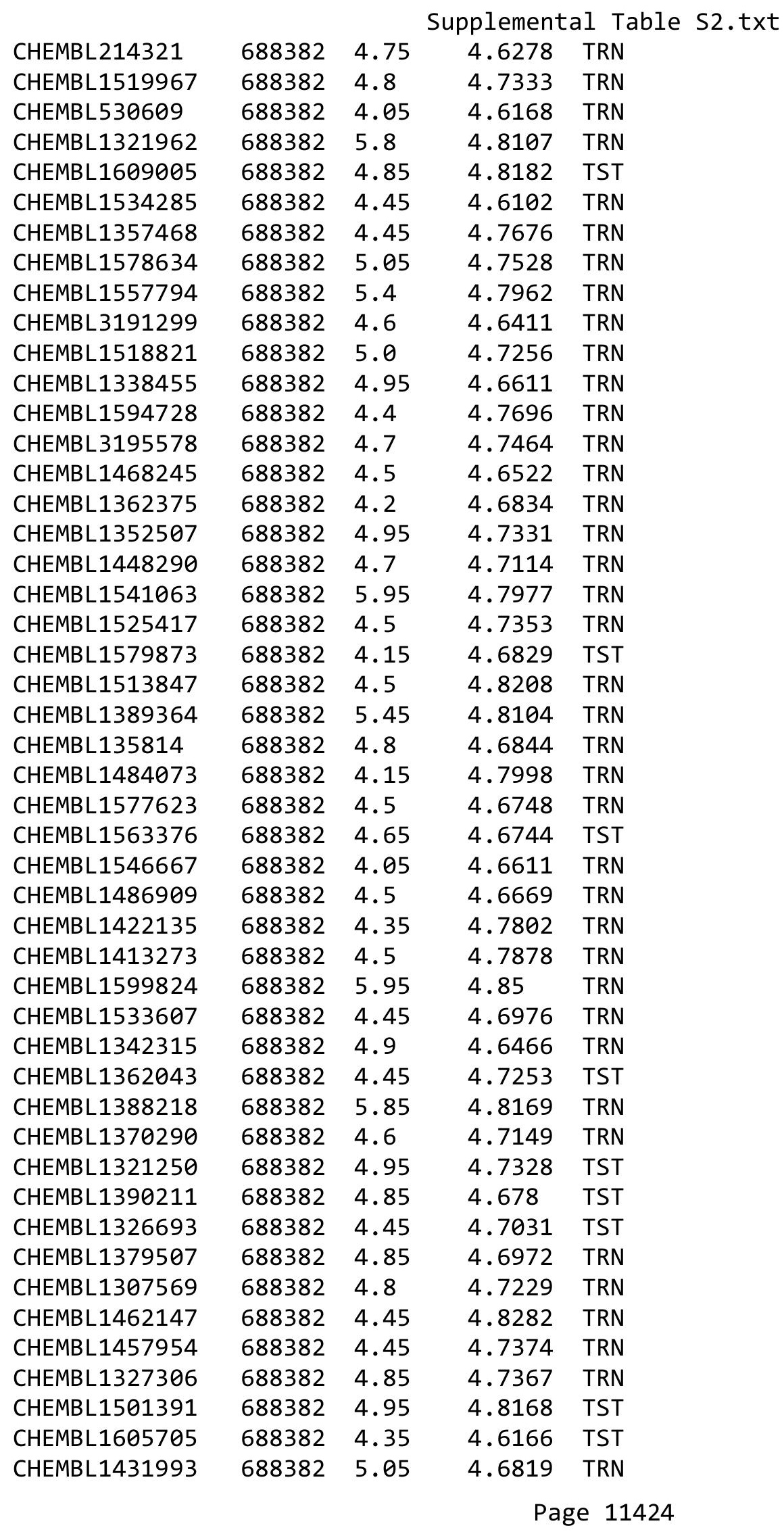




\begin{tabular}{|c|c|c|c|c|c|}
\hline \multicolumn{6}{|c|}{ Supplemental Table S2.txt } \\
\hline CHEMBL1583835 & 688382 & 4.4 & 4.7175 & TRN & \\
\hline CHEMBL1605346 & 688382 & 4.15 & 4.6146 & TRN & \\
\hline CHEMBL1320501 & 688382 & 5.85 & 4.6995 & TRN & \\
\hline CHEMBL1560640 & 688382 & 4.75 & 4.6394 & TRN & \\
\hline CHEMBL1521988 & 688382 & 5.05 & 4.6838 & TRN & \\
\hline CHEMBL1542105 & 688382 & 4.35 & 4.7618 & TRN & \\
\hline CHEMBL 2005653 & 688382 & 4.55 & 4.6959 & TRN & \\
\hline CHEMBL1511475 & 688382 & 4.5 & 4.8592 & TRN & \\
\hline CHEMBL1313730 & 688382 & 4.35 & 4.752 & TRN & \\
\hline CHEMBL1311831 & 688382 & 4.35 & 4.7307 & TRN & \\
\hline CHEMBL1490437 & 688382 & 5.95 & 4.7338 & TRN & \\
\hline CHEMBL 3198572 & 688382 & 4.2 & 4.6113 & TRN & \\
\hline CHEMBL11475 & 688382 & 4.5 & 4.6712 & TST & \\
\hline CHEMBL1328314 & 688382 & 4.45 & 4.7743 & TRN & \\
\hline CHEMBL1538928 & 688382 & 5.95 & 4.6992 & TRN & \\
\hline CHEMBL1556954 & 688382 & 4.9 & 4.7278 & TRN & \\
\hline CHEMBL1535230 & 688382 & 4.5 & 4.8059 & TRN & \\
\hline CHEMBL1598843 & 688382 & 5.15 & 4.6689 & TRN & \\
\hline CHEMBL1486503 & 688382 & 4.5 & 4.657 & TRN & \\
\hline CHEMBL1532510 & 688382 & 4.5 & 4.6692 & TRN & \\
\hline CHEMBL1595489 & 688382 & 6.0 & 4.8314 & TST & \\
\hline CHEMBL1313522 & 688382 & 4.55 & 4.6818 & TRN & \\
\hline CHEMBL1341346 & 688382 & 4.5 & 4.6939 & TRN & \\
\hline CHEMBL1359338 & 688382 & 6.0 & 4.8212 & TRN & \\
\hline CHEMBL1453136 & 688382 & 5.2 & 4.5845 & TRN & \\
\hline CHEMBL1484998 & 688382 & 4.25 & 4.6681 & TRN & \\
\hline CHEMBL3195215 & 688382 & 4.1 & 4.6557 & TRN & \\
\hline CHEMBL1346554 & 688382 & 4.15 & 4.7271 & TRN & \\
\hline CHEMBL1436590 & 688382 & 3.95 & 4.7422 & TRN & \\
\hline CHEMBL1377822 & 688382 & 5.75 & 4.793 & TRN & \\
\hline CHEMBL1451935 & 688382 & 4.55 & 4.6329 & TRN & \\
\hline CHEMBL1607657 & 688382 & 4.45 & 4.729 & TST & \\
\hline CHEMBL1547114 & 688382 & 5.15 & 4.7911 & TRN & \\
\hline CHEMBL1353006 & 688382 & 4.85 & 4.723 & TRN & \\
\hline CHEMBL1538676 & 688382 & 4.6 & 4.7275 & TST & \\
\hline CHEMBL1565156 & 688382 & 5.05 & 4.7517 & TRN & \\
\hline CHEMBL1555996 & 688382 & 4.5 & 4.6723 & TRN & \\
\hline CHEMBL1975069 & 688382 & 5.05 & 4.6477 & TRN & \\
\hline CHEMBL1584072 & 688382 & 4.4 & 4.6989 & TST & \\
\hline CHEMBL1310912 & 688382 & 4.95 & 4.6958 & TRN & \\
\hline CHEMBL1488455 & 688382 & 5.95 & 4.7399 & TRN & \\
\hline CHEMBL1323462 & 688382 & 4.4 & 4.6615 & TST & \\
\hline CHEMBL1385200 & 688382 & 5.6 & 4.6278 & TST & \\
\hline CHEMBL1422146 & 688382 & 4.8 & 4.7162 & TRN & \\
\hline CHEMBL1485817 & 688382 & 4.95 & 4.8147 & TRN & \\
\hline CHEMBL1539789 & 688382 & 4.5 & 4.5962 & TRN & \\
\hline CHEMBL1423622 & 688382 & 4.7 & 4.6982 & TRN & \\
\hline CHEMBL1584433 & 688382 & 4.15 & 4.80399 & 9999999999 & TST \\
\hline & & & & 11425 & \\
\hline
\end{tabular}




\begin{tabular}{|c|c|c|c|c|}
\hline & & & upplemen & al $\mathrm{T}$ \\
\hline CHEMBL1359878 & 688382 & 5.9 & 4.6418 & TRN \\
\hline CHEMBL1374186 & 688382 & 4.5 & 4.6085 & TRN \\
\hline CHEMBL1383426 & 688382 & 4.35 & 4.6959 & TST \\
\hline CHEMBL1569394 & 688382 & 4.8 & 4.6459 & TRN \\
\hline CHEMBL3207852 & 688382 & 4.4 & 4.6072 & TRN \\
\hline CHEMBL1541519 & 688382 & 4.05 & 4.7112 & TRN \\
\hline CHEMBL1575857 & 688382 & 5.05 & 4.7652 & TRN \\
\hline CHEMBL1486978 & 688382 & 6.0 & 4.7305 & TRN \\
\hline CHEMBL1542045 & 688382 & 4.4 & 4.6112 & TST \\
\hline CHEMBL1367717 & 688382 & 4.7 & 4.6568 & TRN \\
\hline CHEMBL1527994 & 688382 & 6.05 & 4.6911 & TRN \\
\hline CHEMBL1584321 & 688382 & 4.05 & 4.6739 & TRN \\
\hline CHEMBL1311198 & 688382 & 4.05 & 4.7192 & TRN \\
\hline CHEMBL1353216 & 688382 & 4.3 & 4.749 & TRN \\
\hline CHEMBL1527973 & 688382 & 4.15 & 4.6846 & TRN \\
\hline CHEMBL1329651 & 688382 & 6.0 & 4.7731 & TRN \\
\hline CHEMBL1438418 & 688382 & 4.8 & 4.8113 & TRN \\
\hline CHEMBL1494001 & 688382 & 4.5 & 4.6911 & TST \\
\hline CHEMBL1380897 & 688382 & 4.8 & 4.7146 & TRN \\
\hline CHEMBL1440889 & 688382 & 4.2 & 4.7533 & TRN \\
\hline CHEMBL1371419 & 688382 & 5.95 & 4.7554 & TRN \\
\hline CHEMBL1465174 & 688382 & 5.05 & 4.6543 & TST \\
\hline CHEMBL1365320 & 688382 & 4.2 & 4.7544 & TRN \\
\hline CHEMBL1575577 & 688382 & 4.05 & 4.825 & TRN \\
\hline CHEMBL498373 & 688382 & 5.45 & 4.6812 & TRN \\
\hline CHEMBL1520528 & 688382 & 4.85 & 4.6936 & TRN \\
\hline CHEMBL1311185 & 688382 & 4.45 & 4.6883 & TST \\
\hline CHEMBL1969001 & 688382 & 4.8 & 4.7237 & TRN \\
\hline CHEMBL1527285 & 688382 & 4.45 & 4.7034 & TRN \\
\hline CHEMBL1891759 & 688382 & 5.15 & 4.6132 & TST \\
\hline CHEMBL1440877 & 688382 & 4.25 & 4.7049 & TRN \\
\hline CHEMBL1547220 & 688382 & 4.8 & 4.7017 & TST \\
\hline CHEMBL1366585 & 688382 & 5.25 & 4.6767 & TRN \\
\hline CHEMBL1964383 & 688382 & 4.45 & 4.6246 & TST \\
\hline CHEMBL1612977 & 688382 & 4.55 & 4.7191 & TRN \\
\hline CHEMBL1524740 & 688382 & 4.5 & 4.7691 & TRN \\
\hline CHEMBL1543524 & 688382 & 4.95 & 4.6703 & TRN \\
\hline CHEMBL1353387 & 688382 & 4.5 & 4.7193 & TRN \\
\hline CHEMBL1386895 & 688382 & 4.05 & 4.7976 & TRN \\
\hline CHEMBL1492470 & 688382 & 4.15 & 4.7404 & TRN \\
\hline CHEMBL1415370 & 688382 & 4.95 & 4.7471 & TRN \\
\hline CHEMBL 3198324 & 688382 & 4.5 & 4.6507 & TRN \\
\hline CHEMBL1581596 & 688382 & 4.5 & 4.6135 & TRN \\
\hline CHEMBL1499734 & 688382 & 4.85 & 4.7663 & TST \\
\hline CHEMBL1335080 & 688382 & 4.8 & 4.7125 & TRN \\
\hline CHEMBL1369132 & 688382 & 4.85 & 4.8712 & TRN \\
\hline CHEMBL1516044 & 688382 & 4.5 & 4.7354 & TRN \\
\hline CHEMBL1597150 & 688382 & 4.15 & 4.6745 & TRN \\
\hline
\end{tabular}




\begin{tabular}{|c|c|c|c|c|c|}
\hline \multicolumn{6}{|c|}{ Supplemental Table S2.txt } \\
\hline CHEMBL1348954 & 688382 & 4.6 & 4.7276 & TRN & \\
\hline CHEMBL1567396 & 688382 & 4.15 & 4.7256 & TRN & \\
\hline CHEMBL1359548 & 688382 & 4.9 & 4.6889 & TRN & \\
\hline CHEMBL1423540 & 688382 & 4.0 & 4.6613 & TRN & \\
\hline CHEMBL1309895 & 688382 & 4.4 & 4.6528 & TRN & \\
\hline CHEMBL1477589 & 688382 & 6.0 & 4.6489 & TRN & \\
\hline CHEMBL1526899 & 688382 & 4.35 & 4.71399 & 99999999995 & TRN \\
\hline CHEMBL1405794 & 688382 & 4.4 & 4.7572 & TRN & \\
\hline CHEMBL1341572 & 688382 & 4.7 & 4.7389 & TRN & \\
\hline CHEMBL1507698 & 688382 & 4.25 & 4.6766 & TRN & \\
\hline CHEMBL1596690 & 688382 & 4.8 & 4.7039 & TRN & \\
\hline CHEMBL1459005 & 688382 & 4.55 & 4.7588 & TRN & \\
\hline CHEMBL1338493 & 688382 & 6.5501 & 4.7248 & TST & \\
\hline CHEMBL1580666 & 688382 & 4.95 & 4.7904 & TRN & \\
\hline CHEMBL1374429 & 688382 & 4.8 & 4.6887 & TST & \\
\hline CHEMBL1546012 & 688382 & 4.05 & 4.735 & TRN & \\
\hline CHEMBL1567335 & 688382 & 4.8 & 4.7071 & TRN & \\
\hline CHEMBL1547468 & 688382 & 4.85 & 4.6291 & TRN & \\
\hline CHEMBL1365638 & 688382 & 4.45 & 4.5968 & TRN & \\
\hline CHEMBL1332860 & 688382 & 4.6 & 4.6428 & TRN & \\
\hline CHEMBL1458593 & 688382 & 4.75 & 4.5879 & TRN & \\
\hline CHEMBL1503307 & 688382 & 4.6 & 4.6119 & TRN & \\
\hline CHEMBL1562840 & 688382 & 5.95 & 4.7289 & TRN & \\
\hline CHEMBL1564153 & 688382 & 4.65 & 4.717 & TRN & \\
\hline CHEMBL1486408 & 688382 & 4.6 & 4.8267 & TRN & \\
\hline CHEMBL1429812 & 688382 & 5.95 & 4.6629 & TRN & \\
\hline CHEMBL1491618 & 688382 & 4.05 & 4.7788 & TRN & \\
\hline CHEMBL1385886 & 688382 & 5.5 & 4.7096 & TRN & \\
\hline CHEMBL1376163 & 688382 & 4.8 & 4.7149 & TRN & \\
\hline CHEMBL1406942 & 688382 & 4.4 & 4.7357 & TST & \\
\hline CHEMBL1578801 & 688382 & 4.8 & 4.7302 & TRN & \\
\hline CHEMBL1562793 & 688382 & 4.25 & 4.7053 & TRN & \\
\hline CHEMBL1472031 & 688382 & 5.15 & 4.7429 & TST & \\
\hline CHEMBL1432768 & 688382 & 5.85 & 4.6999 & TRN & \\
\hline CHEMBL1346590 & 688382 & 4.0 & 4.6203 & TRN & \\
\hline CHEMBL1546361 & 688382 & 5.0 & 4.7405 & TRN & \\
\hline CHEMBL1609427 & 688382 & 5.8 & 4.7433 & TRN & \\
\hline CHEMBL1572827 & 688382 & 4.1 & 4.703 & TRN & \\
\hline CHEMBL1972755 & 688382 & 5.0 & 4.6578 & TRN & \\
\hline CHEMBL1322910 & 688382 & 5.0 & 4.7968 & TRN & \\
\hline CHEMBL1535333 & 688382 & 5.05 & 4.7658 & TRN & \\
\hline CHEMBL1994371 & 688382 & 5.1 & 4.6689 & TRN & \\
\hline CHEMBL1556612 & 688382 & 4.85 & 4.6742 & TRN & \\
\hline CHEMBL1510999 & 688382 & 5.5 & 4.7039 & TRN & \\
\hline CHEMBL1374660 & 688382 & 5.25 & 4.7287 & TRN & \\
\hline CHEMBL1372404 & 688382 & 4.45 & 4.7228 & TRN & \\
\hline CHEMBL1525194 & 688382 & 4.45 & 4.6646 & TST & \\
\hline CHEMBL1419841 & 688382 & 4.8 & 4.7004 & TST & \\
\hline
\end{tabular}




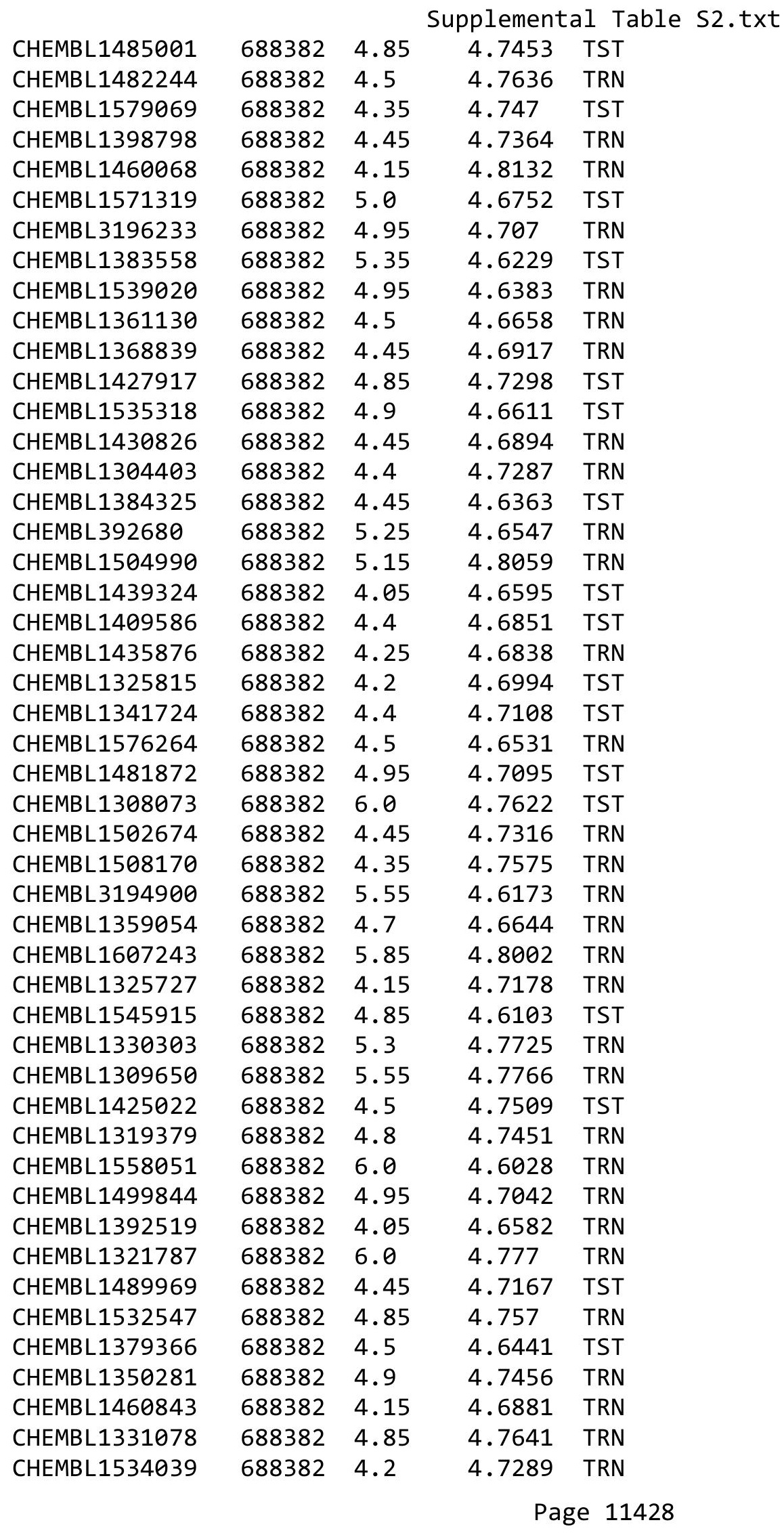




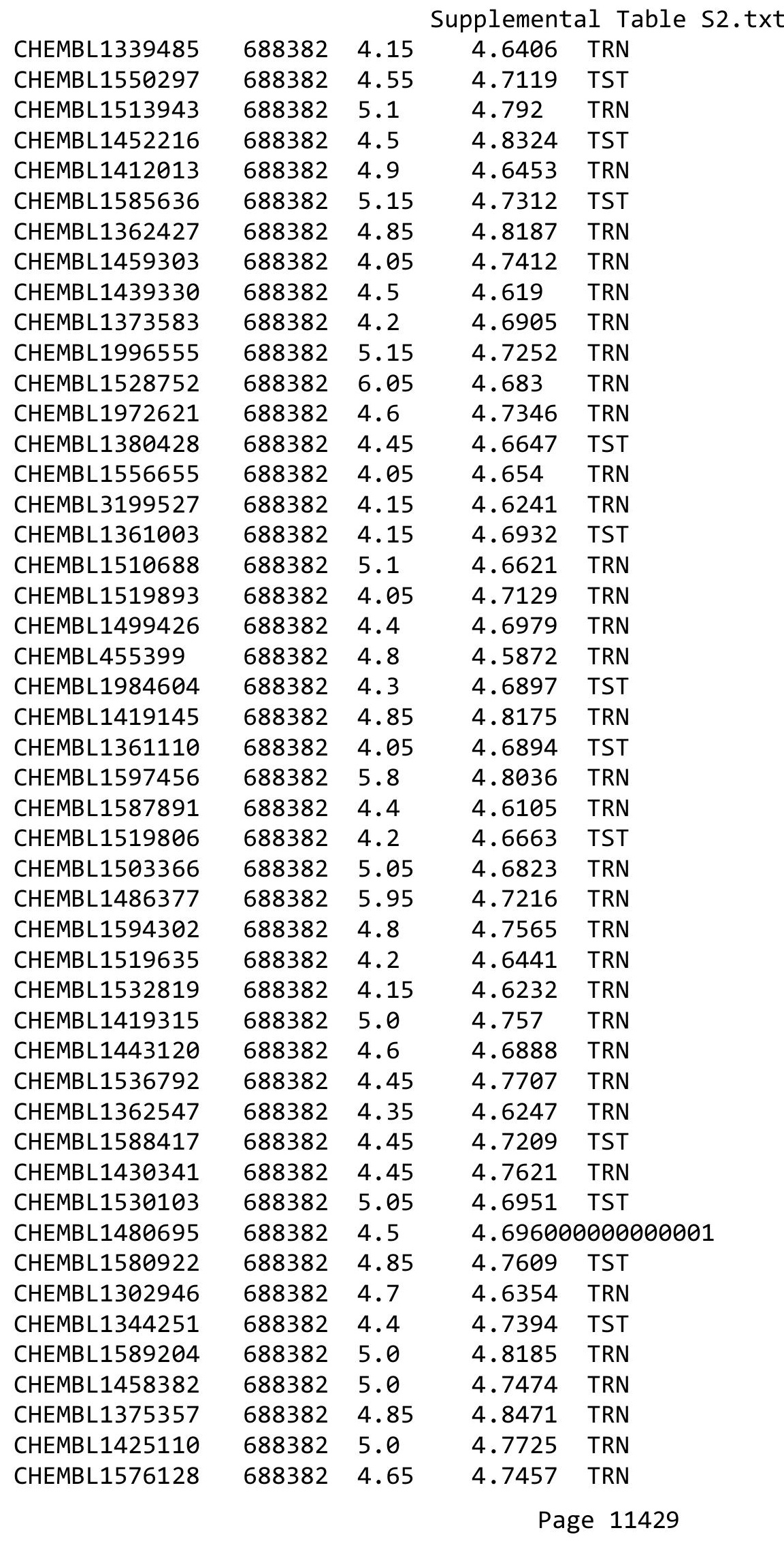




\begin{tabular}{|c|c|c|c|c|}
\hline \multicolumn{5}{|c|}{ Supplemental Table S2.txt } \\
\hline CHEMBL1487372 & 688382 & 4.2 & 4.7506 & TRN \\
\hline CHEMBL1577946 & 688382 & 4.35 & 4.7664 & TRN \\
\hline CHEMBL1385840 & 688382 & 4.45 & 4.7777 & TRN \\
\hline CHEMBL1470581 & 688382 & 5.05 & 4.7529 & TRN \\
\hline CHEMBL1535727 & 688382 & 4.05 & 4.7274 & TRN \\
\hline CHEMBL3197687 & 688382 & 4.45 & 4.6662 & TST \\
\hline CHEMBL1455056 & 688382 & 4.45 & 4.7238 & TRN \\
\hline CHEMBL1522186 & 688382 & 4.45 & 4.6925 & TST \\
\hline CHEMBL1559026 & 688382 & 6.0 & 4.8072 & TRN \\
\hline CHEMBL1568466 & 688382 & 4.15 & 4.7644 & TRN \\
\hline CHEMBL493863 & 688382 & 4.6 & 4.6481 & TRN \\
\hline CHEMBL1429799 & 688382 & 4.65 & 4.7508 & TRN \\
\hline CHEMBL1580142 & 688382 & 4.4 & 4.6539 & TST \\
\hline CHEMBL1340920 & 688382 & 4.2 & 4.7107 & TRN \\
\hline CHEMBL1377382 & 688382 & 4.8 & 4.6498 & TRN \\
\hline CHEMBL1406450 & 688382 & 5.15 & 4.8074 & TRN \\
\hline CHEMBL1563807 & 688382 & 3.95 & 4.7391 & TRN \\
\hline CHEMBL1331564 & 688382 & 5.4 & 4.6689 & TRN \\
\hline CHEMBL1453844 & 688382 & 4.1 & 4.7608 & TST \\
\hline CHEMBL1359775 & 688382 & 4.05 & 4.6566 & TRN \\
\hline CHEMBL1572235 & 688382 & 4.5 & 4.7307 & TRN \\
\hline CHEMBL1313466 & 688382 & 4.95 & 4.7082 & TST \\
\hline CHEMBL1549564 & 688382 & 4.9 & 4.8163 & TRN \\
\hline CHEMBL3190394 & 688382 & 4.2 & 4.6261 & TRN \\
\hline CHEMBL1342778 & 688382 & 4.2 & 4.7215 & TRN \\
\hline CHEMBL1497112 & 688382 & 4.85 & 4.6667 & TST \\
\hline CHEMBL1988686 & 688382 & 4.15 & 4.6783 & TRN \\
\hline CHEMBL1467854 & 688382 & 4.5 & 4.6956 & TRN \\
\hline CHEMBL261259 & 688382 & 4.45 & 4.7245 & TST \\
\hline CHEMBL1522476 & 688382 & 4.8 & 4.7004 & TST \\
\hline CHEMBL1349970 & 688382 & 5.8 & 4.8116 & TRN \\
\hline CHEMBL1412296 & 688382 & 5.4 & 4.7804 & TRN \\
\hline CHEMBL1510804 & 688382 & 4.55 & 4.6549 & TRN \\
\hline CHEMBL3195223 & 688382 & 4.45 & 4.7399 & TRN \\
\hline CHEMBL579919 & 688382 & 4.65 & 4.6753 & TRN \\
\hline CHEMBL1570544 & 688382 & 4.2 & 4.7392 & TRN \\
\hline CHEMBL1356202 & 688382 & 6.0 & 4.6667 & TRN \\
\hline CHEMBL1520077 & 688382 & 4.3 & 4.7125 & TRN \\
\hline CHEMBL1364266 & 688382 & 4.85 & 4.6537 & TRN \\
\hline CHEMBL1442103 & 688382 & 4.65 & 4.6576 & TST \\
\hline CHEMBL1387133 & 688382 & 4.45 & 4.7253 & TRN \\
\hline CHEMBL1574349 & 688382 & 5.9 & 4.8087 & TRN \\
\hline CHEMBL1493944 & 688382 & 5.3 & 4.6833 & TRN \\
\hline CHEMBL1431412 & 688382 & 4.8 & 4.8002 & TRN \\
\hline CHEMBL1611039 & 688382 & 4.95 & 4.7096 & TRN \\
\hline CHEMBL1583026 & 688382 & 4.55 & 4.5933 & TST \\
\hline CHEMBL3190363 & 688382 & 4.85 & 4.8122 & TRN \\
\hline CHEMBL1368909 & 688382 & 5.8 & 4.7875 & TST \\
\hline
\end{tabular}




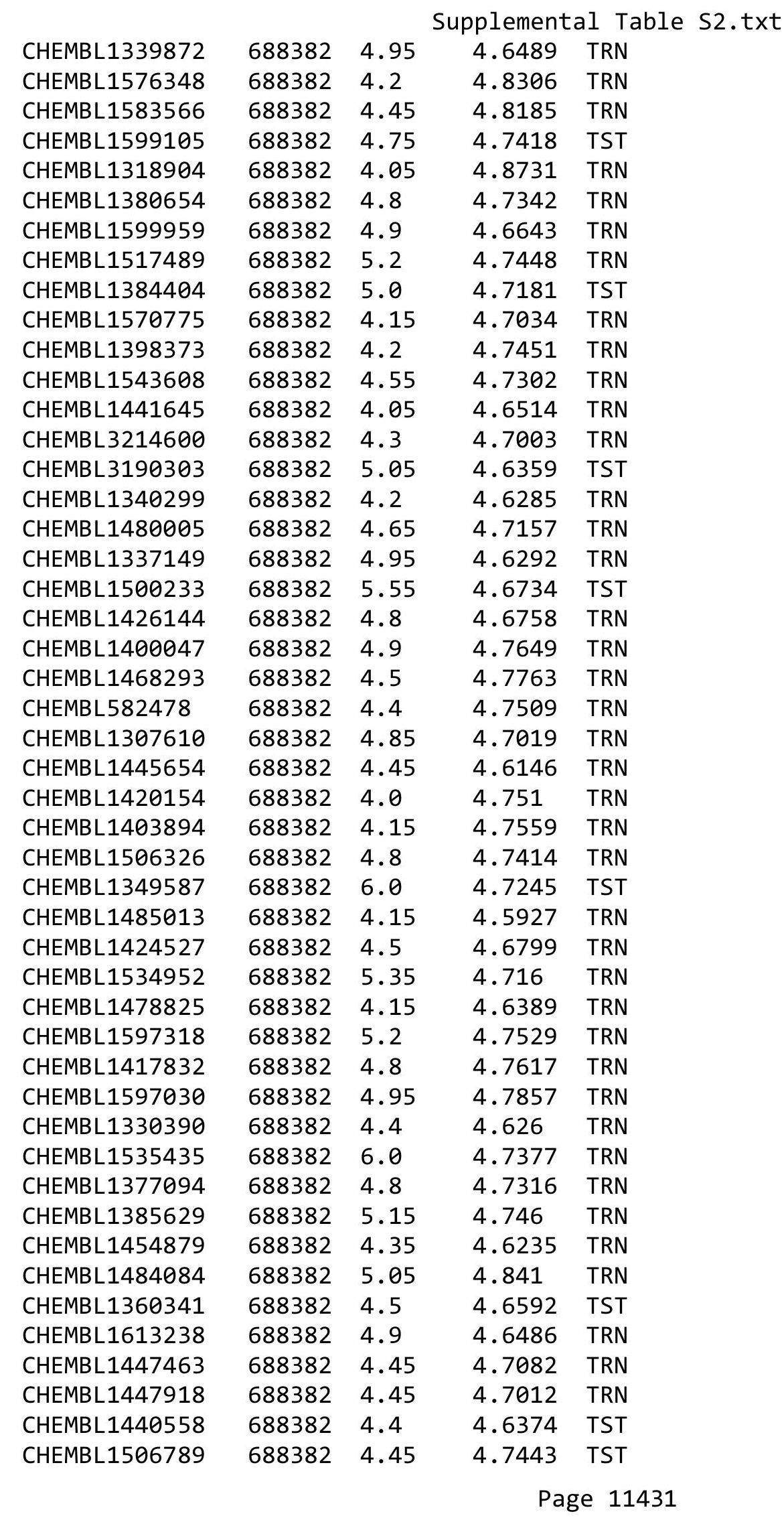




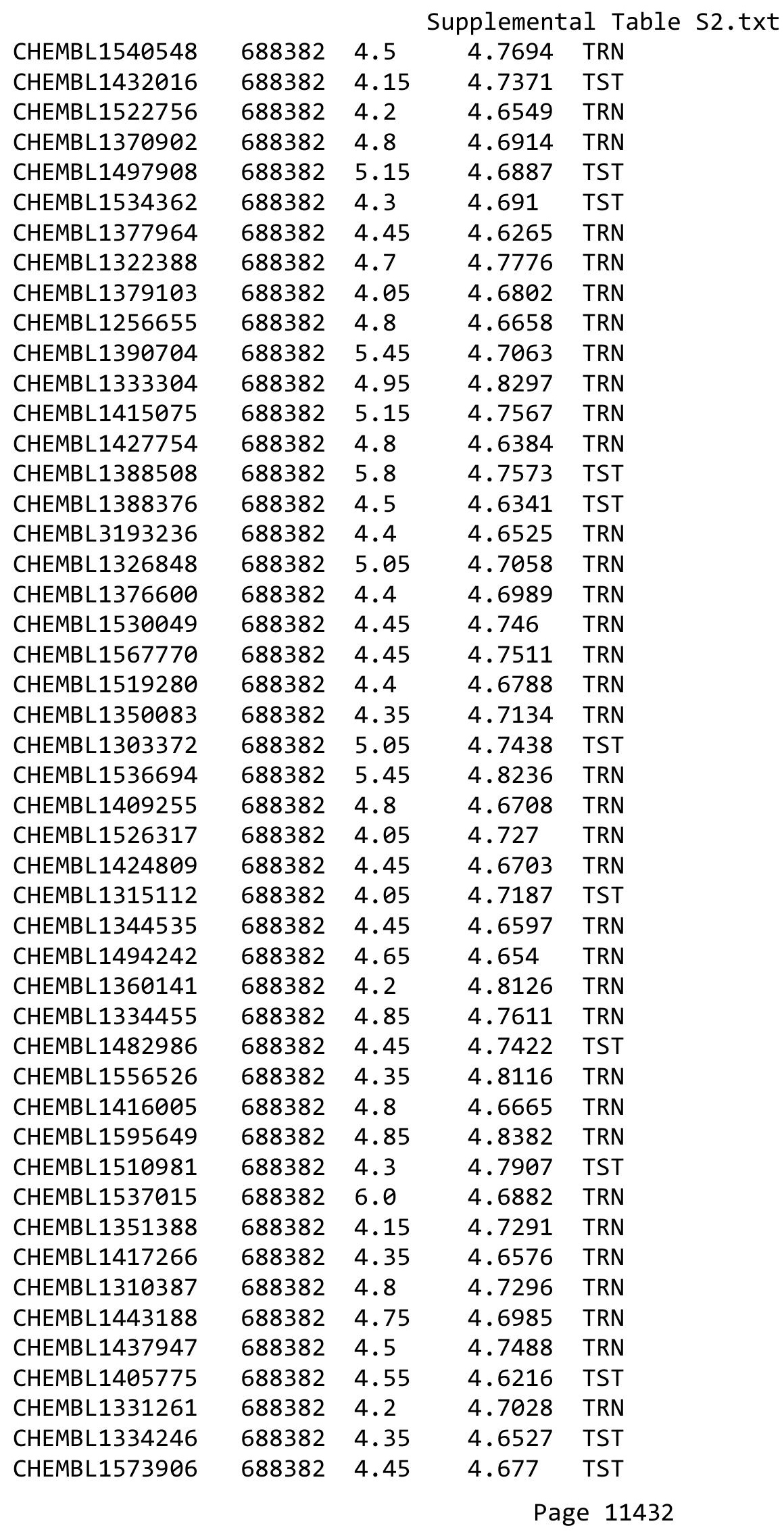




\begin{tabular}{|c|c|c|c|c|}
\hline \multicolumn{5}{|c|}{ Supplemental Table S2.txt } \\
\hline CHEMBL1604012 & 688382 & 5.5 & 4.6146 & TRN \\
\hline CHEMBL1381535 & 688382 & 5.85 & 4.7173 & TRN \\
\hline CHEMBL1453501 & 688382 & 4.35 & 4.776 & TRN \\
\hline CHEMBL1471730 & 688382 & 4.4 & 4.6444 & TRN \\
\hline CHEMBL 1345486 & 688382 & 4.05 & 4.6432 & TRN \\
\hline CHEMBL3196493 & 688382 & 4.5 & 4.688 & TRN \\
\hline CHEMBL1312938 & 688382 & 4.15 & 4.7043 & TRN \\
\hline CHEMBL1336403 & 688382 & 4.2 & 4.5971 & TRN \\
\hline CHEMBL1346963 & 688382 & 4.95 & 4.7367 & TRN \\
\hline CHEMBL1443389 & 688382 & 4.8 & 4.6697 & TRN \\
\hline CHEMBL1465481 & 688382 & 5.05 & 4.7283 & TST \\
\hline CHEMBL3208166 & 688382 & 4.45 & 4.6246 & TST \\
\hline CHEMBL1563262 & 688382 & 4.25 & 4.7044 & TRN \\
\hline CHEMBL1400768 & 688382 & 4.4 & 4.6406 & TRN \\
\hline CHEMBL1537712 & 688382 & 4.4 & 4.7417 & TRN \\
\hline CHEMBL1482128 & 688382 & 4.8 & 4.6796 & TST \\
\hline CHEMBL1508414 & 688382 & 4.35 & 4.6444 & TST \\
\hline CHEMBL1518292 & 688382 & 6.0 & 4.7348 & TRN \\
\hline CHEMBL1605589 & 688382 & 5.05 & 4.7372 & TRN \\
\hline CHEMBL1972688 & 688382 & 4.5 & 4.6803 & TRN \\
\hline CHEMBL1566076 & 688382 & 4.6 & 4.5793 & TRN \\
\hline CHEMBL1437942 & 688382 & 4.8 & 4.6486 & TRN \\
\hline CHEMBL1304046 & 688382 & 4.35 & 4.6418 & TRN \\
\hline CHEMBL601135 & 688382 & 4.45 & 4.7268 & TRN \\
\hline CHEMBL1471046 & 688382 & 4.65 & 4.8463 & TRN \\
\hline CHEMBL1535877 & 688382 & 4.15 & 4.7642 & TRN \\
\hline CHEMBL1547887 & 688382 & 4.5 & 4.5855 & TRN \\
\hline CHEMBL1977877 & 688382 & 4.55 & 4.6 & TST \\
\hline CHEMBL1307491 & 688382 & 5.0 & 4.7655 & TRN \\
\hline CHEMBL1387952 & 688382 & 4.0 & 4.8316 & TRN \\
\hline CHEMBL1576706 & 688382 & 4.9 & 4.7393 & TRN \\
\hline CHEMBL1444604 & 688382 & 4.0 & 4.662 & TST \\
\hline CHEMBL1394121 & 688382 & 5.15 & 4.7249 & TST \\
\hline CHEMBL1479509 & 688382 & 5.0 & 4.5967 & TST \\
\hline CHEMBL1605738 & 688382 & 4.75 & 4.6611 & TRN \\
\hline CHEMBL193872 & 688382 & 4.5 & 4.6389 & TRN \\
\hline CHEMBL1529528 & 688382 & 4.55 & 4.648 & TRN \\
\hline CHEMBL1546761 & 688382 & 4.45 & 4.6601 & TRN \\
\hline CHEMBL1409120 & 688382 & 4.45 & 4.6769 & TST \\
\hline CHEMBL1505152 & 688382 & 4.2 & 4.7966 & TRN \\
\hline CHEMBL1497336 & 688382 & 4.85 & 4.7208 & TST \\
\hline CHEMBL1567018 & 688382 & 4.8 & 4.7446 & TRN \\
\hline CHEMBL1448271 & 688382 & 4.5 & 4.7195 & TST \\
\hline CHEMBL1468698 & 688382 & 4.85 & 4.8194 & TRN \\
\hline CHEMBL1442155 & 688382 & 4.4 & 4.6614 & TST \\
\hline CHEMBL1323828 & 688382 & 7.0501 & 4.7234 & TRN \\
\hline CHEMBL1604934 & 688382 & 6.0 & 4.7409 & TRN \\
\hline CHEMBL1448606 & 688382 & 4.2 & 4.6912 & TRN \\
\hline
\end{tabular}




\begin{tabular}{|c|c|c|c|c|c|}
\hline \multicolumn{6}{|c|}{ Supplemental Table S2.txt } \\
\hline CHEMBL1335123 & 688382 & 4.05 & 4.7008 & TRN & \\
\hline CHEMBL1598218 & 688382 & 4.2 & 4.704 & TRN & \\
\hline CHEMBL1510590 & 688382 & 4.95 & 4.6949 & TRN & \\
\hline CHEMBL1339933 & 688382 & 4.5 & 4.6835 & TST & \\
\hline CHEMBL1576694 & 688382 & 4.5 & 4.7556 & TST & \\
\hline CHEMBL1371576 & 688382 & 4.5 & 4.6583 & TRN & \\
\hline CHEMBL1607100 & 688382 & 4.35 & 4.687 & TRN & \\
\hline CHEMBL1389373 & 688382 & 4.55 & 4.7808 & TRN & \\
\hline CHEMBL 3198339 & 688382 & 4.2 & 4.6204 & TRN & \\
\hline CHEMBL1371556 & 688382 & 4.4 & 4.6491 & TRN & \\
\hline CHEMBL1499683 & 688382 & 5.0 & 4.7041 & TRN & \\
\hline CHEMBL1993989 & 688382 & 4.1 & 4.7111 & TRN & \\
\hline CHEMBL1580708 & 688382 & 4.4 & 4.6824 & TRN & \\
\hline CHEMBL1429515 & 688382 & 6.0 & 4.7878 & TST & \\
\hline CHEMBL1604267 & 688382 & 4.8 & 4.6856 & TST & \\
\hline CHEMBL1539255 & 688382 & 4.4 & 4.7417 & TST & \\
\hline CHEMBL1343489 & 688382 & 4.35 & 4.6372 & TRN & \\
\hline CHEMBL1345362 & 688382 & 4.45 & 4.711 & TST & \\
\hline CHEMBL1570935 & 688382 & 4.6 & 4.6733 & TRN & \\
\hline CHEMBL1309147 & 688382 & 5.5 & 4.7705 & TRN & \\
\hline CHEMBL1608157 & 688382 & 4.4 & 4.7457 & TRN & \\
\hline CHEMBL1978885 & 688382 & 4.05 & 4.655 & TRN & \\
\hline CHEMBL1388320 & 688382 & 4.9 & 4.6626 & TRN & \\
\hline CHEMBL1544806 & 688382 & 5.85 & 4.7751 & TST & \\
\hline CHEMBL1327634 & 688382 & 4.95 & 4.7187 & TRN & \\
\hline CHEMBL1382305 & 688382 & 4.5 & 4.7462 & TRN & \\
\hline CHEMBL1470146 & 688382 & 4.45 & 4.6923 & TST & \\
\hline CHEMBL1545436 & 688382 & 5.9 & 4.73300 & 00000000005 & TRN \\
\hline CHEMBL1413146 & 688382 & 4.2 & 4.6839 & TRN & \\
\hline CHEMBL579621 & 688382 & 5.0 & 4.6061 & TST & \\
\hline CHEMBL1386592 & 688382 & 4.05 & 4.6704 & TRN & \\
\hline CHEMBL1594229 & 688382 & 4.5 & 4.7454 & TRN & \\
\hline CHEMBL1433033 & 688382 & 4.45 & 4.6965 & TRN & \\
\hline CHEMBL1494677 & 688382 & 4.15 & 4.7039 & TRN & \\
\hline CHEMBL1537820 & 688382 & 5.25 & 4.8197 & TRN & \\
\hline CHEMBL1438380 & 688382 & 4.75 & 4.743 & TRN & \\
\hline CHEMBL1611147 & 688382 & 4.25 & 4.7595 & TRN & \\
\hline CHEMBL1571874 & 688382 & 4.0 & 4.6698 & TST & \\
\hline CHEMBL1351992 & 688382 & 4.15 & 4.6431 & TRN & \\
\hline CHEMBL1606520 & 688382 & 5.15 & 4.7217 & TRN & \\
\hline CHEMBL1609094 & 688382 & 4.15 & 4.7858 & TRN & \\
\hline CHEMBL 1405917 & 688382 & 4.05 & 4.7281 & TRN & \\
\hline CHEMBL3194461 & 688382 & 4.8 & 4.6951 & TRN & \\
\hline CHEMBL1472417 & 688382 & 4.8 & 4.7978 & TRN & \\
\hline CHEMBL1399183 & 688382 & 5.1 & 4.6867 & TST & \\
\hline CHEMBL1606285 & 688382 & 4.65 & 4.6866 & TRN & \\
\hline CHEMBL1392420 & 688382 & 4.5 & 4.6066 & TST & \\
\hline CHEMBL1347020 & 688382 & 4.15 & 4.7537 & TRN & \\
\hline
\end{tabular}




\begin{tabular}{|c|c|c|c|c|}
\hline \multicolumn{5}{|c|}{ Supplemental Table S2.txt } \\
\hline CHEMBL1425496 & 688382 & 5.05 & 4.7447 & TRN \\
\hline CHEMBL1401522 & 688382 & 4.4 & 4.5828 & TRN \\
\hline CHEMBL1489131 & 688382 & 4.8 & 4.7461 & TST \\
\hline CHEMBL1468663 & 688382 & 4.1 & 4.7219 & TRN \\
\hline CHEMBL1417125 & 688382 & 4.5 & 4.6749 & TRN \\
\hline CHEMBL1242180 & 688382 & 4.5 & 4.6129 & TRN \\
\hline CHEMBL1198108 & 688382 & 5.85 & 4.7399 & TRN \\
\hline CHEMBL1982662 & 688382 & 5.05 & 4.6457 & TRN \\
\hline CHEMBL1523103 & 688382 & 4.55 & 4.7589 & TRN \\
\hline CHEMBL1500463 & 688382 & 6.0 & 4.7431 & TRN \\
\hline CHEMBL1318033 & 688382 & 4.5 & 4.6812 & TRN \\
\hline CHEMBL1502008 & 688382 & 4.8 & 4.7425 & TST \\
\hline CHEMBL584868 & 688382 & 4.35 & 4.8188 & TRN \\
\hline CHEMBL1409707 & 688382 & 4.45 & 4.7232 & TST \\
\hline CHEMBL1322780 & 688382 & 4.45 & 4.6891 & TST \\
\hline CHEMBL1479531 & 688382 & 5.1 & 4.7298 & TRN \\
\hline CHEMBL3190491 & 688382 & 4.8 & 4.5908 & TRN \\
\hline CHEMBL1491066 & 688382 & 5.05 & 4.6763 & TRN \\
\hline CHEMBL1371294 & 688382 & 4.1 & 4.711 & TRN \\
\hline CHEMBL1328472 & 688382 & 4.45 & 4.6728 & TRN \\
\hline CHEMBL1402226 & 688382 & 4.15 & 4.6964 & TRN \\
\hline CHEMBL1499111 & 688382 & 4.15 & 4.6355 & TRN \\
\hline CHEMBL3213993 & 688382 & 4.45 & 4.5961 & TRN \\
\hline CHEMBL1560847 & 688382 & 4.7 & 4.7037 & TRN \\
\hline CHEMBL1555907 & 688382 & 4.15 & 4.7585 & TRN \\
\hline CHEMBL1569354 & 688382 & 4.65 & 4.6877 & TST \\
\hline CHEMBL1580556 & 688382 & 6.05 & 4.7138 & TRN \\
\hline CHEMBL1420386 & 688382 & 4.2 & 4.6125 & TRN \\
\hline CHEMBL1389905 & 688382 & 4.5 & 4.6929 & TRN \\
\hline CHEMBL1361266 & 688382 & 4.0 & 4.8334 & TRN \\
\hline CHEMBL1362734 & 688382 & 4.8 & 4.6314 & TRN \\
\hline CHEMBL1529836 & 688382 & 3.95 & 4.7384 & TST \\
\hline CHEMBL1488184 & 688382 & 5.85 & 4.7303 & TRN \\
\hline CHEMBL1500896 & 688382 & 4.85 & 4.7085 & TST \\
\hline CHEMBL1422633 & 688382 & 5.05 & 4.6451 & TRN \\
\hline CHEMBL1541795 & 688382 & 4.5 & 4.7078 & TRN \\
\hline CHEMBL1351989 & 688382 & 4.45 & 4.6845 & TRN \\
\hline CHEMBL1482410 & 688382 & 5.0 & 4.8145 & TRN \\
\hline CHEMBL1370675 & 688382 & 4.95 & 4.6844 & TRN \\
\hline CHEMBL1450551 & 688382 & 5.0 & 4.7122 & TRN \\
\hline CHEMBL3211795 & 688382 & 4.4 & 4.6811 & TRN \\
\hline CHEMBL1548071 & 688382 & 4.8 & 4.6625 & TST \\
\hline CHEMBL1356981 & 688382 & 4.6 & 4.7073 & TRN \\
\hline CHEMBL1499017 & 688382 & 4.6 & 4.6666 & TRN \\
\hline CHEMBL1390748 & 688382 & 4.8 & 4.6711 & TST \\
\hline CHEMBL1313554 & 688382 & 4.45 & 4.7871 & TRN \\
\hline CHEMBL1353872 & 688382 & 3.9 & 4.7537 & TRN \\
\hline CHEMBL1421228 & 688382 & 6.0 & 4.8149 & TRN \\
\hline
\end{tabular}




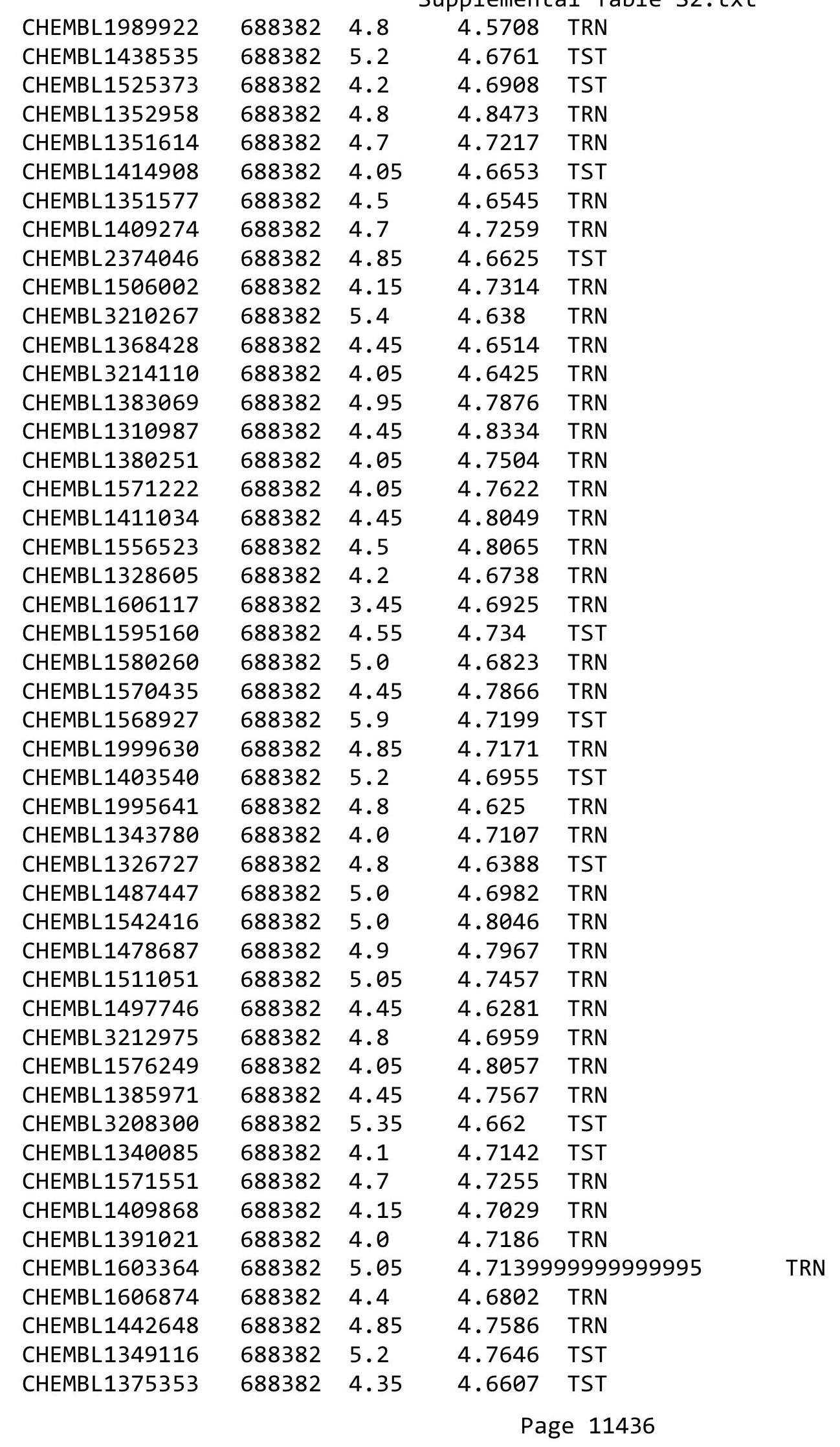




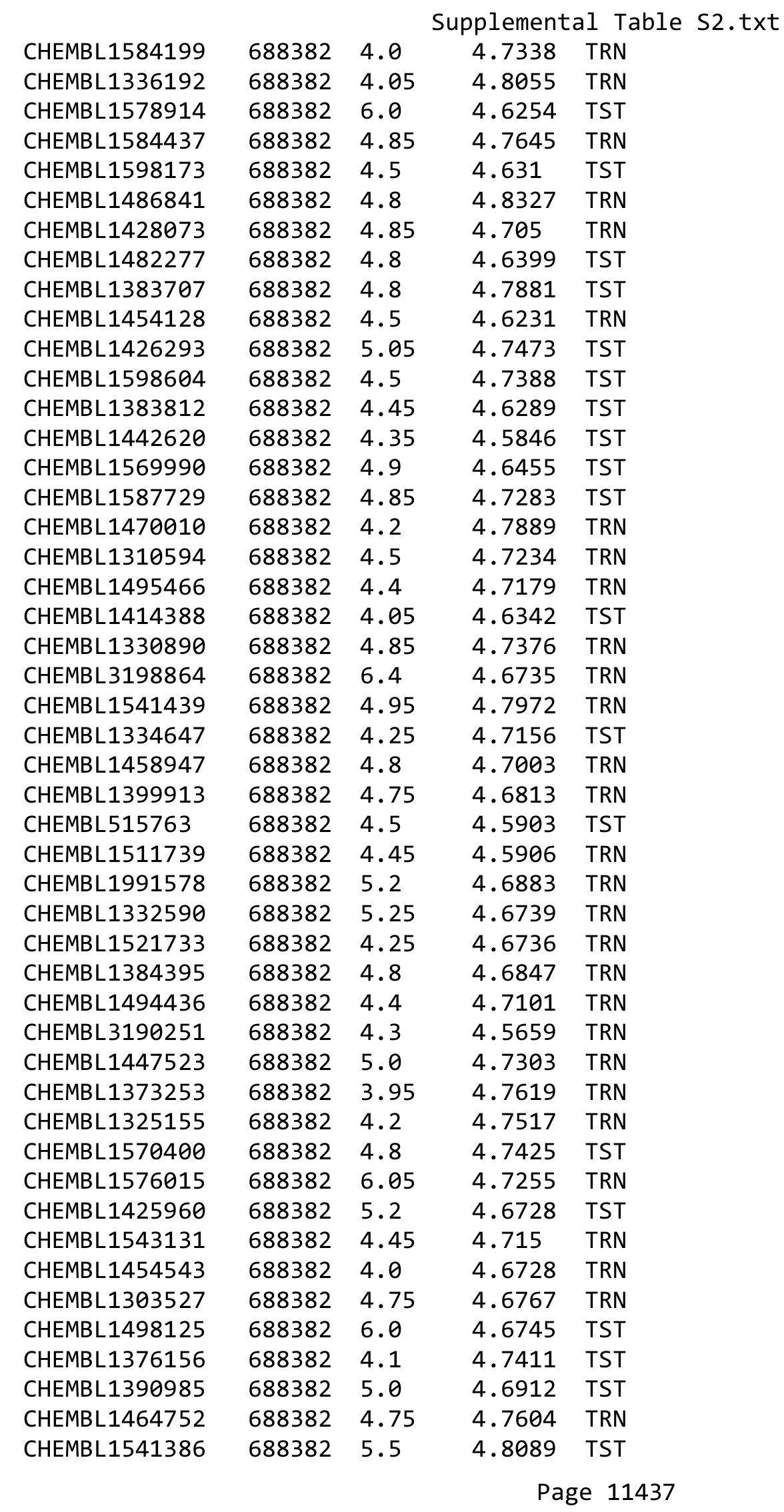




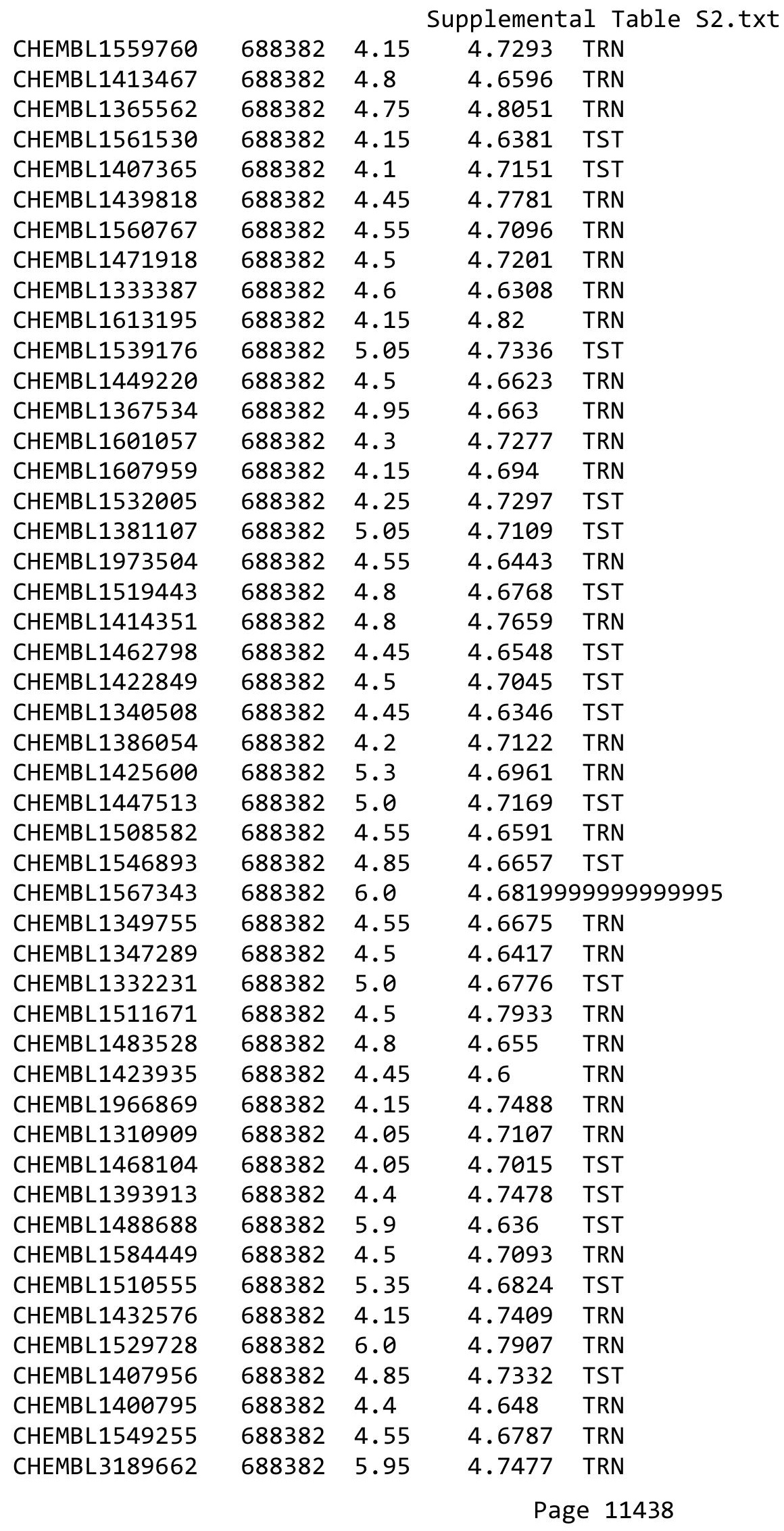




\begin{tabular}{|c|c|c|c|c|}
\hline \multicolumn{5}{|c|}{ Supplemental Table S2.txt } \\
\hline CHEMBL1503517 & 688382 & 4.35 & 4.6692 & TST \\
\hline CHEMBL1431118 & 688382 & 4.55 & 4.6196 & TRN \\
\hline CHEMBL1548904 & 688382 & 4.5 & 4.6651 & TRN \\
\hline CHEMBL3194677 & 688382 & 4.9 & 4.6291 & TRN \\
\hline CHEMBL1612322 & 688382 & 4.4 & 4.7063 & TST \\
\hline CHEMBL1465883 & 688382 & 5.0 & 4.7346 & TST \\
\hline CHEMBL1325368 & 688382 & 4.15 & 4.7928 & TST \\
\hline CHEMBL1581410 & 688382 & 4.15 & 4.6919 & TRN \\
\hline CHEMBL1407845 & 688382 & 4.95 & 4.7241 & TRN \\
\hline CHEMBL1380904 & 688382 & 4.85 & 4.7013 & TRN \\
\hline CHEMBL1574100 & 688382 & 4.15 & 4.7361 & TRN \\
\hline CHEMBL1301097 & 688382 & 4.85 & 4.7042 & TRN \\
\hline CHEMBL1507407 & 688382 & 4.45 & 4.6628 & TST \\
\hline CHEMBL1388334 & 688382 & 4.5 & 4.6515 & TRN \\
\hline CHEMBL1529282 & 688382 & 5.95 & 4.7179 & TST \\
\hline CHEMBL1496897 & 688382 & 4.95 & 4.6293 & TRN \\
\hline CHEMBL1331499 & 688382 & 5.4 & 4.7313 & TST \\
\hline CHEMBL1576644 & 688382 & 3.0 & 4.777 & TRN \\
\hline CHEMBL1358997 & 688382 & 4.5 & 4.8017 & TST \\
\hline CHEMBL1409392 & 688382 & 4.5 & 4.6944 & TRN \\
\hline CHEMBL1345662 & 688382 & 4.45 & 4.7067 & TST \\
\hline CHEMBL1397729 & 688382 & 4.85 & 4.7207 & TST \\
\hline CHEMBL1582880 & 688382 & 4.2 & 4.6445 & TRN \\
\hline CHEMBL3191453 & 688382 & 4.5 & 4.6661 & TRN \\
\hline CHEMBL1374208 & 688382 & 5.05 & 4.7207 & TRN \\
\hline CHEMBL1486807 & 688382 & 5.8 & 4.7444 & TRN \\
\hline CHEMBL3193266 & 688382 & 4.35 & 4.676 & TRN \\
\hline CHEMBL1563291 & 688382 & 4.55 & 4.7339 & TRN \\
\hline CHEMBL1524230 & 688382 & 6.0 & 4.7745 & TRN \\
\hline CHEMBL1484008 & 688382 & 4.5 & 4.7433 & TRN \\
\hline CHEMBL1577958 & 688382 & 4.85 & 4.6965 & TRN \\
\hline CHEMBL1388521 & 688382 & 4.9 & 4.7032 & TRN \\
\hline CHEMBL1497812 & 688382 & 4.45 & 4.7768 & TRN \\
\hline CHEMBL1613022 & 688382 & 4.4 & 4.7763 & TRN \\
\hline CHEMBL1496630 & 688382 & 4.75 & 4.6713 & TRN \\
\hline CHEMBL1305930 & 688382 & 4.55 & 4.6282 & TRN \\
\hline CHEMBL1421802 & 688382 & 4.85 & 4.7946 & TRN \\
\hline CHEMBL3207558 & 688382 & 4.5 & 4.663 & TRN \\
\hline CHEMBL1454951 & 688382 & 4.75 & 4.6535 & TST \\
\hline CHEMBL1387149 & 688382 & 4.4 & 4.7812 & TRN \\
\hline CHEMBL1489448 & 688382 & 4.5 & 4.7534 & TRN \\
\hline CHEMBL3208355 & 688382 & 4.6 & 4.6785 & TST \\
\hline CHEMBL3214558 & 688382 & 4.05 & 4.6939 & TRN \\
\hline CHEMBL1348445 & 688382 & 4.55 & 4.6579 & TRN \\
\hline CHEMBL1444550 & 688382 & 4.45 & 4.6978 & TRN \\
\hline CHEMBL1391321 & 688382 & 4.5 & 4.7719 & TST \\
\hline CHEMBL1481095 & 688382 & 4.2 & 4.581 & TST \\
\hline CHEMBL1506775 & 688382 & 4.05 & 4.808 & TST \\
\hline
\end{tabular}




\begin{tabular}{|c|c|c|c|c|}
\hline \multicolumn{5}{|c|}{ Supplemental Table S2.txt } \\
\hline CHEMBL1421434 & 688382 & 4.4 & 4.65 & TRN \\
\hline CHEMBL1534718 & 688382 & 5.25 & 4.7464 & TRN \\
\hline CHEMBL1535082 & 688382 & 5.0 & 4.7305 & TRN \\
\hline CHEMBL1430528 & 688382 & 4.7 & 4.6666 & TST \\
\hline CHEMBL 1490340 & 688382 & 5.8 & 4.7124 & TRN \\
\hline CHEMBL1589412 & 688382 & 4.15 & 4.7949 & TRN \\
\hline CHEMBL1528570 & 688382 & 4.65 & 4.6716 & TRN \\
\hline CHEMBL1497652 & 688382 & 4.05 & 4.8302 & TRN \\
\hline CHEMBL1589188 & 688382 & 4.2 & 4.789 & TRN \\
\hline CHEMBL1535758 & 688382 & 4.6 & 4.6695 & TRN \\
\hline CHEMBL1448089 & 688382 & 4.1 & 4.7827 & TRN \\
\hline CHEMBL1424378 & 688382 & 4.5 & 4.7311 & TST \\
\hline CHEMBL1610777 & 688382 & 5.15 & 4.8061 & TRN \\
\hline CHEMBL1580564 & 688382 & 5.85 & 4.698 & TST \\
\hline CHEMBL390559 & 688382 & 4.45 & 4.655 & TRN \\
\hline CHEMBL1548590 & 688382 & 4.7 & 4.744 & TRN \\
\hline CHEMBL3213413 & 688382 & 5.05 & 4.7208 & TST \\
\hline CHEMBL1465662 & 688382 & 5.0 & 4.755 & TRN \\
\hline CHEMBL1511427 & 688382 & 4.5 & 4.6997 & TRN \\
\hline CHEMBL1429280 & 688382 & 4.45 & 4.687 & TRN \\
\hline CHEMBL1530476 & 688382 & 4.45 & 4.857 & TRN \\
\hline CHEMBL1520217 & 688382 & 5.1 & 4.7651 & TRN \\
\hline CHEMBL1361884 & 688382 & 4.85 & 4.6108 & TRN \\
\hline CHEMBL1452060 & 688382 & 4.5 & 4.6923 & TST \\
\hline CHEMBL1482979 & 688382 & 4.15 & 4.6595 & TRN \\
\hline CHEMBL1416528 & 688382 & 4.4 & 4.6939 & TRN \\
\hline CHEMBL1507459 & 688382 & 4.6 & 4.8223 & TRN \\
\hline CHEMBL1517606 & 688382 & 5.4 & 4.6021 & TRN \\
\hline CHEMBL1539393 & 688382 & 4.45 & 4.7583 & TRN \\
\hline CHEMBL2002274 & 688382 & 4.75 & 4.6457 & TRN \\
\hline CHEMBL1309733 & 688382 & 5.85 & 4.6723 & TRN \\
\hline CHEMBL1564872 & 688382 & 4.1 & 4.8319 & TRN \\
\hline CHEMBL1408332 & 688382 & 4.45 & 4.6874 & TST \\
\hline CHEMBL1374858 & 688382 & 4.85 & 4.7525 & TRN \\
\hline CHEMBL1439512 & 688382 & 4.15 & 4.7411 & TRN \\
\hline CHEMBL1496859 & 688382 & 5.85 & 4.8015 & TRN \\
\hline CHEMBL1495643 & 688382 & 4.85 & 4.8069 & TRN \\
\hline CHEMBL1487407 & 688382 & 4.05 & 4.6818 & TRN \\
\hline CHEMBL1324154 & 688382 & 4.15 & 4.806 & TRN \\
\hline CHEMBL1339792 & 688382 & 4.8 & 4.6857 & TRN \\
\hline CHEMBL1481719 & 688382 & 4.05 & 4.7802 & TST \\
\hline CHEMBL1540746 & 688382 & 4.5 & 4.7242 & TST \\
\hline CHEMBL1308784 & 688382 & 4.45 & 4.7352 & TRN \\
\hline CHEMBL1578899 & 688382 & 4.45 & 4.6802 & TST \\
\hline CHEMBL3194896 & 688382 & 4.5 & 4.7401 & TRN \\
\hline CHEMBL1525093 & 688382 & 5.05 & 4.694 & TRN \\
\hline CHEMBL1345618 & 688382 & 4.8 & 4.82 & TRN \\
\hline CHEMBL1427627 & 688382 & 4.5 & 4.6713 & TRN \\
\hline
\end{tabular}




\begin{tabular}{|c|c|c|c|c|c|}
\hline \multicolumn{6}{|c|}{ Supplemental Table S2.txt } \\
\hline CHEMBL1548460 & 688382 & 4.65 & 4.7838 & TRN & \\
\hline CHEMBL1530926 & 688382 & 4.15 & 4.681 & TRN & \\
\hline CHEMBL1375323 & 688382 & 4.95 & 4.7637 & TRN & \\
\hline CHEMBL1437933 & 688382 & 4.45 & 4.8075 & TRN & \\
\hline CHEMBL1495847 & 688382 & 4.2 & 4.7786 & TRN & \\
\hline CHEMBL1580109 & 688382 & 4.95 & 4.6821 & TRN & \\
\hline CHEMBL1604655 & 688382 & 3.55 & 4.8216 & TRN & \\
\hline CHEMBL3211732 & 688382 & 4.05 & 4.6721 & TST & \\
\hline CHEMBL1343917 & 688382 & 4.15 & 4.6974 & TRN & \\
\hline CHEMBL1574004 & 688382 & 4.15 & 4.7233 & TRN & \\
\hline CHEMBL 3194557 & 688382 & 4.4 & 4.6558 & TST & \\
\hline CHEMBL1303780 & 688382 & 5.45 & 4.6853 & TRN & \\
\hline CHEMBL1486444 & 688382 & 4.2 & 4.7601 & TRN & \\
\hline CHEMBL1458899 & 688382 & 5.9 & 4.7444 & TST & \\
\hline CHEMBL1376692 & 688382 & 4.45 & 4.6161 & TRN & \\
\hline CHEMBL1588275 & 688382 & 4.45 & 4.738 & TRN & \\
\hline CHEMBL1301426 & 688382 & 4.85 & 4.6332 & TRN & \\
\hline CHEMBL1325310 & 688382 & 4.45 & 4.7418 & TRN & \\
\hline CHEMBL1447202 & 688382 & 4.05 & 4.7912 & TRN & \\
\hline CHEMBL1320911 & 688382 & 4.5 & 4.6917 & TRN & \\
\hline CHEMBL1546722 & 688382 & 4.5 & 4.7292 & TRN & \\
\hline CHEMBL1517469 & 688382 & 4.95 & 4.7417 & TRN & \\
\hline CHEMBL1576205 & 688382 & 4.5 & 4.5886 & TRN & \\
\hline CHEMBL1425139 & 688382 & 4.5 & 4.8049 & TST & \\
\hline CHEMBL1471177 & 688382 & 4.7 & 4.6647 & TRN & \\
\hline CHEMBL1538922 & 688382 & 5.85 & 4.7479 & TST & \\
\hline CHEMBL1325489 & 688382 & 4.45 & 4.6821 & TST & \\
\hline CHEMBL3196477 & 688382 & 4.95 & 4.6488 & TST & \\
\hline CHEMBL1491362 & 688382 & 5.95 & 4.78600 & 00000000005 & TRN \\
\hline CHEMBL1966367 & 688382 & 4.55 & 4.6938 & TRN & \\
\hline CHEMBL1550202 & 688382 & 4.5 & 4.6833 & TRN & \\
\hline CHEMBL1350560 & 688382 & 5.85 & 4.687 & TRN & \\
\hline CHEMBL1399533 & 688382 & 4.8 & 4.6614 & TRN & \\
\hline CHEMBL1490639 & 688382 & 4.8 & 4.8006 & TST & \\
\hline CHEMBL1585632 & 688382 & 4.15 & 4.6239 & TST & \\
\hline CHEMBL1362414 & 688382 & 5.5 & 4.672 & TST & \\
\hline CHEMBL1539592 & 688382 & 4.85 & 4.7312 & TRN & \\
\hline CHEMBL1516408 & 688382 & 5.55 & 4.6354 & TRN & \\
\hline CHEMBL1419220 & 688382 & 4.9 & 4.6409 & TST & \\
\hline CHEMBL1559818 & 688382 & 4.15 & 4.7938 & TRN & \\
\hline CHEMBL1582587 & 688382 & 4.05 & 4.6486 & TST & \\
\hline CHEMBL1351120 & 688382 & 4.05 & 4.7621 & TRN & \\
\hline CHEMBL3194510 & 688382 & 4.85 & 4.6144 & TST & \\
\hline CHEMBL1524161 & 688382 & 5.45 & 4.7451 & TST & \\
\hline CHEMBL1600032 & 688382 & 4.4 & 4.7818 & TST & \\
\hline CHEMBL1430854 & 688382 & 5.05 & 4.7237 & TST & \\
\hline CHEMBL 3212777 & 688382 & 4.05 & 4.6681 & TRN & \\
\hline CHEMBL1364613 & 688382 & 5.45 & 4.6882 & TST & \\
\hline
\end{tabular}




\begin{tabular}{|c|c|c|c|c|}
\hline \multicolumn{5}{|c|}{ Supplemental Table s2.txt } \\
\hline CHEMBL1537882 & 688382 & 5.5 & 4.6736 & TST \\
\hline CHEMBL1324123 & 688382 & 6.0 & 4.7312 & TRN \\
\hline CHEMBL1407343 & 688382 & 4.45 & 4.6791 & TST \\
\hline CHEMBL1612745 & 688382 & 4.45 & 4.7994 & TST \\
\hline CHEMBL1484745 & 688382 & 5.0 & 4.8235 & TRN \\
\hline CHEMBL587801 & 688382 & 4.75 & 4.726 & TRN \\
\hline CHEMBL1419487 & 688382 & 4.8 & 4.8341 & TRN \\
\hline CHEMBL1994635 & 688382 & 4.75 & 4.6082 & TRN \\
\hline CHEMBL1391268 & 688382 & 5.1 & 4.783 & TRN \\
\hline CHEMBL1422613 & 688382 & 4.9 & 4.7093 & TRN \\
\hline CHEMBL1470616 & 688382 & 6.05 & 4.8161 & TRN \\
\hline CHEMBL1464279 & 688382 & 4.5 & 4.8371 & TRN \\
\hline CHEMBL1439609 & 688382 & 4.8 & 4.7581 & TST \\
\hline CHEMBL1426358 & 688382 & 4.6 & 4.7241 & TRN \\
\hline CHEMBL1578862 & 688382 & 4.9 & 4.6965 & TST \\
\hline CHEMBL1613388 & 688382 & 4.05 & 4.747 & TRN \\
\hline CHEMBL1709970 & 688382 & 4.4 & 4.6437 & TST \\
\hline CHEMBL1334173 & 688382 & 4.2 & 4.7472 & TRN \\
\hline CHEMBL1307813 & 688382 & 4.8 & 4.6922 & TRN \\
\hline CHEMBL1442479 & 688382 & 4.0 & 4.6628 & TRN \\
\hline CHEMBL1313397 & 688382 & 4.8 & 4.6212 & TRN \\
\hline CHEMBL1547739 & 688382 & 4.45 & 4.5938 & TRN \\
\hline CHEMBL3208411 & 688382 & 4.2 & 4.663 & TST \\
\hline CHEMBL1462803 & 688382 & 4.4 & 4.5822 & TRN \\
\hline CHEMBL1568700 & 688382 & 5.0 & 4.7923 & TRN \\
\hline CHEMBL1362862 & 688382 & 4.5 & 4.6822 & TRN \\
\hline CHEMBL1485565 & 688382 & 4.6 & 4.7683 & TRN \\
\hline CHEMBL1386658 & 688382 & 4.95 & 4.7182 & TST \\
\hline CHEMBL1539703 & 688382 & 4.85 & 4.7719 & TST \\
\hline CHEMBL1997450 & 688382 & 4.5 & 4.6424 & TRN \\
\hline CHEMBL 3190224 & 688382 & 4.95 & 4.7007 & TRN \\
\hline CHEMBL1481001 & 688382 & 4.6 & 4.6777 & TRN \\
\hline CHEMBL3211594 & 688382 & 4.4 & 4.7503 & TST \\
\hline CHEMBL1556908 & 688382 & 5.4 & 4.6256 & TRN \\
\hline CHEMBL405110 & 688382 & 4.7 & 4.6278 & TST \\
\hline CHEMBL1457149 & 688382 & 4.4 & 4.6373 & TRN \\
\hline CHEMBL1384408 & 688382 & 5.15 & 4.6841 & TST \\
\hline CHEMBL3208749 & 688382 & 4.05 & 4.7145 & TRN \\
\hline CHEMBL1427089 & 688382 & 4.3 & 4.7867 & TST \\
\hline CHEMBL420265 & 688382 & 4.45 & 4.6558 & TRN \\
\hline CHEMBL1477395 & 688382 & 4.05 & 4.7633 & TRN \\
\hline CHEMBL1346762 & 688382 & 5.8 & 4.6288 & TRN \\
\hline CHEMBL1976817 & 688382 & 3.95 & 4.628 & TRN \\
\hline CHEMBL1385289 & 688382 & 4.15 & 4.6825 & TST \\
\hline CHEMBL1302499 & 688382 & 4.8 & $4.7360 e$ & 0000000001 \\
\hline CHEMBL1499876 & 688382 & 4.05 & 4.7205 & TRN \\
\hline CHEMBL80658 & 688382 & 4.75 & 4.6056 & TRN \\
\hline CHEMBL1524179 & 688382 & 5.85 & 4.709 & TST \\
\hline
\end{tabular}




\begin{tabular}{|c|c|c|c|c|c|}
\hline & & \multicolumn{4}{|c|}{ Supplemental Table S2.txt } \\
\hline CHEMBL1516651 & 688382 & 4.35 & 4.7127 & TST & \\
\hline CHEMBL1491374 & 688382 & 4.5 & 4.7139 & TRN & \\
\hline CHEMBL1459475 & 688382 & 4.15 & 4.6794 & TST & \\
\hline CHEMBL1355983 & 688382 & 5.95 & 4.69300 & 00000000005 & TRN \\
\hline CHEMBL1494909 & 688382 & 4.85 & 4.699 & TRN & \\
\hline CHEMBL1344350 & 688382 & 5.1 & 4.8157 & TST & \\
\hline CHEMBL1539545 & 688382 & 6.0 & 4.6925 & TST & \\
\hline CHEMBL1460577 & 688382 & 5.0 & 4.6439 & TST & \\
\hline CHEMBL1374966 & 688382 & 4.9 & 4.7362 & TRN & \\
\hline CHEMBL1308123 & 688382 & 4.15 & 4.6757 & TRN & \\
\hline CHEMBL472334 & 688382 & 4.5 & 4.675 & TST & \\
\hline CHEMBL1510427 & 688382 & 4.5 & 4.6174 & TRN & \\
\hline CHEMBL1348313 & 688382 & 5.0 & 4.6618 & TST & \\
\hline CHEMBL1382262 & 688382 & 4.45 & 4.7056 & TST & \\
\hline CHEMBL1541198 & 688382 & 5.85 & 4.6969 & TRN & \\
\hline CHEMBL1386675 & 688382 & 4.5 & 4.75899 & 99999999995 & TRN \\
\hline CHEMBL1602499 & 688382 & 4.8 & 4.6214 & TRN & \\
\hline CHEMBL428496 & 688382 & 4.4 & 4.7584 & TST & \\
\hline CHEMBL1471750 & 688382 & 4.6 & 4.6806 & TRN & \\
\hline CHEMBL1504421 & 688382 & 4.75 & 4.7222 & TRN & \\
\hline CHEMBL1569770 & 688382 & 4.85 & 4.74 & TRN & \\
\hline CHEMBL1446051 & 688382 & 5.15 & 4.7689 & TRN & \\
\hline CHEMBL1497703 & 688382 & 4.55 & 4.6858 & TST & \\
\hline CHEMBL1521225 & 688382 & 4.5 & 4.7479 & TRN & \\
\hline CHEMBL1386308 & 688382 & 4.1 & 4.7167 & TST & \\
\hline CHEMBL1393132 & 688382 & 5.85 & 4.6515 & TST & \\
\hline CHEMBL1373939 & 688382 & 4.0 & 4.7576 & TRN & \\
\hline CHEMBL1550380 & 688382 & 5.85 & 4.7736 & TRN & \\
\hline CHEMBL1456403 & 688382 & 4.35 & 4.7022 & TST & \\
\hline CHEMBL1501501 & 688382 & 4.6 & 4.6853 & TRN & \\
\hline CHEMBL1402482 & 688382 & 5.0 & 4.7893 & TRN & \\
\hline CHEMBL1964628 & 688382 & 4.5 & 4.6465 & TST & \\
\hline CHEMBL1414519 & 688382 & 5.9 & 4.78 & TRN & \\
\hline CHEMBL1329689 & 688382 & 5.0 & 4.6646 & TRN & \\
\hline CHEMBL1560766 & 688382 & 4.5 & 4.8322 & TRN & \\
\hline CHEMBL 2369172 & 688382 & 4.05 & 4.6437 & TRN & \\
\hline CHEMBL1545897 & 688382 & 4.85 & 4.6929 & TRN & \\
\hline CHEMBL1329033 & 688382 & 4.85 & 4.7178 & TST & \\
\hline CHEMBL1375224 & 688382 & 4.45 & 4.65300 & 00000000005 & TRN \\
\hline CHEMBL1452871 & 688382 & 4.85 & 4.8631 & TRN & \\
\hline CHEMBL1501577 & 688382 & 4.4 & 4.7505 & TRN & \\
\hline CHEMBL1334099 & 688382 & 4.4 & 4.8297 & TRN & \\
\hline CHEMBL1520195 & 688382 & 4.2 & 4.7892 & TRN & \\
\hline CHEMBL1379761 & 688382 & 4.8 & 4.8069 & TST & \\
\hline CHEMBL1599181 & 688382 & 4.8 & 4.8708 & TRN & \\
\hline CHEMBL1380734 & 688382 & 4.0 & 4.7488 & TST & \\
\hline CHEMBL3197726 & 688382 & 4.55 & 4.6466 & TRN & \\
\hline CHEMBL1589062 & 688382 & 4.15 & 4.6207 & TRN & \\
\hline
\end{tabular}




\begin{tabular}{|c|c|c|c|c|c|}
\hline \multicolumn{6}{|c|}{ Supplemental Table S2.txt } \\
\hline CHEMBL1595978 & 688382 & 4.85 & 4.8033 & TRN & \\
\hline CHEMBL1609867 & 688382 & 4.05 & 4.6703 & TRN & \\
\hline CHEMBL1569232 & 688382 & 5.4 & 4.6703 & TRN & \\
\hline CHEMBL1446983 & 688382 & 4.35 & 4.6303 & TRN & \\
\hline CHEMBL1333973 & 688382 & 5.0 & 4.6681 & TRN & \\
\hline CHEMBL1489865 & 688382 & 5.95 & 4.6945 & TRN & \\
\hline CHEMBL3198924 & 688382 & 4.75 & 4.6967 & TRN & \\
\hline CHEMBL1502426 & 688382 & 4.8 & 4.7604 & TST & \\
\hline CHEMBL1358810 & 688382 & 4.8 & 4.6873 & TRN & \\
\hline CHEMBL1390860 & 688382 & 6.0 & 4.5963 & TRN & \\
\hline CHEMBL1444201 & 688382 & 5.85 & 4.7013 & TRN & \\
\hline CHEMBL1441003 & 688382 & 4.15 & 4.7575 & TRN & \\
\hline CHEMBL1418511 & 688382 & 4.55 & 4.762 & TRN & \\
\hline CHEMBL1433022 & 688382 & 4.05 & 4.751 & TRN & \\
\hline CHEMBL1447251 & 688382 & 4.5 & 4.5509 & TRN & \\
\hline CHEMBL3199395 & 688382 & 4.5 & 4.5984 & TRN & \\
\hline CHEMBL1340553 & 688382 & 4.95 & 4.6379 & TRN & \\
\hline CHEMBL1592917 & 688382 & 4.95 & 4.735 & TRN & \\
\hline CHEMBL1504775 & 688382 & 6.05 & 4.7521 & TRN & \\
\hline CHEMBL1477630 & 688382 & 6.0 & 4.6999 & TST & \\
\hline CHEMBL1589563 & 688382 & 4.15 & 4.6441 & TST & \\
\hline CHEMBL1309936 & 688382 & 4.95 & 4.666 & TST & \\
\hline CHEMBL1440262 & 688382 & 5.85 & 4.7445 & TRN & \\
\hline CHEMBL1329967 & 688382 & 5.6 & 4.6675 & TRN & \\
\hline CHEMBL1494737 & 688382 & 4.35 & 4.6995 & TRN & \\
\hline CHEMBL362941 & 688382 & 5.2 & 4.6556 & TRN & \\
\hline CHEMBL3212312 & 688382 & 5.0 & 4.6484 & TRN & \\
\hline CHEMBL416615 & 688382 & 4.2 & 4.6987 & TST & \\
\hline CHEMBL269163 & 688382 & 5.55 & 4.6195 & TRN & \\
\hline CHEMBL1489789 & 688382 & 4.8 & 4.768 & TRN & \\
\hline CHEMBL1321895 & 688382 & 4.6 & 4.76399 & 9999999999 & TRN \\
\hline CHEMBL533226 & 688382 & 4.5 & 4.6633 & TST & \\
\hline CHEMBL1338972 & 688382 & 4.15 & 4.7404 & TRN & \\
\hline CHEMBL1421225 & 688382 & 4.15 & 4.7811 & TRN & \\
\hline CHEMBL1517858 & 688382 & 4.05 & 4.6639 & TRN & \\
\hline CHEMBL1371179 & 688382 & 4.2 & 4.6243 & TRN & \\
\hline CHEMBL1313060 & 688382 & 4.45 & 4.6339 & TRN & \\
\hline CHEMBL1399698 & 688382 & 4.05 & 4.6088 & TST & \\
\hline CHEMBL1564363 & 688382 & 4.5 & 4.7753 & TRN & \\
\hline CHEMBL3191504 & 688382 & 4.7 & 4.6323 & TRN & \\
\hline CHEMBL1487650 & 688382 & 4.55 & 4.6954 & TRN & \\
\hline CHEMBL1424307 & 688382 & 4.5 & 4.6931 & TST & \\
\hline CHEMBL1303166 & 688382 & 4.05 & 4.8006 & TRN & \\
\hline CHEMBL1544511 & 688382 & 5.55 & 4.7509 & TRN & \\
\hline CHEMBL1333821 & 688382 & 5.1 & $4.6530 e$ & 00000000005 & TRN \\
\hline CHEMBL1367111 & 688382 & 4.35 & 4.7446 & TST & \\
\hline CHEMBL1504800 & 688382 & 5.15 & 4.6496 & TST & \\
\hline CHEMBL1584955 & 688382 & 5.45 & 4.6644 & TST & \\
\hline
\end{tabular}




\begin{tabular}{|c|c|c|c|c|c|}
\hline \multicolumn{6}{|c|}{ Supplemental Table S2.txt } \\
\hline CHEMBL 3212013 & 688382 & 4.9 & 4.7489 & TRN & \\
\hline CHEMBL1464881 & 688382 & 5.1 & 4.7973 & TST & \\
\hline CHEMBL1393703 & 688382 & 4.25 & 4.6879 & TRN & \\
\hline CHEMBL1478577 & 688382 & 4.15 & 4.6609 & TRN & \\
\hline CHEMBL1391235 & 688382 & 4.45 & 4.6702 & TST & \\
\hline CHEMBL1532956 & 688382 & 4.8 & 4.6235 & TRN & \\
\hline CHEMBL1378163 & 688382 & 5.05 & 4.773 & TRN & \\
\hline CHEMBL1466435 & 688382 & 5.45 & 4.6836 & TRN & \\
\hline CHEMBL1429419 & 688382 & 4.85 & 4.6875 & TRN & \\
\hline CHEMBL1372847 & 688382 & 4.9 & 4.6896 & TRN & \\
\hline CHEMBL1306962 & 688382 & 4.8 & 4.7334 & TRN & \\
\hline CHEMBL1377204 & 688382 & 4.15 & 4.7662 & TRN & \\
\hline CHEMBL1439349 & 688382 & 4.2 & 4.7393 & TRN & \\
\hline CHEMBL1309176 & 688382 & 5.0 & 4.6993 & TRN & \\
\hline CHEMBL1992044 & 688382 & 5.15 & 4.5992 & TST & \\
\hline CHEMBL1561934 & 688382 & 4.2 & 4.7413 & TRN & \\
\hline CHEMBL1511138 & 688382 & 6.05 & 4.6572 & TST & \\
\hline CHEMBL1604863 & 688382 & 4.15 & 4.7521 & TRN & \\
\hline CHEMBL1545172 & 688382 & 4.85 & 4.7062 & TST & \\
\hline CHEMBL3144976 & 688382 & 4.9 & 4.6329 & TRN & \\
\hline CHEMBL 2000525 & 688382 & 4.5 & 4.6134 & TRN & \\
\hline CHEMBL1601648 & 688382 & 5.05 & 4.7538 & TRN & \\
\hline CHEMBL1331797 & 688382 & 4.4 & 4.7093 & TRN & \\
\hline CHEMBL1487574 & 688382 & 4.55 & 4.7606 & TRN & \\
\hline CHEMBL1559031 & 688382 & 5.55 & 4.67399 & 99999999995 & TST \\
\hline CHEMBL 2000517 & 688382 & 4.15 & 4.6245 & TRN & \\
\hline CHEMBL1422585 & 688382 & 5.0 & 4.6731 & TRN & \\
\hline CHEMBL1299418 & 688382 & 4.65 & 4.6823 & TRN & \\
\hline CHEMBL1547672 & 688382 & 6.0 & 4.7551 & TRN & \\
\hline CHEMBL1564494 & 688382 & 4.05 & 4.7385 & TST & \\
\hline CHEMBL1359250 & 688382 & 4.7 & 4.6563 & TRN & \\
\hline CHEMBL1347547 & 688382 & 4.15 & 4.5986 & TRN & \\
\hline CHEMBL1353229 & 688382 & 4.5 & 4.59399 & & TRN \\
\hline CHEMBL1469233 & 688382 & 5.95 & 4.8286 & TRN & \\
\hline CHEMBL1402998 & 688382 & 4.8 & 4.7853 & TST & \\
\hline CHEMBL1493461 & 688382 & 4.45 & 4.6503 & TST & \\
\hline CHEMBL1445532 & 688382 & 4.8 & 4.7056 & TRN & \\
\hline CHEMBL3189951 & 688382 & 4.35 & 4.6395 & TRN & \\
\hline CHEMBL1373459 & 688382 & 4.85 & 4.7467 & TRN & \\
\hline CHEMBL1542752 & 688382 & 4.6 & 4.7509 & TRN & \\
\hline CHEMBL1414077 & 688382 & 4.1 & 4.7632 & TRN & \\
\hline CHEMBL1557812 & 688382 & 4.15 & 4.6871 & TRN & \\
\hline CHEMBL1445686 & 688382 & 4.55 & 4.8401 & TRN & \\
\hline CHEMBL1531267 & 688382 & 4.35 & 4.6755 & TRN & \\
\hline CHEMBL1431717 & 688382 & 4.0 & 4.7002 & TRN & \\
\hline CHEMBL1364604 & 688382 & 6.0 & 4.6852 & TRN & \\
\hline CHEMBL1391921 & 688382 & 5.05 & 4.6821 & TRN & \\
\hline CHEMBL1565883 & 688382 & 4.9 & 4.6312 & TST & \\
\hline
\end{tabular}




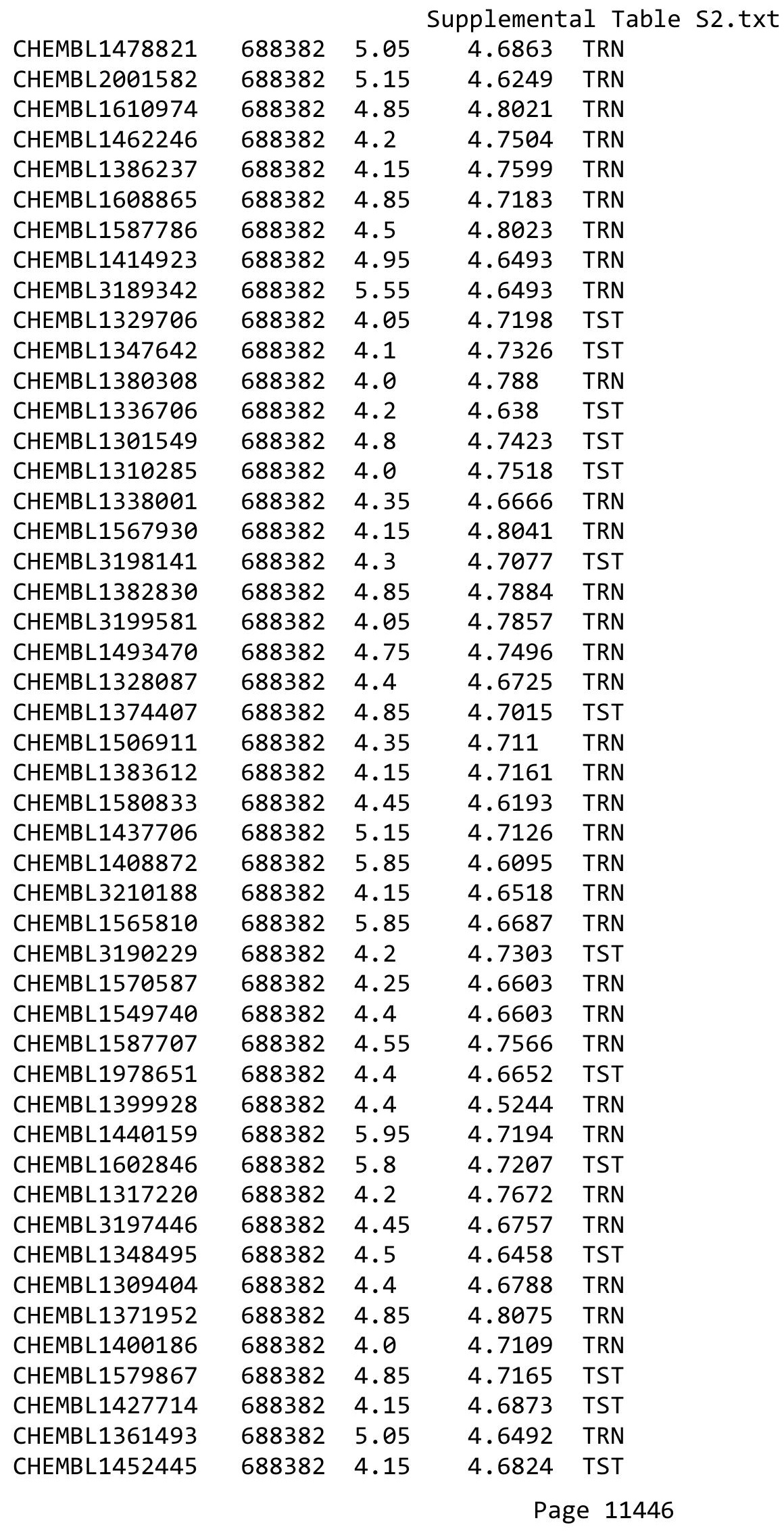




\begin{tabular}{|c|c|c|c|c|c|}
\hline \multicolumn{6}{|c|}{ Supplemental Table S2.txt } \\
\hline CHEMBL3214367 & 688382 & 5.3 & 4.6485 & TRN & \\
\hline CHEMBL1495883 & 688382 & 4.4 & 4.6629 & TST & \\
\hline CHEMBL1429161 & 688382 & 4.8 & 4.7835 & TRN & \\
\hline CHEMBL1422986 & 688382 & 4.35 & 4.7968 & TRN & \\
\hline CHEMBL1505071 & 688382 & 4.45 & 4.7045 & TRN & \\
\hline CHEMBL1392669 & 688382 & 4.45 & 4.7136 & TST & \\
\hline CHEMBL1530336 & 688382 & 4.45 & 4.6747 & TRN & \\
\hline CHEMBL1468123 & 688382 & 4.15 & 4.7374 & TST & \\
\hline CHEMBL1325458 & 688382 & 4.55 & 4.6673 & TRN & \\
\hline CHEMBL1469333 & 688382 & 4.45 & 4.6722 & TRN & \\
\hline CHEMBL1560819 & 688382 & 4.95 & 4.816 & TST & \\
\hline CHEMBL1446447 & 688382 & 4.05 & 4.7556 & TRN & \\
\hline CHEMBL3213622 & 688382 & 4.25 & 4.618 & TST & \\
\hline CHEMBL1404922 & 688382 & 6.0 & 4.7146 & TST & \\
\hline CHEMBL1426096 & 688382 & 4.25 & 4.7004 & TRN & \\
\hline CHEMBL1307207 & 688382 & 4.45 & 4.7463 & TST & \\
\hline CHEMBL1341812 & 688382 & 4.95 & 4.7714 & TRN & \\
\hline CHEMBL3193300 & 688382 & 4.65 & 4.6445 & TRN & \\
\hline CHEMBL1509629 & 688382 & 4.4 & 4.6972 & TRN & \\
\hline CHEMBL1304304 & 688382 & 4.5 & 4.669 & TST & \\
\hline CHEMBL1612971 & 688382 & 4.2 & 4.7149 & TRN & \\
\hline CHEMBL1337283 & 688382 & 4.5 & 4.7532 & TRN & \\
\hline CHEMBL1352552 & 688382 & 5.15 & 4.7504 & TRN & \\
\hline CHEMBL1369402 & 688382 & 4.15 & 4.6991 & TST & \\
\hline CHEMBL1391911 & 688382 & 4.85 & 4.5965 & TRN & \\
\hline CHEMBL1423306 & 688382 & 5.5 & 4.757 & TST & \\
\hline CHEMBL1445923 & 688382 & 5.0 & 4.7341 & TRN & \\
\hline CHEMBL1973906 & 688382 & 4.15 & 4.644 & TRN & \\
\hline CHEMBL1583729 & 688382 & 4.05 & 4.7007 & TRN & \\
\hline CHEMBL1612864 & 688382 & 5.75 & 4.67399 & 99999999995 & TRN \\
\hline CHEMBL1516820 & 688382 & 4.8 & 4.7983 & TST & \\
\hline CHEMBL1533494 & 688382 & 4.65 & 4.8103 & TRN & \\
\hline CHEMBL1573771 & 688382 & 5.45 & 4.6523 & TRN & \\
\hline CHEMBL1322002 & 688382 & 4.3 & 4.6268 & TRN & \\
\hline CHEMBL1377685 & 688382 & 4.85 & 4.7153 & TRN & \\
\hline CHEMBL1570171 & 688382 & 4.05 & 4.8047 & TRN & \\
\hline CHEMBL1400480 & 688382 & 5.0 & 4.7183 & TRN & \\
\hline CHEMBL1463409 & 688382 & 5.1 & 4.7772 & TRN & \\
\hline CHEMBL1469991 & 688382 & 5.25 & 4.7516 & TRN & \\
\hline CHEMBL1341584 & 688382 & 6.0 & 4.66100 & 00000000005 & TRN \\
\hline CHEMBL1433124 & 688382 & 4.7 & 4.6239 & TRN & \\
\hline CHEMBL1462984 & 688382 & 4.85 & 4.8139 & TRN & \\
\hline CHEMBL1566633 & 688382 & 4.35 & 4.6227 & TRN & \\
\hline CHEMBL1353821 & 688382 & 4.85 & 4.6249 & TRN & \\
\hline CHEMBL1505060 & 688382 & 4.4 & 4.7423 & TRN & \\
\hline CHEMBL1351973 & 688382 & 4.7 & 4.6171 & TRN & \\
\hline CHEMBL1425931 & 688382 & 4.6 & 4.732 & TRN & \\
\hline CHEMBL1464544 & 688382 & 4.9 & 4.6695 & TST & \\
\hline
\end{tabular}




\begin{tabular}{|c|c|c|c|c|}
\hline & & & upplement & al $\mathrm{T}$ \\
\hline CHEMBL1570844 & 688382 & 4.3 & 4.6117 & TST \\
\hline CHEMBL1367851 & 688382 & 4.45 & 4.7752 & TST \\
\hline CHEMBL1400549 & 688382 & 4.85 & 4.707 & TRN \\
\hline CHEMBL1499026 & 688382 & 5.0 & 4.6256 & TST \\
\hline CHEMBL1412599 & 688382 & 5.95 & 4.7974 & TRN \\
\hline CHEMBL1527907 & 688382 & 3.95 & 4.7599 & TRN \\
\hline CHEMBL1968376 & 688382 & 5.25 & 4.6875 & TRN \\
\hline CHEMBL1392489 & 688382 & 4.5 & 4.7237 & TST \\
\hline CHEMBL1408091 & 688382 & 4.85 & 4.7779 & TRN \\
\hline CHEMBL1417290 & 688382 & 4.45 & 4.6763 & TRN \\
\hline CHEMBL1412192 & 688382 & 5.05 & 4.7652 & TRN \\
\hline CHEMBL1382714 & 688382 & 5.4 & 4.7601 & TRN \\
\hline CHEMBL10284 & 688382 & 4.8 & 4.6499 & TST \\
\hline CHEMBL1519574 & 688382 & 4.45 & 4.7106 & TRN \\
\hline CHEMBL3210104 & 688382 & 4.85 & 4.6881 & TRN \\
\hline CHEMBL1549574 & 688382 & 4.7 & 4.6777 & TRN \\
\hline CHEMBL1404924 & 688382 & 4.95 & 4.7417 & TST \\
\hline CHEMBL1585162 & 688382 & 4.8 & 4.7034 & TRN \\
\hline CHEMBL1412529 & 688382 & 4.4 & 4.71 & TRN \\
\hline CHEMBL1523864 & 688382 & 4.8 & 4.6862 & TST \\
\hline CHEMBL1323586 & 688382 & 4.45 & 4.668 & TRN \\
\hline CHEMBL459529 & 688382 & 4.95 & 4.8338 & TRN \\
\hline CHEMBL1449349 & 688382 & 4.5 & 4.7294 & TRN \\
\hline CHEMBL1561427 & 688382 & 4.2 & 4.7756 & TST \\
\hline CHEMBL1441571 & 688382 & 5.2 & 4.7439 & TRN \\
\hline CHEMBL1468097 & 688382 & 4.8 & 4.6644 & TST \\
\hline CHEMBL1493481 & 688382 & 4.05 & 4.5986 & TST \\
\hline CHEMBL1570532 & 688382 & 4.5 & 4.6102 & TST \\
\hline CHEMBL 3197024 & 688382 & 4.45 & 4.6444 & TRN \\
\hline CHEMBL 3208035 & 688382 & 4.85 & 4.6521 & TRN \\
\hline CHEMBL1427706 & 688382 & 5.55 & 4.7131 & TST \\
\hline CHEMBL1608044 & 688382 & 4.4 & 4.6343 & TST \\
\hline CHEMBL1968986 & 688382 & 4.35 & 4.6582 & TRN \\
\hline CHEMBL1484895 & 688382 & 4.5 & 4.8251 & TST \\
\hline CHEMBL 3211017 & 688382 & 4.6 & 4.6407 & TRN \\
\hline CHEMBL1476584 & 688382 & 4.85 & 4.6769 & TST \\
\hline CHEMBL1344466 & 688382 & 4.05 & 4.7701 & TRN \\
\hline CHEMBL1563105 & 688382 & 5.55 & 4.7257 & TST \\
\hline CHEMBL1319202 & 688382 & 4.35 & 4.7672 & TST \\
\hline CHEMBL1311073 & 688382 & 5.05 & 4.8517 & TRN \\
\hline CHEMBL1527352 & 688382 & 4.4 & 4.6018 & TST \\
\hline CHEMBL1370292 & 688382 & 4.75 & 4.6838 & TRN \\
\hline CHEMBL3212140 & 688382 & 4.05 & 4.7133 & TST \\
\hline CHEMBL1496108 & 688382 & 4.8 & 4.7203 & TRN \\
\hline CHEMBL1531654 & 688382 & 4.95 & 4.646 & TRN \\
\hline CHEMBL1466606 & 688382 & 4.45 & 4.5941 & TRN \\
\hline CHEMBL1479430 & 688382 & 4.35 & 4.6628 & TRN \\
\hline CHEMBL1322871 & 688382 & 4.35 & 4.7202 & TRN \\
\hline
\end{tabular}




\begin{tabular}{|c|c|c|c|c|}
\hline & & & pplement & al $\mathrm{Tc}$ \\
\hline CHEMBL1453467 & 688382 & 4.8 & 4.7672 & TRN \\
\hline CHEMBL1425392 & 688382 & 4.15 & 4.8218 & TRN \\
\hline CHEMBL2006431 & 688382 & 5.2 & 4.6942 & TRN \\
\hline CHEMBL1532890 & 688382 & 4.75 & 4.6654 & TRN \\
\hline CHEMBL 3208703 & 688382 & 4.35 & 4.7209 & TRN \\
\hline CHEMBL1566359 & 688382 & 4.35 & 4.6786 & TRN \\
\hline CHEMBL1388892 & 688382 & 4.65 & 4.6184 & TST \\
\hline CHEMBL1531187 & 688382 & 4.3 & 4.6854 & TST \\
\hline CHEMBL1581707 & 688382 & 5.1 & 4.6188 & TRN \\
\hline CHEMBL1421852 & 688382 & 4.95 & 4.7371 & TRN \\
\hline CHEMBL3209989 & 688382 & 4.05 & 4.6927 & TRN \\
\hline CHEMBL1502328 & 688382 & 4.4 & 4.7263 & TST \\
\hline CHEMBL3198428 & 688382 & 5.15 & 4.6689 & TRN \\
\hline CHEMBL1424265 & 688382 & 4.9 & 4.7592 & TST \\
\hline CHEMBL1606239 & 688382 & 4.15 & 4.6334 & TST \\
\hline CHEMBL 3191028 & 688382 & 4.35 & 4.6784 & TRN \\
\hline CHEMBL1550208 & 688382 & 5.05 & 4.6646 & TST \\
\hline CHEMBL1547387 & 688382 & 5.0 & 4.6249 & TST \\
\hline CHEMBL1341840 & 688382 & 4.5 & 4.6625 & TRN \\
\hline CHEMBL1426009 & 688382 & 4.5 & 4.7805 & TRN \\
\hline CHEMBL1574271 & 688382 & 4.35 & 4.6779 & TRN \\
\hline CHEMBL1389816 & 688382 & 5.1 & 4.7983 & TRN \\
\hline CHEMBL1311601 & 688382 & 6.0 & 4.7532 & TRN \\
\hline CHEMBL1546752 & 688382 & 5.6 & 4.73 & TRN \\
\hline CHEMBL1378096 & 688382 & 5.95 & 4.8333 & TST \\
\hline CHEMBL1343640 & 688382 & 6.05 & 4.7664 & TRN \\
\hline CHEMBL1387823 & 688382 & 5.0 & 4.757 & TRN \\
\hline CHEMBL1379195 & 688382 & 4.45 & 4.6678 & TST \\
\hline CHEMBL3193125 & 688382 & 4.5 & 4.7426 & TST \\
\hline CHEMBL3208512 & 688382 & 5.85 & 4.7062 & TRN \\
\hline CHEMBL1414580 & 688382 & 4.95 & 4.6611 & TST \\
\hline CHEMBL1328225 & 688382 & 5.15 & 4.6721 & TRN \\
\hline CHEMBL1322861 & 688382 & 5.05 & 4.6979 & TST \\
\hline CHEMBL1588157 & 688382 & 5.0 & 4.6727 & TRN \\
\hline CHEMBL490106 & 688382 & 4.55 & 4.6632 & TRN \\
\hline CHEMBL1567844 & 688382 & 4.05 & 4.7057 & TRN \\
\hline CHEMBL1565193 & 688382 & 4.15 & 4.6512 & TRN \\
\hline CHEMBL1579193 & 688382 & 4.05 & 4.6907 & TRN \\
\hline CHEMBL1332190 & 688382 & 5.95 & 4.8002 & TRN \\
\hline CHEMBL1320613 & 688382 & 4.5 & 4.6927 & TST \\
\hline CHEMBL1409015 & 688382 & 4.5 & 4.687 & TRN \\
\hline CHEMBL1305933 & 688382 & 4.5 & 4.7957 & TRN \\
\hline CHEMBL1411344 & 688382 & 4.15 & 4.6356 & TRN \\
\hline CHEMBL1425088 & 688382 & 4.8 & 4.6576 & TRN \\
\hline CHEMBL1429237 & 688382 & 5.85 & 4.7154 & TST \\
\hline CHEMBL 1487540 & 688382 & 4.15 & 4.6936 & TRN \\
\hline CHEMBL1458732 & 688382 & 4.65 & 4.7139 & TST \\
\hline CHEMBL1990619 & 688382 & 4.35 & 4.7054 & TRN \\
\hline
\end{tabular}




\begin{tabular}{|c|c|c|c|c|}
\hline \multicolumn{5}{|c|}{ Supplemental Table S2.txt } \\
\hline CHEMBL1376540 & 688382 & 4.75 & 4.6793 & TRN \\
\hline CHEMBL1504111 & 688382 & 5.0 & 4.7113 & TRN \\
\hline CHEMBL1571941 & 688382 & 4.15 & 4.697 & TRN \\
\hline CHEMBL1387563 & 688382 & 4.45 & 4.6038 & TRN \\
\hline CHEMBL1346745 & 688382 & 4.15 & 4.7064 & TRN \\
\hline CHEMBL1343691 & 688382 & 4.85 & 4.6395 & TST \\
\hline CHEMBL1341273 & 688382 & 5.45 & 4.7366 & TRN \\
\hline CHEMBL1301852 & 688382 & 4.9 & 4.6138 & TRN \\
\hline CHEMBL1558977 & 688382 & 4.4 & 4.5887 & TRN \\
\hline CHEMBL1572307 & 688382 & 4.85 & 4.7057 & TRN \\
\hline CHEMBL1508483 & 688382 & 5.0 & 4.7756 & TRN \\
\hline CHEMBL1421437 & 688382 & 4.8 & 4.8437 & TRN \\
\hline CHEMBL1462066 & 688382 & 4.5 & 4.7611 & TRN \\
\hline CHEMBL1401840 & 688382 & 4.4 & 4.7724 & TRN \\
\hline CHEMBL3197550 & 688382 & 5.1 & 4.6415 & TRN \\
\hline CHEMBL1364014 & 688382 & 5.8 & 4.6819 & TRN \\
\hline CHEMBL3209610 & 688382 & 4.05 & 4.7104 & TRN \\
\hline CHEMBL1580893 & 688382 & 4.05 & 4.8053 & TRN \\
\hline CHEMBL1470157 & 688382 & 4.35 & 4.7706 & TRN \\
\hline CHEMBL1378599 & 688382 & 4.15 & 4.7684 & TST \\
\hline CHEMBL1555592 & 688382 & 4.45 & 4.6575 & TRN \\
\hline CHEMBL1566597 & 688382 & 4.4 & 4.7146 & TRN \\
\hline CHEMBL1544463 & 688382 & 5.15 & 4.7767 & TST \\
\hline CHEMBL1466060 & 688382 & 4.55 & 4.6518 & TRN \\
\hline CHEMBL1335068 & 688382 & 4.45 & 4.8224 & TRN \\
\hline CHEMBL1534503 & 688382 & 4.55 & 4.8015 & TRN \\
\hline CHEMBL1587341 & 688382 & 5.05 & 4.8096 & TRN \\
\hline CHEMBL1336555 & 688382 & 6.05 & 4.648 & TST \\
\hline CHEMBL1583987 & 688382 & 4.95 & 4.8126 & TRN \\
\hline CHEMBL1402076 & 688382 & 4.4 & 4.6586 & TRN \\
\hline CHEMBL3196856 & 688382 & 4.75 & 4.6066 & TST \\
\hline CHEMBL478754 & 688382 & 4.5 & 4.7198 & TST \\
\hline CHEMBL1446892 & 688382 & 5.1 & 4.6867 & TRN \\
\hline CHEMBL 78150 & 688382 & 4.5 & 4.6407 & TST \\
\hline CHEMBL1409119 & 688382 & 5.35 & 4.7931 & TRN \\
\hline CHEMBL1987461 & 688382 & 4.45 & 4.683 & TRN \\
\hline CHEMBL1578612 & 688382 & 4.2 & 4.6837 & TST \\
\hline CHEMBL1301025 & 688382 & 6.0 & 4.8065 & TRN \\
\hline CHEMBL1332327 & 688382 & 4.4 & 4.7416 & TRN \\
\hline CHEMBL1401362 & 688382 & 4.2 & 4.6399 & TST \\
\hline CHEMBL1359249 & 688382 & 4.6 & 4.7753 & TRN \\
\hline CHEMBL1556148 & 688382 & 4.8 & 4.6134 & TRN \\
\hline CHEMBL1433212 & 688382 & 5.2 & 4.8398 & TRN \\
\hline CHEMBL1482905 & 688382 & 4.8 & 4.7417 & TST \\
\hline CHEMBL3197324 & 688382 & 4.45 & 4.7112 & TRN \\
\hline CHEMBL1344219 & 688382 & 5.25 & 4.7281 & TRN \\
\hline CHEMBL3196494 & 688382 & 4.55 & 4.7228 & TRN \\
\hline CHEMBL1403024 & 688382 & 4.8 & 4.6285 & TRN \\
\hline
\end{tabular}




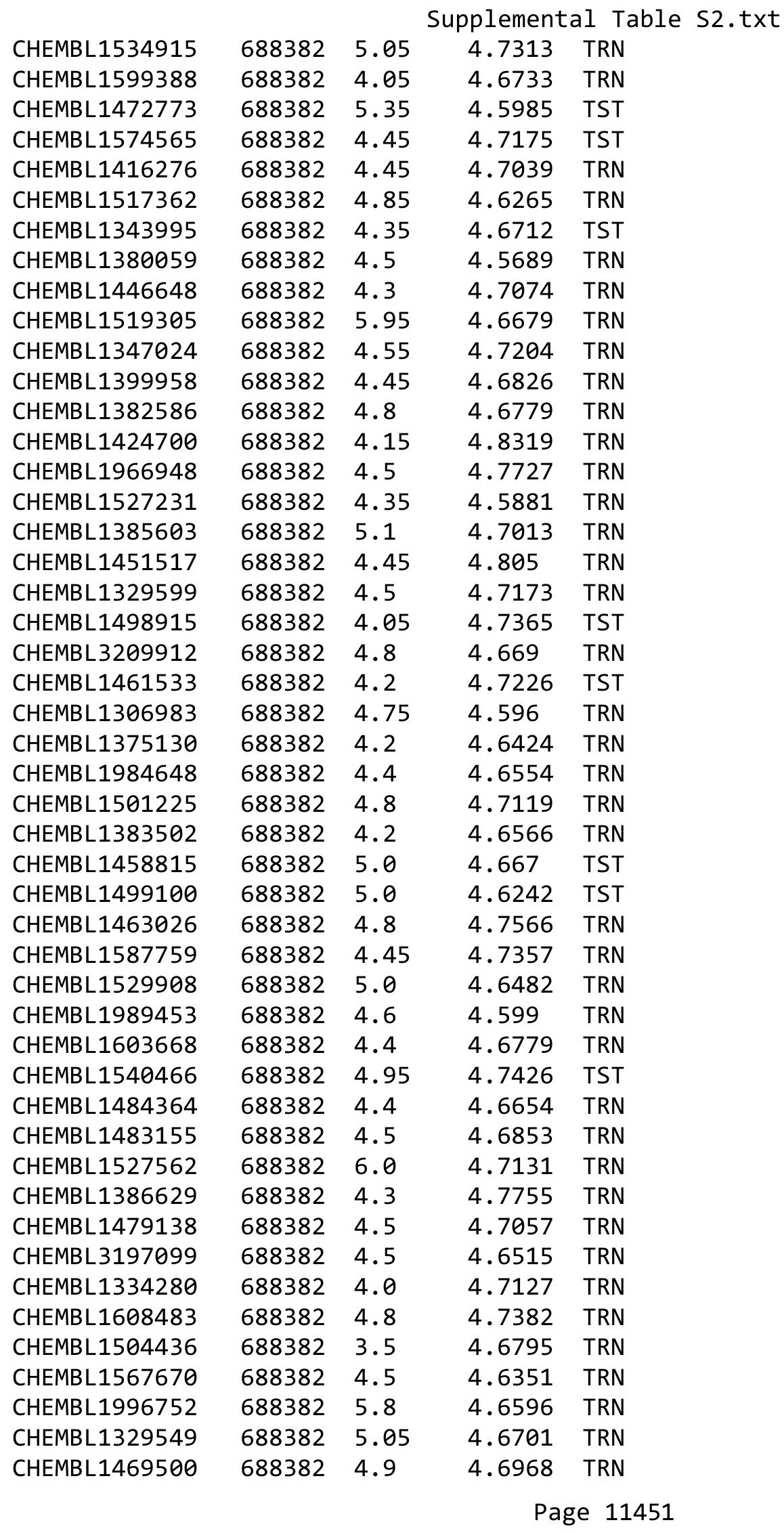




\begin{tabular}{|c|c|c|c|c|c|}
\hline & & \multicolumn{4}{|c|}{ Supplemental Table s2.txt } \\
\hline CHEMBL1460865 & 688382 & 5.05 & 4.7239 & TST & \\
\hline CHEMBL1349328 & 688382 & 4.45 & 4.7129 & TRN & \\
\hline CHEMBL3199129 & 688382 & 5.95 & 4.6886 & TRN & \\
\hline CHEMBL3189903 & 688382 & 4.3 & 4.6898 & TRN & \\
\hline CHEMBL1408095 & 688382 & 4.5 & 4.6945 & TRN & \\
\hline CHEMBL1483112 & 688382 & 4.8 & 4.6525 & TRN & \\
\hline CHEMBL1571638 & 688382 & 5.05 & 4.6807 & TST & \\
\hline CHEMBL1365454 & 688382 & 4.25 & 4.8395 & TST & \\
\hline CHEMBL1978925 & 688382 & 4.65 & 4.6315 & TRN & \\
\hline CHEMBL1964614 & 688382 & 4.05 & 4.64 & TRN & \\
\hline CHEMBL1340098 & 688382 & 4.0 & 4.7626 & TST & \\
\hline CHEMBL1505477 & 688382 & 4.5 & 4.6526 & TRN & \\
\hline CHEMBL1458448 & 688382 & 4.8 & 4.7108 & TRN & \\
\hline CHEMBL1560870 & 688382 & 4.45 & 4.6637 & TRN & \\
\hline CHEMBL1362746 & 688382 & 5.15 & 4.7294 & TRN & \\
\hline CHEMBL1502215 & 688382 & 4.05 & 4.6674 & TRN & \\
\hline CHEMBL1416100 & 688382 & 4.9 & 4.5835 & TRN & \\
\hline CHEMBL1511495 & 688382 & 4.45 & 4.6707 & TRN & \\
\hline CHEMBL1603312 & 688382 & 4.25 & 4.6707 & TST & \\
\hline CHEMBL1345607 & 688382 & 4.55 & 4.6007 & TST & \\
\hline CHEMBL1320575 & 688382 & 4.2 & 4.6771 & TRN & \\
\hline CHEMBL1573330 & 688382 & 4.5 & 4.8 & TRN & \\
\hline CHEMBL1410122 & 688382 & 4.85 & 4.6918 & TRN & \\
\hline CHEMBL1550536 & 688382 & 4.15 & 4.8307 & TRN & \\
\hline CHEMBL3208538 & 688382 & 4.45 & 4.6738 & TRN & \\
\hline CHEMBL1588849 & 688382 & 5.15 & 4.7198 & TRN & \\
\hline CHEMBL1484737 & 688382 & 4.0 & 4.7836 & TST & \\
\hline CHEMBL1401621 & 688382 & 5.05 & 4.8122 & TRN & \\
\hline CHEMBL1299690 & 688382 & 5.45 & 4.6686 & TRN & \\
\hline CHEMBL1200938 & 688382 & 6.0 & 4.7652 & TRN & \\
\hline CHEMBL1478491 & 688382 & 4.3 & 4.6156 & TRN & \\
\hline CHEMBL1352482 & 688382 & 5.25 & 4.6791 & TRN & \\
\hline CHEMBL1299279 & 688382 & 4.15 & 4.7226 & TRN & \\
\hline CHEMBL1488989 & 688382 & 4.95 & 4.7931 & TRN & \\
\hline CHEMBL1411755 & 688382 & 5.0 & 4.76399 & 9999999999 & TST \\
\hline CHEMBL1335685 & 688382 & 4.7 & 4.7267 & TRN & \\
\hline CHEMBL1447821 & 688382 & 4.9 & 4.7175 & TRN & \\
\hline CHEMBL1488474 & 688382 & 4.5 & 4.6451 & TRN & \\
\hline CHEMBL1309588 & 688382 & 4.8 & 4.7629 & TRN & \\
\hline CHEMBL1887153 & 688382 & 5.15 & 4.6639 & TST & \\
\hline CHEMBL1459764 & 688382 & 4.15 & 4.729 & TRN & \\
\hline CHEMBL1486391 & 688382 & 4.45 & 4.6509 & TRN & \\
\hline CHEMBL1577203 & 688382 & 4.7 & 4.5733 & TST & \\
\hline CHEMBL1376238 & 688382 & 4.85 & 4.7372 & TST & \\
\hline CHEMBL1595996 & 688382 & 5.1 & 4.6553 & TRN & \\
\hline CHEMBL3197557 & 688382 & 4.8 & 4.5888 & TRN & \\
\hline CHEMBL1320653 & 688382 & 4.5 & 4.6481 & TRN & \\
\hline CHEMBL1371744 & 688382 & 5.9 & 4.7368 & TRN & \\
\hline
\end{tabular}




\begin{tabular}{|c|c|c|c|c|}
\hline \multicolumn{5}{|c|}{ Supplemental Table } \\
\hline CHEMBL1334845 & 688382 & 4.85 & 4.7353 & TRN \\
\hline CHEMBL1349285 & 688382 & 4.2 & 4.7234 & TRN \\
\hline CHEMBL1433315 & 688382 & 4.05 & 4.7522 & TRN \\
\hline CHEMBL1560513 & 688382 & 5.95 & 4.7097 & TRN \\
\hline CHEMBL1349147 & 688382 & 4.6 & 4.6728 & TRN \\
\hline CHEMBL1439891 & 688382 & 4.1 & 4.7117 & TRN \\
\hline CHEMBL1613182 & 688382 & 4.7 & 4.709 & TRN \\
\hline CHEMBL1467625 & 688382 & 5.5 & 4.6321 & TRN \\
\hline CHEMBL1375168 & 688382 & 5.55 & 4.7309 & TST \\
\hline CHEMBL1441948 & 688382 & 4.05 & 4.7422 & TRN \\
\hline CHEMBL1372286 & 688382 & 4.2 & 4.6925 & TRN \\
\hline CHEMBL1472513 & 688382 & 4.85 & 4.8013 & TRN \\
\hline CHEMBL1338689 & 688382 & 4.5 & 4.6495 & TRN \\
\hline CHEMBL1451710 & 688382 & 4.45 & 4.8122 & TRN \\
\hline CHEMBL1544136 & 688382 & 4.4 & 4.7048 & TRN \\
\hline CHEMBL1444418 & 688382 & 4.25 & 4.7061 & TST \\
\hline CHEMBL1325039 & 688382 & 4.5 & 4.6887 & TRN \\
\hline CHEMBL1588234 & 688382 & 5.0 & 4.633 & TRN \\
\hline CHEMBL1312523 & 688382 & 4.5 & 4.6371 & TRN \\
\hline CHEMBL1455877 & 688382 & 5.05 & 4.6113 & TST \\
\hline CHEMBL1596980 & 688382 & 4.65 & 4.6737 & TRN \\
\hline CHEMBL1346716 & 688382 & 4.5 & 4.6571 & TRN \\
\hline CHEMBL1365444 & 688382 & 4.4 & 4.6789 & TRN \\
\hline CHEMBL1571984 & 688382 & 4.2 & 4.6693 & TST \\
\hline CHEMBL1541642 & 688382 & 4.45 & 4.7845 & TRN \\
\hline CHEMBL3210359 & 688382 & 4.15 & 4.6515 & TRN \\
\hline CHEMBL1328168 & 688382 & 5.85 & 4.6062 & TST \\
\hline CHEMBL1383757 & 688382 & 5.0 & 4.7245 & TST \\
\hline CHEMBL1571648 & 688382 & 4.8 & 4.6225 & TST \\
\hline CHEMBL1485652 & 688382 & 4.95 & 4.6333 & TRN \\
\hline CHEMBL1361940 & 688382 & 4.55 & 4.6701 & TRN \\
\hline CHEMBL1611956 & 688382 & 4.5 & 4.7059 & TRN \\
\hline CHEMBL1492396 & 688382 & 4.3 & 4.6364 & TRN \\
\hline CHEMBL1338736 & 688382 & 4.35 & 4.6911 & TRN \\
\hline CHEMBL1347600 & 688382 & 4.45 & 4.6599 & TRN \\
\hline CHEMBL1602427 & 688382 & 4.0 & 4.6688 & TST \\
\hline CHEMBL1539421 & 688382 & 4.9 & 4.7125 & TST \\
\hline CHEMBL1378418 & 688382 & 4.95 & 4.7109 & TRN \\
\hline CHEMBL1576163 & 688382 & 4.4 & 4.7876 & TRN \\
\hline CHEMBL1497153 & 688382 & 4.6 & 4.6447 & TST \\
\hline CHEMBL1404070 & 688382 & 5.2 & 4.8384 & TRN \\
\hline CHEMBL1537354 & 688382 & 4.9 & 4.7521 & TRN \\
\hline CHEMBL1970753 & 688382 & 4.55 & 4.6154 & TRN \\
\hline CHEMBL1409378 & 688382 & 4.4 & 4.738 & TRN \\
\hline CHEMBL1528517 & 688382 & 4.45 & 4.8395 & TRN \\
\hline CHEMBL1540663 & 688382 & 4.4 & 4.5645 & TRN \\
\hline CHEMBL1325688 & 688382 & 5.2 & 4.8353 & TST \\
\hline CHEMBL3145281 & 688382 & 4.5 & 4.6487 & TRN \\
\hline
\end{tabular}




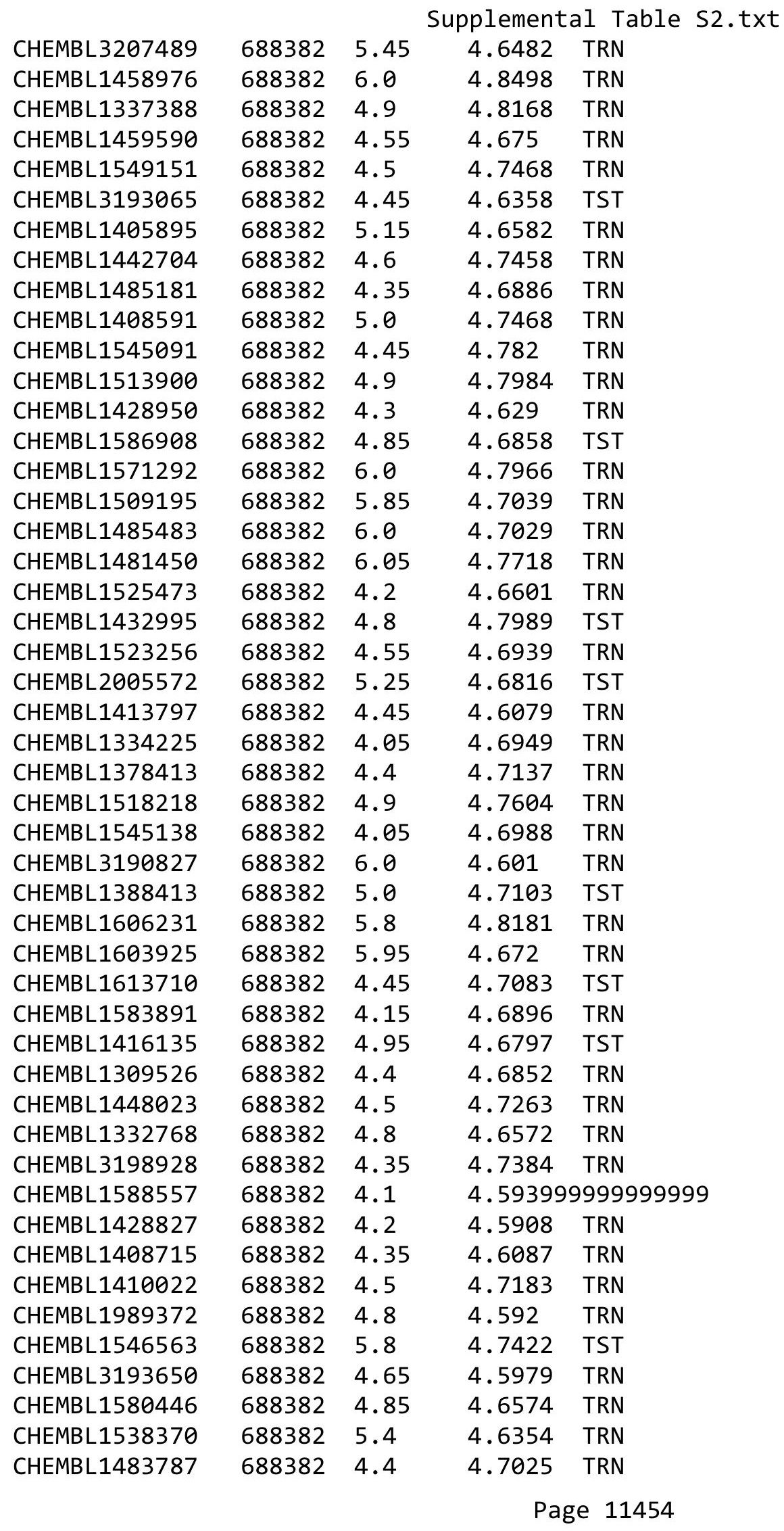




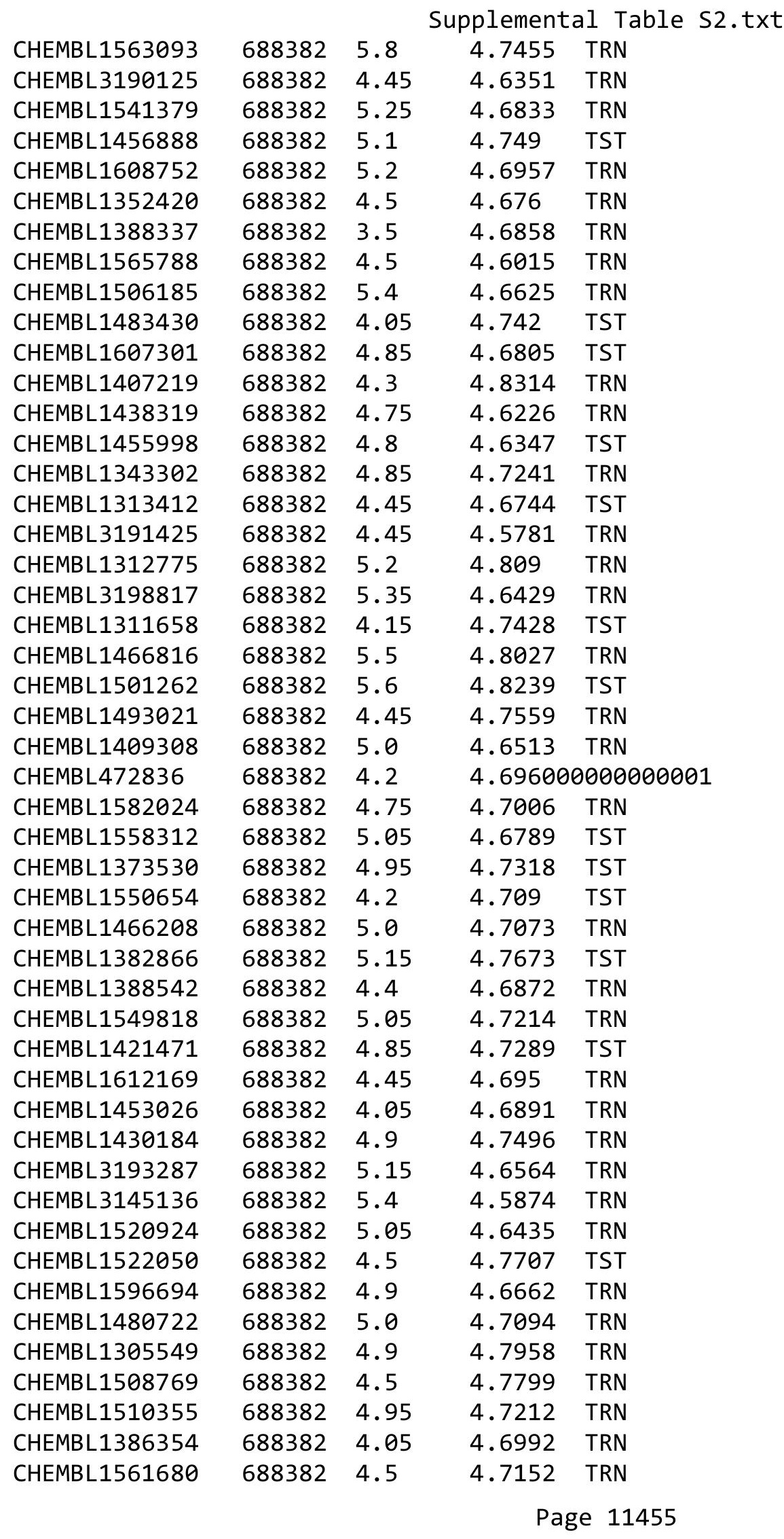




\begin{tabular}{|c|c|c|c|c|c|}
\hline & & \multicolumn{4}{|c|}{ Supplemental Table s2.txt } \\
\hline CHEMBL1526379 & 688382 & 5.95 & 4.776 & TRN & \\
\hline CHEMBL1528276 & 688382 & 4.85 & 4.7974 & TST & \\
\hline CHEMBL1350225 & 688382 & 4.85 & 4.6413 & TST & \\
\hline CHEMBL1517408 & 688382 & 4.05 & 4.6717 & TRN & \\
\hline CHEMBL1585706 & 688382 & 4.2 & 4.7544 & TRN & \\
\hline CHEMBL1334770 & 688382 & 4.85 & 4.7176 & TRN & \\
\hline CHEMBL1351250 & 688382 & 4.6 & 4.6921 & TRN & \\
\hline CHEMBL1594799 & 688382 & 5.05 & 4.694 & TST & \\
\hline CHEMBL1409545 & 688382 & 4.5 & 4.6965 & TRN & \\
\hline CHEMBL1459706 & 688382 & 5.5 & 4.7165 & TST & \\
\hline CHEMBL1482189 & 688382 & 5.5 & 4.7161 & TRN & \\
\hline CHEMBL 2005238 & 688382 & 4.55 & 4.68199 & 99999999995 & TRN \\
\hline CHEMBL1412395 & 688382 & 4.8 & 4.7062 & TST & \\
\hline CHEMBL1503364 & 688382 & 4.8 & 4.6487 & TST & \\
\hline CHEMBL1323910 & 688382 & 4.5 & 4.6487 & TST & \\
\hline CHEMBL1609503 & 688382 & 4.2 & 4.6765 & TST & \\
\hline CHEMBL1480178 & 688382 & 4.05 & 4.6188 & TST & \\
\hline CHEMBL1386028 & 688382 & 4.85 & 4.7012 & TST & \\
\hline CHEMBL1971727 & 688382 & 4.55 & 4.6177 & TRN & \\
\hline CHEMBL1373049 & 688382 & 5.0 & 4.6619 & TRN & \\
\hline CHEMBL1306943 & 688382 & 4.5 & 4.6922 & TRN & \\
\hline CHEMBL1579740 & 688382 & 5.15 & 4.7197 & TST & \\
\hline CHEMBL3192551 & 688382 & 4.5 & 4.5847 & TRN & \\
\hline CHEMBL1448732 & 688382 & 4.4 & 4.6486 & TRN & \\
\hline CHEMBL1426779 & 688382 & 5.0 & 4.6972 & TST & \\
\hline CHEMBL3196217 & 688382 & 5.25 & 4.6418 & TRN & \\
\hline CHEMBL1370730 & 688382 & 4.5 & 4.6797 & TRN & \\
\hline CHEMBL3192752 & 688382 & 4.35 & 4.6999 & TRN & \\
\hline CHEMBL1608310 & 688382 & 5.5 & 4.7261 & TST & \\
\hline CHEMBL1331059 & 688382 & 5.05 & 4.7468 & TRN & \\
\hline CHEMBL1441841 & 688382 & 4.75 & 4.8006 & TST & \\
\hline CHEMBL1462248 & 688382 & 4.85 & 4.7466 & TRN & \\
\hline CHEMBL1391686 & 688382 & 4.7 & 4.6253 & TRN & \\
\hline CHEMBL1329886 & 688382 & 4.5 & 4.6914 & TST & \\
\hline CHEMBL1334346 & 688382 & 4.85 & 4.7022 & TRN & \\
\hline CHEMBL1312785 & 688382 & 4.8 & 4.7698 & TST & \\
\hline CHEMBL1581303 & 688382 & 4.2 & 4.7992 & TRN & \\
\hline CHEMBL1529946 & 688382 & 4.5 & 4.621 & TRN & \\
\hline CHEMBL1358278 & 688382 & 4.2 & 4.6467 & TRN & \\
\hline CHEMBL1338802 & 688382 & 4.95 & 4.7632 & TRN & \\
\hline CHEMBL1417127 & 688382 & 4.2 & 4.7984 & TRN & \\
\hline CHEMBL1324351 & 688382 & 4.6 & 4.6172 & TRN & \\
\hline CHEMBL1604510 & 688382 & 6.0 & 4.5946 & TRN & \\
\hline CHEMBL1396256 & 688382 & 4.25 & 4.6786 & TRN & \\
\hline CHEMBL1329339 & 688382 & 4.8 & 4.711 & TST & \\
\hline CHEMBL1306393 & 688382 & 4.15 & 4.8268 & TRN & \\
\hline CHEMBL1323548 & 688382 & 5.0 & 4.774 & TRN & \\
\hline CHEMBL1452431 & 688382 & 4.9 & 4.709 & TST & \\
\hline
\end{tabular}




\begin{tabular}{|c|c|c|c|c|}
\hline \multicolumn{5}{|c|}{ Supplemental Table S2.txt } \\
\hline CHEMBL1366523 & 688382 & 4.45 & 4.6698 & TRN \\
\hline CHEMBL1534107 & 688382 & 4.85 & 4.8059 & TRN \\
\hline CHEMBL1470932 & 688382 & 5.0 & 4.7619 & TRN \\
\hline CHEMBL1575748 & 688382 & 4.35 & 4.6562 & TRN \\
\hline CHEMBL1310220 & 688382 & 4.9 & 4.7022 & TRN \\
\hline CHEMBL1301688 & 688382 & 4.45 & 4.709 & TST \\
\hline CHEMBL1467383 & 688382 & 4.6 & 4.7094 & TRN \\
\hline CHEMBL1548494 & 688382 & 4.15 & 4.7745 & TST \\
\hline CHEMBL1477354 & 688382 & 5.0 & 4.6727 & TRN \\
\hline CHEMBL1511723 & 688382 & 4.95 & 4.6948 & TRN \\
\hline CHEMBL1598769 & 688382 & 5.15 & 4.6988 & TRN \\
\hline CHEMBL1409638 & 688382 & 4.6 & 4.7288 & TRN \\
\hline CHEMBL1598350 & 688382 & 5.0 & 4.748 & TRN \\
\hline CHEMBL1505968 & 688382 & 4.05 & 4.6859 & TST \\
\hline CHEMBL1471458 & 688382 & 4.05 & 4.6608 & TST \\
\hline CHEMBL1495518 & 688382 & 4.45 & 4.672 & TRN \\
\hline CHEMBL1508452 & 688382 & 4.55 & 4.7185 & TRN \\
\hline CHEMBL1377323 & 688382 & 4.8 & 4.6604 & TST \\
\hline CHEMBL1580228 & 688382 & 4.95 & 4.8348 & TRN \\
\hline CHEMBL1598116 & 688382 & 4.15 & 4.6676 & TRN \\
\hline CHEMBL1326893 & 688382 & 4.15 & 4.7122 & TRN \\
\hline CHEMBL1313812 & 688382 & 5.7 & 4.8432 & TRN \\
\hline CHEMBL1499202 & 688382 & 4.7 & 4.6383 & TST \\
\hline CHEMBL1594987 & 688382 & 5.85 & 4.7445 & TRN \\
\hline CHEMBL1464874 & 688382 & 5.05 & 4.7277 & TRN \\
\hline CHEMBL1991441 & 688382 & 4.45 & 4.7077 & TRN \\
\hline CHEMBL1306499 & 688382 & 5.8 & 4.7403 & TRN \\
\hline CHEMBL1411943 & 688382 & 5.8 & 4.8162 & TRN \\
\hline CHEMBL1323049 & 688382 & 5.85 & 4.6726 & TRN \\
\hline CHEMBL1499295 & 688382 & 4.45 & 4.6494 & TRN \\
\hline CHEMBL1350474 & 688382 & 4.4 & 4.7299 & TRN \\
\hline CHEMBL1613510 & 688382 & 4.55 & 4.6302 & TRN \\
\hline CHEMBL3193599 & 688382 & 5.0 & 4.6632 & TRN \\
\hline CHEMBL1546699 & 688382 & 4.45 & 4.7184 & TRN \\
\hline CHEMBL3196963 & 688382 & 4.8 & 4.7263 & TRN \\
\hline CHEMBL1517447 & 688382 & 4.85 & 4.7425 & TRN \\
\hline CHEMBL1523328 & 688382 & 5.4 & 4.6866 & TRN \\
\hline CHEMBL1508839 & 688382 & 4.05 & 4.6501 & TRN \\
\hline CHEMBL1579180 & 688382 & 4.3 & 4.6782 & TST \\
\hline CHEMBL1336788 & 688382 & 4.2 & 4.7014 & TRN \\
\hline CHEMBL1480373 & 688382 & 4.45 & 4.8087 & TRN \\
\hline CHEMBL3193326 & 688382 & 4.45 & 4.7474 & TRN \\
\hline CHEMBL1386067 & 688382 & 4.5 & 4.7076 & TRN \\
\hline CHEMBL1337832 & 688382 & 4.85 & 4.71899 & 9999999999 \\
\hline CHEMBL1594192 & 688382 & 4.55 & 4.7103 & TRN \\
\hline CHEMBL1450795 & 688382 & 4.45 & 4.7296 & TRN \\
\hline CHEMBL1433015 & 688382 & 4.7 & 4.6502 & TRN \\
\hline CHEMBL1505811 & 688382 & 5.05 & 4.7288 & TRN \\
\hline
\end{tabular}

TRN 


\begin{tabular}{|c|c|c|c|c|}
\hline \multicolumn{5}{|c|}{ Supplemental Table S2.txt } \\
\hline CHEMBL1333001 & 688382 & 4.65 & 4.7274 & TRN \\
\hline CHEMBL1427484 & 688382 & 4.85 & 4.7632 & TRN \\
\hline CHEMBL1550381 & 688382 & 4.35 & 4.6502 & TRN \\
\hline CHEMBL1458009 & 688382 & 4.45 & 4.6004 & TRN \\
\hline CHEMBL1588820 & 688382 & 4.6 & 4.7226 & TRN \\
\hline CHEMBL1361854 & 688382 & 5.15 & 4.6546 & TRN \\
\hline CHEMBL1470141 & 688382 & 6.05 & 4.7626 & TRN \\
\hline CHEMBL1407607 & 688382 & 4.45 & 4.6943 & TRN \\
\hline CHEMBL 3197688 & 688382 & 4.5 & 4.7065 & TRN \\
\hline CHEMBL1606916 & 688382 & 4.25 & 4.6539 & TRN \\
\hline CHEMBL1421165 & 688382 & 4.45 & 4.6907 & TRN \\
\hline CHEMBL1529683 & 688382 & 5.1 & 4.6522 & TST \\
\hline CHEMBL1450575 & 688382 & 5.9 & 4.7446 & TRN \\
\hline CHEMBL3194820 & 688382 & 4.5 & 4.6889 & TRN \\
\hline CHEMBL1349300 & 688382 & 4.45 & 4.743 & TST \\
\hline CHEMBL1583217 & 688382 & 4.85 & 4.7413 & TRN \\
\hline CHEMBL1564416 & 688382 & 5.95 & 4.6484 & TRN \\
\hline CHEMBL1495335 & 688382 & 5.9 & 4.6476 & TST \\
\hline CHEMBL1460737 & 688382 & 4.25 & 4.7001 & TST \\
\hline CHEMBL1362625 & 688382 & 4.2 & 4.6383 & TRN \\
\hline CHEMBL1596826 & 688382 & 4.4 & 4.6856 & TST \\
\hline CHEMBL1305120 & 688382 & 4.55 & 4.7802 & TRN \\
\hline CHEMBL1610635 & 688382 & 4.5 & 4.703 & TRN \\
\hline CHEMBL1308416 & 688382 & 4.95 & 4.6875 & TRN \\
\hline CHEMBL1542748 & 688382 & 5.15 & 4.6356 & TRN \\
\hline CHEMBL1338564 & 688382 & 4.85 & 4.78 & TRN \\
\hline CHEMBL1381902 & 688382 & 6.0 & 4.7009 & TRN \\
\hline CHEMBL1574327 & 688382 & 4.95 & 4.7371 & TRN \\
\hline CHEMBL1469275 & 688382 & 5.05 & 4.671 & TRN \\
\hline CHEMBL1541152 & 688382 & 6.1 & 4.7593 & TRN \\
\hline CHEMBL1336814 & 688382 & 4.8 & 4.7066 & TST \\
\hline CHEMBL1338417 & 688382 & 4.0 & 4.7518 & TRN \\
\hline CHEMBL1378824 & 688382 & 4.85 & 4.7131 & TRN \\
\hline CHEMBL 3192475 & 688382 & 4.35 & 4.6627 & TST \\
\hline CHEMBL1509712 & 688382 & 4.5 & 4.7633 & TRN \\
\hline CHEMBL1500300 & 688382 & 4.2 & 4.7644 & TRN \\
\hline CHEMBL1388871 & 688382 & 4.55 & 4.6259 & TST \\
\hline CHEMBL1606279 & 688382 & 4.0 & 4.6463 & TST \\
\hline CHEMBL 3194091 & 688382 & 4.15 & 4.6132 & TRN \\
\hline CHEMBL3195436 & 688382 & 4.35 & 4.6741 & TRN \\
\hline CHEMBL494474 & 688382 & 4.5 & 4.7385 & TRN \\
\hline CHEMBL1600163 & 688382 & 4.3 & 4.6872 & TRN \\
\hline CHEMBL1425982 & 688382 & 4.25 & 4.8586 & TRN \\
\hline CHEMBL1548190 & 688382 & 4.75 & 4.6865 & TRN \\
\hline CHEMBL1522119 & 688382 & 4.8 & 4.6884 & TRN \\
\hline CHEMBL1504157 & 688382 & 4.4 & 4.6539 & TST \\
\hline CHEMBL3190109 & 688382 & 4.2 & 4.6925 & TRN \\
\hline CHEMBL1362871 & 688382 & 4.45 & 4.6827 & TST \\
\hline
\end{tabular}




\begin{tabular}{|c|c|c|c|c|}
\hline \multicolumn{5}{|c|}{ Supplemental Table S2.txt } \\
\hline CHEMBL1405057 & 688382 & 5.5 & 4.6737 & TRN \\
\hline CHEMBL1575701 & 688382 & 4.5 & 4.631 & TST \\
\hline CHEMBL1439833 & 688382 & 4.35 & 4.7237 & TRN \\
\hline CHEMBL1488654 & 688382 & 5.0 & 4.8433 & TRN \\
\hline CHEMBL1482411 & 688382 & 4.85 & 4.7166 & TRN \\
\hline CHEMBL1599023 & 688382 & 4.4 & 4.6771 & TST \\
\hline CHEMBL1499306 & 688382 & 4.2 & 4.6775 & TST \\
\hline CHEMBL1405062 & 688382 & 5.1 & 4.8116 & TRN \\
\hline CHEMBL1466770 & 688382 & 4.55 & 4.7436 & TRN \\
\hline CHEMBL1499087 & 688382 & 4.5 & 4.6846 & TRN \\
\hline CHEMBL1538784 & 688382 & 4.8 & 4.8396 & TRN \\
\hline CHEMBL1402636 & 688382 & 4.9 & 4.7121 & TRN \\
\hline CHEMBL3191946 & 688382 & 4.8 & 4.6914 & TST \\
\hline CHEMBL1972650 & 688382 & 4.5 & 4.6652 & TRN \\
\hline CHEMBL1375284 & 688382 & 4.2 & 4.6902 & TRN \\
\hline CHEMBL1256869 & 688382 & 4.45 & 4.7166 & TRN \\
\hline CHEMBL1613588 & 688382 & 4.45 & 4.6909 & TRN \\
\hline CHEMBL1497108 & 688382 & 5.0 & 4.7959 & TRN \\
\hline CHEMBL1547684 & 688382 & 4.85 & 4.6962 & TRN \\
\hline CHEMBL1458340 & 688382 & 5.0 & 4.7546 & TRN \\
\hline CHEMBL1484075 & 688382 & 4.3 & 4.7064 & TRN \\
\hline CHEMBL1382684 & 688382 & 4.2 & 4.675 & TRN \\
\hline CHEMBL1402930 & 688382 & 4.9 & 4.8645 & TRN \\
\hline CHEMBL1477736 & 688382 & 4.45 & 4.7199 & TST \\
\hline CHEMBL1499101 & 688382 & 4.55 & 4.6957 & TRN \\
\hline CHEMBL16687 & 688382 & 6.0 & 4.5778 & TST \\
\hline CHEMBL1503723 & 688382 & 5.85 & 4.6648 & TRN \\
\hline CHEMBL3207753 & 688382 & 4.5 & 4.6568 & TRN \\
\hline CHEMBL1574212 & 688382 & 4.45 & 4.7151 & TRN \\
\hline CHEMBL1369765 & 688382 & 4.8 & 4.7616 & TRN \\
\hline CHEMBL1468519 & 688382 & 4.5 & 4.7447 & TRN \\
\hline CHEMBL1349564 & 688382 & 5.1 & 4.7275 & TRN \\
\hline CHEMBL1404302 & 688382 & 4.5 & 4.695 & TRN \\
\hline CHEMBL1415171 & 688382 & 6.05 & 4.8186 & TST \\
\hline CHEMBL1538432 & 688382 & 5.85 & 4.7703 & TRN \\
\hline CHEMBL1382336 & 688382 & 4.7 & 4.7142 & TRN \\
\hline CHEMBL1543856 & 688382 & 5.9 & 4.6283 & TRN \\
\hline CHEMBL1511682 & 688382 & 4.4 & 4.6225 & TST \\
\hline CHEMBL1446282 & 688382 & 4.5 & 4.7623 & TST \\
\hline CHEMBL1585011 & 688382 & 4.95 & 4.708 & TRN \\
\hline CHEMBL1429734 & 688382 & 4.4 & 4.7978 & TRN \\
\hline CHEMBL486817 & 688382 & 5.05 & 4.6512 & TST \\
\hline CHEMBL532160 & 688382 & 4.45 & 4.6356 & TST \\
\hline CHEMBL3196762 & 688382 & 4.5 & 4.6767 & TRN \\
\hline CHEMBL1416490 & 688382 & 4.15 & 4.7327 & TST \\
\hline CHEMBL1331399 & 688382 & 5.45 & 4.6116 & TRN \\
\hline CHEMBL1542843 & 688382 & 4.8 & 4.7393 & TRN \\
\hline CHEMBL1505525 & 688382 & 4.85 & 4.7796 & TRN \\
\hline
\end{tabular}




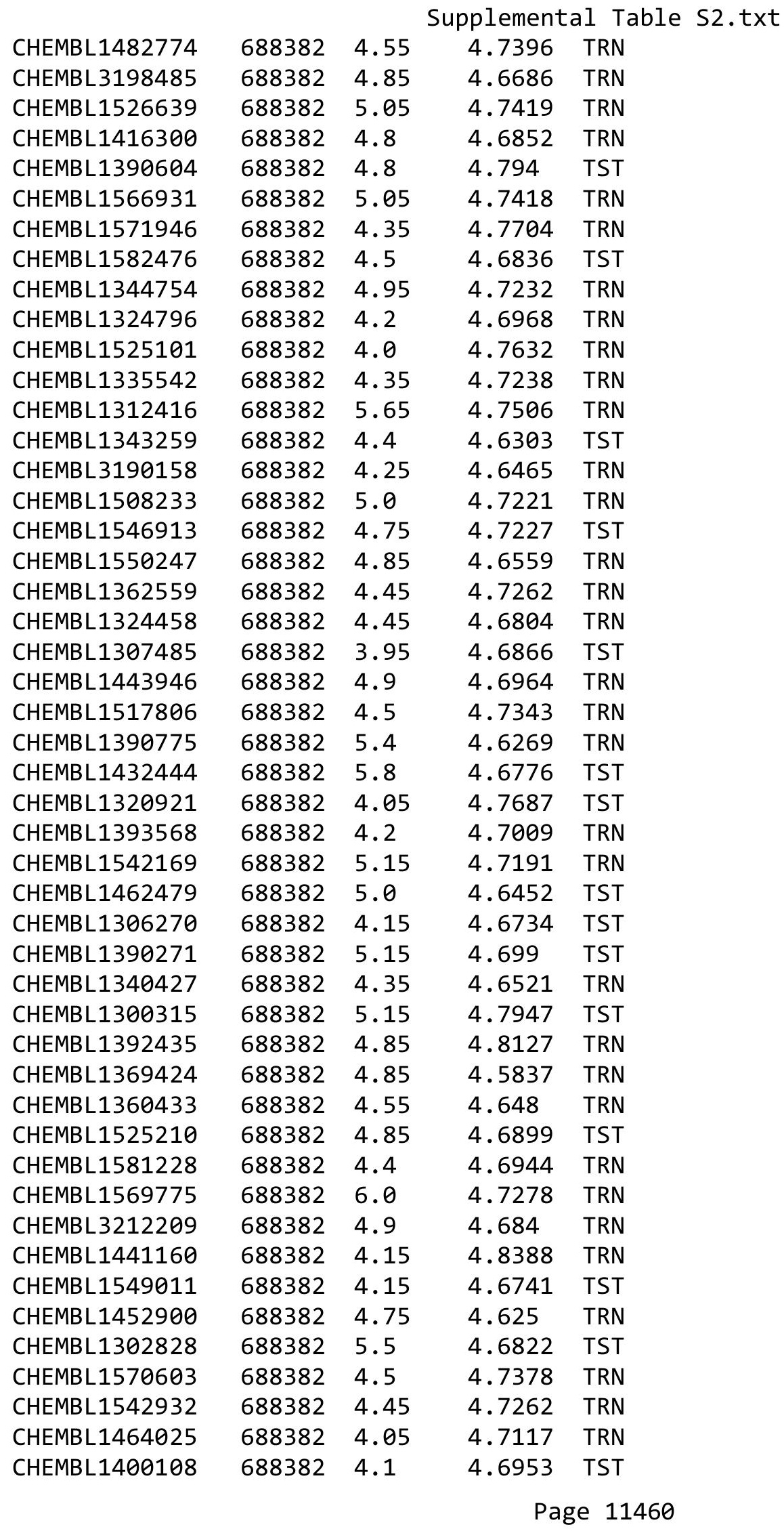




\begin{tabular}{|c|c|c|c|c|c|}
\hline \multicolumn{6}{|c|}{ Supplemental Table S2.txt } \\
\hline CHEMBL1516388 & 688382 & 4.55 & 4.7178 & TST & \\
\hline CHEMBL1586704 & 688382 & 4.55 & 4.7222 & TRN & \\
\hline CHEMBL1304341 & 688382 & 5.85 & 4.7911 & TRN & \\
\hline CHEMBL1577640 & 688382 & 4.4 & 4.7012 & TRN & \\
\hline CHEMBL1531694 & 688382 & 4.6 & 4.6883 & TRN & \\
\hline CHEMBL1372577 & 688382 & 4.7 & 4.7398 & TRN & \\
\hline CHEMBL1588815 & 688382 & 4.8 & 4.5959 & TRN & \\
\hline CHEMBL1416381 & 688382 & 5.0 & 4.7136 & TRN & \\
\hline CHEMBL1594727 & 688382 & 5.0 & 4.7182 & TRN & \\
\hline CHEMBL3212255 & 688382 & 5.95 & 4.6973 & TRN & \\
\hline CHEMBL 3207518 & 688382 & 4.4 & 4.6503 & TRN & \\
\hline CHEMBL1393637 & 688382 & 4.9 & 4.8325 & TRN & \\
\hline CHEMBL1555470 & 688382 & 4.8 & 4.7711 & TST & \\
\hline CHEMBL1594931 & 688382 & 4.5 & 4.6831 & TRN & \\
\hline CHEMBL1571882 & 688382 & 4.05 & 4.692 & TRN & \\
\hline CHEMBL1518905 & 688382 & 5.0 & 4.6563 & TRN & \\
\hline CHEMBL1403417 & 688382 & 4.8 & 4.6661 & TRN & \\
\hline CHEMBL1485017 & 688382 & 5.05 & 4.7238 & TRN & \\
\hline CHEMBL1563307 & 688382 & 4.8 & 4.73300 & 20000000005 & TRN \\
\hline CHEMBL1516559 & 688382 & 5.25 & 4.7825 & TRN & \\
\hline CHEMBL1387778 & 688382 & 6.0 & 4.71 & TRN & \\
\hline CHEMBL1544046 & 688382 & 3.95 & 4.7661 & TST & \\
\hline CHEMBL1532617 & 688382 & 4.15 & 4.7033 & TRN & \\
\hline CHEMBL3212981 & 688382 & 4.45 & 4.6696 & TRN & \\
\hline CHEMBL1460546 & 688382 & 4.35 & 4.7125 & TST & \\
\hline CHEMBL1535963 & 688382 & 4.8 & 4.748 & TRN & \\
\hline CHEMBL1549596 & 688382 & 4.75 & 4.6847 & TRN & \\
\hline CHEMBL1459612 & 688382 & 5.95 & 4.7691 & TRN & \\
\hline CHEMBL1468971 & 688382 & 4.05 & 4.7088 & TRN & \\
\hline CHEMBL1471742 & 688382 & 4.2 & 4.7024 & TRN & \\
\hline CHEMBL1308042 & 688382 & 4.05 & 4.7448 & TRN & \\
\hline CHEMBL1351923 & 688382 & 4.85 & 4.716 & TRN & \\
\hline CHEMBL1376995 & 688382 & 4.85 & 4.8018 & TRN & \\
\hline CHEMBL1584849 & 688382 & 4.2 & 4.6687 & TRN & \\
\hline CHEMBL1536430 & 688382 & 4.0 & 4.9014 & TST & \\
\hline CHEMBL1609454 & 688382 & 4.8 & 4.7105 & TRN & \\
\hline CHEMBL1405036 & 688382 & 5.2 & 4.658 & TRN & \\
\hline CHEMBL 3190466 & 688382 & 4.7 & 4.7123 & TRN & \\
\hline CHEMBL1586526 & 688382 & 4.85 & 4.6157 & TRN & \\
\hline CHEMBL1366239 & 688382 & 4.45 & 4.5798 & TST & \\
\hline CHEMBL1428492 & 688382 & 4.95 & 4.8241 & TRN & \\
\hline CHEMBL1412661 & 688382 & 4.4 & 4.7235 & TRN & \\
\hline CHEMBL1378036 & 688382 & 4.15 & 4.709 & TST & \\
\hline CHEMBL1418563 & 688382 & 4.05 & 4.7878 & TST & \\
\hline CHEMBL1370818 & 688382 & 4.6 & 4.6374 & TRN & \\
\hline CHEMBL1403050 & 688382 & 5.0 & 4.7549 & TRN & \\
\hline CHEMBL3195551 & 688382 & 5.55 & 4.6746 & TRN & \\
\hline CHEMBL1359160 & 688382 & 4.55 & 4.6706 & TRN & \\
\hline
\end{tabular}




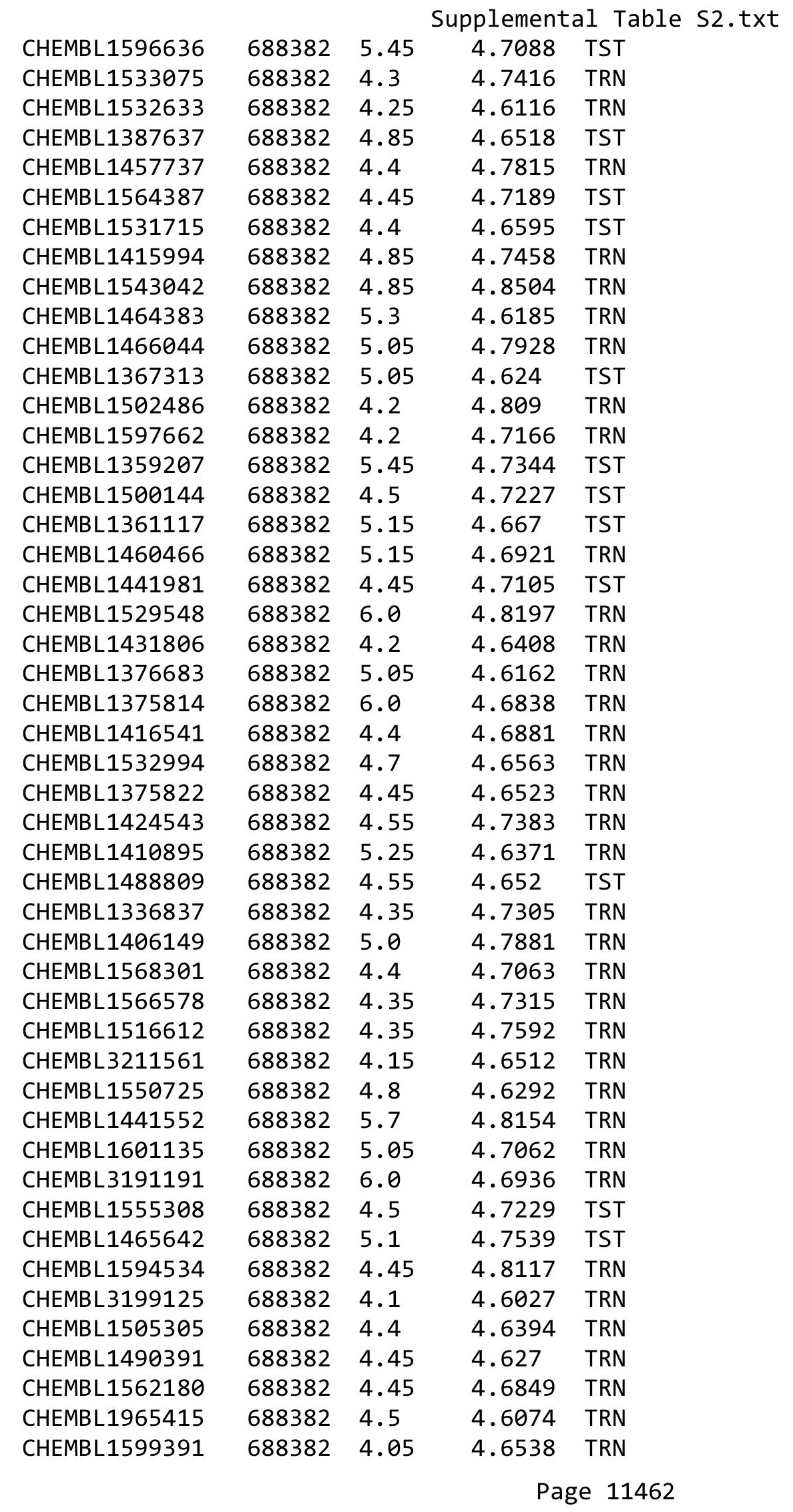




\begin{tabular}{|c|c|c|c|c|c|}
\hline \multicolumn{6}{|c|}{ Supplemental Table S2.txt } \\
\hline CHEMBL1581086 & 688382 & 4.1 & 4.7286 & TST & \\
\hline CHEMBL1599946 & 688382 & 4.5 & 4.6166 & TRN & \\
\hline CHEMBL1378757 & 688382 & 6.0 & 4.7731 & TRN & \\
\hline CHEMBL1478089 & 688382 & 5.5 & 4.6506 & TRN & \\
\hline CHEMBL1413275 & 688382 & 4.5 & 4.7634 & TRN & \\
\hline CHEMBL1313434 & 688382 & 6.0 & 4.7381 & TRN & \\
\hline CHEMBL1454588 & 688382 & 4.25 & 4.7818 & TST & \\
\hline CHEMBL1401161 & 688382 & 4.4 & 4.6671 & TRN & \\
\hline CHEMBL1430001 & 688382 & 5.0 & 4.8598 & TRN & \\
\hline CHEMBL1407274 & 688382 & 4.5 & 4.6572 & TRN & \\
\hline CHEMBL3193867 & 688382 & 5.8 & 4.6758 & TRN & \\
\hline CHEMBL1322883 & 688382 & 4.45 & 4.7451 & TRN & \\
\hline CHEMBL1356482 & 688382 & 4.7 & 4.6653 & TRN & \\
\hline CHEMBL1443489 & 688382 & 5.05 & 4.7927 & TRN & \\
\hline CHEMBL3199144 & 688382 & 5.1 & $4.6960 e$ & 0000000001 & TRN \\
\hline CHEMBL1339119 & 688382 & 4.2 & 4.7011 & TST & \\
\hline CHEMBL1523190 & 688382 & 4.05 & 4.7146 & TST & \\
\hline CHEMBL1592785 & 688382 & 4.5 & $4.6960 e$ & 2000000001 & TST \\
\hline CHEMBL2005664 & 688382 & 4.9 & 4.6342 & TRN & \\
\hline CHEMBL496758 & 688382 & 6.45 & 4.6805 & TRN & \\
\hline CHEMBL1607332 & 688382 & 4.9 & 4.7737 & TRN & \\
\hline CHEMBL3189770 & 688382 & 4.55 & 4.6834 & TST & \\
\hline CHEMBL1483080 & 688382 & 4.05 & 4.6042 & TRN & \\
\hline CHEMBL1481547 & 688382 & 6.0 & 4.721 & TRN & \\
\hline CHEMBL1533327 & 688382 & 4.85 & 4.7189 & TRN & \\
\hline CHEMBL1359133 & 688382 & 4.15 & 4.6671 & TRN & \\
\hline CHEMBL1534191 & 688382 & 4.1 & 4.7995 & TRN & \\
\hline CHEMBL1610899 & 688382 & 4.3 & 4.7162 & TST & \\
\hline CHEMBL1411687 & 688382 & 4.15 & 4.6682 & TRN & \\
\hline CHEMBL1420292 & 688382 & 4.85 & 4.6759 & TRN & \\
\hline CHEMBL1571046 & 688382 & 4.5 & 4.8159 & TRN & \\
\hline CHEMBL1985295 & 688382 & 4.25 & 4.7101 & TRN & \\
\hline CHEMBL1445477 & 688382 & 4.15 & 4.7561 & TRN & \\
\hline CHEMBL3191669 & 688382 & 3.95 & 4.6627 & TRN & \\
\hline CHEMBL1403085 & 688382 & 4.4 & 4.6291 & TRN & \\
\hline CHEMBL1574942 & 688382 & 4.15 & 4.6734 & TRN & \\
\hline CHEMBL1379167 & 688382 & 4.85 & 4.7302 & TRN & \\
\hline CHEMBL1564638 & 688382 & 4.05 & 4.6481 & TRN & \\
\hline CHEMBL1310510 & 688382 & 4.55 & 4.8321 & TRN & \\
\hline CHEMBL1540039 & 688382 & 5.05 & 4.8032 & TRN & \\
\hline CHEMBL1611444 & 688382 & 4.5 & 4.6644 & TRN & \\
\hline CHEMBL1563006 & 688382 & 5.05 & 4.7671 & TRN & \\
\hline CHEMBL1584858 & 688382 & 4.85 & 4.7177 & TST & \\
\hline CHEMBL1425262 & 688382 & 4.45 & 4.731 & TRN & \\
\hline CHEMBL53268 & 688382 & 5.85 & 4.6733 & TST & \\
\hline CHEMBL1595338 & 688382 & 4.4 & 4.7015 & TST & \\
\hline CHEMBL1451845 & 688382 & 4.5 & 4.749 & TRN & \\
\hline CHEMBL1370719 & 688382 & 4.9 & 4.5947 & TRN & \\
\hline
\end{tabular}




\begin{tabular}{|c|c|c|c|c|}
\hline & & & pplement & \\
\hline CHEMBL1558633 & 688382 & 4.5 & 4.6928 & TRN \\
\hline CHEMBL1360826 & 688382 & 6.6 & 4.7328 & TRN \\
\hline CHEMBL3213271 & 688382 & 5.5 & 4.6644 & TRN \\
\hline CHEMBL3209148 & 688382 & 4.0 & 4.6899 & TRN \\
\hline CHEMBL1448963 & 688382 & 4.4 & 4.6923 & TRN \\
\hline CHEMBL1382191 & 688382 & 4.4 & 4.6509 & TST \\
\hline CHEMBL1610416 & 688382 & 4.8 & 4.6229 & TRN \\
\hline CHEMBL1416832 & 688382 & 4.8 & 4.6616 & TST \\
\hline CHEMBL1388398 & 688382 & 4.15 & 4.7086 & TRN \\
\hline CHEMBL1535130 & 688382 & 5.05 & 4.7353 & TRN \\
\hline CHEMBL1558400 & 688382 & 4.45 & 4.6492 & TST \\
\hline CHEMBL1459044 & 688382 & 4.4 & 4.7076 & TRN \\
\hline CHEMBL1452557 & 688382 & 4.15 & 4.8524 & TRN \\
\hline CHEMBL1469255 & 688382 & 4.35 & 4.7552 & TRN \\
\hline CHEMBL1343235 & 688382 & 6.3 & 4.8097 & TST \\
\hline CHEMBL1532649 & 688382 & 4.55 & 4.6989 & TRN \\
\hline CHEMBL1305050 & 688382 & 4.15 & 4.7398 & TRN \\
\hline CHEMBL1564198 & 688382 & 4.55 & 4.7625 & TRN \\
\hline CHEMBL1422371 & 688382 & 4.85 & 4.7791 & TRN \\
\hline CHEMBL1596518 & 688382 & 5.15 & 4.7758 & TRN \\
\hline CHEMBL3196420 & 688382 & 5.85 & 4.7032 & TRN \\
\hline CHEMBL1332791 & 688382 & 5.0 & 4.7693 & TRN \\
\hline CHEMBL1529238 & 688382 & 4.5 & 4.7084 & TRN \\
\hline CHEMBL1341586 & 688382 & 4.55 & 4.6295 & TRN \\
\hline CHEMBL1589778 & 688382 & 4.45 & 4.6899 & TST \\
\hline CHEMBL1526942 & 688382 & 5.25 & 4.7522 & TRN \\
\hline CHEMBL1400885 & 688382 & 4.5 & 4.6887 & TST \\
\hline CHEMBL1455873 & 688382 & 4.95 & 4.6731 & TRN \\
\hline CHEMBL1526714 & 688382 & 5.5 & 4.762 & TST \\
\hline CHEMBL1517372 & 688382 & 4.5 & 4.6831 & TST \\
\hline CHEMBL1478224 & 688382 & 6.0 & 4.7657 & TRN \\
\hline CHEMBL1431956 & 688382 & 4.9 & 4.7365 & TRN \\
\hline CHEMBL3195313 & 688382 & 4.45 & 4.7307 & TRN \\
\hline CHEMBL1598879 & 688382 & 4.1 & 4.6713 & TST \\
\hline CHEMBL3198822 & 688382 & 4.45 & 4.6507 & TRN \\
\hline CHEMBL1573026 & 688382 & 4.2 & 4.6524 & TRN \\
\hline CHEMBL1609062 & 688382 & 5.8 & 4.6057 & TRN \\
\hline CHEMBL1536781 & 688382 & 4.05 & 4.7674 & TRN \\
\hline CHEMBL1328972 & 688382 & 4.15 & 4.6167 & TST \\
\hline CHEMBL1536243 & 688382 & 4.45 & 4.748 & TRN \\
\hline CHEMBL1306347 & 688382 & 4.75 & 4.595 & TRN \\
\hline CHEMBL3198954 & 688382 & 5.1 & 4.7248 & TRN \\
\hline CHEMBL1412068 & 688382 & 5.05 & 4.6632 & TRN \\
\hline CHEMBL1519899 & 688382 & 4.4 & 4.6563 & TST \\
\hline CHEMBL3214598 & 688382 & 4.4 & 4.6498 & TRN \\
\hline CHEMBL1612985 & 688382 & 4.6 & 4.7626 & TRN \\
\hline CHEMBL1529180 & 688382 & 4.85 & 4.7132 & TRN \\
\hline CHEMBL1596386 & 688382 & 5.95 & 4.7865 & TRN \\
\hline
\end{tabular}




\begin{tabular}{|c|c|c|c|c|c|}
\hline \\
\hline CHEMBL1608380 & 688382 & 4.8 & 4.8454 & TRN & \\
\hline CHEMBL1379105 & 688382 & 4.8 & 4.8024 & TRN & \\
\hline CHEMBL1579157 & 688382 & 4.65 & 4.6708 & TRN & \\
\hline CHEMBL1586179 & 688382 & 5.1 & 4.6579 & TRN & \\
\hline CHEMBL1485238 & 688382 & 4.45 & 4.75899 & 99999999995 & TRN \\
\hline CHEMBL1600541 & 688382 & 5.25 & 4.6913 & TRN & \\
\hline CHEMBL1404163 & 688382 & 4.5 & 4.6316 & TRN & \\
\hline CHEMBL1576986 & 688382 & 4.55 & 4.7862 & TRN & \\
\hline CHEMBL1400233 & 688382 & 4.45 & 4.7654 & TRN & \\
\hline CHEMBL1452415 & 688382 & 4.35 & 4.6832 & TST & \\
\hline CHEMBL1318751 & 688382 & 4.45 & 4.6763 & TRN & \\
\hline CHEMBL1466552 & 688382 & 3.95 & 4.6907 & TST & \\
\hline CHEMBL1570486 & 688382 & 6.05 & 4.7041 & TST & \\
\hline CHEMBL1373531 & 688382 & 5.0 & 4.7342 & TRN & \\
\hline CHEMBL1306355 & 688382 & 4.45 & 4.7132 & TRN & \\
\hline CHEMBL1561061 & 688382 & 5.1 & 4.7568 & TRN & \\
\hline CHEMBL1354031 & 688382 & 4.5 & 4.6134 & TRN & \\
\hline CHEMBL1462176 & 688382 & 4.15 & 4.6487 & TRN & \\
\hline CHEMBL1487455 & 688382 & 4.8 & 4.7786 & TST & \\
\hline CHEMBL1310361 & 688382 & 4.85 & 4.707 & TRN & \\
\hline CHEMBL1496097 & 688382 & 5.55 & 4.7817 & TRN & \\
\hline CHEMBL1392303 & 688382 & 4.85 & 4.7839 & TRN & \\
\hline CHEMBL1465630 & 688382 & 4.45 & 4.6887 & TST & \\
\hline CHEMBL1516590 & 688382 & 6.05 & 4.6942 & TST & \\
\hline CHEMBL1491475 & 688382 & 4.05 & 4.6765 & TRN & \\
\hline CHEMBL1548102 & 688382 & 4.45 & 4.7474 & TRN & \\
\hline CHEMBL1583892 & 688382 & 4.7 & 4.80399 & 9999999999 & TRN \\
\hline CHEMBL1559722 & 688382 & 4.2 & 4.7188 & TRN & \\
\hline CHEMBL1500393 & 688382 & 5.05 & 4.7334 & TRN & \\
\hline CHEMBL3192566 & 688382 & 4.05 & 4.6779 & TST & \\
\hline CHEMBL3209591 & 688382 & 4.5 & 4.6502 & TRN & \\
\hline CHEMBL1540357 & 688382 & 4.5 & 4.8116 & TST & \\
\hline CHEMBL1576676 & 688382 & 4.15 & 4.6957 & TRN & \\
\hline CHEMBL1305435 & 688382 & 4.0 & 4.7732 & TRN & \\
\hline CHEMBL1484972 & 688382 & 4.45 & 4.6536 & TRN & \\
\hline CHEMBL1499429 & 688382 & 4.45 & 4.6744 & TRN & \\
\hline CHEMBL1303579 & 688382 & 4.45 & 4.7116 & TRN & \\
\hline CHEMBL1497261 & 688382 & 5.95 & 4.7022 & TRN & \\
\hline CHEMBL1503992 & 688382 & 4.4 & 4.787 & TRN & \\
\hline CHEMBL1415937 & 688382 & 4.45 & 4.6938 & TST & \\
\hline CHEMBL1538805 & 688382 & 4.85 & 4.6317 & TST & \\
\hline CHEMBL1439393 & 688382 & 5.8 & 4.7274 & TRN & \\
\hline CHEMBL1435015 & 688382 & 5.8 & 4.6954 & TRN & \\
\hline CHEMBL1444135 & 688382 & 4.5 & 4.7057 & TST & \\
\hline CHEMBL1277546 & 688382 & 4.5 & 4.5827 & TST & \\
\hline CHEMBL1515423 & 688382 & 5.0 & 4.7175 & TRN & \\
\hline CHEMBL1523192 & 688382 & 4.45 & 4.5895 & TRN & \\
\hline CHEMBL1462718 & 688382 & 4.5 & 4.8246 & TST & \\
\hline
\end{tabular}




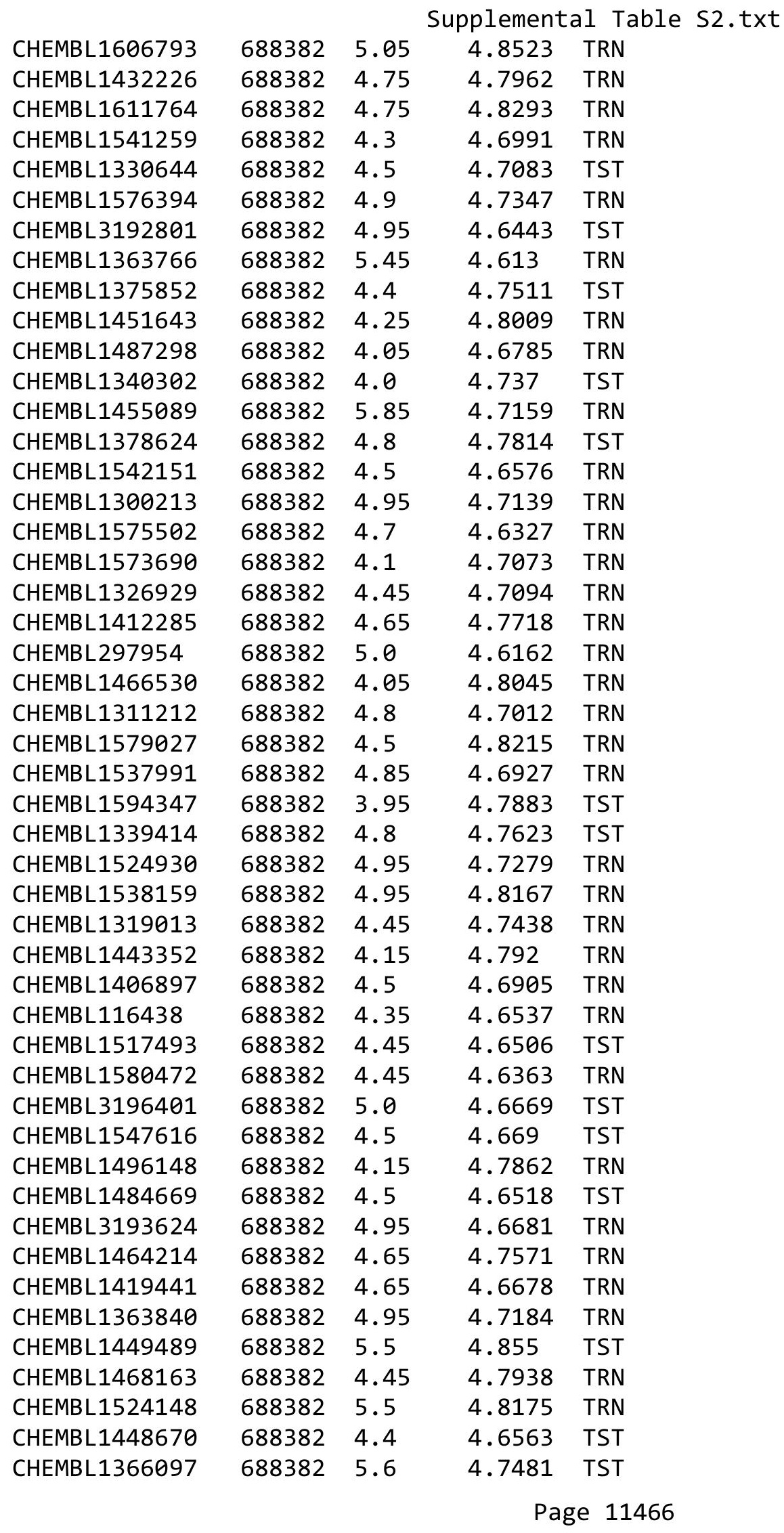




\begin{tabular}{|c|c|c|c|c|c|}
\hline & & \multicolumn{4}{|c|}{ Supplemental Table s2.txt } \\
\hline CHEMBL1495805 & 688382 & 4.45 & 4.6622 & TRN & \\
\hline CHEMBL1507312 & 688382 & 4.55 & 4.6808 & TST & \\
\hline CHEMBL1320143 & 688382 & 5.3 & 4.7409 & TRN & \\
\hline CHEMBL1562832 & 688382 & 4.2 & 4.7314 & TST & \\
\hline CHEMBL1409714 & 688382 & 4.25 & 4.6582 & TST & \\
\hline CHEMBL1470096 & 688382 & 4.7 & 4.8381 & TRN & \\
\hline CHEMBL1458817 & 688382 & 4.95 & 4.7388 & TRN & \\
\hline CHEMBL 3144962 & 688382 & 4.5 & 4.6486 & TRN & \\
\hline CHEMBL1305728 & 688382 & 5.05 & 4.7444 & TRN & \\
\hline CHEMBL1341999 & 688382 & 5.4 & 4.7153 & TRN & \\
\hline CHEMBL1438084 & 688382 & 4.3 & 4.6373 & TST & \\
\hline CHEMBL1399231 & 688382 & 4.4 & 4.8164 & TST & \\
\hline CHEMBL1522743 & 688382 & 5.05 & 4.6606 & TRN & \\
\hline CHEMBL1302656 & 688382 & 4.2 & 4.6373 & TRN & \\
\hline CHEMBL1381873 & 688382 & 4.45 & 4.6065 & TST & \\
\hline CHEMBL1455605 & 688382 & 5.0 & 4.7357 & TRN & \\
\hline CHEMBL1404369 & 688382 & 4.05 & 4.763 & TRN & \\
\hline CHEMBL1413031 & 688382 & 4.65 & 4.7373 & TRN & \\
\hline CHEMBL1404230 & 688382 & 4.25 & 4.6485 & TST & \\
\hline CHEMBL1350514 & 688382 & 4.5 & 4.7032 & TRN & \\
\hline CHEMBL1578424 & 688382 & 5.2 & 4.7978 & TRN & \\
\hline CHEMBL1344001 & 688382 & 5.8 & 4.8088 & TRN & \\
\hline CHEMBL1443244 & 688382 & 5.05 & 4.7643 & TRN & \\
\hline CHEMBL1424661 & 688382 & 4.05 & 4.5961 & TST & \\
\hline CHEMBL1557756 & 688382 & 5.55 & 4.6754 & TST & \\
\hline CHEMBL1376523 & 688382 & 4.15 & 4.86 & TRN & \\
\hline CHEMBL1973435 & 688382 & 5.2 & 4.6358 & TST & \\
\hline CHEMBL1348540 & 688382 & 3.95 & 4.8381 & TRN & \\
\hline CHEMBL175434 & 688382 & 4.5 & 4.6826 & TRN & \\
\hline CHEMBL1538642 & 688382 & 5.3 & 4.7631 & TRN & \\
\hline CHEMBL1569824 & 688382 & 4.85 & 4.7809 & TST & \\
\hline CHEMBL1350637 & 688382 & 5.1 & 4.7429 & TRN & \\
\hline CHEMBL1377181 & 688382 & 4.05 & 4.6379 & TRN & \\
\hline CHEMBL1541410 & 688382 & 4.2 & 4.6031 & TRN & \\
\hline CHEMBL1458704 & 688382 & 4.35 & 4.7033 & TRN & \\
\hline CHEMBL1361720 & 688382 & 5.9 & 4.7625 & TST & \\
\hline CHEMBL1425226 & 688382 & 5.0 & 4.6444 & TRN & \\
\hline CHEMBL1579957 & 688382 & 4.8 & 4.77800 & 00000000005 & TRN \\
\hline CHEMBL1492002 & 688382 & 4.15 & 4.7131 & TRN & \\
\hline CHEMBL1349499 & 688382 & 5.85 & 4.7399 & TRN & \\
\hline CHEMBL1548678 & 688382 & 5.1 & 4.6384 & TST & \\
\hline CHEMBL1588153 & 688382 & 5.1 & 4.6807 & TRN & \\
\hline CHEMBL1608184 & 688382 & 4.95 & 4.6854 & TRN & \\
\hline CHEMBL1348043 & 688382 & 4.5 & 4.7956 & TRN & \\
\hline CHEMBL1321838 & 688382 & 4.45 & 4.6611 & TRN & \\
\hline CHEMBL1611767 & 688382 & 4.5 & 4.6278 & TRN & \\
\hline CHEMBL1524962 & 688382 & 4.85 & 4.7951 & TRN & \\
\hline CHEMBL339587 & 688382 & 4.5 & 4.6364 & TRN & \\
\hline
\end{tabular}




\begin{tabular}{|c|c|c|c|c|}
\hline \multicolumn{5}{|c|}{ Supplemental T } \\
\hline CHEMBL1354737 & 688382 & 5.0 & 4.7739 & TRN \\
\hline CHEMBL1335223 & 688382 & 4.5 & 4.6721 & TRN \\
\hline CHEMBL1392292 & 688382 & 4.4 & 4.5875 & TRN \\
\hline CHEMBL1406828 & 688382 & 4.15 & 4.6763 & TRN \\
\hline CHEMBL1347383 & 688382 & 5.0 & 4.7305 & TRN \\
\hline CHEMBL1503780 & 688382 & 4.1 & 4.643 & TRN \\
\hline CHEMBL1582387 & 688382 & 3.95 & 4.796 & TST \\
\hline CHEMBL1320710 & 688382 & 4.8 & 4.7855 & TST \\
\hline CHEMBL1581773 & 688382 & 4.9 & 4.6684 & TRN \\
\hline CHEMBL394197 & 688382 & 4.6 & 4.6587 & TRN \\
\hline CHEMBL1327478 & 688382 & 4.95 & 4.655 & TRN \\
\hline CHEMBL1547443 & 688382 & 4.05 & 4.6901 & TST \\
\hline CHEMBL1344177 & 688382 & 4.8 & 4.7643 & TST \\
\hline CHEMBL1387172 & 688382 & 4.7 & 4.6126 & TRN \\
\hline CHEMBL1403704 & 688382 & 4.2 & 4.8292 & TRN \\
\hline CHEMBL1507537 & 688382 & 5.0 & 4.6347 & TST \\
\hline CHEMBL1562170 & 688382 & 4.5 & 4.5937 & TRN \\
\hline CHEMBL1579430 & 688382 & 5.9 & 4.7411 & TRN \\
\hline CHEMBL3193862 & 688382 & 4.5 & 4.6188 & TRN \\
\hline CHEMBL1583864 & 688382 & 5.05 & 4.7208 & TRN \\
\hline CHEMBL1522102 & 688382 & 3.9 & 4.7732 & TRN \\
\hline CHEMBL1484839 & 688382 & 4.55 & 4.6424 & TST \\
\hline CHEMBL1464622 & 688382 & 5.2 & 4.6184 & TRN \\
\hline CHEMBL3194013 & 688382 & 4.5 & 4.6425 & TRN \\
\hline CHEMBL1573255 & 688382 & 5.05 & 4.8001 & TRN \\
\hline CHEMBL1310341 & 688382 & 4.4 & 4.6278 & TRN \\
\hline CHEMBL1465425 & 688382 & 4.05 & 4.6976 & TST \\
\hline CHEMBL1503333 & 688382 & 5.0 & 4.6444 & TST \\
\hline CHEMBL1429570 & 688382 & 4.4 & 4.6722 & TST \\
\hline CHEMBL3190790 & 688382 & 4.95 & 4.7087 & TST \\
\hline CHEMBL1453598 & 688382 & 4.05 & 4.817 & TRN \\
\hline CHEMBL1577457 & 688382 & 4.7 & 4.717 & TRN \\
\hline CHEMBL1607663 & 688382 & 4.25 & 4.6814 & TRN \\
\hline CHEMBL1571892 & 688382 & 4.55 & 4.6981 & TRN \\
\hline CHEMBL1404761 & 688382 & 4.45 & 4.6195 & TRN \\
\hline CHEMBL1528118 & 688382 & 5.85 & 4.8102 & TRN \\
\hline CHEMBL1412894 & 688382 & 4.6 & 4.7547 & TRN \\
\hline CHEMBL1350952 & 688382 & 4.5 & 4.6861 & TRN \\
\hline CHEMBL3196426 & 688382 & 4.2 & 4.6561 & TST \\
\hline CHEMBL3199331 & 688382 & 4.7 & 4.6484 & TRN \\
\hline CHEMBL1489743 & 688382 & 4.45 & 4.6524 & TST \\
\hline CHEMBL1429797 & 688382 & 4.5 & 4.6486 & TRN \\
\hline CHEMBL1594468 & 688382 & 4.45 & 4.7166 & TRN \\
\hline CHEMBL1460034 & 688382 & 5.2 & 4.7115 & TRN \\
\hline CHEMBL1544987 & 688382 & 4.5 & 4.6979 & TRN \\
\hline CHEMBL1362528 & 688382 & 4.85 & 4.8782 & TRN \\
\hline CHEMBL1604400 & 688382 & 4.85 & 4.8077 & TST \\
\hline CHEMBL1484076 & 688382 & 4.45 & 4.7268 & TRN \\
\hline
\end{tabular}




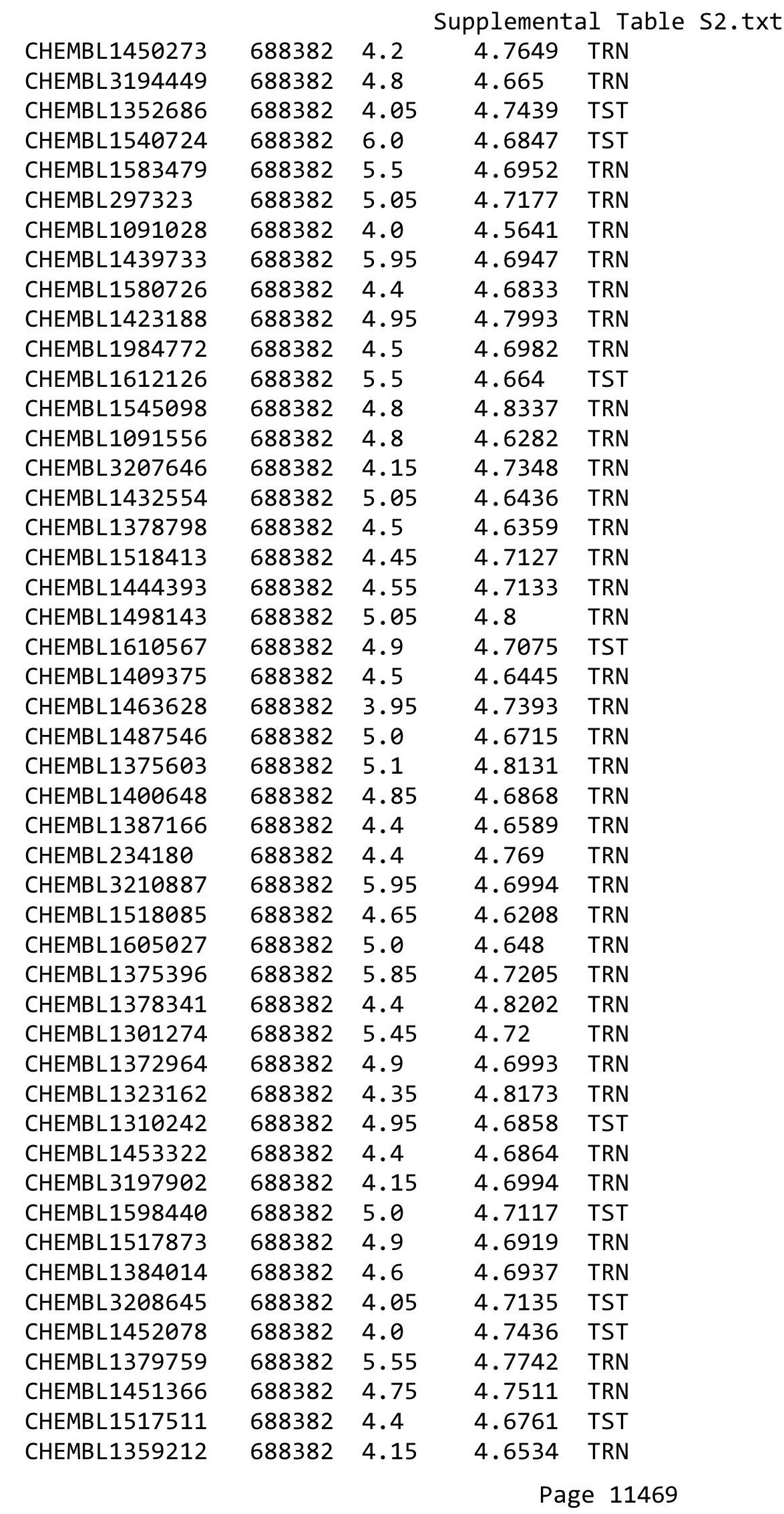




\begin{tabular}{|c|c|c|c|c|c|}
\hline \multicolumn{6}{|c|}{ Supplemental Table S2.txt } \\
\hline CHEMBL1435026 & 688382 & 4.15 & 4.6896 & TST & \\
\hline CHEMBL1402878 & 688382 & 4.45 & 4.649 & TRN & \\
\hline CHEMBL1533425 & 688382 & 5.85 & 4.7974 & TRN & \\
\hline CHEMBL1560273 & 688382 & 5.45 & 4.6665 & TST & \\
\hline CHEMBL1516725 & 688382 & 5.8 & 4.6954 & TRN & \\
\hline CHEMBL3212050 & 688382 & 4.55 & 4.6857 & TRN & \\
\hline CHEMBL1543182 & 688382 & 4.7 & 4.7062 & TRN & \\
\hline CHEMBL1556344 & 688382 & 4.45 & 4.769 & TRN & \\
\hline CHEMBL1413510 & 688382 & 5.35 & 4.617 & TRN & \\
\hline CHEMBL1304166 & 688382 & 4.35 & 4.7432 & TRN & \\
\hline CHEMBL1509753 & 688382 & 4.4 & 4.7115 & TST & \\
\hline CHEMBL1979607 & 688382 & 4.05 & 4.633 & TRN & \\
\hline CHEMBL1454185 & 688382 & 4.15 & 4.7544 & TRN & \\
\hline CHEMBL1353194 & 688382 & 4.5 & 4.6653 & TRN & \\
\hline CHEMBL1546658 & 688382 & 4.55 & 4.6905 & TRN & \\
\hline CHEMBL1092114 & 688382 & 4.6 & 4.6439 & TRN & \\
\hline CHEMBL1352684 & 688382 & 5.0 & 4.7436 & TST & \\
\hline CHEMBL1344289 & 688382 & 4.5 & 4.6873 & TRN & \\
\hline CHEMBL 3212487 & 688382 & 4.15 & 4.7438 & TST & \\
\hline CHEMBL1433803 & 688382 & 4.0 & 4.8324 & TST & \\
\hline CHEMBL3191307 & 688382 & 4.15 & 4.7197 & TRN & \\
\hline CHEMBL1998302 & 688382 & 4.65 & 4.7031 & TRN & \\
\hline CHEMBL1381728 & 688382 & 4.8 & 4.6976 & TRN & \\
\hline CHEMBL1467332 & 688382 & 4.1 & 4.651 & TRN & \\
\hline CHEMBL1373589 & 688382 & 5.0 & 4.7594 & TRN & \\
\hline CHEMBL1566138 & 688382 & 4.2 & 4.6492 & TST & \\
\hline CHEMBL1978607 & 688382 & 5.1 & 4.5943 & TRN & \\
\hline CHEMBL1565940 & 688382 & 5.25 & 4.7933 & TST & \\
\hline CHEMBL1457740 & 688382 & 4.0 & 4.7196 & TST & \\
\hline CHEMBL1604340 & 688382 & 5.5 & 4.7772 & TRN & \\
\hline CHEMBL1376921 & 688382 & 4.85 & 4.8114 & TRN & \\
\hline CHEMBL1585940 & 688382 & 4.5 & 4.7173 & TRN & \\
\hline CHEMBL1499859 & 688382 & 4.5 & 4.7317 & TRN & \\
\hline CHEMBL1343136 & 688382 & 5.0 & 4.7811 & TST & \\
\hline CHEMBL1470428 & 688382 & 4.6 & 4.7558 & TRN & \\
\hline CHEMBL1391684 & 688382 & 4.85 & 4.6158 & TRN & \\
\hline CHEMBL1371718 & 688382 & 4.2 & 4.7576 & TRN & \\
\hline CHEMBL1539404 & 688382 & 4.8 & 4.6807 & TRN & \\
\hline CHEMBL1324988 & 688382 & 4.9 & 4.6843 & TST & \\
\hline CHEMBL3199876 & 688382 & 4.35 & 4.6622 & TST & \\
\hline CHEMBL1457875 & 688382 & 5.85 & 4.7261 & TST & \\
\hline CHEMBL1565780 & 688382 & 4.45 & 4.6772 & TRN & \\
\hline CHEMBL1323517 & 688382 & 4.2 & 4.77 & TST & \\
\hline CHEMBL1555663 & 688382 & 4.45 & 4.6595 & TRN & \\
\hline CHEMBL1352509 & 688382 & 4.0 & 4.7277 & TST & \\
\hline CHEMBL1481408 & 688382 & 4.5 & 4.7647 & TRN & \\
\hline CHEMBL1443717 & 688382 & 4.45 & 4.77800 & 00000000005 & TRN \\
\hline CHEMBL1506968 & 688382 & 5.8 & 4.7203 & TRN & \\
\hline
\end{tabular}




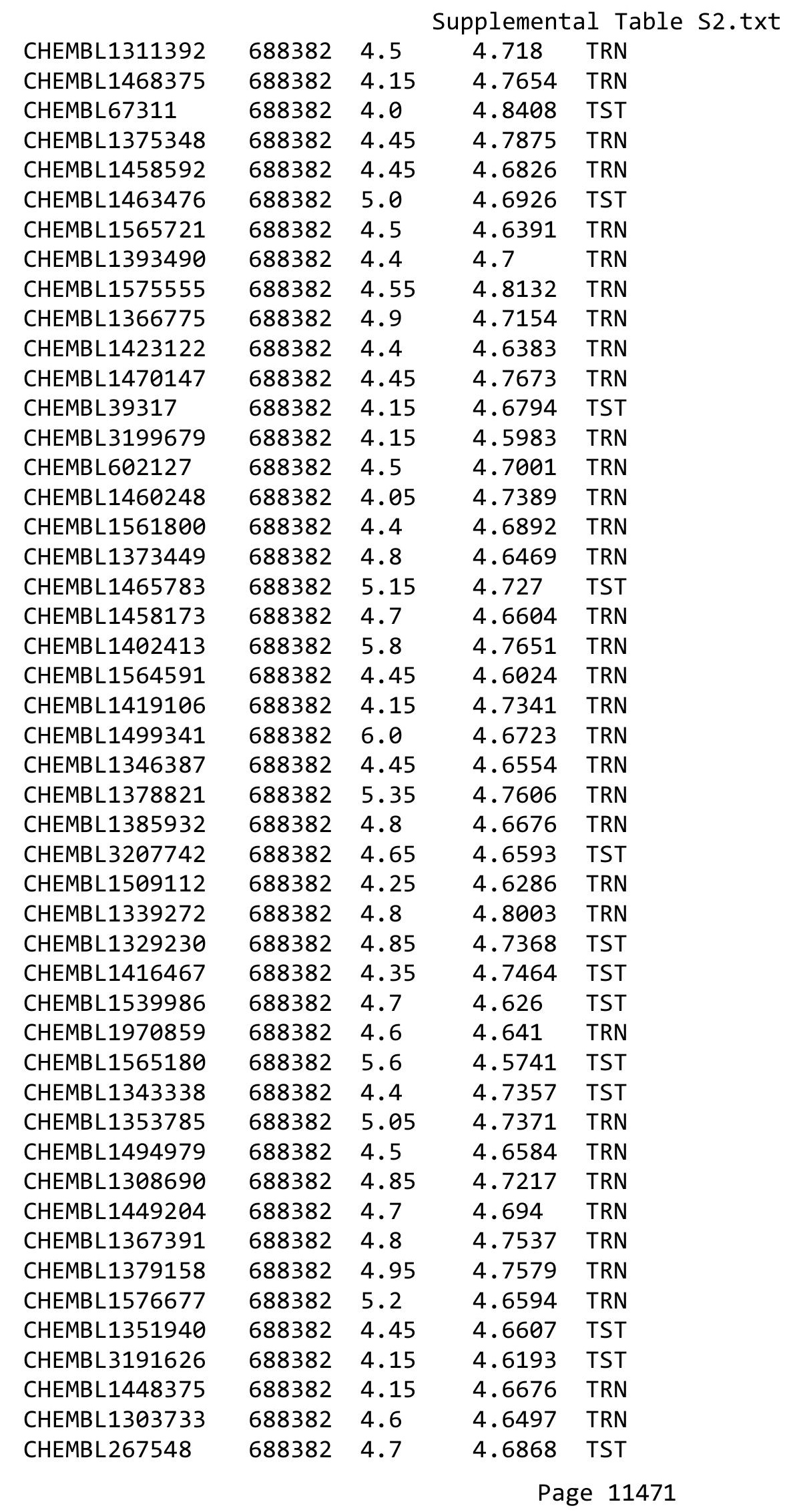




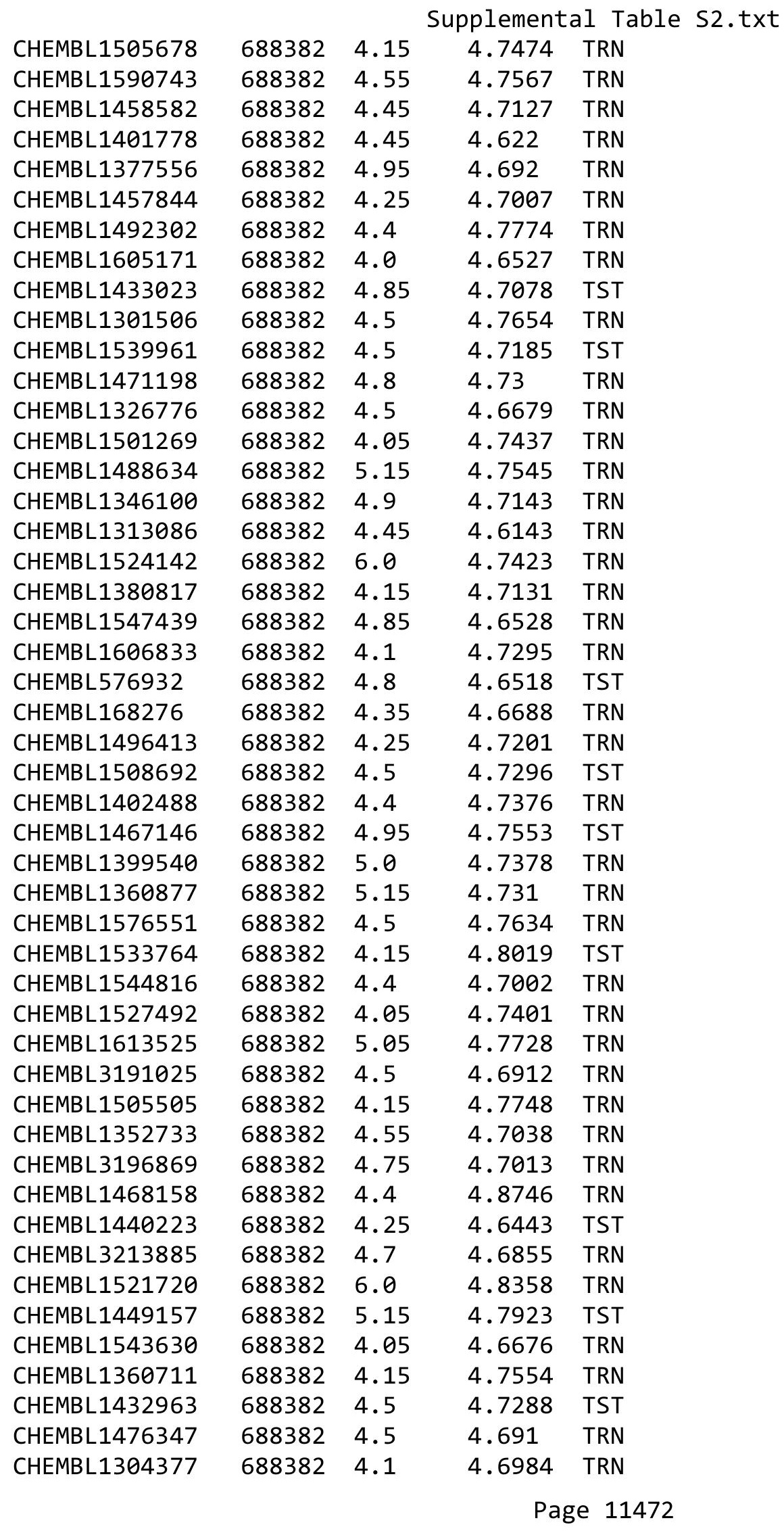




\begin{tabular}{|c|c|c|c|c|}
\hline & & \multicolumn{3}{|c|}{ Supplemental Table S2.txt } \\
\hline CHEMBL1387404 & 688382 & 4.15 & 4.6785 & TRN \\
\hline CHEMBL1408718 & 688382 & 6.9 & 4.7614 & TRN \\
\hline CHEMBL1343502 & 688382 & 4.95 & 4.7145 & TRN \\
\hline CHEMBL1516638 & 688382 & 4.5 & 4.6863 & TST \\
\hline CHEMBL1613213 & 688382 & 4.55 & 4.612 & TRN \\
\hline CHEMBL1320259 & 688382 & 5.9 & 4.792 & TST \\
\hline CHEMBL1495945 & 688382 & 4.05 & 4.7803 & TRN \\
\hline CHEMBL1543364 & 688382 & 4.8 & 4.7082 & TST \\
\hline CHEMBL3190756 & 688382 & 4.45 & 4.5469 & TST \\
\hline CHEMBL1608313 & 688382 & 5.8 & 4.704 & TRN \\
\hline CHEMBL1496834 & 688382 & 4.4 & 4.7621 & TRN \\
\hline CHEMBL1528575 & 688382 & 4.8 & 4.6271 & TRN \\
\hline CHEMBL1434292 & 688382 & 4.95 & 4.6316 & TRN \\
\hline CHEMBL1346176 & 688382 & 4.4 & 4.7874 & TRN \\
\hline CHEMBL1324013 & 688382 & 5.05 & 4.7925 & TRN \\
\hline CHEMBL1548210 & 688382 & 4.5 & 4.7187 & TRN \\
\hline CHEMBL1346019 & 688382 & 5.55 & 4.7293 & TST \\
\hline CHEMBL1352736 & 688382 & 4.85 & 4.8185 & TRN \\
\hline CHEMBL1330184 & 688382 & 4.45 & 4.6792 & TRN \\
\hline CHEMBL1558560 & 688382 & 4.0 & 4.83 & TRN \\
\hline CHEMBL1336552 & 688382 & 6.05 & 4.7518 & TST \\
\hline CHEMBL3191797 & 688382 & 4.05 & 4.6811 & TRN \\
\hline CHEMBL1424152 & 688382 & 6.0 & 4.6616 & TRN \\
\hline CHEMBL1551865 & 688382 & 4.15 & 4.7305 & TRN \\
\hline CHEMBL1559583 & 688382 & 4.95 & 4.6965 & TRN \\
\hline CHEMBL1344676 & 688382 & 4.8 & 4.8317 & TRN \\
\hline CHEMBL1580237 & 688382 & 4.3 & 4.6523 & TST \\
\hline CHEMBL1369592 & 688382 & 4.3 & 4.6579 & TRN \\
\hline CHEMBL1581949 & 688382 & 4.05 & 4.6716 & TST \\
\hline CHEMBL1511630 & 688382 & 4.95 & 4.744 & TRN \\
\hline CHEMBL 2448506 & 688382 & 4.6 & 4.7408 & TST \\
\hline CHEMBL1452554 & 688382 & 4.45 & 4.7839 & TRN \\
\hline CHEMBL1565723 & 688382 & 4.8 & 4.8191 & TRN \\
\hline CHEMBL1433359 & 688382 & 4.75 & 4.5758 & TRN \\
\hline CHEMBL3191088 & 688382 & 4.5 & 4.6854 & TST \\
\hline CHEMBL1344392 & 688382 & 4.45 & 4.6699 & TRN \\
\hline CHEMBL1381086 & 688382 & 5.05 & 4.6844 & TRN \\
\hline CHEMBL3190328 & 688382 & 5.05 & 4.6807 & TST \\
\hline CHEMBL1471012 & 688382 & 4.5 & 4.6606 & TST \\
\hline CHEMBL3192514 & 688382 & 5.0 & 4.621 & TST \\
\hline CHEMBL1603917 & 688382 & 5.15 & 4.7328 & TRN \\
\hline CHEMBL1994540 & 688382 & 4.75 & 4.6336 & TRN \\
\hline CHEMBL1393283 & 688382 & 4.35 & 4.6992 & TRN \\
\hline CHEMBL1494611 & 688382 & 4.45 & 4.6756 & TST \\
\hline CHEMBL1540862 & 688382 & 4.5 & 4.6576 & TRN \\
\hline CHEMBL1431353 & 688382 & 4.3 & 4.676 & TRN \\
\hline CHEMBL1420077 & 688382 & 4.55 & 4.6908 & TRN \\
\hline CHEMBL1361820 & 688382 & 4.15 & 4.7586 & TRN \\
\hline
\end{tabular}




\begin{tabular}{|c|c|c|c|c|c|}
\hline \multicolumn{6}{|c|}{ Supplemental Table s2.txt } \\
\hline CHEMBL1528768 & 688382 & 4.9 & 4.6617 & TRN & \\
\hline CHEMBL1361290 & 688382 & 4.45 & 4.73 & TST & \\
\hline CHEMBL1599995 & 688382 & 4.15 & 4.717 & TRN & \\
\hline CHEMBL1567327 & 688382 & 4.8 & 4.7274 & TRN & \\
\hline CHEMBL1494725 & 688382 & 4.45 & 4.7259 & TST & \\
\hline CHEMBL1319175 & 688382 & 4.05 & 4.6919 & TRN & \\
\hline CHEMBL1450350 & 688382 & 5.8 & 4.6972 & TRN & \\
\hline CHEMBL1332020 & 688382 & 4.15 & 4.7424 & TRN & \\
\hline CHEMBL1390632 & 688382 & 4.7 & 4.63 & TRN & \\
\hline CHEMBL1351233 & 688382 & 4.85 & 4.7704 & TST & \\
\hline CHEMBL3190990 & 688382 & 4.7 & 4.6297 & TRN & \\
\hline CHEMBL1448070 & 688382 & 4.15 & 4.6151 & TST & \\
\hline CHEMBL1537106 & 688382 & 4.45 & 4.6649 & TRN & \\
\hline CHEMBL1505675 & 688382 & 4.0 & 4.7593 & TRN & \\
\hline CHEMBL1601697 & 688382 & 5.15 & 4.6845 & TST & \\
\hline CHEMBL1494767 & 688382 & 4.5 & 4.5995 & TRN & \\
\hline CHEMBL1303303 & 688382 & 4.5 & 4.644 & TRN & \\
\hline CHEMBL1521076 & 688382 & 4.9 & 4.687 & TRN & \\
\hline CHEMBL1388603 & 688382 & 4.6 & 4.6347 & TRN & \\
\hline CHEMBL1391503 & 688382 & 4.5 & 4.7583 & TRN & \\
\hline CHEMBL1586510 & 688382 & 5.5 & 4.6907 & TST & \\
\hline CHEMBL1505711 & 688382 & 5.0 & 4.6473 & TST & \\
\hline CHEMBL3193654 & 688382 & 4.15 & 4.705 & TST & \\
\hline CHEMBL1301371 & 688382 & 4.8 & 4.6907 & TRN & \\
\hline CHEMBL1430498 & 688382 & 4.35 & 4.7371 & TRN & \\
\hline CHEMBL1390351 & 688382 & 4.4 & 4.7483 & TRN & \\
\hline CHEMBL1392191 & 688382 & 4.5 & 4.7521 & TRN & \\
\hline CHEMBL1383746 & 688382 & 5.05 & 4.717 & TRN & \\
\hline CHEMBL1354016 & 688382 & 4.35 & 4.6531 & TRN & \\
\hline CHEMBL3197553 & 688382 & 4.4 & 4.5808 & TST & \\
\hline CHEMBL1538730 & 688382 & 4.5 & 4.8126 & TRN & \\
\hline CHEMBL1328817 & 688382 & 4.5 & 4.6694 & TRN & \\
\hline CHEMBL1479738 & 688382 & 4.5 & 4.6727 & TRN & \\
\hline CHEMBL3191438 & 688382 & 4.85 & 4.6884 & TST & \\
\hline CHEMBL1979367 & 688382 & 4.75 & 4.652 & TRN & \\
\hline CHEMBL1467616 & 688382 & 4.15 & 4.7055 & TRN & \\
\hline CHEMBL1442893 & 688382 & 4.05 & 4.6475 & TST & \\
\hline CHEMBL1427130 & 688382 & 5.75 & $4.7410 e$ & 00000000005 & TRN \\
\hline CHEMBL1521984 & 688382 & 4.75 & 4.8412 & TST & \\
\hline CHEMBL1981303 & 688382 & 4.45 & 4.66 & TST & \\
\hline CHEMBL 2002849 & 688382 & 4.35 & 4.6123 & TRN & \\
\hline CHEMBL3145193 & 688382 & 4.65 & 4.6624 & TRN & \\
\hline CHEMBL1415238 & 688382 & 4.65 & 4.6917 & TST & \\
\hline CHEMBL1603478 & 688382 & 4.5 & 4.6621 & TRN & \\
\hline CHEMBL3208288 & 688382 & 4.65 & 4.6669 & TRN & \\
\hline CHEMBL458402 & 688382 & 4.05 & 4.6998 & TST & \\
\hline CHEMBL1611661 & 688382 & 4.85 & 4.7849 & TRN & \\
\hline CHEMBL3207752 & 688382 & 4.15 & 4.7259 & TST & \\
\hline
\end{tabular}




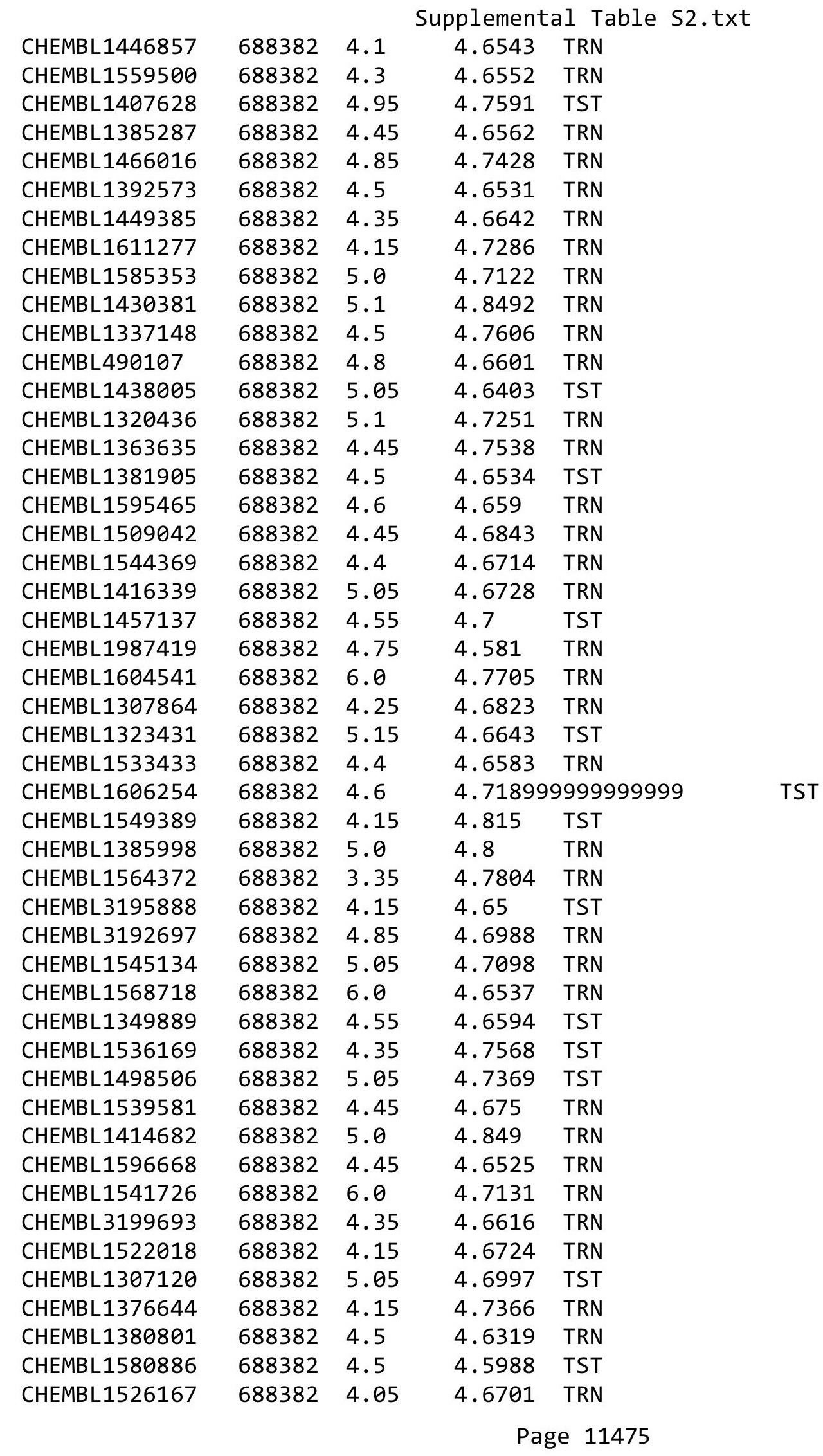




\begin{tabular}{|c|c|c|c|c|c|}
\hline & & \multicolumn{4}{|c|}{ Supplemental Table s2.txt } \\
\hline CHEMBL1405475 & 688382 & 5.05 & 4.6268 & TRN & \\
\hline CHEMBL1587920 & 688382 & 4.4 & 4.6306 & TRN & \\
\hline CHEMBL1401074 & 688382 & 2.75 & 4.7735 & TRN & \\
\hline CHEMBL357170 & 688382 & 4.95 & 4.677 & TST & \\
\hline CHEMBL1491957 & 688382 & 4.35 & 4.6267 & TRN & \\
\hline CHEMBL3190079 & 688382 & 5.3 & 4.6627 & TST & \\
\hline CHEMBL1510465 & 688382 & 4.5 & 4.6875 & TRN & \\
\hline CHEMBL446827 & 688382 & 4.15 & 4.6476 & TRN & \\
\hline CHEMBL1366790 & 688382 & 4.45 & 4.6143 & TRN & \\
\hline CHEMBL1560563 & 688382 & 4.7 & 4.7874 & TRN & \\
\hline CHEMBL1995109 & 688382 & 4.15 & 4.6864 & TRN & \\
\hline CHEMBL1520579 & 688382 & 4.15 & 4.7013 & TST & \\
\hline CHEMBL1312363 & 688382 & 5.35 & 4.6787 & TST & \\
\hline CHEMBL3196884 & 688382 & 4.5 & 4.6569 & TRN & \\
\hline CHEMBL1341557 & 688382 & 4.5 & 4.7286 & TRN & \\
\hline CHEMBL1575303 & 688382 & 4.45 & 4.579 & TST & \\
\hline CHEMBL1438842 & 688382 & 4.0 & 4.7573 & TRN & \\
\hline CHEMBL1611002 & 688382 & 5.95 & 4.64199 & 99999999995 & TRN \\
\hline CHEMBL1613143 & 688382 & 4.25 & 4.7137 & TST & \\
\hline CHEMBL1380812 & 688382 & 4.15 & 4.7478 & TRN & \\
\hline CHEMBL1495087 & 688382 & 5.0 & 4.7865 & TRN & \\
\hline CHEMBL3214312 & 688382 & 5.0 & 4.643 & TRN & \\
\hline CHEMBL1442330 & 688382 & 6.0 & 4.7752 & TST & \\
\hline CHEMBL1310419 & 688382 & 4.8 & 4.7636 & TRN & \\
\hline CHEMBL609030 & 688382 & 4.95 & 4.6796 & TST & \\
\hline CHEMBL1324661 & 688382 & 4.85 & 4.6593 & TRN & \\
\hline CHEMBL1369296 & 688382 & 4.8 & 4.5726 & TRN & \\
\hline CHEMBL1401042 & 688382 & 6.0 & 4.6776 & TRN & \\
\hline CHEMBL1360724 & 688382 & 4.85 & 4.7488 & TRN & \\
\hline CHEMBL1428046 & 688382 & 3.95 & 4.6783 & TRN & \\
\hline CHEMBL1400013 & 688382 & 5.1 & 4.7185 & TRN & \\
\hline CHEMBL1313151 & 688382 & 5.85 & 4.6484 & TST & \\
\hline CHEMBL1324168 & 688382 & 4.55 & 4.7344 & TRN & \\
\hline CHEMBL1329990 & 688382 & 4.15 & 4.7045 & TST & \\
\hline CHEMBL1566401 & 688382 & 4.45 & 4.7558 & TRN & \\
\hline CHEMBL1410204 & 688382 & 5.1 & 4.7172 & TST & \\
\hline CHEMBL1534810 & 688382 & 6.0 & 4.8384 & TRN & \\
\hline CHEMBL3209157 & 688382 & 4.8 & 4.6286 & TRN & \\
\hline CHEMBL1302765 & 688382 & 4.8 & 4.8014 & TRN & \\
\hline CHEMBL1534155 & 688382 & 4.45 & 4.7148 & TST & \\
\hline CHEMBL1583083 & 688382 & 4.8 & 4.8468 & TST & \\
\hline CHEMBL1534034 & 688382 & 4.7 & 4.69 & TRN & \\
\hline CHEMBL1526385 & 688382 & 4.8 & 4.7802 & TRN & \\
\hline CHEMBL1549546 & 688382 & 4.8 & 4.7028 & TRN & \\
\hline CHEMBL1484429 & 688382 & 4.55 & 4.7291 & TRN & \\
\hline CHEMBL1418090 & 688382 & 4.5 & 4.7265 & TRN & \\
\hline CHEMBL1386884 & 688382 & 4.85 & 4.7619 & TST & \\
\hline CHEMBL1460836 & 688382 & 6.0 & 4.6496 & TRN & \\
\hline
\end{tabular}




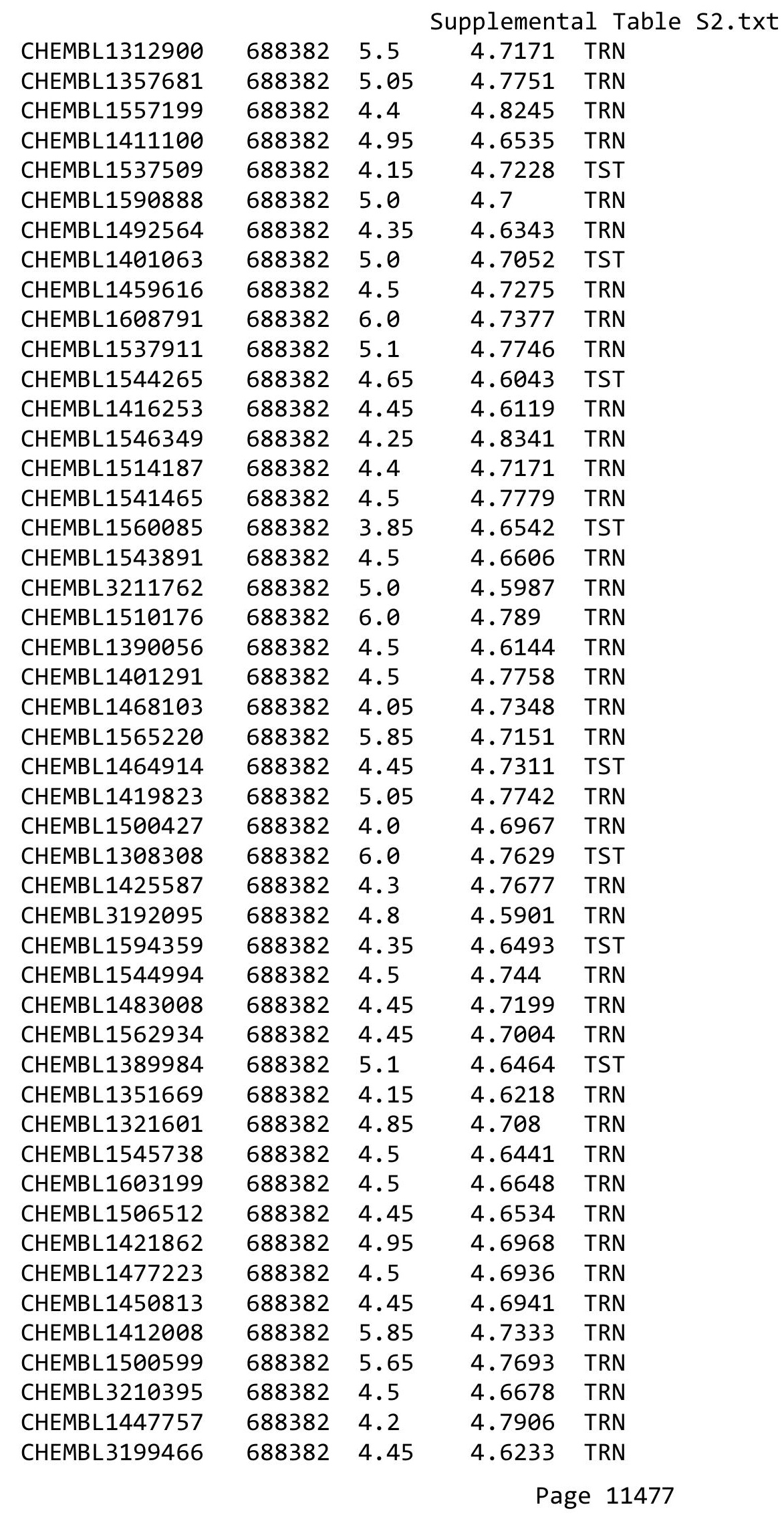




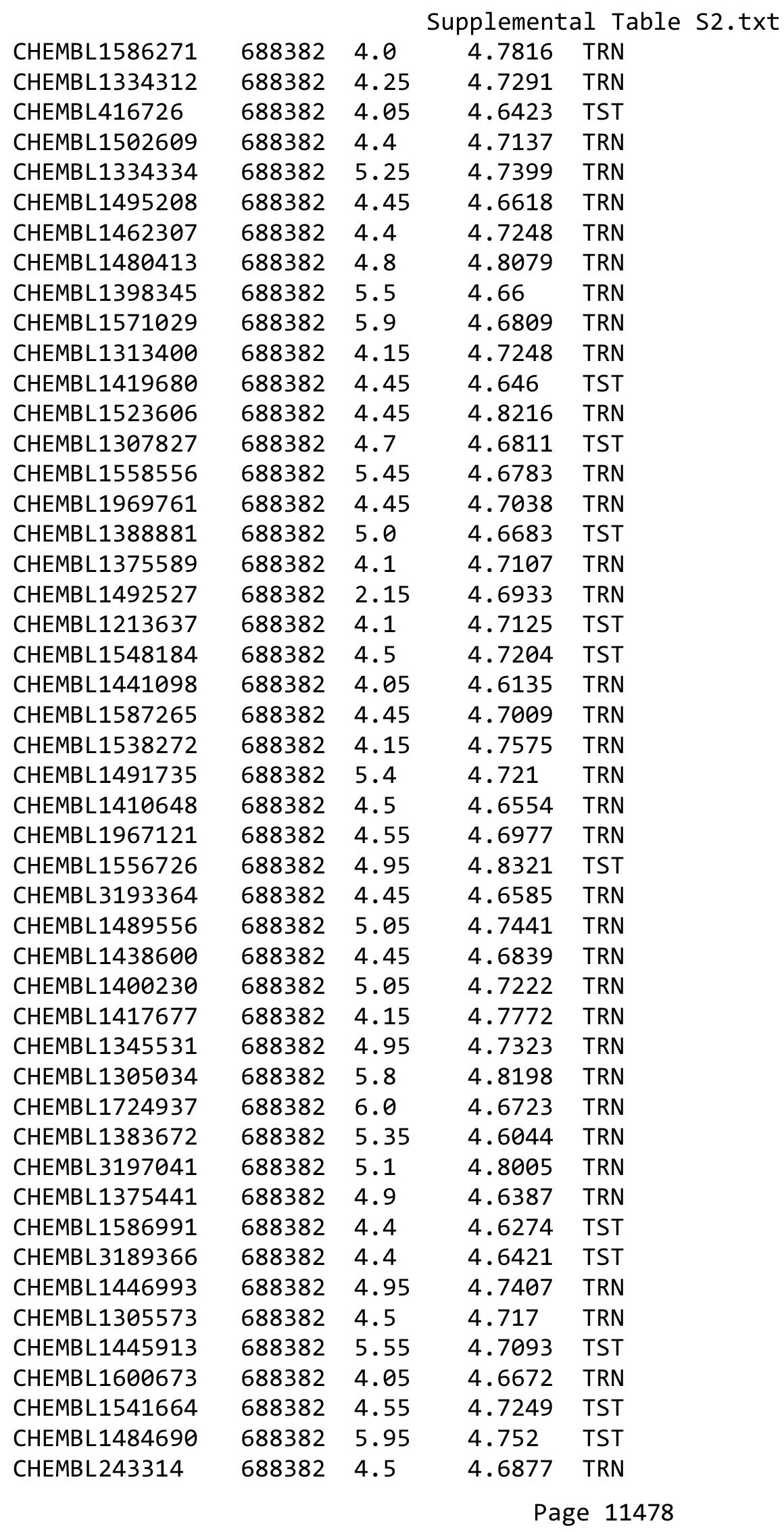




\begin{tabular}{|c|c|c|c|c|c|}
\hline \multicolumn{6}{|c|}{ Supplemental Table S2.txt } \\
\hline CHEMBL1598415 & 688382 & 4.25 & 4.6588 & TRN & \\
\hline CHEMBL1385598 & 688382 & 4.95 & 4.6967 & TST & \\
\hline CHEMBL1530545 & 688382 & 5.0 & 4.7011 & TRN & \\
\hline CHEMBL1477288 & 688382 & 4.45 & 4.6912 & TST & \\
\hline CHEMBL3189462 & 688382 & 4.55 & 4.7336 & TRN & \\
\hline CHEMBL1303651 & 688382 & 4.55 & 4.6183 & TRN & \\
\hline CHEMBL1481507 & 688382 & 5.0 & 4.8177 & TST & \\
\hline CHEMBL1490352 & 688382 & 5.4 & 4.7912 & TRN & \\
\hline CHEMBL1573290 & 688382 & 5.0 & 4.7019 & TRN & \\
\hline CHEMBL1371172 & 688382 & 4.05 & 4.6904 & TRN & \\
\hline CHEMBL1542029 & 688382 & 4.7 & 4.6468 & TRN & \\
\hline CHEMBL1586917 & 688382 & 4.85 & 4.7815 & TRN & \\
\hline CHEMBL1495180 & 688382 & 4.8 & 4.723 & TRN & \\
\hline CHEMBL 2374060 & 688382 & 4.9 & 4.703 & TST & \\
\hline CHEMBL1456923 & 688382 & 4.45 & 4.723 & TRN & \\
\hline CHEMBL1599965 & 688382 & 4.2 & 4.7464 & TST & \\
\hline CHEMBL1327037 & 688382 & 4.75 & 4.8165 & TRN & \\
\hline CHEMBL1330295 & 688382 & 5.15 & 4.8192 & TRN & \\
\hline CHEMBL1430780 & 688382 & 4.35 & 4.67399 & 99999999995 & TST \\
\hline CHEMBL3191380 & 688382 & 3.95 & 4.672 & TRN & \\
\hline CHEMBL1526165 & 688382 & 5.25 & 4.6892 & TRN & \\
\hline CHEMBL1309191 & 688382 & 4.45 & 4.6999 & TST & \\
\hline CHEMBL1558301 & 688382 & 4.75 & 4.7203 & TRN & \\
\hline CHEMBL1595827 & 688382 & 4.05 & 4.6747 & TRN & \\
\hline CHEMBL1542716 & 688382 & 4.4 & 4.814 & TRN & \\
\hline CHEMBL1501508 & 688382 & 4.5 & 4.6306 & TRN & \\
\hline CHEMBL1443081 & 688382 & 4.5 & 4.7469 & TRN & \\
\hline CHEMBL1586592 & 688382 & 4.45 & 4.6902 & TST & \\
\hline CHEMBL1481156 & 688382 & 6.0 & 4.7192 & TRN & \\
\hline CHEMBL1524511 & 688382 & 4.45 & 4.739 & TST & \\
\hline CHEMBL1415451 & 688382 & 4.65 & 4.738 & TRN & \\
\hline CHEMBL1533863 & 688382 & 5.8 & 4.6965 & TST & \\
\hline CHEMBL1359953 & 688382 & 4.85 & 4.7463 & TRN & \\
\hline CHEMBL1324359 & 688382 & 3.95 & 4.7766 & TRN & \\
\hline CHEMBL1608989 & 688382 & 4.45 & 4.6016 & TRN & \\
\hline CHEMBL1573040 & 688382 & 4.5 & 4.7836 & TRN & \\
\hline CHEMBL1338930 & 688382 & 4.95 & 4.6744 & TST & \\
\hline CHEMBL1388381 & 688382 & 4.05 & 4.7507 & TRN & \\
\hline CHEMBL1399066 & 688382 & 4.8 & 4.6629 & TST & \\
\hline CHEMBL1561194 & 688382 & 4.3 & 4.754 & TRN & \\
\hline CHEMBL1548927 & 688382 & 5.4 & 4.8331 & TST & \\
\hline CHEMBL1402072 & 688382 & 4.15 & 4.6289 & TRN & \\
\hline CHEMBL1358038 & 688382 & 4.5 & 4.6107 & TRN & \\
\hline CHEMBL193627 & 688382 & 4.45 & 4.6064 & TRN & \\
\hline CHEMBL1599517 & 688382 & 4.2 & 4.7884 & TST & \\
\hline CHEMBL1493214 & 688382 & 4.4 & 4.7437 & TRN & \\
\hline CHEMBL3198751 & 688382 & 5.5 & 4.6674 & TRN & \\
\hline CHEMBL1536434 & 688382 & 4.85 & 4.6443 & TRN & \\
\hline
\end{tabular}




\begin{tabular}{|c|c|c|c|c|}
\hline \multicolumn{5}{|c|}{ Supplemental Table S2.txt } \\
\hline CHEMBL1485950 & 688382 & 5.0 & 4.7948 & TRN \\
\hline CHEMBL1308133 & 688382 & 4.35 & 4.6821 & TRN \\
\hline CHEMBL600713 & 688382 & 4.55 & 4.6908 & TRN \\
\hline CHEMBL1504960 & 688382 & 4.5 & 4.737 & TRN \\
\hline CHEMBL1363085 & 688382 & 4.4 & 4.7706 & TRN \\
\hline CHEMBL1484421 & 688382 & 4.4 & 4.7468 & TRN \\
\hline CHEMBL522809 & 688382 & 4.45 & 4.6468 & TRN \\
\hline CHEMBL1595441 & 688382 & 5.05 & 4.6996 & TRN \\
\hline CHEMBL1566248 & 688382 & 5.8 & 4.8087 & TST \\
\hline CHEMBL1367431 & 688382 & 4.15 & 4.8007 & TRN \\
\hline CHEMBL1488522 & 688382 & 4.4 & 4.621 & TRN \\
\hline CHEMBL3198699 & 688382 & 5.05 & 4.6633 & TRN \\
\hline CHEMBL1541787 & 688382 & 5.9 & 4.7671 & TRN \\
\hline CHEMBL1351967 & 688382 & 4.3 & 4.6223 & TRN \\
\hline CHEMBL1349377 & 688382 & 4.1 & 4.7122 & TST \\
\hline CHEMBL1499267 & 688382 & 4.65 & 4.7382 & TRN \\
\hline CHEMBL1585193 & 688382 & 4.55 & 4.7753 & TRN \\
\hline CHEMBL1494117 & 688382 & 4.2 & 4.6069 & TRN \\
\hline CHEMBL1380476 & 688382 & 4.55 & 4.7116 & TRN \\
\hline CHEMBL495778 & 688382 & 4.7 & 4.6837 & TST \\
\hline CHEMBL1359223 & 688382 & 4.8 & 4.7602 & TRN \\
\hline CHEMBL1608947 & 688382 & 4.4 & 4.6372 & TRN \\
\hline CHEMBL3213065 & 688382 & 5.8 & 4.705 & TRN \\
\hline CHEMBL1491497 & 688382 & 4.9 & 4.776 & TST \\
\hline CHEMBL1484104 & 688382 & 5.55 & 4.7137 & TRN \\
\hline CHEMBL1365026 & 688382 & 4.3 & 4.7569 & TRN \\
\hline CHEMBL1370959 & 688382 & 5.0 & 4.7607 & TRN \\
\hline CHEMBL3194086 & 688382 & 4.45 & 4.7102 & TRN \\
\hline CHEMBL1973003 & 688382 & 4.6 & 4.6214 & TST \\
\hline CHEMBL1357255 & 688382 & 4.5 & 4.6367 & TRN \\
\hline CHEMBL1446496 & 688382 & 4.45 & 4.8183 & TRN \\
\hline CHEMBL1425999 & 688382 & 4.4 & 4.7458 & TRN \\
\hline CHEMBL1333039 & 688382 & 4.5 & 4.6946 & TRN \\
\hline CHEMBL1381017 & 688382 & 4.5 & 4.7023 & TST \\
\hline CHEMBL1414326 & 688382 & 4.95 & 4.6776 & TST \\
\hline CHEMBL1609823 & 688382 & 4.55 & 4.6781 & TRN \\
\hline CHEMBL1431079 & 688382 & 4.95 & 4.7775 & TST \\
\hline CHEMBL1502002 & 688382 & 5.35 & 4.7955 & TRN \\
\hline CHEMBL1492629 & 688382 & 4.05 & 4.7098 & TST \\
\hline CHEMBL1577005 & 688382 & 4.35 & 4.6522 & TRN \\
\hline CHEMBL1307685 & 688382 & 4.3 & 4.8176 & TRN \\
\hline CHEMBL1587783 & 688382 & 4.5 & 4.7447 & TRN \\
\hline CHEMBL1407208 & 688382 & 5.65 & 4.7273 & TRN \\
\hline CHEMBL1521714 & 688382 & 4.85 & 4.7566 & TST \\
\hline CHEMBL1579462 & 688382 & 4.5 & 4.6748 & TST \\
\hline CHEMBL405358 & 688382 & 5.6 & 4.5944 & TRN \\
\hline CHEMBL1507781 & 688382 & 4.45 & 4.6907 & TST \\
\hline CHEMBL1341957 & 688382 & 4.15 & 4.8206 & TST \\
\hline
\end{tabular}




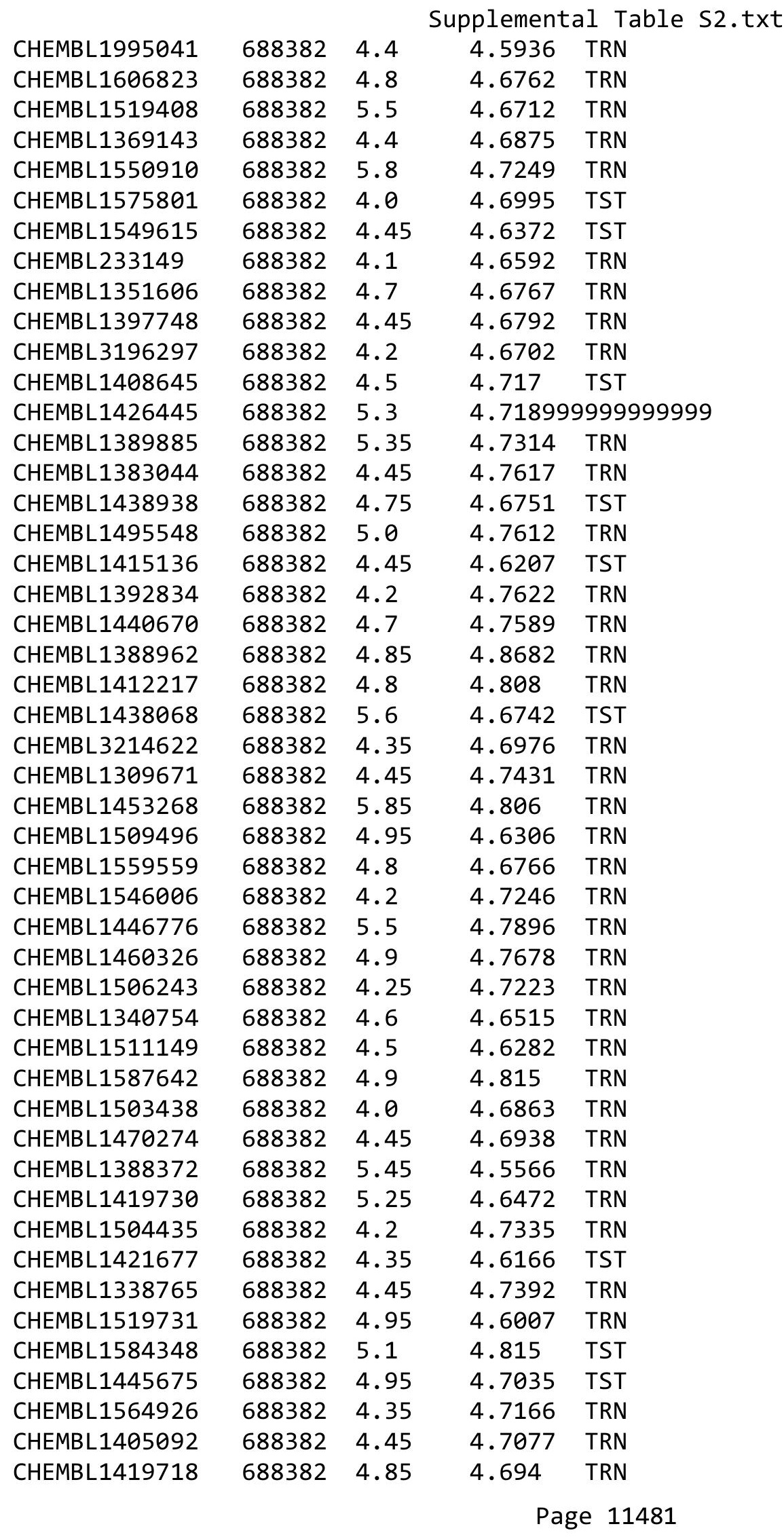




\begin{tabular}{|c|c|c|c|c|}
\hline & & & ipplement & al $\mathrm{T}$ \\
\hline CHEMBL1505451 & 688382 & 5.8 & 4.6756 & TRN \\
\hline CHEMBL1990825 & 688382 & 4.5 & 4.6092 & TRN \\
\hline CHEMBL1461130 & 688382 & 5.0 & 4.7716 & TRN \\
\hline CHEMBL1495985 & 688382 & 4.25 & 4.718 & TRN \\
\hline CHEMBL1376266 & 688382 & 4.4 & 4.6531 & TST \\
\hline CHEMBL1547903 & 688382 & 4.9 & 4.6616 & TRN \\
\hline CHEMBL1390797 & 688382 & 4.5 & 4.6016 & TRN \\
\hline CHEMBL1427486 & 688382 & 4.45 & 4.6543 & TRN \\
\hline CHEMBL1404233 & 688382 & 4.95 & 4.7508 & TST \\
\hline CHEMBL1303489 & 688382 & 4.3 & 4.7789 & TST \\
\hline CHEMBL1485596 & 688382 & 5.05 & 4.6796 & TRN \\
\hline CHEMBL1436668 & 688382 & 5.45 & 4.7299 & TST \\
\hline CHEMBL1566241 & 688382 & 4.5 & 4.6983 & TST \\
\hline CHEMBL1341388 & 688382 & 5.05 & 4.6334 & TRN \\
\hline CHEMBL1453667 & 688382 & 4.8 & 4.7489 & TRN \\
\hline CHEMBL1591926 & 688382 & 5.25 & 4.7388 & TRN \\
\hline CHEMBL1427272 & 688382 & 4.45 & 4.6579 & TRN \\
\hline CHEMBL1536664 & 688382 & 4.5 & 4.7568 & TRN \\
\hline CHEMBL1530165 & 688382 & 4.5 & 4.7047 & TRN \\
\hline CHEMBL1536022 & 688382 & 5.05 & 4.7854 & TRN \\
\hline CHEMBL1506159 & 688382 & 6.0 & 4.6861 & TRN \\
\hline CHEMBL1319660 & 688382 & 4.05 & 4.6696 & TST \\
\hline CHEMBL1976299 & 688382 & 4.5 & 4.6417 & TRN \\
\hline CHEMBL1305824 & 688382 & 4.5 & 4.6359 & TRN \\
\hline CHEMBL1369234 & 688382 & 4.05 & 4.7115 & TRN \\
\hline CHEMBL1469881 & 688382 & 4.25 & 4.7701 & TRN \\
\hline CHEMBL1608375 & 688382 & 4.45 & 4.6234 & TST \\
\hline CHEMBL1549687 & 688382 & 5.1 & 4.7351 & TRN \\
\hline CHEMBL1574344 & 688382 & 4.55 & 4.6652 & TRN \\
\hline CHEMBL1331995 & 688382 & 4.45 & 4.6712 & TRN \\
\hline CHEMBL1388816 & 688382 & 5.7 & 4.6855 & TRN \\
\hline CHEMBL1352138 & 688382 & 4.8 & 4.6738 & TST \\
\hline CHEMBL3196579 & 688382 & 5.95 & 4.7194 & TRN \\
\hline CHEMBL1471115 & 688382 & 4.85 & 4.6913 & TRN \\
\hline CHEMBL1430969 & 688382 & 5.05 & 4.6865 & TRN \\
\hline CHEMBL1982305 & 688382 & 4.5 & 4.6933 & TRN \\
\hline CHEMBL1465875 & 688382 & 5.9 & 4.8081 & TST \\
\hline CHEMBL1348128 & 688382 & 4.8 & 4.7322 & TST \\
\hline CHEMBL1386330 & 688382 & 2.3 & 4.7824 & TST \\
\hline CHEMBL1300178 & 688382 & 4.6 & 4.7697 & TRN \\
\hline CHEMBL1499379 & 688382 & 4.5 & 4.7823 & TST \\
\hline CHEMBL20936 & 688382 & 4.15 & 4.6514 & TST \\
\hline CHEMBL1448634 & 688382 & 4.85 & 4.7802 & TST \\
\hline CHEMBL1321036 & 688382 & 5.05 & 4.7496 & TRN \\
\hline CHEMBL1464656 & 688382 & 4.0 & 4.7023 & TRN \\
\hline CHEMBL241898 & 688382 & 4.2 & 4.6443 & TRN \\
\hline CHEMBL1600207 & 688382 & 5.0 & 4.7582 & TRN \\
\hline CHEMBL1453878 & 688382 & 4.85 & 4.7467 & TRN \\
\hline
\end{tabular}




\begin{tabular}{|c|c|c|c|c|c|}
\hline \multirow{3}{*}{$\begin{array}{l}\text { CHEMBL } 2000736 \\
\text { CHEMBL } 1518296\end{array}$} & \multirow[b]{2}{*}{688382} & \multicolumn{4}{|c|}{ Supplemental Table S2.txt } \\
\hline & & 4.9 & 4.7639 & 9999999999 & TRN \\
\hline & 688382 & 4.4 & 4.6462 & TRN & \\
\hline CHEMBL1579252 & 688382 & 4.5 & 4.7933 & TRN & \\
\hline CHEMBL1546048 & 688382 & 4.45 & 4.6237 & TST & \\
\hline CHEMBL1420694 & 688382 & 4.15 & 4.7467 & TRN & \\
\hline CHEMBL1509656 & 688382 & 4.5 & 4.7322 & TST & \\
\hline CHEMBL1557243 & 688382 & 4.4 & 4.6331 & TRN & \\
\hline CHEMBL1348991 & 688382 & 4.55 & 4.7563 & TRN & \\
\hline CHEMBL1467266 & 688382 & 5.5 & 4.7718 & TST & \\
\hline CHEMBL1365984 & 688382 & 4.25 & 4.6469 & TRN & \\
\hline CHEMBL258893 & 688382 & 4.65 & 4.6798 & TST & \\
\hline CHEMBL1582815 & 688382 & 4.85 & 4.7555 & TRN & \\
\hline CHEMBL1967050 & 688382 & 4.6 & 4.6365 & TRN & \\
\hline CHEMBL1520961 & 688382 & 4.8 & 4.6681 & TST & \\
\hline CHEMBL1582298 & 688382 & 4.5 & 4.6532 & TRN & \\
\hline CHEMBL1370129 & 688382 & 4.2 & 4.7494 & TST & \\
\hline CHEMBL1494349 & 688382 & 4.85 & 4.7471 & TRN & \\
\hline CHEMBL1401003 & 688382 & 4.0 & 4.704 & TRN & \\
\hline CHEMBL1562010 & 688382 & 4.6 & 4.6138 & TRN & \\
\hline CHEMBL1425946 & 688382 & 4.5 & 4.6834 & TRN & \\
\hline CHEMBL1548101 & 688382 & 4.45 & 4.6321 & TRN & \\
\hline CHEMBL1471370 & 688382 & 4.95 & 4.7234 & TRN & \\
\hline CHEMBL1487052 & 688382 & 4.45 & 4.7852 & TRN & \\
\hline CHEMBL1581415 & 688382 & 4.45 & 4.7147 & TRN & \\
\hline CHEMBL1385479 & 688382 & 4.8 & 4.688 & TRN & \\
\hline CHEMBL1380025 & 688382 & 4.5 & 4.7339 & TRN & \\
\hline CHEMBL1322624 & 688382 & 4.55 & 4.6636 & TRN & \\
\hline CHEMBL1999237 & 688382 & 4.5 & 4.6525 & TRN & \\
\hline CHEMBL1525366 & 688382 & 4.9 & 4.8052 & TRN & \\
\hline CHEMBL3211034 & 688382 & 6.0 & 4.7134 & TRN & \\
\hline CHEMBL1581218 & 688382 & 4.6 & 4.757 & TRN & \\
\hline CHEMBL1576762 & 688382 & 5.35 & 4.7158 & TRN & \\
\hline CHEMBL1346837 & 688382 & 5.05 & 4.8125 & TRN & \\
\hline CHEMBL1323409 & 688382 & 4.8 & 4.727 & TRN & \\
\hline CHEMBL1329884 & 688382 & 4.7 & 4.6845 & TRN & \\
\hline CHEMBL1304406 & 688382 & 5.2 & 4.648 & TRN & \\
\hline CHEMBL1518768 & 688382 & 4.85 & 4.7043 & TRN & \\
\hline CHEMBL3039775 & 688382 & 4.05 & 4.6414 & TRN & \\
\hline CHEMBL1399556 & 688382 & 4.35 & 4.6445 & TST & \\
\hline CHEMBL1555641 & 688382 & 4.85 & 4.7919 & TRN & \\
\hline CHEMBL1386263 & 688382 & 5.0 & 4.7707 & TRN & \\
\hline CHEMBL1508663 & 688382 & 4.85 & 4.7893 & TRN & \\
\hline CHEMBL1375877 & 688382 & 4.95 & 4.7704 & TST & \\
\hline CHEMBL1448678 & 688382 & 5.05 & 4.676 & TRN & \\
\hline CHEMBL1366873 & 688382 & 5.05 & 4.7428 & TRN & \\
\hline CHEMBL1503172 & 688382 & 4.85 & 4.6565 & TRN & \\
\hline CHEMBL1491238 & 688382 & 4.5 & 4.6412 & TRN & \\
\hline CHEMBL1576905 & 688382 & 4.5 & 4.6459 & TST & \\
\hline
\end{tabular}




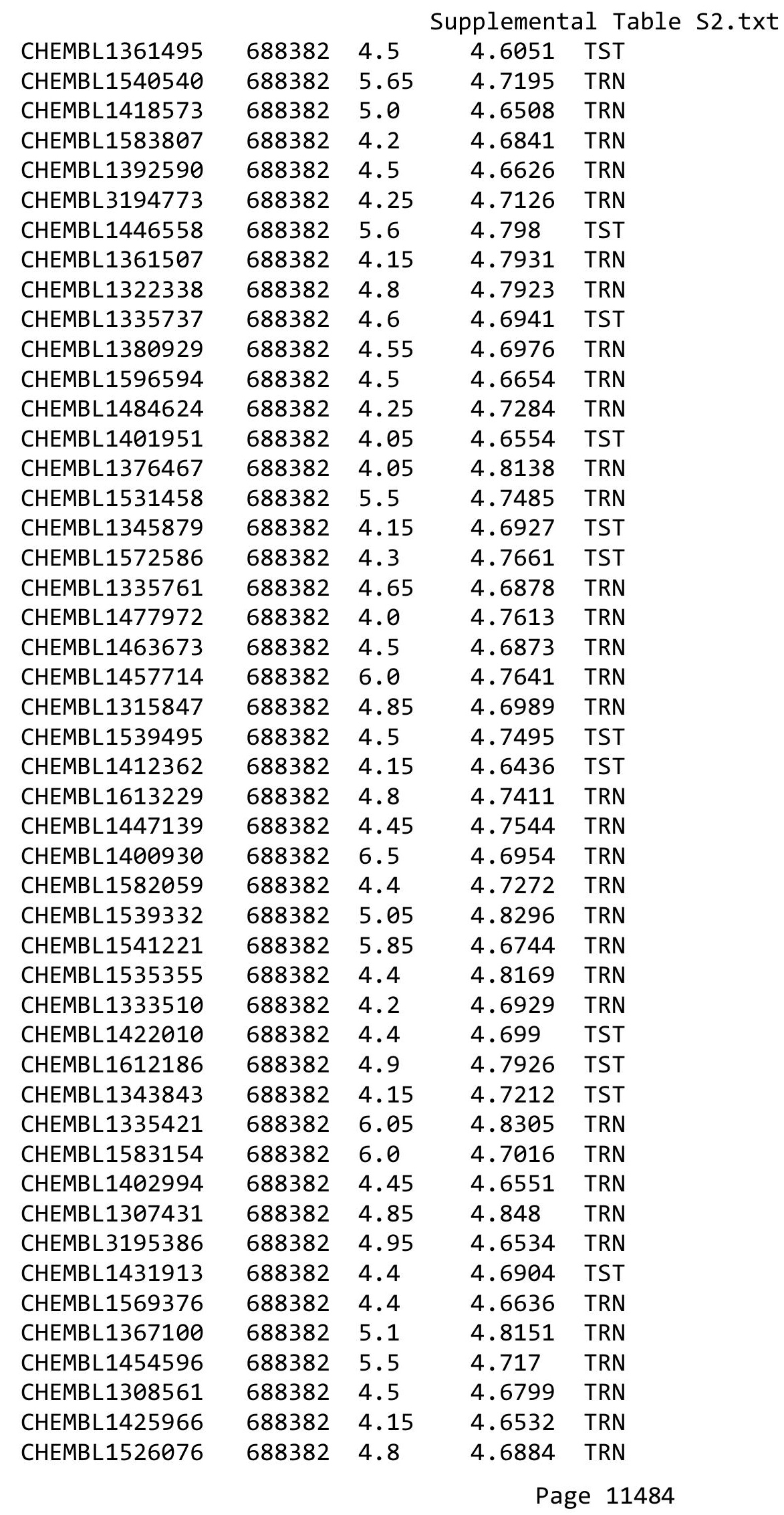




\begin{tabular}{|c|c|c|c|c|c|}
\hline \multirow{3}{*}{$\begin{array}{l}\text { CHEMBL1479969 } \\
\text { CHEMBL1347560 }\end{array}$} & \multirow{3}{*}{$\begin{array}{l}688382 \\
688382\end{array}$} & \multicolumn{4}{|c|}{ Supplemental Table S2.txt } \\
\hline & & 5.1 & 4.8469 & 99999999995 & TST \\
\hline & & 4.55 & 4.6792 & TRN & \\
\hline CHEMBL1370254 & 688382 & 4.6 & 4.655 & TRN & \\
\hline CHEMBL1437962 & 688382 & 4.2 & 4.6707 & TST & \\
\hline CHEMBL1459949 & 688382 & 5.0 & 4.6844 & TRN & \\
\hline CHEMBL1459305 & 688382 & 4.4 & 4.6781 & TST & \\
\hline CHEMBL1494906 & 688382 & 5.8 & 4.7912 & TRN & \\
\hline CHEMBL1369507 & 688382 & 4.05 & 4.6826 & TRN & \\
\hline CHEMBL1428904 & 688382 & 4.4 & 4.8189 & TRN & \\
\hline CHEMBL1339776 & 688382 & 4.4 & 4.6819 & TRN & \\
\hline CHEMBL1466707 & 688382 & 4.8 & 4.7269 & TRN & \\
\hline CHEMBL1525455 & 688382 & 4.5 & 4.6509 & TRN & \\
\hline CHEMBL1458891 & 688382 & 4.55 & 4.5948 & TRN & \\
\hline CHEMBL1473383 & 688382 & 4.35 & 4.6088 & TRN & \\
\hline CHEMBL1549907 & 688382 & 4.5 & 4.6981 & TRN & \\
\hline CHEMBL1459551 & 688382 & 4.95 & 4.7909 & TRN & \\
\hline CHEMBL1543123 & 688382 & 4.55 & 4.6313 & TRN & \\
\hline CHEMBL1510455 & 688382 & 4.65 & 4.6376 & TRN & \\
\hline CHEMBL1502177 & 688382 & 4.15 & 4.7525 & TST & \\
\hline CHEMBL1605210 & 688382 & 5.0 & 4.5772 & TST & \\
\hline CHEMBL1171206 & 688382 & 5.15 & 4.686 & TRN & \\
\hline CHEMBL1338283 & 688382 & 5.35 & 4.7133 & TST & \\
\hline CHEMBL1599354 & 688382 & 5.1 & 4.6646 & TRN & \\
\hline CHEMBL1382643 & 688382 & 5.0 & 4.7878 & TST & \\
\hline CHEMBL1530989 & 688382 & 4.4 & 4.7362 & TRN & \\
\hline CHEMBL1479061 & 688382 & 4.95 & 4.7588 & TRN & \\
\hline CHEMBL1575516 & 688382 & 4.05 & 4.7109 & TRN & \\
\hline CHEMBL3212884 & 688382 & 5.35 & 4.7199 & TRN & \\
\hline CHEMBL1393402 & 688382 & 4.95 & 4.7514 & TRN & \\
\hline CHEMBL1332467 & 688382 & 4.5 & 4.7213 & TST & \\
\hline CHEMBL1307098 & 688382 & 4.15 & 4.6786 & TST & \\
\hline CHEMBL1449112 & 688382 & 4.55 & 4.6066 & TRN & \\
\hline CHEMBL1439351 & 688382 & 4.95 & 4.7222 & TRN & \\
\hline CHEMBL1510088 & 688382 & 4.0 & 4.785 & TRN & \\
\hline CHEMBL1541043 & 688382 & 4.45 & 4.7678 & TRN & \\
\hline CHEMBL1338701 & 688382 & 4.85 & 4.7542 & TRN & \\
\hline CHEMBL1380005 & 688382 & 4.55 & 4.6829 & TST & \\
\hline CHEMBL1567649 & 688382 & 4.8 & 4.7767 & TST & \\
\hline CHEMBL1342894 & 688382 & 4.5 & 4.6224 & TRN & \\
\hline CHEMBL1335373 & 688382 & 4.5 & 4.7684 & TRN & \\
\hline CHEMBL1496983 & 688382 & 5.3 & 4.7072 & TST & \\
\hline CHEMBL1573061 & 688382 & 4.85 & 4.6332 & TRN & \\
\hline CHEMBL1427249 & 688382 & 4.5 & 4.6762 & TRN & \\
\hline CHEMBL1587726 & 688382 & 4.05 & 4.7968 & TST & \\
\hline CHEMBL1489726 & 688382 & 4.15 & 4.806 & TST & \\
\hline CHEMBL1437999 & 688382 & 4.4 & 4.6861 & TRN & \\
\hline CHEMBL1334149 & 688382 & 4.4 & 4.7212 & TRN & \\
\hline CHEMBL1490697 & 688382 & 4.45 & 4.6393 & TST & \\
\hline
\end{tabular}




\begin{tabular}{|c|c|c|c|c|}
\hline \multicolumn{5}{|c|}{ Supplemental Table S2.txt } \\
\hline CHEMBL1368145 & 688382 & 4.0 & 4.8225 & TRN \\
\hline CHEMBL1347265 & 688382 & 4.6 & 4.7514 & TRN \\
\hline CHEMBL1572592 & 688382 & 4.15 & 4.7655 & TRN \\
\hline CHEMBL1516926 & 688382 & 4.45 & 4.7909 & TRN \\
\hline CHEMBL1560992 & 688382 & 4.15 & 4.7759 & TRN \\
\hline CHEMBL1558975 & 688382 & 4.15 & 4.7123 & TST \\
\hline CHEMBL1459607 & 688382 & 4.5 & 4.7162 & TST \\
\hline CHEMBL1413949 & 688382 & 4.95 & 4.6671 & TST \\
\hline CHEMBL1491823 & 688382 & 4.45 & 4.7688 & TRN \\
\hline CHEMBL1504533 & 688382 & 4.5 & 4.7008 & TRN \\
\hline CHEMBL1543409 & 688382 & 4.5 & 4.7074 & TRN \\
\hline CHEMBL1515998 & 688382 & 5.4 & 4.6889 & TRN \\
\hline CHEMBL1359508 & 688382 & 4.6 & 4.5977 & TRN \\
\hline CHEMBL1419659 & 688382 & 4.45 & 4.6285 & TRN \\
\hline CHEMBL1479418 & 688382 & 4.7 & 4.7901 & TRN \\
\hline CHEMBL1507990 & 688382 & 4.0 & 4.6528 & TRN \\
\hline CHEMBL1994490 & 688382 & 4.4 & 4.7115 & TRN \\
\hline CHEMBL1346831 & 688382 & 4.5 & 4.6989 & TRN \\
\hline CHEMBL1494820 & 688382 & 4.5 & 4.6824 & TRN \\
\hline CHEMBL1329450 & 688382 & 4.05 & 4.7704 & TRN \\
\hline CHEMBL1460905 & 688382 & 5.0 & 4.7424 & TST \\
\hline CHEMBL1525082 & 688382 & 4.35 & 4.7942 & TRN \\
\hline CHEMBL1503106 & 688382 & 4.65 & 4.6625 & TRN \\
\hline CHEMBL1487279 & 688382 & 4.15 & 4.797 & TRN \\
\hline CHEMBL1528666 & 688382 & 4.55 & 4.7645 & TST \\
\hline CHEMBL1522801 & 688382 & 5.15 & 4.6449 & TRN \\
\hline CHEMBL1419954 & 688382 & 4.45 & 4.7503 & TRN \\
\hline CHEMBL1514474 & 688382 & 4.45 & 4.7215 & TRN \\
\hline CHEMBL1312555 & 688382 & 5.3 & 4.8133 & TRN \\
\hline CHEMBL1342217 & 688382 & 5.8 & 4.8249 & TST \\
\hline CHEMBL1533968 & 688382 & 4.6 & 4.6876 & TRN \\
\hline CHEMBL1550445 & 688382 & 4.45 & 4.5519 & TRN \\
\hline CHEMBL1468618 & 688382 & 4.95 & 4.8535 & TRN \\
\hline CHEMBL1412520 & 688382 & 4.15 & 4.7473 & TRN \\
\hline CHEMBL1560745 & 688382 & 4.45 & 4.66 & TRN \\
\hline CHEMBL1444351 & 688382 & 5.35 & 4.7001 & TRN \\
\hline CHEMBL3199005 & 688382 & 4.4 & 4.7071 & TRN \\
\hline CHEMBL1387788 & 688382 & 4.45 & 4.6756 & TRN \\
\hline CHEMBL1546605 & 688382 & 4.4 & 4.6802 & TRN \\
\hline CHEMBL1563495 & 688382 & 4.45 & 4.6979 & TRN \\
\hline CHEMBL1313926 & 688382 & 4.55 & 4.7535 & TRN \\
\hline CHEMBL1454841 & 688382 & 4.4 & 4.6935 & TST \\
\hline CHEMBL1538216 & 688382 & 5.05 & 4.7241 & TRN \\
\hline CHEMBL1560399 & 688382 & 5.55 & 4.7074 & TRN \\
\hline CHEMBL1607418 & 688382 & 5.15 & 4.6233 & TRN \\
\hline CHEMBL1544947 & 688382 & 5.25 & 4.6559 & TRN \\
\hline CHEMBL1576025 & 688382 & 4.0 & 4.7037 & TRN \\
\hline CHEMBL1572236 & 688382 & 6.0 & $4.7010 e$ & 00000000005 \\
\hline & & & & 11486 \\
\hline
\end{tabular}




\begin{tabular}{|c|c|c|c|c|}
\hline \multicolumn{5}{|c|}{ Supplemental Table S2.txt } \\
\hline CHEMBL1537386 & 688382 & 4.5 & 4.6874 & TRN \\
\hline CHEMBL1580042 & 688382 & 4.5 & 4.729 & TRN \\
\hline CHEMBL1459865 & 688382 & 4.55 & 4.619 & TRN \\
\hline CHEMBL1335795 & 688382 & 6.0 & 4.6904 & TST \\
\hline CHEMBL1527972 & 688382 & 4.85 & 4.6387 & TRN \\
\hline CHEMBL1403451 & 688382 & 5.0 & 4.8224 & TRN \\
\hline CHEMBL1308778 & 688382 & 4.5 & 4.7373 & TRN \\
\hline CHEMBL1445360 & 688382 & 4.55 & 4.6471 & TRN \\
\hline CHEMBL1303845 & 688382 & 4.15 & 4.5917 & TST \\
\hline CHEMBL1351033 & 688382 & 4.15 & 4.7235 & TST \\
\hline CHEMBL1506757 & 688382 & 4.5 & 4.6621 & TRN \\
\hline CHEMBL1411916 & 688382 & 4.65 & 4.6828 & TRN \\
\hline CHEMBL1439307 & 688382 & 4.4 & 4.7715 & TRN \\
\hline CHEMBL1331402 & 688382 & 5.05 & 4.8281 & TRN \\
\hline CHEMBL1565876 & 688382 & 4.5 & 4.7219 & TST \\
\hline CHEMBL1525521 & 688382 & 4.9 & 4.6616 & TRN \\
\hline CHEMBL1364380 & 688382 & 4.8 & 4.7313 & TST \\
\hline CHEMBL1439753 & 688382 & 5.65 & 4.777 & TRN \\
\hline CHEMBL1458691 & 688382 & 4.6 & 4.6948 & TST \\
\hline CHEMBL3193693 & 688382 & 4.45 & 4.6733 & TST \\
\hline CHEMBL1604040 & 688382 & 5.05 & 4.8021 & TRN \\
\hline CHEMBL1414512 & 688382 & 5.5 & 4.7782 & TRN \\
\hline CHEMBL3199393 & 688382 & 4.85 & 4.711 & TRN \\
\hline CHEMBL3196997 & 688382 & 4.45 & 4.6205 & TRN \\
\hline CHEMBL1466646 & 688382 & 4.45 & 4.6319 & TRN \\
\hline CHEMBL1433128 & 688382 & 4.8 & 4.6685 & TRN \\
\hline CHEMBL1365049 & 688382 & 4.45 & 4.6789 & TRN \\
\hline CHEMBL601550 & 688382 & 4.5 & 4.6222 & TRN \\
\hline CHEMBL1304245 & 688382 & 4.5 & 4.7348 & TRN \\
\hline CHEMBL1391952 & 688382 & 5.05 & 4.7209 & TST \\
\hline CHEMBL1440207 & 688382 & 4.35 & 4.6356 & TST \\
\hline CHEMBL1453902 & 688382 & 4.9 & 4.6427 & TRN \\
\hline CHEMBL3199817 & 688382 & 4.4 & 4.6637 & TRN \\
\hline CHEMBL1455898 & 688382 & 4.5 & 4.7096 & TRN \\
\hline CHEMBL3210314 & 688382 & 4.5 & 4.6554 & TRN \\
\hline CHEMBL1299302 & 688382 & 5.15 & 4.8018 & TRN \\
\hline CHEMBL1485635 & 688382 & 4.95 & 4.6489 & TST \\
\hline CHEMBL1427153 & 688382 & 5.0 & 4.7738 & TRN \\
\hline CHEMBL1505522 & 688382 & 5.4 & 4.627 & TRN \\
\hline CHEMBL1349288 & 688382 & 5.05 & 4.8249 & TRN \\
\hline CHEMBL3212872 & 688382 & 4.45 & 4.7222 & TRN \\
\hline CHEMBL1343545 & 688382 & 4.3 & 4.7033 & TRN \\
\hline CHEMBL1504139 & 688382 & 5.15 & 4.6995 & TRN \\
\hline CHEMBL1428507 & 688382 & 4.3 & 4.6834 & TRN \\
\hline CHEMBL1345551 & 688382 & 4.15 & 4.6892 & TRN \\
\hline CHEMBL1306555 & 688382 & 4.85 & 4.6882 & TRN \\
\hline CHEMBL1304572 & 688382 & 4.05 & 4.7904 & TRN \\
\hline CHEMBL1346907 & 688382 & 3.9 & 4.7103 & TST \\
\hline
\end{tabular}




\begin{tabular}{|c|c|c|c|c|c|}
\hline \multicolumn{6}{|c|}{ plemental } \\
\hline CHEMBL1468009 & 688382 & 6.0 & 4.7354 & TRN & \\
\hline CHEMBL1476885 & 688382 & 6.0 & 4.8557 & TRN & \\
\hline CHEMBL1563247 & 688382 & 4.75 & 4.745 & TRN & \\
\hline CHEMBL1536957 & 688382 & 4.45 & 4.6486 & TRN & \\
\hline CHEMBL1367980 & 688382 & 4.0 & 4.8094 & TRN & \\
\hline CHEMBL1520268 & 688382 & 4.45 & 4.6242 & TRN & \\
\hline CHEMBL1548074 & 688382 & 4.15 & 4.6495 & TRN & \\
\hline CHEMBL1347116 & 688382 & 5.2 & 4.6466 & TST & \\
\hline CHEMBL3208503 & 688382 & 4.2 & 4.8138 & TRN & \\
\hline CHEMBL1506873 & 688382 & 4.5 & 4.8008 & TRN & \\
\hline CHEMBL3193949 & 688382 & 4.7 & 4.6554 & TST & \\
\hline CHEMBL1405367 & 688382 & 5.45 & 4.7621 & TRN & \\
\hline CHEMBL1565603 & 688382 & 4.4 & 4.7706 & TRN & \\
\hline CHEMBL1498666 & 688382 & 4.6 & 4.6355 & TRN & \\
\hline CHEMBL1363638 & 688382 & 5.05 & 4.7774 & TST & \\
\hline CHEMBL1353151 & 688382 & 5.95 & 4.797 & TST & \\
\hline CHEMBL1582062 & 688382 & 5.1 & 4.6863 & TST & \\
\hline CHEMBL1329974 & 688382 & 4.05 & 4.7415 & TST & \\
\hline CHEMBL1572146 & 688382 & 5.05 & 4.6848 & TRN & \\
\hline CHEMBL3193098 & 688382 & 4.15 & 4.6129 & TRN & \\
\hline CHEMBL1498782 & 688382 & 5.9 & 4.6735 & TRN & \\
\hline CHEMBL1308732 & 688382 & 4.75 & 4.71399 & 99999999995 & TST \\
\hline CHEMBL1547104 & 688382 & 4.95 & 4.6781 & TST & \\
\hline CHEMBL1607628 & 688382 & 4.5 & 4.6916 & TRN & \\
\hline CHEMBL1397889 & 688382 & 5.35 & 4.776 & TRN & \\
\hline CHEMBL1463965 & 688382 & 4.8 & 4.8218 & TST & \\
\hline CHEMBL1365884 & 688382 & 4.85 & 4.8105 & TST & \\
\hline CHEMBL3193963 & 688382 & 4.6 & 4.6698 & TRN & \\
\hline CHEMBL3210913 & 688382 & 4.4 & 4.6436 & TRN & \\
\hline CHEMBL437061 & 688382 & 4.7 & 4.6841 & TRN & \\
\hline CHEMBL 3208249 & 688382 & 4.55 & 4.7069 & TRN & \\
\hline CHEMBL1382500 & 688382 & 4.05 & 4.6632 & TRN & \\
\hline CHEMBL3209659 & 688382 & 4.5 & 4.7408 & TST & \\
\hline CHEMBL1519239 & 688382 & 4.85 & 4.6837 & TRN & \\
\hline CHEMBL3209551 & 688382 & 5.55 & 4.7006 & TRN & \\
\hline CHEMBL1454790 & 688382 & 5.05 & 4.6713 & TRN & \\
\hline CHEMBL1357072 & 688382 & 4.1 & 4.6733 & TRN & \\
\hline CHEMBL1965669 & 688382 & 4.3 & 4.59699 & 99999999995 & TRN \\
\hline CHEMBL1446747 & 688382 & 5.15 & 4.7047 & TRN & \\
\hline CHEMBL1560506 & 688382 & 5.15 & 4.6862 & TRN & \\
\hline CHEMBL 3214085 & 688382 & 4.7 & 4.6596 & TST & \\
\hline CHEMBL1600974 & 688382 & 4.9 & 4.7205 & TST & \\
\hline CHEMBL1336874 & 688382 & 4.45 & 4.6565 & TRN & \\
\hline CHEMBL1372040 & 688382 & 4.3 & 4.6594 & TRN & \\
\hline CHEMBL1494506 & 688382 & 4.15 & 4.6831 & TRN & \\
\hline CHEMBL1307762 & 688382 & 5.9 & 4.7455 & TRN & \\
\hline CHEMBL1968467 & 688382 & 4.65 & 4.6483 & TST & \\
\hline CHEMBL1500013 & 688382 & 4.4 & 4.6183 & TRN & \\
\hline
\end{tabular}




\begin{tabular}{|c|c|c|c|c|c|}
\hline \multicolumn{6}{|c|}{ Supplemental Table S2.txt } \\
\hline CHEMBL1520426 & 688382 & 4.5 & 4.6694 & TRN & \\
\hline CHEMBL1568887 & 688382 & 4.35 & 4.6227 & TRN & \\
\hline CHEMBL1558441 & 688382 & 4.15 & 4.6504 & TRN & \\
\hline CHEMBL1586322 & 688382 & 4.2 & 4.6835 & TRN & \\
\hline CHEMBL3210022 & 688382 & 5.1 & 4.7456 & TRN & \\
\hline CHEMBL1386043 & 688382 & 4.8 & 4.7794 & TRN & \\
\hline CHEMBL1390618 & 688382 & 4.85 & 4.7657 & TST & \\
\hline CHEMBL1488391 & 688382 & 4.4 & 4.6926 & TST & \\
\hline CHEMBL1561422 & 688382 & 6.0 & 4.7344 & TST & \\
\hline CHEMBL1393598 & 688382 & 5.3 & 4.6882 & TRN & \\
\hline CHEMBL1611067 & 688382 & 5.0 & 4.6358 & TRN & \\
\hline CHEMBL1583838 & 688382 & 4.5 & 4.6838 & TRN & \\
\hline CHEMBL199405 & 688382 & 5.2 & 4.651 & TRN & \\
\hline CHEMBL1338885 & 688382 & 5.05 & 4.7689 & TRN & \\
\hline CHEMBL1461801 & 688382 & 4.3 & 4.7925 & TST & \\
\hline CHEMBL1439177 & 688382 & 4.6 & 4.7461 & TRN & \\
\hline CHEMBL1462191 & 688382 & 4.5 & 4.6885 & TRN & \\
\hline CHEMBL1558174 & 688382 & 4.5 & 4.8229 & TRN & \\
\hline CHEMBL3190227 & 688382 & 5.9 & 4.6794 & TRN & \\
\hline CHEMBL1508252 & 688382 & 4.3 & 4.7069 & TRN & \\
\hline CHEMBL1501758 & 688382 & 4.5 & 4.6867 & TRN & \\
\hline CHEMBL1462831 & 688382 & 4.45 & 4.7765 & TRN & \\
\hline CHEMBL1432649 & 688382 & 5.15 & 4.6267 & TST & \\
\hline CHEMBL1529746 & 688382 & 4.5 & 4.8218 & TST & \\
\hline CHEMBL1529381 & 688382 & 3.55 & 4.6796 & TST & \\
\hline CHEMBL1488661 & 688382 & 4.5 & 4.7788 & TRN & \\
\hline CHEMBL1511616 & 688382 & 4.3 & 4.6496 & TST & \\
\hline CHEMBL1307467 & 688382 & 4.95 & 4.6161 & TRN & \\
\hline CHEMBL1433169 & 688382 & 4.85 & 4.7489 & TRN & \\
\hline CHEMBL1562003 & 688382 & 4.5 & 4.6345 & TRN & \\
\hline CHEMBL 3207878 & 688382 & 5.85 & 4.6808 & TRN & \\
\hline CHEMBL3212779 & 688382 & 4.85 & 4.711 & TRN & \\
\hline CHEMBL1430529 & 688382 & 4.55 & 4.8078 & TRN & \\
\hline CHEMBL1558993 & 688382 & 4.5 & 4.6401 & TRN & \\
\hline CHEMBL1532469 & 688382 & 4.05 & 4.7613 & TRN & \\
\hline CHEMBL1326863 & 688382 & 5.0 & 4.6721 & TRN & \\
\hline CHEMBL1332067 & 688382 & 4.8 & 4.8077 & TRN & \\
\hline CHEMBL1410306 & 688382 & 4.6 & $4.6530 e$ & 00000000005 & TST \\
\hline CHEMBL3189464 & 688382 & 4.15 & 4.6488 & TRN & \\
\hline CHEMBL1423633 & 688382 & 4.5 & 4.6351 & TRN & \\
\hline CHEMBL1570438 & 688382 & 6.05 & 4.7548 & TRN & \\
\hline CHEMBL1520096 & 688382 & 6.0 & 4.6392 & TST & \\
\hline CHEMBL1337004 & 688382 & 5.25 & 4.7663 & TRN & \\
\hline CHEMBL1554726 & 688382 & 4.4 & 4.7687 & TRN & \\
\hline CHEMBL1340779 & 688382 & 5.1 & 4.8032 & TRN & \\
\hline CHEMBL1550366 & 688382 & 4.3 & 4.6122 & TRN & \\
\hline CHEMBL1544434 & 688382 & 4.35 & 4.6854 & TST & \\
\hline CHEMBL1466958 & 688382 & 4.8 & 4.763 & TRN & \\
\hline
\end{tabular}




\begin{tabular}{|c|c|c|c|c|c|}
\hline \multicolumn{6}{|c|}{ Supplemental Table S2.txt } \\
\hline CHEMBL1487303 & 688382 & 4.4 & 4.7478 & TST & \\
\hline CHEMBL1351518 & 688382 & 5.4 & 4.6728 & TRN & \\
\hline CHEMBL1500785 & 688382 & 4.0 & 4.8193 & TRN & \\
\hline CHEMBL1399390 & 688382 & 4.15 & 4.6179 & TRN & \\
\hline CHEMBL1404067 & 688382 & 4.8 & 4.628 & TRN & \\
\hline CHEMBL1335541 & 688382 & 6.0 & 4.7025 & TRN & \\
\hline CHEMBL1309651 & 688382 & 4.85 & 4.7498 & TRN & \\
\hline CHEMBL1454037 & 688382 & 3.85 & 4.6108 & TST & \\
\hline CHEMBL3195352 & 688382 & 4.85 & 4.6258 & TRN & \\
\hline CHEMBL1345447 & 688382 & 4.05 & 4.6205 & TRN & \\
\hline CHEMBL1347941 & 688382 & 4.5 & 4.7534 & TRN & \\
\hline CHEMBL1348667 & 688382 & 4.4 & 4.6978 & TRN & \\
\hline CHEMBL1441340 & 688382 & 4.35 & 4.6872 & TRN & \\
\hline CHEMBL1500372 & 688382 & 4.4 & 4.6713 & TRN & \\
\hline CHEMBL1367036 & 688382 & 5.55 & 4.6874 & TRN & \\
\hline CHEMBL1582395 & 688382 & 5.0 & 4.7086 & TRN & \\
\hline CHEMBL1545465 & 688382 & 4.15 & 4.7528 & TRN & \\
\hline CHEMBL1418435 & 688382 & 4.9 & 4.686 & TST & \\
\hline CHEMBL1477969 & 688382 & 4.25 & 4.6829 & TRN & \\
\hline CHEMBL1568655 & 688382 & 3.95 & 4.7007 & TRN & \\
\hline CHEMBL1386734 & 688382 & 4.15 & 4.7501 & TRN & \\
\hline CHEMBL1402266 & 688382 & 5.15 & 4.8335 & TRN & \\
\hline CHEMBL1371763 & 688382 & 4.35 & 4.8419 & TRN & \\
\hline CHEMBL1579037 & 688382 & 4.85 & 4.7084 & TRN & \\
\hline CHEMBL1420735 & 688382 & 4.45 & 4.7419 & TRN & \\
\hline CHEMBL1332184 & 688382 & 4.95 & 4.6002 & TRN & \\
\hline CHEMBL1447015 & 688382 & 4.8 & 4.6814 & TRN & \\
\hline CHEMBL3198213 & 688382 & 4.4 & 4.6657 & TST & \\
\hline CHEMBL1302170 & 688382 & 4.75 & 4.672 & TRN & \\
\hline CHEMBL1999193 & 688382 & 5.4 & 4.6995 & TRN & \\
\hline CHEMBL1324423 & 688382 & 4.85 & 4.6923 & TRN & \\
\hline CHEMBL1541178 & 688382 & 5.05 & 4.8282 & TRN & \\
\hline CHEMBL 289764 & 688382 & 4.15 & 4.6368 & TRN & \\
\hline CHEMBL1364834 & 688382 & 4.2 & 4.7096 & TRN & \\
\hline CHEMBL1331586 & 688382 & 6.1 & $4.6610 e$ & 00000000005 & TRN \\
\hline CHEMBL1459810 & 688382 & 4.5 & 4.8242 & TRN & \\
\hline CHEMBL1573579 & 688382 & 4.5 & 4.7106 & TRN & \\
\hline CHEMBL1545905 & 688382 & 5.15 & 4.6969 & TRN & \\
\hline CHEMBL1510761 & 688382 & 4.5 & 4.6602 & TST & \\
\hline CHEMBL1510495 & 688382 & 4.85 & 4.725 & TRN & \\
\hline CHEMBL1608479 & 688382 & 4.2 & 4.7181 & TST & \\
\hline CHEMBL1536639 & 688382 & 4.05 & 4.787 & TRN & \\
\hline CHEMBL1309949 & 688382 & 4.85 & 4.673 & TRN & \\
\hline CHEMBL1605241 & 688382 & 4.65 & 4.8207 & TRN & \\
\hline CHEMBL1503612 & 688382 & 4.15 & 4.6478 & TRN & \\
\hline CHEMBL1374698 & 688382 & 5.05 & 4.7776 & TRN & \\
\hline CHEMBL1430028 & 688382 & 4.85 & 4.7889 & TRN & \\
\hline CHEMBL1405878 & 688382 & 4.15 & 4.7414 & TRN & \\
\hline
\end{tabular}




\begin{tabular}{|c|c|c|c|c|c|}
\hline \multicolumn{6}{|c|}{ Supplemental Table s2.txt } \\
\hline CHEMBL1539016 & 688382 & 4.9 & 4.5868 & TST & \\
\hline CHEMBL1493697 & 688382 & 4.4 & 4.6838 & TRN & \\
\hline CHEMBL1581499 & 688382 & 4.85 & 4.6878 & TRN & \\
\hline CHEMBL1465021 & 688382 & 4.4 & 4.6446 & TST & \\
\hline CHEMBL1314584 & 688382 & 4.45 & 4.7095 & TST & \\
\hline CHEMBL1381517 & 688382 & 4.9 & 4.7931 & TST & \\
\hline CHEMBL3197665 & 688382 & 4.45 & 4.6678 & TRN & \\
\hline CHEMBL1504290 & 688382 & 4.15 & 4.7412 & TRN & \\
\hline CHEMBL1478873 & 688382 & 5.0 & 4.6604 & TRN & \\
\hline CHEMBL1412067 & 688382 & 4.3 & 4.6441 & TRN & \\
\hline CHEMBL3193664 & 688382 & 4.5 & 4.5937 & TRN & \\
\hline CHEMBL1387226 & 688382 & 4.05 & 4.7092 & TST & \\
\hline CHEMBL1321615 & 688382 & 5.0 & 4.782 & TRN & \\
\hline CHEMBL1466603 & 688382 & 4.95 & 4.7537 & TRN & \\
\hline CHEMBL1604716 & 688382 & 5.05 & 4.6143 & TRN & \\
\hline CHEMBL1353808 & 688382 & 5.1 & 4.6294 & TRN & \\
\hline CHEMBL1492865 & 688382 & 4.85 & 4.675 & TRN & \\
\hline CHEMBL1393578 & 688382 & 6.0 & 4.758 & TRN & \\
\hline CHEMBL1376872 & 688382 & 4.4 & 4.6439 & TRN & \\
\hline CHEMBL1511371 & 688382 & 4.75 & 4.6238 & TRN & \\
\hline CHEMBL1529396 & 688382 & 4.15 & 4.7686 & TRN & \\
\hline CHEMBL1360394 & 688382 & 4.05 & 4.7071 & TST & \\
\hline CHEMBL1453794 & 688382 & 4.5 & 4.7021 & TRN & \\
\hline CHEMBL3191531 & 688382 & 5.0 & 4.6313 & TRN & \\
\hline CHEMBL1496133 & 688382 & 4.55 & 4.7572 & TRN & \\
\hline CHEMBL1471017 & 688382 & 5.8 & 4.7316 & TRN & \\
\hline CHEMBL1386883 & 688382 & 4.3 & 4.6734 & TRN & \\
\hline CHEMBL1380354 & 688382 & 4.55 & 4.7679 & TRN & \\
\hline CHEMBL1417970 & 688382 & 4.6 & 4.7087 & TRN & \\
\hline CHEMBL1561553 & 688382 & 4.05 & 4.7408 & TRN & \\
\hline CHEMBL1321477 & 688382 & 4.65 & 4.7466 & TRN & \\
\hline CHEMBL1506150 & 688382 & 4.5 & 4.7367 & TST & \\
\hline CHEMBL1588992 & 688382 & 4.75 & 4.677 & TRN & \\
\hline CHEMBL1429547 & 688382 & 4.85 & 4.7161 & TRN & \\
\hline CHEMBL1414210 & 688382 & 4.5 & 4.738 & TRN & \\
\hline CHEMBL1330147 & 688382 & 4.25 & 4.7032 & TST & \\
\hline CHEMBL1498871 & 688382 & 4.5 & 4.6786 & TRN & \\
\hline CHEMBL1328115 & 688382 & 4.3 & 4.6553 & TRN & \\
\hline CHEMBL1523945 & 688382 & 4.25 & 4.6252 & TST & \\
\hline CHEMBL1465347 & 688382 & 4.8 & 4.7099 & TRN & \\
\hline CHEMBL1454718 & 688382 & 4.8 & 4.7145 & TRN & \\
\hline CHEMBL1539075 & 688382 & 4.45 & 4.6051 & TRN & \\
\hline CHEMBL1354038 & 688382 & 4.4 & 4.7810 & 0000000001 & TRN \\
\hline CHEMBL3210841 & 688382 & 5.05 & 4.6798 & TST & \\
\hline CHEMBL1409337 & 688382 & 7.5003 & 4.6726 & TST & \\
\hline CHEMBL1299470 & 688382 & 4.5 & 4.6842 & TST & \\
\hline CHEMBL1309331 & 688382 & 5.8 & 4.7974 & TRN & \\
\hline CHEMBL1351858 & 688382 & 4.85 & 4.7356 & TST & \\
\hline
\end{tabular}




\begin{tabular}{|c|c|c|c|c|}
\hline \multicolumn{5}{|c|}{ Supplemental Table S2.txt } \\
\hline CHEMBL1546706 & 688382 & 4.45 & 4.6531 & TRN \\
\hline CHEMBL1299966 & 688382 & 4.9 & 4.7223 & TRN \\
\hline CHEMBL1347323 & 688382 & 5.85 & 4.7134 & TST \\
\hline CHEMBL1602750 & 688382 & 4.4 & 4.6992 & TRN \\
\hline CHEMBL1508945 & 688382 & 4.55 & 4.7022 & TRN \\
\hline CHEMBL1308937 & 688382 & 4.1 & 4.6461 & TST \\
\hline CHEMBL1531517 & 688382 & 4.5 & 4.7389 & TRN \\
\hline CHEMBL1515093 & 688382 & 5.5 & 4.6583 & TRN \\
\hline CHEMBL1546964 & 688382 & 4.4 & 4.7185 & TRN \\
\hline CHEMBL1349066 & 688382 & 4.05 & 4.7158 & TRN \\
\hline CHEMBL1564403 & 688382 & 4.4 & 4.7555 & TRN \\
\hline CHEMBL1384540 & 688382 & 4.45 & 4.7701 & TRN \\
\hline CHEMBL1444988 & 688382 & 4.85 & 4.7282 & TRN \\
\hline CHEMBL1449377 & 688382 & 4.5 & 4.698 & TRN \\
\hline CHEMBL1334707 & 688382 & 4.45 & 4.6101 & TRN \\
\hline CHEMBL1501890 & 688382 & 4.85 & 4.6531 & TRN \\
\hline CHEMBL1574205 & 688382 & 4.25 & 4.7754 & TRN \\
\hline CHEMBL1585782 & 688382 & 5.15 & 4.8085 & TRN \\
\hline CHEMBL1560906 & 688382 & 5.6 & 4.7969 & TST \\
\hline CHEMBL1497991 & 688382 & 4.85 & 4.6656 & TRN \\
\hline CHEMBL1366019 & 688382 & 4.7 & 4.7826 & TRN \\
\hline CHEMBL1426615 & 688382 & 4.8 & 4.7287 & TRN \\
\hline CHEMBL1373001 & 688382 & 4.0 & 4.7136 & TST \\
\hline CHEMBL1528332 & 688382 & 4.9 & 4.6457 & TRN \\
\hline CHEMBL1417932 & 688382 & 4.65 & 4.6606 & TRN \\
\hline CHEMBL1519814 & 688382 & 3.95 & 4.6887 & TRN \\
\hline CHEMBL1518925 & 688382 & 4.45 & 4.663 & TRN \\
\hline CHEMBL1562181 & 688382 & 6.0 & 4.6276 & TST \\
\hline CHEMBL1351666 & 688382 & 4.55 & 4.7482 & TRN \\
\hline CHEMBL1343320 & 688382 & 4.45 & 4.7906 & TRN \\
\hline CHEMBL1454926 & 688382 & 4.5 & 4.716 & TRN \\
\hline CHEMBL1525735 & 688382 & 4.45 & 4.8138 & TRN \\
\hline CHEMBL1305371 & 688382 & 4.8 & 4.7432 & TRN \\
\hline CHEMBL3210157 & 688382 & 4.9 & 4.637 & TST \\
\hline CHEMBL1561283 & 688382 & 6.0 & 4.7464 & TRN \\
\hline CHEMBL1466543 & 688382 & 4.45 & 4.6344 & TRN \\
\hline CHEMBL1594585 & 688382 & 4.85 & 4.7307 & TRN \\
\hline CHEMBL1418134 & 688382 & 4.45 & 4.6116 & TRN \\
\hline CHEMBL1455528 & 688382 & 4.5 & 4.6422 & TST \\
\hline CHEMBL1431083 & 688382 & 4.8 & 4.8257 & TRN \\
\hline CHEMBL1576199 & 688382 & 4.05 & 4.7504 & TST \\
\hline CHEMBL2003063 & 688382 & 4.15 & 4.6591 & TRN \\
\hline CHEMBL1467115 & 688382 & 4.65 & 4.6465 & TST \\
\hline CHEMBL1539645 & 688382 & 4.4 & 4.6822 & TST \\
\hline CHEMBL1612995 & 688382 & 4.45 & 4.6798 & TRN \\
\hline CHEMBL1561235 & 688382 & 4.5 & 4.6655 & TRN \\
\hline CHEMBL1479046 & 688382 & 5.05 & 4.7038 & TRN \\
\hline CHEMBL1480026 & 688382 & 4.8 & 4.6731 & TST \\
\hline
\end{tabular}




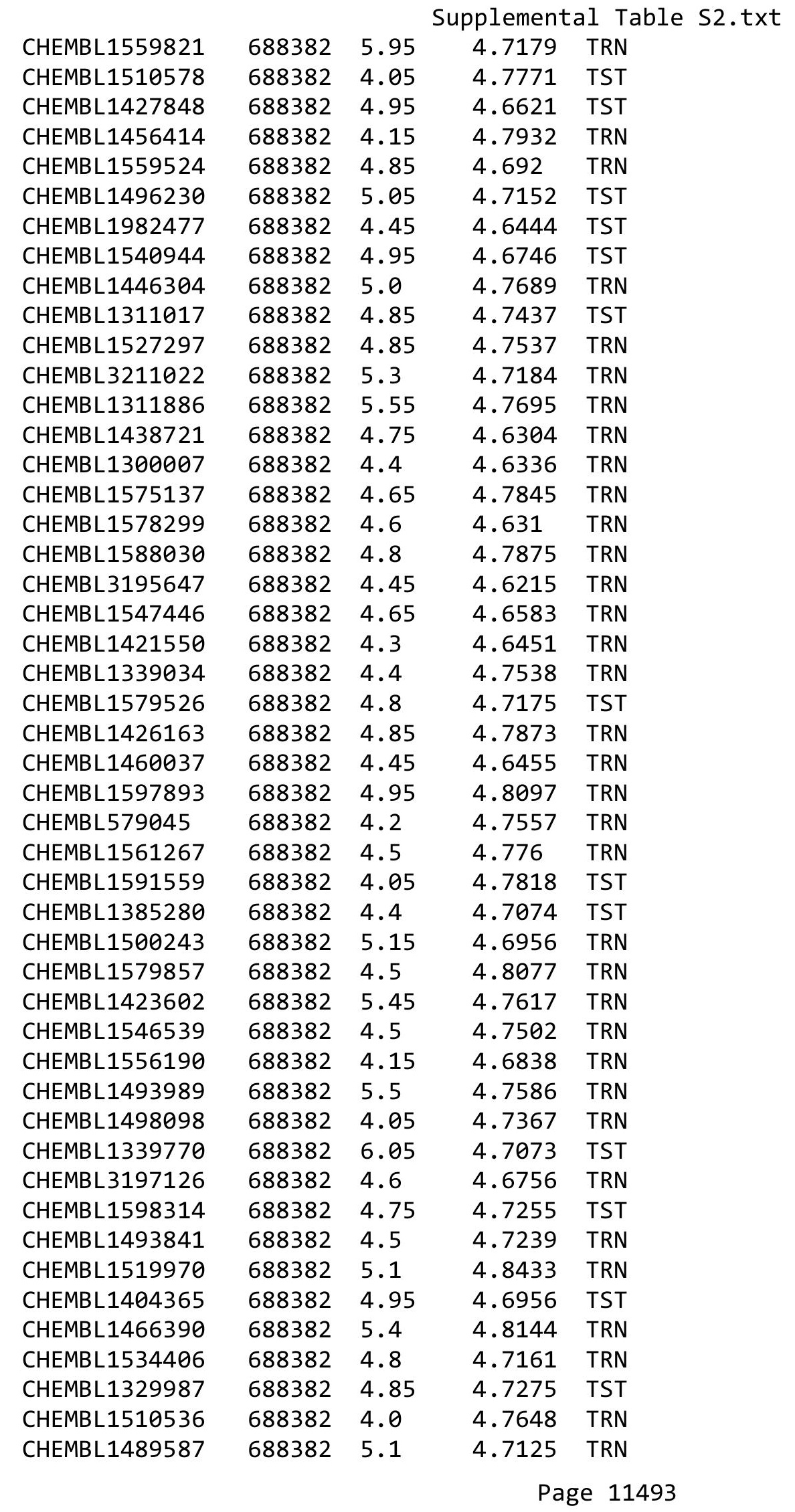




\begin{tabular}{|c|c|c|c|c|c|}
\hline & & \multicolumn{4}{|c|}{ Supplemental Table s2.txt } \\
\hline CHEMBL1377796 & 688382 & 4.45 & 4.6993 & TST & \\
\hline CHEMBL1374808 & 688382 & 4.35 & 4.7388 & TRN & \\
\hline CHEMBL1318272 & 688382 & 4.0 & 4.6563 & TRN & \\
\hline CHEMBL1345498 & 688382 & 4.5 & 4.7731 & TRN & \\
\hline CHEMBL1497196 & 688382 & 4.6 & 4.7061 & TRN & \\
\hline CHEMBL1300612 & 688382 & 5.45 & 4.709 & TRN & \\
\hline CHEMBL1564472 & 688382 & 5.85 & 4.7589 & TRN & \\
\hline CHEMBL 3192585 & 688382 & 4.85 & 4.7606 & TRN & \\
\hline CHEMBL1970780 & 688382 & 4.45 & 4.7375 & TST & \\
\hline CHEMBL1364652 & 688382 & 4.55 & 4.7354 & TST & \\
\hline CHEMBL1500840 & 688382 & 5.8 & 4.655 & TRN & \\
\hline CHEMBL3191622 & 688382 & 4.45 & 4.6741 & TRN & \\
\hline CHEMBL1576288 & 688382 & 5.05 & 4.646 & TRN & \\
\hline CHEMBL1304014 & 688382 & 4.15 & 4.6786 & TRN & \\
\hline CHEMBL1529775 & 688382 & 4.45 & 4.7399 & TRN & \\
\hline CHEMBL1584152 & 688382 & 4.05 & 4.6535 & TRN & \\
\hline CHEMBL1319932 & 688382 & 5.0 & 4.63399 & 99999999995 & TRN \\
\hline CHEMBL1337301 & 688382 & 5.25 & 4.6257 & TRN & \\
\hline CHEMBL1383265 & 688382 & 4.05 & 4.6635 & TRN & \\
\hline CHEMBL1517514 & 688382 & 4.8 & 4.6804 & TST & \\
\hline CHEMBL1505092 & 688382 & 4.45 & 4.6871 & TRN & \\
\hline CHEMBL3213559 & 688382 & 4.45 & 4.6545 & TST & \\
\hline CHEMBL1393237 & 688382 & 4.45 & 4.6868 & TRN & \\
\hline CHEMBL1471449 & 688382 & 4.9 & 4.7759 & TRN & \\
\hline CHEMBL1503807 & 688382 & 5.0 & 4.7163 & TRN & \\
\hline CHEMBL1496052 & 688382 & 5.2 & 4.6397 & TST & \\
\hline CHEMBL3189489 & 688382 & 4.4 & 4.6523 & TRN & \\
\hline CHEMBL1970711 & 688382 & 5.25 & 4.6096 & TRN & \\
\hline CHEMBL1453122 & 688382 & 4.45 & 4.7578 & TRN & \\
\hline CHEMBL1529081 & 688382 & 4.45 & 4.6724 & TST & \\
\hline CHEMBL1410151 & 688382 & 4.6 & 4.6587 & TST & \\
\hline CHEMBL1587718 & 688382 & 4.15 & 4.6584 & TRN & \\
\hline CHEMBL1463156 & 688382 & 5.0 & 4.6768 & TST & \\
\hline CHEMBL1559963 & 688382 & 4.3 & 4.8444 & TRN & \\
\hline CHEMBL1343643 & 688382 & 4.4 & 4.6752 & TST & \\
\hline CHEMBL1407642 & 688382 & 4.5 & 4.5827 & TRN & \\
\hline CHEMBL1465652 & 688382 & 5.5 & 4.7602 & TST & \\
\hline CHEMBL1566861 & 688382 & 5.0 & 4.7422 & TST & \\
\hline CHEMBL1518546 & 688382 & 4.85 & 4.6213 & TRN & \\
\hline CHEMBL1386279 & 688382 & 4.45 & 4.6871 & TST & \\
\hline CHEMBL1437982 & 688382 & 4.5 & 4.6565 & TST & \\
\hline CHEMBL1467811 & 688382 & 4.05 & 4.7036 & TRN & \\
\hline CHEMBL3197847 & 688382 & 4.45 & 4.5971 & TRN & \\
\hline CHEMBL1351683 & 688382 & 4.5 & 4.6633 & TRN & \\
\hline CHEMBL97846 & 688382 & 4.9 & 4.6747 & TRN & \\
\hline CHEMBL1979806 & 688382 & 4.9 & 4.6166 & TRN & \\
\hline CHEMBL3214315 & 688382 & 5.8 & 4.6566 & TRN & \\
\hline CHEMBL1529209 & 688382 & 4.2 & 4.6466 & TRN & \\
\hline
\end{tabular}




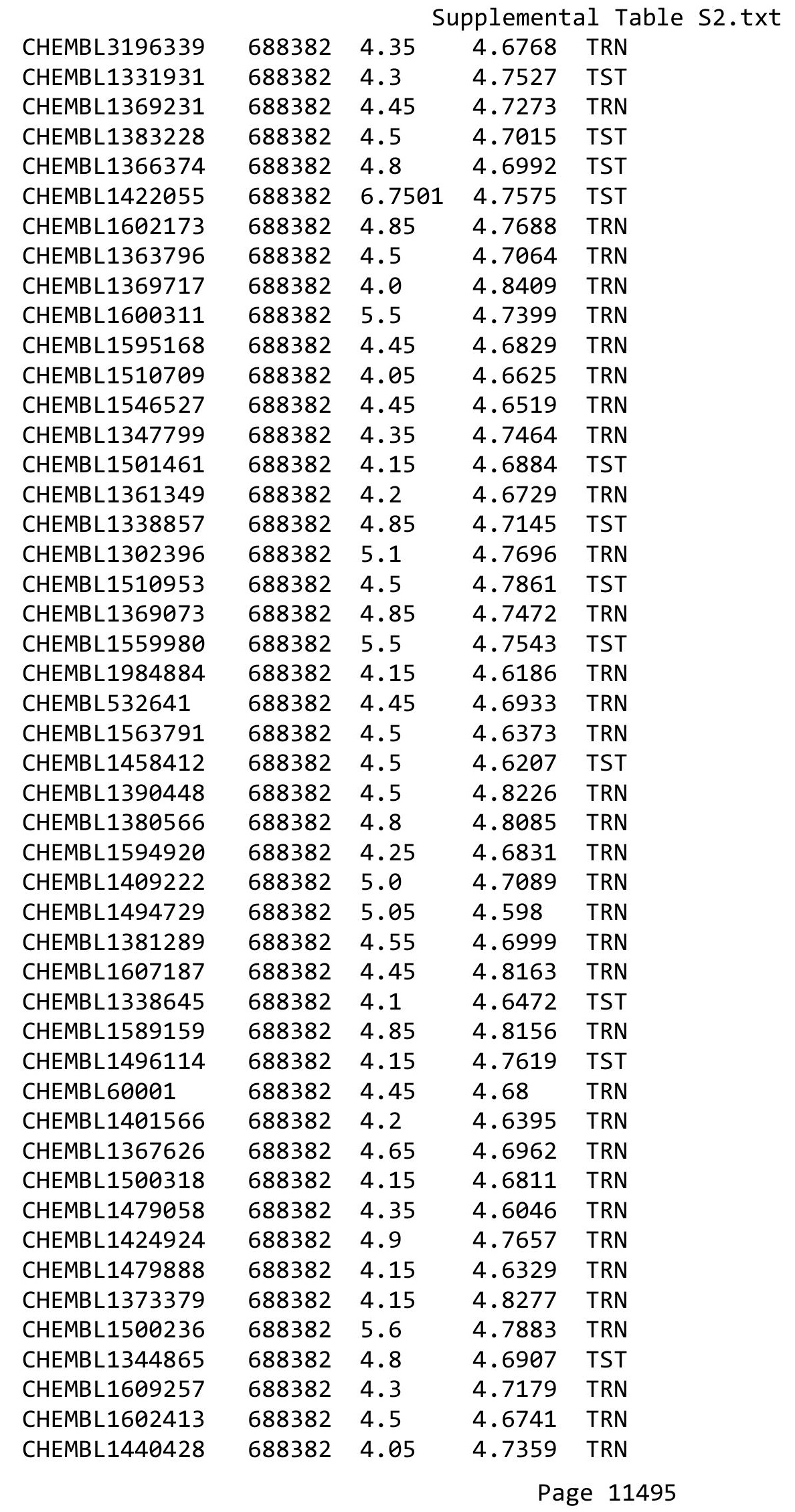




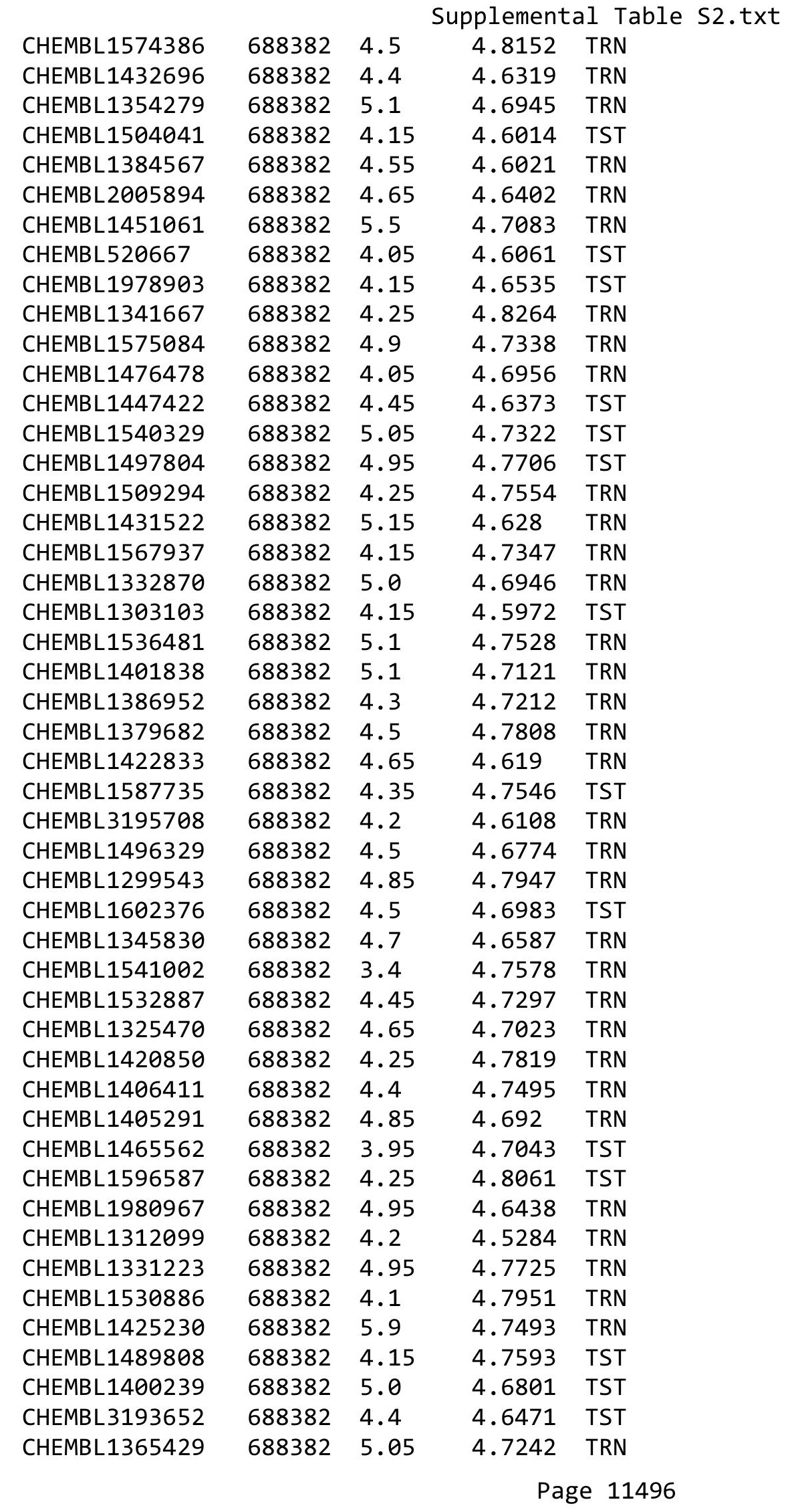




\begin{tabular}{|c|c|c|c|c|c|}
\hline \multicolumn{6}{|c|}{ Supplemental Table S2.txt } \\
\hline CHEMBL1530209 & 688382 & 4.5 & 4.6914 & TRN & \\
\hline CHEMBL1308971 & 688382 & 5.15 & 4.6313 & TRN & \\
\hline CHEMBL1413243 & 688382 & 5.1 & 4.6942 & TST & \\
\hline CHEMBL3210997 & 688382 & 4.4 & 4.6394 & TRN & \\
\hline CHEMBL1335312 & 688382 & 4.85 & 4.7312 & TRN & \\
\hline CHEMBL1484978 & 688382 & 4.15 & 4.6801 & TST & \\
\hline CHEMBL1342949 & 688382 & 4.05 & 4.6488 & TRN & \\
\hline CHEMBL1570876 & 688382 & 3.95 & 4.8764 & TRN & \\
\hline CHEMBL1392340 & 688382 & 4.55 & 4.8077 & TST & \\
\hline CHEMBL3190340 & 688382 & 4.45 & 4.6574 & TRN & \\
\hline CHEMBL1452677 & 688382 & 3.9 & 4.7255 & TRN & \\
\hline CHEMBL1350124 & 688382 & 4.2 & 4.677 & TST & \\
\hline CHEMBL1986363 & 688382 & 5.2 & 4.7301 & TRN & \\
\hline CHEMBL1586217 & 688382 & 5.2 & 4.7698 & TRN & \\
\hline CHEMBL1351911 & 688382 & 4.75 & 4.7559 & TRN & \\
\hline CHEMBL1304218 & 688382 & 4.5 & 4.7929 & TRN & \\
\hline CHEMBL1394044 & 688382 & 4.8 & 4.8729 & TRN & \\
\hline CHEMBL1548395 & 688382 & 6.0 & 4.7994 & TRN & \\
\hline CHEMBL1557611 & 688382 & 4.4 & 4.6345 & TRN & \\
\hline CHEMBL1480451 & 688382 & 6.0 & 4.7665 & TRN & \\
\hline CHEMBL1410192 & 688382 & 4.4 & 4.6316 & TRN & \\
\hline CHEMBL1327863 & 688382 & 4.95 & 4.6727 & TST & \\
\hline CHEMBL1490525 & 688382 & 4.45 & 4.6905 & TRN & \\
\hline CHEMBL1596464 & 688382 & 5.6 & 4.5913 & TST & \\
\hline CHEMBL1461830 & 688382 & 4.25 & 4.727 & TRN & \\
\hline CHEMBL1427857 & 688382 & 5.0 & 4.6751 & TRN & \\
\hline CHEMBL3195940 & 688382 & 4.55 & 4.6454 & TRN & \\
\hline CHEMBL1461032 & 688382 & 4.4 & 4.7338 & TST & \\
\hline CHEMBL1412711 & 688382 & 4.05 & 4.7999 & TRN & \\
\hline CHEMBL1429340 & 688382 & 3.95 & 4.7719 & TRN & \\
\hline CHEMBL1310626 & 688382 & 5.2 & 4.6553 & TRN & \\
\hline CHEMBL1385716 & 688382 & 4.9 & 4.6157 & TRN & \\
\hline CHEMBL1351229 & 688382 & 4.2 & 4.6032 & TRN & \\
\hline CHEMBL1550843 & 688382 & 6.0 & 4.726 & TRN & \\
\hline CHEMBL1510317 & 688382 & 5.25 & 4.6673 & TST & \\
\hline CHEMBL1566995 & 688382 & 4.05 & 4.6747 & TRN & \\
\hline CHEMBL1599476 & 688382 & 5.15 & 4.7676 & TRN & \\
\hline CHEMBL3193332 & 688382 & 5.85 & 4.6509 & TRN & \\
\hline CHEMBL1381624 & 688382 & 5.15 & $4.6960 e$ & 0000000001 & TRN \\
\hline CHEMBL3207977 & 688382 & 4.85 & 4.6827 & TRN & \\
\hline CHEMBL1407199 & 688382 & 4.15 & 4.6469 & TRN & \\
\hline CHEMBL1563668 & 688382 & 4.8 & 4.7891 & TST & \\
\hline CHEMBL57013 & 688382 & 5.1 & 4.6777 & TST & \\
\hline CHEMBL1412786 & 688382 & 5.15 & 4.633 & TRN & \\
\hline CHEMBL1517284 & 688382 & 4.5 & 4.5981 & TRN & \\
\hline CHEMBL1487063 & 688382 & 4.5 & 4.6648 & TRN & \\
\hline CHEMBL1330666 & 688382 & 4.8 & 4.6912 & TRN & \\
\hline CHEMBL1977173 & 688382 & 5.2 & 4.6555 & TRN & \\
\hline
\end{tabular}




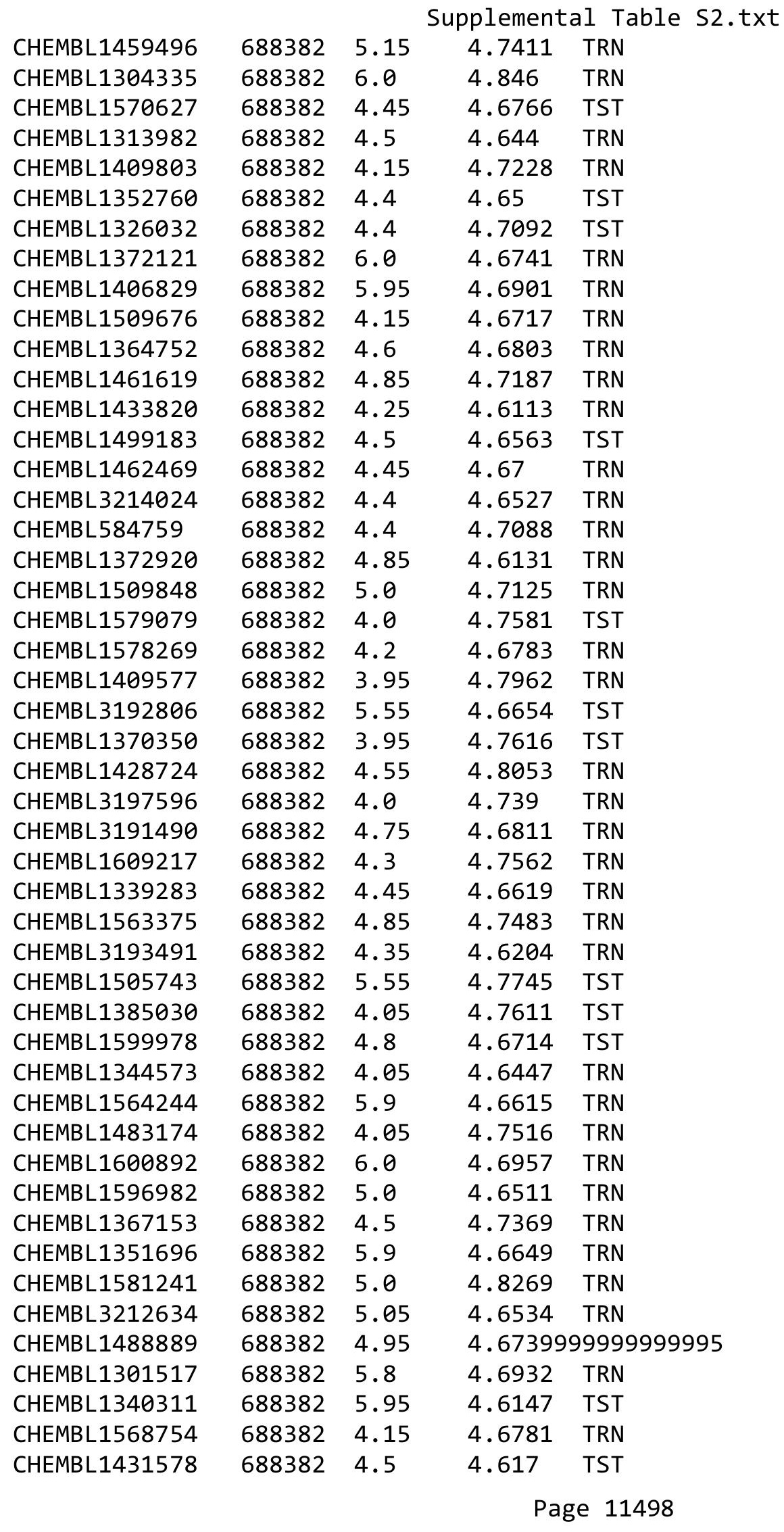




\begin{tabular}{|c|c|c|c|c|}
\hline \multicolumn{5}{|c|}{ Supplemental Table S2.txt } \\
\hline CHEMBL3195302 & 688382 & 4.35 & 4.6868 & TST \\
\hline CHEMBL1589545 & 688382 & 4.2 & 4.683 & TRN \\
\hline CHEMBL1592020 & 688382 & 5.8 & 4.6743 & TRN \\
\hline CHEMBL1498850 & 688382 & 5.25 & 4.8234 & TRN \\
\hline CHEMBL1438259 & 688382 & 4.95 & 4.7539 & TRN \\
\hline CHEMBL1578605 & 688382 & 4.95 & 4.7346 & TRN \\
\hline CHEMBL1352307 & 688382 & 4.35 & 4.7284 & TRN \\
\hline CHEMBL1379875 & 688382 & 5.15 & 4.6311 & TST \\
\hline CHEMBL3213889 & 688382 & 4.15 & 4.6665 & TRN \\
\hline CHEMBL1541882 & 688382 & 5.1 & 4.6796 & TRN \\
\hline CHEMBL1359741 & 688382 & 5.05 & 4.8107 & TRN \\
\hline CHEMBL1493275 & 688382 & 4.5 & 4.6321 & TST \\
\hline CHEMBL1307021 & 688382 & 4.45 & 4.6622 & TRN \\
\hline CHEMBL1417823 & 688382 & 4.55 & 4.7259 & TRN \\
\hline CHEMBL1306703 & 688382 & 4.05 & 4.784 & TST \\
\hline CHEMBL1340215 & 688382 & 4.8 & 4.7582 & TRN \\
\hline CHEMBL1306553 & 688382 & 4.15 & 4.6964 & TST \\
\hline CHEMBL1353529 & 688382 & 4.2 & 4.6687 & TRN \\
\hline CHEMBL1334360 & 688382 & 4.35 & 4.6688 & TRN \\
\hline CHEMBL1360537 & 688382 & 4.35 & 4.7472 & TRN \\
\hline CHEMBL1988969 & 688382 & 4.45 & 4.7003 & TRN \\
\hline CHEMBL1339480 & 688382 & 4.4 & 4.6613 & TST \\
\hline CHEMBL1401955 & 688382 & 4.5 & 4.68 & TRN \\
\hline CHEMBL1568099 & 688382 & 4.0 & 4.8187 & TRN \\
\hline CHEMBL1541913 & 688382 & 5.0 & 4.6757 & TST \\
\hline CHEMBL1562475 & 688382 & 5.1 & 4.6927 & TRN \\
\hline CHEMBL1492731 & 688382 & 4.85 & 4.6777 & TST \\
\hline CHEMBL1305911 & 688382 & 4.85 & 4.7619 & TRN \\
\hline CHEMBL1307435 & 688382 & 5.0 & 4.8105 & TRN \\
\hline CHEMBL1449729 & 688382 & 4.9 & 4.6848 & TRN \\
\hline CHEMBL1594779 & 688382 & 5.0 & 4.6325 & TST \\
\hline CHEMBL1989294 & 688382 & 4.5 & 4.7644 & TRN \\
\hline CHEMBL1544132 & 688382 & 4.9 & 4.6316 & TRN \\
\hline CHEMBL1519089 & 688382 & 4.95 & 4.7518 & TRN \\
\hline CHEMBL1984454 & 688382 & 4.8 & 4.6908 & TRN \\
\hline CHEMBL1329069 & 688382 & 4.45 & 4.7099 & TRN \\
\hline CHEMBL1438119 & 688382 & 5.1 & 4.7574 & TRN \\
\hline CHEMBL1322554 & 688382 & 4.15 & 4.794 & TRN \\
\hline CHEMBL1602655 & 688382 & 4.75 & 4.5595 & TRN \\
\hline CHEMBL1600780 & 688382 & 4.4 & 4.6432 & TST \\
\hline CHEMBL1399606 & 688382 & 5.1 & 4.6988 & TRN \\
\hline CHEMBL1428730 & 688382 & 5.0 & 4.6552 & TST \\
\hline CHEMBL1384529 & 688382 & 4.8 & 4.6465 & TRN \\
\hline CHEMBL1416807 & 688382 & 4.4 & 4.6626 & TRN \\
\hline CHEMBL1353358 & 688382 & 4.45 & 4.7332 & TRN \\
\hline CHEMBL1423544 & 688382 & 6.05 & 4.7765 & TRN \\
\hline CHEMBL1448013 & 688382 & 4.75 & 4.7746 & TRN \\
\hline CHEMBL1309201 & 688382 & 5.05 & 4.7209 & TRN \\
\hline
\end{tabular}




\begin{tabular}{|c|c|c|c|c|c|}
\hline \multicolumn{6}{|c|}{ Supplemental Table S2.txt } \\
\hline CHEMBL1558595 & 688382 & 5.0 & 4.671 & TRN & \\
\hline CHEMBL1350949 & 688382 & 4.55 & 4.6645 & TRN & \\
\hline CHEMBL1331438 & 688382 & 4.05 & 4.7115 & TRN & \\
\hline CHEMBL1517481 & 688382 & 4.05 & 4.8272 & TRN & \\
\hline CHEMBL1432719 & 688382 & 5.05 & 4.7933 & TST & \\
\hline CHEMBL1579571 & 688382 & 4.85 & 4.783 & TRN & \\
\hline CHEMBL1507021 & 688382 & 4.55 & 4.721 & TRN & \\
\hline CHEMBL1356280 & 688382 & 4.1 & 4.7522 & TST & \\
\hline CHEMBL1555916 & 688382 & 4.05 & 4.8226 & TRN & \\
\hline CHEMBL1556113 & 688382 & 4.85 & 4.7498 & TRN & \\
\hline CHEMBL1522842 & 688382 & 5.65 & 4.7166 & TRN & \\
\hline CHEMBL233896 & 688382 & 4.45 & 4.6367 & TST & \\
\hline CHEMBL1409556 & 688382 & 4.15 & 4.7656 & TRN & \\
\hline CHEMBL1511402 & 688382 & 4.15 & 4.6636 & TRN & \\
\hline CHEMBL1491266 & 688382 & 4.85 & 4.6948 & TRN & \\
\hline CHEMBL1363213 & 688382 & 4.55 & 4.8205 & TRN & \\
\hline CHEMBL1392042 & 688382 & 4.2 & 4.6937 & TST & \\
\hline CHEMBL1594993 & 688382 & 4.85 & 4.7144 & TRN & \\
\hline CHEMBL1269862 & 688382 & 4.45 & 4.6669 & TRN & \\
\hline CHEMBL1401477 & 688382 & 6.0 & 4.7253 & TST & \\
\hline CHEMBL1459234 & 688382 & 4.25 & 4.7565 & TRN & \\
\hline CHEMBL1381601 & 688382 & 4.5 & 4.7242 & TRN & \\
\hline CHEMBL1499214 & 688382 & 4.75 & 4.6312 & TRN & \\
\hline CHEMBL1451984 & 688382 & 5.05 & 4.7724 & TST & \\
\hline CHEMBL1472224 & 688382 & 6.0 & 4.7876 & TRN & \\
\hline CHEMBL1331241 & 688382 & 5.05 & 4.7998 & TRN & \\
\hline CHEMBL1497344 & 688382 & 5.05 & 4.6651 & TST & \\
\hline CHEMBL1460664 & 688382 & 4.35 & 4.6709 & TRN & \\
\hline CHEMBL 3196292 & 688382 & 4.8 & 4.6795 & TRN & \\
\hline CHEMBL1360263 & 688382 & 4.5 & 4.6997 & TRN & \\
\hline CHEMBL1483540 & 688382 & 4.95 & 4.7482 & TRN & \\
\hline CHEMBL1408698 & 688382 & 5.15 & 4.7925 & TRN & \\
\hline CHEMBL1340019 & 688382 & 4.35 & 4.7632 & TRN & \\
\hline CHEMBL1429086 & 688382 & 5.25 & 4.7109 & TRN & \\
\hline CHEMBL1510918 & 688382 & 4.45 & 4.6343 & TST & \\
\hline CHEMBL1559669 & 688382 & 5.1 & 4.6252 & TRN & \\
\hline CHEMBL1312911 & 688382 & 4.25 & 4.7487 & TRN & \\
\hline CHEMBL1468491 & 688382 & 4.85 & 4.7142 & TST & \\
\hline CHEMBL1498801 & 688382 & 4.5 & 4.6530 & 00000000005 & TRN \\
\hline CHEMBL1605373 & 688382 & 4.85 & 4.7875 & TRN & \\
\hline CHEMBL1346334 & 688382 & 5.4 & 4.7528 & TST & \\
\hline CHEMBL1367991 & 688382 & 5.0 & 4.6863 & TST & \\
\hline CHEMBL1411113 & 688382 & 4.95 & 4.7238 & TST & \\
\hline CHEMBL1491979 & 688382 & 4.85 & 4.7088 & TRN & \\
\hline CHEMBL1469890 & 688382 & 5.2 & 4.6819 & 99999999995 & TST \\
\hline CHEMBL1421305 & 688382 & 4.5 & 4.7072 & TRN & \\
\hline CHEMBL1488258 & 688382 & 4.05 & 4.7449 & TST & \\
\hline CHEMBL1420567 & 688382 & 4.15 & 4.6703 & TRN & \\
\hline
\end{tabular}




\begin{tabular}{|c|c|c|c|c|}
\hline \multicolumn{5}{|c|}{ Supplemental Table S2.txt } \\
\hline CHEMBL1609951 & 688382 & 4.4 & 4.7015 & TRN \\
\hline CHEMBL1725279 & 688382 & 4.5 & 4.6059 & TST \\
\hline CHEMBL1504880 & 688382 & 4.15 & 4.6261 & TRN \\
\hline CHEMBL1337325 & 688382 & 4.45 & 4.6675 & TRN \\
\hline CHEMBL1540627 & 688382 & 4.7 & 4.63899 & 9999999999 \\
\hline CHEMBL1502272 & 688382 & 5.2 & 4.6826 & TRN \\
\hline CHEMBL1459226 & 688382 & 6.0 & 4.7168 & TRN \\
\hline CHEMBL1347779 & 688382 & 4.05 & 4.8255 & TRN \\
\hline CHEMBL1527172 & 688382 & 5.8 & 4.7726 & TRN \\
\hline CHEMBL1319402 & 688382 & 4.85 & 4.7195 & TST \\
\hline CHEMBL1497437 & 688382 & 4.35 & 4.7475 & TRN \\
\hline CHEMBL1467111 & 688382 & 4.45 & 4.7069 & TST \\
\hline CHEMBL3193688 & 688382 & 4.5 & 4.6053 & TRN \\
\hline CHEMBL1324447 & 688382 & 3.95 & 4.7738 & TRN \\
\hline CHEMBL579837 & 688382 & 4.35 & 4.6258 & TRN \\
\hline CHEMBL1562635 & 688382 & 4.35 & 4.621 & TST \\
\hline CHEMBL3193804 & 688382 & 5.85 & 4.6815 & TRN \\
\hline CHEMBL1582871 & 688382 & 4.4 & 4.6286 & TRN \\
\hline CHEMBL1533866 & 688382 & 6.0 & 4.7851 & TRN \\
\hline CHEMBL1374971 & 688382 & 4.5 & 4.5456 & TST \\
\hline CHEMBL1380144 & 688382 & 4.5 & 4.691 & TRN \\
\hline CHEMBL1546894 & 688382 & 4.4 & 4.7748 & TRN \\
\hline CHEMBL1572379 & 688382 & 4.15 & 4.7662 & TRN \\
\hline CHEMBL1539667 & 688382 & 5.05 & 4.6684 & TRN \\
\hline CHEMBL1379486 & 688382 & 5.6 & 4.8436 & TRN \\
\hline CHEMBL3213926 & 688382 & 4.4 & 4.7185 & TRN \\
\hline CHEMBL1371851 & 688382 & 4.5 & 4.665 & TST \\
\hline CHEMBL1536638 & 688382 & 4.15 & 4.7655 & TRN \\
\hline CHEMBL1409380 & 688382 & 4.35 & 4.6478 & TRN \\
\hline CHEMBL1497115 & 688382 & 4.85 & 4.6854 & TST \\
\hline CHEMBL1477068 & 688382 & 4.95 & 4.6128 & TRN \\
\hline CHEMBL1540436 & 688382 & 5.05 & 4.5747 & TRN \\
\hline CHEMBL1563638 & 688382 & 5.05 & 4.7961 & TRN \\
\hline CHEMBL1500119 & 688382 & 4.6 & 4.7359 & TRN \\
\hline CHEMBL1489494 & 688382 & 4.8 & 4.8015 & TRN \\
\hline CHEMBL1483999 & 688382 & 4.75 & 4.6388 & TRN \\
\hline CHEMBL1310321 & 688382 & 4.2 & 4.7083 & TRN \\
\hline CHEMBL1426607 & 688382 & 5.0 & 4.6675 & TRN \\
\hline CHEMBL1492969 & 688382 & 5.05 & 4.7976 & TRN \\
\hline CHEMBL1343809 & 688382 & 4.75 & 4.7152 & TRN \\
\hline CHEMBL3198896 & 688382 & 4.55 & 4.7292 & TST \\
\hline CHEMBL3211387 & 688382 & 4.95 & 4.6756 & TST \\
\hline CHEMBL1321603 & 688382 & 4.8 & 4.6678 & TRN \\
\hline CHEMBL1546958 & 688382 & 4.15 & 4.7466 & TRN \\
\hline CHEMBL1303029 & 688382 & 5.2 & 4.7548 & TST \\
\hline CHEMBL1378004 & 688382 & 4.05 & 4.7201 & TRN \\
\hline CHEMBL1309208 & 688382 & 4.5 & 4.7188 & TRN \\
\hline CHEMBL1392546 & 688382 & 4.25 & 4.6669 & TST \\
\hline
\end{tabular}




\begin{tabular}{|c|c|c|c|c|c|}
\hline & & \multicolumn{4}{|c|}{ Supplemental Table S2.txt } \\
\hline CHEMBL1339114 & 688382 & 4.15 & 4.6776 & TRN & \\
\hline CHEMBL1583656 & 688382 & 4.15 & 4.6673 & TST & \\
\hline CHEMBL1354029 & 688382 & 5.05 & 4.8183 & TRN & \\
\hline CHEMBL1549227 & 688382 & 4.85 & 4.6701 & TRN & \\
\hline CHEMBL1426069 & 688382 & 4.4 & 4.6692 & TRN & \\
\hline CHEMBL1428123 & 688382 & 4.8 & 4.67899 & 9999999999 & TRN \\
\hline CHEMBL1500933 & 688382 & 4.5 & 4.671 & TRN & \\
\hline CHEMBL1464398 & 688382 & 4.5 & 4.6585 & TRN & \\
\hline CHEMBL 3207824 & 688382 & 4.05 & 4.7029 & TRN & \\
\hline CHEMBL3197486 & 688382 & 4.05 & 4.6744 & TST & \\
\hline CHEMBL1975825 & 688382 & 4.3 & 4.7045 & TRN & \\
\hline CHEMBL1978534 & 688382 & 4.5 & 4.756 & TRN & \\
\hline CHEMBL1340358 & 688382 & 4.85 & 4.8243 & TRN & \\
\hline CHEMBL1455507 & 688382 & 5.05 & 4.6887 & TST & \\
\hline CHEMBL1423775 & 688382 & 4.85 & 4.7302 & TRN & \\
\hline CHEMBL1412995 & 688382 & 5.0 & 4.8589 & TST & \\
\hline CHEMBL1341096 & 688382 & 4.35 & 4.6806 & TRN & \\
\hline CHEMBL 3189445 & 688382 & 4.45 & 4.6603 & TST & \\
\hline CHEMBL1423071 & 688382 & 4.4 & 4.564 & TRN & \\
\hline CHEMBL1478784 & 688382 & 5.05 & 4.6514 & TST & \\
\hline CHEMBL1461297 & 688382 & 4.85 & 4.772 & TRN & \\
\hline CHEMBL1385838 & 688382 & 4.55 & 4.8276 & TRN & \\
\hline CHEMBL1501179 & 688382 & 4.0 & 4.6959 & TRN & \\
\hline CHEMBL1597117 & 688382 & 5.95 & 4.7178 & TRN & \\
\hline CHEMBL1882125 & 688382 & 4.45 & 4.7622 & TST & \\
\hline CHEMBL1339391 & 688382 & 5.05 & 4.7098 & TRN & \\
\hline CHEMBL1370184 & 688382 & 4.85 & 4.6421 & TST & \\
\hline CHEMBL1378959 & 688382 & 4.5 & 4.734 & TST & \\
\hline CHEMBL1348459 & 688382 & 4.6 & 4.7527 & TRN & \\
\hline CHEMBL1481843 & 688382 & 4.65 & 4.7477 & TRN & \\
\hline CHEMBL1538602 & 688382 & 4.65 & 4.7288 & TRN & \\
\hline CHEMBL1365457 & 688382 & 6.0 & 4.6849 & TRN & \\
\hline CHEMBL152214 & 688382 & 4.95 & 4.752 & TRN & \\
\hline CHEMBL1370977 & 688382 & 4.2 & 4.7297 & TST & \\
\hline CHEMBL1500776 & 688382 & 4.9 & 4.8043 & TRN & \\
\hline CHEMBL3210517 & 688382 & 4.15 & 4.7104 & TRN & \\
\hline CHEMBL1559041 & 688382 & 6.05 & 4.6674 & TRN & \\
\hline CHEMBL1429575 & 688382 & 4.15 & 4.6491 & TST & \\
\hline CHEMBL1430735 & 688382 & 4.15 & 4.7522 & TST & \\
\hline CHEMBL1420436 & 688382 & 4.8 & 4.8449 & TRN & \\
\hline CHEMBL1322814 & 688382 & 5.0 & 4.7152 & TRN & \\
\hline CHEMBL3196945 & 688382 & 4.1 & 4.5925 & TST & \\
\hline CHEMBL1402553 & 688382 & 4.7 & 4.6093 & TRN & \\
\hline CHEMBL1419575 & 688382 & 4.9 & 4.8103 & TRN & \\
\hline CHEMBL1499268 & 688382 & 5.1 & 4.8158 & TRN & \\
\hline CHEMBL1500511 & 688382 & 4.0 & 4.7193 & TST & \\
\hline CHEMBL1492243 & 688382 & 4.8 & 4.7204 & TST & \\
\hline CHEMBL1363194 & 688382 & 5.85 & 4.8038 & TRN & \\
\hline
\end{tabular}




\begin{tabular}{|c|c|c|c|c|}
\hline \multicolumn{5}{|c|}{ Supplemental Table S2.txt } \\
\hline CHEMBL1599867 & 688382 & 4.5 & 4.6645 & TRN \\
\hline CHEMBL120734 & 688382 & 4.9 & 4.5927 & TRN \\
\hline CHEMBL1398736 & 688382 & 4.2 & 4.7503 & TRN \\
\hline CHEMBL1590794 & 688382 & 4.4 & 4.7651 & TRN \\
\hline CHEMBL1470621 & 688382 & 4.05 & 4.7686 & TRN \\
\hline CHEMBL1581317 & 688382 & 5.4 & 4.7535 & TRN \\
\hline CHEMBL1478653 & 688382 & 4.8 & 4.6946 & TST \\
\hline CHEMBL1307814 & 688382 & 4.35 & 4.7608 & TRN \\
\hline CHEMBL1541938 & 688382 & 4.8 & 4.8065 & TRN \\
\hline CHEMBL1564203 & 688382 & 5.1 & 4.6635 & TRN \\
\hline CHEMBL1977694 & 688382 & 4.1 & 4.6521 & TRN \\
\hline CHEMBL1483005 & 688382 & 4.8 & 4.6493 & TST \\
\hline CHEMBL1418620 & 688382 & 4.5 & 4.7344 & TST \\
\hline CHEMBL1345100 & 688382 & 4.4 & 4.6618 & TST \\
\hline CHEMBL1530614 & 688382 & 4.9 & 4.7868 & TST \\
\hline CHEMBL1530503 & 688382 & 4.25 & 4.7416 & TST \\
\hline CHEMBL1578482 & 688382 & 5.35 & 4.5881 & TRN \\
\hline CHEMBL1305470 & 688382 & 4.5 & 4.6905 & TRN \\
\hline CHEMBL1347474 & 688382 & 6.0 & 4.7055 & TRN \\
\hline CHEMBL3197958 & 688382 & 4.45 & 4.6485 & TRN \\
\hline CHEMBL1585863 & 688382 & 4.35 & 4.7196 & TRN \\
\hline CHEMBL1461065 & 688382 & 4.05 & 4.7364 & TRN \\
\hline CHEMBL1326873 & 688382 & 4.15 & 4.6957 & TRN \\
\hline CHEMBL1392588 & 688382 & 6.0 & 4.7925 & TRN \\
\hline CHEMBL1529516 & 688382 & 4.4 & 4.6625 & TRN \\
\hline CHEMBL1429522 & 688382 & 5.95 & 4.7226 & TRN \\
\hline CHEMBL1457184 & 688382 & 4.35 & 4.6976 & TRN \\
\hline CHEMBL1563466 & 688382 & 4.15 & 4.6858 & TRN \\
\hline CHEMBL3210922 & 688382 & 4.15 & 4.6943 & TST \\
\hline CHEMBL1996724 & 688382 & 4.75 & 4.6737 & TRN \\
\hline CHEMBL1451352 & 688382 & 5.1 & 4.732 & TRN \\
\hline CHEMBL1395030 & 688382 & 4.4 & 4.7645 & TST \\
\hline CHEMBL1425761 & 688382 & 5.15 & 4.6672 & TRN \\
\hline CHEMBL3213310 & 688382 & 4.3 & 4.7018 & TST \\
\hline CHEMBL1333706 & 688382 & 4.9 & 4.7397 & TRN \\
\hline CHEMBL442906 & 688382 & 4.35 & 4.7172 & TRN \\
\hline CHEMBL1420088 & 688382 & 4.6 & 4.6445 & TRN \\
\hline CHEMBL1455144 & 688382 & 4.45 & 4.7383 & TRN \\
\hline CHEMBL1547546 & 688382 & 4.15 & 4.7989 & TRN \\
\hline CHEMBL1336772 & 688382 & 4.15 & 4.784 & TRN \\
\hline CHEMBL1402297 & 688382 & 4.5 & 4.8223 & TRN \\
\hline CHEMBL1518948 & 688382 & 4.85 & 4.7456 & TRN \\
\hline CHEMBL1461153 & 688382 & 4.4 & 4.6773 & TST \\
\hline CHEMBL1339694 & 688382 & 4.2 & 4.6926 & TST \\
\hline CHEMBL3191493 & 688382 & 4.9 & 4.7075 & TRN \\
\hline CHEMBL1409935 & 688382 & 5.9 & 4.6917 & TST \\
\hline CHEMBL3193812 & 688382 & 5.85 & 4.7505 & TRN \\
\hline CHEMBL1305936 & 688382 & 4.45 & 4.7284 & TRN \\
\hline
\end{tabular}




\begin{tabular}{|c|c|c|c|c|}
\hline \multicolumn{5}{|c|}{ Supplemental Table S2.txt } \\
\hline CHEMBL1507476 & 688382 & 4.35 & 4.7439 & TST \\
\hline CHEMBL1584584 & 688382 & 4.15 & 4.6794 & TRN \\
\hline CHEMBL1256625 & 688382 & 4.15 & 4.6835 & TST \\
\hline CHEMBL1536442 & 688382 & 4.5 & 4.6579 & TRN \\
\hline CHEMBL1301253 & 688382 & 4.15 & 4.6045 & TRN \\
\hline CHEMBL1582403 & 688382 & 4.35 & 4.6505 & TRN \\
\hline CHEMBL1326629 & 688382 & 4.35 & 4.7698 & TST \\
\hline CHEMBL1300456 & 688382 & 4.85 & 4.7683 & TRN \\
\hline CHEMBL1320055 & 688382 & 4.6 & 4.7837 & TRN \\
\hline CHEMBL1483235 & 688382 & 4.45 & 4.6825 & TRN \\
\hline CHEMBL1541769 & 688382 & 4.4 & 4.6006 & TRN \\
\hline CHEMBL1508375 & 688382 & 6.0 & 4.6651 & TRN \\
\hline CHEMBL1611563 & 688382 & 5.05 & 4.7422 & TRN \\
\hline CHEMBL1485538 & 688382 & 4.2 & 4.708 & TRN \\
\hline CHEMBL1465770 & 688382 & 4.3 & 4.7998 & TST \\
\hline CHEMBL1345407 & 688382 & 5.05 & 4.7348 & TRN \\
\hline CHEMBL1485272 & 688382 & 4.95 & 4.6933 & TRN \\
\hline CHEMBL1975361 & 688382 & 4.5 & 4.6372 & TRN \\
\hline CHEMBL1495278 & 688382 & 4.45 & 4.8287 & TRN \\
\hline CHEMBL1539055 & 688382 & 4.85 & 4.7441 & TRN \\
\hline CHEMBL1448094 & 688382 & 4.7 & 4.6442 & TRN \\
\hline CHEMBL1423308 & 688382 & 4.45 & 4.7067 & TST \\
\hline CHEMBL1559370 & 688382 & 4.2 & 4.6654 & TRN \\
\hline CHEMBL1408267 & 688382 & 4.25 & 4.6339 & TST \\
\hline CHEMBL1333214 & 688382 & 4.85 & 4.8297 & TRN \\
\hline CHEMBL1482998 & 688382 & 5.65 & 4.6262 & TST \\
\hline CHEMBL1451034 & 688382 & 4.45 & 4.7579 & TRN \\
\hline CHEMBL1426320 & 688382 & 5.05 & 4.6892 & TST \\
\hline CHEMBL1462624 & 688382 & 4.3 & 4.7308 & TRN \\
\hline CHEMBL1428728 & 688382 & 4.15 & 4.7826 & TRN \\
\hline CHEMBL 3207730 & 688382 & 5.05 & 4.6405 & TRN \\
\hline CHEMBL1508598 & 688382 & 4.45 & 4.6345 & TRN \\
\hline CHEMBL1412794 & 688382 & 5.15 & 4.7253 & TST \\
\hline CHEMBL1597624 & 688382 & 5.95 & 4.758 & TST \\
\hline CHEMBL1438432 & 688382 & 5.45 & 4.8557 & TRN \\
\hline CHEMBL1498680 & 688382 & 4.5 & 4.7723 & TRN \\
\hline CHEMBL1362596 & 688382 & 4.95 & 4.7389 & TRN \\
\hline CHEMBL1393944 & 688382 & 4.4 & 4.619 & TRN \\
\hline CHEMBL1447316 & 688382 & 4.5 & 4.6321 & TRN \\
\hline CHEMBL1444952 & 688382 & 4.4 & 4.7668 & TRN \\
\hline CHEMBL1549804 & 688382 & 5.0 & 4.6343 & TRN \\
\hline CHEMBL1343719 & 688382 & 5.5 & 4.6203 & TST \\
\hline CHEMBL1385153 & 688382 & 5.05 & 4.8592 & TRN \\
\hline CHEMBL 1477530 & 688382 & 6.0 & 4.7039 & TRN \\
\hline CHEMBL1417143 & 688382 & 4.45 & 4.7181 & TRN \\
\hline CHEMBL1438296 & 688382 & 5.05 & 4.7425 & TST \\
\hline CHEMBL1543835 & 688382 & 4.5 & 4.6041 & TST \\
\hline CHEMBL1505026 & 688382 & 5.0 & 4.7619 & TRN \\
\hline
\end{tabular}




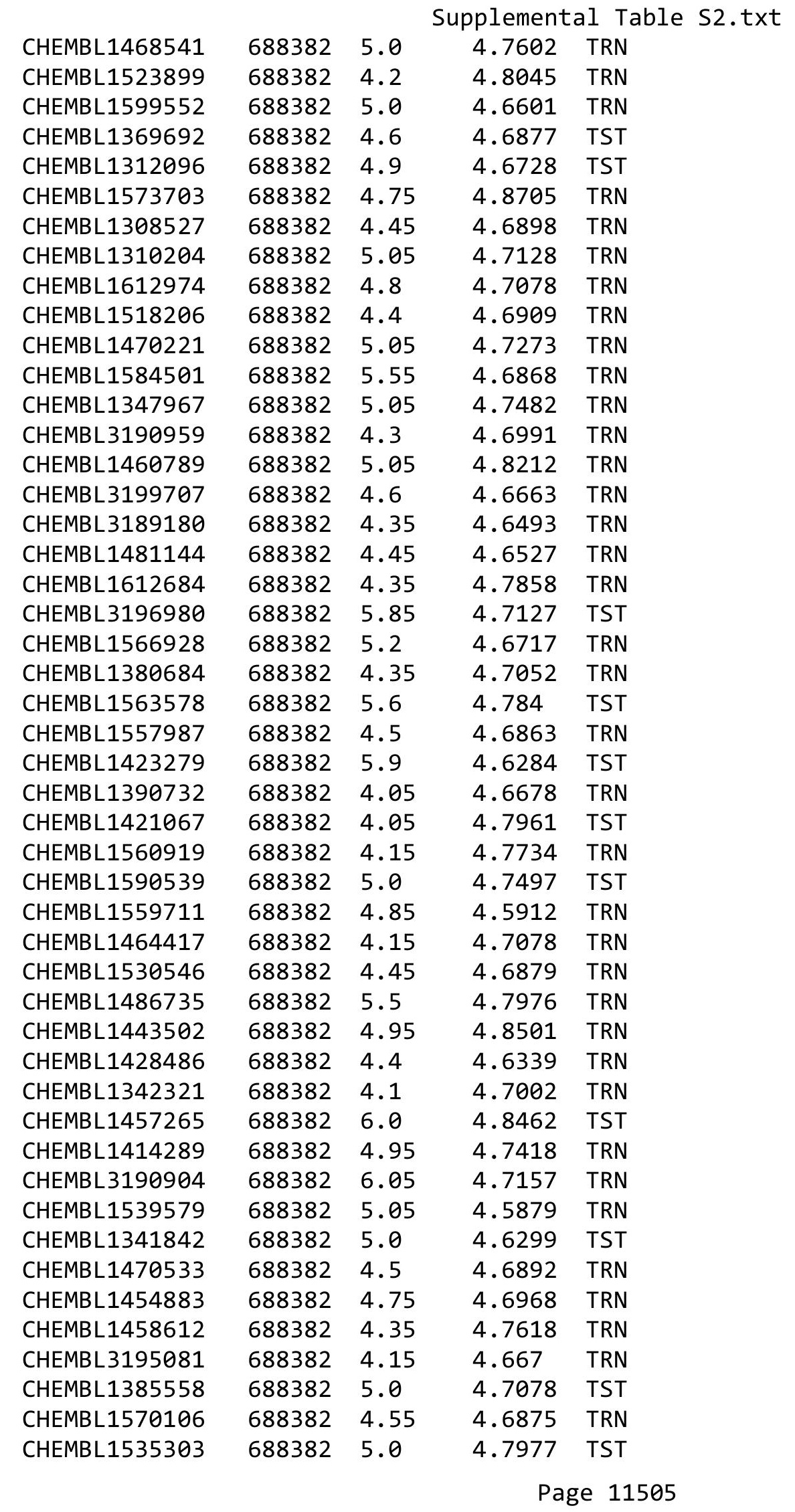




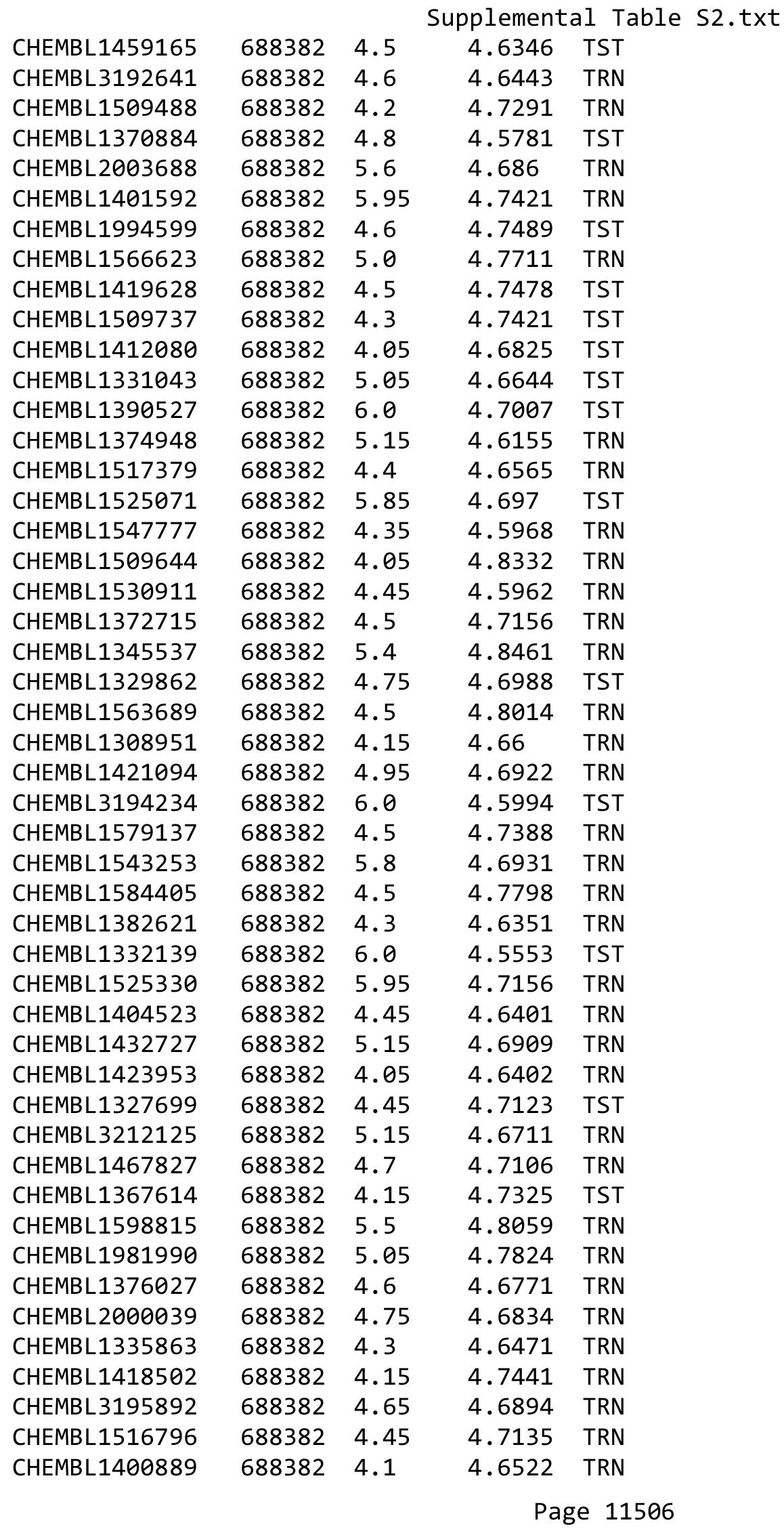




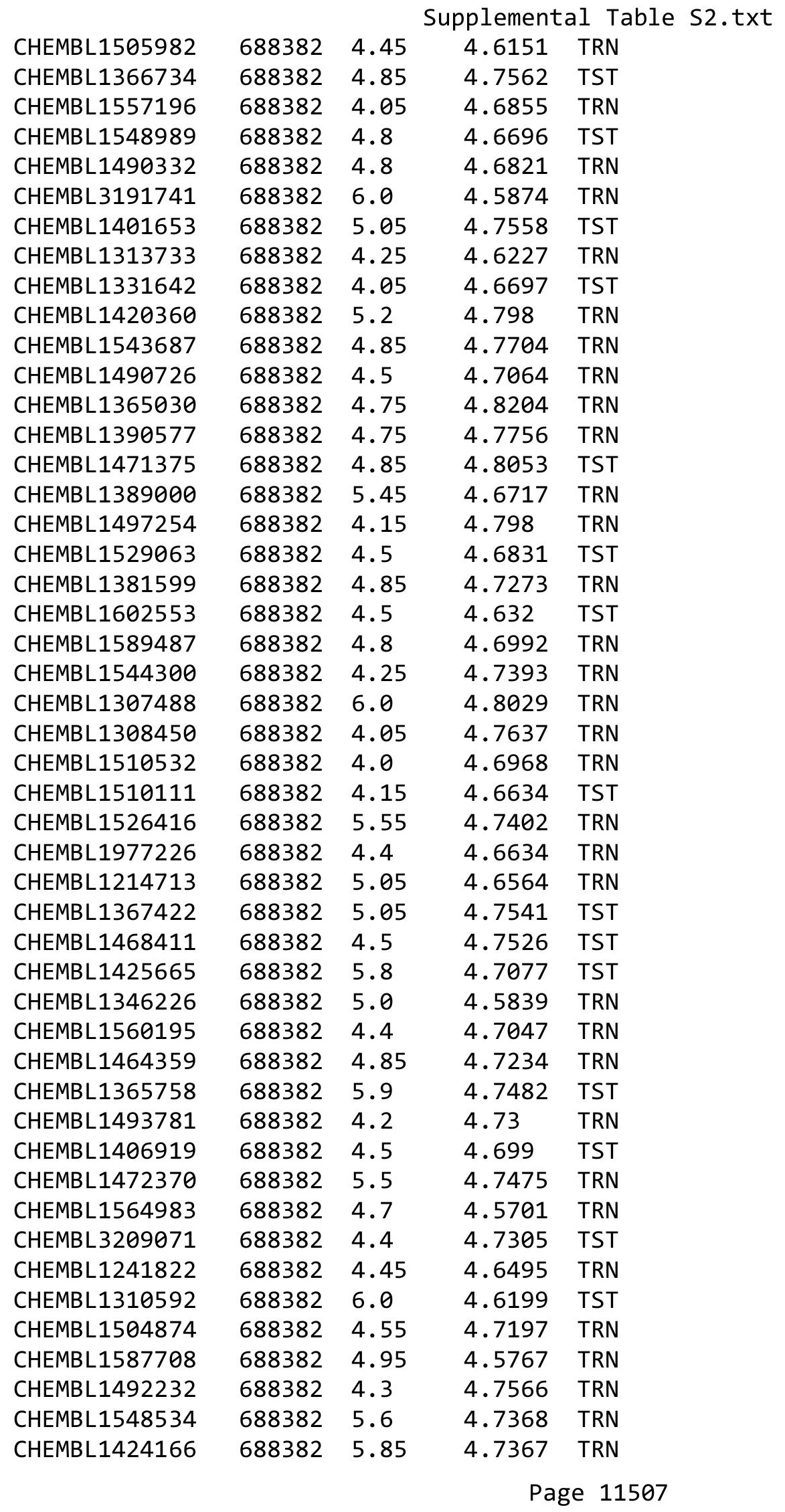




\begin{tabular}{|c|c|c|c|c|c|}
\hline \\
\hline CHEMBL1407924 & 688382 & 4.5 & 4.7518 & TRN & \\
\hline CHEMBL1468963 & 688382 & 4.5 & 4.6459 & TST & \\
\hline CHEMBL1497878 & 688382 & 4.45 & 4.6118 & TST & \\
\hline CHEMBL1496376 & 688382 & 6.05 & 4.73300 & 00000000005 & TST \\
\hline CHEMBL3145300 & 688382 & 4.25 & 4.6142 & TRN & \\
\hline CHEMBL1305980 & 688382 & 4.75 & 4.7285 & TRN & \\
\hline CHEMBL1412674 & 688382 & 5.4 & 4.66100 & 00000000005 & TST \\
\hline CHEMBL1406040 & 688382 & 4.9 & 4.6731 & TRN & \\
\hline CHEMBL1453142 & 688382 & 4.8 & 4.7214 & TRN & \\
\hline CHEMBL1547011 & 688382 & 5.05 & 4.717 & TRN & \\
\hline CHEMBL1789983 & 688382 & 4.5 & 4.7018 & TRN & \\
\hline CHEMBL1439414 & 688382 & 4.55 & 4.5801 & TRN & \\
\hline CHEMBL1531027 & 688382 & 4.9 & 4.7195 & TST & \\
\hline CHEMBL1529397 & 688382 & 4.15 & 4.7822 & TRN & \\
\hline CHEMBL1467699 & 688382 & 5.45 & 4.6896 & TRN & \\
\hline CHEMBL1505708 & 688382 & 4.05 & 4.7198 & TRN & \\
\hline CHEMBL1373119 & 688382 & 5.05 & 4.7528 & TRN & \\
\hline CHEMBL3208294 & 688382 & 4.85 & 4.6499 & TRN & \\
\hline CHEMBL1370684 & 688382 & 2.45 & 4.6776 & TRN & \\
\hline CHEMBL1506234 & 688382 & 6.0 & 4.7287 & TRN & \\
\hline CHEMBL1573908 & 688382 & 4.15 & 4.6555 & TST & \\
\hline CHEMBL3213030 & 688382 & 4.5 & 4.6613 & TST & \\
\hline CHEMBL1575204 & 688382 & 4.05 & 4.7786 & TRN & \\
\hline CHEMBL1412959 & 688382 & 6.0 & 4.6592 & TRN & \\
\hline CHEMBL1456576 & 688382 & 4.5 & 4.7164 & TRN & \\
\hline CHEMBL1310631 & 688382 & 4.15 & 4.6629 & TRN & \\
\hline CHEMBL1527248 & 688382 & 4.2 & 4.7586 & TST & \\
\hline CHEMBL1555359 & 688382 & 4.8 & 4.7242 & TRN & \\
\hline CHEMBL1370332 & 688382 & 6.0 & 4.7083 & TRN & \\
\hline CHEMBL1529254 & 688382 & 4.15 & 4.5923 & TRN & \\
\hline CHEMBL1551540 & 688382 & 5.5 & 4.6987 & TRN & \\
\hline CHEMBL1366791 & 688382 & 5.8 & 4.7388 & TRN & \\
\hline CHEMBL1507368 & 688382 & 4.0 & 4.8057 & TRN & \\
\hline CHEMBL1530501 & 688382 & 4.1 & 4.6268 & TST & \\
\hline CHEMBL1597452 & 688382 & 4.15 & 4.6073 & TRN & \\
\hline CHEMBL1573463 & 688382 & 4.5 & 4.6324 & TRN & \\
\hline CHEMBL1336398 & 688382 & 4.15 & 4.7719 & TST & \\
\hline CHEMBL1999515 & 688382 & 5.35 & 4.6535 & TRN & \\
\hline CHEMBL1588780 & 688382 & 5.2 & 4.6786 & TST & \\
\hline CHEMBL1521668 & 688382 & 4.95 & 4.7584 & TST & \\
\hline CHEMBL1405691 & 688382 & 4.95 & 4.6717 & TRN & \\
\hline CHEMBL1507732 & 688382 & 4.5 & 4.6783 & TST & \\
\hline CHEMBL1544241 & 688382 & 4.35 & 4.6492 & TRN & \\
\hline CHEMBL1386291 & 688382 & 4.05 & 4.6906 & TRN & \\
\hline CHEMBL1449425 & 688382 & 5.4 & 4.6879 & TRN & \\
\hline CHEMBL1542446 & 688382 & 4.5 & 4.6935 & TRN & \\
\hline CHEMBL1538461 & 688382 & 4.4 & 4.7086 & TST & \\
\hline CHEMBL1529477 & 688382 & 4.45 & 4.717 & TRN & \\
\hline
\end{tabular}




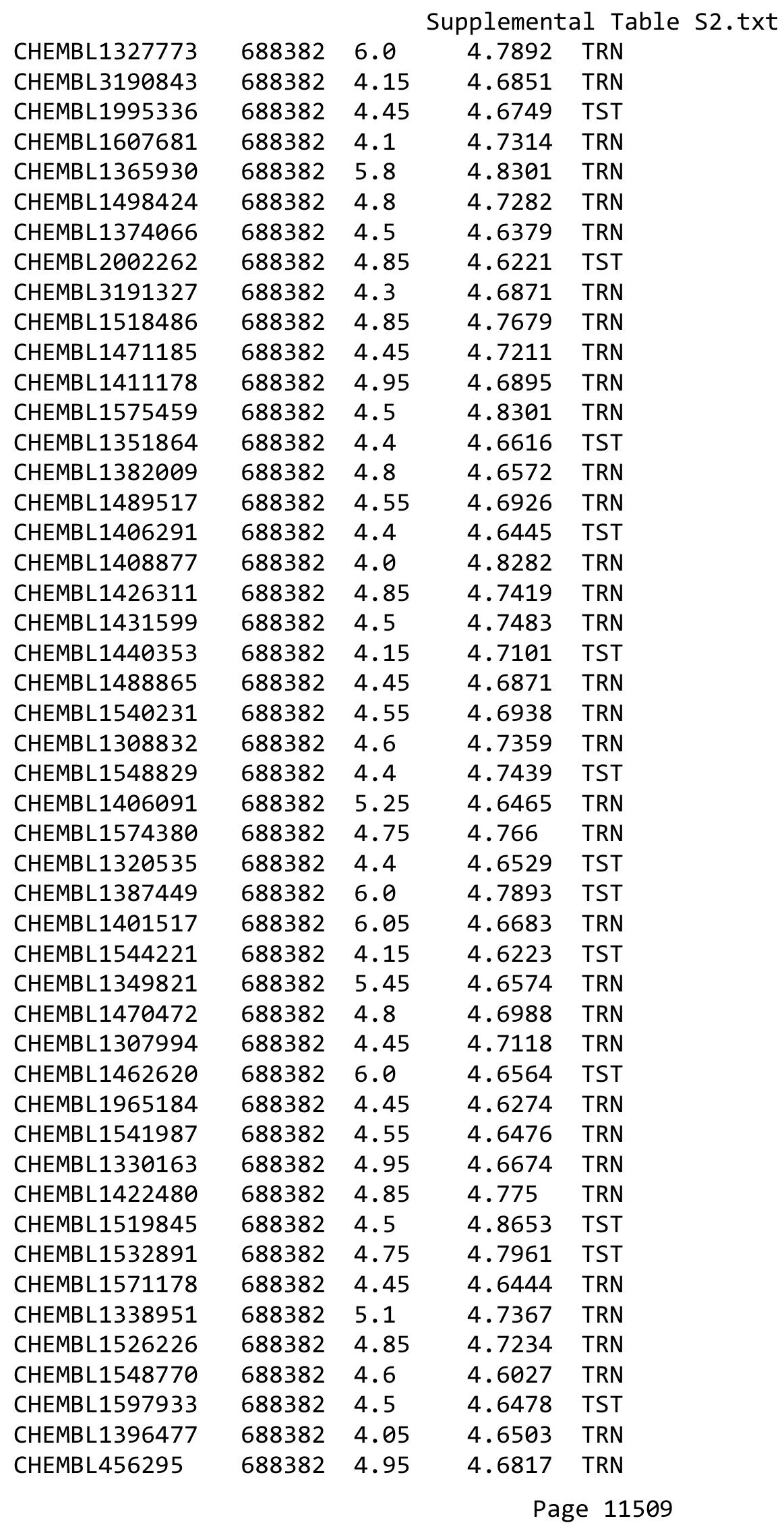




\begin{tabular}{|c|c|c|c|c|c|}
\hline \multicolumn{6}{|c|}{ Supplemental Table S2.txt } \\
\hline CHEMBL1508634 & 688382 & 4.5 & 4.8084 & TRN & \\
\hline CHEMBL1535491 & 688382 & 4.35 & 4.6699 & TRN & \\
\hline CHEMBL1362648 & 688382 & 5.8 & 4.7255 & TST & \\
\hline CHEMBL1549562 & 688382 & 4.7 & 4.756 & TRN & \\
\hline CHEMBL1491658 & 688382 & 5.5 & 4.7252 & TRN & \\
\hline CHEMBL1485885 & 688382 & 4.95 & 4.8601 & TRN & \\
\hline CHEMBL1597975 & 688382 & 5.15 & 4.6898 & TRN & \\
\hline CHEMBL1553293 & 688382 & 4.6 & 4.7092 & TRN & \\
\hline CHEMBL1467993 & 688382 & 4.3 & 4.5943 & TRN & \\
\hline CHEMBL3210755 & 688382 & 4.7 & 4.6862 & TRN & \\
\hline CHEMBL1316002 & 688382 & 4.65 & 4.6224 & TRN & \\
\hline CHEMBL1308386 & 688382 & 4.45 & 4.6473 & TRN & \\
\hline CHEMBL1390058 & 688382 & 4.8 & 4.7855 & TRN & \\
\hline CHEMBL1336226 & 688382 & 4.15 & 4.7274 & TST & \\
\hline CHEMBL1545989 & 688382 & 4.8 & 4.70100 & 00000000005 & TRN \\
\hline CHEMBL1508950 & 688382 & 4.85 & 4.7461 & TRN & \\
\hline CHEMBL1422660 & 688382 & 5.1 & 4.7417 & TRN & \\
\hline CHEMBL1393506 & 688382 & 4.45 & 4.7487 & TST & \\
\hline CHEMBL 1545832 & 688382 & 4.3 & 4.7111 & TST & \\
\hline CHEMBL1603053 & 688382 & 5.1 & 4.6574 & TST & \\
\hline CHEMBL1499083 & 688382 & 4.45 & 4.6925 & TRN & \\
\hline CHEMBL3211923 & 688382 & 5.2 & 4.6654 & TRN & \\
\hline CHEMBL1443718 & 688382 & 4.6 & 4.7072 & TRN & \\
\hline CHEMBL1599144 & 688382 & 4.85 & 4.7339 & TST & \\
\hline CHEMBL1404147 & 688382 & 4.75 & 4.749 & TRN & \\
\hline CHEMBL1533281 & 688382 & 4.2 & 4.6808 & TRN & \\
\hline CHEMBL1413704 & 688382 & 4.15 & 4.6801 & TST & \\
\hline CHEMBL1548182 & 688382 & 4.8 & 4.7041 & TRN & \\
\hline CHEMBL1605611 & 688382 & 4.55 & 4.8276 & TST & \\
\hline CHEMBL1613639 & 688382 & 4.35 & 4.7535 & TRN & \\
\hline CHEMBL1426304 & 688382 & 4.45 & 4.7337 & TRN & \\
\hline CHEMBL1425941 & 688382 & 4.4 & 4.6842 & TRN & \\
\hline CHEMBL1385874 & 688382 & 4.9 & 4.8138 & TST & \\
\hline CHEMBL1422748 & 688382 & 4.1 & 4.6436 & TRN & \\
\hline CHEMBL530682 & 688382 & 4.45 & 4.7427 & TRN & \\
\hline CHEMBL1424718 & 688382 & 5.3 & 4.71899 & 9999999999 & TRN \\
\hline CHEMBL1579372 & 688382 & 5.05 & 4.8413 & TST & \\
\hline CHEMBL1540774 & 688382 & 4.45 & 4.7387 & TRN & \\
\hline CHEMBL1400983 & 688382 & 4.5 & 4.7509 & TST & \\
\hline CHEMBL1460371 & 688382 & 6.0 & 4.7838 & TST & \\
\hline CHEMBL1559687 & 688382 & 4.7 & 4.6714 & TRN & \\
\hline CHEMBL1576289 & 688382 & 4.4 & 4.6357 & TRN & \\
\hline CHEMBL1368220 & 688382 & 4.45 & 4.7589 & TRN & \\
\hline CHEMBL1428985 & 688382 & 4.35 & 4.6836 & TRN & \\
\hline CHEMBL584269 & 688382 & 4.4 & 4.6284 & TRN & \\
\hline CHEMBL 2002008 & 688382 & 4.65 & 4.6262 & TRN & \\
\hline CHEMBL3197364 & 688382 & 5.85 & 4.7218 & TST & \\
\hline CHEMBL1574794 & 688382 & 5.05 & 4.7871 & TRN & \\
\hline
\end{tabular}




\begin{tabular}{|c|c|c|c|c|c|}
\hline & & \multicolumn{4}{|c|}{ Supplemental Table S2.txt } \\
\hline CHEMBL 3210100 & 688382 & 4.05 & 4.6303 & TRN & \\
\hline CHEMBL1548745 & 688382 & 4.1 & 4.7066 & TRN & \\
\hline CHEMBL1523627 & 688382 & 5.5 & 4.7115 & TRN & \\
\hline CHEMBL1401316 & 688382 & 4.4 & 4.7634 & TRN & \\
\hline CHEMBL1365553 & 688382 & 5.0 & 4.6482 & TST & \\
\hline CHEMBL189584 & 688382 & 4.35 & 4.7191 & TST & \\
\hline CHEMBL1560144 & 688382 & 4.9 & 4.7051 & TRN & \\
\hline CHEMBL1329487 & 688382 & 4.0 & 4.6958 & TRN & \\
\hline CHEMBL1613634 & 688382 & 4.45 & 4.7092 & TRN & \\
\hline CHEMBL1482620 & 688382 & 4.5 & 4.6995 & TRN & \\
\hline CHEMBL265698 & 688382 & 4.45 & 4.6695 & TST & \\
\hline CHEMBL1487222 & 688382 & 5.25 & 4.6867 & TRN & \\
\hline CHEMBL1564389 & 688382 & 5.6 & 4.7468 & TRN & \\
\hline CHEMBL1195077 & 688382 & 4.5 & 4.6364 & TST & \\
\hline CHEMBL1559887 & 688382 & 4.9 & 4.6385 & TRN & \\
\hline CHEMBL3195498 & 688382 & 5.9 & 4.6766 & TRN & \\
\hline CHEMBL1463329 & 688382 & 4.95 & 4.684 & TST & \\
\hline CHEMBL1326683 & 688382 & 6.0 & 4.7002 & TST & \\
\hline CHEMBL1376419 & 688382 & 4.95 & 4.6481 & TRN & \\
\hline CHEMBL1459398 & 688382 & 4.35 & 4.6938 & TRN & \\
\hline CHEMBL1605297 & 688382 & 4.4 & 4.76699 & 99999999995 & TRN \\
\hline CHEMBL1392659 & 688382 & 4.45 & 4.7023 & TRN & \\
\hline CHEMBL1607128 & 688382 & 4.85 & 4.73 & TRN & \\
\hline CHEMBL1429953 & 688382 & 4.0 & 4.7672 & TST & \\
\hline CHEMBL1497064 & 688382 & 6.0 & 4.6355 & TST & \\
\hline CHEMBL1333307 & 688382 & 4.8 & 4.6728 & TST & \\
\hline CHEMBL1493155 & 688382 & 5.8 & 4.7547 & TST & \\
\hline CHEMBL1160544 & 688382 & 4.9 & 4.712 & TST & \\
\hline CHEMBL1517426 & 688382 & 4.4 & 4.6477 & TST & \\
\hline CHEMBL1462763 & 688382 & 5.85 & 4.7123 & TRN & \\
\hline CHEMBL1533614 & 688382 & 5.05 & 4.6901 & TRN & \\
\hline CHEMBL1570242 & 688382 & 4.45 & 4.6452 & TST & \\
\hline CHEMBL1562949 & 688382 & 5.1 & 4.664 & TRN & \\
\hline CHEMBL1388222 & 688382 & 4.9 & 4.7204 & TRN & \\
\hline CHEMBL1456111 & 688382 & 5.05 & 4.6598 & TST & \\
\hline CHEMBL1979316 & 688382 & 4.15 & 4.70100 & 00000000005 & TST \\
\hline CHEMBL1450570 & 688382 & 4.5 & 4.702 & TRN & \\
\hline CHEMBL1511646 & 688382 & 4.4 & 4.7579 & TRN & \\
\hline CHEMBL1336436 & 688382 & 4.35 & 4.6471 & TRN & \\
\hline CHEMBL1538363 & 688382 & 4.35 & 4.646 & TRN & \\
\hline CHEMBL1403553 & 688382 & 5.8 & 4.8362 & TRN & \\
\hline CHEMBL1978101 & 688382 & 4.6 & 4.6846 & TRN & \\
\hline CHEMBL1509707 & 688382 & 4.55 & 4.6569 & TRN & \\
\hline CHEMBL1990071 & 688382 & 3.95 & 4.6192 & TST & \\
\hline CHEMBL1995715 & 688382 & 4.05 & 4.6982 & TRN & \\
\hline CHEMBL1446197 & 688382 & 4.55 & 4.6927 & TST & \\
\hline CHEMBL1463310 & 688382 & 4.4 & 4.7547 & TRN & \\
\hline CHEMBL1468136 & 688382 & 4.35 & 4.7452 & TRN & \\
\hline
\end{tabular}




\begin{tabular}{|c|c|c|c|c|}
\hline \multicolumn{5}{|c|}{ Supplemental Tabl } \\
\hline CHEMBL1353537 & 688382 & 3.95 & 4.8317 & TRN \\
\hline CHEMBL1416272 & 688382 & 4.5 & 4.6286 & TRN \\
\hline CHEMBL1527828 & 688382 & 5.5 & 4.6967 & TRN \\
\hline CHEMBL 3197458 & 688382 & 4.2 & 4.63 & TRN \\
\hline CHEMBL1305593 & 688382 & 4.4 & 4.6616 & TST \\
\hline CHEMBL1384198 & 688382 & 4.3 & 4.6703 & TRN \\
\hline CHEMBL1413411 & 688382 & 4.75 & 4.6647 & TST \\
\hline CHEMBL3197767 & 688382 & 5.1 & 4.6688 & TRN \\
\hline CHEMBL1307145 & 688382 & 4.2 & 4.7 & TRN \\
\hline CHEMBL1484655 & 688382 & 5.2 & 4.7788 & TRN \\
\hline CHEMBL1470815 & 688382 & 4.95 & 4.7702 & TRN \\
\hline CHEMBL1401000 & 688382 & 4.55 & 4.695 & TRN \\
\hline CHEMBL1372536 & 688382 & 4.5 & 4.6471 & TRN \\
\hline CHEMBL1549310 & 688382 & 4.4 & 4.7049 & TRN \\
\hline CHEMBL1415459 & 688382 & 5.1 & 4.7775 & TRN \\
\hline CHEMBL1600481 & 688382 & 4.6 & 4.7083 & TRN \\
\hline CHEMBL1484023 & 688382 & 4.5 & 4.7238 & TRN \\
\hline CHEMBL1597954 & 688382 & 4.55 & 4.7215 & TRN \\
\hline CHEMBL1353309 & 688382 & 5.8 & 4.7071 & TRN \\
\hline CHEMBL1300821 & 688382 & 4.45 & 4.6622 & TRN \\
\hline CHEMBL1600537 & 688382 & 5.9 & 4.7886 & TRN \\
\hline CHEMBL1539369 & 688382 & 5.25 & 4.7183 & TRN \\
\hline CHEMBL3196213 & 688382 & 4.85 & 4.7136 & TRN \\
\hline CHEMBL1557913 & 688382 & 4.05 & 4.5872 & TRN \\
\hline CHEMBL1409826 & 688382 & 4.7 & 4.749 & TRN \\
\hline CHEMBL1461610 & 688382 & 4.4 & 4.6135 & TRN \\
\hline CHEMBL1405321 & 688382 & 4.05 & 4.6706 & TST \\
\hline CHEMBL1456653 & 688382 & 4.15 & 4.6474 & TRN \\
\hline CHEMBL1449544 & 688382 & 4.6 & 4.7463 & TRN \\
\hline CHEMBL1575076 & 688382 & 4.15 & 4.8317 & TST \\
\hline CHEMBL1967859 & 688382 & 4.65 & 4.6774 & TRN \\
\hline CHEMBL1571090 & 688382 & 5.35 & 4.6444 & TRN \\
\hline CHEMBL1391043 & 688382 & 4.5 & 4.6759 & TST \\
\hline CHEMBL1341126 & 688382 & 6.0 & 4.7395 & TRN \\
\hline CHEMBL1466323 & 688382 & 4.4 & 4.7381 & TST \\
\hline CHEMBL1333762 & 688382 & 4.55 & 4.7417 & TST \\
\hline CHEMBL1426270 & 688382 & 4.15 & 4.7446 & TRN \\
\hline CHEMBL551196 & 688382 & 4.5 & 4.6875 & TRN \\
\hline CHEMBL1490487 & 688382 & 4.85 & 4.758 & TRN \\
\hline CHEMBL1407002 & 688382 & 4.3 & 4.6923 & TRN \\
\hline CHEMBL1464434 & 688382 & 4.4 & 4.6864 & TRN \\
\hline CHEMBL1308498 & 688382 & 4.45 & 4.7148 & TRN \\
\hline CHEMBL1483189 & 688382 & 4.8 & 4.6744 & TST \\
\hline CHEMBL1583856 & 688382 & 4.6 & 4.6891 & TRN \\
\hline CHEMBL1422732 & 688382 & 4.5 & 4.6699 & TRN \\
\hline CHEMBL1562802 & 688382 & 4.8 & 4.7189 & TRN \\
\hline CHEMBL1454650 & 688382 & 4.15 & 4.7453 & TRN \\
\hline CHEMBL373137 & 688382 & 5.25 & 4.676 & TST \\
\hline
\end{tabular}




\begin{tabular}{|c|c|c|c|c|c|}
\hline & & \multicolumn{4}{|c|}{ Supplemental Table S2.txt } \\
\hline CHEMBL1306440 & 688382 & 5.05 & 4.8387 & TST & \\
\hline CHEMBL1545689 & 688382 & 4.45 & 4.6301 & TST & \\
\hline CHEMBL1383939 & 688382 & 4.45 & 4.6956 & TRN & \\
\hline CHEMBL1444010 & 688382 & 4.2 & 4.7008 & TST & \\
\hline CHEMBL1546304 & 688382 & 4.85 & 4.7608 & TST & \\
\hline CHEMBL3196174 & 688382 & 4.8 & 4.6931 & TRN & \\
\hline CHEMBL1393647 & 688382 & 4.45 & 4.7287 & TRN & \\
\hline CHEMBL67378 & 688382 & 4.0 & 4.7524 & TST & \\
\hline CHEMBL1589449 & 688382 & 4.2 & 4.7952 & TRN & \\
\hline CHEMBL3194278 & 688382 & 4.15 & 4.6832 & TRN & \\
\hline CHEMBL1373658 & 688382 & 5.05 & 4.7221 & TST & \\
\hline CHEMBL1464357 & 688382 & 6.0 & 4.6286 & TST & \\
\hline CHEMBL1522733 & 688382 & 4.4 & 4.7499 & TRN & \\
\hline CHEMBL1545010 & 688382 & 4.15 & 4.7884 & TRN & \\
\hline CHEMBL1506478 & 688382 & 5.05 & 4.6833 & TRN & \\
\hline CHEMBL3198022 & 688382 & 4.85 & 4.6361 & TRN & \\
\hline CHEMBL1413164 & 688382 & 4.05 & 4.6838 & TST & \\
\hline CHEMBL603897 & 688382 & 5.8 & 4.7464 & TRN & \\
\hline CHEMBL1582769 & 688382 & 4.4 & 4.6813 & TST & \\
\hline CHEMBL1348800 & 688382 & 4.85 & 4.6724 & TST & \\
\hline CHEMBL1350750 & 688382 & 4.95 & 4.7596 & TRN & \\
\hline CHEMBL1393802 & 688382 & 6.0 & 4.8392 & TRN & \\
\hline CHEMBL1327312 & 688382 & 4.5 & 4.7185 & TRN & \\
\hline CHEMBL1571910 & 688382 & 4.45 & 4.7618 & TRN & \\
\hline CHEMBL3190870 & 688382 & 5.75 & 4.6943 & TST & \\
\hline CHEMBL1449708 & 688382 & 3.55 & 4.7098 & TST & \\
\hline CHEMBL1467129 & 688382 & 5.15 & 4.6935 & TRN & \\
\hline CHEMBL1407021 & 688382 & 5.6 & 4.7577 & TRN & \\
\hline CHEMBL1612455 & 688382 & 5.2 & 4.6888 & TRN & \\
\hline CHEMBL1377684 & 688382 & 4.75 & 4.6358 & TRN & \\
\hline CHEMBL1586957 & 688382 & 4.05 & 4.7014 & TRN & \\
\hline CHEMBL1508712 & 688382 & 4.45 & 4.6944 & TRN & \\
\hline CHEMBL1456456 & 688382 & 4.4 & 4.8244 & TRN & \\
\hline CHEMBL1611426 & 688382 & 4.3 & 4.763 & TRN & \\
\hline CHEMBL3211505 & 688382 & 4.5 & 4.6912 & TRN & \\
\hline CHEMBL1510913 & 688382 & 5.2 & 4.6433 & TST & \\
\hline CHEMBL1333441 & 688382 & 4.15 & 4.70100 & 00000000005 & TRN \\
\hline CHEMBL1376643 & 688382 & 4.05 & 4.7047 & TST & \\
\hline CHEMBL1345666 & 688382 & 4.4 & 4.7188 & TST & \\
\hline CHEMBL1496411 & 688382 & 4.0 & 4.6683 & TRN & \\
\hline CHEMBL3193499 & 688382 & 5.05 & 4.6397 & TRN & \\
\hline CHEMBL3212328 & 688382 & 4.5 & 4.6338 & TRN & \\
\hline CHEMBL1366092 & 688382 & 4.8 & 4.8365 & TRN & \\
\hline CHEMBL1367501 & 688382 & 5.55 & 4.7349 & TST & \\
\hline CHEMBL1392071 & 688382 & 5.7 & 4.7945 & TRN & \\
\hline CHEMBL3191597 & 688382 & 4.75 & 4.6778 & TRN & \\
\hline CHEMBL1326353 & 688382 & 4.05 & 4.725 & TST & \\
\hline CHEMBL1537894 & 688382 & 4.85 & 4.7666 & TRN & \\
\hline
\end{tabular}




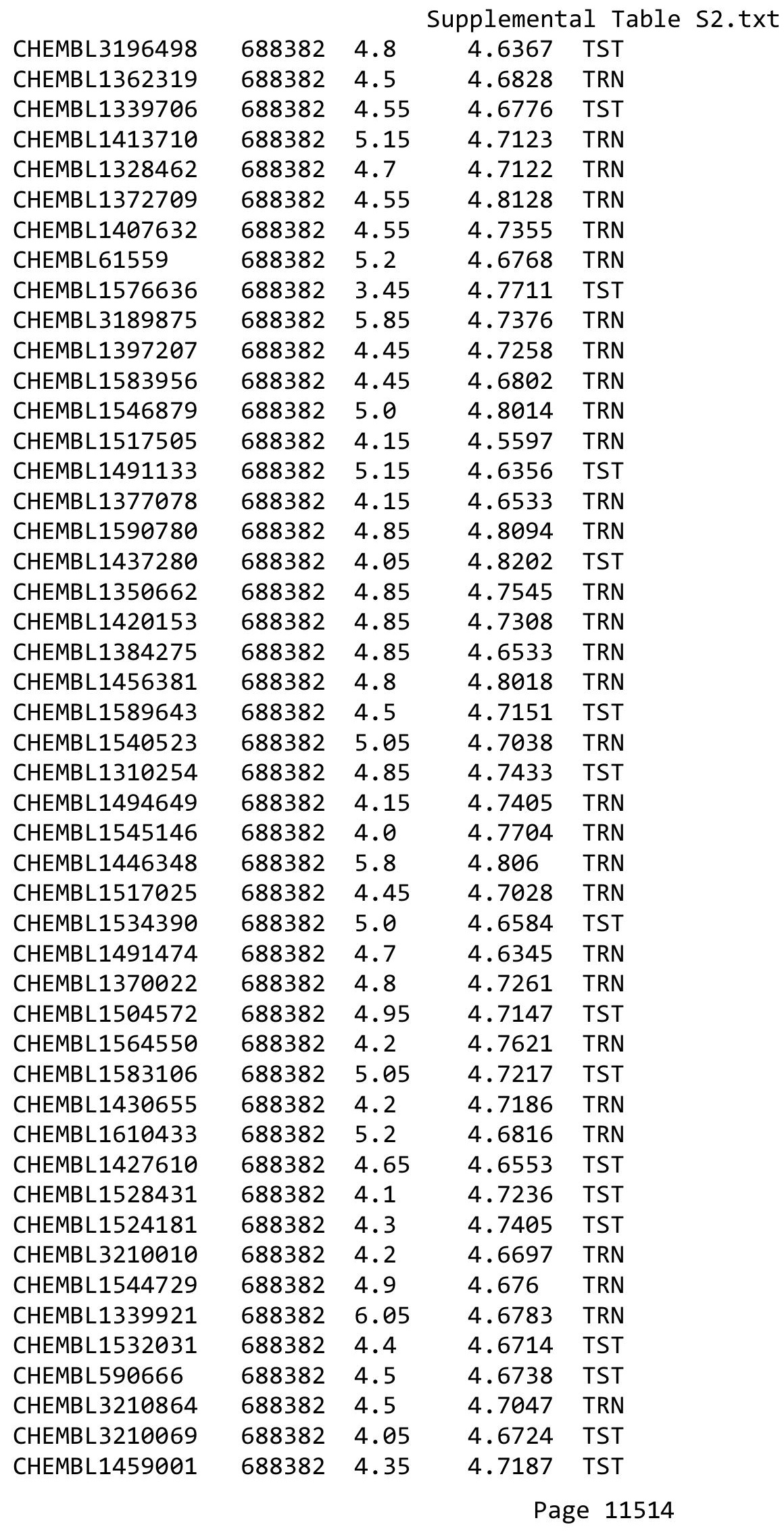




\begin{tabular}{|c|c|c|c|c|}
\hline \multicolumn{5}{|c|}{ Supplemental Table s2.txt } \\
\hline CHEMBL1509491 & 688382 & 6.0 & 4.7601 & TRN \\
\hline CHEMBL1405320 & 688382 & 4.7 & 4.6322 & TST \\
\hline CHEMBL1328666 & 688382 & 4.55 & 4.7182 & TRN \\
\hline CHEMBL1454236 & 688382 & 5.95 & 4.7272 & TRN \\
\hline CHEMBL1489904 & 688382 & 4.95 & 4.6475 & TRN \\
\hline CHEMBL1367535 & 688382 & 4.8 & 4.7227 & TRN \\
\hline CHEMBL1393199 & 688382 & 4.05 & 4.8069 & TRN \\
\hline CHEMBL1456393 & 688382 & 4.85 & 4.6957 & TST \\
\hline CHEMBL1580190 & 688382 & 5.15 & 4.7754 & TST \\
\hline CHEMBL1968290 & 688382 & 4.4 & 4.5861 & TST \\
\hline CHEMBL3213436 & 688382 & 4.4 & 4.6736 & TRN \\
\hline CHEMBL1503488 & 688382 & 5.05 & 4.73 & TST \\
\hline CHEMBL1573664 & 688382 & 4.8 & 4.7332 & TRN \\
\hline CHEMBL1592320 & 688382 & 4.95 & 4.6313 & TRN \\
\hline CHEMBL1536609 & 688382 & 4.2 & 4.7668 & TRN \\
\hline CHEMBL1580769 & 688382 & 4.4 & 4.6792 & TRN \\
\hline CHEMBL1502769 & 688382 & 4.4 & 4.6544 & TRN \\
\hline CHEMBL1322925 & 688382 & 4.5 & 4.6487 & TRN \\
\hline CHEMBL1539916 & 688382 & 4.15 & 4.7389 & TRN \\
\hline CHEMBL1375207 & 688382 & 4.4 & 4.6074 & TST \\
\hline CHEMBL1537845 & 688382 & 4.8 & 4.6843 & TST \\
\hline CHEMBL3198479 & 688382 & 4.8 & 4.6505 & TRN \\
\hline CHEMBL1529509 & 688382 & 5.8 & 4.7011 & TRN \\
\hline CHEMBL1502418 & 688382 & 5.65 & 4.867 & TRN \\
\hline CHEMBL1576674 & 688382 & 6.0 & 4.6523 & TRN \\
\hline CHEMBL1516531 & 688382 & 4.4 & 4.6405 & TRN \\
\hline CHEMBL1429597 & 688382 & 5.4 & 4.7813 & TRN \\
\hline CHEMBL1465359 & 688382 & 6.0 & 4.8441 & TRN \\
\hline CHEMBL1461633 & 688382 & 4.45 & 4.6776 & TRN \\
\hline CHEMBL1389133 & 688382 & 6.0 & 4.7467 & TST \\
\hline CHEMBL1317842 & 688382 & 4.5 & 4.7318 & TRN \\
\hline CHEMBL1548542 & 688382 & 6.0 & 4.7853 & TRN \\
\hline CHEMBL1485490 & 688382 & 4.0 & 4.7227 & TST \\
\hline CHEMBL1379025 & 688382 & 4.15 & 4.7923 & TRN \\
\hline CHEMBL1503001 & 688382 & 4.5 & 4.7151 & TRN \\
\hline CHEMBL1541898 & 688382 & 5.1 & 4.7073 & TRN \\
\hline CHEMBL1517559 & 688382 & 4.6 & 4.6738 & TRN \\
\hline CHEMBL1468260 & 688382 & 4.05 & 4.5935 & TRN \\
\hline CHEMBL1344658 & 688382 & 4.4 & 4.7076 & TRN \\
\hline CHEMBL1370196 & 688382 & 4.8 & 4.6557 & TRN \\
\hline CHEMBL1564166 & 688382 & 6.0 & 4.7778 & TRN \\
\hline CHEMBL1607614 & 688382 & 4.65 & 4.6352 & TRN \\
\hline CHEMBL3197593 & 688382 & 6.4 & 4.6051 & TST \\
\hline CHEMBL1565821 & 688382 & 5.2 & 4.7188 & TRN \\
\hline CHEMBL1441129 & 688382 & 4.5 & 4.7972 & TRN \\
\hline CHEMBL1429447 & 688382 & 4.85 & 4.7971 & TRN \\
\hline CHEMBL1460152 & 688382 & 4.8 & 4.8195 & TRN \\
\hline CHEMBL1334190 & 688382 & 4.8 & 4.7993 & TRN \\
\hline
\end{tabular}




\begin{tabular}{|c|c|c|c|c|c|}
\hline & & \multicolumn{4}{|c|}{ Supplemental Table S2.txt } \\
\hline CHEMBL569561 & 688382 & 4.55 & 4.6899 & TRN & \\
\hline CHEMBL1594162 & 688382 & 4.75 & 4.7481 & TRN & \\
\hline CHEMBL1309295 & 688382 & 4.65 & 4.667 & TRN & \\
\hline CHEMBL581449 & 688382 & 4.5 & 4.6894 & TST & \\
\hline CHEMBL1537022 & 688382 & 4.5 & 4.7714 & TRN & \\
\hline CHEMBL1550093 & 688382 & 4.8 & 4.8137 & TRN & \\
\hline CHEMBL1546374 & 688382 & 4.45 & 4.6119 & TST & \\
\hline CHEMBL3198062 & 688382 & 4.35 & 4.75899 & 99999999995 & TRN \\
\hline CHEMBL1465272 & 688382 & 6.0 & 4.6704 & TST & \\
\hline CHEMBL1568444 & 688382 & 4.5 & 4.6232 & TRN & \\
\hline CHEMBL1333203 & 688382 & 4.5 & 4.6851 & TST & \\
\hline CHEMBL1514043 & 688382 & 5.25 & 4.7634 & TRN & \\
\hline CHEMBL1349248 & 688382 & 4.9 & 4.7204 & TRN & \\
\hline CHEMBL1573583 & 688382 & 4.45 & 4.6834 & TRN & \\
\hline CHEMBL1504549 & 688382 & 4.8 & 4.7791 & TRN & \\
\hline CHEMBL1304024 & 688382 & 4.85 & 4.6021 & TST & \\
\hline CHEMBL1306375 & 688382 & 6.0 & 4.7371 & TRN & \\
\hline CHEMBL1334577 & 688382 & 4.4 & 4.7383 & TST & \\
\hline CHEMBL 1600440 & 688382 & 4.5 & 4.7026 & TRN & \\
\hline CHEMBL1403754 & 688382 & 5.95 & 4.6805 & TRN & \\
\hline CHEMBL1594893 & 688382 & 4.8 & 4.6592 & TRN & \\
\hline CHEMBL1324113 & 688382 & 4.4 & 4.6029 & TRN & \\
\hline CHEMBL1377749 & 688382 & 4.65 & 4.6843 & TRN & \\
\hline CHEMBL 1376090 & 688382 & 4.15 & 4.7736 & TRN & \\
\hline CHEMBL3145026 & 688382 & 4.4 & 4.7098 & TST & \\
\hline CHEMBL1561046 & 688382 & 5.1 & 4.7422 & TRN & \\
\hline CHEMBL1538348 & 688382 & 5.8 & 4.7493 & TST & \\
\hline CHEMBL1358473 & 688382 & 4.4 & 4.7203 & TRN & \\
\hline CHEMBL1400603 & 688382 & 4.8 & 4.8195 & TST & \\
\hline CHEMBL1428563 & 688382 & 4.45 & 4.6004 & TRN & \\
\hline CHEMBL1534996 & 688382 & 4.75 & 4.8692 & TRN & \\
\hline CHEMBL1466683 & 688382 & 5.05 & 4.7037 & TRN & \\
\hline CHEMBL1439059 & 688382 & 4.4 & 4.6529 & TRN & \\
\hline CHEMBL1576654 & 688382 & 5.05 & 4.8093 & TRN & \\
\hline CHEMBL1483965 & 688382 & 4.85 & 4.7457 & TRN & \\
\hline CHEMBL1482973 & 688382 & 4.15 & 4.8373 & TRN & \\
\hline CHEMBL1500055 & 688382 & 5.2 & 4.7072 & TST & \\
\hline CHEMBL3195304 & 688382 & 4.15 & 4.6665 & TST & \\
\hline CHEMBL1531087 & 688382 & 5.15 & 4.8235 & TRN & \\
\hline CHEMBL1482695 & 688382 & 4.3 & 4.7411 & TST & \\
\hline CHEMBL1323214 & 688382 & 4.3 & 4.7575 & TRN & \\
\hline CHEMBL1347828 & 688382 & 4.8 & 4.8247 & TRN & \\
\hline CHEMBL1414980 & 688382 & 5.1 & 4.7143 & TRN & \\
\hline CHEMBL1598223 & 688382 & 4.4 & 4.6596 & TRN & \\
\hline CHEMBL1443637 & 688382 & 5.8 & 4.7891 & TRN & \\
\hline CHEMBL1580765 & 688382 & 5.6 & 4.7782 & TRN & \\
\hline CHEMBL1505051 & 688382 & 4.25 & 4.78 & TRN & \\
\hline CHEMBL1458526 & 688382 & 4.15 & 4.7312 & TRN & \\
\hline
\end{tabular}




\begin{tabular}{|c|c|c|c|c|}
\hline & & & \multicolumn{2}{|c|}{ Supplemental Table s2.txt } \\
\hline CHEMBL1466971 & 688382 & 4.05 & 4.7185 & TST \\
\hline CHEMBL1600480 & 688382 & 4.75 & 4.6425 & TRN \\
\hline CHEMBL1576159 & 688382 & 4.95 & 4.6889 & TRN \\
\hline CHEMBL1400717 & 688382 & 4.85 & 4.6542 & TST \\
\hline CHEMBL1980197 & 688382 & 4.55 & 4.6371 & TRN \\
\hline CHEMBL1463442 & 688382 & 4.55 & 4.6635 & TRN \\
\hline CHEMBL1583557 & 688382 & 5.65 & 4.7019 & TRN \\
\hline CHEMBL1522526 & 688382 & 4.0 & 4.7155 & TST \\
\hline CHEMBL1568022 & 688382 & 4.6 & 4.732 & TRN \\
\hline CHEMBL1361596 & 688382 & 4.6 & 4.7876 & TRN \\
\hline CHEMBL1412784 & 688382 & 4.5 & 4.662 & TRN \\
\hline CHEMBL1416815 & 688382 & 4.15 & 4.5722 & TST \\
\hline CHEMBL1454442 & 688382 & 4.05 & 4.8269 & TRN \\
\hline CHEMBL1596456 & 688382 & 4.85 & 4.7516 & TRN \\
\hline CHEMBL1509453 & 688382 & 5.25 & 4.6493 & TRN \\
\hline CHEMBL1519557 & 688382 & 5.8 & 4.7172 & TRN \\
\hline CHEMBL3210866 & 688382 & 4.8 & 4.7082 & TRN \\
\hline CHEMBL1498846 & 688382 & 5.1 & 4.7806 & TRN \\
\hline CHEMBL1371171 & 688382 & 4.0 & 4.6578 & TST \\
\hline CHEMBL1352646 & 688382 & 4.5 & 4.6669 & TRN \\
\hline CHEMBL1345438 & 688382 & 4.8 & 4.7399 & TST \\
\hline CHEMBL1598161 & 688382 & 4.8 & 4.6629 & TST \\
\hline CHEMBL1606183 & 688382 & 5.05 & 4.8475 & TRN \\
\hline CHEMBL1367446 & 688382 & 4.5 & 4.731 & TRN \\
\hline CHEMBL1609052 & 688382 & 5.0 & 4.5833 & TST \\
\hline CHEMBL1368137 & 688382 & 4.85 & 4.7139 & TST \\
\hline CHEMBL1596353 & 688382 & 4.45 & 4.6625 & TRN \\
\hline CHEMBL1371983 & 688382 & 4.8 & 4.7816 & TST \\
\hline CHEMBL1366962 & 688382 & 4.75 & 4.7177 & TRN \\
\hline CHEMBL1522767 & 688382 & 4.45 & 4.6436 & TRN \\
\hline CHEMBL1468303 & 688382 & 4.3 & 4.6691 & TRN \\
\hline CHEMBL1988859 & 688382 & 4.15 & 4.6069 & TRN \\
\hline CHEMBL1414746 & 688382 & 4.45 & 4.6795 & TRN \\
\hline CHEMBL1337192 & 688382 & 4.35 & 4.7499 & TRN \\
\hline CHEMBL1450705 & 688382 & 4.15 & 4.6782 & TST \\
\hline CHEMBL1403546 & 688382 & 4.4 & 4.7101 & TRN \\
\hline CHEMBL1971946 & 688382 & 4.95 & 4.7109 & TRN \\
\hline CHEMBL1464060 & 688382 & 4.4 & 4.7366 & TRN \\
\hline CHEMBL1299780 & 688382 & 4.2 & 4.6066 & TRN \\
\hline CHEMBL1493394 & 688382 & 6.0 & 4.7405 & TRN \\
\hline CHEMBL1421993 & 688382 & 4.5 & 4.6572 & TST \\
\hline CHEMBL1572802 & 688382 & 4.9 & 4.7234 & TST \\
\hline CHEMBL1350682 & 688382 & 4.5 & 4.632 & TRN \\
\hline CHEMBL1527360 & 688382 & 4.5 & 4.7318 & TRN \\
\hline CHEMBL1463173 & 688382 & 4.45 & 4.7215 & TRN \\
\hline CHEMBL1403108 & 688382 & 5.85 & 4.6377 & TRN \\
\hline CHEMBL1428483 & 688382 & 4.55 & 4.694 & TRN \\
\hline CHEMBL1416167 & 688382 & 4.15 & 4.6971 & TRN \\
\hline
\end{tabular}




\begin{tabular}{|c|c|c|c|c|c|}
\hline \multirow[b]{2}{*}{ CHEMBL1405189 } & \multicolumn{5}{|c|}{ Supplemental Table S2.txt } \\
\hline & 688382 & 6.5501 & 4.7087 & TST & \\
\hline CHEMBL1519102 & 688382 & 4.5 & 4.6864 & TST & \\
\hline CHEMBL1360042 & 688382 & 4.45 & 4.7684 & TRN & \\
\hline CHEMBL1352770 & 688382 & 4.5 & 4.6441 & TST & \\
\hline CHEMBL114544 & 688382 & 4.5 & 4.6513 & TST & \\
\hline CHEMBL1489474 & 688382 & 4.85 & 4.5752 & TRN & \\
\hline CHEMBL1432648 & 688382 & 4.15 & 4.7604 & TST & \\
\hline CHEMBL1305565 & 688382 & 5.5 & 4.8026 & TST & \\
\hline CHEMBL153036 & 688382 & 4.35 & 4.6895 & TST & \\
\hline CHEMBL1306663 & 688382 & 4.55 & 4.7183 & TRN & \\
\hline CHEMBL1338241 & 688382 & 4.8 & 4.7335 & TRN & \\
\hline CHEMBL1466811 & 688382 & 4.05 & 4.7159 & TRN & \\
\hline CHEMBL1420140 & 688382 & 4.45 & 4.6726 & TRN & \\
\hline CHEMBL1509492 & 688382 & 4.2 & 4.7266 & TRN & \\
\hline CHEMBL1562080 & 688382 & 4.85 & 4.7398 & TRN & \\
\hline CHEMBL1503068 & 688382 & 4.8 & 4.7065 & TRN & \\
\hline CHEMBL1481390 & 688382 & 4.9 & 4.6828 & TRN & \\
\hline CHEMBL1426215 & 688382 & 4.15 & 4.6548 & TST & \\
\hline CHEMBL1536552 & 688382 & 4.8 & 4.6907 & TRN & \\
\hline CHEMBL1426193 & 688382 & 4.15 & 4.7759 & TRN & \\
\hline CHEMBL1402448 & 688382 & 4.85 & 4.851 & TRN & \\
\hline CHEMBL1599406 & 688382 & 4.5 & 4.7185 & TRN & \\
\hline CHEMBL587475 & 688382 & 4.15 & 4.7647 & TRN & \\
\hline CHEMBL1370609 & 688382 & 4.4 & 4.6924 & TRN & \\
\hline CHEMBL1384373 & 688382 & 4.6 & 4.7 & TRN & \\
\hline CHEMBL1426212 & 688382 & 4.5 & 4.629 & TST & \\
\hline CHEMBL1510736 & 688382 & 5.8 & 4.8225 & TRN & \\
\hline CHEMBL1403463 & 688382 & 4.05 & 4.6333 & TRN & \\
\hline CHEMBL1363156 & 688382 & 5.9 & 4.6652 & TRN & \\
\hline CHEMBL1389555 & 688382 & 4.4 & 4.6094 & TST & \\
\hline CHEMBL1424476 & 688382 & 5.15 & 4.6799 & TST & \\
\hline CHEMBL1324249 & 688382 & 5.1 & 4.6697 & TRN & \\
\hline CHEMBL1368236 & 688382 & 4.95 & 4.7405 & TRN & \\
\hline CHEMBL1564810 & 688382 & 4.5 & 4.6879 & TRN & \\
\hline CHEMBL1570776 & 688382 & 4.75 & 4.7892 & TRN & \\
\hline CHEMBL1550332 & 688382 & 4.8 & 4.7425 & TST & \\
\hline CHEMBL1394092 & 688382 & 5.15 & 4.7425 & TRN & \\
\hline CHEMBL1573564 & 688382 & 4.5 & 4.717 & TST & \\
\hline CHEMBL3211927 & 688382 & 4.4 & 4.6576 & TRN & \\
\hline CHEMBL1497160 & 688382 & 4.2 & 4.80399 & 9999999999 & TRN \\
\hline CHEMBL1976308 & 688382 & 4.7 & 4.6202 & TRN & \\
\hline CHEMBL1602681 & 688382 & 4.85 & 4.8094 & TRN & \\
\hline CHEMBL1435407 & 688382 & 4.45 & 4.7303 & TRN & \\
\hline CHEMBL1408736 & 688382 & 4.95 & 4.7406 & TRN & \\
\hline CHEMBL3213034 & 688382 & 5.0 & 4.6534 & TRN & \\
\hline CHEMBL570345 & 688382 & 4.45 & 4.6598 & TST & \\
\hline CHEMBL1613512 & 688382 & 4.4 & 4.6856 & TRN & \\
\hline CHEMBL1345911 & 688382 & 4.55 & 4.5992 & TRN & \\
\hline
\end{tabular}




\begin{tabular}{|c|c|c|c|c|}
\hline \multicolumn{5}{|c|}{ Supplemental Table S2.txt } \\
\hline CHEMBL1428310 & 688382 & 5.0 & 4.7177 & TRN \\
\hline CHEMBL1506733 & 688382 & 5.95 & 4.6902 & TRN \\
\hline CHEMBL1576144 & 688382 & 4.95 & 4.6381 & TRN \\
\hline CHEMBL1612013 & 688382 & 4.3 & 4.7344 & TRN \\
\hline CHEMBL1521149 & 688382 & 5.0 & 4.737 & TRN \\
\hline CHEMBL1438018 & 688382 & 3.95 & 4.7247 & TRN \\
\hline CHEMBL1608420 & 688382 & 4.45 & 4.6838 & TRN \\
\hline CHEMBL1509772 & 688382 & 4.8 & 4.8612 & TRN \\
\hline CHEMBL1532049 & 688382 & 5.0 & 4.6841 & TRN \\
\hline CHEMBL1608720 & 688382 & 4.2 & 4.6502 & TRN \\
\hline CHEMBL1467683 & 688382 & 4.8 & 4.7668 & TRN \\
\hline CHEMBL1493302 & 688382 & 4.5 & 4.6029 & TST \\
\hline CHEMBL1563255 & 688382 & 4.8 & 4.7256 & TRN \\
\hline CHEMBL1511582 & 688382 & 5.15 & 4.7712 & TST \\
\hline CHEMBL1346030 & 688382 & 5.5 & 4.704 & TRN \\
\hline CHEMBL1418695 & 688382 & 4.45 & 4.6136 & TRN \\
\hline CHEMBL1570535 & 688382 & 4.3 & 4.6225 & TRN \\
\hline CHEMBL3190728 & 688382 & 6.05 & 4.7526 & TRN \\
\hline CHEMBL1408392 & 688382 & 4.75 & 4.6732 & TRN \\
\hline CHEMBL1327506 & 688382 & 5.95 & 4.7719 & TRN \\
\hline CHEMBL1388546 & 688382 & 4.65 & 4.7613 & TRN \\
\hline CHEMBL1386322 & 688382 & 4.85 & 4.6472 & TRN \\
\hline CHEMBL1312077 & 688382 & 4.1 & 4.7585 & TRN \\
\hline CHEMBL1482438 & 688382 & 6.0 & 4.6807 & TST \\
\hline CHEMBL1518886 & 688382 & 4.45 & 4.7472 & TRN \\
\hline CHEMBL3208759 & 688382 & 4.75 & 4.6923 & TRN \\
\hline CHEMBL3207988 & 688382 & 4.5 & 4.6701 & TRN \\
\hline CHEMBL3195899 & 688382 & 4.8 & 4.5627 & TRN \\
\hline CHEMBL1605142 & 688382 & 4.15 & 4.6575 & TRN \\
\hline CHEMBL1983351 & 688382 & 4.15 & 4.6454 & TRN \\
\hline CHEMBL316966 & 688382 & 6.9 & 4.7073 & TRN \\
\hline CHEMBL549216 & 688382 & 4.65 & 4.7591 & TRN \\
\hline CHEMBL1484575 & 688382 & 4.4 & 4.7742 & TRN \\
\hline CHEMBL1447917 & 688382 & 4.45 & 4.7128 & TRN \\
\hline CHEMBL1486150 & 688382 & 4.35 & 4.6797 & TRN \\
\hline CHEMBL1398812 & 688382 & 4.85 & 4.7412 & TRN \\
\hline CHEMBL3195455 & 688382 & 4.7 & 4.6298 & TRN \\
\hline CHEMBL1370528 & 688382 & 4.15 & 4.7754 & TRN \\
\hline CHEMBL1428681 & 688382 & 4.6 & 4.6048 & TST \\
\hline CHEMBL1502435 & 688382 & 4.4 & 4.6685 & TST \\
\hline CHEMBL1455952 & 688382 & 4.8 & 4.6875 & TRN \\
\hline CHEMBL1579719 & 688382 & 5.5 & 4.7679 & TRN \\
\hline CHEMBL1586967 & 688382 & 4.2 & 4.6851 & TRN \\
\hline CHEMBL1332013 & 688382 & 6.0 & 4.7541 & TRN \\
\hline CHEMBL3191539 & 688382 & 4.35 & 4.7177 & TRN \\
\hline CHEMBL1411837 & 688382 & 4.95 & 4.7474 & TST \\
\hline CHEMBL1568223 & 688382 & 6.05 & 4.7168 & TRN \\
\hline CHEMBL1303552 & 688382 & 4.45 & 4.707 & TRN \\
\hline
\end{tabular}




\begin{tabular}{|c|c|c|c|c|c|}
\hline & & \multicolumn{4}{|c|}{ Supplemental Table S2.txt } \\
\hline CHEMBL1428078 & 688382 & 5.45 & 4.6535 & TRN & \\
\hline CHEMBL1579908 & 688382 & 5.15 & 4.7276 & TRN & \\
\hline CHEMBL1571576 & 688382 & 5.05 & 4.6591 & TRN & \\
\hline CHEMBL1527448 & 688382 & 4.8 & 4.6781 & TST & \\
\hline CHEMBL1431215 & 688382 & 4.8 & 4.7229 & TRN & \\
\hline CHEMBL1301822 & 688382 & 4.15 & 4.7226 & TRN & \\
\hline CHEMBL1345119 & 688382 & 4.95 & 4.7823 & TRN & \\
\hline CHEMBL1431314 & 688382 & 5.05 & 4.6185 & TRN & \\
\hline CHEMBL1345535 & 688382 & 4.45 & 4.7046 & TRN & \\
\hline CHEMBL1519877 & 688382 & 5.0 & 4.7743 & TST & \\
\hline CHEMBL1607304 & 688382 & 4.8 & 4.6522 & TRN & \\
\hline CHEMBL1570297 & 688382 & 4.9 & 4.6801 & TRN & \\
\hline CHEMBL1389403 & 688382 & 3.9 & 4.8114 & TRN & \\
\hline CHEMBL1995825 & 688382 & 4.55 & 4.6222 & TRN & \\
\hline CHEMBL1444793 & 688382 & 4.35 & 4.6413 & TST & \\
\hline CHEMBL1612107 & 688382 & 5.0 & 4.7287 & TST & \\
\hline CHEMBL456850 & 688382 & 4.5 & 4.5947 & TRN & \\
\hline CHEMBL1352200 & 688382 & 4.45 & 4.6553 & TRN & \\
\hline CHEMBL 388676 & 688382 & 4.4 & 4.6993 & TST & \\
\hline CHEMBL1408058 & 688382 & 4.05 & 4.6869 & TRN & \\
\hline CHEMBL1304722 & 688382 & 4.45 & 4.7386 & TST & \\
\hline CHEMBL1974392 & 688382 & 5.05 & 4.6258 & TRN & \\
\hline CHEMBL1557362 & 688382 & 4.6 & 4.7687 & TRN & \\
\hline CHEMBL1440114 & 688382 & 5.1 & 4.6832 & TST & \\
\hline CHEMBL1352857 & 688382 & 4.85 & 4.73600 & 3000000001 & TRN \\
\hline CHEMBL1544489 & 688382 & 4.95 & 4.5816 & TST & \\
\hline CHEMBL1352285 & 688382 & 5.55 & 4.7396 & TRN & \\
\hline CHEMBL1425108 & 688382 & 4.4 & 4.7058 & TST & \\
\hline CHEMBL1449302 & 688382 & 4.05 & 4.6986 & TRN & \\
\hline CHEMBL1458415 & 688382 & 4.05 & 4.6774 & TRN & \\
\hline CHEMBL1344269 & 688382 & 4.5 & 4.5825 & TRN & \\
\hline CHEMBL1507054 & 688382 & 5.4 & 4.6614 & TST & \\
\hline CHEMBL1431902 & 688382 & 4.95 & 4.704 & TRN & \\
\hline CHEMBL1385051 & 688382 & 4.25 & 4.6549 & TRN & \\
\hline CHEMBL1985765 & 688382 & 4.35 & 4.6797 & TST & \\
\hline CHEMBL1422267 & 688382 & 4.2 & 4.8328 & TRN & \\
\hline CHEMBL1385609 & 688382 & 4.35 & 4.7019 & TRN & \\
\hline CHEMBL1477703 & 688382 & 5.1 & 4.6524 & TRN & \\
\hline CHEMBL 3195410 & 688382 & 4.9 & 4.7275 & TRN & \\
\hline CHEMBL1586081 & 688382 & 4.2 & 4.7142 & TRN & \\
\hline CHEMBL1606122 & 688382 & 5.95 & 4.688 & TRN & \\
\hline CHEMBL1524576 & 688382 & 5.1 & 4.7188 & TRN & \\
\hline CHEMBL1342463 & 688382 & 6.05 & 4.7029 & TST & \\
\hline CHEMBL1425060 & 688382 & 6.0 & 4.7285 & TST & \\
\hline CHEMBL1997827 & 688382 & 4.05 & 4.655 & TRN & \\
\hline CHEMBL1547140 & 688382 & 5.2 & 4.7074 & TRN & \\
\hline CHEMBL1531802 & 688382 & 5.4 & 4.7757 & TST & \\
\hline CHEMBL1493516 & 688382 & 4.85 & 4.5944 & TST & \\
\hline
\end{tabular}




\begin{tabular}{|c|c|c|c|c|}
\hline \multicolumn{5}{|c|}{ Supplemental Table S2.txt } \\
\hline CHEMBL1322754 & 688382 & 4.45 & 4.6791 & TST \\
\hline CHEMBL1500936 & 688382 & 5.05 & 4.7559 & TST \\
\hline CHEMBL1583451 & 688382 & 4.8 & 4.7243 & TRN \\
\hline CHEMBL1604130 & 688382 & 4.8 & 4.8113 & TRN \\
\hline CHEMBL1571635 & 688382 & 4.05 & 4.7672 & TRN \\
\hline CHEMBL1323551 & 688382 & 5.55 & 4.707 & TST \\
\hline CHEMBL3193547 & 688382 & 4.5 & 4.5517 & TRN \\
\hline CHEMBL1374060 & 688382 & 4.05 & 4.7371 & TRN \\
\hline CHEMBL1578866 & 688382 & 4.5 & 4.6954 & TRN \\
\hline CHEMBL1441284 & 688382 & 4.4 & 4.6757 & TRN \\
\hline CHEMBL1392228 & 688382 & 5.95 & 4.6918 & TRN \\
\hline CHEMBL1527922 & 688382 & 4.4 & 4.7014 & TRN \\
\hline CHEMBL1466074 & 688382 & 4.25 & 4.7739 & TRN \\
\hline CHEMBL1472447 & 688382 & 4.9 & 4.7639 & TRN \\
\hline CHEMBL3191778 & 688382 & 4.6 & 4.6123 & TRN \\
\hline CHEMBL1532788 & 688382 & 4.2 & 4.7705 & TRN \\
\hline CHEMBL1329016 & 688382 & 4.7 & 4.7661 & TRN \\
\hline CHEMBL3208079 & 688382 & 4.4 & 4.6614 & TRN \\
\hline CHEMBL1359263 & 688382 & 4.55 & 4.6744 & TST \\
\hline CHEMBL1546670 & 688382 & 4.85 & 4.7866 & TRN \\
\hline CHEMBL1313262 & 688382 & 4.45 & 4.6278 & TST \\
\hline CHEMBL1610663 & 688382 & 4.8 & 4.824 & TRN \\
\hline CHEMBL3196852 & 688382 & 4.95 & 4.6573 & TST \\
\hline CHEMBL1605546 & 688382 & 4.4 & 4.7062 & TST \\
\hline CHEMBL1507930 & 688382 & 5.6 & 4.5943 & TRN \\
\hline CHEMBL1388299 & 688382 & 4.05 & 4.6756 & TRN \\
\hline CHEMBL1496432 & 688382 & 4.4 & 4.628 & TST \\
\hline CHEMBL1527095 & 688382 & 4.2 & 4.5681 & TRN \\
\hline CHEMBL1361002 & 688382 & 4.45 & 4.7537 & TST \\
\hline CHEMBL3212266 & 688382 & 5.55 & 4.6955 & TRN \\
\hline CHEMBL1511266 & 688382 & 7.2 & 4.7938 & TRN \\
\hline CHEMBL1311354 & 688382 & 4.8 & 4.6062 & TRN \\
\hline CHEMBL1990081 & 688382 & 4.25 & 4.6634 & TRN \\
\hline CHEMBL1585293 & 688382 & 5.0 & 4.7675 & TST \\
\hline CHEMBL1369591 & 688382 & 3.85 & 4.7368 & TRN \\
\hline CHEMBL3196236 & 688382 & 4.0 & 4.6781 & TST \\
\hline CHEMBL1507404 & 688382 & 4.3 & 4.7009 & TST \\
\hline CHEMBL1440750 & 688382 & 4.45 & 4.7161 & TRN \\
\hline CHEMBL1416287 & 688382 & 4.5 & 4.7542 & TRN \\
\hline CHEMBL1464108 & 688382 & 4.6 & 4.6264 & TST \\
\hline CHEMBL1396532 & 688382 & 4.45 & 4.7362 & TST \\
\hline CHEMBL1470449 & 688382 & 4.95 & 4.7432 & TRN \\
\hline CHEMBL1459726 & 688382 & 4.25 & 4.6819 & TRN \\
\hline CHEMBL1526409 & 688382 & 5.9 & 4.7892 & TRN \\
\hline CHEMBL1607353 & 688382 & 4.45 & 4.6293 & TRN \\
\hline CHEMBL1995385 & 688382 & 4.55 & 4.6281 & TRN \\
\hline CHEMBL 2006740 & 688382 & 4.8 & 4.7118 & TRN \\
\hline CHEMBL1547101 & 688382 & 4.2 & 4.7263 & TST \\
\hline
\end{tabular}




\begin{tabular}{|c|c|c|c|c|}
\hline & & & ıpplemen & \\
\hline CHEMBL1449743 & 688382 & 4.45 & 4.6392 & TRN \\
\hline CHEMBL1527611 & 688382 & 4.45 & 4.6717 & TRN \\
\hline CHEMBL576607 & 688382 & 6.0 & 4.6495 & TRN \\
\hline CHEMBL1489207 & 688382 & 4.8 & 4.6756 & TRN \\
\hline CHEMBL1402354 & 688382 & 5.95 & 4.7721 & TRN \\
\hline CHEMBL1603525 & 688382 & 4.5 & 4.7886 & TRN \\
\hline CHEMBL1496072 & 688382 & 4.2 & 4.6422 & TRN \\
\hline CHEMBL1471476 & 688382 & 4.9 & 4.7432 & TRN \\
\hline CHEMBL1346215 & 688382 & 4.5 & 4.6976 & TRN \\
\hline CHEMBL1465527 & 688382 & 4.25 & 4.6983 & TST \\
\hline CHEMBL1538106 & 688382 & 4.5 & 4.6779 & TRN \\
\hline CHEMBL1413188 & 688382 & 4.45 & 4.6748 & TRN \\
\hline CHEMBL1517609 & 688382 & 4.8 & 4.6409 & TST \\
\hline CHEMBL1480648 & 688382 & 5.15 & 4.703 & TRN \\
\hline CHEMBL1441604 & 688382 & 4.05 & 4.7123 & TRN \\
\hline CHEMBL3190644 & 688382 & 4.5 & 4.7019 & TST \\
\hline CHEMBL3207475 & 688382 & 4.85 & 4.7844 & TRN \\
\hline CHEMBL1503416 & 688382 & 4.95 & 4.79 & TRN \\
\hline CHEMBL1460525 & 688382 & 4.5 & 4.7126 & TRN \\
\hline CHEMBL1352429 & 688382 & 5.8 & 4.6599 & TST \\
\hline CHEMBL1549222 & 688382 & 5.2 & 4.5607 & TST \\
\hline CHEMBL1505953 & 688382 & 5.15 & 4.6056 & TRN \\
\hline CHEMBL1309254 & 688382 & 4.25 & 4.6258 & TST \\
\hline CHEMBL1378310 & 688382 & 4.15 & 4.7351 & TRN \\
\hline CHEMBL1607169 & 688382 & 4.8 & 4.8345 & TST \\
\hline CHEMBL1576840 & 688382 & 4.55 & 4.6958 & TRN \\
\hline CHEMBL1588969 & 688382 & 5.1 & 4.6776 & TRN \\
\hline CHEMBL1335892 & 688382 & 4.9 & 4.7463 & TST \\
\hline CHEMBL1385087 & 688382 & 4.85 & 4.8278 & TRN \\
\hline CHEMBL1438583 & 688382 & 4.6 & 4.6783 & TRN \\
\hline CHEMBL1453846 & 688382 & 5.05 & 4.6976 & TST \\
\hline CHEMBL1509885 & 688382 & 4.95 & 4.792 & TRN \\
\hline CHEMBL1303781 & 688382 & 5.45 & 4.7992 & TRN \\
\hline CHEMBL3392070 & 688382 & 4.45 & 4.6604 & TRN \\
\hline CHEMBL1313274 & 688382 & 4.25 & 4.6285 & TRN \\
\hline CHEMBL1310914 & 688382 & 4.15 & 4.772 & TRN \\
\hline CHEMBL1499423 & 688382 & 4.95 & 4.8194 & TRN \\
\hline CHEMBL1588656 & 688382 & 4.45 & 4.7451 & TRN \\
\hline CHEMBL1447211 & 688382 & 4.45 & 4.6369 & TST \\
\hline CHEMBL1595659 & 688382 & 4.15 & 4.6095 & TST \\
\hline CHEMBL1999595 & 688382 & 4.45 & 4.6293 & TRN \\
\hline CHEMBL1597053 & 688382 & 5.05 & 4.8016 & TST \\
\hline CHEMBL1488035 & 688382 & 4.45 & 4.6082 & TRN \\
\hline CHEMBL1423836 & 688382 & 4.45 & 4.6857 & TRN \\
\hline CHEMBL1365953 & 688382 & 5.95 & 4.7473 & TRN \\
\hline CHEMBL1560400 & 688382 & 5.5 & 4.6712 & TRN \\
\hline CHEMBL1379677 & 688382 & 5.45 & 4.7178 & TRN \\
\hline CHEMBL1325293 & 688382 & 4.5 & 4.6604 & TRN \\
\hline
\end{tabular}




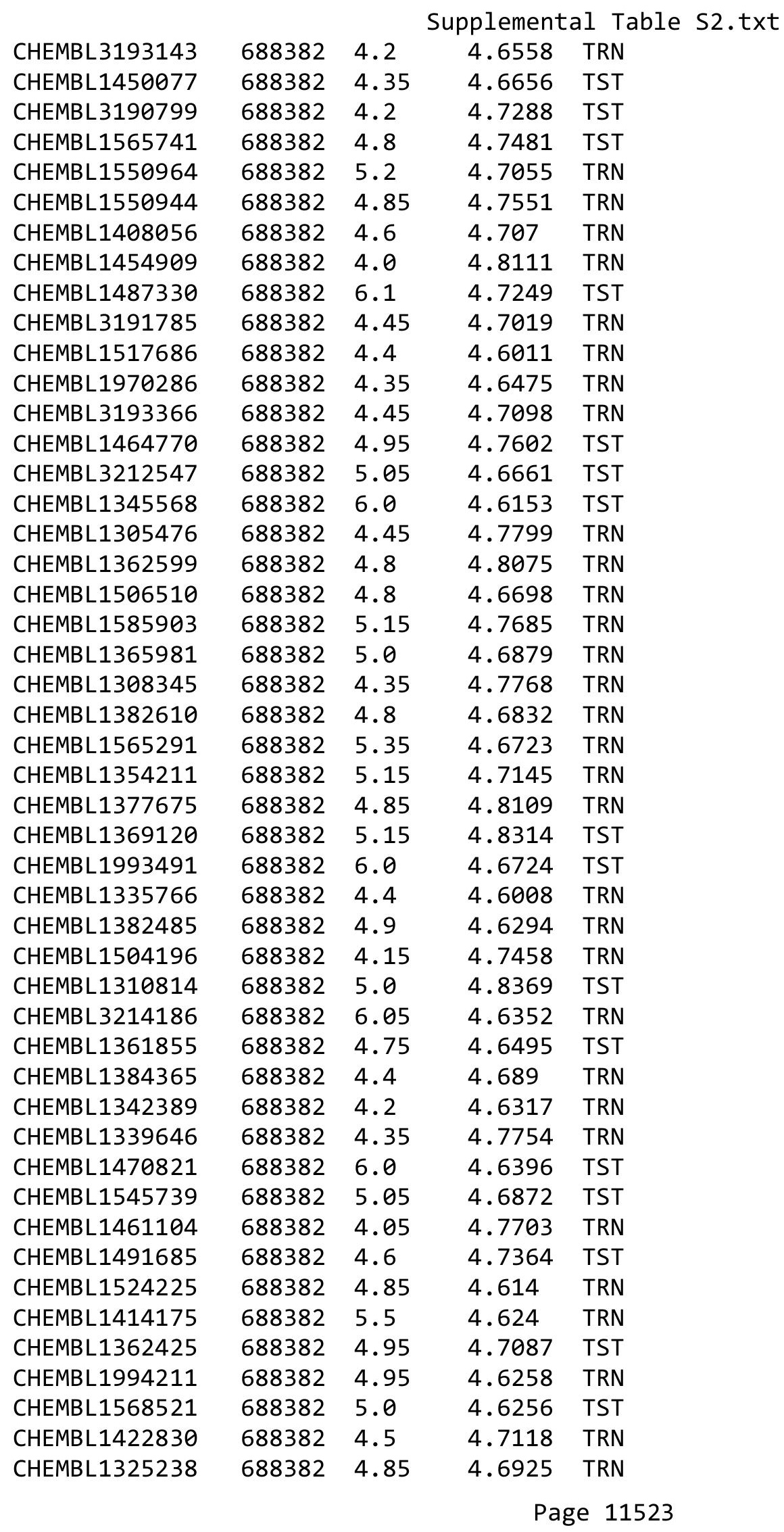




\begin{tabular}{|c|c|c|c|c|}
\hline & & & upplement & al Table \\
\hline CHEMBL1500052 & 688382 & 3.95 & 4.6674 & TST \\
\hline CHEMBL1381628 & 688382 & 4.85 & 4.7166 & TRN \\
\hline CHEMBL1971144 & 688382 & 5.25 & 4.6339 & TRN \\
\hline CHEMBL1309030 & 688382 & 4.5 & 4.647 & TRN \\
\hline CHEMBL3212944 & 688382 & 4.5 & 4.6656 & TRN \\
\hline CHEMBL1375133 & 688382 & 4.55 & 4.6827 & TRN \\
\hline CHEMBL1384581 & 688382 & 4.05 & 4.5936 & TRN \\
\hline CHEMBL1420625 & 688382 & 4.45 & 4.6028 & TRN \\
\hline CHEMBL1459491 & 688382 & 4.4 & 4.6674 & TRN \\
\hline CHEMBL579265 & 688382 & 4.85 & 4.7925 & TRN \\
\hline CHEMBL1445687 & 688382 & 4.5 & 4.641 & TRN \\
\hline CHEMBL1557585 & 688382 & 4.2 & 4.7914 & TST \\
\hline CHEMBL1385630 & 688382 & 4.85 & 4.7926 & TST \\
\hline CHEMBL1449911 & 688382 & 5.05 & 4.769 & TRN \\
\hline CHEMBL1478138 & 688382 & 4.85 & 4.8301 & TRN \\
\hline CHEMBL1426455 & 688382 & 4.4 & 4.7338 & TRN \\
\hline CHEMBL1572206 & 688382 & 4.5 & 4.7028 & TRN \\
\hline CHEMBL1421156 & 688382 & 4.15 & 4.6893 & TST \\
\hline CHEMBL1561847 & 688382 & 4.45 & 4.6859 & TRN \\
\hline CHEMBL1505010 & 688382 & 4.65 & 4.7373 & TST \\
\hline CHEMBL1341951 & 688382 & 6.0 & 4.6353 & TRN \\
\hline CHEMBL1582314 & 688382 & 5.3 & 4.6664 & TST \\
\hline CHEMBL1299345 & 688382 & 4.5 & 4.6707 & TRN \\
\hline CHEMBL1461496 & 688382 & 4.5 & 4.6407 & TRN \\
\hline CHEMBL1398921 & 688382 & 4.1 & 4.6367 & TRN \\
\hline CHEMBL1433404 & 688382 & 4.85 & 4.7854 & TRN \\
\hline CHEMBL1351883 & 688382 & 4.4 & 4.7527 & TRN \\
\hline CHEMBL1439587 & 688382 & 4.8 & 4.7399 & TRN \\
\hline CHEMBL1438011 & 688382 & 4.85 & 4.7081 & TST \\
\hline CHEMBL1384154 & 688382 & 4.45 & 4.7665 & TRN \\
\hline CHEMBL1387268 & 688382 & 6.0 & 4.7851 & TRN \\
\hline CHEMBL1364125 & 688382 & 4.15 & 4.6502 & TST \\
\hline CHEMBL586830 & 688382 & 4.55 & 4.6058 & TRN \\
\hline CHEMBL1487248 & 688382 & 6.0 & 4.7927 & TST \\
\hline CHEMBL1415826 & 688382 & 4.05 & 4.7523 & TRN \\
\hline CHEMBL1539840 & 688382 & 4.45 & 4.7371 & TST \\
\hline CHEMBL1380166 & 688382 & 3.75 & 4.7021 & TRN \\
\hline CHEMBL3195540 & 688382 & 4.95 & 4.64 & TST \\
\hline CHEMBL3196672 & 688382 & 4.4 & 4.5962 & TST \\
\hline CHEMBL1369775 & 688382 & 4.4 & 4.7527 & TRN \\
\hline CHEMBL1366479 & 688382 & 4.5 & 4.6683 & TRN \\
\hline CHEMBL1497986 & 688382 & 4.15 & 4.6886 & TRN \\
\hline CHEMBL1399891 & 688382 & 4.45 & 4.6643 & TRN \\
\hline CHEMBL3210112 & 688382 & 4.85 & 4.6986 & TRN \\
\hline CHEMBL1330139 & 688382 & 4.2 & 4.6867 & TST \\
\hline CHEMBL1497969 & 688382 & 4.9 & 4.7147 & TST \\
\hline CHEMBL1556273 & 688382 & 4.5 & 4.6407 & TST \\
\hline CHEMBL1374157 & 688382 & 6.0 & 4.7387 & TST \\
\hline
\end{tabular}




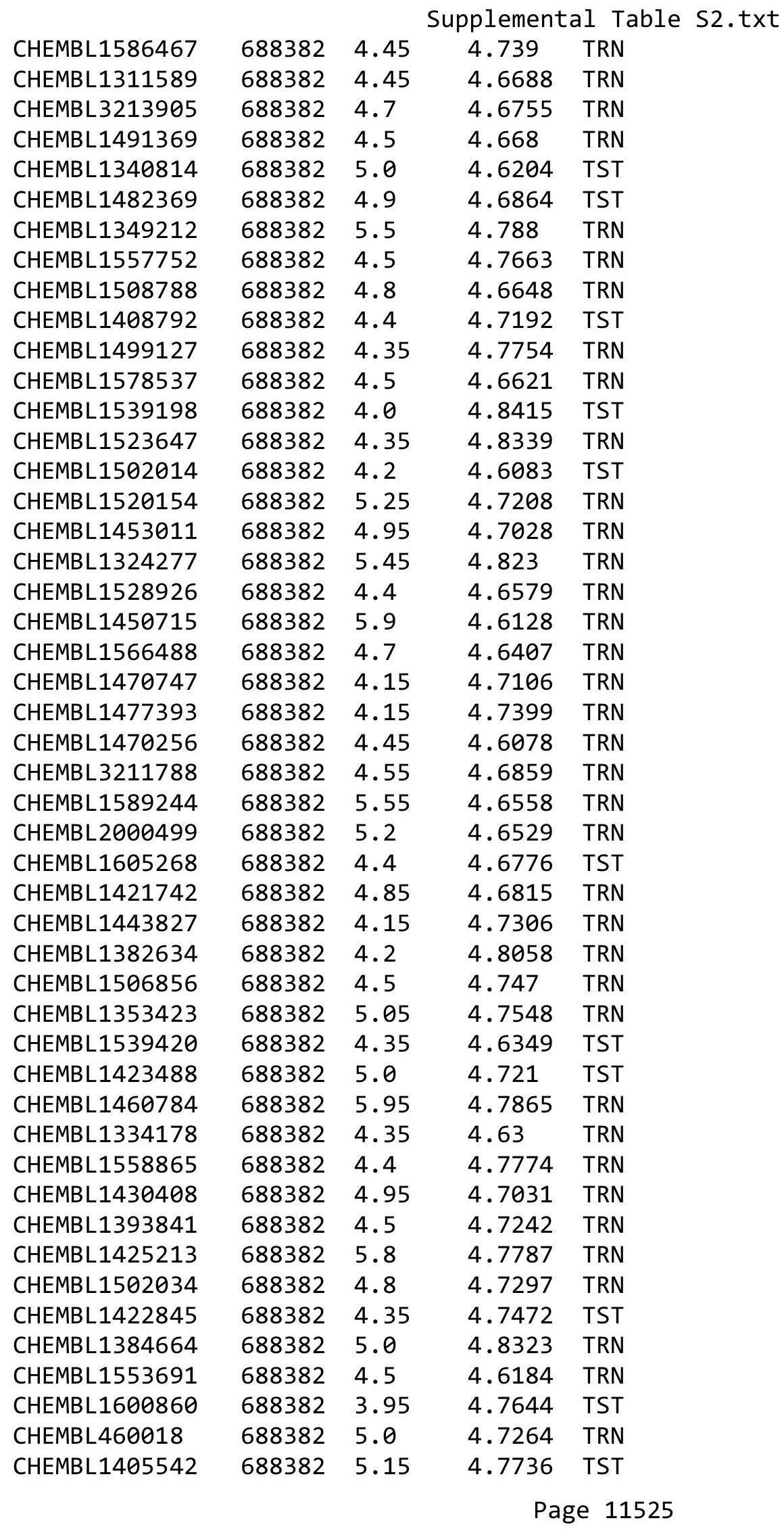




\begin{tabular}{|c|c|c|c|c|}
\hline \multicolumn{5}{|c|}{ Supplemental Table s2.txt } \\
\hline CHEMBL1386791 & 688382 & 4.2 & 4.6467 & TST \\
\hline CHEMBL1463126 & 688382 & 5.05 & 4.7396 & TRN \\
\hline CHEMBL1449083 & 688382 & 4.45 & 4.7401 & TRN \\
\hline CHEMBL1609515 & 688382 & 5.05 & 4.7655 & TRN \\
\hline CHEMBL1372775 & 688382 & 4.95 & 4.7038 & TRN \\
\hline CHEMBL1462685 & 688382 & 4.05 & 4.7386 & TRN \\
\hline CHEMBL1578981 & 688382 & 4.05 & 4.7237 & TST \\
\hline CHEMBL1366035 & 688382 & 4.8 & 4.725 & TRN \\
\hline CHEMBL1386922 & 688382 & 4.2 & 4.5834 & TST \\
\hline CHEMBL1307719 & 688382 & 5.05 & 4.7834 & TRN \\
\hline CHEMBL1413393 & 688382 & 4.45 & 4.7402 & TRN \\
\hline CHEMBL539507 & 688382 & 4.85 & 4.6726 & TST \\
\hline CHEMBL1353722 & 688382 & 4.85 & 4.7593 & TRN \\
\hline CHEMBL 3190268 & 688382 & 4.4 & 4.6472 & TRN \\
\hline CHEMBL1510534 & 688382 & 4.95 & 4.6856 & TRN \\
\hline CHEMBL1477307 & 688382 & 4.6 & 4.6415 & TRN \\
\hline CHEMBL1555848 & 688382 & 5.15 & 4.8144 & TRN \\
\hline CHEMBL1376657 & 688382 & 4.85 & 4.8132 & TRN \\
\hline CHEMBL1493589 & 688382 & 5.25 & 4.7042 & TRN \\
\hline CHEMBL1360227 & 688382 & 4.8 & 4.742 & TRN \\
\hline CHEMBL1549049 & 688382 & 4.55 & 4.6196 & TST \\
\hline CHEMBL1376198 & 688382 & 5.3 & 4.6986 & TST \\
\hline CHEMBL1472543 & 688382 & 4.45 & 4.7535 & TST \\
\hline CHEMBL1609374 & 688382 & 4.8 & 4.7123 & TRN \\
\hline CHEMBL1463574 & 688382 & 5.0 & 4.6654 & TRN \\
\hline CHEMBL 263972 & 688382 & 4.5 & 4.6576 & TST \\
\hline CHEMBL1587067 & 688382 & 4.05 & 4.6916 & TRN \\
\hline CHEMBL1370012 & 688382 & 4.35 & 4.7309 & TRN \\
\hline CHEMBL1422535 & 688382 & 4.5 & 4.604 & TST \\
\hline CHEMBL1441430 & 688382 & 4.5 & 4.6626 & TRN \\
\hline CHEMBL1607258 & 688382 & 4.15 & 4.7555 & TRN \\
\hline CHEMBL1410818 & 688382 & 4.45 & 4.6848 & TRN \\
\hline CHEMBL1431747 & 688382 & 4.85 & 4.6671 & TST \\
\hline CHEMBL1991242 & 688382 & 5.15 & 4.662 & TRN \\
\hline CHEMBL1526174 & 688382 & 5.2 & 4.6303 & TRN \\
\hline CHEMBL1524113 & 688382 & 5.55 & 4.7584 & TRN \\
\hline CHEMBL1458761 & 688382 & 4.85 & 4.7587 & TRN \\
\hline CHEMBL1336627 & 688382 & 4.95 & 4.7136 & TRN \\
\hline CHEMBL1578997 & 688382 & 4.3 & 4.6833 & TRN \\
\hline CHEMBL1517294 & 688382 & 6.05 & 4.7044 & TRN \\
\hline CHEMBL1526494 & 688382 & 5.2 & 4.6287 & TRN \\
\hline CHEMBL1428294 & 688382 & 7.5003 & 4.6632 & TST \\
\hline CHEMBL1540898 & 688382 & 4.2 & 4.7376 & TST \\
\hline CHEMBL1327523 & 688382 & 5.3 & 4.6422 & TRN \\
\hline CHEMBL1965472 & 688382 & 4.4 & 4.6739 & TRN \\
\hline CHEMBL1337587 & 688382 & 4.05 & 4.645 & TST \\
\hline CHEMBL1337794 & 688382 & 4.9 & 4.6642 & TRN \\
\hline CHEMBL1555908 & 688382 & 6.0 & 4.7317 & TRN \\
\hline
\end{tabular}




\begin{tabular}{|c|c|c|c|c|c|}
\hline \multicolumn{6}{|c|}{ Supplemental Table S2.txt } \\
\hline CHEMBL1570871 & 688382 & 4.9 & 4.5946 & TRN & \\
\hline CHEMBL1349662 & 688382 & 4.95 & 4.6791 & TST & \\
\hline CHEMBL1381614 & 688382 & 5.2 & 4.825 & TRN & \\
\hline CHEMBL1337633 & 688382 & 6.0 & 4.58899 & 99999999995 & TST \\
\hline CHEMBL1534631 & 688382 & 4.45 & 4.7313 & TRN & \\
\hline CHEMBL1466419 & 688382 & 4.5 & 4.6916 & TRN & \\
\hline CHEMBL1573586 & 688382 & 4.35 & 4.6618 & TST & \\
\hline CHEMBL1305020 & 688382 & 4.8 & 4.7171 & TRN & \\
\hline CHEMBL 3197637 & 688382 & 4.8 & 4.7194 & TRN & \\
\hline CHEMBL1508096 & 688382 & 5.95 & 4.7567 & TST & \\
\hline CHEMBL1417288 & 688382 & 4.15 & 4.7753 & TRN & \\
\hline CHEMBL1486131 & 688382 & 4.2 & 4.6537 & TRN & \\
\hline CHEMBL1501247 & 688382 & 5.05 & 4.7271 & TRN & \\
\hline CHEMBL1500060 & 688382 & 4.5 & 4.7296 & TRN & \\
\hline CHEMBL1301701 & 688382 & 4.5 & 4.7764 & TRN & \\
\hline CHEMBL1522472 & 688382 & 4.15 & 4.6341 & TST & \\
\hline CHEMBL1973131 & 688382 & 4.5 & 4.6497 & TRN & \\
\hline CHEMBL1492309 & 688382 & 4.55 & 4.7095 & TRN & \\
\hline CHEMBL1360526 & 688382 & 5.05 & 4.7569 & TRN & \\
\hline CHEMBL1400157 & 688382 & 4.85 & 4.6244 & TRN & \\
\hline CHEMBL1408468 & 688382 & 4.05 & 4.6385 & TRN & \\
\hline CHEMBL1387422 & 688382 & 5.55 & 4.7333 & TRN & \\
\hline CHEMBL1517667 & 688382 & 4.15 & 4.7207 & TRN & \\
\hline CHEMBL1576349 & 688382 & 4.5 & 4.6064 & TRN & \\
\hline CHEMBL3198991 & 688382 & 4.45 & 4.644 & TRN & \\
\hline CHEMBL1564558 & 688382 & 4.45 & 4.6694 & TRN & \\
\hline CHEMBL1459813 & 688382 & 4.5 & 4.6277 & TRN & \\
\hline CHEMBL1498433 & 688382 & 4.85 & 4.7729 & TST & \\
\hline CHEMBL1454975 & 688382 & 4.9 & 4.6408 & TRN & \\
\hline CHEMBL1599398 & 688382 & 4.15 & 4.6801 & TRN & \\
\hline CHEMBL1543559 & 688382 & 5.5 & 4.704 & TRN & \\
\hline CHEMBL1463386 & 688382 & 5.15 & 4.7107 & TRN & \\
\hline CHEMBL1312277 & 688382 & 5.0 & 4.8512 & TRN & \\
\hline CHEMBL1504096 & 688382 & 4.0 & 4.7271 & TRN & \\
\hline CHEMBL1419568 & 688382 & 4.8 & 4.6937 & TRN & \\
\hline CHEMBL1308908 & 688382 & 4.5 & 4.7001 & TRN & \\
\hline CHEMBL3191151 & 688382 & 5.45 & 4.6438 & TRN & \\
\hline CHEMBL 2001567 & 688382 & 4.3 & 4.6568 & TRN & \\
\hline CHEMBL1478174 & 688382 & 4.05 & 4.7605 & TRN & \\
\hline CHEMBL1302827 & 688382 & 4.65 & 4.6439 & TRN & \\
\hline CHEMBL1437991 & 688382 & 4.55 & 4.6443 & TRN & \\
\hline CHEMBL1408414 & 688382 & 4.55 & 4.6755 & TST & \\
\hline CHEMBL1507244 & 688382 & 4.2 & 4.6383 & TST & \\
\hline CHEMBL1585764 & 688382 & 4.4 & 4.6864 & TRN & \\
\hline CHEMBL1557277 & 688382 & 4.85 & 4.6792 & TRN & \\
\hline CHEMBL1495669 & 688382 & 4.95 & 4.7171 & TST & \\
\hline CHEMBL1421040 & 688382 & 5.95 & 4.8063 & TST & \\
\hline CHEMBL1307202 & 688382 & 4.0 & 4.7796 & TRN & \\
\hline
\end{tabular}




\begin{tabular}{|c|c|c|c|c|c|}
\hline \multicolumn{6}{|c|}{ Supplemental Table S2.txt } \\
\hline CHEMBL1399837 & 688382 & 4.8 & 4.6928 & TST & \\
\hline CHEMBL1385958 & 688382 & 4.15 & 4.7275 & TST & \\
\hline CHEMBL1472210 & 688382 & 4.05 & 4.6716 & TRN & \\
\hline CHEMBL1311149 & 688382 & 5.0 & 4.7813 & TRN & \\
\hline CHEMBL1416539 & 688382 & 4.05 & 4.6775 & TRN & \\
\hline CHEMBL1606893 & 688382 & 4.15 & 4.789 & TST & \\
\hline CHEMBL1530338 & 688382 & 5.95 & 4.7727 & TRN & \\
\hline CHEMBL1307453 & 688382 & 4.15 & 4.7156 & TRN & \\
\hline CHEMBL1469797 & 688382 & 4.65 & 4.7531 & TRN & \\
\hline CHEMBL1527097 & 688382 & 4.45 & 4.7741 & TRN & \\
\hline CHEMBL1601619 & 688382 & 4.85 & 4.6785 & TRN & \\
\hline CHEMBL3208307 & 688382 & 5.0 & 4.7155 & TST & \\
\hline CHEMBL1603594 & 688382 & 4.8 & 4.6978 & TST & \\
\hline CHEMBL1319353 & 688382 & 6.3 & 4.8414 & TRN & \\
\hline CHEMBL1581222 & 688382 & 6.0 & 4.7109 & TRN & \\
\hline CHEMBL1367906 & 688382 & 4.05 & 4.792 & TRN & \\
\hline CHEMBL1337935 & 688382 & 5.95 & 4.7552 & TRN & \\
\hline CHEMBL1323392 & 688382 & 6.0 & 4.8199 & TRN & \\
\hline CHEMBL1459914 & 688382 & 4.35 & 4.5917 & TRN & \\
\hline CHEMBL1503502 & 688382 & 4.45 & 4.6964 & TRN & \\
\hline CHEMBL1992394 & 688382 & 5.1 & 4.6347 & TRN & \\
\hline CHEMBL1361487 & 688382 & 4.1 & 4.5671 & TRN & \\
\hline CHEMBL1469601 & 688382 & 4.95 & 4.7867 & TRN & \\
\hline CHEMBL1324829 & 688382 & 3.95 & 4.6317 & TRN & \\
\hline CHEMBL3210095 & 688382 & 4.95 & 4.728 & TST & \\
\hline CHEMBL1570922 & 688382 & 4.2 & 4.7483 & TRN & \\
\hline CHEMBL1580066 & 688382 & 4.45 & 4.7054 & TRN & \\
\hline CHEMBL1543845 & 688382 & 4.45 & 4.636 & TRN & \\
\hline CHEMBL1522443 & 688382 & 4.65 & 4.7097 & TRN & \\
\hline CHEMBL1586067 & 688382 & 5.3 & 4.7284 & TRN & \\
\hline CHEMBL1365815 & 688382 & 4.5 & 4.7539 & TRN & \\
\hline CHEMBL3209918 & 688382 & 4.0 & 4.7077 & TRN & \\
\hline CHEMBL1468527 & 688382 & 4.35 & 4.6383 & TRN & \\
\hline CHEMBL1598011 & 688382 & 4.6 & 4.6468 & TRN & \\
\hline CHEMBL3192147 & 688382 & 4.45 & 4.7521 & TST & \\
\hline CHEMBL1387238 & 688382 & 4.6 & 4.711 & TRN & \\
\hline CHEMBL1369953 & 688382 & 4.15 & 4.584 & TRN & \\
\hline CHEMBL1387849 & 688382 & 4.9 & 4.692 & TRN & \\
\hline CHEMBL1498431 & 688382 & 5.45 & 4.6333 & TRN & \\
\hline CHEMBL1502183 & 688382 & 4.8 & 4.6964 & TRN & \\
\hline CHEMBL1410348 & 688382 & 4.55 & 4.6928 & TRN & \\
\hline CHEMBL1595332 & 688382 & 4.2 & 4.8555 & TRN & \\
\hline CHEMBL1349163 & 688382 & 5.05 & 4.8049 & TRN & \\
\hline CHEMBL1523528 & 688382 & 4.45 & $4.6560 e$ & 0000000001 & TRN \\
\hline CHEMBL1585909 & 688382 & 4.9 & 4.7788 & TRN & \\
\hline CHEMBL1348102 & 688382 & 4.95 & 4.7582 & TRN & \\
\hline CHEMBL105226 & 688382 & 4.95 & 4.6819 & TST & \\
\hline CHEMBL1366532 & 688382 & 4.6 & 4.7742 & TST & \\
\hline
\end{tabular}




\begin{tabular}{|c|c|c|c|c|}
\hline \multicolumn{5}{|c|}{ Supplemental Table S2.txt } \\
\hline CHEMBL1430984 & 688382 & 5.2 & 4.6808 & TRN \\
\hline CHEMBL3193671 & 688382 & 4.95 & 4.6838 & TST \\
\hline CHEMBL1480201 & 688382 & 5.9 & 4.7905 & TST \\
\hline CHEMBL587433 & 688382 & 4.15 & 4.5703 & TST \\
\hline CHEMBL1527241 & 688382 & 6.05 & 4.6823 & TRN \\
\hline CHEMBL1508335 & 688382 & 4.4 & 4.7395 & TRN \\
\hline CHEMBL1609479 & 688382 & 4.8 & 4.8083 & TRN \\
\hline CHEMBL1423520 & 688382 & 4.0 & 4.7402 & TST \\
\hline CHEMBL1365618 & 688382 & 4.6 & 4.6981 & TRN \\
\hline CHEMBL1308253 & 688382 & 4.4 & 4.6474 & TST \\
\hline CHEMBL1481915 & 688382 & 4.15 & 4.8437 & TRN \\
\hline CHEMBL1548872 & 688382 & 4.4 & 4.6958 & TRN \\
\hline CHEMBL1426273 & 688382 & 4.3 & 4.6586 & TST \\
\hline CHEMBL1451621 & 688382 & 4.85 & 4.7425 & TRN \\
\hline CHEMBL1602026 & 688382 & 4.3 & 4.8142 & TST \\
\hline CHEMBL1519869 & 688382 & 4.4 & 4.6807 & TST \\
\hline CHEMBL1509658 & 688382 & 5.8 & 4.7549 & TRN \\
\hline CHEMBL1552657 & 688382 & 4.8 & 4.6854 & TRN \\
\hline CHEMBL1470125 & 688382 & 6.05 & 4.7754 & TRN \\
\hline CHEMBL1494637 & 688382 & 4.2 & 4.7326 & TRN \\
\hline CHEMBL1612786 & 688382 & 4.3 & 4.7729 & TST \\
\hline CHEMBL1416066 & 688382 & 4.15 & 4.6944 & TRN \\
\hline CHEMBL1601870 & 688382 & 4.05 & 4.6321 & TRN \\
\hline CHEMBL1375755 & 688382 & 4.55 & 4.7366 & TRN \\
\hline CHEMBL1493103 & 688382 & 4.8 & 4.7472 & TST \\
\hline CHEMBL1556764 & 688382 & 4.35 & 4.6147 & TRN \\
\hline CHEMBL1411572 & 688382 & 4.9 & 4.6724 & TST \\
\hline CHEMBL1549267 & 688382 & 4.5 & 4.6587 & TST \\
\hline CHEMBL3209340 & 688382 & 4.45 & 4.5918 & TRN \\
\hline CHEMBL1368998 & 688382 & 4.45 & 4.7681 & TRN \\
\hline CHEMBL1585388 & 688382 & 5.0 & 4.811 & TRN \\
\hline CHEMBL1501376 & 688382 & 4.5 & 4.5846 & TRN \\
\hline CHEMBL1557598 & 688382 & 4.5 & 4.6891 & TRN \\
\hline CHEMBL1393335 & 688382 & 4.0 & 4.7626 & TRN \\
\hline CHEMBL179611 & 688382 & 4.6 & 4.6319 & TST \\
\hline CHEMBL1379084 & 688382 & 4.55 & 4.8167 & TRN \\
\hline CHEMBL 3195243 & 688382 & 4.35 & 4.5757 & TRN \\
\hline CHEMBL1611196 & 688382 & 5.1 & 4.7347 & TRN \\
\hline CHEMBL1548905 & 688382 & 5.1 & 4.8072 & TST \\
\hline CHEMBL1373863 & 688382 & 5.1 & 4.8272 & TRN \\
\hline CHEMBL1604088 & 688382 & 4.45 & 4.7191 & TRN \\
\hline CHEMBL1972824 & 688382 & 4.4 & 4.6711 & TRN \\
\hline CHEMBL1520363 & 688382 & 4.8 & 4.7132 & TST \\
\hline CHEMBL1496777 & 688382 & 4.85 & 4.8108 & TRN \\
\hline CHEMBL1549418 & 688382 & 4.05 & 4.7505 & TST \\
\hline CHEMBL1536554 & 688382 & 4.95 & 4.7457 & TST \\
\hline CHEMBL1303270 & 688382 & 6.05 & 4.6833 & TRN \\
\hline CHEMBL1539972 & 688382 & 4.9 & 4.6835 & TRN \\
\hline
\end{tabular}




\begin{tabular}{|c|c|c|c|c|}
\hline \multicolumn{5}{|c|}{ Supplemental Table S2.txt } \\
\hline CHEMBL1535225 & 688382 & 4.7 & 4.6035 & TRN \\
\hline CHEMBL1590747 & 688382 & 4.4 & 4.6824 & TRN \\
\hline CHEMBL1303398 & 688382 & 4.8 & 4.8161 & TRN \\
\hline CHEMBL1363608 & 688382 & 4.85 & 4.6812 & TST \\
\hline CHEMBL1507882 & 688382 & 4.8 & 4.7097 & TRN \\
\hline CHEMBL1541547 & 688382 & 4.55 & 4.7522 & TRN \\
\hline CHEMBL1489894 & 688382 & 5.1 & 4.8553 & TRN \\
\hline CHEMBL1594182 & 688382 & 5.15 & 4.6339 & TRN \\
\hline CHEMBL3351063 & 688382 & 4.45 & 4.72 & TST \\
\hline CHEMBL1412429 & 688382 & 4.15 & 4.6955 & TST \\
\hline CHEMBL1351253 & 688382 & 5.85 & 4.7294 & TRN \\
\hline CHEMBL1337591 & 688382 & 4.4 & 4.8197 & TRN \\
\hline CHEMBL3190931 & 688382 & 4.6 & 4.7086 & TRN \\
\hline CHEMBL585591 & 688382 & 4.5 & 4.6336 & TST \\
\hline CHEMBL1428460 & 688382 & 4.35 & 4.6728 & TRN \\
\hline CHEMBL1459928 & 688382 & 6.0 & 4.7388 & TST \\
\hline CHEMBL1498950 & 688382 & 4.45 & 4.7409 & TRN \\
\hline CHEMBL1560066 & 688382 & 4.35 & 4.6718 & TRN \\
\hline CHEMBL1584366 & 688382 & 4.05 & 4.7366 & TRN \\
\hline CHEMBL1613273 & 688382 & 4.85 & 4.6802 & TRN \\
\hline CHEMBL1336657 & 688382 & 5.95 & 4.7721 & TRN \\
\hline CHEMBL1387837 & 688382 & 5.6 & 4.7148 & TRN \\
\hline CHEMBL1412637 & 688382 & 4.5 & 4.6659 & TRN \\
\hline CHEMBL1544096 & 688382 & 4.6 & 4.6851 & TRN \\
\hline CHEMBL1400347 & 688382 & 5.85 & 4.7976 & TRN \\
\hline CHEMBL1386329 & 688382 & 4.15 & 4.7456 & TST \\
\hline CHEMBL590285 & 688382 & 5.15 & 4.6295 & TRN \\
\hline CHEMBL1533129 & 688382 & 5.0 & 4.7386 & TST \\
\hline CHEMBL1330113 & 688382 & 5.3 & 4.6756 & TST \\
\hline CHEMBL1576664 & 688382 & 6.05 & 4.7308 & TST \\
\hline CHEMBL3191552 & 688382 & 4.5 & 4.7625 & TST \\
\hline CHEMBL1374155 & 688382 & 4.45 & 4.7328 & TRN \\
\hline CHEMBL1459360 & 688382 & 4.75 & 4.6606 & TRN \\
\hline CHEMBL1549507 & 688382 & 4.05 & 4.7301 & TST \\
\hline CHEMBL1457483 & 688382 & 4.8 & 4.689 & TST \\
\hline CHEMBL1596898 & 688382 & 4.5 & 4.7095 & TST \\
\hline CHEMBL1360824 & 688382 & 4.55 & 4.7044 & TRN \\
\hline CHEMBL539906 & 688382 & 5.0 & 4.6791 & TRN \\
\hline CHEMBL1503156 & 688382 & 6.0 & 4.7358 & TRN \\
\hline CHEMBL1406421 & 688382 & 4.5 & 4.6659 & TST \\
\hline CHEMBL1366055 & 688382 & 4.2 & 4.7332 & TRN \\
\hline CHEMBL1351173 & 688382 & 4.2 & 4.6963 & TST \\
\hline CHEMBL1454050 & 688382 & 4.85 & 4.6982 & TRN \\
\hline CHEMBL1350178 & 688382 & 4.15 & 4.6899 & TRN \\
\hline CHEMBL1410202 & 688382 & 4.4 & 4.7044 & TRN \\
\hline CHEMBL1466366 & 688382 & 4.45 & 4.7145 & TRN \\
\hline CHEMBL1098425 & 688382 & 6.0 & 4.697 & TRN \\
\hline CHEMBL1361443 & 688382 & 4.7 & 4.663 & TRN \\
\hline
\end{tabular}




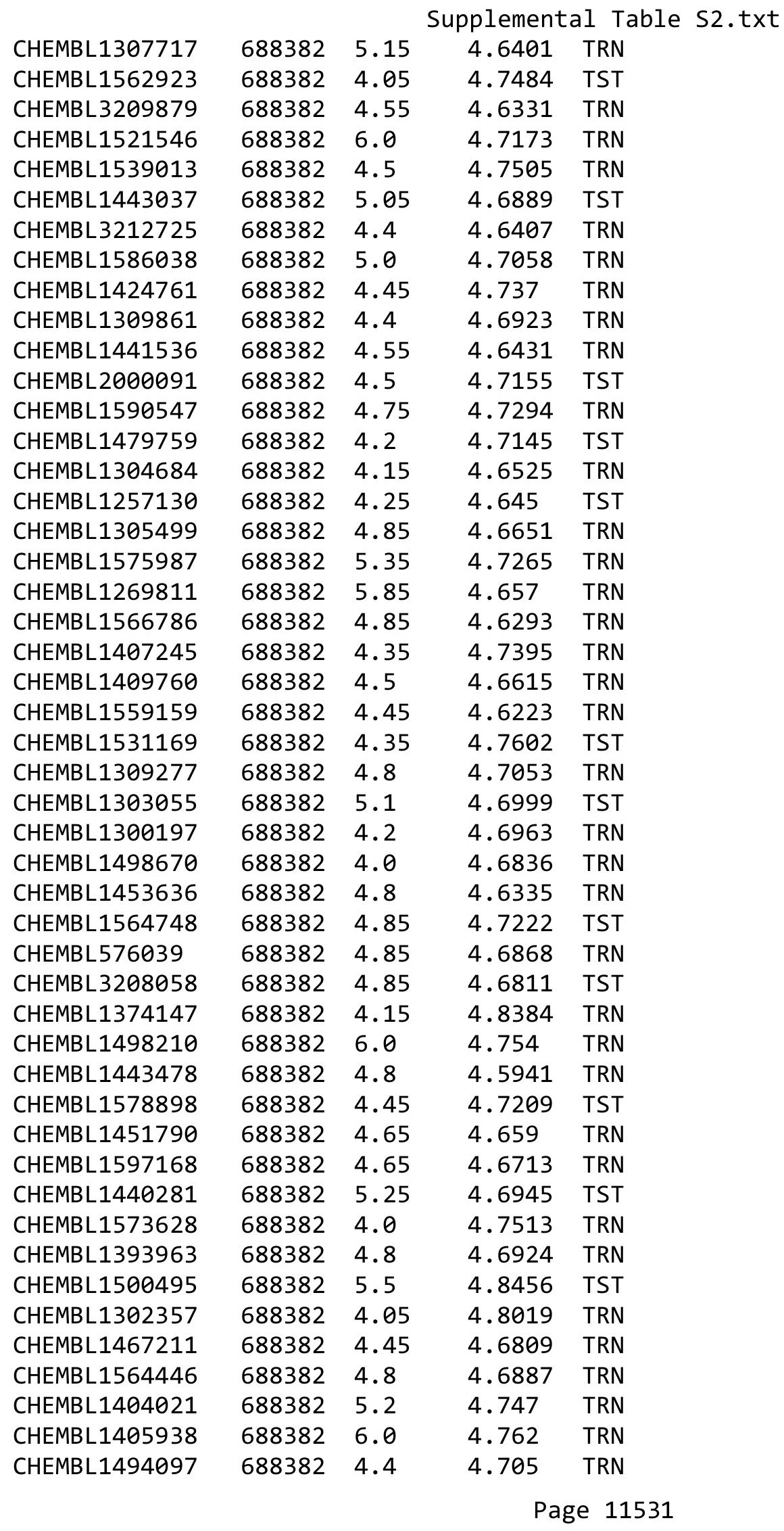




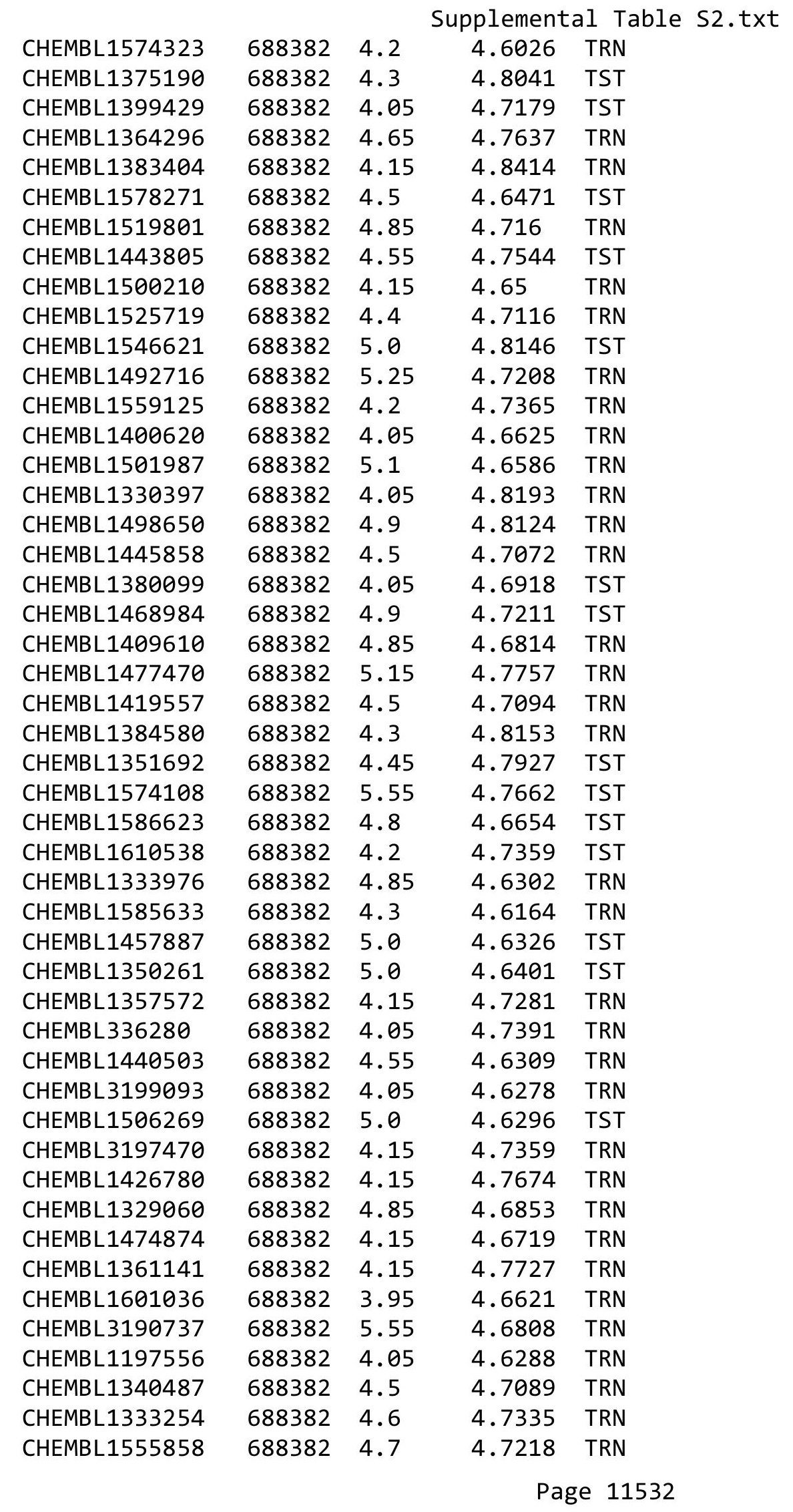




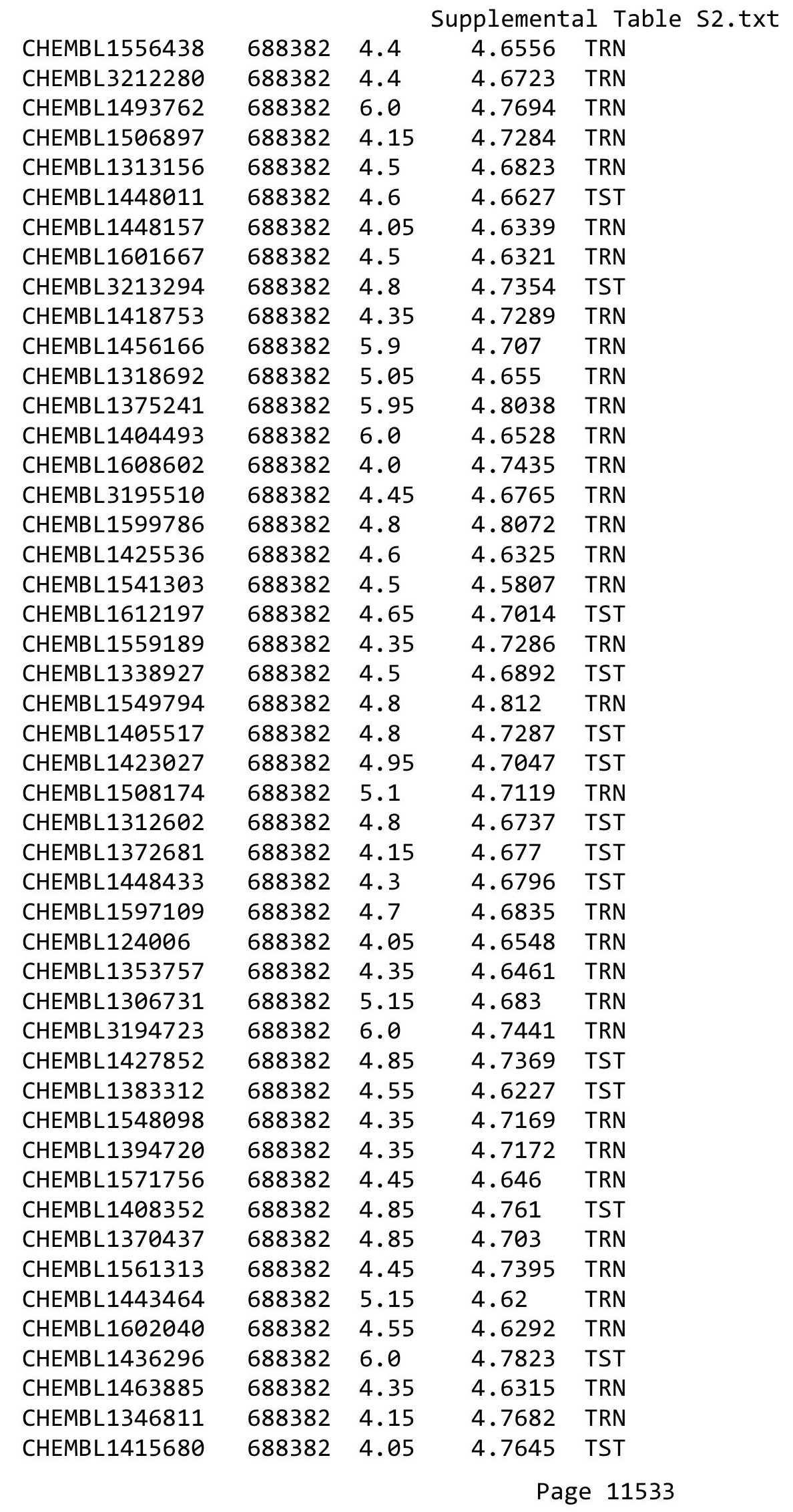




\begin{tabular}{|c|c|c|c|c|c|}
\hline \multicolumn{6}{|c|}{ Supplemental Table S2.txt } \\
\hline CHEMBL1301717 & 688382 & 5.0 & 4.7888 & TST & \\
\hline CHEMBL1485941 & 688382 & 4.2 & 4.7613 & TRN & \\
\hline CHEMBL1574140 & 688382 & 4.9 & 4.67 & TRN & \\
\hline CHEMBL1423797 & 688382 & 4.2 & 4.6713 & TRN & \\
\hline CHEMBL1509956 & 688382 & 5.5 & 4.7514 & TRN & \\
\hline CHEMBL1458849 & 688382 & 4.5 & 4.7405 & TST & \\
\hline CHEMBL1340439 & 688382 & 4.15 & 4.754 & TRN & \\
\hline CHEMBL1428093 & 688382 & 4.15 & 4.7336 & TRN & \\
\hline CHEMBL1472751 & 688382 & 4.55 & 4.6394 & TST & \\
\hline CHEMBL1479965 & 688382 & 4.55 & 4.7166 & TRN & \\
\hline CHEMBL3207316 & 688382 & 4.9 & 4.7428 & TRN & \\
\hline CHEMBL3192789 & 688382 & 5.1 & 4.6167 & TST & \\
\hline CHEMBL1603188 & 688382 & 4.3 & 4.7841 & TRN & \\
\hline CHEMBL1391002 & 688382 & 3.55 & 4.7866 & TRN & \\
\hline CHEMBL1447602 & 688382 & 4.2 & 4.6839 & TST & \\
\hline CHEMBL1389456 & 688382 & 4.85 & 4.8263 & TST & \\
\hline CHEMBL3197908 & 688382 & 4.5 & 4.5969 & TRN & \\
\hline CHEMBL1308329 & 688382 & 5.35 & 4.6664 & TRN & \\
\hline CHEMBL1361323 & 688382 & 4.05 & 4.8357 & TRN & \\
\hline CHEMBL1557036 & 688382 & 4.5 & 4.6748 & TRN & \\
\hline CHEMBL1577981 & 688382 & 4.15 & 4.6252 & TRN & \\
\hline CHEMBL1370471 & 688382 & 4.7 & 4.6873 & TRN & \\
\hline CHEMBL1320205 & 688382 & 4.95 & 4.7472 & TRN & \\
\hline CHEMBL1588352 & 688382 & 4.5 & 4.787 & TRN & \\
\hline CHEMBL1347273 & 688382 & 4.95 & 4.745 & TRN & \\
\hline CHEMBL1408874 & 688382 & 4.45 & 4.6949 & TRN & \\
\hline CHEMBL1389603 & 688382 & 4.3 & 4.8205 & TRN & \\
\hline CHEMBL1481600 & 688382 & 6.4 & 4.7574 & TST & \\
\hline CHEMBL1361890 & 688382 & 4.8 & 4.7482 & TRN & \\
\hline CHEMBL592184 & 688382 & 6.0 & 4.6822 & TST & \\
\hline CHEMBL1558739 & 688382 & 4.15 & 4.7277 & TRN & \\
\hline CHEMBL1432008 & 688382 & 4.85 & 4.6135 & TRN & \\
\hline CHEMBL1538197 & 688382 & 4.9 & $4.6560 e$ & $\partial 000000001$ & TRN \\
\hline CHEMBL1481940 & 688382 & 4.25 & 4.7003 & TRN & \\
\hline CHEMBL1541141 & 688382 & 4.15 & 4.6943 & TRN & \\
\hline CHEMBL1458801 & 688382 & 4.15 & 4.7021 & TRN & \\
\hline CHEMBL3192098 & 688382 & 4.4 & 4.6156 & TRN & \\
\hline CHEMBL1389474 & 688382 & 4.8 & 4.8295 & TRN & \\
\hline CHEMBL608699 & 688382 & 4.45 & 4.6276 & TST & \\
\hline CHEMBL602413 & 688382 & 4.55 & 4.6325 & TRN & \\
\hline CHEMBL1369760 & 688382 & 4.0 & 4.7819 & TRN & \\
\hline CHEMBL1392210 & 688382 & 4.5 & 4.7009 & TRN & \\
\hline CHEMBL1535299 & 688382 & 5.05 & 4.6349 & TST & \\
\hline CHEMBL1569627 & 688382 & 4.5 & 4.6763 & TRN & \\
\hline CHEMBL1448687 & 688382 & 4.05 & 4.7689 & TST & \\
\hline CHEMBL1330946 & 688382 & 4.05 & 4.8053 & TRN & \\
\hline CHEMBL1336908 & 688382 & 4.8 & 4.8121 & TST & \\
\hline CHEMBL1579760 & 688382 & 6.0 & 4.6769 & TRN & \\
\hline
\end{tabular}




\begin{tabular}{|c|c|c|c|c|c|}
\hline & & \multicolumn{4}{|c|}{ Supplemental Table s2.txt } \\
\hline CHEMBL1373659 & 688382 & 4.85 & 4.6511 & TRN & \\
\hline CHEMBL1538920 & 688382 & 4.75 & 4.7334 & TRN & \\
\hline CHEMBL1573910 & 688382 & 4.45 & 4.7481 & TST & \\
\hline CHEMBL 383475 & 688382 & 4.0 & 4.657 & TRN & \\
\hline CHEMBL1391903 & 688382 & 4.55 & 4.7338 & TRN & \\
\hline CHEMBL1582664 & 688382 & 4.85 & 4.7851 & TST & \\
\hline CHEMBL1455482 & 688382 & 5.05 & 4.6301 & TST & \\
\hline CHEMBL1581334 & 688382 & 4.55 & 4.7365 & TST & \\
\hline CHEMBL1578629 & 688382 & 4.15 & 4.76 & TRN & \\
\hline CHEMBL1566180 & 688382 & 5.95 & 4.7654 & TRN & \\
\hline CHEMBL1495381 & 688382 & 4.05 & 4.6723 & TST & \\
\hline CHEMBL581225 & 688382 & 4.9 & 4.7151 & TST & \\
\hline CHEMBL1446608 & 688382 & 4.4 & 4.6807 & TST & \\
\hline CHEMBL1408840 & 688382 & 4.8 & 4.6856 & TST & \\
\hline CHEMBL1305292 & 688382 & 4.7 & 4.7122 & TRN & \\
\hline CHEMBL1483045 & 688382 & 4.05 & 4.7235 & TRN & \\
\hline CHEMBL1519584 & 688382 & 5.7 & 4.77800 & 00000000005 & TST \\
\hline CHEMBL1518574 & 688382 & 5.35 & 4.8342 & TRN & \\
\hline CHEMBL1390090 & 688382 & 4.5 & 4.7622 & TRN & \\
\hline CHEMBL1332481 & 688382 & 4.5 & 4.6424 & TST & \\
\hline CHEMBL1324199 & 688382 & 5.15 & 4.8436 & TRN & \\
\hline CHEMBL1343272 & 688382 & 5.5 & 4.7311 & TRN & \\
\hline CHEMBL1451539 & 688382 & 5.9 & 4.7379 & TRN & \\
\hline CHEMBL1503620 & 688382 & 4.05 & 4.7304 & TST & \\
\hline CHEMBL1605976 & 688382 & 4.45 & 4.6865 & TST & \\
\hline CHEMBL1531496 & 688382 & 4.9 & 4.7358 & TST & \\
\hline CHEMBL374632 & 688382 & 6.35 & 4.636 & TRN & \\
\hline CHEMBL1392672 & 688382 & 4.8 & 4.8203 & TRN & \\
\hline CHEMBL1367051 & 688382 & 4.15 & 4.6928 & TST & \\
\hline CHEMBL1421391 & 688382 & 5.25 & 4.6898 & TRN & \\
\hline CHEMBL1471665 & 688382 & 4.85 & 4.6995 & TRN & \\
\hline CHEMBL1339115 & 688382 & 5.8 & 4.629 & TST & \\
\hline CHEMBL1504340 & 688382 & 5.0 & 4.7628 & TRN & \\
\hline CHEMBL1603855 & 688382 & 4.5 & 4.688 & TRN & \\
\hline CHEMBL1989852 & 688382 & 4.5 & 4.6503 & TST & \\
\hline CHEMBL1353281 & 688382 & 5.35 & 4.7281 & TRN & \\
\hline CHEMBL1578693 & 688382 & 4.85 & 4.7977 & TRN & \\
\hline CHEMBL1530961 & 688382 & 4.0 & 4.7314 & TRN & \\
\hline CHEMBL1519447 & 688382 & 3.95 & 4.7304 & TST & \\
\hline CHEMBL1455886 & 688382 & 4.15 & 4.6893 & TST & \\
\hline CHEMBL1571717 & 688382 & 5.1 & 4.6153 & TST & \\
\hline CHEMBL1332876 & 688382 & 5.7 & 4.8201 & TRN & \\
\hline CHEMBL1599864 & 688382 & 4.95 & 4.7694 & TRN & \\
\hline CHEMBL1577110 & 688382 & 4.85 & 4.632 & TRN & \\
\hline CHEMBL1409183 & 688382 & 4.9 & 4.7706 & TRN & \\
\hline CHEMBL1519249 & 688382 & 4.5 & 4.72 & TRN & \\
\hline CHEMBL1304357 & 688382 & 4.5 & 4.6352 & TST & \\
\hline CHEMBL1606532 & 688382 & 4.3 & 4.8171 & TRN & \\
\hline
\end{tabular}




\begin{tabular}{|c|c|c|c|c|c|}
\hline & & \multicolumn{4}{|c|}{ Supplemental Table s2.txt } \\
\hline CHEMBL1370217 & 688382 & 4.15 & 4.6385 & TST & \\
\hline CHEMBL1370908 & 688382 & 4.45 & 4.8265 & TRN & \\
\hline CHEMBL3211463 & 688382 & 4.95 & 4.6633 & TRN & \\
\hline CHEMBL1391884 & 688382 & 4.3 & 4.6815 & TRN & \\
\hline CHEMBL1351511 & 688382 & 5.8 & 4.6678 & TRN & \\
\hline CHEMBL1466560 & 688382 & 4.0 & 4.8259 & TST & \\
\hline CHEMBL1343590 & 688382 & 5.15 & 4.687 & TST & \\
\hline CHEMBL1605699 & 688382 & 4.35 & 4.7249 & TRN & \\
\hline CHEMBL1349690 & 688382 & 5.25 & 4.6956 & TRN & \\
\hline CHEMBL1336475 & 688382 & 4.4 & 4.831 & TRN & \\
\hline CHEMBL1567607 & 688382 & 4.05 & 4.667 & TRN & \\
\hline CHEMBL1584573 & 688382 & 4.15 & 4.7031 & TRN & \\
\hline CHEMBL1448877 & 688382 & 4.4 & 4.6997 & TST & \\
\hline CHEMBL1978997 & 688382 & 5.15 & 4.6625 & TRN & \\
\hline CHEMBL1373682 & 688382 & 4.8 & 4.71399 & 99999999995 & TST \\
\hline CHEMBL1612733 & 688382 & 4.1 & 4.7071 & TST & \\
\hline CHEMBL1469972 & 688382 & 4.05 & 4.6451 & TST & \\
\hline CHEMBL1347431 & 688382 & 4.9 & 4.7346 & TRN & \\
\hline CHEMBL1544403 & 688382 & 4.2 & 4.6482 & TST & \\
\hline CHEMBL1517010 & 688382 & 5.0 & 4.6515 & TST & \\
\hline CHEMBL1376280 & 688382 & 4.8 & 4.6636 & TRN & \\
\hline CHEMBL1302012 & 688382 & 4.4 & 4.6175 & TRN & \\
\hline CHEMBL1484632 & 688382 & 4.05 & 4.6839 & TST & \\
\hline CHEMBL1480111 & 688382 & 5.8 & 4.7673 & TRN & \\
\hline CHEMBL1530797 & 688382 & 4.5 & 4.7436 & TRN & \\
\hline CHEMBL1451945 & 688382 & 4.35 & 4.7153 & TST & \\
\hline CHEMBL1576666 & 688382 & 4.8 & 4.6199 & TRN & \\
\hline CHEMBL1445092 & 688382 & 4.95 & 4.7388 & TST & \\
\hline CHEMBL1537159 & 688382 & 4.9 & 4.7258 & TRN & \\
\hline CHEMBL3211025 & 688382 & 4.85 & 4.6718 & TRN & \\
\hline CHEMBL1467222 & 688382 & 4.45 & 4.622 & TST & \\
\hline CHEMBL1390437 & 688382 & 4.85 & 4.7629 & TRN & \\
\hline CHEMBL3190589 & 688382 & 4.05 & 4.6627 & TRN & \\
\hline CHEMBL1584252 & 688382 & 4.05 & 4.709 & TRN & \\
\hline CHEMBL1421190 & 688382 & 4.15 & 4.6881 & TRN & \\
\hline CHEMBL1384851 & 688382 & 4.05 & 4.7299 & TRN & \\
\hline CHEMBL1384951 & 688382 & 5.05 & 4.8015 & TRN & \\
\hline CHEMBL1383735 & 688382 & 4.55 & 4.6408 & TRN & \\
\hline CHEMBL1403434 & 688382 & 4.45 & 4.6895 & TRN & \\
\hline CHEMBL1539391 & 688382 & 4.8 & 4.7201 & TRN & \\
\hline CHEMBL1985479 & 688382 & 4.95 & 4.6741 & TRN & \\
\hline CHEMBL1507012 & 688382 & 4.4 & 4.6988 & TRN & \\
\hline CHEMBL1613677 & 688382 & 4.8 & 4.7623 & TRN & \\
\hline CHEMBL3196922 & 688382 & 4.5 & 4.7087 & TRN & \\
\hline CHEMBL1564790 & 688382 & 4.0 & 4.6564 & TRN & \\
\hline CHEMBL1342505 & 688382 & 4.85 & 4.7296 & TST & \\
\hline CHEMBL1586493 & 688382 & 4.15 & 4.6664 & TST & \\
\hline CHEMBL546580 & 688382 & 6.4 & 4.726 & TST & \\
\hline
\end{tabular}




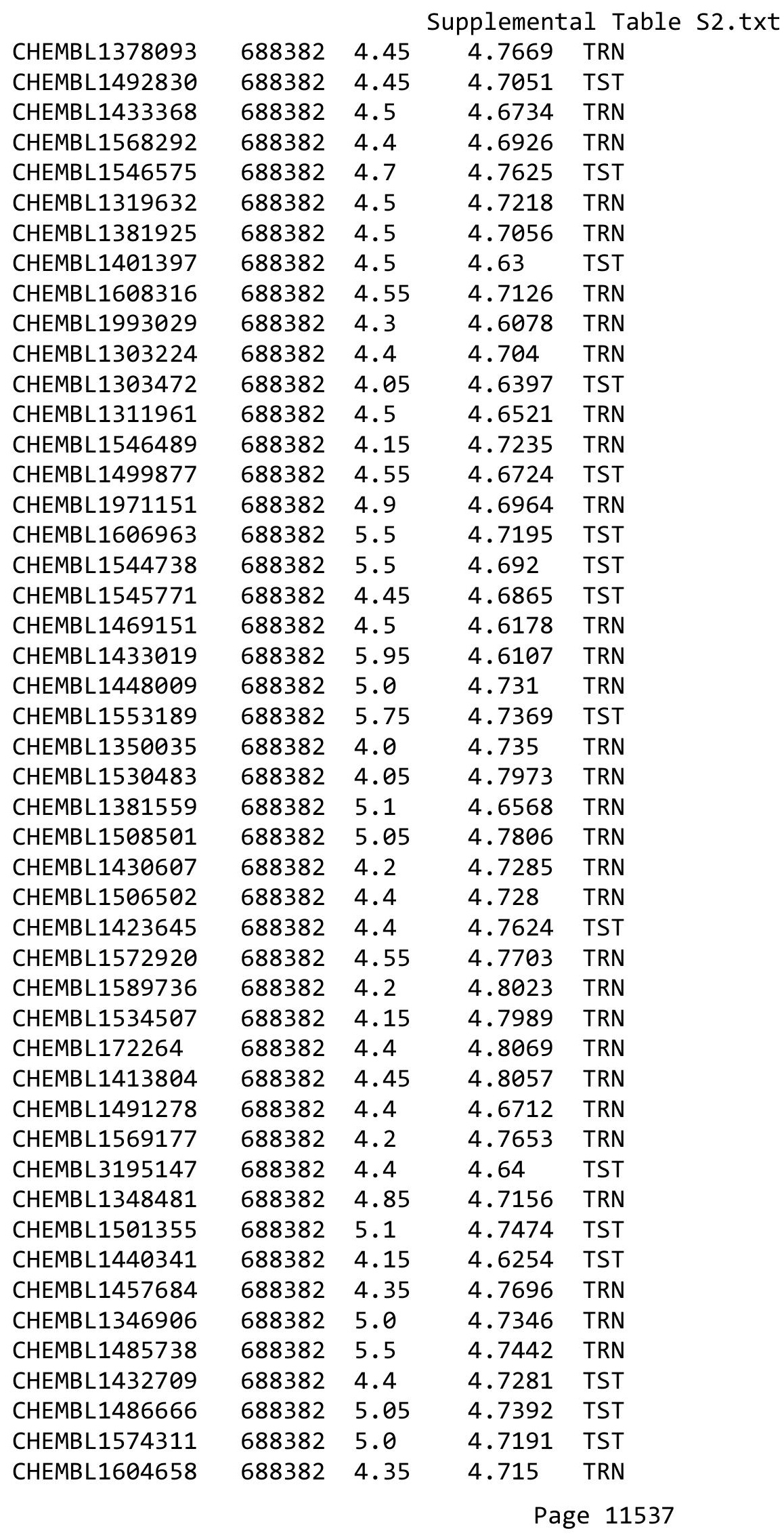




\begin{tabular}{|c|c|c|c|c|c|}
\hline & & \multicolumn{4}{|c|}{ Supplemental Table s2.txt } \\
\hline CHEMBL1582843 & 688382 & 5.95 & 4.7158 & TRN & \\
\hline CHEMBL1522401 & 688382 & 4.6 & 4.7946 & TRN & \\
\hline CHEMBL1449470 & 688382 & 5.25 & 4.7487 & TST & \\
\hline CHEMBL1317288 & 688382 & 4.9 & 4.708 & TRN & \\
\hline CHEMBL1443880 & 688382 & 4.95 & 4.7897 & TST & \\
\hline CHEMBL1580896 & 688382 & 5.0 & 4.6245 & TRN & \\
\hline CHEMBL1464715 & 688382 & 4.9 & 4.6475 & TRN & \\
\hline CHEMBL1376578 & 688382 & 4.85 & 4.6507 & TST & \\
\hline CHEMBL1349226 & 688382 & 4.2 & 4.6713 & TRN & \\
\hline CHEMBL1322290 & 688382 & 4.5 & 4.7774 & TST & \\
\hline CHEMBL1300736 & 688382 & 4.9 & 4.63 & TRN & \\
\hline CHEMBL1575144 & 688382 & 4.8 & 4.6757 & TRN & \\
\hline CHEMBL1350557 & 688382 & 4.5 & 4.7797 & TST & \\
\hline CHEMBL 3190235 & 688382 & 5.0 & 4.6784 & TST & \\
\hline CHEMBL1609099 & 688382 & 4.2 & 4.6939 & TRN & \\
\hline CHEMBL 2007425 & 688382 & 4.05 & 4.6452 & TST & \\
\hline CHEMBL1516500 & 688382 & 4.95 & 4.7526 & TRN & \\
\hline CHEMBL1442687 & 688382 & 4.35 & 4.7523 & TRN & \\
\hline CHEMBL1610643 & 688382 & 4.35 & 4.729 & TST & \\
\hline CHEMBL1406456 & 688382 & 4.3 & 4.6801 & TRN & \\
\hline CHEMBL1538590 & 688382 & 4.95 & 4.6289 & TRN & \\
\hline CHEMBL1572824 & 688382 & 4.45 & 4.7311 & TRN & \\
\hline CHEMBL1416192 & 688382 & 4.4 & 4.6886 & TRN & \\
\hline CHEMBL1549940 & 688382 & 4.15 & 4.7216 & TRN & \\
\hline CHEMBL1462570 & 688382 & 5.7 & 4.6449 & TST & \\
\hline CHEMBL1478490 & 688382 & 4.4 & 4.6439 & TST & \\
\hline CHEMBL3194207 & 688382 & 4.5 & 4.718 & TRN & \\
\hline CHEMBL1494563 & 688382 & 4.05 & 4.72199 & 99999999995 & TRN \\
\hline CHEMBL1604057 & 688382 & 4.85 & 4.8356 & TRN & \\
\hline CHEMBL3198029 & 688382 & 4.45 & 4.7498 & TRN & \\
\hline CHEMBL1537300 & 688382 & 4.35 & 4.7588 & TRN & \\
\hline CHEMBL1320390 & 688382 & 4.5 & 4.7355 & TRN & \\
\hline CHEMBL1409617 & 688382 & 5.45 & 4.6934 & TST & \\
\hline CHEMBL1322166 & 688382 & 4.8 & 4.7247 & TRN & \\
\hline CHEMBL3199799 & 688382 & 4.9 & 4.6384 & TST & \\
\hline CHEMBL1532416 & 688382 & 6.0 & 4.7938 & TRN & \\
\hline CHEMBL1992346 & 688382 & 4.5 & 4.5917 & TST & \\
\hline CHEMBL3193774 & 688382 & 4.15 & 4.6749 & TRN & \\
\hline CHEMBL1574846 & 688382 & 5.1 & 4.7213 & TRN & \\
\hline CHEMBL1499361 & 688382 & 4.5 & 4.7099 & TRN & \\
\hline CHEMBL1312842 & 688382 & 4.4 & 4.63 & TRN & \\
\hline CHEMBL1079460 & 688382 & 4.05 & 4.7544 & TST & \\
\hline CHEMBL1482051 & 688382 & 5.8 & 4.7491 & TRN & \\
\hline CHEMBL1404423 & 688382 & 4.45 & 4.7238 & TRN & \\
\hline CHEMBL1550351 & 688382 & 5.1 & 4.644 & TST & \\
\hline CHEMBL 2005486 & 688382 & 6.0 & 4.6571 & TRN & \\
\hline CHEMBL318727 & 688382 & 4.2 & 4.675 & TRN & \\
\hline CHEMBL1454931 & 688382 & 4.45 & 4.7517 & TRN & \\
\hline
\end{tabular}




\begin{tabular}{|c|c|c|c|c|}
\hline & & & \multicolumn{2}{|c|}{ Supplemental Table S2.txt } \\
\hline CHEMBL1381497 & 688382 & 4.75 & 4.7696 & TRN \\
\hline CHEMBL1422185 & 688382 & 4.75 & 4.6422 & TRN \\
\hline CHEMBL1388036 & 688382 & 4.9 & 4.7414 & TRN \\
\hline CHEMBL1547330 & 688382 & 4.95 & 4.8114 & TRN \\
\hline CHEMBL1597418 & 688382 & 5.0 & 4.709 & TRN \\
\hline CHEMBL1320975 & 688382 & 6.0 & 4.6571 & TST \\
\hline CHEMBL1495048 & 688382 & 4.4 & 4.6709 & TRN \\
\hline CHEMBL1606510 & 688382 & 5.95 & 4.7109 & TRN \\
\hline CHEMBL1303380 & 688382 & 4.0 & 4.7571 & TRN \\
\hline CHEMBL1976600 & 688382 & 4.5 & 4.6332 & TRN \\
\hline CHEMBL3196038 & 688382 & 4.05 & 4.6515 & TRN \\
\hline CHEMBL1214034 & 688382 & 4.65 & 4.6392 & TRN \\
\hline CHEMBL1328848 & 688382 & 5.6 & 4.7067 & TST \\
\hline CHEMBL1397841 & 688382 & 6.0 & 4.7461 & TRN \\
\hline CHEMBL1301346 & 688382 & 4.55 & 4.7757 & TRN \\
\hline CHEMBL1368690 & 688382 & 6.0 & 4.6551 & TST \\
\hline CHEMBL1576095 & 688382 & 4.45 & 4.7358 & TRN \\
\hline CHEMBL1606769 & 688382 & 5.8 & 4.824 & TRN \\
\hline CHEMBL1584439 & 688382 & 5.85 & 4.76 & TRN \\
\hline CHEMBL1381197 & 688382 & 4.55 & 4.6297 & TST \\
\hline CHEMBL1545387 & 688382 & 4.2 & 4.766 & TRN \\
\hline CHEMBL1450147 & 688382 & 5.1 & 4.7249 & TRN \\
\hline CHEMBL1326189 & 688382 & 4.2 & 4.8343 & TST \\
\hline CHEMBL1570920 & 688382 & 4.15 & 4.6845 & TST \\
\hline CHEMBL3199831 & 688382 & 4.45 & 4.6454 & TST \\
\hline CHEMBL1304568 & 688382 & 5.8 & 4.8175 & TRN \\
\hline CHEMBL1474443 & 688382 & 4.45 & 4.6987 & TRN \\
\hline CHEMBL1387236 & 688382 & 4.6 & 4.7371 & TST \\
\hline CHEMBL1600063 & 688382 & 4.0 & 4.7983 & TRN \\
\hline CHEMBL3191746 & 688382 & 4.5 & 4.6732 & TST \\
\hline CHEMBL1417660 & 688382 & 5.05 & 4.7961 & TRN \\
\hline CHEMBL1405052 & 688382 & 5.0 & 4.7136 & TRN \\
\hline CHEMBL1503291 & 688382 & 5.6 & 4.6978 & TST \\
\hline CHEMBL1576852 & 688382 & 4.15 & 4.6303 & TRN \\
\hline CHEMBL1506468 & 688382 & 5.9 & 4.7623 & TST \\
\hline CHEMBL1597692 & 688382 & 4.45 & 4.7487 & TRN \\
\hline CHEMBL1986073 & 688382 & 4.45 & 4.6191 & TRN \\
\hline CHEMBL1613239 & 688382 & 5.65 & 4.7301 & TRN \\
\hline CHEMBL1441075 & 688382 & 5.1 & 4.7188 & TRN \\
\hline CHEMBL1510803 & 688382 & 4.6 & 4.6827 & TST \\
\hline CHEMBL1324738 & 688382 & 4.95 & 4.8018 & TRN \\
\hline CHEMBL1328822 & 688382 & 4.85 & 4.6891 & TRN \\
\hline CHEMBL1366851 & 688382 & 4.45 & 4.7458 & TRN \\
\hline CHEMBL1521165 & 688382 & 4.65 & 4.6837 & TRN \\
\hline CHEMBL1492657 & 688382 & 4.9 & 4.6668 & TST \\
\hline CHEMBL1326196 & 688382 & 4.45 & 4.7164 & TRN \\
\hline CHEMBL1992589 & 688382 & 4.95 & 4.6487 & TRN \\
\hline CHEMBL1419318 & 688382 & 4.85 & 4.6897 & TST \\
\hline
\end{tabular}




\begin{tabular}{|c|c|c|c|c|c|}
\hline \multicolumn{6}{|c|}{ Supplemental Table S2.txt } \\
\hline CHEMBL1581730 & 688382 & 4.15 & 4.7023 & TST & \\
\hline CHEMBL1373210 & 688382 & 4.55 & 4.6656 & TRN & \\
\hline CHEMBL1444975 & 688382 & 4.4 & 4.8403 & TRN & \\
\hline CHEMBL1420313 & 688382 & 4.8 & 4.7019 & TRN & \\
\hline CHEMBL1340192 & 688382 & 4.4 & 4.8207 & TRN & \\
\hline CHEMBL1428171 & 688382 & 4.4 & 4.6775 & TST & \\
\hline CHEMBL1351925 & 688382 & 4.2 & 4.6855 & TRN & \\
\hline CHEMBL1546517 & 688382 & 4.85 & 4.8076 & TRN & \\
\hline CHEMBL1528300 & 688382 & 4.9 & 4.8182 & TRN & \\
\hline CHEMBL1530741 & 688382 & 4.4 & 4.7118 & TRN & \\
\hline CHEMBL1423835 & 688382 & 4.05 & 4.8084 & TRN & \\
\hline CHEMBL1342022 & 688382 & 5.85 & 4.6677 & TRN & \\
\hline CHEMBL1421317 & 688382 & 4.95 & 4.7742 & TRN & \\
\hline CHEMBL104255 & 688382 & 4.75 & 4.6244 & TRN & \\
\hline CHEMBL1447391 & 688382 & 4.5 & 4.6178 & TST & \\
\hline CHEMBL1405939 & 688382 & 4.4 & 4.7391 & TRN & \\
\hline CHEMBL1569650 & 688382 & 4.6 & 4.6856 & TRN & \\
\hline CHEMBL1333755 & 688382 & 4.5 & 4.6855 & TRN & \\
\hline CHEMBL1341833 & 688382 & 4.45 & 4.7326 & TRN & \\
\hline CHEMBL1406404 & 688382 & 5.15 & 4.7043 & TST & \\
\hline CHEMBL3208104 & 688382 & 5.1 & 4.7055 & TRN & \\
\hline CHEMBL1603935 & 688382 & 5.9 & 4.7089 & TST & \\
\hline CHEMBL3189181 & 688382 & 1.7 & 4.7189 & TRN & \\
\hline CHEMBL1547638 & 688382 & 4.5 & 4.6231 & TRN & \\
\hline CHEMBL1411164 & 688382 & 4.3 & 4.7496 & TRN & \\
\hline CHEMBL1531446 & 688382 & 4.95 & 4.7624 & TST & \\
\hline CHEMBL1503017 & 688382 & 4.1 & 4.7314 & TST & \\
\hline CHEMBL1439143 & 688382 & 4.15 & 4.6252 & TRN & \\
\hline CHEMBL1519655 & 688382 & 4.4 & 4.773 & TRN & \\
\hline CHEMBL1559423 & 688382 & 4.05 & 4.6987 & TRN & \\
\hline CHEMBL1415092 & 688382 & 4.8 & 4.75899 & 99999999995 & TRN \\
\hline CHEMBL1568959 & 688382 & 4.5 & 4.7509 & TRN & \\
\hline CHEMBL1350177 & 688382 & 4.85 & 4.7298 & TST & \\
\hline CHEMBL1504933 & 688382 & 4.15 & 4.6666 & TRN & \\
\hline CHEMBL1408252 & 688382 & 4.45 & 4.6868 & TRN & \\
\hline CHEMBL1471553 & 688382 & 4.6 & 4.6352 & TRN & \\
\hline CHEMBL1431658 & 688382 & 4.1 & 4.7051 & TRN & \\
\hline CHEMBL1537925 & 688382 & 4.65 & 4.7931 & TST & \\
\hline CHEMBL1398682 & 688382 & 6.0 & 4.7255 & TRN & \\
\hline CHEMBL1319447 & 688382 & 4.45 & 4.6457 & TRN & \\
\hline CHEMBL1440753 & 688382 & 4.3 & 4.665 & TST & \\
\hline CHEMBL1352220 & 688382 & 4.35 & 4.6746 & TST & \\
\hline CHEMBL1386415 & 688382 & 4.8 & 4.7288 & TRN & \\
\hline CHEMBL1380526 & 688382 & 5.05 & 4.6585 & TRN & \\
\hline CHEMBL1339061 & 688382 & 4.2 & 4.7633 & TRN & \\
\hline CHEMBL1387378 & 688382 & 5.35 & 4.7229 & TRN & \\
\hline CHEMBL1325341 & 688382 & 4.45 & 4.7058 & TRN & \\
\hline CHEMBL1586525 & 688382 & 4.4 & 4.6196 & TRN & \\
\hline
\end{tabular}




\begin{tabular}{|c|c|c|c|c|}
\hline \multicolumn{5}{|c|}{ Supplemental Table S2.txt } \\
\hline CHEMBL1600838 & 688382 & 5.05 & 4.7184 & TRN \\
\hline CHEMBL1459117 & 688382 & 5.4 & 4.8252 & TRN \\
\hline CHEMBL1361651 & 688382 & 6.0 & 4.8094 & TRN \\
\hline CHEMBL1549247 & 688382 & 5.0 & 4.6802 & TRN \\
\hline CHEMBL1555679 & 688382 & 4.9 & 4.7542 & TRN \\
\hline CHEMBL1570389 & 688382 & 5.5 & 4.7951 & TRN \\
\hline CHEMBL1415258 & 688382 & 4.55 & 4.6307 & TRN \\
\hline CHEMBL1488719 & 688382 & 4.45 & 4.6761 & TRN \\
\hline CHEMBL1576646 & 688382 & 4.35 & 4.6624 & TRN \\
\hline CHEMBL3209205 & 688382 & 4.05 & 4.7084 & TRN \\
\hline CHEMBL411070 & 688382 & 4.3 & 4.8163 & TST \\
\hline CHEMBL1486301 & 688382 & 5.95 & 4.7609 & TST \\
\hline CHEMBL2369292 & 688382 & 4.05 & 4.7509 & TRN \\
\hline CHEMBL1606389 & 688382 & 4.45 & 4.8001 & TRN \\
\hline CHEMBL1391330 & 688382 & 4.5 & 4.6515 & TRN \\
\hline CHEMBL1427469 & 688382 & 4.35 & 4.6967 & TRN \\
\hline CHEMBL1450669 & 688382 & 4.5 & 4.6426 & TRN \\
\hline CHEMBL1471146 & 688382 & 4.25 & 4.7112 & TRN \\
\hline CHEMBL1333452 & 688382 & 4.55 & 4.7872 & TRN \\
\hline CHEMBL3199907 & 688382 & 4.45 & 4.6698 & TRN \\
\hline CHEMBL1558680 & 688382 & 4.55 & 4.7959 & TRN \\
\hline CHEMBL1517303 & 688382 & 5.25 & 4.665 & TRN \\
\hline CHEMBL1564293 & 688382 & 4.65 & 4.7101 & TST \\
\hline CHEMBL1986343 & 688382 & 4.15 & 4.6444 & TRN \\
\hline CHEMBL1507192 & 688382 & 5.15 & 4.6311 & TRN \\
\hline CHEMBL1524744 & 688382 & 4.95 & 4.6787 & TRN \\
\hline CHEMBL1421172 & 688382 & 4.2 & 4.6725 & TRN \\
\hline CHEMBL3196459 & 688382 & 4.5 & 4.6494 & TRN \\
\hline CHEMBL1496367 & 688382 & 4.75 & 4.8154 & TST \\
\hline CHEMBL1558210 & 688382 & 4.5 & 4.6337 & TRN \\
\hline CHEMBL1546204 & 688382 & 5.0 & 4.7286 & TST \\
\hline CHEMBL1432980 & 688382 & 5.0 & 4.7208 & TST \\
\hline CHEMBL1414323 & 688382 & 4.2 & 4.7416 & TRN \\
\hline CHEMBL1570640 & 688382 & 4.9 & 4.6108 & TRN \\
\hline CHEMBL1309121 & 688382 & 4.8 & 4.7426 & TRN \\
\hline CHEMBL1553454 & 688382 & 4.45 & 4.6271 & TST \\
\hline CHEMBL1383461 & 688382 & 4.4 & 4.6823 & TRN \\
\hline CHEMBL1312698 & 688382 & 4.75 & 4.6563 & TRN \\
\hline CHEMBL1363064 & 688382 & 5.05 & 4.8015 & TRN \\
\hline CHEMBL1455850 & 688382 & 5.0 & 4.6577 & TRN \\
\hline CHEMBL1607638 & 688382 & 4.45 & 4.6796 & TRN \\
\hline CHEMBL1508723 & 688382 & 6.05 & 4.6341 & TRN \\
\hline CHEMBL1416552 & 688382 & 4.85 & 4.7825 & TRN \\
\hline CHEMBL171325 & 688382 & 4.5 & 4.5832 & TST \\
\hline CHEMBL1604859 & 688382 & 5.0 & 4.7334 & TRN \\
\hline CHEMBL3209134 & 688382 & 4.8 & 4.651 & TST \\
\hline CHEMBL1378780 & 688382 & 5.1 & 4.6772 & TRN \\
\hline CHEMBL1303955 & 688382 & 4.15 & 4.6825 & TST \\
\hline
\end{tabular}




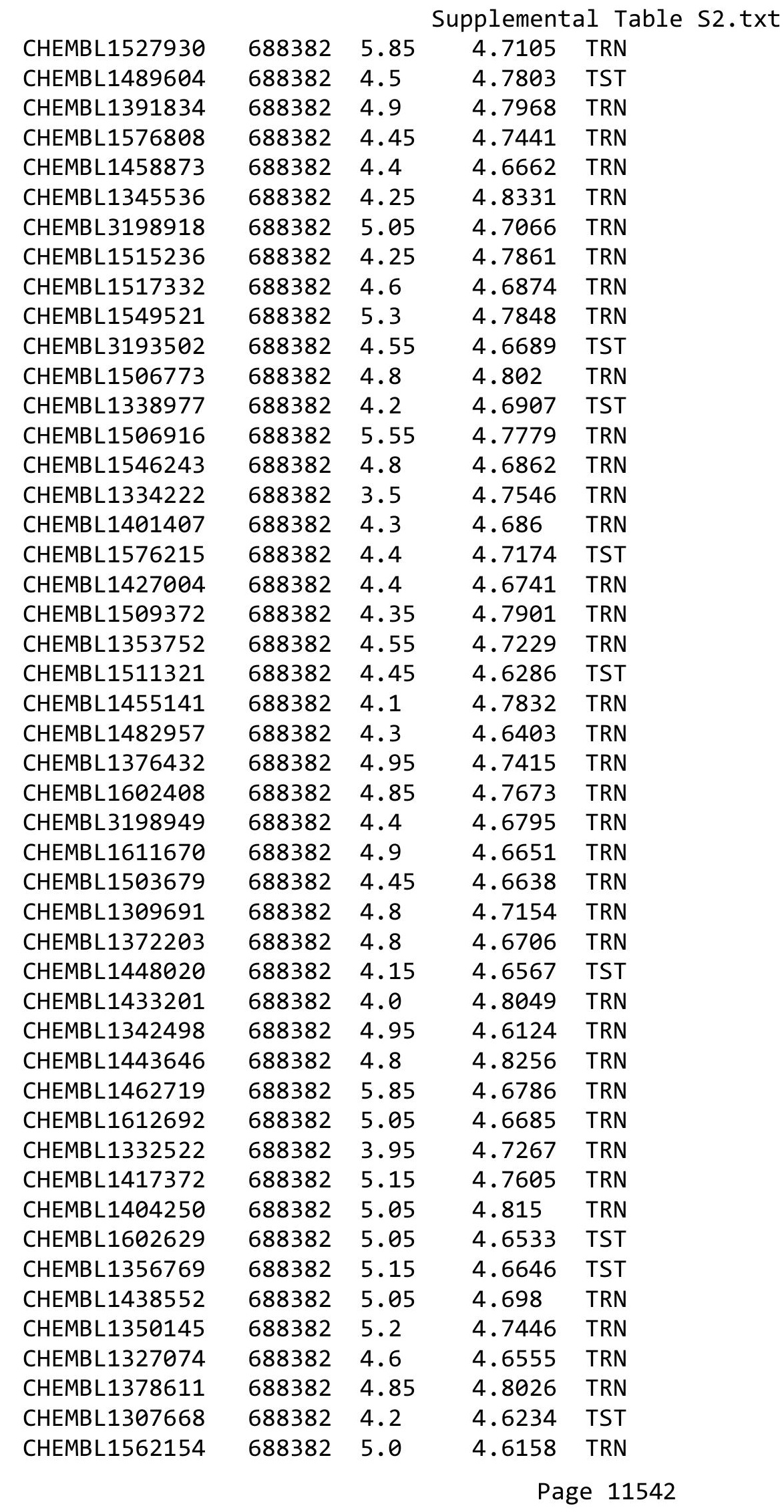




\begin{tabular}{|c|c|c|c|c|c|}
\hline \multicolumn{6}{|c|}{ Supplemental Table S2.txt } \\
\hline CHEMBL1341997 & 688382 & 4.5 & 4.7263 & TST & \\
\hline CHEMBL1513210 & 688382 & 6.45 & 4.8411 & TRN & \\
\hline CHEMBL1993761 & 688382 & 4.65 & 4.7106 & TST & \\
\hline CHEMBL1483695 & 688382 & 4.45 & 4.7421 & TRN & \\
\hline CHEMBL1313612 & 688382 & 5.05 & 4.8253 & TRN & \\
\hline CHEMBL338790 & 688382 & 5.25 & 4.6229 & TRN & \\
\hline CHEMBL22062 & 688382 & 4.35 & 4.655 & TRN & \\
\hline CHEMBL1480910 & 688382 & 4.35 & 4.7359 & TRN & \\
\hline CHEMBL1330789 & 688382 & 5.85 & 4.7578 & TRN & \\
\hline CHEMBL1450825 & 688382 & 4.15 & 4.68 & TST & \\
\hline CHEMBL1443801 & 688382 & 4.45 & 4.5972 & TRN & \\
\hline CHEMBL1428344 & 688382 & 4.2 & 4.6585 & TST & \\
\hline CHEMBL1587992 & 688382 & 5.55 & 4.7111 & TST & \\
\hline CHEMBL3191594 & 688382 & 5.4 & 4.6269 & TRN & \\
\hline CHEMBL1575778 & 688382 & 5.05 & 4.793 & TRN & \\
\hline CHEMBL1313603 & 688382 & 5.25 & 4.6792 & TST & \\
\hline CHEMBL1390378 & 688382 & 4.75 & 4.6748 & TRN & \\
\hline CHEMBL1374756 & 688382 & 5.4 & 4.74 & TST & \\
\hline CHEMBL1363136 & 688382 & 4.5 & 4.6163 & TST & \\
\hline CHEMBL1490721 & 688382 & 5.25 & 4.734 & TRN & \\
\hline CHEMBL1391956 & 688382 & 4.4 & 4.6852 & TRN & \\
\hline CHEMBL1524562 & 688382 & 4.45 & 4.6676 & TRN & \\
\hline CHEMBL1412256 & 688382 & 4.1 & 4.7444 & TRN & \\
\hline CHEMBL1464976 & 688382 & 4.5 & 4.6558 & TRN & \\
\hline CHEMBL1582641 & 688382 & 4.45 & 4.6291 & TRN & \\
\hline CHEMBL1611768 & 688382 & 4.5 & $4.7010 e$ & 00000000005 & TRN \\
\hline CHEMBL1507195 & 688382 & 4.5 & 4.7013 & TST & \\
\hline CHEMBL1524363 & 688382 & 4.4 & 4.6547 & TRN & \\
\hline CHEMBL1575226 & 688382 & 4.75 & 4.8096 & TRN & \\
\hline CHEMBL1438825 & 688382 & 4.15 & 4.7211 & TRN & \\
\hline CHEMBL1400469 & 688382 & 5.8 & 4.7711 & TST & \\
\hline CHEMBL1413760 & 688382 & 4.5 & 4.7479 & TRN & \\
\hline CHEMBL1503013 & 688382 & 4.4 & 4.7377 & TRN & \\
\hline CHEMBL570408 & 688382 & 4.5 & 4.6488 & TRN & \\
\hline CHEMBL1323473 & 688382 & 4.5 & 4.7583 & TRN & \\
\hline CHEMBL1612478 & 688382 & 5.1 & 4.8264 & TRN & \\
\hline CHEMBL1565785 & 688382 & 4.35 & 4.6724 & TRN & \\
\hline CHEMBL1524129 & 688382 & 4.2 & 4.7682 & TRN & \\
\hline CHEMBL1564217 & 688382 & 4.45 & 4.6583 & TST & \\
\hline CHEMBL1479566 & 688382 & 4.15 & 4.7209 & TRN & \\
\hline CHEMBL3209191 & 688382 & 5.1 & 4.6864 & TRN & \\
\hline CHEMBL1485706 & 688382 & 4.5 & 4.5923 & TST & \\
\hline CHEMBL1985338 & 688382 & 4.9 & 4.7127 & TRN & \\
\hline CHEMBL1590826 & 688382 & 4.05 & 4.7186 & TRN & \\
\hline CHEMBL1562279 & 688382 & 3.4 & 4.7782 & TRN & \\
\hline CHEMBL1585874 & 688382 & 4.8 & 4.7944 & TRN & \\
\hline CHEMBL1362237 & 688382 & 6.05 & 4.7971 & TRN & \\
\hline CHEMBL1364514 & 688382 & 5.0 & 4.7375 & TST & \\
\hline
\end{tabular}




\begin{tabular}{|c|c|c|c|c|}
\hline \multicolumn{5}{|c|}{ Supplemental Table S2.txt } \\
\hline CHEMBL1537156 & 688382 & 4.85 & 4.8312 & TRN \\
\hline CHEMBL1609960 & 688382 & 4.3 & 4.6433 & TRN \\
\hline CHEMBL1330309 & 688382 & 4.85 & 4.8322 & TRN \\
\hline CHEMBL1531179 & 688382 & 4.9 & 4.7511 & TRN \\
\hline CHEMBL1375182 & 688382 & 4.15 & 4.7449 & TST \\
\hline CHEMBL1316903 & 688382 & 4.5 & 4.7112 & TRN \\
\hline CHEMBL1578647 & 688382 & 4.15 & 4.7102 & TRN \\
\hline CHEMBL1365589 & 688382 & 5.85 & 4.7092 & TST \\
\hline CHEMBL1603121 & 688382 & 4.8 & 4.7717 & TRN \\
\hline CHEMBL1376516 & 688382 & 4.5 & 4.6725 & TRN \\
\hline CHEMBL1542068 & 688382 & 5.05 & 4.6749 & TST \\
\hline CHEMBL1463514 & 688382 & 4.05 & 4.8231 & TRN \\
\hline CHEMBL1506668 & 688382 & 5.8 & 4.7803 & TRN \\
\hline CHEMBL1416493 & 688382 & 4.3 & 4.6317 & TRN \\
\hline CHEMBL1310970 & 688382 & 4.05 & 4.8239 & TRN \\
\hline CHEMBL1302607 & 688382 & 4.05 & 4.8527 & TRN \\
\hline CHEMBL1572074 & 688382 & 4.85 & 4.6296 & TRN \\
\hline CHEMBL1303988 & 688382 & 4.5 & 4.6797 & TRN \\
\hline CHEMBL1329225 & 688382 & 5.2 & 4.7714 & TST \\
\hline CHEMBL1517269 & 688382 & 6.0 & 4.7111 & TST \\
\hline CHEMBL1975615 & 688382 & 4.9 & 4.6454 & TRN \\
\hline CHEMBL1371305 & 688382 & 4.5 & 4.712 & TRN \\
\hline CHEMBL1474143 & 688382 & 4.5 & 4.65 & TST \\
\hline CHEMBL1501741 & 688382 & 4.6 & 4.6978 & TST \\
\hline CHEMBL1536896 & 688382 & 5.0 & 4.6509 & TST \\
\hline CHEMBL1361492 & 688382 & 4.95 & 4.7115 & TRN \\
\hline CHEMBL1492654 & 688382 & 4.2 & 4.7453 & TRN \\
\hline CHEMBL1428154 & 688382 & 4.5 & 4.6683 & TRN \\
\hline CHEMBL1708510 & 688382 & 5.1 & 4.7276 & TST \\
\hline CHEMBL1460834 & 688382 & 3.95 & 4.7166 & TRN \\
\hline CHEMBL1563461 & 688382 & 5.1 & 4.7062 & TRN \\
\hline CHEMBL1302956 & 688382 & 4.7 & 4.8048 & TRN \\
\hline CHEMBL1500948 & 688382 & 4.85 & 4.6827 & TST \\
\hline CHEMBL1343865 & 688382 & 4.8 & 4.8491 & TRN \\
\hline CHEMBL1450610 & 688382 & 5.0 & 4.803 & TRN \\
\hline CHEMBL1306981 & 688382 & 4.95 & 4.6829 & TRN \\
\hline CHEMBL1585573 & 688382 & 4.05 & 4.7099 & TRN \\
\hline CHEMBL3189177 & 688382 & 5.1 & 4.6842 & TRN \\
\hline CHEMBL1359860 & 688382 & 4.5 & 4.6726 & TRN \\
\hline CHEMBL1411022 & 688382 & 4.5 & 4.6505 & TRN \\
\hline CHEMBL1608531 & 688382 & 4.45 & 4.6933 & TRN \\
\hline CHEMBL1989527 & 688382 & 4.2 & 4.6605 & TRN \\
\hline CHEMBL1464257 & 688382 & 4.6 & 4.7115 & TRN \\
\hline CHEMBL1305136 & 688382 & 4.05 & 4.7206 & TRN \\
\hline CHEMBL1393254 & 688382 & 5.6 & 4.7321 & TRN \\
\hline CHEMBL3189626 & 688382 & 5.0 & 4.6322 & TRN \\
\hline CHEMBL1393570 & 688382 & 4.15 & 4.6952 & TST \\
\hline CHEMBL1982888 & 688382 & 4.15 & 4.612 & TRN \\
\hline
\end{tabular}




\begin{tabular}{|c|c|c|c|c|c|}
\hline & & \multicolumn{4}{|c|}{ Supplemental Table S2.txt } \\
\hline CHEMBL1398889 & 688382 & 4.95 & 4.762 & TRN & \\
\hline CHEMBL1574197 & 688382 & 4.4 & 4.5982 & TRN & \\
\hline CHEMBL1529190 & 688382 & 4.45 & 4.6456 & TRN & \\
\hline CHEMBL1363782 & 688382 & 4.5 & 4.6803 & TRN & \\
\hline CHEMBL1323779 & 688382 & 5.0 & 4.76399 & 9999999999 & TRN \\
\hline CHEMBL1554411 & 688382 & 4.5 & 4.6411 & TST & \\
\hline CHEMBL1543045 & 688382 & 5.05 & 4.6747 & TRN & \\
\hline CHEMBL1479083 & 688382 & 4.15 & 4.7089 & TRN & \\
\hline CHEMBL 3198316 & 688382 & 4.85 & 4.6717 & TRN & \\
\hline CHEMBL1374228 & 688382 & 4.35 & 4.6504 & TRN & \\
\hline CHEMBL1547505 & 688382 & 5.05 & 4.7677 & TST & \\
\hline CHEMBL1487583 & 688382 & 4.2 & 4.751 & TRN & \\
\hline CHEMBL1480390 & 688382 & 4.15 & 4.7632 & TRN & \\
\hline CHEMBL 3197626 & 688382 & 4.45 & 4.6739 & TRN & \\
\hline CHEMBL1390623 & 688382 & 4.45 & 4.6645 & TRN & \\
\hline CHEMBL1570405 & 688382 & 4.65 & 4.6467 & TRN & \\
\hline CHEMBL1596578 & 688382 & 5.0 & 4.6556 & TRN & \\
\hline CHEMBL1441275 & 688382 & 4.4 & 4.6486 & TRN & \\
\hline CHEMBL1419661 & 688382 & 4.65 & 4.7 & TRN & \\
\hline CHEMBL1421106 & 688382 & 4.85 & 4.7717 & TRN & \\
\hline CHEMBL1331385 & 688382 & 4.25 & 4.7585 & TRN & \\
\hline CHEMBL1371583 & 688382 & 4.0 & 4.6447 & TRN & \\
\hline CHEMBL1323872 & 688382 & 4.4 & 4.6151 & TRN & \\
\hline CHEMBL1446303 & 688382 & 5.05 & 4.7055 & TST & \\
\hline CHEMBL1303111 & 688382 & 4.5 & 4.6492 & TRN & \\
\hline CHEMBL1314232 & 688382 & 4.0 & 4.7153 & TST & \\
\hline CHEMBL1353720 & 688382 & 4.2 & 4.7885 & TRN & \\
\hline CHEMBL1485953 & 688382 & 4.25 & 4.7297 & TRN & \\
\hline CHEMBL1432251 & 688382 & 5.0 & 4.7103 & TST & \\
\hline CHEMBL1771411 & 688382 & 4.45 & 4.5954 & TRN & \\
\hline CHEMBL1519025 & 688382 & 4.2 & 4.6991 & TRN & \\
\hline CHEMBL1413672 & 688382 & 4.15 & 4.7279 & TRN & \\
\hline CHEMBL3189153 & 688382 & 4.1 & 4.5819 & TRN & \\
\hline CHEMBL1426066 & 688382 & 4.45 & 4.8451 & TRN & \\
\hline CHEMBL1576815 & 688382 & 4.2 & 4.6369 & TST & \\
\hline CHEMBL1566354 & 688382 & 5.0 & 4.7976 & TRN & \\
\hline CHEMBL1400917 & 688382 & 4.45 & 4.6805 & TRN & \\
\hline CHEMBL1973429 & 688382 & 4.55 & 4.6871 & TST & \\
\hline CHEMBL1550169 & 688382 & 4.15 & 4.8557 & TRN & \\
\hline CHEMBL1510860 & 688382 & 5.0 & 4.61600 & 00000000005 & TRN \\
\hline CHEMBL1546029 & 688382 & 5.45 & 4.8139 & TST & \\
\hline CHEMBL1518840 & 688382 & 5.05 & 4.6624 & TRN & \\
\hline CHEMBL1307125 & 688382 & 4.5 & 4.7619 & TST & \\
\hline CHEMBL1423574 & 688382 & 4.4 & 4.7097 & TRN & \\
\hline CHEMBL1443570 & 688382 & 4.0 & 4.7059 & TST & \\
\hline CHEMBL 3197277 & 688382 & 4.5 & 4.6174 & TRN & \\
\hline CHEMBL1542833 & 688382 & 4.45 & 4.6852 & TRN & \\
\hline CHEMBL1381406 & 688382 & 5.0 & 4.7884 & TST & \\
\hline
\end{tabular}




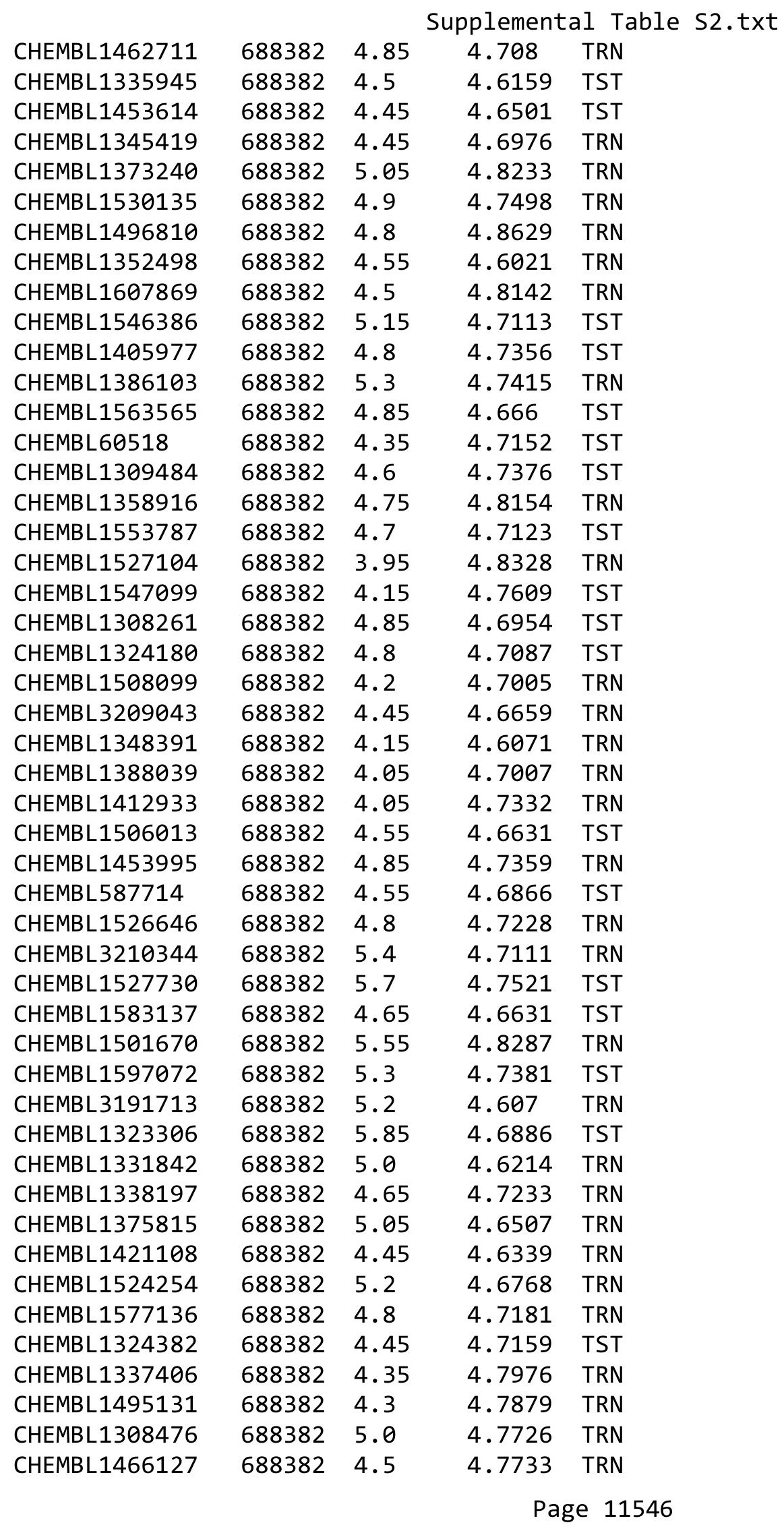




\begin{tabular}{|c|c|c|c|c|}
\hline \multicolumn{5}{|c|}{ lemental T } \\
\hline CHEMBL1511178 & 688382 & 4.5 & 4.7122 & TRN \\
\hline CHEMBL3189562 & 688382 & 5.1 & 4.6512 & TRN \\
\hline CHEMBL1598441 & 688382 & 4.65 & 4.6843 & TRN \\
\hline CHEMBL1977974 & 688382 & 4.55 & 4.6368 & TRN \\
\hline CHEMBL1341074 & 688382 & 4.55 & 4.745 & TRN \\
\hline CHEMBL1459366 & 688382 & 5.05 & 4.7724 & TRN \\
\hline CHEMBL1305977 & 688382 & 4.05 & 4.7921 & TST \\
\hline CHEMBL1347201 & 688382 & 5.05 & 4.7684 & TRN \\
\hline CHEMBL1541545 & 688382 & 5.05 & 4.6619 & TRN \\
\hline CHEMBL1424388 & 688382 & 4.5 & 4.7339 & TRN \\
\hline CHEMBL 1454015 & 688382 & 4.05 & 4.707 & TST \\
\hline CHEMBL1549333 & 688382 & 4.35 & 4.6208 & TRN \\
\hline CHEMBL1585886 & 688382 & 5.2 & 4.7275 & TRN \\
\hline CHEMBL1612743 & 688382 & 6.0 & 4.7302 & TST \\
\hline CHEMBL1308295 & 688382 & 4.15 & 4.6218 & TST \\
\hline CHEMBL1609739 & 688382 & 4.8 & 4.7151 & TRN \\
\hline CHEMBL1562323 & 688382 & 4.7 & 4.7553 & TRN \\
\hline CHEMBL1410788 & 688382 & 4.4 & 4.6402 & TRN \\
\hline CHEMBL1344817 & 688382 & 4.8 & 4.7428 & TRN \\
\hline CHEMBL1413785 & 688382 & 4.8 & 4.6722 & TST \\
\hline CHEMBL 1478651 & 688382 & 4.2 & 4.7037 & TRN \\
\hline CHEMBL1521708 & 688382 & 4.5 & 4.7411 & TRN \\
\hline CHEMBL1382075 & 688382 & 4.2 & 4.7308 & TRN \\
\hline CHEMBL1587276 & 688382 & 4.65 & 4.6495 & TRN \\
\hline CHEMBL1385643 & 688382 & 4.8 & 4.7084 & TRN \\
\hline CHEMBL1465436 & 688382 & 4.6 & 4.6891 & TRN \\
\hline CHEMBL1392576 & 688382 & 4.5 & 4.7418 & TST \\
\hline CHEMBL1307378 & 688382 & 4.8 & 4.6971 & TST \\
\hline CHEMBL3211278 & 688382 & 6.0 & 4.671 & TRN \\
\hline CHEMBL1459668 & 688382 & 4.25 & 4.7464 & TST \\
\hline CHEMBL3196505 & 688382 & 4.35 & 4.6088 & TRN \\
\hline CHEMBL1300387 & 688382 & 4.5 & 4.6817 & TRN \\
\hline CHEMBL1306913 & 688382 & 4.45 & 4.867 & TRN \\
\hline CHEMBL1438496 & 688382 & 4.15 & 4.6738 & TRN \\
\hline CHEMBL1363342 & 688382 & 5.95 & 4.7135 & TRN \\
\hline CHEMBL189438 & 688382 & 4.4 & 4.7498 & TRN \\
\hline CHEMBL146525 & 688382 & 4.8 & 4.5838 & TRN \\
\hline CHEMBL1398246 & 688382 & 4.85 & 4.7162 & TST \\
\hline CHEMBL1532407 & 688382 & 4.7 & 4.6419 & TST \\
\hline CHEMBL1377744 & 688382 & 4.8 & 4.6466 & TRN \\
\hline CHEMBL1370844 & 688382 & 4.15 & 4.6533 & TST \\
\hline CHEMBL1366082 & 688382 & 4.35 & 4.7807 & TRN \\
\hline CHEMBL1326157 & 688382 & 5.25 & 4.6431 & TRN \\
\hline CHEMBL1378470 & 688382 & 4.5 & 4.6606 & TRN \\
\hline CHEMBL1557644 & 688382 & 4.15 & 4.7727 & TRN \\
\hline CHEMBL1459841 & 688382 & 4.2 & 4.6959 & TRN \\
\hline CHEMBL1362339 & 688382 & 4.4 & 4.7453 & TRN \\
\hline CHEMBL1353270 & 688382 & 4.4 & 4.6502 & TST \\
\hline
\end{tabular}




\begin{tabular}{|c|c|c|c|c|c|}
\hline \multicolumn{6}{|c|}{ Supplemental Table S2.txt } \\
\hline CHEMBL1426489 & 688382 & 5.1 & 4.836 & TRN & \\
\hline CHEMBL1164861 & 688382 & 5.3 & 4.5834 & TRN & \\
\hline CHEMBL1525170 & 688382 & 4.9 & 4.7199 & TRN & \\
\hline CHEMBL3210331 & 688382 & 4.4 & 4.6699 & TST & \\
\hline CHEMBL1548502 & 688382 & 5.95 & 4.7408 & TRN & \\
\hline CHEMBL1430759 & 688382 & 4.15 & 4.8583 & TRN & \\
\hline CHEMBL1488502 & 688382 & 4.5 & 4.7384 & TRN & \\
\hline CHEMBL1446911 & 688382 & 4.5 & 4.6642 & TRN & \\
\hline CHEMBL1579104 & 688382 & 4.75 & 4.7072 & TRN & \\
\hline CHEMBL1586710 & 688382 & 5.0 & 4.6902 & TRN & \\
\hline CHEMBL1426966 & 688382 & 4.2 & 4.5835 & TRN & \\
\hline CHEMBL1312626 & 688382 & 5.8 & 4.823 & TRN & \\
\hline CHEMBL1396129 & 688382 & 4.45 & 4.7127 & TRN & \\
\hline CHEMBL1403154 & 688382 & 4.5 & 4.6886 & TST & \\
\hline CHEMBL1311256 & 688382 & 5.0 & 4.74 & TRN & \\
\hline CHEMBL1428683 & 688382 & 4.45 & 4.7006 & TRN & \\
\hline CHEMBL1411217 & 688382 & 4.85 & 4.7983 & TRN & \\
\hline CHEMBL1350581 & 688382 & 4.15 & 4.6 & TST & \\
\hline CHEMBL1480449 & 688382 & 4.85 & 4.7151 & TRN & \\
\hline CHEMBL1585487 & 688382 & 4.15 & 4.6551 & TRN & \\
\hline CHEMBL1333130 & 688382 & 4.15 & 4.7702 & TRN & \\
\hline CHEMBL1608332 & 688382 & 4.45 & 4.6625 & TRN & \\
\hline CHEMBL1352882 & 688382 & 4.45 & 4.715 & TRN & \\
\hline CHEMBL1441349 & 688382 & 4.9 & 4.6791 & TRN & \\
\hline CHEMBL1519374 & 688382 & 4.65 & 4.6006 & TRN & \\
\hline CHEMBL1567873 & 688382 & 4.4 & 4.66100 & 00000000005 & TRN \\
\hline CHEMBL1548300 & 688382 & 4.85 & 4.6728 & TRN & \\
\hline CHEMBL3195443 & 688382 & 4.2 & 4.7215 & TRN & \\
\hline CHEMBL1446248 & 688382 & 5.1 & 4.742 & TST & \\
\hline CHEMBL1385965 & 688382 & 4.5 & 4.6603 & TST & \\
\hline CHEMBL3208334 & 688382 & 5.15 & 4.6554 & TRN & \\
\hline CHEMBL1497731 & 688382 & 4.15 & 4.7073 & TRN & \\
\hline CHEMBL1539265 & 688382 & 4.4 & 4.6285 & TRN & \\
\hline CHEMBL3199796 & 688382 & 4.15 & 4.6995 & TRN & \\
\hline CHEMBL1577754 & 688382 & 4.4 & 4.7812 & TRN & \\
\hline CHEMBL3193971 & 688382 & 4.6 & 4.7318 & TRN & \\
\hline CHEMBL1600133 & 688382 & 4.5 & 4.6429 & TRN & \\
\hline CHEMBL1462578 & 688382 & 4.15 & 4.6509 & TRN & \\
\hline CHEMBL1531266 & 688382 & 5.8 & 4.6181 & TST & \\
\hline CHEMBL1382406 & 688382 & 4.5 & 4.6672 & TRN & \\
\hline CHEMBL1501720 & 688382 & 4.8 & 4.6505 & TST & \\
\hline CHEMBL1400962 & 688382 & 4.25 & 4.784 & TRN & \\
\hline CHEMBL1541425 & 688382 & 4.85 & 4.62 & TRN & \\
\hline CHEMBL1544940 & 688382 & 5.15 & 4.8248 & TRN & \\
\hline CHEMBL 3199186 & 688382 & 4.15 & 4.6604 & TRN & \\
\hline CHEMBL1467316 & 688382 & 5.9 & 4.691 & TRN & \\
\hline CHEMBL 2004884 & 688382 & 4.55 & 4.6481 & TRN & \\
\hline CHEMBL1537039 & 688382 & 5.4 & 4.6938 & TRN & \\
\hline
\end{tabular}




\begin{tabular}{|c|c|c|c|c|}
\hline \multicolumn{5}{|c|}{ Supplemental Table } \\
\hline CHEMBL1479302 & 688382 & 5.05 & 4.6524 & TRN \\
\hline CHEMBL1475940 & 688382 & 5.1 & 4.7218 & TRN \\
\hline CHEMBL1344434 & 688382 & 5.05 & 4.7674 & TST \\
\hline CHEMBL1432454 & 688382 & 4.15 & 4.7317 & TRN \\
\hline CHEMBL1299945 & 688382 & 5.5 & 4.6498 & TRN \\
\hline CHEMBL1458441 & 688382 & 4.4 & 4.5901 & TRN \\
\hline CHEMBL1555728 & 688382 & 4.5 & 4.7011 & TRN \\
\hline CHEMBL1449738 & 688382 & 4.95 & 4.7735 & TRN \\
\hline CHEMBL1576423 & 688382 & 4.3 & 4.6437 & TRN \\
\hline CHEMBL1436199 & 688382 & 4.5 & 4.8162 & TRN \\
\hline CHEMBL605708 & 688382 & 3.95 & 4.7429 & TRN \\
\hline CHEMBL1555947 & 688382 & 4.1 & 4.7357 & TST \\
\hline CHEMBL1545004 & 688382 & 5.15 & 4.7242 & TRN \\
\hline CHEMBL581251 & 688382 & 4.9 & 4.6227 & TST \\
\hline CHEMBL1333349 & 688382 & 4.5 & 4.6617 & TRN \\
\hline CHEMBL1505911 & 688382 & 6.0 & 4.7441 & TRN \\
\hline CHEMBL3210637 & 688382 & 4.85 & 4.6657 & TRN \\
\hline CHEMBL1453835 & 688382 & 4.05 & 4.6892 & TRN \\
\hline CHEMBL1362561 & 688382 & 4.45 & 4.7655 & TST \\
\hline CHEMBL1536289 & 688382 & 5.25 & 4.6591 & TRN \\
\hline CHEMBL1361452 & 688382 & 4.85 & 4.6466 & TRN \\
\hline CHEMBL1571365 & 688382 & 4.85 & 4.7452 & TRN \\
\hline CHEMBL1610926 & 688382 & 4.85 & 4.7268 & TRN \\
\hline CHEMBL1441992 & 688382 & 4.55 & 4.7061 & TRN \\
\hline CHEMBL1346417 & 688382 & 5.0 & 4.6854 & TST \\
\hline CHEMBL1568638 & 688382 & 4.15 & 4.7397 & TRN \\
\hline CHEMBL1386978 & 688382 & 5.85 & 4.6057 & TRN \\
\hline CHEMBL1542328 & 688382 & 4.4 & 4.6234 & TRN \\
\hline CHEMBL1400246 & 688382 & 4.9 & 4.72 & TST \\
\hline CHEMBL1410435 & 688382 & 4.8 & 4.7762 & TST \\
\hline CHEMBL1348284 & 688382 & 4.8 & 4.8108 & TRN \\
\hline CHEMBL1386762 & 688382 & 4.2 & 4.755 & TRN \\
\hline CHEMBL1507857 & 688382 & 4.5 & 4.7642 & TRN \\
\hline CHEMBL1456542 & 688382 & 4.45 & 4.705 & TRN \\
\hline CHEMBL3197701 & 688382 & 5.15 & 4.7261 & TRN \\
\hline CHEMBL1345105 & 688382 & 4.45 & 4.7281 & TRN \\
\hline CHEMBL1357786 & 688382 & 3.95 & 4.6323 & TST \\
\hline CHEMBL1500194 & 688382 & 4.5 & 4.706 & TRN \\
\hline CHEMBL1343720 & 688382 & 4.45 & 4.6804 & TRN \\
\hline CHEMBL1429464 & 688382 & 4.9 & 4.705 & TRN \\
\hline CHEMBL1306282 & 688382 & 4.15 & 4.7216 & TRN \\
\hline CHEMBL1498407 & 688382 & 4.45 & 4.8476 & TRN \\
\hline CHEMBL1311701 & 688382 & 4.4 & 4.7118 & TST \\
\hline CHEMBL1336321 & 688382 & 4.4 & 4.6855 & TRN \\
\hline CHEMBL1508909 & 688382 & 4.4 & 4.7207 & TRN \\
\hline CHEMBL1456504 & 688382 & 5.0 & 4.6803 & TST \\
\hline CHEMBL1381754 & 688382 & 4.4 & 4.6416 & TST \\
\hline CHEMBL1370638 & 688382 & 4.8 & 4.6582 & TST \\
\hline
\end{tabular}




\begin{tabular}{|c|c|c|c|c|c|}
\hline & & \multicolumn{4}{|c|}{ Supplemental Table S2.txt } \\
\hline CHEMBL1386236 & 688382 & 4.5 & 4.6912 & TRN & \\
\hline CHEMBL1498340 & 688382 & 5.0 & 4.7102 & TRN & \\
\hline CHEMBL1388598 & 688382 & 5.0 & 4.7408 & TRN & \\
\hline CHEMBL1366536 & 688382 & 4.8 & 4.7281 & TRN & \\
\hline CHEMBL1584153 & 688382 & 6.0 & 4.6919 & TRN & \\
\hline CHEMBL1507345 & 688382 & 5.8 & 4.6766 & TST & \\
\hline CHEMBL1500672 & 688382 & 4.15 & 4.7661 & TRN & \\
\hline CHEMBL1401461 & 688382 & 4.85 & 4.6206 & TRN & \\
\hline CHEMBL1402972 & 688382 & 4.45 & 4.7119 & TRN & \\
\hline CHEMBL1533497 & 688382 & 4.55 & 4.6558 & TRN & \\
\hline CHEMBL1380180 & 688382 & 4.4 & 4.8066 & TST & \\
\hline CHEMBL1570159 & 688382 & 4.95 & 4.715 & TST & \\
\hline CHEMBL 3208482 & 688382 & 4.75 & 4.6275 & TRN & \\
\hline CHEMBL3209362 & 688382 & 4.85 & 4.6945 & TRN & \\
\hline CHEMBL1369691 & 688382 & 6.0 & 4.6642 & TRN & \\
\hline CHEMBL1420190 & 688382 & 4.3 & 4.8004 & TRN & \\
\hline CHEMBL1336104 & 688382 & 3.95 & 4.76399 & 9999999999 & TRN \\
\hline CHEMBL1493408 & 688382 & 4.9 & 4.729 & TST & \\
\hline CHEMBL1460273 & 688382 & 4.15 & 4.6645 & TRN & \\
\hline CHEMBL1336643 & 688382 & 4.45 & 4.7122 & TRN & \\
\hline CHEMBL1444999 & 688382 & 4.95 & 4.7887 & TRN & \\
\hline CHEMBL1571371 & 688382 & 4.5 & 4.7292 & TRN & \\
\hline CHEMBL1481417 & 688382 & 4.85 & 4.5905 & TST & \\
\hline CHEMBL1502178 & 688382 & 5.5 & 4.7699 & TRN & \\
\hline CHEMBL1404910 & 688382 & 4.35 & 4.7189 & TRN & \\
\hline CHEMBL1605892 & 688382 & 4.2 & 4.7103 & TRN & \\
\hline CHEMBL1386136 & 688382 & 5.45 & 4.731 & TRN & \\
\hline CHEMBL1456631 & 688382 & 4.4 & 4.7124 & TST & \\
\hline CHEMBL1995681 & 688382 & 5.45 & 4.6088 & TST & \\
\hline CHEMBL1471788 & 688382 & 5.0 & 4.7537 & TST & \\
\hline CHEMBL1382198 & 688382 & 4.15 & 4.6536 & TRN & \\
\hline CHEMBL1513035 & 688382 & 4.7 & 4.637 & TRN & \\
\hline CHEMBL1418910 & 688382 & 6.05 & 4.7459 & TRN & \\
\hline CHEMBL578741 & 688382 & 4.55 & 4.5751 & TRN & \\
\hline CHEMBL 384903 & 688382 & 5.75 & 4.666 & TST & \\
\hline CHEMBL1532601 & 688382 & 4.45 & 4.6873 & TST & \\
\hline CHEMBL1398893 & 688382 & 4.45 & 4.7189 & TRN & \\
\hline CHEMBL1584382 & 688382 & 4.85 & 4.7831 & TST & \\
\hline CHEMBL1447403 & 688382 & 4.7 & 4.6409 & TRN & \\
\hline CHEMBL3195094 & 688382 & 4.95 & 4.6619 & TRN & \\
\hline CHEMBL3191794 & 688382 & 4.45 & 4.6773 & TRN & \\
\hline CHEMBL1388592 & 688382 & 4.8 & 4.814 & TRN & \\
\hline CHEMBL1405483 & 688382 & 4.5 & 4.7322 & TRN & \\
\hline CHEMBL1386268 & 688382 & 4.95 & 4.8235 & TST & \\
\hline CHEMBL1350845 & 688382 & 4.4 & 4.6991 & TRN & \\
\hline CHEMBL610056 & 688382 & 4.35 & 4.8047 & TST & \\
\hline CHEMBL1321313 & 688382 & 4.8 & 4.7342 & TRN & \\
\hline CHEMBL1359524 & 688382 & 5.0 & 4.7896 & TRN & \\
\hline
\end{tabular}




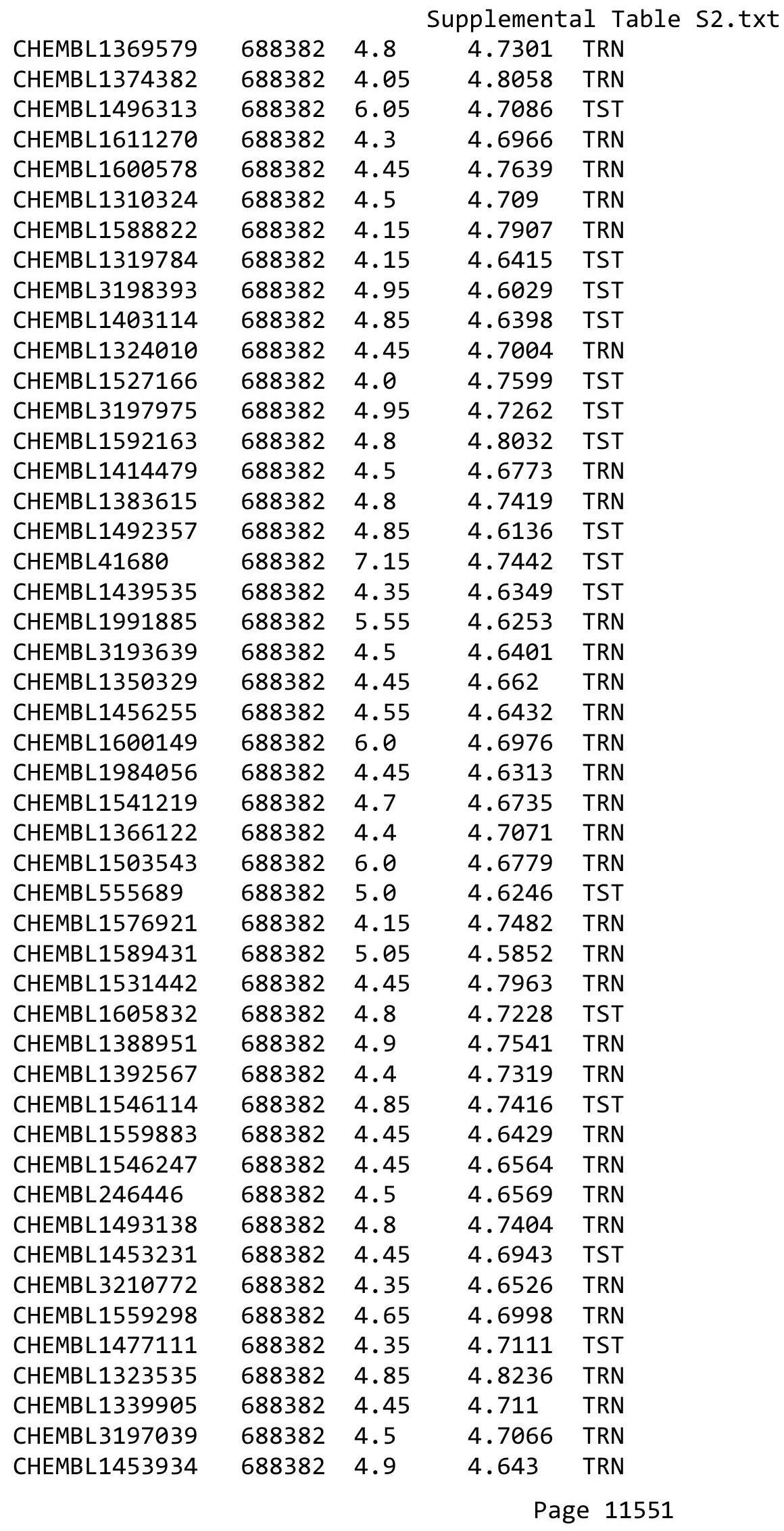




\begin{tabular}{|c|c|c|c|c|}
\hline & & & upplement & \\
\hline CHEMBL1426097 & 688382 & 4.5 & 4.7213 & TRN \\
\hline CHEMBL1386793 & 688382 & 4.6 & 4.6356 & TRN \\
\hline CHEMBL1468199 & 688382 & 5.8 & 4.7667 & TRN \\
\hline CHEMBL1477707 & 688382 & 4.4 & 4.5992 & TST \\
\hline CHEMBL1471689 & 688382 & 5.0 & 4.7074 & TST \\
\hline CHEMBL1524689 & 688382 & 4.95 & 4.7775 & TRN \\
\hline CHEMBL1463420 & 688382 & 4.95 & 4.6064 & TST \\
\hline CHEMBL1390821 & 688382 & 4.85 & 4.7951 & TRN \\
\hline CHEMBL1594490 & 688382 & 4.45 & 4.6534 & TST \\
\hline CHEMBL1509124 & 688382 & 4.45 & 4.8007 & TST \\
\hline CHEMBL1455808 & 688382 & 4.45 & 4.7061 & TST \\
\hline CHEMBL1476946 & 688382 & 4.4 & 4.6988 & TST \\
\hline CHEMBL1609129 & 688382 & 4.5 & 4.7015 & TRN \\
\hline CHEMBL1398792 & 688382 & 5.1 & 4.7018 & TST \\
\hline CHEMBL1313324 & 688382 & 6.0 & 4.6153 & TRN \\
\hline CHEMBL1351958 & 688382 & 4.8 & 4.7497 & TRN \\
\hline CHEMBL1447893 & 688382 & 6.45 & 4.7346 & TRN \\
\hline CHEMBL1361028 & 688382 & 4.1 & 4.7018 & TST \\
\hline CHEMBL3209280 & 688382 & 5.8 & 4.756 & TRN \\
\hline CHEMBL1491014 & 688382 & 3.5 & 4.6911 & TRN \\
\hline CHEMBL1462657 & 688382 & 4.45 & 4.5831 & TRN \\
\hline CHEMBL1427095 & 688382 & 4.45 & 4.6461 & TRN \\
\hline CHEMBL1976374 & 688382 & 5.2 & 4.6587 & TST \\
\hline CHEMBL1415441 & 688382 & 4.05 & 4.7107 & TRN \\
\hline CHEMBL489947 & 688382 & 4.35 & 4.657 & TRN \\
\hline CHEMBL1408566 & 688382 & 4.75 & 4.724 & TRN \\
\hline CHEMBL1537333 & 688382 & 4.45 & 4.7087 & TRN \\
\hline CHEMBL1304846 & 688382 & 4.05 & 4.6584 & TRN \\
\hline CHEMBL1480334 & 688382 & 6.0 & 4.6737 & TRN \\
\hline CHEMBL1349436 & 688382 & 4.5 & 4.7317 & TRN \\
\hline CHEMBL1338996 & 688382 & 4.8 & 4.6539 & TRN \\
\hline CHEMBL1388943 & 688382 & 4.45 & 4.6733 & TST \\
\hline CHEMBL1575884 & 688382 & 5.05 & 4.6232 & TRN \\
\hline CHEMBL1497442 & 688382 & 4.15 & 4.6481 & TST \\
\hline CHEMBL1436519 & 688382 & 4.5 & 4.7415 & TST \\
\hline CHEMBL1547915 & 688382 & 5.0 & 4.7657 & TST \\
\hline CHEMBL1608113 & 688382 & 4.8 & 4.823 & TRN \\
\hline CHEMBL 3213443 & 688382 & 4.8 & 4.7339 & TRN \\
\hline CHEMBL1455361 & 688382 & 5.05 & 4.6322 & TRN \\
\hline CHEMBL1578932 & 688382 & 4.8 & 4.8436 & TRN \\
\hline CHEMBL1532055 & 688382 & 4.5 & 4.6902 & TST \\
\hline CHEMBL1381788 & 688382 & 4.15 & 4.7363 & TST \\
\hline CHEMBL1551717 & 688382 & 4.6 & 4.7365 & TST \\
\hline CHEMBL1332105 & 688382 & 4.9 & 4.7127 & TST \\
\hline CHEMBL1973532 & 688382 & 4.4 & 4.6392 & TST \\
\hline CHEMBL583555 & 688382 & 4.55 & 4.6161 & TST \\
\hline CHEMBL1543548 & 688382 & 4.45 & 4.7602 & TRN \\
\hline CHEMBL1431626 & 688382 & 4.3 & 4.7288 & TRN \\
\hline
\end{tabular}




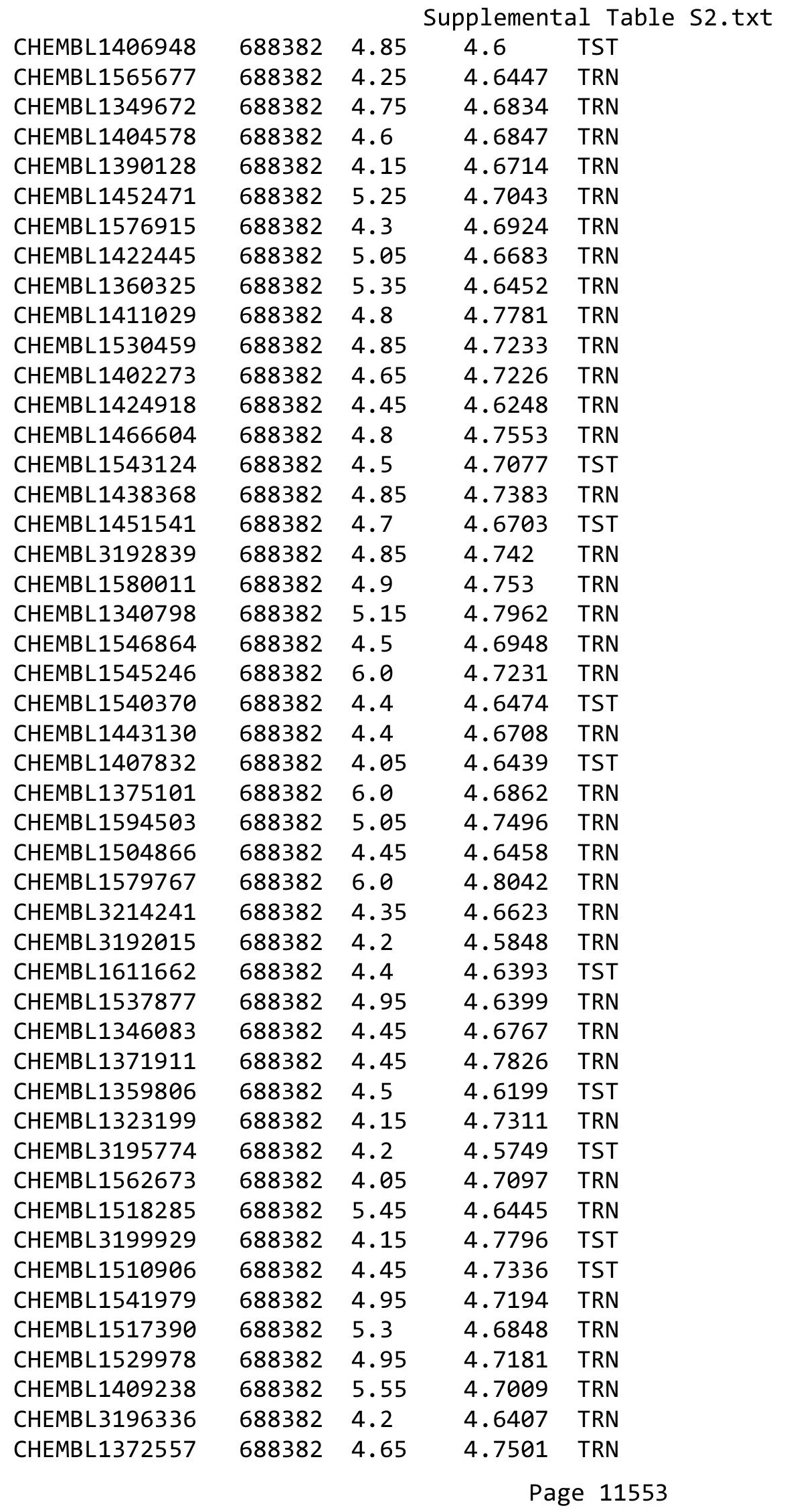




\begin{tabular}{|c|c|c|c|c|}
\hline \multicolumn{5}{|c|}{ Supplemental Table S2.txt } \\
\hline CHEMBL1438228 & 688382 & 5.2 & 4.7229 & TRN \\
\hline CHEMBL1309986 & 688382 & 4.8 & 4.6157 & TST \\
\hline CHEMBL1330650 & 688382 & 4.85 & 4.7405 & TRN \\
\hline CHEMBL1559609 & 688382 & 4.2 & 4.646 & TRN \\
\hline CHEMBL1958251 & 688382 & 5.5 & 4.6345 & TRN \\
\hline CHEMBL1583546 & 688382 & 4.85 & 4.67899 & 9999999999 \\
\hline CHEMBL1334489 & 688382 & 4.5 & 4.7535 & TRN \\
\hline CHEMBL1503108 & 688382 & 4.25 & 4.7038 & TRN \\
\hline CHEMBL1572737 & 688382 & 4.45 & 4.6856 & TRN \\
\hline CHEMBL1606516 & 688382 & 4.35 & 4.6682 & TRN \\
\hline CHEMBL1595770 & 688382 & 4.85 & 4.7756 & TRN \\
\hline CHEMBL1464778 & 688382 & 4.5 & 4.7659 & TRN \\
\hline CHEMBL1307295 & 688382 & 4.75 & 4.6802 & TRN \\
\hline CHEMBL1578881 & 688382 & 4.4 & 4.6758 & TRN \\
\hline CHEMBL1608859 & 688382 & 4.15 & 4.815 & TRN \\
\hline CHEMBL1510858 & 688382 & 4.15 & 4.7251 & TST \\
\hline CHEMBL1975523 & 688382 & 4.15 & 4.6683 & TRN \\
\hline CHEMBL1348725 & 688382 & 4.8 & 4.6478 & TST \\
\hline CHEMBL1349077 & 688382 & 5.0 & 4.7228 & TRN \\
\hline CHEMBL1402989 & 688382 & 4.05 & 4.724 & TRN \\
\hline CHEMBL1508987 & 688382 & 6.0 & 4.7195 & TRN \\
\hline CHEMBL1490312 & 688382 & 5.55 & 4.6773 & TST \\
\hline CHEMBL1449810 & 688382 & 4.15 & 4.811 & TRN \\
\hline CHEMBL1325771 & 688382 & 4.1 & 4.8428 & TRN \\
\hline CHEMBL551842 & 688382 & 4.4 & 4.7042 & TST \\
\hline CHEMBL1456700 & 688382 & 6.0 & 4.7233 & TRN \\
\hline CHEMBL1409687 & 688382 & 4.45 & 4.7093 & TRN \\
\hline CHEMBL1572028 & 688382 & 4.45 & 4.6505 & TRN \\
\hline CHEMBL1397224 & 688382 & 6.0 & 4.7285 & TRN \\
\hline CHEMBL1373556 & 688382 & 4.55 & 4.6467 & TRN \\
\hline CHEMBL1334659 & 688382 & 5.1 & 4.6207 & TST \\
\hline CHEMBL1601599 & 688382 & 5.55 & 4.69 & TRN \\
\hline CHEMBL1484984 & 688382 & 4.5 & 4.8157 & TRN \\
\hline CHEMBL1550816 & 688382 & 5.3 & 4.588 & TST \\
\hline CHEMBL1339138 & 688382 & 4.45 & 4.6381 & TRN \\
\hline CHEMBL1439660 & 688382 & 5.85 & 4.6638 & TRN \\
\hline CHEMBL3199838 & 688382 & 4.85 & 4.7043 & TRN \\
\hline CHEMBL1523427 & 688382 & 4.85 & 4.7157 & TRN \\
\hline CHEMBL1494330 & 688382 & 4.2 & 4.7159 & TRN \\
\hline CHEMBL1529958 & 688382 & 5.05 & 4.6188 & TRN \\
\hline CHEMBL3193220 & 688382 & 4.2 & 4.6939 & TRN \\
\hline CHEMBL1320240 & 688382 & 4.45 & 4.7168 & TRN \\
\hline CHEMBL1608333 & 688382 & 4.05 & 4.6647 & TST \\
\hline CHEMBL1983902 & 688382 & 4.45 & 4.7403 & TST \\
\hline CHEMBL3392069 & 688382 & 4.4 & 4.659 & TRN \\
\hline CHEMBL1544625 & 688382 & 5.25 & 4.7948 & TRN \\
\hline CHEMBL1574704 & 688382 & 5.2 & 4.7292 & TRN \\
\hline CHEMBL1460488 & 688382 & 4.45 & 4.7578 & TRN \\
\hline
\end{tabular}




\begin{tabular}{|c|c|c|c|c|}
\hline \multicolumn{5}{|c|}{ Supplemental Table S2.txt } \\
\hline CHEMBL1573302 & 688382 & 5.2 & 4.6918 & TST \\
\hline CHEMBL1581104 & 688382 & 4.4 & 4.7842 & TST \\
\hline CHEMBL1981344 & 688382 & 5.15 & 4.6698 & TRN \\
\hline CHEMBL1419968 & 688382 & 4.05 & 4.7297 & TRN \\
\hline CHEMBL3193283 & 688382 & 4.5 & 4.6651 & TRN \\
\hline CHEMBL1471810 & 688382 & 4.85 & 4.7584 & TST \\
\hline CHEMBL1421875 & 688382 & 4.45 & 4.7227 & TRN \\
\hline CHEMBL1549283 & 688382 & 4.4 & 4.6658 & TRN \\
\hline CHEMBL1360140 & 688382 & 4.4 & 4.7531 & TRN \\
\hline CHEMBL3191541 & 688382 & 4.65 & 4.6512 & TRN \\
\hline CHEMBL1600952 & 688382 & 6.0 & 4.726 & TST \\
\hline CHEMBL1497084 & 688382 & 5.4 & 4.6961 & TRN \\
\hline CHEMBL3197462 & 688382 & 4.45 & 4.6489 & TRN \\
\hline CHEMBL1500513 & 688382 & 4.05 & 4.7358 & TRN \\
\hline CHEMBL1312398 & 688382 & 4.5 & 4.6456 & TST \\
\hline CHEMBL3190674 & 688382 & 4.9 & 4.6969 & TST \\
\hline CHEMBL591370 & 688382 & 4.6 & 4.6139 & TRN \\
\hline CHEMBL1539263 & 688382 & 4.55 & 4.6413 & TRN \\
\hline CHEMBL1307992 & 688382 & 4.25 & 4.7677 & TRN \\
\hline CHEMBL1310478 & 688382 & 4.0 & 4.7884 & TRN \\
\hline CHEMBL1524958 & 688382 & 4.05 & 4.6766 & TST \\
\hline CHEMBL1543933 & 688382 & 4.85 & 4.6018 & TRN \\
\hline CHEMBL1555644 & 688382 & 4.85 & 4.6751 & TST \\
\hline CHEMBL1360288 & 688382 & 4.8 & 4.7352 & TST \\
\hline CHEMBL1532482 & 688382 & 6.0 & 4.7741 & TRN \\
\hline CHEMBL1572119 & 688382 & 4.8 & 4.5974 & TRN \\
\hline CHEMBL 3213178 & 688382 & 4.5 & 4.7189 & TRN \\
\hline CHEMBL 80155 & 688382 & 4.5 & 4.6167 & TRN \\
\hline CHEMBL1444622 & 688382 & 4.4 & 4.6927 & TST \\
\hline CHEMBL1467900 & 688382 & 4.7 & 4.6387 & TRN \\
\hline CHEMBL3207381 & 688382 & 4.45 & 4.6403 & TRN \\
\hline CHEMBL3208906 & 688382 & 6.0 & 4.6809 & TST \\
\hline CHEMBL1467844 & 688382 & 5.4 & 4.8004 & TRN \\
\hline CHEMBL1343565 & 688382 & 5.15 & 4.667 & TRN \\
\hline CHEMBL1607757 & 688382 & 6.0 & 4.7399 & TRN \\
\hline CHEMBL1529536 & 688382 & 4.4 & 4.7088 & TRN \\
\hline CHEMBL1351970 & 688382 & 4.4 & 4.7346 & TST \\
\hline CHEMBL583109 & 688382 & 5.9 & 4.6419 & TST \\
\hline CHEMBL1339388 & 688382 & 4.8 & 4.8216 & TRN \\
\hline CHEMBL1570190 & 688382 & 4.5 & 4.6756 & TRN \\
\hline CHEMBL1600814 & 688382 & 5.2 & 4.6193 & TRN \\
\hline CHEMBL1387618 & 688382 & 4.45 & 4.686 & TST \\
\hline CHEMBL1540703 & 688382 & 5.05 & 4.8528 & TRN \\
\hline CHEMBL2369277 & 688382 & 4.2 & 4.6267 & TRN \\
\hline CHEMBL1372094 & 688382 & 4.05 & 4.6184 & TRN \\
\hline CHEMBL1540281 & 688382 & 4.45 & 4.762 & TRN \\
\hline CHEMBL1362112 & 688382 & 4.7 & 4.6817 & TST \\
\hline CHEMBL1542877 & 688382 & 5.35 & 4.6332 & TRN \\
\hline
\end{tabular}




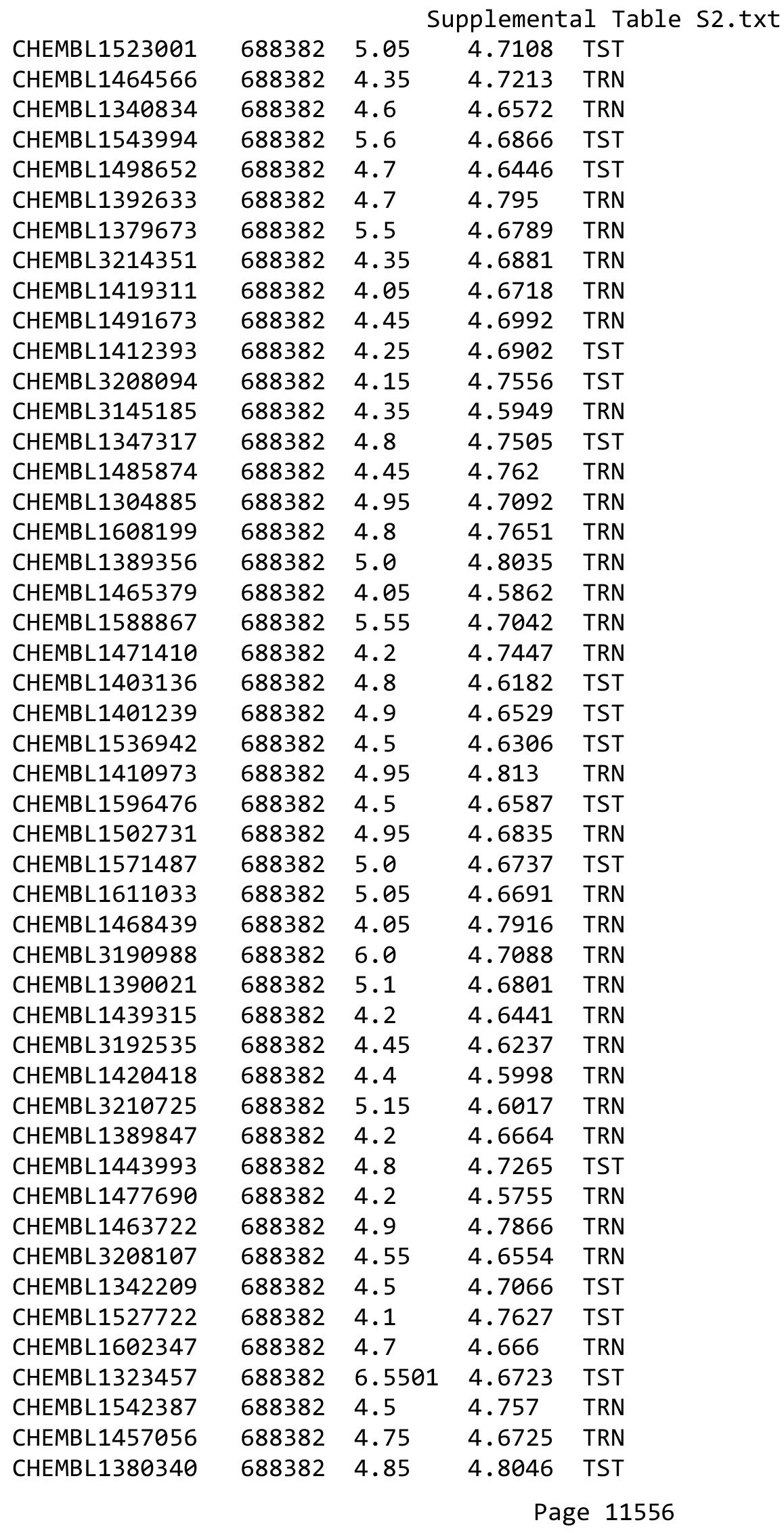




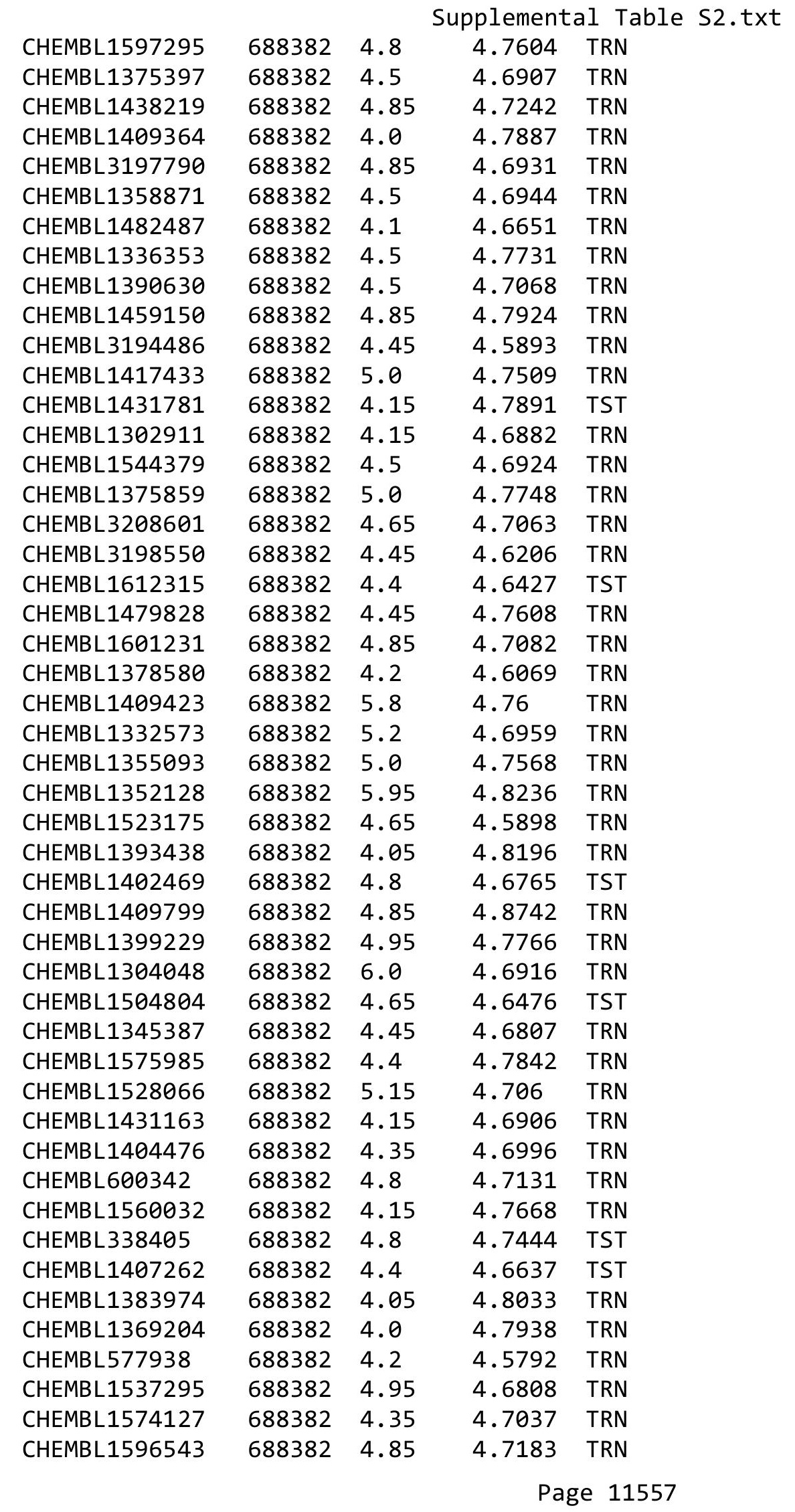




\begin{tabular}{|c|c|c|c|c|}
\hline \multicolumn{5}{|c|}{ Supplemental Table S2.txt } \\
\hline CHEMBL1449816 & 688382 & 4.5 & 4.6762 & TRN \\
\hline CHEMBL1328628 & 688382 & 4.5 & 4.7968 & TRN \\
\hline CHEMBL1302279 & 688382 & 4.65 & 4.7314 & TRN \\
\hline CHEMBL1544141 & 688382 & 5.5 & 4.6595 & TRN \\
\hline CHEMBL1342082 & 688382 & 4.65 & 4.6362 & TRN \\
\hline CHEMBL1444646 & 688382 & 4.05 & 4.7033 & TST \\
\hline CHEMBL1495636 & 688382 & 4.4 & 4.72 & TST \\
\hline CHEMBL1438545 & 688382 & 4.25 & 4.6041 & TRN \\
\hline CHEMBL1608853 & 688382 & 4.5 & 4.7017 & TRN \\
\hline CHEMBL1369027 & 688382 & 5.0 & 4.8048 & TRN \\
\hline CHEMBL1506437 & 688382 & 4.5 & 4.7341 & TRN \\
\hline CHEMBL1477572 & 688382 & 5.5 & 4.7212 & TRN \\
\hline CHEMBL1547803 & 688382 & 4.4 & 4.7882 & TRN \\
\hline CHEMBL1424442 & 688382 & 5.05 & 4.6492 & TRN \\
\hline CHEMBL1379382 & 688382 & 5.05 & 4.7967 & TRN \\
\hline CHEMBL1992109 & 688382 & 5.25 & 4.7032 & TRN \\
\hline CHEMBL1363391 & 688382 & 4.8 & 4.6965 & TRN \\
\hline CHEMBL1332506 & 688382 & 4.5 & 4.6581 & TRN \\
\hline CHEMBL1506580 & 688382 & 4.4 & 4.6103 & TRN \\
\hline CHEMBL1563333 & 688382 & 4.8 & 4.6696 & TST \\
\hline CHEMBL1599779 & 688382 & 5.0 & 4.7216 & TRN \\
\hline CHEMBL1334747 & 688382 & 4.15 & 4.7074 & TST \\
\hline CHEMBL1611237 & 688382 & 4.5 & 4.6902 & TRN \\
\hline CHEMBL3212952 & 688382 & 4.55 & 4.6546 & TRN \\
\hline CHEMBL3189574 & 688382 & 4.5 & 4.6637 & TRN \\
\hline CHEMBL1601348 & 688382 & 4.3 & 4.6415 & TRN \\
\hline CHEMBL3196362 & 688382 & 4.6 & 4.5795 & TRN \\
\hline CHEMBL3213873 & 688382 & 5.05 & 4.6723 & TRN \\
\hline CHEMBL1493011 & 688382 & 4.5 & 4.6956 & TRN \\
\hline CHEMBL1301925 & 688382 & 4.65 & 4.5981 & TRN \\
\hline CHEMBL1427068 & 688382 & 5.5 & 4.765 & TRN \\
\hline CHEMBL1463714 & 688382 & 4.6 & 4.6613 & TRN \\
\hline CHEMBL1378422 & 688382 & 4.55 & 4.6239 & TRN \\
\hline CHEMBL1456158 & 688382 & 4.45 & 4.6481 & TST \\
\hline CHEMBL1448565 & 688382 & 5.25 & 4.7188 & TRN \\
\hline CHEMBL3192531 & 688382 & 4.6 & 4.601 & TST \\
\hline CHEMBL1375104 & 688382 & 4.25 & 4.6833 & TRN \\
\hline CHEMBL1577898 & 688382 & 4.1 & 4.7602 & TRN \\
\hline CHEMBL1336522 & 688382 & 5.15 & 4.8081 & TRN \\
\hline CHEMBL1545814 & 688382 & 4.5 & 4.6908 & TST \\
\hline CHEMBL3210603 & 688382 & 5.45 & 4.708 & TRN \\
\hline CHEMBL1509829 & 688382 & 4.5 & 4.6826 & TRN \\
\hline CHEMBL1968123 & 688382 & 4.15 & 4.6583 & TRN \\
\hline CHEMBL1462893 & 688382 & 4.15 & 4.7425 & TRN \\
\hline CHEMBL1558431 & 688382 & 4.75 & 4.6774 & TRN \\
\hline CHEMBL1542586 & 688382 & 4.95 & 4.7445 & TRN \\
\hline CHEMBL1535276 & 688382 & 4.5 & 4.6885 & TRN \\
\hline CHEMBL1348076 & 688382 & 4.9 & 4.7134 & TST \\
\hline
\end{tabular}




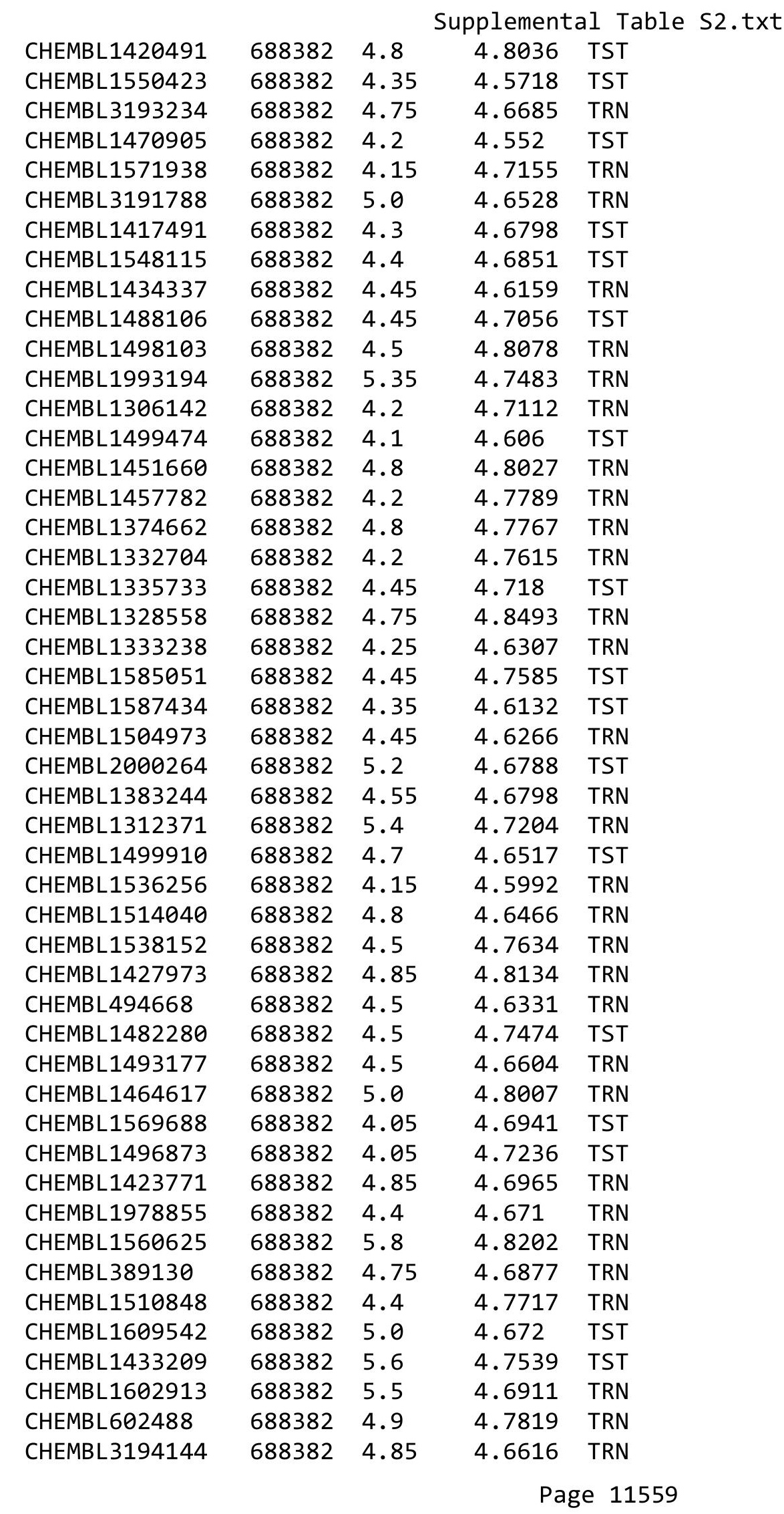




\begin{tabular}{|c|c|c|c|c|c|}
\hline \multicolumn{6}{|c|}{ Supplemental Table S2.txt } \\
\hline CHEMBL1610681 & 688382 & 5.45 & 4.8335 & TRN & \\
\hline CHEMBL1539518 & 688382 & 4.8 & 4.5849 & TST & \\
\hline CHEMBL1574717 & 688382 & 4.95 & 4.7677 & TST & \\
\hline CHEMBL1547553 & 688382 & 4.85 & 4.6941 & TST & \\
\hline CHEMBL1373436 & 688382 & 4.15 & 4.7043 & TRN & \\
\hline CHEMBL1445128 & 688382 & 4.45 & 4.7598 & TRN & \\
\hline CHEMBL399506 & 688382 & 4.45 & 4.6798 & TRN & \\
\hline CHEMBL1368640 & 688382 & 4.5 & 4.7119 & TRN & \\
\hline CHEMBL1371149 & 688382 & 4.0 & 4.7336 & TST & \\
\hline CHEMBL1329757 & 688382 & 4.5 & 4.63399 & 99999999995 & TRN \\
\hline CHEMBL2007274 & 688382 & 4.15 & 4.6102 & TRN & \\
\hline CHEMBL 3195263 & 688382 & 4.45 & 4.6687 & TRN & \\
\hline CHEMBL1402170 & 688382 & 5.1 & 4.6909 & TST & \\
\hline CHEMBL1349284 & 688382 & 4.95 & 4.8195 & TRN & \\
\hline CHEMBL1486934 & 688382 & 4.5 & 4.7167 & TRN & \\
\hline CHEMBL1507625 & 688382 & 5.05 & 4.7008 & TRN & \\
\hline CHEMBL1482065 & 688382 & 5.15 & 4.7032 & TRN & \\
\hline CHEMBL1584115 & 688382 & 5.85 & 4.7325 & TRN & \\
\hline CHEMBL1388894 & 688382 & 5.15 & 4.6534 & TST & \\
\hline CHEMBL1493358 & 688382 & 4.5 & 4.7531 & TRN & \\
\hline CHEMBL1583190 & 688382 & 5.1 & 4.6293 & TRN & \\
\hline CHEMBL1382798 & 688382 & 4.85 & 4.6755 & TST & \\
\hline CHEMBL3198603 & 688382 & 4.05 & 4.6031 & TRN & \\
\hline CHEMBL1452000 & 688382 & 4.5 & 4.7389 & TRN & \\
\hline CHEMBL1580013 & 688382 & 5.65 & 4.6956 & TST & \\
\hline CHEMBL1539829 & 688382 & 6.1 & 4.7864 & TRN & \\
\hline CHEMBL1470029 & 688382 & 6.0 & 4.8254 & TRN & \\
\hline CHEMBL1425733 & 688382 & 4.35 & 4.6851 & TST & \\
\hline CHEMBL1549660 & 688382 & 4.65 & 4.6606 & TRN & \\
\hline CHEMBL1503119 & 688382 & 5.9 & 4.8189 & TRN & \\
\hline CHEMBL1426115 & 688382 & 4.5 & 4.725 & TRN & \\
\hline CHEMBL1467023 & 688382 & 6.0 & 4.7549 & TRN & \\
\hline CHEMBL1468961 & 688382 & 4.45 & 4.6956 & TRN & \\
\hline CHEMBL1610169 & 688382 & 4.85 & 4.6004 & TRN & \\
\hline CHEMBL1328560 & 688382 & 4.45 & 4.7365 & TRN & \\
\hline CHEMBL1340284 & 688382 & 4.5 & 4.6155 & TRN & \\
\hline CHEMBL1312353 & 688382 & 4.65 & 4.6685 & TRN & \\
\hline CHEMBL1533827 & 688382 & 4.8 & 4.7977 & TRN & \\
\hline CHEMBL1519679 & 688382 & 5.0 & 4.7607 & TST & \\
\hline CHEMBL1525006 & 688382 & 4.0 & 4.6785 & TRN & \\
\hline CHEMBL1319464 & 688382 & 4.95 & 4.6553 & TRN & \\
\hline CHEMBL1544821 & 688382 & 4.05 & 4.6412 & TST & \\
\hline CHEMBL1309836 & 688382 & 4.2 & 4.6272 & TRN & \\
\hline CHEMBL 2006012 & 688382 & 6.0 & 4.6414 & TRN & \\
\hline CHEMBL1336656 & 688382 & 4.85 & 4.7531 & TRN & \\
\hline CHEMBL1496382 & 688382 & 4.9 & 4.8175 & TRN & \\
\hline CHEMBL1992104 & 688382 & 3.95 & 4.6314 & TRN & \\
\hline CHEMBL1423864 & 688382 & 3.35 & 4.6523 & TRN & \\
\hline
\end{tabular}




\begin{tabular}{|c|c|c|c|c|}
\hline \multicolumn{5}{|c|}{ Supplemental Table S2.txt } \\
\hline CHEMBL1496966 & 688382 & 4.5 & 4.7406 & TRN \\
\hline CHEMBL1548704 & 688382 & 4.35 & 4.6888 & TST \\
\hline CHEMBL1405239 & 688382 & 5.0 & 4.6938 & TRN \\
\hline CHEMBL1455647 & 688382 & 4.95 & 4.802 & TST \\
\hline CHEMBL1483355 & 688382 & 4.15 & 4.7229 & TRN \\
\hline CHEMBL1583711 & 688382 & 4.0 & 4.6731 & TST \\
\hline CHEMBL1503525 & 688382 & 5.05 & 4.7445 & TST \\
\hline CHEMBL1439902 & 688382 & 4.8 & 4.7109 & TST \\
\hline CHEMBL1459316 & 688382 & 4.5 & 4.7075 & TRN \\
\hline CHEMBL1454149 & 688382 & 4.5 & 4.7188 & TRN \\
\hline CHEMBL1569277 & 688382 & 4.45 & 4.5895 & TRN \\
\hline CHEMBL1338446 & 688382 & 4.5 & 4.6847 & TRN \\
\hline CHEMBL1604781 & 688382 & 4.05 & 4.6678 & TRN \\
\hline CHEMBL1416107 & 688382 & 4.35 & 4.8078 & TRN \\
\hline CHEMBL1425594 & 688382 & 4.95 & 4.6535 & TST \\
\hline CHEMBL1309050 & 688382 & 4.2 & 4.7788 & TST \\
\hline CHEMBL1970183 & 688382 & 4.9 & 4.6567 & TRN \\
\hline CHEMBL 3198222 & 688382 & 5.1 & 4.6832 & TRN \\
\hline CHEMBL1518982 & 688382 & 4.5 & 4.6523 & TRN \\
\hline CHEMBL1462008 & 688382 & 4.9 & 4.7313 & TRN \\
\hline CHEMBL1569151 & 688382 & 4.05 & 4.7913 & TST \\
\hline CHEMBL1383500 & 688382 & 4.05 & 4.7078 & TRN \\
\hline CHEMBL1545638 & 688382 & 5.95 & 4.6594 & TRN \\
\hline CHEMBL1335615 & 688382 & 4.5 & 4.6831 & TRN \\
\hline CHEMBL1465511 & 688382 & 4.5 & 4.6326 & TST \\
\hline CHEMBL3192793 & 688382 & 5.9 & 4.6267 & TRN \\
\hline CHEMBL1379959 & 688382 & 4.9 & 4.6764 & TRN \\
\hline CHEMBL 3192739 & 688382 & 5.5 & 4.7064 & TST \\
\hline CHEMBL 288096 & 688382 & 4.95 & 4.7139 & TRN \\
\hline CHEMBL463563 & 688382 & 5.05 & 4.6268 & TRN \\
\hline CHEMBL1368438 & 688382 & 4.2 & 4.7179 & TRN \\
\hline CHEMBL1341827 & 688382 & 4.2 & 4.7014 & TRN \\
\hline CHEMBL1363259 & 688382 & 4.7 & 4.6742 & TRN \\
\hline CHEMBL1587056 & 688382 & 4.15 & 4.6625 & TRN \\
\hline CHEMBL1377103 & 688382 & 6.05 & 4.6196 & TST \\
\hline CHEMBL1352866 & 688382 & 4.8 & 4.7267 & TRN \\
\hline CHEMBL1440929 & 688382 & 5.5 & 4.7498 & TST \\
\hline CHEMBL1430005 & 688382 & 4.45 & 4.6367 & TST \\
\hline CHEMBL1367823 & 688382 & 4.35 & 4.6111 & TRN \\
\hline CHEMBL1972143 & 688382 & 5.0 & 4.6555 & TST \\
\hline CHEMBL1321438 & 688382 & 4.8 & 4.7249 & TRN \\
\hline CHEMBL1422162 & 688382 & 4.55 & 4.787 & TRN \\
\hline CHEMBL1598785 & 688382 & 4.65 & 4.6739 & TRN \\
\hline CHEMBL3198459 & 688382 & 4.5 & 4.6884 & TRN \\
\hline CHEMBL1447131 & 688382 & 4.35 & 4.7141 & TRN \\
\hline CHEMBL1579026 & 688382 & 4.8 & 4.695 & TRN \\
\hline CHEMBL1089894 & 688382 & 4.35 & 4.6665 & TRN \\
\hline CHEMBL1323010 & 688382 & 5.05 & 4.748 & TRN \\
\hline
\end{tabular}




\begin{tabular}{|c|c|c|c|c|c|}
\hline & & \multicolumn{4}{|c|}{ Supplemental Table S2.txt } \\
\hline CHEMBL1535192 & 688382 & 4.4 & 4.6486 & TRN & \\
\hline CHEMBL3195486 & 688382 & 4.95 & 4.6761 & TST & \\
\hline CHEMBL1547152 & 688382 & 4.6 & 4.7663 & TRN & \\
\hline CHEMBL3209956 & 688382 & 4.8 & 4.6496 & TRN & \\
\hline CHEMBL1596558 & 688382 & 4.8 & $4.8260 e$ & 00000000005 & TRN \\
\hline CHEMBL1543414 & 688382 & 4.85 & 4.7822 & TRN & \\
\hline CHEMBL1389310 & 688382 & 4.95 & 4.7348 & TRN & \\
\hline CHEMBL1301176 & 688382 & 4.35 & 4.7413 & TRN & \\
\hline CHEMBL1608798 & 688382 & 4.45 & 4.6625 & TRN & \\
\hline CHEMBL1456359 & 688382 & 4.95 & 4.7366 & TRN & \\
\hline CHEMBL1310315 & 688382 & 4.45 & 4.7842 & TRN & \\
\hline CHEMBL1315139 & 688382 & 4.45 & 4.7127 & TRN & \\
\hline CHEMBL1451606 & 688382 & 4.6 & 4.7589 & TRN & \\
\hline CHEMBL1307427 & 688382 & 6.0 & 4.7403 & TST & \\
\hline CHEMBL1595261 & 688382 & 4.0 & 4.6834 & TRN & \\
\hline CHEMBL1428459 & 688382 & 4.45 & 4.6783 & TRN & \\
\hline CHEMBL3208113 & 688382 & 5.1 & 4.604 & TST & \\
\hline CHEMBL1608811 & 688382 & 4.4 & 4.7565 & TRN & \\
\hline CHEMBL1503777 & 688382 & 5.25 & 4.7775 & TRN & \\
\hline CHEMBL1359144 & 688382 & 4.75 & 4.6831 & TRN & \\
\hline CHEMBL1518446 & 688382 & 4.8 & 4.6473 & TRN & \\
\hline CHEMBL1304807 & 688382 & 4.6 & 4.7229 & TRN & \\
\hline CHEMBL1446580 & 688382 & 4.5 & 4.666 & TRN & \\
\hline CHEMBL1479423 & 688382 & 4.3 & 4.7102 & TRN & \\
\hline CHEMBL1500423 & 688382 & 5.4 & 4.6296 & TST & \\
\hline CHEMBL1419909 & 688382 & 4.15 & 4.6514 & TRN & \\
\hline CHEMBL1372708 & 688382 & 4.4 & 4.6444 & TRN & \\
\hline CHEMBL591598 & 688382 & 4.4 & 4.5975 & TRN & \\
\hline CHEMBL1430433 & 688382 & 4.2 & 4.6788 & TRN & \\
\hline CHEMBL1578081 & 688382 & 4.95 & 4.6499 & TRN & \\
\hline CHEMBL1370838 & 688382 & 4.5 & 4.635 & TST & \\
\hline CHEMBL1385536 & 688382 & 5.05 & 4.7799 & TRN & \\
\hline CHEMBL1528330 & 688382 & 4.85 & 4.6483 & TRN & \\
\hline CHEMBL1438889 & 688382 & 4.65 & 4.7045 & TRN & \\
\hline CHEMBL1518665 & 688382 & 4.05 & 4.6695 & TST & \\
\hline CHEMBL3189768 & 688382 & 4.9 & 4.6637 & TRN & \\
\hline CHEMBL1452409 & 688382 & 4.5 & 4.545 & TRN & \\
\hline CHEMBL1581796 & 688382 & 4.9 & 4.7842 & TRN & \\
\hline CHEMBL1320594 & 688382 & 5.7 & 4.6883 & TRN & \\
\hline CHEMBL1379965 & 688382 & 4.15 & 4.6489 & TRN & \\
\hline CHEMBL1428671 & 688382 & 4.8 & 4.6694 & TST & \\
\hline CHEMBL1336467 & 688382 & 4.2 & 4.6925 & TST & \\
\hline CHEMBL1482835 & 688382 & 4.95 & 4.8112 & TRN & \\
\hline CHEMBL1497285 & 688382 & 4.75 & 4.8162 & TRN & \\
\hline CHEMBL3193419 & 688382 & 4.65 & 4.64 & TRN & \\
\hline CHEMBL3214494 & 688382 & 4.55 & 4.6955 & TRN & \\
\hline CHEMBL3210781 & 688382 & 4.05 & 4.7227 & TRN & \\
\hline CHEMBL3193642 & 688382 & 4.15 & 4.596 & TRN & \\
\hline
\end{tabular}




\begin{tabular}{|c|c|c|c|c|}
\hline \multicolumn{5}{|c|}{ Supplemental Table S2.txt } \\
\hline CHEMBL1423477 & 688382 & 4.4 & 4.6992 & TRN \\
\hline CHEMBL1544313 & 688382 & 4.4 & 4.7379 & TRN \\
\hline CHEMBL1365441 & 688382 & 4.4 & 4.7639 & TRN \\
\hline CHEMBL1458563 & 688382 & 4.55 & 4.6558 & TRN \\
\hline CHEMBL1470392 & 688382 & 4.5 & 4.7449 & TRN \\
\hline CHEMBL1362438 & 688382 & 4.55 & 4.7603 & TST \\
\hline CHEMBL3193916 & 688382 & 4.2 & 4.6521 & TRN \\
\hline CHEMBL1419009 & 688382 & 4.6 & 4.7418 & TRN \\
\hline CHEMBL1410733 & 688382 & 5.6 & 4.6152 & TRN \\
\hline CHEMBL1582820 & 688382 & 4.05 & 4.8266 & TRN \\
\hline CHEMBL1500914 & 688382 & 5.05 & 4.6968 & TST \\
\hline CHEMBL1340331 & 688382 & 4.45 & 4.6092 & TST \\
\hline CHEMBL1453611 & 688382 & 4.5 & 4.6964 & TRN \\
\hline CHEMBL1309198 & 688382 & 4.5 & 4.6452 & TRN \\
\hline CHEMBL1314128 & 688382 & 5.85 & 4.7301 & TRN \\
\hline CHEMBL1404013 & 688382 & 5.85 & 4.6947 & TRN \\
\hline CHEMBL1350609 & 688382 & 5.05 & 4.6417 & TRN \\
\hline CHEMBL1416920 & 688382 & 4.8 & 4.7127 & TRN \\
\hline CHEMBL1329999 & 688382 & 4.05 & 4.7658 & TST \\
\hline CHEMBL1464920 & 688382 & 4.55 & 4.7365 & TST \\
\hline CHEMBL1613649 & 688382 & 4.15 & 4.7112 & TRN \\
\hline CHEMBL3194874 & 688382 & 4.6 & 4.6193 & TRN \\
\hline CHEMBL1522881 & 688382 & 4.8 & 4.7579 & TST \\
\hline CHEMBL1503949 & 688382 & 4.05 & 4.6517 & TST \\
\hline CHEMBL1544295 & 688382 & 4.45 & 4.6757 & TRN \\
\hline CHEMBL1560629 & 688382 & 4.9 & 4.706 & TRN \\
\hline CHEMBL1359641 & 688382 & 4.65 & 4.6364 & TST \\
\hline CHEMBL1339174 & 688382 & 5.0 & 4.6933 & TRN \\
\hline CHEMBL3197538 & 688382 & 4.15 & 4.5797 & TRN \\
\hline CHEMBL1299844 & 688382 & 4.5 & 4.7296 & TRN \\
\hline CHEMBL1562347 & 688382 & 5.3 & 4.7693 & TRN \\
\hline CHEMBL1344703 & 688382 & 4.5 & 4.6547 & TRN \\
\hline CHEMBL1471682 & 688382 & 4.15 & 4.6971 & TRN \\
\hline CHEMBL1566513 & 688382 & 4.35 & 4.6282 & TRN \\
\hline CHEMBL1599585 & 688382 & 4.15 & 4.6809 & TRN \\
\hline CHEMBL1378060 & 688382 & 4.5 & 4.7297 & TRN \\
\hline CHEMBL1431082 & 688382 & 4.05 & 4.7587 & TST \\
\hline CHEMBL1393417 & 688382 & 4.6 & 4.6594 & TRN \\
\hline CHEMBL1545059 & 688382 & 4.85 & 4.7575 & TST \\
\hline CHEMBL1530043 & 688382 & 4.2 & 4.7376 & TRN \\
\hline CHEMBL1571602 & 688382 & 4.45 & 4.6427 & TRN \\
\hline CHEMBL1390800 & 688382 & 6.05 & 4.6653 & TST \\
\hline CHEMBL1568145 & 688382 & 4.8 & 4.6847 & TRN \\
\hline CHEMBL1409354 & 688382 & 4.6 & 4.6509 & TRN \\
\hline CHEMBL1447294 & 688382 & 4.2 & 4.7293 & TST \\
\hline CHEMBL1545659 & 688382 & 4.65 & 4.6601 & TRN \\
\hline CHEMBL228448 & 688382 & 4.05 & 4.6926 & TRN \\
\hline CHEMBL1468965 & 688382 & 4.5 & 4.6576 & TRN \\
\hline
\end{tabular}




\begin{tabular}{|c|c|c|c|c|c|}
\hline \multirow[b]{2}{*}{ CHEMBL1343263 } & \multirow[b]{2}{*}{688382} & \multicolumn{4}{|c|}{ Supplemental Table s2.txt } \\
\hline & & 4.15 & 4.7801 & TRN & \\
\hline CHEMBL1543673 & 688382 & 5.55 & 4.6469 & TRN & \\
\hline CHEMBL1416110 & 688382 & 4.55 & 4.7685 & TRN & \\
\hline CHEMBL1309754 & 688382 & 4.85 & 4.7177 & TRN & \\
\hline CHEMBL1361860 & 688382 & 4.2 & 4.8372 & TST & \\
\hline CHEMBL1492632 & 688382 & 4.2 & 4.6665 & TST & \\
\hline CHEMBL1423996 & 688382 & 5.8 & 4.82600 & 00000000005 & TRN \\
\hline CHEMBL1576156 & 688382 & 5.15 & 4.6502 & TRN & \\
\hline CHEMBL1422737 & 688382 & 4.85 & 4.6258 & TRN & \\
\hline CHEMBL1516772 & 688382 & 4.15 & 4.6363 & TRN & \\
\hline CHEMBL1487272 & 688382 & 4.8 & 4.6814 & TRN & \\
\hline CHEMBL1417769 & 688382 & 4.15 & 4.6846 & TST & \\
\hline CHEMBL3194730 & 688382 & 4.85 & 4.6731 & TST & \\
\hline CHEMBL1505275 & 688382 & 5.6 & 4.7455 & TRN & \\
\hline CHEMBL1256687 & 688382 & 4.45 & 4.6873 & TST & \\
\hline CHEMBL1451088 & 688382 & 4.5 & 4.7191 & TRN & \\
\hline CHEMBL1482456 & 688382 & 5.85 & 4.8199 & TST & \\
\hline CHEMBL1581327 & 688382 & 4.15 & 4.731 & TRN & \\
\hline CHEMBL1378065 & 688382 & 5.05 & 4.813 & TRN & \\
\hline CHEMBL3191152 & 688382 & 4.5 & 4.6081 & TRN & \\
\hline CHEMBL1699206 & 688382 & 4.5 & 4.6859 & TST & \\
\hline CHEMBL1382772 & 688382 & 4.45 & 4.6576 & TRN & \\
\hline CHEMBL1544970 & 688382 & 4.95 & 4.8101 & TRN & \\
\hline CHEMBL1469489 & 688382 & 4.9 & 4.6655 & TRN & \\
\hline CHEMBL1307689 & 688382 & 4.55 & 4.6787 & TST & \\
\hline CHEMBL1383332 & 688382 & 4.5 & 4.6046 & TRN & \\
\hline CHEMBL1374242 & 688382 & 4.5 & 4.6959 & TRN & \\
\hline CHEMBL1460470 & 688382 & 4.15 & 4.7314 & TRN & \\
\hline CHEMBL1463351 & 688382 & 5.5 & 4.67 & TRN & \\
\hline CHEMBL1569122 & 688382 & 4.85 & 4.7424 & TRN & \\
\hline CHEMBL1524275 & 688382 & 5.05 & 4.7985 & TRN & \\
\hline CHEMBL1342725 & 688382 & 4.35 & 4.763 & TRN & \\
\hline CHEMBL1509057 & 688382 & 4.8 & 4.667 & TRN & \\
\hline CHEMBL1587841 & 688382 & 4.4 & 4.797 & TRN & \\
\hline CHEMBL1409647 & 688382 & 4.8 & 4.7765 & TRN & \\
\hline CHEMBL1389240 & 688382 & 4.2 & 4.7123 & TRN & \\
\hline CHEMBL1302623 & 688382 & 4.0 & 4.8501 & TRN & \\
\hline CHEMBL1345138 & 688382 & 4.15 & 4.7405 & TRN & \\
\hline CHEMBL1503052 & 688382 & 4.8 & 4.7147 & TRN & \\
\hline CHEMBL1328361 & 688382 & 5.4 & 4.6875 & TRN & \\
\hline CHEMBL1440420 & 688382 & 5.15 & 4.659 & TRN & \\
\hline CHEMBL1444487 & 688382 & 6.0 & 4.8186 & TRN & \\
\hline CHEMBL1552770 & 688382 & 5.15 & 4.6381 & TST & \\
\hline CHEMBL1468685 & 688382 & 4.35 & 4.7027 & TRN & \\
\hline CHEMBL3209924 & 688382 & 4.4 & 4.68199 & 99999999995 & TRN \\
\hline CHEMBL1459396 & 688382 & 4.35 & 4.7413 & TST & \\
\hline CHEMBL1449439 & 688382 & 4.6 & 4.7721 & TRN & \\
\hline CHEMBL3208441 & 688382 & 4.8 & 4.6271 & TRN & \\
\hline
\end{tabular}




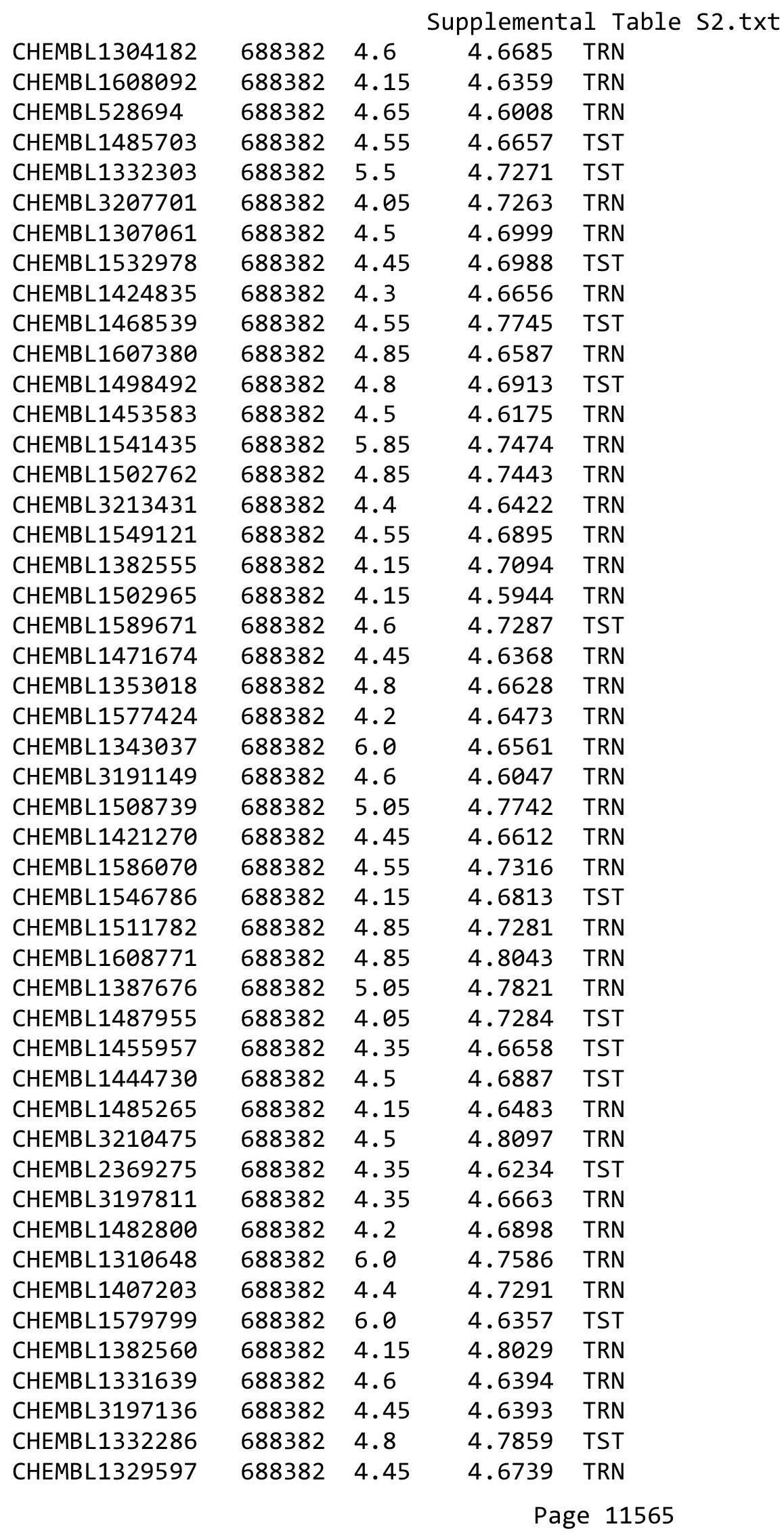




\begin{tabular}{|c|c|c|c|c|c|}
\hline \multicolumn{6}{|c|}{ Supplemental Table s2.txt } \\
\hline CHEMBL1365213 & 688382 & 4.8 & 4.7479 & TST & \\
\hline CHEMBL1561916 & 688382 & 4.45 & 4.7184 & TRN & \\
\hline CHEMBL1546785 & 688382 & 4.85 & 4.7556 & TRN & \\
\hline CHEMBL1450950 & 688382 & 4.15 & 4.7992 & TRN & \\
\hline CHEMBL1439856 & 688382 & 4.8 & 4.6976 & TRN & \\
\hline CHEMBL1409702 & 688382 & 4.4 & 4.7186 & TRN & \\
\hline CHEMBL1581168 & 688382 & 4.85 & 4.7898 & TRN & \\
\hline CHEMBL1978479 & 688382 & 4.5 & 4.6849 & TST & \\
\hline CHEMBL1875040 & 688382 & 5.25 & 4.5957 & TST & \\
\hline CHEMBL1299959 & 688382 & 4.75 & 4.7353 & TRN & \\
\hline CHEMBL1350120 & 688382 & 4.7 & 4.6959 & TST & \\
\hline CHEMBL 3211060 & 688382 & 4.05 & 4.6959 & TRN & \\
\hline CHEMBL1534832 & 688382 & 4.8 & 4.723 & TRN & \\
\hline CHEMBL1353417 & 688382 & 5.0 & 4.7888 & TRN & \\
\hline CHEMBL 2003886 & 688382 & 5.6 & 4.5875 & TRN & \\
\hline CHEMBL1498843 & 688382 & 5.15 & 4.7011 & TRN & \\
\hline CHEMBL1400005 & 688382 & 4.45 & 4.6774 & TST & \\
\hline CHEMBL1601912 & 688382 & 4.5 & 4.6508 & TRN & \\
\hline CHEMBL1418981 & 688382 & 4.5 & 4.7352 & TRN & \\
\hline CHEMBL1538988 & 688382 & 5.3 & 4.7478 & TST & \\
\hline CHEMBL1301022 & 688382 & 4.85 & 4.7442 & TRN & \\
\hline CHEMBL1964535 & 688382 & 4.55 & 4.6315 & TST & \\
\hline CHEMBL1597816 & 688382 & 6.0 & 4.6408 & TRN & \\
\hline CHEMBL3190961 & 688382 & 4.15 & 4.6453 & TRN & \\
\hline CHEMBL3196847 & 688382 & 4.15 & 4.6937 & TRN & \\
\hline CHEMBL1509867 & 688382 & 4.5 & 4.6882 & TRN & \\
\hline CHEMBL1501140 & 688382 & 5.2 & 4.6948 & TRN & \\
\hline CHEMBL1401172 & 688382 & 4.3 & 4.7318 & TRN & \\
\hline CHEMBL1499085 & 688382 & 4.75 & 4.6519 & TRN & \\
\hline CHEMBL1494180 & 688382 & 4.45 & 4.77 & TRN & \\
\hline CHEMBL1525089 & 688382 & 6.05 & 4.7756 & TRN & \\
\hline CHEMBL1531752 & 688382 & 4.4 & 4.7794 & TRN & \\
\hline CHEMBL1379815 & 688382 & 4.45 & 4.74100 & 00000000005 & TRN \\
\hline CHEMBL1304050 & 688382 & 5.05 & 4.721 & TRN & \\
\hline CHEMBL1536791 & 688382 & 5.45 & 4.6455 & TRN & \\
\hline CHEMBL1485816 & 688382 & 5.65 & 4.6683 & TRN & \\
\hline CHEMBL1395180 & 688382 & 4.95 & 4.7521 & TST & \\
\hline CHEMBL1421794 & 688382 & 4.5 & 4.7075 & TRN & \\
\hline CHEMBL1318282 & 688382 & 6.05 & 4.8337 & TRN & \\
\hline CHEMBL1382542 & 688382 & 4.95 & 4.6659 & TRN & \\
\hline CHEMBL1461321 & 688382 & 4.45 & 4.6411 & TRN & \\
\hline CHEMBL1567448 & 688382 & 5.15 & 4.73600 & 0000000001 & TRN \\
\hline CHEMBL1380028 & 688382 & 4.55 & 4.6246 & TST & \\
\hline CHEMBL1443088 & 688382 & 4.4 & 4.5758 & TRN & \\
\hline CHEMBL1487868 & 688382 & 5.2 & 4.6822 & TRN & \\
\hline CHEMBL1433057 & 688382 & 4.15 & 4.7102 & TRN & \\
\hline CHEMBL1384989 & 688382 & 4.35 & 4.6527 & TRN & \\
\hline CHEMBL 264141 & 688382 & 5.95 & 4.6683 & TRN & \\
\hline
\end{tabular}




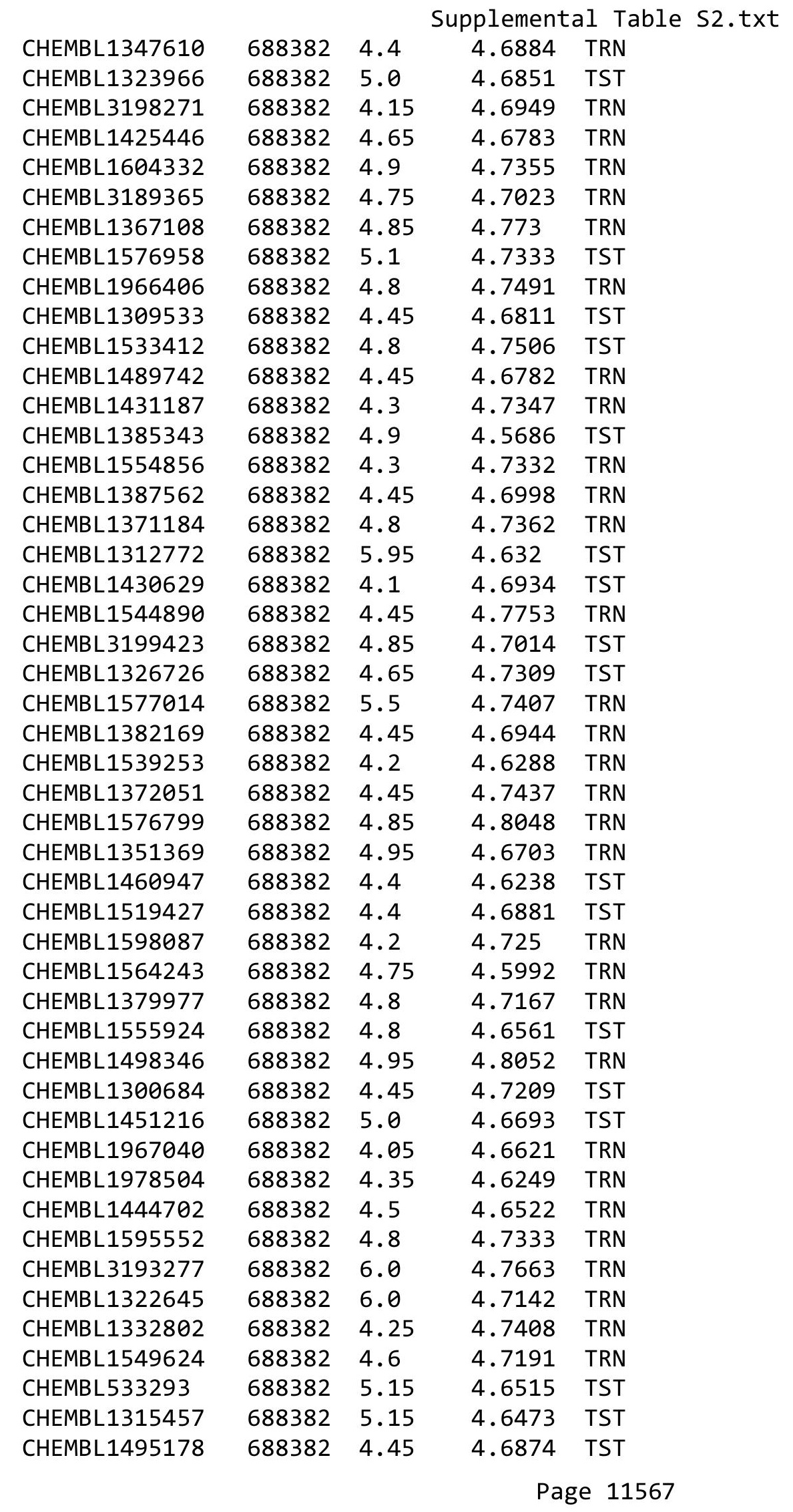




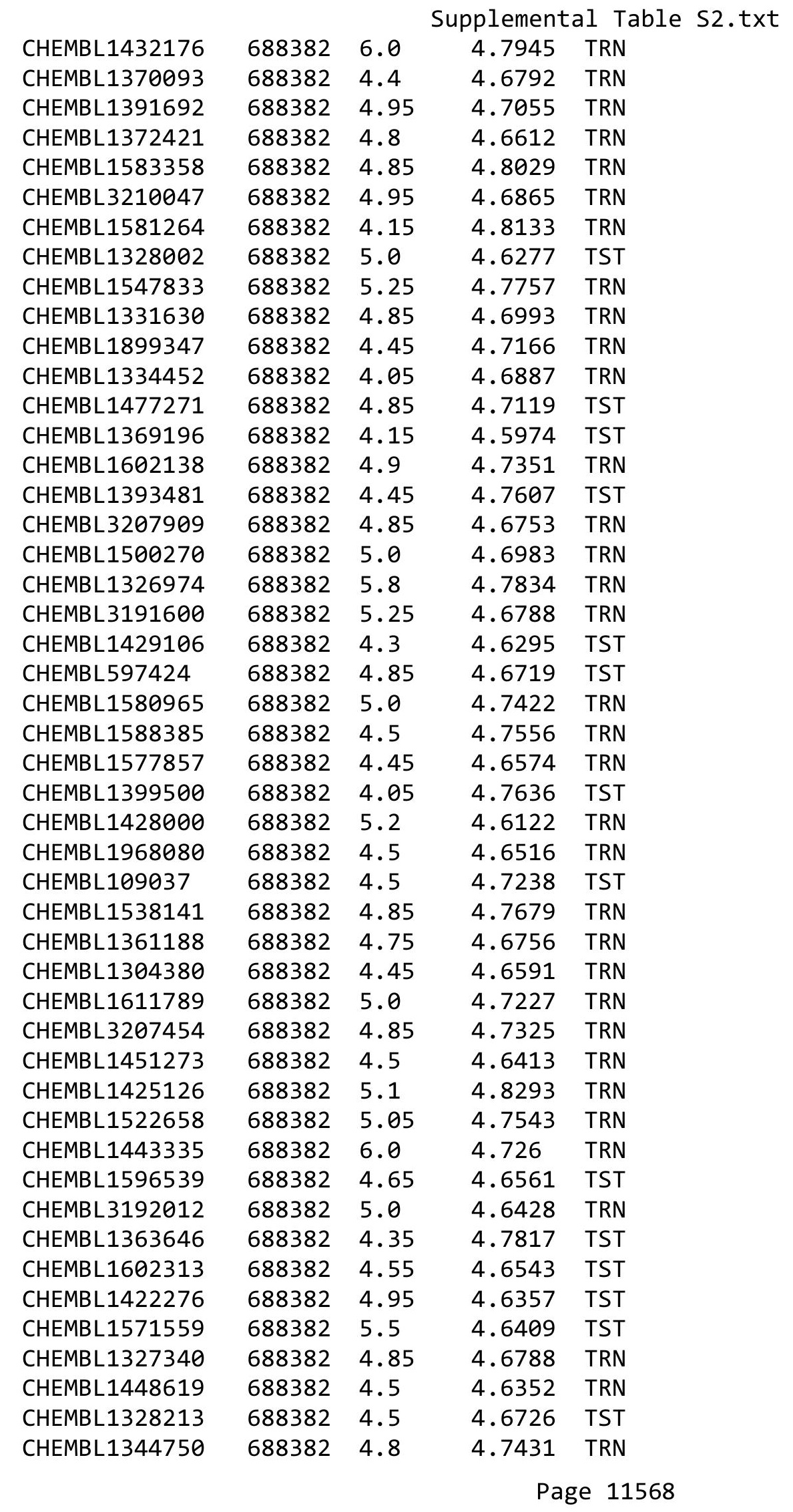




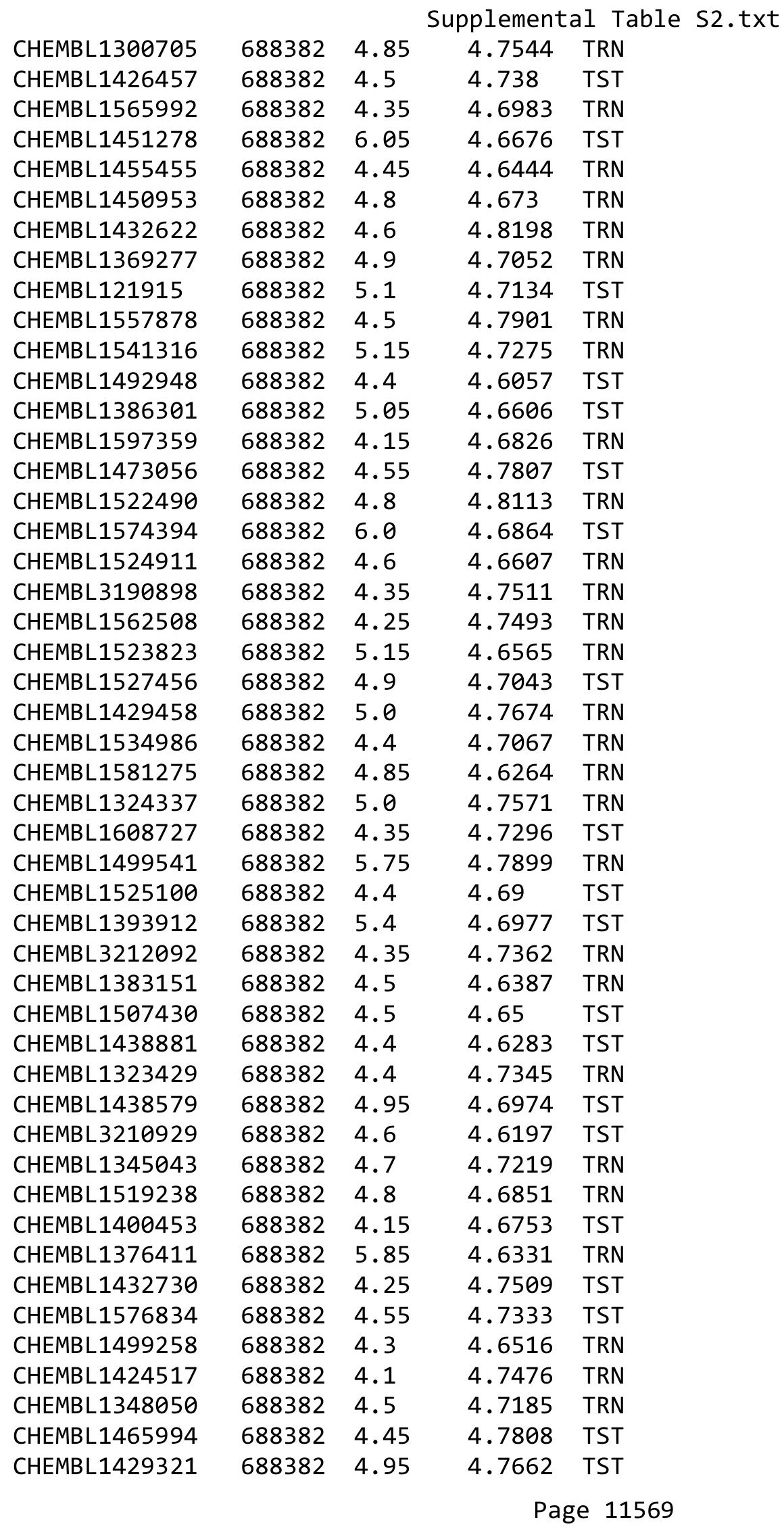




\begin{tabular}{|c|c|c|c|c|}
\hline \multicolumn{5}{|c|}{ Supplemental Table S2.txt } \\
\hline CHEMBL1403659 & 688382 & 4.05 & 4.8204 & TRN \\
\hline CHEMBL1445952 & 688382 & 5.1 & 4.776 & TRN \\
\hline CHEMBL3198884 & 688382 & 5.25 & 4.6651 & TRN \\
\hline CHEMBL1423904 & 688382 & 4.5 & 4.6874 & TRN \\
\hline CHEMBL1459412 & 688382 & 5.15 & 4.6315 & TRN \\
\hline CHEMBL1552506 & 688382 & 4.05 & 4.6891 & TRN \\
\hline CHEMBL1410354 & 688382 & 4.8 & 4.8077 & TRN \\
\hline CHEMBL1357292 & 688382 & 4.8 & 4.7054 & TRN \\
\hline CHEMBL1340970 & 688382 & 4.15 & 4.6884 & TRN \\
\hline CHEMBL1382423 & 688382 & 4.45 & 4.6858 & TST \\
\hline CHEMBL1520089 & 688382 & 4.45 & 4.7076 & TRN \\
\hline CHEMBL1410295 & 688382 & 4.45 & 4.74 & TRN \\
\hline CHEMBL1588075 & 688382 & 4.5 & 4.7454 & TRN \\
\hline CHEMBL1384050 & 688382 & 4.85 & 4.7808 & TRN \\
\hline CHEMBL1507849 & 688382 & 4.85 & 4.8693 & TST \\
\hline CHEMBL1589168 & 688382 & 4.25 & 4.7366 & TRN \\
\hline CHEMBL1348199 & 688382 & 4.15 & 4.7336 & TRN \\
\hline CHEMBL1378848 & 688382 & 4.1 & 4.7285 & TRN \\
\hline CHEMBL1447804 & 688382 & 4.05 & 4.7824 & TRN \\
\hline CHEMBL1420593 & 688382 & 4.1 & 4.6267 & TRN \\
\hline CHEMBL1392873 & 688382 & 4.05 & 4.648 & TRN \\
\hline CHEMBL1995314 & 688382 & 4.7 & 4.7691 & TRN \\
\hline CHEMBL1438661 & 688382 & 4.45 & 4.6753 & TRN \\
\hline CHEMBL1391943 & 688382 & 4.5 & 4.7813 & TRN \\
\hline CHEMBL1452370 & 688382 & 4.15 & 4.6784 & TRN \\
\hline CHEMBL1426380 & 688382 & 4.35 & 4.7253 & TRN \\
\hline CHEMBL1387392 & 688382 & 4.15 & 4.666 & TRN \\
\hline CHEMBL1380247 & 688382 & 5.15 & 4.7852 & TRN \\
\hline CHEMBL1478565 & 688382 & 4.8 & 4.6303 & TRN \\
\hline CHEMBL1595012 & 688382 & 4.6 & 4.62 & TST \\
\hline CHEMBL1349640 & 688382 & 4.05 & $4.6930 e$ & 00000000005 \\
\hline CHEMBL1416218 & 688382 & 4.65 & 4.6935 & TST \\
\hline CHEMBL1568009 & 688382 & 4.05 & 4.6502 & TST \\
\hline CHEMBL1496478 & 688382 & 4.9 & 4.77 & TRN \\
\hline CHEMBL1549044 & 688382 & 4.5 & 4.7418 & TRN \\
\hline CHEMBL3192507 & 688382 & 4.45 & 4.5762 & TRN \\
\hline CHEMBL1463981 & 688382 & 4.75 & 4.7106 & TRN \\
\hline CHEMBL1445177 & 688382 & 5.05 & 4.7369 & TRN \\
\hline CHEMBL1306428 & 688382 & 4.5 & 4.7764 & TRN \\
\hline CHEMBL1501571 & 688382 & 4.8 & 4.7718 & TST \\
\hline CHEMBL1306430 & 688382 & 5.25 & 4.7027 & TRN \\
\hline CHEMBL1501843 & 688382 & 4.45 & 4.6686 & TRN \\
\hline CHEMBL1494193 & 688382 & 5.05 & 4.7468 & TRN \\
\hline CHEMBL3189428 & 688382 & 4.75 & 4.6332 & TST \\
\hline CHEMBL3192630 & 688382 & 4.85 & 4.6142 & TRN \\
\hline CHEMBL1382527 & 688382 & 5.5 & 4.7392 & TST \\
\hline CHEMBL1433075 & 688382 & 5.85 & 4.6062 & TRN \\
\hline CHEMBL528791 & 688382 & 4.15 & 4.743 & TRN \\
\hline
\end{tabular}




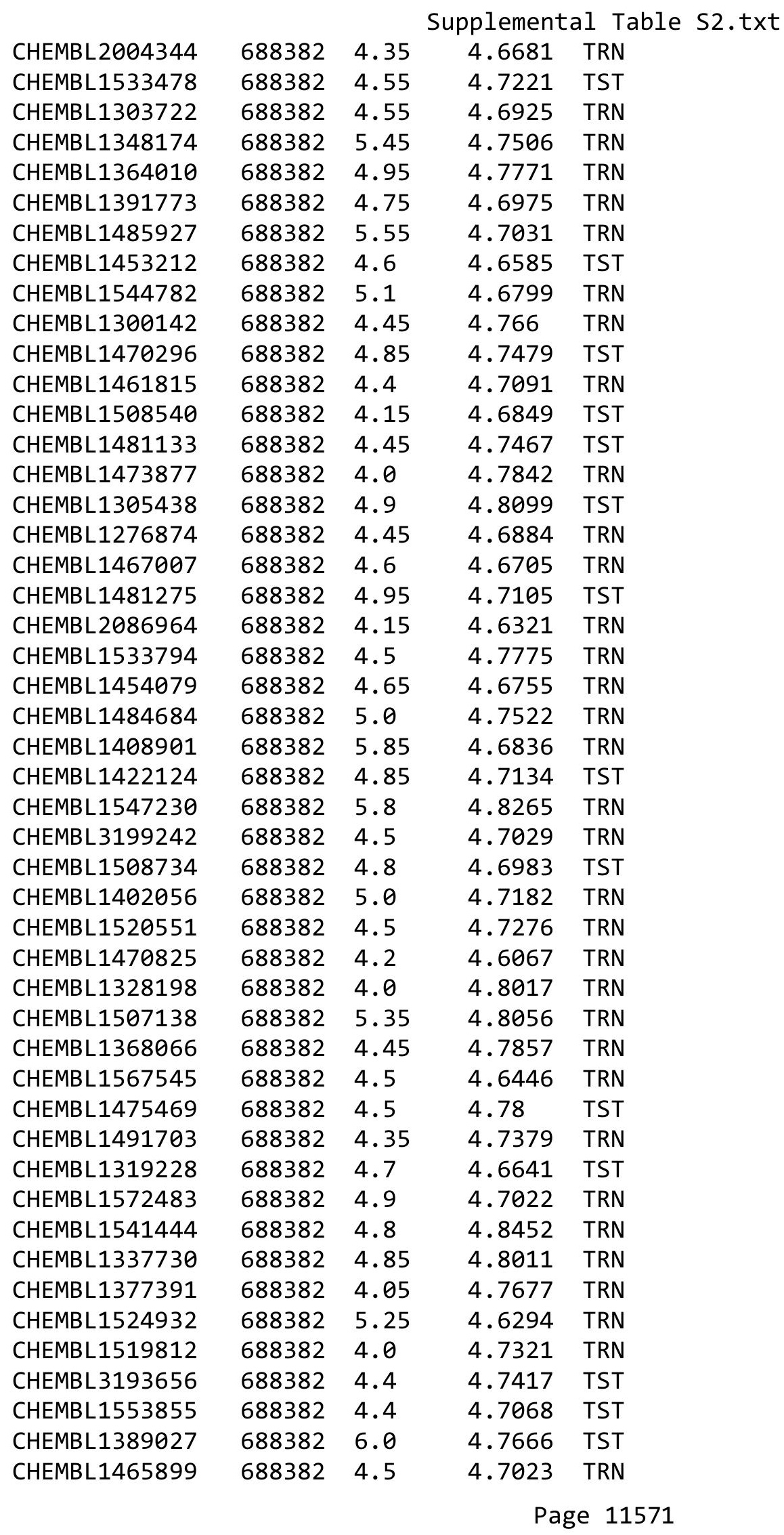




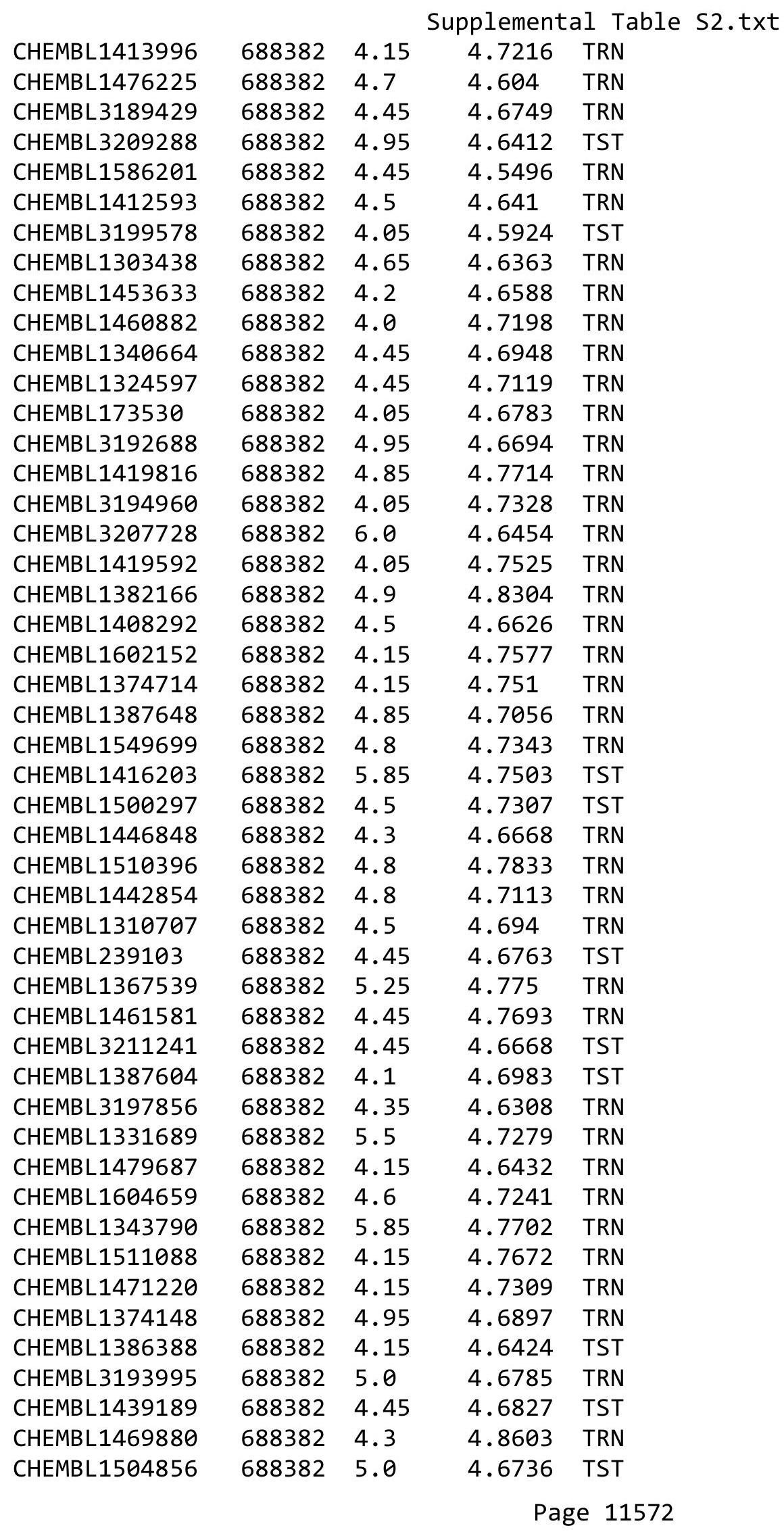




\begin{tabular}{|c|c|c|c|c|c|}
\hline & & \multicolumn{4}{|c|}{ Supplemental Table S2.txt } \\
\hline CHEMBL1372692 & 688382 & 4.75 & 4.6949 & TRN & \\
\hline CHEMBL1306094 & 688382 & 4.35 & 4.8638 & TRN & \\
\hline CHEMBL1533587 & 688382 & 4.05 & 4.6971 & TRN & \\
\hline CHEMBL1501629 & 688382 & 4.65 & 4.6835 & TRN & \\
\hline CHEMBL1317919 & 688382 & 4.15 & 4.705 & TRN & \\
\hline CHEMBL1340915 & 688382 & 3.95 & 4.6648 & TRN & \\
\hline CHEMBL1570379 & 688382 & 4.3 & 4.7299 & TRN & \\
\hline CHEMBL1531428 & 688382 & 4.45 & 4.6627 & TRN & \\
\hline CHEMBL1447429 & 688382 & 5.2 & 4.7115 & TRN & \\
\hline CHEMBL1346239 & 688382 & 4.55 & 4.6415 & TRN & \\
\hline CHEMBL1432920 & 688382 & 4.05 & 4.717 & TRN & \\
\hline CHEMBL1313945 & 688382 & 4.45 & 4.63899 & 9999999999 & TRN \\
\hline CHEMBL1385664 & 688382 & 3.95 & 4.6708 & TST & \\
\hline CHEMBL1576502 & 688382 & 4.8 & 4.7439 & TST & \\
\hline CHEMBL1345795 & 688382 & 4.8 & 4.8164 & TRN & \\
\hline CHEMBL1558655 & 688382 & 5.05 & 4.773 & TST & \\
\hline CHEMBL1463652 & 688382 & 4.45 & 4.6716 & TRN & \\
\hline CHEMBL1598172 & 688382 & 5.05 & 4.7287 & TST & \\
\hline CHEMBL1522033 & 688382 & 4.55 & 4.6746 & TRN & \\
\hline CHEMBL1558383 & 688382 & 6.0 & 4.8059 & TRN & \\
\hline CHEMBL1342984 & 688382 & 4.8 & 4.7407 & TRN & \\
\hline CHEMBL1339786 & 688382 & 4.1 & 4.6206 & TRN & \\
\hline CHEMBL3199665 & 688382 & 5.7 & 4.6439 & TRN & \\
\hline CHEMBL1337401 & 688382 & 5.0 & 4.7704 & TRN & \\
\hline CHEMBL1436318 & 688382 & 5.9 & 4.6987 & TRN & \\
\hline CHEMBL1323770 & 688382 & 4.85 & 4.7524 & TRN & \\
\hline CHEMBL1398204 & 688382 & 4.85 & 4.7213 & TRN & \\
\hline CHEMBL1424360 & 688382 & 5.6 & 4.6657 & TRN & \\
\hline CHEMBL1415885 & 688382 & 4.7 & 4.6452 & TRN & \\
\hline CHEMBL1341066 & 688382 & 4.75 & 4.6727 & TRN & \\
\hline CHEMBL1550591 & 688382 & 4.8 & 4.6083 & TST & \\
\hline CHEMBL1464261 & 688382 & 4.95 & 4.6403 & TST & \\
\hline CHEMBL1349683 & 688382 & 4.8 & 4.6548 & TST & \\
\hline CHEMBL1547228 & 688382 & 4.6 & 4.7325 & TST & \\
\hline CHEMBL1545945 & 688382 & 4.8 & 4.6821 & TRN & \\
\hline CHEMBL1531968 & 688382 & 4.35 & 4.7202 & TRN & \\
\hline CHEMBL1471049 & 688382 & 5.0 & 4.7232 & TRN & \\
\hline CHEMBL3192251 & 688382 & 5.8 & 4.6565 & TRN & \\
\hline CHEMBL1494509 & 688382 & 4.4 & 4.6993 & TRN & \\
\hline CHEMBL1582709 & 688382 & 5.85 & 4.6954 & TST & \\
\hline CHEMBL1460878 & 688382 & 4.35 & 4.6203 & TRN & \\
\hline CHEMBL1310197 & 688382 & 4.45 & 4.7001 & TST & \\
\hline CHEMBL1470380 & 688382 & 4.15 & 4.6556 & TRN & \\
\hline CHEMBL1357187 & 688382 & 4.1 & 4.7513 & TRN & \\
\hline CHEMBL1580410 & 688382 & 5.0 & 4.7541 & TRN & \\
\hline CHEMBL1424641 & 688382 & 4.95 & 4.7599 & TST & \\
\hline CHEMBL1425152 & 688382 & 4.95 & 4.8326 & TRN & \\
\hline CHEMBL1324266 & 688382 & 5.4 & 4.6463 & TRN & \\
\hline
\end{tabular}




\begin{tabular}{|c|c|c|c|c|c|}
\hline & & \multicolumn{4}{|c|}{ Supplemental Table s2.txt } \\
\hline CHEMBL1354443 & 688382 & 4.05 & 4.6152 & TRN & \\
\hline CHEMBL1468183 & 688382 & 4.45 & 4.7159 & TRN & \\
\hline CHEMBL3192672 & 688382 & 5.35 & 4.6128 & TRN & \\
\hline CHEMBL1523640 & 688382 & 4.0 & 4.658 & TST & \\
\hline CHEMBL1595743 & 688382 & 4.15 & 4.6995 & TRN & \\
\hline CHEMBL600100 & 688382 & 5.05 & 4.6587 & TRN & \\
\hline CHEMBL1558589 & 688382 & 5.8 & 4.7155 & TRN & \\
\hline CHEMBL1404105 & 688382 & 4.05 & 4.7576 & TST & \\
\hline CHEMBL1471761 & 688382 & 5.35 & 4.7574 & TRN & \\
\hline CHEMBL1483220 & 688382 & 4.45 & 4.6443 & TST & \\
\hline CHEMBL1327569 & 688382 & 6.0 & 4.8438 & TRN & \\
\hline CHEMBL1997392 & 688382 & 5.45 & 4.6388 & TRN & \\
\hline CHEMBL1339736 & 688382 & 4.45 & 4.7364 & TRN & \\
\hline CHEMBL1427431 & 688382 & 5.05 & 4.5862 & TRN & \\
\hline CHEMBL1377778 & 688382 & 5.85 & 4.7672 & TRN & \\
\hline CHEMBL1579118 & 688382 & 4.4 & 4.7175 & TRN & \\
\hline CHEMBL1377130 & 688382 & 4.05 & 4.6771 & TRN & \\
\hline CHEMBL1609869 & 688382 & 5.6 & 4.746 & TRN & \\
\hline CHEMBL1477137 & 688382 & 4.1 & 4.7767 & TST & \\
\hline CHEMBL580819 & 688382 & 4.55 & 4.6208 & TRN & \\
\hline CHEMBL492418 & 688382 & 4.5 & 4.6669 & TST & \\
\hline CHEMBL1499629 & 688382 & 4.95 & 4.6843 & TRN & \\
\hline CHEMBL1384532 & 688382 & 4.85 & 4.7491 & TST & \\
\hline CHEMBL1379192 & 688382 & 6.0 & 4.8572 & TRN & \\
\hline CHEMBL1586875 & 688382 & 5.0 & 4.6355 & TRN & \\
\hline CHEMBL1595968 & 688382 & 4.2 & 4.7298 & TRN & \\
\hline CHEMBL1392882 & 688382 & 5.55 & 4.8598 & TRN & \\
\hline CHEMBL1606301 & 688382 & 4.5 & 4.65300 & 00000000005 & TRN \\
\hline CHEMBL1372491 & 688382 & 4.15 & 4.7075 & TST & \\
\hline CHEMBL1577124 & 688382 & 4.15 & 4.6933 & TRN & \\
\hline CHEMBL1568200 & 688382 & 4.85 & 4.6678 & TRN & \\
\hline CHEMBL1462585 & 688382 & 4.05 & 4.6852 & TST & \\
\hline CHEMBL1585040 & 688382 & 5.5 & 4.6728 & TRN & \\
\hline CHEMBL1497172 & 688382 & 4.85 & 4.748 & TRN & \\
\hline CHEMBL1456458 & 688382 & 4.15 & 4.7253 & TRN & \\
\hline CHEMBL1445857 & 688382 & 4.35 & 4.6116 & TRN & \\
\hline CHEMBL3197080 & 688382 & 4.15 & 4.6786 & TRN & \\
\hline CHEMBL3196255 & 688382 & 5.05 & 4.6722 & TRN & \\
\hline CHEMBL1439668 & 688382 & 4.5 & 4.6132 & TST & \\
\hline CHEMBL1325275 & 688382 & 4.15 & 4.6949 & TRN & \\
\hline CHEMBL1986541 & 688382 & 5.05 & 4.7063 & TRN & \\
\hline CHEMBL1487080 & 688382 & 4.5 & 4.6569 & TRN & \\
\hline CHEMBL3194626 & 688382 & 4.05 & 4.6216 & TRN & \\
\hline CHEMBL1526452 & 688382 & 4.55 & 4.7328 & TRN & \\
\hline CHEMBL1319707 & 688382 & 5.0 & 4.7173 & TRN & \\
\hline CHEMBL1529565 & 688382 & 6.0 & 4.74100 & 00000000005 & TRN \\
\hline CHEMBL1470729 & 688382 & 4.05 & 4.6482 & TRN & \\
\hline CHEMBL1495728 & 688382 & 4.3 & 4.73600 & 0000000001 & TRN \\
\hline & & & & 11574 & \\
\hline
\end{tabular}




\begin{tabular}{|c|c|c|c|c|}
\hline \multicolumn{5}{|c|}{ Supplemental Table S2.txt } \\
\hline CHEMBL1483038 & 688382 & 5.2 & 4.7013 & TST \\
\hline CHEMBL1300052 & 688382 & 4.95 & 4.7232 & TRN \\
\hline CHEMBL1344469 & 688382 & 5.0 & 4.7775 & TRN \\
\hline CHEMBL1325331 & 688382 & 5.1 & 4.7464 & TST \\
\hline CHEMBL1520776 & 688382 & 4.5 & 4.7511 & TRN \\
\hline CHEMBL1300038 & 688382 & 4.5 & 4.8141 & TRN \\
\hline CHEMBL1328239 & 688382 & 4.8 & 4.6605 & TST \\
\hline CHEMBL1334989 & 688382 & 4.9 & 4.586 & TRN \\
\hline CHEMBL1393502 & 688382 & 4.45 & 4.6542 & TRN \\
\hline CHEMBL1468034 & 688382 & 4.45 & 4.7952 & TRN \\
\hline CHEMBL1540177 & 688382 & 4.5 & 4.6717 & TRN \\
\hline CHEMBL1510504 & 688382 & 4.15 & 4.6165 & TRN \\
\hline CHEMBL1524257 & 688382 & 5.15 & 4.6286 & TRN \\
\hline CHEMBL1447720 & 688382 & 4.5 & 4.7839 & TRN \\
\hline CHEMBL1438647 & 688382 & 4.95 & 4.7833 & TRN \\
\hline CHEMBL361845 & 688382 & 4.5 & 4.6879 & TST \\
\hline CHEMBL1366612 & 688382 & 4.85 & 4.7549 & TRN \\
\hline CHEMBL1523560 & 688382 & 5.0 & 4.6528 & TST \\
\hline CHEMBL1526460 & 688382 & 4.85 & 4.7795 & TRN \\
\hline CHEMBL1573469 & 688382 & 5.1 & 4.6601 & TRN \\
\hline CHEMBL1578386 & 688382 & 4.7 & 4.724 & TRN \\
\hline CHEMBL550174 & 688382 & 5.8 & 4.6235 & TRN \\
\hline CHEMBL1325251 & 688382 & 4.2 & 4.7622 & TRN \\
\hline CHEMBL1409152 & 688382 & 5.0 & 4.7298 & TRN \\
\hline CHEMBL1519240 & 688382 & 4.5 & 4.6995 & TRN \\
\hline CHEMBL1338486 & 688382 & 4.05 & 4.6518 & TRN \\
\hline CHEMBL1539170 & 688382 & 4.5 & 4.7134 & TRN \\
\hline CHEMBL1599930 & 688382 & 4.4 & 4.6742 & TRN \\
\hline CHEMBL1411850 & 688382 & 4.4 & 4.6911 & TRN \\
\hline CHEMBL1431608 & 688382 & 4.05 & 4.7079 & TST \\
\hline CHEMBL1345187 & 688382 & 4.05 & 4.6452 & TRN \\
\hline CHEMBL1305071 & 688382 & 4.45 & 4.7881 & TST \\
\hline CHEMBL1477697 & 688382 & 4.75 & 4.7024 & TRN \\
\hline CHEMBL1406911 & 688382 & 4.9 & 4.6254 & TRN \\
\hline CHEMBL1583332 & 688382 & 4.6 & 4.7341 & TST \\
\hline CHEMBL1337281 & 688382 & 4.75 & 4.713 & TRN \\
\hline CHEMBL1331195 & 688382 & 6.05 & 4.6678 & TST \\
\hline CHEMBL1407698 & 688382 & 4.5 & 4.7993 & TRN \\
\hline CHEMBL1458549 & 688382 & 4.4 & 4.7438 & TRN \\
\hline CHEMBL490550 & 688382 & 4.55 & 4.6452 & TRN \\
\hline CHEMBL56731 & 688382 & 4.4 & 4.6286 & TRN \\
\hline CHEMBL1364528 & 688382 & 4.25 & 4.6475 & TRN \\
\hline CHEMBL1402915 & 688382 & 4.85 & 4.7181 & TST \\
\hline CHEMBL1346297 & 688382 & 4.25 & 4.73 & TRN \\
\hline CHEMBL1300506 & 688382 & 4.2 & 4.6032 & TST \\
\hline CHEMBL1584528 & 688382 & 4.25 & 4.6987 & TRN \\
\hline CHEMBL547833 & 688382 & 4.6 & 4.6829 & TRN \\
\hline CHEMBL1432400 & 688382 & 4.8 & 4.6404 & TST \\
\hline
\end{tabular}




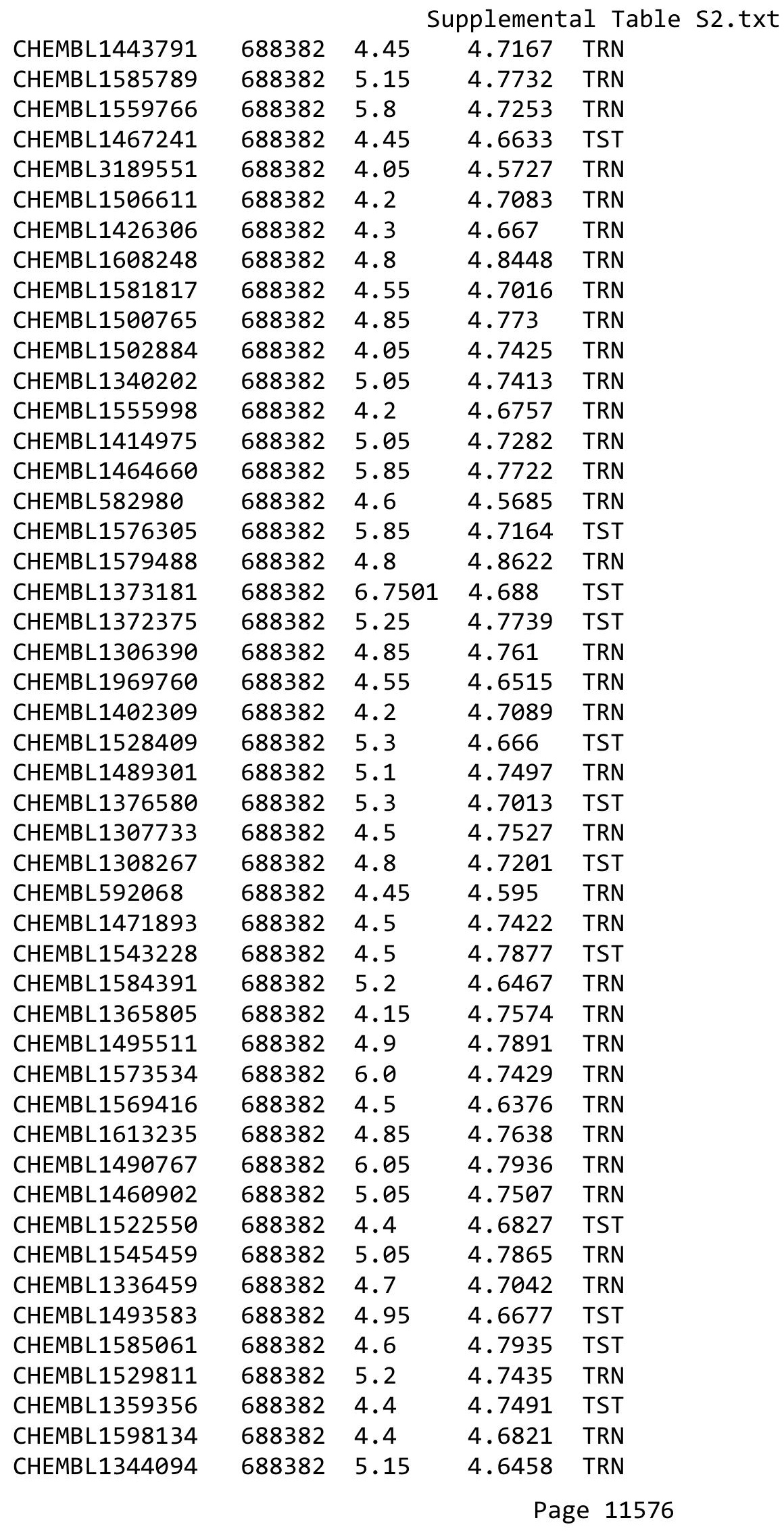




\begin{tabular}{|c|c|c|c|c|c|}
\hline \multicolumn{6}{|c|}{ Supplemental Table S2.txt } \\
\hline CHEMBL1414470 & 688382 & 4.45 & 4.8357 & TRN & \\
\hline CHEMBL3211253 & 688382 & 4.65 & 4.6473 & TRN & \\
\hline CHEMBL1337309 & 688382 & 5.65 & 4.7284 & TRN & \\
\hline CHEMBL1538230 & 688382 & 4.5 & 4.6289 & TST & \\
\hline CHEMBL1601179 & 688382 & 4.05 & 4.7113 & TRN & \\
\hline CHEMBL1496042 & 688382 & 4.2 & 4.7504 & TRN & \\
\hline CHEMBL1453077 & 688382 & 4.45 & 4.6829 & TRN & \\
\hline CHEMBL1565061 & 688382 & 4.15 & 4.6612 & TST & \\
\hline CHEMBL1575637 & 688382 & 6.25 & 4.7788 & TRN & \\
\hline CHEMBL1342880 & 688382 & 5.3 & 4.7112 & TST & \\
\hline CHEMBL1452228 & 688382 & 4.9 & 4.8126 & TRN & \\
\hline CHEMBL1482951 & 688382 & 5.75 & 4.6943 & TRN & \\
\hline CHEMBL1406807 & 688382 & 4.9 & 4.6672 & TRN & \\
\hline CHEMBL1346539 & 688382 & 5.85 & 4.6957 & TRN & \\
\hline CHEMBL1594913 & 688382 & 4.45 & 4.7763 & TST & \\
\hline CHEMBL1306613 & 688382 & 5.55 & 4.7637 & TST & \\
\hline CHEMBL1339186 & 688382 & 5.15 & 4.6738 & TST & \\
\hline CHEMBL1495255 & 688382 & 4.85 & 4.6795 & TST & \\
\hline CHEMBL1382139 & 688382 & 5.05 & 4.7289 & TST & \\
\hline CHEMBL1531322 & 688382 & 4.4 & 4.752 & TRN & \\
\hline CHEMBL1545424 & 688382 & 4.8 & 4.5814 & TRN & \\
\hline CHEMBL1549595 & 688382 & 5.0 & 4.7089 & TST & \\
\hline CHEMBL3209550 & 688382 & 4.55 & 4.7116 & TRN & \\
\hline CHEMBL1362219 & 688382 & 4.65 & 4.7212 & TST & \\
\hline CHEMBL1391382 & 688382 & 5.1 & 4.6366 & TRN & \\
\hline CHEMBL1557819 & 688382 & 2.9 & 4.7362 & TRN & \\
\hline CHEMBL3198951 & 688382 & 4.45 & 4.59699 & 99999999995 & TRN \\
\hline CHEMBL1300084 & 688382 & 4.45 & 4.7032 & TRN & \\
\hline CHEMBL602135 & 688382 & 4.45 & 4.6233 & TRN & \\
\hline CHEMBL1352102 & 688382 & 4.3 & 4.673 & TRN & \\
\hline CHEMBL580340 & 688382 & 4.25 & 4.617 & TRN & \\
\hline CHEMBL3189533 & 688382 & 6.0 & 4.6988 & TRN & \\
\hline CHEMBL1432266 & 688382 & 4.15 & 4.7819 & TRN & \\
\hline CHEMBL1577198 & 688382 & 5.05 & 4.7063 & TRN & \\
\hline CHEMBL1326194 & 688382 & 4.9 & 4.5866 & TRN & \\
\hline CHEMBL1334617 & 688382 & 4.75 & 4.6814 & TST & \\
\hline CHEMBL1339242 & 688382 & 4.45 & 4.6857 & TRN & \\
\hline CHEMBL1352934 & 688382 & 5.25 & 4.6795 & TRN & \\
\hline CHEMBL1607175 & 688382 & 4.05 & 4.6766 & TRN & \\
\hline CHEMBL1352290 & 688382 & 6.0 & 4.7414 & TRN & \\
\hline CHEMBL1444961 & 688382 & 5.05 & 4.6902 & TRN & \\
\hline CHEMBL1313599 & 688382 & 5.85 & 4.7683 & TRN & \\
\hline CHEMBL1405120 & 688382 & 4.8 & 4.6957 & TRN & \\
\hline CHEMBL1559324 & 688382 & 4.2 & 4.6656 & TRN & \\
\hline CHEMBL1369501 & 688382 & 4.4 & 4.7382 & TST & \\
\hline CHEMBL578285 & 688382 & 4.45 & 4.6132 & TST & \\
\hline CHEMBL1509741 & 688382 & 4.15 & 4.8079 & TST & \\
\hline CHEMBL1531161 & 688382 & 4.05 & 4.6977 & TRN & \\
\hline
\end{tabular}




\begin{tabular}{|c|c|c|c|c|}
\hline & & & pplement & $a \perp T a$ \\
\hline CHEMBL1308860 & 688382 & 4.5 & 4.7008 & TST \\
\hline CHEMBL3190461 & 688382 & 4.05 & 4.683 & TRN \\
\hline CHEMBL1455113 & 688382 & 4.5 & 4.6823 & TRN \\
\hline CHEMBL1348630 & 688382 & 4.4 & 4.649 & TRN \\
\hline CHEMBL1463614 & 688382 & 4.4 & 4.6812 & TRN \\
\hline CHEMBL1344873 & 688382 & 5.55 & 4.7805 & TRN \\
\hline CHEMBL1331637 & 688382 & 4.0 & 4.8151 & TRN \\
\hline CHEMBL1577612 & 688382 & 4.35 & 4.6705 & TRN \\
\hline CHEMBL1443839 & 688382 & 5.05 & 4.8001 & TRN \\
\hline CHEMBL1364626 & 688382 & 5.05 & 4.7584 & TRN \\
\hline CHEMBL1531287 & 688382 & 4.45 & 4.7077 & TST \\
\hline CHEMBL1350017 & 688382 & 4.75 & 4.6991 & TRN \\
\hline CHEMBL1429479 & 688382 & 4.35 & 4.652 & TRN \\
\hline CHEMBL3208173 & 688382 & 4.95 & 4.7075 & TST \\
\hline CHEMBL3197906 & 688382 & 5.1 & 4.6403 & TRN \\
\hline CHEMBL1333910 & 688382 & 4.3 & 4.7013 & TRN \\
\hline CHEMBL1489163 & 688382 & 4.5 & 4.7639 & TRN \\
\hline CHEMBL142816 & 688382 & 4.45 & 4.6374 & TST \\
\hline CHEMBL1584813 & 688382 & 4.25 & 4.7154 & TST \\
\hline CHEMBL1470388 & 688382 & 4.9 & 4.8205 & TRN \\
\hline CHEMBL1409059 & 688382 & 4.4 & 4.7089 & TRN \\
\hline CHEMBL1313291 & 688382 & 5.3 & 4.7083 & TRN \\
\hline CHEMBL3191909 & 688382 & 5.05 & 4.6689 & TRN \\
\hline CHEMBL1380823 & 688382 & 4.65 & 4.7308 & TST \\
\hline CHEMBL1538198 & 688382 & 4.45 & 4.6655 & TRN \\
\hline CHEMBL1990491 & 688382 & 4.5 & 4.6576 & TRN \\
\hline CHEMBL1385350 & 688382 & 4.75 & 4.5971 & TST \\
\hline CHEMBL1577302 & 688382 & 4.95 & 4.6495 & TRN \\
\hline CHEMBL1419585 & 688382 & 4.5 & 4.772 & TST \\
\hline CHEMBL1346693 & 688382 & 5.95 & 4.8237 & TRN \\
\hline CHEMBL1469411 & 688382 & 4.45 & 4.6563 & TST \\
\hline CHEMBL1507776 & 688382 & 4.35 & 4.6951 & TRN \\
\hline CHEMBL1393353 & 688382 & 4.4 & 4.756 & TST \\
\hline CHEMBL 2005729 & 688382 & 4.4 & 4.7163 & TST \\
\hline CHEMBL1410722 & 688382 & 4.8 & 4.7047 & TRN \\
\hline CHEMBL1559890 & 688382 & 5.45 & 4.6588 & TRN \\
\hline CHEMBL1508461 & 688382 & 4.6 & 4.6412 & TRN \\
\hline CHEMBL1389578 & 688382 & 4.15 & 4.6824 & TRN \\
\hline CHEMBL1345574 & 688382 & 4.15 & 4.7232 & TRN \\
\hline CHEMBL1575102 & 688382 & 4.15 & 4.6752 & TRN \\
\hline CHEMBL1464390 & 688382 & 4.85 & 4.6548 & TRN \\
\hline CHEMBL1352607 & 688382 & 5.0 & 4.6476 & TRN \\
\hline CHEMBL1541336 & 688382 & 4.45 & 4.6407 & TST \\
\hline CHEMBL1583503 & 688382 & 4.15 & 4.7001 & TRN \\
\hline CHEMBL1376472 & 688382 & 4.4 & 4.6531 & TST \\
\hline CHEMBL1612209 & 688382 & 4.8 & 4.8115 & TRN \\
\hline CHEMBL1461095 & 688382 & 4.75 & 4.7267 & TRN \\
\hline CHEMBL1561726 & 688382 & 4.5 & 4.6905 & TRN \\
\hline
\end{tabular}




\begin{tabular}{|c|c|c|c|c|c|}
\hline \multicolumn{6}{|c|}{ Supplemental Table S2.txt } \\
\hline CHEMBL1310857 & 688382 & 4.7 & 4.6458 & TRN & \\
\hline CHEMBL1311827 & 688382 & 4.8 & 4.76 & TST & \\
\hline CHEMBL1504042 & 688382 & 4.85 & 4.6802 & TRN & \\
\hline CHEMBL1568216 & 688382 & 4.2 & 4.7599 & TST & \\
\hline CHEMBL1580987 & 688382 & 5.0 & 4.7921 & TST & \\
\hline CHEMBL1532225 & 688382 & 4.25 & 4.7603 & TRN & \\
\hline CHEMBL1578360 & 688382 & 4.35 & 4.6732 & TRN & \\
\hline CHEMBL1543251 & 688382 & 5.0 & 4.65600 & 0000000001 & TRN \\
\hline CHEMBL1374564 & 688382 & 4.5 & 4.7522 & TRN & \\
\hline CHEMBL1511872 & 688382 & 4.2 & 4.6877 & TST & \\
\hline CHEMBL1373882 & 688382 & 4.45 & 4.6557 & TRN & \\
\hline CHEMBL1492648 & 688382 & 4.7 & 4.6672 & TRN & \\
\hline CHEMBL1476084 & 688382 & 4.4 & 4.6886 & TST & \\
\hline CHEMBL1494397 & 688382 & 4.0 & 4.6094 & TRN & \\
\hline CHEMBL1540486 & 688382 & 4.45 & 4.6969 & TRN & \\
\hline CHEMBL1563016 & 688382 & 5.05 & 4.7436 & TST & \\
\hline CHEMBL1301480 & 688382 & 4.4 & 4.606 & TRN & \\
\hline CHEMBL1479911 & 688382 & 6.6499 & 4.6842 & TST & \\
\hline CHEMBL1348121 & 688382 & 4.5 & 4.7806 & TST & \\
\hline CHEMBL1419450 & 688382 & 4.5 & 4.7374 & TST & \\
\hline CHEMBL1586898 & 688382 & 4.9 & 4.7715 & TRN & \\
\hline CHEMBL1344074 & 688382 & 4.8 & 4.6255 & TRN & \\
\hline CHEMBL1514785 & 688382 & 6.0 & 4.7197 & TRN & \\
\hline CHEMBL1415851 & 688382 & 5.1 & 4.6238 & TRN & \\
\hline CHEMBL1497054 & 688382 & 4.45 & 4.7567 & TRN & \\
\hline CHEMBL1979455 & 688382 & 5.05 & 4.6677 & TRN & \\
\hline CHEMBL1522786 & 688382 & 4.4 & 4.6663 & TRN & \\
\hline CHEMBL1597246 & 688382 & 4.95 & 4.7035 & TRN & \\
\hline CHEMBL1564313 & 688382 & 4.65 & 4.7511 & TST & \\
\hline CHEMBL1969492 & 688382 & 4.4 & 4.6049 & TST & \\
\hline CHEMBL1367813 & 688382 & 4.05 & 4.7463 & TRN & \\
\hline CHEMBL1573796 & 688382 & 4.5 & 4.7027 & TRN & \\
\hline CHEMBL1449746 & 688382 & 4.8 & 4.6804 & TRN & \\
\hline CHEMBL1468779 & 688382 & 4.65 & 4.7105 & TRN & \\
\hline CHEMBL1416242 & 688382 & 4.8 & 4.6279 & TST & \\
\hline CHEMBL1536153 & 688382 & 4.15 & 4.7002 & TRN & \\
\hline CHEMBL1404349 & 688382 & 4.15 & 4.6957 & TRN & \\
\hline CHEMBL3212041 & 688382 & 4.9 & 4.6876 & TRN & \\
\hline CHEMBL1495889 & 688382 & 4.5 & 4.8048 & TRN & \\
\hline CHEMBL1413116 & 688382 & 5.8 & 4.7648 & TRN & \\
\hline CHEMBL1460950 & 688382 & 5.8 & 4.738 & TRN & \\
\hline CHEMBL1342548 & 688382 & 4.4 & 4.6818 & TRN & \\
\hline CHEMBL1383546 & 688382 & 4.65 & 4.7117 & TRN & \\
\hline CHEMBL1254918 & 688382 & 4.45 & 4.6508 & TRN & \\
\hline CHEMBL1975679 & 688382 & 6.05 & 4.6484 & TST & \\
\hline CHEMBL398765 & 688382 & 5.15 & 4.7024 & TRN & \\
\hline CHEMBL3192762 & 688382 & 4.55 & 4.6141 & TRN & \\
\hline CHEMBL1532549 & 688382 & 5.5 & 4.6371 & TRN & \\
\hline
\end{tabular}




\begin{tabular}{|c|c|c|c|c|c|}
\hline \multicolumn{6}{|c|}{ Supplemental Table s2.txt } \\
\hline CHEMBL579102 & 688382 & 4.4 & 4.5955 & TST & \\
\hline CHEMBL1390878 & 688382 & 4.15 & 4.7466 & TST & \\
\hline CHEMBL1371202 & 688382 & 5.05 & 4.671 & TRN & \\
\hline CHEMBL1516897 & 688382 & 5.2 & 4.627 & TRN & \\
\hline CHEMBL3192998 & 688382 & 4.15 & 4.6841 & TST & \\
\hline CHEMBL1585475 & 688382 & 4.8 & 4.7219 & TRN & \\
\hline CHEMBL1480466 & 688382 & 5.05 & 4.7045 & TRN & \\
\hline CHEMBL1579575 & 688382 & 5.85 & 4.6744 & TRN & \\
\hline CHEMBL1323677 & 688382 & 4.95 & 4.7118 & TRN & \\
\hline CHEMBL1373173 & 688382 & 4.85 & 4.8037 & TRN & \\
\hline CHEMBL1484468 & 688382 & 4.5 & 4.758 & TRN & \\
\hline CHEMBL1546050 & 688382 & 6.05 & 4.8007 & TRN & \\
\hline CHEMBL1372723 & 688382 & 4.45 & 4.697 & TRN & \\
\hline CHEMBL1307314 & 688382 & 4.25 & 4.7509 & TRN & \\
\hline CHEMBL1556737 & 688382 & 4.4 & 4.6427 & TRN & \\
\hline CHEMBL1322906 & 688382 & 5.05 & 4.6314 & TST & \\
\hline CHEMBL1611657 & 688382 & 5.5 & 4.7846 & TRN & \\
\hline CHEMBL1344533 & 688382 & 4.5 & 4.6395 & TRN & \\
\hline CHEMBL1410352 & 688382 & 4.8 & 4.6463 & TRN & \\
\hline CHEMBL1392968 & 688382 & 5.15 & 4.6967 & TRN & \\
\hline CHEMBL1422397 & 688382 & 4.25 & 4.6401 & TRN & \\
\hline CHEMBL3191769 & 688382 & 4.5 & 4.6507 & TRN & \\
\hline CHEMBL1449901 & 688382 & 5.65 & 4.7005 & TRN & \\
\hline CHEMBL1550554 & 688382 & 4.45 & 4.6726 & TRN & \\
\hline CHEMBL1403239 & 688382 & 5.05 & 4.8341 & TRN & \\
\hline CHEMBL1531374 & 688382 & 4.9 & 4.7360 & 0000000001 & TST \\
\hline CHEMBL1896831 & 688382 & 5.0 & 4.6956 & TRN & \\
\hline CHEMBL1492810 & 688382 & 4.4 & 4.7163 & TST & \\
\hline CHEMBL3192702 & 688382 & 6.0 & 4.6765 & TRN & \\
\hline CHEMBL1409812 & 688382 & 5.05 & 4.7623 & TRN & \\
\hline CHEMBL1508897 & 688382 & 4.15 & 4.7543 & TRN & \\
\hline CHEMBL1514691 & 688382 & 4.55 & 4.6469 & TRN & \\
\hline CHEMBL1582702 & 688382 & 4.5 & 4.6838 & TRN & \\
\hline CHEMBL1438110 & 688382 & 4.4 & 4.7379 & TST & \\
\hline CHEMBL1303508 & 688382 & 4.7 & 4.6044 & TRN & \\
\hline CHEMBL1378309 & 688382 & 4.5 & 4.6812 & TRN & \\
\hline CHEMBL1444656 & 688382 & 6.0 & 4.6947 & TST & \\
\hline CHEMBL1449500 & 688382 & 4.3 & 4.7062 & TRN & \\
\hline CHEMBL1464446 & 688382 & 4.85 & 4.6979 & TRN & \\
\hline CHEMBL1608315 & 688382 & 4.45 & 4.7161 & TST & \\
\hline CHEMBL1467787 & 688382 & 4.8 & 4.6772 & TRN & \\
\hline CHEMBL1372672 & 688382 & 4.5 & 4.7354 & TRN & \\
\hline CHEMBL1987798 & 688382 & 4.65 & 4.5837 & TRN & \\
\hline CHEMBL1362940 & 688382 & 4.45 & 4.6011 & TRN & \\
\hline CHEMBL1466276 & 688382 & 2.3 & 4.7195 & TST & \\
\hline CHEMBL1525565 & 688382 & 4.5 & 4.6960 & 0000000001 & TST \\
\hline CHEMBL1406403 & 688382 & 4.75 & 4.817 & TRN & \\
\hline CHEMBL1556097 & 688382 & 4.85 & 4.7279 & TRN & \\
\hline
\end{tabular}




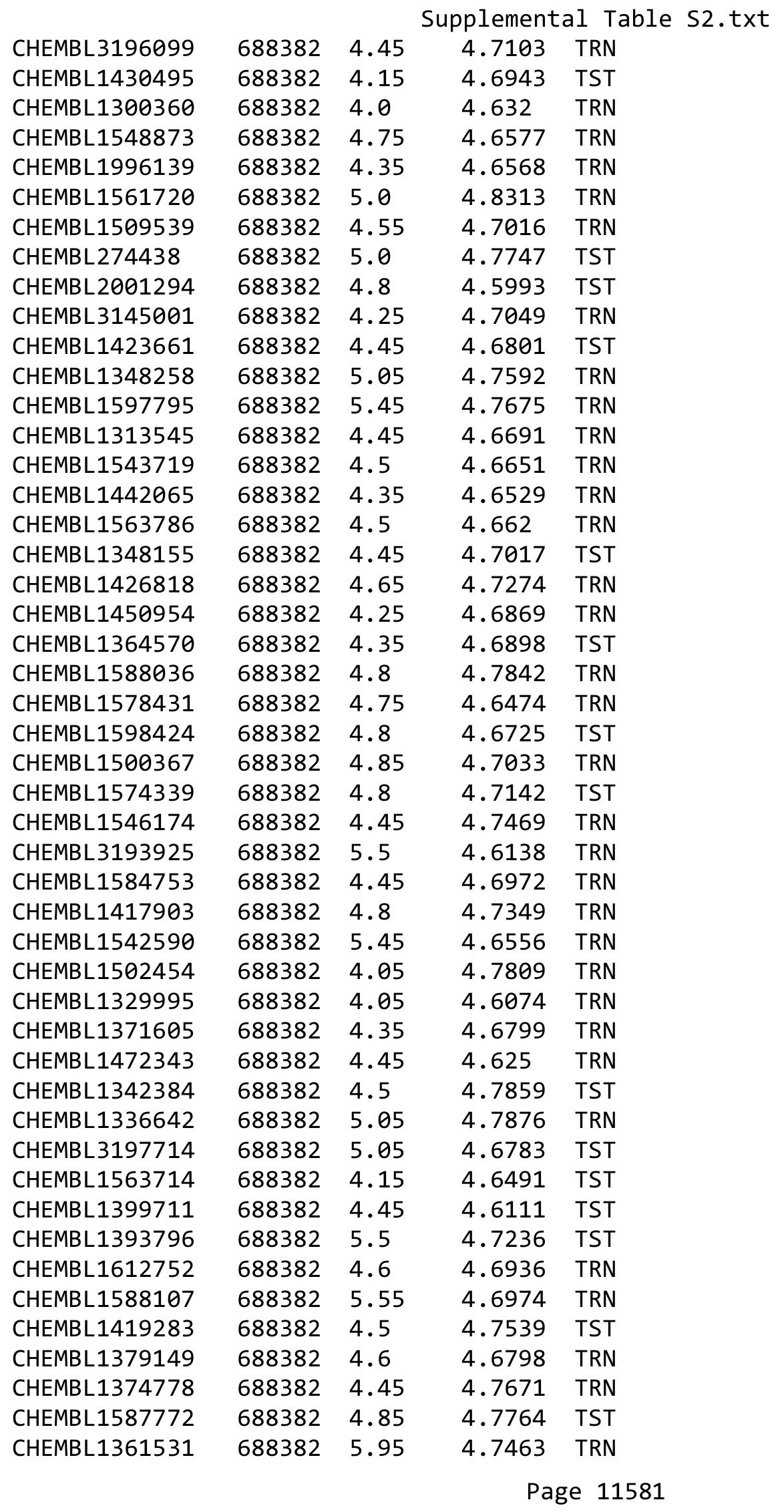




\begin{tabular}{|c|c|c|c|c|c|}
\hline & & \multicolumn{4}{|c|}{ Supplemental Table s2.txt } \\
\hline CHEMBL1482544 & 688382 & 4.85 & 4.7453 & TRN & \\
\hline CHEMBL 2002792 & 688382 & 4.35 & 4.7054 & TRN & \\
\hline CHEMBL1423198 & 688382 & 4.5 & 4.6682 & TRN & \\
\hline CHEMBL1986765 & 688382 & 4.45 & 4.6684 & TRN & \\
\hline CHEMBL1999700 & 688382 & 4.55 & 4.6154 & TRN & \\
\hline CHEMBL1549457 & 688382 & 4.35 & 4.7998 & TRN & \\
\hline CHEMBL1391776 & 688382 & 5.15 & 4.7571 & TRN & \\
\hline CHEMBL1360478 & 688382 & 5.2 & 4.6947 & TST & \\
\hline CHEMBL1373412 & 688382 & 4.55 & 4.6449 & TRN & \\
\hline CHEMBL1586232 & 688382 & 4.55 & 4.7238 & TRN & \\
\hline CHEMBL1522851 & 688382 & 4.35 & 4.73300 & 00000000005 & TRN \\
\hline CHEMBL1572848 & 688382 & 4.5 & 4.6844 & TRN & \\
\hline CHEMBL1532468 & 688382 & 5.4 & 4.797 & TRN & \\
\hline CHEMBL461579 & 688382 & 4.95 & 4.5899 & TST & \\
\hline CHEMBL1556840 & 688382 & 5.0 & 4.6937 & TST & \\
\hline CHEMBL1471413 & 688382 & 4.15 & 4.6905 & TST & \\
\hline CHEMBL1384262 & 688382 & 4.5 & 4.6778 & TRN & \\
\hline CHEMBL1309683 & 688382 & 4.55 & 4.6411 & TRN & \\
\hline CHEMBL1327810 & 688382 & 4.8 & 4.6685 & TST & \\
\hline CHEMBL1465850 & 688382 & 4.5 & 4.6339 & TST & \\
\hline CHEMBL77675 & 688382 & 4.5 & 4.6815 & TST & \\
\hline CHEMBL1527793 & 688382 & 4.05 & 4.7097 & TRN & \\
\hline CHEMBL3208214 & 688382 & 6.0 & 4.7377 & TRN & \\
\hline CHEMBL1499059 & 688382 & 3.95 & 4.7795 & TRN & \\
\hline CHEMBL1311740 & 688382 & 4.85 & 4.6613 & TST & \\
\hline CHEMBL1432420 & 688382 & 4.4 & 4.7247 & TRN & \\
\hline CHEMBL1605813 & 688382 & 4.35 & 4.5906 & TRN & \\
\hline CHEMBL1567792 & 688382 & 4.45 & 4.6522 & TRN & \\
\hline CHEMBL1455556 & 688382 & 4.2 & 4.6882 & TRN & \\
\hline CHEMBL1364934 & 688382 & 4.05 & 4.7296 & TRN & \\
\hline CHEMBL 2002824 & 688382 & 4.15 & 4.6018 & TST & \\
\hline CHEMBL1469895 & 688382 & 4.5 & 4.7451 & TRN & \\
\hline CHEMBL1334062 & 688382 & 4.5 & 4.5844 & TRN & \\
\hline CHEMBL1510245 & 688382 & 4.95 & 4.7336 & TRN & \\
\hline CHEMBL1530557 & 688382 & 5.0 & 4.7984 & TRN & \\
\hline CHEMBL1545835 & 688382 & 4.2 & 4.7594 & TST & \\
\hline CHEMBL1400182 & 688382 & 4.4 & 4.6752 & TRN & \\
\hline CHEMBL1595638 & 688382 & 5.75 & 4.7105 & TRN & \\
\hline CHEMBL1493703 & 688382 & 4.95 & 4.6749 & TST & \\
\hline CHEMBL1585812 & 688382 & 6.0 & 4.757 & TRN & \\
\hline CHEMBL1300932 & 688382 & 5.25 & 4.7566 & TST & \\
\hline CHEMBL1369922 & 688382 & 4.05 & 4.644 & TRN & \\
\hline CHEMBL1331772 & 688382 & 4.85 & 4.8098 & TRN & \\
\hline CHEMBL1507097 & 688382 & 5.1 & 4.6186 & TRN & \\
\hline CHEMBL1302522 & 688382 & 4.5 & 4.6976 & TRN & \\
\hline CHEMBL1368601 & 688382 & 4.5 & 4.65600 & 0000000001 & TST \\
\hline CHEMBL1336568 & 688382 & 4.8 & 4.8172 & TRN & \\
\hline CHEMBL1541755 & 688382 & 4.0 & 4.7489 & TST & \\
\hline
\end{tabular}




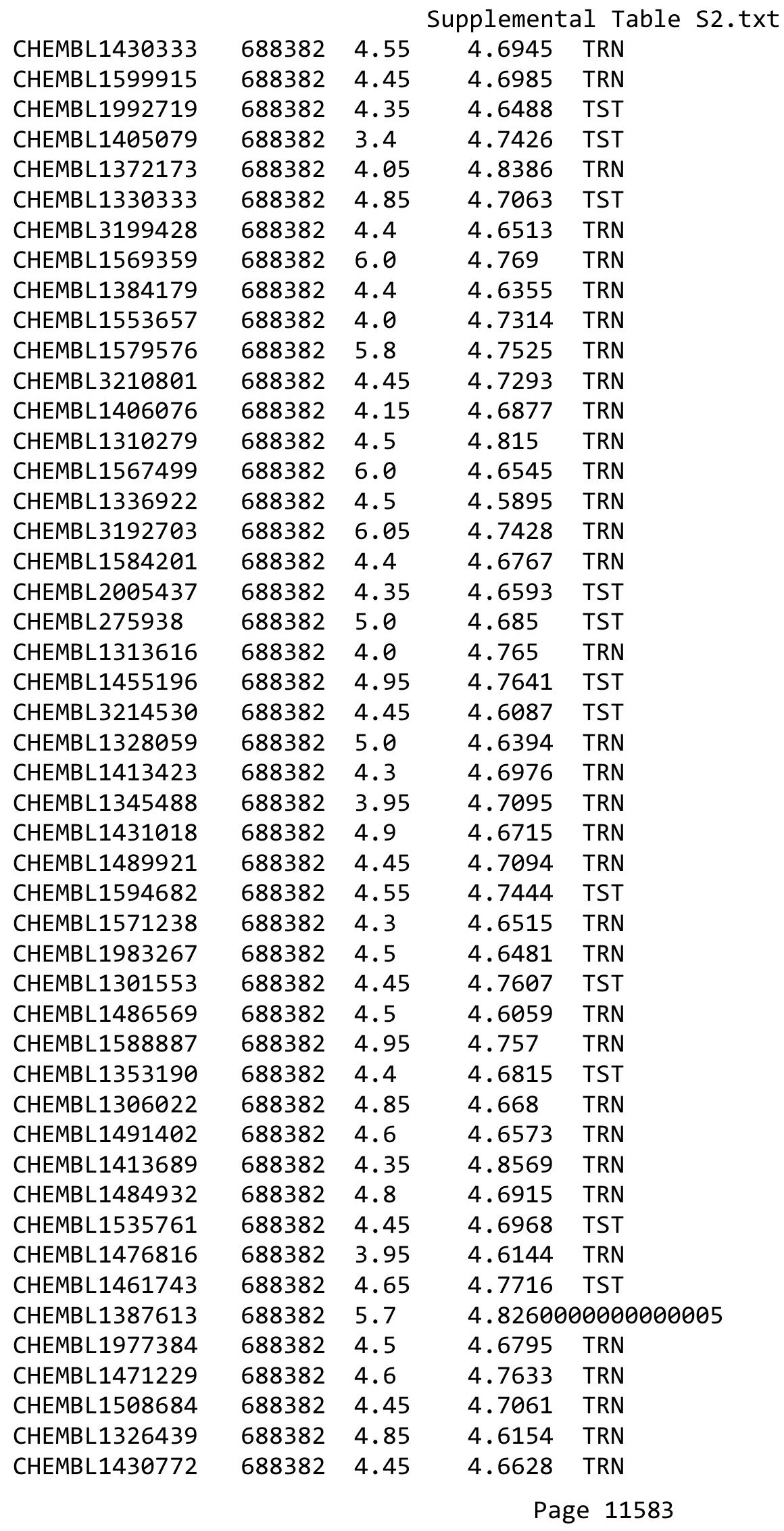

TRN 


\begin{tabular}{|c|c|c|c|c|c|}
\hline & & \multicolumn{4}{|c|}{ Supplemental Table S2.txt } \\
\hline CHEMBL1979243 & 688382 & 5.05 & 4.7054 & TRN & \\
\hline CHEMBL1571247 & 688382 & 4.8 & 4.751 & TRN & \\
\hline CHEMBL1334397 & 688382 & 4.15 & 4.7306 & TST & \\
\hline CHEMBL1570651 & 688382 & 4.15 & 4.7153 & TRN & \\
\hline CHEMBL1520090 & 688382 & 4.4 & 4.7688 & TRN & \\
\hline CHEMBL1405266 & 688382 & 5.9 & 4.7265 & TRN & \\
\hline CHEMBL1371086 & 688382 & 3.95 & 4.7355 & TRN & \\
\hline CHEMBL1538105 & 688382 & 4.5 & 4.6951 & TST & \\
\hline CHEMBL1499570 & 688382 & 4.85 & 4.73600 & 2000000001 & TRN \\
\hline CHEMBL1409601 & 688382 & 6.0 & 4.6853 & TRN & \\
\hline CHEMBL547304 & 688382 & 4.35 & 4.7769 & TRN & \\
\hline CHEMBL 3192423 & 688382 & 4.8 & 4.7028 & TST & \\
\hline CHEMBL1439036 & 688382 & 4.5 & 4.5822 & TST & \\
\hline CHEMBL1452186 & 688382 & 4.7 & 4.6409 & TRN & \\
\hline CHEMBL1335637 & 688382 & 4.4 & 4.6795 & TRN & \\
\hline CHEMBL1348774 & 688382 & 5.5 & 4.7556 & TRN & \\
\hline CHEMBL1459709 & 688382 & 5.2 & 4.7091 & TRN & \\
\hline CHEMBL1464645 & 688382 & 5.1 & 4.583 & TRN & \\
\hline CHEMBL1430175 & 688382 & 4.2 & 4.7108 & TRN & \\
\hline CHEMBL1422161 & 688382 & 4.65 & 4.729 & TRN & \\
\hline CHEMBL1470794 & 688382 & 4.75 & 4.7234 & TST & \\
\hline CHEMBL1516834 & 688382 & 4.2 & 4.6227 & TST & \\
\hline CHEMBL1578670 & 688382 & 4.85 & 4.6704 & TST & \\
\hline CHEMBL1361099 & 688382 & 4.7 & 4.7634 & TRN & \\
\hline CHEMBL1429070 & 688382 & 5.15 & 4.6082 & TRN & \\
\hline CHEMBL1392082 & 688382 & 4.6 & 4.7093 & TRN & \\
\hline CHEMBL1366104 & 688382 & 4.4 & 4.6789 & TST & \\
\hline CHEMBL1336697 & 688382 & 4.4 & 4.6935 & TRN & \\
\hline CHEMBL1401441 & 688382 & 5.0 & 4.7589 & TRN & \\
\hline CHEMBL1518374 & 688382 & 4.5 & 4.6912 & TRN & \\
\hline CHEMBL1351171 & 688382 & 4.95 & 4.6474 & TRN & \\
\hline CHEMBL1377948 & 688382 & 5.1 & 4.8548 & TST & \\
\hline CHEMBL1448405 & 688382 & 4.85 & 4.7174 & TRN & \\
\hline CHEMBL1529500 & 688382 & 4.75 & 4.6605 & TRN & \\
\hline CHEMBL1335316 & 688382 & 4.8 & 4.76 & TRN & \\
\hline CHEMBL1341440 & 688382 & 4.85 & 4.7303 & TST & \\
\hline CHEMBL 244683 & 688382 & 4.4 & 4.6852 & TRN & \\
\hline CHEMBL1405514 & 688382 & 6.0 & 4.7279 & TRN & \\
\hline CHEMBL1612052 & 688382 & 4.5 & 4.6685 & TRN & \\
\hline CHEMBL1567302 & 688382 & 4.75 & 4.7432 & TRN & \\
\hline CHEMBL1406794 & 688382 & 4.0 & 4.7226 & TRN & \\
\hline CHEMBL1322167 & 688382 & 4.75 & 4.6085 & TST & \\
\hline CHEMBL3195667 & 688382 & 5.45 & 4.6255 & TRN & \\
\hline CHEMBL601119 & 688382 & 5.2 & 4.628 & TRN & \\
\hline CHEMBL1385755 & 688382 & 5.1 & 4.7233 & TST & \\
\hline CHEMBL1503134 & 688382 & 4.45 & 4.6966 & TRN & \\
\hline CHEMBL1605791 & 688382 & 4.8 & 4.6282 & TST & \\
\hline CHEMBL1463694 & 688382 & 4.95 & 4.7554 & TRN & \\
\hline
\end{tabular}




\begin{tabular}{|c|c|c|c|c|}
\hline & & & ipplement & al Table S \\
\hline CHEMBL3189490 & 688382 & 5.9 & 4.6723 & TRN \\
\hline CHEMBL122314 & 688382 & 5.2 & 4.7086 & TRN \\
\hline CHEMBL1561191 & 688382 & 6.8 & 4.6258 & TRN \\
\hline CHEMBL1490734 & 688382 & 4.95 & 4.633 & TST \\
\hline CHEMBL1470099 & 688382 & 4.5 & 4.5811 & TRN \\
\hline CHEMBL1439190 & 688382 & 4.4 & 4.7198 & TST \\
\hline CHEMBL1554761 & 688382 & 6.0 & 4.628 & TST \\
\hline CHEMBL1323831 & 688382 & 4.15 & 4.6098 & TST \\
\hline CHEMBL1608855 & 688382 & 4.35 & 4.6873 & TST \\
\hline CHEMBL1426581 & 688382 & 4.45 & 4.6295 & TRN \\
\hline CHEMBL1419674 & 688382 & 5.85 & 4.752 & TST \\
\hline CHEMBL1542862 & 688382 & 4.5 & 4.6557 & TRN \\
\hline CHEMBL1400989 & 688382 & 5.2 & 4.6689 & TRN \\
\hline CHEMBL1444007 & 688382 & 4.95 & 4.7301 & TRN \\
\hline CHEMBL1370048 & 688382 & 5.05 & 4.635 & TRN \\
\hline CHEMBL1460522 & 688382 & 4.75 & 4.6377 & TRN \\
\hline CHEMBL1387426 & 688382 & 4.95 & 4.6579 & TRN \\
\hline CHEMBL1428409 & 688382 & 4.15 & 4.5846 & TST \\
\hline CHEMBL1560580 & 688382 & 4.3 & 4.6975 & TRN \\
\hline CHEMBL1481849 & 688382 & 4.9 & 4.7606 & TRN \\
\hline CHEMBL1328034 & 688382 & 5.15 & 4.73600 & 0000000001 \\
\hline CHEMBL1399704 & 688382 & 5.3 & 4.6153 & TST \\
\hline CHEMBL1435592 & 688382 & 4.55 & 4.6881 & TRN \\
\hline CHEMBL1465816 & 688382 & 4.85 & 4.8767 & TRN \\
\hline CHEMBL1328847 & 688382 & 4.45 & 4.7668 & TRN \\
\hline CHEMBL579742 & 688382 & 4.45 & 4.7533 & TRN \\
\hline CHEMBL1462454 & 688382 & 5.1 & 4.7154 & TRN \\
\hline CHEMBL1571682 & 688382 & 4.6 & 4.7406 & TRN \\
\hline CHEMBL1306199 & 688382 & 4.45 & 4.6526 & TRN \\
\hline CHEMBL1311158 & 688382 & 4.95 & 4.8342 & TRN \\
\hline CHEMBL1588870 & 688382 & 4.45 & 4.6637 & TRN \\
\hline CHEMBL3192966 & 688382 & 5.45 & 4.7457 & TST \\
\hline CHEMBL1404342 & 688382 & 4.95 & 4.7905 & TRN \\
\hline CHEMBL1301936 & 688382 & 4.0 & 4.7279 & TRN \\
\hline CHEMBL1382125 & 688382 & 4.8 & 4.621 & TST \\
\hline CHEMBL1321577 & 688382 & 4.45 & 4.7629 & TST \\
\hline CHEMBL1499913 & 688382 & 5.05 & 4.6928 & TRN \\
\hline CHEMBL1431221 & 688382 & 3.95 & 4.8604 & TRN \\
\hline CHEMBL1315948 & 688382 & 4.4 & 4.6321 & TRN \\
\hline CHEMBL3194919 & 688382 & 4.55 & 4.7034 & TRN \\
\hline CHEMBL1542892 & 688382 & 4.35 & 4.734 & TRN \\
\hline CHEMBL1519835 & 688382 & 4.15 & 4.6858 & TRN \\
\hline CHEMBL1371364 & 688382 & 4.5 & 4.7217 & TRN \\
\hline CHEMBL1336458 & 688382 & 4.0 & 4.7184 & TRN \\
\hline CHEMBL3209411 & 688382 & 5.5 & 4.6236 & TST \\
\hline CHEMBL1535999 & 688382 & 5.05 & 4.6409 & TST \\
\hline CHEMBL3213290 & 688382 & 4.45 & 4.6778 & TRN \\
\hline CHEMBL146710 & 688382 & 4.5 & 4.5919 & TST \\
\hline
\end{tabular}




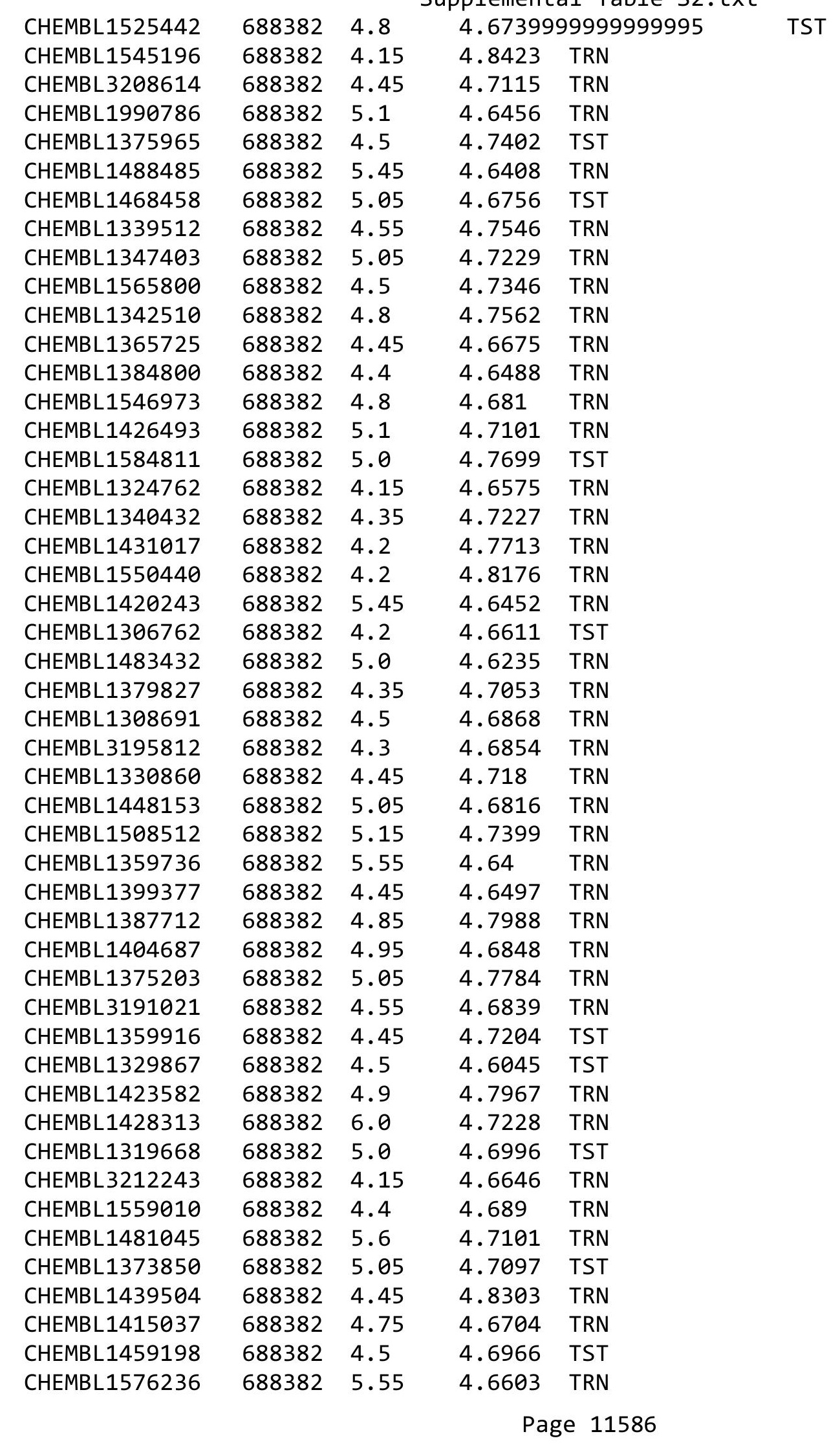




\begin{tabular}{|c|c|c|c|c|}
\hline \multicolumn{5}{|c|}{ Supplemental Table S2.txt } \\
\hline CHEMBL1535282 & 688382 & 4.45 & 4.7203 & TRN \\
\hline CHEMBL1344966 & 688382 & 4.45 & 4.6245 & TRN \\
\hline CHEMBL1324002 & 688382 & 4.35 & 4.6389 & TRN \\
\hline CHEMBL1442714 & 688382 & 4.5 & 4.6905 & TRN \\
\hline CHEMBL1551203 & 688382 & 4.55 & 4.694 & TRN \\
\hline CHEMBL270605 & 688382 & 4.85 & 4.6754 & TRN \\
\hline CHEMBL1313222 & 688382 & 4.45 & 4.7076 & TRN \\
\hline CHEMBL1589272 & 688382 & 4.85 & 4.6893 & TRN \\
\hline CHEMBL1427961 & 688382 & 4.15 & 4.6192 & TRN \\
\hline CHEMBL1525769 & 688382 & 4.5 & 4.6483 & TRN \\
\hline CHEMBL1309626 & 688382 & 4.9 & 4.7618 & TST \\
\hline CHEMBL1417813 & 688382 & 6.95 & 4.7884 & TRN \\
\hline CHEMBL1346556 & 688382 & 5.05 & 4.7991 & TRN \\
\hline CHEMBL1399048 & 688382 & 4.6 & 4.6198 & TRN \\
\hline CHEMBL1477122 & 688382 & 4.2 & 4.6482 & TRN \\
\hline CHEMBL1399792 & 688382 & 4.75 & 4.7408 & TRN \\
\hline CHEMBL1502664 & 688382 & 4.15 & 4.7763 & TRN \\
\hline CHEMBL1491222 & 688382 & 4.6 & 4.6933 & TRN \\
\hline CHEMBL1300722 & 688382 & 4.85 & 4.7579 & TRN \\
\hline CHEMBL1340320 & 688382 & 4.2 & 4.7592 & TRN \\
\hline CHEMBL3184468 & 688382 & 4.6 & 4.7379 & TST \\
\hline CHEMBL1349445 & 688382 & 4.05 & 4.7774 & TRN \\
\hline CHEMBL1565506 & 688382 & 4.6 & 4.6798 & TRN \\
\hline CHEMBL1587889 & 688382 & 5.05 & 4.8074 & TRN \\
\hline CHEMBL1597897 & 688382 & 5.9 & 4.726 & TRN \\
\hline CHEMBL1300601 & 688382 & 4.0 & $4.7410 e$ & 00000000005 \\
\hline CHEMBL1452640 & 688382 & 5.85 & 4.6993 & TRN \\
\hline CHEMBL1555992 & 688382 & 4.4 & 4.6751 & TRN \\
\hline CHEMBL3196577 & 688382 & 5.1 & 4.789 & TRN \\
\hline CHEMBL3199654 & 688382 & 4.3 & 4.6937 & TST \\
\hline CHEMBL1536575 & 688382 & 4.7 & 4.7578 & TRN \\
\hline CHEMBL3191874 & 688382 & 6.0 & 4.6774 & TRN \\
\hline CHEMBL1491888 & 688382 & 4.15 & 4.6842 & TRN \\
\hline CHEMBL1364729 & 688382 & 4.05 & 4.7428 & TST \\
\hline CHEMBL1426075 & 688382 & 4.05 & 4.8212 & TRN \\
\hline CHEMBL1586831 & 688382 & 4.0 & 4.8799 & TRN \\
\hline CHEMBL1311455 & 688382 & 4.35 & 4.6743 & TRN \\
\hline CHEMBL1588263 & 688382 & 4.3 & 4.6903 & TST \\
\hline CHEMBL1300488 & 688382 & 4.35 & 4.7172 & TRN \\
\hline CHEMBL3193391 & 688382 & 5.25 & 4.6285 & TST \\
\hline CHEMBL1448985 & 688382 & 4.9 & 4.6852 & TRN \\
\hline CHEMBL1382700 & 688382 & 4.8 & 4.713 & TST \\
\hline CHEMBL1312237 & 688382 & 4.4 & 4.7781 & TST \\
\hline CHEMBL1438365 & 688382 & 4.05 & 4.8182 & TRN \\
\hline CHEMBL1334412 & 688382 & 4.45 & 4.7268 & TRN \\
\hline CHEMBL1363491 & 688382 & 6.0 & 4.7286 & TST \\
\hline CHEMBL1459984 & 688382 & 4.15 & 4.7038 & TRN \\
\hline CHEMBL1317562 & 688382 & 5.2 & 4.8054 & TST \\
\hline
\end{tabular}




\begin{tabular}{|c|c|c|c|c|}
\hline \multicolumn{5}{|c|}{ Supplemental Table } \\
\hline CHEMBL1385226 & 688382 & 4.45 & 4.7712 & TRN \\
\hline CHEMBL1400949 & 688382 & 5.5 & 4.6069 & TST \\
\hline CHEMBL1482975 & 688382 & 4.15 & 4.7664 & TRN \\
\hline CHEMBL1519960 & 688382 & 4.15 & 4.6984 & TRN \\
\hline CHEMBL1480481 & 688382 & 5.0 & 4.7289 & TRN \\
\hline CHEMBL1484819 & 688382 & 4.5 & 4.699 & TST \\
\hline CHEMBL1393201 & 688382 & 4.8 & 4.7497 & TRN \\
\hline CHEMBL1301821 & 688382 & 4.45 & 4.7838 & TST \\
\hline CHEMBL1364900 & 688382 & 4.85 & 4.7112 & TRN \\
\hline CHEMBL1466257 & 688382 & 4.95 & 4.6923 & TST \\
\hline CHEMBL1405611 & 688382 & 4.05 & 4.6998 & TRN \\
\hline CHEMBL1368094 & 688382 & 4.15 & 4.7869 & TRN \\
\hline CHEMBL1409093 & 688382 & 4.35 & 4.75 & TRN \\
\hline CHEMBL1499431 & 688382 & 4.5 & 4.7243 & TST \\
\hline CHEMBL3191590 & 688382 & 4.15 & 4.623 & TRN \\
\hline CHEMBL1517496 & 688382 & 4.9 & 4.6721 & TRN \\
\hline CHEMBL1360628 & 688382 & 4.35 & 4.6953 & TRN \\
\hline CHEMBL1300028 & 688382 & 6.0 & 4.729 & TRN \\
\hline CHEMBL1490866 & 688382 & 4.45 & 4.7636 & TRN \\
\hline CHEMBL1555379 & 688382 & 6.0 & 4.7864 & TRN \\
\hline CHEMBL1341119 & 688382 & 4.45 & 4.7085 & TRN \\
\hline CHEMBL1403399 & 688382 & 4.8 & 4.6147 & TRN \\
\hline CHEMBL3191790 & 688382 & 4.45 & 4.7103 & TRN \\
\hline CHEMBL1485671 & 688382 & 4.45 & 4.6524 & TRN \\
\hline CHEMBL1428641 & 688382 & 5.0 & 4.7265 & TRN \\
\hline CHEMBL1313513 & 688382 & 4.85 & 4.7645 & TST \\
\hline CHEMBL1458100 & 688382 & 4.45 & 4.7531 & TRN \\
\hline CHEMBL1601129 & 688382 & 4.15 & 4.7715 & TRN \\
\hline CHEMBL1429555 & 688382 & 5.5 & 4.7925 & TRN \\
\hline CHEMBL1350392 & 688382 & 4.05 & 4.6981 & TRN \\
\hline CHEMBL1359173 & 688382 & 6.0 & 4.6759 & TST \\
\hline CHEMBL1469418 & 688382 & 4.35 & 4.754 & TRN \\
\hline CHEMBL1322068 & 688382 & 5.8 & 4.6878 & TST \\
\hline CHEMBL1412082 & 688382 & 4.4 & 4.7813 & TST \\
\hline CHEMBL1584416 & 688382 & 6.0 & 4.789 & TST \\
\hline CHEMBL50175 & 688382 & 5.15 & 4.6197 & TRN \\
\hline CHEMBL 1448770 & 688382 & 4.45 & 4.6866 & TRN \\
\hline CHEMBL1450827 & 688382 & 4.5 & 4.6257 & TRN \\
\hline CHEMBL1342181 & 688382 & 4.4 & 4.7134 & TRN \\
\hline CHEMBL1576216 & 688382 & 5.0 & 4.6735 & TRN \\
\hline CHEMBL1579886 & 688382 & 4.8 & 4.7831 & TRN \\
\hline CHEMBL1360256 & 688382 & 4.15 & 4.7444 & TRN \\
\hline CHEMBL1313150 & 688382 & 4.8 & 4.7014 & TST \\
\hline CHEMBL1501333 & 688382 & 6.05 & 4.7822 & TRN \\
\hline CHEMBL3207974 & 688382 & 4.05 & 4.6585 & TRN \\
\hline CHEMBL1600925 & 688382 & 4.45 & 4.6501 & TRN \\
\hline CHEMBL1514337 & 688382 & 6.05 & 4.7634 & TRN \\
\hline CHEMBL3197072 & 688382 & 4.5 & 4.6928 & TRN \\
\hline
\end{tabular}




\begin{tabular}{|c|c|c|c|c|c|}
\hline \multicolumn{6}{|c|}{ Supplemental Table S2.txt } \\
\hline CHEMBL17331 & 688382 & 4.3 & 4.6295 & TST & \\
\hline CHEMBL1532479 & 688382 & 4.4 & 4.6566 & TST & \\
\hline CHEMBL1340397 & 688382 & 4.45 & 4.5865 & TST & \\
\hline CHEMBL1560869 & 688382 & 4.15 & 4.796 & TRN & \\
\hline CHEMBL1441872 & 688382 & 4.8 & 4.7918 & TRN & \\
\hline CHEMBL1524986 & 688382 & 5.1 & 4.7349 & TRN & \\
\hline CHEMBL3191418 & 688382 & 4.75 & 4.7172 & TRN & \\
\hline CHEMBL1589526 & 688382 & 5.3 & 4.6373 & TRN & \\
\hline CHEMBL1492331 & 688382 & 4.4 & 4.6622 & TST & \\
\hline CHEMBL3198806 & 688382 & 6.0 & 4.6647 & TRN & \\
\hline CHEMBL1308873 & 688382 & 4.4 & 4.7126 & TRN & \\
\hline CHEMBL1587686 & 688382 & 5.5 & 4.6361 & TRN & \\
\hline CHEMBL1376361 & 688382 & 4.95 & 4.7979 & TRN & \\
\hline CHEMBL1349185 & 688382 & 4.5 & 4.7327 & TRN & \\
\hline CHEMBL1420642 & 688382 & 4.55 & 4.6427 & TST & \\
\hline CHEMBL1380440 & 688382 & 4.65 & 4.6589 & TRN & \\
\hline CHEMBL1347992 & 688382 & 4.4 & 4.648 & TRN & \\
\hline CHEMBL1480624 & 688382 & 4.8 & 4.8144 & TRN & \\
\hline CHEMBL1423298 & 688382 & 5.45 & 4.8059 & TRN & \\
\hline CHEMBL1589935 & 688382 & 5.05 & 4.6496 & TST & \\
\hline CHEMBL1311321 & 688382 & 4.45 & 4.7044 & TRN & \\
\hline CHEMBL1449136 & 688382 & 4.75 & 4.6348 & TRN & \\
\hline CHEMBL1376522 & 688382 & 5.05 & 4.6329 & TRN & \\
\hline CHEMBL1363771 & 688382 & 5.3 & 4.65300 & 00000000005 & TRN \\
\hline CHEMBL1325070 & 688382 & 5.2 & 4.6916 & TRN & \\
\hline CHEMBL1578253 & 688382 & 4.9 & 4.6919 & TRN & \\
\hline CHEMBL1363687 & 688382 & 4.05 & 4.7741 & TST & \\
\hline CHEMBL1333929 & 688382 & 4.35 & 4.6717 & TRN & \\
\hline CHEMBL1407301 & 688382 & 4.65 & 4.7006 & TRN & \\
\hline CHEMBL1519014 & 688382 & 5.25 & 4.6364 & TRN & \\
\hline CHEMBL1362863 & 688382 & 4.7 & 4.6864 & TRN & \\
\hline CHEMBL1415735 & 688382 & 4.8 & 4.6706 & TST & \\
\hline CHEMBL1492247 & 688382 & 5.05 & 4.7088 & TST & \\
\hline CHEMBL576407 & 688382 & 6.0 & 4.7684 & TRN & \\
\hline CHEMBL500996 & 688382 & 4.5 & 4.6825 & TRN & \\
\hline CHEMBL129795 & 688382 & 4.5 & 4.6557 & TRN & \\
\hline CHEMBL3208876 & 688382 & 5.5 & 4.6435 & TRN & \\
\hline CHEMBL1320955 & 688382 & 4.35 & 4.7759 & TRN & \\
\hline CHEMBL1443812 & 688382 & 4.55 & 4.6653 & TRN & \\
\hline CHEMBL1390159 & 688382 & 4.95 & 4.8558 & TRN & \\
\hline CHEMBL1414809 & 688382 & 4.85 & 4.652 & TRN & \\
\hline CHEMBL1566684 & 688382 & 4.4 & 4.6581 & TRN & \\
\hline CHEMBL1305827 & 688382 & 4.85 & 4.7588 & TRN & \\
\hline CHEMBL1509428 & 688382 & 3.95 & 4.7501 & TRN & \\
\hline CHEMBL1304440 & 688382 & 4.15 & 4.6203 & TST & \\
\hline CHEMBL1336895 & 688382 & 4.35 & 4.6949 & TRN & \\
\hline CHEMBL1353070 & 688382 & 4.8 & 4.7747 & TRN & \\
\hline CHEMBL1442271 & 688382 & 4.7 & 4.6611 & TRN & \\
\hline
\end{tabular}




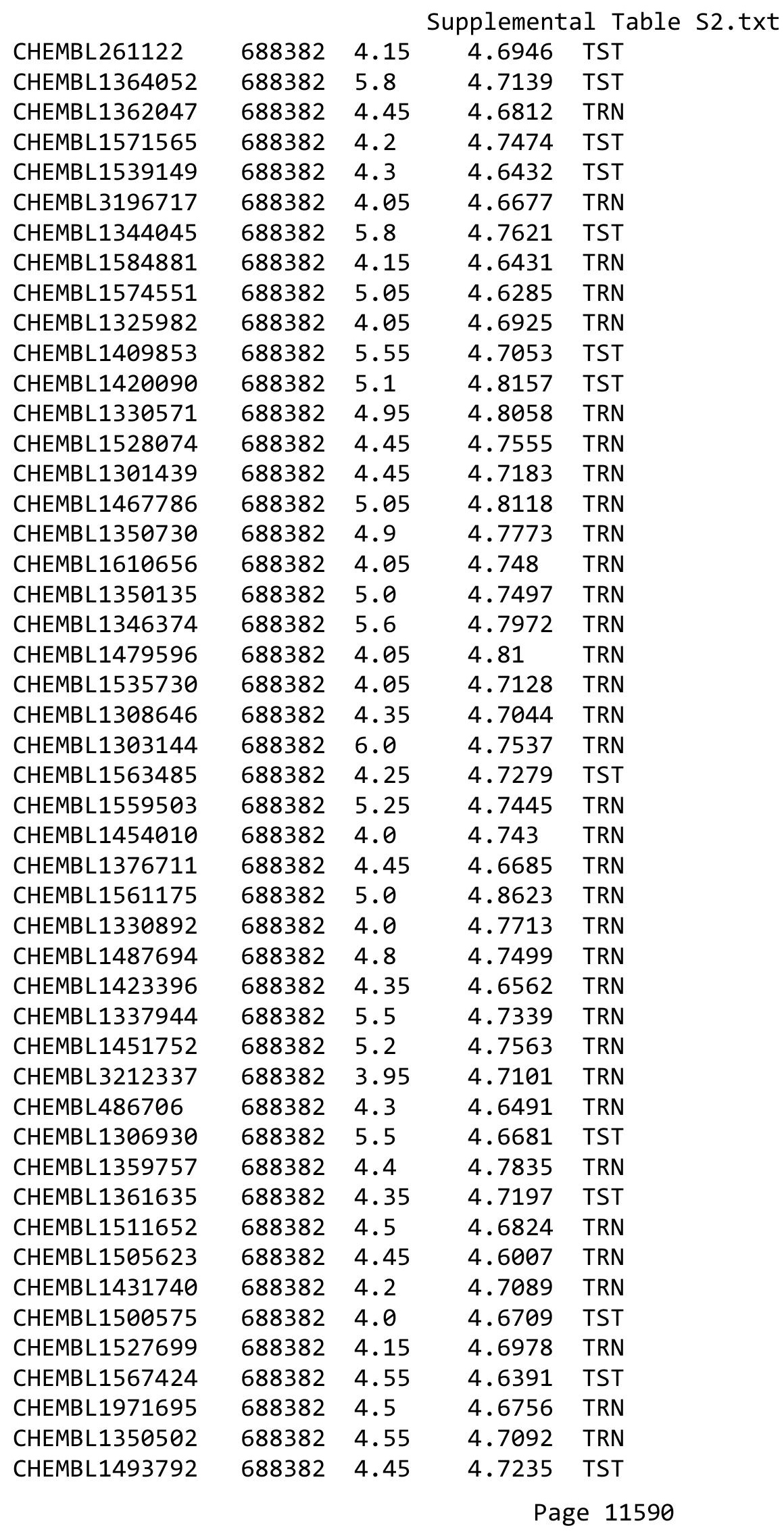




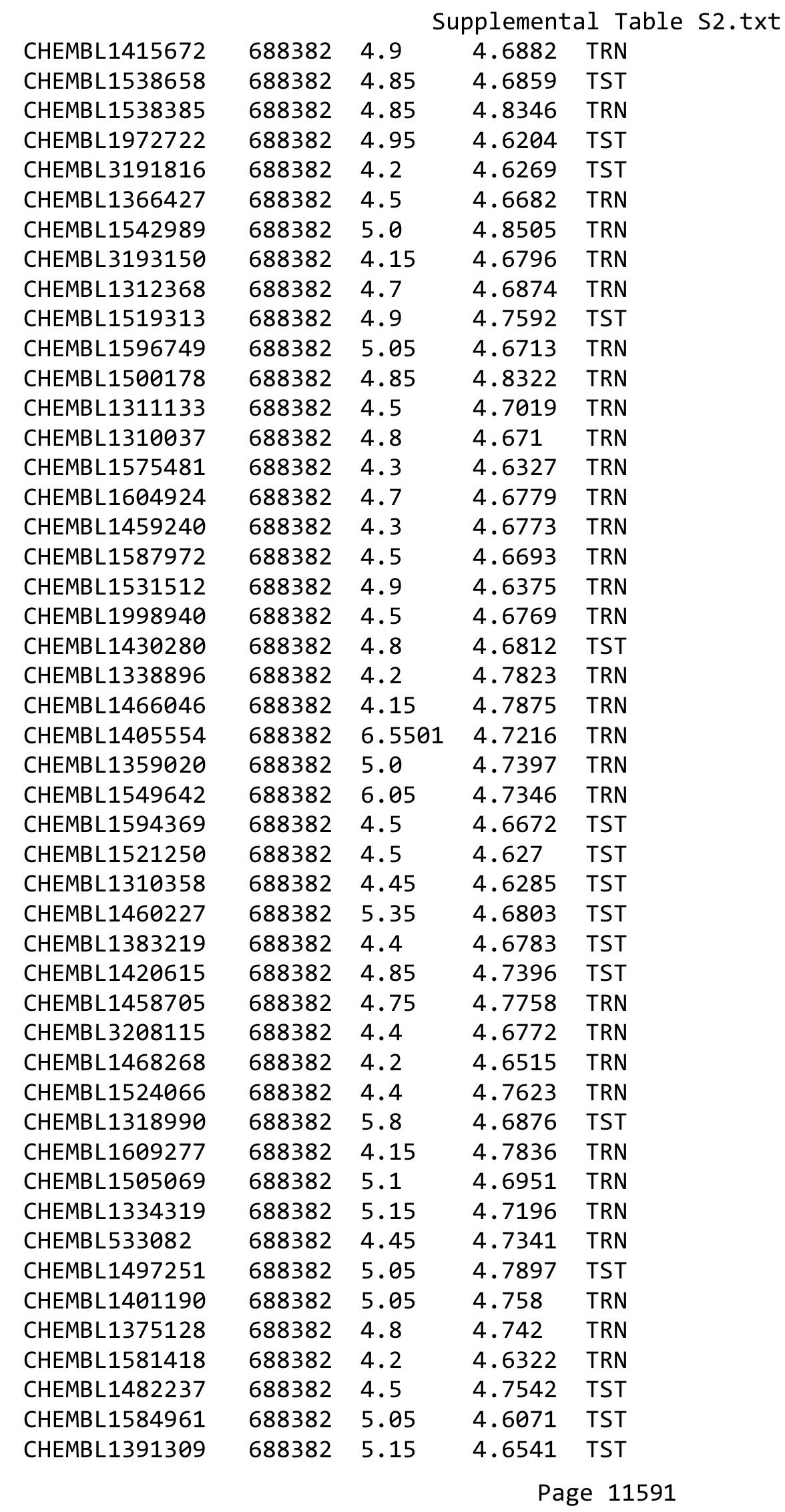




\begin{tabular}{|c|c|c|c|c|c|}
\hline & & \multicolumn{4}{|c|}{ Supplemental Table S2.txt } \\
\hline CHEMBL1572516 & 688382 & 5.05 & 4.6622 & TST & \\
\hline CHEMBL1548992 & 688382 & 4.5 & 4.6082 & TRN & \\
\hline CHEMBL1485340 & 688382 & 4.45 & 4.7309 & TST & \\
\hline CHEMBL1551135 & 688382 & 4.75 & 4.6714 & TRN & \\
\hline CHEMBL1342722 & 688382 & 4.8 & 4.7768 & TRN & \\
\hline CHEMBL1418682 & 688382 & 5.0 & 4.7402 & TRN & \\
\hline CHEMBL1332370 & 688382 & 4.95 & 4.6909 & TRN & \\
\hline CHEMBL1378294 & 688382 & 5.45 & 4.6224 & TST & \\
\hline CHEMBL1533603 & 688382 & 4.85 & 4.695 & TRN & \\
\hline CHEMBL1312487 & 688382 & 5.0 & 4.6947 & TST & \\
\hline CHEMBL1450562 & 688382 & 4.5 & 4.694 & TRN & \\
\hline CHEMBL1481034 & 688382 & 4.45 & 4.69300 & 00000000005 & TRN \\
\hline CHEMBL1390390 & 688382 & 4.85 & 4.76399 & 9999999999 & TRN \\
\hline CHEMBL1343292 & 688382 & 6.0 & 4.8659 & TRN & \\
\hline CHEMBL1613032 & 688382 & 4.5 & 4.74 & TST & \\
\hline CHEMBL1504678 & 688382 & 5.15 & 4.8298 & TRN & \\
\hline CHEMBL1544953 & 688382 & 4.2 & 4.6809 & TRN & \\
\hline CHEMBL1370019 & 688382 & 4.45 & 4.7778 & TRN & \\
\hline CHEMBL1566846 & 688382 & 5.0 & 4.6468 & TST & \\
\hline CHEMBL1358401 & 688382 & 4.05 & 4.6598 & TRN & \\
\hline CHEMBL1322761 & 688382 & 6.0 & 4.7141 & TRN & \\
\hline CHEMBL1562781 & 688382 & 4.45 & 4.7102 & TRN & \\
\hline CHEMBL1477785 & 688382 & 4.45 & 4.6428 & TRN & \\
\hline CHEMBL1305045 & 688382 & 4.85 & 4.7602 & TST & \\
\hline CHEMBL1380856 & 688382 & 4.1 & 4.6688 & TRN & \\
\hline CHEMBL1996426 & 688382 & 4.5 & 4.6639 & TST & \\
\hline CHEMBL1336689 & 688382 & 4.5 & 4.5868 & TST & \\
\hline CHEMBL1470101 & 688382 & 4.5 & 4.6806 & TST & \\
\hline CHEMBL1427106 & 688382 & 4.15 & 4.7865 & TRN & \\
\hline CHEMBL3194951 & 688382 & 4.45 & 4.6827 & TRN & \\
\hline CHEMBL1398073 & 688382 & 4.55 & 4.6208 & TRN & \\
\hline CHEMBL1429243 & 688382 & 4.0 & 4.6854 & TST & \\
\hline CHEMBL1411312 & 688382 & 4.95 & 4.8156 & TRN & \\
\hline CHEMBL1423461 & 688382 & 4.15 & 4.6414 & TRN & \\
\hline CHEMBL1541295 & 688382 & 4.45 & 4.709 & TST & \\
\hline CHEMBL1376551 & 688382 & 5.05 & 4.7018 & TRN & \\
\hline CHEMBL1571082 & 688382 & 5.5 & 4.7161 & TRN & \\
\hline CHEMBL1587999 & 688382 & 4.05 & 4.7199 & TST & \\
\hline CHEMBL1479038 & 688382 & 4.25 & 4.8562 & TRN & \\
\hline CHEMBL1349452 & 688382 & 5.0 & 4.7765 & TRN & \\
\hline CHEMBL1334615 & 688382 & 4.05 & 4.809 & TRN & \\
\hline CHEMBL1411770 & 688382 & 4.5 & 4.7047 & TRN & \\
\hline CHEMBL1597275 & 688382 & 6.0 & 4.7558 & TST & \\
\hline CHEMBL1406465 & 688382 & 4.95 & 4.7178 & TRN & \\
\hline CHEMBL3210989 & 688382 & 5.0 & 4.7168 & TST & \\
\hline CHEMBL1372044 & 688382 & 4.95 & 4.6898 & TST & \\
\hline CHEMBL1362762 & 688382 & 4.45 & 4.7092 & TRN & \\
\hline CHEMBL1497886 & 688382 & 5.35 & 4.8134 & TRN & \\
\hline
\end{tabular}




\begin{tabular}{|c|c|c|c|c|c|}
\hline \\
\hline CHEMBL1330679 & 688382 & 4.6 & 4.6349 & TST & \\
\hline CHEMBL1581423 & 688382 & 6.2 & 4.7836 & TST & \\
\hline CHEMBL1480675 & 688382 & 4.05 & 4.672 & TRN & \\
\hline CHEMBL1577151 & 688382 & 4.45 & 4.7456 & TRN & \\
\hline CHEMBL1548083 & 688382 & 5.05 & 4.6538 & TRN & \\
\hline CHEMBL1438538 & 688382 & 4.85 & 4.5986 & TRN & \\
\hline CHEMBL1544720 & 688382 & 4.3 & 4.8192 & TRN & \\
\hline CHEMBL1564480 & 688382 & 4.05 & 4.7882 & TRN & \\
\hline CHEMBL1498358 & 688382 & 4.65 & 4.8256 & TRN & \\
\hline CHEMBL1350495 & 688382 & 4.05 & 4.7001 & TRN & \\
\hline CHEMBL1386123 & 688382 & 4.7 & 4.7095 & TRN & \\
\hline CHEMBL1300564 & 688382 & 4.05 & 4.8335 & TRN & \\
\hline CHEMBL1500032 & 688382 & 4.4 & 4.6907 & TST & \\
\hline CHEMBL410063 & 688382 & 4.4 & 4.6994 & TST & \\
\hline CHEMBL1454988 & 688382 & 4.45 & 4.6848 & TRN & \\
\hline CHEMBL1575279 & 688382 & 4.95 & 4.6988 & TRN & \\
\hline CHEMBL1602384 & 688382 & 4.55 & 4.7576 & TRN & \\
\hline CHEMBL3198927 & 688382 & 5.45 & 4.6458 & TRN & \\
\hline CHEMBL1591589 & 688382 & 4.4 & 4.7327 & TRN & \\
\hline CHEMBL1979976 & 688382 & 4.45 & 4.7129 & TRN & \\
\hline CHEMBL1562794 & 688382 & 5.45 & 4.6821 & TRN & \\
\hline CHEMBL1457980 & 688382 & 5.0 & 4.7064 & TRN & \\
\hline CHEMBL3214379 & 688382 & 4.45 & 4.6825 & TRN & \\
\hline CHEMBL1431810 & 688382 & 4.7 & 4.6149 & TRN & \\
\hline CHEMBL1595248 & 688382 & 4.6 & 4.6905 & TRN & \\
\hline CHEMBL1341880 & 688382 & 4.85 & 4.7456 & TRN & \\
\hline CHEMBL1973501 & 688382 & 4.25 & 4.6851 & TRN & \\
\hline CHEMBL1550294 & 688382 & 4.8 & 4.6585 & TRN & \\
\hline CHEMBL1586256 & 688382 & 4.45 & 4.6645 & TRN & \\
\hline CHEMBL1564716 & 688382 & 5.1 & 4.694 & TRN & \\
\hline CHEMBL1392195 & 688382 & 4.2 & 4.7923 & TST & \\
\hline CHEMBL1493934 & 688382 & 5.8 & 4.6973 & TRN & \\
\hline CHEMBL1430250 & 688382 & 4.7 & 4.7062 & TST & \\
\hline CHEMBL3192270 & 688382 & 4.85 & 4.6326 & TRN & \\
\hline CHEMBL1596021 & 688382 & 4.5 & 4.6673 & TRN & \\
\hline CHEMBL1600875 & 688382 & 4.4 & 4.6993 & TST & \\
\hline CHEMBL1437887 & 688382 & 4.5 & 4.6834 & TRN & \\
\hline CHEMBL1504009 & 688382 & 4.3 & 4.6693 & TRN & \\
\hline CHEMBL1421446 & 688382 & 4.8 & 4.6921 & TRN & \\
\hline CHEMBL1988303 & 688382 & 4.2 & 4.6395 & TRN & \\
\hline CHEMBL1332886 & 688382 & 4.15 & 4.7049 & TST & \\
\hline CHEMBL1372721 & 688382 & 4.45 & 4.76699 & 99999999995 & TRN \\
\hline CHEMBL1598150 & 688382 & 4.6 & 4.6575 & TRN & \\
\hline CHEMBL1996714 & 688382 & 5.4 & 4.6435 & TRN & \\
\hline CHEMBL1385478 & 688382 & 5.0 & 4.7631 & TRN & \\
\hline CHEMBL1604160 & 688382 & 4.4 & 4.6706 & TST & \\
\hline CHEMBL1604735 & 688382 & 4.45 & 4.7709 & TRN & \\
\hline CHEMBL1504817 & 688382 & 4.95 & 4.6445 & TRN & \\
\hline & & & & 11593 & \\
\hline
\end{tabular}




\begin{tabular}{|c|c|c|c|c|c|}
\hline & & \multicolumn{4}{|c|}{ Supplemental Table s2.txt } \\
\hline CHEMBL1575188 & 688382 & 5.05 & 4.7403 & TST & \\
\hline CHEMBL1505025 & 688382 & 4.5 & 4.7138 & TRN & \\
\hline CHEMBL3207548 & 688382 & 4.2 & 4.6794 & TRN & \\
\hline CHEMBL583594 & 688382 & 4.85 & 4.762 & TST & \\
\hline CHEMBL1333810 & 688382 & 5.45 & 4.69 & TRN & \\
\hline CHEMBL1354168 & 688382 & 5.0 & 4.8503 & TRN & \\
\hline CHEMBL1388353 & 688382 & 5.5 & 4.6381 & TRN & \\
\hline CHEMBL1408321 & 688382 & 4.45 & 4.6948 & TRN & \\
\hline CHEMBL1570163 & 688382 & 5.05 & 4.6711 & TRN & \\
\hline CHEMBL1585048 & 688382 & 4.45 & 4.8307 & TST & \\
\hline CHEMBL1557057 & 688382 & 5.05 & 4.7438 & TRN & \\
\hline CHEMBL581870 & 688382 & 4.15 & 4.742 & TRN & \\
\hline CHEMBL1508256 & 688382 & 4.5 & 4.8635 & TST & \\
\hline CHEMBL1370611 & 688382 & 5.0 & 4.6066 & TST & \\
\hline CHEMBL1546750 & 688382 & 4.35 & 4.8118 & TRN & \\
\hline CHEMBL1347200 & 688382 & 4.35 & 4.6522 & TRN & \\
\hline CHEMBL1990694 & 688382 & 5.4 & 4.6691 & TRN & \\
\hline CHEMBL1563367 & 688382 & 4.4 & 4.6521 & TRN & \\
\hline CHEMBL1313476 & 688382 & 4.5 & 4.6611 & TST & \\
\hline CHEMBL1469866 & 688382 & 4.15 & 4.7288 & TRN & \\
\hline CHEMBL1578242 & 688382 & 4.5 & 4.7115 & TRN & \\
\hline CHEMBL1315029 & 688382 & 5.85 & 4.7301 & TST & \\
\hline CHEMBL1575877 & 688382 & 4.9 & 4.8399 & TRN & \\
\hline CHEMBL1483129 & 688382 & 4.5 & 4.6764 & TRN & \\
\hline CHEMBL1528717 & 688382 & 4.15 & 4.7931 & TST & \\
\hline CHEMBL1409733 & 688382 & 4.45 & 4.6998 & TST & \\
\hline CHEMBL1454878 & 688382 & 5.8 & 4.6359 & TRN & \\
\hline CHEMBL1465061 & 688382 & 6.0 & 4.7394 & TRN & \\
\hline CHEMBL1393520 & 688382 & 4.95 & 4.6656 & TRN & \\
\hline CHEMBL1432498 & 688382 & 4.55 & 4.7214 & TST & \\
\hline CHEMBL1491115 & 688382 & 5.1 & 4.7902 & TRN & \\
\hline CHEMBL1371180 & 688382 & 4.0 & 4.6483 & TST & \\
\hline CHEMBL1406923 & 688382 & 4.0 & 4.7286 & TRN & \\
\hline CHEMBL1530120 & 688382 & 4.45 & 4.6577 & TRN & \\
\hline CHEMBL1560051 & 688382 & 4.55 & 4.67899 & 9999999999 & TRN \\
\hline CHEMBL1450995 & 688382 & 4.55 & 4.6581 & TRN & \\
\hline CHEMBL1467194 & 688382 & 4.35 & 4.6558 & TST & \\
\hline CHEMBL1999911 & 688382 & 4.5 & 4.7763 & TRN & \\
\hline CHEMBL1502141 & 688382 & 4.55 & 4.6596 & TST & \\
\hline CHEMBL1340112 & 688382 & 5.05 & 4.7148 & TRN & \\
\hline CHEMBL1608338 & 688382 & 4.95 & 4.7284 & TST & \\
\hline CHEMBL1452351 & 688382 & 4.8 & 4.6492 & TST & \\
\hline CHEMBL1549392 & 688382 & 6.0 & 4.7214 & TRN & \\
\hline CHEMBL1423032 & 688382 & 4.55 & 4.6665 & TRN & \\
\hline CHEMBL1604831 & 688382 & 4.35 & 4.663 & TRN & \\
\hline CHEMBL1428408 & 688382 & 5.0 & 4.8302 & TRN & \\
\hline CHEMBL1446786 & 688382 & 4.8 & 4.7593 & TST & \\
\hline CHEMBL1529574 & 688382 & 4.25 & 4.7554 & TRN & \\
\hline
\end{tabular}




\begin{tabular}{|c|c|c|c|c|c|}
\hline & & \multicolumn{4}{|c|}{ Supplemental Table S2.txt } \\
\hline CHEMBL1564415 & 688382 & 5.2 & 4.8017 & TRN & \\
\hline CHEMBL1375949 & 688382 & 6.05 & 4.7211 & TRN & \\
\hline CHEMBL3193838 & 688382 & 4.45 & 4.6756 & TRN & \\
\hline CHEMBL1457811 & 688382 & 4.05 & 4.6079 & TST & \\
\hline CHEMBL3197122 & 688382 & 4.8 & 4.6846 & TRN & \\
\hline CHEMBL1401861 & 688382 & 4.95 & 4.8221 & TRN & \\
\hline CHEMBL3210341 & 688382 & 4.65 & 4.7484 & TST & \\
\hline CHEMBL1234751 & 688382 & 4.55 & 4.7603 & TST & \\
\hline CHEMBL1465169 & 688382 & 4.5 & 4.8282 & TRN & \\
\hline CHEMBL1301666 & 688382 & 5.85 & 4.6862 & TRN & \\
\hline CHEMBL3208795 & 688382 & 4.15 & 4.643 & TRN & \\
\hline CHEMBL1385680 & 688382 & 4.8 & 4.7482 & TST & \\
\hline CHEMBL1595121 & 688382 & 4.05 & 4.6008 & TRN & \\
\hline CHEMBL1345478 & 688382 & 5.05 & 4.7366 & TRN & \\
\hline CHEMBL1426053 & 688382 & 4.45 & 4.7104 & TRN & \\
\hline CHEMBL1420231 & 688382 & 4.85 & 4.7439 & TST & \\
\hline CHEMBL1549223 & 688382 & 4.35 & 4.763 & TRN & \\
\hline CHEMBL1543229 & 688382 & 4.35 & 4.6473 & TRN & \\
\hline CHEMBL1445496 & 688382 & 4.45 & 4.6836 & TST & \\
\hline CHEMBL1334389 & 688382 & 4.25 & 4.6608 & TST & \\
\hline CHEMBL1459453 & 688382 & 5.8 & 4.7586 & TRN & \\
\hline CHEMBL1483305 & 688382 & 5.0 & 4.7436 & TST & \\
\hline CHEMBL1489048 & 688382 & 4.85 & 4.746 & TRN & \\
\hline CHEMBL1523065 & 688382 & 4.75 & 4.761 & TST & \\
\hline CHEMBL1440703 & 688382 & 4.8 & 4.7127 & TST & \\
\hline CHEMBL1462492 & 688382 & 4.85 & 4.7555 & TST & \\
\hline CHEMBL1612014 & 688382 & 5.75 & 4.7235 & TRN & \\
\hline CHEMBL1600016 & 688382 & 6.0 & 4.7286 & TST & \\
\hline CHEMBL1438914 & 688382 & 4.45 & 4.6747 & TRN & \\
\hline CHEMBL1569933 & 688382 & 4.45 & 4.738 & TRN & \\
\hline CHEMBL1546371 & 688382 & 4.75 & 4.7384 & TRN & \\
\hline CHEMBL1407575 & 688382 & 4.05 & 4.67899 & 9999999999 & TRN \\
\hline CHEMBL1547501 & 688382 & 4.35 & 4.5613 & TRN & \\
\hline CHEMBL1541785 & 688382 & 5.45 & 4.689 & TST & \\
\hline CHEMBL1446234 & 688382 & 4.45 & 4.7711 & TRN & \\
\hline CHEMBL1416782 & 688382 & 4.55 & 4.6629 & TRN & \\
\hline CHEMBL1466978 & 688382 & 4.05 & 4.7045 & TST & \\
\hline CHEMBL1326856 & 688382 & 5.0 & 4.7286 & TRN & \\
\hline CHEMBL1399047 & 688382 & 4.5 & 4.7525 & TST & \\
\hline CHEMBL1370407 & 688382 & 4.85 & 4.8281 & TRN & \\
\hline CHEMBL1491049 & 688382 & 4.35 & 4.7544 & TRN & \\
\hline CHEMBL1387702 & 688382 & 5.65 & 4.7223 & TRN & \\
\hline CHEMBL1563539 & 688382 & 5.0 & 4.6628 & TRN & \\
\hline CHEMBL3209451 & 688382 & 5.0 & 4.6908 & TST & \\
\hline CHEMBL1360980 & 688382 & 5.2 & 4.6908 & TRN & \\
\hline CHEMBL1583108 & 688382 & 4.45 & 4.723 & TRN & \\
\hline CHEMBL1504600 & 688382 & 4.55 & 4.6474 & TST & \\
\hline CHEMBL1425525 & 688382 & 4.05 & 4.7126 & TRN & \\
\hline
\end{tabular}




\begin{tabular}{|c|c|c|c|c|c|}
\hline & & \multicolumn{4}{|c|}{ Supplemental Table s2.txt } \\
\hline CHEMBL1585211 & 688382 & 4.45 & 4.7788 & TRN & \\
\hline CHEMBL1309918 & 688382 & 4.95 & 4.7658 & TRN & \\
\hline CHEMBL1537503 & 688382 & 4.15 & 4.7091 & TST & \\
\hline CHEMBL1538108 & 688382 & 4.4 & 4.7854 & TRN & \\
\hline CHEMBL1417099 & 688382 & 4.4 & 4.6193 & TST & \\
\hline CHEMBL1549419 & 688382 & 5.05 & 4.6189 & TRN & \\
\hline CHEMBL1538335 & 688382 & 5.0 & 4.8923 & TRN & \\
\hline CHEMBL1539771 & 688382 & 5.8 & 4.7529 & TRN & \\
\hline CHEMBL1365770 & 688382 & 5.3 & 4.7712 & TRN & \\
\hline CHEMBL3191529 & 688382 & 4.5 & 4.6359 & TRN & \\
\hline CHEMBL1423286 & 688382 & 4.45 & 4.5769 & TRN & \\
\hline CHEMBL1345986 & 688382 & 5.05 & 4.7783 & TRN & \\
\hline CHEMBL1422453 & 688382 & 4.15 & 4.6635 & TRN & \\
\hline CHEMBL1511384 & 688382 & 6.0 & 4.6909 & TRN & \\
\hline CHEMBL1463893 & 688382 & 5.15 & 4.8166 & TRN & \\
\hline CHEMBL3210131 & 688382 & 4.3 & 4.6677 & TST & \\
\hline CHEMBL1391133 & 688382 & 4.4 & 4.7817 & TST & \\
\hline CHEMBL1341350 & 688382 & 4.2 & 4.6898 & TRN & \\
\hline CHEMBL3190261 & 688382 & 4.85 & 4.6538 & TRN & \\
\hline CHEMBL1419225 & 688382 & 5.55 & 4.7959 & TRN & \\
\hline CHEMBL1546470 & 688382 & 4.6 & 4.6266 & TRN & \\
\hline CHEMBL3191784 & 688382 & 4.85 & 4.6147 & TRN & \\
\hline CHEMBL1353562 & 688382 & 4.95 & 4.8372 & TRN & \\
\hline CHEMBL72365 & 688382 & 5.55 & 4.6331 & TST & \\
\hline CHEMBL1469840 & 688382 & 5.0 & 4.6706 & TRN & \\
\hline CHEMBL1508682 & 688382 & 4.45 & 4.7336 & TST & \\
\hline CHEMBL1391624 & 688382 & 5.8 & 4.6793 & TRN & \\
\hline CHEMBL1364137 & 688382 & 4.55 & 4.6316 & TRN & \\
\hline CHEMBL1555694 & 688382 & 5.1 & 4.6101 & TST & \\
\hline CHEMBL1468060 & 688382 & 4.2 & 4.7983 & TRN & \\
\hline CHEMBL1329902 & 688382 & 4.35 & 4.8056 & TRN & \\
\hline CHEMBL1543789 & 688382 & 4.5 & 4.6198 & TST & \\
\hline CHEMBL1389748 & 688382 & 4.5 & 4.6789 & TRN & \\
\hline CHEMBL1323163 & 688382 & 5.15 & 4.7098 & TRN & \\
\hline CHEMBL1539483 & 688382 & 4.5 & 4.6697 & TRN & \\
\hline CHEMBL1604161 & 688382 & 4.2 & 4.6945 & TRN & \\
\hline CHEMBL1440966 & 688382 & 4.25 & 4.7899 & TRN & \\
\hline CHEMBL1342622 & 688382 & 4.85 & 4.6208 & TRN & \\
\hline CHEMBL1400925 & 688382 & 4.3 & 4.5549 & TST & \\
\hline CHEMBL1472221 & 688382 & 4.55 & 4.7557 & TRN & \\
\hline CHEMBL1342886 & 688382 & 5.0 & 4.7208 & TRN & \\
\hline CHEMBL1474608 & 688382 & 4.55 & 4.7182 & TRN & \\
\hline CHEMBL1672292 & 688382 & 4.4 & 4.663 & TRN & \\
\hline CHEMBL1439773 & 688382 & 4.6 & 4.6447 & TRN & \\
\hline CHEMBL1570679 & 688382 & 4.8 & $4.7410 t$ & 00000000005 & TRN \\
\hline CHEMBL1555739 & 688382 & 4.5 & 4.6163 & TRN & \\
\hline CHEMBL1320246 & 688382 & 5.05 & 4.6544 & TST & \\
\hline CHEMBL1525141 & 688382 & 4.05 & 4.7136 & TRN & \\
\hline
\end{tabular}




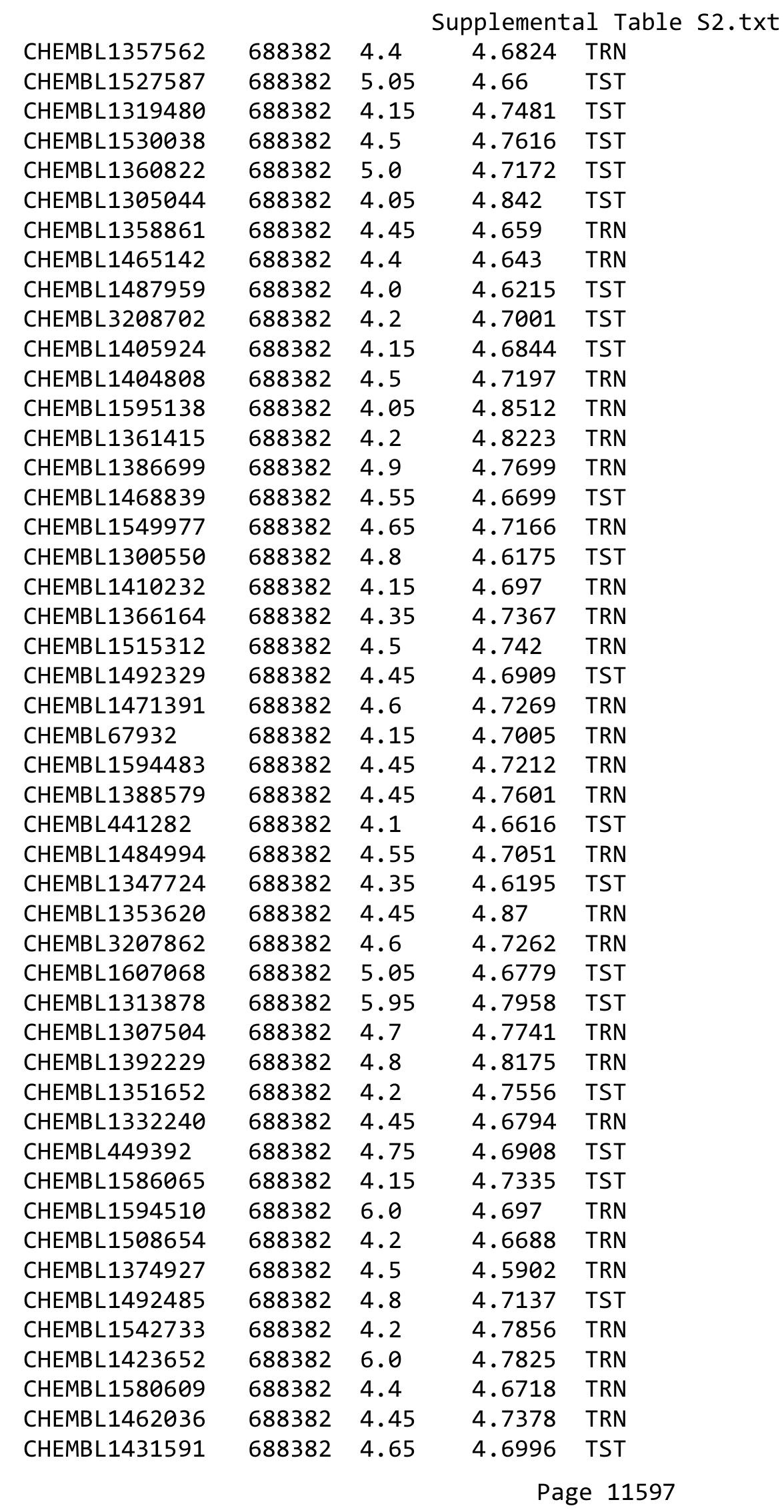




\begin{tabular}{|c|c|c|c|c|c|}
\hline & & \multicolumn{4}{|c|}{ Supplemental Table S2.txt } \\
\hline CHEMBL1392958 & 688382 & 4.85 & 4.7812 & TRN & \\
\hline CHEMBL1333725 & 688382 & 4.2 & 4.7208 & TRN & \\
\hline CHEMBL1425297 & 688382 & 4.55 & 4.6666 & TRN & \\
\hline CHEMBL1424411 & 688382 & 5.1 & 4.7795 & TRN & \\
\hline CHEMBL 1440180 & 688382 & 4.45 & 4.6676 & TST & \\
\hline CHEMBL1409748 & 688382 & 4.85 & 4.668 & TRN & \\
\hline CHEMBL1452943 & 688382 & 4.4 & 4.69300 & 00000000005 & TRN \\
\hline CHEMBL1312419 & 688382 & 4.45 & 4.6425 & TRN & \\
\hline CHEMBL1389672 & 688382 & 6.0 & 4.8008 & TRN & \\
\hline CHEMBL1598861 & 688382 & 4.8 & 4.7297 & TST & \\
\hline CHEMBL604119 & 688382 & 4.75 & 4.7277 & TST & \\
\hline CHEMBL1579899 & 688382 & 5.0 & 4.7319 & TRN & \\
\hline CHEMBL1387790 & 688382 & 4.15 & 4.6897 & TRN & \\
\hline CHEMBL1410740 & 688382 & 4.5 & 4.6422 & TRN & \\
\hline CHEMBL1467910 & 688382 & 4.05 & 4.6674 & TST & \\
\hline CHEMBL1586431 & 688382 & 5.95 & 4.8532 & TRN & \\
\hline CHEMBL1307546 & 688382 & 5.05 & 4.8201 & TRN & \\
\hline CHEMBL1366384 & 688382 & 5.8 & 4.6778 & TST & \\
\hline CHEMBL1336194 & 688382 & 4.4 & 4.7812 & TRN & \\
\hline CHEMBL1341027 & 688382 & 4.65 & 4.8217 & TST & \\
\hline CHEMBL1352068 & 688382 & 5.8 & 4.6966 & TST & \\
\hline CHEMBL1525721 & 688382 & 4.8 & 4.7749 & TRN & \\
\hline CHEMBL1349192 & 688382 & 4.15 & 4.7262 & TRN & \\
\hline CHEMBL1405218 & 688382 & 5.15 & 4.721 & TST & \\
\hline CHEMBL1535532 & 688382 & 4.35 & 4.67899 & 9999999999 & TRN \\
\hline CHEMBL1353726 & 688382 & 4.15 & 4.6948 & TRN & \\
\hline CHEMBL1499619 & 688382 & 5.45 & 4.7458 & TRN & \\
\hline CHEMBL1505157 & 688382 & 4.85 & 4.7612 & TST & \\
\hline CHEMBL1527031 & 688382 & 4.5 & 4.6771 & TST & \\
\hline CHEMBL1409667 & 688382 & 4.85 & 4.725 & TST & \\
\hline CHEMBL1408882 & 688382 & 4.5 & 4.8151 & TRN & \\
\hline CHEMBL1387299 & 688382 & 4.55 & 4.6685 & TST & \\
\hline CHEMBL1482914 & 688382 & 4.2 & 4.7503 & TRN & \\
\hline CHEMBL1377536 & 688382 & 5.55 & 4.7286 & TRN & \\
\hline CHEMBL1568374 & 688382 & 4.9 & 4.6381 & TRN & \\
\hline CHEMBL582317 & 688382 & 4.8 & 4.6844 & TRN & \\
\hline CHEMBL 1385798 & 688382 & 5.05 & 4.6567 & TRN & \\
\hline CHEMBL1501005 & 688382 & 4.85 & 4.6588 & TRN & \\
\hline CHEMBL1450734 & 688382 & 4.4 & 4.7095 & TRN & \\
\hline CHEMBL 3212008 & 688382 & 4.2 & 4.6656 & TRN & \\
\hline CHEMBL1401523 & 688382 & 5.0 & 4.7566 & TRN & \\
\hline CHEMBL1307084 & 688382 & 5.2 & 4.7186 & TRN & \\
\hline CHEMBL1435093 & 688382 & 5.5 & 4.7225 & TRN & \\
\hline CHEMBL1463043 & 688382 & 4.8 & 4.7266 & TST & \\
\hline CHEMBL1444013 & 688382 & 4.5 & 4.7278 & TRN & \\
\hline CHEMBL1983600 & 688382 & 4.6 & 4.7347 & TRN & \\
\hline CHEMBL1566022 & 688382 & 4.15 & 4.7099 & TRN & \\
\hline CHEMBL3191499 & 688382 & 4.4 & 4.6521 & TRN & \\
\hline
\end{tabular}




\begin{tabular}{|c|c|c|c|c|c|}
\hline \multicolumn{6}{|c|}{ Supplemental Table S2.txt } \\
\hline CHEMBL1497008 & 688382 & 4.95 & 4.706 & TST & \\
\hline CHEMBL1468409 & 688382 & 4.8 & 4.6788 & TRN & \\
\hline CHEMBL1399496 & 688382 & 4.6 & 4.7145 & TRN & \\
\hline CHEMBL1421587 & 688382 & 4.3 & 4.6431 & TRN & \\
\hline CHEMBL1487635 & 688382 & 4.8 & 4.6895 & TRN & \\
\hline CHEMBL1577616 & 688382 & 4.45 & 4.7098 & TRN & \\
\hline CHEMBL1381155 & 688382 & 4.35 & 4.6491 & TRN & \\
\hline CHEMBL1604083 & 688382 & 4.95 & 4.6127 & TRN & \\
\hline CHEMBL1431480 & 688382 & 4.15 & 4.7282 & TST & \\
\hline CHEMBL1425478 & 688382 & 4.8 & 4.6053 & TRN & \\
\hline CHEMBL1309430 & 688382 & 4.45 & 4.7697 & TRN & \\
\hline CHEMBL1531882 & 688382 & 4.9 & 4.6879 & TRN & \\
\hline CHEMBL1538293 & 688382 & 4.7 & 4.7094 & TRN & \\
\hline CHEMBL528506 & 688382 & 4.65 & 4.689 & TST & \\
\hline CHEMBL3190688 & 688382 & 6.5 & 4.6697 & TRN & \\
\hline CHEMBL1422369 & 688382 & 6.0 & 4.7219 & TRN & \\
\hline CHEMBL1411862 & 688382 & 4.45 & 4.6923 & TRN & \\
\hline CHEMBL1500453 & 688382 & 4.5 & 4.6528 & TST & \\
\hline CHEMBL1564354 & 688382 & 5.2 & 4.6381 & TRN & \\
\hline CHEMBL1381831 & 688382 & 4.15 & 4.684 & TST & \\
\hline CHEMBL3197156 & 688382 & 4.15 & 4.6588 & TST & \\
\hline CHEMBL1424983 & 688382 & 4.15 & 4.6759 & TRN & \\
\hline CHEMBL1601916 & 688382 & 5.05 & 4.6697 & TRN & \\
\hline CHEMBL1442170 & 688382 & 5.25 & 4.7187 & TRN & \\
\hline CHEMBL3211836 & 688382 & 5.0 & 4.667 & TRN & \\
\hline CHEMBL1384019 & 688382 & 4.1 & 4.7266 & TRN & \\
\hline CHEMBL1505757 & 688382 & 4.45 & 4.6421 & TRN & \\
\hline CHEMBL1527806 & 688382 & 4.75 & 4.6787 & TRN & \\
\hline CHEMBL1503705 & 688382 & 4.4 & 4.7581 & TRN & \\
\hline CHEMBL1410964 & 688382 & 4.7 & 4.7076 & TRN & \\
\hline CHEMBL1304296 & 688382 & 4.55 & 4.7066 & TRN & \\
\hline CHEMBL1974937 & 688382 & 4.55 & 4.6106 & TRN & \\
\hline CHEMBL1329140 & 688382 & 4.15 & 4.6788 & TRN & \\
\hline CHEMBL1611199 & 688382 & 5.25 & 4.6979 & TRN & \\
\hline CHEMBL1501625 & 688382 & 4.85 & 4.6428 & TRN & \\
\hline CHEMBL1431441 & 688382 & 4.4 & 4.7529 & TRN & \\
\hline CHEMBL1339446 & 688382 & 4.5 & 4.68 & TRN & \\
\hline CHEMBL1376888 & 688382 & 4.55 & 4.6465 & TST & \\
\hline CHEMBL1454775 & 688382 & 4.5 & 4.6482 & TRN & \\
\hline CHEMBL1444442 & 688382 & 4.45 & 4.6324 & TRN & \\
\hline CHEMBL1349884 & 688382 & 5.0 & 4.6697 & TRN & \\
\hline CHEMBL1376996 & 688382 & 4.5 & 4.7278 & TRN & \\
\hline CHEMBL1369310 & 688382 & 4.5 & 4.6886 & TRN & \\
\hline CHEMBL1557554 & 688382 & 4.4 & 4.67399 & 99999999995 & TRN \\
\hline CHEMBL1309397 & 688382 & 5.8 & 4.6401 & TST & \\
\hline CHEMBL1389473 & 688382 & 4.85 & 4.624 & TRN & \\
\hline CHEMBL3209615 & 688382 & 4.15 & 4.6722 & TST & \\
\hline CHEMBL1547321 & 688382 & 4.5 & 4.7191 & TRN & \\
\hline
\end{tabular}




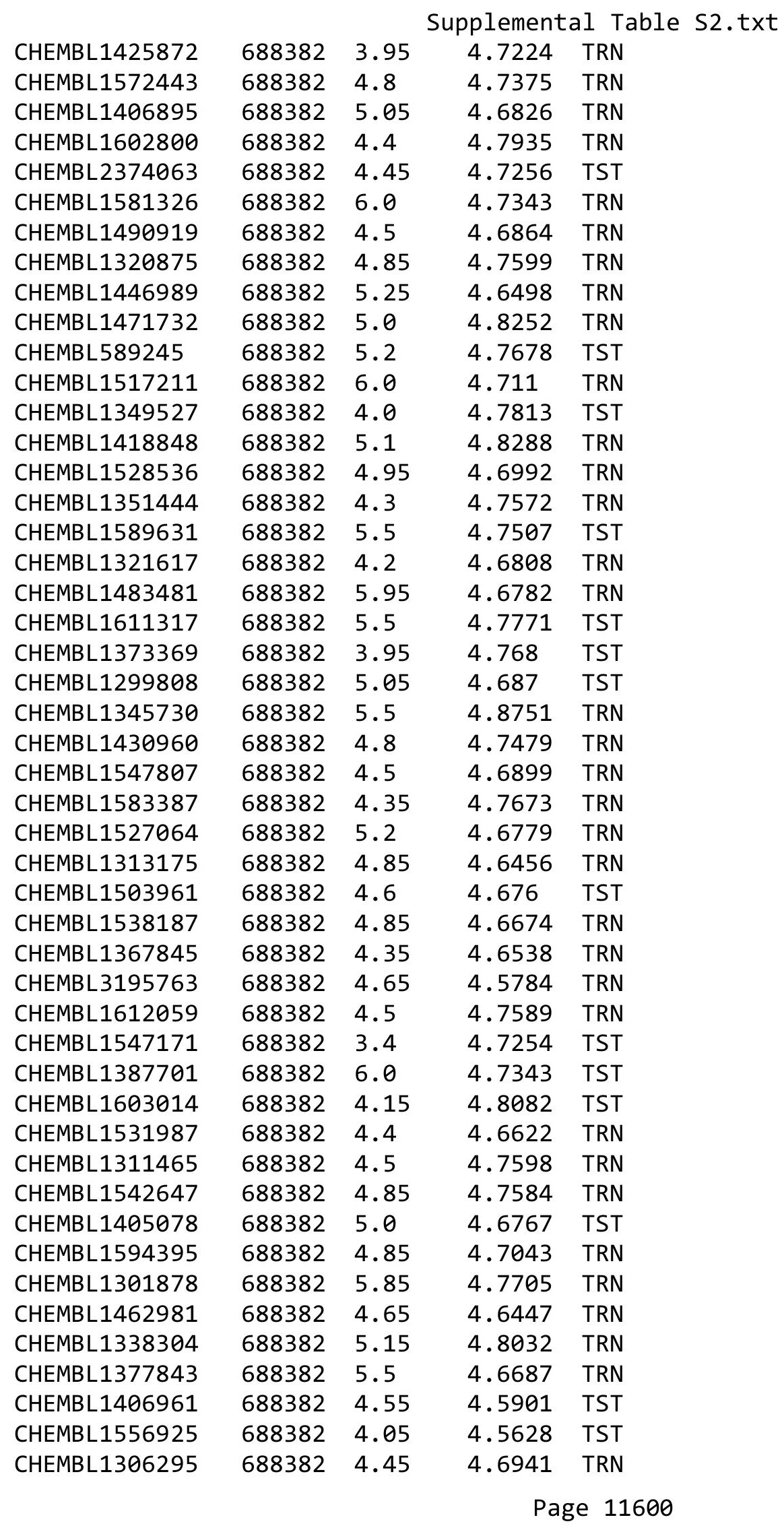




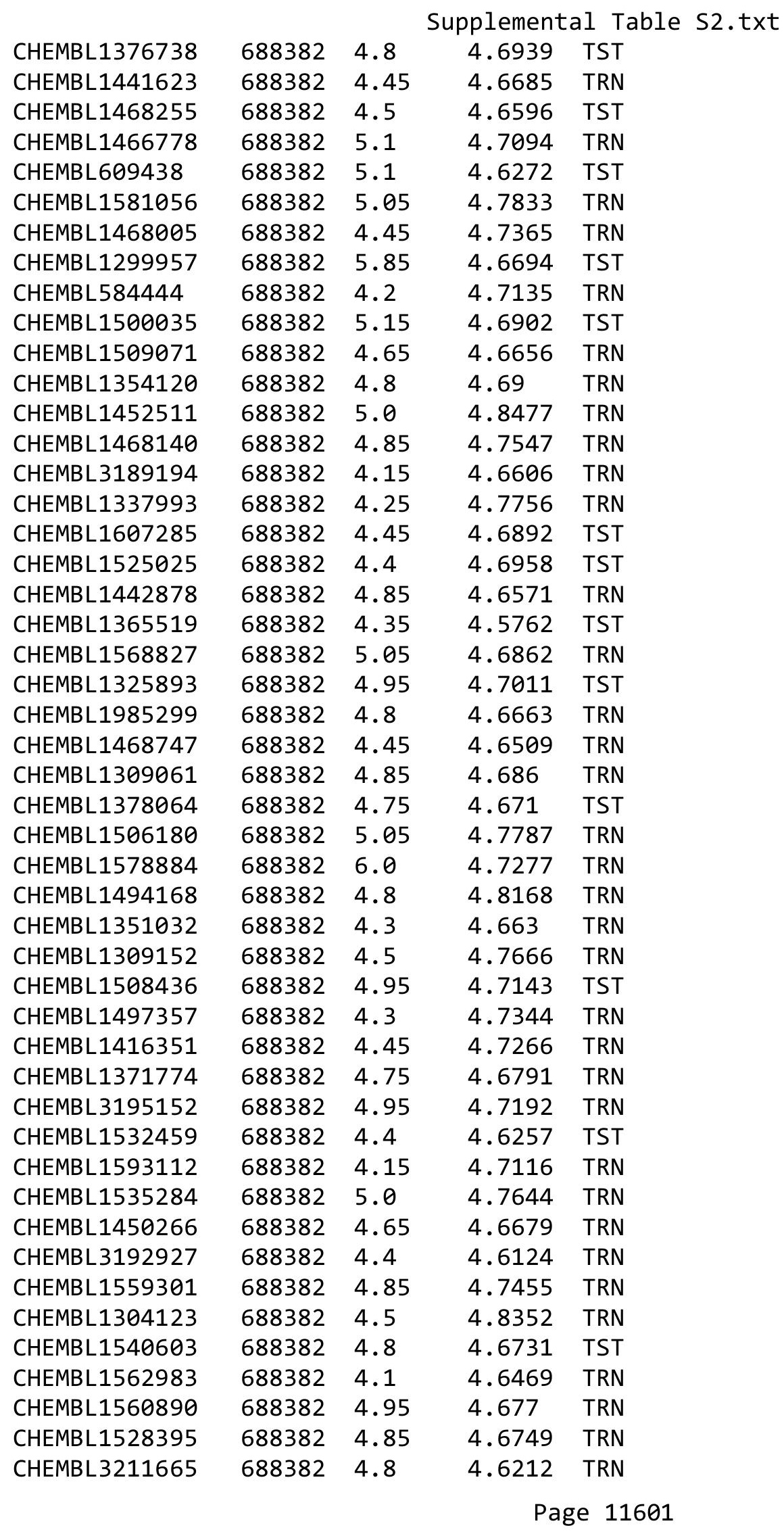




\begin{tabular}{|c|c|c|c|c|}
\hline \multicolumn{5}{|c|}{ Supplemental Table S2.txt } \\
\hline CHEMBL1594851 & 688382 & 4.55 & 4.7953 & TRN \\
\hline CHEMBL1424559 & 688382 & 5.15 & 4.6972 & TRN \\
\hline CHEMBL1581004 & 688382 & 4.85 & 4.7823 & TRN \\
\hline CHEMBL1340861 & 688382 & 4.4 & 4.7546 & TST \\
\hline CHEMBL1536397 & 688382 & 4.1 & 4.7152 & TRN \\
\hline CHEMBL1342132 & 688382 & 4.15 & 4.8344 & TST \\
\hline CHEMBL1465074 & 688382 & 4.4 & 4.6183 & TST \\
\hline CHEMBL1471806 & 688382 & 4.8 & 4.7855 & TRN \\
\hline CHEMBL1550089 & 688382 & 4.6 & 4.6834 & TRN \\
\hline CHEMBL1381286 & 688382 & 5.55 & 4.726 & TRN \\
\hline CHEMBL1556369 & 688382 & 4.95 & 4.7167 & TRN \\
\hline CHEMBL545050 & 688382 & 7.9508 & 4.742 & TST \\
\hline CHEMBL1970422 & 688382 & 5.85 & 4.7074 & TST \\
\hline CHEMBL1439022 & 688382 & 4.45 & 4.7127 & TST \\
\hline CHEMBL1510215 & 688382 & 5.15 & 4.7434 & TRN \\
\hline CHEMBL1306053 & 688382 & 4.35 & 4.734 & TRN \\
\hline CHEMBL1580581 & 688382 & 4.85 & 4.8099 & TRN \\
\hline CHEMBL1606437 & 688382 & 5.05 & 4.6955 & TRN \\
\hline CHEMBL 245264 & 688382 & 4.7 & 4.6922 & TRN \\
\hline CHEMBL1300389 & 688382 & 4.45 & 4.7028 & TRN \\
\hline CHEMBL1487074 & 688382 & 4.45 & 4.7186 & TRN \\
\hline CHEMBL1374061 & 688382 & 4.5 & 4.654 & TST \\
\hline CHEMBL1531863 & 688382 & 4.8 & 4.7441 & TST \\
\hline CHEMBL2003332 & 688382 & 4.15 & 4.6741 & TST \\
\hline CHEMBL1455407 & 688382 & 4.0 & 4.7713 & TRN \\
\hline CHEMBL1453859 & 688382 & 4.25 & 4.707 & TRN \\
\hline CHEMBL1459970 & 688382 & 5.5 & 4.7914 & TRN \\
\hline CHEMBL1458050 & 688382 & 5.2 & 4.7781 & TRN \\
\hline CHEMBL1383995 & 688382 & 4.35 & 4.6908 & TRN \\
\hline CHEMBL1497276 & 688382 & 4.85 & 4.6939 & TRN \\
\hline CHEMBL1507424 & 688382 & 4.8 & 4.7517 & TRN \\
\hline CHEMBL1366599 & 688382 & 4.4 & 4.6767 & TRN \\
\hline CHEMBL1330811 & 688382 & 4.4 & 4.644 & TRN \\
\hline CHEMBL1481420 & 688382 & 5.85 & 4.6731 & TRN \\
\hline CHEMBL1368000 & 688382 & 6.0 & 4.7501 & TRN \\
\hline CHEMBL1541861 & 688382 & 5.2 & 4.6072 & TRN \\
\hline CHEMBL1409207 & 688382 & 4.45 & 4.6482 & TRN \\
\hline CHEMBL1360676 & 688382 & 4.15 & 4.7158 & TRN \\
\hline CHEMBL2001631 & 688382 & 4.15 & 4.6682 & TRN \\
\hline CHEMBL1550522 & 688382 & 4.25 & 4.8138 & TRN \\
\hline CHEMBL3211243 & 688382 & 5.15 & 4.6788 & TRN \\
\hline CHEMBL1369154 & 688382 & 4.45 & 4.6646 & TRN \\
\hline CHEMBL1369361 & 688382 & 4.95 & 4.7009 & TRN \\
\hline CHEMBL1587271 & 688382 & 4.8 & 4.8049 & TST \\
\hline CHEMBL1443259 & 688382 & 4.8 & 4.7005 & TRN \\
\hline CHEMBL1470327 & 688382 & 4.05 & 4.6952 & TRN \\
\hline CHEMBL1344259 & 688382 & 5.0 & 4.6904 & TST \\
\hline CHEMBL1456198 & 688382 & 4.5 & 4.6854 & TRN \\
\hline
\end{tabular}




\begin{tabular}{|c|c|c|c|c|}
\hline \multicolumn{5}{|c|}{ Supplemental Table S2.txt } \\
\hline CHEMBL1593531 & 688382 & 5.05 & 4.7219 & TST \\
\hline CHEMBL600298 & 688382 & 3.95 & 4.6992 & TRN \\
\hline CHEMBL1998521 & 688382 & 4.9 & 4.6183 & TRN \\
\hline CHEMBL1477276 & 688382 & 4.15 & 4.7242 & TST \\
\hline CHEMBL1329915 & 688382 & 4.25 & 4.6836 & TRN \\
\hline CHEMBL1348424 & 688382 & 4.4 & 4.6937 & TRN \\
\hline CHEMBL1487921 & 688382 & 4.2 & 4.6405 & TRN \\
\hline CHEMBL1432382 & 688382 & 4.5 & 4.6517 & TST \\
\hline CHEMBL1495991 & 688382 & 4.95 & 4.7414 & TST \\
\hline CHEMBL3195117 & 688382 & 4.6 & 4.5958 & TRN \\
\hline CHEMBL2001396 & 688382 & 5.2 & 4.6286 & TRN \\
\hline CHEMBL1553272 & 688382 & 4.05 & 4.6478 & TRN \\
\hline CHEMBL1452671 & 688382 & 4.65 & 4.6809 & TRN \\
\hline CHEMBL1518723 & 688382 & 4.2 & 4.7059 & TRN \\
\hline CHEMBL1537648 & 688382 & 4.95 & 4.7921 & TRN \\
\hline CHEMBL1303565 & 688382 & 4.45 & 4.6808 & TRN \\
\hline CHEMBL1306708 & 688382 & 4.45 & 4.6665 & TRN \\
\hline CHEMBL1606059 & 688382 & 4.8 & 4.7424 & TRN \\
\hline CHEMBL1549289 & 688382 & 3.95 & 4.7366 & TST \\
\hline CHEMBL1468692 & 688382 & 4.9 & 4.6608 & TRN \\
\hline CHEMBL1510189 & 688382 & 3.95 & 4.6868 & TRN \\
\hline CHEMBL1503562 & 688382 & 4.45 & 4.6492 & TRN \\
\hline CHEMBL3191651 & 688382 & 4.8 & 4.6065 & TRN \\
\hline CHEMBL1598890 & 688382 & 4.8 & 4.76 & TRN \\
\hline CHEMBL306946 & 688382 & 4.5 & 4.628 & TRN \\
\hline CHEMBL1341410 & 688382 & 6.0 & 4.7869 & TRN \\
\hline CHEMBL1488248 & 688382 & 4.35 & 4.7255 & TRN \\
\hline CHEMBL1603646 & 688382 & 4.6 & 4.7072 & TRN \\
\hline CHEMBL1480590 & 688382 & 4.45 & 4.7496 & TRN \\
\hline CHEMBL1426405 & 688382 & 4.8 & 4.6889 & TRN \\
\hline CHEMBL1463401 & 688382 & 5.0 & 4.6778 & TST \\
\hline CHEMBL1306782 & 688382 & 4.4 & 4.6734 & TRN \\
\hline CHEMBL1331446 & 688382 & 4.5 & 4.612 & TRN \\
\hline CHEMBL1355735 & 688382 & 4.25 & 4.6868 & TST \\
\hline CHEMBL1323394 & 688382 & 6.0 & 4.7388 & TRN \\
\hline CHEMBL1602364 & 688382 & 4.8 & 4.7675 & TRN \\
\hline CHEMBL1408466 & 688382 & 4.45 & 4.8068 & TRN \\
\hline CHEMBL1988042 & 688382 & 4.6 & 4.6672 & TRN \\
\hline CHEMBL1371414 & 688382 & 4.85 & 4.7083 & TRN \\
\hline CHEMBL1308904 & 688382 & 4.5 & 4.6349 & TRN \\
\hline CHEMBL1568890 & 688382 & 4.6 & 4.7519 & TRN \\
\hline CHEMBL1575284 & 688382 & 4.45 & 4.7169 & TST \\
\hline CHEMBL1427346 & 688382 & 4.85 & 4.7511 & TRN \\
\hline CHEMBL1302149 & 688382 & 4.35 & 4.7312 & TRN \\
\hline CHEMBL1544730 & 688382 & 6.1 & 4.7947 & TRN \\
\hline CHEMBL1479119 & 688382 & 5.05 & 4.6689 & TRN \\
\hline CHEMBL1399873 & 688382 & 4.15 & 4.6424 & TRN \\
\hline CHEMBL3208762 & 688382 & 4.85 & 4.6838 & TRN \\
\hline
\end{tabular}




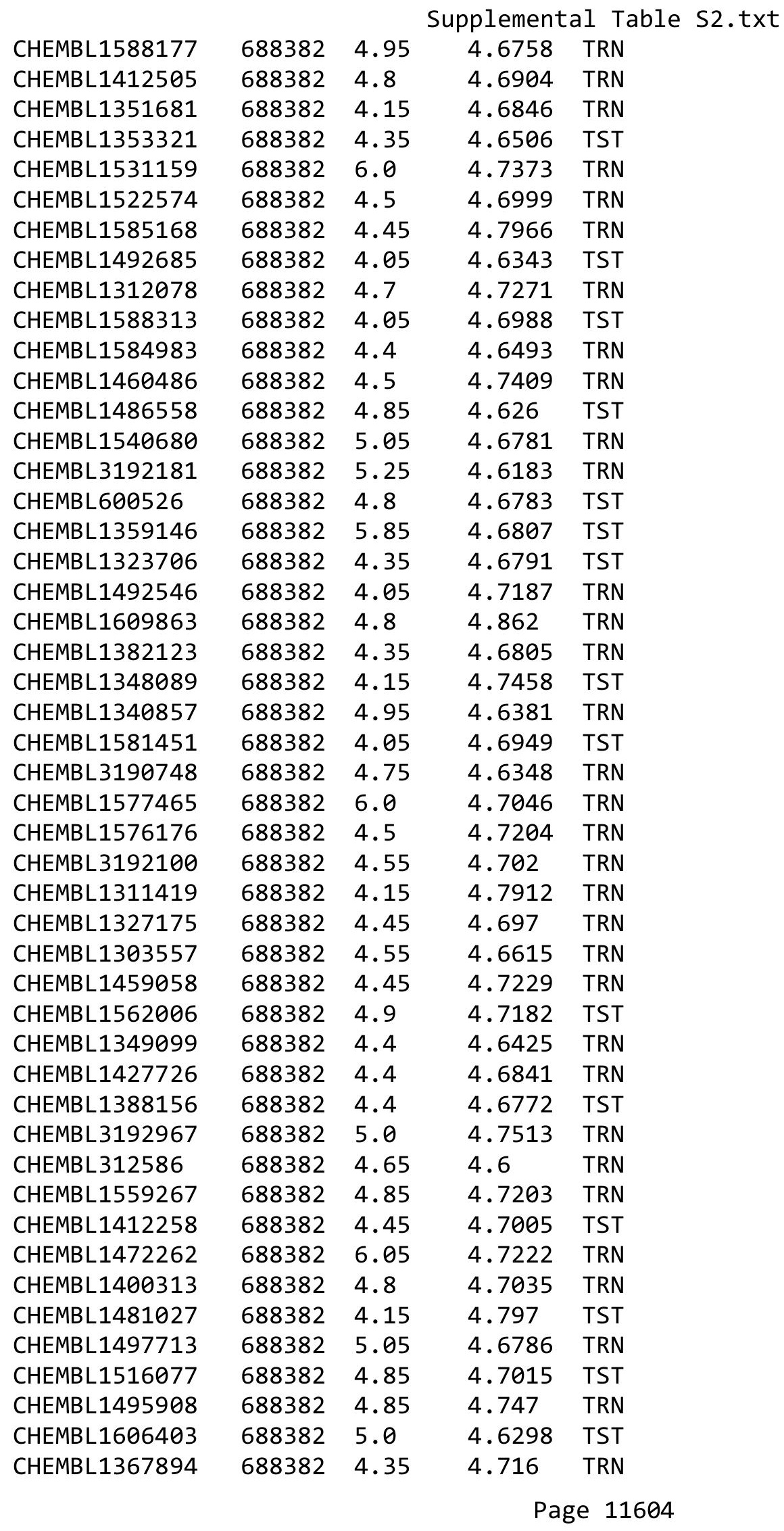




\begin{tabular}{|c|c|c|c|c|c|}
\hline \multicolumn{6}{|c|}{ Supplemental Table S2.txt } \\
\hline CHEMBL1455086 & 688382 & 4.55 & 4.7352 & TRN & \\
\hline CHEMBL1411838 & 688382 & 6.05 & 4.7209 & TRN & \\
\hline CHEMBL1463185 & 688382 & 4.95 & 4.6882 & TRN & \\
\hline CHEMBL1453517 & 688382 & 4.55 & 4.7933 & TRN & \\
\hline CHEMBL1535892 & 688382 & 5.05 & 4.8036 & TRN & \\
\hline CHEMBL1587354 & 688382 & 4.85 & 4.6388 & TRN & \\
\hline CHEMBL1603203 & 688382 & 4.85 & 4.6352 & TST & \\
\hline CHEMBL1499498 & 688382 & 5.4 & 4.756 & TRN & \\
\hline CHEMBL1419786 & 688382 & 5.8 & 4.67399 & 99999999995 & TRN \\
\hline CHEMBL1305075 & 688382 & 4.05 & 4.5848 & TST & \\
\hline CHEMBL1398087 & 688382 & 4.8 & 4.751 & TRN & \\
\hline CHEMBL1604324 & 688382 & 5.0 & 4.7891 & TST & \\
\hline CHEMBL1342724 & 688382 & 4.5 & 4.7882 & TRN & \\
\hline CHEMBL1393636 & 688382 & 5.8 & 4.6882 & TST & \\
\hline CHEMBL3189581 & 688382 & 5.8 & 4.6795 & TRN & \\
\hline CHEMBL 3212524 & 688382 & 5.55 & 4.6596 & TRN & \\
\hline CHEMBL1346144 & 688382 & 4.4 & 4.7373 & TRN & \\
\hline CHEMBL 2005638 & 688382 & 5.0 & 4.6657 & TRN & \\
\hline CHEMBL1502742 & 688382 & 4.05 & 4.8098 & TRN & \\
\hline CHEMBL1536626 & 688382 & 4.95 & 4.7033 & TRN & \\
\hline CHEMBL1482106 & 688382 & 5.2 & 4.7617 & TRN & \\
\hline CHEMBL1382925 & 688382 & 5.5 & 4.6918 & TST & \\
\hline CHEMBL1412628 & 688382 & 5.3 & 4.7287 & TRN & \\
\hline CHEMBL1365258 & 688382 & 4.05 & 4.784 & TRN & \\
\hline CHEMBL518575 & 688382 & 5.0 & 4.7012 & TRN & \\
\hline CHEMBL1424451 & 688382 & 4.95 & 4.697 & TST & \\
\hline CHEMBL1538798 & 688382 & 4.8 & 4.6368 & TST & \\
\hline CHEMBL1567155 & 688382 & 4.95 & 4.8549 & TST & \\
\hline CHEMBL1306455 & 688382 & 4.15 & 4.6697 & TRN & \\
\hline CHEMBL1446973 & 688382 & 4.5 & 4.7009 & TRN & \\
\hline CHEMBL1966121 & 688382 & 5.0 & 4.6705 & TRN & \\
\hline CHEMBL1535020 & 688382 & 4.5 & 4.6341 & TRN & \\
\hline CHEMBL1387433 & 688382 & 5.1 & 4.7738 & TRN & \\
\hline CHEMBL1387310 & 688382 & 4.95 & 4.8228 & TRN & \\
\hline CHEMBL1343788 & 688382 & 4.5 & 4.7917 & TRN & \\
\hline CHEMBL1587212 & 688382 & 4.55 & 4.6987 & TRN & \\
\hline CHEMBL1471895 & 688382 & 4.5 & 4.7646 & TST & \\
\hline CHEMBL1452230 & 688382 & 5.0 & 4.8338 & TRN & \\
\hline CHEMBL528734 & 688382 & 4.5 & 4.6345 & TST & \\
\hline CHEMBL1307160 & 688382 & 4.0 & 4.823 & TRN & \\
\hline CHEMBL1494560 & 688382 & 4.8 & 4.7072 & TST & \\
\hline CHEMBL1417120 & 688382 & 5.5 & 4.721 & TST & \\
\hline CHEMBL1595602 & 688382 & 4.35 & 4.7802 & TRN & \\
\hline CHEMBL1478065 & 688382 & 5.8 & 4.7127 & TRN & \\
\hline CHEMBL1416201 & 688382 & 4.05 & 4.7547 & TST & \\
\hline CHEMBL1472254 & 688382 & 5.5 & 4.7208 & TRN & \\
\hline CHEMBL1403543 & 688382 & 6.0 & 4.7521 & TRN & \\
\hline CHEMBL1333412 & 688382 & 4.45 & 4.5869 & TST & \\
\hline
\end{tabular}




\begin{tabular}{|c|c|c|c|c|c|}
\hline \\
\hline CHEMBL1604128 & 688382 & 4.9 & 4.7117 & TRN & \\
\hline CHEMBL1540360 & 688382 & 4.85 & 4.706 & TRN & \\
\hline CHEMBL1439895 & 688382 & 4.6 & 4.6498 & TRN & \\
\hline CHEMBL1301455 & 688382 & 4.55 & 4.6899 & TRN & \\
\hline CHEMBL1386750 & 688382 & 4.2 & 4.5768 & TRN & \\
\hline CHEMBL1582370 & 688382 & 4.9 & 4.7325 & TRN & \\
\hline CHEMBL1544445 & 688382 & 4.1 & 4.687 & TRN & \\
\hline CHEMBL1305762 & 688382 & 5.5 & 4.8552 & TRN & \\
\hline CHEMBL1404684 & 688382 & 5.0 & 4.6473 & TRN & \\
\hline CHEMBL1601016 & 688382 & 4.85 & 4.731 & TRN & \\
\hline CHEMBL1588250 & 688382 & 6.1 & 4.8076 & TRN & \\
\hline CHEMBL1536599 & 688382 & 4.5 & 4.67399 & 99999999995 & TST \\
\hline CHEMBL3198340 & 688382 & 4.2 & 4.5997 & TST & \\
\hline CHEMBL1383586 & 688382 & 4.45 & 4.6955 & TST & \\
\hline CHEMBL1611953 & 688382 & 4.75 & 4.6887 & TRN & \\
\hline CHEMBL1416262 & 688382 & 4.6 & 4.6504 & TRN & \\
\hline CHEMBL3195792 & 688382 & 4.4 & 4.6856 & TRN & \\
\hline CHEMBL1972217 & 688382 & 4.4 & 4.6321 & TRN & \\
\hline CHEMBL1366885 & 688382 & 6.0 & 4.6681 & TRN & \\
\hline CHEMBL1590124 & 688382 & 4.85 & 4.7206 & TST & \\
\hline CHEMBL1463778 & 688382 & 4.25 & 4.8555 & TRN & \\
\hline CHEMBL1340575 & 688382 & 4.8 & 4.74100 & 00000000005 & TRN \\
\hline CHEMBL1409237 & 688382 & 5.4 & 4.6755 & TST & \\
\hline CHEMBL1508829 & 688382 & 4.95 & 4.7897 & TRN & \\
\hline CHEMBL3194853 & 688382 & 4.85 & 4.6933 & TRN & \\
\hline CHEMBL1472465 & 688382 & 4.85 & 4.7293 & TRN & \\
\hline CHEMBL1440613 & 688382 & 4.45 & 4.7747 & TRN & \\
\hline CHEMBL3194575 & 688382 & 5.0 & 4.604 & TRN & \\
\hline CHEMBL1412704 & 688382 & 4.85 & 4.7315 & TRN & \\
\hline CHEMBL1308255 & 688382 & 4.6 & 4.7316 & TRN & \\
\hline CHEMBL1462641 & 688382 & 4.05 & 4.7043 & TST & \\
\hline CHEMBL1455050 & 688382 & 5.0 & 4.7989 & TRN & \\
\hline CHEMBL1531172 & 688382 & 4.5 & 4.7353 & TRN & \\
\hline CHEMBL1331727 & 688382 & 4.9 & 4.6541 & TST & \\
\hline CHEMBL1595977 & 688382 & 4.5 & 4.7267 & TST & \\
\hline CHEMBL1403210 & 688382 & 4.45 & 4.7049 & TST & \\
\hline CHEMBL1580607 & 688382 & 4.5 & 4.8176 & TRN & \\
\hline CHEMBL1550158 & 688382 & 5.4 & 4.7105 & TRN & \\
\hline CHEMBL3191970 & 688382 & 4.45 & 4.6552 & TRN & \\
\hline CHEMBL1533534 & 688382 & 4.2 & 4.6513 & TRN & \\
\hline CHEMBL1415315 & 688382 & 4.8 & 4.6508 & TST & \\
\hline CHEMBL1402837 & 688382 & 4.95 & 4.6314 & TST & \\
\hline CHEMBL1461160 & 688382 & 4.55 & 4.6843 & TST & \\
\hline CHEMBL1432122 & 688382 & 4.2 & 4.6728 & TRN & \\
\hline CHEMBL1403149 & 688382 & 6.0 & 4.7413 & TRN & \\
\hline CHEMBL3211499 & 688382 & 4.2 & 4.687 & TRN & \\
\hline CHEMBL1983266 & 688382 & 5.55 & 4.6204 & TST & \\
\hline CHEMBL1545453 & 688382 & 3.95 & 4.7225 & TRN & \\
\hline
\end{tabular}




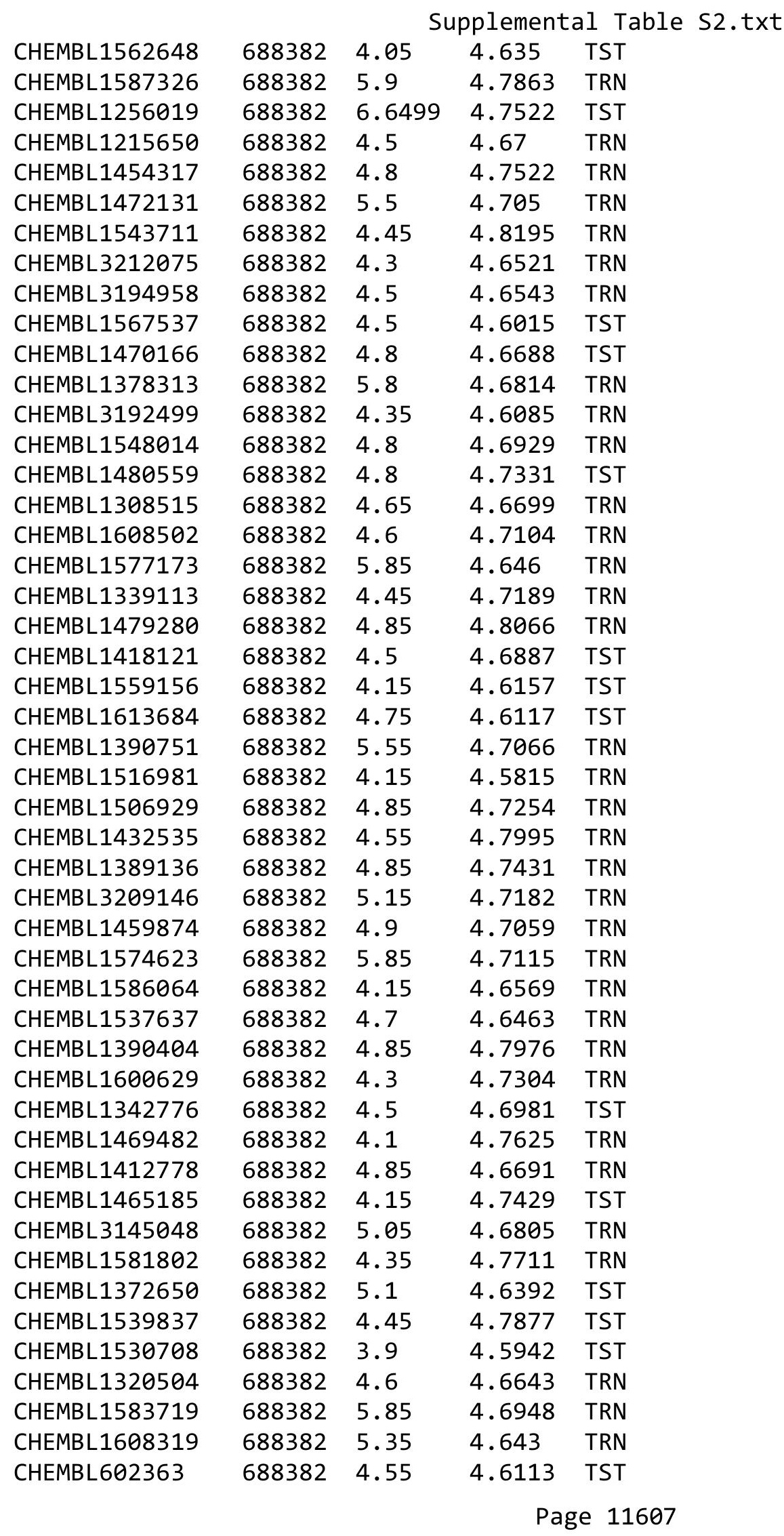




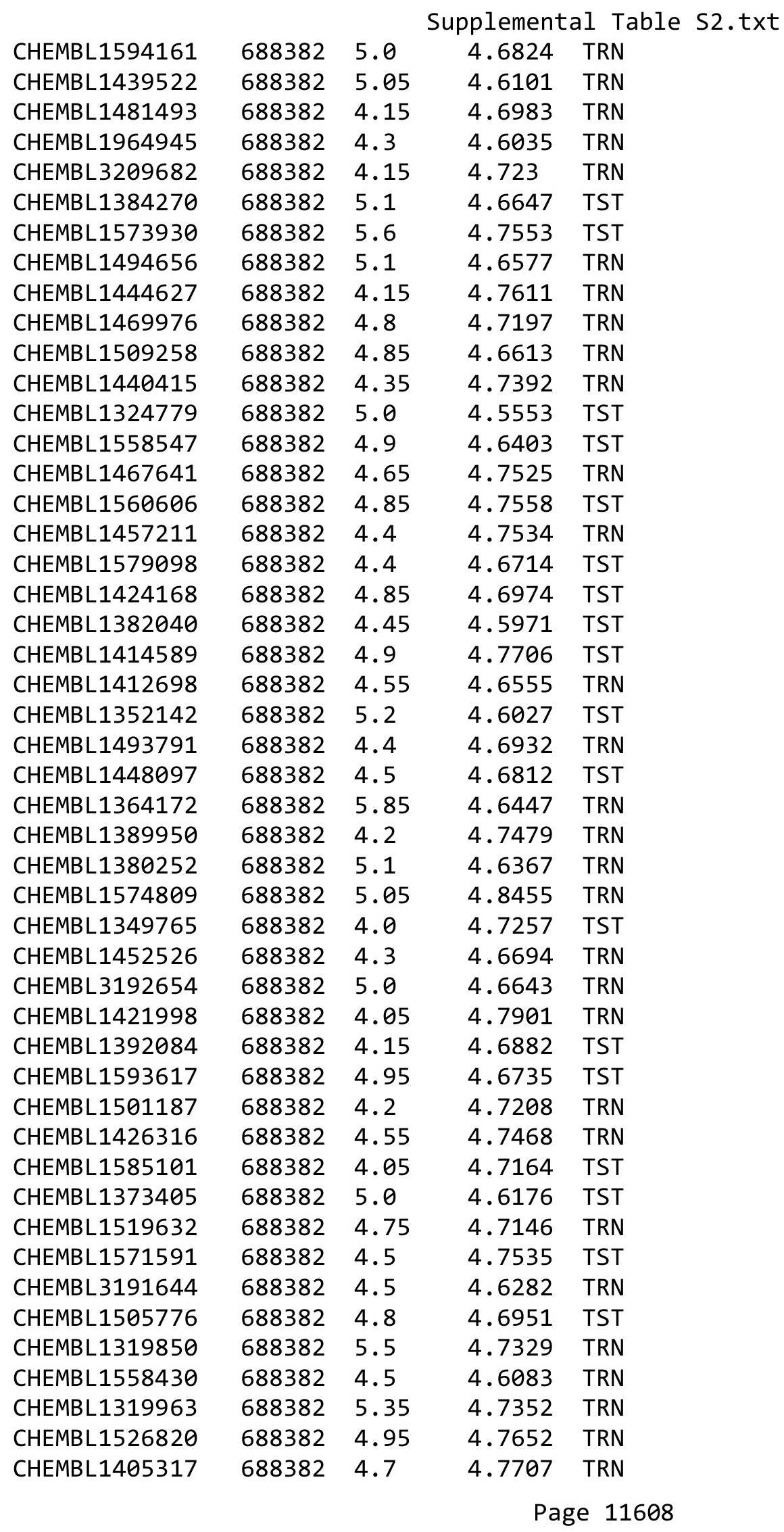




\begin{tabular}{|c|c|c|c|c|}
\hline \multicolumn{5}{|c|}{ Supplemental Table S2.txt } \\
\hline CHEMBL3199827 & 688382 & 4.85 & 4.7087 & TRN \\
\hline CHEMBL1386071 & 688382 & 4.2 & 4.7335 & TRN \\
\hline CHEMBL1308187 & 688382 & 4.45 & 4.6654 & TRN \\
\hline CHEMBL1586747 & 688382 & 4.1 & 4.7204 & TST \\
\hline CHEMBL1467637 & 688382 & 5.0 & 4.7096 & TRN \\
\hline CHEMBL1864040 & 688382 & 4.5 & 4.6377 & TRN \\
\hline CHEMBL1517301 & 688382 & 5.1 & 4.7015 & TST \\
\hline CHEMBL364893 & 688382 & 4.6 & 4.6979 & TRN \\
\hline CHEMBL1325819 & 688382 & 4.05 & 4.6932 & TRN \\
\hline CHEMBL1610398 & 688382 & 4.35 & 4.7471 & TRN \\
\hline CHEMBL1392250 & 688382 & 5.0 & 4.7827 & TRN \\
\hline CHEMBL1481657 & 688382 & 4.45 & 4.7783 & TRN \\
\hline CHEMBL1387159 & 688382 & 5.8 & 4.7187 & TST \\
\hline CHEMBL3198060 & 688382 & 4.95 & 4.6799 & TRN \\
\hline CHEMBL1432641 & 688382 & 4.95 & 4.8062 & TRN \\
\hline CHEMBL1984924 & 688382 & 4.8 & 4.6627 & TRN \\
\hline CHEMBL3193298 & 688382 & 4.65 & 4.6449 & TRN \\
\hline CHEMBL1439702 & 688382 & 4.8 & 4.6756 & TRN \\
\hline CHEMBL1526980 & 688382 & 4.05 & 4.6416 & TRN \\
\hline CHEMBL1489545 & 688382 & 4.5 & 4.6934 & TRN \\
\hline CHEMBL1404835 & 688382 & 4.45 & 4.6968 & TST \\
\hline CHEMBL 2005721 & 688382 & 4.4 & 4.6081 & TRN \\
\hline CHEMBL 3145293 & 688382 & 4.85 & 4.6344 & TRN \\
\hline CHEMBL1587519 & 688382 & 4.4 & 4.6884 & TRN \\
\hline CHEMBL1600441 & 688382 & 4.6 & 4.6608 & TRN \\
\hline CHEMBL1560895 & 688382 & 4.8 & 4.8149 & TRN \\
\hline CHEMBL1598275 & 688382 & 5.25 & 4.8327 & TRN \\
\hline CHEMBL1370424 & 688382 & 4.0 & 4.7042 & TRN \\
\hline CHEMBL1589393 & 688382 & 4.5 & 4.6665 & TRN \\
\hline CHEMBL1506624 & 688382 & 4.95 & 4.7567 & TRN \\
\hline CHEMBL1462642 & 688382 & 4.95 & 4.6779 & TRN \\
\hline CHEMBL 3214581 & 688382 & 4.35 & 4.6728 & TRN \\
\hline CHEMBL1568328 & 688382 & 6.05 & 4.7563 & TRN \\
\hline CHEMBL1507744 & 688382 & 4.85 & 4.705 & TRN \\
\hline CHEMBL1564265 & 688382 & 5.25 & 4.7421 & TST \\
\hline CHEMBL1412571 & 688382 & 4.65 & 4.6599 & TST \\
\hline CHEMBL1384981 & 688382 & 4.8 & 4.6637 & TST \\
\hline CHEMBL1502194 & 688382 & 4.85 & 4.7473 & TST \\
\hline CHEMBL1333252 & 688382 & 4.85 & 4.6848 & TST \\
\hline CHEMBL1508357 & 688382 & 4.65 & 4.6939 & TRN \\
\hline CHEMBL1456658 & 688382 & 4.35 & 4.7439 & TRN \\
\hline CHEMBL1581881 & 688382 & 5.7 & 4.6709 & TRN \\
\hline CHEMBL1451290 & 688382 & 5.05 & 4.6837 & TRN \\
\hline CHEMBL1579902 & 688382 & 4.4 & $4.6610 e$ & 00000000005 \\
\hline CHEMBL505670 & 688382 & 4.45 & 4.6408 & TST \\
\hline CHEMBL1361241 & 688382 & 4.15 & 4.7472 & TRN \\
\hline CHEMBL1565142 & 688382 & 5.2 & 4.7594 & TST \\
\hline CHEMBL1601816 & 688382 & 4.6 & 4.7044 & TRN \\
\hline
\end{tabular}




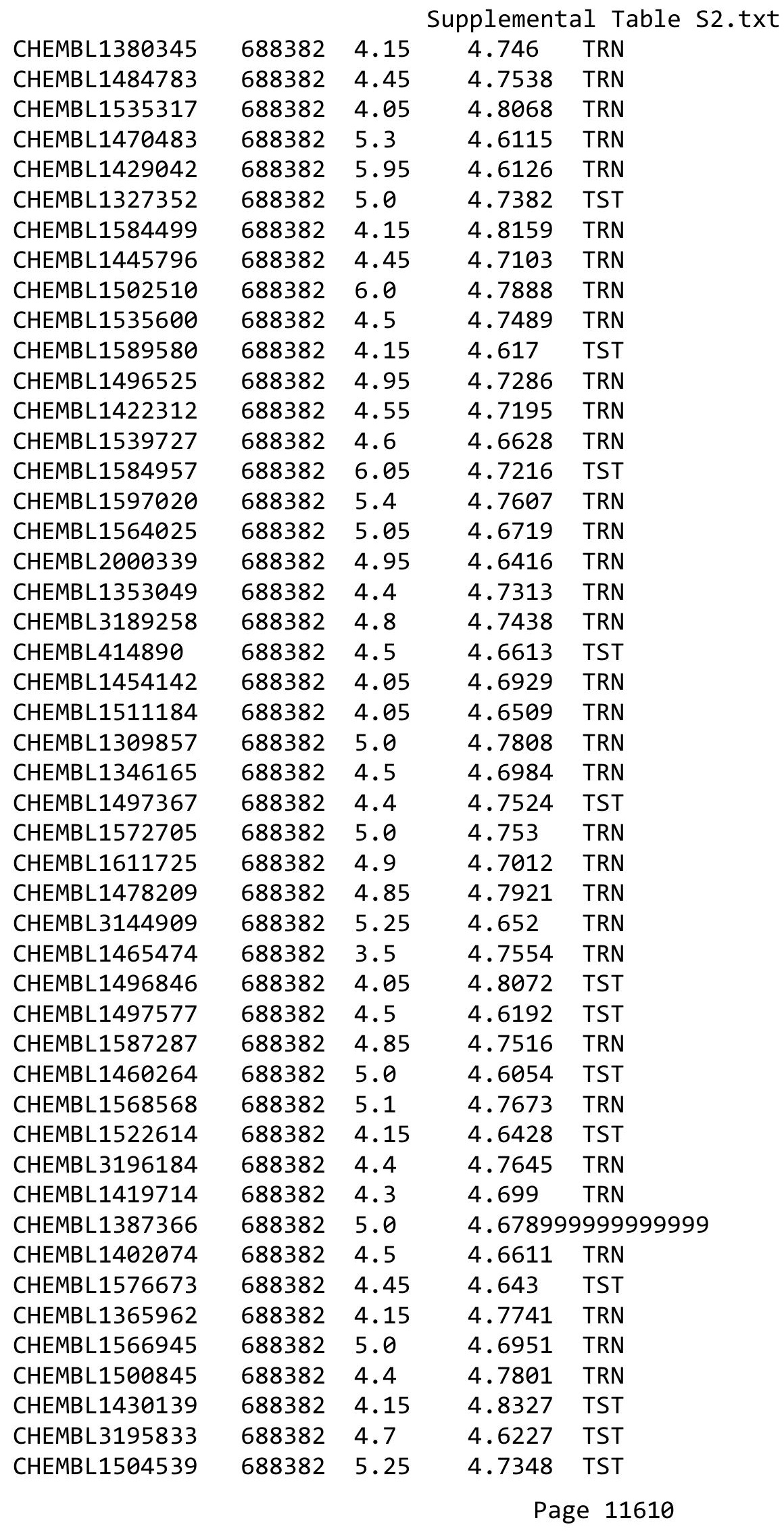




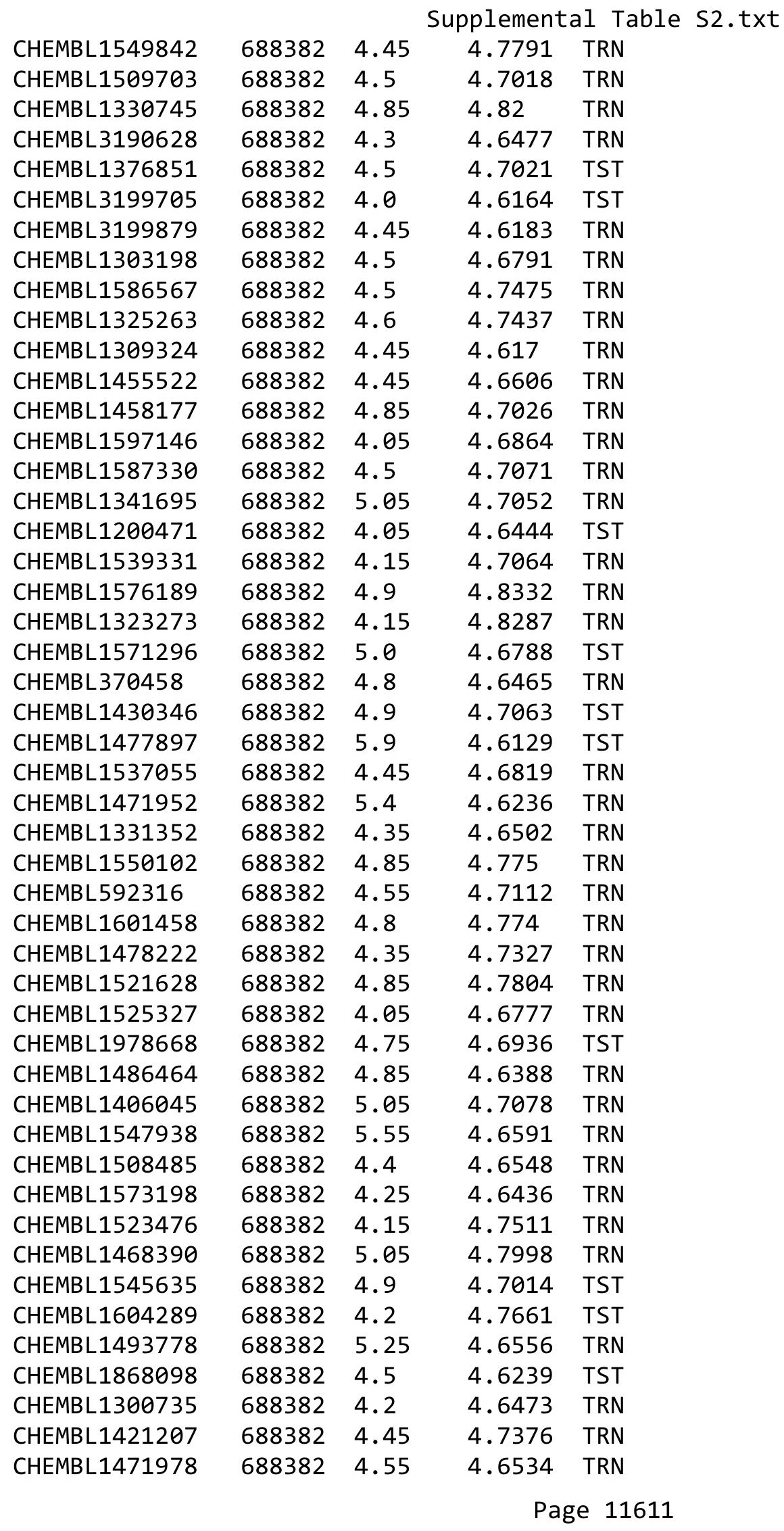




\begin{tabular}{|c|c|c|c|c|}
\hline & & & \multicolumn{2}{|c|}{ Supplemental Table S2.txt } \\
\hline CHEMBL3196985 & 688382 & 4.15 & 4.6299 & TST \\
\hline CHEMBL1459162 & 688382 & 4.45 & 4.6617 & TRN \\
\hline CHEMBL1594787 & 688382 & 5.5 & 4.5706 & TST \\
\hline CHEMBL1588043 & 688382 & 4.15 & 4.5945 & TRN \\
\hline CHEMBL1407549 & 688382 & 4.5 & 4.7163 & TRN \\
\hline CHEMBL1599120 & 688382 & 4.8 & 4.6854 & TRN \\
\hline CHEMBL3194268 & 688382 & 5.25 & 4.6609 & TRN \\
\hline CHEMBL1343769 & 688382 & 4.45 & 4.7494 & TRN \\
\hline CHEMBL1387894 & 688382 & 4.15 & 4.7253 & TRN \\
\hline CHEMBL1445448 & 688382 & 4.85 & 4.7362 & TRN \\
\hline CHEMBL1320193 & 688382 & 4.45 & 4.6889 & TRN \\
\hline CHEMBL1330325 & 688382 & 4.45 & 4.6576 & TRN \\
\hline CHEMBL1420732 & 688382 & 4.9 & 4.8546 & TRN \\
\hline CHEMBL1341555 & 688382 & 4.5 & 4.8379 & TRN \\
\hline CHEMBL1479120 & 688382 & 4.15 & 4.6395 & TST \\
\hline CHEMBL1351367 & 688382 & 4.4 & 4.676 & TRN \\
\hline CHEMBL1577774 & 688382 & 4.95 & 4.7963 & TRN \\
\hline CHEMBL428909 & 688382 & 4.5 & 4.6445 & TRN \\
\hline CHEMBL1484305 & 688382 & 4.45 & 4.7434 & TRN \\
\hline CHEMBL1376672 & 688382 & 5.15 & 4.7714 & TRN \\
\hline CHEMBL1391485 & 688382 & 4.6 & 4.6967 & TST \\
\hline CHEMBL236615 & 688382 & 5.95 & 4.598 & TRN \\
\hline CHEMBL1444121 & 688382 & 4.45 & 4.7304 & TST \\
\hline CHEMBL1611472 & 688382 & 4.85 & 4.6669 & TST \\
\hline CHEMBL1432397 & 688382 & 4.45 & 4.6568 & TRN \\
\hline CHEMBL1401167 & 688382 & 4.4 & 4.7155 & TRN \\
\hline CHEMBL1388069 & 688382 & 4.55 & 4.606 & TRN \\
\hline CHEMBL1383639 & 688382 & 5.1 & 4.7487 & TRN \\
\hline CHEMBL1605984 & 688382 & 4.8 & 4.7036 & TRN \\
\hline CHEMBL3214029 & 688382 & 4.4 & 4.7333 & TST \\
\hline CHEMBL1547701 & 688382 & 4.4 & 4.6815 & TRN \\
\hline CHEMBL1610660 & 688382 & 4.2 & 4.7311 & TRN \\
\hline CHEMBL1307244 & 688382 & 5.2 & 4.6283 & TRN \\
\hline CHEMBL1973669 & 688382 & 5.5 & 4.6229 & TST \\
\hline CHEMBL1539012 & 688382 & 4.85 & 4.7051 & TST \\
\hline CHEMBL1560623 & 688382 & 4.4 & 4.6916 & TST \\
\hline CHEMBL1463848 & 688382 & 4.3 & 4.7301 & TRN \\
\hline CHEMBL1478852 & 688382 & 4.55 & 4.6079 & TRN \\
\hline CHEMBL1367263 & 688382 & 4.45 & 4.7177 & TRN \\
\hline CHEMBL1352080 & 688382 & 4.85 & 4.7056 & TRN \\
\hline CHEMBL1299824 & 688382 & 5.05 & 4.7878 & TRN \\
\hline CHEMBL1382476 & 688382 & 4.45 & 4.6618 & TRN \\
\hline CHEMBL1380848 & 688382 & 4.5 & 4.6636 & TRN \\
\hline CHEMBL1397920 & 688382 & 6.5 & 4.6845 & TRN \\
\hline CHEMBL3212625 & 688382 & 5.15 & 4.6786 & TRN \\
\hline CHEMBL1477915 & 688382 & 5.5 & 4.6626 & TRN \\
\hline CHEMBL1604027 & 688382 & 4.35 & 4.6579 & TRN \\
\hline CHEMBL3193481 & 688382 & 5.0 & 4.7109 & TRN \\
\hline
\end{tabular}




\begin{tabular}{|c|c|c|c|c|c|}
\hline & & \multicolumn{4}{|c|}{ Supplemental Table s2.txt } \\
\hline CHEMBL1438157 & 688382 & 4.15 & 4.6742 & TRN & \\
\hline CHEMBL1544206 & 688382 & 4.9 & 4.7337 & TST & \\
\hline CHEMBL1519510 & 688382 & 4.85 & 4.7043 & TST & \\
\hline CHEMBL1419721 & 688382 & 5.05 & 4.6699 & TST & \\
\hline CHEMBL1578869 & 688382 & 4.5 & 4.7801 & TRN & \\
\hline CHEMBL1411652 & 688382 & 4.5 & 4.7747 & TRN & \\
\hline CHEMBL1456444 & 688382 & 5.5 & 4.6192 & TST & \\
\hline CHEMBL1409446 & 688382 & 4.8 & 4.6787 & TRN & \\
\hline CHEMBL1496509 & 688382 & 4.8 & 4.7813 & TRN & \\
\hline CHEMBL1418301 & 688382 & 4.7 & 4.6862 & TRN & \\
\hline CHEMBL1540400 & 688382 & 4.15 & 4.695 & TST & \\
\hline CHEMBL1468862 & 688382 & 4.55 & 4.675 & TRN & \\
\hline CHEMBL1561395 & 688382 & 4.35 & 4.6965 & TST & \\
\hline CHEMBL1436898 & 688382 & 4.4 & 4.648 & TRN & \\
\hline CHEMBL1589238 & 688382 & 4.4 & 4.7107 & TRN & \\
\hline CHEMBL1308931 & 688382 & 4.5 & 4.7373 & TST & \\
\hline CHEMBL1546778 & 688382 & 4.95 & 4.7269 & TST & \\
\hline CHEMBL1381281 & 688382 & 4.45 & 4.791 & TRN & \\
\hline CHEMBL1498441 & 688382 & 4.25 & 4.6871 & TRN & \\
\hline CHEMBL1349251 & 688382 & 5.95 & 4.734 & TRN & \\
\hline CHEMBL1524981 & 688382 & 4.4 & 4.7155 & TRN & \\
\hline CHEMBL1302466 & 688382 & 4.8 & 4.7919 & TRN & \\
\hline CHEMBL1426332 & 688382 & 4.85 & 4.7521 & TST & \\
\hline CHEMBL1972190 & 688382 & 4.35 & 4.6322 & TRN & \\
\hline CHEMBL1456071 & 688382 & 4.75 & 4.6657 & TRN & \\
\hline CHEMBL1467492 & 688382 & 4.15 & 4.7727 & TRN & \\
\hline CHEMBL1308981 & 688382 & 4.15 & 4.6776 & TRN & \\
\hline CHEMBL1349494 & 688382 & 4.45 & 4.7293 & TRN & \\
\hline CHEMBL1544331 & 688382 & 4.85 & 4.6841 & TST & \\
\hline CHEMBL1418163 & 688382 & 4.3 & 4.6677 & TRN & \\
\hline CHEMBL1570380 & 688382 & 4.8 & 4.6686 & TRN & \\
\hline CHEMBL1504918 & 688382 & 4.5 & 4.5697 & TRN & \\
\hline CHEMBL1446950 & 688382 & 4.05 & 4.7039 & TRN & \\
\hline CHEMBL1559478 & 688382 & 4.45 & 4.694 & TST & \\
\hline CHEMBL1418299 & 688382 & 5.3 & 4.6787 & TRN & \\
\hline CHEMBL1431732 & 688382 & 4.9 & 4.68199 & 99999999995 & TRN \\
\hline CHEMBL1392392 & 688382 & 4.15 & 4.7549 & TRN & \\
\hline CHEMBL1342024 & 688382 & 4.45 & 4.692 & TRN & \\
\hline CHEMBL1428376 & 688382 & 4.15 & 4.6831 & TST & \\
\hline CHEMBL1507863 & 688382 & 4.6 & 4.7507 & TST & \\
\hline CHEMBL1373319 & 688382 & 4.05 & 4.6084 & TRN & \\
\hline CHEMBL3195670 & 688382 & 4.9 & 4.6986 & TST & \\
\hline CHEMBL1556248 & 688382 & 5.9 & 4.6687 & TST & \\
\hline CHEMBL1466559 & 688382 & 4.8 & 4.7468 & TRN & \\
\hline CHEMBL1441170 & 688382 & 4.4 & 4.7121 & TST & \\
\hline CHEMBL1538417 & 688382 & 4.8 & 4.7199 & TRN & \\
\hline CHEMBL1462375 & 688382 & 5.05 & 4.6676 & TRN & \\
\hline CHEMBL1391794 & 688382 & 5.6 & 4.8153 & TST & \\
\hline
\end{tabular}




\begin{tabular}{|c|c|c|c|c|c|}
\hline \multicolumn{6}{|c|}{ Supplemental Table S2.txt } \\
\hline CHEMBL1543585 & 688382 & 4.85 & 4.6344 & TRN & \\
\hline CHEMBL1611585 & 688382 & 4.85 & 4.7337 & TRN & \\
\hline CHEMBL1568311 & 688382 & 4.15 & 4.8344 & TRN & \\
\hline CHEMBL3207597 & 688382 & 4.4 & 4.7148 & TRN & \\
\hline CHEMBL1587658 & 688382 & 4.25 & 4.77800 & 00000000005 & TRN \\
\hline CHEMBL1302557 & 688382 & 5.05 & 4.7836 & TRN & \\
\hline CHEMBL1368515 & 688382 & 4.2 & 4.6743 & TST & \\
\hline CHEMBL1550509 & 688382 & 4.4 & 4.6303 & TRN & \\
\hline CHEMBL1327511 & 688382 & 4.8 & 4.7573 & TRN & \\
\hline CHEMBL1572142 & 688382 & 4.45 & 4.6777 & TST & \\
\hline CHEMBL1606204 & 688382 & 4.85 & 4.7842 & TRN & \\
\hline CHEMBL1444946 & 688382 & 4.45 & 4.686 & TRN & \\
\hline CHEMBL 3194737 & 688382 & 5.0 & 4.6117 & TRN & \\
\hline CHEMBL1416611 & 688382 & 4.8 & 4.8692 & TRN & \\
\hline CHEMBL1320168 & 688382 & 4.55 & 4.664 & TRN & \\
\hline CHEMBL1383918 & 688382 & 4.85 & 4.7829 & TRN & \\
\hline CHEMBL3196841 & 688382 & 4.9 & 4.6423 & TRN & \\
\hline CHEMBL1576732 & 688382 & 4.8 & 4.6258 & TRN & \\
\hline CHEMBL1558309 & 688382 & 5.05 & 4.8078 & TRN & \\
\hline CHEMBL1567268 & 688382 & 4.15 & 4.6475 & TRN & \\
\hline CHEMBL1414712 & 688382 & 4.5 & 4.668 & TRN & \\
\hline CHEMBL3209256 & 688382 & 4.2 & 4.7295 & TST & \\
\hline CHEMBL1424481 & 688382 & 4.4 & 4.7068 & TRN & \\
\hline CHEMBL1448711 & 688382 & 4.4 & 4.6559 & TRN & \\
\hline CHEMBL1303682 & 688382 & 4.2 & 4.69600 & 0000000001 & TST \\
\hline CHEMBL1497656 & 688382 & 4.4 & 4.6951 & TRN & \\
\hline CHEMBL1565173 & 688382 & 4.0 & 4.8486 & TRN & \\
\hline CHEMBL1322893 & 688382 & 4.6 & 4.6071 & TST & \\
\hline CHEMBL1487484 & 688382 & 4.45 & 4.7382 & TRN & \\
\hline CHEMBL1334598 & 688382 & 4.5 & 4.7367 & TST & \\
\hline CHEMBL1578141 & 688382 & 4.15 & 4.6302 & TRN & \\
\hline CHEMBL 237444 & 688382 & 4.8 & 4.8018 & TRN & \\
\hline CHEMBL1546868 & 688382 & 4.05 & 4.6558 & TST & \\
\hline CHEMBL1406632 & 688382 & 4.6 & 4.6901 & TST & \\
\hline CHEMBL1389912 & 688382 & 4.95 & 4.7072 & TRN & \\
\hline CHEMBL1377470 & 688382 & 4.85 & 4.8312 & TRN & \\
\hline CHEMBL1517409 & 688382 & 4.8 & 4.6884 & TST & \\
\hline CHEMBL1584852 & 688382 & 4.5 & 4.7033 & TRN & \\
\hline CHEMBL 3144989 & 688382 & 4.45 & 4.6175 & TRN & \\
\hline CHEMBL1605998 & 688382 & 4.05 & 4.7199 & TRN & \\
\hline CHEMBL1470378 & 688382 & 5.1 & 4.6691 & TRN & \\
\hline CHEMBL1410641 & 688382 & 4.5 & 4.6627 & TST & \\
\hline CHEMBL1604593 & 688382 & 5.15 & 4.7458 & TRN & \\
\hline CHEMBL 3197433 & 688382 & 4.45 & 4.6068 & TST & \\
\hline CHEMBL1424017 & 688382 & 4.15 & 4.6325 & TST & \\
\hline CHEMBL1349894 & 688382 & 5.95 & 4.749 & TST & \\
\hline CHEMBL1479756 & 688382 & 4.55 & 4.7694 & TRN & \\
\hline CHEMBL1372038 & 688382 & 4.8 & 4.7265 & TRN & \\
\hline
\end{tabular}




\begin{tabular}{|c|c|c|c|c|}
\hline & & & upplement & al $\mathrm{T}$ \\
\hline CHEMBL1307450 & 688382 & 6.45 & 4.7497 & TST \\
\hline CHEMBL1323085 & 688382 & 6.45 & 4.7817 & TRN \\
\hline CHEMBL1581901 & 688382 & 4.85 & 4.7838 & TRN \\
\hline CHEMBL1586098 & 688382 & 4.15 & 4.6936 & TRN \\
\hline CHEMBL1502362 & 688382 & 4.95 & 4.7061 & TST \\
\hline CHEMBL1479933 & 688382 & 5.85 & 4.6328 & TRN \\
\hline CHEMBL1347107 & 688382 & 4.05 & 4.6537 & TRN \\
\hline CHEMBL1383694 & 688382 & 4.25 & 4.7018 & TRN \\
\hline CHEMBL1518862 & 688382 & 4.25 & 4.7365 & TST \\
\hline CHEMBL1600644 & 688382 & 4.95 & 4.6779 & TRN \\
\hline CHEMBL1382269 & 688382 & 5.05 & 4.7849 & TST \\
\hline CHEMBL1538885 & 688382 & 4.45 & 4.7095 & TRN \\
\hline CHEMBL1462414 & 688382 & 6.0 & 4.6692 & TRN \\
\hline CHEMBL1455109 & 688382 & 4.45 & 4.6861 & TST \\
\hline CHEMBL1331008 & 688382 & 4.15 & 4.6799 & TRN \\
\hline CHEMBL1566146 & 688382 & 4.8 & 4.7147 & TRN \\
\hline CHEMBL1502340 & 688382 & 4.5 & 4.7342 & TRN \\
\hline CHEMBL1302268 & 688382 & 4.05 & 4.7756 & TRN \\
\hline CHEMBL1428277 & 688382 & 4.95 & 4.7574 & TRN \\
\hline CHEMBL1467279 & 688382 & 4.3 & 4.766 & TRN \\
\hline CHEMBL1362155 & 688382 & 5.1 & 4.7028 & TST \\
\hline CHEMBL1426290 & 688382 & 5.15 & 4.7451 & TST \\
\hline CHEMBL1504280 & 688382 & 5.0 & 4.7571 & TST \\
\hline CHEMBL1601680 & 688382 & 4.5 & 4.7302 & TRN \\
\hline CHEMBL1322995 & 688382 & 4.9 & 4.6883 & TRN \\
\hline CHEMBL1488681 & 688382 & 4.4 & 4.6734 & TRN \\
\hline CHEMBL1371627 & 688382 & 4.8 & 4.6794 & TRN \\
\hline CHEMBL1353234 & 688382 & 4.95 & 4.7569 & TST \\
\hline CHEMBL1538427 & 688382 & 4.75 & 4.7126 & TRN \\
\hline CHEMBL1312678 & 688382 & 6.0 & 4.7657 & TRN \\
\hline CHEMBL1560607 & 688382 & 4.85 & 4.7629 & TST \\
\hline CHEMBL1404195 & 688382 & 4.85 & 4.8367 & TRN \\
\hline CHEMBL1504655 & 688382 & 4.95 & 4.708 & TST \\
\hline CHEMBL1499701 & 688382 & 4.5 & 4.6434 & TRN \\
\hline CHEMBL11697 & 688382 & 4.45 & 4.6989 & TST \\
\hline CHEMBL1561996 & 688382 & 5.1 & 4.8286 & TRN \\
\hline CHEMBL1479110 & 688382 & 4.75 & 4.8825 & TRN \\
\hline CHEMBL1510453 & 688382 & 4.15 & 4.6118 & TRN \\
\hline CHEMBL3212428 & 688382 & 4.2 & 4.6459 & TRN \\
\hline CHEMBL1602743 & 688382 & 5.0 & 4.8627 & TRN \\
\hline CHEMBL1492909 & 688382 & 4.45 & 4.6492 & TRN \\
\hline CHEMBL3194692 & 688382 & 4.7 & 4.7088 & TRN \\
\hline CHEMBL1323496 & 688382 & 5.65 & 4.7461 & TRN \\
\hline CHEMBL1583312 & 688382 & 4.35 & 4.6666 & TRN \\
\hline CHEMBL3191281 & 688382 & 4.55 & 4.6821 & TRN \\
\hline CHEMBL3194430 & 688382 & 4.6 & 4.6543 & TST \\
\hline CHEMBL1517129 & 688382 & 4.35 & 4.673 & TRN \\
\hline CHEMBL1500641 & 688382 & 4.35 & 4.7079 & TRN \\
\hline
\end{tabular}




\begin{tabular}{|c|c|c|c|c|}
\hline & & & oplement & al $\mathrm{T}$ \\
\hline CHEMBL1449331 & 688382 & 5.35 & 4.6734 & TRN \\
\hline CHEMBL1467361 & 688382 & 4.95 & 4.7137 & TST \\
\hline CHEMBL1370360 & 688382 & 4.35 & 4.7529 & TRN \\
\hline CHEMBL1579232 & 688382 & 4.85 & 4.7403 & TST \\
\hline CHEMBL1582199 & 688382 & 4.4 & 4.6556 & TST \\
\hline CHEMBL1386546 & 688382 & 4.4 & 4.6692 & TST \\
\hline CHEMBL1337696 & 688382 & 5.1 & 4.7206 & TST \\
\hline CHEMBL1347531 & 688382 & 4.3 & 4.6943 & TRN \\
\hline CHEMBL1577737 & 688382 & 6.0 & 4.6596 & TST \\
\hline CHEMBL1481284 & 688382 & 4.5 & 4.6898 & TRN \\
\hline CHEMBL1447342 & 688382 & 4.15 & 4.7086 & TRN \\
\hline CHEMBL1419598 & 688382 & 4.3 & 4.7208 & TRN \\
\hline CHEMBL175822 & 688382 & 4.05 & 4.7114 & TRN \\
\hline CHEMBL1326182 & 688382 & 4.4 & 4.6242 & TRN \\
\hline CHEMBL1336347 & 688382 & 4.6 & 4.691 & TRN \\
\hline CHEMBL1346340 & 688382 & 4.85 & 4.8064 & TRN \\
\hline CHEMBL1404410 & 688382 & 4.85 & 4.7324 & TRN \\
\hline CHEMBL1331573 & 688382 & 4.5 & 4.6914 & TRN \\
\hline CHEMBL1595988 & 688382 & 4.05 & 4.7481 & TRN \\
\hline CHEMBL1466582 & 688382 & 4.4 & 4.6698 & TRN \\
\hline CHEMBL1587991 & 688382 & 5.9 & 4.7568 & TRN \\
\hline CHEMBL1613647 & 688382 & 4.8 & 4.6927 & TST \\
\hline CHEMBL1583188 & 688382 & 4.85 & 4.7268 & TST \\
\hline CHEMBL1590086 & 688382 & 5.1 & 4.7697 & TRN \\
\hline CHEMBL1503446 & 688382 & 4.45 & 4.6741 & TRN \\
\hline CHEMBL1256364 & 688382 & 8.0506 & 4.6428 & TRN \\
\hline CHEMBL1581558 & 688382 & 4.85 & 4.7102 & TST \\
\hline CHEMBL1487213 & 688382 & 4.75 & 4.7285 & TRN \\
\hline CHEMBL3196221 & 688382 & 4.85 & 4.5978 & TRN \\
\hline CHEMBL1347956 & 688382 & 4.15 & 4.6436 & TRN \\
\hline CHEMBL1327840 & 688382 & 4.05 & 4.6708 & TST \\
\hline CHEMBL1490880 & 688382 & 4.15 & 4.8476 & TRN \\
\hline CHEMBL1366656 & 688382 & 5.9 & 4.6711 & TRN \\
\hline CHEMBL1524197 & 688382 & 5.5 & 4.7397 & TRN \\
\hline CHEMBL1418742 & 688382 & 4.3 & 4.6442 & TRN \\
\hline CHEMBL3214631 & 688382 & 6.0 & 4.7367 & TRN \\
\hline CHEMBL1506306 & 688382 & 4.15 & 4.6911 & TRN \\
\hline CHEMBL1332048 & 688382 & 5.5 & 4.6534 & TRN \\
\hline CHEMBL3208152 & 688382 & 4.45 & 4.7931 & TRN \\
\hline CHEMBL1464399 & 688382 & 4.5 & 4.6704 & TRN \\
\hline CHEMBL1494383 & 688382 & 4.85 & 4.7814 & TST \\
\hline CHEMBL1310703 & 688382 & 4.2 & 4.8212 & TRN \\
\hline CHEMBL3189535 & 688382 & 4.0 & 4.6929 & TST \\
\hline CHEMBL1562873 & 688382 & 4.55 & 4.5761 & TST \\
\hline CHEMBL1322402 & 688382 & 5.1 & 4.7908 & TRN \\
\hline CHEMBL1422188 & 688382 & 4.5 & 4.6929 & TRN \\
\hline CHEMBL1334288 & 688382 & 6.0 & 4.6805 & TRN \\
\hline CHEMBL1995112 & 688382 & 4.35 & 4.6577 & TRN \\
\hline
\end{tabular}




\begin{tabular}{|c|c|c|c|c|c|}
\hline & & \multicolumn{4}{|c|}{ Supplemental Table S2.txt } \\
\hline CHEMBL1313396 & 688382 & 4.05 & 4.7711 & TRN & \\
\hline CHEMBL1606648 & 688382 & 4.45 & 4.6701 & TRN & \\
\hline CHEMBL1497568 & 688382 & 4.5 & 4.6989 & TRN & \\
\hline CHEMBL1595366 & 688382 & 4.6 & 4.6694 & TRN & \\
\hline CHEMBL1373977 & 688382 & 4.8 & 4.706 & TRN & \\
\hline CHEMBL1491928 & 688382 & 4.55 & 4.6368 & TRN & \\
\hline CHEMBL3192466 & 688382 & 4.85 & 4.6627 & TRN & \\
\hline CHEMBL1463953 & 688382 & 5.0 & 4.6346 & TRN & \\
\hline CHEMBL1402368 & 688382 & 4.5 & 4.6019 & TRN & \\
\hline CHEMBL1449062 & 688382 & 4.0 & 4.794 & TRN & \\
\hline CHEMBL1582996 & 688382 & 4.45 & 4.6916 & TRN & \\
\hline CHEMBL1300454 & 688382 & 4.45 & 4.669 & TST & \\
\hline CHEMBL1522724 & 688382 & 4.15 & 4.6712 & TRN & \\
\hline CHEMBL1521435 & 688382 & 5.85 & 4.6735 & TRN & \\
\hline CHEMBL1607929 & 688382 & 4.0 & 4.7368 & TRN & \\
\hline CHEMBL1324473 & 688382 & 4.15 & 4.7053 & TST & \\
\hline CHEMBL1312115 & 688382 & 5.4 & 4.7149 & TST & \\
\hline CHEMBL1540557 & 688382 & 4.35 & 4.647 & TRN & \\
\hline CHEMBL1461558 & 688382 & 4.2 & 4.6524 & TST & \\
\hline CHEMBL1431075 & 688382 & 4.35 & 4.7169 & TRN & \\
\hline CHEMBL1558653 & 688382 & 4.2 & 4.7593 & TRN & \\
\hline CHEMBL1595975 & 688382 & 5.05 & 4.6225 & TST & \\
\hline CHEMBL1469744 & 688382 & 4.85 & 4.7968 & TRN & \\
\hline CHEMBL3213365 & 688382 & 4.05 & 4.7011 & TRN & \\
\hline CHEMBL1416121 & 688382 & 4.7 & 4.7343 & TRN & \\
\hline CHEMBL1365682 & 688382 & 4.15 & 4.77800 & 00000000005 & TRN \\
\hline CHEMBL1567840 & 688382 & 4.8 & 4.6935 & TST & \\
\hline CHEMBL60907 & 688382 & 4.85 & 4.7316 & TRN & \\
\hline CHEMBL1469246 & 688382 & 4.55 & 4.7854 & TRN & \\
\hline CHEMBL1475023 & 688382 & 4.9 & 4.6714 & TRN & \\
\hline CHEMBL1449581 & 688382 & 4.6 & 4.6609 & TRN & \\
\hline CHEMBL1340842 & 688382 & 5.05 & 4.6667 & TRN & \\
\hline CHEMBL1497002 & 688382 & 5.15 & 4.7084 & TRN & \\
\hline CHEMBL3197248 & 688382 & 4.45 & 4.6529 & TST & \\
\hline CHEMBL1588049 & 688382 & 4.0 & 4.7679 & TRN & \\
\hline CHEMBL1578760 & 688382 & 4.7 & 4.6872 & TRN & \\
\hline CHEMBL3213245 & 688382 & 4.3 & 4.6448 & TRN & \\
\hline CHEMBL1410957 & 688382 & 4.65 & 4.7613 & TRN & \\
\hline CHEMBL1337019 & 688382 & 4.05 & 4.7419 & TRN & \\
\hline CHEMBL1385361 & 688382 & 4.4 & 4.7358 & TRN & \\
\hline CHEMBL1359272 & 688382 & 4.25 & 4.6288 & TRN & \\
\hline CHEMBL1381140 & 688382 & 4.3 & 4.6424 & TRN & \\
\hline CHEMBL1502551 & 688382 & 4.45 & 4.7597 & TRN & \\
\hline CHEMBL1408890 & 688382 & 4.45 & 4.6755 & TRN & \\
\hline CHEMBL1538460 & 688382 & 4.2 & 4.6474 & TRN & \\
\hline CHEMBL1463492 & 688382 & 4.95 & 4.6258 & TST & \\
\hline CHEMBL3195278 & 688382 & 5.15 & 4.6119 & TST & \\
\hline CHEMBL1572093 & 688382 & 4.85 & 4.728 & TRN & \\
\hline
\end{tabular}




\begin{tabular}{|c|c|c|c|c|c|}
\hline \multicolumn{6}{|c|}{ Supplemental Table S2.txt } \\
\hline CHEMBL1387015 & 688382 & 4.9 & 4.7879 & TRN & \\
\hline CHEMBL1501971 & 688382 & 4.3 & 4.6577 & TRN & \\
\hline CHEMBL1358231 & 688382 & 4.05 & 4.772 & TRN & \\
\hline CHEMBL1339474 & 688382 & 5.85 & 4.6966 & TRN & \\
\hline CHEMBL1331111 & 688382 & 5.3 & 4.6655 & TRN & \\
\hline CHEMBL1507408 & 688382 & 4.15 & 4.7384 & TRN & \\
\hline CHEMBL1466378 & 688382 & 6.0 & 4.7963 & TRN & \\
\hline CHEMBL1542344 & 688382 & 4.4 & 4.713 & TRN & \\
\hline CHEMBL1474290 & 688382 & 4.5 & 4.6243 & TRN & \\
\hline CHEMBL1343383 & 688382 & 4.15 & \multicolumn{2}{|c|}{4.6930000000000005} & TRN \\
\hline CHEMBL1612490 & 688382 & 4.0 & 4.7037 & TRN & \\
\hline CHEMBL1360236 & 688382 & 5.45 & 4.7946 & TRN & \\
\hline CHEMBL1407169 & 688382 & 4.15 & 4.5621 & TST & \\
\hline CHEMBL1305161 & 688382 & 5.0 & 4.8454 & TRN & \\
\hline CHEMBL1564066 & 688382 & 4.15 & 4.6835 & TRN & \\
\hline CHEMBL1313283 & 688382 & 4.8 & 4.6971 & TRN & \\
\hline CHEMBL1352851 & 688382 & 4.5 & 4.7371 & TST & \\
\hline CHEMBL1531651 & 688382 & 4.45 & 4.6829 & TRN & \\
\hline CHEMBL1563860 & 688382 & 4.5 & 4.754 & TRN & \\
\hline CHEMBL1412535 & 688382 & 4.8 & 4.6648 & TST & \\
\hline CHEMBL1458130 & 688382 & 4.5 & 4.6767 & TRN & \\
\hline CHEMBL1388841 & 688382 & 6.0 & 4.8582 & TRN & \\
\hline CHEMBL1347730 & 688382 & 5.15 & 4.605 & TST & \\
\hline CHEMBL1578099 & 688382 & 5.45 & 4.7934 & TRN & \\
\hline CHEMBL1528333 & 688382 & 6.0 & 4.6943 & TRN & \\
\hline CHEMBL1546076 & 688382 & 4.8 & 4.7357 & TRN & \\
\hline CHEMBL1371923 & 688382 & 4.15 & 4.7728 & TST & \\
\hline CHEMBL1459492 & 688382 & 5.05 & 4.7608 & TRN & \\
\hline CHEMBL1505665 & 688382 & 4.55 & 4.7269 & TRN & \\
\hline CHEMBL1442754 & 688382 & 5.1 & 4.7041 & TST & \\
\hline CHEMBL1566915 & 688382 & 4.5 & 4.6629 & TST & \\
\hline CHEMBL1376406 & 688382 & 4.4 & 4.6064 & TRN & \\
\hline CHEMBL1551649 & 688382 & 4.5 & 4.6148 & TRN & \\
\hline CHEMBL600336 & 688382 & 5.25 & 4.6122 & TRN & \\
\hline CHEMBL1370890 & 688382 & 4.1 & 4.7227 & TRN & \\
\hline CHEMBL1324399 & 688382 & 4.05 & 4.6756 & TST & \\
\hline CHEMBL1967987 & 688382 & 4.75 & 4.7325 & TRN & \\
\hline CHEMBL1340426 & 688382 & 4.7 & 4.6348 & TRN & \\
\hline CHEMBL1441249 & 688382 & 4.5 & 4.8521 & TRN & \\
\hline CHEMBL1528985 & 688382 & 4.45 & 4.6768 & TRN & \\
\hline CHEMBL1359225 & 688382 & 4.6 & 4.7485 & TRN & \\
\hline CHEMBL1526943 & 688382 & 4.6 & 4.6781 & TRN & \\
\hline CHEMBL1549244 & 688382 & 4.3 & 4.8257 & TRN & \\
\hline CHEMBL1439606 & 688382 & 4.85 & 4.6609 & TRN & \\
\hline CHEMBL6634 & 688382 & 7.6003 & 4.7546 & TST & \\
\hline CHEMBL1310272 & 688382 & 4.85 & 4.8076 & TRN & \\
\hline CHEMBL1530170 & 688382 & 5.1 & 4.6474 & TRN & \\
\hline \multirow[t]{2}{*}{ CHEMBL1401029 } & 688382 & 5.3 & \multicolumn{2}{|c|}{4.7010000000000005} & TRN \\
\hline & & & & 11618 & \\
\hline
\end{tabular}




\begin{tabular}{|c|c|c|c|c|c|}
\hline & & \multicolumn{4}{|c|}{ Supplemental Table S2.txt } \\
\hline CHEMBL1421296 & 688382 & 4.3 & 4.7115 & TST & \\
\hline CHEMBL1604666 & 688382 & 4.45 & 4.6579 & TRN & \\
\hline CHEMBL1447215 & 688382 & 4.8 & 4.7972 & TRN & \\
\hline CHEMBL1429382 & 688382 & 4.35 & 4.662 & TRN & \\
\hline CHEMBL1509380 & 688382 & 4.15 & 4.6567 & TRN & \\
\hline CHEMBL1323030 & 688382 & 4.35 & 4.7591 & TRN & \\
\hline CHEMBL1479296 & 688382 & 4.15 & 4.6435 & TRN & \\
\hline CHEMBL1442261 & 688382 & 3.9 & 4.8259 & TRN & \\
\hline CHEMBL1382374 & 688382 & 5.6 & 4.7163 & TRN & \\
\hline CHEMBL1412413 & 688382 & 4.35 & 4.5948 & TRN & \\
\hline CHEMBL1393676 & 688382 & 4.6 & 4.6514 & TRN & \\
\hline CHEMBL1306457 & 688382 & 4.85 & 4.702 & TRN & \\
\hline CHEMBL1559266 & 688382 & 4.2 & 4.6619 & TRN & \\
\hline CHEMBL1609345 & 688382 & 4.95 & 4.8454 & TRN & \\
\hline CHEMBL1311041 & 688382 & 4.8 & 4.7824 & TRN & \\
\hline CHEMBL1504675 & 688382 & 4.4 & 4.6381 & TRN & \\
\hline CHEMBL1447875 & 688382 & 4.55 & 4.6332 & TRN & \\
\hline CHEMBL1412496 & 688382 & 5.4 & 4.7096 & TRN & \\
\hline CHEMBL1422071 & 688382 & 4.2 & 4.6961 & TST & \\
\hline CHEMBL3192524 & 688382 & 4.0 & 4.6613 & TRN & \\
\hline CHEMBL1403362 & 688382 & 5.05 & 4.7507 & TRN & \\
\hline CHEMBL1335592 & 688382 & 5.05 & 4.703 & TST & \\
\hline CHEMBL1340045 & 688382 & 6.05 & 4.6415 & TST & \\
\hline CHEMBL1378638 & 688382 & 5.15 & 4.7352 & TRN & \\
\hline CHEMBL1441398 & 688382 & 4.3 & 4.7531 & TST & \\
\hline CHEMBL1415765 & 688382 & 4.8 & 4.6124 & TRN & \\
\hline CHEMBL1465615 & 688382 & 4.45 & 4.7353 & TRN & \\
\hline CHEMBL1586602 & 688382 & 4.15 & 4.6782 & TRN & \\
\hline CHEMBL1605217 & 688382 & 4.85 & 4.7977 & TST & \\
\hline CHEMBL1492146 & 688382 & 5.1 & 4.7241 & TST & \\
\hline CHEMBL1393000 & 688382 & 4.05 & 4.6845 & TRN & \\
\hline CHEMBL1569715 & 688382 & 4.15 & 4.64199 & 99999999995 & TRN \\
\hline CHEMBL1346473 & 688382 & 4.45 & 4.6949 & TRN & \\
\hline CHEMBL1564332 & 688382 & 4.4 & 4.6753 & TRN & \\
\hline CHEMBL3199591 & 688382 & 4.35 & 4.709 & TRN & \\
\hline CHEMBL1565600 & 688382 & 4.6 & 4.7182 & TRN & \\
\hline CHEMBL3191570 & 688382 & 4.4 & 4.6606 & TRN & \\
\hline CHEMBL3213047 & 688382 & 4.4 & 4.6395 & TRN & \\
\hline CHEMBL1502686 & 688382 & 4.8 & 4.7566 & TRN & \\
\hline CHEMBL1322349 & 688382 & 4.45 & 4.6705 & TRN & \\
\hline CHEMBL1422763 & 688382 & 4.45 & 4.6783 & TRN & \\
\hline CHEMBL1330044 & 688382 & 5.85 & 4.7283 & TRN & \\
\hline CHEMBL1595164 & 688382 & 4.8 & 4.8025 & TRN & \\
\hline CHEMBL3199604 & 688382 & 4.85 & 4.7044 & TST & \\
\hline CHEMBL1523009 & 688382 & 4.6 & 4.7116 & TST & \\
\hline CHEMBL1381312 & 688382 & 4.65 & 4.5833 & TRN & \\
\hline CHEMBL1520763 & 688382 & 4.55 & 4.6824 & TRN & \\
\hline CHEMBL1379122 & 688382 & 4.35 & 4.7661 & TRN & \\
\hline
\end{tabular}




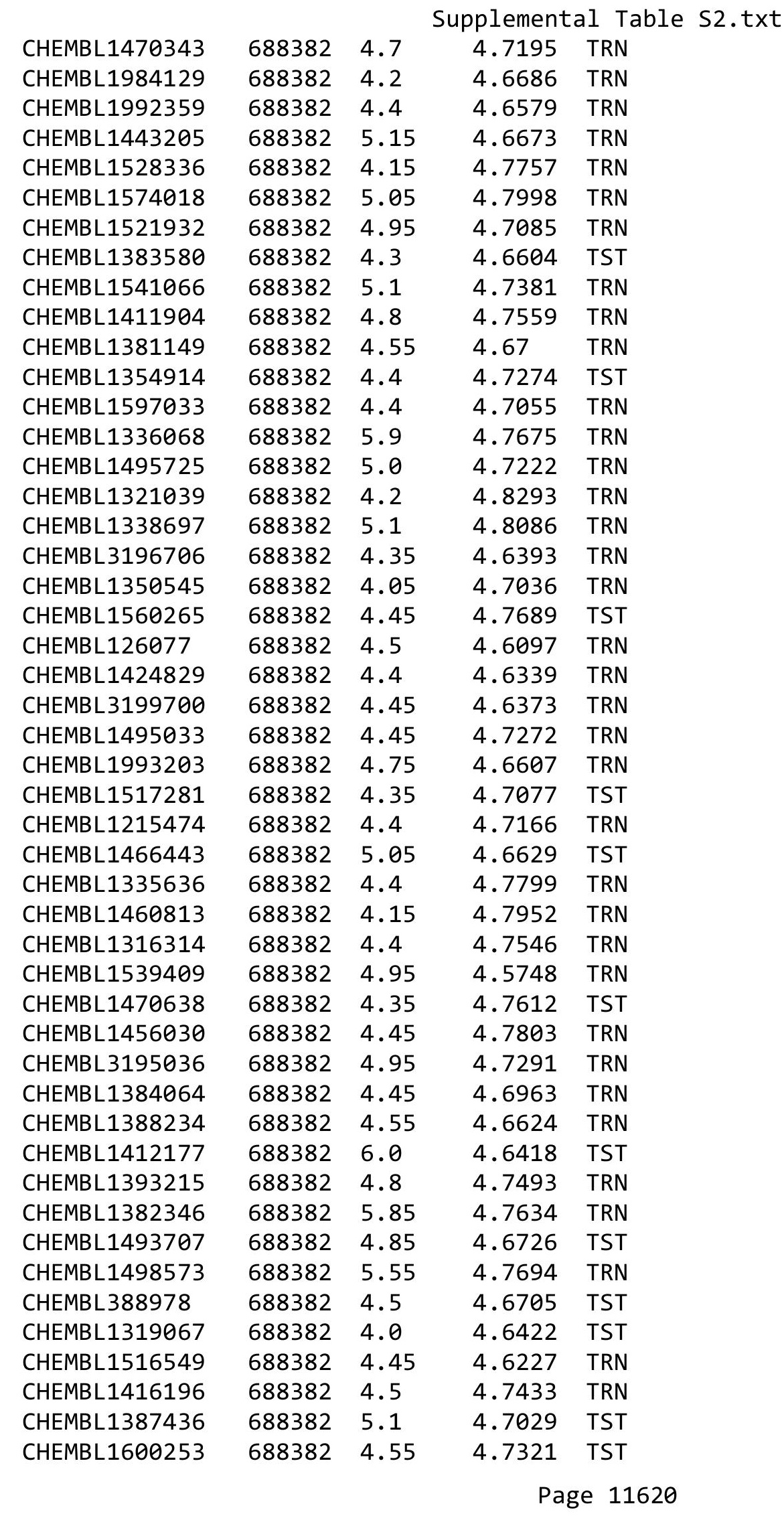




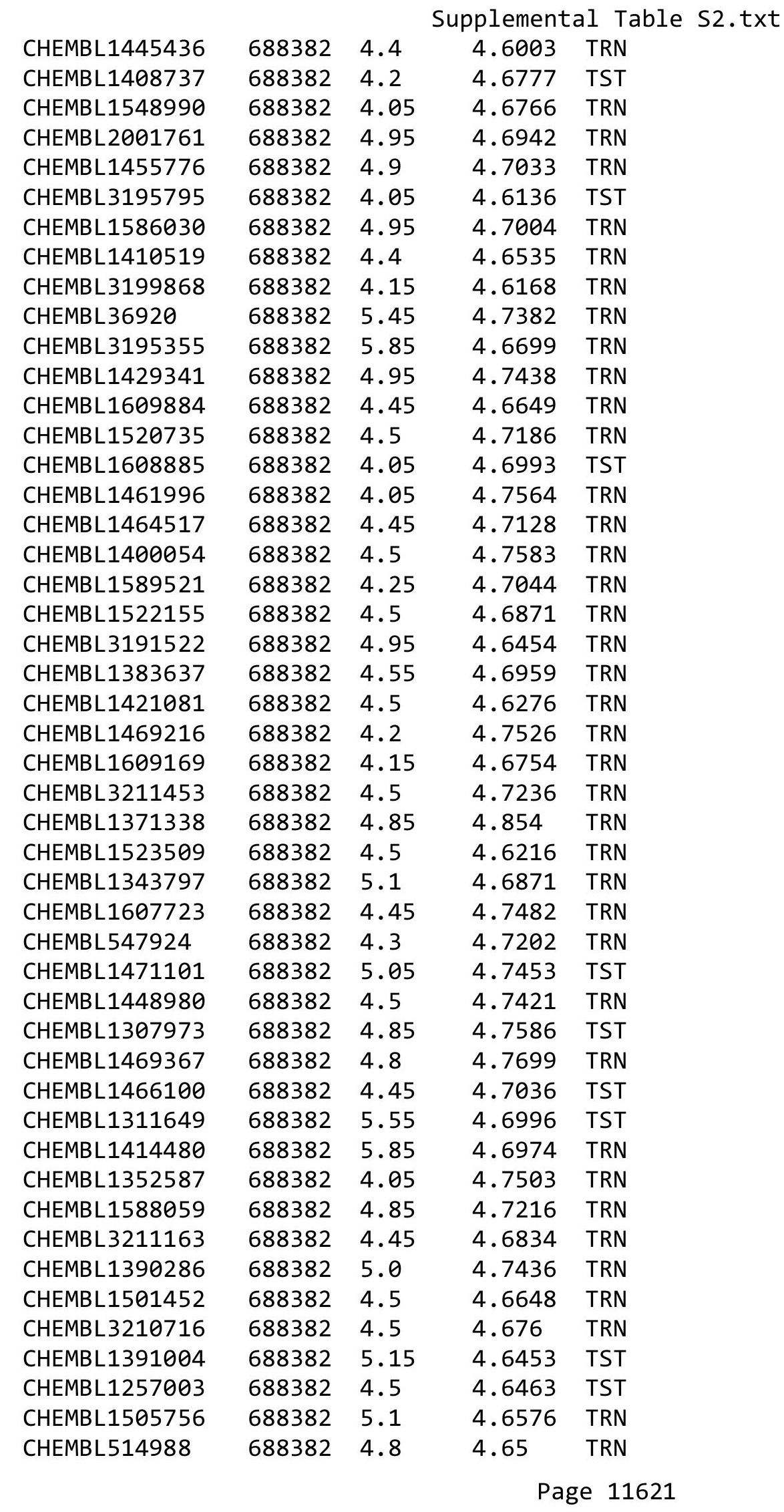




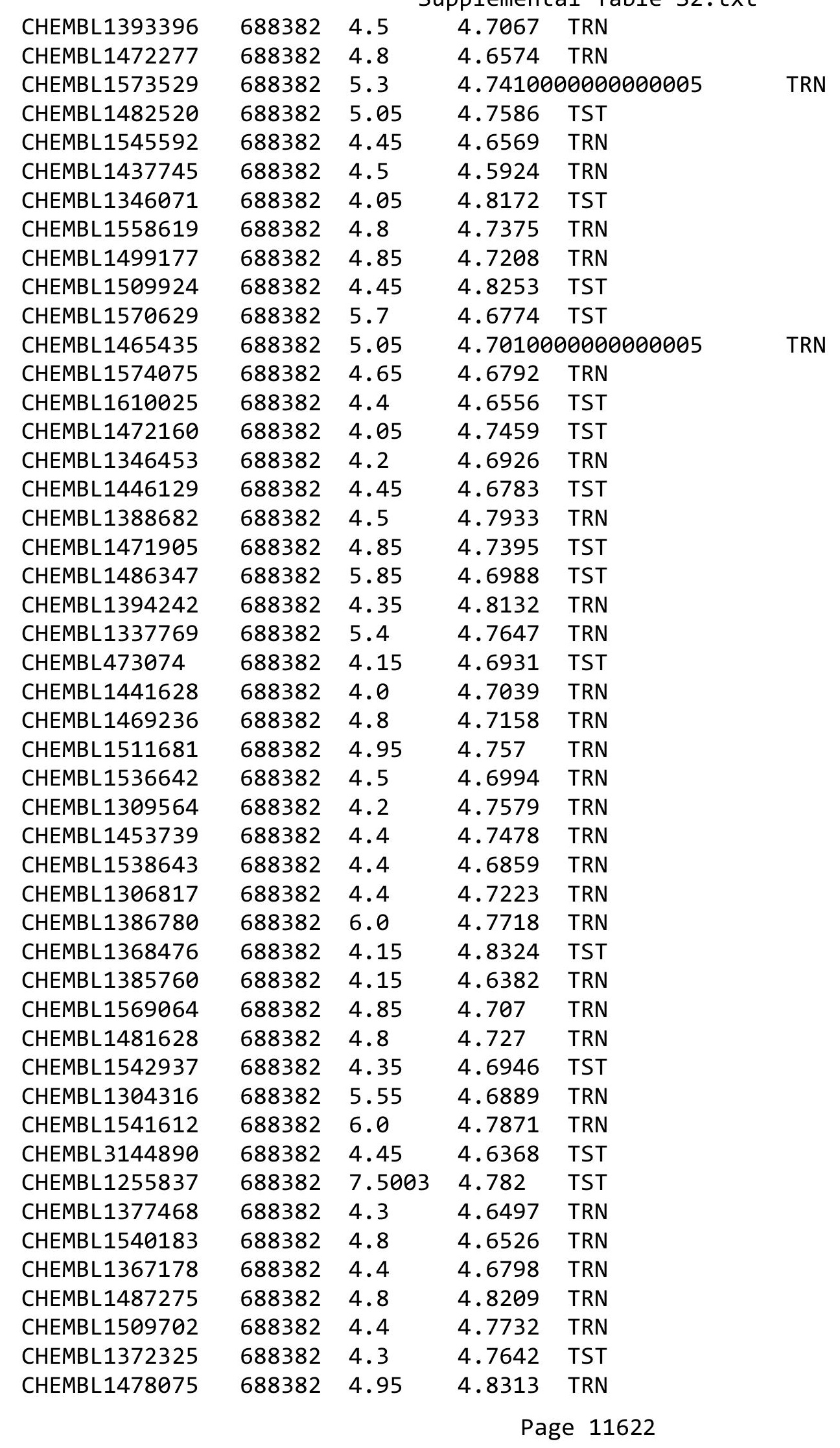




\begin{tabular}{|c|c|c|c|c|c|}
\hline & & \multicolumn{4}{|c|}{ Supplemental Table S2.txt } \\
\hline CHEMBL1559202 & 688382 & 4.45 & 4.7404 & TST & \\
\hline CHEMBL1548641 & 688382 & 4.4 & 4.7015 & TRN & \\
\hline CHEMBL1549764 & 688382 & 5.5 & 4.6149 & TRN & \\
\hline CHEMBL1453686 & 688382 & 4.85 & 4.6916 & TRN & \\
\hline CHEMBL1407368 & 688382 & 4.6 & 4.6574 & TRN & \\
\hline CHEMBL1490483 & 688382 & 4.5 & 4.7041 & TRN & \\
\hline CHEMBL1312257 & 688382 & 5.45 & 4.7529 & TRN & \\
\hline CHEMBL1448106 & 688382 & 5.8 & 4.717 & TST & \\
\hline CHEMBL1545256 & 688382 & 4.85 & 4.6299 & TRN & \\
\hline CHEMBL1518780 & 688382 & 4.95 & 4.7338 & TST & \\
\hline CHEMBL1399486 & 688382 & 4.2 & 4.6181 & TRN & \\
\hline CHEMBL1374965 & 688382 & 5.85 & 4.7333 & TRN & \\
\hline CHEMBL1385703 & 688382 & 4.95 & 4.8187 & TRN & \\
\hline CHEMBL1606665 & 688382 & 5.2 & 4.8401 & TRN & \\
\hline CHEMBL1418243 & 688382 & 4.9 & 4.6967 & TRN & \\
\hline CHEMBL1337756 & 688382 & 5.15 & 4.67899 & 9999999999 & TRN \\
\hline CHEMBL1597937 & 688382 & 4.4 & 4.686 & TRN & \\
\hline CHEMBL1564636 & 688382 & 4.4 & 4.7332 & TST & \\
\hline CHEMBL1557311 & 688382 & 4.4 & 4.7758 & TRN & \\
\hline CHEMBL1594984 & 688382 & 4.65 & 4.63899 & 9999999999 & TRN \\
\hline CHEMBL1410504 & 688382 & 4.5 & 4.6729 & TRN & \\
\hline CHEMBL1576744 & 688382 & 4.9 & 4.7619 & TRN & \\
\hline CHEMBL1472381 & 688382 & 5.85 & 4.86100 & 0000000001 & TRN \\
\hline CHEMBL1550742 & 688382 & 4.5 & 4.7373 & TST & \\
\hline CHEMBL1603616 & 688382 & 4.45 & 4.6874 & TST & \\
\hline CHEMBL1502019 & 688382 & 4.15 & 4.7286 & TRN & \\
\hline CHEMBL1530303 & 688382 & 4.6 & 4.6948 & TRN & \\
\hline CHEMBL1547826 & 688382 & 4.35 & 4.7903 & TRN & \\
\hline CHEMBL1598364 & 688382 & 4.5 & 4.7816 & TST & \\
\hline CHEMBL1440995 & 688382 & 5.15 & 4.6857 & TRN & \\
\hline CHEMBL1581683 & 688382 & 4.7 & 4.7149 & TST & \\
\hline CHEMBL1411910 & 688382 & 4.85 & 4.7306 & TRN & \\
\hline CHEMBL1442168 & 688382 & 4.5 & 4.8189 & TST & \\
\hline CHEMBL1429158 & 688382 & 4.45 & 4.621 & TRN & \\
\hline CHEMBL1515088 & 688382 & 4.45 & 4.6139 & TRN & \\
\hline CHEMBL1409110 & 688382 & 4.45 & 4.7398 & TRN & \\
\hline CHEMBL1344924 & 688382 & 5.95 & 4.8318 & TRN & \\
\hline CHEMBL1558820 & 688382 & 5.0 & 4.6451 & TST & \\
\hline CHEMBL1368314 & 688382 & 4.0 & 4.8225 & TRN & \\
\hline CHEMBL3193840 & 688382 & 4.55 & 4.6511 & TRN & \\
\hline CHEMBL1303697 & 688382 & 4.05 & 4.6816 & TRN & \\
\hline CHEMBL1549674 & 688382 & 4.5 & 4.6735 & TRN & \\
\hline CHEMBL1303952 & 688382 & 4.45 & 4.6899 & TRN & \\
\hline CHEMBL1499010 & 688382 & 6.0 & 4.7032 & TRN & \\
\hline CHEMBL1575373 & 688382 & 4.9 & 4.8037 & TRN & \\
\hline CHEMBL1404690 & 688382 & 5.0 & 4.7388 & TST & \\
\hline CHEMBL1525052 & 688382 & 4.95 & 4.7058 & TRN & \\
\hline CHEMBL1583264 & 688382 & 4.45 & 4.6354 & TRN & \\
\hline
\end{tabular}




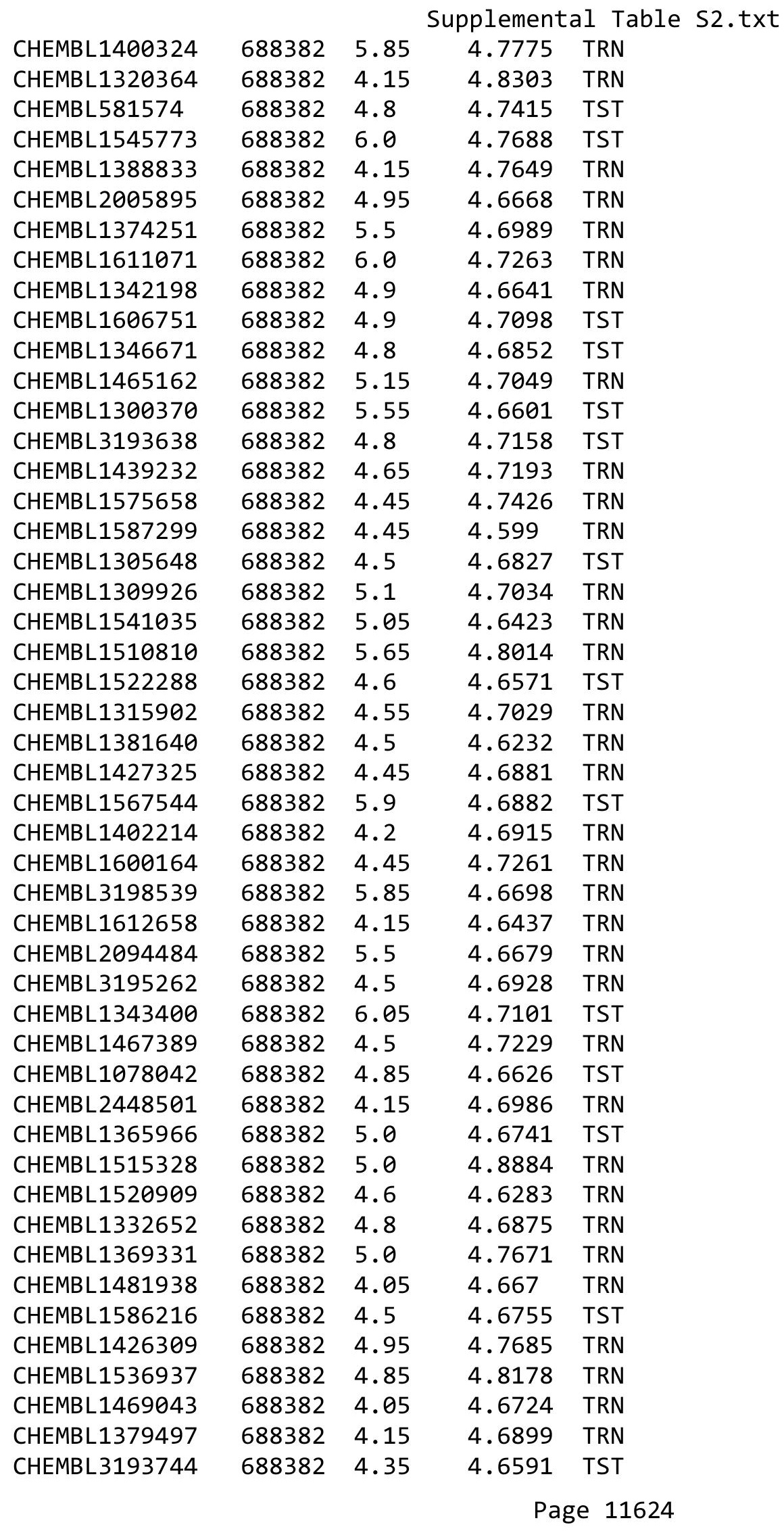




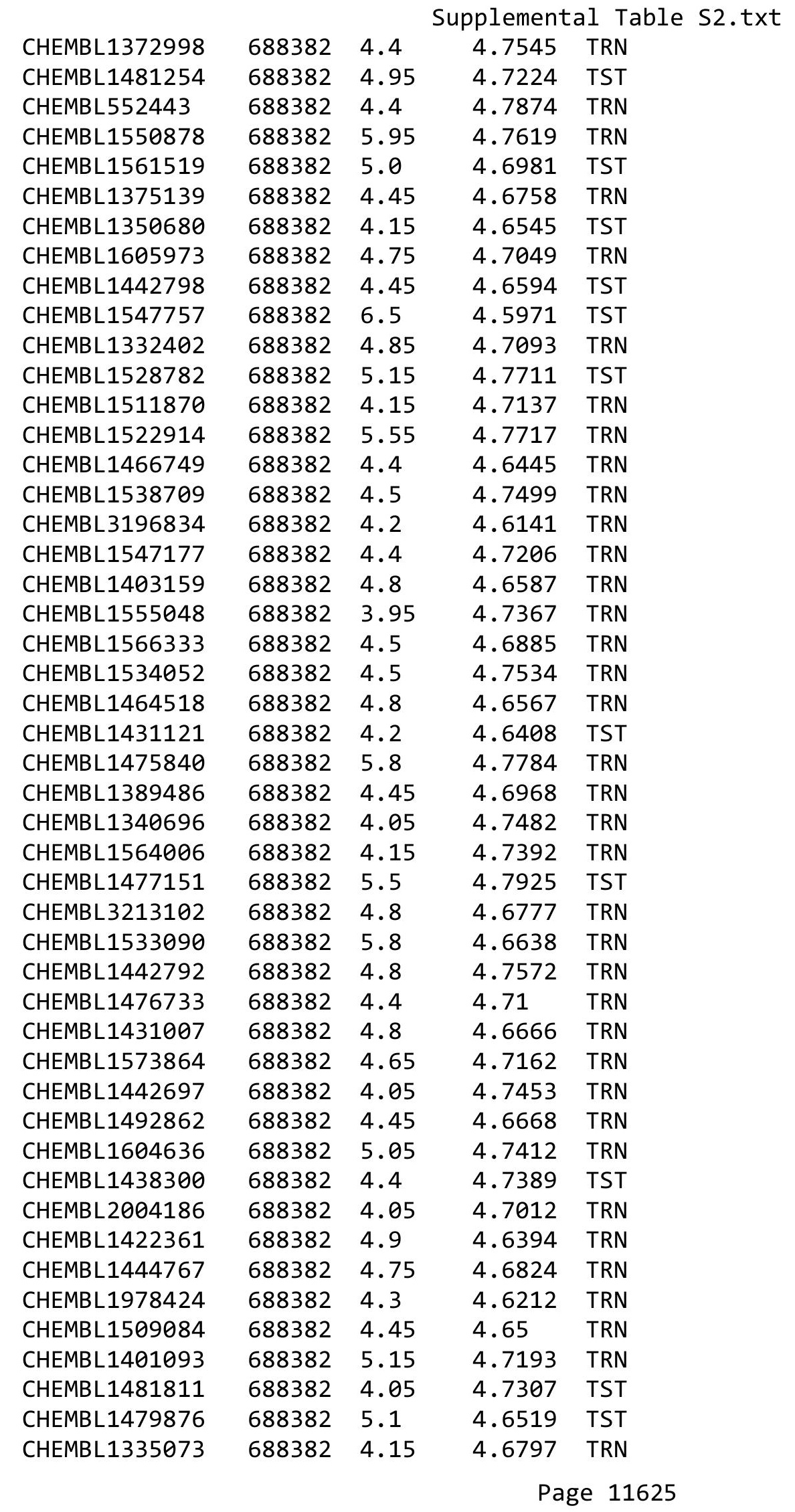




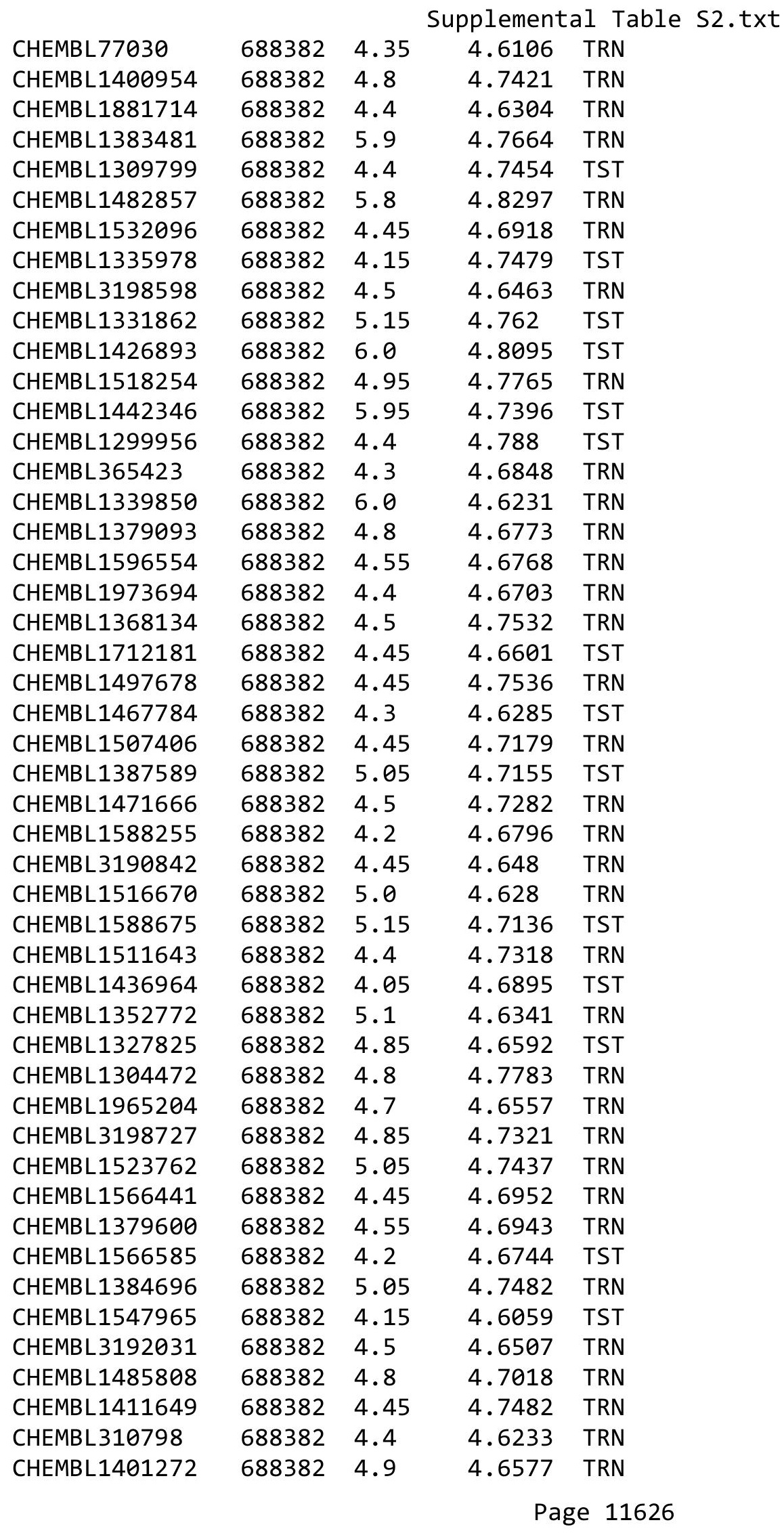




\begin{tabular}{|c|c|c|c|c|}
\hline & & & pplemen & \\
\hline CHEMBL1383879 & 688382 & 4.95 & 4.7137 & TRN \\
\hline CHEMBL1359006 & 688382 & 4.45 & 4.6309 & TRN \\
\hline CHEMBL1601427 & 688382 & 4.45 & 4.6202 & TRN \\
\hline CHEMBL1365551 & 688382 & 5.95 & 4.7235 & TRN \\
\hline CHEMBL1576038 & 688382 & 4.05 & 4.7793 & TRN \\
\hline CHEMBL1522731 & 688382 & 6.0 & 4.7932 & TRN \\
\hline CHEMBL1400783 & 688382 & 4.0 & 4.7485 & TRN \\
\hline CHEMBL1405785 & 688382 & 4.55 & 4.7527 & TRN \\
\hline CHEMBL1599410 & 688382 & 4.2 & 4.7206 & TST \\
\hline CHEMBL1584309 & 688382 & 4.85 & 4.6347 & TST \\
\hline CHEMBL1304888 & 688382 & 5.0 & 4.6509 & TRN \\
\hline CHEMBL1311825 & 688382 & 4.8 & 4.7091 & TRN \\
\hline CHEMBL1338359 & 688382 & 4.9 & 4.7046 & TST \\
\hline CHEMBL1449203 & 688382 & 4.35 & 4.6493 & TRN \\
\hline CHEMBL1597859 & 688382 & 5.8 & 4.7153 & TST \\
\hline CHEMBL1450113 & 688382 & 4.8 & 4.692 & TST \\
\hline CHEMBL1380580 & 688382 & 4.8 & 4.6248 & TRN \\
\hline CHEMBL1320118 & 688382 & 4.0 & 4.7258 & TRN \\
\hline CHEMBL1325668 & 688382 & 4.45 & 4.7076 & TRN \\
\hline CHEMBL1588803 & 688382 & 4.15 & 4.6874 & TRN \\
\hline CHEMBL3209782 & 688382 & 5.2 & 4.6689 & TRN \\
\hline CHEMBL1309847 & 688382 & 4.8 & 4.6897 & TST \\
\hline CHEMBL1329705 & 688382 & 5.05 & 4.7003 & TRN \\
\hline CHEMBL1464017 & 688382 & 4.6 & 4.6923 & TRN \\
\hline CHEMBL239322 & 688382 & 4.5 & 4.5999 & TST \\
\hline CHEMBL1361313 & 688382 & 4.85 & 4.6529 & TRN \\
\hline CHEMBL1486195 & 688382 & 4.45 & 4.6845 & TRN \\
\hline CHEMBL1487265 & 688382 & 5.1 & 4.7474 & TRN \\
\hline CHEMBL1532019 & 688382 & 4.85 & 4.6835 & TRN \\
\hline CHEMBL1550759 & 688382 & 4.3 & 4.7236 & TRN \\
\hline CHEMBL1596056 & 688382 & 4.2 & 4.6082 & TRN \\
\hline CHEMBL1398887 & 688382 & 5.05 & 4.8348 & TRN \\
\hline CHEMBL1547386 & 688382 & 4.5 & 4.7146 & TRN \\
\hline CHEMBL1466415 & 688382 & 4.6 & 4.6559 & TRN \\
\hline CHEMBL1441802 & 688382 & 4.95 & 4.6685 & TRN \\
\hline CHEMBL1346781 & 688382 & 5.05 & 4.8268 & TST \\
\hline CHEMBL3191808 & 688382 & 5.05 & 4.7403 & TRN \\
\hline CHEMBL1568468 & 688382 & 5.15 & 4.729 & TRN \\
\hline CHEMBL1343148 & 688382 & 6.0 & 4.8223 & TRN \\
\hline CHEMBL1423757 & 688382 & 4.45 & 4.7039 & TRN \\
\hline CHEMBL3212376 & 688382 & 4.4 & 4.7101 & TST \\
\hline CHEMBL1478270 & 688382 & 4.85 & 4.783 & TRN \\
\hline CHEMBL1416089 & 688382 & 5.55 & 4.7252 & TRN \\
\hline CHEMBL1596219 & 688382 & 4.4 & 4.6242 & TRN \\
\hline CHEMBL1456659 & 688382 & 4.45 & 4.6109 & TST \\
\hline CHEMBL1431803 & 688382 & 4.15 & 4.7409 & TRN \\
\hline CHEMBL1324438 & 688382 & 4.8 & 4.7292 & TRN \\
\hline CHEMBL548017 & 688382 & 4.45 & 4.6875 & TRN \\
\hline
\end{tabular}




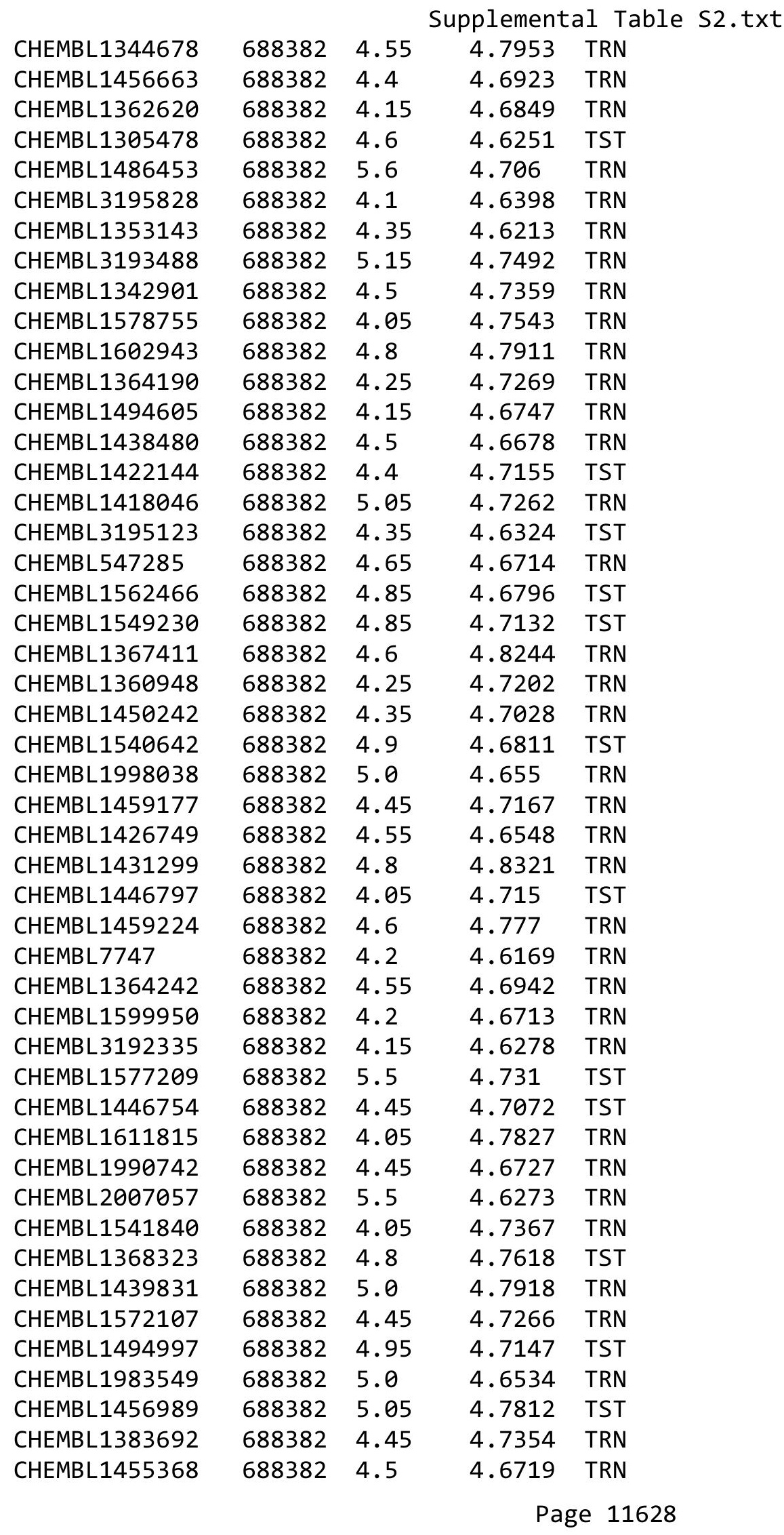




\begin{tabular}{|c|c|c|c|c|}
\hline & & & upplement & al $\mathrm{T}$ \\
\hline CHEMBL1405336 & 688382 & 4.95 & 4.7183 & TST \\
\hline CHEMBL1400766 & 688382 & 4.95 & 4.7389 & TRN \\
\hline CHEMBL1488925 & 688382 & 6.0 & 4.6476 & TRN \\
\hline CHEMBL1308139 & 688382 & 4.5 & 4.732 & TRN \\
\hline CHEMBL1165723 & 688382 & 4.05 & 4.6494 & TRN \\
\hline CHEMBL1529872 & 688382 & 4.95 & 4.7661 & TRN \\
\hline CHEMBL1329466 & 688382 & 4.85 & 4.63 & TRN \\
\hline CHEMBL1411477 & 688382 & 4.05 & 4.7643 & TST \\
\hline CHEMBL1471213 & 688382 & 4.15 & 4.6836 & TRN \\
\hline CHEMBL1464343 & 688382 & 5.55 & 4.7354 & TRN \\
\hline CHEMBL3198837 & 688382 & 4.15 & 4.6428 & TST \\
\hline CHEMBL 3192255 & 688382 & 4.8 & 4.7321 & TRN \\
\hline CHEMBL1425279 & 688382 & 4.85 & 4.7319 & TRN \\
\hline CHEMBL1543907 & 688382 & 4.5 & 4.7576 & TRN \\
\hline CHEMBL1313572 & 688382 & 5.85 & 4.7213 & TRN \\
\hline CHEMBL1577625 & 688382 & 4.8 & 4.7973 & TRN \\
\hline CHEMBL1964843 & 688382 & 4.15 & 4.6717 & TRN \\
\hline CHEMBL1392490 & 688382 & 5.0 & 4.7878 & TRN \\
\hline CHEMBL1583919 & 688382 & 4.95 & 4.7848 & TRN \\
\hline CHEMBL1593878 & 688382 & 4.6 & 4.739 & TST \\
\hline CHEMBL1523540 & 688382 & 4.85 & 4.7455 & TST \\
\hline CHEMBL1546024 & 688382 & 4.15 & 4.7389 & TRN \\
\hline CHEMBL1586359 & 688382 & 4.05 & 4.6952 & TST \\
\hline CHEMBL1518757 & 688382 & 4.2 & 4.7722 & TRN \\
\hline CHEMBL1441627 & 688382 & 6.05 & 4.7039 & TRN \\
\hline CHEMBL1418096 & 688382 & 5.6 & 4.5918 & TRN \\
\hline CHEMBL1487969 & 688382 & 4.25 & 4.7544 & TRN \\
\hline CHEMBL1498818 & 688382 & 5.55 & 4.6823 & TRN \\
\hline CHEMBL3192976 & 688382 & 5.15 & 4.6449 & TRN \\
\hline CHEMBL1339981 & 688382 & 5.25 & 4.7063 & TRN \\
\hline CHEMBL1545734 & 688382 & 4.15 & 4.6941 & TRN \\
\hline CHEMBL1341525 & 688382 & 5.15 & 4.7797 & TRN \\
\hline CHEMBL1604125 & 688382 & 4.5 & 4.8065 & TRN \\
\hline CHEMBL1077990 & 688382 & 5.15 & 4.637 & TRN \\
\hline CHEMBL1494669 & 688382 & 4.0 & 4.6889 & TST \\
\hline CHEMBL1348609 & 688382 & 4.7 & 4.6795 & TRN \\
\hline CHEMBL1608349 & 688382 & 4.15 & 4.684 & TST \\
\hline CHEMBL1328819 & 688382 & 5.05 & 4.6859 & TRN \\
\hline CHEMBL1585412 & 688382 & 5.1 & 4.8023 & TRN \\
\hline CHEMBL1494475 & 688382 & 4.6 & 4.6651 & TRN \\
\hline CHEMBL3194440 & 688382 & 4.05 & 4.6962 & TRN \\
\hline CHEMBL1612672 & 688382 & 4.8 & 4.6404 & TRN \\
\hline CHEMBL1524537 & 688382 & 5.0 & 4.7225 & TRN \\
\hline CHEMBL1440727 & 688382 & 4.2 & 4.6133 & TST \\
\hline CHEMBL1555496 & 688382 & 4.35 & 4.6836 & TST \\
\hline CHEMBL1332342 & 688382 & 4.35 & 4.6556 & TST \\
\hline CHEMBL1498164 & 688382 & 4.25 & 4.7586 & TRN \\
\hline CHEMBL1429017 & 688382 & 4.45 & 4.7407 & TRN \\
\hline
\end{tabular}




\begin{tabular}{|c|c|c|c|c|c|}
\hline & & \multicolumn{4}{|c|}{ Supplemental Table S2.txt } \\
\hline CHEMBL1379313 & 688382 & 4.15 & 4.6074 & TRN & \\
\hline CHEMBL1341821 & 688382 & 4.8 & 4.7561 & TRN & \\
\hline CHEMBL1432627 & 688382 & 4.25 & 4.6152 & TRN & \\
\hline CHEMBL1253351 & 688382 & 5.45 & 4.7507 & TRN & \\
\hline CHEMBL1478140 & 688382 & 4.6 & 4.612 & TRN & \\
\hline CHEMBL 2000748 & 688382 & 4.4 & 4.6584 & TRN & \\
\hline CHEMBL1527623 & 688382 & 4.4 & 4.7784 & TRN & \\
\hline CHEMBL1323186 & 688382 & 4.6 & 4.7361 & TRN & \\
\hline CHEMBL1610321 & 688382 & 4.55 & 4.7235 & TST & \\
\hline CHEMBL1606011 & 688382 & 4.85 & 4.8 & TRN & \\
\hline CHEMBL1366338 & 688382 & 4.2 & 4.7075 & TRN & \\
\hline CHEMBL1412551 & 688382 & 4.4 & 4.8087 & TRN & \\
\hline CHEMBL1339044 & 688382 & 4.4 & 4.6663 & TRN & \\
\hline CHEMBL1459526 & 688382 & 5.85 & 4.7468 & TST & \\
\hline CHEMBL1496158 & 688382 & 5.85 & 4.7289 & TRN & \\
\hline CHEMBL1350698 & 688382 & 5.0 & 4.7146 & TRN & \\
\hline CHEMBL1507210 & 688382 & 4.8 & 4.7481 & TRN & \\
\hline CHEMBL1576342 & 688382 & 4.5 & 4.7253 & TRN & \\
\hline CHEMBL1427579 & 688382 & 4.45 & 4.6797 & TST & \\
\hline CHEMBL3190566 & 688382 & 4.05 & 4.6856 & TRN & \\
\hline CHEMBL1361676 & 688382 & 4.9 & 4.7321 & TRN & \\
\hline CHEMBL1571696 & 688382 & 4.8 & 4.782 & TST & \\
\hline CHEMBL1428663 & 688382 & 6.0 & 4.6608 & TRN & \\
\hline CHEMBL1353925 & 688382 & 4.5 & 4.6373 & TRN & \\
\hline CHEMBL1586471 & 688382 & 4.15 & 4.8344 & TRN & \\
\hline CHEMBL1399467 & 688382 & 5.15 & 4.7443 & TRN & \\
\hline CHEMBL1341132 & 688382 & 6.0 & 4.6229 & TST & \\
\hline CHEMBL1430398 & 688382 & 4.7 & 4.6887 & TST & \\
\hline CHEMBL1572703 & 688382 & 4.5 & 4.7084 & TRN & \\
\hline CHEMBL3193007 & 688382 & 4.15 & 4.7041 & TRN & \\
\hline CHEMBL1487813 & 688382 & 5.0 & 4.6496 & TRN & \\
\hline CHEMBL1352344 & 688382 & 5.2 & 4.7144 & TST & \\
\hline CHEMBL1408203 & 688382 & 5.9 & 4.695 & TRN & \\
\hline CHEMBL1512605 & 688382 & 4.4 & 4.75899 & 99999999995 & TST \\
\hline CHEMBL1384093 & 688382 & 4.15 & 4.6735 & TST & \\
\hline CHEMBL1309091 & 688382 & 4.6 & 4.5693 & TRN & \\
\hline CHEMBL3208087 & 688382 & 4.45 & 4.7521 & TST & \\
\hline CHEMBL1464241 & 688382 & 4.55 & 4.7394 & TST & \\
\hline CHEMBL3195851 & 688382 & 4.55 & 4.6567 & TRN & \\
\hline CHEMBL1420815 & 688382 & 6.0 & 4.6694 & TRN & \\
\hline CHEMBL576656 & 688382 & 4.5 & 4.7491 & TRN & \\
\hline CHEMBL1568738 & 688382 & 4.8 & 4.6711 & TRN & \\
\hline CHEMBL1467195 & 688382 & 4.55 & 4.8397 & TRN & \\
\hline CHEMBL1425610 & 688382 & 4.95 & 4.6775 & TST & \\
\hline CHEMBL1522294 & 688382 & 5.55 & 4.757 & TRN & \\
\hline CHEMBL1430289 & 688382 & 5.45 & 4.7099 & TRN & \\
\hline CHEMBL3193432 & 688382 & 4.05 & 4.6609 & TRN & \\
\hline CHEMBL1458674 & 688382 & 4.75 & 4.7412 & TRN & \\
\hline
\end{tabular}




\begin{tabular}{|c|c|c|c|c|}
\hline \multicolumn{5}{|c|}{ Supplemental Table S2.txt } \\
\hline CHEMBL1420239 & 688382 & 4.5 & 4.754 & TRN \\
\hline CHEMBL1506064 & 688382 & 5.8 & 4.7597 & TST \\
\hline CHEMBL1482215 & 688382 & 4.6 & 4.5652 & TRN \\
\hline CHEMBL1447348 & 688382 & 5.5 & 4.8212 & TRN \\
\hline CHEMBL1319982 & 688382 & 4.2 & 4.7234 & TRN \\
\hline CHEMBL2003511 & 688382 & 4.15 & 4.683 & TRN \\
\hline CHEMBL3210791 & 688382 & 4.85 & 4.6737 & TRN \\
\hline CHEMBL3195271 & 688382 & 4.45 & 4.7343 & TRN \\
\hline CHEMBL1499349 & 688382 & 5.0 & 4.7679 & TRN \\
\hline CHEMBL1517945 & 688382 & 4.4 & 4.5943 & TRN \\
\hline CHEMBL1469138 & 688382 & 4.8 & 4.7252 & TRN \\
\hline CHEMBL1452938 & 688382 & 5.1 & 4.6604 & TRN \\
\hline CHEMBL3191197 & 688382 & 4.2 & 4.6264 & TRN \\
\hline CHEMBL1559094 & 688382 & 4.45 & 4.6441 & TST \\
\hline CHEMBL1389171 & 688382 & 4.45 & 4.7085 & TRN \\
\hline CHEMBL3191821 & 688382 & 5.0 & 4.7686 & TRN \\
\hline CHEMBL1361545 & 688382 & 4.45 & 4.7208 & TST \\
\hline CHEMBL1557186 & 688382 & 4.5 & 4.6582 & TRN \\
\hline CHEMBL1577605 & 688382 & 4.35 & 4.6772 & TST \\
\hline CHEMBL1568704 & 688382 & 4.0 & 4.7728 & TST \\
\hline CHEMBL1544311 & 688382 & 4.85 & 4.7807 & TST \\
\hline CHEMBL1399280 & 688382 & 5.35 & 4.8165 & TRN \\
\hline CHEMBL1466146 & 688382 & 5.15 & 4.8627 & TRN \\
\hline CHEMBL1525024 & 688382 & 4.05 & 4.7044 & TRN \\
\hline CHEMBL3212159 & 688382 & 4.2 & 4.7294 & TRN \\
\hline CHEMBL1321103 & 688382 & 4.5 & 4.6482 & TRN \\
\hline CHEMBL1404194 & 688382 & 4.95 & 4.7354 & TRN \\
\hline CHEMBL1482881 & 688382 & 5.9 & 4.7753 & TRN \\
\hline CHEMBL1452124 & 688382 & 4.7 & 4.7128 & TRN \\
\hline CHEMBL1389678 & 688382 & 4.2 & 4.6989 & TST \\
\hline CHEMBL1448028 & 688382 & 4.8 & 4.681 & TRN \\
\hline CHEMBL1520777 & 688382 & 4.45 & 4.6612 & TRN \\
\hline CHEMBL1305403 & 688382 & 4.15 & 4.6764 & TRN \\
\hline CHEMBL1548064 & 688382 & 4.85 & 4.8505 & TRN \\
\hline CHEMBL1415134 & 688382 & 4.1 & 4.6538 & TST \\
\hline CHEMBL1465600 & 688382 & 5.05 & 4.6722 & TST \\
\hline CHEMBL1471041 & 688382 & 4.45 & 4.7677 & TST \\
\hline CHEMBL1443403 & 688382 & 4.55 & 4.694 & TRN \\
\hline CHEMBL1414422 & 688382 & 4.95 & 4.7506 & TRN \\
\hline CHEMBL1308932 & 688382 & 4.0 & 4.8064 & TST \\
\hline CHEMBL1429266 & 688382 & 4.6 & 4.6966 & TST \\
\hline CHEMBL1448477 & 688382 & 4.8 & 4.7001 & TST \\
\hline CHEMBL1379110 & 688382 & 4.8 & 4.6848 & TRN \\
\hline CHEMBL1468557 & 688382 & 4.6 & 4.6668 & TRN \\
\hline CHEMBL1502001 & 688382 & 4.5 & 4.7047 & TRN \\
\hline CHEMBL1383777 & 688382 & 4.8 & 4.659 & TRN \\
\hline CHEMBL3392047 & 688382 & 4.6 & 4.7531 & TRN \\
\hline CHEMBL1482388 & 688382 & 4.15 & 4.7914 & TST \\
\hline
\end{tabular}




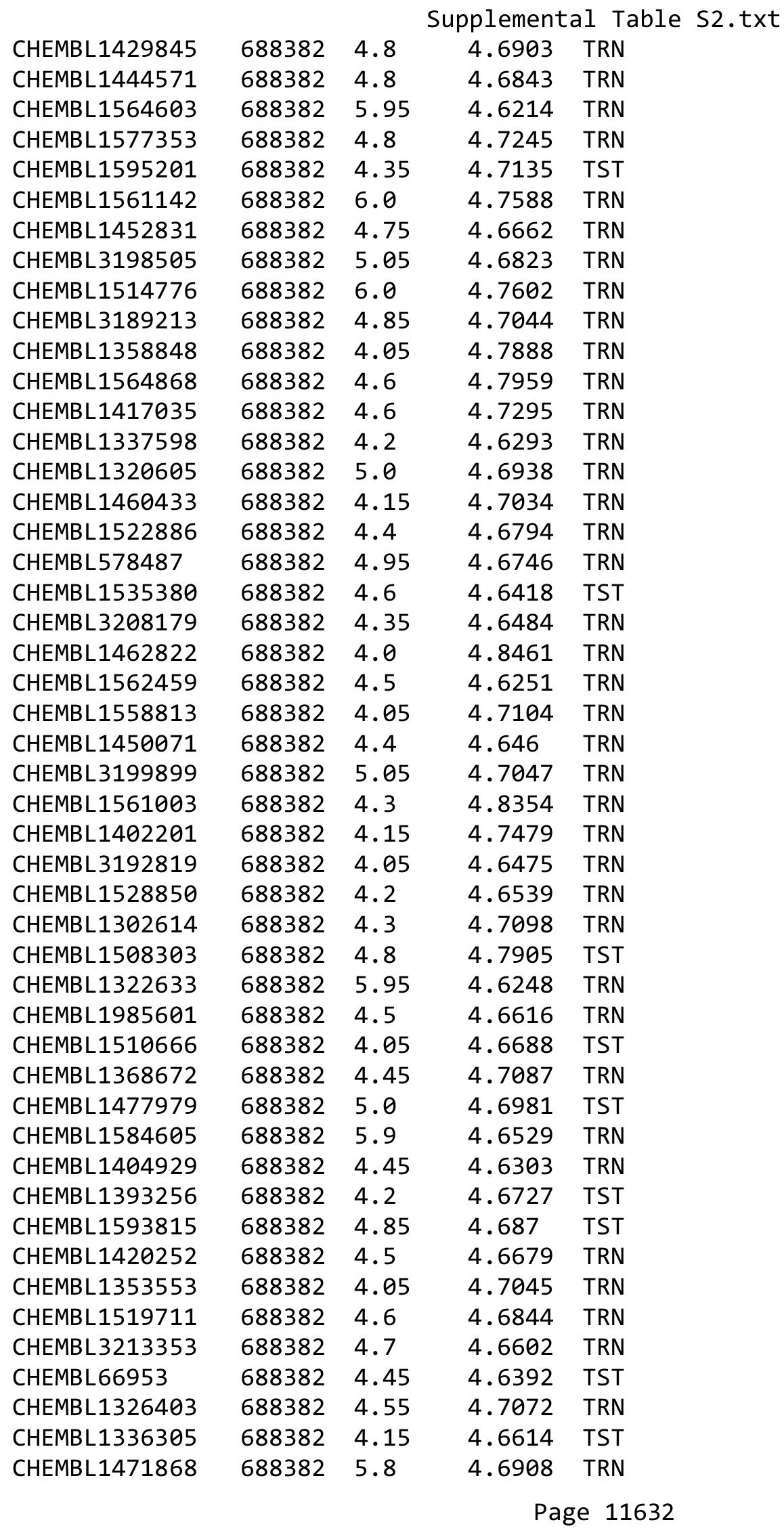




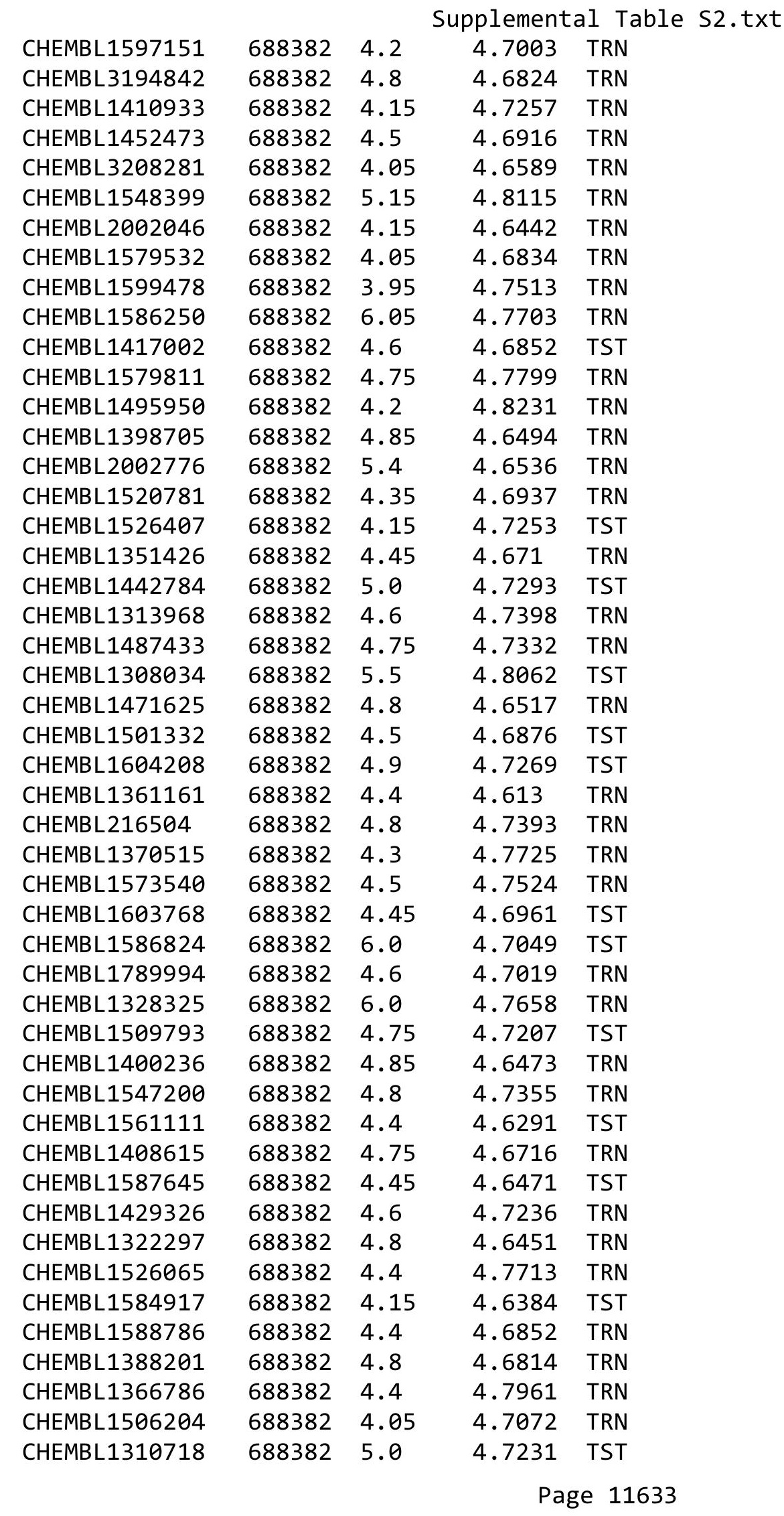




\begin{tabular}{|c|c|c|c|c|c|}
\hline CHEMBL1381118 & 688382 & 4.8 & \multicolumn{2}{|c|}{4.736000000000001} & TST \\
\hline CHEMBL1502258 & 688382 & 4.0 & 4.8531 & TRN & \\
\hline CHEMBL1385602 & 688382 & 4.5 & 4.6587 & TRN & \\
\hline CHEMBL1568335 & 688382 & 4.6 & 4.6956 & TRN & \\
\hline CHEMBL532239 & 688382 & 4.4 & 4.6181 & TRN & \\
\hline CHEMBL1334679 & 688382 & 4.8 & 4.7462 & TRN & \\
\hline CHEMBL1326528 & 688382 & 4.05 & 4.7688 & TRN & \\
\hline CHEMBL1563263 & 688382 & 6.05 & 4.7117 & TRN & \\
\hline CHEMBL1479139 & 688382 & 4.5 & 4.7462 & TRN & \\
\hline CHEMBL1969707 & 688382 & 4.85 & \multicolumn{2}{|c|}{4.5969999999999995} & TRN \\
\hline CHEMBL1611494 & 688382 & 4.85 & 4.7298 & TRN & \\
\hline CHEMBL1323644 & 688382 & 4.2 & 4.6205 & TRN & \\
\hline CHEMBL369513 & 688382 & 4.75 & 4.6835 & TRN & \\
\hline CHEMBL1568043 & 688382 & 4.4 & 4.6837 & TRN & \\
\hline CHEMBL1462838 & 688382 & 4.45 & 4.6964 & TRN & \\
\hline CHEMBL123 & 688382 & 6.0 & 4.6273 & TRN & \\
\hline CHEMBL1300117 & 688382 & 6.0 & 4.7055 & TRN & \\
\hline CHEMBL1303641 & 688382 & 6.4 & 4.6831 & TST & \\
\hline CHEMBL1587236 & 688382 & 4.15 & 4.7114 & TRN & \\
\hline CHEMBL1505610 & 688382 & 5.05 & 4.6331 & TRN & \\
\hline CHEMBL1313095 & 688382 & 4.15 & 4.6164 & TRN & \\
\hline CHEMBL1388368 & 688382 & 4.95 & 4.7496 & TST & \\
\hline CHEMBL1504764 & 688382 & 4.85 & 4.7506 & TRN & \\
\hline CHEMBL1490121 & 688382 & 4.8 & 4.6815 & TRN & \\
\hline CHEMBL1517741 & 688382 & 4.5 & 4.603 & TRN & \\
\hline CHEMBL1477809 & 688382 & 4.8 & 4.6636 & TRN & \\
\hline CHEMBL1486163 & 688382 & 4.55 & 4.7134 & TRN & \\
\hline CHEMBL1428028 & 688382 & 4.5 & 4.6988 & TRN & \\
\hline CHEMBL3189892 & 688382 & 5.6 & 4.7767 & TRN & \\
\hline CHEMBL1309478 & 688382 & 4.3 & 4.6376 & TRN & \\
\hline CHEMBL1328699 & 688382 & 4.95 & 4.7285 & TRN & \\
\hline CHEMBL1390028 & 688382 & 4.45 & 4.6846 & TRN & \\
\hline CHEMBL1555822 & 688382 & 5.05 & 4.6728 & TRN & \\
\hline CHEMBL1339294 & 688382 & 4.5 & 4.5698 & TRN & \\
\hline CHEMBL1349796 & 688382 & 5.1 & 4.7693 & TRN & \\
\hline CHEMBL1505196 & 688382 & 5.15 & 4.7398 & TRN & \\
\hline CHEMBL1444974 & 688382 & 4.1 & 4.6779 & TST & \\
\hline CHEMBL1442217 & 688382 & 4.05 & 4.7418 & TST & \\
\hline CHEMBL3193187 & 688382 & 4.45 & 4.6583 & TRN & \\
\hline CHEMBL1998853 & 688382 & 5.6 & 4.7133 & TRN & \\
\hline CHEMBL3208050 & 688382 & 5.65 & 4.6746 & TRN & \\
\hline CHEMBL1609251 & 688382 & 4.2 & 4.5915 & TRN & \\
\hline CHEMBL1974501 & 688382 & 4.6 & 4.612 & TRN & \\
\hline CHEMBL1313432 & 688382 & 4.2 & 4.725 & TRN & \\
\hline CHEMBL1339870 & 688382 & 4.45 & 4.7093 & TRN & \\
\hline CHEMBL1523171 & 688382 & 4.05 & 4.6467 & TRN & \\
\hline CHEMBL1311174 & 688382 & 4.55 & 4.7197 & TST & \\
\hline CHEMBL1363173 & 688382 & 5.25 & 4.7222 & TRN & \\
\hline
\end{tabular}




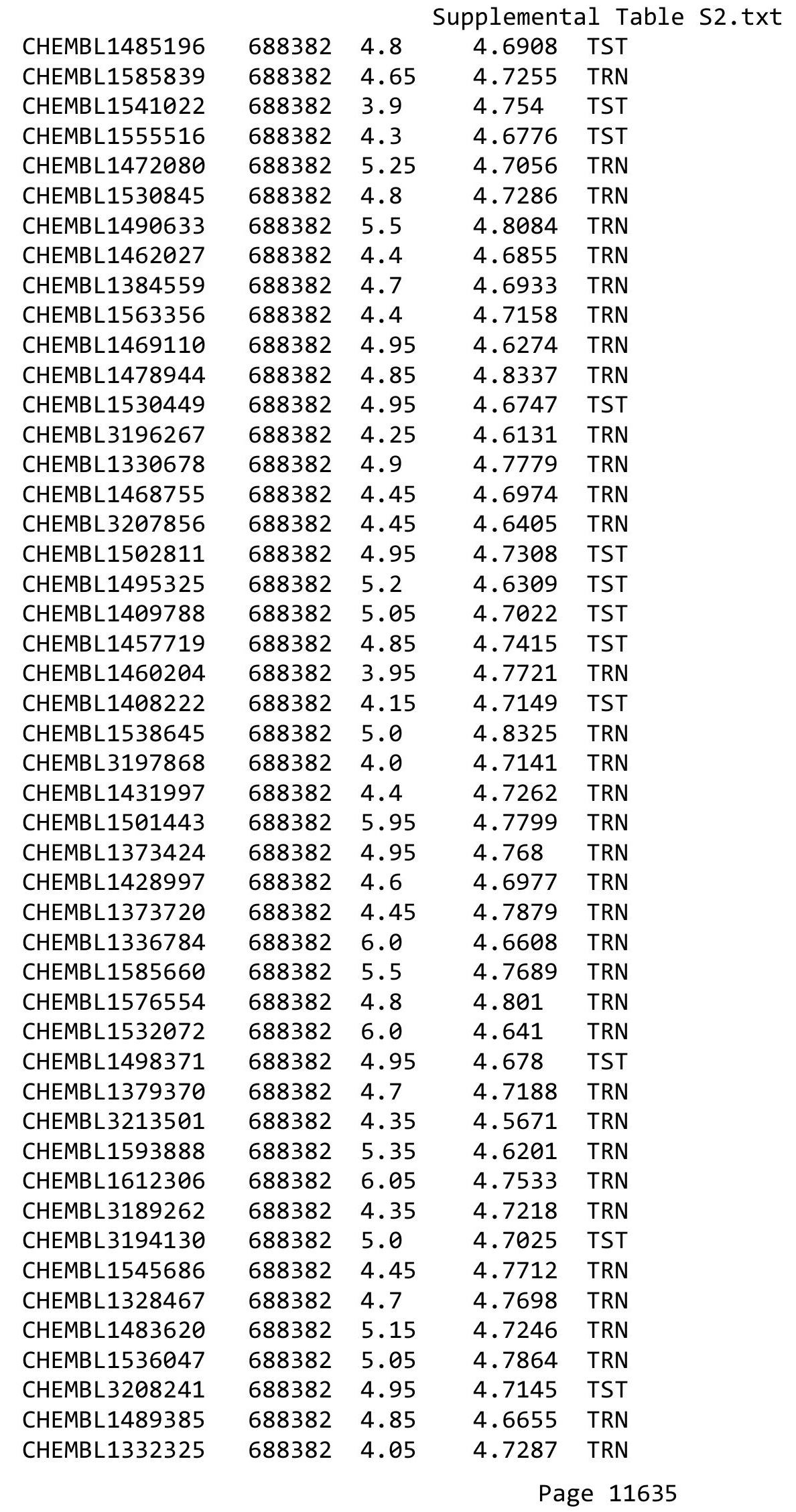




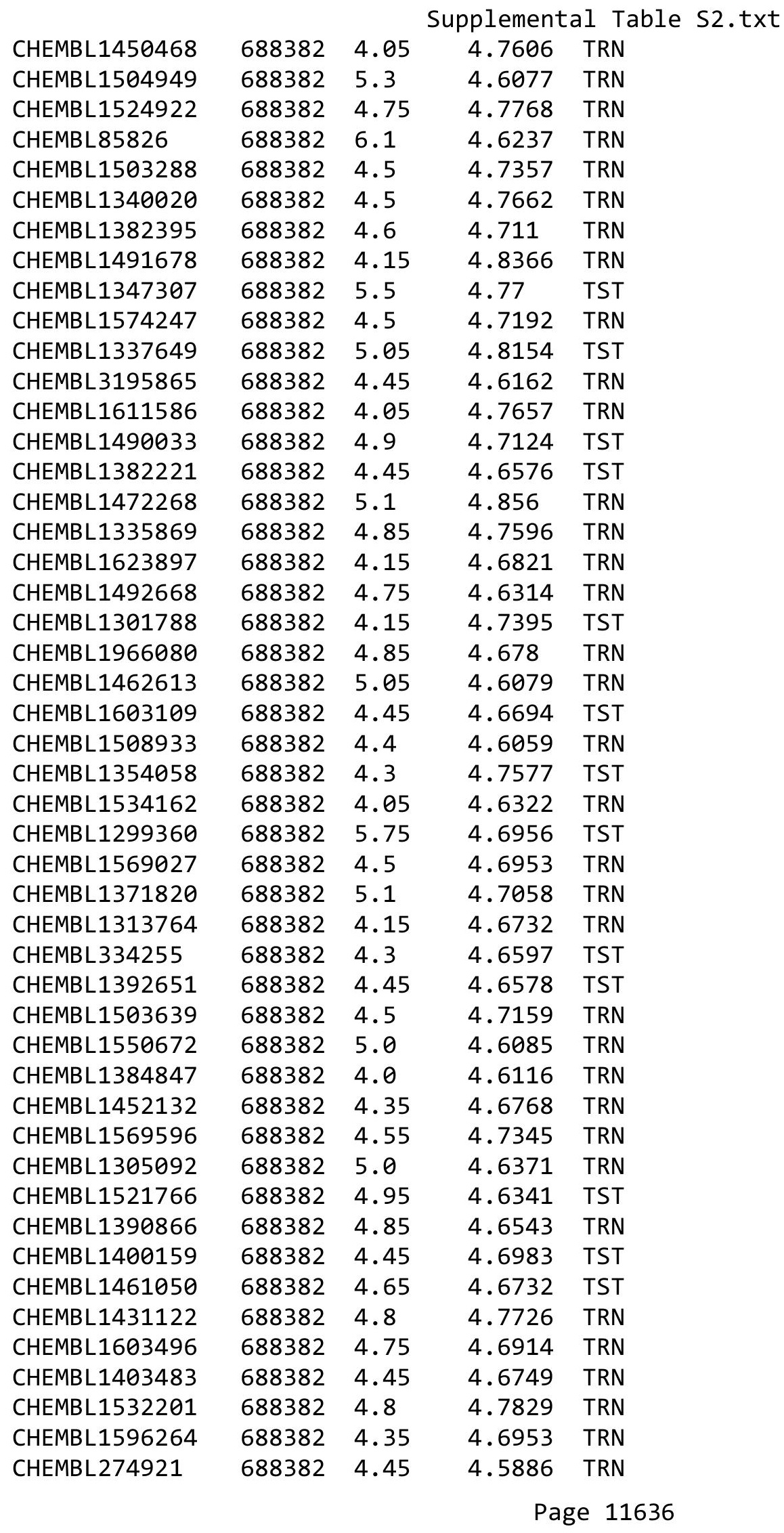




\begin{tabular}{|c|c|c|c|c|}
\hline \multicolumn{5}{|c|}{ Supplemental Table S2.txt } \\
\hline CHEMBL1601871 & 688382 & 4.05 & 4.713 & TRN \\
\hline CHEMBL3196317 & 688382 & 4.5 & 4.7031 & TRN \\
\hline CHEMBL1325037 & 688382 & 4.85 & 4.7235 & TRN \\
\hline CHEMBL592842 & 688382 & 4.2 & 4.699 & TRN \\
\hline CHEMBL1430879 & 688382 & 5.0 & 4.7564 & TST \\
\hline CHEMBL1412989 & 688382 & 4.85 & 4.6826 & TRN \\
\hline CHEMBL1498349 & 688382 & 4.05 & 4.721 & TST \\
\hline CHEMBL1347153 & 688382 & 4.2 & 4.581 & TRN \\
\hline CHEMBL1319179 & 688382 & 4.85 & 4.6872 & TRN \\
\hline CHEMBL1422784 & 688382 & 5.1 & 4.8301 & TRN \\
\hline CHEMBL32810 & 688382 & 4.05 & 4.6495 & TST \\
\hline CHEMBL1997978 & 688382 & 5.0 & 4.7015 & TRN \\
\hline CHEMBL1446007 & 688382 & 4.45 & 4.6808 & TRN \\
\hline CHEMBL1601808 & 688382 & 5.1 & 4.7082 & TRN \\
\hline CHEMBL1326397 & 688382 & 5.65 & 4.7397 & TRN \\
\hline CHEMBL1508268 & 688382 & 4.35 & 4.6692 & TRN \\
\hline CHEMBL1390206 & 688382 & 4.4 & 4.6874 & TRN \\
\hline CHEMBL1301368 & 688382 & 5.1 & 4.6738 & TRN \\
\hline CHEMBL1572614 & 688382 & 5.05 & 4.7211 & TRN \\
\hline CHEMBL1432112 & 688382 & 4.0 & 4.699 & TRN \\
\hline CHEMBL1373772 & 688382 & 5.2 & 4.7542 & TRN \\
\hline CHEMBL1559215 & 688382 & 5.05 & 4.7383 & TRN \\
\hline CHEMBL1407070 & 688382 & 4.05 & 4.7754 & TRN \\
\hline CHEMBL3194790 & 688382 & 5.55 & 4.7652 & TRN \\
\hline CHEMBL1391193 & 688382 & 4.8 & 4.6503 & TRN \\
\hline CHEMBL1365813 & 688382 & 5.4 & 4.662 & TRN \\
\hline CHEMBL210329 & 688382 & 4.25 & 4.7062 & TRN \\
\hline CHEMBL1584288 & 688382 & 4.95 & 4.6619 & TRN \\
\hline CHEMBL1358934 & 688382 & 4.8 & 4.7005 & TRN \\
\hline CHEMBL1440097 & 688382 & 4.45 & 4.6288 & TRN \\
\hline CHEMBL1521965 & 688382 & 4.15 & 4.7304 & TRN \\
\hline CHEMBL1409616 & 688382 & 4.2 & 4.6429 & TRN \\
\hline CHEMBL1982674 & 688382 & 5.05 & 4.6859 & TRN \\
\hline CHEMBL1429167 & 688382 & 4.8 & 4.7153 & TRN \\
\hline CHEMBL3207649 & 688382 & 4.45 & 4.6712 & TRN \\
\hline CHEMBL1471478 & 688382 & 4.4 & 4.7248 & TRN \\
\hline CHEMBL1448640 & 688382 & 4.55 & 4.6465 & TRN \\
\hline CHEMBL1347928 & 688382 & 4.15 & 4.8026 & TRN \\
\hline CHEMBL1487430 & 688382 & 4.5 & 4.6994 & TRN \\
\hline CHEMBL1322799 & 688382 & 4.5 & 4.8233 & TRN \\
\hline CHEMBL1545846 & 688382 & 4.2 & 4.6492 & TRN \\
\hline CHEMBL1504378 & 688382 & 4.8 & 4.5945 & TRN \\
\hline CHEMBL1365832 & 688382 & 6.0 & 4.7551 & TRN \\
\hline CHEMBL1413356 & 688382 & 4.8 & 4.84 & TRN \\
\hline CHEMBL141159 & 688382 & 4.45 & 4.6758 & TRN \\
\hline CHEMBL1346659 & 688382 & 5.15 & 4.6736 & TRN \\
\hline CHEMBL1537451 & 688382 & 4.85 & 4.7231 & TRN \\
\hline CHEMBL1299859 & 688382 & 4.85 & 4.7638 & TRN \\
\hline
\end{tabular}




\begin{tabular}{|c|c|c|c|c|c|}
\hline & & \multicolumn{4}{|c|}{ Supplemental Table S2.txt } \\
\hline CHEMBL3192829 & 688382 & 5.5 & 4.7119 & TRN & \\
\hline CHEMBL1600270 & 688382 & 4.5 & 4.6877 & TRN & \\
\hline CHEMBL3211409 & 688382 & 4.4 & 4.6972 & TRN & \\
\hline CHEMBL1376723 & 688382 & 4.45 & 4.6338 & TRN & \\
\hline CHEMBL1427914 & 688382 & 5.5 & 4.7463 & TRN & \\
\hline CHEMBL1465772 & 688382 & 4.45 & 4.6135 & TRN & \\
\hline CHEMBL1574048 & 688382 & 4.85 & 4.7279 & TST & \\
\hline CHEMBL1313642 & 688382 & 5.05 & 4.7389 & TST & \\
\hline CHEMBL1394394 & 688382 & 4.15 & 4.6869 & TST & \\
\hline CHEMBL3211475 & 688382 & 4.15 & 4.6638 & TST & \\
\hline CHEMBL1574154 & 688382 & 4.9 & 4.6695 & TST & \\
\hline CHEMBL1536069 & 688382 & 6.45 & 4.7098 & TRN & \\
\hline CHEMBL1581782 & 688382 & 5.05 & 4.6623 & TRN & \\
\hline CHEMBL1576292 & 688382 & 4.85 & 4.6499 & TRN & \\
\hline CHEMBL1505170 & 688382 & 5.05 & 4.7104 & TST & \\
\hline CHEMBL1420353 & 688382 & 5.0 & 4.8451 & TRN & \\
\hline CHEMBL1610509 & 688382 & 6.0 & 4.71899 & 9999999999 & TST \\
\hline CHEMBL1533445 & 688382 & 6.0 & 4.7409 & TRN & \\
\hline CHEMBL1514935 & 688382 & 4.5 & 4.7182 & TRN & \\
\hline CHEMBL1556843 & 688382 & 5.15 & 4.7225 & TRN & \\
\hline CHEMBL1507251 & 688382 & 4.95 & 4.6331 & TRN & \\
\hline CHEMBL1550051 & 688382 & 4.4 & 4.7259 & TRN & \\
\hline CHEMBL1405734 & 688382 & 4.4 & 4.6766 & TRN & \\
\hline CHEMBL1425187 & 688382 & 4.85 & 4.7972 & TST & \\
\hline CHEMBL1382693 & 688382 & 4.4 & 4.6332 & TST & \\
\hline CHEMBL1308455 & 688382 & 4.45 & 4.6714 & TRN & \\
\hline CHEMBL1497247 & 688382 & 4.55 & 4.7269 & TST & \\
\hline CHEMBL1382460 & 688382 & 4.05 & 4.7831 & TRN & \\
\hline CHEMBL1509900 & 688382 & 4.15 & 4.5979 & TRN & \\
\hline CHEMBL1325094 & 688382 & 4.8 & 4.7385 & TST & \\
\hline CHEMBL1492926 & 688382 & 4.95 & 4.6607 & TRN & \\
\hline CHEMBL1389109 & 688382 & 5.25 & 4.6847 & TRN & \\
\hline CHEMBL1300284 & 688382 & 4.45 & 4.6227 & TST & \\
\hline CHEMBL1540217 & 688382 & 4.4 & 4.7371 & TRN & \\
\hline CHEMBL1966798 & 688382 & 5.05 & 4.6603 & TRN & \\
\hline CHEMBL1596299 & 688382 & 4.2 & 4.687 & TRN & \\
\hline CHEMBL1331487 & 688382 & 4.5 & 4.6854 & TRN & \\
\hline CHEMBL1568845 & 688382 & 4.95 & 4.7655 & TRN & \\
\hline CHEMBL1392012 & 688382 & 4.55 & 4.6563 & TRN & \\
\hline CHEMBL1556118 & 688382 & 4.95 & 4.7076 & TRN & \\
\hline CHEMBL1454112 & 688382 & 4.95 & 4.8307 & TRN & \\
\hline CHEMBL1418133 & 688382 & 4.85 & 4.7444 & TRN & \\
\hline CHEMBL1416345 & 688382 & 4.95 & 4.6729 & TRN & \\
\hline CHEMBL1402375 & 688382 & 4.45 & 4.695 & TRN & \\
\hline CHEMBL1451825 & 688382 & 4.15 & 4.7057 & TRN & \\
\hline CHEMBL1538522 & 688382 & 4.65 & 4.6434 & TRN & \\
\hline CHEMBL1432843 & 688382 & 4.35 & 4.7265 & TRN & \\
\hline CHEMBL45068 & 688382 & 4.5 & 4.6825 & TST & \\
\hline
\end{tabular}




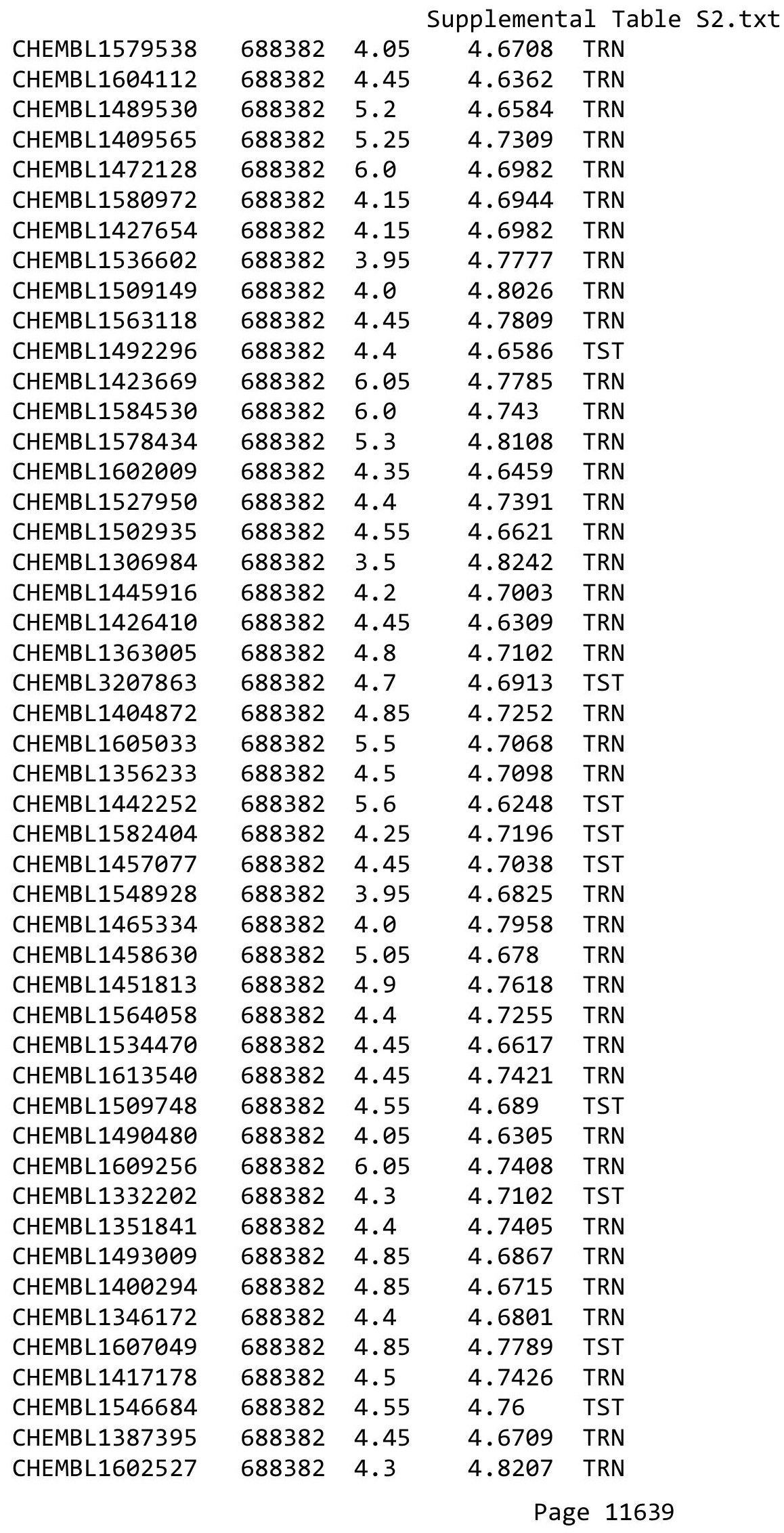




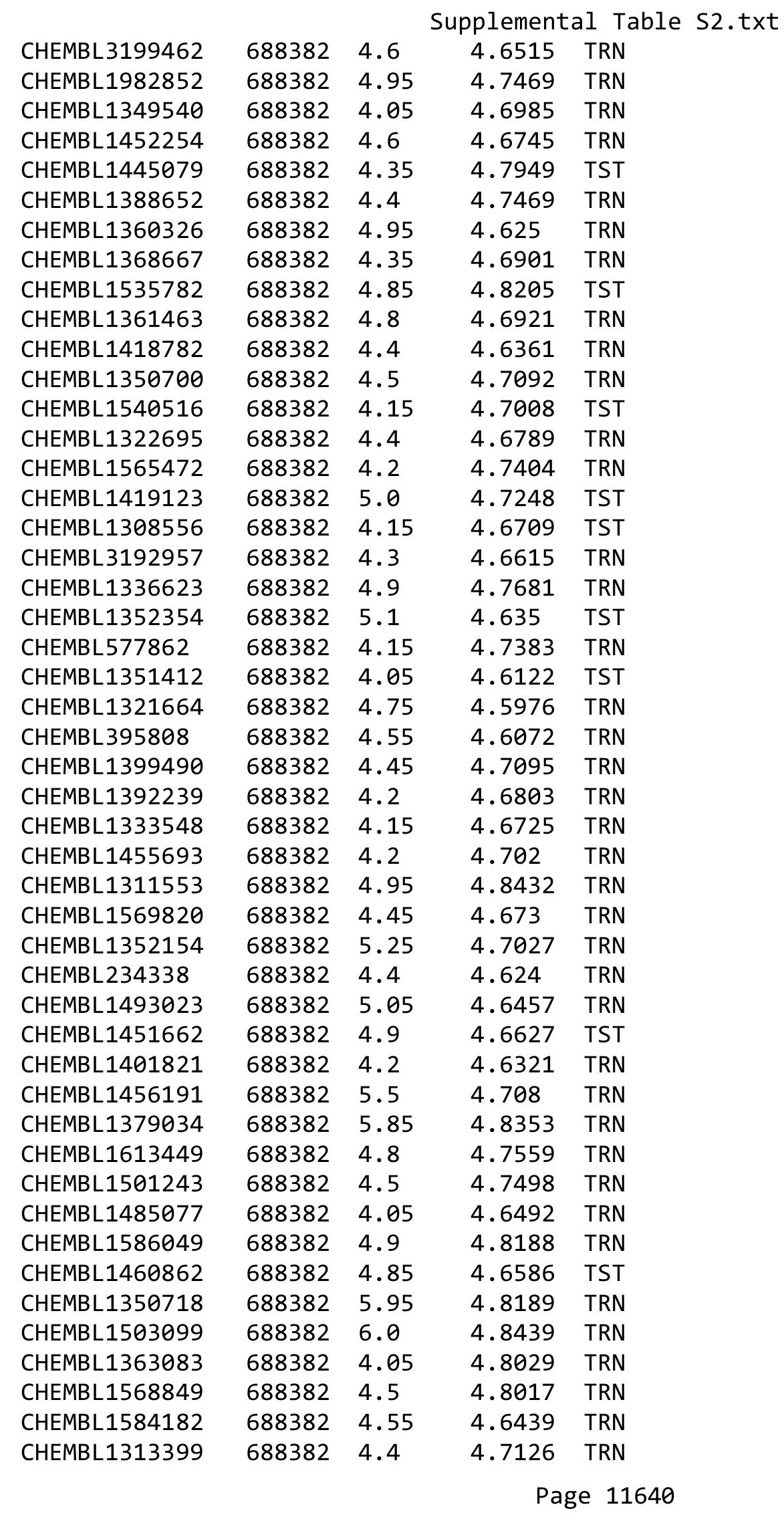




\begin{tabular}{|c|c|c|c|c|}
\hline \multicolumn{5}{|c|}{ Supplemental Table S2.txt } \\
\hline CHEMBL1413543 & 688382 & 4.95 & 4.6097 & TST \\
\hline CHEMBL1405306 & 688382 & 5.95 & 4.6394 & TRN \\
\hline CHEMBL1367913 & 688382 & 4.65 & 4.7918 & TRN \\
\hline CHEMBL1394760 & 688382 & 5.6 & 4.6899 & TST \\
\hline CHEMBL28626 & 688382 & 4.45 & 4.6461 & TRN \\
\hline CHEMBL1460192 & 688382 & 6.0 & 4.7137 & TST \\
\hline CHEMBL1579840 & 688382 & 4.85 & 4.6655 & TRN \\
\hline CHEMBL1426443 & 688382 & 5.8 & 4.8016 & TRN \\
\hline CHEMBL1495474 & 688382 & 4.85 & 4.7264 & TRN \\
\hline CHEMBL1606873 & 688382 & 4.5 & 4.6842 & TST \\
\hline CHEMBL1299826 & 688382 & 4.65 & 4.7934 & TST \\
\hline CHEMBL1549712 & 688382 & 4.75 & 4.7697 & TRN \\
\hline CHEMBL1520912 & 688382 & 4.8 & 4.6641 & TRN \\
\hline CHEMBL1600877 & 688382 & 5.85 & 4.7555 & TRN \\
\hline CHEMBL1331680 & 688382 & 4.4 & 4.5738 & TRN \\
\hline CHEMBL1304172 & 688382 & 4.4 & 4.6389 & TRN \\
\hline CHEMBL1482111 & 688382 & 6.0 & 4.7374 & TRN \\
\hline CHEMBL1388796 & 688382 & 4.2 & 4.7405 & TST \\
\hline CHEMBL1548004 & 688382 & 4.5 & 4.6797 & TRN \\
\hline CHEMBL1608439 & 688382 & 4.85 & 4.7747 & TRN \\
\hline CHEMBL1371909 & 688382 & 4.15 & 4.7638 & TRN \\
\hline CHEMBL1460353 & 688382 & 4.0 & 4.7876 & TRN \\
\hline CHEMBL1530653 & 688382 & 4.5 & 4.6324 & TRN \\
\hline CHEMBL1568799 & 688382 & 4.4 & 4.6761 & TRN \\
\hline CHEMBL1504130 & 688382 & 4.4 & 4.7221 & TRN \\
\hline CHEMBL1479154 & 688382 & 4.8 & 4.5818 & TRN \\
\hline CHEMBL1570497 & 688382 & 4.8 & 4.7318 & TST \\
\hline CHEMBL1353615 & 688382 & 4.45 & 4.6433 & TRN \\
\hline CHEMBL1350900 & 688382 & 4.8 & 4.6801 & TST \\
\hline CHEMBL1588743 & 688382 & 4.8 & 4.7461 & TRN \\
\hline CHEMBL1597868 & 688382 & 4.15 & 4.7485 & TRN \\
\hline CHEMBL1479068 & 688382 & 4.2 & 4.7494 & TRN \\
\hline CHEMBL1332795 & 688382 & 4.85 & 4.7195 & TRN \\
\hline CHEMBL1582195 & 688382 & 4.2 & 4.5749 & TRN \\
\hline CHEMBL1329243 & 688382 & 5.85 & 4.6837 & TRN \\
\hline CHEMBL1407436 & 688382 & 4.65 & 4.6394 & TST \\
\hline CHEMBL1412825 & 688382 & 4.2 & 4.6117 & TST \\
\hline CHEMBL1463097 & 688382 & 4.55 & 4.8212 & TRN \\
\hline CHEMBL606532 & 688382 & 4.5 & 4.6701 & TRN \\
\hline CHEMBL1330335 & 688382 & 4.5 & 4.7251 & TRN \\
\hline CHEMBL1401797 & 688382 & 4.3 & 4.6316 & TRN \\
\hline CHEMBL1493998 & 688382 & 4.55 & 4.6614 & TST \\
\hline CHEMBL1580994 & 688382 & 4.5 & 4.7136 & TRN \\
\hline CHEMBL1375749 & 688382 & 5.5 & 4.7368 & TRN \\
\hline CHEMBL1547092 & 688382 & 4.3 & 4.6932 & TRN \\
\hline CHEMBL3210763 & 688382 & 4.1 & 4.6324 & TST \\
\hline CHEMBL1370661 & 688382 & 4.8 & 4.7284 & TRN \\
\hline CHEMBL1537555 & 688382 & 5.5 & 4.828 & TRN \\
\hline
\end{tabular}




\begin{tabular}{|c|c|c|c|c|c|}
\hline \\
\hline CHEMBL1308178 & 688382 & 4.3 & 4.7481 & TST & \\
\hline CHEMBL1495626 & 688382 & 4.45 & 4.7115 & TRN & \\
\hline CHEMBL1309370 & 688382 & 4.05 & 4.7235 & TRN & \\
\hline CHEMBL1428331 & 688382 & 6.0 & 4.8099 & TST & \\
\hline CHEMBL1611930 & 688382 & 4.15 & 4.705 & TST & \\
\hline CHEMBL1527786 & 688382 & 6.0 & 4.863 & TRN & \\
\hline CHEMBL1459930 & 688382 & 6.0 & 4.6249 & TRN & \\
\hline CHEMBL1407218 & 688382 & 4.15 & 4.6192 & TST & \\
\hline CHEMBL1427800 & 688382 & 4.9 & 4.787 & TRN & \\
\hline CHEMBL1522776 & 688382 & 6.0 & 4.7965 & TST & \\
\hline CHEMBL1707275 & 688382 & 4.35 & 4.6544 & TRN & \\
\hline CHEMBL1417882 & 688382 & 4.15 & 4.72199 & 99999999995 & TRN \\
\hline CHEMBL1429968 & 688382 & 5.0 & 4.72 & TST & \\
\hline CHEMBL1415737 & 688382 & 4.15 & 4.8218 & TRN & \\
\hline CHEMBL1560614 & 688382 & 5.15 & 4.8097 & TRN & \\
\hline CHEMBL1572351 & 688382 & 4.65 & 4.6359 & TRN & \\
\hline CHEMBL1378869 & 688382 & 4.15 & 4.7514 & TRN & \\
\hline CHEMBL3198098 & 688382 & 4.5 & 4.6496 & TRN & \\
\hline CHEMBL1373105 & 688382 & 5.1 & 4.8129 & TRN & \\
\hline CHEMBL3212470 & 688382 & 4.25 & 4.7358 & TRN & \\
\hline CHEMBL1407291 & 688382 & 4.9 & 4.6747 & TRN & \\
\hline CHEMBL1446856 & 688382 & 4.5 & 4.7377 & TRN & \\
\hline CHEMBL1392845 & 688382 & 4.45 & 4.6928 & TST & \\
\hline CHEMBL1504845 & 688382 & 4.8 & 4.7808 & TRN & \\
\hline CHEMBL1587288 & 688382 & 5.05 & 4.6923 & TRN & \\
\hline CHEMBL1578626 & 688382 & 4.4 & 4.6481 & TRN & \\
\hline CHEMBL1584724 & 688382 & 4.2 & 4.7439 & TRN & \\
\hline CHEMBL1564772 & 688382 & 4.8 & 4.704 & TRN & \\
\hline CHEMBL1571610 & 688382 & 4.45 & 4.6222 & TRN & \\
\hline CHEMBL1505619 & 688382 & 4.8 & 4.6966 & TST & \\
\hline CHEMBL1382333 & 688382 & 4.05 & 4.6927 & TST & \\
\hline CHEMBL1510734 & 688382 & 4.8 & 4.7142 & TRN & \\
\hline CHEMBL1341034 & 688382 & 5.15 & 4.7582 & TRN & \\
\hline CHEMBL1443659 & 688382 & 4.2 & 4.7605 & TRN & \\
\hline CHEMBL3198613 & 688382 & 5.0 & 4.7044 & TRN & \\
\hline CHEMBL1458632 & 688382 & 4.2 & 4.732 & TRN & \\
\hline CHEMBL1986921 & 688382 & 4.5 & 4.7168 & TRN & \\
\hline CHEMBL1425528 & 688382 & 4.7 & 4.84699 & 99999999995 & TRN \\
\hline CHEMBL1609048 & 688382 & 4.4 & 4.7142 & TRN & \\
\hline CHEMBL1612177 & 688382 & 4.75 & 4.7404 & TRN & \\
\hline CHEMBL1571446 & 688382 & 5.3 & 4.6616 & TRN & \\
\hline CHEMBL1549493 & 688382 & 4.2 & 4.6987 & TRN & \\
\hline CHEMBL1446020 & 688382 & 5.8 & 4.7194 & TRN & \\
\hline CHEMBL1536061 & 688382 & 4.9 & 4.6795 & TRN & \\
\hline CHEMBL1567369 & 688382 & 4.5 & 4.7345 & TRN & \\
\hline CHEMBL1487750 & 688382 & 5.25 & 4.681 & TRN & \\
\hline CHEMBL1555936 & 688382 & 4.45 & 4.7034 & TRN & \\
\hline CHEMBL1320484 & 688382 & 5.1 & 4.7286 & TRN & \\
\hline
\end{tabular}




\begin{tabular}{|c|c|c|c|c|}
\hline \multicolumn{5}{|c|}{ Supplemental Table S2.txt } \\
\hline CHEMBL 285540 & 688382 & 4.5 & 4.7058 & TRN \\
\hline CHEMBL3190793 & 688382 & 4.05 & 4.6688 & TRN \\
\hline CHEMBL1364277 & 688382 & 4.5 & 4.6247 & TRN \\
\hline CHEMBL1577224 & 688382 & 4.7 & 4.6406 & TRN \\
\hline CHEMBL1448259 & 688382 & 4.05 & 4.7649 & TST \\
\hline CHEMBL3197234 & 688382 & 4.45 & 4.6339 & TST \\
\hline CHEMBL1305450 & 688382 & 4.55 & 4.5987 & TRN \\
\hline CHEMBL1497963 & 688382 & 4.85 & 4.6796 & TRN \\
\hline CHEMBL1433394 & 688382 & 4.4 & 4.6394 & TRN \\
\hline CHEMBL1414287 & 688382 & 5.1 & 4.6496 & TRN \\
\hline CHEMBL3207650 & 688382 & 5.95 & 4.7002 & TRN \\
\hline CHEMBL1481819 & 688382 & 5.05 & 4.742 & TRN \\
\hline CHEMBL1369395 & 688382 & 5.05 & 4.6888 & TST \\
\hline CHEMBL3192078 & 688382 & 4.5 & 4.6491 & TRN \\
\hline CHEMBL 3193400 & 688382 & 4.8 & 4.7502 & TRN \\
\hline CHEMBL1562497 & 688382 & 4.85 & 4.7501 & TST \\
\hline CHEMBL1431718 & 688382 & 4.85 & 4.7139 & TRN \\
\hline CHEMBL1405798 & 688382 & 5.05 & 4.7485 & TRN \\
\hline CHEMBL1480837 & 688382 & 4.85 & 4.8063 & TRN \\
\hline CHEMBL1511924 & 688382 & 5.05 & 4.6877 & TRN \\
\hline CHEMBL470881 & 688382 & 4.8 & 4.6729 & TRN \\
\hline CHEMBL1345017 & 688382 & 4.45 & 4.7132 & TRN \\
\hline CHEMBL1448291 & 688382 & 4.45 & 4.6389 & TRN \\
\hline CHEMBL1574089 & 688382 & 4.5 & 4.7903 & TRN \\
\hline CHEMBL1589224 & 688382 & 4.05 & 4.6523 & TRN \\
\hline CHEMBL1502838 & 688382 & 4.95 & 4.7695 & TRN \\
\hline CHEMBL1528748 & 688382 & 5.85 & 4.832 & TRN \\
\hline CHEMBL1565008 & 688382 & 4.8 & 4.6698 & TRN \\
\hline CHEMBL1495225 & 688382 & 4.45 & 4.6799 & TRN \\
\hline CHEMBL1427901 & 688382 & 5.0 & 4.7801 & TRN \\
\hline CHEMBL394385 & 688382 & 4.95 & 4.6535 & TRN \\
\hline CHEMBL1562963 & 688382 & 4.4 & 4.6207 & TRN \\
\hline CHEMBL3213264 & 688382 & 4.9 & 4.6712 & TRN \\
\hline CHEMBL1997990 & 688382 & 4.0 & 4.6531 & TST \\
\hline CHEMBL1510493 & 688382 & 4.7 & 4.6988 & TRN \\
\hline CHEMBL1523961 & 688382 & 4.65 & 4.6006 & TRN \\
\hline CHEMBL1518992 & 688382 & 4.55 & 4.7228 & TST \\
\hline CHEMBL1417531 & 688382 & 5.05 & 4.7371 & TST \\
\hline CHEMBL1568064 & 688382 & 5.05 & 4.7469 & TRN \\
\hline CHEMBL331372 & 688382 & 7.15 & 4.7321 & TRN \\
\hline CHEMBL1328529 & 688382 & 4.5 & 4.581 & TRN \\
\hline CHEMBL1463458 & 688382 & 4.95 & 4.6671 & TRN \\
\hline CHEMBL1594295 & 688382 & 4.35 & 4.7141 & TRN \\
\hline CHEMBL1582216 & 688382 & 4.35 & 4.6703 & TRN \\
\hline CHEMBL1456232 & 688382 & 4.5 & 4.6298 & TRN \\
\hline CHEMBL1444791 & 688382 & 4.5 & 4.5988 & TRN \\
\hline CHEMBL1324204 & 688382 & 5.25 & 4.6657 & TRN \\
\hline CHEMBL1429754 & 688382 & 4.05 & 4.7192 & TRN \\
\hline
\end{tabular}




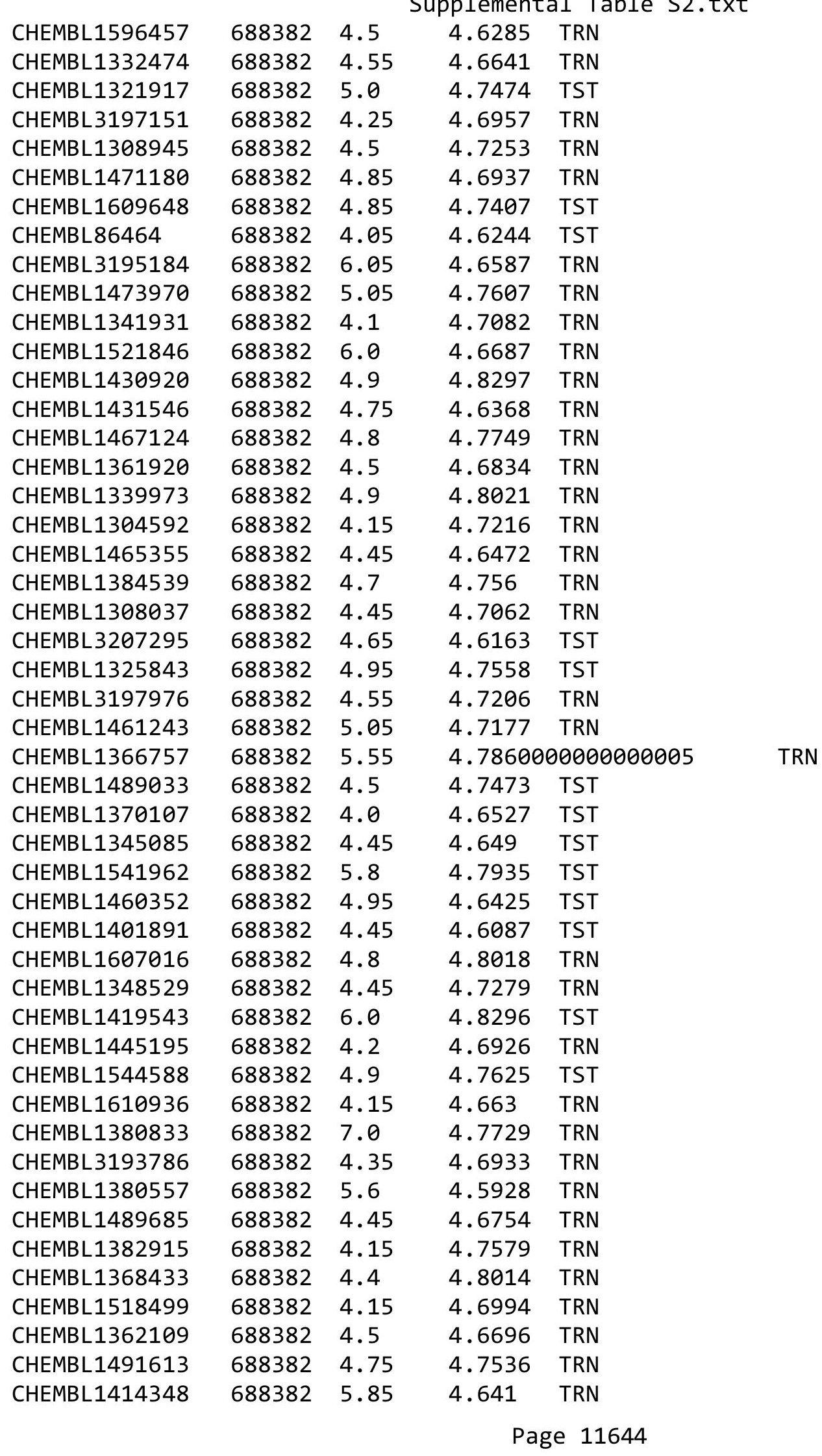




\begin{tabular}{|c|c|c|c|c|}
\hline \multicolumn{5}{|c|}{ Supplemental Table S2.txt } \\
\hline CHEMBL1336695 & 688382 & 5.15 & 4.7421 & TST \\
\hline CHEMBL1507664 & 688382 & 4.9 & 4.7427 & TRN \\
\hline CHEMBL1300439 & 688382 & 4.5 & 4.6658 & TST \\
\hline CHEMBL1559622 & 688382 & 4.85 & 4.6693 & TRN \\
\hline CHEMBL3191111 & 688382 & 4.5 & 4.6758 & TRN \\
\hline CHEMBL1599137 & 688382 & 4.95 & 4.7364 & TST \\
\hline CHEMBL1483033 & 688382 & 4.45 & 4.7365 & TRN \\
\hline CHEMBL1311230 & 688382 & 4.95 & 4.8229 & TRN \\
\hline CHEMBL1322031 & 688382 & 4.15 & 4.7239 & TRN \\
\hline CHEMBL1427694 & 688382 & 4.2 & 4.7255 & TST \\
\hline CHEMBL1981539 & 688382 & 5.0 & 4.7385 & TST \\
\hline CHEMBL1521669 & 688382 & 4.95 & 4.6925 & TST \\
\hline CHEMBL1563898 & 688382 & 4.35 & 4.6433 & TRN \\
\hline CHEMBL1319588 & 688382 & 6.0 & 4.7345 & TRN \\
\hline CHEMBL1327415 & 688382 & 4.2 & 4.7482 & TRN \\
\hline CHEMBL1571268 & 688382 & 4.1 & 4.6803 & TRN \\
\hline CHEMBL1309658 & 688382 & 5.0 & 4.7458 & TRN \\
\hline CHEMBL1583440 & 688382 & 4.35 & 4.6943 & TRN \\
\hline CHEMBL572531 & 688382 & 4.5 & 4.6408 & TRN \\
\hline CHEMBL1501864 & 688382 & 4.55 & 4.6204 & TRN \\
\hline CHEMBL1533351 & 688382 & 4.15 & 4.7054 & TRN \\
\hline CHEMBL1490273 & 688382 & 4.5 & 4.7989 & TRN \\
\hline CHEMBL1417108 & 688382 & 4.9 & 4.7324 & TRN \\
\hline CHEMBL1333372 & 688382 & 4.75 & 4.7473 & TRN \\
\hline CHEMBL1408695 & 688382 & 4.05 & 4.708 & TST \\
\hline CHEMBL1559705 & 688382 & 4.5 & 4.8244 & TRN \\
\hline CHEMBL3191443 & 688382 & 4.2 & 4.7222 & TRN \\
\hline CHEMBL1492763 & 688382 & 4.2 & 4.7028 & TRN \\
\hline CHEMBL1534355 & 688382 & 4.85 & 4.7673 & TRN \\
\hline CHEMBL1493741 & 688382 & 4.05 & 4.7373 & TRN \\
\hline CHEMBL1559967 & 688382 & 4.2 & 4.8113 & TRN \\
\hline CHEMBL1455707 & 688382 & 4.5 & 4.6421 & TRN \\
\hline CHEMBL1432966 & 688382 & 4.8 & 4.6994 & TST \\
\hline CHEMBL1523419 & 688382 & 4.75 & 4.6897 & TRN \\
\hline CHEMBL3197935 & 688382 & 4.55 & 4.74 & TRN \\
\hline CHEMBL1968580 & 688382 & 4.45 & 4.575 & TRN \\
\hline CHEMBL1464123 & 688382 & 4.6 & 4.7257 & TRN \\
\hline CHEMBL3193510 & 688382 & 4.5 & 4.6007 & TRN \\
\hline CHEMBL1399123 & 688382 & 4.2 & 4.7416 & TRN \\
\hline CHEMBL1977242 & 688382 & 4.8 & 4.6549 & TRN \\
\hline CHEMBL1594756 & 688382 & 4.45 & 4.6441 & TRN \\
\hline CHEMBL1492844 & 688382 & 4.25 & 4.6496 & TRN \\
\hline CHEMBL1302974 & 688382 & 4.25 & 4.6725 & TRN \\
\hline CHEMBL1318428 & 688382 & 5.1 & 4.7355 & TRN \\
\hline CHEMBL1451538 & 688382 & 4.05 & 4.6549 & TST \\
\hline CHEMBL1567662 & 688382 & 5.05 & 4.7034 & TRN \\
\hline CHEMBL1425162 & 688382 & 5.05 & 4.7284 & TRN \\
\hline CHEMBL1559554 & 688382 & 4.85 & 4.6994 & TRN \\
\hline
\end{tabular}




\begin{tabular}{|c|c|c|c|c|}
\hline \multicolumn{5}{|c|}{ Supplemental Table S2.txt } \\
\hline CHEMBL1601450 & 688382 & 4.6 & 4.774 & TRN \\
\hline CHEMBL1349935 & 688382 & 4.1 & 4.7651 & TRN \\
\hline CHEMBL3213159 & 688382 & 5.45 & 4.6738 & TRN \\
\hline CHEMBL1348802 & 688382 & 4.4 & 4.6244 & TRN \\
\hline CHEMBL1535981 & 688382 & 5.7 & 4.6069 & TST \\
\hline CHEMBL1464024 & 688382 & 4.3 & 4.8124 & TRN \\
\hline CHEMBL3197921 & 688382 & 5.2 & 4.6225 & TRN \\
\hline CHEMBL1429529 & 688382 & 4.05 & 4.7081 & TST \\
\hline CHEMBL1492143 & 688382 & 4.15 & 4.6758 & TRN \\
\hline CHEMBL1564746 & 688382 & 4.45 & 4.6762 & TRN \\
\hline CHEMBL3209533 & 688382 & 4.55 & 4.6049 & TRN \\
\hline CHEMBL1455872 & 688382 & 6.0 & 4.7578 & TRN \\
\hline CHEMBL1519084 & 688382 & 5.0 & 4.6568 & TRN \\
\hline CHEMBL1526028 & 688382 & 4.8 & 4.7562 & TRN \\
\hline CHEMBL1365380 & 688382 & 5.75 & 4.6673 & TRN \\
\hline CHEMBL1301508 & 688382 & 4.35 & 4.6543 & TRN \\
\hline CHEMBL1414433 & 688382 & 5.85 & 4.7015 & TST \\
\hline CHEMBL1407796 & 688382 & 4.15 & 4.7188 & TST \\
\hline CHEMBL1359384 & 688382 & 6.0 & 4.7364 & TRN \\
\hline CHEMBL1392442 & 688382 & 4.9 & 4.6336 & TST \\
\hline CHEMBL2369243 & 688382 & 6.0 & 4.7365 & TRN \\
\hline CHEMBL1463178 & 688382 & 4.9 & 4.6781 & TRN \\
\hline CHEMBL1451059 & 688382 & 4.35 & 4.6903 & TST \\
\hline CHEMBL1982896 & 688382 & 4.9 & 4.64 & TRN \\
\hline CHEMBL1342329 & 688382 & 4.3 & 4.8047 & TRN \\
\hline CHEMBL1405111 & 688382 & 4.15 & 4.6866 & TRN \\
\hline CHEMBL3212494 & 688382 & 4.25 & 4.6482 & TST \\
\hline CHEMBL1496705 & 688382 & 4.5 & 4.6612 & TRN \\
\hline CHEMBL1456091 & 688382 & 4.2 & 4.7902 & TRN \\
\hline CHEMBL1560958 & 688382 & 4.6 & 4.8099 & TST \\
\hline CHEMBL1338175 & 688382 & 4.8 & 4.7586 & TST \\
\hline CHEMBL1495552 & 688382 & 4.15 & 4.754 & TRN \\
\hline CHEMBL1407360 & 688382 & 5.15 & 4.7198 & TRN \\
\hline CHEMBL1369537 & 688382 & 4.1 & 4.8151 & TRN \\
\hline CHEMBL1365006 & 688382 & 4.9 & 4.676 & TRN \\
\hline CHEMBL1464020 & 688382 & 4.5 & 4.7192 & TRN \\
\hline CHEMBL1462751 & 688382 & 4.15 & 4.6941 & TRN \\
\hline CHEMBL1370379 & 688382 & 4.2 & 4.6634 & TRN \\
\hline CHEMBL1380253 & 688382 & 5.9 & 4.7028 & TST \\
\hline CHEMBL1462594 & 688382 & 4.2 & 4.6423 & TRN \\
\hline CHEMBL1384436 & 688382 & 4.5 & 4.6662 & TST \\
\hline CHEMBL1332711 & 688382 & 4.85 & 4.6076 & TST \\
\hline CHEMBL1420523 & 688382 & 4.8 & 4.7134 & TRN \\
\hline CHEMBL1560335 & 688382 & 5.85 & 4.7232 & TRN \\
\hline CHEMBL1466809 & 688382 & 5.0 & 4.7481 & TST \\
\hline CHEMBL1588125 & 688382 & 4.15 & 4.6813 & TRN \\
\hline CHEMBL1491176 & 688382 & 4.35 & 4.7665 & TRN \\
\hline CHEMBL1390449 & 688382 & 3.5 & 4.6776 & TST \\
\hline
\end{tabular}




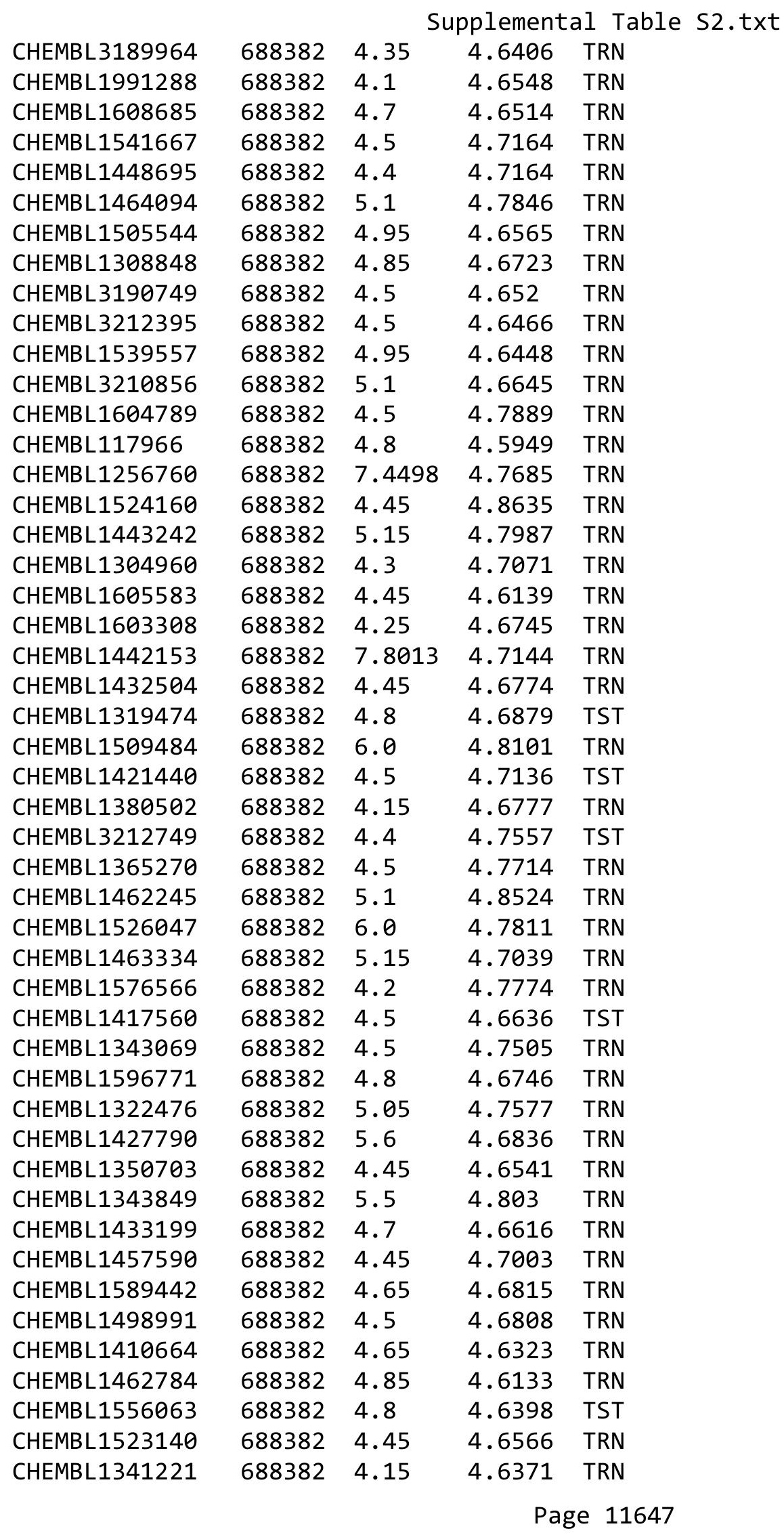




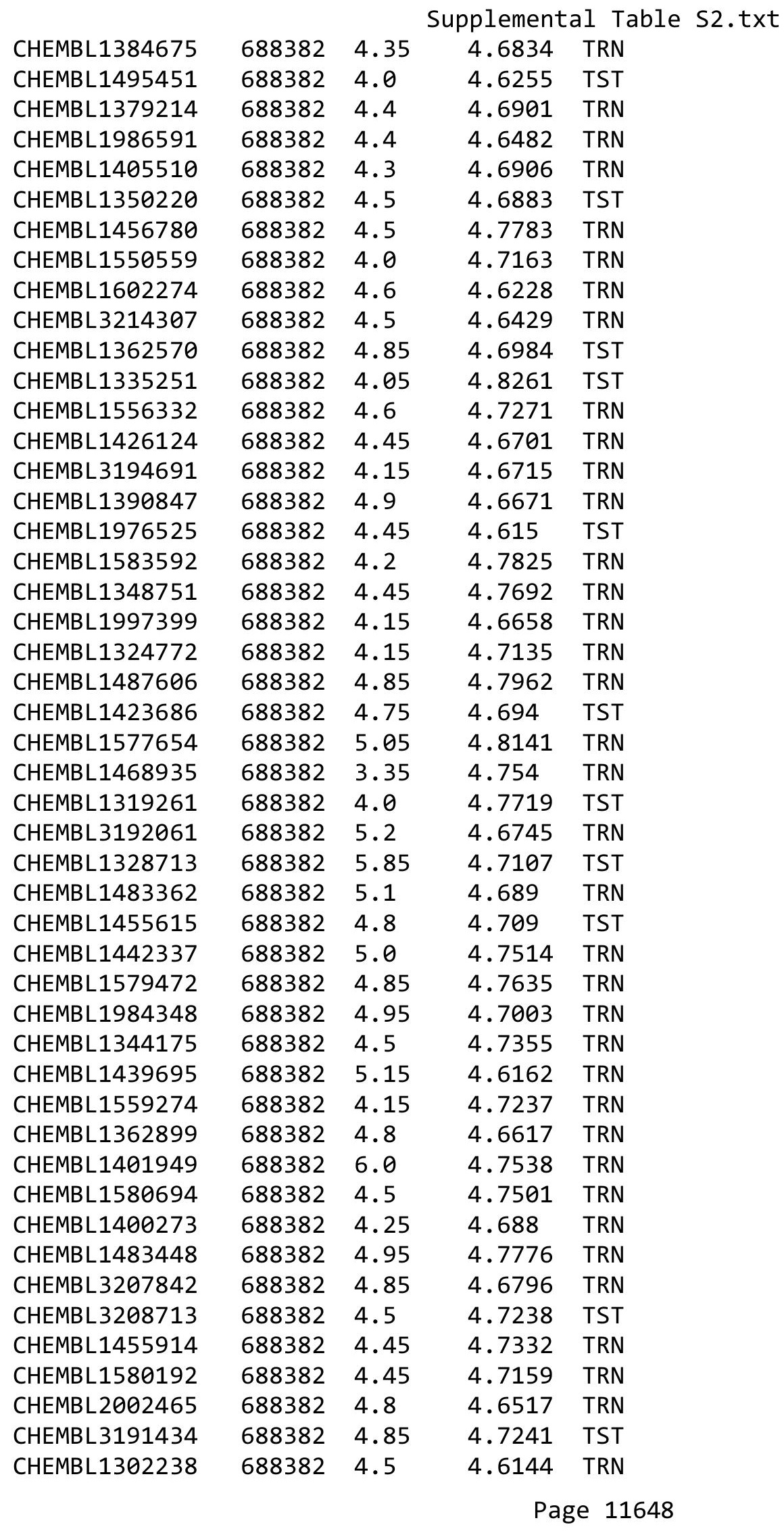




\begin{tabular}{|c|c|c|c|c|c|}
\hline & & \multicolumn{4}{|c|}{ Supplemental Table S2.txt } \\
\hline CHEMBL1576107 & 688382 & 4.45 & 4.6565 & TST & \\
\hline CHEMBL3186069 & 688382 & 6.0 & 4.6122 & TRN & \\
\hline CHEMBL 3190275 & 688382 & 6.0 & 4.7482 & TRN & \\
\hline CHEMBL1609581 & 688382 & 4.15 & 4.7034 & TRN & \\
\hline CHEMBL1549763 & 688382 & 5.1 & 4.8019 & TRN & \\
\hline CHEMBL1583335 & 688382 & 4.95 & 4.7591 & TRN & \\
\hline CHEMBL 1457823 & 688382 & 5.15 & 4.649 & TRN & \\
\hline CHEMBL546257 & 688382 & 6.0 & 4.652 & TRN & \\
\hline CHEMBL1347984 & 688382 & 5.45 & 4.6532 & TRN & \\
\hline CHEMBL1459644 & 688382 & 5.05 & 4.7598 & TRN & \\
\hline CHEMBL1471563 & 688382 & 4.45 & 4.84699 & 99999999995 & TRN \\
\hline CHEMBL1547369 & 688382 & 4.15 & 4.7722 & TST & \\
\hline CHEMBL1462808 & 688382 & 4.85 & 4.691 & TRN & \\
\hline CHEMBL1561495 & 688382 & 4.6 & 4.6296 & TST & \\
\hline CHEMBL1611098 & 688382 & 4.45 & 4.6607 & TRN & \\
\hline CHEMBL1579178 & 688382 & 4.7 & 4.6919 & TST & \\
\hline CHEMBL1388354 & 688382 & 4.85 & 4.7682 & TRN & \\
\hline CHEMBL1502315 & 688382 & 4.4 & 4.7934 & TRN & \\
\hline CHEMBL1534221 & 688382 & 4.5 & 4.7359 & TRN & \\
\hline CHEMBL1366313 & 688382 & 5.0 & 4.6198 & TRN & \\
\hline CHEMBL1313997 & 688382 & 5.4 & 4.6966 & TRN & \\
\hline CHEMBL1414875 & 688382 & 4.45 & 4.7371 & TRN & \\
\hline CHEMBL1461778 & 688382 & 5.05 & 4.7683 & TST & \\
\hline CHEMBL 3196321 & 688382 & 4.6 & 4.7272 & TRN & \\
\hline CHEMBL1404917 & 688382 & 4.05 & 4.7956 & TRN & \\
\hline CHEMBL1996136 & 688382 & 4.5 & 4.7259 & TRN & \\
\hline CHEMBL1299471 & 688382 & 5.0 & 4.8171 & TRN & \\
\hline CHEMBL1609690 & 688382 & 4.05 & 4.6774 & TST & \\
\hline CHEMBL1578365 & 688382 & 5.1 & 4.6301 & TRN & \\
\hline CHEMBL 1575033 & 688382 & 4.5 & 4.578 & TRN & \\
\hline CHEMBL1383412 & 688382 & 4.55 & 4.7028 & TRN & \\
\hline CHEMBL1509720 & 688382 & 4.45 & 4.6908 & TRN & \\
\hline CHEMBL1562039 & 688382 & 4.4 & 4.6486 & TRN & \\
\hline CHEMBL1491016 & 688382 & 4.55 & 4.6165 & TRN & \\
\hline CHEMBL3198654 & 688382 & 4.9 & 4.6744 & TRN & \\
\hline CHEMBL1475139 & 688382 & 5.2 & 4.7124 & TST & \\
\hline CHEMBL1495485 & 688382 & 4.3 & 4.6848 & TRN & \\
\hline CHEMBL578742 & 688382 & 4.05 & 4.6688 & TRN & \\
\hline CHEMBL1584801 & 688382 & 4.4 & 4.6634 & TST & \\
\hline CHEMBL1321212 & 688382 & 5.05 & 4.7738 & TRN & \\
\hline CHEMBL1565855 & 688382 & 4.5 & 4.6049 & TRN & \\
\hline CHEMBL1460141 & 688382 & 4.55 & 4.6741 & TST & \\
\hline CHEMBL1303255 & 688382 & 4.5 & 4.6022 & TST & \\
\hline CHEMBL1390611 & 688382 & 4.8 & 4.7082 & TST & \\
\hline CHEMBL1577913 & 688382 & 6.05 & 4.7932 & TRN & \\
\hline CHEMBL1546100 & 688382 & 4.5 & 4.6628 & TRN & \\
\hline CHEMBL1581269 & 688382 & 4.8 & 4.8444 & TRN & \\
\hline CHEMBL1528436 & 688382 & 4.6 & 4.6542 & TRN & \\
\hline
\end{tabular}




\begin{tabular}{|c|c|c|c|c|c|}
\hline \multicolumn{6}{|c|}{ Supplemental Table S2.txt } \\
\hline CHEMBL1300054 & 688382 & 4.15 & 4.6651 & TRN & \\
\hline CHEMBL1585228 & 688382 & 4.9 & 4.8154 & TRN & \\
\hline CHEMBL1430562 & 688382 & 4.75 & 4.67899 & 9999999999 & TRN \\
\hline CHEMBL1415259 & 688382 & 4.55 & 4.7094 & TRN & \\
\hline CHEMBL1499092 & 688382 & 5.05 & 4.6472 & TRN & \\
\hline CHEMBL1374047 & 688382 & 4.45 & 4.7618 & TRN & \\
\hline CHEMBL1575301 & 688382 & 6.0 & 4.7052 & TST & \\
\hline CHEMBL1393439 & 688382 & 4.8 & 4.7904 & TRN & \\
\hline CHEMBL1558792 & 688382 & 4.45 & 4.7176 & TST & \\
\hline CHEMBL 2003087 & 688382 & 4.35 & 4.7157 & TRN & \\
\hline CHEMBL1416570 & 688382 & 4.15 & 4.6661 & TRN & \\
\hline CHEMBL1384073 & 688382 & 4.35 & 4.7766 & TRN & \\
\hline CHEMBL1424749 & 688382 & 4.35 & 4.7044 & TRN & \\
\hline CHEMBL1327534 & 688382 & 5.05 & 4.6467 & TRN & \\
\hline CHEMBL120768 & 688382 & 4.3 & 4.7257 & TST & \\
\hline CHEMBL1405730 & 688382 & 4.3 & 4.7934 & TRN & \\
\hline CHEMBL1498161 & 688382 & 4.6 & 4.6265 & TRN & \\
\hline CHEMBL1587481 & 688382 & 4.85 & 4.7737 & TRN & \\
\hline CHEMBL1498530 & 688382 & 4.35 & 4.7695 & TRN & \\
\hline CHEMBL1419724 & 688382 & 4.65 & 4.6745 & TRN & \\
\hline CHEMBL1372464 & 688382 & 5.0 & 4.7033 & TRN & \\
\hline CHEMBL1541269 & 688382 & 4.55 & 4.6909 & TRN & \\
\hline CHEMBL1336817 & 688382 & 4.4 & 4.6782 & TRN & \\
\hline CHEMBL3193980 & 688382 & 5.25 & 4.6429 & TRN & \\
\hline CHEMBL1387085 & 688382 & 5.05 & 4.78600 & 00000000005 & TRN \\
\hline CHEMBL1994034 & 688382 & 4.85 & 4.6598 & TRN & \\
\hline CHEMBL1497889 & 688382 & 4.9 & 4.6649 & TRN & \\
\hline CHEMBL1524248 & 688382 & 4.95 & 4.8068 & TST & \\
\hline CHEMBL1526294 & 688382 & 4.9 & 4.6609 & TRN & \\
\hline CHEMBL1485357 & 688382 & 4.15 & 4.6713 & TRN & \\
\hline CHEMBL1598990 & 688382 & 4.5 & 4.699 & TRN & \\
\hline CHEMBL1489882 & 688382 & 4.4 & 4.7692 & TRN & \\
\hline CHEMBL1508178 & 688382 & 4.4 & 4.5812 & TRN & \\
\hline CHEMBL1427219 & 688382 & 4.95 & 4.6693 & TST & \\
\hline CHEMBL1543353 & 688382 & 4.8 & 4.7938 & TRN & \\
\hline CHEMBL1375292 & 688382 & 4.45 & 4.6673 & TRN & \\
\hline CHEMBL1346093 & 688382 & 4.35 & 4.6563 & TRN & \\
\hline CHEMBL1430840 & 688382 & 4.0 & 4.7873 & TRN & \\
\hline CHEMBL1416421 & 688382 & 4.55 & 4.6575 & TRN & \\
\hline CHEMBL3189780 & 688382 & 4.15 & 4.5935 & TRN & \\
\hline CHEMBL1304029 & 688382 & 4.2 & 4.6353 & TRN & \\
\hline CHEMBL1337693 & 688382 & 4.05 & 4.7201 & TRN & \\
\hline CHEMBL1494458 & 688382 & 4.45 & 4.6254 & TRN & \\
\hline CHEMBL1366916 & 688382 & 4.8 & 4.7565 & TRN & \\
\hline CHEMBL1409368 & 688382 & 4.45 & 4.6426 & TRN & \\
\hline CHEMBL227432 & 688382 & 4.0 & 4.7169 & TRN & \\
\hline CHEMBL3194455 & 688382 & 4.45 & 4.6472 & TRN & \\
\hline CHEMBL1546064 & 688382 & 4.0 & 4.7809 & TRN & \\
\hline
\end{tabular}




\begin{tabular}{|c|c|c|c|c|c|}
\hline \multicolumn{6}{|c|}{ Supplemental Table S2.txt } \\
\hline CHEMBL3210192 & 688382 & 4.5 & 4.6945 & TRN & \\
\hline CHEMBL1364272 & 688382 & 4.45 & 4.7514 & TRN & \\
\hline CHEMBL1361056 & 688382 & 4.35 & 4.6915 & TRN & \\
\hline CHEMBL1345065 & 688382 & 4.45 & 4.7109 & TRN & \\
\hline CHEMBL591404 & 688382 & 5.1 & 4.6283 & TRN & \\
\hline CHEMBL1580724 & 688382 & 4.45 & 4.7976 & TRN & \\
\hline CHEMBL1319891 & 688382 & 5.85 & 4.7168 & TST & \\
\hline CHEMBL1610256 & 688382 & 5.85 & 4.5706 & TST & \\
\hline CHEMBL1602000 & 688382 & 4.5 & 4.7735 & TRN & \\
\hline CHEMBL1587771 & 688382 & 4.45 & 4.5911 & TST & \\
\hline CHEMBL1424880 & 688382 & 4.75 & 4.6861 & TRN & \\
\hline CHEMBL3190804 & 688382 & 4.65 & 4.6152 & TRN & \\
\hline CHEMBL1580969 & 688382 & 4.05 & 4.6678 & TRN & \\
\hline CHEMBL1561045 & 688382 & 4.15 & 4.7544 & TRN & \\
\hline CHEMBL1337145 & 688382 & 4.15 & 4.6459 & TST & \\
\hline CHEMBL1380138 & 688382 & 4.9 & 4.67899 & 9999999999 & TRN \\
\hline CHEMBL1538677 & 688382 & 4.5 & 4.6662 & TRN & \\
\hline CHEMBL1527676 & 688382 & 5.55 & 4.8096 & TRN & \\
\hline CHEMBL1494762 & 688382 & 4.5 & 4.6932 & TRN & \\
\hline CHEMBL1429863 & 688382 & 4.6 & 4.6812 & TRN & \\
\hline CHEMBL1347469 & 688382 & 4.5 & 4.6716 & TRN & \\
\hline CHEMBL1517286 & 688382 & 5.05 & 4.7534 & TRN & \\
\hline CHEMBL1345203 & 688382 & 5.05 & 4.7577 & TRN & \\
\hline CHEMBL1384433 & 688382 & 6.0 & 4.644 & TST & \\
\hline CHEMBL1974081 & 688382 & 4.6 & 4.6672 & TRN & \\
\hline CHEMBL1517461 & 688382 & 4.9 & 4.7973 & TST & \\
\hline CHEMBL1366279 & 688382 & 4.05 & 4.7542 & TRN & \\
\hline CHEMBL1419027 & 688382 & 4.65 & 4.7661 & TRN & \\
\hline CHEMBL1580341 & 688382 & 4.95 & 4.7674 & TRN & \\
\hline CHEMBL1440137 & 688382 & 4.85 & 4.7098 & TRN & \\
\hline CHEMBL1523258 & 688382 & 4.0 & 4.7805 & TRN & \\
\hline CHEMBL1313146 & 688382 & 5.85 & 4.6895 & TST & \\
\hline CHEMBL1528447 & 688382 & 5.05 & 4.8035 & TRN & \\
\hline CHEMBL1321902 & 688382 & 4.05 & 4.8305 & TRN & \\
\hline CHEMBL 3198377 & 688382 & 4.45 & 4.6602 & TRN & \\
\hline CHEMBL1612870 & 688382 & 4.1 & 4.70100 & 00000000005 & TST \\
\hline CHEMBL3198433 & 688382 & 4.5 & 4.6929 & TRN & \\
\hline CHEMBL1302808 & 688382 & 4.85 & 4.7319 & TST & \\
\hline CHEMBL1498309 & 688382 & 4.7 & 4.7516 & TRN & \\
\hline CHEMBL1338004 & 688382 & 4.9 & 4.68 & TRN & \\
\hline CHEMBL1557398 & 688382 & 4.4 & 4.6803 & TRN & \\
\hline CHEMBL3191918 & 688382 & 5.05 & 4.7096 & TRN & \\
\hline CHEMBL1531242 & 688382 & 4.4 & 4.7031 & TST & \\
\hline CHEMBL3209964 & 688382 & 4.35 & 4.6908 & TRN & \\
\hline CHEMBL1535439 & 688382 & 4.35 & 4.596 & TRN & \\
\hline CHEMBL1495697 & 688382 & 4.15 & 4.7262 & TST & \\
\hline CHEMBL1613256 & 688382 & 4.45 & 4.7043 & TRN & \\
\hline CHEMBL3190578 & 688382 & 5.15 & 4.6524 & TRN & \\
\hline
\end{tabular}




\begin{tabular}{|c|c|c|c|c|}
\hline \multicolumn{5}{|c|}{ Supplemental Table S2.txt } \\
\hline CHEMBL1431364 & 688382 & 5.1 & 4.6217 & TST \\
\hline CHEMBL1476297 & 688382 & 4.35 & 4.6692 & TST \\
\hline CHEMBL1428245 & 688382 & 4.15 & 4.7028 & TRN \\
\hline CHEMBL 2003358 & 688382 & 4.05 & 4.7012 & TRN \\
\hline CHEMBL1564605 & 688382 & 4.6 & 4.7174 & TRN \\
\hline CHEMBL1349410 & 688382 & 4.45 & 4.6935 & TST \\
\hline CHEMBL1346784 & 688382 & 4.35 & 4.7624 & TST \\
\hline CHEMBL1534852 & 688382 & 4.5 & 4.7912 & TST \\
\hline CHEMBL1379070 & 688382 & 5.4 & 4.7339 & TST \\
\hline CHEMBL1406900 & 688382 & 4.9 & 4.7993 & TRN \\
\hline CHEMBL1346887 & 688382 & 3.05 & 4.6682 & TRN \\
\hline CHEMBL1612218 & 688382 & 4.8 & 4.7038 & TST \\
\hline CHEMBL1586223 & 688382 & 4.45 & 4.6944 & TRN \\
\hline CHEMBL1340080 & 688382 & 4.2 & 4.6143 & TRN \\
\hline CHEMBL1499088 & 688382 & 4.15 & 4.7456 & TST \\
\hline CHEMBL1392676 & 688382 & 4.35 & 4.6481 & TRN \\
\hline CHEMBL1361805 & 688382 & 4.35 & 4.6631 & TRN \\
\hline CHEMBL1439530 & 688382 & 4.8 & 4.7892 & TRN \\
\hline CHEMBL1590024 & 688382 & 4.4 & 4.7111 & TRN \\
\hline CHEMBL1530129 & 688382 & 4.75 & 4.7288 & TRN \\
\hline CHEMBL1517517 & 688382 & 4.5 & 4.7033 & TRN \\
\hline CHEMBL1482045 & 688382 & 4.45 & 4.69 & TRN \\
\hline CHEMBL1507018 & 688382 & 4.85 & 4.6983 & TRN \\
\hline CHEMBL1543537 & 688382 & 5.8 & 4.8382 & TRN \\
\hline CHEMBL1301059 & 688382 & 4.15 & 4.6136 & TST \\
\hline CHEMBL 1479603 & 688382 & 5.05 & 4.7682 & TRN \\
\hline CHEMBL1386143 & 688382 & 5.05 & 4.7977 & TRN \\
\hline CHEMBL1333360 & 688382 & 5.3 & 4.7006 & TRN \\
\hline CHEMBL1412449 & 688382 & 4.4 & 4.6406 & TRN \\
\hline CHEMBL 3207850 & 688382 & 4.95 & 4.6801 & TRN \\
\hline CHEMBL 1422057 & 688382 & 5.0 & 4.6944 & TRN \\
\hline CHEMBL1607942 & 688382 & 4.95 & 4.734 & TRN \\
\hline CHEMBL1452759 & 688382 & 4.0 & 4.7152 & TRN \\
\hline CHEMBL1362948 & 688382 & 4.85 & 4.5995 & TST \\
\hline CHEMBL1548374 & 688382 & 4.65 & 4.6523 & TRN \\
\hline CHEMBL1525390 & 688382 & 5.25 & 4.6315 & TRN \\
\hline CHEMBL1310439 & 688382 & 4.8 & 4.8588 & TRN \\
\hline CHEMBL1571042 & 688382 & 4.4 & 4.7038 & TRN \\
\hline CHEMBL1386294 & 688382 & 5.85 & 4.8252 & TRN \\
\hline CHEMBL1606361 & 688382 & 4.6 & 4.6879 & TRN \\
\hline CHEMBL1612858 & 688382 & 5.9 & 4.636 & TRN \\
\hline CHEMBL1508562 & 688382 & 4.45 & 4.7525 & TRN \\
\hline CHEMBL1350704 & 688382 & 4.4 & 4.7577 & TRN \\
\hline CHEMBL1432241 & 688382 & 4.8 & 4.7482 & TST \\
\hline CHEMBL1540679 & 688382 & 4.1 & 4.7623 & TRN \\
\hline CHEMBL 1541758 & 688382 & 4.45 & 4.7185 & TST \\
\hline CHEMBL 2021431 & 688382 & 4.55 & 4.7255 & TST \\
\hline CHEMBL1330075 & 688382 & 4.85 & 4.6824 & TST \\
\hline
\end{tabular}




\begin{tabular}{|c|c|c|c|c|}
\hline \multicolumn{5}{|c|}{ Supplemental Table } \\
\hline CHEMBL1587514 & 688382 & 4.15 & 4.7427 & TRN \\
\hline CHEMBL1378941 & 688382 & 4.15 & 4.7662 & TRN \\
\hline CHEMBL1303976 & 688382 & 4.45 & 4.6567 & TST \\
\hline CHEMBL1447791 & 688382 & 4.2 & 4.648 & TRN \\
\hline CHEMBL1314787 & 688382 & 5.15 & 4.6995 & TRN \\
\hline CHEMBL1494711 & 688382 & 4.85 & 4.8147 & TST \\
\hline CHEMBL3191401 & 688382 & 4.85 & 4.6656 & TRN \\
\hline CHEMBL1353247 & 688382 & 5.85 & 4.6981 & TRN \\
\hline CHEMBL1345452 & 688382 & 5.05 & 4.6735 & TRN \\
\hline CHEMBL1383148 & 688382 & 5.0 & 4.7607 & TST \\
\hline CHEMBL1497391 & 688382 & 4.4 & 4.5776 & TST \\
\hline CHEMBL1303978 & 688382 & 4.85 & 4.7916 & TST \\
\hline CHEMBL1371743 & 688382 & 5.9 & 4.7192 & TST \\
\hline CHEMBL1431610 & 688382 & 5.45 & 4.7388 & TRN \\
\hline CHEMBL1586566 & 688382 & 4.85 & 4.6183 & TST \\
\hline CHEMBL1477640 & 688382 & 4.85 & 4.6039 & TRN \\
\hline CHEMBL1400571 & 688382 & 4.75 & 4.6521 & TST \\
\hline CHEMBL1698513 & 688382 & 4.5 & 4.7443 & TRN \\
\hline CHEMBL3211101 & 688382 & 4.4 & 4.7074 & TRN \\
\hline CHEMBL1561728 & 688382 & 4.95 & 4.7183 & TST \\
\hline CHEMBL1382318 & 688382 & 5.2 & 4.6714 & TRN \\
\hline CHEMBL1384612 & 688382 & 5.05 & 4.7824 & TRN \\
\hline CHEMBL1556859 & 688382 & 5.0 & 4.7716 & TRN \\
\hline CHEMBL1449741 & 688382 & 4.8 & 4.8285 & TST \\
\hline CHEMBL1506027 & 688382 & 4.15 & 4.6795 & TRN \\
\hline CHEMBL1521373 & 688382 & 4.4 & 4.6264 & TRN \\
\hline CHEMBL1594721 & 688382 & 4.15 & 4.7537 & TRN \\
\hline CHEMBL1462634 & 688382 & 4.05 & 4.7306 & TRN \\
\hline CHEMBL1557908 & 688382 & 5.25 & 4.7296 & TRN \\
\hline CHEMBL1319043 & 688382 & 4.65 & 4.7145 & TRN \\
\hline CHEMBL1432278 & 688382 & 4.35 & 4.6932 & TRN \\
\hline CHEMBL1419944 & 688382 & 4.8 & 4.761 & TRN \\
\hline CHEMBL1546831 & 688382 & 6.0 & 4.7345 & TRN \\
\hline CHEMBL1443141 & 688382 & 5.8 & 4.8477 & TST \\
\hline CHEMBL1465406 & 688382 & 5.65 & 4.7075 & TRN \\
\hline CHEMBL1370843 & 688382 & 4.95 & 4.8032 & TRN \\
\hline CHEMBL1573396 & 688382 & 4.5 & 4.686 & TRN \\
\hline CHEMBL1544912 & 688382 & 5.4 & 4.7286 & TST \\
\hline CHEMBL1419482 & 688382 & 4.45 & 4.7552 & TRN \\
\hline CHEMBL1323989 & 688382 & 4.35 & 4.6441 & TRN \\
\hline CHEMBL1303587 & 688382 & 4.5 & 4.6617 & TRN \\
\hline CHEMBL1536183 & 688382 & 5.05 & 4.6943 & TRN \\
\hline CHEMBL1405288 & 688382 & 4.75 & 4.7707 & TST \\
\hline CHEMBL1505413 & 688382 & 4.5 & 4.6612 & TRN \\
\hline CHEMBL1338897 & 688382 & 4.2 & 4.6959 & TRN \\
\hline CHEMBL1334640 & 688382 & 5.05 & 4.7855 & TRN \\
\hline CHEMBL3199190 & 688382 & 4.2 & 4.6574 & TRN \\
\hline CHEMBL1516722 & 688382 & 6.0 & 4.8111 & TRN \\
\hline
\end{tabular}




\begin{tabular}{|c|c|c|c|c|}
\hline \multicolumn{5}{|c|}{ Supplemental Table S2.txt } \\
\hline CHEMBL1510336 & 688382 & 4.4 & 4.7225 & TST \\
\hline CHEMBL1583707 & 688382 & 5.15 & 4.8026 & TRN \\
\hline CHEMBL1468182 & 688382 & 5.85 & 4.7983 & TRN \\
\hline CHEMBL3189399 & 688382 & 4.35 & 4.655 & TRN \\
\hline CHEMBL1308990 & 688382 & 4.05 & 4.6561 & TRN \\
\hline CHEMBL1443643 & 688382 & 5.55 & 4.6847 & TRN \\
\hline CHEMBL1480257 & 688382 & 4.35 & 4.6911 & TRN \\
\hline CHEMBL1411464 & 688382 & 4.45 & 4.7035 & TRN \\
\hline CHEMBL 3192850 & 688382 & 4.65 & 4.5931 & TRN \\
\hline CHEMBL1425723 & 688382 & 4.15 & 4.6715 & TRN \\
\hline CHEMBL1563174 & 688382 & 4.5 & 4.7999 & TRN \\
\hline CHEMBL1299788 & 688382 & 5.85 & 4.748 & TRN \\
\hline CHEMBL1419566 & 688382 & 4.4 & 4.6997 & TRN \\
\hline CHEMBL1350913 & 688382 & 4.2 & 4.6457 & TRN \\
\hline CHEMBL1425710 & 688382 & 5.35 & 4.6455 & TRN \\
\hline CHEMBL1459420 & 688382 & 4.7 & 4.6025 & TRN \\
\hline CHEMBL1480056 & 688382 & 4.6 & 4.5972 & TRN \\
\hline CHEMBL1578048 & 688382 & 4.7 & 4.7405 & TRN \\
\hline CHEMBL1413853 & 688382 & 4.05 & 4.8833 & TRN \\
\hline CHEMBL1321162 & 688382 & 5.45 & 4.7108 & TRN \\
\hline CHEMBL3213604 & 688382 & 4.05 & 4.648 & TRN \\
\hline CHEMBL1380637 & 688382 & 4.25 & 4.6775 & TRN \\
\hline CHEMBL 3192347 & 688382 & 4.5 & 4.6863 & TST \\
\hline CHEMBL1428242 & 688382 & 4.15 & 4.785 & TRN \\
\hline CHEMBL1561705 & 688382 & 4.35 & 4.645 & TST \\
\hline CHEMBL1321335 & 688382 & 4.9 & 4.756 & TRN \\
\hline CHEMBL1537832 & 688382 & 4.55 & 4.7353 & TST \\
\hline CHEMBL 3191015 & 688382 & 4.7 & 4.5921 & TRN \\
\hline CHEMBL1603586 & 688382 & 4.15 & 4.6905 & TRN \\
\hline CHEMBL1338328 & 688382 & 5.0 & 4.8274 & TRN \\
\hline CHEMBL1529991 & 688382 & 4.0 & 4.7781 & TRN \\
\hline CHEMBL1490050 & 688382 & 4.45 & 4.8025 & TRN \\
\hline CHEMBL3211958 & 688382 & 4.5 & 4.6781 & TRN \\
\hline CHEMBL1307233 & 688382 & 5.5 & 4.6827 & TST \\
\hline CHEMBL1422217 & 688382 & 4.35 & 4.6628 & TRN \\
\hline CHEMBL1343001 & 688382 & 4.4 & 4.6578 & TRN \\
\hline CHEMBL1362408 & 688382 & 4.5 & 4.6691 & TRN \\
\hline CHEMBL1402565 & 688382 & 4.35 & 4.7879 & TRN \\
\hline CHEMBL1392176 & 688382 & 4.5 & 4.7209 & TRN \\
\hline CHEMBL1505230 & 688382 & 4.05 & 4.6856 & TRN \\
\hline CHEMBL3199543 & 688382 & 4.5 & 4.6332 & TRN \\
\hline CHEMBL1594856 & 688382 & 4.05 & 4.7065 & TRN \\
\hline CHEMBL1531665 & 688382 & 4.5 & 4.6304 & TRN \\
\hline CHEMBL1317690 & 688382 & 4.15 & 4.7105 & TST \\
\hline CHEMBL1359155 & 688382 & 4.2 & 4.6682 & TRN \\
\hline CHEMBL1386532 & 688382 & 5.6 & 4.7282 & TRN \\
\hline CHEMBL1410209 & 688382 & 4.45 & 4.6865 & TRN \\
\hline CHEMBL1490775 & 688382 & 4.4 & 4.665 & TRN \\
\hline
\end{tabular}




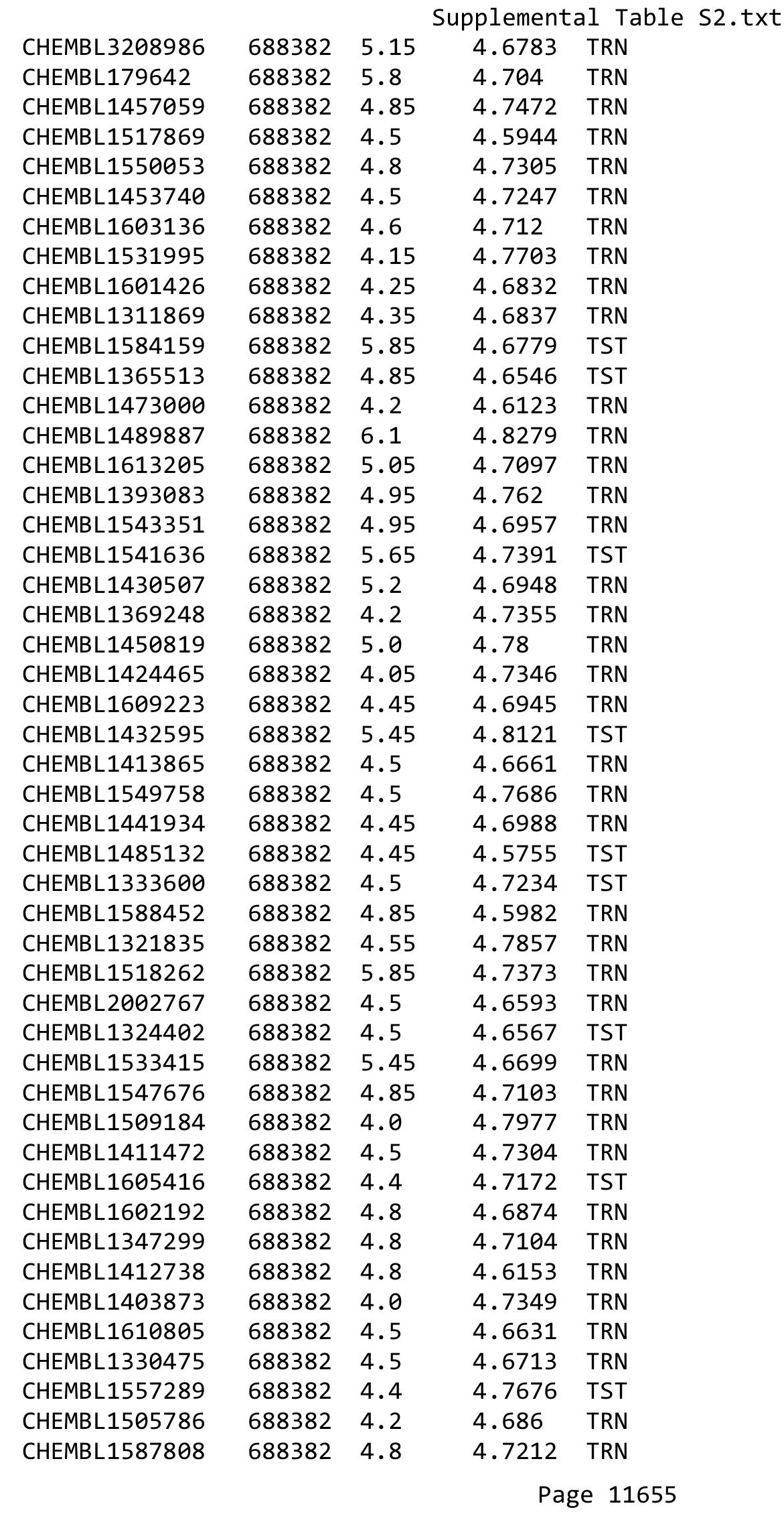




\begin{tabular}{|c|c|c|c|c|c|}
\hline \multicolumn{6}{|c|}{ Supplemental Table S2.txt } \\
\hline CHEMBL99967 & 688382 & 5.8 & 4.6762 & TST & \\
\hline CHEMBL1337150 & 688382 & 4.65 & 4.6633 & TRN & \\
\hline CHEMBL1304839 & 688382 & 5.6 & 4.626 & TRN & \\
\hline CHEMBL1443377 & 688382 & 4.9 & 4.6561 & TST & \\
\hline CHEMBL1388361 & 688382 & 4.8 & 4.6707 & TST & \\
\hline CHEMBL1496053 & 688382 & 4.85 & 4.7127 & TRN & \\
\hline CHEMBL1570931 & 688382 & 5.2 & 4.6975 & TST & \\
\hline CHEMBL1414530 & 688382 & 4.45 & 4.7194 & TRN & \\
\hline CHEMBL1325117 & 688382 & 4.35 & 4.6735 & TRN & \\
\hline CHEMBL1499025 & 688382 & 5.0 & 4.8176 & TRN & \\
\hline CHEMBL1335787 & 688382 & 4.45 & 4.6929 & TRN & \\
\hline CHEMBL1446485 & 688382 & 4.4 & 4.7391 & TST & \\
\hline CHEMBL1329727 & 688382 & 4.4 & 4.69600 & 0000000001 & TST \\
\hline CHEMBL1379181 & 688382 & 4.45 & 4.6726 & TRN & \\
\hline CHEMBL1410701 & 688382 & 4.4 & 4.7733 & TST & \\
\hline CHEMBL 3189408 & 688382 & 4.4 & 4.7 & TST & \\
\hline CHEMBL57978 & 688382 & 4.4 & 4.6878 & TRN & \\
\hline CHEMBL1549536 & 688382 & 5.55 & 4.8022 & TRN & \\
\hline CHEMBL1424229 & 688382 & 4.2 & 4.6384 & TRN & \\
\hline CHEMBL1420127 & 688382 & 5.5 & 4.72 & TRN & \\
\hline CHEMBL69612 & 688382 & 4.45 & 4.6382 & TST & \\
\hline CHEMBL1555938 & 688382 & 4.05 & 4.6581 & TRN & \\
\hline CHEMBL1360126 & 688382 & 4.8 & 4.6701 & TRN & \\
\hline CHEMBL1563589 & 688382 & 5.15 & 4.7194 & TRN & \\
\hline CHEMBL1504773 & 688382 & 5.0 & 4.7367 & TST & \\
\hline CHEMBL1504519 & 688382 & 5.5 & 4.7168 & TRN & \\
\hline CHEMBL1561420 & 688382 & 4.8 & 4.6971 & TST & \\
\hline CHEMBL160145 & 688382 & 4.45 & 4.6411 & TRN & \\
\hline CHEMBL1517387 & 688382 & 4.45 & 4.6313 & TRN & \\
\hline CHEMBL1581029 & 688382 & 4.75 & 4.7482 & TRN & \\
\hline CHEMBL1494730 & 688382 & 5.35 & 4.7322 & TST & \\
\hline CHEMBL1378907 & 688382 & 4.15 & 4.7644 & TST & \\
\hline CHEMBL1344236 & 688382 & 5.15 & 4.6433 & TRN & \\
\hline CHEMBL1983839 & 688382 & 5.1 & 4.6601 & TRN & \\
\hline CHEMBL1534813 & 688382 & 5.0 & 4.6517 & TRN & \\
\hline CHEMBL3212381 & 688382 & 4.35 & 4.6882 & TRN & \\
\hline CHEMBL1582155 & 688382 & 5.5 & 4.6396 & TRN & \\
\hline CHEMBL1585717 & 688382 & 4.2 & 4.80699 & 99999999995 & TRN \\
\hline CHEMBL1442619 & 688382 & 4.1 & 4.6114 & TRN & \\
\hline CHEMBL1430358 & 688382 & 4.6 & 4.6979 & TRN & \\
\hline CHEMBL1498154 & 688382 & 4.5 & 4.7326 & TST & \\
\hline CHEMBL1575887 & 688382 & 4.0 & 4.7495 & TST & \\
\hline CHEMBL1352865 & 688382 & 4.45 & 4.7694 & TST & \\
\hline CHEMBL1308965 & 688382 & 4.15 & 4.6708 & TRN & \\
\hline CHEMBL1301380 & 688382 & 5.0 & 4.7367 & TRN & \\
\hline CHEMBL1474098 & 688382 & 4.45 & 4.7688 & TRN & \\
\hline CHEMBL1443877 & 688382 & 4.15 & 4.6963 & TRN & \\
\hline CHEMBL1520323 & 688382 & 4.95 & 4.6741 & TRN & \\
\hline
\end{tabular}




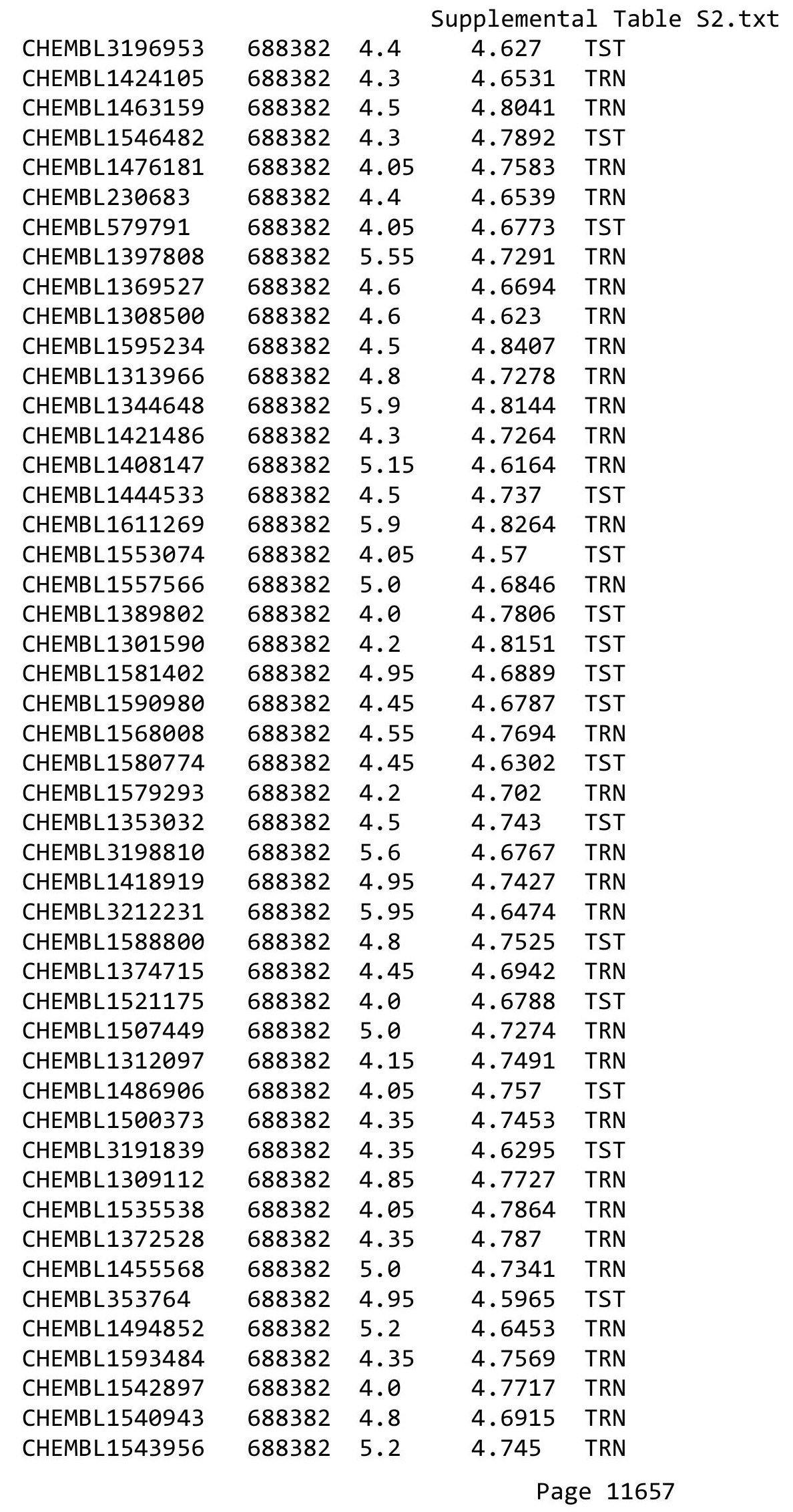




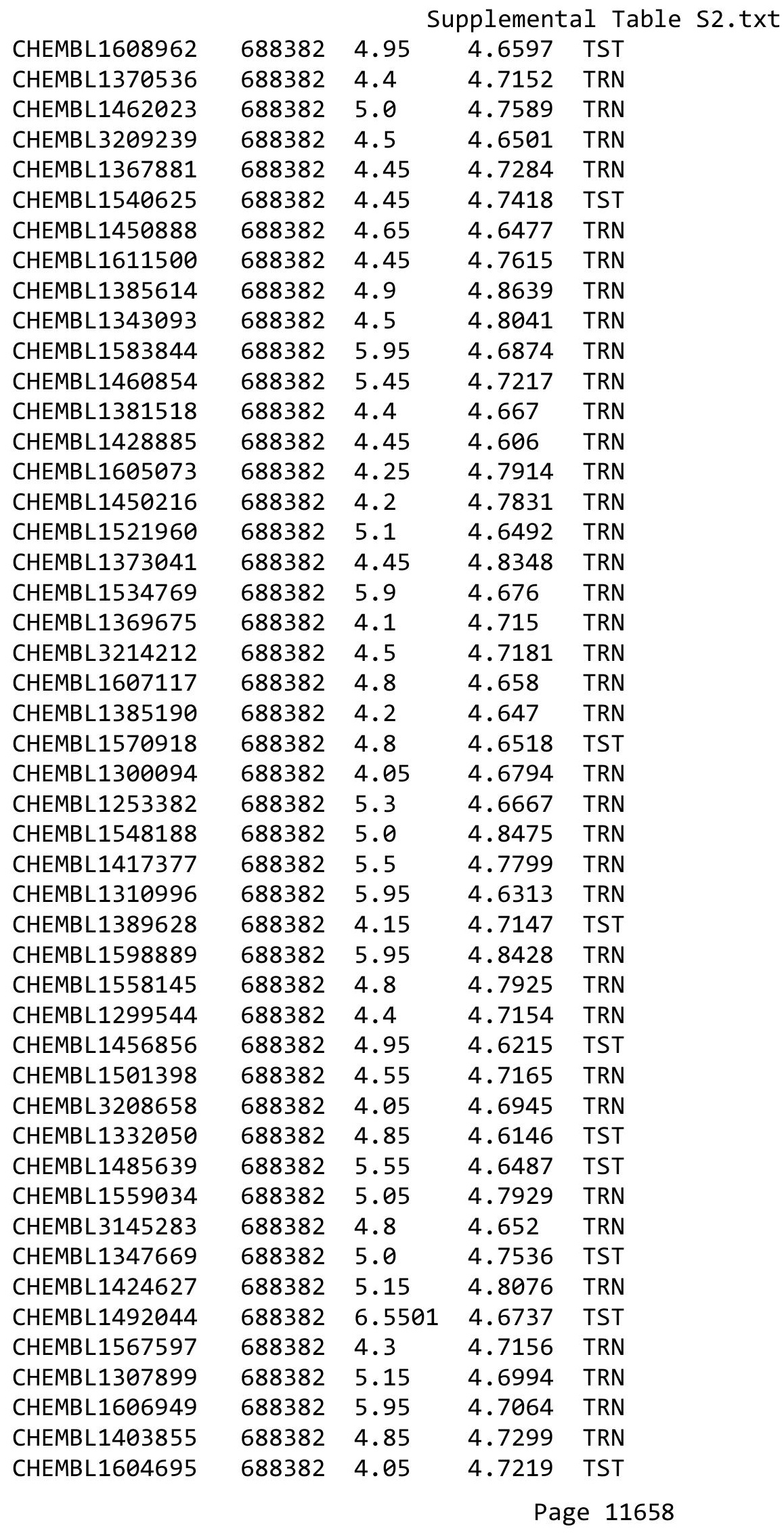




\begin{tabular}{|c|c|c|c|c|}
\hline \multicolumn{5}{|c|}{ Supplemental Table s2.txt } \\
\hline CHEMBL1472546 & 688382 & 4.5 & 4.6823 & TRN \\
\hline CHEMBL1387864 & 688382 & 4.15 & 4.6893 & TRN \\
\hline CHEMBL1598454 & 688382 & 4.9 & 4.7079 & TRN \\
\hline CHEMBL1561556 & 688382 & 5.1 & 4.7356 & TRN \\
\hline CHEMBL1345667 & 688382 & 4.85 & 4.7329 & TRN \\
\hline CHEMBL1299315 & 688382 & 6.0 & 4.7539 & TST \\
\hline CHEMBL1388670 & 688382 & 4.8 & 4.6924 & TRN \\
\hline CHEMBL1583351 & 688382 & 4.15 & 4.7103 & TST \\
\hline CHEMBL1385546 & 688382 & 5.0 & 4.6488 & TRN \\
\hline CHEMBL1301134 & 688382 & 4.6 & 4.7377 & TRN \\
\hline CHEMBL 2005998 & 688382 & 4.2 & 4.603 & TST \\
\hline CHEMBL3193036 & 688382 & 5.05 & 4.6753 & TRN \\
\hline CHEMBL3189861 & 688382 & 5.0 & 4.6707 & TRN \\
\hline CHEMBL3192706 & 688382 & 4.8 & 4.6704 & TRN \\
\hline CHEMBL1612899 & 688382 & 4.05 & 4.6805 & TRN \\
\hline CHEMBL1505964 & 688382 & 4.85 & 4.7998 & TRN \\
\hline CHEMBL1511605 & 688382 & 4.05 & 4.7137 & TRN \\
\hline CHEMBL1416343 & 688382 & 4.85 & 4.7034 & TRN \\
\hline CHEMBL1467421 & 688382 & 4.95 & 4.6971 & TRN \\
\hline CHEMBL1415397 & 688382 & 4.05 & 4.7249 & TRN \\
\hline CHEMBL1499030 & 688382 & 5.05 & 4.7471 & TRN \\
\hline CHEMBL1350090 & 688382 & 4.5 & 4.7498 & TRN \\
\hline CHEMBL1611125 & 688382 & 4.0 & 4.7588 & TRN \\
\hline CHEMBL1313058 & 688382 & 4.9 & 4.8034 & TRN \\
\hline CHEMBL1420403 & 688382 & 5.95 & 4.687 & TRN \\
\hline CHEMBL1426792 & 688382 & 4.65 & 4.6326 & TRN \\
\hline CHEMBL1535511 & 688382 & 4.85 & 4.6734 & TRN \\
\hline CHEMBL1461953 & 688382 & 4.5 & 4.6792 & TRN \\
\hline CHEMBL1347655 & 688382 & 4.6 & 4.6798 & TST \\
\hline CHEMBL1612205 & 688382 & 5.0 & 4.7568 & TRN \\
\hline CHEMBL 3198180 & 688382 & 4.25 & 4.7508 & TRN \\
\hline CHEMBL1581203 & 688382 & 4.5 & 4.6816 & TRN \\
\hline CHEMBL1388693 & 688382 & 4.2 & 4.7168 & TRN \\
\hline CHEMBL3208439 & 688382 & 4.5 & 4.6732 & TRN \\
\hline CHEMBL11608 & 688382 & 6.4 & 4.6593 & TST \\
\hline CHEMBL1482130 & 688382 & 4.45 & 4.7314 & TRN \\
\hline CHEMBL1587214 & 688382 & 5.0 & 4.7506 & TRN \\
\hline CHEMBL1543841 & 688382 & 4.6 & 4.7191 & TST \\
\hline CHEMBL1399116 & 688382 & 4.55 & 4.8019 & TST \\
\hline CHEMBL1387789 & 688382 & 4.8 & 4.6295 & TST \\
\hline CHEMBL1418515 & 688382 & 4.8 & 4.83 & TRN \\
\hline CHEMBL1383607 & 688382 & 4.45 & 4.7398 & TRN \\
\hline CHEMBL3208799 & 688382 & 4.35 & 4.7228 & TRN \\
\hline CHEMBL157351 & 688382 & 4.45 & 4.6465 & TST \\
\hline CHEMBL1408860 & 688382 & 4.4 & 4.7898 & TRN \\
\hline CHEMBL1328611 & 688382 & 5.6 & 4.7212 & TRN \\
\hline CHEMBL1465862 & 688382 & 5.15 & 4.721 & TRN \\
\hline CHEMBL1561063 & 688382 & 4.55 & 4.6794 & TRN \\
\hline
\end{tabular}




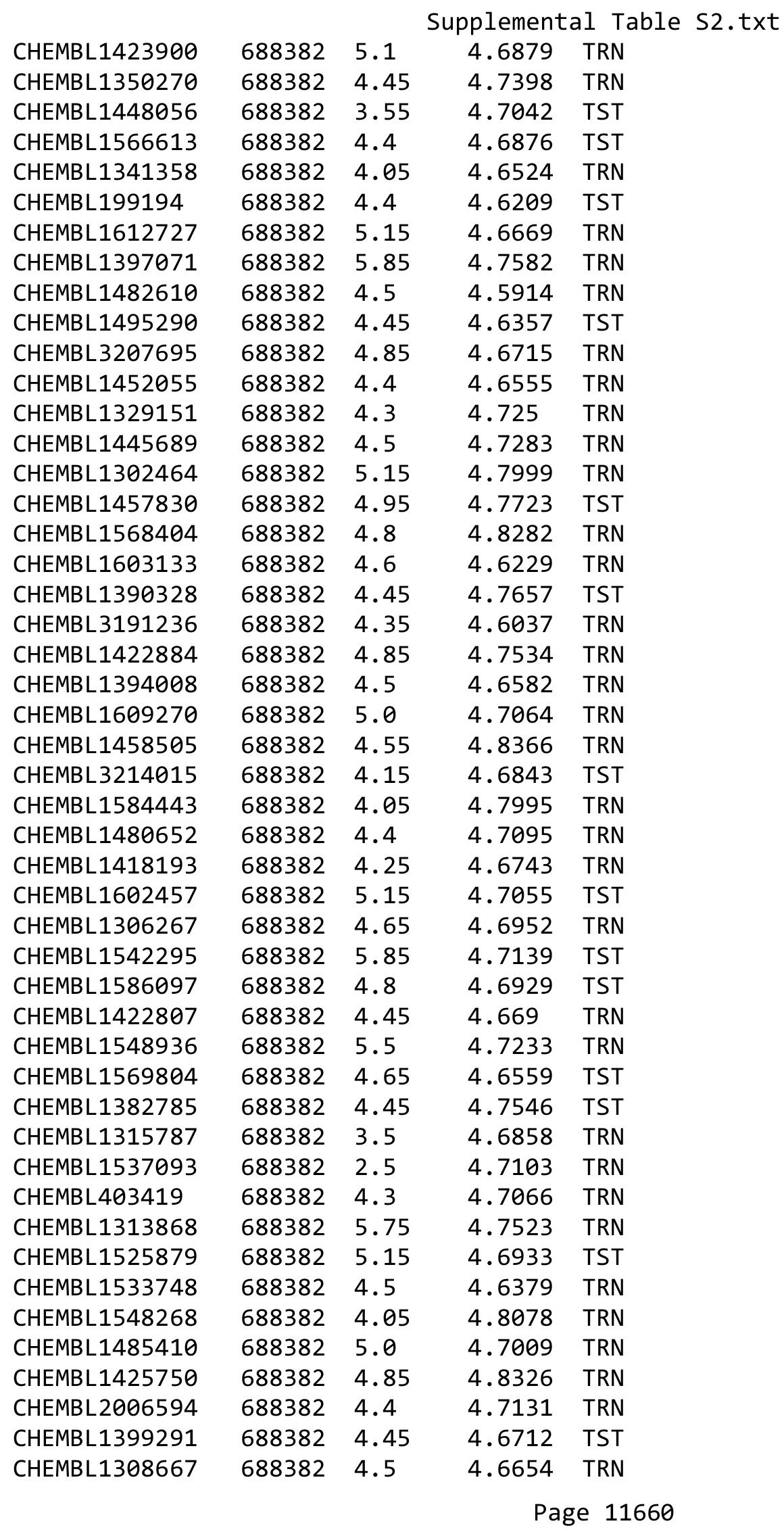




\begin{tabular}{|c|c|c|c|c|c|}
\hline \multicolumn{6}{|c|}{ Supplemental Table S2.txt } \\
\hline CHEMBL1342103 & 688382 & 5.0 & 4.6533 & TST & \\
\hline CHEMBL1414560 & 688382 & 4.35 & 4.7245 & TRN & \\
\hline CHEMBL1469662 & 688382 & 5.05 & 4.6467 & TST & \\
\hline CHEMBL1301060 & 688382 & 4.7 & 4.6257 & TRN & \\
\hline CHEMBL1494927 & 688382 & 4.85 & 4.673 & TST & \\
\hline CHEMBL1307836 & 688382 & 5.05 & 4.7917 & TRN & \\
\hline CHEMBL1449387 & 688382 & 5.05 & 4.6816 & TST & \\
\hline CHEMBL1517267 & 688382 & 5.25 & 4.7895 & TRN & \\
\hline CHEMBL1498254 & 688382 & 4.2 & 4.6986 & TST & \\
\hline CHEMBL1528906 & 688382 & 4.15 & 4.7431 & TRN & \\
\hline CHEMBL1532897 & 688382 & 4.5 & 4.6629 & TRN & \\
\hline CHEMBL1363438 & 688382 & 5.85 & 4.7747 & TST & \\
\hline CHEMBL1445880 & 688382 & 4.15 & 4.7326 & TRN & \\
\hline CHEMBL1516857 & 688382 & 5.05 & 4.7172 & TST & \\
\hline CHEMBL1430895 & 688382 & 4.85 & 4.6804 & TRN & \\
\hline CHEMBL 3207925 & 688382 & 4.85 & 4.649 & TRN & \\
\hline CHEMBL1442865 & 688382 & 5.9 & 4.7909 & TST & \\
\hline CHEMBL3213531 & 688382 & 4.15 & 4.7466 & TRN & \\
\hline CHEMBL1562310 & 688382 & 4.6 & 4.775 & TRN & \\
\hline CHEMBL1587868 & 688382 & 4.4 & 4.7368 & TRN & \\
\hline CHEMBL1309708 & 688382 & 4.0 & 4.8145 & TRN & \\
\hline CHEMBL1402134 & 688382 & 4.85 & 4.6533 & TRN & \\
\hline CHEMBL3195471 & 688382 & 4.95 & 4.5768 & TST & \\
\hline CHEMBL1522563 & 688382 & 4.9 & 4.6026 & TST & \\
\hline CHEMBL1453924 & 688382 & 4.8 & 4.7054 & TST & \\
\hline CHEMBL1331247 & 688382 & 5.0 & 4.7887 & TST & \\
\hline CHEMBL1525271 & 688382 & 4.1 & 4.6193 & TRN & \\
\hline CHEMBL1466241 & 688382 & 4.4 & 4.6615 & TRN & \\
\hline CHEMBL3193699 & 688382 & 4.8 & 4.71899 & 9999999999 & TST \\
\hline CHEMBL1964407 & 688382 & 4.5 & 4.6768 & TST & \\
\hline CHEMBL1575470 & 688382 & 4.95 & 4.6013 & TRN & \\
\hline CHEMBL1605174 & 688382 & 4.8 & 4.8066 & TRN & \\
\hline CHEMBL1567552 & 688382 & 5.05 & 4.7917 & TRN & \\
\hline CHEMBL1416397 & 688382 & 5.35 & 4.7652 & TRN & \\
\hline CHEMBL1320902 & 688382 & 4.5 & 4.6691 & TST & \\
\hline CHEMBL1572854 & 688382 & 4.15 & 4.8229 & TRN & \\
\hline CHEMBL1479271 & 688382 & 5.0 & 4.7579 & TRN & \\
\hline CHEMBL1601519 & 688382 & 4.75 & 4.738 & TST & \\
\hline CHEMBL1408648 & 688382 & 4.4 & 4.7517 & TRN & \\
\hline CHEMBL1486027 & 688382 & 5.4 & 4.6479 & TRN & \\
\hline CHEMBL1403238 & 688382 & 5.2 & 4.7528 & TRN & \\
\hline CHEMBL1543366 & 688382 & 5.05 & 4.6549 & TST & \\
\hline CHEMBL1463938 & 688382 & 4.1 & 4.732 & TRN & \\
\hline CHEMBL1521685 & 688382 & 4.5 & 4.7174 & TRN & \\
\hline CHEMBL1605652 & 688382 & 4.15 & 4.7887 & TRN & \\
\hline CHEMBL1412497 & 688382 & 4.55 & 4.7063 & TST & \\
\hline CHEMBL1468702 & 688382 & 4.6 & 4.7047 & TRN & \\
\hline CHEMBL1372166 & 688382 & 4.8 & 4.8005 & TRN & \\
\hline
\end{tabular}




\begin{tabular}{|c|c|c|c|c|c|}
\hline \multicolumn{6}{|c|}{ Supplemental Table S2.txt } \\
\hline CHEMBL1460461 & 688382 & 4.7 & 4.6858 & TST & \\
\hline CHEMBL1506790 & 688382 & 4.3 & 4.7253 & TRN & \\
\hline CHEMBL1586754 & 688382 & 4.0 & 4.658 & TST & \\
\hline CHEMBL1596624 & 688382 & 5.0 & 4.6658 & TRN & \\
\hline CHEMBL1307633 & 688382 & 4.95 & 4.7251 & TRN & \\
\hline CHEMBL1347736 & 688382 & 4.5 & 4.6905 & TRN & \\
\hline CHEMBL3191618 & 688382 & 4.45 & 4.6017 & TRN & \\
\hline CHEMBL1484301 & 688382 & 4.85 & 4.7163 & TRN & \\
\hline CHEMBL1312076 & 688382 & 4.85 & 4.7258 & TRN & \\
\hline CHEMBL1506394 & 688382 & 4.85 & 4.6874 & TRN & \\
\hline CHEMBL1510557 & 688382 & 4.5 & 4.7556 & TRN & \\
\hline CHEMBL1334517 & 688382 & 4.8 & 4.7086 & TRN & \\
\hline CHEMBL3197218 & 688382 & 4.8 & 4.7353 & TRN & \\
\hline CHEMBL1319010 & 688382 & 4.4 & 4.6827 & TRN & \\
\hline CHEMBL1458957 & 688382 & 4.5 & 4.7459 & TRN & \\
\hline CHEMBL1492808 & 688382 & 5.05 & 4.8919 & TST & \\
\hline CHEMBL3196181 & 688382 & 4.4 & 4.7482 & TST & \\
\hline CHEMBL1497139 & 688382 & 4.45 & 4.64199 & 99999999995 & TRN \\
\hline CHEMBL1482087 & 688382 & 4.2 & 4.7048 & TRN & \\
\hline CHEMBL1397345 & 688382 & 4.8 & 4.7737 & TRN & \\
\hline CHEMBL1522930 & 688382 & 5.25 & 4.8185 & TRN & \\
\hline CHEMBL1488252 & 688382 & 5.0 & 4.8261 & TRN & \\
\hline CHEMBL1325568 & 688382 & 4.85 & 4.7299 & TST & \\
\hline CHEMBL1587876 & 688382 & 5.0 & 4.6528 & TRN & \\
\hline CHEMBL1389370 & 688382 & 5.2 & 4.7692 & TRN & \\
\hline CHEMBL1427734 & 688382 & 5.85 & 4.7311 & TRN & \\
\hline CHEMBL1383236 & 688382 & 5.15 & 4.7569 & TRN & \\
\hline CHEMBL1390903 & 688382 & 5.8 & 4.8014 & TRN & \\
\hline CHEMBL1341444 & 688382 & 4.6 & 4.6374 & TRN & \\
\hline CHEMBL1581907 & 688382 & 4.45 & 4.8295 & TRN & \\
\hline CHEMBL1609463 & 688382 & 4.05 & 4.6089 & TST & \\
\hline CHEMBL1518038 & 688382 & 4.55 & 4.7343 & TRN & \\
\hline CHEMBL1367521 & 688382 & 5.4 & 4.6409 & TRN & \\
\hline CHEMBL3208028 & 688382 & 5.6 & 4.6633 & TST & \\
\hline CHEMBL1453652 & 688382 & 5.1 & 4.6815 & TRN & \\
\hline CHEMBL1607405 & 688382 & 4.4 & 4.7159 & TST & \\
\hline CHEMBL1522013 & 688382 & 5.0 & 4.7058 & TRN & \\
\hline CHEMBL1510680 & 688382 & 5.15 & 4.8212 & TST & \\
\hline CHEMBL1489403 & 688382 & 4.0 & 4.8765 & TRN & \\
\hline CHEMBL1340278 & 688382 & 6.0 & 4.6753 & TRN & \\
\hline CHEMBL1388783 & 688382 & 4.35 & 4.6186 & TRN & \\
\hline CHEMBL177938 & 688382 & 4.35 & 4.626 & TRN & \\
\hline CHEMBL1523676 & 688382 & 4.0 & 4.742 & TRN & \\
\hline CHEMBL3145089 & 688382 & 5.55 & 4.6551 & TRN & \\
\hline CHEMBL1338452 & 688382 & 5.05 & 4.6692 & TRN & \\
\hline CHEMBL1470952 & 688382 & 4.05 & 4.698 & TRN & \\
\hline CHEMBL1560736 & 688382 & 5.05 & 4.732 & TRN & \\
\hline CHEMBL1467376 & 688382 & 4.15 & 4.7884 & TRN & \\
\hline
\end{tabular}




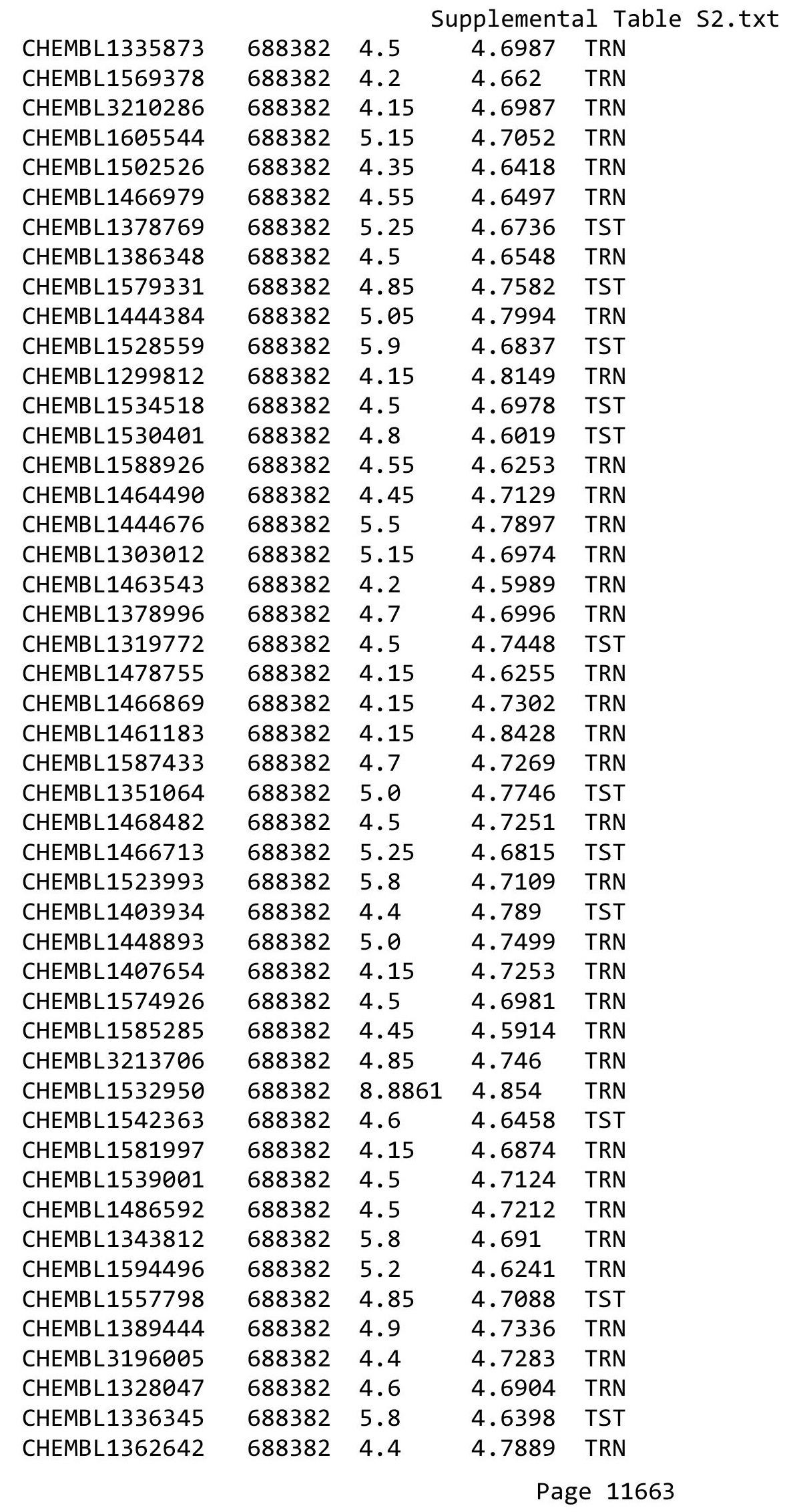




\begin{tabular}{|c|c|c|c|c|}
\hline \multicolumn{5}{|c|}{ Supplemental Table S2.txt } \\
\hline CHEMBL1310942 & 688382 & 4.05 & 4.7937 & TRN \\
\hline CHEMBL1608144 & 688382 & 4.25 & 4.6369 & TRN \\
\hline CHEMBL1451635 & 688382 & 4.2 & 4.8067 & TRN \\
\hline CHEMBL 3193274 & 688382 & 4.5 & 4.6299 & TRN \\
\hline CHEMBL1342447 & 688382 & 4.4 & 4.7404 & TRN \\
\hline CHEMBL1519414 & 688382 & 4.5 & 4.6513 & TRN \\
\hline CHEMBL1527138 & 688382 & 4.45 & 4.6815 & TRN \\
\hline CHEMBL3198502 & 688382 & 4.5 & 4.6081 & TRN \\
\hline CHEMBL3198491 & 688382 & 4.0 & 4.6721 & TRN \\
\hline CHEMBL3210250 & 688382 & 5.1 & 4.6503 & TRN \\
\hline CHEMBL1538664 & 688382 & 4.5 & 4.6727 & TRN \\
\hline CHEMBL1307673 & 688382 & 4.55 & 4.7126 & TRN \\
\hline CHEMBL1424188 & 688382 & 4.4 & 4.698 & TRN \\
\hline CHEMBL1569439 & 688382 & 4.95 & 4.7274 & TST \\
\hline CHEMBL1367087 & 688382 & 4.35 & 4.6817 & TST \\
\hline CHEMBL1438260 & 688382 & 4.35 & 4.7582 & TST \\
\hline CHEMBL1585760 & 688382 & 4.4 & 4.7103 & TRN \\
\hline CHEMBL1563751 & 688382 & 4.5 & 4.7844 & TRN \\
\hline CHEMBL1457568 & 688382 & 4.45 & 4.7381 & TRN \\
\hline CHEMBL1512825 & 688382 & 3.5 & 4.7478 & TRN \\
\hline CHEMBL1431266 & 688382 & 5.05 & 4.7535 & TRN \\
\hline CHEMBL1467008 & 688382 & 4.45 & 4.7361 & TST \\
\hline CHEMBL1608913 & 688382 & 4.2 & 4.7918 & TRN \\
\hline CHEMBL1462078 & 688382 & 4.85 & 4.7271 & TRN \\
\hline CHEMBL1422380 & 688382 & 5.85 & 4.7086 & TRN \\
\hline CHEMBL1500134 & 688382 & 4.4 & 4.6505 & TRN \\
\hline CHEMBL1362886 & 688382 & 4.3 & 4.6539 & TST \\
\hline CHEMBL1500673 & 688382 & 4.95 & 4.6574 & TST \\
\hline CHEMBL1510503 & 688382 & 5.1 & 4.7237 & TST \\
\hline CHEMBL1384085 & 688382 & 4.85 & 4.8241 & TST \\
\hline CHEMBL1372357 & 688382 & 5.65 & 4.5887 & TST \\
\hline CHEMBL1498722 & 688382 & 3.95 & 4.8456 & TRN \\
\hline CHEMBL1323334 & 688382 & 4.6 & 4.7223 & TST \\
\hline CHEMBL1558352 & 688382 & 5.05 & 4.697 & TRN \\
\hline CHEMBL1559844 & 688382 & 6.05 & 4.745 & TRN \\
\hline CHEMBL1995169 & 688382 & 4.9 & 4.5993 & TRN \\
\hline CHEMBL1343044 & 688382 & 4.2 & 4.6213 & TRN \\
\hline CHEMBL1409828 & 688382 & 4.4 & 4.6785 & TRN \\
\hline CHEMBL1333983 & 688382 & 4.6 & 4.7114 & TST \\
\hline CHEMBL1574536 & 688382 & 5.85 & 4.695 & TST \\
\hline CHEMBL1467520 & 688382 & 4.45 & 4.7419 & TRN \\
\hline CHEMBL1361737 & 688382 & 4.8 & 4.7565 & TRN \\
\hline CHEMBL1309652 & 688382 & 4.95 & 4.6863 & TRN \\
\hline CHEMBL3189925 & 688382 & 4.15 & 4.6438 & TRN \\
\hline CHEMBL1341257 & 688382 & 4.8 & 4.7574 & TST \\
\hline CHEMBL1563038 & 688382 & 4.95 & 4.7981 & TRN \\
\hline CHEMBL1373148 & 688382 & 4.15 & 4.7419 & TRN \\
\hline CHEMBL1500070 & 688382 & 4.15 & 4.6378 & TRN \\
\hline
\end{tabular}




\begin{tabular}{|c|c|c|c|c|c|}
\hline \multicolumn{6}{|c|}{ Supplemental Table s2.txt } \\
\hline CHEMBL1338631 & 688382 & 5.7 & 4.7237 & TRN & \\
\hline CHEMBL1524329 & 688382 & 4.7 & 4.7861 & TRN & \\
\hline CHEMBL1348181 & 688382 & 4.8 & 4.6863 & TRN & \\
\hline CHEMBL1469641 & 688382 & 5.05 & 4.7336 & TRN & \\
\hline CHEMBL3213103 & 688382 & 4.45 & 4.7327 & TRN & \\
\hline CHEMBL1472386 & 688382 & 4.15 & 4.6523 & TRN & \\
\hline CHEMBL3192366 & 688382 & 4.8 & 4.7147 & TRN & \\
\hline CHEMBL1446074 & 688382 & 4.8 & 4.7073 & TRN & \\
\hline CHEMBL1466003 & 688382 & 5.3 & 4.6719 & TST & \\
\hline CHEMBL1484415 & 688382 & 4.8 & 4.7044 & TST & \\
\hline CHEMBL1430428 & 688382 & 4.0 & 4.6496 & TST & \\
\hline CHEMBL437571 & 688382 & 4.65 & 4.6465 & TRN & \\
\hline CHEMBL1410536 & 688382 & 4.4 & 4.6403 & TST & \\
\hline CHEMBL1564475 & 688382 & 4.85 & 4.7329 & TST & \\
\hline CHEMBL1498087 & 688382 & 4.05 & 4.6917 & TRN & \\
\hline CHEMBL3211859 & 688382 & 4.5 & 4.6549 & TRN & \\
\hline CHEMBL1500026 & 688382 & 4.4 & 4.6462 & TRN & \\
\hline CHEMBL1337514 & 688382 & 4.5 & 4.7384 & TST & \\
\hline CHEMBL1371487 & 688382 & 4.4 & \multicolumn{2}{|c|}{4.7410000000000005} & TST \\
\hline CHEMBL1333429 & 688382 & 4.45 & 4.6888 & TRN & \\
\hline CHEMBL1447150 & 688382 & 4.5 & 4.6813 & TRN & \\
\hline CHEMBL1611003 & 688382 & 5.0 & 4.57 & TRN & \\
\hline CHEMBL1976414 & 688382 & 4.35 & 4.6722 & TRN & \\
\hline CHEMBL1469196 & 688382 & 4.8 & 4.6628 & TRN & \\
\hline CHEMBL1305066 & 688382 & 4.5 & 4.6415 & TRN & \\
\hline CHEMBL1484185 & 688382 & 4.45 & 4.6532 & TRN & \\
\hline CHEMBL 3212814 & 688382 & 4.15 & 4.7193 & TRN & \\
\hline CHEMBL1613285 & 688382 & 4.4 & 4.6566 & TRN & \\
\hline CHEMBL1595062 & 688382 & 6.0 & 4.7639 & TST & \\
\hline CHEMBL1579176 & 688382 & 5.1 & 4.6676 & TRN & \\
\hline CHEMBL1500251 & 688382 & 5.0 & 4.6313 & TRN & \\
\hline CHEMBL1502534 & 688382 & 4.15 & 4.8018 & TRN & \\
\hline CHEMBL1528707 & 688382 & 4.45 & 4.663 & TRN & \\
\hline CHEMBL1507157 & 688382 & 4.95 & 4.6631 & TRN & \\
\hline CHEMBL1543281 & 688382 & 4.35 & 4.7472 & TRN & \\
\hline CHEMBL1482740 & 688382 & 4.65 & 4.626 & TRN & \\
\hline CHEMBL1528902 & 688382 & 5.8 & 4.834 & TRN & \\
\hline CHEMBL1504457 & 688382 & 4.4 & 4.7456 & TRN & \\
\hline CHEMBL1301898 & 688382 & 4.45 & 4.7317 & TRN & \\
\hline CHEMBL1441595 & 688382 & 4.4 & 4.6912 & TRN & \\
\hline CHEMBL1486628 & 688382 & 4.3 & 4.6892 & TST & \\
\hline CHEMBL1393140 & 688382 & 4.85 & 4.7838 & TRN & \\
\hline CHEMBL1544516 & 688382 & 5.0 & 4.6274 & TRN & \\
\hline CHEMBL3208118 & 688382 & 4.45 & 4.7113 & TRN & \\
\hline CHEMBL1483382 & 688382 & 5.5 & 4.681 & TRN & \\
\hline CHEMBL1336939 & 688382 & 4.15 & 4.7026 & TST & \\
\hline CHEMBL1335598 & 688382 & 4.2 & $4.6530 e$ & 00000000005 & TRN \\
\hline CHEMBL1574573 & 688382 & 4.5 & 4.686 & TRN & \\
\hline
\end{tabular}




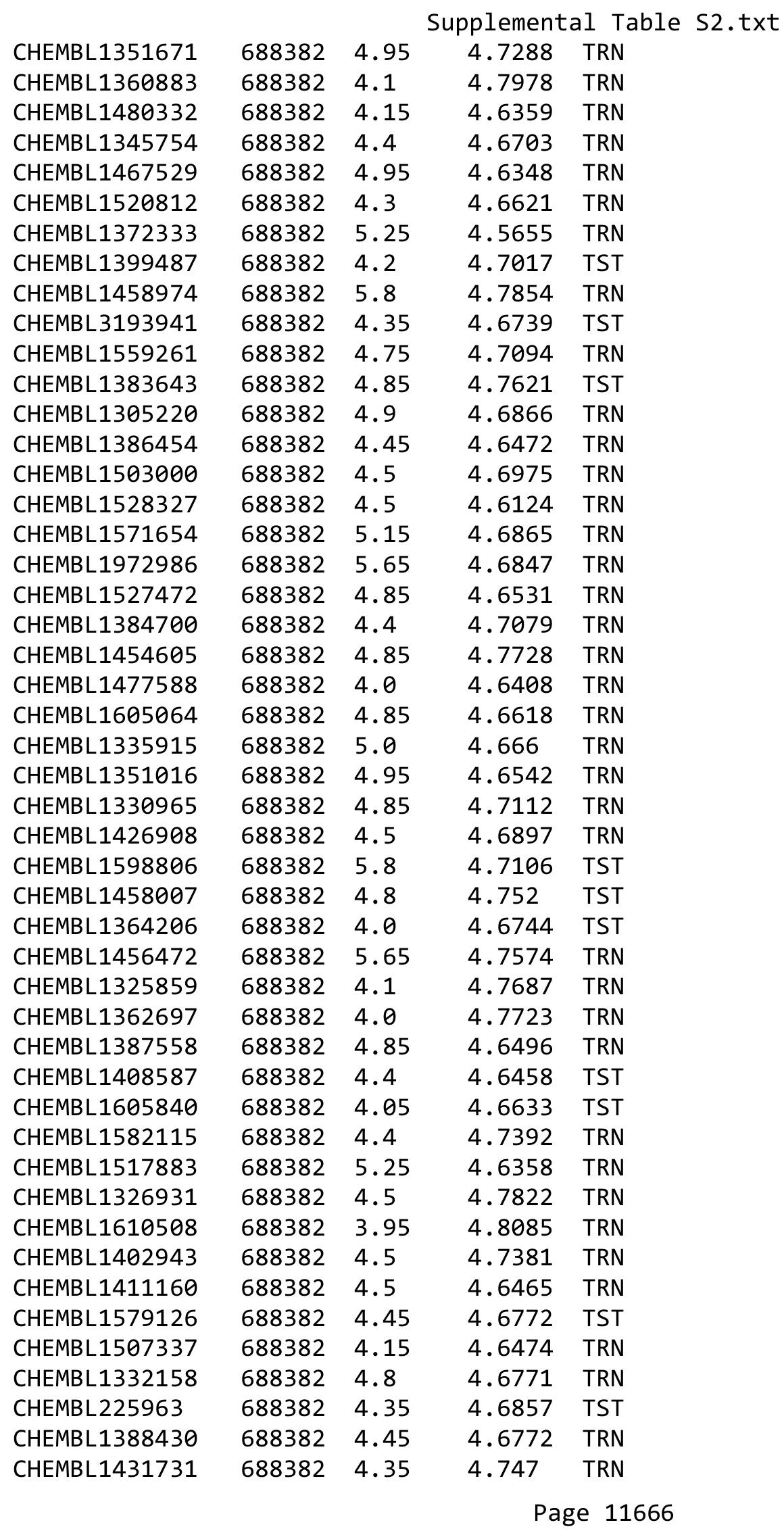




\begin{tabular}{|c|c|c|c|c|}
\hline \multicolumn{5}{|c|}{ Supplemental Table S2.txt } \\
\hline CHEMBL1377950 & 688382 & 4.5 & 4.8153 & TRN \\
\hline CHEMBL1599886 & 688382 & 5.15 & 4.6603 & TST \\
\hline CHEMBL1376317 & 688382 & 4.15 & 4.7345 & TRN \\
\hline CHEMBL1545828 & 688382 & 4.45 & 4.6844 & TRN \\
\hline CHEMBL1609727 & 688382 & 4.55 & 4.7113 & TRN \\
\hline CHEMBL1348702 & 688382 & 4.9 & 4.7934 & TRN \\
\hline CHEMBL1369826 & 688382 & 4.95 & 4.652 & TRN \\
\hline CHEMBL1344150 & 688382 & 4.85 & 4.7307 & TRN \\
\hline CHEMBL1505366 & 688382 & 4.45 & 4.6634 & TRN \\
\hline CHEMBL1409381 & 688382 & 4.5 & 4.7594 & TST \\
\hline CHEMBL1495923 & 688382 & 4.8 & 4.8091 & TRN \\
\hline CHEMBL1542250 & 688382 & 4.45 & 4.7026 & TRN \\
\hline CHEMBL1352599 & 688382 & 5.1 & 4.7769 & TRN \\
\hline CHEMBL1390971 & 688382 & 4.85 & 4.6341 & TRN \\
\hline CHEMBL1530080 & 688382 & 4.15 & 4.6539 & TRN \\
\hline CHEMBL1563868 & 688382 & 4.8 & 4.6716 & TRN \\
\hline CHEMBL1577396 & 688382 & 5.85 & 4.768 & TRN \\
\hline CHEMBL1446227 & 688382 & 4.85 & 4.7204 & TRN \\
\hline CHEMBL1468445 & 688382 & 5.95 & 4.7918 & TRN \\
\hline CHEMBL1313123 & 688382 & 5.8 & 4.7383 & TRN \\
\hline CHEMBL1332165 & 688382 & 4.35 & 4.6428 & TRN \\
\hline CHEMBL1523373 & 688382 & 4.4 & 4.7184 & TRN \\
\hline CHEMBL1359829 & 688382 & 4.5 & 4.6174 & TRN \\
\hline CHEMBL1374058 & 688382 & 4.5 & 4.7518 & TRN \\
\hline CHEMBL1408828 & 688382 & 4.2 & 4.6164 & TRN \\
\hline CHEMBL1323749 & 688382 & 4.6 & 4.7528 & TRN \\
\hline CHEMBL1380484 & 688382 & 6.6499 & 4.7022 & TST \\
\hline CHEMBL1406170 & 688382 & 4.1 & 4.6326 & TST \\
\hline CHEMBL1491063 & 688382 & 4.9 & 4.7364 & TST \\
\hline CHEMBL3193714 & 688382 & 4.85 & 4.6187 & TRN \\
\hline CHEMBL1406758 & 688382 & 4.55 & 4.5951 & TRN \\
\hline CHEMBL1587103 & 688382 & 4.05 & 4.8162 & TRN \\
\hline CHEMBL1391051 & 688382 & 4.45 & 4.7561 & TRN \\
\hline CHEMBL3196817 & 688382 & 5.65 & 4.6359 & TST \\
\hline CHEMBL1411435 & 688382 & 5.4 & 4.6683 & TRN \\
\hline CHEMBL1470091 & 688382 & 4.8 & 4.7549 & TRN \\
\hline CHEMBL1498608 & 688382 & 4.6 & 4.6819 & TRN \\
\hline CHEMBL1448793 & 688382 & 4.4 & 4.6701 & TRN \\
\hline CHEMBL1518458 & 688382 & 4.0 & 4.8144 & TST \\
\hline CHEMBL1596619 & 688382 & 4.05 & 4.6678 & TRN \\
\hline CHEMBL1510448 & 688382 & 4.85 & 4.7377 & TRN \\
\hline CHEMBL1405042 & 688382 & 5.0 & 4.6842 & TRN \\
\hline CHEMBL1300876 & 688382 & 4.65 & 4.6637 & TRN \\
\hline CHEMBL1305901 & 688382 & 4.35 & 4.6934 & TST \\
\hline CHEMBL1370225 & 688382 & 4.15 & 4.7423 & TRN \\
\hline CHEMBL1459838 & 688382 & 4.7 & 4.7629 & TRN \\
\hline CHEMBL1533926 & 688382 & 6.0 & 4.8293 & TRN \\
\hline CHEMBL1606690 & 688382 & 5.25 & 4.6088 & TRN \\
\hline
\end{tabular}




\begin{tabular}{|c|c|c|c|c|c|}
\hline \multicolumn{6}{|c|}{ Supplemental Table S2.txt } \\
\hline CHEMBL1331119 & 688382 & 4.5 & 4.6996 & TRN & \\
\hline CHEMBL1461485 & 688382 & 5.9 & 4.6468 & TST & \\
\hline CHEMBL1491798 & 688382 & 4.55 & 4.7221 & TRN & \\
\hline CHEMBL1306048 & 688382 & 4.5 & 4.8065 & TRN & \\
\hline CHEMBL1401993 & 688382 & 4.0 & 4.7377 & TRN & \\
\hline CHEMBL1573476 & 688382 & 4.05 & 4.7351 & TRN & \\
\hline CHEMBL1558458 & 688382 & 4.15 & 4.7237 & TRN & \\
\hline CHEMBL1422901 & 688382 & 4.8 & 4.7906 & TRN & \\
\hline CHEMBL1339581 & 688382 & 5.95 & 4.6612 & TRN & \\
\hline CHEMBL3192682 & 688382 & 4.2 & 4.7354 & TRN & \\
\hline CHEMBL1525698 & 688382 & 5.5 & 4.7104 & TRN & \\
\hline CHEMBL1465584 & 688382 & 4.85 & 4.6978 & TST & \\
\hline CHEMBL1481739 & 688382 & 4.3 & 4.7322 & TRN & \\
\hline CHEMBL1359165 & 688382 & 4.5 & 4.7525 & TRN & \\
\hline CHEMBL1519285 & 688382 & 4.05 & 4.8348 & TRN & \\
\hline CHEMBL1524496 & 688382 & 4.8 & 4.6845 & TRN & \\
\hline CHEMBL1597985 & 688382 & 4.55 & 4.67899 & 9999999999 & TRN \\
\hline CHEMBL1481497 & 688382 & 4.4 & 4.7294 & TRN & \\
\hline CHEMBL1506541 & 688382 & 4.65 & 4.7412 & TST & \\
\hline CHEMBL1450275 & 688382 & 4.15 & 4.797 & TST & \\
\hline CHEMBL1572398 & 688382 & 6.0 & 4.7833 & TRN & \\
\hline CHEMBL1351342 & 688382 & 4.55 & 4.6276 & TRN & \\
\hline CHEMBL1320884 & 688382 & 4.6 & 4.6341 & TRN & \\
\hline CHEMBL1412839 & 688382 & 4.85 & 4.7649 & TST & \\
\hline CHEMBL1479251 & 688382 & 4.1 & 4.6807 & TST & \\
\hline CHEMBL1392829 & 688382 & 5.55 & 4.6594 & TRN & \\
\hline CHEMBL1557816 & 688382 & 4.6 & 4.6675 & TRN & \\
\hline CHEMBL29097 & 688382 & 4.05 & 4.6852 & TST & \\
\hline CHEMBL3210717 & 688382 & 4.7 & 4.694 & TRN & \\
\hline CHEMBL1533521 & 688382 & 5.1 & 4.7464 & TST & \\
\hline CHEMBL1498603 & 688382 & 4.45 & 4.6693 & TRN & \\
\hline CHEMBL1472407 & 688382 & 4.85 & 4.7002 & TRN & \\
\hline CHEMBL1327600 & 688382 & 4.2 & 4.7016 & TRN & \\
\hline CHEMBL1468371 & 688382 & 5.1 & 4.6337 & TRN & \\
\hline CHEMBL3208638 & 688382 & 4.3 & 4.6637 & TST & \\
\hline CHEMBL1563260 & 688382 & 4.85 & 4.80399 & 9999999999 & TRN \\
\hline CHEMBL1559083 & 688382 & 6.05 & 4.7615 & TRN & \\
\hline CHEMBL1508299 & 688382 & 4.5 & 4.6923 & TRN & \\
\hline CHEMBL1602290 & 688382 & 4.5 & 4.7041 & TRN & \\
\hline CHEMBL1375750 & 688382 & 4.95 & 4.6689 & TRN & \\
\hline CHEMBL1568474 & 688382 & 4.7 & 4.6148 & TST & \\
\hline CHEMBL1513162 & 688382 & 6.0 & 4.6592 & TST & \\
\hline CHEMBL1349747 & 688382 & 4.0 & 4.6401 & TST & \\
\hline CHEMBL1347788 & 688382 & 4.45 & 4.7082 & TRN & \\
\hline CHEMBL243651 & 688382 & 4.05 & 4.6934 & TRN & \\
\hline CHEMBL337821 & 688382 & 4.45 & 4.624 & TRN & \\
\hline CHEMBL1588984 & 688382 & 4.85 & 4.8074 & TRN & \\
\hline CHEMBL1461944 & 688382 & 4.6 & 4.8271 & TRN & \\
\hline
\end{tabular}




\begin{tabular}{|c|c|c|c|c|}
\hline & & & upplemen & \\
\hline CHEMBL1583960 & 688382 & 5.05 & 4.6811 & TRN \\
\hline CHEMBL1541005 & 688382 & 4.45 & 4.6494 & TRN \\
\hline CHEMBL1981638 & 688382 & 4.95 & 4.6452 & TRN \\
\hline CHEMBL1412517 & 688382 & 5.0 & 4.8041 & TRN \\
\hline CHEMBL1543017 & 688382 & 5.0 & 4.7375 & TRN \\
\hline CHEMBL1522537 & 688382 & 4.0 & 4.6712 & TST \\
\hline CHEMBL1389510 & 688382 & 4.5 & 4.6504 & TRN \\
\hline CHEMBL 3212133 & 688382 & 4.3 & 4.7032 & TRN \\
\hline CHEMBL1335214 & 688382 & 4.5 & 4.7119 & TRN \\
\hline CHEMBL1458284 & 688382 & 4.45 & 4.6401 & TRN \\
\hline CHEMBL1973866 & 688382 & 4.45 & 4.6129 & TRN \\
\hline CHEMBL1318212 & 688382 & 4.15 & 4.7384 & TRN \\
\hline CHEMBL1522871 & 688382 & 4.7 & 4.7834 & TRN \\
\hline CHEMBL1510263 & 688382 & 4.45 & 4.7571 & TRN \\
\hline CHEMBL1486775 & 688382 & 5.15 & 4.6625 & TRN \\
\hline CHEMBL1546009 & 688382 & 4.45 & 4.7643 & TRN \\
\hline CHEMBL1529079 & 688382 & 4.85 & 4.6805 & TRN \\
\hline CHEMBL1502160 & 688382 & 4.4 & 4.6824 & TRN \\
\hline CHEMBL1520785 & 688382 & 4.4 & 4.6756 & TRN \\
\hline CHEMBL1328085 & 688382 & 4.45 & 4.6653 & TRN \\
\hline CHEMBL1463317 & 688382 & 4.45 & 4.6539 & TST \\
\hline CHEMBL1327392 & 688382 & 4.85 & 4.7515 & TRN \\
\hline CHEMBL1547349 & 688382 & 4.35 & 4.6485 & TRN \\
\hline CHEMBL1507567 & 688382 & 4.85 & 4.7474 & TRN \\
\hline CHEMBL1486674 & 688382 & 4.9 & 4.8061 & TST \\
\hline CHEMBL313163 & 688382 & 4.55 & 4.5745 & TRN \\
\hline CHEMBL1386488 & 688382 & 5.85 & 4.7114 & TST \\
\hline CHEMBL1527428 & 688382 & 5.0 & 4.8079 & TRN \\
\hline CHEMBL1447352 & 688382 & 4.5 & 4.7461 & TRN \\
\hline CHEMBL1456995 & 688382 & 4.8 & 4.7451 & TRN \\
\hline CHEMBL1337601 & 688382 & 3.95 & 4.8713 & TRN \\
\hline CHEMBL3192516 & 688382 & 5.7 & 4.6411 & TRN \\
\hline CHEMBL1390530 & 688382 & 4.5 & 4.7291 & TRN \\
\hline CHEMBL1600733 & 688382 & 4.55 & 4.6584 & TST \\
\hline CHEMBL1462673 & 688382 & 4.8 & 4.8067 & TRN \\
\hline CHEMBL1465731 & 688382 & 5.55 & 4.816 & TRN \\
\hline CHEMBL1492787 & 688382 & 3.95 & 4.7224 & TST \\
\hline CHEMBL1398908 & 688382 & 4.45 & 4.8099 & TRN \\
\hline CHEMBL1208858 & 688382 & 4.55 & 4.6464 & TST \\
\hline CHEMBL1382290 & 688382 & 4.8 & 4.6366 & TST \\
\hline CHEMBL1368997 & 688382 & 4.5 & 4.7747 & TRN \\
\hline CHEMBL3198878 & 688382 & 4.85 & 4.7611 & TRN \\
\hline CHEMBL1463530 & 688382 & 4.9 & 4.6637 & TRN \\
\hline CHEMBL1487613 & 688382 & 5.3 & 4.6833 & TST \\
\hline CHEMBL1543478 & 688382 & 4.8 & 4.7489 & TRN \\
\hline CHEMBL1370626 & 688382 & 5.5 & 4.7483 & TST \\
\hline CHEMBL1393010 & 688382 & 4.85 & 4.8258 & TRN \\
\hline CHEMBL1304603 & 688382 & 4.8 & 4.6716 & TRN \\
\hline
\end{tabular}




\begin{tabular}{|c|c|c|c|c|c|}
\hline \multicolumn{6}{|c|}{ Supplemental Table S2.txt } \\
\hline CHEMBL1425431 & 688382 & 4.4 & 4.74 & TRN & \\
\hline CHEMBL1432707 & 688382 & 4.65 & 4.7734 & TST & \\
\hline CHEMBL1601108 & 688382 & 4.0 & 4.7784 & TRN & \\
\hline CHEMBL1327442 & 688382 & 4.45 & 4.6581 & TST & \\
\hline CHEMBL1578042 & 688382 & 4.95 & 4.6532 & TRN & \\
\hline CHEMBL3193760 & 688382 & 4.2 & 4.7403 & TRN & \\
\hline CHEMBL1540229 & 688382 & 4.6 & 4.7151 & TST & \\
\hline CHEMBL1411039 & 688382 & 5.05 & 4.6883 & TST & \\
\hline CHEMBL1607859 & 688382 & 4.9 & 4.7053 & TST & \\
\hline CHEMBL1533621 & 688382 & 4.5 & 4.6446 & TST & \\
\hline CHEMBL1478207 & 688382 & 5.2 & 4.6411 & TST & \\
\hline CHEMBL 1571642 & 688382 & 4.65 & 4.7123 & TRN & \\
\hline CHEMBL1524759 & 688382 & 5.8 & 4.7244 & TRN & \\
\hline CHEMBL1313483 & 688382 & 4.95 & 4.6812 & TRN & \\
\hline CHEMBL1433155 & 688382 & 4.8 & $4.7010 e$ & 00000000005 & TRN \\
\hline CHEMBL1559308 & 688382 & 4.8 & 4.6963 & TST & \\
\hline CHEMBL1422542 & 688382 & 5.15 & 4.7443 & TRN & \\
\hline CHEMBL1569666 & 688382 & 4.85 & 4.6866 & TST & \\
\hline CHEMBL1995645 & 688382 & 5.4 & 4.6069 & TRN & \\
\hline CHEMBL1306923 & 688382 & 4.85 & 4.6702 & TRN & \\
\hline CHEMBL1440052 & 688382 & 5.0 & 4.754 & TST & \\
\hline CHEMBL51085 & 688382 & 4.35 & 4.6269 & TST & \\
\hline CHEMBL1382265 & 688382 & 4.3 & 4.6922 & TRN & \\
\hline CHEMBL1347889 & 688382 & 5.45 & 4.8775 & TRN & \\
\hline CHEMBL 7257 & 688382 & 4.3 & 4.663 & TRN & \\
\hline CHEMBL1346039 & 688382 & 4.25 & 4.7124 & TRN & \\
\hline CHEMBL1425503 & 688382 & 5.0 & 4.7012 & TRN & \\
\hline CHEMBL3196102 & 688382 & 5.15 & 4.5565 & TRN & \\
\hline CHEMBL1486519 & 688382 & 4.25 & 4.6591 & TRN & \\
\hline CHEMBL1404325 & 688382 & 4.8 & 4.6643 & TRN & \\
\hline CHEMBL 3208419 & 688382 & 4.15 & 4.7664 & TRN & \\
\hline CHEMBL1526026 & 688382 & 4.85 & 4.7834 & TRN & \\
\hline CHEMBL1382829 & 688382 & 5.05 & 4.7294 & TST & \\
\hline CHEMBL1385255 & 688382 & 4.05 & 4.6859 & TRN & \\
\hline CHEMBL1485239 & 688382 & 4.15 & $4.6530 e$ & 00000000005 & TRN \\
\hline CHEMBL1588133 & 688382 & 4.85 & 4.72199 & 99999999995 & TRN \\
\hline CHEMBL600778 & 688382 & 4.4 & 4.6284 & TRN & \\
\hline CHEMBL3194164 & 688382 & 4.75 & 4.6093 & TRN & \\
\hline CHEMBL1584450 & 688382 & 4.45 & 4.59699 & 99999999995 & TRN \\
\hline CHEMBL1329463 & 688382 & 4.4 & 4.7439 & TRN & \\
\hline CHEMBL1517716 & 688382 & 5.95 & 4.7773 & TRN & \\
\hline CHEMBL1562320 & 688382 & 4.45 & 4.613 & TRN & \\
\hline CHEMBL1403844 & 688382 & 4.95 & 4.7624 & TRN & \\
\hline CHEMBL1568072 & 688382 & 4.4 & 4.6266 & TST & \\
\hline CHEMBL1476738 & 688382 & 4.45 & 4.7613 & TRN & \\
\hline CHEMBL 3212338 & 688382 & 5.45 & 4.6499 & TRN & \\
\hline CHEMBL1433216 & 688382 & 4.35 & 4.7923 & TRN & \\
\hline CHEMBL1559902 & 688382 & 4.8 & 4.7424 & TRN & \\
\hline
\end{tabular}




\begin{tabular}{|c|c|c|c|c|c|}
\hline \multirow[b]{2}{*}{ CHEMBL1503583 } & \multirow[b]{2}{*}{688382} & \multicolumn{4}{|c|}{ Supplemental Table s2.txt } \\
\hline & & 4.05 & 4.6882 & TRN & \\
\hline CHEMBL1332756 & 688382 & 4.45 & 4.6735 & TRN & \\
\hline CHEMBL1410655 & 688382 & 6.0 & 4.76 & TRN & \\
\hline CHEMBL1460101 & 688382 & 4.9 & 4.6957 & TRN & \\
\hline CHEMBL1450399 & 688382 & 5.1 & 4.6919 & TST & \\
\hline CHEMBL1364855 & 688382 & 4.95 & 4.854 & TRN & \\
\hline CHEMBL1538632 & 688382 & 5.85 & 4.6813 & TST & \\
\hline CHEMBL1985415 & 688382 & 4.15 & 4.6647 & TRN & \\
\hline CHEMBL1453283 & 688382 & 6.0 & 4.7836 & TRN & \\
\hline CHEMBL1471175 & 688382 & 4.35 & 4.7058 & TRN & \\
\hline CHEMBL1380020 & 688382 & 4.5 & 4.7242 & TRN & \\
\hline CHEMBL1444501 & 688382 & 5.35 & 4.7657 & TRN & \\
\hline CHEMBL1987820 & 688382 & 4.4 & 4.5897 & TRN & \\
\hline CHEMBL1568784 & 688382 & 4.0 & 4.6888 & TST & \\
\hline CHEMBL1594895 & 688382 & 4.05 & 4.6741 & TST & \\
\hline CHEMBL1544447 & 688382 & 4.8 & 4.7076 & TRN & \\
\hline CHEMBL3208810 & 688382 & 4.9 & 4.6493 & TST & \\
\hline CHEMBL 3212093 & 688382 & 4.4 & 4.6787 & TRN & \\
\hline CHEMBL1421497 & 688382 & 5.6 & 4.6952 & TRN & \\
\hline CHEMBL1585541 & 688382 & 4.8 & $4.7780 e$ & 00000000005 & TRN \\
\hline CHEMBL1513713 & 688382 & 4.15 & 4.6237 & TRN & \\
\hline CHEMBL3207492 & 688382 & 5.05 & 4.6667 & TRN & \\
\hline CHEMBL1547025 & 688382 & 4.45 & 4.6244 & TRN & \\
\hline CHEMBL1350052 & 688382 & 4.5 & 4.6511 & TRN & \\
\hline CHEMBL1601997 & 688382 & 4.4 & 4.6916 & TST & \\
\hline CHEMBL1369656 & 688382 & 4.8 & 4.7427 & TST & \\
\hline CHEMBL1305408 & 688382 & 4.8 & 4.769 & TRN & \\
\hline CHEMBL1370272 & 688382 & 4.15 & 4.7861 & TRN & \\
\hline CHEMBL1372725 & 688382 & 4.05 & 4.6237 & TRN & \\
\hline CHEMBL1538442 & 688382 & 5.45 & 4.6232 & TRN & \\
\hline CHEMBL1538208 & 688382 & 4.2 & 4.6837 & TRN & \\
\hline CHEMBL1570662 & 688382 & 4.05 & 4.6819 & TRN & \\
\hline CHEMBL340416 & 688382 & 4.5 & 4.6899 & TST & \\
\hline CHEMBL1529027 & 688382 & 4.15 & 4.7736 & TRN & \\
\hline CHEMBL1542777 & 688382 & 5.1 & 4.8192 & TRN & \\
\hline CHEMBL1347373 & 688382 & 4.5 & 4.6516 & TRN & \\
\hline CHEMBL1454715 & 688382 & 4.95 & 4.7192 & TRN & \\
\hline CHEMBL1407234 & 688382 & 4.45 & 4.6801 & TRN & \\
\hline CHEMBL1606343 & 688382 & 4.55 & 4.6809 & TRN & \\
\hline CHEMBL179033 & 688382 & 5.75 & 4.6737 & TRN & \\
\hline CHEMBL391877 & 688382 & 4.45 & 4.6574 & TRN & \\
\hline CHEMBL1489358 & 688382 & 5.1 & 4.6165 & TRN & \\
\hline CHEMBL1533496 & 688382 & 4.55 & 4.7108 & TRN & \\
\hline CHEMBL1577645 & 688382 & 4.4 & 4.6391 & TRN & \\
\hline CHEMBL1583080 & 688382 & 5.15 & 4.817 & TRN & \\
\hline CHEMBL1447137 & 688382 & 4.05 & 4.6368 & TRN & \\
\hline CHEMBL1484183 & 688382 & 5.9 & 4.8055 & TRN & \\
\hline CHEMBL1419358 & 688382 & 4.15 & $4.7410 e$ & 00000000005 & TRN \\
\hline & & & & 11671 & \\
\hline
\end{tabular}




\begin{tabular}{|c|c|c|c|c|}
\hline \multicolumn{5}{|c|}{ Supplemental Table S2.txt } \\
\hline CHEMBL1550348 & 688382 & 4.2 & 4.6848 & TRN \\
\hline CHEMBL1536452 & 688382 & 4.65 & 4.7077 & TRN \\
\hline CHEMBL1548984 & 688382 & 4.8 & 4.6795 & TST \\
\hline CHEMBL1504786 & 688382 & 4.5 & 4.6357 & TST \\
\hline CHEMBL1575945 & 688382 & 4.15 & 4.6915 & TRN \\
\hline CHEMBL1531194 & 688382 & 4.4 & 4.7248 & TRN \\
\hline CHEMBL1524249 & 688382 & 5.2 & 4.7551 & TRN \\
\hline CHEMBL1364379 & 688382 & 4.95 & 4.6604 & TST \\
\hline CHEMBL1402212 & 688382 & 5.0 & 4.7298 & TRN \\
\hline CHEMBL1348491 & 688382 & 4.45 & 4.7173 & TRN \\
\hline CHEMBL1424418 & 688382 & 5.05 & 4.6373 & TRN \\
\hline CHEMBL1330108 & 688382 & 5.85 & 4.7239 & TRN \\
\hline CHEMBL3198643 & 688382 & 4.15 & 4.6469 & TST \\
\hline CHEMBL1345530 & 688382 & 4.5 & 4.7142 & TRN \\
\hline CHEMBL1605815 & 688382 & 4.5 & 4.7291 & TST \\
\hline CHEMBL598952 & 688382 & 4.55 & 4.6396 & TST \\
\hline CHEMBL1362053 & 688382 & 5.15 & 4.6429 & TST \\
\hline CHEMBL1371735 & 688382 & 4.15 & 4.7194 & TST \\
\hline CHEMBL1500586 & 688382 & 4.55 & 4.7451 & TRN \\
\hline CHEMBL1346534 & 688382 & 4.45 & 4.6162 & TST \\
\hline CHEMBL1380936 & 688382 & 4.5 & 4.7354 & TRN \\
\hline CHEMBL81805 & 688382 & 4.15 & 4.6813 & TRN \\
\hline CHEMBL1436201 & 688382 & 4.15 & 4.8058 & TRN \\
\hline CHEMBL1423464 & 688382 & 4.8 & 4.7585 & TRN \\
\hline CHEMBL1545504 & 688382 & 4.05 & 4.7281 & TRN \\
\hline CHEMBL1507516 & 688382 & 5.05 & 4.8038 & TRN \\
\hline CHEMBL1580091 & 688382 & 4.35 & 4.6135 & TRN \\
\hline CHEMBL1480024 & 688382 & 4.5 & 4.7836 & TST \\
\hline CHEMBL1503860 & 688382 & 5.7 & 4.6995 & TRN \\
\hline CHEMBL1486288 & 688382 & 5.8 & 4.7748 & TST \\
\hline CHEMBL1324908 & 688382 & 5.2 & 4.7559 & TRN \\
\hline CHEMBL102714 & 688382 & 6.0 & 4.6192 & TST \\
\hline CHEMBL1400813 & 688382 & 6.1 & 4.7729 & TRN \\
\hline CHEMBL1388692 & 688382 & 5.85 & 4.699 & TRN \\
\hline CHEMBL53898 & 688382 & 6.0 & 4.681 & TRN \\
\hline CHEMBL1378475 & 688382 & 5.15 & 4.6158 & TRN \\
\hline CHEMBL1488591 & 688382 & 4.2 & 4.7266 & TST \\
\hline CHEMBL1467760 & 688382 & 4.6 & 4.694 & TST \\
\hline CHEMBL1540672 & 688382 & 4.15 & 4.6335 & TRN \\
\hline CHEMBL1586920 & 688382 & 4.3 & 4.7374 & TST \\
\hline CHEMBL1531400 & 688382 & 4.05 & 4.8223 & TRN \\
\hline CHEMBL3192782 & 688382 & 4.4 & 4.7519 & TRN \\
\hline CHEMBL3196093 & 688382 & 5.1 & 4.7127 & TST \\
\hline CHEMBL1378626 & 688382 & 6.05 & 4.7872 & TRN \\
\hline CHEMBL1459840 & 688382 & 4.25 & 4.7135 & TRN \\
\hline CHEMBL1565684 & 688382 & 4.1 & 4.7317 & TRN \\
\hline CHEMBL1415653 & 688382 & 4.6 & 4.6639 & TRN \\
\hline CHEMBL1308909 & 688382 & 4.85 & 4.6456 & TRN \\
\hline
\end{tabular}




\begin{tabular}{|c|c|c|c|c|c|}
\hline & & \multicolumn{4}{|c|}{ Supplemental Table S2.txt } \\
\hline CHEMBL1576310 & 688382 & 4.55 & 4.6883 & TRN & \\
\hline CHEMBL1414705 & 688382 & 4.45 & 4.7331 & TRN & \\
\hline CHEMBL1390262 & 688382 & 4.6 & 4.7482 & TST & \\
\hline CHEMBL1311226 & 688382 & 4.75 & 4.6157 & TRN & \\
\hline CHEMBL1381654 & 688382 & 5.0 & 4.7413 & TST & \\
\hline CHEMBL490551 & 688382 & 4.8 & 4.667 & TRN & \\
\hline CHEMBL1429438 & 688382 & 4.45 & 4.7599 & TST & \\
\hline CHEMBL1586721 & 688382 & 5.2 & 4.79899 & 99999999995 & TRN \\
\hline CHEMBL1420975 & 688382 & 4.85 & 4.6672 & TST & \\
\hline CHEMBL1383045 & 688382 & 5.2 & 4.7295 & TST & \\
\hline CHEMBL1523096 & 688382 & 4.85 & 4.7007 & TRN & \\
\hline CHEMBL 2000888 & 688382 & 4.45 & 4.6756 & TRN & \\
\hline CHEMBL1406586 & 688382 & 4.75 & 4.7889 & TRN & \\
\hline CHEMBL1355917 & 688382 & 4.6 & 4.6811 & TRN & \\
\hline CHEMBL 7664 & 688382 & 4.75 & 4.7176 & TRN & \\
\hline CHEMBL1460020 & 688382 & 4.85 & 4.7097 & TST & \\
\hline CHEMBL1311053 & 688382 & 4.65 & 4.7062 & TST & \\
\hline CHEMBL1370068 & 688382 & 4.55 & 4.6836 & TRN & \\
\hline CHEMBL1560534 & 688382 & 5.55 & 4.7392 & TRN & \\
\hline CHEMBL1497822 & 688382 & 4.65 & 4.7206 & TST & \\
\hline CHEMBL1970784 & 688382 & 4.4 & 4.6531 & TST & \\
\hline CHEMBL1595906 & 688382 & 4.15 & 4.6911 & TRN & \\
\hline CHEMBL1407187 & 688382 & 4.9 & 4.6988 & TRN & \\
\hline CHEMBL1505547 & 688382 & 5.2 & 4.7068 & TST & \\
\hline CHEMBL1982235 & 688382 & 4.45 & 4.6778 & TRN & \\
\hline CHEMBL1383651 & 688382 & 5.6 & 4.7491 & TRN & \\
\hline CHEMBL1494783 & 688382 & 4.2 & 4.6918 & TRN & \\
\hline CHEMBL1304202 & 688382 & 6.0 & 4.7375 & TRN & \\
\hline CHEMBL1497477 & 688382 & 4.15 & 4.6501 & TRN & \\
\hline CHEMBL1340686 & 688382 & 4.8 & 4.7506 & TRN & \\
\hline CHEMBL1587031 & 688382 & 4.85 & 4.6637 & TRN & \\
\hline CHEMBL1489071 & 688382 & 4.0 & 4.6245 & TST & \\
\hline CHEMBL1452955 & 688382 & 5.15 & 4.7232 & TRN & \\
\hline CHEMBL3194876 & 688382 & 5.3 & 4.6309 & TRN & \\
\hline CHEMBL1367080 & 688382 & 5.0 & 4.6239 & TRN & \\
\hline CHEMBL1496922 & 688382 & 5.65 & 4.8298 & TRN & \\
\hline CHEMBL1302504 & 688382 & 4.5 & 4.7138 & TRN & \\
\hline CHEMBL1374916 & 688382 & 4.5 & 4.6811 & TRN & \\
\hline CHEMBL1384772 & 688382 & 5.5 & 4.6715 & TRN & \\
\hline CHEMBL1383957 & 688382 & 5.2 & 4.6668 & TRN & \\
\hline CHEMBL1577185 & 688382 & 4.85 & 4.6752 & TST & \\
\hline CHEMBL1320839 & 688382 & 4.5 & 4.7139 & TRN & \\
\hline CHEMBL1431042 & 688382 & 4.7 & 4.7126 & TRN & \\
\hline CHEMBL1613567 & 688382 & 4.4 & 4.7461 & TRN & \\
\hline CHEMBL1467523 & 688382 & 4.15 & 4.725 & TRN & \\
\hline CHEMBL1542336 & 688382 & 4.45 & 4.6357 & TRN & \\
\hline CHEMBL3196134 & 688382 & 4.6 & 4.6804 & TRN & \\
\hline CHEMBL1517040 & 688382 & 4.8 & 4.6825 & TRN & \\
\hline
\end{tabular}




\begin{tabular}{|c|c|c|c|c|c|}
\hline & & \multicolumn{4}{|c|}{ Supplemental Table S2.txt } \\
\hline CHEMBL1573614 & 688382 & 4.75 & 4.7018 & TST & \\
\hline CHEMBL1527646 & 688382 & 5.25 & 4.6702 & TRN & \\
\hline CHEMBL1449103 & 688382 & 4.55 & 4.6335 & TRN & \\
\hline CHEMBL1465693 & 688382 & 4.95 & 4.7362 & TST & \\
\hline CHEMBL2369192 & 688382 & 5.1 & 4.6879 & TRN & \\
\hline CHEMBL1415214 & 688382 & 4.2 & 4.7058 & TRN & \\
\hline CHEMBL1456347 & 688382 & 4.8 & 4.7958 & TRN & \\
\hline CHEMBL1418334 & 688382 & 4.5 & 4.7299 & TRN & \\
\hline CHEMBL1453786 & 688382 & 5.8 & 4.8078 & TRN & \\
\hline CHEMBL1563624 & 688382 & 4.4 & 4.6962 & TRN & \\
\hline CHEMBL1583854 & 688382 & 4.0 & 4.7869 & TRN & \\
\hline CHEMBL1570600 & 688382 & 4.15 & 4.7095 & TST & \\
\hline CHEMBL1467590 & 688382 & 4.45 & 4.8163 & TST & \\
\hline CHEMBL1328066 & 688382 & 4.15 & 4.8089 & TRN & \\
\hline CHEMBL1583531 & 688382 & 5.25 & 4.6054 & TRN & \\
\hline CHEMBL1479091 & 688382 & 4.5 & 4.6891 & TRN & \\
\hline CHEMBL1269202 & 688382 & 4.6 & 4.6678 & TST & \\
\hline CHEMBL1598944 & 688382 & 5.05 & 4.6466 & TRN & \\
\hline CHEMBL1257125 & 688382 & 4.05 & 4.7056 & TST & \\
\hline CHEMBL1575886 & 688382 & 5.0 & 4.7341 & TRN & \\
\hline CHEMBL1340425 & 688382 & 4.05 & 4.7809 & TRN & \\
\hline CHEMBL1385611 & 688382 & 4.95 & 4.6265 & TST & \\
\hline CHEMBL1306790 & 688382 & 4.8 & 4.7064 & TRN & \\
\hline CHEMBL1569148 & 688382 & 4.8 & 4.7172 & TRN & \\
\hline CHEMBL1337032 & 688382 & 4.2 & 4.7255 & TRN & \\
\hline CHEMBL1525737 & 688382 & 4.15 & 4.747 & TRN & \\
\hline CHEMBL1450324 & 688382 & 4.05 & 4.7242 & TRN & \\
\hline CHEMBL1333303 & 688382 & 4.95 & 4.7608 & TST & \\
\hline CHEMBL1440095 & 688382 & 5.0 & 4.7419 & TRN & \\
\hline CHEMBL1583577 & 688382 & 4.45 & 4.5799 & TST & \\
\hline CHEMBL1348038 & 688382 & 4.1 & 4.6699 & TRN & \\
\hline CHEMBL3192017 & 688382 & 4.55 & 4.6903 & TRN & \\
\hline CHEMBL1490006 & 688382 & 4.45 & 4.7171 & TST & \\
\hline CHEMBL1351987 & 688382 & 4.05 & 4.7095 & TRN & \\
\hline CHEMBL1601421 & 688382 & 4.0 & 4.753 & TRN & \\
\hline CHEMBL1393344 & 688382 & 4.05 & 4.6959 & TRN & \\
\hline CHEMBL1163685 & 688382 & 4.15 & 4.77800 & 00000000005 & TRN \\
\hline CHEMBL1597500 & 688382 & 4.5 & 4.689 & TRN & \\
\hline CHEMBL1583237 & 688382 & 4.65 & 4.7576 & TRN & \\
\hline CHEMBL1588357 & 688382 & 5.05 & 4.7821 & TRN & \\
\hline CHEMBL1405438 & 688382 & 4.6 & 4.6916 & TST & \\
\hline CHEMBL1446075 & 688382 & 5.55 & 4.8163 & TRN & \\
\hline CHEMBL1444458 & 688382 & 6.0 & 4.6866 & TRN & \\
\hline CHEMBL1408647 & 688382 & 4.8 & 4.6957 & TST & \\
\hline CHEMBL1462134 & 688382 & 4.5 & 4.7251 & TRN & \\
\hline CHEMBL602400 & 688382 & 4.4 & 4.6315 & TRN & \\
\hline CHEMBL1509274 & 688382 & 4.5 & 4.7731 & TRN & \\
\hline CHEMBL1473975 & 688382 & 4.5 & 4.6003 & TST & \\
\hline
\end{tabular}




\begin{tabular}{|c|c|c|c|c|}
\hline \multicolumn{5}{|c|}{ Supplemental Table S2.txt } \\
\hline CHEMBL1533225 & 688382 & 4.7 & 4.6255 & TRN \\
\hline CHEMBL1330649 & 688382 & 3.95 & 4.7207 & TST \\
\hline CHEMBL1366357 & 688382 & 5.15 & 4.7453 & TRN \\
\hline CHEMBL 3190587 & 688382 & 4.8 & 4.6426 & TST \\
\hline CHEMBL1477488 & 688382 & 4.3 & 4.6944 & TST \\
\hline CHEMBL1583793 & 688382 & 4.15 & 4.6622 & TRN \\
\hline CHEMBL1503984 & 688382 & 4.25 & 4.7282 & TST \\
\hline CHEMBL1347421 & 688382 & 4.55 & 4.6748 & TRN \\
\hline CHEMBL1564441 & 688382 & 4.65 & 4.7213 & TRN \\
\hline CHEMBL1601897 & 688382 & 4.25 & 4.6485 & TST \\
\hline CHEMBL1986425 & 688382 & 4.5 & 4.7459 & TRN \\
\hline CHEMBL1311005 & 688382 & 4.15 & 4.6247 & TST \\
\hline CHEMBL1540051 & 688382 & 4.4 & 4.6362 & TRN \\
\hline CHEMBL1542171 & 688382 & 4.85 & 4.7586 & TST \\
\hline CHEMBL 2004247 & 688382 & 4.15 & 4.6699 & TRN \\
\hline CHEMBL1416934 & 688382 & 4.35 & 4.7777 & TRN \\
\hline CHEMBL1612715 & 688382 & 5.8 & 4.7253 & TRN \\
\hline CHEMBL1400974 & 688382 & 4.5 & 4.6165 & TRN \\
\hline CHEMBL1401463 & 688382 & 4.4 & 4.7007 & TST \\
\hline CHEMBL 2004847 & 688382 & 5.4 & 4.7005 & TRN \\
\hline CHEMBL1596400 & 688382 & 4.45 & 4.6748 & TRN \\
\hline CHEMBL1342938 & 688382 & 4.85 & 4.7196 & TRN \\
\hline CHEMBL1371138 & 688382 & 4.45 & 4.7758 & TRN \\
\hline CHEMBL1419357 & 688382 & 5.15 & 4.6649 & TRN \\
\hline CHEMBL1344237 & 688382 & 4.45 & 4.7511 & TRN \\
\hline CHEMBL1303182 & 688382 & 4.55 & 4.6899 & TRN \\
\hline CHEMBL1568503 & 688382 & 4.85 & 4.585 & TST \\
\hline CHEMBL1537914 & 688382 & 4.5 & 4.7771 & TRN \\
\hline CHEMBL1393356 & 688382 & 3.0 & 4.7562 & TRN \\
\hline CHEMBL1407640 & 688382 & 4.45 & 4.7499 & TRN \\
\hline CHEMBL1429655 & 688382 & 4.9 & 4.6505 & TST \\
\hline CHEMBL2001105 & 688382 & 5.05 & 4.6822 & TRN \\
\hline CHEMBL3191358 & 688382 & 5.8 & 4.7527 & TST \\
\hline CHEMBL1308724 & 688382 & 4.5 & 4.6914 & TRN \\
\hline CHEMBL1300855 & 688382 & 4.85 & 4.8308 & TRN \\
\hline CHEMBL1540202 & 688382 & 4.4 & 4.667 & TRN \\
\hline CHEMBL1414553 & 688382 & 5.15 & 4.6672 & TRN \\
\hline CHEMBL1453560 & 688382 & 4.15 & 4.7921 & TRN \\
\hline CHEMBL1565329 & 688382 & 4.5 & 4.6664 & TRN \\
\hline CHEMBL3214562 & 688382 & 4.45 & 4.7207 & TST \\
\hline CHEMBL1983389 & 688382 & 4.35 & 4.6276 & TST \\
\hline CHEMBL390485 & 688382 & 4.45 & 4.7132 & TRN \\
\hline CHEMBL1561455 & 688382 & 4.5 & 4.6792 & TRN \\
\hline CHEMBL1581153 & 688382 & 4.4 & 4.6206 & TRN \\
\hline CHEMBL1560033 & 688382 & 4.5 & 4.6904 & TRN \\
\hline CHEMBL1596372 & 688382 & 5.85 & 4.8054 & TRN \\
\hline CHEMBL1398895 & 688382 & 4.95 & 4.7182 & TST \\
\hline CHEMBL1464432 & 688382 & 4.35 & 4.6962 & TRN \\
\hline
\end{tabular}




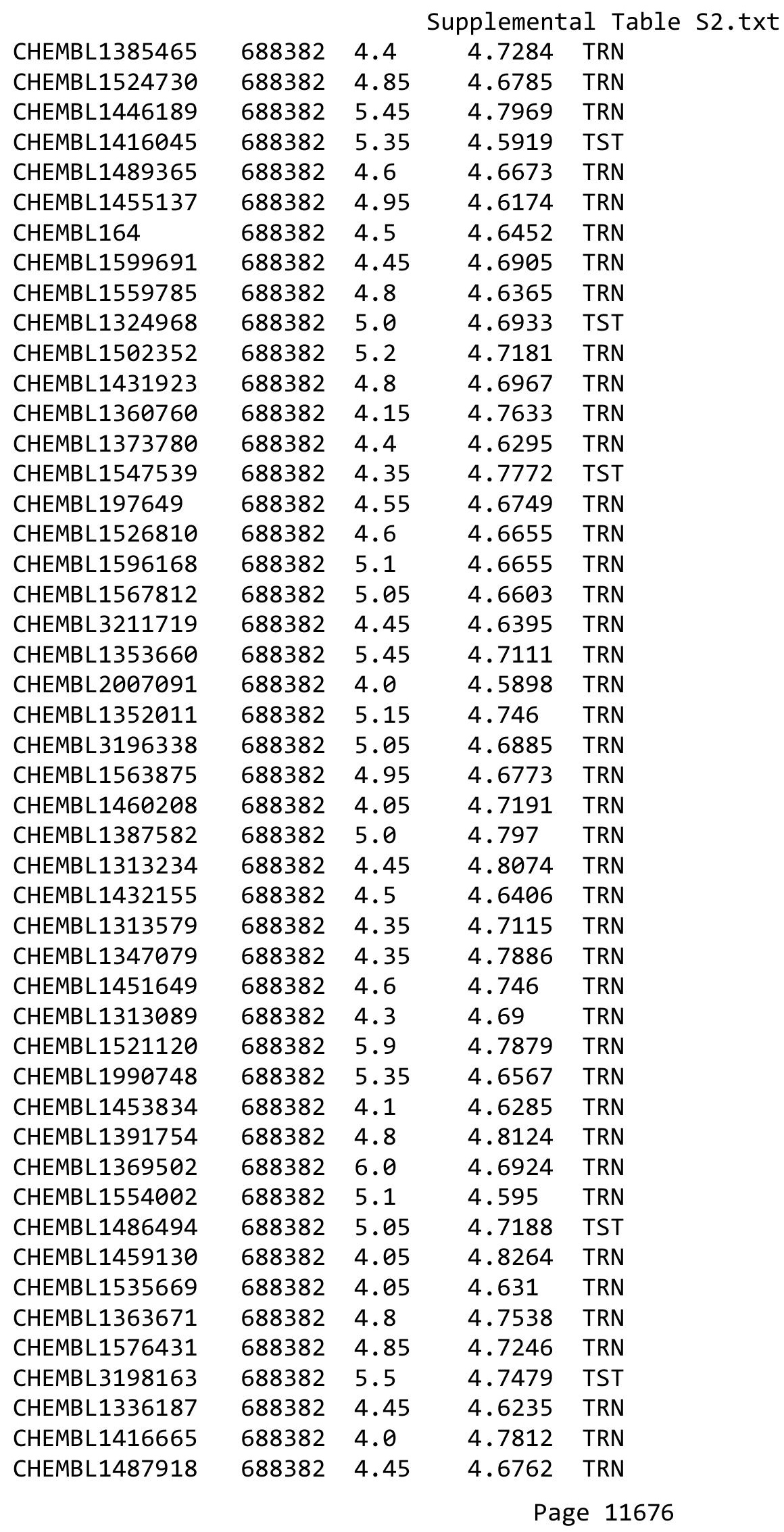




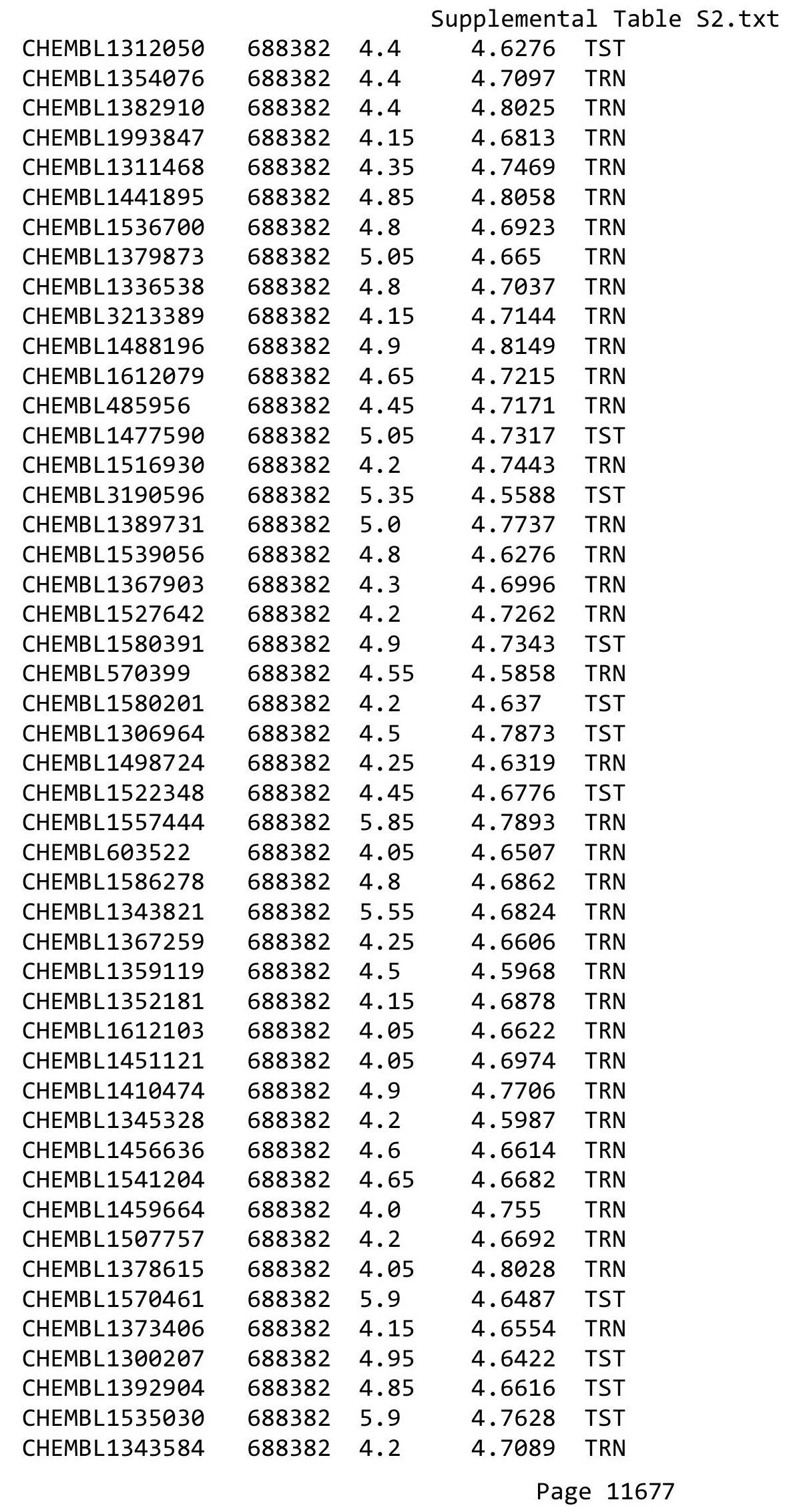




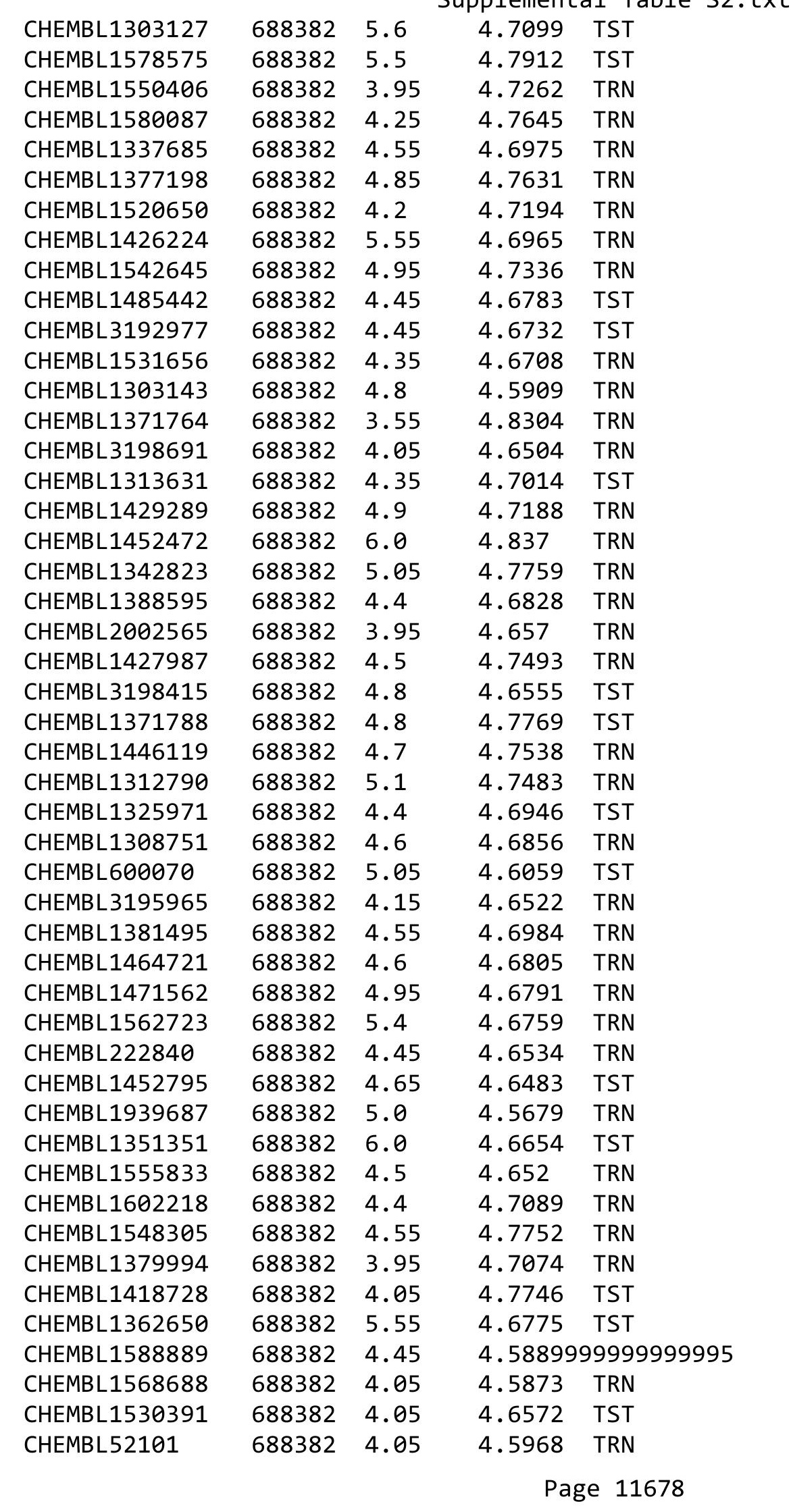




\begin{tabular}{|c|c|c|c|c|c|}
\hline \multicolumn{6}{|c|}{ pıemental } \\
\hline CHEMBL1611689 & 688382 & 6.0 & 4.7013 & TRN & \\
\hline CHEMBL1302281 & 688382 & 4.05 & 4.6585 & TRN & \\
\hline CHEMBL1302961 & 688382 & 4.2 & 4.78100 & 0000000001 & TRN \\
\hline CHEMBL 3197962 & 688382 & 4.0 & 4.6754 & TRN & \\
\hline CHEMBL1582242 & 688382 & 4.05 & 4.6723 & TRN & \\
\hline CHEMBL3192904 & 688382 & 4.4 & 4.6717 & TRN & \\
\hline CHEMBL1416195 & 688382 & 4.85 & 4.6297 & TST & \\
\hline CHEMBL1608308 & 688382 & 4.0 & 4.6974 & TRN & \\
\hline CHEMBL1418750 & 688382 & 4.8 & 4.6782 & TRN & \\
\hline CHEMBL1390176 & 688382 & 5.8 & 4.7223 & TST & \\
\hline CHEMBL1493576 & 688382 & 4.65 & 4.6314 & TRN & \\
\hline CHEMBL1569759 & 688382 & 4.05 & 4.7042 & TST & \\
\hline CHEMBL1438603 & 688382 & 4.5 & 4.7101 & TRN & \\
\hline CHEMBL1449022 & 688382 & 5.0 & 4.6973 & TST & \\
\hline CHEMBL1375576 & 688382 & 4.55 & 4.6807 & TRN & \\
\hline CHEMBL1977678 & 688382 & 5.0 & 4.6535 & TRN & \\
\hline CHEMBL546597 & 688382 & 4.05 & 4.8088 & TRN & \\
\hline CHEMBL1495691 & 688382 & 4.45 & 4.6215 & TRN & \\
\hline CHEMBL1361473 & 688382 & 4.75 & 4.7801 & TRN & \\
\hline CHEMBL1359070 & 688382 & 5.05 & 4.6547 & TRN & \\
\hline CHEMBL1540846 & 688382 & 5.0 & 4.691 & TST & \\
\hline CHEMBL1401740 & 688382 & 6.0 & 4.7429 & TST & \\
\hline CHEMBL1566802 & 688382 & 5.85 & 4.7958 & TRN & \\
\hline CHEMBL1433607 & 688382 & 4.45 & 4.7902 & TRN & \\
\hline CHEMBL1508982 & 688382 & 4.9 & 4.6059 & TRN & \\
\hline CHEMBL1507271 & 688382 & 4.15 & 4.7002 & TRN & \\
\hline CHEMBL1359426 & 688382 & 4.85 & 4.6872 & TRN & \\
\hline CHEMBL1518328 & 688382 & 4.35 & 4.7237 & TRN & \\
\hline CHEMBL299155 & 688382 & 4.3 & 4.6665 & TST & \\
\hline CHEMBL1576602 & 688382 & 4.5 & 4.6521 & TRN & \\
\hline CHEMBL1308088 & 688382 & 4.3 & 4.57100 & 0000000001 & TRN \\
\hline CHEMBL1518801 & 688382 & 4.45 & 4.6912 & TRN & \\
\hline CHEMBL1606294 & 688382 & 4.8 & 4.7583 & TST & \\
\hline CHEMBL3197412 & 688382 & 5.0 & 4.6107 & TRN & \\
\hline CHEMBL370109 & 688382 & 4.45 & 4.6934 & TST & \\
\hline CHEMBL1410696 & 688382 & 5.05 & 4.7294 & TRN & \\
\hline CHEMBL3211683 & 688382 & 4.65 & 4.6315 & TRN & \\
\hline CHEMBL1457175 & 688382 & 4.45 & 4.6739 & TST & \\
\hline CHEMBL1343384 & 688382 & 4.15 & 4.715 & TST & \\
\hline CHEMBL1427136 & 688382 & 4.45 & 4.6301 & TRN & \\
\hline CHEMBL1465718 & 688382 & 5.6 & 4.7932 & TST & \\
\hline CHEMBL3198685 & 688382 & 4.4 & 4.6836 & TRN & \\
\hline CHEMBL1423706 & 688382 & 5.1 & 4.7862 & TST & \\
\hline CHEMBL1470058 & 688382 & 4.4 & 4.7224 & TRN & \\
\hline CHEMBL1488251 & 688382 & 4.3 & 4.7135 & TST & \\
\hline CHEMBL1580128 & 688382 & 4.75 & 4.7603 & TRN & \\
\hline CHEMBL1549232 & 688382 & 5.0 & 4.5838 & TRN & \\
\hline CHEMBL1343219 & 688382 & 4.2 & 4.6588 & TRN & \\
\hline
\end{tabular}




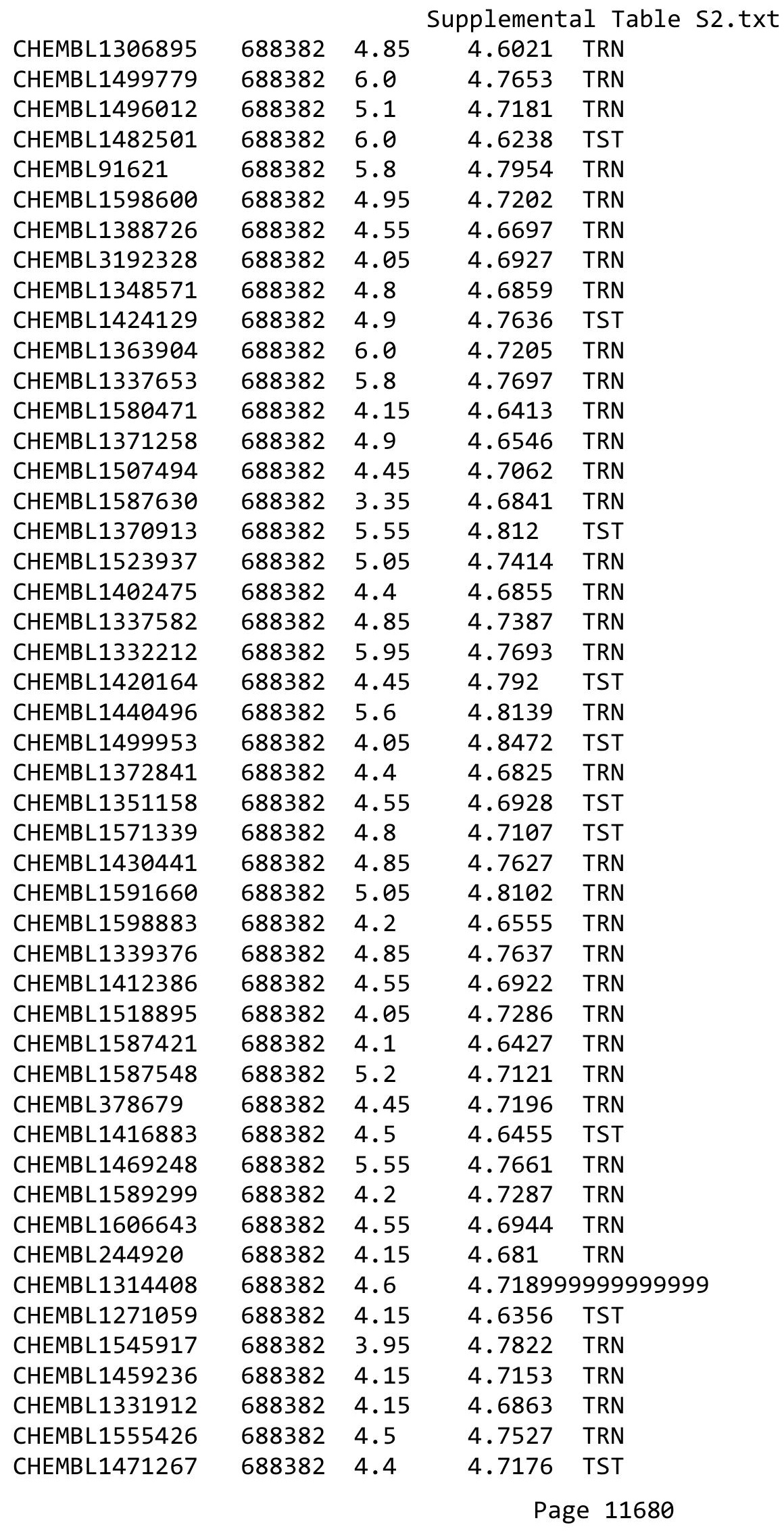

TRN 


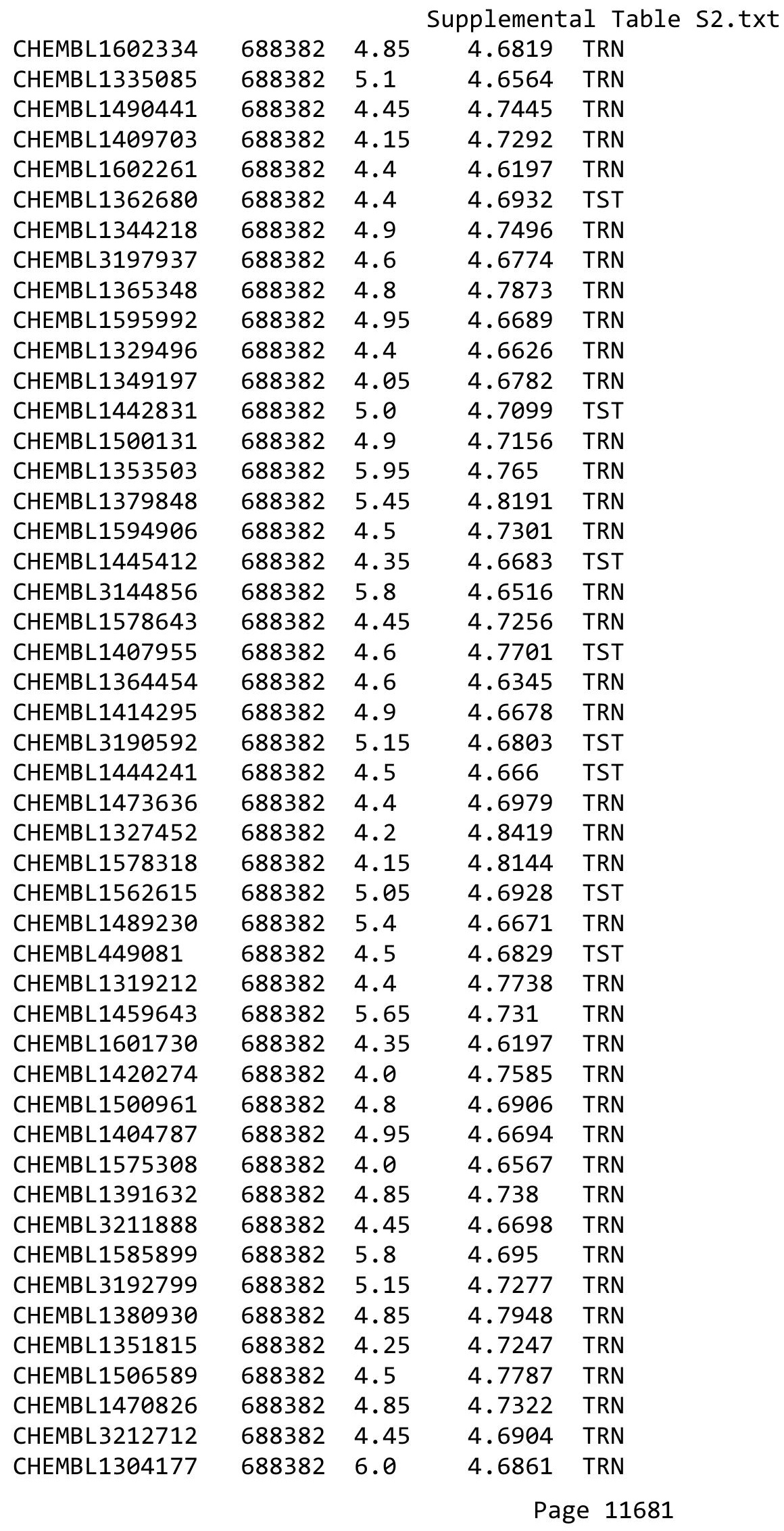




\begin{tabular}{|c|c|c|c|c|c|}
\hline \multicolumn{6}{|c|}{ Supplemental Table S2.txt } \\
\hline CHEMBL1418149 & 688382 & 4.95 & 4.8096 & TST & \\
\hline CHEMBL1389513 & 688382 & 5.8 & 4.859 & TRN & \\
\hline CHEMBL1351953 & 688382 & 5.0 & 4.7345 & TST & \\
\hline CHEMBL1433010 & 688382 & 4.4 & 4.6619 & TRN & \\
\hline CHEMBL1500653 & 688382 & 5.55 & 4.7016 & TRN & \\
\hline CHEMBL1534359 & 688382 & 4.8 & 4.6326 & TST & \\
\hline CHEMBL1349513 & 688382 & 4.85 & 4.7513 & TST & \\
\hline CHEMBL1487005 & 688382 & 4.5 & 4.6162 & TRN & \\
\hline CHEMBL530049 & 688382 & 4.5 & 4.6075 & TST & \\
\hline CHEMBL1453695 & 688382 & 4.8 & 4.7096 & TRN & \\
\hline CHEMBL1574986 & 688382 & 4.05 & 4.7094 & TRN & \\
\hline CHEMBL1484630 & 688382 & 5.85 & 4.7775 & TRN & \\
\hline CHEMBL1559019 & 688382 & 4.15 & 4.7347 & TRN & \\
\hline CHEMBL1977271 & 688382 & 4.15 & 4.6179 & TRN & \\
\hline CHEMBL1365826 & 688382 & 4.75 & 4.7989 & TRN & \\
\hline CHEMBL3214366 & 688382 & 4.5 & 4.6571 & TRN & \\
\hline CHEMBL226876 & 688382 & 4.4 & 4.7789 & TRN & \\
\hline CHEMBL1310807 & 688382 & 4.8 & 4.7977 & TRN & \\
\hline CHEMBL330320 & 688382 & 5.5 & 4.7472 & TRN & \\
\hline CHEMBL1414535 & 688382 & 4.15 & 4.7215 & TRN & \\
\hline CHEMBL1438845 & 688382 & 5.2 & 4.7398 & TRN & \\
\hline CHEMBL1529511 & 688382 & 4.5 & 4.6521 & TRN & \\
\hline CHEMBL1371901 & 688382 & 3.9 & 4.7814 & TRN & \\
\hline CHEMBL1488041 & 688382 & 6.0 & 4.7376 & TRN & \\
\hline CHEMBL1504986 & 688382 & 5.0 & 4.7049 & TRN & \\
\hline CHEMBL1562280 & 688382 & 5.05 & 4.6488 & TRN & \\
\hline CHEMBL1606637 & 688382 & 4.05 & 4.76699 & 99999999995 & TRN \\
\hline CHEMBL1441921 & 688382 & 4.75 & 4.6655 & TRN & \\
\hline CHEMBL1603553 & 688382 & 4.8 & 4.756 & TRN & \\
\hline CHEMBL1420142 & 688382 & 5.2 & 4.6943 & TRN & \\
\hline CHEMBL1608156 & 688382 & 4.5 & 4.7221 & TRN & \\
\hline CHEMBL1986557 & 688382 & 5.45 & 4.6171 & TST & \\
\hline CHEMBL1463138 & 688382 & 5.0 & 4.7917 & TRN & \\
\hline CHEMBL3191497 & 688382 & 4.25 & 4.7229 & TST & \\
\hline CHEMBL1376776 & 688382 & 4.05 & 4.6428 & TST & \\
\hline CHEMBL1463593 & 688382 & 4.8 & 4.7496 & TST & \\
\hline CHEMBL1464876 & 688382 & 6.0 & 4.7428 & TST & \\
\hline CHEMBL1579519 & 688382 & 4.4 & 4.74100 & 00000000005 & TRN \\
\hline CHEMBL1584960 & 688382 & 5.05 & 4.7352 & TST & \\
\hline CHEMBL1554395 & 688382 & 4.3 & 4.7194 & TRN & \\
\hline CHEMBL1595416 & 688382 & 5.5 & 4.7611 & TRN & \\
\hline CHEMBL1407859 & 688382 & 4.2 & 4.8236 & TRN & \\
\hline CHEMBL56543 & 688382 & 4.55 & 4.6688 & TRN & \\
\hline CHEMBL1408989 & 688382 & 4.9 & 4.6351 & TRN & \\
\hline CHEMBL1388543 & 688382 & 4.35 & 4.7467 & TRN & \\
\hline CHEMBL1302479 & 688382 & 4.8 & 4.7023 & TST & \\
\hline CHEMBL1307672 & 688382 & 5.45 & 4.72199 & 99999999995 & TRN \\
\hline CHEMBL1341187 & 688382 & 4.85 & 4.7615 & TRN & \\
\hline
\end{tabular}




\begin{tabular}{|c|c|c|c|c|c|}
\hline & & \multicolumn{4}{|c|}{ Supplemental Table s2.txt } \\
\hline CHEMBL1313816 & 688382 & 5.05 & 4.7143 & TRN & \\
\hline CHEMBL1601574 & 688382 & 4.15 & 4.6881 & TST & \\
\hline CHEMBL1608760 & 688382 & 5.8 & 4.8259 & TRN & \\
\hline CHEMBL1365110 & 688382 & 4.5 & 4.7746 & TRN & \\
\hline CHEMBL1364881 & 688382 & 4.45 & 4.6876 & TRN & \\
\hline CHEMBL1549034 & 688382 & 4.3 & 4.7736 & TRN & \\
\hline CHEMBL1475077 & 688382 & 4.05 & 4.7026 & TRN & \\
\hline CHEMBL1540228 & 688382 & 4.4 & 4.7673 & TRN & \\
\hline CHEMBL1398814 & 688382 & 4.45 & 4.6651 & TRN & \\
\hline CHEMBL1400337 & 688382 & 4.8 & 4.7659 & TRN & \\
\hline CHEMBL3192149 & 688382 & 5.0 & 4.7868 & TRN & \\
\hline CHEMBL1359784 & 688382 & 4.95 & 4.708 & TRN & \\
\hline CHEMBL1373992 & 688382 & 5.0 & 4.7107 & TST & \\
\hline CHEMBL1977096 & 688382 & 4.55 & 4.5705 & TRN & \\
\hline CHEMBL1486924 & 688382 & 4.6 & 4.7431 & TRN & \\
\hline CHEMBL1336374 & 688382 & 5.5 & 4.7662 & TST & \\
\hline CHEMBL1388574 & 688382 & 6.0 & 4.824 & TRN & \\
\hline CHEMBL1610608 & 688382 & 4.6 & 4.7981 & TST & \\
\hline CHEMBL1349703 & 688382 & 4.4 & 4.7131 & TRN & \\
\hline CHEMBL1421140 & 688382 & 4.8 & 4.7097 & TRN & \\
\hline CHEMBL74090 & 688382 & 4.15 & 4.7815 & TRN & \\
\hline CHEMBL1452530 & 688382 & 4.8 & 4.7802 & TRN & \\
\hline CHEMBL1303738 & 688382 & 4.55 & 4.7263 & TRN & \\
\hline CHEMBL1327384 & 688382 & 3.95 & 4.71899 & 9999999999 & TRN \\
\hline CHEMBL1981538 & 688382 & 5.05 & 4.6177 & TRN & \\
\hline CHEMBL1501454 & 688382 & 4.45 & 4.6 & TST & \\
\hline CHEMBL1487782 & 688382 & 5.5 & 4.7168 & TRN & \\
\hline CHEMBL1446210 & 688382 & 4.15 & 4.7878 & TRN & \\
\hline CHEMBL1539244 & 688382 & 4.65 & 4.7044 & TST & \\
\hline CHEMBL1604749 & 688382 & 4.55 & 4.737 & TRN & \\
\hline CHEMBL1543043 & 688382 & 4.3 & 4.7413 & TRN & \\
\hline CHEMBL1594160 & 688382 & 4.2 & 4.6789 & TRN & \\
\hline CHEMBL1400044 & 688382 & 4.4 & 4.67399 & 99999999995 & TRN \\
\hline CHEMBL1544329 & 688382 & 4.4 & 4.8234 & TRN & \\
\hline CHEMBL1538744 & 688382 & 4.8 & 4.7499 & TRN & \\
\hline CHEMBL1490256 & 688382 & 4.5 & 4.6931 & TRN & \\
\hline CHEMBL175266 & 688382 & 6.0 & 4.6675 & TRN & \\
\hline CHEMBL1455988 & 688382 & 4.15 & 4.8001 & TRN & \\
\hline CHEMBL1518891 & 688382 & 5.55 & 4.6773 & TRN & \\
\hline CHEMBL1477392 & 688382 & 5.85 & 4.7416 & TST & \\
\hline CHEMBL1363310 & 688382 & 4.95 & 4.7668 & TST & \\
\hline CHEMBL1563296 & 688382 & 5.0 & 4.7211 & TST & \\
\hline CHEMBL3190705 & 688382 & 4.5 & 4.7038 & TST & \\
\hline CHEMBL1398645 & 688382 & 4.5 & 4.6391 & TRN & \\
\hline CHEMBL1556805 & 688382 & 4.4 & 4.6323 & TRN & \\
\hline CHEMBL1399083 & 688382 & 4.95 & 4.6985 & TRN & \\
\hline CHEMBL1429946 & 688382 & 4.45 & 4.699 & TRN & \\
\hline CHEMBL1479099 & 688382 & 4.4 & 4.6314 & TRN & \\
\hline
\end{tabular}




\begin{tabular}{|c|c|c|c|c|c|}
\hline & & \multicolumn{4}{|c|}{ Supplemental Table s2.txt } \\
\hline CHEMBL1325958 & 688382 & 4.2 & 4.6538 & TRN & \\
\hline CHEMBL1984130 & 688382 & 4.05 & 4.665 & TRN & \\
\hline CHEMBL1432364 & 688382 & 5.0 & 4.6439 & TST & \\
\hline CHEMBL1368048 & 688382 & 4.15 & 4.7081 & TRN & \\
\hline CHEMBL1546193 & 688382 & 4.8 & 4.7612 & TST & \\
\hline CHEMBL1511157 & 688382 & 4.5 & 4.6889 & TRN & \\
\hline CHEMBL1406249 & 688382 & 4.3 & 4.6488 & TST & \\
\hline CHEMBL1425563 & 688382 & 4.85 & 4.7344 & TRN & \\
\hline CHEMBL1605334 & 688382 & 4.6 & 4.6546 & TRN & \\
\hline CHEMBL3191856 & 688382 & 4.05 & 4.667 & TST & \\
\hline CHEMBL495991 & 688382 & 4.5 & 4.699 & TRN & \\
\hline CHEMBL1369513 & 688382 & 5.35 & 4.6596 & TRN & \\
\hline CHEMBL1305574 & 688382 & 6.0 & 4.7541 & TRN & \\
\hline CHEMBL1543857 & 688382 & 4.65 & 4.6622 & TRN & \\
\hline CHEMBL1328510 & 688382 & 4.8 & 4.6596 & TRN & \\
\hline CHEMBL1429594 & 688382 & 4.35 & 4.6151 & TST & \\
\hline CHEMBL1308064 & 688382 & 5.5 & 4.8252 & TRN & \\
\hline CHEMBL1487460 & 688382 & 5.1 & 4.7247 & TRN & \\
\hline CHEMBL1537629 & 688382 & 5.25 & $4.6610 e$ & 00000000005 & TRN \\
\hline CHEMBL1599954 & 688382 & 4.05 & 4.685 & TST & \\
\hline CHEMBL1354000 & 688382 & 4.5 & 4.6423 & TRN & \\
\hline CHEMBL1389368 & 688382 & 4.5 & 4.7543 & TRN & \\
\hline CHEMBL3191440 & 688382 & 4.45 & 4.7161 & TRN & \\
\hline CHEMBL1392963 & 688382 & 4.25 & 4.6548 & TST & \\
\hline CHEMBL1450945 & 688382 & 4.2 & 4.7126 & TRN & \\
\hline CHEMBL1485806 & 688382 & 4.85 & 4.6562 & TRN & \\
\hline CHEMBL1550090 & 688382 & 4.65 & 4.6784 & TST & \\
\hline CHEMBL473106 & 688382 & 4.35 & 4.6677 & TRN & \\
\hline CHEMBL1430372 & 688382 & 4.45 & 4.6202 & TRN & \\
\hline CHEMBL1465189 & 688382 & 5.2 & 4.6728 & TRN & \\
\hline CHEMBL1587789 & 688382 & 4.35 & 4.6911 & TRN & \\
\hline CHEMBL1987094 & 688382 & 4.6 & 4.6391 & TRN & \\
\hline CHEMBL1525079 & 688382 & 6.0 & 4.7397 & TRN & \\
\hline CHEMBL1467081 & 688382 & 5.85 & 4.6874 & TRN & \\
\hline CHEMBL1576913 & 688382 & 4.45 & 4.7635 & TRN & \\
\hline CHEMBL1568993 & 688382 & 4.0 & 4.6698 & TRN & \\
\hline CHEMBL1605229 & 688382 & 4.55 & 4.7085 & TRN & \\
\hline CHEMBL1309472 & 688382 & 4.45 & 4.7005 & TRN & \\
\hline CHEMBL1461861 & 688382 & 4.9 & 4.8195 & TRN & \\
\hline CHEMBL1422273 & 688382 & 4.05 & 4.7856 & TRN & \\
\hline CHEMBL1307663 & 688382 & 4.15 & 4.7243 & TRN & \\
\hline CHEMBL1401976 & 688382 & 5.2 & 4.7243 & TRN & \\
\hline CHEMBL1567439 & 688382 & 5.8 & 4.6859 & TRN & \\
\hline CHEMBL587884 & 688382 & 4.55 & 4.6226 & TST & \\
\hline CHEMBL1324136 & 688382 & 4.6 & 4.73 & TRN & \\
\hline CHEMBL1599393 & 688382 & 4.4 & 4.7073 & TRN & \\
\hline CHEMBL589694 & 688382 & 4.3 & 4.7245 & TRN & \\
\hline CHEMBL1372031 & 688382 & 5.05 & 4.7636 & TRN & \\
\hline
\end{tabular}




\begin{tabular}{|c|c|c|c|c|c|}
\hline \multicolumn{6}{|c|}{ Supplemental Table S2.txt } \\
\hline CHEMBL1547018 & 688382 & 6.0 & 4.726 & TRN & \\
\hline CHEMBL1313820 & 688382 & 4.3 & 4.6874 & TST & \\
\hline CHEMBL3191445 & 688382 & 4.7 & 4.6928 & TRN & \\
\hline CHEMBL1569558 & 688382 & 4.4 & 4.7228 & TST & \\
\hline CHEMBL1474521 & 688382 & 4.9 & 4.6837 & TST & \\
\hline CHEMBL1381055 & 688382 & 5.15 & 4.7299 & TRN & \\
\hline CHEMBL1381264 & 688382 & 4.8 & 4.6789 & TRN & \\
\hline CHEMBL1582047 & 688382 & 4.2 & 4.7798 & TRN & \\
\hline CHEMBL1509789 & 688382 & 4.45 & 4.5752 & TST & \\
\hline CHEMBL1348406 & 688382 & 6.0 & 4.6783 & TRN & \\
\hline CHEMBL1378872 & 688382 & 6.0 & 4.6703 & TST & \\
\hline CHEMBL1442776 & 688382 & 4.45 & 4.7125 & TRN & \\
\hline CHEMBL1388596 & 688382 & 4.15 & 4.63 & TST & \\
\hline CHEMBL1399505 & 688382 & 4.4 & 4.6519 & TRN & \\
\hline CHEMBL1556961 & 688382 & 4.0 & 4.8006 & TRN & \\
\hline CHEMBL1503586 & 688382 & 4.5 & 4.6511 & TST & \\
\hline CHEMBL1372547 & 688382 & 4.15 & 4.7573 & TST & \\
\hline CHEMBL1386932 & 688382 & 4.15 & 4.7167 & TRN & \\
\hline CHEMBL1448595 & 688382 & 4.55 & 4.6552 & TRN & \\
\hline CHEMBL1440446 & 688382 & 4.8 & 4.7276 & TRN & \\
\hline CHEMBL1572461 & 688382 & 4.95 & 4.6954 & TST & \\
\hline CHEMBL1547776 & 688382 & 5.8 & 4.8371 & TRN & \\
\hline CHEMBL1497174 & 688382 & 4.45 & 4.7006 & TRN & \\
\hline CHEMBL1601627 & 688382 & 4.8 & 4.6627 & TRN & \\
\hline CHEMBL1461131 & 688382 & 4.6 & 4.6946 & TRN & \\
\hline CHEMBL1327047 & 688382 & 4.95 & 4.6437 & TRN & \\
\hline CHEMBL1421385 & 688382 & 5.0 & 4.7094 & TST & \\
\hline CHEMBL1309054 & 688382 & 5.05 & 4.77 & TRN & \\
\hline CHEMBL1966952 & 688382 & 4.65 & 4.6572 & TST & \\
\hline CHEMBL1327383 & 688382 & 4.8 & 4.6586 & TRN & \\
\hline CHEMBL1429356 & 688382 & 4.35 & 4.6667 & TRN & \\
\hline CHEMBL1451963 & 688382 & 5.0 & 4.5992 & TST & \\
\hline CHEMBL1508848 & 688382 & 4.9 & 4.6358 & TST & \\
\hline CHEMBL1500885 & 688382 & 5.0 & 4.6679 & TRN & \\
\hline CHEMBL1508455 & 688382 & 4.25 & 4.7125 & TRN & \\
\hline CHEMBL1454062 & 688382 & 5.95 & 4.7789 & TRN & \\
\hline CHEMBL1463795 & 688382 & 6.0 & $4.7360 e$ & 0000000001 & TRN \\
\hline CHEMBL1447204 & 688382 & 5.05 & 4.8457 & TRN & \\
\hline CHEMBL3209728 & 688382 & 5.2 & 4.6809 & TRN & \\
\hline CHEMBL1536672 & 688382 & 4.8 & 4.7697 & TRN & \\
\hline CHEMBL1596336 & 688382 & 4.8 & 4.7718 & TRN & \\
\hline CHEMBL1349146 & 688382 & 4.95 & 4.6048 & TST & \\
\hline CHEMBL1594252 & 688382 & 5.8 & 4.8153 & TRN & \\
\hline CHEMBL1304827 & 688382 & 5.4 & 4.8085 & TRN & \\
\hline CHEMBL1381180 & 688382 & 4.6 & 4.6588 & TRN & \\
\hline CHEMBL1410758 & 688382 & 4.5 & 4.6843 & TRN & \\
\hline CHEMBL1402697 & 688382 & 4.55 & 4.7338 & TRN & \\
\hline CHEMBL1561328 & 688382 & 4.6 & 4.6605 & TST & \\
\hline
\end{tabular}




\begin{tabular}{|c|c|c|c|c|}
\hline \multicolumn{5}{|c|}{ Supplemental Table } \\
\hline CHEMBL1334927 & 688382 & 4.35 & 4.7933 & TRN \\
\hline CHEMBL1303948 & 688382 & 4.15 & 4.7175 & TRN \\
\hline CHEMBL1547037 & 688382 & 5.25 & 4.6901 & TRN \\
\hline CHEMBL1424745 & 688382 & 3.9 & 4.7313 & TRN \\
\hline CHEMBL1463976 & 688382 & 4.1 & 4.7684 & TRN \\
\hline CHEMBL1987173 & 688382 & 4.0 & 4.6293 & TRN \\
\hline CHEMBL1336632 & 688382 & 4.8 & 4.6262 & TRN \\
\hline CHEMBL1528713 & 688382 & 4.95 & 4.6996 & TRN \\
\hline CHEMBL1339028 & 688382 & 4.15 & 4.7203 & TRN \\
\hline CHEMBL1306109 & 688382 & 4.95 & 4.8163 & TRN \\
\hline CHEMBL1482688 & 688382 & 5.4 & 4.7552 & TST \\
\hline CHEMBL1437965 & 688382 & 4.75 & 4.5814 & TRN \\
\hline CHEMBL1464548 & 688382 & 3.05 & 4.6551 & TST \\
\hline CHEMBL1505670 & 688382 & 4.4 & 4.7421 & TRN \\
\hline CHEMBL1504727 & 688382 & 4.15 & 4.7709 & TRN \\
\hline CHEMBL1319536 & 688382 & 5.0 & 4.7059 & TRN \\
\hline CHEMBL1402050 & 688382 & 4.95 & 4.7824 & TRN \\
\hline CHEMBL1321393 & 688382 & 4.45 & 4.6794 & TRN \\
\hline CHEMBL1477486 & 688382 & 4.5 & 4.6365 & TRN \\
\hline CHEMBL1341488 & 688382 & 4.45 & 4.6685 & TRN \\
\hline CHEMBL 245265 & 688382 & 4.65 & 4.7306 & TRN \\
\hline CHEMBL1582719 & 688382 & 5.5 & 4.7763 & TRN \\
\hline CHEMBL1369945 & 688382 & 4.5 & 4.6058 & TRN \\
\hline CHEMBL1430927 & 688382 & 4.5 & 4.7072 & TRN \\
\hline CHEMBL1407680 & 688382 & 4.15 & 4.6706 & TST \\
\hline CHEMBL1464158 & 688382 & 4.85 & 4.7201 & TRN \\
\hline CHEMBL 1448448 & 688382 & 4.6 & 4.7064 & TST \\
\hline CHEMBL1426857 & 688382 & 4.85 & 4.697 & TRN \\
\hline CHEMBL1518509 & 688382 & 4.15 & 4.7481 & TRN \\
\hline CHEMBL 1510025 & 688382 & 4.8 & 4.7058 & TRN \\
\hline CHEMBL1353488 & 688382 & 4.45 & 4.5767 & TRN \\
\hline CHEMBL193054 & 688382 & 4.05 & 4.6423 & TRN \\
\hline CHEMBL1388662 & 688382 & 4.5 & 4.7146 & TRN \\
\hline CHEMBL1475781 & 688382 & 4.95 & 4.6387 & TRN \\
\hline CHEMBL1386483 & 688382 & 4.45 & 4.7116 & TRN \\
\hline CHEMBL1371380 & 688382 & 4.4 & 4.7006 & TST \\
\hline CHEMBL1479153 & 688382 & 4.4 & 4.7422 & TRN \\
\hline CHEMBL1541209 & 688382 & 4.8 & 4.7572 & TRN \\
\hline CHEMBL1486972 & 688382 & 5.05 & 4.6537 & TRN \\
\hline CHEMBL1420769 & 688382 & 5.15 & 4.7825 & TRN \\
\hline CHEMBL3208836 & 688382 & 4.3 & 4.7274 & TRN \\
\hline CHEMBL52347 & 688382 & 5.05 & 4.629 & TST \\
\hline CHEMBL1463208 & 688382 & 4.75 & 4.7934 & TRN \\
\hline CHEMBL1417435 & 688382 & 4.5 & 4.666 & TRN \\
\hline CHEMBL 2006258 & 688382 & 4.5 & 4.6888 & TRN \\
\hline CHEMBL1580764 & 688382 & 4.95 & 4.7548 & TRN \\
\hline CHEMBL1526206 & 688382 & 5.2 & 4.8055 & TST \\
\hline CHEMBL1322615 & 688382 & 4.5 & 4.7319 & TRN \\
\hline
\end{tabular}




\begin{tabular}{|c|c|c|c|c|}
\hline \multicolumn{5}{|c|}{ Supplemental Table s2.txt } \\
\hline CHEMBL1572210 & 688382 & 4.8 & 4.6786 & TRN \\
\hline CHEMBL1482394 & 688382 & 4.45 & 4.671 & TRN \\
\hline CHEMBL1311206 & 688382 & 6.0 & 4.6549 & TRN \\
\hline CHEMBL1450004 & 688382 & 4.45 & 4.6998 & TST \\
\hline CHEMBL1365486 & 688382 & 4.2 & 4.8183 & TRN \\
\hline CHEMBL1557309 & 688382 & 4.95 & 4.6654 & TRN \\
\hline CHEMBL1343588 & 688382 & 4.2 & 4.6698 & TST \\
\hline CHEMBL1516748 & 688382 & 6.1 & 4.8007 & TST \\
\hline CHEMBL1391575 & 688382 & 5.0 & 4.7328 & TRN \\
\hline CHEMBL1559260 & 688382 & 4.45 & 4.6729 & TRN \\
\hline CHEMBL1299947 & 688382 & 5.3 & 4.7854 & TST \\
\hline CHEMBL1332497 & 688382 & 5.45 & 4.8251 & TRN \\
\hline CHEMBL1505688 & 688382 & 4.3 & 4.6328 & TRN \\
\hline CHEMBL1386554 & 688382 & 4.85 & 4.7256 & TRN \\
\hline CHEMBL1393889 & 688382 & 4.65 & 4.8347 & TRN \\
\hline CHEMBL1491786 & 688382 & 4.6 & 4.606 & TRN \\
\hline CHEMBL1501315 & 688382 & 4.4 & 4.713 & TRN \\
\hline CHEMBL 2005134 & 688382 & 5.35 & 4.6562 & TRN \\
\hline CHEMBL1482069 & 688382 & 5.0 & 4.7084 & TRN \\
\hline CHEMBL1385069 & 688382 & 4.15 & 4.6715 & TRN \\
\hline CHEMBL1394448 & 688382 & 4.75 & 4.624 & TRN \\
\hline CHEMBL1517036 & 688382 & 4.5 & 4.6503 & TRN \\
\hline CHEMBL1565692 & 688382 & 4.8 & 4.7039 & TRN \\
\hline CHEMBL1993173 & 688382 & 4.7 & 4.6535 & TRN \\
\hline CHEMBL1322846 & 688382 & 4.1 & 4.7377 & TRN \\
\hline CHEMBL1370289 & 688382 & 4.95 & 4.6743 & TST \\
\hline CHEMBL1441283 & 688382 & 4.35 & 4.6231 & TRN \\
\hline CHEMBL1605267 & 688382 & 5.0 & 4.78 & TRN \\
\hline CHEMBL1388110 & 688382 & 4.8 & 4.6427 & TST \\
\hline CHEMBL1968781 & 688382 & 4.05 & 4.5791 & TRN \\
\hline CHEMBL1498389 & 688382 & 5.0 & 4.7491 & TRN \\
\hline CHEMBL1562074 & 688382 & 5.5 & 4.7812 & TRN \\
\hline CHEMBL1422379 & 688382 & 4.95 & 4.717 & TRN \\
\hline CHEMBL1346546 & 688382 & 4.5 & 4.7327 & TRN \\
\hline CHEMBL1546847 & 688382 & 5.65 & 4.7308 & TST \\
\hline CHEMBL1525655 & 688382 & 4.5 & 4.724 & TRN \\
\hline CHEMBL1310108 & 688382 & 4.2 & 4.6562 & TRN \\
\hline CHEMBL1325440 & 688382 & 4.4 & 4.7094 & TRN \\
\hline CHEMBL1313671 & 688382 & 5.2 & 4.6255 & TRN \\
\hline CHEMBL1364218 & 688382 & 4.05 & 4.7364 & TRN \\
\hline CHEMBL1353531 & 688382 & 4.05 & 4.7733 & TRN \\
\hline CHEMBL1479128 & 688382 & 4.65 & 4.6777 & TRN \\
\hline CHEMBL1566878 & 688382 & 4.45 & 4.7314 & TRN \\
\hline CHEMBL3193507 & 688382 & 5.85 & 4.5819 & TRN \\
\hline CHEMBL1430760 & 688382 & 6.0 & 4.6858 & TST \\
\hline CHEMBL1530667 & 688382 & 4.45 & 4.8109 & TST \\
\hline CHEMBL1462647 & 688382 & 4.45 & 4.7385 & TRN \\
\hline CHEMBL399293 & 688382 & 4.3 & 4.6895 & TST \\
\hline
\end{tabular}




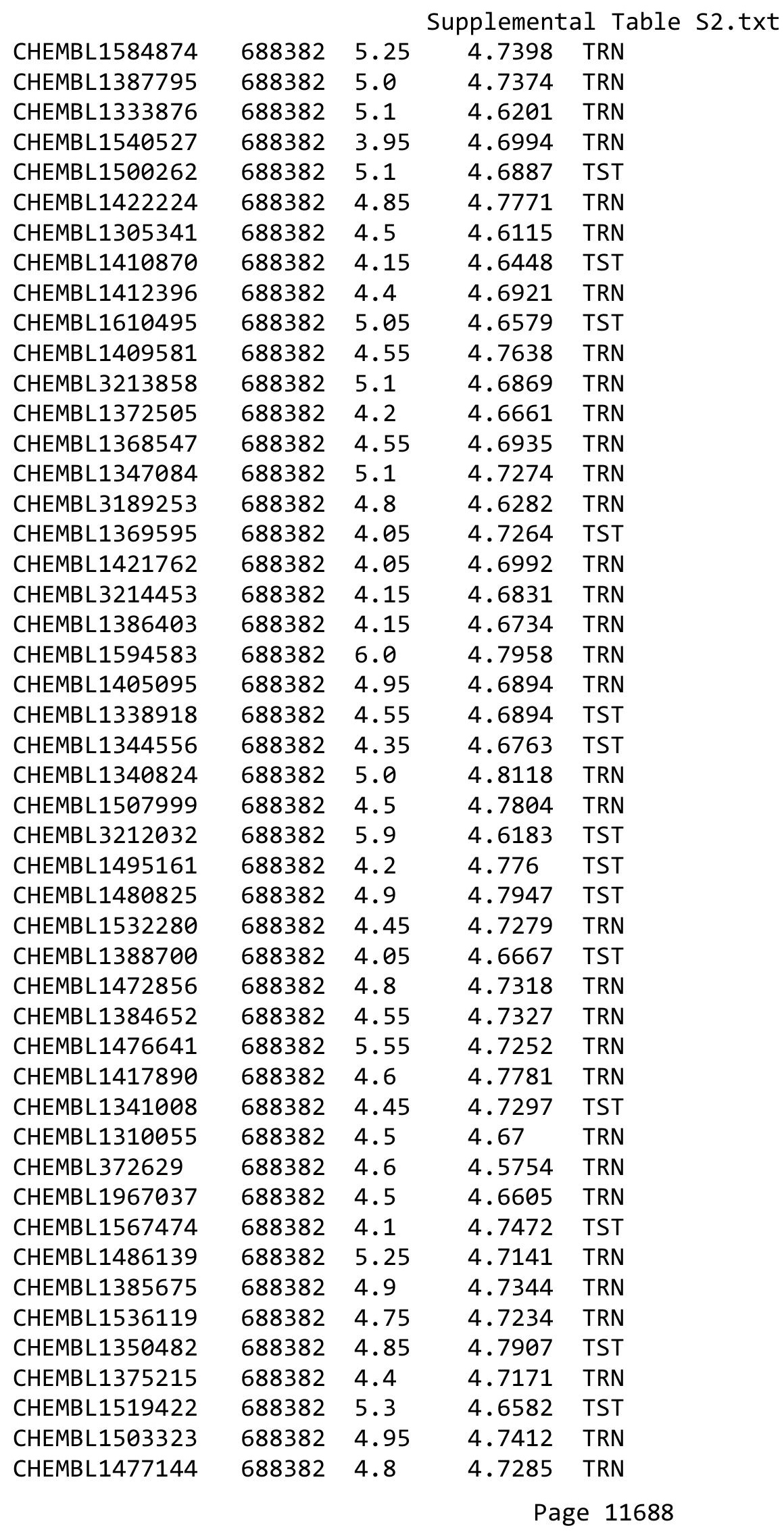




\begin{tabular}{|c|c|c|c|c|c|}
\hline \multicolumn{6}{|c|}{ Supplemental Table S2.txt } \\
\hline CHEMBL3208184 & 688382 & 4.4 & 4.6078 & TRN & \\
\hline CHEMBL1405669 & 688382 & 4.8 & 4.7266 & TRN & \\
\hline CHEMBL1581240 & 688382 & 5.4 & 4.6827 & TRN & \\
\hline CHEMBL1429944 & 688382 & 4.25 & 4.6899 & TRN & \\
\hline CHEMBL1342243 & 688382 & 4.8 & 4.7083 & TRN & \\
\hline CHEMBL3195166 & 688382 & 4.05 & 4.6303 & TRN & \\
\hline CHEMBL1321106 & 688382 & 5.45 & 4.7392 & TRN & \\
\hline CHEMBL1424000 & 688382 & 4.35 & 4.7189 & TST & \\
\hline CHEMBL3192253 & 688382 & 4.45 & 4.6039 & TRN & \\
\hline CHEMBL1352168 & 688382 & 4.45 & 4.7041 & TRN & \\
\hline CHEMBL1477085 & 688382 & 4.15 & 4.7631 & TRN & \\
\hline CHEMBL1608265 & 688382 & 4.3 & 4.7192 & TRN & \\
\hline CHEMBL1568126 & 688382 & 4.7 & 4.6866 & TRN & \\
\hline CHEMBL1520104 & 688382 & 4.95 & 4.7628 & TRN & \\
\hline CHEMBL1498140 & 688382 & 4.15 & 4.6836 & TST & \\
\hline CHEMBL1375209 & 688382 & 4.95 & 4.7383 & TST & \\
\hline CHEMBL1305934 & 688382 & 4.45 & 4.7039 & TRN & \\
\hline CHEMBL1310484 & 688382 & 4.5 & 4.6447 & TST & \\
\hline CHEMBL1349262 & 688382 & 7.5498 & 4.7989 & TRN & \\
\hline CHEMBL3196282 & 688382 & 4.8 & 4.6591 & TRN & \\
\hline CHEMBL1536682 & 688382 & 4.5 & 4.7139 & TRN & \\
\hline CHEMBL379350 & 688382 & 5.05 & 4.71399 & 99999999995 & TRN \\
\hline CHEMBL3199614 & 688382 & 6.0 & 4.7277 & TST & \\
\hline CHEMBL1312018 & 688382 & 5.0 & 4.6743 & TST & \\
\hline CHEMBL1340965 & 688382 & 4.8 & 4.7668 & TRN & \\
\hline CHEMBL1322107 & 688382 & 7.0501 & 4.7742 & TRN & \\
\hline CHEMBL3198097 & 688382 & 4.9 & 4.7011 & TRN & \\
\hline CHEMBL1312235 & 688382 & 4.5 & 4.6818 & TRN & \\
\hline CHEMBL1501199 & 688382 & 4.4 & 4.7701 & TRN & \\
\hline CHEMBL1376288 & 688382 & 4.65 & 4.6788 & TST & \\
\hline CHEMBL1564714 & 688382 & 4.15 & 4.7158 & TRN & \\
\hline CHEMBL3209737 & 688382 & 5.05 & 4.6538 & TRN & \\
\hline CHEMBL1453551 & 688382 & 4.5 & 4.6487 & TRN & \\
\hline CHEMBL1486366 & 688382 & 4.6 & 4.6763 & TRN & \\
\hline CHEMBL1353237 & 688382 & 4.95 & 4.7202 & TRN & \\
\hline CHEMBL1490983 & 688382 & 5.95 & 4.7175 & TST & \\
\hline CHEMBL1421623 & 688382 & 4.5 & 4.7106 & TST & \\
\hline CHEMBL1352113 & 688382 & 5.25 & 4.6928 & TST & \\
\hline CHEMBL1490984 & 688382 & 4.35 & 4.8457 & TRN & \\
\hline CHEMBL1573877 & 688382 & 4.5 & 4.7157 & TRN & \\
\hline CHEMBL1452434 & 688382 & 5.7 & 4.7527 & TRN & \\
\hline CHEMBL1408834 & 688382 & 4.75 & 4.6507 & TRN & \\
\hline CHEMBL3145321 & 688382 & 4.45 & 4.6568 & TRN & \\
\hline CHEMBL1491764 & 688382 & 4.5 & 4.681 & TRN & \\
\hline CHEMBL1560341 & 688382 & 4.65 & 4.69300 & 00000000005 & TRN \\
\hline CHEMBL56281 & 688382 & 4.45 & 4.6387 & TST & \\
\hline CHEMBL1482660 & 688382 & 5.95 & 4.7544 & TRN & \\
\hline CHEMBL1460635 & 688382 & 4.95 & 4.7435 & TST & \\
\hline
\end{tabular}




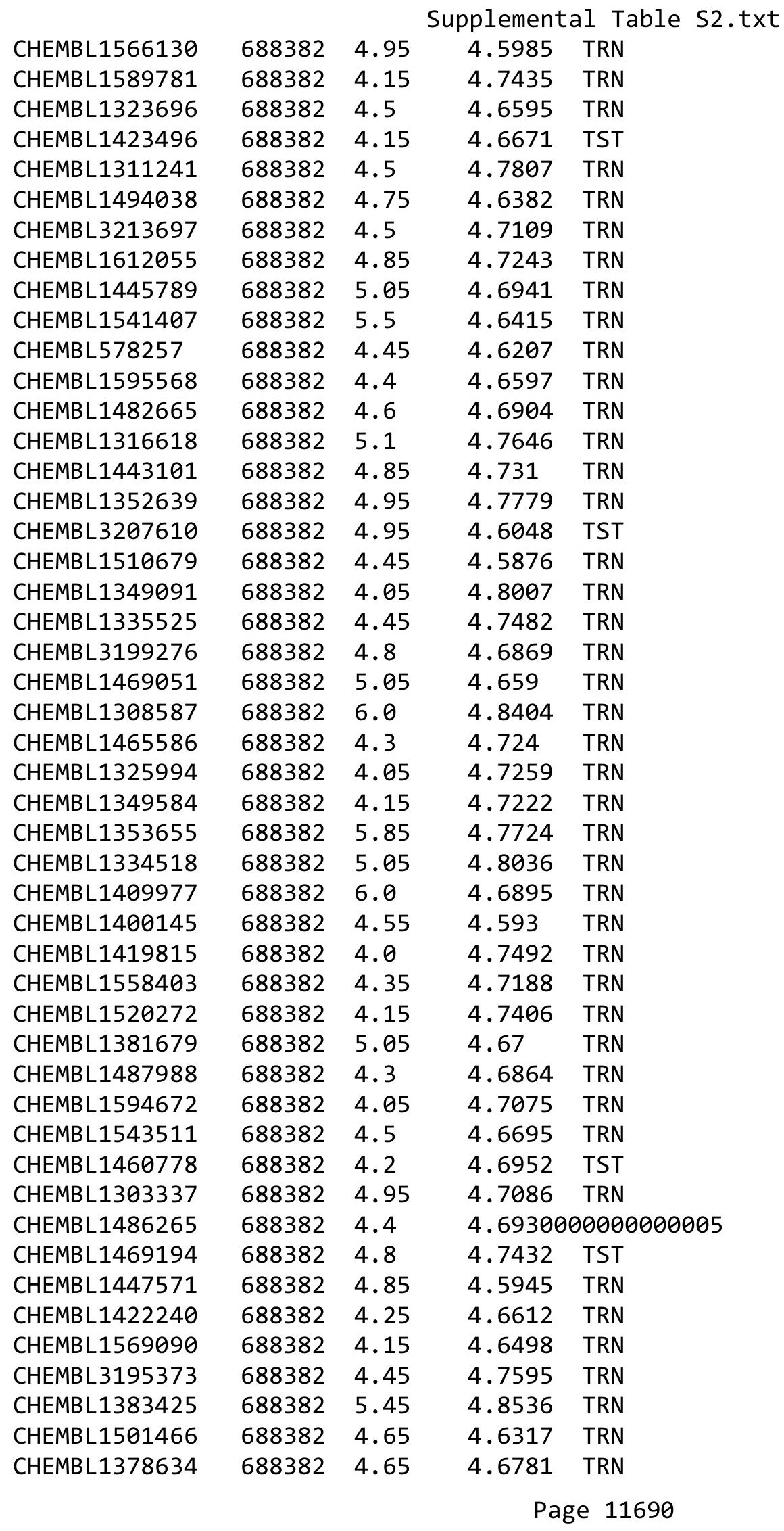




\begin{tabular}{|c|c|c|c|c|c|}
\hline \multicolumn{6}{|c|}{ Supplemental Table S2.txt } \\
\hline CHEMBL1559104 & 688382 & 4.7 & 4.753 & TRN & \\
\hline CHEMBL1368422 & 688382 & 4.15 & 4.7305 & TRN & \\
\hline CHEMBL1335610 & 688382 & 4.5 & 4.7203 & TRN & \\
\hline CHEMBL1409226 & 688382 & 4.9 & 4.7235 & TST & \\
\hline CHEMBL1408772 & 688382 & 4.3 & 4.6824 & TST & \\
\hline CHEMBL1359331 & 688382 & 6.0 & 4.7388 & TRN & \\
\hline CHEMBL1459803 & 688382 & 4.2 & 4.762 & TRN & \\
\hline CHEMBL1306466 & 688382 & 4.85 & 4.7361 & TRN & \\
\hline CHEMBL1338143 & 688382 & 4.55 & 4.7327 & TRN & \\
\hline CHEMBL1319300 & 688382 & 4.15 & 4.6982 & TRN & \\
\hline CHEMBL1498656 & 688382 & 4.55 & 4.6791 & TRN & \\
\hline CHEMBL1442066 & 688382 & 5.0 & 4.7066 & TRN & \\
\hline CHEMBL1472000 & 688382 & 4.0 & 4.6447 & TST & \\
\hline CHEMBL1313260 & 688382 & 5.6 & 4.8623 & TRN & \\
\hline CHEMBL1986972 & 688382 & 4.45 & 4.6399 & TRN & \\
\hline CHEMBL1331518 & 688382 & 4.85 & 4.8012 & TST & \\
\hline CHEMBL1541812 & 688382 & 5.05 & 4.8281 & TRN & \\
\hline CHEMBL1304169 & 688382 & 4.95 & 4.6619 & TRN & \\
\hline CHEMBL1418656 & 688382 & 4.1 & 4.6396 & TRN & \\
\hline CHEMBL1487461 & 688382 & 5.2 & 4.7869 & TRN & \\
\hline CHEMBL1373418 & 688382 & 4.95 & 4.8361 & TRN & \\
\hline CHEMBL1455451 & 688382 & 4.85 & 4.7274 & TST & \\
\hline CHEMBL1325804 & 688382 & 4.25 & 4.6798 & TRN & \\
\hline CHEMBL1463853 & 688382 & 4.95 & 4.7885 & TRN & \\
\hline CHEMBL1432375 & 688382 & 4.8 & 4.8274 & TRN & \\
\hline CHEMBL1540643 & 688382 & 5.3 & 4.6982 & TRN & \\
\hline CHEMBL1599510 & 688382 & 4.8 & 4.6437 & TST & \\
\hline CHEMBL1600082 & 688382 & 4.5 & 4.6504 & TRN & \\
\hline CHEMBL1345981 & 688382 & 4.45 & 4.6697 & TRN & \\
\hline CHEMBL3196833 & 688382 & 4.5 & 4.6509 & TRN & \\
\hline CHEMBL1491417 & 688382 & 4.4 & 4.6399 & TST & \\
\hline CHEMBL1543190 & 688382 & 4.2 & 4.7297 & TST & \\
\hline CHEMBL1332225 & 688382 & 4.45 & 4.6648 & TRN & \\
\hline CHEMBL1560418 & 688382 & 4.65 & 4.7446 & TRN & \\
\hline CHEMBL1394592 & 688382 & 4.05 & 4.7227 & TRN & \\
\hline CHEMBL 2001933 & 688382 & 5.25 & 4.6704 & TRN & \\
\hline CHEMBL1414588 & 688382 & 5.0 & 4.76699 & 99999999995 & TST \\
\hline CHEMBL1369719 & 688382 & 4.9 & 4.8072 & TRN & \\
\hline CHEMBL1304988 & 688382 & 4.5 & 4.78600 & 20000000005 & TRN \\
\hline CHEMBL1603380 & 688382 & 3.9 & 4.7016 & TRN & \\
\hline CHEMBL1376763 & 688382 & 4.0 & 4.75899 & 99999999995 & TST \\
\hline CHEMBL1356633 & 688382 & 4.95 & 4.7016 & TRN & \\
\hline CHEMBL1495862 & 688382 & 4.7 & 4.6858 & TST & \\
\hline CHEMBL1497481 & 688382 & 4.4 & 4.6864 & TST & \\
\hline CHEMBL1874415 & 688382 & 5.55 & 4.6375 & TST & \\
\hline CHEMBL1489872 & 688382 & 4.45 & 4.6972 & TST & \\
\hline CHEMBL1451958 & 688382 & 4.4 & 4.6836 & TST & \\
\hline CHEMBL1425648 & 688382 & 5.85 & 4.6162 & TST & \\
\hline
\end{tabular}




\begin{tabular}{|c|c|c|c|c|c|}
\hline \multirow[b]{2}{*}{ CHEMBL1500747 } & \multirow[b]{2}{*}{688382} & \\
\hline & & 5.9 & 4.7721 & TRN & \\
\hline CHEMBL1583199 & 688382 & 4.55 & 4.681 & TST & \\
\hline CHEMBL1457752 & 688382 & 4.45 & 4.7707 & TRN & \\
\hline CHEMBL1964891 & 688382 & 4.45 & 4.6994 & TRN & \\
\hline CHEMBL1350415 & 688382 & 4.4 & 4.6864 & TRN & \\
\hline CHEMBL1431622 & 688382 & 6.0 & 4.7084 & TRN & \\
\hline CHEMBL1502293 & 688382 & 4.6 & 4.7457 & TST & \\
\hline CHEMBL1503622 & 688382 & 4.2 & 4.7055 & TRN & \\
\hline CHEMBL1598245 & 688382 & 4.45 & 4.7262 & TRN & \\
\hline CHEMBL1600669 & 688382 & 4.5 & 4.6649 & TRN & \\
\hline CHEMBL1450685 & 688382 & 4.0 & 4.7565 & TRN & \\
\hline CHEMBL1420276 & 688382 & 4.6 & 4.6625 & TRN & \\
\hline CHEMBL586628 & 688382 & 4.85 & 4.7213 & TRN & \\
\hline CHEMBL1459993 & 688382 & 5.05 & 4.6966 & TRN & \\
\hline CHEMBL1390569 & 688382 & 4.2 & 4.8295 & TRN & \\
\hline CHEMBL1489605 & 688382 & 4.65 & 4.6071 & TST & \\
\hline CHEMBL1540401 & 688382 & 5.0 & 4.6984 & TRN & \\
\hline CHEMBL1469061 & 688382 & 5.45 & 4.6996 & TRN & \\
\hline CHEMBL3214610 & 688382 & 4.45 & 4.6609 & TRN & \\
\hline CHEMBL1579169 & 688382 & 4.5 & 4.7004 & TRN & \\
\hline CHEMBL1588072 & 688382 & 4.45 & 4.7538 & TST & \\
\hline CHEMBL1444925 & 688382 & 4.3 & 4.73600 & $\partial 000000001$ & TRN \\
\hline CHEMBL1325502 & 688382 & 4.65 & 4.6921 & TRN & \\
\hline CHEMBL1979784 & 688382 & 4.8 & 4.802 & TRN & \\
\hline CHEMBL1605867 & 688382 & 4.5 & 4.6978 & TRN & \\
\hline CHEMBL1540372 & 688382 & 4.25 & 4.6208 & TST & \\
\hline CHEMBL1478235 & 688382 & 4.55 & 4.69600 & 2000000001 & TRN \\
\hline CHEMBL1431087 & 688382 & 4.85 & 4.8467 & TRN & \\
\hline CHEMBL1547561 & 688382 & 4.85 & 4.6637 & TST & \\
\hline CHEMBL1598704 & 688382 & 4.4 & 4.7088 & TRN & \\
\hline CHEMBL1603789 & 688382 & 5.05 & 4.7322 & TST & \\
\hline CHEMBL1613005 & 688382 & 4.5 & 4.8247 & TRN & \\
\hline CHEMBL1386316 & 688382 & 4.45 & 4.5967 & TRN & \\
\hline CHEMBL1306583 & 688382 & 4.15 & 4.6866 & TRN & \\
\hline CHEMBL1348586 & 688382 & 4.5 & 4.6472 & TRN & \\
\hline CHEMBL1383231 & 688382 & 4.95 & 4.6953 & TST & \\
\hline CHEMBL1351708 & 688382 & 4.75 & 4.6153 & TRN & \\
\hline CHEMBL1423780 & 688382 & 4.05 & 4.8527 & TRN & \\
\hline CHEMBL1304197 & 688382 & 4.5 & 4.7159 & TST & \\
\hline CHEMBL1544789 & 688382 & 4.5 & 4.6038 & TST & \\
\hline CHEMBL1544810 & 688382 & 4.8 & 4.7245 & TRN & \\
\hline CHEMBL1319849 & 688382 & 4.45 & 4.7598 & TST & \\
\hline CHEMBL1544727 & 688382 & 4.85 & 4.6835 & TRN & \\
\hline CHEMBL1546485 & 688382 & 5.05 & 4.8115 & TST & \\
\hline CHEMBL1336864 & 688382 & 4.75 & 4.7936 & TST & \\
\hline CHEMBL1399686 & 688382 & 4.9 & 4.8615 & TRN & \\
\hline CHEMBL266997 & 688382 & 5.05 & 4.65 & TRN & \\
\hline CHEMBL1310818 & 688382 & 5.8 & 4.7343 & TST & \\
\hline & & & & 11692 & \\
\hline
\end{tabular}




\begin{tabular}{|c|c|c|c|c|c|}
\hline & & \multicolumn{4}{|c|}{ Supplemental Table S2.txt } \\
\hline CHEMBL1555566 & 688382 & 4.15 & 4.6961 & TRN & \\
\hline CHEMBL1568260 & 688382 & 4.45 & 4.6894 & TRN & \\
\hline CHEMBL3192306 & 688382 & 5.05 & 4.6341 & TRN & \\
\hline CHEMBL536375 & 688382 & 4.2 & 4.7127 & TRN & \\
\hline CHEMBL1389584 & 688382 & 4.85 & 4.6928 & TRN & \\
\hline CHEMBL1482170 & 688382 & 4.75 & 4.7506 & TRN & \\
\hline CHEMBL1512410 & 688382 & 4.4 & 4.6987 & TRN & \\
\hline CHEMBL1604203 & 688382 & 5.15 & 4.6943 & TRN & \\
\hline CHEMBL1607215 & 688382 & 4.8 & 4.7785 & TRN & \\
\hline CHEMBL1325328 & 688382 & 4.35 & 4.7166 & TRN & \\
\hline CHEMBL1375056 & 688382 & 5.95 & 4.76699 & 99999999995 & TST \\
\hline CHEMBL1375428 & 688382 & 4.85 & 4.6303 & TRN & \\
\hline CHEMBL1424041 & 688382 & 4.5 & 4.646 & TRN & \\
\hline CHEMBL1380769 & 688382 & 5.0 & 4.6127 & TRN & \\
\hline CHEMBL1422429 & 688382 & 4.4 & 4.5976 & TRN & \\
\hline CHEMBL3196231 & 688382 & 4.45 & 4.6265 & TRN & \\
\hline CHEMBL1339747 & 688382 & 4.5 & 4.717 & TRN & \\
\hline CHEMBL1486984 & 688382 & 4.15 & 4.6476 & TRN & \\
\hline CHEMBL1406019 & 688382 & 4.45 & 4.788 & TRN & \\
\hline CHEMBL3198983 & 688382 & 4.8 & 4.6922 & TRN & \\
\hline CHEMBL1526321 & 688382 & 4.15 & 4.80399 & 9999999999 & TST \\
\hline CHEMBL1343853 & 688382 & 4.7 & 4.6729 & TRN & \\
\hline CHEMBL1299295 & 688382 & 5.4 & 4.7148 & TST & \\
\hline CHEMBL1319389 & 688382 & 4.8 & 4.7437 & TRN & \\
\hline CHEMBL1509523 & 688382 & 4.45 & 4.5409 & TRN & \\
\hline CHEMBL1496452 & 688382 & 4.95 & 4.8234 & TRN & \\
\hline CHEMBL1490618 & 688382 & 4.25 & 4.7034 & TST & \\
\hline CHEMBL1359553 & 688382 & 4.95 & 4.7148 & TRN & \\
\hline CHEMBL1454583 & 688382 & 4.8 & 4.8083 & TRN & \\
\hline CHEMBL1532996 & 688382 & 4.85 & 4.752 & TST & \\
\hline CHEMBL1491155 & 688382 & 5.0 & 4.6919 & TRN & \\
\hline CHEMBL1520332 & 688382 & 4.45 & 4.6651 & TRN & \\
\hline CHEMBL1606761 & 688382 & 4.6 & 4.7118 & TRN & \\
\hline CHEMBL1448906 & 688382 & 4.5 & 4.6717 & TRN & \\
\hline CHEMBL1458190 & 688382 & 4.8 & 4.7436 & TRN & \\
\hline CHEMBL1392433 & 688382 & 5.0 & 4.8221 & TRN & \\
\hline CHEMBL3191459 & 688382 & 4.1 & 4.6375 & TRN & \\
\hline CHEMBL1566080 & 688382 & 4.2 & 4.6205 & TRN & \\
\hline CHEMBL1428367 & 688382 & 4.75 & 4.6051 & TRN & \\
\hline CHEMBL1308434 & 688382 & 4.05 & 4.7439 & TRN & \\
\hline CHEMBL1979844 & 688382 & 4.45 & 4.6373 & TRN & \\
\hline CHEMBL1455599 & 688382 & 4.8 & 4.8093 & TST & \\
\hline CHEMBL1602385 & 688382 & 5.5 & 4.6416 & TRN & \\
\hline CHEMBL1409496 & 688382 & 4.8 & 4.7223 & TST & \\
\hline CHEMBL3192134 & 688382 & 4.15 & 4.7621 & TRN & \\
\hline CHEMBL1390329 & 688382 & 4.8 & 4.7794 & TRN & \\
\hline CHEMBL3198904 & 688382 & 5.0 & 4.7552 & TRN & \\
\hline CHEMBL1533772 & 688382 & 5.25 & 4.6705 & TRN & \\
\hline
\end{tabular}




\begin{tabular}{|c|c|c|c|c|}
\hline \multicolumn{5}{|c|}{ Supplemental Table S2.txt } \\
\hline CHEMBL1976839 & 688382 & 4.35 & 4.6679 & TRN \\
\hline CHEMBL3192018 & 688382 & 4.35 & 4.6186 & TRN \\
\hline CHEMBL1524487 & 688382 & 4.95 & 4.6922 & TST \\
\hline CHEMBL1538332 & 688382 & 4.85 & 4.7485 & TRN \\
\hline CHEMBL1501073 & 688382 & 4.5 & 4.6507 & TRN \\
\hline CHEMBL1502980 & 688382 & 4.95 & 4.6715 & TRN \\
\hline CHEMBL1996630 & 688382 & 4.15 & 4.6997 & TRN \\
\hline CHEMBL1346529 & 688382 & 4.5 & 4.6857 & TRN \\
\hline CHEMBL1321371 & 688382 & 4.5 & 4.727 & TRN \\
\hline CHEMBL1384531 & 688382 & 4.05 & 4.6746 & TRN \\
\hline CHEMBL1324821 & 688382 & 4.85 & 4.7913 & TST \\
\hline CHEMBL1438409 & 688382 & 4.15 & 4.7788 & TRN \\
\hline CHEMBL1485358 & 688382 & 4.95 & 4.753 & TRN \\
\hline CHEMBL1308468 & 688382 & 4.65 & 4.771 & TRN \\
\hline CHEMBL1580973 & 688382 & 5.45 & 4.6941 & TRN \\
\hline CHEMBL1526946 & 688382 & 4.05 & 4.7432 & TST \\
\hline CHEMBL3197581 & 688382 & 4.95 & 4.7577 & TST \\
\hline CHEMBL1383783 & 688382 & 5.1 & 4.7155 & TST \\
\hline CHEMBL1578102 & 688382 & 5.05 & 4.7348 & TRN \\
\hline CHEMBL1332998 & 688382 & 5.25 & 4.7149 & TRN \\
\hline CHEMBL1578170 & 688382 & 4.4 & 4.6375 & TRN \\
\hline CHEMBL1577883 & 688382 & 5.0 & 4.6947 & TST \\
\hline CHEMBL1490893 & 688382 & 4.5 & 4.7765 & TST \\
\hline CHEMBL1438681 & 688382 & 5.05 & 4.6673 & TRN \\
\hline CHEMBL1332059 & 688382 & 4.5 & 4.6777 & TRN \\
\hline CHEMBL1311088 & 688382 & 4.9 & 4.7459 & TRN \\
\hline CHEMBL1611481 & 688382 & 5.75 & 4.718 & TRN \\
\hline CHEMBL1532596 & 688382 & 4.8 & 4.7618 & TRN \\
\hline CHEMBL1354012 & 688382 & 4.5 & 4.711 & TST \\
\hline CHEMBL1539367 & 688382 & 4.8 & 4.7471 & TRN \\
\hline CHEMBL1510596 & 688382 & 4.95 & 4.7179 & TRN \\
\hline CHEMBL1583342 & 688382 & 5.5 & 4.7725 & TRN \\
\hline CHEMBL1492561 & 688382 & 4.7 & 4.6414 & TRN \\
\hline CHEMBL1371722 & 688382 & 4.15 & 4.668 & TRN \\
\hline CHEMBL1584387 & 688382 & 5.25 & 4.6015 & TRN \\
\hline CHEMBL1351259 & 688382 & 4.5 & 4.833 & TRN \\
\hline CHEMBL1983075 & 688382 & 4.0 & 4.6665 & TST \\
\hline CHEMBL1533326 & 688382 & 4.35 & 4.6686 & TRN \\
\hline CHEMBL1388509 & 688382 & 4.8 & 4.6869 & TST \\
\hline CHEMBL1564142 & 688382 & 5.85 & 4.7689 & TST \\
\hline CHEMBL1311935 & 688382 & 4.05 & 4.7141 & TST \\
\hline CHEMBL1573171 & 688382 & 4.4 & 4.7302 & TST \\
\hline CHEMBL1453098 & 688382 & 4.5 & 4.6517 & TRN \\
\hline CHEMBL1360870 & 688382 & 4.15 & 4.6513 & TRN \\
\hline CHEMBL1391204 & 688382 & 4.5 & 4.7657 & TRN \\
\hline CHEMBL1309577 & 688382 & 5.2 & 4.7805 & TRN \\
\hline CHEMBL1530695 & 688382 & 4.05 & 4.7351 & TRN \\
\hline CHEMBL1331003 & 688382 & 4.35 & 4.6999 & TRN \\
\hline
\end{tabular}




\begin{tabular}{|c|c|c|c|c|}
\hline \multicolumn{5}{|c|}{ Supplemental Table S2.txt } \\
\hline CHEMBL1539577 & 688382 & 4.2 & 4.695 & TRN \\
\hline CHEMBL1526171 & 688382 & 4.4 & 4.7576 & TRN \\
\hline CHEMBL1511711 & 688382 & 4.15 & 4.7422 & TRN \\
\hline CHEMBL3191218 & 688382 & 4.5 & 4.6647 & TRN \\
\hline CHEMBL1577147 & 688382 & 5.05 & 4.6434 & TST \\
\hline CHEMBL1383000 & 688382 & 5.05 & 4.7558 & TRN \\
\hline CHEMBL1350924 & 688382 & 5.4 & 4.6472 & TRN \\
\hline CHEMBL1527442 & 688382 & 4.05 & \multicolumn{2}{|c|}{4.7010000000000005} \\
\hline CHEMBL1415476 & 688382 & 5.2 & 4.668 & TRN \\
\hline CHEMBL1420426 & 688382 & 4.05 & 4.8562 & TRN \\
\hline CHEMBL3198026 & 688382 & 4.95 & 4.6611 & TRN \\
\hline CHEMBL1390469 & 688382 & 5.8 & 4.7121 & TST \\
\hline CHEMBL1492819 & 688382 & 4.45 & 4.5975 & TRN \\
\hline CHEMBL1522066 & 688382 & 4.75 & 4.7031 & TRN \\
\hline CHEMBL1509065 & 688382 & 4.95 & 4.644 & TRN \\
\hline CHEMBL1399043 & 688382 & 4.45 & 4.6773 & TRN \\
\hline CHEMBL1561021 & 688382 & 4.4 & 4.7947 & TST \\
\hline CHEMBL1509711 & 688382 & 4.15 & 4.6242 & TRN \\
\hline CHEMBL1528476 & 688382 & 4.75 & 4.7181 & TRN \\
\hline CHEMBL1503149 & 688382 & 4.0 & 4.8128 & TRN \\
\hline CHEMBL1366868 & 688382 & 4.15 & 4.6651 & TST \\
\hline CHEMBL1356947 & 688382 & 4.4 & 4.8259 & TRN \\
\hline CHEMBL1474905 & 688382 & 5.05 & 4.711 & TRN \\
\hline CHEMBL1360649 & 688382 & 4.15 & 4.6345 & TRN \\
\hline CHEMBL1308380 & 688382 & 4.6 & 4.6863 & TRN \\
\hline CHEMBL1403843 & 688382 & 5.6 & 4.7318 & TRN \\
\hline CHEMBL1456904 & 688382 & 4.5 & 4.7502 & TRN \\
\hline CHEMBL3209296 & 688382 & 4.75 & 4.6534 & TRN \\
\hline CHEMBL1481335 & 688382 & 4.55 & 4.6279 & TRN \\
\hline CHEMBL1400840 & 688382 & 4.4 & 4.6143 & TRN \\
\hline CHEMBL1517176 & 688382 & 4.5 & 4.7834 & TRN \\
\hline CHEMBL1511348 & 688382 & 4.0 & 4.7506 & TRN \\
\hline CHEMBL1479726 & 688382 & 4.45 & 4.7327 & TRN \\
\hline CHEMBL1377815 & 688382 & 5.05 & 4.7266 & TRN \\
\hline CHEMBL1478195 & 688382 & 4.45 & 4.627 & TRN \\
\hline CHEMBL1539671 & 688382 & 4.4 & 4.7367 & TRN \\
\hline CHEMBL1612953 & 688382 & 4.35 & 4.6674 & TRN \\
\hline CHEMBL1372949 & 688382 & 4.8 & 4.5982 & TRN \\
\hline CHEMBL1301851 & 688382 & 4.5 & 4.7271 & TRN \\
\hline CHEMBL1598031 & 688382 & 4.05 & 4.7843 & TRN \\
\hline CHEMBL1432211 & 688382 & 5.15 & 4.7624 & TRN \\
\hline CHEMBL1547667 & 688382 & 4.45 & 4.6637 & TRN \\
\hline CHEMBL1571237 & 688382 & 4.7 & 4.6992 & TRN \\
\hline CHEMBL1426974 & 688382 & 4.55 & 4.7523 & TST \\
\hline CHEMBL1410335 & 688382 & 4.6 & 4.665 & TRN \\
\hline CHEMBL1571034 & 688382 & 5.25 & 4.6572 & TRN \\
\hline CHEMBL3196183 & 688382 & 6.0 & 4.6608 & TST \\
\hline CHEMBL582706 & 688382 & 5.25 & 4.7917 & TRN \\
\hline
\end{tabular}




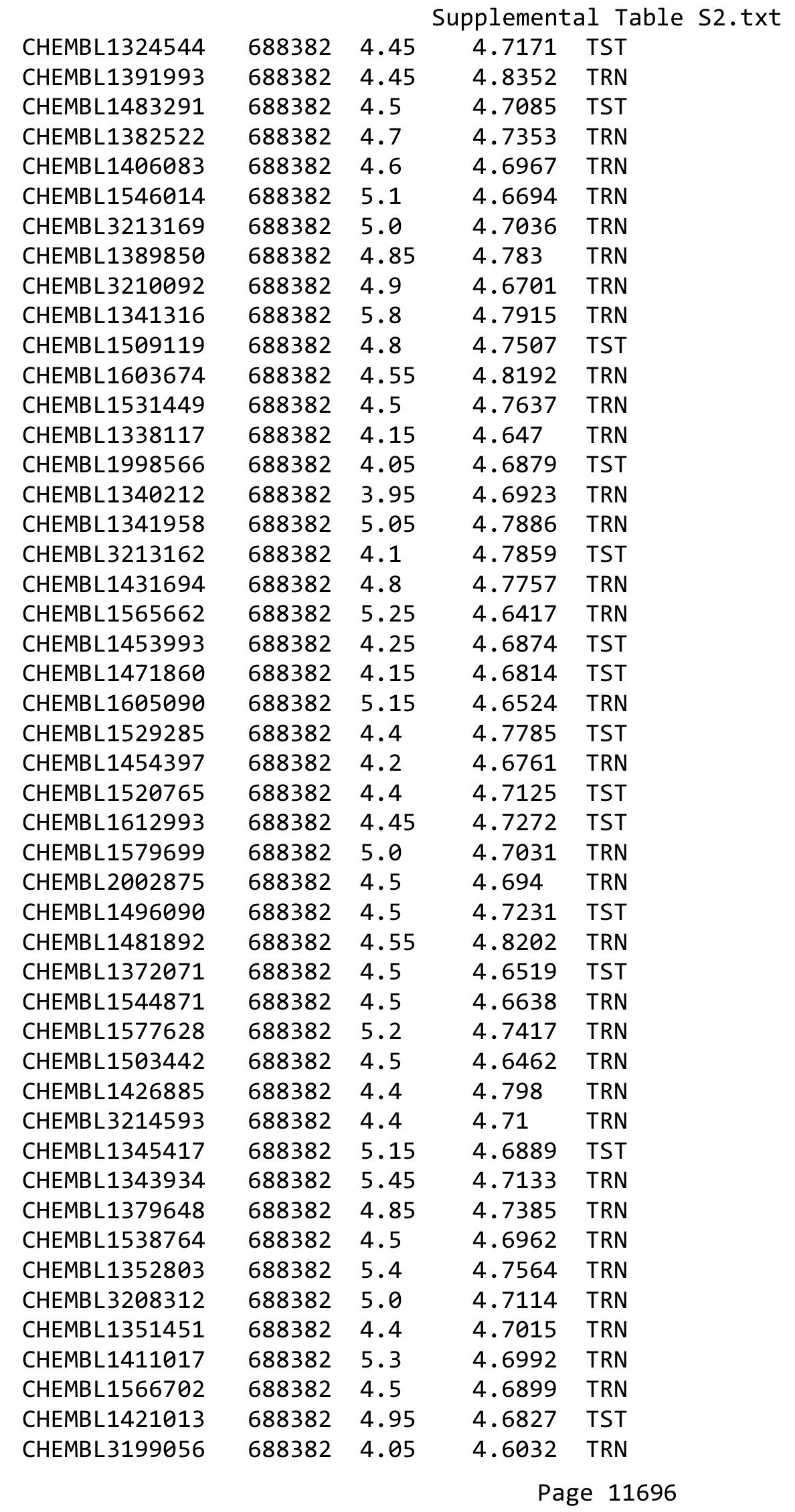




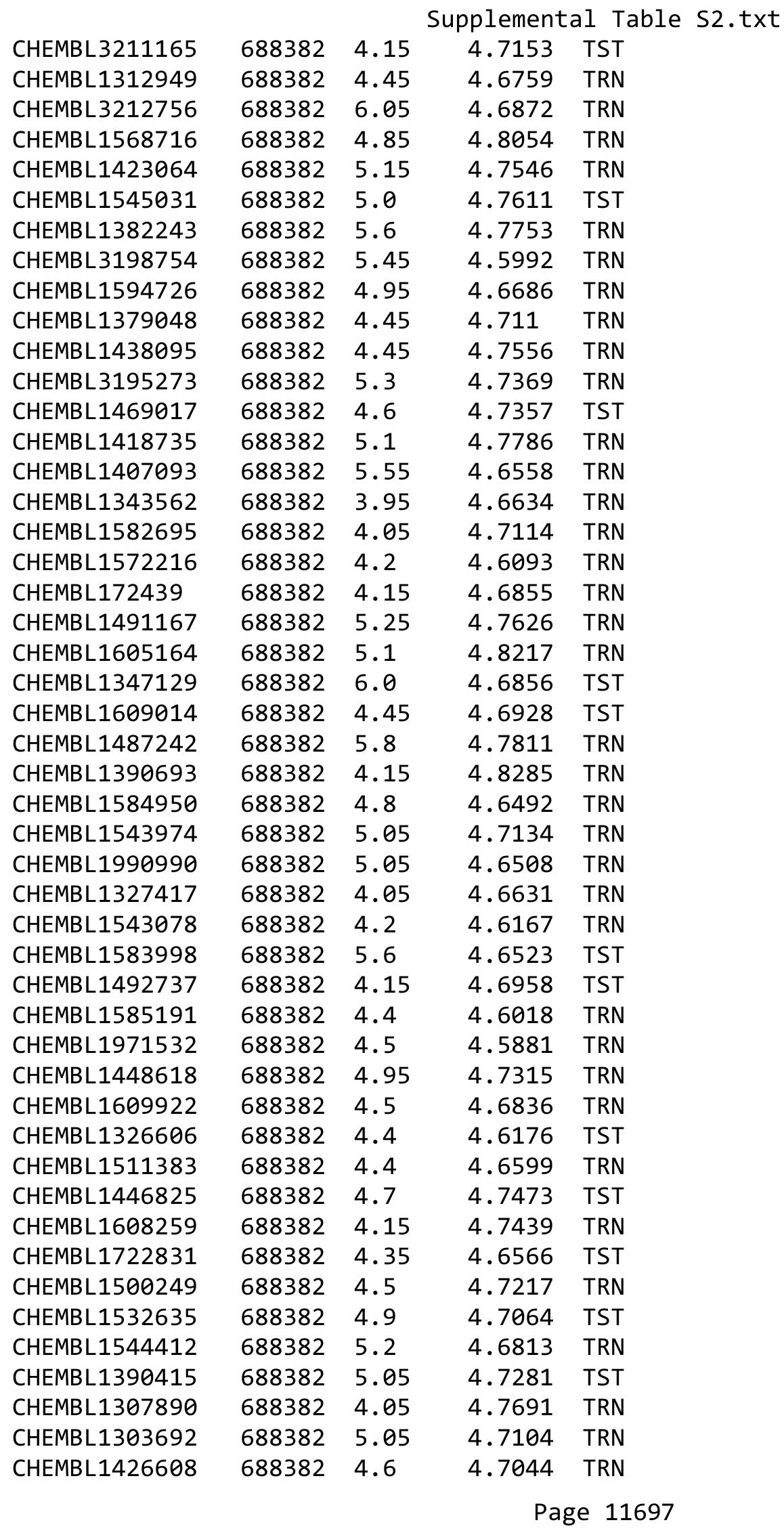




\begin{tabular}{|c|c|c|c|c|c|}
\hline & & \multicolumn{4}{|c|}{ Supplemental Table s2.txt } \\
\hline CHEMBL1540719 & 688382 & 4.75 & 4.6454 & TRN & \\
\hline CHEMBL1566165 & 688382 & 4.05 & 4.7424 & TRN & \\
\hline CHEMBL1479924 & 688382 & 4.0 & 4.7408 & TRN & \\
\hline CHEMBL225951 & 688382 & 5.0 & 4.6039 & TRN & \\
\hline CHEMBL1385160 & 688382 & 4.8 & 4.6587 & TRN & \\
\hline CHEMBL1491315 & 688382 & 5.0 & 4.6602 & TRN & \\
\hline CHEMBL1423166 & 688382 & 5.05 & 4.6696 & TRN & \\
\hline CHEMBL1466912 & 688382 & 4.15 & 4.6503 & TRN & \\
\hline CHEMBL1429390 & 688382 & 4.8 & 4.7836 & TRN & \\
\hline CHEMBL1486162 & 688382 & 5.05 & 4.7989 & TRN & \\
\hline CHEMBL1449380 & 688382 & 4.5 & 4.7646 & TRN & \\
\hline CHEMBL1596255 & 688382 & 5.0 & 4.7136 & TRN & \\
\hline CHEMBL1529970 & 688382 & 4.75 & 4.8268 & TRN & \\
\hline CHEMBL1500573 & 688382 & 4.5 & 4.6201 & TRN & \\
\hline CHEMBL1325870 & 688382 & 4.05 & 4.7748 & TRN & \\
\hline CHEMBL3190646 & 688382 & 4.4 & 4.6502 & TRN & \\
\hline CHEMBL1335650 & 688382 & 4.45 & 4.6808 & TRN & \\
\hline CHEMBL1500059 & 688382 & 4.4 & 4.6753 & TRN & \\
\hline CHEMBL1308279 & 688382 & 5.5 & 4.7233 & TRN & \\
\hline CHEMBL1420901 & 688382 & 4.45 & 4.624 & TRN & \\
\hline CHEMBL1561462 & 688382 & 4.7 & 4.6944 & TRN & \\
\hline CHEMBL1547415 & 688382 & 4.2 & 4.8295 & TRN & \\
\hline CHEMBL1445432 & 688382 & 4.65 & 4.7532 & TST & \\
\hline CHEMBL1310606 & 688382 & 4.85 & 4.6457 & TRN & \\
\hline CHEMBL1364081 & 688382 & 4.8 & 4.7608 & TRN & \\
\hline CHEMBL1500751 & 688382 & 4.7 & 4.6652 & TST & \\
\hline CHEMBL1416322 & 688382 & 4.05 & 4.6041 & TRN & \\
\hline CHEMBL1346867 & 688382 & 4.85 & 4.7359 & TRN & \\
\hline CHEMBL3212657 & 688382 & 4.45 & 4.7029 & TRN & \\
\hline CHEMBL1380511 & 688382 & 4.4 & 4.6201 & TRN & \\
\hline CHEMBL1414504 & 688382 & 4.45 & 4.7045 & TST & \\
\hline CHEMBL1401358 & 688382 & 4.5 & 4.7157 & TST & \\
\hline CHEMBL1372767 & 688382 & 4.35 & 4.7087 & TRN & \\
\hline CHEMBL1371019 & 688382 & 5.35 & 4.7659 & TRN & \\
\hline CHEMBL1392517 & 688382 & 4.45 & 4.6662 & TRN & \\
\hline CHEMBL1611828 & 688382 & 6.0 & 4.6533 & TST & \\
\hline CHEMBL1484436 & 688382 & 5.15 & 4.7038 & TRN & \\
\hline CHEMBL1561821 & 688382 & 5.85 & 4.6687 & TRN & \\
\hline CHEMBL1535316 & 688382 & 4.9 & 4.6871 & TRN & \\
\hline CHEMBL1478664 & 688382 & 4.15 & 4.6501 & TRN & \\
\hline CHEMBL1351659 & 688382 & 5.0 & 4.766 & TST & \\
\hline CHEMBL1544151 & 688382 & 5.85 & 4.7634 & TRN & \\
\hline CHEMBL1597210 & 688382 & 5.1 & 4.768 & TRN & \\
\hline CHEMBL1527341 & 688382 & 4.45 & 4.6795 & TRN & \\
\hline CHEMBL1581406 & 688382 & 4.85 & 4.64199 & 99999999995 & TRN \\
\hline CHEMBL1313411 & 688382 & 4.8 & 4.7765 & TRN & \\
\hline CHEMBL1427406 & 688382 & 4.8 & 4.7869 & TRN & \\
\hline CHEMBL1531824 & 688382 & 4.6 & 4.6944 & TRN & \\
\hline
\end{tabular}




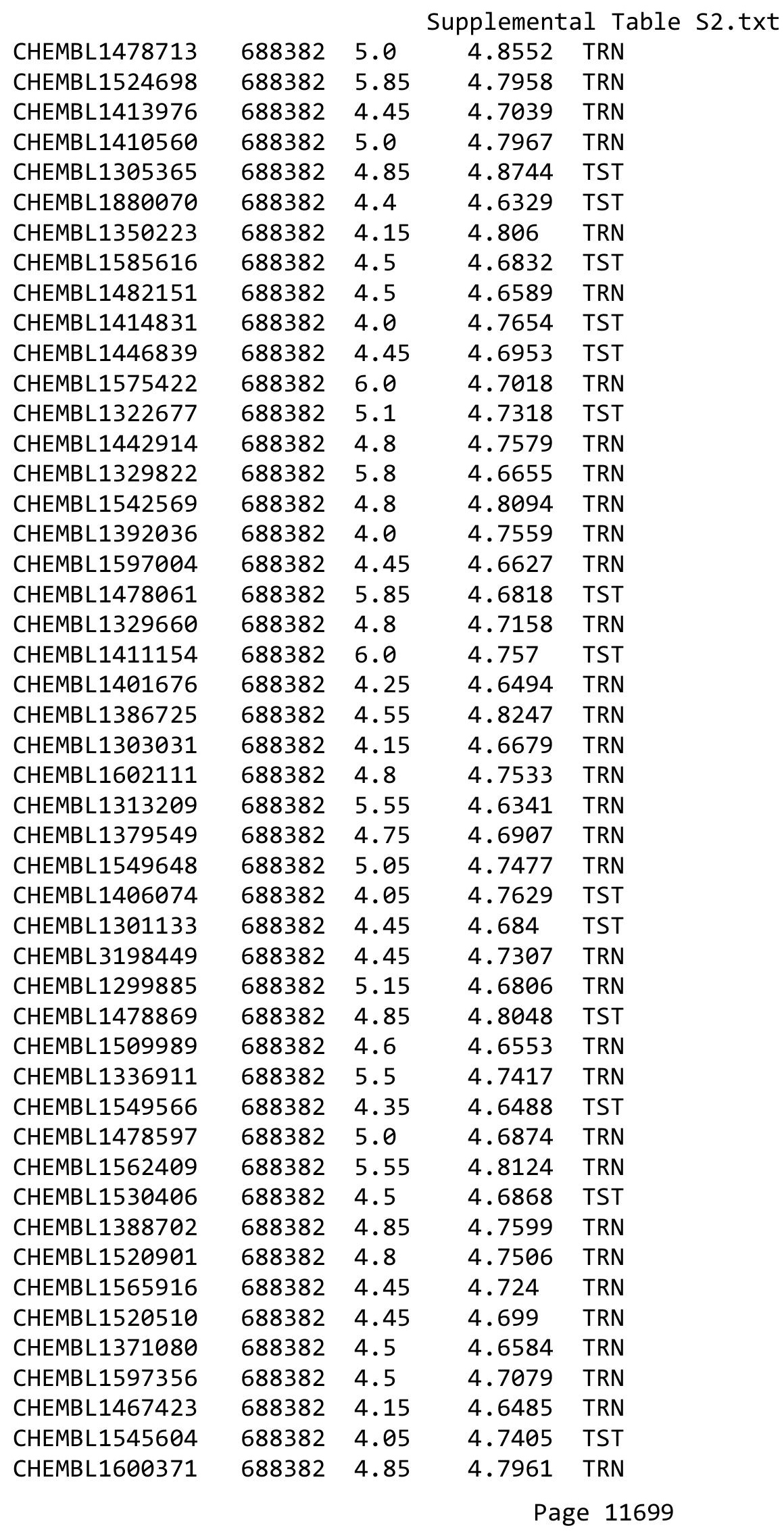




\begin{tabular}{|c|c|c|c|c|}
\hline \multicolumn{5}{|c|}{ lemental T } \\
\hline CHEMBL1544048 & 688382 & 4.8 & 4.7493 & TRN \\
\hline CHEMBL1561722 & 688382 & 4.5 & 4.6307 & TRN \\
\hline CHEMBL1331683 & 688382 & 5.0 & 4.7311 & TRN \\
\hline CHEMBL1562329 & 688382 & 5.9 & 4.8398 & TRN \\
\hline CHEMBL1406375 & 688382 & 5.5 & 4.6967 & TRN \\
\hline CHEMBL1328384 & 688382 & 5.4 & 4.6937 & TST \\
\hline CHEMBL3198404 & 688382 & 4.05 & 4.6553 & TRN \\
\hline CHEMBL1320651 & 688382 & 4.5 & 4.7468 & TRN \\
\hline CHEMBL1307494 & 688382 & 4.45 & 4.6602 & TRN \\
\hline CHEMBL1541023 & 688382 & 4.3 & 4.6223 & TRN \\
\hline CHEMBL1330201 & 688382 & 4.05 & 4.6075 & TRN \\
\hline CHEMBL1454000 & 688382 & 4.5 & 4.6303 & TRN \\
\hline CHEMBL1447855 & 688382 & 4.05 & 4.7409 & TRN \\
\hline CHEMBL1464295 & 688382 & 4.85 & 4.7686 & TRN \\
\hline CHEMBL1543871 & 688382 & 4.45 & 4.7078 & TRN \\
\hline CHEMBL1438378 & 688382 & 4.5 & 4.7438 & TRN \\
\hline CHEMBL1395977 & 688382 & 4.6 & 4.6808 & TRN \\
\hline CHEMBL1522422 & 688382 & 4.4 & 4.6491 & TRN \\
\hline CHEMBL1346754 & 688382 & 5.2 & 4.8004 & TRN \\
\hline CHEMBL1598985 & 688382 & 4.5 & 4.6903 & TRN \\
\hline CHEMBL1544753 & 688382 & 4.45 & 4.6445 & TRN \\
\hline CHEMBL1391511 & 688382 & 4.05 & 4.7517 & TST \\
\hline CHEMBL1580784 & 688382 & 4.75 & 4.7738 & TRN \\
\hline CHEMBL1521222 & 688382 & 4.8 & 4.6865 & TRN \\
\hline CHEMBL1556137 & 688382 & 4.15 & 4.7076 & TRN \\
\hline CHEMBL1510018 & 688382 & 4.1 & 4.7504 & TST \\
\hline CHEMBL1304415 & 688382 & 5.5 & 4.6703 & TRN \\
\hline CHEMBL1329395 & 688382 & 4.5 & 4.7272 & TRN \\
\hline CHEMBL1341374 & 688382 & 5.45 & 4.7544 & TRN \\
\hline CHEMBL1299462 & 688382 & 4.45 & 4.7571 & TST \\
\hline CHEMBL1506598 & 688382 & 6.0 & 4.7653 & TST \\
\hline CHEMBL1419088 & 688382 & 4.0 & 4.7863 & TRN \\
\hline CHEMBL1597981 & 688382 & 4.5 & 4.6772 & TRN \\
\hline CHEMBL590184 & 688382 & 4.6 & 4.5833 & TRN \\
\hline CHEMBL1548815 & 688382 & 4.45 & 4.6409 & TRN \\
\hline CHEMBL1312174 & 688382 & 4.15 & 4.6749 & TRN \\
\hline CHEMBL1516434 & 688382 & 4.9 & 4.6856 & TST \\
\hline CHEMBL1521729 & 688382 & 4.5 & 4.761 & TRN \\
\hline CHEMBL1481039 & 688382 & 5.05 & 4.7586 & TRN \\
\hline CHEMBL1490887 & 688382 & 4.5 & 4.8036 & TST \\
\hline CHEMBL1361070 & 688382 & 5.45 & 4.6817 & TRN \\
\hline CHEMBL1424878 & 688382 & 4.5 & 4.6374 & TST \\
\hline CHEMBL1555766 & 688382 & 4.95 & 4.7926 & TRN \\
\hline CHEMBL1342450 & 688382 & 4.4 & 4.7004 & TST \\
\hline CHEMBL1583532 & 688382 & 4.4 & 4.7051 & TRN \\
\hline CHEMBL1527986 & 688382 & 4.5 & 4.6546 & TRN \\
\hline CHEMBL1361924 & 688382 & 4.5 & 4.711 & TRN \\
\hline CHEMBL1366884 & 688382 & 5.9 & 4.7418 & TRN \\
\hline
\end{tabular}




\begin{tabular}{|c|c|c|c|c|}
\hline \multicolumn{5}{|c|}{ Supplemental Table S2.txt } \\
\hline CHEMBL1530294 & 688382 & 4.45 & 4.6032 & TRN \\
\hline CHEMBL1333377 & 688382 & 4.05 & 4.7496 & TRN \\
\hline CHEMBL1404472 & 688382 & 4.35 & 4.6653 & TRN \\
\hline CHEMBL1404616 & 688382 & 5.85 & 4.8375 & TRN \\
\hline CHEMBL1608898 & 688382 & 5.05 & 4.7848 & TRN \\
\hline CHEMBL1613681 & 688382 & 4.45 & 4.6441 & TRN \\
\hline CHEMBL3191010 & 688382 & 4.15 & 4.6833 & TRN \\
\hline CHEMBL1428197 & 688382 & 4.05 & 4.6027 & TRN \\
\hline CHEMBL1331663 & 688382 & 5.2 & 4.7873 & TRN \\
\hline CHEMBL1393003 & 688382 & 5.0 & 4.6831 & TRN \\
\hline CHEMBL1459729 & 688382 & 4.05 & 4.8014 & TRN \\
\hline CHEMBL1301879 & 688382 & 4.15 & 4.8007 & TRN \\
\hline CHEMBL1342954 & 688382 & 4.35 & 4.6406 & TRN \\
\hline CHEMBL1323359 & 688382 & 4.85 & 4.7328 & TST \\
\hline CHEMBL1352920 & 688382 & 4.8 & 4.772 & TRN \\
\hline CHEMBL1326655 & 688382 & 4.05 & 4.6316 & TRN \\
\hline CHEMBL1382760 & 688382 & 4.15 & 4.6572 & TST \\
\hline CHEMBL1372631 & 688382 & 4.45 & 4.7219 & TRN \\
\hline CHEMBL1383152 & 688382 & 4.8 & 4.7527 & TRN \\
\hline CHEMBL1387410 & 688382 & 4.45 & 4.6646 & TRN \\
\hline CHEMBL1521860 & 688382 & 4.5 & 4.6606 & TRN \\
\hline CHEMBL1508138 & 688382 & 5.1 & 4.6644 & TRN \\
\hline CHEMBL1427520 & 688382 & 4.4 & 4.7707 & TRN \\
\hline CHEMBL1353221 & 688382 & 4.45 & 4.6824 & TST \\
\hline CHEMBL1519735 & 688382 & 4.8 & 4.7909 & TST \\
\hline CHEMBL1172995 & 688382 & 5.5 & 4.7009 & TST \\
\hline CHEMBL1354301 & 688382 & 5.55 & 4.6768 & TST \\
\hline CHEMBL1307019 & 688382 & 5.25 & 4.6698 & TRN \\
\hline CHEMBL1580318 & 688382 & 5.8 & 4.5992 & TST \\
\hline CHEMBL1430795 & 688382 & 4.45 & 4.6988 & TST \\
\hline CHEMBL1430518 & 688382 & 5.0 & 4.7794 & TRN \\
\hline CHEMBL1300894 & 688382 & 5.3 & 4.7067 & TST \\
\hline CHEMBL1480762 & 688382 & 4.8 & 4.7666 & TRN \\
\hline CHEMBL1607656 & 688382 & 4.5 & 4.7042 & TRN \\
\hline CHEMBL3208367 & 688382 & 4.4 & 4.6876 & TRN \\
\hline CHEMBL1306740 & 688382 & 4.05 & 4.8379 & TRN \\
\hline CHEMBL1370827 & 688382 & 4.8 & 4.7677 & TRN \\
\hline CHEMBL1407370 & 688382 & 4.45 & 4.6891 & TRN \\
\hline CHEMBL1452723 & 688382 & 5.3 & 4.6589 & TRN \\
\hline CHEMBL1544385 & 688382 & 4.1 & 4.6854 & TRN \\
\hline CHEMBL1489801 & 688382 & 5.85 & 4.7355 & TRN \\
\hline CHEMBL1594294 & 688382 & 4.8 & 4.7806 & TRN \\
\hline CHEMBL1609880 & 688382 & 4.15 & 4.6883 & TRN \\
\hline CHEMBL1439010 & 688382 & 4.8 & 4.8359 & TRN \\
\hline CHEMBL3195445 & 688382 & 4.5 & 4.7507 & TST \\
\hline CHEMBL1417758 & 688382 & 4.75 & 4.7112 & TRN \\
\hline CHEMBL1439933 & 688382 & 4.5 & 4.8386 & TRN \\
\hline CHEMBL3199116 & 688382 & 4.15 & 4.5956 & TRN \\
\hline
\end{tabular}




\begin{tabular}{|c|c|c|c|c|c|}
\hline & & \multicolumn{4}{|c|}{ Supplemental Table s2.txt } \\
\hline CHEMBL1411112 & 688382 & 4.85 & 4.726 & TRN & \\
\hline CHEMBL1546791 & 688382 & 4.2 & 4.6039 & TRN & \\
\hline CHEMBL1521196 & 688382 & 4.3 & 4.645 & TRN & \\
\hline CHEMBL1546197 & 688382 & 4.6 & 4.6649 & TRN & \\
\hline CHEMBL1377477 & 688382 & 4.0 & 4.7158 & TRN & \\
\hline CHEMBL1421758 & 688382 & 4.05 & 4.6859 & TST & \\
\hline CHEMBL1431374 & 688382 & 5.05 & 4.7004 & TRN & \\
\hline CHEMBL1516809 & 688382 & 4.0 & 4.8503 & TRN & \\
\hline CHEMBL1564961 & 688382 & 4.85 & 4.7631 & TRN & \\
\hline CHEMBL1490141 & 688382 & 4.45 & 4.7258 & TST & \\
\hline CHEMBL1508549 & 688382 & 4.5 & 4.8143 & TRN & \\
\hline CHEMBL1517167 & 688382 & 4.8 & 4.7275 & TST & \\
\hline CHEMBL1507774 & 688382 & 4.35 & 4.7692 & TRN & \\
\hline CHEMBL1599823 & 688382 & 4.9 & 4.7305 & TRN & \\
\hline CHEMBL1438746 & 688382 & 4.8 & 4.7012 & TST & \\
\hline CHEMBL1463622 & 688382 & 4.15 & 4.6992 & TRN & \\
\hline CHEMBL1444918 & 688382 & 4.65 & 4.6433 & TRN & \\
\hline CHEMBL1613254 & 688382 & 5.05 & 4.7201 & TRN & \\
\hline CHEMBL1323381 & 688382 & 4.9 & 4.6492 & TST & \\
\hline CHEMBL1483471 & 688382 & 5.25 & 4.6686 & TRN & \\
\hline CHEMBL1448362 & 688382 & 4.35 & 4.7306 & TST & \\
\hline CHEMBL1323013 & 688382 & 4.7 & 4.7197 & TST & \\
\hline CHEMBL1402216 & 688382 & 5.0 & 4.7153 & TST & \\
\hline CHEMBL1541370 & 688382 & 4.45 & 4.7395 & TRN & \\
\hline CHEMBL1421865 & 688382 & 5.85 & 4.8386 & TRN & \\
\hline CHEMBL1372183 & 688382 & 4.05 & 4.6899 & TRN & \\
\hline CHEMBL1526459 & 688382 & 5.5 & 4.7208 & TRN & \\
\hline CHEMBL1532858 & 688382 & 4.05 & 4.7633 & TRN & \\
\hline CHEMBL1427545 & 688382 & 6.0 & 4.6912 & TRN & \\
\hline CHEMBL1310865 & 688382 & 4.5 & 4.7501 & TRN & \\
\hline CHEMBL1349563 & 688382 & 4.8 & 4.7832 & TRN & \\
\hline CHEMBL1456108 & 688382 & 5.1 & 4.8342 & TRN & \\
\hline CHEMBL1499239 & 688382 & 4.75 & 4.7369 & TST & \\
\hline CHEMBL1313166 & 688382 & 4.15 & 4.603 & TST & \\
\hline CHEMBL1318965 & 688382 & 4.8 & 4.7154 & TST & \\
\hline CHEMBL1382236 & 688382 & 5.45 & 4.71899 & 9999999999 & TRN \\
\hline CHEMBL1318159 & 688382 & 4.5 & 4.687 & TRN & \\
\hline CHEMBL1400103 & 688382 & 4.5 & 4.7233 & TRN & \\
\hline CHEMBL1601174 & 688382 & 5.5 & 4.6397 & TST & \\
\hline CHEMBL1532412 & 688382 & 4.35 & 4.6241 & TRN & \\
\hline CHEMBL1405269 & 688382 & 4.45 & 4.7059 & TST & \\
\hline CHEMBL1368867 & 688382 & 4.55 & 4.7003 & TST & \\
\hline CHEMBL1370090 & 688382 & 4.8 & 4.7205 & TST & \\
\hline CHEMBL1410838 & 688382 & 4.5 & 4.6576 & TRN & \\
\hline CHEMBL1499281 & 688382 & 4.9 & 4.7189 & TRN & \\
\hline CHEMBL278691 & 688382 & 5.15 & 4.6617 & TST & \\
\hline CHEMBL1336930 & 688382 & 5.95 & 4.6448 & TRN & \\
\hline CHEMBL1442003 & 688382 & 4.95 & 4.8673 & TRN & \\
\hline
\end{tabular}




\begin{tabular}{|c|c|c|c|c|c|}
\hline \multicolumn{6}{|c|}{ Supplemental Table s2.txt } \\
\hline CHEMBL1380649 & 688382 & 4.0 & 4.7869 & TRN & \\
\hline CHEMBL1460585 & 688382 & 4.95 & 4.6275 & TST & \\
\hline CHEMBL1351320 & 688382 & 5.0 & 4.7487 & TST & \\
\hline CHEMBL1597644 & 688382 & 4.55 & 4.74100 & 00000000005 & TRN \\
\hline CHEMBL1466664 & 688382 & 4.4 & 4.731 & TRN & \\
\hline CHEMBL1482757 & 688382 & 4.8 & 4.6797 & TST & \\
\hline CHEMBL1377567 & 688382 & 4.05 & 4.6699 & TRN & \\
\hline CHEMBL1578385 & 688382 & 4.5 & 4.6959 & TRN & \\
\hline CHEMBL531322 & 688382 & 4.15 & 4.6226 & TRN & \\
\hline CHEMBL1490742 & 688382 & 5.1 & 4.7598 & TRN & \\
\hline CHEMBL1537018 & 688382 & 4.15 & 4.6697 & TRN & \\
\hline CHEMBL1559047 & 688382 & 5.45 & 4.6131 & TRN & \\
\hline CHEMBL1472065 & 688382 & 4.85 & 4.7439 & TRN & \\
\hline CHEMBL1986274 & 688382 & 5.1 & 4.66100 & 00000000005 & TRN \\
\hline CHEMBL1989897 & 688382 & 5.9 & 4.6363 & TRN & \\
\hline CHEMBL1389404 & 688382 & 4.45 & 4.7819 & TRN & \\
\hline CHEMBL3145106 & 688382 & 4.9 & 4.6643 & TST & \\
\hline CHEMBL1411782 & 688382 & 4.2 & 4.6141 & TRN & \\
\hline CHEMBL3192419 & 688382 & 5.05 & 4.6956 & TRN & \\
\hline CHEMBL1366488 & 688382 & 4.4 & 4.6796 & TRN & \\
\hline CHEMBL1430913 & 688382 & 5.1 & 4.7651 & TRN & \\
\hline CHEMBL1537411 & 688382 & 4.5 & 4.6772 & TRN & \\
\hline CHEMBL1405041 & 688382 & 5.2 & 4.6749 & TRN & \\
\hline CHEMBL1575583 & 688382 & 4.15 & 4.8215 & TRN & \\
\hline CHEMBL1607013 & 688382 & 5.05 & 4.6242 & TRN & \\
\hline CHEMBL1405622 & 688382 & 4.8 & 4.6693 & TRN & \\
\hline CHEMBL1603865 & 688382 & 5.15 & 4.6112 & TST & \\
\hline CHEMBL1510343 & 688382 & 6.0 & 4.7226 & TST & \\
\hline CHEMBL1332816 & 688382 & 5.85 & 4.7503 & TST & \\
\hline CHEMBL11908 & 688382 & 4.15 & 4.6344 & TRN & \\
\hline CHEMBL1412647 & 688382 & 4.05 & 4.625 & TST & \\
\hline CHEMBL35228 & 688382 & 4.95 & 4.6855 & TST & \\
\hline CHEMBL1462733 & 688382 & 4.9 & 4.72 & TST & \\
\hline CHEMBL569146 & 688382 & 4.55 & 4.717 & TST & \\
\hline CHEMBL1370870 & 688382 & 4.9 & 4.6374 & TST & \\
\hline CHEMBL1596179 & 688382 & 5.9 & 4.7656 & TRN & \\
\hline CHEMBL3210706 & 688382 & 5.15 & 4.75 & TRN & \\
\hline CHEMBL1375332 & 688382 & 4.85 & 4.6411 & TRN & \\
\hline CHEMBL1543749 & 688382 & 4.05 & 4.7274 & TRN & \\
\hline CHEMBL1588668 & 688382 & 5.35 & 4.7668 & TRN & \\
\hline CHEMBL3191365 & 688382 & 4.3 & 4.6651 & TRN & \\
\hline CHEMBL1527135 & 688382 & 4.05 & 4.7299 & TST & \\
\hline CHEMBL1427683 & 688382 & 4.75 & 4.81 & TRN & \\
\hline CHEMBL1498173 & 688382 & 4.9 & 4.6993 & TRN & \\
\hline CHEMBL1459009 & 688382 & 4.0 & 4.7894 & TRN & \\
\hline CHEMBL1568036 & 688382 & 5.15 & 4.6942 & TST & \\
\hline CHEMBL1343339 & 688382 & 5.3 & 4.8487 & TRN & \\
\hline CHEMBL1517382 & 688382 & 4.65 & 4.6832 & TRN & \\
\hline
\end{tabular}




\begin{tabular}{|c|c|c|c|c|c|}
\hline \multicolumn{6}{|c|}{ Supplemental Table S2.txt } \\
\hline CHEMBL1518152 & 688382 & 4.8 & 4.7866 & TRN & \\
\hline CHEMBL1545104 & 688382 & 4.4 & 4.657 & TRN & \\
\hline CHEMBL 2003840 & 688382 & 4.35 & 4.6877 & TRN & \\
\hline CHEMBL1417095 & 688382 & 4.15 & 4.6644 & TST & \\
\hline CHEMBL1371906 & 688382 & 4.45 & 4.7227 & TST & \\
\hline CHEMBL1344297 & 688382 & 4.95 & 4.6924 & TST & \\
\hline CHEMBL1393375 & 688382 & 4.55 & 4.8028 & TRN & \\
\hline CHEMBL1372728 & 688382 & 5.25 & 4.7401 & TRN & \\
\hline CHEMBL1569415 & 688382 & 4.5 & 4.7122 & TRN & \\
\hline CHEMBL1610558 & 688382 & 4.95 & 4.7556 & TST & \\
\hline CHEMBL1336267 & 688382 & 4.75 & 4.7608 & TRN & \\
\hline CHEMBL1578749 & 688382 & 4.85 & 4.7524 & TRN & \\
\hline CHEMBL3208444 & 688382 & 4.5 & 4.6302 & TST & \\
\hline CHEMBL1527877 & 688382 & 4.4 & 4.6745 & TRN & \\
\hline CHEMBL1365410 & 688382 & 4.85 & 4.7664 & TST & \\
\hline CHEMBL1484527 & 688382 & 4.5 & 4.8953 & TRN & \\
\hline CHEMBL1314092 & 688382 & 4.45 & 4.6756 & TST & \\
\hline CHEMBL1438612 & 688382 & 4.05 & 4.7471 & TRN & \\
\hline CHEMBL1302565 & 688382 & 4.4 & 4.6721 & TRN & \\
\hline CHEMBL1545687 & 688382 & 5.1 & 4.7401 & TST & \\
\hline CHEMBL1428893 & 688382 & 5.1 & 4.8202 & TRN & \\
\hline CHEMBL1402491 & 688382 & 4.55 & 4.6854 & TST & \\
\hline CHEMBL1585640 & 688382 & 4.95 & 4.7081 & TRN & \\
\hline CHEMBL1596402 & 688382 & 4.85 & 4.7529 & TRN & \\
\hline CHEMBL1579579 & 688382 & 4.2 & 4.6557 & TRN & \\
\hline CHEMBL1484293 & 688382 & 4.05 & 4.6325 & TRN & \\
\hline CHEMBL1450397 & 688382 & 5.05 & 4.7559 & TRN & \\
\hline CHEMBL1431407 & 688382 & 4.55 & 4.6376 & TRN & \\
\hline CHEMBL1520346 & 688382 & 4.5 & 4.6506 & TRN & \\
\hline CHEMBL1598648 & 688382 & 4.0 & 4.771 & TRN & \\
\hline CHEMBL1556687 & 688382 & 4.4 & 4.6966 & TRN & \\
\hline CHEMBL1409525 & 688382 & 5.4 & 4.64199 & 99999999995 & TRN \\
\hline CHEMBL1467031 & 688382 & 4.8 & 4.7109 & TRN & \\
\hline CHEMBL1534694 & 688382 & 4.15 & 4.6989 & TRN & \\
\hline CHEMBL1374415 & 688382 & 4.95 & 4.7659 & TRN & \\
\hline CHEMBL1442533 & 688382 & 5.05 & 4.7067 & TST & \\
\hline CHEMBL1457383 & 688382 & 4.45 & 4.8473 & TRN & \\
\hline CHEMBL1606709 & 688382 & 4.9 & 4.6713 & TRN & \\
\hline CHEMBL1484618 & 688382 & 4.45 & 4.6449 & TST & \\
\hline CHEMBL586782 & 688382 & 4.85 & 4.8449 & TRN & \\
\hline CHEMBL1433181 & 688382 & 4.25 & 4.8149 & TRN & \\
\hline CHEMBL1391157 & 688382 & 4.05 & 4.76699 & 99999999995 & TST \\
\hline CHEMBL1604488 & 688382 & 4.55 & 4.675 & TST & \\
\hline CHEMBL1461337 & 688382 & 4.15 & 4.7198 & TRN & \\
\hline CHEMBL1403532 & 688382 & 4.8 & 4.8107 & TRN & \\
\hline CHEMBL1601529 & 688382 & 4.75 & 4.6622 & TST & \\
\hline CHEMBL1534257 & 688382 & 4.7 & 4.6469 & TRN & \\
\hline CHEMBL1463659 & 688382 & 4.9 & 4.6179 & TRN & \\
\hline
\end{tabular}




\begin{tabular}{|c|c|c|c|c|c|}
\hline & & \multicolumn{4}{|c|}{ Supplemental Table s2.txt } \\
\hline CHEMBL1587291 & 688382 & 4.45 & 4.6182 & TRN & \\
\hline CHEMBL1489137 & 688382 & 4.05 & 4.776 & TST & \\
\hline CHEMBL1611925 & 688382 & 4.0 & 4.7013 & TST & \\
\hline CHEMBL1345029 & 688382 & 4.95 & 4.6962 & TST & \\
\hline CHEMBL1325173 & 688382 & 3.95 & 4.7433 & TRN & \\
\hline CHEMBL1499794 & 688382 & 4.1 & 4.6075 & TRN & \\
\hline CHEMBL1517001 & 688382 & 4.95 & 4.7292 & TST & \\
\hline CHEMBL1307388 & 688382 & 4.15 & 4.7758 & TRN & \\
\hline CHEMBL1342312 & 688382 & 4.6 & 4.7416 & TRN & \\
\hline CHEMBL1437829 & 688382 & 4.6 & 4.587 & TST & \\
\hline CHEMBL 3197345 & 688382 & 4.9 & 4.6632 & TRN & \\
\hline CHEMBL3196761 & 688382 & 4.45 & 4.6891 & TST & \\
\hline CHEMBL1547311 & 688382 & 4.65 & 4.6851 & TRN & \\
\hline CHEMBL1482219 & 688382 & 4.2 & 4.6601 & TST & \\
\hline CHEMBL1405077 & 688382 & 5.0 & 4.705 & TRN & \\
\hline CHEMBL1498832 & 688382 & 4.6 & 4.7936 & TRN & \\
\hline CHEMBL1445413 & 688382 & 3.95 & 4.7056 & TRN & \\
\hline CHEMBL1526458 & 688382 & 5.25 & 4.8219 & TRN & \\
\hline CHEMBL1578290 & 688382 & 4.0 & 4.7194 & TRN & \\
\hline CHEMBL1577410 & 688382 & 4.5 & 4.671 & TRN & \\
\hline CHEMBL1359749 & 688382 & 6.0 & 4.6297 & TST & \\
\hline CHEMBL1427757 & 688382 & 4.7 & 4.6337 & TST & \\
\hline CHEMBL1381340 & 688382 & 4.1 & 4.6603 & TST & \\
\hline CHEMBL1608343 & 688382 & 5.65 & 4.7985 & TST & \\
\hline CHEMBL1413316 & 688382 & 5.95 & 4.7824 & TRN & \\
\hline CHEMBL1467892 & 688382 & 4.15 & 4.762 & TRN & \\
\hline CHEMBL3213659 & 688382 & 4.0 & 4.5783 & TRN & \\
\hline CHEMBL1521874 & 688382 & 4.45 & 4.6639 & TRN & \\
\hline CHEMBL1344900 & 688382 & 4.45 & 4.7089 & TRN & \\
\hline CHEMBL1544430 & 688382 & 4.85 & 4.6448 & TRN & \\
\hline CHEMBL1388152 & 688382 & 4.8 & 4.6832 & TRN & \\
\hline CHEMBL1504738 & 688382 & 4.8 & 4.7098 & TRN & \\
\hline CHEMBL1350504 & 688382 & 5.25 & 4.6622 & TRN & \\
\hline CHEMBL1507242 & 688382 & 4.15 & 4.6035 & TRN & \\
\hline CHEMBL1439906 & 688382 & 4.5 & 4.7093 & TRN & \\
\hline CHEMBL1342644 & 688382 & 4.5 & 4.72199 & 99999999995 & TRN \\
\hline CHEMBL1574592 & 688382 & 5.8 & 4.6632 & TRN & \\
\hline CHEMBL1602950 & 688382 & 4.15 & 4.6662 & TST & \\
\hline CHEMBL 3212065 & 688382 & 4.0 & 4.7439 & TRN & \\
\hline CHEMBL1587145 & 688382 & 4.5 & 4.5975 & TRN & \\
\hline CHEMBL1428334 & 688382 & 4.5 & 4.6605 & TRN & \\
\hline CHEMBL1336571 & 688382 & 4.55 & 4.7911 & TRN & \\
\hline CHEMBL1600976 & 688382 & 4.15 & 4.6393 & TRN & \\
\hline CHEMBL1311093 & 688382 & 5.85 & 4.7783 & TRN & \\
\hline CHEMBL1586004 & 688382 & 4.9 & 4.6389 & TRN & \\
\hline CHEMBL1428797 & 688382 & 5.0 & 4.7416 & TRN & \\
\hline CHEMBL1351799 & 688382 & 4.45 & 4.6408 & TRN & \\
\hline CHEMBL1319154 & 688382 & 4.65 & 4.7141 & TST & \\
\hline
\end{tabular}




\begin{tabular}{|c|c|c|c|c|}
\hline & & & upplemen & \\
\hline CHEMBL1320322 & 688382 & 4.75 & 4.7367 & TRN \\
\hline CHEMBL1381105 & 688382 & 4.35 & 4.7062 & TST \\
\hline CHEMBL1561277 & 688382 & 6.05 & 4.6203 & TRN \\
\hline CHEMBL1460089 & 688382 & 4.45 & 4.7957 & TRN \\
\hline CHEMBL1465284 & 688382 & 4.8 & 4.808 & TRN \\
\hline CHEMBL1489641 & 688382 & 5.05 & 4.6756 & TRN \\
\hline CHEMBL1478385 & 688382 & 4.5 & 4.7619 & TRN \\
\hline CHEMBL1319429 & 688382 & 6.0 & 4.7465 & TRN \\
\hline CHEMBL1548566 & 688382 & 4.45 & 4.6732 & TST \\
\hline CHEMBL1413888 & 688382 & 4.6 & 4.6681 & TRN \\
\hline CHEMBL1420559 & 688382 & 4.15 & 4.7595 & TST \\
\hline CHEMBL1571873 & 688382 & 4.35 & 4.742 & TRN \\
\hline CHEMBL1470315 & 688382 & 5.2 & 4.6633 & TST \\
\hline CHEMBL1485581 & 688382 & 4.4 & 4.7083 & TST \\
\hline CHEMBL1425113 & 688382 & 4.85 & 4.8221 & TRN \\
\hline CHEMBL1878966 & 688382 & 4.45 & 4.6438 & TST \\
\hline CHEMBL1405340 & 688382 & 4.3 & 4.7662 & TRN \\
\hline CHEMBL1479085 & 688382 & 4.85 & 4.8318 & TRN \\
\hline CHEMBL1506282 & 688382 & 4.45 & 4.7632 & TRN \\
\hline CHEMBL1608346 & 688382 & 4.4 & 4.7459 & TRN \\
\hline CHEMBL1575956 & 688382 & 4.8 & 4.6855 & TST \\
\hline CHEMBL1328659 & 688382 & 4.15 & 4.8496 & TRN \\
\hline CHEMBL1339881 & 688382 & 5.15 & 4.699 & TRN \\
\hline CHEMBL3197584 & 688382 & 4.95 & 4.6866 & TST \\
\hline CHEMBL1472515 & 688382 & 4.15 & 4.673 & TRN \\
\hline CHEMBL1542579 & 688382 & 4.85 & 4.7528 & TRN \\
\hline CHEMBL1503018 & 688382 & 5.5 & 4.791 & TST \\
\hline CHEMBL1308845 & 688382 & 4.7 & 4.6565 & TRN \\
\hline CHEMBL1311529 & 688382 & 6.0 & 4.8174 & TRN \\
\hline CHEMBL1360969 & 688382 & 4.45 & 4.7888 & TRN \\
\hline CHEMBL1576746 & 688382 & 4.95 & 4.7083 & TST \\
\hline CHEMBL1400433 & 688382 & 3.95 & 4.7066 & TRN \\
\hline CHEMBL1309321 & 688382 & 4.0 & 4.6788 & TRN \\
\hline CHEMBL1389804 & 688382 & 4.0 & 4.7398 & TRN \\
\hline CHEMBL1387999 & 688382 & 4.55 & 4.7492 & TRN \\
\hline CHEMBL3191954 & 688382 & 4.35 & 4.6427 & TRN \\
\hline CHEMBL1377448 & 688382 & 4.45 & 4.7081 & TRN \\
\hline CHEMBL1386495 & 688382 & 5.8 & 4.7923 & TRN \\
\hline CHEMBL1336988 & 688382 & 4.4 & 4.7643 & TRN \\
\hline CHEMBL240332 & 688382 & 4.6 & 4.5708 & TRN \\
\hline CHEMBL1334682 & 688382 & 4.85 & 4.7366 & TRN \\
\hline CHEMBL3196561 & 688382 & 6.0 & 4.6676 & TRN \\
\hline CHEMBL1425980 & 688382 & 4.4 & 4.6693 & TRN \\
\hline CHEMBL1339165 & 688382 & 5.0 & 4.7383 & TST \\
\hline CHEMBL1440163 & 688382 & 4.55 & 4.7856 & TRN \\
\hline CHEMBL1517227 & 688382 & 4.1 & 4.7767 & TRN \\
\hline CHEMBL1424604 & 688382 & 4.85 & 4.7906 & TRN \\
\hline CHEMBL1455362 & 688382 & 4.5 & 4.7042 & TRN \\
\hline
\end{tabular}




\begin{tabular}{|c|c|c|c|c|}
\hline \multicolumn{5}{|c|}{ Supplemental Table S2.txt } \\
\hline CHEMBL3208900 & 688382 & 4.5 & 4.6944 & TST \\
\hline CHEMBL226664 & 688382 & 4.15 & 4.69 & TRN \\
\hline CHEMBL1527042 & 688382 & 5.0 & 4.6508 & TST \\
\hline CHEMBL1484115 & 688382 & 5.05 & 4.725 & TRN \\
\hline CHEMBL1331469 & 688382 & 4.3 & 4.7506 & TRN \\
\hline CHEMBL1385477 & 688382 & 5.25 & 4.7304 & TRN \\
\hline CHEMBL1386448 & 688382 & 4.3 & 4.5807 & TST \\
\hline CHEMBL1577543 & 688382 & 4.8 & 4.7641 & TST \\
\hline CHEMBL1578863 & 688382 & 6.0 & 4.7885 & TRN \\
\hline CHEMBL1510630 & 688382 & 5.05 & 4.795 & TRN \\
\hline CHEMBL1409161 & 688382 & 4.05 & 4.7788 & TST \\
\hline CHEMBL1416504 & 688382 & 5.15 & 4.6653 & TRN \\
\hline CHEMBL1469753 & 688382 & 4.15 & 4.6803 & TST \\
\hline CHEMBL1531626 & 688382 & 4.85 & 4.687 & TRN \\
\hline CHEMBL1322306 & 688382 & 5.65 & 4.6829 & TST \\
\hline CHEMBL1538502 & 688382 & 4.5 & 4.7341 & TRN \\
\hline CHEMBL1495589 & 688382 & 4.65 & 4.6826 & TRN \\
\hline CHEMBL1498457 & 688382 & 4.0 & 4.7154 & TRN \\
\hline CHEMBL1459175 & 688382 & 4.45 & 4.7522 & TRN \\
\hline CHEMBL1465870 & 688382 & 4.15 & 4.7691 & TRN \\
\hline CHEMBL1393524 & 688382 & 4.2 & 4.6478 & TRN \\
\hline CHEMBL1565989 & 688382 & 4.4 & 4.583 & TST \\
\hline CHEMBL1509160 & 688382 & 4.2 & 4.7291 & TRN \\
\hline CHEMBL1500846 & 688382 & 5.55 & 4.6798 & TRN \\
\hline CHEMBL1452026 & 688382 & 4.35 & 4.6872 & TRN \\
\hline CHEMBL1602315 & 688382 & 4.15 & 4.7181 & TRN \\
\hline CHEMBL1408623 & 688382 & 4.05 & 4.7701 & TST \\
\hline CHEMBL1524548 & 688382 & 5.1 & 4.6886 & TRN \\
\hline CHEMBL1327635 & 688382 & 4.5 & 4.669 & TRN \\
\hline CHEMBL1481671 & 688382 & 4.15 & 4.6176 & TRN \\
\hline CHEMBL1424716 & 688382 & 4.15 & 4.7943 & TRN \\
\hline CHEMBL1468467 & 688382 & 6.0 & 4.8319 & TRN \\
\hline CHEMBL1409835 & 688382 & 4.45 & 4.6397 & TRN \\
\hline CHEMBL1382905 & 688382 & 4.35 & 4.6527 & TRN \\
\hline CHEMBL1362990 & 688382 & 4.4 & 4.7315 & TRN \\
\hline CHEMBL1326280 & 688382 & 4.8 & 4.7515 & TRN \\
\hline CHEMBL1407743 & 688382 & 4.5 & 4.6785 & TRN \\
\hline CHEMBL1576228 & 688382 & 4.2 & 4.631 & TST \\
\hline CHEMBL1483308 & 688382 & 4.45 & 4.6761 & TRN \\
\hline CHEMBL1335942 & 688382 & 5.35 & 4.71399 & 99999999995 \\
\hline CHEMBL3214100 & 688382 & 4.65 & 4.6328 & TRN \\
\hline CHEMBL1504565 & 688382 & 4.35 & 4.6964 & TRN \\
\hline CHEMBL1516989 & 688382 & 5.1 & 4.6486 & TST \\
\hline CHEMBL1365771 & 688382 & 4.5 & 4.7098 & TRN \\
\hline CHEMBL1532172 & 688382 & 4.0 & 4.7847 & TRN \\
\hline CHEMBL1311152 & 688382 & 5.0 & 4.7286 & TST \\
\hline CHEMBL1491958 & 688382 & 4.45 & 4.6909 & TRN \\
\hline CHEMBL1465510 & 688382 & 4.4 & 4.6473 & TST \\
\hline
\end{tabular}




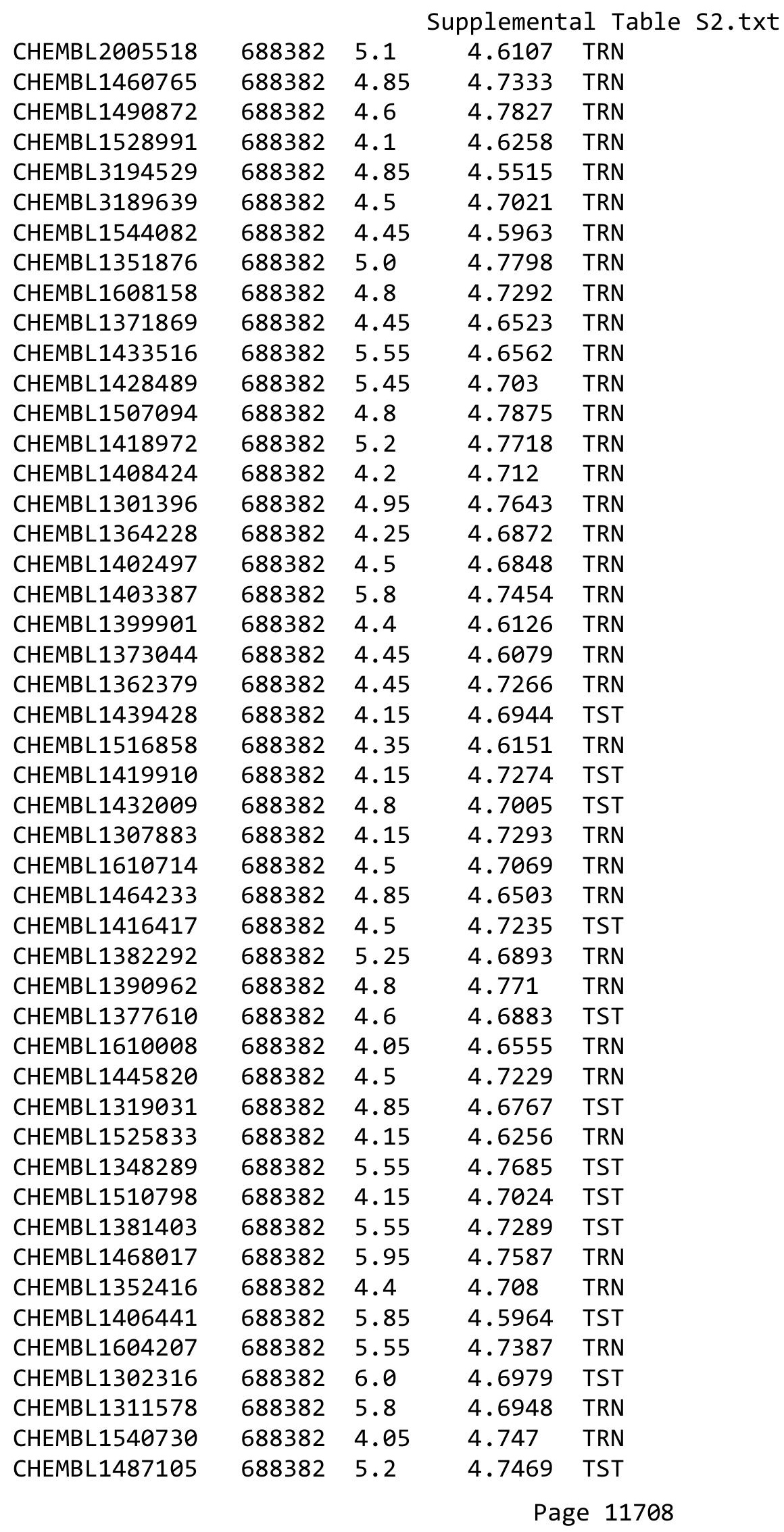




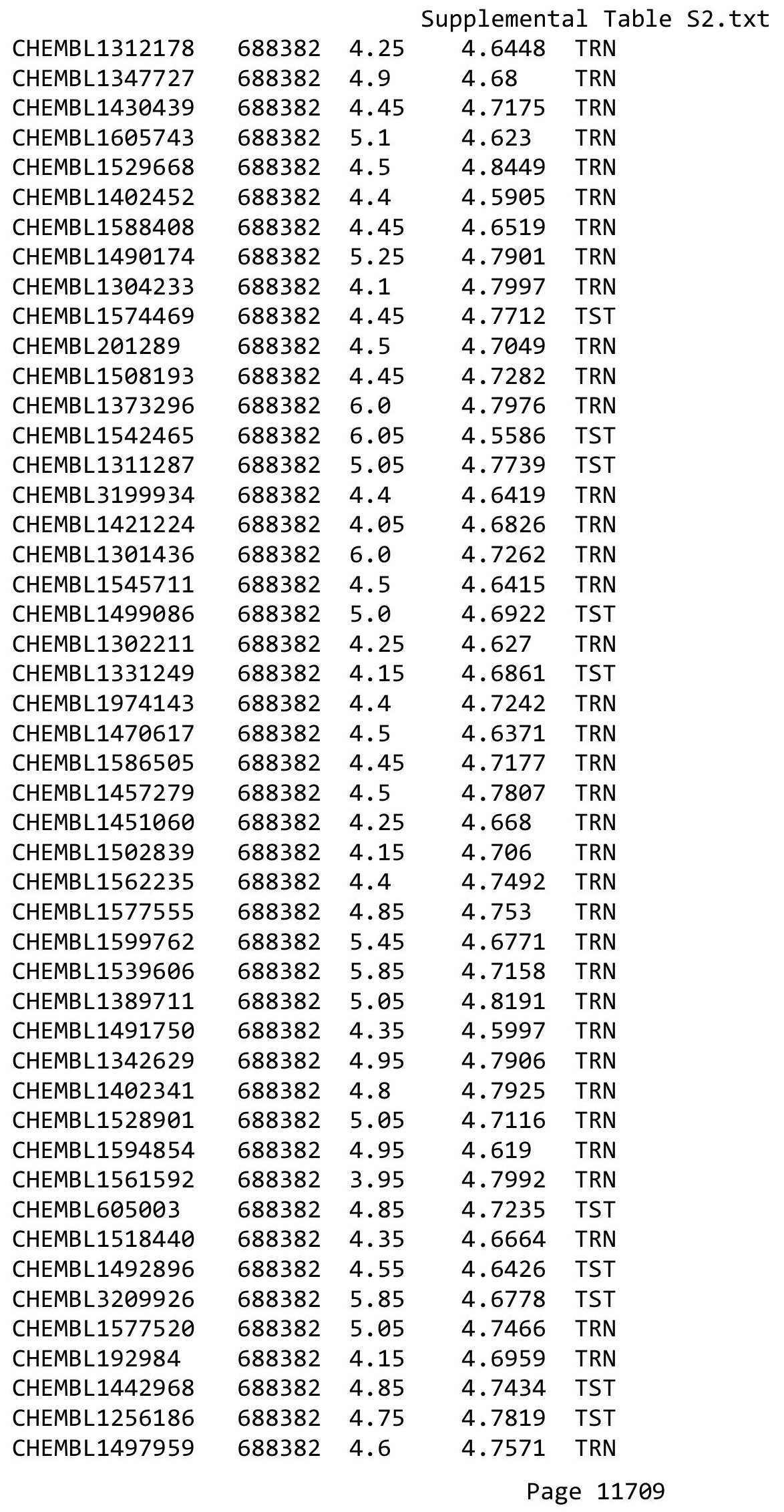




\begin{tabular}{|c|c|c|c|c|c|}
\hline \multicolumn{6}{|c|}{ Supplemental Table S2.txt } \\
\hline CHEMBL1358995 & 688382 & 5.8 & 4.7164 & TST & \\
\hline CHEMBL1471897 & 688382 & 6.0 & 4.7616 & TRN & \\
\hline CHEMBL1500239 & 688382 & 3.35 & 4.7913 & TRN & \\
\hline CHEMBL 3211481 & 688382 & 4.5 & 4.6773 & TST & \\
\hline CHEMBL204850 & 688382 & 4.85 & 4.7345 & TRN & \\
\hline CHEMBL1368559 & 688382 & 4.85 & 4.6425 & TRN & \\
\hline CHEMBL1493957 & 688382 & 4.4 & 4.6646 & TRN & \\
\hline CHEMBL1609234 & 688382 & 4.95 & 4.7275 & TST & \\
\hline CHEMBL1610623 & 688382 & 6.0 & 4.7274 & TRN & \\
\hline CHEMBL1384861 & 688382 & 4.55 & 4.7326 & TST & \\
\hline CHEMBL1425360 & 688382 & 4.75 & 4.7539 & TST & \\
\hline CHEMBL1526835 & 688382 & 4.4 & 4.6633 & TRN & \\
\hline CHEMBL2354875 & 688382 & 4.15 & 4.6178 & TRN & \\
\hline CHEMBL2359911 & 688382 & 5.2 & 4.6853 & TRN & \\
\hline CHEMBL1533047 & 688382 & 5.0 & 4.6817 & TRN & \\
\hline CHEMBL1390716 & 688382 & 5.9 & 4.6275 & TRN & \\
\hline CHEMBL1545081 & 688382 & 5.05 & 4.7736 & TRN & \\
\hline CHEMBL1534628 & 688382 & 5.0 & 4.6469 & TRN & \\
\hline CHEMBL1382997 & 688382 & 4.85 & 4.7109 & TST & \\
\hline CHEMBL1562325 & 688382 & 4.85 & 4.7719 & TRN & \\
\hline CHEMBL1348029 & 688382 & 5.1 & 4.6512 & TRN & \\
\hline CHEMBL3197074 & 688382 & 4.85 & 4.63899 & 9999999999 & TRN \\
\hline CHEMBL1367154 & 688382 & 4.5 & 4.6513 & TRN & \\
\hline CHEMBL1579102 & 688382 & 4.8 & 4.6528 & TST & \\
\hline CHEMBL1323758 & 688382 & 4.45 & 4.6406 & TRN & \\
\hline CHEMBL1462901 & 688382 & 6.0 & 4.7739 & TST & \\
\hline CHEMBL1522339 & 688382 & 4.95 & 4.6864 & TRN & \\
\hline CHEMBL1603812 & 688382 & 5.0 & 4.655 & TRN & \\
\hline CHEMBL 291558 & 688382 & 5.5 & 4.6927 & TRN & \\
\hline CHEMBL1391283 & 688382 & 5.2 & 4.7799 & TST & \\
\hline CHEMBL1427962 & 688382 & 4.5 & 4.6712 & TRN & \\
\hline CHEMBL1410625 & 688382 & 6.0 & 4.7023 & TRN & \\
\hline CHEMBL1468444 & 688382 & 5.5 & 4.6903 & TRN & \\
\hline CHEMBL1607536 & 688382 & 5.85 & 4.6057 & TST & \\
\hline CHEMBL1569579 & 688382 & 4.7 & 4.6609 & TRN & \\
\hline CHEMBL1491255 & 688382 & 4.5 & 4.6788 & TST & \\
\hline CHEMBL1511684 & 688382 & 5.65 & 4.7973 & TRN & \\
\hline CHEMBL1539019 & 688382 & 5.45 & 4.7339 & TRN & \\
\hline CHEMBL1323059 & 688382 & 4.85 & 4.7267 & TRN & \\
\hline CHEMBL3207351 & 688382 & 4.9 & 4.6901 & TRN & \\
\hline CHEMBL1408892 & 688382 & 5.0 & 4.7808 & TST & \\
\hline CHEMBL1469430 & 688382 & 5.85 & 4.6344 & TRN & \\
\hline CHEMBL1343532 & 688382 & 4.35 & 4.6395 & TST & \\
\hline CHEMBL3191621 & 688382 & 6.0 & 4.7102 & TRN & \\
\hline CHEMBL1569891 & 688382 & 4.45 & 4.633 & TST & \\
\hline CHEMBL 3189545 & 688382 & 4.85 & 4.6702 & TRN & \\
\hline CHEMBL1490604 & 688382 & 5.65 & 4.8263 & TST & \\
\hline CHEMBL1335258 & 688382 & 5.85 & 4.6659 & TRN & \\
\hline
\end{tabular}




\begin{tabular}{|c|c|c|c|c|c|}
\hline \multirow[b]{2}{*}{ CHEMBL1395710 } & & \multicolumn{4}{|c|}{ Supplemental Table S2.txt } \\
\hline & 688382 & 4.85 & 4.7405 & TRN & \\
\hline CHEMBL1583715 & 688382 & 4.2 & 4.73306 & 00000000005 & TRN \\
\hline CHEMBL1567143 & 688382 & 4.0 & 4.6505 & TRN & \\
\hline CHEMBL1599906 & 688382 & 4.8 & 4.7804 & TRN & \\
\hline CHEMBL1587913 & 688382 & 4.85 & 4.7815 & TRN & \\
\hline CHEMBL1388369 & 688382 & 4.5 & 4.6785 & TST & \\
\hline CHEMBL1412043 & 688382 & 4.15 & 4.6774 & TRN & \\
\hline CHEMBL1338501 & 688382 & 5.5 & 4.8222 & TRN & \\
\hline CHEMBL1598707 & 688382 & 5.15 & 4.6634 & TST & \\
\hline CHEMBL1561790 & 688382 & 5.1 & 4.7794 & TRN & \\
\hline CHEMBL1403575 & 688382 & 4.45 & 4.7594 & TRN & \\
\hline CHEMBL1534977 & 688382 & 4.8 & 4.7724 & TST & \\
\hline CHEMBL1525815 & 688382 & 4.75 & 4.7047 & TST & \\
\hline CHEMBL1417742 & 688382 & 5.0 & 4.8862 & TRN & \\
\hline CHEMBL1550124 & 688382 & 5.0 & 4.6238 & TRN & \\
\hline CHEMBL1491074 & 688382 & 4.45 & 4.7275 & TRN & \\
\hline CHEMBL1373849 & 688382 & 4.85 & 4.6107 & TRN & \\
\hline CHEMBL1343876 & 688382 & 5.05 & 4.7674 & TRN & \\
\hline CHEMBL1516020 & 688382 & 4.5 & 4.5464 & TRN & \\
\hline CHEMBL1503955 & 688382 & 4.05 & 4.7407 & TRN & \\
\hline CHEMBL1333848 & 688382 & 5.95 & 4.7332 & TRN & \\
\hline CHEMBL1470984 & 688382 & 5.9 & 4.7155 & TST & \\
\hline CHEMBL1406349 & 688382 & 5.0 & 4.7194 & TRN & \\
\hline CHEMBL1319721 & 688382 & 5.5 & 4.7146 & TRN & \\
\hline CHEMBL1359099 & 688382 & 4.5 & 4.6502 & TRN & \\
\hline CHEMBL1578974 & 688382 & 4.45 & 4.7614 & TRN & \\
\hline CHEMBL1334695 & 688382 & 4.15 & 4.7838 & TRN & \\
\hline CHEMBL1345823 & 688382 & 4.35 & 4.7959 & TRN & \\
\hline CHEMBL1442156 & 688382 & 5.5 & 4.7351 & TST & \\
\hline CHEMBL1509915 & 688382 & 4.6 & 4.6848 & TRN & \\
\hline CHEMBL1524138 & 688382 & 4.45 & 4.6602 & TST & \\
\hline CHEMBL1341142 & 688382 & 4.5 & 4.7393 & TST & \\
\hline CHEMBL1495539 & 688382 & 4.4 & 4.7273 & TRN & \\
\hline CHEMBL3194191 & 688382 & 4.6 & 4.6759 & TRN & \\
\hline CHEMBL1979849 & 688382 & 4.45 & 4.6671 & TRN & \\
\hline CHEMBL1392 & 688382 & 4.55 & 4.6493 & TRN & \\
\hline CHEMBL1524294 & 688382 & 4.6 & 4.6724 & TRN & \\
\hline CHEMBL1304500 & 688382 & 5.05 & 4.6952 & TRN & \\
\hline CHEMBL1501301 & 688382 & 4.3 & 4.6582 & TRN & \\
\hline CHEMBL1481831 & 688382 & 4.0 & 4.7711 & TRN & \\
\hline CHEMBL1464228 & 688382 & 4.7 & 4.6935 & TRN & \\
\hline CHEMBL1340979 & 688382 & 5.8 & 4.8135 & TRN & \\
\hline CHEMBL3145055 & 688382 & 4.2 & 4.6392 & TST & \\
\hline CHEMBL1508302 & 688382 & 5.15 & 4.7098 & TST & \\
\hline CHEMBL1588231 & 688382 & 6.5 & 4.8105 & TRN & \\
\hline CHEMBL1350139 & 688382 & 5.0 & 4.7812 & TRN & \\
\hline CHEMBL1361211 & 688382 & 4.2 & 4.6341 & TST & \\
\hline CHEMBL572189 & 688382 & 4.5 & 4.6766 & TRN & \\
\hline
\end{tabular}




\begin{tabular}{|c|c|c|c|c|c|}
\hline \multicolumn{6}{|c|}{ Supplemental Table S2.txt } \\
\hline CHEMBL3189712 & 688382 & 5.3 & 4.6007 & TRN & \\
\hline CHEMBL1411778 & 688382 & 4.15 & 4.7078 & TRN & \\
\hline CHEMBL1378339 & 688382 & 4.45 & 4.5767 & TRN & \\
\hline CHEMBL1455861 & 688382 & 4.15 & 4.6152 & TRN & \\
\hline CHEMBL1305760 & 688382 & 4.45 & 4.6672 & TST & \\
\hline CHEMBL1411951 & 688382 & 4.2 & 4.68199 & 99999999995 & TRN \\
\hline CHEMBL1347907 & 688382 & 4.2 & 4.697 & TRN & \\
\hline CHEMBL1532268 & 688382 & 4.95 & 4.6078 & TRN & \\
\hline CHEMBL1424629 & 688382 & 4.8 & 4.7711 & TRN & \\
\hline CHEMBL1580061 & 688382 & 4.95 & 4.7899 & TST & \\
\hline CHEMBL491908 & 688382 & 4.35 & 4.6505 & TRN & \\
\hline CHEMBL1350080 & 688382 & 4.8 & 4.6842 & TRN & \\
\hline CHEMBL1462387 & 688382 & 4.4 & 4.6705 & TRN & \\
\hline CHEMBL1598137 & 688382 & 4.2 & 4.7123 & TRN & \\
\hline CHEMBL1505960 & 688382 & 5.5 & 4.6504 & TRN & \\
\hline CHEMBL1364823 & 688382 & 4.85 & 4.6899 & TST & \\
\hline CHEMBL1493631 & 688382 & 4.15 & 4.7606 & TST & \\
\hline CHEMBL1383012 & 688382 & 4.85 & 4.75 & TRN & \\
\hline CHEMBL1440264 & 688382 & 4.15 & 4.7977 & TRN & \\
\hline CHEMBL1407280 & 688382 & 4.2 & 4.666 & TRN & \\
\hline CHEMBL1375246 & 688382 & 4.5 & 4.7318 & TRN & \\
\hline CHEMBL1579048 & 688382 & 6.05 & 4.8259 & TRN & \\
\hline CHEMBL1585284 & 688382 & 4.15 & 4.7088 & TRN & \\
\hline CHEMBL1301935 & 688382 & 4.05 & 4.7079 & TRN & \\
\hline CHEMBL1459895 & 688382 & 6.0 & 4.7606 & TRN & \\
\hline CHEMBL1609054 & 688382 & 4.15 & 4.6277 & TST & \\
\hline CHEMBL1300180 & 688382 & 5.05 & 4.8256 & TRN & \\
\hline CHEMBL1582332 & 688382 & 4.5 & 4.6671 & TRN & \\
\hline CHEMBL1504888 & 688382 & 6.05 & 4.8406 & TRN & \\
\hline CHEMBL1391063 & 688382 & 4.55 & 4.6946 & TRN & \\
\hline CHEMBL1387130 & 688382 & 5.0 & 4.8187 & TST & \\
\hline CHEMBL1423610 & 688382 & 5.0 & 4.6861 & TRN & \\
\hline CHEMBL1352747 & 688382 & 4.75 & 4.6577 & TRN & \\
\hline CHEMBL1582157 & 688382 & 4.4 & 4.79 & TST & \\
\hline CHEMBL1465625 & 688382 & 4.85 & 4.718 & TRN & \\
\hline CHEMBL3214154 & 688382 & 4.45 & 4.6697 & TRN & \\
\hline CHEMBL1353657 & 688382 & 4.5 & 4.7042 & TRN & \\
\hline CHEMBL1369057 & 688382 & 4.2 & 4.8353 & TRN & \\
\hline CHEMBL1463602 & 688382 & 4.85 & 4.6442 & TRN & \\
\hline CHEMBL1308497 & 688382 & 4.95 & 4.7453 & TRN & \\
\hline CHEMBL1429235 & 688382 & 4.9 & 4.7754 & TRN & \\
\hline CHEMBL1597256 & 688382 & 4.2 & 4.7671 & TRN & \\
\hline CHEMBL1505913 & 688382 & 4.5 & 4.7376 & TST & \\
\hline CHEMBL1327956 & 688382 & 4.15 & 4.6826 & TRN & \\
\hline CHEMBL1441877 & 688382 & 4.9 & 4.752 & TST & \\
\hline CHEMBL1365530 & 688382 & 4.75 & 4.7474 & TST & \\
\hline CHEMBL1501180 & 688382 & 5.0 & 4.7327 & TRN & \\
\hline CHEMBL1373348 & 688382 & 4.95 & 4.7768 & TRN & \\
\hline
\end{tabular}




\begin{tabular}{|c|c|c|c|c|}
\hline \multicolumn{5}{|c|}{ Supplemental Table S2.txt } \\
\hline CHEMBL3197938 & 688382 & 4.85 & 4.7411 & TRN \\
\hline CHEMBL1322857 & 688382 & 4.5 & 4.6472 & TRN \\
\hline CHEMBL1496301 & 688382 & 5.8 & 4.7687 & TRN \\
\hline CHEMBL1429929 & 688382 & 4.6 & 4.6965 & TRN \\
\hline CHEMBL1611911 & 688382 & 4.35 & 4.7133 & TST \\
\hline CHEMBL1402055 & 688382 & 4.65 & 4.7151 & TST \\
\hline CHEMBL1366411 & 688382 & 6.0 & 4.8677 & TRN \\
\hline CHEMBL1377813 & 688382 & 4.4 & 4.7589 & TRN \\
\hline CHEMBL515248 & 688382 & 5.55 & 4.6565 & TRN \\
\hline CHEMBL1468795 & 688382 & 4.2 & 4.6722 & TRN \\
\hline CHEMBL1351104 & 688382 & 3.95 & 4.6423 & TRN \\
\hline CHEMBL1504982 & 688382 & 4.5 & 4.6705 & TRN \\
\hline CHEMBL1370600 & 688382 & 4.95 & 4.6932 & TRN \\
\hline CHEMBL1602918 & 688382 & 4.45 & 4.6995 & TRN \\
\hline CHEMBL1384140 & 688382 & 4.15 & 4.702 & TRN \\
\hline CHEMBL3210878 & 688382 & 5.1 & 4.6776 & TRN \\
\hline CHEMBL1492837 & 688382 & 5.05 & 4.8172 & TRN \\
\hline CHEMBL1339777 & 688382 & 4.15 & 4.7285 & TST \\
\hline CHEMBL1534166 & 688382 & 4.05 & 4.7913 & TRN \\
\hline CHEMBL1384785 & 688382 & 4.85 & 4.7642 & TRN \\
\hline CHEMBL1327834 & 688382 & 4.45 & 4.7236 & TRN \\
\hline CHEMBL1599765 & 688382 & 5.3 & 4.6869 & TRN \\
\hline CHEMBL1440314 & 688382 & 4.45 & 4.6161 & TRN \\
\hline CHEMBL1391267 & 688382 & 4.45 & 4.7665 & TRN \\
\hline CHEMBL1546715 & 688382 & 4.1 & 4.6866 & TRN \\
\hline CHEMBL1526785 & 688382 & 4.85 & 4.619 & TST \\
\hline CHEMBL3198228 & 688382 & 4.4 & 4.7124 & TRN \\
\hline CHEMBL1558954 & 688382 & 4.55 & 4.6462 & TRN \\
\hline CHEMBL1504556 & 688382 & 5.2 & 4.6708 & TRN \\
\hline CHEMBL3191682 & 688382 & 4.15 & 4.6553 & TRN \\
\hline CHEMBL1479146 & 688382 & 4.95 & 4.7052 & TRN \\
\hline CHEMBL1460542 & 688382 & 4.4 & 4.6808 & TRN \\
\hline CHEMBL1170485 & 688382 & 5.2 & 4.6571 & TST \\
\hline CHEMBL1503026 & 688382 & 4.15 & 4.7849 & TRN \\
\hline CHEMBL1387190 & 688382 & 5.1 & 4.8645 & TRN \\
\hline CHEMBL1474350 & 688382 & 5.15 & 4.7455 & TRN \\
\hline CHEMBL1482799 & 688382 & 4.45 & 4.6787 & TRN \\
\hline CHEMBL1574275 & 688382 & 4.4 & 4.7653 & TST \\
\hline CHEMBL1421842 & 688382 & 4.8 & 4.8386 & TRN \\
\hline CHEMBL1567864 & 688382 & 4.8 & 4.6978 & TRN \\
\hline CHEMBL1213769 & 688382 & 4.35 & 4.6699 & TRN \\
\hline CHEMBL1377039 & 688382 & 4.9 & 4.6832 & TST \\
\hline CHEMBL1336765 & 688382 & 4.2 & 4.5792 & TST \\
\hline CHEMBL1308783 & 688382 & 5.05 & 4.6704 & TRN \\
\hline CHEMBL1491195 & 688382 & 4.45 & 4.7631 & TRN \\
\hline CHEMBL1483046 & 688382 & 4.4 & 4.6862 & TRN \\
\hline CHEMBL1327785 & 688382 & 4.2 & 4.6814 & TRN \\
\hline CHEMBL1509768 & 688382 & 4.95 & 4.677 & TRN \\
\hline
\end{tabular}




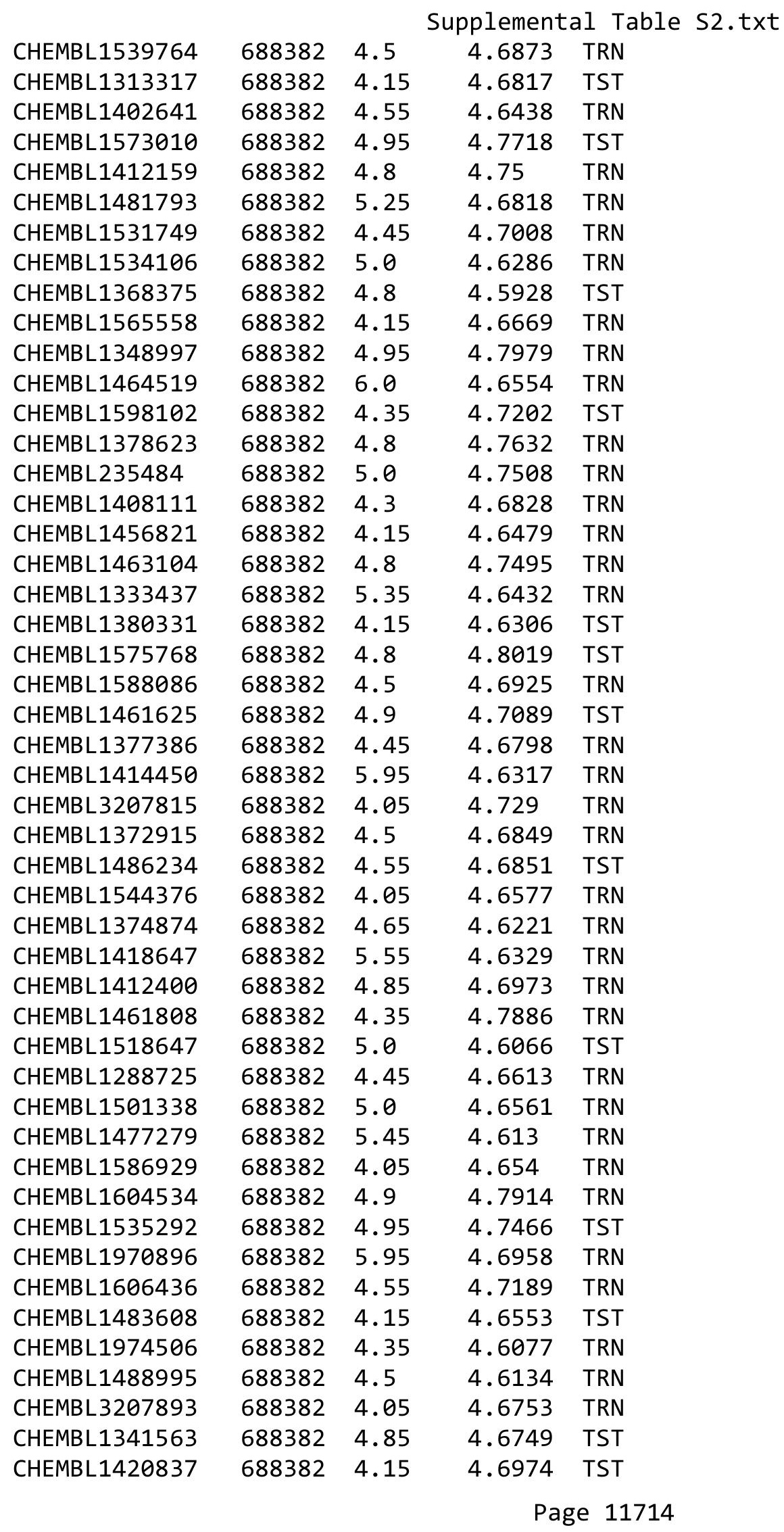




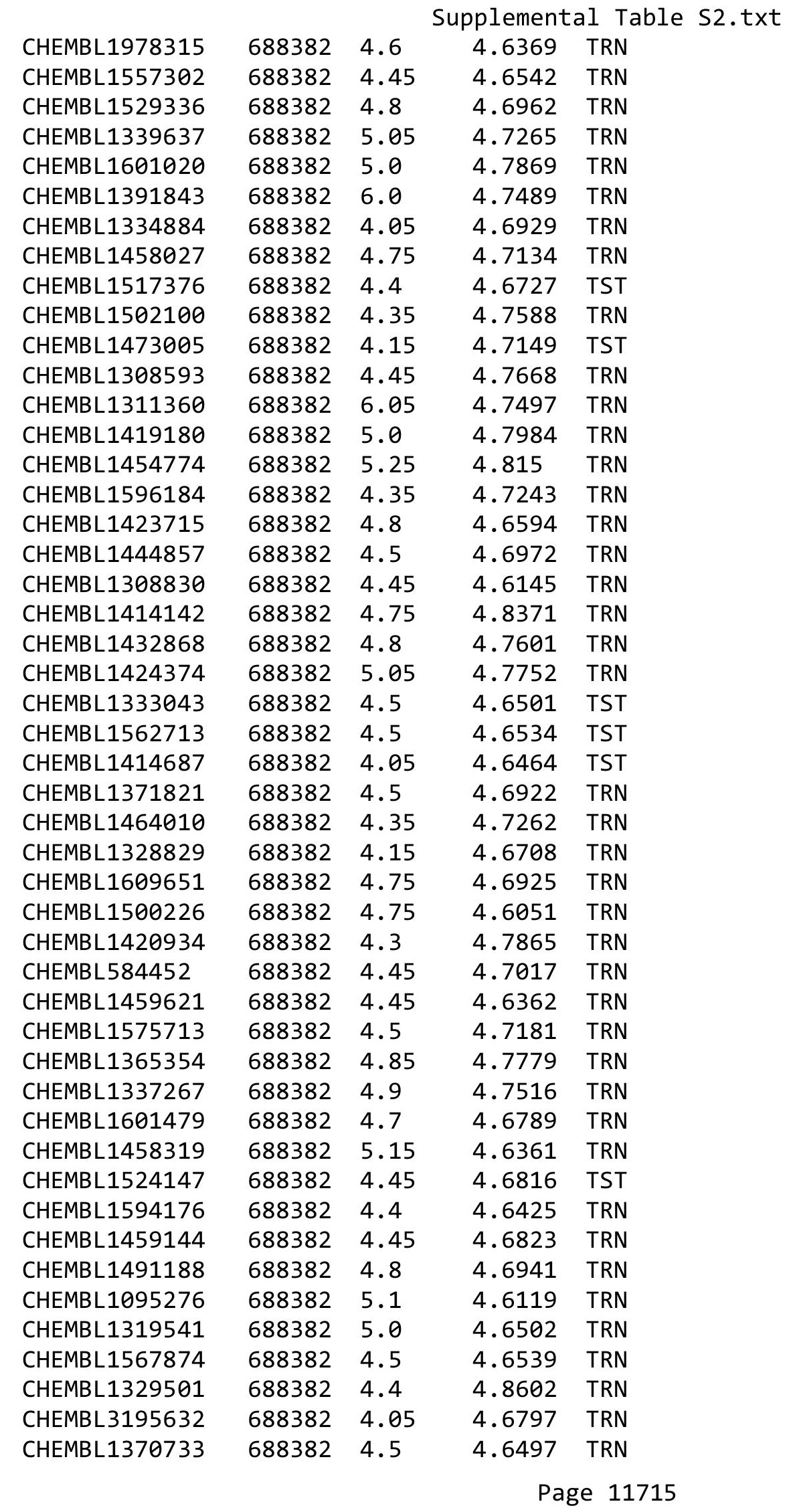




\begin{tabular}{|c|c|c|c|c|}
\hline & & & opsement & \\
\hline CHEMBL1426484 & 688382 & 5.1 & 4.6938 & TST \\
\hline CHEMBL1463837 & 688382 & 6.0 & 4.7434 & TRN \\
\hline CHEMBL1387872 & 688382 & 5.0 & 4.6546 & TRN \\
\hline CHEMBL1352898 & 688382 & 4.6 & 4.684 & TRN \\
\hline CHEMBL222409 & 688382 & 4.8 & 4.6746 & TRN \\
\hline CHEMBL1428271 & 688382 & 5.4 & 4.6657 & TRN \\
\hline CHEMBL1447432 & 688382 & 6.0 & 4.7256 & TRN \\
\hline CHEMBL1503667 & 688382 & 4.15 & 4.6981 & TST \\
\hline CHEMBL1327425 & 688382 & 4.45 & 4.704 & TRN \\
\hline CHEMBL1467254 & 688382 & 4.95 & 4.8127 & TRN \\
\hline CHEMBL1559626 & 688382 & 5.45 & 4.7934 & TRN \\
\hline CHEMBL1485858 & 688382 & 5.05 & 4.6346 & TRN \\
\hline CHEMBL1572169 & 688382 & 4.3 & 4.7112 & TRN \\
\hline CHEMBL1603073 & 688382 & 4.5 & 4.7945 & TRN \\
\hline CHEMBL1162110 & 688382 & 4.45 & 4.686 & TRN \\
\hline CHEMBL1509199 & 688382 & 4.85 & 4.6927 & TRN \\
\hline CHEMBL1544602 & 688382 & 4.95 & 4.7123 & TRN \\
\hline CHEMBL1529160 & 688382 & 4.45 & 4.8524 & TRN \\
\hline CHEMBL1536977 & 688382 & 4.95 & 4.6784 & TST \\
\hline CHEMBL1324914 & 688382 & 4.55 & 4.756 & TRN \\
\hline CHEMBL3193166 & 688382 & 4.5 & 4.6656 & TRN \\
\hline CHEMBL1374067 & 688382 & 4.35 & 4.6825 & TRN \\
\hline CHEMBL1522986 & 688382 & 4.5 & 4.6832 & TRN \\
\hline CHEMBL1368472 & 688382 & 4.4 & 4.7188 & TRN \\
\hline CHEMBL1360461 & 688382 & 5.95 & 4.6558 & TRN \\
\hline CHEMBL1550491 & 688382 & 4.15 & 4.7211 & TRN \\
\hline CHEMBL1424310 & 688382 & 5.05 & 4.709 & TRN \\
\hline CHEMBL1542963 & 688382 & 4.45 & 4.7066 & TRN \\
\hline CHEMBL274499 & 688382 & 4.65 & 4.7635 & TRN \\
\hline CHEMBL1506726 & 688382 & 4.05 & 4.7351 & TST \\
\hline CHEMBL1416736 & 688382 & 3.95 & 4.7679 & TST \\
\hline CHEMBL3196406 & 688382 & 4.9 & 4.6141 & TRN \\
\hline CHEMBL1525427 & 688382 & 8.0506 & 4.8299 & TRN \\
\hline CHEMBL1546443 & 688382 & 4.9 & 4.7715 & TRN \\
\hline CHEMBL1315464 & 688382 & 5.8 & 4.6491 & TRN \\
\hline CHEMBL1312393 & 688382 & 4.55 & 4.7021 & TRN \\
\hline CHEMBL1345141 & 688382 & 5.25 & 4.6978 & TST \\
\hline CHEMBL1515703 & 688382 & 4.8 & 4.7198 & TRN \\
\hline CHEMBL1431490 & 688382 & 4.15 & 4.6896 & TRN \\
\hline CHEMBL1409645 & 688382 & 4.0 & 4.7257 & TST \\
\hline CHEMBL1468361 & 688382 & 4.95 & 4.7154 & TRN \\
\hline CHEMBL1487205 & 688382 & 4.95 & 4.604 & TST \\
\hline CHEMBL1383891 & 688382 & 4.5 & 4.6603 & TRN \\
\hline CHEMBL1546423 & 688382 & 4.5 & 4.632 & TRN \\
\hline CHEMBL1531133 & 688382 & 5.1 & 4.7381 & TRN \\
\hline CHEMBL1324491 & 688382 & 4.4 & 4.6993 & TRN \\
\hline CHEMBL3191832 & 688382 & 4.6 & 4.7117 & TRN \\
\hline CHEMBL1503689 & 688382 & 4.45 & 4.7271 & TRN \\
\hline
\end{tabular}




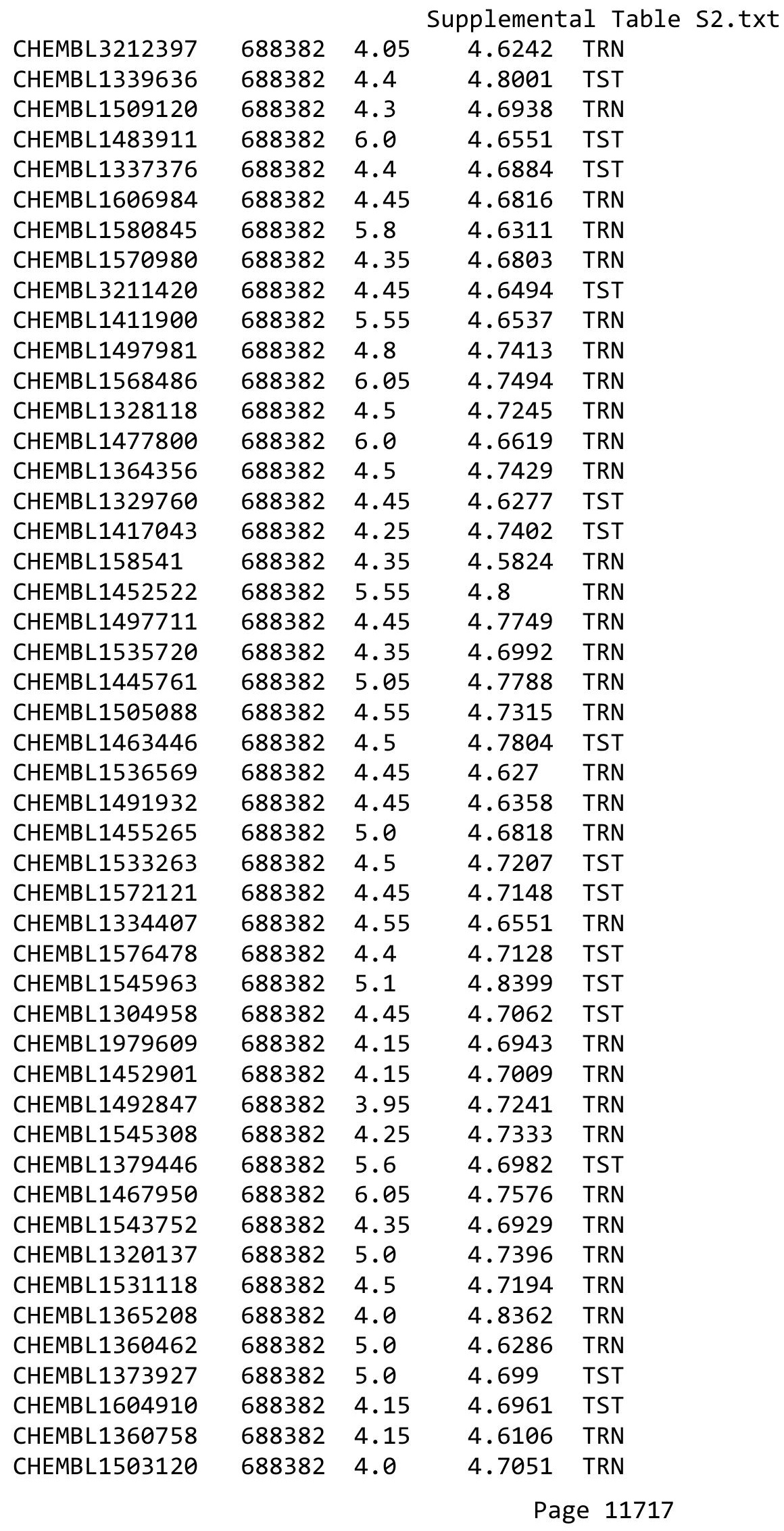




\begin{tabular}{|c|c|c|c|c|}
\hline & & & pplemen & \\
\hline CHEMBL1393720 & 688382 & 5.55 & 4.7127 & TRN \\
\hline CHEMBL1346024 & 688382 & 3.85 & 4.7245 & TRN \\
\hline CHEMBL1487129 & 688382 & 5.15 & 4.7702 & TRN \\
\hline CHEMBL1482076 & 688382 & 4.05 & 4.6708 & TRN \\
\hline CHEMBL1555684 & 688382 & 4.65 & 4.6433 & TRN \\
\hline CHEMBL1256656 & 688382 & 4.55 & 4.7227 & TRN \\
\hline CHEMBL1579784 & 688382 & 4.2 & 4.7145 & TRN \\
\hline CHEMBL1477090 & 688382 & 4.4 & 4.63 & TRN \\
\hline CHEMBL1611802 & 688382 & 5.3 & 4.6847 & TRN \\
\hline CHEMBL1370447 & 688382 & 4.45 & 4.6817 & TRN \\
\hline CHEMBL1575780 & 688382 & 4.45 & 4.8011 & TRN \\
\hline CHEMBL1430260 & 688382 & 5.0 & 4.6563 & TRN \\
\hline CHEMBL1997915 & 688382 & 4.35 & 4.7132 & TRN \\
\hline CHEMBL1382078 & 688382 & 4.9 & 4.6831 & TRN \\
\hline CHEMBL3189791 & 688382 & 5.45 & 4.6513 & TRN \\
\hline CHEMBL 2003651 & 688382 & 4.65 & 4.7196 & TRN \\
\hline CHEMBL1331858 & 688382 & 4.15 & 4.7618 & TRN \\
\hline CHEMBL1495462 & 688382 & 4.95 & 4.5752 & TST \\
\hline CHEMBL1444386 & 688382 & 4.4 & 4.7279 & TRN \\
\hline CHEMBL1466884 & 688382 & 4.4 & 4.7531 & TRN \\
\hline CHEMBL1533092 & 688382 & 5.1 & 4.6747 & TST \\
\hline CHEMBL1492305 & 688382 & 4.45 & 4.6185 & TRN \\
\hline CHEMBL1601286 & 688382 & 5.0 & 4.7195 & TRN \\
\hline CHEMBL1460675 & 688382 & 4.45 & 4.7582 & TRN \\
\hline CHEMBL1299980 & 688382 & 4.45 & 4.6719 & TRN \\
\hline CHEMBL1341509 & 688382 & 5.5 & 4.6456 & TST \\
\hline CHEMBL1514790 & 688382 & 4.65 & 4.687 & TRN \\
\hline CHEMBL1382469 & 688382 & 5.05 & 4.7812 & TRN \\
\hline CHEMBL1585528 & 688382 & 4.45 & 4.6164 & TRN \\
\hline CHEMBL1327921 & 688382 & 4.85 & 4.7331 & TRN \\
\hline CHEMBL1416286 & 688382 & 5.0 & 4.7449 & TRN \\
\hline CHEMBL1424874 & 688382 & 4.95 & 4.7363 & TST \\
\hline CHEMBL1427904 & 688382 & 4.95 & 4.735 & TRN \\
\hline CHEMBL1486974 & 688382 & 4.9 & 4.7079 & TRN \\
\hline CHEMBL1561806 & 688382 & 4.0 & 4.7681 & TRN \\
\hline CHEMBL3208177 & 688382 & 4.85 & 4.593 & TST \\
\hline CHEMBL1400492 & 688382 & 5.05 & 4.6968 & TRN \\
\hline CHEMBL1540463 & 688382 & 4.9 & 4.7033 & TRN \\
\hline CHEMBL1439672 & 688382 & 5.45 & 4.6412 & TRN \\
\hline CHEMBL1461759 & 688382 & 4.4 & 4.7216 & TRN \\
\hline CHEMBL3199400 & 688382 & 4.75 & 4.6063 & TRN \\
\hline CHEMBL1480647 & 688382 & 4.2 & 4.7115 & TST \\
\hline CHEMBL1350042 & 688382 & 5.95 & 4.7705 & TRN \\
\hline CHEMBL1386800 & 688382 & 4.3 & 4.7241 & TRN \\
\hline CHEMBL1324923 & 688382 & 5.95 & 4.6995 & TST \\
\hline CHEMBL1352978 & 688382 & 4.15 & 4.8661 & TRN \\
\hline CHEMBL1314002 & 688382 & 4.3 & 4.8315 & TRN \\
\hline CHEMBL1582494 & 688382 & 4.45 & 4.6235 & TRN \\
\hline
\end{tabular}




\begin{tabular}{|c|c|c|c|c|c|}
\hline & & & & & \\
\hline CHEMBL1408689 & 688382 & 4.5 & 4.7443 & TRN & \\
\hline CHEMBL1516758 & 688382 & 5.2 & 4.7046 & TRN & \\
\hline CHEMBL1399539 & 688382 & 4.2 & 4.7418 & TRN & \\
\hline CHEMBL1313937 & 688382 & 4.3 & 4.7171 & TRN & \\
\hline CHEMBL1452460 & 688382 & 4.95 & 4.6339 & TST & \\
\hline CHEMBL1560957 & 688382 & 4.15 & 4.6822 & TRN & \\
\hline CHEMBL1319108 & 688382 & 4.15 & 4.8608 & TST & \\
\hline CHEMBL1495157 & 688382 & 4.45 & 4.6622 & TST & \\
\hline CHEMBL3193918 & 688382 & 4.2 & 4.6411 & TST & \\
\hline CHEMBL1409201 & 688382 & 4.85 & 4.7181 & TST & \\
\hline CHEMBL1515679 & 688382 & 5.05 & 4.6854 & TRN & \\
\hline CHEMBL51931 & 688382 & 4.55 & 4.6461 & TRN & \\
\hline CHEMBL1406380 & 688382 & 4.95 & 4.7393 & TRN & \\
\hline CHEMBL1568701 & 688382 & 5.15 & 4.7429 & TRN & \\
\hline CHEMBL1563031 & 688382 & 4.8 & 4.8088 & TRN & \\
\hline CHEMBL1541806 & 688382 & 4.95 & 4.7076 & TST & \\
\hline CHEMBL1348634 & 688382 & 4.1 & 4.7761 & TRN & \\
\hline CHEMBL1479072 & 688382 & 4.3 & 4.82100 & 2000000001 & TRN \\
\hline CHEMBL1435418 & 688382 & 4.4 & 4.7265 & TRN & \\
\hline CHEMBL3194287 & 688382 & 4.45 & 4.6278 & TST & \\
\hline CHEMBL1438667 & 688382 & 4.85 & 4.5775 & TRN & \\
\hline CHEMBL1461574 & 688382 & 4.2 & 4.713 & TRN & \\
\hline CHEMBL1400699 & 688382 & 6.0 & 4.7873 & TRN & \\
\hline CHEMBL1333718 & 688382 & 4.5 & 4.7105 & TRN & \\
\hline CHEMBL1431541 & 688382 & 4.9 & 4.7223 & TRN & \\
\hline CHEMBL1500140 & 688382 & 4.55 & 4.6366 & TRN & \\
\hline CHEMBL1562277 & 688382 & 4.35 & 4.637 & TRN & \\
\hline CHEMBL1416556 & 688382 & 4.45 & 4.5793 & TRN & \\
\hline CHEMBL417727 & 688382 & 4.35 & 4.6354 & TRN & \\
\hline CHEMBL1426092 & 688382 & 4.95 & 4.6856 & TST & \\
\hline CHEMBL1595788 & 688382 & 4.5 & 4.7165 & TRN & \\
\hline CHEMBL1541890 & 688382 & 4.75 & 4.663 & TST & \\
\hline CHEMBL1580259 & 688382 & 4.5 & 4.6099 & TRN & \\
\hline CHEMBL1461201 & 688382 & 4.85 & 4.6825 & TST & \\
\hline CHEMBL1313126 & 688382 & 4.05 & 4.7078 & TRN & \\
\hline CHEMBL1372891 & 688382 & 4.45 & 4.6959 & TRN & \\
\hline CHEMBL1579555 & 688382 & 4.8 & 4.6412 & TRN & \\
\hline CHEMBL1310640 & 688382 & 4.95 & 4.8159 & TRN & \\
\hline CHEMBL1579278 & 688382 & 4.35 & 4.6602 & TRN & \\
\hline CHEMBL1580790 & 688382 & 4.5 & 4.7232 & TRN & \\
\hline CHEMBL1428264 & 688382 & 4.4 & 4.6896 & TRN & \\
\hline CHEMBL574181 & 688382 & 7.4001 & 4.6945 & TRN & \\
\hline CHEMBL1567340 & 688382 & 4.15 & 4.6784 & TST & \\
\hline CHEMBL3194562 & 688382 & 5.5 & 4.6296 & TRN & \\
\hline CHEMBL1457455 & 688382 & 4.3 & 4.789 & TST & \\
\hline CHEMBL1512990 & 688382 & 4.4 & 4.7779 & TRN & \\
\hline CHEMBL1609173 & 688382 & 6.0 & 4.86600 & 00000000005 & TRN \\
\hline CHEMBL1598538 & 688382 & 4.45 & 4.7217 & TRN & \\
\hline & & & & 11719 & \\
\hline
\end{tabular}




\begin{tabular}{|c|c|c|c|c|c|}
\hline & & & & & \\
\hline CHEMBL1548109 & 688382 & 4.9 & 4.6291 & TRN & \\
\hline CHEMBL3193006 & 688382 & 4.0 & 4.7345 & TRN & \\
\hline CHEMBL1361412 & 688382 & 4.8 & 4.7626 & TST & \\
\hline CHEMBL1378590 & 688382 & 4.8 & 4.6748 & TRN & \\
\hline CHEMBL1385634 & 688382 & 4.15 & 4.6419 & TST & \\
\hline CHEMBL1402126 & 688382 & 4.15 & 4.7147 & TRN & \\
\hline CHEMBL1456441 & 688382 & 4.5 & 4.7034 & TST & \\
\hline CHEMBL1493438 & 688382 & 6.0 & 4.7365 & TRN & \\
\hline CHEMBL1498133 & 688382 & 4.15 & 4.6272 & TST & \\
\hline CHEMBL1608556 & 688382 & 4.4 & 4.7755 & TRN & \\
\hline CHEMBL1522662 & 688382 & 4.65 & 4.7498 & TRN & \\
\hline CHEMBL1352456 & 688382 & 5.5 & 4.8139 & TRN & \\
\hline CHEMBL3207838 & 688382 & 4.15 & 4.6925 & TRN & \\
\hline CHEMBL1304083 & 688382 & 4.35 & 4.7526 & TST & \\
\hline CHEMBL1507174 & 688382 & 4.45 & 4.7061 & TRN & \\
\hline CHEMBL1516707 & 688382 & 5.55 & 4.6646 & TRN & \\
\hline CHEMBL1388539 & 688382 & 4.5 & 4.7104 & TRN & \\
\hline CHEMBL3210896 & 688382 & 4.65 & 4.6434 & TRN & \\
\hline CHEMBL1606583 & 688382 & 4.55 & 4.6714 & TRN & \\
\hline CHEMBL1371109 & 688382 & 4.75 & 4.6217 & TRN & \\
\hline CHEMBL1469631 & 688382 & 4.75 & 4.7189 & TRN & \\
\hline CHEMBL1536624 & 688382 & 4.15 & $4.6960 e$ & 0000000001 & TST \\
\hline CHEMBL1360190 & 688382 & 4.35 & 4.6806 & TRN & \\
\hline CHEMBL1588695 & 688382 & 5.0 & 4.6991 & TST & \\
\hline CHEMBL1439813 & 688382 & 4.05 & 4.676 & TRN & \\
\hline CHEMBL1392296 & 688382 & 4.5 & 4.7903 & TST & \\
\hline CHEMBL1379913 & 688382 & 5.2 & 4.7327 & TST & \\
\hline CHEMBL1371173 & 688382 & 5.05 & 4.6901 & TST & \\
\hline CHEMBL1485626 & 688382 & 4.05 & 4.761 & TRN & \\
\hline CHEMBL1409611 & 688382 & 5.15 & 4.7111 & TRN & \\
\hline CHEMBL1361413 & 688382 & 4.55 & 4.7161 & TRN & \\
\hline CHEMBL1592141 & 688382 & 4.35 & 4.7046 & TRN & \\
\hline CHEMBL1329895 & 688382 & 4.05 & 4.6211 & TST & \\
\hline CHEMBL1335428 & 688382 & 4.5 & 4.6991 & TST & \\
\hline CHEMBL1310213 & 688382 & 4.5 & 4.7968 & TRN & \\
\hline CHEMBL1601077 & 688382 & 4.5 & 4.6744 & TRN & \\
\hline CHEMBL462627 & 688382 & 4.8 & 4.7061 & TST & \\
\hline CHEMBL1574250 & 688382 & 5.25 & 4.7508 & TRN & \\
\hline CHEMBL1546888 & 688382 & 4.05 & 4.6172 & TRN & \\
\hline CHEMBL1381828 & 688382 & 4.45 & 4.8482 & TRN & \\
\hline CHEMBL1577371 & 688382 & 4.85 & 4.7195 & TST & \\
\hline CHEMBL1573329 & 688382 & 5.1 & 4.7931 & TST & \\
\hline CHEMBL3211846 & 688382 & 4.8 & 4.6311 & TRN & \\
\hline CHEMBL1546101 & 688382 & 5.15 & 4.7677 & TST & \\
\hline CHEMBL1475836 & 688382 & 4.8 & $4.7330 e$ & 00000000005 & TRN \\
\hline CHEMBL1602250 & 688382 & 4.15 & 4.6865 & TRN & \\
\hline CHEMBL1387464 & 688382 & 6.0 & 4.7293 & TRN & \\
\hline CHEMBL3198656 & 688382 & 4.6 & 4.7294 & TRN & \\
\hline & & & & 11720 & \\
\hline
\end{tabular}




\begin{tabular}{|c|c|c|c|c|c|}
\hline & & \multicolumn{4}{|c|}{ Supplemental Table S2.txt } \\
\hline CHEMBL1517749 & 688382 & 4.85 & 4.7313 & TRN & \\
\hline CHEMBL1599733 & 688382 & 5.7 & 4.7329 & TRN & \\
\hline CHEMBL1552516 & 688382 & 4.25 & 4.6567 & TRN & \\
\hline CHEMBL1391908 & 688382 & 3.65 & 4.8238 & TRN & \\
\hline CHEMBL1508093 & 688382 & 6.0 & 4.74 & TRN & \\
\hline CHEMBL1461285 & 688382 & 5.85 & 4.7371 & TRN & \\
\hline CHEMBL1565696 & 688382 & 3.35 & 4.6925 & TRN & \\
\hline CHEMBL1393064 & 688382 & 4.95 & 4.71399 & 99999999995 & TRN \\
\hline CHEMBL1420151 & 688382 & 4.6 & 4.6852 & TRN & \\
\hline CHEMBL1429696 & 688382 & 4.95 & 4.8253 & TRN & \\
\hline CHEMBL1567460 & 688382 & 5.8 & 4.7101 & TRN & \\
\hline CHEMBL1309419 & 688382 & 4.6 & 4.6608 & TRN & \\
\hline CHEMBL1325286 & 688382 & 4.4 & 4.7206 & TRN & \\
\hline CHEMBL1304336 & 688382 & 4.45 & 4.7446 & TRN & \\
\hline CHEMBL1434448 & 688382 & 4.05 & 4.6886 & TRN & \\
\hline CHEMBL1586806 & 688382 & 4.6 & 4.5921 & TRN & \\
\hline CHEMBL1970641 & 688382 & 4.6 & 4.6365 & TST & \\
\hline CHEMBL1440170 & 688382 & 4.3 & 4.7233 & TRN & \\
\hline CHEMBL1521830 & 688382 & 4.45 & 4.6736 & TRN & \\
\hline CHEMBL1308319 & 688382 & 5.05 & 4.6576 & TST & \\
\hline CHEMBL1505098 & 688382 & 4.95 & 4.6822 & TRN & \\
\hline CHEMBL1578788 & 688382 & 4.65 & 4.6447 & TRN & \\
\hline CHEMBL1469575 & 688382 & 4.85 & 4.7226 & TRN & \\
\hline CHEMBL1406235 & 688382 & 4.4 & 4.7531 & TRN & \\
\hline CHEMBL1439729 & 688382 & 5.05 & 4.8217 & TRN & \\
\hline CHEMBL1479860 & 688382 & 4.55 & 4.6909 & TRN & \\
\hline CHEMBL1598402 & 688382 & 5.25 & 4.6706 & TST & \\
\hline CHEMBL1453121 & 688382 & 4.95 & 4.6669 & TRN & \\
\hline CHEMBL1452669 & 688382 & 4.45 & 4.6854 & TRN & \\
\hline CHEMBL1299341 & 688382 & 4.8 & 4.6237 & TRN & \\
\hline CHEMBL3194007 & 688382 & 4.85 & 4.6665 & TRN & \\
\hline CHEMBL1460118 & 688382 & 4.75 & 4.7117 & TST & \\
\hline CHEMBL1369699 & 688382 & 4.2 & 4.621 & TRN & \\
\hline CHEMBL1599262 & 688382 & 4.8 & 4.7154 & TST & \\
\hline CHEMBL1505421 & 688382 & 4.5 & 4.7219 & TST & \\
\hline CHEMBL1444360 & 688382 & 4.4 & 4.7613 & TST & \\
\hline CHEMBL1324703 & 688382 & 4.15 & 4.6856 & TRN & \\
\hline CHEMBL1512159 & 688382 & 5.15 & 4.6018 & TST & \\
\hline CHEMBL1325863 & 688382 & 4.9 & 4.6887 & TRN & \\
\hline CHEMBL1445714 & 688382 & 5.85 & 4.755 & TST & \\
\hline CHEMBL1371790 & 688382 & 4.5 & 4.6079 & TST & \\
\hline CHEMBL1556574 & 688382 & 4.75 & 4.8426 & TRN & \\
\hline CHEMBL1462590 & 688382 & 4.05 & 4.7589 & TRN & \\
\hline CHEMBL1347659 & 688382 & 5.1 & 4.662 & TRN & \\
\hline CHEMBL504791 & 688382 & 4.15 & 4.6006 & TST & \\
\hline CHEMBL1502512 & 688382 & 4.4 & 4.6916 & TST & \\
\hline CHEMBL1301607 & 688382 & 5.0 & 4.6818 & TRN & \\
\hline CHEMBL1299532 & 688382 & 4.45 & 4.723 & TRN & \\
\hline
\end{tabular}




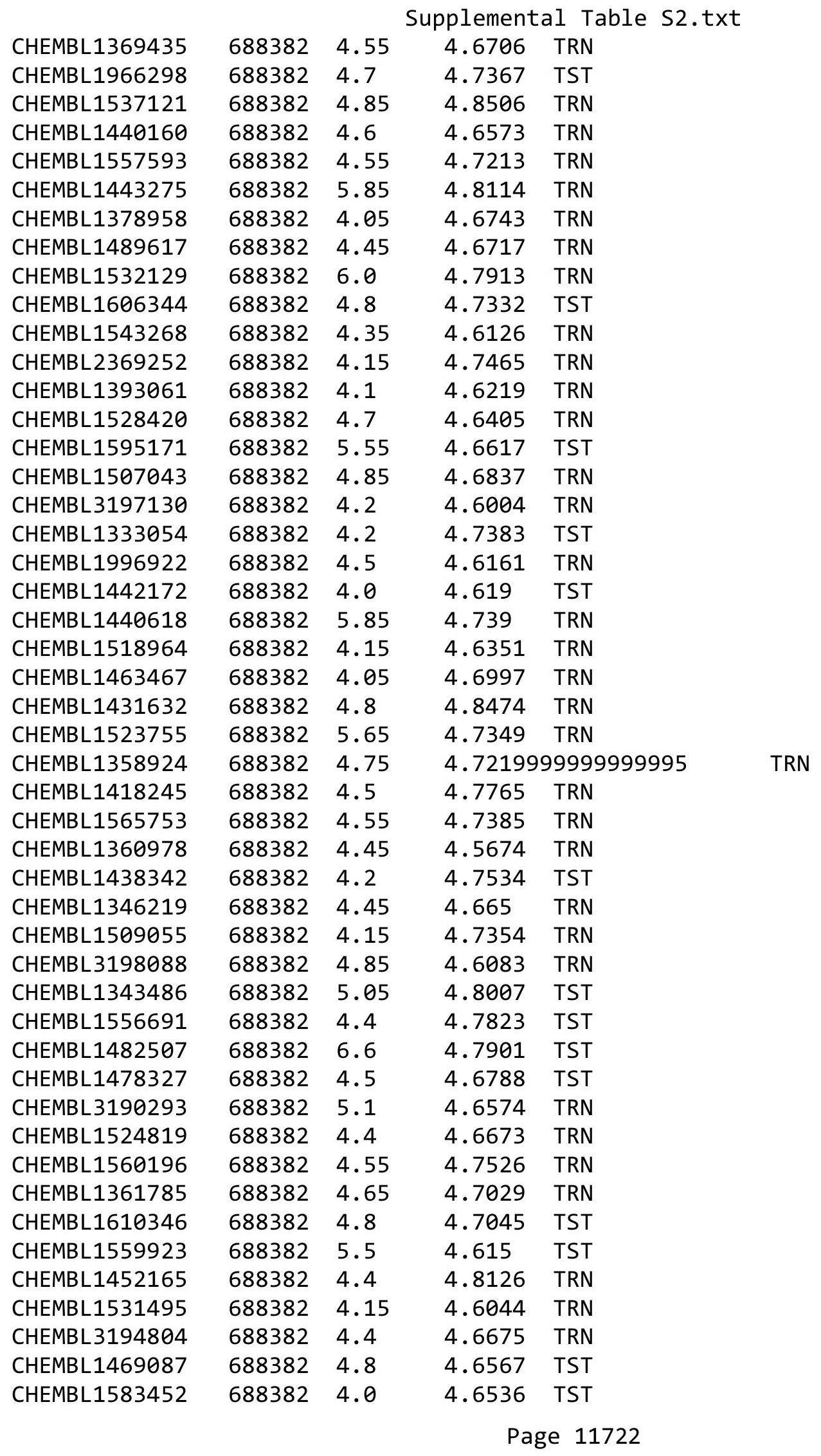




\begin{tabular}{|c|c|c|c|c|c|}
\hline \multicolumn{6}{|c|}{ Supplemental Table S2.txt } \\
\hline CHEMBL1409870 & 688382 & 4.95 & 4.7763 & TRN & \\
\hline CHEMBL1523814 & 688382 & 4.05 & 4.598 & TRN & \\
\hline CHEMBL1319294 & 688382 & 4.45 & 4.747 & TRN & \\
\hline CHEMBL1317783 & 688382 & 4.65 & 4.6645 & TRN & \\
\hline CHEMBL3207506 & 688382 & 4.95 & 4.5763 & TRN & \\
\hline CHEMBL1609135 & 688382 & 5.3 & 4.7356 & TRN & \\
\hline CHEMBL1544695 & 688382 & 4.45 & 4.6301 & TRN & \\
\hline CHEMBL1407500 & 688382 & 4.5 & 4.7127 & TRN & \\
\hline CHEMBL1456632 & 688382 & 4.8 & 4.6359 & TRN & \\
\hline CHEMBL1326857 & 688382 & 5.1 & 4.7937 & TRN & \\
\hline CHEMBL1497296 & 688382 & 4.05 & 4.7042 & TRN & \\
\hline CHEMBL1489577 & 688382 & 5.55 & 4.6794 & TRN & \\
\hline CHEMBL1425994 & 688382 & 4.85 & 4.7452 & TRN & \\
\hline CHEMBL3198064 & 688382 & 4.7 & 4.61600 & 00000000005 & TRN \\
\hline CHEMBL1336264 & 688382 & 5.2 & 4.6385 & TRN & \\
\hline CHEMBL1446812 & 688382 & 4.85 & 4.6917 & TRN & \\
\hline CHEMBL1609236 & 688382 & 4.65 & 4.6331 & TRN & \\
\hline CHEMBL1313817 & 688382 & 5.05 & 4.7862 & TRN & \\
\hline CHEMBL1312490 & 688382 & 5.0 & 4.6862 & TST & \\
\hline CHEMBL1461822 & 688382 & 5.0 & 4.6408 & TST & \\
\hline CHEMBL1579820 & 688382 & 4.8 & 4.8035 & TST & \\
\hline CHEMBL1406277 & 688382 & 4.5 & 4.6779 & TRN & \\
\hline CHEMBL1367316 & 688382 & 4.5 & 4.6914 & TRN & \\
\hline CHEMBL3195024 & 688382 & 4.35 & 4.61600 & 20000000005 & TRN \\
\hline CHEMBL1361227 & 688382 & 4.15 & 4.6533 & TRN & \\
\hline CHEMBL1595864 & 688382 & 4.65 & 4.69600 & 0000000001 & TRN \\
\hline CHEMBL1386300 & 688382 & 4.4 & 4.7648 & TST & \\
\hline CHEMBL1604604 & 688382 & 4.85 & 4.6824 & TRN & \\
\hline CHEMBL1453276 & 688382 & 4.45 & 4.6891 & TRN & \\
\hline CHEMBL1345421 & 688382 & 4.4 & 4.7034 & TRN & \\
\hline CHEMBL1541096 & 688382 & 4.2 & 4.6555 & TST & \\
\hline CHEMBL1380339 & 688382 & 4.5 & 4.699 & TRN & \\
\hline CHEMBL1563630 & 688382 & 4.35 & 4.7745 & TST & \\
\hline CHEMBL1425695 & 688382 & 5.15 & 4.8082 & TRN & \\
\hline CHEMBL1390450 & 688382 & 5.05 & 4.7306 & TRN & \\
\hline CHEMBL1310701 & 688382 & 4.4 & 4.6937 & TST & \\
\hline CHEMBL1344184 & 688382 & 4.5 & 4.6656 & TRN & \\
\hline CHEMBL1385892 & 688382 & 4.15 & 4.8788 & TRN & \\
\hline CHEMBL1508871 & 688382 & 4.45 & 4.6613 & TRN & \\
\hline CHEMBL1589822 & 688382 & 4.05 & 4.7708 & TRN & \\
\hline CHEMBL1609915 & 688382 & 4.8 & 4.6914 & TST & \\
\hline CHEMBL1410678 & 688382 & 4.35 & 4.7299 & TRN & \\
\hline CHEMBL1464392 & 688382 & 4.5 & 4.6666 & TRN & \\
\hline CHEMBL1431014 & 688382 & 4.4 & 4.6062 & TRN & \\
\hline CHEMBL1411165 & 688382 & 4.85 & 4.663 & TRN & \\
\hline CHEMBL1504679 & 688382 & 5.0 & 4.5671 & TRN & \\
\hline CHEMBL1354447 & 688382 & 4.35 & 4.7526 & TRN & \\
\hline CHEMBL1443292 & 688382 & 4.6 & 4.7292 & TRN & \\
\hline
\end{tabular}




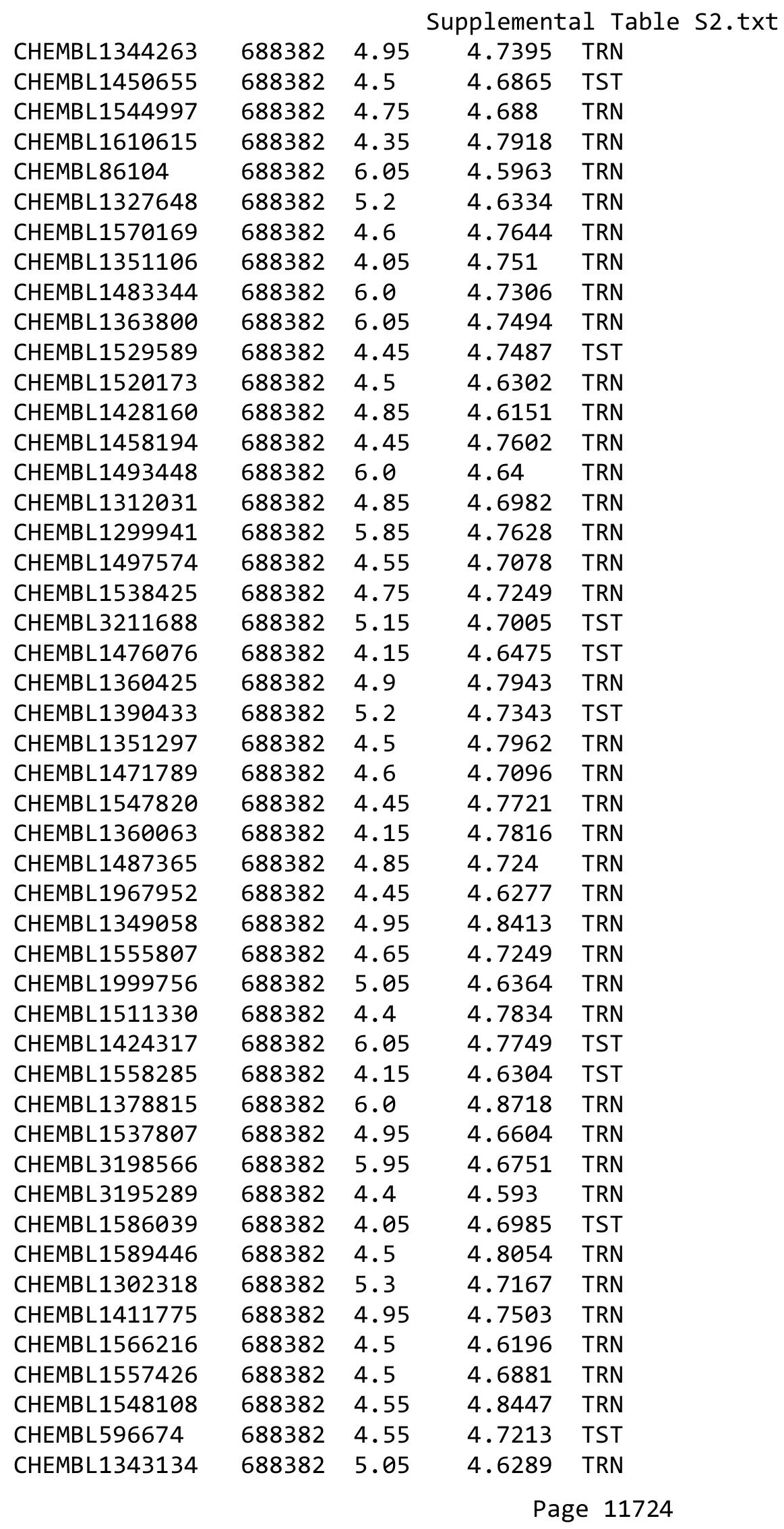




\begin{tabular}{|c|c|c|c|c|c|}
\hline & & \multicolumn{4}{|c|}{ Supplemental Table s2.txt } \\
\hline CHEMBL1393008 & 688382 & 4.75 & 4.6638 & TRN & \\
\hline CHEMBL1536174 & 688382 & 4.4 & 4.6544 & TRN & \\
\hline CHEMBL1330829 & 688382 & 4.8 & 4.6894 & TST & \\
\hline CHEMBL1471980 & 688382 & 4.15 & 4.7224 & TST & \\
\hline CHEMBL1552290 & 688382 & 5.1 & 4.6943 & TRN & \\
\hline CHEMBL1538652 & 688382 & 4.4 & 4.6636 & TST & \\
\hline CHEMBL1608376 & 688382 & 4.1 & 4.8423 & TST & \\
\hline CHEMBL 3194277 & 688382 & 4.15 & 4.6448 & TRN & \\
\hline CHEMBL1537583 & 688382 & 4.5 & 4.6625 & TRN & \\
\hline CHEMBL1713905 & 688382 & 5.6 & 4.677 & TRN & \\
\hline CHEMBL1344741 & 688382 & 4.5 & 4.7763 & TRN & \\
\hline CHEMBL1405311 & 688382 & 4.5 & 4.6438 & TRN & \\
\hline CHEMBL1320704 & 688382 & 4.4 & 4.7681 & TRN & \\
\hline CHEMBL1420457 & 688382 & 4.6 & 4.7185 & TST & \\
\hline CHEMBL1324202 & 688382 & 4.8 & 4.707 & TST & \\
\hline CHEMBL1587965 & 688382 & 4.85 & 4.8556 & TRN & \\
\hline CHEMBL1415090 & 688382 & 4.9 & 4.7271 & TRN & \\
\hline CHEMBL1359255 & 688382 & 4.45 & 4.69600 & 0000000001 & TRN \\
\hline CHEMBL1353682 & 688382 & 4.55 & 4.6973 & TRN & \\
\hline CHEMBL1406106 & 688382 & 5.2 & 4.6445 & TST & \\
\hline CHEMBL1496575 & 688382 & 4.8 & 4.7064 & TST & \\
\hline CHEMBL1575649 & 688382 & 5.15 & 4.614 & TRN & \\
\hline CHEMBL1427482 & 688382 & 4.5 & 4.7617 & TRN & \\
\hline CHEMBL3208859 & 688382 & 4.5 & 4.6776 & TST & \\
\hline CHEMBL1404581 & 688382 & 4.85 & 4.7744 & TRN & \\
\hline CHEMBL1384338 & 688382 & 4.3 & 4.6773 & TST & \\
\hline CHEMBL1347189 & 688382 & 4.45 & 4.7398 & TST & \\
\hline CHEMBL1967821 & 688382 & 5.0 & 4.7415 & TRN & \\
\hline CHEMBL1562056 & 688382 & 5.55 & 4.7423 & TRN & \\
\hline CHEMBL1528986 & 688382 & 4.95 & 4.5673 & TRN & \\
\hline CHEMBL1419480 & 688382 & 4.6 & 4.7182 & TRN & \\
\hline CHEMBL1466611 & 688382 & 4.2 & 4.8018 & TRN & \\
\hline CHEMBL1348626 & 688382 & 4.75 & 4.6876 & TST & \\
\hline CHEMBL1334858 & 688382 & 6.0 & 4.7566 & TRN & \\
\hline CHEMBL1308747 & 688382 & 4.45 & 4.7402 & TRN & \\
\hline CHEMBL1318929 & 688382 & 4.8 & 4.6783 & TST & \\
\hline CHEMBL1509103 & 688382 & 4.5 & 4.6658 & TST & \\
\hline CHEMBL1368719 & 688382 & 6.0 & 4.7072 & TRN & \\
\hline CHEMBL1470064 & 688382 & 4.95 & 4.7949 & TRN & \\
\hline CHEMBL1499442 & 688382 & 4.3 & 4.6791 & TRN & \\
\hline CHEMBL1502222 & 688382 & 4.8 & 4.7441 & TRN & \\
\hline CHEMBL1980744 & 688382 & 4.4 & 4.6375 & TRN & \\
\hline CHEMBL1416532 & 688382 & 4.05 & 4.7982 & TRN & \\
\hline CHEMBL1537687 & 688382 & 4.4 & 4.6439 & TRN & \\
\hline CHEMBL1462855 & 688382 & 4.5 & 4.6775 & TST & \\
\hline CHEMBL1578675 & 688382 & 5.1 & 4.6176 & TRN & \\
\hline CHEMBL3199424 & 688382 & 4.6 & 4.6736 & TRN & \\
\hline CHEMBL1351248 & 688382 & 4.5 & 4.6974 & TRN & \\
\hline
\end{tabular}




\begin{tabular}{|c|c|c|c|c|c|}
\hline \multicolumn{6}{|c|}{ Supplemental Table s2.txt } \\
\hline CHEMBL1989723 & 688382 & 4.4 & 4.629 & TST & \\
\hline CHEMBL3197081 & 688382 & 4.35 & 4.6778 & TRN & \\
\hline CHEMBL1453634 & 688382 & 4.5 & 4.6594 & TRN & \\
\hline CHEMBL1378118 & 688382 & 4.5 & 4.6272 & TRN & \\
\hline CHEMBL1528596 & 688382 & 4.65 & 4.6566 & TST & \\
\hline CHEMBL1416185 & 688382 & 4.2 & 4.7526 & TRN & \\
\hline CHEMBL1459252 & 688382 & 4.8 & 4.7674 & TRN & \\
\hline CHEMBL1545823 & 688382 & 4.05 & 4.6674 & TRN & \\
\hline CHEMBL1579995 & 688382 & 5.65 & 4.7355 & TRN & \\
\hline CHEMBL1517769 & 688382 & 5.2 & 4.7694 & TST & \\
\hline CHEMBL1503658 & 688382 & 5.95 & 4.6332 & TST & \\
\hline CHEMBL1555748 & 688382 & 4.85 & 4.7633 & TST & \\
\hline CHEMBL1531345 & 688382 & 4.0 & 4.7173 & TRN & \\
\hline CHEMBL1304092 & 688382 & 4.4 & 4.7032 & TRN & \\
\hline CHEMBL1504070 & 688382 & 4.45 & 4.706 & TRN & \\
\hline CHEMBL1586944 & 688382 & 4.95 & 4.7312 & TRN & \\
\hline CHEMBL3189627 & 688382 & 4.05 & 4.6521 & TRN & \\
\hline CHEMBL1467648 & 688382 & 4.55 & 4.6848 & TRN & \\
\hline CHEMBL1366823 & 688382 & 5.0 & $4.6530 e$ & 00000000005 & TRN \\
\hline CHEMBL1343378 & 688382 & 4.2 & 4.8011 & TRN & \\
\hline CHEMBL1566379 & 688382 & 4.2 & 4.7266 & TRN & \\
\hline CHEMBL1992943 & 688382 & 5.8 & 4.6936 & TRN & \\
\hline CHEMBL1339164 & 688382 & 4.8 & 4.7565 & TRN & \\
\hline CHEMBL1382917 & 688382 & 4.6 & 4.6252 & TRN & \\
\hline CHEMBL1990932 & 688382 & 4.2 & 4.6234 & TST & \\
\hline CHEMBL1409198 & 688382 & 9.0 & 4.742 & TRN & \\
\hline CHEMBL1374100 & 688382 & 4.2 & 4.7351 & TST & \\
\hline CHEMBL1305678 & 688382 & 4.45 & 4.6433 & TRN & \\
\hline CHEMBL1605206 & 688382 & 5.85 & 4.7292 & TRN & \\
\hline CHEMBL1353084 & 688382 & 4.55 & 4.7387 & TRN & \\
\hline CHEMBL1528560 & 688382 & 4.2 & 4.7009 & TST & \\
\hline CHEMBL3208213 & 688382 & 4.0 & 4.7012 & TRN & \\
\hline CHEMBL1497177 & 688382 & 5.35 & 4.7229 & TRN & \\
\hline CHEMBL1448556 & 688382 & 4.15 & 4.6838 & TST & \\
\hline CHEMBL1333442 & 688382 & 5.4 & 4.7242 & TRN & \\
\hline CHEMBL1365292 & 688382 & 4.6 & 4.6623 & TRN & \\
\hline CHEMBL1359446 & 688382 & 4.2 & 4.6613 & TRN & \\
\hline CHEMBL1584754 & 688382 & 4.35 & 4.598 & TST & \\
\hline CHEMBL1346373 & 688382 & 4.2 & 4.6637 & TST & \\
\hline CHEMBL1544308 & 688382 & 4.65 & 4.7097 & TRN & \\
\hline CHEMBL1441619 & 688382 & 5.5 & 4.5973 & TRN & \\
\hline CHEMBL1506025 & 688382 & 5.05 & 4.6701 & TRN & \\
\hline CHEMBL1524544 & 688382 & 5.0 & 4.8003 & TRN & \\
\hline CHEMBL1583378 & 688382 & 5.85 & 4.7856 & TRN & \\
\hline CHEMBL1511424 & 688382 & 4.35 & 4.6174 & TRN & \\
\hline CHEMBL1511942 & 688382 & 4.05 & 4.7033 & TRN & \\
\hline CHEMBL1303110 & 688382 & 4.85 & 4.6921 & TRN & \\
\hline CHEMBL1561799 & 688382 & 5.2 & 4.6615 & TRN & \\
\hline
\end{tabular}




\begin{tabular}{|c|c|c|c|c|}
\hline \multicolumn{5}{|c|}{ Supplemental Table S2.txt } \\
\hline CHEMBL1344941 & 688382 & 5.4 & 4.7674 & TST \\
\hline CHEMBL1392957 & 688382 & 4.8 & 4.6089 & TRN \\
\hline CHEMBL1498392 & 688382 & 4.95 & 4.7889 & TST \\
\hline CHEMBL1389949 & 688382 & 5.15 & 4.7857 & TRN \\
\hline CHEMBL1300751 & 688382 & 4.85 & 4.7278 & TRN \\
\hline CHEMBL1307906 & 688382 & 4.75 & 4.662 & TRN \\
\hline CHEMBL1378915 & 688382 & 5.05 & 4.6956 & TRN \\
\hline CHEMBL1304735 & 688382 & 5.15 & 4.6588 & TRN \\
\hline CHEMBL1350224 & 688382 & 4.15 & 4.6797 & TRN \\
\hline CHEMBL1589588 & 688382 & 4.5 & 4.6696 & TRN \\
\hline CHEMBL1603140 & 688382 & 4.5 & 4.6255 & TRN \\
\hline CHEMBL1587740 & 688382 & 5.65 & 4.6648 & TST \\
\hline CHEMBL1503128 & 688382 & 4.5 & 4.6825 & TRN \\
\hline CHEMBL1393632 & 688382 & 5.8 & 4.6941 & TST \\
\hline CHEMBL1533523 & 688382 & 4.15 & 4.6591 & TST \\
\hline CHEMBL1967862 & 688382 & 4.3 & 4.6638 & TST \\
\hline CHEMBL1507675 & 688382 & 5.45 & 4.7742 & TRN \\
\hline CHEMBL1337790 & 688382 & 4.9 & 4.6268 & TRN \\
\hline CHEMBL3145323 & 688382 & 4.15 & 4.6917 & TST \\
\hline CHEMBL1609853 & 688382 & 4.85 & 4.71 & TRN \\
\hline CHEMBL1528177 & 688382 & 4.55 & 4.6974 & TRN \\
\hline CHEMBL1528625 & 688382 & 4.75 & 4.7499 & TRN \\
\hline CHEMBL1465106 & 688382 & 4.45 & 4.7169 & TRN \\
\hline CHEMBL1412387 & 688382 & 4.0 & 4.7342 & TST \\
\hline CHEMBL1550685 & 688382 & 4.4 & 4.6316 & TRN \\
\hline CHEMBL1419129 & 688382 & 4.75 & 4.7791 & TRN \\
\hline CHEMBL1444129 & 688382 & 6.05 & 4.8013 & TRN \\
\hline CHEMBL187460 & 688382 & 4.5 & 4.7244 & TST \\
\hline CHEMBL1374850 & 688382 & 4.45 & 4.7494 & TRN \\
\hline CHEMBL1332624 & 688382 & 4.25 & 4.6912 & TRN \\
\hline CHEMBL1340454 & 688382 & 5.1 & 4.6915 & TRN \\
\hline CHEMBL1332422 & 688382 & 4.8 & 4.7208 & TRN \\
\hline CHEMBL1535326 & 688382 & 4.0 & 4.745 & TST \\
\hline CHEMBL1579355 & 688382 & 5.0 & 4.7499 & TRN \\
\hline CHEMBL1581804 & 688382 & 5.3 & 4.8537 & TRN \\
\hline CHEMBL1332356 & 688382 & 4.5 & 4.7166 & TRN \\
\hline CHEMBL1407782 & 688382 & 4.5 & 4.6026 & TRN \\
\hline CHEMBL1389086 & 688382 & 5.55 & 4.7474 & TRN \\
\hline CHEMBL1576806 & 688382 & 4.5 & 4.6941 & TST \\
\hline CHEMBL1308210 & 688382 & 6.0 & 4.6616 & TRN \\
\hline CHEMBL1599654 & 688382 & 6.0 & 4.625 & TRN \\
\hline CHEMBL1465727 & 688382 & 4.45 & 4.6804 & TRN \\
\hline CHEMBL1470232 & 688382 & 4.35 & 4.6011 & TRN \\
\hline CHEMBL3213813 & 688382 & 4.8 & 4.6879 & TST \\
\hline CHEMBL1547163 & 688382 & 4.0 & 4.7247 & TRN \\
\hline CHEMBL1402856 & 688382 & 4.5 & 4.6861 & TST \\
\hline CHEMBL1347346 & 688382 & 4.4 & 4.6461 & TRN \\
\hline CHEMBL1337227 & 688382 & 4.45 & 4.731 & TRN \\
\hline
\end{tabular}




\begin{tabular}{|c|c|c|c|c|c|}
\hline \multirow{2}{*}{ CHEMBL1522238 } & \multirow{2}{*}{688382} & \\
\hline & & 4.3 & 4.7439 & TRN & \\
\hline CHEMBL1610004 & 688382 & 4.8 & 4.7318 & TRN & \\
\hline CHEMBL1304637 & 688382 & 5.55 & 4.80699 & 99999999995 & TRN \\
\hline CHEMBL1361228 & 688382 & 5.05 & 4.6854 & TST & \\
\hline CHEMBL1466658 & 688382 & 4.35 & 4.7027 & TRN & \\
\hline CHEMBL1521445 & 688382 & 5.3 & 4.7962 & TRN & \\
\hline CHEMBL1457859 & 688382 & 4.3 & 4.7066 & TRN & \\
\hline CHEMBL1374437 & 688382 & 4.15 & 4.6343 & TRN & \\
\hline CHEMBL1446353 & 688382 & 4.8 & 4.7024 & TRN & \\
\hline CHEMBL1313582 & 688382 & 4.5 & 4.6389 & 9999999999 & TRN \\
\hline CHEMBL1424726 & 688382 & 4.95 & 4.8032 & TRN & \\
\hline CHEMBL3209277 & 688382 & 4.55 & 4.638 & TRN & \\
\hline CHEMBL 1455047 & 688382 & 4.8 & 4.8044 & TRN & \\
\hline CHEMBL505057 & 688382 & 4.45 & 4.6308 & TST & \\
\hline CHEMBL1480739 & 688382 & 4.6 & 4.6961 & TRN & \\
\hline CHEMBL1577157 & 688382 & 4.35 & 4.5838 & TRN & \\
\hline CHEMBL1405238 & 688382 & 5.95 & 4.6759 & TST & \\
\hline CHEMBL1499187 & 688382 & 4.95 & 4.7478 & TST & \\
\hline CHEMBL577102 & 688382 & 4.65 & 4.5928 & TRN & \\
\hline CHEMBL1584540 & 688382 & 4.85 & 4.6675 & TRN & \\
\hline CHEMBL1534196 & 688382 & 4.45 & 4.7268 & TST & \\
\hline CHEMBL1467414 & 688382 & 4.8 & 4.7032 & TST & \\
\hline CHEMBL1572064 & 688382 & 4.15 & 4.8025 & TRN & \\
\hline CHEMBL1353371 & 688382 & 4.1 & 4.6579 & TST & \\
\hline CHEMBL1503175 & 688382 & 4.45 & 4.7015 & TRN & \\
\hline CHEMBL1401761 & 688382 & 4.15 & 4.6673 & TRN & \\
\hline CHEMBL1544075 & 688382 & 4.55 & 4.7186 & TRN & \\
\hline CHEMBL3197710 & 688382 & 4.2 & 4.6095 & TRN & \\
\hline CHEMBL1586757 & 688382 & 5.0 & 4.8293 & TRN & \\
\hline CHEMBL1509624 & 688382 & 4.8 & 4.755 & TRN & \\
\hline CHEMBL1328756 & 688382 & 4.35 & 4.775 & TRN & \\
\hline CHEMBL1304270 & 688382 & 4.5 & 4.7454 & TRN & \\
\hline CHEMBL1485394 & 688382 & 5.5 & 4.7245 & TRN & \\
\hline CHEMBL1432642 & 688382 & 4.45 & 4.7219 & TRN & \\
\hline CHEMBL1539334 & 688382 & 4.4 & 4.6473 & TRN & \\
\hline CHEMBL1600471 & 688382 & 5.05 & 4.8435 & TST & \\
\hline CHEMBL1439554 & 688382 & 4.5 & 4.6702 & TRN & \\
\hline CHEMBL1433318 & 688382 & 4.5 & 4.7456 & TRN & \\
\hline CHEMBL1441437 & 688382 & 5.05 & 4.6605 & TRN & \\
\hline CHEMBL1389231 & 688382 & 5.1 & 4.7273 & TST & \\
\hline CHEMBL1349390 & 688382 & 4.15 & 4.6794 & TRN & \\
\hline CHEMBL1383289 & 688382 & 4.15 & 4.746 & TRN & \\
\hline CHEMBL1456520 & 688382 & 4.8 & 4.7105 & TRN & \\
\hline CHEMBL1366301 & 688382 & 4.5 & 4.6344 & TRN & \\
\hline CHEMBL1468368 & 688382 & 4.45 & 4.6761 & TRN & \\
\hline CHEMBL1361112 & 688382 & 4.5 & 4.6874 & TST & \\
\hline CHEMBL1494450 & 688382 & 4.85 & 4.7802 & TRN & \\
\hline CHEMBL1420167 & 688382 & 4.55 & 4.6469 & TRN & \\
\hline
\end{tabular}




\begin{tabular}{|c|c|c|c|c|c|}
\hline & & \multicolumn{4}{|c|}{ Supplemental Table s2.txt } \\
\hline CHEMBL1532119 & 688382 & 4.2 & 4.6454 & TRN & \\
\hline CHEMBL1359773 & 688382 & 5.55 & 4.7191 & TST & \\
\hline CHEMBL1458452 & 688382 & 4.85 & 4.7902 & TRN & \\
\hline CHEMBL1575744 & 688382 & 4.9 & 4.796 & TRN & \\
\hline CHEMBL1604527 & 688382 & 4.65 & 4.6696 & TRN & \\
\hline CHEMBL1479368 & 688382 & 4.05 & 4.7111 & TST & \\
\hline CHEMBL1312872 & 688382 & 4.5 & 4.7793 & TRN & \\
\hline CHEMBL1539338 & 688382 & 4.2 & 4.6785 & TRN & \\
\hline CHEMBL1310080 & 688382 & 5.85 & 4.7643 & TRN & \\
\hline CHEMBL1433291 & 688382 & 4.5 & 4.7112 & TRN & \\
\hline CHEMBL1422389 & 688382 & 6.0 & 4.7629 & TRN & \\
\hline CHEMBL1973773 & 688382 & 4.9 & 4.6656 & TRN & \\
\hline CHEMBL1468219 & 688382 & 6.4 & 4.7589 & TRN & \\
\hline CHEMBL1467655 & 688382 & 4.55 & 4.6452 & TST & \\
\hline CHEMBL1464619 & 688382 & 4.15 & 4.6484 & TRN & \\
\hline CHEMBL1310249 & 688382 & 4.2 & 4.6988 & TRN & \\
\hline CHEMBL1579763 & 688382 & 6.0 & 4.7244 & TRN & \\
\hline CHEMBL1569931 & 688382 & 4.8 & 4.6651 & TRN & \\
\hline CHEMBL1308453 & 688382 & 4.4 & 4.6904 & TST & \\
\hline CHEMBL1349709 & 688382 & 4.3 & 4.7146 & TRN & \\
\hline CHEMBL1424938 & 688382 & 5.3 & 4.614 & TST & \\
\hline CHEMBL1398966 & 688382 & 5.1 & 4.6029 & TRN & \\
\hline CHEMBL1330058 & 688382 & 4.85 & 4.6098 & TRN & \\
\hline CHEMBL1505393 & 688382 & 5.55 & 4.6837 & TRN & \\
\hline CHEMBL1604739 & 688382 & 4.4 & 4.6554 & TRN & \\
\hline CHEMBL1524877 & 688382 & 4.9 & 4.6815 & TRN & \\
\hline CHEMBL1578198 & 688382 & 4.65 & 4.7362 & TST & \\
\hline CHEMBL1360532 & 688382 & 4.8 & 4.6717 & TRN & \\
\hline CHEMBL1520591 & 688382 & 4.8 & 4.8169 & TST & \\
\hline CHEMBL1407906 & 688382 & 4.4 & 4.6274 & TRN & \\
\hline CHEMBL3213374 & 688382 & 4.5 & 4.6998 & TRN & \\
\hline CHEMBL1985744 & 688382 & 4.45 & 4.7037 & TRN & \\
\hline CHEMBL355318 & 688382 & 4.5 & 4.7083 & TRN & \\
\hline CHEMBL1334081 & 688382 & 4.45 & 4.6766 & TST & \\
\hline CHEMBL3187596 & 688382 & 4.2 & 4.7121 & TRN & \\
\hline CHEMBL1544996 & 688382 & 4.55 & 4.6903 & TRN & \\
\hline CHEMBL3199737 & 688382 & 4.5 & 4.6418 & TRN & \\
\hline CHEMBL1312833 & 688382 & 4.85 & 4.7188 & TRN & \\
\hline CHEMBL1347345 & 688382 & 4.8 & 4.7012 & TRN & \\
\hline CHEMBL225230 & 688382 & 4.5 & 4.7167 & TRN & \\
\hline CHEMBL1582931 & 688382 & 4.35 & 4.7185 & TRN & \\
\hline CHEMBL1598094 & 688382 & 6.0 & 4.6662 & TRN & \\
\hline CHEMBL1440979 & 688382 & 4.35 & 4.8546 & TRN & \\
\hline CHEMBL1487196 & 688382 & 5.05 & 4.64199 & 99999999995 & TRN \\
\hline CHEMBL1406174 & 688382 & 4.85 & 4.753 & TRN & \\
\hline CHEMBL1598252 & 688382 & 4.4 & 4.6857 & TRN & \\
\hline CHEMBL1434255 & 688382 & 4.45 & 4.6604 & TRN & \\
\hline CHEMBL1546215 & 688382 & 4.5 & 4.6799 & TRN & \\
\hline
\end{tabular}




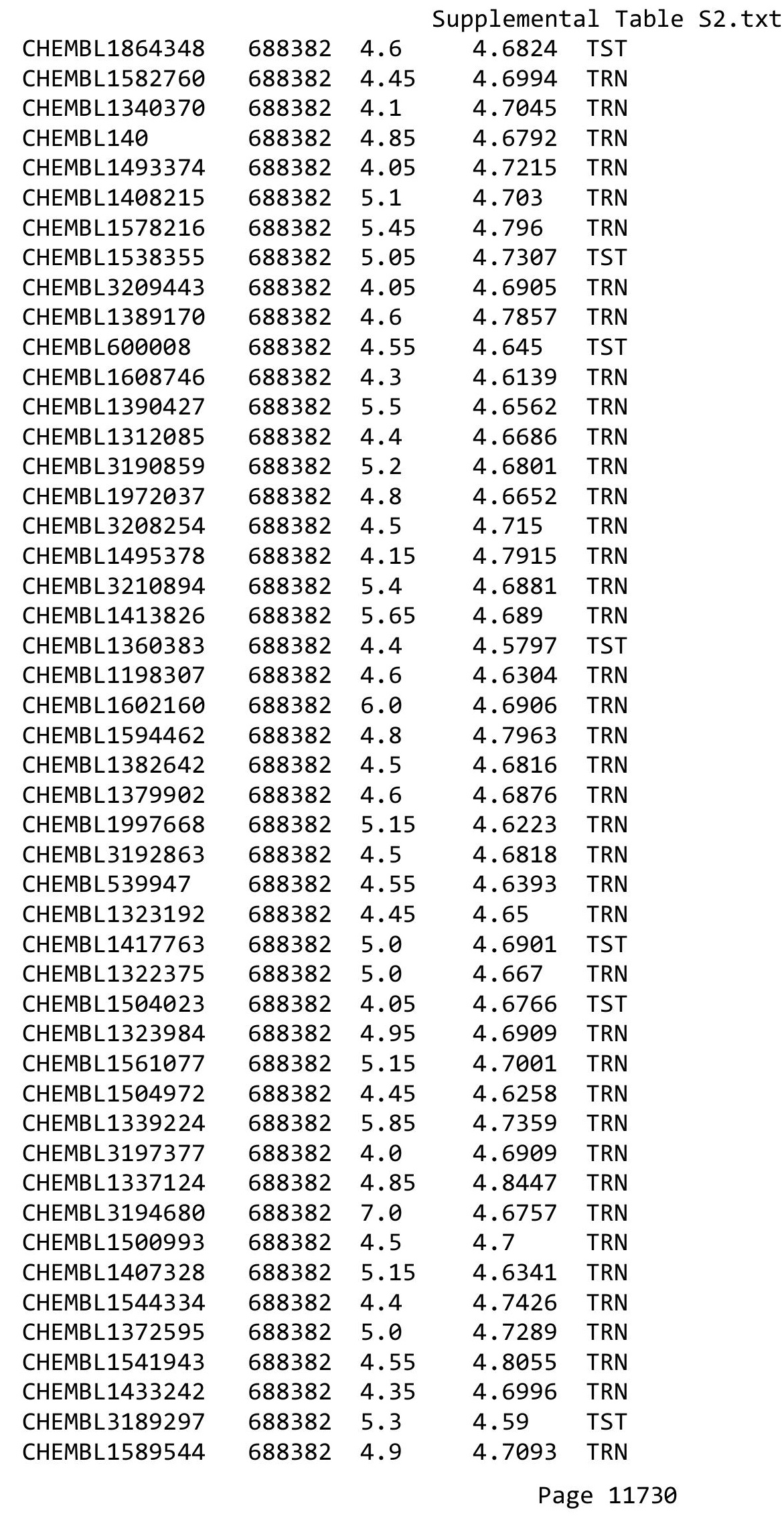




\begin{tabular}{|c|c|c|c|c|c|}
\hline \multicolumn{6}{|c|}{ Supplemental Table S2.txt } \\
\hline CHEMBL196814 & 688382 & 4.4 & 4.6251 & TRN & \\
\hline CHEMBL1343101 & 688382 & 4.5 & 4.6841 & TRN & \\
\hline CHEMBL1366942 & 688382 & 4.5 & 4.6127 & TRN & \\
\hline CHEMBL1588594 & 688382 & 5.8 & 4.7186 & TRN & \\
\hline CHEMBL1599948 & 688382 & 4.75 & 4.6106 & TRN & \\
\hline CHEMBL1460128 & 688382 & 4.85 & 4.7149 & TRN & \\
\hline CHEMBL1585652 & 688382 & 5.45 & 4.6686 & TRN & \\
\hline CHEMBL1605915 & 688382 & 4.85 & 4.754 & TRN & \\
\hline CHEMBL1564226 & 688382 & 4.8 & 4.7026 & TST & \\
\hline CHEMBL1496906 & 688382 & 6.0 & 4.688 & TST & \\
\hline CHEMBL1321085 & 688382 & 4.85 & 4.7626 & TRN & \\
\hline CHEMBL1365812 & 688382 & 5.95 & 4.8315 & TRN & \\
\hline CHEMBL1456506 & 688382 & 5.05 & 4.7084 & TRN & \\
\hline CHEMBL3197552 & 688382 & 4.55 & 4.6444 & TRN & \\
\hline CHEMBL1606887 & 688382 & 4.95 & 4.6863 & TRN & \\
\hline CHEMBL1461489 & 688382 & 4.5 & 4.6612 & TRN & \\
\hline CHEMBL3194267 & 688382 & 4.25 & 4.6449 & TST & \\
\hline CHEMBL1581188 & 688382 & 4.9 & 4.6118 & TRN & \\
\hline CHEMBL1588507 & 688382 & 4.15 & 4.8638 & TRN & \\
\hline CHEMBL3198332 & 688382 & 4.45 & 4.6968 & TRN & \\
\hline CHEMBL1456307 & 688382 & 5.55 & 4.7298 & TRN & \\
\hline CHEMBL3211752 & 688382 & 4.85 & 4.6635 & TRN & \\
\hline CHEMBL1506072 & 688382 & 4.95 & 4.672 & TST & \\
\hline CHEMBL1436378 & 688382 & 5.05 & 4.7767 & TRN & \\
\hline CHEMBL1299502 & 688382 & 5.05 & 4.6521 & TRN & \\
\hline CHEMBL1362531 & 688382 & 4.45 & 4.6988 & TRN & \\
\hline CHEMBL3196116 & 688382 & 4.85 & 4.6333 & TRN & \\
\hline CHEMBL1420859 & 688382 & 6.0 & 4.8513 & TST & \\
\hline CHEMBL1312664 & 688382 & 4.4 & 4.79899 & 99999999995 & TRN \\
\hline CHEMBL1416720 & 688382 & 5.0 & 4.6769 & TST & \\
\hline CHEMBL1491471 & 688382 & 4.8 & 4.7835 & TRN & \\
\hline CHEMBL1309228 & 688382 & 4.45 & 4.6814 & TST & \\
\hline CHEMBL1471212 & 688382 & 4.8 & 4.7936 & TRN & \\
\hline CHEMBL1503212 & 688382 & 5.0 & 4.8123 & TRN & \\
\hline CHEMBL1502397 & 688382 & 4.5 & 4.6949 & TRN & \\
\hline CHEMBL1451749 & 688382 & 4.95 & 4.6189 & TRN & \\
\hline CHEMBL1523485 & 688382 & 4.85 & 4.732 & TRN & \\
\hline CHEMBL1372724 & 688382 & 5.05 & 4.7355 & TRN & \\
\hline CHEMBL1328177 & 688382 & 4.8 & 4.7403 & TRN & \\
\hline CHEMBL1550238 & 688382 & 4.35 & 4.7454 & TRN & \\
\hline CHEMBL3190890 & 688382 & 4.15 & 4.6174 & TRN & \\
\hline CHEMBL1372346 & 688382 & 4.85 & 4.7996 & TRN & \\
\hline CHEMBL1350797 & 688382 & 6.05 & 4.7477 & TRN & \\
\hline CHEMBL1425760 & 688382 & 4.35 & 4.703 & TRN & \\
\hline CHEMBL1594571 & 688382 & 4.0 & 4.775 & TRN & \\
\hline CHEMBL1430148 & 688382 & 4.4 & 4.7539 & TRN & \\
\hline CHEMBL3191182 & 688382 & 4.15 & 4.6702 & TRN & \\
\hline CHEMBL1437954 & 688382 & 4.05 & 4.7518 & TRN & \\
\hline
\end{tabular}




\begin{tabular}{|c|c|c|c|c|c|}
\hline & & \multicolumn{4}{|c|}{ Supplemental Table S2.txt } \\
\hline CHEMBL1538376 & 688382 & 4.4 & 4.688 & TST & \\
\hline CHEMBL1386044 & 688382 & 4.5 & 4.7426 & TRN & \\
\hline CHEMBL1469004 & 688382 & 4.6 & 4.7067 & TRN & \\
\hline CHEMBL1413397 & 688382 & 4.5 & 4.8116 & TRN & \\
\hline CHEMBL1401494 & 688382 & 5.0 & 4.6958 & TRN & \\
\hline CHEMBL1490888 & 688382 & 4.85 & 4.6624 & TRN & \\
\hline CHEMBL1511674 & 688382 & 4.45 & 4.7296 & TRN & \\
\hline CHEMBL578512 & 688382 & 5.0 & 4.6348 & TRN & \\
\hline CHEMBL1588196 & 688382 & 6.0 & 4.6616 & TRN & \\
\hline CHEMBL1421032 & 688382 & 5.0 & 4.631 & TST & \\
\hline CHEMBL1416987 & 688382 & 4.55 & 4.7223 & TRN & \\
\hline CHEMBL3194477 & 688382 & 4.45 & 4.6239 & TRN & \\
\hline CHEMBL1524850 & 688382 & 5.2 & 4.6936 & TRN & \\
\hline CHEMBL1541949 & 688382 & 4.05 & 4.7756 & TRN & \\
\hline CHEMBL1497676 & 688382 & 4.5 & 4.8095 & TST & \\
\hline CHEMBL1463640 & 688382 & 4.05 & 4.7935 & TRN & \\
\hline CHEMBL1588722 & 688382 & 4.1 & 4.7038 & TRN & \\
\hline CHEMBL1590745 & 688382 & 4.45 & 4.59699 & 99999999995 & TRN \\
\hline CHEMBL3197901 & 688382 & 4.3 & 4.6284 & TST & \\
\hline CHEMBL1447782 & 688382 & 4.2 & 4.7126 & TRN & \\
\hline CHEMBL1531965 & 688382 & 4.2 & 4.7218 & TST & \\
\hline CHEMBL1529032 & 688382 & 5.85 & 4.7385 & TRN & \\
\hline CHEMBL1344788 & 688382 & 4.35 & 4.6664 & TRN & \\
\hline CHEMBL3213753 & 688382 & 5.1 & 4.6517 & TRN & \\
\hline CHEMBL1581429 & 688382 & 4.6 & 4.6346 & TRN & \\
\hline CHEMBL1371416 & 688382 & 5.1 & 4.7059 & TRN & \\
\hline CHEMBL355496 & 688382 & 6.0 & 4.5953 & TST & \\
\hline CHEMBL1585546 & 688382 & 4.5 & 4.782 & TRN & \\
\hline CHEMBL1580617 & 688382 & 5.05 & 4.8183 & TRN & \\
\hline CHEMBL1339529 & 688382 & 4.95 & 4.7558 & TST & \\
\hline CHEMBL1301496 & 688382 & 4.9 & 4.8194 & TRN & \\
\hline CHEMBL1611135 & 688382 & 5.85 & 4.6992 & TRN & \\
\hline CHEMBL1410249 & 688382 & 4.4 & 4.6857 & TRN & \\
\hline CHEMBL1399373 & 688382 & 5.8 & 4.7726 & TRN & \\
\hline CHEMBL1393310 & 688382 & 4.5 & 4.6124 & TRN & \\
\hline CHEMBL1365071 & 688382 & 4.4 & 4.6906 & TST & \\
\hline CHEMBL1455016 & 688382 & 5.05 & 4.8191 & TRN & \\
\hline CHEMBL1604191 & 688382 & 4.15 & 4.6062 & TRN & \\
\hline CHEMBL1978733 & 688382 & 5.15 & 4.5896 & TRN & \\
\hline CHEMBL602218 & 688382 & 5.15 & 4.6521 & TRN & \\
\hline CHEMBL1461033 & 688382 & 4.4 & 4.7382 & TST & \\
\hline CHEMBL3193044 & 688382 & 4.5 & 4.7893 & TST & \\
\hline CHEMBL1441315 & 688382 & 4.1 & 4.6903 & TRN & \\
\hline CHEMBL1323868 & 688382 & 4.45 & 4.707 & TRN & \\
\hline CHEMBL1390552 & 688382 & 5.95 & 4.6165 & TRN & \\
\hline CHEMBL1707818 & 688382 & 4.15 & 4.6496 & TRN & \\
\hline CHEMBL1345211 & 688382 & 4.5 & 4.721 & TST & \\
\hline CHEMBL1466820 & 688382 & 4.2 & 4.7561 & TRN & \\
\hline
\end{tabular}




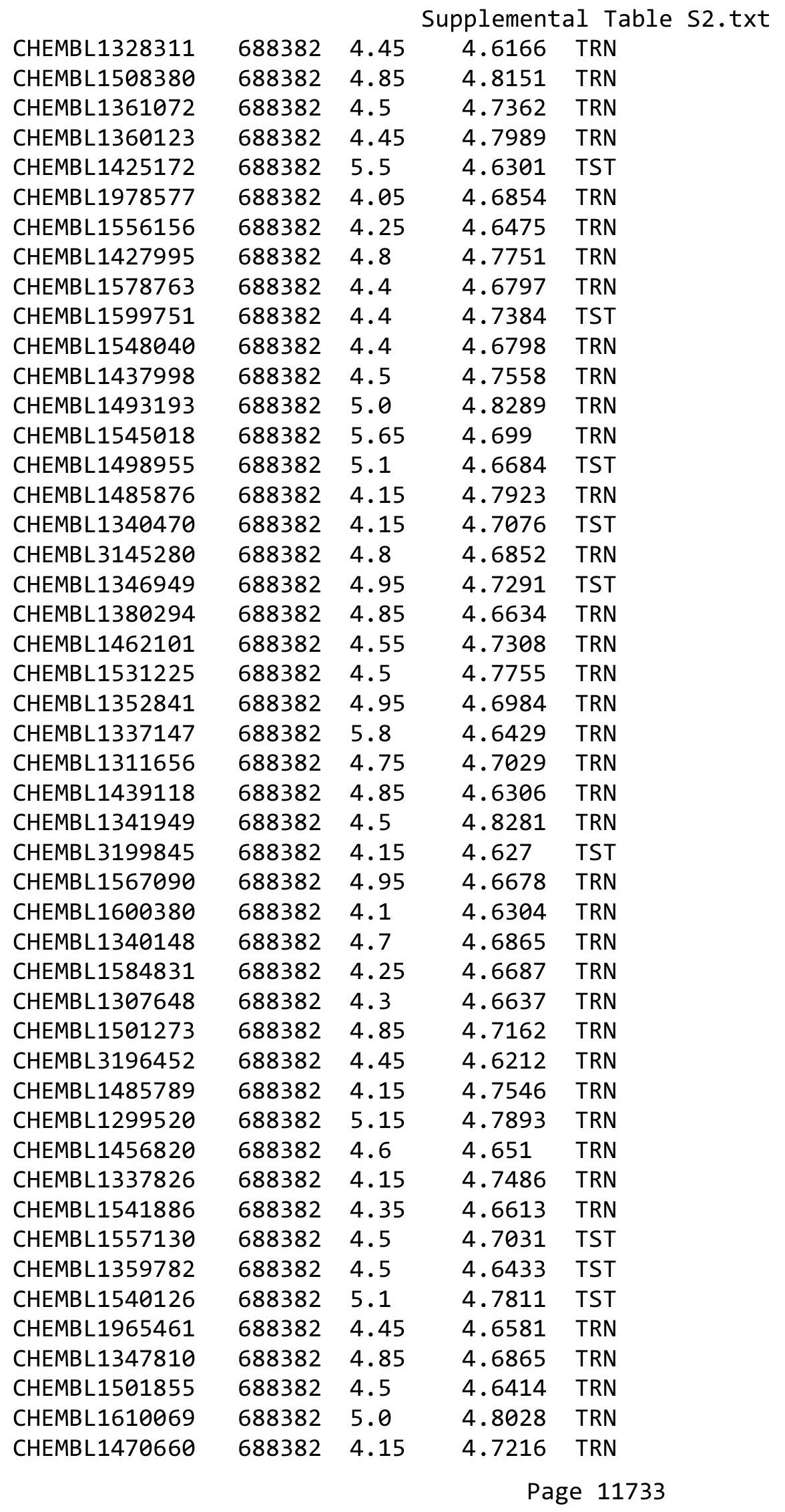




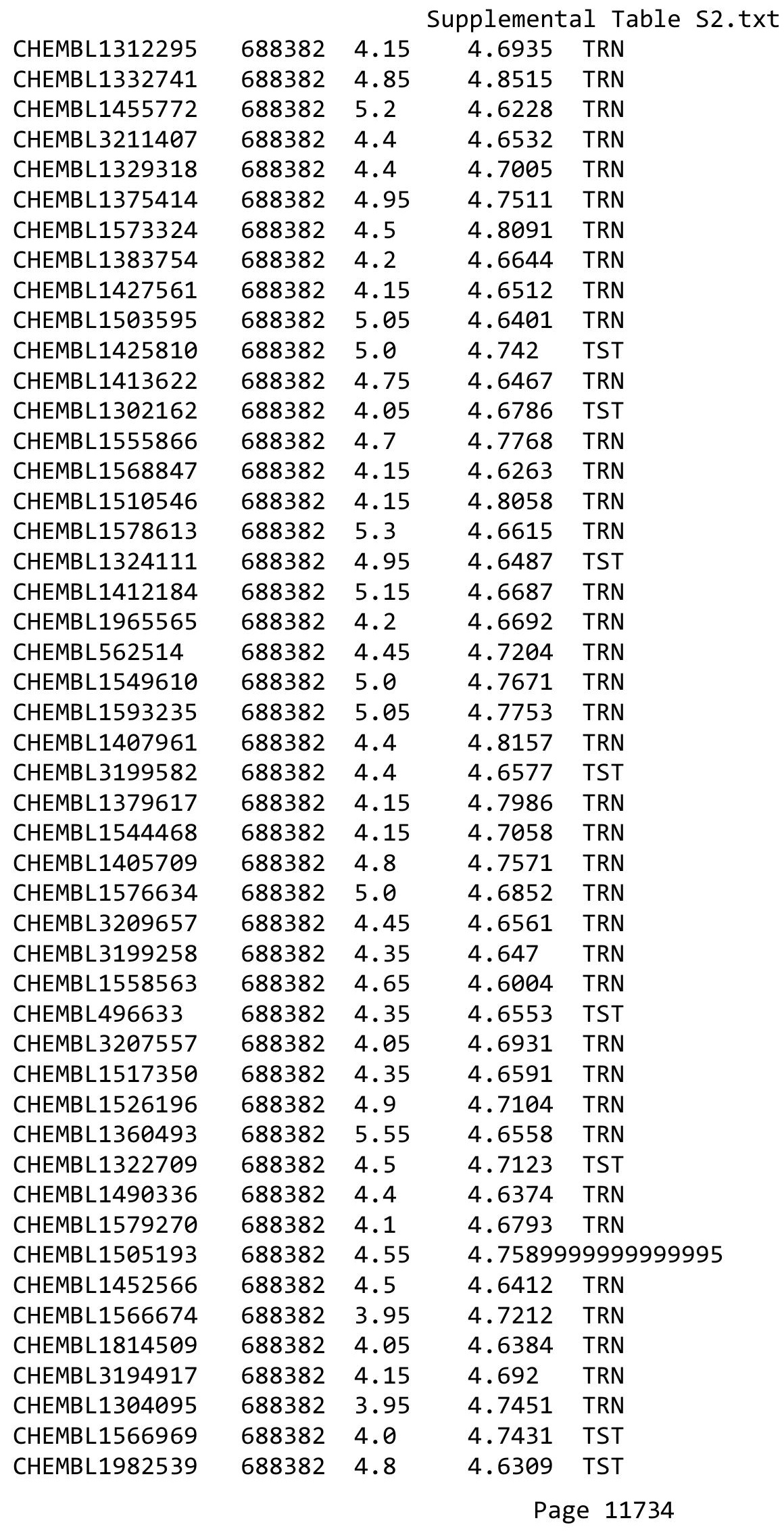




\begin{tabular}{|c|c|c|c|c|c|}
\hline & & \multicolumn{4}{|c|}{ Supplemental Table S2.txt } \\
\hline CHEMBL1418713 & 688382 & 4.6 & 4.6584 & TRN & \\
\hline CHEMBL1560833 & 688382 & 4.45 & 4.6424 & TRN & \\
\hline CHEMBL1472594 & 688382 & 4.5 & 4.7143 & TRN & \\
\hline CHEMBL1572217 & 688382 & 4.65 & 4.6866 & TRN & \\
\hline CHEMBL1305523 & 688382 & 4.85 & 4.74 & TRN & \\
\hline CHEMBL1605987 & 688382 & 5.0 & 4.6558 & TST & \\
\hline CHEMBL3199851 & 688382 & 4.5 & 4.6391 & TRN & \\
\hline CHEMBL1978821 & 688382 & 4.9 & 4.6332 & TRN & \\
\hline CHEMBL1442390 & 688382 & 4.3 & 4.7405 & TRN & \\
\hline CHEMBL1441603 & 688382 & 4.65 & 4.6328 & TRN & \\
\hline CHEMBL1442096 & 688382 & 4.5 & 4.6511 & TRN & \\
\hline CHEMBL1412931 & 688382 & 4.8 & 4.7479 & TST & \\
\hline CHEMBL1352503 & 688382 & 5.95 & 4.7787 & TRN & \\
\hline CHEMBL1561865 & 688382 & 5.65 & 4.6494 & TST & \\
\hline CHEMBL1507045 & 688382 & 4.4 & 4.72199 & 99999999995 & TRN \\
\hline CHEMBL3194938 & 688382 & 4.5 & 4.6453 & TST & \\
\hline CHEMBL1497617 & 688382 & 4.45 & 4.7622 & TRN & \\
\hline CHEMBL1426027 & 688382 & 4.85 & 4.5919 & TST & \\
\hline CHEMBL1345471 & 688382 & 4.5 & 4.6776 & TRN & \\
\hline CHEMBL1301619 & 688382 & 5.2 & 4.7261 & TST & \\
\hline CHEMBL1611744 & 688382 & 5.05 & 4.6409 & TRN & \\
\hline CHEMBL1504818 & 688382 & 4.15 & 4.6705 & TST & \\
\hline CHEMBL1173475 & 688382 & 6.0 & 4.6233 & TRN & \\
\hline CHEMBL1340548 & 688382 & 4.15 & 4.7787 & TRN & \\
\hline CHEMBL1338993 & 688382 & 4.9 & 4.7705 & TST & \\
\hline CHEMBL1379735 & 688382 & 4.8 & 4.7623 & TRN & \\
\hline CHEMBL1392848 & 688382 & 5.1 & 4.665 & TRN & \\
\hline CHEMBL1328473 & 688382 & 5.6 & 4.5971 & TRN & \\
\hline CHEMBL1359162 & 688382 & 4.8 & 4.7017 & TRN & \\
\hline CHEMBL1320895 & 688382 & 6.0 & 4.7498 & TRN & \\
\hline CHEMBL3213768 & 688382 & 4.15 & 4.6255 & TST & \\
\hline CHEMBL602625 & 688382 & 5.05 & 4.6315 & TRN & \\
\hline CHEMBL1488565 & 688382 & 4.4 & 4.8609 & TRN & \\
\hline CHEMBL1421110 & 688382 & 4.8 & 4.8095 & TRN & \\
\hline CHEMBL1359004 & 688382 & 4.25 & 4.626 & TRN & \\
\hline CHEMBL1381856 & 688382 & 4.45 & 4.6634 & TRN & \\
\hline CHEMBL1460225 & 688382 & 5.55 & 4.6841 & TRN & \\
\hline CHEMBL1491002 & 688382 & 4.4 & 4.6703 & TRN & \\
\hline CHEMBL1452084 & 688382 & 4.85 & 4.7038 & TRN & \\
\hline CHEMBL1383386 & 688382 & 4.55 & 4.7629 & TRN & \\
\hline CHEMBL1492072 & 688382 & 4.85 & 4.7085 & TST & \\
\hline CHEMBL1405672 & 688382 & 5.0 & 4.5982 & TST & \\
\hline CHEMBL1312148 & 688382 & 5.8 & 4.8077 & TRN & \\
\hline CHEMBL1390116 & 688382 & 4.15 & 4.6827 & TRN & \\
\hline CHEMBL3193281 & 688382 & 5.15 & 4.644 & TST & \\
\hline CHEMBL1480661 & 688382 & 5.2 & 4.7635 & TRN & \\
\hline CHEMBL1538035 & 688382 & 4.55 & 4.6643 & TRN & \\
\hline CHEMBL1465339 & 688382 & 4.25 & 4.647 & TRN & \\
\hline
\end{tabular}




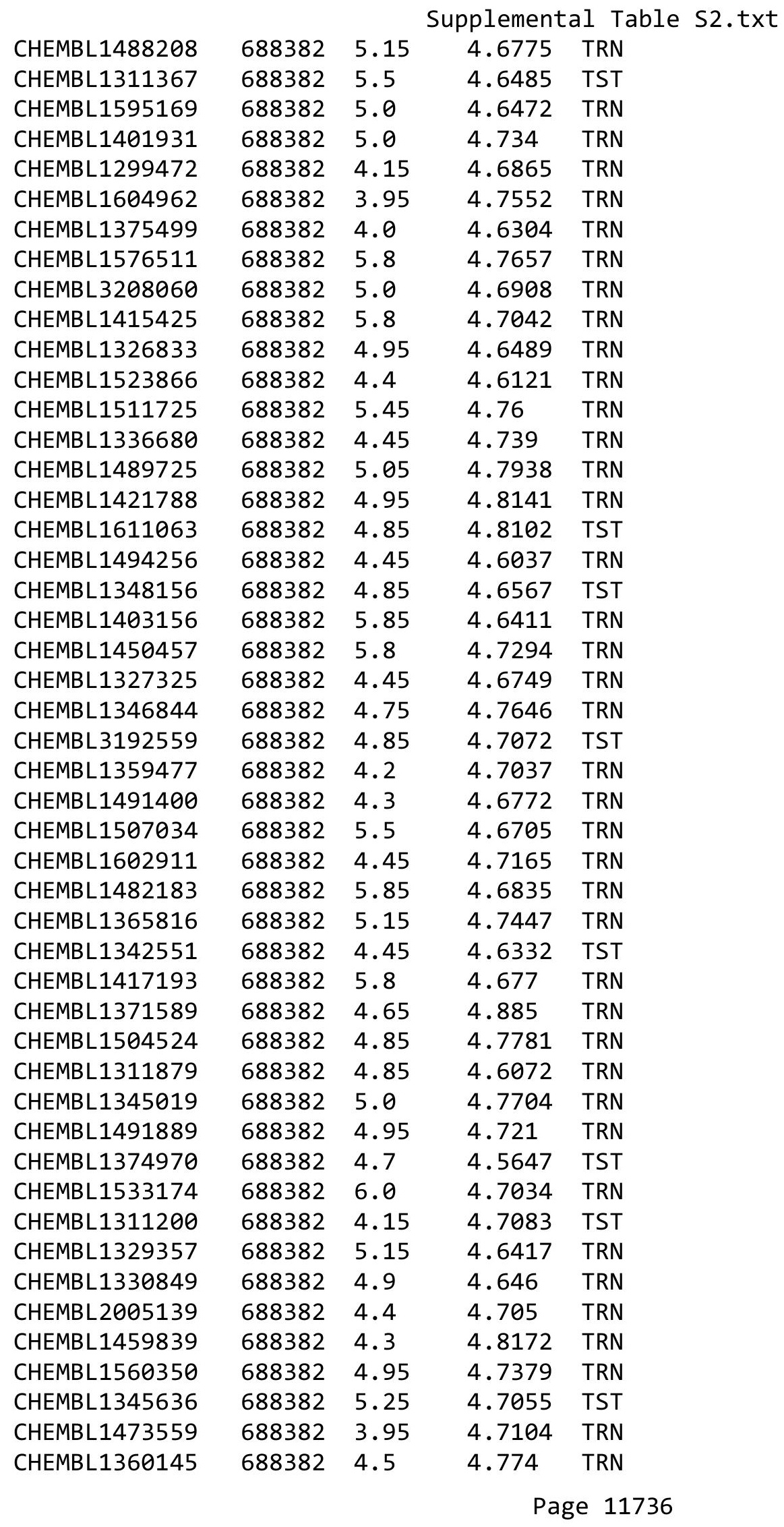




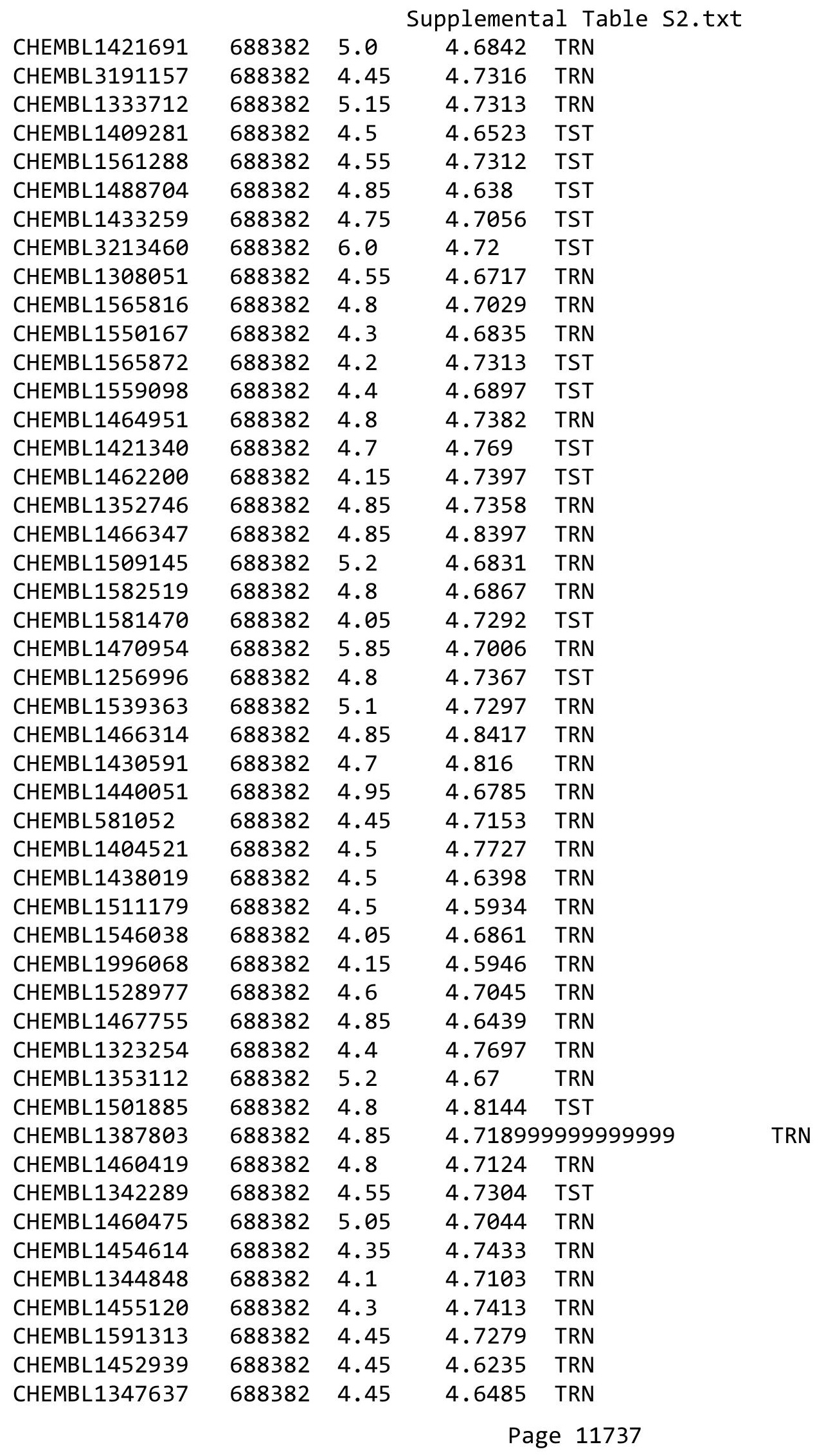




\begin{tabular}{|c|c|c|c|c|c|}
\hline \multicolumn{6}{|c|}{ Supplemental Table S2.txt } \\
\hline CHEMBL1332119 & 688382 & 4.75 & 4.5832 & TRN & \\
\hline CHEMBL1599715 & 688382 & 5.1 & 4.815 & TRN & \\
\hline CHEMBL3190243 & 688382 & 4.95 & 4.6944 & TRN & \\
\hline CHEMBL1337594 & 688382 & 4.15 & 4.7558 & TRN & \\
\hline CHEMBL 1417780 & 688382 & 4.15 & 4.6744 & TRN & \\
\hline CHEMBL1411953 & 688382 & 4.95 & 4.63399 & 99999999995 & TRN \\
\hline CHEMBL1983116 & 688382 & 4.45 & 4.6319 & TST & \\
\hline CHEMBL1425051 & 688382 & 4.85 & 4.6591 & TRN & \\
\hline CHEMBL1407672 & 688382 & 4.6 & 4.6557 & TST & \\
\hline CHEMBL1584156 & 688382 & 4.9 & 4.6801 & TRN & \\
\hline CHEMBL1369992 & 688382 & 6.6 & 4.8296 & TRN & \\
\hline CHEMBL1306414 & 688382 & 4.5 & 4.7445 & TST & \\
\hline CHEMBL1416841 & 688382 & 4.15 & 4.6365 & TRN & \\
\hline CHEMBL1302165 & 688382 & 4.2 & 4.8003 & TRN & \\
\hline CHEMBL1417289 & 688382 & 4.2 & 4.7317 & TRN & \\
\hline CHEMBL1392993 & 688382 & 4.85 & 4.7981 & TRN & \\
\hline CHEMBL1526293 & 688382 & 4.15 & 4.6784 & TRN & \\
\hline CHEMBL1569320 & 688382 & 4.85 & 4.7753 & TST & \\
\hline CHEMBL1309953 & 688382 & 4.1 & 4.6959 & TRN & \\
\hline CHEMBL1366785 & 688382 & 4.8 & 4.7137 & TRN & \\
\hline CHEMBL1313430 & 688382 & 4.4 & 4.7623 & TRN & \\
\hline CHEMBL1457670 & 688382 & 5.1 & 4.7356 & TRN & \\
\hline CHEMBL1595360 & 688382 & 5.9 & 4.7778 & TRN & \\
\hline CHEMBL1592941 & 688382 & 4.15 & 4.7061 & TRN & \\
\hline CHEMBL1489522 & 688382 & 4.35 & 4.7094 & TRN & \\
\hline CHEMBL1373512 & 688382 & 4.5 & 4.6213 & TRN & \\
\hline CHEMBL1464107 & 688382 & 4.2 & 4.6609 & TRN & \\
\hline CHEMBL1526763 & 688382 & 4.75 & 4.6892 & TRN & \\
\hline CHEMBL1510293 & 688382 & 5.1 & 4.6964 & TRN & \\
\hline CHEMBL1346114 & 688382 & 4.55 & 4.65 & TST & \\
\hline CHEMBL1565911 & 688382 & 4.35 & 4.6861 & TRN & \\
\hline CHEMBL1368429 & 688382 & 4.8 & 4.7418 & TST & \\
\hline CHEMBL1349911 & 688382 & 5.1 & 4.6588 & TRN & \\
\hline CHEMBL1327428 & 688382 & 5.1 & 4.698 & TRN & \\
\hline CHEMBL1463544 & 688382 & 4.05 & 4.7433 & TRN & \\
\hline CHEMBL1422557 & 688382 & 5.45 & 4.6869 & TRN & \\
\hline CHEMBL1490450 & 688382 & 4.85 & 4.7152 & TRN & \\
\hline CHEMBL1440495 & 688382 & 5.45 & 4.789 & TST & \\
\hline CHEMBL1468367 & 688382 & 5.05 & 4.6955 & TRN & \\
\hline CHEMBL1603119 & 688382 & 4.7 & 4.734 & TRN & \\
\hline CHEMBL1588034 & 688382 & 4.85 & 4.6129 & TRN & \\
\hline CHEMBL1375779 & 688382 & 5.0 & 4.7212 & TRN & \\
\hline CHEMBL1588727 & 688382 & 4.2 & 4.7058 & TRN & \\
\hline CHEMBL1477426 & 688382 & 4.25 & 4.596 & TRN & \\
\hline CHEMBL1452072 & 688382 & 4.15 & 4.7455 & TRN & \\
\hline CHEMBL1529529 & 688382 & 4.35 & 4.7241 & TRN & \\
\hline CHEMBL1553406 & 688382 & 4.15 & 4.7711 & TRN & \\
\hline CHEMBL1364339 & 688382 & 4.85 & 4.5761 & TRN & \\
\hline
\end{tabular}




\begin{tabular}{|c|c|c|c|c|}
\hline \multicolumn{5}{|c|}{ Supplemental Table S2.txt } \\
\hline CHEMBL1348446 & 688382 & 4.0 & 4.7444 & TRN \\
\hline CHEMBL1606062 & 688382 & 4.5 & 4.7529 & TST \\
\hline CHEMBL1430917 & 688382 & 5.85 & 4.7241 & TRN \\
\hline CHEMBL1495138 & 688382 & 4.65 & 4.6248 & TRN \\
\hline CHEMBL1538023 & 688382 & 5.0 & 4.6452 & TRN \\
\hline CHEMBL1605032 & 688382 & 4.5 & 4.6677 & TRN \\
\hline CHEMBL1588106 & 688382 & 4.7 & 4.6296 & TRN \\
\hline CHEMBL1545927 & 688382 & 4.5 & 4.6781 & TRN \\
\hline CHEMBL3194851 & 688382 & 4.5 & 4.6179 & TRN \\
\hline CHEMBL1478797 & 688382 & 4.8 & 4.7102 & TRN \\
\hline CHEMBL1564520 & 688382 & 5.85 & 4.7819 & TRN \\
\hline CHEMBL1355541 & 688382 & 4.05 & 4.7263 & TST \\
\hline CHEMBL1510251 & 688382 & 4.0 & 4.6947 & TRN \\
\hline CHEMBL1411634 & 688382 & 4.15 & 4.6568 & TRN \\
\hline CHEMBL1343551 & 688382 & 4.95 & 4.6877 & TRN \\
\hline CHEMBL1557148 & 688382 & 4.2 & 4.6984 & TRN \\
\hline CHEMBL1441706 & 688382 & 4.7 & 4.7034 & TRN \\
\hline CHEMBL1578012 & 688382 & 4.35 & 4.7068 & TRN \\
\hline CHEMBL1980600 & 688382 & 4.2 & 4.7255 & TRN \\
\hline CHEMBL1375138 & 688382 & 4.2 & 4.7259 & TRN \\
\hline CHEMBL597047 & 688382 & 4.45 & 4.6301 & TRN \\
\hline CHEMBL1598643 & 688382 & 5.0 & 4.6863 & TRN \\
\hline CHEMBL3213002 & 688382 & 5.9 & 4.7368 & TRN \\
\hline CHEMBL1300739 & 688382 & 4.05 & 4.7043 & TRN \\
\hline CHEMBL1583634 & 688382 & 4.9 & 4.672 & TST \\
\hline CHEMBL1493572 & 688382 & 5.0 & 4.7462 & TST \\
\hline CHEMBL1400548 & 688382 & 4.05 & 4.676 & TRN \\
\hline CHEMBL1510714 & 688382 & 4.1 & 4.604 & TRN \\
\hline CHEMBL1359528 & 688382 & 4.45 & 4.635 & TRN \\
\hline CHEMBL1550548 & 688382 & 4.45 & 4.8241 & TRN \\
\hline CHEMBL1523184 & 688382 & 5.05 & 4.7943 & TRN \\
\hline CHEMBL1498822 & 688382 & 4.9 & 4.6881 & TRN \\
\hline CHEMBL1334670 & 688382 & 5.05 & 4.7778 & TRN \\
\hline CHEMBL1499643 & 688382 & 4.9 & 4.769 & TRN \\
\hline CHEMBL1515973 & 688382 & 6.05 & 4.6439 & TST \\
\hline CHEMBL1605316 & 688382 & 4.05 & 4.694 & TRN \\
\hline CHEMBL1457627 & 688382 & 5.0 & 4.7686 & TRN \\
\hline CHEMBL1420858 & 688382 & 4.95 & 4.6468 & TST \\
\hline CHEMBL1256749 & 688382 & 4.45 & 4.6745 & TST \\
\hline CHEMBL1489599 & 688382 & 4.2 & 4.7348 & TST \\
\hline CHEMBL1336082 & 688382 & 4.45 & 4.6652 & TRN \\
\hline CHEMBL1498698 & 688382 & 4.3 & 4.6541 & TST \\
\hline CHEMBL1566726 & 688382 & 4.7 & 4.6974 & TRN \\
\hline CHEMBL1613571 & 688382 & 5.0 & 4.6711 & TRN \\
\hline CHEMBL1376068 & 688382 & 5.55 & 4.7297 & TST \\
\hline CHEMBL1523189 & 688382 & 4.8 & 4.6907 & TST \\
\hline CHEMBL1319591 & 688382 & 4.2 & 4.7653 & TRN \\
\hline CHEMBL597861 & 688382 & 4.45 & 4.8083 & TRN \\
\hline
\end{tabular}




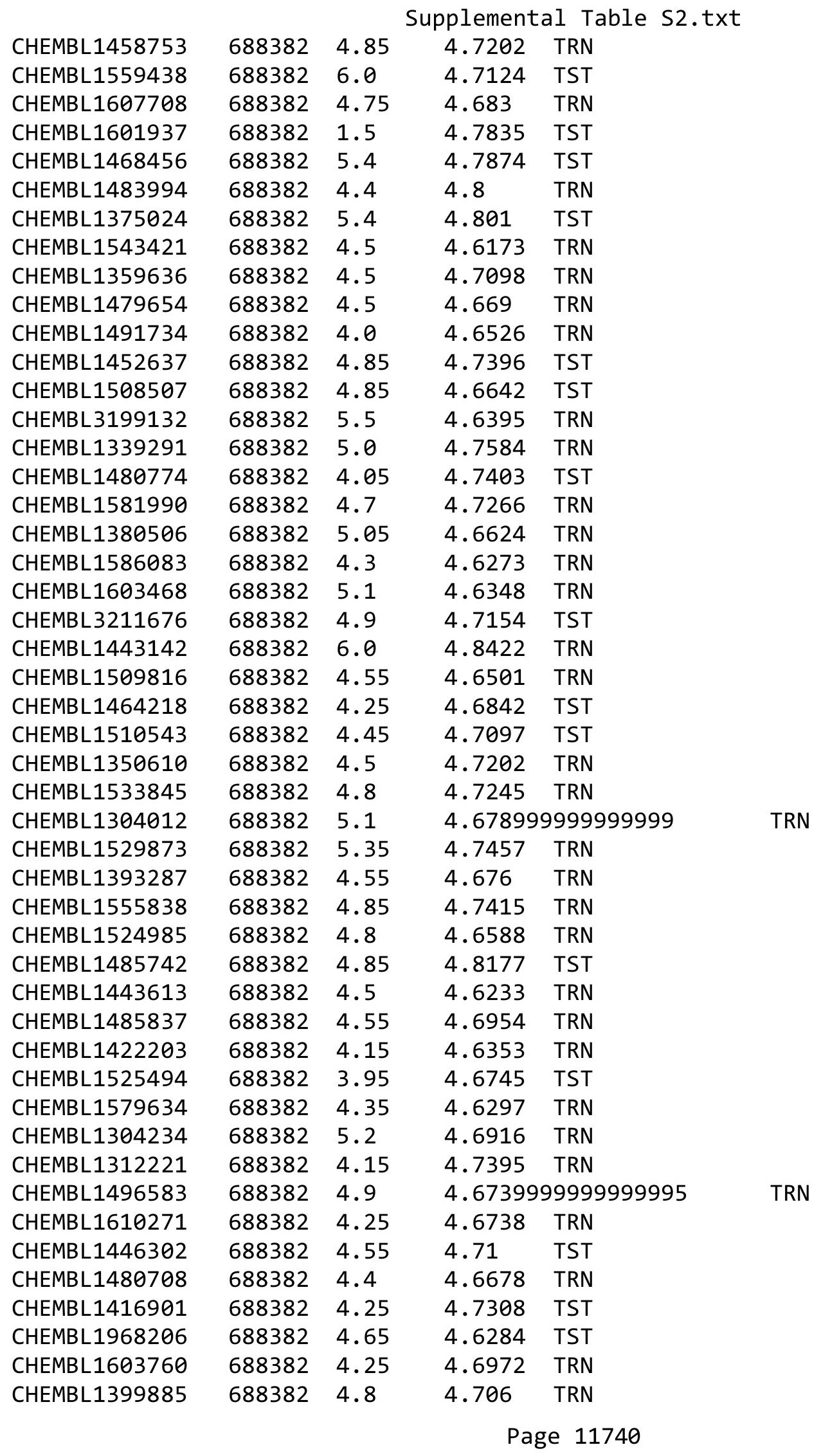




\begin{tabular}{|c|c|c|c|c|c|}
\hline \multicolumn{6}{|c|}{ Supplemental Table S2.txt } \\
\hline CHEMBL1343049 & 688382 & 4.4 & 4.6919 & TRN & \\
\hline CHEMBL1569910 & 688382 & 4.75 & 4.6123 & TRN & \\
\hline CHEMBL1385701 & 688382 & 4.65 & 4.6766 & TRN & \\
\hline CHEMBL1427330 & 688382 & 4.5 & 4.6538 & TRN & \\
\hline CHEMBL1505151 & 688382 & 4.15 & 4.6625 & TRN & \\
\hline CHEMBL1463851 & 688382 & 4.1 & 4.6383 & TRN & \\
\hline CHEMBL1382001 & 688382 & 4.35 & 4.5725 & TRN & \\
\hline CHEMBL1311547 & 688382 & 4.7 & 4.6715 & TRN & \\
\hline CHEMBL1365175 & 688382 & 4.4 & 4.7471 & TRN & \\
\hline CHEMBL1391539 & 688382 & 5.05 & 4.8763 & TRN & \\
\hline CHEMBL3191879 & 688382 & 4.55 & 4.6562 & TRN & \\
\hline CHEMBL1311199 & 688382 & 4.45 & 4.7373 & TST & \\
\hline CHEMBL1523824 & 688382 & 6.0 & 4.5985 & TST & \\
\hline CHEMBL1324371 & 688382 & 5.55 & 4.5853 & TRN & \\
\hline CHEMBL1453664 & 688382 & 4.8 & 4.7999 & TRN & \\
\hline CHEMBL1333161 & 688382 & 4.5 & 4.8144 & TRN & \\
\hline CHEMBL1388665 & 688382 & 4.35 & 4.6937 & TRN & \\
\hline CHEMBL1576647 & 688382 & 4.4 & 4.5644 & TRN & \\
\hline CHEMBL1302369 & 688382 & 4.45 & 4.6263 & TRN & \\
\hline CHEMBL1308748 & 688382 & 4.8 & 4.7512 & TRN & \\
\hline CHEMBL1526836 & 688382 & 4.55 & 4.7823 & TRN & \\
\hline CHEMBL1889837 & 688382 & 4.5 & 4.73600 & 0000000001 & TRN \\
\hline CHEMBL1589801 & 688382 & 4.35 & 4.6961 & TST & \\
\hline CHEMBL1596412 & 688382 & 4.5 & 4.732 & TST & \\
\hline CHEMBL1470728 & 688382 & 4.95 & 4.6343 & TST & \\
\hline CHEMBL1448702 & 688382 & 5.0 & 4.7723 & TRN & \\
\hline CHEMBL1425097 & 688382 & 4.2 & 4.7375 & TST & \\
\hline CHEMBL1522547 & 688382 & 4.5 & 4.716 & TRN & \\
\hline CHEMBL1600024 & 688382 & 4.4 & 4.774 & TST & \\
\hline CHEMBL1380192 & 688382 & 4.45 & 4.7131 & TRN & \\
\hline CHEMBL1549568 & 688382 & 4.85 & 4.5715 & TST & \\
\hline CHEMBL1355753 & 688382 & 4.45 & 4.6018 & TRN & \\
\hline CHEMBL1542567 & 688382 & 4.85 & 4.7481 & TRN & \\
\hline CHEMBL1560561 & 688382 & 4.5 & 4.6115 & TST & \\
\hline CHEMBL1542128 & 688382 & 5.0 & 4.6525 & TRN & \\
\hline CHEMBL1581301 & 688382 & 4.0 & 4.7518 & TST & \\
\hline CHEMBL1438766 & 688382 & 4.65 & 4.7097 & TRN & \\
\hline CHEMBL1582293 & 688382 & 5.05 & 4.6904 & TRN & \\
\hline CHEMBL1568920 & 688382 & 4.55 & 4.7199 & TRN & \\
\hline CHEMBL1416673 & 688382 & 5.2 & 4.7757 & TRN & \\
\hline CHEMBL1982152 & 688382 & 4.5 & 4.6934 & TST & \\
\hline CHEMBL1558416 & 688382 & 5.1 & 4.7088 & TRN & \\
\hline CHEMBL1448676 & 688382 & 3.5 & 4.6823 & TST & \\
\hline CHEMBL1427500 & 688382 & 4.4 & 4.6322 & TRN & \\
\hline CHEMBL1493429 & 688382 & 4.2 & 4.5734 & TRN & \\
\hline CHEMBL1370237 & 688382 & 4.45 & 4.6933 & TST & \\
\hline CHEMBL1492536 & 688382 & 4.8 & 4.6801 & TST & \\
\hline CHEMBL1595901 & 688382 & 4.4 & 4.6996 & TST & \\
\hline
\end{tabular}




\begin{tabular}{|c|c|c|c|c|c|}
\hline & & \multicolumn{4}{|c|}{ Supplemental Table S2.txt } \\
\hline CHEMBL1301919 & 688382 & 4.15 & 4.8462 & TRN & \\
\hline CHEMBL1347103 & 688382 & 5.35 & 4.6439 & TRN & \\
\hline CHEMBL1432142 & 688382 & 4.05 & 4.7593 & TRN & \\
\hline CHEMBL1609156 & 688382 & 5.5 & 4.6735 & TRN & \\
\hline CHEMBL1545902 & 688382 & 4.45 & 4.6573 & TRN & \\
\hline CHEMBL1369376 & 688382 & 5.1 & 4.6509 & TST & \\
\hline CHEMBL3194498 & 688382 & 4.05 & 4.6547 & TST & \\
\hline CHEMBL1533783 & 688382 & 4.35 & 4.6901 & TRN & \\
\hline CHEMBL1327298 & 688382 & 5.2 & 4.6269 & TRN & \\
\hline CHEMBL3198596 & 688382 & 4.7 & 4.6237 & TRN & \\
\hline CHEMBL1504124 & 688382 & 4.9 & 4.7456 & TST & \\
\hline CHEMBL1376513 & 688382 & 4.05 & 4.7111 & TRN & \\
\hline CHEMBL1375860 & 688382 & 4.05 & 4.6767 & TST & \\
\hline CHEMBL1422476 & 688382 & 4.05 & 4.6492 & TRN & \\
\hline CHEMBL1387281 & 688382 & 4.4 & 4.6603 & TST & \\
\hline CHEMBL1418904 & 688382 & 5.0 & 4.7536 & TST & \\
\hline CHEMBL1511054 & 688382 & 5.15 & 4.8747 & TRN & \\
\hline CHEMBL1559856 & 688382 & 4.45 & 4.7765 & TST & \\
\hline CHEMBL1309303 & 688382 & 4.6 & 4.6793 & TRN & \\
\hline CHEMBL1458309 & 688382 & 4.15 & 4.6444 & TST & \\
\hline CHEMBL1573003 & 688382 & 4.95 & 4.7322 & TRN & \\
\hline CHEMBL1423248 & 688382 & 4.15 & 4.6572 & TRN & \\
\hline CHEMBL1538421 & 688382 & 5.15 & 4.80699 & 99999999995 & TRN \\
\hline CHEMBL1607716 & 688382 & 4.5 & 4.6974 & TRN & \\
\hline CHEMBL1560778 & 688382 & 4.5 & 4.6507 & TRN & \\
\hline CHEMBL1307446 & 688382 & 4.85 & 4.6553 & TST & \\
\hline CHEMBL3199656 & 688382 & 4.65 & 4.666 & TRN & \\
\hline CHEMBL1589032 & 688382 & 4.8 & 4.7211 & TRN & \\
\hline CHEMBL1525491 & 688382 & 4.9 & 4.7842 & TRN & \\
\hline CHEMBL1418474 & 688382 & 4.2 & 4.718 & TRN & \\
\hline CHEMBL1539594 & 688382 & 4.95 & 4.7857 & TRN & \\
\hline CHEMBL1984639 & 688382 & 4.55 & 4.6488 & TRN & \\
\hline CHEMBL1593748 & 688382 & 4.2 & 4.6948 & TRN & \\
\hline CHEMBL1478535 & 688382 & 4.45 & 4.7353 & TST & \\
\hline CHEMBL1319522 & 688382 & 5.8 & 4.7492 & TST & \\
\hline CHEMBL136344 & 688382 & 4.15 & 4.6538 & TRN & \\
\hline CHEMBL1609075 & 688382 & 4.5 & 4.6885 & TRN & \\
\hline CHEMBL1342086 & 688382 & 5.2 & 4.73300 & 00000000005 & TRN \\
\hline CHEMBL1573905 & 688382 & 4.5 & 4.7602 & TST & \\
\hline CHEMBL1334649 & 688382 & 4.0 & 4.864 & TRN & \\
\hline CHEMBL1457906 & 688382 & 5.0 & 4.6762 & TST & \\
\hline CHEMBL3145137 & 688382 & 4.85 & 4.6924 & TRN & \\
\hline CHEMBL1596755 & 688382 & 4.55 & 4.7712 & TRN & \\
\hline CHEMBL1584360 & 688382 & 5.45 & 4.8569 & TST & \\
\hline CHEMBL1372985 & 688382 & 4.5 & 4.5933 & TST & \\
\hline CHEMBL1387110 & 688382 & 4.45 & 4.6008 & TRN & \\
\hline CHEMBL1349958 & 688382 & 5.45 & 4.6408 & TRN & \\
\hline CHEMBL3214325 & 688382 & 4.6 & 4.6577 & TRN & \\
\hline
\end{tabular}




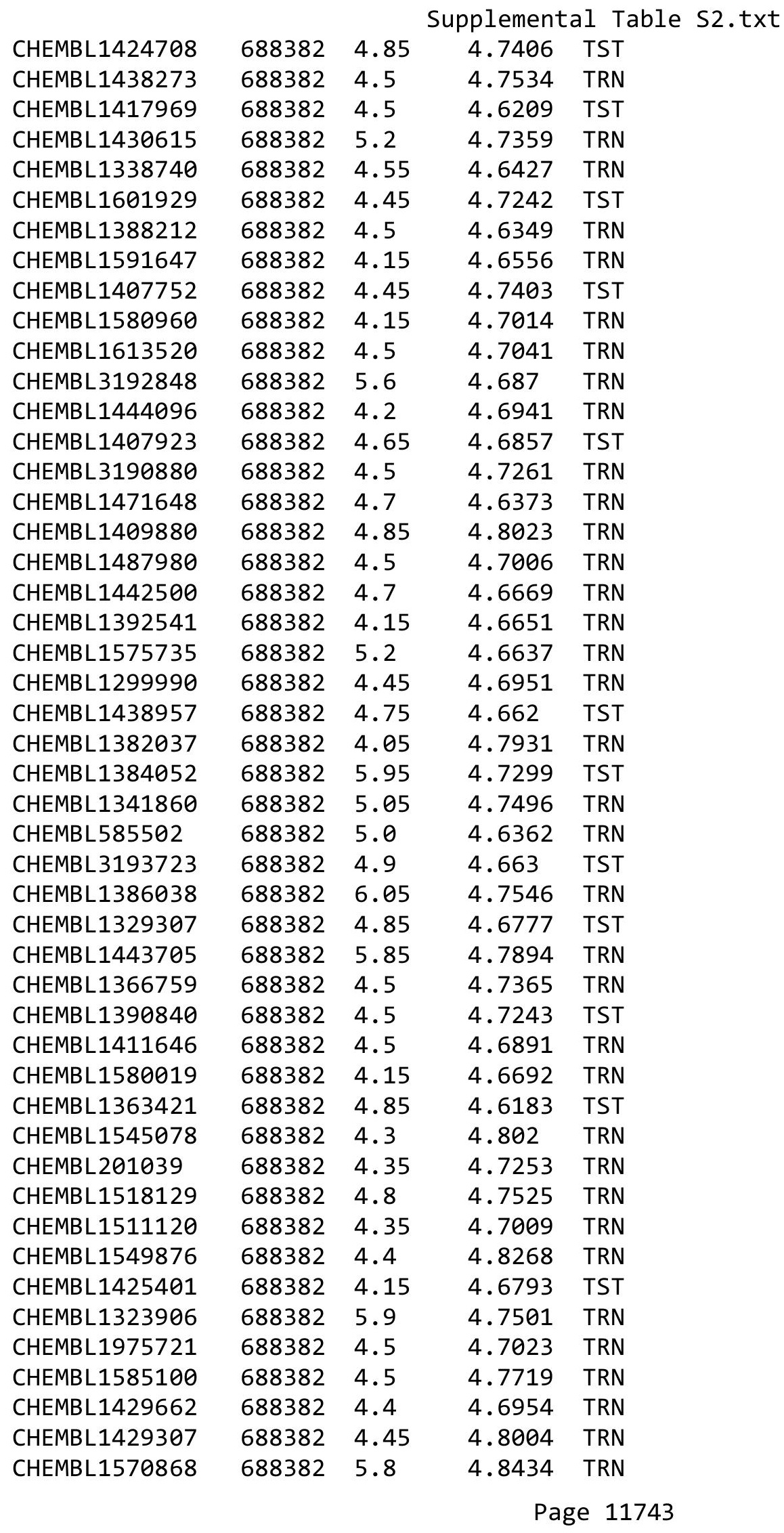




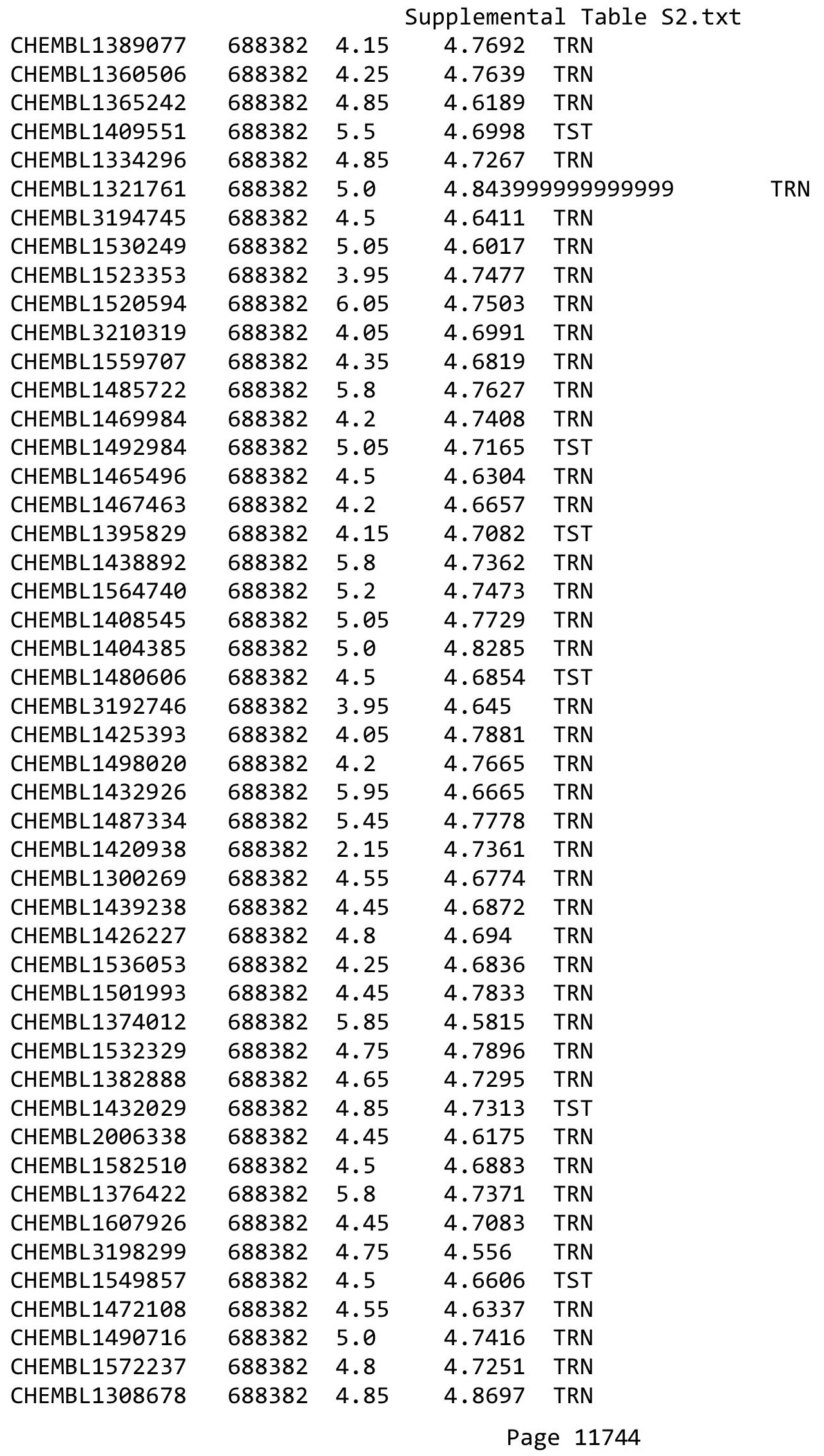




\begin{tabular}{|c|c|c|c|c|c|}
\hline & & \multicolumn{4}{|c|}{ Supplemental Table S2.txt } \\
\hline CHEMBL1481262 & 688382 & 4.9 & 4.7289 & TRN & \\
\hline CHEMBL1363104 & 688382 & 4.45 & 4.667 & TRN & \\
\hline CHEMBL1576452 & 688382 & 5.85 & 4.7014 & TST & \\
\hline CHEMBL1346174 & 688382 & 4.5 & 4.756 & TRN & \\
\hline CHEMBL1463036 & 688382 & 4.85 & 4.7358 & TRN & \\
\hline CHEMBL1583598 & 688382 & 4.65 & 4.683 & TRN & \\
\hline CHEMBL1325881 & 688382 & 4.35 & 4.7423 & TRN & \\
\hline CHEMBL581860 & 688382 & 4.5 & 4.6105 & TRN & \\
\hline CHEMBL1542251 & 688382 & 4.15 & 4.7948 & TRN & \\
\hline CHEMBL3190551 & 688382 & 4.5 & 4.6771 & TRN & \\
\hline CHEMBL1610073 & 688382 & 4.85 & 4.7147 & TST & \\
\hline CHEMBL1459238 & 688382 & 4.45 & 4.7336 & TRN & \\
\hline CHEMBL1610377 & 688382 & 4.6 & 4.6649 & TRN & \\
\hline CHEMBL1441791 & 688382 & 4.05 & 4.7916 & TRN & \\
\hline CHEMBL1345710 & 688382 & 5.3 & 4.6847 & TST & \\
\hline CHEMBL1507023 & 688382 & 5.0 & 4.6616 & TRN & \\
\hline CHEMBL1321840 & 688382 & 4.45 & 4.6805 & TRN & \\
\hline CHEMBL1463896 & 688382 & 4.5 & 4.6925 & TST & \\
\hline CHEMBL1469768 & 688382 & 5.0 & 4.7321 & TRN & \\
\hline CHEMBL1413205 & 688382 & 4.45 & 4.654 & TRN & \\
\hline CHEMBL1548445 & 688382 & 4.95 & 4.6715 & TST & \\
\hline CHEMBL1471827 & 688382 & 4.4 & 4.6507 & TRN & \\
\hline CHEMBL1420870 & 688382 & 4.15 & 4.7613 & TRN & \\
\hline CHEMBL1432806 & 688382 & 4.2 & 4.7708 & TRN & \\
\hline CHEMBL3197201 & 688382 & 4.8 & 4.7091 & TRN & \\
\hline CHEMBL1361231 & 688382 & 4.5 & 4.6635 & TRN & \\
\hline CHEMBL1411247 & 688382 & 4.15 & 4.6313 & TRN & \\
\hline CHEMBL1550537 & 688382 & 4.95 & 4.7203 & TST & \\
\hline CHEMBL1504287 & 688382 & 4.05 & 4.8498 & TRN & \\
\hline CHEMBL3212316 & 688382 & 6.0 & 4.7635 & TST & \\
\hline CHEMBL1542462 & 688382 & 4.25 & 4.6632 & TRN & \\
\hline CHEMBL1373799 & 688382 & 4.35 & 4.6997 & TRN & \\
\hline CHEMBL1598626 & 688382 & 4.9 & 4.7815 & TRN & \\
\hline CHEMBL1342950 & 688382 & 4.05 & 4.7415 & TRN & \\
\hline CHEMBL1389785 & 688382 & 4.05 & 4.7778 & TRN & \\
\hline CHEMBL1299582 & 688382 & 5.85 & $4.6560 e$ & 3000000001 & TRN \\
\hline CHEMBL1460092 & 688382 & 4.9 & 4.6127 & TRN & \\
\hline CHEMBL1387346 & 688382 & 5.05 & 4.7677 & TRN & \\
\hline CHEMBL3190761 & 688382 & 4.3 & 4.6364 & TRN & \\
\hline CHEMBL1493457 & 688382 & 4.15 & 4.657 & TST & \\
\hline CHEMBL1466368 & 688382 & 3.95 & 4.7871 & TST & \\
\hline CHEMBL1380639 & 688382 & 4.55 & 4.7181 & TST & \\
\hline CHEMBL3198914 & 688382 & 4.95 & 4.6898 & TRN & \\
\hline CHEMBL3209638 & 688382 & 5.05 & 4.6227 & TRN & \\
\hline CHEMBL1380312 & 688382 & 5.0 & 4.728 & TRN & \\
\hline CHEMBL1486602 & 688382 & 4.45 & 4.6739 & TST & \\
\hline CHEMBL1602972 & 688382 & 5.85 & 4.7796 & TRN & \\
\hline CHEMBL3194972 & 688382 & 4.05 & 4.6527 & TST & \\
\hline
\end{tabular}




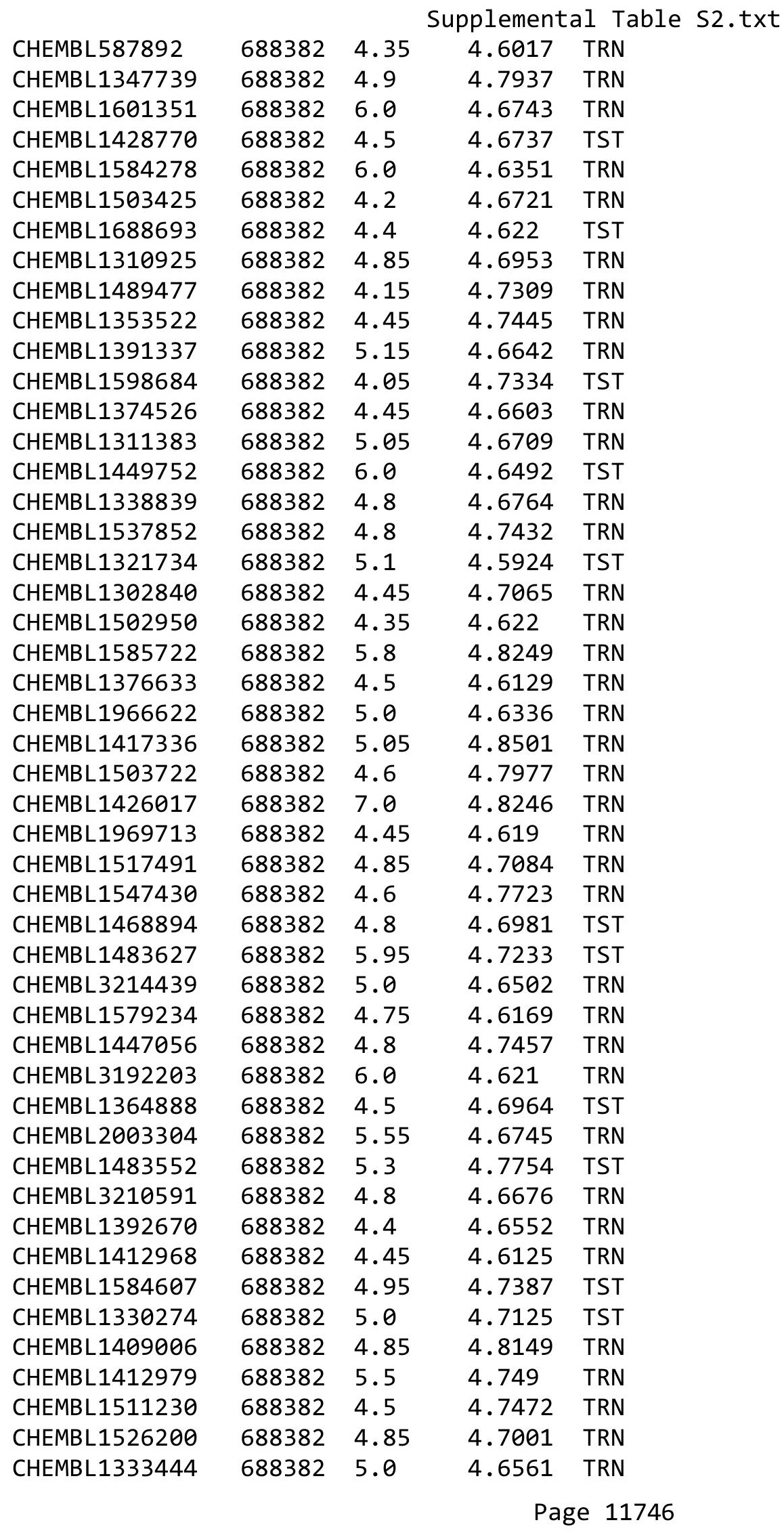




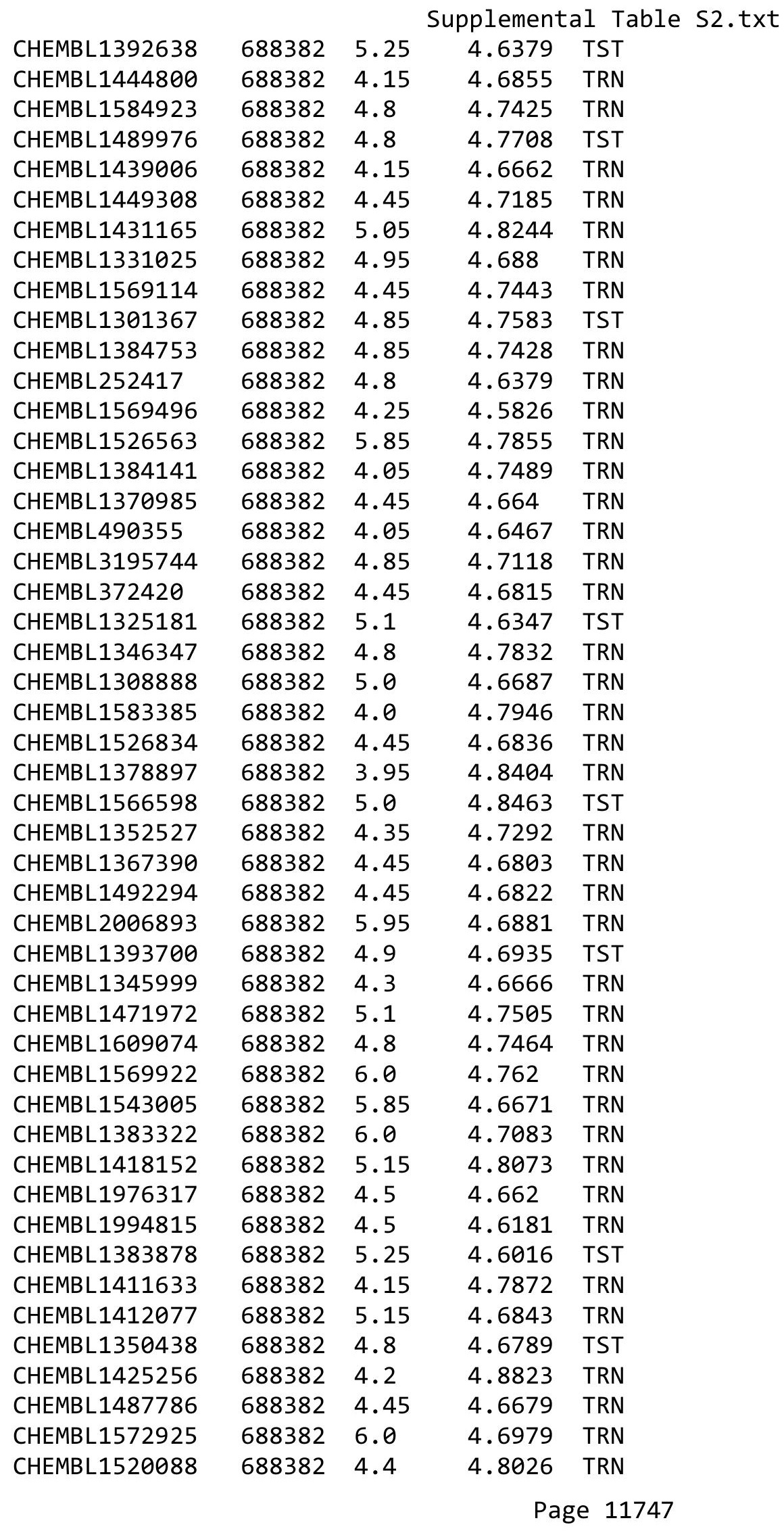




\begin{tabular}{|c|c|c|c|c|}
\hline \multicolumn{5}{|c|}{ Supplemental Tabl } \\
\hline CHEMBL1523522 & 688382 & 4.85 & 4.6811 & TRN \\
\hline CHEMBL1341338 & 688382 & 5.5 & 4.7459 & TRN \\
\hline CHEMBL1326665 & 688382 & 4.5 & 4.6055 & TST \\
\hline CHEMBL1328906 & 688382 & 4.4 & 4.6924 & TRN \\
\hline CHEMBL1340149 & 688382 & 4.35 & 4.8132 & TRN \\
\hline CHEMBL1504324 & 688382 & 4.45 & 4.6277 & TRN \\
\hline CHEMBL1419935 & 688382 & 4.05 & 4.6198 & TRN \\
\hline CHEMBL1387897 & 688382 & 4.5 & 4.7172 & TRN \\
\hline CHEMBL1333950 & 688382 & 4.15 & 4.6675 & TST \\
\hline CHEMBL1543233 & 688382 & 4.0 & 4.7373 & TRN \\
\hline CHEMBL1359474 & 688382 & 4.5 & 4.7273 & TRN \\
\hline CHEMBL1968421 & 688382 & 4.5 & 4.7219 & TRN \\
\hline CHEMBL1415627 & 688382 & 5.8 & 4.6773 & TRN \\
\hline CHEMBL1400468 & 688382 & 4.45 & 4.716 & TST \\
\hline CHEMBL1425385 & 688382 & 5.0 & 4.776 & TST \\
\hline CHEMBL1305195 & 688382 & 4.45 & 4.7599 & TRN \\
\hline CHEMBL1480397 & 688382 & 4.8 & 4.7934 & TRN \\
\hline CHEMBL1372939 & 688382 & 4.8 & 4.6306 & TST \\
\hline CHEMBL1383357 & 688382 & 6.0 & 4.7333 & TRN \\
\hline CHEMBL1329726 & 688382 & 4.45 & 4.6582 & TST \\
\hline CHEMBL1503189 & 688382 & 4.8 & 4.7464 & TRN \\
\hline CHEMBL1610182 & 688382 & 4.3 & 4.6068 & TRN \\
\hline CHEMBL1572861 & 688382 & 5.05 & 4.7068 & TST \\
\hline CHEMBL1301723 & 688382 & 4.55 & 4.6354 & TRN \\
\hline CHEMBL1308657 & 688382 & 4.45 & 4.647 & TRN \\
\hline CHEMBL1379849 & 688382 & 4.8 & 4.6855 & TRN \\
\hline CHEMBL1491623 & 688382 & 5.2 & 4.6992 & TRN \\
\hline CHEMBL1563142 & 688382 & 4.5 & 4.7806 & TRN \\
\hline CHEMBL1382853 & 688382 & 4.4 & 4.765 & TRN \\
\hline CHEMBL1363263 & 688382 & 4.15 & 4.7281 & TRN \\
\hline CHEMBL1448356 & 688382 & 6.0 & 4.6438 & TST \\
\hline CHEMBL1446824 & 688382 & 4.45 & 4.6494 & TRN \\
\hline CHEMBL1330703 & 688382 & 5.1 & 4.7402 & TRN \\
\hline CHEMBL1412423 & 688382 & 4.15 & 4.6344 & TRN \\
\hline CHEMBL1573608 & 688382 & 4.15 & 4.7095 & TRN \\
\hline CHEMBL1257080 & 688382 & 4.4 & 4.6885 & TRN \\
\hline CHEMBL1603966 & 688382 & 5.0 & 4.6659 & TRN \\
\hline CHEMBL1330284 & 688382 & 4.4 & 4.6759 & TRN \\
\hline CHEMBL1429494 & 688382 & 4.15 & 4.7047 & TST \\
\hline CHEMBL1568337 & 688382 & 4.9 & 4.7116 & TRN \\
\hline CHEMBL1416358 & 688382 & 5.2 & 4.7092 & TRN \\
\hline CHEMBL3196704 & 688382 & 4.15 & 4.6513 & TST \\
\hline CHEMBL1561049 & 688382 & 4.45 & 4.6803 & TRN \\
\hline CHEMBL1571889 & 688382 & 4.35 & 4.6686 & TRN \\
\hline CHEMBL 3190380 & 688382 & 5.95 & 4.6817 & TST \\
\hline CHEMBL1499364 & 688382 & 5.15 & 4.6732 & TRN \\
\hline CHEMBL1366571 & 688382 & 4.5 & 4.7184 & TRN \\
\hline CHEMBL1542605 & 688382 & 5.0 & 4.6726 & TRN \\
\hline
\end{tabular}




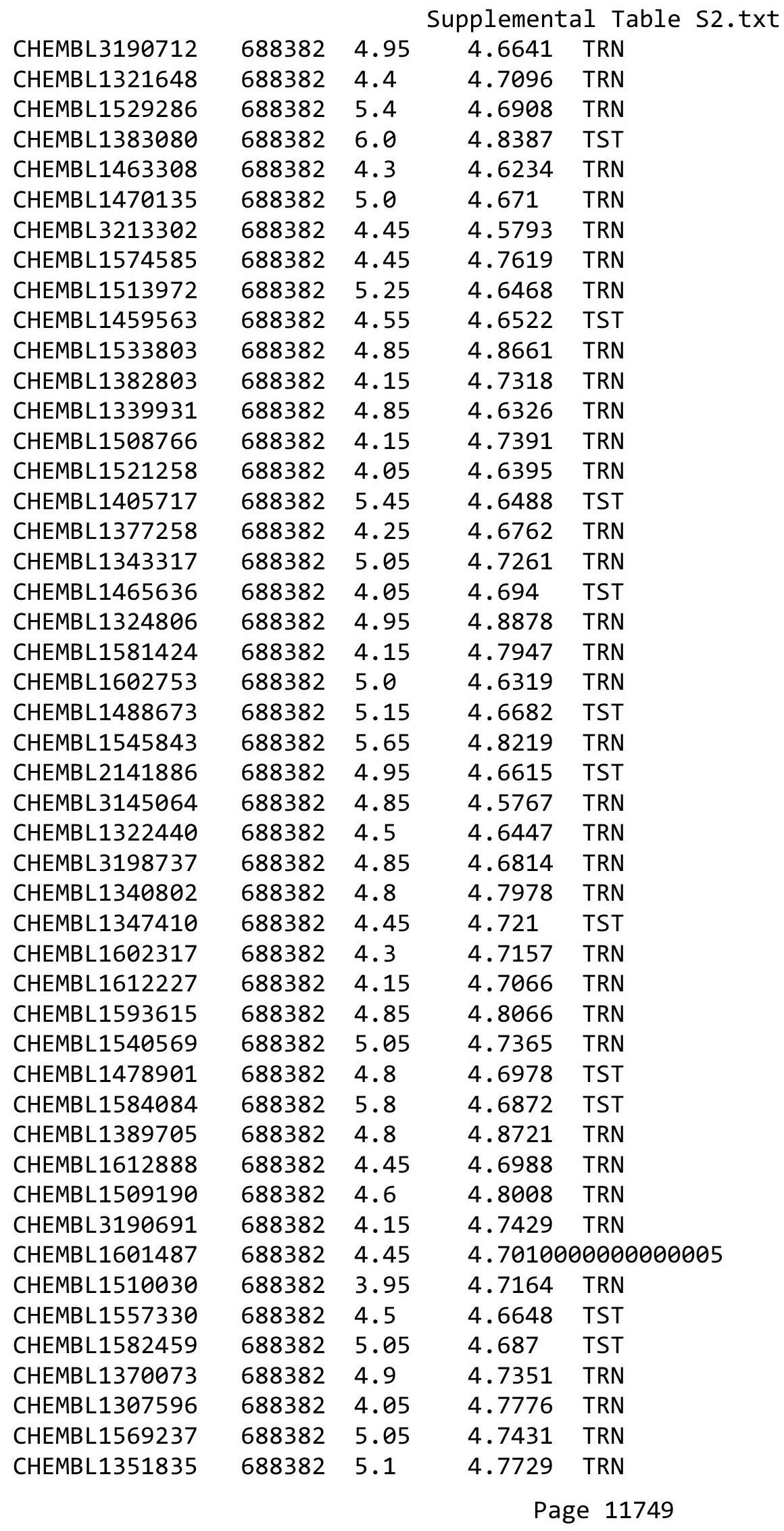




\begin{tabular}{|c|c|c|c|c|c|}
\hline & & \multicolumn{4}{|c|}{ Supplemental Table S2.txt } \\
\hline CHEMBL1490920 & 688382 & 5.85 & 4.6981 & TST & \\
\hline CHEMBL1506492 & 688382 & 4.9 & 4.7279 & TST & \\
\hline CHEMBL1613682 & 688382 & 4.4 & 4.6629 & TRN & \\
\hline CHEMBL1482175 & 688382 & 4.5 & 4.7392 & TRN & \\
\hline CHEMBL1412821 & 688382 & 4.45 & 4.685 & TRN & \\
\hline CHEMBL1588154 & 688382 & 4.85 & 4.6846 & TRN & \\
\hline CHEMBL1479883 & 688382 & 5.0 & 4.6294 & TST & \\
\hline CHEMBL1607007 & 688382 & 6.0 & 4.72199 & 99999999995 & TRN \\
\hline CHEMBL1350841 & 688382 & 4.4 & 4.6279 & TRN & \\
\hline CHEMBL1380071 & 688382 & 6.0 & 4.7141 & TST & \\
\hline CHEMBL1504999 & 688382 & 4.45 & 4.6671 & TRN & \\
\hline CHEMBL1387692 & 688382 & 4.05 & 4.587 & TRN & \\
\hline CHEMBL1381981 & 688382 & 4.35 & 4.6638 & TRN & \\
\hline CHEMBL1535228 & 688382 & 4.0 & 4.8244 & TRN & \\
\hline CHEMBL1977886 & 688382 & 5.85 & 4.7059 & TRN & \\
\hline CHEMBL1303071 & 688382 & 4.3 & 4.7452 & TST & \\
\hline CHEMBL1458487 & 688382 & 4.2 & 4.7684 & TRN & \\
\hline CHEMBL1604398 & 688382 & 4.6 & 4.7393 & TRN & \\
\hline CHEMBL1312495 & 688382 & 4.85 & 4.6871 & TST & \\
\hline CHEMBL1482710 & 688382 & 5.1 & 4.6221 & TRN & \\
\hline CHEMBL1978894 & 688382 & 4.45 & 4.6675 & TRN & \\
\hline CHEMBL3193289 & 688382 & 5.35 & 4.5958 & TRN & \\
\hline CHEMBL1313061 & 688382 & 5.15 & 4.6739 & TRN & \\
\hline CHEMBL1529823 & 688382 & 4.4 & 4.6637 & TST & \\
\hline CHEMBL1601569 & 688382 & 4.65 & 4.7216 & TRN & \\
\hline CHEMBL3193569 & 688382 & 5.85 & 4.6945 & TST & \\
\hline CHEMBL1465674 & 688382 & 4.85 & 4.7674 & TRN & \\
\hline CHEMBL1510346 & 688382 & 4.8 & 4.8497 & TRN & \\
\hline CHEMBL1449919 & 688382 & 4.35 & 4.69 & TRN & \\
\hline CHEMBL1594548 & 688382 & 6.0 & 4.7083 & TST & \\
\hline CHEMBL1460728 & 688382 & 6.0 & 4.6965 & TST & \\
\hline CHEMBL1507932 & 688382 & 4.15 & 4.7666 & TRN & \\
\hline CHEMBL1360369 & 688382 & 6.6 & 4.6634 & TST & \\
\hline CHEMBL1429604 & 688382 & 4.05 & 4.7039 & TST & \\
\hline CHEMBL3190046 & 688382 & 4.45 & 4.6953 & TRN & \\
\hline CHEMBL1580494 & 688382 & 5.0 & 4.7578 & TRN & \\
\hline CHEMBL1500736 & 688382 & 4.1 & 4.7557 & TRN & \\
\hline CHEMBL1597668 & 688382 & 6.5 & 4.6866 & TRN & \\
\hline CHEMBL1328969 & 688382 & 4.6 & 4.6946 & TST & \\
\hline CHEMBL1360564 & 688382 & 4.5 & 4.7502 & TRN & \\
\hline CHEMBL1517416 & 688382 & 4.65 & 4.6846 & TST & \\
\hline CHEMBL1417909 & 688382 & 4.8 & 4.7689 & TRN & \\
\hline CHEMBL1493936 & 688382 & 4.75 & 4.5788 & TRN & \\
\hline CHEMBL1529292 & 688382 & 4.05 & 4.7151 & TRN & \\
\hline CHEMBL1464312 & 688382 & 4.1 & 4.7002 & TST & \\
\hline CHEMBL1342182 & 688382 & 4.45 & 4.7125 & TRN & \\
\hline CHEMBL1504006 & 688382 & 4.85 & 4.8086 & TRN & \\
\hline CHEMBL1449875 & 688382 & 5.15 & 4.6053 & TRN & \\
\hline
\end{tabular}




\begin{tabular}{|c|c|c|c|c|}
\hline \multicolumn{5}{|c|}{ Supplemental Table S2.txt } \\
\hline CHEMBL1967497 & 688382 & 4.55 & 4.5907 & TRN \\
\hline CHEMBL1306683 & 688382 & 4.5 & 4.6096 & TRN \\
\hline CHEMBL1477065 & 688382 & 4.0 & 4.7358 & TRN \\
\hline CHEMBL1446867 & 688382 & 5.55 & 4.7744 & TRN \\
\hline CHEMBL1585219 & 688382 & 4.35 & 4.6499 & TRN \\
\hline CHEMBL1450068 & 688382 & 4.8 & 4.6974 & TRN \\
\hline CHEMBL1540143 & 688382 & 4.75 & 4.7036 & TRN \\
\hline CHEMBL1439209 & 688382 & 4.55 & 4.7071 & TST \\
\hline CHEMBL1493311 & 688382 & 4.2 & 4.7541 & TST \\
\hline CHEMBL1361472 & 688382 & 4.5 & 4.7695 & TRN \\
\hline CHEMBL1430384 & 688382 & 4.5 & 4.7738 & TRN \\
\hline CHEMBL1364489 & 688382 & 4.35 & 4.7214 & TRN \\
\hline CHEMBL1541048 & 688382 & 4.75 & 4.647 & TRN \\
\hline CHEMBL3191291 & 688382 & 4.7 & 4.774 & TRN \\
\hline CHEMBL1435154 & 688382 & 4.5 & 4.7018 & TRN \\
\hline CHEMBL1304257 & 688382 & 4.0 & 4.7478 & TRN \\
\hline CHEMBL3211823 & 688382 & 4.7 & 4.6228 & TST \\
\hline CHEMBL1562933 & 688382 & 4.35 & 4.7159 & TRN \\
\hline CHEMBL1558638 & 688382 & 4.95 & 4.7023 & TST \\
\hline CHEMBL1365080 & 688382 & 4.4 & 4.6377 & TRN \\
\hline CHEMBL1525659 & 688382 & 4.6 & 4.7171 & TRN \\
\hline CHEMBL1420210 & 688382 & 5.0 & 4.7135 & TRN \\
\hline CHEMBL1511037 & 688382 & 4.4 & 4.6244 & TRN \\
\hline CHEMBL1612237 & 688382 & 4.95 & 4.7644 & TRN \\
\hline CHEMBL3196811 & 688382 & 4.95 & 4.7416 & TRN \\
\hline CHEMBL1451931 & 688382 & 4.15 & 4.6796 & TRN \\
\hline CHEMBL1458390 & 688382 & 4.35 & 4.6763 & TRN \\
\hline CHEMBL1414384 & 688382 & 4.8 & 4.609 & TRN \\
\hline CHEMBL1406957 & 688382 & 5.45 & 4.604 & TRN \\
\hline CHEMBL1583876 & 688382 & 4.45 & 4.6539 & TRN \\
\hline CHEMBL1582192 & 688382 & 4.6 & 4.6705 & TRN \\
\hline CHEMBL1562498 & 688382 & 4.5 & 4.6179 & TRN \\
\hline CHEMBL1584444 & 688382 & 5.1 & 4.7163 & TRN \\
\hline CHEMBL1320045 & 688382 & 4.15 & 4.7441 & TRN \\
\hline CHEMBL1488269 & 688382 & 4.75 & 4.7401 & TRN \\
\hline CHEMBL1388300 & 688382 & 4.55 & 4.6798 & TRN \\
\hline CHEMBL1463874 & 688382 & 4.2 & 4.7859 & TST \\
\hline CHEMBL2001481 & 688382 & 4.05 & 4.6008 & TRN \\
\hline CHEMBL1479054 & 688382 & 5.0 & 4.7123 & TST \\
\hline CHEMBL1459967 & 688382 & 4.8 & 4.754 & TRN \\
\hline CHEMBL1302216 & 688382 & 5.0 & 4.7826 & TST \\
\hline CHEMBL1403401 & 688382 & 4.95 & 4.7714 & TRN \\
\hline CHEMBL1444474 & 688382 & 4.85 & 4.89199 & 99999999995 \\
\hline CHEMBL1472137 & 688382 & 4.15 & 4.7416 & TRN \\
\hline CHEMBL1549471 & 688382 & 4.3 & 4.6345 & TRN \\
\hline CHEMBL1459099 & 688382 & 4.3 & 4.6867 & TRN \\
\hline CHEMBL1257041 & 688382 & 4.55 & 4.6949 & TRN \\
\hline CHEMBL3210023 & 688382 & 4.35 & 4.6658 & TRN \\
\hline
\end{tabular}

TRN 


\begin{tabular}{|c|c|c|c|c|c|}
\hline \multicolumn{6}{|c|}{ Supplemental Table S2.txt } \\
\hline CHEMBL1582927 & 688382 & 6.0 & 4.7198 & TST & \\
\hline CHEMBL1469314 & 688382 & 4.05 & 4.6347 & TST & \\
\hline CHEMBL1405346 & 688382 & 4.35 & 4.775 & TRN & \\
\hline CHEMBL1482156 & 688382 & 4.2 & 4.7233 & TST & \\
\hline CHEMBL1495349 & 688382 & 4.8 & 4.7513 & TRN & \\
\hline CHEMBL1302883 & 688382 & 6.0 & 4.7891 & TRN & \\
\hline CHEMBL1583344 & 688382 & 4.15 & 4.7044 & TRN & \\
\hline CHEMBL 3214021 & 688382 & 3.95 & 4.6762 & TRN & \\
\hline CHEMBL3190312 & 688382 & 5.1 & 4.7042 & TRN & \\
\hline CHEMBL1380985 & 688382 & 4.25 & 4.7618 & TRN & \\
\hline CHEMBL2001408 & 688382 & 4.85 & 4.6749 & TST & \\
\hline CHEMBL1342223 & 688382 & 5.85 & 4.7543 & TST & \\
\hline CHEMBL1467605 & 688382 & 4.15 & 4.6236 & TST & \\
\hline CHEMBL1509449 & 688382 & 5.8 & 4.7186 & TRN & \\
\hline CHEMBL1575281 & 688382 & 5.2 & 4.6881 & TRN & \\
\hline CHEMBL1490719 & 688382 & 4.25 & 4.7723 & TRN & \\
\hline CHEMBL1508995 & 688382 & 4.45 & 4.7336 & TRN & \\
\hline CHEMBL1419512 & 688382 & 4.45 & 4.7338 & TST & \\
\hline CHEMBL1607305 & 688382 & 4.9 & 4.7703 & TST & \\
\hline CHEMBL3208197 & 688382 & 4.4 & 4.6751 & TRN & \\
\hline CHEMBL1358791 & 688382 & 4.4 & 4.6957 & TRN & \\
\hline CHEMBL1492288 & 688382 & 4.4 & 4.7584 & TRN & \\
\hline CHEMBL1484449 & 688382 & 4.45 & 4.7597 & TST & \\
\hline CHEMBL1572849 & 688382 & 4.15 & 4.7359 & TRN & \\
\hline CHEMBL1575311 & 688382 & 4.5 & 4.68 & TRN & \\
\hline CHEMBL1400358 & 688382 & 4.5 & 4.6975 & TRN & \\
\hline CHEMBL1506652 & 688382 & 5.45 & 4.6668 & TRN & \\
\hline CHEMBL1447058 & 688382 & 4.6 & 4.7024 & TRN & \\
\hline CHEMBL1427661 & 688382 & 4.85 & 4.6158 & TST & \\
\hline CHEMBL1389770 & 688382 & 4.45 & 4.6523 & TRN & \\
\hline CHEMBL3198000 & 688382 & 4.8 & 4.6149 & TST & \\
\hline CHEMBL1476339 & 688382 & 4.05 & 4.7205 & TRN & \\
\hline CHEMBL1328041 & 688382 & 6.1 & 4.6888 & TRN & \\
\hline CHEMBL1458368 & 688382 & 4.95 & 4.6644 & TRN & \\
\hline CHEMBL1577065 & 688382 & 4.85 & 4.8306 & TRN & \\
\hline CHEMBL1332969 & 688382 & 5.1 & 4.7947 & TST & \\
\hline CHEMBL1578828 & 688382 & 5.05 & 4.6928 & TRN & \\
\hline CHEMBL585827 & 688382 & 4.95 & 4.6701 & TRN & \\
\hline CHEMBL3196266 & 688382 & 4.9 & $4.5760 e$ & 00000000005 & TRN \\
\hline CHEMBL1416566 & 688382 & 5.05 & 4.7126 & TRN & \\
\hline CHEMBL1738986 & 688382 & 4.95 & 4.7411 & TRN & \\
\hline CHEMBL1401395 & 688382 & 3.95 & 4.7399 & TST & \\
\hline CHEMBL1530005 & 688382 & 4.9 & 4.8006 & TST & \\
\hline CHEMBL1524995 & 688382 & 4.05 & 4.681 & TRN & \\
\hline CHEMBL1608056 & 688382 & 4.5 & 4.6803 & TRN & \\
\hline CHEMBL1439693 & 688382 & 3.95 & 4.6793 & TRN & \\
\hline CHEMBL1511943 & 688382 & 4.8 & 4.6729 & TRN & \\
\hline CHEMBL1400758 & 688382 & 5.55 & 4.7384 & TST & \\
\hline
\end{tabular}




\begin{tabular}{|c|c|c|c|c|c|}
\hline & & \multicolumn{4}{|c|}{ Supplemental Table S2.txt } \\
\hline CHEMBL1430538 & 688382 & 4.15 & 4.7821 & TRN & \\
\hline CHEMBL1428589 & 688382 & 4.95 & 4.7641 & TRN & \\
\hline CHEMBL1441730 & 688382 & 4.85 & 4.8151 & TRN & \\
\hline CHEMBL1994556 & 688382 & 4.45 & 4.6381 & TRN & \\
\hline CHEMBL1417391 & 688382 & 4.85 & 4.7839 & TRN & \\
\hline CHEMBL1369862 & 688382 & 4.05 & 4.6386 & TST & \\
\hline CHEMBL1585076 & 688382 & 5.95 & 4.8308 & TRN & \\
\hline CHEMBL1446172 & 688382 & 4.4 & 4.68199 & 99999999995 & TRN \\
\hline CHEMBL1440167 & 688382 & 4.85 & 4.6964 & TRN & \\
\hline CHEMBL578504 & 688382 & 4.45 & 4.6647 & TRN & \\
\hline CHEMBL1438078 & 688382 & 4.9 & 4.6827 & TRN & \\
\hline CHEMBL1333003 & 688382 & 4.9 & 4.8389 & TRN & \\
\hline CHEMBL1310196 & 688382 & 4.1 & 4.6792 & TRN & \\
\hline CHEMBL1384354 & 688382 & 4.45 & 4.6999 & TRN & \\
\hline CHEMBL1440230 & 688382 & 4.4 & 4.7816 & TRN & \\
\hline CHEMBL1608268 & 688382 & 4.5 & 4.6713 & TRN & \\
\hline CHEMBL1574521 & 688382 & 4.5 & 4.737 & TRN & \\
\hline CHEMBL1441206 & 688382 & 4.1 & 4.7299 & TRN & \\
\hline CHEMBL1462271 & 688382 & 4.55 & 4.6859 & TRN & \\
\hline CHEMBL3211679 & 688382 & 4.95 & 4.6371 & TST & \\
\hline CHEMBL1418273 & 688382 & 5.1 & 4.6967 & TRN & \\
\hline CHEMBL1530700 & 688382 & 4.15 & 4.7462 & TRN & \\
\hline CHEMBL1464855 & 688382 & 4.1 & 4.6832 & TST & \\
\hline CHEMBL1534536 & 688382 & 4.3 & 4.7403 & TST & \\
\hline CHEMBL1409340 & 688382 & 5.25 & 4.72 & TRN & \\
\hline CHEMBL554041 & 688382 & 4.1 & 4.7366 & TST & \\
\hline CHEMBL222759 & 688382 & 4.4 & 4.6455 & TRN & \\
\hline CHEMBL3192931 & 688382 & 4.8 & 4.7112 & TRN & \\
\hline CHEMBL1538775 & 688382 & 5.85 & 4.6425 & TRN & \\
\hline CHEMBL1583872 & 688382 & 6.05 & 4.7472 & TRN & \\
\hline CHEMBL1365432 & 688382 & 4.15 & 4.7298 & TST & \\
\hline CHEMBL1339696 & 688382 & 4.75 & 4.6718 & TRN & \\
\hline CHEMBL1542991 & 688382 & 5.0 & 4.5836 & TRN & \\
\hline CHEMBL1377854 & 688382 & 4.05 & 4.7335 & TRN & \\
\hline CHEMBL1405616 & 688382 & 4.05 & 4.7188 & TRN & \\
\hline CHEMBL1388112 & 688382 & 4.45 & 4.69300 & 00000000005 & TRN \\
\hline CHEMBL1551405 & 688382 & 4.45 & 4.6127 & TRN & \\
\hline CHEMBL1340604 & 688382 & 4.7 & 4.6442 & TRN & \\
\hline CHEMBL1300552 & 688382 & 4.5 & 4.7107 & TRN & \\
\hline CHEMBL1377447 & 688382 & 4.5 & 4.796 & TRN & \\
\hline CHEMBL1359228 & 688382 & 4.15 & 4.7182 & TRN & \\
\hline CHEMBL1539852 & 688382 & 5.05 & 4.7053 & TST & \\
\hline CHEMBL1465947 & 688382 & 6.0 & 4.8411 & TRN & \\
\hline CHEMBL1310813 & 688382 & 5.05 & 4.633 & TST & \\
\hline CHEMBL1365596 & 688382 & 4.6 & 4.6828 & TRN & \\
\hline CHEMBL1519104 & 688382 & 4.15 & 4.6921 & TRN & \\
\hline CHEMBL1594293 & 688382 & 4.8 & 4.7323 & TRN & \\
\hline CHEMBL1609688 & 688382 & 5.0 & 4.7186 & TST & \\
\hline
\end{tabular}




\begin{tabular}{|c|c|c|c|c|c|}
\hline & & \multicolumn{4}{|c|}{ Supplemental Table S2.txt } \\
\hline CHEMBL1563713 & 688382 & 4.15 & 4.8357 & TRN & \\
\hline CHEMBL 3210240 & 688382 & 4.0 & 4.6577 & TRN & \\
\hline CHEMBL1363546 & 688382 & 6.0 & 4.7658 & TST & \\
\hline CHEMBL1505894 & 688382 & 4.05 & 4.7267 & TRN & \\
\hline CHEMBL1513489 & 688382 & 4.4 & 4.6251 & TRN & \\
\hline CHEMBL1341553 & 688382 & 4.5 & 4.7092 & TRN & \\
\hline CHEMBL1326102 & 688382 & 5.8 & 4.8332 & TRN & \\
\hline CHEMBL1501439 & 688382 & 5.5 & 4.7335 & TRN & \\
\hline CHEMBL1611041 & 688382 & 5.25 & 4.6826 & TRN & \\
\hline CHEMBL1533528 & 688382 & 4.0 & 4.6224 & TRN & \\
\hline CHEMBL1566893 & 688382 & 4.05 & 4.7212 & TST & \\
\hline CHEMBL1447887 & 688382 & 4.35 & 4.69600 & 0000000001 & TRN \\
\hline CHEMBL1500166 & 688382 & 4.45 & 4.6996 & TRN & \\
\hline CHEMBL1332174 & 688382 & 4.65 & 4.7755 & TRN & \\
\hline CHEMBL1457774 & 688382 & 4.5 & 4.6035 & TRN & \\
\hline CHEMBL3211675 & 688382 & 6.0 & 4.7099 & TST & \\
\hline CHEMBL1307404 & 688382 & 4.65 & 4.6863 & TST & \\
\hline CHEMBL1423612 & 688382 & 4.8 & 4.7781 & TRN & \\
\hline CHEMBL1589497 & 688382 & 4.85 & 4.6589 & TRN & \\
\hline CHEMBL1417416 & 688382 & 4.8 & 4.7393 & TRN & \\
\hline CHEMBL3199742 & 688382 & 4.5 & 4.7037 & TRN & \\
\hline CHEMBL1336222 & 688382 & 4.85 & 4.69 & TST & \\
\hline CHEMBL 2002166 & 688382 & 4.1 & 4.6366 & TRN & \\
\hline CHEMBL1377121 & 688382 & 4.15 & 4.6764 & TRN & \\
\hline CHEMBL1454343 & 688382 & 5.0 & 4.7723 & TRN & \\
\hline CHEMBL1504166 & 688382 & 4.5 & 4.7234 & TRN & \\
\hline CHEMBL3199281 & 688382 & 4.15 & 4.7246 & TST & \\
\hline CHEMBL1419164 & 688382 & 5.1 & 4.637 & TRN & \\
\hline CHEMBL1492623 & 688382 & 4.5 & 4.6671 & TRN & \\
\hline CHEMBL1984721 & 688382 & 4.35 & 4.6971 & TRN & \\
\hline CHEMBL1578956 & 688382 & 4.15 & 4.6638 & TRN & \\
\hline CHEMBL1544337 & 688382 & 4.3 & 4.6678 & TRN & \\
\hline CHEMBL1544349 & 688382 & 4.05 & 4.6348 & TRN & \\
\hline CHEMBL1494600 & 688382 & 4.5 & 4.6602 & TRN & \\
\hline CHEMBL1505457 & 688382 & 5.85 & 4.6902 & TRN & \\
\hline CHEMBL1406232 & 688382 & 4.5 & 4.6297 & TRN & \\
\hline CHEMBL1477171 & 688382 & 4.55 & 4.6443 & TRN & \\
\hline CHEMBL1536810 & 688382 & 5.0 & 4.7543 & TRN & \\
\hline CHEMBL1431808 & 688382 & 4.8 & 4.7342 & TRN & \\
\hline CHEMBL1493805 & 688382 & 4.65 & 4.7381 & TRN & \\
\hline CHEMBL1520431 & 688382 & 5.95 & 4.8312 & TRN & \\
\hline CHEMBL1400487 & 688382 & 4.4 & 4.6459 & TST & \\
\hline CHEMBL1563698 & 688382 & 4.8 & 4.7537 & TST & \\
\hline CHEMBL1968273 & 688382 & 5.1 & 4.6078 & TRN & \\
\hline CHEMBL1556155 & 688382 & 4.15 & 4.6299 & TRN & \\
\hline CHEMBL3190277 & 688382 & 4.2 & 4.5979 & TRN & \\
\hline CHEMBL1488079 & 688382 & 4.45 & 4.6483 & TRN & \\
\hline CHEMBL 3214385 & 688382 & 4.35 & 4.659 & TRN & \\
\hline
\end{tabular}




\begin{tabular}{|c|c|c|c|c|c|}
\hline \multicolumn{6}{|c|}{ Supplemental Table S2.txt } \\
\hline CHEMBL1404420 & 688382 & 4.05 & 4.7399 & TRN & \\
\hline CHEMBL1542673 & 688382 & 4.45 & 4.811 & TST & \\
\hline CHEMBL1578151 & 688382 & 4.5 & 4.6626 & TRN & \\
\hline CHEMBL1606773 & 688382 & 4.7 & 4.7275 & TST & \\
\hline CHEMBL1451918 & 688382 & 4.5 & 4.6832 & TRN & \\
\hline CHEMBL1477434 & 688382 & 5.65 & 4.8187 & TRN & \\
\hline CHEMBL1968085 & 688382 & 4.5 & 4.6019 & TST & \\
\hline CHEMBL1536285 & 688382 & 4.8 & 4.7986 & TRN & \\
\hline CHEMBL1372481 & 688382 & 5.0 & 4.6771 & TRN & \\
\hline CHEMBL1306353 & 688382 & 5.85 & 4.699 & TRN & \\
\hline CHEMBL1537070 & 688382 & 4.4 & 4.6377 & TRN & \\
\hline CHEMBL1610045 & 688382 & 4.45 & 4.6429 & TRN & \\
\hline CHEMBL1504674 & 688382 & 4.4 & 4.6475 & TRN & \\
\hline CHEMBL 2369168 & 688382 & 4.25 & 4.64199 & 99999999995 & TRN \\
\hline CHEMBL1502698 & 688382 & 4.2 & 4.5902 & TRN & \\
\hline CHEMBL1332881 & 688382 & 4.3 & 4.7371 & TRN & \\
\hline CHEMBL1340250 & 688382 & 4.95 & 4.7327 & TRN & \\
\hline CHEMBL585654 & 688382 & 4.45 & 4.6789 & TRN & \\
\hline CHEMBL1416783 & 688382 & 5.8 & 4.765 & TRN & \\
\hline CHEMBL1988927 & 688382 & 3.95 & 4.6897 & TRN & \\
\hline CHEMBL1440728 & 688382 & 6.0 & 4.7984 & TRN & \\
\hline CHEMBL3191087 & 688382 & 4.5 & 4.6697 & TRN & \\
\hline CHEMBL3194060 & 688382 & 4.2 & 4.667 & TST & \\
\hline CHEMBL1572981 & 688382 & 4.8 & 4.8329 & TRN & \\
\hline CHEMBL 2005207 & 688382 & 4.7 & 4.6747 & TRN & \\
\hline CHEMBL520043 & 688382 & 4.85 & 4.7242 & TST & \\
\hline CHEMBL3197689 & 688382 & 4.4 & 4.6489 & TRN & \\
\hline CHEMBL1420548 & 688382 & 4.45 & 4.6869 & TRN & \\
\hline CHEMBL1486962 & 688382 & 4.8 & 4.6635 & TRN & \\
\hline CHEMBL1380123 & 688382 & 4.85 & 4.7556 & TRN & \\
\hline CHEMBL1522755 & 688382 & 4.65 & 4.6983 & TRN & \\
\hline CHEMBL1393780 & 688382 & 4.5 & 4.6172 & TRN & \\
\hline CHEMBL1452089 & 688382 & 5.0 & 4.6776 & TRN & \\
\hline CHEMBL1549100 & 688382 & 4.0 & 4.7514 & TST & \\
\hline CHEMBL1388022 & 688382 & 4.4 & 4.6386 & TRN & \\
\hline CHEMBL1613597 & 688382 & 4.0 & 4.6931 & TRN & \\
\hline CHEMBL1503956 & 688382 & 4.35 & 4.7057 & TRN & \\
\hline CHEMBL1604992 & 688382 & 5.0 & 4.6917 & TST & \\
\hline CHEMBL1546225 & 688382 & 4.8 & 4.7268 & TRN & \\
\hline CHEMBL3194898 & 688382 & 3.95 & 4.6326 & TRN & \\
\hline CHEMBL3212362 & 688382 & 4.5 & 4.6543 & TRN & \\
\hline CHEMBL1419985 & 688382 & 4.8 & 4.6252 & TRN & \\
\hline CHEMBL1485454 & 688382 & 5.55 & 4.7073 & TRN & \\
\hline CHEMBL1478726 & 688382 & 4.65 & 4.6913 & TRN & \\
\hline CHEMBL1572785 & 688382 & 4.5 & 4.6421 & TST & \\
\hline CHEMBL1319715 & 688382 & 5.05 & 4.79 & TST & \\
\hline CHEMBL1382913 & 688382 & 5.65 & 4.7859 & TRN & \\
\hline CHEMBL1560829 & 688382 & 4.85 & 4.677 & TST & \\
\hline
\end{tabular}




\begin{tabular}{|c|c|c|c|c|c|}
\hline & & \multicolumn{4}{|c|}{ Supplemental Table S2.txt } \\
\hline CHEMBL3195131 & 688382 & 5.05 & 4.6252 & TST & \\
\hline CHEMBL1349273 & 688382 & 4.8 & 4.6877 & TST & \\
\hline CHEMBL1312151 & 688382 & 4.5 & 4.6711 & TRN & \\
\hline CHEMBL1500098 & 688382 & 5.1 & 4.6948 & TRN & \\
\hline CHEMBL1299583 & 688382 & 5.2 & 4.7268 & TRN & \\
\hline CHEMBL1301418 & 688382 & 4.85 & 4.6909 & TRN & \\
\hline CHEMBL1967241 & 688382 & 4.2 & 4.655 & TRN & \\
\hline CHEMBL1511276 & 688382 & 6.0 & 4.6294 & TRN & \\
\hline CHEMBL1410084 & 688382 & 5.0 & 4.7999 & TRN & \\
\hline CHEMBL1482927 & 688382 & 4.8 & 4.7332 & TRN & \\
\hline CHEMBL1404610 & 688382 & 4.95 & 4.7675 & TST & \\
\hline CHEMBL1977709 & 688382 & 4.6 & 4.6382 & TRN & \\
\hline CHEMBL1390852 & 688382 & 4.2 & 4.6402 & TST & \\
\hline CHEMBL1585796 & 688382 & 5.05 & 4.6195 & TST & \\
\hline CHEMBL3193912 & 688382 & 4.8 & 4.7411 & TRN & \\
\hline CHEMBL1502089 & 688382 & 4.8 & 4.8134 & TST & \\
\hline CHEMBL1606575 & 688382 & 4.15 & 4.76399 & 9999999999 & TRN \\
\hline CHEMBL1389759 & 688382 & 4.8 & 4.7335 & TRN & \\
\hline CHEMBL1606299 & 688382 & 4.85 & 4.7722 & TRN & \\
\hline CHEMBL1486087 & 688382 & 5.1 & 4.8197 & TRN & \\
\hline CHEMBL1463537 & 688382 & 4.8 & 4.7247 & TST & \\
\hline CHEMBL1500938 & 688382 & 5.85 & 4.7436 & TRN & \\
\hline CHEMBL1431497 & 688382 & 6.0 & 4.6608 & TST & \\
\hline CHEMBL1301052 & 688382 & 4.35 & 4.6821 & TRN & \\
\hline CHEMBL1450440 & 688382 & 6.0 & 4.6942 & TRN & \\
\hline CHEMBL1392626 & 688382 & 4.5 & 4.7351 & TST & \\
\hline CHEMBL1504676 & 688382 & 5.15 & 4.5558 & TRN & \\
\hline CHEMBL3199740 & 688382 & 4.05 & 4.7217 & TST & \\
\hline CHEMBL1361206 & 688382 & 4.15 & 4.7382 & TRN & \\
\hline CHEMBL1372876 & 688382 & 5.8 & 4.686 & TST & \\
\hline CHEMBL1546860 & 688382 & 4.8 & 4.7973 & TRN & \\
\hline CHEMBL1401938 & 688382 & 4.5 & 4.6729 & TRN & \\
\hline CHEMBL1413589 & 688382 & 4.45 & 4.6515 & TRN & \\
\hline CHEMBL1323491 & 688382 & 4.45 & 4.606 & TRN & \\
\hline CHEMBL1575221 & 688382 & 5.2 & 4.57100 & 0000000001 & TRN \\
\hline CHEMBL1450202 & 688382 & 5.3 & 4.6321 & TRN & \\
\hline CHEMBL3145312 & 688382 & 4.05 & 4.6756 & TRN & \\
\hline CHEMBL1584702 & 688382 & 4.4 & 4.6447 & TRN & \\
\hline CHEMBL1464492 & 688382 & 5.05 & 4.6772 & TRN & \\
\hline CHEMBL1462074 & 688382 & 4.9 & 4.6794 & TST & \\
\hline CHEMBL1300463 & 688382 & 4.95 & 4.8095 & TRN & \\
\hline CHEMBL269550 & 688382 & 4.85 & 4.7005 & TST & \\
\hline CHEMBL1492211 & 688382 & 4.8 & 4.6461 & TRN & \\
\hline CHEMBL1432574 & 688382 & 4.8 & 4.7554 & TRN & \\
\hline CHEMBL1387363 & 688382 & 6.0 & 4.8229 & TST & \\
\hline CHEMBL3211315 & 688382 & 5.0 & 4.7658 & TRN & \\
\hline CHEMBL1378438 & 688382 & 4.4 & 4.6378 & TRN & \\
\hline CHEMBL1340499 & 688382 & 4.55 & 4.7545 & TRN & \\
\hline
\end{tabular}




\begin{tabular}{|c|c|c|c|c|c|}
\hline & & \multicolumn{4}{|c|}{ Supplemental Table S2.txt } \\
\hline CHEMBL1505198 & 688382 & 4.75 & 4.7004 & TST & \\
\hline CHEMBL1413039 & 688382 & 4.85 & 4.7035 & TRN & \\
\hline CHEMBL1319241 & 688382 & 4.2 & 4.7235 & TRN & \\
\hline CHEMBL1492784 & 688382 & 4.45 & 4.71399 & 99999999995 & TRN \\
\hline CHEMBL1570893 & 688382 & 5.0 & 4.753 & TRN & \\
\hline CHEMBL1364308 & 688382 & 4.0 & 4.6957 & TRN & \\
\hline CHEMBL1451897 & 688382 & 4.5 & 4.7228 & TRN & \\
\hline CHEMBL1495276 & 688382 & 4.45 & 4.7193 & TRN & \\
\hline CHEMBL1599407 & 688382 & 4.3 & 4.8288 & TRN & \\
\hline CHEMBL1470321 & 688382 & 4.95 & 4.7335 & TST & \\
\hline CHEMBL1479455 & 688382 & 4.95 & 4.7566 & TRN & \\
\hline CHEMBL1402172 & 688382 & 4.2 & 4.758 & TRN & \\
\hline CHEMBL1393048 & 688382 & 4.15 & 4.6651 & TRN & \\
\hline CHEMBL1528909 & 688382 & 4.15 & 4.8278 & TRN & \\
\hline CHEMBL1593208 & 688382 & 4.2 & 4.7972 & TST & \\
\hline CHEMBL1439070 & 688382 & 5.15 & 4.8369 & TST & \\
\hline CHEMBL1511603 & 688382 & 4.4 & 4.6614 & TRN & \\
\hline CHEMBL1471243 & 688382 & 5.5 & 4.7007 & TST & \\
\hline CHEMBL1540308 & 688382 & 4.0 & 4.7066 & TST & \\
\hline CHEMBL1393108 & 688382 & 4.85 & 4.8337 & TRN & \\
\hline CHEMBL1570982 & 688382 & 4.15 & 4.6648 & TRN & \\
\hline CHEMBL1389114 & 688382 & 4.0 & 4.6976 & TRN & \\
\hline CHEMBL1969300 & 688382 & 4.35 & 4.6749 & TRN & \\
\hline CHEMBL1424042 & 688382 & 4.25 & 4.7313 & TRN & \\
\hline CHEMBL1413295 & 688382 & 5.7 & 4.6381 & TRN & \\
\hline CHEMBL1408705 & 688382 & 4.75 & 4.6422 & TRN & \\
\hline CHEMBL1509248 & 688382 & 5.55 & 4.7741 & TST & \\
\hline CHEMBL1390396 & 688382 & 4.55 & 4.617 & TST & \\
\hline CHEMBL1335043 & 688382 & 4.15 & 4.5793 & TRN & \\
\hline CHEMBL1330594 & 688382 & 5.8 & 4.6981 & TRN & \\
\hline CHEMBL1309334 & 688382 & 5.75 & 4.6409 & TRN & \\
\hline CHEMBL1560564 & 688382 & 4.8 & 4.6879 & TST & \\
\hline CHEMBL1335433 & 688382 & 5.95 & 4.6834 & TRN & \\
\hline CHEMBL1572154 & 688382 & 4.15 & 4.6849 & TST & \\
\hline CHEMBL1319984 & 688382 & 4.75 & 4.6187 & TRN & \\
\hline CHEMBL1561496 & 688382 & 4.65 & 4.697 & TRN & \\
\hline CHEMBL3191760 & 688382 & 4.8 & 4.7209 & TRN & \\
\hline CHEMBL1342183 & 688382 & 4.85 & 4.7125 & TRN & \\
\hline CHEMBL1300240 & 688382 & 4.05 & 4.7849 & TRN & \\
\hline CHEMBL1507203 & 688382 & 4.8 & 4.8299 & TRN & \\
\hline CHEMBL1369958 & 688382 & 4.05 & 4.6852 & TRN & \\
\hline CHEMBL1494498 & 688382 & 6.5 & 4.7902 & TRN & \\
\hline CHEMBL1431041 & 688382 & 4.8 & 4.6932 & TRN & \\
\hline CHEMBL1310992 & 688382 & 5.5 & 4.7463 & TRN & \\
\hline CHEMBL1611442 & 688382 & 6.0 & 4.8253 & TRN & \\
\hline CHEMBL1482749 & 688382 & 5.8 & 4.7097 & TST & \\
\hline CHEMBL1477942 & 688382 & 4.05 & 4.7656 & TRN & \\
\hline CHEMBL1360793 & 688382 & 4.4 & 4.6161 & TRN & \\
\hline
\end{tabular}




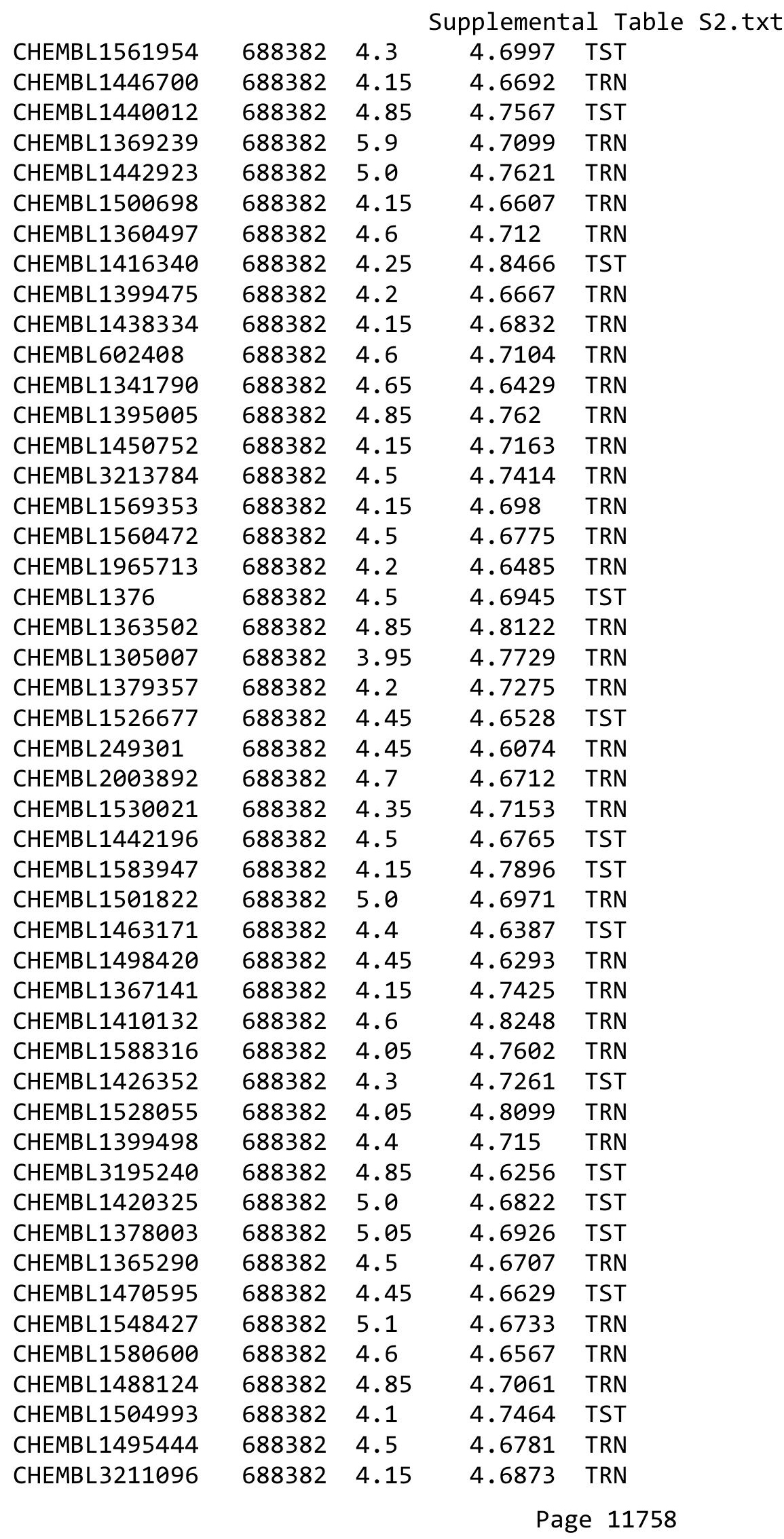




\begin{tabular}{|c|c|c|c|c|}
\hline \multicolumn{5}{|c|}{ Supplemental Tabl } \\
\hline CHEMBL1457085 & 688382 & 4.15 & 4.6828 & TRN \\
\hline CHEMBL3192331 & 688382 & 4.5 & 4.5846 & TST \\
\hline CHEMBL1427470 & 688382 & 4.2 & 4.6952 & TRN \\
\hline CHEMBL1598589 & 688382 & 4.15 & 4.6598 & TRN \\
\hline CHEMBL1325577 & 688382 & 4.45 & 4.6666 & TRN \\
\hline CHEMBL579322 & 688382 & 4.45 & 4.6804 & TRN \\
\hline CHEMBL 3191261 & 688382 & 4.15 & 4.6508 & TRN \\
\hline CHEMBL1396206 & 688382 & 5.05 & 4.692 & TST \\
\hline CHEMBL3211938 & 688382 & 4.45 & 4.6672 & TRN \\
\hline CHEMBL1519821 & 688382 & 5.8 & 4.673 & TRN \\
\hline CHEMBL1560715 & 688382 & 4.05 & 4.6677 & TRN \\
\hline CHEMBL1442948 & 688382 & 4.6 & 4.7956 & TRN \\
\hline CHEMBL1991573 & 688382 & 5.1 & 4.624 & TRN \\
\hline CHEMBL1548062 & 688382 & 4.0 & 4.6738 & TRN \\
\hline CHEMBL1489906 & 688382 & 4.45 & 4.7611 & TST \\
\hline CHEMBL1499420 & 688382 & 4.4 & 4.7067 & TRN \\
\hline CHEMBL3190857 & 688382 & 5.15 & 4.628 & TRN \\
\hline CHEMBL1392332 & 688382 & 4.75 & 4.6516 & TRN \\
\hline CHEMBL1387907 & 688382 & 5.8 & 4.7423 & TRN \\
\hline CHEMBL1330846 & 688382 & 4.4 & 4.6545 & TST \\
\hline CHEMBL1461405 & 688382 & 5.0 & 4.6767 & TRN \\
\hline CHEMBL1458495 & 688382 & 4.0 & 4.6763 & TST \\
\hline CHEMBL1519363 & 688382 & 4.8 & 4.7545 & TRN \\
\hline CHEMBL585622 & 688382 & 4.3 & 4.6174 & TRN \\
\hline CHEMBL1564903 & 688382 & 4.45 & 4.7716 & TRN \\
\hline CHEMBL1507977 & 688382 & 4.2 & 4.6876 & TST \\
\hline CHEMBL1487396 & 688382 & 5.05 & 4.7825 & TST \\
\hline CHEMBL1562055 & 688382 & 5.0 & 4.7622 & TST \\
\hline CHEMBL1608681 & 688382 & 6.0 & 4.8199 & TRN \\
\hline CHEMBL1546538 & 688382 & 4.8 & 4.7437 & TST \\
\hline CHEMBL1583539 & 688382 & 5.0 & 4.7177 & TRN \\
\hline CHEMBL1398590 & 688382 & 4.8 & 4.7762 & TST \\
\hline CHEMBL1460053 & 688382 & 4.55 & 4.7275 & TST \\
\hline CHEMBL1172912 & 688382 & 5.2 & 4.732 & TRN \\
\hline CHEMBL1587615 & 688382 & 4.25 & 4.762 & TRN \\
\hline CHEMBL1604122 & 688382 & 5.25 & 4.6269 & TRN \\
\hline CHEMBL1335725 & 688382 & 5.1 & 4.7584 & TST \\
\hline CHEMBL1387413 & 688382 & 4.5 & 4.697 & TRN \\
\hline CHEMBL1410976 & 688382 & 4.35 & 4.6404 & TRN \\
\hline CHEMBL1350979 & 688382 & 4.35 & 4.6983 & TRN \\
\hline CHEMBL1592638 & 688382 & 4.2 & 4.7273 & TRN \\
\hline CHEMBL1545966 & 688382 & 4.95 & 4.657 & TRN \\
\hline CHEMBL1387615 & 688382 & 4.4 & 4.6593 & TRN \\
\hline CHEMBL1990599 & 688382 & 4.35 & 4.6823 & TRN \\
\hline CHEMBL1506826 & 688382 & 4.75 & 4.7896 & TRN \\
\hline CHEMBL1437921 & 688382 & 4.2 & 4.712 & TRN \\
\hline CHEMBL1505013 & 688382 & 4.55 & 4.7093 & TRN \\
\hline CHEMBL1553978 & 688382 & 4.45 & 4.6381 & TST \\
\hline
\end{tabular}




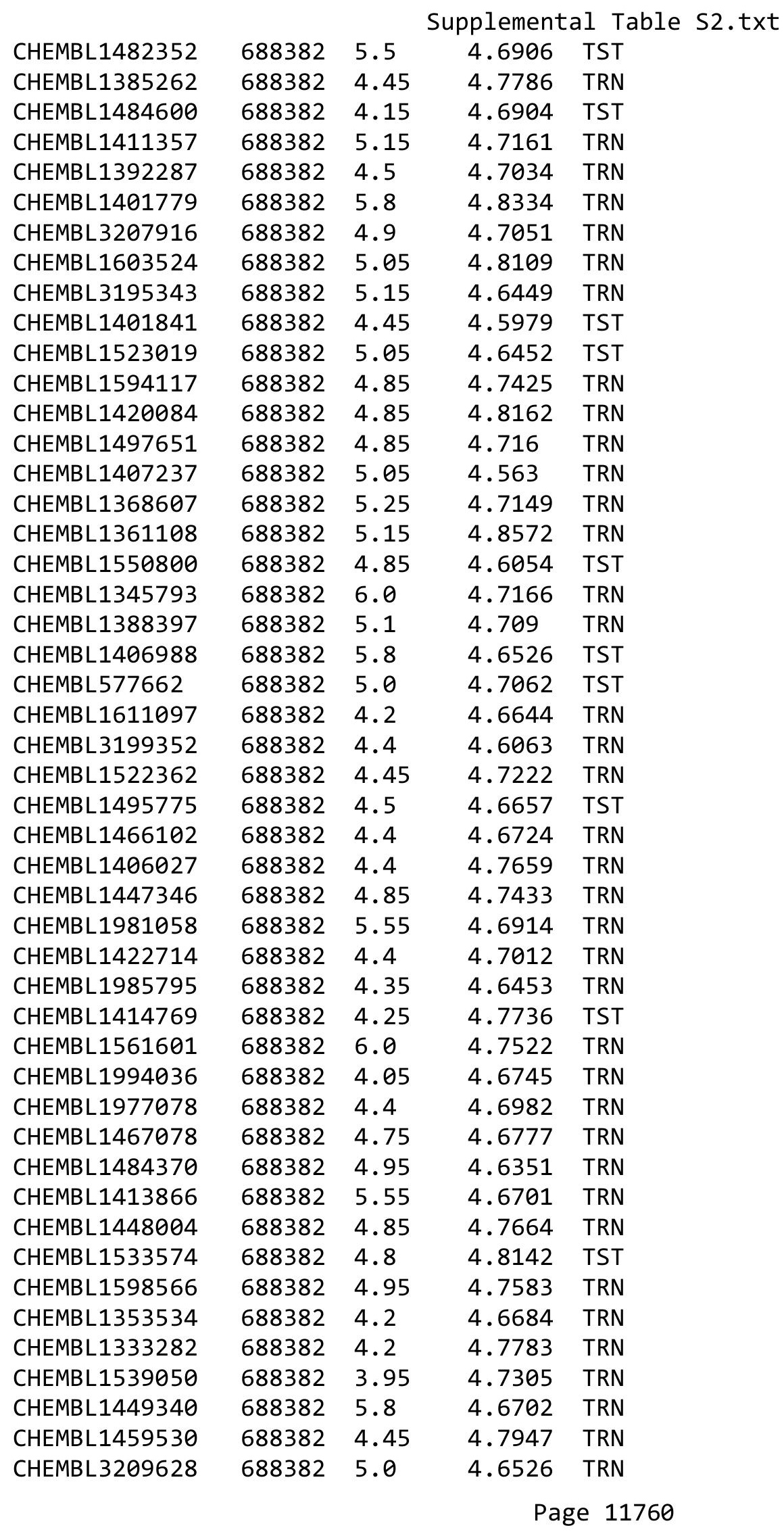




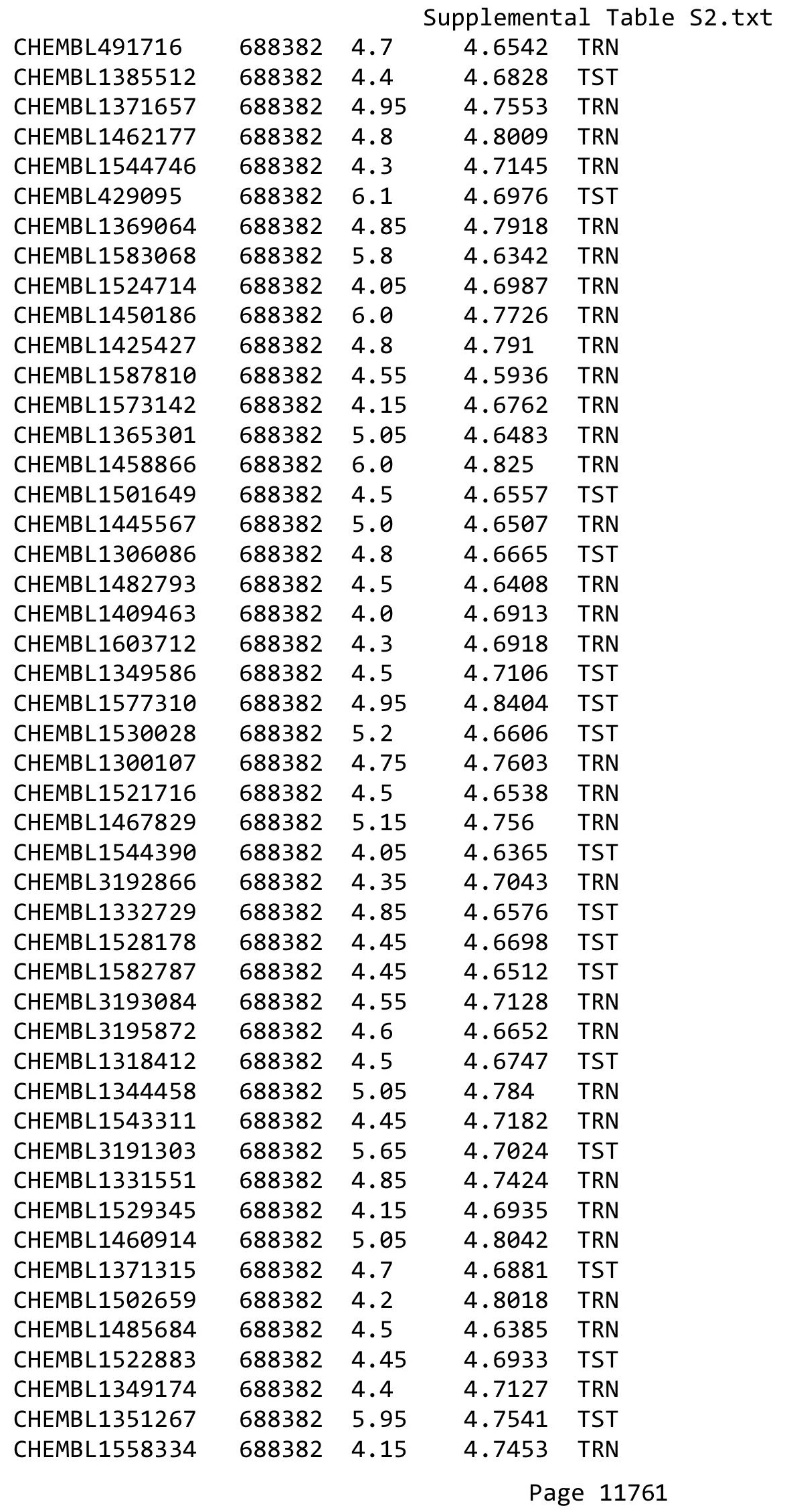




\begin{tabular}{|c|c|c|c|c|c|}
\hline \multicolumn{6}{|c|}{ Supplemental Table s2.txt } \\
\hline CHEMBL1573092 & 688382 & 5.5 & 4.7308 & TRN & \\
\hline CHEMBL1411471 & 688382 & 4.05 & 4.7127 & TRN & \\
\hline CHEMBL1499517 & 688382 & 4.85 & 4.641 & TRN & \\
\hline CHEMBL1531875 & 688382 & 4.05 & 4.7241 & TST & \\
\hline CHEMBL1379901 & 688382 & 4.75 & 4.731 & TRN & \\
\hline CHEMBL1548290 & 688382 & 4.05 & 4.6681 & TRN & \\
\hline CHEMBL1454495 & 688382 & 5.0 & 4.7076 & TST & \\
\hline CHEMBL1312940 & 688382 & 4.5 & 4.7613 & TRN & \\
\hline CHEMBL1487214 & 688382 & 5.0 & 4.6916 & TST & \\
\hline CHEMBL1383156 & 688382 & 4.0 & 4.7844 & TRN & \\
\hline CHEMBL1323864 & 688382 & 4.4 & 4.6853 & TRN & \\
\hline CHEMBL1528252 & 688382 & 5.25 & 4.6636 & TRN & \\
\hline CHEMBL1459091 & 688382 & 4.5 & 4.7907 & TST & \\
\hline CHEMBL1360125 & 688382 & 4.4 & 4.7298 & TRN & \\
\hline CHEMBL1323021 & 688382 & 5.0 & 4.6999 & TRN & \\
\hline CHEMBL31966 & 688382 & 5.2 & 4.683 & TST & \\
\hline CHEMBL1431277 & 688382 & 4.05 & 4.7237 & TRN & \\
\hline CHEMBL1325424 & 688382 & 4.5 & 4.7414 & TRN & \\
\hline CHEMBL1570607 & 688382 & 4.15 & $4.8180 e$ & 00000000005 & TRN \\
\hline CHEMBL1531018 & 688382 & 4.85 & 4.7364 & TST & \\
\hline CHEMBL1585579 & 688382 & 5.05 & 4.7371 & TRN & \\
\hline CHEMBL1589648 & 688382 & 4.8 & 4.7954 & TRN & \\
\hline CHEMBL1362867 & 688382 & 4.35 & 4.7328 & TRN & \\
\hline CHEMBL1411111 & 688382 & 5.15 & 4.6038 & TST & \\
\hline CHEMBL1517916 & 688382 & 4.85 & 4.7033 & TRN & \\
\hline CHEMBL1306764 & 688382 & 5.5 & 4.8056 & TRN & \\
\hline CHEMBL1493030 & 688382 & 4.8 & 4.7196 & TRN & \\
\hline CHEMBL3197999 & 688382 & 4.45 & 4.6734 & TRN & \\
\hline CHEMBL1299619 & 688382 & 4.15 & 4.6973 & TRN & \\
\hline CHEMBL1430224 & 688382 & 5.1 & 4.5781 & TST & \\
\hline CHEMBL1593651 & 688382 & 5.25 & 4.7503 & TRN & \\
\hline CHEMBL1334690 & 688382 & 4.65 & 4.7758 & TRN & \\
\hline CHEMBL1361270 & 688382 & 5.1 & 4.7259 & TRN & \\
\hline CHEMBL1337484 & 688382 & 4.35 & $4.6960 e$ & 3000000001 & TRN \\
\hline CHEMBL3195281 & 688382 & 4.05 & 4.677 & TST & \\
\hline CHEMBL1568687 & 688382 & 5.05 & 4.819 & TST & \\
\hline CHEMBL1408344 & 688382 & 4.85 & 4.7411 & TST & \\
\hline CHEMBL1506960 & 688382 & 5.05 & 4.7095 & TST & \\
\hline CHEMBL1538943 & 688382 & 4.9 & 4.7216 & TST & \\
\hline CHEMBL1464915 & 688382 & 4.4 & 4.6298 & TST & \\
\hline CHEMBL1385685 & 688382 & 5.7 & 4.7164 & TST & \\
\hline CHEMBL1576690 & 688382 & 5.95 & 4.6692 & TRN & \\
\hline CHEMBL1491154 & 688382 & 4.2 & 4.6911 & TRN & \\
\hline CHEMBL1587404 & 688382 & 4.85 & 4.8055 & TRN & \\
\hline CHEMBL1350587 & 688382 & 4.2 & 4.6157 & TRN & \\
\hline CHEMBL1462069 & 688382 & 5.4 & 4.8776 & TRN & \\
\hline CHEMBL1519798 & 688382 & 4.45 & 4.662 & TRN & \\
\hline CHEMBL1317142 & 688382 & 4.6 & 4.7124 & TST & \\
\hline
\end{tabular}




\begin{tabular}{|c|c|c|c|c|c|}
\hline \multicolumn{6}{|c|}{ Supplemental Table S2.txt } \\
\hline CHEMBL1606630 & 688382 & 4.85 & 4.687 & TST & \\
\hline CHEMBL1543805 & 688382 & 4.6 & 4.6514 & TST & \\
\hline CHEMBL1449492 & 688382 & 4.4 & 4.7691 & TRN & \\
\hline CHEMBL1325643 & 688382 & 5.0 & 4.7615 & TRN & \\
\hline CHEMBL1581971 & 688382 & 4.45 & 4.7042 & TRN & \\
\hline CHEMBL1464805 & 688382 & 4.75 & 4.6486 & TST & \\
\hline CHEMBL1540981 & 688382 & 4.8 & 4.7936 & TRN & \\
\hline CHEMBL1579644 & 688382 & 4.5 & 4.7294 & TRN & \\
\hline CHEMBL1349046 & 688382 & 4.55 & 4.6924 & TRN & \\
\hline CHEMBL1493441 & 688382 & 4.25 & 4.7656 & TST & \\
\hline CHEMBL1483312 & 688382 & 4.45 & 4.7467 & TST & \\
\hline CHEMBL1348169 & 688382 & 4.4 & 4.6554 & TRN & \\
\hline CHEMBL1439124 & 688382 & 4.5 & 4.7025 & TRN & \\
\hline CHEMBL1368770 & 688382 & 4.95 & 4.7309 & TRN & \\
\hline CHEMBL1421273 & 688382 & 5.3 & 4.7485 & TST & \\
\hline CHEMBL1403542 & 688382 & 4.15 & 4.754 & TST & \\
\hline CHEMBL1342931 & 688382 & 5.2 & 4.8902 & TRN & \\
\hline CHEMBL1390679 & 688382 & 5.05 & 4.768 & TRN & \\
\hline CHEMBL1460203 & 688382 & 4.15 & 4.7385 & TST & \\
\hline CHEMBL1612400 & 688382 & 4.8 & 4.721999 & 99999999995 & TST \\
\hline CHEMBL1609244 & 688382 & 5.0 & 4.7093 & TRN & \\
\hline CHEMBL1595667 & 688382 & 4.15 & 4.6738 & TST & \\
\hline CHEMBL1456128 & 688382 & 5.0 & 4.7377 & TRN & \\
\hline CHEMBL1998516 & 688382 & 4.55 & 4.6805 & TST & \\
\hline CHEMBL1536853 & 688382 & 4.45 & 4.7058 & TST & \\
\hline CHEMBL1411785 & 688382 & 5.4 & 4.7595 & TRN & \\
\hline CHEMBL1523307 & 688382 & 5.15 & 4.7726 & TST & \\
\hline CHEMBL3192176 & 688382 & 4.35 & 4.6941 & TST & \\
\hline CHEMBL1513515 & 688382 & 4.85 & 4.7456 & TST & \\
\hline CHEMBL1502830 & 688382 & 4.05 & 4.6558 & TST & \\
\hline CHEMBL1367243 & 688382 & 4.7 & 4.8013 & TRN & \\
\hline CHEMBL3191948 & 688382 & 4.5 & 4.671 & TST & \\
\hline CHEMBL1415823 & 688382 & 5.05 & 4.6902 & TRN & \\
\hline CHEMBL 3823126 & 1586856 & 9.9586 & 9.7431 & TRN & \\
\hline CHEMBL 3823411 & 1586856 & 9.9586 & 9.4777 & TRN & \\
\hline CHEMBL 3823043 & 1586856 & 10.0458 & 9.6308 & TRN & \\
\hline CHEMBL 3823889 & 1586856 & 10.0 & 9.6322 & TST & \\
\hline CHEMBL3822636 & 1586856 & 9.9586 & 9.6457 & TRN & \\
\hline CHEMBL 3823976 & 1586856 & 10.5229 & 10.0259 & TST & \\
\hline CHEMBL 3823786 & 1586856 & 10.0 & 9.6531 & TST & \\
\hline CHEMBL 3824226 & 1586856 & 6.5229 & 7.5598 & TRN & \\
\hline CHEMBL 3823936 & 1586856 & 9.7212 & 9.9152 & TRN & \\
\hline CHEMBL3823334 & 1586856 & 10.1549 & 9.6469 & TST & \\
\hline CHEMBL 3824136 & 1586856 & 9.5376 & 9.0649 & TRN & \\
\hline CHEMBL3824232 & 1586856 & 10.2218 & 9.8007 & TRN & \\
\hline CHEMBL 3823878 & 1586856 & 9.8861 & 9.6397 & TRN & \\
\hline CHEMBL 3823835 & 1586856 & 10.3979 & 9.6397 & TRN & \\
\hline CHEMBL3823333 & 1586856 & 6.0 & 9.6397 & TRN & \\
\hline
\end{tabular}


Supplemental Table S2.txt

\begin{tabular}{|c|c|c|c|c|c|c|}
\hline CHEMBL 3822792 & 1586856 & 10.3979 & 10.4422 & TRN & & \\
\hline CHEMBL 3824332 & 1586856 & 9.8861 & 9.6308 & TRN & & \\
\hline CHEMBL 3824079 & 1586856 & 10.1549 & 9.7844 & TST & & \\
\hline CHEMBL 3822975 & 1586856 & 9.9586 & 9.5036 & TRN & & \\
\hline CHEMBL 3824241 & 1586856 & 10.0969 & 9.6322 & TST & & \\
\hline CHEMBL 3823722 & 1586856 & 10.0458 & 9.6397 & TRN & & \\
\hline CHEMBL 3824227 & 1586856 & 8.9586 & 7.8272 & TRN & & \\
\hline CHEMBL 3822888 & 1586856 & 10.0969 & 9.6397 & TRN & & \\
\hline CHEMBL 3822928 & 1586856 & 10.5229 & 10.0598 & TST & & \\
\hline CHEMBL3823755 & 1586856 & 9.7447 & 9.6457 & TRN & & \\
\hline CHEMBL 3822701 & 1586856 & 9.2924 & 9.6531 & TST & & \\
\hline CHEMBL 2177395 & 1586856 & 10.1549 & 9.4702 & TRN & & \\
\hline CHEMBL 3822981 & 1586856 & 6.0 & 9.6397 & TRN & & \\
\hline CHEMBL 3823671 & 1586856 & 9.1805 & 9.6604 & TRN & & \\
\hline CHEMBL3824197 & 1586856 & 9.6576 & 8.6512 & TRN & & \\
\hline CHEMBL 3822727 & 1586856 & 10.0 & 9.6397 & TRN & & \\
\hline CHEMBL3823985 & 1586856 & 10.2218 & 10.1027 & TRN & & \\
\hline CHEMBL 3823117 & 1586856 & 9.3188 & 9.0704 & TRN & & \\
\hline CHEMBL 3823225 & 1586856 & 9.699 & 9.6637 & TRN & & \\
\hline CHEMBL3824179 & 1586856 & 9.6576 & 8.8526 & TST & & \\
\hline CHEMBL 3823818 & 1586856 & 9.8861 & 9.2636 & TRN & & \\
\hline CHEMBL 3823541 & 1586856 & 10.5229 & 9.8007 & TRN & & \\
\hline CHEMBL 3823291 & 1586856 & 10.0969 & 9.6322 & TST & & \\
\hline CHEMBL 3823421 & 1586856 & 10.1549 & 9.6457 & TRN & & \\
\hline CHEMBL 3824278 & 1586856 & 9.699 & 9.6322 & TST & & \\
\hline CHEMBL 3822774 & 1586856 & 9.5376 & 9.6462 & TRN & & \\
\hline CHEMBL3823681 & 1586856 & 8.9586 & 7.8708 & TST & & \\
\hline CHEMBL 3823051 & 1586856 & 6.0 & 7.4911 & TRN & & \\
\hline CHEMBL3823133 & 1586856 & 10.5229 & 10.2372 & TRN & & \\
\hline CHEMBL 3823327 & 1586856 & 10.30099 & 99999999 & 998 & 10.1752 & TRN \\
\hline CHEMBL 3824272 & 1586856 & 9.8861 & 9.4006 & TRN & & \\
\hline CHEMBL 3823847 & 1586856 & 10.30099 & 99999999 & 998 & 9.7844 & TST \\
\hline CHEMBL 3823144 & 1586856 & 10.0 & 10.1527 & TRN & & \\
\hline CHEMBL 3823082 & 1586856 & 9.3768 & 9.6397 & TRN & & \\
\hline CHEMBL 3822459 & 1586856 & 10.2218 & 10.2372 & TRN & & \\
\hline CHEMBL 3822569 & 1586856 & 6.0 & 8.6512 & TRN & & \\
\hline CHEMBL 3823994 & 1586856 & 9.8239 & 9.6397 & TRN & & \\
\hline CHEMBL 3822809 & 1586856 & 9.4559 & 7.4911 & TRN & & \\
\hline CHEMBL 3823088 & 1586856 & 9.2007 & 8.0959 & TST & & \\
\hline CHEMBL 3823221 & 1586856 & 10.0458 & 9.7008 & TST & & \\
\hline CHEMBL 3823643 & 1586856 & 9.8539 & 9.6397 & TRN & & \\
\hline CHEMBL 3823893 & 1586856 & 9.2924 & 9.2707 & TRN & & \\
\hline CHEMBL3730354 & 1537418 & 5.3335 & 5.4107 & TST & & \\
\hline CHEMBL3729699 & 1537418 & 6.7399 & 6.555 & TRN & & \\
\hline CHEMBL 3732094 & 1537418 & 5.3546 & 5.4726 & TRN & & \\
\hline CHEMBL3731889 & 1537418 & 6.9355 & 7.2758 & TRN & & \\
\hline CHEMBL3728190 & 1537418 & 6.4789 & 6.9524 & TRN & & \\
\hline CHEMBL3727702 & 1537418 & 4.8182 & 4.9547 & TRN & & \\
\hline
\end{tabular}

Page 11764 
Supplemental Table S2.txt

\begin{tabular}{|c|c|c|c|c|}
\hline |EI & 8 & 27 & 89 & TR \\
\hline & & 6.9508 & 6.6911 & \\
\hline$-\sigma_{2}$ & & & & \\
\hline AEMBL 3727450 & & 7.041 & 041 & \\
\hline AEMBL3732813 & 37418 & 645 & 7312 & \\
\hline HEMBL3729225 & 537418 & 6.3605 & 7451 & \\
\hline 748 & & 5.2984 & 3062 & \\
\hline 535 & & 7.9208 & 883 & \\
\hline HEMBL3 & 18 & 6021 & 4801 & \\
\hline HEMBL3732516 & 537418 & 5.4921 & 5965 & \\
\hline AEMBL3 & 18 & 6.6517 & 7918 & \\
\hline IEMBL: & 18 & 354 & 462 & \\
\hline AEMBL & & & 145 & \\
\hline HEMBL3 & 18 & 6.0 & 4328 & \\
\hline AEMBL3 & 18 & & 7461 & \\
\hline AEMBL3 & 18 & 22 & 5182 & \\
\hline HEMBL & 8 & & 753 & \\
\hline HEMBL & & & & \\
\hline HEMBL3 & & 36 & 3336 & \\
\hline HEMBL3 & & 6. & & \\
\hline AEMBL & 8 & 5. & 19 & \\
\hline HEMBL & & 3. & 57 & \\
\hline HEMBL & & 25 & 54 & \\
\hline HEMBL & & 6 & & \\
\hline AEMBL3 & & & & RN \\
\hline HEMBL & & & 849 & \\
\hline HEMBL & & 25 & 47 & \\
\hline HFMRI & & 68 & 27 & ST \\
\hline HEMBL3 & & & & $\mathrm{RN}$ \\
\hline HEMBL3 & 18 & & 35 & RIN \\
\hline HEMBL3 & & 96 & 747 & \\
\hline AFMB & & & & ודת \\
\hline HEMBL & & & 662 & ST \\
\hline HEMBL37 & & & 253 & RN \\
\hline HEMBL 372957 & 8 & 6.3206 & 3036 & $\mathrm{RN}$ \\
\hline HEMBL3 & & 29 & 383 & \\
\hline HEMRI & & & 399 & RN \\
\hline HEMBL3 & & & 2695 & RN \\
\hline HEMBL37 & 18 & 5.8861 & & TRN \\
\hline IEMBL3 & 8 & & 719 & RN \\
\hline HEMBL3 & & 819 & 816 & \\
\hline CHEMBL3 & & & & RN \\
\hline HEMBL3 & 18 & 5.6253 & 1359 & $\mathrm{RN}$ \\
\hline HEMBL37 & 537 & 5.3179 & 3972 & TRN \\
\hline $\mathrm{MPI}=$ & & 5021 & 642 & \\
\hline CHEMBL 3 & & & .9038 & \\
\hline HEMBL 3 & & .0269 & .7262 & \\
\hline CHEMBL3732041 & 1537418 & 5.2457 & 5.0734 & ГRN \\
\hline
\end{tabular}

Page 11765 
Supplemental Table S2.txt

\begin{tabular}{|c|c|c|c|c|c|}
\hline CHEMBL3730289 & 1537418 & 6.7799 & 6.8223 & TRN & \\
\hline CHEMBL3731632 & 1537418 & 5.0701 & 5.0956 & TST & \\
\hline CHEMBL3728471 & 1537418 & 6.5719 & 6.7955 & TRN & \\
\hline CHEMBL3730279 & 1537418 & 5.3851 & 5.3559 & TRN & \\
\hline CHEMBL3731064 & 1537418 & 7.699 & 6.8058 & TST & \\
\hline CHEMBL 3730424 & 1537418 & 3.6021 & 3.9959 & TRN & \\
\hline CHEMBL3731561 & 1537418 & 5.6635 & 5.8136 & TRN & \\
\hline CHEMBL3730306 & 1537418 & 5.983 & 5.9098 & TST & \\
\hline CHEMBL3730944 & 1537418 & 3.6021 & 4.8828 & TRN & \\
\hline CHEMBL3729552 & 1537418 & 6.0 & 6.1169 & TRN & \\
\hline CHEMBL 3728104 & 1537418 & 3.6021 & 3.7538 & TRN & \\
\hline CHEMBL 3728012 & 1537418 & 5.5872 & 5.6455 & TST & \\
\hline CHEMBL3733130 & 1537418 & 5.9172 & 5.8855 & TRN & \\
\hline CHEMBL3728337 & 1537418 & 4.6402 & 6.1428 & TRN & \\
\hline CHEMBL3732990 & 1537418 & 6.2441 & 6.0973 & TRN & \\
\hline CHEMBL3729027 & 1537418 & 6.5114 & 6.4635 & TRN & \\
\hline CHEMBL3727840 & 1537418 & 5.6819 & 5.3742 & TRN & \\
\hline CHEMBL3732166 & 1537418 & 3.6021 & 4.3042 & TRN & \\
\hline CHEMBL3729214 & 1537418 & 5.2749 & 5.5065 & TRN & \\
\hline CHEMBL3730474 & 1537418 & 5.7471 & 5.0541 & TST & \\
\hline CHEMBL3733047 & 1537418 & 5.433 & 4.6987 & TRN & \\
\hline CHEMBL3729228 & 1537418 & 6.1391 & 6.5054 & TRN & \\
\hline CHEMBL3727544 & 1537418 & 5.9666 & 5.4935 & TRN & \\
\hline CHEMBL3731680 & 1537418 & 7.1938 & 7.0184 & TRN & \\
\hline CHEMBL3728237 & 1537418 & 6.1273 & 6.2999 & TRN & \\
\hline CHEMBL3730874 & 1537418 & 3.6021 & 4.8251 & TRN & \\
\hline CHEMBL3730203 & 1537418 & 6.5952 & 6.6941 & TRN & \\
\hline CHEMBL3728360 & 1537418 & 5.6517 & 5.63 & TST & \\
\hline CHEMBL3728194 & 1537418 & \multicolumn{2}{|c|}{5.4510000000000005} & 5.3777 & TRN \\
\hline CHEMBL3730378 & 1537418 & 6.7144 & 7.0108 & TRN & \\
\hline CHEMBL3729010 & 1537418 & 6.2565 & 5.3811 & TST & \\
\hline CHEMBL3731359 & 1537418 & 5.0477 & 5.5511 & TST & \\
\hline CHEMBL3728646 & 1537418 & 7.1739 & 6.229 & TST & \\
\hline CHEMBL3727798 & 1537418 & 5.767 & 5.5474 & TRN & \\
\hline CHEMBL3728558 & 1537418 & 5.8861 & 5.8115 & TST & \\
\hline CHEMBL3728092 & 1537418 & 5.614 & 6.2121 & TST & \\
\hline CHEMBL3731737 & 1537418 & 6.3799 & 6.5351 & TRN & \\
\hline CHEMBL3729273 & 1537418 & 7.1805 & 7.1457 & TRN & \\
\hline CHEMBL3731035 & 1537418 & 7.8239 & 7.2163 & TRN & \\
\hline CHEMBL3730159 & 1537418 & 7.0223 & 6.7913 & TRN & \\
\hline CHEMBL3729760 & 1537418 & 6.2055 & 6.4429 & TST & \\
\hline CHEMBL3732502 & 1537418 & 6.15 & 6.2509 & TST & \\
\hline CHEMBL3731251 & 1537418 & 5.5143 & 5.4591 & TST & \\
\hline CHEMBL3732907 & 1537418 & 6.4101 & 6.2758 & TRN & \\
\hline CHEMBL3729343 & 1537418 & 5.1585 & 6.1215 & TST & \\
\hline CHEMBL3731113 & 1537418 & 5.585 & 6.1326 & TST & \\
\hline CHEMBL3730211 & 1537418 & 5.5258 & 5.302006 & 00000000005 & TRN \\
\hline CHEMBL3731971 & 1537418 & 6.6904 & 6.176 & TRN & \\
\hline
\end{tabular}


Supplemental Table S2.txt

\begin{tabular}{|c|c|c|c|c|}
\hline CHEMBL3732930 & 1537418 & 6.3045 & 5.9073 & TRN \\
\hline CHEMBL 3732612 & 1537418 & 6.1891 & 6.2182 & TST \\
\hline CHEMBL3729899 & 1537418 & 6.9872 & 7.0548 & TRN \\
\hline CHEMBL 3732870 & 1537418 & 5.3587 & 5.3267 & TST \\
\hline CHEMBL 3730873 & 1537418 & 6.3107 & 6.5223 & TRN \\
\hline CHEMBL 3729493 & 1537418 & 7.5376 & 7.7655 & TRN \\
\hline CHEMBL 3730902 & 1537418 & 5.9318 & 5.9628 & TRN \\
\hline CHEMBL 3730523 & 1537418 & 6.4295 & 6.3296 & TRN \\
\hline CHEMBL 3730904 & 1537418 & 5.7959 & 6.31 & TST \\
\hline CHEMBL3730991 & 1537418 & 5.8277 & 6.0527 & TRN \\
\hline CHEMBL 3733264 & 1537418 & 5.6445 & 5.9864 & TST \\
\hline CHEMBL 3729542 & 1537418 & 5.3872 & 5.724 & TST \\
\hline CHEMBL 3728585 & 1537418 & 5.8601 & 5.50899 & 99999999995 \\
\hline CHEMBL 3730852 & 1537418 & 5.9172 & 5.2799 & TRN \\
\hline CHEMBL 3727729 & 1537418 & 6.266 & 5.7788 & TRN \\
\hline CHEMBL 3730978 & 1537418 & 5.7683 & 6.1245 & TST \\
\hline CHEMBL3729822 & 1537418 & 5.3206 & 4.9383 & TRN \\
\hline CHEMBL 3730922 & 1537418 & 7.0044 & 6.41299 & 9999999999 \\
\hline CHEMBL 3730548 & 1537418 & 5.3288 & 5.3814 & TRN \\
\hline CHEMBL 3728352 & 1537418 & 7.3279 & 5.5828 & TST \\
\hline CHEMBL 3730671 & 1537418 & 6.5346 & 6.1698 & TRN \\
\hline CHEMBL3728279 & 1537418 & 6.5935 & 6.58 & TRN \\
\hline CHEMBL 3732163 & 1537418 & 7.0269 & 6.3348 & TRN \\
\hline CHEMBL 3732960 & 1537418 & 6.1891 & 6.4094 & TRN \\
\hline CHEMBL 3728109 & 1537418 & 3.6021 & 4.4602 & TRN \\
\hline CHEMBL3729761 & 1537418 & 3.6021 & 4.368 & TRN \\
\hline CHEMBL 3727588 & 1537418 & 6.4498 & 6.1417 & TRN \\
\hline CHEMBL 3729617 & 1537418 & 5.7878 & 6.0501 & TRN \\
\hline CHEMBL3729299 & 1537418 & 6.2874 & 6.4303 & TRN \\
\hline CHEMBL 3730231 & 1537418 & 5.6538 & 5.9124 & TRN \\
\hline CHEMBL 3728159 & 1537418 & 5.9066 & 5.4394 & TRN \\
\hline CHEMBL 3731677 & 1537418 & 6.4724 & 6.4521 & TRN \\
\hline CHEMBL 3730955 & 1537418 & 7.2218 & 7.0981 & TRN \\
\hline CHEMBL3730542 & 1537418 & 6.4763 & 6.6548 & TRN \\
\hline CHEMBL3732039 & 1537418 & 6.4365 & 6.5876 & TRN \\
\hline CHEMBL3732009 & 1537418 & 5.4895 & 4.742 & TST \\
\hline CHEMBL 3728649 & 1537418 & 7.7959 & 7.3056 & TRN \\
\hline CHEMBL 3728932 & 1537418 & 5.699 & 5.9625 & TST \\
\hline CHEMBL 3727646 & 1537418 & 6.4023 & 6.2106 & TRN \\
\hline CHEMBL 3733330 & 1537418 & 3.6021 & 3.7966 & TRN \\
\hline CHEMBL3728771 & 1537418 & 5.3904 & 4.5343 & TRN \\
\hline CHEMBL 3730777 & 1537418 & 5.3809 & 5.5617 & TRN \\
\hline CHEMBL3728119 & 1537418 & 7.1739 & 6.6802 & TRN \\
\hline CHEMBL3728166 & 1537418 & 6.2132 & \multicolumn{2}{|c|}{6.127000000000001} \\
\hline CHEMBL 3732842 & 1537418 & 6.3799 & \multicolumn{2}{|c|}{6.792000000000001} \\
\hline CHEMBL3731406 & 1537418 & 5.1057 & 5.2596 & TRN \\
\hline CHEMBL 3728857 & 1537418 & 6.3316 & 6.2151 & TRN \\
\hline CHEMBL3727795 & 1537418 & 6.8477 & 6.6161 & TRN \\
\hline
\end{tabular}


Supplemental Table S2.txt

\begin{tabular}{|c|c|c|c|c|c|c|}
\hline CHEMBL 3732601 & 1537418 & 6.3072 & 6.0546 & TRN & & \\
\hline CHEMBL 3727812 & 1537418 & 4.7932 & 4.6687 & TRN & & \\
\hline CHEMBL3727591 & 1537418 & 5.1421 & 5.4353 & TRN & & \\
\hline CHEMBL 3731311 & 1537418 & 5.7959 & 5.8255 & TRN & & \\
\hline CHEMBL3728506 & 1537418 & 5.8416 & 4.8783 & TRN & & \\
\hline CHEMBL3728174 & 1537418 & 6.1463 & 5.8223 & TST & & \\
\hline CHEMBL 3729807 & 1537418 & 5.7328 & 5.2804 & TST & & \\
\hline CHEMBL 3732885 & 1537418 & 7.1024 & 6.9624 & TRN & & \\
\hline CHEMBL 3728603 & 1537418 & 5.3696 & 4.6808 & TRN & & \\
\hline CHEMBL3728150 & 1537418 & 7.5229 & 7.7783 & TRN & & \\
\hline CHEMBL 3732223 & 1537418 & 5.9318 & 5.6785 & TST & & \\
\hline CHEMBL 3728508 & 1537418 & 6.857 & 6.5067 & TRN & & \\
\hline CHEMBL 3732978 & 1537418 & 7.284 & 7.5441 & TRN & & \\
\hline CHEMBL 3731544 & 1537418 & 5.3904 & 5.9361 & TST & & \\
\hline CHEMBL3729460 & 1537418 & 7.3872 & 7.3371 & TRN & & \\
\hline CHEMBL3731166 & 1537418 & 6.38399 & 79999999 & 995 & 6.385 & TRN \\
\hline CHEMBL3727668 & 1537418 & 6.1494 & 6.0824 & TST & & \\
\hline CHEMBL 3730081 & 1537418 & 5.6566 & 5.4812 & TRN & & \\
\hline CHEMBL3730629 & 1537418 & 5.2531 & 5.3583 & TRN & & \\
\hline CHEMBL3730658 & 1537418 & 6.9747 & 6.439 & TRN & & \\
\hline CHEMBL3729916 & 1537418 & 5.6882 & 5.3447 & TRN & & \\
\hline CHEMBL 3728633 & 1537418 & 5.9172 & 5.3402 & TRN & & \\
\hline CHEMBL 3730215 & 1537418 & 5.5324 & 5.171 & TST & & \\
\hline CHEMBL3729034 & 1537418 & 5.1967 & 5.5785 & TRN & & \\
\hline CHEMBL 3732081 & 1537418 & 6.1765 & 6.4961 & TRN & & \\
\hline CHEMBL3728536 & 1537418 & 5.1599 & 5.6355 & TRN & & \\
\hline CHEMBL3732371 & 1537418 & 6.0 & 5.8003 & TST & & \\
\hline CHEMBL 3728062 & 1537418 & \multicolumn{3}{|c|}{5.757000000000001} & 6.2135 & TST \\
\hline CHEMBL3731223 & 1537418 & \multicolumn{3}{|c|}{5.7620000000000005} & 5.6871 & TST \\
\hline CHEMBL 3733039 & 1537418 & 6.3401 & 4.7045 & TST & & \\
\hline CHEMBL 3733127 & 1537418 & 5.1524 & 4.9635 & TRN & & \\
\hline CHEMBL3731316 & 1537418 & 7.7959 & 7.8085 & TRN & & \\
\hline CHEMBL 3731172 & 1537418 & 6.2055 & 5.9319 & TST & & \\
\hline CHEMBL 3730024 & 1537418 & 6.1284 & 6.3853 & TST & & \\
\hline CHEMBL 3732281 & 1537418 & 7.041 & 5.8985 & TST & & \\
\hline CHEMBL 3730534 & 1537418 & 6.7773 & 5.9375 & TRN & & \\
\hline CHEMBL3731200 & 1537418 & 3.6021 & 4.5139 & TRN & & \\
\hline CHEMBL 3732539 & 1537418 & 7.5528 & 7.4134 & TRN & & \\
\hline CHEMBL 3731308 & 1537418 & 6.9788 & 6.879 & TRN & & \\
\hline CHEMBL 3729170 & 1537418 & 6.0 & 6.2546 & TRN & & \\
\hline CHEMBL3730819 & 1537418 & 6.4895 & 6.2053 & TRN & & \\
\hline CHEMBL3731384 & 1537418 & 3.6021 & 4.7336 & TST & & \\
\hline CHEMBL3732017 & 1537418 & 5.0367 & 5.081 & TRN & & \\
\hline CHEMBL3729966 & 1537418 & 5.9245 & 6.1821 & TRN & & \\
\hline CHEMBL 3728538 & 1537418 & 4.7878 & 4.9532 & TRN & & \\
\hline CHEMBL3730683 & 1537418 & 4.6696 & 4.4062 & TRN & & \\
\hline CHEMBL3730490 & 1537418 & 5.1057 & 5.079 & TRN & & \\
\hline CHEMBL3733253 & 1537418 & 7.0506 & 6.6437 & TRN & & \\
\hline
\end{tabular}

Page 11768 


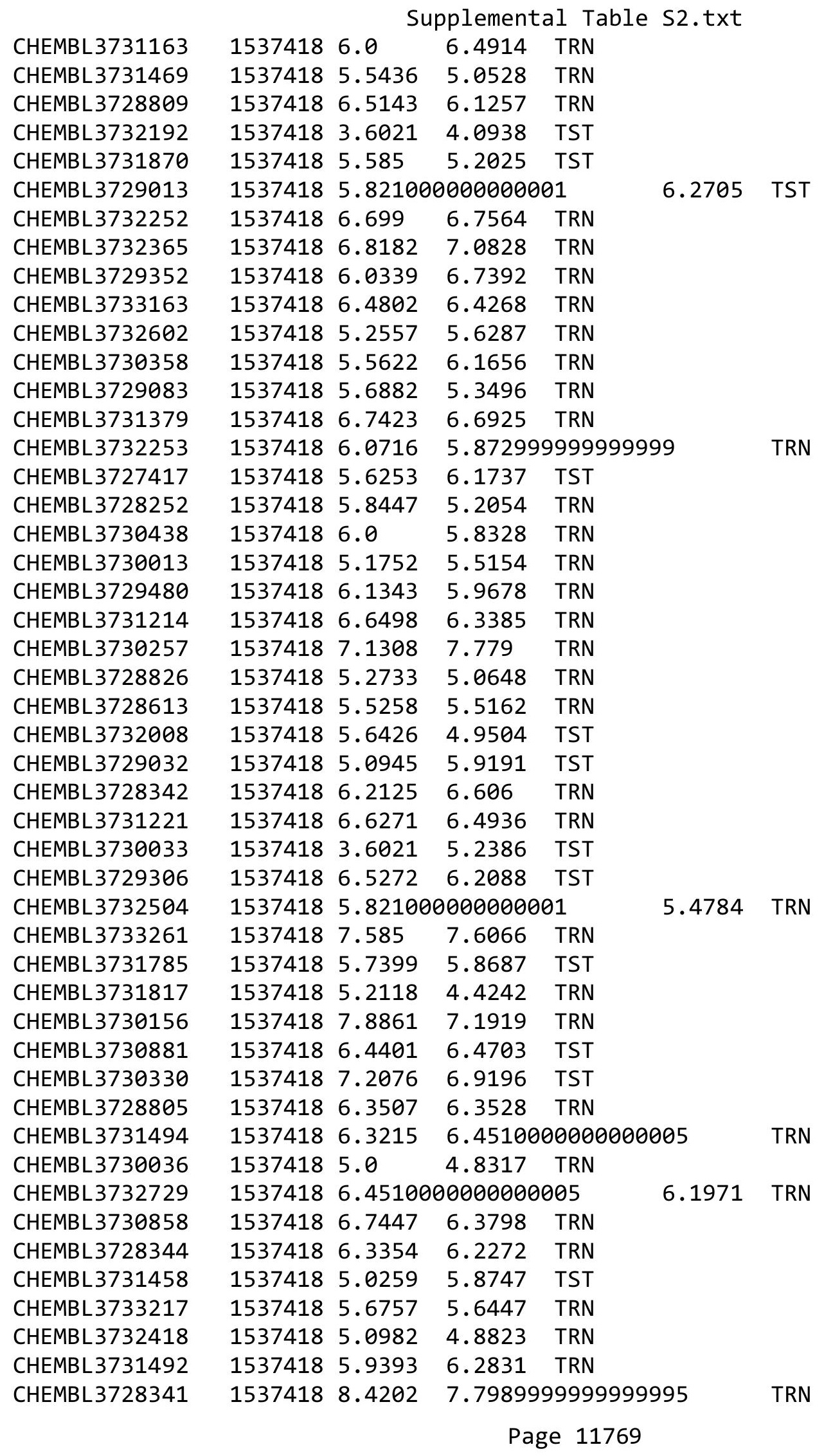


Supplemental Table S2.txt

\begin{tabular}{|c|c|c|c|c|c|}
\hline CHEMBL3728769 & 1537418 & 7.3372 & 7.3904 & TRN & \\
\hline CHEMBL3727408 & 1537418 & 6.0 & 6.3907 & TRN & \\
\hline CHEMBL3728812 & 1537418 & 6.0595 & 5.3071 & TRN & \\
\hline CHEMBL3732051 & 1537418 & 6.1605 & 6.3894 & TRN & \\
\hline CHEMBL3729130 & 1537418 & 6.5817 & 6.5374 & TRN & \\
\hline CHEMBL3727378 & 1537418 & 5.5784 & 5.6991 & TRN & \\
\hline CHEMBL3729246 & 1537418 & 6.4828 & 6.712999 & 9999999999 & TRN \\
\hline CHEMBL 3728370 & 1537418 & 5.9281 & 5.9398 & TRN & \\
\hline CHEMBL 3727620 & 1537418 & 5.9666 & 6.7186 & TRN & \\
\hline CHEMBL3727911 & 1537418 & 6.4559 & 6.2797 & TRN & \\
\hline CHEMBL3733076 & 1537418 & 4.8153 & 5.3632 & TRN & \\
\hline CHEMBL3731426 & 1537418 & 5.1013 & 5.4427 & TRN & \\
\hline CHEMBL3730502 & 1537418 & 5.7721 & 5.7684 & TRN & \\
\hline CHEMBL3733191 & 1537418 & 8.1805 & 7.5466 & TRN & \\
\hline CHEMBL3732895 & 1537418 & 5.8294 & 4.9129 & TRN & \\
\hline CHEMBL3728768 & 1537418 & 5.7399 & 6.0896 & TRN & \\
\hline CHEMBL3732416 & 1537418 & 5.2612 & 5.9921 & TRN & \\
\hline CHEMBL3730714 & 1537418 & 5.059 & 4.8962 & TST & \\
\hline CHEMBL 3728559 & 1537418 & 5.644 & 5.3887 & TRN & \\
\hline CHEMBL3732392 & 1537418 & 6.7986 & 6.5687 & TRN & \\
\hline CHEMBL3727847 & 1537418 & 6.0232 & 6.1493 & TRN & \\
\hline CHEMBL3732621 & 1537418 & 5.8996 & 5.6902 & TRN & \\
\hline CHEMBL3731893 & 1537418 & 5.6383 & 6.33 & TRN & \\
\hline CHEMBL 3729082 & 1537418 & 6.0 & 6.966 & TRN & \\
\hline CHEMBL3727532 & 1537418 & 6.4449 & 6.2472 & TRN & \\
\hline CHEMBL3729242 & 1537418 & 6.5129 & 6.6796 & TRN & \\
\hline CHEMBL3727736 & 1537418 & 6.8665 & 5.9302 & TST & \\
\hline CHEMBL3730804 & 1537418 & 5.8416 & 6.1801 & TRN & \\
\hline CHEMBL 3732583 & 1537418 & 5.6946 & 6.1361 & TST & \\
\hline CHEMBL3727461 & 1537418 & 5.7305 & 5.9834 & TRN & \\
\hline CHEMBL3731107 & 1537418 & 6.6383 & 6.5233 & TRN & \\
\hline CHEMBL3728965 & 1537418 & 6.3526 & 6.2978 & TRN & \\
\hline CHEMBL3733280 & 1537418 & 3.6021 & 5.3263 & TST & \\
\hline CHEMBL 3728947 & 1537418 & 5.1662 & 5.3912 & TRN & \\
\hline CHEMBL3730675 & 1537418 & 6.1688 & 5.7083 & TST & \\
\hline CHEMBL3733092 & 1537418 & 5.9666 & 5.7286 & TST & \\
\hline CHEMBL3729988 & 1537418 & 5.3089 & 5.657 & TRN & \\
\hline CHEMBL3728393 & 1537418 & 6.7545 & 6.8708 & TRN & \\
\hline CHEMBL 3730255 & 1537418 & 5.4498 & 5.1708 & TST & \\
\hline CHEMBL3730609 & 1537418 & 5.3358 & 5.0379 & TST & \\
\hline CHEMBL3731489 & 1537418 & 3.6021 & 4.563 & TRN & \\
\hline CHEMBL3732201 & 1537418 & 3.6021 & 4.5413 & TRN & \\
\hline CHEMBL3731264 & 1537418 & 6.08299 & 999999999 & 6.6601 & TRN \\
\hline CHEMBL 3730697 & 1537418 & 6.3261 & 6.3809 & TRN & \\
\hline CHEMBL 3733201 & 1537418 & 6.3536 & 5.8354 & TRN & \\
\hline CHEMBL3728830 & 1537418 & 7.8239 & 7.111000 & 3000000001 & $1 \mathrm{KI}$ \\
\hline CHEMBL3730856 & 1537418 & 3.6021 & 4.0384 & TRN & \\
\hline CHEMBL3730632 & 1537418 & 6.3645 & 6.3699 & TRN & \\
\hline
\end{tabular}

Page 11770 
Supplemental Table S2.txt

\begin{tabular}{|c|c|c|c|c|c|}
\hline CHEMBL3727914 & 1537418 & 5.4634 & 5.3844 & TRN & \\
\hline CHEMBL3729813 & 1537418 & 5.1037 & 5.1083 & TRN & \\
\hline CHEMBL3732799 & 1537418 & 6.4789 & \multicolumn{2}{|c|}{6.5520000000000005} & TRN \\
\hline CHEMBL 3729600 & 1537418 & 5.6968 & 5.1687 & TRN & \\
\hline CHEMBL 3732493 & 1537418 & 5.7077 & 5.3405 & TRN & \\
\hline CHEMBL 3728511 & 1537418 & 7.0 & 6.61 & TRN & \\
\hline CHEMBL3733084 & 1537418 & 6.2588 & 6.4012 & TST & \\
\hline CHEMBL 3732345 & 1537418 & 7.5686 & 7.2058 & TRN & \\
\hline CHEMBL 3729722 & 1537418 & 6.0 & 6.4864 & TRN & \\
\hline CHEMBL 3732087 & 1537418 & 6.5376 & 6.7241 & TRN & \\
\hline CHEMBL3729866 & 1537418 & 5.0809 & 5.113 & TRN & \\
\hline CHEMBL 3727801 & 1537418 & 5.8097 & 5.9052 & TRN & \\
\hline CHEMBL 3730217 & 1537418 & 7.2366 & 7.5193 & TRN & \\
\hline CHEMBL3729585 & 1537418 & 6.7545 & 6.4951 & TRN & \\
\hline CHEMBL 3732419 & 1537418 & 5.129 & 5.2295 & TRN & \\
\hline CHEMBL 3727690 & 1537418 & 3.6021 & 4.6567 & TRN & \\
\hline CHEMBL3729706 & 1537418 & 6.2757 & 6.1932 & TRN & \\
\hline CHEMBL3730664 & 1537418 & 6.0 & 5.9196 & TST & \\
\hline CHEMBL 3729342 & 1537418 & 7.3565 & 6.9168 & TRN & \\
\hline CHEMBL 3728546 & 1537418 & 5.5591 & 5.6869 & TST & \\
\hline CHEMBL 3728025 & 1537418 & 6.4449 & 6.8533 & TRN & \\
\hline CHEMBL3728238 & 1537418 & 6.8268 & 6.5131 & TRN & \\
\hline CHEMBL3728451 & 1537418 & 5.7799 & 5.4247 & TRN & \\
\hline CHEMBL 3727697 & 1537418 & 7.2441 & 6.4326 & TST & \\
\hline CHEMBL 3729487 & 1537418 & 5.2798 & 5.5665 & TST & \\
\hline CHEMBL3729111 & 1537418 & 6.4815 & 6.1804 & TRN & \\
\hline CHEMBL3728499 & 1537418 & 6.1798 & 4.92899 & 9999999999 & TRN \\
\hline CHEMBL3733012 & 1537418 & 5.6968 & 5.7387 & TRN & \\
\hline CHEMBL3729765 & 1537418 & 3.6021 & 4.1147 & TST & \\
\hline CHEMBL 3727442 & 1537418 & 4.9393 & 4.7771 & TRN & \\
\hline CHEMBL3729697 & 1537418 & 6.2941 & 6.1613 & TRN & \\
\hline CHEMBL 3728843 & 1537418 & 6.4461 & 6.2354 & TRN & \\
\hline CHEMBL3730690 & 1537418 & 6.6696 & 6.6881 & TRN & \\
\hline CHEMBL 3729198 & 1537418 & 5.3363 & 5.4877 & TRN & \\
\hline CHEMBL 3727601 & 1537418 & 5.8861 & 6.4714 & TRN & \\
\hline CHEMBL3730197 & 1537418 & 5.7721 & 6.3415 & TST & \\
\hline CHEMBL3731259 & 1537418 & 6.4698 & 6.5637 & TRN & \\
\hline CHEMBL 3728604 & 1537418 & 3.8385 & 4.4251 & TRN & \\
\hline CHEMBL 3733207 & 1537418 & 6.6904 & 6.8378 & TRN & \\
\hline CHEMBL3730919 & 1537418 & 7.7447 & 7.4396 & TRN & \\
\hline CHEMBL 3728852 & 1537418 & 5.2083 & 4.934 & TRN & \\
\hline CHEMBL 3727613 & 1537418 & 6.0 & 5.8427 & TRN & \\
\hline CHEMBL3733305 & 1537418 & 6.7167 & 6.5751 & TRN & \\
\hline CHEMBL 3729615 & 1537418 & 5.1813 & 5.5895 & TST & \\
\hline CHEMBL 3730133 & 1537418 & 6.0 & 5.6536 & TRN & \\
\hline CHEMBL3731167 & 1537418 & 5.1244 & 5.6558 & TRN & \\
\hline CHEMBL 3729434 & 1537418 & 6.699 & 7.1819 & TRN & \\
\hline CHEMBL3728722 & 1537418 & 6.1911 & 6.2536 & TRN & \\
\hline
\end{tabular}

Page 11771 
Supplemental Table S2.txt

\begin{tabular}{|c|c|c|c|c|c|c|}
\hline CHEMBL3730950 & 1537418 & 6.6904 & 7.0741 & TRN & & \\
\hline CHEMBL3729231 & 1537418 & 5.327006 & 00000000 & & 5.188 & TRN \\
\hline CHEMBL3729817 & 1537418 & 6.0783 & 6.1955 & TRN & & \\
\hline CHEMBL3727453 & 1537418 & 5.9318 & 5.1825 & TRN & & \\
\hline CHEMBL3729752 & 1537418 & 5.6055 & 5.3993 & TRN & & \\
\hline CHEMBL3730506 & 1537418 & 6.3354 & 6.1238 & TRN & & \\
\hline CHEMBL3731244 & 1537418 & 6.6596 & 6.584 & TRN & & \\
\hline CHEMBL3728562 & 1537418 & 5.0841 & 5.2706 & TST & & \\
\hline CHEMBL 3728573 & 1537418 & 5.1163 & 5.7717 & TRN & & \\
\hline CHEMBL3733198 & 1537418 & 6.5918 & 6.8137 & TRN & & \\
\hline CHEMBL3731705 & 1537418 & 5.2137 & 4.8172 & TST & & \\
\hline CHEMBL3731595 & 1537418 & 6.567 & 6.0657 & TRN & & \\
\hline CHEMBL3732146 & 1537418 & 6.9586 & 6.8806 & TRN & & \\
\hline CHEMBL3731133 & 1537418 & 3.6021 & 4.2226 & TRN & & \\
\hline CHEMBL3728781 & 1537418 & 7.1427 & 7.4832 & TRN & & \\
\hline CHEMBL3727715 & 1537418 & $5.75200 t$ & & 6.4147 & TRN \\
\hline CHEMBL3728125 & 1537418 & 7.1871 & \multicolumn{3}{|c|}{6.7589999999999995} & TRN \\
\hline CHEMBL3729806 & 1537418 & 5.3507 & 5.2972 & TRN & & \\
\hline CHEMBL3728389 & 1537418 & 5.5735 & 5.9208 & TST & & \\
\hline CHEMBL3729495 & 1537418 & 6.38299 & 99999999 & 99 & 6.2788 & TRN \\
\hline CHEMBL3732403 & 1537418 & 6.5287 & 7.0191 & TRN & & \\
\hline CHEMBL3730082 & 1537418 & 6.857 & 6.9149 & TRN & & \\
\hline CHEMBL3731370 & 1537418 & 6.2396 & \multicolumn{3}{|c|}{5.332000000000001} & \\
\hline CHEMBL 3730283 & 1537418 & 5.082 & 4.9824 & TST & & \\
\hline CHEMBL3732432 & 1537418 & 6.3429 & 6.4846 & TRN & & \\
\hline CHEMBL3732195 & 1537418 & 6.5243 & 6.3443 & TRN & & \\
\hline CHEMBL3731822 & 1537418 & 7.5686 & 7.3831 & TRN & & \\
\hline CHEMBL3727924 & 1537418 & 3.8502 & 5.52 & TST & & \\
\hline CHEMBL 3729427 & 1537418 & 6.4449 & 5.9201 & TRN & & \\
\hline CHEMBL3730960 & 1537418 & 5.8111 & 5.7393 & TRN & & \\
\hline CHEMBL3730618 & 1537418 & 6.4584 & 6.4141 & TRN & & \\
\hline CHEMBL3731671 & 1537418 & 7.8239 & 7.3745 & TRN & & \\
\hline CHEMBL3728007 & 1537418 & 5.0588 & 5.6913 & TST & & \\
\hline CHEMBL3729485 & 1537418 & 6.6778 & 6.4603 & TRN & & \\
\hline CHEMBL3729885 & 1537418 & 6.0315 & 6.7034 & TRN & & \\
\hline CHEMBL3732049 & 1537418 & 6.4377 & 6.3346 & TRN & & \\
\hline CHEMBL3732086 & 1537418 & 3.6021 & 4.4569 & TRN & & \\
\hline CHEMBL3732650 & 1537418 & 5.0506 & 6.2365 & TST & & \\
\hline CHEMBL3728716 & 1537418 & 6.7055 & 6.4737 & TRN & & \\
\hline CHEMBL3729805 & 1537418 & 7.2147 & 7.1108 & TRN & & \\
\hline CHEMBL3731297 & 1537418 & 6.3925 & 6.6409 & TRN & & \\
\hline CHEMBL3732566 & 1537418 & 7.1487 & 7.056 & TRN & & \\
\hline CHEMBL3729543 & 1537418 & 4.7399 & 4.6875 & TRN & & \\
\hline CHEMBL3733287 & 1537418 & 7.1249 & 7.006 & TRN & & \\
\hline CHEMBL3732090 & 1537418 & 5.3215 & 5.7513 & TRN & & \\
\hline CHEMBL3729189 & 1537418 & 6.3197 & 6.2121 & TRN & & \\
\hline CHEMBL3728739 & 1537418 & 6.4711 & 5.8368 & TRN & & \\
\hline CHEMBL3730596 & 1537418 & 5.7167 & 5.9426 & TRN & & \\
\hline
\end{tabular}

Page 11772 
Supplemental Table S2.txt

\begin{tabular}{|c|c|c|c|c|c|}
\hline CHEMBL3731396 & 1537418 & 5.8508 & 5.1362 & TRN & \\
\hline CHEMBL3728870 & 1537418 & 6.0186 & 6.4578 & TST & \\
\hline CHEMBL3732803 & 1537418 & 5.4841 & 5.8637 & TST & \\
\hline CHEMBL3729642 & 1537418 & 6.0773 & 6.3923 & TST & \\
\hline CHEMBL3731186 & 1537418 & 6.6459 & 6.2904 & TST & \\
\hline CHEMBL3732225 & 1537418 & 5.4283 & 5.6489 & TST & \\
\hline CHEMBL3730451 & 1537418 & 6.2534 & 6.6871 & TST & \\
\hline CHEMBL3728644 & 1537418 & 6.3737 & 6.2794 & TST & \\
\hline CHEMBL3728883 & 1537418 & 5.6078 & 5.2273 & TST & \\
\hline CHEMBL3731739 & 1537418 & 5.8297 & 6.1568 & TST & \\
\hline CHEMBL3729977 & 1537418 & 5.0348 & 4.8944 & TST & \\
\hline CHEMBL3728133 & 1537418 & 6.6253 & 6.5173 & TST & \\
\hline CHEMBL3729500 & 1537418 & 5.3565 & 5.3811 & TST & \\
\hline CHEMBL3729199 & 1537418 & 6.8239 & 6.5451 & TST & \\
\hline CHEMBL487810 & 490576 & 7.553 & 7.3808 & TRN & \\
\hline CHEMBL484663 & 490576 & 5.28 & 6.9551 & TST & \\
\hline CHEMBL6492 & 490576 & 5.64 & 6.41700 & 0000000001 & TST \\
\hline CHEMBL475908 & 490576 & 5.78 & 7.0384 & TST & \\
\hline CHEMBL517676 & 490576 & 3.0 & 5.2655 & TST & \\
\hline CHEMBL181896 & 490576 & 3.0 & 5.1985 & TST & \\
\hline CHEMBL477574 & 490576 & 3.5 & 5.1553 & TST & \\
\hline CHEMBL452974 & 490576 & 3.54 & 4.276 & TRN & \\
\hline CHEMBL478416 & 490576 & 3.96 & 4.6114 & TRN & \\
\hline CHEMBL74272 & 490576 & 4.34 & 4.6304 & TRN & \\
\hline CHEMBL504325 & 490576 & 4.53 & 4.5717 & TRN & \\
\hline CHEMBL477358 & 490576 & 4.68 & 4.6968 & TRN & \\
\hline CHEMBL225703 & 490576 & 4.73 & 5.113 & TRN & \\
\hline CHEMBL477357 & 490576 & 4.74 & 4.6936 & TRN & \\
\hline CHEMBL514558 & 490576 & 4.79 & 4.7971 & TRN & \\
\hline CHEMBL476097 & 490576 & 4.88 & 4.6113 & TRN & \\
\hline CHEMBL514993 & 490576 & 5.086 & 5.3141 & TRN & \\
\hline CHEMBL476096 & 490576 & 5.05 & 4.9624 & TRN & \\
\hline CHEMBL477981 & 490576 & \multicolumn{3}{|c|}{5.0760000000000005} & TRN \\
\hline CHEMBL477980 & 490576 & 5.09 & 4.9863 & TRN & \\
\hline CHEMBL312073 & 490576 & 5.14 & 4.9645 & TRN & \\
\hline CHEMBL487213 & 490576 & 5.17 & 5.2365 & TRN & \\
\hline CHEMBL477767 & 490576 & 5.2 & 4.8833 & TRN & \\
\hline CHEMBL479233 & 490576 & 5.35 & 5.2888 & TRN & \\
\hline CHEMBL82242 & 490576 & 5.933 & 6.8716 & TST & \\
\hline CHEMBL348436 & 490576 & 5.85 & 6.1137 & TRN & \\
\hline CHEMBL447936 & 490576 & 5.92 & 5.3202 & TRN & \\
\hline CHEMBL516438 & 490576 & 5.92 & 6.6047 & TRN & \\
\hline CHEMBL478426 & 490576 & 6.07 & 5.9654 & TRN & \\
\hline CHEMBL485677 & 490576 & 6.09 & 6.4069 & TRN & \\
\hline CHEMBL476121 & 490576 & 6.27 & 5.9783 & TRN & \\
\hline CHEMBL476120 & 490576 & 6.39 & 6.5905 & TRN & \\
\hline CHEMBL491366 & 490576 & \multicolumn{2}{|c|}{6.457999999999999} & 6.6618 & TRN \\
\hline CHEMBL477803 & 490576 & 6.52 & 6.5446 & TRN & \\
\hline
\end{tabular}




\begin{tabular}{|c|c|c|c|c|c|c|}
\hline & & \multicolumn{5}{|c|}{ Supplemental Table S2.txt } \\
\hline CHEMBL476314 & 490576 & 6.52 & 6.3337 & TRN & & \\
\hline CHEMBL476940 & 490576 & 6.52 & 4.275 & TST & & \\
\hline CHEMBL476731 & 490576 & 6.55 & 6.7526 & TRN & & \\
\hline CHEMBL476730 & 490576 & 6.55 & 6.8394 & TRN & & \\
\hline CHEMBL477562 & 490576 & 6.57 & 6.5922 & TRN & & \\
\hline CHEMBL507644 & 490576 & 6.6 & 6.3037 & TRN & & \\
\hline CHEMBL162550 & 490576 & 6.62 & 6.4687 & TRN & & \\
\hline CHEMBL449222 & 490576 & 6.64 & 6.6254 & TRN & & \\
\hline CHEMBL72637 & 490576 & 6.77 & 6.7879 & TRN & & \\
\hline CHEMBL464107 & 490576 & 6.69 & 6.4318 & TRN & & \\
\hline CHEMBL476364 & 490576 & 6.77 & 6.7011 & TRN & & \\
\hline CHEMBL479078 & 490576 & 6.79 & 6.643 & TRN & & \\
\hline CHEMBL479077 & 490576 & 6.796 & \multicolumn{3}{|c|}{6.5760000000000005} & TRN \\
\hline CHEMBL478875 & 490576 & 6.85 & 6.9726 & TRN & & \\
\hline CHEMBL478874 & 490576 & 6.92 & 7.0697 & TRN & & \\
\hline CHEMBL73016 & 490576 & 7.04 & 7.024 & TRN & & \\
\hline CHEMBL 76188 & 490576 & 7.11 & 6.7687 & TRN & & \\
\hline CHEMBL478441 & 490576 & 7.13 & 6.9294 & TRN & & \\
\hline CHEMBL478440 & 490576 & 7.19 & 6.391 & TST & & \\
\hline CHEMBL478439 & 490576 & 7.24 & 6.5768 & TST & & \\
\hline CHEMBL72807 & 490576 & 7.35 & 6.8341 & TST & & \\
\hline CHEMBL312790 & 490576 & 7.41 & 6.4069 & TST & & \\
\hline CHEMBL476553 & 490576 & 7.47 & 6.3992 & TST & & \\
\hline CHEMBL476554 & 490576 & 7.456 & 6.6711 & TST & & \\
\hline CHEMBL438292 & 490576 & 7.49 & 6.9671 & TST & & \\
\hline CHEMBL 203970 & 334961 & 8.0969 & 7.5563 & TRN & & \\
\hline CHEMBL204975 & 334961 & 7.7212 & 7.7295 & TRN & & \\
\hline CHEMBL203987 & 334961 & 6.6289 & 7.1124 & TRN & & \\
\hline CHEMBL 205060 & 334961 & 5.9158 & 5.7494 & TRN & & \\
\hline CHEMBL382428 & 334961 & 7.8861 & 7.2779 & TST & & \\
\hline CHEMBL425938 & 334961 & 6.2125 & 6.2934 & TRN & & \\
\hline CHEMBL 205180 & 334961 & 6.9431 & 6.3444 & TST & & \\
\hline CHEMBL381401 & 334961 & 6.7077 & 7.5825 & TRN & & \\
\hline CHEMBL204746 & 334961 & 7.8539 & 7.5062 & TRN & & \\
\hline CHEMBL203502 & 334961 & 6.4776 & 7.0167 & TST & & \\
\hline CHEMBL204712 & 334961 & 8.1549 & 6.6232 & TST & & \\
\hline CHEMBL380976 & 334961 & 8.301 & 8.2959 & TRN & & \\
\hline CHEMBL 378818 & 334961 & \multicolumn{3}{|c|}{5.997000000000001} & 6.1719 & TST \\
\hline CHEMBL 380115 & 334961 & 6.8962 & 7.2327 & TRN & & \\
\hline CHEMBL382678 & 334961 & 6.301 & 5.9036 & TRN & & \\
\hline CHEMBL381811 & 334961 & 8.1549 & 8.3727 & TRN & & \\
\hline CHEMBL205066 & 334961 & 6.3979 & 6.7382 & TRN & & \\
\hline CHEMBL382152 & 334961 & 8.2218 & 8.0421 & TRN & & \\
\hline CHEMBL381586 & 334961 & 7.8539 & 7.1988 & TST & & \\
\hline CHEMBL203587 & 334961 & 7.9586 & 7.3732 & TRN & & \\
\hline CHEMBL204076 & 334961 & 7.9586 & 8.0315 & TRN & & \\
\hline CHEMBL439163 & 334961 & 7.284 & 7.4397 & TRN & & \\
\hline CHEMBL203806 & 334961 & 8.0969 & 7.9803 & TRN & & \\
\hline
\end{tabular}

Page 11774 
Supplemental Table S2.txt

\begin{tabular}{|c|c|c|c|c|c|}
\hline CHEMBL437131 & 334961 & 6.8097 & 6.059 & TST & \\
\hline CHEMBL382176 & 334961 & 6.7352 & 6.9639 & TRN & \\
\hline CHEMBL203794 & 334961 & 7.8239 & 7.5788 & TRN & \\
\hline CHEMBL381348 & 334961 & 7.3188 & 7.0375 & TRN & \\
\hline CHEMBL437887 & 334961 & 7.2007 & 7.1145 & TST & \\
\hline CHEMBL263830 & 334961 & 7.2924 & 8.0017 & TRN & \\
\hline CHEMBL205006 & 334961 & 7.8239 & 7.2811 & TRN & \\
\hline CHEMBL437513 & 334961 & 7.8539 & 7.5498 & TRN & \\
\hline CHEMBL427204 & 334961 & 6.7878 & 7.3097 & TRN & \\
\hline CHEMBL203915 & 334961 & 7.2441 & 7.3932 & TRN & \\
\hline CHEMBL204482 & 334961 & 5.7786 & 6.7332 & TST & \\
\hline CHEMBL203717 & 334961 & 7.6383 & 7.8982 & TRN & \\
\hline CHEMBL203656 & 334961 & 5.7144 & 6.0938 & TRN & \\
\hline CHEMBL205067 & 334961 & 6.5346 & 6.6614 & TRN & \\
\hline CHEMBL204876 & 334961 & 7.8861 & 7.2986 & TRN & \\
\hline CHEMBL204435 & 334961 & 5.9223 & 6.6623 & TST & \\
\hline CHEMBL204089 & 334961 & 7.1249 & 7.1299 & TRN & \\
\hline CHEMBL380913 & 334961 & 7.3098 & 7.3764 & TRN & \\
\hline CHEMBL204444 & 334961 & 7.6778 & 8.3888 & TST & \\
\hline CHEMBL440763 & 334961 & 7.2076 & 6.8788 & TST & \\
\hline CHEMBL381332 & 334961 & 7.5686 & 7.8015 & TRN & \\
\hline CHEMBL204971 & 334961 & 7.4202 & 7.0599 & TRN & \\
\hline CHEMBL380736 & 334961 & 8.0969 & 7.6832 & TRN & \\
\hline CHEMBL383047 & 334961 & 7.4685 & 7.522 & TRN & \\
\hline CHEMBL 383330 & 334961 & 8.5229 & 8.302999 & 7999999999 & TRN \\
\hline CHEMBL202834 & 334961 & 6.1831 & 7.4255 & TRN & \\
\hline CHEMBL379454 & 334961 & 7.8239 & 7.4925 & TRN & \\
\hline CHEMBL381762 & 334961 & 6.2269 & 6.477 & TST & \\
\hline CHEMBL380930 & 334961 & 5.0738 & 5.1014 & TRN & \\
\hline CHEMBL 381880 & 334961 & 8.3979 & 7.6832 & TRN & \\
\hline CHEMBL381152 & 334961 & 7.8239 & 7.8945 & TRN & \\
\hline CHEMBL382205 & 334961 & 7.9586 & 7.8796 & TRN & \\
\hline CHEMBL203966 & 334961 & 8.0 & 7.775 & TRN & \\
\hline CHEMBL383023 & 334961 & 6.4342 & 6.7052 & TST & \\
\hline CHEMBL 383003 & 334961 & 7.1249 & 7.6606 & TST & \\
\hline CHEMBL3121054 & 1292759 & 8.3188 & 8.3485 & TRN & \\
\hline CHEMBL3121168 & 1292759 & 6.75200 & 000000000 & 7.2902 & TRN \\
\hline CHEMBL3120175 & 1292759 & 8.6576 & 8.6686 & TRN & \\
\hline CHEMBL3120932 & 1292759 & 8.6576 & 8.9614 & TRN & \\
\hline CHEMBL3121046 & 1292759 & 8.3768 & 8.4031 & TRN & \\
\hline CHEMBL 3121181 & 1292759 & 6.7305 & 7.6002 & TST & \\
\hline CHEMBL3121185 & 1292759 & 8.6198 & 8.8256 & TRN & \\
\hline CHEMBL3120947 & 1292759 & 9.0 & 8.9633 & TRN & \\
\hline CHEMBL3121061 & 1292759 & 7.9586 & 8.5572 & TRN & \\
\hline CHEMBL3120920 & 1292759 & 9.0 & 8.9087 & TRN & \\
\hline CHEMBL3120915 & 1292759 & 7.9208 & 8.306000 & 0000000001 & TST \\
\hline CHEMBL3121178 & 1292759 & 4.8275 & 7.5863 & TST & \\
\hline CHEMBL3120916 & 1292759 & 8.5229 & 8.4887 & TST & \\
\hline
\end{tabular}


Supplemental Table S2.txt

\begin{tabular}{|c|c|c|c|c|c|}
\hline CHEMBL 3121052 & 1292759 & 8.7447 & 8.8908 & TRN & \\
\hline CHEMBL 3121055 & 1292759 & 7.4318 & 8.2691 & TRN & \\
\hline CHEMBL 3121170 & 1292759 & 5.4634 & 7.7476 & TST & \\
\hline CHEMBL 3121050 & 1292759 & 8.699 & 8.7015 & TRN & \\
\hline CHEMBL3121189 & 1292759 & 9.0 & 8.9614 & TRN & \\
\hline CHEMBL 3121047 & 1292759 & 8.6198 & 8.4397 & TRN & \\
\hline CHEMBL 3120939 & 1292759 & 8.9208 & 9.0807 & TRN & \\
\hline CHEMBL 3120907 & 1292759 & 8.8539 & 8.6467 & TST & \\
\hline CHEMBL 3121182 & 1292759 & 9.0 & 8.8119 & TRN & \\
\hline CHEMBL 3120921 & 1292759 & 8.8239 & \multicolumn{2}{|c|}{8.847000000000001} & TRN \\
\hline CHEMBL 3120933 & 1292759 & 8.8239 & 8.8516 & TRN & \\
\hline CHEMBL 3121171 & 1292759 & 6.0783 & 7.7498 & TST & \\
\hline CHEMBL 3121070 & 1292759 & 8.699 & 8.5068 & TRN & \\
\hline CHEMBL 3121041 & 1292759 & 9.301 & 8.5349 & TRN & \\
\hline CHEMBL 3120942 & 1292759 & 7.1549 & 8.2843 & TRN & \\
\hline CHEMBL 3121186 & 1292759 & 8.699 & 8.7394 & TRN & \\
\hline CHEMBL 3120936 & 1292759 & 8.7447 & 8.9039 & TRN & \\
\hline CHEMBL 3120909 & 1292759 & 8.4559 & 8.6363 & TST & \\
\hline CHEMBL 3120937 & 1292759 & 8.9208 & 8.9344 & TRN & \\
\hline CHEMBL 3120925 & 1292759 & 8.1549 & 8.6516 & TRN & \\
\hline CHEMBL 3121177 & 1292759 & 5.3679 & 7.5863 & TST & \\
\hline CHEMBL 3121179 & 1292759 & 6.1337 & 7.6368 & TST & \\
\hline CHEMBL 3121058 & 1292759 & 8.5229 & 8.4237 & TRN & \\
\hline CHEMBL 3121082 & 1292759 & 8.0 & 7.5265 & TRN & \\
\hline CHEMBL 3121043 & 1292759 & 8.5229 & 8.7238 & TRN & \\
\hline CHEMBL 3120913 & 1292759 & 7.1249 & 8.3244 & TST & \\
\hline CHEMBL 3120935 & 1292759 & 9.1549 & 9.0002 & TRN & \\
\hline CHEMBL 3121053 & 1292759 & 8.1805 & 8.3549 & TRN & \\
\hline CHEMBL 3121035 & 1292759 & 8.6198 & 8.7497 & TRN & \\
\hline CHEMBL 3121062 & 1292759 & 8.5229 & 8.8332 & TRN & \\
\hline CHEMBL 3121079 & 1292759 & 8.9208 & 8.8204 & TRN & \\
\hline CHEMBL 3120924 & 1292759 & 8.7447 & 8.8179 & TRN & \\
\hline CHEMBL 3121064 & 1292759 & 8.9208 & 8.8792 & TRN & \\
\hline CHEMBL 3121076 & 1292759 & 8.9586 & 8.9291 & TRN & \\
\hline CHEMBL 3121039 & 1292759 & 8.3372 & 8.3792 & TRN & \\
\hline CHEMBL 3121183 & 1292759 & 9.0969 & 8.8748 & TRN & \\
\hline CHEMBL 3121084 & 1292759 & 6.9586 & 7.0371 & TRN & \\
\hline CHEMBL 3121044 & 1292759 & 8.7959 & 8.5292 & TRN & \\
\hline CHEMBL 3121172 & 1292759 & 5.5599 & 7.5872 & TST & \\
\hline CHEMBL 3120927 & 1292759 & 8.8861 & 8.9069 & TRN & \\
\hline CHEMBL 3120941 & 1292759 & 7.7696 & 8.3305 & TRN & \\
\hline CHEMBL 3120174 & 1292759 & 7.4202 & 7.2253 & TRN & \\
\hline CHEMBL 3120919 & 1292759 & 9.1549 & 9.0737 & TRN & \\
\hline CHEMBL 3121190 & 1292759 & 6.699 & 7.5506 & TST & \\
\hline CHEMBL 3121180 & 1292759 & 6.699 & 7.5958 & TST & \\
\hline CHEMBL 3121051 & 1292759 & 8.3665 & 8.5685 & TRN & \\
\hline CHEMBL 3121187 & 1292759 & 8.585 & 8.3569 & TRN & \\
\hline CHEMBL 3120910 & 1292759 & 8.28399 & 79999999 & 8.3854 & ST \\
\hline
\end{tabular}


Supplemental Table S2.txt

\begin{tabular}{|c|c|c|}
\hline HEMBL3121069 & 1292759 & \\
\hline HEMBL 3121085 & 1292759 & \\
\hline AEMBL3121042 & 1292759 & \\
\hline HEMBL3121167 & 1292759 & \\
\hline HEMBL3121075 & 1292759 & \\
\hline CHEMBL3120943 & L292759 & \\
\hline HEMBL3121074 & 1292759 & 9 \\
\hline AEMBL3121081 & 1292759 & \\
\hline HEMBL3121175 & 1292759 & \\
\hline HEMBL3121169 & 1292759 & \\
\hline HEMBL3121083 & 1292759 & 6.71 \\
\hline HEMBL3121038 & 1292759 & \\
\hline CHEMBL3121184 & 1292 & \\
\hline CHEMBL3120917 & 1292759 & 7.69 \\
\hline HEMBL3120923 & 1292759 & \\
\hline CHEMBL3121073 & 1292 & \\
\hline HEMBL3121174 & 1292 & 4 . \\
\hline CHEMBL3121080 & 1292 & \\
\hline AEMBL3121057 & 1292 & \\
\hline HEMBL3120938 & 1292 & \\
\hline HEMBL3120946 & 1292 & \\
\hline HEMBL3121037 & 1292 & \\
\hline CHEMBL3120929 & 129 & \\
\hline HEMBL3120948 & 1292 & \\
\hline CHEMBL3121059 & 129 & \\
\hline CHEMBL3121071 & 1292 & \\
\hline CHEMBL31 & 1292 & \\
\hline CHEMBL 3120944 & 1292 & \\
\hline CHEMBL3121034 & 1292 & \\
\hline CHEMBL3121078 & 1292 & \\
\hline CHEMBL3121040 & 1292 & 9.3 \\
\hline CHEMBL3] & 1292 & \\
\hline CHEMBL 31 & 1292 & \\
\hline CHEMBL3120922 & 1292 & 9.36 \\
\hline CHEMBL3120934 & 1292 & \\
\hline CHEMBL3120914 & 129 & \\
\hline CHEMBL 31 & 1292 & \\
\hline CHEMBL3121068 & 1292 & \\
\hline CHEMBL3121036 & 1292759 & 9 \\
\hline CHEMBL3121191 & 1292759 & 6 . \\
\hline CHEMBL3121060 & 1292 & \\
\hline CHEMBL3121049 & 1292759 & \\
\hline CHEMBL3120928 & 1292759 & 0 \\
\hline CHEMBL3120945 & 1292759 & 70 \\
\hline CHEMBL3121166 & 1292759 & \\
\hline CHEMBL3121067 & 1292759 & \\
\hline CHEMBL3120940 & 1292759 & \\
\hline CHEMBL3121173 & 129275 & \\
\hline
\end{tabular}

8.5405 TRN

6.9198 TRN

8.6206 TRN

8.7724 TRN

8.8327 TRN

8.2372 TRN

8.4485 TRN

7.3903 TRN

7.7387 TST

8.699 TRN

6.8619 TRN

8.4771 TRN

8.9029 TRN

8.905 TST

8.6108 TRN

8.6889 TRN

7.7662 TST

7.2571 TRN

8.4137 TRN

8.8731 TRN

8.1021 TRN

8.3734 TRN

8.577 TRN

8.9826 TRN

8.4838 TRN

8.6109 TRN

8.4397 TRN

8.2088 TRN

8.7208 TST

8.8933 TRN

8.4036 TRN

8.8459 TRN

8.275 TRN

8.8896 TRN

9.0002 TRN

8.2608 TST

8.8177 TRN

8.515 TRN

8.9132 TRN

7.6283 TST

8.5011 TRN

8.5857 TRN

8.5107 TRN

8.1997 TRN

7.2236 TRN

8.312999999999999 TRN

8.2359 TRN

7.7125 TST

Page 11777 
Supplemental Table S2.txt

\begin{tabular}{|c|c|c|c|c|}
\hline CHEMBL3121176 & 1292759 & 5.2596 & 7.7692 & TST \\
\hline CHEMBL 3120904 & 1292759 & 6.3279 & 8.3725 & TST \\
\hline CHEMBL 3120908 & 1292759 & 8.8539 & 8.6928 & TST \\
\hline CHEMBL 2311191 & 1292759 & 9.0 & 8.9743 & TRN \\
\hline CHEMBL 3121045 & 1292759 & 8.6021 & 8.4287 & TRN \\
\hline CHEMBL 3120906 & 1292759 & 7.6778 & 8.4253 & TST \\
\hline CHEMBL3120918 & 1292759 & 8.5229 & 8.8475 & TST \\
\hline CHEMBL3120912 & 1292759 & 3.301 & 7.1316 & TST \\
\hline CHEMBL 3121188 & 1292759 & 8.3872 & 8.4739 & TRN \\
\hline CHEMBL 3120926 & 1292759 & 9.0969 & 9.0273 & TRN \\
\hline CHEMBL 3120911 & 1292759 & 8.1938 & 8.5417 & TST \\
\hline CHEMBL 3121077 & 1292759 & 8.6778 & 8.7449 & TRN \\
\hline CHEMBL 3121066 & 1292759 & 8.5229 & 8.7058 & TRN \\
\hline CHEMBL 3121065 & 1292759 & 9.699 & 8.9309 & TST \\
\hline CHEMBL 3120905 & 1292759 & 8.0862 & 8.5562 & TST \\
\hline CHEMBL250106 & 456311 & 5.8386 & 5.8974 & TRN \\
\hline CHEMBL 249481 & 456311 & 6.8861 & 6.7269 & TRN \\
\hline CHEMBL 249721 & 456311 & 5.9318 & 6.016 & TRN \\
\hline CHEMBL 249103 & 456311 & 5.5528 & 5.5604 & TRN \\
\hline CHEMBL 251724 & 456311 & 5.9957 & 6.1 & TRN \\
\hline CHEMBL437586 & 456311 & 6.1871 & 6.2083 & TRN \\
\hline CHEMBL 249720 & 456311 & 5.7011 & 5.5813 & TRN \\
\hline CHEMBL 249681 & 456311 & 5.9666 & 6.0838 & TRN \\
\hline CHEMBL398513 & 456311 & 5.9066 & 5.9433 & TRN \\
\hline CHEMBL 249886 & 456311 & 5.8996 & 5.7835 & TRN \\
\hline CHEMBL 249480 & 456311 & 6.0862 & 6.2929 & TRN \\
\hline CHEMBL428754 & 456311 & 6.2924 & 6.2052 & TRN \\
\hline CHEMBL399486 & 456311 & 6.1675 & 6.2957 & TRN \\
\hline CHEMBL398514 & 456311 & 5.5331 & 5.599 & TRN \\
\hline CHEMBL 399368 & 456311 & 6.4815 & 6.4279 & TRN \\
\hline CHEMBL398512 & 456311 & 5.4134 & 5.3933 & TRN \\
\hline CHEMBL 249280 & 456311 & 6.7696 & 6.75799 & 9999999999 \\
\hline CHEMBL399383 & 456311 & 5.1871 & 5.1717 & TRN \\
\hline CHEMBL 249515 & 456311 & 6.041 & 6.0442 & TRN \\
\hline CHEMBL 249104 & 456311 & 6.3468 & 6.3299 & TRN \\
\hline CHEMBL 249902 & 456311 & 6.0269 & 6.0726 & TRN \\
\hline CHEMBL 249508 & 456311 & 5.6326 & 5.5827 & TRN \\
\hline CHEMBL 250336 & 456311 & 5.5045 & 5.4436 & TRN \\
\hline CHEMBL 248899 & 456311 & 4.8861 & 4.8019 & TRN \\
\hline CHEMBL 250337 & 456311 & 5.4584 & 5.4784 & TRN \\
\hline CHEMBL 249073 & 456311 & 5.1062 & 5.4106 & TST \\
\hline CHEMBL 398253 & 456311 & 6.4089 & 6.1785 & TRN \\
\hline CHEMBL 249929 & 456311 & 3.6021 & 3.737 & TRN \\
\hline CHEMBL 249102 & 456311 & 6.1612 & 6.1239 & TRN \\
\hline CHEMBL 249683 & 456311 & 5.8729 & 5.8747 & TRN \\
\hline CHEMBL398511 & 456311 & 5.9547 & 5.9411 & TRN \\
\hline CHEMBL 250105 & 456311 & 5.8996 & 5.9476 & TRN \\
\hline CHEMBL249697 & 456311 & 5.1308 & 5.516 & TST \\
\hline
\end{tabular}




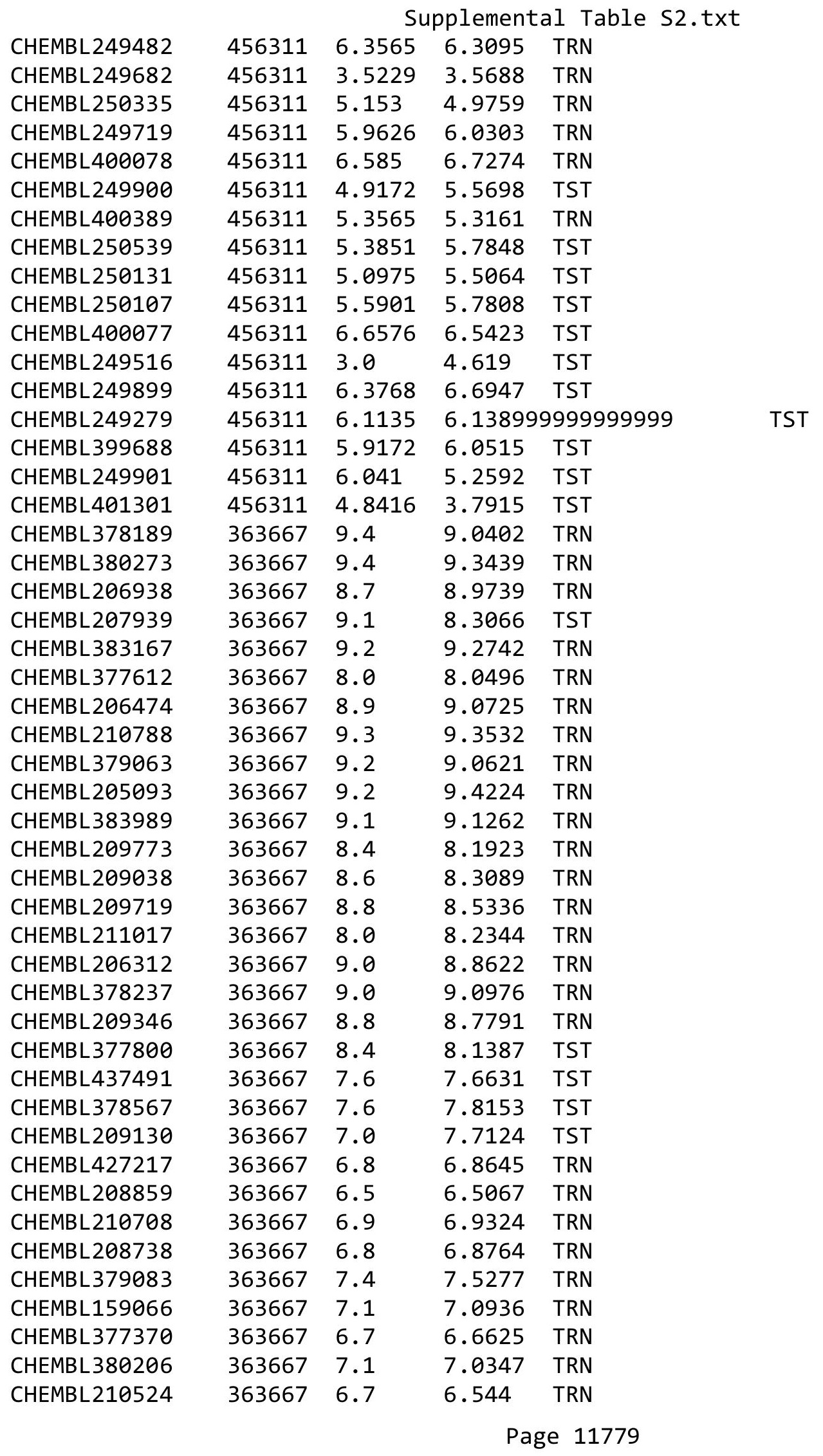




\begin{tabular}{|c|c|c|c|c|c|}
\hline \multirow{2}{*}{ CHEMBL 379541} & \multicolumn{5}{|c|}{ plemental labıe s } \\
\hline & 363667 & 6.1 & \multicolumn{2}{|c|}{6.2620000000000005} & TRN \\
\hline CHEMBL 210662 & 363667 & 6.4 & 6.2598 & TRN & \\
\hline CHEMBL379806 & 363667 & 6.7 & 6.4047 & TRN & \\
\hline CHEMBL209117 & 363667 & 6.6 & 7.2781 & TST & \\
\hline CHEMBL208807 & 363667 & 6.2 & 7.2827 & TST & \\
\hline CHEMBL 380045 & 363667 & 5.6 & 7.1423 & TST & \\
\hline CHEMBL377966 & 363667 & 6.5 & 7.1621 & TST & \\
\hline CHEMBL380260 & 363667 & 6.8 & 7.2138 & TST & \\
\hline CHEMBL 210100 & 363667 & 7.1 & 7.0273 & TST & \\
\hline CHEMBL209873 & 363667 & 7.4 & 7.47 & TRN & \\
\hline CHEMBL 210217 & 363667 & 7.7 & 7.3665 & TRN & \\
\hline CHEMBL377835 & 363667 & 7.2 & \multicolumn{2}{|c|}{6.9270000000000005} & TST \\
\hline CHEMBL 207692 & 363667 & 6.7 & 6.8939 & TRN & \\
\hline CHEMBL379259 & 363667 & 6.7 & 7.0893 & TRN & \\
\hline CHEMBL208223 & 363667 & 7.6 & 7.4999 & TRN & \\
\hline CHEMBL 380282 & 363667 & 6.8 & 7.1174 & TRN & \\
\hline CHEMBL 207465 & 363667 & 7.0 & \multicolumn{2}{|c|}{6.877000000000001} & TRN \\
\hline CHEMBL 209819 & 363667 & 6.4 & 6.0083 & TRN & \\
\hline CHEMBL 209068 & 363667 & 5.1 & 5.3817 & TRN & \\
\hline CHEMBL210706 & 363667 & 6.0 & 6.2152 & TRN & \\
\hline CHEMBL 211016 & 363667 & 6.0 & 6.0341 & TRN & \\
\hline CHEMBL378676 & 363667 & 6.0 & 6.0935 & TRN & \\
\hline CHEMBL 210427 & 363667 & 5.1 & 4.9579 & TRN & \\
\hline CHEMBL 210472 & 363667 & 7.7 & 6.6913 & TST & \\
\hline CHEMBL380086 & 363667 & 8.1 & 7.0626 & TST & \\
\hline CHEMBL570509 & 726362 & 5.3468 & 5.6405 & TRN & \\
\hline CHEMBL1681879 & 726362 & 5.5086 & 5.5858 & TRN & \\
\hline CHEMBL1681878 & 726362 & 6.041 & 5.9889 & TRN & \\
\hline CHEMBL1681863 & 726362 & 7.0969 & 7.0677 & TRN & \\
\hline CHEMBL578779 & 726362 & 7.4559 & 7.0101 & TRN & \\
\hline CHEMBL1681843 & 726362 & 7.2366 & 7.1697 & TRN & \\
\hline CHEMBL1681845 & 726362 & 6.6778 & 6.7153 & TRN & \\
\hline CHEMBL1681835 & 726362 & 7.7447 & 7.6921 & TRN & \\
\hline CHEMBL1681875 & 726362 & 6.585 & 6.5751 & TRN & \\
\hline CHEMBL1681857 & 726362 & 5.8539 & 5.8486 & TRN & \\
\hline CHEMBL1681846 & 726362 & 4.0 & 3.9624 & TRN & \\
\hline CHEMBL1681855 & 726362 & 7.5086 & 7.4568 & TRN & \\
\hline CHEMBL1681836 & 726362 & 7.0605 & 7.1051 & TRN & \\
\hline CHEMBL472288 & 726362 & 9.5229 & 9.4717 & TRN & \\
\hline CHEMBL1681867 & 726362 & 7.4089 & 7.4502 & TRN & \\
\hline CHEMBL1681849 & 726362 & 8.2218 & 8.3306 & TRN & \\
\hline CHEMBL1681838 & 726362 & 5.0975 & 5.0893 & TRN & \\
\hline CHEMBL1681839 & 726362 & 5.0937 & 4.8822 & TST & \\
\hline CHEMBL1681862 & 726362 & 6.284 & 6.2011 & TRN & \\
\hline CHEMBL1681837 & 726362 & 4.0 & 3.9849 & TRN & \\
\hline CHEMBL1681873 & 726362 & 6.2007 & 6.24 & TRN & \\
\hline CHEMBL1681853 & 726362 & 5.5686 & 7.3622 & TST & \\
\hline CHEMBL1681858 & 726362 & 5.1549 & 5.1885 & TRN & \\
\hline
\end{tabular}


Supplemental Table S2.txt

\begin{tabular}{|c|c|c|c|c|}
\hline HEMBL & 26362 & .2007 & 5.7165 & (1) \\
\hline HEMBL1681874 & 26362 & .5229 & 8.5541 & \\
\hline 350 & & 9959 & & \\
\hline AEMBL1 & 362 & $\partial 506$ & & 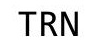 \\
\hline HEMBL1681847 & 26362 & & 259 & \\
\hline HEMBL1681865 & 26362 & 8.0969 & . 1593 & \\
\hline HEMBL1681844 & 26362 & & 5441 & \\
\hline IEMBL168 & 26362 & & & RN \\
\hline HEMBL1681861 & 26362 & 528 & 3865 & RN \\
\hline HEMBL1681868 & 26362 & 383 & 5233 & \\
\hline HEMBL1681876 & 26362 & 809 & 1436 & \\
\hline AEMBL1681 & 26362 & 979 & 099 & \\
\hline HEMBL168 & & & & RN \\
\hline HEMBL1681856 & 26362 & 686 & 6.7332 & \\
\hline AEMBL168. & 26362 & 15 & 1514 & \\
\hline AEMBL1681 & 26362 & 58 & $\partial 285$ & \\
\hline HEMBL168 & 26362 & 49 & 5047 & \\
\hline HEMBL168 & 26362 & 38 & 3175 & \\
\hline HEMBL565 & 26362 & 518 & 3953 & \\
\hline HEMBL168 & 26362 & & & \\
\hline HEMBL168 & 26362 & 949 & 2957 & NIV \\
\hline HEMBL16 & 52 & & 352 & ודים \\
\hline HEMBL16 & 26362 & 6 & 28 & \\
\hline HEMBL168 & 26362 & & 228 & \\
\hline HEMBL168 & & & & בנו \\
\hline HEMBL168 & 26362 & 576 & 671 & SI \\
\hline HEMBL16 & 26362 & & 975 & ST \\
\hline HEMBL 168 & 26362 & 383 & 415 & ST \\
\hline HEMBL168 & 26362 & & & TS \\
\hline HEMBL168. & 26362 & & 252 & TST \\
\hline HEMBL548 & 592863 & 86 & 284 & $\mathrm{RN}$ \\
\hline HEMBL5 & 3 & & 292 & RN \\
\hline HEMBL 5 & 363 & 4 & 24 & RN \\
\hline HEMBL524 & 592863 & & 285 & IRN \\
\hline HEMBL545949 & 592863 & & 3965 & 「RN \\
\hline HEMBL6 & & & 132 & ГRN \\
\hline HEMRI 5 & 53 & 4. & 988 & $\Gamma \mathrm{RN}$ \\
\hline HEMBL 267 & 592863 & & 094 & ГRN \\
\hline HEMBL1197 & 592863 & 4 & 1852 & TST \\
\hline HEMBL602 & 592863 & & 3464 & TRN \\
\hline HEMBL536 & 803 & & 972 & I RIV \\
\hline CHEMBL581 & 592863 & & 5.7943 & TRN \\
\hline HEMBL5819 & 592863 & 5.8508 & 0565 & ГRN \\
\hline HEMBL $529 €$ & 592863 & 6.4949 & 5699 & $\Gamma R$ \\
\hline HEMBL363 & 592863 & 4 & 5.1765 & TST \\
\hline HEMBL 27 & 592863 & 4 & 5097 & \\
\hline CHEMBL363 & 592863 & 4.0 & 3.7707 & \\
\hline HEMBL580443 & 1592863 & $5.739 s$ & 5.3802 & TRN \\
\hline
\end{tabular}

Page 11781 


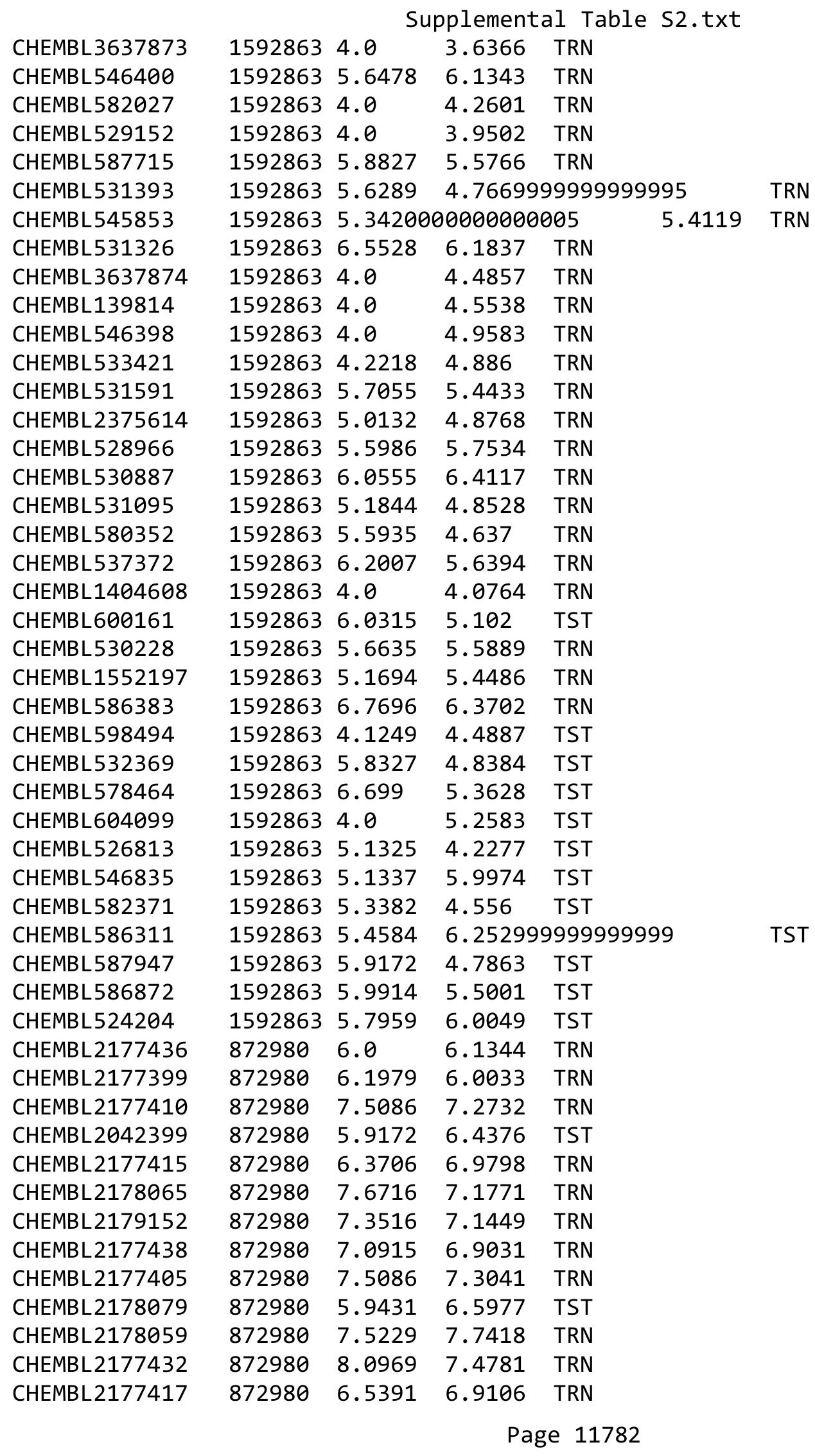




\begin{tabular}{|c|c|c|c|c|c|c|}
\hline & & \multicolumn{5}{|c|}{ Supplemental Table S2.txt } \\
\hline CHEMBL 2177414 & 872980 & 7.3449 & 7.1885 & TRN & & \\
\hline CHEMBL 2177403 & 872980 & 6.0044 & 7.1053 & TRN & & \\
\hline CHEMBL2177419 & 872980 & 7.556 & 6.7426 & TRN & & \\
\hline CHEMBL 2177425 & 872980 & 7.9172 & 7.3157 & TRN & & \\
\hline CHEMBL 2177404 & 872980 & 7.7033 & 7.402 & TRN & & \\
\hline CHEMBL 2177418 & 872980 & 7.6003 & 6.7426 & TRN & & \\
\hline CHEMBL 2178067 & 872980 & 6.6757 & 7.1522 & TRN & & \\
\hline CHEMBL 2178072 & 872980 & 7.301 & 6.8192 & TRN & & \\
\hline CHEMBL 2178085 & 872980 & \multicolumn{3}{|c|}{6.382999999999999} & 6.2292 & TRN \\
\hline CHEMBL2177409 & 872980 & 6.2132 & 7.2645 & TRN & & \\
\hline CHEMBL 2178076 & 872980 & 6.5331 & 6.7493 & TST & & \\
\hline CHEMBL 2179151 & 872980 & 6.9318 & 7.2887 & TRN & & \\
\hline CHEMBL191247 & 872980 & 6.9355 & 6.8971 & TST & & \\
\hline CHEMBL 2177408 & 872980 & 6.5528 & 7.1381 & TRN & & \\
\hline CHEMBL 2179153 & 872980 & 6.9666 & 7.2145 & TRN & & \\
\hline CHEMBL 2178077 & 872980 & 6.585 & 6.4936 & TST & & \\
\hline CHEMBL 2179148 & 872980 & 7.4168 & 7.2152 & TRN & & \\
\hline CHEMBL 2177440 & 872980 & 7.3979 & 7.532 & TRN & & \\
\hline CHEMBL2179147 & 872980 & 7.4067 & 7.2111 & TRN & & \\
\hline CHEMBL 2177413 & 872980 & 6.857 & 7.1175 & TRN & & \\
\hline CHEMBL 2177401 & 872980 & 5.9626 & 6.7391 & TRN & & \\
\hline CHEMBL 2178083 & 872980 & 6.8539 & 6.4314 & TST & & \\
\hline CHEMBL 2177441 & 872980 & 7.7696 & 7.6879 & TRN & & \\
\hline CHEMBL 2178062 & 872980 & 6.8297 & 6.9289 & TST & & \\
\hline CHEMBL 2178061 & 872980 & 5.6216 & 6.7021 & TST & & \\
\hline CHEMBL 2177439 & 872980 & 6.7986 & 6.9556 & TRN & & \\
\hline CHEMBL 2177108 & 872980 & 6.3188 & 6.4811 & TRN & & \\
\hline CHEMBL 2177433 & 872980 & 7.5918 & 7.1639 & TRN & & \\
\hline CHEMBL 2177437 & 872980 & 7.3665 & 7.0523 & TRN & & \\
\hline CHEMBL 2177400 & 872980 & 6.7721 & 7.1684 & TRN & & \\
\hline CHEMBL 2179150 & 872980 & 7.6364 & 7.3818 & TRN & & \\
\hline CHEMBL 2177431 & 872980 & 7.0119 & 7.3299 & TRN & & \\
\hline CHEMBL 2177411 & 872980 & 7.5498 & 7.1793 & TRN & & \\
\hline CHEMBL 2178071 & 872980 & 6.6799 & 6.9977 & TST & & \\
\hline CHEMBL 2178078 & 872980 & 5.9469 & 6.6308 & TST & & \\
\hline CHEMBL 2178084 & 872980 & 6.6925 & 6.3536 & TST & & \\
\hline CHEMBL 2178082 & 872980 & 5.9355 & 6.269 & TST & & \\
\hline CHEMBL 2178080 & 872980 & 5.8539 & 6.1463 & TST & & \\
\hline CHEMBL2177422 & 872980 & 6.7167 & 6.5081 & TRN & & \\
\hline CHEMBL 2177424 & 872980 & 6.0 & 6.7426 & TRN & & \\
\hline CHEMBL 2179149 & 872980 & 7.4685 & 7.1669 & TRN & & \\
\hline CHEMBL 2178064 & 872980 & 7.9788 & 7.3545 & TST & & \\
\hline CHEMBL 2178063 & 872980 & 7.8327 & 7.3849 & TST & & \\
\hline CHEMBL2179154 & 872980 & 6.9318 & 6.7819 & TRN & & \\
\hline CHEMBL 2179146 & 872980 & 7.5129 & 7.2829 & TRN & & \\
\hline CHEMBL 2178066 & 872980 & 7.2411 & 6.8271 & TST & & \\
\hline CHEMBL 2177416 & 872980 & 6.5513 & 6.7672 & TRN & & \\
\hline CHEMBL 2177402 & 872980 & 7.6198 & 7.5489 & TRN & & \\
\hline
\end{tabular}

Page 11783 


\begin{tabular}{|c|c|c|c|c|c|}
\hline \multicolumn{6}{|c|}{ Supplemental Table s2.txt } \\
\hline CHEMBL100273 & 458933 & 5.7 & 6.8781 & TST & \\
\hline CHEMBL329298 & 458933 & 7.7 & 7.7474 & TRN & \\
\hline CHEMBL98017 & 458933 & 7.1 & 7.0021 & TRN & \\
\hline CHEMBL318716 & 458933 & 7.4 & 7.285 & TRN & \\
\hline CHEMBL99189 & 458933 & 7.4 & 7.2445 & TRN & \\
\hline CHEMBL329313 & 458933 & 8.0 & 8.6799 & TRN & \\
\hline CHEMBL99981 & 458933 & 7.4 & 7.1677 & TRN & \\
\hline CHEMBL318455 & 458933 & 6.22 & 6.7822 & TRN & \\
\hline CHEMBL95614 & 458933 & 7.0 & \multicolumn{2}{|c|}{6.712999999999999} & TRN \\
\hline CHEMBL318023 & 458933 & 6.7 & \multicolumn{2}{|c|}{6.627000000000001} & TRN \\
\hline CHEMBL329287 & 458933 & 6.7 & 6.5224 & TRN & \\
\hline CHEMBL97936 & 458933 & 8.1 & 7.9492 & TRN & \\
\hline CHEMBL100100 & 458933 & 8.1 & 8.208 & TRN & \\
\hline CHEMBL328162 & 458933 & 7.7 & \multicolumn{2}{|c|}{7.667000000000001} & TRN \\
\hline CHEMBL99148 & 458933 & 7.4 & 7.0926 & TRN & \\
\hline CHEMBL98044 & 458933 & 6.4 & 6.9213 & TRN & \\
\hline CHEMBL315114 & 458933 & 9.0 & 8.4478 & TRN & \\
\hline CHEMBL253261 & 458933 & 8.52 & 8.4087 & TRN & \\
\hline CHEMBL312100 & 458933 & 8.62 & 8.5173 & TRN & \\
\hline CHEMBL85026 & 458933 & 6.1 & 6.8922 & TRN & \\
\hline CHEMBL82113 & 458933 & 6.85 & 6.9256 & TRN & \\
\hline CHEMBL313340 & 458933 & 7.26 & 7.8711 & TRN & \\
\hline CHEMBL311004 & 458933 & 9.0 & 8.3132 & TRN & \\
\hline CHEMBL311266 & 458933 & 8.46 & 7.979 & TRN & \\
\hline CHEMBL83282 & 458933 & 8.74 & 8.4162 & TRN & \\
\hline CHEMBL79267 & 458933 & 7.86 & 7.95 & TRN & \\
\hline CHEMBL 83368 & 458933 & 9.0 & 8.2626 & TRN & \\
\hline CHEMBL83955 & 458933 & 8.27 & 8.0721 & TRN & \\
\hline CHEMBL311097 & 458933 & 7.53 & 8.1378 & TRN & \\
\hline CHEMBL308305 & 458933 & 6.26 & 7.0102 & TRN & \\
\hline CHEMBL76974 & 458933 & 8.4 & 7.9893 & TRN & \\
\hline CHEMBL80300 & 458933 & 8.22 & 7.5458 & TRN & \\
\hline CHEMBL80272 & 458933 & 9.0 & 7.8226 & TRN & \\
\hline CHEMBL 308084 & 458933 & 6.87 & 7.7573 & TST & \\
\hline CHEMBL80894 & 458933 & 6.27 & 7.5195 & TST & \\
\hline CHEMBL311368 & 458933 & 7.38 & 7.435 & TST & \\
\hline CHEMBL311509 & 458933 & 6.86 & 7.606 & TST & \\
\hline CHEMBL70176 & 458933 & 8.1 & 8.0668 & TST & \\
\hline CHEMBL76606 & 458933 & 7.3 & 7.5284 & TST & \\
\hline CHEMBL419868 & 458933 & 7.19 & \multicolumn{2}{|c|}{7.712000000000001} & TRN \\
\hline CHEMBL313168 & 458933 & 7.77 & 7.8365 & TRN & \\
\hline CHEMBL252461 & 458933 & 8.29 & 8.2386 & TST & \\
\hline CHEMBL310655 & 458933 & 7.59 & 7.9821 & TRN & \\
\hline CHEMBL328255 & 458933 & 7.96 & 8.0381 & TRN & \\
\hline CHEMBL252266 & 458933 & 7.34 & 7.9039 & TRN & \\
\hline CHEMBL253904 & 458933 & 7.8 & 7.8486 & TRN & \\
\hline CHEMBL327442 & 458933 & 8.34 & 8.3995 & TRN & \\
\hline CHEMBL329558 & 458933 & 8.21 & 8.6615 & TRN & \\
\hline
\end{tabular}




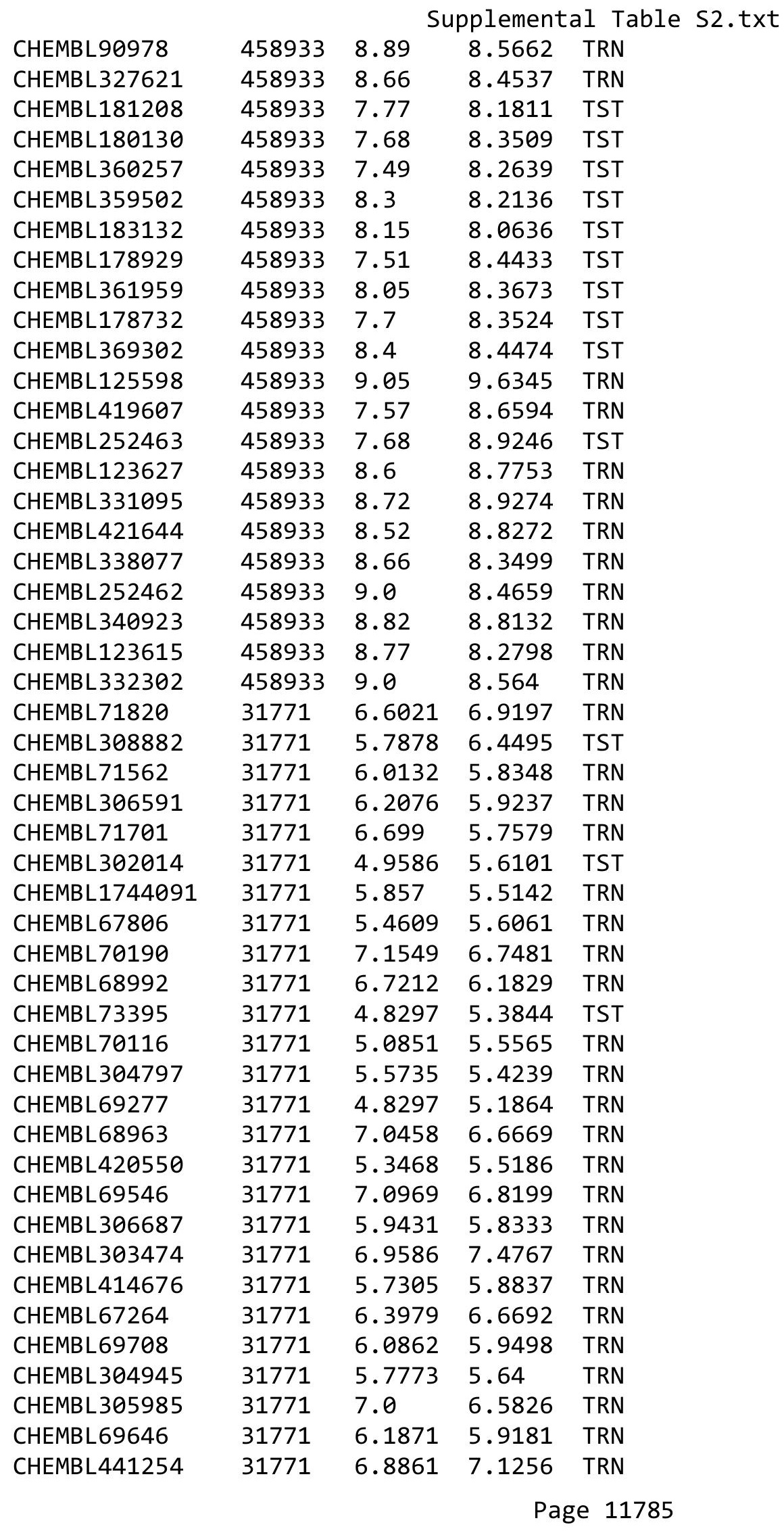



Supplemental Table S2.txt

\begin{tabular}{|c|c|c|c|c|c|}
\hline CHEMBL 3968601 & 1640708 & 7.5918 & 7.2247 & TRN & \\
\hline CHEMBL 3940607 & 1640708 & 6.0 & 7.0673 & TRN & \\
\hline CHEMBL 3965561 & 1640708 & 8.0605 & 7.9359 & TRN & \\
\hline CHEMBL 3970419 & 1640708 & 6.0223 & \multicolumn{2}{|c|}{7.1770000000000005} & TRN \\
\hline CHEMBL 3930535 & 1640708 & 8.3768 & 7.0916 & TRN & \\
\hline CHEMBL 3932945 & 1640708 & 6.0 & 7.0673 & TRN & \\
\hline CHEMBL 3978641 & 1640708 & 6.0 & 7.308 & TRN & \\
\hline CHEMBL 3965621 & 1640708 & 8.6383 & 7.9925 & TRN & \\
\hline CHEMBL 3901290 & 1640708 & 7.9281 & 8.1693 & TRN & \\
\hline CHEMBL 3925313 & 1640708 & 7.0635 & 6.517 & TRN & \\
\hline CHEMBL 3984755 & 1640708 & 8.4318 & \multicolumn{2}{|c|}{7.7010000000000005} & TRN \\
\hline CHEMBL 3915413 & 1640708 & 8.1367 & 7.718 & TRN & \\
\hline CHEMBL 3955066 & 1640708 & 7.8041 & 7.3565 & TRN & \\
\hline CHEMBL 3973179 & 1640708 & 6.3261 & 7.6168 & TRN & \\
\hline CHEMBL 3969285 & 1640708 & 8.9208 & 7.9359 & TRN & \\
\hline CHEMBL 3972052 & 1640708 & 8.0915 & 7.8732 & TRN & \\
\hline CHEMBL 3937242 & 1640708 & 6.0 & 6.6798 & TRN & \\
\hline CHEMBL 3911598 & 1640708 & 8.1549 & 7.7069 & TRN & \\
\hline CHEMBL 3909968 & 1640708 & 6.0 & \multicolumn{2}{|c|}{7.1770000000000005} & \\
\hline CHEMBL 3896506 & 1640708 & 6.067 & 6.6223 & TRN & \\
\hline CHEMBL 3895441 & 1640708 & 6.3089 & 6.9796 & TRN & \\
\hline CHEMBL 3984614 & 1640708 & 7.4921 & 7.1493 & TRN & \\
\hline CHEMBL 3961027 & 1640708 & 6.6596 & 7.0443 & TST & \\
\hline CHEMBL 3942447 & 1640708 & 8.301 & 7.5733 & TRN & \\
\hline CHEMBL 3899249 & 1640708 & 7.0762 & 7.1178 & TRN & \\
\hline CHEMBL 3959365 & 1640708 & 8.699 & 7.5627 & TRN & \\
\hline CHEMBL 3904676 & 1640708 & 8.0506 & 7.784 & TRN & \\
\hline CHEMBL 3949566 & 1640708 & 6.1349 & 7.8198 & TRN & \\
\hline CHEMBL 3962766 & 1640708 & 8.2441 & 7.4095 & TRN & \\
\hline CHEMBL 3904863 & 1640708 & 8.6576 & 8.6867 & TST & \\
\hline CHEMBL 3944585 & 1640708 & 7.1367 & 7.0436 & TRN & \\
\hline CHEMBL 3958361 & 1640708 & 8.5229 & 6.6051 & TRN & \\
\hline CHEMBL 3985401 & 1640708 & 7.2076 & 7.4095 & TRN & \\
\hline CHEMBL 3900876 & 1640708 & 8.4685 & 8.2303 & TRN & \\
\hline CHEMBL 3938604 & 1640708 & 8.7696 & 6.9043 & TRN & \\
\hline CHEMBL 3903833 & 1640708 & 8.8539 & 8.1217 & TRN & \\
\hline CHEMBL 3926691 & 1640708 & 6.0 & 7.0785 & TRN & \\
\hline CHEMBL 3907672 & 1640708 & 8.0132 & 7.7213 & TRN & \\
\hline CHEMBL 3939303 & 1640708 & 8.0269 & 7.2785 & TRN & \\
\hline CHEMBL 3916496 & 1640708 & 6.0 & 7.3968 & TRN & \\
\hline CHEMBL 3919947 & 1640708 & 6.1688 & 8.2215 & TST & \\
\hline CHEMBL 3973722 & 1640708 & 8.2596 & 7.8073 & TRN & \\
\hline CHEMBL3910999 & 1640708 & 7.51 & 6.903 & TRN & \\
\hline CHEMBL 3944302 & 1640708 & 6.0246 & 7.2018 & TST & \\
\hline CHEMBL 3918066 & 1640708 & 9.3979 & 8.2682 & TRN & \\
\hline CHEMBL 3916227 & 1640708 & 8.0223 & 7.7322 & TRN & \\
\hline CHEMBL 3918562 & 1640708 & 7.3851 & 7.8019 & TST & \\
\hline CHEMBL 3924007 & 1640708 & 7.75200 & 3000000 & 7.6112 & \\
\hline
\end{tabular}


Supplemental Table S2.txt

\begin{tabular}{|c|c|c|c|c|}
\hline CHEMBL 3890911 & 1640708 & 8.1871 & 7.4268 & TRN \\
\hline CHEMBL3917145 & 1640708 & 8.3188 & 8.353 & TRN \\
\hline CHEMBL3935140 & 1640708 & 7.7447 & 7.3139 & TST \\
\hline CHEMBL3896656 & 1640708 & 7.7496 & 7.2584 & TRN \\
\hline CHEMBL3952758 & 1640708 & 8.7959 & 7.6249 & TST \\
\hline CHEMBL3973013 & 1640708 & 6.0 & 7.8282 & TRN \\
\hline CHEMBL3961257 & 1640708 & 7.4101 & \multicolumn{2}{|c|}{7.627000000000001} \\
\hline CHEMBL3910423 & 1640708 & 6.0 & 6.6351 & TRN \\
\hline CHEMBL3905433 & 1640708 & 8.0809 & 8.1673 & TRN \\
\hline CHEMBL3921709 & 1640708 & 8.1871 & 6.8843 & TRN \\
\hline CHEMBL3981594 & 1640708 & 8.4559 & 7.6826 & TRN \\
\hline CHEMBL3955125 & 1640708 & 7.8416 & 7.7798 & TST \\
\hline CHEMBL3932129 & 1640708 & 7.8996 & 7.1686 & TRN \\
\hline CHEMBL3960215 & 1640708 & 8.5528 & 7.3558 & TRN \\
\hline CHEMBL3965332 & 1640708 & 7.2248 & 7.8963 & TST \\
\hline CHEMBL3942063 & 1640708 & 6.0 & 6.9895 & TRN \\
\hline CHEMBL3980528 & 1640708 & 7.1824 & 6.6051 & TRN \\
\hline CHEMBL3944167 & 1640708 & 7.767 & 7.0584 & TST \\
\hline CHEMBL3897937 & 1640708 & 8.1938 & 7.9124 & TST \\
\hline CHEMBL3933785 & 1640708 & 6.9066 & 7.1861 & TST \\
\hline CHEMBL3930968 & 1640708 & 7.0585 & 7.3275 & TST \\
\hline CHEMBL3967677 & 1640708 & 6.6904 & 7.0085 & TST \\
\hline CHEMBL3909133 & 1640708 & 8.8861 & 8.1043 & TST \\
\hline CHEMBL3892037 & 1640708 & 7.3458 & 7.2585 & TST \\
\hline CHEMBL3973713 & 1640708 & 6.0 & 7.3946 & TST \\
\hline CHEMBL3972488 & 1640708 & 7.8477 & 6.5691 & TST \\
\hline CHEMBL3946435 & 1640708 & 7.6635 & 7.7883 & TST \\
\hline CHEMBL3971521 & 1640708 & 8.4559 & 7.4293 & TST \\
\hline CHEMBL3975722 & 1641338 & 7.699 & 8.4913 & TRN \\
\hline CHEMBL3964409 & 1641338 & 8.6021 & 8.6055 & TRN \\
\hline CHEMBL 3932164 & 1641338 & 8.6021 & 9.1804 & TRN \\
\hline CHEMBL 3904271 & 1641338 & 9.0 & 8.2375 & TST \\
\hline CHEMBL 3944627 & 1641338 & 9.0 & 9.0525 & TRN \\
\hline CHEMBL3894416 & 1641338 & 8.0 & 8.8817 & TST \\
\hline CHEMBL3955659 & 1641338 & 9.0 & 8.485 & TRN \\
\hline CHEMBL3913331 & 1641338 & 8.6021 & 8.2975 & TRN \\
\hline CHEMBL3890924 & 1641338 & 9.0 & 8.7747 & TRN \\
\hline CHEMBL3951034 & 1641338 & 9.0 & 9.1948 & TRN \\
\hline CHEMBL3906663 & 1641338 & 7.6021 & 7.7934 & TRN \\
\hline CHEMBL3979987 & 1641338 & 9.0 & 8.8107 & TRN \\
\hline CHEMBL3923387 & 1641338 & 8.301 & 7.9818 & TRN \\
\hline CHEMBL3931131 & 1641338 & 10.0 & 8.5316 & TRN \\
\hline CHEMBL3910570 & 1641338 & 10.0 & 9.0835 & TRN \\
\hline CHEMBL3907882 & 1641338 & 8.301 & 8.4002 & TRN \\
\hline CHEMBL3946463 & 1641338 & 9.0 & 8.8962 & TRN \\
\hline CHEMBL3943944 & 1641338 & 9.0 & 8.98 & TRN \\
\hline CHEMBL3935847 & 1641338 & 9.0 & 8.3622 & TRN \\
\hline CHEMBL3947698 & 1641338 & 8.1249 & 8.0282 & TRN \\
\hline
\end{tabular}

Page 11788 
Supplemental Table S2.txt

\begin{tabular}{|c|c|c|c|c|c|}
\hline CHEMBL3970069 & 1641338 & 8.6021 & 8.9101 & TRN & \\
\hline CHEMBL3915108 & 1641338 & 7.4168 & 8.5404 & TST & \\
\hline CHEMBL3951406 & 1641338 & 8.1249 & 7.9381 & TRN & \\
\hline CHEMBL3946651 & 1641338 & 7.4622 & 8.0465 & TRN & \\
\hline CHEMBL3905096 & 1641338 & 7.5952 & 7.9429 & TRN & \\
\hline CHEMBL3951829 & 1641338 & 8.6021 & 8.5335 & TRN & \\
\hline CHEMBL3980342 & 1641338 & 7.75700 & 00000000 & & 8.1056 \\
\hline CHEMBL3918850 & 1641338 & 7.7747 & 8.1499 & TRN & \\
\hline CHEMBL3890019 & 1641338 & 8.6021 & 8.8044 & TRN & \\
\hline CHEMBL3924760 & 1641338 & 7.8962 & 8.6738 & TRN & \\
\hline CHEMBL3944787 & 1641338 & 9.0 & 8.5496 & TRN & \\
\hline CHEMBL3961251 & 1641338 & 7.8239 & 7.9815 & TRN & \\
\hline CHEMBL3947894 & 1641338 & 7.4214 & 8.3482 & TST & \\
\hline CHEMBL3938680 & 1641338 & 8.6021 & 8.7173 & TRN & \\
\hline CHEMBL3958979 & 1641338 & 9.0 & 8.6454 & TRN & \\
\hline CHEMBL3952318 & 1641338 & 8.0 & 8.4732 & TRN & \\
\hline CHEMBL3953719 & 1641338 & 8.6021 & 8.6232 & TRN & \\
\hline CHEMBL3975967 & 1641338 & 8.1549 & 8.2417 & TRN & \\
\hline CHEMBL3968580 & 1641338 & 7.9031 & 8.4887 & TRN & \\
\hline CHEMBL3906146 & 1641338 & 7.699 & 8.0533 & TRN & \\
\hline CHEMBL3982441 & 1641338 & 8.6021 & 8.5558 & TRN & \\
\hline CHEMBL3986701 & 1641338 & 9.0 & 8.532 & TRN & \\
\hline CHEMBL3913931 & 1641338 & 9.0 & 8.5367 & TRN & \\
\hline CHEMBL3930018 & 1641338 & 7.7496 & 8.1049 & TRN & \\
\hline CHEMBL3959437 & 1641338 & 9.0 & 8.5654 & TRN & \\
\hline CHEMBL3929522 & 1641338 & 8.3979 & 8.2149 & TST & \\
\hline CHEMBL3970724 & 1641338 & 9.0 & 8.5933 & TST & \\
\hline CHEMBL3975150 & 1641338 & 9.0 & 8.1263 & TST & \\
\hline CHEMBL3986561 & 1641338 & 7.8239 & 8.1027 & TRN & \\
\hline CHEMBL3913282 & 1641338 & 8.0 & 8.0399 & TRN & \\
\hline CHEMBL3954376 & 1641338 & 8.301 & 8.6931 & TRN & \\
\hline CHEMBL3904934 & 1641338 & 9.0 & 7.9875 & TRN & \\
\hline CHEMBL3893192 & 1641338 & 9.0 & 8.6275 & TRN & \\
\hline CHEMBL 3899459 & 1641338 & 8.301 & 8.4946 & TST & \\
\hline CHEMBL3916966 & 1641338 & 9.0 & 9.1692 & TRN & \\
\hline CHEMBL3895120 & 1641338 & 8.301 & 8.7068 & TRN & \\
\hline CHEMBL3960357 & 1641338 & 7.6478 & 8.6273 & TRN & \\
\hline CHEMBL3925063 & 1641338 & 9.0 & 8.384 & TRN & \\
\hline CHEMBL3931946 & 1641338 & 9.0 & 8.285 & TST & \\
\hline CHEMBL3959678 & 1641338 & 9.0 & 8.5836 & TST & \\
\hline CHEMBL3939042 & 1641338 & 8.301 & 8.1301 & TST & \\
\hline CHEMBL3957095 & 1641338 & 9.0 & 8.0716 & TST & \\
\hline CHEMBL3898804 & 1641338 & 9.0 & 8.2155 & TST & \\
\hline CHEMBL 3949646 & 1641338 & 7.5302 & 8.2991 & TST & \\
\hline CHEMBL3987192 & 1641338 & 10.0 & 8.0334 & TST & \\
\hline CHEMBL3921111 & 1641338 & 9.0 & 8.646 & TST & \\
\hline CHEMBL3889645 & 1641338 & 9.0 & 8.6701 & TST & \\
\hline CHEMBL3648468 & 1527912 & 9.301 & 9.7118 & TST & \\
\hline
\end{tabular}




$$
\text { Supplemental Table S2.txt }
$$

\begin{tabular}{|c|c|c|c|c|c|c|}
\hline CHEMBL3648502 & 1527912 & 9.699 & 9.6937 & TRN & & \\
\hline CHEMBL3648506 & 1527912 & 7.7595 & 7.6974 & TRN & & \\
\hline CHEMBL3648509 & 1527912 & 9.301 & 9.2711 & TRN & & \\
\hline CHEMBL 3648499 & 1527912 & 9.3979 & 9.3886 & TRN & & \\
\hline CHEMBL 3648478 & 1527912 & 9.5229 & 9.5862 & TRN & & \\
\hline CHEMBL3648504 & 1527912 & 9.3979 & 9.5032 & TRN & & \\
\hline CHEMBL3648487 & 1527912 & 6.522 & 6.5113 & TRN & & \\
\hline CHEMBL3648491 & 1527912 & 9.5229 & 9.433 & TRN & & \\
\hline CHEMBL 3648483 & 1527912 & 9.301 & 9.2292 & TRN & & \\
\hline CHEMBL3648484 & 1527912 & 9.2218 & 9.1226 & TRN & & \\
\hline CHEMBL3648493 & 1527912 & 8.3279 & 8.2995 & TRN & & \\
\hline CHEMBL3648459 & 1527912 & 7.08299 & 799999999 & & 7.5767 & TST \\
\hline CHEMBL 3648507 & 1527912 & 8.3188 & 8.6577 & TST & & \\
\hline CHEMBL 3648495 & 1527912 & 8.3979 & 8.4782 & TRN & & \\
\hline CHEMBL3648488 & 1527912 & 9.699 & 9.7357 & TRN & & \\
\hline CHEMBL3648470 & 1527912 & 8.4437 & 8.6882 & TST & & \\
\hline CHEMBL3648451 & 1527912 & 5.6478 & 6.1164 & TST & & \\
\hline CHEMBL 3648460 & 1527912 & 6.9281 & 7.0985 & TST & & \\
\hline CHEMBL 3648498 & 1527912 & 8.3665 & 8.3656 & TRN & & \\
\hline CHEMBL3648473 & 1527912 & 6.4789 & 6.4831 & TRN & & \\
\hline CHEMBL3648481 & 1527912 & 6.8687 & 7.0518 & TRN & & \\
\hline CHEMBL3648501 & 1527912 & 7.21399 & 999999999 & 995 & 7.1969 & TRN \\
\hline CHEMBL 3648461 & 1527912 & 8.3979 & 8.4027 & TRN & & \\
\hline CHEMBL 3648500 & 1527912 & 8.2366 & 8.4005 & TRN & & \\
\hline CHEMBL3648464 & 1527912 & 7.6055 & 7.7804 & TRN & & \\
\hline CHEMBL3648496 & 1527912 & 9.3979 & 9.3671 & TRN & & \\
\hline CHEMBL3648475 & 1527912 & 10.0 & 10.1802 & TRN & & \\
\hline CHEMBL 3648472 & 1527912 & 9.0969 & 9.1457 & TST & & \\
\hline CHEMBL3648510 & 1527912 & 9.699 & 9.4324 & TST & & \\
\hline CHEMBL3648486 & 1527912 & 8.4437 & 8.0944 & TRN & & \\
\hline CHEMBL3648467 & 1527912 & 9.2218 & 9.7918 & TST & & \\
\hline CHEMBL3648453 & 1527912 & 7.3242 & 7.2676 & TST & & \\
\hline CHEMBL 3648458 & 1527912 & 7.6126 & 7.6076 & TST & & \\
\hline CHEMBL 3648471 & 1527912 & 8.6383 & 8.5687 & TRN & & \\
\hline CHEMBL3648508 & 1527912 & 9.699 & 10.1888 & TST & & \\
\hline CHEMBL3648456 & 1527912 & 6.34200 & 000000000 & 305 & 6.2574 & TST \\
\hline CHEMBL3648477 & 1527912 & 9.3979 & 9.3338 & TRN & & \\
\hline CHEMBL 3648490 & 1527912 & 9.699 & 9.711 & TRN & & \\
\hline CHEMBL 3648503 & 1527912 & 9.3979 & 9.4811 & TRN & & \\
\hline CHEMBL3648480 & 1527912 & 10.0 & 9.8786 & TRN & & \\
\hline CHEMBL3648457 & 1527912 & 7.5436 & 7.4004 & TRN & & \\
\hline CHEMBL3648463 & 1527912 & 9.301 & 9.137 & TRN & & \\
\hline CHEMBL3648476 & 1527912 & 9.699 & 9.8343 & TRN & & \\
\hline CHEMBL 3648479 & 1527912 & 8.4685 & 8.5572 & TRN & & \\
\hline CHEMBL3648505 & 1527912 & 9.5229 & 9.5052 & TRN & & \\
\hline CHEMBL 3648474 & 1527912 & 8.301 & 8.2429 & TRN & & \\
\hline CHEMBL3648466 & 1527912 & 9.301 & 9.2123 & TRN & & \\
\hline CHEMBL 3648485 & 1527912 & 9.301 & 9.2726 & TRN & & \\
\hline
\end{tabular}


Supplemental Table S2.txt

\begin{tabular}{|c|c|c|c|c|}
\hline CHEMBL3648465 & 1527912 & 7.6091 & 8.0899 & TST \\
\hline CHEMBL3648492 & 1527912 & 6.1545 & 6.1492 & TRN \\
\hline CHEMBL3648462 & 1527912 & 9.301 & 9.4881 & TRN \\
\hline CHEMBL3648452 & 1527912 & 7.1146 & 7.5555 & TST \\
\hline CHEMBL3648497 & 1527912 & 8.5686 & 8.5235 & TRN \\
\hline CHEMBL3648494 & 1527912 & 9.699 & 9.6293 & TRN \\
\hline CHEMBL3648469 & 1527912 & 8.3468 & 8.3559 & TRN \\
\hline CHEMBL3648482 & 1527912 & 7.0195 & 7.1876 & TRN \\
\hline CHEMBL1964290 & 809283 & 5.4 & 5.6325 & TRN \\
\hline CHEMBL2003768 & 809283 & 5.2 & 4.7073 & TRN \\
\hline CHEMBL213505 & 809283 & 4.1 & 4.0733 & TRN \\
\hline CHEMBL1982880 & 809283 & 4.1 & 3.9629 & TRN \\
\hline CHEMBL1993941 & 809283 & 4.1 & 4.5407 & TRN \\
\hline CHEMBL1980435 & 809283 & 5.5 & 4.8383 & TRN \\
\hline CHEMBL1989293 & 809283 & 6.0 & 5.2744 & TRN \\
\hline CHEMBL 377383 & 809283 & 4.1 & 3.5974 & TRN \\
\hline CHEMBL578061 & 809283 & 3.7 & 4.3528 & TRN \\
\hline CHEMBL1973142 & 809283 & 5.4 & 5.6332 & TST \\
\hline CHEMBL1973145 & 809283 & 4.1 & 4.1621 & TRN \\
\hline CHEMBL1982924 & 809283 & 4.1 & 4.3272 & TRN \\
\hline CHEMBL1964948 & 809283 & 4.9 & 4.8496 & TRN \\
\hline CHEMBL1971141 & 809283 & 4.1 & 3.8622 & TRN \\
\hline CHEMBL1995813 & 809283 & 7.6 & 7.7409 & TRN \\
\hline CHEMBL1979718 & 809283 & 6.6 & 5.5324 & TRN \\
\hline CHEMBL206236 & 809283 & 6.9 & 7.1618 & TRN \\
\hline CHEMBL1964288 & 809283 & 4.1 & 5.6013 & TRN \\
\hline CHEMBL523823 & 809283 & 4.1 & 4.9018 & TST \\
\hline CHEMBL244378 & 809283 & 6.0 & 5.6957 & TRN \\
\hline CHEMBL1990583 & 809283 & 4.1 & 4.2748 & TRN \\
\hline CHEMBL1986943 & 809283 & 7.5 & 8.2827 & TRN \\
\hline CHEMBL289959 & 809283 & 4.4 & 4.0853 & TRN \\
\hline CHEMBL 2006263 & 809283 & 4.1 & 4.1402 & TST \\
\hline CHEMBL1993584 & 809283 & 6.4 & 6.5573 & TRN \\
\hline CHEMBL 2000114 & 809283 & 5.3 & 4.2299 & TRN \\
\hline CHEMBL210618 & 809283 & 4.1 & 4.5568 & TRN \\
\hline CHEMBL1971172 & 809283 & 6.7 & 6.6768 & TRN \\
\hline CHEMBL1975647 & 809283 & 4.1 & 4.5381 & TRN \\
\hline CHEMBL1968380 & 809283 & 4.1 & 3.6017 & TRN \\
\hline CHEMBL1997643 & 809283 & 4.1 & 4.6344 & TRN \\
\hline CHEMBL1991734 & 809283 & 6.1 & 6.12799 & 9999999999 \\
\hline CHEMBL1990912 & 809283 & 4.1 & 4.206 & TRN \\
\hline CHEMBL1991782 & 809283 & 3.6 & 3.3569 & TRN \\
\hline CHEMBL1968394 & 809283 & 3.3 & 3.3842 & TRN \\
\hline CHEMBL1988163 & 809283 & 5.9 & 5.5511 & TRN \\
\hline CHEMBL1974480 & 809283 & 6.0 & 5.0993 & TST \\
\hline CHEMBL1980671 & 809283 & 3.3 & 4.383 & TRN \\
\hline CHEMBL2006493 & 809283 & 4.1 & 3.6159 & TST \\
\hline CHEMBL1996923 & 809283 & 4.1 & 4.2652 & TST \\
\hline
\end{tabular}




\begin{tabular}{|c|c|c|c|c|c|}
\hline \multicolumn{6}{|c|}{ Supplemental Table S2.txt } \\
\hline CHEMBL1969735 & 809283 & 4.1 & 4.3029 & TRN & \\
\hline CHEMBL 2003524 & 809283 & 4.1 & 3.9534 & TST & \\
\hline CHEMBL2002649 & 809283 & 4.1 & 4.9943 & TRN & \\
\hline CHEMBL1989423 & 809283 & 3.3 & 3.6732 & TRN & \\
\hline CHEMBL1985367 & 809283 & 4.9 & 5.1045 & TST & \\
\hline CHEMBL1971227 & 809283 & 5.9 & 5.25299 & 9999999999 & TST \\
\hline CHEMBL1994321 & 809283 & 4.1 & 3.9925 & TRN & \\
\hline CHEMBL1978562 & 809283 & 5.9 & 4.9571 & TST & \\
\hline CHEMBL1964307 & 809283 & 6.4 & 6.1774 & TRN & \\
\hline CHEMBL1989471 & 809283 & 4.9 & 4.2425 & TST & \\
\hline CHEMBL 2000508 & 809283 & 4.1 & 4.5929 & TRN & \\
\hline CHEMBL1971694 & 809283 & 4.1 & 4.0589 & TST & \\
\hline CHEMBL1978195 & 809283 & 6.5 & 5.845 & TRN & \\
\hline CHEMBL1994361 & 809283 & 4.1 & 4.5783 & TRN & \\
\hline CHEMBL1986603 & 809283 & 4.1 & 4.0968 & TST & \\
\hline CHEMBL1977148 & 809283 & 4.1 & 4.1945 & TRN & \\
\hline CHEMBL1966842 & 809283 & 4.9 & 5.2756 & TRN & \\
\hline CHEMBL2004443 & 809283 & 4.1 & 4.3291 & TRN & \\
\hline CHEMBL2003286 & 809283 & 4.1 & 3.83699 & 99999999997 & TRN \\
\hline CHEMBL1992306 & 809283 & 4.1 & 3.7161 & TRN & \\
\hline CHEMBL2002165 & 809283 & 4.1 & 4.2197 & TRN & \\
\hline CHEMBL1979318 & 809283 & 4.1 & 3.9491 & TRN & \\
\hline CHEMBL206382 & 809283 & 6.2 & 6.5249 & TRN & \\
\hline CHEMBL127898 & 809283 & 4.1 & 4.4654 & TST & \\
\hline CHEMBL519697 & 809283 & 4.1 & 4.0773 & TST & \\
\hline CHEMBL1968459 & 809283 & 6.0 & 6.2948 & TRN & \\
\hline CHEMBL1996345 & 809283 & 4.9 & $4.1610 e$ & 00000000005 & TST \\
\hline CHEMBL1975128 & 809283 & 7.0 & 7.41700 & 0000000001 & TRN \\
\hline CHEMBL1970369 & 809283 & 4.1 & 4.103 & TRN & \\
\hline CHEMBL1965033 & 809283 & 4.9 & 4.6879 & TRN & \\
\hline CHEMBL2001485 & 809283 & 4.1 & 4.26 & TRN & \\
\hline CHEMBL504950 & 809283 & 5.7 & 5.5063 & TRN & \\
\hline CHEMBL1966425 & 809283 & 4.1 & 4.6055 & TRN & \\
\hline CHEMBL1988608 & 809283 & 6.4 & 7.0118 & TRN & \\
\hline CHEMBL184847 & 809283 & 4.1 & 3.9116 & TRN & \\
\hline CHEMBL178737 & 809283 & 4.1 & 4.6206 & TST & \\
\hline CHEMBL1982563 & 809283 & 4.1 & 4.37 & TRN & \\
\hline CHEMBL539474 & 809283 & 4.1 & 4.1817 & TST & \\
\hline CHEMBL575824 & 809283 & 6.5 & 6.24799 & 9999999999 & TRN \\
\hline CHEMBL1988387 & 809283 & 4.1 & 4.58 & TRN & \\
\hline CHEMBL1973868 & 809283 & 4.9 & 5.2677 & TRN & \\
\hline CHEMBL1990288 & 809283 & 4.1 & 4.002 & TRN & \\
\hline CHEMBL1965702 & 809283 & 7.7 & 7.48799 & 99999999995 & TRN \\
\hline CHEMBL1986970 & 809283 & 6.5 & 6.6847 & TRN & \\
\hline CHEMBL2002456 & 809283 & 6.8 & 6.5302 & TRN & \\
\hline CHEMBL1958401 & 809283 & 5.4 & 5.0352 & TRN & \\
\hline CHEMBL1984044 & 809283 & 4.1 & 4.1124 & TRN & \\
\hline CHEMBL1972584 & 809283 & 4.1 & 3.9831 & TRN & \\
\hline
\end{tabular}




\begin{tabular}{|c|c|c|c|c|c|}
\hline \\
\hline CHEMBL1982700 & 809283 & 4.9 & 3.6975 & TST & \\
\hline CHEMBL326282 & 809283 & 4.1 & 4.5233 & TST & \\
\hline CHEMBL1992732 & 809283 & 4.1 & 4.273 & TST & \\
\hline CHEMBL1971186 & 809283 & 4.1 & 4.3105 & TRN & \\
\hline CHEMBL 2003482 & 809283 & 4.1 & 4.7401 & TRN & \\
\hline CHEMBL1976872 & 809283 & 3.3 & 3.4303 & TRN & \\
\hline CHEMBL 2006456 & 809283 & 7.2 & 7.5658 & TRN & \\
\hline CHEMBL1969156 & 809283 & 4.6 & 4.3085 & TRN & \\
\hline CHEMBL1973211 & 809283 & 4.1 & 3.9758 & TRN & \\
\hline CHEMBL1964340 & 809283 & 6.8 & 6.5678 & TRN & \\
\hline CHEMBL1999120 & 809283 & 3.3 & 3.5286 & TST & \\
\hline CHEMBL1976134 & 809283 & 4.1 & 4.6148 & TRN & \\
\hline CHEMBL1965131 & 809283 & 5.5 & 6.0125 & TST & \\
\hline CHEMBL1981215 & 809283 & 4.9 & 4.7735 & TRN & \\
\hline CHEMBL1974457 & 809283 & 4.1 & 4.545 & TRN & \\
\hline CHEMBL1967662 & 809283 & 7.5 & 7.057 & TRN & \\
\hline CHEMBL 2006580 & 809283 & 4.1 & 4.6073 & TRN & \\
\hline CHEMBL 2001228 & 809283 & 4.9 & 4.9724 & TRN & \\
\hline CHEMBL2006581 & 809283 & 4.1 & 3.7214 & TRN & \\
\hline CHEMBL1979855 & 809283 & 4.1 & 4.4997 & TRN & \\
\hline CHEMBL1970340 & 809283 & 5.6 & 5.9589 & TRN & \\
\hline CHEMBL 2005186 & 809283 & 4.1 & 4.4833 & TRN & \\
\hline CHEMBL1995927 & 809283 & 4.1 & 3.8831 & TST & \\
\hline CHEMBL 2006450 & 809283 & 6.5 & 5.7909 & TRN & \\
\hline CHEMBL 2001987 & 809283 & 4.9 & 4.5775 & TRN & \\
\hline CHEMBL 243518 & 809283 & 4.1 & 4.8136 & TRN & \\
\hline CHEMBL1994555 & 809283 & 4.9 & 5.2278 & TST & \\
\hline CHEMBL1997554 & 809283 & 6.7 & 6.1896 & TRN & \\
\hline CHEMBL1997023 & 809283 & 5.2 & 4.657 & TST & \\
\hline CHEMBL1971943 & 809283 & 6.9 & 6.5015 & TRN & \\
\hline CHEMBL1997924 & 809283 & 7.2 & 6.4336 & TRN & \\
\hline CHEMBL1969049 & 809283 & 7.1 & 6.9043 & TRN & \\
\hline CHEMBL 2005828 & 809283 & 4.1 & 4.2775 & TRN & \\
\hline CHEMBL1991143 & 809283 & 4.1 & 4.3311 & TRN & \\
\hline CHEMBL1998611 & 809283 & 5.6 & 5.7498 & TST & \\
\hline CHEMBL1975900 & 809283 & 6.8 & 6.8059 & TRN & \\
\hline CHEMBL 255822 & 809283 & 4.1 & 3.7329 & TRN & \\
\hline CHEMBL 2006778 & 809283 & 4.1 & $3.9610 e$ & 00000000003 & TRN \\
\hline CHEMBL378627 & 809283 & 4.1 & 3.7322 & TRN & \\
\hline CHEMBL1996979 & 809283 & 4.1 & 4.0421 & TRN & \\
\hline CHEMBL1997025 & 809283 & 4.1 & 3.8482 & TRN & \\
\hline CHEMBL1968406 & 809283 & 4.1 & 4.1206 & TRN & \\
\hline CHEMBL1975921 & 809283 & 3.3 & 3.9112 & TRN & \\
\hline CHEMBL1982476 & 809283 & 4.1 & 4.4414 & TRN & \\
\hline CHEMBL 2005449 & 809283 & 4.9 & 5.5422 & TRN & \\
\hline CHEMBL2006010 & 809283 & 4.1 & 4.4395 & TRN & \\
\hline CHEMBL1682558 & 809283 & 4.1 & 4.6272 & TRN & \\
\hline CHEMBL1990496 & 809283 & 5.7 & 4.7378 & TST & \\
\hline & & & & 11793 & \\
\hline
\end{tabular}




\begin{tabular}{|c|c|c|c|c|c|}
\hline \\
\hline CHEMBL1998068 & 809283 & 6.6 & 6.3709 & TRN & \\
\hline CHEMBL1993166 & 809283 & 4.1 & 5.3886 & TRN & \\
\hline CHEMBL1967094 & 809283 & 4.1 & 4.4293 & TRN & \\
\hline CHEMBL 2003341 & 809283 & 6.7 & 6.8948 & TRN & \\
\hline CHEMBL1992644 & 809283 & 6.1 & 5.3611 & TRN & \\
\hline CHEMBL1992645 & 809283 & 4.1 & 3.9322 & TST & \\
\hline CHEMBL1998110 & 809283 & 4.9 & 5.5663 & TRN & \\
\hline CHEMBL1999590 & 809283 & 4.1 & 4.3112 & TST & \\
\hline CHEMBL1981079 & 809283 & 5.5 & 6.1001 & TRN & \\
\hline CHEMBL1978166 & 809283 & 6.7 & 5.9231 & TRN & \\
\hline CHEMBL1980489 & 809283 & 6.3 & 6.1155 & TRN & \\
\hline CHEMBL 2000832 & 809283 & 4.1 & 4.7601 & TRN & \\
\hline CHEMBL1967116 & 809283 & 4.1 & 4.3274 & TRN & \\
\hline CHEMBL1972454 & 809283 & 3.3 & 4.0826 & TST & \\
\hline CHEMBL1990590 & 809283 & 4.9 & 5.4166 & TRN & \\
\hline CHEMBL1977814 & 809283 & 4.4 & 4.2351 & TRN & \\
\hline CHEMBL513846 & 809283 & 4.1 & 4.0194 & TRN & \\
\hline CHEMBL1974617 & 809283 & 5.3 & 5.5478 & TRN & \\
\hline CHEMBL1965660 & 809283 & 6.4 & 6.9362 & TRN & \\
\hline CHEMBL1998112 & 809283 & 4.1 & 3.4687 & TRN & \\
\hline CHEMBL1969126 & 809283 & 4.1 & $3.8160 e$ & j0000000003 & TRN \\
\hline CHEMBL1980896 & 809283 & 4.1 & 3.5815 & TRN & \\
\hline CHEMBL1975208 & 809283 & 4.1 & 3.6948 & TST & \\
\hline CHEMBL1991429 & 809283 & 4.1 & 4.6068 & TRN & \\
\hline CHEMBL1971149 & 809283 & 4.1 & 4.5292 & TRN & \\
\hline CHEMBL1999714 & 809283 & 4.1 & 3.6129 & TRN & \\
\hline CHEMBL1994040 & 809283 & 4.1 & 4.3753 & TRN & \\
\hline CHEMBL 388978 & 809283 & 9.1 & 8.5644 & TST & \\
\hline CHEMBL 2004716 & 809283 & 4.1 & 4.9579 & TRN & \\
\hline CHEMBL1975233 & 809283 & 4.1 & 4.1024 & TRN & \\
\hline CHEMBL1982135 & 809283 & 4.1 & 3.7044 & TRN & \\
\hline CHEMBL1976090 & 809283 & 5.8 & 5.3833 & TRN & \\
\hline CHEMBL 2004771 & 809283 & 4.1 & 4.4128 & TRN & \\
\hline CHEMBL1992922 & 809283 & 5.8 & 6.0485 & TRN & \\
\hline CHEMBL1997597 & 809283 & 4.1 & 4.5056 & TRN & \\
\hline CHEMBL1976093 & 809283 & 4.1 & 4.4863 & TRN & \\
\hline CHEMBL1996543 & 809283 & 4.1 & 5.7328 & TRN & \\
\hline CHEMBL1975256 & 809283 & 4.1 & 5.1949 & TST & \\
\hline CHEMBL1949855 & 809283 & 5.0 & 4.4404 & TST & \\
\hline CHEMBL1999126 & 809283 & 4.1 & 4.1333 & TST & \\
\hline CHEMBL1997503 & 809283 & 4.1 & 3.7168 & TST & \\
\hline CHEMBL116070 & 809283 & 5.4 & $5.2970 e$ & 0000000001 & TRN \\
\hline CHEMBL1990821 & 809283 & 4.1 & 3.6954 & TST & \\
\hline CHEMBL 2004871 & 809283 & 4.1 & 4.2095 & TRN & \\
\hline CHEMBL 2004872 & 809283 & 6.4 & 6.1381 & TRN & \\
\hline CHEMBL1727312 & 809283 & 3.3 & 3.353 & TRN & \\
\hline CHEMBL1969879 & 809283 & 4.1 & 4.5461 & TRN & \\
\hline CHEMBL1995932 & 809283 & 6.8 & 6.7852 & TRN & \\
\hline
\end{tabular}




\begin{tabular}{|c|c|c|c|c|}
\hline & & & 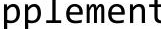 & al \\
\hline CHEMBL1964382 & 809283 & 4.9 & 5.1296 & TST \\
\hline CHEMBL101311 & 809283 & 5.9 & 5.6603 & TRN \\
\hline CHEMBL1981720 & 809283 & 4.1 & 4.7136 & TRN \\
\hline CHEMBL1967704 & 809283 & 5.2 & 5.8262 & TRN \\
\hline CHEMBL419932 & 809283 & 6.6 & 7.0102 & TRN \\
\hline CHEMBL 2005699 & 809283 & 4.9 & 4.8702 & TRN \\
\hline CHEMBL1976328 & 809283 & 4.1 & 4.7424 & TRN \\
\hline CHEMBL1964399 & 809283 & 4.1 & 3.3552 & TRN \\
\hline CHEMBL1996831 & 809283 & 4.1 & 3.6543 & TST \\
\hline CHEMBL1980253 & 809283 & 6.8 & 7.3827 & TRN \\
\hline CHEMBL1978167 & 809283 & 4.9 & 4.865 & TST \\
\hline CHEMBL1969221 & 809283 & 6.2 & 7.0944 & TRN \\
\hline CHEMBL1682357 & 809283 & 6.5 & 5.9301 & TRN \\
\hline CHEMBL225519 & 809283 & 5.7 & 5.9189 & TRN \\
\hline CHEMBL1978200 & 809283 & 4.1 & 4.2059 & TRN \\
\hline CHEMBL1970522 & 809283 & 4.1 & 4.1839 & TRN \\
\hline CHEMBL1990415 & 809283 & 4.1 & 4.383 & TRN \\
\hline CHEMBL1996931 & 809283 & 6.3 & 6.1325 & TRN \\
\hline CHEMBL1964413 & 809283 & 5.3 & 5.2845 & TRN \\
\hline CHEMBL1984432 & 809283 & 7.0 & 5.5261 & TRN \\
\hline CHEMBL1998470 & 809283 & 6.7 & 5.7766 & TRN \\
\hline CHEMBL1996980 & 809283 & 7.9 & 7.8751 & TRN \\
\hline CHEMBL1969920 & 809283 & 7.4 & 7.0742 & TRN \\
\hline CHEMBL1975903 & 809283 & 4.9 & 4.3057 & TRN \\
\hline CHEMBL 2004365 & 809283 & 4.1 & 4.2744 & TST \\
\hline CHEMBL1522508 & 809283 & 3.7 & 4.1179 & TRN \\
\hline CHEMBL1989474 & 809283 & 4.1 & 4.4465 & TRN \\
\hline CHEMBL1090360 & 809283 & 4.1 & 4.3406 & TRN \\
\hline CHEMBL 210887 & 809283 & 4.1 & 3.9385 & TST \\
\hline CHEMBL1969942 & 809283 & 4.9 & 5.0423 & TRN \\
\hline CHEMBL1978567 & 809283 & 4.9 & 5.5663 & TRN \\
\hline CHEMBL1994693 & 809283 & 4.1 & 3.93 & TRN \\
\hline CHEMBL86755 & 809283 & 4.9 & 4.7037 & TRN \\
\hline CHEMBL1975138 & 809283 & 4.1 & 4.1134 & TST \\
\hline CHEMBL424872 & 809283 & 4.3 & 3.8376 & TRN \\
\hline CHEMBL1971947 & 809283 & 4.1 & 4.4727 & TRN \\
\hline CHEMBL 2004447 & 809283 & 4.1 & 4.2166 & TRN \\
\hline CHEMBL1992231 & 809283 & 4.4 & 4.6057 & TRN \\
\hline CHEMBL1983111 & 809283 & 6.9 & 6.9772 & TRN \\
\hline CHEMBL1973860 & 809283 & 4.1 & 3.9743 & TRN \\
\hline CHEMBL1977713 & 809283 & 4.1 & 4.7143 & TRN \\
\hline CHEMBL1983157 & 809283 & 6.4 & 6.244 & TRN \\
\hline CHEMBL1982610 & 809283 & 4.1 & 4.5254 & TRN \\
\hline CHEMBL1999496 & 809283 & 5.5 & 4.5178 & TRN \\
\hline CHEMBL1988300 & 809283 & 4.1 & 4.3766 & TRN \\
\hline CHEMBL1975212 & 809283 & 5.1 & 5.1118 & TRN \\
\hline CHEMBL 2001613 & 809283 & 4.7 & 4.4132 & TRN \\
\hline CHEMBL1993904 & 809283 & 6.2 & 5.6119 & TRN \\
\hline
\end{tabular}




\begin{tabular}{|c|c|c|c|c|}
\hline & & & pplement & al $\mathrm{Ta}$ \\
\hline CHEMBL1982660 & 809283 & 4.9 & 4.6035 & TRN \\
\hline CHEMBL1989265 & 809283 & 4.1 & 4.4067 & TST \\
\hline CHEMBL1965910 & 809283 & 4.1 & 4.1209 & TRN \\
\hline CHEMBL1996447 & 809283 & 5.9 & 6.1335 & TRN \\
\hline CHEMBL1983963 & 809283 & 4.1 & 4.3289 & TRN \\
\hline CHEMBL1985092 & 809283 & 5.6 & 5.7362 & TRN \\
\hline CHEMBL1981410 & 809283 & 4.1 & 4.2025 & TRN \\
\hline CHEMBL 383264 & 809283 & 4.9 & 6.6727 & TRN \\
\hline CHEMBL2007421 & 809283 & 4.9 & 5.2925 & TST \\
\hline CHEMBL1991434 & 809283 & 4.1 & 4.0927 & TST \\
\hline CHEMBL1973138 & 809283 & 4.9 & 4.7454 & TRN \\
\hline CHEMBL340384 & 809283 & 7.2 & 6.6165 & TRN \\
\hline CHEMBL1969151 & 809283 & 7.6 & 8.3834 & TRN \\
\hline CHEMBL1996587 & 809283 & 4.1 & 4.178 & TRN \\
\hline CHEMBL1981492 & 809283 & 5.0 & 3.9289 & TRN \\
\hline CHEMBL1988692 & 809283 & 4.9 & 4.0573 & TRN \\
\hline CHEMBL592030 & 809283 & 7.4 & 7.2021 & TST \\
\hline CHEMBL 2000071 & 809283 & 5.4 & 5.6618 & TRN \\
\hline CHEMBL1979176 & 809283 & 4.1 & 4.3179 & TRN \\
\hline CHEMBL 2002613 & 809283 & 4.4 & 4.6972 & TRN \\
\hline CHEMBL1983195 & 809283 & 4.1 & 3.6551 & TST \\
\hline CHEMBL1964444 & 809283 & 4.1 & 4.2425 & TRN \\
\hline CHEMBL1989957 & 809283 & 4.1 & 4.0469 & TRN \\
\hline CHEMBL1980540 & 809283 & 4.1 & 3.9749 & TRN \\
\hline CHEMBL 278041 & 809283 & 6.0 & 5.3749 & TRN \\
\hline CHEMBL1984162 & 809283 & 5.3 & 4.562 & TRN \\
\hline CHEMBL1998432 & 809283 & 8.0 & 7.7364 & TRN \\
\hline CHEMBL1870106 & 809283 & 8.5 & 7.4945 & TRN \\
\hline CHEMBL1996791 & 809283 & 5.3 & 5.1016 & TRN \\
\hline CHEMBL371206 & 809283 & 4.1 & 3.9093 & TRN \\
\hline CHEMBL1974664 & 809283 & 4.1 & 4.2774 & TST \\
\hline CHEMBL1970104 & 809283 & 5.2 & 5.0936 & TRN \\
\hline CHEMBL482538 & 809283 & 6.8 & 5.7565 & TRN \\
\hline CHEMBL196363 & 809283 & 4.1 & 4.2413 & TRN \\
\hline CHEMBL1996837 & 809283 & 4.4 & 4.3657 & TST \\
\hline CHEMBL1190711 & 809283 & 4.1 & 3.7383 & TRN \\
\hline CHEMBL1964441 & 809283 & 4.9 & 4.3762 & TRN \\
\hline CHEMBL546797 & 809283 & 6.2 & 5.3174 & TRN \\
\hline CHEMBL404367 & 809283 & 4.1 & 4.2911 & TRN \\
\hline CHEMBL1966343 & 809283 & 5.7 & 5.2411 & TRN \\
\hline CHEMBL1967887 & 809283 & 6.6 & 6.8178 & TRN \\
\hline CHEMBL 2000568 & 809283 & 4.4 & 3.9815 & TRN \\
\hline CHEMBL 2000335 & 809283 & 4.1 & 4.0466 & TRN \\
\hline CHEMBL 2007097 & 809283 & 4.3 & 4.2317 & TRN \\
\hline CHEMBL1993648 & 809283 & 5.6 & 5.7867 & TRN \\
\hline CHEMBL243298 & 809283 & 6.2 & 4.9036 & TRN \\
\hline CHEMBL1971951 & 809283 & 4.1 & 4.298 & TRN \\
\hline CHEMBL143703 & 809283 & 3.3 & 3.7209 & TRN \\
\hline
\end{tabular}




\begin{tabular}{|c|c|c|c|c|c|}
\hline \multirow{2}{*}{ CHEMBL1973808 } & \multirow{2}{*}{809283} & \\
\hline & & 4.1 & 4.8103 & TRN & \\
\hline CHEMBL 2000429 & 809283 & 4.1 & 3.7166 & TRN & \\
\hline CHEMBL1972576 & 809283 & 4.1 & 3.99 & TRN & \\
\hline CHEMBL1992555 & 809283 & 4.1 & 4.2212 & TST & \\
\hline CHEMBL 2003682 & 809283 & 5.2 & 5.3905 & TRN & \\
\hline CHEMBL1988173 & 809283 & 4.1 & 4.8527 & TST & \\
\hline CHEMBL535331 & 809283 & 4.1 & 4.176 & TRN & \\
\hline CHEMBL1989805 & 809283 & 4.1 & 3.55899 & 99999999997 & TST \\
\hline CHEMBL1982980 & 809283 & 4.1 & 3.8659 & TST & \\
\hline CHEMBL1983025 & 809283 & 4.1 & 4.4978 & TRN & \\
\hline CHEMBL1975927 & 809283 & 6.2 & 5.5421 & TRN & \\
\hline CHEMBL 2002322 & 809283 & 4.1 & 4.7176 & TRN & \\
\hline CHEMBL1985654 & 809283 & 6.3 & 6.3771 & TRN & \\
\hline CHEMBL1997119 & 809283 & 4.4 & 4.4274 & TRN & \\
\hline CHEMBL 2002323 & 809283 & 4.1 & 4.4216 & TST & \\
\hline CHEMBL 2000879 & 809283 & 4.5 & 4.2208 & TST & \\
\hline CHEMBL1983855 & 809283 & 6.1 & 5.9678 & TRN & \\
\hline CHEMBL 2005548 & 809283 & 6.1 & 5.9232 & TRN & \\
\hline CHEMBL1987793 & 809283 & 4.1 & 4.3235 & TST & \\
\hline CHEMBL21156 & 809283 & 6.3 & 5.1731 & TST & \\
\hline CHEMBL1992740 & 809283 & 4.1 & 4.2764 & TRN & \\
\hline CHEMBL1989267 & 809283 & 5.9 & 5.3164 & TRN & \\
\hline CHEMBL 2002373 & 809283 & 4.1 & 4.3722 & TRN & \\
\hline CHEMBL439340 & 809283 & 4.1 & 3.75399 & 99999999996 & TRN \\
\hline CHEMBL 2006188 & 809283 & 7.1 & 6.63299 & 9999999999 & TRN \\
\hline CHEMBL1973893 & 809283 & 4.1 & 4.1202 & TRN & \\
\hline CHEMBL 2004631 & 809283 & 6.2 & 6.7276 & TRN & \\
\hline CHEMBL1995736 & 809283 & 4.1 & 4.2883 & TRN & \\
\hline CHEMBL1985095 & 809283 & 6.2 & 6.3917 & TST & \\
\hline CHEMBL1996500 & 809283 & 4.6 & 4.4542 & TRN & \\
\hline CHEMBL1973363 & 809283 & 6.0 & 5.2231 & TRN & \\
\hline CHEMBL1682540 & 809283 & 5.3 & 5.3328 & TRN & \\
\hline CHEMBL413779 & 809283 & 4.1 & 5.1344 & TST & \\
\hline CHEMBL497151 & 809283 & 5.4 & 5.0278 & TRN & \\
\hline CHEMBL 2000029 & 809283 & 8.1 & 7.9315 & TRN & \\
\hline CHEMBL1973961 & 809283 & 4.7 & 3.9939 & TRN & \\
\hline CHEMBL1994977 & 809283 & 4.9 & 4.8839 & TRN & \\
\hline CHEMBL 373598 & 809283 & 4.1 & 5.0102 & TST & \\
\hline CHEMBL1999718 & 809283 & 4.1 & 4.135 & TRN & \\
\hline CHEMBL1987073 & 809283 & 4.5 & 5.3376 & TRN & \\
\hline CHEMBL 2000078 & 809283 & 4.9 & 5.1169 & TRN & \\
\hline CHEMBL1996646 & 809283 & 5.9 & 5.5184 & TRN & \\
\hline CHEMBL1979773 & 809283 & 4.9 & 5.15600 & 0000000001 & TRN \\
\hline CHEMBL1977346 & 809283 & 4.1 & 3.5414 & TRN & \\
\hline CHEMBL1996702 & 809283 & 4.9 & 4.7349 & TRN & \\
\hline CHEMBL1975440 & 809283 & 5.7 & 5.7811 & TRN & \\
\hline CHEMBL1998435 & 809283 & 4.1 & 4.467 & TRN & \\
\hline CHEMBL1969190 & 809283 & 4.1 & 3.8168 & TRN & \\
\hline
\end{tabular}




\begin{tabular}{|c|c|c|c|c|c|}
\hline \multicolumn{6}{|c|}{ Supplemental Table S2.txt } \\
\hline CHEMBL1973937 & 809283 & 4.1 & 4.6935 & TRN & \\
\hline CHEMBL1982711 & 809283 & 7.1 & 6.8777 & TRN & \\
\hline CHEMBL1987982 & 809283 & 4.1 & 4.1778 & TST & \\
\hline CHEMBL1969102 & 809283 & 5.3 & 4.3443 & TRN & \\
\hline CHEMBL 2004118 & 809283 & 4.9 & \multicolumn{2}{|c|}{5.5120000000000005} & TRN \\
\hline CHEMBL1682346 & 809283 & 6.5 & 5.8388 & TRN & \\
\hline CHEMBL1994241 & 809283 & 4.1 & 4.6328 & TRN & \\
\hline CHEMBL 2007044 & 809283 & 4.1 & 4.0623 & TST & \\
\hline CHEMBL 2001998 & 809283 & 4.1 & 3.5495 & TST & \\
\hline CHEMBL50894 & 809283 & 4.4 & 4.5613 & TRN & \\
\hline CHEMBL1995211 & 809283 & 6.5 & 6.3048 & TRN & \\
\hline CHEMBL1988838 & 809283 & 6.3 & 5.3047 & TRN & \\
\hline CHEMBL1981725 & 809283 & 4.1 & 4.2804 & TRN & \\
\hline CHEMBL1982753 & 809283 & 5.9 & 5.5523 & TRN & \\
\hline CHEMBL1965169 & 809283 & 4.9 & 4.9608 & TST & \\
\hline CHEMBL1081312 & 809283 & 6.1 & 6.1449 & TRN & \\
\hline CHEMBL1965170 & 809283 & 6.1 & 4.6312 & TRN & \\
\hline CHEMBL2004156 & 809283 & 4.1 & 4.2907 & TRN & \\
\hline CHEMBL 2005792 & 809283 & 4.4 & 4.4165 & TRN & \\
\hline CHEMBL1984206 & 809283 & 4.1 & 4.3942 & TRN & \\
\hline CHEMBL462120 & 809283 & 4.1 & 4.4264 & TST & \\
\hline CHEMBL1991577 & 809283 & 4.1 & 4.2897 & TRN & \\
\hline CHEMBL 2007592 & 809283 & 4.1 & 3.9589 & TRN & \\
\hline CHEMBL1997892 & 809283 & 4.9 & 5.3547 & TRN & \\
\hline CHEMBL1976936 & 809283 & 7.1 & 6.9277 & TRN & \\
\hline CHEMBL210963 & 809283 & 4.1 & 4.1007 & TRN & \\
\hline CHEMBL1984633 & 809283 & 6.2 & 5.7928 & TRN & \\
\hline CHEMBL1982400 & 809283 & 5.4 & 5.5841 & TRN & \\
\hline CHEMBL1965845 & 809283 & 7.9 & 7.0225 & TRN & \\
\hline CHEMBL1983715 & 809283 & 6.3 & \multicolumn{2}{|c|}{5.9079999999999995} & TRN \\
\hline CHEMBL402846 & 809283 & 4.1 & 4.2732 & TRN & \\
\hline CHEMBL1682545 & 809283 & 4.1 & 4.9901 & TRN & \\
\hline CHEMBL1976732 & 809283 & 4.1 & 3.8188 & TRN & \\
\hline CHEMBL1982982 & 809283 & 4.1 & 5.2816 & TRN & \\
\hline CHEMBL1980163 & 809283 & 4.1 & 3.8906 & TRN & \\
\hline CHEMBL1989856 & 809283 & 4.1 & 4.3628 & TST & \\
\hline CHEMBL1972568 & 809283 & 5.5 & 5.6765 & TRN & \\
\hline CHEMBL259850 & 809283 & 4.1 & 4.2525 & TRN & \\
\hline CHEMBL1987745 & 809283 & 6.1 & \multicolumn{2}{|c|}{5.3229999999999995} & TRN \\
\hline CHEMBL105739 & 809283 & 4.1 & 4.2469 & TRN & \\
\hline CHEMBL203673 & 809283 & 6.9 & 7.3894 & TRN & \\
\hline CHEMBL1972583 & 809283 & 3.3 & 3.7758 & TRN & \\
\hline CHEMBL 2003785 & 809283 & 5.0 & 4.9372 & TRN & \\
\hline CHEMBL1983070 & 809283 & 4.9 & 5.23 & TRN & \\
\hline CHEMBL1981045 & 809283 & 4.1 & 3.8148 & TRN & \\
\hline CHEMBL387971 & 809283 & 4.1 & 3.6804 & TST & \\
\hline CHEMBL1975418 & 809283 & 6.5 & 7.0191 & TRN & \\
\hline CHEMBL1992796 & 809283 & 6.0 & 4.8818 & TST & \\
\hline
\end{tabular}




\begin{tabular}{|c|c|c|c|c|}
\hline & & & pplement & al $\mathrm{Ta}$ \\
\hline CHEMBL1968515 & 809283 & 4.4 & 4.3701 & TST \\
\hline CHEMBL1164180 & 809283 & 4.8 & 5.2797 & TST \\
\hline CHEMBL223257 & 809283 & 4.1 & 4.9229 & TST \\
\hline CHEMBL1516890 & 809283 & 4.1 & 5.0721 & TRN \\
\hline CHEMBL 2001751 & 809283 & 7.9 & 7.5324 & TRN \\
\hline CHEMBL1984586 & 809283 & 4.1 & 4.0556 & TRN \\
\hline CHEMBL1999774 & 809283 & 4.1 & 4.052 & TST \\
\hline CHEMBL1972659 & 809283 & 6.4 & 5.3144 & TST \\
\hline CHEMBL1973395 & 809283 & 5.9 & 5.7441 & TRN \\
\hline CHEMBL1969843 & 809283 & 4.1 & 4.5861 & TRN \\
\hline CHEMBL 2007002 & 809283 & 4.1 & 3.7062 & TRN \\
\hline CHEMBL1992073 & 809283 & 6.7 & 6.2786 & TRN \\
\hline CHEMBL484390 & 809283 & 4.1 & 4.3887 & TST \\
\hline CHEMBL 2007559 & 809283 & 4.9 & 5.5494 & TRN \\
\hline CHEMBL 2004290 & 809283 & 4.4 & 4.5369 & TRN \\
\hline CHEMBL 2000393 & 809283 & 4.1 & 5.4439 & TST \\
\hline CHEMBL 2004072 & 809283 & 4.1 & 4.3677 & TRN \\
\hline CHEMBL1983573 & 809283 & 3.3 & 4.0498 & TRN \\
\hline CHEMBL1242373 & 809283 & 4.1 & 4.0216 & TRN \\
\hline CHEMBL 2000433 & 809283 & 4.1 & 4.4065 & TST \\
\hline CHEMBL56543 & 809283 & 4.1 & 4.7609 & TST \\
\hline CHEMBL1984402 & 809283 & 3.3 & 3.8812 & TRN \\
\hline CHEMBL1988075 & 809283 & 4.1 & 3.8203 & TRN \\
\hline CHEMBL1988076 & 809283 & 4.9 & 4.8038 & TRN \\
\hline CHEMBL 2001239 & 809283 & 4.1 & 6.4439 & TST \\
\hline CHEMBL 2001288 & 809283 & 4.1 & 4.6578 & TRN \\
\hline CHEMBL1992363 & 809283 & 6.4 & 5.5505 & TRN \\
\hline CHEMBL1999811 & 809283 & 5.7 & 5.2135 & TRN \\
\hline CHEMBL 235157 & 809283 & 4.9 & 4.3988 & TST \\
\hline CHEMBL 2000481 & 809283 & 5.3 & 4.9893 & TRN \\
\hline CHEMBL1992242 & 809283 & 4.1 & 4.3932 & TRN \\
\hline CHEMBL1982271 & 809283 & 7.6 & 7.9781 & TRN \\
\hline CHEMBL 2007138 & 809283 & 3.7 & 3.9951 & TST \\
\hline CHEMBL 2004159 & 809283 & 6.5 & 5.5754 & TRN \\
\hline CHEMBL1986530 & 809283 & 4.1 & 4.0791 & TST \\
\hline CHEMBL440084 & 809283 & 4.9 & 4.9138 & TRN \\
\hline CHEMBL1999321 & 809283 & 4.1 & 4.6273 & TRN \\
\hline CHEMBL1968590 & 809283 & 4.1 & 3.9828 & TRN \\
\hline CHEMBL 2005375 & 809283 & 4.1 & 3.6679 & TRN \\
\hline CHEMBL1972183 & 809283 & 4.1 & 4.6277 & TST \\
\hline CHEMBL1995391 & 809283 & 3.7 & 4.117 & TRN \\
\hline CHEMBL1980592 & 809283 & 4.1 & 4.2122 & TRN \\
\hline CHEMBL1974702 & 809283 & 4.1 & 4.569 & TST \\
\hline CHEMBL474432 & 809283 & 4.1 & 4.2034 & TST \\
\hline CHEMBL1965387 & 809283 & 4.9 & 4.9079 & TRN \\
\hline CHEMBL 2001539 & 809283 & 4.8 & 4.7612 & TST \\
\hline CHEMBL1997041 & 809283 & 5.6 & 5.7739 & TRN \\
\hline CHEMBL550418 & 809283 & 4.9 & 4.2096 & TRN \\
\hline
\end{tabular}




\begin{tabular}{|c|c|c|c|c|c|}
\hline & & & & & \\
\hline CHEMBL2003637 & 809283 & 4.1 & 3.639 & TST & \\
\hline CHEMBL1986666 & 809283 & 5.4 & 5.3361 & TRN & \\
\hline CHEMBL1971289 & 809283 & 4.9 & 4.7837 & TRN & \\
\hline CHEMBL1999556 & 809283 & 5.7 & 5.3937 & TRN & \\
\hline CHEMBL1988437 & 809283 & 4.5 & 3.9674 & TRN & \\
\hline CHEMBL1991800 & 809283 & 4.1 & 4.3691 & TRN & \\
\hline CHEMBL379835 & 809283 & 4.1 & 4.2899 & TRN & \\
\hline CHEMBL1980802 & 809283 & 4.1 & 4.6054 & TST & \\
\hline CHEMBL1996649 & 809283 & 4.9 & 4.6377 & TRN & \\
\hline CHEMBL1979554 & 809283 & 7.8 & 7.0427 & TRN & \\
\hline CHEMBL1986756 & 809283 & 4.9 & 4.7508 & TRN & \\
\hline CHEMBL3197315 & 809283 & 4.1 & 5.3313 & TST & \\
\hline CHEMBL468280 & 809283 & 4.1 & 4.5799 & TST & \\
\hline CHEMBL1990884 & 809283 & 4.1 & 4.3639 & TRN & \\
\hline CHEMBL 3109278 & 809283 & 4.7 & 4.5674 & TRN & \\
\hline CHEMBL2006276 & 809283 & 4.1 & 4.3169 & TRN & \\
\hline CHEMBL191003 & 809283 & 4.5 & 4.7747 & TRN & \\
\hline CHEMBL 2006785 & 809283 & 4.1 & 4.5116 & TST & \\
\hline CHEMBL1973359 & 809283 & 6.3 & 5.4941 & TST & \\
\hline CHEMBL1995740 & 809283 & 4.1 & 3.9597 & TRN & \\
\hline CHEMBL1979690 & 809283 & 7.0 & 6.9741 & TRN & \\
\hline CHEMBL1995832 & 809283 & 4.1 & 3.9314 & TRN & \\
\hline CHEMBL 2000345 & 809283 & 4.1 & 4.5076 & TRN & \\
\hline CHEMBL1988622 & 809283 & 5.3 & 4.9801 & TRN & \\
\hline CHEMBL1983575 & 809283 & 6.5 & 6.6936 & TRN & \\
\hline CHEMBL1375418 & 809283 & 4.1 & 4.2185 & TRN & \\
\hline CHEMBL 302449 & 809283 & 6.8 & 6.3289 & TST & \\
\hline CHEMBL1981047 & 809283 & 4.5 & 3.8383 & TRN & \\
\hline CHEMBL1976196 & 809283 & 4.9 & 4.3936 & TST & \\
\hline CHEMBL 2002432 & 809283 & 4.9 & 4.4968 & TRN & \\
\hline CHEMBL1976240 & 809283 & 8.3 & 8.0265 & TRN & \\
\hline CHEMBL1987948 & 809283 & 6.8 & 6.9782 & TRN & \\
\hline CHEMBL1983630 & 809283 & 3.3 & 3.90100 & 00000000002 & TRN \\
\hline CHEMBL1979093 & 809283 & 4.1 & 4.1309 & TRN & \\
\hline CHEMBL336961 & 809283 & 4.1 & 3.9932 & TRN & \\
\hline CHEMBL1970083 & 809283 & 4.1 & 4.7783 & TRN & \\
\hline CHEMBL1994938 & 809283 & 4.1 & 4.2915 & TRN & \\
\hline CHEMBL1977223 & 809283 & 5.2 & 4.6215 & TRN & \\
\hline CHEMBL1976290 & 809283 & 3.3 & 3.5521 & TRN & \\
\hline CHEMBL1236126 & 809283 & 4.1 & 3.8758 & TST & \\
\hline CHEMBL1997846 & 809283 & 6.4 & 6.5297 & TRN & \\
\hline CHEMBL 2004419 & 809283 & 4.1 & 4.0287 & TRN & \\
\hline CHEMBL1992937 & 809283 & 4.5 & 3.9835 & TST & \\
\hline CHEMBL1985566 & 809283 & 4.1 & 4.1436 & TRN & \\
\hline CHEMBL1972119 & 809283 & 4.1 & 3.6715 & TRN & \\
\hline CHEMBL95692 & 809283 & 5.9 & 4.6446 & TRN & \\
\hline CHEMBL1976455 & 809283 & 4.1 & 4.5678 & TRN & \\
\hline CHEMBL1983923 & 809283 & 4.5 & 5.07600 & 00000000005 & TRN \\
\hline & & & & 11800 & \\
\hline
\end{tabular}




\begin{tabular}{|c|c|c|c|c|}
\hline \multicolumn{5}{|c|}{ Supplemental Table S2.txt } \\
\hline CHEMBL1983534 & 809283 & 6.7 & 6.4407 & TRN \\
\hline CHEMBL1982361 & 809283 & 6.4 & 6.0153 & TRN \\
\hline CHEMBL 2000801 & 809283 & 4.1 & 4.3443 & TRN \\
\hline CHEMBL1991395 & 809283 & 4.1 & 4.1675 & TRN \\
\hline CHEMBL1971245 & 809283 & 4.1 & 3.4775 & TRN \\
\hline CHEMBL1987648 & 809283 & 4.1 & 4.3338 & TRN \\
\hline CHEMBL1972142 & 809283 & 4.1 & 3.7788 & TRN \\
\hline CHEMBL1966514 & 809283 & 4.1 & 3.7924 & TRN \\
\hline CHEMBL 2003638 & 809283 & 5.9 & 5.3377 & TRN \\
\hline CHEMBL1983393 & 809283 & 6.1 & 4.9528 & TRN \\
\hline CHEMBL516429 & 809283 & 8.0 & 7.3751 & TRN \\
\hline CHEMBL1970806 & 809283 & 4.1 & 3.9233 & TRN \\
\hline CHEMBL1992371 & 809283 & 4.9 & 4.8608 & TRN \\
\hline CHEMBL1979970 & 809283 & 4.1 & 4.1296 & TRN \\
\hline CHEMBL1967252 & 809283 & 5.6 & 5.6276 & TRN \\
\hline CHEMBL1970821 & 809283 & 6.6 & 6.6013 & TRN \\
\hline CHEMBL 2004637 & 809283 & 6.2 & 5.7878 & TRN \\
\hline CHEMBL1969264 & 809283 & 4.1 & 4.0697 & TRN \\
\hline CHEMBL 2006237 & 809283 & 4.1 & 3.7508 & TRN \\
\hline CHEMBL 2005509 & 809283 & 7.5 & 7.6072 & TRN \\
\hline CHEMBL1572266 & 809283 & 4.1 & 4.0143 & TST \\
\hline CHEMBL1979516 & 809283 & 4.1 & 3.9013 & TRN \\
\hline CHEMBL1972820 & 809283 & 4.1 & 4.1371 & TST \\
\hline CHEMBL1605605 & 809283 & 4.9 & 5.6548 & TRN \\
\hline CHEMBL1989029 & 809283 & 4.1 & 3.3304 & TRN \\
\hline CHEMBL392642 & 809283 & 4.1 & 4.6764 & TRN \\
\hline CHEMBL1682554 & 809283 & 6.0 & 6.2035 & TRN \\
\hline CHEMBL1980167 & 809283 & 6.0 & 4.2391 & TST \\
\hline CHEMBL1972849 & 809283 & 4.1 & 3.9815 & TRN \\
\hline CHEMBL1986855 & 809283 & 7.1 & 7.0395 & TRN \\
\hline CHEMBL1975357 & 809283 & 4.1 & 4.3489 & TST \\
\hline CHEMBL1989136 & 809283 & 5.9 & 5.0041 & TRN \\
\hline CHEMBL259922 & 809283 & 4.1 & 4.3047 & TST \\
\hline CHEMBL1997617 & 809283 & 4.1 & 4.3154 & TRN \\
\hline CHEMBL1969301 & 809283 & 4.1 & 4.3235 & TST \\
\hline CHEMBL1983932 & 809283 & 4.1 & 4.2764 & TRN \\
\hline CHEMBL1987910 & 809283 & 4.1 & 4.3904 & TRN \\
\hline CHEMBL1983980 & 809283 & 6.0 & 5.7855 & TST \\
\hline CHEMBL1973399 & 809283 & 3.3 & 3.4737 & TST \\
\hline CHEMBL1966069 & 809283 & 6.3 & 6.0787 & TRN \\
\hline CHEMBL1986899 & 809283 & 4.9 & 5.2081 & TRN \\
\hline CHEMBL 243088 & 809283 & 5.7 & 5.3848 & TRN \\
\hline CHEMBL1993661 & 809283 & 7.1 & 7.9368 & TRN \\
\hline CHEMBL1834385 & 809283 & 5.4 & 4.8491 & TRN \\
\hline CHEMBL202721 & 809283 & 4.9 & 4.8365 & TRN \\
\hline CHEMBL1987034 & 809283 & 7.0 & 6.0361 & TRN \\
\hline CHEMBL 2005886 & 809283 & 6.0 & 4.6469 & TST \\
\hline CHEMBL1682345 & 809283 & 6.9 & 5.8614 & TRN \\
\hline
\end{tabular}




\begin{tabular}{|c|c|c|c|c|c|}
\hline \multicolumn{6}{|c|}{ Supplemental Table s2.txt } \\
\hline CHEMBL481491 & 809283 & 4.1 & 4.1653 & TST & \\
\hline CHEMBL388311 & 809283 & 8.9 & 8.2783 & TRN & \\
\hline CHEMBL1807515 & 809283 & 7.3 & 7.9091 & TRN & \\
\hline CHEMBL2005936 & 809283 & 7.2 & 6.5936 & TRN & \\
\hline CHEMBL1987430 & 809283 & 4.9 & 4.4985 & TRN & \\
\hline CHEMBL1562756 & 809283 & 4.1 & 4.5566 & TST & \\
\hline CHEMBL1993413 & 809283 & 4.6 & 4.8605 & TRN & \\
\hline CHEMBL1969372 & 809283 & 4.1 & 3.9366 & TRN & \\
\hline CHEMBL2001957 & 809283 & 4.1 & 4.32100 & 0000000001 & TRN \\
\hline CHEMBL1988662 & 809283 & 5.5 & 6.0604 & TRN & \\
\hline CHEMBL1986263 & 809283 & 4.1 & 4.4958 & TRN & \\
\hline CHEMBL1986265 & 809283 & 4.9 & 4.6998 & TST & \\
\hline CHEMBL1964644 & 809283 & 4.1 & 4.3907 & TRN & \\
\hline CHEMBL1967211 & 809283 & 3.3 & 3.7423 & TRN & \\
\hline CHEMBL1981782 & 809283 & 6.7 & 6.977 & TRN & \\
\hline CHEMBL1970142 & 809283 & 4.1 & 4.4339 & TRN & \\
\hline CHEMBL1977681 & 809283 & 4.1 & 3.69199 & 99999999997 & TRN \\
\hline CHEMBL2002105 & 809283 & 4.4 & 4.6233 & TRN & \\
\hline CHEMBL1983348 & 809283 & 6.0 & 6.0385 & TRN & \\
\hline CHEMBL1995592 & 809283 & 5.9 & 5.8138 & TRN & \\
\hline CHEMBL1986177 & 809283 & 4.9 & 4.8489 & TRN & \\
\hline CHEMBL1982541 & 809283 & 4.1 & 3.8887 & TRN & \\
\hline CHEMBL1992323 & 809283 & 4.1 & 4.2185 & TST & \\
\hline CHEMBL1983449 & 809283 & 5.9 & 5.6673 & TRN & \\
\hline CHEMBL1983589 & 809283 & 7.1 & 7.6247 & TRN & \\
\hline CHEMBL1996510 & 809283 & 7.5 & 5.7654 & TST & \\
\hline CHEMBL 2005718 & 809283 & 7.4 & 6.6667 & TRN & \\
\hline CHEMBL437747 & 809283 & 6.1 & 5.9852 & TRN & \\
\hline CHEMBL1995172 & 809283 & 3.5 & 4.0303 & TST & \\
\hline CHEMBL507936 & 809283 & 4.1 & 3.7728 & TRN & \\
\hline CHEMBL2001584 & 809283 & 4.9 & 4.8718 & TRN & \\
\hline CHEMBL1967998 & 809283 & 7.0 & 7.171 & TRN & \\
\hline CHEMBL104264 & 809283 & 7.9 & 6.1589 & TST & \\
\hline CHEMBL1997129 & 809283 & 4.1 & 4.935 & TRN & \\
\hline CHEMBL1984788 & 809283 & 4.1 & 3.9437 & TRN & \\
\hline CHEMBL451964 & 809283 & 4.1 & 3.8975 & TRN & \\
\hline CHEMBL1974875 & 809283 & 4.3 & 3.9076 & TST & \\
\hline CHEMBL2001547 & 809283 & 4.1 & 4.2528 & TRN & \\
\hline CHEMBL 210928 & 809283 & 4.1 & 3.9857 & TRN & \\
\hline CHEMBL1972840 & 809283 & 7.2 & 7.0925 & TRN & \\
\hline CHEMBL 2001668 & 809283 & 4.1 & 4.6033 & TRN & \\
\hline CHEMBL1998585 & 809283 & 4.1 & 4.0905 & TRN & \\
\hline CHEMBL 2004934 & 809283 & 7.3 & 6.7827 & TRN & \\
\hline CHEMBL1987261 & 809283 & 7.4 & 7.3088 & TRN & \\
\hline CHEMBL1996048 & 809283 & 6.9 & 5.6097 & TST & \\
\hline CHEMBL 2004025 & 809283 & 6.0 & 4.8759 & TST & \\
\hline CHEMBL461876 & 809283 & 4.9 & 5.1479 & TST & \\
\hline CHEMBL1971519 & 809283 & 7.1 & 6.3114 & TRN & \\
\hline
\end{tabular}




\begin{tabular}{|c|c|c|c|c|}
\hline & & & pl & \\
\hline CHEMBL1997335 & 809283 & 4.9 & 5.1908 & TRN \\
\hline CHEMBL1978099 & 809283 & 5.2 & 4.5849 & TRN \\
\hline CHEMBL1984363 & 809283 & 6.1 & 6.1668 & TRN \\
\hline CHEMBL1977041 & 809283 & 4.1 & 4.6477 & TRN \\
\hline CHEMBL1968070 & 809283 & 4.1 & 3.793 & TRN \\
\hline CHEMBL1985723 & 809283 & 7.7 & 7.3298 & TRN \\
\hline CHEMBL1984367 & 809283 & 4.1 & 3.9759 & TRN \\
\hline CHEMBL1977128 & 809283 & 4.4 & 5.1827 & TRN \\
\hline CHEMBL1997759 & 809283 & 4.1 & 4.0864 & TRN \\
\hline CHEMBL1970074 & 809283 & 4.1 & 4.9511 & TRN \\
\hline CHEMBL1974803 & 809283 & 4.1 & 4.797 & TST \\
\hline CHEMBL 2005112 & 809283 & 4.1 & 4.3342 & TST \\
\hline CHEMBL 2003456 & 809283 & 4.1 & 3.633 & TRN \\
\hline CHEMBL1966816 & 809283 & 4.1 & 4.1777 & TRN \\
\hline CHEMBL 2002992 & 809283 & 7.1 & 6.2907 & TRN \\
\hline CHEMBL560813 & 809283 & 4.1 & 4.3196 & TRN \\
\hline CHEMBL207253 & 809283 & 4.1 & 4.448 & TRN \\
\hline CHEMBL1968791 & 809283 & 4.1 & 3.9173 & TRN \\
\hline CHEMBL 2002682 & 809283 & 4.1 & 4.4324 & TST \\
\hline CHEMBL1984700 & 809283 & 4.1 & 3.8542 & TRN \\
\hline CHEMBL1998953 & 809283 & 4.4 & 4.9593 & TRN \\
\hline CHEMBL 2007151 & 809283 & 4.1 & 3.9208 & TRN \\
\hline CHEMBL1971606 & 809283 & 6.0 & 6.6076 & TRN \\
\hline CHEMBL1972125 & 809283 & 4.1 & 4.1526 & TRN \\
\hline CHEMBL1461728 & 809283 & 4.1 & 4.4497 & TRN \\
\hline CHEMBL1999279 & 809283 & 7.9 & 7.1518 & TRN \\
\hline CHEMBL1995448 & 809283 & 5.8 & 5.0556 & TRN \\
\hline CHEMBL1972158 & 809283 & 7.3 & 7.1033 & TRN \\
\hline CHEMBL1999414 & 809283 & 4.9 & 4.9284 & TRN \\
\hline CHEMBL1967336 & 809283 & 4.9 & 4.5647 & TRN \\
\hline CHEMBL 2006481 & 809283 & 4.1 & 4.0948 & TRN \\
\hline CHEMBL1967992 & 809283 & 6.4 & 6.0043 & TRN \\
\hline CHEMBL1993424 & 809283 & 4.1 & 5.1409 & TRN \\
\hline CHEMBL1975534 & 809283 & 5.2 & 4.9519 & TRN \\
\hline CHEMBL1966703 & 809283 & 4.1 & 4.3934 & TST \\
\hline CHEMBL1969561 & 809283 & 6.6 & 6.7444 & TRN \\
\hline CHEMBL1983640 & 809283 & 4.9 & 4.938 & TRN \\
\hline CHEMBL1964687 & 809283 & 4.1 & 4.3385 & TRN \\
\hline CHEMBL1999918 & 809283 & 5.5 & 5.8896 & TRN \\
\hline CHEMBL1974254 & 809283 & 4.1 & 4.5792 & TRN \\
\hline CHEMBL1988537 & 809283 & 5.7 & 5.6594 & TST \\
\hline CHEMBL 2002240 & 809283 & 4.1 & 3.9405 & TRN \\
\hline CHEMBL1978267 & 809283 & 4.9 & 4.6505 & TRN \\
\hline CHEMBL1980178 & 809283 & 6.8 & 6.9884 & TRN \\
\hline CHEMBL485556 & 809283 & 4.1 & 4.1369 & TST \\
\hline CHEMBL1981511 & 809283 & 4.1 & 4.0866 & TRN \\
\hline CHEMBL1972221 & 809283 & 4.1 & 4.2876 & TRN \\
\hline CHEMBL1984274 & 809283 & 4.1 & 4.7474 & TST \\
\hline
\end{tabular}




\begin{tabular}{|c|c|c|c|c|}
\hline & & & CIIC & al Ta \\
\hline CHEMBL1998545 & 809283 & 6.6 & 6.4743 & TRN \\
\hline CHEMBL1986869 & 809283 & 4.1 & 4.6462 & TRN \\
\hline CHEMBL1971534 & 809283 & 5.4 & 5.1373 & TRN \\
\hline CHEMBL 242865 & 809283 & 4.9 & 4.7948 & TRN \\
\hline CHEMBL1997623 & 809283 & 4.1 & 4.2638 & TRN \\
\hline CHEMBL 2002479 & 809283 & 5.1 & 4.601 & TRN \\
\hline CHEMBL1966035 & 809283 & 4.1 & 4.5281 & TRN \\
\hline CHEMBL1990708 & 809283 & 4.1 & 4.783 & TRN \\
\hline CHEMBL1982992 & 809283 & 5.2 & 5.033 & TRN \\
\hline CHEMBL1972276 & 809283 & 4.1 & 3.9458 & TRN \\
\hline CHEMBL1970709 & 809283 & 6.5 & 6.3967 & TRN \\
\hline CHEMBL1992125 & 809283 & 6.0 & 5.5957 & TRN \\
\hline CHEMBL1972290 & 809283 & 7.8 & 7.4719 & TRN \\
\hline CHEMBL1964777 & 809283 & 5.5 & 4.8556 & TRN \\
\hline CHEMBL1987533 & 809283 & 4.1 & 4.7935 & TRN \\
\hline CHEMBL1984548 & 809283 & 7.6 & 7.4129 & TRN \\
\hline CHEMBL579246 & 809283 & 6.4 & 6.3299 & TRN \\
\hline CHEMBL398951 & 809283 & 4.5 & 4.0072 & TST \\
\hline CHEMBL1982506 & 809283 & 4.1 & 3.8099 & TST \\
\hline CHEMBL1968127 & 809283 & 4.1 & 4.3022 & TRN \\
\hline CHEMBL1985406 & 809283 & 4.1 & 4.1314 & TRN \\
\hline CHEMBL 2000894 & 809283 & 6.1 & 6.0058 & TRN \\
\hline CHEMBL 207400 & 809283 & 4.1 & 4.3139 & TRN \\
\hline CHEMBL1968130 & 809283 & 3.3 & 4.2959 & TRN \\
\hline CHEMBL1993243 & 809283 & 4.1 & 4.0126 & TRN \\
\hline CHEMBL 399021 & 809283 & 4.1 & 4.2077 & TRN \\
\hline CHEMBL1969537 & 809283 & 4.1 & 4.3459 & TST \\
\hline CHEMBL210032 & 809283 & 4.1 & 4.2613 & TRN \\
\hline CHEMBL508928 & 809283 & 4.1 & 4.0035 & TRN \\
\hline CHEMBL1991356 & 809283 & 4.1 & 3.8388 & TST \\
\hline CHEMBL1983309 & 809283 & 4.1 & 4.1595 & TRN \\
\hline CHEMBL 2004892 & 809283 & 4.1 & 4.6028 & TRN \\
\hline CHEMBL1972339 & 809283 & 8.2 & 7.6906 & TRN \\
\hline CHEMBL1970314 & 809283 & 4.1 & 3.4986 & TRN \\
\hline CHEMBL 262433 & 809283 & 4.1 & 3.9576 & TRN \\
\hline CHEMBL 306380 & 809283 & 5.8 & 5.6895 & TRN \\
\hline CHEMBL1966722 & 809283 & 4.1 & 4.4808 & TST \\
\hline CHEMBL1983595 & 809283 & 4.4 & 4.9922 & TRN \\
\hline CHEMBL1988581 & 809283 & 7.1 & 6.2627 & TST \\
\hline CHEMBL1975500 & 809283 & 4.1 & 3.9893 & TRN \\
\hline CHEMBL394619 & 809283 & 4.1 & 4.5738 & TRN \\
\hline CHEMBL 2006564 & 809283 & 6.1 & 5.7285 & TRN \\
\hline CHEMBL411903 & 809283 & 4.1 & 4.0521 & TRN \\
\hline CHEMBL1965988 & 809283 & 4.1 & 4.5259 & TRN \\
\hline CHEMBL418203 & 809283 & 4.4 & 5.3704 & TST \\
\hline CHEMBL1989646 & 809283 & 6.1 & 6.7274 & TRN \\
\hline CHEMBL 209534 & 809283 & 4.1 & 4.2316 & TRN \\
\hline CHEMBL1994159 & 809283 & 4.4 & 3.8889 & TRN \\
\hline
\end{tabular}




\begin{tabular}{|c|c|c|c|c|}
\hline & & & EII & al Ta \\
\hline CHEMBL1966087 & 809283 & 6.4 & 6.0884 & TRN \\
\hline CHEMBL1964692 & 809283 & 4.1 & 4.1483 & TRN \\
\hline CHEMBL1986767 & 809283 & 5.3 & 5.0708 & TRN \\
\hline CHEMBL1973483 & 809283 & 4.1 & 4.3726 & TRN \\
\hline CHEMBL 219722 & 809283 & 5.7 & 5.6595 & TRN \\
\hline CHEMBL1970735 & 809283 & 4.1 & 3.8538 & TRN \\
\hline CHEMBL1997340 & 809283 & 4.1 & 4.2482 & TRN \\
\hline CHEMBL1994669 & 809283 & 7.8 & 7.4159 & TRN \\
\hline CHEMBL 226232 & 809283 & 4.1 & 4.4116 & TRN \\
\hline CHEMBL458997 & 809283 & 4.4 & 5.0431 & TRN \\
\hline CHEMBL1988805 & 809283 & 5.9 & 4.5368 & TST \\
\hline CHEMBL1971021 & 809283 & 4.1 & 4.4672 & TRN \\
\hline CHEMBL1974310 & 809283 & 5.4 & 5.102 & TRN \\
\hline CHEMBL583144 & 809283 & 4.1 & 5.1194 & TST \\
\hline CHEMBL1982957 & 809283 & 4.1 & 4.7312 & TRN \\
\hline CHEMBL1725279 & 809283 & 4.1 & 5.0223 & TST \\
\hline CHEMBL 2002346 & 809283 & 7.2 & 6.9748 & TRN \\
\hline CHEMBL 2006836 & 809283 & 4.1 & 4.3132 & TST \\
\hline CHEMBL412142 & 809283 & 4.1 & 5.1675 & TST \\
\hline CHEMBL1985153 & 809283 & 4.1 & 4.8653 & TRN \\
\hline CHEMBL 2003271 & 809283 & 5.5 & 5.9138 & TST \\
\hline CHEMBL1980704 & 809283 & 4.1 & 4.3558 & TST \\
\hline CHEMBL1966808 & 809283 & 4.1 & 4.173 & TRN \\
\hline CHEMBL260135 & 809283 & 5.3 & 5.2865 & TRN \\
\hline CHEMBL 220241 & 809283 & 7.5 & 7.6478 & TRN \\
\hline CHEMBL 2004544 & 809283 & 4.1 & 4.1511 & TST \\
\hline CHEMBL1966040 & 809283 & 6.0 & 6.7045 & TRN \\
\hline CHEMBL1988141 & 809283 & 7.0 & 6.3934 & TST \\
\hline CHEMBL1977134 & 809283 & 4.9 & 4.7207 & TRN \\
\hline CHEMBL1970873 & 809283 & 3.5 & 3.6186 & TRN \\
\hline CHEMBL1985206 & 809283 & 4.9 & 4.7617 & TST \\
\hline CHEMBL 2006933 & 809283 & 6.2 & 5.5687 & TST \\
\hline CHEMBL1991078 & 809283 & 6.3 & 5.3466 & TRN \\
\hline CHEMBL1987359 & 809283 & 4.1 & 3.7659 & TST \\
\hline CHEMBL1977749 & 809283 & 4.9 & 5.7446 & TST \\
\hline CHEMBL 2000685 & 809283 & 5.8 & 5.6169 & TRN \\
\hline CHEMBL1994438 & 809283 & 8.5 & 7.7775 & TRN \\
\hline CHEMBL1967513 & 809283 & 4.9 & 4.6942 & TRN \\
\hline CHEMBL1980376 & 809283 & 5.0 & 5.1934 & TRN \\
\hline CHEMBL1985311 & 809283 & 6.5 & 6.1256 & TRN \\
\hline CHEMBL 2000724 & 809283 & 4.9 & 4.6368 & TRN \\
\hline CHEMBL1982413 & 809283 & 4.9 & 5.1352 & TST \\
\hline CHEMBL1682553 & 809283 & 6.4 & 6.3542 & TRN \\
\hline CHEMBL1969502 & 809283 & 6.4 & 6.3464 & TRN \\
\hline CHEMBL 2004647 & 809283 & 4.1 & 3.8714 & TST \\
\hline CHEMBL1971430 & 809283 & 4.1 & 4.7749 & TST \\
\hline CHEMBL 2000271 & 809283 & 8.4 & 7.9594 & TRN \\
\hline CHEMBL1997764 & 809283 & 4.1 & 4.3676 & TRN \\
\hline
\end{tabular}




\begin{tabular}{|c|c|c|c|c|c|}
\hline & & \multicolumn{4}{|c|}{ Supplemental Table S2.txt } \\
\hline CHEMBL1987535 & 809283 & 7.2 & 7.13299 & 9999999999 & TRN \\
\hline CHEMBL1981792 & 809283 & 4.9 & 4.7914 & TRN & \\
\hline CHEMBL 2002586 & 809283 & 4.9 & 5.5401 & TRN & \\
\hline CHEMBL 2004692 & 809283 & 4.1 & 5.308 & TST & \\
\hline CHEMBL1987815 & 809283 & 4.3 & 4.1214 & TST & \\
\hline CHEMBL1996234 & 809283 & 4.1 & 4.2169 & TRN & \\
\hline CHEMBL1967544 & 809283 & 7.3 & 6.7982 & TRN & \\
\hline CHEMBL1992673 & 809283 & 4.5 & 3.9601 & TST & \\
\hline CHEMBL223367 & 809283 & 4.1 & 5.0871 & TST & \\
\hline CHEMBL407391 & 809283 & 4.8 & 4.4206 & TST & \\
\hline CHEMBL1993335 & 809283 & 6.0 & 5.39 & TST & \\
\hline CHEMBL 2007574 & 809283 & 7.7 & 7.6387 & TRN & \\
\hline CHEMBL1964804 & 809283 & 5.9 & 5.4258 & TRN & \\
\hline CHEMBL443962 & 809283 & 4.1 & 3.9692 & TST & \\
\hline CHEMBL1965507 & 809283 & 4.1 & 4.194 & TRN & \\
\hline CHEMBL 2000354 & 809283 & 4.1 & 4.2271 & TRN & \\
\hline CHEMBL274064 & 809283 & 5.8 & 5.0339 & TRN & \\
\hline CHEMBL1967564 & 809283 & 4.1 & 4.0806 & TRN & \\
\hline CHEMBL1970317 & 809283 & 4.1 & 4.1984 & TRN & \\
\hline CHEMBL 2000408 & 809283 & 4.1 & 4.1839 & TRN & \\
\hline CHEMBL1978014 & 809283 & 4.1 & 4.14 & TRN & \\
\hline CHEMBL248757 & 809283 & 4.1 & 5.0689 & TST & \\
\hline CHEMBL1974250 & 809283 & 5.4 & 4.9308 & TRN & \\
\hline CHEMBL1997007 & 809283 & 4.9 & 5.29200 & 0000000001 & TRN \\
\hline CHEMBL1994538 & 809283 & 4.1 & 4.2299 & TRN & \\
\hline CHEMBL1975490 & 809283 & 4.1 & 4.6803 & TRN & \\
\hline CHEMBL 2002690 & 809283 & 4.9 & 4.9846 & TRN & \\
\hline CHEMBL383527 & 809283 & 6.7 & 6.7762 & TRN & \\
\hline CHEMBL1975503 & 809283 & 4.3 & 4.3042 & TST & \\
\hline CHEMBL1986139 & 809283 & 4.1 & 4.2474 & TRN & \\
\hline CHEMBL 2006567 & 809283 & 4.1 & 4.0154 & TRN & \\
\hline CHEMBL 2003229 & 809283 & 6.3 & 6.1082 & TRN & \\
\hline CHEMBL1979883 & 809283 & 4.1 & 4.0459 & TRN & \\
\hline CHEMBL1997051 & 809283 & 4.9 & 4.843 & TRN & \\
\hline CHEMBL1988331 & 809283 & 6.8 & 7.1239 & TRN & \\
\hline CHEMBL491758 & 809283 & 4.1 & 4.8846 & TRN & \\
\hline CHEMBL1986590 & 809283 & 4.9 & 4.7323 & TRN & \\
\hline CHEMBL1998826 & 809283 & 6.2 & 6.0227 & TRN & \\
\hline CHEMBL1682360 & 809283 & 5.6 & 5.282 & TRN & \\
\hline CHEMBL549730 & 809283 & 4.1 & 4.154 & TRN & \\
\hline CHEMBL1970189 & 809283 & 4.1 & 4.0647 & TRN & \\
\hline CHEMBL406845 & 809283 & 6.3 & 5.7964 & TRN & \\
\hline CHEMBL1974288 & 809283 & 7.6 & 8.0434 & TRN & \\
\hline CHEMBL213207 & 809283 & 6.7 & 6.8197 & TRN & \\
\hline CHEMBL1990346 & 809283 & 6.9 & 6.3727 & TRN & \\
\hline CHEMBL1964718 & 809283 & 3.3 & 3.7361 & TST & \\
\hline CHEMBL1991410 & 809283 & 4.6 & 4.955 & TRN & \\
\hline CHEMBL1968705 & 809283 & 4.5 & 5.4072 & TRN & \\
\hline
\end{tabular}




\begin{tabular}{|c|c|c|c|c|c|}
\hline \\
\hline CHEMBL1986684 & 809283 & 3.3 & 3.7016 & TST & \\
\hline CHEMBL1978271 & 809283 & 4.9 & 4.8413 & TRN & \\
\hline CHEMBL 2007266 & 809283 & 4.9 & 5.0798 & TRN & \\
\hline CHEMBL1977604 & 809283 & 4.1 & 4.3898 & TST & \\
\hline CHEMBL1974328 & 809283 & 6.8 & 7.0944 & TRN & \\
\hline CHEMBL1988717 & 809283 & 4.1 & 3.8018 & TRN & \\
\hline CHEMBL509032 & 809283 & 6.6 & 6.2305 & TRN & \\
\hline CHEMBL1992342 & 809283 & 5.6 & 5.0115 & TRN & \\
\hline CHEMBL 2002202 & 809283 & 4.3 & 3.8464 & TRN & \\
\hline CHEMBL1973013 & 809283 & 4.9 & 5.5539 & TRN & \\
\hline CHEMBL1164265 & 809283 & 4.9 & 4.9169 & TST & \\
\hline CHEMBL1966204 & 809283 & 5.7 & 5.7886 & TRN & \\
\hline CHEMBL1965423 & 809283 & 4.1 & 4.0035 & TRN & \\
\hline CHEMBL205415 & 809283 & 7.9 & 7.2611 & TRN & \\
\hline CHEMBL1977135 & 809283 & 7.0 & 6.7658 & TRN & \\
\hline CHEMBL1969473 & 809283 & 7.5 & 7.1439 & TRN & \\
\hline CHEMBL1999153 & 809283 & 7.2 & 7.1657 & TRN & \\
\hline CHEMBL 2001920 & 809283 & 4.1 & 4.6204 & TST & \\
\hline CHEMBL1977138 & 809283 & 6.1 & 5.7066 & TST & \\
\hline CHEMBL1241473 & 809283 & 6.5 & 5.9131 & TRN & \\
\hline CHEMBL1978448 & 809283 & 4.4 & 3.5954 & TST & \\
\hline CHEMBL 2004513 & 809283 & 4.1 & 4.0138 & TRN & \\
\hline CHEMBL1972258 & 809283 & 6.1 & 6.3378 & TRN & \\
\hline CHEMBL1969483 & 809283 & 4.9 & 5.0999 & TRN & \\
\hline CHEMBL 2001257 & 809283 & 4.1 & 4.0639 & TRN & \\
\hline CHEMBL 2004515 & 809283 & 5.8 & 6.0658 & TRN & \\
\hline CHEMBL1980329 & 809283 & 4.9 & 5.2662 & TRN & \\
\hline CHEMBL1992042 & 809283 & 5.9 & 5.3664 & TST & \\
\hline CHEMBL1992536 & 809283 & 4.1 & 5.4662 & TRN & \\
\hline CHEMBL1994724 & 809283 & 7.1 & 6.6333 & TRN & \\
\hline CHEMBL1970290 & 809283 & 6.5 & 5.8477 & TRN & \\
\hline CHEMBL1967531 & 809283 & 4.1 & 4.3592 & TRN & \\
\hline CHEMBL1970913 & 809283 & 4.1 & 4.0751 & TRN & \\
\hline CHEMBL1997534 & 809283 & 5.9 & 6.0534 & TRN & \\
\hline CHEMBL1993877 & 809283 & 6.1 & $5.7070 e$ & 0000000001 & TRN \\
\hline CHEMBL1977374 & 809283 & 4.1 & 3.8375 & TRN & \\
\hline CHEMBL1998551 & 809283 & 4.1 & 3.9983 & TRN & \\
\hline CHEMBL1991180 & 809283 & 7.7 & 5.7478 & TST & \\
\hline CHEMBL1983315 & 809283 & 8.4 & 7.9 & TRN & \\
\hline CHEMBL1978656 & 809283 & 4.1 & 4.1466 & TRN & \\
\hline CHEMBL1976420 & 809283 & 4.4 & 5.1105 & TST & \\
\hline CHEMBL1981744 & 809283 & 4.9 & 4.9953 & TRN & \\
\hline CHEMBL1994864 & 809283 & 6.0 & 5.9332 & TRN & \\
\hline CHEMBL 2002446 & 809283 & 4.1 & 4.6503 & TST & \\
\hline CHEMBL246970 & 809283 & 5.3 & 5.0241 & TRN & \\
\hline CHEMBL340921 & 809283 & 5.9 & 5.8511 & TRN & \\
\hline CHEMBL 2005478 & 809283 & 5.9 & 4.8991 & TST & \\
\hline CHEMBL1276446 & 809283 & 5.4 & 5.5665 & TST & \\
\hline & & & & 11807 & \\
\hline
\end{tabular}




\begin{tabular}{|c|c|c|c|c|}
\hline & & & & \\
\hline CHEMBL1995712 & 809283 & 7.4 & 7.1417 & TRN \\
\hline CHEMBL1971649 & 809283 & 4.1 & 3.9548 & TRN \\
\hline CHEMBL 2003657 & 809283 & 4.1 & 3.7633 & TRN \\
\hline CHEMBL 2005482 & 809283 & 4.9 & 5.2019 & TRN \\
\hline CHEMBL1992723 & 809283 & 5.0 & 4.1563 & TRN \\
\hline CHEMBL 2007124 & 809283 & 4.9 & 4.6697 & TRN \\
\hline CHEMBL1997909 & 809283 & 4.9 & 5.3019 & TRN \\
\hline CHEMBL 2006439 & 809283 & 6.6 & 6.8637 & TRN \\
\hline CHEMBL 2006156 & 809283 & 4.1 & 3.1022 & TST \\
\hline CHEMBL1985681 & 809283 & 4.9 & 5.0191 & TST \\
\hline CHEMBL1991674 & 809283 & 6.9 & 7.3687 & TRN \\
\hline CHEMBL 262623 & 809283 & 4.9 & 4.4952 & TRN \\
\hline CHEMBL1984842 & 809283 & 4.4 & 4.2635 & TRN \\
\hline CHEMBL 223460 & 809283 & 4.1 & 4.649 & TST \\
\hline CHEMBL1998829 & 809283 & 4.1 & 4.0915 & TRN \\
\hline CHEMBL 2006299 & 809283 & 7.4 & 6.4874 & TRN \\
\hline CHEMBL375284 & 809283 & 4.1 & 4.6773 & TRN \\
\hline CHEMBL1972346 & 809283 & 5.8 & 6.0284 & TST \\
\hline CHEMBL1980562 & 809283 & 7.3 & 7.2053 & TRN \\
\hline CHEMBL1982866 & 809283 & 4.1 & 4.4214 & TRN \\
\hline CHEMBL1968926 & 809283 & 4.1 & 5.0186 & TRN \\
\hline CHEMBL1991867 & 809283 & 4.5 & 4.601 & TST \\
\hline CHEMBL1979933 & 809283 & 4.4 & 5.0081 & TRN \\
\hline CHEMBL1965570 & 809283 & 4.1 & 4.2471 & TRN \\
\hline CHEMBL1972355 & 809283 & 6.3 & 5.1451 & TST \\
\hline CHEMBL 2001641 & 809283 & 5.0 & 5.2266 & TRN \\
\hline CHEMBL1997193 & 809283 & 6.6 & 5.5777 & TST \\
\hline CHEMBL1964902 & 809283 & 4.9 & 4.7648 & TRN \\
\hline CHEMBL 2005387 & 809283 & 6.5 & 7.0198 & TRN \\
\hline CHEMBL1082440 & 809283 & 6.7 & 5.693 & TST \\
\hline CHEMBL1614705 & 809283 & 5.9 & 5.2746 & TRN \\
\hline CHEMBL1972362 & 809283 & 4.1 & 4.8991 & TRN \\
\hline CHEMBL1972988 & 809283 & 5.9 & 6.0824 & TRN \\
\hline CHEMBL 2007372 & 809283 & 4.1 & 4.1454 & TRN \\
\hline CHEMBL1982167 & 809283 & 4.1 & 3.6904 & TRN \\
\hline CHEMBL1986597 & 809283 & 4.1 & 4.1318 & TRN \\
\hline CHEMBL 2006715 & 809283 & 4.1 & 4.1476 & TRN \\
\hline CHEMBL1971017 & 809283 & 5.3 & 5.2398 & TRN \\
\hline CHEMBL1990482 & 809283 & 5.4 & 5.0955 & TRN \\
\hline CHEMBL1990904 & 809283 & 4.1 & 4.2225 & TRN \\
\hline CHEMBL1987448 & 809283 & 6.8 & 7.1109 & TRN \\
\hline CHEMBL 2005475 & 809283 & 4.1 & 3.4191 & TRN \\
\hline CHEMBL 2000104 & 809283 & 4.1 & 4.9695 & TRN \\
\hline CHEMBL183844 & 809283 & 4.1 & 3.9993 & TRN \\
\hline CHEMBL1997349 & 809283 & 4.1 & $4.3210 e$ & 0000000001 \\
\hline CHEMBL220057 & 809283 & 5.6 & 5.5584 & TRN \\
\hline CHEMBL 383541 & 809283 & 7.5 & 7.4752 & TRN \\
\hline CHEMBL 2001224 & 809283 & 4.1 & 4.5357 & TRN \\
\hline
\end{tabular}




\begin{tabular}{|c|c|c|c|c|}
\hline & & & ipplement & al Table S2 \\
\hline CHEMBL10 & 809283 & 4.6 & 4.9958 & TRN \\
\hline CHEMBL 2005216 & 809283 & 7.2 & 6.7669 & TRN \\
\hline CHEMBL1964937 & 809283 & 6.9 & 7.0816 & TRN \\
\hline CHEMBL1980763 & 809283 & 4.9 & 5.1955 & TRN \\
\hline CHEMBL1969506 & 809283 & 4.1 & 4.7792 & TRN \\
\hline CHEMBL590109 & 809283 & 7.3 & 6.9804 & TST \\
\hline CHEMBL1977931 & 809283 & 4.8 & 4.3411 & TRN \\
\hline CHEMBL1970879 & 809283 & 4.1 & 4.1496 & TRN \\
\hline CHEMBL2005899 & 809283 & 4.1 & 4.3775 & TRN \\
\hline CHEMBL1682552 & 809283 & 6.6 & 6.2343 & TRN \\
\hline CHEMBL2007479 & 809283 & 4.9 & 4.9273 & TRN \\
\hline CHEMBL1996155 & 809283 & 4.1 & 5.4013 & TST \\
\hline CHEMBL1682359 & 809283 & 4.1 & 5.2103 & TRN \\
\hline CHEMBL379300 & 809283 & 8.3 & 7.477 & TRN \\
\hline CHEMBL1972220 & 809283 & 5.9 & 4.8664 & TRN \\
\hline CHEMBL1973720 & 809283 & 8.1 & 8.7643 & TRN \\
\hline CHEMBL1969523 & 809283 & 4.1 & 3.8199 & TRN \\
\hline CHEMBL 207995 & 809283 & 4.1 & 4.2583 & TRN \\
\hline CHEMBL1988995 & 809283 & 4.1 & 3.6374 & TRN \\
\hline CHEMBL1986781 & 809283 & 4.1 & 4.0526 & TRN \\
\hline CHEMBL 2001923 & 809283 & 4.4 & 4.9938 & TRN \\
\hline CHEMBL526133 & 809283 & 4.1 & 4.7064 & TRN \\
\hline CHEMBL 2003514 & 809283 & 6.9 & 6.4253 & TRN \\
\hline CHEMBL1989043 & 809283 & 4.9 & 4.5723 & TRN \\
\hline CHEMBL1979057 & 809283 & 4.1 & 3.7104 & TRN \\
\hline CHEMBL1967538 & 809283 & 4.3 & 4.0787 & TST \\
\hline CHEMBL1999428 & 809283 & 7.4 & 6.7611 & TRN \\
\hline CHEMBL1967560 & 809283 & 4.1 & 4.1639 & TRN \\
\hline CHEMBL1682358 & 809283 & 6.5 & 5.8213 & TRN \\
\hline CHEMBL 211378 & 809283 & 4.1 & 4.0085 & TRN \\
\hline CHEMBL1982465 & 809283 & 4.1 & 4.0904 & TRN \\
\hline CHEMBL 2003420 & 809283 & 4.1 & 3.9028 & TRN \\
\hline CHEMBL 2002723 & 809283 & 5.9 & 4.7833 & TST \\
\hline CHEMBL 272453 & 809283 & 4.1 & 4.4441 & TRN \\
\hline CHEMBL1971801 & 809283 & 4.1 & 3.6998 & TRN \\
\hline CHEMBL1970217 & 809283 & 7.6 & 7.2995 & TRN \\
\hline CHEMBL1968850 & 809283 & 4.1 & 3.8668 & TRN \\
\hline CHEMBL 2005528 & 809283 & 4.1 & 4.1923 & TST \\
\hline CHEMBL185569 & 809283 & 4.1 & 4.0193 & TRN \\
\hline CHEMBL1987007 & 809283 & 4.1 & 3.8022 & TRN \\
\hline CHEMBL1973793 & 809283 & 4.9 & 4.5611 & TST \\
\hline CHEMBL1969588 & 809283 & 7.7 & 7.5977 & TRN \\
\hline CHEMBL1984711 & 809283 & 4.1 & 4.3709 & TRN \\
\hline CHEMBL1990212 & 809283 & 4.1 & 3.9201 & TRN \\
\hline CHEMBL1986143 & 809283 & 7.5 & 7.6089 & TRN \\
\hline CHEMBL1979252 & 809283 & 6.6 & 6.15799 & 99999999995 \\
\hline CHEMBL1972934 & 809283 & 4.5 & 4.5559 & TRN \\
\hline CHEMBL1682341 & 809283 & 5.8 & 5.8423 & TRN \\
\hline
\end{tabular}

TRN 


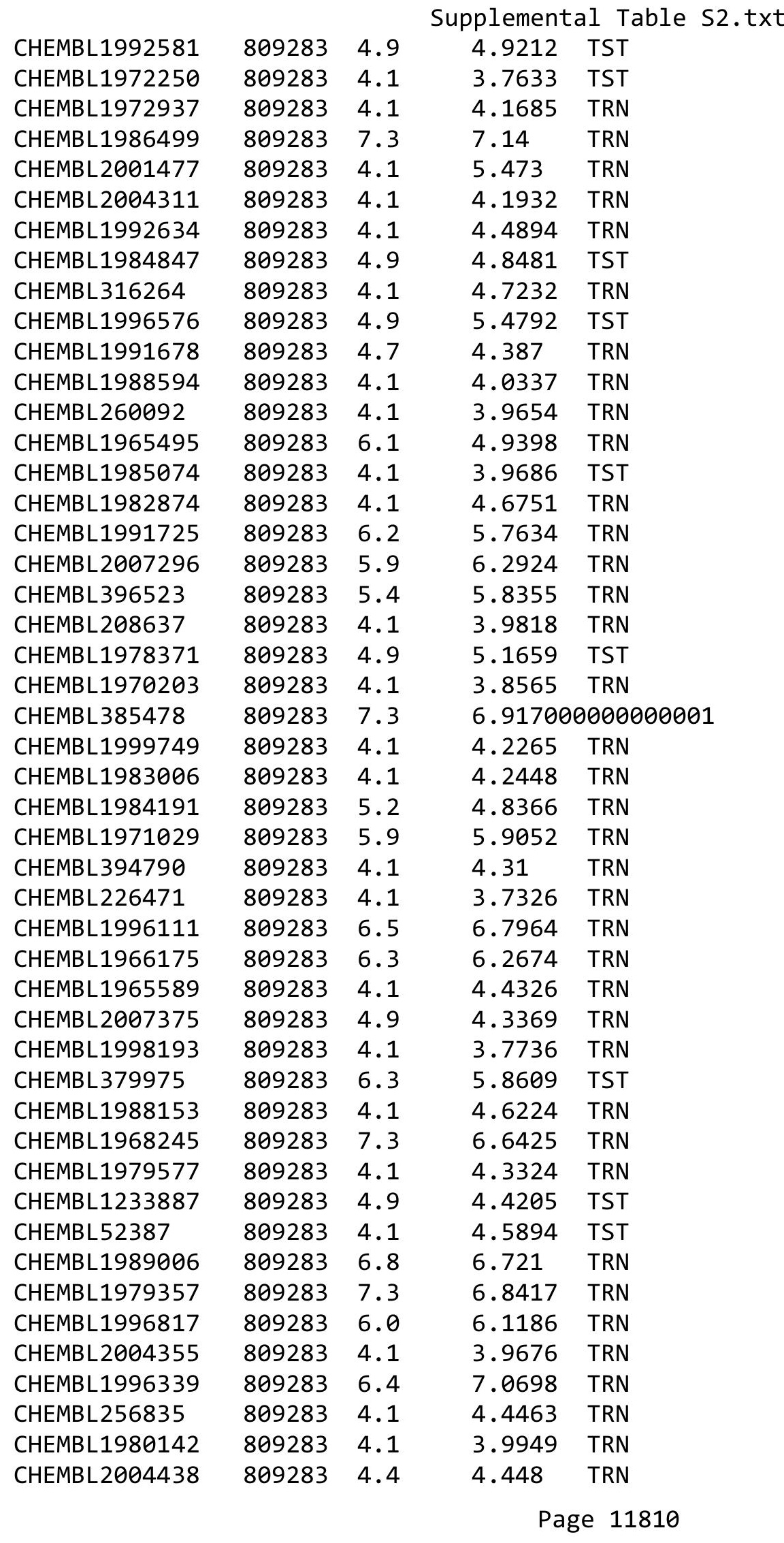




\begin{tabular}{|c|c|c|c|c|}
\hline & & & plem & \\
\hline CHEMBL41783 & 809283 & 4.1 & 4.3494 & TRN \\
\hline CHEMBL271381 & 809283 & 4.1 & 3.9399 & TRN \\
\hline CHEMBL1982466 & 809283 & 4.1 & 4.6202 & TRN \\
\hline CHEMBL1990162 & 809283 & 4.4 & 5.6672 & TRN \\
\hline CHEMBL1996390 & 809283 & 5.1 & 4.7563 & TRN \\
\hline CHEMBL1992220 & 809283 & 7.6 & 7.6273 & TRN \\
\hline CHEMBL234085 & 809283 & 4.5 & 5.1941 & TRN \\
\hline CHEMBL1998414 & 809283 & 4.1 & 4.1752 & TRN \\
\hline CHEMBL1969042 & 809283 & 4.1 & 4.9416 & TRN \\
\hline CHEMBL1999931 & 809283 & 6.7 & 5.604 & TRN \\
\hline CHEMBL1976376 & 809283 & 4.9 & 4.957 & TRN \\
\hline CHEMBL1991640 & 809283 & 4.1 & 5.2716 & TST \\
\hline CHEMBL1968868 & 809283 & 4.9 & 4.6397 & TRN \\
\hline CHEMBL 2007064 & 809283 & 4.1 & 4.7064 & TRN \\
\hline CHEMBL1997197 & 809283 & 4.9 & 4.9047 & TRN \\
\hline CHEMBL1968151 & 809283 & 4.1 & 4.3133 & TRN \\
\hline CHEMBL1381197 & 809283 & 4.1 & 4.2499 & TRN \\
\hline CHEMBL1987009 & 809283 & 4.1 & 4.3439 & TST \\
\hline CHEMBL1973795 & 809283 & 3.3 & 3.5995 & TST \\
\hline CHEMBL379218 & 809283 & 7.7 & 7.8741 & TST \\
\hline CHEMBL 2003817 & 809283 & 4.1 & 4.582 & TST \\
\hline CHEMBL1994830 & 809283 & 4.1 & 5.0531 & TST \\
\hline CHEMBL1987054 & 809283 & 5.2 & 4.7967 & TST \\
\hline CHEMBL226403 & 809283 & 4.1 & 3.2242 & TST \\
\hline CHEMBL 2005631 & 809283 & 4.1 & 4.4913 & TST \\
\hline CHEMBL1995765 & 809283 & 4.8 & 4.3183 & TST \\
\hline CHEMBL1966279 & 809283 & 4.1 & 4.8479 & TST \\
\hline CHEMBL1984760 & 809283 & 4.9 & 5.5191 & TST \\
\hline CHEMBL1991728 & 809283 & 4.1 & 5.4903 & TST \\
\hline CHEMBL360847 & 809283 & 6.2 & 5.0898 & TST \\
\hline CHEMBL1995811 & 809283 & 4.6 & 5.0894 & TST \\
\hline CHEMBL1975787 & 809283 & 5.7 & 5.2701 & TST \\
\hline CHEMBL 2002407 & 809283 & 4.1 & 4.3576 & TST \\
\hline CHEMBL1995916 & 809283 & 3.3 & 3.1228 & TST \\
\hline CHEMBL1972489 & 809283 & 4.1 & 4.1324 & TST \\
\hline CHEMBL1994074 & 809283 & 4.1 & 4.1688 & TST \\
\hline CHEMBL451401 & 809283 & 3.3 & 3.9819 & TST \\
\hline CHEMBL1968930 & 809283 & 8.4 & 8.0989 & TST \\
\hline CHEMBL1090356 & 809283 & 4.1 & 4.0808 & TST \\
\hline CHEMBL1986328 & 809283 & 4.1 & 3.4377 & TST \\
\hline CHEMBL 2002450 & 809283 & 3.3 & 3.5508 & TST \\
\hline CHEMBL261849 & 809283 & 4.9 & 4.7513 & TST \\
\hline CHEMBL1970950 & 809283 & 4.1 & 4.9385 & TST \\
\hline CHEMBL1982122 & 809283 & 6.9 & 6.5257 & TST \\
\hline CHEMBL1999112 & 809283 & 4.1 & 3.7785 & TST \\
\hline CHEMBL1682546 & 809283 & 6.0 & 5.8735 & TST \\
\hline CHEMBL1996780 & 809283 & 5.9 & 5.9054 & TST \\
\hline CHEMBL1996066 & 809283 & 4.1 & 3.8112 & TST \\
\hline
\end{tabular}




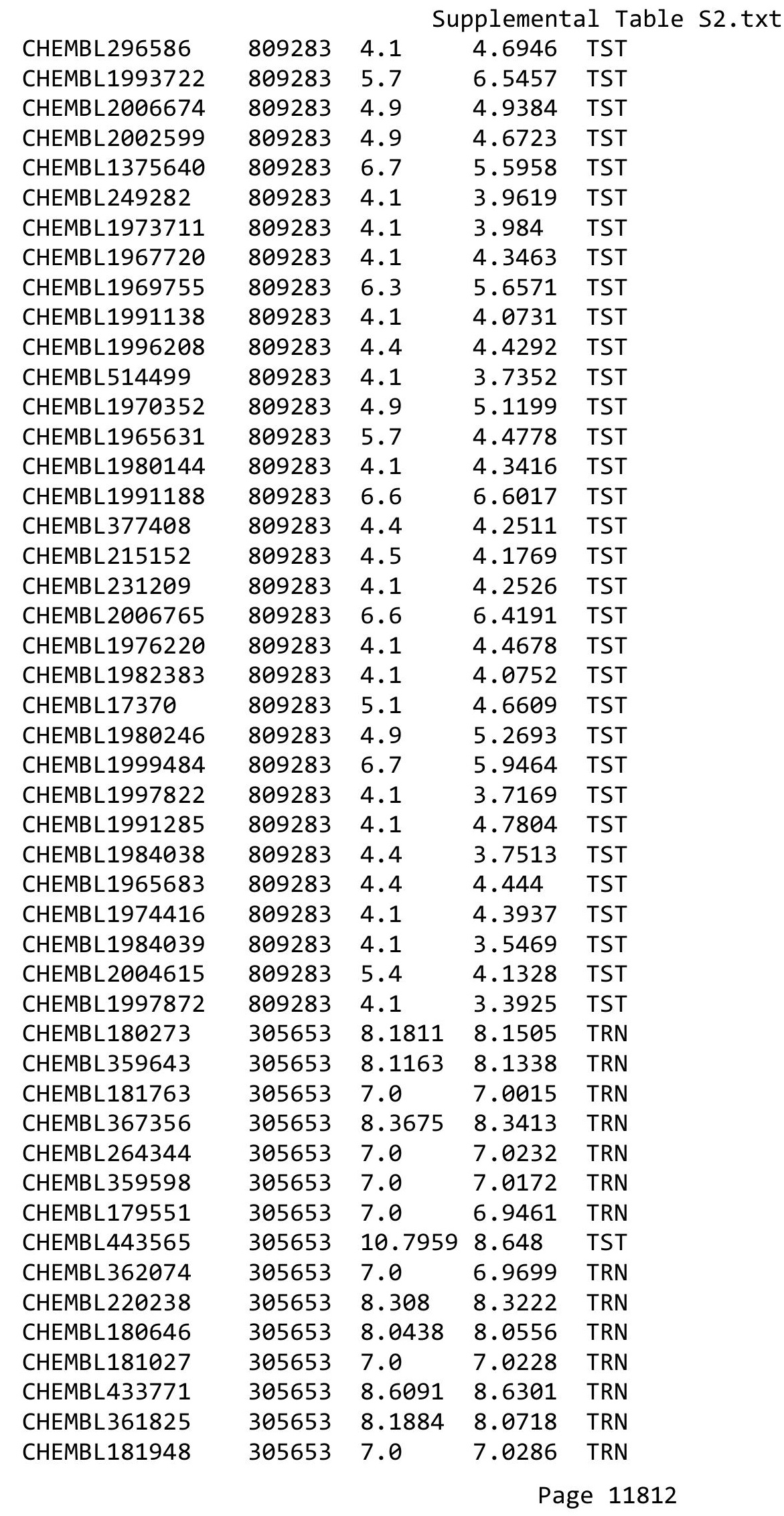




\begin{tabular}{|c|c|c|c|c|c|}
\hline \multicolumn{6}{|c|}{ suppıemental labıe S2 } \\
\hline CHEMBL178280 & 305653 & 8.1215 & 8.128 & TRN & \\
\hline CHEMBL434147 & 305653 & 7.0 & 7.0519 & TRN & \\
\hline CHEMBL179066 & 305653 & 8.0191 & 8.0303 & TRN & \\
\hline CHEMBL441118 & 305653 & 8.2204 & 8.2134 & TRN & \\
\hline CHEMBL178514 & 305653 & 7.0 & 7.0172 & TRN & \\
\hline CHEMBL178116 & 305653 & 9.6576 & 8.8064 & TST & \\
\hline CHEMBL180623 & 305653 & 8.2774 & 8.2682 & TRN & \\
\hline CHEMBL181768 & 305653 & 8.757 & 8.7619 & TRN & \\
\hline CHEMBL178775 & 305653 & 7.0 & 7.0215 & TRN & \\
\hline CHEMBL180763 & 305653 & 8.4815 & 8.5143 & TRN & \\
\hline CHEMBL178339 & 305653 & 8.0 & 7.94799 & 99999999995 & TRN \\
\hline CHEMBL366927 & 305653 & 8.6778 & 8.7183 & TRN & \\
\hline CHEMBL182103 & 305653 & 8.0035 & 8.0141 & TRN & \\
\hline CHEMBL 360355 & 305653 & 9.0044 & 9.0017 & TRN & \\
\hline CHEMBL181274 & 305653 & 8.0334 & 8.0575 & TRN & \\
\hline CHEMBL178674 & 305653 & 8.0353 & 8.0611 & TRN & \\
\hline CHEMBL361983 & 305653 & 7.0 & 6.9608 & TRN & \\
\hline CHEMBL369290 & 305653 & 8.0205 & 8.0193 & TRN & \\
\hline CHEMBL181295 & 305653 & 7.0 & 7.0003 & TRN & \\
\hline CHEMBL361613 & 305653 & 8.6799 & 8.6619 & TRN & \\
\hline CHEMBL424789 & 305653 & 8.2062 & 8.1224 & TRN & \\
\hline CHEMBL180669 & 305653 & 8.2255 & 8.3229 & TRN & \\
\hline CHEMBL 360020 & 305653 & 8.7799 & 8.77 & TRN & \\
\hline CHEMBL360915 & 305653 & 8.041 & 8.0187 & TRN & \\
\hline CHEMBL362191 & 305653 & 8.5376 & 8.5793 & TST & \\
\hline CHEMBL 360956 & 305653 & 8.1925 & 7.9601 & TST & \\
\hline CHEMBL179503 & 305653 & 8.3947 & 8.859 & TST & \\
\hline CHEMBL181623 & 305653 & 7.0 & 7.1422 & TST & \\
\hline CHEMBL 362213 & 305653 & 8.0851 & 8.1216 & TST & \\
\hline CHEMBL425699 & 305653 & 9.3098 & 9.3616 & TST & \\
\hline CHEMBL181775 & 305653 & 8.5638 & 8.7376 & TST & \\
\hline CHEMBL359542 & 305653 & 7.0 & 8.682 & TST & \\
\hline CHEMBL181396 & 305653 & 7.0 & 7.0963 & TST & \\
\hline CHEMBL447233 & 305653 & 8.6459 & 7.9841 & TST & \\
\hline CHEMBL 360788 & 305653 & 8.1319 & 8.1892 & TST & \\
\hline CHEMBL1470091 & 737284 & 4.3458 & 3.6443 & TRN & \\
\hline CHEMBL1318350 & 737284 & 4.209 & 4.3044 & TRN & \\
\hline CHEMBL1418124 & 737284 & 3.0 & 2.9083 & TRN & \\
\hline CHEMBL146710 & 737284 & 4.1421 & 4.0143 & TRN & \\
\hline CHEMBL1968928 & 737284 & 4.5638 & 4.1263 & TRN & \\
\hline CHEMBL1559307 & 737284 & 4.1649 & 3.7736 & TST & \\
\hline CHEMBL1503793 & 737284 & 4.2941 & 3.8031 & TRN & \\
\hline CHEMBL 234338 & 737284 & 4.0915 & 4.1831 & TRN & \\
\hline CHEMBL1993780 & 737284 & 4.1805 & 4.0552 & TRN & \\
\hline CHEMBL1606907 & 737284 & 4.1791 & 3.7999 & TRN & \\
\hline CHEMBL1498044 & 737284 & 3.0 & 3.7277 & TRN & \\
\hline CHEMBL1315784 & 737284 & 4.8239 & 4.3267 & TRN & \\
\hline CHEMBL1519162 & 737284 & 4.6478 & 4.2987 & TRN & \\
\hline
\end{tabular}




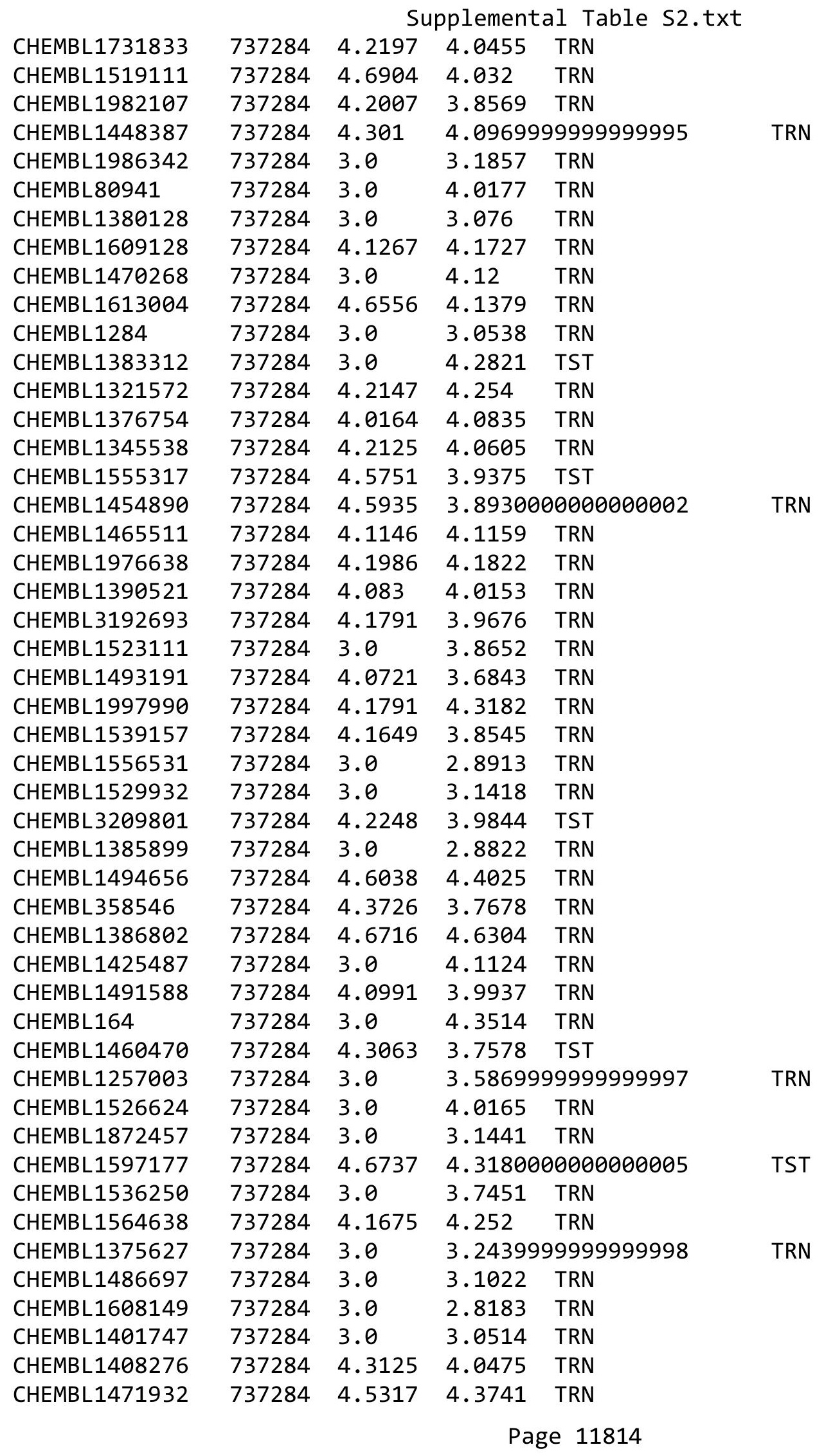




\begin{tabular}{|c|c|c|c|c|c|}
\hline \multicolumn{6}{|c|}{ Supplemental Table S2.txt } \\
\hline CHEMBL1717396 & 737284 & 4.4353 & 3.9509 & TRN & \\
\hline CHEMBL1383878 & 737284 & 4.0888 & 3.7568 & TRN & \\
\hline CHEMBL1416439 & 737284 & 3.0 & 2.7299 & TRN & \\
\hline CHEMBL56393 & 737284 & 5.1965 & 4.6796 & TRN & \\
\hline CHEMBL1417159 & 737284 & 4.9469 & 4.4208 & TRN & \\
\hline CHEMBL307893 & 737284 & 4.2976 & 4.1102 & TRN & \\
\hline CHEMBL1307459 & 737284 & 4.1296 & 4.0123 & TST & \\
\hline CHEMBL1714903 & 737284 & 3.0 & 2.9481 & TRN & \\
\hline CHEMBL1546048 & 737284 & 3.0 & 3.9905 & TRN & \\
\hline CHEMBL1701518 & 737284 & 4.3686 & 3.9019 & TST & \\
\hline CHEMBL1381289 & 737284 & 4.4413 & 4.2919 & TST & \\
\hline CHEMBL1609006 & 737284 & 5.0132 & 4.8203 & TST & \\
\hline CHEMBL1567396 & 737284 & 3.0 & 3.8858 & TST & \\
\hline CHEMBL1578652 & 737284 & 4.4295 & 3.6891 & TST & \\
\hline CHEMBL156383 & 737284 & 3.0 & 3.2077 & TST & \\
\hline CHEMBL1429158 & 737284 & 4.383 & 4.1547 & TST & \\
\hline CHEMBL1412423 & 737284 & 4.2284 & 3.8304 & TST & \\
\hline CHEMBL1378661 & 737284 & 4.9245 & 4.8324 & TST & \\
\hline CHEMBL1325366 & 737284 & 4.6576 & 4.6186 & TST & \\
\hline CHEMBL1543835 & 737284 & 4.1911 & 3.945 & TST & \\
\hline CHEMBL585591 & 737284 & 4.6162 & 3.9973 & TST & \\
\hline CHEMBL463175 & 737284 & 4.6635 & 4.4701 & TST & \\
\hline CHEMBL1407474 & 737284 & 4.2277 & 3.6628 & TST & \\
\hline CHEMBL2028179 & 737284 & 3.0 & 3.2978 & TST & \\
\hline CHEMBL 3667549 & 1528770 & 7.699 & 7.6655 & TST & \\
\hline CHEMBL 3667570 & 1528770 & 6.6308 & 6.6336 & TRN & \\
\hline CHEMBL3667586 & 1528770 & 6.6289 & 6.6438 & TRN & \\
\hline CHEMBL 3667552 & 1528770 & 7.041 & 7.0398 & TRN & \\
\hline CHEMBL 3667604 & 1528770 & 7.2076 & 7.2233 & TRN & \\
\hline CHEMBL 3667580 & 1528770 & 6.8894 & 6.9079 & TRN & \\
\hline CHEMBL 3667585 & 1528770 & 6.5171 & 6.5032 & TRN & \\
\hline CHEMBL 3667565 & 1528770 & 7.2596 & 7.2717 & TRN & \\
\hline CHEMBL 3667568 & 1528770 & 6.6696 & 6.6651 & TRN & \\
\hline CHEMBL 3667571 & 1528770 & 6.7595 & 6.75799 & 9999999999 & TRN \\
\hline CHEMBL 3667567 & 1528770 & 7.1024 & 7.1251 & TRN & \\
\hline CHEMBL 3667577 & 1528770 & 7.0655 & 7.051 & TRN & \\
\hline CHEMBL 3667557 & 1528770 & 7.8239 & 7.8138 & TRN & \\
\hline CHEMBL 3667597 & 1528770 & 5.8019 & 5.8044 & TRN & \\
\hline CHEMBL 3667550 & 1528770 & 6.8268 & 6.8592 & TST & \\
\hline CHEMBL3667579 & 1528770 & 6.8729 & 6.876 & TRN & \\
\hline CHEMBL 3667561 & 1528770 & 7.6576 & 7.6504 & TRN & \\
\hline CHEMBL3667592 & 1528770 & 6.7799 & 6.7696 & TRN & \\
\hline CHEMBL3667558 & 1528770 & 7.2441 & 7.2403 & TRN & \\
\hline CHEMBL 3667587 & 1528770 & 6.8861 & 6.8467 & TRN & \\
\hline CHEMBL 3667564 & 1528770 & 7.1938 & 7.2199 & TRN & \\
\hline CHEMBL 3667584 & 1528770 & 7.1549 & 7.1257 & TRN & \\
\hline CHEMBL3667605 & 1528770 & 6.7471 & 6.7464 & TRN & \\
\hline CHEMBL 3667581 & 1528770 & 7.2676 & 7.2736 & TRN & \\
\hline
\end{tabular}

Page 11815 
Supplemental Table S2.txt

\begin{tabular}{|c|c|c|c|c|c|c|}
\hline CHEMBL 3667600 & 1528770 & 7.3188 & 7.3238 & TRN & & \\
\hline CHEMBL 3667566 & 1528770 & 7.0809 & 7.0785 & TRN & & \\
\hline CHEMBL 3667602 & 1528770 & 6.6308 & 6.6161 & TRN & & \\
\hline CHEMBL 3667594 & 1528770 & 6.7235 & 6.7173 & TRN & & \\
\hline CHEMBL 3667595 & 1528770 & 7.3665 & 7.3864 & TRN & & \\
\hline CHEMBL 3667596 & 1528770 & 7.7959 & 6.8063 & TST & & \\
\hline CHEMBL 3667589 & 1528770 & 6.6655 & 7.1031 & TST & & \\
\hline CHEMBL 3667556 & 1528770 & 7.2007 & 7.2066 & TRN & & \\
\hline CHEMBL 3667551 & 1528770 & 7.5528 & 7.5675 & TRN & & \\
\hline CHEMBL3667591 & 1528770 & 6.9626 & 6.4403 & TST & & \\
\hline CHEMBL 3667598 & 1528770 & 7.0969 & 6.5416 & TST & & \\
\hline CHEMBL 3667554 & 1528770 & 7.6778 & 7.6605 & TRN & & \\
\hline CHEMBL 3667603 & 1528770 & 6.6757 & 6.8981 & TST & & \\
\hline CHEMBL 3667601 & 1528770 & 6.6615 & 7.0686 & TST & & \\
\hline CHEMBL 3667588 & 1528770 & 7.1024 & 7.0161 & TST & & \\
\hline CHEMBL 3667576 & 1528770 & 6.2041 & 6.207999 & 999999999 & & TRN \\
\hline CHEMBL 3667572 & 1528770 & 6.5702 & 6.1056 & TST & & \\
\hline CHEMBL 3667578 & 1528770 & 7.1308 & 7.1289 & TRN & & \\
\hline CHEMBL 3667574 & 1528770 & 6.9172 & 6.9071 & TRN & & \\
\hline CHEMBL 3667599 & 1528770 & 7.0506 & 6.8671 & TST & & \\
\hline CHEMBL 3667569 & 1528770 & 6.7399 & 6.7081 & TRN & & \\
\hline CHEMBL 3667562 & 1528770 & 8.1549 & 8.1927 & TRN & & \\
\hline CHEMBL 3667555 & 1528770 & 8.0969 & 8.0938 & TRN & & \\
\hline CHEMBL 3667590 & 1528770 & 7.1367 & 7.2723 & TST & & \\
\hline CHEMBL 3667582 & 1528770 & 6.1463 & 6.1661 & TRN & & \\
\hline CHEMBL 3667559 & 1528770 & 8.1549 & 8.1528 & TRN & & \\
\hline CHEMBL 3667573 & 1528770 & 6.0026 & 6.0046 & TRN & & \\
\hline CHEMBL 3667553 & 1528770 & 6.8928 & 8.0667 & TST & & \\
\hline CHEMBL 3667575 & 1528770 & 6.5157 & 6.5061 & TRN & & \\
\hline CHEMBL 3667563 & 1528770 & 6.4776 & 6.9181 & TST & & \\
\hline CHEMBL 3667583 & 1528770 & 6.2449 & 6.2721 & TRN & & \\
\hline CHEMBL 3667593 & 1528770 & 7.4559 & 6.9615 & TST & & \\
\hline CHEMBL 3667560 & 1528770 & 8.301 & 8.2759 & TRN & & \\
\hline CHEMBL3929779 & 1641067 & 6.7427 & 7.4475 & TRN & & \\
\hline CHEMBL 3962378 & 1641067 & \multicolumn{3}{|c|}{8.767000000000001} & 7.9726 & I KIV \\
\hline CHEMBL3951909 & 1641067 & 8.1707 & 8.163 & TST & & \\
\hline CHEMBL 3957201 & 1641067 & 7.8233 & 7.8426 & TST & & \\
\hline CHEMBL3935949 & 1641067 & 6.3617 & 7.1222 & TRN & & \\
\hline CHEMBL 3939440 & 1641067 & \multicolumn{3}{|c|}{7.372000000000001} & 7.3734 & $1 \mathrm{KI}$ \\
\hline CHEMBL 3909246 & 1641067 & 8.9547 & 9.0308 & TRN & & \\
\hline CHEMBL 3985656 & 1641067 & 9.1549 & 9.0013 & TRN & & \\
\hline CHEMBL 3974588 & 1641067 & 7.4152 & 8.0131 & TRN & & \\
\hline CHEMBL3923565 & 1641067 & 8.5607 & 8.1073 & TRN & & \\
\hline CHEMBL 3910267 & 1641067 & 10.1549 & 8.9333 & TRN & & \\
\hline CHEMBL 3938649 & 1641067 & 8.6003 & 8.9283 & TST & & \\
\hline CHEMBL 3974171 & 1641067 & 8.2604 & 7.9817 & TRN & & \\
\hline CHEMBL 3933218 & 1641067 & 8.5591 & 8.2703 & TRN & & \\
\hline CHEMBL3925010 & 1641067 & 7.2886 & 7.3313 & TRN & & \\
\hline
\end{tabular}

Page 11816 
Supplemental Table S2.txt

\begin{tabular}{|c|c|c|c|c|c|}
\hline CHEMBL 3927878 & 1641067 & 9.3665 & 9.0462 & TRN & \\
\hline CHEMBL3938866 & 1641067 & 7.791 & 7.6969 & TST & \\
\hline CHEMBL3977810 & 1641067 & 8.6144 & 7.7926 & TST & \\
\hline CHEMBL 3909928 & 1641067 & 8.3575 & 9.0898 & TRN & \\
\hline CHEMBL3919268 & 1641067 & 8.5436 & 8.6522 & TRN & \\
\hline CHEMBL 3936020 & 1641067 & 8.9914 & 8.5763 & TRN & \\
\hline CHEMBL3933323 & 1641067 & 10.3979 & 9.4629 & TRN & \\
\hline CHEMBL 3905610 & 1641067 & 7.8187 & 8.0264 & TRN & \\
\hline CHEMBL 3893643 & 1641067 & 10.0 & 10.4488 & TRN & \\
\hline CHEMBL3923805 & 1641067 & 7.1902 & 7.1107 & TRN & \\
\hline CHEMBL 3972343 & 1641067 & 9.2757 & 8.7381 & TST & \\
\hline CHEMBL3899017 & 1641067 & 7.5804 & 7.9015 & TRN & \\
\hline CHEMBL3909419 & 1641067 & 7.4859 & 8.5303 & TRN & \\
\hline CHEMBL3960194 & 1641067 & 9.6198 & 9.2042 & TRN & \\
\hline CHEMBL3914891 & 1641067 & 7.3254 & 7.3734 & TRN & \\
\hline CHEMBL3946094 & 1641067 & 7.3421 & 7.902 & TST & \\
\hline CHEMBL3938757 & 1641067 & 9.3372 & 9.4363 & TST & \\
\hline CHEMBL3908063 & 1641067 & 9.1367 & 8.9871 & TRN & \\
\hline CHEMBL 3930454 & 1641067 & 7.9944 & 8.9442 & TRN & \\
\hline CHEMBL3907239 & 1641067 & 6.3354 & 6.8886 & TST & \\
\hline CHEMBL3959095 & 1641067 & 7.4313 & 7.5417 & TRN & \\
\hline CHEMBL3916653 & 1641067 & 8.8041 & 7.7311 & TRN & \\
\hline CHEMBL3907607 & 1641067 & 9.6383 & 9.2507 & TRN & \\
\hline CHEMBL3921264 & 1641067 & 9.699 & 9.5918 & TRN & \\
\hline CHEMBL3964356 & 1641067 & 7.3598 & 7.2396 & TRN & \\
\hline CHEMBL3956960 & 1641067 & 7.9183 & 7.9112 & TRN & \\
\hline CHEMBL 3896260 & 1641067 & 6.2869 & 7.0349 & TRN & \\
\hline CHEMBL3969184 & 1641067 & 8.9706 & 9.7213 & TRN & \\
\hline CHEMBL3976519 & 1641067 & 7.7033 & 7.9403 & TRN & \\
\hline CHEMBL 3905600 & 1641067 & \multicolumn{2}{|c|}{10.300999999999998} & 10.4261 & TRN \\
\hline CHEMBL3930597 & 1641067 & 8.1785 & 8.1142 & TRN & \\
\hline CHEMBL 3965843 & 1641067 & 7.8011 & 7.7844 & TRN & \\
\hline CHEMBL3985467 & 1641067 & 9.0315 & 10.4622 & TST & \\
\hline CHEMBL 3976894 & 1641067 & 9.8539 & 9.9437 & TRN & \\
\hline CHEMBL3971535 & 1641067 & 9.5376 & 9.5836 & TRN & \\
\hline CHEMBL3907582 & 1641067 & 9.9586 & 10.258 & TRN & \\
\hline CHEMBL 3952490 & 1641067 & 9.8239 & 10.5068 & TRN & \\
\hline CHEMBL 3960438 & 1641067 & 7.9974 & 8.275 & TRN & \\
\hline CHEMBL 3897068 & 1641067 & 10.0458 & 9.4562 & TST & \\
\hline CHEMBL3935620 & 1641067 & 8.8633 & 8.9726 & TRN & \\
\hline CHEMBL3921651 & 1641067 & 10.8539 & 9.7184 & TRN & \\
\hline CHEMBL3954782 & 1641067 & 10.1549 & 10.5629 & 99999999999 & TRN \\
\hline CHEMBL3954701 & 1641067 & 7.0591 & 7.5519 & TRN & \\
\hline CHEMBL3984591 & 1641067 & 7.5312 & 7.3503 & TRN & \\
\hline CHEMBL3946612 & 1641067 & 9.3665 & 9.4554 & TRN & \\
\hline CHEMBL3930729 & 1641067 & 8.5935 & 8.3361 & TST & \\
\hline CHEMBL3900417 & 1641067 & 7.6859 & 8.0394 & TRN & \\
\hline CHEMBL3946475 & 1641067 & 7.3273 & 7.5417 & TRN & \\
\hline
\end{tabular}

Page 11817 
Supplemental Table S2.txt

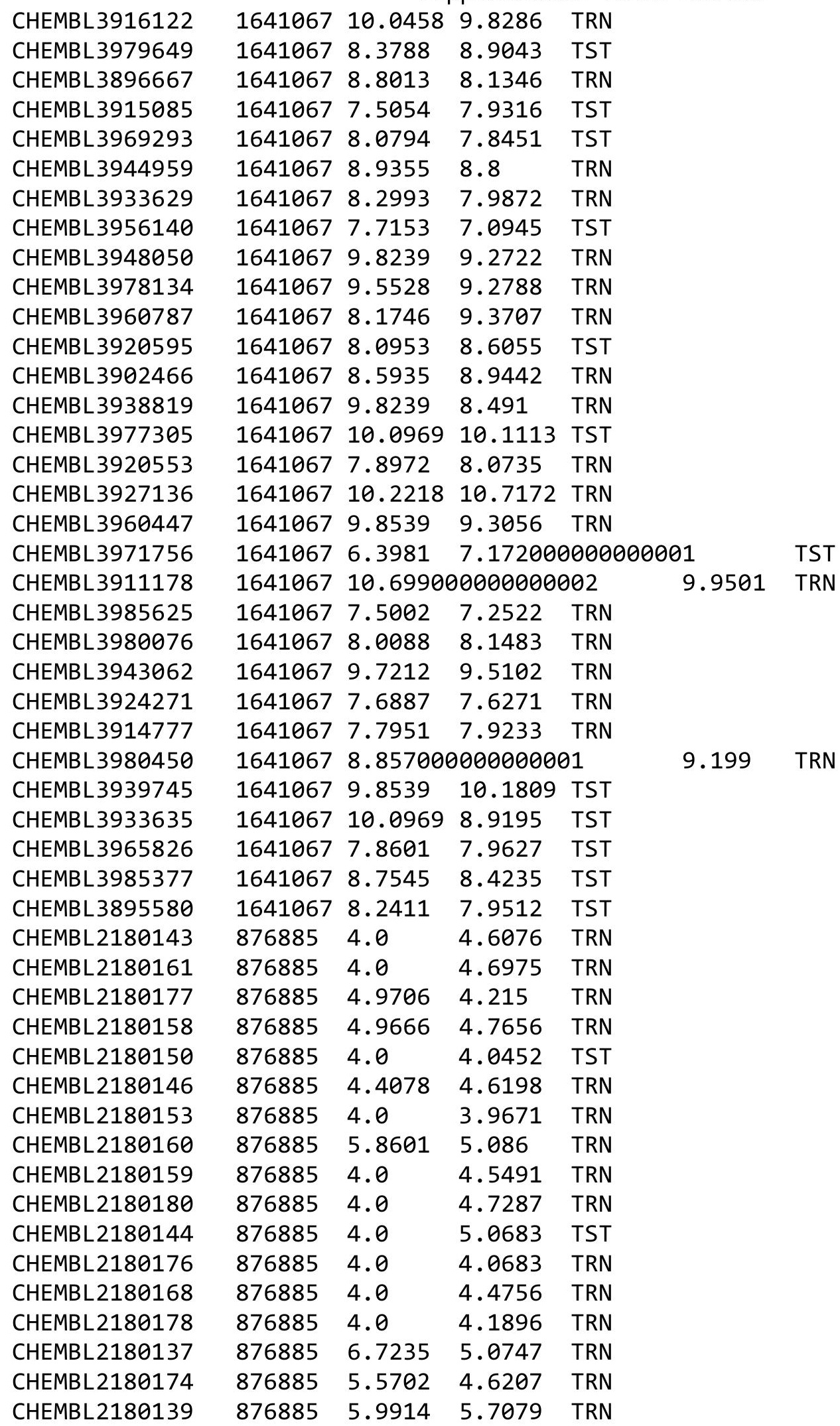

Page 11818 


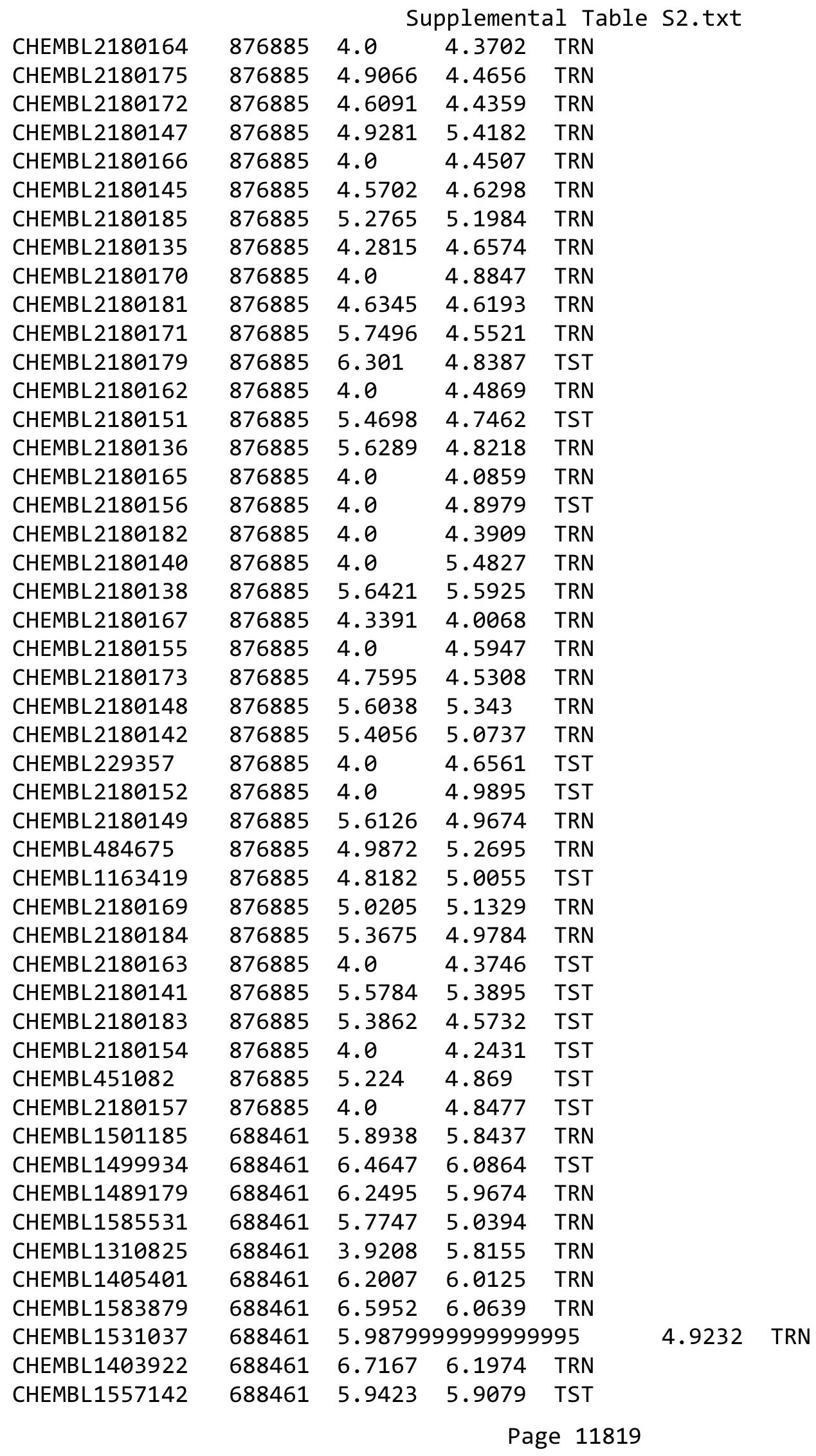




\begin{tabular}{|c|c|c|c|c|c|}
\hline \multirow[b]{2}{*}{ CHEMBL1559251 } & \multicolumn{5}{|c|}{ Supplemental Table S2.txt } \\
\hline & 688461 & 6.3536 & 6.1004 & TRN & \\
\hline CHEMBL1522903 & 688461 & 5.9638 & 5.50899 & 99999999995 & TRN \\
\hline CHEMBL1382917 & 688461 & 3.9208 & 4.8541 & TST & \\
\hline CHEMBL1323422 & 688461 & 6.466 & 6.1935 & TRN & \\
\hline CHEMBL 1448605 & 688461 & 5.9169 & 4.9482 & TRN & \\
\hline CHEMBL1325354 & 688461 & 6.0048 & 6.154 & TRN & \\
\hline CHEMBL1531764 & 688461 & 5.8505 & 6.2132 & TRN & \\
\hline CHEMBL1564332 & 688461 & 6.5157 & 6.1803 & TRN & \\
\hline CHEMBL1485806 & 688461 & 6.1993 & 6.2249 & TRN & \\
\hline CHEMBL1506203 & 688461 & 5.6936 & 4.8415 & TRN & \\
\hline CHEMBL1330191 & 688461 & 5.7357 & 5.976 & TRN & \\
\hline CHEMBL1321104 & 688461 & 3.9208 & 5.9641 & TRN & \\
\hline CHEMBL1468618 & 688461 & 6.0511 & 6.039 & TRN & \\
\hline CHEMBL1424373 & 688461 & 6.1662 & 6.1194 & TRN & \\
\hline CHEMBL1427062 & 688461 & 5.4781 & 5.5306 & TRN & \\
\hline CHEMBL1402437 & 688461 & 5.6546 & 6.0221 & TRN & \\
\hline CHEMBL1520035 & 688461 & 5.9743 & 4.9048 & TRN & \\
\hline CHEMBL1381195 & 688461 & 5.6029 & 4.8733 & TST & \\
\hline CHEMBL1501255 & 688461 & 6.4377 & 6.2397 & TRN & \\
\hline CHEMBL1599411 & 688461 & 6.3706 & 6.2423 & TRN & \\
\hline CHEMBL1560147 & 688461 & 6.4935 & 6.0806 & TRN & \\
\hline CHEMBL1582862 & 688461 & 6.4202 & 6.0752 & TRN & \\
\hline CHEMBL1478232 & 688461 & 6.1278 & 4.8645 & TST & \\
\hline CHEMBL1606705 & 688461 & 3.9208 & 5.8184 & TRN & \\
\hline CHEMBL1393784 & 688461 & 3.9208 & 4.845 & TRN & \\
\hline CHEMBL1978063 & 688461 & 6.5003 & 6.1249 & TRN & \\
\hline CHEMBL1325762 & 688461 & 5.8636 & 5.1252 & TRN & \\
\hline CHEMBL1587805 & 688461 & 6.5513 & 6.2419 & TRN & \\
\hline CHEMBL1499681 & 688461 & 3.9208 & 4.8445 & TRN & \\
\hline CHEMBL1419233 & 688461 & 6.5258 & 6.0991 & TRN & \\
\hline CHEMBL3195212 & 688461 & 6.5031 & 6.146 & TRN & \\
\hline CHEMBL1490334 & 688461 & 6.2668 & 6.1374 & TRN & \\
\hline CHEMBL1577624 & 688461 & 3.9208 & 6.13200 & 0000000001 & TRN \\
\hline CHEMBL1885024 & 688461 & 3.9208 & 5.3266 & TRN & \\
\hline CHEMBL1547901 & 688461 & 5.9144 & 6.0457 & TRN & \\
\hline CHEMBL1361693 & 688461 & 6.1952 & 6.1044 & TRN & \\
\hline CHEMBL1464721 & 688461 & 3.9208 & 6.2633 & TRN & \\
\hline CHEMBL1511008 & 688461 & 6.1662 & 5.7808 & TRN & \\
\hline CHEMBL1301732 & 688461 & 6.27 & 6.1057 & TRN & \\
\hline CHEMBL1441858 & 688461 & 6.4248 & 6.2475 & TRN & \\
\hline CHEMBL1581089 & 688461 & 5.6972 & 6.2412 & TRN & \\
\hline CHEMBL1588285 & 688461 & 6.5058 & 6.0503 & TRN & \\
\hline CHEMBL1374706 & 688461 & 6.2161 & 6.1322 & TRN & \\
\hline CHEMBL1355755 & 688461 & 6.0026 & 6.0716 & TRN & \\
\hline CHEMBL 3190273 & 688461 & 6.2381 & 6.2102 & TRN & \\
\hline CHEMBL1518080 & 688461 & 6.2604 & 4.8821 & TST & \\
\hline CHEMBL3195432 & 688461 & 5.6511 & 4.8946 & TRN & \\
\hline CHEMBL3195612 & 688461 & 5.8918 & 5.9585 & TRN & \\
\hline
\end{tabular}


Supplemental Table S2.txt

\begin{tabular}{|c|c|c|c|c|c|}
\hline CHEMBL1586026 & 688461 & 6.2967 & 6.2565 & TRN & \\
\hline CHEMBL1367908 & 688461 & 5.9504 & 5.7896 & TST & \\
\hline CHEMBL1566003 & 688461 & 6.4584 & 6.1576 & TRN & \\
\hline CHEMBL1460534 & 688461 & 5.9144 & 5.8821 & TRN & \\
\hline CHEMBL1520273 & 688461 & 6.2848 & 6.1169 & TRN & \\
\hline CHEMBL1518032 & 688461 & 6.5229 & 6.109 & TRN & \\
\hline CHEMBL3199639 & 688461 & 6.4584 & 6.0816 & TST & \\
\hline CHEMBL1462008 & 688461 & 6.4881 & 6.0222 & TRN & \\
\hline CHEMBL1607208 & 688461 & 6.3344 & 6.1737 & TRN & \\
\hline CHEMBL1494524 & 688461 & 6.1129 & 6.0796 & TRN & \\
\hline CHEMBL1366816 & 688461 & 6.0645 & 4.9977 & TRN & \\
\hline CHEMBL1431210 & 688461 & 5.9863 & 6.098 & TRN & \\
\hline CHEMBL1491745 & 688461 & 5.3427 & 4.9818 & TRN & \\
\hline CHEMBL1411596 & 688461 & 3.9208 & 4.7722 & TRN & \\
\hline CHEMBL1565691 & 688461 & 6.2161 & 6.0366 & TRN & \\
\hline CHEMBL1441319 & 688461 & 6.1898 & 5.9417 & TRN & \\
\hline CHEMBL473106 & 688461 & 6.5045 & 6.0955 & TST & \\
\hline CHEMBL1602928 & 688461 & 6.5272 & 6.2261 & TRN & \\
\hline CHEMBL1335318 & 688461 & 5.8847 & 5.982 & TRN & \\
\hline CHEMBL1454245 & 688461 & 6.5544 & 6.1753 & TRN & \\
\hline CHEMBL1510913 & 688461 & 6.52 & 5.9861 & TRN & \\
\hline CHEMBL1323133 & 688461 & 6.4056 & 4.852 & TRN & \\
\hline CHEMBL1536507 & 688461 & 5.9574 & 6.0497 & TRN & \\
\hline CHEMBL1377188 & 688461 & 3.9208 & 4.9481 & TRN & \\
\hline CHEMBL580324 & 688461 & 3.9208 & 6.0338 & TRN & \\
\hline CHEMBL1334136 & 688461 & 6.2373 & 6.1473 & TRN & \\
\hline CHEMBL1542533 & 688461 & 5.8359 & 5.367999 & 9999999999 & TRN \\
\hline CHEMBL3211154 & 688461 & 6.5214 & 6.12 & TRN & \\
\hline CHEMBL1343527 & 688461 & 6.1221 & 6.131 & TRN & \\
\hline CHEMBL1343460 & 688461 & 3.9208 & 4.8478 & TRN & \\
\hline CHEMBL1572118 & 688461 & 5.8085 & 5.9839 & TRN & \\
\hline CHEMBL1495474 & 688461 & 5.96899 & 999999999 & 6.1797 & TRN \\
\hline CHEMBL1328025 & 688461 & 5.9634 & 6.1688 & TRN & \\
\hline CHEMBL1586145 & 688461 & 6.0942 & 6.1143 & TRN & \\
\hline CHEMBL1608267 & 688461 & 6.4498 & 6.1905 & TRN & \\
\hline CHEMBL1336531 & 688461 & 6.0214 & 6.2161 & TRN & \\
\hline CHEMBL1561135 & 688461 & 5.6842 & 6.0665 & TRN & \\
\hline CHEMBL1349436 & 688461 & 6.4168 & 6.131 & TRN & \\
\hline CHEMBL1477375 & 688461 & 6.1141 & 5.6003 & TRN & \\
\hline CHEMBL1401361 & 688461 & 6.4283 & 5.5528 & TRN & \\
\hline CHEMBL1428673 & 688461 & 6.5513 & 6.2377 & TRN & \\
\hline CHEMBL1523458 & 688461 & 6.2604 & 6.0068 & TST & \\
\hline CHEMBL1987082 & 688461 & 6.3215 & 6.2054 & TRN & \\
\hline CHEMBL 3191975 & 688461 & 6.5045 & 5.987 & TST & \\
\hline CHEMBL1493921 & 688461 & 6.2628 & 6.2112 & TRN & \\
\hline CHEMBL1469054 & 688461 & 5.99700 & 000000000 & 6.157 & TRN \\
\hline CHEMBL1363615 & 688461 & 6.1656 & 5.7793 & TRN & \\
\hline CHEMBL1977589 & 688461 & 6.5784 & 6.1023 & TRN & \\
\hline
\end{tabular}

Page 11821 


\begin{tabular}{|c|c|c|c|c|}
\hline \multicolumn{5}{|c|}{ Supplemental Tabl } \\
\hline CHEMBL3195196 & 688461 & 6.4425 & 6.1536 & TRN \\
\hline CHEMBL1490976 & 688461 & 6.1238 & 5.9987 & TRN \\
\hline CHEMBL1504256 & 688461 & 6.4101 & 6.2388 & TRN \\
\hline CHEMBL1501851 & 688461 & 6.2441 & 6.2375 & TRN \\
\hline CHEMBL1324123 & 688461 & 6.4908 & 6.2876 & TRN \\
\hline CHEMBL1364646 & 688461 & 6.6055 & 6.0233 & TRN \\
\hline CHEMBL1461878 & 688461 & 3.9208 & 4.8581 & TRN \\
\hline CHEMBL1358014 & 688461 & 5.9158 & 5.8031 & TST \\
\hline CHEMBL600090 & 688461 & 5.8156 & 6.1359 & TRN \\
\hline CHEMBL1360086 & 688461 & 6.4012 & 6.2168 & TRN \\
\hline CHEMBL3196102 & 688461 & 6.4572 & 6.0695 & TRN \\
\hline CHEMBL1595774 & 688461 & 6.5607 & 6.0256 & TRN \\
\hline CHEMBL1342667 & 688461 & 6.4789 & 6.1805 & TRN \\
\hline CHEMBL1525755 & 688461 & 3.9208 & 4.8975 & TST \\
\hline CHEMBL1602693 & 688461 & 3.9208 & 5.7342 & TST \\
\hline CHEMBL1417174 & 688461 & 6.2147 & 6.1854 & TRN \\
\hline CHEMBL1300939 & 688461 & 6.4078 & 6.0823 & TST \\
\hline CHEMBL1556952 & 688461 & 6.3893 & 6.1445 & TST \\
\hline CHEMBL1490429 & 688461 & 6.475 & 6.1409 & TRN \\
\hline CHEMBL1387251 & 688461 & 3.9208 & 4.8604 & TRN \\
\hline CHEMBL1383379 & 688461 & 6.2832 & 6.2443 & TRN \\
\hline CHEMBL1605528 & 688461 & 6.5114 & 5.5871 & TRN \\
\hline CHEMBL1328527 & 688461 & 6.3335 & 6.1728 & TRN \\
\hline CHEMBL1571509 & 688461 & 6.4989 & 6.2188 & TRN \\
\hline CHEMBL1987798 & 688461 & 6.5017 & 6.0879 & TRN \\
\hline CHEMBL1597921 & 688461 & 6.4789 & 6.1976 & TRN \\
\hline CHEMBL1338750 & 688461 & 6.6517 & 6.1958 & TRN \\
\hline CHEMBL1527038 & 688461 & 6.5214 & 6.1872 & TRN \\
\hline CHEMBL1578372 & 688461 & 6.4868 & 6.1847 & TRN \\
\hline CHEMBL1533107 & 688461 & 6.4609 & 5.8299 & TRN \\
\hline CHEMBL1541948 & 688461 & 6.3625 & 6.1116 & TRN \\
\hline CHEMBL1327517 & 688461 & 3.9208 & 4.9418 & TRN \\
\hline CHEMBL41384 & 688461 & 3.9208 & 4.904 & TRN \\
\hline CHEMBL1519639 & 688461 & 5.9179 & 5.8556 & TRN \\
\hline CHEMBL1557898 & 688461 & 5.1402 & 4.8137 & TRN \\
\hline CHEMBL1523841 & 688461 & 6.6216 & 6.1655 & TST \\
\hline CHEMBL1419848 & 688461 & 6.2976 & 6.0107 & TRN \\
\hline CHEMBL581251 & 688461 & 3.9208 & 4.8094 & TST \\
\hline CHEMBL 3197234 & 688461 & 6.4935 & 6.1585 & TRN \\
\hline CHEMBL1570344 & 688461 & 6.0799 & 6.0496 & TRN \\
\hline CHEMBL1440560 & 688461 & 3.9208 & 4.8547 & TRN \\
\hline CHEMBL3210095 & 688461 & 5.9817 & 6.1427 & TST \\
\hline CHEMBL1363291 & 688461 & 6.3696 & 6.0746 & TRN \\
\hline CHEMBL1584476 & 688461 & 6.295 & 6.1797 & TRN \\
\hline CHEMBL1577922 & 688461 & 5.813 & 6.1657 & TRN \\
\hline CHEMBL1986090 & 688461 & 5.8837 & 6.1876 & TRN \\
\hline CHEMBL3191398 & 688461 & 3.9208 & 5.6988 & TRN \\
\hline CHEMBL1530943 & 688461 & 6.5045 & 6.1408 & TRN \\
\hline
\end{tabular}


Supplemental Table S2.txt

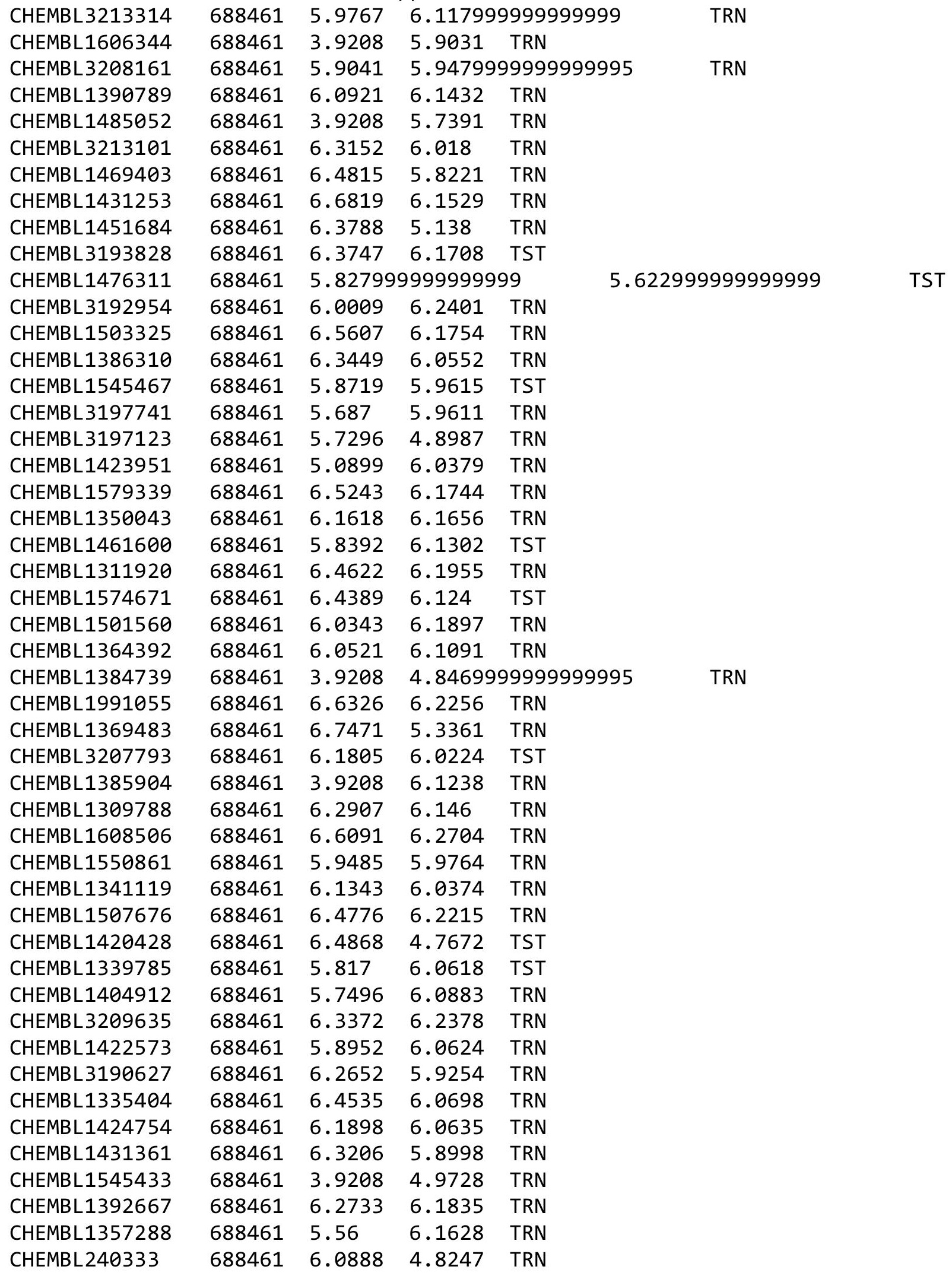

Page 11823 
Supplemental Table S2.txt

\begin{tabular}{|c|c|c|c|c|}
\hline CHEMBL1543948 & 688461 & 3.9208 & 6.0253 & TRN \\
\hline CHEMBL1566026 & 688461 & 3.9208 & 6.1766 & TST \\
\hline CHEMBL3214547 & 688461 & 5.8324 & 6.2195 & TST \\
\hline CHEMBL1433155 & 688461 & 6.5143 & 6.0587 & TST \\
\hline CHEMBL1588860 & 688461 & 6.1284 & 6.1523 & TST \\
\hline CHEMBL1479595 & 688461 & 6.4168 & 6.0473 & TST \\
\hline CHEMBL1388901 & 688461 & 6.5702 & 6.2375 & TST \\
\hline CHEMBL1510400 & 688461 & 6.4989 & 6.0524 & TST \\
\hline CHEMBL1545291 & 688461 & 6.5467 & 6.2457 & TST \\
\hline CHEMBL 3198303 & 688461 & 6.3288 & 6.2173 & TST \\
\hline CHEMBL1312289 & 688461 & 6.2262 & 6.2704 & TST \\
\hline CHEMBL 3197870 & 688461 & 6.068 & 6.1031 & TST \\
\hline CHEMBL1569442 & 688461 & 3.9208 & 4.8644 & TST \\
\hline CHEMBL1408969 & 688461 & 6.4318 & 5.8219 & TST \\
\hline CHEMBL1581941 & 688461 & 6.3635 & 6.1105 & TST \\
\hline CHEMBL3191418 & 688461 & 3.9208 & 4.9897 & TST \\
\hline CHEMBL1322727 & 688461 & 5.4939 & 4.9742 & TST \\
\hline CHEMBL1404163 & 688461 & 5.0281 & 5.8538 & TST \\
\hline CHEMBL1600749 & 688461 & 6.5072 & 6.255 & TST \\
\hline CHEMBL1984052 & 688461 & 6.0711 & 6.31 & TST \\
\hline CHEMBL 3191871 & 688461 & 6.4157 & 6.1666 & TST \\
\hline CHEMBL1499250 & 688461 & 5.8976 & 6.055 & TST \\
\hline CHEMBL1502465 & 688461 & 6.1643 & 6.0214 & TST \\
\hline CHEMBL1427221 & 688461 & 3.9208 & 6.05399 & э999999999 \\
\hline CHEMBL1422230 & 688461 & 6.4841 & 6.0421 & TST \\
\hline CHEMBL1471700 & 688461 & 6.5452 & 6.1924 & TST \\
\hline CHEMBL1564261 & 688461 & 6.5622 & 6.1723 & TST \\
\hline CHEMBL1524533 & 688461 & 6.51 & 6.164 & TST \\
\hline CHEMBL1572929 & 688461 & 3.9208 & 4.8715 & TST \\
\hline CHEMBL1309378 & 688461 & 6.5129 & 6.2987 & TST \\
\hline CHEMBL1327977 & 688461 & 5.6445 & 5.9145 & TST \\
\hline CHEMBL1543054 & 688461 & 3.9208 & 4.9122 & TST \\
\hline CHEMBL1575402 & 688461 & 6.3757 & 6.1061 & TST \\
\hline CHEMBL 3916311 & 1642257 & 6.0 & 5.9818 & TST \\
\hline CHEMBL 3954954 & 1642257 & 5.6253 & 5.42 & TRN \\
\hline CHEMBL1290144 & 1642257 & 6.585 & 6.6843 & TRN \\
\hline CHEMBL 3912051 & 1642257 & 6.2291 & 6.4643 & TRN \\
\hline CHEMBL 3934700 & 1642257 & 6.0 & 5.8138 & TST \\
\hline CHEMBL3907452 & 1642257 & 3.699 & 4.4273 & TRN \\
\hline CHEMBL 3980937 & 1642257 & 5.9508 & 4.7734 & TST \\
\hline CHEMBL 3960981 & 1642257 & 7.041 & 6.4856 & TRN \\
\hline CHEMBL 3946236 & 1642257 & 5.6198 & 5.5621 & TST \\
\hline CHEMBL 3928447 & 1642257 & 7.0458 & 6.6071 & TRN \\
\hline CHEMBL 3947794 & 1642257 & 6.7696 & 6.6419 & TRN \\
\hline CHEMBL1289818 & 1642257 & 7.2218 & 7.2931 & TRN \\
\hline CHEMBL 3978657 & 1642257 & 6.0177 & 6.1123 & TST \\
\hline CHEMBL 3902239 & 1642257 & 7.5229 & 6.9013 & TST \\
\hline CHEMBL 3922972 & 1642257 & 6.9586 & 6.5581 & TST \\
\hline
\end{tabular}


Supplemental Table S2.txt

\begin{tabular}{|c|c|c|c|c|c|}
\hline CHEMBL1289933 & 1642257 & 6.0 & 6.1985 & TRN & \\
\hline CHEMBL3893500 & 1642257 & 4.1739 & 4.1597 & TST & \\
\hline CHEMBL3896446 & 1642257 & 5.8861 & 6.1832 & TRN & \\
\hline CHEMBL3932609 & 1642257 & 4.1759 & 5.7074 & TRN & \\
\hline CHEMBL1289817 & 1642257 & 3.699 & 3.8724 & TRN & \\
\hline CHEMBL3950918 & 1642257 & 4.1759 & 5.3408 & TRN & \\
\hline CHEMBL3935014 & 1642257 & 6.3098 & 7.3385 & TRN & \\
\hline CHEMBL3926895 & 1642257 & 6.699 & 6.6847 & TRN & \\
\hline CHEMBL3945761 & 1642257 & 6.699 & 6.8121 & TRN & \\
\hline CHEMBL3929929 & 1642257 & 5.153 & 5.0784 & TRN & \\
\hline CHEMBL 3894502 & 1642257 & 6.8861 & 6.2896 & TST & \\
\hline CHEMBL3976774 & 1642257 & 3.699 & 4.6983 & TRN & \\
\hline CHEMBL3921404 & 1642257 & 5.6968 & 6.0654 & TRN & \\
\hline CHEMBL1289384 & 1642257 & 7.1938 & 7.0368 & TRN & \\
\hline CHEMBL 3967074 & 1642257 & 5.3645 & 5.6356 & TRN & \\
\hline CHEMBL3985029 & 1642257 & 4.1739 & 4.7538 & TST & \\
\hline CHEMBL3936744 & 1642257 & 4.1759 & 4.5875 & TST & \\
\hline CHEMBL3929077 & 1642257 & 6.9586 & 6.7512 & TRN & \\
\hline CHEMBL3904206 & 1642257 & 5.7447 & 6.2789 & TRN & \\
\hline CHEMBL3901879 & 1642257 & 5.9281 & 5.2005 & TRN & \\
\hline CHEMBL3902950 & 1642257 & 3.699 & 4.6954 & TRN & \\
\hline CHEMBL3943496 & 1642257 & 7.3979 & 7.4317 & TRN & \\
\hline CHEMBL3974091 & 1642257 & 7.2757 & 6.5783 & TRN & \\
\hline CHEMBL3924788 & 1642257 & 7.0969 & 6.632006 & 0000000001 & TRN \\
\hline CHEMBL3951500 & 1642257 & 6.0 & 6.5853 & TRN & \\
\hline CHEMBL3977116 & 1642257 & 6.041 & 6.2129 & TRN & \\
\hline CHEMBL3965022 & 1642257 & 4.1759 & 5.8249 & TRN & \\
\hline CHEMBL3982994 & 1642257 & 5.4089 & 4.9442 & TRN & \\
\hline CHEMBL3962534 & 1642257 & 6.4685 & 5.6333 & TRN & \\
\hline CHEMBL3968598 & 1642257 & 7.6383 & 7.6235 & TRN & \\
\hline CHEMBL3946942 & 1642257 & 6.9586 & 6.9558 & TRN & \\
\hline CHEMBL3981027 & 1642257 & 6.6383 & 6.5713 & TRN & \\
\hline CHEMBL3917392 & 1642257 & 7.4685 & 6.7514 & TRN & \\
\hline CHEMBL3959968 & 1642257 & 5.8665 & 6.0689 & TRN & \\
\hline CHEMBL3890396 & 1642257 & 6.8239 & 6.6142 & TRN & \\
\hline CHEMBL3912372 & 1642257 & 5.8861 & 6.4815 & TST & \\
\hline CHEMBL1290372 & 1642257 & 5.7144 & 5.4694 & TST & \\
\hline CHEMBL3907261 & 1642257 & 8.0 & 7.4259 & TRN & \\
\hline CHEMBL3942185 & 1642257 & 6.8861 & 6.1797 & TRN & \\
\hline CHEMBL3897250 & 1642257 & 5.8477 & 4.6047 & TRN & \\
\hline CHEMBL3937221 & 1642257 & 6.0044 & 5.1903 & TRN & \\
\hline CHEMBL3983573 & 1642257 & 6.1024 & 5.8012 & TRN & \\
\hline CHEMBL3971009 & 1642257 & 6.8239 & 6.5108 & TRN & \\
\hline CHEMBL3981968 & 1642257 & 5.6289 & 5.8603 & TRN & \\
\hline CHEMBL3892895 & 1642257 & 7.0458 & 6.6458 & TRN & \\
\hline CHEMBL 3908270 & 1642257 & 6.1675 & 6.5123 & TST & \\
\hline CHEMBL1630298 & 1642257 & 6.8539 & 6.6953 & TRN & \\
\hline CHEMBL3899617 & 1642257 & 4.1759 & 4.3525 & TST & \\
\hline
\end{tabular}


Supplemental Table S2.txt

\begin{tabular}{|c|c|c|c|c|}
\hline - & 2257 & 7.4318 & & \\
\hline & 642257 & 7.3979 & & \\
\hline & & & & \\
\hline 939060 & 257 & & & \\
\hline AEMBL3925734 & 257 & & & \\
\hline HEMBL3983523 & 642257 & 8539 & 9633 & \\
\hline HEMBL; & & & & \\
\hline IFMRI 390 & & & & \\
\hline AEMBL3926698 & 257 & & .7772 & \\
\hline HEMBL3894053 & 257 & & . 3427 & \\
\hline HEMBL3944354 & 57 & & 26 & \\
\hline IEMBL12 & 57 & & .02 & \\
\hline AEMBL12 & & & & RN \\
\hline HEMBL3931928 & 57 & & & \\
\hline AEMBL3901202 & 57 & & & \\
\hline AEMBL1289036 & 62 & 6 & 7.0184 & \\
\hline AEMBL3S & 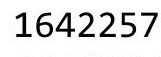 & & 71 & \\
\hline HEMBL3\& & & & 273 & \\
\hline HEMBL3891722 & & & 7.2595 & \\
\hline AEMBL12 & & & & \\
\hline HEIMBLSS & 6 & & & \\
\hline AEMBL & & 9 & 08 & \\
\hline HEMBL3S & & 7 & 23 & \\
\hline HEMBL3S & & & 5702 & \\
\hline AEMBL3S & & & & I RIV \\
\hline HEMBL38 & 6 & & 11 & RN \\
\hline AEMBL3 & & & & NIV \\
\hline HFMBI 36 & & 47 & 55 & \\
\hline HEMBL3S & & & & 「RN \\
\hline HEMBL 396 & & & & IK \\
\hline HEMBL3S & 6 & & 39 & RIV \\
\hline HEMBL; & & & 49 & ST \\
\hline 18 & & & 64 & TT \\
\hline HEMBL1289713 & & & 13 & IRN \\
\hline HEMBL1290373 & 6 & & 5.5076 & TST \\
\hline AEMBL3S & 57 & $\partial 2$ & 719 & TST \\
\hline HFMRI $=$ & & & & \\
\hline HEMBL3 & & & 5.9866 & IRIV \\
\hline HEMBL3985228 & 57 & & 378 & TRN \\
\hline IEMBL389 & 57 & & 59 & TST \\
\hline HEMBL1289266 & 64 & 79 & 88 & RN \\
\hline HEMBL3907323 & & & & RN \\
\hline HEMBL3899600 & & & 6.2752 & RN \\
\hline HEMBL3917900 & 257 & 318 & 5637 & $-S_{2}+2$ \\
\hline 34 & & & & $\mathrm{~N}$ \\
\hline HEMBL3S & & 7 & 5.4376 & \\
\hline LHEMBL3960122 & & .4572 & 5.336 & \\
\hline CHEMBL3929653 & 1642257 & 6.0 & 6.5126 & ГRN \\
\hline
\end{tabular}

Page 11826 
Supplemental Table S2.txt

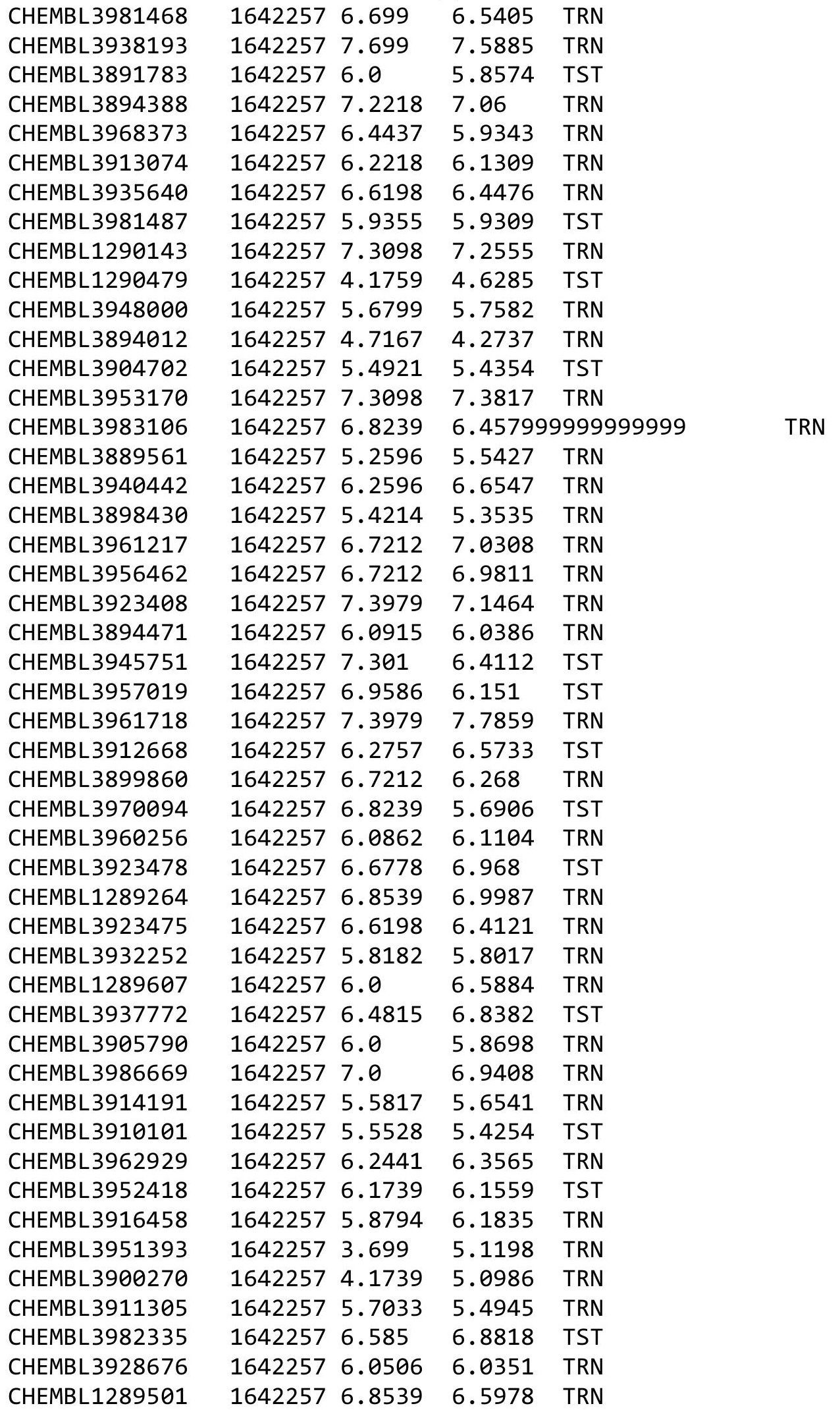

Page 11827 
Supplemental Table S2.txt

\begin{tabular}{|c|c|c|c|c|c|}
\hline CHEMBL3949329 & 1642257 & 7.0969 & 7.4655 & TRN & \\
\hline CHEMBL 3976577 & 1642257 & 6.301 & 6.722 & TRN & \\
\hline CHEMBL3917198 & 1642257 & 6.0 & 6.4704 & TRN & \\
\hline CHEMBL1289932 & 1642257 & 5.1427 & 5.3162 & TRN & \\
\hline CHEMBL1630296 & 1642257 & 6.5686 & 5.692 & TRN & \\
\hline CHEMBL3970608 & 1642257 & 6.1249 & 4.7594 & TRN & \\
\hline CHEMBL1289934 & 1642257 & 7.1549 & 7.1902 & TRN & \\
\hline CHEMBL1290034 & 1642257 & 7.0458 & 7.00899 & 99999999995 & TRN \\
\hline CHEMBL3929597 & 1642257 & 6.6576 & 6.147 & TRN & \\
\hline CHEMBL3906486 & 1642257 & 5.8861 & 6.0661 & TRN & \\
\hline CHEMBL 3960200 & 1642257 & 5.6904 & 6.1212 & TRN & \\
\hline CHEMBL 3951149 & 1642257 & 7.5229 & 8.0723 & TRN & \\
\hline CHEMBL3974334 & 1642257 & 4.1739 & 5.0531 & TST & \\
\hline CHEMBL3930741 & 1642257 & 6.585 & 6.9113 & TRN & \\
\hline CHEMBL3969989 & 1642257 & 6.8539 & 6.6334 & TST & \\
\hline CHEMBL3972018 & 1642257 & 6.0862 & 6.5124 & TRN & \\
\hline CHEMBL1290255 & 1642257 & 7.1549 & 7.2543 & TRN & \\
\hline CHEMBL 3928587 & 1642257 & 6.1135 & 4.7753 & TRN & \\
\hline CHEMBL 3982572 & 1642257 & 7.8861 & 5.8022 & TST & \\
\hline CHEMBL3973746 & 1642257 & 6.0706 & 5.8488 & TRN & \\
\hline CHEMBL3954525 & 1642257 & 6.0757 & 6.5202 & TST & \\
\hline CHEMBL3962123 & 1642257 & 5.8239 & 5.7221 & TST & \\
\hline CHEMBL3912852 & 1642257 & 5.5452 & 5.8473 & TRN & \\
\hline CHEMBL 3973310 & 1642257 & 6.0809 & 6.7268 & TRN & \\
\hline CHEMBL3918048 & 1642257 & 6.7447 & 5.8588 & TST & \\
\hline CHEMBL3963288 & 1642257 & 7.699 & 7.2595 & TRN & \\
\hline CHEMBL 3915243 & 1642257 & 6.2924 & 6.0399 & TRN & \\
\hline CHEMBL1289385 & 1642257 & 5.71 & \multicolumn{2}{|c|}{5.412000000000001} & TRN \\
\hline CHEMBL1290705 & 1642257 & 7.0458 & 6.9456 & TRN & \\
\hline CHEMBL 3947827 & 1642257 & 6.4949 & 6.4276 & TRN & \\
\hline CHEMBL3919951 & 1642257 & 5.9136 & 5.8091 & TRN & \\
\hline CHEMBL1289035 & 1642257 & 7.0 & 6.9785 & TRN & \\
\hline CHEMBL3901704 & 1642257 & 6.5086 & 6.5247 & TRN & \\
\hline CHEMBL3985130 & 1642257 & 6.3979 & 6.3738 & TRN & \\
\hline CHEMBL1290145 & 1642257 & 5.0241 & 5.3637 & TST & \\
\hline CHEMBL3978834 & 1642257 & 5.4949 & 6.1142 & TRN & \\
\hline CHEMBL 3970882 & 1642257 & 5.6021 & 6.1596 & TRN & \\
\hline CHEMBL 3891201 & 1642257 & 6.2596 & 6.5258 & TRN & \\
\hline CHEMBL 3892235 & 1642257 & 7.2218 & 6.6599 & TST & \\
\hline CHEMBL 3944460 & 1642257 & 7.1308 & 7.0329 & TRN & \\
\hline CHEMBL3982151 & 1642257 & \multicolumn{3}{|c|}{5.7620000000000005} & TRN \\
\hline CHEMBL3956609 & 1642257 & 5.8508 & 5.6637 & TRN & \\
\hline CHEMBL3916996 & 1642257 & 6.4089 & 6.7841 & TRN & \\
\hline CHEMBL1290036 & 1642257 & 5.0696 & 5.2444 & TST & \\
\hline CHEMBL 3914660 & 1642257 & 7.2218 & 6.7313 & TST & \\
\hline CHEMBL 3891298 & 1642257 & 6.4089 & 6.3835 & TST & \\
\hline CHEMBL3911794 & 1642257 & 4.1739 & 4.2303 & TRN & \\
\hline CHEMBL3980130 & 1642257 & 5.7852 & 6.3738 & TRN & \\
\hline
\end{tabular}

Page 11828 
Supplemental Table S2.txt

\begin{tabular}{|c|c|c|}
\hline HEMBL3902956 & 2257 & \\
\hline HEMBL 3972932 & 642257 & \\
\hline IEMBL3964103 & 1642257 & \\
\hline HEMBL3959449 & 1642257 & \\
\hline HEMBL3945933 & 1642257 & 1.00 \\
\hline CHEMBL3986482 & 1642257 & 7.0 \\
\hline HEMBL3932437 & 257 & \\
\hline IEMBL3956088 & 257 & \\
\hline HEMBL3901792 & 1642257 & \\
\hline HEMBL3965026 & 1642257 & \\
\hline HEMBL3899524 & 257 & \\
\hline HEMBL3929305 & 1642257 & \\
\hline HEMBL 3977828 & 257 & \\
\hline HEMBL3915916 & 1642257 & \\
\hline HEMBL3953798 & 257 & \\
\hline CHEMBL3945067 & 257 & \\
\hline HEMBL3973014 & 257 & \\
\hline HEMBL 3959930 & 257 & \\
\hline AEMBL3984642 & 257 & \\
\hline HEMBL3939734 & 257 & \\
\hline HEMBL3975235 & 257 & \\
\hline HEMBL3967 & 257 & \\
\hline CHEMBL3956653 & 257 & \\
\hline AEMBL3985157 & 257 & \\
\hline HEMBL3972081 & 164 & \\
\hline CHEMBL1289383 & 257 & \\
\hline CHEMBL3923415 & 257 & \\
\hline CHEMBL 3967194 & 257 & 8.0 \\
\hline HEMBL1290035 & 257 & \\
\hline CHEMBL3890569 & 257 & \\
\hline CHEMBL1290587 & 257 & \\
\hline CHEMBL3942372 & 257 & \\
\hline CHEMBL398 & 257 & \\
\hline CHEMBL3985031 & 1642257 & 4. \\
\hline CHEMBL3893009 & 1642257 & 4.87 \\
\hline CHEMBL3897854 & 257 & \\
\hline CHEMBL394 & 257 & \\
\hline CHEMBL3937061 & 1642257 & \\
\hline CHEMBL3936281 & 1642257 & 3.6 \\
\hline CHEMBL 3924746 & 1642257 & \\
\hline CHEMBL1289265 & 257 & \\
\hline CHEMBL3944699 & 1642257 & 7. \\
\hline CHEMBL3902301 & 1642257 & 6.2 \\
\hline CHEMBL3955605 & 1642257 & 73 \\
\hline CHEMBL3911358 & 1642257 & \\
\hline CHEMBL3924126 & 1642257 & \\
\hline CHEMBL3927557 & 1642257 & \\
\hline CHEMBL3934522 & 1642257 & \\
\hline
\end{tabular}

6.5137 TRN

5.2779 TRN

6.7446 TRN

6.2666 TST

7.4073 TRN

6.4357 TRN

5.8654 TRN

6.1448 TRN

7.2768 TRN

7.0828 TRN

4.6253 TRN

6.7775 TRN

6.5605 TRN

6.8757 TRN

4.3932 TST

5.2065 TRN

6.5709 TRN

5.8977 TST

6.0357 TST

6.1221 TRN

6.9631 TST

6.3011 TRN

6.4751 TRN

6.8867 TRN

7.0724 TRN

6.6113 TRN

6.5124 TRN

7.3817 TRN

5.8144 TRN

6.4695 TRN

6.5199 TRN

6.9167 TRN

5.1994 TST

4.7961 TRN

4.5193 TRN

6.2828 TRN

5.9424 TRN

5.6794 TRN

4.9398 TST

5.9348 TRN

5.8266 TRN

6.5853 TRN

6.9599 TRN

6.8834 TRN

6.5085 TST

5.8336 TRN

6.053999999999999

6.3858 TST

Page 11829 
Supplemental Table S2.txt

\begin{tabular}{|c|c|c|c|c|c|}
\hline CHEMBL3902775 & 1642257 & 6.4559 & 6.439 & TRN & \\
\hline CHEMBL3932316 & 1642257 & 6.0809 & 5.9553 & TST & \\
\hline CHEMBL 3980220 & 1642257 & 6.0044 & 6.1157 & TRN & \\
\hline CHEMBL 3894994 & 1642257 & 8.0 & 7.4229 & TRN & \\
\hline CHEMBL1630619 & 1642257 & 6.0 & 5.8782 & TRN & \\
\hline CHEMBL 3897716 & 1642257 & 6.6021 & 6.0399 & TRN & \\
\hline CHEMBL 3978324 & 1642257 & 6.0862 & 6.04899 & 99999999995 & TRN \\
\hline CHEMBL 3925687 & 1642257 & 6.8861 & 6.1761 & TRN & \\
\hline CHEMBL1290256 & 1642257 & 6.4318 & 6.13299 & 9999999999 & TRN \\
\hline CHEMBL 3956727 & 1642257 & 4.1759 & 4.7858 & TST & \\
\hline CHEMBL 3977078 & 1642257 & 4.9059 & 5.6373 & TRN & \\
\hline CHEMBL 3938880 & 1642257 & 7.2218 & 6.4376 & TRN & \\
\hline CHEMBL 3978435 & 1642257 & 6.7696 & 7.2619 & TRN & \\
\hline CHEMBL3936993 & 1642257 & 6.9208 & 6.7959 & TST & \\
\hline CHEMBL1290257 & 1642257 & 5.6946 & 4.9548 & TST & \\
\hline CHEMBL 3927232 & 1642257 & 7.1549 & 7.0231 & TRN & \\
\hline CHEMBL3891662 & 1642257 & 4.1739 & 5.8225 & TRN & \\
\hline CHEMBL 3930858 & 1642257 & 6.5376 & 6.3971 & TST & \\
\hline CHEMBL3891989 & 1642257 & 6.8861 & 6.8279 & TRN & \\
\hline CHEMBL 3965749 & 1642257 & 6.6383 & 6.5126 & TST & \\
\hline CHEMBL3916834 & 1642257 & 5.2581 & 5.3114 & TRN & \\
\hline CHEMBL 3957371 & 1642257 & 5.9172 & 5.4693 & TST & \\
\hline CHEMBL3958353 & 1642257 & 5.6421 & 6.0846 & TST & \\
\hline CHEMBL1289500 & 1642257 & 7.2076 & \multicolumn{2}{|c|}{7.4670000000000005} & TRN \\
\hline CHEMBL 3959645 & 1642257 & 6.3468 & 6.6424 & TRN & \\
\hline CHEMBL3928234 & 1642257 & 6.3098 & 6.4391 & TRN & \\
\hline CHEMBL 3934718 & 1642257 & 7.2218 & 6.3894 & TRN & \\
\hline CHEMBL3899858 & 1642257 & 3.699 & 4.4658 & TRN & \\
\hline CHEMBL3914173 & 1642257 & 5.9586 & 5.5363 & TST & \\
\hline CHEMBL 3929543 & 1642257 & 7.0223 & 6.9407 & TRN & \\
\hline CHEMBL3910339 & 1642257 & 6.5376 & 6.1852 & TRN & \\
\hline CHEMBL 3939207 & 1642257 & 7.0969 & 6.9803 & TRN & \\
\hline CHEMBL3975868 & 1642257 & 6.2596 & 5.9761 & TRN & \\
\hline CHEMBL 3950920 & 1642257 & 7.1549 & 6.2866 & TRN & \\
\hline CHEMBL 3930940 & 1642257 & 3.699 & 4.2394 & TRN & \\
\hline CHEMBL3979001 & 1642257 & 6.6383 & 5.8504 & TST & \\
\hline CHEMBL 3969333 & 1642257 & 7.0 & 6.6519 & TRN & \\
\hline CHEMBL3970771 & 1642257 & 4.1759 & 4.9522 & TST & \\
\hline CHEMBL 3938772 & 1642257 & 7.0862 & 6.1463 & TST & \\
\hline CHEMBL 3900201 & 1642257 & 5.7986 & 6.3089 & TRN & \\
\hline CHEMBL3917868 & 1642257 & 8.0 & 7.2028 & TRN & \\
\hline CHEMBL 3986546 & 1642257 & 6.6021 & 5.3065 & TRN & \\
\hline CHEMBL 3962240 & 1642257 & 6.2518 & 5.6976 & TRN & \\
\hline CHEMBL3928469 & 1642257 & 7.3979 & 7.1985 & TRN & \\
\hline CHEMBL3961241 & 1642257 & 6.0269 & 6.4629 & TRN & \\
\hline CHEMBL3933769 & 1642257 & 6.2366 & 6.2659 & TRN & \\
\hline CHEMBL 3980089 & 1642257 & 7.1549 & 7.477 & TRN & \\
\hline CHEMBL3922399 & 1642257 & 6.9586 & 6.619 & TRN & \\
\hline
\end{tabular}


Supplemental Table S2.txt

\begin{tabular}{|c|c|c|c|c|}
\hline CHEMBL3953429 & 1642257 & 7.699 & 7.2619 & TRN \\
\hline CHEMBL3954474 & 1642257 & 5.6635 & 5.8716 & TRN \\
\hline CHEMBL 3894121 & 1642257 & 6.7447 & 6.8668 & TRN \\
\hline CHEMBL 3921782 & 1642257 & 6.0 & 5.9893 & TRN \\
\hline CHEMBL3910905 & 1642257 & 6.8861 & 6.2044 & TRN \\
\hline CHEMBL3942472 & 1642257 & 6.8239 & 7.7209 & TRN \\
\hline CHEMBL3959471 & 1642257 & 5.7282 & 5.4773 & TRN \\
\hline CHEMBL 3968132 & 1642257 & 6.301 & 6.2563 & TRN \\
\hline CHEMBL3949949 & 1642257 & 6.8239 & \multicolumn{2}{|c|}{5.6979999999999995} \\
\hline CHEMBL1289150 & 1642257 & 6.0 & 5.9062 & TRN \\
\hline CHEMBL3936874 & 1642257 & 5.9666 & 5.5919 & TST \\
\hline CHEMBL 3896041 & 1642257 & 6.6198 & 7.0913 & TRN \\
\hline CHEMBL1289935 & 1642257 & 5.0 & 4.7549 & TRN \\
\hline CHEMBL3915362 & 1642257 & 7.699 & 7.5611 & TRN \\
\hline CHEMBL3957794 & 1642257 & 6.4437 & \multicolumn{2}{|c|}{5.787000000000001} \\
\hline CHEMBL3978165 & 1642257 & 8.0 & 6.6004 & TRN \\
\hline CHEMBL3965802 & 1642257 & 6.0269 & 5.9385 & TRN \\
\hline CHEMBL3970805 & 1642257 & 7.5229 & 7.4655 & TRN \\
\hline CHEMBL3925517 & 1642257 & 6.1739 & 5.9225 & TST \\
\hline CHEMBL3959755 & 1642257 & 6.1427 & 5.9137 & TRN \\
\hline CHEMBL3931987 & 1642257 & 4.1739 & 4.0523 & TRN \\
\hline CHEMBL3931981 & 1642257 & 6.0044 & 6.4222 & TRN \\
\hline CHEMBL 3916228 & 1642257 & 7.0458 & 7.1572 & TRN \\
\hline CHEMBL3945467 & 1642257 & 6.9208 & 6.1828 & TST \\
\hline CHEMBL3971194 & 1642257 & 5.699 & 5.3745 & TST \\
\hline CHEMBL3984931 & 1642257 & 7.0 & 6.9269 & TRN \\
\hline CHEMBL3925809 & 1642257 & 7.2218 & 6.545 & TRN \\
\hline CHEMBL3941057 & 1642257 & 5.5229 & 4.3556 & TST \\
\hline CHEMBL3954599 & 1642257 & 4.1759 & 5.1795 & TST \\
\hline CHEMBL3963151 & 1642257 & 5.8356 & 6.3449 & TST \\
\hline CHEMBL3938061 & 1642257 & 7.2218 & 6.4448 & TRN \\
\hline CHEMBL 3953844 & 1642257 & 4.1759 & 6.6816 & TRN \\
\hline CHEMBL 3927160 & 1642257 & 3.699 & 4.5481 & TRN \\
\hline CHEMBL3922130 & 1642257 & 5.1739 & 4.7953 & TST \\
\hline CHEMBL3899439 & 1642257 & 7.5229 & 6.1135 & TRN \\
\hline CHEMBL3932917 & 1642257 & 5.7852 & 5.9971 & TRN \\
\hline CHEMBL3925536 & 1642257 & 6.8239 & 6.478 & TRN \\
\hline CHEMBL 3894440 & 1642257 & 6.7447 & 6.5839 & TST \\
\hline CHEMBL3914649 & 1642257 & 6.4949 & 5.7773 & TRN \\
\hline CHEMBL3920198 & 1642257 & 6.8861 & 7.1722 & TRN \\
\hline CHEMBL3899510 & 1642257 & 7.301 & 6.6486 & TST \\
\hline CHEMBL3922486 & 1642257 & 5.8729 & 6.1547 & TRN \\
\hline CHEMBL3935389 & 1642257 & 6.7212 & 5.3535 & TST \\
\hline CHEMBL3973472 & 1642257 & 6.0 & 6.3061 & TRN \\
\hline CHEMBL3969429 & 1642257 & 8.0 & 7.4504 & TRN \\
\hline CHEMBL3930212 & 1642257 & 5.9957 & 6.4082 & TST \\
\hline CHEMBL3938521 & 1642257 & 7.0 & 6.0717 & TST \\
\hline CHEMBL1289712 & 1642257 & 7.5086 & 6.9412 & TRN \\
\hline
\end{tabular}

Page 11831 
Supplemental Table S2.txt

\begin{tabular}{|c|c|c|c|c|}
\hline CHEMBL 3933748 & 1642257 & 5.4841 & 5.4674 & TRN \\
\hline CHEMBL 3916532 & 1642257 & 5.9245 & 5.4384 & TST \\
\hline CHEMBL3921022 & 1642257 & 6.301 & 5.7822 & TST \\
\hline CHEMBL 3909840 & 1642257 & 6.7447 & 6.485 & TST \\
\hline CHEMBL 3892896 & 1642257 & 6.0315 & 6.3881 & TRN \\
\hline CHEMBL 3941281 & 1642257 & 6.7959 & 7.4158 & TRN \\
\hline CHEMBL1289034 & 1642257 & 6.0 & 5.9552 & TRN \\
\hline CHEMBL3961136 & 1642257 & 6.8239 & 6.747999 & 9999999999 \\
\hline CHEMBL 3960675 & 1642257 & 7.2757 & 6.1973 & TRN \\
\hline CHEMBL1289608 & 1642257 & 5.8125 & 6.4652 & TRN \\
\hline CHEMBL 3920308 & 1642257 & 5.8153 & 6.2812 & TRN \\
\hline CHEMBL 3954625 & 1642257 & 4.1759 & 6.0412 & TRN \\
\hline CHEMBL 379300 & 954647 & 4.7313 & 4.7137 & TRN \\
\hline CHEMBL191334 & 954647 & 5.1703 & 5.3969 & TRN \\
\hline CHEMBL1970879 & 954647 & 3.4706 & 3.661 & TRN \\
\hline CHEMBL483849 & 954647 & 2.9854 & 2.102 & TST \\
\hline CHEMBL1230020 & 954647 & 3.8223 & 3.465 & TRN \\
\hline CHEMBL 2137530 & 954647 & 4.8109 & 4.8126 & TRN \\
\hline CHEMBL 3392440 & 954647 & 3.7464 & 3.7749 & TRN \\
\hline CHEMBL 3186408 & 954647 & 4.2135 & 3.3771 & TST \\
\hline CHEMBL259181 & 954647 & 4.6114 & 4.6435 & TRN \\
\hline CHEMBL217354 & 954647 & 6.0753 & 6.0402 & TRN \\
\hline CHEMBL509032 & 954647 & 3.7201 & 3.36 & TRN \\
\hline CHEMBL189584 & 954647 & 3.8929 & 4.1385 & TRN \\
\hline CHEMBL 222102 & 954647 & 3.7204 & 3.7075 & TRN \\
\hline CHEMBL 258844 & 954647 & 3.5047 & 3.3858 & TRN \\
\hline CHEMBL1256459 & 954647 & 3.8044 & 3.8215 & TRN \\
\hline CHEMBL 221137 & 954647 & 4.9045 & 4.524 & TST \\
\hline CHEMBL1909414 & 954647 & 3.5237 & 3.3445 & TRN \\
\hline CHEMBL1643959 & 954647 & 3.1664 & 2.9866 & TRN \\
\hline CHEMBL1673039 & 954647 & 2.7846 & 3.0108 & TRN \\
\hline CHEMBL514499 & 954647 & 4.2576 & 4.2758 & TRN \\
\hline CHEMBL1590308 & 954647 & 2.6104 & 2.6392 & TST \\
\hline CHEMBL65 & 954647 & 8.3558 & 8.2817 & TRN \\
\hline CHEMBL92309 & 954647 & 3.1755 & 2.4045 & TST \\
\hline CHEMBL 2144069 & 954647 & 4.7047 & 4.7969 & TRN \\
\hline CHEMBL1516890 & 954647 & 4.2991 & 4.2402 & TRN \\
\hline CHEMBL1404918 & 954647 & 2.6059 & 2.9177 & TRN \\
\hline CHEMBL220241 & 954647 & 5.1389 & 5.2884 & TRN \\
\hline CHEMBL512504 & 954647 & 7.1911 & 7.1125 & TRN \\
\hline CHEMBL472940 & 954647 & 4.6635 & 4.4153 & TRN \\
\hline CHEMBL 255342 & 954647 & 3.7075 & 3.7518 & TRN \\
\hline CHEMBL585951 & 954647 & 5.954 & \multicolumn{2}{|c|}{6.172999999999999} \\
\hline CHEMBL 2134202 & 954647 & 3.6508 & 3.964 & TRN \\
\hline CHEMBL392695 & 954647 & 3.1869 & 3.3812 & TRN \\
\hline CHEMBL412142 & 954647 & 3.358 & 3.4155 & TRN \\
\hline CHEMBL102714 & 954647 & 2.9781 & 3.0318 & TRN \\
\hline CHEMBL3199475 & 954647 & 4.6957 & 4.5132 & TRN \\
\hline
\end{tabular}

Page 11832 


\begin{tabular}{|c|c|c|c|c|c|}
\hline \multicolumn{6}{|c|}{ Supplemental Table S2.txt } \\
\hline CHEMBL188678 & 954647 & 4.522 & 4.3679 & TRN & \\
\hline CHEMBL 210618 & 954647 & 3.5637 & 3.6739 & TRN & \\
\hline CHEMBL1190711 & 954647 & 4.8789 & 4.9861 & TRN & \\
\hline CHEMBL1788116 & 954647 & 3.8628 & 3.6364 & TRN & \\
\hline CHEMBL573107 & 954647 & 3.888 & 4.2132 & TRN & \\
\hline CHEMBL 213100 & 954647 & 3.1706 & 3.3416 & TRN & \\
\hline CHEMBL483847 & 954647 & 3.4846 & 3.6704 & TRN & \\
\hline CHEMBL 2005886 & 954647 & 4.1155 & 4.0665 & TRN & \\
\hline CHEMBL135561 & 954647 & 4.7252 & 4.5405 & TRN & \\
\hline CHEMBL1357247 & 954647 & 3.3858 & 3.2542 & TRN & \\
\hline CHEMBL379975 & 954647 & 4.2461 & 4.2084 & TRN & \\
\hline CHEMBL1186585 & 954647 & 4.7924 & 4.5235 & TRN & \\
\hline CHEMBL180127 & 954647 & 3.8918 & 3.7933 & TRN & \\
\hline CHEMBL577784 & 954647 & 4.8101 & 4.7574 & TRN & \\
\hline CHEMBL558642 & 954647 & 3.9914 & 3.8232 & TRN & \\
\hline CHEMBL192566 & 954647 & 7.8294 & 7.1946 & TST & \\
\hline CHEMBL393929 & 954647 & 3.4262 & 3.4164 & TRN & \\
\hline CHEMBL300389 & 954647 & 5.4156 & 5.3791 & TRN & \\
\hline CHEMBL515416 & 954647 & 3.36 & 3.9199 & TST & \\
\hline CHEMBL1242367 & 954647 & 3.2677 & 2.9609 & TST & \\
\hline CHEMBL 9470 & 954647 & 7.0163 & 5.49700 & 0000000001 & TST \\
\hline CHEMBL240954 & 954647 & 4.2236 & 3.5823 & TST & \\
\hline CHEMBL399530 & 954647 & 4.7084 & 4.8046 & TST & \\
\hline CHEMBL449158 & 954647 & 6.0267 & 6.7762 & TST & \\
\hline CHEMBL 2363137 & 954647 & 4.725 & 4.5594 & TST & \\
\hline CHEMBL3349342 & 954647 & 4.9491 & 4.2673 & TST & \\
\hline CHEMBL373751 & 954647 & 3.2715 & 3.4139 & TST & \\
\hline CHEMBL 209148 & 954647 & 3.8654 & 3.4755 & TST & \\
\hline CHEMBL 202721 & 954647 & 3.6413 & 4.9327 & TST & \\
\hline CHEMBL 3717257 & 1536645 & 5.0223 & 5.3839 & TRN & \\
\hline CHEMBL3719322 & 1536645 & 7.6383 & 6.6628 & TRN & \\
\hline CHEMBL 3717208 & 1536645 & 3.5229 & 3.4946 & TRN & \\
\hline CHEMBL3718638 & 1536645 & 7.0132 & 6.5239 & TRN & \\
\hline CHEMBL3716436 & 1536645 & 7.8239 & 8.0007 & TRN & \\
\hline CHEMBL3717606 & 1536645 & 6.5258 & 6.4514 & TRN & \\
\hline CHEMBL3717675 & 1536645 & 6.4202 & 6.5522 & TRN & \\
\hline CHEMBL 3717124 & 1536645 & 4.7399 & 5.0586 & TRN & \\
\hline CHEMBL3716140 & 1536645 & 6.9788 & 5.7824 & TRN & \\
\hline CHEMBL 3717337 & 1536645 & 5.9666 & 5.7615 & TRN & \\
\hline CHEMBL3719134 & 1536645 & 8.301 & 8.0405 & TRN & \\
\hline CHEMBL3716430 & 1536645 & 4.6882 & 4.6057 & TRN & \\
\hline CHEMBL 3719362 & 1536645 & 5.2147 & 5.4628 & TRN & \\
\hline CHEMBL3717912 & 1536645 & 7.585 & 7.1112 & TRN & \\
\hline CHEMBL 3717460 & 1536645 & 7.4815 & 7.478 & TRN & \\
\hline CHEMBL3715720 & 1536645 & 6.3072 & 5.9756 & TRN & \\
\hline CHEMBL3716277 & 1536645 & 5.4123 & 5.7701 & TRN & \\
\hline CHEMBL 3718493 & 1536645 & 4.7607 & 4.95 & TRN & \\
\hline CHEMBL 3717131 & 1536645 & 4.6198 & 5.0648 & TRN & \\
\hline
\end{tabular}


Supplemental Table S2.txt

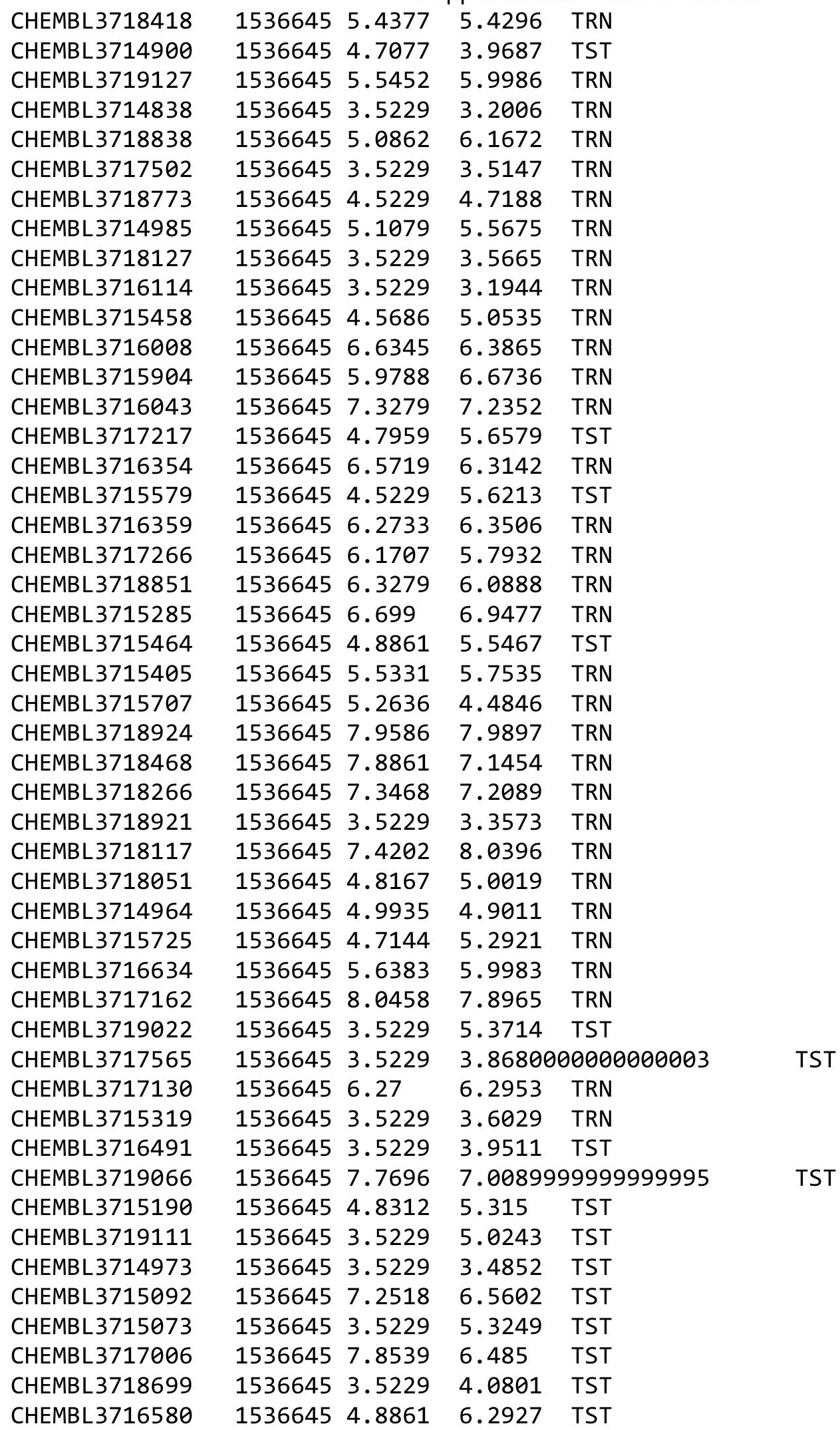

Page 11834 
Supplemental Table S2.txt

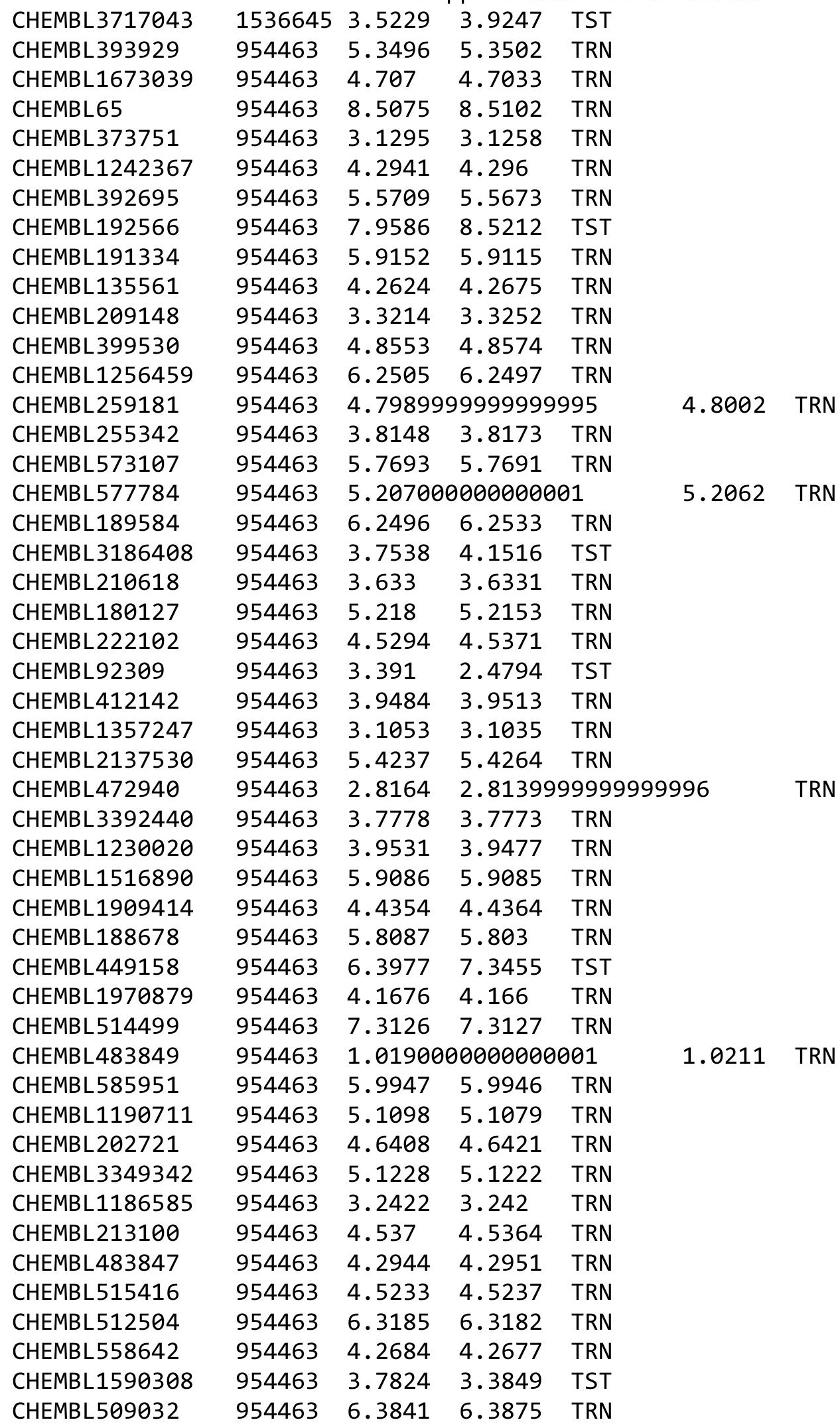

Page 11835 


\begin{tabular}{|c|c|c|c|c|}
\hline & & & oplement & al Ta \\
\hline CHEMBL1404918 & 954463 & 2.628 & 2.6301 & TRN \\
\hline CHEMBL1643959 & 954463 & 3.4326 & 3.4325 & TRN \\
\hline CHEMBL2363137 & 954463 & 4.6643 & 4.6593 & TRN \\
\hline CHEMBL221137 & 954463 & 5.1617 & 4.505 & TST \\
\hline CHEMBL3199475 & 954463 & 4.428 & 4.4278 & TRN \\
\hline CHEMBL1788116 & 954463 & 4.0735 & 4.072 & TRN \\
\hline CHEMBL 2144069 & 954463 & 5.2451 & 4.7813 & TST \\
\hline CHEMBL2134202 & 954463 & 3.0805 & 3.7683 & TST \\
\hline CHEMBL220241 & 954463 & 3.9387 & 4.0164 & TST \\
\hline CHEMBL300389 & 954463 & 5.4139 & 7.4651 & TST \\
\hline CHEMBL240954 & 954463 & 3.5947 & 3.7165 & TST \\
\hline CHEMBL 379300 & 954463 & 5.4788 & 6.9856 & TST \\
\hline CHEMBL2005886 & 954463 & 4.6294 & 5.5734 & TST \\
\hline CHEMBL 258844 & 954463 & 3.4497 & 4.3203 & TST \\
\hline CHEMBL 217354 & 954463 & 6.8378 & 6.1702 & TST \\
\hline CHEMBL9470 & 954463 & 6.0758 & 5.8853 & TST \\
\hline CHEMBL1443294 & 688279 & 2.8239 & 3.1585 & TRN \\
\hline CHEMBL1376224 & 688279 & 2.7959 & 2.9535 & TRN \\
\hline CHEMBL1532413 & 688279 & 4.2737 & 3.0341 & TRN \\
\hline CHEMBL1603982 & 688279 & 4.6954 & 3.3213 & TRN \\
\hline CHEMBL581880 & 688279 & 2.7959 & 3.5509 & TRN \\
\hline CHEMBL527584 & 688279 & 4.3182 & 3.1636 & TST \\
\hline CHEMBL1460301 & 688279 & 2.7959 & 3.4544 & TST \\
\hline CHEMBL1451169 & 688279 & 2.7959 & 3.5392 & TRN \\
\hline CHEMBL1570176 & 688279 & 3.813 & 3.3851 & TRN \\
\hline CHEMBL 3190322 & 688279 & 2.7959 & 3.3219 & TRN \\
\hline CHEMBL1520187 & 688279 & 2.7959 & 3.2316 & TST \\
\hline CHEMBL1550584 & 688279 & 4.2682 & 3.7302 & TRN \\
\hline CHEMBL1387847 & 688279 & 2.7959 & 2.9544 & TRN \\
\hline CHEMBL1613503 & 688279 & 2.7959 & 3.0213 & TRN \\
\hline CHEMBL1353996 & 688279 & 2.7959 & 3.5438 & TST \\
\hline CHEMBL1550430 & 688279 & 2.8239 & 3.7232 & TRN \\
\hline CHEMBL3213939 & 688279 & 2.7959 & 3.1883 & TRN \\
\hline CHEMBL1536869 & 688279 & 2.8239 & 3.3702 & TRN \\
\hline CHEMBL3192659 & 688279 & 2.7959 & 3.2815 & TRN \\
\hline CHEMBL1366656 & 688279 & 4.524 & 3.3432 & TRN \\
\hline CHEMBL1091556 & 688279 & 2.7959 & 3.7825 & TRN \\
\hline CHEMBL1430353 & 688279 & 2.7959 & 3.1296 & TRN \\
\hline CHEMBL3198627 & 688279 & 2.8239 & 3.1658 & TRN \\
\hline CHEMBL1602503 & 688279 & 2.8239 & 2.7604 & TRN \\
\hline CHEMBL 2004978 & 688279 & 4.9795 & 3.7113 & TRN \\
\hline CHEMBL 36654 & 688279 & 2.8239 & 4.1099 & TST \\
\hline CHEMBL1572967 & 688279 & 5.7338 & 4.9884 & TRN \\
\hline CHEMBL1465297 & 688279 & 2.8239 & 3.7692 & TRN \\
\hline CHEMBL582652 & 688279 & 2.8239 & 3.1937 & TST \\
\hline CHEMBL1603001 & 688279 & 2.8239 & 3.266 & TRN \\
\hline CHEMBL1319643 & 688279 & 4.1719 & 3.5146 & TRN \\
\hline CHEMBL1370536 & 688279 & 4.5992 & 3.6001 & TST \\
\hline
\end{tabular}


Supplemental Table S2.txt

\begin{tabular}{|c|c|c|c|c|}
\hline CHEMBL3192181 & 688279 & 4.6459 & 3.7326 & TRN \\
\hline CHEMBL586031 & 688279 & 4.3803 & 3.7429 & TRN \\
\hline CHEMBL1609759 & 688279 & 2.7959 & 3.3407 & TRN \\
\hline CHEMBL3208179 & 688279 & 4.0906 & 3.3664 & TRN \\
\hline CHEMBL577662 & 688279 & 2.7959 & 3.7417 & TRN \\
\hline CHEMBL1524828 & 688279 & 2.7959 & 3.2313 & TRN \\
\hline CHEMBL1365796 & 688279 & 2.8239 & 3.2733 & TRN \\
\hline CHEMBL1997827 & 688279 & 2.8239 & 3.9183 & TRN \\
\hline CHEMBL1385760 & 688279 & 2.8239 & 3.4203 & TRN \\
\hline CHEMBL1508931 & 688279 & 2.7959 & 3.6995 & TRN \\
\hline CHEMBL1548613 & 688279 & 3.9625 & 3.61899 & 99999999998 \\
\hline CHEMBL1437130 & 688279 & 2.7959 & 3.21 & TRN \\
\hline CHEMBL1307453 & 688279 & 4.6524 & 3.3376 & TRN \\
\hline CHEMBL 2005246 & 688279 & 2.7959 & 3.9303 & TRN \\
\hline CHEMBL1496767 & 688279 & 2.8239 & 3.0879 & TRN \\
\hline CHEMBL580955 & 688279 & 4.6555 & 5.0272 & TRN \\
\hline CHEMBL1383805 & 688279 & 2.7959 & 3.1612 & TRN \\
\hline CHEMBL1481740 & 688279 & 2.8239 & 3.3065 & TRN \\
\hline CHEMBL1449892 & 688279 & 2.8239 & 3.2076 & TRN \\
\hline CHEMBL1576945 & 688279 & 3.8636 & 3.444 & TRN \\
\hline CHEMBL3211998 & 688279 & 5.1775 & 3.4366 & TRN \\
\hline CHEMBL1506580 & 688279 & 4.4731 & 4.473 & TRN \\
\hline CHEMBL1613016 & 688279 & 2.8239 & 3.2533 & TST \\
\hline CHEMBL1405070 & 688279 & 2.7959 & 3.3944 & TRN \\
\hline CHEMBL1981612 & 688279 & 2.7959 & 3.1885 & TRN \\
\hline CHEMBL571501 & 688279 & 2.8239 & 3.9097 & TRN \\
\hline CHEMBL1603456 & 688279 & 2.7959 & 3.4423 & TRN \\
\hline CHEMBL1464110 & 688279 & 5.0004 & 3.6529 & TRN \\
\hline CHEMBL3196726 & 688279 & 2.7959 & 3.9929 & TRN \\
\hline CHEMBL1561050 & 688279 & 2.8239 & 3.1729 & TRN \\
\hline CHEMBL1361917 & 688279 & 4.0077 & 3.4906 & TRN \\
\hline CHEMBL405927 & 688279 & 3.8741 & 3.3754 & TRN \\
\hline CHEMBL1583719 & 688279 & 2.7959 & 2.9895 & TRN \\
\hline CHEMBL 3209395 & 688279 & 2.8239 & 2.9765 & TRN \\
\hline CHEMBL1519955 & 688279 & 2.8239 & 3.2518 & TRN \\
\hline CHEMBL1452636 & 688279 & 2.7959 & 3.2572 & TST \\
\hline CHEMBL1428287 & 688279 & 2.8239 & 3.4801 & TRN \\
\hline CHEMBL1964793 & 688279 & 2.7959 & 3.7508 & TRN \\
\hline CHEMBL1607404 & 688279 & 4.1983 & 3.7216 & TRN \\
\hline CHEMBL1609663 & 688279 & 2.8239 & 2.9859 & TRN \\
\hline CHEMBL1449523 & 688279 & 2.7959 & 3.7526 & TRN \\
\hline CHEMBL89445 & 688279 & 5.8781 & 3.9168 & TRN \\
\hline CHEMBL3197735 & 688279 & 4.7871 & 3.3809 & TRN \\
\hline CHEMBL1504461 & 688279 & 2.8239 & 3.7823 & TRN \\
\hline CHEMBL1425546 & 688279 & 2.8239 & 3.1932 & TRN \\
\hline CHEMBL1346822 & 688279 & 4.6283 & 3.7395 & TRN \\
\hline CHEMBL1378218 & 688279 & 2.7959 & 3.187 & TRN \\
\hline CHEMBL1487576 & 688279 & 2.8239 & 3.1324 & TRN \\
\hline
\end{tabular}




\begin{tabular}{|c|c|c|c|c|c|}
\hline & & \multicolumn{4}{|c|}{ Supplemental Table S2.txt } \\
\hline CHEMBL1411526 & 688279 & 2.8239 & 3.0449 & TRN & \\
\hline CHEMBL1432784 & 688279 & 2.7959 & 3.7654 & TRN & \\
\hline CHEMBL1993194 & 688279 & 5.4827 & 3.8834 & TRN & \\
\hline CHEMBL 2000750 & 688279 & 2.7959 & 3.6404 & TRN & \\
\hline CHEMBL1455556 & 688279 & 4.3331 & 3.5324 & TRN & \\
\hline CHEMBL1556838 & 688279 & 2.8239 & 3.6262 & TRN & \\
\hline CHEMBL1454012 & 688279 & 2.7959 & 3.5462 & TRN & \\
\hline CHEMBL1390492 & 688279 & 4.1729 & 3.484 & TRN & \\
\hline CHEMBL1344321 & 688279 & 2.7959 & 3.4557 & TRN & \\
\hline CHEMBL1347656 & 688279 & 2.7959 & 3.2465 & TST & \\
\hline CHEMBL1541834 & 688279 & 2.7959 & 3.9199 & TRN & \\
\hline CHEMBL1501041 & 688279 & 2.8239 & 3.3445 & TRN & \\
\hline CHEMBL1360400 & 688279 & \multicolumn{2}{|c|}{ 4.76699999999999995 } & 3.2154 & TRN \\
\hline CHEMBL3197625 & 688279 & 3.9714 & 3.4616 & TRN & \\
\hline CHEMBL1567688 & 688279 & 2.8239 & 3.3962 & TRN & \\
\hline CHEMBL1459060 & 688279 & 4.7753 & 3.576 & TRN & \\
\hline CHEMBL1322883 & 688279 & 2.7959 & 3.1367 & TRN & \\
\hline CHEMBL1328182 & 688279 & 2.7959 & 3.9232 & TRN & \\
\hline CHEMBL3189997 & 688279 & 4.4928 & 3.5567 & TRN & \\
\hline CHEMBL1612118 & 688279 & 2.8239 & 2.83399 & 99999999996 & TRN \\
\hline CHEMBL1496313 & 688279 & 5.121 & 3.9595 & TRN & \\
\hline CHEMBL325841 & 688279 & 2.7959 & 3.512 & TRN & \\
\hline CHEMBL1386851 & 688279 & 2.8239 & 3.3904 & TRN & \\
\hline CHEMBL1327470 & 688279 & 2.8239 & 3.2075 & TST & \\
\hline CHEMBL1502351 & 688279 & 4.6883 & 4.159 & TRN & \\
\hline CHEMBL1509327 & 688279 & 2.7959 & 3.3131 & TRN & \\
\hline CHEMBL1337500 & 688279 & 5.5758 & 4.1608 & TST & \\
\hline CHEMBL1523281 & 688279 & 3.8545 & 3.3039 & TRN & \\
\hline CHEMBL1522797 & 688279 & 4.1806 & 3.115 & TRN & \\
\hline CHEMBL1547746 & 688279 & 4.1986 & 3.3229 & TRN & \\
\hline CHEMBL1548086 & 688279 & 2.8239 & 3.6659 & TST & \\
\hline CHEMBL1609233 & 688279 & 2.7959 & 3.2866 & TRN & \\
\hline CHEMBL1542861 & 688279 & 2.7959 & 3.2739 & TRN & \\
\hline CHEMBL1606097 & 688279 & 5.595 & 3.9718 & TRN & \\
\hline CHEMBL1588513 & 688279 & 4.8878 & 4.5452 & TRN & \\
\hline CHEMBL569708 & 688279 & 4.6014 & 3.091 & TRN & \\
\hline CHEMBL1327172 & 688279 & 4.4975 & 3.9751 & TRN & \\
\hline CHEMBL3199328 & 688279 & 2.8239 & 3.7367 & TRN & \\
\hline CHEMBL1419164 & 688279 & 4.0671 & 3.6945 & TRN & \\
\hline CHEMBL3199724 & 688279 & 4.8549 & 3.7806 & TRN & \\
\hline CHEMBL1543939 & 688279 & 4.7028 & 3.49399 & 99999999998 & כו \\
\hline CHEMBL 3145303 & 688279 & 5.6349 & 3.7343 & TRN & \\
\hline CHEMBL1336834 & 688279 & 4.67 & 3.3779 & TRN & \\
\hline CHEMBL3196241 & 688279 & 2.7959 & 4.0012 & TRN & \\
\hline CHEMBL1432726 & 688279 & 2.7959 & 3.1568 & TRN & \\
\hline CHEMBL1371081 & 688279 & 2.8239 & 3.2731 & TRN & \\
\hline CHEMBL1608990 & 688279 & 2.7959 & 3.281 & TRN & \\
\hline CHEMBL1420684 & 688279 & 2.7959 & 3.3769 & TST & \\
\hline
\end{tabular}




\begin{tabular}{|c|c|c|c|c|}
\hline & & & oplement & al $\mathrm{T}$ \\
\hline CHEMBL1599610 & 688279 & 4.1742 & 3.4713 & TRN \\
\hline CHEMBL1330716 & 688279 & 2.8239 & 3.1982 & TRN \\
\hline CHEMBL3198912 & 688279 & 4.6246 & 3.7971 & TRN \\
\hline CHEMBL1467655 & 688279 & 2.8239 & 3.2916 & TST \\
\hline CHEMBL1987579 & 688279 & 4.686 & 3.7346 & TRN \\
\hline CHEMBL1471909 & 688279 & 4.5456 & 3.2833 & TRN \\
\hline CHEMBL1422696 & 688279 & 3.8505 & 2.9033 & TRN \\
\hline CHEMBL1404086 & 688279 & 2.8239 & 4.0538 & TRN \\
\hline CHEMBL 3212148 & 688279 & 2.7959 & 3.7619 & TRN \\
\hline CHEMBL1469579 & 688279 & 2.7959 & 3.8739 & TRN \\
\hline CHEMBL1338466 & 688279 & 2.7959 & 3.2456 & TRN \\
\hline CHEMBL1430893 & 688279 & 2.7959 & 3.5422 & TRN \\
\hline CHEMBL1484330 & 688279 & 2.7959 & 3.3259 & TRN \\
\hline CHEMBL3208223 & 688279 & 4.3257 & 3.5192 & TRN \\
\hline CHEMBL1505875 & 688279 & 2.7959 & 3.5614 & TRN \\
\hline CHEMBL1487639 & 688279 & 4.7922 & 3.8657 & TRN \\
\hline CHEMBL1977301 & 688279 & 2.7959 & 3.7098 & TRN \\
\hline CHEMBL1353757 & 688279 & 2.7959 & 3.5573 & TRN \\
\hline CHEMBL1360687 & 688279 & 2.8239 & 3.5545 & TRN \\
\hline CHEMBL1535759 & 688279 & 2.7959 & 3.5841 & TRN \\
\hline CHEMBL1500144 & 688279 & 4.7701 & 3.2534 & TRN \\
\hline CHEMBL1582834 & 688279 & 4.8889 & 3.2644 & TRN \\
\hline CHEMBL3197761 & 688279 & 2.7959 & 3.5041 & TRN \\
\hline CHEMBL1406697 & 688279 & 2.8239 & 3.1172 & TRN \\
\hline CHEMBL3208133 & 688279 & 2.7959 & 3.2346 & TRN \\
\hline CHEMBL1505623 & 688279 & 2.7959 & 3.3127 & TRN \\
\hline CHEMBL1420598 & 688279 & 2.7959 & 3.6612 & TRN \\
\hline CHEMBL1403085 & 688279 & 4.8452 & 3.4688 & TRN \\
\hline CHEMBL1453766 & 688279 & 2.8239 & 3.2308 & TRN \\
\hline CHEMBL1200847 & 688279 & 2.8239 & 3.6088 & TST \\
\hline CHEMBL1412223 & 688279 & 2.7959 & 3.5942 & TRN \\
\hline CHEMBL1438970 & 688279 & 2.8239 & 3.5927 & TRN \\
\hline CHEMBL3209453 & 688279 & 2.7959 & 3.2022 & TST \\
\hline CHEMBL1500363 & 688279 & 2.7959 & 3.6507 & TRN \\
\hline CHEMBL1256876 & 688279 & 2.8239 & 3.5324 & TST \\
\hline CHEMBL1303953 & 688279 & 5.3381 & 4.734 & TRN \\
\hline CHEMBL1386472 & 688279 & 2.7959 & 3.0736 & TRN \\
\hline CHEMBL1388646 & 688279 & 2.7959 & 3.3362 & TRN \\
\hline CHEMBL1326457 & 688279 & 4.3866 & 3.3671 & TRN \\
\hline CHEMBL1426430 & 688279 & 2.8239 & 3.0588 & TRN \\
\hline CHEMBL1985582 & 688279 & 5.9961 & 3.5925 & TRN \\
\hline CHEMBL1352998 & 688279 & 2.7959 & 3.1869 & TRN \\
\hline CHEMBL1583292 & 688279 & 2.8239 & 3.7857 & TST \\
\hline CHEMBL1491815 & 688279 & 2.7959 & 3.3876 & TRN \\
\hline CHEMBL1437579 & 688279 & 2.7959 & 3.4974 & TRN \\
\hline CHEMBL1332555 & 688279 & 2.8239 & 3.5505 & TRN \\
\hline CHEMBL251055 & 688279 & 2.7959 & 3.5942 & TST \\
\hline CHEMBL1456703 & 688279 & 2.8239 & 3.1616 & TRN \\
\hline
\end{tabular}




\begin{tabular}{|c|c|c|c|c|c|}
\hline \multirow[b]{2}{*}{ CHEMBL1497081 } & \multicolumn{5}{|c|}{ Supplemental Table S2.txt } \\
\hline & 688279 & 2.8239 & 3.156 & TST & \\
\hline CHEMBL1538232 & 688279 & 2.8239 & 3.3888 & TRN & \\
\hline CHEMBL1585075 & 688279 & 2.8239 & 3.1021 & TRN & \\
\hline CHEMBL1381627 & 688279 & 2.8239 & 3.3536 & TRN & \\
\hline CHEMBL1418792 & 688279 & 2.8239 & 3.3779 & TRN & \\
\hline CHEMBL1457949 & 688279 & 2.8239 & 3.2524 & TRN & \\
\hline CHEMBL1981928 & 688279 & 2.8239 & 3.2262 & TRN & \\
\hline CHEMBL1313283 & 688279 & 4.4605 & 3.2484 & TRN & \\
\hline CHEMBL1994179 & 688279 & 4.6363 & 3.6354 & TRN & \\
\hline CHEMBL1458210 & 688279 & 2.7959 & 3.7479 & TST & \\
\hline CHEMBL1369060 & 688279 & 2.7959 & 3.043 & TST & \\
\hline CHEMBL1318350 & 688279 & 4.6752 & 3.8882 & TRN & \\
\hline CHEMBL1527022 & 688279 & 2.8239 & 3.4466 & TRN & \\
\hline CHEMBL1510332 & 688279 & 4.5465 & 4.1458 & TRN & \\
\hline CHEMBL1424999 & 688279 & 2.8239 & 3.0073 & TRN & \\
\hline CHEMBL1364010 & 688279 & 2.7959 & 3.7597 & TRN & \\
\hline CHEMBL579322 & 688279 & 4.2324 & 3.5461 & TRN & \\
\hline CHEMBL1573697 & 688279 & 4.7806 & 3.4579 & TRN & \\
\hline CHEMBL3198207 & 688279 & 2.8239 & 3.3909 & TRN & \\
\hline CHEMBL254576 & 688279 & 2.8239 & 3.5132 & TST & \\
\hline CHEMBL478791 & 688279 & 2.7959 & 3.6718 & TRN & \\
\hline CHEMBL585827 & 688279 & 4.7003 & 4.8596 & TRN & \\
\hline CHEMBL1452711 & 688279 & 4.7899 & 3.9824 & TRN & \\
\hline CHEMBL528181 & 688279 & 2.8239 & 3.3979 & TRN & \\
\hline CHEMBL1519370 & 688279 & 2.8239 & 3.1105 & TRN & \\
\hline CHEMBL3191858 & 688279 & 2.8239 & 3.2424 & TRN & \\
\hline CHEMBL1611574 & 688279 & 2.7959 & 3.1371 & TRN & \\
\hline CHEMBL1311585 & 688279 & 2.7959 & 3.6886 & TRN & \\
\hline CHEMBL1449883 & 688279 & 4.9008 & 4.5555 & TRN & \\
\hline CHEMBL1498022 & 688279 & 2.8239 & 3.12600 & 00000000003 & TST \\
\hline CHEMBL3195273 & 688279 & 5.2658 & 3.6415 & TRN & \\
\hline CHEMBL1511029 & 688279 & 2.8239 & 3.0762 & TRN & \\
\hline CHEMBL1513972 & 688279 & 2.7959 & 3.6721 & TST & \\
\hline CHEMBL1342295 & 688279 & 2.7959 & 3.0027 & TRN & \\
\hline CHEMBL1350252 & 688279 & 2.7959 & 3.4359 & TRN & \\
\hline CHEMBL1388595 & 688279 & 4.9159 & 3.35699 & 99999999998 & TRN \\
\hline CHEMBL1534309 & 688279 & 2.8239 & 3.3704 & TRN & \\
\hline CHEMBL1535900 & 688279 & 4.7462 & 3.5187 & TST & \\
\hline CHEMBL1339696 & 688279 & 2.8239 & 3.1825 & TST & \\
\hline CHEMBL1301107 & 688279 & 4.5285 & 3.4298 & TRN & \\
\hline CHEMBL1391582 & 688279 & 2.7959 & 3.5556 & TST & \\
\hline CHEMBL1381600 & 688279 & 4.0136 & 3.3997 & TRN & \\
\hline CHEMBL1587453 & 688279 & 2.8239 & 3.5838 & TRN & \\
\hline CHEMBL1558065 & 688279 & 4.7117 & 4.3412 & TRN & \\
\hline CHEMBL3199428 & 688279 & 2.8239 & 3.9095 & TRN & \\
\hline CHEMBL1310438 & 688279 & 2.8239 & 3.3538 & TRN & \\
\hline CHEMBL1563898 & 688279 & 5.0834 & 3.6316 & TST & \\
\hline CHEMBL1430319 & 688279 & 4.0287 & 3.6154 & TST & \\
\hline
\end{tabular}




\begin{tabular}{|c|c|c|c|c|c|c|}
\hline & & \multicolumn{5}{|c|}{ Supplemental Table S2.txt } \\
\hline CHEMBL1602088 & 688279 & 2.8239 & 3.7759 & TRN & & \\
\hline CHEMBL 3192541 & 688279 & 2.8239 & 3.57 & TRN & & \\
\hline CHEMBL1338502 & 688279 & 4.2 & 3.50100 & 00006 & 003 & TRN \\
\hline CHEMBL1520777 & 688279 & 2.8239 & 3.2168 & TRN & & \\
\hline CHEMBL1403955 & 688279 & 2.8239 & 3.448 & TRN & & \\
\hline CHEMBL1424331 & 688279 & 2.7959 & 3.7307 & TRN & & \\
\hline CHEMBL1379894 & 688279 & 3.97300 & 20000000 & 003 & 3.4995 & TST \\
\hline CHEMBL1453309 & 688279 & 5.4233 & 3.5446 & TRN & & \\
\hline CHEMBL1499496 & 688279 & 3.8952 & 3.2488 & TST & & \\
\hline CHEMBL1490772 & 688279 & 5.11100 & 00000000 & 01 & 3.3819 & TRN \\
\hline CHEMBL1426155 & 688279 & 2.7959 & 3.4147 & TRN & & \\
\hline CHEMBL1324985 & 688279 & 2.8239 & 3.2678 & TRN & & \\
\hline CHEMBL1483825 & 688279 & 3.8803 & 2.9448 & TRN & & \\
\hline CHEMBL3191432 & 688279 & 4.6365 & 3.5819 & TRN & & \\
\hline CHEMBL1440476 & 688279 & 4.6509 & 3.4089 & TST & & \\
\hline CHEMBL1519558 & 688279 & 2.7959 & 3.178 & TRN & & \\
\hline CHEMBL1346637 & 688279 & 3.9322 & 3.6208 & TRN & & \\
\hline CHEMBL1465485 & 688279 & 4.6538 & 3.4866 & TRN & & \\
\hline CHEMBL1366104 & 688279 & 2.8239 & 3.1348 & TRN & & \\
\hline CHEMBL1404493 & 688279 & 5.0149 & 3.9319 & TRN & & \\
\hline CHEMBL1581627 & 688279 & 2.8239 & 3.4912 & TRN & & \\
\hline CHEMBL1309033 & 688279 & 2.8239 & 3.3945 & TRN & & \\
\hline CHEMBL1492078 & 688279 & 2.8239 & 3.5711 & TST & & \\
\hline CHEMBL1476264 & 688279 & 4.8349 & 4.6389 & TRN & & \\
\hline CHEMBL578944 & 688279 & 2.7959 & 3.516 & TRN & & \\
\hline CHEMBL1434756 & 688279 & 2.8239 & 3.3438 & TST & & \\
\hline CHEMBL1460249 & 688279 & 2.8239 & 3.5017 & TRN & & \\
\hline CHEMBL1502851 & 688279 & 2.7959 & 3.634 & TRN & & \\
\hline CHEMBL547285 & 688279 & 4.6278 & 4.9577 & TRN & & \\
\hline CHEMBL3189255 & 688279 & 3.8593 & 3.2857 & TRN & & \\
\hline CHEMBL602218 & 688279 & 2.7959 & 4.0739 & TRN & & \\
\hline CHEMBL1443898 & 688279 & 2.8239 & 3.5183 & TST & & \\
\hline CHEMBL1541582 & 688279 & 2.8239 & 3.3054 & TRN & & \\
\hline CHEMBL1362096 & 688279 & 4.9369 & 3.3975 & TRN & & \\
\hline CHEMBL3192707 & 688279 & 2.7959 & 3.2208 & TST & & \\
\hline CHEMBL1346226 & 688279 & 4.7639 & 3.5056 & TRN & & \\
\hline CHEMBL1477212 & 688279 & 5.1265 & 3.5967 & TRN & & \\
\hline CHEMBL1343392 & 688279 & 5.513 & 4.8563 & TRN & & \\
\hline CHEMBL1583585 & 688279 & 2.7959 & 3.7239 & TRN & & \\
\hline CHEMBL1313518 & 688279 & 2.7959 & 2.9763 & TRN & & \\
\hline CHEMBL 2028186 & 688279 & 2.8239 & 3.8719 & TST & & \\
\hline CHEMBL1328504 & 688279 & 4.9367 & 3.4423 & TRN & & \\
\hline CHEMBL1502352 & 688279 & 2.8239 & 3.1866 & TRN & & \\
\hline CHEMBL1481849 & 688279 & 5.1232 & 3.4998 & TST & & \\
\hline CHEMBL3193134 & 688279 & 2.8239 & 3.5035 & TRN & & \\
\hline CHEMBL1401052 & 688279 & 4.4284 & 3.2198 & TRN & & \\
\hline CHEMBL1528049 & 688279 & 2.7959 & 3.2603 & TRN & & \\
\hline CHEMBL1420188 & 688279 & 2.7959 & 3.1455 & TRN & & \\
\hline
\end{tabular}




\begin{tabular}{|c|c|c|c|c|c|}
\hline & & \multicolumn{4}{|c|}{ Supplemental Table S2.txt } \\
\hline CHEMBL1426693 & 688279 & 4.7185 & 3.8265 & TRN & \\
\hline CHEMBL1450261 & 688279 & 2.8239 & 3.2127 & TRN & \\
\hline CHEMBL1547925 & 688279 & 2.8239 & 2.9261 & TRN & \\
\hline CHEMBL 3397122 & 688279 & 2.8239 & 3.47899 & 99999999996 & TRN \\
\hline CHEMBL1301480 & 688279 & 2.7959 & 3.3451 & TRN & \\
\hline CHEMBL1309059 & 688279 & 2.7959 & 3.5623 & TRN & \\
\hline CHEMBL1968316 & 688279 & 2.8239 & 3.025 & TRN & \\
\hline CHEMBL 3210143 & 688279 & 2.8239 & 3.4494 & TRN & \\
\hline CHEMBL1306749 & 688279 & 2.7959 & 3.2063 & TRN & \\
\hline CHEMBL1302895 & 688279 & 2.7959 & 3.6162 & TST & \\
\hline CHEMBL1491847 & 688279 & 3.8666 & 3.4787 & TST & \\
\hline CHEMBL1597276 & 688279 & 2.8239 & 3.3979 & TRN & \\
\hline CHEMBL1463847 & 688279 & 5.5017 & 3.5253 & TST & \\
\hline CHEMBL1471200 & 688279 & 2.8239 & 3.3041 & TRN & \\
\hline CHEMBL1417624 & 688279 & 2.7959 & 3.2719 & TST & \\
\hline CHEMBL1563714 & 688279 & 5.574 & 3.4695 & TRN & \\
\hline CHEMBL473314 & 688279 & 2.8239 & 4.1192 & TRN & \\
\hline CHEMBL1499658 & 688279 & 2.8239 & 3.1858 & TRN & \\
\hline CHEMBL1450527 & 688279 & 2.8239 & 3.5163 & TRN & \\
\hline CHEMBL1328925 & 688279 & 2.7959 & 3.1366 & TRN & \\
\hline CHEMBL1989897 & 688279 & 2.7959 & 3.7808 & TRN & \\
\hline CHEMBL 3189845 & 688279 & 2.7959 & 3.7679 & TRN & \\
\hline CHEMBL1362036 & 688279 & 2.7959 & 3.1149 & TRN & \\
\hline CHEMBL1505039 & 688279 & 2.8239 & 3.5181 & TRN & \\
\hline CHEMBL1327791 & 688279 & 2.7959 & 3.6402 & TRN & \\
\hline CHEMBL1539860 & 688279 & 2.7959 & 3.33699 & 99999999997 & TRN \\
\hline CHEMBL1517151 & 688279 & 2.8239 & 3.3097 & TRN & \\
\hline CHEMBL1981150 & 688279 & 2.8239 & 3.6478 & TRN & \\
\hline CHEMBL1391457 & 688279 & 4.4921 & 3.7901 & TRN & \\
\hline CHEMBL1547329 & 688279 & 2.7959 & 3.4719 & TST & \\
\hline CHEMBL1317657 & 688279 & 3.8243 & 3.8133 & TRN & \\
\hline CHEMBL1311226 & 688279 & 2.8239 & 3.5321 & TRN & \\
\hline CHEMBL3210988 & 688279 & 4.0238 & 3.1601 & TRN & \\
\hline CHEMBL1563323 & 688279 & 2.7959 & 3.2792 & TRN & \\
\hline CHEMBL1529553 & 688279 & 4.6196 & 3.1512 & TRN & \\
\hline CHEMBL1363249 & 688279 & 2.8239 & 3.7358 & TRN & \\
\hline CHEMBL1572031 & 688279 & 2.8239 & 3.3672 & TRN & \\
\hline CHEMBL1336526 & 688279 & 3.9219 & 3.1718 & TST & \\
\hline CHEMBL1444103 & 688279 & 5.4013 & 3.2915 & TST & \\
\hline CHEMBL3192165 & 688279 & 4.9372 & 3.5961 & TRN & \\
\hline CHEMBL1333088 & 688279 & 2.7959 & 3.1002 & TST & \\
\hline CHEMBL1490481 & 688279 & 4.6874 & 3.3866 & TRN & \\
\hline CHEMBL3196364 & 688279 & 5.3063 & 3.9933 & TRN & \\
\hline CHEMBL1439576 & 688279 & 2.7959 & 3.3716 & TRN & \\
\hline CHEMBL1463786 & 688279 & 2.8239 & 3.7946 & TRN & \\
\hline CHEMBL1391837 & 688279 & 4.7304 & 3.0907 & TRN & \\
\hline CHEMBL1575649 & 688279 & 4.3811 & 3.7334 & TRN & \\
\hline CHEMBL1588483 & 688279 & 4.998 & 3.6445 & TRN & \\
\hline
\end{tabular}




\begin{tabular}{|c|c|c|c|c|c|}
\hline & & \multicolumn{4}{|c|}{ Supplemental Table S2.txt } \\
\hline CHEMBL1338492 & 688279 & 2.8239 & 3.2527 & TRN & \\
\hline CHEMBL1535533 & 688279 & 2.7959 & 3.2724 & TRN & \\
\hline CHEMBL3209027 & 688279 & 2.8239 & 3.3109 & TRN & \\
\hline CHEMBL1537190 & 688279 & 4.5542 & 3.3163 & TRN & \\
\hline CHEMBL1391974 & 688279 & 2.7959 & 3.5989 & TRN & \\
\hline CHEMBL1422799 & 688279 & 2.7959 & 3.2621 & TRN & \\
\hline CHEMBL 3208002 & 688279 & 2.8239 & 3.5685 & TRN & \\
\hline CHEMBL3197662 & 688279 & 2.7959 & 3.7041 & TRN & \\
\hline CHEMBL1989683 & 688279 & 2.8239 & 3.3787 & TRN & \\
\hline CHEMBL1433075 & 688279 & 2.7959 & 3.8727 & TST & \\
\hline CHEMBL1370871 & 688279 & 2.7959 & 3.4183 & TST & \\
\hline CHEMBL1485006 & 688279 & 2.7959 & 3.3211 & TRN & \\
\hline CHEMBL1393266 & 688279 & 2.7959 & 3.0951 & TRN & \\
\hline CHEMBL1587031 & 688279 & 4.8435 & 3.4378 & TST & \\
\hline CHEMBL1308502 & 688279 & 4.651 & 3.02399 & 99999999996 & TRN \\
\hline CHEMBL1492474 & 688279 & 2.8239 & 3.4622 & TRN & \\
\hline CHEMBL1466831 & 688279 & 2.8239 & 3.361 & TRN & \\
\hline CHEMBL1372492 & 688279 & 2.7959 & 4.6832 & TRN & \\
\hline CHEMBL1566224 & 688279 & 2.7959 & 3.25100 & 00000000003 & TRN \\
\hline CHEMBL1472105 & 688279 & 2.7959 & 3.6422 & TRN & \\
\hline CHEMBL1334791 & 688279 & 4.1409 & 3.2888 & TRN & \\
\hline CHEMBL1392643 & 688279 & 5.83 & 3.9277 & TRN & \\
\hline CHEMBL1328566 & 688279 & 2.7959 & 3.0574 & TRN & \\
\hline CHEMBL1346781 & 688279 & 2.8239 & 3.2425 & TST & \\
\hline CHEMBL1432888 & 688279 & 2.7959 & 3.6338 & TRN & \\
\hline CHEMBL1335817 & 688279 & 2.8239 & 3.1961 & TRN & \\
\hline CHEMBL1509727 & 688279 & 2.7959 & 3.3287 & TRN & \\
\hline CHEMBL1320281 & 688279 & 2.8239 & 3.3439 & TRN & \\
\hline CHEMBL1563219 & 688279 & 2.8239 & 3.5149 & TRN & \\
\hline CHEMBL1604650 & 688279 & 2.8239 & 3.2216 & TRN & \\
\hline CHEMBL1540973 & 688279 & 2.8239 & 3.0745 & TRN & \\
\hline CHEMBL1392500 & 688279 & 2.8239 & 3.8982 & TRN & \\
\hline CHEMBL1321271 & 688279 & 4.0711 & 3.4446 & TRN & \\
\hline CHEMBL1300225 & 688279 & 2.8239 & 3.0315 & TRN & \\
\hline CHEMBL375781 & 688279 & 3.8326 & 3.4339 & TST & \\
\hline CHEMBL1466593 & 688279 & 5.2781 & 3.3384 & TST & \\
\hline CHEMBL1598581 & 688279 & 4.5879 & 3.5295 & TRN & \\
\hline CHEMBL1555271 & 688279 & 4.8346 & 4.9304 & TRN & \\
\hline CHEMBL 3197978 & 688279 & 5.5039 & 3.7213 & TRN & \\
\hline CHEMBL1599337 & 688279 & 2.7959 & 3.3746 & TRN & \\
\hline CHEMBL393287 & 688279 & 2.7959 & 3.2701 & TRN & \\
\hline CHEMBL1493533 & 688279 & 2.7959 & 3.2825 & TRN & \\
\hline CHEMBL1448584 & 688279 & 4.1642 & 3.9221 & TRN & \\
\hline CHEMBL1337528 & 688279 & 2.7959 & 3.2993 & TRN & \\
\hline CHEMBL1242180 & 688279 & 2.8239 & 3.9466 & TRN & \\
\hline CHEMBL1409333 & 688279 & 4.5789 & 3.3034 & TRN & \\
\hline CHEMBL 3213034 & 688279 & 4.3583 & 4.2485 & TRN & \\
\hline CHEMBL1582831 & 688279 & 4.8243 & 4.2599 & TRN & \\
\hline
\end{tabular}




\begin{tabular}{|c|c|c|c|c|c|c|}
\hline & & \multicolumn{5}{|c|}{ Supplemental Table S2.txt } \\
\hline CHEMBL1445436 & 688279 & 2.8239 & 3.5367 & TRN & & \\
\hline CHEMBL1433124 & 688279 & 4.7971 & 3.7544 & TRN & & \\
\hline CHEMBL1442878 & 688279 & 2.8239 & 3.2363 & TRN & & \\
\hline CHEMBL1578908 & 688279 & 4.0633 & 3.09 & TRN & & \\
\hline CHEMBL3196257 & 688279 & 2.8239 & 3.8509 & TRN & & \\
\hline CHEMBL1992631 & 688279 & 4.9652 & 4.035 & TRN & & \\
\hline CHEMBL 2000445 & 688279 & 4.8415 & 3.6043 & TRN & & \\
\hline CHEMBL1543977 & 688279 & 5.5867 & 3.6404 & TRN & & \\
\hline CHEMBL1349146 & 688279 & 2.7959 & 3.4688 & TRN & & \\
\hline CHEMBL1500266 & 688279 & 2.8239 & 3.6037 & TRN & & \\
\hline CHEMBL1310713 & 688279 & 4.72199 & 99999999 & 995 & 3.783 & TRN \\
\hline CHEMBL1349502 & 688279 & 4.5201 & 3.2827 & TRN & & \\
\hline CHEMBL1530885 & 688279 & 2.7959 & 3.2165 & TRN & & \\
\hline CHEMBL3190720 & 688279 & 2.8239 & 3.5924 & TRN & & \\
\hline CHEMBL590665 & 688279 & 4.8764 & 5.066 & TRN & & \\
\hline CHEMBL1484227 & 688279 & 2.8239 & 3.4161 & TST & & \\
\hline CHEMBL147514 & 688279 & 2.7959 & 3.4794 & TST & & \\
\hline CHEMBL1543839 & 688279 & 5.5904 & 5.0175 & TRN & & \\
\hline CHEMBL1608104 & 688279 & 2.8239 & 3.6527 & TST & & \\
\hline CHEMBL1417569 & 688279 & 2.8239 & 3.1509 & TST & & \\
\hline CHEMBL1581668 & 688279 & 4.0487 & 3.431 & TRN & & \\
\hline CHEMBL3192856 & 688279 & 2.8239 & 3.7919 & TRN & & \\
\hline CHEMBL1566205 & 688279 & 2.7959 & 3.1583 & TRN & & \\
\hline CHEMBL1388882 & 688279 & 2.8239 & 3.346 & TST & & \\
\hline CHEMBL 3193241 & 688279 & 5.0013 & 3.6321 & TRN & & \\
\hline CHEMBL1505192 & 688279 & 2.7959 & 3.3257 & TRN & & \\
\hline CHEMBL1350865 & 688279 & 2.8239 & 3.3107 & TRN & & \\
\hline CHEMBL1324163 & 688279 & 2.7959 & 3.0157 & TRN & & \\
\hline CHEMBL1544114 & 688279 & 2.7959 & 4.287 & TRN & & \\
\hline CHEMBL1519902 & 688279 & 2.8239 & 4.2863 & TRN & & \\
\hline CHEMBL391877 & 688279 & 2.8239 & 3.4383 & TRN & & \\
\hline CHEMBL1469827 & 688279 & 5.2378 & 3.6866 & TRN & & \\
\hline CHEMBL585221 & 688279 & 2.7959 & 3.2811 & TRN & & \\
\hline CHEMBL1430895 & 688279 & 5.3354 & 4.0885 & TRN & & \\
\hline CHEMBL1422542 & 688279 & 2.8239 & 3.0005 & TRN & & \\
\hline CHEMBL1309890 & 688279 & 4.3259 & 4.81 & TRN & & \\
\hline CHEMBL1595934 & 688279 & 4.4644 & 3.8218 & TRN & & \\
\hline CHEMBL1087588 & 688279 & 2.7959 & 3.2692 & TRN & & \\
\hline CHEMBL1323553 & 688279 & 4.7633 & 4.0007 & TRN & & \\
\hline CHEMBL3190558 & 688279 & 2.8239 & 3.6718 & TRN & & \\
\hline CHEMBL1557784 & 688279 & 2.7959 & 3.3831 & TRN & & \\
\hline CHEMBL3199452 & 688279 & 2.8239 & 3.3613 & TRN & & \\
\hline CHEMBL3213919 & 688279 & 2.8239 & 3.2392 & TRN & & \\
\hline CHEMBL3192656 & 688279 & 2.7959 & 3.6535 & TRN & & \\
\hline CHEMBL1587075 & 688279 & 4.3677 & 3.2252 & TST & & \\
\hline CHEMBL1425575 & 688279 & 2.8239 & 3.0118 & TRN & & \\
\hline CHEMBL1566967 & 688279 & 2.8239 & 3.094 & TST & & \\
\hline CHEMBL580727 & 688279 & 4.6046 & 4.4044 & TRN & & \\
\hline
\end{tabular}




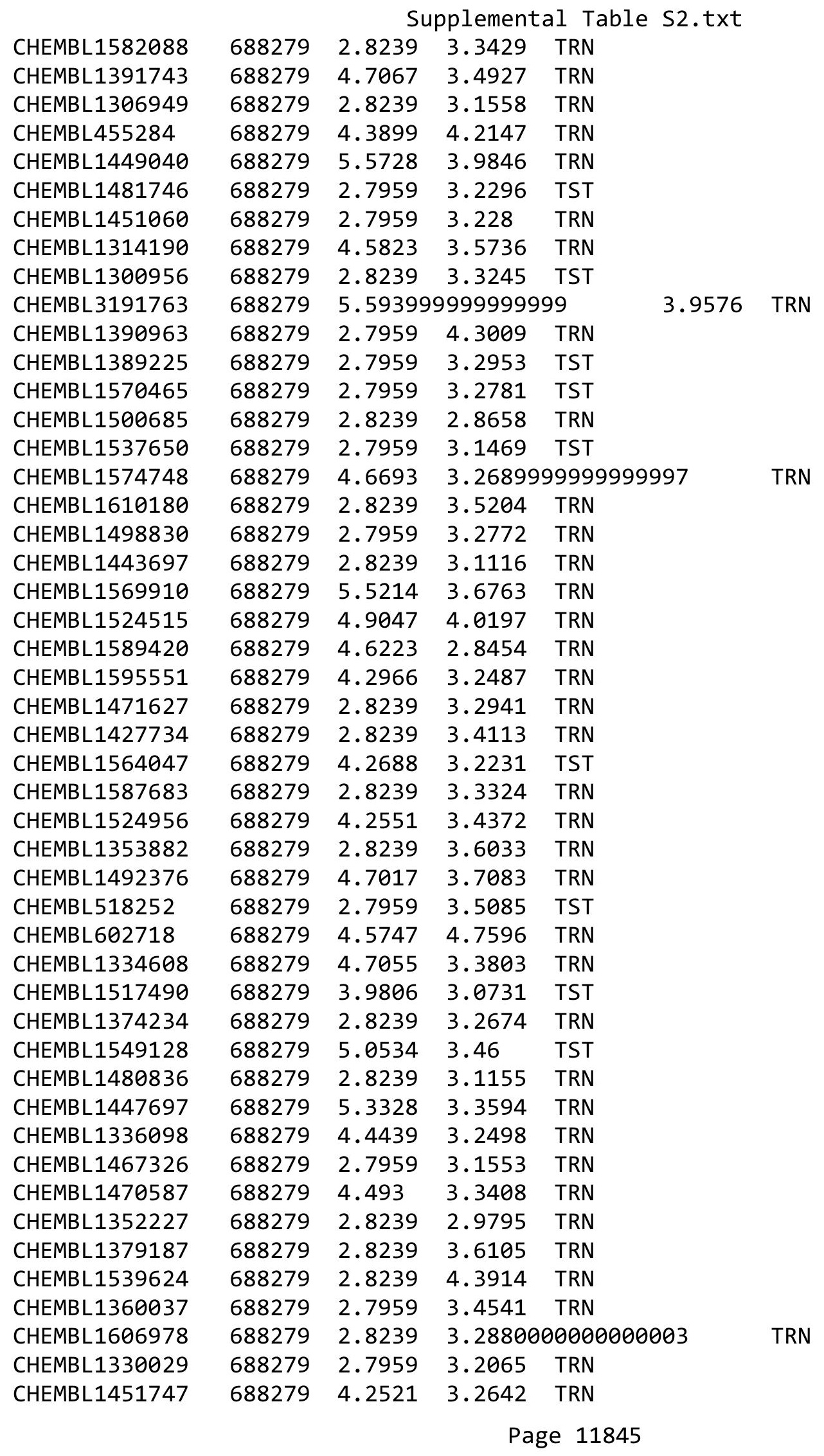




\begin{tabular}{|c|c|c|c|c|}
\hline & & & pplement & al $\mathrm{T}$ \\
\hline CHEMBL1375251 & 688279 & 2.8239 & 3.4698 & TRN \\
\hline CHEMBL586602 & 688279 & 4.2201 & 3.8195 & TRN \\
\hline CHEMBL1577590 & 688279 & 4.8566 & 3.7369 & TRN \\
\hline CHEMBL1450648 & 688279 & 3.9959 & 3.8589 & TRN \\
\hline CHEMBL1569124 & 688279 & 4.4457 & 3.3606 & TRN \\
\hline CHEMBL1535361 & 688279 & 4.7374 & 4.5535 & TRN \\
\hline CHEMBL1389295 & 688279 & 2.7959 & 3.0472 & TRN \\
\hline CHEMBL3198692 & 688279 & 2.8239 & 3.7617 & TRN \\
\hline CHEMBL1487401 & 688279 & 2.7959 & 3.8826 & TRN \\
\hline CHEMBL1530274 & 688279 & 4.5773 & 3.0245 & TST \\
\hline CHEMBL1442280 & 688279 & 5.0673 & 4.5133 & TRN \\
\hline CHEMBL1372207 & 688279 & 2.7959 & 3.4652 & TST \\
\hline CHEMBL1568337 & 688279 & 2.8239 & 3.3238 & TRN \\
\hline CHEMBL1424729 & 688279 & 5.0631 & 3.2607 & TRN \\
\hline CHEMBL3193971 & 688279 & 4.4703 & 3.2158 & TRN \\
\hline CHEMBL1447186 & 688279 & 2.8239 & 3.0102 & TRN \\
\hline CHEMBL3192055 & 688279 & 2.7959 & 3.6409 & TRN \\
\hline CHEMBL1390196 & 688279 & 2.7959 & 3.3555 & TRN \\
\hline CHEMBL1552591 & 688279 & 2.7959 & 3.3205 & TRN \\
\hline CHEMBL1420516 & 688279 & 2.7959 & 3.4654 & TRN \\
\hline CHEMBL1422472 & 688279 & 2.7959 & 3.4032 & TRN \\
\hline CHEMBL1325275 & 688279 & 2.7959 & 3.3101 & TRN \\
\hline CHEMBL1995800 & 688279 & 4.8248 & 3.3139 & TST \\
\hline CHEMBL1489113 & 688279 & 5.0721 & 3.2919 & TRN \\
\hline CHEMBL1542594 & 688279 & 2.7959 & 3.787 & TRN \\
\hline CHEMBL1426078 & 688279 & 2.8239 & 3.3699 & TST \\
\hline CHEMBL1351838 & 688279 & 2.7959 & 3.7333 & TRN \\
\hline CHEMBL1387387 & 688279 & 3.9305 & 2.9282 & TRN \\
\hline CHEMBL3197232 & 688279 & 2.7959 & 3.3996 & TRN \\
\hline CHEMBL585591 & 688279 & 5.5005 & 3.568 & TRN \\
\hline CHEMBL1383777 & 688279 & 2.7959 & 3.2453 & TRN \\
\hline CHEMBL537692 & 688279 & 2.8239 & 3.135 & TRN \\
\hline CHEMBL1452116 & 688279 & 2.8239 & 4.0196 & TST \\
\hline CHEMBL1536303 & 688279 & 2.8239 & 3.3453 & TRN \\
\hline CHEMBL1391737 & 688279 & 2.8239 & 3.2514 & TRN \\
\hline CHEMBL1301513 & 688279 & 2.8239 & 3.0445 & TRN \\
\hline CHEMBL1483724 & 688279 & 2.8239 & 3.4436 & TRN \\
\hline CHEMBL1383334 & 688279 & 5.9169 & 3.9119 & TRN \\
\hline CHEMBL1550278 & 688279 & 2.7959 & 3.61 & TRN \\
\hline CHEMBL 3195271 & 688279 & 2.8239 & 3.2891 & TRN \\
\hline CHEMBL1576976 & 688279 & 2.8239 & 3.6576 & TST \\
\hline CHEMBL1575805 & 688279 & 4.551 & 3.5985 & TRN \\
\hline CHEMBL1534596 & 688279 & 2.7959 & 3.3543 & TRN \\
\hline CHEMBL1351542 & 688279 & 4.9621 & 4.513 & TRN \\
\hline CHEMBL3189959 & 688279 & 2.7959 & 3.1702 & TST \\
\hline CHEMBL1964614 & 688279 & 5.0084 & 3.8493 & TRN \\
\hline CHEMBL1501432 & 688279 & 2.7959 & 3.3736 & TST \\
\hline CHEMBL1599674 & 688279 & 2.7959 & 3.4119 & TST \\
\hline
\end{tabular}


Supplemental Table S2.txt

\begin{tabular}{|c|c|c|c|c|}
\hline CHEMBL1408342 & 688279 & 2.7959 & 2.9819 & TRN \\
\hline CHEMBL1385118 & 688279 & 2.8239 & 3.0268 & TRN \\
\hline CHEMBL1542802 & 688279 & 4.4857 & 3.3368 & TRN \\
\hline CHEMBL1334044 & 688279 & 2.8239 & 3.2177 & TRN \\
\hline CHEMBL3197825 & 688279 & 4.8891 & 3.924 & TRN \\
\hline CHEMBL1522592 & 688279 & 2.7959 & 3.3829 & TRN \\
\hline CHEMBL1587806 & 688279 & 3.8253 & 3.5323 & TRN \\
\hline CHEMBL1597208 & 688279 & 2.8239 & 3.1762 & TRN \\
\hline CHEMBL1347212 & 688279 & 2.8239 & 3.2532 & TST \\
\hline CHEMBL1423518 & 688279 & 2.8239 & 3.5201 & TST \\
\hline CHEMBL1312049 & 688279 & 2.8239 & 3.5521 & TRN \\
\hline CHEMBL1400620 & 688279 & 2.8239 & 3.3822 & TRN \\
\hline CHEMBL1379535 & 688279 & 2.7959 & 3.6303 & TRN \\
\hline CHEMBL 2006545 & 688279 & 2.8239 & 3.7236 & TRN \\
\hline CHEMBL1548492 & 688279 & 4.6393 & 4.9486 & TRN \\
\hline CHEMBL1428377 & 688279 & 2.7959 & 3.3881 & TRN \\
\hline CHEMBL3209305 & 688279 & 4.3964 & 3.7375 & TRN \\
\hline CHEMBL1309909 & 688279 & 2.7959 & 3.49300 & 00000000003 \\
\hline CHEMBL1339909 & 688279 & 5.3591 & 4.3892 & TRN \\
\hline CHEMBL1339997 & 688279 & 2.7959 & 3.1043 & TRN \\
\hline CHEMBL3198576 & 688279 & 3.8105 & 3.9901 & TRN \\
\hline CHEMBL1574132 & 688279 & 2.7959 & 3.9268 & TRN \\
\hline CHEMBL1392617 & 688279 & 2.8239 & 3.5731 & TRN \\
\hline CHEMBL1310309 & 688279 & 2.7959 & 3.3035 & TRN \\
\hline CHEMBL1578127 & 688279 & 4.7971 & 3.6668 & TRN \\
\hline CHEMBL1447307 & 688279 & 2.8239 & 3.3741 & TRN \\
\hline CHEMBL1422453 & 688279 & 2.7959 & 3.2368 & TRN \\
\hline CHEMBL1401057 & 688279 & 2.8239 & 3.3932 & TRN \\
\hline CHEMBL2006909 & 688279 & 2.8239 & 3.9239 & TRN \\
\hline CHEMBL1335030 & 688279 & 2.7959 & 4.4014 & TRN \\
\hline CHEMBL1385356 & 688279 & 2.7959 & 3.5793 & TST \\
\hline CHEMBL1379888 & 688279 & 2.8239 & 3.5371 & TST \\
\hline CHEMBL1341308 & 688279 & 4.0335 & 3.6268 & TRN \\
\hline CHEMBL1334557 & 688279 & 4.4014 & 3.2475 & TST \\
\hline CHEMBL 3189472 & 688279 & 2.7959 & 3.3251 & TRN \\
\hline CHEMBL1577971 & 688279 & 2.8239 & 3.1979 & TST \\
\hline CHEMBL1447219 & 688279 & 4.9523 & 4.5478 & TRN \\
\hline CHEMBL1306283 & 688279 & 4.8624 & 4.2712 & TRN \\
\hline CHEMBL1570820 & 688279 & 2.8239 & 3.361 & TST \\
\hline CHEMBL1419381 & 688279 & 4.5097 & 3.3726 & TRN \\
\hline CHEMBL1542804 & 688279 & 5.3015 & 4.0764 & TRN \\
\hline CHEMBL582073 & 688279 & 4.2934 & 3.2366 & TRN \\
\hline CHEMBL1485676 & 688279 & 2.7959 & 3.0286 & TST \\
\hline CHEMBL1578164 & 688279 & 4.2051 & 3.1987 & TRN \\
\hline CHEMBL1488279 & 688279 & 2.8239 & 3.2147 & TRN \\
\hline CHEMBL1789998 & 688279 & 4.1876 & 3.4125 & TRN \\
\hline CHEMBL1970872 & 688279 & 4.4653 & 3.9214 & TRN \\
\hline CHEMBL1310139 & 688279 & 2.8239 & 2.9661 & TRN \\
\hline
\end{tabular}

Page 11847 


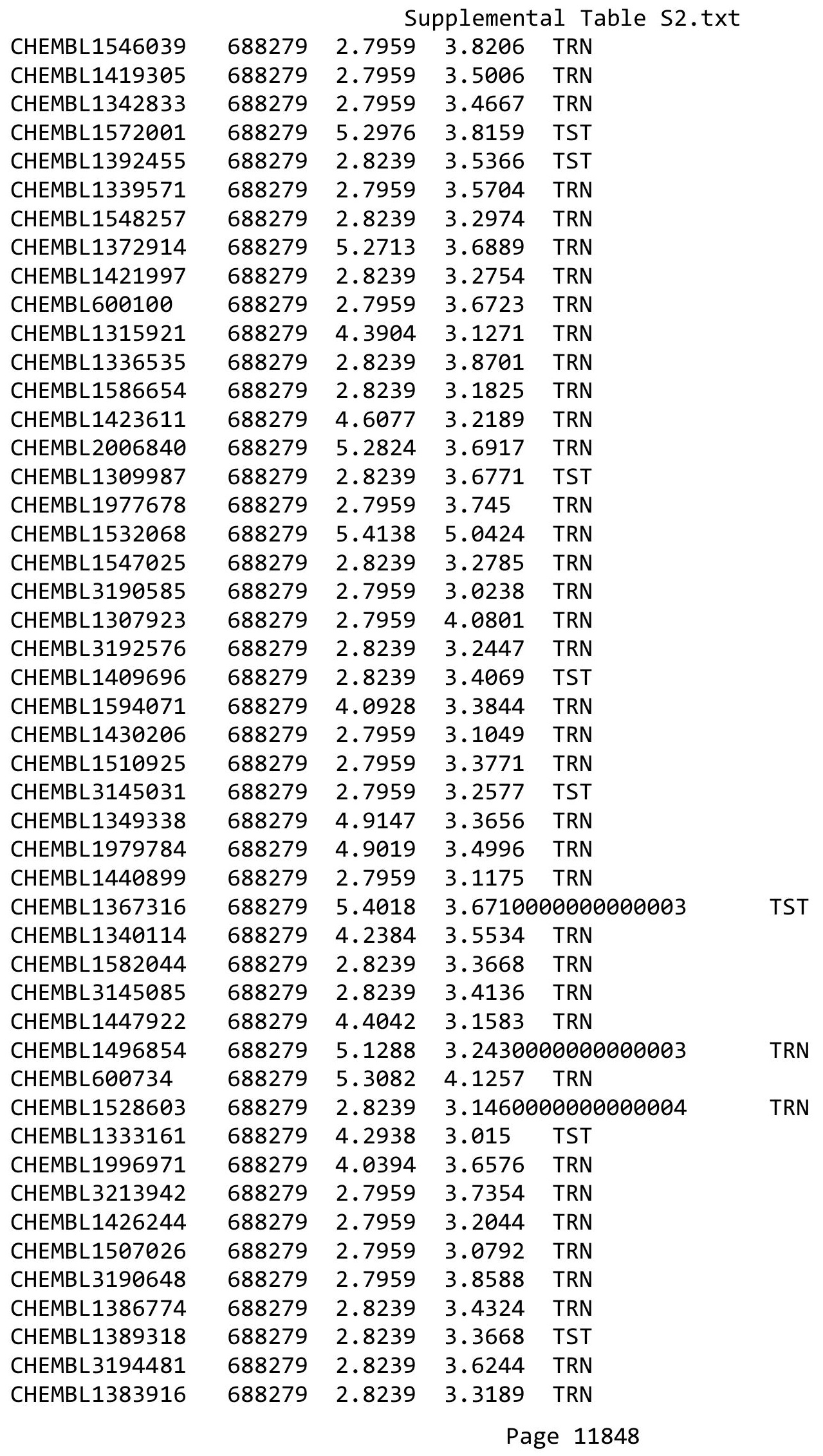




\begin{tabular}{|c|c|c|c|c|c|}
\hline & & \multicolumn{4}{|c|}{ Supplemental Table s2.txt } \\
\hline CHEMBL1339488 & 688279 & 2.8239 & 3.2297 & TST & \\
\hline CHEMBL1372534 & 688279 & 2.8239 & 3.4411 & TST & \\
\hline CHEMBL1368802 & 688279 & 2.7959 & 3.1819 & TRN & \\
\hline CHEMBL1995715 & 688279 & 2.8239 & 3.4803 & TRN & \\
\hline CHEMBL1431710 & 688279 & 3.8893 & 3.2998 & TRN & \\
\hline CHEMBL1352766 & 688279 & 2.7959 & \multicolumn{2}{|c|}{3.2760000000000002} & TRN \\
\hline CHEMBL1511757 & 688279 & 4.9805 & 3.1912 & TRN & \\
\hline CHEMBL1408075 & 688279 & 2.8239 & 3.3943 & TRN & \\
\hline CHEMBL1322516 & 688279 & 2.8239 & 3.1579 & TST & \\
\hline CHEMBL1526167 & 688279 & 2.7959 & \multicolumn{2}{|c|}{3.6439999999999997} & TRN \\
\hline CHEMBL1469379 & 688279 & 2.7959 & 3.0813 & TRN & \\
\hline CHEMBL 3184468 & 688279 & 5.0582 & 3.3767 & TST & \\
\hline CHEMBL1470139 & 688279 & 2.7959 & 3.3121 & TST & \\
\hline CHEMBL1427969 & 688279 & 4.3194 & 3.3588 & TRN & \\
\hline CHEMBL1582221 & 688279 & 2.8239 & \multicolumn{2}{|c|}{3.2739999999999996} & TRN \\
\hline CHEMBL 2369277 & 688279 & 2.8239 & 3.1818 & TRN & \\
\hline CHEMBL1501268 & 688279 & 2.7959 & 3.1351 & TST & \\
\hline CHEMBL1299335 & 688279 & 2.7959 & 3.4609 & TRN & \\
\hline CHEMBL1508474 & 688279 & 2.8239 & 3.8152 & TRN & \\
\hline CHEMBL1536073 & 688279 & 2.8239 & 3.5302 & TRN & \\
\hline CHEMBL1475477 & 688279 & 4.2922 & 3.5507 & TRN & \\
\hline CHEMBL1443564 & 688279 & 2.8239 & 3.449 & TRN & \\
\hline CHEMBL3193326 & 688279 & 2.8239 & 3.3138 & TRN & \\
\hline CHEMBL1431928 & 688279 & 2.7959 & 3.4508 & TRN & \\
\hline CHEMBL1581503 & 688279 & 2.7959 & 3.5717 & TRN & \\
\hline CHEMBL1483252 & 688279 & 5.4161 & 4.3553 & TRN & \\
\hline CHEMBL1349452 & 688279 & 4.3757 & 3.0635 & TRN & \\
\hline CHEMBL1460823 & 688279 & 2.7959 & 3.6275 & TRN & \\
\hline CHEMBL1389335 & 688279 & 2.8239 & 3.3177 & TRN & \\
\hline CHEMBL1304950 & 688279 & 2.8239 & 3.0922 & TRN & \\
\hline CHEMBL1503688 & 688279 & 2.8239 & 3.1834 & TRN & \\
\hline CHEMBL1564403 & 688279 & 4.6532 & 3.1302 & TRN & \\
\hline CHEMBL1559931 & 688279 & 2.7959 & 3.0979 & TRN & \\
\hline CHEMBL1994623 & 688279 & 4.3451 & 4.0031 & TRN & \\
\hline CHEMBL1341995 & 688279 & 2.7959 & 3.5473 & TRN & \\
\hline CHEMBL1404163 & 688279 & 2.8239 & 3.4501 & TRN & \\
\hline CHEMBL1350245 & 688279 & 2.7959 & 3.2193 & TRN & \\
\hline CHEMBL3144960 & 688279 & 2.8239 & 3.2322 & TRN & \\
\hline CHEMBL1379480 & 688279 & 2.8239 & 3.4136 & TRN & \\
\hline CHEMBL1518071 & 688279 & 4.6253 & 3.2237 & TRN & \\
\hline CHEMBL1402715 & 688279 & 2.7959 & 3.5008 & TRN & \\
\hline CHEMBL1558285 & 688279 & 4.0171 & 3.5083 & TRN & \\
\hline CHEMBL1462295 & 688279 & 2.8239 & 3.12 & TRN & \\
\hline CHEMBL3208391 & 688279 & 4.5243 & 3.3477 & TRN & \\
\hline CHEMBL3209126 & 688279 & 4.6826 & 3.5482 & TRN & \\
\hline CHEMBL1528425 & 688279 & 4.2465 & 3.781 & TRN & \\
\hline CHEMBL1418430 & 688279 & 2.8239 & 3.35699 & 99999999998 & TRN \\
\hline CHEMBL1382191 & 688279 & 2.8239 & 3.2085 & TRN & \\
\hline
\end{tabular}




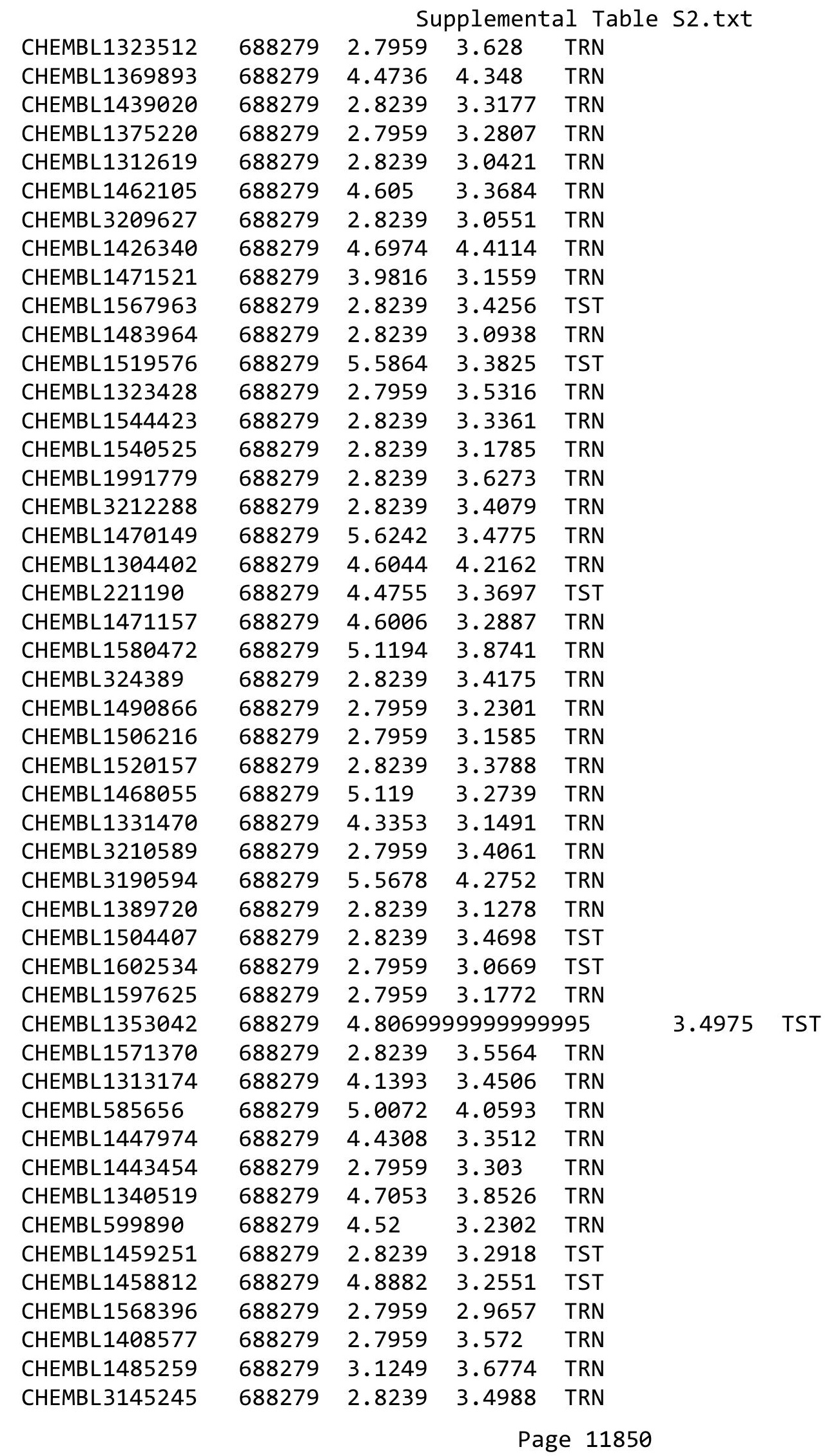


Supplemental Table S2.txt

\begin{tabular}{|c|c|c|c|c|}
\hline HEMBL & 279 & 6873 & & \\
\hline & 88279 & .5702 & 3.7656 & \\
\hline & 279 & & & \\
\hline IEMBL1 & & & & ג \\
\hline AEMBL1 & 38279 & & & \\
\hline HEMBL1442895 & 88279 & .8239 & 8737 & \\
\hline 595 & 279 & & & \\
\hline 1232 & & & & \\
\hline AEMBL1349075 & & & & \\
\hline HEMBL3195177 & 88279 & & 4777 & \\
\hline AEMBL1563462 & 88279 & & 1821 & \\
\hline IEMBL3 & & & 062 & \\
\hline HEMBL: & & & & \\
\hline AEMBL3209142 & & & 5141 & \\
\hline AEMBL1309248 & & & 5473 & \\
\hline HEMBL1 & 79 & 4 & 75 & \\
\hline HEMBL1 & & & 032 & \\
\hline HEMBL1 & & & & \\
\hline HEMBL1 & & & 1495 & \\
\hline AEMBL1 & & & & \\
\hline IEMB: & & & 914 & MTV \\
\hline HEMBL & & & 37 & 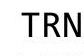 \\
\hline HEMBL: & & & & \\
\hline 255 & & & 207 & \\
\hline AEMBL1 & & & & ( \\
\hline HEMBLI & & & 31 & 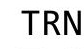 \\
\hline HEMBL & & & 17 & RN \\
\hline AFMRI & & & 585 & \\
\hline HEMBL1 & & & 1022 & RIV \\
\hline HEMBL1352732 & & & & s \\
\hline HEMBL3 & & & 713 & RIV \\
\hline HEMBL & & & 41 & ST \\
\hline HEMPI & & & 966 & RN \\
\hline HEMBL1 & & & 302 & $\mathrm{IR}$ \\
\hline HEMBL3193835 & & & 552 & TS \\
\hline HEMBL & & & 407 & ГST \\
\hline HFMRI & & & 372 & $\Gamma \mathrm{RN}$ \\
\hline & & & 976 & TRN \\
\hline HEMBL1497549 & & & 361 & TRN \\
\hline AEMBL1 & & & 977 & ГRN \\
\hline HEMBL1 & & & 454 & \\
\hline HEMBL1. & & & & TRN \\
\hline HEMBL1 & & & 5192 & $\Gamma \mathrm{RN}$ \\
\hline AEMBL142167 & 79 & & 1228 & TS \\
\hline HEMBL1 & & & 2128 & $n$ \\
\hline CHEMBL1 & & & & \\
\hline HEMBL13 & & 5.22 & 3934 & \\
\hline CHEMBL1381962 & 688279 & 2.7959 & 3.0052 & ГRN \\
\hline
\end{tabular}

Page 11851 
Supplemental Table S2.txt

\begin{tabular}{|c|c|c|c|c|c|}
\hline CHEMBL1533086 & 688279 & 2.7959 & 3.5822 & TST & \\
\hline CHEMBL1364071 & 688279 & 4.7369 & 3.1523 & TRN & \\
\hline CHEMBL1789993 & 688279 & 2.8239 & 3.4317 & TRN & \\
\hline CHEMBL 3194368 & 688279 & 2.7959 & 3.5416 & TRN & \\
\hline CHEMBL1558361 & 688279 & 4.3546 & 3.355 & TRN & \\
\hline CHEMBL602363 & 688279 & 2.8239 & 4.18 & TRN & \\
\hline CHEMBL 3192121 & 688279 & 2.8239 & 4.2897 & TRN & \\
\hline CHEMBL1341697 & 688279 & 2.8239 & 3.5452 & TRN & \\
\hline CHEMBL597251 & 688279 & 5.0433 & 3.0285 & TST & \\
\hline CHEMBL1306690 & 688279 & 2.8239 & 3.3178 & TST & \\
\hline CHEMBL1887153 & 688279 & 5.4985 & 4.0465 & TRN & \\
\hline CHEMBL1503114 & 688279 & 2.7959 & 2.8972 & TRN & \\
\hline CHEMBL1478310 & 688279 & 2.7959 & 3.4878 & TRN & \\
\hline CHEMBL1340602 & 688279 & 2.7959 & 3.1268 & TST & \\
\hline CHEMBL1486214 & 688279 & 4.4982 & 3.8006 & TRN & \\
\hline CHEMBL1506750 & 688279 & 2.8239 & 3.1319 & TRN & \\
\hline CHEMBL1353710 & 688279 & 2.8239 & 3.1871 & TRN & \\
\hline CHEMBL1373688 & 688279 & 4.4956 & 3.2413 & TRN & \\
\hline CHEMBL1491555 & 688279 & 2.8239 & 3.2902 & TRN & \\
\hline CHEMBL1612493 & 688279 & 2.8239 & 4.159 & TRN & \\
\hline CHEMBL1600855 & 688279 & 2.8239 & 3.4344 & TST & \\
\hline CHEMBL1320542 & 688279 & 4.5439 & 3.3256 & TRN & \\
\hline CHEMBL1308432 & 688279 & 2.8239 & 3.3207 & TRN & \\
\hline CHEMBL1545223 & 688279 & 2.8239 & 3.501006 & 00000000003 & TRN \\
\hline CHEMBL1311007 & 688279 & 2.7959 & 3.0064 & TRN & \\
\hline CHEMBL1320059 & 688279 & 2.8239 & 3.163006 & 00000000003 & TRN \\
\hline CHEMBL3214345 & 688279 & 2.8239 & 3.3862 & TRN & \\
\hline CHEMBL1605956 & 688279 & 5.5702 & 4.516 & TRN & \\
\hline CHEMBL1477033 & 688279 & 2.8239 & 3.2724 & TRN & \\
\hline CHEMBL1499893 & 688279 & 5.2747 & 4.9615 & TRN & \\
\hline CHEMBL1448793 & 688279 & 2.7959 & 3.319 & TRN & \\
\hline CHEMBL1359871 & 688279 & 4.0163 & 3.9994 & TRN & \\
\hline CHEMBL1333095 & 688279 & 4.6207 & 3.5175 & TST & \\
\hline CHEMBL1332450 & 688279 & 2.7959 & 3.9844 & TRN & \\
\hline CHEMBL1422860 & 688279 & 2.7959 & 3.1873 & TRN & \\
\hline CHEMBL1599520 & 688279 & 3.1249 & 3.41 & TRN & \\
\hline CHEMBL1499914 & 688279 & 4.4498 & 3.5199 & TRN & \\
\hline CHEMBL1574024 & 688279 & 3.9108 & 3.2791 & TRN & \\
\hline CHEMBL1429789 & 688279 & 2.7959 & 3.4332 & TRN & \\
\hline CHEMBL1345665 & 688279 & 2.8239 & 3.0836 & TST & \\
\hline CHEMBL1517847 & 688279 & 4.3653 & 3.0773 & TST & \\
\hline CHEMBL1505071 & 688279 & 2.8239 & 3.3329 & TRN & \\
\hline CHEMBL1405150 & 688279 & 4.4592 & 4.6336 & TRN & \\
\hline CHEMBL1389836 & 688279 & 2.8239 & 3.5154 & TRN & \\
\hline CHEMBL1517609 & 688279 & 2.8239 & 3.3479 & TRN & \\
\hline CHEMBL1319079 & 688279 & 2.7959 & 3.6836 & TRN & \\
\hline CHEMBL1585527 & 688279 & 2.7959 & 4.2464 & TRN & \\
\hline CHEMBL1553408 & 688279 & 4.5153 & 3.3584 & TRN & \\
\hline
\end{tabular}




\begin{tabular}{|c|c|c|c|c|c|}
\hline & & \multicolumn{4}{|c|}{ Supplemental Table S2.txt } \\
\hline CHEMBL1327372 & 688279 & 2.8239 & 3.5343 & TRN & \\
\hline CHEMBL1542349 & 688279 & 2.7959 & 3.6383 & TRN & \\
\hline CHEMBL1509676 & 688279 & 2.8239 & 3.4496 & TRN & \\
\hline CHEMBL1362788 & 688279 & 2.7959 & 3.3191 & TRN & \\
\hline CHEMBL461820 & 688279 & 4.7829 & 3.7316 & TST & \\
\hline CHEMBL1468811 & 688279 & 5.2663 & 4.0824 & TRN & \\
\hline CHEMBL3193305 & 688279 & 4.8114 & 3.3041 & TRN & \\
\hline CHEMBL1537973 & 688279 & 4.5942 & 3.4463 & TRN & \\
\hline CHEMBL1416660 & 688279 & 2.7959 & 3.4064 & TRN & \\
\hline CHEMBL1333987 & 688279 & 2.7959 & 4.4104 & TRN & \\
\hline CHEMBL1442500 & 688279 & 4.4916 & 4.2707 & TRN & \\
\hline CHEMBL1419016 & 688279 & 2.8239 & 3.3341 & TST & \\
\hline CHEMBL1370513 & 688279 & 5.4454 & 4.713 & TRN & \\
\hline CHEMBL1491222 & 688279 & 4.5839 & 3.9986 & TRN & \\
\hline CHEMBL1583101 & 688279 & 2.7959 & 3.8312 & TST & \\
\hline CHEMBL1595088 & 688279 & 4.3215 & 3.4282 & TRN & \\
\hline CHEMBL1502020 & 688279 & 4.0891 & 3.4647 & TRN & \\
\hline CHEMBL1987472 & 688279 & 4.8254 & 3.8564 & TRN & \\
\hline CHEMBL1326817 & 688279 & 5.0367 & 3.3209 & TST & \\
\hline CHEMBL1496187 & 688279 & 2.7959 & 3.313 & TRN & \\
\hline CHEMBL1567865 & 688279 & 2.7959 & 3.6651 & TRN & \\
\hline CHEMBL3196754 & 688279 & 2.8239 & 3.6548 & TRN & \\
\hline CHEMBL600315 & 688279 & 2.8239 & 3.5015 & TRN & \\
\hline CHEMBL1609004 & 688279 & 2.8239 & 3.2563 & TST & \\
\hline CHEMBL1375115 & 688279 & 4.3 & 3.5742 & TST & \\
\hline CHEMBL1457139 & 688279 & 5.2198 & 4.3846 & TRN & \\
\hline CHEMBL1608579 & 688279 & 2.7959 & 3.30899 & 99999999997 & TRN \\
\hline CHEMBL1538399 & 688279 & 4.3524 & 3.4336 & TRN & \\
\hline CHEMBL1995550 & 688279 & 2.8239 & 3.7423 & TRN & \\
\hline CHEMBL1429560 & 688279 & 2.7959 & 3.4007 & TRN & \\
\hline CHEMBL1416456 & 688279 & 2.7959 & 3.5908 & TRN & \\
\hline CHEMBL1544103 & 688279 & 2.8239 & 3.6422 & TST & \\
\hline CHEMBL1364999 & 688279 & 5.3327 & 3.8328 & TRN & \\
\hline CHEMBL1392918 & 688279 & 2.8239 & 3.1345 & TRN & \\
\hline CHEMBL1513713 & 688279 & 2.7959 & 3.5508 & TRN & \\
\hline CHEMBL1602972 & 688279 & 4.4407 & 3.1349 & TRN & \\
\hline CHEMBL1353536 & 688279 & 2.7959 & 2.9749 & TST & \\
\hline CHEMBL1521297 & 688279 & 4.5538 & 4.1032 & TRN & \\
\hline CHEMBL1341726 & 688279 & 4.414 & 3.1101 & TRN & \\
\hline CHEMBL1528505 & 688279 & 2.8239 & 3.6017 & TRN & \\
\hline CHEMBL1440303 & 688279 & 5.2963 & 4.0716 & TRN & \\
\hline CHEMBL1441467 & 688279 & 2.7959 & 3.4772 & TRN & \\
\hline CHEMBL1471206 & 688279 & 2.8239 & 2.8314 & TRN & \\
\hline CHEMBL1578484 & 688279 & 2.8239 & 3.3095 & TRN & \\
\hline CHEMBL1382854 & 688279 & 4.7087 & 3.2516 & TRN & \\
\hline CHEMBL1305208 & 688279 & 2.7959 & 3.42199 & 99999999997 & TST \\
\hline CHEMBL1612201 & 688279 & 2.8239 & 2.9952 & TST & \\
\hline CHEMBL1337700 & 688279 & 2.8239 & 3.2948 & TST & \\
\hline
\end{tabular}




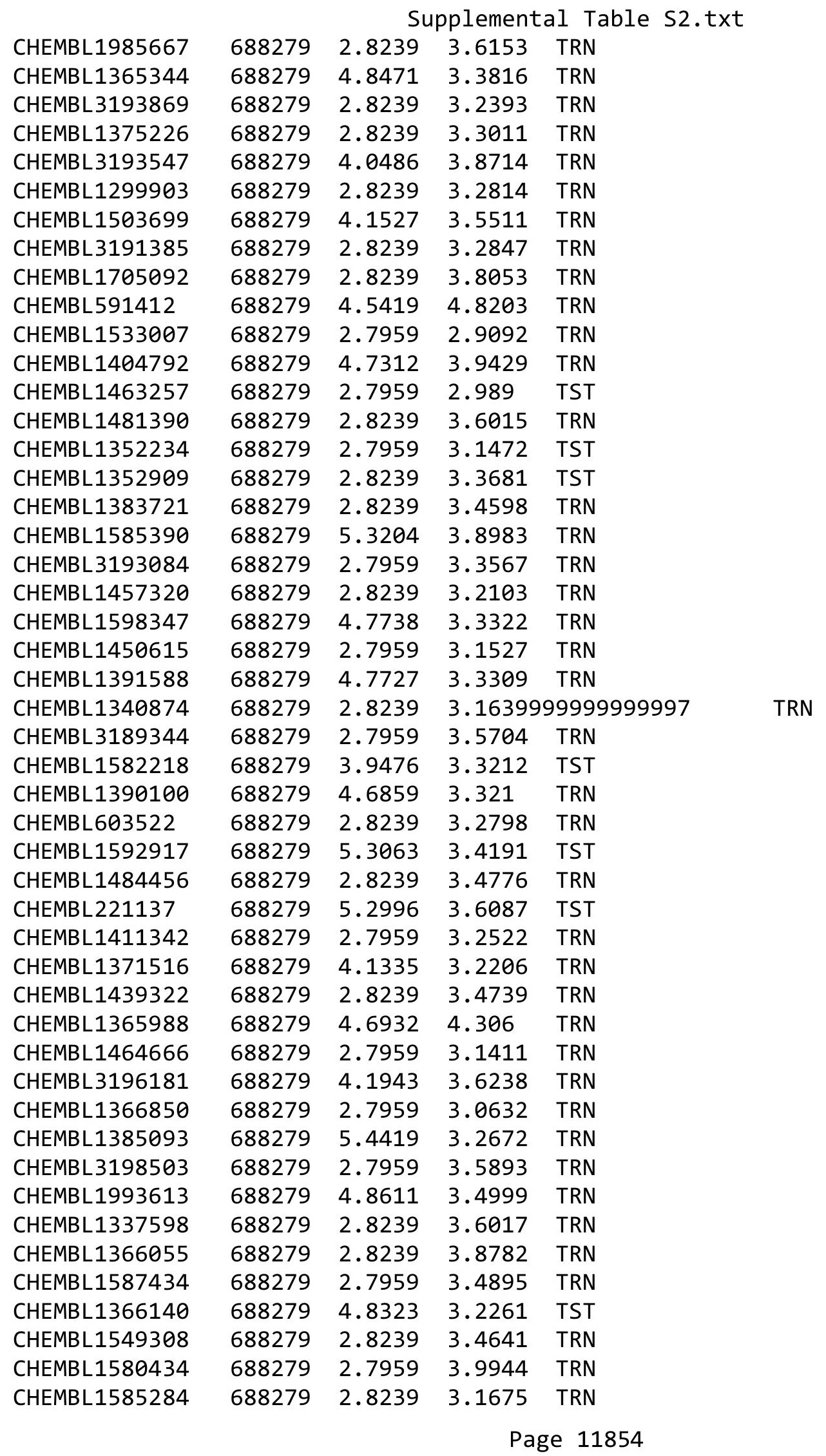




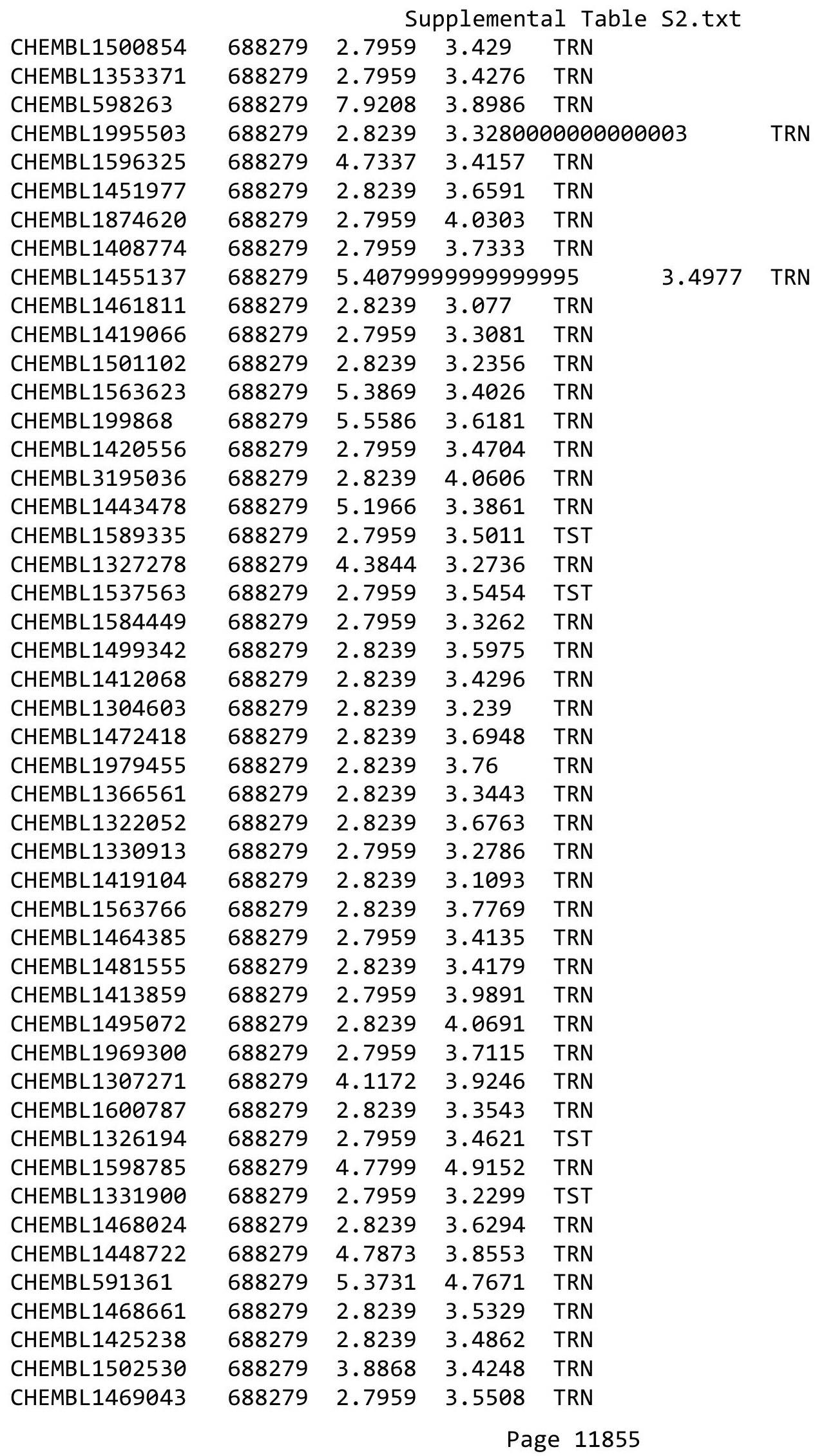




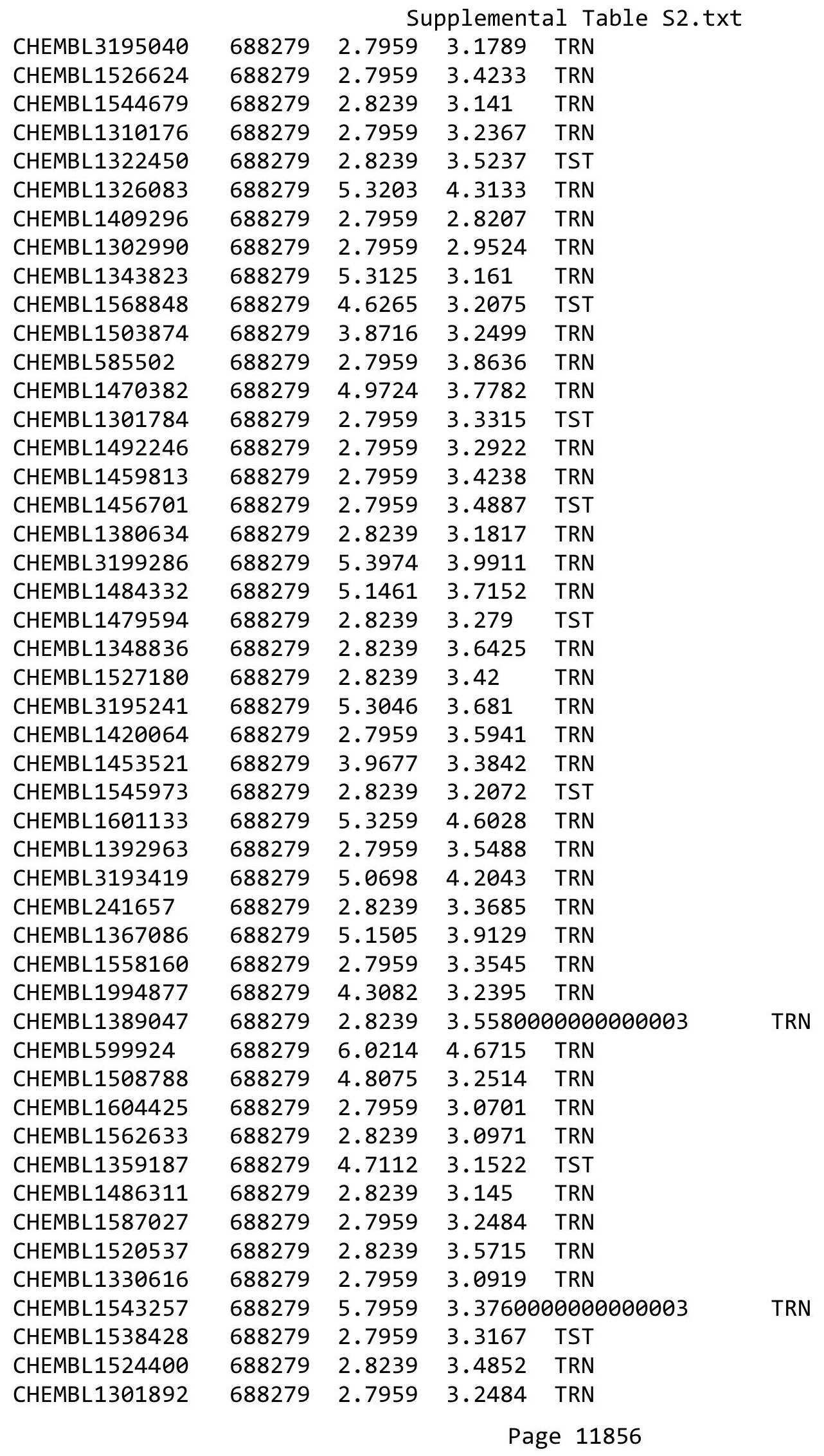




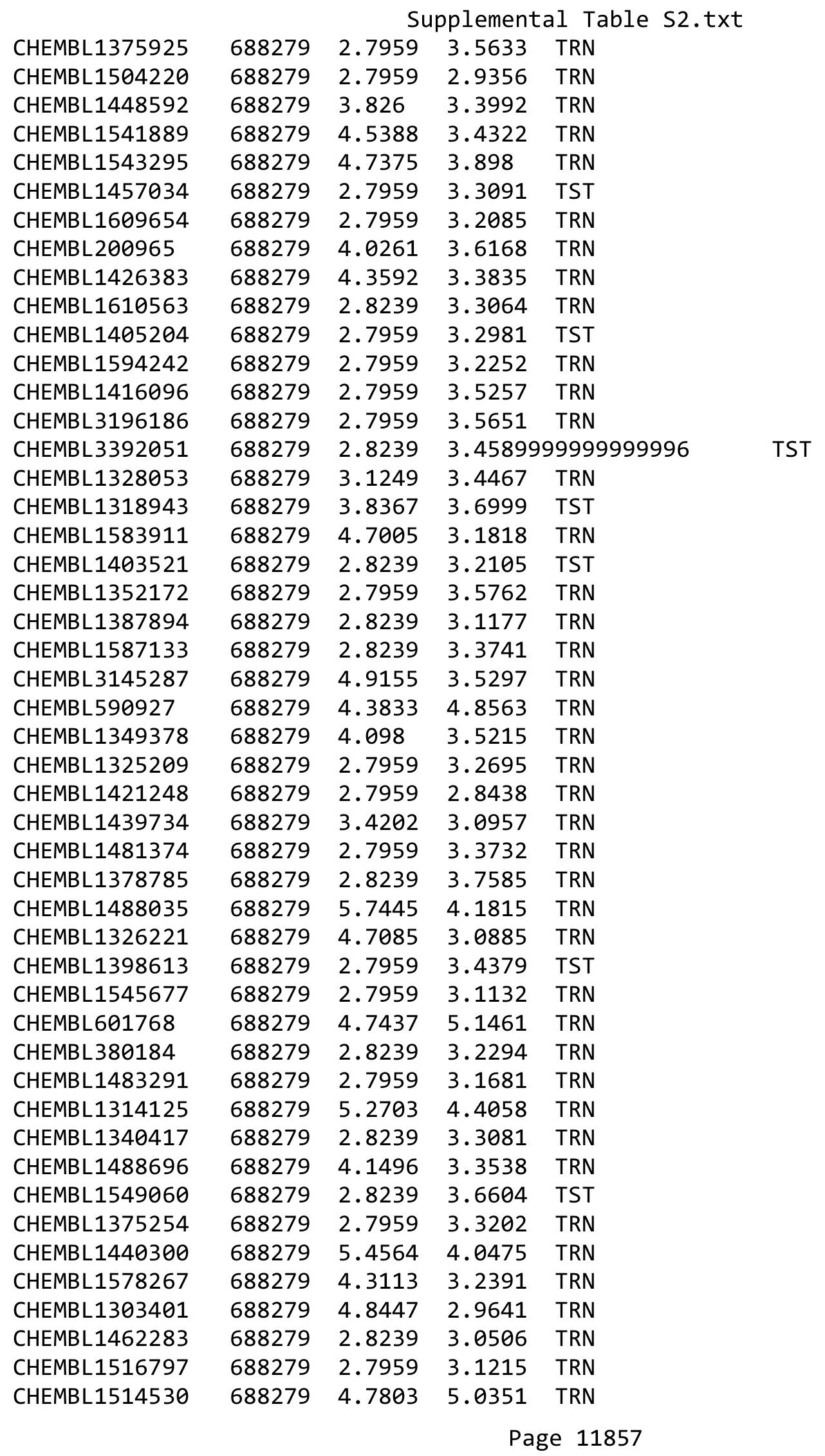




\begin{tabular}{|c|c|c|c|c|c|}
\hline \multicolumn{6}{|c|}{ Supplemental Table S2.txt } \\
\hline CHEMBL3213566 & 688279 & 4.5313 & 3.5419 & TRN & \\
\hline CHEMBL590947 & 688279 & 3.8675 & 4.0535 & TRN & \\
\hline CHEMBL1432427 & 688279 & 3.9179 & 3.9385 & TRN & \\
\hline CHEMBL1451931 & 688279 & 5.5834 & 3.9287 & TRN & \\
\hline CHEMBL483768 & 688279 & 2.8239 & 3.1136 & TRN & \\
\hline CHEMBL1374462 & 688279 & 3.8839 & 3.5452 & TST & \\
\hline CHEMBL225963 & 688279 & 3.9869 & 3.7727 & TRN & \\
\hline CHEMBL1566084 & 688279 & 4.2155 & 4.2953 & TRN & \\
\hline CHEMBL1407632 & 688279 & 2.7959 & 3.0558 & TRN & \\
\hline CHEMBL1333510 & 688279 & 5.0445 & 3.8426 & TRN & \\
\hline CHEMBL3199752 & 688279 & 2.7959 & 3.6467 & TRN & \\
\hline CHEMBL1402166 & 688279 & 3.9959 & 3.25399 & 99999999996 & TRN \\
\hline CHEMBL1380406 & 688279 & 5.5168 & 3.5407 & TRN & \\
\hline CHEMBL1349793 & 688279 & 2.8239 & 3.4397 & TRN & \\
\hline CHEMBL1421854 & 688279 & 3.9834 & 3.46 & TRN & \\
\hline CHEMBL1425849 & 688279 & 4.5483 & 3.8383 & TRN & \\
\hline CHEMBL1312320 & 688279 & 4.4756 & 3.4541 & TRN & \\
\hline CHEMBL240329 & 688279 & 2.8239 & 3.3972 & TRN & \\
\hline CHEMBL1418460 & 688279 & 2.8239 & 3.3311 & TST & \\
\hline CHEMBL1352200 & 688279 & 4.3111 & 3.6299 & TRN & \\
\hline CHEMBL3193008 & 688279 & 4.5216 & 3.4325 & TRN & \\
\hline CHEMBL1453929 & 688279 & 2.8239 & 3.5696 & TRN & \\
\hline CHEMBL3193010 & 688279 & 2.7959 & 3.8301 & TRN & \\
\hline CHEMBL1510020 & 688279 & 4.6721 & 3.2804 & TRN & \\
\hline CHEMBL 1453870 & 688279 & 2.8239 & 3.3071 & TRN & \\
\hline CHEMBL1518827 & 688279 & 2.8239 & 3.3004 & TST & \\
\hline CHEMBL1439987 & 688279 & 3.8674 & 2.9792 & TRN & \\
\hline CHEMBL1388738 & 688279 & 2.8239 & 3.3139 & TRN & \\
\hline CHEMBL1347211 & 688279 & 4.8387 & 3.3104 & TRN & \\
\hline CHEMBL1864040 & 688279 & 4.7575 & 4.0346 & TRN & \\
\hline CHEMBL1401188 & 688279 & 4.7386 & 4.0302 & TRN & \\
\hline CHEMBL1547468 & 688279 & 2.8239 & 3.6112 & TRN & \\
\hline CHEMBL3194528 & 688279 & 2.7959 & 3.8775 & TRN & \\
\hline CHEMBL3198729 & 688279 & 2.7959 & 3.6158 & TRN & \\
\hline CHEMBL1324011 & 688279 & 4.7699 & 4.2462 & TRN & \\
\hline CHEMBL1479804 & 688279 & 2.7959 & 3.1155 & TRN & \\
\hline CHEMBL1408965 & 688279 & 2.7959 & 3.2597 & TRN & \\
\hline CHEMBL1534520 & 688279 & 2.7959 & 3.2555 & TRN & \\
\hline CHEMBL1426112 & 688279 & 4.308 & 3.2196 & TST & \\
\hline CHEMBL 1478465 & 688279 & 2.8239 & 3.0416 & TRN & \\
\hline CHEMBL1406348 & 688279 & 4.6632 & 3.4613 & TRN & \\
\hline CHEMBL1345299 & 688279 & 2.8239 & 3.4879 & TRN & \\
\hline CHEMBL1467755 & 688279 & 4.2516 & 3.2678 & TRN & \\
\hline CHEMBL1328184 & 688279 & 4.0026 & 3.3498 & TRN & \\
\hline CHEMBL1578007 & 688279 & 2.8239 & 3.3302 & TRN & \\
\hline CHEMBL1987461 & 688279 & 5.1651 & 3.7661 & TRN & \\
\hline CHEMBL1306343 & 688279 & 2.8239 & 3.7508 & TRN & \\
\hline CHEMBL1593571 & 688279 & 2.7959 & 3.2697 & TRN & \\
\hline
\end{tabular}

Page 11858 


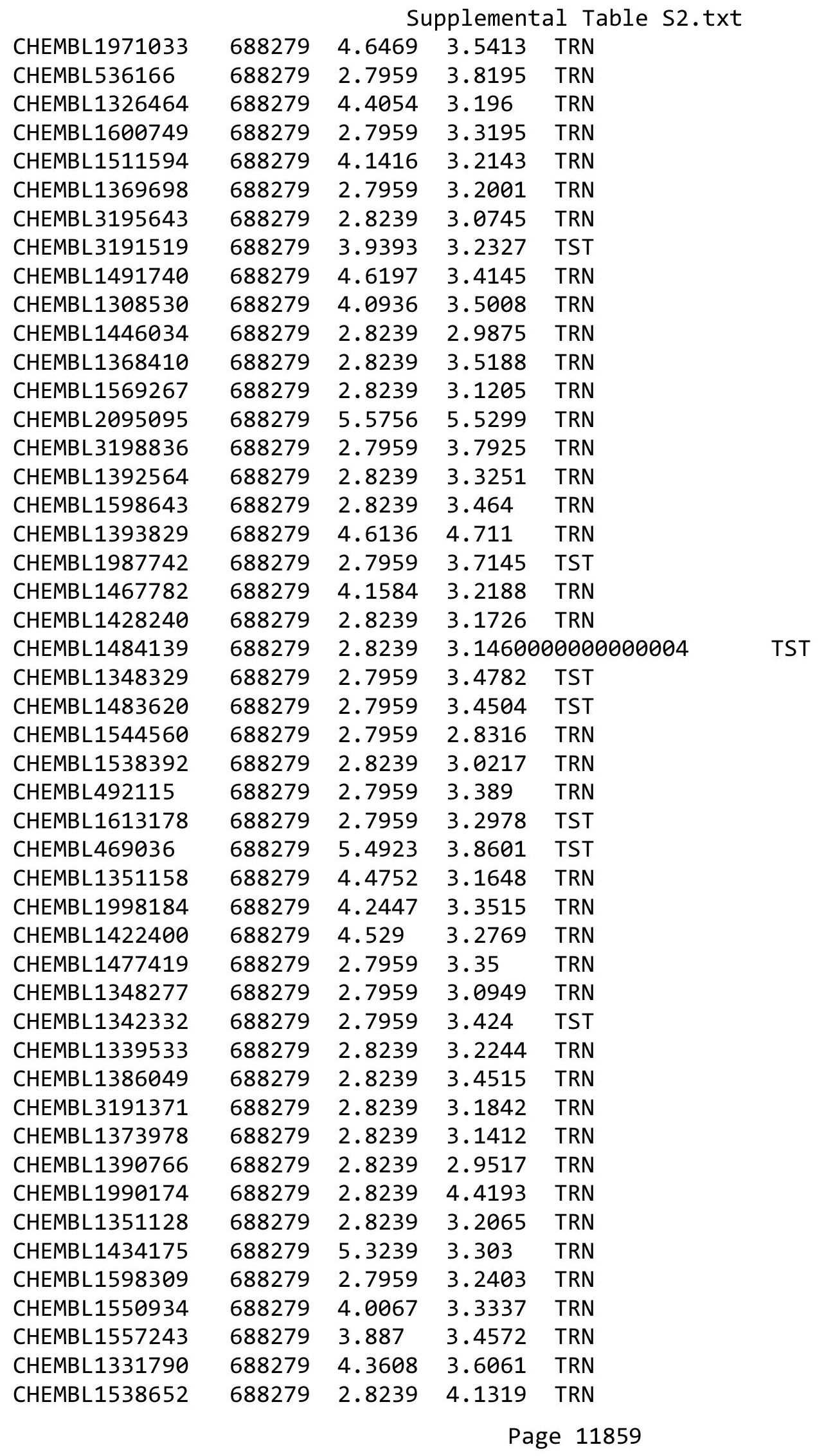




\begin{tabular}{|c|c|c|c|c|c|c|}
\hline & & \multicolumn{5}{|c|}{ Supplemental Table S2.txt } \\
\hline CHEMBL1964389 & 688279 & 5.2622 & 3.7169 & TRN & & \\
\hline CHEMBL3196320 & 688279 & 2.8239 & 3.29100 & 00000000 & 004 & TRN \\
\hline CHEMBL3213908 & 688279 & 2.8239 & 3.3012 & TRN & & \\
\hline CHEMBL3199737 & 688279 & 5.5938 & 3.4944 & TST & & \\
\hline CHEMBL 1525526 & 688279 & 4.6591 & 3.4835 & TRN & & \\
\hline CHEMBL1406457 & 688279 & 2.7959 & 3.1683 & TRN & & \\
\hline CHEMBL1366992 & 688279 & 4.7039 & 3.2643 & TST & & \\
\hline CHEMBL1337224 & 688279 & 4.1178 & 3.5468 & TRN & & \\
\hline CHEMBL1362893 & 688279 & 4.3971 & 3.1307 & TRN & & \\
\hline CHEMBL548615 & 688279 & 2.7959 & 4.2842 & TRN & & \\
\hline CHEMBL1494713 & 688279 & 4.2489 & 3.5736 & TST & & \\
\hline CHEMBL1538671 & 688279 & 2.7959 & 3.2044 & TRN & & \\
\hline CHEMBL1407420 & 688279 & 2.8239 & 3.0806 & TST & & \\
\hline CHEMBL1335846 & 688279 & 4.7347 & 3.2436 & TRN & & \\
\hline CHEMBL1382821 & 688279 & 2.7959 & 3.4734 & TRN & & \\
\hline CHEMBL1595820 & 688279 & 4.4829 & 4.2107 & TRN & & \\
\hline CHEMBL1336054 & 688279 & 2.7959 & 3.8833 & TRN & & \\
\hline CHEMBL1984447 & 688279 & 2.7959 & 3.2503 & TRN & & \\
\hline CHEMBL609027 & 688279 & 2.8239 & 3.6946 & TRN & & \\
\hline CHEMBL1549103 & 688279 & 4.64199 & 99999999 & 995 & 3.5781 & TRN \\
\hline CHEMBL1969712 & 688279 & 2.7959 & 3.7916 & TRN & & \\
\hline CHEMBL1197556 & 688279 & 4.9201 & 3.6844 & TRN & & \\
\hline CHEMBL1557142 & 688279 & 2.7959 & 3.6019 & TRN & & \\
\hline CHEMBL1308332 & 688279 & 4.6664 & 3.4987 & TST & & \\
\hline CHEMBL1535366 & 688279 & 2.8239 & 3.0745 & TRN & & \\
\hline CHEMBL1572286 & 688279 & 2.8239 & 3.3263 & TRN & & \\
\hline CHEMBL3210642 & 688279 & 4.9312 & 3.5483 & TRN & & \\
\hline CHEMBL1602947 & 688279 & 2.7959 & 3.2573 & TRN & & \\
\hline CHEMBL1309156 & 688279 & 2.7959 & 3.1797 & TRN & & \\
\hline CHEMBL1348012 & 688279 & 2.7959 & 3.4376 & TST & & \\
\hline CHEMBL1490887 & 688279 & 2.8239 & 3.2233 & TST & & \\
\hline CHEMBL1382865 & 688279 & 3.8387 & 3.5368 & TST & & \\
\hline CHEMBL1454827 & 688279 & 2.8239 & 3.415 & TRN & & \\
\hline CHEMBL3193302 & 688279 & 2.7959 & 3.4978 & TST & & \\
\hline CHEMBL1442341 & 688279 & 4.4401 & 3.2757 & TRN & & \\
\hline CHEMBL1537127 & 688279 & 2.7959 & 3.3161 & TRN & & \\
\hline CHEMBL1575594 & 688279 & 5.1767 & 3.5673 & TST & & \\
\hline CHEMBL1556805 & 688279 & 4.0815 & 3.5875 & TRN & & \\
\hline CHEMBL1335117 & 688279 & 2.7959 & 3.5759 & TST & & \\
\hline CHEMBL1369287 & 688279 & 4.1859 & 3.2081 & TST & & \\
\hline CHEMBL1582111 & 688279 & 2.7959 & 3.7856 & TRN & & \\
\hline CHEMBL1410441 & 688279 & 4.2378 & 3.6542 & TRN & & \\
\hline CHEMBL1579999 & 688279 & 4.445 & 3.2718 & TRN & & \\
\hline CHEMBL3193652 & 688279 & 5.0677 & 3.639 & TRN & & \\
\hline CHEMBL1391911 & 688279 & 4.5088 & 3.6006 & TRN & & \\
\hline CHEMBL1500960 & 688279 & 4.2296 & 3.6066 & TST & & \\
\hline CHEMBL3194778 & 688279 & 2.8239 & 3.3502 & TRN & & \\
\hline CHEMBL581868 & 688279 & 2.8239 & 3.2625 & TRN & & \\
\hline
\end{tabular}




\begin{tabular}{|c|c|c|c|c|c|}
\hline & & \multicolumn{4}{|c|}{ Supplemental Table S2.txt } \\
\hline CHEMBL 3207597 & 688279 & 2.8239 & 3.1902 & TRN & \\
\hline CHEMBL1456728 & 688279 & 2.7959 & 3.0849 & TRN & \\
\hline CHEMBL1606685 & 688279 & 4.5633 & 3.9323 & TRN & \\
\hline CHEMBL1420535 & 688279 & 2.8239 & 3.1384 & TRN & \\
\hline CHEMBL578675 & 688279 & 4.6361 & 3.8376 & TRN & \\
\hline CHEMBL 305686 & 688279 & 2.8239 & 3.323 & TST & \\
\hline CHEMBL3145366 & 688279 & 2.8239 & 3.4455 & TRN & \\
\hline CHEMBL1299576 & 688279 & 2.8239 & 3.035 & TRN & \\
\hline CHEMBL334707 & 688279 & 4.9542 & 4.1379 & TRN & \\
\hline CHEMBL1928483 & 688279 & 2.8239 & 3.7436 & TRN & \\
\hline CHEMBL 3195688 & 688279 & 4.415 & 3.6809 & TRN & \\
\hline CHEMBL1322948 & 688279 & 2.8239 & 3.3421 & TRN & \\
\hline CHEMBL1545971 & 688279 & 2.7959 & 3.2936 & TRN & \\
\hline CHEMBL1519338 & 688279 & 2.8239 & 3.7693 & TRN & \\
\hline CHEMBL1407461 & 688279 & 4.1264 & 3.5031 & TRN & \\
\hline CHEMBL1425019 & 688279 & 3.9502 & 3.61899 & 99999999998 & TRN \\
\hline CHEMBL1365622 & 688279 & 2.7959 & 3.5834 & TRN & \\
\hline CHEMBL1503173 & 688279 & 2.7959 & 3.2622 & TRN & \\
\hline CHEMBL1419772 & 688279 & 4.7395 & 3.5138 & TST & \\
\hline CHEMBL1382011 & 688279 & 2.8239 & 3.1176 & TRN & \\
\hline CHEMBL1430488 & 688279 & 2.7959 & 3.0979 & TRN & \\
\hline CHEMBL1455627 & 688279 & 2.8239 & 3.4582 & TRN & \\
\hline CHEMBL1303524 & 688279 & 4.9717 & 3.7827 & TRN & \\
\hline CHEMBL1469888 & 688279 & 4.3159 & 3.1253 & TRN & \\
\hline CHEMBL1400007 & 688279 & 2.7959 & 2.9478 & TST & \\
\hline CHEMBL3210536 & 688279 & 2.7959 & 3.5891 & TRN & \\
\hline CHEMBL1327238 & 688279 & 4.41100 & 30000000 & 3.2994 & TST \\
\hline CHEMBL3209306 & 688279 & 5.3709 & 3.9711 & TRN & \\
\hline CHEMBL1496096 & 688279 & 2.8239 & 3.1173 & TRN & \\
\hline CHEMBL1549472 & 688279 & 2.7959 & 3.3456 & TRN & \\
\hline CHEMBL 3191387 & 688279 & 4.5862 & 3.2325 & TRN & \\
\hline CHEMBL1560221 & 688279 & 2.8239 & 3.0521 & TRN & \\
\hline CHEMBL1481347 & 688279 & 4.5835 & 3.5123 & TRN & \\
\hline CHEMBL1463647 & 688279 & 2.8239 & 3.5223 & TST & \\
\hline CHEMBL1427508 & 688279 & 4.7556 & 3.3746 & TRN & \\
\hline CHEMBL1417904 & 688279 & 2.8239 & 3.29399 & 99999999996 & TST \\
\hline CHEMBL 3198754 & 688279 & 4.4141 & 3.62399 & 99999999997 & TRN \\
\hline CHEMBL1361307 & 688279 & 2.8239 & 3.2349 & TRN & \\
\hline CHEMBL1966798 & 688279 & 4.3425 & 3.6724 & TRN & \\
\hline CHEMBL1417242 & 688279 & 2.7959 & 3.3827 & TRN & \\
\hline CHEMBL1384718 & 688279 & 2.8239 & 3.2067 & TRN & \\
\hline CHEMBL1458975 & 688279 & 4.6834 & 3.3898 & TRN & \\
\hline CHEMBL1377705 & 688279 & 4.9589 & 3.3321 & TRN & \\
\hline CHEMBL1300319 & 688279 & 2.8239 & 3.6699 & TRN & \\
\hline CHEMBL3194699 & 688279 & 4.6093 & 3.51899 & 99999999997 & TRN \\
\hline CHEMBL1601830 & 688279 & 2.7959 & 3.2871 & TRN & \\
\hline CHEMBL1493512 & 688279 & 4.6495 & 3.0649 & TRN & \\
\hline CHEMBL1515702 & 688279 & 2.7959 & 3.2589 & TRN & \\
\hline
\end{tabular}




\begin{tabular}{|c|c|c|c|c|c|}
\hline & & \multicolumn{4}{|c|}{ Supplemental Table s2.txt } \\
\hline CHEMBL1458478 & 688279 & 2.7959 & 3.2251 & TST & \\
\hline CHEMBL1390521 & 688279 & 4.3794 & 3.3816 & TRN & \\
\hline CHEMBL1517473 & 688279 & 2.7959 & 3.3178 & TRN & \\
\hline CHEMBL1460056 & 688279 & 2.8239 & 3.18399 & 99999999997 & TST \\
\hline CHEMBL1565403 & 688279 & 2.8239 & 3.4569 & TRN & \\
\hline CHEMBL1331633 & 688279 & 2.7959 & 3.2296 & TRN & \\
\hline CHEMBL1486934 & 688279 & 5.2927 & 3.2772 & TST & \\
\hline CHEMBL1474564 & 688279 & 2.7959 & 3.6661 & TRN & \\
\hline CHEMBL1414068 & 688279 & 4.0733 & 3.4255 & TRN & \\
\hline CHEMBL1538246 & 688279 & 2.8239 & 3.5208 & TST & \\
\hline CHEMBL1344283 & 688279 & 2.7959 & 3.0885 & TRN & \\
\hline CHEMBL1596969 & 688279 & 2.8239 & 3.3609 & TRN & \\
\hline CHEMBL1566955 & 688279 & 2.7959 & 3.0325 & TRN & \\
\hline CHEMBL1311826 & 688279 & 4.9543 & 4.2074 & TRN & \\
\hline CHEMBL1307255 & 688279 & 2.7959 & 3.0883 & TRN & \\
\hline CHEMBL1308052 & 688279 & 4.81 & 3.5845 & TRN & \\
\hline CHEMBL3190095 & 688279 & 2.8239 & 3.3916 & TST & \\
\hline CHEMBL1905194 & 688279 & 2.8239 & 3.3465 & TST & \\
\hline CHEMBL1471845 & 688279 & 2.8239 & 3.7514 & TRN & \\
\hline CHEMBL1519688 & 688279 & 2.8239 & 3.2018 & TRN & \\
\hline CHEMBL1469885 & 688279 & 4.655 & 3.8314 & TRN & \\
\hline CHEMBL1607901 & 688279 & 2.8239 & 3.0473 & TST & \\
\hline CHEMBL1365375 & 688279 & 2.8239 & 3.0971 & TRN & \\
\hline CHEMBL313163 & 688279 & 2.8239 & 3.4827 & TRN & \\
\hline CHEMBL1359020 & 688279 & 2.8239 & 3.03 & TRN & \\
\hline CHEMBL1503033 & 688279 & 4.0592 & 3.2476 & TST & \\
\hline CHEMBL1341270 & 688279 & 5.5829 & 3.7159 & TST & \\
\hline CHEMBL1588660 & 688279 & 4.3722 & 3.6991 & TRN & \\
\hline CHEMBL1390658 & 688279 & 2.7959 & 3.2073 & TRN & \\
\hline CHEMBL1986418 & 688279 & 4.9426 & 4.3809 & TRN & \\
\hline CHEMBL3194042 & 688279 & 2.7959 & 3.6422 & TRN & \\
\hline CHEMBL1445902 & 688279 & 2.7959 & 3.0195 & TRN & \\
\hline CHEMBL1976839 & 688279 & 3.8331 & 3.1236 & TRN & \\
\hline CHEMBL1401645 & 688279 & 2.8239 & 3.4457 & TRN & \\
\hline CHEMBL1496625 & 688279 & 2.8239 & 3.5028 & TST & \\
\hline CHEMBL1561540 & 688279 & 4.1602 & 3.2674 & TRN & \\
\hline CHEMBL1455523 & 688279 & 4.4676 & 3.2901 & TST & \\
\hline CHEMBL1468668 & 688279 & 2.7959 & 3.60100 & 00000000004 & TST \\
\hline CHEMBL1373038 & 688279 & 4.4156 & 3.1588 & TRN & \\
\hline CHEMBL1586201 & 688279 & 4.3016 & 3.6293 & TRN & \\
\hline CHEMBL3210051 & 688279 & 2.7959 & 4.01399 & 9999999999 & TRN \\
\hline CHEMBL1518057 & 688279 & 4.1145 & 3.6678 & TRN & \\
\hline CHEMBL1500742 & 688279 & 2.7959 & 3.0802 & TRN & \\
\hline CHEMBL 2000368 & 688279 & 2.8239 & 3.6069 & TRN & \\
\hline CHEMBL530499 & 688279 & 2.8239 & 4.6509 & TRN & \\
\hline CHEMBL3199008 & 688279 & 2.7959 & 3.6055 & TRN & \\
\hline CHEMBL1499233 & 688279 & 4.6019 & 4.4503 & TRN & \\
\hline CHEMBL1582488 & 688279 & 2.7959 & 3.3019 & TRN & \\
\hline
\end{tabular}


Supplemental Table S2.txt

\begin{tabular}{|c|c|c|c|c|c|}
\hline CHEMBL2006418 & 688279 & 4.6031 & 3.7191 & TRN & \\
\hline CHEMBL1502943 & 688279 & 4.5048 & \multicolumn{2}{|c|}{3.7230000000000003} & TST \\
\hline CHEMBL1484231 & 688279 & 2.7959 & 3.4956 & TRN & \\
\hline CHEMBL187263 & 688279 & 4.5505 & 3.2933 & TRN & \\
\hline CHEMBL1461196 & 688279 & 4.1 & 4.0442 & TRN & \\
\hline CHEMBL1402899 & 688279 & 2.7959 & 3.3392 & TST & \\
\hline CHEMBL1588832 & 688279 & 3.8701 & 3.7349 & TRN & \\
\hline CHEMBL 3212594 & 688279 & 2.8239 & 3.7371 & TRN & \\
\hline CHEMBL 3197902 & 688279 & 4.8123 & 3.6414 & TRN & \\
\hline CHEMBL1523997 & 688279 & 5.3414 & 3.4994 & TRN & \\
\hline CHEMBL1469362 & 688279 & 2.8239 & 3.0981 & TRN & \\
\hline CHEMBL1362878 & 688279 & 2.8239 & 3.3603 & TRN & \\
\hline CHEMBL1347156 & 688279 & 2.8239 & 3.2956 & TRN & \\
\hline CHEMBL1339626 & 688279 & 4.0293 & 3.5953 & TRN & \\
\hline CHEMBL1378479 & 688279 & 5.3061 & 3.4164 & TST & \\
\hline CHEMBL1301505 & 688279 & 2.8239 & 3.1737 & TRN & \\
\hline CHEMBL1485727 & 688279 & 2.7959 & 3.3445 & TRN & \\
\hline CHEMBL1448700 & 688279 & 2.7959 & 3.2977 & TRN & \\
\hline CHEMBL1463750 & 688279 & 2.8239 & 3.7933 & TRN & \\
\hline CHEMBL1466179 & 688279 & 2.7959 & 3.1989 & TST & \\
\hline CHEMBL1371877 & 688279 & 2.7959 & 3.6038 & TRN & \\
\hline CHEMBL1342093 & 688279 & 2.8239 & 3.7671 & TRN & \\
\hline CHEMBL1487171 & 688279 & 4.8872 & 3.3089 & TRN & \\
\hline CHEMBL1536196 & 688279 & 2.8239 & 3.6695 & TST & \\
\hline CHEMBL3189966 & 688279 & 4.4087 & 3.61800 & 30000000003 & TRN \\
\hline CHEMBL1348803 & 688279 & 5.2175 & 3.4145 & TRN & \\
\hline CHEMBL1500188 & 688279 & 2.7959 & 3.4289 & TRN & \\
\hline CHEMBL3198496 & 688279 & 2.8239 & 4.0313 & TRN & \\
\hline CHEMBL453974 & 688279 & 4.3519 & 3.841 & TST & \\
\hline CHEMBL1393700 & 688279 & 2.8239 & 3.4694 & TRN & \\
\hline CHEMBL1448895 & 688279 & 4.5137 & 3.2016 & TRN & \\
\hline CHEMBL1566678 & 688279 & 5.1026 & 3.417 & TRN & \\
\hline CHEMBL1563943 & 688279 & 2.7959 & 3.6183 & TRN & \\
\hline CHEMBL1351099 & 688279 & 2.8239 & 3.2516 & TRN & \\
\hline CHEMBL1602841 & 688279 & 4.6935 & 3.6577 & TRN & \\
\hline CHEMBL1324917 & 688279 & 2.7959 & 3.1199 & TRN & \\
\hline CHEMBL1431312 & 688279 & 2.8239 & 3.2512 & TRN & \\
\hline CHEMBL1605026 & 688279 & 2.7959 & 3.5219 & TRN & \\
\hline CHEMBL1429917 & 688279 & 2.8239 & 3.7458 & TRN & \\
\hline CHEMBL1440514 & 688279 & 4.0973 & 3.4533 & TRN & \\
\hline CHEMBL1594846 & 688279 & 2.8239 & 3.2624 & TRN & \\
\hline CHEMBL1580637 & 688279 & 2.8239 & 3.0057 & TRN & \\
\hline CHEMBL1329129 & 688279 & 4.377 & 4.2802 & TRN & \\
\hline CHEMBL1520276 & 688279 & 5.3722 & 4.2366 & TRN & \\
\hline CHEMBL1444424 & 688279 & 2.8239 & 3.2074 & TRN & \\
\hline CHEMBL1528707 & 688279 & 2.7959 & 3.5996 & TST & \\
\hline CHEMBL1431093 & 688279 & 2.7959 & 3.2452 & TRN & \\
\hline CHEMBL1460270 & 688279 & 2.8239 & 2.9836 & TRN & \\
\hline
\end{tabular}

Page 11863 
Supplemental Table S2.txt

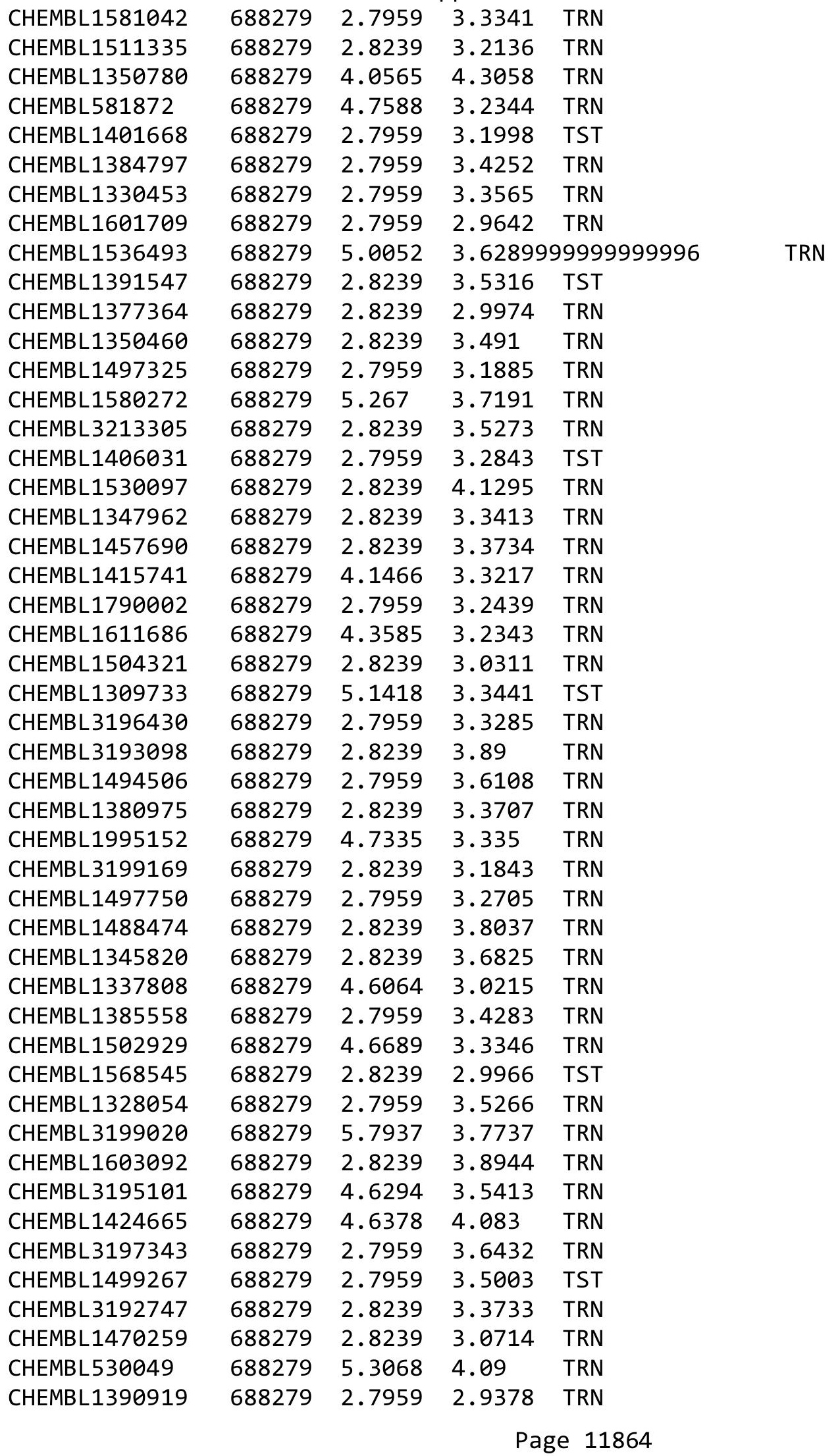




\begin{tabular}{|c|c|c|c|c|c|}
\hline & & \multicolumn{4}{|c|}{ Supplemental Table S2.txt } \\
\hline CHEMBL1373678 & 688279 & 2.7959 & 3.262 & TRN & \\
\hline CHEMBL3211050 & 688279 & 2.8239 & 3.8554 & TRN & \\
\hline CHEMBL1576754 & 688279 & 5.3755 & 3.923 & TRN & \\
\hline CHEMBL1575613 & 688279 & 2.8239 & 3.023 & TRN & \\
\hline CHEMBL1305864 & 688279 & 2.8239 & 3.2122 & TRN & \\
\hline CHEMBL1605966 & 688279 & 2.8239 & 3.0184 & TRN & \\
\hline CHEMBL1330558 & 688279 & 4.3755 & 3.9601 & TRN & \\
\hline CHEMBL1449718 & 688279 & 2.7959 & 3.0406 & TRN & \\
\hline CHEMBL591834 & 688279 & 2.8239 & 3.5981 & TST & \\
\hline CHEMBL 1348342 & 688279 & 2.8239 & 3.4518 & TRN & \\
\hline CHEMBL1370113 & 688279 & 2.8239 & 3.42100 & 00000000003 & TRN \\
\hline CHEMBL1524014 & 688279 & 2.8239 & 3.3226 & TST & \\
\hline CHEMBL3197628 & 688279 & 2.8239 & 3.3208 & TRN & \\
\hline CHEMBL389162 & 688279 & 2.8239 & 3.5278 & TRN & \\
\hline CHEMBL1603036 & 688279 & 2.8239 & 3.1235 & TRN & \\
\hline CHEMBL1332684 & 688279 & 2.8239 & 3.1003 & TRN & \\
\hline CHEMBL1998436 & 688279 & 2.8239 & 3.647 & TRN & \\
\hline CHEMBL1605988 & 688279 & 2.7959 & 3.3272 & TRN & \\
\hline CHEMBL1483015 & 688279 & 2.8239 & 3.8261 & TRN & \\
\hline CHEMBL1478041 & 688279 & 2.8239 & 3.8527 & TRN & \\
\hline CHEMBL1505451 & 688279 & 2.8239 & 3.2839 & TRN & \\
\hline CHEMBL1428244 & 688279 & 2.8239 & 3.7161 & TRN & \\
\hline CHEMBL1317642 & 688279 & 2.8239 & 2.8129 & TRN & \\
\hline CHEMBL 3192257 & 688279 & 2.7959 & 3.4529 & TRN & \\
\hline CHEMBL1318693 & 688279 & 2.7959 & 3.4492 & TRN & \\
\hline CHEMBL1484777 & 688279 & 2.7959 & 3.8142 & TRN & \\
\hline CHEMBL1464485 & 688279 & 2.8239 & 3.3716 & TRN & \\
\hline CHEMBL1405220 & 688279 & 2.7959 & 3.6285 & TRN & \\
\hline CHEMBL1502711 & 688279 & 2.7959 & 3.0499 & TRN & \\
\hline CHEMBL1377316 & 688279 & 4.8742 & 4.409 & TRN & \\
\hline CHEMBL1535160 & 688279 & 2.7959 & 3.4729 & TRN & \\
\hline CHEMBL1495396 & 688279 & 2.7959 & 3.3689 & TST & \\
\hline CHEMBL1324454 & 688279 & 2.7959 & 3.0861 & TRN & \\
\hline CHEMBL1985664 & 688279 & 4.5224 & 3.3618 & TRN & \\
\hline CHEMBL1349566 & 688279 & 2.7959 & 3.4834 & TRN & \\
\hline CHEMBL1436213 & 688279 & 2.8239 & 3.42 & TRN & \\
\hline CHEMBL1393007 & 688279 & 2.7959 & 3.4007 & TRN & \\
\hline CHEMBL1347108 & 688279 & 5.3398 & 3.5073 & TRN & \\
\hline CHEMBL1577186 & 688279 & 4.2881 & 3.0505 & TST & \\
\hline CHEMBL3191534 & 688279 & 4.5495 & 3.5319 & TRN & \\
\hline CHEMBL1597174 & 688279 & 2.7959 & 3.5594 & TRN & \\
\hline CHEMBL3213808 & 688279 & 4.4635 & 3.3888 & TRN & \\
\hline CHEMBL1438619 & 688279 & 2.8239 & 3.2532 & TRN & \\
\hline CHEMBL1319004 & 688279 & 2.7959 & 3.392 & TRN & \\
\hline CHEMBL1583801 & 688279 & 2.8239 & 3.7189 & TRN & \\
\hline CHEMBL1529521 & 688279 & 2.8239 & 3.3833 & TRN & \\
\hline CHEMBL3194161 & 688279 & 2.7959 & 3.7505 & TRN & \\
\hline CHEMBL1536643 & 688279 & 5.5325 & 3.7741 & TRN & \\
\hline
\end{tabular}




\begin{tabular}{|c|c|c|c|c|c|}
\hline & & \multicolumn{4}{|c|}{ Supplemental Table S2.txt } \\
\hline CHEMBL1447341 & 688279 & 5.3836 & 5.0163 & TRN & \\
\hline CHEMBL1489407 & 688279 & 2.8239 & 4.4151 & TRN & \\
\hline CHEMBL1587766 & 688279 & 2.7959 & 3.3152 & TRN & \\
\hline CHEMBL1302283 & 688279 & 2.7959 & 3.1465 & TRN & \\
\hline CHEMBL1459101 & 688279 & 2.8239 & 3.1138 & TRN & \\
\hline CHEMBL1500500 & 688279 & 2.8239 & 3.2011 & TRN & \\
\hline CHEMBL1413798 & 688279 & 2.8239 & 3.50100 & 00000000003 & TRN \\
\hline CHEMBL1481697 & 688279 & 2.8239 & 3.4203 & TRN & \\
\hline CHEMBL1608901 & 688279 & 2.8239 & 3.0937 & TRN & \\
\hline CHEMBL1534035 & 688279 & 4.595 & 3.8376 & TRN & \\
\hline CHEMBL140425 & 688279 & 4.8092 & 4.1419 & TRN & \\
\hline CHEMBL1319294 & 688279 & 2.8239 & 3.1577 & TRN & \\
\hline CHEMBL1541539 & 688279 & 2.8239 & 3.3491 & TRN & \\
\hline CHEMBL1441218 & 688279 & 5.527 & 3.7637 & TRN & \\
\hline CHEMBL1566358 & 688279 & 2.7959 & 3.4453 & TRN & \\
\hline CHEMBL1995280 & 688279 & 4.2042 & 3.1527 & TRN & \\
\hline CHEMBL1336675 & 688279 & 2.7959 & 3.5441 & TRN & \\
\hline CHEMBL1594897 & 688279 & 2.8239 & 3.4011 & TRN & \\
\hline CHEMBL1455877 & 688279 & 2.7959 & 3.3555 & TRN & \\
\hline CHEMBL3199526 & 688279 & 2.8239 & 3.352 & TRN & \\
\hline CHEMBL1305011 & 688279 & 4.6605 & 3.4658 & TRN & \\
\hline CHEMBL1443836 & 688279 & 2.8239 & 3.1665 & TRN & \\
\hline CHEMBL1591171 & 688279 & 2.8239 & 3.5118 & TST & \\
\hline CHEMBL 75967 & 688279 & 4.1229 & 3.6261 & TST & \\
\hline CHEMBL2359911 & 688279 & 5.2607 & 4.025 & TRN & \\
\hline CHEMBL1398571 & 688279 & 2.8239 & 3.2929 & TST & \\
\hline CHEMBL512366 & 688279 & 4.9545 & 3.3641 & TRN & \\
\hline CHEMBL1462215 & 688279 & 2.8239 & 3.9051 & TRN & \\
\hline CHEMBL3190873 & 688279 & 4.1892 & 3.5884 & TRN & \\
\hline CHEMBL1544131 & 688279 & 5.6444 & 4.4654 & TRN & \\
\hline CHEMBL1716494 & 688279 & 5.0625 & 3.2754 & TRN & \\
\hline CHEMBL1534203 & 688279 & 2.8239 & 3.2846 & TRN & \\
\hline CHEMBL1347784 & 688279 & 2.8239 & 3.0845 & TRN & \\
\hline CHEMBL1388684 & 688279 & 2.8239 & 3.1184 & TRN & \\
\hline CHEMBL1324755 & 688279 & 2.7959 & 3.2584 & TRN & \\
\hline CHEMBL1528696 & 688279 & 2.7959 & 3.2453 & TST & \\
\hline CHEMBL3145381 & 688279 & 2.7959 & 3.3321 & TRN & \\
\hline CHEMBL1337045 & 688279 & 2.7959 & 3.531 & TRN & \\
\hline CHEMBL1455850 & 688279 & 2.8239 & 3.6173 & TRN & \\
\hline CHEMBL1489956 & 688279 & 4.6022 & 3.725 & TRN & \\
\hline CHEMBL1505060 & 688279 & 2.8239 & 3.432 & TRN & \\
\hline CHEMBL461579 & 688279 & 4.0459 & 3.7465 & TRN & \\
\hline CHEMBL1339092 & 688279 & 2.8239 & 3.2514 & TST & \\
\hline CHEMBL1562664 & 688279 & 4.647 & 3.4571 & TRN & \\
\hline CHEMBL1467876 & 688279 & 4.6606 & 3.5626 & TRN & \\
\hline CHEMBL1487498 & 688279 & 2.8239 & 3.2235 & TST & \\
\hline CHEMBL1312953 & 688279 & 2.8239 & 3.8811 & TRN & \\
\hline CHEMBL1305499 & 688279 & 2.7959 & 3.5581 & TRN & \\
\hline
\end{tabular}




\begin{tabular}{|c|c|c|c|c|c|}
\hline \multirow[b]{2}{*}{ CHEMBL3189582 } & \multicolumn{5}{|c|}{ Supplemental Table S2.txt } \\
\hline & 688279 & 2.8239 & 3.5817 & TRN & \\
\hline CHEMBL1414440 & 688279 & 2.8239 & 3.02699 & 99999999997 & TRN \\
\hline CHEMBL1994094 & 688279 & 2.7959 & 3.5413 & TRN & \\
\hline CHEMBL 3213934 & 688279 & 4.18 & 3.4557 & TST & \\
\hline CHEMBL1377849 & 688279 & 5.4878 & 3.622 & TRN & \\
\hline CHEMBL1503392 & 688279 & 4.382 & 3.1098 & TRN & \\
\hline CHEMBL1585127 & 688279 & 4.832 & 3.3788 & TRN & \\
\hline CHEMBL1481045 & 688279 & 2.8239 & 2.8635 & TST & \\
\hline CHEMBL1313101 & 688279 & 4.8486 & 3.3799 & TRN & \\
\hline CHEMBL1570025 & 688279 & 2.8239 & 2.9092 & TRN & \\
\hline CHEMBL1598391 & 688279 & 2.7959 & 3.0752 & TRN & \\
\hline CHEMBL1533308 & 688279 & 4.5717 & 3.3873 & TRN & \\
\hline CHEMBL1600203 & 688279 & 2.7959 & 4.4302 & TRN & \\
\hline CHEMBL1585777 & 688279 & 4.8107 & 3.6259 & TRN & \\
\hline CHEMBL3194562 & 688279 & 2.8239 & 3.7663 & TRN & \\
\hline CHEMBL1565454 & 688279 & 2.8239 & 3.1382 & TRN & \\
\hline CHEMBL3194214 & 688279 & 2.8239 & 4.0263 & TRN & \\
\hline CHEMBL1993662 & 688279 & 4.4494 & 3.5176 & TRN & \\
\hline CHEMBL1383409 & 688279 & 4.5443 & 3.3055 & TRN & \\
\hline CHEMBL1324531 & 688279 & 2.8239 & 3.1526 & TRN & \\
\hline CHEMBL1430800 & 688279 & 2.8239 & 3.7824 & TRN & \\
\hline CHEMBL1563370 & 688279 & 4.6589 & 3.6253 & TST & \\
\hline CHEMBL1348119 & 688279 & 2.8239 & 3.7616 & TRN & \\
\hline CHEMBL1351171 & 688279 & 4.6449 & 3.5356 & TRN & \\
\hline CHEMBL1334233 & 688279 & 2.8239 & 3.6069 & TRN & \\
\hline CHEMBL1310989 & 688279 & 2.8239 & 3.3443 & TRN & \\
\hline CHEMBL1470483 & 688279 & 2.7959 & 3.8595 & TRN & \\
\hline CHEMBL1310341 & 688279 & 4.7943 & 3.6056 & TRN & \\
\hline CHEMBL1388803 & 688279 & 2.8239 & 3.3271 & TRN & \\
\hline CHEMBL1596066 & 688279 & 2.8239 & 2.9582 & TRN & \\
\hline CHEMBL1342031 & 688279 & 4.5432 & 3.4287 & TST & \\
\hline CHEMBL1444553 & 688279 & 2.8239 & 3.1511 & TRN & \\
\hline CHEMBL1324005 & 688279 & 2.7959 & 3.4348 & TST & \\
\hline CHEMBL1465367 & 688279 & 2.7959 & 3.014 & TRN & \\
\hline CHEMBL1343568 & 688279 & 5.11 & 3.6388 & TRN & \\
\hline CHEMBL3191817 & 688279 & 2.8239 & 3.7404 & TRN & \\
\hline CHEMBL3192681 & 688279 & 4.5265 & 3.6849 & TRN & \\
\hline CHEMBL1389542 & 688279 & 2.7959 & 3.6615 & TRN & \\
\hline CHEMBL1994988 & 688279 & 2.7959 & 3.693 & TRN & \\
\hline CHEMBL1310527 & 688279 & 4.1312 & 3.2999 & TRN & \\
\hline CHEMBL1352575 & 688279 & 2.7959 & 3.3143 & TRN & \\
\hline CHEMBL1480135 & 688279 & 2.8239 & 3.3881 & TRN & \\
\hline CHEMBL1348263 & 688279 & 4.7206 & 3.4682 & TRN & \\
\hline CHEMBL1360505 & 688279 & 2.8239 & 2.9633 & TRN & \\
\hline CHEMBL3191080 & 688279 & 2.7959 & 3.6926 & TST & \\
\hline CHEMBL1348654 & 688279 & 4.7441 & 3.2499 & TRN & \\
\hline CHEMBL1522211 & 688279 & 4.4552 & 3.4055 & TRN & \\
\hline CHEMBL1587043 & 688279 & 4.7249 & 3.5184 & TRN & \\
\hline
\end{tabular}




\begin{tabular}{|c|c|c|c|c|c|}
\hline \multirow[b]{2}{*}{ CHEMBL1545702 } & \multicolumn{5}{|c|}{ Supplemental Table S2.txt } \\
\hline & 688279 & 2.8239 & 3.7144 & TST & \\
\hline CHEMBL1465741 & 688279 & 2.8239 & 3.332 & TRN & \\
\hline CHEMBL3213054 & 688279 & 2.7959 & 3.7197 & TST & \\
\hline CHEMBL1442114 & 688279 & 2.8239 & 3.3559 & TRN & \\
\hline CHEMBL1457944 & 688279 & 2.7959 & 3.5763 & TRN & \\
\hline CHEMBL1420321 & 688279 & 2.7959 & 3.2517 & TRN & \\
\hline CHEMBL1349470 & 688279 & 2.8239 & 2.9658 & TRN & \\
\hline CHEMBL1576118 & 688279 & 2.8239 & 3.3713 & TRN & \\
\hline CHEMBL1299925 & 688279 & 2.8239 & 3.2058 & TRN & \\
\hline CHEMBL1376851 & 688279 & 4.1181 & 3.4998 & TST & \\
\hline CHEMBL1409365 & 688279 & 4.7427 & 3.0953 & TST & \\
\hline CHEMBL3199324 & 688279 & 5.3286 & 3.9404 & TRN & \\
\hline CHEMBL1310009 & 688279 & 2.7959 & 3.1322 & TST & \\
\hline CHEMBL1609315 & 688279 & 2.8239 & 3.3501 & TST & \\
\hline CHEMBL1598222 & 688279 & 2.8239 & 3.6668 & TRN & \\
\hline CHEMBL1455405 & 688279 & 2.7959 & 3.685 & TRN & \\
\hline CHEMBL1537417 & 688279 & 5.082 & 3.3996 & TST & \\
\hline CHEMBL 3198723 & 688279 & 5.5738 & 3.7852 & TRN & \\
\hline CHEMBL1607272 & 688279 & 2.8239 & 3.2669 & TRN & \\
\hline CHEMBL1519744 & 688279 & 2.7959 & 3.0864 & TRN & \\
\hline CHEMBL3198720 & 688279 & 5.6029 & 4.0576 & TRN & \\
\hline CHEMBL1594485 & 688279 & 2.7959 & 3.3772 & TRN & \\
\hline CHEMBL1587732 & 688279 & 4.1752 & 3.2204 & TRN & \\
\hline CHEMBL193627 & 688279 & 4.8089 & 3.9046 & TRN & \\
\hline CHEMBL1518873 & 688279 & 2.7959 & 3.5355 & TST & \\
\hline CHEMBL3207925 & 688279 & 2.8239 & 3.8799 & TRN & \\
\hline CHEMBL1470712 & 688279 & 2.8239 & 3.802 & TRN & \\
\hline CHEMBL1345042 & 688279 & 2.7959 & 3.2719 & TST & \\
\hline CHEMBL1502143 & 688279 & 2.7959 & 3.1214 & TST & \\
\hline CHEMBL1412002 & 688279 & 4.5464 & 4.8674 & TRN & \\
\hline CHEMBL1537448 & 688279 & 2.8239 & 3.2112 & TRN & \\
\hline CHEMBL1524829 & 688279 & 4.1706 & 3.4755 & TRN & \\
\hline CHEMBL1584387 & 688279 & 2.7959 & 3.5427 & TRN & \\
\hline CHEMBL479107 & 688279 & 2.7959 & 3.81699 & 99999999997 & TRN \\
\hline CHEMBL1382884 & 688279 & 4.379 & 3.2349 & TRN & \\
\hline CHEMBL1505070 & 688279 & 2.8239 & 3.29 & TRN & \\
\hline CHEMBL1444022 & 688279 & 2.8239 & 3.3825 & TRN & \\
\hline CHEMBL1458786 & 688279 & 4.6105 & 3.5416 & TST & \\
\hline CHEMBL1990091 & 688279 & 4.7405 & 3.9866 & TRN & \\
\hline CHEMBL1376904 & 688279 & 4.2948 & 3.2912 & TRN & \\
\hline CHEMBL1514790 & 688279 & 2.8239 & 3.5042 & TST & \\
\hline CHEMBL1494743 & 688279 & 4.7047 & 3.0851 & TST & \\
\hline CHEMBL1348582 & 688279 & 4.331 & 4.5332 & TRN & \\
\hline CHEMBL1578482 & 688279 & 5.0069 & 4.1899 & TRN & \\
\hline CHEMBL1967081 & 688279 & 4.2148 & 3.7423 & TRN & \\
\hline CHEMBL1526730 & 688279 & 2.8239 & 3.4537 & TST & \\
\hline CHEMBL1609038 & 688279 & 2.7959 & 3.1747 & TRN & \\
\hline CHEMBL591404 & 688279 & 4.6773 & 3.4321 & TRN & \\
\hline
\end{tabular}




\begin{tabular}{|c|c|c|c|c|c|}
\hline & & \multicolumn{4}{|c|}{ Supplemental Table S2.txt } \\
\hline CHEMBL1355133 & 688279 & 2.8239 & 4.012 & TRN & \\
\hline CHEMBL1222385 & 688279 & 2.7959 & 3.3134 & TRN & \\
\hline CHEMBL3197024 & 688279 & 2.7959 & 4.1751 & TRN & \\
\hline CHEMBL1303554 & 688279 & 2.7959 & 3.1001 & TST & \\
\hline CHEMBL1420628 & 688279 & 2.8239 & 3.1499 & TRN & \\
\hline CHEMBL1997747 & 688279 & 4.2911 & 3.6444 & TRN & \\
\hline CHEMBL1486827 & 688279 & 2.8239 & 3.7281 & TST & \\
\hline CHEMBL1403434 & 688279 & 2.7959 & 3.1259 & TRN & \\
\hline CHEMBL1483387 & 688279 & 2.8239 & 3.1088 & TRN & \\
\hline CHEMBL584442 & 688279 & 3.9003 & 3.3332 & TRN & \\
\hline CHEMBL1584524 & 688279 & 2.7959 & 3.5383 & TRN & \\
\hline CHEMBL1445971 & 688279 & 2.8239 & 3.0355 & TRN & \\
\hline CHEMBL1581275 & 688279 & 2.7959 & 3.3187 & TRN & \\
\hline CHEMBL523200 & 688279 & 5.2348 & 4.1168 & TRN & \\
\hline CHEMBL1301769 & 688279 & 4.1734 & 3.9088 & TST & \\
\hline CHEMBL3190138 & 688279 & 2.7959 & 3.2233 & TRN & \\
\hline CHEMBL1353862 & 688279 & 2.8239 & 2.9718 & TRN & \\
\hline CHEMBL1329076 & 688279 & 2.8239 & 3.3111 & TRN & \\
\hline CHEMBL1455396 & 688279 & 2.7959 & 3.3179 & TST & \\
\hline CHEMBL1988042 & 688279 & 4.5696 & 4.1606 & TRN & \\
\hline CHEMBL1519958 & 688279 & 2.7959 & 3.4626 & TRN & \\
\hline CHEMBL1369425 & 688279 & 4.907 & 3.0979 & TRN & \\
\hline CHEMBL1468306 & 688279 & 2.8239 & 3.437 & TRN & \\
\hline CHEMBL1521991 & 688279 & 2.7959 & 3.4627 & TRN & \\
\hline CHEMBL1470758 & 688279 & 2.7959 & 3.4163 & TRN & \\
\hline CHEMBL1352792 & 688279 & 2.7959 & 3.2581 & TRN & \\
\hline CHEMBL1452090 & 688279 & 4.6625 & 4.4492 & TRN & \\
\hline CHEMBL1380557 & 688279 & 2.8239 & 3.3802 & TRN & \\
\hline CHEMBL1526793 & 688279 & 2.7959 & 3.2335 & TRN & \\
\hline CHEMBL1324371 & 688279 & 2.7959 & 3.5005 & TRN & \\
\hline CHEMBL1533353 & 688279 & 2.8239 & 3.0326 & TRN & \\
\hline CHEMBL1306983 & 688279 & 2.8239 & 3.537 & TRN & \\
\hline CHEMBL1545499 & 688279 & 2.7959 & 3.1664 & TRN & \\
\hline CHEMBL600862 & 688279 & 4.7422 & 4.8263 & TRN & \\
\hline CHEMBL1447039 & 688279 & 2.8239 & 3.3529 & TRN & \\
\hline CHEMBL1386508 & 688279 & 4.0238 & 3.3894 & TRN & \\
\hline CHEMBL1548429 & 688279 & 2.8239 & 3.3773 & TRN & \\
\hline CHEMBL1586169 & 688279 & 4.9522 & 3.14300 & 00000000002 & TRN \\
\hline CHEMBL1547141 & 688279 & 2.8239 & 3.1921 & TRN & \\
\hline CHEMBL1546228 & 688279 & 2.7959 & 3.4559 & TRN & \\
\hline CHEMBL1347084 & 688279 & 4.6986 & 3.1871 & TRN & \\
\hline CHEMBL1558957 & 688279 & 2.8239 & 3.3601 & TRN & \\
\hline CHEMBL1433919 & 688279 & 2.7959 & 3.4398 & TST & \\
\hline CHEMBL1492378 & 688279 & 2.8239 & 3.2853 & TST & \\
\hline CHEMBL3191808 & 688279 & 4.4532 & 4.0579 & TST & \\
\hline CHEMBL1526249 & 688279 & 2.8239 & 3.5353 & TST & \\
\hline CHEMBL1333504 & 688279 & 2.7959 & 3.0763 & TST & \\
\hline CHEMBL597047 & 688279 & 3.9207 & 3.3386 & TST & \\
\hline
\end{tabular}


Supplemental Table S2.txt

\begin{tabular}{|c|c|c|c|c|c|}
\hline CHEMBL1340678 & 688279 & 5.1737 & 3.7195 & TST & \\
\hline CHEMBL1377176 & 688279 & 4.7366 & 3.7569 & TST & \\
\hline CHEMBL1326523 & 688279 & 2.7959 & 3.1526 & TST & \\
\hline CHEMBL1569309 & 688279 & 2.8239 & 3.2273 & TST & \\
\hline CHEMBL1383706 & 688279 & 2.7959 & 3.5693 & TST & \\
\hline CHEMBL1562545 & 688279 & 4.2316 & 3.4002 & TST & \\
\hline CHEMBL1329395 & 688279 & 2.8239 & 3.2606 & TST & \\
\hline CHEMBL1302439 & 688279 & 3.9186 & 3.2478 & TST & \\
\hline CHEMBL3856090 & 688279 & 2.8239 & 3.3452 & TST & \\
\hline CHEMBL1300301 & 688279 & 2.8239 & 3.6942 & TST & \\
\hline CHEMBL1305001 & 688279 & 4.7997 & 3.2222 & TST & \\
\hline CHEMBL1519450 & 688279 & 4.3965 & 4.7248 & TST & \\
\hline CHEMBL3194039 & 688279 & 4.7894 & 3.5264 & TST & \\
\hline CHEMBL1528658 & 688279 & 2.8239 & 3.1107 & TST & \\
\hline CHEMBL1419335 & 688279 & 5.1619 & 3.6508 & TST & \\
\hline CHEMBL1564599 & 688279 & 2.7959 & 3.1685 & TST & \\
\hline CHEMBL1504569 & 688279 & 2.8239 & 4.3808 & TST & \\
\hline CHEMBL1400950 & 688279 & 4.2546 & 3.74300 & 00000000003 & TST \\
\hline CHEMBL1521380 & 688279 & 2.8239 & 3.1722 & TST & \\
\hline CHEMBL1362077 & 688279 & 2.8239 & 3.0957 & TST & \\
\hline CHEMBL1337614 & 688279 & 2.7959 & 3.5509 & TST & \\
\hline CHEMBL595700 & 688279 & 2.8239 & 3.3119 & TST & \\
\hline CHEMBL1348448 & 688279 & 2.7959 & 3.36800 & 00000000003 & TST \\
\hline CHEMBL1386593 & 688279 & 2.8239 & 3.2995 & TST & \\
\hline CHEMBL1508647 & 688279 & 2.7959 & 3.5628 & TST & \\
\hline CHEMBL1351290 & 688279 & 2.8239 & 3.3836 & TST & \\
\hline CHEMBL1467211 & 688279 & 2.8239 & 3.5925 & TST & \\
\hline CHEMBL1368792 & 688279 & 2.8239 & 3.3227 & TST & \\
\hline CHEMBL1520111 & 688279 & 2.8239 & 3.1034 & TST & \\
\hline CHEMBL1520556 & 688279 & 2.7959 & 3.0689 & TST & \\
\hline CHEMBL19954 & 688279 & 5.3608 & 3.5102 & TST & \\
\hline CHEMBL459022 & 688279 & 2.8239 & 3.6875 & TST & \\
\hline CHEMBL1472489 & 688279 & 2.8239 & 3.2803 & TST & \\
\hline CHEMBL1442383 & 688279 & 2.7959 & 3.7936 & TST & \\
\hline CHEMBL1388116 & 688279 & 2.7959 & 3.3687 & TST & \\
\hline CHEMBL1610676 & 688279 & 2.7959 & 3.4714 & TST & \\
\hline CHEMBL1372734 & 688279 & 2.8239 & 3.7026 & TST & \\
\hline CHEMBL1470934 & 688279 & 2.8239 & \multicolumn{2}{|c|}{3.1830000000000003} & TST \\
\hline CHEMBL1550442 & 688279 & 2.7959 & \multicolumn{2}{|c|}{3.3489999999999998} & TST \\
\hline CHEMBL1400965 & 688279 & 4.1601 & 3.8509 & TST & \\
\hline CHEMBL1339082 & 688279 & 2.8239 & 3.355 & TST & \\
\hline CHEMBL1564030 & 688279 & 2.8239 & 3.4839 & TST & \\
\hline CHEMBL3209845 & 688279 & 2.8239 & 3.7715 & TST & \\
\hline CHEMBL1416961 & 688279 & 2.7959 & 3.1371 & TST & \\
\hline CHEMBL1312909 & 688279 & 2.7959 & 3.6023 & TST & \\
\hline CHEMBL1390645 & 688279 & 2.8239 & 2.9683 & TST & \\
\hline CHEMBL1471948 & 688279 & 2.7959 & 3.5919 & TST & \\
\hline CHEMBL1381679 & 688279 & 2.8239 & 3.3451 & TST & \\
\hline
\end{tabular}




\begin{tabular}{|c|c|c|c|c|c|}
\hline & & \multicolumn{4}{|c|}{ Supplemental Table S2.txt } \\
\hline CHEMBL1371004 & 688279 & 5.1831 & 3.1943 & TST & \\
\hline CHEMBL1503006 & 688279 & 2.8239 & 4.0114 & TST & \\
\hline CHEMBL1496349 & 688279 & 4.5161 & 3.3881 & TST & \\
\hline CHEMBL3212271 & 688279 & 4.5284 & 4.0008 & TST & \\
\hline CHEMBL1607643 & 688279 & 2.8239 & 3.3375 & TST & \\
\hline CHEMBL1578670 & 688279 & 2.7959 & 4.2797 & TST & \\
\hline CHEMBL1334286 & 688279 & 2.8239 & 3.4281 & TST & \\
\hline CHEMBL1338258 & 688279 & 2.8239 & 3.4152 & TST & \\
\hline CHEMBL1365660 & 688279 & 2.7959 & 3.1651 & TST & \\
\hline CHEMBL3197187 & 688279 & 2.7959 & 3.1353 & TST & \\
\hline CHEMBL1497897 & 688279 & 2.8239 & 3.3185 & TST & \\
\hline CHEMBL1529188 & 688279 & $5.3210 e$ & 00000000 & 3.3911 & TST \\
\hline CHEMBL3209413 & 688279 & 2.7959 & 3.0566 & TST & \\
\hline CHEMBL193872 & 688279 & 4.1094 & 3.4855 & TST & \\
\hline CHEMBL1504794 & 688279 & 2.7959 & 3.4625 & TST & \\
\hline CHEMBL1452779 & 688279 & 2.8239 & 3.304 & TST & \\
\hline CHEMBL3211846 & 688279 & 2.7959 & 3.5562 & TST & \\
\hline CHEMBL1462375 & 688279 & 5.0595 & 4.0822 & TST & \\
\hline CHEMBL3190974 & 688279 & 2.8239 & 3.8007 & TST & \\
\hline CHEMBL1407169 & 688279 & 5.2678 & 3.7754 & TST & \\
\hline CHEMBL1327205 & 688279 & 2.7959 & 3.4709 & TST & \\
\hline CHEMBL1560928 & 688279 & 2.8239 & 3.1323 & TST & \\
\hline CHEMBL1442155 & 688279 & 2.8239 & 3.68399 & 99999999997 & TST \\
\hline CHEMBL1327455 & 688279 & 2.7959 & 3.3253 & TST & \\
\hline CHEMBL3195031 & 688279 & 5.1363 & 3.6784 & TST & \\
\hline CHEMBL1371773 & 688279 & 2.8239 & 3.5089 & TST & \\
\hline CHEMBL1329232 & 688279 & 2.8239 & 3.2095 & TST & \\
\hline CHEMBL1482184 & 688279 & 5.0164 & 3.5777 & TST & \\
\hline CHEMBL 1327656 & 688279 & 2.7959 & 3.5043 & TST & \\
\hline CHEMBL1429980 & 688279 & 2.8239 & 3.2327 & TST & \\
\hline CHEMBL3199301 & 688279 & 3.8601 & 3.6372 & TST & \\
\hline CHEMBL1323744 & 688279 & 4.3303 & 4.3141 & TST & \\
\hline CHEMBL3190697 & 688279 & 2.8239 & 3.4289 & TST & \\
\hline CHEMBL1446245 & 688279 & 4.1678 & 3.1116 & TST & \\
\hline CHEMBL1390391 & 688279 & 2.7959 & 3.2935 & TST & \\
\hline CHEMBL1349480 & 688279 & 2.8239 & 3.4607 & TST & \\
\hline CHEMBL1408094 & 688279 & 2.7959 & 3.2557 & TST & \\
\hline CHEMBL3193664 & 688279 & 5.1355 & 3.9798 & TST & \\
\hline CHEMBL1301999 & 688279 & 2.7959 & 3.2232 & TST & \\
\hline CHEMBL1569989 & 688279 & 2.7959 & 3.9803 & TST & \\
\hline CHEMBL1545105 & 688279 & 2.8239 & 3.6525 & TST & \\
\hline CHEMBL1993746 & 688279 & 4.5802 & 3.6935 & TST & \\
\hline CHEMBL1492918 & 688279 & 2.7959 & 3.5305 & TST & \\
\hline CHEMBL1348468 & 688279 & 2.8239 & 3.6052 & TST & \\
\hline CHEMBL1352904 & 688279 & 2.8239 & 3.1788 & TST & \\
\hline CHEMBL1478797 & 688279 & 2.8239 & 3.0881 & TST & \\
\hline CHEMBL1414734 & 688279 & 2.8239 & 3.5709 & TST & \\
\hline CHEMBL1397742 & 688279 & 2.7959 & 3.5391 & TST & \\
\hline
\end{tabular}




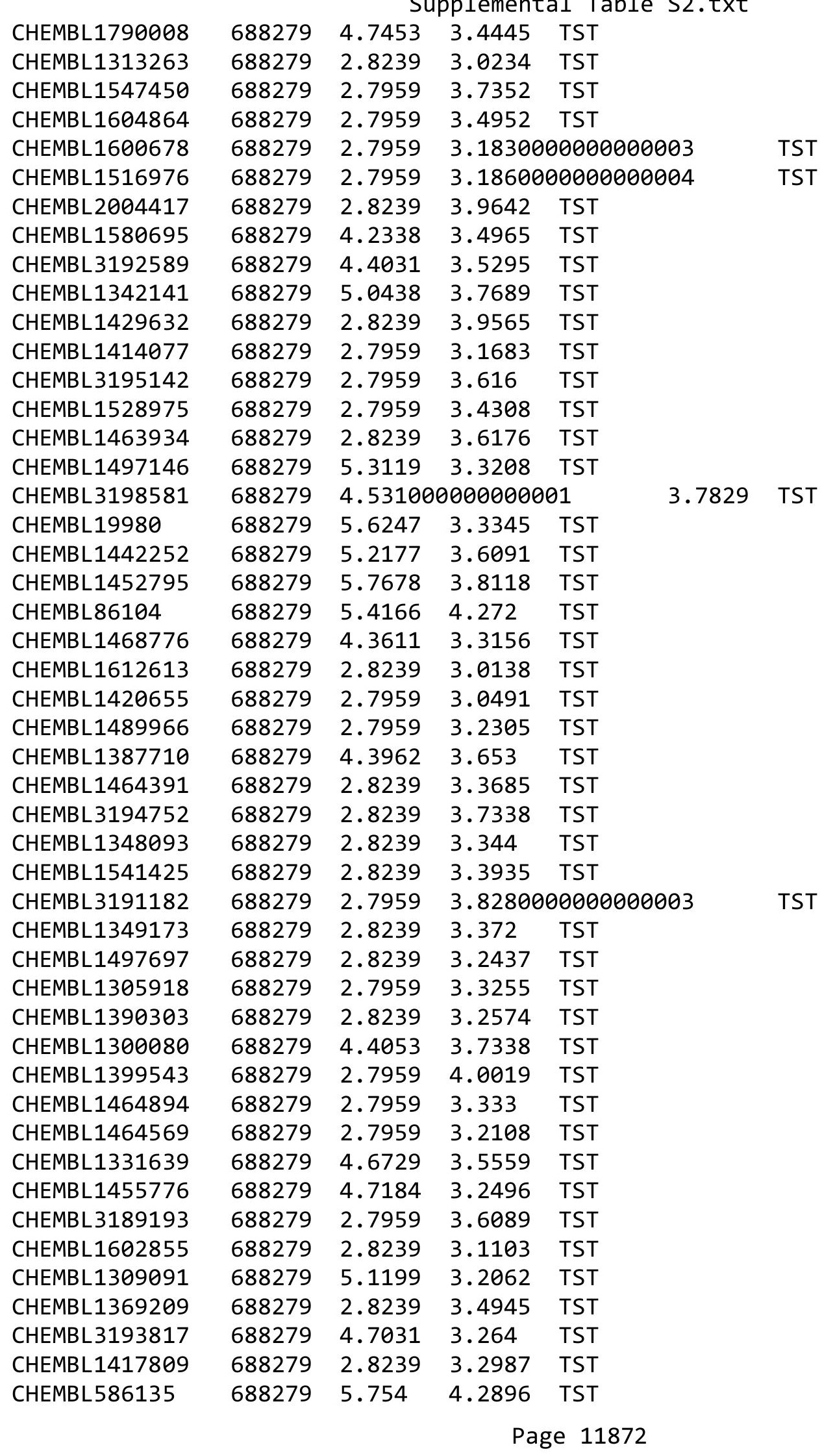




\begin{tabular}{|c|c|c|c|c|c|}
\hline \multicolumn{6}{|c|}{ Supplemental Table S2.txt } \\
\hline CHEMBL3197076 & 688279 & 5.5439 & 3.3993 & TST & \\
\hline CHEMBL1328373 & 688279 & 2.7959 & 3.5576 & TST & \\
\hline CHEMBL1352025 & 688279 & 2.7959 & 3.3917 & TST & \\
\hline CHEMBL3191022 & 688279 & 3.9821 & 3.7699 & TST & \\
\hline CHEMBL22062 & 688279 & 4.9796 & 4.1075 & TST & \\
\hline CHEMBL1374970 & 688279 & 2.7959 & 3.5113 & TST & \\
\hline CHEMBL1363032 & 688279 & 4.6914 & 3.5572 & TST & \\
\hline CHEMBL1569162 & 688279 & 2.8239 & 4.3365 & TST & \\
\hline CHEMBL1360446 & 688279 & 2.7959 & \multicolumn{2}{|c|}{3.4939999999999998} & TST \\
\hline CHEMBL1538158 & 688279 & 2.7959 & 3.3189 & TST & \\
\hline CHEMBL1541536 & 688279 & 4.4143 & 3.8673 & TST & \\
\hline CHEMBL3191233 & 688279 & 2.7959 & 3.8491 & TST & \\
\hline CHEMBL1339135 & 688279 & 2.7959 & 3.2383 & TST & \\
\hline CHEMBL1400761 & 688279 & 2.8239 & 3.5049 & TST & \\
\hline CHEMBL1338986 & 688279 & 2.7959 & 2.9379 & TST & \\
\hline CHEMBL3190230 & 688279 & 2.7959 & 3.2806 & TST & \\
\hline CHEMBL1402615 & 688279 & 4.5889 & 3.6639 & TST & \\
\hline CHEMBL1385466 & 688279 & 2.8239 & 3.4267 & TST & \\
\hline CHEMBL1594440 & 688279 & 4.7725 & 3.4452 & TST & \\
\hline CHEMBL1465946 & 688279 & 2.7959 & 3.3605 & TST & \\
\hline CHEMBL1594475 & 688279 & 5.4116 & 4.7926 & TST & \\
\hline CHEMBL1414580 & 688279 & 3.8441 & 3.5577 & TST & \\
\hline CHEMBL3190961 & 688279 & 2.8239 & 3.2324 & TST & \\
\hline CHEMBL1411277 & 688279 & 4.0792 & 3.1586 & TST & \\
\hline CHEMBL1337416 & 688279 & 2.8239 & 3.8509 & TST & \\
\hline CHEMBL1978354 & 688279 & 2.8239 & 3.295 & TST & \\
\hline CHEMBL1359343 & 688279 & 2.8239 & 3.2204 & TST & \\
\hline CHEMBL1350258 & 688279 & 5.3774 & 3.583 & TST & \\
\hline CHEMBL3189613 & 688279 & 2.7959 & 3.52 & TST & \\
\hline CHEMBL1460522 & 688279 & 2.8239 & 3.2849 & TST & \\
\hline CHEMBL1580948 & 688279 & 2.7959 & 3.4063 & TST & \\
\hline CHEMBL1347600 & 688279 & 2.8239 & 3.4337 & TST & \\
\hline CHEMBL1528330 & 688279 & 4.5618 & 3.2494 & TST & \\
\hline CHEMBL1481132 & 688279 & 4.8463 & 3.4828 & TST & \\
\hline CHEMBL1580315 & 688279 & 2.7959 & \multicolumn{2}{|c|}{3.5439999999999996} & TST \\
\hline CHEMBL1312275 & 688279 & 4.5473 & 3.6126 & TST & \\
\hline CHEMBL588804 & 688279 & 4.6583 & 4.7304 & TST & \\
\hline CHEMBL1611301 & 688279 & 2.8239 & 3.2787 & TST & \\
\hline CHEMBL1486894 & 688279 & 2.8239 & 3.003 & TST & \\
\hline CHEMBL1329507 & 688279 & 2.8239 & 3.4657 & TST & \\
\hline CHEMBL3192779 & 688279 & 2.8239 & 3.4202 & TST & \\
\hline CHEMBL1347598 & 688279 & 4.1215 & 3.6338 & TST & \\
\hline CHEMBL1420309 & 688279 & 4.7032 & 3.2353 & TST & \\
\hline CHEMBL1522807 & 688279 & 2.8239 & 4.1406 & TST & \\
\hline CHEMBL3193092 & 688279 & 2.8239 & 3.3231 & TST & \\
\hline CHEMBL1525081 & 688279 & 4.7144 & 3.2734 & TST & \\
\hline CHEMBL1417389 & 688279 & 2.7959 & \multicolumn{2}{|c|}{3.4930000000000003} & TST \\
\hline CHEMBL1454030 & 688279 & 2.7959 & 3.677 & TST & \\
\hline
\end{tabular}




\begin{tabular}{|c|c|c|c|c|c|}
\hline \multicolumn{6}{|c|}{ Supplemental Table S2.txt } \\
\hline CHEMBL 2048902 & 828061 & 4.1245 & 4.0615 & TST & \\
\hline CHEMBL 2049029 & 828061 & 4.1245 & 4.3954 & TST & \\
\hline CHEMBL 2049052 & 828061 & 3.9359 & 4.2069 & TRN & \\
\hline CHEMBL 2049041 & 828061 & 4.1245 & 4.1016 & TST & \\
\hline CHEMBL 2049043 & 828061 & 8.1308 & 4.5152 & TRN & \\
\hline CHEMBL 2049073 & 828061 & 3.8235 & 4.3635 & TRN & \\
\hline CHEMBL 2048892 & 828061 & 3.8235 & 3.5986 & TRN & \\
\hline CHEMBL 2049204 & 828061 & 3.8235 & 3.6149 & TRN & \\
\hline CHEMBL 2049218 & 828061 & 3.8235 & 3.8186 & TRN & \\
\hline CHEMBL2048900 & 828061 & 3.8235 & 4.7362 & TST & \\
\hline CHEMBL 2049205 & 828061 & 3.8235 & 3.6632 & TRN & \\
\hline CHEMBL 2049057 & 828061 & 3.8235 & 4.1781 & TRN & \\
\hline CHEMBL 2049085 & 828061 & 3.9637 & 3.6805 & TRN & \\
\hline CHEMBL 2049216 & 828061 & 3.8235 & 3.7686 & TRN & \\
\hline CHEMBL 2048874 & 828061 & 5.7394 & 4.9398 & TRN & \\
\hline CHEMBL 2049078 & 828061 & 3.9044 & 3.8861 & TRN & \\
\hline CHEMBL 2049077 & 828061 & 3.8235 & 4.1991 & TRN & \\
\hline CHEMBL 2049048 & 828061 & 3.8235 & 4.1855 & TRN & \\
\hline CHEMBL 2049089 & 828061 & 3.8692 & 3.9865 & TRN & \\
\hline CHEMBL2049059 & 828061 & 3.8235 & 4.1804 & TRN & \\
\hline CHEMBL 2049024 & 828061 & 3.8235 & 4.1926 & TST & \\
\hline CHEMBL 2049035 & 828061 & 4.1245 & 4.2284 & TST & \\
\hline CHEMBL 2049036 & 828061 & 4.1245 & 4.1586 & TST & \\
\hline CHEMBL 2049047 & 828061 & 3.8235 & 5.3622 & TRN & \\
\hline CHEMBL 2049067 & 828061 & 3.8235 & 4.371 & TRN & \\
\hline CHEMBL 2049045 & 828061 & 3.8235 & $5.1720 e$ & 0000000001 & TRN \\
\hline CHEMBL 2049025 & 828061 & 4.1245 & 4.0519 & TST & \\
\hline CHEMBL 2049211 & 828061 & 3.8235 & 3.693 & TRN & \\
\hline CHEMBL2048882 & 828061 & 3.8235 & 4.2719 & TRN & \\
\hline CHEMBL 2049039 & 828061 & 4.1245 & 4.2433 & TST & \\
\hline CHEMBL 2048887 & 828061 & 3.8235 & 3.677 & TRN & \\
\hline CHEMBL 2049053 & 828061 & 3.9381 & 4.1499 & TRN & \\
\hline CHEMBL 2048877 & 828061 & 6.0326 & 4.9973 & TRN & \\
\hline CHEMBL 2048888 & 828061 & 6.3588 & 5.267 & TRN & \\
\hline CHEMBL 2049051 & 828061 & 3.8235 & 4.2238 & TRN & \\
\hline CHEMBL 2049070 & 828061 & 3.8235 & 4.3568 & TRN & \\
\hline CHEMBL 2048893 & 828061 & 3.8235 & 3.7033 & TRN & \\
\hline CHEMBL 2049214 & 828061 & 3.8235 & 4.2778 & TRN & \\
\hline CHEMBL2049199 & 828061 & 3.8235 & 3.5545 & TRN & \\
\hline CHEMBL 291083 & 828061 & 4.1245 & 4.2411 & TST & \\
\hline CHEMBL 2049222 & 828061 & 3.8235 & 3.6501 & TRN & \\
\hline CHEMBL 2049031 & 828061 & 4.1245 & 4.5005 & TST & \\
\hline CHEMBL 2048894 & 828061 & 3.8235 & 3.7616 & TRN & \\
\hline CHEMBL 2049212 & 828061 & 3.8235 & 3.7137 & TRN & \\
\hline CHEMBL 2046470 & 828061 & 3.8235 & 4.2894 & TRN & \\
\hline CHEMBL 2049064 & 828061 & 3.8235 & 4.191 & TRN & \\
\hline CHEMBL 2048883 & 828061 & 3.8235 & 4.3355 & TRN & \\
\hline CHEMBL 2049032 & 828061 & 4.1245 & 4.4504 & TST & \\
\hline
\end{tabular}


Supplemental Table S2.txt

\begin{tabular}{|c|c|c|c|c|c|}
\hline CHEMBL 2049038 & 828061 & 4.1245 & 4.2187 & TST & \\
\hline CHEMBL 2048899 & 828061 & 4.1245 & 4.4305 & TST & \\
\hline CHEMBL 2049063 & 828061 & 3.9171 & 4.413 & TRN & \\
\hline CHEMBL 2049076 & 828061 & 3.8235 & 4.1475 & TRN & \\
\hline CHEMBL2049088 & 828061 & 3.9075 & 3.6319 & TRN & \\
\hline CHEMBL 2048885 & 828061 & 3.8235 & 3.7315 & TRN & \\
\hline CHEMBL 2048878 & 828061 & 3.8235 & 4.7854 & TRN & \\
\hline CHEMBL 2049215 & 828061 & 3.8235 & 3.8366 & TRN & \\
\hline CHEMBL 2048891 & 828061 & 3.8235 & 3.5627 & TRN & \\
\hline CHEMBL2049217 & 828061 & 3.8235 & 3.7262 & TRN & \\
\hline CHEMBL2049037 & 828061 & 4.1245 & 4.1332 & TST & \\
\hline CHEMBL2049091 & 828061 & 3.8235 & 3.6201 & TRN & \\
\hline CHEMBL 2049203 & 828061 & 3.8235 & 3.6125 & TRN & \\
\hline CHEMBL 2049030 & 828061 & 4.1245 & 4.2474 & TST & \\
\hline CHEMBL2048898 & 828061 & 3.8235 & 3.7772 & TRN & \\
\hline CHEMBL2049208 & 828061 & 3.8235 & 3.5941 & TRN & \\
\hline CHEMBL 2049027 & 828061 & 4.1245 & 4.4199 & TST & \\
\hline CHEMBL 2049071 & 828061 & 3.8235 & 4.4177 & TRN & \\
\hline CHEMBL 2049033 & 828061 & 4.1245 & 4.1137 & TST & \\
\hline CHEMBL 2049200 & 828061 & 3.8235 & 3.5585 & TRN & \\
\hline CHEMBL 2049201 & 828061 & 3.8235 & 3.598999 & 99999999998 & TRN \\
\hline CHEMBL 2049026 & 828061 & 4.1245 & 3.8347 & TST & \\
\hline CHEMBL 2049046 & 828061 & 3.8235 & 4.2597 & TRN & \\
\hline CHEMBL 2049049 & 828061 & 3.8235 & 4.2413 & TRN & \\
\hline CHEMBL 2049054 & 828061 & 3.9171 & 4.7473 & TRN & \\
\hline CHEMBL 2049058 & 828061 & 3.8235 & 4.1487 & TRN & \\
\hline CHEMBL 2049021 & 828061 & 3.8235 & 4.0253 & TST & \\
\hline CHEMBL 2049087 & 828061 & 3.9336 & 3.588 & TRN & \\
\hline CHEMBL 2049050 & 828061 & 3.9846 & 4.237 & TRN & \\
\hline CHEMBL 2049086 & 828061 & 3.8235 & 3.6748 & TRN & \\
\hline CHEMBL 2049034 & 828061 & 5.5137 & 4.4422 & TST & \\
\hline CHEMBL 2048897 & 828061 & 3.8235 & 3.7526 & TRN & \\
\hline CHEMBL 2049220 & 828061 & 3.8235 & 3.7413 & TRN & \\
\hline CHEMBL 2048881 & 828061 & 3.8235 & 4.0304 & TRN & \\
\hline CHEMBL 2049213 & 828061 & 9.0969 & 5.3836 & TRN & \\
\hline CHEMBL2049080 & 828061 & 3.8235 & 3.7814 & TRN & \\
\hline CHEMBL 2048901 & 828061 & 3.8235 & 4.6747 & TST & \\
\hline CHEMBL 2049066 & 828061 & 3.8235 & 4.3106 & TRN & \\
\hline CHEMBL150924 & 828061 & 3.8235 & 4.3415 & TST & \\
\hline CHEMBL 2049209 & 828061 & 3.8235 & 3.775 & TRN & \\
\hline CHEMBL2049079 & 828061 & 3.8235 & 3.6144 & TRN & \\
\hline CHEMBL 2049028 & 828061 & 4.1245 & 3.9874 & TST & \\
\hline CHEMBL2048879 & 828061 & 3.9044 & 4.1287 & TRN & \\
\hline CHEMBL 2048896 & 828061 & 3.8235 & 4.2051 & TRN & \\
\hline CHEMBL2049219 & 828061 & 3.8235 & 3.8153 & TRN & \\
\hline CHEMBL 2048889 & 828061 & 3.8235 & 3.6579 & TRN & \\
\hline CHEMBL 2049062 & 828061 & \multicolumn{4}{|c|}{7.757000000000001} \\
\hline CHEMBL 2049082 & 828061 & 3.8235 & 4.0032 & TRN & \\
\hline
\end{tabular}

Page 11875 


\begin{tabular}{|c|c|c|c|c|c|c|}
\hline \multirow[b]{2}{*}{ CHEMBL2049055 } & \multicolumn{6}{|c|}{ Supplemental Table S2.txt } \\
\hline & 828061 & 3.8235 & 4.1788 & TRN & & \\
\hline CHEMBL2049221 & 828061 & 3.8235 & 3.6298 & TRN & & \\
\hline CHEMBL 2049223 & 828061 & 3.8235 & 3.6611 & TRN & & \\
\hline CHEMBL 2049207 & 828061 & 3.991 & 3.7936 & TRN & & \\
\hline CHEMBL2049065 & 828061 & 3.8235 & 5.1829 & TRN & & \\
\hline CHEMBL 2048895 & 828061 & 3.8235 & 3.6609 & TRN & & \\
\hline CHEMBL2048884 & 828061 & 3.8235 & 4.1503 & TRN & & \\
\hline CHEMBL 2049075 & 828061 & 3.8235 & 4.2013 & TRN & & \\
\hline CHEMBL 2049074 & 828061 & 4.8235 & 4.394 & TRN & & \\
\hline CHEMBL1369462 & 828061 & 3.8235 & 4.4968 & TST & & \\
\hline CHEMBL2049081 & 828061 & 3.8235 & 3.6976 & TRN & & \\
\hline CHEMBL 2048890 & 828061 & 3.8235 & 3.7417 & TRN & & \\
\hline CHEMBL 2049056 & 828061 & 3.8235 & 4.2364 & TRN & & \\
\hline CHEMBL 2049202 & 828061 & 3.8235 & 3.6641 & TRN & & \\
\hline CHEMBL 2049084 & 828061 & 3.8235 & 3.6095 & TRN & & \\
\hline CHEMBL2049069 & 828061 & 3.8235 & 4.4264 & TRN & & \\
\hline CHEMBL2049072 & 828061 & 3.8235 & 4.2817 & TRN & & \\
\hline CHEMBL 2049224 & 828061 & 3.8235 & 3.6466 & TRN & & \\
\hline CHEMBL 2049210 & 828061 & 3.8235 & 3.8079 & TRN & & \\
\hline CHEMBL 2049040 & 828061 & 4.1245 & 4.3087 & TST & & \\
\hline CHEMBL 2049225 & 828061 & 3.8235 & 3.6055 & TRN & & \\
\hline CHEMBL2049044 & 828061 & 3.8235 & 4.2874 & TRN & & \\
\hline CHEMBL 2048880 & 828061 & 3.8235 & 4.2133 & TRN & & \\
\hline CHEMBL 2048875 & 828061 & 3.8235 & 4.6777 & TRN & & \\
\hline CHEMBL 2049083 & 828061 & 3.8235 & 3.5678 & TRN & & \\
\hline CHEMBL 2048876 & 828061 & 6.00200 & 00000000 & 01 & 5.3296 & TRN \\
\hline CHEMBL2049023 & 828061 & 6.0851 & 4.8804 & TST & & \\
\hline CHEMBL 2048886 & 828061 & 3.8235 & 3.9757 & TRN & & \\
\hline CHEMBL 2049042 & 828061 & 4.1245 & 4.047 & TST & & \\
\hline CHEMBL 2049206 & 828061 & 3.8235 & 4.0973 & TRN & & \\
\hline CHEMBL 2049022 & 828061 & 3.8235 & 4.856 & TST & & \\
\hline CHEMBL2049068 & 828061 & 6.2837 & 5.6083 & TST & & \\
\hline CHEMBL 2049060 & 828061 & 3.8235 & 4.2243 & TST & & \\
\hline CHEMBL 2049061 & 828061 & 3.8235 & 4.2342 & TST & & \\
\hline CHEMBL 2049090 & 828061 & 3.8235 & 3.5697 & TST & & \\
\hline CHEMBL15192 & 1449389 & 6.0458 & 4.8481 & TST & & \\
\hline CHEMBL3314755 & 1449389 & 3.5229 & 3.5189 & TRN & & \\
\hline CHEMBL3314726 & 1449389 & 5.4559 & 5.3138 & TRN & & \\
\hline CHEMBL3314729 & 1449389 & 3.5229 & 5.6637 & TST & & \\
\hline CHEMBL3314761 & 1449389 & 6.5376 & 6.5527 & TRN & & \\
\hline CHEMBL3314725 & 1449389 & 6.3979 & 6.4302 & TRN & & \\
\hline CHEMBL3314777 & 1449389 & 3.5229 & 3.6168 & TRN & & \\
\hline CHEMBL3314715 & 1449389 & 5.5607 & 5.8447 & TRN & & \\
\hline CHEMBL3314730 & 1449389 & 5.2757 & 5.1512 & TRN & & \\
\hline CHEMBL3314764 & 1449389 & 6.1192 & 6.1656 & TRN & & \\
\hline CHEMBL 3314747 & 1449389 & 4.6345 & 4.6848 & TRN & & \\
\hline CHEMBL3314743 & 1449389 & 4.5901 & 4.5944 & TRN & & \\
\hline CHEMBL3314742 & 1449389 & 4.8477 & 4.9392 & TRN & & \\
\hline
\end{tabular}

Page 11876 
Supplemental Table S2.txt

\begin{tabular}{|c|c|c|c|c|c|}
\hline CHEMBL3314724 & 1449389 & 5.9208 & 5.5107 & TST & \\
\hline CHEMBL3314749 & 1449389 & 5.9208 & 5.7087 & TRN & \\
\hline CHEMBL3314744 & 1449389 & 3.5229 & 3.4614 & TRN & \\
\hline CHEMBL3314719 & 1449389 & 5.6021 & 5.5735 & TRN & \\
\hline CHEMBL 3314737 & 1449389 & 3.5229 & 3.5214 & TRN & \\
\hline CHEMBL3314775 & 1449389 & 5.2441 & 5.5665 & TRN & \\
\hline CHEMBL3314723 & 1449389 & 6.0458 & 3.6924 & TST & \\
\hline CHEMBL3314752 & 1449389 & 6.4202 & 6.3684 & TRN & \\
\hline CHEMBL 3314780 & 1449389 & 6.301 & 6.2086 & TRN & \\
\hline CHEMBL3314741 & 1449389 & 4.7773 & 4.7935 & TRN & \\
\hline CHEMBL 3314727 & 1449389 & 5.8928 & 5.9929 & TRN & \\
\hline CHEMBL3314731 & 1449389 & 4.9431 & 5.0784 & TRN & \\
\hline CHEMBL 3314722 & 1449389 & 3.5229 & 5.6741 & TST & \\
\hline CHEMBL3314773 & 1449389 & 3.5229 & 3.4411 & TRN & \\
\hline CHEMBL3314776 & 1449389 & 3.5229 & 3.6338 & TRN & \\
\hline CHEMBL3314721 & 1449389 & 3.5229 & 5.5088 & TST & \\
\hline CHEMBL3314763 & 1449389 & 3.5229 & 3.5711 & TRN & \\
\hline CHEMBL 3314765 & 1449389 & 6.0362 & 5.9801 & TRN & \\
\hline CHEMBL3314757 & 1449389 & 6.0969 & 6.069 & TRN & \\
\hline CHEMBL3314774 & 1449389 & 5.4559 & 5.564 & TRN & \\
\hline CHEMBL3314768 & 1449389 & 6.4437 & 6.3524 & TRN & \\
\hline CHEMBL3314756 & 1449389 & 4.9527 & 4.882 & TRN & \\
\hline CHEMBL3314716 & 1449389 & 5.4237 & 5.2799 & TRN & \\
\hline CHEMBL1567800 & 1449389 & 3.5229 & 6.0593 & TST & \\
\hline CHEMBL3314734 & 1449389 & 5.5528 & 5.4431 & TRN & \\
\hline CHEMBL3314754 & 1449389 & 5.3546 & 5.3354 & TRN & \\
\hline CHEMBL 3314720 & 1449389 & 5.2132 & 4.7553 & TST & \\
\hline CHEMBL3314769 & 1449389 & 6.7212 & 6.8152 & TRN & \\
\hline CHEMBL3314758 & 1449389 & 5.2487 & 5.2435 & TRN & \\
\hline CHEMBL3314738 & 1449389 & 5.0706 & 5.0387 & TRN & \\
\hline CHEMBL3314753 & 1449389 & 6.3468 & 6.2754 & TRN & \\
\hline CHEMBL 3314762 & 1449389 & 6.5229 & 6.3815 & TRN & \\
\hline CHEMBL3314759 & 1449389 & 5.3261 & 5.4537 & TRN & \\
\hline CHEMBL3314739 & 1449389 & 4.9957 & 5.00899 & 99999999995 & TRN \\
\hline CHEMBL3314779 & 1449389 & 5.5686 & 5.6879 & TRN & \\
\hline CHEMBL3314750 & 1449389 & 6.1549 & 6.255 & TRN & \\
\hline CHEMBL 3314736 & 1449389 & 5.3468 & 5.3087 & TRN & \\
\hline CHEMBL3314771 & 1449389 & 3.5229 & 3.5067 & TRN & \\
\hline CHEMBL 3314767 & 1449389 & 3.5229 & 3.6004 & TRN & \\
\hline CHEMBL3314717 & 1449389 & 3.5229 & 3.5183 & TRN & \\
\hline CHEMBL3314746 & 1449389 & 3.5229 & 3.5227 & TRN & \\
\hline CHEMBL 3314733 & 1449389 & 4.6676 & 4.6976 & TRN & \\
\hline CHEMBL3314772 & 1449389 & 3.5229 & 3.3896 & TRN & \\
\hline CHEMBL3314778 & 1449389 & 5.4535 & 5.4072 & TRN & \\
\hline CHEMBL93347 & 1449389 & 6.3565 & 6.3567 & TRN & \\
\hline CHEMBL3314770 & 1449389 & 6.3188 & 6.3015 & TRN & \\
\hline CHEMBL3356075 & 1449389 & 3.5229 & 3.5334 & TRN & \\
\hline CHEMBL 3314760 & 1449389 & 5.1506 & 5.1404 & TRN & \\
\hline
\end{tabular}


Supplemental Table S2.txt

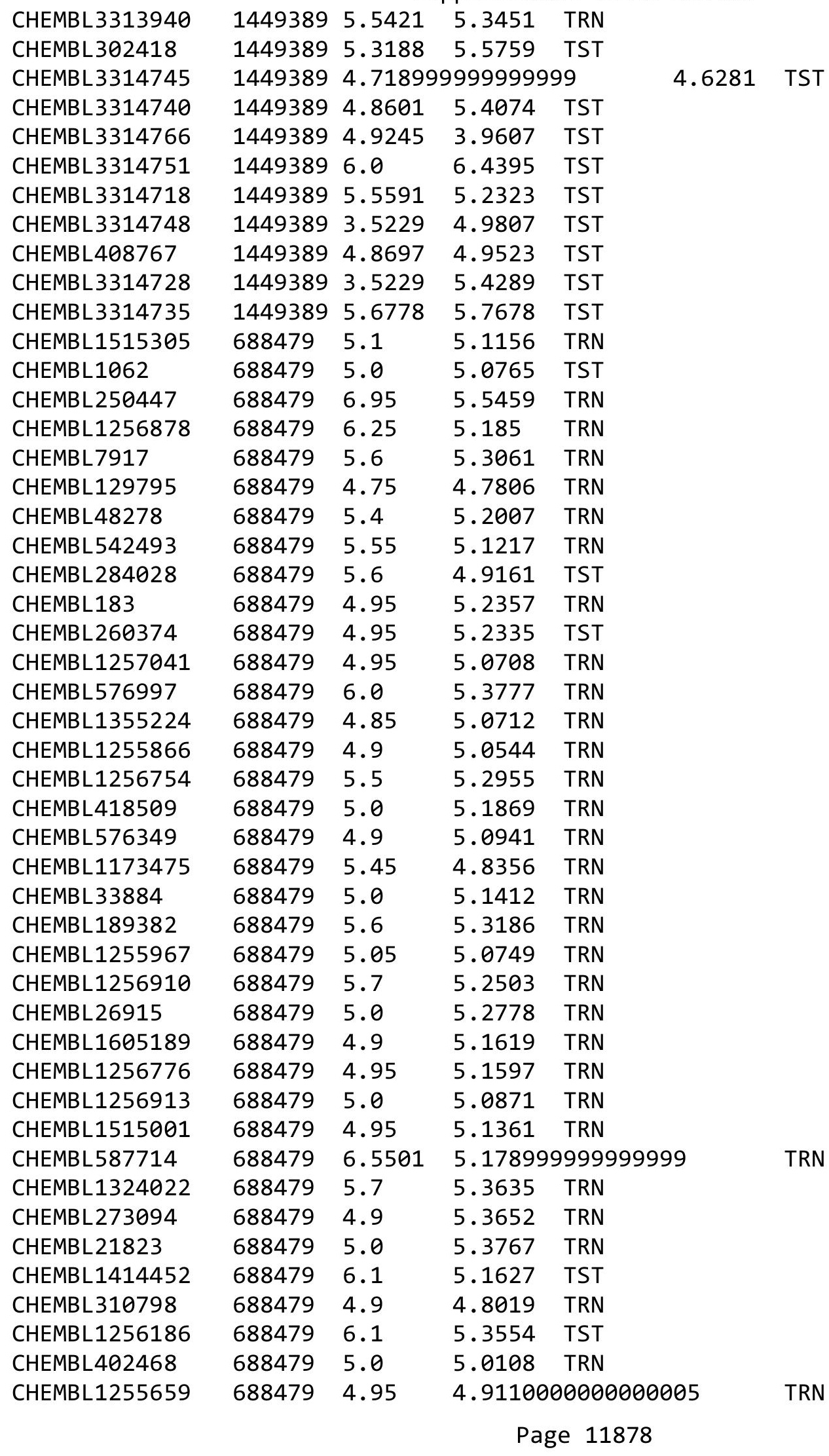




\begin{tabular}{|c|c|c|c|c|c|}
\hline & & \multicolumn{4}{|c|}{ Supplemental Table S2.txt } \\
\hline CHEMBL1256024 & 688479 & 4.95 & 5.0301 & TST & \\
\hline CHEMBL 8747 & 688479 & 4.85 & 5.4092 & TRN & \\
\hline CHEMBL1255650 & 688479 & 5.0 & 5.1957 & TST & \\
\hline CHEMBL311158 & 688479 & 4.9 & 5.225 & TRN & \\
\hline CHEMBL17331 & 688479 & 5.45 & 5.2422 & TRN & \\
\hline CHEMBL1256914 & 688479 & 5.9 & 5.235 & TRN & \\
\hline CHEMBL17468 & 688479 & 4.9 & 5.1887 & TRN & \\
\hline CHEMBL1256735 & 688479 & 5.0 & 5.16799 & 9999999999 & TRN \\
\hline CHEMBL1553428 & 688479 & 4.7 & 5.1884 & TRN & \\
\hline CHEMBL305195 & 688479 & 4.85 & 5.21299 & 9999999999 & TRN \\
\hline CHEMBL126077 & 688479 & 6.45 & 5.1024 & TRN & \\
\hline CHEMBL541585 & 688479 & 5.45 & 5.1226 & TRN & \\
\hline CHEMBL1256364 & 688479 & 5.1 & 5.0699 & TRN & \\
\hline CHEMBL313833 & 688479 & 4.95 & 4.95 & TRN & \\
\hline CHEMBL1338358 & 688479 & 5.0 & 5.0957 & TRN & \\
\hline CHEMBL1256719 & 688479 & 4.95 & 5.2941 & TRN & \\
\hline CHEMBL77387 & 688479 & 4.8 & 4.7806 & TRN & \\
\hline CHEMBL63329 & 688479 & 5.05 & 5.2484 & TRN & \\
\hline CHEMBL405358 & 688479 & 4.95 & 4.9571 & TRN & \\
\hline CHEMBL542700 & 688479 & 4.75 & 4.9013 & TRN & \\
\hline CHEMBL1527442 & 688479 & 4.85 & 5.0839 & TST & \\
\hline CHEMBL1355762 & 688479 & 6.1 & 5.1183 & TRN & \\
\hline CHEMBL60718 & 688479 & 4.8 & 5.1467 & TRN & \\
\hline CHEMBL267014 & 688479 & 4.75 & 5.2683 & TRN & \\
\hline CHEMBL559612 & 688479 & 5.3 & 5.3022 & TST & \\
\hline CHEMBL1487371 & 688479 & 5.05 & 5.2708 & TST & \\
\hline CHEMBL8488 & 688479 & 5.0 & 5.103 & TRN & \\
\hline CHEMBL1322702 & 688479 & 5.5 & 5.2876 & TRN & \\
\hline CHEMBL1377507 & 688479 & 5.0 & 5.4024 & TST & \\
\hline CHEMBL 76904 & 688479 & 5.0 & 4.74 & TRN & \\
\hline CHEMBL1255867 & 688479 & 4.9 & 5.0749 & TRN & \\
\hline CHEMBL1478857 & 688479 & 5.0 & 5.2003 & TRN & \\
\hline CHEMBL1256911 & 688479 & 5.55 & 5.5014 & TRN & \\
\hline CHEMBL416657 & 688479 & 5.2 & 5.2255 & TRN & \\
\hline CHEMBL263972 & 688479 & 7.2 & 5.2654 & TRN & \\
\hline CHEMBL434063 & 688479 & 4.9 & 5.41700 & 0000000001 & TRN \\
\hline CHEMBL1200462 & 688479 & 5.25 & 5.1936 & TRN & \\
\hline CHEMBL1571692 & 688479 & 4.95 & 5.2855 & TRN & \\
\hline CHEMBL40998 & 688479 & 5.55 & 5.3507 & TRN & \\
\hline CHEMBL1256869 & 688479 & 4.9 & 5.2131 & TRN & \\
\hline CHEMBL1200450 & 688479 & 5.7 & 5.2088 & TRN & \\
\hline CHEMBL1256814 & 688479 & 4.95 & 5.0907 & TRN & \\
\hline CHEMBL1593765 & 688479 & 4.75 & 5.3338 & TRN & \\
\hline CHEMBL97760 & 688479 & 4.75 & 4.952 & TRN & \\
\hline CHEMBL299052 & 688479 & 4.75 & 5.279 & TRN & \\
\hline CHEMBL1710 & 688479 & 5.15 & 5.4266 & TRN & \\
\hline CHEMBL517986 & 688479 & 5.0 & 5.2431 & TRN & \\
\hline CHEMBL1513654 & 688479 & 5.3 & 5.3003 & TRN & \\
\hline
\end{tabular}




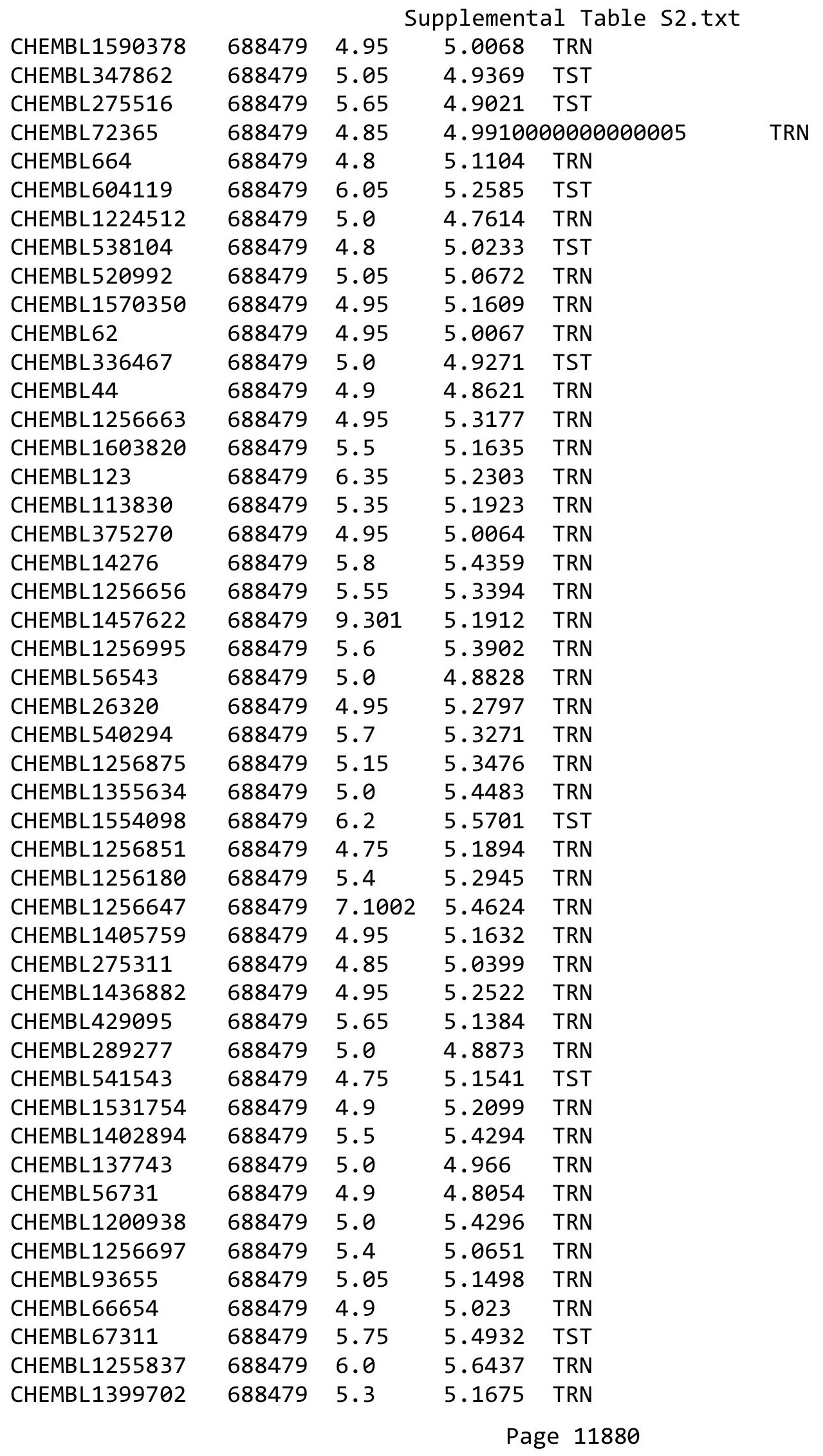




\begin{tabular}{|c|c|c|c|c|c|}
\hline \multicolumn{6}{|c|}{ Supplemental Table s2.txt } \\
\hline CHEMBL1559663 & 688479 & 5.7 & 5.1794 & TST & \\
\hline CHEMBL1256687 & 688479 & 5.9 & 5.4453 & TRN & \\
\hline CHEMBL546257 & 688479 & 7.0 & 5.5768 & TRN & \\
\hline CHEMBL1256844 & 688479 & 5.0 & 5.0672 & TRN & \\
\hline CHEMBL501701 & 688479 & 5.35 & 5.16299 & 9999999999 & TRN \\
\hline CHEMBL1256716 & 688479 & 5.0 & 5.3325 & TRN & \\
\hline CHEMBL1437846 & 688479 & 7.2 & 5.568 & TST & \\
\hline CHEMBL67535 & 688479 & 5.65 & 4.8855 & TRN & \\
\hline CHEMBL1480516 & 688479 & 6.4 & 5.4118 & TRN & \\
\hline CHEMBL500996 & 688479 & 6.05 & 5.1986 & TRN & \\
\hline CHEMBL1335406 & 688479 & 4.95 & 5.2657 & TST & \\
\hline CHEMBL295212 & 688479 & 4.75 & 5.4381 & TST & \\
\hline CHEMBL1515948 & 688479 & 4.75 & 5.1509 & TRN & \\
\hline CHEMBL333985 & 688479 & 4.9 & 5.1319 & TRN & \\
\hline CHEMBL164 & 688479 & 5.0 & 4.8525 & TRN & \\
\hline CHEMBL1455369 & 688479 & 4.95 & 5.1834 & TRN & \\
\hline CHEMBL56 & 688479 & 5.0 & 5.1965 & TRN & \\
\hline CHEMBL1201091 & 688479 & 4.9 & 5.1591 & TRN & \\
\hline CHEMBL111545 & 688479 & 4.75 & 5.2274 & TRN & \\
\hline CHEMBL1234696 & 688479 & 4.9 & 5.0856 & TRN & \\
\hline CHEMBL1367076 & 688479 & 4.95 & 5.0722 & TRN & \\
\hline CHEMBL 296586 & 688479 & 4.95 & 5.1594 & TRN & \\
\hline CHEMBL1376723 & 688479 & 5.15 & 4.8704 & TRN & \\
\hline CHEMBL45068 & 688479 & 4.8 & 4.894 & TRN & \\
\hline CHEMBL1257003 & 688479 & 4.95 & 4.9369 & TRN & \\
\hline CHEMBL395915 & 688479 & 4.95 & 5.0062 & TRN & \\
\hline CHEMBL402063 & 688479 & 5.0 & 5.1215 & TST & \\
\hline CHEMBL1256923 & 688479 & 4.85 & 5.4541 & TRN & \\
\hline CHEMBL1590980 & 688479 & 5.65 & 5.3823 & TRN & \\
\hline CHEMBL1255649 & 688479 & 4.9 & 5.1706 & TRN & \\
\hline CHEMBL80155 & 688479 & 4.95 & 4.8881 & TRN & \\
\hline CHEMBL110739 & 688479 & 4.9 & 5.1675 & TST & \\
\hline CHEMBL1256940 & 688479 & 5.5 & 5.369 & TRN & \\
\hline CHEMBL47940 & 688479 & 5.0 & 5.2229 & TRN & \\
\hline CHEMBL93403 & 688479 & 4.75 & 5.2392 & TRN & \\
\hline CHEMBL573214 & 688479 & 4.95 & 5.1853 & TRN & \\
\hline CHEMBL8618 & 688479 & 4.9 & 5.2854 & TRN & \\
\hline CHEMBL1334874 & 688479 & 4.7 & 5.0927 & TRN & \\
\hline CHEMBL280998 & 688479 & 4.95 & 4.7779 & TRN & \\
\hline CHEMBL293749 & 688479 & 4.95 & 4.8933 & TRN & \\
\hline CHEMBL16687 & 688479 & 5.0 & 5.1979 & TST & \\
\hline CHEMBL34241 & 688479 & 5.4 & 5.2051 & TST & \\
\hline CHEMBL1256686 & 688479 & 6.0 & 5.4378 & TST & \\
\hline CHEMBL1082832 & 688479 & 4.9 & 5.2441 & TRN & \\
\hline CHEMBL1493117 & 688479 & 4.7 & 5.0381 & TST & \\
\hline CHEMBL513116 & 688479 & 5.0 & 5.1995 & TRN & \\
\hline CHEMBL1528565 & 688479 & 5.45 & 5.6212 & TRN & \\
\hline CHEMBL1256761 & 688479 & 4.75 & 5.313 & TRN & \\
\hline
\end{tabular}




\begin{tabular}{|c|c|c|c|c|}
\hline \multicolumn{5}{|c|}{ Supplemental Table } \\
\hline CHEMBL1372997 & 688479 & 5.05 & 5.3699 & TRN \\
\hline CHEMBL 225230 & 688479 & 5.6 & 5.1792 & TRN \\
\hline CHEMBL1593930 & 688479 & 5.4 & 5.2554 & TRN \\
\hline CHEMBL 275938 & 688479 & 5.1 & 5.0459 & TST \\
\hline CHEMBL391997 & 688479 & 4.75 & 5.1428 & TRN \\
\hline CHEMBL1256654 & 688479 & 6.05 & 5.3938 & TRN \\
\hline CHEMBL1256646 & 688479 & 5.0 & 4.9659 & TRN \\
\hline CHEMBL344127 & 688479 & 5.05 & 5.3031 & TRN \\
\hline CHEMBL1413371 & 688479 & 5.0 & 5.1275 & TRN \\
\hline CHEMBL294590 & 688479 & 5.15 & 5.1337 & TRN \\
\hline CHEMBL1256924 & 688479 & 4.9 & 5.3591 & TRN \\
\hline CHEMBL1316314 & 688479 & 5.45 & 5.4704 & TRN \\
\hline CHEMBL268868 & 688479 & 4.9 & 5.0067 & TRN \\
\hline CHEMBL567175 & 688479 & 5.0 & 5.2563 & TRN \\
\hline CHEMBL1079460 & 688479 & 6.3 & 5.5279 & TRN \\
\hline CHEMBL52 & 688479 & 4.9 & 5.0445 & TRN \\
\hline CHEMBL1253351 & 688479 & 5.1 & 5.0907 & TST \\
\hline CHEMBL104264 & 688479 & 4.95 & 5.1825 & TRN \\
\hline CHEMBL64119 & 688479 & 4.75 & 5.3754 & TRN \\
\hline CHEMBL1408519 & 688479 & 5.4 & 5.2597 & TRN \\
\hline CHEMBL536950 & 688479 & 4.75 & 5.0053 & TRN \\
\hline CHEMBL1329033 & 688479 & 5.45 & 5.0459 & TRN \\
\hline CHEMBL1256740 & 688479 & 4.95 & 5.2901 & TST \\
\hline CHEMBL1600780 & 688479 & 5.0 & 5.3493 & TRN \\
\hline CHEMBL 279556 & 688479 & 4.95 & 5.1016 & TRN \\
\hline CHEMBL13790 & 688479 & 4.95 & 5.1519 & TRN \\
\hline CHEMBL 279998 & 688479 & 4.85 & 4.8847 & TST \\
\hline CHEMBL49247 & 688479 & 4.9 & 5.0834 & TRN \\
\hline CHEMBL280074 & 688479 & 5.35 & 5.3227 & TRN \\
\hline CHEMBL 2374063 & 688479 & 6.1 & 5.2698 & TST \\
\hline CHEMBL 244948 & 688479 & 4.75 & 4.8254 & TRN \\
\hline CHEMBL1256749 & 688479 & 4.9 & 5.1473 & TRN \\
\hline CHEMBL1257039 & 688479 & 5.45 & 5.4753 & TRN \\
\hline CHEMBL 277120 & 688479 & 4.95 & 5.0743 & TRN \\
\hline CHEMBL1440857 & 688479 & 5.55 & 5.277 & TRN \\
\hline CHEMBL 28 & 688479 & 4.9 & 4.8441 & TRN \\
\hline CHEMBL578741 & 688479 & 6.45 & 5.1372 & TRN \\
\hline CHEMBL1256998 & 688479 & 5.05 & 5.239 & TRN \\
\hline CHEMBL12014 & 688479 & 4.95 & 5.2378 & TRN \\
\hline CHEMBL1590552 & 688479 & 4.85 & 5.2406 & TRN \\
\hline CHEMBL429023 & 688479 & 5.05 & 5.2269 & TRN \\
\hline CHEMBL 327708 & 688479 & 4.9 & 5.3614 & TRN \\
\hline CHEMBL1605916 & 688479 & 5.0 & 5.2764 & TST \\
\hline CHEMBL1594626 & 688479 & 5.6 & 5.3426 & TST \\
\hline CHEMBL420060 & 688479 & 5.05 & 5.3234 & TRN \\
\hline CHEMBL1434513 & 688479 & 4.95 & 5.0434 & TRN \\
\hline CHEMBL35482 & 688479 & 5.0 & 5.0789 & TRN \\
\hline CHEMBL68534 & 688479 & 4.9 & 4.9463 & TRN \\
\hline
\end{tabular}




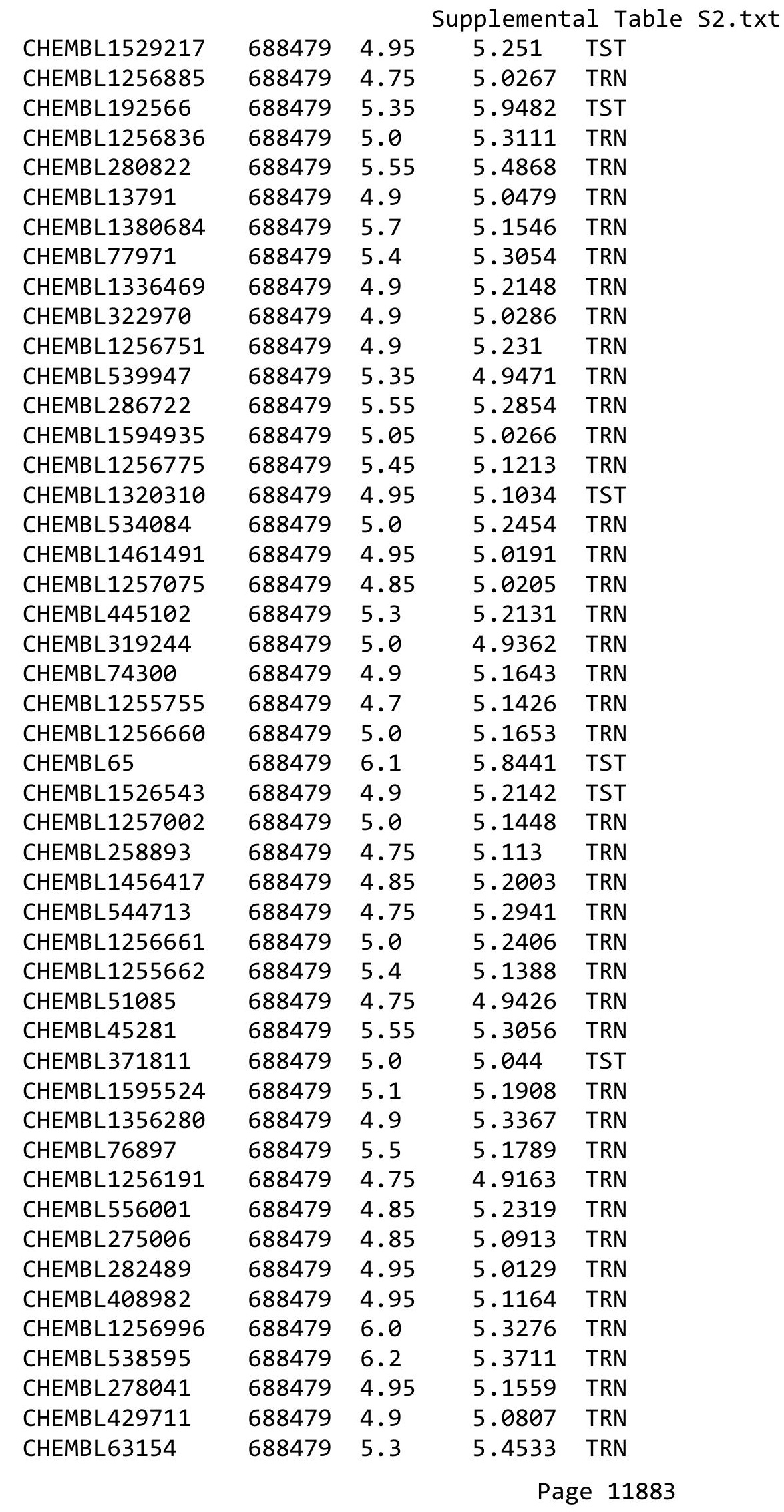




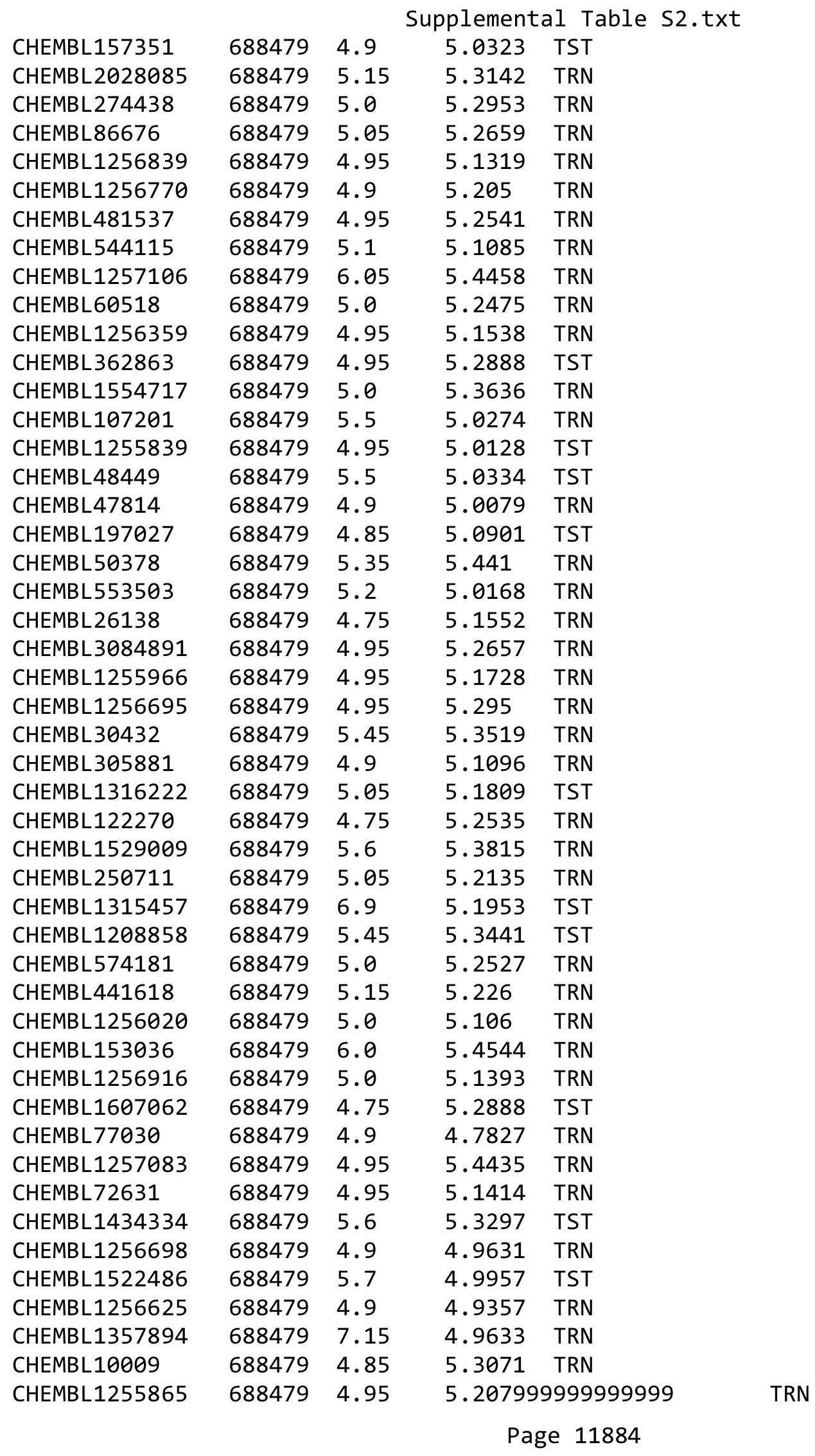




\begin{tabular}{|c|c|c|c|c|}
\hline \multicolumn{5}{|c|}{ Supplemental Table S2.txt } \\
\hline CHEMBL309176 & 688479 & 5.4 & 5.0331 & TRN \\
\hline CHEMBL34704 & 688479 & 5.4 & 5.0231 & TST \\
\hline CHEMBL270299 & 688479 & 5.0 & 5.0012 & TST \\
\hline CHEMBL 3186408 & 688479 & 5.0 & 5.0268 & TST \\
\hline CHEMBL1336727 & 688479 & 5.0 & 5.2125 & TRN \\
\hline CHEMBL1256760 & 688479 & 4.95 & 5.1485 & TST \\
\hline CHEMBL 280065 & 688479 & 5.4 & 5.2684 & TRN \\
\hline CHEMBL543467 & 688479 & 4.95 & 5.0969 & TRN \\
\hline CHEMBL1526455 & 688479 & 5.05 & 5.1501 & TRN \\
\hline CHEMBL1534566 & 688479 & 5.2 & 5.3695 & TRN \\
\hline CHEMBL384903 & 688479 & 4.8 & 5.2195 & TRN \\
\hline CHEMBL1255664 & 688479 & 4.95 & 4.9761 & TRN \\
\hline CHEMBL1256709 & 688479 & 5.15 & 5.3204 & TRN \\
\hline CHEMBL1256655 & 688479 & 6.05 & 5.1641 & TRN \\
\hline CHEMBL432608 & 688479 & 5.4 & 5.3097 & TRN \\
\hline CHEMBL101168 & 688479 & 4.9 & 5.0276 & TRN \\
\hline CHEMBL1436268 & 688479 & 5.0 & 5.131 & TRN \\
\hline CHEMBL21260 & 688479 & 4.75 & 5.1183 & TRN \\
\hline CHEMBL1374843 & 688479 & 5.05 & 5.0793 & TRN \\
\hline CHEMBL1256659 & 688479 & 5.15 & 5.0682 & TRN \\
\hline CHEMBL25236 & 688479 & 5.7 & 5.3496 & TRN \\
\hline CHEMBL1257109 & 688479 & 5.45 & 5.221 & TRN \\
\hline CHEMBL428496 & 688479 & 4.9 & 5.2987 & TST \\
\hline CHEMBL1597692 & 688479 & 4.85 & 5.4786 & TRN \\
\hline CHEMBL598952 & 688479 & 5.0 & 5.0742 & TRN \\
\hline CHEMBL10284 & 688479 & 4.95 & 5.2498 & TRN \\
\hline CHEMBL410873 & 688479 & 5.05 & 5.2966 & TRN \\
\hline CHEMBL68500 & 688479 & 5.0 & 5.077 & TRN \\
\hline CHEMBL1528648 & 688479 & 5.05 & 5.193 & TRN \\
\hline CHEMBL1256876 & 688479 & 5.65 & 5.0268 & TST \\
\hline CHEMBL1257014 & 688479 & 5.05 & 5.2062 & TRN \\
\hline CHEMBL161343 & 688479 & 4.75 & 5.1867 & TRN \\
\hline CHEMBL1255758 & 688479 & 5.0 & 5.0522 & TRN \\
\hline CHEMBL77456 & 688479 & 5.1 & 4.8981 & TRN \\
\hline CHEMBL1316953 & 688479 & 5.05 & 5.1354 & TST \\
\hline CHEMBL323356 & 688479 & 4.9 & 5.1005 & TRN \\
\hline CHEMBL 76589 & 688479 & 4.9 & 4.7914 & TRN \\
\hline CHEMBL288174 & 688479 & 4.95 & 5.4837 & TST \\
\hline CHEMBL338790 & 688479 & 5.05 & 5.0475 & TRN \\
\hline CHEMBL27403 & 688479 & 5.1 & 5.3421 & TRN \\
\hline CHEMBL 2374027 & 688479 & 5.65 & 5.2258 & TRN \\
\hline CHEMBL 67378 & 688479 & 5.5 & 5.3433 & TRN \\
\hline CHEMBL494887 & 688479 & 5.0 & 5.113 & TST \\
\hline CHEMBL454761 & 688479 & 4.95 & 4.9986 & TRN \\
\hline CHEMBL1256737 & 688479 & 5.05 & 5.1763 & TRN \\
\hline CHEMBL24510 & 688479 & 4.95 & 5.1894 & TRN \\
\hline CHEMBL1449651 & 688479 & 5.5 & 4.9738 & TST \\
\hline CHEMBL328710 & 688479 & 4.75 & 5.09 & TRN \\
\hline
\end{tabular}




\begin{tabular}{|c|c|c|c|c|c|}
\hline & & \multicolumn{4}{|c|}{ Supplemental Table S2.txt } \\
\hline CHEMBL310310 & 688479 & 5.65 & 5.28 & TRN & \\
\hline CHEMBL3216928 & 688479 & 6.05 & 5.5631 & TRN & \\
\hline CHEMBL1972346 & 688479 & 5.0 & 4.7616 & TRN & \\
\hline CHEMBL1256984 & 688479 & 5.0 & 5.1308 & TRN & \\
\hline CHEMBL1256147 & 688479 & 5.4 & 5.0475 & TST & \\
\hline CHEMBL2373602 & 688479 & 5.1 & 5.1831 & TRN & \\
\hline CHEMBL1331383 & 688479 & 4.75 & 5.1027 & TRN & \\
\hline CHEMBL355496 & 688479 & 5.7 & 5.135 & TRN & \\
\hline CHEMBL1256865 & 688479 & 4.75 & 5.1736 & TRN & \\
\hline CHEMBL540851 & 688479 & 4.95 & 5.0496 & TRN & \\
\hline CHEMBL1439696 & 688479 & 4.95 & 5.01699 & 99999999995 & TRN \\
\hline CHEMBL15192 & 688479 & 5.0 & 5.0506 & TST & \\
\hline CHEMBL1725279 & 688479 & 4.9 & 5.0041 & TST & \\
\hline CHEMBL 3216363 & 688479 & 4.95 & 5.1614 & TST & \\
\hline CHEMBL1235242 & 688479 & 4.95 & 5.2474 & TST & \\
\hline CHEMBL1373007 & 688479 & 5.55 & 5.2519 & TST & \\
\hline CHEMBL394171 & 688479 & 5.0 & 5.19799 & 99999999995 & TST \\
\hline CHEMBL602375 & 688479 & 6.25 & 5.4745 & TST & \\
\hline CHEMBL1200567 & 688479 & 6.0 & 5.1808 & TST & \\
\hline CHEMBL 261642 & 688479 & 5.0 & 5.211 & TST & \\
\hline CHEMBL1256666 & 688479 & 5.25 & 5.2137 & TST & \\
\hline CHEMBL1256360 & 688479 & 5.3 & 5.1387 & TST & \\
\hline CHEMBL1257012 & 688479 & 4.95 & 5.2784 & TST & \\
\hline CHEMBL1256974 & 688479 & 7.0 & 5.1911 & TST & \\
\hline CHEMBL1256835 & 688479 & 4.9 & 5.1157 & TST & \\
\hline CHEMBL543876 & 688479 & 5.15 & 5.4136 & TST & \\
\hline CHEMBL 288096 & 688479 & 5.6 & 5.1299 & TST & \\
\hline CHEMBL66 & 688479 & 4.85 & 4.8965 & TST & \\
\hline CHEMBL 297784 & 688479 & 4.75 & 5.2111 & TST & \\
\hline CHEMBL303579 & 688479 & 4.95 & 5.1651 & TST & \\
\hline CHEMBL1437831 & 688479 & 7.0 & 5.0759 & TST & \\
\hline CHEMBL1255660 & 688479 & 4.95 & 4.8005 & TST & \\
\hline CHEMBL542448 & 688479 & 4.9 & 4.8557 & TST & \\
\hline CHEMBL56393 & 688479 & 5.0 & 4.7621 & TST & \\
\hline CHEMBL1256797 & 688479 & 5.0 & 5.0976 & TST & \\
\hline CHEMBL1255747 & 688479 & 4.75 & 5.0282 & TST & \\
\hline CHEMBL1256484 & 688479 & 4.9 & 4.9838 & TST & \\
\hline CHEMBL605003 & 688479 & 5.45 & 5.1709 & TST & \\
\hline CHEMBL1523894 & 688479 & 4.9 & 5.2002 & TST & \\
\hline CHEMBL53898 & 688479 & 4.9 & 4.9677 & TST & \\
\hline CHEMBL1315073 & 688479 & 4.9 & 5.0957 & TST & \\
\hline CHEMBL2374058 & 688479 & 5.0 & 5.546 & TST & \\
\hline CHEMBL1256667 & 688479 & 4.95 & 5.2576 & TST & \\
\hline CHEMBL6640 & 688479 & 4.75 & 5.1198 & TST & \\
\hline CHEMBL102714 & 688479 & 4.9 & 5.02800 & 00000000005 & TST \\
\hline CHEMBL326958 & 688479 & 5.05 & 5.2421 & TST & \\
\hline CHEMBL 78150 & 688479 & 6.15 & 4.931 & TST & \\
\hline CHEMBL8197 & 688479 & 5.0 & 5.2433 & TST & \\
\hline
\end{tabular}




\begin{tabular}{|c|c|c|c|c|c|}
\hline \multicolumn{6}{|c|}{ Supplemental Table S2.txt } \\
\hline CHEMBL285819 & 688479 & 5.15 & 5.1331 & TST & \\
\hline CHEMBL1256959 & 688479 & 6.0 & 5.0695 & TST & \\
\hline CHEMBL1437711 & 688479 & 4.95 & 5.1693 & TST & \\
\hline CHEMBL188 & 688479 & 5.0 & 5.1519 & TST & \\
\hline CHEMBL1398537 & 688479 & 5.05 & 5.2844 & TST & \\
\hline CHEMBL165 & 688479 & 5.0 & 4.7837 & TST & \\
\hline CHEMBL 3975577 & 1641137 & 7.8239 & 7.8734 & TRN & \\
\hline CHEMBL3912708 & 1641137 & 6.5719 & 6.9886 & TST & \\
\hline CHEMBL 3898744 & 1641137 & 8.5229 & 8.4547 & TRN & \\
\hline CHEMBL3911152 & 1641137 & 8.3979 & 8.3594 & TRN & \\
\hline CHEMBL3970850 & 1641137 & 7.4089 & 7.3758 & TRN & \\
\hline CHEMBL 3892658 & 1641137 & 7.4949 & 7.4919 & TRN & \\
\hline CHEMBL3890328 & 1641137 & 7.8539 & 7.7956 & TRN & \\
\hline CHEMBL3925575 & 1641137 & 7.9208 & 7.8329 & TRN & \\
\hline CHEMBL3893827 & 1641137 & 8.1549 & 8.1156 & TRN & \\
\hline CHEMBL3922174 & 1641137 & 8.0969 & 8.02700 & 0000000001 & TRN \\
\hline CHEMBL3903877 & 1641137 & 7.6576 & 7.6346 & TRN & \\
\hline CHEMBL3920100 & 1641137 & 7.3565 & 7.346 & TRN & \\
\hline CHEMBL3901596 & 1641137 & 7.3372 & 7.3919 & TRN & \\
\hline CHEMBL3938601 & 1641137 & 7.0506 & 7.0208 & TRN & \\
\hline CHEMBL3970470 & 1641137 & 7.0655 & 7.0474 & TRN & \\
\hline CHEMBL 3933224 & 1641137 & 7.7959 & 7.978 & TRN & \\
\hline CHEMBL3967214 & 1641137 & 7.6576 & 7.6882 & TRN & \\
\hline CHEMBL3968164 & 1641137 & 6.9281 & 6.5919 & TST & \\
\hline CHEMBL3928029 & 1641137 & 8.1549 & 8.1608 & TRN & \\
\hline CHEMBL3903244 & 1641137 & 5.8854 & 5.8702 & TRN & \\
\hline CHEMBL3907640 & 1641137 & 8.1549 & 8.0954 & TRN & \\
\hline CHEMBL3906184 & 1641137 & 7.9208 & 7.8234 & TRN & \\
\hline CHEMBL3970373 & 1641137 & 8.1549 & 8.10700 & 0000000001 & TRN \\
\hline CHEMBL3981765 & 1641137 & 7.9586 & 8.0149 & TRN & \\
\hline CHEMBL3954050 & 1641137 & 8.0458 & 8.2013 & TRN & \\
\hline CHEMBL3893200 & 1641137 & 8.0 & 8.0946 & TRN & \\
\hline CHEMBL3981693 & 1641137 & 6.7959 & 6.7952 & TRN & \\
\hline CHEMBL3960972 & 1641137 & 8.0458 & 7.9639 & TRN & \\
\hline CHEMBL3894588 & 1641137 & 8.5229 & 8.5359 & TRN & \\
\hline CHEMBL3938170 & 1641137 & 8.0969 & 8.1742 & TRN & \\
\hline CHEMBL3913725 & 1641137 & 8.0 & 8.0028 & TRN & \\
\hline CHEMBL3916024 & 1641137 & 6.6421 & 6.6644 & TRN & \\
\hline CHEMBL3948616 & 1641137 & 7.3188 & 7.3875 & TRN & \\
\hline CHEMBL3948670 & 1641137 & 8.0458 & 7.8459 & TRN & \\
\hline CHEMBL3957259 & 1641137 & 7.5086 & 7.5219 & TRN & \\
\hline CHEMBL3944075 & 1641137 & 7.9208 & 8.0341 & TRN & \\
\hline CHEMBL3918309 & 1641137 & 8.3979 & 8.4894 & TRN & \\
\hline CHEMBL3959306 & 1641137 & 8.5229 & 8.4732 & TRN & \\
\hline CHEMBL3970712 & 1641137 & 8.0458 & 7.9733 & TRN & \\
\hline CHEMBL3963900 & 1641137 & 8.0969 & 7.0987 & TST & \\
\hline CHEMBL3983276 & 1641137 & 7.1938 & 7.2311 & TRN & \\
\hline CHEMBL3915153 & 1641137 & 7.3468 & 7.3461 & TRN & \\
\hline
\end{tabular}


Supplemental Table S2.txt

\begin{tabular}{|c|c|c|c|c|c|}
\hline CHEMBL3892145 & 1641137 & 7.2007 & 7.4465 & TRN & \\
\hline CHEMBL3931458 & 1641137 & 7.5528 & 7.5617 & TRN & \\
\hline CHEMBL3982717 & 1641137 & 8.5229 & 8.3842 & TRN & \\
\hline CHEMBL3971001 & 1641137 & 7.3565 & 7.4117 & TRN & \\
\hline CHEMBL3973562 & 1641137 & 8.301 & 8.213 & TRN & \\
\hline CHEMBL3926124 & 1641137 & 7.6383 & 7.4797 & TRN & \\
\hline CHEMBL3949389 & 1641137 & 7.8861 & 8.001 & TRN & \\
\hline CHEMBL3900906 & 1641137 & 7.5686 & 7.6677 & TRN & \\
\hline CHEMBL 3892486 & 1641137 & 7.6576 & 7.6367 & TRN & \\
\hline CHEMBL3946260 & 1641137 & 7.7696 & 7.6871 & TRN & \\
\hline CHEMBL 3908745 & 1641137 & 6.0 & 5.9523 & TRN & \\
\hline CHEMBL3963494 & 1641137 & 8.2218 & 8.2083 & TRN & \\
\hline CHEMBL3937825 & 1641137 & 7.3279 & 6.7022 & TST & \\
\hline CHEMBL3918369 & 1641137 & 8.1549 & 7.5657 & TST & \\
\hline CHEMBL3918715 & 1641137 & 6.308 & 5.8053 & TST & \\
\hline CHEMBL3917694 & 1641137 & 8.0 & 8.0622 & TRN & \\
\hline CHEMBL3938508 & 1641137 & 7.5528 & 7.0537 & TST & \\
\hline CHEMBL3976872 & 1641137 & 6.8125 & 7.0281 & TST & \\
\hline CHEMBL 3980022 & 1641137 & 7.9586 & 7.8253 & TST & \\
\hline CHEMBL3891581 & 1641137 & 9.0 & 7.819 & TST & \\
\hline CHEMBL3986325 & 1641137 & 7.2218 & 7.5096 & TST & \\
\hline CHEMBL3931510 & 1641137 & 8.3979 & 8.8902 & TST & \\
\hline CHEMBL3909401 & 1641137 & 8.0 & 7.916 & TST & \\
\hline CHEMBL3908239 & 1641137 & 8.699 & 7.2589 & TST & \\
\hline CHEMBL3899188 & 1641137 & 7.699 & 7.5329 & TST & \\
\hline CHEMBL3981577 & 1641137 & 8.5229 & 7.8587 & TST & \\
\hline CHEMBL3946227 & 1641137 & 6.0 & 7.0851 & TST & \\
\hline CHEMBL3891977 & 1641137 & 8.1549 & 8.4655 & TST & \\
\hline CHEMBL1257554 & 665493 & 7.1427 & 7.1601 & TRN & \\
\hline CHEMBL1258486 & 665493 & 6.9469 & 7.2224 & TST & \\
\hline CHEMBL1258483 & 665493 & 6.5376 & 6.5306 & TRN & \\
\hline CHEMBL1258373 & 665493 & 5.857 & 5.8643 & TRN & \\
\hline CHEMBL1258599 & 665493 & 7.3872 & 6.8775 & TST & \\
\hline CHEMBL1257797 & 665493 & 8.0458 & 8.055 & TRN & \\
\hline CHEMBL1258144 & 665493 & 7.0458 & 7.0819 & TRN & \\
\hline CHEMBL1257326 & 665493 & 6.1135 & 7.0777 & TST & \\
\hline CHEMBL1258024 & 665493 & 7.3768 & 7.3721 & TRN & \\
\hline CHEMBL1258597 & 665493 & 7.0655 & 7.4636 & TST & \\
\hline CHEMBL1257204 & 665493 & 6.8268 & 6.8286 & TRN & \\
\hline CHEMBL1258259 & 665493 & 6.3019 & 6.2612 & TRN & \\
\hline CHEMBL1257675 & 665493 & 9.0 & 9.0038 & TRN & \\
\hline CHEMBL1257916 & 665493 & 7.1249 & 7.1268 & TRN & \\
\hline CHEMBL1258705 & 665493 & 7.3279 & 7.3434 & TRN & \\
\hline CHEMBL1257915 & 665493 & 7.6383 & 7.6274 & TRN & \\
\hline CHEMBL1258596 & 665493 & 6.9706 & 6.9801 & TRN & \\
\hline CHEMBL1258825 & 665493 & 7.0706 & 7.0742 & TRN & \\
\hline CHEMBL1257913 & 665493 & 8.0706 & 8.0633 & TRN & \\
\hline CHEMBL1258372 & 665493 & 6.82100 & 30000000 & $\partial 1$ & 6.8232 \\
\hline
\end{tabular}




\begin{tabular}{|c|c|c|c|c|c|}
\hline \multicolumn{6}{|c|}{ Supplemental Table s2.txt } \\
\hline CHEMBL1258706 & 665493 & 5.8586 & 5.3978 & TST & \\
\hline CHEMBL1257676 & 665493 & 7.5229 & 7.5181 & TRN & \\
\hline CHEMBL1258704 & 665493 & 7.1938 & 7.2002 & TRN & \\
\hline CHEMBL1257439 & 665493 & 5.0969 & 6.8272 & TST & \\
\hline CHEMBL1258370 & 665493 & 7.0555 & 7.0694 & TRN & \\
\hline CHEMBL1258484 & 665493 & 7.2007 & 7.2023 & TRN & \\
\hline CHEMBL1257555 & 665493 & 8.1367 & 8.1275 & TRN & \\
\hline CHEMBL1257674 & 665493 & 5.8861 & 6.1008 & TST & \\
\hline CHEMBL1257323 & 665493 & 5.5774 & 5.5779 & TRN & \\
\hline CHEMBL1258025 & 665493 & 7.9586 & 7.96299 & 9999999999 & TRN \\
\hline CHEMBL1257437 & 665493 & 6.0367 & 6.0321 & TRN & \\
\hline CHEMBL1258142 & 665493 & 7.2291 & 7.2278 & TRN & \\
\hline CHEMBL1257914 & 665493 & 6.8297 & 6.8671 & TRN & \\
\hline CHEMBL1258598 & 665493 & 6.1739 & 6.4417 & TST & \\
\hline CHEMBL1258023 & 665493 & 7.9586 & 7.9516 & TRN & \\
\hline CHEMBL1255596 & 665493 & 7.7696 & 7.7203 & TRN & \\
\hline CHEMBL1258485 & 665493 & 6.0048 & 5.9987 & TRN & \\
\hline CHEMBL1257325 & 665493 & 6.4318 & 7.1144 & TST & \\
\hline CHEMBL1258707 & 665493 & 6.2218 & 6.0761 & TST & \\
\hline CHEMBL1257438 & 665493 & 6.0306 & 6.0296 & TRN & \\
\hline CHEMBL1258258 & 665493 & 7.7696 & 7.767 & TRN & \\
\hline CHEMBL1257324 & 665493 & 6.2076 & 6.20700 & 0000000001 & TRN \\
\hline CHEMBL1258824 & 665493 & 7.4318 & 7.4302 & TRN & \\
\hline CHEMBL1258026 & 665493 & 7.1192 & 7.1085 & TRN & \\
\hline CHEMBL1083995 & 665493 & 6.3372 & 6.3336 & TRN & \\
\hline CHEMBL1258940 & 665493 & 6.4802 & 6.4792 & TRN & \\
\hline CHEMBL1258143 & 665493 & 7.2076 & 7.21399 & 99999999995 & TRN \\
\hline CHEMBL1258260 & 665493 & 6.5229 & 6.5206 & TRN & \\
\hline CHEMBL1257798 & 665493 & 5.4559 & 5.4535 & TRN & \\
\hline CHEMBL1258257 & 665493 & 7.8539 & 7.8772 & TST & \\
\hline CHEMBL1257440 & 665493 & 5.4815 & 7.3795 & TST & \\
\hline CHEMBL1258371 & 665493 & 7.3098 & 7.2253 & TST & \\
\hline CHEMBL3931676 & 1637151 & 4.0 & 4.0614 & TRN & \\
\hline CHEMBL3969082 & 1637151 & 4.0 & 4.7939 & TRN & \\
\hline CHEMBL3928847 & 1637151 & 4.0 & 4.0314 & TRN & \\
\hline CHEMBL3917962 & 1637151 & 6.301 & 4.5725 & TRN & \\
\hline CHEMBL3913674 & 1637151 & 5.301 & 4.6412 & TST & \\
\hline CHEMBL3981313 & 1637151 & 4.0 & 4.0724 & TRN & \\
\hline CHEMBL3948750 & 1637151 & 4.0 & 4.2283 & TRN & \\
\hline CHEMBL3980636 & 1637151 & 4.0 & 3.96199 & 99999999997 & TRN \\
\hline CHEMBL3919966 & 1637151 & 5.301 & 4.8303 & TRN & \\
\hline CHEMBL3904681 & 1637151 & 4.0 & 4.2008 & TRN & \\
\hline CHEMBL3986998 & 1637151 & 5.301 & 4.3297 & TRN & \\
\hline CHEMBL3896039 & 1637151 & 6.301 & 4.775 & TST & \\
\hline CHEMBL3939013 & 1637151 & 4.0 & 4.1787 & TRN & \\
\hline CHEMBL3968497 & 1637151 & 4.0 & 4.0908 & TRN & \\
\hline CHEMBL3907402 & 1637151 & 5.301 & 4.7581 & TRN & \\
\hline CHEMBL3904645 & 1637151 & 5.301 & 4.739 & TRN & \\
\hline
\end{tabular}




\begin{tabular}{|c|c|c|c|c|}
\hline \multicolumn{5}{|c|}{ Supplemental Table s2.txt } \\
\hline CHEMBL 3890467 & 1637151 & 4.0 & 3.9687 & TRN \\
\hline CHEMBL 3949992 & 1637151 & 6.301 & 4.7512 & TST \\
\hline CHEMBL3899101 & 1637151 & 4.0 & 4.0145 & TRN \\
\hline CHEMBL 3979607 & 1637151 & 4.0 & 4.01 & TRN \\
\hline CHEMBL3964025 & 1637151 & 5.301 & 4.7813 & TRN \\
\hline CHEMBL 3896422 & 1637151 & 4.0 & 4.1682 & TRN \\
\hline CHEMBL 3928075 & 1637151 & 6.301 & 4.7901 & TRN \\
\hline CHEMBL3904333 & 1637151 & 5.301 & 4.7678 & TRN \\
\hline CHEMBL3979361 & 1637151 & 5.301 & 4.782 & TRN \\
\hline CHEMBL3952336 & 1637151 & 5.301 & 4.6986 & TST \\
\hline CHEMBL 3934437 & 1637151 & 4.0 & 3.9549 & TRN \\
\hline CHEMBL 3890797 & 1637151 & 4.0 & 3.9675 & TST \\
\hline CHEMBL3956999 & 1637151 & 4.0 & 4.0734 & TRN \\
\hline CHEMBL3907089 & 1637151 & 4.0 & 4.7279 & TRN \\
\hline CHEMBL 3904980 & 1637151 & 4.0 & 4.4241 & TRN \\
\hline CHEMBL 3954978 & 1637151 & 5.301 & 4.7689 & TST \\
\hline CHEMBL3942988 & 1637151 & 4.0 & 4.3304 & TRN \\
\hline CHEMBL 3895266 & 1637151 & 4.0 & 4.3032 & TRN \\
\hline CHEMBL3921859 & 1637151 & 4.0 & 4.6812 & TRN \\
\hline CHEMBL3947313 & 1637151 & 4.0 & 4.7426 & TRN \\
\hline CHEMBL 3968460 & 1637151 & 5.301 & 4.7347 & TRN \\
\hline CHEMBL 3893235 & 1637151 & 4.0 & 4.0287 & TST \\
\hline CHEMBL3955478 & 1637151 & 4.0 & 4.7483 & TRN \\
\hline CHEMBL 3935744 & 1637151 & 4.0 & 4.5705 & TRN \\
\hline CHEMBL3914107 & 1637151 & 4.0 & 4.0651 & TST \\
\hline CHEMBL 3966021 & 1637151 & 4.0 & 4.0729 & TST \\
\hline CHEMBL 3968095 & 1637151 & 4.0 & 4.6461 & TRN \\
\hline CHEMBL3958968 & 1637151 & 5.301 & 4.814 & TST \\
\hline CHEMBL3933168 & 1637151 & 4.0 & 4.7438 & TRN \\
\hline CHEMBL3944290 & 1637151 & 4.0 & 4.0569 & TRN \\
\hline CHEMBL 3941703 & 1637151 & 4.0 & 4.0736 & TRN \\
\hline CHEMBL 3942381 & 1637151 & 4.0 & 4.7064 & TRN \\
\hline CHEMBL 3954395 & 1637151 & 4.0 & 4.0999 & TRN \\
\hline CHEMBL 3985717 & 1637151 & 4.0 & 4.7854 & TST \\
\hline CHEMBL3979042 & 1637151 & 4.0 & 4.6814 & TST \\
\hline CHEMBL 3912374 & 1637151 & 5.301 & 4.7803 & TRN \\
\hline CHEMBL3949599 & 1637151 & 4.0 & 4.1993 & TST \\
\hline CHEMBL 3899027 & 1637151 & 5.301 & 4.7289 & TRN \\
\hline CHEMBL3967303 & 1637151 & 4.0 & 4.0327 & TRN \\
\hline CHEMBL3951586 & 1637151 & 4.0 & 4.0523 & TST \\
\hline CHEMBL 3941565 & 1637151 & 6.301 & 4.8145 & TST \\
\hline CHEMBL3918722 & 1637151 & 5.301 & 4.3193 & TRN \\
\hline CHEMBL3926189 & 1637151 & 4.0 & 4.1022 & TST \\
\hline CHEMBL3896589 & 1637151 & 5.301 & 4.7774 & TRN \\
\hline CHEMBL3940360 & 1637151 & 4.0 & 4.3293 & TRN \\
\hline CHEMBL 3897700 & 1637151 & 5.301 & 4.7718 & TRN \\
\hline CHEMBL3968167 & 1637151 & 4.0 & 4.1421 & TRN \\
\hline CHEMBL 3945707 & 1637151 & 5.301 & 4.5828 & TST \\
\hline
\end{tabular}


Supplemental Table S2.txt

\begin{tabular}{|c|c|c|c|c|}
\hline HEMBL 3985076 & 637151 & 5.301 & 4.7333 & 1 \\
\hline HEMBL3923610 & 1637151 & 4.0 & 4.5649 & \\
\hline HEMBL & 637151 & 4.0 & & \\
\hline AEMBL3948349 & 51 & 5.301 & 5741 & \\
\hline HEMBL3917210 & 637151 & 4.0 & .7706 & \\
\hline HEMBL3911079 & 637151 & 4.0 & 4.6758 & \\
\hline AEMBL3 & 537151 & 5.301 & 7539 & \\
\hline AEMBL3916725 & 637151 & 6.301 & 1362 & \\
\hline HEMBL3981784 & 637151 & 4.0 & 4.6998 & \\
\hline HEMBL3945059 & 637151 & 4.0 & 7229 & \\
\hline HEMBL3971789 & 637 & 4.0 & 1971 & \\
\hline AEMBL3 & 637151 & 5.301 & 453 & \\
\hline HEMBL3 & 637151 & 4.0 & 374 & \\
\hline HEMBL3920821 & 1637151 & 4.0 & 6532 & \\
\hline HEMBL3956565 & 637151 & 4.0 & & \\
\hline HEMBL3935100 & 63 & 4.0 & 217 & \\
\hline HEMBL3919462 & 51 & 4.0 & 101 & \\
\hline HEMBL3 & 51 & 4.0 & 613 & \\
\hline HEMBL3903656 & 51 & 4.0 & 1823 & \\
\hline HEMBL3928507 & 1 & 4.0 & & \\
\hline HEMBL & 64 & 7.97 & 945 & \\
\hline HEMBL: & 2 & 8.1192 & 211 & \\
\hline HEMBL; & 22 & 8.5229 & 8.2291 & \\
\hline HEMBL3 & & 7.1062 & 934 & \\
\hline HEMBL3952858 & $\partial 2$ & 7.9469 & & \\
\hline HEMBL3 & 64 & 6.0 & 84 & \\
\hline HEMBL & 2 & 7.17 & 23 & \\
\hline 021 & 2 & 8.0031 & 167 & \\
\hline HEMBL3 & & 7.9547 & & \\
\hline HEMBL3954911 & 642 & 7.721 & 2831 & \\
\hline HEMBL3 & 642 & 6.0 & & \\
\hline$H F M B I$ & 2 & 6.0 & 28 & \\
\hline HEMBL & & 7.12 & & \\
\hline HEMBL3898825 & 32 & 7.1889 & & \\
\hline HEMBL3893499 & 1642 & 7.2291 & 103 & \\
\hline AEMBL & 1642 & 8.3809 & 69 & \\
\hline 93 & 2 & 8. & 78 & \\
\hline HEMBL3932625 & & 7.5229 & 7.8444 & \\
\hline HEMBL3895039 & 164 & 7.8097 & 753 & \\
\hline EMBL & & 8.2007 & & \\
\hline HEMBL3 & 164 & 8.2924 & 347 & \\
\hline CHEMBL3 & 1642 & 8.382 & 8.4233 & \\
\hline CHEMBL3966843 & 1642102 & 8.0088 & 7.6867 & \\
\hline CHEMBL3914163 & 1642 & 7.6198 & 7.7181 & \\
\hline CHEMBL3 & & 8.1612 & & \\
\hline HEMBL3 & 1642 & 7.1733 & .5874 & \\
\hline CHEMBL 3975802 & 1642102 & 8.2774 & 8.0806 & \\
\hline CHEMBL3958420 & 1642102 & 8.6383 & 8.6355 & \\
\hline
\end{tabular}

Page 11891 
Supplemental Table S2.txt

\begin{tabular}{|c|c|c|c|c|c|c|}
\hline CHEMBL3964035 & 1642102 & 8.5686 & \multicolumn{2}{|c|}{8.193999999999995} & & \multirow[t]{2}{*}{ TRN } \\
\hline CHEMBL3942557 & 1642102 & 6.4684 & 6.3214 & TRN & & \\
\hline CHEMBL3895621 & 1642102 & 7.2899 & 7.8529 & TRN & & \\
\hline CHEMBL3934167 & 1642102 & 8.7878 & 8.586 & TRN & & \\
\hline CHEMBL3919965 & 1642102 & 8.2676 & 8.1449 & TRN & & \\
\hline CHEMBL3908109 & 1642102 & 7.45100 & 000000006 & 005 & 7.1678 & TRN \\
\hline CHEMBL3891365 & 1642102 & 7.7773 & 7.4887 & TRN & & \\
\hline CHEMBL3914466 & 1642102 & 8.0757 & 7.7583 & TST & & \\
\hline CHEMBL3939653 & 1642102 & 8.5482 & 8.2006 & TRN & & \\
\hline CHEMBL3966846 & 1642102 & 7.8665 & 7.8954 & TRN & & \\
\hline CHEMBL3946512 & 1642102 & 8.2518 & 7.9556 & TRN & & \\
\hline CHEMBL3950044 & 1642102 & 8.3841 & 8.1533 & TRN & & \\
\hline CHEMBL3959543 & 1642102 & 6.8 & 8.4227 & TST & & \\
\hline CHEMBL3936325 & 1642102 & 8.15 & 6.7358 & TST & & \\
\hline CHEMBL3951760 & 1642102 & 8.2676 & 8.5887 & TRN & & \\
\hline CHEMBL3985545 & 1642102 & 8.3706 & 8.2438 & TRN & & \\
\hline CHEMBL3927749 & 1642102 & 8.6655 & 8.5774 & TRN & & \\
\hline CHEMBL3958909 & 1642102 & 7.2366 & 7.49799 & 999999999 & & TRN \\
\hline CHEMBL3919142 & 1642102 & 8.5884 & 8.8517 & TRN & & \\
\hline CHEMBL3981561 & 1642102 & 8.5467 & 8.3308 & TST & & \\
\hline CHEMBL3891016 & 1642102 & 6.7652 & 6.7162 & TRN & & \\
\hline CHEMBL3968354 & 1642102 & 7.7399 & 7.4964 & TRN & & \\
\hline CHEMBL3968954 & 1642102 & 7.9508 & 7.8655 & TRN & & \\
\hline CHEMBL3931530 & 1642102 & 8.2518 & 8.3449 & TRN & & \\
\hline CHEMBL3949082 & 1642102 & 7.7852 & 6.1536 & TST & & \\
\hline CHEMBL3941371 & 1642102 & 7.5867 & 7.5148 & TRN & & \\
\hline CHEMBL3960371 & 1642102 & 8.3615 & 8.5126 & TRN & & \\
\hline CHEMBL3895725 & 1642102 & 8.5528 & 8.3823 & TRN & & \\
\hline CHEMBL3935320 & 1642102 & 8.6216 & 7.3988 & TRN & & \\
\hline CHEMBL3955624 & 1642102 & 8.1487 & 8.0777 & TST & & \\
\hline CHEMBL3905784 & 1642102 & 8.3605 & 8.2613 & TRN & & \\
\hline CHEMBL3939048 & 1642102 & 8.6576 & 8.6344 & TRN & & \\
\hline CHEMBL3915912 & 1642102 & 7.6459 & 7.8559 & TRN & & \\
\hline CHEMBL3934846 & 1642102 & 6.8677 & 7.1835 & TST & & \\
\hline CHEMBL3986785 & 1642102 & 8.1549 & 8.2121 & TRN & & \\
\hline CHEMBL3945269 & 1642102 & 7.1337 & 7.111006 & 000000000 & & TRN \\
\hline CHEMBL3931569 & 1642102 & 7.2111 & 9.3203 & TST & & \\
\hline CHEMBL3973863 & 1642102 & 8.4437 & 8.0102 & TRN & & \\
\hline CHEMBL3893775 & 1642102 & 7.75200 & 00000000 & & 7.5143 & TRN \\
\hline CHEMBL3897367 & 1642102 & 7.8761 & 8.0177 & TRN & & \\
\hline CHEMBL3933109 & 1642102 & 6.0 & 6.5113 & TRN & & \\
\hline CHEMBL3894498 & 1642102 & 6.0 & 7.2909 & TRN & & \\
\hline CHEMBL3965207 & 1642102 & 7.1707 & 7.4457 & TRN & & \\
\hline CHEMBL3952893 & 1642102 & 8.3575 & 8.2853 & TRN & & \\
\hline CHEMBL3895221 & 1642102 & 6.0 & 5.9042 & TRN & & \\
\hline CHEMBL3973695 & 1642102 & 8.2147 & 7.6575 & TST & & \\
\hline CHEMBL3980416 & 1642102 & 7.4389 & 6.9364 & TRN & & \\
\hline CHEMBL3946914 & 1642102 & 7.5751 & 7.9351 & TRN & & \\
\hline
\end{tabular}

Page 11892 
Supplemental Table S2.txt

\begin{tabular}{|c|c|c|c|c|}
\hline CHEMBL 3965950 & 1642102 & 7.1159 & 6.7756 & TRN \\
\hline CHEMBL 3890121 & 1642102 & 6.0 & 5.9548 & TRN \\
\hline CHEMBL3909057 & 1642102 & 7.251 & 6.9767 & TST \\
\hline CHEMBL 3947673 & 1642102 & 8.3645 & 8.6298 & TRN \\
\hline CHEMBL 3896900 & 1642102 & 7.9073 & 7.5523 & TRN \\
\hline CHEMBL 3910578 & 1642102 & 6.0 & 5.9723 & TRN \\
\hline CHEMBL 3907548 & 1642102 & 8.0706 & 8.3009 & TRN \\
\hline CHEMBL 3933137 & 1642102 & 8.2518 & 7.5301 & TRN \\
\hline CHEMBL 3906572 & 1642102 & 7.9547 & 6.6739 & TST \\
\hline CHEMBL 3962458 & 1642102 & 8.1805 & 8.1959 & TRN \\
\hline CHEMBL 3960072 & 1642102 & 8.7645 & 8.2701 & TRN \\
\hline CHEMBL 3943811 & 1642102 & 8.6308 & 9.3527 & TRN \\
\hline CHEMBL 3933792 & 1642102 & 8.1765 & 8.3001 & TRN \\
\hline CHEMBL 3950786 & 1642102 & 7.4437 & 7.9055 & TRN \\
\hline CHEMBL 3975665 & 1642102 & 7.7375 & 7.8924 & TRN \\
\hline CHEMBL3901269 & 1642102 & 6.751 & 6.8102 & TRN \\
\hline CHEMBL3923675 & 1642102 & 8.2218 & 8.0075 & TRN \\
\hline CHEMBL 3920983 & 1642102 & 6.9702 & 6.8446 & TRN \\
\hline CHEMBL 3890072 & 1642102 & 7.6925 & 7.4988 & TST \\
\hline CHEMBL 3901531 & 1642102 & 7.4303 & 7.7287 & TRN \\
\hline CHEMBL 3964546 & 1642102 & 8.4306 & 8.3297 & TRN \\
\hline CHEMBL 3902480 & 1642102 & 8.5258 & 8.7087 & TRN \\
\hline CHEMBL 3921038 & 1642102 & 8.1367 & 8.1805 & TRN \\
\hline CHEMBL3920769 & 1642102 & 8.4437 & 7.9731 & TRN \\
\hline CHEMBL 3962713 & 1642102 & 8.1959 & 8.0747 & TRN \\
\hline CHEMBL 3943668 & 1642102 & 6.8094 & 7.0836 & TRN \\
\hline CHEMBL3915967 & 1642102 & 7.5758 & 7.8563 & TRN \\
\hline CHEMBL 3978913 & 1642102 & 7.8945 & 7.5105 & TRN \\
\hline CHEMBL3967326 & 1642102 & 8.3799 & 8.2573 & TRN \\
\hline CHEMBL 3903928 & 1642102 & 6.2165 & 6.7604 & TST \\
\hline CHEMBL 3975424 & 1642102 & 7.6498 & 7.7127 & TRN \\
\hline CHEMBL 3906216 & 1642102 & 7.0645 & 7.235 & TRN \\
\hline CHEMBL 3926502 & 1642102 & 7.0899 & 7.0587 & TRN \\
\hline CHEMBL 3938243 & 1642102 & 8.8996 & 9.3016 & TRN \\
\hline CHEMBL 3936066 & 1642102 & 7.5331 & 7.1704 & TRN \\
\hline CHEMBL3919816 & 1642102 & 8.6778 & 8.3822 & TST \\
\hline CHEMBL 3900144 & 1642102 & 6.6196 & 6.8459 & TRN \\
\hline CHEMBL 3894715 & 1642102 & 7.5058 & 7.0117 & TRN \\
\hline CHEMBL3986612 & 1642102 & 8.4949 & 8.1361 & TRN \\
\hline CHEMBL 3901271 & 1642102 & 8.2565 & 7.6549 & TRN \\
\hline CHEMBL 3942829 & 1642102 & 8.2526 & 8.1353 & TRN \\
\hline CHEMBL 3967186 & 1642102 & 7.4685 & 7.8919 & TRN \\
\hline CHEMBL 3953662 & 1642102 & 7.1925 & \multicolumn{2}{|c|}{6.547000000000001} \\
\hline CHEMBL3953830 & 1642102 & 7.8251 & 8.4834 & TST \\
\hline CHEMBL 3980263 & 1642102 & 6.8586 & 7.1788 & TRN \\
\hline CHEMBL 3931039 & 1642102 & 7.4828 & 7.9657 & TST \\
\hline CHEMBL 3954916 & 1642102 & 6.6002 & 6.7146 & TRN \\
\hline CHEMBL 3967800 & 1642102 & 8.0443 & 8.0794 & TRN \\
\hline
\end{tabular}


Supplemental Table S2.txt

\begin{tabular}{|c|c|c|c|c|c|}
\hline CHEMBL 3897489 & 1642102 & 6.4587 & 7.0 & TRN & \\
\hline CHEMBL3914976 & 1642102 & 7.6576 & 7.8198 & TRN & \\
\hline CHEMBL3984439 & 1642102 & 6.9219 & 7.435 & TST & \\
\hline CHEMBL 3946828 & 1642102 & 7.3665 & 7.6198 & TST & \\
\hline CHEMBL3977651 & 1642102 & 8.0862 & 8.2328 & TRN & \\
\hline CHEMBL3932649 & 1642102 & 8.58 & 8.4673 & TRN & \\
\hline CHEMBL3908542 & 1642102 & 8.4815 & 8.3743 & TRN & \\
\hline CHEMBL3897651 & 1642102 & 7.8416 & 6.8466 & TST & \\
\hline CHEMBL3942624 & 1642102 & 7.7447 & 7.6573 & TRN & \\
\hline CHEMBL3971024 & 1642102 & 7.3862 & 7.4526 & TRN & \\
\hline CHEMBL3948540 & 1642102 & 8.0506 & 8.5973 & TRN & \\
\hline CHEMBL3902073 & 1642102 & 6.0 & 6.77 & TRN & \\
\hline CHEMBL 3944061 & 1642102 & 8.8539 & 8.1412 & TRN & \\
\hline CHEMBL3981708 & 1642102 & 6.8837 & 6.7445 & TRN & \\
\hline CHEMBL3929219 & 1642102 & 7.3197 & 7.3422 & TRN & \\
\hline CHEMBL3895440 & 1642102 & 6.0721 & 7.209 & TST & \\
\hline CHEMBL3944943 & 1642102 & 7.4413 & 7.1695 & TRN & \\
\hline CHEMBL 3933018 & 1642102 & 8.0555 & 7.0287 & TST & \\
\hline CHEMBL3946947 & 1642102 & 6.5743 & 6.3836 & TRN & \\
\hline CHEMBL3922699 & 1642102 & 8.8239 & 8.5741 & TRN & \\
\hline CHEMBL3928726 & 1642102 & 8.51 & 8.4968 & TRN & \\
\hline CHEMBL3946757 & 1642102 & 7.3054 & 7.28 & TRN & \\
\hline CHEMBL3931097 & 1642102 & 7.8362 & 7.7573 & TRN & \\
\hline CHEMBL3975412 & 1642102 & 7.4856 & 7.3871 & TRN & \\
\hline CHEMBL3939472 & 1642102 & 7.58 & 7.8062 & TST & \\
\hline CHEMBL3959252 & 1642102 & 6.0 & 5.8513 & TRN & \\
\hline CHEMBL3925366 & 1642102 & 8.6383 & 8.0469 & TRN & \\
\hline CHEMBL3977672 & 1642102 & 8.399 & 8.3037 & TRN & \\
\hline CHEMBL3949695 & 1642102 & 7.3904 & \multicolumn{2}{|c|}{7.457999999999999} & TRN \\
\hline CHEMBL3911917 & 1642102 & 8.3372 & 7.7344 & TRN & \\
\hline CHEMBL3948602 & 1642102 & 8.1024 & 8.2777 & TRN & \\
\hline CHEMBL 3954003 & 1642102 & 7.5243 & 7.5592 & TRN & \\
\hline CHEMBL 3897407 & 1642102 & 8.5229 & 8.3167 & TRN & \\
\hline CHEMBL3978210 & 1642102 & 7.5406 & 7.3008 & TST & \\
\hline CHEMBL3915706 & 1642102 & 8.7447 & 9.0648 & TRN & \\
\hline CHEMBL3937091 & 1642102 & 7.1945 & \multicolumn{2}{|c|}{7.3389999999999995} & TRN \\
\hline CHEMBL 3896174 & 1642102 & 8.3872 & 8.1169 & TRN & \\
\hline CHEMBL3951996 & 1642102 & 6.8292 & \multicolumn{2}{|c|}{ 7.037999999999999 } & TRN \\
\hline CHEMBL3931365 & 1642102 & 6.0 & 7.1403 & TRN & \\
\hline CHEMBL3934301 & 1642102 & 8.1938 & 8.0078 & TST & \\
\hline CHEMBL 3927621 & 1642102 & 6.8945 & 7.0535 & TRN & \\
\hline CHEMBL3925427 & 1642102 & 7.3125 & 7.3048 & TRN & \\
\hline CHEMBL3917993 & 1642102 & 7.4237 & 7.9248 & TST & \\
\hline CHEMBL3919113 & 1642102 & 8.6021 & 8.2297 & TRN & \\
\hline CHEMBL 3900243 & 1642102 & 8.2291 & 8.0356 & TRN & \\
\hline CHEMBL3914638 & 1642102 & 7.6144 & 7.5333 & TRN & \\
\hline CHEMBL 3894116 & 1642102 & 7.7852 & 6.9262 & TST & \\
\hline CHEMBL3970173 & 1642102 & 8.6904 & 8.0508 & TRN & \\
\hline
\end{tabular}

Page 11894 
Supplemental Table S2.txt

\begin{tabular}{|c|c|c|c|c|}
\hline . & 102 & 6.7151 & & \\
\hline & 642102 & 6.0 & 2983 & \\
\hline & 102 & 35 & & \\
\hline HEMBL393 & 102 & 5198 & & \\
\hline AEMBL3953571 & 102 & 6.0 & & \\
\hline HEMBL3911871 & 642102 & 8.2076 & 4923 & \\
\hline 356 & 02 & 595 & & \\
\hline IFMR| 391 & & & & \\
\hline AEMBL3984092 & 102 & 3979 & 7333 & \\
\hline AEMBL3985716 & 102 & 8.1308 & .2253 & \\
\hline HEMBL3937664 & 102 & 7. & 7.3985 & \\
\hline IEMBL 3910517 & 02 & 08 & 65 & \\
\hline IEMBL39 & & & & \\
\hline HEMBL3976073 & 02 & & 7.6391 & \\
\hline AEMBL3932899 & 02 & 88 & 95 & \\
\hline AEMBL3971462 & 02 & 61 & 7512 & \\
\hline AEMBL39 & 32 & 97 & 756 & \\
\hline HEMBL39 & & & & \\
\hline HEMBL3909835 & & 96 & 7.5919 & \\
\hline AEMBL39 & & 6. & & \\
\hline HEIMBLSS & 12 & 6 & 44 & NIV \\
\hline AEMBL3S & & & 65 & 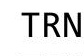 \\
\hline AEMBL3S & & & 56 & \\
\hline 915 & & & & \\
\hline AEMBL39 & & & & \\
\hline HEMBL3S & $\partial 2$ & & 97 & RN \\
\hline HEMBL3 & & & & ST \\
\hline HFMBI 38 & & & & \\
\hline HEMBL392 & & 6 & & 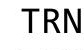 \\
\hline HEMBL3910461 & & & & 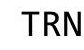 \\
\hline HEMBL 389 & $\partial 2$ & & 121 & RIN \\
\hline HEMBL3 & 2 & & 54 & KIV \\
\hline 58 & & 75 & 195 & $\mathrm{~N}$ \\
\hline HEMBL3893371 & 32 & & 8.3841 & IRN \\
\hline HEMBL3964794 & & & 9541 & TST \\
\hline HEMBL395 & & & 788 & TRN \\
\hline HFMRI 3 & 12 & 9 & 45 & RN \\
\hline HEMBL3 & & & & RN \\
\hline HEMBL3963291 & 02 & 8. & 8.4282 & $\Gamma \mathrm{RN}$ \\
\hline HEMBL397 & 02 & 7. & 557 & $\Gamma \mathrm{RN}$ \\
\hline HEMBL 390 & $\partial 2$ & 6 & 6.7944 & \\
\hline CHEMBL3964216 & & & & RN \\
\hline HEMBL3977201 & 02 & & 9.1338 & IST \\
\hline AEMBL3959561 & 02 & 7.7167 & 5939 & ГRN \\
\hline $\mathrm{MB} \mid 3$ & & & & \\
\hline HEMBL 3903923 & & & 8.3541 & \\
\hline CHEMBL 3890426 & & 7.8539 & 8.3628 & \\
\hline CHEMBL3932856 & 1642102 & 7.2358 & 7.2248 & RN \\
\hline
\end{tabular}

Page 11895 
Supplemental Table S2.txt

\begin{tabular}{|c|c|c|}
\hline 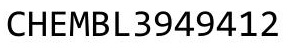 & & \\
\hline CHEMBL3903521 & 102 & \\
\hline HEMBL3929129 & 642102 & \\
\hline CHEMBL 3957537 & L642102 & \\
\hline HEMBL3958879 & 1642102 & \\
\hline HEMBL3922487 & 1642102 & \\
\hline HEMBL3931403 & 1642102 & \\
\hline CHEMBL3973774 & L642102 & 6.0 \\
\hline CHEMBL3897231 & 1642102 & \\
\hline HEMBL3928101 & 642102 & \\
\hline IEMBL 3901594 & 1642102 & \\
\hline HEMBL3922591 & 1642102 & \\
\hline HEMBL3966175 & 1642102 & 7.85 \\
\hline CHEMBL3952422 & 1642102 & \\
\hline HEMBL3918499 & 1642102 & \\
\hline HEMBL3892022 & 1642102 & \\
\hline HEMBL3972368 & 1642102 & \\
\hline HEMBL3924286 & 1642102 & \\
\hline HEMBL3959858 & 1642102 & \\
\hline HEMBL3927721 & 1642102 & \\
\hline CHEMBL3972675 & 1642102 & \\
\hline CHEMBL3895733 & 1642102 & \\
\hline CHEMBL3907065 & 1642102 & \\
\hline CHEMBL3917028 & 1642102 & \\
\hline CHEMBL3975329 & 1642102 & \\
\hline CHEMBL3960834 & 1642102 & \\
\hline CHEMBL3944448 & 1642102 & \\
\hline CHEMBL3931593 & 164 & \\
\hline CHEMBL3899059 & 1642102 & \\
\hline CHEMBL3897235 & 1642102 & \\
\hline CHEMBL3970331 & 1642102 & \\
\hline CHEMBL3953967 & 1642102 & 6.0 \\
\hline CHEMBL3932912 & 164 & \\
\hline CHEMBL3979762 & 1642102 & \\
\hline CHEMBL 3946083 & 1642102 & 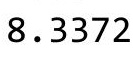 \\
\hline CHEMBL3904679 & 1642 & \\
\hline CHEMBL3940460 & 1642102 & \\
\hline CHEMBL3974673 & 1642102 & 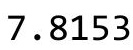 \\
\hline CHEMBL3948671 & 1642102 & כ. \\
\hline CHEMBL 3921447 & 1642102 & \\
\hline CHEMBL3939517 & 1642102 & \\
\hline CHEMBL3967256 & 1642102 & 8.5 \\
\hline CHEMBL3898450 & 1642102 & \\
\hline CHEMBL3926035 & 1642102 & \\
\hline CHEMBL3936589 & 1642102 & \\
\hline CHEMBL3956871 & 1642102 & \\
\hline CHEMBL3919519 & 1642102 & \\
\hline CHEMBL3945097 & 1642102 & \\
\hline
\end{tabular}

8

7.6876 TRN

6.7292 TST

8.3204 TRN

8.0303 TRN

8.408 TRN

7.2539 TRN

7.7729 TRN

6.3055 TRN

8.3613 TRN

7.6293 TRN

6.778 TRN

8.2542 TRN

8.2271 TRN

8.3432 TRN

8.2092 TRN

7.4653 TRN

6.6216 TST

7.5951 TRN

8.1327 TST

8.3646 TRN

7.9345 TRN

7.5751 TRN

8.3716 TRN

7.3442 TRN

7.9084 TRN

8.4214 TRN

8.8003 TRN

8.7637 TRN

7.4835 TST

8.6931 TRN

6.5068 TRN

7.2229 TRN

8.1001 TRN

7.541 TRN

8.4085 TST

8.7167 TST

7.881 TRN

7.9327 TRN

7.4474 TRN

8.0601 TRN

6.6653 TRN

8.3839 TST

6.4677 TST

8.5487 TRN

7.1806 TRN

7.981 TRN

8.8158 TRN

8.267999999999999 TST

Page 11896 
Supplemental Table S2.txt

\begin{tabular}{|c|c|c|c|c|c|}
\hline CHEMBL3981913 & 1642102 & 6.4 & 7.7878 & TST & \\
\hline CHEMBL3985770 & 1642102 & 7.9914 & 8.0163 & TRN & \\
\hline CHEMBL3895380 & 1642102 & 7.6968 & 8.1053 & TRN & \\
\hline CHEMBL3983779 & 1642102 & 8.082 & 7.9182 & TRN & \\
\hline CHEMBL3971726 & 1642102 & 6.0 & 6.2136 & TRN & \\
\hline CHEMBL3891819 & 1642102 & 8.2262 & 7.5285 & TST & \\
\hline CHEMBL3948696 & 1642102 & 8.1079 & 7.5511 & TRN & \\
\hline CHEMBL3984695 & 1642102 & 8.1024 & 8.3187 & TST & \\
\hline CHEMBL3899511 & 1642102 & 7.4413 & 7.8032 & TST & \\
\hline CHEMBL3905416 & 1642102 & 6.0 & 5.6304 & TRN & \\
\hline CHEMBL3969038 & 1642102 & 8.0894 & 7.8472 & TRN & \\
\hline CHEMBL3979339 & 1642102 & 7.3401 & 7.0814 & TST & \\
\hline CHEMBL3972965 & 1642102 & 8.0655 & 8.2296 & TST & \\
\hline CHEMBL3906191 & 1642102 & 8.6596 & 8.4167 & TRN & \\
\hline CHEMBL3962905 & 1642102 & 8.5376 & 8.7396 & TST & \\
\hline CHEMBL3968941 & 1642102 & 7.1451 & 7.2772 & TST & \\
\hline CHEMBL3934311 & 1642102 & 7.8539 & 8.0954 & TST & \\
\hline CHEMBL3918208 & 1642102 & 7.7778 & 7.795 & TRN & \\
\hline CHEMBL3921703 & 1642102 & 7.5498 & 7.7025 & TRN & \\
\hline CHEMBL 3980373 & 1642102 & 7.5719 & 7.6842 & TST & \\
\hline CHEMBL3935418 & 1642102 & 6.0389 & 6.3342 & TST & \\
\hline CHEMBL3930214 & 1642102 & 7.8996 & 7.4982 & TST & \\
\hline CHEMBL3930335 & 1642102 & 8.5421 & 8.4519 & TRN & \\
\hline CHEMBL 3893444 & 1642102 & 7.7033 & 7.4345 & TRN & \\
\hline CHEMBL 3941596 & 1642102 & 6.7545 & 9.0521 & TST & \\
\hline CHEMBL 3944850 & 1642102 & 8.0079 & 7.2411 & TRN & \\
\hline CHEMBL3917197 & 1642102 & 8.6968 & 8.5579 & TST & \\
\hline CHEMBL3928556 & 1642102 & 6.0 & 5.8247 & TRN & \\
\hline CHEMBL3916009 & 1642102 & 8.1427 & 7.9323 & TRN & \\
\hline CHEMBL 3891431 & 1642102 & 7.9318 & 7.1529 & TST & \\
\hline CHEMBL3940938 & 1642102 & 7.0146 & 6.9393 & TST & \\
\hline CHEMBL3921329 & 1642102 & 9.1249 & 8.6692 & TST & \\
\hline CHEMBL3957927 & 1642102 & 8.8416 & 8.7445 & TST & \\
\hline CHEMBL3918740 & 1642102 & 8.8761 & 8.4268 & TRN & \\
\hline CHEMBL 3904862 & 1642102 & 7.5528 & 7.9003 & TRN & \\
\hline CHEMBL3984432 & 1642102 & 7.1494 & 7.1001 & TST & \\
\hline CHEMBL3906334 & 1642102 & 8.0315 & 8.3185 & TST & \\
\hline CHEMBL 3944894 & 1642102 & 8.0605 & 8.1645 & TRN & \\
\hline CHEMBL3984978 & 1642102 & 8.0655 & 7.763999 & 9999999999 & TRN \\
\hline CHEMBL3963980 & 1642102 & 8.0969 & 7.4789 & TRN & \\
\hline CHEMBL 3939844 & 1642102 & 7.75200 & 000000000 & 8.1084 & TRN \\
\hline CHEMBL3955660 & 1642102 & 8.8013 & 8.6691 & TST & \\
\hline CHEMBL 3891762 & 1642102 & 8.5575 & 8.6953 & TRN & \\
\hline CHEMBL3956173 & 1642102 & 7.5214 & 8.0309 & TST & \\
\hline CHEMBL3953035 & 1642102 & 7.1637 & 7.487999 & 99999999995 & TP \\
\hline CHEMBL 3924185 & 1642102 & 8.1024 & 8.3259 & TRN & \\
\hline CHEMBL3902903 & 1642102 & 8.2218 & 8.0271 & TST & \\
\hline CHEMBL3961170 & 1642102 & 7.9547 & 7.0789 & TST & \\
\hline
\end{tabular}

Page 11897 
Supplemental Table S2.txt

\begin{tabular}{|c|c|c|c|c|}
\hline CHEMBL3967666 & 1642102 & 7.5186 & 7.8222 & TST \\
\hline CHEMBL3950303 & 1642102 & 8.5686 & 8.0576 & TRN \\
\hline CHEMBL3902701 & 1642102 & 9.1367 & 8.6814 & TST \\
\hline CHEMBL3966268 & 1642102 & 7.9007 & 7.5496 & TRN \\
\hline CHEMBL3977482 & 1642102 & 8.3936 & 8.058 & TRN \\
\hline CHEMBL3910233 & 1642102 & 8.7878 & 7.2433 & TST \\
\hline CHEMBL3952812 & 1642102 & 8.5017 & 8.2434 & TST \\
\hline CHEMBL3926553 & 1642102 & 8.2676 & 8.446 & TRN \\
\hline CHEMBL3959075 & 1642102 & 8.2857 & 8.055 & TST \\
\hline CHEMBL3912556 & 1642102 & 6.0 & 7.6163 & TRN \\
\hline CHEMBL3922655 & 1642102 & 8.5452 & 8.433 & TST \\
\hline CHEMBL 3891437 & 1642102 & 7.1948 & 7.7056 & TST \\
\hline CHEMBL3942757 & 1642102 & 8.6576 & 8.5599 & TST \\
\hline CHEMBL3917266 & 1642102 & 6.0 & 7.0316 & TRN \\
\hline CHEMBL3977607 & 1642102 & 7.5701 & 7.9772 & TRN \\
\hline CHEMBL3972322 & 1642102 & 7.8697 & 8.4888 & TST \\
\hline CHEMBL3966383 & 1642102 & 7.0133 & 6.8823 & TRN \\
\hline CHEMBL3951349 & 1642102 & 7.1726 & 7.369 & TRN \\
\hline CHEMBL3967517 & 1642102 & 8.1308 & 7.8688 & TRN \\
\hline CHEMBL3936351 & 1642102 & 8.1024 & 7.9942 & TRN \\
\hline CHEMBL3952806 & 1642102 & 7.813 & 7.4724 & TRN \\
\hline CHEMBL3946347 & 1642102 & 6.5662 & 7.1434 & TST \\
\hline CHEMBL1934963 & 795623 & 5.0814 & 4.7396 & TRN \\
\hline CHEMBL1934951 & 795623 & 4.3722 & 4.4151 & TRN \\
\hline CHEMBL1934955 & 795623 & 4.5974 & 4.4879 & TRN \\
\hline CHEMBL1934946 & 795623 & 4.8595 & 5.0406 & TRN \\
\hline CHEMBL1933086 & 795623 & 5.2692 & 4.8744 & TST \\
\hline CHEMBL1934962 & 795623 & 4.1596 & 4.8826 & TRN \\
\hline CHEMBL1934952 & 795623 & 4.4226 & 4.6794 & TRN \\
\hline CHEMBL1934964 & 795623 & 4.9151 & 4.4373 & TRN \\
\hline CHEMBL1934947 & 795623 & 5.52 & 4.886 & TRN \\
\hline CHEMBL1934935 & 795623 & 5.1273 & 5.1103 & TRN \\
\hline CHEMBL1934961 & 795623 & 4.9867 & 4.3566 & TRN \\
\hline CHEMBL1935073 & 795623 & 4.2444 & 4.8477 & TRN \\
\hline CHEMBL1934944 & 795623 & 4.1284 & 4.6015 & TST \\
\hline CHEMBL1934950 & 795623 & 4.2409 & 4.4359 & TRN \\
\hline CHEMBL1934953 & 795623 & 4.3286 & 4.5091 & TRN \\
\hline CHEMBL1934942 & 795623 & 4.4089 & 4.4342 & TST \\
\hline CHEMBL1934933 & 795623 & 4.4702 & 4.66100 & 00000000005 \\
\hline CHEMBL1934940 & 795623 & 4.5084 & 4.8928 & TST \\
\hline CHEMBL1934929 & 795623 & 4.0201 & 4.7006 & TRN \\
\hline CHEMBL1934954 & 795623 & 3.9252 & 4.6165 & TRN \\
\hline CHEMBL1934945 & 795623 & 4.2976 & 4.8648 & TRN \\
\hline CHEMBL1934926 & 795623 & 5.2262 & 4.8873 & TRN \\
\hline CHEMBL1934927 & 795623 & 4.3636 & 4.4722 & TST \\
\hline CHEMBL1934928 & 795623 & 6.3279 & 5.0091 & TST \\
\hline CHEMBL1934938 & 795623 & 5.0101 & 4.8935 & TRN \\
\hline CHEMBL1934970 & 795623 & 6.3279 & 4.9735 & TRN \\
\hline
\end{tabular}




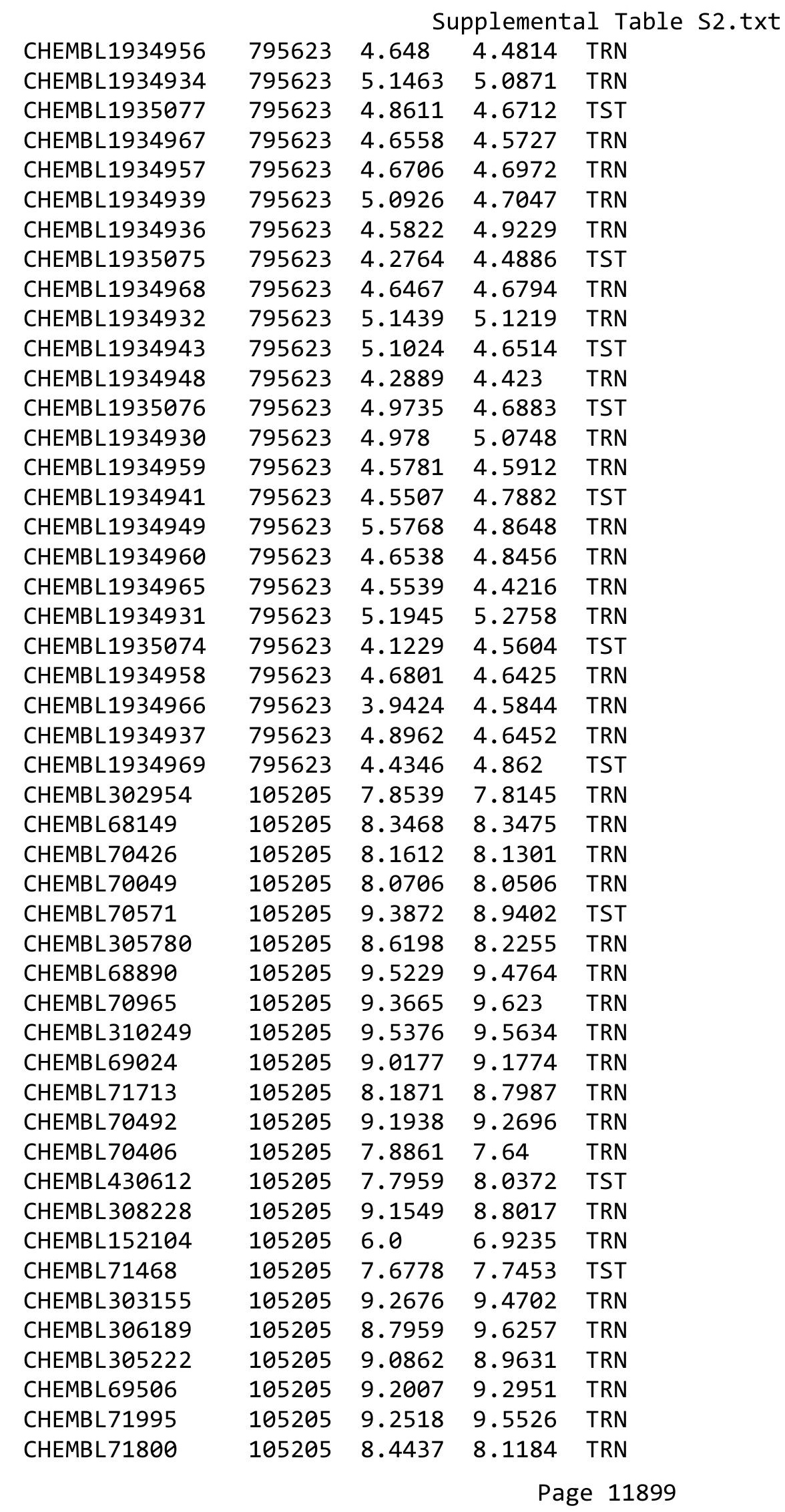




\begin{tabular}{|c|c|c|c|c|c|c|c|}
\hline \multicolumn{8}{|c|}{ Supplemental Table S2.txt } \\
\hline CHEMBL306912 & 105205 & 9.3468 & 9.2611 & TRN & & & \\
\hline CHEMBL69072 & 105205 & 7.7696 & 7.7861 & TRN & & & \\
\hline CHEMBL308598 & 105205 & 7.5686 & 7.6994 & TRN & & & \\
\hline CHEMBL 306524 & 105205 & 10.0 & 9.2764 & TRN & & & \\
\hline CHEMBL306470 & 105205 & 8.7959 & 8.7159 & TRN & & & \\
\hline CHEMBL 303918 & 105205 & 7.7696 & 7.4192 & TST & & & \\
\hline CHEMBL70354 & 105205 & 8.1675 & 8.0169 & TRN & & & \\
\hline CHEMBL 71482 & 105205 & 9.6198 & 9.6257 & TRN & & & \\
\hline CHEMBL70417 & 105205 & 9.9586 & 9.7831 & TRN & & & \\
\hline CHEMBL 74182 & 105205 & 9.0269 & 9.0212 & TRN & & & \\
\hline CHEMBL70570 & 105205 & 9.1871 & 8.9211 & TST & & & \\
\hline CHEMBL 70398 & 105205 & 9.2757 & 9.0416 & TST & & & \\
\hline CHEMBL71630 & 105205 & 7.8861 & 8.1232 & TRN & & & \\
\hline CHEMBL 306224 & 105205 & 9.4685 & 8.9664 & TRN & & & \\
\hline CHEMBL 302368 & 105205 & 8.9208 & 8.9744 & TRN & & & \\
\hline CHEMBL71014 & 105205 & 8.1079 & 8.0317 & TRN & & & \\
\hline CHEMBL 302311 & 105205 & 9.4815 & 9.186 & TRN & & & \\
\hline CHEMBL 72337 & 105205 & 8.1135 & 8.1601 & TRN & & & \\
\hline CHEMBL 72678 & 105205 & 9.1805 & 9.1944 & TST & & & \\
\hline CHEMBL 70430 & 105205 & 9.5229 & 9.1952 & TRN & & & \\
\hline CHEMBL 71071 & 105205 & 9.1249 & 8.7063 & TRN & & & \\
\hline CHEMBL 307090 & 105205 & 9.2291 & 9.5391 & TRN & & & \\
\hline CHEMBL70639 & 105205 & 7.9208 & 7.9793 & TRN & & & \\
\hline CHEMBL 74175 & 105205 & 8.7696 & 9.3031 & TRN & & & \\
\hline CHEMBL422948 & 105205 & 9.4089 & 9.0091 & TRN & & & \\
\hline CHEMBL420932 & 105205 & 9.4559 & 9.1992 & TRN & & & \\
\hline CHEMBL 306871 & 105205 & 9.3098 & 9.607999 & 999999999 & & TRN & \\
\hline CHEMBL 308032 & 105205 & 6.3372 & 6.5556 & TST & & & \\
\hline CHEMBL 308397 & 105205 & 8.3468 & 8.2513 & TRN & & & \\
\hline CHEMBL71618 & 105205 & 8.8861 & 8.7445 & TST & & & \\
\hline CHEMBL68049 & 105205 & 7.1135 & 7.5429 & TST & & & \\
\hline CHEMBL 72743 & 105205 & 8.28399 & 999999999 & 99 & 8.9847 & TST & \\
\hline CHEMBL 308012 & 105205 & 8.4318 & 8.524 & TST & & & \\
\hline CHEMBL 70315 & 105205 & 9.0 & 9.3393 & TST & & & \\
\hline CHEMBL 308429 & 105205 & 8.1135 & 8.1293 & TST & & & \\
\hline CHEMBL 72788 & 105205 & 9.3098 & 9.0403 & TST & & & \\
\hline CHEMBL 2133413 & 845095 & 8.6992 & 9.1944 & TRN & & & \\
\hline CHEMBL 2136710 & 845095 & 11.7721 & 11.8053 & TRN & & & \\
\hline CHEMBL2135890 & 845095 & 11.9208 & 11.29 & TRN & & & \\
\hline CHEMBL 2133117 & 845095 & 11.4634 & 11.0032 & TRN & & & \\
\hline CHEMBL 2140410 & 845095 & 11.1559 & 999999999 & 999 & 11.790 & 99999999999 & TRN \\
\hline CHEMBL 2141711 & 845095 & 11.5287 & 12.2768 & TRN & & & \\
\hline CHEMBL 2144131 & 845095 & 11.7305 & 11.8114 & TRN & & & \\
\hline CHEMBL 2133477 & 845095 & 11.4191 & 11.9354 & TRN & & & \\
\hline CHEMBL 2138737 & 845095 & 11.7399 & 11.5962 & TRN & & & \\
\hline CHEMBL 2143465 & 845095 & 11.5421 & 11.4254 & TRN & & & \\
\hline CHEMBL 2133727 & 845095 & 10.321 & 11.2616 & TST & & & \\
\hline CHEMBL 2133784 & 845095 & 11.7773 & 11.2514 & TRN & & & \\
\hline
\end{tabular}




\begin{tabular}{|c|c|c|c|c|c|}
\hline \multirow[b]{2}{*}{ CHEMBL2139757 } & \multirow[b]{2}{*}{845095} & \multicolumn{4}{|c|}{ Supplemental Table S2.txt } \\
\hline & & 6.3406 & 7.9967 & TRN & \\
\hline CHEMBL 2145384 & 845095 & 10.9944 & 10.7187 & TRN & \\
\hline CHEMBL2138767 & 845095 & 11.6757 & 11.7084 & TRN & \\
\hline CHEMBL2141371 & 845095 & 7.5589 & 8.9828 & TRN & \\
\hline CHEMBL2138028 & 845095 & 11.0308 & 11.035 & TRN & \\
\hline CHEMBL2133181 & 845095 & 11.7167 & 11.7075 & TRN & \\
\hline CHEMBL 2139235 & 845095 & 11.3799 & 12.1134 & TST & \\
\hline CHEMBL2135424 & 845095 & 11.4498 & 12.8391 & TST & \\
\hline CHEMBL1865934 & 845095 & 12.3372 & 11.7487 & TRN & \\
\hline CHEMBL2137680 & 845095 & 10.388 & 11.7155 & TST & \\
\hline CHEMBL 2138501 & 845095 & 12.0496 & 12.0944 & TRN & \\
\hline CHEMBL 2134880 & 845095 & 11.5662 & 11.35406 & 00000000001 & TST \\
\hline CHEMBL2133979 & 845095 & 12.1543 & 12.5191 & TRN & \\
\hline CHEMBL2137849 & 845095 & 11.1487 & 11.3939 & TRN & \\
\hline CHEMBL1565753 & 845095 & 11.8447 & 11.245 & TRN & \\
\hline CHEMBL2142519 & 845095 & 11.7282 & 12.0903 & TRN & \\
\hline CHEMBL2134144 & 845095 & 11.2204 & 11.0454 & TRN & \\
\hline CHEMBL2133411 & 845095 & 11.0521 & 11.5993 & TST & \\
\hline CHEMBL1884699 & 845095 & 11.0737 & 11.1048 & TST & \\
\hline CHEMBL1867569 & 845095 & 11.7905 & 12.0492 & TRN & \\
\hline CHEMBL 2143184 & 845095 & 11.0255 & 12.5628 & TST & \\
\hline CHEMBL2134161 & 845095 & 11.5969 & 11.5208 & TRN & \\
\hline CHEMBL2131986 & 845095 & 11.1169 & 11.1572 & TRN & \\
\hline CHEMBL2143182 & 845095 & 12.2125 & 11.4379 & TRN & \\
\hline CHEMBL2134695 & 845095 & 11.1878 & 11.6096 & TST & \\
\hline CHEMBL1900518 & 845095 & 11.4168 & 11.2142 & TRN & \\
\hline CHEMBL2142058 & 845095 & 11.9136 & 11.7516 & TRN & \\
\hline CHEMBL 2140364 & 845095 & 11.5719 & 11.5664 & TRN & \\
\hline CHEMBL2138719 & 845095 & 11.0872 & 11.1568 & TRN & \\
\hline CHEMBL2135201 & 845095 & 12.2984 & 12.2809 & 99999999999 & TRN \\
\hline CHEMBL2140595 & 845095 & 12.1778 & 10.9044 & TRN & \\
\hline CHEMBL2141666 & 845095 & 10.6388 & 11.9732 & TRN & \\
\hline CHEMBL 2130718 & 845095 & 10.6312 & 11.3686 & TST & \\
\hline CHEMBL2130929 & 845095 & 11.8386 & 11.8835 & TRN & \\
\hline CHEMBL2135979 & 845095 & 12.0696 & $12.2190 t$ & 00000000001 & TRN \\
\hline CHEMBL 2137394 & 845095 & 12.1035 & 11.3724 & TRN & \\
\hline CHEMBL2139895 & 845095 & 11.8665 & 11.2481 & TST & \\
\hline CHEMBL 2140567 & 845095 & 11.5638 & 11.7415 & TRN & \\
\hline CHEMBL2142391 & 845095 & 12.2676 & 11.5319 & TRN & \\
\hline CHEMBL2132766 & 845095 & 11.1433 & 11.2748 & TRN & \\
\hline CHEMBL2142496 & 845095 & 11.7447 & 12.0022 & TRN & \\
\hline CHEMBL2131595 & 845095 & 11.7799 & 11.5388 & TRN & \\
\hline CHEMBL2141052 & 845095 & 11.7747 & 12.6551 & TRN & \\
\hline CHEMBL1565361 & 845095 & 11.7167 & 9.3826 & TST & \\
\hline CHEMBL2138113 & 845095 & 12.2034 & 12.1528 & TRN & \\
\hline CHEMBL2138502 & 845095 & 11.1945 & 11.2037 & TRN & \\
\hline CHEMBL2132526 & 845095 & 9.5952 & 10.4998 & TRN & \\
\hline CHEMBL2138693 & 845095 & 12.1568 & 11.2197 & TRN & \\
\hline
\end{tabular}

Page 11901 


\begin{tabular}{|c|c|c|c|c|c|c|c|}
\hline \multicolumn{8}{|c|}{ Supplemental Table S2.txt } \\
\hline CHEMBL2135699 & 845095 & 11.8386 & 11.5328 & TRN & & & \\
\hline CHEMBL 2132333 & 845095 & 11.7986 & 11.6128 & TRN & & & \\
\hline CHEMBL2142216 & 845095 & 11.4776 & 11.7075 & TRN & & & \\
\hline CHEMBL 2142712 & 845095 & 11.7747 & 12.1988 & TRN & & & \\
\hline CHEMBL2142245 & 845095 & 10.9634 & 11.431 & TST & & & \\
\hline CHEMBL 2136218 & 845095 & 11.5654 & 11.382 & TRN & & & \\
\hline CHEMBL 2141796 & 845095 & 10.9918 & 10.6351 & TRN & & & \\
\hline CHEMBL2140166 & 845095 & 10.3945 & 9.8041 & TRN & & & \\
\hline CHEMBL 2131314 & 845095 & 12.4056 & 12.1027 & TST & & & \\
\hline CHEMBL1971465 & 845095 & 11.6383 & 11.3648 & TRN & & & \\
\hline CHEMBL2137928 & 845095 & 10.9176 & 11.4114 & TRN & & & \\
\hline CHEMBL 2135811 & 845095 & 11.4389 & 12.0492 & TRN & & & \\
\hline CHEMBL 2132650 & 845095 & 11.4413 & 11.72206 & 20000000001 & & TRN & \\
\hline CHEMBL 2141998 & 845095 & 11.9872 & 10.0027 & TRN & & & \\
\hline CHEMBL 2137688 & 845095 & 11.6271 & 11.384 & TRN & & & \\
\hline CHEMBL 2139052 & 845095 & 11.3401 & 11.4002 & TRN & & & \\
\hline CHEMBL2133585 & 845095 & 11.6055 & 11.0108 & TRN & & & \\
\hline CHEMBL 2135227 & 845095 & 10.3547 & 11.8399 & TST & & & \\
\hline CHEMBL1325873 & 845095 & 11.1238 & 11.8962 & TST & & & \\
\hline CHEMBL 2139350 & 845095 & 11.5346 & 11.8867 & TRN & & & \\
\hline CHEMBL 2134322 & 845095 & 8.0348 & 11.3566 & TST & & & \\
\hline CHEMBL2139197 & 845095 & 11.6126 & 11.0137 & TRN & & & \\
\hline CHEMBL 2137696 & 845095 & 11.0414 & 11.7392 & TRN & & & \\
\hline CHEMBL2135657 & 845095 & 11.69900 & 300000006 & 002 & 0.7995 & TST & \\
\hline CHEMBL 2136204 & 845095 & 11.821 & 12.4059 & 9999999999 & & TST & \\
\hline CHEMBL 2132316 & 845095 & 11.8348 & 11.802 & TST & & & \\
\hline CHEMBL2132529 & 845095 & 11.4921 & 11.7616 & TST & & & \\
\hline CHEMBL 2136603 & 845095 & 11.3696 & 11.2928 & TST & & & \\
\hline CHEMBL409345 & 468987 & 4.3917 & 4.2783 & TRN & & & \\
\hline CHEMBL 270551 & 468987 & 5.7496 & 5.5343 & TRN & & & \\
\hline CHEMBL429762 & 468987 & 2.3985 & 3.0385 & TRN & & & \\
\hline CHEMBL429783 & 468987 & 4.1341 & 4.2051 & TRN & & & \\
\hline CHEMBL 272178 & 468987 & 3.5669 & 3.9697 & TRN & & & \\
\hline CHEMBL402449 & 468987 & 2.3807 & 2.5324 & TRN & & & \\
\hline CHEMBL 271742 & 468987 & 5.1765 & 5.1331 & TRN & & & \\
\hline CHEMBL 273056 & 468987 & 5.2757 & 5.2761 & TRN & & & \\
\hline CHEMBL406233 & 468987 & 2.2489 & 2.1194 & TRN & & & \\
\hline CHEMBL485807 & 468987 & 5.0343 & 5.1295 & TRN & & & \\
\hline CHEMBL406654 & 468987 & 5.4535 & 5.4977 & TRN & & & \\
\hline CHEMBL1257707 & 468987 & 5.4535 & 5.3186 & TRN & & & \\
\hline CHEMBL411908 & 468987 & 4.4753 & 4.588 & TRN & & & \\
\hline CHEMBL490324 & 468987 & 3.4421 & 3.1836 & TRN & & & \\
\hline CHEMBL272639 & 468987 & 3.6964 & 3.1772 & TST & & & \\
\hline CHEMBL 270297 & 468987 & 4.9416 & 5.1394 & TRN & & & \\
\hline CHEMBL509159 & 468987 & 3.5996 & 3.4952 & TRN & & & \\
\hline CHEMBL409627 & 468987 & 5.0516 & 4.9198 & TRN & & & \\
\hline CHEMBL 248564 & 468987 & 3.603999 & 99999999 & 996 & .768000 & 00000000002 & TST \\
\hline CHEMBL406391 & 468987 & 3.9161 & 4.1106 & TRN & & & \\
\hline
\end{tabular}




\begin{tabular}{|c|c|c|c|c|c|}
\hline \multicolumn{6}{|c|}{ Supplemental Table S2.txt } \\
\hline CHEMBL272222 & 468987 & 5.1993 & 5.1379 & TRN & \\
\hline CHEMBL271959 & 468987 & 2.3429 & 2.8807 & TST & \\
\hline CHEMBL270061 & 468987 & 4.9935 & 5.0829 & TST & \\
\hline CHEMBL272221 & 468987 & 5.2175 & 5.2808 & TRN & \\
\hline CHEMBL401149 & 468987 & 3.8884 & 4.1526 & TST & \\
\hline CHEMBL272177 & 468987 & 2.6784 & 2.6551 & TRN & \\
\hline CHEMBL270060 & 468987 & 4.356 & 3.5876 & TST & \\
\hline CHEMBL430091 & 468987 & 4.5691 & 4.7329 & TST & \\
\hline CHEMBL270307 & 468987 & 5.2351 & 5.2447 & TRN & \\
\hline CHEMBL271164 & 468987 & 2.8706 & 3.16399 & 99999999997 & TRN \\
\hline CHEMBL408129 & 468987 & 2.2117 & 2.77600 & 00000000002 & TST \\
\hline CHEMBL407710 & 468987 & 3.99399 & 99999999 & 4.0046 & TRN \\
\hline CHEMBL463559 & 468987 & 5.3298 & 5.1739 & TRN & \\
\hline CHEMBL270742 & 468987 & 5.1494 & 5.2772 & TRN & \\
\hline CHEMBL 206765 & 468987 & 5.0575 & 4.8861 & TRN & \\
\hline CHEMBL270743 & 468987 & 2.6996 & 2.6354 & TRN & \\
\hline CHEMBL409039 & 468987 & 3.5564 & 4.5243 & TST & \\
\hline CHEMBL271958 & 468987 & 4.654 & 4.4787 & TST & \\
\hline CHEMBL338474 & 468987 & 5.3686 & 5.1211 & TRN & \\
\hline CHEMBL 259471 & 468987 & 4.7513 & 4.8355 & TRN & \\
\hline CHEMBL269841 & 468987 & 4.6794 & 4.129 & TST & \\
\hline CHEMBL405877 & 468987 & 5.2388 & 5.0572 & TST & \\
\hline CHEMBL3186408 & 468987 & 5.5186 & 5.0845 & TRN & \\
\hline CHEMBL 273055 & 468987 & 4.2213 & 4.4426 & TRN & \\
\hline CHEMBL411470 & 468987 & 4.573 & 4.7273 & TRN & \\
\hline CHEMBL410453 & 468987 & 5.0214 & 4.9586 & TRN & \\
\hline CHEMBL264922 & 468987 & 5.6904 & 5.443 & TST & \\
\hline CHEMBL410051 & 468987 & 2.384 & 2.0046 & TRN & \\
\hline CHEMBL272870 & 468987 & 4.9948 & 5.29799 & 9999999999 & TRN \\
\hline CHEMBL 272445 & 468987 & 4.2394 & 3.7692 & TRN & \\
\hline CHEMBL89311 & 468987 & 4.0709 & 4.1418 & TRN & \\
\hline CHEMBL406387 & 468987 & 2.3115 & 3.3787 & TST & \\
\hline CHEMBL137803 & 468987 & 2.2872 & 2.2394 & TRN & \\
\hline CHEMBL 3347493 & 1390741 & 8.699 & 8.6038 & TST & \\
\hline CHEMBL3347505 & 1390741 & 8.5376 & 8.6522 & TRN & \\
\hline CHEMBL3347536 & 1390741 & 8.6383 & 8.5457 & TRN & \\
\hline CHEMBL3347382 & 1390741 & 8.0862 & 8.5462 & TRN & \\
\hline CHEMBL3347517 & 1390741 & 8.4202 & 8.5457 & TRN & \\
\hline CHEMBL 3347278 & 1390741 & 8.4949 & 8.6522 & TRN & \\
\hline CHEMBL3347533 & 1390741 & 8.6778 & 8.5457 & TRN & \\
\hline CHEMBL3347518 & 1390741 & 9.301 & 8.5457 & TRN & \\
\hline CHEMBL3347587 & 1390741 & 8.4559 & 8.1674 & TRN & \\
\hline CHEMBL3347336 & 1390741 & 6.4815 & 8.5457 & TRN & \\
\hline CHEMBL 3347307 & 1390741 & 8.7212 & 8.3926 & TST & \\
\hline CHEMBL 3347296 & 1390741 & 8.7212 & 9.0521 & TRN & \\
\hline CHEMBL3347325 & 1390741 & 6.4815 & 8.1674 & TRN & \\
\hline CHEMBL3347609 & 1390741 & 8.6576 & 8.5462 & TRN & \\
\hline CHEMBL3347653 & 1390741 & 8.6198 & 8.6522 & TRN & \\
\hline
\end{tabular}


Supplemental Table S2.txt

\begin{tabular}{|c|c|c|c|c|}
\hline . & 390741 & & & \\
\hline & & 8.5376 & & \\
\hline & & & & \\
\hline AEMBL3 & & 6021 & & \\
\hline IEMBL 33 & 390741 & 559 & & \\
\hline HEMBL3347327 & 390741 & 8.5528 & 5457 & \\
\hline HEMBL & 390741 & 372 & & \\
\hline 39 & & & & \\
\hline HEMBL33 & 390741 & 8.9586 & & \\
\hline HEMBL33 & 390741 & & & \\
\hline AEMBL3: & 390741 & 8.6021 & 22 & \\
\hline IEMBL: & 390741 & 239 & & \\
\hline AEMBL & & & & \\
\hline HEMBL3. & 390 & 376 & 3506 & \\
\hline AEMBL3 & 390741 & & & \\
\hline AEMBL3 & 390 & 8. & 46 & \\
\hline HEMBL & +1 & 29 & & \\
\hline HEMBL; & & & & \\
\hline HEMBL3 & 390741 & & & \\
\hline AEMBL3 & 41 & & & \\
\hline AEMIBL & 390 & 9. & 57 & Niv \\
\hline AEMBL & $\perp$ & & & RN \\
\hline HEMBL & & & & \\
\hline AFMRI & & 8 & & \\
\hline AEMBL3 & & & & I RIV \\
\hline HEMBL & 39 & & 73 & | \\
\hline HEMBL & \pm & & 73 & ST \\
\hline HFMRI & 41 & & & \\
\hline HEMBL3 & & & & RIV \\
\hline HEMBL3 & & & & I RN \\
\hline HEMBL3 & 1 & 861 & 162 & RN \\
\hline HEMBL & 1 & 39 & & RN \\
\hline HEMBL & 1 & & 62 & Pח \\
\hline HEMBL3 & & & 462 & IRN \\
\hline HEMBL33 & 90741 & 8 . & 5069 & TST \\
\hline HEMBL & 0 & & 522 & TRN \\
\hline HCMDI & & & & \\
\hline HEMBL & & & 3679 & IRN \\
\hline HEMBL3 & 390741 & 7. & 212 & TST \\
\hline EMBL. & $\perp$ & & & IRN \\
\hline HEMBL3 & +1 & 8 & 243 & \\
\hline CHEMBL3 & 1390741 & 5 . & & ГST \\
\hline HEMBL3 & 390741 & 8.16 & 8.5457 & RN \\
\hline HEMBL3 & 390741 & 7.8239 & 5462 & TR \\
\hline 1. & & & & \\
\hline HEMBL3 & 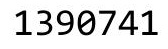 & & & \\
\hline CHEMBL3 & 390741 & 7.2366 & 8.5076 & \\
\hline LHEMBL 3347294 & 1390741 & 6.5528 & 7.869 & ГRN \\
\hline
\end{tabular}

Page 11904 
Supplemental Table S2.txt

\begin{tabular}{|c|c|c|c|c|c|}
\hline CHEMBL 3347535 & 1390741 & 8.6021 & 8.5457 & TRN & \\
\hline CHEMBL3347319 & 1390741 & 8.7212 & 8.5462 & TRN & \\
\hline CHEMBL3347328 & 1390741 & 9.3979 & 8.3922 & TST & \\
\hline CHEMBL3347559 & 1390741 & 8.6021 & 8.024 & TRN & \\
\hline CHEMBL3347588 & 1390741 & 8.4202 & 8.5457 & TRN & \\
\hline CHEMBL3347485 & 1390741 & 8.5686 & 8.6522 & TRN & \\
\hline CHEMBL3347350 & 1390741 & 6.4949 & 6.59 & TRN & \\
\hline CHEMBL3347326 & 1390741 & 6.6383 & 8.5457 & TRN & \\
\hline CHEMBL3347362 & 1390741 & 8.301 & 8.5457 & TST & \\
\hline CHEMBL3347353 & 1390741 & 7.699 & 8.5457 & TST & \\
\hline CHEMBL605624 & 1390741 & 9.0 & 8.6522 & TST & \\
\hline CHEMBL3910815 & 1638064 & 6.4737 & 6.5595 & TRN & \\
\hline CHEMBL93960 & 1638064 & 7.3872 & 7.5148 & TRN & \\
\hline CHEMBL3983217 & 1638064 & 8.0458 & 7.7626 & TRN & \\
\hline CHEMBL328066 & 1638064 & 7.0862 & 6.9202 & TRN & \\
\hline CHEMBL3947447 & 1638064 & 7.1427 & 6.9361 & TRN & \\
\hline CHEMBL3910303 & 1638064 & 7.7212 & 7.4335 & TRN & \\
\hline CHEMBL91236 & 1638064 & 7.0177 & 6.9524 & TRN & \\
\hline CHEMBL316101 & 1638064 & 7.2291 & 7.0061 & TRN & \\
\hline CHEMBL327683 & 1638064 & 6.8182 & 6.9743 & TST & \\
\hline CHEMBL3944828 & 1638064 & 8.0 & 7.9779 & TRN & \\
\hline CHEMBL1199648 & 1638064 & 6.7258 & 6.4366 & TRN & \\
\hline CHEMBL3966591 & 1638064 & 7.7959 & 7.5957 & TRN & \\
\hline CHEMBL90185 & 1638064 & 7.9208 & 7.5901 & TRN & \\
\hline CHEMBL3945053 & 1638064 & 7.1487 & 7.3257 & TRN & \\
\hline CHEMBL205821 & 1638064 & 6.2262 & 7.4101 & TST & \\
\hline CHEMBL327207 & 1638064 & 7.0 & 7.2728 & TRN & \\
\hline CHEMBL3930460 & 1638064 & 7.7212 & 7.7861 & TST & \\
\hline CHEMBL91423 & 1638064 & 8.0458 & 8.1167 & TRN & \\
\hline CHEMBL3913186 & 1638064 & 7.3768 & 7.5018 & TRN & \\
\hline CHEMBL3968852 & 1638064 & 7.6576 & 7.6435 & TST & \\
\hline CHEMBL3895160 & 1638064 & 6.8477 & 7.1492 & TRN & \\
\hline CHEMBL 88540 & 1638064 & 7.7959 & 7.6686 & TRN & \\
\hline CHEMBL3907290 & 1638064 & 7.6383 & 7.6772 & TRN & \\
\hline CHEMBL90914 & 1638064 & 7.6021 & 7.6038 & TRN & \\
\hline CHEMBL330110 & 1638064 & 7.3979 & 7.6707 & TRN & \\
\hline CHEMBL3906503 & 1638064 & 7.4318 & \multicolumn{2}{|c|}{7.4639999999999995} & TRN \\
\hline CHEMBL316450 & 1638064 & 6.75700 & 00000000 & 6.6759 & TRN \\
\hline CHEMBL3917051 & 1638064 & 6.4191 & 6.8801 & TRN & \\
\hline CHEMBL3928643 & 1638064 & 7.699 & 7.598 & TRN & \\
\hline CHEMBL197579 & 1638064 & 6.2644 & 6.9876 & TRN & \\
\hline CHEMBL199253 & 1638064 & 7.8239 & 7.4438 & TRN & \\
\hline CHEMBL197674 & 1638064 & 7.8861 & 7.8706 & TRN & \\
\hline CHEMBL371926 & 1638064 & 8.0458 & 8.0076 & TRN & \\
\hline CHEMBL91305 & 1638064 & 7.0223 & 7.2044 & TRN & \\
\hline CHEMBL3917557 & 1638064 & 8.2007 & 8.1853 & TRN & \\
\hline CHEMBL90268 & 1638064 & 7.699 & 7.4487 & TRN & \\
\hline CHEMBL3976524 & 1638064 & 7.3665 & 7.5327 & TRN & \\
\hline
\end{tabular}

Page 11905 


\begin{tabular}{|c|c|c|c|c|c|}
\hline \multicolumn{6}{|c|}{ Supplemental Table S2.txt } \\
\hline CHEMBL90589 & 1638064 & 7.0555 & 7.3276 & TRN & \\
\hline CHEMBL 3926784 & 1638064 & 7.9586 & 7.6101 & TRN & \\
\hline CHEMBL430839 & 1638064 & 7.3768 & 7.5918 & TRN & \\
\hline CHEMBL 372185 & 1638064 & 7.8239 & 7.6818 & TRN & \\
\hline CHEMBL 3954160 & 1638064 & 5.8447 & 6.3862 & TRN & \\
\hline CHEMBL 3960740 & 1638064 & 8.1367 & 7.9121 & TST & \\
\hline CHEMBL440211 & 1638064 & 7.6576 & 7.4396 & TRN & \\
\hline CHEMBL315868 & 1638064 & 8.0969 & 7.7252 & TRN & \\
\hline CHEMBL194235 & 1638064 & 7.3098 & 7.8511 & TRN & \\
\hline CHEMBL3897550 & 1638064 & 7.1675 & 7.0702 & TST & \\
\hline CHEMBL327821 & 1638064 & 7.7212 & 7.4752 & TRN & \\
\hline CHEMBL194207 & 1638064 & 7.9586 & 8.1815 & TRN & \\
\hline CHEMBL1199647 & 1638064 & 7.7696 & 7.2052 & TRN & \\
\hline CHEMBL262735 & 1638064 & 7.9586 & 7.7709 & TRN & \\
\hline CHEMBL314733 & 1638064 & 7.2291 & 7.1635 & TRN & \\
\hline CHEMBL3950285 & 1638064 & 7.6576 & 7.334 & TRN & \\
\hline CHEMBL 92848 & 1638064 & 7.585 & 7.4819 & TRN & \\
\hline CHEMBL1199895 & 1638064 & 6.1931 & 5.8643 & TRN & \\
\hline CHEMBL314096 & 1638064 & 7.699 & 7.36799 & 9999999999 & TRN \\
\hline CHEMBL3961549 & 1638064 & 7.9586 & 8.0143 & TRN & \\
\hline CHEMBL316102 & 1638064 & 6.6345 & 7.2467 & TRN & \\
\hline CHEMBL3934331 & 1638064 & 7.7696 & 8.1179 & TRN & \\
\hline CHEMBL3927125 & 1638064 & 8.1308 & 7.6538 & TST & \\
\hline CHEMBL91281 & 1638064 & 7.9586 & 7.9391 & TRN & \\
\hline CHEMBL3983710 & 1638064 & 7.1079 & 7.2559 & TRN & \\
\hline CHEMBL315954 & 1638064 & 6.9031 & 7.2078 & TRN & \\
\hline CHEMBL 3914770 & 1638064 & 7.6021 & 7.7889 & TST & \\
\hline CHEMBL91442 & 1638064 & 7.0706 & 7.1028 & TRN & \\
\hline CHEMBL197242 & 1638064 & 7.1549 & 6.8886 & TST & \\
\hline CHEMBL330534 & 1638064 & 7.8861 & 7.4618 & TST & \\
\hline CHEMBL196266 & 1638064 & 7.6021 & 7.5857 & TST & \\
\hline CHEMBL3922955 & 1638064 & 7.4815 & 7.4162 & TST & \\
\hline CHEMBL3909635 & 1638064 & 7.7212 & 7.5765 & TST & \\
\hline CHEMBL88795 & 1638064 & 7.9586 & 7.7344 & TST & \\
\hline CHEMBL382967 & 1638064 & 8.1549 & 8.2015 & TST & \\
\hline CHEMBL 3981787 & 1638064 & 7.1549 & 7.4094 & TST & \\
\hline CHEMBL 3951248 & 1638064 & 6.5952 & 7.0748 & TST & \\
\hline CHEMBL90516 & 1638064 & 6.6556 & 6.9418 & TST & \\
\hline CHEMBL 3977587 & 1638064 & 8.2218 & 8.1754 & TST & \\
\hline CHEMBL92355 & 1638064 & 5.9393 & 7.0953 & TST & \\
\hline CHEMBL3329737 & 1457820 & 6.0315 & 5.4685 & TRN & \\
\hline CHEMBL3329763 & 1457820 & 6.8239 & 6.2507 & TRN & \\
\hline CHEMBL3329740 & 1457820 & 6.1192 & 5.9545 & TRN & \\
\hline CHEMBL3329746 & 1457820 & 5.585 & 5.5874 & TRN & \\
\hline CHEMBL3329729 & 1457820 & 5.6198 & 5.0458 & TRN & \\
\hline CHEMBL3329736 & 1457820 & 6.0132 & 5.2234 & TST & \\
\hline CHEMBL1602658 & 1457820 & 5.0 & 4.8108 & TRN & \\
\hline CHEMBL3329723 & 1457820 & 4.0 & 4.8229 & TST & \\
\hline
\end{tabular}


Supplemental Table S2.txt

\begin{tabular}{|c|c|c|c|c|c|}
\hline CHEMBL3329754 & 1457820 & 6.4559 & 6.1422 & TRN & \\
\hline CHEMBL3329732 & 1457820 & 5.5229 & 4.8935 & TRN & \\
\hline CHEMBL3329738 & 1457820 & 5.9547 & 5.3416 & TST & \\
\hline CHEMBL3329761 & 1457820 & 4.0 & 6.1033 & TRN & \\
\hline CHEMBL3329764 & 1457820 & 6.9208 & 6.1896 & TRN & \\
\hline CHEMBL3329750 & 1457820 & 6.1938 & 5.9513 & TRN & \\
\hline CHEMBL3329731 & 1457820 & 5.7696 & 5.4876 & TRN & \\
\hline CHEMBL3329752 & 1457820 & 5.2518 & 5.6704 & TRN & \\
\hline CHEMBL3329756 & 1457820 & 6.7959 & 6.2276 & TRN & \\
\hline CHEMBL3329745 & 1457820 & 5.7959 & 5.6949 & TRN & \\
\hline CHEMBL3329730 & 1457820 & 5.7959 & 5.6699 & TRN & \\
\hline CHEMBL3329755 & 1457820 & 6.7212 & 6.144 & TRN & \\
\hline CHEMBL3329725 & 1457820 & 4.0 & 4.5078 & TRN & \\
\hline CHEMBL3329719 & 1457820 & 4.0 & 4.6849 & TRN & \\
\hline CHEMBL3329744 & 1457820 & 5.6778 & 5.8681 & TRN & \\
\hline CHEMBL3329716 & 1457820 & 5.4815 & 4.7277 & TRN & \\
\hline CHEMBL3329717 & 1457820 & 5.5086 & 4.7374 & TRN & \\
\hline CHEMBL3329748 & 1457820 & 6.0605 & 5.909 & TRN & \\
\hline CHEMBL3329724 & 1457820 & 4.0 & 4.7158 & TRN & \\
\hline CHEMBL3329741 & 1457820 & 6.1308 & 6.0641 & TRN & \\
\hline CHEMBL3329726 & 1457820 & 4.0 & 4.5192 & TRN & \\
\hline CHEMBL3329727 & 1457820 & 4.0 & 4.644 & TST & \\
\hline CHEMBL3329765 & 1457820 & 6.9208 & 6.1899 & TRN & \\
\hline CHEMBL3329720 & 1457820 & 4.0 & 4.749 & TST & \\
\hline CHEMBL3329715 & 1457820 & 5.2076 & 4.5509 & TST & \\
\hline CHEMBL3329747 & 1457820 & 6.0605 & 5.6626 & TRN & \\
\hline CHEMBL3329751 & 1457820 & 6.3188 & 6.0512 & TRN & \\
\hline CHEMBL3329743 & 1457820 & 5.8239 & 5.575 & TRN & \\
\hline CHEMBL3329766 & 1457820 & 6.8861 & 6.2392 & TRN & \\
\hline CHEMBL3329742 & 1457820 & 4.0 & 5.4885 & TRN & \\
\hline CHEMBL3329733 & 1457820 & 4.0 & 4.8696 & TST & \\
\hline CHEMBL3329749 & 1457820 & 6.1249 & 5.7969 & TRN & \\
\hline CHEMBL3329758 & 1457820 & 4.0 & 6.19600 & 0000000001 & TRN \\
\hline CHEMBL3329739 & 1457820 & 6.1367 & 5.3469 & TST & \\
\hline CHEMBL3329718 & 1457820 & 4.0 & 4.6415 & TST & \\
\hline CHEMBL3329762 & 1457820 & 5.8861 & 6.1732 & TRN & \\
\hline CHEMBL3329722 & 1457820 & 4.0 & 4.7929 & TST & \\
\hline CHEMBL3329757 & 1457820 & 5.7447 & 6.2171 & TRN & \\
\hline CHEMBL3329734 & 1457820 & 5.1308 & 4.854 & TST & \\
\hline CHEMBL3329760 & 1457820 & 5.7447 & 6.1575 & TRN & \\
\hline CHEMBL3329728 & 1457820 & 4.0 & 4.9866 & TST & \\
\hline CHEMBL3329721 & 1457820 & 4.0 & 4.8204 & TST & \\
\hline CHEMBL1802575 & 755720 & 7.2676 & 7.3996 & TRN & \\
\hline CHEMBL1803058 & 755720 & 6.6576 & 6.8779 & TRN & \\
\hline CHEMBL1803066 & 755720 & 5.0 & 5.1795 & TRN & \\
\hline CHEMBL1802494 & 755720 & 6.6198 & 6.2737 & TRN & \\
\hline CHEMBL1802568 & 755720 & 6.0362 & 5.4619 & TRN & \\
\hline CHEMBL1803061 & 755720 & 5.0 & 5.0606 & TRN & \\
\hline
\end{tabular}


Supplemental Table S2.txt

\begin{tabular}{|c|c|c|c|c|}
\hline CHEMBL1802505 & 755720 & 6.7696 & 6.6849 & TRN \\
\hline CHEMBL1802560 & 755720 & 7.4089 & 7.3764 & TRN \\
\hline CHEMBL1802562 & 755720 & 6.2757 & 6.4931 & TRN \\
\hline CHEMBL1802515 & 755720 & 6.4437 & 6.5687 & TRN \\
\hline CHEMBL1802503 & 755720 & 8.0 & 7.9281 & TRN \\
\hline CHEMBL1802996 & 755720 & 7.7696 & 7.6538 & TRN \\
\hline CHEMBL1802504 & 755720 & 7.3188 & 7.2027 & TRN \\
\hline CHEMBL1802997 & 755720 & 7.4089 & 7.4901 & TRN \\
\hline CHEMBL1802995 & 755720 & 6.8239 & 6.9266 & TST \\
\hline CHEMBL1803065 & 755720 & 5.0 & 5.2666 & TRN \\
\hline CHEMBL1802571 & 755720 & 6.5376 & 6.352 & TST \\
\hline CHEMBL1802495 & 755720 & 5.0 & 5.2652 & TRN \\
\hline CHEMBL1802576 & 755720 & 7.0315 & 6.9113 & TRN \\
\hline CHEMBL1802999 & 755720 & 7.3872 & 7.6206 & TRN \\
\hline CHEMBL1803059 & 755720 & 5.0 & 4.9406 & TRN \\
\hline CHEMBL1802583 & 755720 & 6.8861 & 7.1686 & TRN \\
\hline CHEMBL1802563 & 755720 & 5.0 & 5.3509 & TST \\
\hline CHEMBL1803060 & 755720 & 5.0 & 4.8942 & TRN \\
\hline CHEMBL1802578 & 755720 & 6.4559 & 6.53 & TRN \\
\hline CHEMBL1802514 & 755720 & 7.3665 & 7.4469 & TRN \\
\hline CHEMBL1802567 & 755720 & 6.2441 & 5.4967 & TRN \\
\hline CHEMBL1802510 & 755720 & 8.3979 & 8.5051 & TRN \\
\hline CHEMBL1802557 & 755720 & 6.9208 & 7.0159 & TRN \\
\hline CHEMBL1802582 & 755720 & 7.2147 & 7.1548 & TRN \\
\hline CHEMBL1802558 & 755720 & 7.2291 & 7.1273 & TRN \\
\hline CHEMBL1802499 & 755720 & 7.6198 & \multicolumn{2}{|c|}{7.696000000000001} \\
\hline CHEMBL1802584 & 755720 & 7.6198 & 7.517 & TRN \\
\hline CHEMBL1802512 & 755720 & 7.3279 & 7.3325 & TRN \\
\hline CHEMBL1802513 & 755720 & 7.8239 & 7.636 & TRN \\
\hline CHEMBL1802561 & 755720 & 7.0177 & 6.9138 & TRN \\
\hline CHEMBL1800100 & 755720 & 7.0 & 7.0501 & TRN \\
\hline CHEMBL1802496 & 755720 & 5.0 & 5.0066 & TRN \\
\hline CHEMBL1802993 & 755720 & 7.4685 & 7.4711 & TRN \\
\hline CHEMBL1802573 & 755720 & 5.0 & 5.1317 & TRN \\
\hline CHEMBL1802501 & 755720 & 8.0362 & 8.0561 & TRN \\
\hline CHEMBL1802508 & 755720 & 7.3468 & 7.5098 & TRN \\
\hline CHEMBL1802498 & 755720 & 7.5686 & 7.5786 & TRN \\
\hline CHEMBL1802500 & 755720 & 7.9208 & 8.0118 & TRN \\
\hline CHEMBL1802580 & 755720 & 5.0 & 5.5986 & TRN \\
\hline CHEMBL1803057 & 755720 & 5.0 & 5.0114 & TRN \\
\hline CHEMBL1803064 & 755720 & 5.0 & 4.9975 & TRN \\
\hline CHEMBL1802511 & 755720 & 8.0862 & 8.1453 & TRN \\
\hline CHEMBL1803062 & 755720 & 5.0 & 5.0868 & TRN \\
\hline CHEMBL1802569 & 755720 & 6.8861 & \multicolumn{2}{|c|}{6.9239999999999995} \\
\hline CHEMBL1802992 & 755720 & 7.3468 & 7.374 & TRN \\
\hline CHEMBL1802994 & 755720 & 7.3979 & 7.4133 & TRN \\
\hline CHEMBL1802564 & 755720 & 7.2366 & 7.0316 & TRN \\
\hline CHEMBL1802566 & 755720 & 6.9586 & 6.8164 & TRN \\
\hline
\end{tabular}


Supplemental Table S2.txt

\begin{tabular}{|c|c|c|c|c|}
\hline CHEMBL1802565 & 755720 & 7.0506 & 6.8939 & TRN \\
\hline CHEMBL1802509 & 755720 & 8.3665 & 8.2443 & TRN \\
\hline CHEMBL1802574 & 755720 & 7.585 & 7.5167 & TRN \\
\hline CHEMBL1802502 & 755720 & 7.5086 & 7.3675 & TRN \\
\hline CHEMBL1802998 & 755720 & 8.0706 & 8.0179 & TRN \\
\hline CHEMBL67 & 755720 & 8.3665 & 7.8021 & TST \\
\hline CHEMBL1803000 & 755720 & 7.5086 & 7.5553 & TRN \\
\hline CHEMBL1802507 & 755720 & 7.8239 & 7.626 & TST \\
\hline CHEMBL441724 & 755720 & 6.6383 & 6.876 & TST \\
\hline CHEMBL1803003 & 755720 & 7.8239 & 7.5959 & TST \\
\hline CHEMBL1802579 & 755720 & 5.0 & 5.5276 & TST \\
\hline CHEMBL1802497 & 755720 & 5.0 & 5.0289 & TST \\
\hline CHEMBL1803001 & 755720 & 6.9208 & 7.13200 & 0000000001 \\
\hline CHEMBL1802581 & 755720 & 7.284 & 7.2497 & TST \\
\hline CHEMBL1803063 & 755720 & 5.0 & 5.0648 & TST \\
\hline CHEMBL1802577 & 755720 & 7.0088 & 7.0695 & TST \\
\hline CHEMBL1802570 & 755720 & 7.1871 & 7.2407 & TST \\
\hline CHEMBL1803002 & 755720 & 7.4559 & 7.5632 & TST \\
\hline CHEMBL1802572 & 755720 & 5.0 & 5.3003 & TST \\
\hline CHEMBL1802506 & 755720 & 7.7959 & 7.6313 & TST \\
\hline CHEMBL1802559 & 755720 & 6.0809 & 6.369 & TST \\
\hline CHEMBL506101 & 560534 & 6.7852 & 6.9457 & TRN \\
\hline CHEMBL461650 & 560534 & 6.7167 & 6.8575 & TRN \\
\hline CHEMBL517417 & 560534 & 6.2007 & 6.5159 & TRN \\
\hline CHEMBL460976 & 560534 & 6.0381 & 6.4887 & TRN \\
\hline CHEMBL459322 & 560534 & 6.4012 & 6.8155 & TRN \\
\hline CHEMBL518178 & 560534 & 6.8794 & 6.15799 & 99999999995 \\
\hline CHEMBL449469 & 560534 & 6.7011 & 7.0584 & TST \\
\hline CHEMBL461858 & 560534 & 5.7501 & 7.0288 & TST \\
\hline CHEMBL467246 & 560534 & 7.6198 & 7.3141 & TRN \\
\hline CHEMBL461649 & 560534 & 6.5867 & 6.7977 & TRN \\
\hline CHEMBL508558 & 560534 & 6.567 & 7.1136 & TST \\
\hline CHEMBL517886 & 560534 & 7.3665 & 7.3146 & TRN \\
\hline CHEMBL511413 & 560534 & 6.3536 & 6.1273 & TRN \\
\hline CHEMBL510134 & 560534 & 6.7423 & 6.7143 & TRN \\
\hline CHEMBL506511 & 560534 & 8.0 & 7.1342 & TRN \\
\hline CHEMBL467035 & 560534 & 6.1979 & 6.6384 & TST \\
\hline CHEMBL467244 & 560534 & 7.1024 & 7.2571 & TRN \\
\hline CHEMBL468701 & 560534 & 6.0778 & 6.7773 & TRN \\
\hline CHEMBL513661 & 560534 & 6.6459 & 7.3502 & TRN \\
\hline CHEMBL467655 & 560534 & 5.8881 & 6.8825 & TST \\
\hline CHEMBL516770 & 560534 & 7.0757 & 7.0496 & TRN \\
\hline CHEMBL468256 & 560534 & 7.2291 & 7.0533 & TRN \\
\hline CHEMBL460799 & 560534 & 7.0555 & 6.8976 & TRN \\
\hline CHEMBL462501 & 560534 & 6.5884 & 6.4742 & TRN \\
\hline CHEMBL516800 & 560534 & 7.6383 & 7.3563 & TRN \\
\hline CHEMBL517429 & 560534 & 6.0424 & 6.0649 & TRN \\
\hline CHEMBL460975 & 560534 & 7.3372 & 6.9172 & TRN \\
\hline
\end{tabular}

Page 11909 


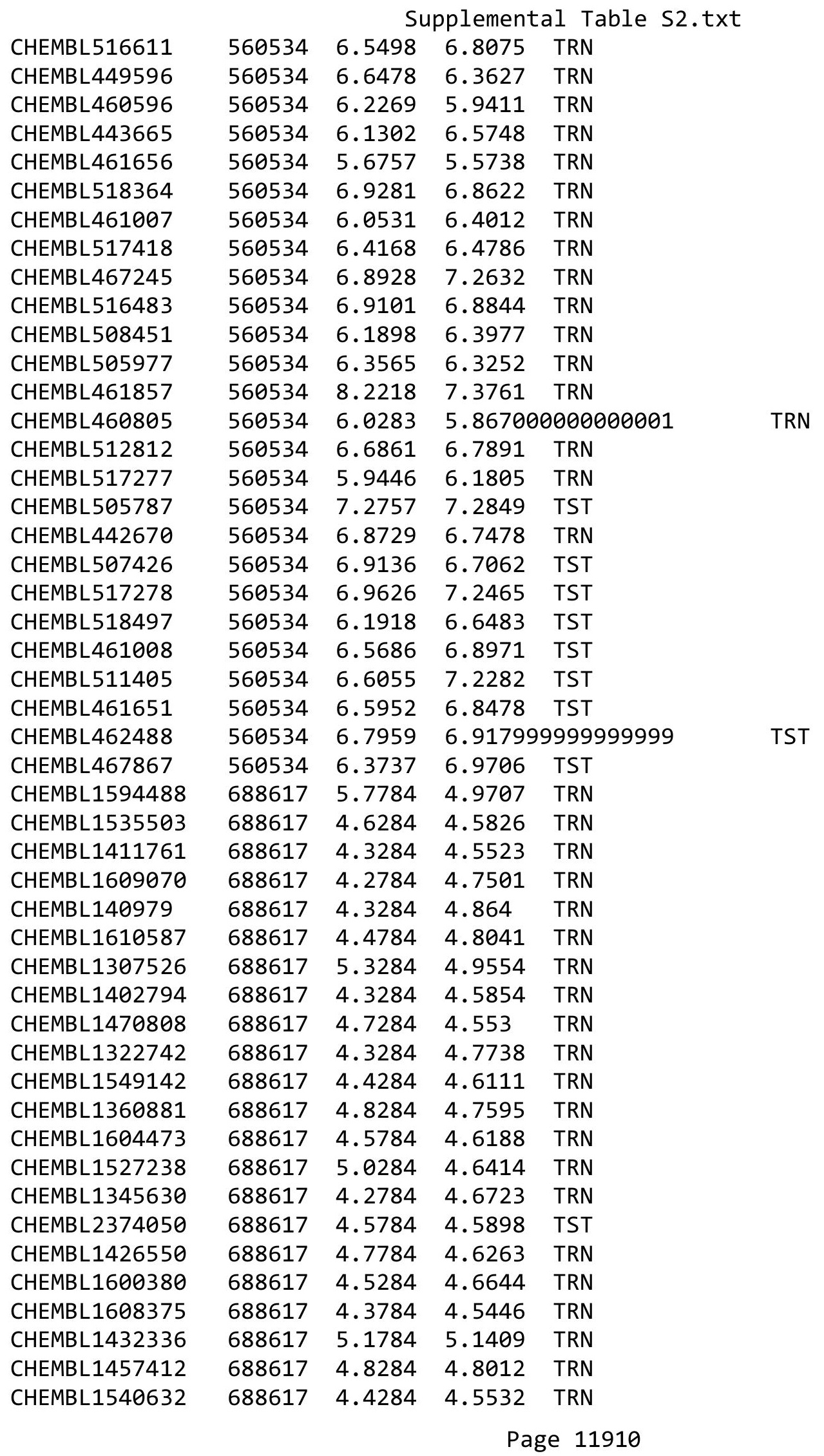




\begin{tabular}{|c|c|c|c|c|c|}
\hline & & \multicolumn{4}{|c|}{ Supplemental Table S2.txt } \\
\hline CHEMBL1423751 & 688617 & 4.9284 & 4.6844 & TRN & \\
\hline CHEMBL1426134 & 688617 & 5.6284 & 4.5598 & TRN & \\
\hline CHEMBL1566507 & 688617 & 4.2784 & 4.6506 & TRN & \\
\hline CHEMBL1564930 & 688617 & 4.7784 & 4.8228 & TRN & \\
\hline CHEMBL1335288 & 688617 & 4.4284 & 5.0958 & TRN & \\
\hline CHEMBL1600326 & 688617 & 5.7784 & 5.1147 & TRN & \\
\hline CHEMBL1528735 & 688617 & 4.4784 & 4.8729 & TRN & \\
\hline CHEMBL1402902 & 688617 & 4.6784 & 4.6158 & TRN & \\
\hline CHEMBL1431575 & 688617 & 4.6784 & 4.6172 & TRN & \\
\hline CHEMBL1423129 & 688617 & 4.2784 & 4.6945 & TRN & \\
\hline CHEMBL1485684 & 688617 & 4.4784 & 4.8829 & TRN & \\
\hline CHEMBL1611955 & 688617 & 4.3284 & 4.5576 & TRN & \\
\hline CHEMBL1489312 & 688617 & 4.7284 & 4.6666 & TRN & \\
\hline CHEMBL1510681 & 688617 & 4.1784 & 4.6152 & TRN & \\
\hline CHEMBL1564339 & 688617 & 4.1784 & 4.5528 & TRN & \\
\hline CHEMBL1390102 & 688617 & 4.2284 & 4.6088 & TRN & \\
\hline CHEMBL1315452 & 688617 & 4.2784 & 4.7361 & TRN & \\
\hline CHEMBL1504221 & 688617 & 4.6784 & 4.8308 & TRN & \\
\hline CHEMBL 1326787 & 688617 & 4.7784 & 4.6394 & TRN & \\
\hline CHEMBL 2374704 & 688617 & 5.348 & 4.5747 & TRN & \\
\hline CHEMBL1372303 & 688617 & 4.6284 & 4.6944 & TRN & \\
\hline CHEMBL1305266 & 688617 & 4.4284 & 4.845 & TRN & \\
\hline CHEMBL1412940 & 688617 & 4.4284 & 4.756 & TRN & \\
\hline CHEMBL1578797 & 688617 & 4.8284 & 5.0708 & TRN & \\
\hline CHEMBL1550642 & 688617 & 4.8284 & 4.57100 & 0000000001 & TRN \\
\hline CHEMBL1591969 & 688617 & 4.2784 & 4.5245 & TRN & \\
\hline CHEMBL1338809 & 688617 & 4.8784 & 4.9087 & TRN & \\
\hline CHEMBL1425290 & 688617 & 5.0784 & 4.665 & TRN & \\
\hline CHEMBL1461615 & 688617 & 4.9284 & 4.6792 & TRN & \\
\hline CHEMBL1555535 & 688617 & 7.9281 & 4.7579 & TST & \\
\hline CHEMBL1332296 & 688617 & 5.2284 & 4.7337 & TRN & \\
\hline CHEMBL1418145 & 688617 & 4.3284 & 4.8006 & TRN & \\
\hline CHEMBL1360144 & 688617 & 5.3284 & 4.8471 & TRN & \\
\hline CHEMBL1604803 & 688617 & 4.3284 & 4.5135 & TRN & \\
\hline CHEMBL1524550 & 688617 & 5.1284 & 4.6151 & TRN & \\
\hline CHEMBL1433233 & 688617 & 4.1784 & 4.5535 & TRN & \\
\hline CHEMBL461431 & 688617 & 4.7284 & 4.5702 & TRN & \\
\hline CHEMBL1539520 & 688617 & 5.4784 & 5.2815 & TRN & \\
\hline CHEMBL1418209 & 688617 & 5.0284 & 4.8942 & TRN & \\
\hline CHEMBL260148 & 688617 & 4.5284 & 5.1633 & TST & \\
\hline CHEMBL1566266 & 688617 & 5.1784 & 4.9136 & TRN & \\
\hline CHEMBL1541779 & 688617 & 4.4284 & 4.5343 & TRN & \\
\hline CHEMBL1525875 & 688617 & 4.6284 & 4.5841 & TRN & \\
\hline CHEMBL1380684 & 688617 & 4.2284 & 4.9262 & TST & \\
\hline CHEMBL1463052 & 688617 & 4.3784 & 4.6296 & TRN & \\
\hline CHEMBL578515 & 688617 & 4.2284 & 4.7053 & TRN & \\
\hline CHEMBL1370648 & 688617 & 4.6284 & 4.8299 & TRN & \\
\hline CHEMBL1537738 & 688617 & 4.3284 & 4.6754 & TRN & \\
\hline
\end{tabular}




\begin{tabular}{|c|c|c|c|c|c|}
\hline & & \multicolumn{4}{|c|}{ Supplemental Table S2.txt } \\
\hline CHEMBL1432087 & 688617 & 4.9284 & 4.6747 & TRN & \\
\hline CHEMBL1453970 & 688617 & 5.1784 & 4.8739 & TRN & \\
\hline CHEMBL1970272 & 688617 & 5.1784 & 4.6447 & TRN & \\
\hline CHEMBL1353907 & 688617 & 4.3284 & 4.5789 & TRN & \\
\hline CHEMBL1410534 & 688617 & 4.3284 & 4.7399 & TRN & \\
\hline CHEMBL388676 & 688617 & 5.0284 & 4.5677 & TST & \\
\hline CHEMBL1563565 & 688617 & 5.0784 & 4.687 & TRN & \\
\hline CHEMBL1608402 & 688617 & 4.8284 & 4.5758 & TRN & \\
\hline CHEMBL1378966 & 688617 & 4.7284 & 4.538 & TST & \\
\hline CHEMBL1519408 & 688617 & 4.5784 & 4.7509 & TRN & \\
\hline CHEMBL1584230 & 688617 & 4.8284 & 5.0985 & TRN & \\
\hline CHEMBL1340454 & 688617 & 4.8784 & 5.0913 & TRN & \\
\hline CHEMBL1561842 & 688617 & 4.8284 & 4.6795 & TST & \\
\hline CHEMBL1496932 & 688617 & 4.4284 & 4.8357 & TRN & \\
\hline CHEMBL1369636 & 688617 & 4.2784 & 4.641 & TRN & \\
\hline CHEMBL1324675 & 688617 & 4.0784 & 4.5547 & TRN & \\
\hline CHEMBL1469996 & 688617 & 4.7284 & 4.8801 & TRN & \\
\hline CHEMBL1424930 & 688617 & 4.2284 & 4.7549 & TRN & \\
\hline CHEMBL1388509 & 688617 & 4.7284 & 4.965 & TRN & \\
\hline CHEMBL1508252 & 688617 & 4.9284 & 5.0478 & TRN & \\
\hline CHEMBL1517862 & 688617 & 4.0784 & 4.6184 & TST & \\
\hline CHEMBL1496606 & 688617 & 5.2284 & 4.5791 & TRN & \\
\hline CHEMBL1381472 & 688617 & 5.1284 & 4.7114 & TRN & \\
\hline CHEMBL1369040 & 688617 & 4.3784 & 4.5648 & TRN & \\
\hline CHEMBL1363585 & 688617 & 4.6784 & 4.8048 & TRN & \\
\hline CHEMBL1493956 & 688617 & 5.5784 & 4.9316 & TST & \\
\hline CHEMBL1484167 & 688617 & 4.2784 & 4.7282 & TST & \\
\hline CHEMBL1311254 & 688617 & 4.9784 & 4.63399 & 99999999995 & TRN \\
\hline CHEMBL1402174 & 688617 & 4.5284 & 4.605 & TRN & \\
\hline CHEMBL1609077 & 688617 & 5.2284 & 4.7547 & TRN & \\
\hline CHEMBL1328353 & 688617 & 5.1284 & 4.6653 & TRN & \\
\hline CHEMBL1599161 & 688617 & 4.8784 & 4.5959 & TRN & \\
\hline CHEMBL1400130 & 688617 & 4.1784 & 5.0843 & TST & \\
\hline CHEMBL1496732 & 688617 & 4.4284 & 4.6774 & TRN & \\
\hline CHEMBL1502229 & 688617 & 4.6284 & 4.6768 & TRN & \\
\hline CHEMBL1328132 & 688617 & 4.7284 & 5.093 & TRN & \\
\hline CHEMBL1333832 & 688617 & 7.9788 & 5.2668 & TRN & \\
\hline CHEMBL1522349 & 688617 & 4.8284 & 4.5743 & TRN & \\
\hline CHEMBL1416273 & 688617 & 4.2784 & 4.6094 & TRN & \\
\hline CHEMBL1458664 & 688617 & 4.3284 & 4.5753 & TRN & \\
\hline CHEMBL1601398 & 688617 & 5.2284 & 4.6756 & TRN & \\
\hline CHEMBL1388790 & 688617 & 5.2284 & 4.7432 & TRN & \\
\hline CHEMBL1488392 & 688617 & 5.0784 & 4.8554 & TRN & \\
\hline CHEMBL1309350 & 688617 & 4.1784 & 4.6525 & TST & \\
\hline CHEMBL1456124 & 688617 & 4.3784 & 4.8097 & TRN & \\
\hline CHEMBL1393205 & 688617 & 5.4784 & 4.8628 & TRN & \\
\hline CHEMBL1984703 & 688617 & 4.3784 & 4.7519 & TRN & \\
\hline CHEMBL1341073 & 688617 & 4.5284 & 4.5318 & TST & \\
\hline
\end{tabular}


Supplemental Table S2.txt

\begin{tabular}{|c|c|c|c|c|c|}
\hline CHEMBL1399056 & 688617 & 5.0784 & 4.6066 & TRN & \\
\hline CHEMBL1449018 & 688617 & 4.9784 & 4.7229 & TRN & \\
\hline CHEMBL112597 & 688617 & 4.2784 & 4.8243 & TRN & \\
\hline CHEMBL1405287 & 688617 & 4.7284 & 4.5481 & TRN & \\
\hline CHEMBL1340442 & 688617 & 4.3784 & 4.7257 & TRN & \\
\hline CHEMBL1556914 & 688617 & 5.0284 & 4.6992 & TRN & \\
\hline CHEMBL1507888 & 688617 & 4.9284 & 4.5307 & TST & \\
\hline CHEMBL1528317 & 688617 & 4.9284 & 4.6683 & TRN & \\
\hline CHEMBL1419086 & 688617 & 4.2784 & 4.7881 & TRN & \\
\hline CHEMBL467987 & 688617 & 4.6784 & 4.8269 & TST & \\
\hline CHEMBL1454269 & 688617 & 4.9784 & 4.7121 & TRN & \\
\hline CHEMBL1556308 & 688617 & 5.0284 & 4.5943 & TRN & \\
\hline CHEMBL1443827 & 688617 & 4.8284 & 4.6627 & TRN & \\
\hline CHEMBL1456364 & 688617 & 5.6784 & 4.5628 & TST & \\
\hline CHEMBL1403074 & 688617 & 5.1284 & 4.5771 & TST & \\
\hline CHEMBL1361042 & 688617 & 4.3284 & 4.522 & TRN & \\
\hline CHEMBL1519397 & 688617 & 4.0784 & 4.6501 & TRN & \\
\hline CHEMBL63426 & 688617 & 4.8784 & 4.6192 & TRN & \\
\hline CHEMBL1347910 & 688617 & 4.7284 & 4.6578 & TST & \\
\hline CHEMBL1565500 & 688617 & 4.6784 & 4.8308 & TRN & \\
\hline CHEMBL1307923 & 688617 & 4.3784 & 5.29700 & 2000000001 & TRN \\
\hline CHEMBL1463248 & 688617 & 4.7784 & 4.6738 & TRN & \\
\hline CHEMBL1333655 & 688617 & 4.6284 & 4.6206 & TRN & \\
\hline CHEMBL1580066 & 688617 & 4.8784 & 4.9703 & TRN & \\
\hline CHEMBL536950 & 688617 & 6.0784 & 4.952 & TRN & \\
\hline CHEMBL1496618 & 688617 & 4.0284 & 4.8942 & TST & \\
\hline CHEMBL596674 & 688617 & 4.8284 & 5.3385 & TRN & \\
\hline CHEMBL1491251 & 688617 & 4.3284 & 4.6509 & TRN & \\
\hline CHEMBL1469169 & 688617 & 4.4784 & 4.542 & TRN & \\
\hline CHEMBL1344274 & 688617 & 4.2784 & 4.9402 & TRN & \\
\hline CHEMBL1456371 & 688617 & 4.8784 & 4.6277 & TRN & \\
\hline CHEMBL3348819 & 688617 & 4.4284 & 4.664 & TRN & \\
\hline CHEMBL1405054 & 688617 & 4.8284 & 4.8017 & TRN & \\
\hline CHEMBL1470732 & 688617 & 4.4284 & 4.6917 & TST & \\
\hline CHEMBL1382702 & 688617 & 4.8284 & 4.7947 & TRN & \\
\hline CHEMBL1556391 & 688617 & 5.5284 & 5.2544 & TRN & \\
\hline CHEMBL1301350 & 688617 & 4.1784 & 4.9283 & TRN & \\
\hline CHEMBL1454903 & 688617 & 4.5784 & 4.6219 & TRN & \\
\hline CHEMBL1570267 & 688617 & 4.3284 & 4.6211 & TST & \\
\hline CHEMBL1386743 & 688617 & 4.4284 & 4.7051 & TRN & \\
\hline CHEMBL1385743 & 688617 & 5.0784 & 4.6185 & TRN & \\
\hline CHEMBL1471788 & 688617 & 4.8284 & 4.6327 & TRN & \\
\hline CHEMBL1546503 & 688617 & 5.1784 & 4.7685 & TRN & \\
\hline CHEMBL1595879 & 688617 & 4.2784 & 4.6849 & TRN & \\
\hline CHEMBL1486387 & 688617 & 4.2784 & 4.6988 & TRN & \\
\hline CHEMBL1546396 & 688617 & 5.0784 & 4.8543 & TRN & \\
\hline CHEMBL1402285 & 688617 & 4.8284 & 4.7153 & TRN & \\
\hline CHEMBL1582178 & 688617 & 4.2784 & 4.5768 & TST & \\
\hline
\end{tabular}


Supplemental Table S2.txt

\begin{tabular}{|c|c|c|c|c|}
\hline & & & 5 & TRN \\
\hline & & & & \\
\hline IEMBL151089 & & & & \\
\hline IEMBL: & 8617 & & & \\
\hline HEMBL1393038 & 88617 & 784 & 837 & \\
\hline 12489 & 88617 & & 202 & \\
\hline 326 & 8617 & & & \\
\hline IEMBL & 88617 & & 395 & \\
\hline 03512 & 88617 & 284 & 764 & \\
\hline 05947 & 88617 & & 051 & \\
\hline 82820 & 88617 & & 262 & \\
\hline EMBL & 38617 & & & \\
\hline AEMBL & 88617 & & 587 & \\
\hline 1457 & 88617 & & 891 & \\
\hline IEMBL & 88617 & & 688 & \\
\hline 3337 & 38617 & & 735 & \\
\hline 563 & 17 & & 02 & \\
\hline 7306 & 88617 & & & \\
\hline 754 & 88617 & & 968 & \\
\hline 04296 & 88617 & & 004 & \\
\hline 399 & 17 & & 278 & \\
\hline 407 & 17 & & 06 & \\
\hline 386 & 17 & & 816 & \\
\hline 546 & 17 & & & \\
\hline 7277 & 88617 & & 54 & \\
\hline 019 & 17 & & 431 & \\
\hline 32 & 7 & & 36 & \\
\hline & & & & \\
\hline 780 & 7 & & & \\
\hline 726 & 88617 & & 4. & \\
\hline 203 & 17 & & 774 & \\
\hline 7 & 7 & & 564 & \\
\hline & & & & \\
\hline 407 & & & & \\
\hline 8892 & 88617 & & 87 & \\
\hline 352 & 17 & & 19 & \\
\hline & & & & \\
\hline & & & & \\
\hline 74044 & 88617 & & & \\
\hline - & 88617 & & 997 & \\
\hline 427 & 88617 & & & \\
\hline & & & & RI \\
\hline TIDL & 17 & & & n \\
\hline MBL & 88617 & & 609 & \\
\hline & & & & \\
\hline CHEMBL1453846 & 688617 & & 4.544 & \\
\hline CHEMBL1504939 & 688617 & & 4.54 & \\
\hline CHEMBL1612666 & 688617 & 4.8784 & 4.5103 & \\
\hline
\end{tabular}

Page 11914 
Supplemental Table S2.txt

\begin{tabular}{|c|c|c|c|c|}
\hline${ }^{2}+0$ & & 284 & 4965 & \\
\hline HEMPI 1207101 & 88617 & 4.5784 & 4.585 & \\
\hline 100 & 17 & & & \\
\hline IEMBL1 & 3617 & & & \\
\hline AEMBL 14 & 3617 & & 873 & \\
\hline HEMBL1351004 & 88617 & 7784 & 6588 & \\
\hline HEMBL13 & 8617 & 284 & 029 & \\
\hline IFMPI 13 & 3617 & & 146 & \\
\hline AEMBL3210043 & 88617 & & 7964 & \\
\hline AEMBL1379862 & 38617 & 784 & 5829 & \\
\hline AEMBL580340 & 88617 & 284 & 339 & \\
\hline EMBL157 & 8617 & & 492 & \\
\hline IEMBL13 & & & & \\
\hline HEMBL1416391 & 88617 & 284 & 242 & \\
\hline IEMBL14 & 8617 & 84 & 21 & \\
\hline AEMBL133 & 88617 & 84 & 3028 & \\
\hline AEMBL13 & 8617 & & 436 & \\
\hline HEMBL 14 & 8617 & & 886 & \\
\hline AEMBL153 & 88617 & 784 & 301 & \\
\hline IEMBL13 & 17 & & & \\
\hline EMBLI & 17 & & 351 & NIV \\
\hline AEMBL1 & 7 & & 482 & S \\
\hline AEMBL1: & 17 & 84 & & \\
\hline 945 & 88617 & & 953 & \\
\hline IEMBL14 & 17 & & & re \\
\hline AEMBL1 & 17 & & 393 & KIV \\
\hline AEMBL1 & & & 84 & RN \\
\hline AFMBI 12 & 17 & 84 & 76 & \\
\hline AEMBL13 & 88617 & & 829 & ונI \\
\hline HEMBL14 & 38617 & & & r \\
\hline HEMBL1 & 3617 & & 75 & KIN \\
\hline AEMBL & & 34 & 63 & ST \\
\hline 87 & 17 & 34 & 175 & RN \\
\hline AEMBL1341945 & & & 126 & IRN \\
\hline HEMBL598679 & 88617 & & 414 & ГRN \\
\hline HEMBL12 & 88617 & & 926 & TRN \\
\hline HᄃMD & & & 19 & $\Gamma \mathrm{RN}$ \\
\hline HEMBL3: & & & & RN \\
\hline HEMBL1431126 & 88617 & & 2875 & TRN \\
\hline IEMBL14 & 88617 & & 9061 & $\Gamma \mathrm{RN}$ \\
\hline HEMBL1 & 88617 & 84 & 795 & $\Gamma \mathrm{RN}$ \\
\hline HᄃMP 15 & 88617 & & 5286 & TRN \\
\hline HEMBL1332375 & & & 3784 & $\mathrm{RN}$ \\
\hline AEMBL1561718 & 38617 & & 5926 & TR \\
\hline MBL13 & 17 & & 5297 & 1 \\
\hline HEMBL136 & & & 8301 & \\
\hline HEMBL14 & 88617 & & 5187 & \\
\hline HEMBL1492385 & 688617 & 4.3784 & 4.6554 & ГRN \\
\hline
\end{tabular}

Page 11915 


\begin{tabular}{|c|c|c|c|c|c|}
\hline \multicolumn{6}{|c|}{ Supplemental Table S2.txt } \\
\hline CHEMBL1510527 & 688617 & 4.3284 & 4.5869 & TRN & \\
\hline CHEMBL1432615 & 688617 & 4.8784 & 4.6283 & TRN & \\
\hline CHEMBL1369716 & 688617 & 4.3784 & 4.8279 & TRN & \\
\hline CHEMBL1376518 & 688617 & 4.3284 & 4.5866 & TRN & \\
\hline CHEMBL1470784 & 688617 & 4.4284 & 4.6432 & TRN & \\
\hline CHEMBL1369918 & 688617 & 4.6784 & 4.5773 & TRN & \\
\hline CHEMBL1269084 & 688617 & 5.1784 & 4.596 & TRN & \\
\hline CHEMBL1399802 & 688617 & 5.2284 & 5.3094 & TST & \\
\hline CHEMBL1579118 & 688617 & 4.7284 & 4.6401 & TST & \\
\hline CHEMBL1536682 & 688617 & 4.2284 & 4.6682 & TST & \\
\hline CHEMBL1612952 & 688617 & 4.8284 & 4.6052 & TST & \\
\hline CHEMBL1452917 & 688617 & 4.9784 & 4.5531 & TST & \\
\hline CHEMBL1604542 & 688617 & 4.2784 & 4.5677 & TST & \\
\hline CHEMBL1465049 & 688617 & 4.9784 & 5.0239 & TST & \\
\hline CHEMBL1438907 & 688617 & 4.3784 & 4.7208 & TST & \\
\hline CHEMBL1529681 & 688617 & 4.7284 & 4.7032 & TST & \\
\hline CHEMBL1560698 & 688617 & 5.0284 & 4.7114 & TST & \\
\hline CHEMBL1502739 & 688617 & 5.0784 & 4.9947 & TST & \\
\hline CHEMBL1340051 & 688617 & 4.7284 & 4.7316 & TST & \\
\hline CHEMBL3210236 & 688617 & 4.9284 & 4.80399 & 9999999999 & TST \\
\hline CHEMBL1392252 & 688617 & 4.6284 & 4.6579 & TST & \\
\hline CHEMBL1469728 & 688617 & 4.3784 & 4.8672 & TST & \\
\hline CHEMBL1368818 & 688617 & 5.4284 & 4.7666 & TST & \\
\hline CHEMBL1422691 & 688617 & 5.4284 & 4.6123 & TST & \\
\hline CHEMBL1529766 & 688617 & 4.3284 & 4.9388 & TST & \\
\hline CHEMBL1538399 & 688617 & 4.2284 & 4.6485 & TST & \\
\hline CHEMBL582005 & 688617 & 4.3284 & 4.6474 & TST & \\
\hline CHEMBL1443354 & 688617 & 4.5784 & 4.75899 & 99999999995 & TST \\
\hline CHEMBL1452838 & 688617 & 4.6784 & 4.575 & TST & \\
\hline CHEMBL333985 & 688617 & 4.8284 & 4.5983 & TST & \\
\hline CHEMBL1546054 & 688617 & 4.7284 & 4.8008 & TST & \\
\hline CHEMBL1300006 & 688617 & 4.3284 & 4.7263 & TST & \\
\hline CHEMBL1439679 & 688617 & 5.0784 & 4.7665 & TST & \\
\hline CHEMBL1505133 & 688617 & 4.2284 & 4.5206 & TST & \\
\hline CHEMBL1581518 & 688617 & 4.9784 & 4.5798 & TST & \\
\hline CHEMBL500430 & 688617 & 4.9284 & 4.6044 & TST & \\
\hline CHEMBL1586360 & 688617 & 4.8784 & 4.5957 & TST & \\
\hline CHEMBL1506252 & 688617 & 4.3784 & 5.0013 & TST & \\
\hline CHEMBL1576341 & 688617 & 7.5784 & 4.8449 & TST & \\
\hline CHEMBL1529460 & 688617 & 4.3284 & 4.9191 & TST & \\
\hline CHEMBL1511442 & 688617 & 4.6284 & 4.4954 & TST & \\
\hline CHEMBL1498077 & 688617 & 4.3284 & 4.6381 & TST & \\
\hline CHEMBL1339349 & 688617 & 6.2784 & 4.8465 & TST & \\
\hline CHEMBL1490504 & 688617 & 4.3284 & 4.6399 & TST & \\
\hline CHEMBL1344075 & 688617 & 4.9284 & 4.5754 & TST & \\
\hline CHEMBL1385949 & 688617 & 5.7284 & 4.623 & TST & \\
\hline CHEMBL1302980 & 688617 & 5.4284 & 4.5968 & TST & \\
\hline CHEMBL1536790 & 688617 & 5.1284 & 4.6536 & TST & \\
\hline
\end{tabular}




\begin{tabular}{|c|c|c|c|c|c|c|}
\hline \multicolumn{7}{|c|}{ Supplemental Table S2.txt } \\
\hline CHEMBL1532477 & 688617 & 4.2784 & 4.4542 & TST & & \\
\hline CHEMBL1428302 & 688617 & 4.4784 & 4.5193 & TST & & \\
\hline CHEMBL3904512 & 1637094 & 8.6576 & 8.2762 & TRN & & \\
\hline CHEMBL 3952732 & 1637094 & 9.699 & 8.629 & TRN & & \\
\hline CHEMBL3962308 & 1637094 & 8.4202 & 8.574 & TST & & \\
\hline CHEMBL3953323 & 1637094 & 8.8239 & 9.1007 & TRN & & \\
\hline CHEMBL 3932563 & 1637094 & 8.283999 & 999999999 & 99 & 7.9297 & TRN \\
\hline CHEMBL 3894747 & 1637094 & 8.5686 & 8.7754 & TRN & & \\
\hline CHEMBL3947283 & 1637094 & 7.9172 & 8.7097 & TRN & & \\
\hline CHEMBL3907272 & 1637094 & 8.699 & 8.5145 & TRN & & \\
\hline CHEMBL3901298 & 1637094 & 6.1226 & 5.7665 & TRN & & \\
\hline CHEMBL 3944194 & 1637094 & 9.7959 & 5.9095 & TST & & \\
\hline CHEMBL3976771 & 1637094 & 7.7235 & 7.5989 & TRN & & \\
\hline CHEMBL3946856 & 1637094 & 7.617999 & 999999999 & 99 & 8.2762 & TRN \\
\hline CHEMBL3914573 & 1637094 & 7.4815 & 7.5679 & TRN & & \\
\hline CHEMBL3967904 & 1637094 & 8.4737 & 8.0965 & TST & & \\
\hline CHEMBL3951758 & 1637094 & 8.1675 & 8.5083 & TRN & & \\
\hline CHEMBL3982672 & 1637094 & 7.1772 & 7.3918 & TRN & & \\
\hline CHEMBL 3944228 & 1637094 & 7.2218 & 7.9568 & TRN & & \\
\hline CHEMBL3941920 & 1637094 & 8.4815 & 8.7745 & TST & & \\
\hline CHEMBL3903246 & 1637094 & 8.4685 & 8.4484 & TRN & & \\
\hline CHEMBL3983862 & 1637094 & 9.5229 & 8.7667 & TRN & & \\
\hline CHEMBL 3979188 & 1637094 & 8.5086 & 8.17 & TRN & & \\
\hline CHEMBL3929807 & 1637094 & 7.1135 & 7.3334 & TRN & & \\
\hline CHEMBL3910471 & 1637094 & 8.6576 & 8.7805 & TRN & & \\
\hline CHEMBL3941990 & 1637094 & 8.7959 & 8.6814 & TRN & & \\
\hline CHEMBL3923123 & 1637094 & 8.1938 & 8.2762 & TRN & & \\
\hline CHEMBL3942065 & 1637094 & 5.6021 & 6.6647 & TRN & & \\
\hline CHEMBL3960359 & 1637094 & 8.9208 & 8.8343 & TRN & & \\
\hline CHEMBL 3889538 & 1637094 & 8.7696 & 8.1345 & TRN & & \\
\hline CHEMBL3904706 & 1637094 & 8.8239 & 8.8424 & TRN & & \\
\hline CHEMBL3982939 & 1637094 & 8.1024 & 7.6664 & TRN & & \\
\hline CHEMBL 3894546 & 1637094 & 6.6759 & 6.8936 & TRN & & \\
\hline CHEMBL 3980433 & 1637094 & 6.9431 & 7.3923 & TRN & & \\
\hline CHEMBL 3970735 & 1637094 & 7.6946 & 7.6664 & TRN & & \\
\hline CHEMBL3934601 & 1637094 & 8.585 & 8.6082 & TRN & & \\
\hline CHEMBL3963362 & 1637094 & 7.821000 & 000000000 & & 8.365 & TRN \\
\hline CHEMBL3904006 & 1637094 & 5.0969 & 5.0207 & TRN & & \\
\hline CHEMBL 3891981 & 1637094 & 8.0044 & 8.6382 & TRN & & \\
\hline CHEMBL 3953912 & 1637094 & 8.9208 & 7.9651 & TRN & & \\
\hline CHEMBL 3890803 & 1637094 & 10.1549 & 8.1733 & TST & & \\
\hline CHEMBL3974709 & 1637094 & 9.0458 & 8.6308 & TRN & & \\
\hline CHEMBL3978233 & 1637094 & 8.6383 & 8.699 & TST & & \\
\hline CHEMBL 3939368 & 1637094 & 7.8539 & 8.0109 & TRN & & \\
\hline CHEMBL3963000 & 1637094 & 6.7932 & 6.2837 & TRN & & \\
\hline CHEMBL 3951222 & 1637094 & 9.0969 & 8.8254 & TST & & \\
\hline CHEMBL 3900523 & 1637094 & 8.7447 & 8.7015 & TST & & \\
\hline CHEMBL3906914 & 1637094 & 7.8861 & 7.8908 & TST & & \\
\hline
\end{tabular}


Supplemental Table S2.txt

\begin{tabular}{|c|c|c|c|c|}
\hline CHEMBL3974250 & 1637094 & 7.983 & 7.8403 & TST \\
\hline CHEMBL403317 & 1637094 & 9.1549 & 5.6113 & TST \\
\hline CHEMBL3971676 & 1637094 & 8.8861 & 9.1005 & TST \\
\hline CHEMBL3954412 & 1637094 & 7.0462 & 7.5055 & TST \\
\hline CHEMBL1436898 & 737105 & 3.0 & 3.8214 & TRN \\
\hline CHEMBL1594374 & 737105 & 3.0 & 3.0979 & TRN \\
\hline CHEMBL1451040 & 737105 & 3.0 & 3.4606 & TRN \\
\hline CHEMBL1497487 & 737105 & 3.0 & 3.8456 & TRN \\
\hline CHEMBL1488474 & 737105 & 4.9031 & 5.4518 & TRN \\
\hline CHEMBL255881 & 737105 & 3.0 & 3.1305 & TRN \\
\hline CHEMBL1322977 & 737105 & 3.0 & 3.7071 & TRN \\
\hline CHEMBL1353324 & 737105 & 3.0 & 2.6946 & TRN \\
\hline CHEMBL1402586 & 737105 & 3.0 & 3.1258 & TRN \\
\hline CHEMBL1974737 & 737105 & 4.4401 & 3.8424 & TST \\
\hline CHEMBL1508847 & 737105 & 3.0 & 3.1195 & TRN \\
\hline CHEMBL1397359 & 737105 & 4.1391 & 3.4704 & TRN \\
\hline CHEMBL1447139 & 737105 & 5.0635 & 5.3602 & TRN \\
\hline CHEMBL3192085 & 737105 & 4.6271 & 4.9364 & TRN \\
\hline CHEMBL1342821 & 737105 & 5.4737 & 3.6507 & TRN \\
\hline CHEMBL1406077 & 737105 & 3.0 & 2.7084 & TRN \\
\hline CHEMBL1363730 & 737105 & 4.2168 & 3.7044 & TRN \\
\hline CHEMBL1417524 & 737105 & 3.0 & 3.4395 & TRN \\
\hline CHEMBL1496952 & 737105 & 4.8447 & 4.7905 & TRN \\
\hline CHEMBL1980661 & 737105 & 3.0 & 3.1109 & TST \\
\hline CHEMBL1727453 & 737105 & 3.0 & 3.1603 & TRN \\
\hline CHEMBL1532097 & 737105 & 4.7375 & 5.0324 & TRN \\
\hline CHEMBL1549540 & 737105 & 5.6737 & 5.4612 & TRN \\
\hline CHEMBL1371869 & 737105 & 3.0 & 3.1051 & TRN \\
\hline CHEMBL1503852 & 737105 & 4.8794 & 4.6657 & TRN \\
\hline CHEMBL1309252 & 737105 & 3.0 & 3.4136 & TRN \\
\hline CHEMBL1398188 & 737105 & 3.0 & 3.3615 & TRN \\
\hline CHEMBL1500102 & 737105 & 5.3915 & 4.9552 & TRN \\
\hline CHEMBL1547446 & 737105 & 5.0186 & 5.1062 & TRN \\
\hline CHEMBL1525897 & 737105 & 5.51 & 4.6281 & TRN \\
\hline CHEMBL1421399 & 737105 & 4.644 & 4.7558 & TRN \\
\hline CHEMBL1566994 & 737105 & 3.0 & 3.9826 & TRN \\
\hline CHEMBL3199065 & 737105 & 3.0 & 3.1119 & TRN \\
\hline CHEMBL1333737 & 737105 & 3.0 & 3.0991 & TRN \\
\hline CHEMBL1487973 & 737105 & 3.0 & 2.8759 & TRN \\
\hline CHEMBL1413866 & 737105 & 3.0 & 2.6998 & TRN \\
\hline CHEMBL1323900 & 737105 & 3.0 & 3.1319 & TRN \\
\hline CHEMBL600956 & 737105 & 3.0 & 3.8306 & TRN \\
\hline CHEMBL1532996 & 737105 & 3.0 & 3.1417 & TRN \\
\hline CHEMBL81782 & 737105 & 3.0 & 3.2543 & TST \\
\hline CHEMBL1370260 & 737105 & 5.1118 & 3.7753 & TRN \\
\hline CHEMBL1446234 & 737105 & 3.0 & 3.7246 & TRN \\
\hline CHEMBL3191063 & 737105 & 3.0 & 4.077 & TRN \\
\hline CHEMBL76904 & 737105 & 3.0 & 4.1041 & TRN \\
\hline
\end{tabular}




\begin{tabular}{|c|c|c|c|c|c|c|}
\hline & & \multicolumn{5}{|c|}{ Supplemental Table S2.txt } \\
\hline CHEMBL1356184 & 737105 & 3.0 & 2.9909 & TRN & & \\
\hline CHEMBL 3190558 & 737105 & 4.0969 & 3.4645 & TRN & & \\
\hline CHEMBL1342091 & 737105 & \multicolumn{3}{|c|}{5.4510000000000005} & 5.6087 & TRN \\
\hline CHEMBL1314787 & 737105 & 3.0 & 3.0097 & TRN & & \\
\hline CHEMBL1563861 & 737105 & 3.0 & 3.7382 & TRN & & \\
\hline CHEMBL1424867 & 737105 & 4.7986 & 4.4498 & TRN & & \\
\hline CHEMBL1496986 & 737105 & 3.0 & 3.1742 & TRN & & \\
\hline CHEMBL1529306 & 737105 & 3.0 & 2.8683 & TRN & & \\
\hline CHEMBL1313502 & 737105 & 4.1543 & 4.8573 & TST & & \\
\hline CHEMBL1345195 & 737105 & 3.0 & 2.7462 & TRN & & \\
\hline CHEMBL490355 & 737105 & 4.1785 & 4.9809 & TRN & & \\
\hline CHEMBL1439675 & 737105 & 3.0 & 3.0369 & TRN & & \\
\hline CHEMBL1499828 & 737105 & 3.0 & 3.0963 & TRN & & \\
\hline CHEMBL1980197 & 737105 & 4.1129 & 4.0635 & TRN & & \\
\hline CHEMBL1493010 & 737105 & 3.0 & 2.696 & TRN & & \\
\hline CHEMBL 2006611 & 737105 & 4.8539 & 5.2685 & TRN & & \\
\hline CHEMBL3198600 & 737105 & 5.7595 & 4.6714 & TST & & \\
\hline CHEMBL1702104 & 737105 & 3.0 & 2.8959 & TRN & & \\
\hline CHEMBL 1574857 & 737105 & 3.0 & 3.3523 & TRN & & \\
\hline CHEMBL1438081 & 737105 & 3.0 & 3.4431 & TRN & & \\
\hline CHEMBL1353033 & 737105 & 3.0 & 3.2769 & TRN & & \\
\hline CHEMBL1307435 & 737105 & 4.9208 & 4.4086 & TRN & & \\
\hline CHEMBL 2003964 & 737105 & 4.8729 & 4.0005 & TRN & & \\
\hline CHEMBL179512 & 737105 & 3.0 & 3.5146 & TRN & & \\
\hline CHEMBL 140 & 737105 & 3.0 & 3.1891 & TRN & & \\
\hline CHEMBL1979849 & 737105 & 3.0 & 3.3074 & TRN & & \\
\hline CHEMBL1503175 & 737105 & 3.0 & 3.4674 & TRN & & \\
\hline CHEMBL1716336 & 737105 & 4.5918 & 2.6665 & TST & & \\
\hline CHEMBL1981446 & 737105 & 3.0 & 3.1976 & TRN & & \\
\hline CHEMBL1350787 & 737105 & 5.3363 & 3.7981 & TRN & & \\
\hline CHEMBL1698793 & 737105 & 3.0 & 3.4886 & TRN & & \\
\hline CHEMBL1340656 & 737105 & 3.0 & 3.3163 & TRN & & \\
\hline CHEMBL1609295 & 737105 & 5.0182 & 4.6132 & TRN & & \\
\hline CHEMBL3189823 & 737105 & 3.0 & 2.8331 & TRN & & \\
\hline CHEMBL1989158 & 737105 & 3.0 & 3.1459 & TST & & \\
\hline CHEMBL1574218 & 737105 & 3.0 & 3.0289 & TST & & \\
\hline CHEMBL1343895 & 737105 & 4.5346 & 3.6377 & TRN & & \\
\hline CHEMBL3190268 & 737105 & 4.2899 & 3.7979 & TRN & & \\
\hline CHEMBL 1705776 & 737105 & 3.0 & 2.641 & TRN & & \\
\hline CHEMBL1472524 & 737105 & 3.0 & 3.0052 & TST & & \\
\hline CHEMBL1320230 & 737105 & 4.5129 & 4.3866 & TRN & & \\
\hline CHEMBL1390605 & 737105 & 3.0 & 2.9543 & TST & & \\
\hline CHEMBL40275 & 737105 & 3.0 & 3.1611 & TST & & \\
\hline CHEMBL1970597 & 737105 & 3.0 & 3.0364 & TRN & & \\
\hline CHEMBL1340344 & 737105 & 4.7033 & 4.7421 & TRN & & \\
\hline CHEMBL116438 & 737105 & 4.3556 & 4.1508 & TRN & & \\
\hline CHEMBL3194421 & 737105 & 7.71 & 7.0048 & TRN & & \\
\hline CHEMBL1534899 & 737105 & 3.0 & 3.1813 & TRN & & \\
\hline
\end{tabular}




\begin{tabular}{|c|c|c|c|c|c|}
\hline \multicolumn{6}{|c|}{ Supplemental Table S2.txt } \\
\hline CHEMBL3196075 & 737105 & 3.0 & 3.3666 & TRN & \\
\hline CHEMBL1518080 & 737105 & 3.0 & 3.2533 & TST & \\
\hline CHEMBL1303188 & 737105 & 3.0 & 2.7968 & TRN & \\
\hline CHEMBL1535695 & 737105 & 3.0 & 3.4272 & TST & \\
\hline CHEMBL1497387 & 737105 & 3.0 & 4.0025 & TRN & \\
\hline CHEMBL1441918 & 737105 & 3.0 & 2.6881 & TRN & \\
\hline CHEMBL1305055 & 737105 & 3.0 & 2.8849 & TRN & \\
\hline CHEMBL1314122 & 737105 & 5.2976 & 4.9481 & TRN & \\
\hline CHEMBL1098175 & 737105 & 3.0 & 3.1136 & TRN & \\
\hline CHEMBL1490685 & 737105 & 3.0 & 2.5792 & TRN & \\
\hline CHEMBL1980281 & 737105 & 3.0 & 2.9149 & TST & \\
\hline CHEMBL1733511 & 737105 & 5.6778 & 5.3191 & TRN & \\
\hline CHEMBL1333659 & 737105 & 5.3625 & 4.7301 & TRN & \\
\hline CHEMBL1712676 & 737105 & 3.0 & 3.0556 & TRN & \\
\hline CHEMBL1588052 & 737105 & 3.0 & 2.9166 & TRN & \\
\hline CHEMBL1208858 & 737105 & 3.0 & 3.20899 & 99999999996 & TST \\
\hline CHEMBL522990 & 737105 & 3.0 & 2.7785 & TRN & \\
\hline CHEMBL3193527 & 737105 & 4.6716 & 3.5106 & TRN & \\
\hline CHEMBL1709713 & 737105 & 4.5702 & 4.1028 & TRN & \\
\hline CHEMBL1310309 & 737105 & 3.0 & 2.9579 & TRN & \\
\hline CHEMBL1562260 & 737105 & 5.1349 & 4.8798 & TRN & \\
\hline CHEMBL1722786 & 737105 & 3.0 & 2.5628 & TRN & \\
\hline CHEMBL1985299 & 737105 & 3.0 & 2.9475 & TRN & \\
\hline CHEMBL250450 & 737105 & 5.0477 & 4.003 & TST & \\
\hline CHEMBL1417168 & 737105 & 3.0 & 3.6164 & TRN & \\
\hline CHEMBL1585758 & 737105 & 4.3726 & 3.4797 & TRN & \\
\hline CHEMBL1311580 & 737105 & 3.0 & 3.3241 & TST & \\
\hline CHEMBL1367272 & 737105 & 3.0 & 3.5276 & TRN & \\
\hline CHEMBL1416189 & 737105 & 5.4214 & 5.2008 & TRN & \\
\hline CHEMBL1349252 & 737105 & 3.0 & 3.8671 & TRN & \\
\hline CHEMBL1334863 & 737105 & 3.0 & 2.7756 & TST & \\
\hline CHEMBL1330039 & 737105 & 3.0 & 3.3718 & TST & \\
\hline CHEMBL1473059 & 737105 & 4.0937 & 4.2553 & TRN & \\
\hline CHEMBL1560432 & 737105 & 4.4711 & 4.3771 & TRN & \\
\hline CHEMBL1481632 & 737105 & 3.0 & 3.3264 & TST & \\
\hline CHEMBL1392573 & 737105 & 3.0 & 4.6194 & TST & \\
\hline CHEMBL1375199 & 737105 & 4.2388 & 4.3019 & TST & \\
\hline CHEMBL1350188 & 737105 & 3.0 & 3.1822 & TST & \\
\hline CHEMBL1987928 & 737105 & 3.0 & 3.5534 & TST & \\
\hline CHEMBL224916 & 737105 & 3.0 & 3.5251 & TST & \\
\hline CHEMBL1589514 & 737105 & 4.3372 & 4.5814 & TST & \\
\hline CHEMBL1602709 & 737105 & 3.0 & 3.5553 & TST & \\
\hline CHEMBL1505816 & 737105 & 4.6055 & 3.92 & TST & \\
\hline CHEMBL1984581 & 737105 & 3.0 & 3.2599 & TST & \\
\hline CHEMBL1446839 & 737105 & 4.5751 & 3.1167 & TST & \\
\hline CHEMBL1310972 & 737105 & 5.0921 & 3.4943 & TST & \\
\hline CHEMBL1508055 & 737105 & 3.0 & 3.4038 & TST & \\
\hline CHEMBL1340338 & 737105 & 3.0 & 3.7931 & TST & \\
\hline
\end{tabular}


Supplemental Table S2.txt

\begin{tabular}{|c|c|c|c|c|c|}
\hline CHEMBL1736894 & 737105 & 5.0259 & 3.6406 & TST & \\
\hline CHEMBL 210208 & 737105 & 3.0 & 3.4233 & TST & \\
\hline CHEMBL1600440 & 737105 & 4.6615 & 3.2594 & TST & \\
\hline CHEMBL1964290 & 809132 & 5.9 & 5.1426 & TRN & \\
\hline CHEMBL1967887 & 809132 & 4.6 & 4.6605 & TRN & \\
\hline CHEMBL213505 & 809132 & 8.1 & 6.8064 & TRN & \\
\hline CHEMBL 2000568 & 809132 & 4.6 & 4.92899 & 9999999999 & TRN \\
\hline CHEMBL 2000335 & 809132 & 7.3 & 7.1838 & TRN & \\
\hline CHEMBL1974328 & 809132 & 8.0 & 6.4014 & TRN & \\
\hline CHEMBL1988717 & 809132 & 8.2 & 8.5563 & TRN & \\
\hline CHEMBL509032 & 809132 & 8.6 & 7.5743 & TRN & \\
\hline CHEMBL1987034 & 809132 & 7.8 & 7.88 & TRN & \\
\hline CHEMBL1993941 & 809132 & 7.6 & 8.5484 & TRN & \\
\hline CHEMBL 377383 & 809132 & 4.6 & 4.7416 & TST & \\
\hline CHEMBL 2005886 & 809132 & 7.9 & 7.6437 & TRN & \\
\hline CHEMBL1973808 & 809132 & 4.6 & 4.7368 & TRN & \\
\hline CHEMBL 2000429 & 809132 & 4.6 & 5.2925 & TRN & \\
\hline CHEMBL481491 & 809132 & 4.6 & 5.2013 & TST & \\
\hline CHEMBL1973142 & 809132 & 4.6 & 5.1451 & TRN & \\
\hline CHEMBL1972576 & 809132 & 4.6 & 4.7293 & TRN & \\
\hline CHEMBL1990254 & 809132 & 4.6 & 4.7724 & TRN & \\
\hline CHEMBL1973145 & 809132 & 4.6 & 5.6722 & TRN & \\
\hline CHEMBL1982924 & 809132 & 4.6 & 5.6088 & TRN & \\
\hline CHEMBL1992342 & 809132 & 4.6 & 4.5094 & TRN & \\
\hline CHEMBL2005936 & 809132 & 5.9 & 4.4323 & TRN & \\
\hline CHEMBL1807515 & 809132 & 6.3 & 5.749 & TRN & \\
\hline CHEMBL1988173 & 809132 & 4.6 & 4.9689 & TRN & \\
\hline CHEMBL1164265 & 809132 & 6.9 & 6.1053 & TST & \\
\hline CHEMBL1971141 & 809132 & 4.6 & 5.0845 & TRN & \\
\hline CHEMBL1995813 & 809132 & 5.8 & 5.5661 & TRN & \\
\hline CHEMBL1989805 & 809132 & 4.6 & 5.4082 & TST & \\
\hline CHEMBL206236 & 809132 & 4.6 & 4.8268 & TRN & \\
\hline CHEMBL244378 & 809132 & 7.5 & 6.4821 & TRN & \\
\hline CHEMBL1965423 & 809132 & 7.5 & 5.2865 & TRN & \\
\hline CHEMBL 2001957 & 809132 & 4.6 & \multicolumn{2}{|c|}{5.207999999999999} & TRN \\
\hline CHEMBL1969372 & 809132 & 5.8 & 5.2039 & TRN & \\
\hline CHEMBL 205415 & 809132 & 4.6 & 4.916 & TRN & \\
\hline CHEMBL1977135 & 809132 & 4.6 & 4.8277 & TRN & \\
\hline CHEMBL1986943 & 809132 & 6.4 & 5.9333 & TRN & \\
\hline CHEMBL 2001920 & 809132 & 4.6 & 4.9495 & TRN & \\
\hline CHEMBL2006263 & 809132 & 4.6 & 4.8492 & TRN & \\
\hline CHEMBL1978448 & 809132 & 4.6 & 5.1334 & TST & \\
\hline CHEMBL1993584 & 809132 & 4.6 & 4.7102 & TRN & \\
\hline CHEMBL1986263 & 809132 & 6.5 & 5.4893 & TRN & \\
\hline CHEMBL2000114 & 809132 & 4.6 & 4.9899 & TRN & \\
\hline CHEMBL2001257 & 809132 & 7.5 & 7.0532 & TRN & \\
\hline CHEMBL1975647 & 809132 & 4.6 & 4.9842 & TRN & \\
\hline CHEMBL1992536 & 809132 & 4.6 & 4.6938 & TRN & \\
\hline
\end{tabular}




\begin{tabular}{|c|c|c|c|c|c|}
\hline \\
\hline CHEMBL1968380 & 809132 & 4.6 & 5.1297 & TRN & \\
\hline CHEMBL1964644 & 809132 & 4.6 & 4.8246 & TRN & \\
\hline CHEMBL1981782 & 809132 & 4.6 & 4.5311 & TRN & \\
\hline CHEMBL1977681 & 809132 & 4.6 & 5.2491 & TRN & \\
\hline CHEMBL1970142 & 809132 & 8.5 & 8.5953 & TRN & \\
\hline CHEMBL1990912 & 809132 & 4.6 & 4.7464 & TRN & \\
\hline CHEMBL2002373 & 809132 & 5.7 & 5.0279 & TRN & \\
\hline CHEMBL439340 & 809132 & 4.6 & 4.7824 & TRN & \\
\hline CHEMBL 2006188 & 809132 & 4.6 & 4.7664 & TRN & \\
\hline CHEMBL1967531 & 809132 & 6.8 & 6.2782 & TRN & \\
\hline CHEMBL1970913 & 809132 & 4.6 & 4.8545 & TRN & \\
\hline CHEMBL1973893 & 809132 & 4.6 & 4.64199 & 99999999995 & TRN \\
\hline CHEMBL1997534 & 809132 & 4.6 & 4.7996 & TRN & \\
\hline CHEMBL1988163 & 809132 & 7.4 & 7.5751 & TRN & \\
\hline CHEMBL1985095 & 809132 & 4.6 & 5.0658 & TST & \\
\hline CHEMBL1996500 & 809132 & 4.6 & 4.8049 & TRN & \\
\hline CHEMBL2006493 & 809132 & 4.6 & 4.8663 & TST & \\
\hline CHEMBL1682540 & 809132 & 4.6 & 4.9027 & TRN & \\
\hline CHEMBL1983449 & 809132 & 4.6 & 4.6598 & TRN & \\
\hline CHEMBL1992323 & 809132 & 4.6 & 4.8892 & TRN & \\
\hline CHEMBL1969735 & 809132 & 4.6 & 5.1494 & TRN & \\
\hline CHEMBL1976420 & 809132 & 6.6 & 6.1029 & TST & \\
\hline CHEMBL 2002649 & 809132 & 7.6 & 5.9085 & TRN & \\
\hline CHEMBL1994864 & 809132 & 4.6 & 4.6032 & TRN & \\
\hline CHEMBL497151 & 809132 & 4.6 & 4.9123 & TST & \\
\hline CHEMBL1973961 & 809132 & 5.9 & 5.3391 & TRN & \\
\hline CHEMBL246970 & 809132 & 6.4 & 5.1011 & TST & \\
\hline CHEMBL340921 & 809132 & 4.6 & 5.1421 & TST & \\
\hline CHEMBL1999718 & 809132 & 4.6 & 4.9391 & TRN & \\
\hline CHEMBL1276446 & 809132 & 7.5 & 7.1498 & TST & \\
\hline CHEMBL1977346 & 809132 & 4.6 & 5.1687 & TRN & \\
\hline CHEMBL1971649 & 809132 & 5.8 & 5.2959 & TRN & \\
\hline CHEMBL 2000508 & 809132 & 6.4 & 5.0561 & TRN & \\
\hline CHEMBL1971694 & 809132 & 4.6 & 4.9206 & TST & \\
\hline CHEMBL 2001547 & 809132 & 4.6 & 4.8525 & TRN & \\
\hline CHEMBL210928 & 809132 & 5.8 & 4.8044 & TST & \\
\hline CHEMBL1986603 & 809132 & 4.6 & 5.0571 & TST & \\
\hline CHEMBL 2006439 & 809132 & 4.6 & 5.3741 & TRN & \\
\hline CHEMBL1969190 & 809132 & 6.4 & 6.5332 & TRN & \\
\hline CHEMBL1977148 & 809132 & 7.8 & 8.5312 & TRN & \\
\hline CHEMBL1973937 & 809132 & 7.3 & 6.2994 & TRN & \\
\hline CHEMBL1991674 & 809132 & 6.0 & 5.3357 & TRN & \\
\hline CHEMBL 2003286 & 809132 & 4.6 & 4.7558 & TRN & \\
\hline CHEMBL1992306 & 809132 & 8.7 & 6.8147 & TRN & \\
\hline CHEMBL 2002165 & 809132 & 7.6 & 8.4932 & TRN & \\
\hline CHEMBL1982711 & 809132 & 5.8 & 5.2868 & TRN & \\
\hline CHEMBL1979318 & 809132 & 4.6 & 4.9889 & TST & \\
\hline CHEMBL 206382 & 809132 & 4.6 & 4.8314 & TRN & \\
\hline
\end{tabular}




\begin{tabular}{|c|c|c|c|c|c|}
\hline \\
\hline CHEMBL1998585 & 809132 & 8.3 & 7.7255 & TRN & \\
\hline CHEMBL127898 & 809132 & 4.6 & 5.0644 & TST & \\
\hline CHEMBL519697 & 809132 & 4.6 & 4.9005 & TST & \\
\hline CHEMBL2004934 & 809132 & 4.6 & 4.8005 & TRN & \\
\hline CHEMBL1975128 & 809132 & 5.8 & 4.6922 & TRN & \\
\hline CHEMBL1996048 & 809132 & 4.6 & 5.4894 & TST & \\
\hline CHEMBL1998829 & 809132 & 6.0 & 5.6954 & TRN & \\
\hline CHEMBL461876 & 809132 & 4.6 & 5.4856 & TRN & \\
\hline CHEMBL1988838 & 809132 & 7.1 & 7.6778 & TRN & \\
\hline CHEMBL2001485 & 809132 & 7.8 & 8.1513 & TRN & \\
\hline CHEMBL1966425 & 809132 & 4.6 & 5.2771 & TRN & \\
\hline CHEMBL1984363 & 809132 & 6.6 & 5.5125 & TRN & \\
\hline CHEMBL1978099 & 809132 & 6.4 & 6.86600 & 20000000005 & TRN \\
\hline CHEMBL1988608 & 809132 & 4.6 & 4.6369 & TRN & \\
\hline CHEMBL184847 & 809132 & 4.6 & 5.2684 & TRN & \\
\hline CHEMBL1982866 & 809132 & 5.8 & 4.8576 & TRN & \\
\hline CHEMBL1984367 & 809132 & 4.6 & 5.0631 & TRN & \\
\hline CHEMBL462120 & 809132 & 5.9 & 5.1419 & TRN & \\
\hline CHEMBL 2007592 & 809132 & 4.6 & 4.8437 & TST & \\
\hline CHEMBL1965570 & 809132 & 7.0 & 7.4798 & TRN & \\
\hline CHEMBL226898 & 809132 & 4.6 & 5.1631 & TRN & \\
\hline CHEMBL1982563 & 809132 & 5.6 & 5.1268 & TRN & \\
\hline CHEMBL539474 & 809132 & 4.6 & 5.3934 & TST & \\
\hline CHEMBL575824 & 809132 & 4.6 & 4.8564 & TRN & \\
\hline CHEMBL210963 & 809132 & 4.6 & 4.7918 & TST & \\
\hline CHEMBL1988387 & 809132 & 8.6 & 8.9986 & TRN & \\
\hline CHEMBL1614705 & 809132 & 6.3 & 4.8748 & TRN & \\
\hline CHEMBL1984633 & 809132 & 4.6 & 4.8189 & TRN & \\
\hline CHEMBL1965845 & 809132 & 4.6 & 4.9657 & TRN & \\
\hline CHEMBL2007372 & 809132 & 4.6 & 4.9917 & TRN & \\
\hline CHEMBL1986970 & 809132 & 4.6 & 4.3722 & TRN & \\
\hline CHEMBL1986597 & 809132 & 4.6 & 4.8012 & TRN & \\
\hline CHEMBL2006715 & 809132 & 7.6 & 7.5854 & TRN & \\
\hline CHEMBL1958401 & 809132 & 4.6 & 4.6881 & TRN & \\
\hline CHEMBL1990482 & 809132 & 4.6 & 4.7112 & TRN & \\
\hline CHEMBL1990904 & 809132 & 6.3 & 5.3059 & TRN & \\
\hline CHEMBL2005475 & 809132 & 4.6 & 5.1563 & TRN & \\
\hline CHEMBL1975121 & 809132 & 4.6 & 4.6275 & TRN & \\
\hline CHEMBL2003456 & 809132 & 4.6 & 5.2122 & TRN & \\
\hline CHEMBL1966816 & 809132 & 6.9 & 4.9217 & TRN & \\
\hline CHEMBL1972584 & 809132 & 7.5 & 6.6545 & TRN & \\
\hline CHEMBL402846 & 809132 & 7.2 & 6.58700 & 0000000001 & TRN \\
\hline CHEMBL2002992 & 809132 & 4.6 & 4.7858 & TRN & \\
\hline CHEMBL183844 & 809132 & 6.8 & 5.5699 & TRN & \\
\hline CHEMBL560813 & 809132 & 4.6 & 5.0183 & TRN & \\
\hline CHEMBL1682545 & 809132 & 4.6 & 5.1552 & TRN & \\
\hline CHEMBL220057 & 809132 & 7.5 & 6.1122 & TRN & \\
\hline CHEMBL383541 & 809132 & 4.6 & 4.9409 & TRN & \\
\hline & & & & 11923 & \\
\hline
\end{tabular}




\begin{tabular}{|c|c|c|c|c|}
\hline \multicolumn{5}{|c|}{ Supplemental Tab } \\
\hline CHEMBL 2001224 & 809132 & 4.6 & 4.9752 & TRN \\
\hline CHEMBL1968791 & 809132 & 7.6 & 6.3536 & TST \\
\hline CHEMBL10 & 809132 & 6.6 & 4.9334 & TRN \\
\hline CHEMBL1976732 & 809132 & 4.6 & 4.9746 & TRN \\
\hline CHEMBL1969506 & 809132 & 4.6 & 5.0475 & TRN \\
\hline CHEMBL1964937 & 809132 & 5.7 & 5.0817 & TRN \\
\hline CHEMBL1980163 & 809132 & 4.6 & 4.8394 & TRN \\
\hline CHEMBL1971186 & 809132 & 4.6 & 4.9721 & TRN \\
\hline CHEMBL 2003482 & 809132 & 4.6 & 4.8521 & TRN \\
\hline CHEMBL1973211 & 809132 & 7.3 & 7.724 & TRN \\
\hline CHEMBL 1984700 & 809132 & 5.8 & 5.2175 & TRN \\
\hline CHEMBL 2005899 & 809132 & 4.6 & 4.965 & TRN \\
\hline CHEMBL1682552 & 809132 & 4.6 & 4.99 & TRN \\
\hline CHEMBL1972125 & 809132 & 4.6 & 4.746 & TRN \\
\hline CHEMBL 229799 & 809132 & 4.6 & 5.0849 & TRN \\
\hline CHEMBL 105739 & 809132 & 5.8 & 6.3133 & TRN \\
\hline CHEMBL1461728 & 809132 & 4.6 & 4.8401 & TRN \\
\hline CHEMBL1976134 & 809132 & 4.6 & 5.8289 & TRN \\
\hline CHEMBL1965131 & 809132 & 4.6 & 5.095 & TRN \\
\hline CHEMBL379300 & 809132 & 4.6 & 5.0232 & TRN \\
\hline CHEMBL1972158 & 809132 & 5.9 & 4.3693 & TRN \\
\hline CHEMBL1986781 & 809132 & 4.6 & 5.0373 & TRN \\
\hline CHEMBL1979855 & 809132 & 6.4 & 4.7197 & TRN \\
\hline CHEMBL526133 & 809132 & 4.6 & 4.8946 & TRN \\
\hline CHEMBL1970340 & 809132 & 7.4 & 4.8909 & TRN \\
\hline CHEMBL 2005186 & 809132 & 4.6 & 4.8959 & TRN \\
\hline CHEMBL1975534 & 809132 & 4.6 & 5.0369 & TRN \\
\hline CHEMBL1993424 & 809132 & 8.0 & 7.5802 & TRN \\
\hline CHEMBL1979057 & 809132 & 4.6 & 4.7077 & TRN \\
\hline CHEMBL1966703 & 809132 & 4.6 & 4.9721 & TST \\
\hline CHEMBL387971 & 809132 & 4.6 & 5.9801 & TST \\
\hline CHEMBL1969561 & 809132 & 4.6 & 4.3549 & TRN \\
\hline CHEMBL1999428 & 809132 & 4.6 & 4.9116 & TRN \\
\hline CHEMBL1967560 & 809132 & 4.6 & 5.1017 & TRN \\
\hline CHEMBL1516890 & 809132 & 6.1 & 6.0872 & TRN \\
\hline CHEMBL211378 & 809132 & 5.8 & 6.1739 & TRN \\
\hline CHEMBL1997023 & 809132 & 4.6 & 4.6363 & TST \\
\hline CHEMBL 2001751 & 809132 & 6.5 & 6.6113 & TRN \\
\hline CHEMBL 2003420 & 809132 & 4.6 & 4.9431 & TRN \\
\hline CHEMBL1964687 & 809132 & 5.8 & 6.1925 & TRN \\
\hline CHEMBL1971943 & 809132 & 6.0 & 5.2304 & TST \\
\hline CHEMBL1984586 & 809132 & 6.4 & 5.4998 & TRN \\
\hline CHEMBL1974254 & 809132 & 7.3 & 8.5317 & TRN \\
\hline CHEMBL1972659 & 809132 & 4.6 & 4.9418 & TST \\
\hline CHEMBL272453 & 809132 & 6.5 & 6.1655 & TRN \\
\hline CHEMBL1970217 & 809132 & 4.6 & 4.7862 & TRN \\
\hline CHEMBL1988537 & 809132 & 5.9 & 4.7919 & TST \\
\hline CHEMBL1969049 & 809132 & 4.6 & 4.8036 & TRN \\
\hline
\end{tabular}




\begin{tabular}{|c|c|c|c|c|c|}
\hline \\
\hline CHEMBL 2005828 & 809132 & 6.5 & 6.022 & TRN & \\
\hline CHEMBL 2005528 & 809132 & 4.6 & 4.7843 & TST & \\
\hline CHEMBL2003405 & 809132 & 5.7 & 5.0027 & TST & \\
\hline CHEMBL1969843 & 809132 & 4.6 & 4.7343 & TRN & \\
\hline CHEMBL185569 & 809132 & 4.6 & 5.5814 & TRN & \\
\hline CHEMBL 2007002 & 809132 & 4.6 & 5.0357 & TRN & \\
\hline CHEMBL1987007 & 809132 & 4.6 & 5.0599 & TRN & \\
\hline CHEMBL1998611 & 809132 & 4.6 & 5.2212 & TRN & \\
\hline CHEMBL1969588 & 809132 & 7.1 & 6.795 & TRN & \\
\hline CHEMBL1975900 & 809132 & 4.6 & 4.5558 & TRN & \\
\hline CHEMBL 255822 & 809132 & 4.6 & 4.7089 & TRN & \\
\hline CHEMBL1972221 & 809132 & 4.6 & 4.664 & TRN & \\
\hline CHEMBL484390 & 809132 & 4.6 & 4.9103 & TST & \\
\hline CHEMBL1979252 & 809132 & 4.6 & 4.6357 & TRN & \\
\hline CHEMBL 378627 & 809132 & 4.6 & 4.8317 & TST & \\
\hline CHEMBL1996979 & 809132 & 8.5 & 7.1173 & TRN & \\
\hline CHEMBL1968406 & 809132 & 7.6 & 6.6911 & TRN & \\
\hline CHEMBL1972937 & 809132 & 4.6 & 4.8226 & TRN & \\
\hline CHEMBL 2004290 & 809132 & 7.2 & 7.9567 & TRN & \\
\hline CHEMBL1986499 & 809132 & 5.8 & 4.4851 & TRN & \\
\hline CHEMBL2000393 & 809132 & 6.9 & 6.027 & TST & \\
\hline CHEMBL2004311 & 809132 & 7.7 & 6.2144 & TRN & \\
\hline CHEMBL1992634 & 809132 & 5.7 & 5.4694 & TRN & \\
\hline CHEMBL1242373 & 809132 & 6.7 & 6.46299 & 9999999999 & TRN \\
\hline CHEMBL1998545 & 809132 & 4.6 & 4.8099 & TRN & \\
\hline CHEMBL1986869 & 809132 & 4.6 & 4.9036 & TRN & \\
\hline CHEMBL316264 & 809132 & 6.2 & 4.8782 & TRN & \\
\hline CHEMBL1988075 & 809132 & 6.4 & 7.0813 & TRN & \\
\hline CHEMBL1991678 & 809132 & 4.6 & 4.8412 & TRN & \\
\hline CHEMBL1682558 & 809132 & 4.6 & 4.8877 & TRN & \\
\hline CHEMBL2001239 & 809132 & 4.6 & 5.2551 & TST & \\
\hline CHEMBL1990496 & 809132 & 4.6 & 5.2373 & TRN & \\
\hline CHEMBL1988594 & 809132 & 4.6 & 4.7152 & TRN & \\
\hline CHEMBL2001288 & 809132 & 4.6 & 5.2775 & TRN & \\
\hline CHEMBL1999811 & 809132 & 4.6 & 5.4758 & TST & \\
\hline CHEMBL1985074 & 809132 & 4.6 & 4.8456 & TST & \\
\hline CHEMBL2000481 & 809132 & 6.0 & 4.9099 & TRN & \\
\hline CHEMBL1982874 & 809132 & 4.6 & 5.4643 & TRN & \\
\hline CHEMBL2002479 & 809132 & 4.6 & 5.2087 & TRN & \\
\hline CHEMBL1991725 & 809132 & 4.6 & 5.0113 & TRN & \\
\hline CHEMBL2007296 & 809132 & 4.6 & 4.7398 & TRN & \\
\hline CHEMBL208637 & 809132 & 4.6 & 4.709 & TST & \\
\hline CHEMBL396523 & 809132 & 7.2 & 6.4681 & TRN & \\
\hline CHEMBL1967094 & 809132 & 4.6 & 5.0909 & TRN & \\
\hline CHEMBL2003341 & 809132 & 4.6 & 4.76 & TRN & \\
\hline CHEMBL1970203 & 809132 & 4.6 & 4.7094 & TRN & \\
\hline CHEMBL1986530 & 809132 & 4.6 & 4.9288 & TST & \\
\hline CHEMBL1965351 & 809132 & 5.8 & 5.6149 & TST & \\
\hline & & & & 1925 & \\
\hline
\end{tabular}




\begin{tabular}{|c|c|c|c|c|}
\hline & & & pplement & al $\mathrm{T}$ \\
\hline CHEMBL1999321 & 809132 & 4.6 & 5.3226 & TRN \\
\hline CHEMBL1968590 & 809132 & 7.4 & 7.8609 & TRN \\
\hline CHEMBL 2005375 & 809132 & 4.6 & 4.9231 & TRN \\
\hline CHEMBL1984191 & 809132 & 6.5 & 5.0059 & TRN \\
\hline CHEMBL1982992 & 809132 & 5.8 & 5.0404 & TRN \\
\hline CHEMBL1999590 & 809132 & 6.3 & 5.9035 & TST \\
\hline CHEMBL1981079 & 809132 & 6.0 & 4.9799 & TRN \\
\hline CHEMBL1972276 & 809132 & 4.6 & 4.8578 & TRN \\
\hline CHEMBL1980489 & 809132 & 4.6 & 4.6151 & TRN \\
\hline CHEMBL 2000832 & 809132 & 4.6 & 5.1115 & TRN \\
\hline CHEMBL394790 & 809132 & 7.4 & 6.2288 & TRN \\
\hline CHEMBL1970709 & 809132 & 4.6 & 4.7101 & TRN \\
\hline CHEMBL1965660 & 809132 & 5.7 & 5.1616 & TRN \\
\hline CHEMBL1974702 & 809132 & 4.6 & 4.9631 & TRN \\
\hline CHEMBL1998112 & 809132 & 4.6 & 5.6952 & TRN \\
\hline CHEMBL1996111 & 809132 & 4.6 & 4.4467 & TRN \\
\hline CHEMBL1969126 & 809132 & 4.6 & 4.9387 & TRN \\
\hline CHEMBL1965589 & 809132 & 4.6 & 5.0158 & TRN \\
\hline CHEMBL1980896 & 809132 & 5.9 & 6.1686 & TRN \\
\hline CHEMBL1970104 & 809132 & 6.2 & 6.5748 & TRN \\
\hline CHEMBL1998193 & 809132 & 4.6 & 5.0387 & TRN \\
\hline CHEMBL1991429 & 809132 & 7.5 & 7.6861 & TRN \\
\hline CHEMBL1964777 & 809132 & 5.7 & 5.0974 & TST \\
\hline CHEMBL1999714 & 809132 & 4.6 & 4.9207 & TRN \\
\hline CHEMBL1971149 & 809132 & 4.6 & 4.8713 & TRN \\
\hline CHEMBL1987533 & 809132 & 4.6 & 4.8746 & TRN \\
\hline CHEMBL1994040 & 809132 & 4.6 & 4.8386 & TRN \\
\hline CHEMBL1988153 & 809132 & 4.6 & 4.977 & TST \\
\hline CHEMBL579246 & 809132 & 4.6 & 4.974 & TRN \\
\hline CHEMBL1982506 & 809132 & 4.6 & 5.0621 & TST \\
\hline CHEMBL 2004716 & 809132 & 8.3 & 8.6128 & TRN \\
\hline CHEMBL1968127 & 809132 & 4.6 & 4.8425 & TRN \\
\hline CHEMBL1975233 & 809132 & 4.6 & 5.1494 & TRN \\
\hline CHEMBL1985406 & 809132 & 4.6 & 5.0077 & TRN \\
\hline CHEMBL 207400 & 809132 & 4.6 & 4.8285 & TST \\
\hline CHEMBL 2000894 & 809132 & 4.6 & 5.1022 & TST \\
\hline CHEMBL1998121 & 809132 & 6.4 & 5.4581 & TRN \\
\hline CHEMBL1982135 & 809132 & 4.6 & 5.404 & TRN \\
\hline CHEMBL1976090 & 809132 & 4.6 & 4.9376 & TRN \\
\hline CHEMBL 52387 & 809132 & 4.6 & 5.2156 & TST \\
\hline CHEMBL1993243 & 809132 & 7.8 & 8.4281 & TRN \\
\hline CHEMBL 2004771 & 809132 & 4.6 & 4.9787 & TRN \\
\hline CHEMBL379835 & 809132 & 4.6 & 4.6925 & TST \\
\hline CHEMBL1997597 & 809132 & 4.6 & 4.5171 & TRN \\
\hline CHEMBL1969537 & 809132 & 4.6 & 5.5445 & TST \\
\hline CHEMBL1976093 & 809132 & 4.6 & 4.8872 & TRN \\
\hline CHEMBL1979357 & 809132 & 4.6 & 4.7553 & TRN \\
\hline CHEMBL1996817 & 809132 & 6.8 & 6.1889 & TRN \\
\hline
\end{tabular}




\begin{tabular}{|c|c|c|c|c|}
\hline & & & pplement & al $\mathrm{T}$ \\
\hline CHEMBL1975256 & 809132 & 4.6 & 4.9326 & TST \\
\hline CHEMBL508928 & 809132 & 7.8 & 8.089 & TRN \\
\hline CHEMBL3197315 & 809132 & 5.8 & 4.9346 & TST \\
\hline CHEMBL1991356 & 809132 & 4.6 & 5.0525 & TRN \\
\hline CHEMBL 2004892 & 809132 & 4.6 & 4.5821 & TRN \\
\hline CHEMBL468280 & 809132 & 4.6 & 4.8846 & TST \\
\hline CHEMBL116070 & 809132 & 4.6 & 5.0641 & TST \\
\hline CHEMBL1990884 & 809132 & 7.1 & 6.7023 & TRN \\
\hline CHEMBL1990821 & 809132 & 5.8 & 5.1582 & TST \\
\hline CHEMBL3109278 & 809132 & 6.9 & 6.7839 & TRN \\
\hline CHEMBL256835 & 809132 & 6.1 & 5.1683 & TRN \\
\hline CHEMBL1970314 & 809132 & 5.7 & 4.7412 & TRN \\
\hline CHEMBL 2004871 & 809132 & 4.6 & 4.8021 & TRN \\
\hline CHEMBL 2004872 & 809132 & 4.6 & 4.7709 & TRN \\
\hline CHEMBL1969879 & 809132 & 4.6 & 4.8292 & TRN \\
\hline CHEMBL1980142 & 809132 & 4.6 & 4.8012 & TRN \\
\hline CHEMBL41783 & 809132 & 4.6 & 4.8578 & TRN \\
\hline CHEMBL1981720 & 809132 & 4.6 & 4.8888 & TRN \\
\hline CHEMBL 2006276 & 809132 & 4.6 & 4.8037 & TRN \\
\hline CHEMBL419932 & 809132 & 4.6 & 4.8182 & TRN \\
\hline CHEMBL271381 & 809132 & 7.7 & 6.9644 & TRN \\
\hline CHEMBL262433 & 809132 & 7.7 & 6.7718 & TRN \\
\hline CHEMBL 2006785 & 809132 & 4.6 & 4.9589 & TRN \\
\hline CHEMBL1982466 & 809132 & 8.3 & 8.6799 & TRN \\
\hline CHEMBL306380 & 809132 & 8.5 & 7.5077 & TRN \\
\hline CHEMBL1966722 & 809132 & 4.6 & 4.7662 & TRN \\
\hline CHEMBL1995740 & 809132 & 4.6 & 4.9227 & TRN \\
\hline CHEMBL1975500 & 809132 & 5.8 & 5.2271 & TRN \\
\hline CHEMBL394619 & 809132 & 6.6 & 6.3385 & TRN \\
\hline CHEMBL1996831 & 809132 & 4.6 & 4.9939 & TST \\
\hline CHEMBL411903 & 809132 & 6.0 & 6.6267 & TRN \\
\hline CHEMBL234085 & 809132 & 4.6 & 4.8209 & TRN \\
\hline CHEMBL1995832 & 809132 & 4.6 & 5.2223 & TRN \\
\hline CHEMBL418203 & 809132 & 4.6 & 5.2828 & TST \\
\hline CHEMBL1969042 & 809132 & 4.6 & 5.3245 & TST \\
\hline CHEMBL1989646 & 809132 & 4.6 & 4.5908 & TRN \\
\hline CHEMBL225519 & 809132 & 4.7 & 4.8169 & TRN \\
\hline CHEMBL1999931 & 809132 & 6.9 & 5.8364 & TRN \\
\hline CHEMBL1978200 & 809132 & 4.6 & 5.1101 & TRN \\
\hline CHEMBL1970522 & 809132 & 4.6 & 4.8253 & TRN \\
\hline CHEMBL1966087 & 809132 & 4.6 & 4.8925 & TRN \\
\hline CHEMBL1375418 & 809132 & 4.6 & 5.3967 & TRN \\
\hline CHEMBL 2007064 & 809132 & 5.7 & 5.9551 & TRN \\
\hline CHEMBL1964692 & 809132 & 8.6 & 7.8479 & TRN \\
\hline CHEMBL1996931 & 809132 & 4.6 & 4.648 & TRN \\
\hline CHEMBL1981047 & 809132 & 8.9 & 8.0021 & TRN \\
\hline CHEMBL229968 & 809132 & 4.6 & 5.0005 & TRN \\
\hline CHEMBL1973483 & 809132 & 4.6 & 4.9333 & TRN \\
\hline
\end{tabular}




\begin{tabular}{|c|c|c|c|c|}
\hline \multicolumn{5}{|c|}{ plemental } \\
\hline CHEMBL1976240 & 809132 & 4.6 & 4.7044 & TRN \\
\hline CHEMBL1997340 & 809132 & 4.6 & 4.8685 & TRN \\
\hline CHEMBL1522508 & 809132 & 4.6 & 4.9324 & TRN \\
\hline CHEMBL1968151 & 809132 & 4.6 & 4.8687 & TST \\
\hline CHEMBL1979093 & 809132 & 6.6 & 6.6991 & TRN \\
\hline CHEMBL1989474 & 809132 & 5.6 & 4.8897 & TRN \\
\hline CHEMBL1090360 & 809132 & 7.5 & 7.7249 & TRN \\
\hline CHEMBL1987009 & 809132 & 4.6 & 5.0194 & TRN \\
\hline CHEMBL 2003817 & 809132 & 4.6 & 4.9098 & TRN \\
\hline CHEMBL379218 & 809132 & 4.6 & 4.8775 & TRN \\
\hline CHEMBL1994830 & 809132 & 4.6 & 5.0023 & TST \\
\hline CHEMBL210887 & 809132 & 4.6 & 4.9685 & TST \\
\hline CHEMBL458997 & 809132 & 7.7 & 6.3182 & TRN \\
\hline CHEMBL226403 & 809132 & 4.6 & 4.5792 & TRN \\
\hline CHEMBL227271 & 809132 & 4.6 & 4.9609 & TRN \\
\hline CHEMBL1971021 & 809132 & 7.5 & 5.7644 & TRN \\
\hline CHEMBL583144 & 809132 & 5.7 & 5.1312 & TRN \\
\hline CHEMBL1974310 & 809132 & 6.4 & 5.0556 & TST \\
\hline CHEMBL1982660 & 809132 & 4.6 & 5.1605 & TRN \\
\hline CHEMBL1994693 & 809132 & 4.6 & 5.9069 & TRN \\
\hline CHEMBL1994938 & 809132 & 8.5 & 8.9739 & TRN \\
\hline CHEMBL1982957 & 809132 & 6.8 & 6.2612 & TRN \\
\hline CHEMBL1725279 & 809132 & 7.2 & 5.9643 & TST \\
\hline CHEMBL1966279 & 809132 & 4.6 & 4.775 & TRN \\
\hline CHEMBL1975138 & 809132 & 4.6 & 4.8452 & TRN \\
\hline CHEMBL1997846 & 809132 & 4.6 & 5.1308 & TRN \\
\hline CHEMBL 2004419 & 809132 & 4.6 & 5.0905 & TRN \\
\hline CHEMBL1980704 & 809132 & 4.6 & 4.8176 & TST \\
\hline CHEMBL 2003271 & 809132 & 4.6 & 5.052 & TRN \\
\hline CHEMBL1966808 & 809132 & 4.6 & 4.8356 & TST \\
\hline CHEMBL 2004447 & 809132 & 4.6 & 4.9049 & TST \\
\hline CHEMBL1983111 & 809132 & 7.1 & 7.2737 & TST \\
\hline CHEMBL1973860 & 809132 & 4.6 & 4.7287 & TRN \\
\hline CHEMBL1972489 & 809132 & 4.6 & 4.8143 & TRN \\
\hline CHEMBL260135 & 809132 & 4.6 & 5.0662 & TRN \\
\hline CHEMBL1994074 & 809132 & 4.6 & 5.0066 & TRN \\
\hline CHEMBL220241 & 809132 & 4.6 & 5.039 & TRN \\
\hline CHEMBL1982610 & 809132 & 4.6 & 5.3311 & TST \\
\hline CHEMBL1999496 & 809132 & 5.8 & 4.9254 & TRN \\
\hline CHEMBL1988300 & 809132 & 6.8 & 7.0548 & TRN \\
\hline CHEMBL1972119 & 809132 & 4.6 & 4.8541 & TRN \\
\hline CHEMBL1991078 & 809132 & 7.1 & 6.1263 & TRN \\
\hline CHEMBL1987359 & 809132 & 4.6 & 5.0768 & TST \\
\hline CHEMBL1986328 & 809132 & 4.6 & 4.855 & TST \\
\hline CHEMBL95692 & 809132 & 4.6 & 5.105 & TRN \\
\hline CHEMBL1090356 & 809132 & 8.2 & 7.2197 & TRN \\
\hline CHEMBL1976455 & 809132 & 4.6 & 4.6924 & TRN \\
\hline CHEMBL1983923 & 809132 & 7.4 & 6.6526 & TST \\
\hline
\end{tabular}




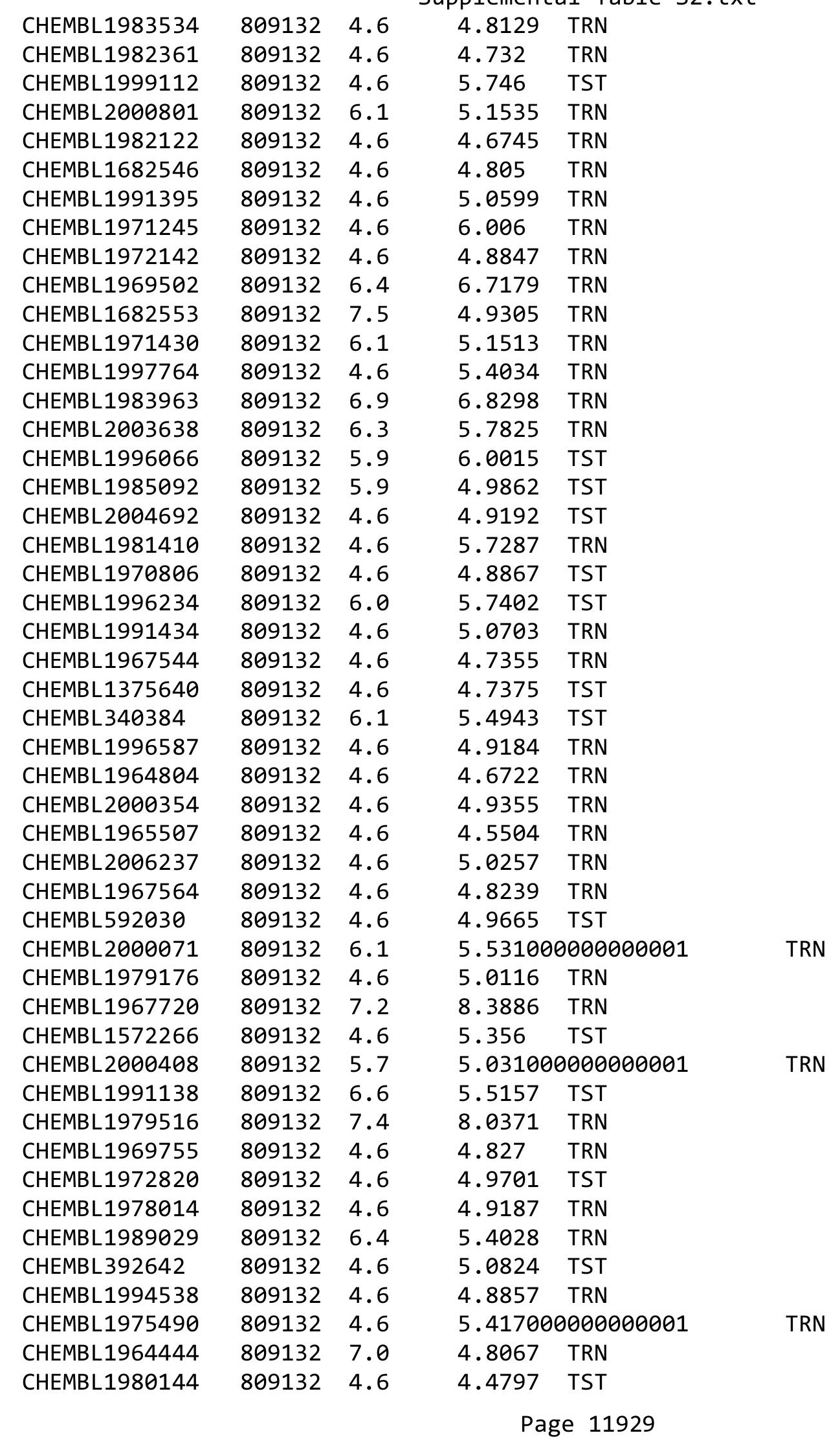




\begin{tabular}{|c|c|c|c|c|c|}
\hline \\
\hline CHEMBL1991188 & 809132 & 4.6 & 4.7733 & TST & \\
\hline CHEMBL1986139 & 809132 & 4.6 & 4.7852 & TST & \\
\hline CHEMBL1972849 & 809132 & 4.6 & 4.8489 & TST & \\
\hline CHEMBL1980540 & 809132 & 4.6 & 4.7556 & TST & \\
\hline CHEMBL1979883 & 809132 & 7.4 & 7.7876 & TST & \\
\hline CHEMBL231209 & 809132 & 6.0 & 5.8838 & TST & \\
\hline CHEMBL1984162 & 809132 & 9.0 & 8.2521 & TST & \\
\hline CHEMBL1976220 & 809132 & 7.3 & 6.5153 & TST & \\
\hline CHEMBL491758 & 809132 & 6.1 & 6.479 & TST & \\
\hline CHEMBL259922 & 809132 & 8.4 & 5.6276 & TST & \\
\hline CHEMBL1969301 & 809132 & 4.6 & 4.7805 & TST & \\
\hline CHEMBL549730 & 809132 & 4.6 & 4.7567 & TST & \\
\hline CHEMBL1982383 & 809132 & 4.6 & 5.0313 & TST & \\
\hline CHEMBL17370 & 809132 & 6.4 & 5.0223 & TST & \\
\hline CHEMBL1970189 & 809132 & 4.6 & 4.9194 & TST & \\
\hline CHEMBL371206 & 809132 & 7.6 & 7.2516 & TST & \\
\hline CHEMBL1996791 & 809132 & 4.6 & 5.8031 & TST & \\
\hline CHEMBL1974664 & 809132 & 6.0 & 6.7634 & TST & \\
\hline CHEMBL1983932 & 809132 & 4.6 & 5.0938 & TST & \\
\hline CHEMBL1987910 & 809132 & 4.6 & 5.5046 & TST & \\
\hline CHEMBL1974288 & 809132 & 4.6 & 4.7976 & TST & \\
\hline CHEMBL1991285 & 809132 & 4.6 & 5.3235 & TST & \\
\hline CHEMBL196363 & 809132 & 7.4 & 7.2424 & TST & \\
\hline CHEMBL243088 & 809132 & 7.2 & 6.3373 & TST & \\
\hline CHEMBL1984038 & 809132 & 4.6 & 5.0468 & TST & \\
\hline CHEMBL1190711 & 809132 & 4.6 & 5.1712 & TST & \\
\hline CHEMBL1974416 & 809132 & 6.4 & 6.5331 & TST & \\
\hline CHEMBL1993661 & 809132 & 9.0 & 8.1123 & TST & \\
\hline CHEMBL1968705 & 809132 & 4.6 & 4.7685 & TST & \\
\hline CHEMBL1997872 & 809132 & 4.6 & 5.0317 & TST & \\
\hline CHEMBL1966343 & 809132 & 4.6 & 4.8615 & TST & \\
\hline CHEMBL404367 & 809132 & 7.1 & 6.4713 & TST & \\
\hline CHEMBL3192701 & 752436 & 6.6576 & 4.3141 & TRN & \\
\hline CHEMBL1454770 & 752436 & 4.8794 & 4.5356 & TRN & \\
\hline CHEMBL1417290 & 752436 & 5.1175 & 4.3245 & TST & \\
\hline CHEMBL3144939 & 752436 & 5.4789 & 5.6762 & TRN & \\
\hline CHEMBL1464042 & 752436 & 6.1543 & 5.6773 & TRN & \\
\hline CHEMBL1467857 & 752436 & 5.2495 & 5.5152 & TRN & \\
\hline CHEMBL1543295 & 752436 & 6.2976 & 5.7039 & TRN & \\
\hline CHEMBL1330558 & 752436 & 5.3372 & 5.5867 & TRN & \\
\hline CHEMBL1390880 & 752436 & 5.7986 & 4.7637 & TRN & \\
\hline CHEMBL1428166 & 752436 & 5.8041 & 5.6572 & TRN & \\
\hline CHEMBL578512 & 752436 & 8.7447 & 7.15799 & 99999999995 & TRN \\
\hline CHEMBL1329726 & 752436 & 7.1379 & 5.3038 & TRN & \\
\hline CHEMBL1565022 & 752436 & 2.4202 & 4.516 & TRN & \\
\hline CHEMBL1304066 & 752436 & 5.7258 & 5.34399 & 9999999999 & TRN \\
\hline CHEMBL1446060 & 752436 & 4.71 & 4.9432 & TRN & \\
\hline CHEMBL1387615 & 752436 & 5.4413 & 4.9262 & TRN & \\
\hline
\end{tabular}




\begin{tabular}{|c|c|c|c|c|c|}
\hline \\
\hline CHEMBL1467381 & 752436 & 2.4202 & 4.8158 & TRN & \\
\hline CHEMBL1598857 & 752436 & 4.9547 & 5.1769 & TRN & \\
\hline CHEMBL1400512 & 752436 & 5.224 & 5.75200 & 0000000001 & TST \\
\hline CHEMBL1597074 & 752436 & 5.4989 & 4.7907 & TST & \\
\hline CHEMBL1322995 & 752436 & 5.3862 & 4.9897 & TRN & \\
\hline CHEMBL1371353 & 752436 & 5.6108 & 5.7091 & TRN & \\
\hline CHEMBL 3192535 & 752436 & 4.7033 & 3.8828 & TRN & \\
\hline CHEMBL1305372 & 752436 & 4.7305 & 5.2169 & TRN & \\
\hline CHEMBL1447306 & 752436 & 6.0097 & 5.8712 & TRN & \\
\hline CHEMBL1445135 & 752436 & 4.8761 & 4.829 & TRN & \\
\hline CHEMBL1427221 & 752436 & 4.8761 & 5.2418 & TRN & \\
\hline CHEMBL1455522 & 752436 & 5.7212 & 6.0106 & TRN & \\
\hline CHEMBL1308783 & 752436 & 5.6635 & 5.6258 & TRN & \\
\hline CHEMBL1359236 & 752436 & 2.4202 & 4.7077 & TRN & \\
\hline CHEMBL 3145200 & 752436 & 5.2676 & 5.3727 & TRN & \\
\hline CHEMBL1566610 & 752436 & 4.3372 & 4.6978 & TST & \\
\hline CHEMBL1544483 & 752436 & 4.2628 & 5.2575 & TST & \\
\hline CHEMBL1587181 & 752436 & 6.3179 & 5.8756 & TRN & \\
\hline CHEMBL1496473 & 752436 & 4.9914 & 5.1582 & TST & \\
\hline CHEMBL1320517 & 752436 & 4.3354 & 6.0748 & TRN & \\
\hline CHEMBL1568820 & 752436 & 2.4202 & 5.7091 & TRN & \\
\hline CHEMBL1341388 & 752436 & 4.6402 & 4.0126 & TRN & \\
\hline CHEMBL1323586 & 752436 & 4.699 & 5.3795 & TRN & \\
\hline CHEMBL1794290 & 752436 & 2.4202 & 4.0383 & TST & \\
\hline CHEMBL1413374 & 752436 & 4.9136 & 4.8022 & TRN & \\
\hline CHEMBL1465227 & 752436 & 5.2832 & 4.6396 & TRN & \\
\hline CHEMBL1417929 & 752436 & 6.9957 & 6.16799 & 9999999999 & TRN \\
\hline CHEMBL1302378 & 752436 & 5.4584 & 5.1304 & TST & \\
\hline CHEMBL1469208 & 752436 & 4.6198 & 5.0067 & TST & \\
\hline CHEMBL 1495610 & 752436 & 5.1898 & 5.197 & TRN & \\
\hline CHEMBL99408 & 752436 & 5.2255 & 5.3694 & TRN & \\
\hline CHEMBL1556187 & 752436 & 4.6326 & 5.1659 & TRN & \\
\hline CHEMBL1569472 & 752436 & 5.0991 & 5.3136 & TRN & \\
\hline CHEMBL3190263 & 752436 & 4.8697 & 5.2635 & TRN & \\
\hline CHEMBL1510765 & 752436 & 4.6271 & 5.3366 & TST & \\
\hline CHEMBL1568537 & 752436 & 2.4202 & 5.0173 & TRN & \\
\hline CHEMBL1494762 & 752436 & 4.9281 & 4.7186 & TRN & \\
\hline CHEMBL1719244 & 752436 & 4.6326 & 4.6352 & TRN & \\
\hline CHEMBL1467136 & 752436 & 4.9431 & 4.4694 & TST & \\
\hline CHEMBL1362714 & 752436 & 6.0009 & 4.9417 & TST & \\
\hline CHEMBL1567670 & 752436 & 5.0035 & 5.295 & TRN & \\
\hline CHEMBL1712864 & 752436 & 2.4202 & 4.0561 & TRN & \\
\hline CHEMBL1981464 & 752436 & 2.4202 & 4.5691 & TRN & \\
\hline CHEMBL1452114 & 752436 & 5.0926 & 5.2048 & TST & \\
\hline CHEMBL1368829 & 752436 & 5.4461 & 5.4445 & TRN & \\
\hline CHEMBL3210650 & 752436 & 5.6271 & 4.717 & TRN & \\
\hline CHEMBL1492010 & 752436 & 6.2782 & 5.8887 & TRN & \\
\hline CHEMBL1570958 & 752436 & 5.8633 & 5.5265 & TRN & \\
\hline
\end{tabular}


Supplemental Table S2.txt

\begin{tabular}{|c|c|c|c|c|}
\hline & & & & \\
\hline AEMBL15 & 436 & 0788 & & \\
\hline AEMBL1477770 & 2436 & 3356 & 9664 & \\
\hline HEMBL3197978 & 2436 & 528 & 9825 & \\
\hline & 2436 & 574 & & \\
\hline AEMBL1302463 & 2436 & 172 & 458 & \\
\hline HEMBL52347 & 52436 & 5.0395 & 5293 & \\
\hline HEMBL1429537 & 52436 & 391 & 047 & \\
\hline HEMBL1581 & 52436 & 202 & 9669 & \\
\hline IEMBL132 & 2436 & 46 & & \\
\hline AEMBL $147 €$ & 136 & & & \\
\hline AEMBL1510478 & 52436 & 202 & 8316 & \\
\hline AEMBL1507 & 52436 & 206 & 167 & \\
\hline IEMBL157] & 36 & 2. & 174 & \\
\hline AEMBL154 & 36 & & 888 & \\
\hline AEMBL $144 \mathrm{C}$ & & & 688 & \\
\hline AEMBL572189 & 36 & 735 & 3834 & \\
\hline AEMBL1569 & & & 937 & \\
\hline AEMBL134 & 6 & 45 & 122 & \\
\hline JEMBL134 & 36 & & 555 & \\
\hline AEMBL 149 & & & & \\
\hline HEMBL1458 & 36 & 4. & 2565 & \\
\hline AEMBL 3193 & & & 358 & \\
\hline EMBL14 & 6 & & 509 & \\
\hline AEMBL13 & & & 582 & \\
\hline AFMR 157 & & & 978 & \\
\hline AEMBL1582 & & & 856 & RN \\
\hline AEMBL134 & & & & \\
\hline HEMBL159 & 36 & 5 . & 461 & $\mathrm{RI}$ \\
\hline HEMBL14 & 6 & 41 & 582 & RN \\
\hline AEMBL19 & 36 & & 04 & RN \\
\hline HEMBL137£ & & & & \\
\hline AEMBL1345 & & & & RI \\
\hline AEMBL14. & 36 & 4. & 235 & RN \\
\hline HEMBL14 & 36 & 4. & 729 & \\
\hline 17 & & & & ST \\
\hline AEMBL1347369 & 524 & & 643 & $\mathrm{R}$ \\
\hline AEMBL1532 & 36 & & & ST \\
\hline IEMBL1384 & 36 & & 049 & RI \\
\hline 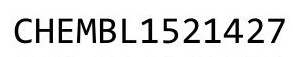 & & & 431 & \\
\hline 154 & & & & RN \\
\hline HEMBL1418568 & 52436 & 5.8894 & 1648 & $\mathrm{R}$ \\
\hline AEMBL145 & 6 & & 781 & TR \\
\hline HEMBL 138 & & & & \\
\hline HEMBL517 & & & & \\
\hline CHEMBL1352 & & & 331 & RN \\
\hline HEMBL15684 & 52436 & 5.7423 & .0801 & $\mathrm{TR}$ \\
\hline HEMBL1326957 & 752436 & 4.6271 & 5.5572 & \\
\hline
\end{tabular}

Page 11932 
Supplemental Table S2.txt

\begin{tabular}{|c|c|c|c|c|c|}
\hline CHEMBL3195410 & 752436 & 6.9066 & 5.454 & TRN & \\
\hline CHEMBL1396260 & 752436 & 2.4202 & 4.0656 & TRN & \\
\hline CHEMBL1309645 & 752436 & 4.2644 & 4.1506 & TRN & \\
\hline CHEMBL1364183 & 752436 & 2.4202 & 4.0315 & TRN & \\
\hline CHEMBL1582351 & 752436 & 2.4202 & 4.3538 & TRN & \\
\hline CHEMBL1326529 & 752436 & 5.2557 & 4.7527 & TRN & \\
\hline CHEMBL3190845 & 752436 & 5.8153 & 5.9376 & TRN & \\
\hline CHEMBL1349651 & 752436 & 5.6716 & 5.3038 & TRN & \\
\hline CHEMBL1330489 & 752436 & 5.4921 & 5.2662 & TST & \\
\hline CHEMBL1330597 & 752436 & 5.4535 & 5.6208 & TRN & \\
\hline CHEMBL1410768 & 752436 & 4.2692 & 4.5437 & TRN & \\
\hline CHEMBL1471984 & 752436 & 2.4202 & 3.9927 & TRN & \\
\hline CHEMBL1483312 & 752436 & 6.2967 & 5.8835 & TRN & \\
\hline CHEMBL1352007 & 752436 & 5.6925 & 5.2607 & TRN & \\
\hline CHEMBL1468635 & 752436 & 4.4828 & 4.1834 & TRN & \\
\hline CHEMBL599924 & 752436 & 7.4342 & 6.6954 & TRN & \\
\hline CHEMBL1488412 & 752436 & 5.4724 & 5.2366 & TRN & \\
\hline CHEMBL1300420 & 752436 & 4.752 & 4.8549 & TRN & \\
\hline CHEMBL1403148 & 752436 & 6.2083 & 5.9476 & TRN & \\
\hline CHEMBL1506031 & 752436 & 5.5591 & 5.3757 & TST & \\
\hline CHEMBL599098 & 752436 & 5.2882 & 5.4407 & TRN & \\
\hline CHEMBL1486335 & 752436 & 5.2487 & 4.7618 & TRN & \\
\hline CHEMBL1463659 & 752436 & 7.71899 & 9999999 & 99 & 6.7901 \\
\hline CHEMBL1360322 & 752436 & 4.6198 & 5.4291 & TRN & \\
\hline CHEMBL1545902 & 752436 & 4.7773 & 5.395 & TST & \\
\hline CHEMBL1416184 & 752436 & 6.1415 & 5.9707 & TRN & \\
\hline CHEMBL1399683 & 752436 & 4.58 & 4.8222 & TRN & \\
\hline CHEMBL1326083 & 752436 & 5.4921 & 5.4197 & TST & \\
\hline CHEMBL1374701 & 752436 & 4.71 & 5.0944 & TRN & \\
\hline CHEMBL1536606 & 752436 & 5.7721 & 5.5955 & TRN & \\
\hline CHEMBL1471088 & 752436 & 4.9626 & 5.0241 & TRN & \\
\hline CHEMBL1418884 & 752436 & 4.9666 & 3.6556 & TRN & \\
\hline CHEMBL1321952 & 752436 & 5.0097 & 5.3652 & TRN & \\
\hline CHEMBL1524399 & 752436 & 6.1713 & 5.6354 & TST & \\
\hline CHEMBL1558809 & 752436 & 6.1124 & 5.7821 & TRN & \\
\hline CHEMBL1530161 & 752436 & 5.466 & 5.6962 & TRN & \\
\hline CHEMBL1520701 & 752436 & 4.8894 & 4.7852 & TRN & \\
\hline CHEMBL1719512 & 752436 & 2.4202 & 3.8546 & TST & \\
\hline CHEMBL1483252 & 752436 & 5.7077 & 4.5815 & TST & \\
\hline CHEMBL 3210540 & 752436 & 5.4295 & 4.9457 & TRN & \\
\hline CHEMBL1449346 & 752436 & 5.3546 & 5.1953 & TRN & \\
\hline CHEMBL1313352 & 752436 & 4.6216 & 5.2552 & TRN & \\
\hline CHEMBL1561949 & 752436 & 5.0472 & 4.5414 & TST & \\
\hline CHEMBL1383664 & 752436 & 2.4202 & 5.5047 & TRN & \\
\hline CHEMBL1991373 & 752436 & 2.4202 & 3.9853 & TRN & \\
\hline CHEMBL1712155 & 752436 & 2.4202 & 4.0021 & TST & \\
\hline CHEMBL1333290 & 752436 & 5.4353 & 4.2681 & TST & \\
\hline CHEMBL1502234 & 752436 & 4.3307 & 4.9836 & TRN & \\
\hline
\end{tabular}

Page 11933 


\begin{tabular}{|c|c|c|c|c|c|}
\hline & & & & & \\
\hline CHEMBL3194896 & 752436 & 2.4202 & 4.4664 & TRN & \\
\hline CHEMBL1452061 & 752436 & 6.8097 & 5.7806 & TST & \\
\hline CHEMBL1365249 & 752436 & 5.3197 & 5.0627 & TST & \\
\hline CHEMBL1427517 & 752436 & 4.6556 & 4.7678 & TRN & \\
\hline CHEMBL1567402 & 752436 & 5.5784 & 4.3878 & TRN & \\
\hline CHEMBL1462950 & 752436 & 5.5376 & 5.4174 & TRN & \\
\hline CHEMBL1456225 & 752436 & 5.6716 & 5.4575 & TRN & \\
\hline CHEMBL390559 & 752436 & 4.8477 & 5.5698 & TRN & \\
\hline CHEMBL1428407 & 752436 & 4.9586 & 5.5519 & TRN & \\
\hline CHEMBL1594740 & 752436 & 5.2441 & 5.2659 & TRN & \\
\hline CHEMBL 1477756 & 752436 & 6.2749 & 5.3968 & TRN & \\
\hline CHEMBL1422133 & 752436 & 2.4202 & 4.6802 & TRN & \\
\hline CHEMBL1965172 & 752436 & 4.6289 & 4.6897 & TRN & \\
\hline CHEMBL1608041 & 752436 & 5.1918 & 4.917 & TRN & \\
\hline CHEMBL3195005 & 752436 & 4.327 & 5.1549 & TRN & \\
\hline CHEMBL1570760 & 752436 & 5.109 & 5.6114 & TRN & \\
\hline CHEMBL1370681 & 752436 & 5.341 & 5.155 & TRN & \\
\hline CHEMBL1466445 & 752436 & 5.055 & 5.3367 & TRN & \\
\hline CHEMBL1557927 & 752436 & 5.466 & 4.9901 & TRN & \\
\hline CHEMBL1535665 & 752436 & 4.8416 & 5.4145 & TRN & \\
\hline CHEMBL1497070 & 752436 & 6.0 & 5.8152 & TST & \\
\hline CHEMBL1499282 & 752436 & 5.8327 & 5.6612 & TRN & \\
\hline CHEMBL1383369 & 752436 & 5.0526 & 4.7525 & TRN & \\
\hline CHEMBL1587432 & 752436 & 4.8508 & 5.4719 & TST & \\
\hline CHEMBL1343144 & 752436 & 5.3125 & 5.2637 & TRN & \\
\hline CHEMBL1587979 & 752436 & 5.3665 & 5.11600 & 00000000005 & TRN \\
\hline CHEMBL1423623 & 752436 & 5.9872 & 5.9811 & TRN & \\
\hline CHEMBL1420007 & 752436 & 5.6234 & 5.3456 & TRN & \\
\hline CHEMBL1403143 & 752436 & 5.1079 & 5.329 & TST & \\
\hline CHEMBL1400469 & 752436 & 4.8386 & 5.5669 & TRN & \\
\hline CHEMBL312032 & 752436 & 5.2857 & 4.2307 & TRN & \\
\hline CHEMBL1385214 & 752436 & 2.4202 & 3.9713 & TRN & \\
\hline CHEMBL339561 & 752436 & 6.0501 & 5.5645 & TRN & \\
\hline CHEMBL1463885 & 752436 & 5.6536 & 5.476 & TRN & \\
\hline CHEMBL1321538 & 752436 & 6.4498 & 6.2047 & TRN & \\
\hline CHEMBL1409091 & 752436 & 4.7235 & 5.0627 & TRN & \\
\hline CHEMBL1332543 & 752436 & 5.5784 & 5.6487 & TRN & \\
\hline CHEMBL1544909 & 752436 & 4.9957 & 5.2405 & TRN & \\
\hline CHEMBL1389827 & 752436 & 4.2733 & 5.1237 & TST & \\
\hline CHEMBL1364004 & 752436 & 4.8827 & 4.8424 & TRN & \\
\hline CHEMBL1458019 & 752436 & 2.4202 & 4.3458 & TRN & \\
\hline CHEMBL1430379 & 752436 & 2.4202 & 4.5089 & TRN & \\
\hline CHEMBL3208859 & 752436 & 5.1215 & 5.0221 & TRN & \\
\hline CHEMBL1496959 & 752436 & 4.3089 & 4.5836 & TST & \\
\hline CHEMBL1423138 & 752436 & 5.4815 & 5.8063 & TRN & \\
\hline CHEMBL1499853 & 752436 & 5.5544 & 5.6821 & TRN & \\
\hline CHEMBL1305092 & 752436 & 4.9547 & 5.808 & TRN & \\
\hline CHEMBL1596753 & 752436 & 4.2557 & 4.2536 & TRN & \\
\hline
\end{tabular}

Page 11934 


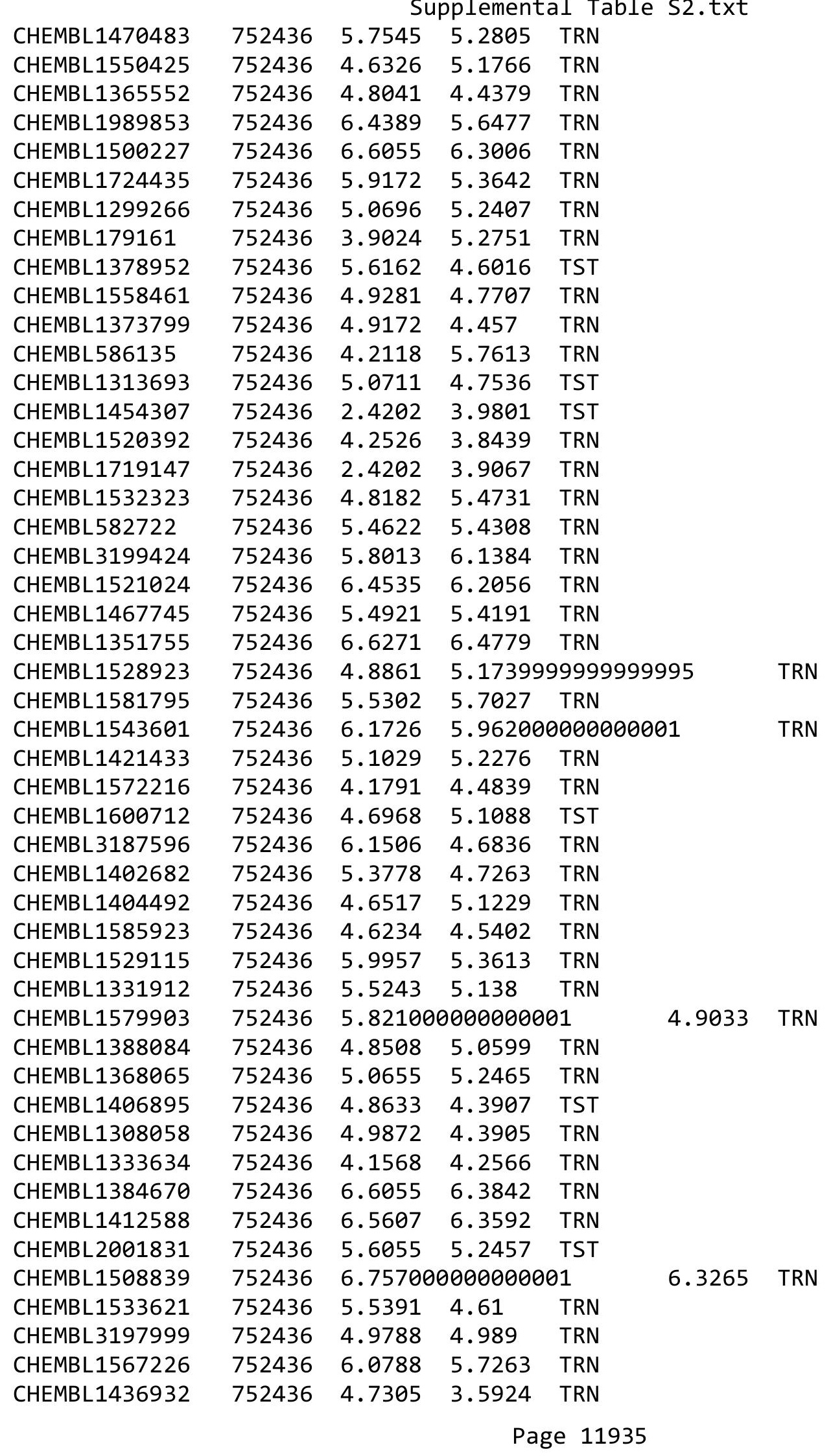


Supplemental Table S2.txt

\begin{tabular}{|c|c|c|c|c|c|c|}
\hline CHEMBL1350983 & 752436 & 5.9031 & 4.9208 & TRN & & \\
\hline CHEMBL1302401 & 752436 & 5.4157 & 5.0948 & TRN & & \\
\hline CHEMBL1577384 & 752436 & 3.6817 & 5.4031 & TRN & & \\
\hline CHEMBL1335893 & 752436 & 2.4202 & 4.4052 & TRN & & \\
\hline CHEMBL 3198793 & 752436 & 6.2741 & 3.9926 & TRN & & \\
\hline CHEMBL1344426 & 752436 & 5.0635 & 5.2956 & TRN & & \\
\hline CHEMBL1576754 & 752436 & 4.9318 & 5.6488 & TRN & & \\
\hline CHEMBL1544793 & 752436 & 6.4425 & 6.227 & TRN & & \\
\hline CHEMBL 3198784 & 752436 & 6.4089 & 4.2903 & TRN & & \\
\hline CHEMBL1479114 & 752436 & 5.4225 & 5.1904 & TRN & & \\
\hline CHEMBL1348529 & 752436 & 4.8539 & 4.7164 & TRN & & \\
\hline CHEMBL1422754 & 752436 & 5.4989 & 5.5972 & TRN & & \\
\hline CHEMBL1730123 & 752436 & 6.117999 & 99999999 & 99 & 5.4956 & TRN \\
\hline CHEMBL 3199919 & 752436 & 5.0526 & 5.4472 & TST & & \\
\hline CHEMBL1351750 & 752436 & 5.1838 & 5.6244 & TRN & & \\
\hline CHEMBL1605956 & 752436 & 5.4237 & 5.7133 & TRN & & \\
\hline CHEMBL1535938 & 752436 & 5.4724 & 5.4984 & TRN & & \\
\hline CHEMBL1313043 & 752436 & 5.4868 & 5.1028 & TRN & & \\
\hline CHEMBL 3195684 & 752436 & 5.3788 & 4.7192 & TRN & & \\
\hline CHEMBL 3145082 & 752436 & 5.9788 & 5.7643 & TRN & & \\
\hline CHEMBL1435915 & 752436 & 5.6517 & 4.7697 & TRN & & \\
\hline CHEMBL1313748 & 752436 & 5.3391 & 4.7601 & TST & & \\
\hline CHEMBL1359933 & 752436 & 6.51 & 6.4215 & TRN & & \\
\hline CHEMBL1584201 & 752436 & 4.7033 & 5.5057 & TRN & & \\
\hline CHEMBL 3191681 & 752436 & 5.8827 & 5.6464 & TRN & & \\
\hline CHEMBL1607263 & 752436 & 6.6635 & 6.2198 & TRN & & \\
\hline CHEMBL1585742 & 752436 & 5.3809 & 5.0922 & TRN & & \\
\hline CHEMBL3196451 & 752436 & 6.9245 & 6.6468 & TRN & & \\
\hline CHEMBL1371896 & 752436 & 3.9431 & 4.2615 & TRN & & \\
\hline CHEMBL 3144856 & 752436 & 5.4815 & 5.9444 & TRN & & \\
\hline CHEMBL1995641 & 752436 & 4.7932 & 3.8726 & TRN & & \\
\hline CHEMBL1561505 & 752436 & 5.0329 & 5.2912 & TST & & \\
\hline CHEMBL1556498 & 752436 & 4.6676 & 5.3605 & TRN & & \\
\hline CHEMBL1490942 & 752436 & 5.9706 & 5.8963 & TRN & & \\
\hline CHEMBL1562713 & 752436 & 4.9747 & 5.1162 & TST & & \\
\hline CHEMBL1498517 & 752436 & 5.2083 & 5.3231 & TRN & & \\
\hline CHEMBL1413355 & 752436 & 4.3925 & 5.0649 & TST & & \\
\hline CHEMBL1520239 & 752436 & 4.5045 & 4.0509 & TRN & & \\
\hline CHEMBL1383240 & 752436 & 5.6676 & 5.921 & TRN & & \\
\hline CHEMBL1567805 & 752436 & 5.0376 & 4.8149 & TRN & & \\
\hline CHEMBL1487749 & 752436 & 2.4202 & 4.4839 & TST & & \\
\hline CHEMBL1419822 & 752436 & 5.2314 & 4.5375 & TRN & & \\
\hline CHEMBL1347736 & 752436 & 5.4168 & 5.1491 & TRN & & \\
\hline CHEMBL1701356 & 752436 & 2.4202 & 3.7449 & TRN & & \\
\hline CHEMBL578502 & 752436 & 4.4157 & 5.2802 & TRN & & \\
\hline CHEMBL1321664 & 752436 & 5.8697 & 5.9073 & TRN & & \\
\hline CHEMBL1526076 & 752436 & \multicolumn{3}{|c|}{5.752000000000001} & 5.3753 & TRN \\
\hline CHEMBL1608727 & 752436 & 2.4202 & 3.9323 & TRN & & \\
\hline
\end{tabular}




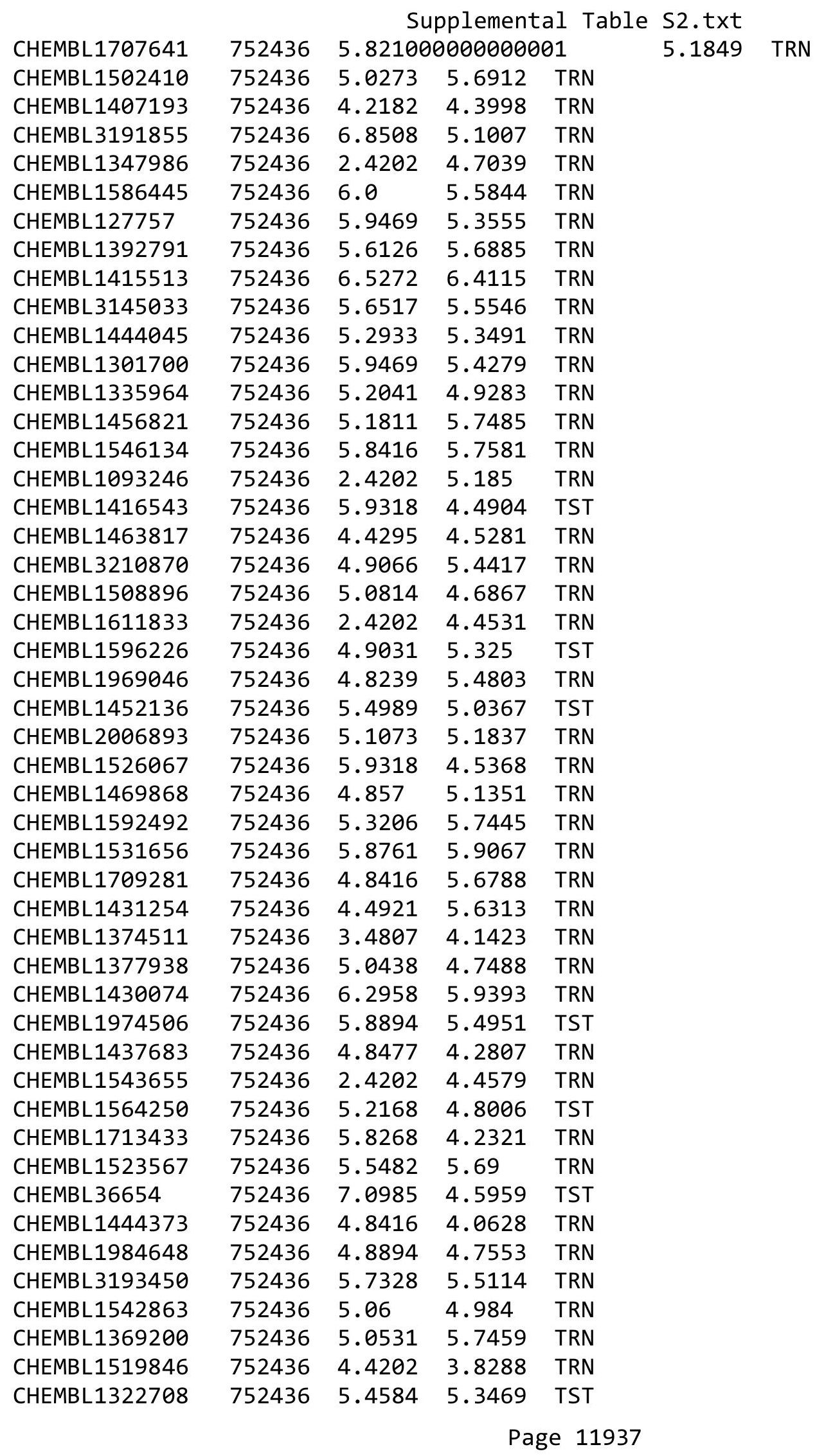




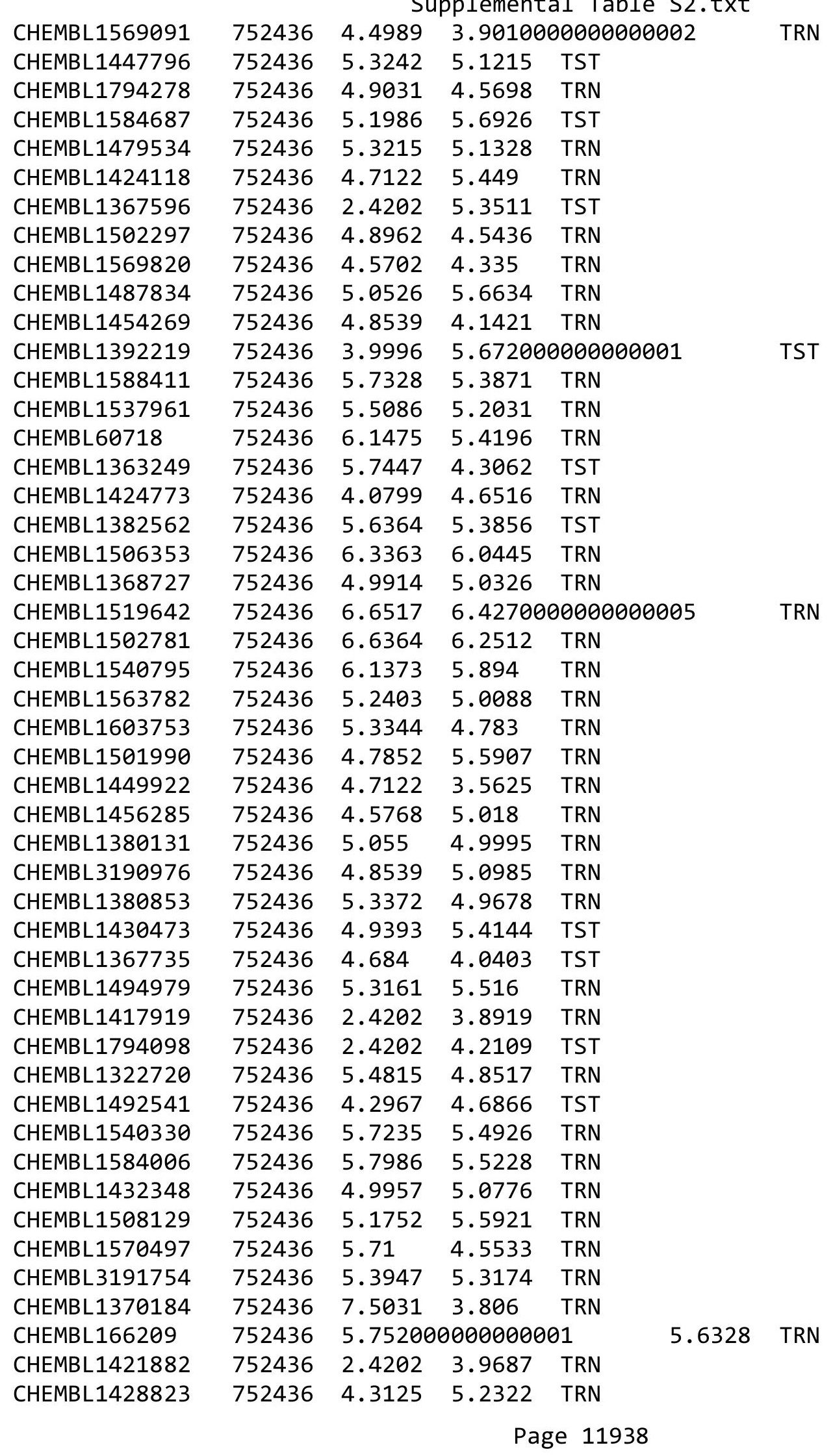


Supplemental Table S2.txt

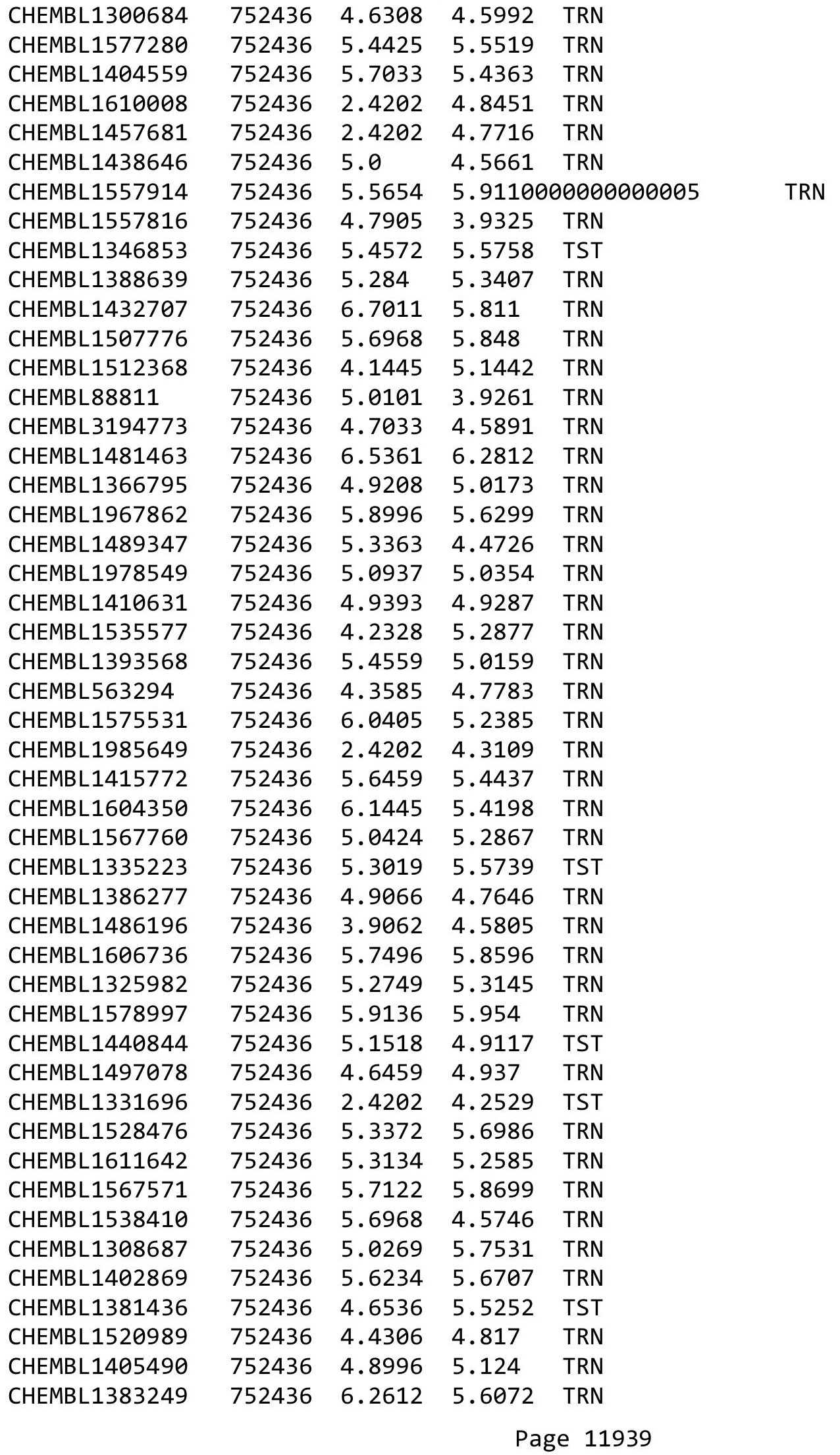


Supplemental Table S2.txt

\begin{tabular}{|c|c|c|c|c|}
\hline 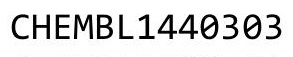 & & 5778 & & \\
\hline HEMBL1388764 & 2436 & 3686 & 5.6757 & \\
\hline HEMBL1418643 & 6 & 097 & 53 & \\
\hline & & 3827 & & \\
\hline AEMBL1424562 & 36 & 277 & & \\
\hline AEMBL3195220 & 52436 & 3788 & 9568 & \\
\hline HEMBL1600294 & 52436 & .8153 & .3989 & \\
\hline HEMBL1372574 & 36 & & & \\
\hline AEMBL3145071 & 36 & & & \\
\hline IEMBL1343392 & & & & \\
\hline HEMBL1399938 & 52436 & .2708 & 2423 & \\
\hline AEMBL1416421 & 52 & .2823 & 4.9506 & \\
\hline HEMBL1443251 & 36 & $\partial 1$ & 5.2907 & \\
\hline IEMBL130 & 36 & 02 & & \\
\hline AEMBL1456 & & & & \\
\hline HEMBL1491652 & 36 & 2.4202 & 4.4969 & \\
\hline AEMBL1401841 & & 19 & & \\
\hline AEMBL15103 & 6 & 1 & 314 & \\
\hline L314 & & & & \\
\hline L162 & & & & \\
\hline AEMBL1349646 & 36 & 45 & 7531 & \\
\hline AEMBL1589425 & & & & \\
\hline HEMBL1586 & 36 & 22 & 12 & \\
\hline L147C & & & & \\
\hline 145 & & & 79 & $\mathrm{RN}$ \\
\hline L1585003 & & & & ST \\
\hline AEMBL1300967 & & & & SI \\
\hline HEMBL1585382 & 6 & & 45 & ST \\
\hline HEN & & & & RN \\
\hline L150 & 6 & & 32 & RN \\
\hline AEMBL1338304 & & & & $\mathrm{RN}$ \\
\hline HEMBL1999049 & 6 & & & RN \\
\hline AEMBL1573 & & & & RN \\
\hline 1323 & 6 & & & RN \\
\hline L3. & 6 & & & $\mathrm{RN}$ \\
\hline IEMBL1478634 & 52 & & & RN \\
\hline HEMBL1379604 & 36 & & 46 & RN \\
\hline 1451836 & 6 & & 67 & RN \\
\hline סבר 1 & 6 & & 71 & RIN \\
\hline IEMBL1503209 & & & & ST \\
\hline AEMBL1387436 & 36 & & 41 & $\mathrm{RN}$ \\
\hline IEMBL1213 & 6 & & & ST \\
\hline 1 & & & & \\
\hline HEMBL1374108 & & & & \\
\hline HEMBL1609009 & & & .2618 & RN \\
\hline IEMBL1539293 & 36 & & 135 & \\
\hline & & & & \\
\hline 1 & 7524 & & 5.5424 & \\
\hline
\end{tabular}

Page 11940 
Supplemental Table S2.txt

\begin{tabular}{|c|c|c|c|c|c|}
\hline CHEMBL1453483 & 752436 & 5.8356 & 5.1717 & TRN & \\
\hline CHEMBL1366838 & 752436 & 6.2351 & 5.9778 & TRN & \\
\hline CHEMBL441282 & 752436 & 5.3116 & 5.7186 & TST & \\
\hline CHEMBL1510647 & 752436 & 4.2644 & 4.1788 & TRN & \\
\hline CHEMBL3189876 & 752436 & 5.0535 & 4.8405 & TRN & \\
\hline CHEMBL1611843 & 752436 & 5.7423 & 5.4346 & TRN & \\
\hline CHEMBL3144906 & 752436 & 5.2418 & 5.7664 & TRN & \\
\hline CHEMBL1411044 & 752436 & 6.7496 & 6.46200 & 0000000001 & II \\
\hline CHEMBL1333487 & 752436 & 4.9666 & 4.5893 & TRN & \\
\hline CHEMBL1308879 & 752436 & 4.9208 & 5.6437 & TRN & \\
\hline CHEMBL175434 & 752436 & 6.1759 & 5.9638 & TRN & \\
\hline CHEMBL1305800 & 752436 & 5.9281 & 5.4831 & TRN & \\
\hline CHEMBL1322046 & 752436 & 4.7352 & 4.8282 & TST & \\
\hline CHEMBL1733474 & 752436 & 7.3316 & 6.7987 & TRN & \\
\hline CHEMBL3145001 & 752436 & 6.1831 & 6.2572 & TRN & \\
\hline CHEMBL1378877 & 752436 & 5.7852 & 5.1627 & TRN & \\
\hline CHEMBL590691 & 752436 & 5.9957 & 5.4501 & TRN & \\
\hline CHEMBL1611931 & 752436 & 5.9586 & 4.8123 & TST & \\
\hline CHEMBL1541259 & 752436 & 5.5867 & 5.4659 & TRN & \\
\hline CHEMBL1456937 & 752436 & 5.0526 & 5.4802 & TRN & \\
\hline CHEMBL1461824 & 752436 & 5.1681 & 5.16700 & 0000000001 & TRN \\
\hline CHEMBL 2003651 & 752436 & 7.1785 & 6.5827 & TRN & \\
\hline CHEMBL1388300 & 752436 & 6.5918 & 6.41700 & 0000000001 & \\
\hline CHEMBL3197333 & 752436 & 6.0915 & 4.9021 & TRN & \\
\hline CHEMBL1577004 & 752436 & 6.1244 & 4.7401 & TRN & \\
\hline CHEMBL1556185 & 752436 & 5.2381 & 5.7136 & TRN & \\
\hline CHEMBL1391390 & 752436 & 5.2062 & 5.3515 & TRN & \\
\hline CHEMBL1996376 & 752436 & 4.9101 & 5.0721 & TRN & \\
\hline CHEMBL1380913 & 752436 & 4.9031 & 5.0462 & TRN & \\
\hline CHEMBL1359282 & 752436 & 6.4828 & 5.3313 & TRN & \\
\hline CHEMBL1557253 & 752436 & 6.3439 & 5.8823 & TRN & \\
\hline CHEMBL1493700 & 752436 & 5.1129 & 5.2715 & TRN & \\
\hline CHEMBL1301371 & 752436 & 4.9747 & 5.166 & TRN & \\
\hline CHEMBL1321179 & 752436 & 5.8356 & 5.2319 & TRN & \\
\hline CHEMBL1402986 & 752436 & 2.4202 & 3.7761 & TRN & \\
\hline CHEMBL1533867 & 752436 & 4.9666 & 4.6782 & TRN & \\
\hline CHEMBL1478145 & 752436 & 4.752 & 5.4585 & TST & \\
\hline CHEMBL1594875 & 752436 & 5.4498 & 5.6085 & TRN & \\
\hline CHEMBL580340 & 752436 & 5.0283 & 5.5468 & TRN & \\
\hline CHEMBL1489956 & 752436 & 5.6819 & 5.3031 & TRN & \\
\hline CHEMBL1707033 & 752436 & 5.8729 & 4.6951 & TRN & \\
\hline CHEMBL1364083 & 752436 & 4.8601 & 5.3041 & TRN & \\
\hline CHEMBL1508040 & 752436 & 5.3516 & 4.7933 & TRN & \\
\hline CHEMBL3191989 & 752436 & \multicolumn{3}{|c|}{4.821000000000001} & \\
\hline CHEMBL1367745 & 752436 & 4.8239 & 5.3569 & TRN & \\
\hline CHEMBL1467905 & 752436 & 5.8013 & 5.5971 & TRN & \\
\hline CHEMBL1454882 & 752436 & 4.51 & 4.7193 & TRN & \\
\hline CHEMBL1379048 & 752436 & 5.7825 & 5.4515 & TST & \\
\hline
\end{tabular}




\begin{tabular}{|c|c|c|c|c|c|}
\hline & & & & & \\
\hline CHEMBL1407253 & 752436 & 5.0685 & 5.2884 & TRN & \\
\hline CHEMBL1409991 & 752436 & 4.6696 & 5.2207 & TRN & \\
\hline CHEMBL602990 & 752436 & 4.8761 & 5.5251 & TRN & \\
\hline CHEMBL1303737 & 752436 & 2.4202 & 4.9475 & TRN & \\
\hline CHEMBL1339245 & 752436 & 5.2765 & 5.4573 & TRN & \\
\hline CHEMBL1501898 & 752436 & 2.4202 & 5.4208 & TST & \\
\hline CHEMBL1519379 & 752436 & 5.4437 & 5.5925 & TST & \\
\hline CHEMBL1300391 & 752436 & 3.7883 & 5.6015 & TST & \\
\hline CHEMBL1511238 & 752436 & 2.9208 & 3.8955 & TRN & \\
\hline CHEMBL1332910 & 752436 & 4.8601 & 5.2318 & TRN & \\
\hline CHEMBL1458150 & 752436 & 5.6216 & 4.9537 & TRN & \\
\hline CHEMBL1529127 & 752436 & 5.5654 & 5.4918 & TRN & \\
\hline CHEMBL600734 & 752436 & 6.1101 & 5.9989 & TRN & \\
\hline CHEMBL1406341 & 752436 & 5.5157 & 4.9457 & TRN & \\
\hline CHEMBL3192605 & 752436 & 4.5376 & 5.3186 & TRN & \\
\hline CHEMBL576208 & 752436 & 5.9626 & 5.1372 & TRN & \\
\hline CHEMBL1403329 & 752436 & 5.4789 & 5.1322 & TRN & \\
\hline CHEMBL1410897 & 752436 & 4.5171 & 4.1808 & TRN & \\
\hline CHEMBL1421056 & 752436 & 5.3675 & 5.1148 & TRN & \\
\hline CHEMBL1597440 & 752436 & 5.4123 & 5.31 & TRN & \\
\hline CHEMBL1495170 & 752436 & 4.8861 & 5.3575 & TRN & \\
\hline CHEMBL1992432 & 752436 & 6.71899 & 99999999 & 4.9366 & TST \\
\hline CHEMBL1364861 & 752436 & 5.062 & 4.6904 & TRN & \\
\hline CHEMBL1606280 & 752436 & 4.8928 & 4.9016 & TRN & \\
\hline CHEMBL1363679 & 752436 & 5.3316 & 5.0709 & TRN & \\
\hline CHEMBL 3189714 & 752436 & 6.1844 & 5.5675 & TRN & \\
\hline CHEMBL1529601 & 752436 & 5.1707 & 5.3679 & TRN & \\
\hline CHEMBL1300870 & 752436 & 2.4202 & 3.91899 & 99999999996 & TST \\
\hline CHEMBL1529482 & 752436 & 5.3686 & 5.5171 & TRN & \\
\hline CHEMBL1445606 & 752436 & 5.0585 & 4.9622 & TST & \\
\hline CHEMBL1460748 & 752436 & 5.0 & 5.4621 & TRN & \\
\hline CHEMBL1398826 & 752436 & 5.2125 & 5.2168 & TRN & \\
\hline CHEMBL1520852 & 752436 & 6.0066 & 6.1813 & TRN & \\
\hline CHEMBL1403980 & 752436 & 6.0969 & 5.8597 & TST & \\
\hline CHEMBL3191438 & 752436 & 6.0 & 6.2252 & TRN & \\
\hline CHEMBL1447473 & 752436 & 5.7399 & 5.9485 & TRN & \\
\hline CHEMBL1568510 & 752436 & 6.6055 & 6.33299 & 9999999999 & TRN \\
\hline CHEMBL505670 & 752436 & 5.3072 & 5.5131 & TRN & \\
\hline CHEMBL1309763 & 752436 & 5.4237 & 5.1278 & TRN & \\
\hline CHEMBL1581228 & 752436 & 4.4473 & 3.83600 & 00000000003 & TRN \\
\hline CHEMBL1544876 & 752436 & 5.5436 & 4.0474 & TRN & \\
\hline CHEMBL1989179 & 752436 & 4.4989 & 5.4155 & TRN & \\
\hline CHEMBL1466804 & 752436 & 4.8996 & 5.5175 & TRN & \\
\hline CHEMBL1460209 & 752436 & 2.4202 & 3.8386 & TRN & \\
\hline CHEMBL171632 & 752436 & 6.5272 & 4.4767 & TST & \\
\hline CHEMBL1505548 & 752436 & 4.8697 & 5.5072 & TRN & \\
\hline CHEMBL1305832 & 752436 & 5.3958 & 4.8958 & TST & \\
\hline CHEMBL1534678 & 752436 & 5.1818 & 4.7549 & TRN & \\
\hline
\end{tabular}




\begin{tabular}{|c|}
\hline CHEMBL1542492 \\
\hline CHEMBL1543839 \\
\hline CHEMBL1301672 \\
\hline CHEMBL1455724 \\
\hline CHEMBL1332532 \\
\hline CHEMBL1340601 \\
\hline CHEMBL1338004 \\
\hline CHEMBL1589428 \\
\hline CHEMBL1579455 \\
\hline CHEMBL1546213 \\
\hline CHEMBL1392176 \\
\hline CHEMBL1604205 \\
\hline CHEMBL1480242 \\
\hline CHEMBL1309419 \\
\hline CHEMBL1415639 \\
\hline CHEMBL1484933 \\
\hline CHEMBL1347117 \\
\hline CHEMBL1710140 \\
\hline CHEMBL3194842 \\
\hline CHEMBL1997668 \\
\hline CHEMBL1794157 \\
\hline CHEMBL3199406 \\
\hline CHEMBL3196831 \\
\hline CHEMBL1582442 \\
\hline CHEMBL1322557 \\
\hline CHEMBL3191602 \\
\hline CHEMBL1345762 \\
\hline CHEMBL1525669 \\
\hline CHEMBL3144975 \\
\hline CHEMBL1706216 \\
\hline CHEMBL1386232 \\
\hline CHEMBL1443601 \\
\hline CHEMBL1378118 \\
\hline CHEMBL1428683 \\
\hline CHEMBL1526391 \\
\hline CHEMBL1794130 \\
\hline CHEMBL1385784 \\
\hline CHEMBL 2006840 \\
\hline CHEMBL1573118 \\
\hline CHEMBL1483809 \\
\hline CHEMBL1447513 \\
\hline CHEMBL1588173 \\
\hline CHEMBL1979747 \\
\hline CHEMBL1395907 \\
\hline CHEMBL1420929 \\
\hline CHEMBL1565816 \\
\hline CHEMBL1485700 \\
\hline CHEMBL1527008 \\
\hline
\end{tabular}

Supplemental Table S2.txt

$\begin{array}{llll}752436 & 4.4559 & 4.0643 & \text { TRN } \\ 752436 & 6.1746 & 6.0834 & \text { TRN } \\ 752436 & 4.2336 & 5.3465 & \text { TST } \\ 752436 & 5.2314 & 4.971 & \text { TRN } \\ 752436 & 4.7773 & 5.6598 & \text { TST } \\ 752436 & 2.4202 & 3.9516 & \text { TRN } \\ 752436 & 5.0132 & 5.7633 & \text { TRN } \\ 752436 & 4.9626 & 5.1834 & \text { TRN } \\ 752436 & 4.9626 & 4.3007 & \text { TRN } \\ 752436 & 5.684 & 4.8349 & \text { TRN } \\ 752436 & 3.8935 & 3.6895 & \text { TRN } \\ 752436 & 5.1325 & 4.4023 & \text { TRN } \\ 752436 & 4.6271 & 3.635 & \text { TRN } \\ 752436 & 4.5229 & 4.6995 & \text { TRN } \\ 752436 & 4.9957 & 5.3672 & \text { TRN } \\ 752436 & 4.8041 & 5.0687 & \text { TRN } \\ 752436 & 5.4828 & 5.1775 & \text { TST } \\ 752436 & 5.9393 & 4.9462 & \text { TST } \\ 752436 & 4.8239 & 4.9498 & \text { TST } \\ 752436 & 5.3893 & 5.3486 & \text { TRN } \\ 752436 & 5.0 & 4.5477 & \text { TRN } \\ 752436 & 5.1952 & 4.455 & \text { TST } \\ 752436 & 6.1586 & 5.7259 & \text { TRN } \\ 752436 & 5.3478 & 5.51 & \text { TST } \\ 752436 & 4.9626 & 4.9168 & \text { TRN } \\ 752436 & 5.3655 & 5.3604 & \text { TRN } \\ 752436 & 4.618 & 5.5429 & \text { TRN } \\ 752436 & 4.8665 & 5.1751 & \text { TRN } \\ 752436 & 5.1314 & 4.9482 & \text { TRN } \\ 752436 & 6.7282 & 6.209 & \text { TRN } \\ 752436 & 5.1494 & 5.1202 & \text { TRN } \\ 752436 & 6.0339 & 4.9106 & \text { TRN } \\ 752436 & 5.0367 & 5.0913 & \text { TRN } \\ 752436 & 4.8297 & 4.8898 & \text { TRN } \\ 752436 & 2.4202 & 4.5776 & \text { TRN } \\ 752436 & 4.8097 & 5.0401 & \text { TRN } \\ 752436 & 6.4609 & 6.3928 & \text { TRN } \\ 752436 & 3.4477 & 4.8973 & \text { TRN } \\ 752436 & 5.1568 & 5.2174 & \text { TRN } \\ 752436 & 4.8416 & 5.0552 & \text { TST } \\ 752436 & 4.3316 & 5.0823 & \text { TRN } \\ 752436 & 6.1805 & 5.1045 & \text { TRN } \\ 752436 & 5.7011 & 5.2672 & \text { TRN } \\ 752436 & 5.9031 & 5.6941 & \text { TRN } \\ 752436 & 6.2857 & 4.2117 & \text { TRN } \\ 752436 & 6.4112 & 6.0015 & \text { TRN } \\ & 5.4425 & 5.6507 & \text { TRN }\end{array}$

Page 11943 


\begin{tabular}{|c|c|c|c|c|c|c|}
\hline & & & & & & \\
\hline CHEMBL1491158 & 752436 & 5.2351 & 4.4937 & TRN & & \\
\hline CHEMBL1439124 & 752436 & 5.9666 & 5.4263 & TRN & & \\
\hline CHEMBL1486463 & 752436 & 2.4202 & 3.8531 & TRN & & \\
\hline CHEMBL1388180 & 752436 & 2.4202 & 4.3898 & TST & & \\
\hline CHEMBL1528757 & 752436 & 5.317 & 5.38 & TST & & \\
\hline CHEMBL1583292 & 752436 & 4.644 & 3.6691 & TST & & \\
\hline CHEMBL1324556 & 752436 & 5.5638 & 5.2643 & TRN & & \\
\hline CHEMBL1306254 & 752436 & 2.4202 & 4.5568 & TRN & & \\
\hline CHEMBL1530927 & 752436 & 5.1007 & 5.2841 & TRN & & \\
\hline CHEMBL1382553 & 752436 & 5.7423 & 5.325 & TRN & & \\
\hline CHEMBL1721990 & 752436 & 3.5385 & 5.6019 & TST & & \\
\hline CHEMBL88326 & 752436 & 4.4089 & 5.0137 & TRN & & \\
\hline CHEMBL1302460 & 752436 & 5.4935 & 5.4354 & TRN & & \\
\hline CHEMBL1426377 & 752436 & 2.4202 & 4.0315 & TST & & \\
\hline CHEMBL2001337 & 752436 & 2.4202 & 4.967 & TRN & & \\
\hline CHEMBL1561089 & 752436 & 5.1965 & 4.8379 & TST & & \\
\hline CHEMBL3144896 & 752436 & 5.5003 & 5.935 & TRN & & \\
\hline CHEMBL1365234 & 752436 & 6.6596 & 6.1413 & TRN & & \\
\hline CHEMBL1518678 & 752436 & 2.4202 & 3.7103 & TST & & \\
\hline CHEMBL1571290 & 752436 & 4.7496 & 4.944 & TRN & & \\
\hline CHEMBL1731689 & 752436 & 6.5017 & 5.5758 & TRN & & \\
\hline CHEMBL1582891 & 752436 & 4.6253 & 4.5453 & TRN & & \\
\hline CHEMBL1347560 & 752436 & 4.8962 & 4.7026 & TRN & & \\
\hline CHEMBL1449204 & 752436 & 5.38200 & 00000000 & $\partial 1$ & 5.4605 & TRN \\
\hline CHEMBL1450196 & 752436 & 5.9245 & 5.475 & TRN & & \\
\hline CHEMBL1325021 & 752436 & 6.0726 & 5.8552 & TRN & & \\
\hline CHEMBL1566134 & 752436 & 5.6021 & 4.9332 & TRN & & \\
\hline CHEMBL1500823 & 752436 & 4.7825 & 5.1288 & TRN & & \\
\hline CHEMBL1576666 & 752436 & 5.2083 & 6.6832 & TRN & & \\
\hline CHEMBL1461198 & 752436 & 2.4202 & 3.9262 & TRN & & \\
\hline CHEMBL1420116 & 752436 & 5.9318 & 4.2099 & TRN & & \\
\hline CHEMBL 3189264 & 752436 & 4.8665 & 4.8503 & TST & & \\
\hline CHEMBL1700040 & 752436 & 5.6696 & 4.4473 & TRN & & \\
\hline CHEMBL1568333 & 752436 & 4.76699 & 99999999 & 995 & 4.5627 & TRN \\
\hline CHEMBL1305537 & 752436 & 2.4202 & 5.0082 & TRN & & \\
\hline CHEMBL579318 & 752436 & 7.1945 & 6.0333 & TRN & & \\
\hline CHEMBL1321472 & 752436 & 4.6968 & 5.2959 & TRN & & \\
\hline CHEMBL3145116 & 752436 & 5.6003 & 5.654 & TRN & & \\
\hline CHEMBL1559156 & 752436 & 6.2358 & 4.0285 & TST & & \\
\hline CHEMBL1516591 & 752436 & 2.4202 & 3.9159 & TST & & \\
\hline CHEMBL1557932 & 752436 & 4.5638 & 4.1709 & TST & & \\
\hline CHEMBL1469314 & 752436 & 2.4202 & 4.9961 & TRN & & \\
\hline CHEMBL1380942 & 752436 & 5.8894 & 5.0322 & TRN & & \\
\hline CHEMBL1611106 & 752436 & 5.6655 & 5.2151 & TRN & & \\
\hline CHEMBL1454614 & 752436 & 6.8239 & 5.949 & TRN & & \\
\hline CHEMBL1596996 & 752436 & 5.1421 & 5.1986 & TRN & & \\
\hline CHEMBL1483562 & 752436 & 6.3179 & 4.3721 & TRN & & \\
\hline CHEMBL1320274 & 752436 & 6.2434 & 6.0952 & TRN & & \\
\hline
\end{tabular}

Page 11944 


\begin{tabular}{|c|c|c|c|c|c|}
\hline & & & & & \\
\hline CHEMBL3193480 & 752436 & 5.2907 & 4.7008 & TRN & \\
\hline CHEMBL3210668 & 752436 & 5.063 & 4.7084 & TRN & \\
\hline CHEMBL1337500 & 752436 & 5.5346 & 5.5831 & TST & \\
\hline CHEMBL1545701 & 752436 & 3.6402 & 4.7743 & TRN & \\
\hline CHEMBL3211966 & 752436 & 5.0079 & 5.1907 & TST & \\
\hline CHEMBL3211571 & 752436 & 5.8125 & 5.5854 & TRN & \\
\hline CHEMBL1596076 & 752436 & 5.1669 & 5.1249 & TRN & \\
\hline CHEMBL1546297 & 752436 & 6.5686 & 6.1759 & TRN & \\
\hline CHEMBL1643542 & 752436 & 5.0 & 5.3143 & TRN & \\
\hline CHEMBL1483112 & 752436 & 4.8386 & 5.3572 & TRN & \\
\hline CHEMBL1486332 & 752436 & 6.0883 & 5.8952 & TRN & \\
\hline CHEMBL1567246 & 752436 & 6.7375 & 6.3813 & TRN & \\
\hline CHEMBL1346860 & 752436 & 6.1739 & 6.19799 & 99999999995 & TRN \\
\hline CHEMBL57013 & 752436 & 6.466 & 4.7687 & TST & \\
\hline CHEMBL1467133 & 752436 & 5.2733 & 5.7671 & TRN & \\
\hline CHEMBL1384489 & 752436 & 3.759 & 5.2885 & TRN & \\
\hline CHEMBL1525505 & 752436 & 5.6757 & 5.2334 & TRN & \\
\hline CHEMBL1734499 & 752436 & 5.4353 & 5.0807 & TRN & \\
\hline CHEMBL1978855 & 752436 & 5.0283 & 4.6803 & TRN & \\
\hline CHEMBL1390139 & 752436 & 6.1113 & 5.7435 & TRN & \\
\hline CHEMBL1572001 & 752436 & 6.0048 & 5.7231 & TRN & \\
\hline CHEMBL3182716 & 752436 & 5.3143 & 6.0752 & TRN & \\
\hline CHEMBL3392069 & 752436 & 5.4473 & 5.345 & TRN & \\
\hline CHEMBL1511042 & 752436 & 4.618 & 5.7477 & TST & \\
\hline CHEMBL1338246 & 752436 & 2.4202 & 3.9913 & TST & \\
\hline CHEMBL592115 & 752436 & 5.5229 & 5.7581 & TRN & \\
\hline CHEMBL1411788 & 752436 & 5.0878 & 5.4241 & TRN & \\
\hline CHEMBL1423501 & 752436 & 6.4486 & 5.6006 & TRN & \\
\hline CHEMBL1419788 & 752436 & 5.0937 & 4.8541 & TRN & \\
\hline CHEMBL1527129 & 752436 & 5.556 & 4.9186 & TRN & \\
\hline CHEMBL1430372 & 752436 & 6.4976 & 4.1656 & TRN & \\
\hline CHEMBL1488050 & 752436 & 5.8477 & 5.58 & TRN & \\
\hline CHEMBL1566496 & 752436 & 5.7878 & 5.44799 & 99999999995 & TRN \\
\hline CHEMBL1384089 & 752436 & 5.7399 & 5.5564 & TRN & \\
\hline CHEMBL1310030 & 752436 & 5.0706 & 5.0908 & TRN & \\
\hline CHEMBL1344573 & 752436 & 5.6478 & 5.3136 & TRN & \\
\hline CHEMBL1495048 & 752436 & 5.0362 & 5.8412 & TRN & \\
\hline CHEMBL1372597 & 752436 & 4.752 & 5.1748 & TRN & \\
\hline CHEMBL1383283 & 752436 & 4.5186 & 5.3379 & TRN & \\
\hline CHEMBL1369655 & 752436 & 5.5544 & 5.479 & TRN & \\
\hline CHEMBL1344806 & 752436 & 5.7773 & 5.3006 & TRN & \\
\hline CHEMBL1361173 & 752436 & 4.8041 & 5.5529 & TRN & \\
\hline CHEMBL1598272 & 752436 & 6.5817 & 6.3359 & TRN & \\
\hline CHEMBL1518895 & 752436 & 5.7033 & 5.8588 & TRN & \\
\hline CHEMBL1349850 & 752436 & 5.3028 & 4.7437 & TRN & \\
\hline CHEMBL1433113 & 752436 & 2.4202 & 3.8343 & TST & \\
\hline CHEMBL1351136 & 752436 & 5.3686 & 4.6975 & TRN & \\
\hline CHEMBL1501421 & 752436 & 2.4202 & 3.8761 & TST & \\
\hline
\end{tabular}




\begin{tabular}{|c|c|c|c|c|c|}
\hline & & & & & \\
\hline CHEMBL1332119 & 752436 & 5.9547 & 5.2912 & TRN & \\
\hline CHEMBL1423919 & 752436 & 4.4486 & 5.3132 & TRN & \\
\hline CHEMBL1429929 & 752436 & 5.4908 & 5.487 & TRN & \\
\hline CHEMBL1540053 & 752436 & 4.8894 & 4.7613 & TST & \\
\hline CHEMBL1600094 & 752436 & 5.4461 & 5.36600 & 00000000005 & TRN \\
\hline CHEMBL1405287 & 752436 & 4.9431 & 4.3763 & TRN & \\
\hline CHEMBL1451336 & 752436 & 4.7645 & 5.007 & TST & \\
\hline CHEMBL1303810 & 752436 & 6.3261 & 5.9826 & TRN & \\
\hline CHEMBL3197625 & 752436 & 4.3778 & 4.772 & TRN & \\
\hline CHEMBL1584739 & 752436 & 5.5735 & 5.6259 & TRN & \\
\hline CHEMBL1462012 & 752436 & 5.0283 & 4.4934 & TRN & \\
\hline CHEMBL1529352 & 752436 & 4.5361 & 5.4796 & TRN & \\
\hline CHEMBL1408577 & 752436 & 5.0241 & 4.7303 & TRN & \\
\hline CHEMBL1503995 & 752436 & 4.9101 & 4.7447 & TRN & \\
\hline CHEMBL1600684 & 752436 & 7.317 & 6.6811 & TRN & \\
\hline CHEMBL1601281 & 752436 & 7.1284 & 5.7552 & TRN & \\
\hline CHEMBL1309228 & 752436 & 5.5751 & 5.3417 & TRN & \\
\hline CHEMBL3144940 & 752436 & 4.0141 & 5.0699 & TRN & \\
\hline CHEMBL1312673 & 752436 & 2.4202 & 4.0424 & TRN & \\
\hline CHEMBL1603720 & 752436 & 2.4202 & 4.3494 & TST & \\
\hline CHEMBL1608963 & 752436 & 2.4202 & 3.9841 & TST & \\
\hline CHEMBL1420830 & 752436 & 5.5058 & 5.5294 & TRN & \\
\hline CHEMBL1471341 & 752436 & 5.1586 & 5.2027 & TRN & \\
\hline CHEMBL1300711 & 752436 & 2.4202 & 4.0821 & TRN & \\
\hline CHEMBL1608044 & 752436 & 4.8601 & 4.9476 & TRN & \\
\hline CHEMBL1387378 & 752436 & 4.6556 & 3.5169 & TRN & \\
\hline CHEMBL1462675 & 752436 & 5.9747 & 5.6017 & TRN & \\
\hline CHEMBL1468055 & 752436 & 4.7905 & 5.4852 & TRN & \\
\hline CHEMBL3144992 & 752436 & 5.3298 & 5.2741 & TRN & \\
\hline CHEMBL523200 & 752436 & 5.8239 & 5.7348 & TRN & \\
\hline CHEMBL1735523 & 752436 & 2.4202 & 3.7041 & TRN & \\
\hline CHEMBL1565520 & 752436 & 5.1163 & 5.74299 & 9999999999 & TRN \\
\hline CHEMBL1990545 & 752436 & 3.6817 & 4.0725 & TRN & \\
\hline CHEMBL 2094422 & 752436 & 5.5591 & 5.6416 & TRN & \\
\hline CHEMBL1508085 & 752436 & 5.2154 & 5.4909 & TRN & \\
\hline CHEMBL1733076 & 752436 & 2.4202 & 3.8865 & TRN & \\
\hline CHEMBL3195106 & 752436 & 5.7011 & 5.0233 & TRN & \\
\hline CHEMBL1431075 & 752436 & 5.5638 & 5.2381 & TRN & \\
\hline CHEMBL1463943 & 752436 & 4.4295 & 5.2496 & TRN & \\
\hline CHEMBL3213571 & 752436 & 2.4202 & 3.8524 & TRN & \\
\hline CHEMBL1609951 & 752436 & 4.4868 & 4.6699 & TRN & \\
\hline CHEMBL1322618 & 752436 & 6.2541 & 5.9207 & TRN & \\
\hline CHEMBL3145176 & 752436 & 6.0675 & 6.2025 & TRN & \\
\hline CHEMBL1531579 & 752436 & 4.0635 & 4.297 & TST & \\
\hline CHEMBL1429260 & 752436 & 4.9101 & 4.4813 & TST & \\
\hline CHEMBL1607989 & 752436 & 6.0 & 5.7204 & TRN & \\
\hline CHEMBL1299526 & 752436 & 5.0605 & 5.3837 & TRN & \\
\hline CHEMBL1346883 & 752436 & 5.5986 & 5.835 & TRN & \\
\hline
\end{tabular}




\begin{tabular}{|c|c|c|c|c|c|}
\hline & & & & & \\
\hline CHEMBL1794145 & 752436 & 2.4202 & 3.8921 & TST & \\
\hline CHEMBL1585380 & 752436 & 5.4486 & 5.2613 & TRN & \\
\hline CHEMBL1463564 & 752436 & 6.3179 & 5.7654 & TRN & \\
\hline CHEMBL1581740 & 752436 & 5.4949 & 5.495 & TRN & \\
\hline CHEMBL1372030 & 752436 & 4.8477 & 3.7944 & TST & \\
\hline CHEMBL1345808 & 752436 & 5.6289 & 4.9447 & TRN & \\
\hline CHEMBL1460524 & 752436 & 5.2055 & 5.3451 & TRN & \\
\hline CHEMBL1341756 & 752436 & 6.0255 & 6.1962 & TRN & \\
\hline CHEMBL1570673 & 752436 & 5.1586 & 4.29 & TRN & \\
\hline CHEMBL1505716 & 752436 & 2.4202 & 4.6266 & TRN & \\
\hline CHEMBL1548297 & 752436 & 4.9626 & 4.7378 & TRN & \\
\hline CHEMBL1431126 & 752436 & 4.8928 & 4.3136 & TST & \\
\hline CHEMBL1578949 & 752436 & 2.4202 & 4.4336 & TRN & \\
\hline CHEMBL1734894 & 752436 & 5.0757 & 4.6477 & TRN & \\
\hline CHEMBL1323536 & 752436 & 4.6946 & 4.1633 & TRN & \\
\hline CHEMBL1308358 & 752436 & 4.7825 & 4.7065 & TRN & \\
\hline CHEMBL1429966 & 752436 & 6.2534 & 4.6222 & TRN & \\
\hline CHEMBL1457500 & 752436 & 5.1952 & 4.8543 & TRN & \\
\hline CHEMBL1365118 & 752436 & 5.9355 & 4.3901 & TRN & \\
\hline CHEMBL1502394 & 752436 & 4.9393 & 5.5967 & TST & \\
\hline CHEMBL1403089 & 752436 & 2.4202 & 3.8243 & TRN & \\
\hline CHEMBL1330781 & 752436 & 5.3125 & 5.1034 & TST & \\
\hline CHEMBL1597748 & 752436 & 5.6459 & 4.8928 & TST & \\
\hline CHEMBL1440300 & 752436 & 6.0292 & 5.6107 & TRN & \\
\hline CHEMBL1519022 & 752436 & 5.8239 & 5.9777 & TRN & \\
\hline CHEMBL 260148 & 752436 & 5.0173 & 5.0623 & TRN & \\
\hline CHEMBL1410350 & 752436 & 6.3969 & 5.6078 & TRN & \\
\hline CHEMBL3212615 & 752436 & 5.7122 & 5.4803 & TRN & \\
\hline CHEMBL1445617 & 752436 & 6.5243 & 6.3871 & TRN & \\
\hline CHEMBL1317919 & 752436 & 5.3595 & 5.1112 & TRN & \\
\hline CHEMBL1442702 & 752436 & 4.3536 & 5.0955 & TRN & \\
\hline CHEMBL1573586 & 752436 & 5.5591 & 5.46399 & 99999999995 & TRN \\
\hline CHEMBL1325451 & 752436 & 5.3635 & 5.4321 & TRN & \\
\hline CHEMBL594707 & 752436 & 5.0448 & 5.17200 & 2000000001 & TRN \\
\hline CHEMBL1466126 & 752436 & 5.382999 & 79999999ऽ & 5.3798 & TRN \\
\hline CHEMBL3214537 & 752436 & 2.4202 & 3.6858 & TRN & \\
\hline CHEMBL1979558 & 752436 & 5.4584 & 5.864 & TRN & \\
\hline CHEMBL1698050 & 752436 & 3.8108 & 5.0131 & TRN & \\
\hline CHEMBL1713763 & 752436 & 4.6253 & 3.8887 & TST & \\
\hline CHEMBL1412448 & 752436 & 5.4737 & 5.0028 & TRN & \\
\hline CHEMBL1301821 & 752436 & 4.5031 & 3.8064 & TST & \\
\hline CHEMBL1301509 & 752436 & 4.4437 & 5.241006 & 20000000005 & TST \\
\hline CHEMBL1559655 & 752436 & 6.7986 & 6.4898 & TRN & \\
\hline CHEMBL1437516 & 752436 & 4.8697 & 5.5142 & TRN & \\
\hline CHEMBL1449794 & 752436 & 5.0685 & 4.9013 & TRN & \\
\hline CHEMBL259018 & 752436 & 5.3316 & 5.2385 & TRN & \\
\hline CHEMBL1565674 & 752436 & 5.2757 & 5.6596 & TRN & \\
\hline CHEMBL3210366 & 752436 & 5.9066 & 5.4223 & TRN & \\
\hline
\end{tabular}


Supplemental Table S2.txt

\begin{tabular}{|c|c|c|c|c|c|}
\hline CHEMBL1432243 & 752436 & 2.4202 & 5.1292 & TRN & \\
\hline CHEMBL1462369 & 752436 & 2.4202 & 4.7088 & TST & \\
\hline CHEMBL1530209 & 752436 & 4.9957 & 4.8181 & TRN & \\
\hline CHEMBL1580896 & 752436 & 5.8013 & 5.8504 & TRN & \\
\hline CHEMBL1477528 & 752436 & 5.5544 & 5.0912 & TRN & \\
\hline CHEMBL1609318 & 752436 & 5.3242 & 4.3993 & TRN & \\
\hline CHEMBL1707500 & 752436 & 5.5391 & 4.1855 & TRN & \\
\hline CHEMBL1497120 & 752436 & 4.9747 & 4.7174 & TRN & \\
\hline CHEMBL1499567 & 752436 & 4.82100 & 000000006 & & 5.3371 \\
\hline CHEMBL1427637 & 752436 & 5.3575 & 5.1526 & TRN & \\
\hline CHEMBL1385690 & 752436 & 5.8962 & 5.4494 & TRN & \\
\hline CHEMBL 3144873 & 752436 & 5.4921 & 5.8172 & TRN & \\
\hline CHEMBL1363844 & 752436 & 4.9666 & 4.5312 & TST & \\
\hline CHEMBL1325219 & 752436 & 6.3298 & 5.9759 & TRN & \\
\hline CHEMBL1548210 & 752436 & 4.6021 & 4.3886 & TRN & \\
\hline CHEMBL1339794 & 752436 & 5.6946 & 5.7568 & TRN & \\
\hline CHEMBL2095095 & 752436 & 6.8447 & 7.1637 & TRN & \\
\hline CHEMBL1413839 & 752436 & 4.7959 & 4.5977 & TRN & \\
\hline CHEMBL1541441 & 752436 & 5.2692 & 4.732 & TST & \\
\hline CHEMBL1428507 & 752436 & 5.4868 & 5.038 & TRN & \\
\hline CHEMBL1396209 & 752436 & 5.0862 & 5.5358 & TST & \\
\hline CHEMBL1555899 & 752436 & 2.4202 & 4.6811 & TST & \\
\hline CHEMBL1402496 & 752436 & 3.8655 & 5.44 & TST & \\
\hline CHEMBL566068 & 752436 & 6.0696 & 5.9408 & TRN & \\
\hline CHEMBL1577151 & 752436 & 5.0246 & 5.789 & TRN & \\
\hline CHEMBL1486359 & 752436 & 4.8761 & 5.3418 & TRN & \\
\hline CHEMBL1330184 & 752436 & 5.3969 & 5.136 & TRN & \\
\hline CHEMBL 3210545 & 752436 & 5.7447 & 5.2105 & TRN & \\
\hline CHEMBL1496053 & 752436 & 4.0297 & 4.909 & TST & \\
\hline CHEMBL1567635 & 752436 & 6.0899 & 5.8014 & TRN & \\
\hline CHEMBL1585072 & 752436 & 5.1007 & 5.6737 & TRN & \\
\hline CHEMBL1200938 & 752436 & 3.6249 & 3.8618 & TST & \\
\hline CHEMBL1700372 & 752436 & 5.3215 & 5.6603 & TRN & \\
\hline CHEMBL3209456 & 752436 & 5.3696 & 4.8757 & TRN & \\
\hline CHEMBL1576509 & 752436 & 7.4486 & 4.8228 & TRN & \\
\hline CHEMBL1428450 & 752436 & 5.5072 & 5.3269 & TRN & \\
\hline CHEMBL1534503 & 752436 & 5.5072 & 5.1813 & TRN & \\
\hline CHEMBL1586481 & 752436 & 5.8861 & 5.4227 & TRN & \\
\hline CHEMBL1433075 & 752436 & 5.6635 & 5.5455 & TRN & \\
\hline CHEMBL1413252 & 752436 & 4.5302 & 4.2234 & TST & \\
\hline CHEMBL3191242 & 752436 & 2.4202 & 4.0508 & TRN & \\
\hline CHEMBL1425245 & 752436 & 5.1549 & 4.721 & TRN & \\
\hline CHEMBL1595403 & 752436 & 5.5452 & 5.4651 & TRN & \\
\hline CHEMBL1453579 & 752436 & 5.4214 & 4.8003 & TRN & \\
\hline CHEMBL1476225 & 752436 & 4.9747 & 4.4044 & TRN & \\
\hline CHEMBL1442141 & 752436 & 4.9914 & 5.0607 & TRN & \\
\hline CHEMBL1374083 & 752436 & 6.2993 & 5.7349 & TRN & \\
\hline CHEMBL1371873 & 752436 & 4.6799 & 5.5171 & TST & \\
\hline
\end{tabular}




\begin{tabular}{|c|c|c|c|c|c|}
\hline & & & & & \\
\hline CHEMBL1417901 & 752436 & 4.4318 & 5.3448 & TRN & \\
\hline CHEMBL1525064 & 752436 & 5.1079 & 5.2104 & TST & \\
\hline CHEMBL1536119 & 752436 & 2.4202 & 4.475 & TRN & \\
\hline CHEMBL1455957 & 752436 & 6.4724 & 5.4056 & TST & \\
\hline CHEMBL1490987 & 752436 & 4.062 & 4.629 & TRN & \\
\hline CHEMBL1469091 & 752436 & 4.1244 & 3.9145 & TST & \\
\hline CHEMBL3214610 & 752436 & 4.9431 & 4.7072 & TRN & \\
\hline CHEMBL1598985 & 752436 & 5.2933 & 5.2669 & TRN & \\
\hline CHEMBL1365287 & 752436 & 5.4413 & 4.242 & TRN & \\
\hline CHEMBL1370899 & 752436 & 5.5834 & 4.9498 & TRN & \\
\hline CHEMBL1510599 & 752436 & 4.9318 & 4.8325 & TST & \\
\hline CHEMBL1720482 & 752436 & 4.9666 & 5.0461 & TRN & \\
\hline CHEMBL1445675 & 752436 & 4.9547 & 4.6769 & TRN & \\
\hline CHEMBL3145051 & 752436 & 4.7721 & 4.891 & TRN & \\
\hline CHEMBL1602856 & 752436 & 5.5406 & 5.3414 & TRN & \\
\hline CHEMBL1369862 & 752436 & 5.5513 & 5.5301 & TRN & \\
\hline CHEMBL1485746 & 752436 & 5.6162 & 5.5843 & TRN & \\
\hline CHEMBL1603293 & 752436 & 4.9957 & 5.3936 & TRN & \\
\hline CHEMBL1391921 & 752436 & 4.7959 & 4.8801 & TRN & \\
\hline CHEMBL1454680 & 752436 & 5.7959 & 5.6925 & TRN & \\
\hline CHEMBL1605394 & 752436 & 4.5258 & 3.6641 & TRN & \\
\hline CHEMBL1449705 & 752436 & 3.7812 & 5.4606 & TRN & \\
\hline CHEMBL1197872 & 752436 & 5.0106 & 5.6014 & TRN & \\
\hline CHEMBL 2369166 & 752436 & 5.062 & 5.3125 & TRN & \\
\hline CHEMBL 299853 & 752436 & 6.1409 & 6.1575 & TRN & \\
\hline CHEMBL1529238 & 752436 & 6.3019 & 3.6883 & TRN & \\
\hline CHEMBL3198718 & 752436 & 2.4202 & 4.0059 & TRN & \\
\hline CHEMBL1608084 & 752436 & 5.0114 & 5.1045 & TRN & \\
\hline CHEMBL1466363 & 752436 & 4.8761 & 4.8227 & TST & \\
\hline CHEMBL571501 & 752436 & 5.2612 & 4.9779 & TRN & \\
\hline CHEMBL1329297 & 752436 & 5.4535 & 5.0596 & TRN & \\
\hline CHEMBL1323351 & 752436 & 5.4855 & 5.484 & TRN & \\
\hline CHEMBL1595409 & 752436 & 5.0088 & 5.2452 & TRN & \\
\hline CHEMBL1553074 & 752436 & 2.4202 & 4.4563 & TRN & \\
\hline CHEMBL1485010 & 752436 & 6.3251 & 5.9381 & TRN & \\
\hline CHEMBL1432044 & 752436 & 4.71899 & 99999999 & 5.5766 & TRN \\
\hline CHEMBL1479080 & 752436 & 5.2366 & 4.6163 & TRN & \\
\hline CHEMBL1499010 & 752436 & 4.8601 & 4.04899 & 99999999995 & TRN \\
\hline CHEMBL1537363 & 752436 & 5.5003 & 5.1414 & TRN & \\
\hline CHEMBL581677 & 752436 & 5.9066 & 5.4895 & TRN & \\
\hline CHEMBL333767 & 752436 & 4.8697 & 5.0265 & TRN & \\
\hline CHEMBL1567419 & 752436 & 5.1421 & 4.7059 & TRN & \\
\hline CHEMBL1310115 & 752436 & 5.0 & 4.0939 & TST & \\
\hline CHEMBL1497049 & 752436 & 4.5867 & 5.2833 & TRN & \\
\hline CHEMBL1376311 & 752436 & 5.0372 & 5.6555 & TRN & \\
\hline CHEMBL1579122 & 752436 & 5.4609 & 5.6912 & TRN & \\
\hline CHEMBL1558070 & 752436 & 4.8894 & 3.6787 & TST & \\
\hline CHEMBL1606109 & 752436 & 2.4202 & 3.9844 & TRN & \\
\hline
\end{tabular}


Supplemental Table S2.txt

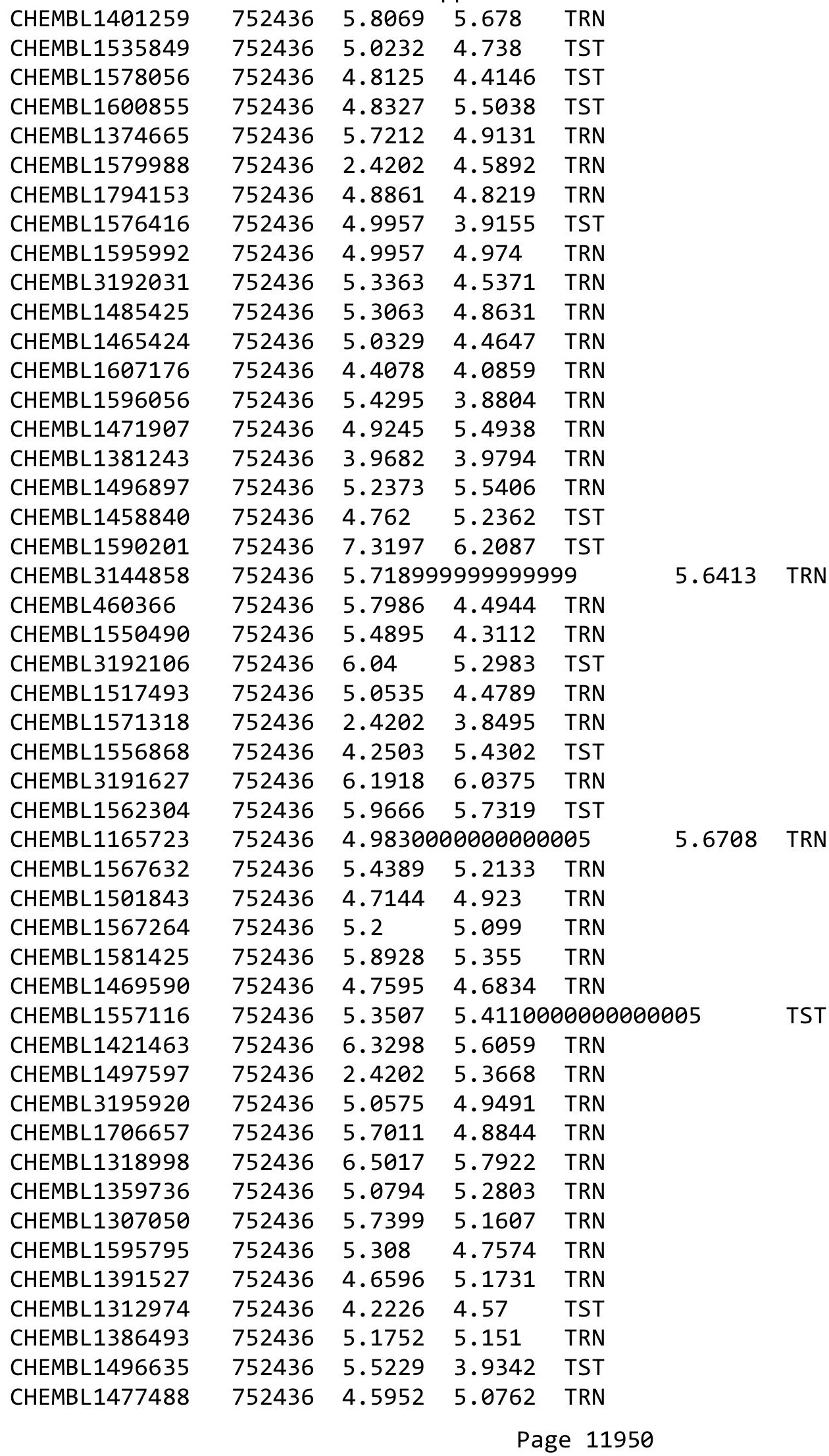




\begin{tabular}{|c|c|c|c|c|c|}
\hline & & & & & \\
\hline CHEMBL1560220 & 752436 & 5.0453 & 4.646 & TRN & \\
\hline CHEMBL1528844 & 752436 & 6.1073 & 4.5657 & TRN & \\
\hline CHEMBL3145078 & 752436 & 5.6946 & 4.7568 & TRN & \\
\hline CHEMBL1590615 & 752436 & 6.0 & 5.9646 & TRN & \\
\hline CHEMBL1494202 & 752436 & 5.0339 & 5.3113 & TRN & \\
\hline CHEMBL1442944 & 752436 & 6.3179 & 5.2407 & TRN & \\
\hline CHEMBL1456115 & 752436 & 4.8633 & 5.507006 & 0000000001 & TRN \\
\hline CHEMBL1560706 & 752436 & 5.1524 & 5.0346 & TRN & \\
\hline CHEMBL1348289 & 752436 & 2.4202 & 3.8801 & TRN & \\
\hline CHEMBL1538796 & 752436 & 5.1215 & 4.7888 & TRN & \\
\hline CHEMBL1568301 & 752436 & 2.4202 & 5.4445 & TRN & \\
\hline CHEMBL1420488 & 752436 & 5.6421 & 4.7882 & TRN & \\
\hline CHEMBL1515286 & 752436 & 5.3458 & 5.4299 & TRN & \\
\hline CHEMBL1557105 & 752436 & 5.3737 & 5.2548 & TRN & \\
\hline CHEMBL1347586 & 752436 & 5.9031 & 5.3 & TRN & \\
\hline CHEMBL1537132 & 752436 & 6.2976 & 5.7626 & TRN & \\
\hline CHEMBL1385073 & 752436 & 5.5452 & 5.5253 & TRN & \\
\hline CHEMBL3199015 & 752436 & 4.8327 & 5.4347 & TRN & \\
\hline CHEMBL1381030 & 752436 & 6.2865 & 5.862 & TRN & \\
\hline CHEMBL1341981 & 752436 & 4.9355 & 4.5026 & TRN & \\
\hline CHEMBL1427272 & 752436 & 4.7447 & 4.2507 & TRN & \\
\hline CHEMBL1585390 & 752436 & 5.75200 & 0000000 & 5.482 & TRN \\
\hline CHEMBL1462257 & 752436 & 5.1427 & 4.6575 & TRN & \\
\hline CHEMBL1377533 & 752436 & 4.762 & 5.41299 & 9999999999 & TRN \\
\hline CHEMBL 327574 & 752436 & 4.9136 & 3.7118 & TRN & \\
\hline CHEMBL1310302 & 752436 & 5.5751 & 5.1227 & TRN & \\
\hline CHEMBL1341919 & 752436 & 5.2013 & 4.1196 & TST & \\
\hline CHEMBL1361855 & 752436 & 4.9393 & 5.2607 & TST & \\
\hline CHEMBL1531210 & 752436 & 5.4078 & 5.3222 & TRN & \\
\hline CHEMBL478754 & 752436 & 6.0214 & 5.095 & TST & \\
\hline CHEMBL1506351 & 752436 & 6.6234 & 5.4009 & TRN & \\
\hline CHEMBL1359931 & 752436 & 5.063 & 4.6396 & TRN & \\
\hline CHEMBL1313973 & 752436 & 6.3925 & 5.9478 & TRN & \\
\hline CHEMBL1377005 & 752436 & 5.5544 & 5.3734 & TRN & \\
\hline CHEMBL1544548 & 752436 & 5.3969 & 4.0452 & TRN & \\
\hline CHEMBL1547025 & 752436 & 5.1062 & 5.2998 & TRN & \\
\hline CHEMBL1577840 & 752436 & 5.2472 & 4.2169 & TRN & \\
\hline CHEMBL171637 & 752436 & 5.4908 & 5.7234 & TST & \\
\hline CHEMBL1994973 & 752436 & 3.9027 & 4.0089 & TRN & \\
\hline CHEMBL1535546 & 752436 & 5.7423 & 5.3574 & TRN & \\
\hline CHEMBL3196913 & 752436 & 5.8996 & 5.9079 & TRN & \\
\hline CHEMBL1453114 & 752436 & 4.7352 & 5.2431 & TST & \\
\hline CHEMBL1494507 & 752436 & 2.4202 & 4.0261 & TRN & \\
\hline CHEMBL1541973 & 752436 & 5.1361 & 5.5965 & TRN & \\
\hline CHEMBL1523699 & 752436 & 5.1403 & 5.1293 & TRN & \\
\hline CHEMBL1345722 & 752436 & 4.8356 & 5.0219 & TRN & \\
\hline CHEMBL1366252 & 752436 & 5.5513 & 5.653 & TRN & \\
\hline CHEMBL1609807 & 752436 & 5.0237 & 5.3421 & TRN & \\
\hline
\end{tabular}




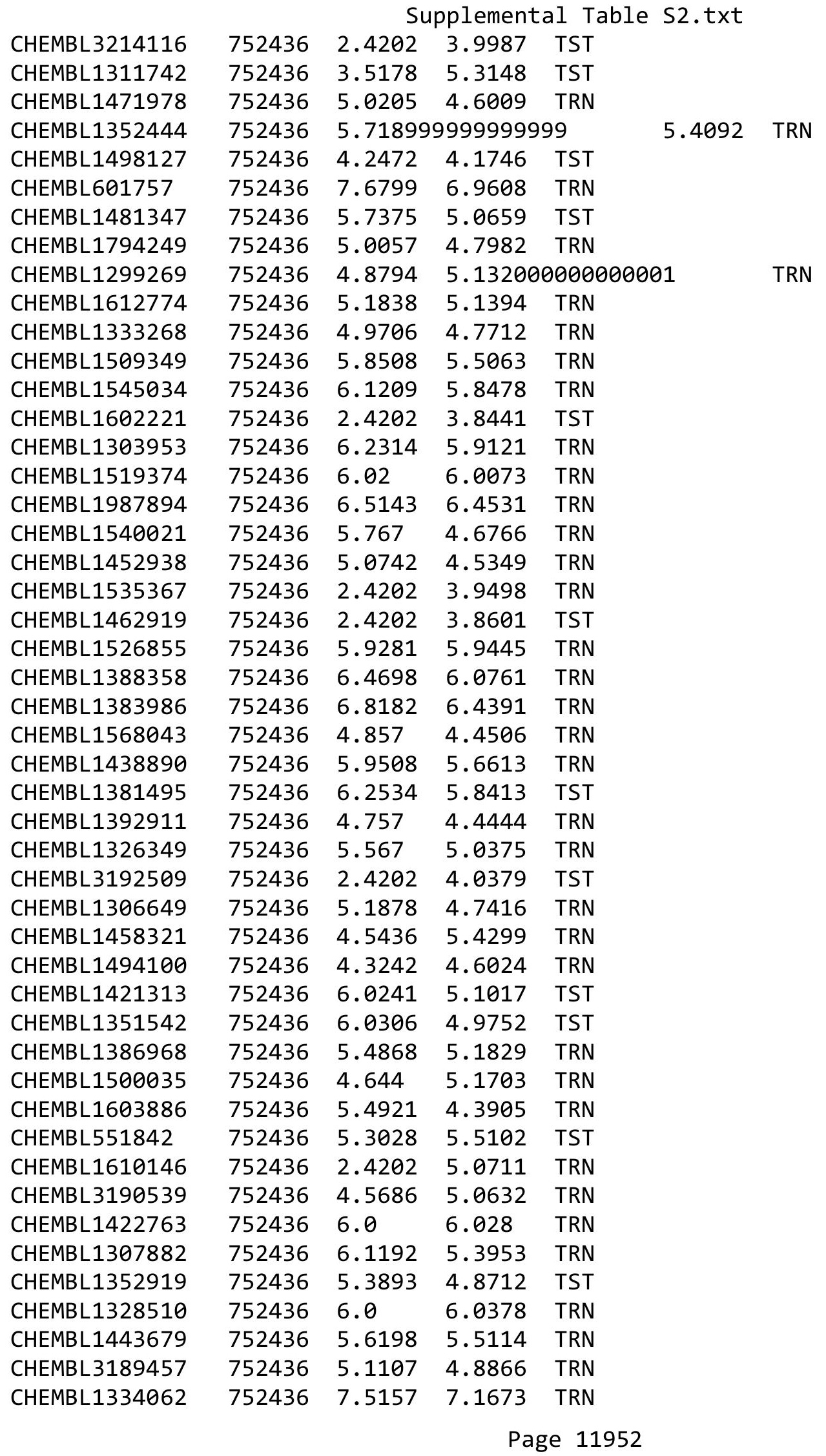




\begin{tabular}{|c|c|c|c|c|c|c|}
\hline & & & & & $\tau$ & \\
\hline CHEMBL1572585 & 752436 & 5.2907 & 4.8902 & TRN & & \\
\hline CHEMBL2006750 & 752436 & 5.38299 & э9999999 & 99 & 5.0643 & TRN \\
\hline CHEMBL1349637 & 752436 & 6.4237 & 6.2809 & TRN & & \\
\hline CHEMBL1541405 & 752436 & 5.0195 & 4.8674 & TRN & & \\
\hline CHEMBL1400437 & 752436 & 4.9508 & 5.0093 & TRN & & \\
\hline CHEMBL1487875 & 752436 & 2.4202 & 4.937 & TRN & & \\
\hline CHEMBL1456352 & 752436 & 4.9172 & 4.57100 & 0000000001 & & TRN \\
\hline CHEMBL1598561 & 752436 & 6.4776 & 6.5545 & TRN & & \\
\hline CHEMBL1318742 & 752436 & 2.4202 & 5.36700 & 0000000001 & & TRN \\
\hline CHEMBL1335953 & 752436 & 5.6615 & 5.7792 & TRN & & \\
\hline CHEMBL1343343 & 752436 & 6.2612 & 5.8991 & TRN & & \\
\hline CHEMBL1324674 & 752436 & 5.1051 & 5.0223 & TRN & & \\
\hline CHEMBL1432870 & 752436 & 4.2291 & 4.5526 & TST & & \\
\hline CHEMBL1406372 & 752436 & 5.3716 & 5.3008 & TRN & & \\
\hline CHEMBL1547143 & 752436 & 5.585 & 5.2467 & TRN & & \\
\hline CHEMBL1347107 & 752436 & 6.4584 & 6.4047 & TRN & & \\
\hline CHEMBL1352082 & 752436 & 4.7545 & 4.6109 & TRN & & \\
\hline CHEMBL1357976 & 752436 & 4.2907 & 5.005 & TRN & & \\
\hline CHEMBL3190880 & 752436 & 6.6655 & 6.5942 & TRN & & \\
\hline CHEMBL1430827 & 752436 & 4.9066 & 5.74700 & 0000000001 & & TRN \\
\hline CHEMBL1389509 & 752436 & 4.0888 & 5.6539 & TST & & \\
\hline CHEMBL3192555 & 752436 & 6.7328 & 6.79299 & 9999999999 & & TRN \\
\hline CHEMBL1386752 & 752436 & 5.8729 & 4.9056 & TST & & \\
\hline CHEMBL1578324 & 752436 & 5.3487 & 4.8164 & TRN & & \\
\hline CHEMBL1607696 & 752436 & 5.0259 & 4.8475 & TRN & & \\
\hline CHEMBL1587942 & 752436 & 2.4202 & 5.0158 & TRN & & \\
\hline CHEMBL1506201 & 752436 & 2.4202 & 3.8535 & TST & & \\
\hline CHEMBL1369671 & 752436 & 5.1993 & 5.755 & TRN & & \\
\hline CHEMBL1271764 & 752436 & 5.6536 & 5.4302 & TRN & & \\
\hline CHEMBL3192544 & 752436 & 5.0348 & 4.7754 & TRN & & \\
\hline CHEMBL1519313 & 752436 & 5.1537 & 5.3528 & TST & & \\
\hline CHEMBL1429937 & 752436 & 4.9393 & 4.7816 & TRN & & \\
\hline CHEMBL3144932 & 752436 & 6.0311 & 6.2526 & TRN & & \\
\hline CHEMBL1563903 & 752436 & 6.7235 & 6.3186 & TRN & & \\
\hline CHEMBL1345195 & 752436 & 5.71 & 4.0308 & TRN & & \\
\hline CHEMBL1337442 & 752436 & 2.4202 & 3.8494 & TST & & \\
\hline CHEMBL 3144884 & 752436 & 6.0472 & 6.084 & TRN & & \\
\hline CHEMBL1390452 & 752436 & 5.8477 & 5.4118 & TST & & \\
\hline CHEMBL1505358 & 752436 & 6.5817 & 6.2708 & TRN & & \\
\hline CHEMBL1403154 & 752436 & 5.1107 & 5.4385 & TRN & & \\
\hline CHEMBL600175 & 752436 & 5.6459 & 5.5221 & TRN & & \\
\hline CHEMBL1702692 & 752436 & 5.7696 & 5.7879 & TRN & & \\
\hline CHEMBL505618 & 752436 & 4.8097 & 4.8172 & TST & & \\
\hline CHEMBL1556484 & 752436 & 2.4202 & 3.8249 & TST & & \\
\hline CHEMBL1579891 & 752436 & 2.4202 & 4.0212 & TRN & & \\
\hline CHEMBL1421441 & 752436 & 5.5003 & 5.1297 & TRN & & \\
\hline CHEMBL1352695 & 752436 & 2.4202 & 4.309 & TRN & & \\
\hline CHEMBL1560679 & 752436 & 5.2472 & 5.541 & TRN & & \\
\hline
\end{tabular}




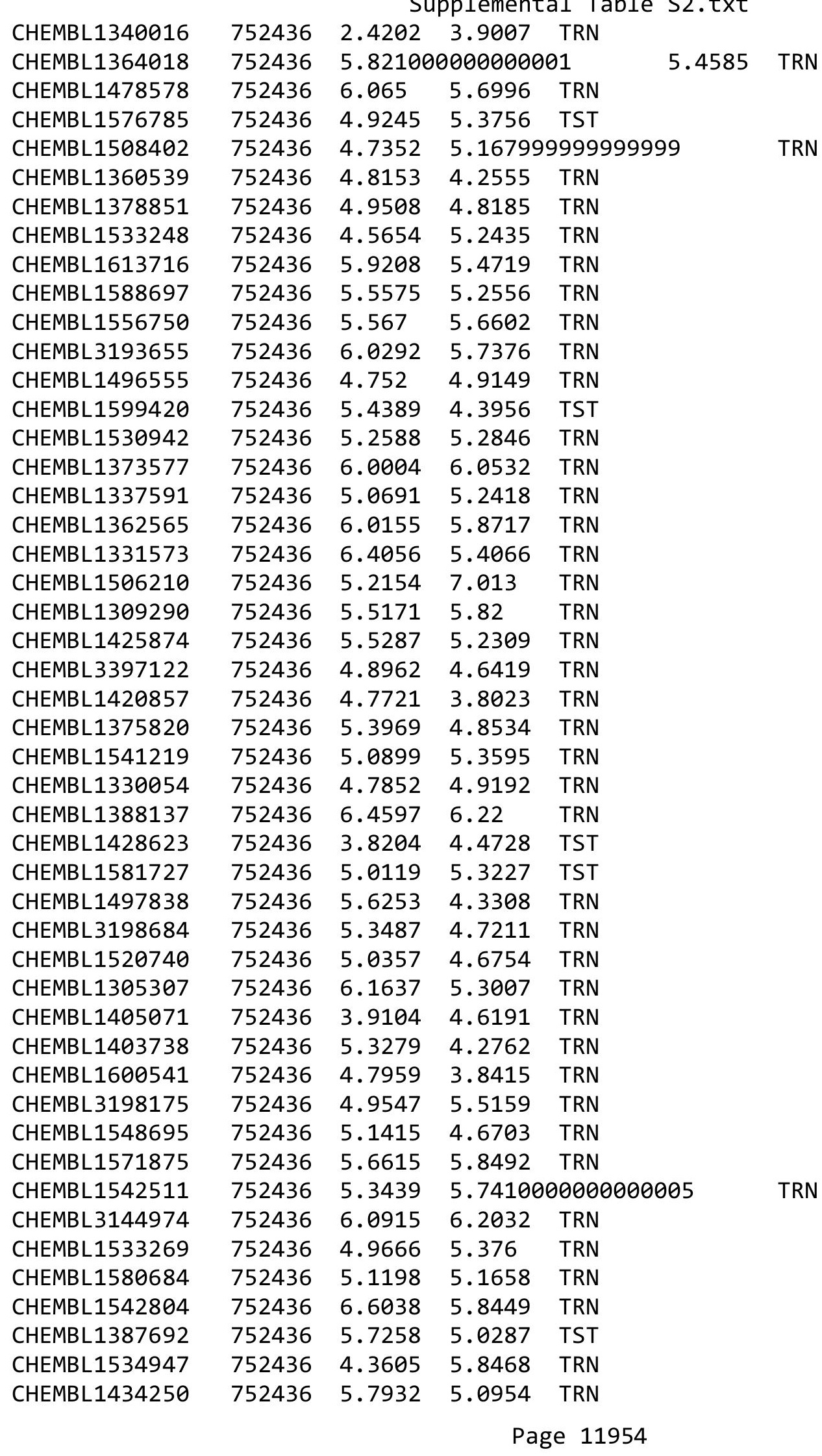


Supplemental Table S2.txt

\begin{tabular}{|c|c|c|c|c|c|c|}
\hline CHEMBL1536089 & 752436 & 5.7773 & 4.8207 & TRN & & \\
\hline CHEMBL1482637 & 752436 & 4.3098 & 4.692 & TST & & \\
\hline CHEMBL1306161 & 752436 & 2.4202 & 5.0447 & TRN & & \\
\hline CHEMBL1981002 & 752436 & 4.9872 & 4.5957 & TRN & & \\
\hline CHEMBL1537149 & 752436 & 6.5157 & 6.369 & TRN & & \\
\hline CHEMBL1390555 & 752436 & 4.5003 & 5.632999 & 999999999 & & TRN \\
\hline CHEMBL1714915 & 752436 & 5.8894 & 5.085 & TRN & & \\
\hline CHEMBL1401582 & 752436 & 5.5834 & 5.4369 & TRN & & \\
\hline CHEMBL1483627 & 752436 & 6.1451 & 6.1262 & TRN & & \\
\hline CHEMBL1577545 & 752436 & 5.1643 & 5.239 & TRN & & \\
\hline CHEMBL1499903 & 752436 & 4.4157 & 5.3931 & TST & & \\
\hline CHEMBL1310967 & 752436 & \multicolumn{3}{|c|}{4.821000000000001} & 5.0677 & TRN \\
\hline CHEMBL1581601 & 752436 & 4.065 & 4.4961 & TRN & & \\
\hline CHEMBL1443497 & 752436 & 4.8182 & 3.7254 & TST & & \\
\hline CHEMBL 3144874 & 752436 & 5.3768 & 6.3063 & TRN & & \\
\hline CHEMBL1493528 & 752436 & 2.9208 & 4.1746 & TRN & & \\
\hline CHEMBL1313206 & 752436 & 5.6216 & 5.7419 & TRN & & \\
\hline CHEMBL1981667 & 752436 & 4.4056 & 4.3712 & TRN & & \\
\hline CHEMBL1450393 & 752436 & 5.8729 & 5.077 & TST & & \\
\hline CHEMBL306946 & 752436 & 6.1918 & 5.1171 & TRN & & \\
\hline CHEMBL1557622 & 752436 & 4.9066 & 5.0195 & TRN & & \\
\hline CHEMBL1576582 & 752436 & \multicolumn{3}{|c|}{5.821000000000001} & 328 & TRN \\
\hline CHEMBL 3145143 & 752436 & 5.2765 & 5.2889 & TRN & & \\
\hline CHEMBL527336 & 752436 & 6.2083 & 5.5773 & TRN & & \\
\hline CHEMBL1510156 & 752436 & 7.3279 & 5.9366 & TRN & & \\
\hline CHEMBL1497295 & 752436 & 6.71 & 6.4953 & TRN & & \\
\hline CHEMBL1516914 & 752436 & 6.4023 & 5.9436 & TRN & & \\
\hline CHEMBL1392225 & 752436 & 4.7747 & 4.9536 & TST & & \\
\hline CHEMBL1383058 & 752436 & 6.6696 & 6.5279 & TRN & & \\
\hline CHEMBL1382518 & 752436 & 4.8125 & 5.3098 & TRN & & \\
\hline CHEMBL1496552 & 752436 & \multicolumn{3}{|c|}{5.757000000000001} & 5.3049 & TRN \\
\hline CHEMBL1460225 & 752436 & 5.4841 & 3.7757 & TRN & & \\
\hline CHEMBL1464786 & 752436 & 5.6308 & 4.2345 & TRN & & \\
\hline CHEMBL1391614 & 752436 & 5.5768 & 5.1644 & TRN & & \\
\hline CHEMBL1610747 & 752436 & 5.4168 & 4.8484 & TRN & & \\
\hline CHEMBL1533676 & 752436 & 5.5391 & 5.1502 & TRN & & \\
\hline CHEMBL1479754 & 752436 & 6.8794 & 3.8936 & TST & & \\
\hline CHEMBL1547684 & 752436 & 5.4248 & 5.3475 & TRN & & \\
\hline CHEMBL1445192 & 752436 & 5.9706 & 5.4837 & TRN & & \\
\hline CHEMBL1445372 & 752436 & 6.0218 & 4.1717 & TST & & \\
\hline CHEMBL1600360 & 752436 & 5.1675 & 4.918 & TRN & & \\
\hline CHEMBL1391118 & 752436 & 5.3915 & 5.4867 & TRN & & \\
\hline CHEMBL1321365 & 752436 & 5.5058 & 5.2661 & TRN & & \\
\hline CHEMBL 2000517 & 752436 & 6.9101 & 7.0923 & TRN & & \\
\hline CHEMBL3145021 & 752436 & 5.5834 & 5.3014 & TRN & & \\
\hline CHEMBL3210913 & 752436 & 4.7496 & 4.9325 & TRN & & \\
\hline CHEMBL1439030 & 752436 & 6.5272 & 4.0046 & TST & & \\
\hline CHEMBL1413380 & 752436 & 2.4202 & 4.5435 & TRN & & \\
\hline
\end{tabular}

Page 11955 
Supplemental Table S2.txt

\begin{tabular}{|c|c|c|c|c|}
\hline CHEMBL1586339 & 752436 & 2.4202 & 4.3908 & TRN \\
\hline CHEMBL1402456 & 752436 & 5.7212 & 4.5914 & TRN \\
\hline CHEMBL1388469 & 752436 & 5.8508 & 5.8059 & TRN \\
\hline CHEMBL1421972 & 752436 & 4.9172 & 5.2535 & TST \\
\hline CHEMBL1540682 & 752436 & 5.1549 & 5.5693 & TST \\
\hline CHEMBL1427646 & 752436 & 2.4202 & 4.4741 & TST \\
\hline CHEMBL1991885 & 752436 & 6.6655 & 5.9483 & TRN \\
\hline CHEMBL1301920 & 752436 & 5.4498 & 4.8206 & TST \\
\hline CHEMBL1308037 & 752436 & 2.4202 & 3.5861 & TRN \\
\hline CHEMBL1409740 & 752436 & 6.4685 & 4.8693 & TRN \\
\hline CHEMBL1351794 & 752436 & 5.5482 & 4.8465 & TRN \\
\hline CHEMBL1420920 & 752436 & 5.8665 & 4.8256 & TRN \\
\hline CHEMBL1597736 & 752436 & 2.4202 & 3.7085 & TST \\
\hline CHEMBL1450139 & 752436 & 2.4202 & 3.9316 & TST \\
\hline CHEMBL1460750 & 752436 & 5.1198 & 4.9575 & TRN \\
\hline CHEMBL1573331 & 752436 & 7.1765 & 6.7251 & TRN \\
\hline CHEMBL1501982 & 752436 & 2.4202 & 3.9864 & TST \\
\hline CHEMBL1727447 & 752436 & 5.5436 & 5.1797 & TRN \\
\hline CHEMBL1485134 & 752436 & 5.4711 & 5.4068 & TRN \\
\hline CHEMBL1521393 & 752436 & 5.5901 & 5.6477 & TRN \\
\hline CHEMBL3196491 & 752436 & 5.6478 & 6.1819 & TRN \\
\hline CHEMBL1499346 & 752436 & 5.4815 & 4.971 & TRN \\
\hline CHEMBL405110 & 752436 & 4.5229 & 4.9224 & TST \\
\hline CHEMBL1416713 & 752436 & 4.9318 & 5.476 & TRN \\
\hline CHEMBL1500315 & 752436 & 4.9508 & 5.1966 & TRN \\
\hline CHEMBL1510510 & 752436 & 5.2916 & 4.7832 & TRN \\
\hline CHEMBL1431334 & 752436 & 5.8447 & 4.7866 & TRN \\
\hline CHEMBL1581648 & 752436 & 5.4828 & 5.282999 & 9999999995 \\
\hline CHEMBL1332955 & 752436 & 4.9626 & 4.7104 & TRN \\
\hline CHEMBL1332768 & 752436 & 4.9136 & 4.6976 & TRN \\
\hline CHEMBL1453636 & 752436 & 4.7747 & 5.0641 & TRN \\
\hline CHEMBL1382853 & 752436 & 6.2807 & 5.6718 & TRN \\
\hline CHEMBL1574908 & 752436 & 5.8697 & 5.7578 & TRN \\
\hline CHEMBL1415423 & 752436 & 4.8153 & 4.6269 & TRN \\
\hline CHEMBL1448321 & 752436 & 5.6271 & 5.6807 & TRN \\
\hline CHEMBL1565268 & 752436 & 5.2815 & 4.696006 & 000000001 \\
\hline CHEMBL1489005 & 752436 & 5.15 & 4.317 & TRN \\
\hline CHEMBL1419538 & 752436 & 5.2941 & 4.6307 & TST \\
\hline CHEMBL1970242 & 752436 & 5.6271 & 5.3529 & TRN \\
\hline CHEMBL1480040 & 752436 & 2.4202 & 4.3754 & TRN \\
\hline CHEMBL1377610 & 752436 & 4.8182 & 4.9213 & TRN \\
\hline CHEMBL1400375 & 752436 & 6.2708 & 5.8111 & TRN \\
\hline CHEMBL1482281 & 752436 & 4.6364 & 4.6813 & TRN \\
\hline CHEMBL3191525 & 752436 & 2.4202 & 4.9838 & TRN \\
\hline CHEMBL1488429 & 752436 & 5.8894 & 5.4208 & TRN \\
\hline CHEMBL1524916 & 752436 & 5.4191 & 4.2467 & TRN \\
\hline CHEMBL1458949 & 752436 & 2.4202 & 3.8523 & TRN \\
\hline CHEMBL1976304 & 752436 & 5.6108 & 4.6508 & TST \\
\hline
\end{tabular}




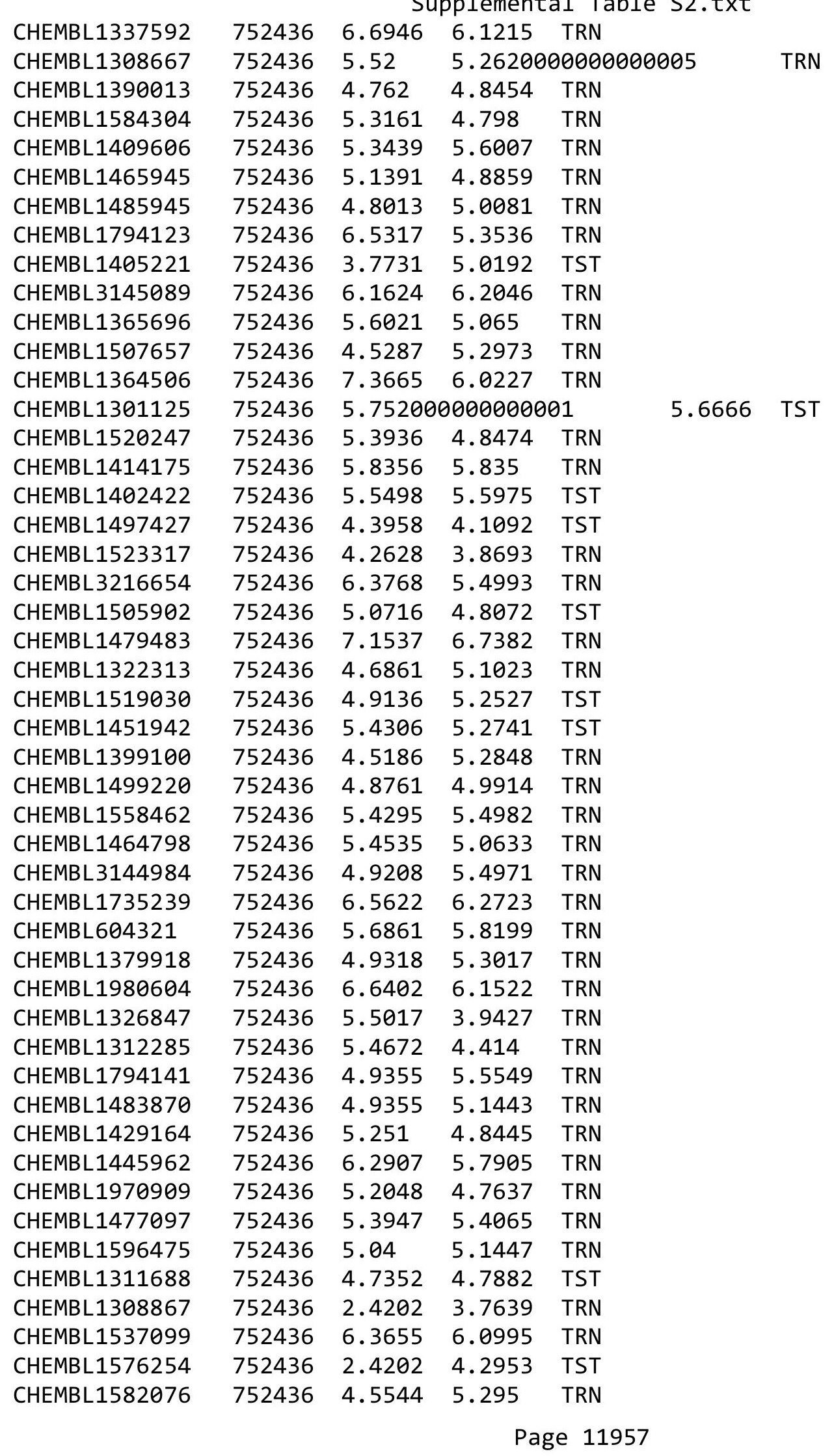




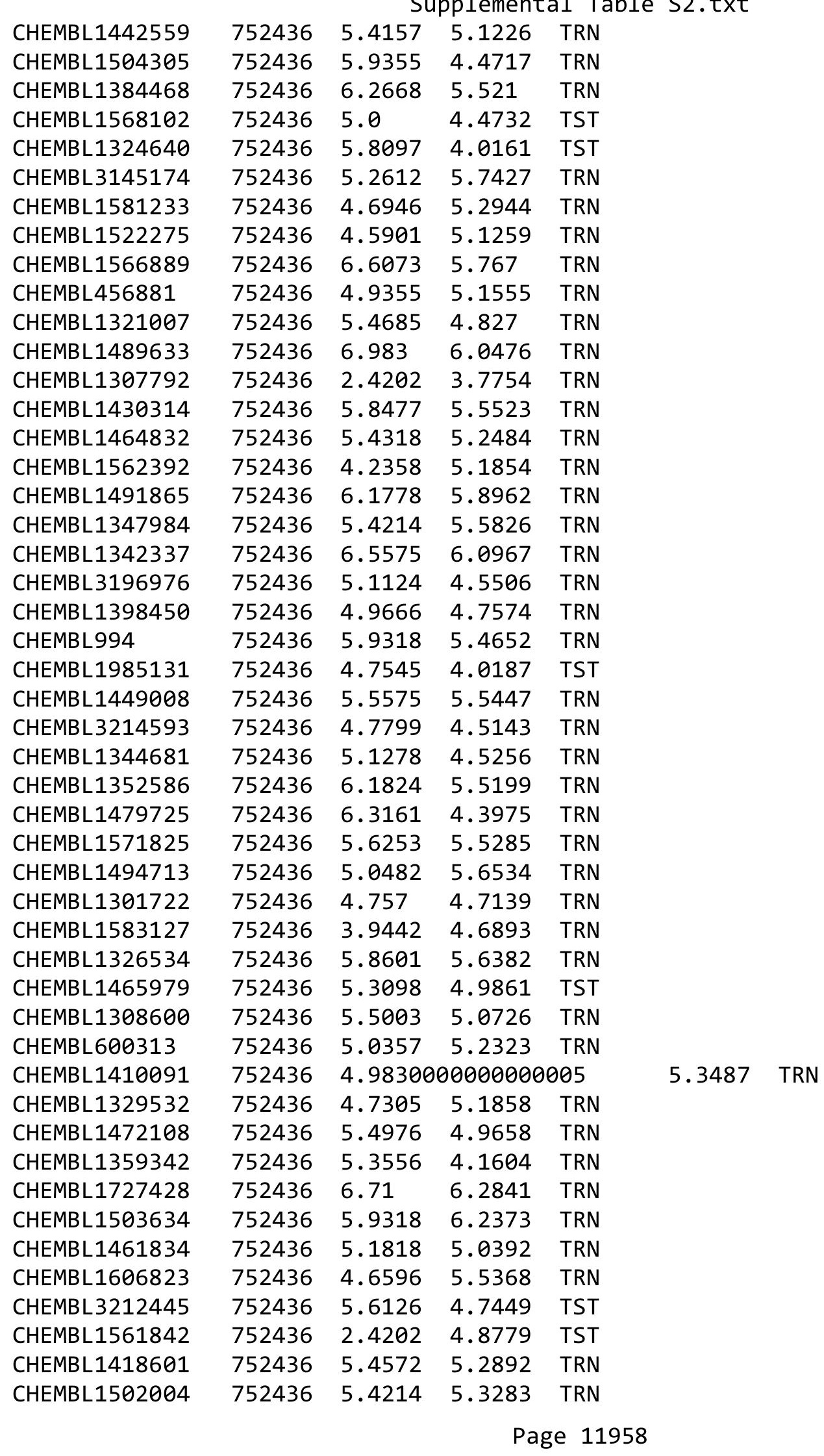


Supplemental Table S2.txt

\begin{tabular}{|c|c|c|c|c|}
\hline HEM & & 872 & & \\
\hline HEMPI 1275001 & & .6596 & & \\
\hline & & & & \\
\hline AEMBL & 6 & & & \\
\hline AEMBL1542809 & 6 & 958 & & \\
\hline HEMBL3144926 & 52436 & 9914 & 8157 & \\
\hline & & & & \\
\hline IFMBL 1491 & & & & \\
\hline AEMBL1372179 & 524 & & & \\
\hline HEMBL3192994 & 52436 & 601 & 5944 & \\
\hline HEMBL1465170 & 524 & 253 & 43 & \\
\hline EMBL15 & 36 & & & \\
\hline AEMBL159 & & & & RN \\
\hline HEMBL159 & 36 & & 972 & \\
\hline AEMBL1375 & 6 & & & \\
\hline AEMBL1580990 & $5<4+2 \times 1$ & 58 & 7562 & \\
\hline AEMBL1733 & 6 & & & \\
\hline HEMBL1352 & & & & \\
\hline HEMBL1981 & 6 & & & \\
\hline IEMBL134 & & & & \\
\hline IE/MBLI4 & 6 & & 946 & MT \\
\hline AEMBL14 & & & & ודת \\
\hline AEMBL14 & & & & \\
\hline IEMBL14 & & & 2055 & \\
\hline AEMBL13 & & & & ras \\
\hline AEMBL50 & 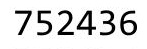 & & 791 & KIV \\
\hline HEMBL15 & & & 46 & RN \\
\hline HFMBI 154 & 6 & & 149 & \\
\hline HEMBL1580910 & & & 5751 & 15 \\
\hline HEMBL15827 & & & & 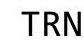 \\
\hline HEMBL138ऽ & 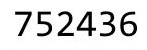 & & 825 & RN \\
\hline HEMBL1 & & & 23 & RN \\
\hline HEMBL2 & 6 & & 36 & RN \\
\hline HEMBL1391217 & 6 & & 316 & IS \\
\hline HEMBL1526966 & 6 & & 535 & TRN \\
\hline HEMBL1404 & & & 168 & \\
\hline HFMRI 15 & 6 & & 28 & \\
\hline HEMBL 14 & & & & RN \\
\hline HEMBL1428095 & 6 & & 9061 & TRN \\
\hline IEMBL14 & 0 & & 935 & $\mathrm{RN}$ \\
\hline HEMBL $200 €$ & & & 269 & \\
\hline CHEMBL1436988 & & & & TRN \\
\hline HEMBL1373969 & 36 & & 9767 & RN \\
\hline AEMBL1698464 & 36 & & 4508 & TRN \\
\hline MBL14 & & & 8862 & $\pi$ \\
\hline HEMBL1302 & & & 5867 & \\
\hline CHEMBL14722 & 52436 & .9914 & .6172 & \\
\hline LHEMBL1574879 & 752436 & 5.5031 & 5.1521 & \\
\hline
\end{tabular}

Page 11959 


\begin{tabular}{|c|c|c|c|c|c|}
\hline & & \multicolumn{4}{|c|}{ Supplemental Table S2.txt } \\
\hline CHEMBL1451931 & 752436 & 6.1113 & 4.8805 & TRN & \\
\hline CHEMBL1491717 & 752436 & 6.4461 & 6.0829 & TRN & \\
\hline CHEMBL1414704 & 752436 & 5.27 & 5.1969 & TRN & \\
\hline CHEMBL1376516 & 752436 & 4.8447 & 5.3899 & TRN & \\
\hline CHEMBL1444473 & 752436 & 5.3883 & 4.6969 & TRN & \\
\hline CHEMBL3145102 & 752436 & 4.8539 & 5.1562 & TRN & \\
\hline CHEMBL1509317 & 752436 & 5.3439 & 4.9055 & TRN & \\
\hline CHEMBL1310969 & 752436 & 4.9957 & 4.9143 & TRN & \\
\hline CHEMBL1485159 & 752436 & 5.6234 & 5.0093 & TRN & \\
\hline CHEMBL1341867 & 752436 & 5.9208 & 5.7397 & TRN & \\
\hline CHEMBL1735634 & 752436 & 4.7399 & 4.4865 & TRN & \\
\hline CHEMBL1569910 & 752436 & 6.3429 & 4.4513 & TRN & \\
\hline CHEMBL1364896 & 752436 & 5.9031 & 5.2716 & TST & \\
\hline CHEMBL1347702 & 752436 & 2.4202 & 4.2065 & TRN & \\
\hline CHEMBL1505679 & 752436 & 4.585 & 4.7186 & TRN & \\
\hline CHEMBL1469676 & 752436 & 6.3179 & 5.9392 & TRN & \\
\hline CHEMBL1463793 & 752436 & 4.6055 & 4.8604 & TST & \\
\hline CHEMBL1576824 & 752436 & 4.7399 & 4.7753 & TST & \\
\hline CHEMBL1098875 & 752436 & 2.4202 & 4.1495 & TRN & \\
\hline CHEMBL1416089 & 752436 & 6.0 & 6.0338 & TRN & \\
\hline CHEMBL1564699 & 752436 & 5.6216 & 5.6838 & TRN & \\
\hline CHEMBL1339869 & 752436 & 4.9281 & 4.6579 & TRN & \\
\hline CHEMBL1395972 & 752436 & 4.2933 & 5.55399 & 9999999999 & TST \\
\hline CHEMBL1500316 & 752436 & 4.7258 & 4.9126 & TST & \\
\hline CHEMBL1505544 & 752436 & 5.6655 & 3.6851 & TRN & \\
\hline CHEMBL1573265 & 752436 & 5.4737 & 4.9484 & TST & \\
\hline CHEMBL1554411 & 752436 & 5.0511 & 5.6227 & TRN & \\
\hline CHEMBL30095 & 752436 & 4.8761 & 5.2355 & TRN & \\
\hline CHEMBL1430291 & 752436 & 5.7932 & 5.596 & TRN & \\
\hline CHEMBL1564294 & 752436 & 6.15799 & (9999999 & 5.8887 & TRN \\
\hline CHEMBL 1455110 & 752436 & 5.2581 & 5.5265 & TST & \\
\hline CHEMBL1481657 & 752436 & 4.9355 & 5.5824 & TST & \\
\hline CHEMBL1409494 & 752436 & 5.5157 & 4.7053 & TRN & \\
\hline CHEMBL1350958 & 752436 & 4.9318 & 5.4643 & TST & \\
\hline CHEMBL1537615 & 752436 & 5.3585 & 5.2009 & TRN & \\
\hline CHEMBL1540463 & 752436 & 6.4547 & 5.7049 & TRN & \\
\hline CHEMBL1388022 & 752436 & 4.6234 & 4.6394 & TRN & \\
\hline CHEMBL1346302 & 752436 & 4.8894 & 5.1953 & TRN & \\
\hline CHEMBL1331111 & 752436 & 5.5406 & 5.5751 & TRN & \\
\hline CHEMBL1503292 & 752436 & 5.5003 & 4.8432 & TRN & \\
\hline CHEMBL3210821 & 752436 & 4.4989 & 4.9736 & TRN & \\
\hline CHEMBL1344648 & 752436 & 4.9586 & 5.3008 & TRN & \\
\hline CHEMBL1516744 & 752436 & 5.9172 & 4.1399 & TRN & \\
\hline CHEMBL1405374 & 752436 & 5.3893 & 4.9856 & TRN & \\
\hline CHEMBL1415002 & 752436 & 4.0605 & 5.1364 & TST & \\
\hline CHEMBL1344292 & 752436 & 5.7799 & 5.6984 & TRN & \\
\hline CHEMBL1308497 & 752436 & 5.2865 & 5.1635 & TRN & \\
\hline CHEMBL1428003 & 752436 & 4.5735 & 5.3506 & TRN & \\
\hline
\end{tabular}




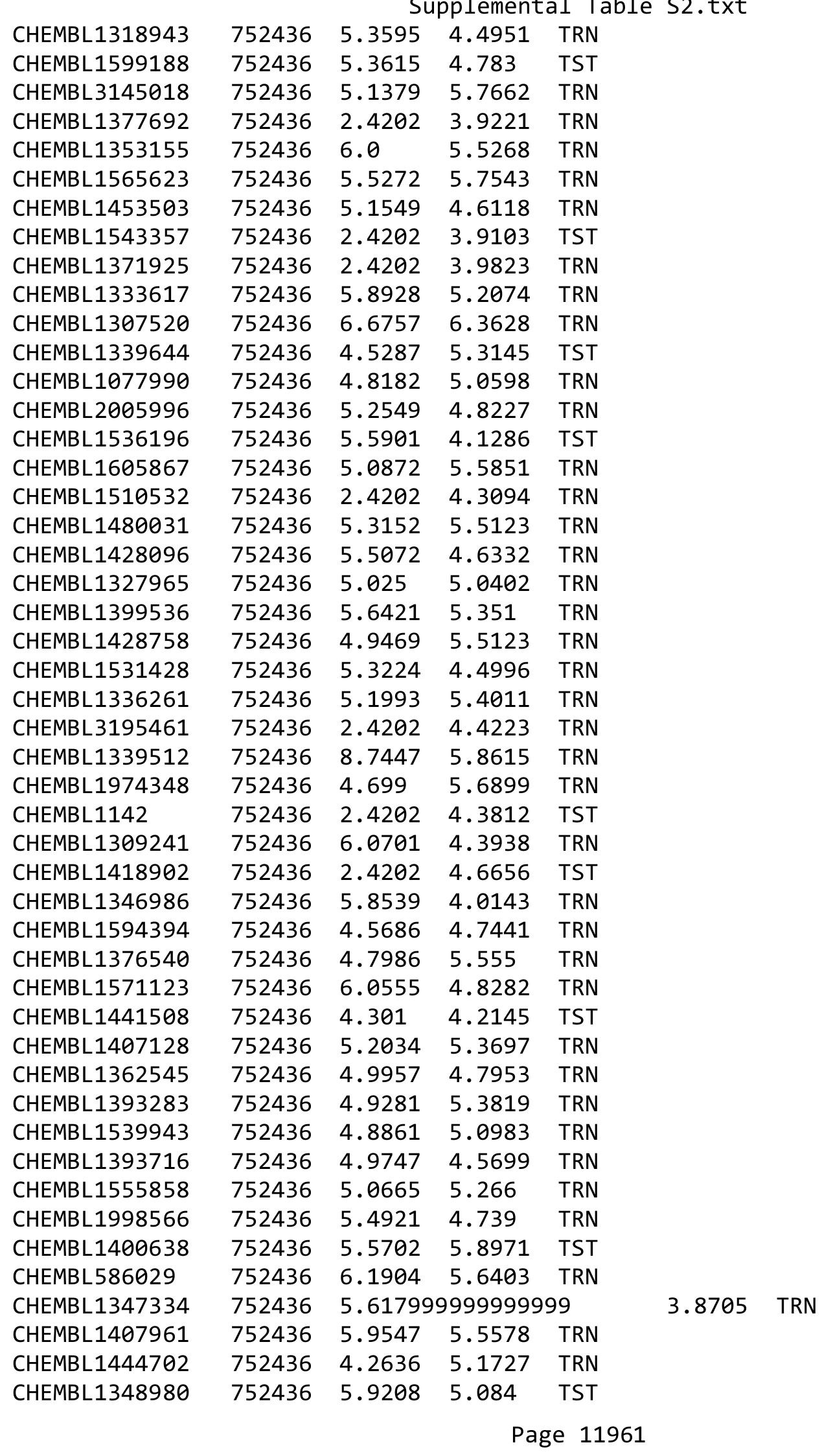


Supplemental Table S2.txt

\begin{tabular}{|c|c|c|c|c|c|}
\hline CHEMBL1409900 & 752436 & 4.1073 & 3.8952 & TRN & \\
\hline CHEMBL3145191 & 752436 & 5.8327 & 4.6459 & TRN & \\
\hline CHEMBL463175 & 752436 & 5.8041 & 5.8713 & TST & \\
\hline CHEMBL1484906 & 752436 & 5.6861 & 5.6662 & TRN & \\
\hline CHEMBL1995112 & 752436 & 6.209 & 4.2522 & TRN & \\
\hline CHEMBL1407708 & 752436 & 4.6799 & 5.0392 & TRN & \\
\hline CHEMBL1471461 & 752436 & 2.4202 & 3.6374 & TST & \\
\hline CHEMBL1313555 & 752436 & 5.8125 & 5.5847 & TRN & \\
\hline CHEMBL1414814 & 752436 & 3.8356 & 4.7253 & TRN & \\
\hline CHEMBL1563469 & 752436 & 2.4202 & 3.8694 & TST & \\
\hline CHEMBL1794259 & 752436 & 2.4202 & 4.4622 & TRN & \\
\hline CHEMBL 2004417 & 752436 & \multicolumn{3}{|c|}{5.172000000000001} & 5.1334 \\
\hline CHEMBL1351159 & 752436 & 4.9431 & 5.2221 & TRN & \\
\hline CHEMBL1347897 & 752436 & 5.6383 & 5.8359 & TRN & \\
\hline CHEMBL1361500 & 752436 & 4.7258 & 4.9989 & TRN & \\
\hline CHEMBL1465186 & 752436 & 4.8182 & 5.5807 & TRN & \\
\hline CHEMBL1432126 & 752436 & 4.7423 & 5.4334 & TRN & \\
\hline CHEMBL1326933 & 752436 & 4.7852 & 4.4016 & TRN & \\
\hline CHEMBL3145178 & 752436 & 6.1113 & 5.8332 & TRN & \\
\hline CHEMBL1503106 & 752436 & 6.6216 & 5.2144 & TRN & \\
\hline CHEMBL1314125 & 752436 & 6.3468 & 5.8966 & TRN & \\
\hline CHEMBL1572480 & 752436 & \multicolumn{3}{|c|}{5.752000000000001} & 5.4707 \\
\hline CHEMBL1341913 & 752436 & 6.0 & 4.8986 & TST & \\
\hline CHEMBL1590402 & 752436 & 5.7773 & 5.6366 & TRN & \\
\hline CHEMBL1465144 & 752436 & 5.8794 & 5.2047 & TRN & \\
\hline CHEMBL1409883 & 752436 & 4.6126 & 5.3678 & TRN & \\
\hline CHEMBL1369737 & 752436 & 5.6091 & 5.5049 & TRN & \\
\hline CHEMBL1568257 & 752436 & 4.7328 & 5.2507 & TRN & \\
\hline CHEMBL1334903 & 752436 & 5.4698 & 5.5027 & TRN & \\
\hline CHEMBL1256974 & 752436 & 4.8996 & 4.2702 & TRN & \\
\hline CHEMBL3194464 & 752436 & 2.4202 & 4.8121 & TRN & \\
\hline CHEMBL1384771 & 752436 & 5.5258 & 5.4594 & TRN & \\
\hline CHEMBL3188273 & 752436 & 5.2588 & 5.435 & TRN & \\
\hline CHEMBL1510262 & 752436 & 5.0872 & 4.9697 & TRN & \\
\hline CHEMBL1463261 & 752436 & 5.4921 & 4.9627 & TRN & \\
\hline CHEMBL1568009 & 752436 & 5.4461 & 5.3434 & TRN & \\
\hline CHEMBL1583184 & 752436 & 2.4202 & 5.2923 & TST & \\
\hline CHEMBL1320781 & 752436 & 5.4023 & 4.6044 & TRN & \\
\hline CHEMBL1586263 & 752436 & 5.2557 & 4.7586 & TRN & \\
\hline CHEMBL1472126 & 752436 & 6.4855 & 6.2124 & TRN & \\
\hline CHEMBL1612699 & 752436 & 5.9706 & 4.1342 & TRN & \\
\hline CHEMBL1444859 & 752436 & 2.4202 & 4.2056 & TRN & \\
\hline CHEMBL1463563 & 752436 & 5.3279 & 5.5248 & TRN & \\
\hline CHEMBL3213220 & 752436 & 2.4202 & 4.7244 & TRN & \\
\hline CHEMBL1420811 & 752436 & 4.9281 & 4.9963 & TRN & \\
\hline CHEMBL1717998 & 752436 & 5.3872 & 5.1717 & TRN & \\
\hline CHEMBL1699978 & 752436 & 6.1415 & 5.2422 & TRN & \\
\hline CHEMBL1501444 & 752436 & 5.4202 & 5.836 & TRN & \\
\hline
\end{tabular}




\begin{tabular}{|c|c|c|c|c|c|}
\hline \multirow[b]{2}{*}{ CHEMBL1586439 } & & \\
\hline & 752436 & 4.9547 & 4.7302 & TRN & \\
\hline CHEMBL1794196 & 752436 & 5.0778 & 5.092 & TRN & \\
\hline CHEMBL1314042 & 752436 & 5.3706 & 5.4828 & TRN & \\
\hline CHEMBL1547262 & 752436 & 5.4522 & 5.0812 & TRN & \\
\hline CHEMBL1399371 & 752436 & 6.1361 & 6.1044 & TRN & \\
\hline CHEMBL1471012 & 752436 & 5.007 & 4.9393 & TRN & \\
\hline CHEMBL1320799 & 752436 & 5.3565 & 5.1223 & TST & \\
\hline CHEMBL1426255 & 752436 & 5.857 & 5.5204 & TRN & \\
\hline CHEMBL1467294 & 752436 & 6.2588 & 4.1441 & TRN & \\
\hline CHEMBL1487321 & 752436 & 5.1726 & 4.9148 & TRN & \\
\hline CHEMBL1559810 & 752436 & 5.7122 & 5.5647 & TRN & \\
\hline CHEMBL1567159 & 752436 & 6.3098 & 5.9478 & TRN & \\
\hline CHEMBL1565888 & 752436 & 5.5171 & 4.8108 & TRN & \\
\hline CHEMBL1794266 & 752436 & 6.1308 & 4.9835 & TRN & \\
\hline CHEMBL1405837 & 752436 & 5.2628 & 4.6933 & TST & \\
\hline CHEMBL1499544 & 752436 & 6.6198 & 6.2527 & TRN & \\
\hline CHEMBL3144936 & 752436 & 5.2226 & 4.9005 & TRN & \\
\hline CHEMBL3191597 & 752436 & 4.7905 & 4.5031 & TRN & \\
\hline CHEMBL179794 & 752436 & 6.1002 & 4.81 & TRN & \\
\hline CHEMBL1348016 & 752436 & 5.5331 & 5.57700 & 0000000001 & TRN \\
\hline CHEMBL1414479 & 752436 & 5.7122 & 6.2172 & TRN & \\
\hline CHEMBL1609519 & 752436 & 2.4202 & 3.748 & TRN & \\
\hline CHEMBL1471206 & 752436 & 2.4202 & 3.7839 & TRN & \\
\hline CHEMBL1470321 & 752436 & 5.266 & 5.1445 & TRN & \\
\hline CHEMBL1558874 & 752436 & 5.1314 & 5.4704 & TST & \\
\hline CHEMBL1334307 & 752436 & 4.8861 & 5.2324 & TRN & \\
\hline CHEMBL1349535 & 752436 & 5.3696 & 5.3518 & TRN & \\
\hline CHEMBL1491275 & 752436 & 5.3307 & 4.665 & TRN & \\
\hline CHEMBL1532174 & 752436 & 4.9245 & 4.1219 & TST & \\
\hline CHEMBL1560229 & 752436 & 5.5686 & 4.4385 & TRN & \\
\hline CHEMBL1587031 & 752436 & 5.0214 & 5.5811 & TST & \\
\hline CHEMBL1548704 & 752436 & 5.6819 & 5.5864 & TRN & \\
\hline CHEMBL1579471 & 752436 & 4.5436 & 4.8969 & TRN & \\
\hline CHEMBL1794229 & 752436 & 2.4202 & 3.8375 & TST & \\
\hline CHEMBL1584428 & 752436 & 5.1284 & 4.6324 & TRN & \\
\hline CHEMBL373839 & 752436 & 5.5735 & 5.8718 & TRN & \\
\hline CHEMBL1597358 & 752436 & 6.4202 & 5.9297 & TRN & \\
\hline CHEMBL1410562 & 752436 & 5.4868 & 5.3516 & TRN & \\
\hline CHEMBL1305658 & 752436 & 5.341 & 5.5846 & TRN & \\
\hline CHEMBL1305275 & 752436 & 5.26200 & 00000000 & 5.4516 & TRN \\
\hline CHEMBL1548411 & 752436 & 4.0259 & 5.2664 & TST & \\
\hline CHEMBL1389371 & 752436 & 4.2495 & 5.1286 & TRN & \\
\hline CHEMBL1306377 & 752436 & 5.0013 & 4.6477 & TRN & \\
\hline CHEMBL1437741 & 752436 & 4.8761 & 4.65600 & 0000000001 & TRN \\
\hline CHEMBL1425350 & 752436 & 5.4353 & 5.4571 & TRN & \\
\hline CHEMBL1464383 & 752436 & 5.9281 & 5.1882 & TRN & \\
\hline CHEMBL1580129 & 752436 & 4.8386 & 4.9905 & TST & \\
\hline CHEMBL1338987 & 752436 & 5.4802 & 5.48600 & $\partial 000000001$ & TST \\
\hline & & & & 11963 & \\
\hline
\end{tabular}


Supplemental Table S2.txt

\begin{tabular}{|c|c|}
\hline CHEMBL1313412 & 752436 \\
\hline CHEMBL1458294 & 752436 \\
\hline CHEMBL3208288 & 752436 \\
\hline CHEMBL1345979 & 752436 \\
\hline CHEMBL1521758 & 752436 \\
\hline CHEMBL1329597 & 752436 \\
\hline CHEMBL1306457 & 752436 \\
\hline CHEMBL1441329 & 752436 \\
\hline CHEMBL172264 & 752436 \\
\hline CHEMBL1572077 & 752436 \\
\hline CHEMBL1558436 & 752436 \\
\hline CHEMBL1719459 & 752436 \\
\hline CHEMBL1586948 & 752436 \\
\hline CHEMBL1535312 & 752436 \\
\hline CHEMBL1525358 & 752436 \\
\hline CHEMBL1341762 & 752436 \\
\hline CHEMBL1606613 & 752436 \\
\hline CHEMBL1483235 & 752436 \\
\hline CHEMBL1466516 & 752436 \\
\hline CHEMBL1401000 & 752436 \\
\hline CHEMBL3189511 & 752436 \\
\hline CHEMBL1472327 & 752436 \\
\hline CHEMBL1516772 & 752436 \\
\hline CHEMBL1575284 & 752436 \\
\hline CHEMBL1611922 & 752436 \\
\hline CHEMBL1368609 & 752436 \\
\hline CHEMBL1532935 & 752436 \\
\hline CHEMBL1560640 & 752436 \\
\hline CHEMBL3191689 & 752436 \\
\hline CHEMBL1368413 & 752436 \\
\hline CHEMBL1483657 & 752436 \\
\hline CHEMBL1387293 & 752436 \\
\hline CHEMBL1461680 & 752436 \\
\hline CHEMBL1453368 & 752436 \\
\hline CHEMBL1972249 & 752436 \\
\hline CHEMBL1988416 & 752436 \\
\hline CHEMBL1496231 & 752436 \\
\hline CHEMBL17551 & 752436 \\
\hline CHEMBL1432432 & 752436 \\
\hline CHEMBL1341778 & 752436 \\
\hline CHEMBL1453212 & 752436 \\
\hline CHEMBL1465185 & 752436 \\
\hline CHEMBL1583024 & 752436 \\
\hline CHEMBL3192493 & 752436 \\
\hline CHEMBL3214581 & 752436 \\
\hline CHEMBL1531735 & 752436 \\
\hline CHEMBL1563864 & 752436 \\
\hline CHEMBL3193639 & 752436 \\
\hline
\end{tabular}

$5.9957 \quad 5.8914$
TRN

$\begin{array}{lll}2.4202 & 4.215 & \text { TRN }\end{array}$

$\begin{array}{llll}4.7773 & 4.4632 & \text { TRN }\end{array}$

$\begin{array}{llll}5.7799 & 5.7775 & \text { TST }\end{array}$

$\begin{array}{lll}7.1278 & 6.5705 & \text { TRN }\end{array}$

$\begin{array}{lll}6.6799 & 6.0292 & \text { TST }\end{array}$

$\begin{array}{lll}2.4202 & 4.798 \quad \text { TRN }\end{array}$

$\begin{array}{lll}4.7545 & 5.4289 & \text { TST }\end{array}$

$2.4202 \quad 4.6772$ TRN

$\begin{array}{lll}6.5622 & 6.2386 & \text { TRN }\end{array}$

$\begin{array}{lll}5.1427 & 4.5915 & \text { TRN }\end{array}$

$\begin{array}{lll}5.7011 & 5.2521 & \text { TRN }\end{array}$

$4.9788 \quad 5.3839$ TRN

$\begin{array}{lll}2.4202 & 4.7391 & \text { TRN }\end{array}$

$5.2941 \quad 5.1111$ TRN

$5.7144 \quad 4.9728$ TRN

$\begin{array}{lll}5.0 & 5.4194 & \text { TRN }\end{array}$

$\begin{array}{lll}5.0052 & 5.8015 & \text { TRN }\end{array}$

$\begin{array}{lll}5.6904 & 3.9722 & \text { TRN }\end{array}$

$5.2823 \quad 5.0722$ TRN

$\begin{array}{lll}6.0501 & 4.9831 & \text { TRN }\end{array}$

$\begin{array}{lll}5.9318 & 5.9416 & \text { TST }\end{array}$

$\begin{array}{lll}5.0575 & 5.7074 & \text { TST }\end{array}$

2.42024 .5881 TRN

$5.2534 \quad 5.2468$ TRN

$5.4012 \quad 5.382000000000001$

$\begin{array}{llll}5.0467 & 4.7478 & \text { TST }\end{array}$

$\begin{array}{lll}4.3507 & 5.4727 & \text { TRN }\end{array}$

$6.1355 \quad 5.4714$ TRN

$\begin{array}{lll}2.4202 & 3.9718 \quad \text { TRN }\end{array}$

$\begin{array}{lll}4.8508 & 4.7307 & \text { TRN }\end{array}$

$\begin{array}{lll}3.9027 & 3.8704 & \text { TRN }\end{array}$

$\begin{array}{lll}5.2062 & 5.3407 & \text { TRN }\end{array}$

$\begin{array}{llll}4.9626 & 5.1038 & \text { TRN }\end{array}$

$5.4473 \quad 5.4531$ TRN

$\begin{array}{lll}4.4572 & 5.58 \quad \text { TRN }\end{array}$

$\begin{array}{lll}5.2226 & 5.0845 & \text { TRN }\end{array}$

$\begin{array}{llll}4.4425 & 4.5777 & \text { TRN }\end{array}$

$\begin{array}{lll}4.8153 & 5.075 & \text { TST }\end{array}$

$\begin{array}{lll}4.5952 & 5.1433 & \text { TST }\end{array}$

$6.1409 \quad 4.0917$ TST

$4.9706 \quad 4.6511$ TRN

$4.9281 \quad 5.1776$ TST

$5.3179 \quad 5.3263$ TRN

$\begin{array}{lll}4.699 & 4.5601 & \text { TRN }\end{array}$

$\begin{array}{llll}5.7471 & 5.4148 & \text { TRN }\end{array}$

$\begin{array}{lll}4.9101 & 5.335 & \text { TRN }\end{array}$

$\begin{array}{lll}6.1146 & 5.7655 & \text { TRN }\end{array}$

Page 11964 


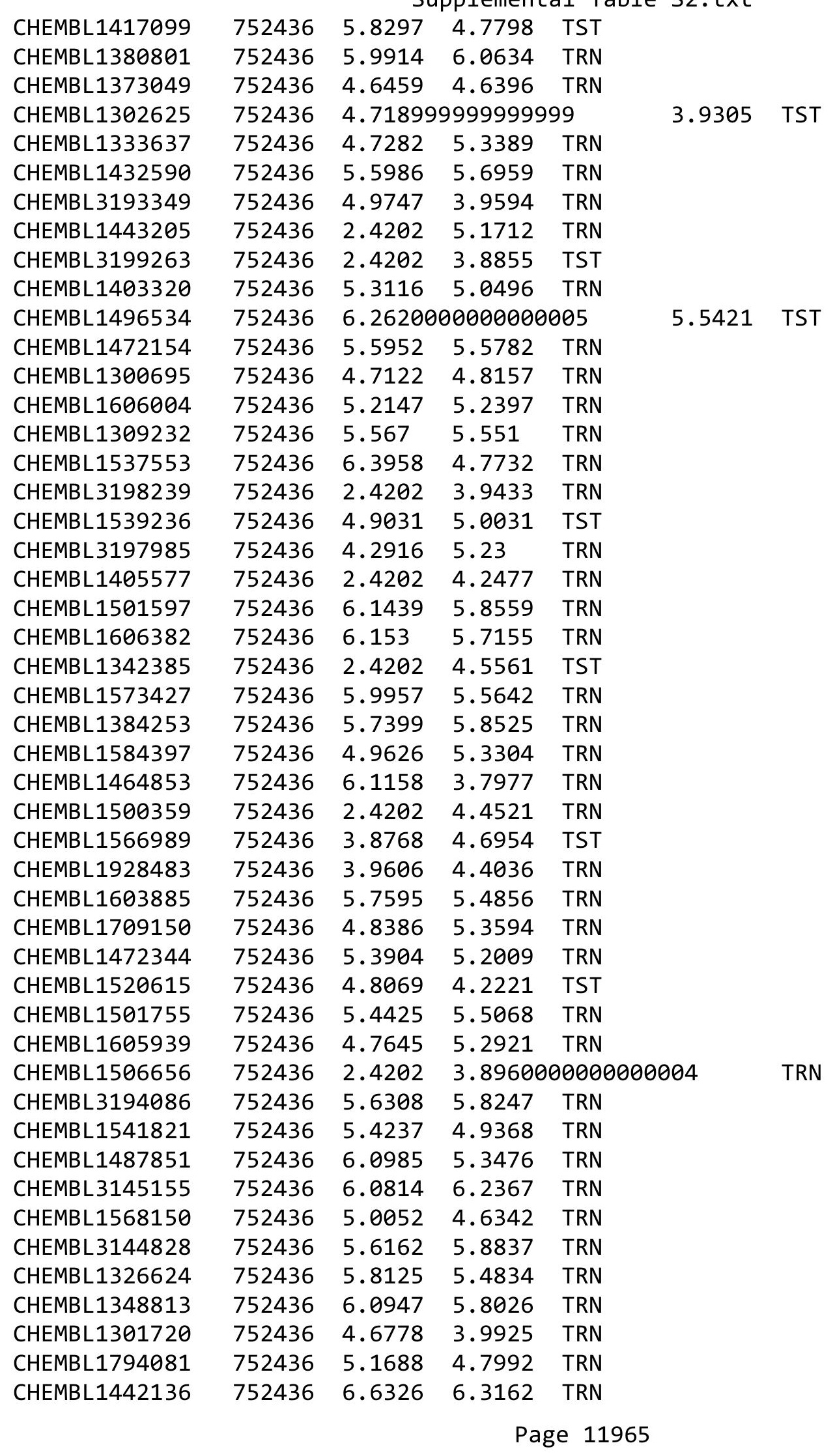




\begin{tabular}{|c|c|c|c|c|c|c|}
\hline & & & & & & \\
\hline CHEMBL1430266 & 752436 & 5.3716 & 4.3108 & TRN & & \\
\hline CHEMBL 3144830 & 752436 & 5.6478 & 5.8299 & TRN & & \\
\hline CHEMBL1332682 & 752436 & 2.4202 & 4.3218 & TST & & \\
\hline CHEMBL1574219 & 752436 & 2.4202 & 3.7877 & TRN & & \\
\hline CHEMBL1336010 & 752436 & 5.6364 & 4.7509 & TRN & & \\
\hline CHEMBL1602084 & 752436 & 5.21899 & 99999999 & 99 & 5.6377 & TRN \\
\hline CHEMBL1304700 & 752436 & 5.4881 & 4.8485 & TRN & & \\
\hline CHEMBL1557820 & 752436 & 5.9872 & 5.2422 & TRN & & \\
\hline CHEMBL1467422 & 752436 & 4.8633 & 4.9446 & TST & & \\
\hline CHEMBL445304 & 752436 & 5.2652 & 4.4288 & TRN & & \\
\hline CHEMBL1307096 & 752436 & 5.5544 & 4.9176 & TST & & \\
\hline CHEMBL1341870 & 752436 & 5.0904 & 5.3034 & TRN & & \\
\hline CHEMBL1520259 & 752436 & 2.4202 & 5.5094 & TST & & \\
\hline CHEMBL1522503 & 752436 & 4.8761 & 5.2873 & TRN & & \\
\hline CHEMBL1374291 & 752436 & 4.9172 & 5.00899 & 999999999 & 95 & TRN \\
\hline CHEMBL1540603 & 752436 & 5.9208 & 5.2239 & TRN & & \\
\hline CHEMBL1374709 & 752436 & 2.4202 & 4.046 & TST & & \\
\hline CHEMBL1492926 & 752436 & 6.3979 & 5.8576 & TRN & & \\
\hline CHEMBL1573221 & 752436 & 5.5867 & 3.653 & TRN & & \\
\hline CHEMBL1407401 & 752436 & 4.9508 & 5.2824 & TST & & \\
\hline CHEMBL1429018 & 752436 & 4.8761 & 5.0886 & TRN & & \\
\hline CHEMBL1303970 & 752436 & 4.9208 & 5.5519 & TRN & & \\
\hline CHEMBL345635 & 752436 & 5.5986 & 5.2223 & TST & & \\
\hline CHEMBL1507534 & 752436 & 4.8894 & 4.601 & TRN & & \\
\hline CHEMBL1523399 & 752436 & 2.4202 & 3.9637 & TST & & \\
\hline CHEMBL1441739 & 752436 & 5.062 & 5.6397 & TRN & & \\
\hline CHEMBL1532436 & 752436 & 3.6165 & 4.9684 & TRN & & \\
\hline CHEMBL1389480 & 752436 & 6.0491 & 5.8421 & TRN & & \\
\hline CHEMBL1497287 & 752436 & 4.9706 & 4.3475 & TRN & & \\
\hline CHEMBL1480059 & 752436 & 5.0696 & 5.4511 & TST & & \\
\hline CHEMBL1389273 & 752436 & 5.2708 & 5.1914 & TRN & & \\
\hline CHEMBL1492922 & 752436 & 5.4271 & 3.9549 & TST & & \\
\hline CHEMBL1418852 & 752436 & 6.6882 & 6.3717 & TRN & & \\
\hline CHEMBL1537588 & 752436 & 6.3507 & 5.4686 & TRN & & \\
\hline CHEMBL1569877 & 752436 & 4.5735 & 5.2278 & TRN & & \\
\hline CHEMBL1601712 & 752436 & 4.6421 & 5.4205 & TRN & & \\
\hline CHEMBL1556273 & 752436 & 4.0809 & 5.129 & TRN & & \\
\hline CHEMBL1608787 & 752436 & 4.5735 & 4.1767 & TST & & \\
\hline CHEMBL1379902 & 752436 & 5.0128 & 4.7626 & TRN & & \\
\hline CHEMBL1478235 & 752436 & 5.9872 & 5.4791 & TRN & & \\
\hline CHEMBL1568691 & 752436 & 6.6345 & 6.3844 & TRN & & \\
\hline CHEMBL1385433 & 752436 & 4.9788 & 5.1768 & TST & & \\
\hline CHEMBL1327934 & 752436 & 5.1002 & 4.5153 & TRN & & \\
\hline CHEMBL1504194 & 752436 & 2.4202 & 4.551 & TRN & & \\
\hline CHEMBL1320429 & 752436 & 4.82100 & 30000000 & & 5.3802 & TRN \\
\hline CHEMBL1550423 & 752436 & 5.2941 & 4.2704 & TRN & & \\
\hline CHEMBL1568113 & 752436 & 6.284 & 5.8357 & TRN & & \\
\hline CHEMBL51931 & 752436 & 5.1278 & 5.6026 & TRN & & \\
\hline
\end{tabular}




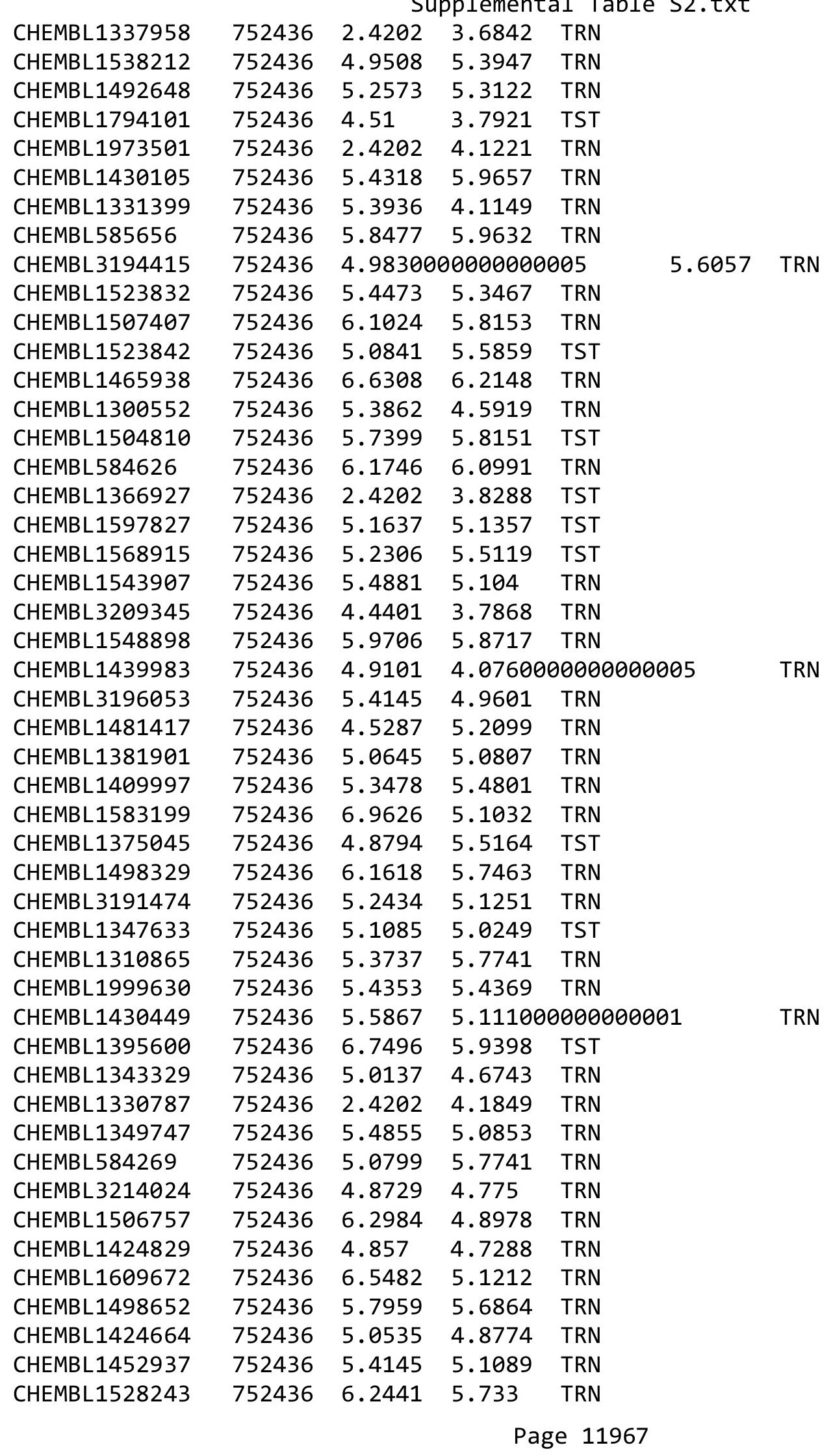




\begin{tabular}{|c|c|c|c|c|c|}
\hline \multicolumn{6}{|c|}{ Supplemental Table s2.txt } \\
\hline CHEMBL3193366 & 752436 & 4.8416 & 4.6494 & TRN & \\
\hline CHEMBL1473521 & 752436 & 5.5186 & 5.5043 & TST & \\
\hline CHEMBL1546217 & 752436 & 5.6459 & 4.7857 & TRN & \\
\hline CHEMBL1604490 & 752436 & 2.4202 & 3.822 & TRN & \\
\hline CHEMBL1304902 & 752436 & 6.4828 & 6.1958 & TRN & \\
\hline CHEMBL1451672 & 752436 & 2.4202 & 3.8196 & TRN & \\
\hline CHEMBL3145170 & 752436 & 4.8894 & 4.8392 & TRN & \\
\hline CHEMBL1555488 & 752436 & 4.7212 & 5.5513 & TRN & \\
\hline CHEMBL1499893 & 752436 & 6.7212 & 6.3035 & TRN & \\
\hline CHEMBL1588306 & 752436 & 4.8297 & 4.5807 & TST & \\
\hline CHEMBL1370838 & 752436 & 6.5272 & 4.7507 & TST & \\
\hline CHEMBL3189879 & 752436 & 4.8416 & 5.1851 & TRN & \\
\hline CHEMBL1558210 & 752436 & 6.3449 & 5.5453 & TRN & \\
\hline CHEMBL1508459 & 752436 & 4.067 & 4.2786 & TRN & \\
\hline CHEMBL1335426 & 752436 & 2.4202 & 3.9983 & TRN & \\
\hline CHEMBL1587473 & 752436 & 6.2765 & 5.9549 & TRN & \\
\hline CHEMBL1449718 & 752436 & 2.4202 & 4.7328 & TRN & \\
\hline CHEMBL1517746 & 752436 & 5.5817 & 4.2964 & TRN & \\
\hline CHEMBL1445431 & 752436 & 2.4202 & 5.2077 & TRN & \\
\hline CHEMBL1547454 & 752436 & 5.3401 & 5.7628 & TRN & \\
\hline CHEMBL1987742 & 752436 & 5.6716 & 5.643 & TST & \\
\hline CHEMBL1606827 & 752436 & 2.4202 & 5.4656 & TRN & \\
\hline CHEMBL1794234 & 752436 & 5.3655 & 4.5882 & TRN & \\
\hline CHEMBL1430331 & 752436 & 4.8962 & 4.8343 & TRN & \\
\hline CHEMBL1444960 & 752436 & 5.341 & 5.2799 & TRN & \\
\hline CHEMBL1432524 & 752436 & 4.9393 & 5.2749 & TRN & \\
\hline CHEMBL1547301 & 752436 & 6.1439 & 6.15600 & 0000000001 & TRN \\
\hline CHEMBL1572967 & 752436 & 6.0278 & 5.9932 & TRN & \\
\hline CHEMBL1417970 & 752436 & 5.4815 & 5.4112 & TRN & \\
\hline CHEMBL1410788 & 752436 & 5.0899 & 4.819 & TRN & \\
\hline CHEMBL1583537 & 752436 & 5.3391 & 5.0929 & TRN & \\
\hline CHEMBL1706100 & 752436 & 4.4547 & 5.0172 & TRN & \\
\hline CHEMBL1589625 & 752436 & 4.8697 & 5.1891 & TRN & \\
\hline CHEMBL1441170 & 752436 & 4.4034 & 4.6455 & TST & \\
\hline CHEMBL1993627 & 752436 & 6.3665 & 4.4148 & TRN & \\
\hline CHEMBL1393844 & 752436 & 5.0635 & 3.9575 & TST & \\
\hline CHEMBL1307306 & 752436 & 3.7747 & 4.9352 & TST & \\
\hline CHEMBL1462615 & 752436 & 5.2628 & 5.4441 & TRN & \\
\hline CHEMBL1469117 & 752436 & 6.71 & 6.4113 & TRN & \\
\hline CHEMBL1337382 & 752436 & 2.4202 & 4.5246 & TRN & \\
\hline CHEMBL600526 & 752436 & 5.1959 & 4.7808 & TRN & \\
\hline CHEMBL1522100 & 752436 & 4.3969 & 3.9189 & TST & \\
\hline CHEMBL3145111 & 752436 & 4.9586 & 5.7555 & TRN & \\
\hline CHEMBL1359835 & 752436 & 5.4089 & 4.7754 & TST & \\
\hline CHEMBL1402954 & 752436 & 5.7447 & 5.6358 & TRN & \\
\hline CHEMBL1451681 & 752436 & 4.5901 & 5.5062 & TRN & \\
\hline CHEMBL1391913 & 752436 & 5.4461 & 4.9277 & TRN & \\
\hline CHEMBL1330951 & 752436 & 4.8539 & 4.4708 & TST & \\
\hline
\end{tabular}


Supplemental Table S2.txt

\begin{tabular}{|c|c|c|c|c|c|}
\hline CHEMBL1493944 & 752436 & 5.7852 & 5.7819 & TRN & \\
\hline CHEMBL1373992 & 752436 & 5.0491 & 5.3045 & TRN & \\
\hline CHEMBL1466241 & 752436 & 4.6073 & 4.673999 & 99999999995 & TRN \\
\hline CHEMBL1330013 & 752436 & 5.9747 & 4.3862 & TRN & \\
\hline CHEMBL1548086 & 752436 & 4.9957 & 4.3835 & TST & \\
\hline CHEMBL1508051 & 752436 & 5.2197 & 4.5139 & TST & \\
\hline CHEMBL1353194 & 752436 & 5.3116 & 5.4661 & TRN & \\
\hline CHEMBL1484934 & 752436 & 6.5702 & 6.38 & TRN & \\
\hline CHEMBL1527616 & 752436 & 4.8153 & 4.7298 & TRN & \\
\hline CHEMBL1560396 & 752436 & 3.8 & 5.1874 & TRN & \\
\hline CHEMBL1302170 & 752436 & 5.8239 & 5.3486 & TRN & \\
\hline CHEMBL1533236 & 752436 & 5.3615 & 5.1602 & TRN & \\
\hline CHEMBL1527341 & 752436 & 5.0501 & 5.7394 & TRN & \\
\hline CHEMBL1580600 & 752436 & 4.6925 & 4.3604 & TRN & \\
\hline CHEMBL1610049 & 752436 & 5.6091 & 5.8233 & TRN & \\
\hline CHEMBL1324416 & 752436 & 4.4225 & 3.9822 & TRN & \\
\hline CHEMBL1522349 & 752436 & 4.9431 & 3.9509 & TRN & \\
\hline CHEMBL 3198685 & 752436 & 4.8386 & 4.561 & TRN & \\
\hline CHEMBL1570005 & 752436 & 4.699 & 5.2106 & TRN & \\
\hline CHEMBL1364176 & 752436 & 6.3526 & 5.9806 & TRN & \\
\hline CHEMBL 3192957 & 752436 & 6.0 & 6.1708 & TRN & \\
\hline CHEMBL1447341 & 752436 & 6.5114 & 6.4332 & TRN & \\
\hline CHEMBL1299841 & 752436 & 4.6073 & 4.4481 & TST & \\
\hline CHEMBL1367316 & 752436 & 5.9586 & 5.2183 & TRN & \\
\hline CHEMBL1428217 & 752436 & 2.4202 & 4.4887 & TRN & \\
\hline CHEMBL1605235 & 752436 & 3.9566 & 5.8241 & TRN & \\
\hline CHEMBL1480387 & 752436 & 6.0731 & 5.3483 & TRN & \\
\hline CHEMBL1499951 & 752436 & 5.3716 & 5.1709 & TRN & \\
\hline CHEMBL1387900 & 752436 & 4.7696 & 4.6345 & TRN & \\
\hline CHEMBL1407208 & 752436 & 4.7305 & 3.7462 & TRN & \\
\hline CHEMBL 3192741 & 752436 & \multicolumn{3}{|c|}{5.7620000000000005} & TRN \\
\hline CHEMBL1532953 & 752436 & 2.4202 & 3.7919 & TRN & \\
\hline CHEMBL 3198015 & 752436 & 5.8928 & 5.8667 & TRN & \\
\hline CHEMBL1599023 & 752436 & 5.0778 & 4.0218 & TST & \\
\hline CHEMBL 3195577 & 752436 & 5.3936 & 5.1448 & TRN & \\
\hline CHEMBL1443448 & 752436 & 5.6925 & 5.5594 & TRN & \\
\hline CHEMBL1419252 & 752436 & 4.9469 & 4.8899 & TRN & \\
\hline CHEMBL 3194941 & 752436 & 5.2725 & 4.1827 & TRN & \\
\hline CHEMBL 3212479 & 752436 & 5.063 & 5.1413 & TST & \\
\hline CHEMBL1608276 & 752436 & 3.9551 & 4.6533 & TRN & \\
\hline CHEMBL1402332 & 752436 & 5.3904 & 5.061 & TRN & \\
\hline CHEMBL1576555 & 752436 & 2.4202 & 5.3944 & TRN & \\
\hline CHEMBL465226 & 752436 & 4.7932 & 5.2838 & TST & \\
\hline CHEMBL1384702 & 752436 & 7.0835 & 6.126 & TRN & \\
\hline CHEMBL1299407 & 752436 & 5.7447 & 5.2332 & TRN & \\
\hline CHEMBL1308904 & 752436 & 5.4724 & 5.4955 & TRN & \\
\hline CHEMBL1328712 & 752436 & 5.6038 & 4.3388 & TRN & \\
\hline CHEMBL1393351 & 752436 & 4.6383 & 5.3911 & TST & \\
\hline
\end{tabular}


Supplemental Table S2.txt

\begin{tabular}{|c|c|c|c|c|}
\hline CHEMBL1342141 & 752436 & 5.1302 & 4.1656 & TRN \\
\hline CHEMBL1501680 & 752436 & 5.5575 & 5.9786 & TRN \\
\hline CHEMBL1549840 & 752436 & 5.4271 & 4.978 & TRN \\
\hline CHEMBL1438154 & 752436 & 5.0306 & 5.3693 & TRN \\
\hline CHEMBL1325970 & 752436 & 4.5784 & 4.6321 & TST \\
\hline CHEMBL1547116 & 752436 & 5.7167 & 4.5946 & TST \\
\hline CHEMBL1522941 & 752436 & 5.9172 & 5.0984 & TRN \\
\hline CHEMBL1726348 & 752436 & 5.0214 & 5.3241 & TST \\
\hline CHEMBL183656 & 752436 & 5.4295 & 4.5923 & TRN \\
\hline CHEMBL1549114 & 752436 & 5.6536 & 4.7944 & TRN \\
\hline CHEMBL1485660 & 752436 & 4.0516 & 4.7763 & TRN \\
\hline CHEMBL1495230 & 752436 & 4.7144 & 5.0841 & TST \\
\hline CHEMBL1370471 & 752436 & 5.1391 & 5.814 & TST \\
\hline CHEMBL1393004 & 752436 & 6.6635 & 6.414 & TST \\
\hline CHEMBL417727 & 752436 & 5.1965 & 5.5566 & TST \\
\hline CHEMBL1459914 & 752436 & 5.1427 & 5.4933 & TST \\
\hline CHEMBL1339956 & 752436 & 4.8794 & 5.3261 & TST \\
\hline CHEMBL1589309 & 752436 & 5.5229 & 5.2808 & TST \\
\hline CHEMBL1372651 & 752436 & 4.9788 & 5.2451 & TST \\
\hline CHEMBL578905 & 752436 & 5.6556 & 5.282 & TST \\
\hline CHEMBL1549691 & 752436 & 5.6021 & 5.4881 & TST \\
\hline CHEMBL1337144 & 752436 & 2.4202 & 4.1783 & TST \\
\hline CHEMBL1610025 & 752436 & 6.2426 & 5.8406 & TST \\
\hline CHEMBL1526410 & 752436 & 5.9914 & 3.9061 & TST \\
\hline CHEMBL1536137 & 752436 & 4.342 & 5.1744 & TST \\
\hline CHEMBL1311185 & 752436 & 6.1662 & 5.4775 & TST \\
\hline CHEMBL1384604 & 752436 & 2.4202 & 5.61 & TST \\
\hline CHEMBL494083 & 752436 & 4.0535 & 5.4567 & TST \\
\hline CHEMBL1392532 & 752436 & 5.6108 & 4.9537 & TST \\
\hline CHEMBL1337235 & 752436 & 4.8928 & 5.12 & TST \\
\hline CHEMBL1575453 & 752436 & 5.4802 & 5.6227 & TST \\
\hline CHEMBL1525860 & 752436 & 4.9706 & 5.4185 & TST \\
\hline CHEMBL 3196684 & 752436 & 4.7235 & 5.3605 & TST \\
\hline CHEMBL1586425 & 752436 & 4.8447 & 5.0229 & TST \\
\hline CHEMBL1353816 & 752436 & 5.5406 & 5.4882 & TST \\
\hline CHEMBL1560379 & 752436 & 5.4711 & $5.74200 e$ & 0000000001 \\
\hline CHEMBL1313900 & 752436 & 5.6003 & 5.5837 & TST \\
\hline CHEMBL1325446 & 752436 & 5.2967 & 5.2652 & TST \\
\hline CHEMBL1462872 & 752436 & 4.9208 & 5.6987 & TST \\
\hline CHEMBL1351412 & 752436 & 5.8097 & 4.4131 & TST \\
\hline CHEMBL3144999 & 752436 & 6.4089 & 6.072 & TST \\
\hline CHEMBL1338846 & 752436 & 5.8861 & 4.9188 & TST \\
\hline CHEMBL533226 & 752436 & 4.7721 & 5.4785 & TST \\
\hline CHEMBL1389212 & 752436 & 5.2027 & 5.6386 & TST \\
\hline CHEMBL 3214331 & 752436 & 4.6091 & 4.6062 & TST \\
\hline CHEMBL1549641 & 752436 & 5.7144 & 5.8458 & TST \\
\hline CHEMBL1516834 & 752436 & 6.2104 & 5.204 & TST \\
\hline CHEMBL1405964 & 752436 & 7.0964 & 3.7919 & TST \\
\hline
\end{tabular}


Supplemental Table S2.txt

\begin{tabular}{|c|c|c|c|c|c|}
\hline CHEMBL1498136 & 752436 & 6.0195 & 4.0036 & TST & \\
\hline CHEMBL1488395 & 752436 & 4.4609 & 4.5013 & TST & \\
\hline CHEMBL1328462 & 752436 & 4.9469 & 4.5104 & TST & \\
\hline CHEMBL1572924 & 752436 & 5.767 & 5.8015 & TST & \\
\hline CHEMBL1308404 & 752436 & 6.0334 & 5.8662 & TST & \\
\hline CHEMBL1422689 & 752436 & 5.4353 & 5.5113 & TST & \\
\hline CHEMBL1969760 & 752436 & 4.8356 & 4.7127 & TST & \\
\hline CHEMBL1494363 & 752436 & 5.5768 & 5.6392 & TST & \\
\hline CHEMBL1433014 & 752436 & 4.6536 & 3.8524 & TST & \\
\hline CHEMBL1432278 & 752436 & 5.3089 & 5.3061 & TST & \\
\hline CHEMBL1496059 & 752436 & 5.4711 & 4.6518 & TST & \\
\hline CHEMBL1585332 & 752436 & 5.1739 & 5.737 & TST & \\
\hline CHEMBL1519280 & 752436 & 4.82100 & 00000000 & 31 & 4.8676 \\
\hline CHEMBL1309059 & 752436 & 4.8827 & 5.5199 & TST & \\
\hline CHEMBL1460342 & 752436 & 5.6517 & 5.8078 & TST & \\
\hline CHEMBL1562359 & 752436 & 5.0088 & 4.8116 & TST & \\
\hline CHEMBL1574609 & 752436 & 5.6326 & 4.1086 & TST & \\
\hline CHEMBL1982305 & 752436 & 6.5751 & 6.6061 & TST & \\
\hline CHEMBL1489430 & 752436 & 6.1221 & 4.6248 & TST & \\
\hline CHEMBL1570637 & 752436 & 5.1945 & 5.5845 & TST & \\
\hline CHEMBL1454239 & 752436 & 5.8447 & 5.6671 & TST & \\
\hline CHEMBL1534860 & 752436 & 5.4559 & 5.3768 & TST & \\
\hline CHEMBL3195749 & 752436 & 7.6819 & 4.8144 & TST & \\
\hline CHEMBL3186541 & 752436 & 5.433 & 6.0978 & TST & \\
\hline CHEMBL 3210642 & 752436 & 4.6737 & 5.5036 & TST & \\
\hline CHEMBL1334554 & 752436 & 2.4202 & 3.8856 & TST & \\
\hline CHEMBL1449387 & 752436 & 5.3706 & 4.5902 & TST & \\
\hline CHEMBL1382760 & 752436 & 5.5498 & 4.5639 & TST & \\
\hline CHEMBL1620590 & 752436 & 6.6556 & 6.0609 & TST & \\
\hline CHEMBL1535578 & 752436 & 3.9846 & 4.6099 & TST & \\
\hline CHEMBL1794088 & 752436 & 5.5482 & 5.0013 & TST & \\
\hline CHEMBL1389508 & 752436 & 5.0315 & 5.1228 & TST & \\
\hline CHEMBL1406350 & 752436 & 4.5986 & 5.386 & TST & \\
\hline CHEMBL1497005 & 752436 & 2.4202 & 3.9079 & TST & \\
\hline CHEMBL1342248 & 752436 & 4.5867 & 5.5913 & TST & \\
\hline CHEMBL1529781 & 752436 & 4.8125 & 5.4498 & TST & \\
\hline CHEMBL1583996 & 752436 & 5.1463 & 5.0247 & TST & \\
\hline CHEMBL3207693 & 752436 & 5.5638 & 5.4355 & TST & \\
\hline CHEMBL1359734 & 752436 & 2.4202 & 4.9038 & TST & \\
\hline CHEMBL1609405 & 752436 & 5.1273 & 4.8532 & TST & \\
\hline CHEMBL1525315 & 752436 & 4.6126 & 5.5576 & TST & \\
\hline CHEMBL1468954 & 752436 & 5.5243 & 5.7241 & TST & \\
\hline CHEMBL602776 & 752436 & 5.118 & 5.6007 & TST & \\
\hline CHEMBL1504283 & 752436 & 5.06 & 5.2736 & TST & \\
\hline CHEMBL1383632 & 752436 & 6.0223 & 6.0031 & TST & \\
\hline CHEMBL1555752 & 752436 & 4.7696 & 5.3508 & TST & \\
\hline CHEMBL1518077 & 752436 & 5.2807 & 5.0621 & TST & \\
\hline CHEMBL1307207 & 752436 & 6.8356 & 6.1494 & TST & \\
\hline
\end{tabular}


Supplemental Table S2.txt

\begin{tabular}{|c|c|c|c|c|c|}
\hline CHEMBL1430882 & 752436 & 5.7055 & 5.3602 & TST & \\
\hline CHEMBL1412143 & 752436 & 5.2182 & 5.2417 & TST & \\
\hline CHEMBL1510362 & 752436 & 5.3242 & 4.8179 & TST & \\
\hline CHEMBL1519108 & 752436 & 5.6421 & 5.5631 & TST & \\
\hline CHEMBL1495412 & 752436 & 5.0531 & 3.8382 & TST & \\
\hline CHEMBL1611041 & 752436 & 5.3716 & 5.732 & TST & \\
\hline CHEMBL1364384 & 752436 & 4.58 & 4.3708 & TST & \\
\hline CHEMBL1559031 & 752436 & 2.4202 & 3.9471 & TST & \\
\hline CHEMBL1979221 & 752436 & 5.3979 & 4.6463 & TST & \\
\hline CHEMBL1576520 & 752436 & 4.7328 & 3.8764 & TST & \\
\hline CHEMBL 3209454 & 752436 & 5.0899 & 4.8079 & TST & \\
\hline CHEMBL1333510 & 752436 & 5.2434 & 5.2851 & TST & \\
\hline CHEMBL1315948 & 752436 & 5.0278 & 5.4944 & TST & \\
\hline CHEMBL1376281 & 752436 & 4.6364 & 4.3509 & TST & \\
\hline CHEMBL1717678 & 752436 & 4.8633 & 5.2305 & TST & \\
\hline CHEMBL1431612 & 752436 & 4.8761 & 4.1515 & TST & \\
\hline CHEMBL 3145304 & 752436 & 4.757 & 5.1729 & TST & \\
\hline CHEMBL1344491 & 752436 & 2.4202 & 4.6061 & TST & \\
\hline CHEMBL 3193444 & 752436 & 5.5272 & 5.282999 & & TS \\
\hline CHEMBL1331211 & 752436 & 6.6126 & 6.1894 & TST & \\
\hline CHEMBL1568897 & 752436 & 6.5058 & 5.9517 & TST & \\
\hline CHEMBL1538652 & 752436 & 4.9281 & 4.565 & TST & \\
\hline CHEMBL1432251 & 752436 & 5.4763 & 5.5078 & TST & \\
\hline CHEMBL1545792 & 752436 & 4.7747 & 5.1844 & TST & \\
\hline CHEMBL1794195 & 752436 & 4.9957 & 5.1824 & TST & \\
\hline CHEMBL1576130 & 752436 & 5.0339 & 5.2905 & TST & \\
\hline CHEMBL1480243 & 752436 & 4.8069 & 4.5185 & TST & \\
\hline CHEMBL1364145 & 752436 & 5.4389 & 4.5788 & TST & \\
\hline CHEMBL1546205 & 752436 & 5.5302 & 5.6721 & TST & \\
\hline CHEMBL1607725 & 752436 & 5.3439 & 5.0062 & TST & \\
\hline CHEMBL1399145 & 752436 & 4.752 & 5.364 & TST & \\
\hline CHEMBL586031 & 752436 & \multicolumn{3}{|c|}{5.821000000000001} & TST \\
\hline CHEMBL1309737 & 752436 & 4.8962 & 5.2005 & TST & \\
\hline CHEMBL 3191991 & 752436 & 5.5045 & 5.0819 & TST & \\
\hline CHEMBL1453311 & 752436 & 5.4789 & 5.2467 & TST & \\
\hline CHEMBL3191961 & 752436 & 5.0311 & 4.3905 & TST & \\
\hline CHEMBL1327390 & 752436 & \multicolumn{3}{|c|}{4.821000000000001} & TST \\
\hline CHEMBL1409588 & 752436 & 4.3429 & 4.5334 & TST & \\
\hline CHEMBL 3145109 & 752436 & 6.0942 & 5.9049 & TST & \\
\hline CHEMBL1471779 & 752436 & 5.3893 & 5.1065 & TST & \\
\hline CHEMBL1718805 & 752436 & 6.8182 & 5.1879 & TST & \\
\hline CHEMBL1495539 & 752436 & 6.2175 & 4.0819 & TST & \\
\hline CHEMBL 3183391 & 752436 & 5.5114 & 6.1321 & TST & \\
\hline CHEMBL1607648 & 752436 & 4.9586 & 4.8808 & TST & \\
\hline CHEMBL1359240 & 752436 & 4.8894 & 4.6637 & TST & \\
\hline CHEMBL1586980 & 752436 & 5.0773 & 5.2389 & TST & \\
\hline CHEMBL 3145223 & 752436 & 5.9957 & 6.0654 & TST & \\
\hline CHEMBL1310221 & 752436 & 5.7375 & 5.1769 & TST & \\
\hline
\end{tabular}




\begin{tabular}{|c|c|c|c|c|c|c|}
\hline \multirow{2}{*}{\multicolumn{2}{|c|}{ CHEMBL 1455639}} & \\
\hline & & 4.4306 & 4.9568 & TST & & \\
\hline CHEMBL577764 & 752436 & 4.1765 & 4.9147 & TST & & \\
\hline CHEMBL3196407 & 752436 & 5.2848 & 5.3824 & TST & & \\
\hline CHEMBL3191836 & 752436 & 2.4202 & 3.9494 & TST & & \\
\hline CHEMBL1551808 & 752436 & 4.7878 & 5.3763 & TST & & \\
\hline CHEMBL1380020 & 752436 & 4.7447 & 3.8765 & TST & & \\
\hline CHEMBL1390923 & 752436 & 4.8761 & 5.6417 & TST & & \\
\hline CHEMBL1332131 & 752436 & 4.6778 & 4.1322 & TST & & \\
\hline CHEMBL1348057 & 752436 & 4.5638 & 4.2129 & TST & & \\
\hline CHEMBL3207440 & 752436 & 5.3019 & 5.5972 & TST & & \\
\hline CHEMBL1426692 & 752436 & 5.0391 & 4.7664 & TST & & \\
\hline CHEMBL1471498 & 752436 & 6.7959 & 5.6312 & TST & & \\
\hline CHEMBL1459167 & 752436 & 5.7375 & 5.5288 & TST & & \\
\hline CHEMBL1492668 & 752436 & 2.4202 & 5.3421 & TST & & \\
\hline CHEMBL1493256 & 752436 & 5.767 & 4.9251 & TST & & \\
\hline CHEMBL1581068 & 752436 & 5.6904 & 5.4425 & TST & & \\
\hline CHEMBL1453825 & 752436 & 2.4202 & 5.1393 & TST & & \\
\hline CHEMBL1734820 & 752436 & 6.8013 & 6.072 & TST & & \\
\hline CHEMBL1432973 & 752436 & 5.9066 & 4.8625 & TST & & \\
\hline CHEMBL1407056 & 752436 & 2.4202 & 4.1886 & TST & & \\
\hline CHEMBL1400164 & 752436 & 4.7447 & 4.5353 & TST & & \\
\hline CHEMBL1305642 & 752436 & 5.6968 & 5.63399 & 99999 & 995 & TST \\
\hline CHEMBL1503656 & 752436 & 6.61799 & 79999999 & 99 & 6.3208 & TST \\
\hline CHEMBL315362 & 752436 & 2.4202 & 3.9882 & TST & & \\
\hline CHEMBL1980681 & 752436 & 5.3354 & 4.0591 & TST & & \\
\hline CHEMBL1584380 & 752436 & 6.7122 & 6.0164 & TST & & \\
\hline CHEMBL233549 & 752436 & 2.4202 & 3.7336 & TST & & \\
\hline CHEMBL1338327 & 752436 & 4.9957 & 4.9113 & TST & & \\
\hline CHEMBL1369492 & 752436 & 4.4763 & 5.6433 & TST & & \\
\hline CHEMBL1964615 & 752436 & 5.8447 & 4.3683 & TST & & \\
\hline CHEMBL1335254 & 752436 & 2.4202 & 3.5602 & TST & & \\
\hline CHEMBL1528469 & 752436 & 5.75700 & 00000006 & $\partial 1$ & 5.4948 & TS \\
\hline CHEMBL1517886 & 752436 & 5.4283 & 4.6827 & TST & & \\
\hline CHEMBL1334552 & 752436 & 5.6799 & 4.9235 & TST & & \\
\hline CHEMBL1602314 & 752436 & 5.1249 & 5.4659 & TST & & \\
\hline CHEMBL1304384 & 752436 & 5.5302 & 5.1428 & TST & & \\
\hline CHEMBL1546947 & 752436 & 5.5918 & 5.6653 & TST & & \\
\hline CHEMBL1428977 & 752436 & 5.2924 & 3.8321 & TST & & \\
\hline CHEMBL1583807 & 752436 & 4.7645 & 3.8805 & TST & & \\
\hline CHEMBL1978279 & 752436 & 4.7305 & 4.098 & TST & & \\
\hline CHEMBL1384581 & 752436 & 5.7773 & 3.9243 & TST & & \\
\hline CHEMBL1374351 & 752436 & 5.6073 & 4.8043 & TST & & \\
\hline CHEMBL1350085 & 752436 & 6.2807 & 6.0643 & TST & & \\
\hline CHEMBL1998946 & 752436 & 4.9957 & 5.4771 & TST & & \\
\hline CHEMBL1533776 & 752436 & 5.4001 & 4.2619 & TST & & \\
\hline CHEMBL1463755 & 752436 & 4.8962 & 5.3758 & TST & & \\
\hline CHEMBL1389505 & 752436 & 4.9508 & 5.0674 & TST & & \\
\hline CHEMBL1548439 & 752436 & 5.1785 & 4.9675 & TST & & \\
\hline
\end{tabular}


Supplemental Table S2.txt

\begin{tabular}{|c|c|c|c|c|c|}
\hline CHEMBL3145187 & 752436 & 5.4271 & 6.7104 & TST & \\
\hline CHEMBL1341835 & 752436 & 4.9586 & 5.3483 & TST & \\
\hline CHEMBL1422056 & 752436 & 5.0205 & 5.5245 & TST & \\
\hline CHEMBL1319867 & 752436 & 5.9172 & 5.9576 & TST & \\
\hline CHEMBL1423410 & 752436 & 5.4647 & 4.893 & TST & \\
\hline CHEMBL1734451 & 752436 & 6.1925 & 5.2689 & TST & \\
\hline CHEMBL1529389 & 752436 & 5.3019 & 5.2167 & TST & \\
\hline CHEMBL 30764 & 162732 & 6.0026 & 6.5229 & TRN & \\
\hline CHEMBL283924 & 162732 & 7.6021 & 7.4079 & TRN & \\
\hline CHEMBL282639 & 162732 & 6.4001 & 6.8502 & TRN & \\
\hline CHEMBL286763 & 162732 & 7.5528 & 6.6161 & TRN & \\
\hline CHEMBL286847 & 162732 & 8.0458 & 7.4726 & TST & \\
\hline CHEMBL542330 & 162732 & 7.2676 & 7.3029 & TRN & \\
\hline CHEMBL 33200 & 162732 & 7.0969 & 7.0002 & TRN & \\
\hline CHEMBL281507 & 162732 & 7.2924 & 6.6781 & TRN & \\
\hline CHEMBL 30844 & 162732 & 6.2218 & 6.3679 & TRN & \\
\hline CHEMBL30369 & 162732 & 5.5513 & 6.4596 & TST & \\
\hline CHEMBL 30335 & 162732 & 7.4202 & 6.9472 & TRN & \\
\hline CHEMBL285857 & 162732 & 7.0506 & 6.8701 & TRN & \\
\hline CHEMBL33209 & 162732 & 7.3188 & 6.7269 & TRN & \\
\hline CHEMBL433621 & 162732 & 7.1192 & 6.8988 & TRN & \\
\hline CHEMBL30639 & 162732 & 6.7905 & 6.4791 & TRN & \\
\hline CHEMBL282099 & 162732 & 7.0655 & 6.75299 & 9999999999 & TRN \\
\hline CHEMBL282149 & 162732 & 8.0458 & 7.5675 & TRN & \\
\hline CHEMBL34569 & 162732 & 6.7799 & 7.0327 & TRN & \\
\hline CHEMBL31101 & 162732 & 6.0 & 6.4902 & TRN & \\
\hline CHEMBL31018 & 162732 & 6.0 & 6.7266 & TRN & \\
\hline CHEMBL 283460 & 162732 & 7.8861 & 7.1461 & TRN & \\
\hline CHEMBL281206 & 162732 & 6.0 & 7.5543 & TRN & \\
\hline CHEMBL432679 & 162732 & 6.9245 & 6.6198 & TRN & \\
\hline CHEMBL285559 & 162732 & 7.1249 & 6.6998 & TST & \\
\hline CHEMBL 33043 & 162732 & 5.9817 & 6.4243 & TRN & \\
\hline CHEMBL 34332 & 162732 & 7.7959 & 7.3901 & TRN & \\
\hline CHEMBL 30924 & 162732 & 6.9318 & 6.87700 & 2000000001 & TRN \\
\hline CHEMBL 30262 & 162732 & 7.4949 & 7.5286 & TRN & \\
\hline CHEMBL412108 & 162732 & 7.585 & 7.4923 & TRN & \\
\hline CHEMBL540261 & 162732 & 7.1192 & 7.098 & TRN & \\
\hline CHEMBL 283920 & 162732 & 7.0132 & 7.0368 & TRN & \\
\hline CHEMBL289008 & 162732 & 6.699 & 6.4593 & TRN & \\
\hline CHEMBL416944 & 162732 & 7.6198 & 7.3454 & TRN & \\
\hline CHEMBL283204 & 162732 & 6.0 & 6.78700 & 2000000001 & TRN \\
\hline CHEMBL 265740 & 162732 & 5.9654 & 6.3755 & TST & \\
\hline CHEMBL 282732 & 162732 & 6.5129 & 6.8419 & TRN & \\
\hline CHEMBL30875 & 162732 & 6.0 & 6.8214 & TRN & \\
\hline CHEMBL 30634 & 162732 & 6.3116 & 6.4265 & TRN & \\
\hline CHEMBL289018 & 162732 & 6.5003 & 6.4916 & TRN & \\
\hline CHEMBL264606 & 162732 & 7.6383 & 7.5296 & TRN & \\
\hline CHEMBL286510 & 162732 & 7.3098 & 7.2894 & TRN & \\
\hline
\end{tabular}




\begin{tabular}{|c|c|c|c|c|c|c|}
\hline \multirow[b]{2}{*}{ CHEMBL443781 } & & \multicolumn{5}{|c|}{ Supplemental Table S2.txt } \\
\hline & 162732 & 7.9208 & 7.5165 & TRN & & \\
\hline CHEMBL280832 & 162732 & 6.2457 & 6.5633 & TRN & & \\
\hline CHEMBL30926 & 162732 & 7.2441 & 6.8128 & TRN & & \\
\hline CHEMBL285657 & 162732 & 7.0223 & 6.6027 & TRN & & \\
\hline CHEMBL31093 & 162732 & 6.8477 & 6.7273 & TST & & \\
\hline CHEMBL30575 & 162732 & 6.7932 & 6.9796 & TRN & & \\
\hline CHEMBL34797 & 162732 & 7.2596 & 6.9866 & TRN & & \\
\hline CHEMBL281559 & 162732 & 6.0 & 7.1699 & TRN & & \\
\hline CHEMBL30756 & 162732 & 6.76200 & 000000000 & 005 & 6.5692 & TRN \\
\hline CHEMBL281671 & 162732 & 6.6326 & 6.5654 & TST & & \\
\hline CHEMBL286941 & 162732 & 7.8861 & 7.6016 & TST & & \\
\hline CHEMBL281490 & 162732 & 6.0 & 6.7885 & TST & & \\
\hline CHEMBL285739 & 162732 & 7.3565 & 6.8363 & TST & & \\
\hline CHEMBL29891 & 162732 & 7.2596 & 6.8017 & TST & & \\
\hline CHEMBL431692 & 162732 & 7.2676 & 6.8996 & TST & & \\
\hline CHEMBL30061 & 162732 & 8.0458 & 7.6209 & TST & & \\
\hline CHEMBL30696 & 162732 & 6.8996 & 6.7892 & TST & & \\
\hline CHEMBL283914 & 162732 & 7.7212 & 7.5215 & TST & & \\
\hline CHEMBL283276 & 162732 & 6.0 & 7.0069 & TST & & \\
\hline CHEMBL433623 & 162732 & 6.9281 & 7.0471 & TST & & \\
\hline CHEMBL1242367 & 954954 & 4.3711 & 4.1129 & TRN & & \\
\hline CHEMBL65 & 954954 & 8.9547 & 8.9348 & TRN & & \\
\hline CHEMBL 2363137 & 954954 & 5.1549 & 5.321000 & 0000000001 & & TRN \\
\hline CHEMBL 2144069 & 954954 & 5.4196 & 5.4192 & TRN & & \\
\hline CHEMBL1516890 & 954954 & 3.8138 & 3.6918 & TRN & & \\
\hline CHEMBL 259181 & 954954 & 4.3779 & 4.4167 & TRN & & \\
\hline CHEMBL392695 & 954954 & 2.8874 & 2.7926 & TRN & & \\
\hline CHEMBL585951 & 954954 & 6.3166 & 6.2717 & TRN & & \\
\hline CHEMBL213100 & 954954 & -0.9118 & -0.7024 & TRN & & \\
\hline CHEMBL191334 & 954954 & 4.629 & 4.8185 & TRN & & \\
\hline CHEMBL3199475 & 954954 & 4.1336 & 4.5343 & TRN & & \\
\hline CHEMBL3349342 & 954954 & 5.058 & 4.9207 & TRN & & \\
\hline CHEMBL3186408 & 954954 & 3.5768 & 3.9282 & TST & & \\
\hline CHEMBL514499 & 954954 & 4.2191 & 4.1587 & TRN & & \\
\hline CHEMBL240954 & 954954 & 4.6569 & 4.6134 & TST & & \\
\hline CHEMBL1590308 & 954954 & 3.3202 & 2.6134 & TST & & \\
\hline CHEMBL222102 & 954954 & 4.7932 & 4.8326 & TRN & & \\
\hline CHEMBL379300 & 954954 & 5.425 & 5.4653 & TRN & & \\
\hline CHEMBL9470 & 954954 & 5.7965 & 5.4821 & TST & & \\
\hline CHEMBL2005886 & 954954 & 4.7288 & 4.9022 & TRN & & \\
\hline CHEMBL573107 & 954954 & 5.4424 & 5.3461 & TRN & & \\
\hline CHEMBL 209148 & 954954 & 4.3223 & 4.3677 & TRN & & \\
\hline CHEMBL483847 & 954954 & 4.5899 & 4.6603 & TRN & & \\
\hline CHEMBL1673039 & 954954 & 3.8141 & 3.92 & TRN & & \\
\hline CHEMBL1909414 & 954954 & 4.9478 & 4.9687 & TRN & & \\
\hline CHEMBL300389 & 954954 & 5.0067 & 4.9549 & TRN & & \\
\hline CHEMBL220241 & 954954 & 4.6202 & 4.7933 & TRN & & \\
\hline CHEMBL558642 & 954954 & 4.7091 & 4.6075 & TRN & & \\
\hline
\end{tabular}




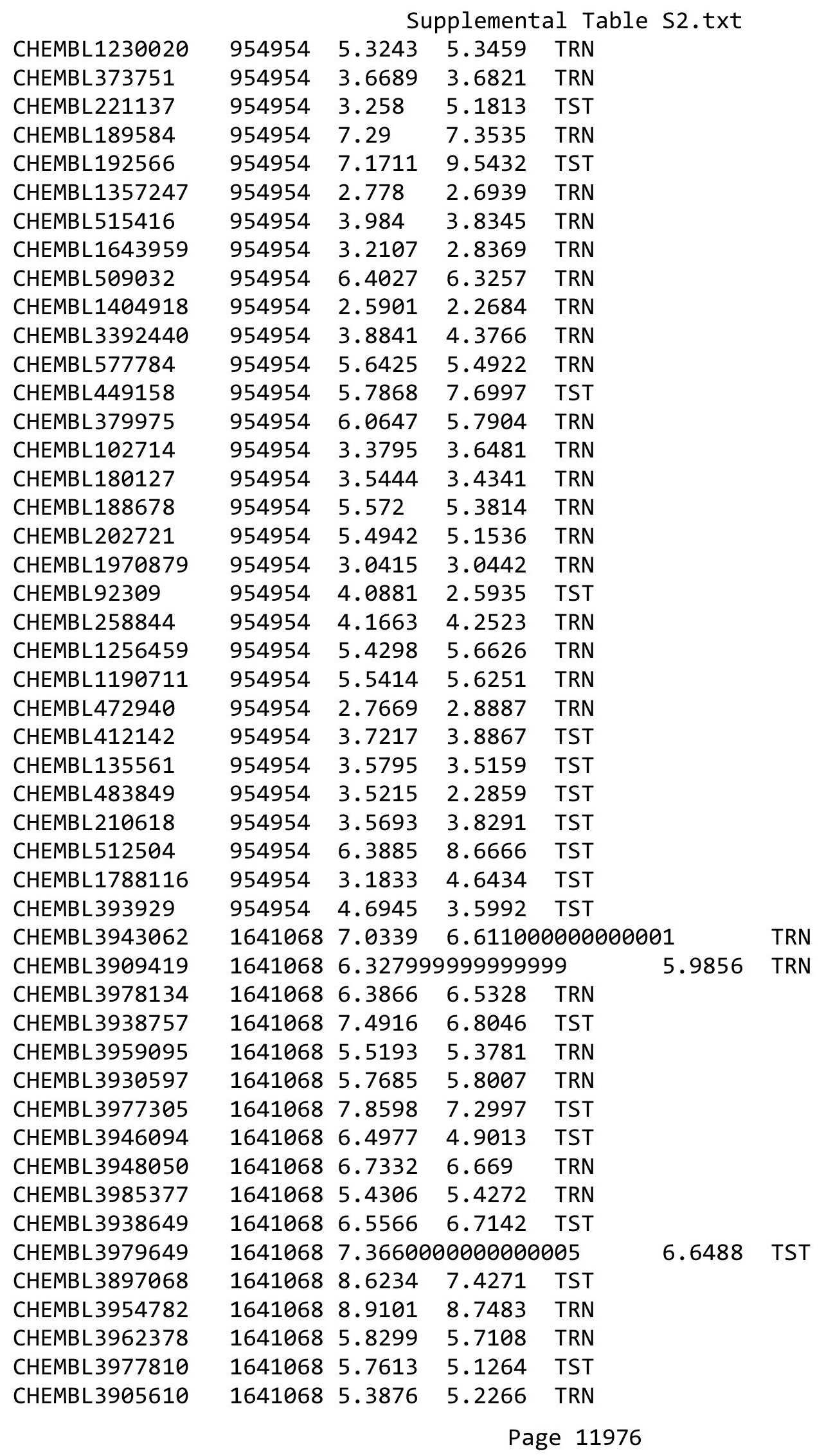


Supplemental Table S2.txt

\begin{tabular}{|c|c|c|c|c|c|}
\hline CHEMBL 3972343 & 1641068 & 6.1288 & 6.0734 & TRN & \\
\hline CHEMBL3956960 & 1641068 & 6.1311 & 6.3921 & TRN & \\
\hline CHEMBL3946612 & 1641068 & 6.4194 & 6.6255 & TRN & \\
\hline CHEMBL3938819 & 1641068 & 6.7438 & 6.8562 & TRN & \\
\hline CHEMBL3960447 & 1641068 & 6.4122 & 6.5564 & TRN & \\
\hline CHEMBL3939440 & 1641068 & 5.9979 & 6.1297 & TRN & \\
\hline CHEMBL3946475 & 1641068 & 5.2573 & 5.3781 & TRN & \\
\hline CHEMBL3915085 & 1641068 & 6.6757 & 5.8319 & TST & \\
\hline CHEMBL3933635 & 1641068 & 6.4666 & 6.4389 & TST & \\
\hline CHEMBL3895580 & 1641068 & 6.1757 & 6.1861 & TRN & \\
\hline CHEMBL3960787 & 1641068 & 5.6152 & 5.6541 & TRN & \\
\hline CHEMBL3933323 & 1641068 & 6.3067 & 6.1718 & TRN & \\
\hline CHEMBL3957201 & 1641068 & 6.2091 & 5.159 & TST & \\
\hline CHEMBL 3935620 & 1641068 & 7.2005 & 7.2796 & TRN & \\
\hline CHEMBL3974171 & 1641068 & 4.8724 & 5.1671 & TRN & \\
\hline CHEMBL3923805 & 1641068 & 4.77 & 4.9799 & TRN & \\
\hline CHEMBL3914777 & 1641068 & 4.974 & 5.1628 & TRN & \\
\hline CHEMBL3920595 & 1641068 & 6.3297 & 5.7768 & TST & \\
\hline CHEMBL3916653 & 1641068 & 5.4875 & 5.3435 & TRN & \\
\hline CHEMBL3930454 & 1641068 & 6.5692 & 6.9695 & TRN & \\
\hline CHEMBL3985625 & 1641068 & 6.4496 & 6.0054 & TRN & \\
\hline CHEMBL3909928 & 1641068 & 6.8599 & 7.2579 & TRN & \\
\hline CHEMBL3916122 & 1641068 & 7.8236 & 7.3652 & TRN & \\
\hline CHEMBL3971756 & 1641068 & 5.0044 & 4.241000 & 00000000005 & TST \\
\hline CHEMBL3938866 & 1641068 & 5.4418 & 5.4396 & TRN & \\
\hline CHEMBL3944959 & 1641068 & 6.82100 & 000000000 & 6.7998 & TRI \\
\hline CHEMBL3923565 & 1641068 & 6.2863 & 6.2493 & TRN & \\
\hline CHEMBL3980076 & 1641068 & 6.9245 & 6.8974 & TRN & \\
\hline CHEMBL3976519 & 1641068 & 5.9768 & 5.9246 & TRN & \\
\hline CHEMBL3911178 & 1641068 & 6.7102 & 7.1289 & TRN & \\
\hline CHEMBL 3927878 & 1641068 & 6.1372 & 6.1659 & TRN & \\
\hline CHEMBL3907607 & 1641068 & 6.7583 & 6.8609 & TRN & \\
\hline CHEMBL3971535 & 1641068 & 6.7802 & 7.0307 & TRN & \\
\hline CHEMBL3902466 & 1641068 & 7.5955 & 6.9695 & TRN & \\
\hline CHEMBL 3896667 & 1641068 & 5.5227 & 5.3657 & TRN & \\
\hline CHEMBL3976894 & 1641068 & 7.0866 & 6.8476 & TST & \\
\hline CHEMBL3914891 & 1641068 & 5.7026 & 6.1297 & TST & \\
\hline CHEMBL3944295 & 1642196 & 6.2013 & 6.2449 & TRN & \\
\hline CHEMBL3951944 & 1642196 & 5.3865 & 6.6874 & TST & \\
\hline CHEMBL3986276 & 1642196 & 5.8245 & 6.737999 & 99999999995 & וכנו \\
\hline CHEMBL3956145 & 1642196 & 6.0 & 6.7084 & TRN & \\
\hline CHEMBL3911376 & 1642196 & 5.9412 & 6.3967 & TRN & \\
\hline CHEMBL3946454 & 1642196 & 5.9059 & 7.0262 & TST & \\
\hline CHEMBL3897023 & 1642196 & 6.0 & 6.2978 & TRN & \\
\hline CHEMBL3944086 & 1642196 & 6.4949 & 6.2954 & TRN & \\
\hline CHEMBL3965462 & 1642196 & 6.9469 & 6.3773 & TRN & \\
\hline CHEMBL3917235 & 1642196 & 5.5569 & 5.7869 & TRN & \\
\hline CHEMBL3906874 & 1642196 & 5.8881 & 5.3821 & TRN & \\
\hline
\end{tabular}

Page 11977 
Supplemental Table S2.txt

\begin{tabular}{|c|c|c|c|c|c|c|}
\hline CHEMBL 3889879 & 1642196 & 6.3862 & 6.101 & TRN & & \\
\hline CHEMBL3942936 & 1642196 & 7.3098 & 7.1033 & TRN & & \\
\hline CHEMBL3905264 & 1642196 & 6.6576 & 6.8775 & TST & & \\
\hline CHEMBL3938540 & 1642196 & 7.2518 & 6.7084 & TRN & & \\
\hline CHEMBL3919567 & 1642196 & 6.0 & 6.5149 & TST & & \\
\hline CHEMBL3942034 & 1642196 & 6.0 & 6.2701 & TRN & & \\
\hline CHEMBL3960324 & 1642196 & 6.7106 & 6.7278 & TRN & & \\
\hline CHEMBL3933513 & 1642196 & 7.5376 & 7.6495 & TRN & & \\
\hline CHEMBL3965133 & 1642196 & \multicolumn{3}{|c|}{5.787000000000001} & 5.7042 & TRN \\
\hline CHEMBL3956119 & 1642196 & 6.3904 & 6.1034 & TRN & & \\
\hline CHEMBL3957783 & 1642196 & 6.4056 & 6.2911 & TRN & & \\
\hline CHEMBL 3975387 & 1642196 & 6.0367 & 5.8653 & TRN & & \\
\hline CHEMBL3948197 & 1642196 & 5.7525 & 5.5527 & TRN & & \\
\hline CHEMBL3912660 & 1642196 & 7.0088 & 6.5904 & TRN & & \\
\hline CHEMBL3981700 & 1642196 & 6.0301 & 5.7558 & TRN & & \\
\hline CHEMBL3953781 & 1642196 & 6.6615 & 6.8461 & TST & & \\
\hline CHEMBL3907056 & 1642196 & 7.7258 & 7.2914 & TRN & & \\
\hline CHEMBL3961507 & 1642196 & \multicolumn{3}{|c|}{6.327000000000001} & 6.1078 & TRN \\
\hline CHEMBL3899579 & 1642196 & \multicolumn{3}{|c|}{6.082999999999999} & 5.8049 & TST \\
\hline CHEMBL3945989 & 1642196 & 6.6925 & 6.4584 & TRN & & \\
\hline CHEMBL3968673 & 1642196 & 6.6383 & 6.4292 & TRN & & \\
\hline CHEMBL3959113 & 1642196 & 5.2218 & 5.4534 & TRN & & \\
\hline CHEMBL3958344 & 1642196 & 6.0004 & 6.522 & TRN & & \\
\hline CHEMBL3929652 & 1642196 & 5.9714 & 5.8757 & TRN & & \\
\hline CHEMBL3968910 & 1642196 & 5.5766 & 6.5764 & TST & & \\
\hline CHEMBL3891231 & 1642196 & 6.0 & 6.6508 & TRN & & \\
\hline CHEMBL3912007 & 1642196 & 6.0017 & 6.164 & TRN & & \\
\hline CHEMBL 3928444 & 1642196 & 4.7802 & 4.8901 & TRN & & \\
\hline CHEMBL3899134 & 1642196 & 5.4546 & 5.8018 & TRN & & \\
\hline CHEMBL3906589 & 1642196 & 6.8182 & 6.5748 & TRN & & \\
\hline CHEMBL3971303 & 1642196 & 7.1244 & 6.6489 & TRN & & \\
\hline CHEMBL3975498 & 1642196 & 7.1602 & 7.1346 & TRN & & \\
\hline CHEMBL3940055 & 1642196 & 5.7716 & 5.5428 & TRN & & \\
\hline CHEMBL3964264 & 1642196 & 6.0 & 6.9092 & TRN & & \\
\hline CHEMBL3971088 & 1642196 & 6.1726 & 6.2642 & TRN & & \\
\hline CHEMBL3926974 & 1642196 & 5.4046 & 5.5796 & TRN & & \\
\hline CHEMBL3898362 & 1642196 & 7.0458 & 6.3337 & TRN & & \\
\hline CHEMBL3921018 & 1642196 & 6.8069 & 6.9187 & TRN & & \\
\hline CHEMBL3930296 & 1642196 & 5.7265 & 5.8314 & TRN & & \\
\hline CHEMBL3906510 & 1642196 & 6.3904 & 5.8051 & TRN & & \\
\hline CHEMBL3986120 & 1642196 & 7.2076 & 7.282 & TRN & & \\
\hline CHEMBL3986903 & 1642196 & 5.8804 & 6.2382 & TRN & & \\
\hline CHEMBL3895713 & 1642196 & 6.9431 & 6.9187 & TRN & & \\
\hline CHEMBL3960069 & 1642196 & 6.0 & 5.8626 & TRN & & \\
\hline CHEMBL3916509 & 1642196 & 5.8392 & 5.772 & TRN & & \\
\hline CHEMBL3905036 & 1642196 & 7.7696 & 6.7841 & TRN & & \\
\hline CHEMBL3963183 & 1642196 & 6.0969 & 5.6673 & TRN & & \\
\hline CHEMBL3927601 & 1642196 & 7.0757 & 7.0351 & TRN & & \\
\hline
\end{tabular}




\begin{tabular}{|c|c|c|c|c|}
\hline \multicolumn{5}{|c|}{ Supplemental Table S2.txt } \\
\hline CHEMBL 3916878 & 1642196 & 6.0 & 6.6771 & TRN \\
\hline CHEMBL3979104 & 1642196 & 6.2716 & 6.3389 & TRN \\
\hline CHEMBL3913773 & 1642196 & 6.0835 & 6.3804 & TRN \\
\hline CHEMBL 3907018 & 1642196 & 6.0555 & 6.5541 & TST \\
\hline CHEMBL 3957211 & 1642196 & 6.0 & 5.7097 & TRN \\
\hline CHEMBL3932103 & 1642196 & 6.1662 & 6.3525 & TRN \\
\hline CHEMBL3931637 & 1642196 & 5.4568 & 6.4382 & TST \\
\hline CHEMBL3920211 & 1642196 & 7.2366 & 6.6402 & TRN \\
\hline CHEMBL3900989 & 1642196 & 7.3638 & 7.4749 & TRN \\
\hline CHEMBL3921366 & 1642196 & 6.2518 & 6.5251 & TRN \\
\hline CHEMBL3912856 & 1642196 & 6.0 & 6.0322 & TRN \\
\hline CHEMBL3964915 & 1642196 & 7.9136 & 7.1466 & TRN \\
\hline CHEMBL3969620 & 1642196 & 7.0605 & 6.6016 & TRN \\
\hline CHEMBL 3964524 & 1642196 & 7.4437 & 7.0732 & TRN \\
\hline CHEMBL3933394 & 1642196 & 6.6615 & 6.8187 & TRN \\
\hline CHEMBL3923239 & 1642196 & 6.8536 & 7.3279 & TRN \\
\hline CHEMBL3909664 & 1642196 & 5.0797 & 5.5917 & TRN \\
\hline CHEMBL3975461 & 1642196 & 4.0606 & 5.8752 & TRN \\
\hline CHEMBL3973699 & 1642196 & 6.5834 & 6.6522 & TRN \\
\hline CHEMBL3915237 & 1642196 & 6.0 & 6.8359 & TRN \\
\hline CHEMBL3940142 & 1642196 & 7.0915 & 6.0387 & TST \\
\hline CHEMBL3922691 & 1642196 & 6.0 & 6.6893 & TST \\
\hline CHEMBL3963516 & 1642196 & 6.0872 & 6.5525 & TST \\
\hline CHEMBL 3896335 & 1642196 & 6.8356 & 5.6122 & TST \\
\hline CHEMBL3903346 & 1642196 & 6.6289 & 5.8981 & TST \\
\hline CHEMBL3895908 & 1642196 & 6.1029 & 6.8172 & TST \\
\hline CHEMBL3914042 & 1642196 & 6.0 & 6.7084 & TST \\
\hline CHEMBL3914033 & 1642196 & 6.7747 & 5.135 & TST \\
\hline CHEMBL3922555 & 1642196 & 7.0706 & 7.1033 & TST \\
\hline CHEMBL3907542 & 1642196 & 6.4283 & 6.5963 & TST \\
\hline CHEMBL3957634 & 1642196 & 6.7258 & 7.4367 & TST \\
\hline CHEMBL 3900276 & 1642196 & 5.7326 & 7.2671 & TST \\
\hline CHEMBL3945138 & 1642196 & 5.9212 & 6.8855 & TST \\
\hline CHEMBL3920675 & 1642196 & 6.1911 & 6.5652 & TST \\
\hline CHEMBL221295 & 425512 & 10.0 & 8.9891 & TRN \\
\hline CHEMBL 374270 & 425512 & 7.699 & 7.7248 & TRN \\
\hline CHEMBL 221708 & 425512 & 7.3372 & 6.9859 & TRN \\
\hline CHEMBL385119 & 425512 & 8.4949 & 9.167 & TRN \\
\hline CHEMBL 375299 & 425512 & 10.0 & 9.3067 & TRN \\
\hline CHEMBL384217 & 425512 & 10.0 & 9.8745 & TRN \\
\hline CHEMBL376659 & 425512 & 8.699 & 8.1189 & TRN \\
\hline CHEMBL 375770 & 425512 & 8.8539 & 9.1999 & TRN \\
\hline CHEMBL 375842 & 425512 & 8.5086 & 9.2527 & TRN \\
\hline CHEMBL 221854 & 425512 & 10.0 & 9.6524 & TRN \\
\hline CHEMBL386955 & 425512 & 8.1871 & 7.6243 & TST \\
\hline CHEMBL 373631 & 425512 & 8.6021 & 8.375 & TST \\
\hline CHEMBL426535 & 425512 & 10.0 & 9.6971 & TRN \\
\hline CHEMBL 374941 & 425512 & 7.1675 & 7.2674 & TST \\
\hline
\end{tabular}




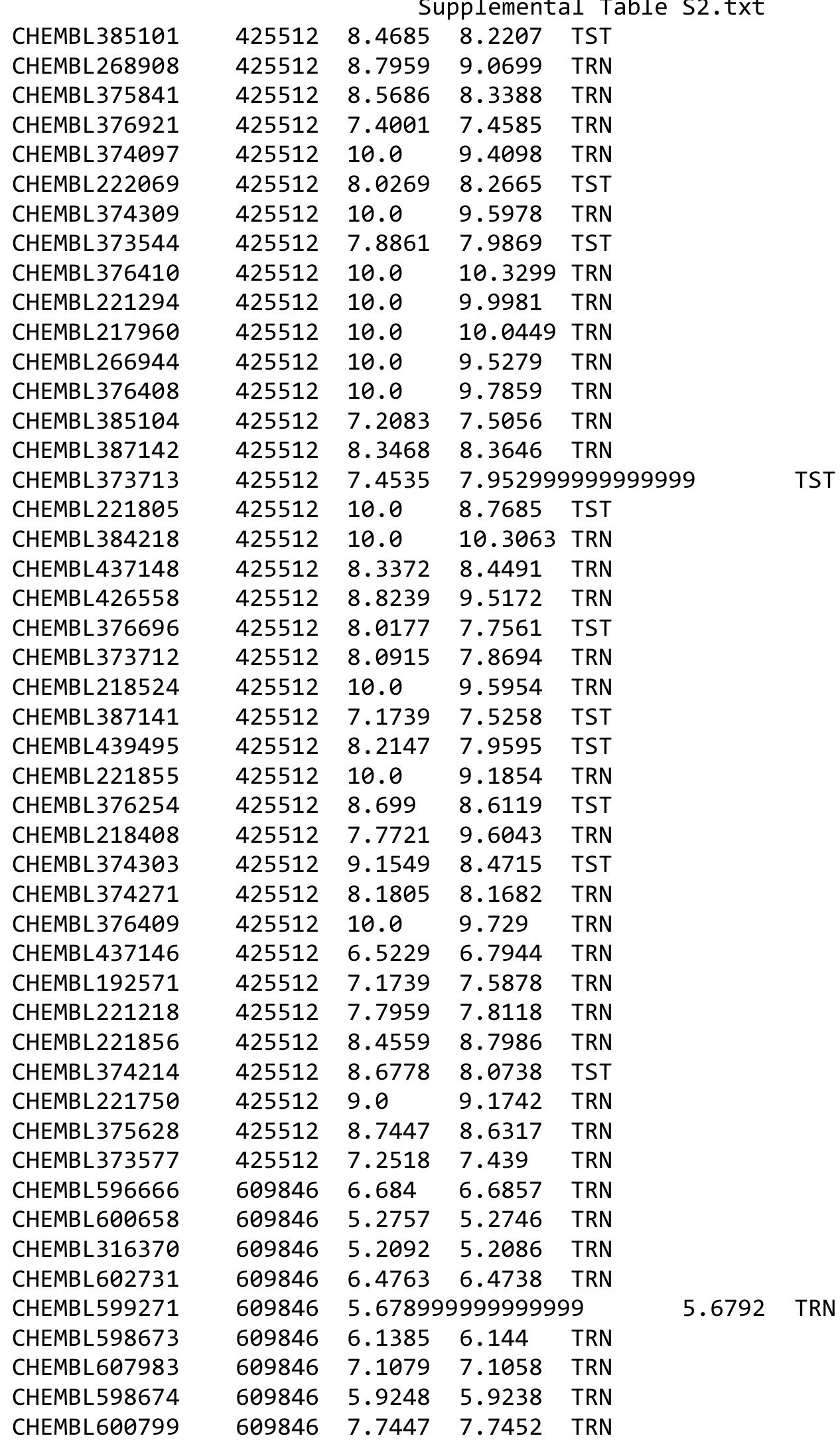

Page 11980 


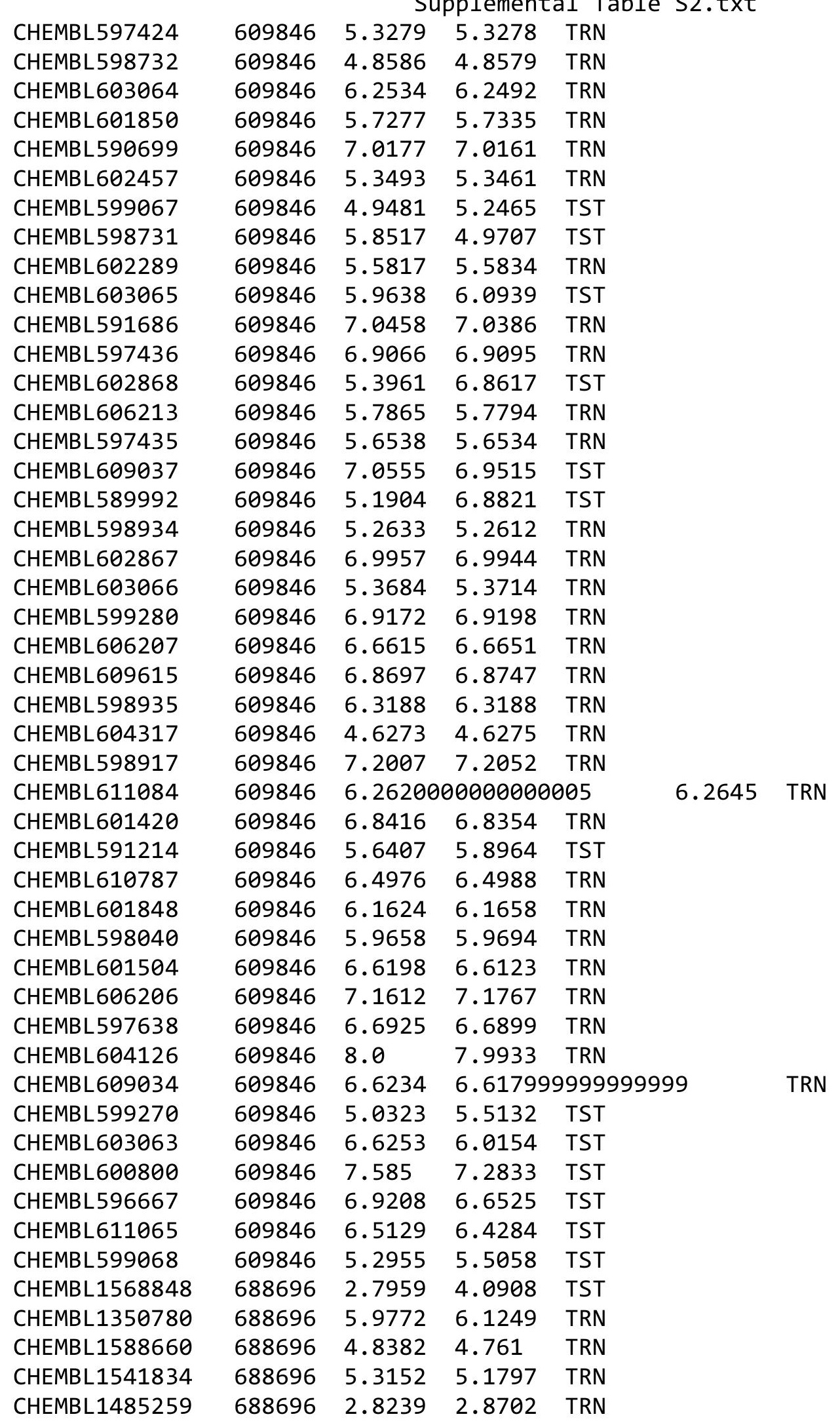

Page 11981 


\begin{tabular}{|c|c|c|c|c|c|}
\hline & & \multicolumn{4}{|c|}{ Supplemental Table s2.txt } \\
\hline CHEMBL1480836 & 688696 & 4.6423 & 4.926 & TRN & \\
\hline CHEMBL1595820 & 688696 & 4.8763 & 5.0586 & TRN & \\
\hline CHEMBL518252 & 688696 & 2.7959 & 2.6371 & TST & \\
\hline CHEMBL1365796 & 688696 & 2.8239 & 2.8056 & TRN & \\
\hline CHEMBL1543255 & 688696 & 2.7959 & 2.7031 & TRN & \\
\hline CHEMBL1332450 & 688696 & 5.6753 & 5.5574 & TRN & \\
\hline CHEMBL1505028 & 688696 & 2.8239 & 2.9953 & TRN & \\
\hline CHEMBL1300080 & 688696 & 2.8239 & 2.7344 & TRN & \\
\hline CHEMBL1596066 & 688696 & 2.8239 & 2.8327 & TRN & \\
\hline CHEMBL1416601 & 688696 & 2.8239 & 2.9736 & TRN & \\
\hline CHEMBL1606685 & 688696 & 5.8496 & 5.9299 & TRN & \\
\hline CHEMBL1585527 & 688696 & 4.8445 & 4.89199 & 99999999995 & TRN \\
\hline CHEMBL1304950 & 688696 & 2.8239 & 2.8484 & TRN & \\
\hline CHEMBL1401645 & 688696 & 2.8239 & 2.5481 & TST & \\
\hline CHEMBL1312049 & 688696 & 2.8239 & 3.1013 & TRN & \\
\hline CHEMBL1484777 & 688696 & 4.8372 & 4.8696 & TRN & \\
\hline CHEMBL1349480 & 688696 & 2.8239 & 2.8288 & TRN & \\
\hline CHEMBL1483964 & 688696 & 4.6028 & 4.4647 & TRN & \\
\hline CHEMBL1509727 & 688696 & 2.7959 & 2.7202 & TRN & \\
\hline CHEMBL1499233 & 688696 & 4.9771 & 5.1692 & TRN & \\
\hline CHEMBL1336535 & 688696 & 2.8239 & 2.8741 & TRN & \\
\hline CHEMBL1539624 & 688696 & 5.48 & 5.6138 & TRN & \\
\hline CHEMBL 3145031 & 688696 & 2.7959 & 4.6933 & TST & \\
\hline CHEMBL1595934 & 688696 & 2.8239 & 3.3257 & TRN & \\
\hline CHEMBL1380975 & 688696 & 4.4528 & 4.246 & TRN & \\
\hline CHEMBL455284 & 688696 & 5.305 & 5.2423 & TRN & \\
\hline CHEMBL1522211 & 688696 & 2.8239 & 2.6673 & TRN & \\
\hline CHEMBL334707 & 688696 & 4.6221 & 4.5374 & TRN & \\
\hline CHEMBL1517151 & 688696 & 2.8239 & 2.5643 & TRN & \\
\hline CHEMBL1370536 & 688696 & 2.7959 & 3.1917 & TST & \\
\hline CHEMBL1310713 & 688696 & 2.8239 & 2.7336 & TRN & \\
\hline CHEMBL1520556 & 688696 & 2.7959 & 2.8446 & TRN & \\
\hline CHEMBL1789993 & 688696 & 5.5979 & 3.8261 & TST & \\
\hline CHEMBL1431710 & 688696 & 2.8239 & 3.0736 & TRN & \\
\hline CHEMBL1323512 & 688696 & 2.7959 & 2.8722 & TRN & \\
\hline CHEMBL1555271 & 688696 & 4.7655 & 4.436 & TRN & \\
\hline CHEMBL 1437579 & 688696 & 2.7959 & 2.7604 & TRN & \\
\hline CHEMBL1527022 & 688696 & 2.8239 & 2.8157 & TRN & \\
\hline CHEMBL1319079 & 688696 & 2.7959 & 2.9517 & TRN & \\
\hline CHEMBL1428240 & 688696 & 2.8239 & 2.8998 & TRN & \\
\hline CHEMBL1545677 & 688696 & 2.7959 & 2.8542 & TRN & \\
\hline CHEMBL580955 & 688696 & 4.9565 & 4.232 & TRN & \\
\hline CHEMBL3190585 & 688696 & 2.7959 & 2.5997 & TRN & \\
\hline CHEMBL1611301 & 688696 & 2.7959 & 2.8156 & TRN & \\
\hline CHEMBL 3213034 & 688696 & 2.7959 & 2.6855 & TRN & \\
\hline CHEMBL1571370 & 688696 & 2.7959 & 3.1112 & TRN & \\
\hline CHEMBL1475477 & 688696 & 2.7959 & 2.7779 & TRN & \\
\hline CHEMBL1362096 & 688696 & 2.7959 & 2.6507 & TRN & \\
\hline
\end{tabular}

Page 11982 


\begin{tabular}{|c|c|c|c|c|c|c|}
\hline & & \multicolumn{5}{|c|}{ Supplemental Table S2.txt } \\
\hline CHEMBL1521297 & 688696 & 4.9694 & 5.1528 & TRN & & \\
\hline CHEMBL1491222 & 688696 & 5.5618 & 5.7097 & TRN & & \\
\hline CHEMBL1587806 & 688696 & 2.8239 & 2.8766 & TRN & & \\
\hline CHEMBL1422472 & 688696 & 2.7959 & \multicolumn{3}{|c|}{2.7310000000000003} & TRN \\
\hline CHEMBL1538246 & 688696 & 2.8239 & 2.5992 & TRN & & \\
\hline CHEMBL1401057 & 688696 & 2.8239 & 2.7856 & TRN & & \\
\hline CHEMBL1986418 & 688696 & 2.8239 & 2.7066 & TRN & & \\
\hline CHEMBL1602947 & 688696 & 2.8239 & 3.0798 & TRN & & \\
\hline CHEMBL1576118 & 688696 & 2.7959 & 2.6556 & TRN & & \\
\hline CHEMBL225963 & 688696 & 2.7959 & \multicolumn{3}{|c|}{3.5439999999999996} & TST \\
\hline CHEMBL1502020 & 688696 & 2.7959 & 2.7018 & TRN & & \\
\hline CHEMBL22062 & 688696 & 2.8239 & 2.9603 & TRN & & \\
\hline CHEMBL1328184 & 688696 & 4.658 & 4.564 & TRN & & \\
\hline CHEMBL1602855 & 688696 & 2.8239 & 2.7918 & TRN & & \\
\hline CHEMBL1393829 & 688696 & 4.8482 & 4.8546 & TRN & & \\
\hline CHEMBL1537190 & 688696 & 2.8239 & 2.97 & TRN & & \\
\hline CHEMBL1545702 & 688696 & 4.784 & 3.6624 & TST & & \\
\hline CHEMBL3193098 & 688696 & 4.6619 & 4.6938 & TRN & & \\
\hline CHEMBL1389318 & 688696 & 2.7959 & 2.8526 & TRN & & \\
\hline CHEMBL1330558 & 688696 & 4.909 & 4.7466 & TRN & & \\
\hline CHEMBL1467211 & 688696 & 2.8239 & 2.8023 & TRN & & \\
\hline CHEMBL1311007 & 688696 & 2.7959 & 3.0492 & TRN & & \\
\hline CHEMBL1318693 & 688696 & 2.7959 & 2.8321 & TRN & & \\
\hline CHEMBL1391911 & 688696 & 4.9407 & 4.7793 & TRN & & \\
\hline CHEMBL1476264 & 688696 & 5.0064 & 4.8269 & TRN & & \\
\hline CHEMBL1477033 & 688696 & 2.7959 & 2.6613 & TRN & & \\
\hline CHEMBL1481132 & 688696 & 2.8239 & 2.6284 & TRN & & \\
\hline CHEMBL 2000750 & 688696 & 2.7959 & 3.0215 & TRN & & \\
\hline CHEMBL1426340 & 688696 & 2.7959 & 3.3215 & TRN & & \\
\hline CHEMBL375781 & 688696 & 2.8239 & 3.5708 & TST & & \\
\hline CHEMBL1595088 & 688696 & 2.7959 & 2.7572 & TRN & & \\
\hline CHEMBL547285 & 688696 & 2.8239 & 3.3383 & TRN & & \\
\hline CHEMBL1348448 & 688696 & 2.7959 & 3.0122 & TRN & & \\
\hline CHEMBL1576945 & 688696 & 2.7959 & 2.6546 & TST & & \\
\hline CHEMBL1328373 & 688696 & 4.7164 & 4.5789 & TRN & & \\
\hline CHEMBL1488279 & 688696 & 2.7959 & 2.535 & TRN & & \\
\hline CHEMBL1393700 & 688696 & 2.8239 & 2.6835 & TRN & & \\
\hline CHEMBL1521991 & 688696 & 2.7959 & 2.7371 & TRN & & \\
\hline CHEMBL1433075 & 688696 & 2.7959 & 3.3318 & TST & & \\
\hline CHEMBL1347656 & 688696 & 2.7959 & 3.4302 & TST & & \\
\hline CHEMBL1322052 & 688696 & 2.8239 & 2.6942 & TRN & & \\
\hline CHEMBL1570820 & 688696 & 2.8239 & 2.7733 & TRN & & \\
\hline CHEMBL3192165 & 688696 & 4.91100 & 00000000 & 005 & 4.6897 & TRN \\
\hline CHEMBL1490555 & 688696 & 2.8239 & 3.6659 & TST & & \\
\hline CHEMBL1383721 & 688696 & 2.8239 & 2.7263 & TST & & \\
\hline CHEMBL1455523 & 688696 & 2.7959 & 2.6124 & TRN & & \\
\hline CHEMBL1470382 & 688696 & 2.7959 & 2.7831 & TRN & & \\
\hline CHEMBL1302439 & 688696 & 2.8239 & 2.7373 & TRN & & \\
\hline
\end{tabular}

Page 11983 


\begin{tabular}{|c|c|c|c|c|c|}
\hline \multirow[b]{2}{*}{ CHEMBL3195688 } & \multicolumn{5}{|c|}{ Supplemental Table S2.txt } \\
\hline & 688696 & 2.7959 & 3.032 & TRN & \\
\hline CHEMBL1346822 & 688696 & 2.8239 & 3.1238 & TRN & \\
\hline CHEMBL1329129 & 688696 & 4.9461 & 5.0234 & TRN & \\
\hline CHEMBL1485579 & 688696 & 2.7959 & 2.9431 & TRN & \\
\hline CHEMBL1548492 & 688696 & 2.7959 & 3.6308 & TRN & \\
\hline CHEMBL87285 & 688696 & 2.8239 & 2.8819 & TST & \\
\hline CHEMBL1519450 & 688696 & 2.8239 & 3.1192 & TRN & \\
\hline CHEMBL1304603 & 688696 & 2.8239 & 2.8139 & TRN & \\
\hline CHEMBL1369425 & 688696 & 2.8239 & 2.844 & TRN & \\
\hline CHEMBL1506580 & 688696 & 4.9288 & 4.8983 & TRN & \\
\hline CHEMBL1350245 & 688696 & 2.7959 & 2.7945 & TST & \\
\hline CHEMBL1222385 & 688696 & 2.7959 & 2.7188 & TRN & \\
\hline CHEMBL1587683 & 688696 & 2.8239 & 3.1105 & TRN & \\
\hline CHEMBL1574132 & 688696 & 5.0148 & 4.8203 & TRN & \\
\hline CHEMBL1359871 & 688696 & 5.1607 & 5.0494 & TRN & \\
\hline CHEMBL1469362 & 688696 & 2.8239 & 2.7326 & TRN & \\
\hline CHEMBL3392051 & 688696 & 2.8239 & 2.5963 & TST & \\
\hline CHEMBL1433124 & 688696 & 4.6758 & 4.7002 & TRN & \\
\hline CHEMBL588804 & 688696 & 5.4526 & 5.343 & TRN & \\
\hline CHEMBL1544423 & 688696 & 2.8239 & 2.8372 & TRN & \\
\hline CHEMBL1472105 & 688696 & 2.7959 & 2.9935 & TRN & \\
\hline CHEMBL3196754 & 688696 & 5.182 & 5.1674 & TRN & \\
\hline CHEMBL3197825 & 688696 & 2.7959 & 2.9363 & TRN & \\
\hline CHEMBL1979455 & 688696 & 2.8239 & 3.5748 & TRN & \\
\hline CHEMBL1524829 & 688696 & 2.8239 & 2.6921 & TRN & \\
\hline CHEMBL1466179 & 688696 & 2.8239 & 2.3826 & TST & \\
\hline CHEMBL1544114 & 688696 & 5.9014 & 5.86700 & 0000000001 & TRN \\
\hline CHEMBL3189966 & 688696 & 2.8239 & 2.7174 & TRN & \\
\hline CHEMBL1524956 & 688696 & 2.8239 & 2.5243 & TRN & \\
\hline CHEMBL1525081 & 688696 & 2.8239 & 2.8225 & TRN & \\
\hline CHEMBL1403955 & 688696 & 2.8239 & 2.8477 & TRN & \\
\hline CHEMBL1603001 & 688696 & 2.8239 & 2.6254 & TST & \\
\hline CHEMBL1609663 & 688696 & 2.7959 & 2.9397 & TRN & \\
\hline CHEMBL1979784 & 688696 & 2.7959 & 2.8393 & TRN & \\
\hline CHEMBL1392564 & 688696 & 2.8239 & 2.6376 & TRN & \\
\hline CHEMBL1242180 & 688696 & 5.1721 & 5.4153 & TRN & \\
\hline CHEMBL1446034 & 688696 & 2.8239 & 2.8878 & TRN & \\
\hline CHEMBL1988042 & 688696 & 5.8468 & 5.0938 & TRN & \\
\hline CHEMBL1327172 & 688696 & 4.7919 & 5.0938 & TRN & \\
\hline CHEMBL3195036 & 688696 & 2.8239 & 2.5543 & TRN & \\
\hline CHEMBL1412002 & 688696 & 4.7004 & 4.265 & TRN & \\
\hline CHEMBL1462215 & 688696 & 2.8239 & 2.8188 & TRN & \\
\hline CHEMBL3198729 & 688696 & 2.7959 & 2.7663 & TRN & \\
\hline CHEMBL1451169 & 688696 & 2.7959 & 2.6868 & TRN & \\
\hline CHEMBL1387710 & 688696 & 2.8239 & 2.8777 & TRN & \\
\hline CHEMBL1351542 & 688696 & 5.6114 & 5.7264 & TRN & \\
\hline CHEMBL1468024 & 688696 & 2.8239 & 2.8965 & TRN & \\
\hline CHEMBL1303401 & 688696 & 2.8239 & 2.8012 & TRN & \\
\hline
\end{tabular}

Page 11984 


\begin{tabular}{|c|c|c|c|c|c|}
\hline & & \multicolumn{4}{|c|}{ Supplemental Table S2.txt } \\
\hline CHEMBL1503033 & 688696 & 2.8239 & 2.6732 & TST & \\
\hline CHEMBL1484227 & 688696 & 2.7959 & 2.8044 & TRN & \\
\hline CHEMBL461579 & 688696 & 5.1176 & 5.3014 & TRN & \\
\hline CHEMBL580727 & 688696 & 4.7193 & 4.5396 & TRN & \\
\hline CHEMBL3193010 & 688696 & 2.7959 & 2.9401 & TRN & \\
\hline CHEMBL1330113 & 688696 & 2.7959 & 4.4706 & TST & \\
\hline CHEMBL3191808 & 688696 & 2.7959 & 2.7607 & TRN & \\
\hline CHEMBL1447219 & 688696 & 5.3618 & 5.1115 & TRN & \\
\hline CHEMBL595700 & 688696 & 2.8239 & 2.72600 & 00000000004 & TRN \\
\hline CHEMBL1330453 & 688696 & 2.7959 & 2.4463 & TRN & \\
\hline CHEMBL193872 & 688696 & 5.6238 & 5.5052 & TRN & \\
\hline CHEMBL1424665 & 688696 & 5.2101 & 5.1442 & TRN & \\
\hline CHEMBL1389335 & 688696 & 2.8239 & 2.8516 & TRN & \\
\hline CHEMBL1492378 & 688696 & 2.8239 & 3.0192 & TRN & \\
\hline CHEMBL3196726 & 688696 & 4.6388 & 3.867 & TRN & \\
\hline CHEMBL1405204 & 688696 & 5.5502 & 5.6286 & TRN & \\
\hline CHEMBL1349146 & 688696 & 2.7959 & 2.5637 & TRN & \\
\hline CHEMBL1995550 & 688696 & 2.8239 & 2.8713 & TRN & \\
\hline CHEMBL1533353 & 688696 & 2.7959 & 2.6844 & TRN & \\
\hline CHEMBL1524014 & 688696 & 2.8239 & 3.0529 & TST & \\
\hline CHEMBL1362036 & 688696 & 2.7959 & 2.8157 & TRN & \\
\hline CHEMBL1561050 & 688696 & 2.7959 & 2.863 & TRN & \\
\hline CHEMBL1439020 & 688696 & 2.8239 & 3.0555 & TRN & \\
\hline CHEMBL1556805 & 688696 & 5.8752 & 5.7951 & TRN & \\
\hline CHEMBL1547468 & 688696 & 2.8239 & 3.3052 & TST & \\
\hline CHEMBL193627 & 688696 & 5.6137 & 5.6625 & TRN & \\
\hline CHEMBL1365988 & 688696 & 2.8239 & 3.155 & TRN & \\
\hline CHEMBL1420556 & 688696 & 5.2754 & 5.0981 & TRN & \\
\hline CHEMBL1612118 & 688696 & 2.8239 & 1.3754 & TST & \\
\hline CHEMBL1534520 & 688696 & 2.7959 & 2.8702 & TRN & \\
\hline CHEMBL1373577 & 688696 & 2.8239 & 2.6384 & TRN & \\
\hline CHEMBL3197343 & 688696 & 4.7108 & 4.8155 & TRN & \\
\hline CHEMBL1579999 & 688696 & 2.7959 & 2.9465 & TRN & \\
\hline CHEMBL1588513 & 688696 & 5.3296 & 4.9593 & TRN & \\
\hline CHEMBL1383916 & 688696 & 2.8239 & 2.7368 & TRN & \\
\hline CHEMBL1478797 & 688696 & 2.8239 & 2.8218 & TRN & \\
\hline CHEMBL1299903 & 688696 & 2.8239 & 2.5237 & TRN & \\
\hline CHEMBL1331790 & 688696 & 2.8239 & 3.028 & TRN & \\
\hline CHEMBL602363 & 688696 & 2.8239 & 2.6741 & TRN & \\
\hline CHEMBL1487498 & 688696 & 2.8239 & 2.7432 & TRN & \\
\hline CHEMBL584442 & 688696 & 2.7959 & 3.2679 & TRN & \\
\hline CHEMBL548615 & 688696 & 4.9931 & 5.0956 & TRN & \\
\hline CHEMBL1609315 & 688696 & 2.8239 & 2.9441 & TRN & \\
\hline CHEMBL1789998 & 688696 & 5.776 & 5.0287 & TST & \\
\hline CHEMBL1374462 & 688696 & 2.8239 & 4.5454 & TST & \\
\hline CHEMBL1329507 & 688696 & 4.7026 & 4.7534 & TRN & \\
\hline CHEMBL3198912 & 688696 & 5.6686 & 5.4635 & TRN & \\
\hline CHEMBL1487639 & 688696 & 5.2045 & 5.3272 & TRN & \\
\hline
\end{tabular}




\begin{tabular}{|c|c|c|c|c|c|}
\hline & & \multicolumn{4}{|c|}{ Supplemental Table S2.txt } \\
\hline CHEMBL591412 & 688696 & 2.7959 & 3.2795 & TRN & \\
\hline CHEMBL1599674 & 688696 & 2.8239 & 2.8041 & TRN & \\
\hline CHEMBL601768 & 688696 & 4.7925 & 4.4063 & TRN & \\
\hline CHEMBL1405150 & 688696 & 4.7865 & 4.874 & TRN & \\
\hline CHEMBL1372734 & 688696 & 2.8239 & 2.9617 & TRN & \\
\hline CHEMBL1352025 & 688696 & 2.7959 & 3.4604 & TST & \\
\hline CHEMBL1609759 & 688696 & 2.7959 & 2.77600 & 00000000002 & TRN \\
\hline CHEMBL1997747 & 688696 & 2.7959 & 2.9573 & TRN & \\
\hline CHEMBL1306256 & 688696 & 2.8239 & 2.66399 & 99999999997 & TRN \\
\hline CHEMBL585591 & 688696 & 5.1842 & 5.0715 & TRN & \\
\hline CHEMBL1385760 & 688696 & 2.8239 & 3.0941 & TRN & \\
\hline CHEMBL1472418 & 688696 & 2.8239 & 2.8423 & TRN & \\
\hline CHEMBL453974 & 688696 & 2.7959 & 4.5239 & TST & \\
\hline CHEMBL1391737 & 688696 & 2.8239 & 2.81399 & 99999999996 & TRN \\
\hline CHEMBL1363249 & 688696 & 4.8059 & 4.61100 & 0000000001 & TRN \\
\hline CHEMBL1464485 & 688696 & 2.7959 & 2.7825 & TRN & \\
\hline CHEMBL1547347 & 688696 & 2.7959 & 3.0416 & TRN & \\
\hline CHEMBL1318350 & 688696 & 5.7582 & 5.9243 & TRN & \\
\hline CHEMBL1528425 & 688696 & 5.9314 & 5.92899 & 9999999999 & TRN \\
\hline CHEMBL1969300 & 688696 & 2.7959 & 2.761 & TRN & \\
\hline CHEMBL3199428 & 688696 & 4.7622 & 4.6989 & TRN & \\
\hline CHEMBL530499 & 688696 & 4.9214 & 4.9194 & TRN & \\
\hline CHEMBL1317642 & 688696 & 2.8239 & 2.7461 & TRN & \\
\hline CHEMBL1360505 & 688696 & 2.8239 & 2.7645 & TRN & \\
\hline CHEMBL585827 & 688696 & 2.8239 & 3.5945 & TRN & \\
\hline CHEMBL1546228 & 688696 & 5.4107 & 3.3156 & TST & \\
\hline CHEMBL586031 & 688696 & 2.7959 & 2.7744 & TRN & \\
\hline CHEMBL1438970 & 688696 & 2.7959 & 3.0796 & TRN & \\
\hline CHEMBL1520157 & 688696 & 2.8239 & 2.5774 & TRN & \\
\hline CHEMBL1460705 & 688696 & 4.649 & 4.7987 & TRN & \\
\hline CHEMBL1594071 & 688696 & 2.7959 & 2.5917 & TRN & \\
\hline CHEMBL1390303 & 688696 & 2.7959 & 2.9099 & TRN & \\
\hline CHEMBL1514530 & 688696 & 5.0034 & 5.1668 & TRN & \\
\hline CHEMBL1497549 & 688696 & 2.7959 & 2.8315 & TRN & \\
\hline CHEMBL1542594 & 688696 & 2.7959 & 4.4437 & TST & \\
\hline CHEMBL1582831 & 688696 & 5.5016 & 5.2932 & TRN & \\
\hline CHEMBL1468776 & 688696 & 2.8239 & 2.6872 & TRN & \\
\hline CHEMBL1309890 & 688696 & 2.7959 & 2.6147 & TRN & \\
\hline CHEMBL1308052 & 688696 & 4.8435 & 4.8702 & TRN & \\
\hline CHEMBL 2004978 & 688696 & 3.9672 & 3.7192 & TRN & \\
\hline CHEMBL1368410 & 688696 & 2.8239 & 3.4356 & TST & \\
\hline CHEMBL1451060 & 688696 & 2.7959 & 2.8217 & TRN & \\
\hline CHEMBL1318943 & 688696 & 2.8239 & 2.781 & TST & \\
\hline CHEMBL1320281 & 688696 & 2.7959 & 2.8715 & TRN & \\
\hline CHEMBL1406031 & 688696 & 2.7959 & 2.8395 & TRN & \\
\hline CHEMBL3190697 & 688696 & 2.8239 & 2.9908 & TRN & \\
\hline CHEMBL3198836 & 688696 & 2.7959 & 2.6716 & TRN & \\
\hline CHEMBL 2005246 & 688696 & 2.7959 & 3.0026 & TRN & \\
\hline
\end{tabular}




\begin{tabular}{|c|c|c|c|c|c|}
\hline \multicolumn{6}{|c|}{ Supplemental Table s2.txt } \\
\hline CHEMBL1534596 & 688696 & 2.7959 & 2.8634 & TRN & \\
\hline CHEMBL3212271 & 688696 & 2.8239 & 2.6097 & TRN & \\
\hline CHEMBL1462283 & 688696 & 2.7959 & 3.0295 & TRN & \\
\hline CHEMBL590927 & 688696 & 2.7959 & 2.6503 & TRN & \\
\hline CHEMBL1404792 & 688696 & 4.8601 & 4.8947 & TRN & \\
\hline CHEMBL1359343 & 688696 & 2.8239 & 2.7779 & TRN & \\
\hline CHEMBL1449883 & 688696 & 2.7959 & 3.0145 & TRN & \\
\hline CHEMBL1500188 & 688696 & 4.9364 & 4.957 & TRN & \\
\hline CHEMBL1311826 & 688696 & 5.5581 & 5.6978 & TRN & \\
\hline CHEMBL1500266 & 688696 & 4.2106 & 4.0836 & TRN & \\
\hline CHEMBL1349566 & 688696 & 2.8239 & 2.9293 & TRN & \\
\hline CHEMBL1301513 & 688696 & 2.8239 & 2.5132 & TRN & \\
\hline CHEMBL 3190648 & 688696 & 2.7959 & 2.6462 & TRN & \\
\hline CHEMBL1491815 & 688696 & 2.8239 & 2.8113 & TRN & \\
\hline CHEMBL1430893 & 688696 & 2.7959 & 2.6122 & TRN & \\
\hline CHEMBL1511029 & 688696 & 2.8239 & 2.6496 & TRN & \\
\hline CHEMBL1452090 & 688696 & 2.8239 & 2.5156 & TRN & \\
\hline CHEMBL3196241 & 688696 & 2.7959 & 3.2182 & TRN & \\
\hline CHEMBL1581627 & 688696 & 2.7959 & 2.806 & TRN & \\
\hline CHEMBL1383706 & 688696 & 2.7959 & 2.8251 & TRN & \\
\hline CHEMBL1334557 & 688696 & 4.8352 & 3.5024 & TST & \\
\hline CHEMBL1598785 & 688696 & 2.7959 & 2.8945 & TRN & \\
\hline CHEMBL1386774 & 688696 & 4.6992 & 4.617 & TRN & \\
\hline CHEMBL1392455 & 688696 & 2.8239 & 3.2985 & TST & \\
\hline CHEMBL1382191 & 688696 & 2.8239 & 4.5924 & TST & \\
\hline CHEMBL1376904 & 688696 & 2.8239 & 2.0806 & TST & \\
\hline CHEMBL1498830 & 688696 & 2.8239 & 2.9422 & TRN & \\
\hline CHEMBL1377705 & 688696 & 2.7959 & 2.7764 & TRN & \\
\hline CHEMBL1377316 & 688696 & 4.8894 & 4.013 & TRN & \\
\hline CHEMBL1448584 & 688696 & 2.7959 & 2.7874 & TRN & \\
\hline CHEMBL600315 & 688696 & 2.8239 & 3.1406 & TST & \\
\hline CHEMBL140425 & 688696 & 4.0059 & 4.3341 & TRN & \\
\hline CHEMBL600862 & 688696 & 5.0656 & 4.6201 & TRN & \\
\hline CHEMBL3195142 & 688696 & 2.7959 & 2.6025 & TRN & \\
\hline CHEMBL1307255 & 688696 & 2.7959 & 2.891 & TRN & \\
\hline CHEMBL1364071 & 688696 & 2.8239 & 2.4552 & TRN & \\
\hline CHEMBL3190873 & 688696 & 4.5422 & 4.5663 & TRN & \\
\hline CHEMBL1348582 & 688696 & 2.8239 & 3.306 & TRN & \\
\hline CHEMBL1550442 & 688696 & 2.7959 & 2.5725 & TRN & \\
\hline CHEMBL1990174 & 688696 & 5.001 & 4.9665 & TRN & \\
\hline CHEMBL1545105 & 688696 & 2.8239 & 2.83399 & 99999999996 & TRN \\
\hline CHEMBL1610563 & 688696 & 2.8239 & 2.8853 & TRN & \\
\hline CHEMBL1346226 & 688696 & 2.7959 & 2.8377 & TRN & \\
\hline CHEMBL1602088 & 688696 & 2.8239 & 2.8354 & TRN & \\
\hline CHEMBL1557142 & 688696 & 2.7959 & 3.1362 & TST & \\
\hline CHEMBL1455627 & 688696 & 2.8239 & 2.5665 & TST & \\
\hline CHEMBL1517325 & 688696 & 4.9178 & 4.7971 & TST & \\
\hline CHEMBL1352792 & 688696 & 2.7959 & 3.8965 & TST & \\
\hline
\end{tabular}


Supplemental Table S2.txt

\begin{tabular}{|c|c|c|c|c|}
\hline CHEMBL1994623 & 688696 & 2.7959 & 4.7607 & TST \\
\hline CHEMBL1468661 & 688696 & 2.7959 & 3.9185 & TST \\
\hline CHEMBL1353371 & 688696 & 2.7959 & 3.227 & TST \\
\hline CHEMBL1563323 & 688696 & 2.7959 & 4.5424 & TST \\
\hline CHEMBL3190230 & 688696 & 5.688 & 2.0225 & TST \\
\hline CHEMBL1317657 & 688696 & 4.9512 & 3.1658 & TST \\
\hline CHEMBL1970872 & 688696 & 2.8239 & 4.3095 & TST \\
\hline CHEMBL1341308 & 688696 & 2.8239 & 2.25699 & 99999999997 \\
\hline CHEMBL1534035 & 688696 & 2.8239 & 2.2384 & TST \\
\hline CHEMBL1424331 & 688696 & 2.7959 & 2.9775 & TST \\
\hline CHEMBL3198503 & 688696 & 2.7959 & 3.4711 & TST \\
\hline CHEMBL1490481 & 688696 & 2.8239 & 1.8658 & TST \\
\hline CHEMBL1414734 & 688696 & 2.8239 & 3.9019 & TST \\
\hline CHEMBL1519902 & 688696 & 5.6386 & 6.4174 & TST \\
\hline CHEMBL1550278 & 688696 & 2.7959 & 2.3028 & TST \\
\hline CHEMBL3199452 & 688696 & 2.8239 & 3.5696 & TST \\
\hline CHEMBL3197761 & 688696 & 2.7959 & 3.5847 & TST \\
\hline CHEMBL1306283 & 688696 & 5.4372 & 6.1766 & TST \\
\hline CHEMBL590665 & 688696 & 4.6907 & 5.6285 & TST \\
\hline CHEMBL3197024 & 688696 & 4.9098 & 4.4872 & TST \\
\hline CHEMBL1361307 & 688696 & 2.7959 & 2.7316 & TST \\
\hline CHEMBL1340519 & 688696 & 2.7959 & 3.0888 & TST \\
\hline CHEMBL1408965 & 688696 & 2.7959 & 2.8571 & TST \\
\hline CHEMBL3189845 & 688696 & 2.7959 & 3.6187 & TST \\
\hline CHEMBL1440514 & 688696 & 2.8239 & 4.0662 & TST \\
\hline CHEMBL1503006 & 688696 & 2.8239 & 3.7063 & TST \\
\hline CHEMBL1426693 & 688696 & 2.8239 & 4.1481 & TST \\
\hline CHEMBL1310176 & 688696 & 2.7959 & 3.6017 & TST \\
\hline CHEMBL1500742 & 688696 & 2.7959 & 1.775 & TST \\
\hline CHEMBL1342093 & 688696 & 2.7959 & 3.4541 & TST \\
\hline CHEMBL1369893 & 688696 & 2.8239 & 3.5941 & TST \\
\hline CHEMBL1483620 & 688696 & 2.7959 & 2.397 & TST \\
\hline CHEMBL1557243 & 688696 & 2.8239 & 3.83699 & 99999999997 \\
\hline CHEMBL1420628 & 688696 & 2.8239 & 4.034 & TST \\
\hline CHEMBL1585127 & 688696 & 2.8239 & 3.3344 & TST \\
\hline CHEMBL1578127 & 688696 & 2.7959 & 2.6009 & TST \\
\hline CHEMBL1478041 & 688696 & 2.8239 & 3.0102 & TST \\
\hline CHEMBL1469579 & 688696 & 4.8857 & 4.3628 & TST \\
\hline CHEMBL3211846 & 688696 & 2.7959 & 3.5146 & TST \\
\hline CHEMBL1371081 & 688696 & 2.8239 & 3.0754 & TST \\
\hline CHEMBL1319004 & 688696 & 2.8239 & 2.9744 & TST \\
\hline CHEMBL1581042 & 688696 & 2.7959 & 2.7357 & TST \\
\hline CHEMBL1392918 & 688696 & 2.8239 & 2.8011 & TST \\
\hline CHEMBL1504569 & 688696 & 5.0804 & 4.7519 & TST \\
\hline CHEMBL145684 & 212750 & 8.4949 & 8.3017 & TRN \\
\hline CHEMBL144021 & 212750 & 8.5528 & 8.7843 & TRN \\
\hline CHEMBL144780 & 212750 & 8.8861 & 8.2177 & TST \\
\hline CHEMBL343021 & 212750 & 8.5376 & 8.4749 & TRN \\
\hline
\end{tabular}




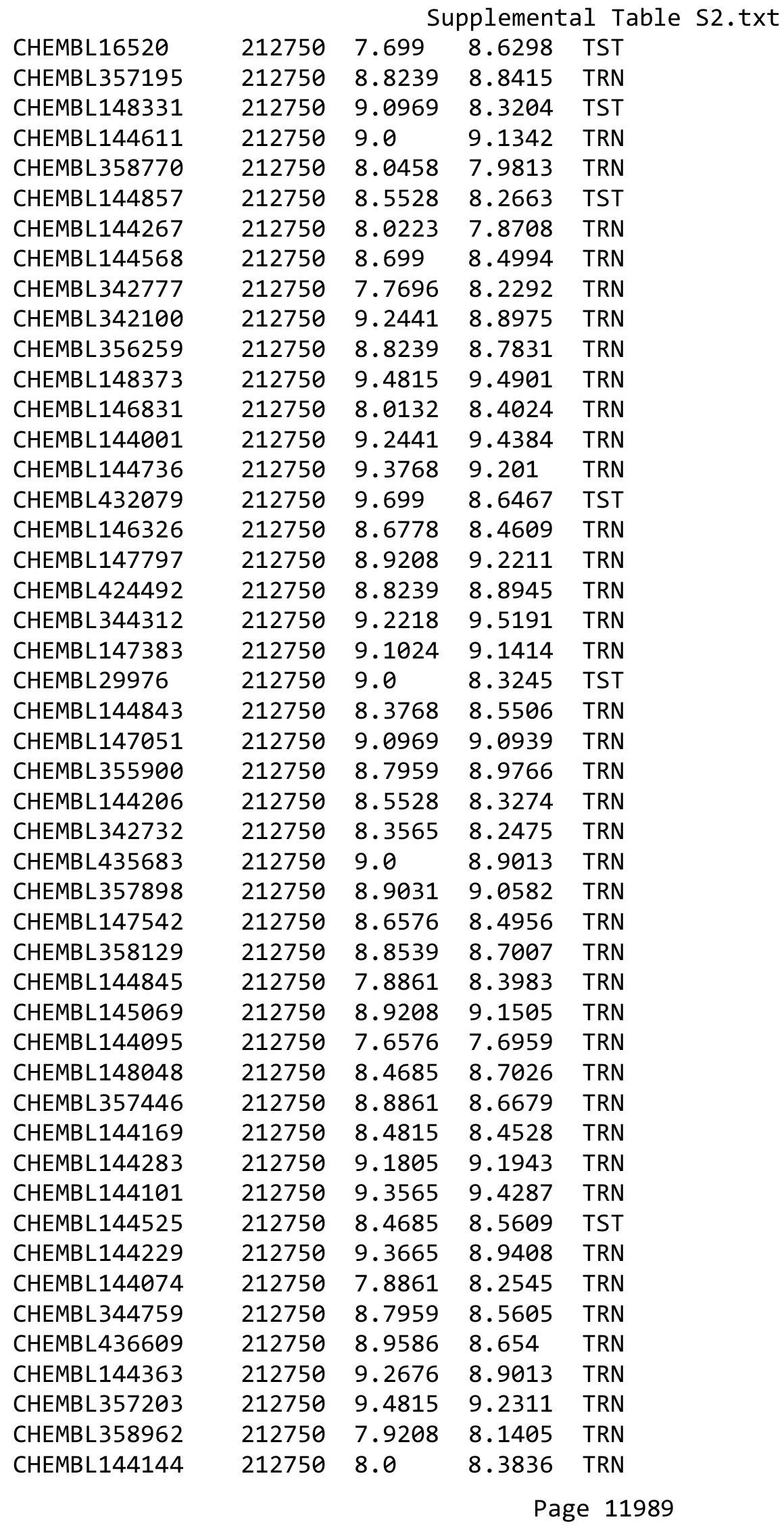




\begin{tabular}{|c|c|c|c|c|c|c|}
\hline & & \multicolumn{5}{|c|}{ Supplemental Table S2.txt } \\
\hline CHEMBL145836 & 212750 & 8.8239 & 8.9196 & TRN & & \\
\hline CHEMBL147956 & 212750 & 9.6778 & 8.7629 & TST & & \\
\hline CHEMBL439983 & 212750 & 9.6383 & 8.8712 & TRN & & \\
\hline CHEMBL144828 & 212750 & 8.0458 & 7.9945 & TRN & & \\
\hline CHEMBL114427 & 212750 & 8.7447 & 8.4878 & TST & & \\
\hline CHEMBL147091 & 212750 & 8.7959 & 8.7913 & TRN & & \\
\hline CHEMBL359217 & 212750 & 9.0 & 9.0353 & TRN & & \\
\hline CHEMBL144293 & 212750 & 8.5086 & 8.5882 & TST & & \\
\hline CHEMBL148395 & 212750 & 8.9586 & 8.9429 & TST & & \\
\hline CHEMBL147149 & 212750 & 8.8539 & 8.6446 & TST & & \\
\hline CHEMBL342069 & 212750 & 9.2007 & 8.492 & TST & & \\
\hline CHEMBL344060 & 212750 & 9.2147 & 8.4851 & TST & & \\
\hline CHEMBL144188 & 212750 & 9.3979 & 8.9623 & TST & & \\
\hline CHEMBL357414 & 212750 & 8.8861 & 8.5286 & TST & & \\
\hline CHEMBL144832 & 212750 & 7.0706 & 8.1856 & TST & & \\
\hline CHEMBL3354574 & 1451726 & 8.0 & 10.0747 & TST & & \\
\hline CHEMBL3354582 & 1451726 & 9.8539 & 10.29 & TRN & & \\
\hline CHEMBL3354592 & 1451726 & \multicolumn{3}{|c|}{10.699000000000002} & 10.1541 & TRN \\
\hline CHEMBL3353948 & 1451726 & 11.0 & 10.5316 & TRN & & \\
\hline CHEMBL3354583 & 1451726 & 9.6383 & 9.5886 & TRN & & \\
\hline CHEMBL3354576 & 1451726 & 9.7959 & 10.0099 & TRN & & \\
\hline CHEMBL3354578 & 1451726 & 9.0706 & 9.1911 & TRN & & \\
\hline CHEMBL3353932 & 1451726 & 11.0 & 10.9193 & TRN & & \\
\hline CHEMBL3354599 & 1451726 & 9.1079 & 9.3066 & TRN & & \\
\hline CHEMBL3353944 & 1451726 & 9.9586 & 10.1785 & TRN & & \\
\hline CHEMBL439044 & 1451726 & 10.0 & 10.5557 & TST & & \\
\hline CHEMBL3354595 & 1451726 & 10.3979 & 10.3631 & TRN & & \\
\hline CHEMBL3353950 & 1451726 & 8.8861 & 8.8031 & TRN & & \\
\hline CHEMBL3353949 & 1451726 & 10.2218 & 10.2992 & TRN & & \\
\hline CHEMBL3354596 & 1451726 & 9.6383 & 9.7641 & TRN & & \\
\hline CHEMBL3354577 & 1451726 & 9.0177 & 9.3554 & TRN & & \\
\hline CHEMBL3354586 & 1451726 & 9.6021 & 10.0406 & TRN & & \\
\hline CHEMBL3353947 & 1451726 & 9.8239 & 10.3154 & TRN & & \\
\hline CHEMBL3354601 & 1451726 & 9.8539 & 10.3907 & TRN & & \\
\hline CHEMBL3354591 & 1451726 & 10.0969 & 10.2089 & TRN & & \\
\hline CHEMBL3354602 & 1451726 & 9.5229 & 9.7464 & TRN & & \\
\hline CHEMBL3354575 & 1451726 & 9.9586 & 10.1052 & TRN & & \\
\hline CHEMBL3354584 & 1451726 & 10.0458 & 9.4668 & TRN & & \\
\hline CHEMBL3354570 & 1451726 & 9.9586 & 10.2482 & TRN & & \\
\hline CHEMBL3354589 & 1451726 & 10.3009 & 99999999 & 998 & 10.0333 & TRN \\
\hline CHEMBL3352839 & 1451726 & 9.0655 & 9.2877 & TRN & & \\
\hline CHEMBL3354580 & 1451726 & 9.8861 & 10.0883 & TRN & & \\
\hline CHEMBL3354571 & 1451726 & 10.69906 & 300000006 & 002 & 10.4365 & TRN \\
\hline CHEMBL3354598 & 1451726 & 10.3009 & 99999999 & 998 & 9.899 & TRN \\
\hline CHEMBL3353936 & 1451726 & 9.6778 & 9.7522 & TST & & \\
\hline CHEMBL3353937 & 1451726 & 9.4318 & 10.025 & TST & & \\
\hline CHEMBL3353939 & 1451726 & 11.0 & 10.8579 & 99999 & & TRN \\
\hline CHEMBL3353943 & 1451726 & 9.4089 & 10.2599 & TRN & & \\
\hline
\end{tabular}

Page 11990 


\begin{tabular}{|c|c|c|c|c|c|c|}
\hline \multicolumn{7}{|c|}{ Supplemental Table S2.txt } \\
\hline CHEMBL3353930 & 1451726 & 11.0 & 10.5239 & TRN & & \\
\hline CHEMBL3354597 & 1451726 & 10.3979 & 9.9943 & TRN & & \\
\hline CHEMBL3354581 & 1451726 & 9.9208 & 10.3574 & TRN & & \\
\hline CHEMBL 3354588 & 1451726 & 10.3979 & 10.0756 & TRN & & \\
\hline CHEMBL3353942 & 1451726 & 10.5229 & 10.1468 & TRN & & \\
\hline CHEMBL3354594 & 1451726 & 10.0969 & 10.4293 & TRN & & \\
\hline CHEMBL3353934 & 1451726 & 9.0862 & 9.9502 & TST & & \\
\hline CHEMBL3354579 & 1451726 & 11.0 & 10.1642 & TRN & & \\
\hline CHEMBL3354590 & 1451726 & 9.3979 & 9.4771 & TRN & & \\
\hline CHEMBL3353933 & 1451726 & 9.0088 & 9.8698 & TST & & \\
\hline CHEMBL3354587 & 1451726 & 10.1549 & 9.4203 & TRN & & \\
\hline CHEMBL3353956 & 1451726 & 11.0 & 10.5073 & TRN & & \\
\hline CHEMBL3354593 & 1451726 & 9.2518 & 9.48899 & 999999999 & & TRN \\
\hline CHEMBL3353938 & 1451726 & 9.8861 & 10.3275 & TRN & & \\
\hline CHEMBL3353931 & 1451726 & 10.2218 & 10.4316 & TRN & & \\
\hline CHEMBL3353940 & 1451726 & 11.0 & 10.3298 & TRN & & \\
\hline CHEMBL3354572 & 1451726 & 10.1549 & 10.3873 & TST & & \\
\hline CHEMBL3353952 & 1451726 & 9.3372 & 9.2157 & TRN & & \\
\hline CHEMBL 3354573 & 1451726 & 7.7212 & 10.2635 & TST & & \\
\hline CHEMBL3353951 & 1451726 & 8.8861 & 8.9049 & TRN & & \\
\hline CHEMBL3353945 & 1451726 & 9.9208 & 10.1136 & TRN & & \\
\hline CHEMBL3353953 & 1451726 & 9.9208 & 10.0762 & TRN & & \\
\hline CHEMBL3354600 & 1451726 & 10.0458 & 10.4094 & TST & & \\
\hline CHEMBL3353946 & 1451726 & 11.0 & 10.3168 & TST & & \\
\hline CHEMBL3353955 & 1451726 & 10.69900 & 00000000 & 002 & 9.2816 & TST \\
\hline CHEMBL3353935 & 1451726 & 10.2218 & 9.8195 & TST & & \\
\hline CHEMBL3354585 & 1451726 & 9.9586 & 10.2828 & TST & & \\
\hline CHEMBL3353929 & 1451726 & 10.30099 & 79999999ऽ & 998 & 10.8163 & TST \\
\hline CHEMBL3353954 & 1451726 & 9.9208 & 8.7964 & TST & & \\
\hline CHEMBL3353941 & 1451726 & 8.8861 & 10.7731 & TST & & \\
\hline CHEMBL3120173 & 1293611 & 7.041 & 7.0092 & TRN & & \\
\hline CHEMBL3120972 & 1293611 & 6.1367 & 6.1641 & TRN & & \\
\hline CHEMBL3120969 & 1293611 & 3.0 & 2.9927 & TRN & & \\
\hline CHEMBL3121007 & 1293611 & 4.9508 & 4.9212 & TRN & & \\
\hline CHEMBL3121000 & 1293611 & 5.7986 & 5.8122 & TRN & & \\
\hline CHEMBL3120966 & 1293611 & 5.8416 & 5.8271 & TRN & & \\
\hline CHEMBL3121006 & 1293611 & 5.2857 & 5.2712 & TRN & & \\
\hline CHEMBL3120998 & 1293611 & 5.8153 & 5.78 & TRN & & \\
\hline CHEMBL3120979 & 1293611 & 6.1308 & 6.095 & TRN & & \\
\hline CHEMBL3120987 & 1293611 & 6.5376 & 6.5436 & TRN & & \\
\hline CHEMBL3121005 & 1293611 & 5.9245 & 5.9088 & TRN & & \\
\hline CHEMBL3120990 & 1293611 & 5.4202 & 5.4171 & TRN & & \\
\hline CHEMBL3120967 & 1293611 & 4.9431 & 4.9692 & TRN & & \\
\hline CHEMBL3120974 & 1293611 & 6.3372 & 6.31 & TRN & & \\
\hline CHEMBL3120997 & 1293611 & 6.0044 & 6.0127 & TRN & & \\
\hline CHEMBL3120988 & 1293611 & 6.0506 & 6.0669 & TRN & & \\
\hline CHEMBL3120986 & 1293611 & 7.0177 & 7.0384 & TRN & & \\
\hline CHEMBL3120960 & 1293611 & 6.8539 & 6.8652 & TRN & & \\
\hline
\end{tabular}


Supplemental Table S2.txt

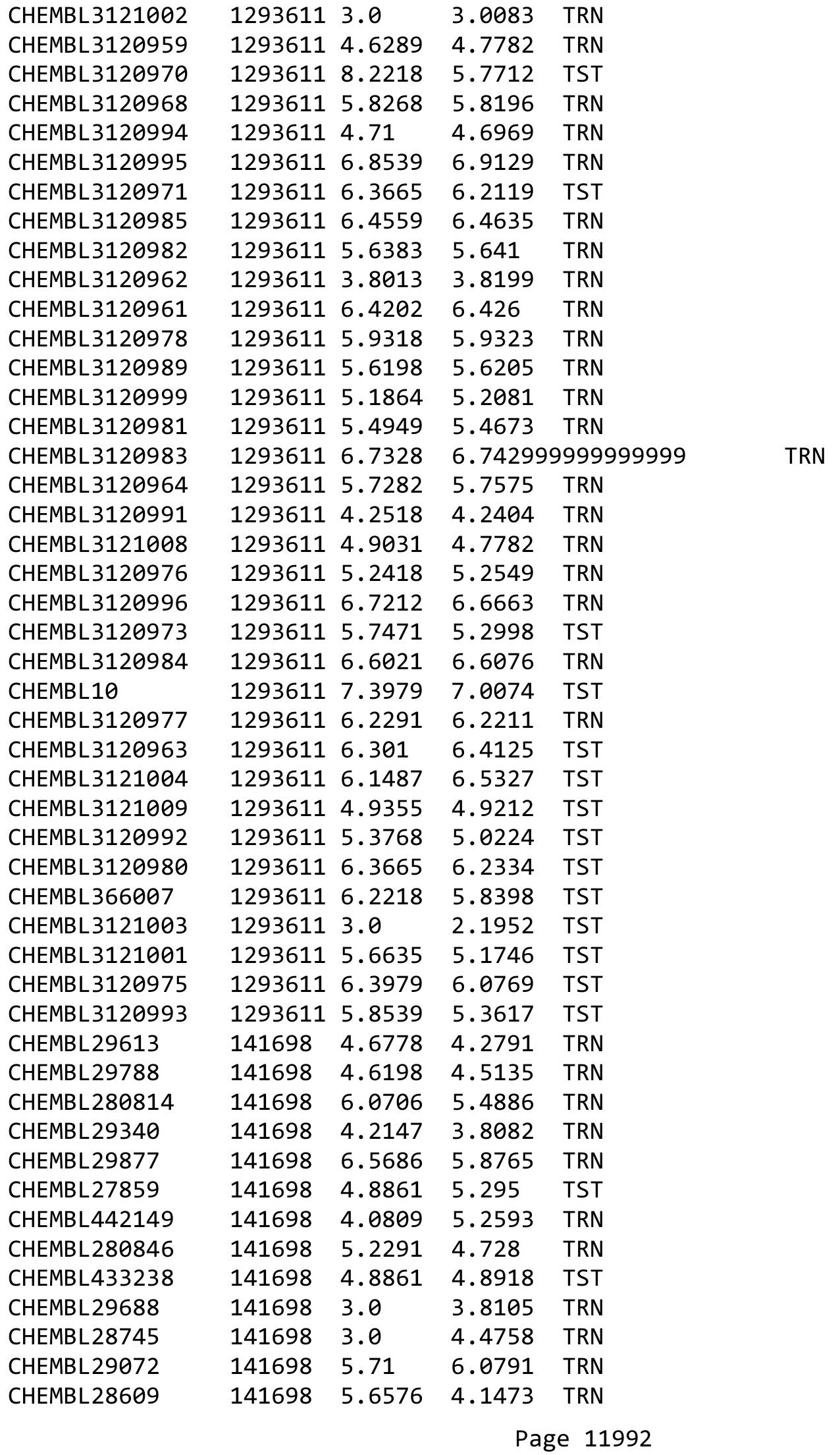




\begin{tabular}{|c|c|c|c|c|c|c|}
\hline \multirow[b]{2}{*}{ CHEMBL280850 } & \multicolumn{6}{|c|}{ Supplemental Table S2.txt } \\
\hline & 141698 & 5.3893 & 5.9735 & TRN & & \\
\hline CHEMBL418204 & 141698 & 5.5528 & 4.3209 & TRN & & \\
\hline CHEMBL282794 & 141698 & 5.0 & 4.6944 & TRN & & \\
\hline CHEMBL 280828 & 141698 & 5.0 & 4.4761 & TST & & \\
\hline CHEMBL 29698 & 141698 & 6.8539 & 5.4789 & TRN & & \\
\hline CHEMBL 280549 & 141698 & 3.0 & 3.85600 & 0000000000 & 03 & TRN \\
\hline CHEMBL29634 & 141698 & 5.0757 & 3.9728 & TRN & & \\
\hline CHEMBL284445 & 141698 & 7.1079 & 6.4437 & TRN & & \\
\hline CHEMBL 29244 & 141698 & 6.4949 & 6.0857 & TRN & & \\
\hline CHEMBL436148 & 141698 & 5.0088 & 5.9496 & TRN & & \\
\hline CHEMBL417847 & 141698 & 3.0 & 4.0758 & TRN & & \\
\hline CHEMBL 28838 & 141698 & 5.7959 & 6.3603 & TRN & & \\
\hline CHEMBL282983 & 141698 & 6.1024 & 6.0484 & TRN & & \\
\hline CHEMBL 284895 & 141698 & 5.0 & 4.6771 & TST & & \\
\hline CHEMBL 2114361 & 141698 & 5.2366 & 5.6512 & TRN & & \\
\hline CHEMBL 29687 & 141698 & 4.0 & 4.7553 & TRN & & \\
\hline CHEMBL 30021 & 141698 & 5.0315 & 4.1073 & TRN & & \\
\hline CHEMBL28931 & 141698 & 4.0 & 5.5505 & TRN & & \\
\hline CHEMBL 287624 & 141698 & 3.0 & 3.7178 & TRN & & \\
\hline CHEMBL22168 & 141698 & 6.0044 & 4.4136 & TRN & & \\
\hline CHEMBL 28582 & 141698 & 3.0 & 3.8212 & TRN & & \\
\hline CHEMBL 279533 & 141698 & 4.3188 & 5.2359 & TRN & & \\
\hline CHEMBL282119 & 141698 & 4.1308 & 4.1692 & TRN & & \\
\hline CHEMBL 28713 & 141698 & 5.5686 & 5.3867 & TRN & & \\
\hline CHEMBL28784 & 141698 & 3.0 & 4.7617 & TRN & & \\
\hline CHEMBL22304 & 141698 & 7.0862 & 5.8837 & TRN & & \\
\hline CHEMBL29811 & 141698 & 7.4559 & 5.1932 & TRN & & \\
\hline CHEMBL28900 & 141698 & 5.0362 & 5.7063 & TRN & & \\
\hline CHEMBL 28523 & 141698 & 7.0969 & 6.0493 & TST & & \\
\hline CHEMBL29081 & 141698 & 4.301 & 4.3471 & TST & & \\
\hline CHEMBL417846 & 141698 & 3.0 & 3.9291 & TST & & \\
\hline CHEMBL29432 & 141698 & 3.0 & 4.1513 & TST & & \\
\hline CHEMBL 280911 & 141698 & 4.3188 & 5.9427 & TST & & \\
\hline CHEMBL 30163 & 141698 & 6.3468 & 4.9508 & TST & & \\
\hline CHEMBL435945 & 141698 & 6.1805 & 4.6283 & TST & & \\
\hline CHEMBL28501 & 141698 & 6.0862 & 6.1213 & TST & & \\
\hline CHEMBL 282546 & 141698 & 3.0 & 4.3014 & TST & & \\
\hline CHEMBL145741 & 213236 & $6.1610 e$ & 30000000 & 205 & 6.1578 & TRN \\
\hline CHEMBL145795 & 213236 & 5.921 & 5.9443 & TRN & & \\
\hline CHEMBL357211 & 213236 & 6.921 & 6.6961 & TRN & & \\
\hline CHEMBL435423 & 213236 & 4.85 & 5.91200 & 0000000001 & & TST \\
\hline CHEMBL1161260 & 213236 & 4.796 & 5.314 & TRN & & \\
\hline CHEMBL1161256 & 213236 & 3.928 & 5.5061 & TST & & \\
\hline CHEMBL142241 & 213236 & $6.1370 e$ & 30000000 & 205 & 6.0172 & TST \\
\hline CHEMBL145517 & 213236 & 6.41 & 6.5219 & TRN & & \\
\hline CHEMBL1161253 & 213236 & 6.2 & 5.9023 & TRN & & \\
\hline CHEMBL358508 & 213236 & 4.538 & 5.0348 & TST & & \\
\hline CHEMBL358970 & 213236 & 6.85 & 6.7234 & TRN & & \\
\hline
\end{tabular}




\begin{tabular}{|c|c|c|c|c|c|c|}
\hline \multicolumn{7}{|c|}{ pplemental Ta } \\
\hline CHEMBL356580 & 213236 & 6.37 & 6.6127 & TRN & & \\
\hline CHEMBL358999 & 213236 & 4.538 & 5.1801 & TST & & \\
\hline CHEMBL 358110 & 213236 & 6.796 & 6.6524 & TRN & & \\
\hline CHEMBL356711 & 213236 & 5.82 & 5.9059 & TST & & \\
\hline CHEMBL144847 & 213236 & \multicolumn{3}{|c|}{3.8539999999999996} & 4.8828 & TST \\
\hline CHEMBL344552 & 213236 & 6.699 & 6.7197 & TRN & & \\
\hline CHEMBL145504 & 213236 & 6.48 & 6.4165 & TRN & & \\
\hline CHEMBL145250 & 213236 & 5.1 & 5.2736 & TRN & & \\
\hline CHEMBL1161263 & 213236 & \multicolumn{3}{|c|}{4.5089999999999995} & 5.8635 & TST \\
\hline CHEMBL323101 & 213236 & 6.721 & 6.732 & TRN & & \\
\hline CHEMBL145108 & 213236 & \multicolumn{3}{|c|}{6.6579999999999995} & 6.6818 & TRN \\
\hline CHEMBL358491 & 213236 & \multicolumn{3}{|c|}{5.6579999999999995} & 5.7303 & TRN \\
\hline CHEMBL1161245 & 213236 & 6.237 & 6.6503 & TRN & & \\
\hline CHEMBL358961 & 213236 & 6.07 & 6.1571 & TRN & & \\
\hline CHEMBL359422 & 213236 & 4.796 & 5.3797 & TST & & \\
\hline CHEMBL609410 & 213236 & 6.0 & 5.8633 & TRN & & \\
\hline CHEMBL145630 & 213236 & 6.26 & 6.4165 & TRN & & \\
\hline CHEMBL143067 & 213236 & 6.108 & 5.9894 & TRN & & \\
\hline CHEMBL 342542 & 213236 & 6.569 & 6.7855 & TRN & & \\
\hline CHEMBL356348 & 213236 & 6.495 & 6.2963 & TRN & & \\
\hline CHEMBL143594 & 213236 & 7.699 & 7.6011 & TRN & & \\
\hline CHEMBL435621 & 213236 & 7.131 & 7.2533 & TRN & & \\
\hline CHEMBL358366 & 213236 & 6.585 & 6.6894 & TRN & & \\
\hline CHEMBL357635 & 213236 & 6.569 & 6.681 & TRN & & \\
\hline CHEMBL 344104 & 213236 & 6.215 & 6.0019 & TRN & & \\
\hline CHEMBL358526 & 213236 & 5.398 & 5.4028 & TRN & & \\
\hline CHEMBL145211 & 213236 & 6.36 & 6.3018 & TRN & & \\
\hline CHEMBL 344790 & 213236 & 5.85 & 6.3576 & TST & & \\
\hline CHEMBL 356792 & 213236 & 7.569 & 7.7474 & TRN & & \\
\hline CHEMBL 344283 & 213236 & 5.96 & 6.0426 & TRN & & \\
\hline CHEMBL342764 & 213236 & 5.444 & 5.4572 & TRN & & \\
\hline CHEMBL143205 & 213236 & 6.796 & 6.6639 & TRN & & \\
\hline CHEMBL356071 & 213236 & 6.0 & 5.5459 & TRN & & \\
\hline CHEMBL145223 & 213236 & \multicolumn{3}{|c|}{6.337000000000001} & 6.2197 & TRN \\
\hline CHEMBL 342722 & 213236 & 6.585 & 6.2365 & TST & & \\
\hline CHEMBL423555 & 213236 & 5.721 & 5.7373 & TRN & & \\
\hline CHEMBL318352 & 213236 & 6.77 & 6.775 & TRN & & \\
\hline CHEMBL142924 & 213236 & 5.6 & 6.1284 & TST & & \\
\hline CHEMBL145132 & 213236 & 5.092 & 5.1593 & TRN & & \\
\hline CHEMBL145343 & 213236 & 4.495 & 5.1316 & TST & & \\
\hline CHEMBL142747 & 213236 & 5.921 & 6.0262 & TRN & & \\
\hline CHEMBL439810 & 213236 & 4.6 & 5.6184 & TST & & \\
\hline CHEMBL1161255 & 213236 & 5.62 & 5.6125 & TRN & & \\
\hline CHEMBL359184 & 213236 & 3.0 & 4.2172 & TST & & \\
\hline CHEMBL141782 & 213236 & 6.119 & 5.9926 & TST & & \\
\hline CHEMBL145148 & 213236 & 6.284 & 6.499 & TST & & \\
\hline CHEMBL343254 & 213236 & 6.1 & 6.1254 & TRN & & \\
\hline CHEMBL343892 & 213236 & 7.444 & 7.3195 & TRN & & \\
\hline
\end{tabular}




\begin{tabular}{|c|c|c|c|c|c|c|c|}
\hline \multicolumn{8}{|c|}{ Supplemental Tab. } \\
\hline CHEMBL145655 & 213236 & 6.004 & 6.0114 & TRN & & & \\
\hline CHEMBL358081 & 213236 & 6.2 & 6.3553 & TRN & & & \\
\hline CHEMBL1161247 & 213236 & 6.886 & 6.6735 & TRN & & & \\
\hline CHEMBL145173 & 213236 & 7.097 & 7.1854 & TRN & & & \\
\hline CHEMBL142312 & 213236 & \multicolumn{3}{|c|}{6.5089999999999995} & 6.489 & TRN & \\
\hline CHEMBL320512 & 213236 & 5.886 & 5.8055 & TRN & & & \\
\hline CHEMBL144993 & 213236 & 6.796 & 6.6733 & TRN & & & \\
\hline CHEMBL143501 & 213236 & 4.337 & 5.0584 & TST & & & \\
\hline CHEMBL1161248 & 213236 & 5.347 & 6.1031 & TST & & & \\
\hline CHEMBL358077 & 213236 & \multicolumn{3}{|c|}{7.1739999999999995} & \multicolumn{2}{|c|}{7.292999999999999} & TRN \\
\hline CHEMBL356295 & 213236 & 6.149 & 6.1472 & TRN & & & \\
\hline CHEMBL142417 & 213236 & 6.284 & 6.2656 & TRN & & & \\
\hline CHEMBL1161244 & 213236 & \multicolumn{3}{|c|}{6.6579999999999995} & 6.6657 & TRN & \\
\hline CHEMBL145206 & 213236 & 6.215 & 6.4165 & TRN & & & \\
\hline CHEMBL357210 & 213236 & 6.2 & 6.2518 & TST & & & \\
\hline CHEMBL356094 & 213236 & 5.745 & 5.6419 & TRN & & & \\
\hline CHEMBL143910 & 213236 & 4.585 & 5.2178 & TST & & & \\
\hline CHEMBL145664 & 213236 & 6.77 & 6.8026 & TRN & & & \\
\hline CHEMBL423195 & 213236 & 5.745 & 5.8806 & TRN & & & \\
\hline CHEMBL142447 & 213236 & 6.678 & 6.6822 & TRN & & & \\
\hline CHEMBL1161250 & 213236 & 6.36 & 6.1689 & TRN & & & \\
\hline CHEMBL341636 & 213236 & 7.638 & 7.285 & TRN & & & \\
\hline CHEMBL104815 & 213236 & 6.85 & 6.7908 & TRN & & & \\
\hline CHEMBL357660 & 213236 & \multicolumn{3}{|c|}{5.6579999999999995} & 5.6526 & TRN & \\
\hline CHEMBL429002 & 213236 & 5.678 & 5.5775 & TRN & & & \\
\hline CHEMBL348255 & 213236 & \multicolumn{3}{|c|}{6.0089999999999995} & 5.9478 & TRN & \\
\hline CHEMBL146492 & 213236 & 5.921 & 5.8435 & TRN & & & \\
\hline CHEMBL444601 & 213236 & 5.398 & 5.7234 & TST & & & \\
\hline CHEMBL358085 & 213236 & 5.921 & 6.1867 & TRN & & & \\
\hline CHEMBL314529 & 143983 & 7.5528 & 7.4653 & TRN & & & \\
\hline CHEMBL84632 & 143983 & 6.1612 & 6.1294 & TRN & & & \\
\hline CHEMBL312841 & 143983 & 7.2518 & 7.2841 & TRN & & & \\
\hline CHEMBL 313007 & 143983 & 7.4437 & 6.9635 & TST & & & \\
\hline CHEMBL557948 & 143983 & 8.1079 & 8.1924 & TRN & & & \\
\hline CHEMBL431990 & 143983 & 7.1805 & 7.2088 & TRN & & & \\
\hline CHEMBL87548 & 143983 & 7.0 & 7.0739 & TRN & & & \\
\hline CHEMBL90562 & 143983 & 4.0 & 3.9354 & TRN & & & \\
\hline CHEMBL86898 & 143983 & 8.1079 & 8.0903 & TRN & & & \\
\hline CHEMBL262904 & 143983 & 8.1367 & 8.1826 & TRN & & & \\
\hline CHEMBL87139 & 143983 & 4.0 & 3.9881 & TRN & & & \\
\hline CHEMBL313612 & 143983 & 6.2147 & 6.1712 & TRN & & & \\
\hline CHEMBL420426 & 143983 & 5.2596 & 5.2792 & TRN & & & \\
\hline CHEMBL314531 & 143983 & 4.0 & 4.02800 & 00000 & 205 & TRN & \\
\hline CHEMBL330095 & 143983 & 7.8239 & 7.8535 & TRN & & & \\
\hline CHEMBL315378 & 143983 & 6.1079 & 6.1221 & TRN & & & \\
\hline CHEMBL329425 & 143983 & 6.3279 & 6.6179 & TST & & & \\
\hline CHEMBL329366 & 143983 & 7.8861 & 7.8797 & TRN & & & \\
\hline CHEMBL314656 & 143983 & 8.1079 & 7.9532 & TRN & & & \\
\hline
\end{tabular}




\begin{tabular}{|c|c|c|c|c|}
\hline \multicolumn{5}{|c|}{ Supplemental Table s2.txt } \\
\hline CHEMBL314123 & 143983 & 7.7696 & 7.6334 & TST \\
\hline CHEMBL431403 & 143983 & 4.0 & 8.185 & TST \\
\hline CHEMBL431994 & 143983 & 6.1612 & 6.2092 & TRN \\
\hline CHEMBL327410 & 143983 & 6.041 & 6.0365 & TRN \\
\hline CHEMBL314169 & 143983 & 5.6778 & 5.7476 & TRN \\
\hline CHEMBL89297 & 143983 & 4.0 & 3.977 & TRN \\
\hline CHEMBL87896 & 143983 & 7.1487 & 7.1855 & TRN \\
\hline CHEMBL330522 & 143983 & 4.0 & 4.1991 & TRN \\
\hline CHEMBL314637 & 143983 & 6.3468 & 6.2774 & TRN \\
\hline CHEMBL86952 & 143983 & 7.6021 & 7.6219 & TRN \\
\hline CHEMBL432188 & 143983 & 7.0862 & 7.0157 & TRN \\
\hline CHEMBL90560 & 143983 & 6.8239 & 6.811 & TRN \\
\hline CHEMBL88576 & 143983 & 6.8539 & 6.8487 & TRN \\
\hline CHEMBL438777 & 143983 & 7.0655 & 7.0553 & TRN \\
\hline CHEMBL432766 & 143983 & 7.7447 & 7.8167 & TRN \\
\hline CHEMBL330574 & 143983 & 7.0969 & 7.1546 & TRN \\
\hline CHEMBL 88450 & 143983 & 6.7959 & 6.8252 & TRN \\
\hline CHEMBL88871 & 143983 & 6.8539 & 6.8539 & TRN \\
\hline CHEMBL312997 & 143983 & 4.0 & 3.9831 & TRN \\
\hline CHEMBL433216 & 143983 & 7.0 & 7.0115 & TRN \\
\hline CHEMBL88347 & 143983 & 4.0 & 6.0571 & TST \\
\hline CHEMBL329997 & 143983 & 7.7447 & 7.7758 & TRN \\
\hline CHEMBL 86775 & 143983 & 7.0809 & 7.1367 & TRN \\
\hline CHEMBL314520 & 143983 & 5.3872 & 5.31 & TRN \\
\hline CHEMBL 313292 & 143983 & 6.6198 & 6.5667 & TRN \\
\hline CHEMBL 84793 & 143983 & 7.6198 & 7.6122 & TRN \\
\hline CHEMBL 88805 & 143983 & 6.699 & 6.7438 & TRN \\
\hline CHEMBL316366 & 143983 & 8.1192 & 7.9281 & TRN \\
\hline CHEMBL315659 & 143983 & 4.0 & 3.8925 & TRN \\
\hline CHEMBL 87667 & 143983 & 5.9208 & 5.975 & TRN \\
\hline CHEMBL315299 & 143983 & 7.585 & 7.6068 & TRN \\
\hline CHEMBL 86433 & 143983 & 7.7696 & 7.7591 & TRN \\
\hline CHEMBL314961 & 143983 & 7.2518 & 7.2211 & TRN \\
\hline CHEMBL314425 & 143983 & 5.8539 & 5.4338 & TST \\
\hline CHEMBL 85297 & 143983 & 7.1871 & 6.3521 & TST \\
\hline CHEMBL328000 & 143983 & 5.1367 & 5.7504 & TST \\
\hline CHEMBL 88742 & 143983 & 7.3665 & 6.5746 & TST \\
\hline CHEMBL314662 & 143983 & 5.4202 & 6.6266 & TST \\
\hline CHEMBL90497 & 143983 & 7.5376 & 7.2875 & TST \\
\hline CHEMBL328288 & 143983 & 8.5376 & 6.801 & TST \\
\hline CHEMBL89078 & 143983 & 8.2924 & 7.0579 & TST \\
\hline CHEMBL 89460 & 143983 & 5.1549 & 6.7878 & TST \\
\hline CHEMBL 88141 & 143983 & 7.1249 & 5.4111 & TST \\
\hline CHEMBL314926 & 143983 & 7.0555 & 7.3157 & TST \\
\hline CHEMBL3973016 & 1641471 & 6.0 & 5.8524 & TRN \\
\hline CHEMBL3936934 & 1641471 & 6.0 & 6.7995 & TST \\
\hline CHEMBL3973165 & 1641471 & 7.0506 & 6.6985 & TST \\
\hline CHEMBL3986098 & 1641471 & 6.9208 & 6.8253 & TRN \\
\hline
\end{tabular}


Supplemental Table S2.txt

\begin{tabular}{|c|c|c|c|c|}
\hline HEMBL 39 & & 458 & & \\
\hline HFMRI 3899725 & 641471 & 6.3947 & 65208 & \\
\hline HEMBL3910327 & & 5.95 & 772 & \\
\hline HEMBL3968389 & 641471 & 469 & 6997 & \\
\hline HEMBL3914984 & 641471 & 7.9586 & 0142 & \\
\hline HEMBL3945179 & 71 & 6.9666 & 8071 & \\
\hline HEMBL 391 & & & 7339 & \\
\hline HEMBL3925789 & 71 & .5376 & 4937 & \\
\hline HEMBL3954722 & 471 & 6.0 & .0276 & \\
\hline HEMBL3915539 & 71 & 6.0 & .4599 & \\
\hline HEMBL3894645 & 71 & 584 & 413 & \\
\hline AEMBL3 & & & & \\
\hline HEMBL3981279 & 71 & 1959 & 7976 & \\
\hline HEMBL3956407 & 71 & 218 & 6591 & \\
\hline HEMBL3985733 & 71 & 7.5229 & 6332 & \\
\hline AEMBL & 71 & & 11 & \\
\hline HEMBL & & & & iv \\
\hline HEMBL & 71 & & 195 & \\
\hline HEMBL3S & & 39 & & \\
\hline AEMBL3890036 & 71 & 6. & 236 & KIV \\
\hline AEMBL & 71 & & & RN \\
\hline AEMBL. & & & & RN \\
\hline HEMBL; & & 76 & 7657 & $\mathrm{RN}$ \\
\hline HEMBL3 & & 28 & & \\
\hline AEMBL3 & 11 & 58 & 79 & $R N$ \\
\hline AEMBL 3 & & & 17 & ST \\
\hline AEMBL & & & & RN \\
\hline ALMP & & 6. & & RN \\
\hline AEMBL & & & & RN \\
\hline AEMBL3986340 & 71 & 6 & 346 & 「RN \\
\hline AEMBL: & & & 76 & $\mathrm{RN}$ \\
\hline HFM & & 6 & & RN \\
\hline & & & & RN \\
\hline AEMBL39276 & & 7.795 & & 「RN \\
\hline HEMBL3980021 & 71 & 6 & 333 & 「RN \\
\hline AFMRI 3 & & 1 & & RN \\
\hline & & & & RN \\
\hline HEMBL3 & & 7.26 & & ГRN \\
\hline HEMBL3979043 & & 7. & 101 & TRN \\
\hline IEMBL3 & & 7.3188 & 536 & 「RN \\
\hline HEMBL3 & & $c$ & 394 & \\
\hline HEMBL3 & & & 097 & RN \\
\hline HEMBL3 & & & 3082 & TST \\
\hline AEMBL3S & & 7. & 067 & TS \\
\hline EBL3 & & & & IST \\
\hline CHEMBL 3899284 & & .9469 & 7.0907 & \\
\hline CHEMBL3973819 & & 7.8861 & 7.3619 & \\
\hline CHEMBL3923020 & 1641471 & 6.0 & 6.4975 & \\
\hline
\end{tabular}

Page 11997 
Supplemental Table S2.txt

\begin{tabular}{|c|c|c|c|c|c|}
\hline CHEMBL3949106 & 1641471 & 5.0914 & 5.3533 & TRN & \\
\hline CHEMBL3949453 & 1641471 & 6.8827 & 7.2402 & TRN & \\
\hline CHEMBL3913083 & 1641471 & 7.6198 & 7.2448 & TRN & \\
\hline CHEMBL3954754 & 1641471 & 6.24799 & 99999999 & 6.7883 & TST \\
\hline CHEMBL3943488 & 1641471 & 7.6576 & 7.9455 & TRN & \\
\hline CHEMBL3909694 & 1641471 & 7.0 & 7.387006 & 00000000005 & TRN \\
\hline CHEMBL3962322 & 1641471 & 8.2218 & 7.6277 & TRN & \\
\hline CHEMBL3901299 & 1641471 & 8.0 & 7.8409 & TRN & \\
\hline CHEMBL3967085 & 1641471 & 6.7986 & 6.437 & TST & \\
\hline CHEMBL3892000 & 1641471 & 6.0 & 6.1809 & TRN & \\
\hline CHEMBL3925120 & 1641471 & 7.3279 & 7.2646 & TRN & \\
\hline CHEMBL3904051 & 1641471 & 7.0506 & 6.6921 & TRN & \\
\hline CHEMBL3960687 & 1641471 & 7.9208 & 6.9564 & TRN & \\
\hline CHEMBL3931126 & 1641471 & 6.2125 & 6.7425 & TRN & \\
\hline CHEMBL3922973 & 1641471 & 6.9508 & 7.1968 & TRN & \\
\hline CHEMBL3945290 & 1641471 & 7.3768 & 7.4857 & TRN & \\
\hline CHEMBL3890148 & 1641471 & 7.2076 & 7.8431 & TRN & \\
\hline CHEMBL3950622 & 1641471 & 5.7799 & 8.3128 & TST & \\
\hline CHEMBL3903714 & 1641471 & 7.4559 & 7.4689 & TST & \\
\hline CHEMBL3957814 & 1641471 & 6.7352 & 6.7878 & TRN & \\
\hline CHEMBL3948825 & 1641471 & 7.0 & 7.3422 & TRN & \\
\hline CHEMBL3950000 & 1641471 & 7.6576 & 7.5952 & TRN & \\
\hline CHEMBL3919457 & 1641471 & 6.4306 & 6.7048 & TST & \\
\hline CHEMBL3896698 & 1641471 & 6.1355 & 5.6266 & TST & \\
\hline CHEMBL3934280 & 1641471 & 6.6091 & 6.6111 & TRN & \\
\hline CHEMBL3893354 & 1641471 & 7.1938 & 7.1956 & TRN & \\
\hline CHEMBL3982919 & 1641471 & 7.3979 & 7.336 & TRN & \\
\hline CHEMBL3943408 & 1641471 & 6.5719 & 6.9364 & TRN & \\
\hline CHEMBL3906638 & 1641471 & 5.9094 & 6.0684 & TRN & \\
\hline CHEMBL3953660 & 1641471 & 7.8239 & 7.5443 & TST & \\
\hline CHEMBL3918767 & 1641471 & 7.0915 & 7.0768 & TRN & \\
\hline CHEMBL3964187 & 1641471 & 6.857 & 6.7315 & TRN & \\
\hline CHEMBL3955637 & 1641471 & 7.5086 & 6.5339 & TRN & \\
\hline CHEMBL3947470 & 1641471 & 6.0 & 7.5893 & TST & \\
\hline CHEMBL3914917 & 1641471 & 8.2218 & 6.4223 & TRN & \\
\hline CHEMBL3958328 & 1641471 & 7.0915 & 6.8052 & TST & \\
\hline CHEMBL3951000 & 1641471 & 6.8665 & 6.8297 & TST & \\
\hline CHEMBL3947693 & 1641471 & 7.1549 & 6.9123 & TRN & \\
\hline CHEMBL3935637 & 1641471 & 7.2596 & 7.3545 & TRN & \\
\hline CHEMBL3942667 & 1641471 & 7.8239 & 7.1873 & TRN & \\
\hline CHEMBL3899250 & 1641471 & 7.2518 & 7.1647 & TRN & \\
\hline CHEMBL3910959 & 1641471 & 6.3372 & 6.7837 & TST & \\
\hline CHEMBL 3898425 & 1641471 & 7.7959 & 7.2713 & TRN & \\
\hline CHEMBL3963618 & 1641471 & 7.8861 & 7.6459 & TRN & \\
\hline CHEMBL3955190 & 1641471 & 7.9208 & 7.3456 & TRN & \\
\hline CHEMBL3902288 & 1641471 & 6.1612 & 6.0577 & TRN & \\
\hline CHEMBL3905275 & 1641471 & 7.2441 & 7.1039 & TRN & \\
\hline CHEMBL3965316 & 1641471 & 7.6198 & 7.5321 & TRN & \\
\hline
\end{tabular}

Page 11998 
Supplemental Table S2.txt

\begin{tabular}{|c|c|c|c|c|c|}
\hline CHEMBL3958169 & 1641471 & 7.8539 & 7.4219 & TRN & \\
\hline CHEMBL3941736 & 1641471 & 8.2218 & 7.6768 & TRN & \\
\hline CHEMBL3899946 & 1641471 & 7.3665 & 6.4901 & TRN & \\
\hline CHEMBL3948535 & 1641471 & 6.0 & 6.0882 & TRN & \\
\hline CHEMBL3951143 & 1641471 & 7.0315 & 7.085 & TRN & \\
\hline CHEMBL3960993 & 1641471 & 6.7747 & 6.3126 & TRN & \\
\hline CHEMBL3935378 & 1641471 & 7.7696 & 7.1628 & TRN & \\
\hline CHEMBL3926259 & 1641471 & 6.0 & 7.0776 & TST & \\
\hline CHEMBL3973283 & 1641471 & 7.7212 & 6.3873 & TST & \\
\hline CHEMBL3921878 & 1641471 & 7.5686 & 7.4995 & TRN & \\
\hline CHEMBL3920355 & 1641471 & 7.4815 & 7.3888 & TRN & \\
\hline CHEMBL3925118 & 1641471 & 5.53 & 6.3999 & TST & \\
\hline CHEMBL3944487 & 1641471 & 7.4815 & 7.4813 & TRN & \\
\hline CHEMBL3980171 & 1641471 & 6.0 & 6.6479 & TRN & \\
\hline CHEMBL3908166 & 1641471 & 7.1249 & 7.6288 & TRN & \\
\hline CHEMBL3933355 & 1641471 & 7.9208 & 7.8413 & TRN & \\
\hline CHEMBL3920803 & 1641471 & 6.0 & 6.532 & TRN & \\
\hline CHEMBL3918204 & 1641471 & 7.585 & 7.724 & TRN & \\
\hline CHEMBL3982664 & 1641471 & 6.2291 & 6.3608 & TRN & \\
\hline CHEMBL3909599 & 1641471 & 6.0 & 5.8198 & TRN & \\
\hline CHEMBL3944275 & 1641471 & 6.0 & 6.5717 & TRN & \\
\hline CHEMBL3915137 & 1641471 & 7.5686 & 7.2019 & TRN & \\
\hline CHEMBL3986635 & 1641471 & 6.0942 & 6.778 & TRN & \\
\hline CHEMBL3969045 & 1641471 & 7.7212 & 7.6596 & TRN & \\
\hline CHEMBL3918988 & 1641471 & 7.6576 & 7.7791 & TRN & \\
\hline CHEMBL3895055 & 1641471 & 7.6198 & 7.6143 & TRN & \\
\hline CHEMBL3968712 & 1641471 & 7.2757 & 7.4683 & TRN & \\
\hline CHEMBL3928877 & 1641471 & 7.0223 & 7.2608 & TRN & \\
\hline CHEMBL3933389 & 1641471 & 6.4815 & 6.1836 & TST & \\
\hline CHEMBL3939477 & 1641471 & 7.4318 & 7.5323 & TRN & \\
\hline CHEMBL3934462 & 1641471 & 6.0 & 6.5629 & TRN & \\
\hline CHEMBL3969913 & 1641471 & 6.0 & 7.0452 & TRN & \\
\hline CHEMBL3898610 & 1641471 & 7.4089 & 6.6215 & TST & \\
\hline CHEMBL3962804 & 1641471 & 7.8539 & 7.1977 & TRN & \\
\hline CHEMBL3967555 & 1641471 & 7.4685 & 7.2819 & TRN & \\
\hline CHEMBL3978599 & 1641471 & 6.9957 & 6.899 & TRN & \\
\hline CHEMBL3902872 & 1641471 & 6.0 & 6.61700 & 0000000001 & TRN \\
\hline CHEMBL3914409 & 1641471 & 7.7696 & 8.2679 & TRN & \\
\hline CHEMBL3981398 & 1641471 & 7.3565 & 7.068 & TRN & \\
\hline CHEMBL3947649 & 1641471 & 7.0506 & 7.0258 & TRN & \\
\hline CHEMBL3922237 & 1641471 & 7.6383 & 6.9323 & TRN & \\
\hline CHEMBL3975763 & 1641471 & 8.0458 & 7.7427 & TRN & \\
\hline CHEMBL3934944 & 1641471 & 8.0969 & 7.3183 & TRN & \\
\hline CHEMBL3953155 & 1641471 & 6.5498 & 6.5295 & TRN & \\
\hline CHEMBL3906264 & 1641471 & 6.0 & 7.0835 & TST & \\
\hline CHEMBL3916109 & 1641471 & 6.8962 & 6.2337 & TST & \\
\hline CHEMBL3910110 & 1641471 & 7.2676 & 6.8146 & TRN & \\
\hline CHEMBL3943766 & 1641471 & 7.6576 & 8.0245 & TRN & \\
\hline
\end{tabular}




\begin{tabular}{|c|c|c|c|c|}
\hline \multicolumn{5}{|c|}{ Supplemental Table S2.txt } \\
\hline CHEMBL 3985870 & 1641471 & 6.71 & 6.1606 & TST \\
\hline CHEMBL 3937208 & 1641471 & 7.5086 & 7.4068 & TST \\
\hline CHEMBL 3892348 & 1641471 & 7.3279 & 7.2625 & TRN \\
\hline CHEMBL 3889553 & 1641471 & 7.2924 & 6.8382 & TRN \\
\hline CHEMBL3913120 & 1641471 & 5.6112 & 5.5377 & TRN \\
\hline CHEMBL 3903425 & 1641471 & 7.4202 & 7.0748 & TST \\
\hline CHEMBL 3917706 & 1641471 & 7.041 & 6.7614 & TRN \\
\hline CHEMBL 3922083 & 1641471 & 7.6778 & 7.2709 & TRN \\
\hline CHEMBL 3958459 & 1641471 & 6.0 & 6.6303 & TRN \\
\hline CHEMBL3970298 & 1641471 & 5.1321 & 6.7334 & TST \\
\hline CHEMBL 3917302 & 1641471 & 8.0458 & 5.8486 & TST \\
\hline CHEMBL3920113 & 1641471 & 7.7212 & 7.5544 & TRN \\
\hline CHEMBL3935679 & 1641471 & 6.0 & 5.8977 & TRN \\
\hline CHEMBL 3902702 & 1641471 & 7.4559 & 7.3042 & TRN \\
\hline CHEMBL3934798 & 1641471 & 5.8438 & 7.0684 & TST \\
\hline CHEMBL 3917875 & 1641471 & 8.5229 & 7.7663 & TST \\
\hline CHEMBL3913271 & 1641471 & 5.551 & 5.6685 & TRN \\
\hline CHEMBL3953978 & 1641471 & 7.2676 & 6.8375 & TRN \\
\hline CHEMBL 3917122 & 1641471 & 7.8239 & 7.5335 & TRN \\
\hline CHEMBL3974685 & 1641471 & 7.8539 & 7.6501 & TRN \\
\hline CHEMBL 3979204 & 1641471 & 7.0915 & 7.1456 & TRN \\
\hline CHEMBL 3894466 & 1641471 & 6.0 & 6.8169 & TRN \\
\hline CHEMBL3905038 & 1641471 & 7.8861 & 7.0138 & TRN \\
\hline CHEMBL3963086 & 1641471 & 7.6383 & 7.5198 & TRN \\
\hline CHEMBL3911809 & 1641471 & 6.0 & 6.6857 & TRN \\
\hline CHEMBL 3982963 & 1641471 & 6.5129 & 6.9357 & TST \\
\hline CHEMBL 3949107 & 1641471 & 6.7986 & 7.4451 & TRN \\
\hline CHEMBL3924050 & 1641471 & 7.5229 & 7.6629 & TRN \\
\hline CHEMBL 3899675 & 1641471 & 7.6021 & 7.3315 & TRN \\
\hline CHEMBL 3904647 & 1641471 & 6.5058 & 7.9228 & TST \\
\hline CHEMBL 3941382 & 1641471 & 6.0 & 6.6901 & TRN \\
\hline CHEMBL 3974024 & 1641471 & 7.699 & 7.4827 & TRN \\
\hline CHEMBL 3890337 & 1641471 & 5.7615 & 6.3236 & TST \\
\hline CHEMBL3936534 & 1641471 & 7.4089 & 7.1811 & TRN \\
\hline CHEMBL3984051 & 1641471 & 6.0 & 7.4851 & TRN \\
\hline CHEMBL3895117 & 1641471 & 5.2055 & 4.9627 & TST \\
\hline CHEMBL 3967814 & 1641471 & 7.284 & 7.0732 & TRN \\
\hline CHEMBL3941759 & 1641471 & 8.0 & 6.9645 & TST \\
\hline CHEMBL3951310 & 1641471 & 6.0 & 6.2453 & TRN \\
\hline CHEMBL3952072 & 1641471 & 6.0 & 5.6581 & TRN \\
\hline CHEMBL3966911 & 1641471 & 7.8539 & 7.9159 & TRN \\
\hline CHEMBL 3940051 & 1641471 & 7.4318 & 7.3125 & TRN \\
\hline CHEMBL3914845 & 1641471 & 7.9586 & 7.2989 & TRN \\
\hline CHEMBL 3902384 & 1641471 & 7.1938 & 7.1318 & TST \\
\hline CHEMBL3908896 & 1641471 & 7.699 & 7.4251 & TRN \\
\hline CHEMBL 3918304 & 1641471 & 7.4089 & 6.3999 & TRN \\
\hline CHEMBL3962735 & 1641471 & 7.699 & 7.3895 & TRN \\
\hline CHEMBL3900019 & 1641471 & 6.2 & 6.1046 & TST \\
\hline
\end{tabular}


Supplemental Table S2.txt

\begin{tabular}{|c|c|c|c|c|c|}
\hline CHEMBL3921690 & 1641471 & 7.7959 & 7.6516 & TRN & \\
\hline CHEMBL3916905 & 1641471 & 4.9974 & 6.0966 & TST & \\
\hline CHEMBL3969987 & 1641471 & 6.0 & 6.8728 & TRN & \\
\hline CHEMBL3917183 & 1641471 & 6.6778 & \multicolumn{2}{|c|}{6.917000000000001} & TRN \\
\hline CHEMBL3944586 & 1641471 & 6.7496 & 6.856 & TRN & \\
\hline CHEMBL3965227 & 1641471 & 7.3872 & 6.8911 & TRN & \\
\hline CHEMBL3916505 & 1641471 & 7.1024 & 6.6444 & TST & \\
\hline CHEMBL3958470 & 1641471 & 7.0177 & 7.3105 & TRN & \\
\hline CHEMBL3909283 & 1641471 & 6.0 & 6.4638 & TRN & \\
\hline CHEMBL3919516 & 1641471 & 7.4559 & 7.9495 & TRN & \\
\hline CHEMBL3911747 & 1641471 & 7.8239 & 7.0992 & TRN & \\
\hline CHEMBL 3957433 & 1641471 & 8.0 & 7.5175 & TRN & \\
\hline CHEMBL 3892449 & 1641471 & 7.6021 & 7.6054 & TRN & \\
\hline CHEMBL 3961435 & 1641471 & 8.0969 & 8.1619 & TRN & \\
\hline CHEMBL3959599 & 1641471 & 7.4949 & 7.5219 & TRN & \\
\hline CHEMBL3907412 & 1641471 & 7.3279 & 7.3419 & TRN & \\
\hline CHEMBL3947692 & 1641471 & 5.3316 & 6.0197 & TST & \\
\hline CHEMBL3960667 & 1641471 & 7.3872 & 7.4492 & TRN & \\
\hline CHEMBL 3961758 & 1641471 & 6.0 & 6.8361 & TRN & \\
\hline CHEMBL3935329 & 1641471 & 8.0 & 7.3683 & TRN & \\
\hline CHEMBL3963539 & 1641471 & 6.8356 & 6.9239 & TRN & \\
\hline CHEMBL3902782 & 1641471 & 6.0 & 6.1935 & TRN & \\
\hline CHEMBL 3980613 & 1641471 & 7.8539 & 6.9087 & TRN & \\
\hline CHEMBL 3973764 & 1641471 & 7.5528 & 7.3869 & TRN & \\
\hline CHEMBL3919209 & 1641471 & 6.8268 & 7.5321 & TRN & \\
\hline CHEMBL3932758 & 1641471 & 7.301 & 7.7428 & TRN & \\
\hline CHEMBL 3894147 & 1641471 & 6.1124 & 7.1113 & TST & \\
\hline CHEMBL3976637 & 1641471 & 7.0555 & 5.9983 & TST & \\
\hline CHEMBL3981907 & 1641471 & 6.466 & 6.7167 & TRN & \\
\hline CHEMBL3987129 & 1641471 & 7.0605 & 7.1604 & TRN & \\
\hline CHEMBL3937914 & 1641471 & 6.0 & 6.3631 & TRN & \\
\hline CHEMBL3928426 & 1641471 & 6.7496 & 6.7743 & TST & \\
\hline CHEMBL 3893797 & 1641471 & 7.0269 & 6.3317 & TST & \\
\hline CHEMBL 3924014 & 1641471 & 7.6198 & 7.7049 & TRN & \\
\hline CHEMBL 3894210 & 1641471 & 7.0044 & 7.3365 & TRN & \\
\hline CHEMBL3893877 & 1641471 & 5.3436 & 8.3289 & TST & \\
\hline CHEMBL3946441 & 1641471 & 6.9172 & 6.398 & TST & \\
\hline CHEMBL3913235 & 1641471 & 7.3872 & 7.2235 & TRN & \\
\hline CHEMBL3943887 & 1641471 & 6.9747 & 7.0154 & TRN & \\
\hline CHEMBL 3907443 & 1641471 & 8.0 & 7.864 & TRN & \\
\hline CHEMBL3923309 & 1641471 & 6.0448 & 6.0853 & TRN & \\
\hline CHEMBL3953605 & 1641471 & 8.0458 & 7.1851 & TRN & \\
\hline CHEMBL3977901 & 1641471 & 6.0 & 6.9193 & TRN & \\
\hline CHEMBL3909406 & 1641471 & 7.4202 & 6.7614 & TRN & \\
\hline CHEMBL 3966241 & 1641471 & 7.0315 & 7.2218 & TRN & \\
\hline CHEMBL3964009 & 1641471 & 4.5664 & 4.3852 & TST & \\
\hline CHEMBL3907619 & 1641471 & 7.0555 & 6.6763 & TST & \\
\hline CHEMBL 3890416 & 1641471 & 6.6253 & 7.4235 & TST & \\
\hline
\end{tabular}


Supplemental Table S2.txt

\begin{tabular}{|c|c|c|c|c|c|c|}
\hline CHEMBL3949908 & 1641471 & 8.1549 & 7.2621 & TRN & & \\
\hline CHEMBL3948613 & 1641471 & 6.5317 & 6.3125 & TRN & & \\
\hline CHEMBL3964847 & 1641471 & 6.0 & 7.1215 & TST & & \\
\hline CHEMBL 3936137 & 1641471 & 8.2218 & 8.2271 & TRN & & \\
\hline CHEMBL3918382 & 1641471 & 6.0 & 6.3031 & TRN & & \\
\hline CHEMBL3890966 & 1641471 & 7.7959 & 7.2626 & TRN & & \\
\hline CHEMBL3909575 & 1641471 & 8.0969 & 7.7702 & TRN & & \\
\hline CHEMBL3907538 & 1641471 & 6.6345 & 7.1571 & TRN & & \\
\hline CHEMBL3935651 & 1641471 & 6.71899 & 99999999 & 99 & 7.5644 & TRN \\
\hline CHEMBL3914476 & 1641471 & 6.5452 & 7.1087 & TRN & & \\
\hline CHEMBL3962898 & 1641471 & 8.0969 & 6.9592 & TST & & \\
\hline CHEMBL3896134 & 1641471 & 8.0 & 7.5614 & TRN & & \\
\hline CHEMBL3976193 & 1641471 & 6.0726 & 5.6907 & TRN & & \\
\hline CHEMBL3940678 & 1641471 & 7.5528 & 7.3336 & TRN & & \\
\hline CHEMBL3928711 & 1641471 & 6.9547 & 7.1609 & TRN & & \\
\hline CHEMBL3931586 & 1641471 & 8.0458 & 7.8461 & TRN & & \\
\hline CHEMBL3941727 & 1641471 & 7.9208 & 7.2145 & TRN & & \\
\hline CHEMBL3974717 & 1641471 & 7.5086 & 7.7979 & TST & & \\
\hline CHEMBL3959456 & 1641471 & 6.0 & 6.5487 & TRN & & \\
\hline CHEMBL3958907 & 1641471 & 6.0 & 7.231 & TRN & & \\
\hline CHEMBL3955224 & 1641471 & 6.9208 & 6.7442 & TRN & & \\
\hline CHEMBL3896569 & 1641471 & 7.6198 & 7.0217 & TRN & & \\
\hline CHEMBL3951431 & 1641471 & 7.2924 & 6.9616 & TRN & & \\
\hline CHEMBL3980143 & 1641471 & 7.5086 & 7.7664 & TRN & & \\
\hline CHEMBL3914854 & 1641471 & 7.6383 & 7.3101 & TRN & & \\
\hline CHEMBL3972298 & 1641471 & 7.2924 & 7.0225 & TRN & & \\
\hline CHEMBL3937744 & 1641471 & 7.699 & 7.7634 & TRN & & \\
\hline CHEMBL3931668 & 1641471 & 6.5287 & 6.8677 & TRN & & \\
\hline CHEMBL3929281 & 1641471 & 7.3565 & 7.2195 & TRN & & \\
\hline CHEMBL3985667 & 1641471 & 8.301 & 7.3709 & TRN & & \\
\hline CHEMBL3986870 & 1641471 & 6.9101 & 7.0997 & TST & & \\
\hline CHEMBL3965976 & 1641471 & 8.0 & 7.4187 & TRN & & \\
\hline CHEMBL3904752 & 1641471 & 7.4318 & 7.7609 & TRN & & \\
\hline CHEMBL3975055 & 1641471 & 6.0 & 6.6893 & TRN & & \\
\hline CHEMBL3980326 & 1641471 & 7.9586 & 6.3535 & TST & & \\
\hline CHEMBL3980347 & 1641471 & 5.3441 & 7.5165 & TST & & \\
\hline CHEMBL3929473 & 1641471 & 7.7696 & 6.4523 & TST & & \\
\hline CHEMBL3982648 & 1641471 & 7.9208 & 7.6089 & TRN & & \\
\hline CHEMBL3916274 & 1641471 & 7.1487 & 7.1206 & TRN & & \\
\hline CHEMBL3918591 & 1641471 & 7.6021 & 7.1433 & TRN & & \\
\hline CHEMBL3919721 & 1641471 & 7.3098 & 7.5 & TRN & & \\
\hline CHEMBL3921274 & 1641471 & 7.1938 & 7.4454 & TRN & & \\
\hline CHEMBL3915009 & 1641471 & 7.6021 & 7.3454 & TRN & & \\
\hline CHEMBL3917579 & 1641471 & 8.1549 & 7.8895 & TRN & & \\
\hline CHEMBL3897161 & 1641471 & 6.1007 & 5.9265 & TST & & \\
\hline CHEMBL3891927 & 1641471 & 6.4283 & 7.2795 & TST & & \\
\hline CHEMBL3930629 & 1641471 & 6.0 & 6.7368 & TRN & & \\
\hline CHEMBL3925586 & 1641471 & 7.3098 & 7.3278 & TRN & & \\
\hline
\end{tabular}

Page 12002 
Supplemental Table S2.txt

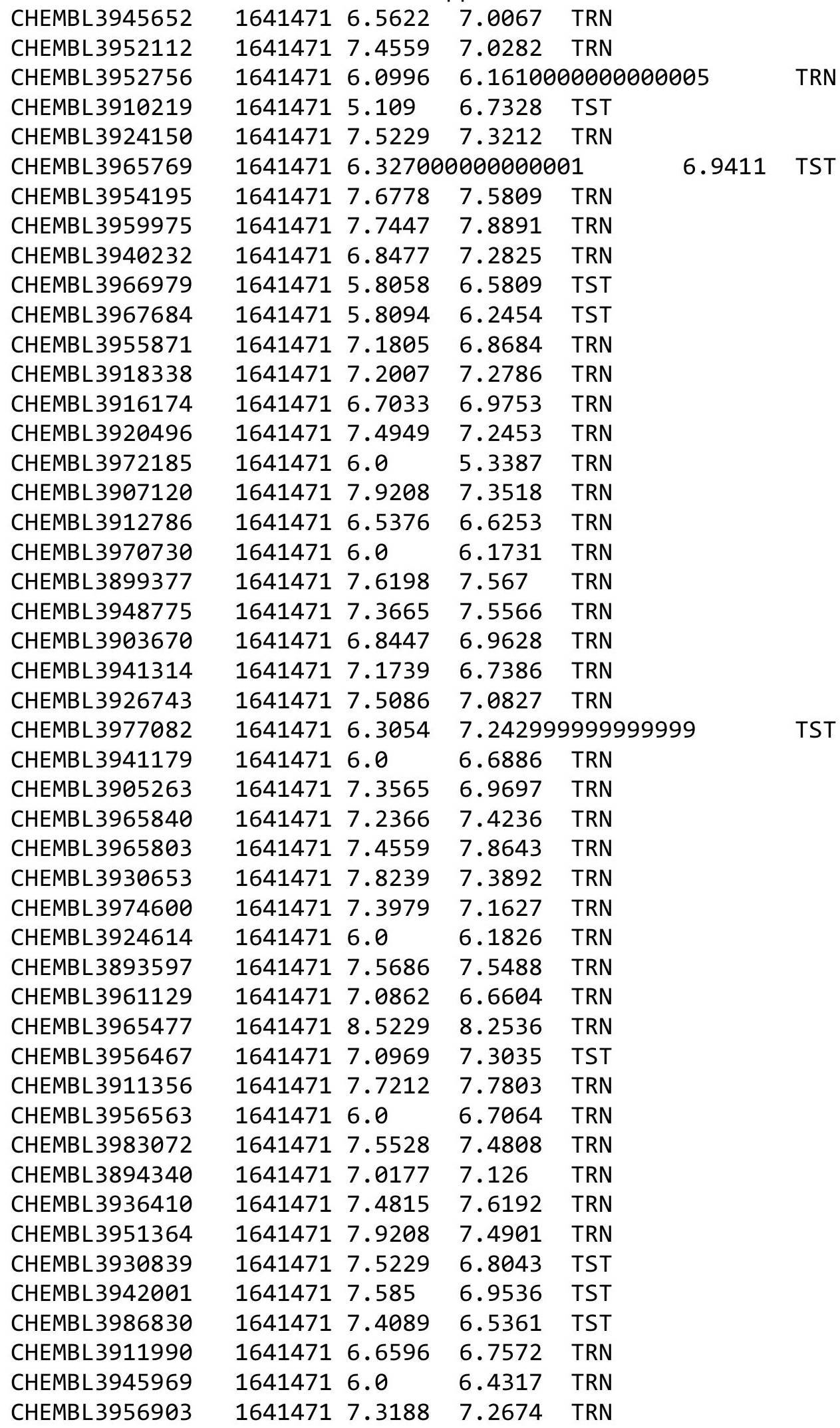

Page 12003 
Supplemental Table S2.txt

\begin{tabular}{|c|c|c|c|c|}
\hline 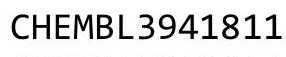 & 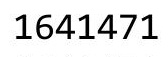 & & & \\
\hline HEMBL3913814 & 641471 & 7.0088 & 7.4531 & \\
\hline HEMBL3915746 & 541471 & 8.1549 & 8918 & \\
\hline 49 & & & & \\
\hline 34820 & 471 & 884 & & \\
\hline AEMBL3963531 & 641471 & 5.4186 & .306 & \\
\hline HEMBL3983606 & 641471 & 7.3979 & .1003 & \\
\hline HEMBL3900046 & 641471 & 4.595 & 7.1318 & \\
\hline HEMBL3 & 641471 & 6.0 & 7414 & \\
\hline AEMBL3S & 471 & & & \\
\hline HEMBL3919660 & 641471 & 7.1427 & 9549 & \\
\hline HEMBL3909558 & 641471 & 6.3809 & 9098 & \\
\hline HEMBL 394 & 641471 & 5.5578 & 0147 & \\
\hline HEMBL3 & 71 & 5.5834 & 67 & \\
\hline HEMBL3 & 71 & 7.284 & 63 & \\
\hline HEMBL39 & 641471 & 6.9431 & 0418 & \\
\hline HEMBL3949027 & 641471 & 969 & & \\
\hline HEMBL3S & 64 & 58 & 142 & \\
\hline HEM & 71 & 47 & 52 & \\
\hline HEM & 71 & 91 & & \\
\hline HEMBL3983627 & 471 & 7.8861 & & \\
\hline AEMBL3916669 & 71 & 49 & & \\
\hline HEMBL3 & 64 & 2541 & & SI \\
\hline HEN & 71 & 809 & & \\
\hline HEM & 71 & 6 & & \\
\hline L3898272 & 71 & 7.5686 & & 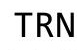 \\
\hline HEMBL3923727 & 71 & 99 & & I RN \\
\hline HEMBL3 & 64 & 576 & & RN \\
\hline HEN & 71 & 79 & & RIV \\
\hline 96 & 71 & 12 & 24 & RN \\
\hline AEMBL3 & 71 & 962 & & IRN \\
\hline AEMBL3960110 & 71 & 6.9393 & & TS \\
\hline AEMBL3 & & 35 & & RN \\
\hline 9 & 71 & & & RN \\
\hline 95 & 71 & 78 & & $\mathrm{RN}$ \\
\hline AEMBL3890589 & 71 & 57 & & IRN \\
\hline AEMBL3985109 & 71 & & 381 & RN \\
\hline 9 & & & 75 & \\
\hline 2 & 71 & 2 & & II \\
\hline HEMBL & & 27 & & $\mathrm{RN}$ \\
\hline AEMBL3980138 & 71 & 6.4123 & 575 & ST \\
\hline HEMBL3 & 71 & 68 & & RN \\
\hline 730 & & & & \\
\hline CHEMBL 3 & 71 & .2518 & 7.2612 & RN \\
\hline HEMBL3 & 71 & .9281 & 6.77 & $\mathrm{RN}$ \\
\hline AEMBL3968917 & 71 & .1192 & 1207 & RN \\
\hline & & & & \\
\hline & 54147 & & & \\
\hline
\end{tabular}

Page 12004 
Supplemental Table S2.txt

\begin{tabular}{|c|c|c|c|c|c|c|}
\hline CHEMBL 3896456 & 1641471 & 6.8539 & 6.824 & TRN & & \\
\hline CHEMBL 3946362 & 1641471 & 5.9038 & 5.9752 & TRN & & \\
\hline CHEMBL 3924475 & 1641471 & 6.75200 & 00000000 & & 6.9299 & TRN \\
\hline CHEMBL 3934523 & 1641471 & 7.2676 & 7.1351 & TRN & & \\
\hline CHEMBL 3897584 & 1641471 & 6.0 & 5.7091 & TRN & & \\
\hline CHEMBL3901460 & 1641471 & 7.1308 & 7.4127 & TRN & & \\
\hline CHEMBL 3890860 & 1641471 & 6.0 & 5.5109 & TST & & \\
\hline CHEMBL 3948633 & 1641471 & 8.0458 & 7.5338 & TRN & & \\
\hline CHEMBL 3951575 & 1641471 & 7.6198 & 6.8878 & TRN & & \\
\hline CHEMBL 3984481 & 1641471 & 5.763 & 5.6624 & TST & & \\
\hline CHEMBL3981650 & 1641471 & 5.4444 & 6.6166 & TST & & \\
\hline CHEMBL3975631 & 1641471 & 6.0 & 6.5673 & TRN & & \\
\hline CHEMBL 3928024 & 1641471 & 6.0 & 6.0313 & TRN & & \\
\hline CHEMBL 3933353 & 1641471 & 6.9547 & 6.9009 & TRN & & \\
\hline CHEMBL 3941888 & 1641471 & 5.0779 & 7.9248 & TST & & \\
\hline CHEMBL3934137 & 1641471 & 6.1662 & 5.97 & TRN & & \\
\hline CHEMBL3905141 & 1641471 & 6.0 & 6.71 & TRN & & \\
\hline CHEMBL 3980083 & 1641471 & 7.5086 & 7.2661 & TRN & & \\
\hline CHEMBL 3986160 & 1641471 & 6.7144 & 7.2239 & TRN & & \\
\hline CHEMBL 3966841 & 1641471 & 6.0 & 6.6811 & TRN & & \\
\hline CHEMBL3942333 & 1641471 & 7.3098 & 7.5062 & TRN & & \\
\hline CHEMBL 3942359 & 1641471 & 6.0 & 5.675 & TRN & & \\
\hline CHEMBL 3927314 & 1641471 & 6.0 & 6.6118 & TRN & & \\
\hline CHEMBL3914991 & 1641471 & 7.2441 & 7.2713 & TRN & & \\
\hline CHEMBL 3931717 & 1641471 & 7.8861 & 7.4253 & TRN & & \\
\hline CHEMBL 3925970 & 1641471 & 7.5229 & 7.8544 & TRN & & \\
\hline CHEMBL 3967427 & 1641471 & 6.7878 & 6.7606 & TRN & & \\
\hline CHEMBL3895694 & 1641471 & 5.7033 & 6.5153 & TST & & \\
\hline CHEMBL 3925355 & 1641471 & 7.7212 & 7.4789 & TRN & & \\
\hline CHEMBL 3919134 & 1641471 & 7.4202 & 7.8365 & TST & & \\
\hline CHEMBL 3980949 & 1641471 & 7.4949 & 7.3244 & TRN & & \\
\hline CHEMBL 3937370 & 1641471 & 7.7696 & 7.3673 & TRN & & \\
\hline CHEMBL3948748 & 1641471 & 7.5086 & 7.5257 & TRN & & \\
\hline CHEMBL 3949600 & 1641471 & 6.0 & 6.8907 & TRN & & \\
\hline CHEMBL 3984808 & 1641471 & 8.301 & 7.7453 & TRN & & \\
\hline CHEMBL 3954745 & 1641471 & 7.5686 & 7.3853 & TRN & & \\
\hline CHEMBL 3986451 & 1641471 & 7.9208 & 7.605 & TRN & & \\
\hline CHEMBL 3894664 & 1641471 & 7.0506 & 7.3657 & TRN & & \\
\hline CHEMBL 3897378 & 1641471 & \multicolumn{3}{|c|}{6.007000000000001} & 6.9611 & TST \\
\hline CHEMBL3900599 & 1641471 & 6.0 & 6.9352 & TST & & \\
\hline CHEMBL3951859 & 1641471 & 6.7305 & 7.1808 & TRN & & \\
\hline CHEMBL 3943913 & 1641471 & 7.2924 & 6.7684 & TRN & & \\
\hline CHEMBL3904834 & 1641471 & 7.2076 & 7.553 & TRN & & \\
\hline CHEMBL3908932 & 1641471 & 6.0 & 7.0178 & TRN & & \\
\hline CHEMBL 3967168 & 1641471 & 7.7212 & 7.58899 & 999999999؛ & 95 & TRN \\
\hline CHEMBL 3979125 & 1641471 & 6.7645 & 6.1946 & TRN & & \\
\hline CHEMBL 3901937 & 1641471 & 6.6635 & 6.7248 & TST & & \\
\hline CHEMBL 3981562 & 1641471 & 7.4202 & 7.2505 & TRN & & \\
\hline
\end{tabular}


Supplemental Table S2.txt

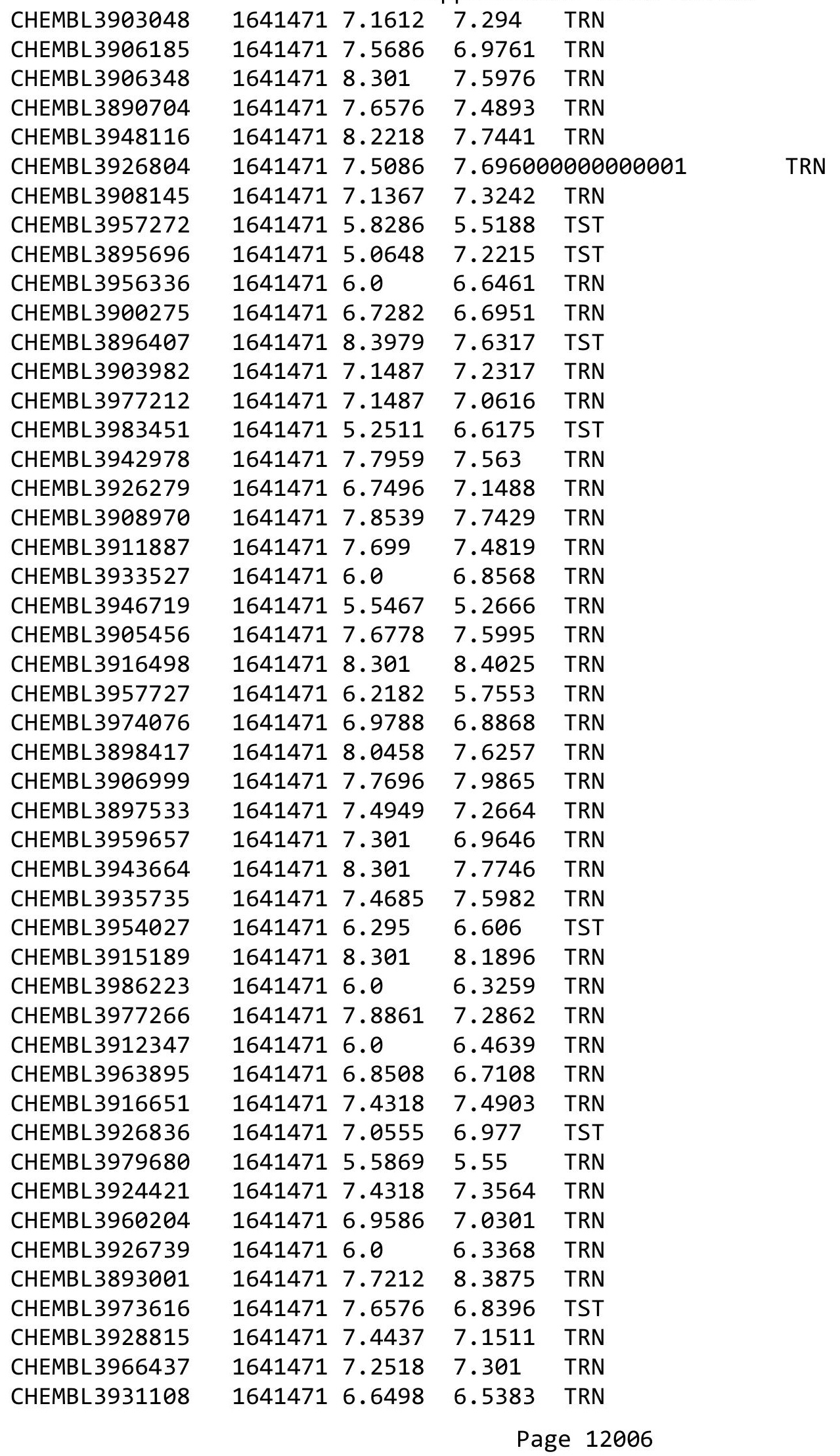


Supplemental Table S2.txt

\begin{tabular}{|c|c|c|c|c|c|}
\hline CHEMBL3972287 & 1641471 & 6.9066 & 5.6565 & TST & \\
\hline CHEMBL3961167 & 1641471 & 6.5058 & 6.6115 & TRN & \\
\hline CHEMBL3985521 & 1641471 & 6.7167 & 6.6744 & TRN & \\
\hline CHEMBL 3969400 & 1641471 & 7.4559 & 7.8954 & TRN & \\
\hline CHEMBL 3962889 & 1641471 & 5.5086 & 5.4222 & TRN & \\
\hline CHEMBL3932051 & 1641471 & 5.7846 & 6.2545 & TST & \\
\hline CHEMBL3901322 & 1641471 & 7.2147 & 7.0523 & TRN & \\
\hline CHEMBL3978547 & 1641471 & 7.1192 & 7.1035 & TRN & \\
\hline CHEMBL3935302 & 1641471 & 6.0 & 6.6068 & TRN & \\
\hline CHEMBL 3893334 & 1641471 & 7.6021 & 7.171 & TRN & \\
\hline CHEMBL3974982 & 1641471 & 7.284 & 6.5645 & TST & \\
\hline CHEMBL3931976 & 1641471 & 8.0458 & 6.9674 & TRN & \\
\hline CHEMBL3972119 & 1641471 & 6.0 & 6.4963 & TRN & \\
\hline CHEMBL 3955290 & 1641471 & 5.6834 & 5.7647 & TRN & \\
\hline CHEMBL 3902847 & 1641471 & 7.1612 & 6.2425 & TST & \\
\hline CHEMBL 3921528 & 1641471 & 8.0458 & 7.4681 & TRN & \\
\hline CHEMBL3916794 & 1641471 & 7.5528 & 7.5033 & TRN & \\
\hline CHEMBL3940717 & 1641471 & 7.301 & 7.1401 & TRN & \\
\hline CHEMBL3936437 & 1641471 & 7.2518 & 7.2077 & TRN & \\
\hline CHEMBL3915343 & 1641471 & 5.9003 & 6.6199 & TRN & \\
\hline CHEMBL 3908368 & 1641471 & 6.0 & 7.1744 & TRN & \\
\hline CHEMBL3929485 & 1641471 & 7.9208 & 7.7596 & TRN & \\
\hline CHEMBL3946191 & 1641471 & 6.0 & 6.2231 & TRN & \\
\hline CHEMBL3954639 & 1641471 & 8.0 & 7.9582 & TRN & \\
\hline CHEMBL3961163 & 1641471 & 6.0 & 7.4822 & TRN & \\
\hline CHEMBL3957517 & 1641471 & 8.2218 & 7.817 & TRN & \\
\hline CHEMBL3892646 & 1641471 & 7.1805 & 7.5235 & TRN & \\
\hline CHEMBL3974834 & 1641471 & 5.6457 & \multicolumn{2}{|c|}{5.6739999999999995} & TST \\
\hline CHEMBL3902051 & 1641471 & 7.0088 & \multicolumn{2}{|c|}{6.763999999999999} & TRN \\
\hline CHEMBL3948915 & 1641471 & 6.5969 & 6.8656 & TRN & \\
\hline CHEMBL3961460 & 1641471 & 8.0 & \multicolumn{2}{|c|}{7.656000000000001} & TRN \\
\hline CHEMBL3975811 & 1641471 & 7.0 & 6.0594 & TST & \\
\hline CHEMBL3941178 & 1641471 & 6.9136 & 6.4228 & TST & \\
\hline CHEMBL 3956827 & 1641471 & 7.0 & 7.9067 & TST & \\
\hline CHEMBL3920739 & 1641471 & 6.0 & 7.0291 & TRN & \\
\hline CHEMBL3985570 & 1641471 & 7.1805 & 6.9574 & TRN & \\
\hline CHEMBL3974674 & 1641471 & 5.0499 & 6.0873 & TST & \\
\hline CHEMBL3927330 & 1641471 & 5.4079 & 7.1705 & TST & \\
\hline CHEMBL3964532 & 1641471 & 6.0 & 5.9138 & TRN & \\
\hline CHEMBL3913847 & 1641471 & 8.0458 & 8.4126 & TRN & \\
\hline CHEMBL3939956 & 1641471 & 7.1024 & 7.2999 & TRN & \\
\hline CHEMBL3940105 & 1641471 & 8.2218 & \multicolumn{2}{|c|}{7.827000000000001} & TRN \\
\hline CHEMBL3904855 & 1641471 & 8.0 & 7.9612 & TRN & \\
\hline CHEMBL3981205 & 1641471 & 6.6799 & 6.7554 & TST & \\
\hline CHEMBL3974868 & 1641471 & 7.2757 & 7.2767 & TRN & \\
\hline CHEMBL 3900238 & 1641471 & 5.9066 & 7.6977 & TST & \\
\hline CHEMBL3934327 & 1641471 & 6.983 & 6.7345 & TRN & \\
\hline CHEMBL 3928880 & 1641471 & 7.4318 & 7.4589 & TRN & \\
\hline
\end{tabular}

Page 12007 
Supplemental Table S2.txt

\begin{tabular}{|c|c|c|c|c|}
\hline HEN & 541471 & 6.3391 & 6.9688 & \\
\hline & 641471 & 4.8356 & 4.3603 & \\
\hline 62 & & & & \\
\hline HEMBL 38910 & & & & \\
\hline HEMBL3892507 & 641471 & 6.0 & 2594 & \\
\hline HEMBL3931681 & 641471 & 6.0 & .4466 & \\
\hline HEMBL & & & 265 & \\
\hline AFMBI 39 & & & 696 & 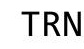 \\
\hline HEMBL3893976 & 471 & 5 & .8101 & \\
\hline HEMBL3966336 & 71 & 6.8097 & .7344 & \\
\hline HEMBL3970003 & 71 & 6.5768 & .1162 & \\
\hline IEMBL389 & 1 & 437 & 792 & \\
\hline AEMBL $39 e$ & & & 068 & \\
\hline HEMBL 397 & 71 & 7.6198 & 7.516 & \\
\hline HEMBL391 & 71 & 576 & 387 & \\
\hline AEMBL 389 & 6 & 7. & 824 & \\
\hline HEMBL39L & $\perp$ & 979 & 17 & \\
\hline HEMBL 392 & & & 75 & \\
\hline HEMBL396 & & 7.2676 & 7.4515 & \\
\hline HEMBL 389 & 71 & 6.0 & & \\
\hline HEMBL39 & 6 & 8 & 217 & RIN \\
\hline HEMBL39 & $\perp$ & & 09 & 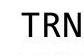 \\
\hline HEMBL39 & & & 46 & \\
\hline HEMBL389 & & & 7.3835 & \\
\hline HEMBL 394 & & & & 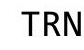 \\
\hline HEMBL39 & 6 & 59 & 348 & RN \\
\hline HEMBL3 & & 72 & .73 & RN \\
\hline HFMBI $3 c$ & & 39 & 899 & \\
\hline HEMBL395 & & 7. & 2933 & iv \\
\hline HEMBL 393 & & 7. & & 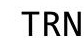 \\
\hline HEMBL 389 & 62 & & 072 & RN \\
\hline HEMBL3 & & & 86 & RN \\
\hline HEMBL3 & & 3 & 308 & N \\
\hline HEMBL392 & 1 & 7. & & IRN \\
\hline HEMBL3949266 & 71 & 7.284 & 5.8791 & TRN \\
\hline HEMBL 395 & 6 & 56 & 522 & TRN \\
\hline HFMRI 3 & & & 03 & RN \\
\hline HEMBL39 & & & 7.1665 & $\Gamma \mathrm{RN}$ \\
\hline HEMBL3918443 & 1 & 5.4738 & 7.7065 & TST \\
\hline IEMBL391 & & & 3039 & IRN \\
\hline HEMBL 397 & 6 & 362 & 154 & \\
\hline CHEMBL391 & & & 7.9684 & RN \\
\hline HEMBL390 & 16 & 7.3872 & 6.9823 & RN \\
\hline HEMBL3905438 & 6 & 6.5003 & .8686 & TST \\
\hline MBL39 & & & 922 & \\
\hline HEMBL 395 & & & .1869 & \\
\hline CHEMBL 3962785 & & 7.79 & .5683 & \\
\hline HEMBL3923836 & 1641471 & 7.3188 & 7.4829 & RN \\
\hline
\end{tabular}

Page 12008 


\begin{tabular}{|c|c|c|c|c|c|c|}
\hline \multicolumn{7}{|c|}{ supplementa1 labıe SL.txt } \\
\hline CHEMBL3919187 & 1641471 & 6.0 & 6.7517 & TST & & \\
\hline CHEMBL3981055 & 1641471 & \multicolumn{3}{|c|}{6.821000000000001} & 6.9698 & TRN \\
\hline CHEMBL3979860 & 1641471 & 7.8239 & 8.048 & TRN & & \\
\hline CHEMBL3969765 & 1641471 & 6.5243 & 6.254 & TRN & & \\
\hline CHEMBL 3941949 & 1641471 & 7.6383 & 7.776 & TRN & & \\
\hline CHEMBL3938902 & 1641471 & 7.5229 & 7.2069 & TST & & \\
\hline CHEMBL 3950707 & 1641471 & 6.0443 & 5.846 & TRN & & \\
\hline CHEMBL3889869 & 1641471 & 8.3979 & 8.8402 & TST & & \\
\hline CHEMBL3969458 & 1641471 & 7.2291 & 7.4634 & TRN & & \\
\hline CHEMBL3915688 & 1641471 & 6.0 & 7.0719 & TRN & & \\
\hline CHEMBL3978066 & 1641471 & 7.0315 & 6.942 & TRN & & \\
\hline CHEMBL3923766 & 1641471 & 7.1079 & 6.5411 & TST & & \\
\hline CHEMBL3936844 & 1641471 & 6.3179 & 6.901 & TST & & \\
\hline CHEMBL3967623 & 1641471 & 6.6144 & 7.0618 & TRN & & \\
\hline CHEMBL3951063 & 1641471 & 6.6676 & 6.685 & TRN & & \\
\hline CHEMBL 3895827 & 1641471 & 5.5129 & 5.7218 & TST & & \\
\hline CHEMBL 3919253 & 1641471 & 7.1612 & 7.9358 & TST & & \\
\hline CHEMBL3977210 & 1641471 & 7.9586 & 7.8781 & TRN & & \\
\hline CHEMBL3978436 & 1641471 & 6.2233 & 6.0673 & TRN & & \\
\hline CHEMBL3907296 & 1641471 & 8.0458 & 7.2906 & TRN & & \\
\hline CHEMBL3910226 & 1641471 & 5.9838 & 6.90606 & 0000000001 & & TST \\
\hline CHEMBL 3962871 & 1641471 & 6.0 & 6.1501 & TRN & & \\
\hline CHEMBL3937968 & 1641471 & 6.0 & 6.4492 & TRN & & \\
\hline CHEMBL3901697 & 1641471 & 7.9586 & 7.3372 & TST & & \\
\hline CHEMBL3959380 & 1641471 & 7.6383 & 7.879 & TST & & \\
\hline CHEMBL3939521 & 1641471 & 6.9914 & 6.5493 & TST & & \\
\hline CHEMBL3934435 & 1641471 & 6.7799 & 7.26 & TST & & \\
\hline CHEMBL3907366 & 1641471 & 6.5702 & 6.7864 & TST & & \\
\hline CHEMBL3981582 & 1641471 & 7.3098 & 7.5379 & TST & & \\
\hline CHEMBL3903309 & 1641471 & 6.8356 & 7.419 & TST & & \\
\hline CHEMBL3890350 & 1641471 & 7.284 & 6.8056 & TST & & \\
\hline CHEMBL3950719 & 1641471 & 7.3188 & 6.9613 & TST & & \\
\hline CHEMBL3982763 & 1641471 & 6.0835 & 6.7122 & TST & & \\
\hline CHEMBL3923941 & 1641471 & 7.1079 & 7.694 & TST & & \\
\hline CHEMBL3970963 & 1641471 & 5.3669 & 4.8199 & TST & & \\
\hline CHEMBL3909243 & 1641471 & 7.3098 & 7.2973 & TST & & \\
\hline CHEMBL3932714 & 1641471 & 7.3098 & 6.3201 & TST & & \\
\hline CHEMBL3964560 & 1641471 & 7.7696 & 7.7008 & TST & & \\
\hline CHEMBL 3923384 & 1641471 & 7.7447 & 7.4061 & TST & & \\
\hline CHEMBL3894624 & 1641471 & 5.5211 & 6.7629 & TST & & \\
\hline CHEMBL3921011 & 1641471 & 8.2218 & 8.3723 & TST & & \\
\hline CHEMBL3905640 & 1641471 & 7.0458 & 7.1416 & TST & & \\
\hline CHEMBL3890773 & 1641471 & 5.6249 & 7.144 & TST & & \\
\hline CHEMBL 3941500 & 1641471 & 7.4559 & 6.2161 & TST & & \\
\hline CHEMBL3974738 & 1641471 & 4.9743 & 7.7973 & TST & & \\
\hline CHEMBL 3924241 & 1641471 & 6.0 & 7.2013 & TST & & \\
\hline CHEMBL3978958 & 1641471 & 6.0 & 6.2834 & TST & & \\
\hline CHEMBL3979598 & 1641471 & 6.6091 & 7.6782 & TST & & \\
\hline
\end{tabular}


Supplemental Table S2.txt

\begin{tabular}{|c|c|c|c|c|}
\hline CHEMBL3983852 & 1641471 & 6.0 & 6.8501 & TST \\
\hline CHEMBL3930288 & 1641471 & 6.0 & 6.6297 & TST \\
\hline CHEMBL3975099 & 1641471 & 8.1549 & 6.7631 & TST \\
\hline CHEMBL3984728 & 1641471 & 8.0969 & 6.58200 & 0000000001 \\
\hline CHEMBL3906003 & 1641471 & 7.7959 & 7.9164 & TST \\
\hline CHEMBL3959661 & 1641471 & 6.0 & 7.4995 & TST \\
\hline CHEMBL39337 & 753968 & 7.7 & 7.2934 & TST \\
\hline CHEMBL39320 & 753968 & 7.89 & 7.8719 & TRN \\
\hline CHEMBL 37543 & 753968 & 6.5 & 6.4977 & TRN \\
\hline CHEMBL287832 & 753968 & 6.58 & 6.5892 & TRN \\
\hline CHEMBL38199 & 753968 & 6.72 & 6.7227 & TRN \\
\hline CHEMBL36819 & 753968 & 5.92 & 5.9147 & TRN \\
\hline CHEMBL40734 & 753968 & 7.66 & 7.5539 & TST \\
\hline CHEMBL 36727 & 753968 & 7.66 & 7.6691 & TRN \\
\hline CHEMBL416611 & 753968 & 7.31 & 7.3172 & TRN \\
\hline CHEMBL37373 & 753968 & 6.84 & 7.5392 & TST \\
\hline CHEMBL287289 & 753968 & 6.64 & 7.2894 & TST \\
\hline CHEMBL40130 & 753968 & 7.8 & 7.5057 & TST \\
\hline CHEMBL1797418 & 753968 & 7.11 & 7.4795 & TST \\
\hline CHEMBL289162 & 753968 & 5.75 & 6.7656 & TST \\
\hline CHEMBL36164 & 753968 & 6.87 & 6.4501 & TST \\
\hline CHEMBL287007 & 753968 & 8.01 & 7.5226 & TST \\
\hline CHEMBL36967 & 753968 & 8.02 & 6.9582 & TST \\
\hline CHEMBL39811 & 753968 & 7.09 & 6.8925 & TST \\
\hline CHEMBL 39715 & 753968 & 8.02 & 7.0495 & TST \\
\hline CHEMBL289213 & 753968 & 6.23 & 6.9649 & TST \\
\hline CHEMBL109212 & 753968 & 6.38 & 6.362 & TRN \\
\hline CHEMBL324045 & 753968 & 6.01 & 6.0663 & TRN \\
\hline CHEMBL111038 & 753968 & 6.72 & 6.7691 & TRN \\
\hline CHEMBL109428 & 753968 & 6.74 & 6.7393 & TRN \\
\hline CHEMBL109503 & 753968 & 5.84 & 5.8489 & TRN \\
\hline CHEMBL 83228 & 753968 & 4.3 & 4.3117 & TRN \\
\hline CHEMBL320479 & 753968 & 6.13 & 6.1073 & TRN \\
\hline CHEMBL111033 & 753968 & 4.85 & 4.8561 & TRN \\
\hline CHEMBL432396 & 753968 & 4.32 & 4.3162 & TRN \\
\hline CHEMBL325760 & 753968 & 5.13 & 5.1358 & TRN \\
\hline CHEMBL110036 & 753968 & 6.09 & 6.084 & TRN \\
\hline CHEMBL1203037 & 753968 & 6.07 & 6.0714 & TRN \\
\hline CHEMBL111520 & 753968 & 6.06 & 6.0718 & TRN \\
\hline CHEMBL109372 & 753968 & 6.27 & 6.2124 & TRN \\
\hline CHEMBL111664 & 753968 & 4.86 & 4.8694 & TRN \\
\hline CHEMBL110577 & 753968 & 5.2 & 5.1967 & TRN \\
\hline CHEMBL109476 & 753968 & 5.56 & 5.557 & TRN \\
\hline CHEMBL323970 & 753968 & 5.11 & 5.1122 & TRN \\
\hline CHEMBL111307 & 753968 & 5.75 & 5.7403 & TRN \\
\hline CHEMBL110945 & 753968 & 5.04 & 5.0343 & TRN \\
\hline CHEMBL419185 & 753968 & 5.5 & 5.5072 & TRN \\
\hline CHEMBL326445 & 753968 & 4.77 & 4.7759 & TRN \\
\hline
\end{tabular}




\begin{tabular}{|c|c|c|c|c|c|}
\hline & & \multicolumn{4}{|c|}{ Supplemental Table s2.txt } \\
\hline CHEMBL1203026 & 753968 & 6.12 & 6.1148 & TRN & \\
\hline CHEMBL109355 & 753968 & 5.83 & 5.8405 & TRN & \\
\hline CHEMBL323424 & 753968 & 6.64 & 6.6299 & TRN & \\
\hline CHEMBL112096 & 753968 & 6.44 & 5.7079 & TST & \\
\hline CHEMBL109625 & 753968 & 4.21 & 4.2138 & TRN & \\
\hline CHEMBL323900 & 753968 & 5.18 & 5.1891 & TRN & \\
\hline CHEMBL109575 & 753968 & 5.38 & 5.3194 & TST & \\
\hline CHEMBL1203088 & 753968 & 6.8 & 6.7973 & TRN & \\
\hline CHEMBL112225 & 753968 & 6.08 & 5.9894 & TST & \\
\hline CHEMBL110055 & 753968 & 6.21 & 6.2068 & TRN & \\
\hline CHEMBL113535 & 753968 & 5.66 & 5.3408 & TST & \\
\hline CHEMBL324399 & 753968 & 4.16 & 4.1581 & TRN & \\
\hline CHEMBL111443 & 753968 & 4.67 & 4.5672 & TRN & \\
\hline CHEMBL110065 & 753968 & 4.48 & 4.5672 & TRN & \\
\hline CHEMBL109332 & 753968 & 5.47 & 6.4842 & TST & \\
\hline CHEMBL541988 & 753968 & 4.47 & 5.1559 & TST & \\
\hline CHEMBL114446 & 753968 & 4.82 & 5.6336 & TST & \\
\hline CHEMBL111586 & 753968 & 6.46 & 6.4519 & TRN & \\
\hline CHEMBL111222 & 753968 & 5.17 & 5.1457 & TRN & \\
\hline CHEMBL109515 & 753968 & 5.96 & 5.9639 & TRN & \\
\hline CHEMBL110062 & 753968 & 5.17 & 5.7059 & TST & \\
\hline CHEMBL325981 & 753968 & 5.29 & 5.6758 & TST & \\
\hline CHEMBL1203047 & 753968 & 4.15 & 4.8137 & TST & \\
\hline CHEMBL109259 & 753968 & 4.05 & 4.7416 & TST & \\
\hline CHEMBL29197 & 753968 & 7.15 & 7.1592 & TST & \\
\hline CHEMBL283682 & 753968 & 6.03 & 6.0223 & TRN & \\
\hline CHEMBL114593 & 753968 & 6.02 & 6.039 & TRN & \\
\hline CHEMBL115440 & 753968 & 6.03 & 6.0168 & TRN & \\
\hline CHEMBL441279 & 753968 & 6.48 & 6.4908 & TRN & \\
\hline CHEMBL327023 & 753968 & 6.26 & 6.26399 & 9999999999 & TRN \\
\hline CHEMBL157128 & 753968 & 6.82 & 6.8141 & TRN & \\
\hline CHEMBL115187 & 753968 & 6.89 & 6.901 & TRN & \\
\hline CHEMBL1797541 & 753968 & 6.6 & 6.5967 & TRN & \\
\hline CHEMBL116525 & 753968 & 6.04 & 6.0362 & TRN & \\
\hline CHEMBL326280 & 753968 & 6.1 & 6.097 & TRN & \\
\hline CHEMBL116853 & 753968 & 7.05 & 7.0567 & TRN & \\
\hline CHEMBL30973 & 753968 & 6.51 & 6.4931 & TRN & \\
\hline CHEMBL263788 & 753968 & 6.1 & 6.0827 & TRN & \\
\hline CHEMBL332497 & 753968 & 5.42 & 5.41299 & 9999999999 & TRN \\
\hline CHEMBL114728 & 753968 & 5.8 & 5.8087 & TRN & \\
\hline CHEMBL116012 & 753968 & 4.99 & 4.992 & TRN & \\
\hline CHEMBL116857 & 753968 & 5.54 & 5.5395 & TRN & \\
\hline CHEMBL113985 & 753968 & 5.27 & 5.2707 & TRN & \\
\hline CHEMBL323630 & 753968 & 6.19 & 6.1897 & TRN & \\
\hline CHEMBL118000 & 753968 & 5.64 & 5.6473 & TRN & \\
\hline CHEMBL114490 & 753968 & 5.63 & 5.6338 & TRN & \\
\hline CHEMBL424252 & 753968 & 5.72 & 5.7103 & TRN & \\
\hline CHEMBL113996 & 753968 & 4.87 & 4.8787 & TRN & \\
\hline
\end{tabular}




\begin{tabular}{|c|c|c|c|c|c|c|}
\hline & & \multicolumn{5}{|c|}{ Supplemental Table S2.txt } \\
\hline CHEMBL421047 & 753968 & 5.58 & \multicolumn{3}{|c|}{5.587999999999999} & TRN \\
\hline CHEMBL113901 & 753968 & 5.28 & 5.2783 & TRN & & \\
\hline CHEMBL325156 & 753968 & 5.32 & 5.3313 & TRN & & \\
\hline CHEMBL114073 & 753968 & 4.98 & 4.9769 & TRN & & \\
\hline CHEMBL 281300 & 753968 & 6.23 & 6.2026 & TRN & & \\
\hline CHEMBL324718 & 753968 & 6.09 & 6.1041 & TRN & & \\
\hline CHEMBL326811 & 753968 & 5.79 & 5.8256 & TRN & & \\
\hline CHEMBL113902 & 753968 & 5.12 & 5.0963 & TRN & & \\
\hline CHEMBL114392 & 753968 & 5.57 & 5.5614 & TRN & & \\
\hline CHEMBL117326 & 753968 & 6.25 & 6.2472 & TRN & & \\
\hline CHEMBL1448466 & 688719 & 5.2594 & 4.753 & TRN & & \\
\hline CHEMBL1346778 & 688719 & 5.0127 & 3.8927 & TRN & & \\
\hline CHEMBL3189877 & 688719 & 3.301 & 5.1001 & TRN & & \\
\hline CHEMBL1481087 & 688719 & 3.301 & 4.1839 & TRN & & \\
\hline CHEMBL3208992 & 688719 & 4.5702 & 4.2034 & TST & & \\
\hline CHEMBL1595731 & 688719 & 3.301 & 4.0033 & TRN & & \\
\hline CHEMBL1533166 & 688719 & 4.8213 & 5.2766 & TRN & & \\
\hline CHEMBL1423560 & 688719 & 3.301 & 4.1605 & TST & & \\
\hline CHEMBL1544707 & 688719 & 3.301 & 3.4492 & TRN & & \\
\hline CHEMBL1424022 & 688719 & 3.301 & 4.0706 & TRN & & \\
\hline CHEMBL1442518 & 688719 & 3.301 & 3.4674 & TRN & & \\
\hline CHEMBL1364290 & 688719 & 3.301 & 4.0041 & TRN & & \\
\hline CHEMBL 240331 & 688719 & 5.3351 & 4.6547 & TRN & & \\
\hline CHEMBL3189821 & 688719 & 5.1891 & 5.0371 & TRN & & \\
\hline CHEMBL1493034 & 688719 & 5.515 & 5.0564 & TRN & & \\
\hline CHEMBL1542349 & 688719 & 3.301 & 3.3126 & TRN & & \\
\hline CHEMBL1572452 & 688719 & 5.2176 & 3.8139 & TRN & & \\
\hline CHEMBL1604955 & 688719 & 5.4407 & 4.7792 & TRN & & \\
\hline CHEMBL3196509 & 688719 & 3.301 & 3.7224 & TRN & & \\
\hline CHEMBL1321357 & 688719 & 5.2263 & 4.665 & TRN & & \\
\hline CHEMBL1566298 & 688719 & 4.8006 & 4.18 & TRN & & \\
\hline CHEMBL3189442 & 688719 & 4.9505 & 4.4375 & TRN & & \\
\hline CHEMBL1586997 & 688719 & 3.301 & 4.0797 & TRN & & \\
\hline CHEMBL1604803 & 688719 & 5.1866 & 5.2058 & TRN & & \\
\hline CHEMBL1509357 & 688719 & 4.8282 & 3.7195 & TRN & & \\
\hline CHEMBL1597481 & 688719 & 4.9345 & 4.337 & TRN & & \\
\hline CHEMBL1522300 & 688719 & 5.2223 & 5.5141 & TRN & & \\
\hline CHEMBL1337575 & 688719 & 5.6613 & 5.1957 & TRN & & \\
\hline CHEMBL1404955 & 688719 & 3.301 & 4.3338 & TRN & & \\
\hline CHEMBL1541075 & 688719 & 3.301 & 3.6926 & TST & & \\
\hline CHEMBL1541229 & 688719 & $5.3820 e$ & 00000000 & $\partial 1$ & 4.3546 & TRN \\
\hline CHEMBL1334570 & 688719 & 4.4603 & 4.4737 & TRN & & \\
\hline CHEMBL1517375 & 688719 & 3.301 & 4.3958 & TRN & & \\
\hline CHEMBL1386982 & 688719 & 4.9957 & 3.9796 & TRN & & \\
\hline CHEMBL1347387 & 688719 & 6.8062 & 5.1815 & TRN & & \\
\hline CHEMBL1542518 & 688719 & 4.9431 & 4.5074 & TRN & & \\
\hline CHEMBL1604120 & 688719 & 3.301 & 4.2471 & TST & & \\
\hline CHEMBL1528124 & 688719 & 4.7361 & 4.9131 & TRN & & \\
\hline
\end{tabular}


Supplemental Table S2.txt

\begin{tabular}{|c|c|c|c|c|c|}
\hline CHEMBL3193597 & 688719 & 3.301 & 4.0625 & TST & \\
\hline CHEMBL3189499 & 688719 & 5.3979 & 3.9733 & TRN & \\
\hline CHEMBL1431081 & 688719 & 5.6338 & 4.1224 & TRN & \\
\hline CHEMBL1308068 & 688719 & 6.8062 & 5.6148 & TRN & \\
\hline CHEMBL1581750 & 688719 & 5.8062 & 4.1459 & TRN & \\
\hline CHEMBL1362841 & 688719 & 4.7754 & 5.0543 & TRN & \\
\hline CHEMBL1501367 & 688719 & 3.301 & 3.5854 & TST & \\
\hline CHEMBL1391916 & 688719 & 3.301 & 4.5786 & TRN & \\
\hline CHEMBL522990 & 688719 & 5.415 & 4.6104 & TRN & \\
\hline CHEMBL1363590 & 688719 & 3.301 & 3.4603 & TRN & \\
\hline CHEMBL1605033 & 688719 & 6.8062 & 4.9257 & TRN & \\
\hline CHEMBL1484998 & 688719 & 3.301 & 4.2234 & TRN & \\
\hline CHEMBL1541353 & 688719 & 4.5131 & 4.7197 & TRN & \\
\hline CHEMBL1607897 & 688719 & 4.686 & 4.5791 & TRN & \\
\hline CHEMBL1423397 & 688719 & 3.301 & 3.5109 & TRN & \\
\hline CHEMBL1480378 & 688719 & 5.5094 & 4.864 & TRN & \\
\hline CHEMBL1408676 & 688719 & 4.9395 & 4.2891 & TRN & \\
\hline CHEMBL1360685 & 688719 & 4.7087 & 4.4991 & TRN & \\
\hline CHEMBL1491936 & 688719 & 5.1871 & 4.459 & TRN & \\
\hline CHEMBL1446793 & 688719 & 3.301 & 4.1011 & TRN & \\
\hline CHEMBL1494897 & 688719 & 3.301 & 3.5412 & TST & \\
\hline CHEMBL1387610 & 688719 & 4.4227 & 4.4104 & TRN & \\
\hline CHEMBL1545631 & 688719 & 3.301 & 3.5437 & TRN & \\
\hline CHEMBL1576714 & 688719 & 3.301 & 3.963 & TRN & \\
\hline CHEMBL1256771 & 688719 & 3.301 & 3.9517 & TRN & \\
\hline CHEMBL1452728 & 688719 & 3.301 & 3.9506 & TRN & \\
\hline CHEMBL1606497 & 688719 & 5.0323 & 4.6444 & TRN & \\
\hline CHEMBL1582133 & 688719 & 4.9906 & 3.8649 & TRN & \\
\hline CHEMBL1303477 & 688719 & 4.7981 & 5.0824 & TRN & \\
\hline CHEMBL402580 & 688719 & 3.301 & 3.8765 & TST & \\
\hline CHEMBL1574240 & 688719 & 3.301 & 3.9203 & TST & \\
\hline CHEMBL1312996 & 688719 & 4.8641 & 4.555 & TRN & \\
\hline CHEMBL1328586 & 688719 & 5.29299 & 999999999 & 9 & 3.718 \\
\hline CHEMBL1412483 & 688719 & 3.301 & 3.5078 & TRN & \\
\hline CHEMBL3192116 & 688719 & 4.9119 & 4.2998 & TRN & \\
\hline CHEMBL1464837 & 688719 & 3.301 & 4.8328 & TRN & \\
\hline CHEMBL1340892 & 688719 & 3.301 & 3.722 & TRN & \\
\hline CHEMBL1568118 & 688719 & 4.8609 & 4.7364 & TRN & \\
\hline CHEMBL1575022 & 688719 & 3.301 & 3.9936 & TRN & \\
\hline CHEMBL1484657 & 688719 & 3.301 & 4.1153 & TRN & \\
\hline CHEMBL1460126 & 688719 & 3.301 & 4.1747 & TRN & \\
\hline CHEMBL1566505 & 688719 & 3.301 & 3.8913 & TRN & \\
\hline CHEMBL1389163 & 688719 & 3.301 & 4.7475 & TRN & \\
\hline CHEMBL1326803 & 688719 & 3.301 & 5.0528 & TRN & \\
\hline CHEMBL1411756 & 688719 & 4.9613 & 4.0058 & TST & \\
\hline CHEMBL1416417 & 688719 & 4.8665 & 4.3517 & TST & \\
\hline CHEMBL1583667 & 688719 & 5.3868 & 3.9844 & TRN & \\
\hline CHEMBL1407157 & 688719 & 3.301 & 3.7545 & TRN & \\
\hline
\end{tabular}




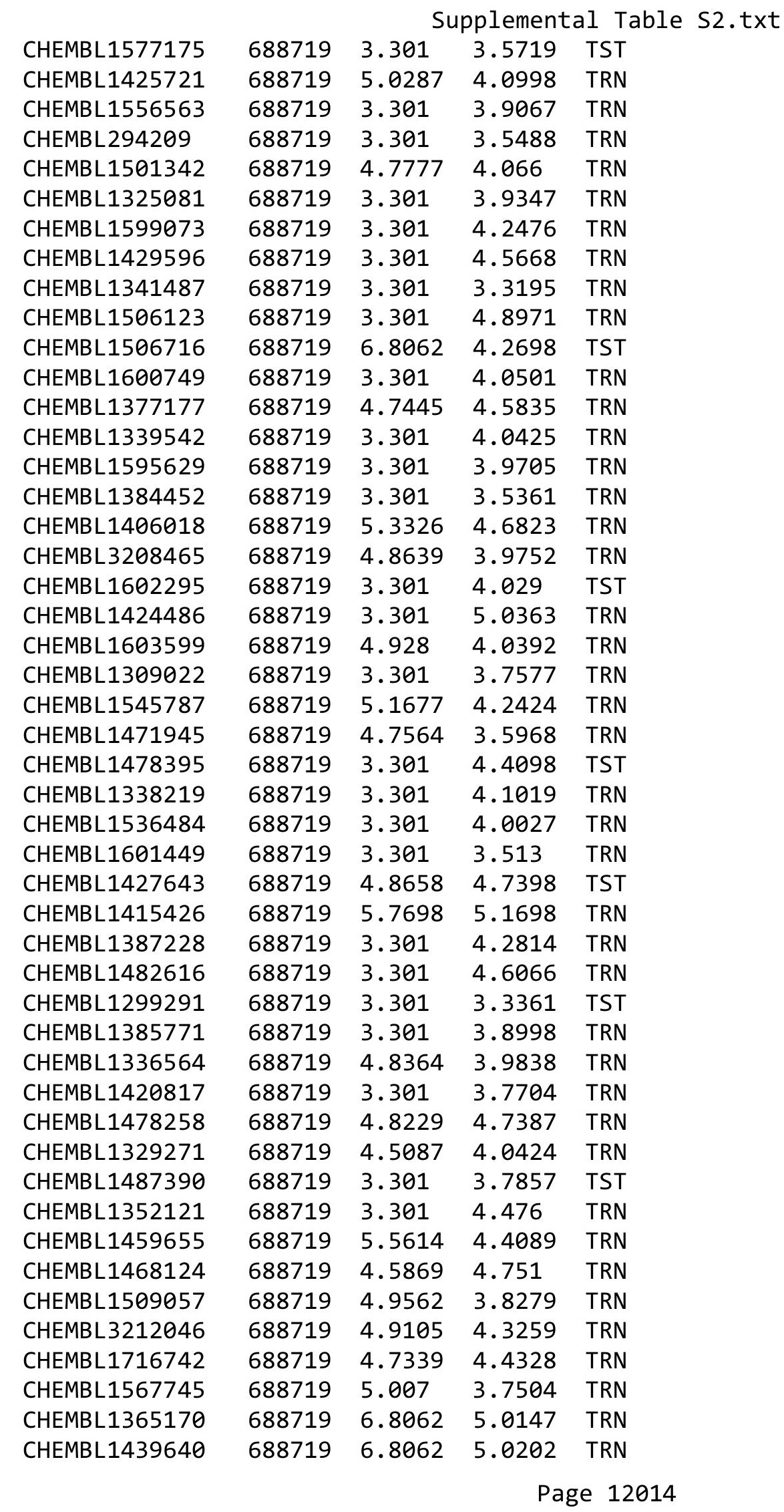




\begin{tabular}{|c|c|c|c|c|c|c|}
\hline \multirow[b]{2}{*}{ CHEMBL1504655 } & \multirow[b]{2}{*}{688719} & \multicolumn{5}{|c|}{ Supplemental Table S2.txt } \\
\hline & & 5.3486 & 5.7497 & TRN & & \\
\hline CHEMBL1518540 & 688719 & 3.301 & 3.6656 & TRN & & \\
\hline CHEMBL1359893 & 688719 & \multicolumn{3}{|c|}{5.0569999999999995} & 4.1447 & TRN \\
\hline CHEMBL1319983 & 688719 & 3.301 & 3.9334 & TRN & & \\
\hline CHEMBL1464539 & 688719 & 5.4225 & 4.7441 & TRN & & \\
\hline CHEMBL1300662 & 688719 & 4.6747 & 3.7141 & TRN & & \\
\hline CHEMBL1608311 & 688719 & 3.301 & 4.6325 & TRN & & \\
\hline CHEMBL 3211570 & 688719 & 3.301 & 4.2592 & TST & & \\
\hline CHEMBL1346703 & 688719 & 3.301 & 4.4706 & TST & & \\
\hline CHEMBL1426947 & 688719 & 5.6673 & 5.2935 & TRN & & \\
\hline CHEMBL1352957 & 688719 & 3.301 & 4.1492 & TRN & & \\
\hline CHEMBL1173787 & 688719 & 3.301 & 4.5985 & TRN & & \\
\hline CHEMBL1603680 & 688719 & 3.301 & 2.858 & TRN & & \\
\hline CHEMBL1589300 & 688719 & 5.013 & 4.5691 & TRN & & \\
\hline CHEMBL3197284 & 688719 & 4.8497 & 4.4785 & TST & & \\
\hline CHEMBL1498999 & 688719 & 3.301 & 4.1088 & TRN & & \\
\hline CHEMBL1529439 & 688719 & 4.458 & 3.7769 & TRN & & \\
\hline CHEMBL1595244 & 688719 & 3.301 & 5.3191 & TRN & & \\
\hline CHEMBL1465890 & 688719 & 4.8641 & 3.9844 & TRN & & \\
\hline CHEMBL1391455 & 688719 & 3.301 & 4.6395 & TRN & & \\
\hline CHEMBL1353227 & 688719 & 6.8062 & 5.3019 & TRN & & \\
\hline CHEMBL1433062 & 688719 & 5.6037 & 4.3504 & TRN & & \\
\hline CHEMBL1576239 & 688719 & \multicolumn{3}{|c|}{5.202999999999999} & 5.0807 & TRN \\
\hline CHEMBL1470395 & 688719 & 5.0667 & 4.4973 & TRN & & \\
\hline CHEMBL3195623 & 688719 & 4.8407 & 4.4829 & TRN & & \\
\hline CHEMBL1305986 & 688719 & \multicolumn{3}{|c|}{5.236000000000001} & 4.4466 & TRN \\
\hline CHEMBL1342721 & 688719 & 3.301 & 3.0593 & TRN & & \\
\hline CHEMBL495123 & 688719 & 4.9908 & 4.5698 & TRN & & \\
\hline CHEMBL 3193247 & 688719 & 3.301 & 4.4853 & TRN & & \\
\hline CHEMBL1511693 & 688719 & 5.3116 & 4.5859 & TRN & & \\
\hline CHEMBL1573389 & 688719 & 5.1626 & 4.4626 & TRN & & \\
\hline CHEMBL1463596 & 688719 & 3.301 & 3.3425 & TRN & & \\
\hline CHEMBL1334493 & 688719 & 3.301 & 3.9731 & TRN & & \\
\hline CHEMBL1507788 & 688719 & 4.8916 & 4.6467 & TRN & & \\
\hline CHEMBL1559043 & 688719 & 4.5677 & 4.6118 & TRN & & \\
\hline CHEMBL1370637 & 688719 & 3.301 & 4.3684 & TST & & \\
\hline CHEMBL 1578546 & 688719 & 5.4237 & 4.8394 & TRN & & \\
\hline CHEMBL1375019 & 688719 & 5.7724 & 4.4825 & TRN & & \\
\hline CHEMBL1972915 & 688719 & \multicolumn{3}{|c|}{5.138999999999999} & 4.6393 & TRN \\
\hline CHEMBL597888 & 688719 & 4.9046 & 4.2765 & TRN & & \\
\hline CHEMBL3208784 & 688719 & 5.0333 & 4.2025 & TRN & & \\
\hline CHEMBL1606318 & 688719 & 3.301 & 4.0831 & TRN & & \\
\hline CHEMBL1441401 & 688719 & 6.8062 & 4.7847 & TRN & & \\
\hline CHEMBL1323006 & 688719 & 5.5661 & 4.6792 & TRN & & \\
\hline CHEMBL1438722 & 688719 & 3.301 & 3.5083 & TRN & & \\
\hline CHEMBL1556956 & 688719 & 3.301 & 4.0627 & TRN & & \\
\hline CHEMBL1606722 & 688719 & 4.769 & 4.7708 & TRN & & \\
\hline CHEMBL1400764 & 688719 & 5.3458 & 4.9912 & TRN & & \\
\hline
\end{tabular}

Page 12015 


\begin{tabular}{|c|c|c|c|c|c|}
\hline & & \multicolumn{4}{|c|}{ Supplemental Table S2.txt } \\
\hline CHEMBL1466894 & 688719 & 3.301 & 3.9176 & TRN & \\
\hline CHEMBL1588072 & 688719 & 4.7649 & 4.0881 & TRN & \\
\hline CHEMBL1586116 & 688719 & 5.1713 & 4.4334 & TRN & \\
\hline CHEMBL1443554 & 688719 & 4.9854 & 4.9458 & TRN & \\
\hline CHEMBL1399420 & 688719 & 3.301 & 3.638 & TST & \\
\hline CHEMBL1509500 & 688719 & 6.8062 & 3.9466 & TRN & \\
\hline CHEMBL1359987 & 688719 & 3.301 & 3.8687 & TRN & \\
\hline CHEMBL1420184 & 688719 & 3.301 & 4.1509 & TRN & \\
\hline CHEMBL1397845 & 688719 & 5.2046 & 4.292 & TRN & \\
\hline CHEMBL1332007 & 688719 & 5.4553 & 3.8383 & TRN & \\
\hline CHEMBL1405097 & 688719 & 5.1648 & 3.2115 & TRN & \\
\hline CHEMBL1398769 & 688719 & 3.301 & 3.8697 & TRN & \\
\hline CHEMBL1539325 & 688719 & 6.8062 & 5.5225 & TST & \\
\hline CHEMBL1559715 & 688719 & 5.5347 & 5.1629 & TRN & \\
\hline CHEMBL1384049 & 688719 & 4.5954 & 4.1386 & TRN & \\
\hline CHEMBL1577661 & 688719 & 5.7188 & 5.0512 & TRN & \\
\hline CHEMBL1307067 & 688719 & 3.301 & 3.517 & TRN & \\
\hline CHEMBL1431555 & 688719 & 5.5779 & 4.3942 & TRN & \\
\hline CHEMBL1495173 & 688719 & 5.0034 & 4.1067 & TST & \\
\hline CHEMBL1561864 & 688719 & 4.7829 & 4.1958 & TRN & \\
\hline CHEMBL3208616 & 688719 & 3.301 & 3.27399 & 99999999996 & TRN \\
\hline CHEMBL3189964 & 688719 & 3.301 & 4.9722 & TRN & \\
\hline CHEMBL1600942 & 688719 & 3.301 & 4.4689 & TRN & \\
\hline CHEMBL 1611750 & 688719 & 5.2558 & 4.2789 & TRN & \\
\hline CHEMBL1319815 & 688719 & 3.301 & 3.5059 & TRN & \\
\hline CHEMBL1583687 & 688719 & 5.2358 & 5.0066 & TRN & \\
\hline CHEMBL1597933 & 688719 & 3.301 & 3.8472 & TST & \\
\hline CHEMBL1496995 & 688719 & 4.62 & 4.6387 & TRN & \\
\hline CHEMBL1549371 & 688719 & 5.0688 & 3.2189 & TRN & \\
\hline CHEMBL1605393 & 688719 & 4.9198 & 4.6593 & TST & \\
\hline CHEMBL1532174 & 688719 & 4.9211 & 4.2576 & TST & \\
\hline CHEMBL377295 & 688719 & 6.8062 & 4.8732 & TRN & \\
\hline CHEMBL600336 & 688719 & 5.5832 & 4.5522 & TRN & \\
\hline CHEMBL3198962 & 688719 & 4.732 & 4.6813 & TRN & \\
\hline CHEMBL1329623 & 688719 & 3.301 & 3.6783 & TST & \\
\hline CHEMBL1540767 & 688719 & 4.5762 & 4.2243 & TRN & \\
\hline CHEMBL1381306 & 688719 & 5.275 & 4.5558 & TRN & \\
\hline CHEMBL1498031 & 688719 & 3.301 & 3.5726 & TRN & \\
\hline CHEMBL1404075 & 688719 & 3.301 & 4.2779 & TST & \\
\hline CHEMBL3856094 & 688719 & 3.301 & 3.9076 & TRN & \\
\hline CHEMBL1331084 & 688719 & 3.301 & 4.8846 & TRN & \\
\hline CHEMBL482642 & 688719 & 4.6074 & 4.6983 & TRN & \\
\hline CHEMBL1382806 & 688719 & 3.301 & 4.3422 & TRN & \\
\hline CHEMBL1464018 & 688719 & 3.301 & 3.3819 & TRN & \\
\hline CHEMBL1463954 & 688719 & 4.7259 & 4.8265 & TRN & \\
\hline CHEMBL1388279 & 688719 & 3.301 & 3.4715 & TRN & \\
\hline CHEMBL1401253 & 688719 & 3.301 & 4.3922 & TRN & \\
\hline CHEMBL1481770 & 688719 & 3.301 & 4.1357 & TRN & \\
\hline
\end{tabular}




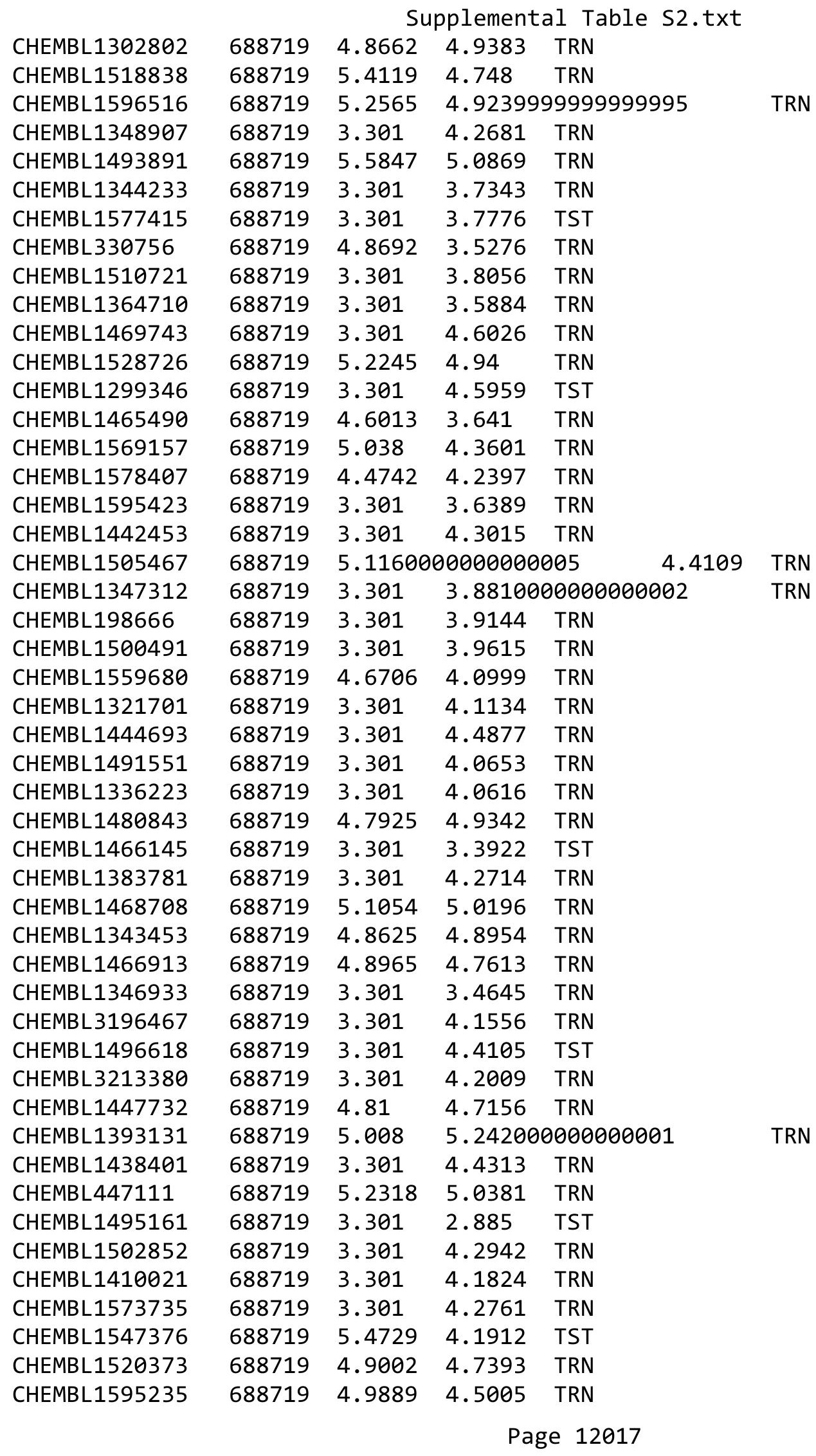




\begin{tabular}{|c|c|c|c|c|}
\hline & & & oplement & al $\mathrm{Tc}$ \\
\hline CHEMBL577758 & 688719 & 5.4118 & 4.63 & TRN \\
\hline CHEMBL1476347 & 688719 & 3.301 & 4.1625 & TRN \\
\hline CHEMBL1584730 & 688719 & 4.5862 & 4.245 & TRN \\
\hline CHEMBL1463692 & 688719 & 3.301 & 3.3936 & TRN \\
\hline CHEMBL1526851 & 688719 & 5.3048 & 4.5847 & TRN \\
\hline CHEMBL1342667 & 688719 & 3.301 & 3.5479 & TRN \\
\hline CHEMBL1530563 & 688719 & 3.301 & 3.9482 & TRN \\
\hline CHEMBL1531320 & 688719 & 5.4474 & 4.7851 & TRN \\
\hline CHEMBL1965461 & 688719 & 3.301 & 3.8919 & TST \\
\hline CHEMBL1440196 & 688719 & 3.301 & 3.6013 & TRN \\
\hline CHEMBL1300008 & 688719 & 5.1827 & 4.9386 & TRN \\
\hline CHEMBL1578520 & 688719 & 3.301 & 4.0991 & TRN \\
\hline CHEMBL1374216 & 688719 & 3.301 & 3.5987 & TRN \\
\hline CHEMBL1374539 & 688719 & 3.301 & 3.8112 & TST \\
\hline CHEMBL1373432 & 688719 & 3.301 & 4.0597 & TRN \\
\hline CHEMBL1445192 & 688719 & 4.6991 & 4.4778 & TST \\
\hline CHEMBL1530009 & 688719 & 3.301 & 4.162 & TRN \\
\hline CHEMBL1325233 & 688719 & 5.1245 & 4.8542 & TRN \\
\hline CHEMBL1307301 & 688719 & 5.2135 & 4.5922 & TRN \\
\hline CHEMBL1542128 & 688719 & 5.5766 & 5.1699 & TRN \\
\hline CHEMBL1605526 & 688719 & 5.1456 & 4.7923 & TRN \\
\hline CHEMBL1444824 & 688719 & 3.301 & 4.0587 & TRN \\
\hline CHEMBL1538135 & 688719 & 3.301 & 3.4129 & TRN \\
\hline CHEMBL1581440 & 688719 & 3.301 & 4.9531 & TRN \\
\hline CHEMBL1372307 & 688719 & 3.301 & 4.5411 & TRN \\
\hline CHEMBL1407483 & 688719 & 3.301 & 4.5468 & TST \\
\hline CHEMBL1467399 & 688719 & 4.965 & 4.3854 & TRN \\
\hline CHEMBL1505049 & 688719 & 4.6242 & 4.5272 & TRN \\
\hline CHEMBL1326210 & 688719 & 5.2211 & 4.2937 & TRN \\
\hline CHEMBL1458938 & 688719 & 4.8509 & 4.0058 & TRN \\
\hline CHEMBL1400512 & 688719 & 3.301 & 4.0514 & TST \\
\hline CHEMBL1407268 & 688719 & 3.301 & 4.7799 & TRN \\
\hline CHEMBL3144992 & 688719 & 3.301 & 3.799 & TRN \\
\hline CHEMBL1601624 & 688719 & 5.142 & 4.0817 & TST \\
\hline CHEMBL3193592 & 688719 & 3.301 & 4.4843 & TRN \\
\hline CHEMBL1490194 & 688719 & 6.8062 & 4.6814 & TRN \\
\hline CHEMBL1367590 & 688719 & 3.301 & 4.6252 & TRN \\
\hline CHEMBL1393548 & 688719 & 4.6649 & 4.3206 & TRN \\
\hline CHEMBL1342429 & 688719 & 3.301 & 4.159 & TRN \\
\hline CHEMBL1342063 & 688719 & 3.301 & 4.4333 & TRN \\
\hline CHEMBL1509453 & 688719 & 5.086 & 4.8873 & TRN \\
\hline CHEMBL1449660 & 688719 & 4.8693 & 3.7075 & TRN \\
\hline CHEMBL1606764 & 688719 & 3.301 & 4.558 & TRN \\
\hline CHEMBL1465900 & 688719 & 3.301 & 3.3188 & TST \\
\hline CHEMBL1427567 & 688719 & 3.301 & 3.9584 & TRN \\
\hline CHEMBL1432915 & 688719 & 3.301 & 3.3195 & TRN \\
\hline CHEMBL1468811 & 688719 & 5.5046 & 4.9545 & TST \\
\hline CHEMBL1413557 & 688719 & 5.473 & 5.1727 & TRN \\
\hline
\end{tabular}




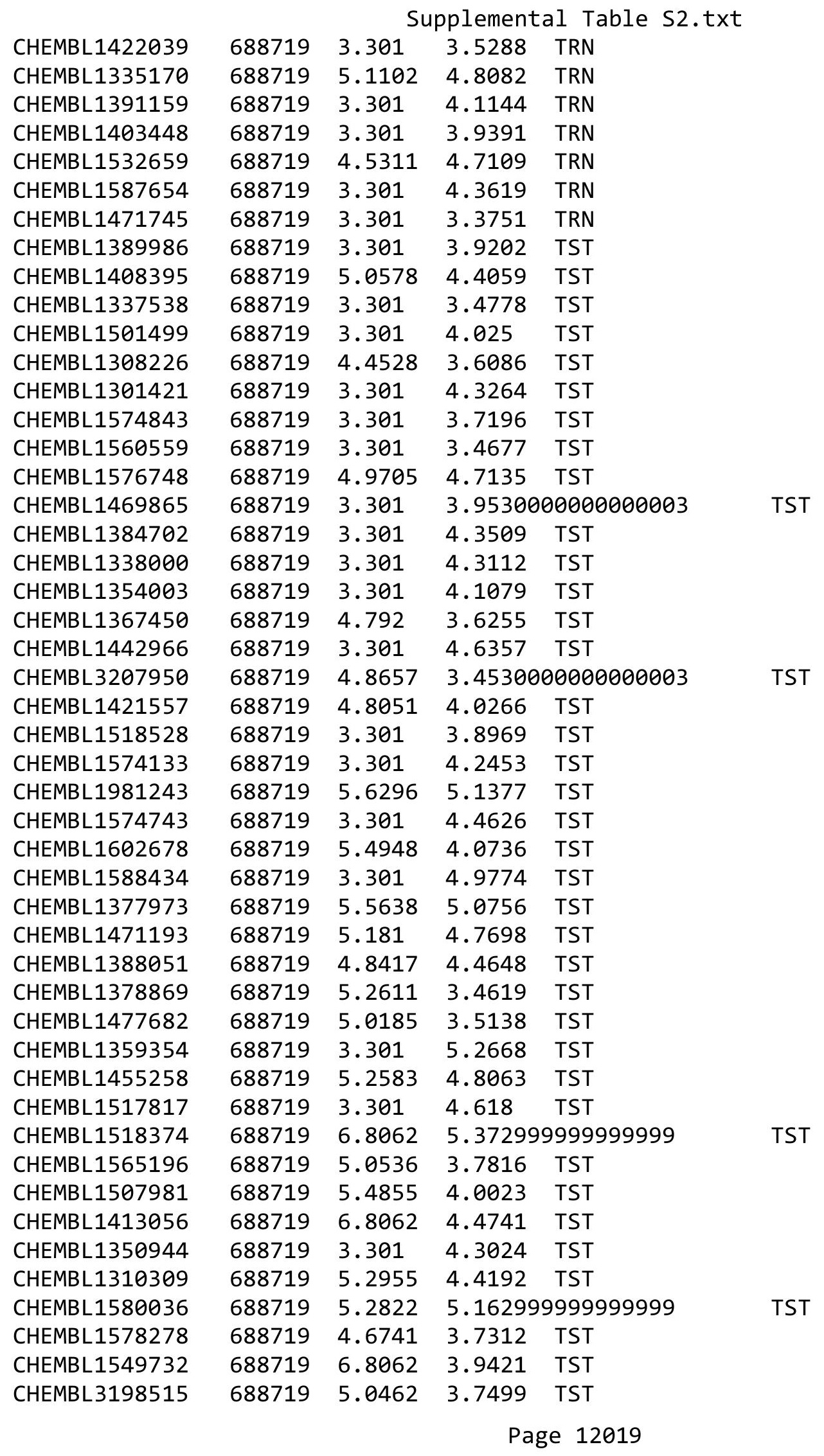




\begin{tabular}{|c|c|c|c|c|c|c|}
\hline \multirow[b]{2}{*}{ CHEMBL1538696 } & \multicolumn{6}{|c|}{ Supplemental Table S2.txt } \\
\hline & 688719 & 4.8576 & 4.3045 & TST & & \\
\hline CHEMBL1469332 & 688719 & 4.94300 & 00000006 & 005 & 4.3081 & TST \\
\hline CHEMBL1374573 & 688719 & 4.6555 & 4.7311 & TST & & \\
\hline CHEMBL1485627 & 688719 & 3.301 & 3.5881 & TST & & \\
\hline CHEMBL1313635 & 688719 & 3.301 & 4.4607 & TST & & \\
\hline CHEMBL1342645 & 688719 & 5.4083 & 4.4879 & TST & & \\
\hline CHEMBL1548361 & 688719 & 4.9389 & 4.0038 & TST & & \\
\hline CHEMBL1345862 & 688719 & 3.301 & 3.7917 & TST & & \\
\hline CHEMBL1562870 & 688719 & 5.0541 & 4.6103 & TST & & \\
\hline CHEMBL3199523 & 688719 & 5.3289 & 3.9565 & TST & & \\
\hline CHEMBL1569742 & 688719 & 5.5672 & 4.8904 & TST & & \\
\hline CHEMBL3392035 & 688719 & 3.301 & 5.2068 & TST & & \\
\hline CHEMBL1221925 & 688218 & 4.3 & 4.2793 & TRN & & \\
\hline CHEMBL1602127 & 688218 & 4.1 & 4.3366 & TRN & & \\
\hline CHEMBL1569226 & 688218 & 5.5 & 5.3813 & TRN & & \\
\hline CHEMBL1559341 & 688218 & 4.8 & 4.4798 & TRN & & \\
\hline CHEMBL280998 & 688218 & 4.8 & 4.4822 & TRN & & \\
\hline CHEMBL230156 & 688218 & 4.3 & 4.1647 & TRN & & \\
\hline CHEMBL389950 & 688218 & 4.1 & 4.1208 & TST & & \\
\hline CHEMBL1526319 & 688218 & 4.4 & 4.3925 & TRN & & \\
\hline CHEMBL462576 & 688218 & 4.3 & 4.21 & TRN & & \\
\hline CHEMBL140 & 688218 & 4.5 & 4.5509 & TRN & & \\
\hline CHEMBL1330518 & 688218 & 4.1 & 4.2549 & TRN & & \\
\hline CHEMBL1528479 & 688218 & 4.1 & 4.1552 & TRN & & \\
\hline CHEMBL3391990 & 688218 & 4.3 & 4.383 & TST & & \\
\hline CHEMBL1303139 & 688218 & 5.4 & 5.3868 & TRN & & \\
\hline CHEMBL1519327 & 688218 & 6.4 & 6.3923 & TRN & & \\
\hline CHEMBL1462419 & 688218 & 4.4 & 4.3712 & TST & & \\
\hline CHEMBL1545634 & 688218 & 6.8 & 6.4282 & TRN & & \\
\hline CHEMBL8739 & 688218 & 4.3 & 4.2465 & TRN & & \\
\hline CHEMBL162598 & 688218 & 4.4 & 4.3301 & TST & & \\
\hline CHEMBL1338613 & 688218 & 4.5 & 4.2441 & TST & & \\
\hline CHEMBL1510786 & 688218 & 4.4 & 4.4998 & TST & & \\
\hline CHEMBL1409985 & 688218 & 5.4 & 5.3924 & TRN & & \\
\hline CHEMBL1407826 & 688218 & 4.6 & 4.982 & TST & & \\
\hline CHEMBL1449018 & 688218 & 4.6 & 4.6738 & TRN & & \\
\hline CHEMBL1612246 & 688218 & 4.4 & 4.501 & TRN & & \\
\hline CHEMBL31425 & 688218 & 4.1 & 4.1535 & TRN & & \\
\hline CHEMBL1393325 & 688218 & 4.3 & 4.2735 & TRN & & \\
\hline CHEMBL1471289 & 688218 & 4.7 & 4.4587 & TRN & & \\
\hline CHEMBL443949 & 688218 & 4.3 & 4.3571 & TRN & & \\
\hline CHEMBL1576086 & 688218 & 4.5 & 4.397 & TRN & & \\
\hline CHEMBL1526721 & 688218 & 5.2 & 5.1216 & TRN & & \\
\hline CHEMBL220845 & 688218 & 4.4 & 4.3687 & TRN & & \\
\hline CHEMBL8320 & 688218 & 4.4 & 4.2952 & TRN & & \\
\hline CHEMBL144530 & 688218 & 4.5 & 4.2537 & TRN & & \\
\hline CHEMBL1530684 & 688218 & 4.4 & 4.4047 & TRN & & \\
\hline CHEMBL28 & 688218 & 4.3 & 4.4966 & TRN & & \\
\hline
\end{tabular}




\begin{tabular}{|c|c|c|c|c|}
\hline \multicolumn{5}{|c|}{ Supplemental Table S2.txt } \\
\hline CHEMBL1369243 & 688218 & 4.0 & 4.2446 & TRN \\
\hline CHEMBL1496957 & 688218 & 4.9 & 4.8701 & TRN \\
\hline CHEMBL1527567 & 688218 & 4.4 & 4.4309 & TRN \\
\hline CHEMBL192627 & 688218 & 4.8 & 4.7006 & TRN \\
\hline CHEMBL1200471 & 688218 & 6.7001 & 6.6937 & TRN \\
\hline CHEMBL1414154 & 688218 & 4.3 & 4.1784 & TRN \\
\hline CHEMBL1602699 & 688218 & 5.4 & 5.2909 & TRN \\
\hline CHEMBL468037 & 688218 & 4.3 & 4.3583 & TRN \\
\hline CHEMBL1450607 & 688218 & 4.7 & 4.8049 & TRN \\
\hline CHEMBL195953 & 688218 & 4.3 & 4.2751 & TRN \\
\hline CHEMBL1565705 & 688218 & 4.1 & 4.1907 & TRN \\
\hline CHEMBL1499545 & 688218 & 5.4 & 5.3559 & TRN \\
\hline CHEMBL1585396 & 688218 & 4.3 & 4.2379 & TRN \\
\hline CHEMBL1492884 & 688218 & 4.4 & 4.3892 & TRN \\
\hline CHEMBL85811 & 688218 & 4.3 & 4.1882 & TRN \\
\hline CHEMBL36296 & 688218 & 4.3 & 4.2697 & TRN \\
\hline CHEMBL 224282 & 688218 & 4.3 & 4.3801 & TRN \\
\hline CHEMBL1489064 & 688218 & 4.3 & 4.3183 & TRN \\
\hline CHEMBL1331245 & 688218 & 4.4 & 4.1969 & TRN \\
\hline CHEMBL1371285 & 688218 & 4.1 & 4.2016 & TRN \\
\hline CHEMBL1522486 & 688218 & 4.8 & 4.6223 & TRN \\
\hline CHEMBL1304981 & 688218 & 4.4 & 4.1931 & TST \\
\hline CHEMBL1448387 & 688218 & 4.6 & 4.6613 & TRN \\
\hline CHEMBL1428964 & 688218 & 4.1 & $4.2360 e$ & 2000000001 \\
\hline CHEMBL1549844 & 688218 & 4.8 & 4.7176 & TST \\
\hline CHEMBL296021 & 688218 & 4.1 & 4.2635 & TRN \\
\hline CHEMBL1142 & 688218 & 4.5 & 4.4972 & TRN \\
\hline CHEMBL513678 & 688218 & 4.4 & 4.6176 & TST \\
\hline CHEMBL1562104 & 688218 & 5.4 & 5.6438 & TRN \\
\hline CHEMBL 242080 & 688218 & 4.3 & 4.5738 & TRN \\
\hline CHEMBL1370662 & 688218 & 4.3 & 4.3813 & TRN \\
\hline CHEMBL1236200 & 688218 & 4.1 & 4.1309 & TRN \\
\hline CHEMBL172064 & 688218 & 4.3 & 4.3226 & TST \\
\hline CHEMBL1319452 & 688218 & 4.6 & 4.6537 & TRN \\
\hline CHEMBL85728 & 688218 & 4.4 & 4.3758 & TRN \\
\hline CHEMBL1566504 & 688218 & 4.4 & 4.4411 & TRN \\
\hline CHEMBL1308088 & 688218 & 5.0 & 4.8845 & TRN \\
\hline CHEMBL1451833 & 688218 & 4.7 & 4.5005 & TST \\
\hline CHEMBL 285235 & 688218 & 4.1 & 4.2562 & TRN \\
\hline CHEMBL105712 & 688218 & 5.0 & 5.1757 & TRN \\
\hline CHEMBL44072 & 688218 & 4.4 & 4.2529 & TRN \\
\hline CHEMBL1309179 & 688218 & 4.9 & 4.8577 & TRN \\
\hline CHEMBL 8145 & 688218 & 4.5 & 4.3736 & TRN \\
\hline CHEMBL 1484480 & 688218 & 4.1 & 3.9864 & TRN \\
\hline CHEMBL1600998 & 688218 & 5.1 & 5.4926 & TRN \\
\hline CHEMBL1492729 & 688218 & 4.9 & 4.8701 & TRN \\
\hline CHEMBL1462995 & 688218 & 4.1 & 4.4445 & TST \\
\hline CHEMBL1545045 & 688218 & 4.3 & 4.4459 & TRN \\
\hline
\end{tabular}




\begin{tabular}{|c|c|c|c|c|}
\hline & & & pplement & $d \perp$ \\
\hline CHEMBL1609459 & 688218 & 5.1 & 5.1954 & TRN \\
\hline CHEMBL445957 & 688218 & 4.3 & 4.3294 & TRN \\
\hline CHEMBL1580759 & 688218 & 4.5 & 4.4589 & TRN \\
\hline CHEMBL 364900 & 688218 & 4.3 & 4.5207 & TRN \\
\hline CHEMBL1485360 & 688218 & 4.4 & 4.6689 & TST \\
\hline CHEMBL1518369 & 688218 & 4.4 & 4.2713 & TRN \\
\hline CHEMBL334255 & 688218 & 4.9 & 4.9736 & TRN \\
\hline CHEMBL1323107 & 688218 & 4.1 & 4.2095 & TRN \\
\hline CHEMBL1558796 & 688218 & 4.4 & 4.6653 & TRN \\
\hline CHEMBL1578983 & 688218 & 4.8 & 4.3824 & TRN \\
\hline CHEMBL1535689 & 688218 & 4.4 & 4.3626 & TRN \\
\hline CHEMBL486193 & 688218 & 4.3 & 4.2503 & TRN \\
\hline CHEMBL1366408 & 688218 & 4.7 & 4.6527 & TST \\
\hline CHEMBL1492104 & 688218 & 4.9 & 4.7499 & TST \\
\hline CHEMBL1365278 & 688218 & 4.2 & 4.7463 & TST \\
\hline CHEMBL440287 & 688218 & 4.4 & 4.503 & TRN \\
\hline CHEMBL935 & 688218 & 4.4 & 4.4367 & TRN \\
\hline CHEMBL1517425 & 688218 & 4.3 & 4.1788 & TST \\
\hline CHEMBL1569493 & 688218 & 6.2 & 6.0282 & TST \\
\hline CHEMBL1524617 & 688218 & 5.3 & 5.3817 & TST \\
\hline CHEMBL509531 & 688218 & 4.8 & 4.7739 & TST \\
\hline CHEMBL402063 & 688218 & 6.0 & 5.6349 & TST \\
\hline CHEMBL1485974 & 688218 & 4.5 & 4.2991 & TST \\
\hline CHEMBL1447588 & 688218 & 5.1 & 4.8728 & TST \\
\hline CHEMBL1456906 & 688218 & 4.4 & 4.5711 & TST \\
\hline CHEMBL1408847 & 688218 & 5.3 & 5.5421 & TST \\
\hline CHEMBL1430204 & 688218 & 4.4 & 4.5524 & TST \\
\hline CHEMBL346918 & 688218 & 4.1 & 4.3257 & TST \\
\hline CHEMBL1452158 & 688218 & 4.3 & 4.2775 & TST \\
\hline CHEMBL1438889 & 737715 & 5.5599 & 5.3416 & TRN \\
\hline CHEMBL1557469 & 737715 & 3.1002 & 3.0427 & TRN \\
\hline CHEMBL1343286 & 737715 & 3.1002 & 3.0473 & TRN \\
\hline CHEMBL1565650 & 737715 & 3.1002 & 3.1215 & TST \\
\hline CHEMBL 570345 & 737715 & 6.9066 & 5.8721 & TRN \\
\hline CHEMBL1359401 & 737715 & 3.1002 & 3.1033 & TRN \\
\hline CHEMBL1371394 & 737715 & 3.1002 & 3.0895 & TRN \\
\hline CHEMBL1344691 & 737715 & 3.1002 & 3.0945 & TRN \\
\hline CHEMBL1424694 & 737715 & 5.3562 & 5.4329 & TRN \\
\hline CHEMBL1493152 & 737715 & 3.1002 & 3.0549 & TRN \\
\hline CHEMBL3190951 & 737715 & 5.0665 & 5.0203 & TRN \\
\hline CHEMBL1442148 & 737715 & 3.1002 & 2.932 & TST \\
\hline CHEMBL1467425 & 737715 & 3.1002 & 3.0346 & TRN \\
\hline CHEMBL1484610 & 737715 & 3.1002 & 3.0506 & TRN \\
\hline CHEMBL1543833 & 737715 & 3.1002 & 2.9987 & TRN \\
\hline CHEMBL1301248 & 737715 & 3.1002 & 3.0682 & TRN \\
\hline CHEMBL1330067 & 737715 & 3.1002 & 3.0855 & TRN \\
\hline CHEMBL 1383176 & 737715 & 3.1002 & 3.1229 & TRN \\
\hline CHEMBL1327743 & 737715 & 3.1002 & 3.0229 & TRN \\
\hline
\end{tabular}


Supplemental Table S2.txt

\begin{tabular}{|c|c|c|c|c|}
\hline CHEMBL1492463 & 737715 & 3.1002 & 3.0371 & TRN \\
\hline CHEMBL1583199 & 737715 & 3.1002 & 3.1591 & TST \\
\hline CHEMBL1578734 & 737715 & 3.1002 & 3.0756 & TRN \\
\hline CHEMBL1471865 & 737715 & 5.0256 & 4.9898 & TRN \\
\hline CHEMBL1443268 & 737715 & 4.8054 & 5.4094 & TRN \\
\hline CHEMBL1413468 & 737715 & 3.1002 & 3.0585 & TRN \\
\hline CHEMBL1546449 & 737715 & 3.1002 & 3.1608 & TRN \\
\hline CHEMBL1385167 & 737715 & 3.1002 & 3.3322 & TRN \\
\hline CHEMBL1302136 & 737715 & 3.1002 & 2.9878 & TRN \\
\hline CHEMBL1323857 & 737715 & 3.1002 & 3.1146 & TRN \\
\hline CHEMBL1549636 & 737715 & 3.1002 & 3.2344 & TRN \\
\hline CHEMBL1338178 & 737715 & 3.1002 & 2.9901 & TRN \\
\hline CHEMBL1503817 & 737715 & 3.1002 & 3.0407 & TRN \\
\hline CHEMBL3209512 & 737715 & 3.1002 & 3.0266 & TRN \\
\hline CHEMBL1416842 & 737715 & 3.1002 & 3.1977 & TRN \\
\hline CHEMBL1306172 & 737715 & 3.1002 & 3.0997 & TRN \\
\hline CHEMBL1993612 & 737715 & 3.1002 & 3.2717 & TRN \\
\hline CHEMBL1360572 & 737715 & 3.1002 & 2.9999 & TRN \\
\hline CHEMBL1439815 & 737715 & 4.9512 & 5.1129 & TRN \\
\hline CHEMBL1976414 & 737715 & 4.4251 & 4.2639 & TRN \\
\hline CHEMBL1444510 & 737715 & 3.1002 & 3.1974 & TRN \\
\hline CHEMBL1426096 & 737715 & 5.6209 & 5.2491 & TRN \\
\hline CHEMBL1309430 & 737715 & 4.208 & 4.1123 & TST \\
\hline CHEMBL1491640 & 737715 & 3.1002 & 3.1124 & TST \\
\hline CHEMBL1444644 & 737715 & 3.1002 & 3.1342 & TRN \\
\hline CHEMBL1341830 & 737715 & 3.1002 & 3.1504 & TST \\
\hline CHEMBL1492668 & 737715 & 3.1002 & 3.3514 & TRN \\
\hline CHEMBL599924 & 737715 & 4.9317 & 4.505 & TRN \\
\hline CHEMBL1443048 & 737715 & 3.1002 & 3.1393 & TRN \\
\hline CHEMBL1529554 & 737715 & 4.8247 & 4.7655 & TRN \\
\hline CHEMBL1508571 & 737715 & 3.1002 & 3.1028 & TRN \\
\hline CHEMBL1448279 & 737715 & 3.1002 & 3.0774 & TRN \\
\hline CHEMBL1499702 & 737715 & 3.1002 & 2.8962 & TRN \\
\hline CHEMBL1335318 & 737715 & 3.1002 & 3.2041 & TRN \\
\hline CHEMBL3196559 & 737715 & 3.1002 & 3.0214 & TST \\
\hline CHEMBL1535241 & 737715 & 3.1002 & 3.188 & TRN \\
\hline CHEMBL1701224 & 737715 & 6.9066 & 7.0058 & TRN \\
\hline CHEMBL1429070 & 737715 & 3.1002 & 3.1813 & TST \\
\hline CHEMBL1444606 & 737715 & 3.1002 & 3.1275 & TRN \\
\hline CHEMBL 2000167 & 737715 & 5.3295 & 5.8373 & TRN \\
\hline CHEMBL1547129 & 737715 & 3.1002 & 2.9655 & TRN \\
\hline CHEMBL1581837 & 737715 & 3.1002 & 3.1959 & TRN \\
\hline CHEMBL1320181 & 737715 & 6.9066 & 6.1795 & TRN \\
\hline CHEMBL 3198585 & 737715 & 3.1002 & 3.2029 & TRN \\
\hline CHEMBL1373137 & 737715 & 3.1002 & 3.1434 & TST \\
\hline CHEMBL1556336 & 737715 & 3.1002 & 3.14399 & 99999999997 \\
\hline CHEMBL1585090 & 737715 & 3.1002 & 3.0613 & TRN \\
\hline CHEMBL1600686 & 737715 & 3.1002 & 3.1357 & TRN \\
\hline
\end{tabular}

Page 12023 
Supplemental Table S2.txt

\begin{tabular}{|c|c|c|c|c|}
\hline AEMBL1486682 & 37715 & 002 & & \\
\hline & 37715 & 3.1002 & 3.1866 & \\
\hline & 15 & & & \\
\hline IEMBL14 & 7715 & 1002 & & \\
\hline AEMBL1 & 37715 & 1002 & & \\
\hline AEMBL3193406 & 37715 & 1002 & 674 & \\
\hline AEMBL] & 715 & 212 & & \\
\hline EMBL & 37715 & 1002 & & \\
\hline AEMBL1574873 & 37715 & 1002 & & \\
\hline 26115 & 37715 & 1002 & 296 & \\
\hline 8328 & 15 & 1002 & & \\
\hline IEMBL: & 715 & 002 & & \\
\hline IEMBL & & & & \\
\hline AEMBL & 37715 & 1002 & & \\
\hline IEMBL: & 715 & 1002 & & \\
\hline IEMBL. & 5 & 002 & & \\
\hline AEMBL & 15 & 02 & & \\
\hline AEMBL & & & & \\
\hline IEMBL & & 002 & & \\
\hline IEMBL & & 066 & & \\
\hline IEMBL & 5 & 02 & & \\
\hline EMBL & 15 & & & \\
\hline EMB & & 02 & & \\
\hline 200 & & 825 & & \\
\hline IEMBL: & & & & \\
\hline IEMBL & 15 & 02 & & \\
\hline EMBL & 15 & 2 & & \\
\hline 52 & 15 & $\partial 2$ & & נת \\
\hline IEMBL & & 3.1002 & & \\
\hline AEMBL] & & & & RN \\
\hline IEMBL & 15 & 02 & & $\mathrm{RI}$ \\
\hline 51 & 15 & 2 & & 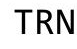 \\
\hline 6 & 15 & $\partial 2$ & & 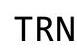 \\
\hline 3895 & & 02 & & RI \\
\hline AEMBL3 & 715 & 3.1002 & & KI \\
\hline IEMBL & 15 & 002 & & RI \\
\hline 8 & 15 & 2 & & 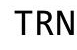 \\
\hline & & 964 & & RN \\
\hline 6746 & 15 & 4.2377 & & \\
\hline EMBL & 15 & 3.1002 & & $\mathrm{RI}$ \\
\hline IEMBL & 15 & .1002 & & \\
\hline & & & & \\
\hline HEMBL: & 37715 & 3.1002 & 034 & RI \\
\hline EMBL: & 37715 & 6946 & 103 & $\mathrm{R}$ \\
\hline 6 & & 002 & & \\
\hline CHEMBL: & 37715 & 6.9066 & & \\
\hline CHEMBL & 37715 & 5.3898 & 4.6694 & \\
\hline CHEMBL1404195 & 737715 & 3.1002 & 3.1576 & $\mathrm{R}$ \\
\hline
\end{tabular}

Page 12024 
Supplemental Table S2.txt

\begin{tabular}{|c|c|c|c|c|c|}
\hline CHEMBL3192388 & 737715 & 3.1002 & 3.0733 & TRN & \\
\hline CHEMBL1455026 & 737715 & 3.1002 & 3.32800 & 00000000003 & TRN \\
\hline CHEMBL3145282 & 737715 & 3.1002 & 3.4254 & TST & \\
\hline CHEMBL1580263 & 737715 & 4.8604 & 5.1104 & TST & \\
\hline CHEMBL1527520 & 737715 & 5.0783 & 4.8647 & TST & \\
\hline CHEMBL3209125 & 737715 & 3.1002 & 3.2336 & TST & \\
\hline CHEMBL1488035 & 737715 & 4.9821 & 4.5893 & TST & \\
\hline CHEMBL1448367 & 737715 & 3.1002 & 2.9933 & TST & \\
\hline CHEMBL1340439 & 737715 & 3.1002 & 3.0173 & TST & \\
\hline CHEMBL 2001743 & 737715 & 6.9066 & 6.0475 & TST & \\
\hline CHEMBL1371816 & 737715 & 5.1922 & 5.6699 & TST & \\
\hline CHEMBL1304417 & 737715 & 3.1002 & 3.0326 & TST & \\
\hline CHEMBL1445488 & 737715 & 6.9066 & 6.8261 & TST & \\
\hline CHEMBL1584670 & 737715 & 3.1002 & 3.1778 & TST & \\
\hline CHEMBL1535167 & 737715 & 3.1002 & 3.1432 & TST & \\
\hline CHEMBL1442305 & 737715 & 3.1002 & 3.2323 & TST & \\
\hline CHEMBL1574353 & 737715 & 3.1002 & 3.1955 & TST & \\
\hline CHEMBL1414751 & 737715 & 3.1002 & 3.1043 & TST & \\
\hline CHEMBL1412887 & 737715 & 3.1002 & 3.1081 & TST & \\
\hline CHEMBL1337760 & 737715 & 3.1002 & 3.0283 & TST & \\
\hline CHEMBL3211928 & 737715 & 3.1002 & 3.0039 & TST & \\
\hline CHEMBL1393012 & 737715 & 3.1002 & 3.1022 & TST & \\
\hline CHEMBL1521466 & 737715 & 3.1002 & 3.3231 & TST & \\
\hline CHEMBL1458343 & 737715 & 3.1002 & 3.4493 & TST & \\
\hline CHEMBL1417070 & 737715 & 4.314 & 4.5758 & TST & \\
\hline CHEMBL346495 & 34799 & 7.1427 & 6.9952 & TRN & \\
\hline CHEMBL1788153 & 34799 & 6.7212 & 7.4226 & TRN & \\
\hline CHEMBL554712 & 34799 & 6.5528 & 6.9066 & TRN & \\
\hline CHEMBL346473 & 34799 & 6.0458 & 5.9613 & TST & \\
\hline CHEMBL406430 & 34799 & 7.3468 & 6.3647 & TRN & \\
\hline CHEMBL350484 & 34799 & 7.3565 & 7.7043 & TRN & \\
\hline CHEMBL346254 & 34799 & 6.5686 & 6.4209 & TRN & \\
\hline CHEMBL350258 & 34799 & 7.2218 & 6.7442 & TRN & \\
\hline CHEMBL26338 & 34799 & 6.5229 & 7.5423 & TRN & \\
\hline CHEMBL347447 & 34799 & 7.1938 & 6.6726 & TRN & \\
\hline CHEMBL159151 & 34799 & 6.5686 & 6.682 & TRN & \\
\hline CHEMBL422013 & 34799 & 7.3565 & 6.9324 & TRN & \\
\hline CHEMBL347861 & 34799 & 6.1938 & 6.9047 & TST & \\
\hline CHEMBL160942 & 34799 & 4.8239 & 5.9693 & TRN & \\
\hline CHEMBL346535 & 34799 & 6.9208 & 7.3447 & TRN & \\
\hline CHEMBL348347 & 34799 & 5.7212 & 6.2467 & TST & \\
\hline CHEMBL158663 & 34799 & 6.1249 & 6.5091 & TST & \\
\hline CHEMBL 23727 & 34799 & 7.6383 & 7.7948 & TRN & \\
\hline CHEMBL345858 & 34799 & 7.4949 & 7.1103 & TRN & \\
\hline CHEMBL345623 & 34799 & 6.2676 & 6.4553 & TRN & \\
\hline CHEMBL350718 & 34799 & 7.0555 & 6.4209 & TRN & \\
\hline CHEMBL347460 & 34799 & 6.4685 & 6.5918 & TRN & \\
\hline CHEMBL158650 & 34799 & 5.3468 & 5.9496 & TRN & \\
\hline
\end{tabular}




\begin{tabular}{|c|c|c|c|c|c|}
\hline \multirow[b]{2}{*}{ CHEMBL160361 } & \multicolumn{5}{|c|}{ Supplemental Table S2.txt } \\
\hline & 34799 & 8.301 & 7.8253 & TRN & \\
\hline CHEMBL1788148 & 34799 & 7.5086 & 7.1858 & TRN & \\
\hline CHEMBL160927 & 34799 & 6.8861 & 7.03600 & 00000000005 & TRN \\
\hline CHEMBL1788147 & 34799 & 7.5086 & 7.3486 & TRN & \\
\hline CHEMBL159075 & 34799 & 7.2924 & 6.9638 & TRN & \\
\hline CHEMBL348043 & 34799 & 7.1249 & 7.0416 & TRN & \\
\hline CHEMBL158994 & 34799 & 6.9586 & 6.9385 & TRN & \\
\hline CHEMBL346588 & 34799 & 7.2596 & 6.5911 & TST & \\
\hline CHEMBL159076 & 34799 & 6.2596 & 6.5805 & TRN & \\
\hline CHEMBL347633 & 34799 & 6.8861 & 6.9883 & TST & \\
\hline CHEMBL158673 & 34799 & 6.0 & 5.8962 & TRN & \\
\hline CHEMBL160473 & 34799 & 6.6576 & 6.4501 & TRN & \\
\hline CHEMBL159000 & 34799 & 6.8861 & 7.1974 & TRN & \\
\hline CHEMBL422535 & 34799 & 7.2596 & 7.24100 & 00000000005 & TST \\
\hline CHEMBL346255 & 34799 & 7.7212 & 7.7858 & TRN & \\
\hline CHEMBL160689 & 34799 & 7.1249 & 7.1085 & TRN & \\
\hline CHEMBL345619 & 34799 & 7.1249 & 6.7474 & TST & \\
\hline CHEMBL 348040 & 34799 & 7.7447 & 7.2205 & TRN & \\
\hline CHEMBL158617 & 34799 & 6.7696 & 7.3341 & TST & \\
\hline CHEMBL160770 & 34799 & 7.0862 & 6.4095 & TRN & \\
\hline CHEMBL157870 & 34799 & 6.1549 & 6.6054 & TST & \\
\hline CHEMBL160567 & 34799 & 6.0 & 6.5996 & TRN & \\
\hline CHEMBL347696 & 34799 & 6.2218 & 7.01399 & 9999999999 & TST \\
\hline CHEMBL158488 & 34799 & 5.2291 & 6.2383 & TRN & \\
\hline CHEMBL160985 & 34799 & 6.6576 & 6.4411 & TRN & \\
\hline CHEMBL349561 & 34799 & 6.5229 & 6.7589 & TST & \\
\hline CHEMBL1788152 & 34799 & 7.4559 & 7.1858 & TRN & \\
\hline CHEMBL 23641 & 34799 & 7.4815 & 7.5802 & TST & \\
\hline CHEMBL158972 & 34799 & 7.1024 & 7.2156 & TRN & \\
\hline CHEMBL345692 & 34799 & 6.5528 & 6.1868 & TRN & \\
\hline CHEMBL157543 & 34799 & 6.6778 & 6.9831 & TST & \\
\hline CHEMBL158962 & 34799 & 7.5229 & 7.2326 & TRN & \\
\hline CHEMBL347259 & 34799 & 7.3188 & 6.8363 & TST & \\
\hline CHEMBL347635 & 34799 & 7.0223 & 7.0598 & TRN & \\
\hline CHEMBL 3718268 & 1536986 & 5.6383 & 5.57100 & $\partial 000000001$ & TRN \\
\hline CHEMBL3716635 & 1536986 & 5.585 & 5.4991 & TRN & \\
\hline CHEMBL3716309 & 1536986 & 4.6576 & 5.1383 & TRN & \\
\hline CHEMBL3717059 & 1536986 & 4.4089 & 3.909 & TRN & \\
\hline CHEMBL3717063 & 1536986 & 5.4685 & 5.6774 & TRN & \\
\hline CHEMBL 3717470 & 1536986 & 6.0 & 5.6991 & TRN & \\
\hline CHEMBL3715121 & 1536986 & 4.7696 & 4.5968 & TRN & \\
\hline CHEMBL3715412 & 1536986 & 5.4949 & 5.8104 & TRN & \\
\hline CHEMBL3715919 & 1536986 & 5.2676 & 5.0852 & TRN & \\
\hline CHEMBL3718956 & 1536986 & 4.0605 & 3.3196 & TRN & \\
\hline CHEMBL3715494 & 1536986 & 5.0706 & 4.8044 & TRN & \\
\hline CHEMBL3717030 & 1536986 & 6.0 & 5.5825 & TRN & \\
\hline CHEMBL 3714773 & 1536986 & 4.2076 & 4.4859 & TRN & \\
\hline CHEMBL3718730 & 1536986 & 5.2076 & 5.1337 & TRN & \\
\hline
\end{tabular}


Supplemental Table S2.txt

\begin{tabular}{|c|c|c|c|c|}
\hline & & & & \\
\hline CHEMBL 3716143 & 536986 & 4.8861 & 4278 & \\
\hline AEMBL3718661 & 536986 & 68 & 3094 & \\
\hline & & & 134 & \\
\hline 9302 & 86 & 3.0 & 441 & \\
\hline AEMBL3716936 & 536986 & 949 & 1993 & \\
\hline AEMBL3716544 & 536986 & 6.1079 & 634 & \\
\hline HEMBL3 & & & & \\
\hline 191 & 86 & 192 & 034 & \\
\hline IEMBL: & 986 & 208 & 693 & \\
\hline AEMBL3716044 & 536986 & 5.7447 & 3716 & \\
\hline 17295 & 536986 & 5.7696 & 587 & \\
\hline 7174 & 536986 & 447 & 91 & \\
\hline 259 & 36 & 147 & & \\
\hline AEMBL & 536986 & 089 & 576 & \\
\hline 5533 & 536986 & 757 & 745 & \\
\hline 157 & 36 & & & \\
\hline 893 & 1536 & 4 & & \\
\hline 776 & 36 & & & \\
\hline 148 & 1536 & & 143 & \\
\hline 636 & 536986 & & 21 & \\
\hline 532 & 6 & & 22 & \\
\hline 825 & 53 & & & \\
\hline 783 & 6 & & & \\
\hline 105 & 152 & 76 & & \\
\hline 067 & & & & \\
\hline 900 & 36 & & & \\
\hline 368 & 6 & & & \\
\hline 27 & 6 & & & \\
\hline 407 & & & & \\
\hline 388 & 36 & & & \\
\hline 598 & 36986 & & 361 & \\
\hline & & & & \\
\hline 9 & 0 & 17 & & \\
\hline 200 & 1536986 & & 999 & \\
\hline 5048 & 1536986 & & 364 & \\
\hline 758 & 536986 & & & \\
\hline & & & & \\
\hline $\mathrm{CH}$ & 153 & & 13 & \\
\hline CHEMBL & 1536986 & & & \\
\hline CHEMBL & 535398 & & & \\
\hline $\mathrm{CH}$ & 535398 & & 47 & \\
\hline CHEMB & & & & \\
\hline CHEMBL & 535398 & & 909 & \\
\hline CHEMBL477176 & 535398 & 4.5686 & 4.336 & K \\
\hline CHEMBL & 535398 & 5.301 & 044 & \\
\hline & 535 & & & \\
\hline CHEMBL & 535398 & 5.3979 & 5.5614 & \\
\hline
\end{tabular}

Page 12027 


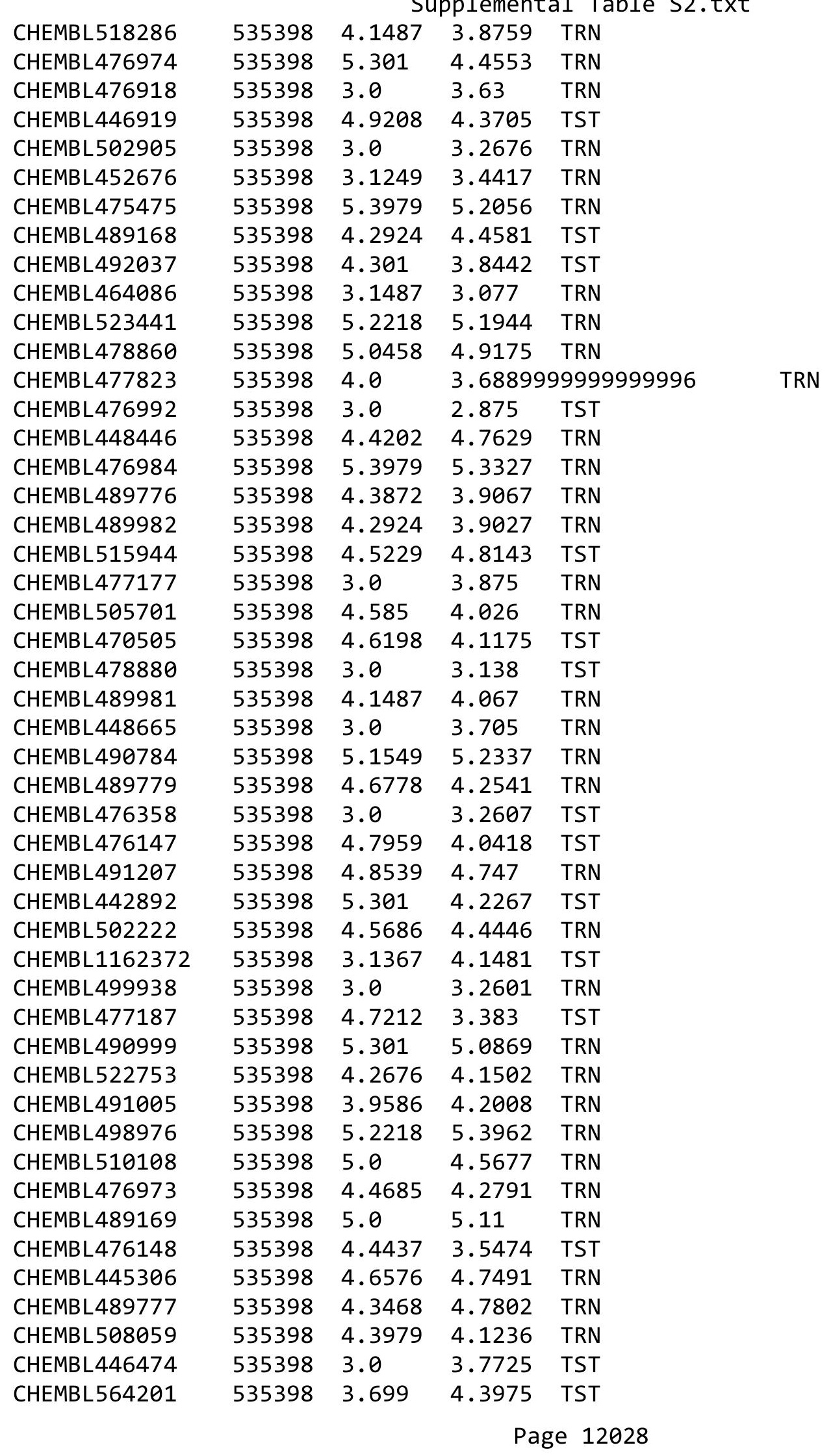




\begin{tabular}{|c|c|c|c|c|c|}
\hline & & & & & \\
\hline CHEMBL1203972 & 535398 & 3.0 & 3.1674 & TRN & \\
\hline CHEMBL452739 & 535398 & 3.0 & 3.032 & TRN & \\
\hline CHEMBL501654 & 535398 & 5.1549 & 5.4958 & TRN & \\
\hline CHEMBL490761 & 535398 & 4.4949 & 4.0928 & TRN & \\
\hline CHEMBL477596 & 535398 & 4.2757 & 3.77600 & 00000000002 & TRN \\
\hline CHEMBL476784 & 535398 & 5.0969 & 3.8131 & TST & \\
\hline CHEMBL522585 & 535398 & 3.0458 & 4.0942 & TRN & \\
\hline CHEMBL450720 & 535398 & 4.7447 & 4.8885 & TRN & \\
\hline CHEMBL478881 & 535398 & 4.2218 & 2.7207 & TST & \\
\hline CHEMBL442570 & 535398 & 4.4559 & 3.8379 & TST & \\
\hline CHEMBL418899 & 535398 & 4.699 & 4.5104 & TST & \\
\hline CHEMBL491007 & 535398 & 3.9586 & 3.8369 & TRN & \\
\hline CHEMBL490997 & 535398 & 5.2218 & 5.4495 & TRN & \\
\hline CHEMBL448250 & 535398 & 3.0 & 3.4679 & TRN & \\
\hline CHEMBL489564 & 535398 & 5.301 & 5.138 & TRN & \\
\hline CHEMBL477606 & 535398 & 4.4685 & 4.3284 & TRN & \\
\hline CHEMBL448063 & 535398 & 4.3768 & 4.6787 & TRN & \\
\hline CHEMBL490998 & 535398 & 6.0458 & 5.6851 & TRN & \\
\hline CHEMBL470987 & 535398 & 4.8539 & 4.1693 & TRN & \\
\hline CHEMBL451317 & 535398 & 5.301 & 5.0477 & TRN & \\
\hline CHEMBL517807 & 535398 & 4.7959 & 4.9757 & TST & \\
\hline CHEMBL492036 & 535398 & 3.0 & 4.4373 & TST & \\
\hline CHEMBL477550 & 535398 & 4.4559 & 4.25899 & 99999999995 & TRN \\
\hline CHEMBL450704 & 535398 & 3.0 & 3.3568 & TRN & \\
\hline CHEMBL477607 & 535398 & 3.0 & 3.31600 & 00000000003 & TRN \\
\hline CHEMBL478859 & 535398 & 4.5229 & 4.8325 & TRN & \\
\hline CHEMBL491006 & 535398 & 5.1549 & 5.3167 & TRN & \\
\hline CHEMBL476983 & 535398 & 4.1192 & 3.628 & TRN & \\
\hline CHEMBL476783 & 535398 & 4.6383 & 5.0471 & TST & \\
\hline CHEMBL576140 & 588141 & 7.0177 & 6.5328 & TRN & \\
\hline CHEMBL574965 & 588141 & 6.8416 & 7.1117 & TST & \\
\hline CHEMBL576142 & 588141 & 6.0757 & 6.1024 & TRN & \\
\hline CHEMBL573099 & 588141 & 6.2518 & 6.169 & TRN & \\
\hline CHEMBL575395 & 588141 & 7.4437 & 7.4394 & TRN & \\
\hline CHEMBL574970 & 588141 & 6.7825 & 6.6159 & TST & \\
\hline CHEMBL574036 & 588141 & 7.3872 & 7.0874 & TRN & \\
\hline CHEMBL576977 & 588141 & 7.0044 & 7.0223 & TRN & \\
\hline CHEMBL579247 & 588141 & 7.0757 & 6.8272 & TRN & \\
\hline CHEMBL574722 & 588141 & 6.8539 & 7.2097 & TRN & \\
\hline CHEMBL576366 & 588141 & 7.1549 & 7.1336 & TRN & \\
\hline CHEMBL410727 & 588141 & 7.5528 & 7.309 & TRN & \\
\hline CHEMBL285932 & 588141 & 8.6383 & 7.5737 & TST & \\
\hline CHEMBL576549 & 588141 & 8.2518 & 8.1121 & TRN & \\
\hline CHEMBL574032 & 588141 & 6.9318 & 6.9774 & TRN & \\
\hline CHEMBL575186 & 588141 & 6.6198 & 6.6239 & TRN & \\
\hline CHEMBL579249 & 588141 & 7.9208 & 8.2318 & TRN & \\
\hline CHEMBL577791 & 588141 & 6.8069 & 6.71299 & 9999999999 & TRN \\
\hline CHEMBL574052 & 588141 & 7.2518 & 7.8099 & TRN & \\
\hline
\end{tabular}

Page 12029 


\begin{tabular}{|c|c|c|c|c|}
\hline & & & oplement & al $\mathrm{Ta}$ \\
\hline CHEMBL573805 & 588141 & 6.8239 & 7.0354 & TRN \\
\hline CHEMBL575193 & 588141 & 7.1549 & 6.6505 & TRN \\
\hline CHEMBL572860 & 588141 & 7.2518 & 6.9494 & TRN \\
\hline CHEMBL575396 & 588141 & 5.6778 & 5.8968 & TRN \\
\hline CHEMBL574499 & 588141 & 7.2518 & 7.1291 & TRN \\
\hline CHEMBL381689 & 588141 & 4.5498 & 7.4957 & TST \\
\hline CHEMBL572854 & 588141 & 7.0458 & 7.2533 & TRN \\
\hline CHEMBL573087 & 588141 & 5.6198 & 5.5322 & TRN \\
\hline CHEMBL572613 & 588141 & 6.9208 & 6.9255 & TRN \\
\hline CHEMBL574053 & 588141 & 6.4685 & 6.8115 & TRN \\
\hline CHEMBL575163 & 588141 & 6.5086 & 6.7829 & TRN \\
\hline CHEMBL572620 & 588141 & 6.2518 & 6.3166 & TRN \\
\hline CHEMBL 272203 & 588141 & 8.2518 & 8.1121 & TRN \\
\hline CHEMBL578848 & 588141 & 7.5086 & 7.1327 & TST \\
\hline CHEMBL577361 & 588141 & 7.0 & 6.7074 & TRN \\
\hline CHEMBL574046 & 588141 & 7.301 & 7.3779 & TRN \\
\hline CHEMBL577165 & 588141 & 7.301 & 7.211 & TRN \\
\hline CHEMBL575382 & 588141 & 8.2518 & 7.4621 & TST \\
\hline CHEMBL574959 & 588141 & 6.644 & 6.6059 & TST \\
\hline CHEMBL574279 & 588141 & 4.5498 & 5.8071 & TST \\
\hline CHEMBL574740 & 588141 & 5.8861 & 5.5763 & TRN \\
\hline CHEMBL578003 & 588141 & 6.4342 & 6.7271 & TRN \\
\hline CHEMBL575184 & 588141 & 7.5229 & 7.5248 & TRN \\
\hline CHEMBL573098 & 588141 & 6.4622 & 6.0029 & TST \\
\hline CHEMBL572887 & 588141 & 7.699 & 7.638 & TRN \\
\hline CHEMBL574031 & 588141 & 6.8041 & 6.5018 & TRN \\
\hline CHEMBL574045 & 588141 & 6.4089 & 6.642 & TRN \\
\hline CHEMBL585177 & 588141 & 6.4202 & 6.5046 & TRN \\
\hline CHEMBL575401 & 588141 & 7.0969 & 6.8567 & TRN \\
\hline CHEMBL573086 & 588141 & 4.5498 & 5.2886 & TRN \\
\hline CHEMBL574270 & 588141 & 7.0969 & 7.4213 & TST \\
\hline CHEMBL575164 & 588141 & 6.0232 & 6.7602 & TST \\
\hline CHEMBL573796 & 588141 & 6.9508 & 7.2587 & TST \\
\hline CHEMBL575178 & 588141 & 6.6615 & 6.2246 & TST \\
\hline CHEMBL574971 & 588141 & 7.2676 & 6.9808 & TST \\
\hline CHEMBL3238229 & 1338728 & 7.5086 & 7.6191 & TRN \\
\hline CHEMBL3238214 & 1338728 & 8.3979 & 7.6645 & TRN \\
\hline CHEMBL3238217 & 1338728 & 7.6383 & 7.6606 & TRN \\
\hline CHEMBL3237889 & 1338728 & 6.0269 & 6.5147 & TRN \\
\hline CHEMBL3238232 & 1338728 & 6.71 & 7.6236 & TRN \\
\hline CHEMBL3237914 & 1338728 & 6.7696 & 6.7528 & TRN \\
\hline CHEMBL3237918 & 1338728 & 6.3279 & 7.0822 & TST \\
\hline CHEMBL3237904 & 1338728 & 7.0706 & 6.7893 & TRN \\
\hline CHEMBL3237922 & 1338728 & 7.0862 & 7.5002 & TRN \\
\hline CHEMBL3238219 & 1338728 & 7.6778 & 7.5967 & TRN \\
\hline CHEMBL3237895 & 1338728 & 7.0177 & 6.6932 & TRN \\
\hline CHEMBL3238220 & 1338728 & 8.1549 & 7.6946 & TRN \\
\hline CHEMBL3238238 & 1338728 & 6.9208 & 7.1426 & TRN \\
\hline
\end{tabular}


Supplemental Table S2.txt

\begin{tabular}{|c|c|c|c|c|}
\hline CHEMBL3237905 & 1338728 & 7.3565 & 6.7413 & TRN \\
\hline CHEMBL3237916 & 1338728 & 6.284 & 6.4383 & TRN \\
\hline CHEMBL3238222 & 1338728 & 7.8861 & 7.6888 & TRN \\
\hline CHEMBL 3238234 & 1338728 & 7.7959 & 6.9612 & TRN \\
\hline CHEMBL3237921 & 1338728 & 7.1427 & 7.479 & TRN \\
\hline CHEMBL3237901 & 1338728 & 6.1427 & 6.7243 & TRN \\
\hline CHEMBL3237913 & 1338728 & 6.4815 & 6.6926 & TRN \\
\hline CHEMBL3237900 & 1338728 & 8.2218 & 6.8148 & TRN \\
\hline CHEMBL3237908 & 1338728 & 7.0223 & 6.6691 & TRN \\
\hline CHEMBL3237924 & 1338728 & 7.6383 & 7.5882 & TRN \\
\hline CHEMBL 3238240 & 1338728 & 6.5686 & 7.0149 & TRN \\
\hline CHEMBL3237887 & 1338728 & 6.1135 & 6.5395 & TRN \\
\hline CHEMBL3237906 & 1338728 & 6.8861 & 6.6429 & TRN \\
\hline CHEMBL 3238230 & 1338728 & 7.3565 & 7.6711 & TRN \\
\hline CHEMBL3237923 & 1338728 & 7.2596 & 7.5744 & TRN \\
\hline CHEMBL3237912 & 1338728 & 6.4685 & 6.6238 & TRN \\
\hline CHEMBL3238226 & 1338728 & 7.4202 & 7.6676 & TRN \\
\hline CHEMBL3238223 & 1338728 & 7.8861 & 7.6631 & TRN \\
\hline CHEMBL3238218 & 1338728 & 7.8539 & 7.5919 & TRN \\
\hline CHEMBL3238228 & 1338728 & 7.6576 & 7.687 & TST \\
\hline CHEMBL3237884 & 1338728 & 6.284 & 6.5834 & TRN \\
\hline CHEMBL3238225 & 1338728 & 7.585 & 7.6257 & TRN \\
\hline CHEMBL3237910 & 1338728 & 6.4437 & 6.4543 & TRN \\
\hline CHEMBL3237899 & 1338728 & 6.7212 & 6.6934 & TRN \\
\hline CHEMBL3238215 & 1338728 & 7.7696 & 7.5232 & TST \\
\hline CHEMBL3238246 & 1338728 & 7.6198 & 7.6415 & TST \\
\hline CHEMBL3237927 & 1338728 & 7.8239 & 7.4708 & TST \\
\hline CHEMBL3237911 & 1338728 & 6.2076 & 6.5622 & TRN \\
\hline CHEMBL 3238243 & 1338728 & 7.1871 & 7.2733 & TST \\
\hline CHEMBL3237909 & 1338728 & 6.3098 & 6.6517 & TRN \\
\hline CHEMBL3237886 & 1338728 & 4.0 & 6.375 & TST \\
\hline CHEMBL3237907 & 1338728 & 6.8239 & 6.5853 & TRN \\
\hline CHEMBL3237902 & 1338728 & 7.2518 & 6.626 & TRN \\
\hline CHEMBL 3237915 & 1338728 & 7.1739 & 6.7377 & TRN \\
\hline CHEMBL3238224 & 1338728 & 7.8239 & 7.5685 & TST \\
\hline CHEMBL3238231 & 1338728 & 7.4437 & 7.6445 & TST \\
\hline CHEMBL3237917 & 1338728 & 6.8861 & 7.1377 & TST \\
\hline CHEMBL3237903 & 1338728 & 5.9586 & 6.4537 & TRN \\
\hline CHEMBL3238235 & 1338728 & 6.2218 & 7.3434 & TST \\
\hline CHEMBL3237897 & 1338728 & 6.7696 & 6.5996 & TRN \\
\hline CHEMBL3238216 & 1338728 & 8.0 & 7.7283 & TST \\
\hline CHEMBL3237925 & 1338728 & 7.6198 & 7.6186 & TST \\
\hline CHEMBL3237898 & 1338728 & 6.0506 & 6.7322 & TRN \\
\hline CHEMBL3237928 & 1338728 & 7.6576 & 7.5166 & TST \\
\hline CHEMBL3238221 & 1338728 & 7.8861 & 7.6749 & TST \\
\hline CHEMBL463270 & 967316 & 5.0 & 4.7449 & TST \\
\hline CHEMBL 2397978 & 967316 & 7.699 & \multicolumn{2}{|c|}{ 7. 712000000000001} \\
\hline CHEMBL 2397970 & 967316 & 4.4559 & 4.9119 & TST \\
\hline
\end{tabular}




\begin{tabular}{|c|c|c|c|c|}
\hline & & & oplement & al Ta \\
\hline CHEMBL 2397985 & 967316 & 4.8239 & 4.8066 & TRN \\
\hline CHEMBL 2397967 & 967316 & 4.1249 & 4.2047 & TRN \\
\hline CHEMBL2397986 & 967316 & 5.301 & 5.2471 & TRN \\
\hline CHEMBL2397963 & 967316 & 5.1249 & 5.1254 & TRN \\
\hline CHEMBL2397989 & 967316 & 8.0969 & 7.5733 & TST \\
\hline CHEMBL2397976 & 967316 & 5.6021 & 5.6608 & TRN \\
\hline CHEMBL2397959 & 967316 & 6.5229 & 6.5468 & TRN \\
\hline CHEMBL2397964 & 967316 & 6.0 & 5.9567 & TRN \\
\hline CHEMBL2397981 & 967316 & 5.301 & 5.2658 & TRN \\
\hline CHEMBL2398006 & 967316 & 4.8239 & 4.8225 & TRN \\
\hline CHEMBL2397997 & 967316 & 5.0 & 4.9637 & TRN \\
\hline CHEMBL2397991 & 967316 & 6.0 & 6.0 & TRN \\
\hline CHEMBL2397972 & 967316 & 6.5229 & 6.5092 & TRN \\
\hline CHEMBL2397987 & 967316 & 7.1249 & 7.2327 & TRN \\
\hline CHEMBL2397980 & 967316 & 8.301 & 8.2965 & TRN \\
\hline CHEMBL2397961 & 967316 & 7.8239 & 7.7807 & TRN \\
\hline CHEMBL2397996 & 967316 & 5.0 & 5.0055 & TRN \\
\hline CHEMBL 2397962 & 967316 & 7.1249 & 7.2483 & TST \\
\hline CHEMBL2397969 & 967316 & 4.4559 & 4.4819 & TRN \\
\hline CHEMBL2397992 & 967316 & 8.5229 & 8.5387 & TRN \\
\hline CHEMBL2398001 & 967316 & 4.699 & 5.1912 & TST \\
\hline CHEMBL 2397983 & 967316 & 4.4559 & 4.6127 & TRN \\
\hline CHEMBL 2398005 & 967316 & 5.301 & 5.3242 & TRN \\
\hline CHEMBL 2397974 & 967316 & 5.6021 & 4.9046 & TST \\
\hline CHEMBL2398002 & 967316 & 5.0 & 5.0444 & TRN \\
\hline CHEMBL2397984 & 967316 & 5.0 & 5.0031 & TRN \\
\hline CHEMBL 2397968 & 967316 & 4.1249 & 4.1426 & TRN \\
\hline CHEMBL 2397971 & 967316 & 6.4559 & 7.5429 & TST \\
\hline CHEMBL2398003 & 967316 & 5.0 & 5.0191 & TRN \\
\hline CHEMBL 2397965 & 967316 & 5.0 & 4.9338 & TRN \\
\hline CHEMBL2397982 & 967316 & 7.1249 & 7.0521 & TRN \\
\hline CHEMBL2398000 & 967316 & 5.0 & 4.9908 & TRN \\
\hline CHEMBL 2397977 & 967316 & 6.0 & 5.3779 & TST \\
\hline CHEMBL2397975 & 967316 & 5.6021 & 5.5069 & TST \\
\hline CHEMBL 2397990 & 967316 & 8.1249 & 8.3294 & TST \\
\hline CHEMBL2397999 & 967316 & 5.301 & 5.234 & TRN \\
\hline CHEMBL2396669 & 967316 & 5.6021 & 5.6382 & TRN \\
\hline CHEMBL2397994 & 967316 & 4.8239 & 4.6773 & TRN \\
\hline CHEMBL2397966 & 967316 & 4.0 & 4.0203 & TRN \\
\hline CHEMBL2397995 & 967316 & 4.0 & 4.0376 & TRN \\
\hline CHEMBL2398004 & 967316 & 5.301 & 5.2727 & TRN \\
\hline CHEMBL2397960 & 967316 & 7.699 & 7.3589 & TST \\
\hline CHEMBL2397998 & 967316 & 4.1249 & 4.0825 & TRN \\
\hline CHEMBL 2397979 & 967316 & 8.0969 & 7.7496 & TST \\
\hline CHEMBL2397973 & 967316 & 6.5229 & 7.0832 & TST \\
\hline CHEMBL2397988 & 967316 & 7.8239 & 7.8394 & TRN \\
\hline CHEMBL2397993 & 967316 & 4.1249 & 4.1015 & TRN \\
\hline CHEMBL206017 & 598612 & 6.9508 & 6.9685 & TRN \\
\hline
\end{tabular}


Supplemental Table S2.txt

\begin{tabular}{|c|c|c|c|c|}
\hline HEMBL & 612 & 7.3372 & 7.0912 & TR \\
\hline CHEMBL 565643 & 98612 & 7.5229 & 7.0136 & \\
\hline HEMBL18 & 8612 & 699 & 4435 & \\
\hline HEMBL568357 & 98612 & 7.5686 & .529 & RN \\
\hline HEMBL121790 & 98612 & 5.8794 & .2112 & \\
\hline HEMBL185238 & 98612 & 8.3979 & 8.2823 & \\
\hline HEMBL445934 & 98612 & 6198 & .5636 & \\
\hline HEMBL565644 & 98612 & 6.4001 & 6.3483 & \\
\hline HEMBL181640 & 98612 & 6.5622 & 7.3585 & \\
\hline HEMBL122583 & 98612 & .1487 & 6.7741 & \\
\hline HEMBL585109 & 98612 & 6.5935 & 6.9339 & \\
\hline HEMBL 268889 & 98612 & 372 & 6.4792 & \\
\hline HEMBL565645 & 98612 & & 7.1755 & \\
\hline HEMBL203791 & 98612 & 6.9136 & 6.9846 & \\
\hline HEMBL584901 & 98612 & 96 & 6.6033 & \\
\hline HEMBL 202943 & 98612 & 7.6021 & 7.6393 & $\mathrm{RN}$ \\
\hline HEMBL 208437 & 98612 & 29 & 7.4056 & \\
\hline HEMBL585117 & 98612 & 7. & 7.1614 & \\
\hline HEMBL 585505 & 98612 & 7.6021 & 7.7983 & \\
\hline CHEMBL229599 & 98612 & 8 & 7.8183 & $2 \mathrm{~N}$ \\
\hline HEMBL 202994 & 98612 & 979 & 7.1065 & NIV \\
\hline HEMBL 585700 & 98612 & 91 & 7.256 & RIN \\
\hline HEMBL120718 & 98612 & 6 . & 6.3516 & RN \\
\hline HEMBL126180 & 98612 & 6.433 & 7.1815 & ST \\
\hline CHEMBL 330814 & 98612 & & 6.977 & TRN \\
\hline HEMBL11 & 8612 & 86 & 7.0026 & RN \\
\hline HEMBL56 & 8612 & 86 & 6.9715 & RN \\
\hline CHEMBL565814 & 98612 & 7 & 6.9373 & TRN \\
\hline CHEMBL425177 & 98612 & 6.4202 & 7.4299 & TST \\
\hline CHEMBL184746 & 98612 & & 6.9229 & TST \\
\hline HEMBL565815 & 98612 & 5 & 7.1154 & TRN \\
\hline CHEMBL44C & 98612 & 7. & 7.3956 & TST \\
\hline CHEMBL566440 & 98612 & 4 . & 5.8653 & TST \\
\hline CHEMBL340203 & 98612 & 7.041 & 6.7589 & TRN \\
\hline CHEMBL 269339 & 98612 & 5.8239 & 6.8099 & TST \\
\hline CHEMBL567706 & 98612 & 7.8239 & 7.5362 & TRN \\
\hline CHEMBL18 & 12 & 7. & 7.7258 & $\Gamma \mathrm{RN}$ \\
\hline CHEMBL338196 & 98612 & 6.6925 & 7.1515 & TST \\
\hline CHEMBL202887 & 98612 & 7.7447 & 7.5397 & TRN \\
\hline CHEMBL 205736 & 98612 & 6.9706 & 7.0748 & TRN \\
\hline CHEMBL382466 & 98612 & 6.6198 & 7.1276 & $\Gamma \mathrm{RN}$ \\
\hline CHEMBL120245 & 598612 & 5.8861 & 6.6353 & TRN \\
\hline CHEMBL205427 & 98612 & 7.2291 & 7.3981 & TRN \\
\hline CHEMBL118339 & 98612 & 5.3979 & 6.0023 & TRN \\
\hline CHEMBL121554 & 8612 & 7.2676 & 6.8451 & TKIV \\
\hline CHEMBL582791 & 98612 & 5.7501 & 7.1111 & \\
\hline CHEMBL584928 & 598612 & 7.3979 & 7.0573 & ГRN \\
\hline CHEMBL378167 & 598612 & 6.6091 & 6.4988 & TRN \\
\hline
\end{tabular}

Page 12033 


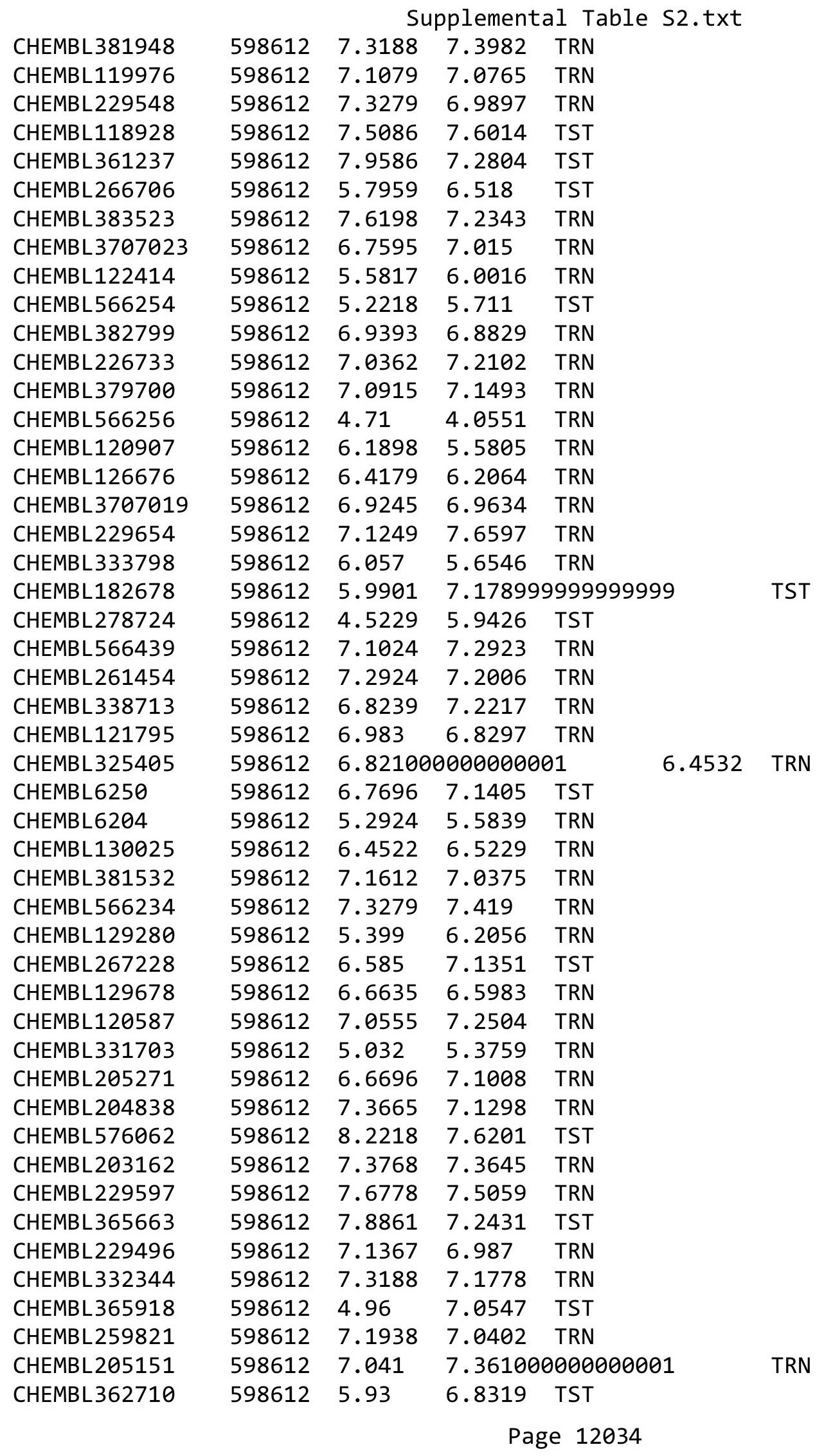




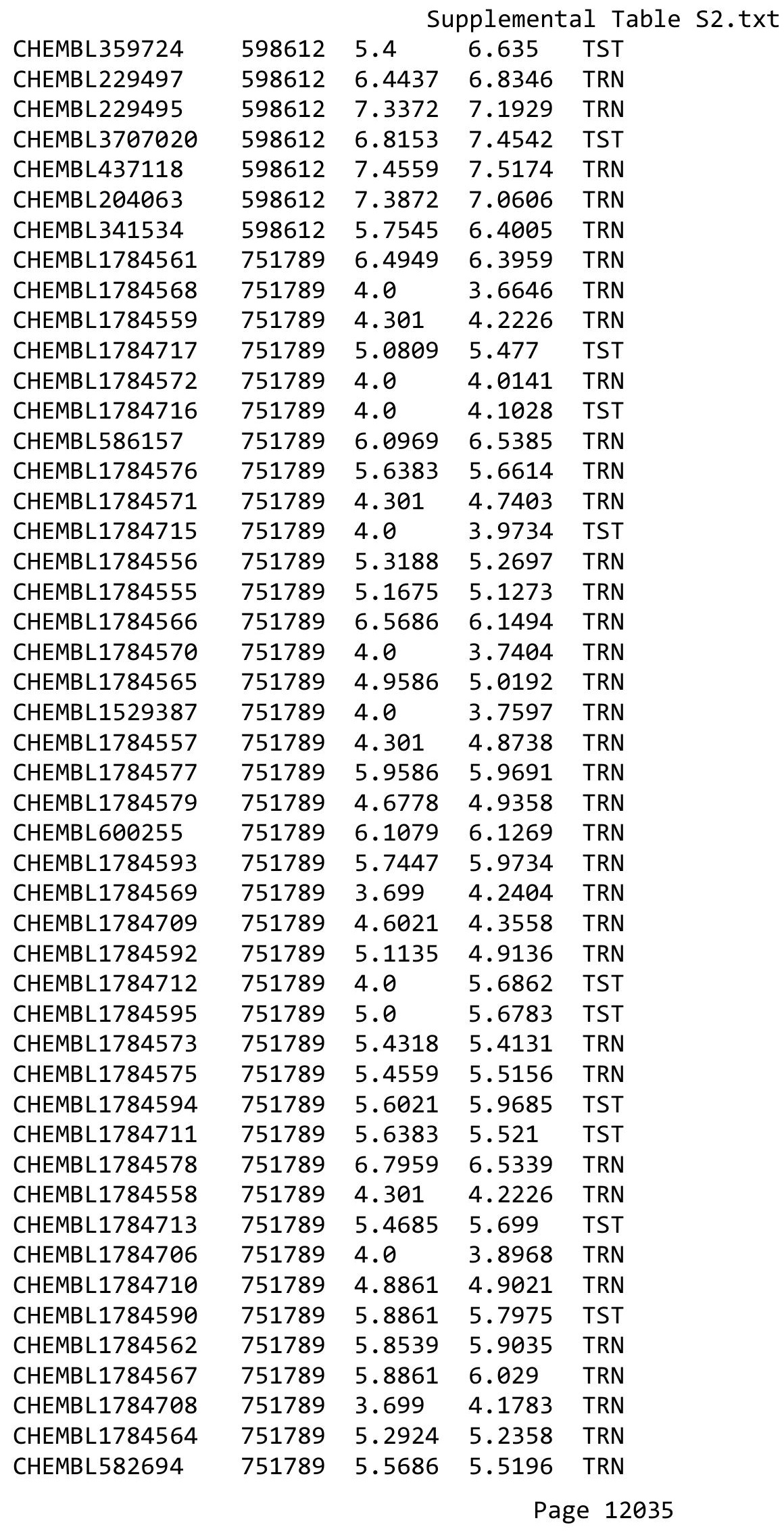




\begin{tabular}{|c|c|c|c|c|c|}
\hline \multicolumn{6}{|c|}{ Supplemental Table s2.txt } \\
\hline CHEMBL1784580 & 751789 & 7.1805 & 6.0841 & TST & \\
\hline CHEMBL1784581 & 751789 & 4.6021 & 4.4308 & TRN & \\
\hline CHEMBL1784574 & 751789 & 7.0132 & 6.675 & TRN & \\
\hline CHEMBL1784589 & 751789 & 6.3979 & 5.7419 & TST & \\
\hline CHEMBL1784714 & 751789 & 4.0 & 5.3729 & TST & \\
\hline CHEMBL1714424 & 751789 & 5.4815 & 5.3093 & TRN & \\
\hline CHEMBL1784591 & 751789 & 5.1805 & 5.7396 & TST & \\
\hline CHEMBL1784560 & 751789 & 4.301 & 4.2226 & TRN & \\
\hline CHEMBL1784563 & 751789 & 6.4685 & 6.4076 & TRN & \\
\hline CHEMBL3917064 & 1640893 & 7.8386 & 7.8637 & TRN & \\
\hline CHEMBL3928795 & 1640893 & 7.2197 & 7.3172 & TRN & \\
\hline CHEMBL3929506 & 1640893 & 8.0 & 7.9734 & TRN & \\
\hline CHEMBL3935477 & 1640893 & 6.9318 & 6.9191 & TRN & \\
\hline CHEMBL 3935522 & 1640893 & 7.1349 & 7.1767 & TRN & \\
\hline CHEMBL3890783 & 1640893 & 8.2381 & 8.2331 & TRN & \\
\hline CHEMBL3930235 & 1640893 & 6.3675 & 6.8884 & TST & \\
\hline CHEMBL3957731 & 1640893 & 6.6635 & 6.7357 & TRN & \\
\hline CHEMBL3972571 & 1640893 & 6.0 & 5.9046 & TRN & \\
\hline CHEMBL3925476 & 1640893 & 7.8041 & 7.6184 & TRN & \\
\hline CHEMBL3918666 & 1640893 & 7.6091 & 7.6505 & TRN & \\
\hline CHEMBL3982060 & 1640893 & 6.4522 & 6.8034 & TST & \\
\hline CHEMBL3898549 & 1640893 & 6.8041 & 6.8703 & TRN & \\
\hline CHEMBL3956668 & 1640893 & 6.1481 & 6.4094 & TST & \\
\hline CHEMBL3906008 & 1640893 & 7.8761 & 7.7696 & TRN & \\
\hline CHEMBL3918851 & 1640893 & 7.475 & 7.6261 & TRN & \\
\hline CHEMBL3955146 & 1640893 & 7.8447 & 7.7681 & TRN & \\
\hline CHEMBL3950080 & 1640893 & 5.8356 & 6.6921 & TST & \\
\hline CHEMBL3959250 & 1640893 & 8.0783 & 8.1609 & TRN & \\
\hline CHEMBL3951810 & 1640893 & 8.1057 & 7.8417 & TRN & \\
\hline CHEMBL3893460 & 1640893 & 8.2612 & 8.3406 & TRN & \\
\hline CHEMBL3946187 & 1640893 & 7.0904 & 7.016 & TRN & \\
\hline CHEMBL3953711 & 1640893 & 7.1952 & 7.2237 & TRN & \\
\hline CHEMBL3898506 & 1640893 & 7.5751 & 7.4777 & TRN & \\
\hline CHEMBL3942982 & 1640893 & 8.4763 & 8.4579 & TRN & \\
\hline CHEMBL3889728 & 1640893 & 5.8665 & 5.8569 & TRN & \\
\hline CHEMBL3981756 & 1640893 & 6.5186 & 6.9276 & TST & \\
\hline CHEMBL3962470 & 1640893 & 7.9431 & 7.8748 & TRN & \\
\hline CHEMBL3982082 & 1640893 & 6.8041 & 6.8811 & TRN & \\
\hline CHEMBL 3965759 & 1640893 & 6.1029 & 6.1107 & TRN & \\
\hline CHEMBL3935854 & 1640893 & 6.0 & 6.647 & TST & \\
\hline CHEMBL3956978 & 1640893 & 6.8356 & 6.9741 & TRN & \\
\hline CHEMBL3908938 & 1640893 & 7.5361 & 7.6547 & TRN & \\
\hline CHEMBL3912132 & 1640893 & 6.8153 & 6.7766 & TRN & \\
\hline CHEMBL3906428 & 1640893 & 7.6021 & 7.7197 & TRN & \\
\hline CHEMBL3913030 & 1640893 & 7.1349 & 7.0791 & TRN & \\
\hline CHEMBL 3924102 & 1640893 & 7.6162 & 7.67399 & 99999999995 & TRN \\
\hline CHEMBL3918962 & 1640893 & 6.3161 & 6.6699 & TST & \\
\hline CHEMBL3905374 & 1640893 & 6.7852 & 6.796 & TRN & \\
\hline
\end{tabular}


Supplemental Table S2.txt

\begin{tabular}{|c|c|c|c|c|}
\hline$x^{-}$ & & & 1684 & \\
\hline UГMDI & & 7.2832 & 7.4201 & \\
\hline 56 & & & & \\
\hline AEMBL & 0893 & & & \\
\hline AEMBL3899746 & 640893 & 229 & 4542 & \\
\hline HEMBL3890892 & 640893 & 6.8539 & . 6981 & \\
\hline HEMBL; & 893 & 07 & 372 & \\
\hline IFMRI $=$ & 893 & & & \\
\hline AEMBL39 & 640893 & 959 & 8687 & \\
\hline HEMBL3980608 & 640893 & 8.041 & 9489 & \\
\hline HEMBL3889603 & 640893 & 6.9508 & .8625 & \\
\hline IEMBL3C & 893 & $\partial 8$ & 1839 & \\
\hline AEMBL3S & & & & \\
\hline HEMBL394 & 640893 & & 3849 & \\
\hline AEMBL39 & 640893 & & 3004 & \\
\hline AEMBL39 & 93 & 39 & 8836 & \\
\hline AEMBL3 & 35 & & 21 & \\
\hline HEMBL3S & & & & \\
\hline HEMBL3S & 893 & 6.0 & 5.9645 & \\
\hline AEMBL3S & 893 & 6 & & \\
\hline HEIMBLSS & 04 & & 75 & \\
\hline HEMBL3 & 93 & & 47 & 2 \\
\hline HEMBL & & & & \\
\hline 730 & 93 & & & \\
\hline AEMBL3S & & & & ras \\
\hline HEMBL3 & 30 & & & RN \\
\hline HEMBL: & & & & Niv \\
\hline HFMBI & & & & \\
\hline HEMBL7 & & & & I KIV \\
\hline HEMBL13 & & & 33 & 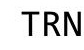 \\
\hline HEMBL1 & 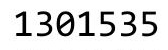 & & 19 & RN \\
\hline HEMBL & & & 04 & RN \\
\hline 08 & & & 265 & RN \\
\hline HEMBL129 & & & & IRN \\
\hline HEMBL3186677 & $2015-2$ & & 4.2476 & TRN \\
\hline HEMBL15 & & & 59 & \\
\hline HFMRI 1 & & & & RIN \\
\hline HEMBL1S & & & 56 & ST \\
\hline HEMBL2133999 & 3015 & 4. & 2148 & $\Gamma \mathrm{RN}$ \\
\hline IEMBL18 & $2 a$ & & 10 & RN \\
\hline HEMBL13 & $20+2+2+1$ & & 7874 & \\
\hline CHEMBL13 & & & 4.3644 & Riv \\
\hline HEMBL154 & 535 & 7.7 & 6.4964 & RN \\
\hline AEMBL1414888 & 30153 & 4.4326 & 2718 & TRN \\
\hline 1 & & & 1308 & \\
\hline HEMBL1C & & & .3355 & \\
\hline HEMBL153 & & & 4.9393 & \\
\hline CHEMBL3199610 & 130153 & 5.0443 & 4.6273 & ГRN \\
\hline
\end{tabular}

Page 12037 
Supplemental Table S2.txt

\begin{tabular}{|c|c|c|c|c|c|c|}
\hline CHEMBL1880686 & 1301535 & 5.9281 & 4.0914 & TRN & & \\
\hline CHEMBL1377696 & 1301535 & 3.4089 & 4.6094 & TRN & & \\
\hline CHEMBL3191857 & 1301535 & 3.4089 & 4.5871 & TST & & \\
\hline CHEMBL1482938 & 1301535 & 6.4685 & 6.513 & TRN & & \\
\hline CHEMBL3182095 & 1301535 & 4.8321 & 5.1908 & TRN & & \\
\hline CHEMBL1343286 & 1301535 & 4.507 & 4.5899 & TRN & & \\
\hline CHEMBL1520808 & 1301535 & 5.0942 & 5.1237 & TRN & & \\
\hline CHEMBL2130961 & 1301535 & 5.1308 & 5.6058 & TRN & & \\
\hline CHEMBL1979530 & 1301535 & 5.1925 & 5.0986 & TRN & & \\
\hline CHEMBL1468277 & 1301535 & 4.7228 & 4.9205 & TRN & & \\
\hline CHEMBL3196103 & 1301535 & 4.8 & 4.4599 & TRN & & \\
\hline CHEMBL16901 & 1301535 & 3.4089 & 5.1594 & TST & & \\
\hline CHEMBL1559614 & 1301535 & 5.0835 & 5.2524 & TRN & & \\
\hline CHEMBL3187917 & 1301535 & 4.5346 & 4.2723 & TRN & & \\
\hline CHEMBL1301253 & 1301535 & 3.4089 & 4.5782 & TRN & & \\
\hline CHEMBL1517251 & 1301535 & 4.9248 & 4.7588 & TRN & & \\
\hline CHEMBL1356278 & 1301535 & 3.4089 & 4.3581 & TRN & & \\
\hline CHEMBL 3196216 & 1301535 & 3.4089 & 3.8299 & TRN & & \\
\hline CHEMBL1581548 & 1301535 & 4.8027 & 3.8896 & TRN & & \\
\hline CHEMBL382111 & 1301535 & 3.4089 & 4.4304 & TRN & & \\
\hline CHEMBL1551662 & 1301535 & 4.5772 & 5.3283 & TRN & & \\
\hline CHEMBL1386393 & 1301535 & 7.7959 & 6.3301 & TRN & & \\
\hline CHEMBL1334768 & 1301535 & \multicolumn{3}{|c|}{5.4510000000000005} & 5.425 & TRN \\
\hline CHEMBL1484746 & 1301535 & 4.7208 & 4.5971 & TRN & & \\
\hline CHEMBL1449167 & 1301535 & 3.4089 & 4.1931 & TRN & & \\
\hline CHEMBL87706 & 1301535 & 5.061 & 4.8531 & TRN & & \\
\hline CHEMBL1432762 & 1301535 & 4.9582 & 4.3145 & TRN & & \\
\hline CHEMBL1578535 & 1301535 & 4.9714 & 4.6212 & TRN & & \\
\hline CHEMBL1878670 & 1301535 & 4.7124 & 5.0751 & TST & & \\
\hline CHEMBL1509460 & 1301535 & 3.4089 & 4.4786 & TRN & & \\
\hline CHEMBL1866557 & 1301535 & 5.3605 & 5.4286 & TRN & & \\
\hline CHEMBL1325890 & 1301535 & 4.919 & 4.4931 & TST & & \\
\hline CHEMBL1432396 & 1301535 & 4.6951 & 5.1608 & TRN & & \\
\hline CHEMBL1698968 & 1301535 & 4.5243 & 4.1291 & TRN & & \\
\hline CHEMBL1432216 & 1301535 & 4.6821 & 4.8048 & TRN & & \\
\hline CHEMBL 2000240 & 1301535 & 3.4089 & 4.4456 & TRN & & \\
\hline CHEMBL3194737 & 1301535 & 4.7886 & 4.5735 & TRN & & \\
\hline CHEMBL 3185290 & 1301535 & 4.658 & 5.4059 & TRN & & \\
\hline CHEMBL1388116 & 1301535 & 6.52 & 5.56 & TRN & & \\
\hline CHEMBL1708283 & 1301535 & 4.5134 & 4.0848 & TRN & & \\
\hline CHEMBL47840 & 1301535 & 4.8871 & 4.5441 & TRN & & \\
\hline CHEMBL3183018 & 1301535 & 6.0 & 5.2309 & TRN & & \\
\hline CHEMBL1438855 & 1301535 & 4.6621 & 4.7306 & TRN & & \\
\hline CHEMBL1708067 & 1301535 & 6.2111 & 4.9886 & TRN & & \\
\hline CHEMBL1971727 & 1301535 & 4.9179 & 4.4185 & TRN & & \\
\hline CHEMBL1594057 & 1301535 & 5.153 & 4.4821 & TRN & & \\
\hline CHEMBL492468 & 1301535 & 3.4089 & 4.7582 & TRN & & \\
\hline CHEMBL1700724 & 1301535 & 5.0195 & 5.0645 & TRN & & \\
\hline
\end{tabular}

Page 12038 
Supplemental Table S2.txt

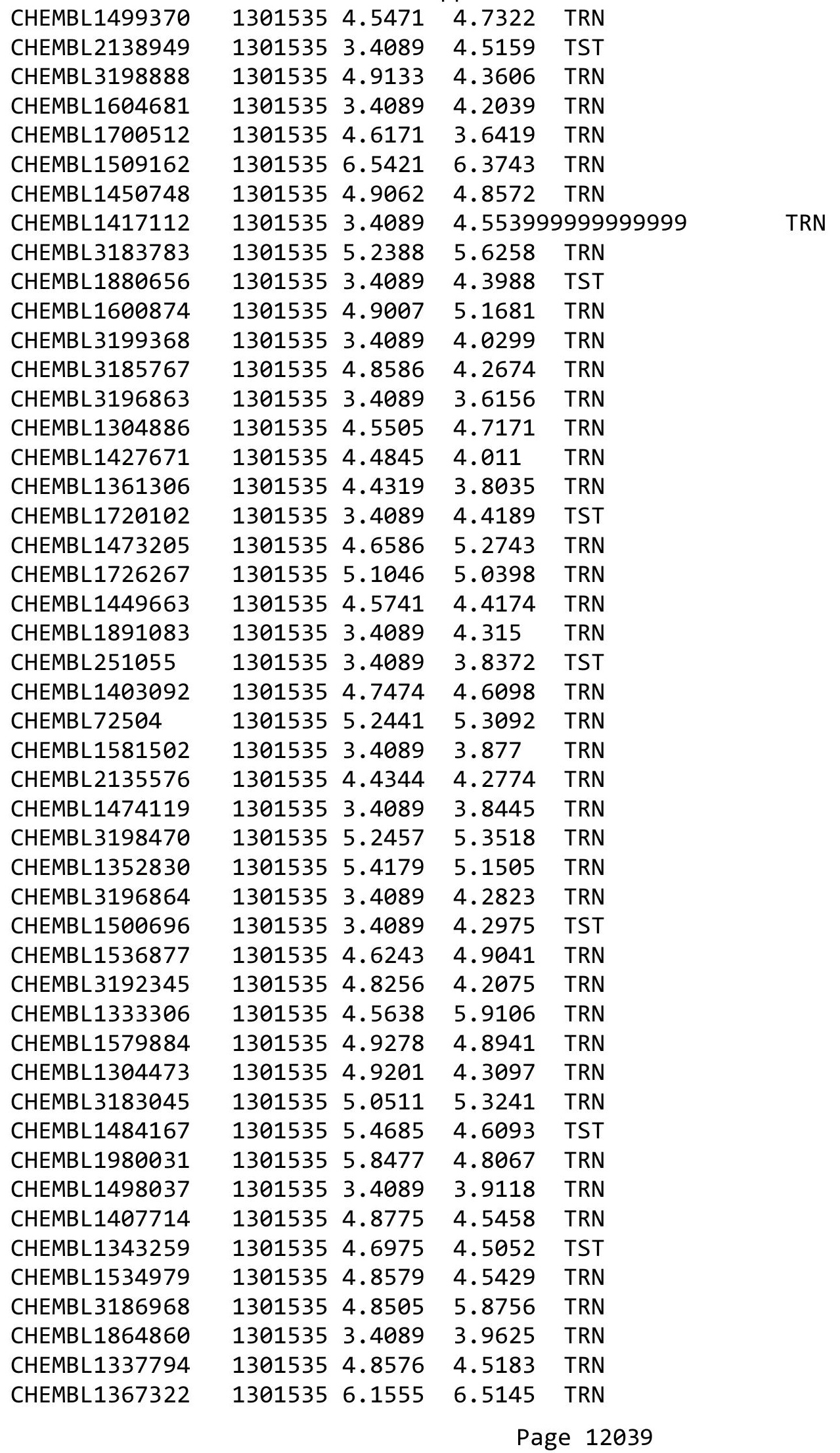


Supplemental Table S2.txt

\begin{tabular}{|c|c|c|c|c|}
\hline CHEMBL1543989 & 1301535 & 5.3478 & 4.4993 & TRN \\
\hline CHEMBL1705379 & 1301535 & 3.4089 & 4.3705 & TRN \\
\hline CHEMBL1460919 & 1301535 & 4.7662 & 4.3483 & TRN \\
\hline CHEMBL 2132810 & 1301535 & 4.9322 & 5.2905 & TRN \\
\hline CHEMBL3184298 & 1301535 & 5.1427 & \multicolumn{2}{|c|}{5.4670000000000005} \\
\hline CHEMBL1485577 & 1301535 & 4.9027 & 5.0811 & TRN \\
\hline CHEMBL1586611 & 1301535 & 4.8333 & 4.5097 & TRN \\
\hline CHEMBL1358679 & 1301535 & 4.5585 & 4.9885 & TRN \\
\hline CHEMBL3193382 & 1301535 & 3.4089 & 4.2254 & TRN \\
\hline CHEMBL266997 & 1301535 & 4.7303 & 4.6874 & TRN \\
\hline CHEMBL1406376 & 1301535 & 4.5711 & 4.5812 & TRN \\
\hline CHEMBL1600910 & 1301535 & 3.4089 & 3.5959 & TRN \\
\hline CHEMBL 2144641 & 1301535 & 4.7167 & 4.5476 & TRN \\
\hline CHEMBL22794 & 1301535 & 5.4921 & 4.9031 & TRN \\
\hline CHEMBL1732754 & 1301535 & 4.5583 & 4.3934 & TRN \\
\hline CHEMBL3184663 & 1301535 & 3.4089 & 4.1947 & TRN \\
\hline CHEMBL363221 & 1301535 & 3.4089 & 3.9853 & TRN \\
\hline CHEMBL1604089 & 1301535 & 3.4089 & 3.7683 & TRN \\
\hline CHEMBL1761063 & 1301535 & 5.1261 & 5.0871 & TRN \\
\hline CHEMBL1700662 & 1301535 & 4.6234 & 4.1254 & TRN \\
\hline CHEMBL1568043 & 1301535 & 3.4089 & 3.9965 & TRN \\
\hline CHEMBL1606437 & 1301535 & 4.4149 & 3.9405 & TRN \\
\hline CHEMBL486817 & 1301535 & 4.6554 & 4.6198 & TST \\
\hline CHEMBL1343743 & 1301535 & 6.058 & 5.0907 & TST \\
\hline CHEMBL1401571 & 1301535 & 6.1904 & 6.4046 & TRN \\
\hline CHEMBL1446966 & 1301535 & 5.1319 & 5.0586 & TRN \\
\hline CHEMBL1541307 & 1301535 & 4.7916 & 4.0131 & TRN \\
\hline CHEMBL493153 & 1301535 & 4.7104 & 4.3202 & TRN \\
\hline CHEMBL1530404 & 1301535 & 3.4089 & 4.7605 & TST \\
\hline CHEMBL1370010 & 1301535 & 4.5065 & 4.283 & TST \\
\hline CHEMBL1981242 & 1301535 & 4.62 & 4.4917 & TRN \\
\hline CHEMBL1305472 & 1301535 & 6.5317 & 6.5147 & TRN \\
\hline CHEMBL1600814 & 1301535 & 4.9363 & 4.3328 & TRN \\
\hline CHEMBL1454784 & 1301535 & 3.4089 & 4.2792 & TRN \\
\hline CHEMBL1380978 & 1301535 & 4.9119 & 3.9936 & TRN \\
\hline CHEMBL1392251 & 1301535 & 3.4089 & 3.3646 & TRN \\
\hline CHEMBL1346252 & 1301535 & 5.0137 & 4.2763 & TST \\
\hline CHEMBL1533994 & 1301535 & 5.2668 & 5.4356 & TRN \\
\hline CHEMBL1455228 & 1301535 & 4.4229 & 4.9217 & TST \\
\hline CHEMBL3192902 & 1301535 & 4.459 & 4.2953 & TRN \\
\hline CHEMBL3182828 & 1301535 & 4.7321 & 3.895 & TRN \\
\hline CHEMBL3185724 & 1301535 & 5.3696 & 5.5123 & TRN \\
\hline CHEMBL1718373 & 1301535 & 3.4089 & 3.7784 & TRN \\
\hline CHEMBL1564141 & 1301535 & 5.129 & 3.9644 & TST \\
\hline CHEMBL1300522 & 1301535 & 3.4089 & 3.7781 & TRN \\
\hline CHEMBL3184373 & 1301535 & 6.0 & 5.4618 & TRN \\
\hline CHEMBL1421731 & 1301535 & 3.4089 & 3.793 & TRN \\
\hline CHEMBL1893344 & 1301535 & 3.4089 & 4.7872 & TST \\
\hline
\end{tabular}


Supplemental Table S2.txt

\begin{tabular}{|c|c|c|c|c|}
\hline 5 & & 604 & & \\
\hline & & 3.4089 & 4.0782 & \\
\hline EM & 35 & 73 & 5568 & \\
\hline AEMBL31 & 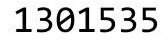 & 817 & & \\
\hline AEMBL1727014 & 301535 & 5.1421 & 8191 & \\
\hline HEMBL1864590 & 301 & 3.4089 & 3454 & \\
\hline HEMBL3 & - & 089 & & \\
\hline AEMBL3 & & 551 & & \\
\hline HEMBL3199866 & 301535 & 3.4089 & .7575 & \\
\hline HEMBL3189445 & 301 & 5.011 & 8866 & \\
\hline HEMBL160 & 30 & 4.6198 & 3701 & \\
\hline HEMBL1 & 0 & & 328 & RN \\
\hline HEMBL1 & 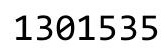 & & & \\
\hline HEMBL141 & 30 & 3693 & 3875 & \\
\hline HEMBL149 & מר & 071 & & TST \\
\hline HEMBL3 & ש & 89 & & וכ \\
\hline HEMBL3 & 30 & & 95 & RN \\
\hline HEMBL3 & 30 & 6. & & RN \\
\hline HEMBL1 & 30 & & & \\
\hline AEMBL1 & 30 & & 26 & I KIV \\
\hline HEMBL: & 30 & & 69 & RI \\
\hline HEMBL & $3 e$ & & & RN \\
\hline HEMBL 3 & 30 & 89 & 24 & RN \\
\hline HEMPI & & 511 & & TRN \\
\hline AEMBL1 & 30 & 56 & 44 & I RN \\
\hline HEMBL1 & 36 & 73 & & 「RN \\
\hline HEME & $3 e$ & & & $\mathrm{RN}$ \\
\hline HEM & 30 & 06 & & 「RN \\
\hline HEMBL 7 & & & & IRIN \\
\hline HEMBL1 & 30 & 186 & 66 & TRN \\
\hline HEMBL1 & 30 & 282 & 51 & RN \\
\hline 6 & 20 & & & 「RN \\
\hline 1 & & 76 & & $\mathrm{RN}$ \\
\hline HEMBL1 & & 61 & & 「RN \\
\hline HEMBL 21 & 30 & 927 & & ГRN \\
\hline $15 M D^{\prime}$ & 20 & & & TRN \\
\hline 3 & & & & $\mathrm{RN}$ \\
\hline HEMBL1 & & & & TST \\
\hline HEMBL3 & 30 & 512 & & $\Gamma R$ \\
\hline 96 & 30 & 089 & & IST \\
\hline HEMBL3 & 30 & 6 & 69 & TRN \\
\hline & & & & TRN \\
\hline HEMBL13 & ת & 4.8972 & 3883 & TST \\
\hline HEMBL1. & 36 & 977 & & $\Gamma R$ \\
\hline 30 & & & & \\
\hline HEMBL1 & & & & \\
\hline HEMBL 15 & $3 a$ & & 001 & \\
\hline CHEMBL1525455 & 1301535 & 4.4131 & 3.9207 & TRN \\
\hline
\end{tabular}

Page 12041 
Supplemental Table S2.txt

\begin{tabular}{|c|c|c|c|c|c|}
\hline CHEMBL1542508 & 1301535 & 4.7324 & 4.6069 & TRN & \\
\hline CHEMBL2362176 & 1301535 & 5.056 & 4.2551 & TRN & \\
\hline CHEMBL3189145 & 1301535 & 4.5354 & 4.01699 & 99999999995 & TRN \\
\hline CHEMBL1479423 & 1301535 & 3.4089 & 4.3918 & TRN & \\
\hline CHEMBL3199844 & 1301535 & 4.5093 & 3.9062 & TRN & \\
\hline CHEMBL1726943 & 1301535 & 3.4089 & 4.4072 & TST & \\
\hline CHEMBL3192403 & 1301535 & 4.8038 & 4.9523 & TRN & \\
\hline CHEMBL1471361 & 1301535 & 3.4089 & 3.6944 & TRN & \\
\hline CHEMBL2361371 & 1301535 & 3.4089 & 4.0045 & TRN & \\
\hline CHEMBL1328249 & 1301535 & 3.4089 & 4.2221 & TRN & \\
\hline CHEMBL1306077 & 1301535 & 4.9586 & 4.2588 & TRN & \\
\hline CHEMBL1383334 & 1301535 & 5.8697 & 5.7078 & TRN & \\
\hline CHEMBL1730544 & 1301535 & 3.4089 & 4.4321 & TST & \\
\hline CHEMBL1705043 & 1301535 & 4.7552 & 5.0098 & TRN & \\
\hline CHEMBL1343898 & 1301535 & 5.0405 & 4.8302 & TRN & \\
\hline CHEMBL1706183 & 1301535 & 3.4089 & 3.2217 & TRN & \\
\hline CHEMBL1413461 & 1301535 & 4.927 & 4.5065 & TRN & \\
\hline CHEMBL1342109 & 1301535 & 4.6853 & 4.1487 & TST & \\
\hline CHEMBL3182511 & 1301535 & 6.0 & 5.6492 & TRN & \\
\hline CHEMBL1371758 & 1301535 & 3.4089 & 4.6632 & TRN & \\
\hline CHEMBL2142609 & 1301535 & 3.4089 & 4.4927 & TST & \\
\hline CHEMBL1867207 & 1301535 & 3.4089 & 4.1686 & TRN & \\
\hline CHEMBL1429797 & 1301535 & 4.453 & 4.5043 & TST & \\
\hline CHEMBL1519610 & 1301535 & 3.4089 & 3.8859 & TRN & \\
\hline CHEMBL1528309 & 1301535 & 4.6317 & 4.484 & TRN & \\
\hline CHEMBL1716858 & 1301535 & 3.4089 & 3.9609 & TRN & \\
\hline CHEMBL21677 & 1301535 & 5.2175 & 5.4223 & TRN & \\
\hline CHEMBL2135960 & 1301535 & 4.9344 & 4.3434 & TRN & \\
\hline CHEMBL1463877 & 1301535 & 6.3969 & 5.5266 & TRN & \\
\hline CHEMBL1531702 & 1301535 & 5.585 & 5.1846 & TRN & \\
\hline CHEMBL3189481 & 1301535 & 4.6099 & 3.7394 & TRN & \\
\hline CHEMBL1729403 & 1301535 & 4.9551 & \multicolumn{2}{|c|}{4.7330000000000005} & TRN \\
\hline CHEMBL1385571 & 1301535 & 4.6953 & 4.4328 & TRN & \\
\hline CHEMBL1413046 & 1301535 & 4.8732 & 4.6543 & TRN & \\
\hline CHEMBL3189898 & 1301535 & 5.9586 & 4.4343 & TRN & \\
\hline CHEMBL1338258 & 1301535 & 5.2418 & 4.421 & TRN & \\
\hline CHEMBL1329412 & 1301535 & 5.0287 & 4.6867 & TST & \\
\hline CHEMBL3185471 & 1301535 & 6.0 & 5.6559 & TRN & \\
\hline CHEMBL3199857 & 1301535 & 3.4089 & 4.4608 & TST & \\
\hline CHEMBL1606817 & 1301535 & 3.4089 & 4.0909 & TRN & \\
\hline CHEMBL3187771 & 1301535 & 4.4995 & 4.765 & TRN & \\
\hline CHEMBL1507198 & 1301535 & 4.7852 & 4.0348 & TRN & \\
\hline CHEMBL1471396 & 1301535 & 4.5864 & 4.4193 & TRN & \\
\hline CHEMBL1454840 & 1301535 & 3.4089 & 4.3667 & TRN & \\
\hline CHEMBL 3186745 & 1301535 & 4.9397 & 5.7508 & TRN & \\
\hline CHEMBL1522595 & 1301535 & 4.8841 & 3.852 & TRN & \\
\hline CHEMBL3196800 & 1301535 & 3.4089 & 3.9056 & TRN & \\
\hline CHEMBL1456301 & 1301535 & 4.7342 & 4.0445 & TRN & \\
\hline
\end{tabular}


Supplemental Table S2.txt

\begin{tabular}{|c|c|c|c|c|c|}
\hline CHEMBL1418161 & 1301535 & 3.4089 & 3.9987 & TRN & \\
\hline CHEMBL1551105 & 1301535 & 3.4089 & 4.1653 & TRN & \\
\hline CHEMBL3192188 & 1301535 & 3.4089 & 3.7559 & TRN & \\
\hline CHEMBL1324698 & 1301535 & 4.5056 & 4.6176 & TRN & \\
\hline CHEMBL1868772 & 1301535 & 4.5566 & 4.6265 & TST & \\
\hline CHEMBL1561788 & 1301535 & 4.6162 & 4.4902 & TST & \\
\hline CHEMBL3191337 & 1301535 & 4.4225 & 3.6307 & TST & \\
\hline CHEMBL1329683 & 1301535 & 6.3645 & 6.1424 & TST & \\
\hline CHEMBL1378083 & 1301535 & 3.4089 & 4.5005 & TST & \\
\hline CHEMBL1587281 & 1301535 & 3.4089 & 4.398 & TST & \\
\hline CHEMBL1381119 & 1301535 & 3.4089 & 3.9756 & TST & \\
\hline CHEMBL 3187608 & 1301535 & 3.4089 & 4.2215 & TST & \\
\hline CHEMBL1723818 & 1301535 & 4.8425 & 4.2622 & TST & \\
\hline CHEMBL1452938 & 1301535 & 4.9122 & 4.1252 & TST & \\
\hline CHEMBL1504159 & 1301535 & 5.1141 & 4.8636 & TST & \\
\hline CHEMBL1346532 & 1301535 & 3.4089 & 3.7879 & TST & \\
\hline CHEMBL 2357578 & 1301535 & 3.4089 & 4.4389 & TST & \\
\hline CHEMBL571436 & 1301535 & 4.6527 & 4.7733 & TST & \\
\hline CHEMBL1456929 & 1301535 & 3.4089 & 4.2794 & TST & \\
\hline CHEMBL1978599 & 1301535 & 3.4089 & 3.5544 & TST & \\
\hline CHEMBL1698013 & 1301535 & 4.8788 & 4.3279 & TST & \\
\hline CHEMBL3192198 & 1301535 & 4.82100 & 00000006 & 11 & 4.6799 \\
\hline CHEMBL1906363 & 1301535 & 3.4089 & 4.6233 & TST & \\
\hline CHEMBL1545839 & 1301535 & 6.4134 & 5.3426 & TST & \\
\hline CHEMBL1447434 & 1301535 & 4.8582 & 4.4138 & TST & \\
\hline CHEMBL1894871 & 1301535 & 3.4089 & 4.8103 & TST & \\
\hline CHEMBL1613238 & 1301535 & 4.9303 & 4.2729 & TST & \\
\hline CHEMBL1377318 & 1301535 & 3.4089 & 4.2686 & TST & \\
\hline CHEMBL348856 & 1301535 & 5.4921 & 4.1662 & TST & \\
\hline CHEMBL1602959 & 1301535 & 4.4861 & 4.1197 & TST & \\
\hline CHEMBL1417689 & 1301535 & 4.863 & 4.4647 & TST & \\
\hline CHEMBL3190352 & 1301535 & 4.5889 & 4.2169 & TST & \\
\hline CHEMBL3195242 & 1301535 & 3.4089 & 4.5338 & TST & \\
\hline CHEMBL3181900 & 1301535 & 3.699 & 5.3257 & TST & \\
\hline CHEMBL1370912 & 1301535 & 3.4089 & 4.1393 & TST & \\
\hline CHEMBL3182263 & 1301535 & 6.0 & 5.2519 & TST & \\
\hline CHEMBL1564773 & 1301535 & 3.4089 & 4.873 & TST & \\
\hline CHEMBL3195977 & 1301535 & 4.9634 & 4.6555 & TST & \\
\hline CHEMBL1362479 & 1301535 & 4.4448 & 4.3911 & TST & \\
\hline CHEMBL1337715 & 1301535 & 4.8904 & 4.7902 & TST & \\
\hline CHEMBL3197691 & 1301535 & 3.4089 & 4.3356 & TST & \\
\hline CHEMBL1507177 & 1301535 & 4.493 & 3.765 & TST & \\
\hline CHEMBL1554827 & 1301535 & 4.6996 & 4.3373 & TST & \\
\hline CHEMBL1698835 & 1301535 & 4.4192 & 4.1234 & TST & \\
\hline CHEMBL1461577 & 1301535 & 6.2262 & 5.1752 & TST & \\
\hline CHEMBL1486521 & 1301535 & 4.8289 & 4.7031 & TST & \\
\hline CHEMBL2006764 & 1301535 & 4.8781 & 4.4184 & TST & \\
\hline CHEMBL225903 & 1301535 & 3.4089 & 3.9848 & TST & \\
\hline
\end{tabular}




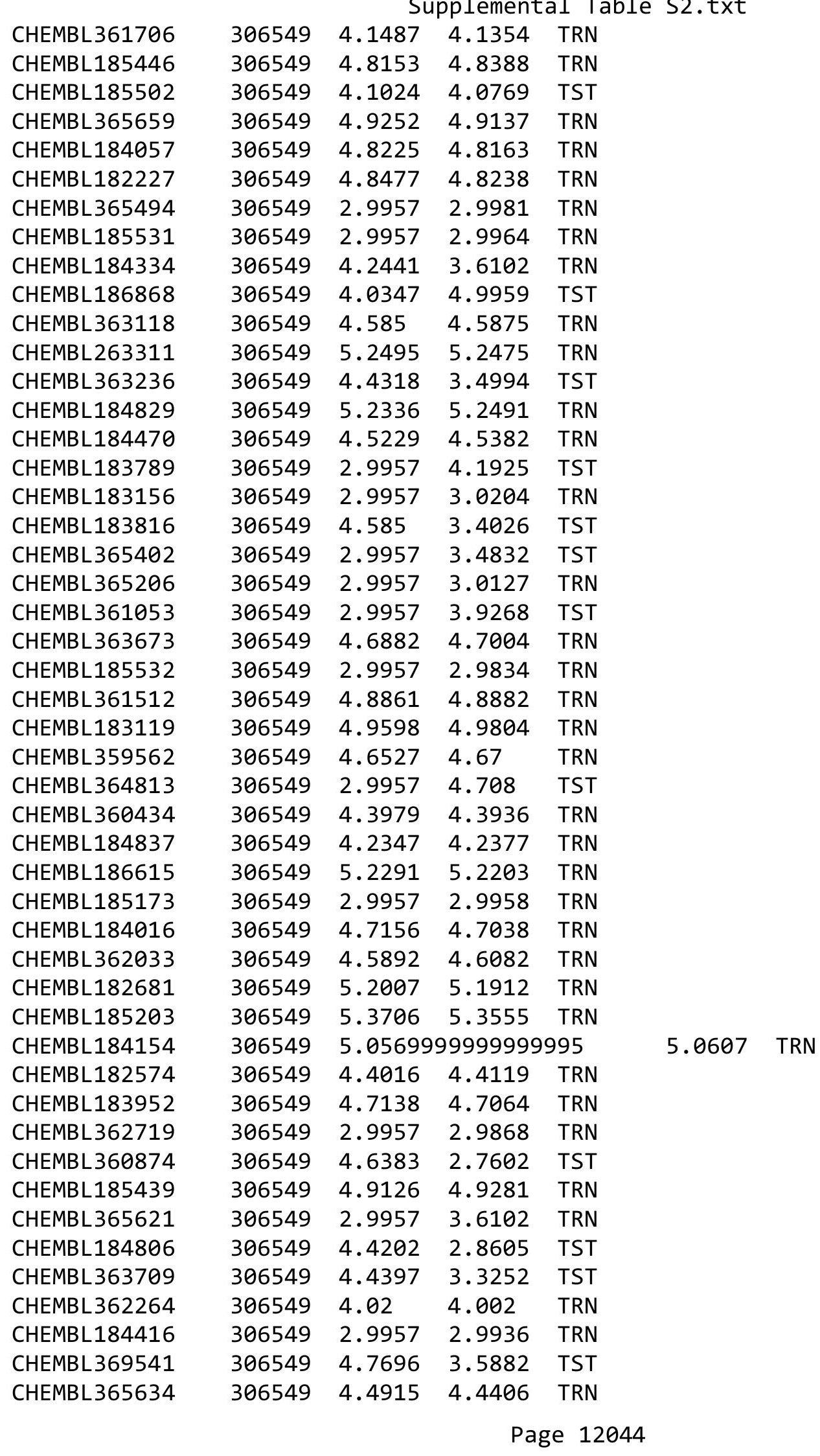




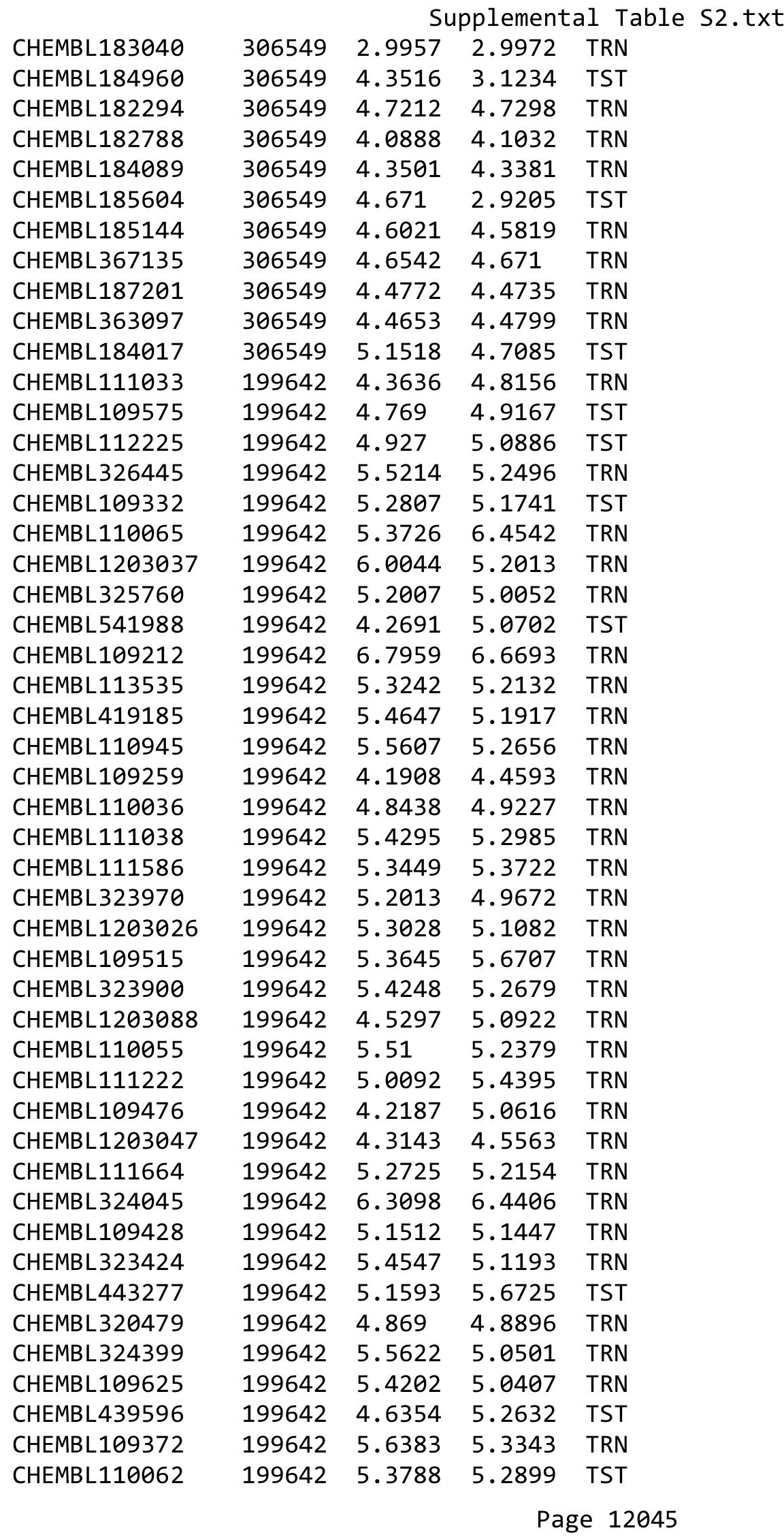


Supplemental Table S2.txt

\begin{tabular}{|c|c|c|c|c|c|}
\hline CHEMBL325981 & 199642 & 5.5376 & 5.2679 & TST & \\
\hline CHEMBL 29197 & 199642 & 4.8557 & 5.3781 & TST & \\
\hline CHEMBL110577 & 199642 & 5.1079 & 5.0513 & TRN & \\
\hline CHEMBL111442 & 199642 & 6.3665 & 5.4083 & TST & \\
\hline CHEMBL 83228 & 199642 & 5.0575 & 4.9649 & TRN & \\
\hline CHEMBL111520 & 199642 & 4.7627 & 4.6565 & TRN & \\
\hline CHEMBL111307 & 199642 & 5.5391 & 5.2846 & TRN & \\
\hline CHEMBL114446 & 199642 & 5.0057 & 5.1035 & TST & \\
\hline CHEMBL109503 & 199642 & 4.4482 & 4.8266 & TRN & \\
\hline CHEMBL111443 & 199642 & 7.2218 & 6.4542 & TRN & \\
\hline CHEMBL1203059 & 199642 & 4.7174 & 5.21 & TRN & \\
\hline CHEMBL112096 & 199642 & 5.3028 & 5.0752 & TST & \\
\hline CHEMBL109355 & 199642 & 4.6028 & 5.2253 & TRN & \\
\hline CHEMBL432396 & 199642 & 5.5421 & 5.066 & TST & \\
\hline CHEMBL123324 & 159458 & 6.7375 & 6.7288 & TRN & \\
\hline CHEMBL421622 & 159458 & 7.2218 & 6.5521 & TRN & \\
\hline CHEMBL124731 & 159458 & 6.8182 & 6.4618 & TRN & \\
\hline CHEMBL125556 & 159458 & 6.7447 & 6.648 & TRN & \\
\hline CHEMBL126166 & 159458 & 6.5686 & 6.5702 & TRN & \\
\hline CHEMBL332603 & 159458 & 5.6778 & 6.9045 & TST & \\
\hline CHEMBL310487 & 159458 & 5.5086 & 6.4681 & TST & \\
\hline CHEMBL126157 & 159458 & 6.8633 & 6.7394 & TRN & \\
\hline CHEMBL338554 & 159458 & 6.4112 & 7.12200 & 0000000001 & TRN \\
\hline CHEMBL334126 & 159458 & 5.6383 & 6.6064 & TST & \\
\hline CHEMBL121855 & 159458 & 7.8539 & 7.4365 & TRN & \\
\hline CHEMBL122292 & 159458 & 6.3565 & 6.5126 & TRN & \\
\hline CHEMBL124529 & 159458 & 6.9245 & 7.3835 & TRN & \\
\hline CHEMBL121995 & 159458 & 8.0 & 7.4258 & TRN & \\
\hline CHEMBL339998 & 159458 & 5.9208 & 6.4771 & TRN & \\
\hline CHEMBL339426 & 159458 & 7.1367 & 7.1788 & TRN & \\
\hline CHEMBL125948 & 159458 & 6.5817 & 6.5363 & TRN & \\
\hline CHEMBL121976 & 159458 & 5.9208 & 6.4583 & TRN & \\
\hline CHEMBL123513 & 159458 & 7.0177 & 6.5638 & TRN & \\
\hline CHEMBL125639 & 159458 & 5.2924 & 6.3618 & TRN & \\
\hline CHEMBL339288 & 159458 & 6.8861 & 6.7862 & TRN & \\
\hline CHEMBL333568 & 159458 & 6.2924 & 6.669 & TRN & \\
\hline CHEMBL340859 & 159458 & 7.0757 & 6.5872 & TRN & \\
\hline CHEMBL340811 & 159458 & 7.2924 & 6.5157 & TRN & \\
\hline CHEMBL125816 & 159458 & 4.9281 & 6.513 & TST & \\
\hline CHEMBL341006 & 159458 & 6.9586 & 6.7081 & TST & \\
\hline CHEMBL121837 & 159458 & 5.8861 & 6.4568 & TRN & \\
\hline CHEMBL14930 & 159458 & 5.7696 & 6.3144 & TST & \\
\hline CHEMBL125448 & 159458 & 8.301 & 6.6736 & TRN & \\
\hline CHEMBL123370 & 159458 & 5.6421 & 6.2484 & TRN & \\
\hline CHEMBL124921 & 159458 & 5.0506 & 6.971 & TST & \\
\hline CHEMBL123561 & 159458 & 6.5686 & 6.5555 & TRN & \\
\hline CHEMBL340206 & 159458 & 5.8996 & 6.6537 & TRN & \\
\hline CHEMBL127754 & 159458 & 6.9508 & 6.6268 & TRN & \\
\hline
\end{tabular}

Page 12046 
Supplemental Table S2.txt

\begin{tabular}{|c|c|c|c|c|c|}
\hline CHEMBL122547 & 159458 & 7.3279 & 7.6461 & TRN & \\
\hline CHEMBL122797 & 159458 & 5.8861 & \multicolumn{2}{|c|}{6.537000000000001} & TST \\
\hline CHEMBL123428 & 159458 & 7.0555 & 6.6893 & TRN & \\
\hline CHEMBL341294 & 159458 & 7.3098 & 7.5236 & TRN & \\
\hline CHEMBL419595 & 159458 & 6.8097 & 6.6811 & TRN & \\
\hline CHEMBL124841 & 159458 & 7.0088 & 6.6143 & TRN & \\
\hline CHEMBL338010 & 159458 & 6.5376 & 6.3853 & TRN & \\
\hline CHEMBL122320 & 159458 & 7.4949 & 7.6468 & TRN & \\
\hline CHEMBL125597 & 159458 & 6.4711 & 6.5603 & TRN & \\
\hline CHEMBL341237 & 159458 & 7.8539 & 7.5624 & TRN & \\
\hline CHEMBL122565 & 159458 & 6.3979 & 6.5341 & TRN & \\
\hline CHEMBL124672 & 159458 & 6.7645 & 6.4166 & TRN & \\
\hline CHEMBL435401 & 159458 & 5.8539 & 6.8609 & TRN & \\
\hline CHEMBL124892 & 159458 & 7.6383 & 7.3667 & TST & \\
\hline CHEMBL338912 & 159458 & 6.8962 & 7.6093 & TST & \\
\hline CHEMBL122480 & 159458 & 7.4202 & 7.3276 & TST & \\
\hline CHEMBL331724 & 159458 & 7.9208 & 7.4772 & TST & \\
\hline CHEMBL421475 & 159458 & 6.1024 & 6.5235 & TST & \\
\hline CHEMBL125506 & 159458 & 7.7696 & 7.3725 & TST & \\
\hline CHEMBL 3663314 & 1528334 & 6.0 & 8.2241 & TST & \\
\hline CHEMBL 3663267 & 1528334 & 8.1024 & 8.3369 & TRN & \\
\hline CHEMBL 3663278 & 1528334 & 6.3 & 7.2606 & TRN & \\
\hline CHEMBL 3663291 & 1528334 & 8.3979 & 7.7556 & TRN & \\
\hline CHEMBL3663275 & 1528334 & 8.1024 & 7.8205 & TRN & \\
\hline CHEMBL 3663271 & 1528334 & 7.8013 & 7.65799 & 99999999995 & TRN \\
\hline CHEMBL 3663279 & 1528334 & 8.2007 & 8.6681 & TRN & \\
\hline CHEMBL 3663307 & 1528334 & 7.5003 & 8.6869 & TST & \\
\hline CHEMBL 3639621 & 1528334 & 7.8996 & 8.2048 & TRN & \\
\hline CHEMBL3663306 & 1528334 & 7.2 & 8.4851 & TST & \\
\hline CHEMBL 3663265 & 1528334 & 7.699 & 8.0972 & TRN & \\
\hline CHEMBL 3663269 & 1528334 & 8.2007 & 8.0176 & TRN & \\
\hline CHEMBL 3663283 & 1528334 & 6.2 & 7.8505 & TST & \\
\hline CHEMBL 3663249 & 1528334 & 8.4949 & 8.1377 & TRN & \\
\hline CHEMBL3663250 & 1528334 & 7.6003 & 7.7757 & TRN & \\
\hline CHEMBL3663290 & 1528334 & 8.1024 & 7.3491 & TRN & \\
\hline CHEMBL 3663236 & 1528334 & 8.0 & 7.6299 & TRN & \\
\hline CHEMBL 3663247 & 1528334 & 8.8539 & 8.4837 & TRN & \\
\hline CHEMBL 3663229 & 1528334 & 7.5406 & 7.954 & TRN & \\
\hline CHEMBL3663301 & 1528334 & 7.5003 & 8.3701 & TST & \\
\hline CHEMBL3663281 & 1528334 & 6.4 & 8.0009 & TST & \\
\hline CHEMBL 3663280 & 1528334 & 7.3002 & 7.7686 & TRN & \\
\hline CHEMBL3663297 & 1528334 & 8.4949 & 8.3658 & TRN & \\
\hline CHEMBL 3663248 & 1528334 & 8.2007 & 8.2422 & TRN & \\
\hline CHEMBL3663296 & 1528334 & 8.0 & 8.2979 & TRN & \\
\hline CHEMBL3663261 & 1528334 & 7.6003 & 7.6596 & TRN & \\
\hline CHEMBL3663316 & 1528334 & 8.699 & 8.1038 & TRN & \\
\hline CHEMBL 3663308 & 1528334 & 8.301 & 8.684 & TST & \\
\hline CHEMBL3663295 & 1528334 & 7.8996 & 7.8825 & TRN & \\
\hline
\end{tabular}

Page 12047 
Supplemental Table S2.txt

\begin{tabular}{|c|c|c|c|c|c|}
\hline CHEMBL3663252 & 1528334 & 8.4949 & 8.2922 & TRN & \\
\hline CHEMBL3663256 & 1528334 & 8.3979 & 8.2667 & TRN & \\
\hline CHEMBL 3663230 & 1528334 & 8.2007 & 7.981 & TRN & \\
\hline CHEMBL 3663228 & 1528334 & 7.2 & \multicolumn{2}{|c|}{7.207000000000001} & TRN \\
\hline CHEMBL3663257 & 1528334 & 8.699 & 8.6999 & TRN & \\
\hline CHEMBL 3663298 & 1528334 & 8.6021 & 8.7046 & TRN & \\
\hline CHEMBL 3663245 & 1528334 & 8.4949 & 8.5513 & TRN & \\
\hline CHEMBL 3663255 & 1528334 & 8.6021 & 8.8578 & TRN & \\
\hline CHEMBL 3663260 & 1528334 & 8.699 & 8.8785 & TRN & \\
\hline CHEMBL3663253 & 1528334 & 8.4949 & 8.4589 & TRN & \\
\hline CHEMBL 3663299 & 1528334 & 7.8013 & 8.6966 & TST & \\
\hline CHEMBL 3663288 & 1528334 & 6.0 & 7.3866 & TRN & \\
\hline CHEMBL3663305 & 1528334 & 8.301 & 8.6912 & TST & \\
\hline CHEMBL 3663293 & 1528334 & 8.1024 & 7.7868 & TRN & \\
\hline CHEMBL3663246 & 1528334 & 8.3979 & 8.5053 & TRN & \\
\hline CHEMBL 3663302 & 1528334 & 7.2 & 8.5702 & TST & \\
\hline CHEMBL3663277 & 1528334 & 8.0 & \multicolumn{2}{|c|}{7.797999999999999} & TRN \\
\hline CHEMBL 3663258 & 1528334 & 8.301 & 8.4451 & TRN & \\
\hline CHEMBL 3663243 & 1528334 & 8.1024 & 7.8079 & TRN & \\
\hline CHEMBL3663239 & 1528334 & 6.0 & 8.5016 & TST & \\
\hline CHEMBL 3663254 & 1528334 & 8.3979 & 8.0264 & TRN & \\
\hline CHEMBL3663262 & 1528334 & 8.699 & 8.1899 & TRN & \\
\hline CHEMBL3663259 & 1528334 & 8.6021 & 8.5067 & TRN & \\
\hline CHEMBL 3663270 & 1528334 & 7.8996 & 7.8002 & TRN & \\
\hline CHEMBL 3663264 & 1528334 & 7.5607 & 7.4998 & TRN & \\
\hline CHEMBL 3663266 & 1528334 & 7.8996 & 8.1352 & TRN & \\
\hline CHEMBL 3663244 & 1528334 & 8.301 & 8.3838 & TRN & \\
\hline CHEMBL3663251 & 1528334 & 7.6003 & 8.0355 & TST & \\
\hline CHEMBL 3663235 & 1528334 & 7.699 & 7.5847 & TST & \\
\hline CHEMBL3663292 & 1528334 & 7.5003 & 8.1483 & TST & \\
\hline CHEMBL 3663285 & 1528334 & 6.0 & 7.965 & TST & \\
\hline CHEMBL3663313 & 1528334 & 6.8 & 8.4993 & TST & \\
\hline CHEMBL3697483 & 1640325 & 8.684 & 8.5197 & TRN & \\
\hline CHEMBL3697472 & 1640325 & 8.5513 & 8.3487 & TRN & \\
\hline CHEMBL3701051 & 1640325 & 8.0862 & 7.8639 & TRN & \\
\hline CHEMBL3701014 & 1640325 & 7.5455 & 7.5553 & TRN & \\
\hline CHEMBL3701019 & 1640325 & 7.8339 & 7.9506 & TST & \\
\hline CHEMBL3701036 & 1640325 & 5.4831 & 5.2735 & TRN & \\
\hline CHEMBL3701023 & 1640325 & 8.289 & 8.0285 & TRN & \\
\hline CHEMBL3697493 & 1640325 & 7.8891 & 8.2714 & TRN & \\
\hline CHEMBL3697433 & 1640325 & 7.9813 & 7.4104 & TST & \\
\hline CHEMBL3697436 & 1640325 & 6.0 & 6.914 & TST & \\
\hline CHEMBL3697488 & 1640325 & 8.5918 & 8.3334 & TRN & \\
\hline CHEMBL3701012 & 1640325 & 7.6749 & 7.8872 & TRN & \\
\hline CHEMBL3701047 & 1640325 & 8.7399 & 9.0272 & TRN & \\
\hline CHEMBL3697475 & 1640325 & 8.9508 & 8.7115 & TRN & \\
\hline CHEMBL3701004 & 1640325 & 8.1018 & 6.9334 & TRN & \\
\hline CHEMBL3701037 & 1640325 & 8.295 & 7.9527 & TRN & \\
\hline
\end{tabular}




\begin{tabular}{|c|c|c|c|c|c|c|}
\hline \multicolumn{7}{|c|}{ Supplemental Table S2.txt } \\
\hline CHEMBL 3697456 & 1640325 & 7.3486 & 8.0422 & TRN & & \\
\hline CHEMBL3697429 & 1640325 & 6.0 & 6.8046 & TST & & \\
\hline CHEMBL3701010 & 1640325 & 7.2526 & 7.2688 & TRN & & \\
\hline CHEMBL3697453 & 1640325 & 7.1658 & 7.1084 & TRN & & \\
\hline CHEMBL3701030 & 1640325 & 9.1192 & 8.7701 & TRN & & \\
\hline CHEMBL3697494 & 1640325 & 7.9727 & 8.0774 & TRN & & \\
\hline CHEMBL3697466 & 1640325 & 6.0 & 7.6112 & TRN & & \\
\hline CHEMBL3701013 & 1640325 & 8.2197 & 7.8849 & TST & & \\
\hline CHEMBL 3697438 & 1640325 & 7.6929 & 7.0308 & TST & & \\
\hline CHEMBL3697451 & 1640325 & 7.38299 & 99999999 & 99 & 7.1538 & TRN \\
\hline CHEMBL3697428 & 1640325 & 8.0731 & 7.5948 & TRN & & \\
\hline CHEMBL 3697443 & 1640325 & 6.0 & 6.9704 & TST & & \\
\hline CHEMBL3701003 & 1640325 & 6.0515 & 6.6693 & TRN & & \\
\hline CHEMBL3697463 & 1640325 & 8.1561 & 8.314 & TRN & & \\
\hline CHEMBL3701026 & 1640325 & 8.0991 & 7.6763 & TRN & & \\
\hline CHEMBL3414621 & 1640325 & 6.0 & 7.6141 & TRN & & \\
\hline CHEMBL3697439 & 1640325 & 6.0 & 6.4919 & TST & & \\
\hline CHEMBL3697462 & 1640325 & 6.0 & 7.4614 & TRN & & \\
\hline CHEMBL3697485 & 1640325 & 6.0 & 7.3076 & TRN & & \\
\hline CHEMBL3701052 & 1640325 & 8.2708 & 8.7715 & TST & & \\
\hline CHEMBL3701049 & 1640325 & 8.5498 & 8.2578 & TRN & & \\
\hline CHEMBL3697491 & 1640325 & 7.8286 & 8.0787 & TRN & & \\
\hline CHEMBL3701035 & 1640325 & 7.9851 & 7.8961 & TRN & & \\
\hline CHEMBL3697459 & 1640325 & 8.585 & 8.3376 & TRN & & \\
\hline CHEMBL3697454 & 1640325 & 7.9083 & 7.9304 & TRN & & \\
\hline CHEMBL3697449 & 1640325 & 7.8202 & 7.0881 & TRN & & \\
\hline CHEMBL3697487 & 1640325 & 8.15 & 8.4135 & TRN & & \\
\hline CHEMBL3697455 & 1640325 & 8.0506 & 8.3503 & TRN & & \\
\hline CHEMBL 3697440 & 1640325 & 6.0 & 6.7911 & TST & & \\
\hline CHEMBL3697421 & 1640325 & 7.5638 & 7.3909 & TST & & \\
\hline CHEMBL3697500 & 1640325 & 7.9654 & 8.1775 & TRN & & \\
\hline CHEMBL 3697482 & 1640325 & 9.0605 & 8.8355 & TRN & & \\
\hline CHEMBL3701011 & 1640325 & 7.4103 & 7.7937 & TRN & & \\
\hline CHEMBL3701039 & 1640325 & 8.0931 & 8.0009 & TRN & & \\
\hline CHEMBL3697452 & 1640325 & 6.57 & 6.8596 & TRN & & \\
\hline CHEMBL3701022 & 1640325 & 8.0022 & 7.9328 & TRN & & \\
\hline CHEMBL 3697492 & 1640325 & 8.0862 & 8.0493 & TRN & & \\
\hline CHEMBL3697419 & 1640325 & 7.9957 & 7.2988 & TST & & \\
\hline CHEMBL3697470 & 1640325 & 8.4112 & 7.7628 & TRN & & \\
\hline CHEMBL3701017 & 1640325 & 8.2933 & 8.1902 & TRN & & \\
\hline CHEMBL3697471 & 1640325 & 7.9694 & 7.854 & TRN & & \\
\hline CHEMBL3697427 & 1640325 & 7.7891 & 7.2581 & TST & & \\
\hline CHEMBL3701044 & 1640325 & 8.4271 & 8.3741 & TST & & \\
\hline CHEMBL3701016 & 1640325 & 8.0894 & 8.067 & TRN & & \\
\hline CHEMBL3701032 & 1640325 & 8.0325 & 8.8991 & TST & & \\
\hline CHEMBL3701034 & 1640325 & 8.02 & 8.0411 & TRN & & \\
\hline CHEMBL3701015 & 1640325 & 7.7562 & 7.8165 & TRN & & \\
\hline CHEMBL3697490 & 1640325 & 7.9344 & 8.07 & TRN & & \\
\hline
\end{tabular}


Supplemental Table S2.txt

\begin{tabular}{|c|c|c|c|c|c|}
\hline CHEMBL 3701018 & 1640325 & 7.9158 & 8.0116 & TST & \\
\hline CHEMBL 3697434 & 1640325 & 6.0 & 6.4763 & TST & \\
\hline CHEMBL 3697445 & 1640325 & 6.0 & 7.0766 & TST & \\
\hline CHEMBL 3697489 & 1640325 & 7.5272 & 8.1478 & TRN & \\
\hline CHEMBL3701008 & 1640325 & 7.6392 & 7.9217 & TRN & \\
\hline CHEMBL3697477 & 1640325 & 8.2284 & 7.9558 & TRN & \\
\hline CHEMBL3701031 & 1640325 & 8.3757 & 8.6011 & TST & \\
\hline CHEMBL 3697481 & 1640325 & 7.7131 & 8.3361 & TRN & \\
\hline CHEMBL 3697480 & 1640325 & 9.28399 & 999999999 & 99 & 8.7007 \\
\hline CHEMBL 3701005 & 1640325 & 8.2573 & 8.054 & TRN & \\
\hline CHEMBL3701029 & 1640325 & 8.7878 & 8.4921 & TST & \\
\hline CHEMBL 3701021 & 1640325 & 8.1681 & 8.0637 & TRN & \\
\hline CHEMBL3701028 & 1640325 & 8.5622 & 7.8427 & TST & \\
\hline CHEMBL3701024 & 1640325 & 8.3028 & 8.1078 & TRN & \\
\hline CHEMBL 3697468 & 1640325 & 8.3224 & 7.8301 & TRN & \\
\hline CHEMBL3701041 & 1640325 & 8.2449 & 7.9917 & TRN & \\
\hline CHEMBL3697469 & 1640325 & 8.109 & 7.8331 & TRN & \\
\hline CHEMBL 3697479 & 1640325 & 8.4425 & 8.342 & TRN & \\
\hline CHEMBL3701020 & 1640325 & 8.327 & 8.073 & TRN & \\
\hline CHEMBL3701033 & 1640325 & 8.5391 & 8.213 & TRN & \\
\hline CHEMBL3701038 & 1640325 & 6.7363 & 6.0992 & TRN & \\
\hline CHEMBL3700996 & 1640325 & 7.3152 & 7.6972 & TST & \\
\hline CHEMBL3701009 & 1640325 & 7.1332 & 7.3299 & TRN & \\
\hline CHEMBL 3697450 & 1640325 & 6.6719 & 6.7526 & TRN & \\
\hline CHEMBL 3697474 & 1640325 & 8.2132 & 7.7832 & TRN & \\
\hline CHEMBL 3701040 & 1640325 & 8.6517 & 8.3254 & TRN & \\
\hline CHEMBL3701006 & 1640325 & 7.8027 & 8.2865 & TRN & \\
\hline CHEMBL3701007 & 1640325 & 8.1002 & 7.7237 & TRN & \\
\hline CHEMBL3701025 & 1640325 & 7.871 & 7.9133 & TST & \\
\hline CHEMBL3697476 & 1640325 & 8.3675 & 8.4273 & TRN & \\
\hline CHEMBL 3697465 & 1640325 & 8.4584 & 8.4446 & TRN & \\
\hline CHEMBL 3697486 & 1640325 & 8.5287 & 8.5133 & TRN & \\
\hline CHEMBL 3697422 & 1640325 & 8.1421 & 7.4984 & TST & \\
\hline CHEMBL3697473 & 1640325 & 8.3788 & 7.7554 & TRN & \\
\hline CHEMBL 3701042 & 1640325 & 8.4123 & 9.0808 & TST & \\
\hline CHEMBL92309 & 954638 & 3.1786 & 1.9909 & TST & \\
\hline CHEMBL217354 & 954638 & 5.8254 & 5.8256 & TRN & \\
\hline CHEMBL515416 & 954638 & 3.6765 & 3.6765 & TRN & \\
\hline CHEMBL 255342 & 954638 & 3.4356 & 3.4357 & TRN & \\
\hline CHEMBL 3199475 & 954638 & 3.9645 & 3.9645 & TRN & \\
\hline CHEMBL1242367 & 954638 & 4.5886 & 4.5886 & TRN & \\
\hline CHEMBL 9470 & 954638 & 7.0867 & 4.6597 & TST & \\
\hline CHEMBL135561 & 954638 & 5.9749 & 5.9749 & TRN & \\
\hline CHEMBL1673039 & 954638 & 5.0848 & 5.0849 & TRN & \\
\hline CHEMBL1230020 & 954638 & 3.9507 & 3.9507 & TRN & \\
\hline CHEMBL240954 & 954638 & 3.2208 & 3.5424 & TST & \\
\hline CHEMBL514499 & 954638 & 5.9375 & 5.9375 & TRN & \\
\hline CHEMBL1256459 & 954638 & 3.859 & 3.859 & TRN & \\
\hline
\end{tabular}




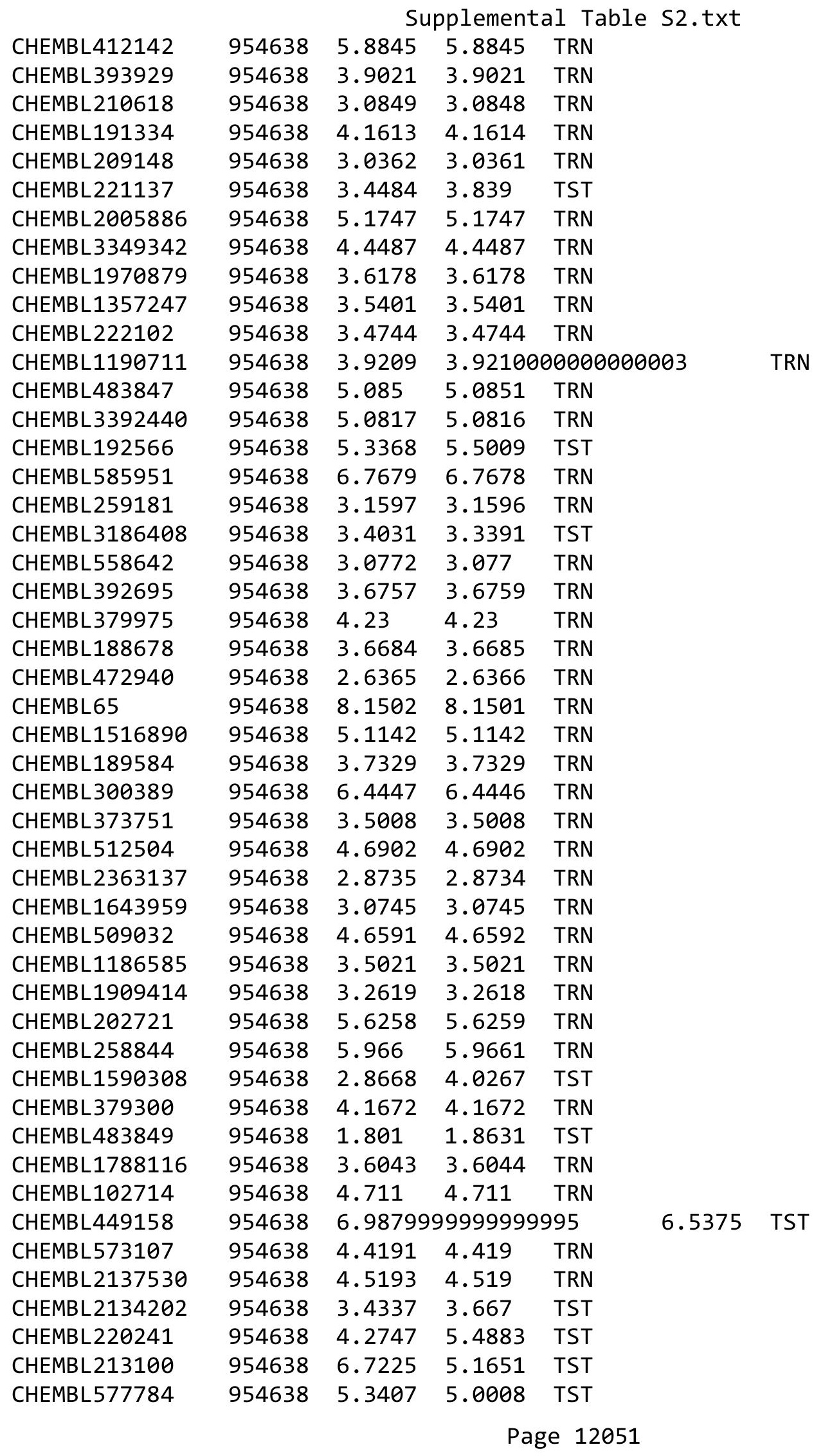




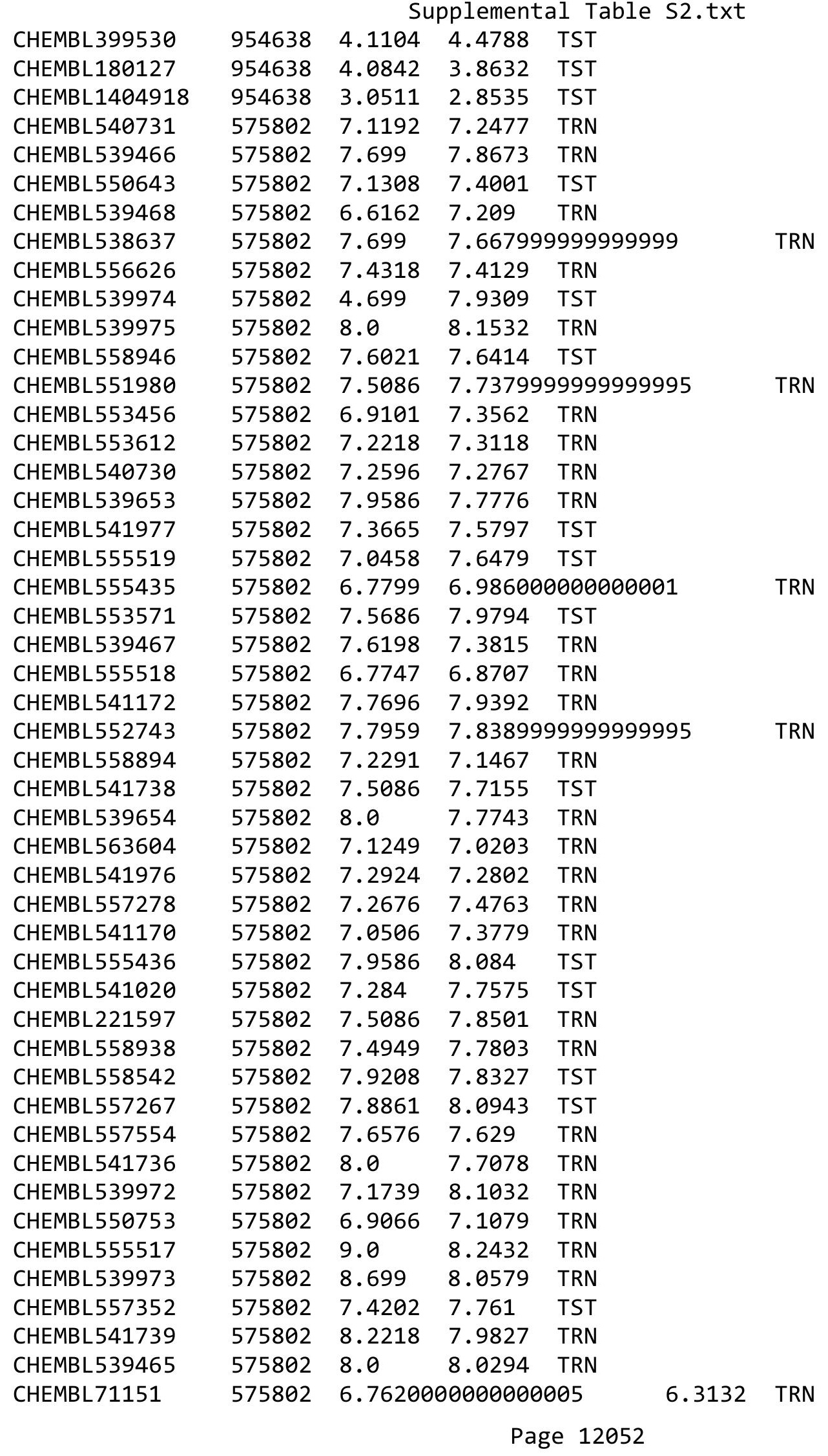




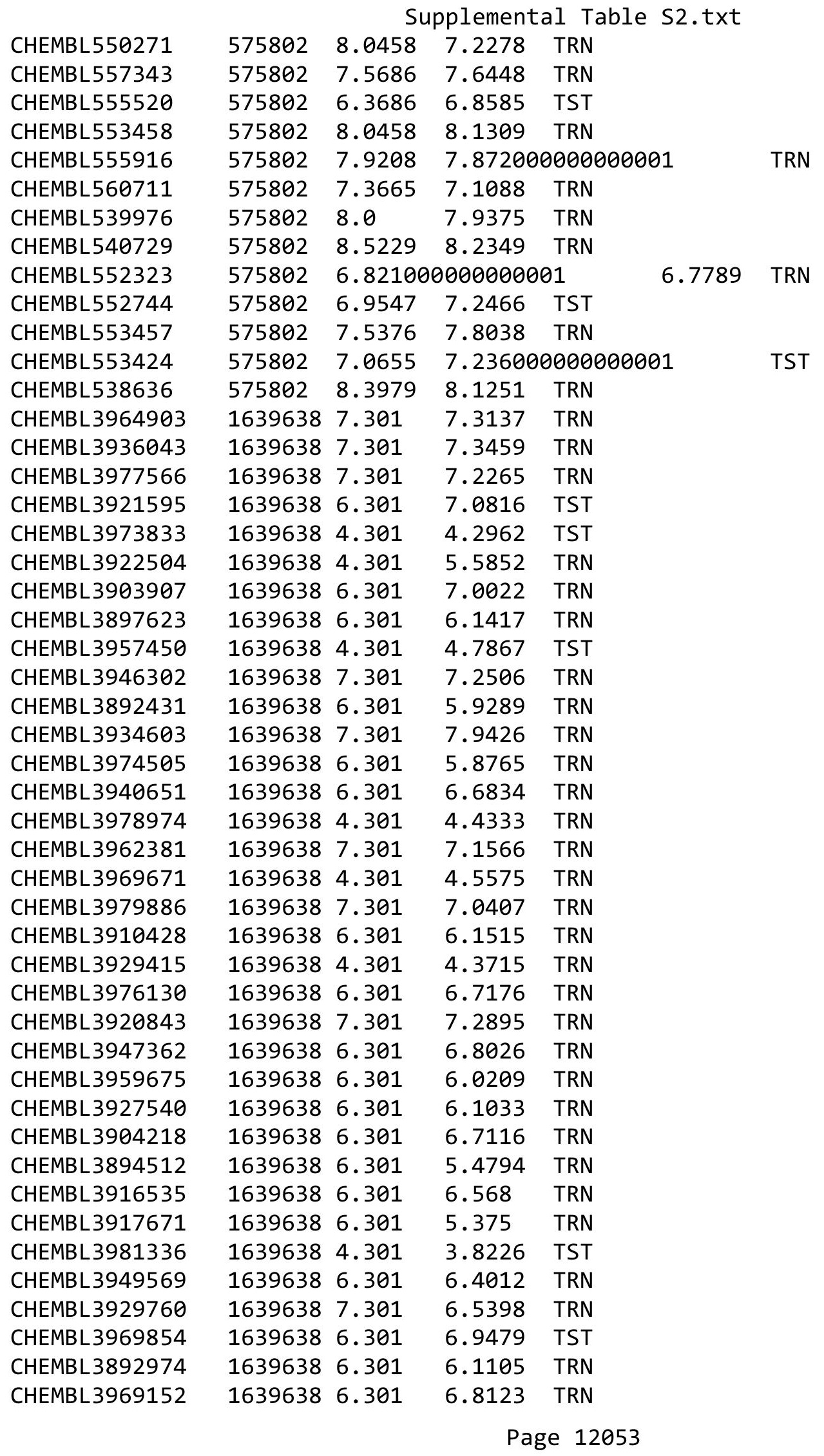


Supplemental Table S2.txt

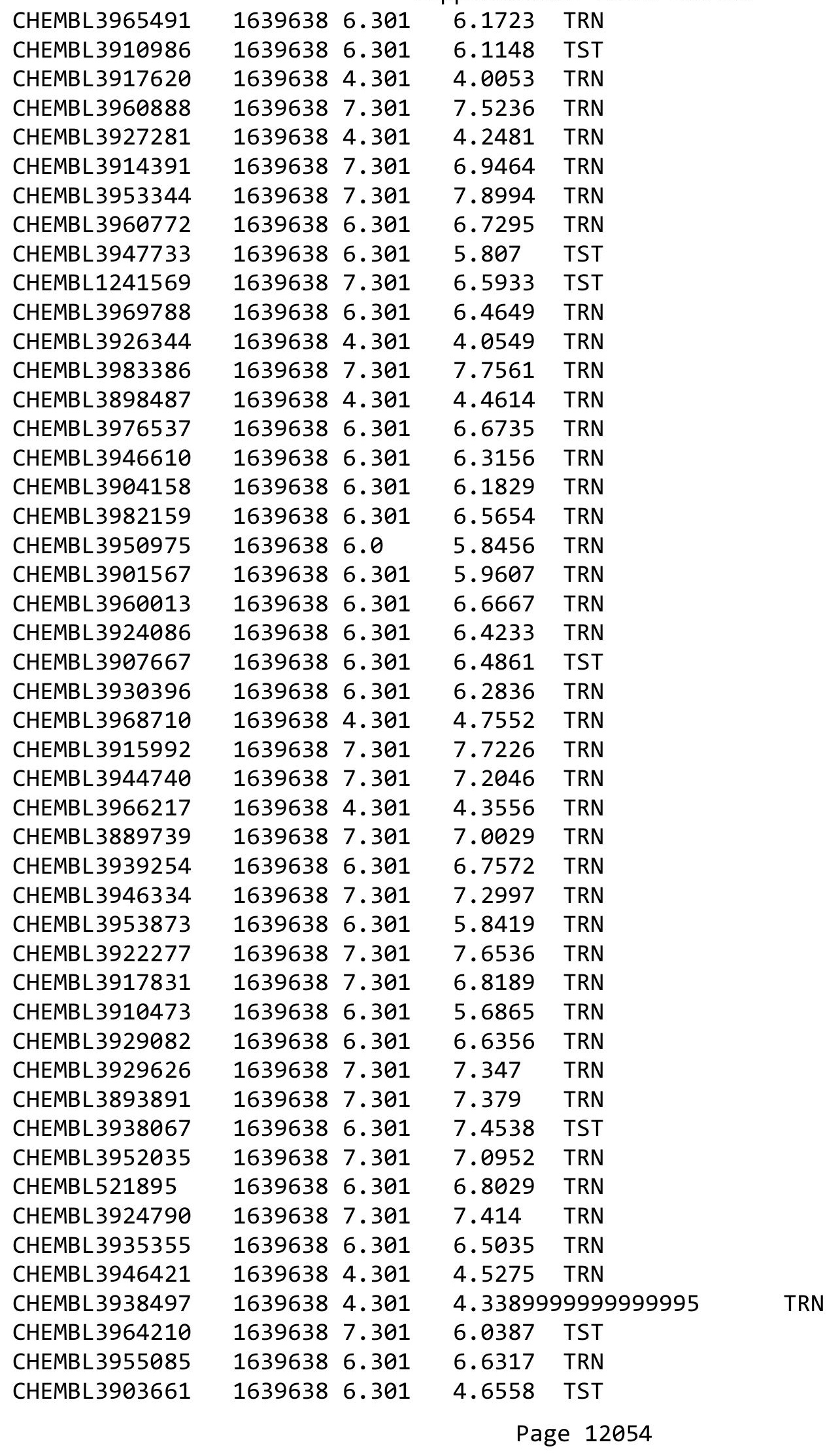


Supplemental Table S2.txt

\begin{tabular}{|c|c|c|c|c|c|}
\hline CHEMBL 3962417 & 1639638 & 7.301 & 7.6504 & TRN & \\
\hline CHEMBL 3957453 & 1639638 & 6.301 & 6.6003 & TRN & \\
\hline CHEMBL 3932715 & 1639638 & 7.301 & 6.8733 & TRN & \\
\hline CHEMBL 3982265 & 1639638 & 7.301 & 6.4898 & TST & \\
\hline CHEMBL 3973676 & 1639638 & 7.301 & 6.8852 & TRN & \\
\hline CHEMBL 3983053 & 1639638 & 4.301 & 4.8396 & TRN & \\
\hline CHEMBL3965789 & 1639638 & 6.301 & 6.1378 & TRN & \\
\hline CHEMBL 3936464 & 1639638 & 7.301 & 7.5312 & TRN & \\
\hline CHEMBL 3946622 & 1639638 & 4.301 & 4.7244 & TST & \\
\hline CHEMBL3913123 & 1639638 & 7.301 & 7.4583 & TRN & \\
\hline CHEMBL 3898655 & 1639638 & 7.301 & 6.8791 & TRN & \\
\hline CHEMBL3938315 & 1639638 & 6.301 & 6.6452 & TRN & \\
\hline CHEMBL 3954598 & 1639638 & 4.301 & 4.3679 & TRN & \\
\hline CHEMBL 3981560 & 1639638 & 6.301 & 6.9156 & TRN & \\
\hline CHEMBL 3948442 & 1639638 & 7.301 & 7.4629 & TRN & \\
\hline CHEMBL 3969323 & 1639638 & 6.301 & \multicolumn{2}{|c|}{6.6370000000000005} & TRN \\
\hline CHEMBL 3931884 & 1639638 & 7.301 & 7.2225 & TRN & \\
\hline CHEMBL3965523 & 1639638 & 4.301 & 4.5751 & TRN & \\
\hline CHEMBL 3963071 & 1639638 & 6.301 & 6.1232 & TST & \\
\hline CHEMBL 3942191 & 1639638 & 6.301 & 5.8831 & TRN & \\
\hline CHEMBL 3902986 & 1639638 & 7.301 & 6.4927 & TRN & \\
\hline CHEMBL 3978191 & 1639638 & 6.301 & 6.1302 & TRN & \\
\hline CHEMBL3983516 & 1639638 & 4.301 & 5.7909 & TST & \\
\hline CHEMBL 3900099 & 1639638 & 6.301 & 6.7583 & TRN & \\
\hline CHEMBL3945808 & 1639638 & 4.301 & 5.7023 & TRN & \\
\hline CHEMBL 3900698 & 1639638 & 7.301 & 7.1385 & TRN & \\
\hline CHEMBL3895926 & 1639638 & 6.301 & 5.7476 & TRN & \\
\hline CHEMBL3948804 & 1639638 & 4.301 & 4.4516 & TST & \\
\hline CHEMBL 3972484 & 1639638 & 6.301 & 5.899 & TRN & \\
\hline CHEMBL3948547 & 1639638 & 7.301 & 6.4728 & TRN & \\
\hline CHEMBL 3957213 & 1639638 & 4.301 & 4.3119 & TST & \\
\hline CHEMBL 3972005 & 1639638 & 6.301 & 5.814 & TST & \\
\hline CHEMBL3939181 & 1639638 & 7.301 & 7.0715 & TRN & \\
\hline CHEMBL 3951713 & 1639638 & 7.301 & 7.5268 & TRN & \\
\hline CHEMBL3950906 & 1639638 & 7.301 & 7.2901 & TRN & \\
\hline CHEMBL69638 & 1639638 & 4.301 & 4.8199 & TST & \\
\hline CHEMBL 3907833 & 1639638 & 7.301 & 6.5099 & TRN & \\
\hline CHEMBL3948864 & 1639638 & 7.301 & 7.2453 & TRN & \\
\hline CHEMBL 3947890 & 1639638 & 7.301 & 7.3983 & TRN & \\
\hline CHEMBL3974700 & 1639638 & 6.301 & 5.5363 & TST & \\
\hline CHEMBL 3929393 & 1639638 & 7.301 & 7.1051 & TRN & \\
\hline CHEMBL3966233 & 1639638 & 4.301 & 5.1068 & TRN & \\
\hline CHEMBL 3891418 & 1639638 & 7.301 & 7.0845 & TRN & \\
\hline CHEMBL 3923119 & 1639638 & 6.301 & 6.0814 & TRN & \\
\hline CHEMBL 3933857 & 1639638 & 6.301 & 5.7986 & TRN & \\
\hline CHEMBL 3926606 & 1639638 & 6.301 & 7.0255 & TRN & \\
\hline CHEMBL 3965216 & 1639638 & 6.301 & 6.8988 & TRN & \\
\hline CHEMBL 3906390 & 1639638 & 4.301 & 4.869 & TRN & \\
\hline
\end{tabular}


Supplemental Table S2.txt

CHEMBL3932168

CHEMBL 3977669

CHEMBL3902925

CHEMBL3920121

CHEMBL 3945764

CHEMBL3984067

CHEMBL 3963544

CHEMBL 3972142

CHEMBL 3934851

CHEMBL3926985

CHEMBL3911864

CHEMBL3922659

CHEMBL3906892

CHEMBL3970961

CHEMBL3946057

CHEMBL3974639

CHEMBL3918901

CHEMBL 3929174

CHEMBL3907622

CHEMBL 3896387

CHEMBL3923238

CHEMBL3973211

CHEMBL 3927637

CHEMBL3906354

CHEMBL 3937191

CHEMBL3916332

CHEMBL 3908678

CHEMBL3969734

CHEMBL3936745

CHEMBL3935077

CHEMBL3898001

CHEMBL3950461

CHEMBL3948445

CHEMBL3918655

CHEMBL 3889700

CHEMBL3921351

CHEMBL3921417

CHEMBL3951485

CHEMBL3958571

CHEMBL3954655

CHEMBL3968205

CHEMBL3944113

CHEMBL3968298

CHEMBL 3922072

CHEMBL3945893

CHEMBL 3892830

CHEMBL3962143

CHEMBL 3971803
16396384.301

16396386.301

$1639638 \quad 6.301$

16396386.301

16396387.301

16396387.301

16396387.301

16396386.301

16396387.301

16396386.301

16396387.301

16396387.301

16396387.301

16396384.301

16396384.301

16396387.301

16396386.301

16396386.301

16396386.301

16396387.301

16396386.301

16396386.301

16396384.301

16396387.301

16396387.301

16396384.301

16396384.301

$1639638 \quad 6.301$

16396384.301

16396386.301

16396387.301

16396386.301

16396386.301

16396386.301

16396387.301

16396384.301

16396386.0

16396386.301

16396384.301

16396387.301

$1639638 \quad 6.301$

16396387.301

16396387.301

16396387.301

16396387.301

16396386.301

16396384.301

16396387.301
4.6394 TRN

6.5704 TRN

6.4408 TRN

5.8025 TST

7.2553 TRN

7.117000000000001

7.3761 TRN

6.4731 TRN

6.9548 TRN

5.3325 TST

7.2067 TRN

7.5139 TRN

7.1316 TRN

4.5271 TST

4.8619 TST

7.27 TRN

6.4445 TRN

6.2366 TRN

6.1006 TRN

7.2718 TRN

6.0905 TRN

6.2022 TRN

4.1836 TST

7.4735 TRN

7.0814 TRN

4.3767 TRN

5.4402 TST

7.0374 TRN

5.1753 TRN

6.5941 TRN

6.9552 TRN

5.2637 TRN

6.5601 TRN

6.1838 TRN

7.0187 TRN

4.7808 TRN

7.1468 TRN

6.2957 TRN

3.9256 TST

7.3682 TRN

6.4657 TRN

7.3301 TST

7.5751 TRN

7.7128 TRN

7.8214 TRN

6.4773 TRN

4.3186 TRN

6.8068 TRN

Page 12056 
Supplemental Table S2.txt

\begin{tabular}{|c|c|c|c|c|}
\hline CHEMBL 3939968 & 1639638 & 7.301 & 6.7315 & TRN \\
\hline CHEMBL 3898581 & 1639638 & 7.301 & 6.0893 & TST \\
\hline CHEMBL 3955163 & 1639638 & 6.301 & 6.6934 & TST \\
\hline CHEMBL 3931389 & 1639638 & 4.301 & 4.5525 & TRN \\
\hline CHEMBL 3945083 & 1639638 & 7.301 & \multicolumn{2}{|c|}{6.962000000000001} \\
\hline CHEMBL 3913705 & 1639638 & 7.301 & 7.1122 & TRN \\
\hline CHEMBL 3980579 & 1639638 & 7.301 & 6.4445 & TRN \\
\hline CHEMBL 3891318 & 1639638 & 7.301 & \multicolumn{2}{|c|}{6.002000000000001} \\
\hline CHEMBL 3938224 & 1639638 & 6.301 & 6.2533 & TRN \\
\hline CHEMBL 3952184 & 1639638 & 6.301 & 6.8151 & TST \\
\hline CHEMBL 3909920 & 1639638 & 7.301 & 7.14 & TRN \\
\hline CHEMBL 3902595 & 1639638 & 7.301 & 7.4076 & TST \\
\hline CHEMBL 3903233 & 1639638 & 6.301 & 6.3404 & TRN \\
\hline CHEMBL 3974050 & 1639638 & 6.301 & 6.5001 & TST \\
\hline CHEMBL 3902663 & 1639638 & 7.301 & 7.3057 & TRN \\
\hline CHEMBL 3983881 & 1639638 & 7.301 & 7.5286 & TRN \\
\hline CHEMBL 3920278 & 1639638 & 6.301 & 6.4082 & TRN \\
\hline CHEMBL 3905368 & 1639638 & 6.301 & 6.306 & TRN \\
\hline CHEMBL 3944408 & 1639638 & 6.301 & 5.6596 & TRN \\
\hline CHEMBL 3913201 & 1639638 & 4.301 & 5.0652 & TRN \\
\hline CHEMBL 3893428 & 1639638 & 6.301 & 5.9882 & TRN \\
\hline CHEMBL 3909945 & 1639638 & 6.301 & 6.1326 & TRN \\
\hline CHEMBL 3933451 & 1639638 & 6.301 & 6.3214 & TST \\
\hline CHEMBL 3916373 & 1639638 & 7.301 & 7.1531 & TRN \\
\hline CHEMBL 3961802 & 1639638 & 6.301 & 6.1257 & TST \\
\hline CHEMBL 3932387 & 1639638 & 7.301 & 7.2331 & TST \\
\hline CHEMBL 3955590 & 1639638 & 6.301 & 5.7489 & TRN \\
\hline CHEMBL 3980001 & 1639638 & 7.301 & 6.6775 & TRN \\
\hline CHEMBL 3949993 & 1639638 & 7.301 & 7.3808 & TRN \\
\hline CHEMBL 3911934 & 1639638 & 4.301 & 5.2341 & TST \\
\hline CHEMBL 3914566 & 1639638 & 4.301 & 4.8927 & TRN \\
\hline CHEMBL 3904363 & 1639638 & 7.301 & 6.6341 & TRN \\
\hline CHEMBL 3955965 & 1639638 & 6.301 & 6.6019 & TRN \\
\hline CHEMBL 3966542 & 1639638 & 7.301 & 7.0391 & TRN \\
\hline CHEMBL 3905592 & 1639638 & 7.301 & 7.0909 & TRN \\
\hline CHEMBL 3943179 & 1639638 & 4.301 & 4.0573 & TST \\
\hline CHEMBL 3945357 & 1639638 & 7.301 & 6.8807 & TRN \\
\hline CHEMBL 3951640 & 1639638 & 7.301 & 7.5596 & TRN \\
\hline CHEMBL 3940331 & 1639638 & 6.301 & 6.2046 & TRN \\
\hline CHEMBL 3902712 & 1639638 & 6.301 & 6.4338 & TRN \\
\hline CHEMBL 3919886 & 1639638 & 6.301 & 5.8133 & TRN \\
\hline CHEMBL 3905214 & 1639638 & 7.301 & 7.4179 & TRN \\
\hline CHEMBL 3977542 & 1639638 & 7.301 & 6.9363 & TRN \\
\hline CHEMBL 3923437 & 1639638 & 6.301 & 6.3222 & TRN \\
\hline CHEMBL 3918853 & 1639638 & 7.301 & 6.9566 & TRN \\
\hline CHEMBL 3924933 & 1639638 & 4.301 & 5.3006 & TST \\
\hline CHEMBL 3923876 & 1639638 & 7.301 & 7.2805 & TRN \\
\hline CHEMBL 3937356 & 1639638 & 6.301 & 6.0168 & TRN \\
\hline
\end{tabular}


Supplemental Table S2.txt

\begin{tabular}{|c|c|c|c|c|c|}
\hline CHEMBL3910573 & 1639638 & 6.301 & 5.7574 & TRN & \\
\hline CHEMBL3929993 & 1639638 & 6.301 & 5.3621 & TRN & \\
\hline CHEMBL3911118 & 1639638 & 7.301 & 7.3819 & TRN & \\
\hline CHEMBL3946183 & 1639638 & 7.301 & 6.5481 & TRN & \\
\hline CHEMBL3984411 & 1639638 & 7.301 & 7.3594 & TRN & \\
\hline CHEMBL3958377 & 1639638 & 7.301 & 7.3629 & TRN & \\
\hline CHEMBL3962213 & 1639638 & 6.301 & 6.2209 & TRN & \\
\hline CHEMBL3892032 & 1639638 & 4.301 & 5.1546 & TST & \\
\hline CHEMBL3901458 & 1639638 & 7.301 & 6.1122 & TST & \\
\hline CHEMBL3920402 & 1639638 & 4.301 & 4.0551 & TRN & \\
\hline CHEMBL3968200 & 1639638 & 7.301 & 7.3814 & TRN & \\
\hline CHEMBL3946147 & 1639638 & 7.301 & 6.8345 & TST & \\
\hline CHEMBL3948500 & 1639638 & 4.301 & 4.6334 & TRN & \\
\hline CHEMBL3959585 & 1639638 & 7.301 & 6.7154 & TRN & \\
\hline CHEMBL3919140 & 1639638 & 7.301 & 7.5633 & TRN & \\
\hline CHEMBL3982043 & 1639638 & 6.301 & 6.3271 & TST & \\
\hline CHEMBL3894208 & 1639638 & 6.301 & 6.4079 & TST & \\
\hline CHEMBL 3977190 & 1639638 & 7.301 & 6.7607 & TRN & \\
\hline CHEMBL3935778 & 1639638 & 7.301 & 7.0124 & TRN & \\
\hline CHEMBL3978787 & 1639638 & 6.301 & 5.3736 & TST & \\
\hline CHEMBL3894511 & 1639638 & 7.301 & 7.1823 & TRN & \\
\hline CHEMBL 3957817 & 1639638 & 6.301 & 5.9529 & TRN & \\
\hline CHEMBL3924996 & 1639638 & 7.301 & 7.6226 & TRN & \\
\hline CHEMBL 3924283 & 1639638 & 6.301 & 6.4897 & TRN & \\
\hline CHEMBL3928679 & 1639638 & 7.301 & 7.3718 & TRN & \\
\hline CHEMBL3894607 & 1639638 & 6.301 & 6.3722 & TRN & \\
\hline CHEMBL3938559 & 1639638 & 7.301 & 6.8366 & TRN & \\
\hline CHEMBL3944239 & 1639638 & 4.301 & 4.6554 & TRN & \\
\hline CHEMBL3911710 & 1639638 & 6.301 & 5.943 & TRN & \\
\hline CHEMBL3932519 & 1639638 & 7.301 & 7.0613 & TRN & \\
\hline CHEMBL3980371 & 1639638 & 7.301 & 7.4732 & TRN & \\
\hline CHEMBL 3941204 & 1639638 & 4.301 & 5.2776 & TST & \\
\hline CHEMBL3983161 & 1639638 & 4.301 & 5.2892 & TRN & \\
\hline CHEMBL 3895688 & 1639638 & 7.301 & 7.2218 & TRN & \\
\hline CHEMBL3916991 & 1639638 & 7.301 & 6.6693 & TRN & \\
\hline CHEMBL3906841 & 1639638 & 6.301 & 7.0928 & TRN & \\
\hline CHEMBL3959219 & 1639638 & 6.301 & 6.9172 & TRN & \\
\hline CHEMBL3967198 & 1639638 & 6.301 & 6.5604 & TRN & \\
\hline CHEMBL3916643 & 1639638 & 7.301 & \multicolumn{2}{|c|}{6.457000000000001} & TRN \\
\hline CHEMBL399021 & 1639638 & 6.301 & 5.2634 & TST & \\
\hline CHEMBL3952643 & 1639638 & 6.301 & 6.1997 & TRN & \\
\hline CHEMBL 3941940 & 1639638 & 6.301 & \multicolumn{2}{|c|}{5.843999999999999} & TRN \\
\hline CHEMBL3929699 & 1639638 & 7.301 & 7.0758 & TRN & \\
\hline CHEMBL3957352 & 1639638 & 7.301 & 7.5082 & TRN & \\
\hline CHEMBL3983956 & 1639638 & 7.301 & 6.8891 & TRN & \\
\hline CHEMBL3925505 & 1639638 & 7.301 & 6.9878 & TRN & \\
\hline CHEMBL3928120 & 1639638 & 4.301 & 4.5881 & TRN & \\
\hline CHEMBL3916941 & 1639638 & 6.301 & 5.9157 & TST & \\
\hline
\end{tabular}


Supplemental Table S2.txt

\begin{tabular}{|c|c|c|c|c|}
\hline HEMBL396 & 639638 & 4.301 & 4.2926 & 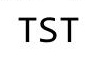 \\
\hline HEMBL3961783 & 639638 & 6.301 & 6.7203 & 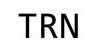 \\
\hline HEMBL3921369 & 539638 & 301 & 9387 & \\
\hline AEMBL3917632 & 539638 & 7.301 & 7392 & CT \\
\hline HEMBL3980577 & 639638 & 7.301 & 8449 & \\
\hline HEMBL3924389 & 639638 & 6.301 & .0253 & \\
\hline HEMBL3966779 & 639638 & 6.301 & 9793 & \\
\hline HEMBL3907416 & 639638 & 7.301 & 7866 & \\
\hline HEMBL3928105 & 639638 & 6.301 & .7389 & \\
\hline HEMBL3960142 & 639638 & 6.301 & 612 & \\
\hline HEMBL3957551 & 639638 & 6.301 & 8036 & \\
\hline HEMBL3936222 & 639638 & 4.301 & 5052 & \\
\hline HEMBL3966870 & 539638 & 6.301 & 9721 & RN \\
\hline HEMBL3901341 & 1639638 & 7.301 & 6713 & \\
\hline HEMBL3952625 & 639638 & 6.301 & 8803 & \\
\hline HEMBL3954797 & 639638 & 4.301 & 8927 & NIV \\
\hline HEMBL3905863 & 639638 & 7.301 & 4712 & RIV \\
\hline HEMBL3962211 & 639638 & 6.301 & & ST \\
\hline HEMBL3936663 & 639638 & 7.301 & 707 & RN \\
\hline HEMBL3932359 & 639638 & 6.301 & & ST \\
\hline HEMBL3892954 & 639638 & 7.301 & 65 & RIV \\
\hline HEMBL3930472 & 639638 & 6.301 & 84 & $R N$ \\
\hline HEMBL3963527 & 639638 & 7.301 & & \\
\hline HEMBL3977623 & 639638 & 6.301 & 509 & ST \\
\hline HEMBL3948152 & 38 & 6.301 & & RN \\
\hline HEMBL3900489 & 639638 & 6.301 & 28 & RN \\
\hline HEMBL3919085 & 639638 & 4.301 & 363 & ST \\
\hline HEMBL3967069 & 38 & 4.301 & 52 & \\
\hline HEMBL3947072 & 1639638 & 7.301 & & RN \\
\hline HEMBL3963029 & 639638 & 7.301 & 51 & RN \\
\hline HEMBL3959574 & 639638 & 7.301 & 442 & RN \\
\hline HEMBL3927102 & 639638 & 6.301 & 58 & ST \\
\hline HEMBL3950919 & 38 & 6.301 & 77 & TRN \\
\hline HEMBL3963363 & 639638 & 7.301 & & IRN \\
\hline HEMBL3942675 & 639638 & 7.301 & 43 & 「RN \\
\hline HEMBL3904134 & 1639638 & 6.301 & 245 & ST \\
\hline HEMBL3946160 & 38 & 4 . & & RN \\
\hline HEMBL3891852 & 1639638 & 6.301 & 925 & TRN \\
\hline HEMBL3965968 & 1639638 & 6.301 & 461 & TRN \\
\hline HEMBL3959703 & 639638 & 7.301 & 796 & TRN \\
\hline CHEMBL3955941 & 1639638 & 4.301 & 985 & ST \\
\hline CHEMBL464179 & 1639638 & 6.301 & 454 & RN \\
\hline HEMBL3956940 & 1639638 & 4.301 & 7415 & ГRN \\
\hline HEMBL3950763 & 1639638 & 7.301 & 7016 & TRN \\
\hline CHEMBL3932122 & 639638 & 7.301 & 666 & RN \\
\hline CHEMBL3926402 & 1639638 & 4.301 & & \\
\hline CHEMBL 3903431 & 1639638 & 6.301 & 5.7817 & RN \\
\hline CHEMBL3946560 & 1639638 & 7.301 & 6.7392 & $\mathrm{RN}$ \\
\hline
\end{tabular}

Page 12059 
Supplemental Table S2.txt

\begin{tabular}{|c|c|c|c|c|c|}
\hline CHEMBL 3928421 & 1639638 & 6.301 & 6.2029 & TRN & \\
\hline CHEMBL3904092 & 1639638 & 7.301 & 6.8629 & TRN & \\
\hline CHEMBL3966891 & 1639638 & 6.301 & \multicolumn{2}{|c|}{6.0120000000000005} & TRN \\
\hline CHEMBL3983968 & 1639638 & 6.301 & 6.5836 & TRN & \\
\hline CHEMBL3967974 & 1639638 & 7.301 & 6.8457 & TRN & \\
\hline CHEMBL 3927723 & 1639638 & 6.301 & 6.3197 & TRN & \\
\hline CHEMBL3939361 & 1639638 & 7.301 & 6.8838 & TRN & \\
\hline CHEMBL3976513 & 1639638 & 6.301 & 5.811 & TRN & \\
\hline CHEMBL3907202 & 1639638 & 4.301 & 4.5312 & TRN & \\
\hline CHEMBL3915074 & 1639638 & 6.301 & 6.5112 & TRN & \\
\hline CHEMBL3923587 & 1639638 & 4.301 & 3.8241 & TRN & \\
\hline CHEMBL3920475 & 1639638 & 7.301 & 6.7186 & TRN & \\
\hline CHEMBL3975149 & 1639638 & 7.301 & 7.0084 & TRN & \\
\hline CHEMBL3898799 & 1639638 & 6.301 & 5.7506 & TRN & \\
\hline CHEMBL3929068 & 1639638 & 4.301 & 5.2218 & TRN & \\
\hline CHEMBL 3894207 & 1639638 & 7.301 & 7.5101 & TRN & \\
\hline CHEMBL3968915 & 1639638 & 4.301 & 5.6317 & TST & \\
\hline CHEMBL 3959430 & 1639638 & 4.301 & \multicolumn{2}{|c|}{5.627000000000001} & TRN \\
\hline CHEMBL3962888 & 1639638 & 6.301 & 6.6225 & TRN & \\
\hline CHEMBL3986321 & 1639638 & 6.301 & 6.8113 & TRN & \\
\hline CHEMBL3898928 & 1639638 & 7.301 & 7.0971 & TRN & \\
\hline CHEMBL3898390 & 1639638 & 6.301 & 6.9202 & TST & \\
\hline CHEMBL3971529 & 1639638 & 7.301 & 6.7545 & TRN & \\
\hline CHEMBL3900069 & 1639638 & 7.301 & 7.532 & TRN & \\
\hline CHEMBL3892480 & 1639638 & 6.301 & 6.5402 & TST & \\
\hline CHEMBL3933017 & 1639638 & 6.301 & 5.0852 & TRN & \\
\hline CHEMBL3913406 & 1639638 & 7.301 & 7.2547 & TRN & \\
\hline CHEMBL3961573 & 1639638 & 7.301 & 6.7402 & TRN & \\
\hline CHEMBL3904605 & 1639638 & 4.301 & 4.5099 & TRN & \\
\hline CHEMBL3903938 & 1639638 & 7.301 & 7.0501 & TRN & \\
\hline CHEMBL3949298 & 1639638 & 6.301 & 6.3747 & TRN & \\
\hline CHEMBL3968474 & 1639638 & 7.301 & 7.0439 & TRN & \\
\hline CHEMBL3959418 & 1639638 & 7.301 & 7.5694 & TRN & \\
\hline CHEMBL3954306 & 1639638 & 7.301 & 6.2963 & TRN & \\
\hline CHEMBL3959579 & 1639638 & 6.301 & 6.4106 & TRN & \\
\hline CHEMBL3891973 & 1639638 & 4.301 & 5.1214 & TRN & \\
\hline CHEMBL3968955 & 1639638 & 4.301 & 5.2528 & TST & \\
\hline CHEMBL3942153 & 1639638 & 7.301 & 7.1716 & TRN & \\
\hline CHEMBL3896752 & 1639638 & 4.301 & 4.8451 & TRN & \\
\hline CHEMBL3894963 & 1639638 & 6.301 & 6.3853 & TST & \\
\hline CHEMBL3935718 & 1639638 & 6.301 & 5.6443 & TRN & \\
\hline CHEMBL3911765 & 1639638 & 7.301 & 6.4676 & TRN & \\
\hline CHEMBL3951073 & 1639638 & 7.301 & 7.0929 & TRN & \\
\hline CHEMBL3984496 & 1639638 & 7.301 & \multicolumn{2}{|c|}{7.832000000000001} & TRN \\
\hline CHEMBL464800 & 1639638 & 4.301 & 5.6805 & TRN & \\
\hline CHEMBL3941712 & 1639638 & 6.301 & 5.6517 & TRN & \\
\hline CHEMBL 3983846 & 1639638 & 4.301 & \multicolumn{2}{|c|}{4.696000000000001} & TRN \\
\hline CHEMBL505965 & 1639638 & 7.301 & 6.6405 & TRN & \\
\hline
\end{tabular}


Supplemental Table S2.txt

\begin{tabular}{|c|c|c|c|c|c|}
\hline CHEMBL3909208 & 1639638 & 4.301 & 4.4017 & TRN & \\
\hline CHEMBL3927018 & 1639638 & 7.301 & 7.6973 & TRN & \\
\hline CHEMBL3890207 & 1639638 & 7.301 & 6.7087 & TST & \\
\hline CHEMBL3903100 & 1639638 & 6.301 & 6.0274 & TRN & \\
\hline CHEMBL3955744 & 1639638 & 7.301 & 7.8012 & TRN & \\
\hline CHEMBL3979147 & 1639638 & 6.301 & 6.6215 & TRN & \\
\hline CHEMBL3919922 & 1639638 & 4.301 & 4.5535 & TST & \\
\hline CHEMBL3962286 & 1639638 & 7.301 & 7.114 & TRN & \\
\hline CHEMBL3966008 & 1639638 & 7.301 & 7.5271 & TRN & \\
\hline CHEMBL3980420 & 1639638 & 4.301 & 5.9905 & TST & \\
\hline CHEMBL3967190 & 1639638 & 6.301 & 7.0658 & TRN & \\
\hline CHEMBL3967785 & 1639638 & 7.301 & 6.9017 & TRN & \\
\hline CHEMBL3947526 & 1639638 & 7.301 & 7.1766 & TRN & \\
\hline CHEMBL3958115 & 1639638 & 6.301 & \multicolumn{2}{|c|}{6.2379999999999995} & TRN \\
\hline CHEMBL3896277 & 1639638 & 6.301 & 7.0993 & TST & \\
\hline CHEMBL3965209 & 1639638 & 4.301 & 5.1162 & TRN & \\
\hline CHEMBL3937923 & 1639638 & 6.301 & 6.1694 & TRN & \\
\hline CHEMBL3898893 & 1639638 & 4.301 & 4.7387 & TST & \\
\hline CHEMBL3900128 & 1639638 & 6.301 & 6.289 & TRN & \\
\hline CHEMBL3914341 & 1639638 & 6.301 & 6.3581 & TRN & \\
\hline CHEMBL3975695 & 1639638 & 6.301 & 6.7642 & TRN & \\
\hline CHEMBL3917091 & 1639638 & 6.301 & 6.3266 & TRN & \\
\hline CHEMBL3891746 & 1639638 & 7.301 & 7.069 & TRN & \\
\hline CHEMBL3912745 & 1639638 & 6.301 & 6.4623 & TRN & \\
\hline CHEMBL3948347 & 1639638 & 6.301 & 6.2483 & TRN & \\
\hline CHEMBL3943970 & 1639638 & 4.301 & 5.595 & TST & \\
\hline CHEMBL3919732 & 1639638 & 7.301 & 6.8519 & TRN & \\
\hline CHEMBL3968695 & 1639638 & 7.301 & 6.9474 & TRN & \\
\hline CHEMBL3974093 & 1639638 & 6.301 & 6.7765 & TRN & \\
\hline CHEMBL3967928 & 1639638 & 7.301 & 6.7784 & TRN & \\
\hline CHEMBL3985643 & 1639638 & 6.301 & \multicolumn{2}{|c|}{6.457000000000001} & TRN \\
\hline CHEMBL3938485 & 1639638 & 7.301 & 7.4315 & TRN & \\
\hline CHEMBL3986630 & 1639638 & 7.301 & 6.7379 & TRN & \\
\hline CHEMBL3922744 & 1639638 & 7.301 & 6.723 & TST & \\
\hline CHEMBL3908210 & 1639638 & 4.301 & 4.802 & TRN & \\
\hline CHEMBL3937979 & 1639638 & 6.301 & 7.02 & TRN & \\
\hline CHEMBL3941890 & 1639638 & 7.301 & 6.6388 & TRN & \\
\hline CHEMBL3951175 & 1639638 & 7.301 & 6.9026 & TRN & \\
\hline CHEMBL3922065 & 1639638 & 6.301 & 5.8948 & TRN & \\
\hline CHEMBL3920221 & 1639638 & 7.301 & 7.231 & TRN & \\
\hline CHEMBL3986771 & 1639638 & 7.301 & 7.2326 & TRN & \\
\hline CHEMBL3982068 & 1639638 & 4.301 & 5.3486 & TST & \\
\hline CHEMBL3892784 & 1639638 & 6.301 & 6.0135 & TRN & \\
\hline CHEMBL3972438 & 1639638 & 4.301 & 6.1236 & TST & \\
\hline CHEMBL3954841 & 1639638 & 4.301 & 4.8704 & TST & \\
\hline CHEMBL3960458 & 1639638 & 4.301 & 6.0152 & TST & \\
\hline CHEMBL3909730 & 1639638 & 6.301 & 6.2975 & TRN & \\
\hline CHEMBL3903945 & 1639638 & 7.301 & 7.2802 & TRN & \\
\hline
\end{tabular}


Supplemental Table S2.txt

\begin{tabular}{|c|c|c|c|c|}
\hline HEMBL3 & 639638 & 7.301 & 7.3164 & $\mathrm{TR}$ \\
\hline HEMBL 3964970 & 639638 & 4.301 & 3478 & \\
\hline 62301 & 9638 & 301 & 8842 & \\
\hline IEMBL 3931212 & 539638 & 7.301 & 2749 & $\mathrm{RN}$ \\
\hline HEMBL3895910 & 539638 & 4.301 & .313 & \\
\hline HEMBL3915614 & 639638 & 8.301 & .7736 & \\
\hline HEMBL3921059 & 639638 & 4.301 & .3821 & \\
\hline AEMBL3894108 & 539638 & 7.301 & 0408 & \\
\hline AEMBL3932034 & 639638 & 6.301 & .0978 & \\
\hline HEMBL3917366 & 639638 & 7.301 & .5629 & \\
\hline HEMBL3929343 & 639638 & 7.301 & .7541 & \\
\hline HEMBL3900251 & 639638 & 7.301 & .7402 & \\
\hline HEMBL3943198 & 539638 & 7.301 & .5863 & KIV \\
\hline HEMBL3976495 & 1639638 & 6.301 & 5.3568 & \\
\hline HEMBL3915864 & 639638 & 6.301 & 9619 & \\
\hline HEMBL3935438 & 639638 & 6.301 & 5.8036 & $\mathrm{RN}$ \\
\hline HEMBL3931926 & 639638 & 6.301 & .3132 & \\
\hline HEMBL3923128 & 639638 & 4.301 & 3765 & RN \\
\hline HEMBL3900086 & 639638 & 6.301 & 5.0718 & \\
\hline HEMBL3963474 & 639638 & 6.301 & 9531 & RN \\
\hline HEMBL3947721 & 639638 & 6.301 & 069 & RN \\
\hline HEMBL3915700 & 639638 & 7.301 & 7.351 & RN \\
\hline HEMBL3963506 & 639638 & 6.301 & 6.2262 & RN \\
\hline HEMBL3966679 & 639638 & 6.301 & 6.0508 & RN \\
\hline HEMBL3901428 & 38 & 4.301 & & ST \\
\hline HEMBL3913015 & 639638 & 6.301 & 1833 & $\mathrm{RN}$ \\
\hline HEMBL3902551 & 639638 & 6.301 & 814 & RN \\
\hline HEMBL3902213 & 38 & 6.301 & 175 & RN \\
\hline HEMBL3893250 & 1639638 & 6.301 & 5.7846 & ST \\
\hline HEMBL3957329 & 639 & 4. & .7467 & RN \\
\hline HEMBL3926 & 539638 & 4.30 & 235 & ST \\
\hline HEMBL 3973 & 8 & 01 & 107 & RN \\
\hline HEMBL396 & 38 & 01 & 7.1524 & RN \\
\hline HEMBL3929460 & 1639638 & 7.301 & 7.5921 & RN \\
\hline HEMBL3904364 & 639638 & 7.301 & 7.3646 & IRN \\
\hline HEMBL3948639 & 639638 & 4.30 & 1.7908 & ST \\
\hline HEMBL395 & 38 & 7. & & RN \\
\hline HEMBL3899065 & 1639638 & 7.301 & 6.6432 & $\mathrm{RN}$ \\
\hline HEMBL3947522 & 639638 & 4.301 & 3.7424 & TST \\
\hline HEMBL3924119 & 639638 & 7.301 & 7.6125 & 「RN \\
\hline HEMBL 3919388 & 1639638 & 6.301 & 5.8559 & $\mathrm{RN}$ \\
\hline CHEMBL3897581 & 1639638 & 7.301 & 6.5703 & ST \\
\hline HEMBL3979018 & 1639638 & 6.301 & 6.8642 & TRN \\
\hline HEMBL3965605 & 1639638 & 4.301 & 4.542 & RN \\
\hline HEMBL 3920708 & 639638 & 4.301 & 5.2377 & RN \\
\hline CHEMBL3939503 & 1639638 & 4.301 & 5.2832 & \\
\hline CHEMBL3918863 & 1639638 & 7.301 & 7.1387 & RN \\
\hline CHEMBL3896196 & 1639638 & 6.301 & 5.9455 & ГRN \\
\hline
\end{tabular}

Page 12062 
Supplemental Table S2.txt

\begin{tabular}{|c|c|c|}
\hline HEMBL 3907121 & 1639638 & 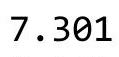 \\
\hline HEMBL3949164 & 639638 & 4.301 \\
\hline HEMBL3975233 & 9638 & 301 \\
\hline HEMBL3980941 & 1639638 & 7.301 \\
\hline HEMBL3943374 & 1639638 & 4.301 \\
\hline HEMBL3896130 & 1639638 & 6.301 \\
\hline HEMBL3955053 & L639638 & 6.301 \\
\hline AEMBL3953633 & 1639638 & 6.301 \\
\hline HEMBL496483 & 1639638 & 6.301 \\
\hline HEMBL3918350 & 1639638 & 8.301 \\
\hline HEMBL3909168 & 1639638 & 6.301 \\
\hline HEMBL3910985 & 1639638 & 4.301 \\
\hline HEMBL3908741 & 38 & 4.301 \\
\hline HEMBL3891655 & 1639638 & 4.301 \\
\hline CHEMBL3896489 & 1639638 & 4.301 \\
\hline HEMBL3952557 & 1639638 & 6.301 \\
\hline HEMBL3958220 & 1639638 & 7.301 \\
\hline CHEMBL3957063 & 163 & 4.301 \\
\hline HEMBL3983006 & 1639638 & 6.301 \\
\hline CHEMBL3929767 & 1639638 & 7.301 \\
\hline HEMBL3957963 & 1639638 & 4.301 \\
\hline HEMBL3921869 & 1639638 & 6.301 \\
\hline CHEMBL3960952 & 163 & 7.301 \\
\hline CHEMBL3905265 & 1639638 & 7.301 \\
\hline CHEMBL3985074 & 1639638 & 7.301 \\
\hline CHEMBL3961989 & 1639638 & 4.301 \\
\hline HEMBL3974826 & 1639638 & 6.301 \\
\hline CHEMBL3952875 & 1635 & 7.301 \\
\hline CHEMBL3959061 & 1639 & 7.301 \\
\hline CHEMBL3895701 & 1639 & 4.301 \\
\hline CHEMBL3917133 & 1639638 & 7.301 \\
\hline CHEMBL3901158 & 1639638 & 7.301 \\
\hline CHEMBL3960387 & 1639 & 7.301 \\
\hline CHEMBL3939897 & 1639 & 6.0 \\
\hline CHEMBL3950789 & 1639638 & 6.301 \\
\hline CHEMBL 3950214 & 1639638 & 6.301 \\
\hline CHEMBL3895878 & 1639638 & 6.301 \\
\hline CHEMBL3919940 & 1639638 & 6.301 \\
\hline CHEMBL3902178 & 1639638 & 6.301 \\
\hline CHEMBL3966630 & 1639638 & 7.301 \\
\hline CHEMBL3919836 & 1639638 & 6.301 \\
\hline CHEMBL3897731 & 1639638 & 7.301 \\
\hline CHEMBL3937123 & 1639638 & 6.301 \\
\hline CHEMBL3971432 & 1639638 & 6.301 \\
\hline CHEMBL 3943472 & 1639638 & 7.301 \\
\hline CHEMBL 25236 & 425703 & 6.68 \\
\hline CHEMBL218150 & 425703 & 5.64 \\
\hline CHEMBL 218638 & 425703 & 6.8 \\
\hline
\end{tabular}

6.8069 TRN

5.1157 TRN

7.3167 TRN

7.3601 TRN

4.829 TST

6.3774 TRN

5.7449 TRN

6.2 TRN

5.981 TST

7.7993 TST

6.6284 TST

4.4751 TST

5.4409 TST

5.6332 TST

4.9129 TST

6.6598 TST

6.9746 TST

4.8535 TST

6.6423 TST

7.479 TST

5.0687 TST

7.1069 TST

7.0433 TST

7.1431 TST

6.7555 TST

4.2542 TST

6.1932 TST

6.7305 TST

5.7451 TST

4.7066 TST

6.5629 TST

7.2991 TST

$7.5 \quad$ TST

5.3843 TST

6.3132 TST

6.2224 TST

6.4176 TST

6.3558 TST

6.6208 TST

7.2369 TST

6.0433 TST

7.4517 TST

5.7536 TST

6.8576 TST

6.922000000000001 TST

6.5666 TRN

5.6395 TRN

6.8565 TRN

Page 12063 


\begin{tabular}{|c|c|c|c|c|c|}
\hline \multicolumn{6}{|c|}{ Supplemental Table S2.txt } \\
\hline CHEMBL218444 & 425703 & 6.96 & 6.996 & TRN & \\
\hline CHEMBL220700 & 425703 & 6.85 & 6.8329 & TRN & \\
\hline CHEMBL346692 & 425703 & 5.51 & 5.4345 & TRN & \\
\hline CHEMBL376020 & 425703 & 6.89 & 6.7955 & TRN & \\
\hline CHEMBL376445 & 425703 & 5.0 & 5.0575 & TRN & \\
\hline CHEMBL221681 & 425703 & 7.02 & 6.8763 & TRN & \\
\hline CHEMBL139926 & 425703 & 6.49 & 6.3533 & TRN & \\
\hline CHEMBL124444 & 425703 & 6.96 & 7.1701 & TRN & \\
\hline CHEMBL218368 & 425703 & 6.7 & 6.7188 & TRN & \\
\hline CHEMBL218318 & 425703 & 7.17 & 7.1835 & TRN & \\
\hline CHEMBL221397 & 425703 & 6.39 & 6.4616 & TRN & \\
\hline CHEMBL59725 & 425703 & 5.44 & 5.5914 & TRN & \\
\hline CHEMBL424294 & 425703 & 7.06 & 6.959 & TRN & \\
\hline CHEMBL374749 & 425703 & 6.89 & 6.9428 & TRN & \\
\hline CHEMBL221549 & 425703 & 6.55 & 6.5786 & TRN & \\
\hline CHEMBL219274 & 425703 & 6.33 & 6.2636 & TRN & \\
\hline CHEMBL218203 & 425703 & 6.34 & 6.3562 & TRN & \\
\hline CHEMBL210955 & 425703 & 5.54 & 5.5496 & TRN & \\
\hline CHEMBL210405 & 425703 & 6.85 & 6.2512 & TST & \\
\hline CHEMBL210404 & 425703 & 7.4 & 6.6237 & TST & \\
\hline CHEMBL425057 & 425703 & 6.47 & 6.5043 & TST & \\
\hline CHEMBL310843 & 425703 & 5.47 & 5.4958 & TST & \\
\hline CHEMBL160952 & 425703 & 5.43 & 5.2844 & TST & \\
\hline CHEMBL423247 & 425703 & 5.31 & 5.6361 & TST & \\
\hline CHEMBL218787 & 425703 & 5.12 & 5.05399 & 9999999999 & TST \\
\hline CHEMBL345357 & 425703 & 4.56 & 5.2461 & TST & \\
\hline CHEMBL7927 & 425703 & 5.55 & 5.4424 & TST & \\
\hline CHEMBL344677 & 425703 & 6.82 & 6.7957 & TRN & \\
\hline CHEMBL342060 & 425703 & 6.72 & 6.7318 & TRN & \\
\hline CHEMBL143352 & 425703 & 6.57 & 6.6199 & TRN & \\
\hline CHEMBL139600 & 425703 & 7.52 & 7.4698 & TRN & \\
\hline CHEMBL141845 & 425703 & 6.54 & 6.6104 & TRN & \\
\hline CHEMBL140968 & 425703 & 7.15 & 7.2388 & TRN & \\
\hline CHEMBL142020 & 425703 & 6.51 & 6.4693 & TRN & \\
\hline CHEMBL357684 & 425703 & 6.08 & 6.0197 & TRN & \\
\hline CHEMBL139722 & 425703 & 6.28 & 6.2648 & TRN & \\
\hline CHEMBL218151 & 425703 & 6.47 & 6.476 & TRN & \\
\hline CHEMBL221129 & 425703 & 8.28 & 8.4063 & TRN & \\
\hline CHEMBL386986 & 425703 & 7.66 & 7.5837 & TRN & \\
\hline CHEMBL217981 & 425703 & 8.31 & 8.2009 & TRN & \\
\hline CHEMBL385289 & 425703 & 7.21 & 7.2851 & TRN & \\
\hline CHEMBL218351 & 425703 & 7.37 & 7.3922 & TRN & \\
\hline CHEMBL220754 & 425703 & 7.77 & 7.8845 & TRN & \\
\hline CHEMBL221866 & 425703 & 8.04 & 8.0045 & TRN & \\
\hline CHEMBL437525 & 425703 & 7.26 & 7.1192 & TRN & \\
\hline CHEMBL218607 & 425703 & 7.24 & 7.2425 & TRN & \\
\hline CHEMBL425285 & 425703 & 7.85 & 7.80200 & 00000000005 & TRN \\
\hline CHEMBL221587 & 425703 & 8.03 & 7.846 & TRN & \\
\hline
\end{tabular}




\begin{tabular}{|c|c|c|c|c|c|}
\hline & & \multirow{2}{*}{\multicolumn{4}{|c|}{81383}} \\
\hline CHEMBL 221897 & 425703 & 8.0 & & & \\
\hline CHEMBL 221843 & 425703 & 6.64 & \multicolumn{2}{|c|}{6.821000000000001} & TRN \\
\hline CHEMBL373873 & 425703 & 7.41 & 7.3337 & TRN & \\
\hline CHEMBL267014 & 425703 & 4.27 & 5.6537 & TST & \\
\hline CHEMBL 221814 & 425703 & 6.66 & 6.6158 & TST & \\
\hline CHEMBL221600 & 425703 & 7.42 & 6.6441 & TST & \\
\hline CHEMBL 377200 & 425703 & 6.2 & 6.4642 & TST & \\
\hline CHEMBL 208018 & 425703 & 7.15 & 6.6521 & TST & \\
\hline CHEMBL 210717 & 425703 & 7.2 & 6.2064 & TST & \\
\hline CHEMBL437490 & 425703 & 6.35 & 5.3895 & TST & \\
\hline CHEMBL 2420830 & 979771 & 7.0 & 6.971 & TST & \\
\hline CHEMBL 2420812 & 979771 & 7.7447 & 7.6668 & TRN & \\
\hline CHEMBL 2420815 & 979771 & 4.4559 & 5.0595 & TRN & \\
\hline CHEMBL 2420847 & 979771 & 5.7212 & 5.0422 & TRN & \\
\hline CHEMBL2420813 & 979771 & 6.7696 & 6.657 & TRN & \\
\hline CHEMBL 2420824 & 979771 & 7.5376 & 7.5484 & TRN & \\
\hline CHEMBL 2420857 & 979771 & 5.4949 & 5.4768 & TRN & \\
\hline CHEMBL 2420814 & 979771 & 4.4559 & \multicolumn{2}{|c|}{5.0760000000000005} & TST \\
\hline CHEMBL 2420840 & 979771 & 5.9208 & 5.8733 & TRN & \\
\hline CHEMBL 2420845 & 979771 & 5.5528 & 5.2122 & TRN & \\
\hline CHEMBL 2420833 & 979771 & 6.0757 & 5.3163 & TRN & \\
\hline CHEMBL 2420846 & 979771 & 4.4559 & 5.6494 & TRN & \\
\hline CHEMBL1327969 & 979771 & 6.6383 & 6.318 & TRN & \\
\hline CHEMBL 2420831 & 979771 & 6.6198 & 7.7167 & TRN & \\
\hline CHEMBL 2420827 & 979771 & 8.3098 & 8.3434 & TRN & \\
\hline CHEMBL 2420828 & 979771 & 8.0 & 7.6906 & TRN & \\
\hline CHEMBL 2420858 & 979771 & 5.9586 & 4.9867 & TRN & \\
\hline CHEMBL 2420820 & 979771 & 5.8239 & \multicolumn{2}{|c|}{5.9879999999999995} & TRN \\
\hline CHEMBL 2420825 & 979771 & 5.9208 & 6.0601 & TRN & \\
\hline CHEMBL 2420859 & 979771 & 4.4559 & 4.7564 & TST & \\
\hline CHEMBL 2420829 & 979771 & 7.7212 & 7.9787 & TRN & \\
\hline CHEMBL2420843 & 979771 & 4.4559 & 4.7285 & TRN & \\
\hline CHEMBL2420839 & 979771 & 6.6021 & 6.2529 & TRN & \\
\hline CHEMBL 2420810 & 979771 & 4.4559 & 5.4667 & TRN & \\
\hline CHEMBL 2420835 & 979771 & 7.0269 & 6.5103 & TRN & \\
\hline CHEMBL 2420844 & 979771 & 6.6383 & 6.3224 & TRN & \\
\hline CHEMBL2420856 & 979771 & 6.4202 & 5.5167 & TRN & \\
\hline CHEMBL 2420821 & 979771 & 7.0177 & 6.7641 & TRN & \\
\hline CHEMBL 2420855 & 979771 & 4.4559 & 4.916 & TRN & \\
\hline CHEMBL 2420860 & 979771 & 4.4559 & 4.7675 & TST & \\
\hline CHEMBL 2420852 & 979771 & 6.0458 & 6.0169 & TRN & \\
\hline CHEMBL2420817 & 979771 & 4.4559 & 5.7287 & TST & \\
\hline CHEMBL 2420853 & 979771 & 5.5528 & 5.2176 & TRN & \\
\hline CHEMBL 2420854 & 979771 & 5.9208 & 6.0143 & TRN & \\
\hline CHEMBL 2420816 & 979771 & 4.4559 & 5.1302 & TST & \\
\hline CHEMBL1370276 & 979771 & 6.2676 & 6.1847 & TRN & \\
\hline CHEMBL2420823 & 979771 & 6.8539 & 6.2388 & TRN & \\
\hline CHEMBL2420819 & 979771 & 6.0315 & 5.8946 & TRN & \\
\hline & & & & 12065 & \\
\hline
\end{tabular}


Supplemental Table S2.txt

\begin{tabular}{|c|c|c|c|c|c|}
\hline CHEMBL2420822 & 979771 & 4.4559 & 5.0571 & TRN & \\
\hline CHEMBL 2420848 & 979771 & 4.4559 & 5.515 & TRN & \\
\hline CHEMBL 2420826 & 979771 & 7.8539 & 7.8241 & TRN & \\
\hline CHEMBL 2420842 & 979771 & 5.6198 & 5.0003 & TRN & \\
\hline CHEMBL 2420834 & 979771 & 4.4559 & 5.0814 & TRN & \\
\hline CHEMBL2420851 & 979771 & 6.1024 & 6.3954 & TRN & \\
\hline CHEMBL 2387224 & 979771 & 8.3188 & 7.9824 & TRN & \\
\hline CHEMBL 2420838 & 979771 & 5.699 & 5.7232 & TRN & \\
\hline CHEMBL 2420811 & 979771 & 5.8239 & 6.0449 & TRN & \\
\hline CHEMBL1702157 & 979771 & 5.9586 & 5.73 & TST & \\
\hline CHEMBL2420850 & 979771 & 4.4559 & 5.4833 & TST & \\
\hline CHEMBL 2420841 & 979771 & 5.5086 & $5.45200 t$ & 0000000001 & TST \\
\hline CHEMBL 2420836 & 979771 & 7.1308 & 6.8246 & TST & \\
\hline CHEMBL 2420849 & 979771 & 4.4559 & 4.8902 & TST & \\
\hline CHEMBL2420818 & 979771 & 4.4559 & 5.5578 & TST & \\
\hline CHEMBL2420837 & 979771 & 6.6198 & 6.1339 & TST & \\
\hline CHEMBL 2420832 & 979771 & 7.1938 & 7.1234 & TST & \\
\hline CHEMBL602913 & 610313 & 5.5229 & 5.2592 & TRN & \\
\hline CHEMBL597583 & 610313 & 5.3188 & 5.5643 & TRN & \\
\hline CHEMBL22477 & 610313 & 4.2197 & 4.4332 & TRN & \\
\hline CHEMBL600412 & 610313 & 4.3979 & 4.609 & TRN & \\
\hline CHEMBL105523 & 610313 & 5.1549 & 4.3163 & TST & \\
\hline CHEMBL103474 & 610313 & 5.7258 & 4.2009 & TST & \\
\hline CHEMBL23297 & 610313 & 4.7905 & 3.9861 & TRN & \\
\hline CHEMBL597784 & 610313 & 3.8861 & 3.7372 & TRN & \\
\hline CHEMBL69363 & 610313 & 4.1549 & 4.3467 & TRN & \\
\hline CHEMBL421594 & 610313 & 6.0458 & 4.0343 & TST & \\
\hline CHEMBL608428 & 610313 & 4.9281 & 5.1451 & TRN & \\
\hline CHEMBL17873 & 610313 & 4.8416 & 4.4156 & TRN & \\
\hline CHEMBL420172 & 610313 & 4.7212 & 4.4348 & TRN & \\
\hline CHEMBL105759 & 610313 & 5.4318 & 4.2388 & TST & \\
\hline CHEMBL 278013 & 610313 & 5.5229 & 4.7125 & TST & \\
\hline CHEMBL102432 & 610313 & 3.5376 & 3.927 & TRN & \\
\hline CHEMBL 105020 & 610313 & 4.8153 & 4.3259 & TST & \\
\hline CHEMBL597382 & 610313 & 3.3372 & 4.0227 & TRN & \\
\hline CHEMBL17430 & 610313 & 5.2757 & 4.7581 & TRN & \\
\hline CHEMBL102303 & 610313 & 5.7959 & 4.359 & TST & \\
\hline CHEMBL597962 & 610313 & 5.9626 & 5.8914 & TRN & \\
\hline CHEMBL17323 & 610313 & 3.8069 & 4.1472 & TRN & \\
\hline CHEMBL432136 & 610313 & 2.5986 & 4.0348 & TRN & \\
\hline CHEMBL23960 & 610313 & 3.8633 & 4.0032 & TRN & \\
\hline CHEMBL596969 & 610313 & 3.61800 & 00000000 & 4.0188 & TST \\
\hline CHEMBL590502 & 610313 & 3.6021 & 4.1806 & TST & \\
\hline CHEMBL101908 & 610313 & 3.9706 & 4.2215 & TST & \\
\hline CHEMBL 277438 & 610313 & 4.1433 & 4.2895 & TRN & \\
\hline CHEMBL591930 & 610313 & 5.8239 & 5.6874 & TRN & \\
\hline CHEMBL598190 & 610313 & 4.0814 & 4.9904 & TRN & \\
\hline CHEMBL608143 & 610313 & 3.4815 & 3.8659 & TRN & \\
\hline
\end{tabular}




\begin{tabular}{|c|c|c|c|c|c|}
\hline \multirow[b]{2}{*}{ CHEMBL105323 } & \multicolumn{5}{|c|}{ Supplemental Table S2.txt } \\
\hline & 610313 & 4.4895 & 4.2676 & TST & \\
\hline CHEMBL596970 & 610313 & 4.3098 & 4.30699 & 99999999995 & TRN \\
\hline CHEMBL610498 & 610313 & 4.4609 & 4.3042 & TRN & \\
\hline CHEMBL605980 & 610313 & 4.1871 & 4.1631 & TRN & \\
\hline CHEMBL 22561 & 610313 & 4.8356 & 4.2054 & TRN & \\
\hline CHEMBL597347 & 610313 & 4.7447 & 4.593 & TRN & \\
\hline CHEMBL431257 & 610313 & 4.8861 & 4.2694 & TST & \\
\hline CHEMBL22820 & 610313 & 3.5986 & 4.0791 & TRN & \\
\hline CHEMBL283311 & 610313 & 4.9101 & 4.2433 & TRN & \\
\hline CHEMBL279914 & 610313 & 4.4377 & 4.0951 & TRN & \\
\hline CHEMBL601520 & 610313 & 4.8996 & 4.4099 & TRN & \\
\hline CHEMBL103203 & 610313 & 4.5214 & 3.9352 & TST & \\
\hline CHEMBL600413 & 610313 & 4.4271 & 4.1363 & TRN & \\
\hline CHEMBL331314 & 610313 & 5.6345 & 4.6365 & TRN & \\
\hline CHEMBL605782 & 610313 & 4.5086 & 4.3528 & TRN & \\
\hline CHEMBL609914 & 610313 & 5.3401 & 5.0225 & TRN & \\
\hline CHEMBL66077 & 610313 & 4.2226 & 3.9407 & TST & \\
\hline CHEMBL598604 & 610313 & 3.2924 & 4.3651 & TRN & \\
\hline CHEMBL312688 & 610313 & 3.5986 & 4.2566 & TST & \\
\hline CHEMBL69681 & 610313 & 4.2495 & 4.2874 & TRN & \\
\hline CHEMBL105906 & 610313 & 3.5528 & 4.0824 & TST & \\
\hline CHEMBL 283515 & 610313 & 4.6383 & 4.4789 & TRN & \\
\hline CHEMBL607583 & 610313 & 5.0655 & 5.5373 & TRN & \\
\hline CHEMBL589525 & 610313 & 5.0862 & 5.1348 & TRN & \\
\hline CHEMBL17235 & 610313 & 4.5918 & 4.3443 & TRN & \\
\hline CHEMBL68439 & 610313 & 3.9355 & 4.2526 & TRN & \\
\hline CHEMBL597346 & 610313 & 3.4547 & 4.0595 & TRN & \\
\hline CHEMBL608865 & 610313 & 4.1938 & 4.2348 & TRN & \\
\hline CHEMBL123984 & 610313 & 5.6861 & 4.4848 & TRN & \\
\hline CHEMBL604090 & 610313 & 4.5086 & 4.3568 & TRN & \\
\hline CHEMBL17431 & 610313 & 4.7773 & 4.7644 & TRN & \\
\hline CHEMBL331456 & 610313 & 3.9586 & 4.5861 & TRN & \\
\hline CHEMBL591935 & 610313 & 4.4089 & 4.4939 & TRN & \\
\hline CHEMBL334198 & 610313 & 4.3215 & 4.575 & TRN & \\
\hline CHEMBL123892 & 610313 & 4.5045 & 4.1911 & TRN & \\
\hline CHEMBL68673 & 610313 & 4.2007 & 3.9287 & TRN & \\
\hline CHEMBL597961 & 610313 & 6.1805 & 5.9483 & TRN & \\
\hline CHEMBL597383 & 610313 & 5.3188 & 5.4162 & TRN & \\
\hline CHEMBL48648 & 610313 & 4.2269 & 4.8411 & TRN & \\
\hline CHEMBL 274278 & 610313 & 4.4535 & 4.2316 & TRN & \\
\hline CHEMBL604709 & 610313 & 4.6073 & 4.4637 & TRN & \\
\hline CHEMBL 278110 & 610313 & 4.4647 & 4.3342 & TRN & \\
\hline CHEMBL23846 & 610313 & 4.9208 & 4.1544 & TRN & \\
\hline CHEMBL598605 & 610313 & 4.0 & 3.9977 & TRN & \\
\hline CHEMBL106070 & 610313 & 5.4559 & 4.1242 & TST & \\
\hline CHEMBL17453 & 610313 & 3.9208 & 4.3954 & TRN & \\
\hline CHEMBL103108 & 610313 & 4.5258 & 4.0726 & TST & \\
\hline CHEMBL331986 & 610313 & 5.1079 & 4.402 & TST & \\
\hline
\end{tabular}




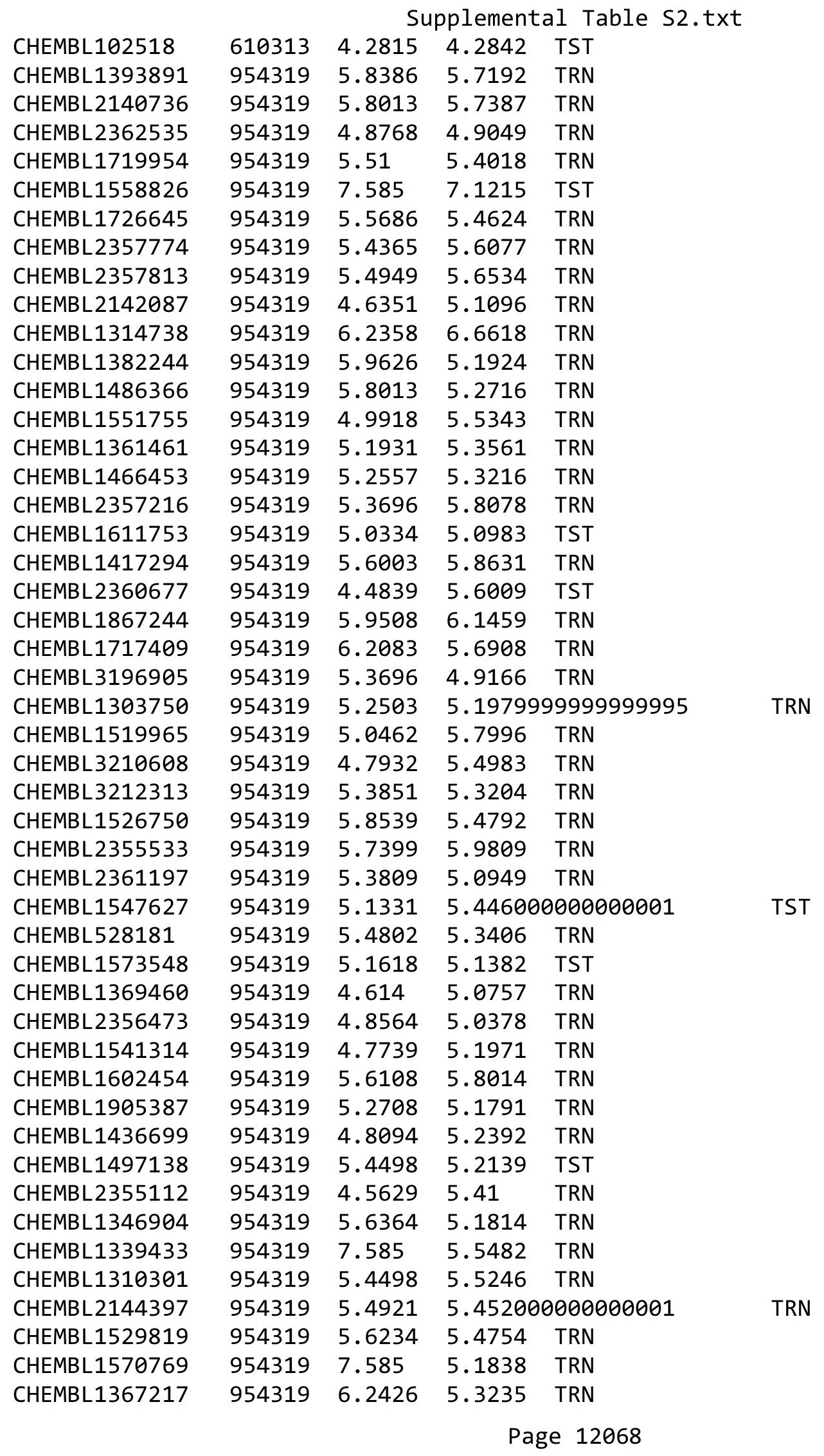


Supplemental Table S2.txt

\begin{tabular}{|c|c|c|c|c|c|}
\hline CHEMBL1573963 & 954319 & 5.0921 & 5.7795 & TST & \\
\hline CHEMBL1712299 & 954319 & 4.9859 & 5.1474 & TRN & \\
\hline CHEMBL1427272 & 954319 & 4.7802 & 5.1232 & TRN & \\
\hline CHEMBL2355909 & 954319 & 5.0768 & 5.5769 & TRN & \\
\hline CHEMBL1511219 & 954319 & 5.7033 & 6.2947 & TRN & \\
\hline CHEMBL1548549 & 954319 & 4.2819 & 5.3805 & TRN & \\
\hline CHEMBL 2360109 & 954319 & 7.585 & 5.7338 & TRN & \\
\hline CHEMBL 2362498 & 954319 & 5.2692 & 5.3275 & TRN & \\
\hline CHEMBL494325 & 954319 & 4.4083 & 5.2839 & TRN & \\
\hline CHEMBL1568497 & 954319 & 5.3372 & 5.3067 & TRN & \\
\hline CHEMBL566283 & 954319 & 5.2336 & 4.9881 & TRN & \\
\hline CHEMBL1448198 & 954319 & 5.4711 & 5.3588 & TRN & \\
\hline CHEMBL1376959 & 954319 & 4.6012 & 5.2679 & TRN & \\
\hline CHEMBL1714018 & 954319 & 5.983 & 5.4041 & TRN & \\
\hline CHEMBL 2134222 & 954319 & 4.9961 & 5.1743 & TRN & \\
\hline CHEMBL1497562 & 954319 & 7.585 & 5.9626 & TRN & \\
\hline CHEMBL1372292 & 954319 & 7.585 & 5.606 & TRN & \\
\hline CHEMBL1455644 & 954319 & 4.9642 & 5.1523 & TRN & \\
\hline CHEMBL1378564 & 954319 & 5.1096 & 5.2204 & TRN & \\
\hline CHEMBL 2356833 & 954319 & 4.968999 & 79999999 & 99 & 5.145 \\
\hline CHEMBL2356526 & 954319 & 4.7799 & 4.9165 & TRN & \\
\hline CHEMBL 2137652 & 954319 & 5.0841 & 5.1752 & TRN & \\
\hline CHEMBL 2358725 & 954319 & 4.6977 & 5.4114 & TRN & \\
\hline CHEMBL1373815 & 954319 & 5.8601 & 5.2906 & TST & \\
\hline CHEMBL1496004 & 954319 & 5.1925 & 5.3533 & TRN & \\
\hline CHEMBL2362165 & 954319 & 6.0 & 5.9393 & TRN & \\
\hline CHEMBL1347664 & 954319 & 5.1618 & 5.0441 & TRN & \\
\hline CHEMBL1577938 & 954319 & 5.9666 & 5.8647 & TRN & \\
\hline CHEMBL 2360646 & 954319 & 4.2666 & 5.6785 & TRN & \\
\hline CHEMBL1419188 & 954319 & 5.7959 & 5.4663 & TRN & \\
\hline CHEMBL1974506 & 954319 & 7.585 & 5.7481 & TST & \\
\hline CHEMBL1306071 & 954319 & 4.4219 & 5.3023 & TRN & \\
\hline CHEMBL1470568 & 954319 & 4.6607 & 5.4018 & TRN & \\
\hline CHEMBL1537739 & 954319 & 5.71 & 5.0076 & TRN & \\
\hline CHEMBL1474759 & 954319 & 4.9401 & 5.1086 & TST & \\
\hline CHEMBL1350387 & 954319 & 4.9359 & 5.3717 & TRN & \\
\hline CHEMBL 2448501 & 954319 & 5.2503 & 5.2649 & TRN & \\
\hline CHEMBL 2354464 & 954319 & 4.4359 & 5.2828 & TRN & \\
\hline CHEMBL1462920 & 954319 & 5.5186 & 5.5776 & TRN & \\
\hline CHEMBL1299835 & 954319 & 6.2757 & 5.7977 & TRN & \\
\hline CHEMBL 1707564 & 954319 & 5.8827 & 5.7469 & TRN & \\
\hline CHEMBL601933 & 954319 & 5.699 & 5.4677 & TRN & \\
\hline CHEMBL1508450 & 954319 & 4.9201 & 5.2628 & TST & \\
\hline CHEMBL 2357842 & 954319 & 4.4279 & 5.5397 & TRN & \\
\hline CHEMBL1886332 & 954319 & 5.1135 & 5.1237 & TRN & \\
\hline CHEMBL1431378 & 954319 & 6.1805 & 5.4775 & TRN & \\
\hline CHEMBL 3211736 & 954319 & 5.5867 & 5.2609 & TRN & \\
\hline CHEMBL 2357708 & 954319 & 6.0 & 5.7398 & TRN & \\
\hline
\end{tabular}




\begin{tabular}{|c|c|c|c|c|c|c|}
\hline \multirow[b]{2}{*}{ CHEMBL1371507 } & \multicolumn{6}{|c|}{ Supplemental Table S2.txt } \\
\hline & 954319 & 5.1068 & 6.0464 & TRN & & \\
\hline CHEMBL2357354 & 954319 & 5.218999 & 99999999 & 99 & 5.3125 & TRN \\
\hline CHEMBL530499 & 954319 & 4.8251 & 5.2862 & TST & & \\
\hline CHEMBL1595792 & 954319 & $6.38200 e$ & 00000000 & & 5.8536 & TRN \\
\hline CHEMBL1429297 & 954319 & 5.0182 & 5.37299 & 999999999 & 99 & TRN \\
\hline CHEMBL3193168 & 954319 & 5.5702 & 5.3895 & TST & & \\
\hline CHEMBL2357719 & 954319 & 5.6882 & 5.7282 & TRN & & \\
\hline CHEMBL1385808 & 954319 & 7.585 & 7.0079 & TST & & \\
\hline CHEMBL 2355244 & 954319 & 5.9355 & 5.9677 & TRN & & \\
\hline CHEMBL1463225 & 954319 & 6.2366 & 6.6234 & TRN & & \\
\hline CHEMBL1898843 & 954319 & 5.8894 & 5.2751 & TRN & & \\
\hline CHEMBL1482207 & 954319 & 5.9136 & 4.7868 & TRN & & \\
\hline CHEMBL2357191 & 954319 & 4.3566 & 5.3963 & TRN & & \\
\hline CHEMBL1611723 & 954319 & 5.5214 & 5.8924 & TRN & & \\
\hline CHEMBL2356909 & 954319 & 4.6897 & 5.0868 & TRN & & \\
\hline CHEMBL2358381 & 954319 & 6.0 & 5.7882 & TRN & & \\
\hline CHEMBL1576870 & 954319 & 7.585 & 6.6609 & TRN & & \\
\hline CHEMBL2360293 & 954319 & 4.3655 & 4.8449 & TRN & & \\
\hline CHEMBL2358431 & 954319 & 4.2896 & 5.2814 & TRN & & \\
\hline CHEMBL1458306 & 954319 & 4.61100 & 00000000 & $\partial 1$ & 5.0171 & TRN \\
\hline CHEMBL1420334 & 954319 & 5.6536 & 5.9683 & TST & & \\
\hline CHEMBL 2358614 & 954319 & 6.0 & 5.8516 & TRN & & \\
\hline CHEMBL1600371 & 954319 & 5.5884 & 5.3512 & TRN & & \\
\hline CHEMBL1368760 & 954319 & 4.6805 & 4.9924 & TRN & & \\
\hline CHEMBL1884536 & 954319 & 5.3429 & 5.4323 & TRN & & \\
\hline CHEMBL1418276 & 954319 & 5.6635 & 5.2001 & TRN & & \\
\hline CHEMBL1459767 & 954319 & 4.7333 & 5.3322 & TST & & \\
\hline CHEMBL1468323 & 954319 & 5.2933 & 5.8572 & TRN & & \\
\hline CHEMBL1706371 & 954319 & 5.4248 & 5.6228 & TRN & & \\
\hline CHEMBL1906549 & 954319 & 6.5171 & 6.5615 & TRN & & \\
\hline CHEMBL1611601 & 954319 & 5.5544 & 5.223 & TRN & & \\
\hline CHEMBL601146 & 954319 & 5.3354 & 5.2243 & TST & & \\
\hline CHEMBL1448592 & 954319 & 4.6291 & 5.1262 & TRN & & \\
\hline CHEMBL1338601 & 954319 & 5.21399 & 99999999 & 995 & 5.3255 & TRN \\
\hline CHEMBL3187467 & 954319 & 4.9223 & 5.431 & TRN & & \\
\hline CHEMBL1505283 & 954319 & 5.1445 & 4.8502 & TST & & \\
\hline CHEMBL1351347 & 954319 & 6.3969 & 5.2772 & TST & & \\
\hline CHEMBL1905114 & 954319 & 5.4486 & 5.2489 & TRN & & \\
\hline CHEMBL1428870 & 954319 & 5.5784 & 5.5524 & TRN & & \\
\hline CHEMBL1525187 & 954319 & 6.065 & 5.3347 & TRN & & \\
\hline CHEMBL2140460 & 954319 & 5.7905 & 6.0198 & TRN & & \\
\hline CHEMBL1895135 & 954319 & 4.9097 & 4.9704 & TRN & & \\
\hline CHEMBL2357524 & 954319 & 5.2815 & 5.2376 & TRN & & \\
\hline CHEMBL102397 & 954319 & 7.585 & 6.8061 & TRN & & \\
\hline CHEMBL1486585 & 954319 & 6.2076 & 5.7996 & TRN & & \\
\hline CHEMBL1440892 & 954319 & 4.7414 & 5.0627 & TST & & \\
\hline CHEMBL1736440 & 954319 & 5.0501 & 5.3332 & TRN & & \\
\hline CHEMBL2357823 & 954319 & 6.0214 & 5.9193 & TRN & & \\
\hline
\end{tabular}




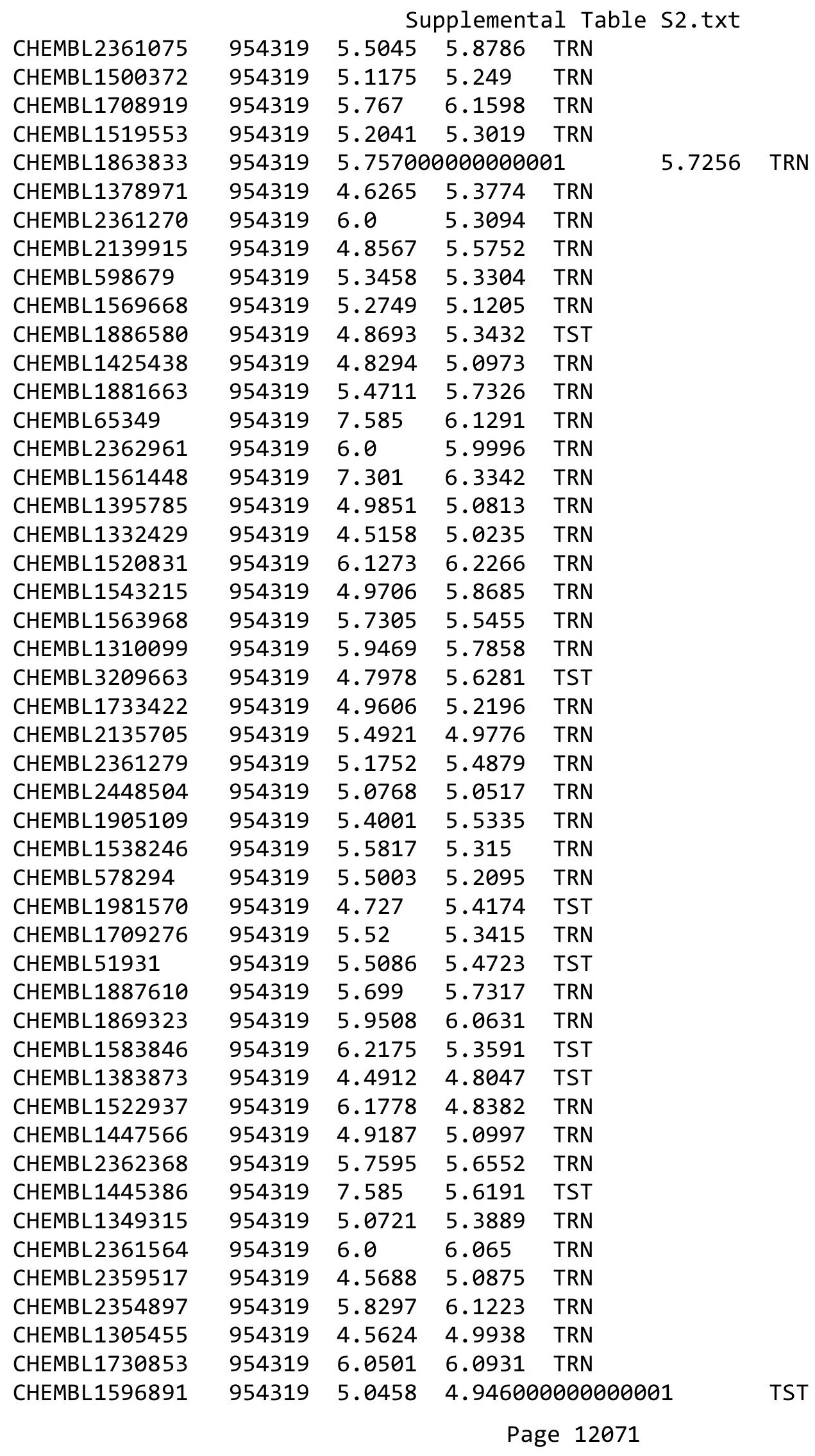




\begin{tabular}{|c|c|c|c|c|c|c|}
\hline & & \multicolumn{5}{|c|}{ Supplemental Table S2.txt } \\
\hline CHEMBL2357859 & 954319 & 5.6556 & 5.5687 & TRN & & \\
\hline CHEMBL1310617 & 954319 & 7.585 & 6.0447 & TST & & \\
\hline CHEMBL1423706 & 954319 & 5.3233 & 5.182 & TRN & & \\
\hline CHEMBL 2362103 & 954319 & 7.585 & 5.7977 & TRN & & \\
\hline CHEMBL1706322 & 954319 & 6.3487 & 5.1985 & TRN & & \\
\hline CHEMBL1551207 & 954319 & 7.585 & 7.5735 & TRN & & \\
\hline CHEMBL1425718 & 954319 & 5.6716 & 5.1478 & TRN & & \\
\hline CHEMBL 2362950 & 954319 & 5.1244 & 5.1456 & TST & & \\
\hline CHEMBL1531675 & 954319 & 6.2 & 5.6447 & TST & & \\
\hline CHEMBL1710730 & 954319 & 5.2757 & 5.3877 & TRN & & \\
\hline CHEMBL441618 & 954319 & 5.0937 & 5.0532 & TRN & & \\
\hline CHEMBL1579166 & 954319 & 5.2899 & 5.4447 & TRN & & \\
\hline CHEMBL1562296 & 954319 & 5.0768 & 5.2208 & TRN & & \\
\hline CHEMBL1594360 & 954319 & 5.1694 & 5.1264 & TRN & & \\
\hline CHEMBL 2358514 & 954319 & 5.041 & 4.9904 & TRN & & \\
\hline CHEMBL1301073 & 954319 & 5.4908 & 5.313 & TRN & & \\
\hline CHEMBL1460004 & 954319 & 4.7852 & 5.1327 & TST & & \\
\hline CHEMBL1392086 & 954319 & 5.2676 & 5.3945 & TRN & & \\
\hline CHEMBL1315948 & 954319 & 4.6319 & 5.1336 & TST & & \\
\hline CHEMBL 2448498 & 954319 & 5.0227 & 5.1879 & TRN & & \\
\hline CHEMBL 2354543 & 954319 & 6.21899 & 99999999 & 99 & .3344 & TRN \\
\hline CHEMBL2355499 & 954319 & 5.4622 & 5.6099 & TRN & & \\
\hline CHEMBL1500059 & 954319 & 5.2069 & 5.3386 & TRN & & \\
\hline CHEMBL1354163 & 954319 & 6.1308 & 5.9391 & TRN & & \\
\hline CHEMBL1546353 & 954319 & 5.2426 & 5.2282 & TRN & & \\
\hline CHEMBL1598066 & 954319 & 6.0353 & 5.2912 & TRN & & \\
\hline CHEMBL1886909 & 954319 & 5.8861 & 5.5754 & TST & & \\
\hline CHEMBL1510823 & 954319 & 5.0048 & 5.2421 & TST & & \\
\hline CHEMBL1321622 & 954319 & 4.9034 & 5.6445 & TRN & & \\
\hline CHEMBL 2361351 & 954319 & 6.4572 & 5.515 & TRN & & \\
\hline CHEMBL1543358 & 954319 & 5.3251 & 5.2869 & TST & & \\
\hline CHEMBL2356600 & 954319 & 5.857 & 4.9962 & TRN & & \\
\hline CHEMBL1447479 & 954319 & 5.9318 & 5.2246 & TRN & & \\
\hline CHEMBL1505743 & 954319 & 5.3458 & 5.2996 & TRN & & \\
\hline CHEMBL1519015 & 954319 & 5.3045 & 5.2996 & TRN & & \\
\hline CHEMBL1547483 & 954319 & 5.4976 & 5.032 & TRN & & \\
\hline CHEMBL1580426 & 954319 & 4.6931 & 5.0924 & TRN & & \\
\hline CHEMBL1329535 & 954319 & 5.2644 & 5.2713 & TRN & & \\
\hline CHEMBL1380943 & 954319 & 4.6633 & 5.1288 & TRN & & \\
\hline CHEMBL1299470 & 954319 & 6.1733 & 5.0075 & TRN & & \\
\hline CHEMBL1312953 & 954319 & 4.3997 & 5.018 & TST & & \\
\hline CHEMBL1299439 & 954319 & 5.2218 & 5.3085 & TRN & & \\
\hline CHEMBL1884845 & 954319 & 5.6459 & 6.1715 & TRN & & \\
\hline CHEMBL 2139616 & 954319 & 6.2358 & 6.3832 & TRN & & \\
\hline CHEMBL 2357481 & 954319 & 5.4547 & 5.8304 & TRN & & \\
\hline CHEMBL1387035 & 954319 & 5.5436 & 5.1776 & TST & & \\
\hline CHEMBL1545631 & 954319 & 7.585 & 5.4159 & TRN & & \\
\hline CHEMBL1464202 & 954319 & 5.1107 & 5.1267 & TRN & & \\
\hline
\end{tabular}




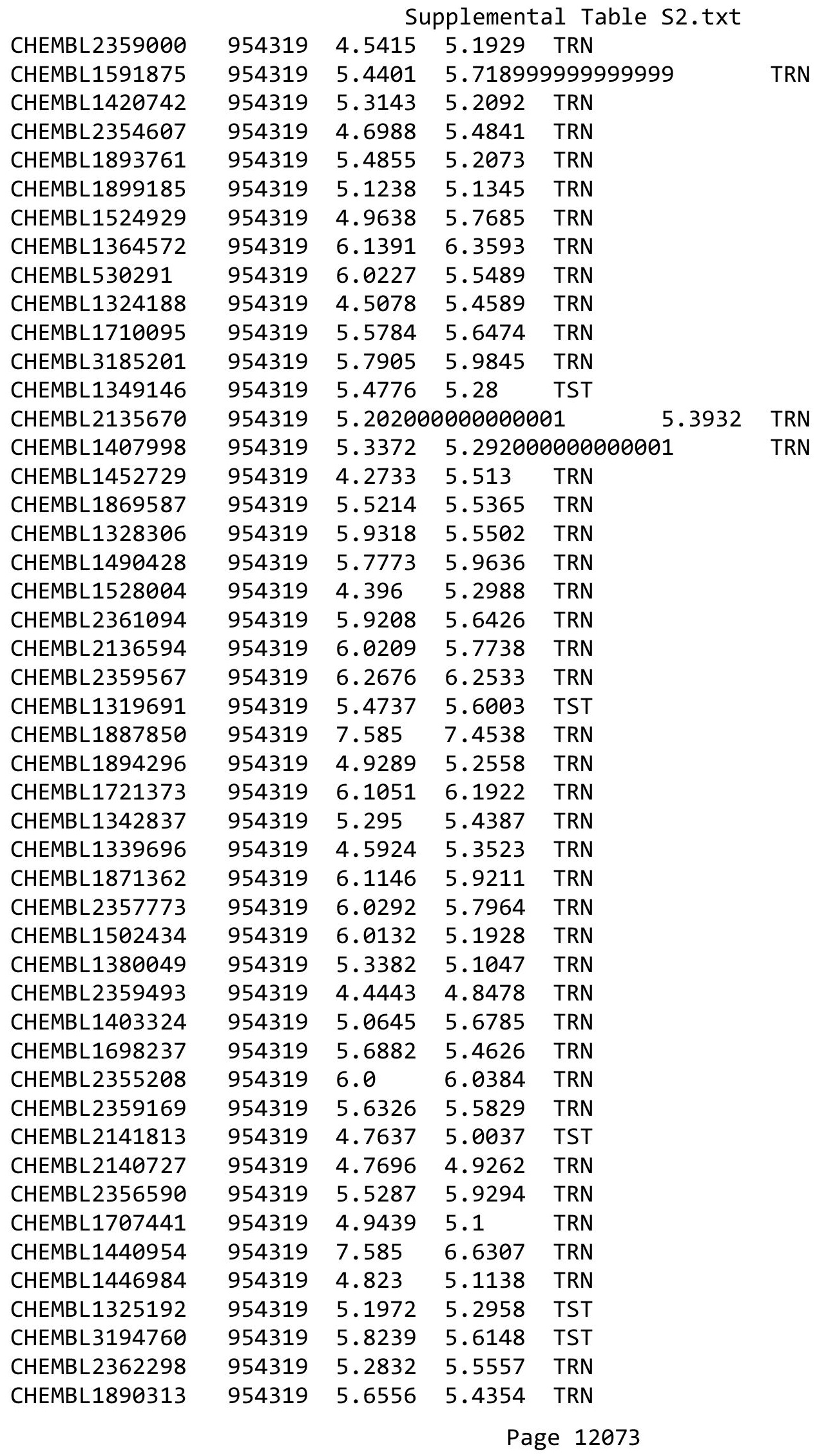




\begin{tabular}{|c|c|c|c|c|c|c|}
\hline \multirow[b]{2}{*}{ CHEMBL3560793 } & \multicolumn{6}{|c|}{ Supplemental Table S2.txt } \\
\hline & 954319 & 5.6308 & 5.2944 & TRN & & \\
\hline CHEMBL 2358509 & 954319 & 5.2976 & 5.3997 & TRN & & \\
\hline CHEMBL3560302 & 954319 & 6.1752 & 5.8354 & TRN & & \\
\hline CHEMBL1439017 & 954319 & 4.4841 & 5.2641 & TRN & & \\
\hline CHEMBL3213599 & 954319 & 5.2958 & 5.3977 & TRN & & \\
\hline CHEMBL1518765 & 954319 & 4.5441 & 5.2856 & TRN & & \\
\hline CHEMBL1605666 & 954319 & $5.0680 e$ & 0000000 & 205 & 5.4516 & TST \\
\hline CHEMBL3194248 & 954319 & 5.1475 & 5.7492 & TRN & & \\
\hline CHEMBL1579968 & 954319 & 6.2534 & 5.8397 & TRN & & \\
\hline CHEMBL3184689 & 954319 & 4.6855 & 4.7875 & TRN & & \\
\hline CHEMBL1550430 & 954319 & 4.8356 & 4.8811 & TRN & & \\
\hline CHEMBL1514666 & 954319 & 5.289 & 5.4468 & TRN & & \\
\hline CHEMBL1390450 & 954319 & 5.8665 & 5.7589 & TRN & & \\
\hline CHEMBL1570857 & 954319 & 5.1244 & 5.2166 & TRN & & \\
\hline CHEMBL1394527 & 954319 & 4.7878 & 5.2666 & TST & & \\
\hline CHEMBL1700596 & 954319 & 5.6162 & 5.4162 & TRN & & \\
\hline CHEMBL 2359735 & 954319 & 6.0035 & 5.0522 & TRN & & \\
\hline CHEMBL2362263 & 954319 & 4.9901 & 5.2868 & TRN & & \\
\hline CHEMBL1406556 & 954319 & 7.585 & 6.4045 & TRN & & \\
\hline CHEMBL1348129 & 954319 & 6.2832 & 5.3582 & TRN & & \\
\hline CHEMBL602828 & 954319 & 4.2267 & 5.2727 & TST & & \\
\hline CHEMBL1360319 & 954319 & 5.7328 & 5.1113 & TRN & & \\
\hline CHEMBL2361012 & 954319 & 5.6716 & 5.6479 & TRN & & \\
\hline CHEMBL1868229 & 954319 & $5.3270 e$ & 00000000 & $\partial 1$ & 5.4754 & TRN \\
\hline CHEMBL1420247 & 954319 & 5.1457 & 5.3982 & TRN & & \\
\hline CHEMBL1462457 & 954319 & 5.4225 & 5.3684 & TRN & & \\
\hline CHEMBL2355574 & 954319 & 7.585 & 6.7285 & TRN & & \\
\hline CHEMBL37430 & 954319 & 5.1858 & 5.4966 & TRN & & \\
\hline CHEMBL1358887 & 954319 & 7.585 & 7.4204 & TRN & & \\
\hline CHEMBL 2362474 & 954319 & 5.0419 & 5.4227 & TRN & & \\
\hline CHEMBL2357620 & 954319 & 5.2749 & 5.3153 & TRN & & \\
\hline CHEMBL1522331 & 954319 & 5.5591 & 5.5454 & TRN & & \\
\hline CHEMBL1447442 & 954319 & 7.585 & 5.2363 & TRN & & \\
\hline CHEMBL3197091 & 954319 & 5.1864 & 5.1367 & TRN & & \\
\hline CHEMBL1884377 & 954319 & 6.2027 & 5.999 & TRN & & \\
\hline CHEMBL1537098 & 954319 & 7.585 & 6.5177 & TST & & \\
\hline CHEMBL1321201 & 954319 & 5.9208 & 5.6302 & TRN & & \\
\hline CHEMBL1559811 & 954319 & 6.5331 & 6.7376 & TRN & & \\
\hline CHEMBL 2362782 & 954319 & 6.3354 & 5.7801 & TRN & & \\
\hline CHEMBL1866960 & 954319 & 6.0585 & 5.8938 & TRN & & \\
\hline CHEMBL1886120 & 954319 & 5.4168 & 5.7173 & TRN & & \\
\hline CHEMBL2354969 & 954319 & 5.0048 & 5.1707 & TRN & & \\
\hline CHEMBL1428735 & 954319 & 4.7474 & 5.7463 & TRN & & \\
\hline CHEMBL 2357036 & 954319 & 6.0 & 6.046 & TRN & & \\
\hline CHEMBL1487901 & 954319 & 5.1244 & 5.3617 & TST & & \\
\hline CHEMBL1360946 & 954319 & 6.4572 & 6.7439 & TRN & & \\
\hline CHEMBL1730380 & 954319 & 5.2069 & 5.3873 & TRN & & \\
\hline CHEMBL 2357349 & 954319 & 5.7959 & 6.2748 & TRN & & \\
\hline
\end{tabular}


Supplemental Table S2.txt

\begin{tabular}{|c|c|c|c|c|}
\hline CHEMBL464467 & 954319 & 5.7852 & 5.6565 & TST \\
\hline CHEMBL1870719 & 954319 & 5.5498 & 5.3196 & TRN \\
\hline CHEMBL1522458 & 954319 & 5.27 & 4.6872 & TRN \\
\hline CHEMBL1871757 & 954319 & 5.1249 & 5.2737 & TRN \\
\hline CHEMBL1305638 & 954319 & 5.6596 & 5.5081 & TRN \\
\hline CHEMBL1308403 & 954319 & 6.2336 & 5.4908 & TST \\
\hline CHEMBL1612194 & 954319 & 5.8861 & 5.0838 & TRN \\
\hline CHEMBL1472420 & 954319 & 5.4078 & 5.4384 & TST \\
\hline CHEMBL1732521 & 954319 & 7.585 & 5.8193 & TRN \\
\hline CHEMBL1475289 & 954319 & 5.5003 & 5.7347 & TRN \\
\hline CHEMBL1383228 & 954319 & 5.7328 & 5.3578 & TRN \\
\hline CHEMBL1716486 & 954319 & 5.2874 & 5.2339 & TRN \\
\hline CHEMBL1510639 & 954319 & 5.3862 & 5.3905 & TRN \\
\hline CHEMBL3195410 & 954319 & 5.1713 & 5.3031 & TRN \\
\hline CHEMBL1539897 & 954319 & 5.4609 & 5.3552 & TRN \\
\hline CHEMBL1442388 & 954319 & 5.3125 & 5.4118 & TST \\
\hline CHEMBL1599566 & 954319 & 5.6253 & 5.0759 & TRN \\
\hline CHEMBL1394445 & 954319 & 5.0762 & 5.2251 & TRN \\
\hline CHEMBL1327046 & 954319 & 4.5417 & 4.7016 & TRN \\
\hline CHEMBL1888955 & 954319 & 5.9666 & 6.0389 & TRN \\
\hline CHEMBL1398919 & 954319 & 4.9834 & 5.3017 & TRN \\
\hline CHEMBL1423575 & 954319 & 5.6676 & 5.1799 & TRN \\
\hline CHEMBL1505232 & 954319 & 4.6461 & 5.0724 & TRN \\
\hline CHEMBL1432670 & 954319 & 5.5272 & 5.4641 & TRN \\
\hline CHEMBL2355211 & 954319 & 5.1656 & 5.0532 & TRN \\
\hline CHEMBL1722184 & 954319 & 5.2373 & 5.2208 & TRN \\
\hline CHEMBL1374363 & 954319 & 5.8729 & 5.2541 & TST \\
\hline CHEMBL1445858 & 954319 & 4.8523 & 5.5622 & TRN \\
\hline CHEMBL1366114 & 954319 & 4.7918 & 5.0361 & TST \\
\hline CHEMBL1468011 & 954319 & 5.3401 & 5.8278 & TRN \\
\hline CHEMBL2133076 & 954319 & 6.0 & 5.8556 & TRN \\
\hline CHEMBL2133625 & 954319 & 4.5772 & 5.2157 & TRN \\
\hline CHEMBL 2134088 & 954319 & 6.0 & 5.8624 & TRN \\
\hline CHEMBL1705854 & 954319 & 6.0942 & 5.8802 & TST \\
\hline CHEMBL1515941 & 954319 & 5.4815 & 5.0721 & TRN \\
\hline CHEMBL2360847 & 954319 & 5.1791 & 5.6875 & TRN \\
\hline CHEMBL1489131 & 954319 & 5.3354 & 5.2525 & TRN \\
\hline CHEMBL1493367 & 954319 & 5.1367 & 5.3432 & TRN \\
\hline CHEMBL1450615 & 954319 & 5.0487 & 5.273 & TST \\
\hline CHEMBL2358936 & 954319 & 5.8665 & 5.5326 & TRN \\
\hline CHEMBL1451348 & 954319 & 5.3904 & 5.3011 & TRN \\
\hline CHEMBL1410745 & 954319 & 4.8435 & 5.0879 & TST \\
\hline CHEMBL1569095 & 954319 & 5.4401 & \multicolumn{2}{|c|}{5.212000000000001} \\
\hline CHEMBL1378226 & 954319 & 5.8297 & 5.8338 & TRN \\
\hline CHEMBL1451002 & 954319 & 5.6968 & 5.3524 & TRN \\
\hline CHEMBL1435670 & 954319 & 4.4435 & 4.7036 & TRN \\
\hline CHEMBL2356031 & 954319 & 6.0 & 5.8272 & TRN \\
\hline CHEMBL1699402 & 954319 & 5.5918 & 5.5076 & TRN \\
\hline
\end{tabular}

Page 12075 


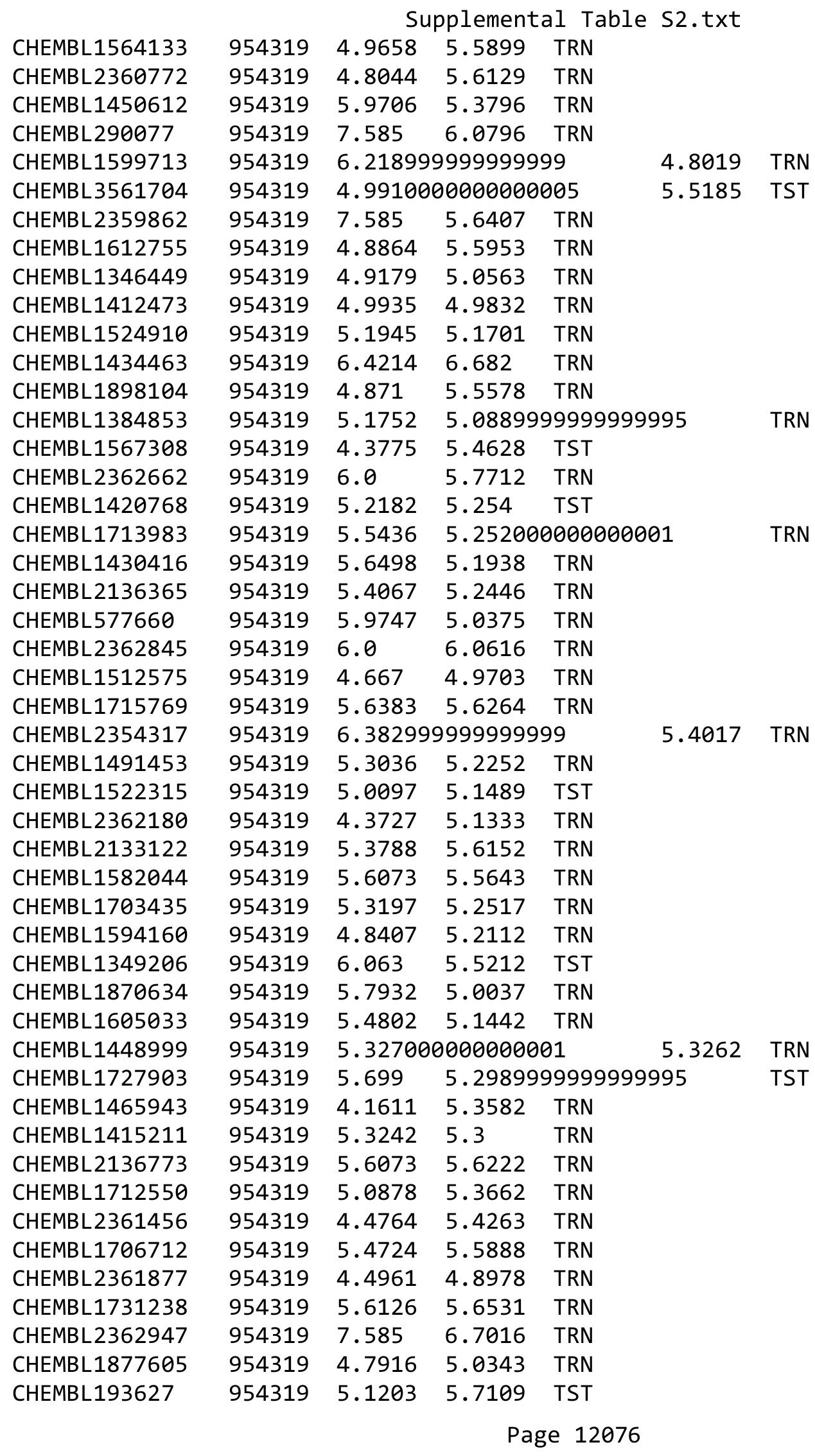




\begin{tabular}{|c|c|c|c|c|c|c|}
\hline & & \multicolumn{5}{|c|}{ Supplemental Table S2.txt } \\
\hline CHEMBL1715756 & 954319 & 5.7696 & 5.9295 & TRN & & \\
\hline CHEMBL1491097 & 954319 & 4.8837 & 5.1882 & TRN & & \\
\hline CHEMBL2358636 & 954319 & 7.585 & 5.5776 & TRN & & \\
\hline CHEMBL1488923 & 954319 & 5.2336 & 5.8586 & TRN & & \\
\hline CHEMBL1430935 & 954319 & \multicolumn{3}{|c|}{5.1579999999999995} & 5.4006 & TST \\
\hline CHEMBL1337961 & 954319 & 4.9722 & 5.2151 & TRN & & \\
\hline CHEMBL1605995 & 954319 & 5.1605 & 5.1241 & TST & & \\
\hline CHEMBL1872193 & 954319 & 6.0462 & 5.4102 & TRN & & \\
\hline CHEMBL1312397 & 954319 & 4.6045 & 5.0535 & TRN & & \\
\hline CHEMBL1370423 & 954319 & 4.8573 & 4.7137 & TRN & & \\
\hline CHEMBL2356184 & 954319 & 5.2549 & 5.4944 & TRN & & \\
\hline CHEMBL2357851 & 954319 & 4.4338 & 4.7505 & TRN & & \\
\hline CHEMBL1319336 & 954319 & 5.9101 & 5.58299 & 9999999999 & & TST \\
\hline CHEMBL1612156 & 954319 & 4.3693 & 5.273 & TRN & & \\
\hline CHEMBL1429129 & 954319 & 5.9469 & 4.8262 & TST & & \\
\hline CHEMBL1329693 & 954319 & 5.0315 & 5.3022 & TRN & & \\
\hline CHEMBL1352181 & 954319 & 5.4112 & 5.147 & TRN & & \\
\hline CHEMBL543876 & 954319 & 5.0585 & 5.1547 & TRN & & \\
\hline CHEMBL2357586 & 954319 & 7.585 & 5.6603 & TRN & & \\
\hline CHEMBL1610477 & 954319 & 4.8256 & 5.2713 & TRN & & \\
\hline CHEMBL1305030 & 954319 & 5.9393 & 5.7819 & TST & & \\
\hline CHEMBL2356673 & 954319 & 7.585 & 6.9466 & TRN & & \\
\hline CHEMBL2355458 & 954319 & 6.0 & 6.1269 & TRN & & \\
\hline CHEMBL1875758 & 954319 & 5.6861 & 5.7338 & TRN & & \\
\hline CHEMBL1594806 & 954319 & 5.1226 & 5.1583 & TRN & & \\
\hline CHEMBL 2354532 & 954319 & 5.0052 & 5.1363 & TRN & & \\
\hline CHEMBL1347745 & 954319 & 5.3686 & 5.2075 & TRN & & \\
\hline CHEMBL2360779 & 954319 & 7.585 & 6.8524 & TRN & & \\
\hline CHEMBL1300237 & 954319 & 4.8639 & 5.5587 & TST & & \\
\hline CHEMBL2359633 & 954319 & 5.8996 & 5.3042 & TRN & & \\
\hline CHEMBL1469715 & 954319 & 6.1331 & 5.862 & TRN & & \\
\hline CHEMBL1332417 & 954319 & 4.9863 & 5.2683 & TRN & & \\
\hline CHEMBL1439985 & 954319 & 4.4238 & 5.4746 & TRN & & \\
\hline CHEMBL2361140 & 954319 & 4.1702 & 5.3561 & TRN & & \\
\hline CHEMBL1396779 & 954319 & 5.1752 & 4.8473 & TRN & & \\
\hline CHEMBL1482680 & 954319 & 6.1457 & 5.4417 & TRN & & \\
\hline CHEMBL 2136838 & 954319 & 5.8013 & 5.6493 & TRN & & \\
\hline CHEMBL1473718 & 954319 & 5.2381 & 5.5084 & TRN & & \\
\hline CHEMBL1438308 & 954319 & 4.3504 & 5.3468 & TRN & & \\
\hline CHEMBL2355071 & 954319 & 6.3458 & 5.2594 & TRN & & \\
\hline CHEMBL1503131 & 954319 & 4.67 & 5.3072 & TRN & & \\
\hline CHEMBL1460361 & 954319 & 5.4389 & 5.5495 & TRN & & \\
\hline CHEMBL1385388 & 954319 & 6.2041 & 6.1352 & TRN & & \\
\hline CHEMBL1551228 & 954319 & 5.9281 & 4.992 & TRN & & \\
\hline CHEMBL1453285 & 954319 & 5.1911 & 5.0348 & TRN & & \\
\hline CHEMBL2354652 & 954319 & 5.7328 & 5.2731 & TRN & & \\
\hline CHEMBL1604143 & 954319 & 5.1391 & 5.5582 & TRN & & \\
\hline CHEMBL1459657 & 954319 & 5.083 & 5.0394 & TST & & \\
\hline
\end{tabular}




\begin{tabular}{|c|c|c|c|c|c|c|}
\hline & & \multicolumn{5}{|c|}{ Supplemental Table S2.txt } \\
\hline CHEMBL1324298 & 954319 & 5.567 & 5.5356 & TRN & & \\
\hline CHEMBL1505224 & 954319 & 5.8539 & 5.2869 & TRN & & \\
\hline CHEMBL1885590 & 954319 & 6.4225 & 6.3454 & TRN & & \\
\hline CHEMBL1515360 & 954319 & 4.4108 & 4.7994 & TRN & & \\
\hline CHEMBL1880788 & 954319 & 5.0088 & 5.1563 & TST & & \\
\hline CHEMBL1610579 & 954319 & 6.1844 & 5.8849 & TRN & & \\
\hline CHEMBL1329817 & 954319 & 4.52 & 4.8067 & TRN & & \\
\hline CHEMBL1882531 & 954319 & 4.7575 & \multicolumn{3}{|c|}{4.8260000000000005} & TRN \\
\hline CHEMBL1535490 & 954319 & 5.1397 & 6.0555 & TRN & & \\
\hline CHEMBL1336290 & 954319 & 7.585 & 5.9111 & TRN & & \\
\hline CHEMBL1329135 & 954319 & 4.7335 & 5.2502 & TST & & \\
\hline CHEMBL1379390 & 954319 & 4.4675 & 5.3769 & TST & & \\
\hline CHEMBL1902683 & 954319 & 5.4157 & 5.7792 & TRN & & \\
\hline CHEMBL 2357316 & 954319 & 4.3893 & 5.45299 & 99999 & & TRN \\
\hline CHEMBL2135379 & 954319 & 4.9867 & 4.9742 & TRN & & \\
\hline CHEMBL2362196 & 954319 & 6.0 & 5.9981 & TRN & & \\
\hline CHEMBL1392611 & 954319 & 5.1798 & 5.9229 & TRN & & \\
\hline CHEMBL1430094 & 954319 & \multicolumn{3}{|c|}{5.218999999999999} & 6.0727 & TRN \\
\hline CHEMBL1388405 & 954319 & 4.7867 & 5.1211 & TRN & & \\
\hline CHEMBL2362755 & 954319 & 4.3834 & 5.4897 & TRN & & \\
\hline CHEMBL1360952 & 954319 & 5.2211 & 5.1212 & TRN & & \\
\hline CHEMBL1600400 & 954319 & 5.4145 & 5.3602 & TRN & & \\
\hline CHEMBL1880486 & 954319 & 5.3391 & 5.115 & TST & & \\
\hline CHEMBL1603932 & 954319 & \multicolumn{3}{|c|}{4.6080000000000005} & 5.0777 & TRN \\
\hline CHEMBL2362241 & 954319 & 4.9905 & 4.7672 & TRN & & \\
\hline CHEMBL1573994 & 954319 & 5.5317 & 6.1985 & TST & & \\
\hline CHEMBL 2144271 & 954319 & 5.3298 & 5.3452 & TRN & & \\
\hline CHEMBL1351357 & 954319 & 7.585 & 5.9052 & TRN & & \\
\hline CHEMBL1554917 & 954319 & 5.3556 & 5.4956 & TRN & & \\
\hline CHEMBL1458209 & 954319 & 5.1314 & 5.47 & TRN & & \\
\hline CHEMBL2362599 & 954319 & 4.8196 & 5.1862 & TRN & & \\
\hline CHEMBL1890660 & 954319 & 5.8153 & 5.6853 & TRN & & \\
\hline CHEMBL 2357287 & 954319 & 7.585 & 7.1332 & TRN & & \\
\hline CHEMBL1610523 & 954319 & 5.5003 & 5.291 & TST & & \\
\hline CHEMBL 2141861 & 954319 & \multicolumn{3}{|c|}{5.757000000000001} & 5.7175 & TRN \\
\hline CHEMBL1894184 & 954319 & 5.8069 & 5.7187 & TRN & & \\
\hline CHEMBL1459468 & 954319 & 5.2161 & 5.9312 & TRN & & \\
\hline CHEMBL2355314 & 954319 & 5.4789 & 5.4297 & TRN & & \\
\hline CHEMBL536166 & 954319 & 5.4895 & 5.5475 & TRN & & \\
\hline CHEMBL1374384 & 954319 & 5.4473 & 5.4761 & TRN & & \\
\hline CHEMBL1870652 & 954319 & 5.8416 & 5.8423 & TRN & & \\
\hline CHEMBL1714012 & 954319 & 5.2676 & 5.2818 & TST & & \\
\hline CHEMBL1323459 & 954319 & 6.0742 & 5.4422 & TRN & & \\
\hline CHEMBL 2360459 & 954319 & 5.1163 & 5.3623 & TST & & \\
\hline CHEMBL3192873 & 954319 & 5.1798 & 6.0132 & TRN & & \\
\hline CHEMBL1470152 & 954319 & 5.4815 & 5.194 & TRN & & \\
\hline CHEMBL 2138317 & 954319 & 5.8761 & 5.3939 & TRN & & \\
\hline CHEMBL2141186 & 954319 & 5.9706 & 5.3046 & TST & & \\
\hline
\end{tabular}


Supplemental Table S2.txt

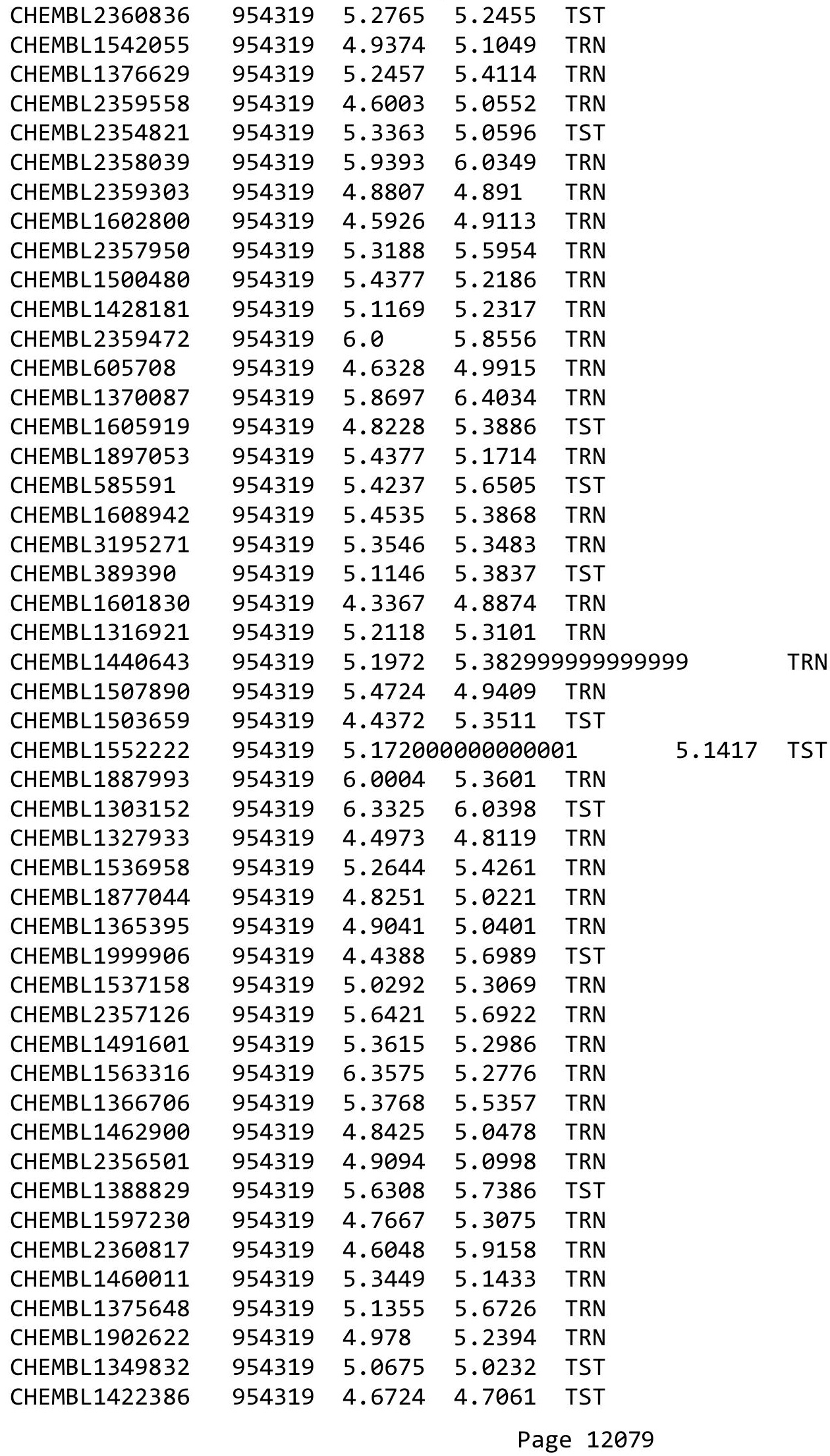




\begin{tabular}{|c|c|c|c|c|c|}
\hline & & \multicolumn{4}{|c|}{ Supplemental Table s2.txt } \\
\hline CHEMBL1709909 & 954319 & 7.585 & 5.8876 & TRN & \\
\hline CHEMBL1427279 & 954319 & 4.8564 & 5.529 & TRN & \\
\hline CHEMBL1354040 & 954319 & 4.8359 & 5.2871 & TRN & \\
\hline CHEMBL1541153 & 954319 & 5.8013 & 5.7883 & TST & \\
\hline CHEMBL1432721 & 954319 & 5.3063 & 5.2553 & TRN & \\
\hline CHEMBL1464930 & 954319 & 5.1549 & 5.1438 & TRN & \\
\hline CHEMBL 2134576 & 954319 & 6.0 & 5.8492 & TRN & \\
\hline CHEMBL1342825 & 954319 & 5.5361 & 4.8592 & TRN & \\
\hline CHEMBL1889375 & 954319 & 5.1007 & 4.9488 & TRN & \\
\hline CHEMBL2361602 & 954319 & 6.0 & 5.9795 & TRN & \\
\hline CHEMBL 2362338 & 954319 & 6.5467 & 6.6899 & TRN & \\
\hline CHEMBL1730354 & 954319 & 5.8861 & 5.7818 & TRN & \\
\hline CHEMBL1506451 & 954319 & 5.4597 & 5.4541 & TRN & \\
\hline CHEMBL1521704 & 954319 & 5.3969 & 5.2387 & TRN & \\
\hline CHEMBL1721043 & 954319 & 5.0419 & 5.1946 & TST & \\
\hline CHEMBL1714479 & 954319 & 6.0 & 5.5769 & TRN & \\
\hline CHEMBL1383554 & 954319 & 4.8554 & 4.9753 & TRN & \\
\hline CHEMBL1355253 & 954319 & 4.7247 & 4.9075 & TRN & \\
\hline CHEMBL 1455730 & 954319 & 5.129 & 5.3582 & TRN & \\
\hline CHEMBL 2361163 & 954319 & 6.0 & 6.245 & TRN & \\
\hline CHEMBL1896918 & 954319 & 5.1487 & 5.1761 & TRN & \\
\hline CHEMBL1562575 & 954319 & 6.1397 & 7.4779 & TRN & \\
\hline CHEMBL1344875 & 954319 & 5.2716 & 5.2513 & TRN & \\
\hline CHEMBL1333339 & 954319 & 4.657 & 5.3747 & TRN & \\
\hline CHEMBL 2359417 & 954319 & 6.0 & 6.0246 & TRN & \\
\hline CHEMBL1341124 & 954319 & 5.8386 & 5.64 & TRN & \\
\hline CHEMBL 2359534 & 954319 & 4.9901 & 5.4174 & TRN & \\
\hline CHEMBL1520051 & 954319 & 5.9788 & 5.1091 & TRN & \\
\hline CHEMBL1699099 & 954319 & 6.0516 & 4.9441 & TRN & \\
\hline CHEMBL1349753 & 954319 & 5.58 & 5.3498 & TRN & \\
\hline CHEMBL1567814 & 954319 & 5.6234 & 5.5293 & TRN & \\
\hline CHEMBL1520544 & 954319 & 5.2941 & 5.0557 & TST & \\
\hline CHEMBL 2359878 & 954319 & 5.71899 & (99999999 & 5.6384 & TRN \\
\hline CHEMBL1434237 & 954319 & 5.4202 & 5.5863 & TRN & \\
\hline CHEMBL1542018 & 954319 & 4.7421 & 5.0811 & TRN & \\
\hline CHEMBL 2361077 & 954319 & 5.4056 & 5.3459 & TRN & \\
\hline CHEMBL1718951 & 954319 & 5.308 & 5.23799 & 99999999995 & TRN \\
\hline CHEMBL1523019 & 954319 & 5.5467 & 5.184 & TRN & \\
\hline CHEMBL3195057 & 954319 & 4.8038 & 5.3732 & TRN & \\
\hline CHEMBL1698730 & 954319 & 5.301 & 5.6547 & TRN & \\
\hline CHEMBL1345227 & 954319 & 5.3072 & 5.061 & TRN & \\
\hline CHEMBL1716540 & 954319 & 5.7595 & 5.152 & TST & \\
\hline CHEMBL1712719 & 954319 & 5.5302 & 5.1661 & TRN & \\
\hline CHEMBL1736950 & 954319 & 5.0269 & 5.3349 & TRN & \\
\hline CHEMBL16288 & 954319 & 6.0851 & 6.0402 & TRN & \\
\hline CHEMBL 2360990 & 954319 & 4.9694 & 5.3893 & TRN & \\
\hline CHEMBL1528960 & 954319 & 5.0788 & 5.7788 & TRN & \\
\hline CHEMBL 2355889 & 954319 & 4.8254 & 6.0224 & TRN & \\
\hline
\end{tabular}




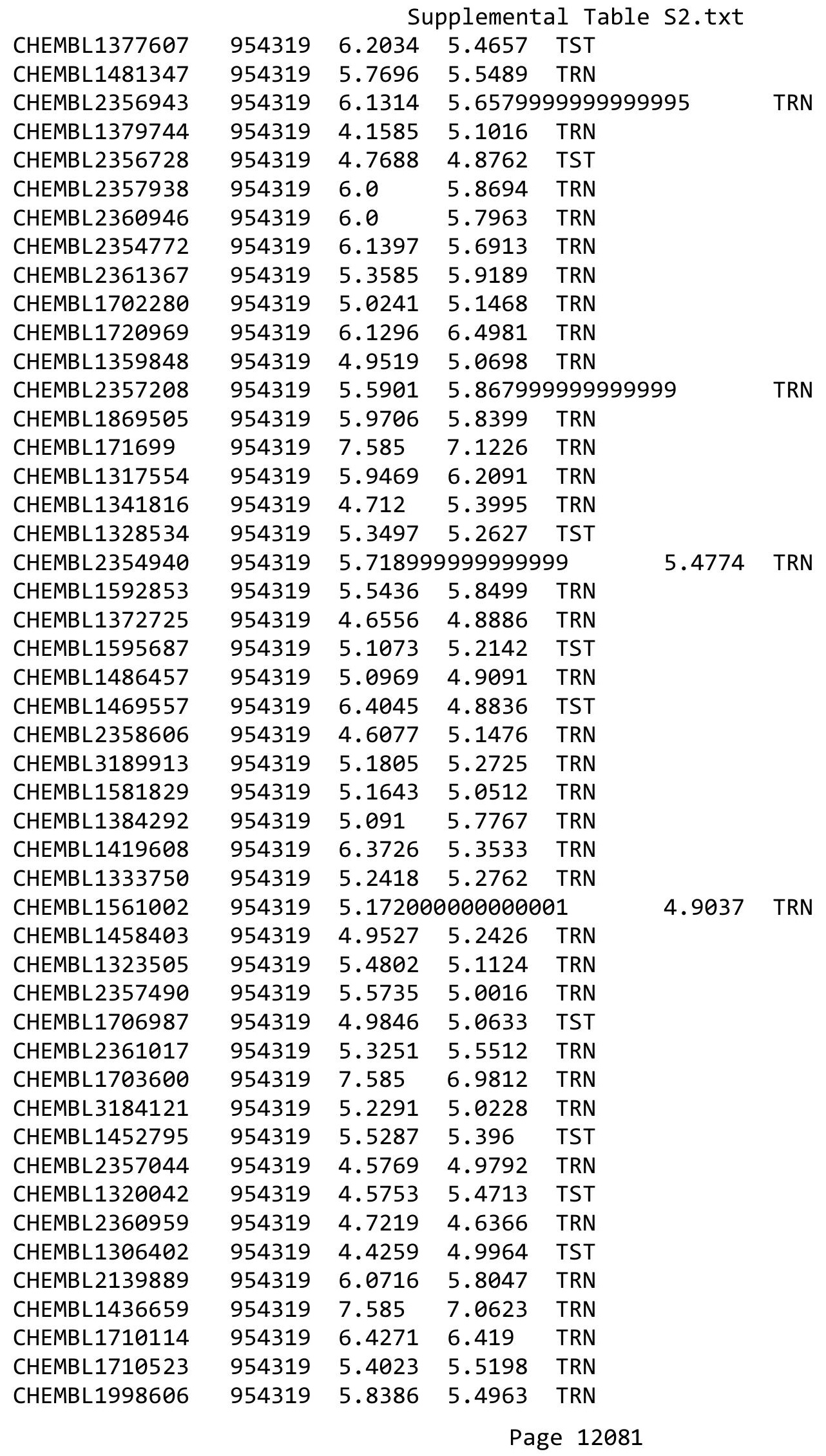




\begin{tabular}{|c|c|c|c|c|c|c|}
\hline & & \multicolumn{5}{|c|}{ Supplemental Table S2.txt } \\
\hline CHEMBL1411646 & 954319 & 4.9314 & 5.0361 & TST & & \\
\hline CHEMBL 2354851 & 954319 & 4.3955 & 5.523 & TRN & & \\
\hline CHEMBL1471330 & 954319 & 4.9165 & 5.2274 & TRN & & \\
\hline CHEMBL1412006 & 954319 & 6.0283 & 6.0535 & TRN & & \\
\hline CHEMBL1441491 & 954319 & 6.21399 & 99999999 & 995 & 5.4503 & TRN \\
\hline CHEMBL2355077 & 954319 & 6.0 & 5.8768 & TRN & & \\
\hline CHEMBL1609759 & 954319 & 6.2441 & 5.3437 & TRN & & \\
\hline CHEMBL1516708 & 954319 & 6.0013 & 5.6551 & TST & & \\
\hline CHEMBL1389871 & 954319 & 5.1096 & 5.2777 & TRN & & \\
\hline CHEMBL1371382 & 954319 & 4.8324 & 5.2349 & TRN & & \\
\hline CHEMBL2359971 & 954319 & 6.0 & 5.78 & TRN & & \\
\hline CHEMBL1388380 & 954319 & 4.7153 & 5.2208 & TRN & & \\
\hline CHEMBL1481301 & 954319 & 4.325 & 4.747 & TRN & & \\
\hline CHEMBL1576543 & 954319 & 5.3089 & 5.5014 & TRN & & \\
\hline CHEMBL1535257 & 954319 & 5.4202 & 5.1162 & TRN & & \\
\hline CHEMBL1345115 & 954319 & 5.7305 & 5.1809 & TRN & & \\
\hline CHEMBL2357917 & 954319 & 4.6946 & 5.4206 & TRN & & \\
\hline CHEMBL1499450 & 954319 & 5.2765 & 5.4316 & TRN & & \\
\hline CHEMBL2359795 & 954319 & 4.1902 & 5.5215 & TRN & & \\
\hline CHEMBL1411209 & 954319 & 5.2636 & 5.3441 & TRN & & \\
\hline CHEMBL3183996 & 954319 & 6.2857 & 5.7781 & TRN & & \\
\hline CHEMBL1570706 & 954319 & 5.0405 & 5.2793 & TRN & & \\
\hline CHEMBL1892704 & 954319 & 4.4799 & 5.0636 & TST & & \\
\hline CHEMBL1444764 & 954319 & 5.4365 & 5.0908 & TRN & & \\
\hline CHEMBL1492073 & 954319 & 4.9158 & 5.2647 & TRN & & \\
\hline CHEMBL2361956 & 954319 & 4.7572 & 5.9977 & TRN & & \\
\hline CHEMBL1310995 & 954319 & 6.2291 & 5.0738 & TRN & & \\
\hline CHEMBL1378490 & 954319 & 5.0904 & 5.27 & TRN & & \\
\hline CHEMBL3197908 & 954319 & 5.0894 & 5.12799 & 9999999999 & & TRN \\
\hline CHEMBL 2362148 & 954319 & 6.0 & 6.0556 & TRN & & \\
\hline CHEMBL1320244 & 954319 & 5.5867 & 5.5793 & TRN & & \\
\hline CHEMBL2355793 & 954319 & 4.6619 & 4.8192 & TRN & & \\
\hline CHEMBL 2357014 & 954319 & 5.2588 & 4.8213 & TRN & & \\
\hline CHEMBL 2448464 & 954319 & 5.0726 & 5.1802 & TRN & & \\
\hline CHEMBL1442319 & 954319 & 5.1175 & 5.6762 & TRN & & \\
\hline CHEMBL1716038 & 954319 & 5.3686 & 5.49 & TST & & \\
\hline CHEMBL1608402 & 954319 & 5.4271 & 5.5249 & TST & & \\
\hline CHEMBL1502133 & 954319 & 5.1024 & 5.6623 & TRN & & \\
\hline CHEMBL1391059 & 954319 & 5.5229 & 5.2354 & TRN & & \\
\hline CHEMBL1436799 & 954319 & 7.585 & 6.9297 & TRN & & \\
\hline CHEMBL1485417 & 954319 & 5.7305 & 5.3357 & TST & & \\
\hline CHEMBL1425552 & 954319 & 5.1198 & 5.4147 & TRN & & \\
\hline CHEMBL2356987 & 954319 & 6.0182 & 5.8392 & TRN & & \\
\hline CHEMBL1562110 & 954319 & 4.9965 & 5.0629 & TRN & & \\
\hline CHEMBL1971142 & 954319 & 5.0232 & 5.5628 & TRN & & \\
\hline CHEMBL1430290 & 954319 & 5.2396 & 5.2489 & TRN & & \\
\hline CHEMBL1873911 & 954319 & 5.8297 & 5.5684 & TRN & & \\
\hline CHEMBL 2144544 & 954319 & 4.644 & 5.0716 & TRN & & \\
\hline
\end{tabular}


Supplemental Table S2.txt

\begin{tabular}{|c|c|c|c|c|}
\hline CHEMBL 2359362 & 954319 & 5.4572 & 6.0557 & TRN \\
\hline CHEMBL116919 & 954319 & 4.6036 & 4.9642 & TRN \\
\hline CHEMBL274070 & 954319 & 6.0 & 5.813 & TST \\
\hline CHEMBL1699398 & 954319 & 5.4622 & 5.5047 & TST \\
\hline CHEMBL1567488 & 954319 & 5.5229 & 5.4927 & TST \\
\hline CHEMBL1451209 & 954319 & 5.6126 & 5.8516 & TRN \\
\hline CHEMBL 2356419 & 954319 & 4.9446 & 5.9138 & TRN \\
\hline CHEMBL1867711 & 954319 & 6.3116 & 5.3567 & TRN \\
\hline CHEMBL1501091 & 954319 & 6.1018 & 4.9746 & TRN \\
\hline CHEMBL2360927 & 954319 & 6.5391 & 5.7928 & TRN \\
\hline CHEMBL1418437 & 954319 & 5.3635 & 5.431 & TST \\
\hline CHEMBL1380862 & 954319 & 5.2596 & 5.7702 & TRN \\
\hline CHEMBL1457403 & 954319 & 5.8928 & 5.4711 & TST \\
\hline CHEMBL1460595 & 954319 & 4.5337 & 5.35 & TST \\
\hline CHEMBL2355799 & 954319 & 5.4377 & 5.4502 & TST \\
\hline CHEMBL 2362244 & 954319 & 5.5243 & 5.3301 & TST \\
\hline CHEMBL1606743 & 954319 & 5.1107 & 5.3105 & TST \\
\hline CHEMBL1895081 & 954319 & 5.2321 & 5.0347 & TST \\
\hline CHEMBL1540036 & 954319 & 4.734 & 4.9264 & TST \\
\hline CHEMBL1368493 & 954319 & 5.7212 & 4.8909 & TST \\
\hline CHEMBL1976507 & 954319 & 5.1864 & 5.87299 & 9999999999 \\
\hline CHEMBL 2356497 & 954319 & 5.3261 & 5.2827 & TST \\
\hline CHEMBL1533776 & 954319 & 4.6047 & 4.9899 & TST \\
\hline CHEMBL 2360993 & 954319 & 6.0 & 5.9281 & TST \\
\hline CHEMBL 2362014 & 954319 & 5.684 & 5.1348 & TST \\
\hline CHEMBL1557954 & 954319 & 5.5591 & 5.8385 & TST \\
\hline CHEMBL 2359661 & 954319 & 5.9172 & 5.4996 & TST \\
\hline CHEMBL1469736 & 954319 & 5.5884 & 5.7365 & TST \\
\hline CHEMBL1429793 & 954319 & 5.5498 & 5.2982 & TST \\
\hline CHEMBL 2355447 & 954319 & 5.4486 & 5.9047 & TST \\
\hline CHEMBL 2448511 & 954319 & 4.9115 & 5.1614 & TST \\
\hline CHEMBL585656 & 954319 & 5.251 & 5.3703 & TST \\
\hline CHEMBL 2142138 & 954319 & 5.3737 & 5.1823 & TST \\
\hline CHEMBL1349063 & 954319 & 6.1002 & 5.8034 & TST \\
\hline CHEMBL1874105 & 954319 & 5.9208 & 5.5343 & TST \\
\hline CHEMBL1437560 & 954319 & 5.9066 & 5.6609 & TST \\
\hline CHEMBL 2357474 & 954319 & 5.7011 & 5.8161 & TST \\
\hline CHEMBL1409464 & 954319 & 5.3028 & 5.22 & TST \\
\hline CHEMBL1508914 & 954319 & 6.2175 & 5.255 & TST \\
\hline CHEMBL1471810 & 954319 & 5.1085 & 5.2239 & TST \\
\hline CHEMBL1435072 & 954319 & 6.317 & 5.49799 & 9999999999 \\
\hline CHEMBL 2131434 & 954319 & 4.4406 & 5.8436 & TST \\
\hline CHEMBL 2362396 & 954319 & 4.7796 & 5.0966 & TST \\
\hline CHEMBL1487368 & 954319 & 6.0348 & 5.7331 & TST \\
\hline CHEMBL 2362799 & 954319 & 4.9682 & 5.7332 & TST \\
\hline CHEMBL1699733 & 954319 & 6.1278 & 5.4489 & TST \\
\hline CHEMBL1488010 & 954319 & 5.2741 & 5.3664 & TST \\
\hline CHEMBL 2361057 & 954319 & 4.6498 & 5.0925 & TST \\
\hline
\end{tabular}




\begin{tabular}{|c|c|c|c|c|c|}
\hline \multicolumn{6}{|c|}{ Supplemental Table S2.txt } \\
\hline CHEMBL1559529 & 954319 & 5.27 & 5.8458 & TST & \\
\hline CHEMBL1322078 & 954319 & 6.0106 & 5.7062 & TST & \\
\hline CHEMBL1904959 & 954319 & 5.2534 & 5.4398 & TST & \\
\hline CHEMBL1321083 & 954319 & 4.756 & 5.3474 & TST & \\
\hline CHEMBL1460239 & 954319 & 5.284 & 5.3182 & TST & \\
\hline CHEMBL1501242 & 954319 & 5.684 & 5.5165 & TST & \\
\hline CHEMBL1607801 & 954319 & 5.9666 & 7.1282 & TST & \\
\hline CHEMBL1423113 & 954319 & 5.8013 & 5.4605 & TST & \\
\hline CHEMBL1577804 & 954319 & 5.1918 & 5.4129 & TST & \\
\hline CHEMBL1346079 & 954319 & 5.5528 & 5.603 & TST & \\
\hline CHEMBL1550584 & 954319 & 5.5834 & 5.2329 & TST & \\
\hline CHEMBL1523841 & 954319 & 5.8861 & 5.8039 & TST & \\
\hline CHEMBL1401504 & 954319 & 5.1952 & 5.2642 & TST & \\
\hline CHEMBL1891205 & 954319 & 5.6162 & 5.7539 & TST & \\
\hline CHEMBL1325003 & 954319 & 6.266 & 6.166 & TST & \\
\hline CHEMBL1700115 & 954319 & 5.9355 & 5.8969 & TST & \\
\hline CHEMBL3198899 & 954319 & 4.7109 & 5.51399 & 9999999999 & TST \\
\hline CHEMBL1328307 & 954319 & 5.1379 & 4.665 & TST & \\
\hline CHEMBL 2134677 & 954319 & 5.52 & 5.7066 & TST & \\
\hline CHEMBL1867339 & 954319 & 5.5452 & 6.0031 & TST & \\
\hline CHEMBL1570537 & 954319 & 6.056 & 5.2091 & TST & \\
\hline CHEMBL1718302 & 954319 & 5.2366 & 5.0848 & TST & \\
\hline CHEMBL1719064 & 954319 & 5.7747 & 5.5055 & TST & \\
\hline CHEMBL1727214 & 954319 & 5.1244 & 5.403 & TST & \\
\hline CHEMBL1415958 & 954319 & 6.5834 & 6.0867 & TST & \\
\hline CHEMBL18115 & 954319 & 5.2197 & 5.3752 & TST & \\
\hline CHEMBL1312619 & 954319 & 5.4634 & 5.4626 & TST & \\
\hline CHEMBL 2361264 & 954319 & 4.5408 & 4.8917 & TST & \\
\hline CHEMBL2358117 & 954319 & 4.6772 & 5.2439 & TST & \\
\hline CHEMBL 2136129 & 954319 & 6.0088 & 5.7495 & TST & \\
\hline CHEMBL1557066 & 954319 & 5.4597 & 5.2072 & TST & \\
\hline CHEMBL1345232 & 954319 & 5.4962 & 5.6149 & TST & \\
\hline CHEMBL1583504 & 954319 & 4.4441 & 4.8921 & TST & \\
\hline CHEMBL3126906 & 954319 & 5.4672 & 5.7004 & TST & \\
\hline CHEMBL1441773 & 954319 & 4.4877 & 5.3749 & TST & \\
\hline CHEMBL1536763 & 954319 & 5.2604 & 5.4784 & TST & \\
\hline CHEMBL1724034 & 954319 & 4.1706 & 5.0188 & TST & \\
\hline CHEMBL1721296 & 954319 & 5.6253 & 5.5923 & TST & \\
\hline CHEMBL1444205 & 954319 & 5.4622 & 5.2984 & TST & \\
\hline CHEMBL1543858 & 954319 & 4.6124 & 5.2567 & TST & \\
\hline CHEMBL393287 & 954319 & 5.066 & 5.0471 & TST & \\
\hline CHEMBL1597625 & 954319 & 6.0665 & 5.0855 & TST & \\
\hline CHEMBL2361455 & 954319 & 5.4271 & 5.1432 & TST & \\
\hline CHEMBL1332776 & 954319 & 5.4342 & 5.2484 & TST & \\
\hline CHEMBL 1727847 & 954319 & 5.6904 & 5.9459 & TST & \\
\hline CHEMBL1405122 & 954319 & 6.4962 & 6.0256 & TST & \\
\hline CHEMBL 2448508 & 954319 & 5.4522 & 5.3564 & TST & \\
\hline CHEMBL1372936 & 954319 & 5.3947 & 5.3943 & TST & \\
\hline
\end{tabular}


Supplemental Table S2.txt

\begin{tabular}{|c|c|c|c|c|c|}
\hline CHEMBL1375402 & 954319 & 5.1118 & 5.2325 & TST & \\
\hline CHEMBL1872984 & 954319 & 5.3799 & 5.4106 & TST & \\
\hline CHEMBL2361826 & 954319 & 4.6108 & 5.6723 & TST & \\
\hline CHEMBL1568152 & 954319 & 4.9614 & 5.3135 & TST & \\
\hline CHEMBL1578679 & 954319 & 6.5302 & 4.6809 & TST & \\
\hline CHEMBL1600736 & 954319 & 5.2111 & 5.3509 & TST & \\
\hline CHEMBL1409430 & 954319 & 4.3826 & 4.9512 & TST & \\
\hline CHEMBL3693291 & 1535621 & 5.4664 & 5.1731 & TRN & \\
\hline CHEMBL3639921 & 1535621 & 6.5952 & 6.8452 & TST & \\
\hline CHEMBL3693364 & 1535621 & 5.6449 & 5.8142 & TRN & \\
\hline CHEMBL3693353 & 1535621 & 5.2258 & 4.5211 & TST & \\
\hline CHEMBL3693294 & 1535621 & 6.0851 & 6.2292 & TRN & \\
\hline CHEMBL3693352 & 1535621 & 5.8636 & 5.7498 & TRN & \\
\hline CHEMBL3693348 & 1535621 & 7.1135 & 6.8028 & TRN & \\
\hline CHEMBL 3693311 & 1535621 & 5.5482 & 5.2333 & TRN & \\
\hline CHEMBL3693374 & 1535621 & 6.0 & 6.3114 & TRN & \\
\hline CHEMBL3693310 & 1535621 & 5.9226 & 6.2094 & TST & \\
\hline CHEMBL3693305 & 1535621 & 6.0696 & 5.8659 & TRN & \\
\hline CHEMBL3693309 & 1535621 & 5.6676 & 6.0371 & TST & \\
\hline CHEMBL 3693290 & 1535621 & 5.1314 & 5.3276 & TRN & \\
\hline CHEMBL3693260 & 1535621 & 6.4498 & 7.3187 & TST & \\
\hline CHEMBL3693365 & 1535621 & 5.99700 & 00000000 & 5.4917 & TRN \\
\hline CHEMBL3693316 & 1535621 & 6.1785 & 6.0097 & TRN & \\
\hline CHEMBL3693266 & 1535621 & 7.7959 & 8.242 & TST & \\
\hline CHEMBL 3693350 & 1535621 & 5.2142 & 5.3682 & TRN & \\
\hline CHEMBL3693269 & 1535621 & 6.9101 & 7.6655 & TST & \\
\hline CHEMBL3693313 & 1535621 & 6.0 & 6.53799 & 9999999999 & TRN \\
\hline CHEMBL3693299 & 1535621 & 5.0601 & 5.5939 & TRN & \\
\hline CHEMBL3693377 & 1535621 & 5.1192 & 4.9581 & TRN & \\
\hline CHEMBL 3693341 & 1535621 & 6.24799 & 99999999 & 6.1504 & TRN \\
\hline CHEMBL3639922 & 1535621 & 6.0 & 5.8288 & TRN & \\
\hline CHEMBL3693360 & 1535621 & 5.0 & 4.7125 & TST & \\
\hline CHEMBL3693318 & 1535621 & 6.2725 & 6.355 & TST & \\
\hline CHEMBL 3693331 & 1535621 & 6.0 & 5.481 & TRN & \\
\hline CHEMBL3693323 & 1535621 & 6.1713 & 6.056 & TRN & \\
\hline CHEMBL3693261 & 1535621 & 7.4815 & 8.2049 & TRN & \\
\hline CHEMBL3693326 & 1535621 & 6.0501 & 6.1915 & TRN & \\
\hline CHEMBL3693367 & 1535621 & 2.09800 & 00000000 & 3.8819 & TRN \\
\hline CHEMBL3693370 & 1535621 & 7.6576 & 6.8341 & TRN & \\
\hline CHEMBL3693359 & 1535621 & 5.4962 & 6.0153 & TRN & \\
\hline CHEMBL 3693320 & 1535621 & 5.767 & 6.3618 & TST & \\
\hline CHEMBL3693335 & 1535621 & 5.5459 & 5.6473 & TRN & \\
\hline CHEMBL3693280 & 1535621 & 5.152 & 5.2655 & TRN & \\
\hline CHEMBL3693337 & 1535621 & 5.2672 & 5.4581 & TRN & \\
\hline CHEMBL3693371 & 1535621 & 6.0 & 5.6824 & TRN & \\
\hline CHEMBL3693356 & 1535621 & 5.1273 & 4.3024 & TST & \\
\hline CHEMBL 3693346 & 1535621 & 6.7282 & 6.2682 & TRN & \\
\hline \multirow[t]{2}{*}{ CHEMBL3693288 } & 1535621 & 5.5381 & 5.25200 & $\partial 000000001$ & TRN \\
\hline & & \multicolumn{4}{|c|}{ Page 12085} \\
\hline
\end{tabular}


Supplemental Table S2.txt

\begin{tabular}{|c|c|c|c|c|c|}
\hline CHEMBL 3693328 & 1535621 & 5.6819 & 5.5627 & TRN & \\
\hline CHEMBL 3693272 & 1535621 & 5.1963 & 5.4706 & TRN & \\
\hline CHEMBL 3693292 & 1535621 & 6.0 & 6.1635 & TRN & \\
\hline CHEMBL 3693271 & 1535621 & 6.7696 & 6.2943 & TRN & \\
\hline CHEMBL 3693317 & 1535621 & 6.5452 & 6.2176 & TST & \\
\hline CHEMBL 3693376 & 1535621 & 4.0 & 4.8756 & TRN & \\
\hline CHEMBL 3693342 & 1535621 & 5.364 & 5.6872 & TRN & \\
\hline CHEMBL 3693375 & 1535621 & 6.0 & 6.4006 & TRN & \\
\hline CHEMBL 3693263 & 1535621 & 6.5918 & 6.9337 & TST & \\
\hline CHEMBL3693306 & 1535621 & 5.8182 & 5.6685 & TRN & \\
\hline CHEMBL 3693270 & 1535621 & 7.3565 & 6.7765 & TRN & \\
\hline CHEMBL 3693336 & 1535621 & 6.5157 & 5.034 & TST & \\
\hline CHEMBL 3693343 & 1535621 & 5.2403 & 5.461 & TRN & \\
\hline CHEMBL 3693378 & 1535621 & 6.0287 & 6.5968 & TST & \\
\hline CHEMBL 3693322 & 1535621 & 5.4504 & 5.3198 & TST & \\
\hline CHEMBL 3693303 & 1535621 & 5.8274 & 5.9857 & TRN & \\
\hline CHEMBL 3693345 & 1535621 & 6.52 & 6.2787 & TRN & \\
\hline CHEMBL 3693327 & 1535621 & 5.0645 & 5.1241 & TST & \\
\hline CHEMBL 3693369 & 1535621 & 6.0 & 5.4293 & TRN & \\
\hline CHEMBL 3693362 & 1535621 & 5.4139 & 5.5049 & TRN & \\
\hline CHEMBL 3693304 & 1535621 & 5.9851 & 5.8733 & TRN & \\
\hline CHEMBL 3693366 & 1535621 & 5.0 & 4.2897 & TRN & \\
\hline CHEMBL 3693267 & 1535621 & 8.0969 & 8.3571 & TST & \\
\hline CHEMBL 3693287 & 1535621 & 5.5896 & 5.6431 & TRN & \\
\hline CHEMBL 3693284 & 1535621 & 6.0186 & 5.8489 & TRN & \\
\hline CHEMBL 3693314 & 1535621 & 6.0 & 6.8417 & TRN & \\
\hline CHEMBL3693349 & 1535621 & 6.2573 & 6.5831 & TRN & \\
\hline CHEMBL 3693354 & 1535621 & 5.0 & 4.2036 & TST & \\
\hline CHEMBL 3693339 & 1535621 & 5.2507 & 5.0607 & TST & \\
\hline CHEMBL 3693307 & 1535621 & 5.4248 & 5.4798 & TRN & \\
\hline CHEMBL 3693357 & 1535621 & 6.0 & 5.9364 & TRN & \\
\hline CHEMBL 3693302 & 1535621 & 5.2192 & 5.4976 & TRN & \\
\hline CHEMBL 3693321 & 1535621 & 5.4123 & 5.6485 & TST & \\
\hline CHEMBL 3693332 & 1535621 & 5.6192 & 5.317 & TRN & \\
\hline CHEMBL 3693286 & 1535621 & 5.2927 & 5.3186 & TRN & \\
\hline CHEMBL 3693351 & 1535621 & 5.5656 & 5.8306 & TRN & \\
\hline CHEMBL 3693277 & 1535621 & 6.0 & 5.7714 & TRN & \\
\hline CHEMBL 3693358 & 1535621 & 6.0 & 5.5646 & TRN & \\
\hline CHEMBL 3693319 & 1535621 & 5.8861 & 6.5064 & TST & \\
\hline CHEMBL 3693361 & 1535621 & 5.0 & 4.6109 & TST & \\
\hline CHEMBL 3693312 & 1535621 & 6.098 & 5.8368 & TST & \\
\hline CHEMBL 3693308 & 1535621 & 5.1475 & 5.0398 & TRN & \\
\hline CHEMBL 3693372 & 1535621 & 6.0 & 6.2457 & TRN & \\
\hline CHEMBL 3693344 & 1535621 & 5.586 & 5.7679 & TRN & \\
\hline CHEMBL 3693265 & 1535621 & 8.0 & 7.8453 & TRN & \\
\hline CHEMBL 3693301 & 1535621 & 5.3458 & 5.4513 & TRN & \\
\hline CHEMBL 3693325 & 1535621 & 5.99700 & 000000000 & 21 & 5.857 \\
\hline CHEMBL 3693324 & 1535621 & 5.4084 & 5.1918 & TST & \\
\hline
\end{tabular}


Supplemental Table S2.txt

\begin{tabular}{|c|c|c|c|c|}
\hline CHEMBL 3693333 & 1535621 & 5.9566 & 5.4752 & TRN \\
\hline CHEMBL3693268 & 1535621 & 7.8239 & 8.1935 & TRN \\
\hline CHEMBL3693363 & 1535621 & 5.9488 & 5.6189 & TRN \\
\hline CHEMBL 3693289 & 1535621 & 5.1737 & 5.3211 & TRN \\
\hline CHEMBL3693329 & 1535621 & 5.5429 & 5.1516 & TST \\
\hline CHEMBL3693334 & 1535621 & 5.8539 & 6.0952 & TRN \\
\hline CHEMBL3693330 & 1535621 & 5.0 & 5.2982 & TRN \\
\hline CHEMBL 3693264 & 1535621 & 8.301 & 8.0089 & TRN \\
\hline CHEMBL3693355 & 1535621 & 5.0 & 4.0538 & TST \\
\hline CHEMBL3693281 & 1535621 & 6.0 & 5.2221 & TRN \\
\hline CHEMBL3693347 & 1535621 & 6.3143 & 6.0151 & TRN \\
\hline CHEMBL3693338 & 1535621 & 5.2689 & 5.2492 & TRN \\
\hline CHEMBL3693300 & 1535621 & 6.0 & 5.5357 & TRN \\
\hline CHEMBL 3693340 & 1535621 & 5.0548 & 5.5864 & TRN \\
\hline CHEMBL3693315 & 1535621 & 6.0 & 6.5399 & TRN \\
\hline CHEMBL3693282 & 1535621 & 5.1347 & 5.2296 & TRN \\
\hline CHEMBL3693279 & 1535621 & 5.0882 & 4.9973 & TRN \\
\hline CHEMBL3693285 & 1535621 & 6.5243 & 6.1488 & TRN \\
\hline CHEMBL3693274 & 1535621 & 5.9516 & 5.7759 & TRN \\
\hline CHEMBL3957402 & 1640953 & 7.0969 & 7.0864 & TRN \\
\hline CHEMBL3935296 & 1640953 & 6.0 & 5.9882 & TRN \\
\hline CHEMBL3909772 & 1640953 & 6.6576 & 6.6794 & TRN \\
\hline CHEMBL3970099 & 1640953 & 6.6198 & 6.5982 & TRN \\
\hline CHEMBL3893441 & 1640953 & 6.4685 & 6.9575 & TRN \\
\hline CHEMBL 3966873 & 1640953 & 7.699 & 7.4739 & TRN \\
\hline CHEMBL3937712 & 1640953 & 6.4949 & 6.6526 & TRN \\
\hline CHEMBL3933519 & 1640953 & 6.6021 & \multicolumn{2}{|c|}{6.8260000000000005} \\
\hline CHEMBL3913475 & 1640953 & 6.0 & 6.494 & TRN \\
\hline CHEMBL3951509 & 1640953 & 7.699 & 7.7821 & TRN \\
\hline CHEMBL3937134 & 1640953 & 6.0 & 6.1689 & TRN \\
\hline CHEMBL3956491 & 1640953 & 7.0 & 6.8862 & TRN \\
\hline CHEMBL3902899 & 1640953 & 6.0 & 5.8912 & TRN \\
\hline CHEMBL3918213 & 1640953 & 6.0 & 5.902 & TRN \\
\hline CHEMBL3924649 & 1640953 & 6.0 & 6.1392 & TRN \\
\hline CHEMBL3911150 & 1640953 & 6.5376 & 5.886 & TST \\
\hline CHEMBL3976581 & 1640953 & 7.3979 & \multicolumn{2}{|c|}{7.587000000000001} \\
\hline CHEMBL3911915 & 1640953 & 7.3979 & 7.3467 & TRN \\
\hline CHEMBL3986501 & 1640953 & 7.3979 & 7.1753 & TRN \\
\hline CHEMBL3901468 & 1640953 & 6.0 & 5.7615 & TST \\
\hline CHEMBL3916760 & 1640953 & 7.5229 & 7.5843 & TRN \\
\hline CHEMBL3951964 & 1640953 & 6.8239 & 6.7971 & TRN \\
\hline CHEMBL3973861 & 1640953 & 6.7447 & 6.8794 & TRN \\
\hline CHEMBL3938047 & 1640953 & 7.5229 & 7.4145 & TRN \\
\hline CHEMBL3889995 & 1640953 & 7.1549 & 7.1109 & TRN \\
\hline CHEMBL3906183 & 1640953 & 8.0 & 6.4783 & TST \\
\hline CHEMBL3929846 & 1640953 & 6.0 & 5.7479 & TRN \\
\hline CHEMBL3891230 & 1640953 & 6.0 & 6.1702 & TRN \\
\hline CHEMBL3950433 & 1640953 & 7.3979 & 7.4142 & TRN \\
\hline
\end{tabular}

Page 12087 


\begin{tabular}{|c|c|c|c|c|c|c|}
\hline \multicolumn{7}{|c|}{ Supplemental Table S2.txt } \\
\hline CHEMBL 3962588 & 1640953 & 8.0 & 7.8768 & TRN & & \\
\hline CHEMBL3961509 & 1640953 & 7.5229 & 7.2598 & TRN & & \\
\hline CHEMBL3975693 & 1640953 & 6.0 & 6.6802 & TST & & \\
\hline CHEMBL 3960223 & 1640953 & 6.9586 & 6.9933 & TRN & & \\
\hline CHEMBL 3904677 & 1640953 & 6.0 & 5.8553 & TRN & & \\
\hline CHEMBL 3921543 & 1640953 & 7.5229 & 7.5712 & TRN & & \\
\hline CHEMBL 3967802 & 1640953 & 7.5229 & 7.4919 & TRN & & \\
\hline CHEMBL3906190 & 1640953 & 6.0 & 5.75 & TRN & & \\
\hline CHEMBL3976313 & 1640953 & 8.0 & 8.1783 & TRN & & \\
\hline CHEMBL3940633 & 1640953 & 6.0 & 5.9577 & TRN & & \\
\hline CHEMBL3895661 & 1640953 & 6.0 & 6.2132 & TRN & & \\
\hline CHEMBL 3975315 & 1640953 & 6.699 & 6.6683 & TRN & & \\
\hline CHEMBL3978489 & 1640953 & 7.3979 & 7.4068 & TRN & & \\
\hline CHEMBL3962455 & 1640953 & 7.699 & 7.2892 & TRN & & \\
\hline CHEMBL 3897405 & 1640953 & 6.0 & 5.771 & TRN & & \\
\hline CHEMBL3904469 & 1640953 & 8.0 & 7.7979 & TRN & & \\
\hline CHEMBL 3902424 & 1640953 & 6.0 & 6.0516 & TRN & & \\
\hline CHEMBL3891643 & 1640953 & 6.5086 & 6.8341 & TRN & & \\
\hline CHEMBL3935104 & 1640953 & 6.6383 & 6.9617 & TST & & \\
\hline CHEMBL 3891382 & 1640953 & 7.301 & 6.4474 & TST & & \\
\hline CHEMBL3925237 & 1640953 & 6.6778 & 6.7992 & TST & & \\
\hline CHEMBL 3929202 & 1640953 & 6.7696 & 6.9651 & TST & & \\
\hline CHEMBL3923794 & 1640953 & 7.0969 & 7.5538 & TST & & \\
\hline CHEMBL 3966510 & 1640953 & 6.4559 & 6.322 & TST & & \\
\hline CHEMBL3966889 & 1640953 & 6.0 & 6.9404 & TST & & \\
\hline CHEMBL3953064 & 1640953 & 6.4318 & 7.2317 & TST & & \\
\hline CHEMBL 3897586 & 1640953 & 6.0 & 6.6093 & TST & & \\
\hline CHEMBL 3892183 & 1640953 & 7.3979 & 7.3432 & TST & & \\
\hline CHEMBL276236 & 34078 & 8.46600 & 000000006 & 31 & 8.3539 TRN & \\
\hline CHEMBL10411 & 34078 & 8.4078 & 8.451 & TRN & & \\
\hline CHEMBL269452 & 34078 & 8.1249 & 8.1027 & TRN & & \\
\hline CHEMBL10102 & 34078 & 8.55600 & 000000006 & & 8.652000000000001 & TRN \\
\hline CHEMBL9810 & 34078 & 6.7352 & 8.4427 & TST & & \\
\hline CHEMBL10410 & 34078 & 8.2733 & 8.3061 & TRN & & \\
\hline CHEMBL 269208 & 34078 & 7.2652 & 8.3272 & TST & & \\
\hline CHEMBL9894 & 34078 & 8.7305 & 8.749 & TRN & & \\
\hline CHEMBL10304 & 34078 & 8.6737 & 8.6249 & TRN & & \\
\hline CHEMBL10066 & 34078 & 8.3307 & 8.4563 & TRN & & \\
\hline CHEMBL10068 & 34078 & 8.3116 & 8.3565 & TRN & & \\
\hline CHEMBL10170 & 34078 & 8.3354 & 8.3035 & TRN & & \\
\hline CHEMBL268258 & 34078 & 8.6968 & 8.5405 & TRN & & \\
\hline CHEMBL 9869 & 34078 & 8.3089 & 8.4017 & TRN & & \\
\hline CHEMBL 276667 & 34078 & 7.9586 & 7.9741 & TRN & & \\
\hline CHEMBL10216 & 34078 & 7.7212 & 7.7183 & TRN & & \\
\hline CHEMBL418336 & 34078 & 6.8477 & 6.7681 & TRN & & \\
\hline CHEMBL9886 & 34078 & 7.9666 & 7.9683 & TRN & & \\
\hline CHEMBL430314 & 34078 & 8.2226 & 8.1676 & TRN & & \\
\hline CHEMBL10369 & 34078 & 8.5768 & 8.4812 & TRN & & \\
\hline
\end{tabular}




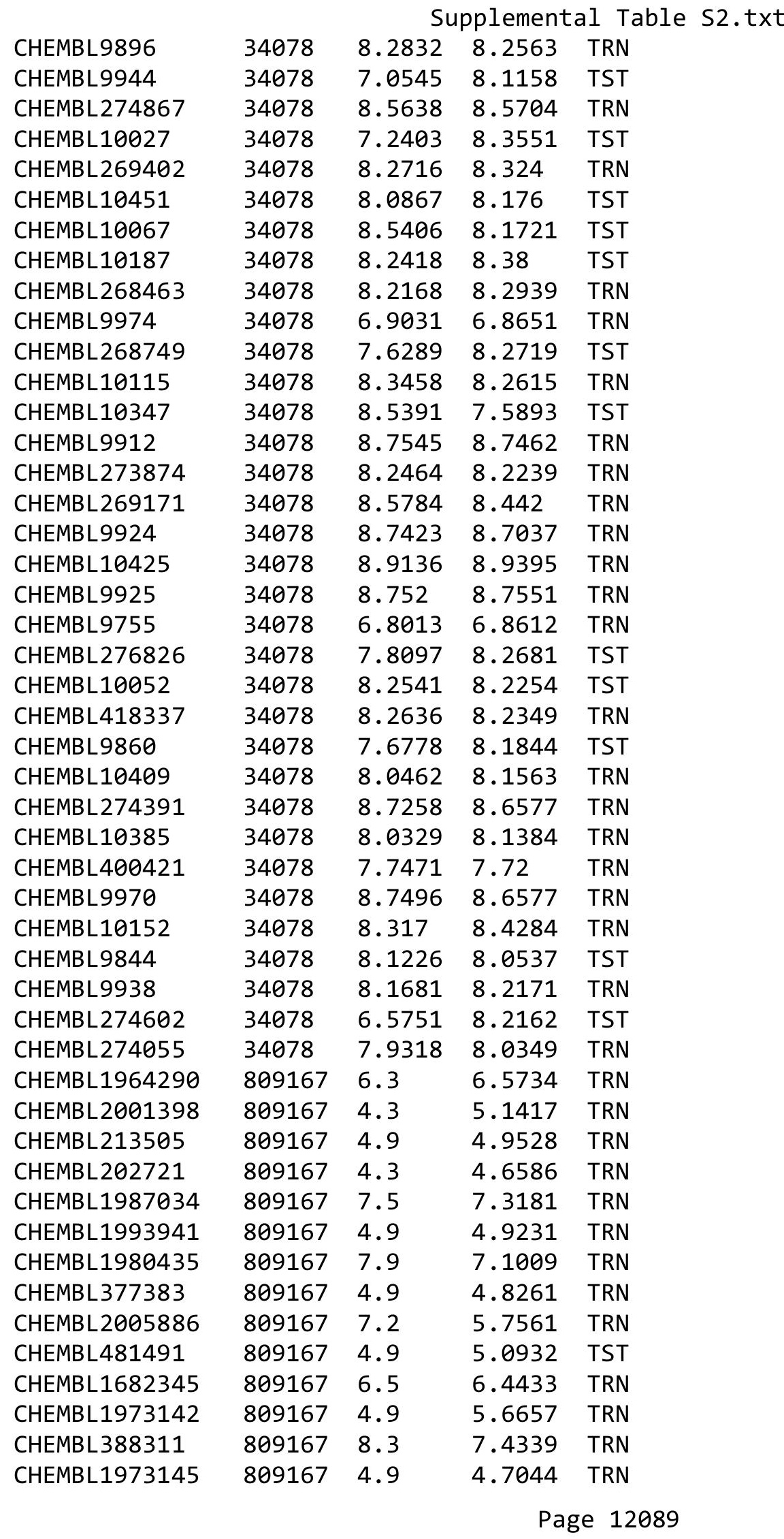




\begin{tabular}{|c|c|c|c|c|c|}
\hline & & & & & \\
\hline CHEMBL1982924 & 809167 & 4.9 & 4.5108 & TRN & \\
\hline CHEMBL2005936 & 809167 & 6.3 & 6.1261 & TRN & \\
\hline CHEMBL1807515 & 809167 & 6.8 & 7.2168 & TRN & \\
\hline CHEMBL1964948 & 809167 & 4.3 & 4.2574 & TRN & \\
\hline CHEMBL1971141 & 809167 & 4.9 & 4.5421 & TRN & \\
\hline CHEMBL1995813 & 809167 & 7.4 & 6.5524 & TRN & \\
\hline CHEMBL1979718 & 809167 & 4.9 & 5.0363 & TRN & \\
\hline CHEMBL206236 & 809167 & 4.9 & 5.5047 & TRN & \\
\hline CHEMBL1989834 & 809167 & 3.6 & $3.9160 e$ & 00000000004 & TRN \\
\hline CHEMBL523823 & 809167 & 7.5 & 5.8981 & TST & \\
\hline CHEMBL1562756 & 809167 & 6.2 & 5.7926 & TST & \\
\hline CHEMBL1987430 & 809167 & 4.3 & 4.2409 & TRN & \\
\hline CHEMBL244378 & 809167 & 7.3 & 8.218 & TRN & \\
\hline CHEMBL 2001957 & 809167 & 4.9 & 4.5566 & TRN & \\
\hline CHEMBL1969372 & 809167 & 4.9 & 4.7724 & TRN & \\
\hline CHEMBL1993413 & 809167 & 4.4 & 5.4518 & TRN & \\
\hline CHEMBL1990583 & 809167 & 4.9 & 5.0502 & TRN & \\
\hline CHEMBL1986943 & 809167 & 7.1 & 7.1731 & TRN & \\
\hline CHEMBL289959 & 809167 & 4.2 & 4.1192 & TRN & \\
\hline CHEMBL 2006263 & 809167 & 4.9 & 5.9947 & TST & \\
\hline CHEMBL1993584 & 809167 & 4.9 & 5.33299 & 9999999999 & TRN \\
\hline CHEMBL1986263 & 809167 & 6.3 & 6.3597 & TRN & \\
\hline CHEMBL 2000114 & 809167 & 4.9 & 4.4635 & TRN & \\
\hline CHEMBL 210618 & 809167 & 4.9 & 4.7669 & TRN & \\
\hline CHEMBL1986265 & 809167 & 4.3 & 4.7194 & TRN & \\
\hline CHEMBL1971172 & 809167 & 7.2 & 6.6667 & TRN & \\
\hline CHEMBL1975647 & 809167 & 4.9 & 4.895 & TRN & \\
\hline CHEMBL1968380 & 809167 & 7.1 & 5.6838 & TRN & \\
\hline CHEMBL1964644 & 809167 & 4.9 & 4.5219 & TRN & \\
\hline CHEMBL1991734 & 809167 & 6.1 & 5.9612 & TST & \\
\hline CHEMBL1981782 & 809167 & 4.9 & 5.5647 & TRN & \\
\hline CHEMBL1977681 & 809167 & 6.4 & 5.9935 & TRN & \\
\hline CHEMBL1970142 & 809167 & 4.9 & 4.9128 & TRN & \\
\hline CHEMBL1990912 & 809167 & 4.9 & 4.9331 & TRN & \\
\hline CHEMBL 2002105 & 809167 & 4.7 & 4.7469 & TRN & \\
\hline CHEMBL1983348 & 809167 & 5.9 & 6.0635 & TRN & \\
\hline CHEMBL1988163 & 809167 & 6.9 & 6.6585 & TRN & \\
\hline CHEMBL1995592 & 809167 & 4.9 & 5.3851 & TST & \\
\hline CHEMBL1980671 & 809167 & 4.8 & 4.7329 & TRN & \\
\hline CHEMBL 2006493 & 809167 & 4.9 & 5.2043 & TST & \\
\hline CHEMBL1986177 & 809167 & 4.3 & 4.5783 & TRN & \\
\hline CHEMBL1992323 & 809167 & 4.9 & 5.5029 & TRN & \\
\hline CHEMBL1969735 & 809167 & 4.9 & 4.5625 & TRN & \\
\hline CHEMBL 2003524 & 809167 & 4.9 & 5.347 & TST & \\
\hline CHEMBL2002649 & 809167 & 4.9 & 5.6485 & TRN & \\
\hline CHEMBL1983589 & 809167 & 6.8 & 6.9651 & TRN & \\
\hline CHEMBL1989423 & 809167 & 4.5 & 4.1945 & TRN & \\
\hline CHEMBL1985367 & 809167 & 4.3 & 4.6876 & TST & \\
\hline & & & & 12090 & \\
\hline
\end{tabular}




\begin{tabular}{|c|c|c|c|c|}
\hline & & & ent & al \\
\hline CHEMBL1996510 & 809167 & 6.2 & 5.6478 & TST \\
\hline CHEMBL437747 & 809167 & 6.5 & 5.4907 & TRN \\
\hline CHEMBL 2005718 & 809167 & 7.3 & 6.6779 & TRN \\
\hline CHEMBL1995172 & 809167 & 4.3 & 4.6814 & TST \\
\hline CHEMBL 2001584 & 809167 & 4.3 & 4.5141 & TST \\
\hline CHEMBL507936 & 809167 & 4.9 & 4.6952 & TRN \\
\hline CHEMBL104264 & 809167 & 6.2 & 5.2337 & TST \\
\hline CHEMBL1967998 & 809167 & 6.7 & 7.3405 & TRN \\
\hline CHEMBL1994321 & 809167 & 4.9 & 5.3556 & TRN \\
\hline CHEMBL1978562 & 809167 & 4.3 & 5.4434 & TST \\
\hline CHEMBL1997129 & 809167 & 7.7 & 7.2115 & TRN \\
\hline CHEMBL451964 & 809167 & 4.9 & 5.1151 & TST \\
\hline CHEMBL1974875 & 809167 & 4.6 & 4.9051 & TST \\
\hline CHEMBL1964307 & 809167 & 4.9 & 4.9894 & TRN \\
\hline CHEMBL1989471 & 809167 & 5.8 & 5.2738 & TST \\
\hline CHEMBL 2000508 & 809167 & 4.9 & 4.6845 & TRN \\
\hline CHEMBL1971694 & 809167 & 6.8 & 5.2596 & TST \\
\hline CHEMBL 2001547 & 809167 & 4.9 & 4.4819 & TRN \\
\hline CHEMBL210928 & 809167 & 4.9 & 4.801 & TRN \\
\hline CHEMBL1978195 & 809167 & 6.5 & 5.4032 & TRN \\
\hline CHEMBL1994361 & 809167 & 4.9 & 5.899 & TRN \\
\hline CHEMBL1986603 & 809167 & 4.9 & 4.8197 & TST \\
\hline CHEMBL1972840 & 809167 & 5.9 & 6.2328 & TRN \\
\hline CHEMBL1977148 & 809167 & 4.9 & 4.5748 & TRN \\
\hline CHEMBL 2003286 & 809167 & 6.9 & 6.7515 & TRN \\
\hline CHEMBL1992306 & 809167 & 4.9 & 4.6547 & TRN \\
\hline CHEMBL 2002165 & 809167 & 4.9 & 5.4404 & TRN \\
\hline CHEMBL1998585 & 809167 & 6.9 & 5.7432 & TRN \\
\hline CHEMBL519697 & 809167 & 4.9 & 5.0945 & TRN \\
\hline CHEMBL 2004934 & 809167 & 4.9 & 4.2666 & TRN \\
\hline CHEMBL1987261 & 809167 & 7.6 & 6.5282 & TRN \\
\hline CHEMBL1996345 & 809167 & 4.3 & 4.9833 & TST \\
\hline CHEMBL1975128 & 809167 & 7.5 & 7.3189 & TRN \\
\hline CHEMBL 2004025 & 809167 & 5.3 & 5.6018 & TRN \\
\hline CHEMBL1996048 & 809167 & 6.7 & 5.0792 & TST \\
\hline CHEMBL1976158 & 809167 & 4.6 & 5.3301 & TST \\
\hline CHEMBL461876 & 809167 & 7.0 & 6.3654 & TRN \\
\hline CHEMBL1965033 & 809167 & 4.3 & 4.5695 & TRN \\
\hline CHEMBL 2001485 & 809167 & 4.9 & 4.9926 & TRN \\
\hline CHEMBL1971519 & 809167 & 4.4 & 4.6316 & TRN \\
\hline CHEMBL504950 & 809167 & 4.9 & 5.3985 & TRN \\
\hline CHEMBL1997335 & 809167 & 6.1 & 6.0377 & TRN \\
\hline CHEMBL1966425 & 809167 & 6.0 & 5.5415 & TRN \\
\hline CHEMBL1984363 & 809167 & 4.9 & 4.7155 & TRN \\
\hline CHEMBL1978099 & 809167 & 6.7 & 6.2011 & TRN \\
\hline CHEMBL1977041 & 809167 & 6.2 & 5.3191 & TRN \\
\hline CHEMBL1968070 & 809167 & 6.0 & 5.5232 & TRN \\
\hline CHEMBL1988608 & 809167 & 5.9 & 6.3206 & TRN \\
\hline
\end{tabular}




\begin{tabular}{|c|c|c|c|c|}
\hline & & & & $a+1 a$ \\
\hline CHEMBL184847 & 809167 & 4.9 & 4.8071 & TRN \\
\hline CHEMBL1971132 & 809167 & 4.3 & 4.4392 & TRN \\
\hline CHEMBL1984367 & 809167 & 4.9 & 5.4424 & TRN \\
\hline CHEMBL1985723 & 809167 & 7.8 & 6.7218 & TRN \\
\hline CHEMBL226898 & 809167 & 8.4 & 6.4068 & TRN \\
\hline CHEMBL1982563 & 809167 & 4.9 & 4.6949 & TRN \\
\hline CHEMBL1991377 & 809167 & 4.3 & 4.8191 & TRN \\
\hline CHEMBL539474 & 809167 & 4.9 & 5.829 & TST \\
\hline CHEMBL575824 & 809167 & 4.9 & 6.039 & TRN \\
\hline CHEMBL1988387 & 809167 & 4.9 & 5.3978 & TRN \\
\hline CHEMBL1973868 & 809167 & 4.3 & 4.9817 & TRN \\
\hline CHEMBL1972462 & 809167 & 4.3 & 4.6319 & TRN \\
\hline CHEMBL1977128 & 809167 & 6.8 & 7.2495 & TRN \\
\hline CHEMBL1990288 & 809167 & 4.9 & 4.7587 & TRN \\
\hline CHEMBL1970074 & 809167 & 4.9 & 4.6819 & TRN \\
\hline CHEMBL1965702 & 809167 & 7.1 & 6.939 & TRN \\
\hline CHEMBL1986970 & 809167 & 4.9 & 5.6704 & TRN \\
\hline CHEMBL1958401 & 809167 & 4.9 & 5.3858 & TRN \\
\hline CHEMBL 2003456 & 809167 & 4.9 & 4.7239 & TRN \\
\hline CHEMBL1966816 & 809167 & 4.9 & 4.81800 & 00000000005 \\
\hline CHEMBL1972584 & 809167 & 4.9 & 5.2228 & TRN \\
\hline CHEMBL2002992 & 809167 & 4.9 & 5.0126 & TRN \\
\hline CHEMBL560813 & 809167 & 4.9 & 5.3542 & TRN \\
\hline CHEMBL1982700 & 809167 & 4.3 & 4.7819 & TST \\
\hline CHEMBL1968791 & 809167 & 4.9 & 4.9292 & TRN \\
\hline CHEMBL326282 & 809167 & 4.9 & 5.4054 & TST \\
\hline CHEMBL 2002682 & 809167 & 6.4 & 5.1434 & TST \\
\hline CHEMBL1977634 & 809167 & 4.3 & 4.3008 & TRN \\
\hline CHEMBL1992732 & 809167 & 4.9 & 5.1457 & TST \\
\hline CHEMBL1971186 & 809167 & 4.9 & 5.1268 & TRN \\
\hline CHEMBL 2003482 & 809167 & 4.9 & 4.7966 & TRN \\
\hline CHEMBL 2006456 & 809167 & 6.5 & 7.0741 & TRN \\
\hline CHEMBL1973211 & 809167 & 4.9 & 5.4523 & TRN \\
\hline CHEMBL1984700 & 809167 & 4.9 & 4.4801 & TRN \\
\hline CHEMBL 2007151 & 809167 & 4.9 & 4.9323 & TRN \\
\hline CHEMBL1971606 & 809167 & 4.3 & 4.323 & TRN \\
\hline CHEMBL1972125 & 809167 & 4.9 & 5.5516 & TRN \\
\hline CHEMBL1976134 & 809167 & 4.9 & 5.9084 & TRN \\
\hline CHEMBL1965131 & 809167 & 4.9 & 5.6966 & TRN \\
\hline CHEMBL1972158 & 809167 & 7.0 & 6.7176 & TRN \\
\hline CHEMBL1981215 & 809167 & 4.3 & 4.3258 & TRN \\
\hline CHEMBL1974457 & 809167 & 6.8 & 5.9183 & TRN \\
\hline CHEMBL1999414 & 809167 & 4.4 & 5.2462 & TRN \\
\hline CHEMBL1967336 & 809167 & 4.3 & 4.5803 & TRN \\
\hline CHEMBL 2006581 & 809167 & 4.9 & 4.7531 & TRN \\
\hline CHEMBL1970340 & 809167 & 3.6 & 4.7873 & TRN \\
\hline CHEMBL1967992 & 809167 & 4.3 & 4.6522 & TRN \\
\hline CHEMBL 2005186 & 809167 & 4.9 & 5.3467 & TRN \\
\hline
\end{tabular}

TRN 


\begin{tabular}{|c|c|c|c|c|}
\hline & & & pमeme & al Ta \\
\hline CHEMBL1981671 & 809167 & 4.3 & 4.8009 & TRN \\
\hline CHEMBL 2006450 & 809167 & 4.5 & 5.2744 & TRN \\
\hline CHEMBL1975534 & 809167 & 4.9 & 4.7358 & TRN \\
\hline CHEMBL1993424 & 809167 & 4.9 & 5.9543 & TRN \\
\hline CHEMBL1966703 & 809167 & 4.9 & 4.7937 & TST \\
\hline CHEMBL 2001987 & 809167 & 4.3 & 4.244 & TRN \\
\hline CHEMBL1969561 & 809167 & 4.9 & 5.9486 & TRN \\
\hline CHEMBL1994555 & 809167 & 4.3 & 4.8487 & TST \\
\hline CHEMBL1975121 & 809167 & 4.3 & 4.2243 & TRN \\
\hline CHEMBL1983640 & 809167 & 4.3 & 5.02 & TRN \\
\hline CHEMBL1997023 & 809167 & 6.7 & 5.5848 & TST \\
\hline CHEMBL1964687 & 809167 & 4.9 & 5.8211 & TRN \\
\hline CHEMBL1971943 & 809167 & 4.5 & 4.7238 & TRN \\
\hline CHEMBL1999918 & 809167 & 6.1 & 5.9414 & TRN \\
\hline CHEMBL1974254 & 809167 & 6.0 & 4.9182 & TRN \\
\hline CHEMBL1988537 & 809167 & 4.9 & 5.6666 & TST \\
\hline CHEMBL1969049 & 809167 & 4.9 & 4.3891 & TRN \\
\hline CHEMBL 2005828 & 809167 & 4.9 & 4.9595 & TRN \\
\hline CHEMBL1980178 & 809167 & 6.9 & 6.8283 & TRN \\
\hline CHEMBL1998611 & 809167 & 5.9 & 5.6974 & TRN \\
\hline CHEMBL485556 & 809167 & 4.9 & 5.1479 & TRN \\
\hline CHEMBL1975900 & 809167 & 4.9 & 6.0368 & TRN \\
\hline CHEMBL 255822 & 809167 & 7.4 & 7.2068 & TRN \\
\hline CHEMBL1972221 & 809167 & 6.4 & 5.7134 & TRN \\
\hline CHEMBL2006778 & 809167 & 4.9 & 5.2372 & TRN \\
\hline CHEMBL 378627 & 809167 & 4.9 & 4.8637 & TRN \\
\hline CHEMBL1996979 & 809167 & 4.9 & 5.1842 & TRN \\
\hline CHEMBL1968406 & 809167 & 4.9 & 5.4611 & TRN \\
\hline CHEMBL1975921 & 809167 & 4.9 & 4.794 & TRN \\
\hline CHEMBL1982476 & 809167 & 6.1 & 5.3847 & TRN \\
\hline CHEMBL1998545 & 809167 & 4.9 & 4.4454 & TRN \\
\hline CHEMBL1986869 & 809167 & 4.9 & 4.8716 & TRN \\
\hline CHEMBL1975923 & 809167 & 4.6 & 5.4798 & TST \\
\hline CHEMBL 2005449 & 809167 & 6.3 & 5.7959 & TRN \\
\hline CHEMBL1987998 & 809167 & 4.3 & 4.4222 & TRN \\
\hline CHEMBL1682558 & 809167 & 4.9 & 4.8644 & TRN \\
\hline CHEMBL1971534 & 809167 & 5.6 & 5.1726 & TRN \\
\hline CHEMBL1990496 & 809167 & 4.6 & 4.5267 & TRN \\
\hline CHEMBL242865 & 809167 & 7.1 & 7.3053 & TRN \\
\hline CHEMBL1997623 & 809167 & 4.9 & 5.0293 & TRN \\
\hline CHEMBL 2002479 & 809167 & 6.3 & 5.8859 & TRN \\
\hline CHEMBL1993166 & 809167 & 6.6 & 5.4911 & TRN \\
\hline CHEMBL1967094 & 809167 & 4.9 & 5.8603 & TRN \\
\hline CHEMBL 2003341 & 809167 & 4.9 & 4.6653 & TRN \\
\hline CHEMBL1982992 & 809167 & 4.9 & 4.9479 & TRN \\
\hline CHEMBL1998110 & 809167 & 4.3 & 4.3283 & TRN \\
\hline CHEMBL1999590 & 809167 & 4.9 & 4.5803 & TST \\
\hline CHEMBL1981079 & 809167 & 6.4 & 6.4555 & TRN \\
\hline
\end{tabular}




\begin{tabular}{|c|c|c|c|c|}
\hline & & & 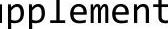 & al Table \\
\hline CHEMBL1978166 & 809167 & 5.8 & 5.9436 & TRN \\
\hline CHEMBL1999632 & 809167 & 5.4 & 4.9908 & TST \\
\hline CHEMBL1980489 & 809167 & 4.9 & 5.3298 & TRN \\
\hline CHEMBL 2000832 & 809167 & 6.6 & 6.1317 & TRN \\
\hline CHEMBL1967116 & 809167 & 4.9 & 5.7113 & TRN \\
\hline CHEMBL1972454 & 809167 & 5.3 & 4.8281 & TRN \\
\hline CHEMBL1990590 & 809167 & 4.3 & 4.76399 & 9999999999 \\
\hline CHEMBL1977814 & 809167 & 4.5 & 4.9695 & TST \\
\hline CHEMBL86755 & 809167 & 5.7 & 5.6233 & TRN \\
\hline CHEMBL1970709 & 809167 & 4.9 & 5.0758 & TRN \\
\hline CHEMBL1974617 & 809167 & 5.4 & 5.1934 & TRN \\
\hline CHEMBL1965660 & 809167 & 6.4 & 7.0286 & TRN \\
\hline CHEMBL1992125 & 809167 & 5.6 & 5.9433 & TRN \\
\hline CHEMBL1998112 & 809167 & 4.9 & 4.7609 & TRN \\
\hline CHEMBL1972290 & 809167 & 7.1 & 6.6877 & TRN \\
\hline CHEMBL1969126 & 809167 & 4.9 & 4.8086 & TRN \\
\hline CHEMBL1980896 & 809167 & 4.9 & 5.0073 & TRN \\
\hline CHEMBL1178727 & 809167 & 4.0 & 4.7063 & TRN \\
\hline CHEMBL1970104 & 809167 & 5.0 & 5.8445 & TRN \\
\hline CHEMBL1991429 & 809167 & 4.9 & 5.0845 & TRN \\
\hline CHEMBL1967612 & 809167 & 4.5 & 4.9561 & TST \\
\hline CHEMBL1971149 & 809167 & 4.9 & 4.5853 & TRN \\
\hline CHEMBL1999714 & 809167 & 4.9 & 4.3429 & TRN \\
\hline CHEMBL1994040 & 809167 & 4.9 & 4.6777 & TRN \\
\hline CHEMBL 388978 & 809167 & 8.7 & 8.204 & TST \\
\hline CHEMBL1984548 & 809167 & 8.3 & 7.5225 & TRN \\
\hline CHEMBL579246 & 809167 & 4.9 & 6.0517 & TRN \\
\hline CHEMBL398951 & 809167 & 4.4 & 4.7342 & TST \\
\hline CHEMBL1982506 & 809167 & 4.9 & 5.2877 & TST \\
\hline CHEMBL 2004716 & 809167 & 5.9 & 5.7962 & TRN \\
\hline CHEMBL1968127 & 809167 & 4.9 & 4.754 & TRN \\
\hline CHEMBL1975233 & 809167 & 4.9 & 4.7191 & TRN \\
\hline CHEMBL1985406 & 809167 & 6.1 & 4.9421 & TRN \\
\hline CHEMBL 207400 & 809167 & 4.9 & 4.9928 & TST \\
\hline CHEMBL 2000894 & 809167 & 4.9 & 4.8569 & TST \\
\hline CHEMBL1421720 & 809167 & 5.3 & 5.2194 & TRN \\
\hline CHEMBL1968130 & 809167 & 5.2 & 4.9445 & TRN \\
\hline CHEMBL1982135 & 809167 & 4.9 & 5.2413 & TRN \\
\hline CHEMBL1976090 & 809167 & 6.4 & 5.7069 & TRN \\
\hline CHEMBL1993243 & 809167 & 4.9 & 4.7403 & TRN \\
\hline CHEMBL 2004771 & 809167 & 4.9 & 5.1235 & TRN \\
\hline CHEMBL1992922 & 809167 & 4.9 & 4.5715 & TRN \\
\hline CHEMBL399021 & 809167 & 4.9 & 4.8761 & TRN \\
\hline CHEMBL1997597 & 809167 & 6.3 & 5.6739 & TRN \\
\hline CHEMBL1969537 & 809167 & 7.5 & 6.2791 & TST \\
\hline CHEMBL576113 & 809167 & 4.3 & 5.1324 & TRN \\
\hline CHEMBL1976093 & 809167 & 4.9 & 4.6754 & TRN \\
\hline CHEMBL1975256 & 809167 & 4.9 & 4.7577 & TST \\
\hline
\end{tabular}

TRN 


\begin{tabular}{|c|c|c|c|c|}
\hline & & & pplement & al Table S \\
\hline CHEMBL508928 & 809167 & 4.9 & 4.9374 & TRN \\
\hline CHEMBL 2004892 & 809167 & 7.0 & 5.6964 & TRN \\
\hline CHEMBL1949855 & 809167 & 4.9 & 5.1982 & TRN \\
\hline CHEMBL1972339 & 809167 & 7.3 & $6.6620 e$ & 0000000001 \\
\hline CHEMBL116070 & 809167 & 4.9 & 5.421 & TRN \\
\hline CHEMBL1970314 & 809167 & 4.9 & 4.9536 & TRN \\
\hline CHEMBL 2004871 & 809167 & 4.9 & 4.5541 & TRN \\
\hline CHEMBL 2004872 & 809167 & 4.9 & 4.3057 & TRN \\
\hline CHEMBL1990223 & 809167 & 4.3 & 4.5469 & TRN \\
\hline CHEMBL1969879 & 809167 & 4.9 & 5.1885 & TRN \\
\hline CHEMBL1964382 & 809167 & 6.3 & 5.0273 & TST \\
\hline CHEMBL101311 & 809167 & 5.3 & 5.8594 & TRN \\
\hline CHEMBL1981720 & 809167 & 4.9 & 5.0625 & TRN \\
\hline CHEMBL419932 & 809167 & 6.0 & 5.6036 & TRN \\
\hline CHEMBL 262433 & 809167 & 4.9 & 4.9212 & TRN \\
\hline CHEMBL 306380 & 809167 & 4.9 & 4.5865 & TRN \\
\hline CHEMBL1966722 & 809167 & 6.1 & 5.6072 & TST \\
\hline CHEMBL1983595 & 809167 & 6.6 & 7.3194 & TRN \\
\hline CHEMBL1988581 & 809167 & 7.0 & 6.745 & TST \\
\hline CHEMBL 2005699 & 809167 & 4.3 & 4.31 & TRN \\
\hline CHEMBL1975500 & 809167 & 6.0 & 5.9134 & TRN \\
\hline CHEMBL1976328 & 809167 & 4.9 & 4.874 & TRN \\
\hline CHEMBL 394619 & 809167 & 4.9 & 5.0877 & TRN \\
\hline CHEMBL 2006564 & 809167 & 6.6 & 6.4767 & TRN \\
\hline CHEMBL1964399 & 809167 & 7.7 & 7.0251 & TRN \\
\hline CHEMBL1996831 & 809167 & 4.9 & 5.3446 & TST \\
\hline CHEMBL411903 & 809167 & 6.1 & 5.685 & TRN \\
\hline CHEMBL1980253 & 809167 & 6.7 & 6.8217 & TRN \\
\hline CHEMBL1978167 & 809167 & 4.3 & 4.9953 & TST \\
\hline CHEMBL1965988 & 809167 & 6.1 & 5.7725 & TRN \\
\hline CHEMBL418203 & 809167 & 4.5 & 5.3986 & TST \\
\hline CHEMBL1989646 & 809167 & 6.8 & 6.6723 & TRN \\
\hline CHEMBL1682357 & 809167 & 6.6 & 5.4482 & TRN \\
\hline CHEMBL 225519 & 809167 & 7.2 & 6.2374 & TRN \\
\hline CHEMBL209534 & 809167 & 4.9 & 4.7992 & TRN \\
\hline CHEMBL1978200 & 809167 & 4.9 & 4.5574 & TRN \\
\hline CHEMBL1994159 & 809167 & 4.1 & 4.5058 & TRN \\
\hline CHEMBL1970522 & 809167 & 7.8 & 6.8735 & TRN \\
\hline CHEMBL402846 & 809167 & 4.9 & 5.0946 & TRN \\
\hline CHEMBL1996931 & 809167 & 4.9 & 4.6096 & TRN \\
\hline CHEMBL1964692 & 809167 & 4.9 & 5.2307 & TRN \\
\hline CHEMBL1971223 & 809167 & 4.3 & 4.3939 & TRN \\
\hline CHEMBL1964413 & 809167 & 4.9 & 5.4877 & TRN \\
\hline CHEMBL1973483 & 809167 & 4.9 & 4.2499 & TRN \\
\hline CHEMBL1998470 & 809167 & 6.5 & 5.599 & TRN \\
\hline CHEMBL1996980 & 809167 & 7.5 & 7.3795 & TRN \\
\hline CHEMBL1984432 & 809167 & 4.9 & 5.5343 & TRN \\
\hline CHEMBL 219722 & 809167 & 4.9 & 4.6871 & TRN \\
\hline
\end{tabular}

TRN 


\begin{tabular}{|c|c|c|c|c|c|}
\hline & & & & & \\
\hline CHEMBL1975903 & 809167 & 4.3 & 5.1088 & TRN & \\
\hline CHEMBL1994669 & 809167 & 7.9 & 7.6033 & TRN & \\
\hline CHEMBL1997340 & 809167 & 4.9 & 5.151 & TRN & \\
\hline CHEMBL1522508 & 809167 & 3.9 & 4.3718 & TRN & \\
\hline CHEMBL1989474 & 809167 & 4.9 & 4.6542 & TRN & \\
\hline CHEMBL1090360 & 809167 & 4.9 & 4.5355 & TRN & \\
\hline CHEMBL 210887 & 809167 & 4.9 & 4.5839 & TRN & \\
\hline CHEMBL1988805 & 809167 & 5.3 & 4.8272 & TST & \\
\hline CHEMBL458997 & 809167 & 7.0 & 6.9846 & TRN & \\
\hline CHEMBL1971021 & 809167 & 4.9 & 4.8848 & TRN & \\
\hline CHEMBL227271 & 809167 & 6.6 & 6.9348 & TRN & \\
\hline CHEMBL583144 & 809167 & 6.8 & 6.2827 & TRN & \\
\hline CHEMBL1974310 & 809167 & 6.2 & 5.7411 & TRN & \\
\hline CHEMBL1969942 & 809167 & 4.3 & 4.7746 & TRN & \\
\hline CHEMBL1978567 & 809167 & 4.3 & 4.3283 & TRN & \\
\hline CHEMBL1982660 & 809167 & 4.9 & 4.6144 & TRN & \\
\hline CHEMBL1994693 & 809167 & 4.9 & 5.5601 & TRN & \\
\hline CHEMBL1982957 & 809167 & 4.9 & 6.3247 & TRN & \\
\hline CHEMBL1725279 & 809167 & 6.4 & 6.0105 & TST & \\
\hline CHEMBL1975138 & 809167 & 6.2 & 5.2716 & TST & \\
\hline CHEMBL424872 & 809167 & 4.9 & 4.7408 & TRN & \\
\hline CHEMBL1971947 & 809167 & 4.9 & 5.4113 & TRN & \\
\hline CHEMBL412142 & 809167 & 4.9 & 5.1161 & TST & \\
\hline CHEMBL 2002802 & 809167 & 5.0 & 4.8844 & TRN & \\
\hline CHEMBL1980704 & 809167 & 6.3 & 5.3298 & TST & \\
\hline CHEMBL 2003271 & 809167 & 4.9 & 5.6245 & TRN & \\
\hline CHEMBL1966808 & 809167 & 7.4 & 6.0086 & TRN & \\
\hline CHEMBL 2004447 & 809167 & 4.9 & 4.4308 & TRN & \\
\hline CHEMBL1992231 & 809167 & 6.2 & 6.2565 & TRN & \\
\hline CHEMBL1983111 & 809167 & 6.6 & 7.0681 & TRN & \\
\hline CHEMBL1973860 & 809167 & 4.9 & 5.1631 & TRN & \\
\hline CHEMBL 260135 & 809167 & 4.9 & 4.51399 & 9999999999 & TRN \\
\hline CHEMBL220241 & 809167 & 6.3 & 5.7172 & TRN & \\
\hline CHEMBL1988141 & 809167 & 6.1 & 6.2069 & TST & \\
\hline CHEMBL1982610 & 809167 & 4.9 & 5.3497 & TST & \\
\hline CHEMBL1977134 & 809167 & 4.3 & 4.4077 & TRN & \\
\hline CHEMBL 2006933 & 809167 & 6.6 & 5.7679 & TST & \\
\hline CHEMBL1985206 & 809167 & 4.3 & 4.9545 & TST & \\
\hline CHEMBL1988300 & 809167 & 4.9 & 4.8812 & TRN & \\
\hline CHEMBL1991078 & 809167 & 7.5 & 7.3472 & TRN & \\
\hline CHEMBL1987359 & 809167 & 4.9 & 4.6976 & TST & \\
\hline CHEMBL1977749 & 809167 & 5.4 & 5.7292 & TST & \\
\hline CHEMBL1975212 & 809167 & 4.1 & 4.6063 & TRN & \\
\hline CHEMBL 2000685 & 809167 & 7.4 & 5.8956 & TRN & \\
\hline CHEMBL 2001613 & 809167 & 5.1 & 5.0635 & TRN & \\
\hline CHEMBL1997275 & 809167 & 4.3 & 5.1282 & TRN & \\
\hline CHEMBL1993904 & 809167 & 4.3 & 5.3436 & TRN & \\
\hline CHEMBL1994438 & 809167 & 7.1 & 6.66100 & 00000000005 & TRN \\
\hline & & & & 12096 & \\
\hline
\end{tabular}




\begin{tabular}{|c|c|c|c|c|}
\hline & & & pplement & al lable s \\
\hline CHEMBL1967513 & 809167 & 5.3 & 4.2478 & TRN \\
\hline CHEMBL2000724 & 809167 & 4.3 & 4.6573 & TRN \\
\hline CHEMBL1985311 & 809167 & 4.9 & 4.7683 & TRN \\
\hline CHEMBL1982413 & 809167 & 4.3 & $5.7120 e$ & 0000000001 \\
\hline CHEMBL1969502 & 809167 & 4.9 & 6.3961 & TST \\
\hline CHEMBL1965910 & 809167 & 4.9 & 4.7792 & TRN \\
\hline CHEMBL1682553 & 809167 & 6.6 & 6.0737 & TRN \\
\hline CHEMBL1983963 & 809167 & 4.9 & 5.3223 & TRN \\
\hline CHEMBL1997764 & 809167 & 4.9 & 4.4992 & TRN \\
\hline CHEMBL2000271 & 809167 & 6.6 & 6.4283 & TRN \\
\hline CHEMBL1985042 & 809167 & 4.2 & 5.1921 & TRN \\
\hline CHEMBL1981792 & 809167 & 4.3 & 4.4008 & TRN \\
\hline CHEMBL1987535 & 809167 & 5.4 & 5.4559 & TRN \\
\hline CHEMBL1985092 & 809167 & 5.9 & 5.4984 & TRN \\
\hline CHEMBL1981410 & 809167 & 4.9 & 4.777 & TRN \\
\hline CHEMBL 2002586 & 809167 & 4.3 & 5.4158 & TRN \\
\hline CHEMBL1996234 & 809167 & 4.9 & 4.6572 & TRN \\
\hline CHEMBL383264 & 809167 & 6.2 & 5.9737 & TRN \\
\hline CHEMBL 2007421 & 809167 & 4.3 & 5.7076 & TST \\
\hline CHEMBL1967544 & 809167 & 6.0 & 6.0247 & TRN \\
\hline CHEMBL1973138 & 809167 & 4.3 & 4.4726 & TST \\
\hline CHEMBL223367 & 809167 & 4.9 & 5.5757 & TST \\
\hline CHEMBL1992673 & 809167 & 4.4 & 4.9059 & TRN \\
\hline CHEMBL340384 & 809167 & 6.4 & 5.3854 & TST \\
\hline CHEMBL1969151 & 809167 & 7.2 & 7.2036 & TRN \\
\hline CHEMBL1996587 & 809167 & 4.9 & 4.7468 & TRN \\
\hline CHEMBL1981492 & 809167 & 4.3 & 4.6704 & TRN \\
\hline CHEMBL1993335 & 809167 & 4.3 & 5.4505 & TST \\
\hline CHEMBL1988692 & 809167 & 4.3 & 5.1914 & TRN \\
\hline CHEMBL 2007574 & 809167 & 6.6 & 6.2487 & TRN \\
\hline CHEMBL1964804 & 809167 & 4.9 & 5.3648 & TRN \\
\hline CHEMBL 2000354 & 809167 & 7.6 & 6.7148 & TRN \\
\hline CHEMBL1965507 & 809167 & 4.7 & 5.0347 & TRN \\
\hline CHEMBL 274064 & 809167 & 4.9 & 5.0643 & TRN \\
\hline CHEMBL1998680 & 809167 & 4.3 & 4.3912 & TRN \\
\hline CHEMBL1967564 & 809167 & 4.9 & 4.5239 & TRN \\
\hline CHEMBL592030 & 809167 & 7.1 & 6.1206 & TST \\
\hline CHEMBL 2000071 & 809167 & 4.9 & 4.5255 & TRN \\
\hline CHEMBL1979176 & 809167 & 4.9 & 4.5272 & TRN \\
\hline CHEMBL1970317 & 809167 & 4.9 & 5.1524 & TRN \\
\hline CHEMBL 2002613 & 809167 & 7.8 & 7.1642 & TRN \\
\hline CHEMBL 2000408 & 809167 & 4.9 & 4.6961 & TRN \\
\hline CHEMBL248757 & 809167 & 4.9 & 5.5428 & TST \\
\hline CHEMBL1978014 & 809167 & 4.9 & 5.3002 & TRN \\
\hline CHEMBL 2002736 & 809167 & 4.3 & 4.9015 & TRN \\
\hline CHEMBL1997007 & 809167 & 5.6 & 5.6037 & TRN \\
\hline CHEMBL1994538 & 809167 & 4.9 & 4.7943 & TRN \\
\hline CHEMBL1975490 & 809167 & 4.9 & 5.5293 & TRN \\
\hline
\end{tabular}

TRN 


\begin{tabular}{|c|c|c|c|c|c|}
\hline \\
\hline CHEMBL1964444 & 809167 & 4.9 & 4.2388 & TRN & \\
\hline CHEMBL 2002690 & 809167 & 4.3 & 4.4569 & TRN & \\
\hline CHEMBL 2006567 & 809167 & 4.9 & 4.9257 & TRN & \\
\hline CHEMBL1986139 & 809167 & 4.9 & 4.8779 & TRN & \\
\hline CHEMBL1975503 & 809167 & 4.1 & 4.823 & TRN & \\
\hline CHEMBL383527 & 809167 & 4.9 & 5.1769 & TRN & \\
\hline CHEMBL1980540 & 809167 & 4.9 & 4.5208 & TRN & \\
\hline CHEMBL278041 & 809167 & 4.3 & 4.5845 & TRN & \\
\hline CHEMBL1979883 & 809167 & 4.9 & 5.4632 & TRN & \\
\hline CHEMBL1984162 & 809167 & 7.2 & 6.5577 & TRN & \\
\hline CHEMBL1998432 & 809167 & 7.9 & 7.1703 & TRN & \\
\hline CHEMBL491758 & 809167 & 4.9 & 5.7295 & TRN & \\
\hline CHEMBL1986590 & 809167 & 5.5 & 5.1502 & TRN & \\
\hline CHEMBL549730 & 809167 & 7.1 & 5.9124 & TRN & \\
\hline CHEMBL1682360 & 809167 & 6.1 & 5.4257 & TRN & \\
\hline CHEMBL1970189 & 809167 & 4.9 & 4.5111 & TRN & \\
\hline CHEMBL1870106 & 809167 & 7.1 & 6.0363 & TRN & \\
\hline CHEMBL1996791 & 809167 & 4.9 & 4.9587 & TRN & \\
\hline CHEMBL371206 & 809167 & 6.0 & 5.2081 & TRN & \\
\hline CHEMBL1974664 & 809167 & 4.9 & 4.8485 & TST & \\
\hline CHEMBL406845 & 809167 & 5.4 & 4.4149 & TRN & \\
\hline CHEMBL482538 & 809167 & 5.0 & 4.79899 & 99999999995 & TRN \\
\hline CHEMBL1974288 & 809167 & 4.9 & 4.57600 & 00000000005 & TRN \\
\hline CHEMBL1984296 & 809167 & 5.3 & 5.33 & TST & \\
\hline CHEMBL196363 & 809167 & 4.9 & 5.443 & TRN & \\
\hline CHEMBL1996837 & 809167 & 4.2 & 4.1548 & TRN & \\
\hline CHEMBL1190711 & 809167 & 4.9 & 4.9871 & TRN & \\
\hline CHEMBL1990346 & 809167 & 4.9 & 4.7088 & TRN & \\
\hline CHEMBL1964718 & 809167 & 4.2 & 5.115 & TST & \\
\hline CHEMBL1968705 & 809167 & 4.6 & 5.1501 & TRN & \\
\hline CHEMBL1991410 & 809167 & 4.5 & 5.6257 & TRN & \\
\hline CHEMBL1964441 & 809167 & 4.3 & 5.1672 & TRN & \\
\hline CHEMBL546797 & 809167 & 4.3 & 5.0363 & TRN & \\
\hline CHEMBL404367 & 809167 & 4.9 & 5.0695 & TRN & \\
\hline CHEMBL1966343 & 809167 & 7.6 & 6.2474 & TRN & \\
\hline CHEMBL1978271 & 809167 & 4.3 & 4.2179 & TRN & \\
\hline CHEMBL1967887 & 809167 & 5.9 & 5.9953 & TRN & \\
\hline CHEMBL 2007266 & 809167 & 4.3 & 4.675 & TRN & \\
\hline CHEMBL1985469 & 809167 & 4.3 & 4.7287 & TST & \\
\hline CHEMBL 2000568 & 809167 & 4.7 & 4.9438 & TRN & \\
\hline CHEMBL1994308 & 809167 & 4.3 & 4.9626 & TST & \\
\hline CHEMBL 2000335 & 809167 & 4.9 & 5.5198 & TRN & \\
\hline CHEMBL 2007097 & 809167 & 4.8 & 4.8739 & TRN & \\
\hline CHEMBL1988717 & 809167 & 4.9 & 4.7157 & TRN & \\
\hline CHEMBL1974328 & 809167 & 7.0 & 6.1821 & TRN & \\
\hline CHEMBL509032 & 809167 & 6.4 & 6.6357 & TRN & \\
\hline CHEMBL243298 & 809167 & 7.0 & 7.681 & TRN & \\
\hline CHEMBL573339 & 809167 & 6.1 & 5.4525 & TRN & \\
\hline
\end{tabular}




\begin{tabular}{|c|c|c|c|c|}
\hline & & & & al Table \\
\hline CHEMBL1973808 & 809167 & 4.9 & 5.1857 & TRN \\
\hline CHEMBL 2000429 & 809167 & 4.9 & 4.6084 & TRN \\
\hline CHEMBL1972576 & 809167 & 4.9 & 4.837 & TRN \\
\hline CHEMBL1992342 & 809167 & 6.6 & 5.8905 & TRN \\
\hline CHEMBL1988173 & 809167 & 6.0 & 5.9686 & TST \\
\hline CHEMBL1973013 & 809167 & 6.4 & 5.7022 & TST \\
\hline CHEMBL1966204 & 809167 & 7.3 & 7.7402 & TRN \\
\hline CHEMBL1965423 & 809167 & 4.9 & 5.2749 & TRN \\
\hline CHEMBL1983025 & 809167 & 4.9 & 5.5648 & TRN \\
\hline CHEMBL1975927 & 809167 & 5.7 & 6.2117 & TRN \\
\hline CHEMBL 205415 & 809167 & 5.8 & 5.3618 & TRN \\
\hline CHEMBL1977135 & 809167 & 4.9 & 4.5268 & TRN \\
\hline CHEMBL 2001920 & 809167 & 6.7 & 6.1653 & TRN \\
\hline CHEMBL 2002322 & 809167 & 4.9 & 5.2183 & TRN \\
\hline CHEMBL1997119 & 809167 & 4.3 & 4.2069 & TRN \\
\hline CHEMBL1977138 & 809167 & 7.0 & 6.397 & TST \\
\hline CHEMBL 2002323 & 809167 & 4.9 & 4.8463 & TST \\
\hline CHEMBL1241473 & 809167 & 6.7 & 7.7649 & TRN \\
\hline CHEMBL 2000879 & 809167 & 4.1 & 4.8522 & TST \\
\hline CHEMBL1978448 & 809167 & 4.5 & 5.7955 & TST \\
\hline CHEMBL1980329 & 809167 & 8.1 & 6.8552 & TRN \\
\hline CHEMBL 2004515 & 809167 & 5.7 & 5.4775 & TRN \\
\hline CHEMBL 2001257 & 809167 & 4.6 & 5.0214 & TRN \\
\hline CHEMBL1992042 & 809167 & 4.3 & 5.1201 & TST \\
\hline CHEMBL 2005548 & 809167 & 4.9 & 5.3596 & TRN \\
\hline CHEMBL1987793 & 809167 & 5.9 & 4.7547 & TST \\
\hline CHEMBL1992536 & 809167 & 4.9 & 5.2425 & TRN \\
\hline CHEMBL21156 & 809167 & 9.0 & 6.3736 & TST \\
\hline CHEMBL1992740 & 809167 & 4.9 & 4.9726 & TRN \\
\hline CHEMBL1994724 & 809167 & 4.3 & 4.5332 & TRN \\
\hline CHEMBL1989267 & 809167 & 4.3 & 5.305 & TRN \\
\hline CHEMBL439340 & 809167 & 4.9 & 5.4902 & TRN \\
\hline CHEMBL1974574 & 809167 & 4.3 & 4.7822 & TST \\
\hline CHEMBL 2006188 & 809167 & 4.9 & 4.5816 & TRN \\
\hline CHEMBL1970290 & 809167 & 5.6 & 4.9633 & TRN \\
\hline CHEMBL1967531 & 809167 & 4.9 & 4.8668 & TRN \\
\hline CHEMBL1970913 & 809167 & 4.9 & 4.5685 & TRN \\
\hline CHEMBL1973893 & 809167 & 6.2 & 5.7137 & TRN \\
\hline CHEMBL1997534 & 809167 & 4.9 & 4.82100 & 0000000001 \\
\hline CHEMBL1993877 & 809167 & 5.4 & 5.3033 & TRN \\
\hline CHEMBL1985095 & 809167 & 6.0 & 5.9769 & TST \\
\hline CHEMBL1996500 & 809167 & 4.3 & 4.4058 & TRN \\
\hline CHEMBL1991180 & 809167 & 6.8 & 6.0447 & TST \\
\hline CHEMBL1682540 & 809167 & 6.0 & 5.7736 & TRN \\
\hline CHEMBL1976420 & 809167 & 4.5 & 4.8205 & TST \\
\hline CHEMBL1998253 & 809167 & 4.3 & 4.7022 & TST \\
\hline CHEMBL413779 & 809167 & 4.9 & 5.4567 & TST \\
\hline CHEMBL1981744 & 809167 & 4.3 & 4.3485 & TRN \\
\hline
\end{tabular}




\begin{tabular}{|c|c|c|c|c|c|}
\hline \\
\hline CHEMBL1994864 & 809167 & 4.9 & 5.1002 & TRN & \\
\hline CHEMBL 2002446 & 809167 & 4.9 & 5.3696 & TST & \\
\hline CHEMBL497151 & 809167 & 6.1 & 6.4721 & TRN & \\
\hline CHEMBL2000029 & 809167 & 6.4 & 6.4791 & TRN & \\
\hline CHEMBL1973961 & 809167 & 5.4 & 5.4691 & TRN & \\
\hline CHEMBL246970 & 809167 & 4.9 & 5.0704 & TRN & \\
\hline CHEMBL340921 & 809167 & 4.9 & 4.9014 & TST & \\
\hline CHEMBL1994977 & 809167 & 4.3 & 4.0758 & TRN & \\
\hline CHEMBL373598 & 809167 & 4.9 & 5.4739 & TST & \\
\hline CHEMBL2001149 & 809167 & 4.3 & 5.2242 & TRN & \\
\hline CHEMBL1999718 & 809167 & 4.9 & 4.547 & TRN & \\
\hline CHEMBL1987073 & 809167 & 6.6 & 7.4485 & TRN & \\
\hline CHEMBL2005478 & 809167 & 4.3 & 5.2846 & TST & \\
\hline CHEMBL1276446 & 809167 & 7.1 & 7.1287 & TST & \\
\hline CHEMBL1996646 & 809167 & 5.4 & 5.9553 & TRN & \\
\hline CHEMBL1995712 & 809167 & 6.6 & 6.7726 & TRN & \\
\hline CHEMBL1979773 & 809167 & 4.3 & 4.2839 & TRN & \\
\hline CHEMBL1977346 & 809167 & 4.9 & 4.8605 & TRN & \\
\hline CHEMBL2003657 & 809167 & 4.9 & 5.2149 & TRN & \\
\hline CHEMBL1971649 & 809167 & 4.9 & 4.7779 & TRN & \\
\hline CHEMBL1996702 & 809167 & 7.2 & 6.084 & TRN & \\
\hline CHEMBL 2007124 & 809167 & 4.3 & 4.4711 & TRN & \\
\hline CHEMBL2006439 & 809167 & 6.3 & 5.9726 & TRN & \\
\hline CHEMBL1985681 & 809167 & 5.9 & 5.5477 & TST & \\
\hline CHEMBL1969190 & 809167 & 4.9 & 4.8267 & TRN & \\
\hline CHEMBL 2002660 & 809167 & 4.3 & 4.3057 & TRN & \\
\hline CHEMBL1973937 & 809167 & 4.9 & 5.1293 & TRN & \\
\hline CHEMBL1991674 & 809167 & 6.5 & $6.6770 e$ & 00000000005 & TRN \\
\hline CHEMBL1982711 & 809167 & 5.9 & 5.7596 & TRN & \\
\hline CHEMBL262623 & 809167 & 5.1 & 4.9915 & TRN & \\
\hline CHEMBL1984842 & 809167 & 4.6 & 4.4383 & TRN & \\
\hline CHEMBL1969102 & 809167 & 6.0 & 5.5558 & TRN & \\
\hline CHEMBL 2004118 & 809167 & 5.8 & 5.7308 & TRN & \\
\hline CHEMBL1682346 & 809167 & 6.6 & 6.7985 & TRN & \\
\hline CHEMBL1996795 & 809167 & 4.3 & 5.2912 & TST & \\
\hline CHEMBL 2007044 & 809167 & 4.9 & 5.1709 & TST & \\
\hline CHEMBL2001998 & 809167 & 4.9 & 4.9954 & TST & \\
\hline CHEMBL1994241 & 809167 & 7.8 & 6.2305 & TRN & \\
\hline CHEMBL 223460 & 809167 & 4.9 & 5.2496 & TST & \\
\hline CHEMBL50894 & 809167 & 4.5 & $5.0280 e$ & 00000000005 & TRN \\
\hline CHEMBL1995211 & 809167 & 4.3 & 4.51 & TRN & \\
\hline CHEMBL1988838 & 809167 & 6.5 & 6.5985 & TRN & \\
\hline CHEMBL1981725 & 809167 & 6.9 & 5.3169 & TRN & \\
\hline CHEMBL 375284 & 809167 & 4.9 & 4.8886 & TRN & \\
\hline CHEMBL2006299 & 809167 & 4.3 & 4.4249 & TRN & \\
\hline CHEMBL1980562 & 809167 & 6.7 & 6.7316 & TRN & \\
\hline CHEMBL1965169 & 809167 & 4.3 & 4.8761 & TST & \\
\hline CHEMBL1991818 & 809167 & 4.3 & 5.3795 & TST & \\
\hline
\end{tabular}




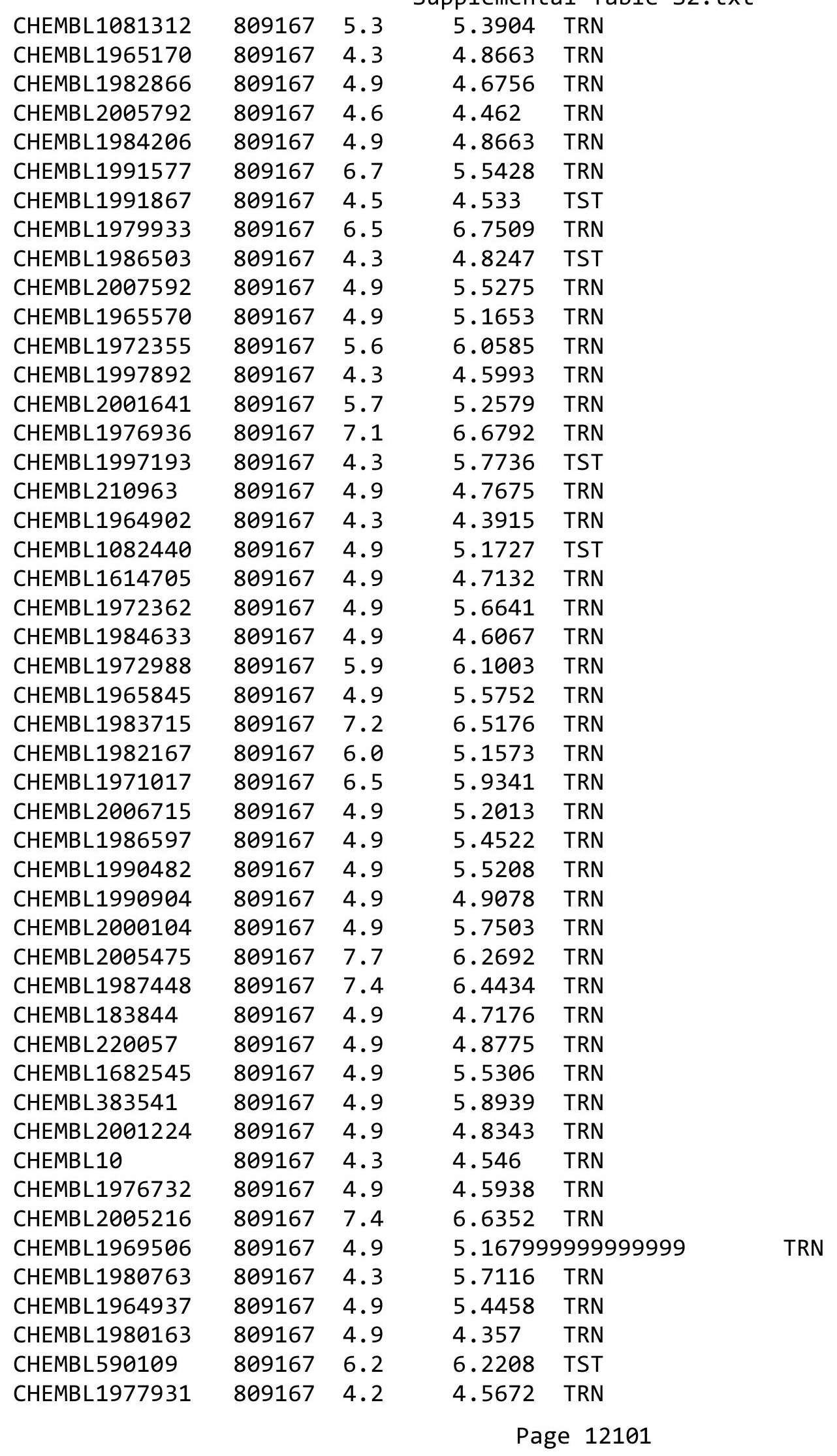




\begin{tabular}{|c|c|c|c|c|c|}
\hline \\
\hline CHEMBL1970879 & 809167 & 4.9 & 5.1337 & TRN & \\
\hline CHEMBL1989856 & 809167 & 6.0 & 5.9116 & TST & \\
\hline CHEMBL2005899 & 809167 & 7.4 & 5.8327 & TRN & \\
\hline CHEMBL1682552 & 809167 & 5.9 & 5.9586 & TRN & \\
\hline CHEMBL259850 & 809167 & 4.9 & 4.4731 & TRN & \\
\hline CHEMBL2007479 & 809167 & 4.3 & 4.6754 & TRN & \\
\hline CHEMBL1996155 & 809167 & 6.6 & 5.0417 & TST & \\
\hline CHEMBL1986851 & 809167 & 5.5 & 5.2585 & TRN & \\
\hline CHEMBL229799 & 809167 & 7.1 & 7.3333 & TRN & \\
\hline CHEMBL105739 & 809167 & 4.9 & 5.5165 & TRN & \\
\hline CHEMBL1682359 & 809167 & 7.0 & 5.4759 & TRN & \\
\hline CHEMBL1972220 & 809167 & 4.3 & 5.1343 & TRN & \\
\hline CHEMBL 379300 & 809167 & 7.0 & 6.7424 & TRN & \\
\hline CHEMBL 203673 & 809167 & 4.9 & 5.4977 & TRN & \\
\hline CHEMBL 2003785 & 809167 & 4.5 & 4.8186 & TST & \\
\hline CHEMBL1973720 & 809167 & 7.3 & 7.5222 & TRN & \\
\hline CHEMBL1969523 & 809167 & 7.8 & 7.12799 & 9999999999 & TRN \\
\hline CHEMBL207995 & 809167 & 4.9 & 4.7161 & TRN & \\
\hline CHEMBL2001923 & 809167 & 4.5 & 5.0298 & TRN & \\
\hline CHEMBL1986781 & 809167 & 4.9 & 5.0527 & TRN & \\
\hline CHEMBL1983070 & 809167 & 4.3 & 4.7091 & TRN & \\
\hline CHEMBL526133 & 809167 & 7.3 & 6.4835 & TRN & \\
\hline CHEMBL 2003514 & 809167 & 4.3 & 4.3117 & TRN & \\
\hline CHEMBL1989043 & 809167 & 4.3 & 5.0092 & TRN & \\
\hline CHEMBL1967538 & 809167 & 4.3 & 5.0807 & TRN & \\
\hline CHEMBL1979057 & 809167 & 4.9 & 5.3667 & TRN & \\
\hline CHEMBL1981045 & 809167 & 4.9 & 5.0648 & TRN & \\
\hline CHEMBL 387971 & 809167 & 4.9 & 4.9073 & TST & \\
\hline CHEMBL1975418 & 809167 & 7.5 & 6.4273 & TRN & \\
\hline CHEMBL1992796 & 809167 & 4.9 & 4.9778 & TRN & \\
\hline CHEMBL1968515 & 809167 & 5.0 & 5.1309 & TST & \\
\hline CHEMBL1164180 & 809167 & 4.4 & 5.8187 & TST & \\
\hline CHEMBL223257 & 809167 & 4.9 & 5.4087 & TST & \\
\hline CHEMBL1999428 & 809167 & 4.9 & 4.644 & TRN & \\
\hline CHEMBL 1967560 & 809167 & 4.9 & 5.2843 & TRN & \\
\hline CHEMBL1997611 & 809167 & 5.4 & 5.3022 & TST & \\
\hline CHEMBL1516890 & 809167 & 4.9 & 5.5877 & TRN & \\
\hline CHEMBL211378 & 809167 & 4.9 & 5.0813 & TRN & \\
\hline CHEMBL1982465 & 809167 & 4.9 & 5.2463 & TRN & \\
\hline CHEMBL2001751 & 809167 & 7.7 & 7.2313 & TRN & \\
\hline CHEMBL 2003420 & 809167 & 4.9 & 4.5358 & TRN & \\
\hline CHEMBL1984586 & 809167 & 4.9 & 4.6654 & TRN & \\
\hline CHEMBL1999774 & 809167 & 4.9 & 5.2922 & TST & \\
\hline CHEMBL1972659 & 809167 & 4.9 & 4.9852 & TST & \\
\hline CHEMBL1984632 & 809167 & 5.5 & 5.2491 & TST & \\
\hline CHEMBL1973395 & 809167 & 4.9 & 5.0913 & TRN & \\
\hline CHEMBL 272453 & 809167 & 4.9 & 4.9221 & TRN & \\
\hline CHEMBL1970217 & 809167 & 4.9 & 4.4896 & TRN & \\
\hline
\end{tabular}




\begin{tabular}{|c|c|c|c|c|}
\hline & & & pplement & al $\mathrm{Ta}$ \\
\hline CHEMBL1968850 & 809167 & 4.9 & 5.0484 & TRN \\
\hline CHEMBL 2005528 & 809167 & 6.3 & 5.8088 & TST \\
\hline CHEMBL1984686 & 809167 & 4.3 & 4.6904 & TRN \\
\hline CHEMBL185569 & 809167 & 4.9 & 4.9899 & TRN \\
\hline CHEMBL1969843 & 809167 & 6.2 & 5.6716 & TRN \\
\hline CHEMBL 2007002 & 809167 & 4.9 & 4.9239 & TRN \\
\hline CHEMBL1987007 & 809167 & 4.9 & 5.8121 & TRN \\
\hline CHEMBL1973793 & 809167 & 4.3 & 5.3977 & TST \\
\hline CHEMBL1969588 & 809167 & 7.2 & 7.1137 & TRN \\
\hline CHEMBL1984711 & 809167 & 4.9 & 5.8114 & TRN \\
\hline CHEMBL1992073 & 809167 & 6.1 & 5.9851 & TRN \\
\hline CHEMBL484390 & 809167 & 4.9 & 4.8832 & TRN \\
\hline CHEMBL1979252 & 809167 & 6.0 & 5.3177 & TRN \\
\hline CHEMBL1986143 & 809167 & 4.3 & 4.3814 & TRN \\
\hline CHEMBL1972934 & 809167 & 4.8 & 4.6892 & TRN \\
\hline CHEMBL 2007559 & 809167 & 4.3 & 4.9637 & TRN \\
\hline CHEMBL1992581 & 809167 & 4.3 & 4.747 & TRN \\
\hline CHEMBL1682341 & 809167 & 6.4 & 5.7297 & TRN \\
\hline CHEMBL 2004290 & 809167 & 4.5 & 4.6929 & TRN \\
\hline CHEMBL1986499 & 809167 & 6.8 & 6.4697 & TRN \\
\hline CHEMBL1972937 & 809167 & 6.6 & 5.8113 & TRN \\
\hline CHEMBL1972250 & 809167 & 4.9 & 5.267 & TST \\
\hline CHEMBL 2000393 & 809167 & 4.9 & 6.0507 & TST \\
\hline CHEMBL1983573 & 809167 & 4.9 & 4.9558 & TRN \\
\hline CHEMBL2004311 & 809167 & 4.9 & 4.8182 & TRN \\
\hline CHEMBL1992634 & 809167 & 4.9 & 4.8441 & TRN \\
\hline CHEMBL1242373 & 809167 & 4.9 & 5.933 & TRN \\
\hline CHEMBL1984847 & 809167 & 4.3 & 4.842 & TRN \\
\hline CHEMBL316264 & 809167 & 4.9 & 4.6149 & TRN \\
\hline CHEMBL1988075 & 809167 & 4.9 & 4.9695 & TRN \\
\hline CHEMBL1996576 & 809167 & 4.3 & 4.7547 & TST \\
\hline CHEMBL1991678 & 809167 & 4.3 & 4.462 & TRN \\
\hline CHEMBL 2001239 & 809167 & 4.9 & 5.5629 & TRN \\
\hline CHEMBL1988594 & 809167 & 4.9 & 4.8188 & TRN \\
\hline CHEMBL2001288 & 809167 & 6.0 & 4.8172 & TRN \\
\hline CHEMBL1992363 & 809167 & 7.4 & 7.4101 & TRN \\
\hline CHEMBL260092 & 809167 & 4.9 & 5.3692 & TRN \\
\hline CHEMBL1999811 & 809167 & 6.1 & 5.7703 & TRN \\
\hline CHEMBL1965495 & 809167 & 4.9 & 4.9709 & TRN \\
\hline CHEMBL 235157 & 809167 & 5.4 & 4.9729 & TST \\
\hline CHEMBL1985074 & 809167 & 6.3 & 5.6651 & TST \\
\hline CHEMBL 2000481 & 809167 & 4.9 & 5.0763 & TRN \\
\hline CHEMBL1982874 & 809167 & 4.9 & 4.9626 & TRN \\
\hline CHEMBL1991725 & 809167 & 4.9 & 5.7802 & TRN \\
\hline CHEMBL1992242 & 809167 & 4.9 & 4.5778 & TRN \\
\hline CHEMBL1982271 & 809167 & 6.6 & 7.1606 & TRN \\
\hline CHEMBL 2007296 & 809167 & 4.9 & 4.2037 & TRN \\
\hline CHEMBL 2004159 & 809167 & 4.3 & 4.4753 & TRN \\
\hline
\end{tabular}




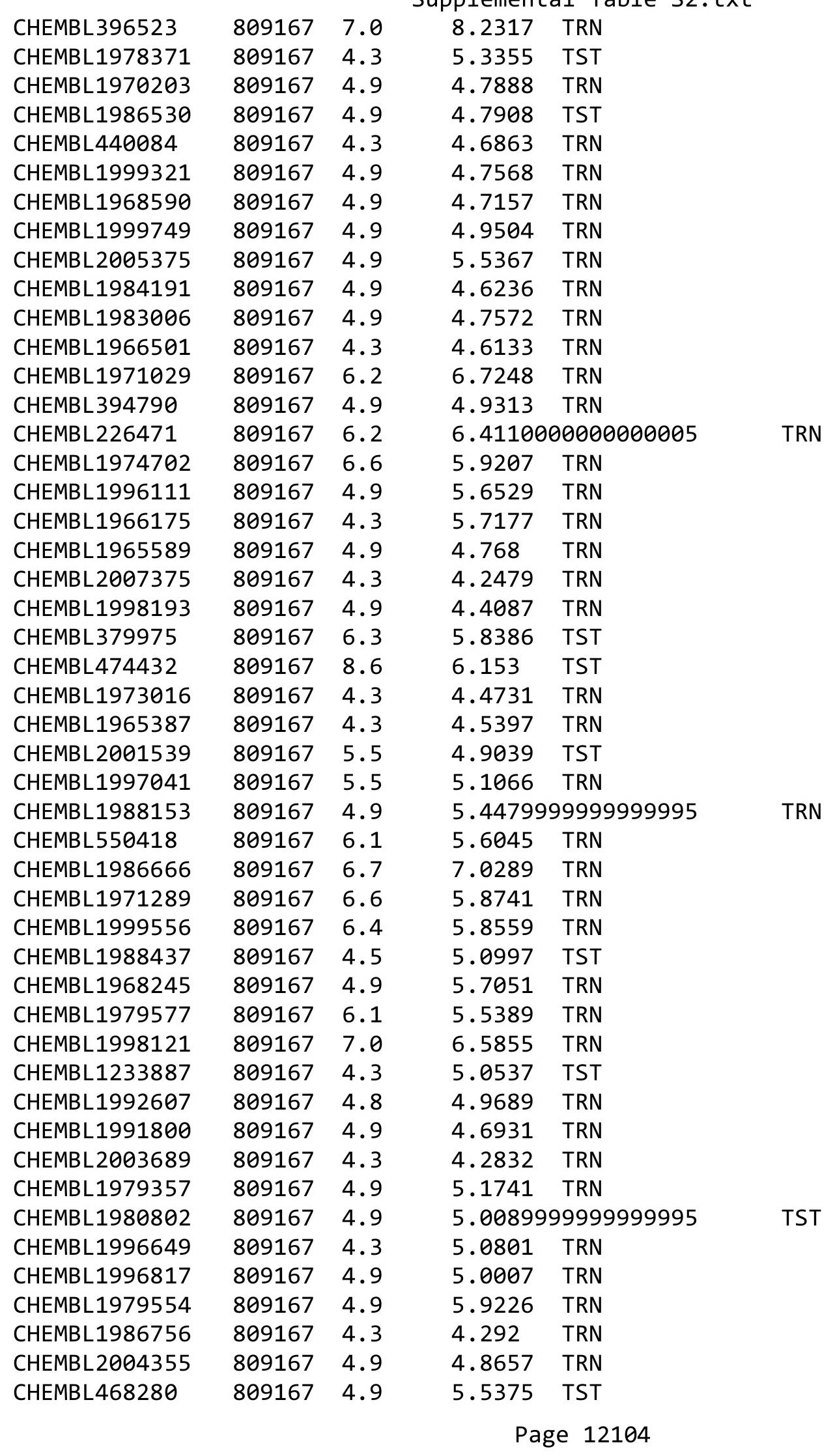




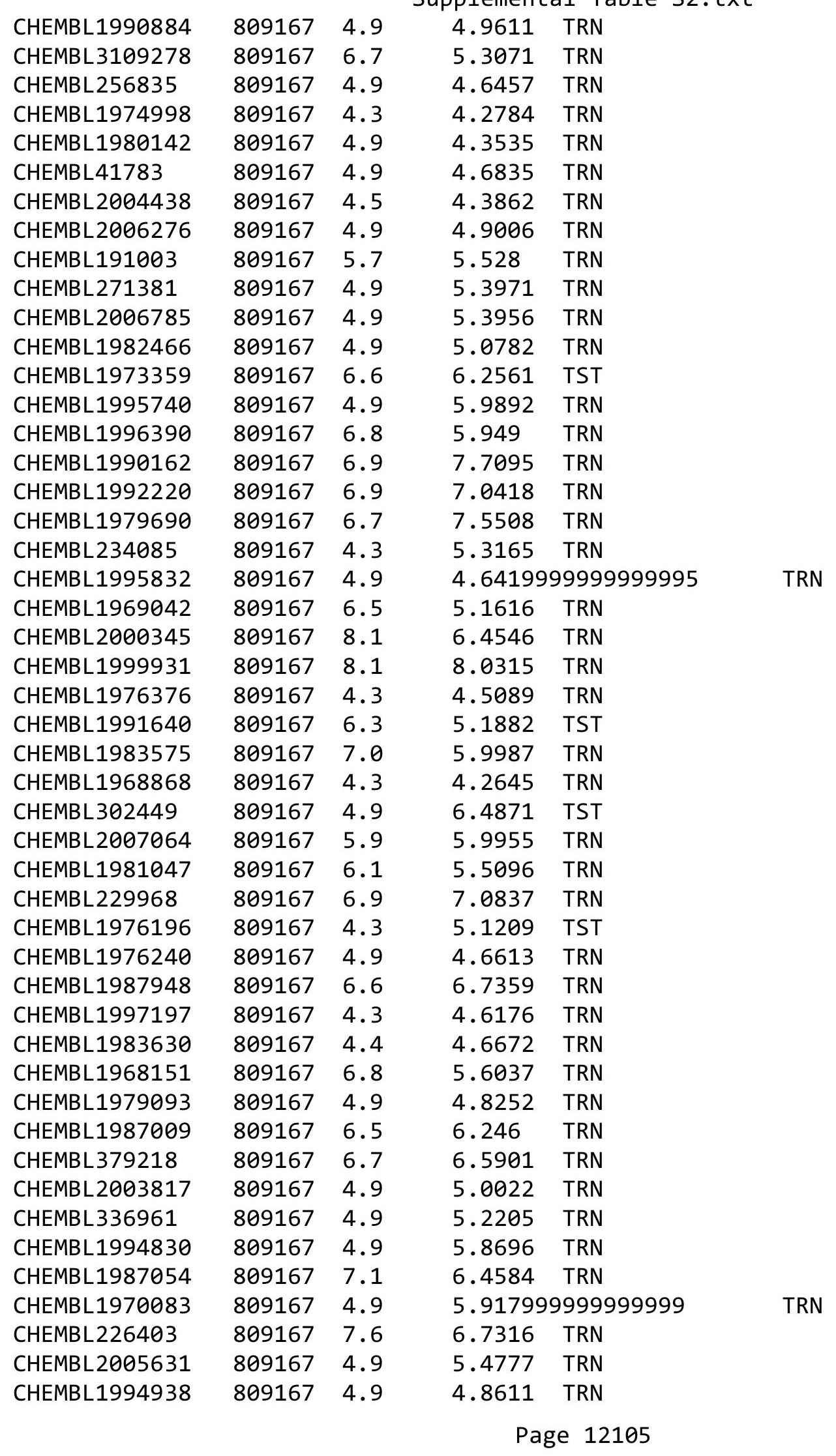




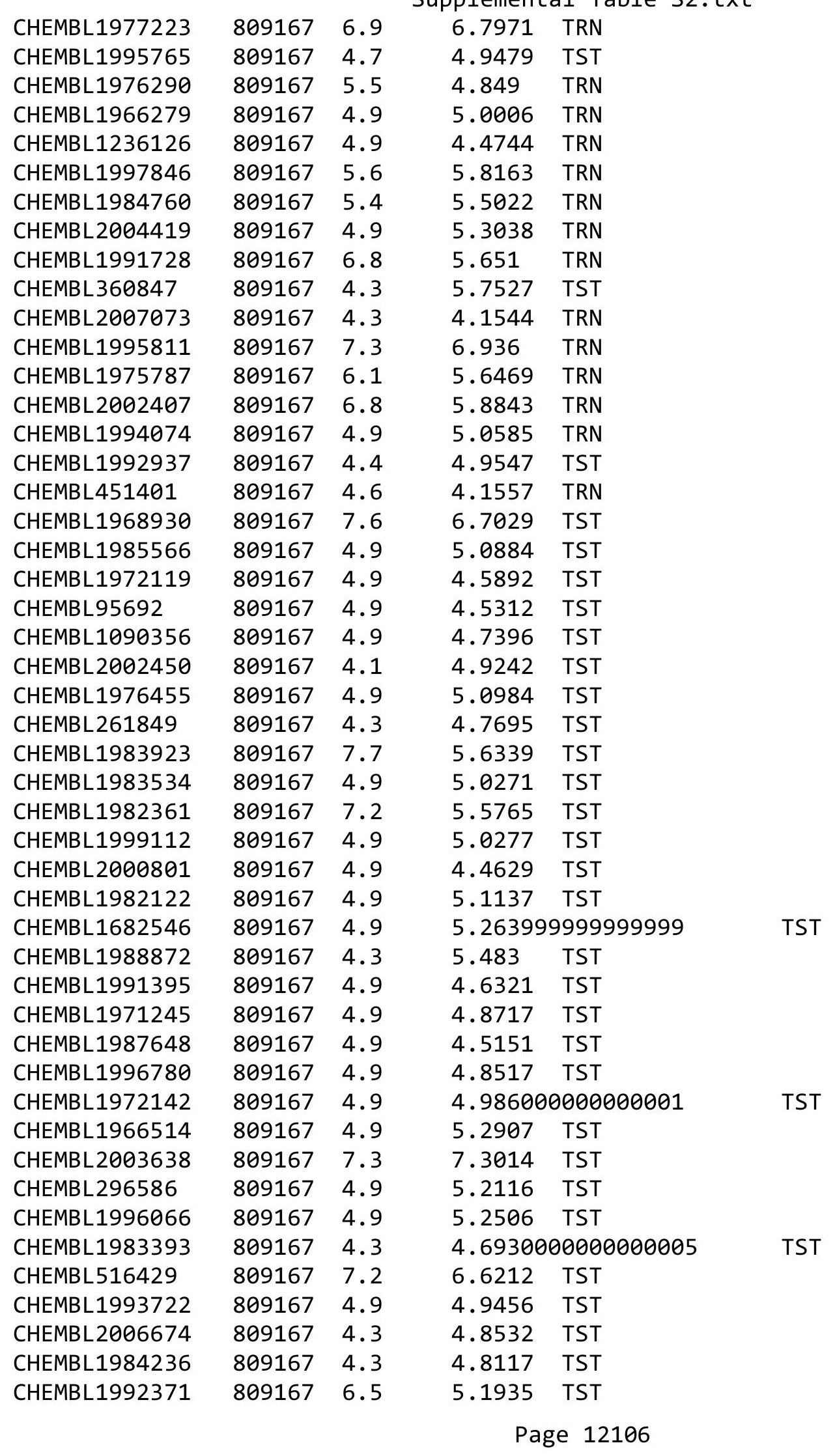




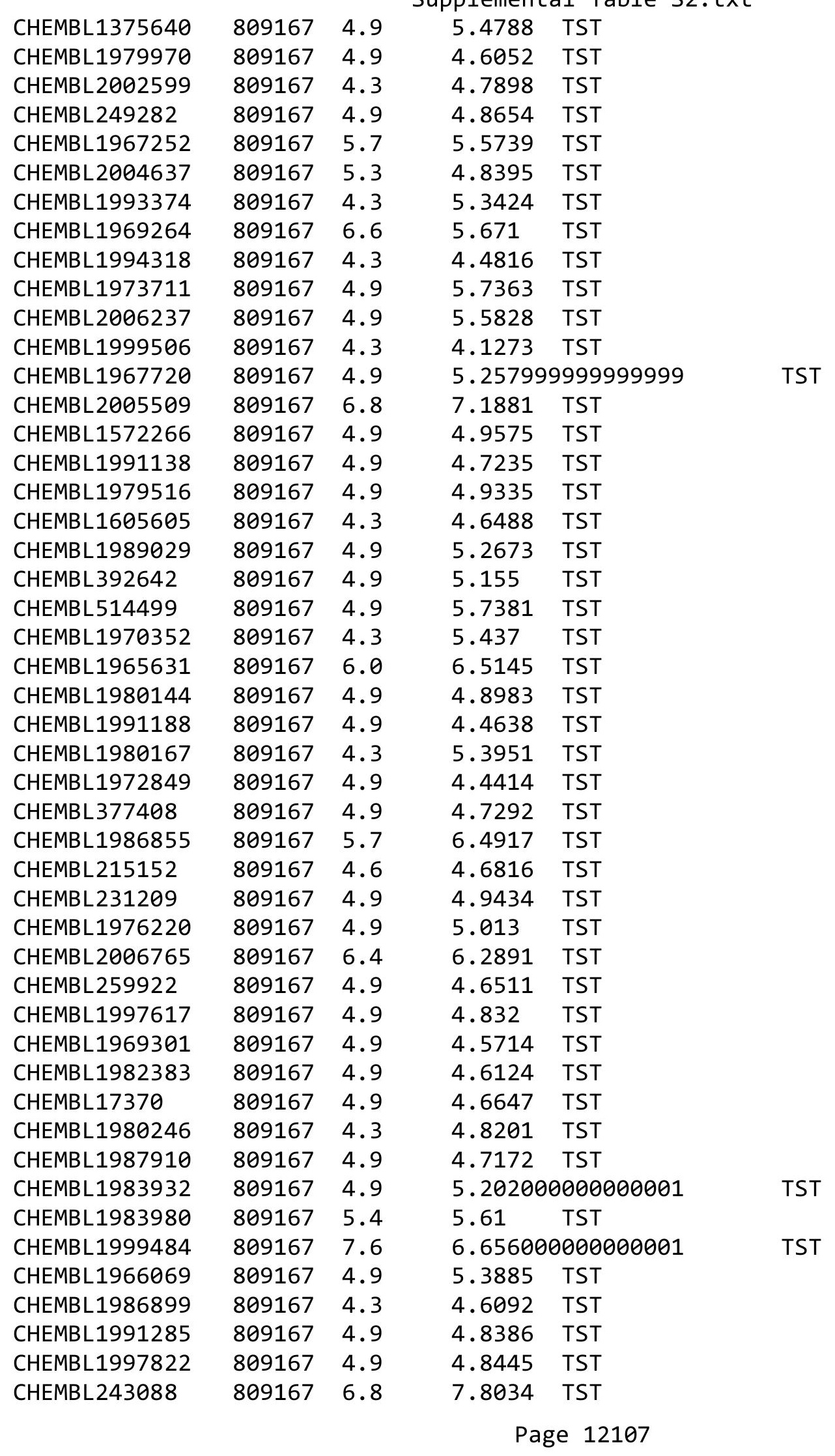




\begin{tabular}{|c|c|c|c|c|c|}
\hline \\
\hline CHEMBL1984038 & 809167 & 4.5 & 4.6715 & TST & \\
\hline CHEMBL1974416 & 809167 & 4.9 & 4.7961 & TST & \\
\hline CHEMBL1993661 & 809167 & 4.3 & 7.7479 & TST & \\
\hline CHEMBL565855 & 597345 & 7.7696 & 7.3944 & TRN & \\
\hline CHEMBL565867 & 597345 & 6.7352 & 6.9004 & TRN & \\
\hline CHEMBL572187 & 597345 & 6.9747 & 6.8195 & TRN & \\
\hline CHEMBL568412 & 597345 & 7.3565 & 7.2912 & TRN & \\
\hline CHEMBL567557 & 597345 & 7.4318 & 7.4812 & TRN & \\
\hline CHEMBL576517 & 597345 & 7.3979 & 7.2037 & TRN & \\
\hline CHEMBL568179 & 597345 & 6.2518 & 6.5145 & TRN & \\
\hline CHEMBL567970 & 597345 & 6.8097 & 6.5269 & TRN & \\
\hline CHEMBL568213 & 597345 & 5.9817 & 6.7506 & TRN & \\
\hline CHEMBL566909 & 597345 & 6.7144 & 7.0015 & TRN & \\
\hline CHEMBL577939 & 597345 & 5.7235 & 5.96899 & 9999999999 & TRN \\
\hline CHEMBL576398 & 597345 & 6.5591 & 6.0981 & TRN & \\
\hline CHEMBL568600 & 597345 & 6.8069 & 6.2788 & TST & \\
\hline CHEMBL577941 & 597345 & 6.8861 & 6.0357 & TST & \\
\hline CHEMBL568624 & 597345 & 6.8697 & 6.5716 & TRN & \\
\hline CHEMBL567780 & 597345 & 6.2007 & 6.9216 & TRN & \\
\hline CHEMBL576251 & 597345 & 5.767 & 6.4164 & TST & \\
\hline CHEMBL567781 & 597345 & 6.6861 & 6.4921 & TRN & \\
\hline CHEMBL576596 & 597345 & 6.8761 & 7.0408 & TRN & \\
\hline CHEMBL566943 & 597345 & 7.301 & 7.3395 & TRN & \\
\hline CHEMBL207675 & 597345 & 8.2218 & 6.3175 & TST & \\
\hline CHEMBL579223 & 597345 & 7.1249 & 6.26 & TST & \\
\hline CHEMBL576035 & 597345 & 6.5768 & 6.4242 & TRN & \\
\hline CHEMBL567574 & 597345 & 6.8239 & 6.4913 & TRN & \\
\hline CHEMBL567966 & 597345 & 7.6778 & 7.4778 & TRN & \\
\hline CHEMBL567968 & 597345 & 4.8955 & 6.1453 & TST & \\
\hline CHEMBL581422 & 597345 & 6.71 & 6.8953 & TRN & \\
\hline CHEMBL567967 & 597345 & 6.0511 & 6.2199 & TRN & \\
\hline CHEMBL576595 & 597345 & 7.699 & 7.4387 & TRN & \\
\hline CHEMBL576396 & 597345 & 6.3979 & 6.4313 & TRN & \\
\hline CHEMBL568214 & 597345 & 6.5686 & 6.8885 & TRN & \\
\hline CHEMBL576421 & 597345 & 5.5607 & 5.5 & TRN & \\
\hline CHEMBL577274 & 597345 & 5.9469 & 6.4065 & TRN & \\
\hline CHEMBL565854 & 597345 & 6.6778 & 6.8178 & TRN & \\
\hline CHEMBL576451 & 597345 & 7.6198 & 7.3645 & TRN & \\
\hline CHEMBL579019 & 597345 & 4.3468 & 6.1902 & TST & \\
\hline CHEMBL1163014 & 597345 & 6.5784 & 6.6365 & TRN & \\
\hline CHEMBL568161 & 597345 & 7.3665 & 7.2084 & TRN & \\
\hline CHEMBL567979 & 597345 & 9.5229 & 9.3618 & TRN & \\
\hline CHEMBL568424 & 597345 & 6.1367 & 6.0728 & TST & \\
\hline CHEMBL577719 & 597345 & 6.8697 & 6.858 & TRN & \\
\hline CHEMBL567179 & 597345 & 4.9151 & 6.0298 & TST & \\
\hline CHEMBL568748 & 597345 & 5.4486 & 6.0461 & TST & \\
\hline CHEMBL568158 & 597345 & 6.71 & 6.8465 & TST & \\
\hline CHEMBL576034 & 597345 & 7.2518 & 6.6595 & TRN & \\
\hline
\end{tabular}




\begin{tabular}{|c|c|c|c|c|c|c|}
\hline & & \multicolumn{5}{|c|}{ Supplemental Table s2.txt } \\
\hline CHEMBL567556 & 597345 & 5.4034 & 5.5703 & TRN & & \\
\hline CHEMBL565869 & 597345 & 5.9318 & 6.3493 & TRN & & \\
\hline CHEMBL576250 & 597345 & 6.7305 & 6.142 & TRN & & \\
\hline CHEMBL579239 & 597345 & 6.5918 & 7.0165 & TRN & & \\
\hline CHEMBL576249 & 597345 & 6.5654 & 6.0132 & TRN & & \\
\hline CHEMBL568425 & 597345 & 5.9809 & 6.4953 & TRN & & \\
\hline CHEMBL577720 & 597345 & 6.4622 & 6.893 & TRN & & \\
\hline CHEMBL578587 & 597345 & 8.5229 & 7.6474 & TRN & & \\
\hline CHEMBL567737 & 597345 & 6.8827 & 7.5078 & TRN & & \\
\hline CHEMBL568413 & 597345 & 6.6904 & 7.1973 & TRN & & \\
\hline CHEMBL576248 & 597345 & 6.9208 & 6.272 & TRN & & \\
\hline CHEMBL567760 & 597345 & 6.1772 & 5.7128 & TST & & \\
\hline CHEMBL585890 & 597345 & 6.5406 & 6.4962 & TRN & & \\
\hline CHEMBL567535 & 597345 & 6.7825 & 6.5718 & TST & & \\
\hline CHEMBL568159 & 597345 & \multicolumn{3}{|c|}{6.718999999999999} & 6.6385 & TRN \\
\hline CHEMBL576865 & 597345 & 6.644 & 6.4898 & TRN & & \\
\hline CHEMBL565868 & 597345 & 7.284 & 7.4135 & TST & & \\
\hline CHEMBL568601 & 597345 & \multicolumn{3}{|c|}{5.752000000000001} & 6.7367 & TST \\
\hline CHEMBL568746 & 597345 & 7.0 & 7.3743 & TST & & \\
\hline CHEMBL568160 & 597345 & 6.7033 & 6.9264 & TST & & \\
\hline CHEMBL3121997 & 1291715 & 8.8861 & 8.6706 & TRN & & \\
\hline CHEMBL 3122007 & 1291715 & 8.2147 & 8.2019 & TRN & & \\
\hline CHEMBL 3121980 & 1291715 & 9.3979 & 9.4046 & TRN & & \\
\hline CHEMBL3121964 & 1291715 & 8.7959 & 8.6751 & TRN & & \\
\hline CHEMBL3121987 & 1291715 & 8.9586 & 8.8126 & TRN & & \\
\hline CHEMBL3121967 & 1291715 & 8.8239 & 7.6616 & TST & & \\
\hline CHEMBL3121999 & 1291715 & 8.7696 & 8.251 & TRN & & \\
\hline CHEMBL3122009 & 1291715 & 7.3188 & 7.2137 & TRN & & \\
\hline CHEMBL3121992 & 1291715 & 7.6778 & 7.9387 & TRN & & \\
\hline CHEMBL3121986 & 1291715 & 8.2218 & 8.6716 & TRN & & \\
\hline CHEMBL 3122008 & 1291715 & 7.9586 & 7.5206 & TRN & & \\
\hline CHEMBL3121982 & 1291715 & 6.0655 & 6.50799 & 9999999999 & & TRN \\
\hline CHEMBL 3122004 & 1291715 & 7.1487 & 7.5764 & TRN & & \\
\hline CHEMBL3121969 & 1291715 & 9.2218 & 8.012 & TST & & \\
\hline CHEMBL3121974 & 1291715 & 7.699 & 8.1597 & TRN & & \\
\hline CHEMBL3121968 & 1291715 & 8.8239 & 8.0385 & TST & & \\
\hline CHEMBL3121961 & 1291715 & 8.8539 & 8.894 & TRN & & \\
\hline CHEMBL3121994 & 1291715 & 8.9208 & 8.6981 & TRN & & \\
\hline CHEMBL3121985 & 1291715 & 9.0458 & 8.1892 & TRN & & \\
\hline CHEMBL3121981 & 1291715 & 8.7959 & 7.5495 & TRN & & \\
\hline CHEMBL3121989 & 1291715 & 9.301 & 8.9413 & TRN & & \\
\hline CHEMBL3105484 & 1291715 & 8.9208 & 8.1558 & TST & & \\
\hline CHEMBL3121972 & 1291715 & 8.3665 & 8.1539 & TST & & \\
\hline CHEMBL3121965 & 1291715 & 8.1805 & 7.9612 & TST & & \\
\hline CHEMBL3121998 & 1291715 & 8.8861 & 8.7815 & TRN & & \\
\hline CHEMBL 3122002 & 1291715 & 7.6778 & 7.662006 & 0000000001 & & TRN \\
\hline CHEMBL3122010 & 1291715 & 8.1549 & 8.1413 & TRN & & \\
\hline CHEMBL3121976 & 1291715 & 7.699 & 8.3545 & TRN & & \\
\hline
\end{tabular}


Supplemental Table S2.txt

\begin{tabular}{|c|c|c|c|c|}
\hline CHEMBL 3121983 & 1291715 & 7.1024 & 7.9356 & TRN \\
\hline CHEMBL 3121979 & 1291715 & 8.9586 & 9.1792 & TRN \\
\hline CHEMBL3121971 & 1291715 & 9.0458 & \multicolumn{2}{|c|}{7.837000000000001} \\
\hline CHEMBL 3122003 & 1291715 & 7.7212 & 7.9768 & TRN \\
\hline CHEMBL 3105478 & 1291715 & 8.8539 & 7.796 & TST \\
\hline CHEMBL 3121995 & 1291715 & 9.2218 & 9.2679 & TRN \\
\hline CHEMBL 3122000 & 1291715 & 8.8239 & 8.516 & TRN \\
\hline CHEMBL 3121984 & 1291715 & 5.7959 & 5.7825 & TRN \\
\hline CHEMBL 3122001 & 1291715 & 8.3372 & 8.8445 & TRN \\
\hline CHEMBL3121963 & 1291715 & 8.1135 & 8.4213 & TST \\
\hline CHEMBL 3121996 & 1291715 & 8.8861 & 8.8139 & TRN \\
\hline CHEMBL 3121993 & 1291715 & 8.3188 & 8.5034 & TRN \\
\hline CHEMBL 3121977 & 1291715 & 9.3979 & 9.1797 & TRN \\
\hline CHEMBL3121970 & 1291715 & 8.3279 & \multicolumn{2}{|c|}{7.571000000000001} \\
\hline CHEMBL 3121962 & 1291715 & 8.5686 & 8.5478 & TST \\
\hline CHEMBL 3120183 & 1291715 & 8.6198 & 8.6624 & TRN \\
\hline CHEMBL3121990 & 1291715 & 8.9208 & 8.9575 & TRN \\
\hline CHEMBL 3121988 & 1291715 & 8.3279 & 8.8813 & TRN \\
\hline CHEMBL 3121966 & 1291715 & 9.301 & 8.0869 & TST \\
\hline CHEMBL3121991 & 1291715 & 8.3665 & 8.0406 & TRN \\
\hline CHEMBL 3121978 & 1291715 & 9.3979 & 9.0208 & TRN \\
\hline CHEMBL3121960 & 1291715 & 8.3279 & 8.4886 & TRN \\
\hline CHEMBL 3122011 & 1291715 & 7.8539 & 7.9599 & TRN \\
\hline CHEMBL3121975 & 1291715 & 8.7447 & 8.6083 & TST \\
\hline CHEMBL1415985 & 752306 & 3.3032 & 3.8807 & TRN \\
\hline CHEMBL1607132 & 752306 & 3.3033 & 4.2188 & TRN \\
\hline CHEMBL1710816 & 752306 & 5.7991 & 5.6982 & TRN \\
\hline CHEMBL1971127 & 752306 & 5.2493 & 4.1818 & TST \\
\hline CHEMBL1508208 & 752306 & 3.3032 & 3.9849 & TRN \\
\hline CHEMBL1316002 & 752306 & 3.3032 & 3.7852 & TRN \\
\hline CHEMBL1558462 & 752306 & 5.6629 & 5.7289 & TRN \\
\hline CHEMBL1487183 & 752306 & 5.3421 & 5.1932 & TST \\
\hline CHEMBL1726287 & 752306 & 3.3032 & 3.8681 & TST \\
\hline CHEMBL1300370 & 752306 & 4.9459 & 4.4525 & TST \\
\hline CHEMBL1359902 & 752306 & 5.7354 & 5.4405 & TRN \\
\hline CHEMBL1608392 & 752306 & 5.4831 & 4.4111 & TRN \\
\hline CHEMBL1470904 & 752306 & 3.3032 & 3.8561 & TRN \\
\hline CHEMBL1453652 & 752306 & 3.303 & 3.7126 & TRN \\
\hline CHEMBL116438 & 752306 & 4.4608 & 4.6598 & TRN \\
\hline CHEMBL1499951 & 752306 & 5.9274 & 5.8424 & TRN \\
\hline CHEMBL1543839 & 752306 & 5.7854 & 6.2192 & TRN \\
\hline CHEMBL1567159 & 752306 & 5.7731 & 5.5591 & TRN \\
\hline CHEMBL1527042 & 752306 & 3.3028 & 4.1797 & TRN \\
\hline CHEMBL1532668 & 752306 & 5.6747 & 5.6147 & TRN \\
\hline CHEMBL1698008 & 752306 & 6.1278 & 5.6766 & TRN \\
\hline CHEMBL1491686 & 752306 & 3.3033 & 3.8366 & TRN \\
\hline CHEMBL1701517 & 752306 & 6.0182 & 5.8524 & TRN \\
\hline CHEMBL1734268 & 752306 & 5.7199 & 5.2936 & TRN \\
\hline
\end{tabular}

Page 12110 


\begin{tabular}{|c|c|c|c|c|c|}
\hline & & & & & \\
\hline CHEMBL1307050 & 752306 & 5.5366 & 5.5675 & TRN & \\
\hline CHEMBL1524932 & 752306 & 4.7333 & 4.2639 & TRN & \\
\hline CHEMBL1583998 & 752306 & 3.303 & 4.0983 & TRN & \\
\hline CHEMBL1449204 & 752306 & 5.3537 & 5.574 & TRN & \\
\hline CHEMBL1458548 & 752306 & 5.6105 & 5.9646 & TRN & \\
\hline CHEMBL1698608 & 752306 & 6.9585 & 4.7033 & TST & \\
\hline CHEMBL3207597 & 752306 & 3.3035 & 3.9387 & TRN & \\
\hline CHEMBL1215650 & 752306 & 3.3035 & 2.8069 & TRN & \\
\hline CHEMBL585591 & 752306 & 5.8392 & 3.6632 & TST & \\
\hline CHEMBL1531308 & 752306 & 5.7397 & 5.544 & TST & \\
\hline CHEMBL1727091 & 752306 & 5.6897 & 4.70100 & 00000000005 & TST \\
\hline CHEMBL1712082 & 752306 & 6.2085 & 4.5309 & TST & \\
\hline CHEMBL1472131 & 752306 & 3.3035 & 4.1516 & TRN & \\
\hline CHEMBL1575594 & 752306 & 5.614 & 4.4385 & TST & \\
\hline CHEMBL1726592 & 752306 & 5.0425 & 4.7003 & TRN & \\
\hline CHEMBL1999014 & 752306 & 4.7974 & 3.4928 & TRN & \\
\hline CHEMBL1301731 & 752306 & 3.3036 & 3.3454 & TRN & \\
\hline CHEMBL140 & 752306 & 4.5364 & 4.8766 & TRN & \\
\hline CHEMBL1469035 & 752306 & 5.654 & 5.3044 & TST & \\
\hline CHEMBL1578341 & 752306 & 5.5648 & 5.697 & TRN & \\
\hline CHEMBL1523192 & 752306 & 4.5472 & 4.5153 & TRN & \\
\hline CHEMBL1460029 & 752306 & 5.9144 & 4.7724 & TRN & \\
\hline CHEMBL1303426 & 752306 & 5.8159 & 5.4863 & TRN & \\
\hline CHEMBL1409883 & 752306 & 5.7411 & 5.6809 & TRN & \\
\hline CHEMBL1586067 & 752306 & 3.3032 & 3.2222 & TRN & \\
\hline CHEMBL1610025 & 752306 & 5.4884 & 6.0329 & TRN & \\
\hline CHEMBL1890919 & 752306 & 3.3035 & 4.4646 & TRN & \\
\hline CHEMBL1492819 & 752306 & 3.3033 & 3.8481 & TRN & \\
\hline CHEMBL1984244 & 752306 & 3.7808 & 4.0712 & TST & \\
\hline CHEMBL1544093 & 752306 & 5.2506 & 5.92700 & 00000000005 & TRN \\
\hline CHEMBL1462078 & 752306 & 3.3032 & 3.576 & TRN & \\
\hline CHEMBL428064 & 752306 & 5.7523 & 5.1163 & TST & \\
\hline CHEMBL1513846 & 752306 & 3.3032 & 3.9303 & TRN & \\
\hline CHEMBL1308255 & 752306 & 4.6975 & 4.1276 & TRN & \\
\hline CHEMBL1471341 & 752306 & 5.3996 & 5.7013 & TRN & \\
\hline CHEMBL3199893 & 752306 & 5.1178 & 4.7555 & TRN & \\
\hline CHEMBL1416184 & 752306 & 5.71200 & 30000000 & 6.2401 & TRN \\
\hline CHEMBL1420325 & 752306 & 5.5619 & 5.2099 & TST & \\
\hline CHEMBL1704261 & 752306 & 6.0502 & 5.9422 & TRN & \\
\hline CHEMBL1484327 & 752306 & 3.3032 & 4.0776 & TRN & \\
\hline CHEMBL1418643 & 752306 & 5.2672 & 5.8194 & TRN & \\
\hline CHEMBL1534390 & 752306 & 4.5455 & 3.6756 & TRN & \\
\hline CHEMBL1539522 & 752306 & 5.2993 & 5.3742 & TRN & \\
\hline CHEMBL1566610 & 752306 & 6.8316 & 4.9013 & TST & \\
\hline CHEMBL1416020 & 752306 & 4.6404 & 3.8484 & TRN & \\
\hline CHEMBL1424562 & 752306 & 5.4605 & 5.7604 & TRN & \\
\hline CHEMBL1609419 & 752306 & 5.5146 & 5.9991 & TRN & \\
\hline CHEMBL1964993 & 752306 & 3.3029 & 4.1141 & TRN & \\
\hline
\end{tabular}




\begin{tabular}{|c|c|c|c|c|c|}
\hline & & & & & \\
\hline CHEMBL1303810 & 752306 & 5.8365 & 6.0126 & TRN & \\
\hline CHEMBL1699845 & 752306 & 6.1319 & 5.735 & TRN & \\
\hline CHEMBL1399957 & 752306 & 4.6689 & 4.3939 & TST & \\
\hline CHEMBL1573592 & 752306 & 5.1977 & 4.666 & TRN & \\
\hline CHEMBL1535665 & 752306 & 5.6164 & 5.4625 & TRN & \\
\hline CHEMBL1865393 & 752306 & 5.9855 & 5.9563 & TRN & \\
\hline CHEMBL1473205 & 752306 & 3.3029 & 3.9264 & TST & \\
\hline CHEMBL1361821 & 752306 & 5.7167 & 5.8564 & TRN & \\
\hline CHEMBL1487952 & 752306 & 5.7111 & 5.4816 & TRN & \\
\hline CHEMBL1319461 & 752306 & 4.4937 & 3.8184 & TRN & \\
\hline CHEMBL1725771 & 752306 & 3.3029 & 3.5006 & TRN & \\
\hline CHEMBL429095 & 752306 & 6.3193 & 6.0489 & TRN & \\
\hline CHEMBL1500409 & 752306 & 3.3032 & 4.0022 & TRN & \\
\hline CHEMBL1899958 & 752306 & 4.4946 & 4.6593 & TRN & \\
\hline CHEMBL1555532 & 752306 & 5.79700 & 00000000 & 5.4929 & TRN \\
\hline CHEMBL1432251 & 752306 & 5.6925 & 6.1273 & TRN & \\
\hline CHEMBL1703189 & 752306 & 4.9178 & 4.775 & TRN & \\
\hline CHEMBL1418079 & 752306 & 5.4008 & 4.6656 & TRN & \\
\hline CHEMBL1585390 & 752306 & 5.7757 & 6.1702 & TRN & \\
\hline CHEMBL1476225 & 752306 & 4.9548 & 4.7678 & TRN & \\
\hline CHEMBL1540557 & 752306 & 3.3032 & 4.1979 & TST & \\
\hline CHEMBL1727997 & 752306 & 5.3162 & 5.5149 & TRN & \\
\hline CHEMBL1611182 & 752306 & 5.8952 & 5.699 & TRN & \\
\hline CHEMBL1712229 & 752306 & 3.3034 & 3.5061 & TRN & \\
\hline CHEMBL1386978 & 752306 & 4.5642 & 4.1665 & TRN & \\
\hline CHEMBL1375338 & 752306 & 5.4849 & 5.6011 & TRN & \\
\hline CHEMBL1419822 & 752306 & 5.6507 & 5.4261 & TRN & \\
\hline CHEMBL1360031 & 752306 & 3.3032 & 3.615 & TRN & \\
\hline CHEMBL1734503 & 752306 & 6.2237 & 5.67299 & 9999999999 & TRN \\
\hline CHEMBL1342053 & 752306 & 5.9863 & 5.9041 & TRN & \\
\hline CHEMBL1731330 & 752306 & 3.3028 & 3.6745 & TRN & \\
\hline CHEMBL1508875 & 752306 & 4.6639 & 4.315 & TRN & \\
\hline CHEMBL3197908 & 752306 & 5.2075 & 5.1867 & TRN & \\
\hline CHEMBL1351081 & 752306 & 5.7706 & 5.2765 & TRN & \\
\hline CHEMBL1538643 & 752306 & 4.8261 & 4.2403 & TRN & \\
\hline CHEMBL1732235 & 752306 & 6.2534 & 5.0008 & TST & \\
\hline CHEMBL1498308 & 752306 & 3.7803 & 3.8537 & TST & \\
\hline CHEMBL1362660 & 752306 & 6.2632 & 5.9031 & TRN & \\
\hline CHEMBL131770 & 752306 & 4.3974 & 4.1369 & TRN & \\
\hline CHEMBL1370844 & 752306 & 3.3033 & 4.1379 & TRN & \\
\hline CHEMBL1390797 & 752306 & 3.3033 & 3.6113 & TRN & \\
\hline CHEMBL1458022 & 752306 & 5.8586 & 5.3801 & TRN & \\
\hline CHEMBL1541918 & 752306 & 4.4353 & 3.653 & TRN & \\
\hline CHEMBL1343392 & 752306 & 5.8139 & 5.8263 & TRN & \\
\hline CHEMBL167542 & 752306 & 3.3028 & 3.5688 & TRN & \\
\hline CHEMBL1387110 & 752306 & 5.2585 & 4.0408 & TRN & \\
\hline CHEMBL137913 & 752306 & 3.3029 & 2.9569 & TRN & \\
\hline CHEMBL1319618 & 752306 & 5.7418 & 5.7565 & TRN & \\
\hline
\end{tabular}




\begin{tabular}{|c|c|c|c|c|c|c|}
\hline \multirow[b]{2}{*}{ CHEMBL432044 } & & \multicolumn{5}{|c|}{ Supplemental Table S2.txt } \\
\hline & 752306 & 3.3032 & 4.2115 & TRN & & \\
\hline CHEMBL1331822 & 752306 & 5.6461 & 5.2718 & TRN & & \\
\hline CHEMBL1372650 & 752306 & 4.776 & 4.4888 & TRN & & \\
\hline CHEMBL1404578 & 752306 & 5.9796 & 5.7821 & TRN & & \\
\hline CHEMBL1508593 & 752306 & 4.6983 & 4.5525 & TST & & \\
\hline CHEMBL1350432 & 752306 & 5.029 & 5.4131 & TST & & \\
\hline CHEMBL1337235 & 752306 & 5.3195 & 4.8577 & TRN & & \\
\hline CHEMBL1340895 & 752306 & 4.9902 & 4.6743 & TRN & & \\
\hline CHEMBL1462613 & 752306 & 4.4336 & 4.0388 & TRN & & \\
\hline CHEMBL1474143 & 752306 & 3.303 & 4.0137 & TST & & \\
\hline CHEMBL1327783 & 752306 & 5.6554 & 5.1914 & TRN & & \\
\hline CHEMBL1520346 & 752306 & 4.5322 & 3.6757 & TRN & & \\
\hline CHEMBL1497139 & 752306 & 5.8066 & 4.4206 & TST & & \\
\hline CHEMBL1494120 & 752306 & 6.334 & 6.725 & TRN & & \\
\hline CHEMBL1504077 & 752306 & 5.5549 & 5.4601 & TRN & & \\
\hline CHEMBL1713905 & 752306 & 3.3028 & 3.9638 & TRN & & \\
\hline CHEMBL1434843 & 752306 & 3.3032 & 4.2623 & TST & & \\
\hline CHEMBL1338304 & 752306 & 5.7421 & 5.4766 & TRN & & \\
\hline CHEMBL1557820 & 752306 & 5.2032 & 4.9342 & TST & & \\
\hline CHEMBL1723955 & 752306 & 5.8005 & 5.9076 & TRN & & \\
\hline CHEMBL1430995 & 752306 & 3.3029 & 4.3729 & TRN & & \\
\hline CHEMBL1564153 & 752306 & 3.3032 & 3.5542 & TRN & & \\
\hline CHEMBL131037 & 752306 & \multicolumn{3}{|c|}{6.2010000000000005} & 6.6319 & TRN \\
\hline CHEMBL1479144 & 752306 & 3.3032 & 3.2311 & TRN & & \\
\hline CHEMBL1502104 & 752306 & 5.439 & 5.0162 & TST & & \\
\hline CHEMBL1375884 & 752306 & 5.5658 & 5.4704 & TRN & & \\
\hline CHEMBL1707429 & 752306 & 5.5672 & 5.6463 & TRN & & \\
\hline CHEMBL1345017 & 752306 & 3.3032 & 3.6759 & TST & & \\
\hline CHEMBL1728153 & 752306 & 5.7387 & 5.7238 & TRN & & \\
\hline CHEMBL1418428 & 752306 & 4.3931 & 4.4306 & TRN & & \\
\hline CHEMBL1527994 & 752306 & 3.3033 & 3.5443 & TRN & & \\
\hline CHEMBL1361913 & 752306 & 5.5563 & 5.4357 & TRN & & \\
\hline CHEMBL1480031 & 752306 & 5.71 & 5.5922 & TRN & & \\
\hline CHEMBL1418162 & 752306 & 5.2788 & 4.6398 & TRN & & \\
\hline CHEMBL1573150 & 752306 & 3.3032 & 4.1532 & TRN & & \\
\hline CHEMBL1988416 & 752306 & 5.9872 & 5.7457 & TRN & & \\
\hline CHEMBL1571123 & 752306 & 5.4799 & 5.5326 & TRN & & \\
\hline CHEMBL1427185 & 752306 & 5.7891 & 5.7946 & TRN & & \\
\hline CHEMBL1535546 & 752306 & 5.5658 & 5.0161 & TRN & & \\
\hline CHEMBL1429929 & 752306 & 5.4569 & 5.3013 & TRN & & \\
\hline CHEMBL1417970 & 752306 & 5.5405 & 5.4381 & TRN & & \\
\hline CHEMBL1407961 & 752306 & \multicolumn{3}{|c|}{5.718999999999999} & 5.0928 & TRN \\
\hline CHEMBL1460491 & 752306 & 4.39 & 3.5878 & TRN & & \\
\hline CHEMBL1428415 & 752306 & 5.5965 & 5.4259 & TRN & & \\
\hline CHEMBL1588411 & 752306 & 5.472 & 6.1602 & TRN & & \\
\hline CHEMBL1510339 & 752306 & 5.5964 & 5.4909 & TRN & & \\
\hline CHEMBL1543956 & 752306 & 3.3034 & 3.9954 & TRN & & \\
\hline \multirow[t]{2}{*}{ CHEMBL1319026 } & 752306 & \multicolumn{3}{|c|}{ 4. 2989999999999995} & 3.7303 & TRN \\
\hline & & \multicolumn{5}{|c|}{ Page 12113} \\
\hline
\end{tabular}




\begin{tabular}{|c|c|c|c|c|c|c|}
\hline \multirow[b]{2}{*}{ CHEMBL1984584 } & \\
\hline & 752306 & 4.3263 & 4.2497 & TRN & & \\
\hline CHEMBL1417212 & 752306 & 3.3032 & 4.0871 & TRN & & \\
\hline CHEMBL1542492 & 752306 & 5.395 & 5.3534 & TRN & & \\
\hline CHEMBL1734763 & 752306 & 5.5929 & 5.6725 & TRN & & \\
\hline CHEMBL61559 & 752306 & 3.3032 & 4.0153 & TRN & & \\
\hline CHEMBL1301723 & 752306 & 5.7841 & 4.7536 & TST & & \\
\hline CHEMBL1352586 & 752306 & 5.3379 & 5.9186 & TRN & & \\
\hline CHEMBL1971913 & 752306 & 4.6312 & 4.1677 & TST & & \\
\hline CHEMBL1440300 & 752306 & 5.9289 & 5.6198 & TRN & & \\
\hline CHEMBL1436864 & 752306 & 3.3032 & 4.1662 & TST & & \\
\hline CHEMBL518575 & 752306 & 3.3032 & 4.3841 & TST & & \\
\hline CHEMBL1554784 & 752306 & 3.3031 & 3.9403 & TST & & \\
\hline CHEMBL1578982 & 752306 & 3.3033 & 4.436 & TRN & & \\
\hline CHEMBL1413680 & 752306 & 5.8877 & 5.7669 & TST & & \\
\hline CHEMBL1459316 & 752306 & 3.3033 & 4.3992 & TST & & \\
\hline CHEMBL1980369 & 752306 & 4.5958 & 4.2805 & TST & & \\
\hline CHEMBL1477528 & 752306 & 5.3973 & 5.6152 & TRN & & \\
\hline CHEMBL1518077 & 752306 & 5.4506 & 5.49799 & 9999999999 & & TRN \\
\hline CHEMBL1406130 & 752306 & 5.2369 & 4.9605 & TRN & & \\
\hline CHEMBL1704703 & 752306 & 6.2445 & 5.5293 & TRN & & \\
\hline CHEMBL505670 & 752306 & 6.3492 & 5.7296 & TRN & & \\
\hline CHEMBL1688693 & 752306 & 3.3033 & 4.7772 & TST & & \\
\hline CHEMBL1534986 & 752306 & 4.6505 & 4.2285 & TRN & & \\
\hline CHEMBL1308404 & 752306 & 5.9469 & 5.7041 & TRN & & \\
\hline CHEMBL1720248 & 752306 & 4.6141 & 4.1276 & TRN & & \\
\hline CHEMBL1315948 & 752306 & 5.1685 & 4.9624 & TRN & & \\
\hline CHEMBL1526126 & 752306 & 3.3037 & 3.4153 & TRN & & \\
\hline CHEMBL1423626 & 752306 & $5.7020 \ell$ & 30000000 & & 5.6005 & TST \\
\hline CHEMBL1705527 & 752306 & 3.3033 & 3.8845 & TRN & & \\
\hline CHEMBL1458470 & 752306 & 3.3036 & 3.6652 & TRN & & \\
\hline CHEMBL1589062 & 752306 & 4.9255 & 4.8965 & TRN & & \\
\hline CHEMBL1428095 & 752306 & 5.1998 & 5.7154 & TRN & & \\
\hline CHEMBL1406758 & 752306 & 4.6547 & 4.1268 & TRN & & \\
\hline CHEMBL1575428 & 752306 & 4.8999 & 5.2924 & TRN & & \\
\hline CHEMBL1526855 & 752306 & 6.0959 & 6.0541 & TRN & & \\
\hline CHEMBL1532571 & 752306 & 5.1367 & 4.0919 & TRN & & \\
\hline CHEMBL1492648 & 752306 & 5.4903 & 5.6545 & TRN & & \\
\hline CHEMBL1440303 & 752306 & 5.6507 & 5.8126 & TRN & & \\
\hline CHEMBL1405830 & 752306 & 3.3035 & 3.5933 & TRN & & \\
\hline CHEMBL1990694 & 752306 & 4.6971 & 3.8957 & TRN & & \\
\hline CHEMBL1991303 & 752306 & 4.30399 & 79999999 & 99 & 4.1046 & TRN \\
\hline CHEMBL1452132 & 752306 & 3.3033 & 3.3314 & TRN & & \\
\hline CHEMBL3189224 & 752306 & 4.6745 & 4.5185 & TST & & \\
\hline CHEMBL1904199 & 752306 & 5.0599 & 3.8751 & TST & & \\
\hline CHEMBL1736537 & 752306 & 5.731 & 5.0997 & TRN & & \\
\hline CHEMBL1608420 & 752306 & 3.3032 & 4.16 & TRN & & \\
\hline CHEMBL1706548 & 752306 & 5.3439 & 4.8345 & TRN & & \\
\hline CHEMBL1999049 & 752306 & 6.0214 & 5.62700 & 0000000001 & & TST \\
\hline & & & & 12114 & & \\
\hline
\end{tabular}




\begin{tabular}{|c|c|c|c|c|c|}
\hline & & \multicolumn{4}{|c|}{ Ible sL.t } \\
\hline CHEMBL1332454 & 752306 & 5.6919 & 5.4073 & TST & \\
\hline CHEMBL1574879 & 752306 & 6.3435 & 6.682 & TST & \\
\hline CHEMBL1385690 & 752306 & 5.4934 & 6.1076 & TST & \\
\hline CHEMBL3195010 & 752306 & 4.3457 & 4.3636 & TST & \\
\hline CHEMBL2005437 & 752306 & 3.3031 & 4.5506 & TST & \\
\hline CHEMBL1361740 & 752306 & 5.9666 & 5.9008 & TST & \\
\hline CHEMBL1446199 & 752306 & 3.3033 & 4.0111 & TST & \\
\hline CHEMBL1993431 & 752306 & 5.1082 & 4.3656 & TST & \\
\hline CHEMBL1711514 & 752306 & 5.8745 & 5.0817 & TST & \\
\hline CHEMBL179512 & 752306 & 4.4051 & 4.2175 & TST & \\
\hline CHEMBL1570958 & 752306 & 5.6227 & 6.1087 & TST & \\
\hline CHEMBL1301371 & 752306 & 5.5839 & 5.4964 & TST & \\
\hline CHEMBL1570323 & 752306 & 3.3033 & 4.2715 & TST & \\
\hline CHEMBL1517505 & 752306 & 3.3032 & 3.473999 & 9999999998 & TST \\
\hline CHEMBL1319867 & 752306 & 5.8652 & 6.1087 & TST & \\
\hline CHEMBL1343705 & 752306 & 5.3623 & 5.3996 & TST & \\
\hline CHEMBL1790039 & 752306 & 6.7432 & 4.2259 & TST & \\
\hline CHEMBL1711797 & 752306 & 5.7724 & 4.8911 & TST & \\
\hline CHEMBL515416 & 954460 & 3.49 & 4.241000 & 0000000005 & TRN \\
\hline CHEMBL1256459 & 954460 & 5.876 & 5.7881 & TRN & \\
\hline CHEMBL 2144069 & 954460 & 6.3489 & 5.5638 & TRN & \\
\hline CHEMBL577784 & 954460 & 5.3779 & 5.6468 & TRN & \\
\hline CHEMBL1643959 & 954460 & 3.1773 & 3.3139 & TRN & \\
\hline CHEMBL 210618 & 954460 & 4.2313 & 4.1986 & TRN & \\
\hline CHEMBL558642 & 954460 & 4.0014 & 3.6272 & TRN & \\
\hline CHEMBL2363137 & 954460 & 4.9672 & 4.956 & TRN & \\
\hline CHEMBL509032 & 954460 & 5.6322 & 4.9465 & TRN & \\
\hline CHEMBL65 & 954460 & 8.9634 & 9.2491 & TRN & \\
\hline CHEMBL483849 & 954460 & 3.3331 & 2.9248 & TRN & \\
\hline CHEMBL102714 & 954460 & 4.6664 & 4.7234 & TRN & \\
\hline CHEMBL 259181 & 954460 & 4.4043 & 4.38 & TRN & \\
\hline CHEMBL 240954 & 954460 & 4.3205 & 4.5765 & TST & \\
\hline CHEMBL 222102 & 954460 & 4.7663 & 4.7456 & TRN & \\
\hline CHEMBL92309 & 954460 & 2.3912 & 2.8308 & TST & \\
\hline CHEMBL 221137 & 954460 & 4.3939 & 4.6554 & TST & \\
\hline CHEMBL220241 & 954460 & 4.2041 & 4.7326 & TRN & \\
\hline CHEMBL3186408 & 954460 & 4.3547 & 4.0999 & TST & \\
\hline CHEMBL189584 & 954460 & 5.6608 & 5.5764 & TRN & \\
\hline CHEMBL1242367 & 954460 & 4.6358 & 4.0576 & TRN & \\
\hline CHEMBL373751 & 954460 & 3.1504 & 3.8482 & TRN & \\
\hline CHEMBL1190711 & 954460 & 5.7009 & 5.4581 & TRN & \\
\hline CHEMBL1970879 & 954460 & 4.4106 & 3.6849 & TRN & \\
\hline CHEMBL3349342 & 954460 & 5.9061 & 5.4992 & TRN & \\
\hline CHEMBL1909414 & 954460 & 5.53700 & 000000000 & 5.2925 & TRN \\
\hline CHEMBL472940 & 954460 & 2.4619 & 3.6757 & TRN & \\
\hline CHEMBL512504 & 954460 & 6.5072 & 6.8535 & TRN & \\
\hline CHEMBL188678 & 954460 & 6.2147 & 5.6425 & TRN & \\
\hline CHEMBL1230020 & 954460 & 4.5537 & 5.0549 & TRN & \\
\hline
\end{tabular}




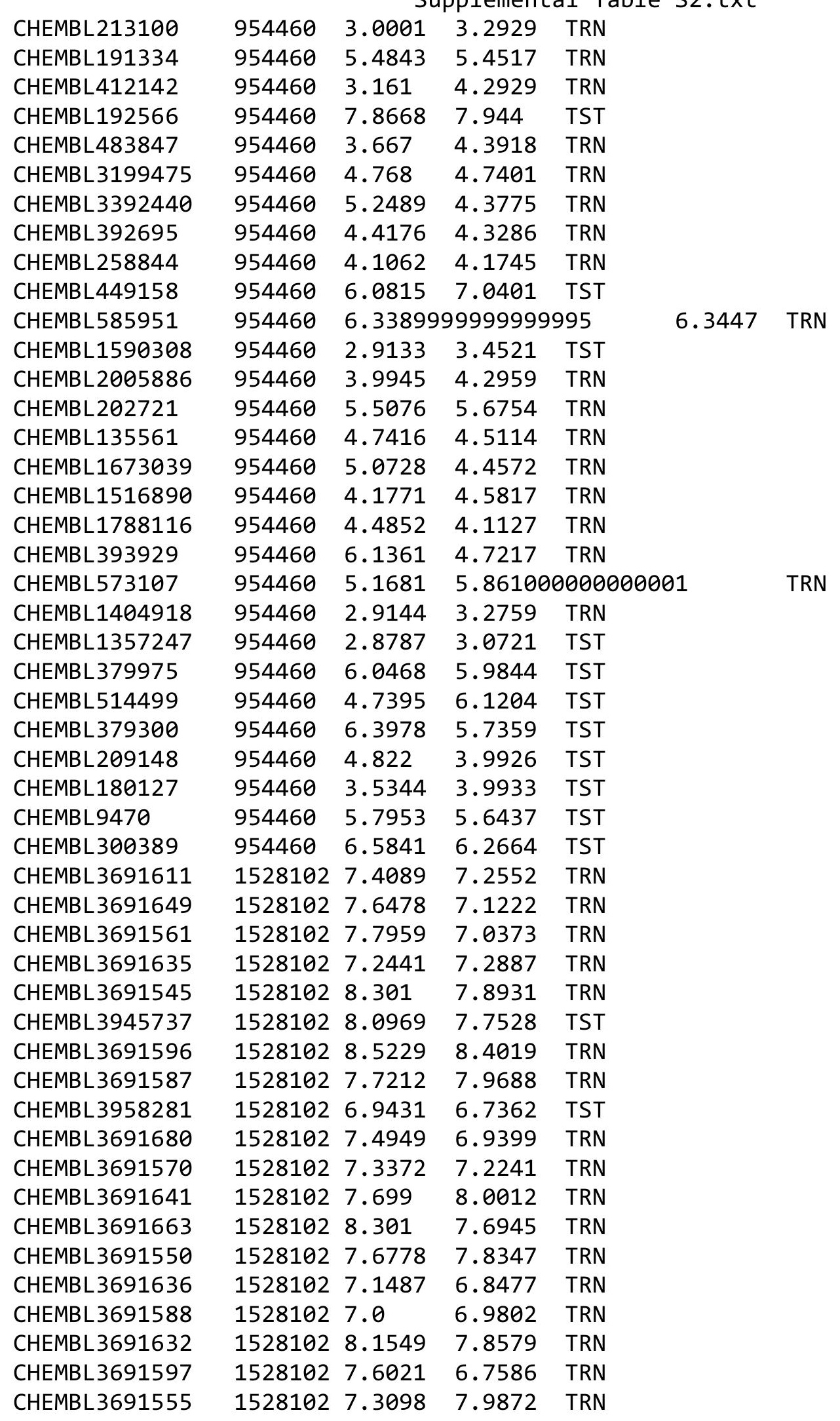

Page 12116 
Supplemental Table S2.txt

\begin{tabular}{|c|c|c|c|c|}
\hline CHEMBL3691603 & 1528102 & 7.699 & 7.5248 & TRN \\
\hline CHEMBL3691584 & 1528102 & 7.7959 & 7.4705 & TRN \\
\hline CHEMBL3691557 & 1528102 & 7.7212 & 7.7508 & TRN \\
\hline CHEMBL3691585 & 1528102 & 7.8239 & 7.3117 & TRN \\
\hline CHEMBL3691569 & 1528102 & 7.4202 & 7.2165 & TRN \\
\hline CHEMBL3691575 & 1528102 & 7.7447 & 7.2408 & TRN \\
\hline CHEMBL3691546 & 1528102 & 9.0 & 8.6235 & TRN \\
\hline CHEMBL3691630 & 1528102 & 9.301 & 8.5944 & TRN \\
\hline CHEMBL3908903 & 1528102 & 8.0 & 7.652 & TST \\
\hline CHEMBL3691634 & 1528102 & 7.2924 & 6.9573 & TST \\
\hline CHEMBL3691645 & 1528102 & 7.8861 & 8.0609 & TRN \\
\hline CHEMBL3914273 & 1528102 & 6.0 & 7.4883 & TST \\
\hline CHEMBL 3900227 & 1528102 & 7.2076 & 6.6923 & TST \\
\hline CHEMBL 3922957 & 1528102 & 7.3279 & 7.0067 & TST \\
\hline CHEMBL3691656 & 1528102 & 7.9208 & 7.2066 & TST \\
\hline CHEMBL3691547 & 1528102 & 8.3979 & 7.6546 & TRN \\
\hline CHEMBL3691602 & 1528102 & 7.7212 & 7.369 & TRN \\
\hline CHEMBL 3691566 & 1528102 & 5.7878 & 6.4008 & TRN \\
\hline CHEMBL3691608 & 1528102 & 8.5229 & 8.6235 & TRN \\
\hline CHEMBL3691562 & 1528102 & 8.1871 & 8.0592 & TRN \\
\hline CHEMBL3691627 & 1528102 & 6.0 & 6.9209 & TRN \\
\hline CHEMBL 3691640 & 1528102 & 6.0 & 7.2962 & TST \\
\hline CHEMBL3691577 & 1528102 & 7.6576 & 7.2592 & TRN \\
\hline CHEMBL3691637 & 1528102 & 7.4559 & 7.4468 & TRN \\
\hline CHEMBL 3691648 & 1528102 & 7.3872 & 7.3277 & TRN \\
\hline CHEMBL3691631 & 1528102 & 7.3716 & 7.7974 & TST \\
\hline CHEMBL3691619 & 1528102 & 7.3768 & 7.5306 & TRN \\
\hline CHEMBL3691590 & 1528102 & 7.6198 & 7.0915 & TST \\
\hline CHEMBL3691650 & 1528102 & 7.7212 & 7.1582 & TST \\
\hline CHEMBL3691670 & 1528102 & 6.0 & 6.3934 & TRN \\
\hline CHEMBL3691560 & 1528102 & 7.1871 & 7.4694 & TRN \\
\hline CHEMBL3691658 & 1528102 & 7.0315 & 7.16700 & 0000000001 \\
\hline CHEMBL 3927256 & 1528102 & 6.9747 & 6.6531 & TST \\
\hline CHEMBL3691583 & 1528102 & 7.3565 & 7.3238 & TRN \\
\hline CHEMBL3639904 & 1528102 & 6.0 & 7.4716 & TST \\
\hline CHEMBL3691618 & 1528102 & 7.1192 & 6.6018 & TRN \\
\hline CHEMBL 3691600 & 1528102 & 7.1308 & 7.0677 & TRN \\
\hline CHEMBL3691614 & 1528102 & 7.1739 & 6.9748 & TRN \\
\hline CHEMBL3691657 & 1528102 & 7.1805 & 7.0014 & TST \\
\hline CHEMBL3691638 & 1528102 & 7.699 & 7.2528 & TST \\
\hline CHEMBL3691589 & 1528102 & 7.5229 & 7.3996 & TRN \\
\hline CHEMBL3691621 & 1528102 & 6.0 & 7.4967 & TRN \\
\hline CHEMBL3691595 & 1528102 & 8.5229 & 8.7461 & TRN \\
\hline CHEMBL3691652 & 1528102 & 7.4498 & 6.7381 & TST \\
\hline CHEMBL3691582 & 1528102 & 7.1135 & 8.2514 & TST \\
\hline CHEMBL3691639 & 1528102 & 7.7447 & 7.9387 & TST \\
\hline CHEMBL3691581 & 1528102 & 6.0 & 6.7032 & TRN \\
\hline CHEMBL3691664 & 1528102 & 6.0 & 6.0282 & TRN \\
\hline
\end{tabular}


Supplemental Table S2.txt

\begin{tabular}{|c|c|c|c|c|}
\hline CHEMBL 3691572 & 1528102 & 7.8097 & 7.8036 & TRN \\
\hline CHEMBL 3986564 & 1528102 & 7.3468 & 7.8295 & TST \\
\hline CHEMBL 3691544 & 1528102 & 7.7696 & 7.2974 & TRN \\
\hline CHEMBL 3691609 & 1528102 & 8.1871 & 8.2984 & TRN \\
\hline CHEMBL 3691613 & 1528102 & 7.1904 & 7.3655 & TRN \\
\hline CHEMBL 3691651 & 1528102 & 6.7212 & 7.4363 & TST \\
\hline CHEMBL 3691565 & 1528102 & 7.1397 & 7.3316 & TRN \\
\hline CHEMBL 3691563 & 1528102 & 7.1938 & 7.2024 & TRN \\
\hline CHEMBL 3691654 & 1528102 & 8.0969 & 7.5968 & TRN \\
\hline CHEMBL 3691598 & 1528102 & 6.9508 & 6.2321 & TRN \\
\hline CHEMBL 3691556 & 1528102 & 8.2218 & 7.7911 & TRN \\
\hline CHEMBL 3691606 & 1528102 & 7.1192 & 6.9383 & TRN \\
\hline CHEMBL 3691653 & 1528102 & 6.0 & 6.7032 & TRN \\
\hline CHEMBL 3691661 & 1528102 & 7.8239 & 6.9747 & TRN \\
\hline CHEMBL 3691567 & 1528102 & 7.3098 & 7.3739 & TRN \\
\hline CHEMBL 3691655 & 1528102 & 8.0223 & 7.0391 & TST \\
\hline CHEMBL 3691548 & 1528102 & 7.9208 & 7.8454 & TRN \\
\hline CHEMBL 3691576 & 1528102 & 6.9245 & 7.1985 & TRN \\
\hline CHEMBL 3691662 & 1528102 & 7.6882 & 7.7099 & TRN \\
\hline CHEMBL 3691679 & 1528102 & 7.7212 & 7.6427 & TRN \\
\hline CHEMBL 3691617 & 1528102 & 7.5686 & 7.7326 & TRN \\
\hline CHEMBL 3691578 & 1528102 & 7.585 & 7.6792 & TRN \\
\hline CHEMBL 3691599 & 1528102 & 5.8052 & 6.6497 & TRN \\
\hline CHEMBL 3691610 & 1528102 & 6.0 & 6.6803 & TRN \\
\hline CHEMBL 3691571 & 1528102 & 7.6576 & 7.95799 & و999999999 \\
\hline CHEMBL 3691551 & 1528102 & 7.4089 & 7.8116 & TRN \\
\hline CHEMBL 3980917 & 1528102 & 7.4685 & 7.2388 & TST \\
\hline CHEMBL 3967212 & 1528102 & 8.0969 & 6.762006 & 30000000005 \\
\hline CHEMBL 3691549 & 1528102 & 6.7282 & 7.8584 & TRN \\
\hline CHEMBL 3691607 & 1528102 & 8.2596 & 7.6546 & TRN \\
\hline CHEMBL 3691592 & 1528102 & 7.6778 & 7.0304 & TRN \\
\hline CHEMBL 3691605 & 1528102 & 6.9014 & 7.1908 & TRN \\
\hline CHEMBL3691579 & 1528102 & 6.0 & 6.1989 & TRN \\
\hline CHEMBL 3691676 & 1528102 & 6.0 & 7.5853 & TRN \\
\hline CHEMBL 3691593 & 1528102 & 7.6383 & 7.6145 & TST \\
\hline CHEMBL 3691594 & 1528102 & 7.5686 & 7.1065 & TRN \\
\hline CHEMBL 3691573 & 1528102 & 6.0 & 7.3691 & TRN \\
\hline CHEMBL 3691633 & 1528102 & 7.6676 & 7.5617 & TST \\
\hline CHEMBL 2311171 & 321687 & 5.77 & 5.765 & TRN \\
\hline CHEMBL194749 & 321687 & 7.05 & 7.0574 & TRN \\
\hline CHEMBL 269003 & 321687 & 4.85 & 4.8527 & TRN \\
\hline CHEMBL 276915 & 321687 & 3.37 & 3.3857 & TRN \\
\hline CHEMBL 7976 & 321687 & 4.19 & 4.2225 & TRN \\
\hline CHEMBL153062 & 321687 & 4.94 & 4.7807 & TRN \\
\hline CHEMBL16217 & 321687 & 3.84 & 3.8312 & TRN \\
\hline CHEMBL 29398 & 321687 & 4.07 & 4.0581 & TRN \\
\hline CHEMBL193558 & 321687 & 4.83 & 4.8352 & TRN \\
\hline CHEMBL194945 & 321687 & 4.69 & 4.6633 & TRN \\
\hline
\end{tabular}




\begin{tabular}{|c|c|c|c|c|c|}
\hline \multicolumn{6}{|c|}{ Supplemental Table S2.txt } \\
\hline CHEMBL196590 & 321687 & 4.81 & 4.8165 & TRN & \\
\hline CHEMBL418971 & 321687 & 4.13 & 4.1564 & TRN & \\
\hline CHEMBL194487 & 321687 & 3.74 & 3.8468 & TRN & \\
\hline CHEMBL196537 & 321687 & 5.0 & 5.5473 & TST & \\
\hline CHEMBL195953 & 321687 & 4.49 & 5.4189 & TST & \\
\hline CHEMBL197309 & 321687 & 8.58 & 8.5771 & TRN & \\
\hline CHEMBL371356 & 321687 & 7.96 & 7.9635 & TRN & \\
\hline CHEMBL196228 & 321687 & 7.8 & 7.8218 & TRN & \\
\hline CHEMBL 373357 & 321687 & 6.42 & 6.4283 & TRN & \\
\hline CHEMBL 3085537 & 321687 & 7.05 & 6.3412 & TST & \\
\hline CHEMBL195836 & 321687 & 6.2 & 6.17700 & 00000000005 & TRN \\
\hline CHEMBL366162 & 321687 & 6.59 & 6.5872 & TRN & \\
\hline CHEMBL87285 & 321687 & 4.39 & 4.3932 & TRN & \\
\hline CHEMBL 3138083 & 321687 & 4.88 & 4.8828 & TRN & \\
\hline CHEMBL363554 & 321687 & 4.53 & 4.5183 & TRN & \\
\hline CHEMBL1412489 & 321687 & 5.59 & 6.8337 & TST & \\
\hline CHEMBL467987 & 321687 & 5.07 & 6.9942 & TST & \\
\hline CHEMBL261406 & 321687 & 4.38 & 5.5556 & TST & \\
\hline CHEMBL1628012 & 321687 & 4.27 & 5.9483 & TST & \\
\hline CHEMBL1627757 & 321687 & 4.43 & 5.6956 & TST & \\
\hline CHEMBL110739 & 321687 & 4.63 & 7.2661 & TST & \\
\hline CHEMBL196731 & 321687 & 4.08 & 4.1316 & TRN & \\
\hline CHEMBL14702 & 321687 & 4.43 & 4.4301 & TRN & \\
\hline CHEMBL196732 & 321687 & 4.89 & 4.9048 & TRN & \\
\hline CHEMBL195624 & 321687 & 4.38 & 4.3445 & TRN & \\
\hline CHEMBL 275638 & 321687 & 4.11 & 4.1065 & TRN & \\
\hline CHEMBL138649 & 321687 & 3.74 & 3.7387 & TRN & \\
\hline CHEMBL 274318 & 321687 & 4.26 & 4.7764 & TST & \\
\hline CHEMBL73933 & 321687 & 4.24 & 4.863 & TST & \\
\hline CHEMBL195033 & 321687 & 4.73 & 4.3448 & TST & \\
\hline CHEMBL44 & 321687 & 4.07 & 4.7368 & TST & \\
\hline CHEMBL30707 & 321687 & 3.37 & 3.3686 & TRN & \\
\hline CHEMBL 276473 & 321687 & 4.24 & 4.2497 & TRN & \\
\hline CHEMBL 7747 & 321687 & 4.32 & 4.2917 & TRN & \\
\hline CHEMBL195437 & 321687 & 4.72 & 4.7807 & TRN & \\
\hline CHEMBL194881 & 321687 & 4.69 & 4.7807 & TRN & \\
\hline CHEMBL195693 & 321687 & 4.11 & 4.1138 & TRN & \\
\hline CHEMBL 30193 & 321687 & 3.99 & 3.9978 & TRN & \\
\hline CHEMBL194121 & 321687 & 3.92 & 3.9501 & TRN & \\
\hline CHEMBL41172 & 321687 & 3.34 & 3.3598 & TRN & \\
\hline CHEMBL445206 & 321687 & 3.69 & 3.66300 & 00000000003 & TRN \\
\hline CHEMBL194034 & 321687 & 4.74 & 4.7367 & TRN & \\
\hline CHEMBL364287 & 321687 & 5.2 & 5.1787 & TRN & \\
\hline CHEMBL362919 & 321687 & 4.55 & 4.5501 & TRN & \\
\hline CHEMBL196585 & 321687 & 5.04 & 5.038 & TRN & \\
\hline CHEMBL194906 & 321687 & 4.31 & 4.3472 & TRN & \\
\hline CHEMBL 364900 & 321687 & 4.83 & 4.8438 & TRN & \\
\hline CHEMBL196239 & 321687 & 4.98 & 4.9836 & TRN & \\
\hline
\end{tabular}




\begin{tabular}{|c|c|c|c|c|}
\hline \multicolumn{5}{|c|}{ Supplemental Table S2.txt } \\
\hline CHEMBL1391 & 321687 & 4.69 & 4.6769 & TRN \\
\hline CHEMBL363207 & 321687 & 4.81 & 4.7998 & TRN \\
\hline CHEMBL371077 & 321687 & 4.42 & 4.4237 & TRN \\
\hline CHEMBL194805 & 321687 & 4.4 & 4.3671 & TRN \\
\hline CHEMBL1392 & 321687 & 3.99 & 3.987 & TRN \\
\hline CHEMBL90039 & 321687 & 3.89 & 3.8201 & TRN \\
\hline CHEMBL194859 & 321687 & 3.84 & 3.7875 & TRN \\
\hline CHEMBL73380 & 321687 & 5.08 & 5.0715 & TRN \\
\hline CHEMBL194399 & 321687 & 4.63 & 5.4075 & TST \\
\hline CHEMBL194400 & 321687 & 4.87 & 5.3791 & TST \\
\hline CHEMBL462576 & 321687 & 4.92 & 4.9537 & TST \\
\hline CHEMBL194458 & 321687 & 3.34 & 4.4012 & TST \\
\hline CHEMBL311000 & 321687 & 4.79 & 4.7826 & TRN \\
\hline CHEMBL195890 & 321687 & 4.79 & 4.7775 & TRN \\
\hline CHEMBL137283 & 321687 & 4.77 & 4.7561 & TRN \\
\hline CHEMBL83116 & 321687 & 4.42 & 4.4292 & TST \\
\hline CHEMBL193377 & 321687 & 4.54 & 5.2553 & TST \\
\hline CHEMBL489 & 321687 & 5.03 & 5.0395 & TRN \\
\hline CHEMBL313011 & 540542 & 6.0 & 5.4872 & TRN \\
\hline CHEMBL472871 & 540542 & 5.585 & 5.5735 & TRN \\
\hline CHEMBL299704 & 540542 & 9.8891 & 8.5989 & TRN \\
\hline CHEMBL346794 & 540542 & 4.8761 & 5.2925 & TST \\
\hline CHEMBL516025 & 540542 & 6.3188 & 5.7746 & TRN \\
\hline CHEMBL 82224 & 540542 & 3.8239 & 5.2977 & TRN \\
\hline CHEMBL129037 & 540542 & 4.0 & 3.8054 & TRN \\
\hline CHEMBL59520 & 540542 & 9.4829 & 8.9909 & TRN \\
\hline CHEMBL82691 & 540542 & 3.699 & 4.7896 & TRN \\
\hline CHEMBL55070 & 540542 & 5.699 & 4.7351 & TST \\
\hline CHEMBL148716 & 540542 & 9.5229 & 10.2963 & TRN \\
\hline CHEMBL57548 & 540542 & 10.7069 & 10.7186 & TRN \\
\hline CHEMBL538904 & 540542 & 6.5229 & 5.0476 & TRN \\
\hline CHEMBL444739 & 540542 & 4.5528 & 5.1469 & TRN \\
\hline CHEMBL288543 & 540542 & 4.0655 & 5.8898 & TST \\
\hline CHEMBL 292138 & 540542 & 6.4318 & 5.7151 & TST \\
\hline CHEMBL231281 & 540542 & 9.0 & 6.9 & TST \\
\hline CHEMBL57384 & 540542 & 9.6054 & 9.6135 & TRN \\
\hline CHEMBL505752 & 540542 & 4.6799 & 4.6983 & TRN \\
\hline CHEMBL150081 & 540542 & 7.3768 & 6.6855 & TRN \\
\hline CHEMBL 358883 & 540542 & 7.0458 & 6.4623 & TRN \\
\hline CHEMBL24006 & 540542 & 3.699 & 4.4177 & TRN \\
\hline CHEMBL378250 & 540542 & 3.699 & 4.3321 & TRN \\
\hline CHEMBL312251 & 540542 & 6.5229 & 6.6393 & TRN \\
\hline CHEMBL202663 & 540542 & 8.6198 & 5.7968 & TST \\
\hline CHEMBL337301 & 540542 & 9.0706 & 4.5406 & TST \\
\hline CHEMBL419108 & 540542 & 7.301 & 7.709 & TRN \\
\hline CHEMBL501841 & 540542 & 5.7375 & 5.6997 & TRN \\
\hline CHEMBL453724 & 540542 & 4.0 & 5.2007 & TRN \\
\hline CHEMBL243876 & 540542 & 3.699 & 3.9884 & TST \\
\hline
\end{tabular}




\begin{tabular}{|c|c|c|c|c|}
\hline & & & oplementa & al $\mathrm{T}$ \\
\hline CHEMBL464972 & 540542 & 6.0 & 5.4294 & TST \\
\hline CHEMBL475514 & 540542 & 5.9208 & 4.5583 & TRN \\
\hline CHEMBL84300 & 540542 & 4.8239 & 5.2779 & TRN \\
\hline CHEMBL470861 & 540542 & 6.2218 & 5.7454 & TST \\
\hline CHEMBL473480 & 540542 & 4.0458 & 3.7983 & TRN \\
\hline CHEMBL 36640 & 540542 & 4.9208 & 4.3832 & TRN \\
\hline CHEMBL348215 & 540542 & 9.5229 & 9.6088 & TRN \\
\hline CHEMBL 309674 & 540542 & 7.5229 & 5.7273 & TST \\
\hline CHEMBL341867 & 540542 & 6.3565 & 5.3709 & TRN \\
\hline CHEMBL516299 & 540542 & 3.699 & 4.5042 & TRN \\
\hline CHEMBL146699 & 540542 & 9.5229 & 10.1448 & TRN \\
\hline CHEMBL124389 & 540542 & 4.0 & 5.4857 & TST \\
\hline CHEMBL51254 & 540542 & 4.0218 & 4.7377 & TRN \\
\hline CHEMBL79826 & 540542 & 5.0458 & 5.9193 & TRN \\
\hline CHEMBL281913 & 540542 & 6.699 & 4.967 & TRN \\
\hline CHEMBL79291 & 540542 & 4.4949 & 5.0771 & TRN \\
\hline CHEMBL504241 & 540542 & 4.8239 & 4.3927 & TRN \\
\hline CHEMBL151152 & 540542 & 7.0044 & 6.3364 & TRN \\
\hline CHEMBL470025 & 540542 & 9.2007 & 7.9026 & TST \\
\hline CHEMBL473682 & 540542 & 4.3615 & 5.0045 & TRN \\
\hline CHEMBL289825 & 540542 & 4.0132 & 4.9119 & TST \\
\hline CHEMBL57452 & 540542 & 5.2211 & 7.1852 & TRN \\
\hline CHEMBL472863 & 540542 & 6.7212 & 4.9467 & TST \\
\hline CHEMBL435418 & 540542 & 4.3979 & 4.7396 & TRN \\
\hline CHEMBL503587 & 540542 & 4.9547 & 4.7394 & TRN \\
\hline CHEMBL106369 & 540542 & 7.585 & 5.0325 & TST \\
\hline CHEMBL320833 & 540542 & 8.5229 & 5.0986 & TST \\
\hline CHEMBL58581 & 540542 & 5.7696 & 5.6732 & TST \\
\hline CHEMBL81097 & 540542 & 8.0 & 6.5286 & TRN \\
\hline CHEMBL84002 & 540542 & 7.8239 & 7.6259 & TRN \\
\hline CHEMBL173790 & 540542 & 7.1549 & 6.061 & TST \\
\hline CHEMBL506938 & 540542 & 4.6383 & 4.673 & TRN \\
\hline CHEMBL475299 & 540542 & 4.0 & 4.3216 & TRN \\
\hline CHEMBL358153 & 540542 & 9.5229 & 10.1792 & TRN \\
\hline CHEMBL513047 & 540542 & 5.6596 & 5.1732 & TST \\
\hline CHEMBL59237 & 540542 & 7.0 & 5.8646 & TST \\
\hline CHEMBL 82106 & 540542 & 9.0 & 7.5687 & TRN \\
\hline CHEMBL 364097 & 540542 & 4.7212 & 3.6569 & TRN \\
\hline CHEMBL144885 & 540542 & 4.0942 & 4.7262 & TRN \\
\hline CHEMBL314618 & 540542 & 5.5086 & 6.1447 & TRN \\
\hline CHEMBL 71728 & 540542 & 9.4949 & 7.8056 & TST \\
\hline CHEMBL37431 & 540542 & 5.0458 & 4.2596 & TRN \\
\hline CHEMBL452964 & 540542 & 6.1549 & 4.7451 & TRN \\
\hline CHEMBL475088 & 540542 & 4.8239 & 5.3013 & TRN \\
\hline CHEMBL150149 & 540542 & 5.1433 & 5.3484 & TRN \\
\hline CHEMBL39301 & 540542 & 4.5229 & 4.7771 & TRN \\
\hline CHEMBL150057 & 540542 & 9.5229 & 9.2659 & TRN \\
\hline CHEMBL514605 & 540542 & 4.0 & 5.1191 & TST \\
\hline
\end{tabular}




\begin{tabular}{|c|c|c|c|c|c|}
\hline \multicolumn{6}{|c|}{ Supplemental Table S2.txt } \\
\hline CHEMBL37845 & 540542 & 5.1675 & 4.7295 & TRN & \\
\hline CHEMBL475300 & 540542 & 5.0969 & 5.1073 & TRN & \\
\hline CHEMBL515244 & 540542 & 4.0 & 5.2841 & TRN & \\
\hline CHEMBL224595 & 540542 & 4.9208 & 4.9003 & TRN & \\
\hline CHEMBL356135 & 540542 & 9.5229 & 8.9886 & TRN & \\
\hline CHEMBL376591 & 540542 & 6.0 & 5.3247 & TRN & \\
\hline CHEMBL514945 & 540542 & 4.8097 & 4.5114 & TRN & \\
\hline CHEMBL473691 & 540542 & 4.0 & 4.9248 & TRN & \\
\hline CHEMBL150124 & 540542 & 9.5229 & 9.7422 & TRN & \\
\hline CHEMBL448849 & 540542 & 7.7447 & 5.7459 & TRN & \\
\hline CHEMBL475712 & 540542 & 6.0 & 5.2129 & TRN & \\
\hline CHEMBL137174 & 540542 & 6.0 & 5.8127 & TRN & \\
\hline CHEMBL475087 & 540542 & 9.2007 & 6.5231 & TST & \\
\hline CHEMBL148304 & 540542 & 9.5229 & 9.3938 & TRN & \\
\hline CHEMBL 278657 & 540542 & 6.1549 & 5.8127 & TRN & \\
\hline CHEMBL312729 & 540542 & 3.699 & 4.8301 & TRN & \\
\hline CHEMBL343457 & 540542 & 4.9355 & 5.4062 & TRN & \\
\hline CHEMBL 82780 & 540542 & 5.4559 & 4.0545 & TRN & \\
\hline CHEMBL 279562 & 540542 & 5.4921 & 4.8845 & TRN & \\
\hline CHEMBL515129 & 540542 & 5.0 & 5.7133 & TRN & \\
\hline CHEMBL472869 & 540542 & 6.284 & 5.33200 & 0000000001 & TRN \\
\hline CHEMBL445364 & 540542 & 5.301 & 5.7891 & TRN & \\
\hline CHEMBL149664 & 540542 & 9.5229 & 8.9053 & TRN & \\
\hline CHEMBL157428 & 540542 & 5.3665 & 5.619 & TST & \\
\hline CHEMBL143997 & 540542 & 4.0 & 4.8241 & TRN & \\
\hline CHEMBL106299 & 540542 & 7.6383 & 4.5847 & TST & \\
\hline CHEMBL504843 & 540542 & 4.0 & 4.7407 & TST & \\
\hline CHEMBL 82103 & 540542 & 3.699 & 4.2811 & TRN & \\
\hline CHEMBL 39883 & 540542 & 4.301 & 4.9105 & TRN & \\
\hline CHEMBL83981 & 540542 & 3.699 & 3.9004 & TRN & \\
\hline CHEMBL149913 & 540542 & 5.6716 & 5.5181 & TRN & \\
\hline CHEMBL344803 & 540542 & 4.301 & 4.6433 & TRN & \\
\hline CHEMBL142072 & 540542 & 7.301 & 4.2417 & TST & \\
\hline CHEMBL504070 & 540542 & 4.8239 & 4.8343 & TRN & \\
\hline CHEMBL52868 & 540542 & 6.2218 & 4.1779 & TST & \\
\hline CHEMBL334566 & 540542 & 4.4949 & 5.0146 & TRN & \\
\hline CHEMBL 301240 & 540542 & 9.4829 & 9.3164 & TRN & \\
\hline CHEMBL512140 & 540542 & 4.4318 & 4.1085 & TRN & \\
\hline CHEMBL41589 & 540542 & 4.3468 & 4.9581 & TST & \\
\hline CHEMBL82992 & 540542 & 3.699 & 4.9374 & TRN & \\
\hline CHEMBL467389 & 540542 & 4.6021 & 5.6923 & TRN & \\
\hline CHEMBL187970 & 540542 & 4.2218 & 4.4776 & TRN & \\
\hline CHEMBL470502 & 540542 & 4.0 & 4.6933 & TRN & \\
\hline CHEMBL 39143 & 540542 & 4.0 & 4.1236 & TRN & \\
\hline CHEMBL56641 & 540542 & 9.8496 & 9.5275 & TRN & \\
\hline CHEMBL 24118 & 540542 & 4.6021 & 4.6837 & TRN & \\
\hline CHEMBL504793 & 540542 & 6.0 & 9.3587 & TRN & \\
\hline CHEMBL150025 & 540542 & 7.2291 & 6.6267 & TRN & \\
\hline
\end{tabular}




\begin{tabular}{|c|c|c|c|c|c|c|}
\hline & & \multicolumn{5}{|c|}{ Supplemental Table s2.txt } \\
\hline CHEMBL36070 & 540542 & 7.3979 & 4.256 & TST & & \\
\hline CHEMBL84217 & 540542 & 8.5229 & 8.0419 & TRN & & \\
\hline CHEMBL 275658 & 540542 & 8.3979 & 5.8198 & TST & & \\
\hline CHEMBL474698 & 540542 & 4.4949 & 4.4308 & TRN & & \\
\hline CHEMBL418613 & 540542 & 4.0223 & 4.4562 & TRN & & \\
\hline CHEMBL475499 & 540542 & 4.4559 & 4.196000 & 000000001 & & TRN \\
\hline CHEMBL512553 & 540542 & 5.1549 & 4.9003 & TST & & \\
\hline CHEMBL138028 & 540542 & 8.8539 & 4.1644 & TST & & \\
\hline CHEMBL 38420 & 540542 & 4.0 & 4.3629 & TRN & & \\
\hline CHEMBL150662 & 540542 & 7.1938 & 6.3158 & TRN & & \\
\hline CHEMBL 356190 & 540542 & 7.5229 & 6.3425 & TRN & & \\
\hline CHEMBL516201 & 540542 & 5.7447 & 6.2055 & TRN & & \\
\hline CHEMBL188686 & 540542 & 3.9747 & 4.0428 & TRN & & \\
\hline CHEMBL 311883 & 540542 & 4.1805 & 4.9716 & TRN & & \\
\hline CHEMBL473685 & 540542 & 6.0 & 5.0811 & TRN & & \\
\hline CHEMBL473489 & 540542 & 6.1871 & 5.4689 & TRN & & \\
\hline CHEMBL357261 & 540542 & $5.82100 e$ & 900000000 & 1 & 5.4967 & TRN \\
\hline CHEMBL344966 & 540542 & 4.3605 & 4.4113 & TRN & & \\
\hline CHEMBL492770 & 540542 & 6.4559 & 5.7446 & TRN & & \\
\hline CHEMBL 84372 & 540542 & 5.3979 & 3.9239 & TRN & & \\
\hline CHEMBL434951 & 540542 & 5.1487 & 5.68 & TST & & \\
\hline CHEMBL39032 & 540542 & 3.699 & 5.6048 & TST & & \\
\hline CHEMBL59548 & 540542 & 4.0969 & 4.2093 & TRN & & \\
\hline CHEMBL314269 & 540542 & 4.8861 & 5.8277 & TRN & & \\
\hline CHEMBL146197 & 540542 & 9.5229 & 8.8021 & TRN & & \\
\hline CHEMBL59144 & 540542 & 9.4487 & 10.1653 & TRN & & \\
\hline CHEMBL502861 & 540542 & 4.8297 & 4.7841 & TRN & & \\
\hline CHEMBL515296 & 540542 & 5.8928 & 6.0247 & TRN & & \\
\hline CHEMBL 312702 & 540542 & 8.2218 & 6.5823 & TRN & & \\
\hline CHEMBL368172 & 540542 & 7.4559 & 6.1535 & TST & & \\
\hline CHEMBL141946 & 540542 & 3.9586 & 4.2723 & TRN & & \\
\hline CHEMBL423652 & 540542 & 3.0 & 4.5218 & TRN & & \\
\hline CHEMBL474697 & 540542 & 4.699 & 4.9653 & TST & & \\
\hline CHEMBL 188190 & 540542 & 4.5086 & 4.1916 & TRN & & \\
\hline CHEMBL515143 & 540542 & 4.0 & 4.9412 & TRN & & \\
\hline CHEMBL 346387 & 540542 & 10.8539 & 9.1335 & TRN & & \\
\hline CHEMBL 309838 & 540542 & 5.301 & 4.7798 & TRN & & \\
\hline CHEMBL50428 & 540542 & 4.2716 & 5.9423 & TRN & & \\
\hline CHEMBL143396 & 540542 & 4.0 & 4.5316 & TRN & & \\
\hline CHEMBL153896 & 540542 & 5.2366 & 5.646 & TST & & \\
\hline CHEMBL502934 & 540542 & 4.7932 & 5.165 & TRN & & \\
\hline CHEMBL149116 & 540542 & 9.5229 & 9.9629 & TRN & & \\
\hline CHEMBL356695 & 540542 & 9.5229 & 9.9262 & TRN & & \\
\hline CHEMBL19464 & 540542 & 7.0 & 5.0773 & TST & & \\
\hline CHEMBL347211 & 540542 & $4.82100 e$ & 300000000 & & 4.5093 & TST \\
\hline CHEMBL515039 & 540542 & 3.699 & 4.5372 & TRN & & \\
\hline CHEMBL472862 & 540542 & 5.0 & 4.8219 & TST & & \\
\hline CHEMBL506380 & 540542 & 4.0 & 3.7902 & TRN & & \\
\hline
\end{tabular}




\begin{tabular}{|c|c|c|c|c|c|}
\hline \multirow[b]{2}{*}{ CHEMBL83793 } & & \multicolumn{4}{|c|}{ Supplemental Table S2.txt } \\
\hline & 540542 & 5.7212 & 5.99299 & 9999999999 & TRN \\
\hline CHEMBL504035 & 540542 & 4.8125 & 4.6844 & TRN & \\
\hline CHEMBL449902 & 540542 & 5.8447 & 5.0619 & TRN & \\
\hline CHEMBL515100 & 540542 & 4.9393 & 4.7991 & TRN & \\
\hline CHEMBL473072 & 540542 & 7.0506 & 5.9829 & TRN & \\
\hline CHEMBL58370 & 540542 & 9.3962 & 8.9513 & TRN & \\
\hline CHEMBL142246 & 540542 & 5.0 & 4.4636 & TRN & \\
\hline CHEMBL311895 & 540542 & 3.699 & 4.8544 & TRN & \\
\hline CHEMBL283950 & 540542 & 5.699 & 6.9059 & TRN & \\
\hline CHEMBL315349 & 540542 & 8.3979 & 7.3747 & TRN & \\
\hline CHEMBL509234 & 540542 & 5.0458 & 3.8023 & TRN & \\
\hline CHEMBL344398 & 540542 & 5.8601 & 5.2733 & TRN & \\
\hline CHEMBL341951 & 540542 & 4.5229 & 4.8723 & TRN & \\
\hline CHEMBL509061 & 540542 & 4.8633 & 4.8343 & TRN & \\
\hline CHEMBL146182 & 540542 & 9.5229 & 9.9441 & TRN & \\
\hline CHEMBL341194 & 540542 & 4.4089 & 5.0882 & TRN & \\
\hline CHEMBL149197 & 540542 & 9.5229 & 10.045 & TRN & \\
\hline CHEMBL39092 & 540542 & 5.8861 & 4.2784 & TRN & \\
\hline CHEMBL142829 & 540542 & 4.8239 & 4.5754 & TRN & \\
\hline CHEMBL312874 & 540542 & 7.0969 & 5.5574 & TST & \\
\hline CHEMBL450389 & 540542 & 4.699 & 4.6356 & TST & \\
\hline CHEMBL312545 & 540542 & 5.2076 & 5.1756 & TRN & \\
\hline CHEMBL140065 & 540542 & 4.699 & 4.5412 & TRN & \\
\hline CHEMBL82094 & 540542 & 5.0969 & 5.7626 & TRN & \\
\hline CHEMBL310476 & 540542 & 9.2007 & 7.5393 & TST & \\
\hline CHEMBL84490 & 540542 & 3.699 & 4.0555 & TRN & \\
\hline CHEMBL473692 & 540542 & 6.0 & 4.4788 & TRN & \\
\hline CHEMBL57772 & 540542 & 7.2218 & 5.7996 & TST & \\
\hline CHEMBL 23428 & 540542 & 4.699 & 4.677 & TRN & \\
\hline CHEMBL503802 & 540542 & 4.0 & 4.5725 & TRN & \\
\hline CHEMBL79468 & 540542 & 5.0 & 5.5561 & TRN & \\
\hline CHEMBL341042 & 540542 & 4.0 & 5.1371 & TST & \\
\hline CHEMBL505677 & 540542 & 4.9355 & 4.878 & TRN & \\
\hline CHEMBL 36586 & 540542 & 4.0969 & 4.9555 & TRN & \\
\hline CHEMBL331659 & 540542 & 5.0 & 4.8718 & TST & \\
\hline CHEMBL142358 & 540542 & 4.699 & 5.0682 & TRN & \\
\hline CHEMBL342022 & 540542 & 4.0348 & 5.0322 & TRN & \\
\hline CHEMBL43416 & 540542 & 5.301 & 5.544 & TST & \\
\hline CHEMBL139607 & 540542 & 8.7696 & 4.1321 & TST & \\
\hline CHEMBL473071 & 540542 & 4.0 & 5.5547 & TRN & \\
\hline CHEMBL84522 & 540542 & 6.8861 & 7.04200 & 0000000001 & TRN \\
\hline CHEMBL412433 & 540542 & 4.4559 & 4.9907 & TST & \\
\hline CHEMBL23358 & 540542 & 5.699 & 5.0478 & TRN & \\
\hline CHEMBL473488 & 540542 & 5.7212 & 4.9527 & TRN & \\
\hline CHEMBL366402 & 540542 & 7.5229 & 5.9637 & TST & \\
\hline CHEMBL458343 & 540542 & 5.0655 & 6.6837 & TRN & \\
\hline CHEMBL142412 & 540542 & 4.9208 & 4.583 & TRN & \\
\hline CHEMBL472870 & 540542 & 5.3665 & 6.0219 & TRN & \\
\hline
\end{tabular}


Supplemental Table S2.txt

\begin{tabular}{|c|c|c|c|c|c|}
\hline CHEMBL356437 & 540542 & 9.5229 & 9.3855 & TRN & \\
\hline CHEMBL137752 & 540542 & 6.4815 & 5.3813 & TRN & \\
\hline CHEMBL309899 & 540542 & 7.0969 & 5.6455 & TST & \\
\hline CHEMBL50948 & 540542 & 6.068 & 5.8028 & TRN & \\
\hline CHEMBL423448 & 540542 & 4.6038 & 4.6796 & TRN & \\
\hline CHEMBL510054 & 540542 & 4.8508 & 3.9309 & TRN & \\
\hline CHEMBL177201 & 540542 & 7.3979 & 6.3429 & TST & \\
\hline CHEMBL474691 & 540542 & 5.5467 & 4.5651 & TST & \\
\hline CHEMBL37139 & 540542 & 4.2676 & 4.0875 & TRN & \\
\hline CHEMBL475089 & 540542 & 6.0 & 5.2928 & TRN & \\
\hline CHEMBL149174 & 540542 & 11.5086 & 9.7509 & TRN & \\
\hline CHEMBL41356 & 540542 & 4.8539 & 5.0558 & TST & \\
\hline CHEMBL517104 & 540542 & 5.567 & 6.4667 & TST & \\
\hline CHEMBL139459 & 540542 & 8.3979 & 5.195 & TST & \\
\hline CHEMBL236161 & 540542 & 8.301 & 5.9193 & TST & \\
\hline CHEMBL451912 & 540542 & 4.8508 & 5.2142 & TRN & \\
\hline CHEMBL 23333 & 540542 & 3.699 & 4.5732 & TRN & \\
\hline CHEMBL475512 & 540542 & 4.3979 & 5.6035 & TRN & \\
\hline CHEMBL390155 & 540542 & 6.0 & 5.1109 & TRN & \\
\hline CHEMBL106247 & 540542 & 8.0 & 4.6551 & TST & \\
\hline CHEMBL58026 & 540542 & 9.4653 & 8.9915 & TRN & \\
\hline CHEMBL472878 & 540542 & 4.0 & 5.1437 & TRN & \\
\hline CHEMBL472673 & 540542 & 6.0 & 5.6296 & TRN & \\
\hline CHEMBL291331 & 540542 & 9.9931 & 9.1357 & TRN & \\
\hline CHEMBL129231 & 540542 & 4.0 & 4.8763 & TRN & \\
\hline CHEMBL515101 & 540542 & 4.0 & 5.24 & TRN & \\
\hline CHEMBL471265 & 540542 & 4.3979 & 4.2044 & TST & \\
\hline CHEMBL449667 & 540542 & 6.0 & 5.5959 & TRN & \\
\hline CHEMBL515437 & 540542 & 6.0 & 5.2947 & TRN & \\
\hline CHEMBL503949 & 540542 & 4.8239 & 5.0423 & TRN & \\
\hline CHEMBL137753 & 540542 & 6.3372 & 5.2733 & TRN & \\
\hline CHEMBL138879 & 540542 & 8.1938 & 4.4265 & TST & \\
\hline CHEMBL449111 & 540542 & 4.8055 & 4.4465 & TST & \\
\hline CHEMBL 291505 & 540542 & 6.3979 & 5.8834 & TST & \\
\hline CHEMBL372043 & 302231 & 3.2076 & 3.2087 & TRN & \\
\hline CHEMBL196998 & 302231 & 2.7696 & 2.76899 & 99999999997 & TRN \\
\hline CHEMBL195643 & 302231 & 2.2441 & 2.245 & TRN & \\
\hline CHEMBL196900 & 302231 & 2.1427 & 2.1418 & TRN & \\
\hline CHEMBL373226 & 302231 & 2.4559 & 2.4573 & TRN & \\
\hline CHEMBL193744 & 302231 & 2.6576 & 2.6578 & TRN & \\
\hline CHEMBL197503 & 302231 & 2.0506 & 2.0489 & TRN & \\
\hline CHEMBL194118 & 302231 & 2.7447 & 2.7458 & TRN & \\
\hline CHEMBL195959 & 302231 & 1.0 & 1.0 & TRN & \\
\hline CHEMBL194048 & 302231 & 2.2218 & 2.2221 & TRN & \\
\hline CHEMBL365361 & 302231 & 4.1739 & 2.7638 & TST & \\
\hline CHEMBL195483 & 302231 & 2.7696 & 2.7699 & TRN & \\
\hline CHEMBL 381231 & 302231 & 1.0 & 1.0007 & TRN & \\
\hline CHEMBL445395 & 302231 & 2.1938 & 2.194 & TRN & \\
\hline
\end{tabular}




\begin{tabular}{|c|c|c|c|c|c|}
\hline \multicolumn{6}{|c|}{ Supplemental Table S2.txt } \\
\hline CHEMBL370622 & 302231 & 3.2596 & 3.2599 & TRN & \\
\hline CHEMBL196136 & 302231 & 3.1612 & 3.1607 & TRN & \\
\hline CHEMBL425018 & 302231 & 2.4815 & 2.4807 & TRN & \\
\hline CHEMBL383819 & 302231 & 1.0 & 1.0001 & TRN & \\
\hline CHEMBL196016 & 302231 & 2.2757 & 2.2761 & TRN & \\
\hline CHEMBL196190 & 302231 & 2.3872 & 2.3872 & TRN & \\
\hline CHEMBL197524 & 302231 & 2.6576 & 2.658 & TRN & \\
\hline CHEMBL426288 & 302231 & 2.1367 & 2.1372 & TRN & \\
\hline CHEMBL363158 & 302231 & 2.6383 & 2.638 & TRN & \\
\hline CHEMBL440036 & 302231 & 1.0 & 1.0 & TRN & \\
\hline CHEMBL193795 & 302231 & 3.4318 & 3.4314 & TRN & \\
\hline CHEMBL2029151 & 302231 & 2.2441 & 2.2444 & TRN & \\
\hline CHEMBL373162 & 302231 & 2.7959 & 2.7955 & TRN & \\
\hline CHEMBL193531 & 302231 & 3.2757 & 3.2761 & TRN & \\
\hline CHEMBL196794 & 302231 & 1.0 & 0.9994 & TRN & \\
\hline CHEMBL372441 & 302231 & 2.7825 & 2.7829 & TRN & \\
\hline CHEMBL196073 & 302231 & 2.2596 & 2.05 & TST & \\
\hline CHEMBL 371437 & 302231 & 3.0757 & 3.0737 & TRN & \\
\hline CHEMBL383556 & 302231 & 3.1079 & 3.1091 & TRN & \\
\hline CHEMBL193702 & 302231 & 2.585 & 2.5856 & TRN & \\
\hline CHEMBL381011 & 302231 & 2.0315 & 2.0302 & TRN & \\
\hline CHEMBL371438 & 302231 & 2.3188 & 2.3184 & TRN & \\
\hline CHEMBL371032 & 302231 & 2.3188 & 2.3636 & TST & \\
\hline CHEMBL196897 & 302231 & 2.5376 & 2.5364 & TRN & \\
\hline CHEMBL372366 & 302231 & 2.8539 & 2.85399 & 99999999996 & TRN \\
\hline CHEMBL425198 & 302231 & 3.4437 & 3.4422 & TRN & \\
\hline CHEMBL370640 & 302231 & 2.7447 & 2.7462 & TRN & \\
\hline CHEMBL 370993 & 302231 & 2.3188 & 2.2724 & TST & \\
\hline CHEMBL 371313 & 302231 & 2.4202 & 2.4206 & TRN & \\
\hline CHEMBL196612 & 302231 & 2.5376 & 2.7623 & TST & \\
\hline CHEMBL195539 & 302231 & 2.7447 & 3.2339 & TST & \\
\hline CHEMBL195363 & 302231 & 2.5086 & 2.1993 & TST & \\
\hline CHEMBL369896 & 302231 & 2.0458 & 2.6616 & TST & \\
\hline CHEMBL196710 & 302231 & 2.3188 & 2.8847 & TST & \\
\hline CHEMBL195961 & 302231 & 1.0 & 2.3362 & TST & \\
\hline CHEMBL381209 & 302231 & 2.6021 & 3.1296 & TST & \\
\hline CHEMBL195670 & 302231 & 2.7959 & 2.3812 & TST & \\
\hline CHEMBL196725 & 302231 & 2.6576 & 3.2346 & TST & \\
\hline CHEMBL3982154 & 1640602 & 6.433 & 6.3512 & TRN & \\
\hline CHEMBL3909223 & 1640602 & 6.767 & 6.6884 & TRN & \\
\hline CHEMBL3901878 & 1640602 & 6.9318 & 6.8673 & TRN & \\
\hline CHEMBL3900153 & 1640602 & 6.0074 & 6.3489 & TRN & \\
\hline CHEMBL3968141 & 1640602 & 6.7258 & 6.5848 & TRN & \\
\hline CHEMBL3906541 & 1640602 & 5.4763 & 5.5515 & TRN & \\
\hline CHEMBL3946635 & 1640602 & 6.4498 & 7.4353 & TST & \\
\hline CHEMBL 3907310 & 1640602 & 5.8554 & 5.5697 & TST & \\
\hline CHEMBL3925326 & 1640602 & 6.8894 & 6.9739 & TRN & \\
\hline CHEMBL 3977023 & 1640602 & 7.2218 & 7.2463 & TRN & \\
\hline
\end{tabular}

Page 12126 
Supplemental Table S2.txt

\begin{tabular}{|c|c|c|c|c|c|}
\hline CHEMBL3931057 & 1640602 & 6.1904 & 6.2293 & TRN & \\
\hline CHEMBL3954756 & 1640602 & 5.7932 & 5.9499 & TRN & \\
\hline CHEMBL3945012 & 1640602 & 7.5086 & 6.4669 & TST & \\
\hline CHEMBL3923356 & 1640602 & 5.6716 & 5.6466 & TRN & \\
\hline CHEMBL 3896431 & 1640602 & 5.6465 & 5.69799 & 99999999995 & TRN \\
\hline CHEMBL3950355 & 1640602 & 5.6234 & 5.6889 & TRN & \\
\hline CHEMBL3932799 & 1640602 & 5.7878 & 6.0829 & TST & \\
\hline CHEMBL3941635 & 1640602 & 6.2351 & 6.1116 & TST & \\
\hline CHEMBL 3904880 & 1640602 & 6.6946 & 6.3486 & TRN & \\
\hline CHEMBL3951941 & 1640602 & 5.8871 & 6.5624 & TST & \\
\hline CHEMBL3942815 & 1640602 & 6.0773 & 6.2429 & TRN & \\
\hline CHEMBL3905303 & 1640602 & 7.9208 & 7.0003 & TST & \\
\hline CHEMBL3909195 & 1640602 & 6.9586 & 6.9361 & TRN & \\
\hline CHEMBL3922611 & 1640602 & 6.4023 & 6.4142 & TRN & \\
\hline CHEMBL 3901346 & 1640602 & 6.0 & 5.5744 & TRN & \\
\hline CHEMBL3949593 & 1640602 & 7.0706 & 6.9228 & TRN & \\
\hline CHEMBL3939249 & 1640602 & 6.3675 & 5.8153 & TST & \\
\hline CHEMBL3921296 & 1640602 & 5.7828 & 6.1274 & TST & \\
\hline CHEMBL 3909876 & 1640602 & 5.7328 & 6.6027 & TST & \\
\hline CHEMBL 3905808 & 1640602 & 7.3979 & 6.8523 & TST & \\
\hline CHEMBL 3904128 & 1640602 & 5.9431 & 5.8578 & TRN & \\
\hline CHEMBL3954732 & 1640602 & 6.0809 & 6.1785 & TRN & \\
\hline CHEMBL3946479 & 1640602 & 7.8861 & 7.9831 & TRN & \\
\hline CHEMBL 3901217 & 1640602 & 6.3098 & 6.4989 & TRN & \\
\hline CHEMBL 3936592 & 1640602 & 6.3233 & 6.3492 & TRN & \\
\hline CHEMBL 3956147 & 1640602 & 5.697 & 5.9437 & TST & \\
\hline CHEMBL 3976034 & 1640602 & 6.5391 & 6.5633 & TRN & \\
\hline CHEMBL 3893504 & 1640602 & 7.5229 & 7.4124 & TRN & \\
\hline CHEMBL 3977273 & 1640602 & 6.5421 & 6.7466 & TRN & \\
\hline CHEMBL3928551 & 1640602 & 5.9817 & 6.1375 & TRN & \\
\hline CHEMBL3922695 & 1640602 & 6.0491 & 5.9291 & TRN & \\
\hline CHEMBL 3970504 & 1640602 & 6.4306 & 6.2294 & TRN & \\
\hline CHEMBL3934350 & 1640602 & 6.7878 & 6.7131 & TRN & \\
\hline CHEMBL 3938822 & 1640602 & 6.644 & 6.6703 & TRN & \\
\hline CHEMBL3967139 & 1640602 & 5.6763 & 5.6583 & TRN & \\
\hline CHEMBL3910447 & 1640602 & 7.2366 & 7.0795 & TST & \\
\hline CHEMBL 3969984 & 1640602 & 6.0851 & 6.0596 & TRN & \\
\hline CHEMBL3916290 & 1640602 & 5.9212 & 5.8395 & TRN & \\
\hline CHEMBL 3963262 & 1640602 & 7.6778 & 7.5913 & TRN & \\
\hline CHEMBL3930630 & 1640602 & 5.8049 & 5.808 & TRN & \\
\hline CHEMBL 3915231 & 1640602 & \multicolumn{3}{|c|}{6.2620000000000005} & $\mathrm{~T}_{\mathrm{K}}$ \\
\hline CHEMBL 3931654 & 1640602 & 6.7545 & 6.5855 & TRN & \\
\hline CHEMBL 3926167 & 1640602 & 5.3526 & 5.3387 & TRN & \\
\hline CHEMBL 3938872 & 1640602 & 5.983 & 6.0977 & TRN & \\
\hline CHEMBL 3895786 & 1640602 & 6.6737 & 6.5913 & TRN & \\
\hline CHEMBL 3895130 & 1640602 & 6.5622 & 6.6058 & TRN & \\
\hline CHEMBL 3936446 & 1640602 & 6.0434 & 6.1887 & TST & \\
\hline CHEMBL 3944222 & 1640602 & 5.4464 & 5.5898 & TRN & \\
\hline
\end{tabular}

Page 12127 
Supplemental Table S2.txt

\begin{tabular}{|c|c|c|c|c|c|c|c|}
\hline CHEMBL3932544 & 1640602 & 5.8199 & 6.0186 & TST & & & \\
\hline CHEMBL3950867 & 1640602 & 6.11799 & 99999999 & & 6.1947 & TRN & \\
\hline CHEMBL3961204 & 1640602 & 6.7986 & 6.6117 & TRN & & & \\
\hline CHEMBL3962055 & 1640602 & 5.7231 & 5.7834 & TRN & & & \\
\hline CHEMBL3952666 & 1640602 & 6.7011 & 6.7266 & TRN & & & \\
\hline CHEMBL3901915 & 1640602 & 5.584 & 5.666 & TRN & & & \\
\hline CHEMBL3963023 & 1640602 & 6.0273 & 6.1812 & TRN & & & \\
\hline CHEMBL3938981 & 1640602 & 6.3936 & 6.4175 & TRN & & & \\
\hline CHEMBL3971116 & 1640602 & 6.5498 & 6.6584 & TST & & & \\
\hline CHEMBL3982996 & 1640602 & 6.475 & 6.5904 & TRN & & & \\
\hline CHEMBL3930115 & 1640602 & 5.6807 & 6.0213 & TRN & & & \\
\hline CHEMBL3954973 & 1640602 & 5.468 & 5.8843 & TST & & & \\
\hline CHEMBL3909701 & 1640602 & 6.6091 & 6.4774 & TRN & & & \\
\hline CHEMBL3977521 & 1640602 & 5.8239 & 5.7396 & TRN & & & \\
\hline CHEMBL3907193 & 1640602 & 5.9318 & 6.004 & TST & & & \\
\hline CHEMBL3898874 & 1640602 & 6.3768 & 6.4253 & TRN & & & \\
\hline CHEMBL3952970 & 1640602 & 5.5795 & 5.8753 & TRN & & & \\
\hline CHEMBL3947667 & 1640602 & 5.9626 & 5.7965 & TRN & & & \\
\hline CHEMBL3959904 & 1640602 & 7.3768 & 7.4807 & TRN & & & \\
\hline CHEMBL3910889 & 1640602 & 5.5764 & 6.0417 & TRN & & & \\
\hline CHEMBL3914317 & 1640602 & 5.8216 & 6.0629 & TST & & & \\
\hline CHEMBL3967125 & 1640602 & 6.6198 & 6.6738 & TRN & & & \\
\hline CHEMBL3938842 & 1640602 & 7.3279 & 7.1544 & TRN & & & \\
\hline CHEMBL3933736 & 1640602 & \multicolumn{3}{|c|}{6.718999999999999} & 6.6617 & TRN & \\
\hline CHEMBL3960556 & 1640602 & 6.0511 & 6.1645 & TRN & & & \\
\hline CHEMBL3967251 & 1640602 & 6.3401 & 6.3183 & TRN & & & \\
\hline CHEMBL3957620 & 1640602 & 5.9465 & 5.9651 & TRN & & & \\
\hline CHEMBL3984705 & 1640602 & 6.9706 & 6.7036 & TST & & & \\
\hline CHEMBL3917550 & 1640602 & 8.0969 & 7.1633 & TST & & & \\
\hline CHEMBL3912376 & 1640602 & 6.475 & 6.2697 & TST & & & \\
\hline CHEMBL3943785 & 1640602 & 5.8162 & 5.8 & TRN & & & \\
\hline CHEMBL3964366 & 1640602 & 5.6716 & 6.1701 & TST & & & \\
\hline CHEMBL3909224 & 1640602 & 7.4089 & 7.1939 & TRN & & & \\
\hline CHEMBL3972733 & 1640602 & \multicolumn{3}{|c|}{6.3420000000000005} & \multicolumn{2}{|c|}{6.4879999999999995} & TST \\
\hline CHEMBL3962710 & 1640602 & 6.4976 & 6.4231 & TRN & & & \\
\hline CHEMBL3978999 & 1640602 & 6.2411 & 6.1787 & TRN & & & \\
\hline CHEMBL3940700 & 1640602 & 7.0177 & 7.21899 & 9999999995 & & TRN & \\
\hline CHEMBL 3907374 & 1640602 & 6.6234 & 6.0699 & TST & & & \\
\hline CHEMBL 3968942 & 1640602 & 6.2774 & 6.1158 & TRN & & & \\
\hline CHEMBL3938211 & 1640602 & 5.3936 & 5.724 & TST & & & \\
\hline CHEMBL3937551 & 1640602 & 5.2154 & 5.2939 & TRN & & & \\
\hline CHEMBL3939766 & 1640602 & 6.2434 & 6.2429 & TRN & & & \\
\hline CHEMBL3942262 & 1640602 & 6.6799 & 6.6347 & TRN & & & \\
\hline CHEMBL3916665 & 1640602 & 6.3615 & 6.5435 & TRN & & & \\
\hline CHEMBL 3914144 & 1640602 & 6.0491 & 6.0332 & TRN & & & \\
\hline CHEMBL3910286 & 1640602 & 5.8874 & 5.9365 & TST & & & \\
\hline CHEMBL3917412 & 1640602 & 5.9101 & 6.36 & TRN & & & \\
\hline CHEMBL3936154 & 1640602 & 6.6402 & 6.4322 & TRN & & & \\
\hline
\end{tabular}


Supplemental Table S2.txt

\begin{tabular}{|c|c|c|c|c|c|}
\hline CHEMBL3932131 & 1640602 & 6.3947 & 6.2983 & TRN & \\
\hline CHEMBL3895759 & 1640602 & 6.1838 & 6.0073 & TRN & \\
\hline CHEMBL3901113 & 1640602 & 6.2958 & 6.2365 & TRN & \\
\hline CHEMBL3951681 & 1640602 & 6.7077 & 6.6051 & TRN & \\
\hline CHEMBL3940958 & 1640602 & 6.3497 & 6.4483 & TRN & \\
\hline CHEMBL3914896 & 1640602 & 6.0462 & 6.2313 & TST & \\
\hline CHEMBL3923760 & 1640602 & 6.5719 & 6.5536 & TRN & \\
\hline CHEMBL3965827 & 1640602 & 6.2034 & 6.1163 & TRN & \\
\hline CHEMBL3949919 & 1640602 & 6.3107 & 6.0396 & TRN & \\
\hline CHEMBL3948499 & 1640602 & 6.1925 & 6.3793 & TRN & \\
\hline CHEMBL3940721 & 1640602 & 6.1379 & 6.2551 & TST & \\
\hline CHEMBL3975507 & 1640602 & 7.0969 & 7.0203 & TRN & \\
\hline CHEMBL3902291 & 1640602 & 6.4737 & 6.4451 & TRN & \\
\hline CHEMBL3971859 & 1640602 & 6.8827 & 6.7368 & TRN & \\
\hline CHEMBL3906374 & 1640602 & 6.9245 & 6.9413 & TRN & \\
\hline CHEMBL3942007 & 1640602 & 6.3458 & 6.2764 & TRN & \\
\hline CHEMBL3913869 & 1640602 & 7.6021 & 7.592000 & 30000000005 & TRN \\
\hline CHEMBL3964719 & 1640602 & 6.0953 & 5.956 & TRN & \\
\hline CHEMBL 3929240 & 1640602 & 6.3915 & 6.4708 & TRN & \\
\hline CHEMBL3910932 & 1640602 & 5.4237 & 5.5572 & TRN & \\
\hline CHEMBL3938386 & 1640602 & 6.7423 & 6.9875 & TST & \\
\hline CHEMBL3924228 & 1640602 & 6.0 & 6.0611 & TST & \\
\hline CHEMBL3985846 & 1640602 & 5.6126 & 5.5925 & TRN & \\
\hline CHEMBL 3901849 & 1640602 & 6.2132 & 6.4386 & TRN & \\
\hline CHEMBL 3978573 & 1640602 & 5.7852 & 5.6746 & TRN & \\
\hline CHEMBL3924060 & 1640602 & 5.7258 & 6.0807 & TRN & \\
\hline CHEMBL3909380 & 1640602 & 6.3143 & 6.4863 & TRN & \\
\hline CHEMBL3939510 & 1640602 & 6.0013 & 5.7878 & TRN & \\
\hline CHEMBL3910117 & 1640602 & 7.6198 & 7.7014 & TRN & \\
\hline CHEMBL 3933744 & 1640602 & 5.3206 & 5.2093 & TRN & \\
\hline CHEMBL3972999 & 1640602 & 6.0035 & 6.008999 & 99999999995 & TRN \\
\hline CHEMBL3922632 & 1640602 & 5.7122 & 5.7887 & TST & \\
\hline CHEMBL3921658 & 1640602 & 6.8356 & 6.7454 & TST & \\
\hline CHEMBL 3904485 & 1640602 & 6.9957 & 7.0001 & TST & \\
\hline CHEMBL 3974582 & 1640602 & 5.585 & 5.9716 & TST & \\
\hline CHEMBL3931945 & 1640602 & 5.7133 & 5.9539 & TRN & \\
\hline CHEMBL3946019 & 1640602 & 7.0809 & 6.8512 & TRN & \\
\hline CHEMBL3932708 & 1640602 & 5.6459 & 5.6366 & TRN & \\
\hline CHEMBL 3956556 & 1640602 & 6.983 & 6.7101 & TRN & \\
\hline CHEMBL3892369 & 1640602 & 6.5622 & 6.6908 & TRN & \\
\hline CHEMBL3981385 & 1640602 & 8.699 & 7.2133 & TST & \\
\hline CHEMBL3927349 & 1640602 & 5.739 & 5.8675 & TRN & \\
\hline CHEMBL3924447 & 1640602 & 5.6968 & 5.6748 & TST & \\
\hline CHEMBL 3953726 & 1640602 & 5.9126 & 6.0391 & TRN & \\
\hline CHEMBL 3897210 & 1640602 & 6.1707 & 6.0147 & TRN & \\
\hline CHEMBL3936920 & 1640602 & 6.2749 & 6.3293 & TRN & \\
\hline CHEMBL3912674 & 1640602 & 6.71899 & 999999999 & 6.8189 & 1 \\
\hline CHEMBL 3972749 & 1640602 & 5.5867 & 5.6597 & TRN & \\
\hline
\end{tabular}

Page 12129 
Supplemental Table S2.txt

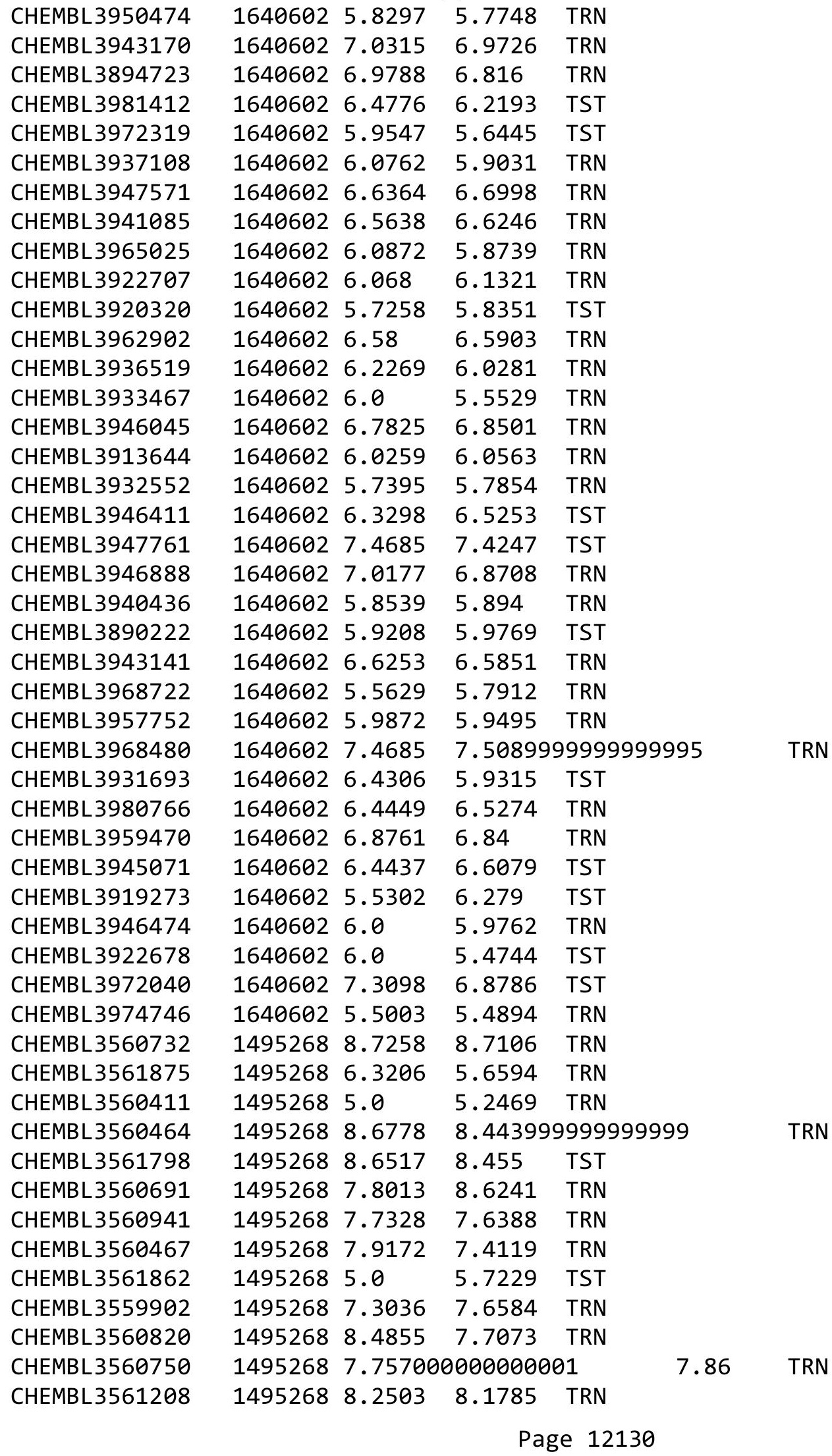


Supplemental Table S2.txt

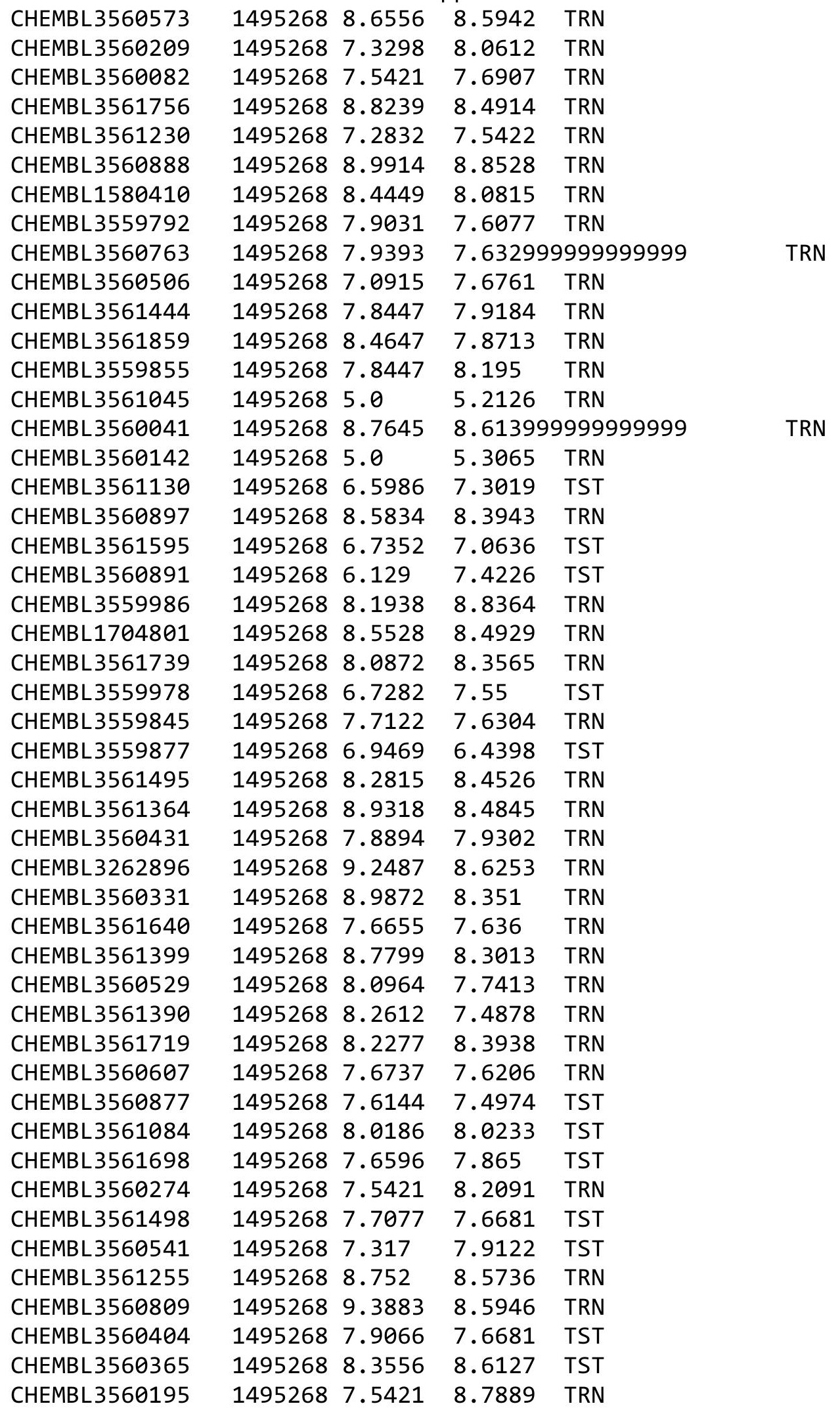

Page 12131 
Supplemental Table S2.txt

\begin{tabular}{|c|c|c|c|c|c|c|}
\hline CHEMBL 3561867 & 1495268 & 6.5086 & 7.6881 & TST & & \\
\hline CHEMBL 3561833 & 1495268 & \multicolumn{3}{|c|}{7.617999999999999} & 7.4248 & TS \\
\hline CHEMBL 3559987 & 1495268 & 8.1152 & 7.6177 & TST & & \\
\hline CHEMBL3560117 & 1495268 & 8.9393 & 7.9503 & TST & & \\
\hline CHEMBL 3560453 & 1495268 & 8.7595 & 9.0227 & TRN & & \\
\hline CHEMBL 3560864 & 1495268 & 9.2076 & 8.7493 & TRN & & \\
\hline CHEMBL 3559757 & 1495268 & 8.0287 & 8.6138 & TRN & & \\
\hline CHEMBL 3561484 & 1495268 & \multicolumn{3}{|c|}{8.091000000000001} & 8.2874 & $T$ \\
\hline CHEMBL 3560415 & 1495268 & 8.4389 & 8.603 & TRN & & \\
\hline CHEMBL 3560513 & 1495268 & 5.0 & 5.3602 & TRN & & \\
\hline CHEMBL 3561800 & 1495268 & \multicolumn{3}{|c|}{7.007000000000001} & 7.7989 & \\
\hline CHEMBL3559896 & 1495268 & 7.1838 & 7.4579 & TST & & \\
\hline CHEMBL1255839 & 688138 & 4.721 & 4.2666 & TST & & \\
\hline CHEMBL1322702 & 688138 & 4.471 & 4.6477 & TRN & & \\
\hline CHEMBL1256661 & 688138 & 4.371 & 4.3655 & TRN & & \\
\hline CHEMBL397209 & 688138 & \multicolumn{3}{|c|}{4.071000000000001} & 4.2612 & \\
\hline CHEMBL145 & 688138 & \multicolumn{3}{|c|}{4.071000000000001} & & \\
\hline CHEMBL10284 & 688138 & 4.171 & 4.5857 & TRN & & \\
\hline CHEMBL80155 & 688138 & 4.371 & 4.6427 & TRN & & \\
\hline CHEMBL1590552 & 688138 & \multicolumn{3}{|c|}{4.071000000000001} & 224 & \\
\hline CHEMBL1256283 & 688138 & 4.421 & 4.177 & TRN & & \\
\hline CHEMBL183 & 688138 & \multicolumn{3}{|c|}{4.071000000000001} & 4.1201 & 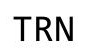 \\
\hline CHEMBL1487371 & 688138 & \multicolumn{3}{|c|}{4.071000000000001} & 4.5944 & \\
\hline CHEMBL7917 & 688138 & 4.121 & 4.7355 & TRN & & \\
\hline CHEMBL 280822 & 688138 & 4.121 & 4.1857 & TRN & & \\
\hline CHEMBL143324 & 688138 & 4.771 & 4.1871 & TRN & & \\
\hline CHEMBL1256911 & 688138 & 4.721 & 4.365 & TRN & & \\
\hline CHEMBL1256998 & 688138 & 4.021 & 4.0309 & TRN & & \\
\hline CHEMBL1257012 & 688138 & 4.021 & 4.2435 & TRN & & \\
\hline CHEMBL 225230 & 688138 & 4.371 & 4.2956 & TRN & & \\
\hline CHEMBL1082832 & 688138 & \multicolumn{3}{|c|}{4.071000000000001} & 4.4509 & \\
\hline CHEMBL 26915 & 688138 & \multicolumn{3}{|c|}{4.071000000000001} & 4.4383 & \\
\hline CHEMBL 76897 & 688138 & 4.921 & 4.454 & TRN & & \\
\hline CHEMBL1725279 & 688138 & \multicolumn{3}{|c|}{4.071000000000001} & 4.6522 & \\
\hline CHEMBL40998 & 688138 & \multicolumn{3}{|c|}{4.071000000000001} & 4.4276 & \\
\hline CHEMBL1256995 & 688138 & 4.721 & 4.3652 & TRN & & \\
\hline CHEMBL93403 & 688138 & \multicolumn{3}{|c|}{ 4.321000000000001 } & 4.2669 & \\
\hline CHEMBL1200450 & 688138 & \multicolumn{3}{|c|}{5.571000000000001} & 4.4025 & \\
\hline CHEMBL543876 & 688138 & 4.771 & 4.383 & TRN & & \\
\hline CHEMBL453066 & 688138 & 4.171 & 4.5626 & TRN & & \\
\hline CHEMBL1528565 & 688138 & 4.471 & 4.3173 & TRN & & \\
\hline CHEMBL388054 & 688138 & 4.121 & 4.5305 & TRN & & \\
\hline CHEMBL 24510 & 688138 & 4.221 & 4.2756 & TRN & & \\
\hline CHEMBL1255778 & 688138 & \multicolumn{3}{|c|}{4.071000000000001} & 4.184 & \\
\hline CHEMBL1256996 & 688138 & 6.0 & 4.1775 & TRN & & \\
\hline CHEMBL 288096 & 688138 & 4.121 & 4.1884 & TRN & & \\
\hline CHEMBL344127 & 688138 & \multicolumn{3}{|c|}{4.071000000000001} & 4.4152 & \\
\hline CHEMBL45068 & 688138 & \multicolumn{3}{|c|}{4.071000000000001} & 4.3041 & \\
\hline
\end{tabular}




\begin{tabular}{|c|c|c|c|c|c|c|}
\hline & & \multicolumn{5}{|c|}{ Supplemental Table S2.txt } \\
\hline CHEMBL1256984 & 688138 & 4.021 & 4.41 & TRN & & \\
\hline CHEMBL1256660 & 688138 & 4.471 & 4.3991 & TRN & & \\
\hline CHEMBL1255940 & 688138 & 4.471 & 4.5448 & TRN & & \\
\hline CHEMBL605003 & 688138 & 4.771 & 4.4424 & TRN & & \\
\hline CHEMBL513116 & 688138 & 4.171 & 4.2661 & TRN & & \\
\hline CHEMBL67378 & 688138 & 4.021 & 4.3827 & TRN & & \\
\hline CHEMBL109037 & 688138 & \multicolumn{3}{|c|}{4.071000000000001} & 4.1575 & TRN \\
\hline CHEMBL1329033 & 688138 & \multicolumn{3}{|c|}{4.571000000000001} & 4.3857 & TRN \\
\hline CHEMBL1256659 & 688138 & \multicolumn{3}{|c|}{4.821000000000001} & 4.4999 & TRN \\
\hline CHEMBL1324022 & 688138 & \multicolumn{3}{|c|}{4.571000000000001} & 4.4748 & TRN \\
\hline CHEMBL1554717 & 688138 & 4.371 & 4.6248 & TRN & & \\
\hline CHEMBL66654 & 688138 & \multicolumn{3}{|c|}{6.321000000000001} & 4.7983 & TRN \\
\hline CHEMBL1255967 & 688138 & \multicolumn{3}{|c|}{4.071000000000001} & 4.2136 & TRN \\
\hline CHEMBL1570350 & 688138 & \multicolumn{3}{|c|}{4.321000000000001} & 4.2575 & TRN \\
\hline CHEMBL546257 & 688138 & \multicolumn{3}{|c|}{4.821000000000001} & 4.5223 & TRN \\
\hline CHEMBL 284028 & 688138 & 4.921 & 4.3294 & TRN & & \\
\hline CHEMBL126077 & 688138 & 4.421 & 4.6286 & TRN & & \\
\hline CHEMBL441282 & 688138 & 4.371 & 4.2922 & TST & & \\
\hline CHEMBL331372 & 688138 & 6.221 & 4.3467 & TRN & & \\
\hline CHEMBL1256656 & 688138 & 4.771 & 4.5466 & TRN & & \\
\hline CHEMBL1449651 & 688138 & 5.121 & 4.1717 & TST & & \\
\hline CHEMBL1256654 & 688138 & \multicolumn{3}{|c|}{4.321000000000001} & 4.5835 & TRN \\
\hline CHEMBL87285 & 688138 & 4.021 & 4.3606 & TST & & \\
\hline CHEMBL1433897 & 688138 & 4.471 & 4.3337 & TRN & & \\
\hline CHEMBL15192 & 688138 & 4.421 & 4.6552 & TRN & & \\
\hline CHEMBL 267014 & 688138 & 4.021 & 4.1969 & TRN & & \\
\hline CHEMBL544713 & 688138 & 4.221 & 4.712 & TRN & & \\
\hline CHEMBL10347 & 688138 & 4.121 & 4.5004 & TRN & & \\
\hline CHEMBL1597692 & 688138 & \multicolumn{3}{|c|}{4.071000000000001} & 4.2338 & TRN \\
\hline CHEMBL362863 & 688138 & \multicolumn{3}{|c|}{4.071000000000001} & 4.3556 & TST \\
\hline CHEMBL1412842 & 688138 & \multicolumn{3}{|c|}{4.071000000000001} & 4.695 & TRN \\
\hline CHEMBL1256131 & 688138 & 4.021 & 4.1441 & TRN & & \\
\hline CHEMBL1256835 & 688138 & 4.171 & 4.0583 & TRN & & \\
\hline CHEMBL395915 & 688138 & 4.371 & 4.3571 & TRN & & \\
\hline CHEMBL278755 & 688138 & 4.121 & 4.4946 & TRN & & \\
\hline CHEMBL429711 & 688138 & \multicolumn{3}{|c|}{4.071000000000001} & 4.7069 & TRN \\
\hline CHEMBL86676 & 688138 & 4.171 & 4.3105 & TRN & & \\
\hline CHEMBL1255649 & 688138 & \multicolumn{3}{|c|}{4.071000000000001} & 4.0658 & TRN \\
\hline CHEMBL1608159 & 688138 & 4.721 & 4.2654 & TRN & & \\
\hline CHEMBL1559663 & 688138 & 5.871 & 4.319 & TST & & \\
\hline CHEMBL 2373602 & 688138 & \multicolumn{3}{|c|}{4.071000000000001} & 4.5013 & TRN \\
\hline CHEMBL1255941 & 688138 & \multicolumn{3}{|c|}{4.071000000000001} & 4.0794 & TRN \\
\hline CHEMBL1335356 & 688138 & \multicolumn{3}{|c|}{4.071000000000001} & 4.2747 & TST \\
\hline CHEMBL517986 & 688138 & 4.171 & 4.0917 & TRN & & \\
\hline CHEMBL420060 & 688138 & 4.721 & 4.6108 & TRN & & \\
\hline CHEMBL25236 & 688138 & 4.421 & 4.553 & TRN & & \\
\hline CHEMBL1256720 & 688138 & 4.421 & 4.1996 & TRN & & \\
\hline CHEMBL1256666 & 688138 & 4.421 & 4.4651 & TRN & & \\
\hline
\end{tabular}




\begin{tabular}{|c|c|c|c|c|c|c|}
\hline \multirow[b]{2}{*}{ CHEMBL1435120 } & \multirow[b]{2}{*}{688138} & \multicolumn{5}{|c|}{ Supplemental Table S2.txt } \\
\hline & & \multicolumn{3}{|c|}{$5.221 \quad 4.5677$ TRN } & & \\
\hline CHEMBL1256693 & 688138 & 4.121 & 4.2103 & TRN & & \\
\hline CHEMBL1373007 & 688138 & 4.621 & 4.5851 & TST & & \\
\hline CHEMBL595227 & 688138 & \multicolumn{3}{|c|}{4.071000000000001} & 4.5148 & TRN \\
\hline CHEMBL1256191 & 688138 & 4.171 & 4.2548 & TRN & & \\
\hline CHEMBL1255866 & 688138 & 4.221 & 4.5428 & TRN & & \\
\hline CHEMBL18238 & 688138 & 4.671 & 4.5281 & TRN & & \\
\hline CHEMBL1256024 & 688138 & 4.271 & 4.1413 & TRN & & \\
\hline CHEMBL1456417 & 688138 & 4.121 & 4.5092 & TRN & & \\
\hline CHEMBL1256839 & 688138 & 6.121 & 4.6746 & TRN & & \\
\hline CHEMBL47940 & 688138 & 5.021 & 4.5247 & TST & & \\
\hline CHEMBL429095 & 688138 & \multicolumn{3}{|c|}{5.071000000000001} & 4.5558 & TRA \\
\hline CHEMBL1256663 & 688138 & 4.171 & 4.2216 & TRN & & \\
\hline CHEMBL1256285 & 688138 & 4.421 & 4.4201 & TST & & \\
\hline CHEMBL45244 & 688138 & 4.021 & 4.3203 & TRN & & \\
\hline CHEMBL 302783 & 688138 & \multicolumn{3}{|c|}{4.071000000000001} & 4.0835 & TRN \\
\hline CHEMBL1256776 & 688138 & 4.271 & 4.3452 & TRN & & \\
\hline CHEMBL540848 & 688138 & 4.221 & 4.4642 & TRN & & \\
\hline CHEMBL267373 & 688138 & 4.021 & 4.555 & TRN & & \\
\hline CHEMBL1437846 & 688138 & 4.021 & 4.6121 & TRN & & \\
\hline CHEMBL52 & 688138 & \multicolumn{3}{|c|}{4.071000000000001} & 4.2859 & TRN \\
\hline CHEMBL222838 & 688138 & 4.421 & 4.0921 & TRN & & \\
\hline CHEMBL1173475 & 688138 & \multicolumn{3}{|c|}{4.321000000000001} & 4.3861 & TRN \\
\hline CHEMBL3216363 & 688138 & 4.121 & 4.3291 & TRN & & \\
\hline CHEMBL543467 & 688138 & \multicolumn{3}{|c|}{4.571000000000001} & 4.5196 & TRN \\
\hline CHEMBL1256775 & 688138 & 4.471 & 4.4963 & TRN & & \\
\hline CHEMBL1257106 & 688138 & 4.171 & 4.0014 & TRN & & \\
\hline CHEMBL1480516 & 688138 & \multicolumn{3}{|c|}{4.071000000000001} & 4.2062 & TRN \\
\hline CHEMBL1377507 & 688138 & 4.121 & 4.2289 & TST & & \\
\hline CHEMBL1257039 & 688138 & 4.371 & 4.1389 & TRN & & \\
\hline CHEMBL 276727 & 688138 & \multicolumn{3}{|c|}{4.071000000000001} & 4.1442 & TRN \\
\hline CHEMBL1523894 & 688138 & 4.271 & 4.2291 & TST & & \\
\hline CHEMBL445102 & 688138 & 4.371 & 4.2417 & TRN & & \\
\hline CHEMBL1461491 & 688138 & 4.171 & 4.5089 & TRN & & \\
\hline CHEMBL1256959 & 688138 & 4.771 & 4.2772 & TRN & & \\
\hline CHEMBL76589 & 688138 & 4.121 & 4.3706 & TRN & & \\
\hline CHEMBL3216928 & 688138 & 4.471 & 4.1349 & TRN & & \\
\hline CHEMBL1256484 & 688138 & 4.171 & 4.2876 & TRN & & \\
\hline CHEMBL311158 & 688138 & 4.721 & 4.5153 & TRN & & \\
\hline CHEMBL376505 & 688138 & 4.371 & 4.5324 & TST & & \\
\hline CHEMBL 313833 & 688138 & 4.671 & 4.605 & TRN & & \\
\hline CHEMBL26318 & 688138 & \multicolumn{3}{|c|}{4.321000000000001} & 4.215 & TST \\
\hline CHEMBL1554131 & 688138 & \multicolumn{3}{|c|}{4.071000000000001} & 4.2947 & TRA \\
\hline CHEMBL13790 & 688138 & 4.371 & 4.3537 & TRN & & \\
\hline CHEMBL48278 & 688138 & 4.121 & 4.2265 & TRN & & \\
\hline CHEMBL410873 & 688138 & \multicolumn{3}{|c|}{4.071000000000001} & 4.1944 & TRN \\
\hline CHEMBL1316314 & 688138 & 4.621 & 4.4796 & TRN & & \\
\hline CHEMBL16081 & 688138 & 5.021 & 4.1974 & TRN & & \\
\hline
\end{tabular}




\begin{tabular}{|c|c|c|c|c|c|c|c|}
\hline \multicolumn{8}{|c|}{ Supplemental Table S2.txt } \\
\hline CHEMBL1365553 & 688138 & 4.521 & 4.6693 & TRN & & & \\
\hline CHEMBL1439172 & 688138 & 4.371 & 4.2428 & TRN & & & \\
\hline CHEMBL17331 & 688138 & 4.221 & 4.333 & TRN & & & \\
\hline CHEMBL1526543 & 688138 & 4.371 & 4.4187 & TST & & & \\
\hline CHEMBL1476762 & 688138 & \multicolumn{3}{|c|}{4.571000000000001} & 4.2301 & TRN & \\
\hline CHEMBL1256132 & 688138 & \multicolumn{3}{|c|}{4.071000000000001} & 4.0952 & TRN & \\
\hline CHEMBL1253351 & 688138 & 4.021 & 4.395 & TRN & & & \\
\hline CHEMBL576349 & 688138 & \multicolumn{3}{|c|}{4.821000000000001} & 4.9682 & TRN & \\
\hline CHEMBL1255836 & 688138 & 4.021 & 4.0593 & TRN & & & \\
\hline CHEMBL270299 & 688138 & \multicolumn{3}{|c|}{5.071000000000001} & 4.4449 & TST & \\
\hline CHEMBL1520394 & 688138 & \multicolumn{3}{|c|}{4.071000000000001} & 4.5089 & TRN & \\
\hline CHEMBL67535 & 688138 & \multicolumn{3}{|c|}{4.071000000000001} & \multicolumn{2}{|c|}{4.2410000000000005} & TRN \\
\hline CHEMBL28 & 688138 & 4.221 & 4.4219 & TRN & & & \\
\hline CHEMBL250711 & 688138 & 4.771 & \multicolumn{3}{|c|}{ 4.178999999999999 } & TRN & \\
\hline CHEMBL1523589 & 688138 & 4.021 & 4.2007 & TRN & & & \\
\hline CHEMBL279556 & 688138 & \multicolumn{3}{|c|}{4.071000000000001} & 4.5043 & TRN & \\
\hline CHEMBL1590378 & 688138 & 4.021 & 4.3251 & TRN & & & \\
\hline CHEMBL49247 & 688138 & 4.621 & 4.4569 & TRN & & & \\
\hline CHEMBL60718 & 688138 & 4.521 & 4.5194 & TRN & & & \\
\hline CHEMBL1256916 & 688138 & \multicolumn{3}{|c|}{4.071000000000001} & 4.4689 & TRN & \\
\hline CHEMBL540294 & 688138 & \multicolumn{3}{|c|}{4.071000000000001} & 4.7167 & TRN & \\
\hline CHEMBL1256647 & 688138 & 4.421 & 4.0265 & TRN & & & \\
\hline CHEMBL45891 & 688138 & 4.121 & 4.2053 & TRN & & & \\
\hline CHEMBL1529009 & 688138 & 4.521 & 4.5033 & TRN & & & \\
\hline CHEMBL45281 & 688138 & 4.021 & 4.2528 & TST & & & \\
\hline CHEMBL1255747 & 688138 & 4.121 & 4.2654 & TRN & & & \\
\hline CHEMBL78150 & 688138 & \multicolumn{3}{|c|}{5.571000000000001} & 4.4257 & TRN & \\
\hline CHEMBL1256695 & 688138 & \multicolumn{3}{|c|}{4.071000000000001} & 4.7567 & TRN & \\
\hline CHEMBL556001 & 688138 & 4.021 & 4.748 & TRN & & & \\
\hline CHEMBL28862 & 688138 & \multicolumn{3}{|c|}{4.821000000000001} & 4.1045 & TRN & \\
\hline CHEMBL319244 & 688138 & 4.421 & 4.5546 & TRN & & & \\
\hline CHEMBL1499 & 688138 & 4.521 & 4.3394 & TST & & & \\
\hline CHEMBL273094 & 688138 & 4.771 & 4.1451 & TRN & & & \\
\hline CHEMBL35482 & 688138 & 5.771 & 4.9686 & TRN & & & \\
\hline CHEMBL1355762 & 688138 & 4.421 & 4.6156 & TRN & & & \\
\hline CHEMBL1395737 & 688138 & 4.021 & 4.2833 & TRN & & & \\
\hline CHEMBL328710 & 688138 & 4.271 & 4.6669 & TRN & & & \\
\hline CHEMBL111545 & 688138 & 4.121 & 4.5066 & TRN & & & \\
\hline CHEMBL545050 & 688138 & 5.421 & 4.4963 & TRN & & & \\
\hline CHEMBL1457622 & 688138 & \multicolumn{3}{|c|}{4.071000000000001} & 4.3109 & TRN & \\
\hline CHEMBL262083 & 688138 & 4.121 & 4.5828 & TRN & & & \\
\hline CHEMBL2110371 & 688138 & \multicolumn{3}{|c|}{5.071000000000001} & 4.4374 & TRN & \\
\hline CHEMBL26138 & 688138 & 4.021 & 4.4254 & TST & & & \\
\hline CHEMBL 2374062 & 688138 & \multicolumn{3}{|c|}{4.071000000000001} & 4.367 & TST & \\
\hline CHEMBL27403 & 688138 & \multicolumn{3}{|c|}{4.071000000000001} & 4.3526 & TRN & \\
\hline CHEMBL876 & 688138 & 4.021 & 4.5147 & TRN & & & \\
\hline CHEMBL 8080 & 688138 & \multicolumn{3}{|c|}{4.321000000000001} & 4.2815 & TRN & \\
\hline CHEMBL1257041 & 688138 & 4.421 & 4.258999 & 99999999 & 995 & TRN & \\
\hline
\end{tabular}




\begin{tabular}{|c|c|c|c|c|c|c|}
\hline \multirow[b]{2}{*}{ CHEMBL1256364 } & \multirow[b]{2}{*}{688138} & \multicolumn{5}{|c|}{ Supplemental Table S2.txt } \\
\hline & & \multicolumn{3}{|c|}{14.6752 TST } & & \\
\hline CHEMBL1256655 & 688138 & 7.0711 & 5.1346 & TRN & & \\
\hline CHEMBL244948 & 688138 & 4.271 & 4.4516 & TRN & & \\
\hline CHEMBL1255865 & 688138 & \multicolumn{3}{|c|}{4.071000000000001} & 4.3306 & TRN \\
\hline CHEMBL935 & 688138 & 4.471 & 4.2227 & TRN & & \\
\hline CHEMBL501701 & 688138 & 4.021 & 4.0236 & TRN & & \\
\hline CHEMBL180427 & 688138 & 4.121 & 4.456 & TRN & & \\
\hline CHEMBL429023 & 688138 & 7.3206 & 4.7436 & TST & & \\
\hline CHEMBL9843 & 688138 & \multicolumn{3}{|c|}{4.071000000000001} & 4.7004 & TRN \\
\hline CHEMBL541543 & 688138 & \multicolumn{3}{|c|}{4.071000000000001} & 4.1987 & TST \\
\hline CHEMBL1256359 & 688138 & \multicolumn{3}{|c|}{4.071000000000001} & 4.1322 & TRN \\
\hline CHEMBL68534 & 688138 & 4.171 & 4.4593 & TRN & & \\
\hline CHEMBL1595524 & 688138 & 4.421 & 4.5025 & TRN & & \\
\hline CHEMBL1315457 & 688138 & 5.721 & 4.5337 & TST & & \\
\hline CHEMBL44 & 688138 & 4.771 & 4.4554 & TRN & & \\
\hline CHEMBL559612 & 688138 & 4.521 & 4.2399 & TST & & \\
\hline CHEMBL192566 & 688138 & 7.2211 & 4.4035 & TST & & \\
\hline CHEMBL58343 & 688138 & 4.021 & 4.0464 & TRN & & \\
\hline CHEMBL56731 & 688138 & \multicolumn{3}{|c|}{4.321000000000001} & 4.6595 & TRN \\
\hline CHEMBL441618 & 688138 & \multicolumn{3}{|c|}{4.071000000000001} & 4.4598 & TRN \\
\hline CHEMBL85139 & 688138 & 4.121 & 4.6414 & TRN & & \\
\hline CHEMBL51085 & 688138 & 4.471 & 4.6658 & TRN & & \\
\hline CHEMBL1256878 & 688138 & 4.271 & 4.5004 & TRN & & \\
\hline CHEMBL1256754 & 688138 & \multicolumn{3}{|c|}{4.071000000000001} & 4.4773 & TRA \\
\hline CHEMBL24983 & 688138 & 5.371 & 4.6041 & TRN & & \\
\hline CHEMBL1561474 & 688138 & 4.371 & 4.1961 & TRN & & \\
\hline CHEMBL1256019 & 688138 & 4.621 & 4.2728 & TRN & & \\
\hline CHEMBL1255837 & 688138 & 4.271 & 4.4329 & TRN & & \\
\hline CHEMBL1597612 & 688138 & 4.721 & 4.3798 & TST & & \\
\hline CHEMBL1256709 & 688138 & \multicolumn{3}{|c|}{4.071000000000001} & 4.2435 & TRA \\
\hline CHEMBL34241 & 688138 & \multicolumn{3}{|c|}{4.321000000000001} & 4.5416 & TST \\
\hline CHEMBL1316953 & 688138 & \multicolumn{3}{|c|}{4.071000000000001} & 4.3102 & TST \\
\hline CHEMBL1256625 & 688138 & 4.671 & 4.4095 & TRN & & \\
\hline CHEMBL500996 & 688138 & 4.171 & 4.7317 & TRN & & \\
\hline CHEMBL48449 & 688138 & 4.671 & 4.3536 & TRN & & \\
\hline CHEMBL63154 & 688138 & \multicolumn{3}{|c|}{4.571000000000001} & 4.3315 & TRN \\
\hline CHEMBL123 & 688138 & 5.121 & 4.6721 & TRN & & \\
\hline CHEMBL77030 & 688138 & 4.171 & 4.332 & TRN & & \\
\hline CHEMBL1440857 & 688138 & 6.671 & 4.789 & TRN & & \\
\hline CHEMBL587714 & 688138 & 4.671 & 4.2308 & TRN & & \\
\hline CHEMBL464251 & 688138 & \multicolumn{3}{|c|}{4.071000000000001} & 4.2715 & TRN \\
\hline CHEMBL1256760 & 688138 & 4.021 & 4.2428 & TST & & \\
\hline CHEMBL23194 & 688138 & 4.171 & 4.1341 & TRN & & \\
\hline CHEMBL275516 & 688138 & 4.771 & \multicolumn{3}{|c|}{4.3389999999999995} & TRA \\
\hline CHEMBL275938 & 688138 & 4.171 & 4.397 & TST & & \\
\hline CHEMBL1436121 & 688138 & 4.121 & 4.3883 & TST & & \\
\hline CHEMBL542493 & 688138 & \multicolumn{3}{|c|}{4.321000000000001} & 4.3469 & TRA \\
\hline CHEMBL278332 & 688138 & \multicolumn{3}{|c|}{4.071000000000001} & 4.176 & TRA \\
\hline
\end{tabular}




\begin{tabular}{|c|c|c|c|c|c|c|}
\hline \multirow[b]{2}{*}{ CHEMBL266084 } & \multirow[b]{2}{*}{688138} & \multicolumn{5}{|c|}{ Supplemental Table S2.txt } \\
\hline & & \multicolumn{3}{|c|}{14.4426 TRN } & & \\
\hline CHEMBL1395058 & 688138 & 4.171 & 4.4664 & TRN & & \\
\hline CHEMBL188 & 688138 & 4.721 & 4.4413 & TRN & & \\
\hline CHEMBL1436268 & 688138 & \multicolumn{3}{|c|}{4.071000000000001} & 4.2558 & TRN \\
\hline CHEMBL428496 & 688138 & 4.421 & 4.4345 & TST & & \\
\hline CHEMBL165 & 688138 & 4.371 & 4.4532 & TRN & & \\
\hline CHEMBL534084 & 688138 & 4.171 & 4.3171 & TRN & & \\
\hline CHEMBL1534566 & 688138 & 4.221 & 4.3304 & TRN & & \\
\hline CHEMBL1394945 & 688138 & 4.221 & 4.2651 & TRN & & \\
\hline CHEMBL333985 & 688138 & 4.421 & 4.5709 & TST & & \\
\hline CHEMBL1531754 & 688138 & 4.171 & 4.6958 & TRN & & \\
\hline CHEMBL18132 & 688138 & 5.871 & 4.8282 & TRN & & \\
\hline CHEMBL1600780 & 688138 & 4.421 & 4.4036 & TRN & & \\
\hline CHEMBL1402894 & 688138 & 4.121 & 4.1857 & TRN & & \\
\hline CHEMBL1256287 & 688138 & 4.021 & 4.5714 & TRN & & \\
\hline CHEMBL1256735 & 688138 & 4.171 & 4.6242 & TRN & & \\
\hline CHEMBL1434334 & 688138 & 4.121 & 4.2543 & TST & & \\
\hline CHEMBL1256974 & 688138 & 4.171 & 4.1442 & TRN & & \\
\hline CHEMBL322970 & 688138 & 4.221 & 4.5214 & TRN & & \\
\hline CHEMBL1603820 & 688138 & \multicolumn{3}{|c|}{4.071000000000001} & 4.3554 & TRA \\
\hline CHEMBL1256697 & 688138 & 4.021 & 4.3247 & TRN & & \\
\hline CHEMBL1256913 & 688138 & 4.121 & 4.3354 & TRN & & \\
\hline CHEMBL258767 & 688138 & 6.0 & 4.598 & TRN & & \\
\hline CHEMBL1374843 & 688138 & 4.521 & 4.3713 & TRN & & \\
\hline CHEMBL1554098 & 688138 & 4.971 & 4.6108 & TRN & & \\
\hline CHEMBL33884 & 688138 & \multicolumn{3}{|c|}{4.071000000000001} & 4.3721 & TRN \\
\hline CHEMBL1338358 & 688138 & \multicolumn{3}{|c|}{4.321000000000001} & 4.4406 & TRN \\
\hline CHEMBL1255662 & 688138 & 4.021 & 4.3904 & TRN & & \\
\hline CHEMBL1158 & 688138 & \multicolumn{3}{|c|}{4.071000000000001} & 4.2489 & TRN \\
\hline CHEMBL1372588 & 688138 & \multicolumn{3}{|c|}{4.071000000000001} & 4.5641 & TRA \\
\hline CHEMBL11348 & 688138 & 4.421 & 4.585 & TRN & & \\
\hline CHEMBL66 & 688138 & 4.121 & 4.4124 & TRN & & \\
\hline CHEMBL1593815 & 688138 & \multicolumn{3}{|c|}{4.821000000000001} & 4.3178 & TRA \\
\hline CHEMBL1256646 & 688138 & \multicolumn{3}{|c|}{4.071000000000001} & 4.2024 & TRN \\
\hline CHEMBL1256759 & 688138 & 5.871 & 4.6255 & TRN & & \\
\hline CHEMBL56 & 688138 & 4.971 & 4.3171 & TRN & & \\
\hline CHEMBL520992 & 688138 & 4.371 & 4.2592 & TRN & & \\
\hline CHEMBL310310 & 688138 & \multicolumn{3}{|c|}{4.821000000000001} & 4.4317 & TRA \\
\hline CHEMBL 274438 & 688138 & 4.121 & 4.5416 & TRN & & \\
\hline CHEMBL1257014 & 688138 & 4.121 & 4.3576 & TRN & & \\
\hline CHEMBL2374027 & 688138 & 4.371 & 4.3462 & TRN & & \\
\hline CHEMBL93655 & 688138 & \multicolumn{3}{|c|}{4.071000000000001} & 4.6265 & TRA \\
\hline CHEMBL1515305 & 688138 & 4.371 & 4.2986 & TRN & & \\
\hline CHEMBL1256814 & 688138 & 4.121 & 4.3731 & TRN & & \\
\hline CHEMBL1441059 & 688138 & \multicolumn{3}{|c|}{4.071000000000001} & 4.3193 & TRN \\
\hline CHEMBL258893 & 688138 & 4.671 & 4.7944 & TRN & & \\
\hline CHEMBL1439696 & 688138 & 4.221 & 4.2772 & TRN & & \\
\hline CHEMBL1257075 & 688138 & \multicolumn{3}{|c|}{4.321000000000001} & 4.2791 & TRA \\
\hline
\end{tabular}




\begin{tabular}{|c|c|c|c|c|c|c|}
\hline & & & pplement & al la & S2. & \\
\hline CHEMBL544115 & 688138 & 4.621 & 4.3896 & TRN & & \\
\hline CHEMBL 8145 & 688138 & $4.321 \epsilon$ & 2000000e & & 4.4531 & TRN \\
\hline CHEMBL408982 & 688138 & 4.171 & 4.4971 & TRN & & \\
\hline CHEMBL164 & 688138 & $4.071 €$ & 00000000 & & 4.3356 & TRN \\
\hline CHEMBL45245 & 688138 & 4.171 & 4.6047 & TRN & & \\
\hline CHEMBL30432 & 688138 & 4.471 & 4.5649 & TRN & & \\
\hline CHEMBL1315073 & 688138 & 4.121 & 4.5428 & TRN & & \\
\hline CHEMBL1257076 & 688138 & 4.021 & 4.2699 & TRN & & \\
\hline CHEMBL 299052 & 688138 & $4.071 €$ & 2000000e & & 4.5889 & TRN \\
\hline CHEMBL1256924 & 688138 & 4.171 & 4.4593 & TRN & & \\
\hline CHEMBL1397559 & 688138 & $4.071 €$ & 00000000 & & 4.3387 & TRN \\
\hline CHEMBL1255655 & 688138 & $4.071 €$ & j000000e & & 4.1873 & TRN \\
\hline CHEMBL1256186 & 688138 & 4.0716 & j000000e & & 4.2954 & TST \\
\hline CHEMBL536950 & 688138 & 4.121 & 4.6733 & TRN & & \\
\hline CHEMBL327708 & 688138 & 4.3216 & j000000e & & 4.0709 & TRN \\
\hline CHEMBL1593930 & 688138 & 4.0716 & $\partial 000000 e$ & 01 & 4.2664 & TRN \\
\hline CHEMBL1256148 & 688138 & 6.0 & 4.5846 & TRN & & \\
\hline CHEMBL1256737 & 688138 & 4.721 & 4.4755 & TRN & & \\
\hline CHEMBL596674 & 688138 & 4.671 & 4.5895 & TRN & & \\
\hline CHEMBL2374259 & 688138 & 4.3216 & j000000e & & 4.2748 & TRN \\
\hline CHEMBL 6640 & 688138 & 4.021 & 4.3964 & TRN & & \\
\hline CHEMBL416657 & 688138 & 4.471 & 4.1974 & TRN & & \\
\hline CHEMBL3186408 & 688138 & 4.421 & 4.4844 & TST & & \\
\hline CHEMBL1256997 & 688138 & 4.5716 & j000000e & & 4.3522 & TRN \\
\hline CHEMBL1255867 & 688138 & 4.171 & 4.2905 & TRN & & \\
\hline CHEMBL 277525 & 688138 & 4.021 & 4.5529 & TST & & \\
\hline CHEMBL1256716 & 688138 & $4.071 €$ & 00000000 & & 4.6408 & TRN \\
\hline CHEMBL1257080 & 688138 & $4.071 €$ & 2000000e & & 4.3756 & TST \\
\hline CHEMBL1256923 & 688138 & 4.121 & 4.3555 & TRN & & \\
\hline CHEMBL1256290 & 688138 & 4.0716 & j000000e & & 4.1918 & TRN \\
\hline CHEMBL104264 & 688138 & 4.3216 & j000000e & & 4.5062 & TRN \\
\hline CHEMBL 2374058 & 688138 & 4.371 & 4.3273 & TST & & \\
\hline CHEMBL1563352 & 688138 & $4.071 €$ & j000000e & & 4.3113 & TST \\
\hline CHEMBL 3084891 & 688138 & 4.0716 & 30000000 & & 4.47 & TRN \\
\hline CHEMBL402063 & 688138 & 4.121 & 4.4491 & TST & & \\
\hline CHEMBL 277120 & 688138 & 4.371 & 4.4007 & TRN & & \\
\hline CHEMBL1257003 & 688138 & 4.171 & 4.5191 & TRN & & \\
\hline CHEMBL 299613 & 688138 & $5.571 €$ & j000000e & & 4.66 & TRN \\
\hline CHEMBL1405759 & 688138 & 4.0716 & j000000e & & 4.5419 & TRN \\
\hline CHEMBL112816 & 688138 & 5.971 & 4.4518 & TRN & & \\
\hline CHEMBL 268868 & 688138 & 4.421 & 4.746 & TRN & & \\
\hline CHEMBL1257078 & 688138 & 4.0716 & j000000e & & 4.523 & TRN \\
\hline CHEMBL41680 & 688138 & $4.821 €$ & j000000e & 01 & 4.2715 & TRN \\
\hline CHEMBL282489 & 688138 & 4.421 & 4.2969 & TRN & & \\
\hline CHEMBL1593765 & 688138 & 4.121 & 4.6661 & TRN & & \\
\hline CHEMBL481537 & 688138 & 4.121 & 4.4899 & TRN & & \\
\hline CHEMBL1256914 & 688138 & 4.121 & 4.567 & TRN & & \\
\hline CHEMBL1256360 & 688138 & 4.021 & 4.2379 & TRN & & \\
\hline
\end{tabular}




\begin{tabular}{|c|c|c|c|c|c|c|}
\hline \multirow[b]{2}{*}{ CHEMBL1257002 } & \multirow[b]{2}{*}{688138} & \multicolumn{5}{|c|}{ Supplemental Table S2.txt } \\
\hline & & \multirow{2}{*}{\multicolumn{3}{|c|}{$\begin{array}{lc}4.221 & 4.4266 \\
4.071000000000001\end{array}$}} & \multirow{2}{*}{4.2128} & \multirow{2}{*}{ TRN } \\
\hline CHEMBL106265 & 688138 & & & & & \\
\hline CHEMBL56543 & 688138 & 4.471 & 4.5642 & TRN & & \\
\hline CHEMBL1256686 & 688138 & 5.221 & 4.3898 & TST & & \\
\hline CHEMBL288174 & 688138 & 4.521 & 4.3288 & TST & & \\
\hline CHEMBL1256869 & 588138 & 4.771 & 4.3789 & TRN & & \\
\hline CHEMBL 275311 & 688138 & \multicolumn{3}{|c|}{4.071000000000001} & \multirow[t]{3}{*}{4.4184} & \\
\hline CHEMBL296586 & 688138 & 6.871 & 4.8756 & TRN & & \\
\hline CHEMBL338790 & 688138 & 4.421 & 4.5056 & TRN & & \\
\hline CHEMBL68500 & 588138 & 4.521 & \multicolumn{3}{|c|}{4.638999999999999} & \\
\hline CHEMBL269733 & 688138 & 4.421 & 4.3676 & TRN & & \\
\hline CHEMBL1079460 & 688138 & \multicolumn{3}{|c|}{4.071000000000001} & 4.2338 & \\
\hline CHEMBL604119 & 688138 & 4.521 & 4.2589 & TST & & \\
\hline CHEMBL1237212 & 688138 & 4.121 & 4.2624 & TRN & & \\
\hline CHEMBL129795 & 688138 & \multicolumn{3}{|c|}{4.821000000000001} & 4.3747 & \\
\hline CHEMBL1358402 & 688138 & 7.6716 & 4.4037 & TST & & \\
\hline CHEMBL578741 & 688138 & 4.121 & 4.3846 & TRN & & \\
\hline CHEMBL1 & 688138 & 5.371 & 4.2746 & TRN & & \\
\hline CHEMBL1 & 688138 & \multicolumn{3}{|c|}{4.071000000000001} & 4.194 & \\
\hline CHEMBL1338900 & 688138 & 4.021 & 4.2426 & TST & & \\
\hline CHEMBL1354914 & 688138 & \multicolumn{3}{|c|}{4.071000000000001} & 735 & \\
\hline CHEMBL1 & 688138 & 4.021 & 4.1661 & TRN & & \\
\hline CHEMBL 2 & 688138 & \multicolumn{3}{|c|}{4.071000000000001} & 4.0598 & \\
\hline CHEMBL1 & 688138 & \multicolumn{3}{|c|}{5.071000000000001} & 4.6365 & \\
\hline CHEMBL355496 & 688138 & 4.771 & 4.6998 & TRN & & \\
\hline CHEMBL286077 & 688138 & 4.021 & 4.0897 & TRN & & \\
\hline CHEMBL280998 & 688138 & 4.121 & 4.5652 & TRN & & \\
\hline CHEMBL1 & 688138 & \multicolumn{3}{|c|}{4.071000000000001} & 4.3214 & $\mathrm{~T}$ \\
\hline CHEMBL407874 & 688138 & 4.371 & 4.604 & TRN & & \\
\hline CHEMBL1256770 & 688138 & \multicolumn{3}{|c|}{4.071000000000001} & 4.1213 & TRN \\
\hline CHEMBL1256740 & 688138 & \multicolumn{3}{|c|}{4.571000000000001} & 4.543 & \\
\hline CHEMBL23957 & 688138 & 5.521 & 4.2448 & TST & & \\
\hline CHEMBL\& & 688138 & 4.371 & 4.4501 & TRN & & \\
\hline CHEMBL1513654 & 688138 & 4.621 & 4.4732 & TRN & & \\
\hline CHEMBL21823 & 688138 & \multicolumn{3}{|c|}{4.071000000000001} & 4.4403 & \\
\hline CHEMBL52030 & 688138 & 4.121 & 4.2987 & TRN & & \\
\hline CHEMBL 278041 & 688138 & \multicolumn{3}{|c|}{4.571000000000001} & 4.3277 & \\
\hline CHEMBL1 & 688138 & 5.521 & 4.7264 & TRN & & \\
\hline CHEMBL1335406 & 688138 & 4.021 & 4.4291 & TST & & \\
\hline CHEMBL1450525 & 688138 & 4.021 & 4.3101 & TST & & \\
\hline CHEMBL1376723 & 688138 & 4.171 & 4.2708 & TRN & & \\
\hline CHEMBL47529 & 688138 & 4.221 & 4.7358 & TRN & & \\
\hline CHEMBL1256813 & 688138 & 4.671 & 4.2229 & TRN & & \\
\hline CHEMBL1357894 & 688138 & 6.671 & 4.7272 & TRN & & \\
\hline CHEMBL70880 & 688138 & 5.521 & 4.9834 & TRN & & \\
\hline CHEMBL64119 & 688138 & \multicolumn{3}{|c|}{4.071000000000001} & 4.454 & TRN \\
\hline CHEMBL67311 & 688138 & 4.0710 & 30000000 & & 4.1157 & 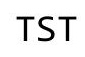 \\
\hline CHEMBL56393 & 688138 & 4.221 & 4.25899 & 0 & 95 & $\mathrm{TR}$ \\
\hline & & & & & & \\
\hline
\end{tabular}




\begin{tabular}{|c|c|c|c|c|c|c|}
\hline \multirow[b]{2}{*}{ CHEMBL602375 } & \multirow[b]{2}{*}{688138} & \multicolumn{5}{|c|}{ Supplemental Table S2.txt } \\
\hline & & \multicolumn{3}{|c|}{14.1817 TST } & & \\
\hline CHEMBL1515948 & 688138 & 5.021 & 4.4378 & TRN & & \\
\hline CHEMBL161343 & 688138 & \multicolumn{3}{|c|}{4.071000000000001} & 4.2088 & $1 \mathrm{KI}$ \\
\hline CHEMBL1255832 & 688138 & 4.721 & 4.6615 & TRN & & \\
\hline CHEMBL 1256749 & 688138 & 4.621 & 4.5733 & TST & & \\
\hline CHEMBL286722 & 688138 & 4.971 & 4.5418 & TRN & & \\
\hline CHEMBL1255936 & 688138 & 4.471 & 4.5435 & TRN & & \\
\hline CHEMBL17468 & 688138 & 4.421 & 4.5146 & TRN & & \\
\hline CHEMBL8747 & 688138 & 4.121 & 4.5592 & TRN & & \\
\hline CHEMBL1527722 & 688138 & 4.021 & 4.1847 & TRN & & \\
\hline CHEMBL1256291 & 688138 & 4.021 & 4.4729 & TRN & & \\
\hline CHEMBL21241 & 688138 & \multicolumn{3}{|c|}{4.071000000000001} & 4.2487 & \\
\hline CHEMBL1323714 & 688138 & \multicolumn{3}{|c|}{4.071000000000001} & & \\
\hline CHEMBL574181 & 688138 & 4.421 & 4.3394 & TRN & & \\
\hline CHEMBL1256180 & 688138 & \multirow{2}{*}{\multicolumn{3}{|c|}{$\begin{array}{l}4.121 \quad 4.1368 \text { TRN } \\
4.071000000000001\end{array}$}} & & \\
\hline CHEMBL1355634 & 688138 & & & & 4.4337 & \\
\hline CHEMBL72365 & 688138 & 4.421 & 4.4358 & TRN & & \\
\hline CHEMBL539 & 688138 & 4.471 & 4.3607 & TRN & & \\
\hline CHEMBL 88 & 688138 & \multicolumn{3}{|c|}{4.071000000000001} & 4.1125 & \\
\hline CHEMBL1255659 & 688138 & 4.671 & 4.4905 & TRN & & \\
\hline CHEMBL65 & 688138 & 6.6211 & 4.6582 & TST & & \\
\hline CHEMBL1256876 & 688138 & 4.721 & 4.2582 & TST & & \\
\hline CHEMBL1 & 688 & 4.421 & 4.377 & TRN & & \\
\hline CHEMBL18 & 688138 & \multicolumn{3}{|c|}{4.321000000000001} & 4.0626 & \\
\hline CHEMBL1408519 & 688138 & 4.521 & 4.3485 & TRN & & \\
\hline CHEMBL8211 & 688138 & 4.371 & 4.2812 & TRN & & \\
\hline CHEMBL48492 & 688138 & 4.021 & 4.4109 & TRN & & \\
\hline CHEMBL 7 & 688138 & \multicolumn{3}{|c|}{4.071000000000001} & 04 & TRN \\
\hline CHEMBL1256875 & 688138 & \multicolumn{3}{|c|}{4.071000000000001} & 308 & \\
\hline CHEMBL1590980 & 688138 & 4.421 & 4.6551 & TRN & & \\
\hline CHEMBL 375270 & 688138 & \multirow{2}{*}{\multicolumn{3}{|c|}{$\begin{array}{lcc}4.721 & 4.6184 & \text { TRN } \\
4.071000000000001\end{array}$}} & & \\
\hline CHEMBL 1256177 & 688138 & & & & 4.0647 & \\
\hline CHEMBL126 & 688138 & 4.421 & 4.2095 & TST & & \\
\hline CHEMBL1316222 & 688138 & \multicolumn{3}{|c|}{4.071000000000001} & 4.2824 & $\mathrm{TS}$ \\
\hline CHEMBL336467 & 688138 & 4.521 & 4.7086 & TST & & \\
\hline CHEMBL1235242 & 688138 & \multicolumn{3}{|c|}{4.571000000000001} & 4.1444 & 17 \\
\hline CHEMBL53898 & 688138 & 4.721 & 4.5295 & TRN & & \\
\hline CHEMBL 371811 & 688138 & \multirow{2}{*}{\multicolumn{3}{|c|}{$\begin{array}{l}0.021 \\
4.071000000000001\end{array}$}} & & \\
\hline CHEMBL1200462 & 688138 & & & & 4.5786 & TRN \\
\hline CHEMBL1515001 & 688138 & \multicolumn{3}{|c|}{4.071000000000001} & 4.4795 & TRN \\
\hline CHEMBL1522486 & 688138 & 5.021 & 4.6184 & TRN & & \\
\hline CHEMBL77971 & 688138 & \multirow{2}{*}{\multicolumn{3}{|c|}{$\begin{array}{lc}4.021 & 4.6603 \\
4.071000000000001\end{array}$}} & & \\
\hline CHEMBL1200938 & 688138 & & & & 4.2442 & $T$ \\
\hline CHEMBL47814 & 688138 & 4.521 & 4.5863 & TST & & \\
\hline CHEMBL1255755 & 688138 & \multicolumn{3}{|c|}{4.071000000000001} & 4.6555 & S1 \\
\hline CHEMBL1710 & 688138 & 4.621 & 4.30617 & TST & & \\
\hline CHEMBL541585 & 688138 & \multicolumn{3}{|c|}{4.321000000000001} & 4.2493 & 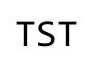 \\
\hline CHEMBL1234696 & 688138 & 4.771 & 4.39797 & TS & & \\
\hline
\end{tabular}




\begin{tabular}{|c|c|c|c|c|c|c|c|}
\hline \multirow[b]{2}{*}{ CHEMBL16687 } & & \\
\hline & 688138 & 4.421 & 4.4855 & TST & & & \\
\hline CHEMBL1520976 & 688138 & 4.921 & 4.3561 & TST & & & \\
\hline CHEMBL26320 & 688138 & 4.421 & 4.4914 & TST & & & \\
\hline CHEMBL1255660 & 688138 & 4.0710 & 20000000 & & 4.2329 & TST & \\
\hline CHEMBL1972346 & 688138 & 4.521 & 4.3902 & TST & & & \\
\hline CHEMBL1224512 & 688138 & 4.0710 & 00000000 & & 4.3371 & TST & \\
\hline CHEMBL1256173 & 688138 & 4.0710 & 00000000 & 01 & 4.2018 & TST & \\
\hline CHEMBL303579 & 688138 & 4.871 & 4.4968 & TST & & & \\
\hline CHEMBL1330357 & 688138 & 5.0710 & 20000000 & & 4.1924 & TST & \\
\hline CHEMBL279998 & 688138 & 4.021 & 4.1996 & TST & & & \\
\hline CHEMBL1256751 & 688138 & 4.171 & 4.2857 & TST & & & \\
\hline CHEMBL1256698 & 688138 & 4.0710 & 00000000 & & 4.49 & TST & \\
\hline CHEMBL1336166 & 688138 & 4.471 & 4.4826 & TST & & & \\
\hline CHEMBL1256873 & 688138 & 4.221 & 4.4702 & TST & & & \\
\hline CHEMBL1256750 & 688138 & 4.021 & 4.2932 & TST & & & \\
\hline CHEMBL293749 & 688138 & 4.671 & 4.5075 & TST & & & \\
\hline CHEMBL280563 & 688138 & 4.0710 & 20000000 & & 4.21399 & 99999999995 & TST \\
\hline CHEMBL273807 & 688138 & 4.021 & 4.2383 & TST & & & \\
\hline CHEMBL113830 & 688138 & 4.371 & 4.5016 & TST & & & \\
\hline CHEMBL261642 & 688138 & 4.0710 & 00000000 & & 4.1223 & TST & \\
\hline CHEMBL2028085 & 688138 & 4.021 & 4.2387 & TST & & & \\
\hline CHEMBL1284 & 688138 & 4.621 & 4.3311 & TST & & & \\
\hline CHEMBL1372997 & 688138 & 4.0710 & 20000000 & & 4.0951 & TST & \\
\hline CHEMBL310798 & 688138 & 4.171 & 4.355 & TST & & & \\
\hline CHEMBL1257083 & 688138 & 4.471 & 4.0646 & TST & & & \\
\hline CHEMBL1256940 & 688138 & 4.0710 & 00000000 & & 4.6621 & TST & \\
\hline CHEMBL1255578 & 688138 & 4.0710 & 00000000 & & 4.2932 & TST & \\
\hline CHEMBL1256667 & 688138 & 4.371 & 4.2335 & TST & & & \\
\hline CHEMBL98350 & 688138 & 4.921 & 4.7198 & TST & & & \\
\hline CHEMBL1256910 & 688138 & 4.471 & 4.6462 & TST & & & \\
\hline CHEMBL124267 & 688138 & 6.421 & 4.2161 & TST & & & \\
\hline CHEMBL384903 & 688138 & 4.121 & 4.3048 & TST & & & \\
\hline CHEMBL153036 & 688138 & 6.0 & 4.5205 & TST & & & \\
\hline CHEMBL 72631 & 688138 & 4.121 & 4.3186 & TST & & & \\
\hline CHEMBL538595 & 688138 & 6.0 & 4.4998 & TST & & & \\
\hline CHEMBL1367076 & 688138 & 4.871 & 4.4575 & TST & & & \\
\hline CHEMBL553503 & 688138 & 4.421 & 4.4367 & TST & & & \\
\hline CHEMBL1526455 & 688138 & 4.621 & 4.244 & TST & & & \\
\hline CHEMBL1571692 & 688138 & 4.021 & 4.3379 & TST & & & \\
\hline CHEMBL97760 & 688138 & 5.721 & 4.652 & TST & & & \\
\hline CHEMBL285819 & 688138 & 4.771 & 4.2424 & TST & & & \\
\hline CHEMBL1398537 & 688138 & 4.0710 & 00000000 & & 4.4642 & TST & \\
\hline CHEMBL1256687 & 688138 & 4.0710 & $\partial 0000000$ & & 4.2453 & TST & \\
\hline CHEMBL1436438 & 688138 & 4.021 & 4.21 & TST & & & \\
\hline CHEMBL1097940 & 688138 & 4.021 & 4.4912 & TST & & & \\
\hline CHEMBL567175 & 688138 & 4.421 & 4.4365 & TST & & & \\
\hline CHEMBL1256885 & 688138 & 4.171 & 4.4802 & TST & & & \\
\hline CHEMBL76904 & 688138 & 4.121 & 4.3977 & TST & & & \\
\hline
\end{tabular}




\begin{tabular}{|c|c|c|c|c|}
\hline \multicolumn{5}{|c|}{ Supplemental Table s2.txt } \\
\hline CHEMBL1256325 & 688138 & 4.021 & 4.2539 & TST \\
\hline CHEMBL 3697787 & 1640340 & 7.3188 & 6.931 & TRN \\
\hline CHEMBL3641162 & 1640340 & 10.0 & 8.5745 & TST \\
\hline CHEMBL3689908 & 1640340 & 8.5229 & 8.703 & TRN \\
\hline CHEMBL3643293 & 1640340 & 8.699 & 8.28399 & 9999999999 \\
\hline CHEMBL 3641245 & 1640340 & 5.0 & 4.8483 & TRN \\
\hline CHEMBL3697935 & 1640340 & 8.3979 & 8.7025 & TRN \\
\hline CHEMBL 3697840 & 1640340 & 7.7696 & 8.2362 & TST \\
\hline CHEMBL3641209 & 1640340 & 8.2218 & 8.4335 & TST \\
\hline CHEMBL3694175 & 1640340 & 8.699 & 8.3238 & TRN \\
\hline CHEMBL3694051 & 1640340 & 7.0177 & 6.6625 & TST \\
\hline CHEMBL3641165 & 1640340 & 8.3979 & 8.1588 & TRN \\
\hline CHEMBL 3641244 & 1640340 & 5.0 & 5.2441 & TRN \\
\hline CHEMBL3641079 & 1640340 & 8.5229 & 8.5666 & TRN \\
\hline CHEMBL3689918 & 1640340 & 7.2441 & 7.5031 & TRN \\
\hline CHEMBL 3641182 & 1640340 & 8.699 & 8.6694 & TRN \\
\hline CHEMBL3694230 & 1640340 & 10.0 & 8.9337 & TRN \\
\hline CHEMBL3697748 & 1640340 & 4.699 & 5.7155 & TRN \\
\hline CHEMBL3694176 & 1640340 & 8.699 & 9.151 & TRN \\
\hline CHEMBL3697775 & 1640340 & 9.0 & 9.1579 & TRN \\
\hline CHEMBL3697785 & 1640340 & 8.2218 & 8.6027 & TRN \\
\hline CHEMBL 3697837 & 1640340 & 7.4437 & 7.9165 & TRN \\
\hline CHEMBL 3697820 & 1640340 & 8.5229 & 7.6312 & TRN \\
\hline CHEMBL3694208 & 1640340 & 10.0 & 9.1736 & TST \\
\hline CHEMBL3641192 & 1640340 & 7.7447 & 7.5432 & TRN \\
\hline CHEMBL 3697788 & 1640340 & 7.7212 & 7.2249 & TRN \\
\hline CHEMBL3694203 & 1640340 & 8.699 & 8.9506 & TRN \\
\hline CHEMBL3694196 & 1640340 & 8.699 & 8.9436 & TRN \\
\hline CHEMBL3641216 & 1640340 & 7.3565 & 7.2396 & TST \\
\hline CHEMBL3641090 & 1640340 & 10.0 & 8.8705 & TRN \\
\hline CHEMBL3641161 & 1640340 & 8.3979 & 8.7238 & TRN \\
\hline CHEMBL3697852 & 1640340 & 6.9431 & 7.444 & TRN \\
\hline CHEMBL3694103 & 1640340 & 8.699 & 9.5581 & TST \\
\hline CHEMBL 3694074 & 1640340 & 8.3979 & 8.9969 & TST \\
\hline CHEMBL3641081 & 1640340 & 9.0 & 8.6578 & TRN \\
\hline CHEMBL3641030 & 1640340 & 8.5229 & 8.6427 & TRN \\
\hline CHEMBL3697917 & 1640340 & 8.1549 & 7.4899 & TST \\
\hline CHEMBL 3689904 & 1640340 & 8.301 & 8.0709 & TRN \\
\hline CHEMBL3641143 & 1640340 & 8.699 & 8.1395 & TST \\
\hline CHEMBL3697796 & 1640340 & 7.3979 & 6.7472 & TRN \\
\hline CHEMBL3694204 & 1640340 & 8.5229 & 8.7769 & TRN \\
\hline CHEMBL3641152 & 1640340 & 7.9208 & 7.7092 & TRN \\
\hline CHEMBL 3641242 & 1640340 & 8.5229 & 8.4347 & TST \\
\hline CHEMBL3697729 & 1640340 & 3.8239 & 4.3749 & TRN \\
\hline CHEMBL3641104 & 1640340 & 8.2218 & 8.1097 & TRN \\
\hline CHEMBL 3694100 & 1640340 & 8.3979 & 9.1558 & TRN \\
\hline CHEMBL3641061 & 1640340 & 9.0 & 8.4214 & TRN \\
\hline CHEMBL3697926 & 1640340 & 9.0 & 9.0 & TST \\
\hline
\end{tabular}




\begin{tabular}{|c|c|c|c|c|c|}
\hline \multicolumn{6}{|c|}{ Supplemental Table S2.txt } \\
\hline CHEMBL 3641040 & 1640340 & 10.0 & 8.8859 & TRN & \\
\hline CHEMBL3641072 & 1640340 & 8.2218 & 8.5469 & TRN & \\
\hline CHEMBL3697826 & 1640340 & 8.301 & 8.1377 & TRN & \\
\hline CHEMBL3694132 & 1640340 & 8.2218 & 8.8504 & TRN & \\
\hline CHEMBL3641131 & 1640340 & 10.0 & 9.2888 & TRN & \\
\hline CHEMBL3697897 & 1640340 & 7.699 & 5.9696 & TST & \\
\hline CHEMBL3641170 & 1640340 & 7.7447 & 8.3559 & TRN & \\
\hline CHEMBL3641142 & 1640340 & 10.0 & 9.042 & TRN & \\
\hline CHEMBL3694137 & 1640340 & 9.0 & 8.9557 & TST & \\
\hline CHEMBL3694119 & 1640340 & 5.7014 & 5.7701 & TRN & \\
\hline CHEMBL 3694070 & 1640340 & 9.0 & 8.3746 & TRN & \\
\hline CHEMBL3641036 & 1640340 & 8.0458 & 8.5454 & TST & \\
\hline CHEMBL3641097 & 1640340 & 9.0 & 8.8012 & TRN & \\
\hline CHEMBL3641197 & 1640340 & 9.0 & 9.1084 & TST & \\
\hline CHEMBL3641073 & 1640340 & 7.8861 & 8.3599 & TRN & \\
\hline CHEMBL3694109 & 1640340 & 6.3458 & 6.3567 & TRN & \\
\hline CHEMBL3694158 & 1640340 & 8.699 & 8.6002 & TRN & \\
\hline CHEMBL 3697834 & 1640340 & 7.8861 & 8.289 & TRN & \\
\hline CHEMBL3641218 & 1640340 & 9.0 & 8.7264 & TRN & \\
\hline CHEMBL 3641130 & 1640340 & 10.0 & 8.9223 & TRN & \\
\hline CHEMBL3697798 & 1640340 & 8.0969 & 7.3413 & TST & \\
\hline CHEMBL 3643298 & 1640340 & 7.8539 & 6.8914 & TST & \\
\hline CHEMBL3641059 & 1640340 & 8.2218 & 7.9827 & TRN & \\
\hline CHEMBL3697738 & 1640340 & 8.699 & 8.0791 & TST & \\
\hline CHEMBL3697810 & 1640340 & 5.585 & 7.563 & TST & \\
\hline CHEMBL3697780 & 1640340 & 7.8239 & 7.91 & TST & \\
\hline CHEMBL3694151 & 1640340 & 8.301 & 8.3018 & TRN & \\
\hline CHEMBL3697886 & 1640340 & 5.6735 & 8.1767 & TST & \\
\hline CHEMBL3697896 & 1640340 & 10.0 & 8.4782 & TST & \\
\hline CHEMBL3641136 & 1640340 & 8.699 & 8.1498 & TRN & \\
\hline CHEMBL3641141 & 1640340 & 8.3979 & 8.8573 & TRN & \\
\hline CHEMBL3641038 & 1640340 & 8.5229 & 8.5644 & TRN & \\
\hline CHEMBL3694207 & 1640340 & 8.699 & 9.2059 & TRN & \\
\hline CHEMBL3694224 & 1640340 & 10.0 & 9.2908 & TRN & \\
\hline CHEMBL3697888 & 1640340 & 8.1549 & 8.3055 & TRN & \\
\hline CHEMBL3641120 & 1640340 & 7.3098 & 7.7134 & TST & \\
\hline CHEMBL3641227 & 1640340 & 8.699 & 8.6088 & TRN & \\
\hline CHEMBL3697883 & 1640340 & 9.0 & 9.2363 & TRN & \\
\hline CHEMBL3641183 & 1640340 & 10.0 & 8.8401 & TST & \\
\hline CHEMBL3694131 & 1640340 & 8.0969 & 8.1361 & TRN & \\
\hline CHEMBL3697727 & 1640340 & 7.7696 & 7.9808 & TST & \\
\hline CHEMBL3697880 & 1640340 & 6.8539 & 7.2081 & TRN & \\
\hline CHEMBL3697877 & 1640340 & 7.2518 & 7.8068 & TRN & \\
\hline CHEMBL3697818 & 1640340 & 8.699 & 8.85799 & 9999999999 & TRN \\
\hline CHEMBL3697739 & 1640340 & 3.8239 & 5.7952 & TST & \\
\hline CHEMBL3641226 & 1640340 & 7.1427 & 6.6822 & TST & \\
\hline CHEMBL3697725 & 1640340 & 4.1549 & 5.1166 & TST & \\
\hline CHEMBL3694128 & 1640340 & 5.3798 & 6.1301 & TRN & \\
\hline
\end{tabular}


Supplemental Table S2.txt

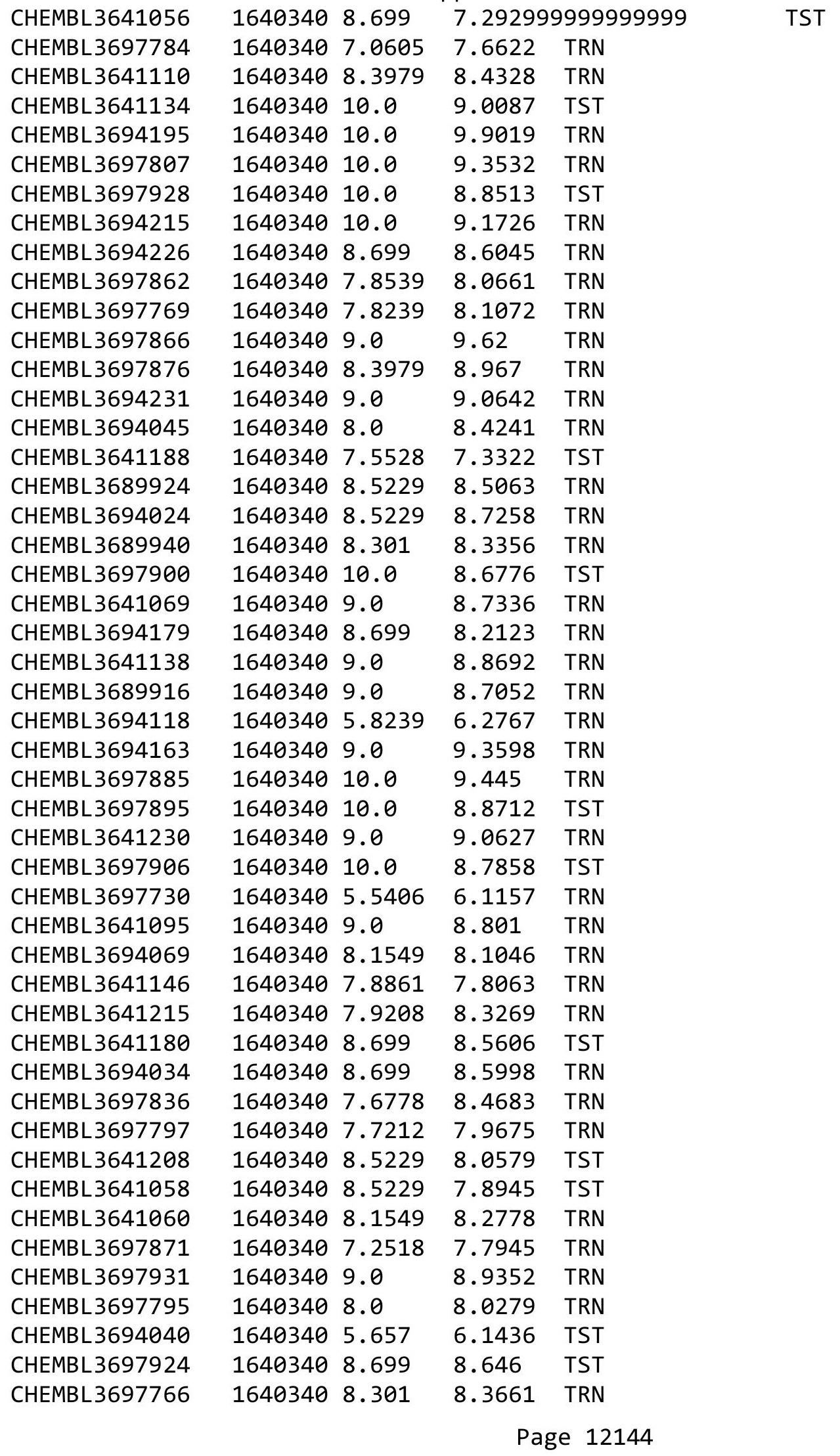


Supplemental Table S2.txt

\begin{tabular}{|c|c|c|c|c|}
\hline CHEMBL3697781 & 1640340 & 8.699 & 8.1152 & TRN \\
\hline CHEMBL3697934 & 1640340 & 9.0 & 9.0294 & TRN \\
\hline CHEMBL3694165 & 1640340 & 8.699 & 8.6874 & TRN \\
\hline CHEMBL3689929 & 1640340 & 7.4559 & 8.1556 & TRN \\
\hline CHEMBL3697855 & 1640340 & 7.301 & 7.2352 & TRN \\
\hline CHEMBL3641198 & 1640340 & 9.0 & 9.8537 & TST \\
\hline CHEMBL 3697821 & 1640340 & 8.699 & 8.8328 & TRN \\
\hline CHEMBL3694052 & 1640340 & 7.8239 & 7.2013 & TST \\
\hline CHEMBL3697767 & 1640340 & 6.767 & 7.1879 & TRN \\
\hline CHEMBL3697811 & 1640340 & 8.3979 & 8.10700 & 0000000001 \\
\hline CHEMBL3697853 & 1640340 & 7.3279 & 7.157 & TRN \\
\hline CHEMBL3697758 & 1640340 & 3.8239 & 5.0455 & TST \\
\hline CHEMBL3697863 & 1640340 & 8.699 & 8.8893 & TRN \\
\hline CHEMBL3697762 & 1640340 & 8.5229 & 8.5991 & TRN \\
\hline CHEMBL3697816 & 1640340 & 7.699 & 8.8184 & TRN \\
\hline CHEMBL3694156 & 1640340 & 9.0 & 8.7275 & TRN \\
\hline CHEMBL3697911 & 1640340 & 8.699 & 8.949 & TRN \\
\hline CHEMBL3641154 & 1640340 & 8.699 & 8.4768 & TST \\
\hline CHEMBL3641115 & 1640340 & 10.0 & 8.9018 & TST \\
\hline CHEMBL3694016 & 1640340 & 9.0 & 9.1475 & TRN \\
\hline CHEMBL3697833 & 1640340 & 8.699 & 8.6332 & TRN \\
\hline CHEMBL3641029 & 1640340 & 8.699 & 8.3035 & TRN \\
\hline CHEMBL3697860 & 1640340 & 10.0 & 9.5754 & TRN \\
\hline CHEMBL3694188 & 1640340 & 10.0 & 8.5667 & TST \\
\hline CHEMBL3694023 & 1640340 & 10.0 & 9.2313 & TRN \\
\hline CHEMBL3689931 & 1640340 & 7.8539 & 8.2282 & TRN \\
\hline CHEMBL 3697765 & 1640340 & 8.0969 & 8.4063 & TRN \\
\hline CHEMBL 3697735 & 1640340 & 3.8239 & 4.4911 & TRN \\
\hline CHEMBL 3641086 & 1640340 & 8.699 & 8.9607 & TRN \\
\hline CHEMBL 3697878 & 1640340 & 8.0 & 7.8081 & TRN \\
\hline CHEMBL3697779 & 1640340 & 6.2434 & 6.3096 & TRN \\
\hline CHEMBL 3641050 & 1640340 & 10.0 & 8.7349 & TRN \\
\hline CHEMBL3641207 & 1640340 & 9.0 & 9.0152 & TRN \\
\hline CHEMBL3697905 & 1640340 & 8.5229 & 8.7021 & TST \\
\hline CHEMBL 3641044 & 1640340 & 10.0 & 9.5495 & TRN \\
\hline CHEMBL3697726 & 1640340 & 8.5229 & 9.0797 & TRN \\
\hline CHEMBL 3689935 & 1640340 & 8.3979 & 8.0504 & TST \\
\hline CHEMBL3697930 & 1640340 & 10.0 & 8.9378 & TST \\
\hline CHEMBL3694113 & 1640340 & 8.301 & 7.0745 & TRN \\
\hline CHEMBL 3694089 & 1640340 & 7.6198 & 7.9527 & TRN \\
\hline CHEMBL 3697753 & 1640340 & 7.9586 & 7.5856 & TRN \\
\hline CHEMBL 3694174 & 1640340 & 8.699 & 8.8524 & TRN \\
\hline CHEMBL3694147 & 1640340 & 8.699 & 8.606 & TRN \\
\hline CHEMBL3641046 & 1640340 & 9.0 & 9.087 & TRN \\
\hline CHEMBL 3697854 & 1640340 & 8.3979 & 8.6219 & TRN \\
\hline CHEMBL 3694170 & 1640340 & 10.0 & 9.0529 & TRN \\
\hline CHEMBL 3697808 & 1640340 & 8.0458 & 8.0201 & TRN \\
\hline \multirow[t]{2}{*}{ CHEMBL3694110 } & 1640340 & 7.0223 & 6.53706 & $\partial 000000001$ \\
\hline & & & \multicolumn{2}{|c|}{ Page 12145} \\
\hline
\end{tabular}


Supplemental Table S2.txt

\begin{tabular}{|c|c|c|c|c|}
\hline CHEMBL3694071 & 1640340 & 8.5229 & 8.4121 & TRN \\
\hline CHEMBL3694044 & 1640340 & 8.0458 & 7.7478 & TRN \\
\hline CHEMBL3641168 & 1640340 & 8.699 & 8.4267 & TRN \\
\hline CHEMBL3694219 & 1640340 & 8.5229 & 8.6261 & TRN \\
\hline CHEMBL3694213 & 1640340 & 9.0 & 9.3249 & TRN \\
\hline CHEMBL3639965 & 1640340 & 8.3979 & 8.737 & TRN \\
\hline CHEMBL 3641174 & 1640340 & 7.8539 & 7.7137 & TRN \\
\hline CHEMBL3641133 & 1640340 & 8.699 & 8.3973 & TST \\
\hline CHEMBL3694167 & 1640340 & 8.5229 & 8.4609 & TRN \\
\hline CHEMBL3641099 & 1640340 & 9.0 & 8.7992 & TRN \\
\hline CHEMBL3697851 & 1640340 & 8.3979 & 8.7827 & TRN \\
\hline CHEMBL3697764 & 1640340 & 6.5331 & 6.9016 & TRN \\
\hline CHEMBL3694017 & 1640340 & 10.0 & 9.1941 & TRN \\
\hline CHEMBL3694028 & 1640340 & 8.1549 & 8.2472 & TRN \\
\hline CHEMBL3697827 & 1640340 & 5.8539 & 7.7197 & TST \\
\hline CHEMBL3697914 & 1640340 & 8.0969 & 6.9137 & TST \\
\hline CHEMBL3641241 & 1640340 & 7.8861 & 7.9093 & TRN \\
\hline CHEMBL3697864 & 1640340 & 8.699 & 8.5326 & TRN \\
\hline CHEMBL3694139 & 1640340 & 7.9586 & 8.0324 & TRN \\
\hline CHEMBL3641155 & 1640340 & 8.301 & 8.8937 & TST \\
\hline CHEMBL 3641080 & 1640340 & 8.3979 & 8.8088 & TRN \\
\hline CHEMBL3643281 & 1640340 & 5.0 & 5.0 & TRN \\
\hline CHEMBL3694079 & 1640340 & 8.699 & 8.834 & TRN \\
\hline CHEMBL3641039 & 1640340 & 8.301 & 8.8208 & TRN \\
\hline CHEMBL3694211 & 1640340 & 10.0 & 9.422 & TRN \\
\hline CHEMBL3641027 & 1640340 & 8.3979 & 8.9412 & TST \\
\hline CHEMBL3641177 & 1640340 & 8.699 & 8.5123 & TRN \\
\hline CHEMBL3694159 & 1640340 & 8.699 & 8.4144 & TRN \\
\hline CHEMBL3697881 & 1640340 & 8.699 & 8.7105 & TRN \\
\hline CHEMBL3697728 & 1640340 & 6.6108 & 7.3586 & TRN \\
\hline CHEMBL3697859 & 1640340 & 8.0458 & 8.9183 & TRN \\
\hline CHEMBL3697819 & 1640340 & 7.5086 & 7.6826 & TRN \\
\hline CHEMBL3697861 & 1640340 & 8.5229 & 8.0597 & TRN \\
\hline CHEMBL3641214 & 1640340 & 10.0 & 9.241 & TRN \\
\hline CHEMBL3641066 & 1640340 & 6.5654 & 8.1012 & TRN \\
\hline CHEMBL3697786 & 1640340 & 8.3979 & 7.8781 & TST \\
\hline CHEMBL3694111 & 1640340 & 5.0 & 6.0442 & TRN \\
\hline CHEMBL3641067 & 1640340 & 8.699 & 8.7308 & TRN \\
\hline CHEMBL3694199 & 1640340 & 8.5229 & 9.1154 & TRN \\
\hline CHEMBL3697869 & 1640340 & 5.8539 & 4.9651 & TRN \\
\hline CHEMBL3643284 & 1640340 & 7.3098 & 4.4805 & TST \\
\hline CHEMBL3643295 & 1640340 & 8.699 & 8.1369 & TST \\
\hline CHEMBL3697865 & 1640340 & 10.0 & 9.5814 & TRN \\
\hline CHEMBL3641210 & 1640340 & 8.5229 & 8.0469 & TST \\
\hline CHEMBL3643289 & 1640340 & 6.2255 & 5.2582 & TST \\
\hline CHEMBL3697887 & 1640340 & 8.699 & 8.73 & TRN \\
\hline CHEMBL3694058 & 1640340 & 8.1549 & 8.0323 & TRN \\
\hline CHEMBL3903788 & 1640340 & 5.1549 & 5.0245 & TST \\
\hline
\end{tabular}


Supplemental Table S2.txt

\begin{tabular}{|c|c|c|c|c|}
\hline HEMB & 640340 & & 8.4014 & . \\
\hline & 640340 & 8.3979 & 8.2646 & \\
\hline HFMRI & 340 & 9.0 & 27 & \\
\hline IEMBL369 & 340 & 99 & 7732 & \\
\hline AEMBL3641116 & 640340 & 7.6021 & 8476 & \\
\hline HEMBL3697916 & 340 & 5.699 & .2288 & \\
\hline HEMBL3 & 340 & 9.0 & 298 & \\
\hline HEMBL364 & & & 1835 & \\
\hline HEMBL3641140 & 640340 & 8.5229 & .7196 & $\Gamma \mathrm{RN}$ \\
\hline HEMBL3689921 & 640340 & 7.8861 & .7403 & \\
\hline HEMBL 369 & 40 & 10.0 & 3081 & \\
\hline AEMBL & 40 & 8.301 & .227 & RN \\
\hline AEMBL & & 229 & 9244 & PN \\
\hline HEMBL3641064 & 340 & 8.2218 & 3.6639 & $m$ \\
\hline AEMBL3697794 & 340 & 8.699 & $\partial 441$ & \\
\hline HEMBL3 & 40 & 9. & .8793 & RIV \\
\hline HEMBL & 40 & 9. & 581 & RN \\
\hline HEMBL & 40 & & 139 & RN \\
\hline HEMBL 364 & 40 & 9 . & 7427 & \\
\hline HEMBL 364 & & & 3627 & r \\
\hline HEMBL & 64 & 6. & 37 & KIV \\
\hline AEM & 10 & & & RN \\
\hline HEMBL & 40 & 4. & 3241 & IST \\
\hline HEMBL3 & & 8. & 3555 & TRN \\
\hline AEMBL3 & 40 & & 7636 & IRN \\
\hline HEMBL3 & 10 & 7. & 1656 & 「RN \\
\hline HEM & $\theta$ & & 374 & RN \\
\hline HEMBL & 40 & 5 . & 5254 & TST \\
\hline HEMBL3 & & & 47 & RIN \\
\hline HEMBL364 & 40 & 8. & 5334 & TST \\
\hline AEMBL. & & 7 & 7144 & IST \\
\hline 43 & 10 & 9. & 958 & TRN \\
\hline נ & & & 396 & TST \\
\hline HEMBL3 & & & 748 & TST \\
\hline HEMBL3641033 & 10 & & 2755 & ГRN \\
\hline AFMRI: & $\theta$ & & 79 & ST \\
\hline 22 & & & & TRN \\
\hline HEMBL3 & & & 8562 & TRN \\
\hline HEMBL3 & & & 3836 & $\mathrm{TR}$ \\
\hline EIMIDL & 10 & 9 & 766 & TST \\
\hline HEMBL3 & & & 5789 & TRN \\
\hline HEMBL3 & & 8.5229 & 5634 & 「RN \\
\hline HEMBL369 & 40 & 9 & 9175 & ГRN \\
\hline HEMBL 364 & 40 & & 885 & TR \\
\hline 15 & & & & $\mathrm{RN}$ \\
\hline HEMBL3 & & 10.0 & .3896 & \\
\hline CHEMBL 3694026 & 164 & 8.699 & 7.898 & ST \\
\hline CHEMBL3697804 & 1640340 & 4.8239 & 4.1926 & TRN \\
\hline
\end{tabular}

Page 12147 
Supplemental Table S2.txt

\begin{tabular}{|c|c|c|c|c|c|}
\hline CHEMBL 3697918 & 1640340 & 8.3979 & 6.7414 & TST & \\
\hline CHEMBL3694173 & 1640340 & 10.0 & 9.77 & TRN & \\
\hline CHEMBL3697815 & 1640340 & 7.4815 & 7.9092 & TRN & \\
\hline CHEMBL 3697759 & 1640340 & 8.5229 & 8.8652 & TRN & \\
\hline CHEMBL3694019 & 1640340 & 8.699 & 9.2096 & TRN & \\
\hline CHEMBL3694094 & 1640340 & 10.0 & 8.5718 & TRN & \\
\hline CHEMBL 3694124 & 1640340 & 5.6494 & 5.8952 & TRN & \\
\hline CHEMBL 3641075 & 1640340 & 8.5229 & 8.7804 & TRN & \\
\hline CHEMBL 3641233 & 1640340 & 8.699 & 8.3098 & TRN & \\
\hline CHEMBL3641025 & 1640340 & 9.0 & 8.415 & TRN & \\
\hline CHEMBL3697742 & 1640340 & 7.7959 & 7.4891 & TST & \\
\hline CHEMBL3689943 & 1640340 & 7.2596 & 7.6823 & TRN & \\
\hline CHEMBL3697809 & 1640340 & 7.8239 & 8.4855 & TRN & \\
\hline CHEMBL 3694171 & 1640340 & 8.699 & 8.3604 & TRN & \\
\hline CHEMBL3697743 & 1640340 & 3.8239 & 5.0163 & TST & \\
\hline CHEMBL3697791 & 1640340 & 6.3372 & 6.6673 & TRN & \\
\hline CHEMBL3641088 & 1640340 & 8.699 & 8.9248 & TRN & \\
\hline CHEMBL3697875 & 1640340 & 8.0 & 8.0129 & TRN & \\
\hline CHEMBL3694080 & 1640340 & 8.5229 & 8.6859 & TRN & \\
\hline CHEMBL3641163 & 1640340 & 8.5229 & 8.6671 & TST & \\
\hline CHEMBL3641148 & 1640340 & 8.2218 & 8.3817 & TRN & \\
\hline CHEMBL3694172 & 1640340 & 9.0 & 9.2513 & TRN & \\
\hline CHEMBL 3694043 & 1640340 & 8.3979 & 8.7359 & TRN & \\
\hline CHEMBL3697894 & 1640340 & 10.0 & 9.2415 & TST & \\
\hline CHEMBL 3694054 & 1640340 & 7.6198 & 8.1434 & TRN & \\
\hline CHEMBL3697925 & 1640340 & 8.699 & 8.7576 & TRN & \\
\hline CHEMBL3641049 & 1640340 & 8.301 & 7.9833 & TRN & \\
\hline CHEMBL 3697923 & 1640340 & 8.3979 & 9.0757 & TRN & \\
\hline CHEMBL3641042 & 1640340 & 8.5229 & 8.5751 & TRN & \\
\hline CHEMBL 3694061 & 1640340 & 7.8861 & 8.2273 & TRN & \\
\hline CHEMBL 3641028 & 1640340 & 8.5229 & 8.7563 & TRN & \\
\hline CHEMBL 3641101 & 1640340 & 8.5229 & 8.2573 & TRN & \\
\hline CHEMBL 3641074 & 1640340 & 8.0969 & 8.5895 & TRN & \\
\hline CHEMBL3641184 & 1640340 & 8.699 & 8.4647 & TRN & \\
\hline CHEMBL3694155 & 1640340 & 9.0 & 9.3033 & TST & \\
\hline CHEMBL3694157 & 1640340 & 8.2218 & 8.9348 & TRN & \\
\hline CHEMBL3641041 & 1640340 & 8.1549 & 8.2296 & TRN & \\
\hline CHEMBL3697756 & 1640340 & 4.699 & 4.6769 & TRN & \\
\hline CHEMBL3641106 & 1640340 & 8.699 & 8.1542 & TRN & \\
\hline CHEMBL 3689920 & 1640340 & 7.6576 & 7.7582 & TRN & \\
\hline CHEMBL3697718 & 1640340 & 8.5229 & 8.7742 & TRN & \\
\hline CHEMBL3697873 & 1640340 & 7.7696 & 8.23299 & 7999999999 & TRN \\
\hline CHEMBL3641201 & 1640340 & 8.301 & 8.4937 & TST & \\
\hline CHEMBL3641159 & 1640340 & 9.0 & 8.397 & TST & \\
\hline CHEMBL3694149 & 1640340 & 10.0 & 8.781 & TRN & \\
\hline CHEMBL3641196 & 1640340 & 10.0 & 9.0757 & TST & \\
\hline CHEMBL3643297 & 1640340 & 8.301 & 7.7086 & TST & \\
\hline CHEMBL3697773 & 1640340 & 7.3872 & 7.1943 & TRN & \\
\hline
\end{tabular}

Page 12148 
Supplemental Table S2.txt

\begin{tabular}{|c|c|c|c|c|}
\hline CHEMBL 3697741 & 1640340 & 7.2291 & 7.6017 & TST \\
\hline CHEMBL3689906 & 1640340 & 8.5229 & 7.8815 & TRN \\
\hline CHEMBL3697932 & 1640340 & 8.5229 & 8.559 & TST \\
\hline CHEMBL 3697740 & 1640340 & 4.699 & 4.9271 & TRN \\
\hline CHEMBL3697724 & 1640340 & 8.699 & 8.9878 & TRN \\
\hline CHEMBL 3697746 & 1640340 & 6.0128 & 6.6508 & TRN \\
\hline CHEMBL 3641190 & 1640340 & 7.1308 & 6.6852 & TST \\
\hline CHEMBL 3694038 & 1640340 & 8.5229 & 8.1324 & TRN \\
\hline CHEMBL 3697870 & 1640340 & 6.5346 & 6.5264 & TRN \\
\hline CHEMBL3641065 & 1640340 & 8.3979 & \multicolumn{2}{|c|}{8.466000000000001} \\
\hline CHEMBL 3694107 & 1640340 & 4.699 & 6.0442 & TRN \\
\hline CHEMBL3697937 & 1640340 & 8.3979 & 8.664 & TRN \\
\hline CHEMBL3689927 & 1640340 & 7.8861 & 7.4729 & TRN \\
\hline CHEMBL 3643299 & 1640340 & 9.0 & 8.2053 & TST \\
\hline CHEMBL3694029 & 1640340 & 7.9208 & 7.6721 & TRN \\
\hline CHEMBL 3694030 & 1640340 & 8.699 & 8.9545 & TRN \\
\hline CHEMBL3697891 & 1640340 & 9.0 & 8.727 & TST \\
\hline CHEMBL3694212 & 1640340 & 8.699 & 8.8151 & TRN \\
\hline CHEMBL 3697801 & 1640340 & 7.6383 & 7.4169 & TST \\
\hline CHEMBL3641084 & 1640340 & 8.699 & 8.7688 & TRN \\
\hline CHEMBL3643294 & 1640340 & 8.5229 & 8.4456 & TRN \\
\hline CHEMBL3694093 & 1640340 & 8.699 & 9.0027 & TRN \\
\hline CHEMBL 3697793 & 1640340 & 9.0 & \multicolumn{2}{|c|}{8.107000000000001} \\
\hline CHEMBL 3641194 & 1640340 & 6.7144 & 6.8961 & TRN \\
\hline CHEMBL 3697822 & 1640340 & 8.2218 & 8.7226 & TRN \\
\hline CHEMBL3697763 & 1640340 & 8.699 & 9.1254 & TRN \\
\hline CHEMBL 3641092 & 1640340 & 8.3979 & 8.2886 & TST \\
\hline CHEMBL3641109 & 1640340 & 8.301 & 8.666 & TRN \\
\hline CHEMBL 3694037 & 1640340 & 8.699 & 9.0886 & TRN \\
\hline CHEMBL 3641193 & 1640340 & 7.5686 & 7.0276 & TST \\
\hline CHEMBL 3694098 & 1640340 & 8.301 & 8.2772 & TRN \\
\hline CHEMBL 3641076 & 1640340 & 8.5229 & 7.6118 & TRN \\
\hline CHEMBL 3689942 & 1640340 & 8.3979 & 8.3878 & TRN \\
\hline CHEMBL 3694135 & 1640340 & 8.3979 & 8.6843 & TRN \\
\hline CHEMBL3694169 & 1640340 & 9.0 & 8.7857 & TRN \\
\hline CHEMBL3694218 & 1640340 & 10.0 & 10.0492 & TRN \\
\hline CHEMBL 3641128 & 1640340 & 9.0 & 8.3846 & TST \\
\hline CHEMBL3694206 & 1640340 & 10.0 & 9.6168 & TRN \\
\hline CHEMBL 3694106 & 1640340 & 6.0123 & 6.3004 & TRN \\
\hline CHEMBL 3641189 & 1640340 & 7.4815 & 6.5428 & TST \\
\hline CHEMBL 3641243 & 1640340 & 7.2291 & 7.485 & TRN \\
\hline CHEMBL 3694190 & 1640340 & 8.5229 & 8.5278 & TRN \\
\hline CHEMBL3641071 & 1640340 & 8.699 & 8.2815 & TRN \\
\hline CHEMBL 3697929 & 1640340 & 10.0 & 8.4974 & TST \\
\hline CHEMBL 3694082 & 1640340 & 9.0 & 8.0455 & TRN \\
\hline CHEMBL3694091 & 1640340 & 8.5229 & 9.252 & TST \\
\hline CHEMBL3697737 & 1640340 & 3.8239 & 4.3608 & TRN \\
\hline CHEMBL 3697872 & 1640340 & 6.3546 & 7.7172 & TST \\
\hline
\end{tabular}

Page 12149 
Supplemental Table S2.txt

\begin{tabular}{|c|c|c|c|c|}
\hline CHEMBL 3697817 & 1640340 & 8.0 & 7.8797 & TRN \\
\hline CHEMBL 3697806 & 1640340 & 5.699 & 4.1882 & TRN \\
\hline CHEMBL3694048 & 1640340 & 7.301 & 6.8879 & TRN \\
\hline CHEMBL 3689937 & 1640340 & 8.2218 & 8.4894 & TRN \\
\hline CHEMBL 3641112 & 1640340 & 8.699 & 8.6134 & TRN \\
\hline CHEMBL 3641171 & 1640340 & 8.1549 & 8.0094 & TRN \\
\hline CHEMBL 3694184 & 1640340 & 8.699 & 8.5538 & TRN \\
\hline CHEMBL 3697731 & 1640340 & 3.8239 & 4.3877 & TRN \\
\hline CHEMBL 3641212 & 1640340 & 8.1549 & 7.2689 & TST \\
\hline CHEMBL 3694085 & 1640340 & 8.2218 & 8.5168 & TRN \\
\hline CHEMBL 3641125 & 1640340 & 10.0 & 9.6624 & TRN \\
\hline CHEMBL 3694068 & 1640340 & 8.699 & 8.363 & TRN \\
\hline CHEMBL 3697813 & 1640340 & 6.0778 & 6.5408 & TRN \\
\hline CHEMBL 3641149 & 1640340 & 6.9747 & 8.2472 & TRN \\
\hline CHEMBL 3641147 & 1640340 & 8.699 & 8.0779 & TRN \\
\hline CHEMBL 3641082 & 1640340 & 8.699 & 8.7551 & TRN \\
\hline CHEMBL 3641083 & 1640340 & 8.3979 & 8.4818 & TRN \\
\hline CHEMBL 3641098 & 1640340 & 8.3979 & 8.1784 & TRN \\
\hline CHEMBL3697904 & 1640340 & 8.699 & 9.1436 & TST \\
\hline CHEMBL 3697922 & 1640340 & 10.0 & 8.9425 & TRN \\
\hline CHEMBL 3694178 & 1640340 & 10.0 & 9.6843 & TRN \\
\hline CHEMBL 3641206 & 1640340 & 8.0458 & 7.9103 & TRN \\
\hline CHEMBL 3694092 & 1640340 & 8.699 & 8.6923 & TRN \\
\hline CHEMBL3694015 & 1640340 & 9.0 & 8.9238 & TRN \\
\hline CHEMBL 3697845 & 1640340 & 8.3979 & 8.48 & TRN \\
\hline CHEMBL 3694220 & 1640340 & 8.1549 & 8.227 & TRN \\
\hline CHEMBL 3694099 & 1640340 & 8.5229 & 9.425 & TST \\
\hline CHEMBL3694101 & 1640340 & 8.301 & 8.1868 & TRN \\
\hline CHEMBL 3694011 & 1640340 & 8.301 & 8.9219 & TRN \\
\hline CHEMBL 3697774 & 1640340 & 8.301 & 8.1279 & TRN \\
\hline CHEMBL 3694140 & 1640340 & 8.699 & 8.2764 & TRN \\
\hline CHEMBL 3694197 & 1640340 & 8.3979 & 8.3378 & TRN \\
\hline CHEMBL 3641150 & 1640340 & 8.3979 & 8.5529 & TRN \\
\hline CHEMBL 3697752 & 1640340 & 8.699 & 9.4322 & TRN \\
\hline CHEMBL 3697856 & 1640340 & 8.699 & 8.2929 & TRN \\
\hline CHEMBL3697790 & 1640340 & 10.0 & 9.3848 & TRN \\
\hline CHEMBL 3697824 & 1640340 & 8.2218 & 8.4612 & TRN \\
\hline CHEMBL 3697832 & 1640340 & 9.0 & 9.3217 & TRN \\
\hline CHEMBL 3641094 & 1640340 & 9.0 & 9.0609 & TRN \\
\hline CHEMBL 3694210 & 1640340 & 9.0 & 9.2151 & TRN \\
\hline CHEMBL 3694041 & 1640340 & 7.9586 & 7.473 & TRN \\
\hline CHEMBL 3641037 & 1640340 & 9.0 & 9.6756 & TRN \\
\hline CHEMBL 3641054 & 1640340 & 8.699 & 8.60799 & 9999999999 \\
\hline CHEMBL 3694032 & 1640340 & 7.2676 & 8.3486 & TST \\
\hline CHEMBL 3694066 & 1640340 & 6.9281 & 6.7006 & TRN \\
\hline CHEMBL 3694222 & 1640340 & 8.5229 & 8.2714 & TRN \\
\hline CHEMBL 3639966 & 1640340 & 7.6383 & 7.5793 & TST \\
\hline CHEMBL 3689922 & 1640340 & 7.8539 & 8.4165 & TRN \\
\hline
\end{tabular}


Supplemental Table S2.txt

\begin{tabular}{|c|c|c|c|c|c|}
\hline CHEMBL3641126 & 1640340 & 8.3979 & 8.0624 & TRN & \\
\hline CHEMBL3694055 & 1640340 & 7.6021 & 7.7708 & TRN & \\
\hline CHEMBL3689901 & 1640340 & 7.585 & 8.7323 & TRN & \\
\hline CHEMBL 3697867 & 1640340 & 7.9586 & 8.5617 & TST & \\
\hline CHEMBL3641096 & 1640340 & 8.3979 & 8.7066 & TST & \\
\hline CHEMBL 3697921 & 1640340 & 5.8539 & 4.9506 & TST & \\
\hline CHEMBL 3694126 & 1640340 & 7.8861 & 6.8756 & TRN & \\
\hline CHEMBL 3694047 & 1640340 & 7.3872 & 7.88299 & 7999999999 & TRN \\
\hline CHEMBL 3639967 & 1640340 & 8.5229 & 8.509 & TST & \\
\hline CHEMBL3697789 & 1640340 & 10.0 & 8.4393 & TRN & \\
\hline CHEMBL 3641185 & 1640340 & 9.0 & 8.5233 & TRN & \\
\hline CHEMBL 3694129 & 1640340 & 5.9435 & 7.3054 & TST & \\
\hline CHEMBL 3697747 & 1640340 & 4.0 & 4.5341 & TST & \\
\hline CHEMBL 3641179 & 1640340 & 7.9586 & 7.6256 & TST & \\
\hline CHEMBL3697901 & 1640340 & 9.0 & 9.049 & TRN & \\
\hline CHEMBL 3694146 & 1640340 & 8.0969 & 8.748 & TRN & \\
\hline CHEMBL3641224 & 1640340 & 8.699 & 8.5608 & TRN & \\
\hline CHEMBL3697835 & 1640340 & 9.0 & 9.3667 & TRN & \\
\hline CHEMBL3694102 & 1640340 & 8.699 & 8.5701 & TRN & \\
\hline CHEMBL3697842 & 1640340 & 9.0 & 8.6848 & TRN & \\
\hline CHEMBL 3689938 & 1640340 & 8.301 & 8.4452 & TRN & \\
\hline CHEMBL3641093 & 1640340 & 8.699 & \multicolumn{2}{|c|}{8.947000000000001} & TRN \\
\hline CHEMBL 3697868 & 1640340 & 7.2596 & 7.8264 & TRN & \\
\hline CHEMBL 3641070 & 1640340 & 8.3979 & 8.378 & TRN & \\
\hline CHEMBL3694046 & 1640340 & 7.585 & 7.8589 & TRN & \\
\hline CHEMBL3641181 & 1640340 & 9.0 & 8.8396 & TST & \\
\hline CHEMBL 3641108 & 1640340 & 8.699 & 8.8982 & TRN & \\
\hline CHEMBL3643287 & 1640340 & 5.0 & 5.5456 & TST & \\
\hline CHEMBL 3689933 & 1640340 & 8.699 & 8.6082 & TRN & \\
\hline CHEMBL3694228 & 1640340 & 8.3979 & 8.5854 & TRN & \\
\hline CHEMBL 3641127 & 1640340 & 8.699 & 7.7464 & TST & \\
\hline CHEMBL3689909 & 1640340 & 9.0 & 8.6637 & TRN & \\
\hline CHEMBL3694112 & 1640340 & 6.2314 & 7.2613 & TST & \\
\hline CHEMBL3689941 & 1640340 & 8.0458 & 8.016 & TRN & \\
\hline CHEMBL3694130 & 1640340 & 8.301 & 8.4916 & TRN & \\
\hline CHEMBL3689930 & 1640340 & 7.2366 & 8.0787 & TRN & \\
\hline CHEMBL3694062 & 1640340 & 8.0458 & 7.3055 & TST & \\
\hline CHEMBL 3641220 & 1640340 & 9.0 & 9.058 & TRN & \\
\hline CHEMBL3697844 & 1640340 & 8.301 & 8.5989 & TRN & \\
\hline CHEMBL3697744 & 1640340 & 7.9586 & 8.6361 & TRN & \\
\hline CHEMBL3641100 & 1640340 & 8.5229 & 9.0054 & TRN & \\
\hline CHEMBL3643285 & 1640340 & 5.699 & 6.2282 & TST & \\
\hline CHEMBL3643296 & 1640340 & 8.3979 & 8.0281 & TRN & \\
\hline CHEMBL3694154 & 1640340 & 9.0 & 8.3444 & TRN & \\
\hline CHEMBL3641105 & 1640340 & 9.0 & 8.7396 & TRN & \\
\hline CHEMBL3694161 & 1640340 & 8.301 & 8.1102 & TRN & \\
\hline CHEMBL3641045 & 1640340 & 8.699 & 9.0507 & TRN & \\
\hline CHEMBL3641119 & 1640340 & 8.699 & 9.0382 & TRN & \\
\hline
\end{tabular}


Supplemental Table S2.txt

\begin{tabular}{|c|c|c|c|c|}
\hline CHEMBL3641156 & 1640340 & 7.8239 & 8.0743 & TST \\
\hline CHEMBL3694138 & 1640340 & 9.0 & 8.7598 & TRN \\
\hline CHEMBL3641078 & 1640340 & 8.0969 & 8.16 & TRN \\
\hline CHEMBL3694187 & 1640340 & 8.3979 & 8.5978 & TRN \\
\hline CHEMBL3697757 & 1640340 & 8.3979 & 7.6403 & TST \\
\hline CHEMBL3643283 & 1640340 & 5.0 & 4.3611 & TST \\
\hline CHEMBL3697803 & 1640340 & 7.2147 & 6.9847 & TRN \\
\hline CHEMBL3694060 & 1640340 & 7.3979 & 7.9972 & TRN \\
\hline CHEMBL3697802 & 1640340 & 4.8239 & 4.9506 & TST \\
\hline CHEMBL3694136 & 1640340 & 8.3979 & 8.1361 & TRN \\
\hline CHEMBL3694065 & 1640340 & 10.0 & 9.2609 & TRN \\
\hline CHEMBL3697910 & 1640340 & 7.8539 & 8.4968 & TRN \\
\hline CHEMBL3641169 & 1640340 & 8.5229 & 8.4287 & TRN \\
\hline CHEMBL3641089 & 1640340 & 10.0 & 8.8648 & TRN \\
\hline CHEMBL3697722 & 1640340 & 10.0 & 9.6128 & TRN \\
\hline CHEMBL3641166 & 1640340 & 9.0 & 8.9154 & TRN \\
\hline CHEMBL3641087 & 1640340 & 8.699 & 7.5264 & TST \\
\hline CHEMBL3697903 & 1640340 & 8.5229 & 8.1478 & TST \\
\hline CHEMBL3694168 & 1640340 & 8.699 & 8.5057 & TRN \\
\hline CHEMBL3697761 & 1640340 & 4.0 & 4.1926 & TRN \\
\hline CHEMBL3641117 & 1640340 & 8.0969 & 8.0371 & TRN \\
\hline CHEMBL3643291 & 1640340 & 5.699 & 5.0787 & TST \\
\hline CHEMBL 3697841 & 1640340 & 6.7033 & 7.8806 & TST \\
\hline CHEMBL 3694042 & 1640340 & 8.1549 & 7.9733 & TRN \\
\hline CHEMBL3694148 & 1640340 & 8.1549 & 8.3018 & TRN \\
\hline CHEMBL3694014 & 1640340 & 10.0 & 9.3364 & TRN \\
\hline CHEMBL3697732 & 1640340 & 7.585 & 7.5234 & TST \\
\hline CHEMBL3694134 & 1640340 & 8.5229 & 8.2009 & TRN \\
\hline CHEMBL3697919 & 1640340 & 8.0969 & 7.2617 & TST \\
\hline CHEMBL3694053 & 1640340 & 8.699 & 7.9274 & TRN \\
\hline CHEMBL3697899 & 1640340 & 10.0 & 8.9336 & TST \\
\hline CHEMBL3694063 & 1640340 & 8.0458 & 8.1952 & TRN \\
\hline CHEMBL 3641034 & 1640340 & 8.0 & 8.7252 & TST \\
\hline CHEMBL3694192 & 1640340 & 8.5229 & 9.1957 & TRN \\
\hline CHEMBL3694078 & 1640340 & 8.301 & 9.2565 & TST \\
\hline CHEMBL3641173 & 1640340 & 7.6383 & 8.6273 & TRN \\
\hline CHEMBL3697771 & 1640340 & 8.699 & 8.3252 & TRN \\
\hline CHEMBL3694090 & 1640340 & 8.0969 & 8.2251 & TRN \\
\hline CHEMBL 3694125 & 1640340 & 6.2628 & 7.1596 & TST \\
\hline CHEMBL 3641213 & 1640340 & 7.8861 & 8.2347 & TRN \\
\hline CHEMBL3697902 & 1640340 & 8.699 & 8.4522 & TST \\
\hline CHEMBL3689936 & 1640340 & 8.3979 & 8.2279 & TRN \\
\hline CHEMBL3689907 & 1640340 & 8.699 & 8.3704 & TRN \\
\hline CHEMBL3694115 & 1640340 & 5.6515 & 6.4126 & TRN \\
\hline CHEMBL3689902 & 1640340 & 8.0458 & \multicolumn{2}{|c|}{7.992999999999999} \\
\hline CHEMBL3641035 & 1640340 & 7.6021 & 8.3357 & TST \\
\hline CHEMBL3694116 & 1640340 & 6.4976 & 7.4566 & TST \\
\hline CHEMBL3641157 & 1640340 & 7.9208 & 8.7059 & TST \\
\hline
\end{tabular}


Supplemental Table S2.txt

\begin{tabular}{|c|c|c|c|c|c|}
\hline CHEMBL3641238 & 1640340 & 8.699 & 9.1608 & TRN & \\
\hline CHEMBL3643302 & 1640340 & 7.8861 & 6.9013 & TST & \\
\hline CHEMBL3694108 & 1640340 & 6.5482 & 6.3885 & TRN & \\
\hline CHEMBL 3697805 & 1640340 & 6.2967 & 5.7451 & TRN & \\
\hline CHEMBL 3697933 & 1640340 & 9.0 & 8.9855 & TRN & \\
\hline CHEMBL3694056 & 1640340 & 7.699 & 8.0532 & TRN & \\
\hline CHEMBL 3697892 & 1640340 & 10.0 & 7.7852 & TST & \\
\hline CHEMBL 3694084 & 1640340 & 8.5229 & 8.3822 & TRN & \\
\hline CHEMBL 3641062 & 1640340 & 8.699 & 8.4909 & TRN & \\
\hline CHEMBL3697850 & 1640340 & 8.699 & 9.1129 & TRN & \\
\hline CHEMBL 3689913 & 1640340 & 8.5229 & 8.3164 & TRN & \\
\hline CHEMBL3641236 & 1640340 & 8.3979 & 8.2847 & TRN & \\
\hline CHEMBL 3694105 & 1640340 & 7.1938 & 6.7163 & TRN & \\
\hline CHEMBL 3697884 & 1640340 & 8.3979 & 8.56200 & 0000000001 & TRN \\
\hline CHEMBL3689939 & 1640340 & 8.5229 & 8.3684 & TRN & \\
\hline CHEMBL 3697812 & 1640340 & 9.0 & 8.7503 & TRN & \\
\hline CHEMBL3643290 & 1640340 & 6.2832 & 4.757 & TST & \\
\hline CHEMBL 3689925 & 1640340 & 7.1549 & 7.3414 & TRN & \\
\hline CHEMBL 3694072 & 1640340 & 8.1549 & 8.5054 & TRN & \\
\hline CHEMBL 3641223 & 1640340 & 8.0458 & 8.0859 & TST & \\
\hline CHEMBL 3641222 & 1640340 & 8.5229 & 8.3941 & TRN & \\
\hline CHEMBL 3694143 & 1640340 & 8.2218 & 8.3679 & TRN & \\
\hline CHEMBL 3689923 & 1640340 & 8.0458 & 8.3975 & TRN & \\
\hline CHEMBL 3689944 & 1640340 & 7.6778 & 8.1332 & TST & \\
\hline CHEMBL3697893 & 1640340 & 10.0 & 9.4641 & TST & \\
\hline CHEMBL 3697843 & 1640340 & 9.0 & 9.2162 & TRN & \\
\hline CHEMBL3641026 & 1640340 & 8.699 & 8.7941 & TRN & \\
\hline CHEMBL 3689928 & 1640340 & 7.8239 & 7.416 & TRN & \\
\hline CHEMBL 3641107 & 1640340 & 8.699 & 8.6769 & TRN & \\
\hline CHEMBL 3641203 & 1640340 & 9.0 & 8.5931 & TRN & \\
\hline CHEMBL 3641217 & 1640340 & 6.8894 & 7.322 & TST & \\
\hline CHEMBL3694039 & 1640340 & 6.1701 & 6.4403 & TST & \\
\hline CHEMBL3639930 & 1640340 & 8.3979 & 8.1079 & TRN & \\
\hline CHEMBL3689917 & 1640340 & 8.5229 & 8.2235 & TRN & \\
\hline CHEMBL 3641176 & 1640340 & 8.0458 & 8.5958 & TRN & \\
\hline CHEMBL3694022 & 1640340 & 10.0 & 8.6971 & TST & \\
\hline CHEMBL3697792 & 1640340 & 7.5376 & 6.8856 & TRN & \\
\hline CHEMBL 3694027 & 1640340 & 8.5229 & 8.5491 & TRN & \\
\hline CHEMBL 3697745 & 1640340 & 7.6383 & 7.4538 & TST & \\
\hline CHEMBL 3697823 & 1640340 & 7.0555 & 7.0079 & TRN & \\
\hline CHEMBL3641132 & 1640340 & 8.5229 & 8.9509 & TRN & \\
\hline CHEMBL 3697848 & 1640340 & 8.1549 & 8.0433 & TRN & \\
\hline CHEMBL3697825 & 1640340 & 5.0 & 7.0815 & TST & \\
\hline CHEMBL 3697723 & 1640340 & 8.3979 & 8.1443 & TRN & \\
\hline CHEMBL 3694020 & 1640340 & 9.0 & 8.8972 & TRN & \\
\hline CHEMBL 3694144 & 1640340 & 8.699 & 8.7754 & TRN & \\
\hline CHEMBL3689934 & 1640340 & 8.699 & 7.9701 & TRN & \\
\hline CHEMBL 3694050 & 1640340 & 7.301 & 7.3282 & TST & \\
\hline
\end{tabular}


Supplemental Table S2.txt

\begin{tabular}{|c|c|c|c|c|c|}
\hline CHEMBL 3694095 & 1640340 & 9.0 & 8.2772 & TRN & \\
\hline CHEMBL3694086 & 1640340 & 8.1549 & 8.0455 & TRN & \\
\hline CHEMBL3694073 & 1640340 & 8.2218 & 8.1046 & TRN & \\
\hline CHEMBL 3689915 & 1640340 & 9.0 & 8.9682 & TRN & \\
\hline CHEMBL 3697721 & 1640340 & 8.699 & 8.8301 & TRN & \\
\hline CHEMBL 3694202 & 1640340 & 8.301 & 8.9101 & TRN & \\
\hline CHEMBL 3641052 & 1640340 & 8.1549 & 8.5629 & TRN & \\
\hline CHEMBL3641032 & 1640340 & 8.301 & 8.4143 & TRN & \\
\hline CHEMBL 3641204 & 1640340 & 8.5229 & 8.3173 & TRN & \\
\hline CHEMBL 3697847 & 1640340 & 6.9393 & 7.1721 & TRN & \\
\hline CHEMBL 3697857 & 1640340 & 7.5686 & 8.3741 & TST & \\
\hline CHEMBL3689912 & 1640340 & 8.3979 & 8.6608 & TRN & \\
\hline CHEMBL3639887 & 1640340 & 8.0458 & 8.1404 & TRN & \\
\hline CHEMBL3689926 & 1640340 & 7.0809 & 7.3264 & TRN & \\
\hline CHEMBL3694186 & 1640340 & 8.5229 & 8.4349 & TRN & \\
\hline CHEMBL3697838 & 1640340 & 8.1549 & 8.3269 & TRN & \\
\hline CHEMBL3694036 & 1640340 & 7.7212 & 7.9379 & TRN & \\
\hline CHEMBL 3694064 & 1640340 & 8.699 & 8.8577 & TRN & \\
\hline CHEMBL 3641031 & 1640340 & 8.2218 & 8.3967 & TRN & \\
\hline CHEMBL 3694127 & 1640340 & 5.0 & 5.84200 & 00000000005 & TRN \\
\hline CHEMBL3694018 & 1640340 & 10.0 & 9.3047 & TRN & \\
\hline CHEMBL 3641144 & 1640340 & 8.5229 & 8.7354 & TRN & \\
\hline CHEMBL 3641137 & 1640340 & 8.5229 & 8.6007 & TST & \\
\hline CHEMBL3641113 & 1640340 & 8.699 & 8.2099 & TST & \\
\hline CHEMBL 3697720 & 1640340 & 9.0 & 8.9797 & TRN & \\
\hline CHEMBL 3641145 & 1640340 & 6.2351 & 7.0897 & TRN & \\
\hline CHEMBL 3697777 & 1640340 & 7.5376 & 8.3483 & TRN & \\
\hline CHEMBL 3694121 & 1640340 & 7.0555 & 6.5346 & TRN & \\
\hline CHEMBL 3641111 & 1640340 & 8.699 & 9.0402 & TRN & \\
\hline CHEMBL3641121 & 1640340 & 8.3979 & 8.4623 & TST & \\
\hline CHEMBL 3643301 & 1640340 & 7.5229 & 6.8823 & TST & \\
\hline CHEMBL 3641077 & 1640340 & 8.3979 & 8.4074 & TRN & \\
\hline CHEMBL 3641221 & 1640340 & 8.5229 & 8.7205 & TST & \\
\hline CHEMBL3697912 & 1640340 & 9.0 & 9.1332 & TRN & \\
\hline CHEMBL 3643288 & 1640340 & 5.699 & 5.3848 & TST & \\
\hline CHEMBL3697915 & 1640340 & 5.699 & 5.3913 & TST & \\
\hline CHEMBL 3641202 & 1640340 & 10.0 & 9.2547 & TRN & \\
\hline CHEMBL 3694097 & 1640340 & 8.699 & 8.6725 & TRN & \\
\hline CHEMBL 3697800 & 1640340 & 5.699 & 4.3059 & TRN & \\
\hline CHEMBL3641191 & 1640340 & 7.4949 & 6.8582 & TST & \\
\hline CHEMBL3697770 & 1640340 & 10.0 & 9.1029 & TRN & \\
\hline CHEMBL3694152 & 1640340 & 8.3979 & 8.9692 & TRN & \\
\hline CHEMBL 3694193 & 1640340 & 8.699 & 8.3902 & TRN & \\
\hline CHEMBL3694182 & 1640340 & 8.5229 & 8.5278 & TRN & \\
\hline CHEMBL 3641047 & 1640340 & 9.0 & 9.2023 & TRN & \\
\hline CHEMBL 3697751 & 1640340 & 4.699 & 5.3912 & TST & \\
\hline CHEMBL3697858 & 1640340 & 6.699 & 8.3049 & TST & \\
\hline CHEMBL 3689911 & 1640340 & 8.699 & 8.3241 & TRN & \\
\hline
\end{tabular}


Supplemental Table S2.txt

\begin{tabular}{|c|c|c|c|c|c|}
\hline CHEMBL 3697828 & 1640340 & 8.5229 & 9.3104 & TRN & \\
\hline CHEMBL3697907 & 1640340 & 9.0 & 8.8771 & TST & \\
\hline CHEMBL3694057 & 1640340 & 8.1549 & 8.0945 & TRN & \\
\hline CHEMBL 3694223 & 1640340 & 8.2218 & 8.311 & TRN & \\
\hline CHEMBL 3697783 & 1640340 & 8.699 & 8.4632 & TRN & \\
\hline CHEMBL3697799 & 1640340 & 6.5702 & 5.9259 & TRN & \\
\hline CHEMBL 3694031 & 1640340 & 8.5229 & 8.1242 & TRN & \\
\hline CHEMBL3689903 & 1640340 & 8.1549 & 8.3024 & TRN & \\
\hline CHEMBL 3641167 & 1640340 & 7.7696 & 8.8963 & TRN & \\
\hline CHEMBL3641232 & 1640340 & 8.301 & 8.833 & TRN & \\
\hline CHEMBL3697717 & 1640340 & 10.0 & 9.895 & TRN & \\
\hline CHEMBL 3697782 & 1640340 & 5.9492 & 6.4114 & TRN & \\
\hline CHEMBL 3641051 & 1640340 & 8.2218 & 8.3096 & TRN & \\
\hline CHEMBL 3697882 & 1640340 & 7.3872 & 7.6384 & TST & \\
\hline CHEMBL 3641200 & 1640340 & 8.699 & 9.1678 & TST & \\
\hline CHEMBL3694177 & 1640340 & 8.699 & 8.7783 & TRN & \\
\hline CHEMBL3641063 & 1640340 & 8.699 & 8.8734 & TRN & \\
\hline CHEMBL3694067 & 1640340 & 8.699 & 8.7767 & TRN & \\
\hline CHEMBL3697909 & 1640340 & 8.699 & 8.7388 & TST & \\
\hline CHEMBL3694096 & 1640340 & 9.0 & 8.6553 & TRN & \\
\hline CHEMBL3697936 & 1640340 & 8.5229 & 8.5583 & TRN & \\
\hline CHEMBL 3697776 & 1640340 & 8.2218 & 8.4837 & TRN & \\
\hline CHEMBL3643282 & 1640340 & 5.0 & 4.2923 & TST & \\
\hline CHEMBL 3694189 & 1640340 & 8.5229 & 8.6388 & TRN & \\
\hline CHEMBL3697889 & 1640340 & 9.0 & 9.1451 & TRN & \\
\hline CHEMBL 3697736 & 1640340 & 5.8139 & 6.16299 & 9999999999 & TRN \\
\hline CHEMBL3697755 & 1640340 & 6.7905 & 6.4176 & TRN & \\
\hline CHEMBL3697734 & 1640340 & 6.983 & 7.4242 & TRN & \\
\hline CHEMBL 3694227 & 1640340 & 10.0 & 8.7753 & TST & \\
\hline CHEMBL3641199 & 1640340 & 9.0 & 9.0571 & TST & \\
\hline CHEMBL3641219 & 1640340 & 6.6556 & 7.2306 & TST & \\
\hline CHEMBL3694033 & 1640340 & 9.0 & 8.9824 & TRN & \\
\hline CHEMBL3641237 & 1640340 & 9.0 & 8.6009 & TRN & \\
\hline CHEMBL 3641225 & 1640340 & 8.3979 & 8.1344 & TST & \\
\hline CHEMBL3697772 & 1640340 & 6.9957 & 6.9148 & TRN & \\
\hline CHEMBL 3694025 & 1640340 & 10.0 & 9.0921 & TRN & \\
\hline CHEMBL3694217 & 1640340 & 8.699 & 9.1971 & TRN & \\
\hline CHEMBL3694012 & 1640340 & 10.0 & 9.0907 & TRN & \\
\hline CHEMBL3694123 & 1640340 & 6.6383 & 6.6289 & TRN & \\
\hline CHEMBL 3694216 & 1640340 & 8.3979 & \multicolumn{2}{|c|}{8.722000000000001} & TRN \\
\hline CHEMBL 3694141 & 1640340 & 8.699 & 9.2055 & TST & \\
\hline CHEMBL3697719 & 1640340 & 8.699 & 8.1877 & TRN & \\
\hline CHEMBL3697814 & 1640340 & 6.9208 & 7.9375 & TRN & \\
\hline CHEMBL3641053 & 1640340 & 10.0 & 9.3601 & TRN & \\
\hline CHEMBL3641211 & 1640340 & 9.0 & 7.1721 & TST & \\
\hline CHEMBL 3697750 & 1640340 & 8.3979 & 7.6781 & TST & \\
\hline CHEMBL 3694035 & 1640340 & 8.0969 & 8.1337 & TRN & \\
\hline CHEMBL3694180 & 1640340 & 8.699 & 8.5593 & TRN & \\
\hline
\end{tabular}


Supplemental Table S2.txt

\begin{tabular}{|c|c|c|c|c|}
\hline CHEMBL 3697830 & 1640340 & 6.5622 & 7.9728 & TST \\
\hline CHEMBL 3641151 & 1640340 & 9.0 & 8.6077 & TRN \\
\hline CHEMBL3689914 & 1640340 & 9.0 & 8.5197 & TRN \\
\hline CHEMBL 3694059 & 1640340 & 8.3979 & 8.2489 & TRN \\
\hline CHEMBL 3641102 & 1640340 & 8.3979 & 9.0483 & TRN \\
\hline CHEMBL 3697898 & 1640340 & 10.0 & 9.2626 & TST \\
\hline CHEMBL 3641240 & 1640340 & 8.699 & 8.5845 & TRN \\
\hline CHEMBL 3641068 & 1640340 & 9.0 & 8.8918 & TRN \\
\hline CHEMBL 3697829 & 1640340 & 8.5229 & 8.1541 & TRN \\
\hline CHEMBL 3697908 & 1640340 & 8.2218 & 8.3742 & TRN \\
\hline CHEMBL 3694077 & 1640340 & 8.5229 & 8.4007 & TRN \\
\hline CHEMBL 3694133 & 1640340 & 8.3979 & 8.5403 & TRN \\
\hline CHEMBL 3639400 & 1640340 & 7.1871 & 6.8548 & TRN \\
\hline CHEMBL 3641114 & 1640340 & 8.5229 & 7.4463 & TST \\
\hline CHEMBL 3694049 & 1640340 & 7.0915 & 7.1408 & TST \\
\hline CHEMBL3694181 & 1640340 & 8.5229 & 9.392000 & 000000001 \\
\hline CHEMBL 3694021 & 1640340 & 10.0 & 9.4362 & TRN \\
\hline CHEMBL 3694205 & 1640340 & 8.699 & 8.9135 & TRN \\
\hline CHEMBL 3697874 & 1640340 & 8.2218 & 8.9789 & TRN \\
\hline CHEMBL 3641123 & 1640340 & 8.5229 & 8.76 & TRN \\
\hline CHEMBL3694164 & 1640340 & 8.3979 & 8.1496 & TRN \\
\hline CHEMBL 3641172 & 1640340 & 8.3979 & 8.6815 & TRN \\
\hline CHEMBL 3697879 & 1640340 & 8.0969 & 8.9727 & TRN \\
\hline CHEMBL 3643300 & 1640340 & 10.0 & 8.0046 & TST \\
\hline CHEMBL 3641103 & 1640340 & 7.8861 & 8.4856 & TRN \\
\hline CHEMBL 3694221 & 1640340 & 8.301 & 8.0304 & TRN \\
\hline CHEMBL 3694120 & 1640340 & 5.7383 & 5.8952 & TRN \\
\hline CHEMBL 3641178 & 1640340 & 9.0 & 8.841000 & 000000001 \\
\hline CHEMBL 3694117 & 1640340 & 6.2652 & 6.6986 & TRN \\
\hline CHEMBL 3697733 & 1640340 & 4.699 & 5.1075 & TST \\
\hline CHEMBL3689905 & 1640340 & 7.1675 & 7.562 & TST \\
\hline CHEMBL 3694214 & 1640340 & 10.0 & 10.2399 & TRN \\
\hline CHEMBL 3641158 & 1640340 & 8.5229 & 8.538 & TST \\
\hline CHEMBL 3641124 & 1640340 & 8.301 & 8.0446 & TRN \\
\hline CHEMBL3694153 & 1640340 & 8.301 & 8.1902 & TRN \\
\hline CHEMBL3641187 & 1640340 & 8.699 & 8.7917 & TST \\
\hline CHEMBL 3641186 & 1640340 & 8.5229 & 8.3522 & TST \\
\hline CHEMBL 3641048 & 1640340 & 7.9208 & 7.9314 & TRN \\
\hline CHEMBL 3641055 & 1640340 & 10.0 & 8.5473 & TST \\
\hline CHEMBL3641153 & 1640340 & 8.0 & 7.9427 & TRN \\
\hline CHEMBL3689932 & 1640340 & 7.9208 & 8.3595 & TRN \\
\hline CHEMBL 3694191 & 1640340 & 8.699 & 9.0557 & TRN \\
\hline CHEMBL3689919 & 1640340 & 7.301 & 7.5766 & TRN \\
\hline CHEMBL3641239 & 1640340 & 8.3979 & 8.4279 & TRN \\
\hline CHEMBL 3694166 & 1640340 & 9.0 & 8.707 & TRN \\
\hline CHEMBL3694198 & 1640340 & 8.5229 & 8.9011 & TRN \\
\hline CHEMBL 3694162 & 1640340 & 8.3979 & 8.3001 & TRN \\
\hline CHEMBL 3697839 & 1640340 & 9.0 & 9.6089 & TRN \\
\hline
\end{tabular}




$$
\text { Supplemental Table S2.txt }
$$

\begin{tabular}{|c|c|c|c|c|c|}
\hline CHEMBL 3641205 & 1640340 & 8.2218 & 7.5768 & TST & \\
\hline CHEMBL 3694225 & 1640340 & 8.0458 & 8.1257 & TRN & \\
\hline CHEMBL3697927 & 1640340 & 8.699 & 8.1925 & TST & \\
\hline CHEMBL3639929 & 1640340 & 7.3468 & 7.6477 & TRN & \\
\hline CHEMBL 3694076 & 1640340 & 8.0458 & 7.9804 & TRN & \\
\hline CHEMBL3694013 & 1640340 & 10.0 & 9.1745 & TRN & \\
\hline CHEMBL 3641228 & 1640340 & 9.0 & 8.6176 & TRN & \\
\hline CHEMBL 3641175 & 1640340 & 8.1549 & 7.8939 & TRN & \\
\hline CHEMBL 3697846 & 1640340 & 10.0 & 9.367 & TRN & \\
\hline CHEMBL 3641195 & 1640340 & 9.0 & 7.1423 & TST & \\
\hline CHEMBL3694150 & 1640340 & 8.5229 & 7.9946 & TRN & \\
\hline CHEMBL 3694142 & 1640340 & 9.0 & 8.078 & TRN & \\
\hline CHEMBL 3697920 & 1640340 & 8.2218 & 7.4419 & TST & \\
\hline CHEMBL 3641229 & 1640340 & 9.0 & 9.3751 & TRN & \\
\hline CHEMBL 3641164 & 1640340 & 8.0969 & 8.7765 & TST & \\
\hline CHEMBL55790 & 34190 & 6.0384 & 6.6277 & TST & \\
\hline CHEMBL294235 & 34190 & 7.267 & 7.2552 & TRN & \\
\hline CHEMBL56 & 34190 & 5.7254 & 5.45200 & 0000000001 & TST \\
\hline CHEMBL55319 & 34190 & 7.8661 & 7.8995 & TRN & \\
\hline CHEMBL431943 & 34190 & 7.2392 & 7.0854 & TRN & \\
\hline CHEMBL299454 & 34190 & 7.4444 & 7.5038 & TRN & \\
\hline CHEMBL299253 & 34190 & 7.6936 & 7.59200 & 00000000005 & TST \\
\hline CHEMBL59149 & 34190 & 6.7138 & 6.831 & TRN & \\
\hline CHEMBL58384 & 34190 & 6.3489 & 6.2218 & TRN & \\
\hline CHEMBL291908 & 34190 & 7.1335 & 7.1477 & TRN & \\
\hline CHEMBL13647 & 34190 & 6.7742 & 6.7426 & TRN & \\
\hline CHEMBL440118 & 34190 & 7.4252 & 7.4498 & TRN & \\
\hline CHEMBL294646 & 34190 & 7.0636 & 7.1007 & TRN & \\
\hline CHEMBL56620 & 34190 & 7.0777 & 7.1612 & TRN & \\
\hline CHEMBL293539 & 34190 & 7.9978 & 8.1877 & TRN & \\
\hline CHEMBL298595 & 34190 & 7.9393 & 7.9431 & TRN & \\
\hline CHEMBL57540 & 34190 & 6.8796 & 7.2519 & TST & \\
\hline CHEMBL431354 & 34190 & 6.774 & 6.8298 & TRN & \\
\hline CHEMBL55882 & 34190 & 7.099 & 7.1529 & TRN & \\
\hline CHEMBL57097 & 34190 & 5.0 & 5.0831 & TRN & \\
\hline CHEMBL57317 & 34190 & 7.36299 & 99999999 & 7.3516 & TRN \\
\hline CHEMBL60699 & 34190 & 6.5804 & 6.5396 & TRN & \\
\hline CHEMBL58476 & 34190 & 6.9238 & 6.7804 & TRN & \\
\hline CHEMBL55655 & 34190 & 6.0901 & 6.0798 & TRN & \\
\hline CHEMBL299691 & 34190 & 7.2033 & 7.3044 & TRN & \\
\hline CHEMBL301019 & 34190 & 5.0 & 5.0358 & TRN & \\
\hline CHEMBL57882 & 34190 & 5.0 & 5.2197 & TRN & \\
\hline CHEMBL556313 & 34190 & 8.2306 & 8.0856 & TRN & \\
\hline CHEMBL 294023 & 34190 & 6.1019 & 5.862 & TRN & \\
\hline CHEMBL57593 & 34190 & 7.0607 & 7.1751 & TRN & \\
\hline CHEMBL59262 & 34190 & 8.2692 & 8.2827 & TRN & \\
\hline CHEMBL 299022 & 34190 & 7.3355 & 7.3301 & TRN & \\
\hline CHEMBL57859 & 34190 & 7.2597 & 7.3002 & TRN & \\
\hline
\end{tabular}




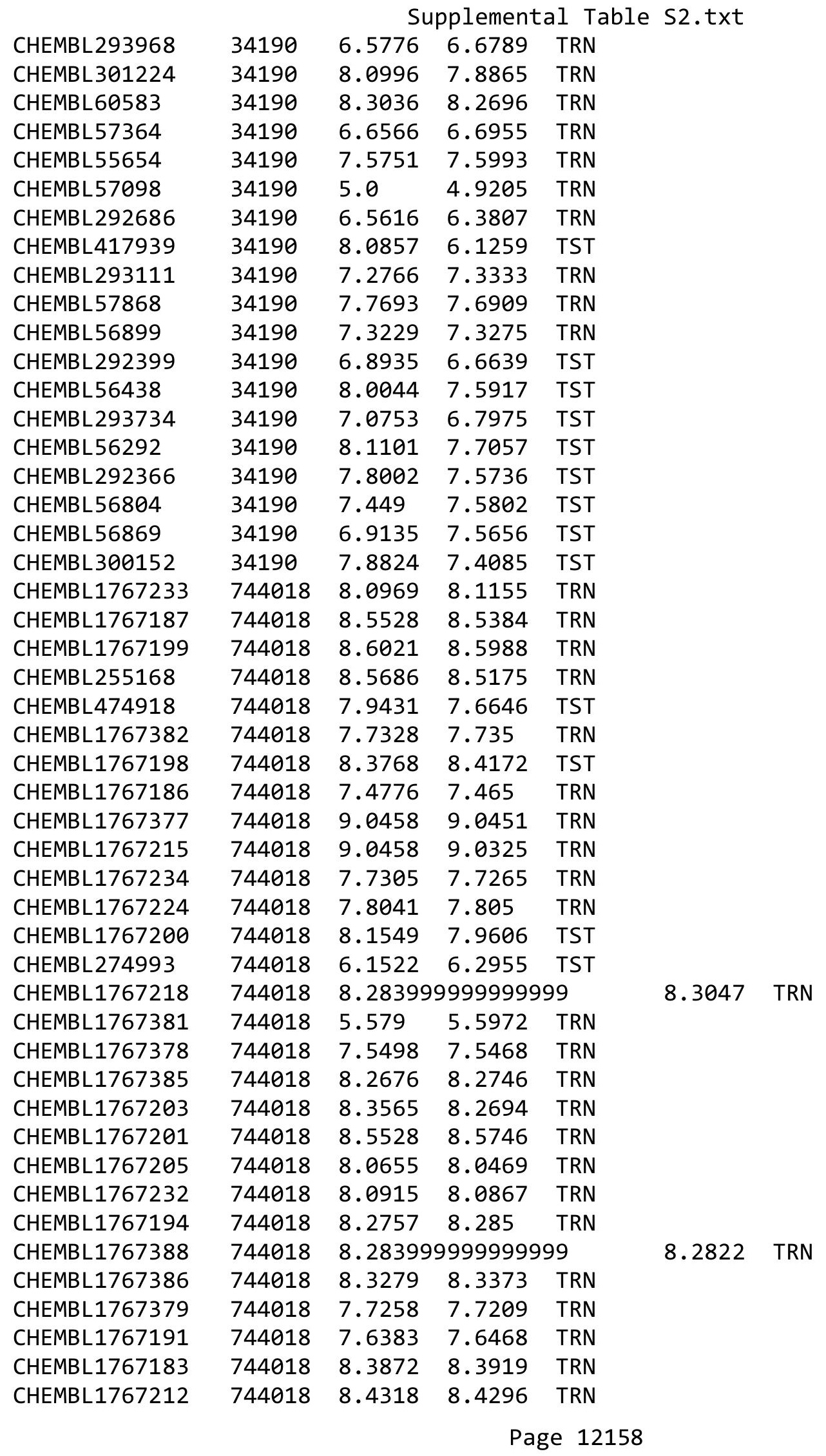


Supplemental Table S2.txt

\begin{tabular}{|c|c|c|c|c|}
\hline CHEMBL1767216 & 744018 & 8.1675 & 8.1732 & TRN \\
\hline CHEMBL482410 & 744018 & 7.6055 & 7.7804 & TST \\
\hline CHEMBL1767226 & 744018 & 8.699 & 8.7047 & TRN \\
\hline CHEMBL584437 & 744018 & 8.1871 & 8.182 & TRN \\
\hline CHEMBL1767389 & 744018 & 7.4078 & 7.396 & TRN \\
\hline CHEMBL1767383 & 744018 & 8.0362 & 8.0334 & TRN \\
\hline CHEMBL17201 & 744018 & 6.6153 & 6.6163 & TRN \\
\hline CHEMBL1767195 & 744018 & 8.4202 & 8.4177 & TRN \\
\hline CHEMBL1767214 & 744018 & 8.5528 & 8.5562 & TRN \\
\hline CHEMBL116438 & 744018 & 7.3028 & 7.1103 & TST \\
\hline CHEMBL1767221 & 744018 & 7.1073 & 7.1078 & TRN \\
\hline CHEMBL404678 & 744018 & 9.0 & 8.1534 & TST \\
\hline CHEMBL1767222 & 744018 & 9.0969 & 9.1067 & TRN \\
\hline CHEMBL1767387 & 744018 & 8.5528 & 8.5571 & TRN \\
\hline CHEMBL1767189 & 744018 & 8.6383 & 8.6462 & TRN \\
\hline CHEMBL1767192 & 744018 & 8.2366 & 8.2406 & TRN \\
\hline CHEMBL1767225 & 744018 & 6.8821 & 6.8748 & TRN \\
\hline CHEMBL1767223 & 744018 & 8.8861 & 8.8856 & TRN \\
\hline CHEMBL1767196 & 744018 & 7.9318 & 7.9132 & TRN \\
\hline CHEMBL496321 & 744018 & 8.0458 & 8.0413 & TRN \\
\hline CHEMBL1767231 & 744018 & 7.8633 & 7.8592 & TRN \\
\hline CHEMBL1767228 & 744018 & 8.7212 & 8.7331 & TRN \\
\hline CHEMBL1767204 & 744018 & 8.1612 & 8.2694 & TRN \\
\hline CHEMBL1767230 & 744018 & 8.3979 & 8.3921 & TRN \\
\hline CHEMBL1767229 & 744018 & 8.2596 & 8.262 & TRN \\
\hline CHEMBL 78012 & 744018 & 7.9788 & 9.2952 & TST \\
\hline CHEMBL1767384 & 744018 & 8.3979 & 8.3848 & TRN \\
\hline CHEMBL1767219 & 744018 & 8.4318 & 8.4345 & TRN \\
\hline CHEMBL1767380 & 744018 & 8.0757 & 8.067 & TRN \\
\hline CHEMBL1767213 & 744018 & 8.9586 & 8.9667 & TRN \\
\hline CHEMBL1767185 & 744018 & 8.4202 & 8.4302 & TRN \\
\hline CHEMBL1767193 & 744018 & 8.0706 & 7.80399 & 9999999999 \\
\hline CHEMBL1767217 & 744018 & 9.1549 & 8.7497 & TST \\
\hline CHEMBL1767227 & 744018 & 8.9208 & 8.1874 & TST \\
\hline CHEMBL1767188 & 744018 & 8.6576 & 8.9875 & TST \\
\hline CHEMBL1767184 & 744018 & 7.7905 & 8.4728 & TST \\
\hline CHEMBL1767202 & 744018 & 8.2518 & 8.4503 & TST \\
\hline CHEMBL1767190 & 744018 & 8.3188 & 8.7955 & TST \\
\hline CHEMBL1767220 & 744018 & 8.5376 & 8.5647 & TST \\
\hline CHEMBL1767211 & 744018 & 8.9208 & 7.6465 & TST \\
\hline CHEMBL1767197 & 744018 & 8.7447 & 8.3116 & TST \\
\hline CHEMBL314047 & 212325 & 6.1249 & 6.0236 & TRN \\
\hline CHEMBL84502 & 212325 & 6.0 & 6.2583 & TRN \\
\hline CHEMBL83054 & 212325 & 5.5686 & 5.575 & TRN \\
\hline CHEMBL81579 & 212325 & 4.301 & 4.7069 & TRN \\
\hline CHEMBL84419 & 212325 & 5.301 & \multicolumn{2}{|c|}{5.7379999999999995} \\
\hline CHEMBL70730 & 212325 & 5.5686 & 5.82 & TRN \\
\hline CHEMBL83779 & 212325 & 4.301 & 3.8087 & TRN \\
\hline
\end{tabular}


Supplemental Table S2.txt

\begin{tabular}{|c|c|c|c|c|}
\hline CHEMBL 309541 & 212325 & 6.1871 & 4.6112 & TST \\
\hline CHEMBL83392 & 212325 & 5.4318 & 5.6391 & TRN \\
\hline LHEMBL81932 & 12325 & 4.301 & 4.5484 & TPN \\
\hline HEMBL83175 & 12325 & 4.301 & 3209 & \\
\hline HEMBL315014 & 12325 & 5.8539 & 4.0664 & IST \\
\hline CHEMBL 81893 & 12325 & 5.5528 & 5.2758 & \\
\hline HEMBL432939 & 12325 & 6.4559 & 4.3773 & ST \\
\hline CHEMBL84437 & 12325 & 6.1249 & 4.7988 & $C T$ \\
\hline HEMBL 79258 & 212325 & 5.7959 & 6.1719 & 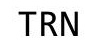 \\
\hline LHEMBL 79828 & 12325 & 6.7959 & 4.6732 & TST \\
\hline CHEMBL82925 & 12325 & 6.0 & 5.9126 & iv \\
\hline HEMBL311788 & 212325 & 4.301 & 4.3359 & RN \\
\hline HEMBL 83925 & 12325 & 5.6778 & 5.4858 & $\mathrm{RN}$ \\
\hline HEMBL 79447 & 212325 & 5.699 & 5.3032 & TRN \\
\hline CHEMBL 314591 & 12325 & 5.6778 & 5.9252 & TRN \\
\hline CHEMBL 83743 & 212325 & 5.5376 & 5.2039 & \\
\hline HEMBL309879 & 212325 & 6.2366 & 4.7802 & ST \\
\hline LHEMBL 309617 & 212325 & 5.3188 & 5.784 & \\
\hline CHEMBL82040 & 12325 & 4.301 & 4.2823 & $R \mathrm{~N}$ \\
\hline CHEMBL 82739 & 12325 & 5.6198 & 5.4687 & in \\
\hline CHEMBL310373 & 212325 & 5. & 4.6989 & Sו \\
\hline HEMBL419661 & 12325 & 5.5376 & 263 & RN \\
\hline CHEMBL 82873 & 212325 & 4.301 & 4.8327 & TRN \\
\hline CHEMBL 83648 & 12325 & 4.301 & 4.863 & RN \\
\hline CHEMBL440311 & 12325 & 4.301 & 4.5159 & TRN \\
\hline CHEMBL 84275 & 212325 & 6.3979 & 2169 & TRN \\
\hline CHEMBL 79929 & 12325 & 4. & 89 & TRN \\
\hline CHEMBL80119 & 212325 & 4.301 & 4.328 & TRN \\
\hline CHEMBL 79344 & 12325 & 4.36 & 84 & TRN \\
\hline CHEMBL84065 & 12325 & 6.6576 & 4.6634 & TST \\
\hline CHEMBL83106 & 12325 & 6.3468 & 3056 & TRN \\
\hline CHEMBL 79303 & 12325 & 6. & 79 & TST \\
\hline CHEMBL 81852 & 212325 & 4.301 & 4.4558 & TRN \\
\hline CHEMBL 84379 & 12325 & 5.3098 & 5.3214 & TRN \\
\hline CHEMBL 84482 & 12325 & 4.301 & 4.4205 & TRN \\
\hline CHEMBL82339 & 212325 & 5.8539 & 1409 & TST \\
\hline CHEMBL 84410 & 212325 & 4.301 & 4.3681 & TRN \\
\hline CHEMBL 82831 & 212325 & 4.301 & 4.6497 & TRN \\
\hline CHEMBL 79996 & 12325 & 4.30 & 4.3801 & TRN \\
\hline CHEMBL311608 & 12325 & 5.3665 & 5.4858 & TRN \\
\hline CHEMBL420963 & 212325 & 5.7212 & 5.6907 & TRN \\
\hline CHEMBL309717 & 212325 & 4.301 & 4.5138 & TRN \\
\hline CHEMBL312592 & 212325 & 6.1367 & 4.9346 & TST \\
\hline CHEMBL 82006 & 212325 & 6.284 & 4.1744 & TST \\
\hline CHEMBL81007 & 2325 & $5.2-3 x-1$ & 5.3102 & $\mathrm{~K}$ \\
\hline CHEMBL419651 & 212325 & 5.9586 & 5.6391 & v \\
\hline CHEMBL 81301 & 212325 & 5.4685 & 5.3383 & ГRN \\
\hline CHEMBL82456 & 212325 & 5.9586 & 5.3477 & TRN \\
\hline
\end{tabular}

Page 12160 


\begin{tabular}{|c|c|c|c|c|c|}
\hline \multicolumn{6}{|c|}{ Supplemental Table S2.txt } \\
\hline CHEMBL441450 & 212325 & 5.7212 & 5.2897 & TRN & \\
\hline CHEMBL48604 & 212325 & 6.2441 & 4.112 & TST & \\
\hline CHEMBL81086 & 212325 & 4.301 & 3.8664 & TRN & \\
\hline CHEMBL 83675 & 212325 & 5.7212 & 5.6525 & TRN & \\
\hline CHEMBL312275 & 212325 & 4.301 & 4.0467 & TRN & \\
\hline CHEMBL49636 & 212325 & 6.0915 & 5.4878 & TRN & \\
\hline CHEMBL 83798 & 212325 & 5.5229 & 5.3259 & TRN & \\
\hline CHEMBL79986 & 212325 & 6.2596 & 6.2981 & TRN & \\
\hline CHEMBL83431 & 212325 & 4.301 & 4.3228 & TRN & \\
\hline CHEMBL 81632 & 212325 & 4.301 & 4.7899 & TRN & \\
\hline CHEMBL 82175 & 212325 & 5.3768 & 5.1225 & TST & \\
\hline CHEMBL 79529 & 212325 & 6.3279 & 4.415 & TST & \\
\hline CHEMBL83324 & 212325 & 5.4815 & 5.9191 & TST & \\
\hline CHEMBL 3683340 & 1528673 & 4.0 & 3.71100 & 00000000003 & TRN \\
\hline CHEMBL3683299 & 1528673 & 7.1308 & 6.0212 & TRN & \\
\hline CHEMBL3683412 & 1528673 & 4.0 & 5.5483 & TRN & \\
\hline CHEMBL3683417 & 1528673 & 6.1007 & 5.4508 & TRN & \\
\hline CHEMBL3683353 & 1528673 & 5.4538 & 4.9115 & TRN & \\
\hline CHEMBL 3688192 & 1528673 & 8.5229 & 7.7698 & TRN & \\
\hline CHEMBL3688198 & 1528673 & 6.4895 & 7.3842 & TST & \\
\hline CHEMBL3683453 & 1528673 & 6.8729 & 6.7146 & TRN & \\
\hline CHEMBL 3683348 & 1528673 & 7.5686 & 7.4801 & TRN & \\
\hline CHEMBL3683403 & 1528673 & 7.0458 & 6.5328 & TRN & \\
\hline CHEMBL 3683372 & 1528673 & 6.3675 & 4.0587 & TST & \\
\hline CHEMBL 3683419 & 1528673 & 4.0 & 4.1753 & TRN & \\
\hline CHEMBL 3683437 & 1528673 & 4.0 & 4.6643 & TRN & \\
\hline CHEMBL3683364 & 1528673 & 7.7212 & 7.7604 & TRN & \\
\hline CHEMBL3683292 & 1528673 & 6.5735 & 5.3249 & TRN & \\
\hline CHEMBL3639822 & 1528673 & 4.0523 & 2.957 & TST & \\
\hline CHEMBL 3683475 & 1528673 & 4.0 & 4.7198 & TRN & \\
\hline CHEMBL 3688194 & 1528673 & 6.5884 & 6.7728 & TRN & \\
\hline CHEMBL3683435 & 1528673 & 4.0 & 5.6845 & TRN & \\
\hline CHEMBL3683465 & 1528673 & 4.0 & 4.7491 & TRN & \\
\hline CHEMBL 3683479 & 1528673 & 7.2757 & 6.9593 & TRN & \\
\hline CHEMBL3683394 & 1528673 & 6.9101 & 5.489 & TRN & \\
\hline CHEMBL3683326 & 1528673 & 6.0052 & 5.4874 & TRN & \\
\hline CHEMBL3683429 & 1528673 & 7.0177 & 6.7152 & TRN & \\
\hline CHEMBL 3688171 & 1528673 & 4.0 & 3.3374 & TST & \\
\hline CHEMBL 3683362 & 1528673 & 7.2441 & 6.3011 & TRN & \\
\hline CHEMBL3683442 & 1528673 & 6.9136 & 6.2709 & TRN & \\
\hline CHEMBL3683328 & 1528673 & 6.4168 & 6.1893 & TRN & \\
\hline CHEMBL3683390 & 1528673 & 4.0 & 5.9364 & TRN & \\
\hline CHEMBL3683324 & 1528673 & 7.2596 & 6.8586 & TRN & \\
\hline CHEMBL 3683393 & 1528673 & 6.0496 & 6.6958 & TRN & \\
\hline CHEMBL 3683313 & 1528673 & 6.5622 & 5.6593 & TRN & \\
\hline CHEMBL 3683470 & 1528673 & 5.4268 & 5.9344 & TRN & \\
\hline CHEMBL 3683287 & 1528673 & 7.8861 & 7.1641 & TRN & \\
\hline CHEMBL3683342 & 1528673 & 6.7399 & 6.4529 & TRN & \\
\hline
\end{tabular}




\begin{tabular}{|c|c|c|c|c|c|}
\hline \multicolumn{6}{|c|}{ Supplemental Table S2.txt } \\
\hline CHEMBL 3683378 & 1528673 & 4.0 & 4.5009 & TST & \\
\hline CHEMBL 3683491 & 1528673 & 4.0 & 5.9741 & TST & \\
\hline CHEMBL 3683375 & 1528673 & 5.7091 & 5.5385 & TRN & \\
\hline CHEMBL 3688175 & 1528673 & 4.0 & 5.61700 & 0000000001 & TST \\
\hline CHEMBL 3683294 & 1528673 & 6.9245 & 6.8772 & TRN & \\
\hline CHEMBL 3688183 & 1528673 & 7.2076 & 7.3968 & TRN & \\
\hline CHEMBL3683369 & 1528673 & 4.0 & 3.4051 & TST & \\
\hline CHEMBL 3683330 & 1528673 & 6.7773 & 6.8174 & TRN & \\
\hline CHEMBL 3683482 & 1528673 & 7.4318 & 6.2935 & TRN & \\
\hline CHEMBL3683363 & 1528673 & 7.3665 & 7.0708 & TRN & \\
\hline CHEMBL 3683401 & 1528673 & 4.0 & 5.1284 & TRN & \\
\hline CHEMBL 3683415 & 1528673 & 4.0 & 3.8523 & TRN & \\
\hline CHEMBL3683383 & 1528673 & 7.5376 & 6.2025 & TST & \\
\hline CHEMBL 3683406 & 1528673 & 7.0044 & 7.0671 & TRN & \\
\hline CHEMBL3688180 & 1528673 & 4.0 & 4.8194 & TST & \\
\hline CHEMBL3688193 & 1528673 & 6.0 & 7.2408 & TST & \\
\hline CHEMBL 3683380 & 1528673 & 4.0 & 5.2345 & TST & \\
\hline CHEMBL3688190 & 1528673 & 8.699 & 8.0995 & TST & \\
\hline CHEMBL 3683484 & 1528673 & 5.5804 & 5.9659 & TRN & \\
\hline CHEMBL3683391 & 1528673 & 7.2366 & 6.78100 & 0000000001 & TRN \\
\hline CHEMBL3683418 & 1528673 & 4.0 & 6.5541 & TRN & \\
\hline CHEMBL 3683368 & 1528673 & 4.2243 & 3.4437 & TST & \\
\hline CHEMBL3683293 & 1528673 & 7.1938 & 6.9392 & TRN & \\
\hline CHEMBL 3683311 & 1528673 & 7.0655 & 5.8048 & TRN & \\
\hline CHEMBL3683351 & 1528673 & 6.7399 & 7.0486 & TRN & \\
\hline CHEMBL3683423 & 1528673 & 4.0 & 4.6153 & TRN & \\
\hline CHEMBL 3683474 & 1528673 & 4.0 & 4.4464 & TRN & \\
\hline CHEMBL3683289 & 1528673 & 6.8508 & 6.1774 & TRN & \\
\hline CHEMBL 3683397 & 1528673 & 4.0 & 3.8223 & TRN & \\
\hline CHEMBL3683382 & 1528673 & 5.4125 & 4.5044 & TST & \\
\hline CHEMBL 3683447 & 1528673 & 4.0 & 4.3896 & TRN & \\
\hline CHEMBL 3688191 & 1528673 & 6.9747 & 8.1772 & TRN & \\
\hline CHEMBL 3683454 & 1528673 & 6.2441 & 6.9884 & TRN & \\
\hline CHEMBL 3683322 & 1528673 & 6.61799 & 99999999 & 6.4344 & TRN \\
\hline CHEMBL3683336 & 1528673 & 4.0 & 4.5342 & TRN & \\
\hline CHEMBL 3683449 & 1528673 & 6.857 & 6.5081 & TRN & \\
\hline CHEMBL3683402 & 1528673 & 4.0 & 4.7943 & TRN & \\
\hline CHEMBL3683290 & 1528673 & 4.0 & 4.3898 & TRN & \\
\hline CHEMBL 3683344 & 1528673 & 6.5421 & 6.5386 & TRN & \\
\hline CHEMBL3683392 & 1528673 & 7.0088 & 7.1385 & TRN & \\
\hline CHEMBL3683462 & 1528673 & 4.0 & 5.6515 & TRN & \\
\hline CHEMBL3683361 & 1528673 & 5.6558 & 5.49299 & 9999999999 & TRN \\
\hline CHEMBL3683450 & 1528673 & 6.9355 & 6.8736 & TRN & \\
\hline CHEMBL 3683320 & 1528673 & 7.0969 & 7.4802 & TRN & \\
\hline CHEMBL3683490 & 1528673 & 4.5232 & 4.6821 & TST & \\
\hline CHEMBL3683452 & 1528673 & 6.2132 & 6.7216 & TRN & \\
\hline CHEMBL3683430 & 1528673 & 6.2958 & 6.5058 & TRN & \\
\hline CHEMBL3683316 & 1528673 & 6.7375 & 6.6099 & TRN & \\
\hline
\end{tabular}




\begin{tabular}{|c|c|c|c|c|c|c|}
\hline \multicolumn{7}{|c|}{ Supplemental Table S2.txt } \\
\hline CHEMBL3683483 & 1528673 & 4.0 & 5.2462 & TRN & & \\
\hline CHEMBL3683323 & 1528673 & 6.7077 & 6.2981 & TRN & & \\
\hline CHEMBL3683411 & 1528673 & 4.0 & 3.8519 & TRN & & \\
\hline CHEMBL 3683407 & 1528673 & 7.041 & 7.1139 & TRN & & \\
\hline CHEMBL 3688170 & 1528673 & 4.0 & 4.4724 & TST & & \\
\hline CHEMBL3683349 & 1528673 & 6.4935 & 6.5832 & TRN & & \\
\hline CHEMBL3683414 & 1528673 & 6.9245 & 6.894 & TRN & & \\
\hline CHEMBL3977539 & 1528673 & 6.3883 & 3.1665 & TST & & \\
\hline CHEMBL 3688195 & 1528673 & 6.3261 & 6.3364 & TRN & & \\
\hline CHEMBL3688185 & 1528673 & 7.9208 & 7.0494 & TRN & & \\
\hline CHEMBL3683459 & 1528673 & 6.34200 & 00000000 & 205 & 5.7813 & TRN \\
\hline CHEMBL3688179 & 1528673 & 5.7498 & 5.6379 & TST & & \\
\hline CHEMBL3683331 & 1528673 & 6.7595 & 7.0353 & TRN & & \\
\hline CHEMBL 3683346 & 1528673 & 7.0362 & 6.7699 & TRN & & \\
\hline CHEMBL3683384 & 1528673 & 4.0 & 4.1041 & TST & & \\
\hline CHEMBL3683416 & 1528673 & 7.4202 & 6.5564 & TRN & & \\
\hline CHEMBL3683441 & 1528673 & 7.2924 & 6.1165 & TRN & & \\
\hline CHEMBL 3683422 & 1528673 & 5.0359 & 4.6777 & TRN & & \\
\hline CHEMBL3683309 & 1528673 & 4.0 & 3.5064 & TRN & & \\
\hline CHEMBL3683408 & 1528673 & 4.0 & 6.2561 & TRN & & \\
\hline CHEMBL3683298 & 1528673 & 7.0757 & 6.8657 & TRN & & \\
\hline CHEMBL3688176 & 1528673 & 4.0 & 3.7745 & TST & & \\
\hline CHEMBL 3688168 & 1528673 & 4.9382 & 5.5846 & TST & & \\
\hline CHEMBL 3683327 & 1528673 & 6.7905 & 7.6889 & TRN & & \\
\hline CHEMBL3683318 & 1528673 & 6.6737 & 7.0167 & TRN & & \\
\hline CHEMBL3683339 & 1528673 & 6.71899 & 99999999 & 99 & 6.684 & TRN \\
\hline CHEMBL3683405 & 1528673 & 4.0 & 4.1267 & TRN & & \\
\hline CHEMBL 3683297 & 1528673 & 7.3279 & 6.8994 & TRN & & \\
\hline CHEMBL 3683445 & 1528673 & 4.0 & 4.5283 & TRN & & \\
\hline CHEMBL3683471 & 1528673 & 6.9872 & 6.5866 & TRN & & \\
\hline CHEMBL 3683487 & 1528673 & 4.0 & 5.2489 & TRN & & \\
\hline CHEMBL 3688188 & 1528673 & 8.0969 & 8.1009 & TRN & & \\
\hline CHEMBL 3683425 & 1528673 & 7.3665 & 7.1538 & TRN & & \\
\hline CHEMBL3683302 & 1528673 & 6.6615 & 6.0001 & TRN & & \\
\hline CHEMBL3688182 & 1528673 & 6.8996 & 6.4052 & TRN & & \\
\hline CHEMBL3683456 & 1528673 & 6.2993 & 6.3314 & TRN & & \\
\hline CHEMBL3683347 & 1528673 & 7.4089 & 6.6866 & TRN & & \\
\hline CHEMBL3683317 & 1528673 & 7.1079 & 6.6551 & TRN & & \\
\hline CHEMBL3683335 & 1528673 & 4.8595 & 5.3443 & TRN & & \\
\hline CHEMBL3683477 & 1528673 & 6.1013 & 5.3545 & TRN & & \\
\hline CHEMBL3683338 & 1528673 & 6.5867 & 5.8793 & TRN & & \\
\hline CHEMBL3688196 & 1528673 & 7.0605 & 6.6863 & TRN & & \\
\hline CHEMBL3683489 & 1528673 & 4.0 & 5.1667 & TST & & \\
\hline CHEMBL3683440 & 1528673 & 4.0 & 3.5548 & TRN & & \\
\hline CHEMBL3683468 & 1528673 & 6.4895 & 7.8608 & TRN & & \\
\hline CHEMBL3683367 & 1528673 & 4.0 & 3.5704 & TST & & \\
\hline CHEMBL3683360 & 1528673 & 4.0 & 5.6905 & TRN & & \\
\hline CHEMBL 3683413 & 1528673 & 4.0 & 3.3788 & TRN & & \\
\hline
\end{tabular}


Supplemental Table S2.txt

\begin{tabular}{|c|c|c|c|c|c|c|}
\hline CHEMBL 3683381 & 1528673 & 4.7762 & 6.3801 & TRN & & \\
\hline CHEMBL 3683466 & 1528673 & 6.75700 & 000000000 & 31 & 6.9359 & TRN \\
\hline CHEMBL 3683306 & 1528673 & 7.0555 & 7.0756 & TRN & & \\
\hline CHEMBL 3683300 & 1528673 & 6.6861 & 5.6758 & TRN & & \\
\hline CHEMBL 3683448 & 1528673 & 5.2102 & 4.8358 & TRN & & \\
\hline CHEMBL 3683409 & 1528673 & 6.6253 & 6.2079 & TRN & & \\
\hline CHEMBL 3683354 & 1528673 & 6.8097 & 7.4485 & TRN & & \\
\hline CHEMBL 3683374 & 1528673 & 4.4464 & 4.5328 & TRN & & \\
\hline CHEMBL 3683288 & 1528673 & 4.0 & 4.0112 & TRN & & \\
\hline CHEMBL 3683388 & 1528673 & 7.8239 & 5.8726 & TST & & \\
\hline CHEMBL 3683443 & 1528673 & 6.289 & 6.6045 & TRN & & \\
\hline CHEMBL 3683488 & 1528673 & 4.0 & 4.3981 & TST & & \\
\hline CHEMBL 3683386 & 1528673 & 5.5045 & 5.0351 & TST & & \\
\hline CHEMBL 3683438 & 1528673 & 4.0 & 4.654 & TRN & & \\
\hline CHEMBL 3683379 & 1528673 & 4.0 & 6.8363 & TST & & \\
\hline CHEMBL 3683476 & 1528673 & 4.0 & 5.0522 & TRN & & \\
\hline CHEMBL 3683398 & 1528673 & 7.1612 & 6.3536 & TRN & & \\
\hline CHEMBL 3683345 & 1528673 & 4.0 & 5.9133 & TRN & & \\
\hline CHEMBL 3683307 & 1528673 & 7.0757 & 6.4488 & TRN & & \\
\hline CHEMBL 3683376 & 1528673 & 6.38299 & 999999999 & 99 & 3.5939 & TST \\
\hline CHEMBL 3683332 & 1528673 & 6.9706 & 7.6817 & TRN & & \\
\hline CHEMBL 3688173 & 1528673 & 4.0 & 2.8259 & TST & & \\
\hline CHEMBL 3683486 & 1528673 & 4.0 & 4.5269 & TRN & & \\
\hline CHEMBL 3683455 & 1528673 & 6.6676 & 7.3793 & TRN & & \\
\hline CHEMBL 3683312 & 1528673 & 7.2441 & 5.9557 & TRN & & \\
\hline CHEMBL 3683377 & 1528673 & 5.5255 & 4.8852 & TST & & \\
\hline CHEMBL 3688187 & 1528673 & 5.9393 & 4.4357 & TRN & & \\
\hline CHEMBL 3688197 & 1528673 & 9.0 & 8.6795 & TRN & & \\
\hline CHEMBL 3683385 & 1528673 & 6.2262 & 5.4189 & TST & & \\
\hline CHEMBL 3688177 & 1528673 & 4.0 & 4.0651 & TST & & \\
\hline CHEMBL 3683305 & 1528673 & 7.2441 & 6.7522 & TRN & & \\
\hline CHEMBL 3683451 & 1528673 & 7.301 & 6.7837 & TRN & & \\
\hline CHEMBL 3683481 & 1528673 & 7.4318 & 6.8157 & TRN & & \\
\hline CHEMBL 3688181 & 1528673 & 6.6126 & 6.6516 & TRN & & \\
\hline CHEMBL 3683480 & 1528673 & 7.1308 & 6.9345 & TRN & & \\
\hline CHEMBL 3683352 & 1528673 & 6.8697 & 6.0465 & TRN & & \\
\hline CHEMBL 3683329 & 1528673 & 7.2757 & 6.5833 & TRN & & \\
\hline CHEMBL 3683420 & 1528673 & 4.0 & 6.2608 & TRN & & \\
\hline CHEMBL 3683463 & 1528673 & 5.1379 & 5.996 & TRN & & \\
\hline CHEMBL 3688189 & 1528673 & 7.0555 & 7.5784 & TRN & & \\
\hline CHEMBL 3683359 & 1528673 & 6.3788 & 6.0993 & TRN & & \\
\hline CHEMBL 3683410 & 1528673 & 4.0 & 3.4419 & TRN & & \\
\hline CHEMBL 3683370 & 1528673 & 4.2731 & 3.3068 & TST & & \\
\hline CHEMBL 3683467 & 1528673 & 6.7375 & 6.347 & TRN & & \\
\hline CHEMBL 3683396 & 1528673 & \multicolumn{3}{|c|}{6.752000000000001} & 6.8644 & $1 \mathrm{~K}$ \\
\hline CHEMBL 3683399 & 1528673 & 7.6198 & 6.5697 & TRN & & \\
\hline CHEMBL 3683428 & 1528673 & 7.3979 & 6.114 & TRN & & \\
\hline CHEMBL 3683337 & 1528673 & 6.767 & 6.369 & TRN & & \\
\hline
\end{tabular}


Supplemental Table S2.txt

\begin{tabular}{|c|c|c|c|c|c|}
\hline CHEMBL3683478 & 1528673 & 6.8894 & 6.0562 & TRN & \\
\hline CHEMBL3688169 & 1528673 & 4.0 & 7.0046 & TST & \\
\hline CHEMBL3683358 & 1528673 & 7.1135 & 6.6174 & TRN & \\
\hline CHEMBL3683400 & 1528673 & 4.0 & 5.5289 & TRN & \\
\hline CHEMBL3683321 & 1528673 & 4.0 & 4.0067 & TRN & \\
\hline CHEMBL3683333 & 1528673 & 7.301 & 7.2607 & TRN & \\
\hline CHEMBL3639823 & 1528673 & 6.4145 & 5.7266 & TRN & \\
\hline CHEMBL3688186 & 1528673 & 6.6326 & 6.4896 & TRN & \\
\hline CHEMBL3683357 & 1528673 & 7.5686 & 6.8171 & TRN & \\
\hline CHEMBL3683371 & 1528673 & 4.115 & 5.0068 & TST & \\
\hline CHEMBL3688184 & 1528673 & 7.2757 & 6.1641 & TRN & \\
\hline CHEMBL3683433 & 1528673 & 7.0223 & 7.3662 & TRN & \\
\hline CHEMBL3948311 & 1528673 & 7.6778 & 6.5887 & TST & \\
\hline CHEMBL3683341 & 1528673 & 6.8894 & 7.1061 & TRN & \\
\hline CHEMBL3683373 & 1528673 & 6.9788 & 6.4625 & TRN & \\
\hline CHEMBL3683432 & 1528673 & 7.2757 & 6.6247 & TRN & \\
\hline CHEMBL3683460 & 1528673 & 5.9914 & 6.6297 & TRN & \\
\hline CHEMBL 3683387 & 1528673 & 6.8386 & 5.317 & TST & \\
\hline CHEMBL3683366 & 1528673 & 6.1379 & 5.9364 & TST & \\
\hline CHEMBL3683296 & 1528673 & 6.9031 & 7.0859 & TRN & \\
\hline CHEMBL3683431 & 1528673 & 6.7282 & 6.4374 & TRN & \\
\hline CHEMBL3683310 & 1528673 & 6.8697 & 6.0259 & TRN & \\
\hline CHEMBL3683458 & 1528673 & 4.0 & 4.1397 & TRN & \\
\hline CHEMBL3683421 & 1528673 & 4.0 & 3.4233 & TRN & \\
\hline CHEMBL3683291 & 1528673 & 6.8297 & 7.007999 & 9999999999 & TRN \\
\hline CHEMBL3683472 & 1528673 & 4.0 & 3.7916 & TRN & \\
\hline CHEMBL3683301 & 1528673 & 6.8697 & 7.5056 & TRN & \\
\hline CHEMBL3688178 & 1528673 & 4.0 & 4.2869 & TRN & \\
\hline CHEMBL3683404 & 1528673 & 4.0 & 5.0768 & TRN & \\
\hline CHEMBL 3683424 & 1528673 & 4.0 & 5.349 & TRN & \\
\hline CHEMBL3683315 & 1528673 & 4.0 & 4.4839 & TRN & \\
\hline CHEMBL 3683427 & 1528673 & 7.1024 & 6.1658 & TRN & \\
\hline CHEMBL3688174 & 1528673 & 4.0 & 3.7154 & TST & \\
\hline CHEMBL3683464 & 1528673 & 6.057 & 7.0787 & TST & \\
\hline CHEMBL3683356 & 1528673 & 7.6021 & 7.0787 & TRN & \\
\hline CHEMBL3683304 & 1528673 & 4.0 & 3.6081 & TRN & \\
\hline CHEMBL3683436 & 1528673 & 7.301 & 6.5449 & TRN & \\
\hline CHEMBL 3683444 & 1528673 & 4.0 & 5.2792 & TRN & \\
\hline CHEMBL 3683434 & 1528673 & 6.4828 & 6.5547 & TRN & \\
\hline CHEMBL3683314 & 1528673 & 7.0362 & 7.8387 & TRN & \\
\hline CHEMBL3683395 & 1528673 & 7.1308 & 6.1317 & TRN & \\
\hline CHEMBL 3683485 & 1528673 & 5.965 & 6.3576 & TST & \\
\hline CHEMBL3683325 & 1528673 & 7.0969 & 7.2329 & TST & \\
\hline CHEMBL3683319 & 1528673 & 6.9318 & 6.4102 & TST & \\
\hline CHEMBL3683439 & 1528673 & 6.71899 & 999999999 & 5.17 & TST \\
\hline CHEMBL3688172 & 1528673 & 4.0 & 5.6089 & TST & \\
\hline CHEMBL3683303 & 1528673 & 6.3054 & 7.3054 & TST & \\
\hline CHEMBL3683334 & 1528673 & 6.1656 & 5.9261 & TST & \\
\hline
\end{tabular}


Supplemental Table S2.txt

\begin{tabular}{|c|c|c|c|c|}
\hline CHEMBL3683308 & 1528673 & 6.6799 & 7.1557 & TST \\
\hline CHEMBL3683295 & 1528673 & 6.6819 & 7.7068 & TST \\
\hline CHEMBL3683426 & 1528673 & 7.1249 & 6.0891 & TST \\
\hline CHEMBL 3683343 & 1528673 & 4.0 & 2.8263 & TST \\
\hline CHEMBL3683457 & 1528673 & 6.8827 & 6.4851 & TST \\
\hline CHEMBL3683461 & 1528673 & 6.6091 & 7.0842 & TST \\
\hline CHEMBL3683469 & 1528673 & 4.0 & 6.5578 & TST \\
\hline CHEMBL 3683350 & 1528673 & 4.9481 & 5.9732 & TST \\
\hline CHEMBL 3683355 & 1528673 & 5.8834 & 6.6801 & TST \\
\hline CHEMBL3683473 & 1528673 & 5.7005 & 6.018 & TST \\
\hline CHEMBL3683446 & 1528673 & 6.9031 & 7.2496 & TST \\
\hline CHEMBL3683389 & 1528673 & 4.0 & 4.4948 & TST \\
\hline CHEMBL1964290 & 809138 & 5.6 & 5.4721 & TRN \\
\hline CHEMBL 2003768 & 809138 & 5.2 & 5.1256 & TRN \\
\hline CHEMBL213505 & 809138 & 5.9 & 5.5206 & TRN \\
\hline CHEMBL202721 & 809138 & 4.7 & 4.4426 & TRN \\
\hline CHEMBL1982880 & 809138 & 4.1 & 4.2402 & TRN \\
\hline CHEMBL1987034 & 809138 & 7.6 & 7.7049 & TRN \\
\hline CHEMBL1993941 & 809138 & 5.9 & 4.9214 & TRN \\
\hline CHEMBL1980435 & 809138 & 4.6 & 5.0821 & TRN \\
\hline CHEMBL377383 & 809138 & 4.1 & 3.7574 & TRN \\
\hline CHEMBL578061 & 809138 & 5.5 & 4.659 & TRN \\
\hline CHEMBL 2005886 & 809138 & 5.7 & 6.0537 & TRN \\
\hline CHEMBL481491 & 809138 & 4.1 & 4.2796 & TST \\
\hline CHEMBL1682345 & 809138 & 4.1 & 5.1306 & TRN \\
\hline CHEMBL1973142 & 809138 & 4.1 & 4.7535 & TRN \\
\hline CHEMBL388311 & 809138 & 8.3 & 8.7944 & TRN \\
\hline CHEMBL1973145 & 809138 & 4.1 & 5.081 & TRN \\
\hline CHEMBL1982924 & 809138 & 5.2 & 5.0126 & TRN \\
\hline CHEMBL 2005936 & 809138 & 5.3 & 4.7354 & TRN \\
\hline CHEMBL1807515 & 809138 & 8.3 & 7.4842 & TRN \\
\hline CHEMBL1964948 & 809138 & 4.4 & 4.468 & TRN \\
\hline CHEMBL1971141 & 809138 & 4.1 & 4.0997 & TRN \\
\hline CHEMBL1995813 & 809138 & 7.0 & 7.223 & TRN \\
\hline CHEMBL1979718 & 809138 & 4.1 & 5.1075 & TRN \\
\hline CHEMBL206236 & 809138 & 4.1 & 5.2153 & TRN \\
\hline CHEMBL1989834 & 809138 & 3.5 & 3.5861 & TRN \\
\hline CHEMBL523823 & 809138 & 5.5 & 4.887 & TST \\
\hline CHEMBL1562756 & 809138 & 4.1 & 4.7697 & TST \\
\hline CHEMBL1987430 & 809138 & 4.4 & 4.1868 & TRN \\
\hline CHEMBL244378 & 809138 & 6.2 & 7.0548 & TRN \\
\hline CHEMBL2001957 & 809138 & 4.1 & 4.0282 & TRN \\
\hline CHEMBL1969372 & 809138 & 4.1 & 4.4205 & TRN \\
\hline CHEMBL1993413 & 809138 & 4.4 & 4.1906 & TRN \\
\hline CHEMBL1990583 & 809138 & 5.2 & 4.8084 & TRN \\
\hline CHEMBL1986943 & 809138 & 7.0 & 7.2429 & TRN \\
\hline CHEMBL289959 & 809138 & 4.1 & 3.8181 & TRN \\
\hline CHEMBL 2006263 & 809138 & 6.1 & 4.8579 & TST \\
\hline
\end{tabular}




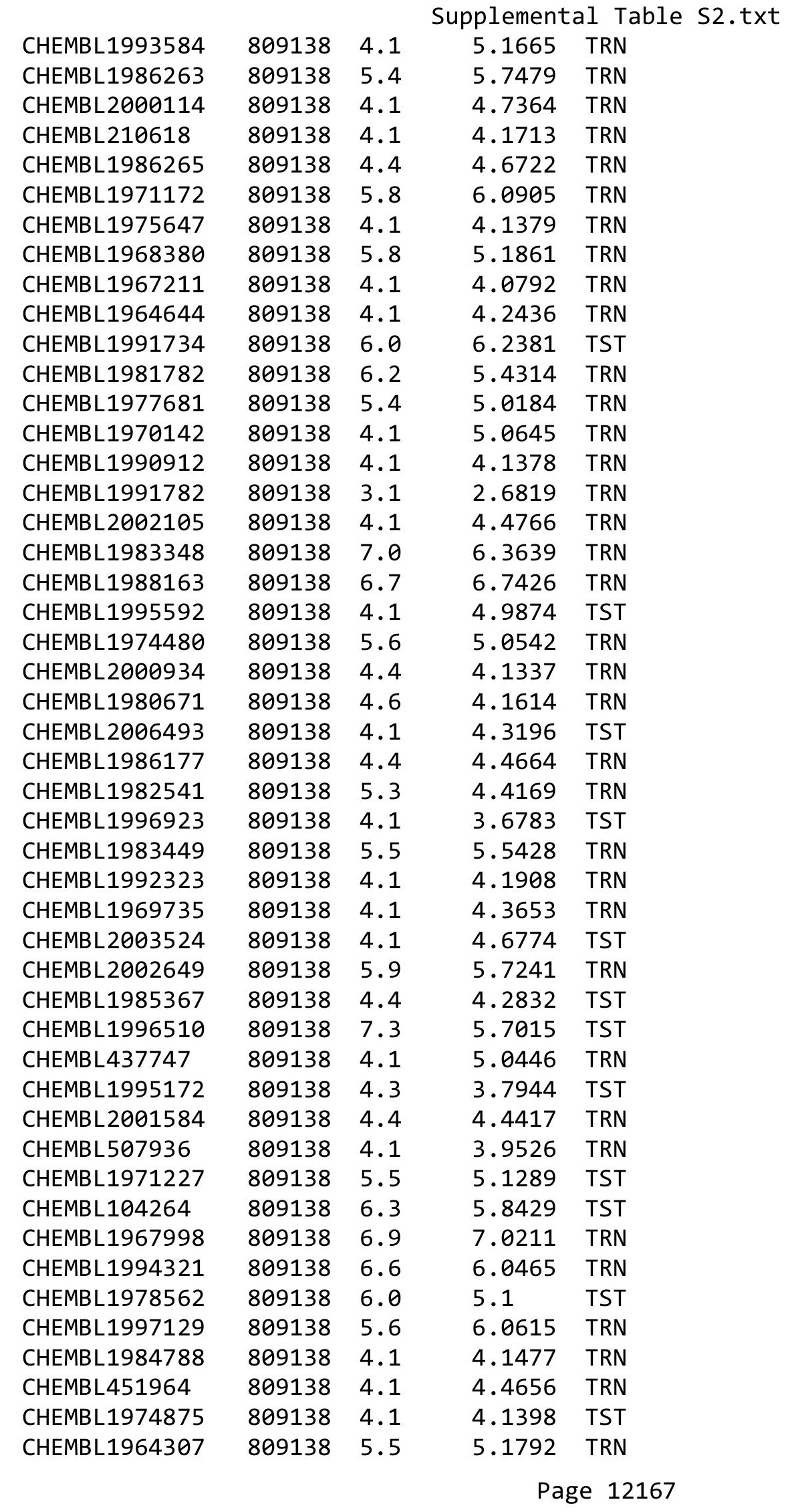




\begin{tabular}{|c|c|c|c|c|c|}
\hline \multicolumn{6}{|c|}{ Supplemental Table S2.txt } \\
\hline CHEMBL1989471 & 809138 & 4.4 & 4.6915 & TST & \\
\hline CHEMBL 2000508 & 809138 & 4.1 & 4.4199 & TRN & \\
\hline CHEMBL1971694 & 809138 & 4.1 & 4.3125 & TST & \\
\hline CHEMBL 2001547 & 809138 & 4.1 & 4.3224 & TRN & \\
\hline CHEMBL210928 & 809138 & 4.1 & 3.8001 & TRN & \\
\hline CHEMBL1978195 & 809138 & 5.5 & 5.6265 & TRN & \\
\hline CHEMBL1994361 & 809138 & 5.2 & 5.356 & TRN & \\
\hline CHEMBL1986603 & 809138 & 4.1 & 3.6733 & TST & \\
\hline CHEMBL1972840 & 809138 & 6.7 & 6.7209 & TRN & \\
\hline CHEMBL1977148 & 809138 & 4.1 & 4.6636 & TRN & \\
\hline CHEMBL1966842 & 809138 & 4.5 & 4.3132 & TRN & \\
\hline CHEMBL 2003286 & 809138 & 4.1 & 4.1484 & TRN & \\
\hline CHEMBL1992306 & 809138 & 4.1 & 4.488 & TRN & \\
\hline CHEMBL 2002165 & 809138 & 6.1 & 5.197 & TRN & \\
\hline CHEMBL 2001668 & 809138 & 4.1 & 4.4143 & TRN & \\
\hline CHEMBL1979318 & 809138 & 4.1 & 4.0115 & TRN & \\
\hline CHEMBL206382 & 809138 & 4.1 & 4.6671 & TRN & \\
\hline CHEMBL1998585 & 809138 & 6.6 & 6.4069 & TRN & \\
\hline CHEMBL127898 & 809138 & 4.1 & 4.832 & TST & \\
\hline CHEMBL519697 & 809138 & 6.4 & 5.6160 & 20000000005 & TRN \\
\hline CHEMBL 2004934 & 809138 & 6.1 & 5.3242 & TRN & \\
\hline CHEMBL1996345 & 809138 & 4.4 & 4.2245 & TST & \\
\hline CHEMBL1975128 & 809138 & 5.6 & 5.3251 & TRN & \\
\hline CHEMBL 2004025 & 809138 & 6.0 & 5.3063 & TST & \\
\hline CHEMBL1996048 & 809138 & 6.1 & 6.0765 & TST & \\
\hline CHEMBL1970369 & 809138 & 4.1 & 3.9119 & TRN & \\
\hline CHEMBL461876 & 809138 & 6.2 & 5.9154 & TST & \\
\hline CHEMBL1965033 & 809138 & 4.4 & 4.6960 & 0000000001 & TRN \\
\hline CHEMBL2001485 & 809138 & 5.9 & 5.0932 & TRN & \\
\hline CHEMBL1971519 & 809138 & 4.7 & 4.4103 & TRN & \\
\hline CHEMBL504950 & 809138 & 4.1 & 4.9309 & TRN & \\
\hline CHEMBL1997335 & 809138 & 5.8 & 5.9098 & TRN & \\
\hline CHEMBL1966425 & 809138 & 5.7 & 6.1732 & TRN & \\
\hline CHEMBL1984363 & 809138 & 5.2 & 5.2029 & 9999999999 & TRN \\
\hline CHEMBL1978099 & 809138 & 5.9 & 5.765 & TRN & \\
\hline CHEMBL1977041 & 809138 & 5.8 & 5.0039 & TRN & \\
\hline CHEMBL1968070 & 809138 & 4.1 & 4.3625 & TRN & \\
\hline CHEMBL1988608 & 809138 & 6.8 & 6.1185 & TRN & \\
\hline CHEMBL184847 & 809138 & 4.1 & 4.8854 & TRN & \\
\hline CHEMBL1984367 & 809138 & 4.1 & 4.9848 & TRN & \\
\hline CHEMBL1985723 & 809138 & 6.1 & 6.5947 & TRN & \\
\hline CHEMBL178737 & 809138 & 5.6 & 4.2647 & TST & \\
\hline CHEMBL226898 & 809138 & 7.8 & 7.3248 & TRN & \\
\hline CHEMBL1982563 & 809138 & 4.1 & 4.3178 & TRN & \\
\hline CHEMBL539474 & 809138 & 6.9 & 4.5852 & TST & \\
\hline CHEMBL575824 & 809138 & 7.9 & 6.647 & TRN & \\
\hline CHEMBL1988387 & 809138 & 6.1 & 5.4387 & TRN & \\
\hline CHEMBL1973868 & 809138 & 4.4 & 4.0104 & TRN & \\
\hline
\end{tabular}




\begin{tabular}{|c|c|c|c|c|}
\hline \multicolumn{5}{|c|}{ plemental I } \\
\hline CHEMBL1972462 & 809138 & 4.4 & 4.1789 & TRN \\
\hline CHEMBL1997759 & 809138 & 4.1 & 4.2625 & TRN \\
\hline CHEMBL1990288 & 809138 & 4.1 & 4.3202 & TRN \\
\hline CHEMBL1989708 & 809138 & 6.7 & 5.4792 & TRN \\
\hline CHEMBL1974803 & 809138 & 5.1 & 4.401 & TRN \\
\hline CHEMBL1970074 & 809138 & 5.6 & 5.6968 & TRN \\
\hline CHEMBL 2002635 & 809138 & 5.1 & 4.4511 & TST \\
\hline CHEMBL1984500 & 809138 & 3.1 & 3.0624 & TRN \\
\hline CHEMBL1986970 & 809138 & 5.7 & 5.4494 & TRN \\
\hline CHEMBL 2005112 & 809138 & 4.1 & 4.6427 & TST \\
\hline CHEMBL1958401 & 809138 & 4.1 & 4.3146 & TRN \\
\hline CHEMBL1984044 & 809138 & 4.1 & 4.3026 & TRN \\
\hline CHEMBL 2003456 & 809138 & 5.2 & 4.3109 & TRN \\
\hline CHEMBL1966816 & 809138 & 5.6 & 4.5664 & TRN \\
\hline CHEMBL 2002992 & 809138 & 5.9 & 5.5966 & TRN \\
\hline CHEMBL560813 & 809138 & 4.1 & 4.921 & TRN \\
\hline CHEMBL207253 & 809138 & 4.1 & 3.8475 & TST \\
\hline CHEMBL1982700 & 809138 & 4.4 & 4.7791 & TST \\
\hline CHEMBL1990635 & 809138 & 5.5 & 5.1835 & TST \\
\hline CHEMBL1968791 & 809138 & 4.1 & 4.5435 & TRN \\
\hline CHEMBL326282 & 809138 & 4.1 & 4.5645 & TST \\
\hline CHEMBL 2002682 & 809138 & 4.1 & 5.2704 & TST \\
\hline CHEMBL1977634 & 809138 & 4.4 & 4.1265 & TRN \\
\hline CHEMBL1992732 & 809138 & 4.1 & 4.7349 & TST \\
\hline CHEMBL1971186 & 809138 & 4.1 & 4.96899 & 9999999999 \\
\hline CHEMBL 2003482 & 809138 & 4.1 & 4.1142 & TRN \\
\hline CHEMBL 2004887 & 809138 & 4.3 & 4.524 & TRN \\
\hline CHEMBL1973211 & 809138 & 6.6 & 6.08 & TRN \\
\hline CHEMBL1984700 & 809138 & 4.1 & 4.3799 & TRN \\
\hline CHEMBL 2007151 & 809138 & 4.1 & 4.4317 & TRN \\
\hline CHEMBL1998953 & 809138 & 4.4 & 4.624 & TRN \\
\hline CHEMBL1971606 & 809138 & 4.4 & 5.1565 & TRN \\
\hline CHEMBL1972125 & 809138 & 5.3 & 5.0405 & TRN \\
\hline CHEMBL1461728 & 809138 & 4.1 & 3.98 & TRN \\
\hline CHEMBL1976134 & 809138 & 5.8 & 5.0162 & TRN \\
\hline CHEMBL1965131 & 809138 & 4.1 & 4.9198 & TRN \\
\hline CHEMBL1995448 & 809138 & 4.1 & 4.5663 & TRN \\
\hline CHEMBL1972158 & 809138 & 5.5 & 4.6476 & TRN \\
\hline CHEMBL1981215 & 809138 & 4.4 & 4.202 & TRN \\
\hline CHEMBL1974457 & 809138 & 4.1 & 4.8203 & TRN \\
\hline CHEMBL 2006580 & 809138 & 5.2 & 4.48 & TRN \\
\hline CHEMBL1999414 & 809138 & 4.7 & 5.6401 & TRN \\
\hline CHEMBL1967336 & 809138 & 4.4 & 4.2105 & TRN \\
\hline CHEMBL 2001228 & 809138 & 4.5 & 3.8569 & TRN \\
\hline CHEMBL 2006581 & 809138 & 4.1 & 3.8397 & TRN \\
\hline CHEMBL 2006481 & 809138 & 4.1 & 3.5929 & TRN \\
\hline CHEMBL1979855 & 809138 & 4.1 & 4.5991 & TRN \\
\hline CHEMBL1970340 & 809138 & 4.7 & 4.2335 & TRN \\
\hline
\end{tabular}

TRN 


\begin{tabular}{|c|c|c|c|c|}
\hline & & & upplement & al Table S \\
\hline CHEMBL1967992 & 809138 & 4.4 & 4.4313 & TRN \\
\hline CHEMBL2005186 & 809138 & 4.1 & 4.6282 & TRN \\
\hline CHEMBL1995927 & 809138 & 4.1 & 4.2176 & TST \\
\hline CHEMBL 2006450 & 809138 & 4.4 & 4.4013 & TRN \\
\hline CHEMBL1975534 & 809138 & 4.1 & 5.0269 & TRN \\
\hline CHEMBL1993424 & 809138 & 5.9 & 6.0283 & TRN \\
\hline CHEMBL1966703 & 809138 & 4.1 & 4.4261 & TST \\
\hline CHEMBL2001987 & 809138 & 4.4 & 4.5168 & TRN \\
\hline CHEMBL1969561 & 809138 & 5.7 & 5.1135 & TRN \\
\hline CHEMBL1994555 & 809138 & 4.4 & 4.609 & TST \\
\hline CHEMBL1983640 & 809138 & 6.3 & 5.4028 & TRN \\
\hline CHEMBL1997023 & 809138 & 5.5 & 4.5591 & TST \\
\hline CHEMBL1964687 & 809138 & 6.7 & 6.5918 & TRN \\
\hline CHEMBL1971943 & 809138 & 4.9 & 5.4128 & TRN \\
\hline CHEMBL1999918 & 809138 & 6.0 & 6.1807 & TRN \\
\hline CHEMBL1974254 & 809138 & 5.5 & 4.9185 & TRN \\
\hline CHEMBL1997924 & 809138 & 7.0 & 6.5483 & TRN \\
\hline CHEMBL1988537 & 809138 & 5.6 & 4.9351 & TST \\
\hline CHEMBL1969049 & 809138 & 5.4 & $5.3210 e$ & 0000000001 \\
\hline CHEMBL2005828 & 809138 & 5.4 & 4.971 & TRN \\
\hline CHEMBL 2002240 & 809138 & 4.1 & 3.8629 & TRN \\
\hline CHEMBL1978267 & 809138 & 4.5 & 3.9573 & TRN \\
\hline CHEMBL1991143 & 809138 & 4.1 & 3.8767 & TST \\
\hline CHEMBL1998611 & 809138 & 4.1 & 4.7768 & TRN \\
\hline CHEMBL485556 & 809138 & 6.0 & 5.3573 & TRN \\
\hline CHEMBL1975900 & 809138 & 6.4 & 6.4262 & TRN \\
\hline CHEMBL 255822 & 809138 & 5.3 & 4.564 & TRN \\
\hline CHEMBL1972221 & 809138 & 4.1 & 4.0851 & TRN \\
\hline CHEMBL2006778 & 809138 & 5.4 & 4.8238 & TRN \\
\hline CHEMBL378627 & 809138 & 5.4 & 4.0399 & TRN \\
\hline CHEMBL1996979 & 809138 & 5.8 & 5.0898 & TRN \\
\hline CHEMBL1997025 & 809138 & 4.1 & 4.3369 & TRN \\
\hline CHEMBL1968406 & 809138 & 7.1 & 6.5417 & TRN \\
\hline CHEMBL1975921 & 809138 & 4.5 & 4.1016 & TRN \\
\hline CHEMBL1982476 & 809138 & 6.3 & 5.285 & TRN \\
\hline CHEMBL1984274 & 809138 & 6.0 & 4.5512 & TST \\
\hline CHEMBL1998545 & 809138 & 4.1 & 4.3619 & TRN \\
\hline CHEMBL1986869 & 809138 & 4.1 & 4.1404 & TRN \\
\hline CHEMBL1975923 & 809138 & 5.8 & 5.0618 & TST \\
\hline CHEMBL2005449 & 809138 & 4.4 & 5.3759 & TRN \\
\hline CHEMBL1987998 & 809138 & 4.4 & 4.2108 & TRN \\
\hline CHEMBL 2006010 & 809138 & 5.7 & 4.5494 & TRN \\
\hline CHEMBL1682558 & 809138 & 4.1 & 4.0628 & TRN \\
\hline CHEMBL1971534 & 809138 & 4.6 & 4.7425 & TRN \\
\hline CHEMBL1990496 & 809138 & 4.3 & 4.6673 & TRN \\
\hline CHEMBL 242865 & 809138 & 6.1 & 5.9429 & TRN \\
\hline CHEMBL1997623 & 809138 & 5.3 & 4.2605 & TRN \\
\hline CHEMBL2002479 & 809138 & 5.2 & 6.1237 & TRN \\
\hline
\end{tabular}




\begin{tabular}{|c|c|c|c|c|c|}
\hline \multirow[b]{2}{*}{ CHEMBL1993166 } & \multirow[b]{2}{*}{809138} & \\
\hline & & 6.1 & 5.8946 & TRN & \\
\hline CHEMBL1967094 & 809138 & 5.3 & 4.8475 & TRN & \\
\hline CHEMBL1966035 & 809138 & 4.1 & 4.4191 & TRN & \\
\hline CHEMBL2003341 & 809138 & 4.1 & 4.9305 & TRN & \\
\hline CHEMBL1992644 & 809138 & 5.4 & 4.3499 & TRN & \\
\hline CHEMBL1992645 & 809138 & 4.1 & \multicolumn{2}{|c|}{4.4910000000000005} & TST \\
\hline CHEMBL1982992 & 809138 & 4.1 & 4.7432 & TRN & \\
\hline CHEMBL1998110 & 809138 & 4.4 & 4.7994 & TRN & \\
\hline CHEMBL1999590 & 809138 & 4.1 & 3.9845 & TST & \\
\hline CHEMBL1981079 & 809138 & 6.5 & 5.4492 & TRN & \\
\hline CHEMBL1978166 & 809138 & 6.5 & \multicolumn{2}{|c|}{7.172999999999999} & TRN \\
\hline CHEMBL1972276 & 809138 & 5.4 & 4.461 & TRN & \\
\hline CHEMBL1980489 & 809138 & 6.0 & 5.8833 & TRN & \\
\hline CHEMBL 2000832 & 809138 & 5.9 & 6.0843 & TRN & \\
\hline CHEMBL1967116 & 809138 & 4.1 & 5.4199 & TRN & \\
\hline CHEMBL1990590 & 809138 & 4.4 & 4.3486 & TRN & \\
\hline CHEMBL1977814 & 809138 & 4.3 & 4.0151 & TST & \\
\hline CHEMBL513846 & 809138 & 4.1 & 4.6525 & TRN & \\
\hline CHEMBL1970709 & 809138 & 4.1 & 4.9142 & TRN & \\
\hline CHEMBL1974617 & 809138 & 4.6 & 4.3859 & TRN & \\
\hline CHEMBL1965660 & 809138 & 7.3 & 5.7849 & TRN & \\
\hline CHEMBL1992125 & 809138 & 5.6 & 5.8818 & TRN & \\
\hline CHEMBL1998112 & 809138 & 5.6 & 3.8915 & TRN & \\
\hline CHEMBL1969126 & 809138 & 4.1 & 4.2353 & TRN & \\
\hline CHEMBL1980896 & 809138 & 4.1 & 4.6119 & TRN & \\
\hline CHEMBL1975208 & 809138 & 4.1 & 4.0028 & TST & \\
\hline CHEMBL1970104 & 809138 & 6.1 & \multicolumn{2}{|c|}{6.0329999999999995} & TRN \\
\hline CHEMBL1991429 & 809138 & 4.1 & 4.5633 & TRN & \\
\hline CHEMBL1964777 & 809138 & 5.8 & 5.2051 & TRN & \\
\hline CHEMBL1971149 & 809138 & 4.1 & 4.2974 & TRN & \\
\hline CHEMBL1999714 & 809138 & 4.1 & 3.8176 & TRN & \\
\hline CHEMBL1987533 & 809138 & 4.1 & 4.1314 & TRN & \\
\hline CHEMBL1994040 & 809138 & 4.1 & 4.34 & TRN & \\
\hline CHEMBL388978 & 809138 & 8.8 & 9.0063 & TST & \\
\hline CHEMBL579246 & 809138 & 8.0 & \multicolumn{2}{|c|}{6.553999999999999} & TRN \\
\hline CHEMBL398951 & 809138 & 6.1 & 4.8622 & TST & \\
\hline CHEMBL1982506 & 809138 & 4.1 & 4.4797 & TST & \\
\hline CHEMBL2004716 & 809138 & 4.7 & 6.1826 & TRN & \\
\hline CHEMBL1968127 & 809138 & 4.1 & 4.383 & TRN & \\
\hline CHEMBL1975233 & 809138 & 5.7 & 5.5792 & TRN & \\
\hline CHEMBL1985406 & 809138 & 4.1 & 4.4738 & TRN & \\
\hline CHEMBL2007603 & 809138 & 4.4 & 4.2059 & TRN & \\
\hline CHEMBL207400 & 809138 & 4.1 & 3.852 & TST & \\
\hline CHEMBL 2000894 & 809138 & 5.6 & 5.4352 & TST & \\
\hline CHEMBL1421720 & 809138 & 5.9 & 5.6064 & TRN & \\
\hline CHEMBL1968130 & 809138 & 4.3 & 4.2921 & TRN & \\
\hline CHEMBL1982135 & 809138 & 4.1 & 4.6576 & TRN & \\
\hline \multirow[t]{2}{*}{ CHEMBL1976090 } & 809138 & 5.6 & 5.3638 & TRN & \\
\hline & & \multicolumn{4}{|c|}{ Page 12171} \\
\hline
\end{tabular}




\begin{tabular}{|c|c|c|c|c|c|}
\hline \multicolumn{6}{|c|}{ Supplemental Table S2.txt } \\
\hline CHEMBL1993243 & 809138 & 4.1 & 4.7495 & TRN & \\
\hline CHEMBL 2004771 & 809138 & 4.1 & 4.9961 & TRN & \\
\hline CHEMBL1992922 & 809138 & 4.1 & 5.4109 & TRN & \\
\hline CHEMBL399021 & 809138 & 4.1 & 4.3831 & TRN & \\
\hline CHEMBL1997597 & 809138 & 4.1 & 4.2119 & TRN & \\
\hline CHEMBL1969537 & 809138 & 6.7 & 5.4627 & TST & \\
\hline CHEMBL1976093 & 809138 & 4.1 & 4.2397 & TRN & \\
\hline CHEMBL 210032 & 809138 & 4.1 & 3.9125 & TRN & \\
\hline CHEMBL1996543 & 809138 & 6.4 & \multicolumn{2}{|c|}{5.5120000000000005} & TRN \\
\hline CHEMBL1975256 & 809138 & 4.1 & 4.5387 & TST & \\
\hline CHEMBL508928 & 809138 & 4.2 & 4.1689 & TRN & \\
\hline CHEMBL1991356 & 809138 & 4.1 & 3.8074 & TST & \\
\hline CHEMBL1983309 & 809138 & 4.1 & 4.3696 & TRN & \\
\hline CHEMBL2004892 & 809138 & 4.1 & 4.0885 & TRN & \\
\hline CHEMBL1949855 & 809138 & 4.5 & 4.4869 & TRN & \\
\hline CHEMBL1999126 & 809138 & 4.1 & 4.5223 & TST & \\
\hline CHEMBL1997503 & 809138 & 4.1 & 4.0186 & TST & \\
\hline CHEMBL116070 & 809138 & 5.6 & 5.0684 & TRN & \\
\hline CHEMBL1990821 & 809138 & 4.1 & 4.3695 & TST & \\
\hline CHEMBL1970314 & 809138 & 4.1 & 4.141 & TRN & \\
\hline CHEMBL 2004871 & 809138 & 4.1 & 4.1019 & TRN & \\
\hline CHEMBL 2004872 & 809138 & 4.1 & 4.9549 & TRN & \\
\hline CHEMBL1727312 & 809138 & 4.1 & \multicolumn{2}{|c|}{3.5860000000000003} & TRN \\
\hline CHEMBL1990223 & 809138 & 4.4 & 4.3541 & TRN & \\
\hline CHEMBL1969879 & 809138 & 4.1 & 4.5242 & TRN & \\
\hline CHEMBL1964382 & 809138 & 6.8 & 4.8204 & TST & \\
\hline CHEMBL101311 & 809138 & 4.4 & 5.0536 & TRN & \\
\hline CHEMBL1981720 & 809138 & 4.1 & 4.7872 & TRN & \\
\hline CHEMBL419932 & 809138 & 5.9 & 5.6684 & TRN & \\
\hline CHEMBL 262433 & 809138 & 5.2 & 5.555 & TRN & \\
\hline CHEMBL 306380 & 809138 & 6.8 & \multicolumn{2}{|c|}{4.781000000000001} & TRN \\
\hline CHEMBL1966722 & 809138 & 6.2 & 5.3242 & TST & \\
\hline CHEMBL1988581 & 809138 & 6.9 & 6.8425 & TST & \\
\hline CHEMBL2005699 & 809138 & 4.4 & 3.9262 & TRN & \\
\hline CHEMBL1975500 & 809138 & 4.1 & 5.1828 & TRN & \\
\hline CHEMBL1976328 & 809138 & 5.8 & 5.216 & TRN & \\
\hline CHEMBL394619 & 809138 & 5.9 & 6.1134 & TRN & \\
\hline CHEMBL 2006564 & 809138 & 7.0 & 6.7742 & TRN & \\
\hline CHEMBL1964399 & 809138 & 4.1 & 5.1047 & TRN & \\
\hline CHEMBL1996831 & 809138 & 5.1 & 4.4443 & TST & \\
\hline CHEMBL411903 & 809138 & 5.5 & 5.9182 & TRN & \\
\hline CHEMBL1980253 & 809138 & 4.6 & 6.2627 & TRN & \\
\hline CHEMBL1978167 & 809138 & 4.4 & 4.6424 & TST & \\
\hline CHEMBL1965988 & 809138 & 6.2 & 6.6035 & TRN & \\
\hline CHEMBL418203 & 809138 & 5.9 & 5.0317 & TST & \\
\hline CHEMBL1989646 & 809138 & 5.4 & 4.7091 & TRN & \\
\hline CHEMBL1682357 & 809138 & 4.1 & 4.3829 & TRN & \\
\hline CHEMBL225519 & 809138 & 5.7 & 5.0738 & TRN & \\
\hline
\end{tabular}




\begin{tabular}{|c|c|c|c|c|}
\hline \multicolumn{5}{|c|}{ Supplemental Table S2.txt } \\
\hline CHEMBL209534 & 809138 & 4.1 & 3.8289 & TRN \\
\hline CHEMBL1978200 & 809138 & 4.1 & 4.5159 & TRN \\
\hline CHEMBL1994159 & 809138 & 4.2 & 4.1719 & TRN \\
\hline CHEMBL1970522 & 809138 & 4.1 & 4.2609 & TRN \\
\hline CHEMBL1990415 & 809138 & 4.1 & 4.0448 & TRN \\
\hline CHEMBL1966087 & 809138 & 4.1 & 4.3613 & TRN \\
\hline CHEMBL1964692 & 809138 & 6.9 & 6.1044 & TRN \\
\hline CHEMBL1996931 & 809138 & 4.1 & 4.5584 & TRN \\
\hline CHEMBL1964413 & 809138 & 4.1 & 4.5774 & TRN \\
\hline CHEMBL1973483 & 809138 & 4.1 & 4.3839 & TRN \\
\hline CHEMBL1998470 & 809138 & 5.5 & 4.4863 & TRN \\
\hline CHEMBL1984432 & 809138 & 4.1 & 4.7561 & TRN \\
\hline CHEMBL1970735 & 809138 & 4.1 & 4.0772 & TRN \\
\hline CHEMBL219722 & 809138 & 5.3 & 4.7758 & TRN \\
\hline CHEMBL1975903 & 809138 & 4.4 & 4.3177 & TRN \\
\hline CHEMBL1994669 & 809138 & 9.0 & 8.0167 & TRN \\
\hline CHEMBL1997340 & 809138 & 4.1 & 3.8825 & TRN \\
\hline CHEMBL 2004365 & 809138 & 5.2 & 4.6353 & TST \\
\hline CHEMBL1522508 & 809138 & 3.4 & 3.3417 & TRN \\
\hline CHEMBL1989474 & 809138 & 4.1 & 4.0764 & TRN \\
\hline CHEMBL1090360 & 809138 & 4.1 & 4.1589 & TRN \\
\hline CHEMBL210887 & 809138 & 4.1 & 4.7804 & TRN \\
\hline CHEMBL1988805 & 809138 & 4.4 & 4.5582 & TST \\
\hline CHEMBL458997 & 809138 & 6.3 & 5.3873 & TRN \\
\hline CHEMBL1971021 & 809138 & 4.1 & 4.7318 & TRN \\
\hline CHEMBL227271 & 809138 & 8.1 & 7.3847 & TRN \\
\hline CHEMBL583144 & 809138 & 4.1 & 4.7735 & TRN \\
\hline CHEMBL1974310 & 809138 & 5.6 & 5.4545 & TRN \\
\hline CHEMBL1969942 & 809138 & 4.4 & 4.3156 & TRN \\
\hline CHEMBL1978567 & 809138 & 4.4 & 4.7994 & TRN \\
\hline CHEMBL1982660 & 809138 & 4.4 & 4.2884 & TRN \\
\hline CHEMBL1994693 & 809138 & 5.6 & 5.3241 & TRN \\
\hline CHEMBL1982957 & 809138 & 6.0 & 5.5454 & TRN \\
\hline CHEMBL1725279 & 809138 & 6.4 & 5.5797 & TST \\
\hline CHEMBL1975138 & 809138 & 5.6 & 4.9849 & TST \\
\hline CHEMBL424872 & 809138 & 4.4 & 3.7186 & TRN \\
\hline CHEMBL 2006836 & 809138 & 4.1 & 4.2117 & TST \\
\hline CHEMBL1971947 & 809138 & 6.0 & 6.1028 & TRN \\
\hline CHEMBL412142 & 809138 & 4.1 & 4.9868 & TST \\
\hline CHEMBL1980704 & 809138 & 5.7 & 4.5533 & TST \\
\hline CHEMBL 2003271 & 809138 & 5.2 & 5.2378 & TRN \\
\hline CHEMBL1966808 & 809138 & 4.1 & 3.9801 & TRN \\
\hline CHEMBL 2004447 & 809138 & 4.1 & 4.0687 & TRN \\
\hline CHEMBL1983111 & 809138 & 8.0 & 7.1192 & TRN \\
\hline CHEMBL1973860 & 809138 & 4.1 & 3.8287 & TRN \\
\hline CHEMBL260135 & 809138 & 4.1 & 4.3693 & TRN \\
\hline CHEMBL220241 & 809138 & 7.4 & 5.8546 & TRN \\
\hline CHEMBL 2004544 & 809138 & 5.3 & 4.25 & TST \\
\hline
\end{tabular}




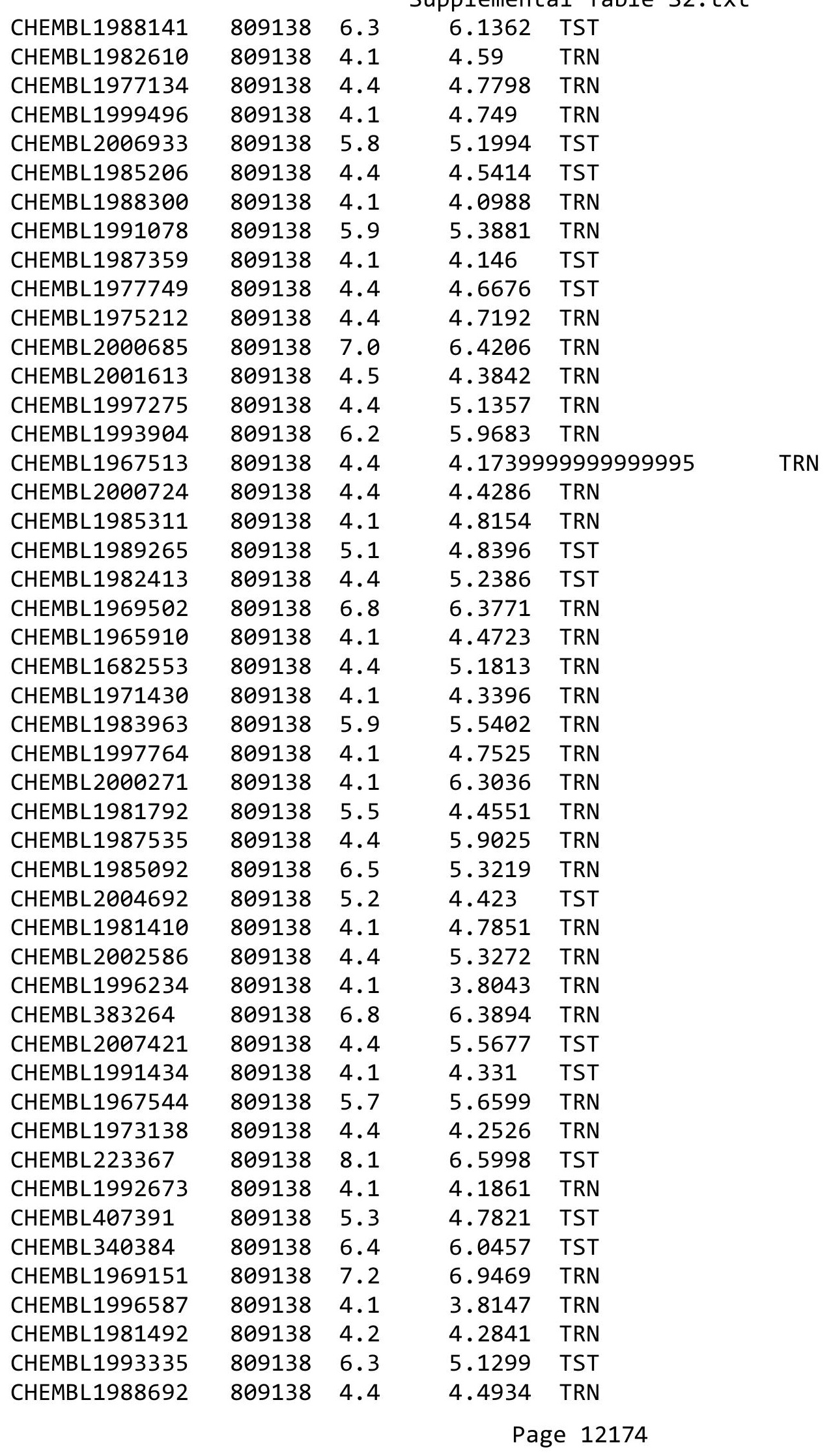




\begin{tabular}{|c|c|c|c|c|}
\hline & & & ipplement & al $\mathrm{T}$ \\
\hline CHEMBL 2007574 & 809138 & 6.1 & 6.4167 & TRN \\
\hline CHEMBL1964804 & 809138 & 5.2 & 5.159 & TRN \\
\hline CHEMBL443962 & 809138 & 4.1 & 3.6003 & TST \\
\hline CHEMBL 2000354 & 809138 & 5.5 & 4.5536 & TRN \\
\hline CHEMBL1965507 & 809138 & 4.5 & 4.3536 & TRN \\
\hline CHEMBL274064 & 809138 & 4.1 & 4.5746 & TRN \\
\hline CHEMBL1998680 & 809138 & 4.4 & 4.0489 & TRN \\
\hline CHEMBL1967564 & 809138 & 4.1 & 3.5209 & TRN \\
\hline CHEMBL592030 & 809138 & 6.0 & 5.604 & TST \\
\hline CHEMBL 2000071 & 809138 & 4.4 & 5.0439 & TRN \\
\hline CHEMBL1979176 & 809138 & 4.1 & 4.0985 & TRN \\
\hline CHEMBL1970317 & 809138 & 4.4 & 4.6723 & TRN \\
\hline CHEMBL 2002613 & 809138 & 4.6 & 4.7827 & TRN \\
\hline CHEMBL 2000408 & 809138 & 4.1 & 4.3862 & TRN \\
\hline CHEMBL248757 & 809138 & 4.1 & 5.4411 & TST \\
\hline CHEMBL1978014 & 809138 & 4.1 & 4.3158 & TRN \\
\hline CHEMBL1997007 & 809138 & 5.7 & 5.6833 & TRN \\
\hline CHEMBL1994538 & 809138 & 4.1 & 4.0051 & TRN \\
\hline CHEMBL1983195 & 809138 & 5.2 & 4.4938 & TST \\
\hline CHEMBL1975490 & 809138 & 6.5 & 6.0552 & TRN \\
\hline CHEMBL1964444 & 809138 & 4.3 & 3.9571 & TRN \\
\hline CHEMBL 2002690 & 809138 & 4.4 & 4.4005 & TRN \\
\hline CHEMBL 2006567 & 809138 & 4.1 & 3.9605 & TRN \\
\hline CHEMBL1986139 & 809138 & 4.1 & 4.1674 & TRN \\
\hline CHEMBL383527 & 809138 & 5.2 & 4.8018 & TRN \\
\hline CHEMBL1980540 & 809138 & 4.1 & 4.1017 & TRN \\
\hline CHEMBL 278041 & 809138 & 4.4 & 4.6373 & TRN \\
\hline CHEMBL1979883 & 809138 & 6.4 & 5.9441 & TRN \\
\hline CHEMBL1984162 & 809138 & 6.8 & 5.8225 & TRN \\
\hline CHEMBL1997051 & 809138 & 4.5 & 4.4826 & TRN \\
\hline CHEMBL1998432 & 809138 & 6.4 & 7.0173 & TRN \\
\hline CHEMBL491758 & 809138 & 5.7 & 5.3389 & TRN \\
\hline CHEMBL1986590 & 809138 & 5.8 & 5.2153 & TRN \\
\hline CHEMBL549730 & 809138 & 4.3 & 4.4637 & TRN \\
\hline CHEMBL1682360 & 809138 & 5.2 & 4.2201 & TRN \\
\hline CHEMBL1970189 & 809138 & 4.1 & 3.9141 & TRN \\
\hline CHEMBL1870106 & 809138 & 7.4 & 6.0626 & TRN \\
\hline CHEMBL1996791 & 809138 & 4.1 & 4.5842 & TRN \\
\hline CHEMBL371206 & 809138 & 6.2 & 5.8666 & TRN \\
\hline CHEMBL1974664 & 809138 & 6.4 & 4.0638 & TST \\
\hline CHEMBL406845 & 809138 & 4.4 & 4.4261 & TRN \\
\hline CHEMBL482538 & 809138 & 5.2 & 4.8607 & TRN \\
\hline CHEMBL1974288 & 809138 & 5.8 & 5.069 & TRN \\
\hline CHEMBL1984296 & 809138 & 5.5 & 5.0707 & TST \\
\hline CHEMBL196363 & 809138 & 6.1 & 5.6286 & TRN \\
\hline CHEMBL1190711 & 809138 & 4.1 & 4.1224 & TRN \\
\hline CHEMBL1990346 & 809138 & 4.1 & 4.4613 & TRN \\
\hline CHEMBL1968705 & 809138 & 4.7 & 4.8074 & TRN \\
\hline
\end{tabular}




\begin{tabular}{|c|c|c|c|c|c|}
\hline & & & & & \\
\hline CHEMBL1991410 & 809138 & 4.4 & 4.1927 & TRN & \\
\hline CHEMBL1964441 & 809138 & 6.1 & 5.8436 & TRN & \\
\hline CHEMBL546797 & 809138 & 4.4 & 4.5502 & TRN & \\
\hline CHEMBL404367 & 809138 & 5.5 & 5.4983 & TRN & \\
\hline CHEMBL1966343 & 809138 & 4.1 & 4.2844 & TRN & \\
\hline CHEMBL1978271 & 809138 & 4.4 & 4.6439 & TRN & \\
\hline CHEMBL1967887 & 809138 & 5.3 & 5.2079 & TRN & \\
\hline CHEMBL 2007266 & 809138 & 4.4 & 4.8113 & TRN & \\
\hline CHEMBL 2000568 & 809138 & 4.3 & 4.2189 & TRN & \\
\hline CHEMBL1994308 & 809138 & 4.4 & 4.329 & TRN & \\
\hline CHEMBL 2000335 & 809138 & 6.9 & 6.394 & TRN & \\
\hline CHEMBL1977604 & 809138 & 4.1 & 4.5699 & TST & \\
\hline CHEMBL 2007097 & 809138 & 4.1 & 4.1963 & TRN & \\
\hline CHEMBL1988717 & 809138 & 4.1 & 4.7789 & TRN & \\
\hline CHEMBL1974328 & 809138 & 6.4 & 7.3974 & TST & \\
\hline CHEMBL509032 & 809138 & 8.0 & 7.1133 & TRN & \\
\hline CHEMBL243298 & 809138 & 6.9 & 6.099 & TRN & \\
\hline CHEMBL1973808 & 809138 & 4.1 & 4.2046 & TRN & \\
\hline CHEMBL 2000429 & 809138 & 4.1 & 4.2238 & TRN & \\
\hline CHEMBL1972576 & 809138 & 6.1 & 4.3124 & TRN & \\
\hline CHEMBL1992555 & 809138 & 4.1 & 4.2332 & TRN & \\
\hline CHEMBL1992342 & 809138 & 4.1 & 4.508 & TRN & \\
\hline CHEMBL1988173 & 809138 & 6.4 & 5.093 & TST & \\
\hline CHEMBL1973013 & 809138 & 5.9 & 5.2179 & TST & \\
\hline CHEMBL1164265 & 809138 & 4.6 & 4.957 & TST & \\
\hline CHEMBL535331 & 809138 & 4.1 & 4.0482 & TRN & \\
\hline CHEMBL1989805 & 809138 & 4.1 & 4.7597 & TST & \\
\hline CHEMBL1982980 & 809138 & 4.1 & 4.3613 & TST & \\
\hline CHEMBL1965423 & 809138 & 4.1 & $4.1080 e$ & 00000000005 & TRN \\
\hline CHEMBL1983025 & 809138 & 6.3 & 6.3609 & TRN & \\
\hline CHEMBL1975927 & 809138 & 6.1 & 5.6517 & TRN & \\
\hline CHEMBL 205415 & 809138 & 5.8 & 5.6787 & TRN & \\
\hline CHEMBL1977135 & 809138 & 4.1 & 4.7987 & TRN & \\
\hline CHEMBL 2001920 & 809138 & 4.1 & 5.14 & TRN & \\
\hline CHEMBL 2002322 & 809138 & 4.1 & 4.814 & TRN & \\
\hline CHEMBL1997119 & 809138 & 4.4 & 4.3652 & TRN & \\
\hline CHEMBL1977138 & 809138 & 5.9 & 6.3704 & TST & \\
\hline CHEMBL 2002323 & 809138 & 4.1 & 3.9643 & TST & \\
\hline CHEMBL1241473 & 809138 & 7.3 & 7.7207 & TRN & \\
\hline CHEMBL 2000879 & 809138 & 4.3 & 4.1094 & TST & \\
\hline CHEMBL1978448 & 809138 & 4.7 & 4.0234 & TST & \\
\hline CHEMBL1972258 & 809138 & 4.1 & 4.7217 & TRN & \\
\hline CHEMBL 2004513 & 809138 & 4.1 & 4.2335 & TRN & \\
\hline CHEMBL1969483 & 809138 & 4.5 & 4.0318 & TRN & \\
\hline CHEMBL1980329 & 809138 & 7.5 & 6.6107 & TRN & \\
\hline CHEMBL 2004515 & 809138 & 5.4 & 5.3682 & TRN & \\
\hline CHEMBL 2001257 & 809138 & 4.8 & $5.6560 e$ & 0000000001 & TRN \\
\hline CHEMBL1992042 & 809138 & 4.4 & 5.4073 & TST & \\
\hline & & & & 12176 & \\
\hline
\end{tabular}




\begin{tabular}{|c|c|c|c|c|}
\hline & & & pplement & al $\mathrm{Ta}$ \\
\hline CHEMBL 2005548 & 809138 & 6.5 & 5.0253 & TRN \\
\hline CHEMBL1987793 & 809138 & 4.1 & 4.8388 & TST \\
\hline CHEMBL1992536 & 809138 & 4.1 & 4.4954 & TRN \\
\hline CHEMBL21156 & 809138 & 6.4 & 6.1678 & TST \\
\hline CHEMBL1992740 & 809138 & 4.1 & 4.324 & TRN \\
\hline CHEMBL1994724 & 809138 & 5.8 & 5.6331 & TRN \\
\hline CHEMBL1989267 & 809138 & 5.7 & 5.4431 & TRN \\
\hline CHEMBL 2002373 & 809138 & 4.1 & 4.1769 & TRN \\
\hline CHEMBL439340 & 809138 & 4.1 & 4.6046 & TRN \\
\hline CHEMBL 2006188 & 809138 & 5.3 & 5.2722 & TRN \\
\hline CHEMBL1970290 & 809138 & 5.9 & 6.1107 & TRN \\
\hline CHEMBL1967531 & 809138 & 5.5 & 5.2458 & TRN \\
\hline CHEMBL1970913 & 809138 & 4.1 & 3.6601 & TRN \\
\hline CHEMBL1973893 & 809138 & 4.1 & 4.2114 & TRN \\
\hline CHEMBL1995736 & 809138 & 4.1 & 4.2697 & TRN \\
\hline CHEMBL1997534 & 809138 & 4.1 & 5.6522 & TRN \\
\hline CHEMBL1993877 & 809138 & 5.8 & 5.2495 & TRN \\
\hline CHEMBL1985095 & 809138 & 5.3 & 5.3622 & TST \\
\hline CHEMBL1996500 & 809138 & 4.4 & 4.2355 & TRN \\
\hline CHEMBL1998551 & 809138 & 4.1 & 3.764 & TRN \\
\hline CHEMBL1977374 & 809138 & 4.1 & 3.7184 & TRN \\
\hline CHEMBL1991180 & 809138 & 7.0 & 5.9665 & TST \\
\hline CHEMBL1682540 & 809138 & 5.2 & 4.8767 & TRN \\
\hline CHEMBL1978656 & 809138 & 4.1 & 4.2819 & TRN \\
\hline CHEMBL1976420 & 809138 & 4.3 & 4.6801 & TST \\
\hline CHEMBL1998253 & 809138 & 4.4 & 4.1877 & TST \\
\hline CHEMBL413779 & 809138 & 8.1 & 6.4802 & TST \\
\hline CHEMBL1994864 & 809138 & 5.6 & 5.5845 & TRN \\
\hline CHEMBL1981744 & 809138 & 4.4 & 4.4517 & TRN \\
\hline CHEMBL 2002446 & 809138 & 5.9 & 5.3365 & TST \\
\hline CHEMBL497151 & 809138 & 5.4 & 5.2836 & TRN \\
\hline CHEMBL 2000029 & 809138 & 5.5 & 5.0204 & TRN \\
\hline CHEMBL1973961 & 809138 & 4.5 & 4.0398 & TRN \\
\hline CHEMBL 246970 & 809138 & 6.9 & 5.8395 & TRN \\
\hline CHEMBL340921 & 809138 & 5.3 & 5.2008 & TST \\
\hline CHEMBL1994977 & 809138 & 4.4 & 4.5799 & TRN \\
\hline CHEMBL 373598 & 809138 & 7.9 & 6.3004 & TST \\
\hline CHEMBL 2001149 & 809138 & 5.6 & 4.9357 & TRN \\
\hline CHEMBL1999718 & 809138 & 4.1 & 4.1726 & TRN \\
\hline CHEMBL 2000078 & 809138 & 4.5 & 4.0182 & TRN \\
\hline CHEMBL1276446 & 809138 & 7.4 & 7.1351 & TST \\
\hline CHEMBL 2005478 & 809138 & 5.9 & 4.8853 & TST \\
\hline CHEMBL1996646 & 809138 & 6.7 & 5.7443 & TRN \\
\hline CHEMBL1979773 & 809138 & 4.4 & 4.4679 & TRN \\
\hline CHEMBL1977346 & 809138 & 4.1 & 4.0839 & TRN \\
\hline CHEMBL 2003657 & 809138 & 4.1 & 4.0143 & TRN \\
\hline CHEMBL1971649 & 809138 & 4.1 & 3.715 & TRN \\
\hline CHEMBL 2005482 & 809138 & 4.5 & 4.1241 & TRN \\
\hline
\end{tabular}




\begin{tabular}{|c|c|c|c|c|c|}
\hline \\
\hline CHEMBL1996702 & 809138 & 4.4 & 5.2685 & TRN & \\
\hline CHEMBL1997909 & 809138 & 4.5 & 4.0727 & TRN & \\
\hline CHEMBL 2007124 & 809138 & 4.4 & 4.7979 & TRN & \\
\hline CHEMBL1998435 & 809138 & 4.1 & 3.912 & TRN & \\
\hline CHEMBL 2006439 & 809138 & 4.7 & 5.0341 & TRN & \\
\hline CHEMBL2006156 & 809138 & 4.1 & 4.1114 & TST & \\
\hline CHEMBL1985681 & 809138 & 6.8 & 5.5587 & TST & \\
\hline CHEMBL1969190 & 809138 & 5.5 & 5.2966 & TRN & \\
\hline CHEMBL1949851 & 809138 & 5.3 & 4.3505 & TRN & \\
\hline CHEMBL1973937 & 809138 & 5.5 & 5.8673 & TRN & \\
\hline CHEMBL1991674 & 809138 & 7.1 & 7.3544 & TRN & \\
\hline CHEMBL1982711 & 809138 & 5.8 & 6.1468 & TRN & \\
\hline CHEMBL262623 & 809138 & 5.0 & 4.3022 & TRN & \\
\hline CHEMBL1987982 & 809138 & 4.1 & 4.3328 & TST & \\
\hline CHEMBL1984842 & 809138 & 4.3 & 3.8725 & TRN & \\
\hline CHEMBL1969102 & 809138 & 6.4 & 5.4422 & TRN & \\
\hline CHEMBL2004118 & 809138 & 5.8 & 5.6029 & TRN & \\
\hline CHEMBL1682346 & 809138 & 5.6 & 4.79899 & 99999999995 & TRN \\
\hline CHEMBL 2007044 & 809138 & 6.4 & 5.2506 & TST & \\
\hline CHEMBL 2001998 & 809138 & 4.1 & 4.7136 & TST & \\
\hline CHEMBL1994241 & 809138 & 6.1 & 5.6049 & TRN & \\
\hline CHEMBL223460 & 809138 & 7.6 & 5.7807 & TST & \\
\hline CHEMBL1998829 & 809138 & 4.1 & 4.1715 & TRN & \\
\hline CHEMBL50894 & 809138 & 4.3 & 4.6226 & TRN & \\
\hline CHEMBL1995211 & 809138 & 5.5 & 5.4892 & TRN & \\
\hline CHEMBL1988838 & 809138 & 6.4 & 6.5087 & TRN & \\
\hline CHEMBL1981725 & 809138 & 5.2 & 4.68 & TRN & \\
\hline CHEMBL1982753 & 809138 & 4.4 & 5.9145 & TST & \\
\hline CHEMBL375284 & 809138 & 5.8 & 4.8554 & TRN & \\
\hline CHEMBL 2006299 & 809138 & 4.4 & 5.0385 & TRN & \\
\hline CHEMBL1972346 & 809138 & 5.8 & 5.6409 & TST & \\
\hline CHEMBL1965169 & 809138 & 4.4 & 4.16100 & 00000000005 & TST \\
\hline CHEMBL1081312 & 809138 & 4.7 & 5.6025 & TRN & \\
\hline CHEMBL1965170 & 809138 & 4.4 & 5.0536 & TRN & \\
\hline CHEMBL1982866 & 809138 & 4.1 & 4.0311 & TRN & \\
\hline CHEMBL 2005792 & 809138 & 4.3 & 3.9811 & TRN & \\
\hline CHEMBL1968926 & 809138 & 4.1 & 3.9105 & TRN & \\
\hline CHEMBL365617 & 809138 & 5.5 & 4.9164 & TRN & \\
\hline CHEMBL1984206 & 809138 & 4.1 & 3.9333 & TRN & \\
\hline CHEMBL462120 & 809138 & 4.1 & 4.0612 & TRN & \\
\hline CHEMBL1991577 & 809138 & 4.1 & 4.6089 & TRN & \\
\hline CHEMBL1986503 & 809138 & 4.4 & 4.3758 & TST & \\
\hline CHEMBL 2007592 & 809138 & 4.1 & 3.8167 & TRN & \\
\hline CHEMBL1965570 & 809138 & 5.5 & 4.9854 & TRN & \\
\hline CHEMBL1972355 & 809138 & 6.1 & 6.1313 & TST & \\
\hline CHEMBL1997892 & 809138 & 4.4 & 4.6493 & TRN & \\
\hline CHEMBL 2001641 & 809138 & 4.4 & 4.077 & TRN & \\
\hline CHEMBL1997193 & 809138 & 6.2 & 5.2134 & TST & \\
\hline & & & & 12178 & \\
\hline
\end{tabular}




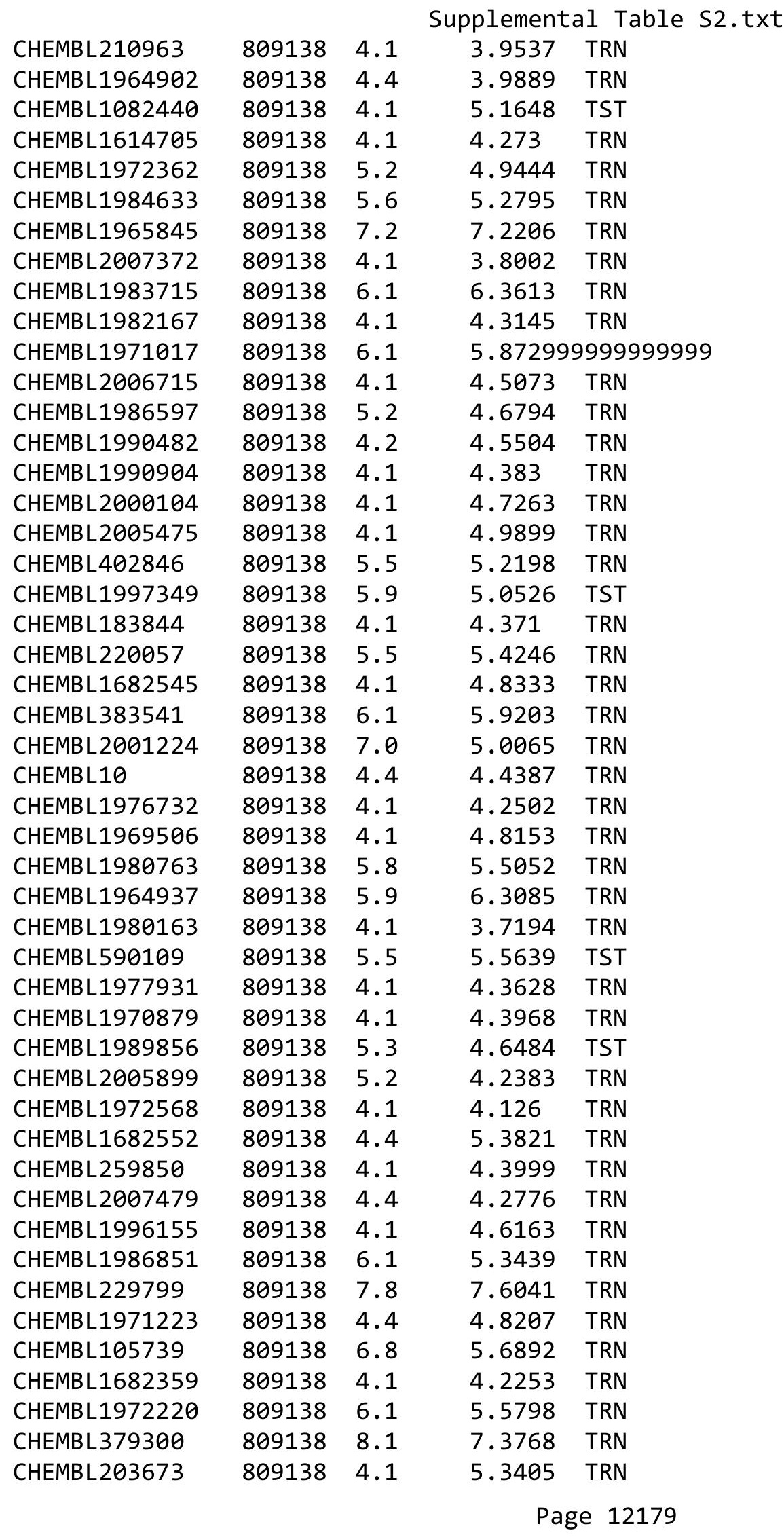

TRN 


\begin{tabular}{|c|c|c|c|c|}
\hline \multicolumn{5}{|c|}{ Supplemental Table S2.txt } \\
\hline CHEMBL 2003785 & 809138 & 4.4 & 4.4874 & TST \\
\hline CHEMBL1973720 & 809138 & 7.9 & 7.5199 & TRN \\
\hline CHEMBL1969523 & 809138 & 4.1 & 5.1298 & TRN \\
\hline CHEMBL1988995 & 809138 & 4.1 & 3.8311 & TRN \\
\hline CHEMBL 207995 & 809138 & 5.6 & 5.5233 & TRN \\
\hline CHEMBL 2001923 & 809138 & 4.3 & 4.5202 & TRN \\
\hline CHEMBL1986781 & 809138 & 4.1 & 4.6568 & TRN \\
\hline CHEMBL1983070 & 809138 & 4.4 & 4.6816 & TRN \\
\hline CHEMBL526133 & 809138 & 6.1 & 4.9134 & TRN \\
\hline CHEMBL 2003514 & 809138 & 4.4 & 5.277 & TRN \\
\hline CHEMBL1989043 & 809138 & 4.4 & 4.8096 & TRN \\
\hline CHEMBL1979057 & 809138 & 4.1 & 4.6713 & TRN \\
\hline CHEMBL1981045 & 809138 & 4.1 & 4.9933 & TRN \\
\hline CHEMBL 387971 & 809138 & 4.3 & 4.1669 & TST \\
\hline CHEMBL1975418 & 809138 & 6.6 & 5.0836 & TRN \\
\hline CHEMBL1992796 & 809138 & 4.1 & 4.4294 & TRN \\
\hline CHEMBL1164180 & 809138 & 5.8 & 5.5438 & TST \\
\hline CHEMBL 223257 & 809138 & 7.3 & 6.0714 & TST \\
\hline CHEMBL1999428 & 809138 & 5.3 & 4.9923 & TRN \\
\hline CHEMBL1967560 & 809138 & 4.1 & 4.6712 & TRN \\
\hline CHEMBL1997611 & 809138 & 4.4 & 4.5539 & TST \\
\hline CHEMBL1516890 & 809138 & 5.5 & 5.968 & TRN \\
\hline CHEMBL 211378 & 809138 & 4.1 & 4.7974 & TRN \\
\hline CHEMBL1982465 & 809138 & 4.1 & 5.4567 & TRN \\
\hline CHEMBL 2003420 & 809138 & 4.1 & 4.231 & TRN \\
\hline CHEMBL1984586 & 809138 & 4.1 & 4.3937 & TRN \\
\hline CHEMBL1999774 & 809138 & 4.1 & 4.4624 & TST \\
\hline CHEMBL1972659 & 809138 & 4.1 & 5.0284 & TST \\
\hline CHEMBL 2002723 & 809138 & 5.5 & 5.1339 & TST \\
\hline CHEMBL1973395 & 809138 & 4.1 & 5.1015 & TRN \\
\hline CHEMBL 272453 & 809138 & 5.8 & 5.527 & TRN \\
\hline CHEMBL1970217 & 809138 & 6.4 & 5.6506 & TRN \\
\hline CHEMBL1971801 & 809138 & 4.1 & 3.7801 & TRN \\
\hline CHEMBL1968850 & 809138 & 4.1 & 3.9745 & TRN \\
\hline CHEMBL 2005528 & 809138 & 4.1 & 4.6429 & TST \\
\hline CHEMBL1984686 & 809138 & 4.4 & 4.0295 & TRN \\
\hline CHEMBL185569 & 809138 & 4.1 & 4.6708 & TRN \\
\hline CHEMBL1969843 & 809138 & 4.1 & 4.164 & TRN \\
\hline CHEMBL 2007002 & 809138 & 4.1 & 4.0065 & TRN \\
\hline CHEMBL1987007 & 809138 & 5.6 & 4.832 & TRN \\
\hline CHEMBL1973793 & 809138 & 4.4 & 4.8252 & TST \\
\hline CHEMBL1984711 & 809138 & 4.1 & 4.4681 & TRN \\
\hline CHEMBL1992073 & 809138 & 4.5 & 5.7477 & TRN \\
\hline CHEMBL1990212 & 809138 & 4.1 & 4.2022 & TRN \\
\hline CHEMBL484390 & 809138 & 6.7 & 5.5992 & TRN \\
\hline CHEMBL1979252 & 809138 & 6.3 & 5.8281 & TRN \\
\hline CHEMBL1986143 & 809138 & 4.4 & 5.1207 & TRN \\
\hline CHEMBL1972934 & 809138 & 4.5 & 4.5485 & TRN \\
\hline
\end{tabular}




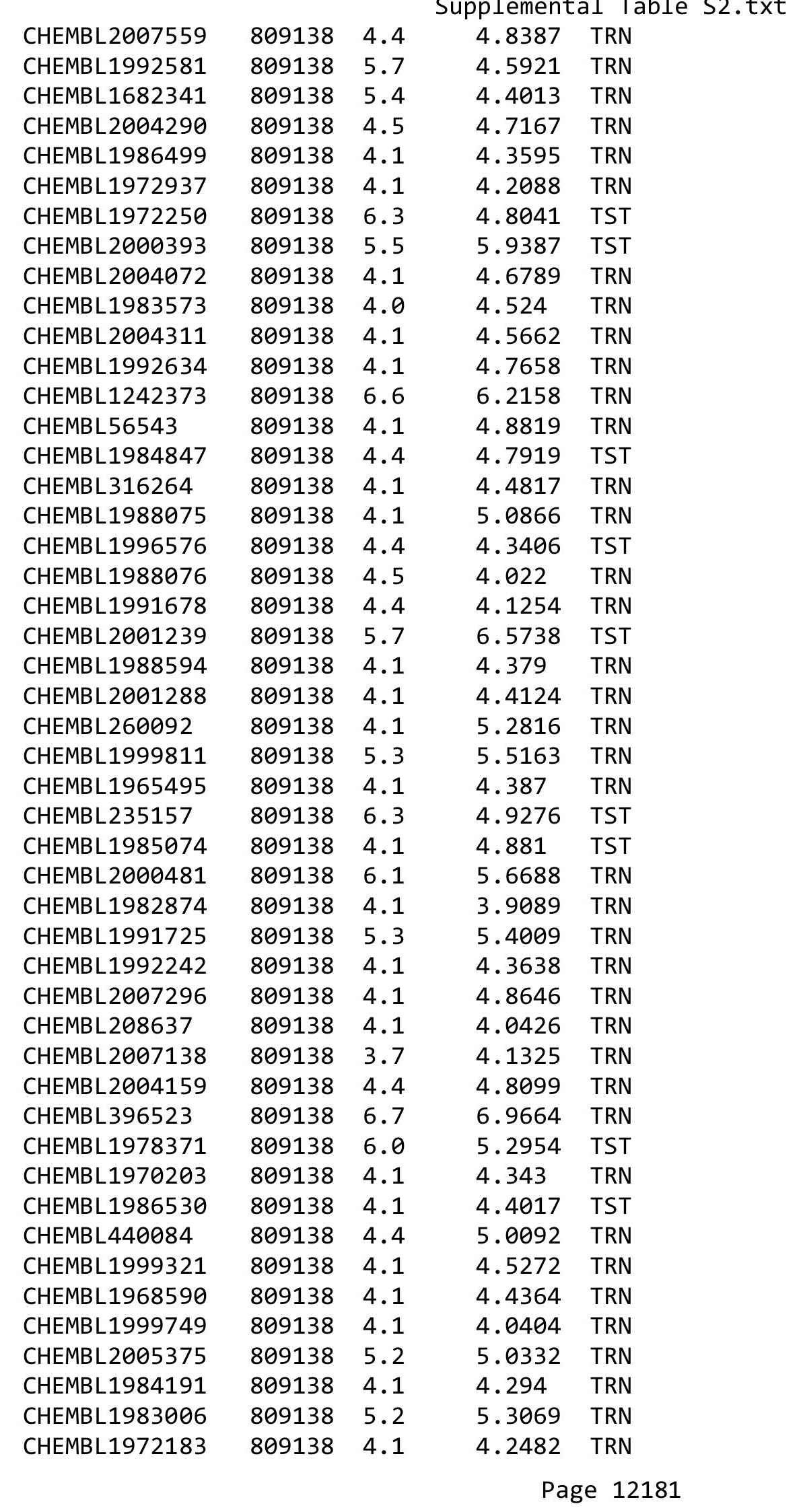




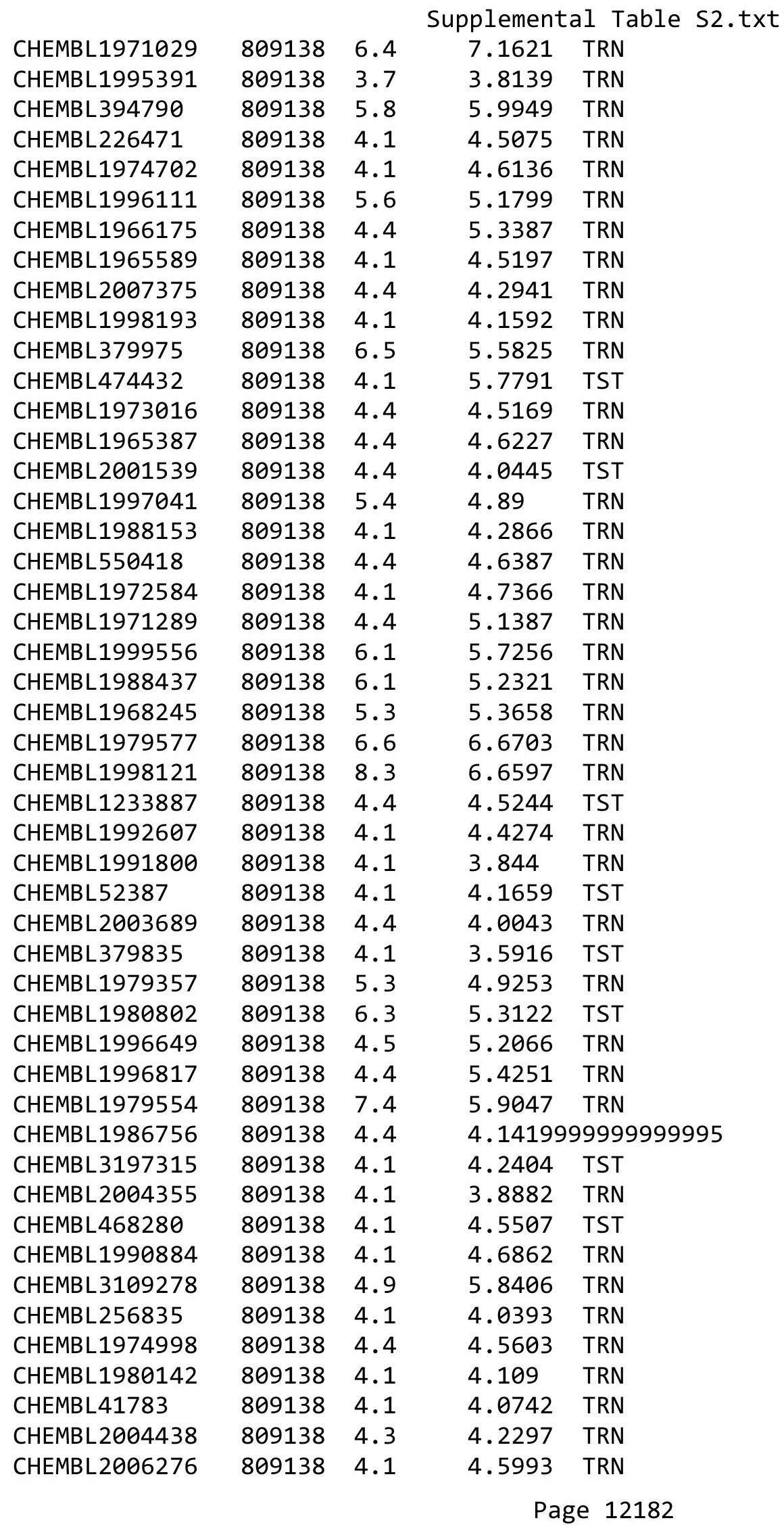




\begin{tabular}{|c|c|c|c|c|}
\hline & & & Supplement & Table S \\
\hline CHEMBL191003 & 809138 & 6.0 & 5.6214 & TRN \\
\hline CHEMBL 271381 & 809138 & 6.2 & 5.6941 & TRN \\
\hline CHEMBL 2006785 & 809138 & 4.1 & 4.3888 & TRN \\
\hline CHEMBL1982466 & 809138 & 4.1 & 4.7611 & TRN \\
\hline CHEMBL1973359 & 809138 & 6.2 & 6.3774 & TST \\
\hline CHEMBL1995740 & 809138 & 5.6 & 5.063 & TRN \\
\hline CHEMBL1996390 & 809138 & 5.4 & 4.8577 & TRN \\
\hline CHEMBL1979690 & 809138 & 6.9 & 7.1178 & TRN \\
\hline CHEMBL234085 & 809138 & 4.4 & 4.9589 & TRN \\
\hline CHEMBL1998414 & 809138 & 4.1 & 4.2495 & TRN \\
\hline CHEMBL1995832 & 809138 & 4.1 & 4.2961 & TRN \\
\hline CHEMBL1969042 & 809138 & 7.8 & 4.8016 & TRN \\
\hline CHEMBL 2000345 & 809138 & 6.5 & 5.6846 & TRN \\
\hline CHEMBL1999931 & 809138 & 6.6 & 6.4167 & TRN \\
\hline CHEMBL1976376 & 809138 & 4.4 & 4.4385 & TRN \\
\hline CHEMBL1991640 & 809138 & 4.1 & 4.9941 & TST \\
\hline CHEMBL1983575 & 809138 & 6.4 & 6.5599 & TRN \\
\hline CHEMBL1968868 & 809138 & 4.4 & 4.5533 & TRN \\
\hline CHEMBL1375418 & 809138 & 4.1 & 4.4859 & TRN \\
\hline CHEMBL 302449 & 809138 & 8.6 & 6.2332 & TST \\
\hline CHEMBL 2007064 & 809138 & 6.6 & 5.7136 & TRN \\
\hline CHEMBL1981047 & 809138 & 4.3 & 5.055 & TRN \\
\hline CHEMBL 229968 & 809138 & 7.8 & 7.646 & TRN \\
\hline CHEMBL1976196 & 809138 & 4.4 & 4.9874 & TST \\
\hline CHEMBL1976240 & 809138 & 6.5 & 6.2367 & TRN \\
\hline CHEMBL1997197 & 809138 & 4.4 & 4.3829 & TRN \\
\hline CHEMBL1983630 & 809138 & 4.2 & 3.9778 & TRN \\
\hline CHEMBL1968151 & 809138 & 4.1 & 4.0645 & TRN \\
\hline CHEMBL1979093 & 809138 & 6.4 & 5.7492 & TRN \\
\hline CHEMBL1381197 & 809138 & 4.1 & 4.1789 & TRN \\
\hline CHEMBL1987009 & 809138 & 5.4 & 5.4831 & TRN \\
\hline CHEMBL 379218 & 809138 & 6.0 & 7.1316 & TRN \\
\hline CHEMBL 2003817 & 809138 & 4.1 & 4.3304 & TRN \\
\hline CHEMBL336961 & 809138 & 4.1 & 4.2757 & TRN \\
\hline CHEMBL1994830 & 809138 & 4.1 & 4.752 & TRN \\
\hline CHEMBL1987054 & 809138 & 6.3 & 5.914 & TRN \\
\hline CHEMBL1970083 & 809138 & 6.8 & 6.1225 & TRN \\
\hline CHEMBL226403 & 809138 & 4.1 & 4.7662 & TRN \\
\hline CHEMBL 2005631 & 809138 & 4.1 & 5.5603 & TRN \\
\hline CHEMBL1994938 & 809138 & 4.1 & 4.7594 & TRN \\
\hline CHEMBL1977223 & 809138 & 4.1 & 4.7449 & TRN \\
\hline CHEMBL1995765 & 809138 & 4.4 & 4.14199 & 99999999995 \\
\hline CHEMBL1966279 & 809138 & 5.2 & 4.9047 & TRN \\
\hline CHEMBL1236126 & 809138 & 4.1 & 4.3115 & TRN \\
\hline CHEMBL1997846 & 809138 & 6.0 & 6.0685 & TRN \\
\hline CHEMBL1984760 & 809138 & 5.9 & 5.5789 & TRN \\
\hline CHEMBL 2004419 & 809138 & 4.1 & 4.5401 & TRN \\
\hline CHEMBL1991728 & 809138 & 6.5 & 6.1022 & TRN \\
\hline
\end{tabular}




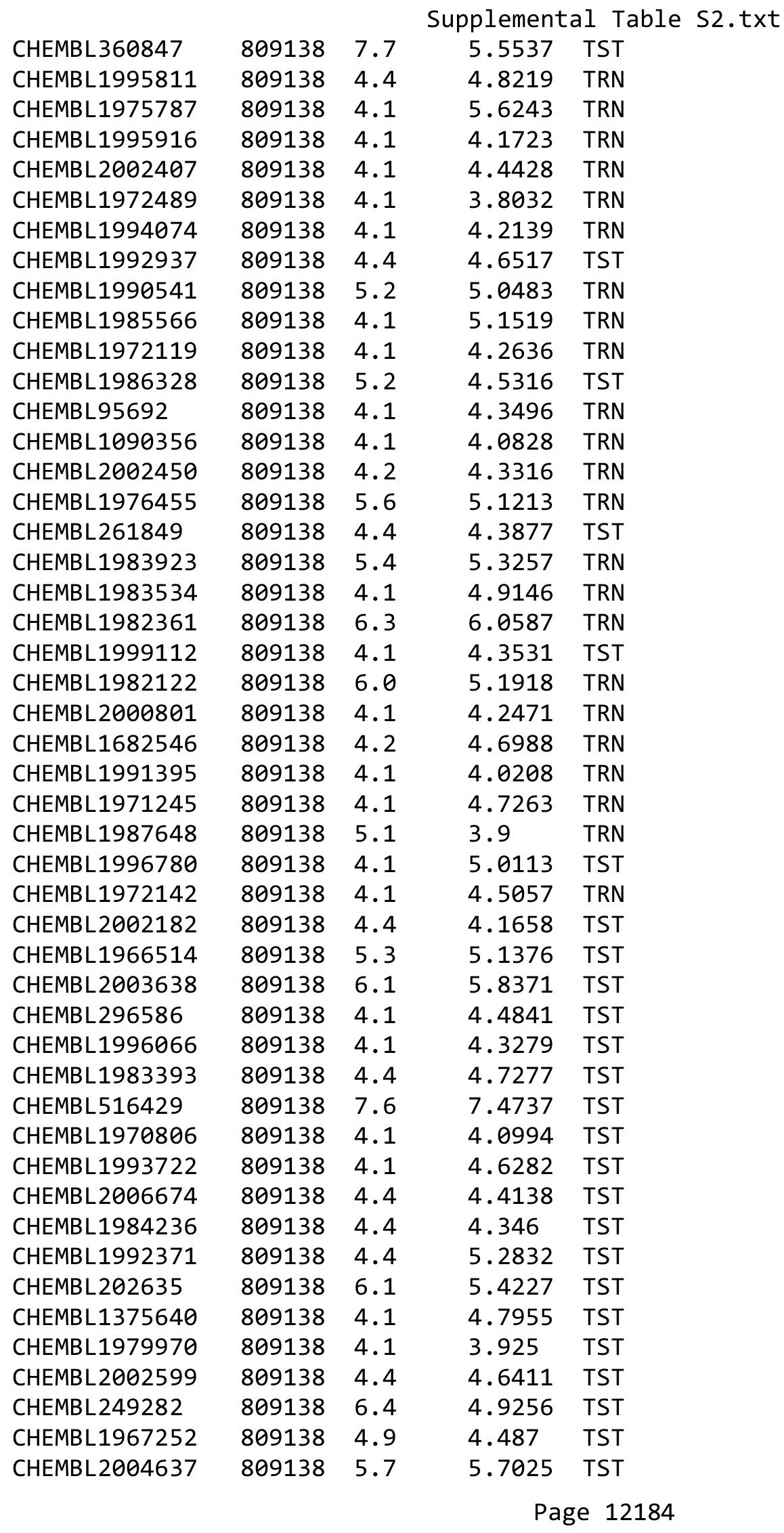




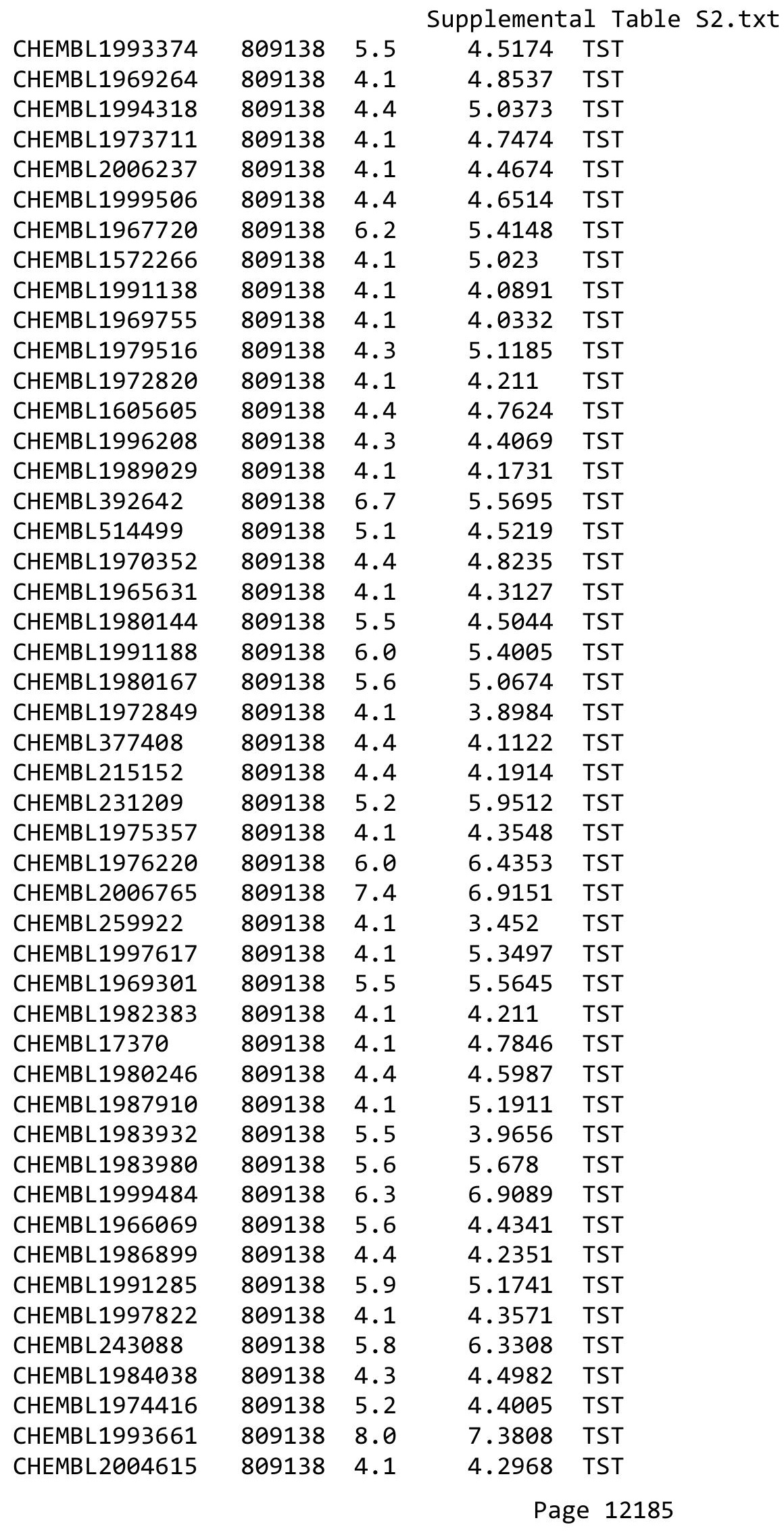




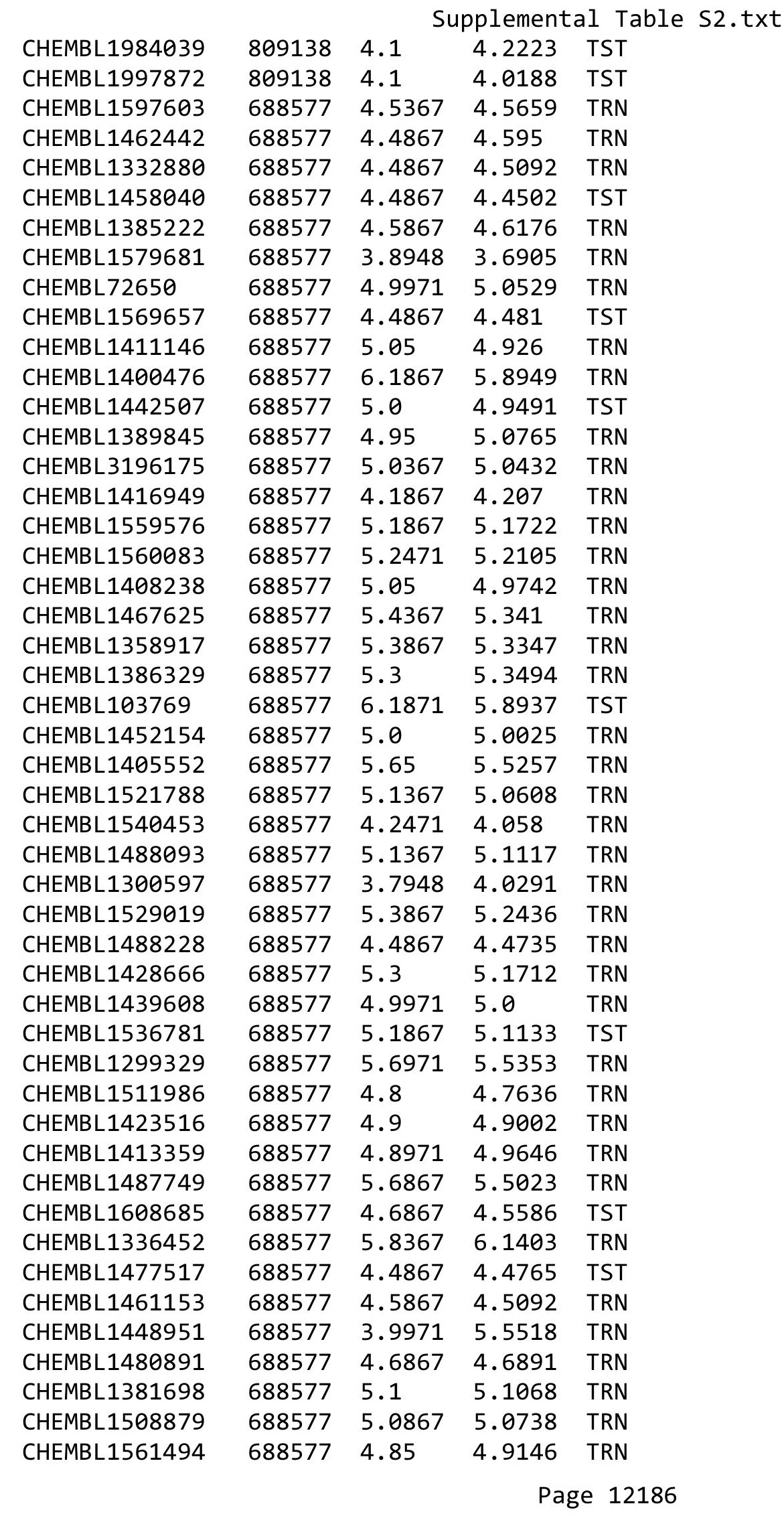




\begin{tabular}{|c|c|c|c|c|}
\hline \multicolumn{5}{|c|}{ Supplemental Table S2.txt } \\
\hline CHEMBL1441203 & 688577 & 5.95 & 5.9134 & TRN \\
\hline CHEMBL1464228 & 688577 & 4.5867 & 4.6365 & TRN \\
\hline CHEMBL1586373 & 688577 & 5.0867 & 5.0303 & TRN \\
\hline CHEMBL1426611 & 688577 & 5.3 & 5.3169 & TRN \\
\hline CHEMBL3211678 & 688577 & 5.0 & 4.9607 & TRN \\
\hline CHEMBL1370189 & 688577 & 4.8 & 4.7109 & TRN \\
\hline CHEMBL1446531 & 688577 & 5.1 & 5.0965 & TRN \\
\hline CHEMBL1568014 & 688577 & 8.1024 & 7.3115 & TRN \\
\hline CHEMBL3210588 & 688577 & 5.3367 & 5.2492 & TRN \\
\hline CHEMBL1402235 & 688577 & 4.5867 & 4.7157 & TRN \\
\hline CHEMBL1490564 & 688577 & 5.05 & 5.0322 & TST \\
\hline CHEMBL1415959 & 688577 & 5.8471 & 5.7291 & TRN \\
\hline CHEMBL1458532 & 688577 & 5.8 & 5.7697 & TRN \\
\hline CHEMBL1484169 & 688577 & 5.35 & 5.2833 & TST \\
\hline CHEMBL1559154 & 688577 & 4.4867 & 4.5617 & TRN \\
\hline CHEMBL1576168 & 688577 & 5.6471 & 5.4627 & TRN \\
\hline CHEMBL1363835 & 688577 & 5.3971 & 5.2682 & TRN \\
\hline CHEMBL1575888 & 688577 & 5.1 & 5.0981 & TRN \\
\hline CHEMBL1331855 & 688577 & 5.55 & 5.5745 & TST \\
\hline CHEMBL1501221 & 688577 & 5.0867 & 4.977 & TRN \\
\hline CHEMBL1371623 & 688577 & 5.0 & 5.0011 & TRN \\
\hline CHEMBL1571023 & 688577 & 5.2367 & 5.1747 & TRN \\
\hline CHEMBL129795 & 688577 & 4.95 & 4.8964 & TST \\
\hline CHEMBL1507941 & 688577 & 4.9 & 4.8896 & TRN \\
\hline CHEMBL1492491 & 688577 & 4.85 & 4.8799 & TRN \\
\hline CHEMBL1461549 & 688577 & 5.4867 & 5.644 & TRN \\
\hline CHEMBL1323898 & 688577 & 4.7 & 4.7942 & TRN \\
\hline CHEMBL1330113 & 688577 & 4.9367 & 5.7722 & TRN \\
\hline CHEMBL1566901 & 688577 & 4.7867 & 4.7628 & TRN \\
\hline CHEMBL1335016 & 688577 & 5.2867 & 5.2234 & TRN \\
\hline CHEMBL1495153 & 688577 & 5.9 & 5.841 & TRN \\
\hline CHEMBL1363195 & 688577 & 5.5867 & 5.7202 & TRN \\
\hline CHEMBL1433148 & 688577 & 4.9367 & 4.9099 & TRN \\
\hline CHEMBL1348672 & 688577 & 5.8367 & 6.1378 & TRN \\
\hline CHEMBL1532388 & 688577 & 5.1867 & 5.2156 & TRN \\
\hline CHEMBL1354148 & 688577 & 5.6 & 5.7621 & TRN \\
\hline CHEMBL1535519 & 688577 & 4.8867 & 4.7298 & TRN \\
\hline CHEMBL1579805 & 688577 & 5.0 & 4.977 & TRN \\
\hline CHEMBL1353362 & 688577 & 5.2367 & 5.1321 & TRN \\
\hline CHEMBL1336198 & 688577 & 5.0367 & 4.9791 & TRN \\
\hline CHEMBL1431629 & 688577 & 4.0471 & 3.8618 & TRN \\
\hline CHEMBL1610640 & 688577 & 5.5867 & 5.3481 & TRN \\
\hline CHEMBL1389883 & 688577 & 4.95 & 5.0002 & TRN \\
\hline CHEMBL1363295 & 688577 & 4.7948 & 4.9542 & TST \\
\hline CHEMBL1406908 & 688577 & 5.9367 & 5.9036 & TST \\
\hline CHEMBL1432838 & 688577 & 4.3371 & 4.2621 & TST \\
\hline CHEMBL1412828 & 688577 & 5.0867 & 4.9752 & TST \\
\hline CHEMBL1346506 & 688577 & 3.7948 & 3.71100 & 20000000003 \\
\hline & & & & 1218 \\
\hline
\end{tabular}




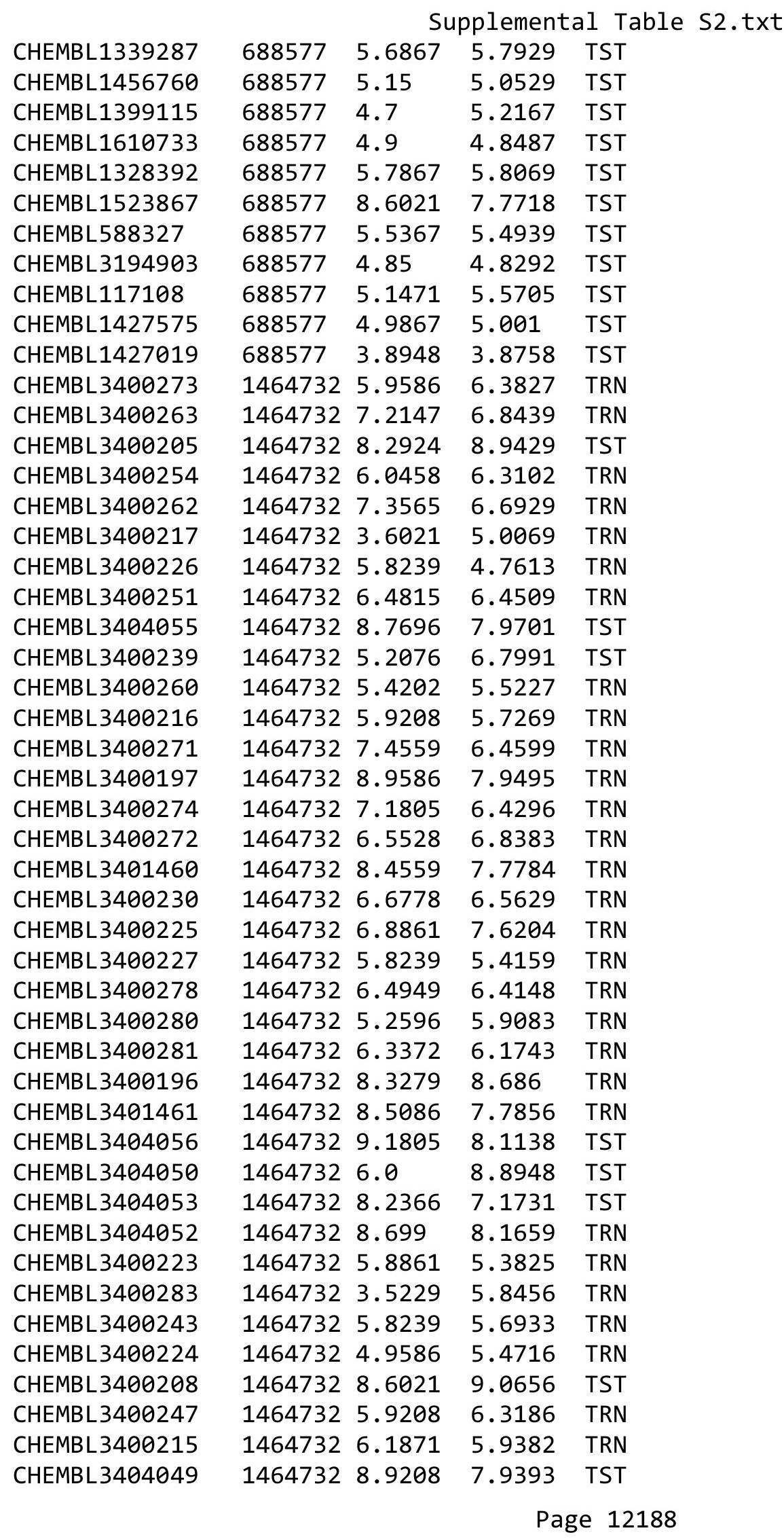


Supplemental Table S2.txt

\begin{tabular}{|c|c|c|c|c|}
\hline CHEMBL3400219 & 1464732 & 3.6021 & 6.4645 & TST \\
\hline CHEMBL3400210 & 1464732 & 5.6576 & 5.0427 & TRN \\
\hline CHEMBL3400241 & 1464732 & 4.8861 & 5.1293 & TRN \\
\hline CHEMBL 3400245 & 1464732 & 5.9208 & 6.2763 & TRN \\
\hline CHEMBL3400235 & 1464732 & 5.8861 & 6.2851 & TST \\
\hline CHEMBL3400275 & 1464732 & 6.9586 & \multicolumn{2}{|c|}{6.582000000000001} \\
\hline CHEMBL3400276 & 1464732 & 6.585 & 6.2624 & TRN \\
\hline CHEMBL3400150 & 1464732 & 3.6021 & 5.9819 & TRN \\
\hline CHEMBL3400201 & 1464732 & 7.9586 & 8.5894 & TRN \\
\hline CHEMBL3400233 & 1464732 & 6.2366 & 5.981 & TRN \\
\hline CHEMBL 3400220 & 1464732 & 6.1135 & 5.6286 & TRN \\
\hline CHEMBL3400234 & 1464732 & 6.1367 & 6.1449 & TST \\
\hline CHEMBL3400206 & 1464732 & 8.3279 & 8.5293 & TST \\
\hline CHEMBL3400232 & 1464732 & 6.3468 & 6.2056 & TRN \\
\hline CHEMBL 3400258 & 1464732 & 5.3468 & 4.8473 & TRN \\
\hline CHEMBL3400265 & 1464732 & 6.4685 & 6.0957 & TRN \\
\hline CHEMBL3400252 & 1464732 & 5.9586 & 5.4876 & TRN \\
\hline CHEMBL3400198 & 1464732 & 9.1675 & 7.7431 & TRN \\
\hline CHEMBL 3400200 & 1464732 & 8.8539 & 8.9994 & TST \\
\hline CHEMBL3400221 & 1464732 & 6.0177 & 5.6791 & TRN \\
\hline CHEMBL3400209 & 1464732 & 5.3665 & 5.5447 & TRN \\
\hline CHEMBL3400204 & 1464732 & 8.699 & 8.924 & TRN \\
\hline CHEMBL3400199 & 1464732 & 9.2441 & 8.6384 & TST \\
\hline CHEMBL 3400237 & 1464732 & 5.8239 & 6.4798 & TST \\
\hline CHEMBL3400229 & 1464732 & 4.7212 & 5.1598 & TRN \\
\hline CHEMBL3400253 & 1464732 & 5.4949 & 5.5217 & TRN \\
\hline CHEMBL 3400244 & 1464732 & 5.699 & 6.4684 & TRN \\
\hline CHEMBL3400222 & 1464732 & 6.1427 & 5.3835 & TRN \\
\hline CHEMBL3400228 & 1464732 & 6.8861 & 7.0144 & TRN \\
\hline CHEMBL3400282 & 1464732 & 5.1938 & 6.2548 & TRN \\
\hline CHEMBL3400268 & 1464732 & 6.9208 & 6.1395 & TRN \\
\hline CHEMBL3400266 & 1464732 & 7.1427 & 6.8058 & TRN \\
\hline CHEMBL3400279 & 1464732 & 5.9208 & 6.2276 & TRN \\
\hline CHEMBL3400255 & 1464732 & 5.6778 & 5.6609 & TRN \\
\hline CHEMBL3400236 & 1464732 & 5.4437 & 6.3137 & TST \\
\hline CHEMBL3400267 & 1464732 & 7.0458 & 6.6353 & TRN \\
\hline CHEMBL3404051 & 1464732 & 6.0 & 7.1127 & TRN \\
\hline CHEMBL3400259 & 1464732 & 6.1938 & 6.1864 & TRN \\
\hline CHEMBL 3400203 & 1464732 & 8.5229 & 8.0997 & TRN \\
\hline CHEMBL 3400257 & 1464732 & 6.1739 & 5.5905 & TRN \\
\hline CHEMBL 3400277 & 1464732 & 6.0088 & 6.2391 & TRN \\
\hline CHEMBL 3400270 & 1464732 & 6.7696 & 6.6968 & TRN \\
\hline CHEMBL3400249 & 1464732 & 5.9208 & 6.0592 & TRN \\
\hline CHEMBL3400218 & 1464732 & 5.7959 & 4.5356 & TRN \\
\hline CHEMBL 3400212 & 1464732 & 5.5229 & 5.2315 & TRN \\
\hline CHEMBL3400202 & 1464732 & 8.0 & 8.329 & TST \\
\hline CHEMBL3400246 & 1464732 & 5.6778 & 6.2959 & TRN \\
\hline CHEMBL3400256 & 1464732 & 5.7959 & 5.7274 & TRN \\
\hline
\end{tabular}


Supplemental Table S2.txt

\begin{tabular}{|c|c|c|c|c|}
\hline 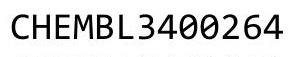 & & 9 & 6769 & \\
\hline HEMBL3400240 & 4732 & 5.0 & 1102 & \\
\hline HEMBL3400238 & 464732 & 4.6383 & 8991 & \\
\hline 0207 & 732 & 805 & 246 & \\
\hline AEMBL 34 & 732 & 9208 & 6726 & \\
\hline HEMBL3400231 & 464732 & 6.4437 & 3847 & \\
\hline HEMBL3400214 & 464732 & 6.2518 & 3446 & \\
\hline HEMBL3400250 & & 5.4685 & 1385 & \\
\hline AEMBL3 & 732 & 6.2218 & 7867 & \\
\hline AEMBL3 & 732 & 7.0269 & .4998 & \\
\hline HEMBL3400211 & 32 & 3.6021 & . 7229 & \\
\hline HEMBL 3400248 & 32 & 6.4437 & .9642 & \\
\hline HEMBL180127 & 54 & 2.6636 & 2101 & \\
\hline HEMBL 2: & & 6.1032 & 2335 & \\
\hline HEMBL5 5 & 5 & 2.4937 & 5733 & \\
\hline HEMBL2005886 & 55 & 4.4158 & 0252 & \\
\hline HEMBL 512504 & 55 & 3.6845 & 4.3148 & \\
\hline HEMBL124 & 154 & 3.8713 & 0828 & RIV \\
\hline HEMBL57 & & 782 & $\partial 525$ & \\
\hline HEMBL31 & 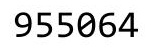 & 3.1056 & 3.2911 & \\
\hline HEMBL22 & 5 & 905 & 4.704 & \\
\hline HEMBL 255342 & & & 1581 & I KIV \\
\hline HEMBL14 & $15=$ & 3.1706 & 2.3978 & \\
\hline HEMBL41 & & 3.6321 & 3.7292 & \\
\hline HEMBL33 & & 111 & 1786 & RN \\
\hline HEMBL13 & & & 9795 & 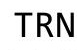 \\
\hline HEMBL 50 & & 5.6575 & 4.9972 & $\mathrm{RN}$ \\
\hline HEMBL1\& & & 316 & 3006 & RN \\
\hline HEMBL1 & & 39 & 538 & RN \\
\hline HEMBL16 & & 971 & 3.9535 & RN \\
\hline HEMBL19e & & & & iv \\
\hline HEMBL192566 & 4 & 6.5331 & 6.7549 & ГST \\
\hline HEMBL1C & & 689 & 7456 & $\mathrm{RN}$ \\
\hline HEM & & 35 & 1994 & RN \\
\hline HEMBL47 & & & 2.6017 & RN \\
\hline HEMBL9470 & 55 & & & TST \\
\hline HEMBL 379975 & 4 & 162 & 4.8516 & RN \\
\hline HEMBL 30 & 55 & 5 . & 641 & RN \\
\hline HEMBL 39 & & & 02 & RN \\
\hline HEMBL $214406 \mathrm{~S}$ & & & 5.2607 & $\mathrm{RN}$ \\
\hline HEMBL 373 & 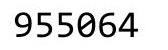 & 479 & 2736 & IRN \\
\hline HEMBL 39 & & 755 & 802 & RN \\
\hline CHEMBL48 & & 2.7604 & 1.3794 & \\
\hline CHEMBL10 & & 2.9932 & 3.4874 & RN \\
\hline HEMBL1590308 & 955 & 2.8578 & 2.7723 & ST \\
\hline HEMBL222102 & 955 & 3.4068 & .4259 & RN \\
\hline 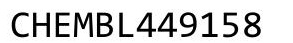 & & & & \\
\hline HEMBL48384 & 55064 & 3.5689 & & \\
\hline
\end{tabular}

Page 12190 


\begin{tabular}{|c|c|c|c|c|c|c|}
\hline & & \multicolumn{5}{|c|}{ Supplemental Table S2.txt } \\
\hline CHEMBL1230020 & 955064 & 3.4701 & 3.8026 & TRN & & \\
\hline CHEMBL 2134202 & 955064 & 2.9203 & 3.4606 & TRN & & \\
\hline CHEMBL209148 & 955064 & 3.187 & 3.3887 & TRN & & \\
\hline CHEMBL399530 & 955064 & 2.8599 & 3.8548 & TRN & & \\
\hline CHEMBL92309 & 955064 & 1.0897 & 2.008 & TST & & \\
\hline CHEMBL1970879 & 955064 & 3.4209 & 3.2566 & TRN & & \\
\hline CHEMBL188678 & 955064 & 4.1708 & 4.1276 & TRN & & \\
\hline CHEMBL213100 & 955064 & 4.5367 & 3.9665 & TRN & & \\
\hline CHEMBL 379300 & 955064 & \multicolumn{3}{|c|}{3.9760000000000004} & 4.9944 & TRN \\
\hline CHEMBL 258844 & 955064 & 3.6119 & 3.3473 & TRN & & \\
\hline CHEMBL3392440 & 955064 & 3.4717 & 3.7099 & TRN & & \\
\hline CHEMBL573107 & 955064 & 4.1647 & 4.8815 & TRN & & \\
\hline CHEMBL2137530 & 955064 & 4.8222 & 4.2992 & TRN & & \\
\hline CHEMBL1788116 & 955064 & 4.461 & 3.4727 & TRN & & \\
\hline CHEMBL191334 & 955064 & 5.5893 & 4.6738 & TRN & & \\
\hline CHEMBL3199475 & 955064 & 3.8038 & 3.6429 & TRN & & \\
\hline CHEMBL221137 & 955064 & 4.0853 & 3.7878 & TST & & \\
\hline CHEMBL 2363137 & 955064 & \multicolumn{3}{|c|}{4.1339999999999995} & 4.2029 & TRN \\
\hline CHEMBL202721 & 955064 & 5.3676 & 4.9835 & TRN & & \\
\hline CHEMBL1516890 & 955064 & 3.9638 & 3.8961 & TRN & & \\
\hline CHEMBL1357247 & 955064 & 2.5436 & 2.4744 & TST & & \\
\hline CHEMBL210618 & 955064 & 3.1714 & 3.1659 & TST & & \\
\hline CHEMBL515416 & 955064 & 3.7978 & 3.695 & TST & & \\
\hline CHEMBL 240954 & 955064 & 3.6953 & 3.0553 & TST & & \\
\hline CHEMBL65 & 955064 & 8.0842 & 7.8194 & TST & & \\
\hline CHEMBL585951 & 955064 & 5.124 & 5.3897 & TST & & \\
\hline CHEMBL514499 & 955064 & 6.1542 & 5.2995 & TST & & \\
\hline CHEMBL 259181 & 955064 & 2.7312 & 3.1874 & TST & & \\
\hline CHEMBL1256459 & 955064 & 5.3779 & 5.2825 & TST & & \\
\hline CHEMBL1502443 & 688183 & 5.3615 & 5.1391 & TRN & & \\
\hline CHEMBL1460619 & 688183 & 3.5243 & 4.29899 & 99999 & 995 & TRN \\
\hline CHEMBL1404881 & 688183 & 5.2291 & 4.9836 & TRN & & \\
\hline CHEMBL1421892 & 688183 & 3.5243 & 5.3742 & TRN & & \\
\hline CHEMBL1469613 & 688183 & 4.4789 & 5.4392 & TRN & & \\
\hline CHEMBL1489778 & 688183 & 5.2596 & 4.4793 & TRN & & \\
\hline CHEMBL1576177 & 688183 & 5.2503 & 5.0398 & TRN & & \\
\hline CHEMBL1466293 & 688183 & 5.684 & 5.3162 & TRN & & \\
\hline CHEMBL1336077 & 688183 & 5.4855 & 5.4248 & TRN & & \\
\hline CHEMBL1361947 & 688183 & 5.3449 & 5.2126 & TRN & & \\
\hline CHEMBL1324866 & 688183 & 5.5498 & 4.9554 & TRN & & \\
\hline CHEMBL1353986 & 688183 & 3.5243 & 5.1616 & TRN & & \\
\hline CHEMBL1328334 & 688183 & 5.5045 & 5.409 & TRN & & \\
\hline CHEMBL1448614 & 688183 & 5.4461 & 5.3608 & TRN & & \\
\hline CHEMBL1340780 & 688183 & 4.4789 & 4.7107 & TRN & & \\
\hline CHEMBL1508357 & 688183 & 4.8153 & 4.5063 & TST & & \\
\hline CHEMBL1443557 & 688183 & 3.5243 & 4.5977 & TRN & & \\
\hline CHEMBL1472554 & 688183 & 5.9066 & 5.67 & TRN & & \\
\hline CHEMBL1339229 & 688183 & 6.1073 & 4.598 & TST & & \\
\hline
\end{tabular}




\begin{tabular}{|c|c|c|c|c|c|c|}
\hline & & \multicolumn{5}{|c|}{ Supplemental Table S2.txt } \\
\hline CHEMBL1521361 & 688183 & 6.0846 & 5.3464 & TRN & & \\
\hline CHEMBL1437613 & 688183 & 5.8447 & 5.3972 & TRN & & \\
\hline CHEMBL1439831 & 688183 & 5.2175 & 5.0788 & TRN & & \\
\hline CHEMBL 7634 & 688183 & 3.5243 & 4.8142 & TST & & \\
\hline CHEMBL1981797 & 688183 & 3.5243 & 4.9305 & TRN & & \\
\hline CHEMBL1422729 & 688183 & 3.5243 & 5.1592 & TRN & & \\
\hline CHEMBL1544798 & 688183 & 5.58 & 4.574 & TRN & & \\
\hline CHEMBL584031 & 688183 & 6.2291 & 5.8698 & TRN & & \\
\hline CHEMBL1540007 & 688183 & 5.2815 & 5.0002 & TRN & & \\
\hline CHEMBL1526936 & 688183 & 5.3382 & 4.6594 & TRN & & \\
\hline CHEMBL1469400 & 688183 & 4.9066 & 4.8352 & TRN & & \\
\hline CHEMBL1324698 & 688183 & 4.9066 & 4.4768 & TRN & & \\
\hline CHEMBL1544658 & 688183 & 5.2765 & 4.8816 & TRN & & \\
\hline CHEMBL1448317 & 688183 & 5.5143 & 5.5528 & TRN & & \\
\hline CHEMBL1532116 & 688183 & 5.4168 & 5.1621 & TRN & & \\
\hline CHEMBL1448963 & 688183 & 4.762 & 4.3923 & TST & & \\
\hline CHEMBL1406072 & 688183 & 5.6055 & 5.2721 & TRN & & \\
\hline CHEMBL1389846 & 688183 & \multicolumn{3}{|c|}{4.9830000000000005} & 4.2846 & $\mathrm{TR}$ \\
\hline CHEMBL1612488 & 688183 & 5.0883 & 5.2177 & TRN & & \\
\hline CHEMBL1461460 & 688183 & 3.5243 & 4.9378 & TRN & & \\
\hline CHEMBL1534723 & 688183 & 5.6383 & 5.1718 & TRN & & \\
\hline CHEMBL1585618 & 688183 & 5.5884 & 5.3418 & TRN & & \\
\hline CHEMBL1560703 & 688183 & 5.7352 & 5.8355 & TRN & & \\
\hline CHEMBL1329490 & 688183 & 3.5243 & 4.3579 & TRN & & \\
\hline CHEMBL1453955 & 688183 & 5.4295 & 5.4101 & TRN & & \\
\hline CHEMBL494559 & 688183 & 5.2924 & 5.3195 & TRN & & \\
\hline CHEMBL1373476 & 688183 & 5.6364 & 4.8742 & TRN & & \\
\hline CHEMBL1489784 & 688183 & 5.7773 & 5.8803 & TRN & & \\
\hline CHEMBL1310077 & 688183 & 4.9547 & 4.5034 & TST & & \\
\hline CHEMBL1329772 & 688183 & 3.5243 & 4.3011 & TRN & & \\
\hline CHEMBL1306608 & 688183 & 5.2765 & 5.4167 & TRN & & \\
\hline CHEMBL1331089 & 688183 & 3.5243 & 4.7031 & TST & & \\
\hline CHEMBL1578467 & 688183 & 4.6904 & 4.9524 & TRN & & \\
\hline CHEMBL1527978 & 688183 & 3.5243 & 5.3687 & TRN & & \\
\hline CHEMBL1321070 & 688183 & 3.5243 & 4.5545 & TST & & \\
\hline CHEMBL1472570 & 688183 & 5.9355 & 4.7791 & TST & & \\
\hline CHEMBL1606000 & 688183 & 5.4225 & $5.3610 e$ & 0000000001 & & $1 \mathrm{~K}$ \\
\hline CHEMBL1388571 & 688183 & 5.0788 & 4.9984 & TRN & & \\
\hline CHEMBL1539706 & 688183 & 3.5243 & 4.2772 & TRN & & \\
\hline CHEMBL1369781 & 688183 & 6.0867 & 5.3334 & TRN & & \\
\hline CHEMBL1540621 & 688183 & 5.75200 & 2000000e & 21 & 5.4146 & $1 \mathrm{~T}$ \\
\hline CHEMBL1534146 & 688183 & 5.8182 & 4.6527 & TRN & & \\
\hline CHEMBL1336358 & 688183 & 5.5214 & 5.2492 & TRN & & \\
\hline CHEMBL1573517 & 688183 & 5.7399 & 5.5058 & TRN & & \\
\hline CHEMBL1322827 & 688183 & 4.0004 & 4.6727 & TRN & & \\
\hline CHEMBL1498988 & 688183 & 5.1759 & 5.5718 & TRN & & \\
\hline CHEMBL1599029 & 688183 & 5.1739 & 5.9564 & TRN & & \\
\hline CHEMBL1496679 & 688183 & 5.4547 & 5.2521 & TRN & & \\
\hline
\end{tabular}




\begin{tabular}{|c|c|c|c|c|c|c|}
\hline & & \multicolumn{5}{|c|}{ Supplemental Table s2.txt } \\
\hline CHEMBL1465176 & 688183 & 5.7423 & 5.2125 & TRN & & \\
\hline CHEMBL1550463 & 688183 & 4.9957 & 5.1375 & TRN & & \\
\hline CHEMBL1485942 & 688183 & 5.4023 & 4.9548 & TRN & & \\
\hline CHEMBL1446056 & 688183 & 5.5467 & 5.7726 & TRN & & \\
\hline CHEMBL1548734 & 688183 & 3.5243 & 4.6284 & TRN & & \\
\hline CHEMBL1309129 & 688183 & 5.7959 & 5.2649 & TRN & & \\
\hline CHEMBL1324170 & 688183 & 5.1593 & 5.2566 & TRN & & \\
\hline CHEMBL1517137 & 688183 & 5.7496 & 5.2836 & TRN & & \\
\hline CHEMBL1345166 & 688183 & 3.5243 & 4.6927 & TRN & & \\
\hline CHEMBL1319618 & 688183 & 5.5017 & 4.6318 & TST & & \\
\hline CHEMBL1444583 & 688183 & 5.6861 & 5.4101 & TRN & & \\
\hline CHEMBL1336678 & 688183 & 5.5591 & 5.4327 & TRN & & \\
\hline CHEMBL1570114 & 688183 & 3.5243 & 4.9296 & TRN & & \\
\hline CHEMBL1447560 & 688183 & 3.5243 & 4.6305 & TRN & & \\
\hline CHEMBL1609760 & 688183 & 5.6459 & 5.2865 & TRN & & \\
\hline CHEMBL1612851 & 688183 & 5.0329 & 5.4273 & TRN & & \\
\hline CHEMBL1348839 & 688183 & 5.399 & 4.6601 & TST & & \\
\hline CHEMBL1458360 & 688183 & 5.5952 & 4.6422 & TRN & & \\
\hline CHEMBL1347779 & 688183 & 3.5243 & 5.0892 & TRN & & \\
\hline CHEMBL1461019 & 688183 & 5.5436 & 5.0292 & TRN & & \\
\hline CHEMBL1448984 & 688183 & 3.5243 & 4.2222 & TRN & & \\
\hline CHEMBL1408062 & 688183 & 5.7212 & 5.8269 & TRN & & \\
\hline CHEMBL1401790 & 688183 & 5.2652 & 5.3423 & TRN & & \\
\hline CHEMBL1452750 & 688183 & 5.4559 & 4.9494 & TRN & & \\
\hline CHEMBL1304621 & 688183 & 5.2111 & 5.2221 & TRN & & \\
\hline CHEMBL1478945 & 688183 & 3.5243 & 4.0666 & TRN & & \\
\hline CHEMBL1527502 & 688183 & 4.0004 & 5.4041 & TRN & & \\
\hline CHEMBL1572983 & 688183 & 5.1605 & 4.6819 & TST & & \\
\hline CHEMBL1504123 & 688183 & 5.433 & 5.3131 & TRN & & \\
\hline CHEMBL1521000 & 688183 & $4.8210 €$ & 30000000 & $\partial 1$ & 5.2436 & TRN \\
\hline CHEMBL1470726 & 688183 & 5.8386 & 4.8842 & TRN & & \\
\hline CHEMBL1382128 & 688183 & 5.7986 & 5.2444 & TRN & & \\
\hline CHEMBL1542307 & 688183 & 5.3788 & 4.7246 & TRN & & \\
\hline CHEMBL1539092 & 688183 & 5.6271 & 4.6692 & TRN & & \\
\hline CHEMBL1448575 & 688183 & 5.4067 & 5.803 & TRN & & \\
\hline CHEMBL1508221 & 688183 & 5.2941 & 5.1562 & TRN & & \\
\hline CHEMBL1523835 & 688183 & 5.3635 & 4.7626 & TST & & \\
\hline CHEMBL1333562 & 688183 & 5.7375 & 4.9757 & TRN & & \\
\hline CHEMBL1409796 & 688183 & 5.6498 & 5.1418 & TRN & & \\
\hline CHEMBL1568833 & 688183 & 5.1979 & 4.9932 & TRN & & \\
\hline CHEMBL1573157 & 688183 & 3.5243 & 4.9159 & TRN & & \\
\hline CHEMBL1471422 & 688183 & 4.9172 & 4.9846 & TRN & & \\
\hline CHEMBL1433195 & 688183 & 5.1675 & 4.9171 & TRN & & \\
\hline CHEMBL1430530 & 688183 & $5.7520 e$ & 00000000 & & 4.872 & TST \\
\hline CHEMBL1504000 & 688183 & 5.6861 & 5.5265 & TRN & & \\
\hline CHEMBL1313527 & 688183 & 5.6021 & 5.2774 & TRN & & \\
\hline CHEMBL1377681 & 688183 & 6.0595 & 5.2933 & TRN & & \\
\hline CHEMBL1341110 & 688183 & 5.3872 & 5.0264 & TRN & & \\
\hline
\end{tabular}




\begin{tabular}{|c|c|c|c|c|}
\hline & & & pplement & al Table s2. \\
\hline CHEMBL3191441 & 688183 & 6.466 & 4.6844 & TRN \\
\hline CHEMBL1370397 & 688183 & 5.8761 & 5.4019 & TRN \\
\hline CHEMBL1422566 & 688183 & 6.4318 & 4.7914 & TST \\
\hline CHEMBL1543943 & 688183 & 5.4685 & 4.7555 & TRN \\
\hline CHEMBL1339961 & 688183 & 5.4225 & 5.1265 & TRN \\
\hline CHEMBL1442405 & 688183 & 3.5243 & 5.2735 & TRN \\
\hline CHEMBL1479177 & 688183 & 5.7352 & 5.4031 & TRN \\
\hline CHEMBL1368140 & 688183 & 5.2916 & 5.4389 & TRN \\
\hline CHEMBL1527508 & 688183 & 5.6038 & 4.9173 & TRN \\
\hline CHEMBL1310638 & 688183 & 3.5243 & 5.2874 & TRN \\
\hline CHEMBL1453170 & 688183 & 5.4672 & 5.0201 & TRN \\
\hline CHEMBL1561400 & 688183 & 5.5735 & 5.6863 & TRN \\
\hline CHEMBL1380043 & 688183 & 5.8665 & 5.3578 & TRN \\
\hline CHEMBL1383916 & 688183 & 5.3585 & 4.8458 & TRN \\
\hline CHEMBL1411259 & 688183 & 3.5243 & 4.8024 & TRN \\
\hline CHEMBL1479781 & 688183 & 5.9355 & 5.1981 & TRN \\
\hline CHEMBL1375102 & 688183 & 5.3224 & 5.0339 & TST \\
\hline CHEMBL1307103 & 688183 & 5.6126 & 5.1428 & TRN \\
\hline CHEMBL1391480 & 688183 & 5.4855 & 4.6932 & TRN \\
\hline CHEMBL1522257 & 688183 & 3.5243 & 4.1097 & TRN \\
\hline CHEMBL1346377 & 688183 & 5.4572 & 5.5501 & TRN \\
\hline CHEMBL1523363 & 688183 & 5.7282 & 4.8878 & TRN \\
\hline CHEMBL1507239 & 688183 & 5.3706 & 5.0621 & TRN \\
\hline CHEMBL548708 & 688183 & 6.4881 & 5.3749 & TRN \\
\hline CHEMBL1492498 & 688183 & 5.9872 & 5.3786 & TRN \\
\hline CHEMBL1579792 & 688183 & 5.4461 & 5.2994 & TRN \\
\hline CHEMBL1462734 & 688183 & 5.1574 & 5.1115 & TST \\
\hline CHEMBL1550026 & 688183 & 5.4067 & 5.3201 & TRN \\
\hline CHEMBL1535190 & 688183 & 4.9788 & 5.0736 & TRN \\
\hline CHEMBL1307636 & 688183 & 5.1129 & 4.9356 & TRN \\
\hline CHEMBL1405843 & 688183 & 5.9355 & 5.3032 & TRN \\
\hline CHEMBL1446118 & 688183 & 5.8447 & 5.4891 & TRN \\
\hline CHEMBL1301329 & 688183 & 5.6234 & 5.7152 & TRN \\
\hline CHEMBL1529824 & 688183 & 5.295 & 5.1261 & TRN \\
\hline CHEMBL 2004226 & 688183 & 3.5243 & 4.1234 & TST \\
\hline CHEMBL1310567 & 688183 & 5.1096 & 4.6503 & TST \\
\hline CHEMBL1359145 & 688183 & 5.3233 & 5.846 & TRN \\
\hline CHEMBL1306390 & 688183 & 5.5528 & 5.0546 & TRN \\
\hline CHEMBL1335117 & 688183 & 3.5243 & 5.0474 & TRN \\
\hline CHEMBL1309598 & 688183 & 5.1244 & 4.8171 & TRN \\
\hline CHEMBL1540576 & 688183 & 4.5622 & 4.6468 & TRN \\
\hline CHEMBL1528306 & 688183 & 5.1073 & 4.7832 & TRN \\
\hline CHEMBL1352208 & 688183 & 5.3045 & 4.3802 & TST \\
\hline CHEMBL1458844 & 688183 & 3.5243 & 5.5432 & TST \\
\hline CHEMBL1531705 & 688183 & 5.0482 & 4.209 & TST \\
\hline CHEMBL1609569 & 688183 & 3.5243 & 4.67399 & 99999999995 \\
\hline CHEMBL1378564 & 688183 & 5.8633 & 5.5905 & TST \\
\hline CHEMBL1546739 & 688183 & 5.2644 & 4.618 & TST \\
\hline
\end{tabular}




\begin{tabular}{|c|c|c|c|c|c|c|}
\hline \multicolumn{7}{|c|}{ Supplemental Table S2.txt } \\
\hline CHEMBL1370522 & 688183 & 5.4698 & 5.4844 & TST & & \\
\hline CHEMBL1966192 & 688183 & 3.5243 & 5.1539 & TST & & \\
\hline CHEMBL1306438 & 688183 & 5.2226 & 4.2504 & TST & & \\
\hline CHEMBL1535933 & 688183 & 5.4498 & 5.4234 & TST & & \\
\hline CHEMBL1428855 & 688183 & 5.767 & 5.2436 & TST & & \\
\hline CHEMBL1563418 & 688183 & 5.4306 & 5.5609 & TST & & \\
\hline CHEMBL1468000 & 688183 & 4.8327 & 4.5036 & TST & & \\
\hline CHEMBL1306270 & 688183 & 5.4023 & 4.8456 & TST & & \\
\hline CHEMBL1308686 & 688183 & 5.2725 & 5.0629 & TST & & \\
\hline CHEMBL1312991 & 688183 & 5.4763 & 5.4097 & TST & & \\
\hline CHEMBL1541349 & 688183 & 4.76699 & 99999999 & 995 & 5.1655 & TST \\
\hline CHEMBL1595964 & 688183 & 5.1415 & 5.1823 & TST & & \\
\hline CHEMBL1349839 & 688183 & 4.8477 & 4.6785 & TST & & \\
\hline CHEMBL1429643 & 688183 & 5.2708 & 4.9088 & TST & & \\
\hline CHEMBL1333679 & 688183 & 5.5482 & 5.1218 & TST & & \\
\hline CHEMBL1478815 & 688183 & 5.2765 & 4.7559 & TST & & \\
\hline CHEMBL1449689 & 688183 & 5.5391 & 4.8896 & TST & & \\
\hline CHEMBL1306290 & 688183 & 5.8761 & 5.0674 & TST & & \\
\hline CHEMBL1375987 & 688183 & 4.5768 & 5.2722 & TST & & \\
\hline CHEMBL1578505 & 688183 & 3.5243 & 4.7539 & TST & & \\
\hline CHEMBL1336532 & 688183 & 5.4802 & 4.5831 & TST & & \\
\hline CHEMBL1497433 & 688183 & 3.5243 & 4.816 & TST & & \\
\hline CHEMBL1570509 & 688183 & 5.2882 & 4.8701 & TST & & \\
\hline CHEMBL3952129 & 1641605 & 7.4559 & 7.4774 & TRN & & \\
\hline CHEMBL3928255 & 1641605 & 7.1675 & 6.6844 & TRN & & \\
\hline CHEMBL 3947774 & 1641605 & 7.7212 & 7.7355 & TST & & \\
\hline CHEMBL 3938992 & 1641605 & 7.7696 & 7.5845 & TST & & \\
\hline CHEMBL3926733 & 1641605 & 6.2306 & 6.8709 & TST & & \\
\hline CHEMBL 3952482 & 1641605 & 6.4486 & 6.4024 & TRN & & \\
\hline CHEMBL3952747 & 1641605 & 7.0555 & 6.9344 & TRN & & \\
\hline CHEMBL 3916445 & 1641605 & 7.301 & 7.5397 & TST & & \\
\hline CHEMBL3898699 & 1641605 & 7.1739 & 6.6308 & TRN & & \\
\hline CHEMBL 3925717 & 1641605 & 6.8182 & 6.9688 & TRN & & \\
\hline CHEMBL3935671 & 1641605 & 7.1805 & 7.0526 & TRN & & \\
\hline CHEMBL3972363 & 1641605 & 7.6021 & 7.7476 & TRN & & \\
\hline CHEMBL3975465 & 1641605 & 7.2518 & 7.4209 & TRN & & \\
\hline CHEMBL3911029 & 1641605 & 6.1965 & 6.9091 & TST & & \\
\hline CHEMBL 3947697 & 1641605 & 6.3516 & 6.4955 & TRN & & \\
\hline CHEMBL3941165 & 1641605 & 6.4802 & 6.8575 & TRN & & \\
\hline CHEMBL3964542 & 1641605 & 6.3206 & 6.3101 & TST & & \\
\hline CHEMBL3910305 & 1641605 & 8.0458 & 7.8534 & TRN & & \\
\hline CHEMBL3962857 & 1641605 & 7.6576 & 7.0563 & TRN & & \\
\hline CHEMBL3935516 & 1641605 & 6.4449 & 6.37700 & 0000000001 & & TRN \\
\hline CHEMBL3939700 & 1641605 & 7.7212 & 7.8919 & TRN & & \\
\hline CHEMBL3917485 & 1641605 & 7.2147 & 7.3387 & TRN & & \\
\hline CHEMBL3937915 & 1641605 & 7.4089 & 7.4789 & TRN & & \\
\hline CHEMBL3936884 & 1641605 & 7.3279 & 7.428 & TST & & \\
\hline CHEMBL3899164 & 1641605 & 6.8268 & 7.8502 & TST & & \\
\hline
\end{tabular}


Supplemental Table S2.txt

\begin{tabular}{|c|c|c|c|c|c|}
\hline CHEMBL3906988 & 1641605 & 7.4089 & 7.1504 & TRN & \\
\hline CHEMBL3904248 & 1641605 & 7.7447 & 7.7291 & TRN & \\
\hline CHEMBL3968407 & 1641605 & 7.7447 & 7.8662 & TRN & \\
\hline CHEMBL3913175 & 1641605 & 5.777 & 6.0324 & TRN & \\
\hline CHEMBL3944475 & 1641605 & 6.3726 & 7.2142 & TST & \\
\hline CHEMBL3943416 & 1641605 & 7.6198 & 7.8339 & TRN & \\
\hline CHEMBL3970803 & 1641605 & 6.7328 & 6.6559 & TRN & \\
\hline CHEMBL3973922 & 1641605 & 6.8182 & 6.7228 & TRN & \\
\hline CHEMBL3925042 & 1641605 & 6.9788 & 6.8397 & TRN & \\
\hline CHEMBL3915672 & 1641605 & 6.5575 & 6.5993 & TST & \\
\hline CHEMBL3942668 & 1641605 & 7.1308 & 6.4286 & TST & \\
\hline CHEMBL3925432 & 1641605 & 7.7447 & 7.4182 & TST & \\
\hline CHEMBL3949929 & 1641605 & 6.4318 & 6.6914 & TRN & \\
\hline CHEMBL3977284 & 1641605 & 7.0915 & 7.1664 & TST & \\
\hline CHEMBL3894959 & 1641605 & 7.1249 & 6.8557 & TRN & \\
\hline CHEMBL3939467 & 1641605 & 6.767 & 6.8994 & TRN & \\
\hline CHEMBL3922937 & 1641605 & 7.1871 & 7.1717 & TRN & \\
\hline CHEMBL 3942345 & 1641605 & 6.5544 & 6.5764 & TRN & \\
\hline CHEMBL3905834 & 1641605 & 5.7354 & 5.8973 & TRN & \\
\hline CHEMBL3977331 & 1641605 & 6.6402 & 6.8792 & TRN & \\
\hline CHEMBL3983776 & 1641605 & 7.3372 & 7.3077 & TRN & \\
\hline CHEMBL3930479 & 1641605 & 7.2757 & 7.2037 & TRN & \\
\hline CHEMBL3901235 & 1641605 & 7.5086 & 7.5766 & TRN & \\
\hline CHEMBL3978910 & 1641605 & 7.585 & 7.4556 & TRN & \\
\hline CHEMBL3980648 & 1641605 & 7.4685 & 7.1444 & TRN & \\
\hline CHEMBL3961421 & 1641605 & 6.9508 & 7.0103 & TRN & \\
\hline CHEMBL3959510 & 1641605 & 7.1675 & 7.2502 & TRN & \\
\hline CHEMBL3969030 & 1641605 & 6.0969 & 6.0989 & TRN & \\
\hline CHEMBL3908538 & 1641605 & 7.2076 & 7.1901 & TRN & \\
\hline CHEMBL3920940 & 1641605 & 7.5528 & 7.4855 & TRN & \\
\hline CHEMBL3933854 & 1641605 & 5.6619 & 5.9962 & TRN & \\
\hline CHEMBL3909825 & 1641605 & 7.4202 & 7.80399 & 9999999999 & TST \\
\hline CHEMBL3923713 & 1641605 & 6.58 & 7.2537 & TST & \\
\hline CHEMBL3953106 & 1641605 & 7.0177 & 7.3856 & TRN & \\
\hline CHEMBL1964290 & 809219 & 7.6 & 7.2783 & TRN & \\
\hline CHEMBL 2003768 & 809219 & 5.5 & 5.6834 & TRN & \\
\hline CHEMBL213505 & 809219 & 4.1 & 4.9154 & TRN & \\
\hline CHEMBL202721 & 809219 & 4.6 & 4.6127 & TRN & \\
\hline CHEMBL1982880 & 809219 & 5.6 & 4.3523 & TRN & \\
\hline CHEMBL1987034 & 809219 & 7.0 & 7.166 & TRN & \\
\hline CHEMBL1993941 & 809219 & 4.1 & 3.8607 & TRN & \\
\hline CHEMBL1980435 & 809219 & 8.2 & 8.1178 & TRN & \\
\hline CHEMBL377383 & 809219 & 4.1 & 3.967 & TRN & \\
\hline CHEMBL 2005886 & 809219 & 6.1 & 5.2095 & TRN & \\
\hline CHEMBL481491 & 809219 & 4.1 & 4.4528 & TST & \\
\hline CHEMBL1682345 & 809219 & 7.0 & 6.9046 & TRN & \\
\hline CHEMBL388311 & 809219 & 8.9 & \multicolumn{2}{|c|}{7.757000000000001} & TRN \\
\hline CHEMBL1973145 & 809219 & 4.1 & 3.9009 & TRN & \\
\hline
\end{tabular}




\begin{tabular}{|c|c|c|c|c|}
\hline & & & pplement & al $\mathrm{Ta}$ \\
\hline CHEMBL1982924 & 809219 & 5.9 & 5.8947 & TRN \\
\hline CHEMBL 2005936 & 809219 & 8.4 & 8.5628 & TRN \\
\hline CHEMBL1807515 & 809219 & 6.8 & 7.2371 & TRN \\
\hline CHEMBL1964948 & 809219 & 4.4 & 4.2152 & TRN \\
\hline CHEMBL1999778 & 809219 & 5.6 & 5.2355 & TST \\
\hline CHEMBL1971141 & 809219 & 4.1 & 3.9814 & TRN \\
\hline CHEMBL1995813 & 809219 & 6.8 & 6.6887 & TRN \\
\hline CHEMBL1979718 & 809219 & 5.8 & 5.5577 & TRN \\
\hline CHEMBL 206236 & 809219 & 5.5 & 4.8802 & TRN \\
\hline CHEMBL1989834 & 809219 & 3.7 & 4.5779 & TRN \\
\hline CHEMBL523823 & 809219 & 4.3 & 4.7608 & TST \\
\hline CHEMBL1562756 & 809219 & 5.5 & 5.5586 & TST \\
\hline CHEMBL1987430 & 809219 & 8.3 & 7.9066 & TRN \\
\hline CHEMBL 2001957 & 809219 & 4.1 & 3.9488 & TRN \\
\hline CHEMBL1969372 & 809219 & 5.6 & 5.5697 & TRN \\
\hline CHEMBL1993413 & 809219 & 4.4 & 4.7296 & TRN \\
\hline CHEMBL1990583 & 809219 & 5.8 & 4.8339 & TRN \\
\hline CHEMBL1986943 & 809219 & 7.2 & 7.4477 & TRN \\
\hline CHEMBL 2006263 & 809219 & 6.5 & 6.1522 & TST \\
\hline CHEMBL1993584 & 809219 & 6.2 & 5.4676 & TRN \\
\hline CHEMBL 2000114 & 809219 & 5.3 & 5.4459 & TRN \\
\hline CHEMBL 210618 & 809219 & 4.1 & 4.1104 & TRN \\
\hline CHEMBL1986265 & 809219 & 4.4 & 4.3298 & TRN \\
\hline CHEMBL1971172 & 809219 & 6.0 & 6.0891 & TRN \\
\hline CHEMBL1975647 & 809219 & 8.3 & 8.1307 & TRN \\
\hline CHEMBL1968380 & 809219 & 4.1 & 3.8878 & TRN \\
\hline CHEMBL1967211 & 809219 & 4.1 & 4.5883 & TRN \\
\hline CHEMBL1964644 & 809219 & 7.1 & 6.2855 & TRN \\
\hline CHEMBL1991734 & 809219 & 5.4 & 5.4739 & TST \\
\hline CHEMBL1981782 & 809219 & 5.6 & 5.0417 & TRN \\
\hline CHEMBL1977681 & 809219 & 6.2 & 5.7481 & TRN \\
\hline CHEMBL1970142 & 809219 & 4.1 & 4.6189 & TRN \\
\hline CHEMBL1990912 & 809219 & 4.1 & 5.7387 & TRN \\
\hline CHEMBL1991782 & 809219 & 3.1 & 3.4421 & TRN \\
\hline CHEMBL1983348 & 809219 & 6.2 & 6.062 & TRN \\
\hline CHEMBL1988163 & 809219 & 7.1 & 6.9935 & TRN \\
\hline CHEMBL1995592 & 809219 & 5.7 & 5.3614 & TST \\
\hline CHEMBL1974480 & 809219 & 5.8 & 5.4991 & TRN \\
\hline CHEMBL1980671 & 809219 & 5.6 & 5.1059 & TRN \\
\hline CHEMBL2006493 & 809219 & 4.1 & 4.3516 & TST \\
\hline CHEMBL1986177 & 809219 & 4.4 & 4.3878 & TRN \\
\hline CHEMBL1996923 & 809219 & 4.1 & 4.4487 & TST \\
\hline CHEMBL1983449 & 809219 & 6.2 & 6.191 & TRN \\
\hline CHEMBL1992323 & 809219 & 5.4 & 4.9698 & TRN \\
\hline CHEMBL1969735 & 809219 & 4.1 & 4.6532 & TRN \\
\hline CHEMBL 2003524 & 809219 & 7.3 & 6.431 & TST \\
\hline CHEMBL 2002649 & 809219 & 7.0 & 6.3734 & TRN \\
\hline CHEMBL1985367 & 809219 & 6.4 & 5.8912 & TST \\
\hline
\end{tabular}




\begin{tabular}{|c|c|c|c|c|}
\hline & & & pमeme & al \\
\hline CHEMBL1996510 & 809219 & 7.4 & 4.8189 & TST \\
\hline CHEMBL437747 & 809219 & 6.9 & 5.51 & TRN \\
\hline CHEMBL1995172 & 809219 & 3.7 & 4.1807 & TST \\
\hline CHEMBL 2001584 & 809219 & 4.4 & 4.2681 & TRN \\
\hline CHEMBL507936 & 809219 & 4.1 & 4.0109 & TRN \\
\hline CHEMBL104264 & 809219 & 4.1 & 4.2975 & TST \\
\hline CHEMBL1967998 & 809219 & 5.5 & 4.7938 & TRN \\
\hline CHEMBL1994321 & 809219 & 4.1 & 4.9938 & TRN \\
\hline CHEMBL1978562 & 809219 & 6.1 & 5.8837 & TST \\
\hline CHEMBL1997129 & 809219 & 6.2 & 5.6839 & TRN \\
\hline CHEMBL1984788 & 809219 & 4.1 & 4.1499 & TRN \\
\hline CHEMBL451964 & 809219 & 4.2 & 4.6029 & TRN \\
\hline CHEMBL1964307 & 809219 & 4.1 & 4.4537 & TRN \\
\hline CHEMBL1989471 & 809219 & 6.6 & 6.0914 & TST \\
\hline CHEMBL 2000508 & 809219 & 4.1 & 5.0055 & TRN \\
\hline CHEMBL1971694 & 809219 & 4.1 & 4.1886 & TST \\
\hline CHEMBL 2001547 & 809219 & 4.1 & 4.015 & TRN \\
\hline CHEMBL210928 & 809219 & 4.1 & 3.9073 & TRN \\
\hline CHEMBL1978195 & 809219 & 7.3 & 7.0615 & TRN \\
\hline CHEMBL1994361 & 809219 & 6.0 & 4.8723 & TRN \\
\hline CHEMBL1986603 & 809219 & 4.1 & 4.3593 & TST \\
\hline CHEMBL1972840 & 809219 & 6.5 & 6.8602 & TRN \\
\hline CHEMBL1977148 & 809219 & 4.1 & 4.8771 & TRN \\
\hline CHEMBL 2003286 & 809219 & 5.3 & 5.4375 & TRN \\
\hline CHEMBL1992306 & 809219 & 4.1 & 4.0856 & TRN \\
\hline CHEMBL 2002165 & 809219 & 4.1 & 3.9686 & TRN \\
\hline CHEMBL 2001668 & 809219 & 4.1 & 4.2899 & TST \\
\hline CHEMBL1979318 & 809219 & 4.1 & 5.0239 & TRN \\
\hline CHEMBL 206382 & 809219 & 4.1 & 4.1264 & TRN \\
\hline CHEMBL1998585 & 809219 & 5.2 & 5.3563 & TRN \\
\hline CHEMBL127898 & 809219 & 4.1 & 5.0973 & TST \\
\hline CHEMBL519697 & 809219 & 4.1 & 4.7946 & TRN \\
\hline CHEMBL 2004934 & 809219 & 6.3 & 6.5122 & TRN \\
\hline CHEMBL1996345 & 809219 & 4.4 & 4.5325 & TST \\
\hline CHEMBL1975128 & 809219 & 7.5 & 8.06 & TRN \\
\hline CHEMBL 2004025 & 809219 & 6.2 & 5.7903 & TRN \\
\hline CHEMBL1996048 & 809219 & 4.4 & 4.5384 & TST \\
\hline CHEMBL1970369 & 809219 & 4.1 & 4.0934 & TRN \\
\hline CHEMBL1976158 & 809219 & 4.7 & 5.3108 & TST \\
\hline CHEMBL461876 & 809219 & 4.4 & 4.8158 & TRN \\
\hline CHEMBL1965033 & 809219 & 4.4 & 4.279 & TRN \\
\hline CHEMBL 2001485 & 809219 & 4.1 & 4.688 & TRN \\
\hline CHEMBL1971519 & 809219 & 4.7 & 4.5295 & TRN \\
\hline CHEMBL504950 & 809219 & 5.3 & 4.4434 & TRN \\
\hline CHEMBL1997335 & 809219 & 4.4 & 4.8763 & TRN \\
\hline CHEMBL1966425 & 809219 & 4.1 & 4.2461 & TRN \\
\hline CHEMBL1984363 & 809219 & 4.1 & 4.9068 & TRN \\
\hline CHEMBL1978099 & 809219 & 6.2 & 6.1009 & TRN \\
\hline
\end{tabular}




\begin{tabular}{|c|c|c|c|c|c|}
\hline \\
\hline CHEMBL1977041 & 809219 & 6.0 & 5.421 & TRN & \\
\hline CHEMBL1968070 & 809219 & 7.6 & 6.7109 & TRN & \\
\hline CHEMBL184847 & 809219 & 4.1 & 4.512 & TRN & \\
\hline CHEMBL1971132 & 809219 & 4.4 & 4.5792 & TRN & \\
\hline CHEMBL1994808 & 809219 & 4.1 & 4.178 & TRN & \\
\hline CHEMBL1984367 & 809219 & 4.1 & 4.8376 & TRN & \\
\hline CHEMBL1985723 & 809219 & 5.6 & 5.3013 & TRN & \\
\hline CHEMBL1982563 & 809219 & 5.2 & 5.1553 & TRN & \\
\hline CHEMBL1991377 & 809219 & 4.4 & 4.7956 & TRN & \\
\hline CHEMBL539474 & 809219 & 6.7 & 6.3116 & TST & \\
\hline CHEMBL575824 & 809219 & 5.6 & 6.1512 & TRN & \\
\hline CHEMBL1988387 & 809219 & 5.1 & 5.5727 & TRN & \\
\hline CHEMBL1973868 & 809219 & 4.4 & 4.5741 & TRN & \\
\hline CHEMBL1972462 & 809219 & 4.4 & 4.2916 & TRN & \\
\hline CHEMBL1997759 & 809219 & 4.1 & 4.1334 & TRN & \\
\hline CHEMBL1994968 & 809219 & 5.1 & 4.6187 & TRN & \\
\hline CHEMBL1989708 & 809219 & 4.1 & 4.0767 & TRN & \\
\hline CHEMBL1974803 & 809219 & 4.1 & 5.3018 & TRN & \\
\hline CHEMBL1970074 & 809219 & 4.1 & 4.2412 & TRN & \\
\hline CHEMBL1984500 & 809219 & 3.1 & 3.43600 & 00000000004 & TRN \\
\hline CHEMBL1986970 & 809219 & 6.9 & 7.0898 & TRN & \\
\hline CHEMBL 2005112 & 809219 & 4.1 & 4.6187 & TST & \\
\hline CHEMBL1958401 & 809219 & 6.8 & 6.2411 & TRN & \\
\hline CHEMBL1984044 & 809219 & 5.1 & 4.0323 & TRN & \\
\hline CHEMBL 2003456 & 809219 & 5.6 & 5.2076 & TRN & \\
\hline CHEMBL1972584 & 809219 & 4.1 & 4.1927 & TRN & \\
\hline CHEMBL 2002992 & 809219 & 4.2 & 4.9314 & TRN & \\
\hline CHEMBL560813 & 809219 & 5.5 & 5.2577 & TRN & \\
\hline CHEMBL 207253 & 809219 & 4.1 & 4.0152 & TST & \\
\hline CHEMBL1890036 & 809219 & 5.5 & 5.3314 & TST & \\
\hline CHEMBL1982700 & 809219 & 4.4 & 4.6061 & TST & \\
\hline CHEMBL1968791 & 809219 & 4.1 & 3.8807 & TRN & \\
\hline CHEMBL 326282 & 809219 & 4.1 & 4.4038 & TST & \\
\hline CHEMBL 2002682 & 809219 & 4.1 & 4.0452 & TST & \\
\hline CHEMBL1985129 & 809219 & 5.5 & 4.3604 & TRN & \\
\hline CHEMBL1977634 & 809219 & 4.4 & 4.2807 & TRN & \\
\hline CHEMBL1992732 & 809219 & 8.2 & 6.3034 & TST & \\
\hline CHEMBL1971186 & 809219 & 5.4 & 5.8571 & TRN & \\
\hline CHEMBL 2003482 & 809219 & 7.0 & 5.9638 & TRN & \\
\hline CHEMBL1973211 & 809219 & 4.1 & 5.2127 & TRN & \\
\hline CHEMBL1984700 & 809219 & 4.1 & 4.9535 & TRN & \\
\hline CHEMBL 2007151 & 809219 & 4.1 & 3.8851 & TRN & \\
\hline CHEMBL1998953 & 809219 & 4.4 & 4.8434 & TRN & \\
\hline CHEMBL1971606 & 809219 & 5.5 & 5.6976 & TRN & \\
\hline CHEMBL1972125 & 809219 & 5.4 & 4.4812 & TRN & \\
\hline CHEMBL1461728 & 809219 & 4.1 & 4.2717 & TRN & \\
\hline CHEMBL1995448 & 809219 & 4.1 & 4.3711 & TRN & \\
\hline CHEMBL1972158 & 809219 & 7.8 & 8.1517 & TRN & \\
\hline
\end{tabular}




\begin{tabular}{|c|c|c|c|c|}
\hline \multicolumn{5}{|c|}{ Supplemental Table S2.txt } \\
\hline CHEMBL1981215 & 809219 & 7.8 & 7.7407 & TRN \\
\hline CHEMBL1974457 & 809219 & 6.4 & 6.5668 & TRN \\
\hline CHEMBL 2006580 & 809219 & 4.1 & 5.3715 & TRN \\
\hline CHEMBL1999414 & 809219 & 4.5 & 4.1579 & TRN \\
\hline CHEMBL1967336 & 809219 & 7.7 & 7.6477 & TRN \\
\hline CHEMBL2006581 & 809219 & 4.1 & 3.9967 & TRN \\
\hline CHEMBL 2006481 & 809219 & 4.1 & 4.0884 & TRN \\
\hline CHEMBL1979855 & 809219 & 4.1 & 5.0786 & TRN \\
\hline CHEMBL1970340 & 809219 & 3.3 & 3.5154 & TRN \\
\hline CHEMBL1967992 & 809219 & 6.2 & 5.7042 & TRN \\
\hline CHEMBL 2005186 & 809219 & 4.1 & 4.8475 & TRN \\
\hline CHEMBL1995927 & 809219 & 4.1 & 5.4369 & TST \\
\hline CHEMBL1981671 & 809219 & 4.4 & 4.6468 & TRN \\
\hline CHEMBL 2006450 & 809219 & 4.4 & 4.6284 & TRN \\
\hline CHEMBL1975534 & 809219 & 4.1 & 4.399 & TST \\
\hline CHEMBL1993424 & 809219 & 6.2 & 6.5527 & TRN \\
\hline CHEMBL1966703 & 809219 & 7.8 & 6.6049 & TST \\
\hline CHEMBL 2001987 & 809219 & 7.9 & 7.5525 & TRN \\
\hline CHEMBL1969561 & 809219 & 7.4 & 7.5584 & TRN \\
\hline CHEMBL1994555 & 809219 & 6.0 & 5.8076 & TRN \\
\hline CHEMBL1983640 & 809219 & 4.4 & 4.9823 & TRN \\
\hline CHEMBL1997023 & 809219 & 5.6 & 5.6635 & TST \\
\hline CHEMBL1964687 & 809219 & 4.1 & 5.3866 & TRN \\
\hline CHEMBL1971943 & 809219 & 4.5 & 4.9653 & TRN \\
\hline CHEMBL1999918 & 809219 & 7.6 & 7.7499 & TRN \\
\hline CHEMBL1974254 & 809219 & 4.1 & 3.9743 & TRN \\
\hline CHEMBL1988537 & 809219 & 5.2 & 5.4442 & TST \\
\hline CHEMBL1969049 & 809219 & 6.6 & 6.4629 & TRN \\
\hline CHEMBL 2005828 & 809219 & 4.1 & 4.7315 & TRN \\
\hline CHEMBL 2002240 & 809219 & 4.1 & 5.0419 & TRN \\
\hline CHEMBL1991143 & 809219 & 4.1 & 4.6439 & TST \\
\hline CHEMBL1998611 & 809219 & 5.7 & 5.6743 & TRN \\
\hline CHEMBL485556 & 809219 & 4.1 & 4.2008 & TRN \\
\hline CHEMBL1975900 & 809219 & 6.7 & 6.5151 & TRN \\
\hline CHEMBL 255822 & 809219 & 5.7 & 5.8754 & TRN \\
\hline CHEMBL1972221 & 809219 & 7.5 & 7.0516 & TRN \\
\hline CHEMBL 2006778 & 809219 & 4.1 & 4.2028 & TRN \\
\hline CHEMBL378627 & 809219 & 4.1 & 4.0328 & TRN \\
\hline CHEMBL1996979 & 809219 & 6.0 & 6.0045 & TRN \\
\hline CHEMBL1997025 & 809219 & 4.1 & 4.0366 & TRN \\
\hline CHEMBL1968406 & 809219 & 4.1 & 5.6046 & TRN \\
\hline CHEMBL1975921 & 809219 & 4.2 & 4.4817 & TRN \\
\hline CHEMBL1982476 & 809219 & 5.4 & 3.9174 & TRN \\
\hline CHEMBL1984274 & 809219 & 4.1 & 4.2298 & TST \\
\hline CHEMBL1998545 & 809219 & 5.4 & 5.2092 & TRN \\
\hline CHEMBL1986869 & 809219 & 4.1 & 4.364 & TRN \\
\hline CHEMBL 2004033 & 809219 & 5.4 & 5.0636 & TST \\
\hline CHEMBL1975923 & 809219 & 4.7 & 4.5686 & TST \\
\hline
\end{tabular}




\begin{tabular}{|c|c|c|c|c|}
\hline & & & pplement & al $\mathrm{Ta}$ \\
\hline CHEMBL 2005449 & 809219 & 7.3 & 6.5533 & TRN \\
\hline CHEMBL1987998 & 809219 & 4.4 & 4.2007 & TRN \\
\hline CHEMBL1682558 & 809219 & 4.1 & 4.3387 & TRN \\
\hline CHEMBL1971534 & 809219 & 5.4 & 5.5881 & TRN \\
\hline CHEMBL1990496 & 809219 & 4.2 & 4.157 & TRN \\
\hline CHEMBL 242865 & 809219 & 7.8 & 7.9343 & TRN \\
\hline CHEMBL1997623 & 809219 & 4.1 & 4.3048 & TRN \\
\hline CHEMBL2002479 & 809219 & 4.1 & 4.18 & TRN \\
\hline CHEMBL1983884 & 809219 & 3.1 & 4.7355 & TST \\
\hline CHEMBL1993166 & 809219 & 4.1 & 4.2637 & TRN \\
\hline CHEMBL1967094 & 809219 & 4.1 & 4.2796 & TRN \\
\hline CHEMBL1966035 & 809219 & 6.1 & 5.5903 & TRN \\
\hline CHEMBL2003341 & 809219 & 6.1 & 5.5915 & TRN \\
\hline CHEMBL1992645 & 809219 & 4.1 & 4.3793 & TST \\
\hline CHEMBL1982992 & 809219 & 5.2 & 5.1841 & TRN \\
\hline CHEMBL1998110 & 809219 & 5.5 & 4.9045 & TRN \\
\hline CHEMBL1999590 & 809219 & 6.2 & 5.8306 & TST \\
\hline CHEMBL1981079 & 809219 & 7.5 & 7.5842 & TRN \\
\hline CHEMBL1978166 & 809219 & 5.9 & 5.5491 & TRN \\
\hline CHEMBL1972276 & 809219 & 5.6 & 4.1043 & TRN \\
\hline CHEMBL1980489 & 809219 & 6.3 & 5.9683 & TRN \\
\hline CHEMBL 2000832 & 809219 & 6.6 & 6.3765 & TRN \\
\hline CHEMBL1967116 & 809219 & 4.1 & 3.7979 & TRN \\
\hline CHEMBL1972454 & 809219 & 4.6 & 4.8065 & TRN \\
\hline CHEMBL1990590 & 809219 & 4.4 & 4.2856 & TRN \\
\hline CHEMBL1977814 & 809219 & 4.2 & 4.1807 & TST \\
\hline CHEMBL513846 & 809219 & 5.4 & 5.524 & TRN \\
\hline CHEMBL86755 & 809219 & 4.4 & 4.5741 & TRN \\
\hline CHEMBL1970709 & 809219 & 4.1 & 4.266 & TRN \\
\hline CHEMBL1974617 & 809219 & 5.6 & 5.2933 & TRN \\
\hline CHEMBL1965660 & 809219 & 8.2 & 8.078 & TRN \\
\hline CHEMBL1992125 & 809219 & 5.8 & 5.3816 & TRN \\
\hline CHEMBL1998112 & 809219 & 4.1 & 4.7457 & TRN \\
\hline CHEMBL1969126 & 809219 & 6.7 & 5.1686 & TRN \\
\hline CHEMBL1980896 & 809219 & 4.2 & 4.2054 & TRN \\
\hline CHEMBL1975208 & 809219 & 4.1 & 4.215 & TST \\
\hline CHEMBL1970104 & 809219 & 5.7 & 5.9564 & TRN \\
\hline CHEMBL1991429 & 809219 & 6.6 & 6.2472 & TRN \\
\hline CHEMBL1964777 & 809219 & 6.7 & 6.7174 & TRN \\
\hline CHEMBL1971149 & 809219 & 4.1 & 5.039 & TRN \\
\hline CHEMBL1999714 & 809219 & 4.1 & 4.0153 & TRN \\
\hline CHEMBL1987533 & 809219 & 4.1 & 4.3278 & TRN \\
\hline CHEMBL1994040 & 809219 & 4.1 & 4.585 & TRN \\
\hline CHEMBL 388978 & 809219 & 7.8 & 7.3376 & TST \\
\hline CHEMBL1984548 & 809219 & 8.1 & 8.059 & TRN \\
\hline CHEMBL579246 & 809219 & 6.2 & 6.7804 & TRN \\
\hline CHEMBL398951 & 809219 & 4.2 & 3.9901 & TST \\
\hline CHEMBL1982506 & 809219 & 7.1 & 6.329 & TST \\
\hline
\end{tabular}




\begin{tabular}{|c|c|c|c|c|c|}
\hline \multicolumn{6}{|c|}{ Supplemental Table S2.txt } \\
\hline CHEMBL 2004716 & 809219 & 4.1 & 4.0838 & TRN & \\
\hline CHEMBL1968127 & 809219 & 4.1 & 4.901 & TRN & \\
\hline CHEMBL1975233 & 809219 & 4.1 & 5.2337 & TRN & \\
\hline CHEMBL207400 & 809219 & 4.1 & 4.2645 & TST & \\
\hline CHEMBL 2000894 & 809219 & 6.1 & 5.7893 & TST & \\
\hline CHEMBL1421720 & 809219 & 4.4 & 5.751 & TRN & \\
\hline CHEMBL1968130 & 809219 & 4.7 & 4.6312 & TST & \\
\hline CHEMBL 2002553 & 809219 & 4.1 & 4.9718 & TST & \\
\hline CHEMBL1982135 & 809219 & 4.1 & 5.3275 & TRN & \\
\hline CHEMBL1976090 & 809219 & 6.7 & 5.4313 & TRN & \\
\hline CHEMBL 2004771 & 809219 & 5.1 & 4.923 & TRN & \\
\hline CHEMBL1992922 & 809219 & 6.4 & 5.79700 & 0000000001 & TRN \\
\hline CHEMBL399021 & 809219 & 4.1 & 3.8134 & TRN & \\
\hline CHEMBL1997597 & 809219 & 5.1 & 4.3864 & TRN & \\
\hline CHEMBL576113 & 809219 & 4.4 & 4.9424 & TRN & \\
\hline CHEMBL1976093 & 809219 & 4.1 & 4.8287 & TRN & \\
\hline CHEMBL210032 & 809219 & 4.1 & 4.2598 & TRN & \\
\hline CHEMBL1996543 & 809219 & 5.8 & 5.6467 & TRN & \\
\hline CHEMBL1975256 & 809219 & 7.3 & 6.2755 & TST & \\
\hline CHEMBL508928 & 809219 & 4.1 & 4.0252 & TRN & \\
\hline CHEMBL1991356 & 809219 & 4.1 & 4.3498 & TST & \\
\hline CHEMBL1983309 & 809219 & 6.0 & 5.7896 & TRN & \\
\hline CHEMBL1949855 & 809219 & 4.6 & 4.6862 & TRN & \\
\hline CHEMBL1999126 & 809219 & 4.1 & 5.3687 & TST & \\
\hline CHEMBL1997503 & 809219 & 4.1 & 4.2992 & TST & \\
\hline CHEMBL116070 & 809219 & 7.0 & 6.79200 & 0000000001 & TRN \\
\hline CHEMBL1990821 & 809219 & 4.1 & 4.0019 & TST & \\
\hline CHEMBL1970314 & 809219 & 4.1 & 4.3346 & TRN & \\
\hline CHEMBL 2004871 & 809219 & 4.1 & 4.1265 & TRN & \\
\hline CHEMBL 2004872 & 809219 & 6.2 & 5.8814 & TRN & \\
\hline CHEMBL1727312 & 809219 & 4.1 & 4.0937 & TRN & \\
\hline CHEMBL1990223 & 809219 & 4.4 & 4.3527 & TRN & \\
\hline CHEMBL1969879 & 809219 & 4.1 & 4.1548 & TRN & \\
\hline CHEMBL1964382 & 809219 & 4.4 & 4.4334 & TST & \\
\hline CHEMBL101311 & 809219 & 4.4 & 4.8351 & TRN & \\
\hline CHEMBL1981720 & 809219 & 7.4 & 8.0335 & TRN & \\
\hline CHEMBL419932 & 809219 & 5.6 & 5.1947 & TRN & \\
\hline CHEMBL262433 & 809219 & 4.1 & 4.6977 & TRN & \\
\hline CHEMBL 306380 & 809219 & 4.1 & 3.9896 & TRN & \\
\hline CHEMBL1966722 & 809219 & 5.8 & 5.9497 & TST & \\
\hline CHEMBL1988581 & 809219 & 6.4 & 6.2986 & TST & \\
\hline CHEMBL 2005699 & 809219 & 4.4 & 4.2104 & TRN & \\
\hline CHEMBL1975500 & 809219 & 6.5 & 6.2665 & TRN & \\
\hline CHEMBL1976328 & 809219 & 4.1 & 4.0006 & TRN & \\
\hline CHEMBL394619 & 809219 & 4.1 & 3.8088 & TRN & \\
\hline CHEMBL 2006564 & 809219 & 5.6 & 5.6553 & TRN & \\
\hline CHEMBL1964399 & 809219 & 5.2 & 5.0844 & TRN & \\
\hline CHEMBL1996831 & 809219 & 4.1 & 5.6217 & TST & \\
\hline
\end{tabular}




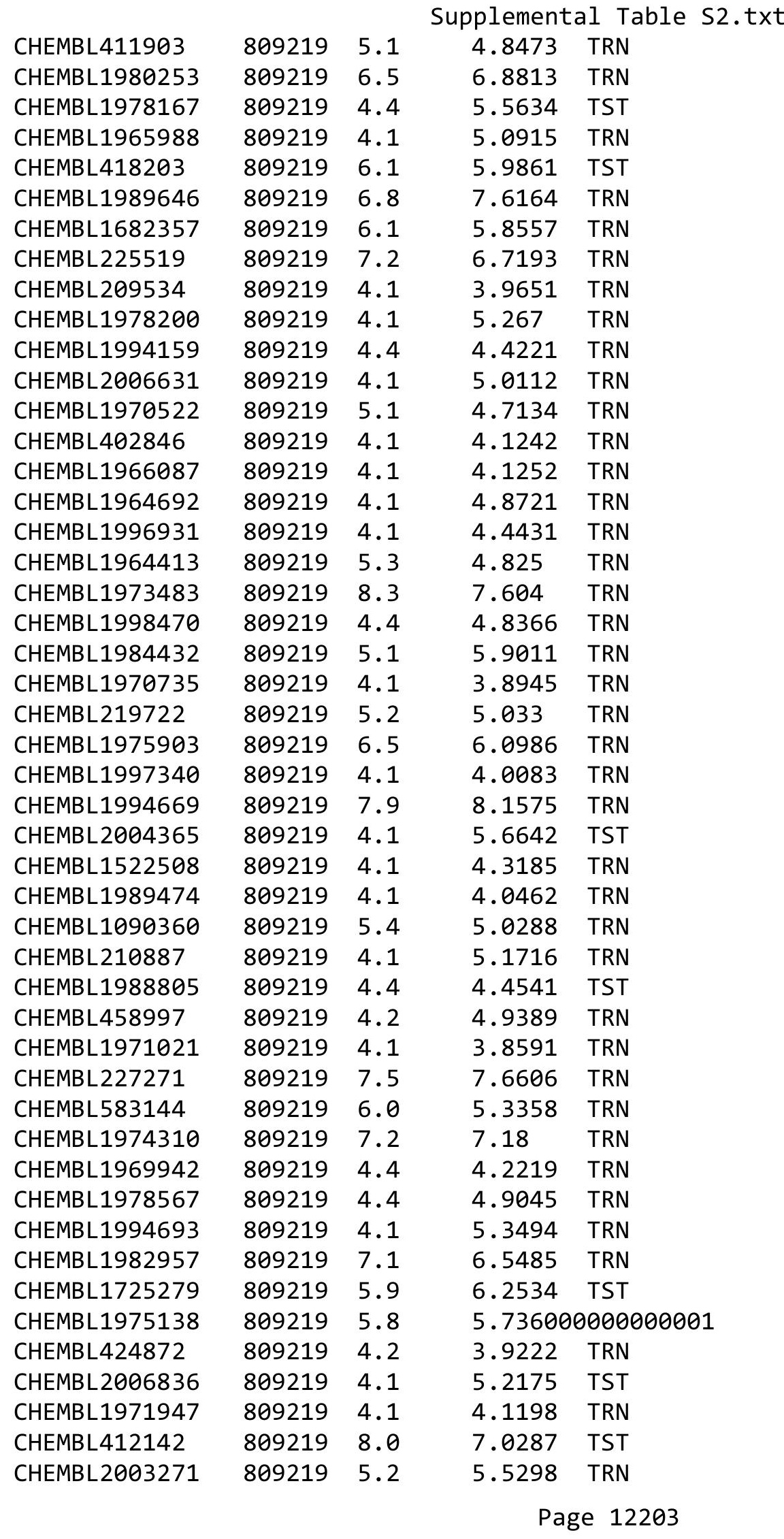




\begin{tabular}{|c|c|c|c|c|c|}
\hline \\
\hline CHEMBL1966808 & 809219 & 7.2 & 6.0728 & TRN & \\
\hline CHEMBL2004447 & 809219 & 4.1 & 4.3784 & TRN & \\
\hline CHEMBL1983111 & 809219 & 6.4 & 6.41200 & 0000000001 & TRN \\
\hline CHEMBL1977713 & 809219 & 4.1 & 5.0569 & TRN & \\
\hline CHEMBL260135 & 809219 & 7.5 & 6.1194 & TRN & \\
\hline CHEMBL220241 & 809219 & 7.3 & 6.1417 & TRN & \\
\hline CHEMBL 2004544 & 809219 & 5.8 & 5.5873 & TST & \\
\hline CHEMBL1988141 & 809219 & 6.5 & 6.18 & TST & \\
\hline CHEMBL1977134 & 809219 & 4.4 & 4.1053 & TRN & \\
\hline CHEMBL1999496 & 809219 & 6.0 & 5.532 & TRN & \\
\hline CHEMBL2006933 & 809219 & 6.4 & 6.6309 & TST & \\
\hline CHEMBL1985206 & 809219 & 4.4 & 4.57100 & 0000000001 & TST \\
\hline CHEMBL1988300 & 809219 & 4.1 & 4.1138 & TRN & \\
\hline CHEMBL1987359 & 809219 & 4.1 & 4.3826 & TST & \\
\hline CHEMBL1977749 & 809219 & 4.4 & 4.5957 & TST & \\
\hline CHEMBL1975212 & 809219 & 4.4 & 4.3308 & TRN & \\
\hline CHEMBL 2000685 & 809219 & 4.1 & 4.4661 & TRN & \\
\hline CHEMBL2001613 & 809219 & 4.4 & 4.762 & TRN & \\
\hline CHEMBL1997275 & 809219 & 4.4 & 4.6528 & TRN & \\
\hline CHEMBL1993904 & 809219 & 6.3 & 5.9189 & TRN & \\
\hline CHEMBL1967513 & 809219 & 7.2 & 7.5574 & TRN & \\
\hline CHEMBL 2000724 & 809219 & 5.4 & 4.2444 & TRN & \\
\hline CHEMBL1985311 & 809219 & 5.1 & 4.5483 & TRN & \\
\hline CHEMBL1989265 & 809219 & 5.6 & 5.2003 & TST & \\
\hline CHEMBL1982413 & 809219 & 4.4 & 5.4798 & TST & \\
\hline CHEMBL 2004647 & 809219 & 4.1 & 4.3723 & TST & \\
\hline CHEMBL1965910 & 809219 & 4.1 & 3.8168 & TRN & \\
\hline CHEMBL1682553 & 809219 & 7.7 & 7.3657 & TRN & \\
\hline CHEMBL1971430 & 809219 & 4.1 & 3.9551 & TRN & \\
\hline CHEMBL1983963 & 809219 & 4.1 & 3.9322 & TRN & \\
\hline CHEMBL1997764 & 809219 & 5.7 & 5.4402 & TRN & \\
\hline CHEMBL 2000271 & 809219 & 6.0 & 6.57799 & 9999999999 & TRN \\
\hline CHEMBL1981792 & 809219 & 7.4 & 7.6184 & TRN & \\
\hline CHEMBL1987535 & 809219 & 4.4 & 5.8174 & TRN & \\
\hline CHEMBL1985092 & 809219 & 4.1 & 5.1143 & TRN & \\
\hline CHEMBL2004692 & 809219 & 6.0 & 5.635 & TST & \\
\hline CHEMBL1981410 & 809219 & 4.1 & 4.0723 & TRN & \\
\hline CHEMBL 2002586 & 809219 & 4.4 & 4.5609 & TRN & \\
\hline CHEMBL1987815 & 809219 & 4.4 & 4.5036 & TST & \\
\hline CHEMBL1996234 & 809219 & 4.1 & 4.1454 & TRN & \\
\hline CHEMBL383264 & 809219 & 6.6 & 6.5987 & TRN & \\
\hline CHEMBL 2007421 & 809219 & 4.4 & 4.7624 & TRN & \\
\hline CHEMBL1991434 & 809219 & 4.1 & 4.5672 & TST & \\
\hline CHEMBL1967544 & 809219 & 4.1 & 4.7613 & TRN & \\
\hline CHEMBL1973138 & 809219 & 4.4 & 4.3536 & TRN & \\
\hline CHEMBL223367 & 809219 & 4.1 & 6.1758 & TST & \\
\hline CHEMBL1992673 & 809219 & 4.3 & 4.4666 & TRN & \\
\hline CHEMBL340384 & 809219 & 6.9 & 6.3787 & TST & \\
\hline
\end{tabular}




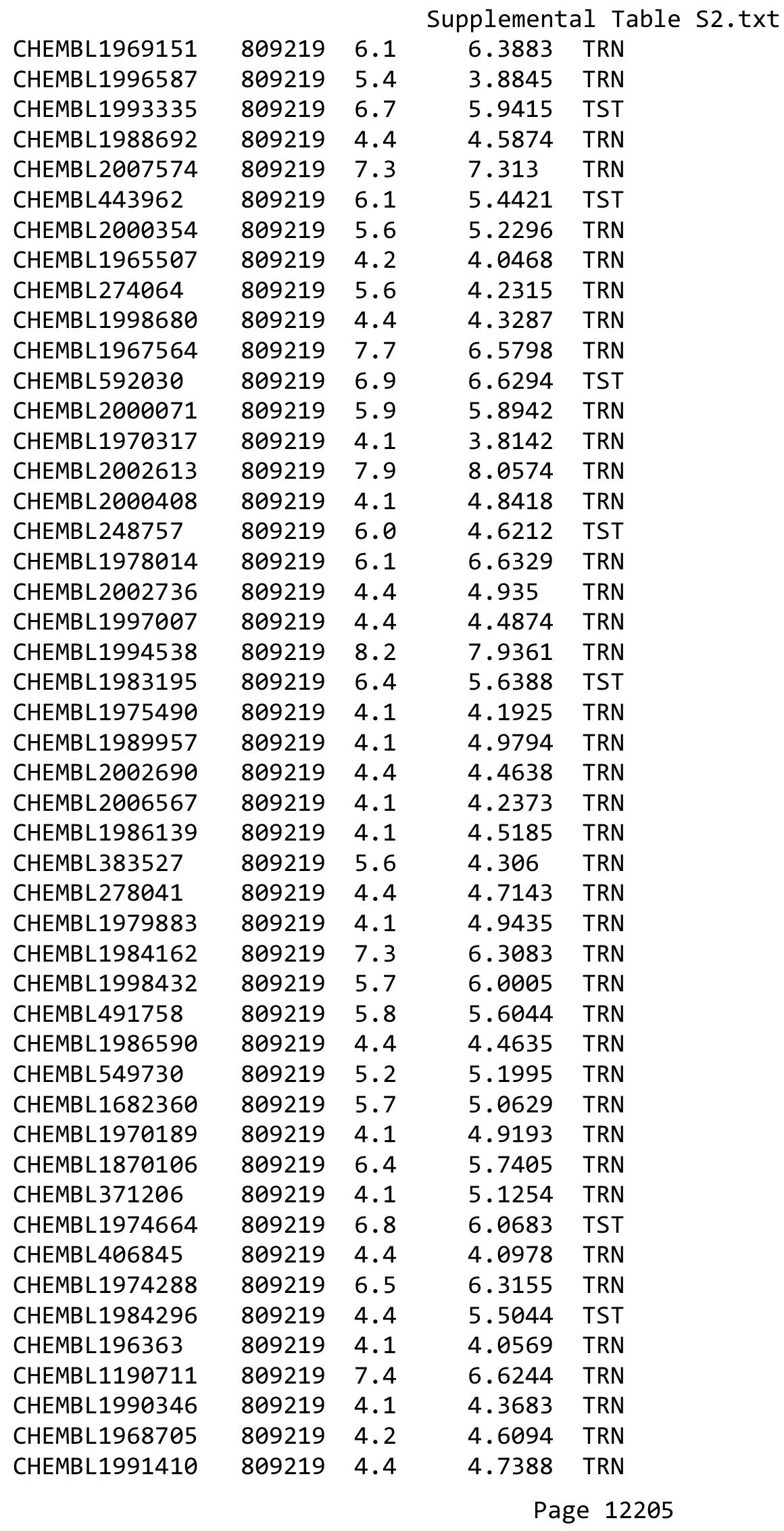




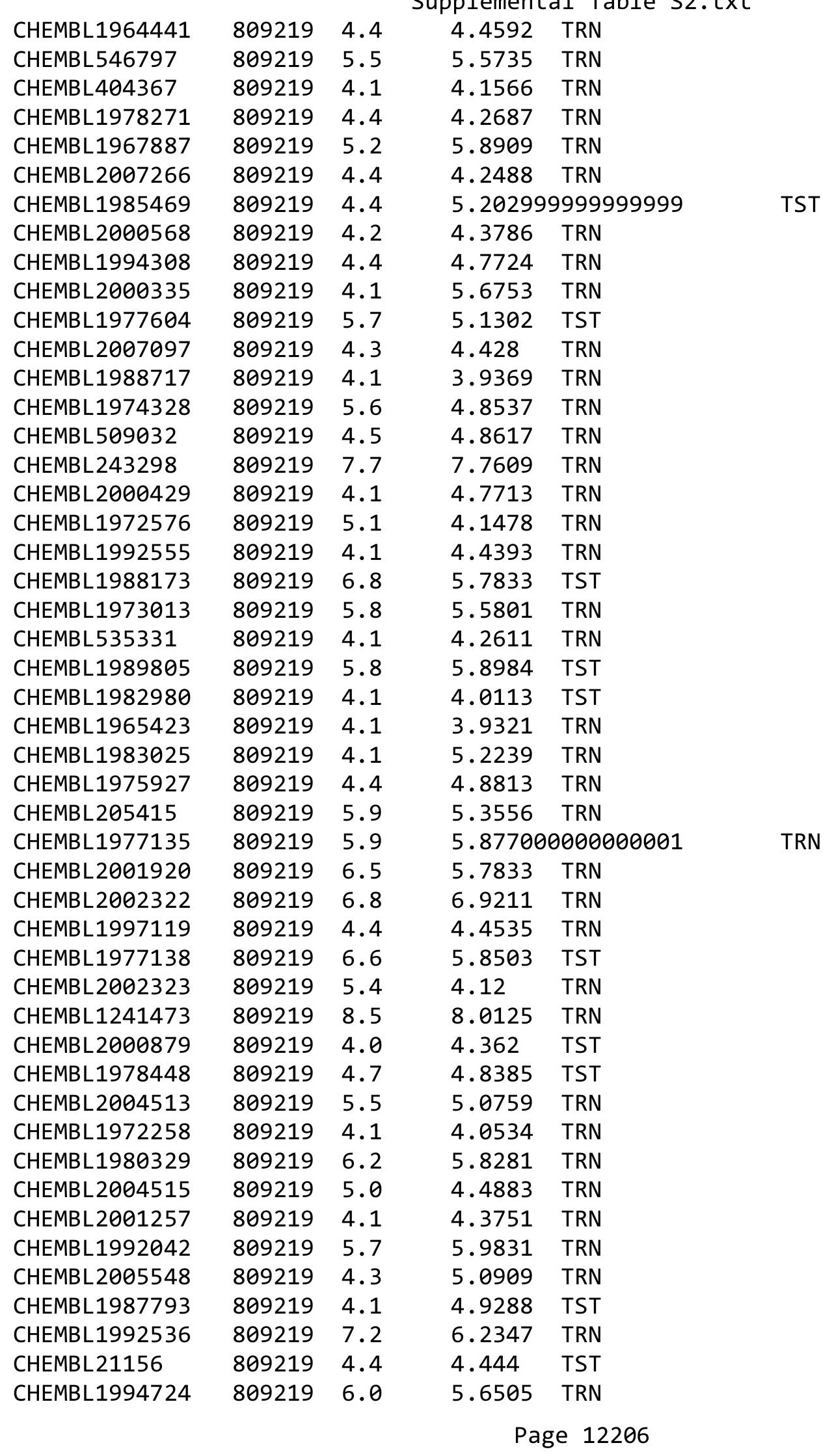




\begin{tabular}{|c|c|c|c|c|}
\hline & & & & $a+1 a$ \\
\hline CHEMBL1989267 & 809219 & 4.4 & 4.9117 & TRN \\
\hline CHEMBL439340 & 809219 & 4.3 & 4.2852 & TRN \\
\hline CHEMBL1974574 & 809219 & 4.4 & 4.7471 & TST \\
\hline CHEMBL 2006188 & 809219 & 5.4 & 5.6449 & TRN \\
\hline CHEMBL1970290 & 809219 & 5.7 & 5.1866 & TRN \\
\hline CHEMBL1967531 & 809219 & 4.1 & 4.6819 & TRN \\
\hline CHEMBL1970913 & 809219 & 7.3 & 6.3519 & TRN \\
\hline CHEMBL1973893 & 809219 & 6.8 & 6.5081 & TRN \\
\hline CHEMBL1995736 & 809219 & 4.1 & 4.1827 & TRN \\
\hline CHEMBL1997534 & 809219 & 7.7 & 6.874 & TRN \\
\hline CHEMBL1993877 & 809219 & 5.4 & 4.618 & TRN \\
\hline CHEMBL1996500 & 809219 & 4.3 & 4.2957 & TRN \\
\hline CHEMBL1985095 & 809219 & 7.3 & 6.6885 & TST \\
\hline CHEMBL1998551 & 809219 & 4.1 & 3.9034 & TRN \\
\hline CHEMBL1977374 & 809219 & 4.1 & 3.877 & TRN \\
\hline CHEMBL1973363 & 809219 & 5.4 & 5.1884 & TRN \\
\hline CHEMBL1991180 & 809219 & 7.0 & 5.9527 & TST \\
\hline CHEMBL1682540 & 809219 & 7.0 & 7.0333 & TRN \\
\hline CHEMBL1978656 & 809219 & 5.1 & 4.1656 & TRN \\
\hline CHEMBL1976420 & 809219 & 5.6 & 5.4919 & TRN \\
\hline CHEMBL1998253 & 809219 & 4.4 & 4.4493 & TST \\
\hline CHEMBL413779 & 809219 & 4.1 & 6.1046 & TST \\
\hline CHEMBL1981744 & 809219 & 7.8 & 7.67399 & 99999999995 \\
\hline CHEMBL1994864 & 809219 & 6.2 & 5.854 & TRN \\
\hline CHEMBL2002446 & 809219 & 4.1 & 5.007 & TST \\
\hline CHEMBL497151 & 809219 & 7.6 & 7.0635 & TRN \\
\hline CHEMBL 2000029 & 809219 & 6.9 & 7.4634 & TRN \\
\hline CHEMBL1973961 & 809219 & 4.4 & 4.7495 & TRN \\
\hline CHEMBL 246970 & 809219 & 6.2 & 5.9498 & TRN \\
\hline CHEMBL340921 & 809219 & 5.8 & 5.5805 & TST \\
\hline CHEMBL1994977 & 809219 & 4.4 & 4.2319 & TRN \\
\hline CHEMBL 373598 & 809219 & 4.1 & 6.0435 & TST \\
\hline CHEMBL 2001149 & 809219 & 4.4 & 4.6817 & TRN \\
\hline CHEMBL1999718 & 809219 & 8.2 & 7.5778 & TRN \\
\hline CHEMBL 2005478 & 809219 & 6.3 & 6.0796 & TST \\
\hline CHEMBL1276446 & 809219 & 8.4 & 7.5213 & TST \\
\hline CHEMBL1996646 & 809219 & 5.7 & 5.5322 & TRN \\
\hline CHEMBL1979773 & 809219 & 4.4 & 4.342 & TRN \\
\hline CHEMBL1977346 & 809219 & 7.1 & 6.4616 & TRN \\
\hline CHEMBL 2003657 & 809219 & 4.1 & 4.0504 & TRN \\
\hline CHEMBL1971649 & 809219 & 4.1 & 4.0235 & TRN \\
\hline CHEMBL1996702 & 809219 & 5.7 & 5.1775 & TRN \\
\hline CHEMBL 2007124 & 809219 & 4.4 & 4.1411 & TRN \\
\hline CHEMBL1998435 & 809219 & 4.1 & 4.9741 & TRN \\
\hline CHEMBL 2006439 & 809219 & 6.1 & 5.8596 & TRN \\
\hline CHEMBL 2006156 & 809219 & 4.1 & 4.6151 & TST \\
\hline CHEMBL1985681 & 809219 & 7.1 & 6.6078 & TST \\
\hline CHEMBL1969190 & 809219 & 4.1 & 3.9605 & TRN \\
\hline
\end{tabular}




\begin{tabular}{|c|c|c|c|c|}
\hline \multicolumn{5}{|c|}{ Supplemental Table S2.txt } \\
\hline CHEMBL1973937 & 809219 & 4.1 & 4.0344 & TRN \\
\hline CHEMBL1991674 & 809219 & 7.5 & 7.1888 & TRN \\
\hline CHEMBL1982711 & 809219 & 6.2 & 6.2029 & TRN \\
\hline CHEMBL262623 & 809219 & 4.2 & 4.2586 & TRN \\
\hline CHEMBL1987982 & 809219 & 4.1 & 4.3449 & TST \\
\hline CHEMBL1984842 & 809219 & 4.1 & 4.0921 & TRN \\
\hline CHEMBL1969102 & 809219 & 4.1 & 3.9288 & TRN \\
\hline CHEMBL 2004118 & 809219 & 4.4 & 4.3344 & TRN \\
\hline CHEMBL1682346 & 809219 & 6.9 & 7.5557 & TRN \\
\hline CHEMBL 2007044 & 809219 & 4.1 & 4.0493 & TST \\
\hline CHEMBL2001998 & 809219 & 4.1 & 3.9173 & TST \\
\hline CHEMBL1994241 & 809219 & 6.5 & 6.0807 & TRN \\
\hline CHEMBL 223460 & 809219 & 4.1 & 5.5832 & TST \\
\hline CHEMBL1998829 & 809219 & 4.1 & 4.5093 & TRN \\
\hline CHEMBL1995211 & 809219 & 6.3 & 5.9962 & TRN \\
\hline CHEMBL1988838 & 809219 & 6.0 & 6.1604 & TRN \\
\hline CHEMBL1981725 & 809219 & 4.1 & 4.2918 & TRN \\
\hline CHEMBL1982753 & 809219 & 4.4 & 4.585 & TRN \\
\hline CHEMBL375284 & 809219 & 4.1 & 4.0746 & TRN \\
\hline CHEMBL2006299 & 809219 & 5.5 & 5.3997 & TRN \\
\hline CHEMBL1972346 & 809219 & 5.5 & 5.4689 & TST \\
\hline CHEMBL1965169 & 809219 & 4.4 & 4.6446 & TST \\
\hline CHEMBL1991818 & 809219 & 4.4 & 5.2322 & TST \\
\hline CHEMBL1081312 & 809219 & 5.7 & 4.6568 & TRN \\
\hline CHEMBL1965170 & 809219 & 4.4 & 5.0552 & TRN \\
\hline CHEMBL1982866 & 809219 & 4.1 & 4.0725 & TRN \\
\hline CHEMBL 2005792 & 809219 & 4.1 & 3.995 & TRN \\
\hline CHEMBL1968926 & 809219 & 4.1 & 4.5891 & TRN \\
\hline CHEMBL2006609 & 809219 & 5.5 & 5.2884 & TST \\
\hline CHEMBL1984206 & 809219 & 4.1 & 4.075 & TRN \\
\hline CHEMBL462120 & 809219 & 5.1 & 5.2393 & TRN \\
\hline CHEMBL1991577 & 809219 & 4.1 & 4.3578 & TRN \\
\hline CHEMBL1986503 & 809219 & 4.4 & 4.4547 & TST \\
\hline CHEMBL1965570 & 809219 & 4.1 & 4.073 & TRN \\
\hline CHEMBL 2007592 & 809219 & 5.4 & 4.6443 & TRN \\
\hline CHEMBL1972355 & 809219 & 6.0 & 6.0 & TRN \\
\hline CHEMBL1997892 & 809219 & 4.4 & 4.409 & TRN \\
\hline CHEMBL 2001641 & 809219 & 4.9 & 5.0915 & TRN \\
\hline CHEMBL1997193 & 809219 & 5.8 & 5.8944 & TST \\
\hline CHEMBL 210963 & 809219 & 4.1 & 3.7966 & TRN \\
\hline CHEMBL1964902 & 809219 & 4.4 & 4.1925 & TRN \\
\hline CHEMBL1082440 & 809219 & 4.1 & 4.4639 & TST \\
\hline CHEMBL1614705 & 809219 & 4.1 & 4.1684 & TRN \\
\hline CHEMBL1972362 & 809219 & 7.4 & 7.1449 & TRN \\
\hline CHEMBL1984633 & 809219 & 6.0 & 5.7139 & TRN \\
\hline CHEMBL1965845 & 809219 & 6.7 & 6.5059 & TRN \\
\hline CHEMBL 2007372 & 809219 & 4.1 & 3.9621 & TRN \\
\hline CHEMBL1983715 & 809219 & 5.8 & 5.5836 & TRN \\
\hline
\end{tabular}




\begin{tabular}{|c|c|c|c|c|}
\hline & & & pplement & al $\mathrm{Ta}$ \\
\hline CHEMBL1982167 & 809219 & 5.2 & 4.0474 & TRN \\
\hline CHEMBL1971017 & 809219 & 7.4 & 7.5212 & TRN \\
\hline CHEMBL2006715 & 809219 & 6.4 & 5.8143 & TRN \\
\hline CHEMBL1986597 & 809219 & 5.4 & 4.9286 & TRN \\
\hline CHEMBL1990482 & 809219 & 5.3 & 4.2791 & TRN \\
\hline CHEMBL1990904 & 809219 & 6.0 & 5.5847 & TRN \\
\hline CHEMBL 2000104 & 809219 & 7.8 & 7.2631 & TRN \\
\hline CHEMBL2005475 & 809219 & 4.1 & 4.9629 & TRN \\
\hline CHEMBL1997349 & 809219 & 4.1 & 5.7725 & TST \\
\hline CHEMBL183844 & 809219 & 4.1 & 3.8043 & TRN \\
\hline CHEMBL220057 & 809219 & 4.1 & 4.7621 & TRN \\
\hline CHEMBL1682545 & 809219 & 6.3 & 5.9424 & TRN \\
\hline CHEMBL383541 & 809219 & 6.4 & 5.4965 & TRN \\
\hline CHEMBL 2001224 & 809219 & 4.1 & 4.2881 & TRN \\
\hline CHEMBL10 & 809219 & 4.4 & 5.4311 & TRN \\
\hline CHEMBL1976732 & 809219 & 4.1 & 5.2382 & TRN \\
\hline CHEMBL1969506 & 809219 & 4.1 & 5.2893 & TRN \\
\hline CHEMBL1980763 & 809219 & 4.4 & 4.3241 & TRN \\
\hline CHEMBL1964937 & 809219 & 5.6 & 5.9047 & TRN \\
\hline CHEMBL1980163 & 809219 & 4.1 & 4.1263 & TRN \\
\hline CHEMBL590109 & 809219 & 6.8 & 6.2831 & TST \\
\hline CHEMBL1977931 & 809219 & 4.2 & 4.3326 & TRN \\
\hline CHEMBL1970879 & 809219 & 4.1 & 4.109 & TRN \\
\hline CHEMBL1989856 & 809219 & 5.4 & 5.3187 & TST \\
\hline CHEMBL2005899 & 809219 & 5.5 & 4.9733 & TRN \\
\hline CHEMBL1682552 & 809219 & 7.2 & 7.0879 & TRN \\
\hline CHEMBL 259850 & 809219 & 7.6 & 6.6543 & TRN \\
\hline CHEMBL1972568 & 809219 & 4.1 & 4.2407 & TRN \\
\hline CHEMBL 2007479 & 809219 & 7.0 & 5.9376 & TRN \\
\hline CHEMBL1996155 & 809219 & 4.1 & 4.035 & TRN \\
\hline CHEMBL229799 & 809219 & 7.3 & 7.7978 & TRN \\
\hline CHEMBL1971223 & 809219 & 4.4 & 4.3609 & TRN \\
\hline CHEMBL105739 & 809219 & 4.1 & 4.291 & TRN \\
\hline CHEMBL1682359 & 809219 & 5.6 & 5.2973 & TRN \\
\hline CHEMBL1972220 & 809219 & 4.4 & 5.4492 & TRN \\
\hline CHEMBL 379300 & 809219 & 6.9 & 7.745 & TRN \\
\hline CHEMBL 203673 & 809219 & 6.2 & 4.922 & TRN \\
\hline CHEMBL 2003785 & 809219 & 4.3 & 4.5298 & TST \\
\hline CHEMBL1973720 & 809219 & 6.4 & 6.8646 & TRN \\
\hline CHEMBL1969523 & 809219 & 6.3 & 5.9804 & TRN \\
\hline CHEMBL1988995 & 809219 & 4.1 & 4.1095 & TRN \\
\hline CHEMBL207995 & 809219 & 5.8 & 5.4153 & TRN \\
\hline CHEMBL2001923 & 809219 & 4.2 & 4.426 & TRN \\
\hline CHEMBL1986781 & 809219 & 6.2 & 6.1535 & TRN \\
\hline CHEMBL1983070 & 809219 & 4.4 & 4.2616 & TRN \\
\hline CHEMBL526133 & 809219 & 7.7 & 6.9232 & TRN \\
\hline CHEMBL 2003514 & 809219 & 5.6 & 5.6681 & TRN \\
\hline CHEMBL1989043 & 809219 & 5.5 & 5.3081 & TRN \\
\hline
\end{tabular}




\begin{tabular}{|c|c|c|c|c|}
\hline & & & $=1$ & al Ta \\
\hline CHEMBL 2002470 & 809219 & 5.4 & 5.3368 & TRN \\
\hline CHEMBL1967538 & 809219 & 4.3 & 4.6454 & TRN \\
\hline CHEMBL1979057 & 809219 & 5.4 & 4.7982 & TRN \\
\hline CHEMBL1981045 & 809219 & 4.1 & 5.2968 & TRN \\
\hline CHEMBL 387971 & 809219 & 4.1 & 4.3997 & TST \\
\hline CHEMBL1975418 & 809219 & 7.8 & 7.4884 & TRN \\
\hline CHEMBL1992796 & 809219 & 5.1 & 5.0202 & TRN \\
\hline CHEMBL1968515 & 809219 & 4.3 & 4.458 & TST \\
\hline CHEMBL1164180 & 809219 & 4.4 & 4.6482 & TST \\
\hline CHEMBL223257 & 809219 & 4.1 & 5.3345 & TST \\
\hline CHEMBL1999428 & 809219 & 6.4 & 6.1795 & TRN \\
\hline CHEMBL1967560 & 809219 & 4.1 & 3.9627 & TRN \\
\hline CHEMBL1997611 & 809219 & 4.4 & 4.7908 & TST \\
\hline CHEMBL1516890 & 809219 & 4.1 & 5.6982 & TRN \\
\hline CHEMBL211378 & 809219 & 4.1 & 4.0934 & TRN \\
\hline CHEMBL1982465 & 809219 & 4.1 & 4.2944 & TRN \\
\hline CHEMBL2001751 & 809219 & 6.4 & 7.1484 & TRN \\
\hline CHEMBL 2003420 & 809219 & 4.1 & 4.1853 & TRN \\
\hline CHEMBL1984586 & 809219 & 4.1 & 4.1435 & TRN \\
\hline CHEMBL1999774 & 809219 & 4.1 & 4.3849 & TST \\
\hline CHEMBL1972659 & 809219 & 4.1 & 4.3504 & TST \\
\hline CHEMBL 2002723 & 809219 & 5.5 & 5.3472 & TST \\
\hline CHEMBL1973395 & 809219 & 5.9 & 5.5136 & TRN \\
\hline CHEMBL272453 & 809219 & 4.1 & 3.988 & TRN \\
\hline CHEMBL1970217 & 809219 & 6.3 & 6.2678 & TRN \\
\hline CHEMBL1971801 & 809219 & 6.7 & 5.485 & TRN \\
\hline CHEMBL1968850 & 809219 & 7.0 & 6.5907 & TRN \\
\hline CHEMBL1984686 & 809219 & 5.4 & 4.7287 & TRN \\
\hline CHEMBL185569 & 809219 & 4.1 & 3.9651 & TRN \\
\hline CHEMBL 2007002 & 809219 & 4.1 & 6.2173 & TRN \\
\hline CHEMBL1987007 & 809219 & 4.1 & 4.2267 & TRN \\
\hline CHEMBL1973793 & 809219 & 4.4 & 4.4795 & TST \\
\hline CHEMBL1984711 & 809219 & 5.9 & 5.5292 & TRN \\
\hline CHEMBL1992073 & 809219 & 4.4 & 4.4951 & TRN \\
\hline CHEMBL1990212 & 809219 & 5.1 & 4.3391 & TRN \\
\hline CHEMBL484390 & 809219 & 4.1 & 4.17 & TRN \\
\hline CHEMBL1979252 & 809219 & 6.3 & 6.0198 & TRN \\
\hline CHEMBL1986143 & 809219 & 5.9 & 5.7755 & TRN \\
\hline CHEMBL1972934 & 809219 & 4.4 & 4.6386 & TRN \\
\hline CHEMBL 2007559 & 809219 & 4.4 & 4.5506 & TRN \\
\hline CHEMBL1992581 & 809219 & 4.4 & 4.5255 & TRN \\
\hline CHEMBL1682341 & 809219 & 6.5 & 5.86 & TRN \\
\hline CHEMBL 2004290 & 809219 & 4.2 & 4.3119 & TRN \\
\hline CHEMBL1986499 & 809219 & 8.0 & 8.0849 & TRN \\
\hline CHEMBL1972937 & 809219 & 4.1 & 4.5267 & TRN \\
\hline CHEMBL1972250 & 809219 & 4.1 & 4.2207 & TST \\
\hline CHEMBL 2000393 & 809219 & 5.3 & 5.2501 & TST \\
\hline CHEMBL 2004072 & 809219 & 6.1 & 6.1468 & TRN \\
\hline
\end{tabular}




\begin{tabular}{|c|c|c|c|c|c|}
\hline \multicolumn{6}{|c|}{ Supplemental Table S2.txt } \\
\hline CHEMBL 2004311 & 809219 & 4.1 & 3.8535 & TRN & \\
\hline CHEMBL1992634 & 809219 & 4.1 & 5.1011 & TRN & \\
\hline CHEMBL1242373 & 809219 & 4.1 & 5.1599 & TRN & \\
\hline CHEMBL 2000433 & 809219 & 4.1 & 5.0945 & TST & \\
\hline CHEMBL56543 & 809219 & 5.6 & 5.3374 & TRN & \\
\hline CHEMBL1984847 & 809219 & 4.4 & 4.5278 & TRN & \\
\hline CHEMBL1984402 & 809219 & 5.1 & 5.06800 & 00000000005 & TRN \\
\hline CHEMBL316264 & 809219 & 4.1 & 5.3409 & TRN & \\
\hline CHEMBL1988075 & 809219 & 4.1 & 3.827 & TRN & \\
\hline CHEMBL1996576 & 809219 & 4.4 & 4.5866 & TST & \\
\hline CHEMBL1991678 & 809219 & 4.3 & 4.1479 & TRN & \\
\hline CHEMBL 2001239 & 809219 & 4.1 & 4.4728 & TST & \\
\hline CHEMBL1988594 & 809219 & 4.1 & 4.2467 & TRN & \\
\hline CHEMBL 2001288 & 809219 & 4.1 & 4.5858 & TST & \\
\hline CHEMBL260092 & 809219 & 5.1 & 4.1282 & TRN & \\
\hline CHEMBL1965495 & 809219 & 6.5 & 5.5206 & TRN & \\
\hline CHEMBL235157 & 809219 & 4.4 & 4.5246 & TST & \\
\hline CHEMBL1985074 & 809219 & 6.8 & 5.8978 & TST & \\
\hline CHEMBL 2000481 & 809219 & 4.1 & 4.9997 & TRN & \\
\hline CHEMBL1982874 & 809219 & 4.1 & 4.029 & TRN & \\
\hline CHEMBL1991725 & 809219 & 5.6 & 5.7326 & TRN & \\
\hline CHEMBL1992242 & 809219 & 4.1 & 3.9257 & TRN & \\
\hline CHEMBL 2007296 & 809219 & 5.9 & 5.7369 & TRN & \\
\hline CHEMBL208637 & 809219 & 4.1 & 3.8298 & TRN & \\
\hline CHEMBL396523 & 809219 & 8.4 & 8.2204 & TRN & \\
\hline CHEMBL 2004159 & 809219 & 4.4 & 4.579 & TRN & \\
\hline CHEMBL1978371 & 809219 & 5.4 & 5.6431 & TST & \\
\hline CHEMBL1970203 & 809219 & 4.1 & 4.084 & TRN & \\
\hline CHEMBL1986530 & 809219 & 4.1 & 4.3525 & TST & \\
\hline CHEMBL440084 & 809219 & 4.4 & 4.6 & TRN & \\
\hline CHEMBL1999321 & 809219 & 4.1 & 4.4695 & TRN & \\
\hline CHEMBL1968590 & 809219 & 4.1 & 4.0282 & TRN & \\
\hline CHEMBL1999749 & 809219 & 4.1 & 4.1398 & TRN & \\
\hline CHEMBL 2005375 & 809219 & 4.1 & 3.9757 & TRN & \\
\hline CHEMBL1984191 & 809219 & 4.1 & 4.97 & TRN & \\
\hline CHEMBL1983006 & 809219 & 5.3 & 5.3066 & TRN & \\
\hline CHEMBL1972183 & 809219 & 4.1 & 4.0496 & TRN & \\
\hline CHEMBL1971029 & 809219 & 6.3 & 5.6626 & TRN & \\
\hline CHEMBL394790 & 809219 & 4.1 & 3.8072 & TRN & \\
\hline CHEMBL226471 & 809219 & 5.4 & 4.8775 & TRN & \\
\hline CHEMBL1974702 & 809219 & 5.7 & 5.7998 & TRN & \\
\hline CHEMBL1996111 & 809219 & 6.5 & 6.9454 & TRN & \\
\hline CHEMBL1966175 & 809219 & 5.6 & 4.36100 & 0000000001 & TRN \\
\hline CHEMBL1965589 & 809219 & 4.1 & 4.9448 & TRN & \\
\hline CHEMBL 2007375 & 809219 & 7.4 & 7.5314 & TRN & \\
\hline CHEMBL1998193 & 809219 & 4.1 & 4.2068 & TRN & \\
\hline CHEMBL379975 & 809219 & 6.2 & 5.7603 & TRN & \\
\hline CHEMBL474432 & 809219 & 5.4 & 5.7077 & TST & \\
\hline
\end{tabular}




\begin{tabular}{|c|c|c|c|c|c|}
\hline \multicolumn{6}{|c|}{ Supplemental Table S2.txt } \\
\hline CHEMBL1973016 & 809219 & 4.4 & 4.381 & TRN & \\
\hline CHEMBL1965387 & 809219 & 4.4 & 4.1965 & TRN & \\
\hline CHEMBL1997041 & 809219 & 5.2 & 4.7845 & TRN & \\
\hline CHEMBL1988153 & 809219 & 8.2 & 8.0264 & TRN & \\
\hline CHEMBL550418 & 809219 & 4.4 & 5.0045 & TRN & \\
\hline CHEMBL1971289 & 809219 & 4.4 & 4.7906 & TRN & \\
\hline CHEMBL1999556 & 809219 & 6.8 & 7.1249 & TRN & \\
\hline CHEMBL1988437 & 809219 & 4.3 & 4.7975 & TST & \\
\hline CHEMBL1968245 & 809219 & 4.1 & 4.4745 & TRN & \\
\hline CHEMBL1979577 & 809219 & 4.1 & 5.0962 & TRN & \\
\hline CHEMBL1233887 & 809219 & 6.0 & 5.7937 & TST & \\
\hline CHEMBL1991800 & 809219 & 4.1 & 4.383 & TRN & \\
\hline CHEMBL52387 & 809219 & 4.1 & 4.7356 & TST & \\
\hline CHEMBL 2003689 & 809219 & 4.4 & 4.2338 & TRN & \\
\hline CHEMBL379835 & 809219 & 4.1 & 4.1294 & TST & \\
\hline CHEMBL1979357 & 809219 & 4.1 & 4.3683 & TRN & \\
\hline CHEMBL1980802 & 809219 & 4.1 & 5.0486 & TST & \\
\hline CHEMBL1996649 & 809219 & 4.4 & 4.1142 & TRN & \\
\hline CHEMBL1996817 & 809219 & 6.6 & 6.17700 & 00000000005 & TRN \\
\hline CHEMBL1979554 & 809219 & 6.3 & 5.5376 & TRN & \\
\hline CHEMBL1986756 & 809219 & 7.3 & 7.4982 & TRN & \\
\hline CHEMBL3197315 & 809219 & 5.9 & 5.1945 & TST & \\
\hline CHEMBL 2004355 & 809219 & 4.1 & 3.9349 & TRN & \\
\hline CHEMBL468280 & 809219 & 5.4 & 4.2578 & TST & \\
\hline CHEMBL3109278 & 809219 & 4.2 & 4.6953 & TRN & \\
\hline CHEMBL256835 & 809219 & 4.1 & 3.9427 & TRN & \\
\hline CHEMBL1970006 & 809219 & 4.1 & 4.9779 & TST & \\
\hline CHEMBL1974998 & 809219 & 4.4 & 4.3907 & TRN & \\
\hline CHEMBL1980142 & 809219 & 7.7 & 7.6344 & TRN & \\
\hline CHEMBL41783 & 809219 & 7.3 & 6.984 & TRN & \\
\hline CHEMBL 2004438 & 809219 & 4.2 & 3.9892 & TRN & \\
\hline CHEMBL 2006276 & 809219 & 4.1 & 4.5804 & TRN & \\
\hline CHEMBL191003 & 809219 & 6.8 & 6.1252 & TRN & \\
\hline CHEMBL271381 & 809219 & 4.1 & 3.9479 & TRN & \\
\hline CHEMBL 2006785 & 809219 & 4.1 & 4.5076 & TRN & \\
\hline CHEMBL1982466 & 809219 & 4.1 & 3.9139 & TRN & \\
\hline CHEMBL1973359 & 809219 & 6.0 & 6.0789 & TST & \\
\hline CHEMBL1995740 & 809219 & 6.4 & 6.2016 & TRN & \\
\hline CHEMBL1996390 & 809219 & 6.2 & 6.4108 & TRN & \\
\hline CHEMBL1979690 & 809219 & 5.4 & 4.8123 & TRN & \\
\hline CHEMBL234085 & 809219 & 4.4 & 4.284 & TRN & \\
\hline CHEMBL1998414 & 809219 & 5.1 & 4.33 & TRN & \\
\hline CHEMBL1995832 & 809219 & 4.1 & 3.9864 & TRN & \\
\hline CHEMBL 2000345 & 809219 & 5.9 & 5.6828 & TRN & \\
\hline CHEMBL1976376 & 809219 & 4.4 & 4.2868 & TRN & \\
\hline CHEMBL1991640 & 809219 & 5.3 & 4.456 & TST & \\
\hline CHEMBL1983575 & 809219 & 6.1 & 5.4912 & TRN & \\
\hline CHEMBL1968868 & 809219 & 7.4 & 7.1867 & TRN & \\
\hline
\end{tabular}




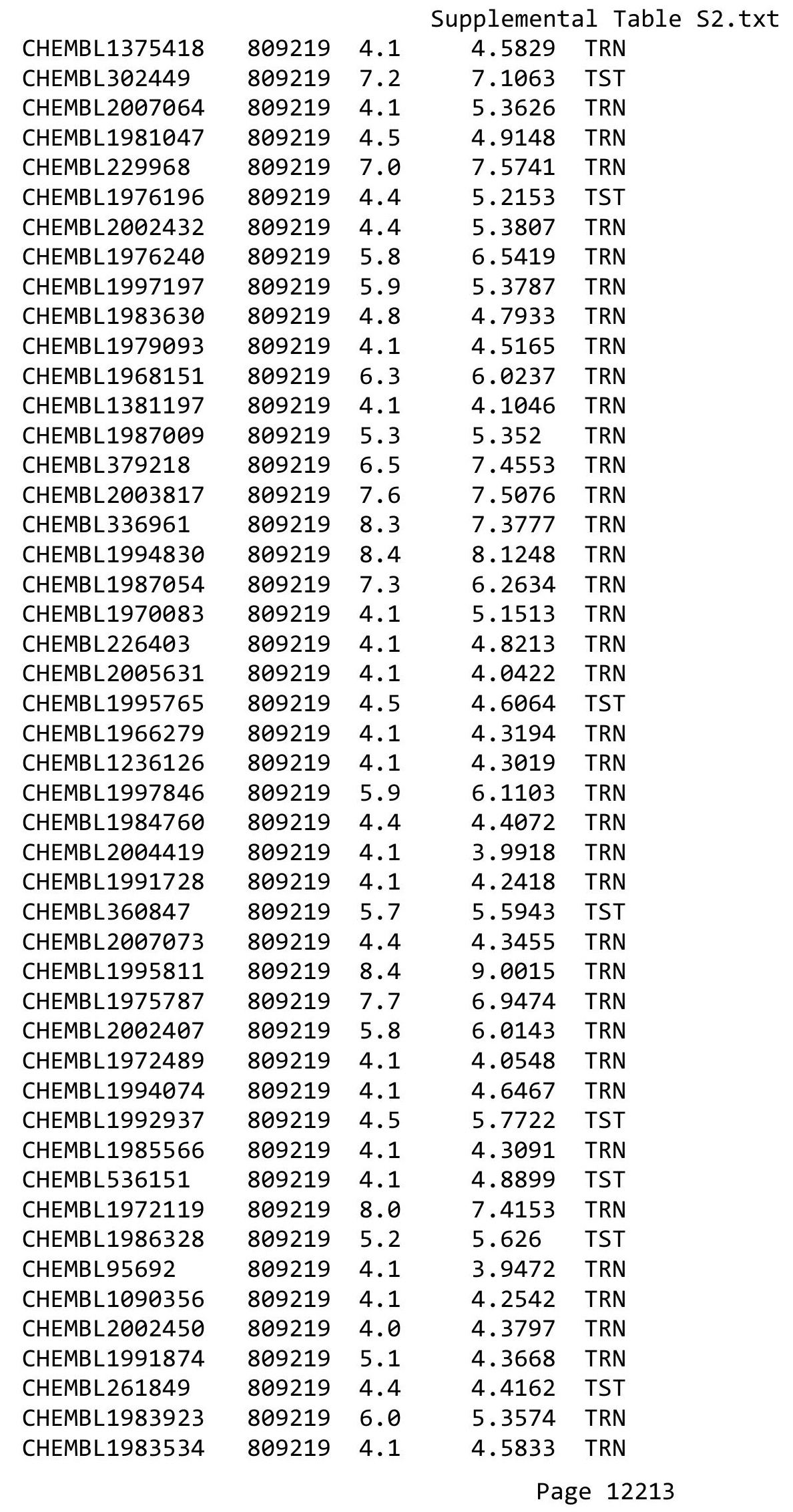




\begin{tabular}{|c|c|c|c|c|c|}
\hline \\
\hline CHEMBL1982361 & 809219 & 6.5 & 6.0789 & TRN & \\
\hline CHEMBL1999112 & 809219 & 5.3 & 5.1715 & TST & \\
\hline CHEMBL1982122 & 809219 & 5.5 & 4.5667 & TRN & \\
\hline CHEMBL 2000801 & 809219 & 4.1 & 4.0178 & TRN & \\
\hline CHEMBL1682546 & 809219 & 5.4 & 5.3416 & TRN & \\
\hline CHEMBL1991395 & 809219 & 4.1 & 4.3029 & TRN & \\
\hline CHEMBL1971245 & 809219 & 5.1 & 5.4459 & TRN & \\
\hline CHEMBL1987648 & 809219 & 4.1 & 4.3071 & TRN & \\
\hline CHEMBL1996780 & 809219 & 5.1 & 4.7748 & TST & \\
\hline CHEMBL1972142 & 809219 & 4.1 & 4.3325 & TRN & \\
\hline CHEMBL1966514 & 809219 & 4.1 & 3.8369 & TRN & \\
\hline CHEMBL296586 & 809219 & 8.1 & 7.4263 & TRN & \\
\hline CHEMBL1996066 & 809219 & 4.1 & 4.6044 & TST & \\
\hline CHEMBL1983393 & 809219 & 4.4 & 4.3207 & TRN & \\
\hline CHEMBL516429 & 809219 & 7.6 & 7.7791 & TRN & \\
\hline CHEMBL1993722 & 809219 & 5.9 & 5.3555 & TST & \\
\hline CHEMBL1970806 & 809219 & 5.2 & 4.3428 & TST & \\
\hline CHEMBL2006674 & 809219 & 5.8 & 5.5928 & TST & \\
\hline CHEMBL1984236 & 809219 & 4.4 & 4.6521 & TST & \\
\hline CHEMBL1992371 & 809219 & 5.8 & 6.5236 & TST & \\
\hline CHEMBL202635 & 809219 & 4.1 & 4.9686 & TST & \\
\hline CHEMBL2002599 & 809219 & 8.0 & 7.7332 & TST & \\
\hline CHEMBL249282 & 809219 & 4.1 & 3.8953 & TST & \\
\hline CHEMBL1967252 & 809219 & 5.4 & 5.6601 & TST & \\
\hline CHEMBL 2004637 & 809219 & 5.6 & 5.0956 & TST & \\
\hline CHEMBL1993374 & 809219 & 4.4 & 4.7509 & TST & \\
\hline CHEMBL1969264 & 809219 & 6.3 & 6.062 & TST & \\
\hline CHEMBL1994318 & 809219 & 4.4 & 4.31800 & 00000000005 & TST \\
\hline CHEMBL1973711 & 809219 & 7.0 & 5.9963 & TST & \\
\hline CHEMBL 2006237 & 809219 & 5.4 & 4.1867 & TST & \\
\hline CHEMBL1999506 & 809219 & 4.4 & 4.2871 & TST & \\
\hline CHEMBL1967720 & 809219 & 4.1 & 4.6365 & TST & \\
\hline CHEMBL1572266 & 809219 & 4.1 & 6.4303 & TST & \\
\hline CHEMBL1991138 & 809219 & 4.1 & 3.9253 & TST & \\
\hline CHEMBL1969755 & 809219 & 4.1 & 5.0672 & TST & \\
\hline CHEMBL1979516 & 809219 & 4.1 & 3.9077 & TST & \\
\hline CHEMBL1972820 & 809219 & 4.1 & 4.34399 & 9999999999 & TST \\
\hline CHEMBL1605605 & 809219 & 4.4 & 4.413 & TST & \\
\hline CHEMBL1996208 & 809219 & 4.1 & 4.26699 & 99999999995 & TST \\
\hline CHEMBL1989029 & 809219 & 5.6 & 4.9557 & TST & \\
\hline CHEMBL392642 & 809219 & 5.9 & 5.9238 & TST & \\
\hline CHEMBL514499 & 809219 & 4.1 & 5.2951 & TST & \\
\hline CHEMBL1970352 & 809219 & 4.4 & 5.2193 & TST & \\
\hline CHEMBL1980144 & 809219 & 4.1 & 4.92399 & 99999999995 & TST \\
\hline CHEMBL1991188 & 809219 & 7.0 & 6.9177 & TST & \\
\hline CHEMBL1980167 & 809219 & 6.1 & 5.7502 & TST & \\
\hline CHEMBL1972849 & 809219 & 4.1 & 4.0398 & TST & \\
\hline CHEMBL377408 & 809219 & 4.4 & 4.0507 & TST & \\
\hline
\end{tabular}




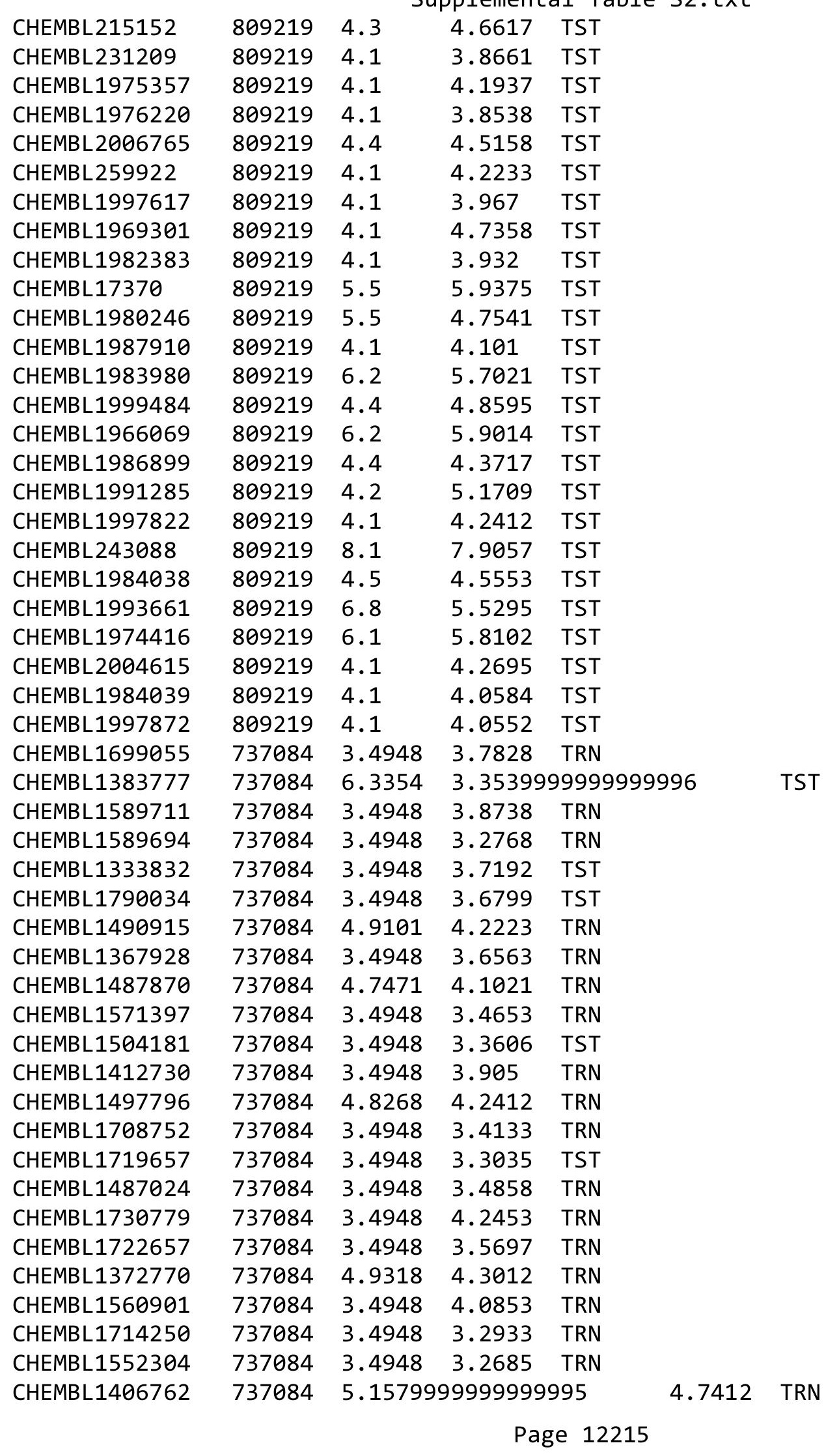




\begin{tabular}{|c|c|c|c|c|c|}
\hline & & \multicolumn{4}{|c|}{ Supplemental Table s2.txt } \\
\hline CHEMBL1333032 & 737084 & 3.4948 & 4.0587 & TRN & \\
\hline CHEMBL1312928 & 737084 & 3.4948 & 3.2809 & TRN & \\
\hline CHEMBL1576905 & 737084 & 5.5544 & 3.49600 & 00000000004 & TST \\
\hline CHEMBL1585203 & 737084 & 5.3054 & 4.5287 & TRN & \\
\hline CHEMBL1517609 & 737084 & 5.8041 & 3.3443 & TST & \\
\hline CHEMBL1716861 & 737084 & 3.4948 & 3.505 & TRN & \\
\hline CHEMBL1428840 & 737084 & 3.4948 & 3.4794 & TRN & \\
\hline CHEMBL1515610 & 737084 & 4.5331 & 3.6762 & TRN & \\
\hline CHEMBL1355774 & 737084 & 3.4948 & 3.9816 & TRN & \\
\hline CHEMBL1410162 & 737084 & 3.4948 & 3.4665 & TST & \\
\hline CHEMBL1720419 & 737084 & 3.4948 & 3.3868 & TST & \\
\hline CHEMBL1529781 & 737084 & 3.4948 & 3.6465 & TRN & \\
\hline CHEMBL1314099 & 737084 & 4.6696 & 4.4293 & TRN & \\
\hline CHEMBL1532025 & 737084 & 4.699 & 4.2455 & TRN & \\
\hline CHEMBL1387749 & 737084 & 3.4948 & 4.086 & TRN & \\
\hline CHEMBL1325250 & 737084 & 3.4948 & 3.5389 & TRN & \\
\hline CHEMBL1368962 & 737084 & 3.4948 & 4.029 & TRN & \\
\hline CHEMBL1410912 & 737084 & 3.4948 & 4.2008 & TRN & \\
\hline CHEMBL1707504 & 737084 & 3.4948 & 3.6828 & TST & \\
\hline CHEMBL1728754 & 737084 & 4.5361 & 3.7827 & TST & \\
\hline CHEMBL1387413 & 737084 & 3.4948 & 3.6502 & TRN & \\
\hline CHEMBL1728517 & 737084 & 3.4948 & 4.1104 & TRN & \\
\hline CHEMBL1387336 & 737084 & 3.4948 & 4.4055 & TRN & \\
\hline CHEMBL1385182 & 737084 & 3.4948 & 3.12 & TST & \\
\hline CHEMBL1311226 & 737084 & 5.466 & 3.4121 & TST & \\
\hline CHEMBL1698910 & 737084 & 3.4948 & 3.7542 & TRN & \\
\hline CHEMBL1444708 & 737084 & 4.567 & 3.9144 & TRN & \\
\hline CHEMBL1413629 & 737084 & 4.762 & 4.0204 & TRN & \\
\hline CHEMBL2165270 & 860486 & 7.2924 & 8.1624 & TST & \\
\hline CHEMBL2165021 & 860486 & 7.2366 & 7.2387 & TRN & \\
\hline CHEMBL 2165025 & 860486 & 8.0458 & 8.0438 & TRN & \\
\hline CHEMBL2165040 & 860486 & 6.1249 & 6.1271 & TRN & \\
\hline CHEMBL2165052 & 860486 & 7.9208 & 9.0981 & TST & \\
\hline CHEMBL2165023 & 860486 & 7.6576 & 7.6577 & TRN & \\
\hline CHEMBL2165003 & 860486 & 7.3372 & 7.3298 & TRN & \\
\hline CHEMBL2165051 & 860486 & 8.3979 & 9.8949 & TST & \\
\hline CHEMBL2165014 & 860486 & 6.8861 & 6.8794 & TRN & \\
\hline CHEMBL2165045 & 860486 & 5.585 & 6.1427 & TST & \\
\hline CHEMBL2165022 & 860486 & 7.3979 & 7.3986 & TRN & \\
\hline CHEMBL 2165042 & 860486 & 6.3468 & 6.3445 & TRN & \\
\hline CHEMBL 2165031 & 860486 & 7.6778 & 7.6773 & TRN & \\
\hline CHEMBL2165039 & 860486 & 7.9208 & 7.5555 & TST & \\
\hline CHEMBL 2165044 & 860486 & 4.0 & 5.2605 & TST & \\
\hline CHEMBL 2165041 & 860486 & 5.9586 & 5.9775 & TST & \\
\hline CHEMBL2165033 & 860486 & 8.2218 & 8.2231 & TRN & \\
\hline CHEMBL 2165007 & 860486 & 8.1549 & 8.1592 & TRN & \\
\hline CHEMBL 2165024 & 860486 & 7.2676 & 7.266 & TRN & \\
\hline CHEMBL 2165004 & 860486 & 8.301 & 8.3001 & TRN & \\
\hline
\end{tabular}




\begin{tabular}{|c|c|c|c|c|c|}
\hline & & \multicolumn{4}{|c|}{ Supplemental Table S2.txt } \\
\hline CHEMBL2165032 & 860486 & 8.0969 & 8.099 & TRN & \\
\hline CHEMBL 2165036 & 860486 & 5.4437 & 5.4425 & TRN & \\
\hline CHEMBL2165015 & 860486 & 7.7447 & 7.74299 & 9999999999 & TRN \\
\hline CHEMBL 2165027 & 860486 & 8.0458 & 8.0449 & TRN & \\
\hline CHEMBL2165034 & 860486 & 6.8539 & 6.8651 & TRN & \\
\hline CHEMBL 2165037 & 860486 & 7.9208 & 7.92200 & 0000000001 & TRN \\
\hline CHEMBL 2165005 & 860486 & 7.5229 & 7.5222 & TRN & \\
\hline CHEMBL2165020 & 860486 & 8.0969 & 8.096 & TRN & \\
\hline CHEMBL2165009 & 860486 & 7.0969 & 7.0825 & TRN & \\
\hline CHEMBL2165019 & 860486 & 8.0458 & 8.0435 & TRN & \\
\hline CHEMBL 2165038 & 860486 & 7.6383 & 8.0166 & TST & \\
\hline CHEMBL 2165017 & 860486 & 8.3979 & 8.4043 & TRN & \\
\hline CHEMBL 2165010 & 860486 & 7.7696 & 7.7731 & TRN & \\
\hline CHEMBL 2165029 & 860486 & 8.3979 & 8.398 & TRN & \\
\hline CHEMBL1762782 & 860486 & 7.1612 & 8.9935 & TST & \\
\hline CHEMBL 2165049 & 860486 & 7.2291 & 7.2267 & TRN & \\
\hline CHEMBL2165026 & 860486 & 7.6198 & 7.6225 & TRN & \\
\hline CHEMBL 2165028 & 860486 & 7.0044 & 7.0011 & TRN & \\
\hline CHEMBL2165268 & 860486 & 7.3468 & 8.1906 & TST & \\
\hline CHEMBL1615182 & 860486 & 6.9208 & 8.5627 & TST & \\
\hline CHEMBL 2165053 & 860486 & 7.0555 & 7.6163 & TST & \\
\hline CHEMBL2165030 & 860486 & 8.699 & 8.6975 & TRN & \\
\hline CHEMBL 2165271 & 860486 & 7.041 & 6.8622 & TST & \\
\hline CHEMBL2165008 & 860486 & 6.6778 & 6.6927 & TRN & \\
\hline CHEMBL 2165048 & 860486 & 6.3188 & 6.3194 & TRN & \\
\hline CHEMBL2165269 & 860486 & 7.5376 & 7.5387 & TRN & \\
\hline CHEMBL2165006 & 860486 & 7.9586 & 7.9569 & TRN & \\
\hline CHEMBL 2165047 & 860486 & 6.1612 & 6.1643 & TRN & \\
\hline CHEMBL 2165018 & 860486 & 8.0458 & 8.0461 & TRN & \\
\hline CHEMBL2165035 & 860486 & 6.4815 & 6.6212 & TST & \\
\hline CHEMBL 2165016 & 860486 & 8.0969 & 8.0961 & TRN & \\
\hline CHEMBL2165013 & 860486 & 6.699 & 6.6961 & TRN & \\
\hline CHEMBL2165012 & 860486 & 7.0 & 7.0016 & TRN & \\
\hline CHEMBL2165046 & 860486 & 6.4202 & 6.4198 & TRN & \\
\hline CHEMBL2165043 & 860486 & 4.0 & 4.6678 & TST & \\
\hline CHEMBL2165011 & 860486 & 6.9586 & 6.961 & TRN & \\
\hline CHEMBL2165050 & 860486 & 7.0458 & 7.0403 & TRN & \\
\hline CHEMBL 258844 & 954475 & 4.4782 & 4.4947 & TRN & \\
\hline CHEMBL1357247 & 954475 & 2.9257 & 2.8418 & TRN & \\
\hline CHEMBL220241 & 954475 & 4.9606 & 5.0739 & TRN & \\
\hline CHEMBL3199475 & 954475 & 3.6669 & 4.5737 & TRN & \\
\hline CHEMBL577784 & 954475 & 5.2653 & 4.9436 & TRN & \\
\hline CHEMBL514499 & 954475 & 7.3022 & 7.1996 & TRN & \\
\hline CHEMBL188678 & 954475 & 4.2358 & 4.11100 & 0000000001 & TRN \\
\hline CHEMBL472940 & 954475 & 5.0935 & 4.7195 & TRN & \\
\hline CHEMBL585951 & 954475 & 6.3023 & 6.42700 & 00000000005 & TRN \\
\hline CHEMBL412142 & 954475 & 3.8492 & 3.6525 & TRN & \\
\hline CHEMBL483849 & 954475 & 2.9393 & 2.7265 & TRN & \\
\hline
\end{tabular}




\begin{tabular}{|c|c|c|c|c|c|c|}
\hline & & \multicolumn{5}{|c|}{ Supplemental Table S2.txt } \\
\hline CHEMBL 2363137 & 954475 & 5.5991 & 5.024 & TRN & & \\
\hline CHEMBL1230020 & 954475 & 3.5077 & 3.5038 & TRN & & \\
\hline CHEMBL221137 & 954475 & 5.0336 & 4.82 & TST & & \\
\hline CHEMBL191334 & 954475 & 4.0013 & 4.0103 & TRN & & \\
\hline CHEMBL1970879 & 954475 & 5.2922 & 4.8166 & TRN & & \\
\hline CHEMBL483847 & 954475 & 3.75399 & 99999999 & 996 & 3.9867 & TRN \\
\hline CHEMBL1404918 & 954475 & 2.7797 & \multicolumn{3}{|c|}{2.8360000000000003} & TRN \\
\hline CHEMBL1673039 & 954475 & 5.4439 & 5.2817 & TRN & & \\
\hline CHEMBL300389 & 954475 & 7.2036 & 6.8496 & TRN & & \\
\hline CHEMBL509032 & 954475 & 6.3158 & 6.032 & TRN & & \\
\hline CHEMBL515416 & 954475 & 4.0924 & 4.1948 & TRN & & \\
\hline CHEMBL1256459 & 954475 & \multicolumn{3}{|c|}{7.542000000000001} & 8.0755 & TRN \\
\hline CHEMBL373751 & 954475 & 2.8813 & 3.4559 & TRN & & \\
\hline CHEMBL379975 & 954475 & 4.3107 & 4.5695 & TRN & & \\
\hline CHEMBL202721 & 954475 & 5.4344 & 5.3775 & TRN & & \\
\hline CHEMBL92309 & 954475 & 3.2999 & 2.8519 & TST & & \\
\hline CHEMBL392695 & 954475 & 5.3752 & 5.5383 & TRN & & \\
\hline CHEMBL449158 & 954475 & 6.289 & 6.5552 & TST & & \\
\hline CHEMBL1909414 & 954475 & 4.7095 & 4.6535 & TRN & & \\
\hline CHEMBL189584 & 954475 & 4.5036 & 4.3618 & TRN & & \\
\hline CHEMBL3392440 & 954475 & 3.7278 & 3.4756 & TRN & & \\
\hline CHEMBL1590308 & 954475 & 4.1139 & 3.2991 & TST & & \\
\hline CHEMBL65 & 954475 & 9.0522 & 8.73299 & 999999999s & & TRN \\
\hline CHEMBL393929 & 954475 & 4.0095 & 3.8917 & TRN & & \\
\hline CHEMBL209148 & 954475 & 5.1262 & 5.4565 & TRN & & \\
\hline CHEMBL213100 & 954475 & \multicolumn{3}{|c|}{3.0869999999999997} & 3.0229 & TRN \\
\hline CHEMBL135561 & 954475 & 4.5174 & 4.3753 & TRN & & \\
\hline CHEMBL512504 & 954475 & 7.2426 & 7.1492 & TRN & & \\
\hline CHEMBL 222102 & 954475 & \multicolumn{3}{|c|}{3.3169999999999997} & 3.2075 & TRN \\
\hline CHEMBL1190711 & 954475 & 5.3482 & 5.9545 & TRN & & \\
\hline CHEMBL102714 & 954475 & 3.0706 & 2.9017 & TRN & & \\
\hline CHEMBL192566 & 954475 & 8.0945 & 8.345 & TST & & \\
\hline CHEMBL1643959 & 954475 & 3.0085 & 3.2306 & TRN & & \\
\hline CHEMBL 2144069 & 954475 & 7.7696 & 7.7451 & TRN & & \\
\hline CHEMBL573107 & 954475 & 4.7055 & 4.6157 & TRN & & \\
\hline CHEMBL 2005886 & 954475 & 5.8816 & 6.05 & TRN & & \\
\hline CHEMBL 379300 & 954475 & \multicolumn{3}{|c|}{6.6770000000000005} & 6.5952 & TRN \\
\hline CHEMBL3349342 & 954475 & 3.6856 & 4.256 & TRN & & \\
\hline CHEMBL 9470 & 954475 & 6.5252 & 5.9424 & TST & & \\
\hline CHEMBL3186408 & 954475 & 3.2159 & 3.9141 & TST & & \\
\hline CHEMBL 240954 & 954475 & 3.7285 & 4.1107 & TST & & \\
\hline CHEMBL558642 & 954475 & 4.6841 & 4.7284 & TST & & \\
\hline CHEMBL1788116 & 954475 & 5.3321 & 4.4696 & TST & & \\
\hline CHEMBL1516890 & 954475 & 4.0269 & 3.8223 & TST & & \\
\hline CHEMBL210618 & 954475 & 3.3591 & 3.2352 & TST & & \\
\hline CHEMBL180127 & 954475 & 4.7982 & 4.7658 & TST & & \\
\hline CHEMBL259181 & 954475 & 5.2391 & 5.3385 & TST & & \\
\hline CHEMBL1242367 & 954475 & 5.2291 & 4.4719 & TST & & \\
\hline
\end{tabular}


Supplemental Table S2.txt

\begin{tabular}{|c|c|c|c|c|}
\hline CHEMBL 3656037 & 1527977 & 7.4815 & 7.4812 & TST \\
\hline CHEMBL3660301 & 1527977 & 5.568 & 7.6028 & TST \\
\hline CHEMBL3656082 & 1527977 & 7.4089 & 7.6581 & TRN \\
\hline CHEMBL 3656096 & 1527977 & 7.8539 & 7.7467 & TRN \\
\hline CHEMBL3656061 & 1527977 & 7.9586 & 7.6231 & TST \\
\hline CHEMBL 3656039 & 1527977 & 7.6778 & 7.0969 & TRN \\
\hline CHEMBL3656111 & 1527977 & 7.7696 & 7.6368 & TST \\
\hline CHEMBL 3656028 & 1527977 & 7.5376 & 7.1348 & TRN \\
\hline CHEMBL3656071 & 1527977 & 7.4949 & 7.6157 & TRN \\
\hline CHEMBL3660285 & 1527977 & 7.5086 & 7.6018 & TRN \\
\hline CHEMBL 3660275 & 1527977 & 7.8239 & 7.7036 & TRN \\
\hline CHEMBL 3656127 & 1527977 & 7.6778 & 7.5198 & TRN \\
\hline CHEMBL 3656090 & 1527977 & 7.6198 & 7.8948 & TRN \\
\hline CHEMBL3656105 & 1527977 & 7.8861 & 7.7274 & TRN \\
\hline CHEMBL 3656094 & 1527977 & 7.9586 & 7.5624 & TST \\
\hline CHEMBL3656052 & 1527977 & 7.4318 & 7.2823 & TRN \\
\hline CHEMBL 3656050 & 1527977 & 7.284 & 7.3248 & TST \\
\hline CHEMBL3656059 & 1527977 & 8.0 & 7.5757 & TRN \\
\hline CHEMBL 3656114 & 1527977 & 8.301 & 7.8227 & TRN \\
\hline CHEMBL3656051 & 1527977 & 7.2596 & 7.1342 & TST \\
\hline CHEMBL 3656121 & 1527977 & 7.8861 & 7.6996 & TRN \\
\hline CHEMBL 3656088 & 1527977 & 7.5086 & 7.7516 & TRN \\
\hline CHEMBL 3656107 & 1527977 & 7.5686 & 7.437 & TRN \\
\hline CHEMBL 3660290 & 1527977 & 7.3665 & 7.5356 & TRN \\
\hline CHEMBL3660277 & 1527977 & 7.7447 & 7.337006 & 0000000001 \\
\hline CHEMBL3660302 & 1527977 & 7.9208 & 7.5359 & TRN \\
\hline CHEMBL 3656055 & 1527977 & 6.0 & 7.0155 & TRN \\
\hline CHEMBL3656054 & 1527977 & 7.3372 & 7.2326 & TRN \\
\hline CHEMBL3656069 & 1527977 & 7.9208 & 7.9089 & TRN \\
\hline CHEMBL3660296 & 1527977 & 7.6576 & 7.4249 & TRN \\
\hline CHEMBL 3656077 & 1527977 & 7.699 & 7.6477 & TRN \\
\hline CHEMBL3656086 & 1527977 & 7.8239 & 7.6246 & TRN \\
\hline CHEMBL3656032 & 1527977 & 7.5528 & 7.3416 & TST \\
\hline CHEMBL3656042 & 1527977 & 7.4318 & 7.6278 & TRN \\
\hline CHEMBL3660270 & 1527977 & 7.4202 & 7.6878 & TRN \\
\hline CHEMBL3656116 & 1527977 & 7.4949 & 7.5753 & TRN \\
\hline CHEMBL3639549 & 1527977 & 7.5376 & 7.5583 & TRN \\
\hline CHEMBL 3656027 & 1527977 & 7.5528 & 7.2696 & TRN \\
\hline CHEMBL 3656048 & 1527977 & 6.9208 & 7.32799 & 9999999999 \\
\hline CHEMBL3660278 & 1527977 & 7.0706 & 7.1782 & TRN \\
\hline CHEMBL3656109 & 1527977 & 6.3215 & 7.2116 & TST \\
\hline CHEMBL 3656047 & 1527977 & 7.6021 & 7.0968 & TRN \\
\hline CHEMBL3656089 & 1527977 & 7.7959 & 7.8596 & TRN \\
\hline CHEMBL3656099 & 1527977 & 7.8239 & 7.8034 & TRN \\
\hline CHEMBL3656046 & 1527977 & 7.6198 & 7.2586 & TRN \\
\hline CHEMBL 3656124 & 1527977 & 7.699 & 7.7922 & TRN \\
\hline CHEMBL 3656026 & 1527977 & 7.5528 & 7.314 & TRN \\
\hline CHEMBL3660267 & 1527977 & 7.6778 & 7.5788 & TRN \\
\hline
\end{tabular}


Supplemental Table S2.txt

\begin{tabular}{|c|c|c|c|c|c|}
\hline CHEMBL3656101 & 1527977 & 7.1612 & 7.2928 & TST & \\
\hline CHEMBL3660269 & 1527977 & 7.6383 & 7.6087 & TRN & \\
\hline CHEMBL3656057 & 1527977 & 4.9988 & 7.6275 & TST & \\
\hline CHEMBL 3660280 & 1527977 & 7.0088 & 7.4357 & TST & \\
\hline CHEMBL3656035 & 1527977 & 7.6383 & 7.6212 & TRN & \\
\hline CHEMBL3660298 & 1527977 & 7.5229 & 7.643 & TRN & \\
\hline CHEMBL3656031 & 1527977 & 7.4685 & 7.3838 & TRN & \\
\hline CHEMBL 3656034 & 1527977 & 7.3872 & 7.4871 & TST & \\
\hline CHEMBL 3656100 & 1527977 & 7.4202 & 7.7032 & TRN & \\
\hline CHEMBL3656113 & 1527977 & 8.0458 & 7.66 & TRN & \\
\hline CHEMBL3656102 & 1527977 & 7.7212 & 7.8284 & TRN & \\
\hline CHEMBL3656103 & 1527977 & 7.7212 & 7.7364 & TRN & \\
\hline CHEMBL 3660268 & 1527977 & 7.8539 & 7.5617 & TRN & \\
\hline CHEMBL3656058 & 1527977 & 5.5834 & 7.1401 & TST & \\
\hline CHEMBL3656072 & 1527977 & 7.7959 & 7.6219 & TRN & \\
\hline CHEMBL3660284 & 1527977 & 7.4437 & 7.6951 & TRN & \\
\hline CHEMBL3660306 & 1527977 & 5.4553 & 7.0132 & TST & \\
\hline CHEMBL 3660307 & 1527977 & 5.8595 & 7.0704 & TST & \\
\hline CHEMBL3656122 & 1527977 & 8.0969 & 7.655 & TRN & \\
\hline CHEMBL 3656078 & 1527977 & 7.3468 & 7.49100 & 00000000005 & TRN \\
\hline CHEMBL3656076 & 1527977 & 7.6383 & 7.5577 & TRN & \\
\hline CHEMBL3656062 & 1527977 & 7.9586 & 7.5131 & TST & \\
\hline CHEMBL 3660274 & 1527977 & 7.6576 & \multicolumn{2}{|c|}{7.537000000000001} & TRN \\
\hline CHEMBL3656033 & 1527977 & 7.3279 & 7.6733 & TRN & \\
\hline CHEMBL 3656115 & 1527977 & 8.2218 & 7.6071 & TRN & \\
\hline CHEMBL 3656060 & 1527977 & 7.6383 & 7.6615 & TRN & \\
\hline CHEMBL3656112 & 1527977 & 7.8539 & 7.54 & TST & \\
\hline CHEMBL3656123 & 1527977 & 7.4559 & 7.6788 & TRN & \\
\hline CHEMBL3656066 & 1527977 & 7.7696 & 7.7633 & TRN & \\
\hline CHEMBL 3660303 & 1527977 & 7.585 & 7.5518 & TST & \\
\hline CHEMBL 3656065 & 1527977 & 7.6198 & 7.7436 & TRN & \\
\hline CHEMBL3656098 & 1527977 & 8.0 & 7.6342 & TRN & \\
\hline CHEMBL 3656080 & 1527977 & 7.5376 & 7.586 & TRN & \\
\hline CHEMBL3656079 & 1527977 & 7.4437 & 7.5763 & TRN & \\
\hline CHEMBL 3656117 & 1527977 & 7.7696 & 7.6891 & TRN & \\
\hline CHEMBL3656043 & 1527977 & 7.5528 & 7.4705 & TRN & \\
\hline CHEMBL3656029 & 1527977 & 5.5293 & 6.2142 & TRN & \\
\hline CHEMBL3656040 & 1527977 & 7.699 & 7.1623 & TST & \\
\hline CHEMBL3656036 & 1527977 & 7.5686 & 7.3867 & TRN & \\
\hline CHEMBL 3656063 & 1527977 & 7.2218 & 7.4955 & TST & \\
\hline CHEMBL3660295 & 1527977 & 7.3279 & 7.4801 & TRN & \\
\hline CHEMBL3656056 & 1527977 & 7.1549 & 7.0764 & TST & \\
\hline CHEMBL3656118 & 1527977 & 7.7447 & 7.7179 & TRN & \\
\hline CHEMBL 3660272 & 1527977 & 7.7447 & 7.7797 & TRN & \\
\hline CHEMBL 3656087 & 1527977 & 7.7696 & 7.8707 & TRN & \\
\hline CHEMBL3656106 & 1527977 & 7.5229 & \multicolumn{2}{|c|}{7.587000000000001} & TRN \\
\hline CHEMBL3656104 & 1527977 & 7.6576 & 7.6535 & TRN & \\
\hline CHEMBL3660299 & 1527977 & 7.5229 & 7.5452 & TRN & \\
\hline
\end{tabular}

Page 12220 
Supplemental Table S2.txt

\begin{tabular}{|c|c|c|c|c|}
\hline ILI & 527977 & 7.4089 & & \\
\hline & 527977 & 7.585 & & \\
\hline$-\mu$ & 27977 & & 85 & \\
\hline AEMBL & 977 & & & \\
\hline AEMBL3660273 & 527977 & 7.6021 & 3847 & \\
\hline HEMBL3656119 & 527977 & 7.2924 & .5505 & \\
\hline 45 & 977 & 7.4559 & 3273 & \\
\hline AEMBL & & 861 & 4146 & \\
\hline HEMBL3660297 & 527977 & 7.4815 & .7206 & \\
\hline HEMBL3656025 & 977 & 7.5528 & 4516 & \\
\hline 56093 & 77 & 7.8239 & 6897 & \\
\hline 83 & 77 & 665 & 6292 & \\
\hline AEMBL: & & & 6736 & \\
\hline HEMBL3660289 & 977 & 6.9914 & .5455 & \\
\hline AEMBL3656091 & 977 & & & \\
\hline HEMBL3 & 1 & 7.76 & 7045 & NIV \\
\hline HEMBL & 77 & & 92 & \\
\hline HEMBL; & & 7. & 341 & \\
\hline 60291 & & 86 & 168 & \\
\hline AEMBL3656095 & & & & 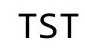 \\
\hline HEMBL & $\boldsymbol{I}$ & 7. & 19 & ГRN \\
\hline HEM & & & & TIV \\
\hline AEMBL & & 72 & 923 & \\
\hline HEMBL & & & & IST \\
\hline HEMBL3660281 & 77 & 7. & 105 & |SI \\
\hline HEMBL & & 686 & 791 & RN \\
\hline HFM & & & & $\mathrm{RN}$ \\
\hline 8 & & 7. & 01 & RN \\
\hline HEMBL & & & & IRN \\
\hline AEMBL3660288 & 77 & 7.2757 & 97 & RN \\
\hline AEMBL & & 59 & 45 & RN \\
\hline I & & & & ГST \\
\hline & & & & 「RN \\
\hline HEMBL3 & & & & TST \\
\hline AEMBL3660286 & 77 & 6. & 326 & RN \\
\hline JEMDI & & 7. & 63 & TRN \\
\hline 10 & & & & IST \\
\hline HEMBL3 & & & & TRN \\
\hline HEMBL3 & 77 & 086 & & $\Gamma R$ \\
\hline Th & & & & IST \\
\hline HEMBL3 & & 7. & 961 & TRN \\
\hline & & & 7.063 & ST \\
\hline HEMBL3656097 & 977 & 7.8539 & 5573 & TRN \\
\hline HEMBL3 & 1 & 7.5528 & 81 & TR \\
\hline CHFMDI 26560 & & & & \\
\hline HEMBL3656125 & 527977 & 7.5686 & 7.506 & \\
\hline CHEMBL 3651993 & 527916 & 9.0 & 8.7795 & \\
\hline CHEMBL3651900 & 1527916 & 9.0 & 8.9395 & $\mathrm{~K}$ \\
\hline
\end{tabular}

Page 12221 
Supplemental Table S2.txt

\begin{tabular}{|c|c|c|c|c|c|}
\hline CHEMBL 3651914 & 1527916 & 8.5229 & 8.4235 & TRN & \\
\hline CHEMBL 3652030 & 1527916 & 6.0 & 5.4777 & TRN & \\
\hline CHEMBL3651932 & 1527916 & 9.0 & \multicolumn{2}{|c|}{9.062999999999999} & TRN \\
\hline CHEMBL3651920 & 1527916 & 9.0 & 9.0486 & TRN & \\
\hline CHEMBL3651928 & 1527916 & 9.0 & 9.0122 & TRN & \\
\hline CHEMBL3651957 & 1527916 & 9.0 & 8.8313 & TRN & \\
\hline CHEMBL3651961 & 1527916 & 6.0 & 6.5337 & TRN & \\
\hline CHEMBL3652013 & 1527916 & 9.0 & 9.0045 & TRN & \\
\hline CHEMBL3651994 & 1527916 & 9.0 & \multicolumn{2}{|c|}{9.466000000000001} & TRN \\
\hline CHEMBL3651974 & 1527916 & 8.699 & 8.7282 & TRN & \\
\hline CHEMBL3651936 & 1527916 & 6.0 & 6.2605 & TRN & \\
\hline CHEMBL3651918 & 1527916 & 9.0 & 8.9821 & TRN & \\
\hline CHEMBL 3651908 & 1527916 & 9.0 & 9.0757 & TRN & \\
\hline CHEMBL 3651998 & 1527916 & 6.0 & 6.0782 & TRN & \\
\hline CHEMBL3651915 & 1527916 & 8.5229 & 8.5296 & TRN & \\
\hline CHEMBL3651917 & 1527916 & 8.699 & 8.7389 & TRN & \\
\hline CHEMBL3651925 & 1527916 & 9.0 & 8.9112 & TRN & \\
\hline CHEMBL 3651921 & 1527916 & 9.0 & 9.1643 & TRN & \\
\hline CHEMBL3651969 & 1527916 & 9.0 & 8.9673 & TRN & \\
\hline CHEMBL3651983 & 1527916 & 8.699 & 8.7589 & TRN & \\
\hline CHEMBL3651971 & 1527916 & 9.0 & 9.0059 & TRN & \\
\hline CHEMBL 3651972 & 1527916 & 6.0 & 6.0554 & TRN & \\
\hline CHEMBL 3651902 & 1527916 & 8.699 & 8.6036 & TRN & \\
\hline CHEMBL3651904 & 1527916 & 9.0 & 8.9452 & TRN & \\
\hline CHEMBL3651965 & 1527916 & 6.0 & 6.2036 & TRN & \\
\hline CHEMBL3652020 & 1527916 & 8.699 & 8.6239 & TRN & \\
\hline CHEMBL3651931 & 1527916 & 9.0 & 9.0523 & TRN & \\
\hline CHEMBL3652006 & 1527916 & 9.0 & 9.0072 & TRN & \\
\hline CHEMBL 3651905 & 1527916 & 9.0 & 9.1549 & TRN & \\
\hline CHEMBL3652014 & 1527916 & 8.5229 & 8.4848 & TST & \\
\hline CHEMBL3651984 & 1527916 & 9.0 & 8.3179 & TRN & \\
\hline CHEMBL3651922 & 1527916 & 9.0 & 9.4798 & TST & \\
\hline CHEMBL 3651907 & 1527916 & 9.0 & 9.0412 & TRN & \\
\hline CHEMBL3651934 & 1527916 & 9.0 & 9.0436 & TRN & \\
\hline CHEMBL3651986 & 1527916 & 8.5229 & 8.3792 & TST & \\
\hline CHEMBL3652029 & 1527916 & 9.0 & 8.3565 & TST & \\
\hline CHEMBL3651910 & 1527916 & 8.2218 & 8.315 & TRN & \\
\hline CHEMBL3651941 & 1527916 & 9.0 & 8.8561 & TRN & \\
\hline CHEMBL3651999 & 1527916 & 9.0 & 9.0229 & TST & \\
\hline CHEMBL 3651942 & 1527916 & 9.0 & 9.0042 & TRN & \\
\hline CHEMBL3652002 & 1527916 & 9.0 & 8.7365 & TRN & \\
\hline CHEMBL3651970 & 1527916 & 9.0 & 8.9486 & TRN & \\
\hline CHEMBL3651953 & 1527916 & 9.0 & 9.1339 & TRN & \\
\hline CHEMBL3651988 & 1527916 & 6.0 & 7.954 & TST & \\
\hline CHEMBL 3651924 & 1527916 & 9.0 & 9.0358 & TRN & \\
\hline CHEMBL3651977 & 1527916 & 8.699 & 8.5344 & TRN & \\
\hline CHEMBL3651954 & 1527916 & 9.0 & 9.2541 & TRN & \\
\hline CHEMBL3651898 & 1527916 & 9.0 & 9.1487 & TRN & \\
\hline
\end{tabular}




\begin{tabular}{|c|c|c|c|c|}
\hline \multicolumn{5}{|c|}{ Supplemental Table S2.txt } \\
\hline CHEMBL3651955 & 1527916 & 9.0 & 9.0629 & TRN \\
\hline CHEMBL3651995 & 1527916 & 8.699 & 8.6142 & TRN \\
\hline CHEMBL 3652023 & 1527916 & 9.0 & 9.0629 & TRN \\
\hline CHEMBL 3651980 & 1527916 & 8.3979 & 8.6113 & TST \\
\hline CHEMBL3651975 & 1527916 & 8.699 & 8.8275 & TRN \\
\hline CHEMBL 3651944 & 1527916 & 8.1549 & 8.0943 & TRN \\
\hline CHEMBL3652000 & 1527916 & 8.301 & 8.40899 & 9999999999 \\
\hline CHEMBL 3652018 & 1527916 & 9.0 & 8.9633 & TRN \\
\hline CHEMBL3651926 & 1527916 & 6.0 & 5.8618 & TRN \\
\hline CHEMBL3651909 & 1527916 & 9.0 & 9.2159 & TST \\
\hline CHEMBL3651937 & 1527916 & 8.699 & 8.5958 & TRN \\
\hline CHEMBL3651935 & 1527916 & 8.1549 & 8.1641 & TRN \\
\hline CHEMBL3651979 & 1527916 & 8.3979 & 8.3931 & TRN \\
\hline CHEMBL 3652003 & 1527916 & 9.0 & 8.5755 & TST \\
\hline CHEMBL3652012 & 1527916 & 8.3979 & 8.0234 & TST \\
\hline CHEMBL3651919 & 1527916 & 8.699 & 8.8798 & TST \\
\hline CHEMBL3651930 & 1527916 & 8.3979 & 8.2828 & TRN \\
\hline CHEMBL3652019 & 1527916 & 9.0 & 8.9459 & TRN \\
\hline CHEMBL 3651943 & 1527916 & 9.0 & 8.8349 & TRN \\
\hline CHEMBL3651976 & 1527916 & 8.2218 & 7.6379 & TST \\
\hline CHEMBL3651964 & 1527916 & 9.0 & 8.9599 & TST \\
\hline CHEMBL 3651985 & 1527916 & 8.0969 & 8.4065 & TST \\
\hline CHEMBL3652022 & 1527916 & 9.0 & 9.1534 & TRN \\
\hline CHEMBL3651963 & 1527916 & 9.0 & 9.1411 & TST \\
\hline CHEMBL3652026 & 1527916 & 6.0 & 6.1579 & TRN \\
\hline CHEMBL3651916 & 1527916 & 9.0 & 8.9652 & TRN \\
\hline CHEMBL3652005 & 1527916 & 8.699 & 8.3487 & TST \\
\hline CHEMBL3652028 & 1527916 & 8.699 & 8.6667 & TRN \\
\hline CHEMBL 3651933 & 1527916 & 8.699 & 8.6705 & TRN \\
\hline CHEMBL3651945 & 1527916 & 9.0 & 8.9862 & TRN \\
\hline CHEMBL3651906 & 1527916 & 9.0 & 8.924 & TRN \\
\hline CHEMBL3105021 & 1527916 & 9.0 & 9.7429 & TST \\
\hline CHEMBL3651901 & 1527916 & 8.5229 & 8.703 & TRN \\
\hline CHEMBL3651960 & 1527916 & 8.699 & 8.6051 & TST \\
\hline CHEMBL3652016 & 1527916 & 9.0 & 9.1483 & TRN \\
\hline CHEMBL3651903 & 1527916 & 9.0 & 9.0388 & TRN \\
\hline CHEMBL3651997 & 1527916 & 8.699 & 9.0541 & TST \\
\hline CHEMBL3652017 & 1527916 & 9.0 & 9.0641 & TRN \\
\hline CHEMBL 3651952 & 1527916 & 6.0 & 6.7656 & TST \\
\hline CHEMBL3652004 & 1527916 & 9.0 & 9.3175 & TRN \\
\hline CHEMBL3651959 & 1527916 & 9.0 & 9.1825 & TRN \\
\hline CHEMBL3652015 & 1527916 & 9.0 & 9.0227 & TRN \\
\hline CHEMBL3651962 & 1527916 & 9.0 & 8.8235 & TRN \\
\hline CHEMBL3652008 & 1527916 & 9.0 & 9.2479 & TST \\
\hline CHEMBL3639508 & 1527916 & 8.5229 & 8.5864 & TST \\
\hline CHEMBL3652031 & 1527916 & 9.0 & 9.0585 & TRN \\
\hline CHEMBL3651929 & 1527916 & 9.0 & 8.8538 & TRN \\
\hline CHEMBL3652009 & 1527916 & 9.0 & 9.6228 & TST \\
\hline & & & & 12223 \\
\hline
\end{tabular}




\begin{tabular}{|c|c|c|c|c|}
\hline & & & pplement & dI \\
\hline CHEMBL3651923 & 1527916 & 9.0 & 9.0054 & TRN \\
\hline CHEMBL3651989 & 1527916 & 6.0 & 6.269 & TRN \\
\hline CHEMBL3651899 & 1527916 & 9.0 & 9.0918 & TST \\
\hline CHEMBL3651973 & 1527916 & 9.0 & 9.1082 & TRN \\
\hline CHEMBL3651958 & 1527916 & 9.0 & 8.9099 & TRN \\
\hline CHEMBL3651939 & 1527916 & 9.0 & 8.9789 & TRN \\
\hline CHEMBL3652021 & 1527916 & 7.9586 & 7.9653 & TRN \\
\hline CHEMBL3651913 & 1527916 & 6.0 & 6.0341 & TRN \\
\hline CHEMBL 3651947 & 1527916 & 9.0 & 7.6638 & TRN \\
\hline CHEMBL3652001 & 1527916 & 8.699 & 8.5173 & TST \\
\hline CHEMBL3651956 & 1527916 & 9.0 & 8.9102 & TRN \\
\hline CHEMBL3652010 & 1527916 & 9.0 & 9.0308 & TST \\
\hline CHEMBL3651912 & 1527916 & 9.0 & 9.1309 & TST \\
\hline CHEMBL 3651978 & 1527916 & 8.5229 & 8.5963 & TRN \\
\hline CHEMBL3652007 & 1527916 & 6.0 & 6.8586 & TST \\
\hline CHEMBL3651938 & 1527916 & 9.0 & 8.8143 & TRN \\
\hline CHEMBL3651968 & 1527916 & 6.0 & 6.5746 & TRN \\
\hline CHEMBL347125 & 64185 & 5.5528 & 5.5261 & TRN \\
\hline CHEMBL347982 & 64185 & 5.1612 & 5.15 & TRN \\
\hline CHEMBL422851 & 64185 & 5.0088 & 4.9981 & TRN \\
\hline CHEMBL149819 & 64185 & 5.6383 & 5.5813 & TRN \\
\hline CHEMBL105490 & 64185 & 5.7696 & 5.7904 & TRN \\
\hline CHEMBL151422 & 64185 & 5.5376 & 5.5475 & TRN \\
\hline CHEMBL151160 & 64185 & 5.8861 & 5.8974 & TRN \\
\hline CHEMBL147521 & 64185 & 5.0757 & 5.0956 & TRN \\
\hline CHEMBL149060 & 64185 & 4.0 & 3.892 & TST \\
\hline CHEMBL 356220 & 64185 & 2.699 & 2.7615 & TRN \\
\hline CHEMBL359167 & 64185 & 5.6778 & 5.7334 & TRN \\
\hline CHEMBL357823 & 64185 & 4.9208 & 4.9519 & TRN \\
\hline CHEMBL146904 & 64185 & 4.9208 & 4.9005 & TRN \\
\hline CHEMBL150891 & 64185 & 2.699 & 2.7282 & TRN \\
\hline CHEMBL357395 & 64185 & 4.9208 & 4.9514 & TRN \\
\hline CHEMBL421955 & 64185 & 6.0269 & 6.0008 & TRN \\
\hline CHEMBL149171 & 64185 & 4.7212 & 4.7255 & TRN \\
\hline CHEMBL106684 & 64185 & 5.7696 & 5.7259 & TRN \\
\hline CHEMBL150269 & 64185 & 5.0088 & 5.0153 & TRN \\
\hline CHEMBL150474 & 64185 & 5.8539 & 5.8234 & TRN \\
\hline CHEMBL151926 & 64185 & 5.7212 & 5.7142 & TRN \\
\hline CHEMBL151440 & 64185 & 5.9208 & 5.9414 & TRN \\
\hline CHEMBL149241 & 64185 & 4.699 & 4.6797 & TRN \\
\hline CHEMBL151971 & 64185 & 4.8239 & 4.8227 & TRN \\
\hline CHEMBL345551 & 64185 & 4.5229 & 4.5202 & TRN \\
\hline CHEMBL1269102 & 64185 & 4.4949 & 2.9139 & TST \\
\hline CHEMBL149050 & 64185 & 3.7696 & 3.8028 & TRN \\
\hline CHEMBL357580 & 64185 & 2.699 & 1.9003 & TST \\
\hline CHEMBL345542 & 64185 & 5.7959 & 5.8274 & TRN \\
\hline CHEMBL 359332 & 64185 & 2.699 & 2.6433 & TRN \\
\hline CHEMBL267458 & 64185 & 2.699 & 1.8526 & TST \\
\hline
\end{tabular}




\begin{tabular}{|c|c|c|c|c|c|}
\hline & & & & & \\
\hline CHEMBL149818 & 64185 & 5.2676 & 5.2288 & TRN & \\
\hline CHEMBL358254 & 64185 & 4.7212 & 4.6953 & TRN & \\
\hline CHEMBL356591 & 64185 & 2.699 & 2.6874 & TRN & \\
\hline CHEMBL151954 & 64185 & 2.699 & 2.6606 & TRN & \\
\hline CHEMBL343477 & 64185 & 4.4202 & 4.3791 & TRN & \\
\hline CHEMBL346853 & 64185 & 5.8239 & 5.8156 & TRN & \\
\hline CHEMBL151395 & 64185 & 3.0 & 3.0982 & TRN & \\
\hline CHEMBL148757 & 64185 & 2.699 & 2.9539 & TST & \\
\hline CHEMBL149111 & 64185 & 4.585 & 4.5794 & TRN & \\
\hline CHEMBL147081 & 64185 & 5.6576 & 5.6802 & TRN & \\
\hline CHEMBL149152 & 64185 & 5.3979 & 5.4001 & TRN & \\
\hline CHEMBL358461 & 64185 & 5.7212 & 5.6911 & TRN & \\
\hline CHEMBL356618 & 64185 & 2.699 & 2.67199 & 99999999997 & TRN \\
\hline CHEMBL 348700 & 64185 & 4.7212 & 4.7608 & TRN & \\
\hline CHEMBL358545 & 64185 & 5.3872 & 5.3362 & TRN & \\
\hline CHEMBL356901 & 64185 & 5.2218 & 5.2499 & TRN & \\
\hline CHEMBL343867 & 64185 & 4.7696 & 4.7498 & TRN & \\
\hline CHEMBL151525 & 64185 & 4.3768 & 4.4068 & TRN & \\
\hline CHEMBL424504 & 64185 & 2.699 & 2.6731 & TRN & \\
\hline CHEMBL310427 & 64185 & 2.699 & 2.7051 & TRN & \\
\hline CHEMBL 347958 & 64185 & 2.699 & 2.6711 & TRN & \\
\hline CHEMBL358226 & 64185 & 5.2518 & 5.2707 & TRN & \\
\hline CHEMBL356972 & 64185 & 4.301 & 3.8782 & TST & \\
\hline CHEMBL422128 & 64185 & 5.699 & 5.7172 & TRN & \\
\hline CHEMBL359152 & 64185 & 5.2076 & 5.2526 & TRN & \\
\hline CHEMBL148853 & 64185 & 4.2676 & 4.2547 & TRN & \\
\hline CHEMBL422496 & 64185 & 3.6021 & 4.6825 & TST & \\
\hline CHEMBL150481 & 64185 & 4.5229 & 3.8493 & TST & \\
\hline CHEMBL423583 & 64185 & 5.0177 & 5.2247 & TST & \\
\hline CHEMBL146845 & 64185 & 5.4318 & 5.7386 & TST & \\
\hline CHEMBL434082 & 64185 & 5.699 & 5.2159 & TST & \\
\hline CHEMBL150273 & 64185 & 4.3565 & 5.006 & TST & \\
\hline CHEMBL 358020 & 64185 & 4.6383 & 4.4916 & TST & \\
\hline CHEMBL149391 & 64185 & 4.6198 & 4.8758 & TST & \\
\hline CHEMBL357099 & 64185 & 2.699 & 3.3394 & TST & \\
\hline CHEMBL348685 & 64185 & 5.2441 & 4.6096 & TST & \\
\hline CHEMBL148953 & 64185 & 5.1308 & 5.8443 & TST & \\
\hline CHEMBL149953 & 64185 & 4.8239 & 5.7226 & TST & \\
\hline CHEMBL3660007 & 1527870 & 7.0223 & 6.9817 & TST & \\
\hline CHEMBL3660054 & 1527870 & 8.3979 & 7.9575 & TRN & \\
\hline CHEMBL 3660020 & 1527870 & 7.7959 & 7.2105 & TRN & \\
\hline CHEMBL3664623 & 1527870 & 7.5086 & 7.3441 & TRN & \\
\hline CHEMBL3664618 & 1527870 & 8.8539 & 8.6609 & TRN & \\
\hline CHEMBL3660012 & 1527870 & 8.301 & 7.7448 & TST & \\
\hline CHEMBL3660052 & 1527870 & 7.1549 & 6.8692 & TRN & \\
\hline CHEMBL 3660074 & 1527870 & 8.0969 & 7.3731 & TRN & \\
\hline CHEMBL 3660026 & 1527870 & 8.3979 & 8.4224 & TRN & \\
\hline CHEMBL 3660025 & 1527870 & 8.699 & 9.0421 & TRN & \\
\hline
\end{tabular}


Supplemental Table S2.txt

\begin{tabular}{|c|c|c|c|c|c|}
\hline CHEMBL3664631 & 1527870 & 7.9957 & 8.2906 & TRN & \\
\hline CHEMBL3660032 & 1527870 & 8.5229 & 8.4575 & TRN & \\
\hline CHEMBL3660078 & 1527870 & 8.5229 & 7.3341 & TRN & \\
\hline CHEMBL3660009 & 1527870 & 6.0 & 7.1805 & TRN & \\
\hline CHEMBL3660019 & 1527870 & 8.699 & 8.2818 & TRN & \\
\hline CHEMBL3660055 & 1527870 & 8.0 & 8.8884 & TRN & \\
\hline CHEMBL3660080 & 1527870 & 8.699 & 8.6516 & TRN & \\
\hline CHEMBL3660063 & 1527870 & 9.0223 & 9.0897 & TRN & \\
\hline CHEMBL3660042 & 1527870 & 7.9208 & 7.7722 & TRN & \\
\hline CHEMBL3660082 & 1527870 & 8.5229 & 8.6834 & TRN & \\
\hline CHEMBL3660029 & 1527870 & 9.0969 & 9.0475 & TRN & \\
\hline CHEMBL3660093 & 1527870 & 8.8539 & 8.9564 & TRN & \\
\hline CHEMBL 3664625 & 1527870 & 7.8477 & 8.1064 & TRN & \\
\hline CHEMBL3664616 & 1527870 & 8.6576 & 8.6481 & TRN & \\
\hline CHEMBL3660083 & 1527870 & 6.7773 & 7.6844 & TST & \\
\hline CHEMBL3660064 & 1527870 & 8.8861 & 8.8726 & TRN & \\
\hline CHEMBL3660059 & 1527870 & 7.4685 & 7.4029 & TRN & \\
\hline CHEMBL3660046 & 1527870 & 7.2007 & 7.5491 & TST & \\
\hline CHEMBL 3660021 & 1527870 & 9.0 & 8.6025 & TRN & \\
\hline CHEMBL3660094 & 1527870 & 8.4089 & 8.4896 & TRN & \\
\hline CHEMBL3660076 & 1527870 & 8.699 & 7.5658 & TRN & \\
\hline CHEMBL3660047 & 1527870 & 7.5702 & 7.7479 & TST & \\
\hline CHEMBL3664627 & 1527870 & 8.2366 & 7.82299 & 99999999995 & TRN \\
\hline CHEMBL3660006 & 1527870 & 8.7959 & 8.1397 & TRN & \\
\hline CHEMBL3660030 & 1527870 & 6.0 & 7.0359 & TRN & \\
\hline CHEMBL3660014 & 1527870 & 8.3979 & 8.0729 & TRN & \\
\hline CHEMBL3664617 & 1527870 & 9.1549 & 9.0643 & TRN & \\
\hline CHEMBL3660034 & 1527870 & 8.301 & 7.9978 & TRN & \\
\hline CHEMBL3664630 & 1527870 & 8.7959 & 8.5704 & TRN & \\
\hline CHEMBL3664622 & 1527870 & 9.0458 & 9.0951 & TRN & \\
\hline CHEMBL3660068 & 1527870 & 8.2757 & 8.2898 & TRN & \\
\hline CHEMBL3660077 & 1527870 & 9.3468 & 8.7734 & TRN & \\
\hline CHEMBL3660086 & 1527870 & 6.0 & 6.9999 & TRN & \\
\hline CHEMBL3660067 & 1527870 & 7.7959 & 7.2997 & TRN & \\
\hline CHEMBL3664611 & 1527870 & 8.1367 & 8.2886 & TRN & \\
\hline CHEMBL3664628 & 1527870 & 8.6383 & 8.2769 & TRN & \\
\hline CHEMBL3660027 & 1527870 & 8.301 & 8.1456 & TRN & \\
\hline CHEMBL3660008 & 1527870 & 8.5229 & 7.8997 & TRN & \\
\hline CHEMBL3660089 & 1527870 & 9.1549 & 7.4276 & TRN & \\
\hline CHEMBL3660081 & 1527870 & 8.699 & 8.5929 & TRN & \\
\hline CHEMBL3664633 & 1527870 & 8.2596 & 8.6941 & TRN & \\
\hline CHEMBL3660091 & 1527870 & 7.8861 & 7.3101 & TRN & \\
\hline CHEMBL3664614 & 1527870 & 8.0809 & 8.3083 & TRN & \\
\hline CHEMBL3664613 & 1527870 & 8.7212 & 8.7795 & TRN & \\
\hline CHEMBL3660096 & 1527870 & 9.301 & 8.9922 & TRN & \\
\hline CHEMBL3660016 & 1527870 & 6.0 & 7.1676 & TRN & \\
\hline CHEMBL3660028 & 1527870 & 8.699 & 8.7084 & TRN & \\
\hline CHEMBL3660024 & 1527870 & 9.1549 & 9.7628 & TRN & \\
\hline
\end{tabular}




\begin{tabular}{|c|c|c|c|c|c|c|}
\hline \multicolumn{7}{|c|}{ Supplemental Table S2.txt } \\
\hline CHEMBL3664629 & 1527870 & 9.0 & 9.0466 & TST & & \\
\hline CHEMBL 3660056 & 1527870 & 7.2596 & 7.4162 & TRN & & \\
\hline CHEMBL3660072 & 1527870 & 6.1884 & 7.2707 & TST & & \\
\hline CHEMBL 3660071 & 1527870 & 6.58 & 7.3287 & TST & & \\
\hline CHEMBL3664615 & 1527870 & 8.4815 & 8.5928 & TST & & \\
\hline CHEMBL3660049 & 1527870 & 8.5229 & 7.9655 & TRN & & \\
\hline CHEMBL3660061 & 1527870 & 9.1938 & 9.2355 & TST & & \\
\hline CHEMBL 3660050 & 1527870 & 6.0 & 8.074 & TRN & & \\
\hline CHEMBL 3660035 & 1527870 & 6.0 & 6.9843 & TST & & \\
\hline CHEMBL3660051 & 1527870 & 6.7496 & 6.8444 & TRN & & \\
\hline CHEMBL 3660060 & 1527870 & 9.1871 & 9.3508 & TST & & \\
\hline CHEMBL 3660065 & 1527870 & 8.7959 & 8.9272 & TRN & & \\
\hline CHEMBL3660039 & 1527870 & 6.0 & 6.8117 & TST & & \\
\hline CHEMBL 3660087 & 1527870 & 8.3565 & 8.0901 & TST & & \\
\hline CHEMBL3664619 & 1527870 & 7.9281 & 8.2542 & TRN & & \\
\hline CHEMBL3660062 & 1527870 & 9.0969 & 9.2014 & TST & & \\
\hline CHEMBL3660037 & 1527870 & 6.0 & 7.0298 & TST & & \\
\hline CHEMBL3660069 & 1527870 & 9.0177 & 9.135 & TRN & & \\
\hline CHEMBL 3660079 & 1527870 & 8.3979 & 8.3063 & TRN & & \\
\hline CHEMBL3660095 & 1527870 & 8.0605 & 8.3674 & TRN & & \\
\hline CHEMBL3660053 & 1527870 & 8.0458 & 8.1673 & TRN & & \\
\hline CHEMBL 3660048 & 1527870 & 6.0 & 6.9099 & TRN & & \\
\hline CHEMBL3664632 & 1527870 & 7.8996 & 8.604 & TST & & \\
\hline CHEMBL 3660092 & 1527870 & 8.3098 & 7.3676 & TRN & & \\
\hline CHEMBL3664620 & 1527870 & 9.0 & 9.1217 & TRN & & \\
\hline CHEMBL 3660073 & 1527870 & 7.7696 & 8.4867 & TRN & & \\
\hline CHEMBL3664626 & 1527870 & 8.3098 & 8.1461 & TRN & & \\
\hline CHEMBL3660015 & 1527870 & 8.5229 & 8.0924 & TST & & \\
\hline CHEMBL 3660075 & 1527870 & 9.699 & 9.1517 & TRN & & \\
\hline CHEMBL3660066 & 1527870 & 9.1249 & 8.9828 & TRN & & \\
\hline CHEMBL3664621 & 1527870 & 6.0 & 7.3338 & TRN & & \\
\hline CHEMBL 3660041 & 1527870 & 9.2596 & 9.3298 & TST & & \\
\hline CHEMBL 3660013 & 1527870 & 7.7959 & 7.3413 & TST & & \\
\hline CHEMBL3660033 & 1527870 & 8.699 & 8.8214 & TST & & \\
\hline CHEMBL3660058 & 1527870 & 6.8794 & 6.8053 & TRN & & \\
\hline CHEMBL 3660090 & 1527870 & 6.0 & 7.0715 & TRN & & \\
\hline CHEMBL3944365 & 1527870 & 9.0969 & 8.6005 & TST & & \\
\hline CHEMBL3660011 & 1527870 & 7.4949 & 7.1271 & TST & & \\
\hline CHEMBL 3664612 & 1527870 & 8.3279 & 8.5908 & TRN & & \\
\hline CHEMBL3660057 & 1527870 & 7.585 & 7.3504 & TRN & & \\
\hline CHEMBL 3660084 & 1527870 & 8.0969 & 8.0236 & TRN & & \\
\hline CHEMBL3660045 & 1527870 & 6.857 & 8.2484 & TST & & \\
\hline CHEMBL3660070 & 1527870 & $6.8210 e$ & 30000000 & 01 & 7.3556 & TST \\
\hline CHEMBL 3664624 & 1527870 & 9.0 & 8.7763 & TRN & & \\
\hline CHEMBL3660023 & 1527870 & 8.8239 & 9.3607 & TST & & \\
\hline CHEMBL3660097 & 1527870 & 8.0269 & 8.0445 & TRN & & \\
\hline CHEMBL3660043 & 1527870 & 8.3979 & 8.6605 & TST & & \\
\hline CHEMBL1986350 & 809050 & 3.0044 & 3.0264 & TRN & & \\
\hline
\end{tabular}




\begin{tabular}{|c|c|c|c|c|}
\hline & & & pplement & al $\mathrm{T}$ \\
\hline CHEMBL1991968 & 809050 & 3.0044 & 3.0635 & TRN \\
\hline CHEMBL1978234 & 809050 & 4.1778 & 4.2111 & TRN \\
\hline CHEMBL1999757 & 809050 & 3.0044 & 3.02 & TRN \\
\hline CHEMBL1967269 & 809050 & 3.0044 & 2.9824 & TRN \\
\hline CHEMBL1977876 & 809050 & 3.0044 & 3.0123 & TRN \\
\hline CHEMBL1976925 & 809050 & 4.1662 & 5.0751 & TST \\
\hline CHEMBL1724713 & 809050 & 5.2248 & 5.1752 & TST \\
\hline CHEMBL 2003536 & 809050 & 3.0044 & 3.2393 & TST \\
\hline CHEMBL1582492 & 809050 & 5.062 & 5.0594 & TRN \\
\hline CHEMBL1970493 & 809050 & 3.0044 & 4.3336 & TST \\
\hline CHEMBL1983591 & 809050 & 3.0044 & 2.9712 & TRN \\
\hline CHEMBL1586803 & 809050 & 3.0044 & 2.997 & TRN \\
\hline CHEMBL1992643 & 809050 & 3.0044 & 2.9812 & TRN \\
\hline CHEMBL1989363 & 809050 & 3.0044 & 2.9743 & TRN \\
\hline CHEMBL1970596 & 809050 & 3.0044 & 4.5601 & TST \\
\hline CHEMBL1979245 & 809050 & 3.0044 & 3.0156 & TRN \\
\hline CHEMBL1974783 & 809050 & 3.0044 & 2.4261 & TST \\
\hline CHEMBL 2028094 & 809050 & 4.3215 & 4.2826 & TRN \\
\hline CHEMBL1447034 & 809050 & 4.5186 & 4.8798 & TST \\
\hline CHEMBL1976718 & 809050 & 3.0044 & 3.0106 & TRN \\
\hline CHEMBL1383031 & 809050 & 4.4559 & 3.5318 & TST \\
\hline CHEMBL255881 & 809050 & 5.6819 & 5.3038 & TST \\
\hline CHEMBL1994995 & 809050 & 3.0044 & 3.1987 & TST \\
\hline CHEMBL1965380 & 809050 & 3.0044 & 3.0393 & TRN \\
\hline CHEMBL1320566 & 809050 & 3.0044 & 5.4752 & TST \\
\hline CHEMBL 2005398 & 809050 & 3.0044 & 2.9828 & TRN \\
\hline CHEMBL1984047 & 809050 & 3.0044 & 2.9782 & TRN \\
\hline CHEMBL1974877 & 809050 & 3.0044 & 3.0215 & TRN \\
\hline CHEMBL1982446 & 809050 & 3.0044 & 2.9644 & TRN \\
\hline CHEMBL1709150 & 809050 & 3.0044 & 3.2346 & TST \\
\hline CHEMBL1986471 & 809050 & 3.0044 & 2.6522 & TST \\
\hline CHEMBL1965135 & 809050 & 3.0044 & 3.0159 & TRN \\
\hline CHEMBL 2000496 & 809050 & 4.3925 & 4.3956 & TRN \\
\hline CHEMBL1998530 & 809050 & 3.0044 & 2.9606 & TRN \\
\hline CHEMBL1386524 & 809050 & 3.0044 & 3.0174 & TRN \\
\hline CHEMBL1999067 & 809050 & 3.0044 & 3.1778 & TST \\
\hline CHEMBL1334528 & 809050 & 5.9245 & 5.8888 & TRN \\
\hline CHEMBL1990773 & 809050 & 4.1107 & 4.488 & TST \\
\hline CHEMBL1393565 & 809050 & 3.0044 & 2.9843 & TST \\
\hline CHEMBL 2000036 & 809050 & 3.0044 & 3.9714 & TST \\
\hline CHEMBL1498363 & 809050 & 6.2596 & 6.2722 & TRN \\
\hline CHEMBL1989633 & 809050 & 3.0044 & 3.0046 & TRN \\
\hline CHEMBL1980903 & 809050 & 3.0044 & 3.0174 & TRN \\
\hline CHEMBL1428519 & 809050 & 4.15 & 4.2092 & TRN \\
\hline CHEMBL1985139 & 809050 & 3.0044 & 3.0014 & TRN \\
\hline CHEMBL1993723 & 809050 & 3.0044 & 2.9948 & TRN \\
\hline CHEMBL1981516 & 809050 & 3.0044 & 2.9556 & TRN \\
\hline CHEMBL1376754 & 809050 & 5.5361 & 5.0474 & TST \\
\hline
\end{tabular}




\begin{tabular}{|c|c|c|c|c|c|c|}
\hline & & \multicolumn{5}{|c|}{ Supplemental Table s2.txt } \\
\hline CHEMBL1978748 & 809050 & 3.0044 & 2.7265 & TST & & \\
\hline CHEMBL408994 & 809050 & 4.4056 & 4.3753 & TRN & & \\
\hline CHEMBL1988369 & 809050 & 3.0044 & 2.991 & TRN & & \\
\hline CHEMBL1974234 & 809050 & 3.0044 & 2.969 & TRN & & \\
\hline CHEMBL1987113 & 809050 & 3.0044 & 3.0324 & TRN & & \\
\hline CHEMBL1587532 & 809050 & 4.2874 & 4.2939 & TRN & & \\
\hline CHEMBL1976492 & 809050 & 3.0044 & 3.0463 & TRN & & \\
\hline CHEMBL1733286 & 809050 & 3.0044 & 2.133 & TST & & \\
\hline CHEMBL1983259 & 809050 & 3.0044 & 2.5846 & TST & & \\
\hline CHEMBL3192708 & 809050 & 4.9101 & 4.1548 & TST & & \\
\hline CHEMBL1996364 & 809050 & 3.0044 & 3.0277 & TRN & & \\
\hline CHEMBL1997264 & 809050 & 3.0044 & 2.9824 & TRN & & \\
\hline CHEMBL 2000190 & 809050 & 3.0044 & 2.969 & TRN & & \\
\hline CHEMBL1985725 & 809050 & 3.0044 & 3.0034 & TRN & & \\
\hline CHEMBL2001755 & 809050 & 3.0044 & 2.9915 & TRN & & \\
\hline CHEMBL1330039 & 809050 & 4.5654 & 3.9252 & TST & & \\
\hline CHEMBL1511078 & 809050 & 5.5017 & 5.3699 & TRN & & \\
\hline CHEMBL1741927 & 809050 & 3.0044 & 2.9473 & TRN & & \\
\hline CHEMBL 2007483 & 809050 & 3.0044 & 3.0084 & TRN & & \\
\hline CHEMBL3209322 & 809050 & 5.6799 & 5.6708 & TRN & & \\
\hline CHEMBL1310492 & 809050 & 5.5654 & 5.7244 & TRN & & \\
\hline CHEMBL1966498 & 809050 & 3.0044 & 3.9864 & TST & & \\
\hline CHEMBL 2005060 & 809050 & 3.0044 & 3.0637 & TRN & & \\
\hline CHEMBL1984384 & 809050 & 3.0044 & 3.05 & TRN & & \\
\hline CHEMBL1980590 & 809050 & 4.5528 & 4.5487 & TRN & & \\
\hline CHEMBL1312653 & 809050 & 5.0376 & 5.0599 & TRN & & \\
\hline CHEMBL1975000 & 809050 & 3.0044 & 2.9911 & TRN & & \\
\hline CHEMBL1990131 & 809050 & 3.0044 & 3.0007 & TRN & & \\
\hline CHEMBL 2002163 & 809050 & 3.0044 & 2.9935 & TRN & & \\
\hline CHEMBL1987231 & 809050 & 3.0044 & 3.0092 & TRN & & \\
\hline CHEMBL1993655 & 809050 & 3.0044 & 3.0121 & TRN & & \\
\hline CHEMBL1412746 & 809050 & 5.9208 & 5.7921 & TRN & & \\
\hline CHEMBL1503187 & 809050 & 5.82299 & 79999999 & 995 & 5.8381 & TRN \\
\hline CHEMBL1458018 & 809050 & 3.0044 & 3.0492 & TRN & & \\
\hline CHEMBL1567396 & 809050 & 5.2984 & 5.0311 & TST & & \\
\hline CHEMBL1301786 & 809050 & 3.0044 & 3.0376 & TRN & & \\
\hline CHEMBL1587985 & 809050 & 5.4584 & 5.5481 & TRN & & \\
\hline CHEMBL1973976 & 809050 & 3.0044 & 2.9674 & TRN & & \\
\hline CHEMBL1975650 & 809050 & 3.0044 & 2.9431 & TRN & & \\
\hline CHEMBL1987203 & 809050 & 3.0044 & 3.0761 & TRN & & \\
\hline CHEMBL1511826 & 809050 & 5.1752 & 5.1367 & TRN & & \\
\hline CHEMBL1386731 & 809050 & 3.0044 & 2.9935 & TRN & & \\
\hline CHEMBL 290545 & 809050 & 6.0783 & 6.0617 & TRN & & \\
\hline CHEMBL1985081 & 809050 & 4.6861 & 4.7048 & TRN & & \\
\hline CHEMBL3198803 & 809050 & 6.0926 & 6.1059 & TRN & & \\
\hline CHEMBL 2001306 & 809050 & 3.0044 & 3.02600 & 00006 & 202 & TRN \\
\hline CHEMBL1990762 & 809050 & 3.0044 & 3.0124 & TRN & & \\
\hline CHEMBL1984849 & 809050 & 3.0044 & 3.0151 & TRN & & \\
\hline
\end{tabular}


Supplemental Table S2.txt

\begin{tabular}{|c|c|c|c|c|c|}
\hline CHEMBL 2028107 & 809050 & 3.0044 & 3.0134 & TRN & \\
\hline CHEMBL3605986 & 1510421 & 7.301 & 7.3319 & TRN & \\
\hline CHEMBL3605978 & 1510421 & 8.5229 & 8.4731 & TRN & \\
\hline CHEMBL3605968 & 1510421 & 6.6576 & 6.6934 & TRN & \\
\hline CHEMBL3606023 & 1510421 & 8.5229 & 8.4334 & TRN & \\
\hline CHEMBL3606018 & 1510421 & 8.5229 & 8.5751 & TRN & \\
\hline CHEMBL3605993 & 1510421 & 8.5229 & 8.441 & TRN & \\
\hline CHEMBL3605995 & 1510421 & 6.9469 & 6.9254 & TRN & \\
\hline CHEMBL3606021 & 1510421 & 8.5229 & 8.522 & TRN & \\
\hline CHEMBL3606019 & 1510421 & 6.8794 & 6.8026 & TRN & \\
\hline CHEMBL3605970 & 1510421 & 7.0458 & 7.0478 & TRN & \\
\hline CHEMBL3605985 & 1510421 & 8.5229 & 8.4 & TRN & \\
\hline CHEMBL3605980 & 1510421 & 5.5867 & 5.6286 & TRN & \\
\hline CHEMBL3606004 & 1510421 & 7.2676 & 7.2827 & TRN & \\
\hline CHEMBL3605994 & 1510421 & 8.5229 & 8.54 & TRN & \\
\hline CHEMBL3605982 & 1510421 & 7.2518 & 7.2706 & TST & \\
\hline CHEMBL3606007 & 1510421 & 7.1427 & 7.1359 & TRN & \\
\hline CHEMBL3605975 & 1510421 & 6.7959 & 6.6669 & TRN & \\
\hline CHEMBL3605969 & 1510421 & 6.1192 & 5.6085 & TST & \\
\hline CHEMBL3606016 & 1510421 & 8.5229 & 7.8916 & TST & \\
\hline CHEMBL3605990 & 1510421 & 8.5229 & 8.5351 & TRN & \\
\hline CHEMBL3606001 & 1510421 & 8.5229 & 8.5164 & TRN & \\
\hline CHEMBL3605992 & 1510421 & 8.5229 & 8.5873 & TRN & \\
\hline CHEMBL3606013 & 1510421 & 8.5229 & 7.6409 & TST & \\
\hline CHEMBL3605973 & 1510421 & 7.4815 & 7.5003 & TRN & \\
\hline CHEMBL3605972 & 1510421 & 7.4949 & 7.5142 & TRN & \\
\hline CHEMBL3606002 & 1510421 & 6.3872 & 6.3866 & TRN & \\
\hline CHEMBL3605971 & 1510421 & 6.4949 & 6.4624 & TRN & \\
\hline CHEMBL3606005 & 1510421 & 7.4089 & 7.3202 & TRN & \\
\hline CHEMBL3605988 & 1510421 & 6.8239 & 6.7754 & TRN & \\
\hline CHEMBL3606000 & 1510421 & 7.2757 & 7.3164 & TRN & \\
\hline CHEMBL3606003 & 1510421 & 7.3372 & 7.3106 & TRN & \\
\hline CHEMBL3605983 & 1510421 & 8.5229 & 8.4801 & TRN & \\
\hline CHEMBL3606015 & 1510421 & 7.4685 & 7.4464 & TRN & \\
\hline CHEMBL3606024 & 1510421 & 8.5229 & 8.5631 & TRN & \\
\hline CHEMBL3605967 & 1510421 & 7.0605 & 7.03700 & 0000000001 & TRN \\
\hline CHEMBL3605977 & 1510421 & 6.5376 & 6.5509 & TRN & \\
\hline CHEMBL3605981 & 1510421 & 7.3098 & 7.2548 & TRN & \\
\hline CHEMBL3605998 & 1510421 & 8.5229 & 8.4474 & TRN & \\
\hline CHEMBL3606009 & 1510421 & 8.5229 & 8.4884 & TRN & \\
\hline CHEMBL3606010 & 1510421 & 8.5229 & 8.5577 & TRN & \\
\hline CHEMBL3605997 & 1510421 & 8.5229 & 8.6345 & TRN & \\
\hline CHEMBL3605987 & 1510421 & 6.6021 & 6.6616 & TRN & \\
\hline CHEMBL1329044 & 1510421 & 7.0757 & 7.0895 & TRN & \\
\hline CHEMBL3606006 & 1510421 & 7.301 & 7.3408 & TRN & \\
\hline CHEMBL3605999 & 1510421 & 7.4685 & 7.5067 & TRN & \\
\hline CHEMBL3605976 & 1510421 & 7.4559 & 7.6179 & TRN & \\
\hline CHEMBL3606022 & 1510421 & 7.0969 & 7.146 & TRN & \\
\hline
\end{tabular}


Supplemental Table S2.txt

\begin{tabular}{|c|c|c|c|c|c|}
\hline CHEMBL3605984 & 1510421 & 7.5086 & 7.6312 & TRN & \\
\hline CHEMBL3606020 & 1510421 & 5.7258 & 8.2074 & TST & \\
\hline CHEMBL3606011 & 1510421 & 8.5229 & 7.8788 & TST & \\
\hline CHEMBL3605979 & 1510421 & 6.4815 & 7.0494 & TST & \\
\hline CHEMBL3606017 & 1510421 & 8.5229 & 6.6762 & TST & \\
\hline CHEMBL3605996 & 1510421 & 7.3768 & 7.5846 & TST & \\
\hline CHEMBL3606008 & 1510421 & 7.3768 & 7.1151 & TST & \\
\hline CHEMBL 3606014 & 1510421 & 7.301 & 8.0191 & TST & \\
\hline CHEMBL3605974 & 1510421 & 8.5229 & 6.9668 & TST & \\
\hline CHEMBL3606012 & 1510421 & 8.5229 & 7.598 & TST & \\
\hline CHEMBL3605991 & 1510421 & 8.5229 & 7.8362 & TST & \\
\hline CHEMBL3605989 & 1510421 & 6.4559 & 6.0546 & TST & \\
\hline CHEMBL521608 & 495672 & 5.21899 & 999999999 & 99 & 5.4299 \\
\hline CHEMBL454369 & 495672 & 6.5086 & 5.322 & TST & \\
\hline CHEMBL460739 & 495672 & 5.3635 & 5.3514 & TRN & \\
\hline CHEMBL460740 & 495672 & 4.7932 & 4.6613 & TRN & \\
\hline CHEMBL473749 & 495672 & 5.1096 & 5.2312 & TRN & \\
\hline CHEMBL460911 & 495672 & 4.8601 & 4.9763 & TRN & \\
\hline CHEMBL491472 & 495672 & 5.5003 & 5.5322 & TRN & \\
\hline CHEMBL517879 & 495672 & 5.209 & 5.2167 & TRN & \\
\hline CHEMBL454169 & 495672 & 5.8125 & 5.8056 & TST & \\
\hline CHEMBL490683 & 495672 & 5.6402 & 5.8167 & TRN & \\
\hline CHEMBL473540 & 495672 & 5.3872 & 5.2278 & TRN & \\
\hline CHEMBL508490 & 495672 & 5.1512 & 5.4739 & TST & \\
\hline CHEMBL473750 & 495672 & 3.5229 & 4.323 & TRN & \\
\hline CHEMBL524131 & 495672 & 5.585 & 4.2687 & TST & \\
\hline CHEMBL514789 & 495672 & 5.8069 & 5.9778 & TRN & \\
\hline CHEMBL517594 & 495672 & 4.8327 & 4.977 & TST & \\
\hline CHEMBL449849 & 495672 & 5.5607 & 5.4348 & TRN & \\
\hline CHEMBL508050 & 495672 & 6.1079 & 5.8558 & TST & \\
\hline CHEMBL510637 & 495672 & 4.7825 & 4.9615 & TRN & \\
\hline CHEMBL514782 & 495672 & 5.8633 & 5.4374 & TRN & \\
\hline CHEMBL517878 & 495672 & 5.7852 & 5.7883 & TRN & \\
\hline CHEMBL515715 & 495672 & 4.8508 & 4.9259 & TRN & \\
\hline CHEMBL491471 & 495672 & 5.767 & 5.7015 & TRN & \\
\hline CHEMBL454398 & 495672 & 5.51 & 4.76 & TST & \\
\hline CHEMBL452140 & 495672 & 5.1643 & 5.3561 & TRN & \\
\hline CHEMBL491479 & 495672 & 6.0862 & 5.1006 & TRN & \\
\hline CHEMBL491674 & 495672 & 4.9872 & 4.9456 & TRN & \\
\hline CHEMBL454168 & 495672 & 6.2518 & 5.646 & TST & \\
\hline CHEMBL491281 & 495672 & 5.1349 & 4.8578 & TRN & \\
\hline CHEMBL523142 & 495672 & 5.0975 & 5.6879 & TRN & \\
\hline CHEMBL461799 & 495672 & 5.1278 & 5.1557 & TRN & \\
\hline CHEMBL11458 & 495672 & 6.6383 & 5.3235 & TST & \\
\hline CHEMBL460738 & 495672 & 4.8894 & 4.5479 & TRN & \\
\hline CHEMBL473744 & 495672 & 6.1739 & 5.8018 & TRN & \\
\hline CHEMBL462140 & 495672 & 5.1051 & 5.2979 & TRN & \\
\hline CHEMBL461800 & 495672 & 3.5229 & 3.444 & TRN & \\
\hline
\end{tabular}




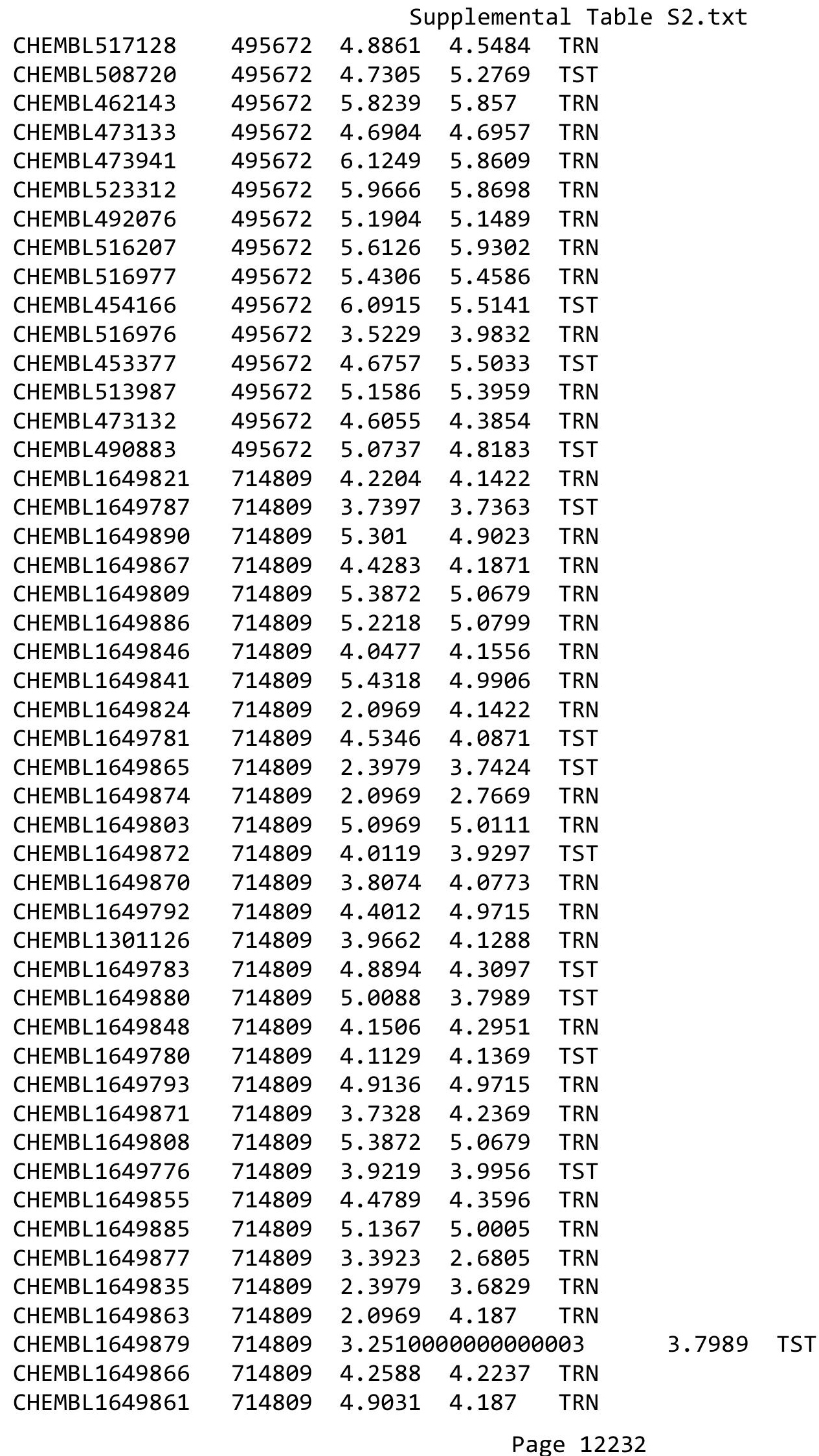


Supplemental Table S2.txt

\begin{tabular}{|c|c|c|c|c|}
\hline IE & & 3 & 79 & \\
\hline 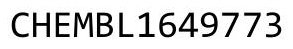 & 14809 & . 3197 & 4.4577 & \\
\hline 87 & & & & \\
\hline AEMBL1 & 809 & & & \\
\hline AEMBL1649798 & 14809 & & & \\
\hline HEMBL1649757 & 14809 & 3854 & 9846 & \\
\hline HEMBL16 & 14809 & & 331 & \\
\hline 771 & 14809 & & & \\
\hline HEMBL164 & 14809 & & & \\
\hline HEMBL164 & 14809 & & 2609 & \\
\hline HEMBL164 & 14809 & & 54 & \\
\hline IEMBL16 & 14809 & & 249 & \\
\hline AEMBL16 & & & & \\
\hline HEMBL16 & 14809 & & & \\
\hline AEMBL16 & 14809 & & & \\
\hline AEMBL14 & 09 & & 09 & \\
\hline HEMBL16 & $\partial 9$ & & & \\
\hline HEMBL16 & 9 & & & \\
\hline HEMBL16 & 09 & & & \\
\hline IEMBL16 & & & & \\
\hline HEMBLIt & 39 & & 15 & \\
\hline AEMBLI & 9 & & 48 & \\
\hline HEMBL1C & 9 & & & \\
\hline 58 & 09 & & & \\
\hline AEMBL16 & & & & ISI \\
\hline HEMBL1C & 99 & & & RI \\
\hline HEMBL1 & 9 & & 22 & \\
\hline HFMBI $1 f$ & & & 36 & ST \\
\hline AEMBL1 & & & & TST \\
\hline HEMBL16 & 9 & & & RIN \\
\hline HEMBL1C & 39 & & & \\
\hline HEMBL1 & 9 & & 96 & \\
\hline 1 & & & & RN \\
\hline HEMBL16 & & & 852 & $\mathrm{R}$ \\
\hline HEMBL164 & $\partial 9$ & & 734 & TST \\
\hline HEMBL1C & $\partial 9$ & & 15 & TRN \\
\hline HFMRI 1 & & & & RN \\
\hline HEMBL1 & & & & RN \\
\hline HEMBL16 & 14809 & & 422 & $\Gamma \mathrm{RN}$ \\
\hline IEMBL16 & $\partial 9$ & & & RN \\
\hline HEMBL1C & 09 & & 56 & \\
\hline CHEMBL16 & & & & RN \\
\hline HEMBL16 & & & 1422 & RN \\
\hline AEMBL16 & 14809 & 4 & 2448 & TRN \\
\hline 1 & & & & \\
\hline HEMBL16 & 14809 & & .3596 & \\
\hline HEMBL16 & 14809 & 3.7557 & . 1777 & \\
\hline HEMBL1649820 & 714809 & 5.2441 & 4.1422 & 「RN \\
\hline
\end{tabular}

Page 12233 


\begin{tabular}{|c|c|c|c|c|c|c|}
\hline & & \multicolumn{5}{|c|}{ Supplemental Table S2.txt } \\
\hline CHEMBL1649812 & 714809 & 3.3436 & 5.0679 & TRN & & \\
\hline CHEMBL1649777 & 714809 & 4.1096 & 4.1458 & TST & & \\
\hline CHEMBL1649839 & 714809 & 5.0706 & 5.2839 & TRN & & \\
\hline CHEMBL1649806 & 714809 & 5.2291 & 5.0679 & TRN & & \\
\hline CHEMBL1649778 & 714809 & 4.762 & 4.2086 & TST & & \\
\hline CHEMBL1649881 & 714809 & 3.7693 & 2.9572 & TST & & \\
\hline CHEMBL1649884 & 714809 & 5.4202 & 4.8941 & TST & & \\
\hline CHEMBL1649873 & 714809 & 3.3693 & 2.8166 & TST & & \\
\hline CHEMBL1649882 & 714809 & 4.4584 & 5.0543 & TST & & \\
\hline CHEMBL1649888 & 714809 & 4.0862 & 4.419 & TST & & \\
\hline CHEMBL1649816 & 714809 & 4.9172 & 4.1422 & TRN & & \\
\hline CHEMBL1649813 & 714809 & 4.8539 & 3.8688 & TRN & & \\
\hline CHEMBL1649794 & 714809 & 4.9245 & 4.9715 & TRN & & \\
\hline CHEMBL1649788 & 714809 & 3.6861 & 3.9981 & TRN & & \\
\hline CHEMBL1649856 & 714809 & 4.8041 & 4.3596 & TRN & & \\
\hline CHEMBL1649817 & 714809 & 5.0315 & 4.1422 & TRN & & \\
\hline CHEMBL1649836 & 714809 & 4.9666 & 5.0034 & TRN & & \\
\hline CHEMBL1649832 & 714809 & 3.94199 & 99999999 & 997 & 3.7298 & TRN \\
\hline CHEMBL1649587 & 714809 & 5.1249 & 3.9266 & TRN & & \\
\hline CHEMBL1649868 & 714809 & 4.5452 & 4.5116 & TRN & & \\
\hline CHEMBL1649853 & 714809 & 4.2612 & 4.4867 & TRN & & \\
\hline CHEMBL1649790 & 714809 & 4.2848 & 4.8904 & TRN & & \\
\hline CHEMBL1649795 & 714809 & 5.2218 & 4.9715 & TRN & & \\
\hline CHEMBL1649814 & 714809 & 4.6757 & 4.4651 & TRN & & \\
\hline CHEMBL1649851 & 714809 & 4.3925 & 4.2448 & TRN & & \\
\hline CHEMBL1649842 & 714809 & 4.9508 & 4.8085 & TRN & & \\
\hline CHEMBL1649784 & 714809 & 4.9666 & 4.3073 & TST & & \\
\hline CHEMBL1649840 & 714809 & 5.1739 & 5.13700 & 9000 & 005 & TRN \\
\hline CHEMBL1649828 & 714809 & 4.7905 & 4.6464 & TRN & & \\
\hline CHEMBL1649837 & 714809 & $4.4510 e$ & 30000000 & 205 & 3.9233 & TRN \\
\hline CHEMBL1649847 & 714809 & 3.9344 & 4.3005 & TRN & & \\
\hline CHEMBL1649829 & 714809 & $3.7910 e$ & 30000000 & 004 & 3.5374 & TRN \\
\hline CHEMBL1649869 & 714809 & 4.1296 & 4.2792 & TRN & & \\
\hline CHEMBL1649850 & 714809 & 4.5702 & 4.2448 & TRN & & \\
\hline CHEMBL1649862 & 714809 & 4.6402 & 4.187 & TRN & & \\
\hline CHEMBL1649878 & 714809 & 4.1965 & 4.615 & TST & & \\
\hline CHEMBL1649854 & 714809 & 4.9355 & 4.6077 & TRN & & \\
\hline CHEMBL1649807 & 714809 & 5.3979 & 5.0679 & TRN & & \\
\hline CHEMBL1649833 & 714809 & 4.2055 & 4.2009 & TRN & & \\
\hline CHEMBL1649827 & 714809 & 3.8993 & 4.0082 & TRN & & \\
\hline CHEMBL1649826 & 714809 & 4.2503 & 4.4125 & TRN & & \\
\hline CHEMBL1649818 & 714809 & 5.4815 & 4.1422 & TRN & & \\
\hline CHEMBL1649800 & 714809 & 5.0605 & 4.9715 & TRN & & \\
\hline CHEMBL1375102 & 737408 & 5.7235 & 5.3426 & TST & & \\
\hline CHEMBL1434941 & 737408 & 5.1851 & 4.945 & TRN & & \\
\hline CHEMBL1505531 & 737408 & 5.5751 & 5.4964 & TST & & \\
\hline CHEMBL1970493 & 737408 & 5.1675 & 4.9568 & TST & & \\
\hline CHEMBL1382116 & 737408 & 5.3288 & 5.2458 & TRN & & \\
\hline
\end{tabular}




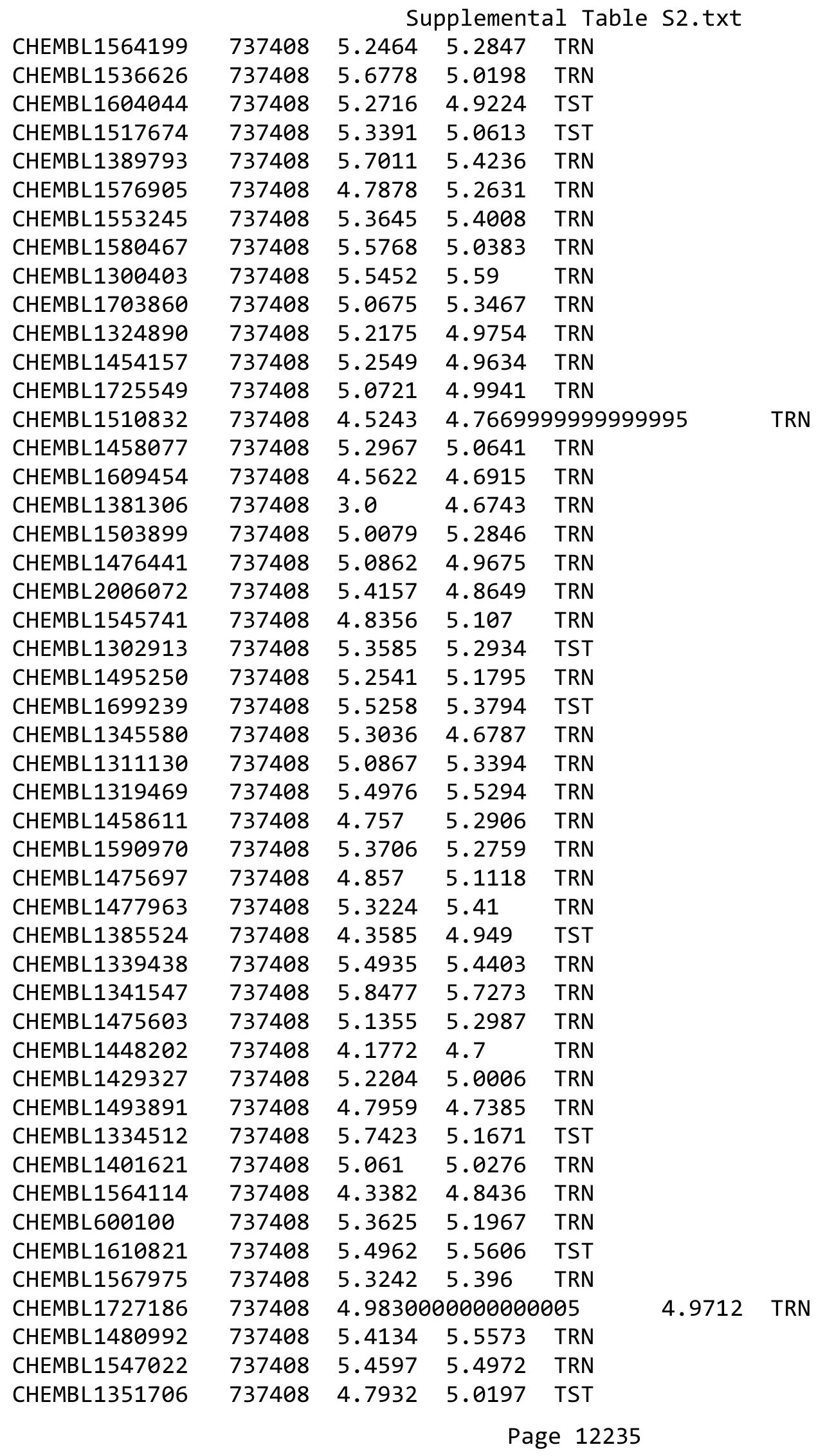




\begin{tabular}{|c|c|c|c|c|c|c|c|}
\hline \multicolumn{7}{|c|}{ Supplemental Table S2.txt } & \\
\hline CHEMBL1324472 & 737408 & 5.5884 & 5.5802 & TRN & & & \\
\hline CHEMBL1302328 & 737408 & 4.3768 & 4.5408 & TRN & & & \\
\hline CHEMBL1448452 & 737408 & 5.6517 & 5.4368 & TRN & & & \\
\hline CHEMBL1522413 & 737408 & 4.6882 & 4.5199 & TRN & & & \\
\hline CHEMBL1544859 & 737408 & 4.6108 & 4.9374 & TST & & & \\
\hline CHEMBL1323320 & 737408 & 4.4318 & 4.4395 & TRN & & & \\
\hline CHEMBL1580846 & 737408 & \multicolumn{3}{|c|}{5.617999999999999} & 4.9742 & TRN & \\
\hline CHEMBL1524102 & 737408 & 5.0372 & 5.0666 & TRN & & & \\
\hline CHEMBL1720952 & 737408 & \multicolumn{3}{|c|}{4.9830000000000005} & 5.3923 & TRN & \\
\hline CHEMBL1548470 & 737408 & 5.0259 & 4.9217 & TRN & & & \\
\hline CHEMBL1523040 & 737408 & 5.5784 & 5.1637 & TRN & & & \\
\hline CHEMBL1528727 & 737408 & 5.3036 & 5.1901 & TRN & & & \\
\hline CHEMBL3190747 & 737408 & 4.3872 & 4.6252 & TRN & & & \\
\hline CHEMBL1303289 & 737408 & 5.4647 & 5.3854 & TRN & & & \\
\hline CHEMBL1540993 & 737408 & 4.3595 & 4.9478 & TRN & & & \\
\hline CHEMBL1423563 & 737408 & \multicolumn{3}{|c|}{5.617999999999999} & 5.4749 & TRN & \\
\hline CHEMBL1441819 & 737408 & 4.644 & 4.6785 & TRN & & & \\
\hline CHEMBL1465029 & 737408 & 5.6596 & 5.4897 & TRN & & & \\
\hline CHEMBL1511826 & 737408 & 4.7352 & 4.8502 & TRN & & & \\
\hline CHEMBL1493133 & 737408 & 3.0 & 4.5097 & TRN & & & \\
\hline CHEMBL1390206 & 737408 & 5.5272 & 5.1878 & TST & & & \\
\hline CHEMBL1450031 & 737408 & 5.2284 & 5.0241 & TST & & & \\
\hline CHEMBL1431954 & 737408 & 4.7122 & 5.1149 & TRN & & & \\
\hline CHEMBL1462800 & 737408 & 4.3675 & 4.4432 & TRN & & & \\
\hline CHEMBL1521841 & 737408 & 5.5406 & 5.1991 & TRN & & & \\
\hline CHEMBL1334080 & 737408 & 5.3354 & 5.1746 & TRN & & & \\
\hline CHEMBL1513113 & 737408 & 5.5391 & 5.1187 & TRN & & & \\
\hline CHEMBL1720428 & 737408 & 4.4237 & 4.7461 & TST & & & \\
\hline CHEMBL1575099 & 737408 & \multicolumn{3}{|c|}{5.2139999999999995} & \multicolumn{2}{|c|}{5.247999999999999} & TRN \\
\hline CHEMBL1305391 & 737408 & 4.3893 & 4.7537 & TRN & & & \\
\hline CHEMBL1732805 & 737408 & 5.2097 & 5.2273 & TRN & & & \\
\hline CHEMBL1347373 & 737408 & 4.5331 & 4.3417 & TST & & & \\
\hline CHEMBL1730603 & 737408 & 4.6271 & 4.3477 & TRN & & & \\
\hline CHEMBL1309327 & 737408 & 5.3089 & 5.3332 & TRN & & & \\
\hline CHEMBL1591536 & 737408 & 5.284 & 5.4655 & TRN & & & \\
\hline CHEMBL1415426 & 737408 & 4.5969 & 4.4307 & TRN & & & \\
\hline CHEMBL1338730 & 737408 & 4.5467 & 4.8637 & TRN & & & \\
\hline CHEMBL1421070 & 737408 & 5.3526 & 5.1008 & TRN & & & \\
\hline CHEMBL269928 & 737408 & 4.7825 & 4.9355 & TRN & & & \\
\hline CHEMBL1438329 & 737408 & 5.4634 & 5.2751 & TST & & & \\
\hline CHEMBL1405682 & 737408 & 5.011 & 4.9704 & TRN & & & \\
\hline CHEMBL1411577 & 737408 & \multicolumn{3}{|c|}{5.382000000000001} & 5.1951 & TRN & \\
\hline CHEMBL1338474 & 737408 & 4.426 & 4.6903 & TRN & & & \\
\hline CHEMBL1403440 & 737408 & 5.301 & 5.271 & TRN & & & \\
\hline CHEMBL1414222 & 737408 & 4.7905 & 4.9563 & TST & & & \\
\hline CHEMBL1533454 & 737408 & 5.2636 & 5.3605 & TRN & & & \\
\hline CHEMBL1546605 & 737408 & 5.1302 & 5.0279 & TRN & & & \\
\hline CHEMBL1499471 & 737408 & 5.3686 & 5.2609 & TST & & & \\
\hline
\end{tabular}


Supplemental Table S2.txt

\begin{tabular}{|c|c|c|c|c|c|c|}
\hline CHEMBL579322 & 737408 & 5.3958 & 5.2968 & TRN & & \\
\hline CHEMBL1426029 & 737408 & 5.1555 & 5.3827 & TRN & & \\
\hline CHEMBL1415236 & 737408 & 5.4949 & 5.4587 & TST & & \\
\hline CHEMBL1318903 & 737408 & 5.3161 & 5.1618 & TRN & & \\
\hline CHEMBL1362702 & 737408 & 5.9508 & 5.2836 & TRN & & \\
\hline CHEMBL1575698 & 737408 & 5.6968 & 5.2836 & TST & & \\
\hline CHEMBL1551307 & 737408 & 5.7645 & 5.5221 & TRN & & \\
\hline CHEMBL1355614 & 737408 & 5.1409 & 5.1221 & TRN & & \\
\hline CHEMBL1540026 & 737408 & 5.2807 & 5.3448 & TRN & & \\
\hline CHEMBL1540472 & 737408 & 5.475 & 5.2565 & TRN & & \\
\hline CHEMBL1306005 & 737408 & 4.6091 & 4.6392 & TST & & \\
\hline CHEMBL1450151 & 737408 & 5.2366 & 4.6503 & TRN & & \\
\hline CHEMBL 3228393 & 737408 & 5.1203 & 5.1962 & TST & & \\
\hline CHEMBL1611996 & 737408 & \multicolumn{3}{|c|}{5.202000000000001} & 5.0426 & TRN \\
\hline CHEMBL 3210060 & 737408 & 4.4056 & 4.4298 & TRN & & \\
\hline CHEMBL586670 & 737408 & 4.7852 & 5.1725 & TRN & & \\
\hline CHEMBL1594235 & 737408 & 5.4461 & 5.3345 & TRN & & \\
\hline CHEMBL1502278 & 737408 & 5.4711 & 5.3666 & TRN & & \\
\hline CHEMBL1586803 & 737408 & 3.0 & 4.7206 & TST & & \\
\hline CHEMBL408982 & 737408 & 5.5391 & 5.3469 & TRN & & \\
\hline CHEMBL1734673 & 737408 & 5.2381 & 5.3192 & TRN & & \\
\hline CHEMBL1369152 & 737408 & 5.2396 & 4.7931 & TRN & & \\
\hline CHEMBL1435090 & 737408 & 4.8539 & 5.2965 & TRN & & \\
\hline CHEMBL1715700 & 737408 & 5.4908 & 5.0084 & TRN & & \\
\hline CHEMBL1556354 & 737408 & 5.3233 & 4.7466 & TRN & & \\
\hline CHEMBL1462665 & 737408 & 5.2967 & 4.8469 & TRN & & \\
\hline CHEMBL1704847 & 737408 & 5.7144 & 5.3971 & TRN & & \\
\hline CHEMBL1415432 & 737408 & 5.2441 & 4.8377 & TST & & \\
\hline CHEMBL 3211324 & 737408 & 5.6289 & 5.2846 & TST & & \\
\hline CHEMBL1338197 & 737408 & 5.1487 & 5.4687 & TRN & & \\
\hline CHEMBL1476418 & 737408 & 5.1733 & 5.4827 & TRN & & \\
\hline CHEMBL1465047 & 737408 & 5.6459 & 5.3519 & TRN & & \\
\hline CHEMBL1467678 & 737408 & 5.5751 & 5.621 & TRN & & \\
\hline CHEMBL1563641 & 737408 & 5.4724 & 5.0953 & TRN & & \\
\hline CHEMBL1363129 & 737408 & 4.2161 & 4.7902 & TRN & & \\
\hline CHEMBL1586116 & 737408 & 4.3344 & 4.8348 & TRN & & \\
\hline CHEMBL1424233 & 737408 & \multicolumn{3}{|c|}{5.3420000000000005} & 5.1036 & TRN \\
\hline CHEMBL1320153 & 737408 & 5.0814 & 5.1397 & TRN & & \\
\hline CHEMBL1422657 & 737408 & 4.5867 & 4.9718 & TRN & & \\
\hline CHEMBL1452833 & 737408 & 5.5969 & 5.256 & TRN & & \\
\hline CHEMBL 225852 & 737408 & 5.7799 & 5.3346 & TST & & \\
\hline CHEMBL601744 & 737408 & 5.5258 & 5.1895 & TRN & & \\
\hline CHEMBL1510800 & 737408 & 5.7423 & 5.3663 & TRN & & \\
\hline CHEMBL1335071 & 737408 & 5.2 & 5.5288 & TRN & & \\
\hline CHEMBL1723788 & 737408 & 5.3799 & 5.1703 & TRN & & \\
\hline CHEMBL1405869 & 737408 & 4.8794 & 5.3527 & TRN & & \\
\hline CHEMBL1386397 & 737408 & 4.4401 & 4.7713 & TRN & & \\
\hline CHEMBL1503015 & 737408 & 5.5607 & 5.5305 & TRN & & \\
\hline
\end{tabular}




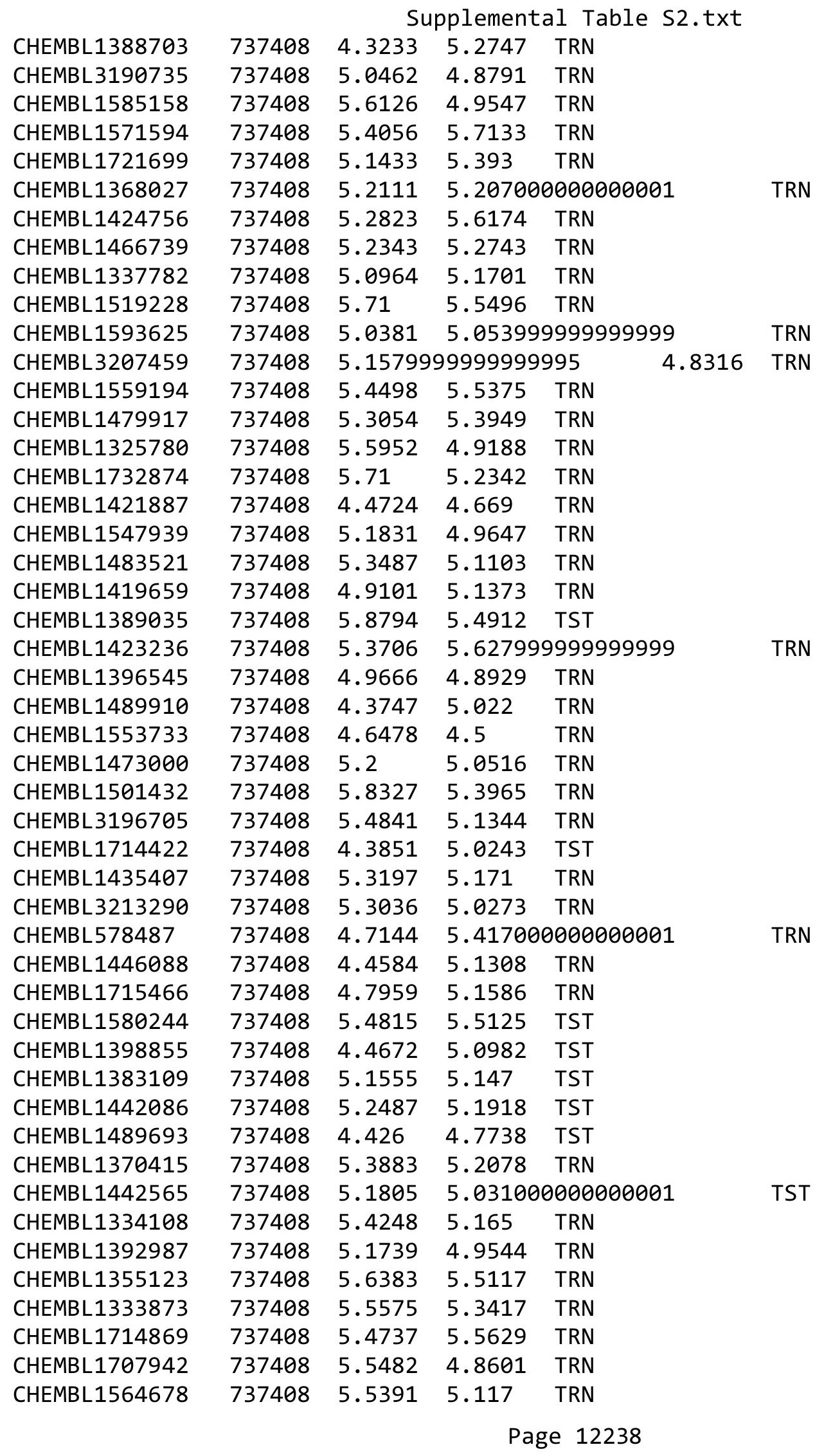


Supplemental Table S2.txt

\begin{tabular}{|c|c|c|c|c|}
\hline HEM & & & & \\
\hline & 37408 & 5.4295 & 5.1803 & \\
\hline 4 & & & & \\
\hline HEMBL1345308 & 408 & & & \\
\hline AEMBL1566241 & 37408 & & & \\
\hline HEMBL1521469 & 37408 & 4365 & 6557 & \\
\hline HEMBL1476481 & 37408 & & 265 & \\
\hline 56666 & & & & \\
\hline AEMBL3196851 & 37408 & & 9098 & \\
\hline HEMBL1387510 & 37408 & 498 & 1946 & \\
\hline AEMBL1333775 & 37408 & 526 & 183 & \\
\hline IEMBL1 & 08 & 75 & 271 & \\
\hline AEMBL & & & & \\
\hline HEMBL1504638 & 37408 & 162 & 291 & \\
\hline AEMBL1734455 & 108 & & & \\
\hline AEMBL1360140 & $\partial 8$ & 86 & 58 & \\
\hline AEMBL139 & $\partial 8$ & 33 & 34 & \\
\hline HEMBL136 & & & & \\
\hline HEMBL1699324 & 08 & 643 & 493 & \\
\hline AEMBL150 & & & & \\
\hline AEMBL: & 88 & & 45 & Niv \\
\hline AEMBL: & & & & וד \\
\hline AEMBL & & & & \\
\hline 73 & & & & \\
\hline AEMBL1 & & & & $\Gamma \mathrm{RN}$ \\
\hline HEMBL: & 8 & & 32 & RN \\
\hline HEMBL & & & & Niv \\
\hline AFMRI & 98 & & & \\
\hline HEMBL1 & & & & in \\
\hline HEMBL1501635 & & & & $1=2$. \\
\hline HEMBL1 & & & & ST \\
\hline HEMBL & & & & RN \\
\hline HEMPI & 8 & & 24 & ג \\
\hline HEMBL1445612 & & & & IR \\
\hline HEMBL1523731 & & & 3741 & 「RN \\
\hline HEMBL1 & & & 03 & RN \\
\hline 1 & & & 44 & RN \\
\hline & & & 172 & RN \\
\hline HEMBL1438060 & 38 & & & $\Gamma \mathrm{RN}$ \\
\hline IEMBL1 & & & 805 & RN \\
\hline HEMBL1 & 88 & & 78 & ГRN \\
\hline HEMBL1330039 & 37408 & & 1.8828 & ГST \\
\hline HEMBL1473924 & 08 & & 2504 & $\Gamma R$ \\
\hline AEMBL1433732 & 08 & 49 & 5371 & TR \\
\hline MBL1 & & & 1965 & ב \\
\hline HEMBL133 & & & 1074 & \\
\hline LHEMBL1312653 & 37408 & & 5.3904 & \\
\hline HEMBL1377153 & 737408 & 5.7825 & 5.2628 & \\
\hline
\end{tabular}

Page 12239 


\begin{tabular}{|c|c|c|c|c|c|}
\hline \multicolumn{6}{|c|}{ Supplemental Table S2.txt } \\
\hline CHEMBL1549332 & 737408 & 5.1649 & 5.1366 & TRN & \\
\hline CHEMBL1565057 & 737408 & 4.2924 & 5.1289 & TRN & \\
\hline CHEMBL1735090 & 737408 & 5.4413 & 5.3858 & TRN & \\
\hline CHEMBL1735462 & 737408 & 5.4634 & 5.0815 & TRN & \\
\hline CHEMBL1322457 & 737408 & 5.063 & 4.9889 & TRN & \\
\hline CHEMBL3194141 & 737408 & 5.1129 & 5.005 & TRN & \\
\hline CHEMBL1451783 & 737408 & 5.2967 & 5.5195 & TRN & \\
\hline CHEMBL1553099 & 737408 & 4.7167 & 5.0129 & TRN & \\
\hline CHEMBL1706764 & 737408 & 5.1805 & 4.9851 & TRN & \\
\hline CHEMBL1558595 & 737408 & 5.6271 & 4.9579 & TRN & \\
\hline CHEMBL1716759 & 737408 & 5.1215 & 4.9715 & TRN & \\
\hline CHEMBL1572059 & 737408 & 5.4522 & 5.1317 & TRN & \\
\hline CHEMBL1461897 & 737408 & 5.0128 & 5.0729 & TRN & \\
\hline CHEMBL1532151 & 737408 & 5.2573 & 5.1439 & TRN & \\
\hline CHEMBL1599488 & 737408 & 5.295 & 5.4765 & TRN & \\
\hline CHEMBL1570909 & 737408 & 5.2255 & $5.2970 e$ & 0000000001 & TRN \\
\hline CHEMBL1715936 & 737408 & 5.3429 & 5.3465 & TRN & \\
\hline CHEMBL1361245 & 737408 & 5.6799 & 5.5578 & TRN & \\
\hline CHEMBL1358136 & 737408 & 4.2798 & $4.6930 e$ & 00000000005 & TRN \\
\hline CHEMBL1526949 & 737408 & 4.9957 & 5.2607 & TRN & \\
\hline CHEMBL589711 & 737408 & 5.5969 & 5.2092 & TRN & \\
\hline CHEMBL1410056 & 737408 & 4.8013 & 4.5867 & TRN & \\
\hline CHEMBL1337904 & 737408 & 5.2076 & 5.1737 & TRN & \\
\hline CHEMBL1540989 & 737408 & 4.6737 & 4.9408 & TRN & \\
\hline CHEMBL1471220 & 737408 & 4.4609 & 4.9426 & TRN & \\
\hline CHEMBL1470414 & 737408 & 5.0283 & 5.0232 & TRN & \\
\hline CHEMBL1345181 & 737408 & 5.5867 & 5.2997 & TRN & \\
\hline CHEMBL1734899 & 737408 & 5.3224 & 5.3001 & TRN & \\
\hline CHEMBL1398584 & 737408 & 5.1568 & 5.2973 & TRN & \\
\hline CHEMBL1383031 & 737408 & 4.248 & 4.51 & TRN & \\
\hline CHEMBL1445897 & 737408 & 4.7144 & 4.3558 & TRN & \\
\hline CHEMBL1304739 & 737408 & 5.5918 & 5.182 & TRN & \\
\hline CHEMBL1550776 & 737408 & 5.1993 & 4.6391 & TRN & \\
\hline CHEMBL1732046 & 737408 & 4.7747 & 5.1885 & TRN & \\
\hline CHEMBL1503187 & 737408 & 5.2708 & 4.9039 & TRN & \\
\hline CHEMBL1417203 & 737408 & 4.5272 & $4.4110 e$ & 00000000005 & TRN \\
\hline CHEMBL1320566 & 737408 & 3.0 & 4.9137 & TRN & \\
\hline CHEMBL1534370 & 737408 & 5.6038 & 5.4746 & TRN & \\
\hline CHEMBL1413595 & 737408 & 5.4498 & 5.2482 & TRN & \\
\hline CHEMBL1327723 & 737408 & 5.4908 & 5.0953 & TRN & \\
\hline CHEMBL1527523 & 737408 & 5.3458 & 5.3383 & TRN & \\
\hline CHEMBL1344441 & 737408 & 5.3809 & 5.0126 & TRN & \\
\hline CHEMBL1549534 & 737408 & 5.5768 & 5.4353 & TRN & \\
\hline CHEMBL1734181 & 737408 & 4.8097 & 4.942 & TRN & \\
\hline CHEMBL1708462 & 737408 & 5.3233 & 5.4581 & TRN & \\
\hline CHEMBL1717994 & 737408 & 4.9136 & 4.9922 & TRN & \\
\hline CHEMBL1314231 & 737408 & 5.4976 & 5.1928 & TRN & \\
\hline CHEMBL1504008 & 737408 & 5.1871 & 5.1129 & TRN & \\
\hline
\end{tabular}


Supplemental Table S2.txt

\begin{tabular}{|c|c|c|c|c|c|}
\hline CHEMBL1698738 & 737408 & 5.6576 & 5.4088 & TRN & \\
\hline CHEMBL590706 & 737408 & 5.6003 & 5.4924 & TST & \\
\hline CHEMBL1711351 & 737408 & 5.644 & 5.4875 & TRN & \\
\hline CHEMBL1485727 & 737408 & 5.6364 & 5.2833 & TST & \\
\hline CHEMBL548062 & 737408 & 5.3936 & 5.0051 & TST & \\
\hline CHEMBL1497457 & 737408 & 5.0752 & 4.8031 & TST & \\
\hline CHEMBL3207528 & 737408 & 5.8996 & 5.4268 & TST & \\
\hline CHEMBL1711889 & 737408 & 4.9245 & 5.1328 & TRN & \\
\hline CHEMBL1419630 & 737408 & 5.2111 & 5.0322 & TRN & \\
\hline CHEMBL1331808 & 737408 & 5.5243 & 5.4231 & TRN & \\
\hline CHEMBL1706489 & 737408 & 4.8508 & 4.9814 & TRN & \\
\hline CHEMBL1707047 & 737408 & 4.9136 & 5.4448 & TRN & \\
\hline CHEMBL1324634 & 737408 & 5.5031 & 5.417006 & 0000000001 & TRN \\
\hline CHEMBL1480280 & 737408 & 5.6536 & 5.3727 & TRN & \\
\hline CHEMBL1573412 & 737408 & 5.2733 & 4.8847 & TST & \\
\hline CHEMBL1374507 & 737408 & 5.2907 & 5.0226 & TRN & \\
\hline CHEMBL1725481 & 737408 & 5.3936 & 5.4337 & TRN & \\
\hline CHEMBL1451864 & 737408 & 5.3979 & 5.1072 & TRN & \\
\hline CHEMBL1470939 & 737408 & 5.098 & 4.9335 & TST & \\
\hline CHEMBL1563637 & 737408 & 5.4214 & 5.4556 & TRN & \\
\hline CHEMBL1334156 & 737408 & 5.1759 & 5.6229 & TRN & \\
\hline CHEMBL1342790 & 737408 & 5.3401 & 5.4439 & TRN & \\
\hline CHEMBL1726488 & 737408 & 5.0434 & 5.4419 & TRN & \\
\hline CHEMBL1339576 & 737408 & 5.0329 & 4.6729 & TRN & \\
\hline CHEMBL1731321 & 737408 & 5.5017 & 5.4652 & TRN & \\
\hline CHEMBL1383779 & 737408 & 5.4572 & 5.577006 & 3000000001 & TRN \\
\hline CHEMBL1471136 & 737408 & 4.0283 & 4.8576 & TRN & \\
\hline CHEMBL1433646 & 737408 & 4.82100 & 0000000 & 5.1731 & TRN \\
\hline CHEMBL1408132 & 737408 & 5.6799 & 4.9762 & TST & \\
\hline CHEMBL1457083 & 737408 & 5.15799 & 99999999 & 5.1455 & TRN \\
\hline CHEMBL1519252 & 737408 & 5.4698 & 5.3389 & TST & \\
\hline CHEMBL1361455 & 737408 & 5.3261 & 5.1488 & TRN & \\
\hline CHEMBL3193117 & 737408 & 4.7986 & 4.8023 & TRN & \\
\hline CHEMBL1359205 & 737408 & 5.0794 & 5.2528 & TRN & \\
\hline CHEMBL1428459 & 737408 & 5.4461 & 5.151 & TRN & \\
\hline CHEMBL1544084 & 737408 & 5.5702 & 5.5175 & TRN & \\
\hline CHEMBL1340231 & 737408 & 5.6162 & 5.5103 & TRN & \\
\hline CHEMBL1459828 & 737408 & 4.4248 & 4.482 & TRN & \\
\hline CHEMBL1493377 & 737408 & 5.2967 & 5.3513 & TRN & \\
\hline CHEMBL1573865 & 737408 & 4.9318 & 5.0808 & TST & \\
\hline CHEMBL1301999 & 737408 & 4.9586 & 5.1604 & TRN & \\
\hline CHEMBL1572009 & 737408 & 5.38200 & 00000000 & 5.3858 & TRN \\
\hline CHEMBL1318277 & 737408 & 4.3206 & 4.5878 & TRN & \\
\hline CHEMBL1991679 & 737408 & 3.0 & 4.5569 & TRN & \\
\hline CHEMBL1345318 & 737408 & 5.4461 & 5.2762 & TRN & \\
\hline CHEMBL1552246 & 737408 & 5.1959 & 5.0853 & TRN & \\
\hline CHEMBL1554345 & 737408 & 4.8327 & 5.4646 & TRN & \\
\hline CHEMBL1451561 & 737408 & 5.6126 & 5.5994 & TRN & \\
\hline
\end{tabular}




\begin{tabular}{|c|c|c|c|c|c|c|}
\hline \multirow[b]{2}{*}{ CHEMBL1480181 } & \multirow[b]{2}{*}{737408} & \multicolumn{5}{|c|}{ Supplemental Table s2.txt } \\
\hline & & \multirow{2}{*}{\multicolumn{3}{|c|}{$5.5544 \quad 5.5646$ TRN }} & & \multirow{3}{*}{ TRN } \\
\hline CHEMBL 2005302 & 737408 & 4.1391 & & \multicolumn{2}{|c|}{4.7989999999999995} & \\
\hline CHEMBL1990990 & 737408 & 4.3809 & 4.6634 & TRN & & \\
\hline CHEMBL1328041 & 737408 & 5.6946 & 5.39 & TRN & & \\
\hline CHEMBL1451147 & 737408 & 5.4342 & 5.3109 & TRN & & \\
\hline CHEMBL1580093 & 737408 & 4.6478 & 4.965 & TRN & & \\
\hline CHEMBL1555995 & 737408 & 4.5467 & 4.6634 & TRN & & \\
\hline CHEMBL3195145 & 737408 & 4.6861 & 4.7079 & TRN & & \\
\hline CHEMBL1599302 & 737408 & 5.4318 & 5.3898 & TRN & & \\
\hline CHEMBL1724713 & 737408 & \multicolumn{3}{|c|}{5.1579999999999995} & 5.2415 & TRN \\
\hline CHEMBL1731550 & 737408 & 5.2269 & 5.1843 & TRN & & \\
\hline CHEMBL1477133 & 737408 & 5.4473 & 5.4837 & TRN & & \\
\hline CHEMBL1703959 & 737408 & \multicolumn{3}{|c|}{5.4510000000000005} & 5.3271 & TRN \\
\hline CHEMBL1567848 & 737408 & 5.3089 & 5.2972 & TRN & & \\
\hline CHEMBL1432423 & 737408 & 5.3778 & 5.5149 & TRN & & \\
\hline CHEMBL1579104 & 737408 & 5.1884 & 4.7386 & TRN & & \\
\hline CHEMBL1306597 & 737408 & 5.3134 & 4.6678 & TRN & & \\
\hline CHEMBL1472602 & 737408 & 4.6882 & 4.9857 & TRN & & \\
\hline CHEMBL1448942 & 737408 & 4.58 & 4.6798 & TRN & & \\
\hline CHEMBL1509500 & 737408 & 4.4112 & 5.2471 & TRN & & \\
\hline CHEMBL3194657 & 737408 & 5.3279 & 4.4532 & TRN & & \\
\hline CHEMBL1309967 & 737408 & 5.4318 & 5.593 & TRN & & \\
\hline CHEMBL1342158 & 737408 & 5.8894 & 5.5292 & TRN & & \\
\hline CHEMBL1478395 & 737408 & 5.1314 & 4.9445 & TST & & \\
\hline CHEMBL1443664 & 737408 & 5.6402 & 5.6808 & TRN & & \\
\hline CHEMBL1701371 & 737408 & \multicolumn{3}{|c|}{5.327000000000001} & 5.3864 & TST \\
\hline CHEMBL1586607 & 737408 & 5.7167 & 5.0325 & TRN & & \\
\hline CHEMBL1722720 & 737408 & 4.8996 & 5.2837 & TRN & & \\
\hline CHEMBL1710658 & 737408 & \multicolumn{3}{|c|}{5.3420000000000005} & 5.4159 & TRN \\
\hline CHEMBL1316602 & 737408 & 3.0 & 4.8144 & TRN & & \\
\hline CHEMBL1556201 & 737408 & 5.5638 & 5.2437 & TRN & & \\
\hline CHEMBL1491764 & 737408 & 4.9666 & 5.233 & TRN & & \\
\hline CHEMBL1481410 & 737408 & 5.3478 & 4.977 & TST & & \\
\hline CHEMBL1373318 & 737408 & 5.4437 & 5.2993 & TRN & & \\
\hline CHEMBL1701867 & 737408 & 4.7235 & 5.3979 & TST & & \\
\hline CHEMBL1561849 & 737408 & 5.3686 & 5.2775 & TRN & & \\
\hline CHEMBL1309714 & 737408 & 5.0026 & 5.09 & TRN & & \\
\hline CHEMBL3192708 & 737408 & 5.1656 & 4.8381 & TST & & \\
\hline CHEMBL1586182 & 737408 & 5.5607 & 5.2218 & TRN & & \\
\hline CHEMBL1396733 & 737408 & 5.3799 & 5.3892 & TRN & & \\
\hline CHEMBL1518805 & 737408 & 5.5072 & 5.1203 & TRN & & \\
\hline CHEMBL1610783 & 737408 & 4.9872 & 4.6137 & TRN & & \\
\hline CHEMBL1419388 & 737408 & 5.4067 & 5.369 & TRN & & \\
\hline CHEMBL582287 & 737408 & 5.3516 & 5.2612 & TRN & & \\
\hline CHEMBL1340045 & 737408 & 5.2636 & 5.1192 & TRN & & \\
\hline CHEMBL1709489 & 737408 & 5.3747 & 5.4687 & TRN & & \\
\hline CHEMBL1378605 & 737408 & 4.5901 & 4.5382 & TRN & & \\
\hline CHEMBL1541667 & 737408 & 5.3893 & 5.2234 & TRN & & \\
\hline
\end{tabular}




\begin{tabular}{|c|c|c|c|c|c|c|}
\hline & & \multicolumn{5}{|c|}{ Supplemental Table s2.txt } \\
\hline CHEMBL1406465 & 737408 & 5.3298 & 5.0298 & TRN & & \\
\hline CHEMBL1400127 & 737408 & 4.5406 & 5.0567 & TST & & \\
\hline CHEMBL1480634 & 737408 & 3.0 & 4.8743 & TRN & & \\
\hline CHEMBL3199718 & 737408 & 4.3958 & 4.475 & TRN & & \\
\hline CHEMBL1450899 & 737408 & 5.3645 & 4.8911 & TST & & \\
\hline CHEMBL1363072 & 737408 & 5.0701 & 5.1909 & TST & & \\
\hline CHEMBL1401536 & 737408 & 5.5986 & 5.2168 & TST & & \\
\hline CHEMBL1722809 & 737408 & 4.3161 & 4.9412 & TST & & \\
\hline CHEMBL1547409 & 737408 & 5.0926 & 4.9535 & TST & & \\
\hline CHEMBL1714353 & 737408 & 5.5376 & 5.176 & TST & & \\
\hline CHEMBL1498859 & 737408 & 5.2549 & 5.0984 & TST & & \\
\hline CHEMBL1559351 & 737408 & 5.5901 & 5.2272 & TST & & \\
\hline CHEMBL1543542 & 737408 & 5.3556 & 5.0541 & TST & & \\
\hline CHEMBL1568720 & 737408 & 5.2534 & 5.4099 & TST & & \\
\hline CHEMBL1706030 & 737408 & $5.7570 e$ & 30000000 & 01 & 5.295 & TST \\
\hline CHEMBL1592491 & 737408 & 5.4157 & 5.2111 & TST & & \\
\hline CHEMBL1476337 & 737408 & 5.1433 & 5.3244 & TST & & \\
\hline CHEMBL1727593 & 737408 & 5.3002 & 5.2139 & TST & & \\
\hline CHEMBL1576239 & 737408 & 4.3625 & 4.6006 & TST & & \\
\hline CHEMBL1405185 & 737408 & 5.2534 & 5.2778 & TST & & \\
\hline CHEMBL1325404 & 737408 & 5.4868 & 4.9592 & TST & & \\
\hline CHEMBL589421 & 737408 & 5.6635 & 5.5632 & TST & & \\
\hline CHEMBL1369573 & 737408 & 5.2899 & 5.37799 & 9999999999 & & TST \\
\hline CHEMBL1704351 & 737408 & 5.2457 & 5.5842 & TST & & \\
\hline CHEMBL1329979 & 737408 & 5.0141 & 5.1951 & TST & & \\
\hline CHEMBL1355983 & 737408 & 4.3468 & 4.7862 & TST & & \\
\hline CHEMBL1445359 & 737408 & 5.3757 & 5.4826 & TST & & \\
\hline CHEMBL1543727 & 737408 & 5.6904 & 5.2193 & TST & & \\
\hline CHEMBL1588608 & 737408 & 4.7282 & 4.9798 & TST & & \\
\hline CHEMBL1599560 & 737408 & 3.0 & 5.5727 & TST & & \\
\hline CHEMBL1525928 & 737408 & 5.4271 & 5.4079 & TST & & \\
\hline CHEMBL1707394 & 737408 & 5.2749 & 5.2245 & TST & & \\
\hline CHEMBL1582492 & 737408 & 3.0 & 5.2358 & TST & & \\
\hline CHEMBL1384015 & 737408 & 5.4949 & 5.3054 & TST & & \\
\hline CHEMBL592314 & 737408 & 5.4365 & 5.0932 & TST & & \\
\hline CHEMBL1567561 & 737408 & 5.2218 & 4.9853 & TST & & \\
\hline CHEMBL1562170 & 737408 & 5.1141 & 4.9392 & TST & & \\
\hline CHEMBL3192723 & 737408 & 4.4001 & 4.6068 & TST & & \\
\hline CHEMBL1716983 & 737408 & 5.3028 & 5.2165 & TST & & \\
\hline CHEMBL1730105 & 737408 & 4.9626 & 5.0173 & TST & & \\
\hline CHEMBL1710726 & 737408 & 5.4776 & 5.3333 & TST & & \\
\hline CHEMBL1419432 & 737408 & 5.61799 & 79999999 & 99 & 5.4711 & TST \\
\hline CHEMBL1529598 & 737408 & 5.4191 & 5.3179 & TST & & \\
\hline CHEMBL1353473 & 737408 & 5.5513 & 4.9775 & TST & & \\
\hline CHEMBL1380802 & 737408 & 5.3391 & 4.7221 & TST & & \\
\hline CHEMBL3192496 & 737408 & 5.308 & 5.1538 & TST & & \\
\hline CHEMBL1599569 & 737408 & 4.5867 & 4.9572 & TST & & \\
\hline CHEMBL1552516 & 737408 & 5.1203 & 4.9238 & TST & & \\
\hline
\end{tabular}


Supplemental Table S2.txt

\begin{tabular}{|c|c|c|c|c|}
\hline 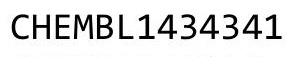 & & & & \\
\hline HEMBL124006 & 37408 & 2366 & 3029 & \\
\hline HEMBL1403816 & 37408 & 3072 & & \\
\hline 1577127 & 7408 & 167 & & \\
\hline AEMBL1498441 & 7408 & & 4251 & \\
\hline AEMBL1364567 & 37408 & 4609 & .1279 & \\
\hline HEMBL1721008 & 37408 & .0883 & .2262 & \\
\hline HEMBL1402702 & 37408 & 9281 & & \\
\hline AEMBL1499690 & 408 & & 35 & \\
\hline HEMBL1814022 & & & & \\
\hline HEMBL1814215 & 50264 & 498 & .8039 & \\
\hline HEMBL1814210 & 50264 & 5672 & .8647 & \\
\hline HEMBL1814035 & 64 & 17 & 65 & \\
\hline AEMBL1814221 & 64 & & & \\
\hline AEMBL1814252 & 54 & & & \\
\hline HEMBL1814006 & 50264 & 5935 & 2823 & \\
\hline HEMBL1813999 & 264 & & & \\
\hline HEMBL1814383 & 54 & & .184 & \\
\hline L181 & 54 & 72 & 65 & \\
\hline HEMBL1814213 & & & & \\
\hline HEMBL1814002 & 64 & 979 & 3.3825 & \\
\hline AEMBL1814216 & & & & \\
\hline HEMBL181 & 64 & 69 & 75 & \\
\hline L164 & & & & \\
\hline 247 & 54 & & 77 & \\
\hline L1814239 & & 208 & 4.6721 & \\
\hline AEMBL1814373 & & & & \\
\hline HEMBL1814014 & 54 & 06 & 22 & \\
\hline HEN & & & 23 & \\
\hline L181 & 54 & 69 & 23 & \\
\hline AEMBL1814244 & & & & \\
\hline AEMBL1814250 & 54 & & & RN \\
\hline AEMBL1814024 & & & & \\
\hline 80 & 4 & & & \\
\hline 78 & & & & ST \\
\hline AEMBL1814224 & 54 & & & RN \\
\hline AEMBL1814001 & 64 & & & $\mathrm{RN}$ \\
\hline 5 & & & & RN \\
\hline HEMD 10 & 4 & & 71 & RIN \\
\hline HEMBL181 & & & & $\mathrm{RN}$ \\
\hline AEMBL1814371 & 54 & 324 & & $\mathrm{RN}$ \\
\hline AEMBL18] & & & & RN \\
\hline 72 & & & & \\
\hline HEMBL1649776 & & & & ST \\
\hline HEMBL1814222 & & & & $\mathrm{RN}$ \\
\hline IEMBL1814259 & 54 & 549 & 209 & RN \\
\hline L181 & & & & \\
\hline 1901421 & & & & \\
\hline
\end{tabular}

Page 12244 


\begin{tabular}{|c|c|c|c|c|c|c|}
\hline & & \multicolumn{5}{|c|}{ Supplemental Table S2.txt } \\
\hline CHEMBL1814015 & 760264 & 4.6038 & 3.7905 & TRN & & \\
\hline CHEMBL1814379 & 760264 & 5.4313 & 4.2446 & TST & & \\
\hline CHEMBL1814375 & 760264 & 4.2612 & 4.4043 & TRN & & \\
\hline CHEMBL1814020 & 760264 & 4.8041 & 3.6951 & TRN & & \\
\hline CHEMBL1814369 & 760264 & 4.6946 & 4.9033 & TRN & & \\
\hline CHEMBL1649757 & 760264 & 4.1391 & 4.6632 & TST & & \\
\hline CHEMBL1814240 & 760264 & 6.0458 & 5.1216 & TRN & & \\
\hline CHEMBL1814382 & 760264 & 3.3415 & 5.2318 & TST & & \\
\hline CHEMBL1814256 & 760264 & 2.0969 & 5.1718 & TRN & & \\
\hline CHEMBL1814227 & 760264 & 4.8416 & 4.3499 & TRN & & \\
\hline CHEMBL1814019 & 760264 & 4.433 & 3.6951 & TRN & & \\
\hline CHEMBL1814032 & 760264 & 4.382 & 4.083 & TRN & & \\
\hline CHEMBL1814218 & 760264 & 3.7467 & 3.9245 & TRN & & \\
\hline CHEMBL1814214 & 760264 & 2.3979 & 3.6826 & TRN & & \\
\hline CHEMBL1814208 & 760264 & 4.4377 & 3.9294 & TRN & & \\
\hline CHEMBL1814209 & 760264 & \multicolumn{3}{|c|}{4.821000000000001} & .6775 & TRN \\
\hline CHEMBL1814017 & 760264 & 3.7854 & 3.6772 & TRN & & \\
\hline CHEMBL1814253 & 760264 & 5.0088 & 5.1378 & TRN & & \\
\hline CHEMBL1649771 & 760264 & 4.8239 & 5.3088 & TST & & \\
\hline CHEMBL1811944 & 760264 & 4.5575 & 4.9575 & TRN & & \\
\hline CHEMBL1814372 & 760264 & 4.6021 & 4.993 & TRN & & \\
\hline CHEMBL1814258 & 760264 & 2.0969 & 4.3127 & TRN & & \\
\hline CHEMBL1814246 & 760264 & 2.0969 & 4.6133 & TRN & & \\
\hline CHEMBL1814010 & 760264 & 2.0969 & 3.2823 & TRN & & \\
\hline CHEMBL1814041 & 760264 & 5.2007 & 4.507 & TRN & & \\
\hline CHEMBL1814027 & 760264 & 2.3979 & 3.6326 & TRN & & \\
\hline CHEMBL1814263 & 760264 & 2.0969 & 4.5648 & TST & & \\
\hline CHEMBL1814223 & 760264 & 4.644 & 4.1543 & TRN & & \\
\hline CHEMBL1649774 & 760264 & 4.4622 & 5.0004 & TST & & \\
\hline CHEMBL1814377 & 760264 & 4.5805 & 4.3368 & TST & & \\
\hline CHEMBL1814219 & 760264 & 3.43 & 4.0214 & TRN & & \\
\hline CHEMBL1814009 & 760264 & 4.5243 & 3.2823 & TRN & & \\
\hline CHEMBL1814004 & 760264 & 3.2476 & 3.2584 & TRN & & \\
\hline CHEMBL1814365 & 760264 & 5.5086 & 4.6331 & TRN & & \\
\hline CHEMBL1814025 & 760264 & 2.0969 & 3.6951 & TRN & & \\
\hline CHEMBL1814026 & 760264 & 2.0969 & 3.6951 & TRN & & \\
\hline CHEMBL1814370 & 760264 & 5.1427 & 5.3321 & TRN & & \\
\hline CHEMBL1814242 & 760264 & 5.7959 & 4.7316 & TRN & & \\
\hline CHEMBL1814011 & 760264 & 2.0969 & 3.2823 & TRN & & \\
\hline CHEMBL1814255 & 760264 & 4.9914 & 5.1642 & TRN & & \\
\hline CHEMBL1814030 & 760264 & 3.838 & 3.8823 & TRN & & \\
\hline CHEMBL1814248 & 760264 & 4.6021 & 4.6757 & TRN & & \\
\hline CHEMBL1814042 & 760264 & 5.3768 & 4.1576 & TRN & & \\
\hline CHEMBL1649773 & 760264 & 5.4949 & 5.4714 & TST & & \\
\hline CHEMBL1814241 & 760264 & 5.2007 & 4.7106 & TST & & \\
\hline CHEMBL1814238 & 760264 & 4.4976 & 4.2627 & TST & & \\
\hline CHEMBL1814016 & 760264 & 4.0788 & 3.9677 & TRN & & \\
\hline CHEMBL1814226 & 760264 & 5.2676 & 4.2902 & TRN & & \\
\hline
\end{tabular}

Page 12245 
Supplemental Table S2.txt

\begin{tabular}{|c|c|c|c|c|}
\hline CHEMBL1814249 & 760264 & 4.5986 & 4.8789 & TST \\
\hline CHEMBL1814031 & 760264 & 3.7174 & 4.0926 & TRN \\
\hline CHEMBL1814033 & 760264 & 4.9066 & 3.8165 & TRN \\
\hline CHEMBL1814211 & 760264 & 4.0004 & 3.7834 & TRN \\
\hline CHEMBL1814212 & 760264 & 3.4735 & 3.3724 & TRN \\
\hline CHEMBL1814028 & 760264 & 2.0969 & 3.7791 & TRN \\
\hline CHEMBL1814245 & 760264 & 3.9834 & 4.6188 & TST \\
\hline CHEMBL1814366 & 760264 & 2.0969 & 4.9485 & TST \\
\hline CHEMBL1814368 & 760264 & 4.8697 & 4.9139 & TST \\
\hline CHEMBL1814367 & 760264 & 4.4711 & 4.5076 & TST \\
\hline CHEMBL1814257 & 760264 & 4.3344 & 4.2696 & TST \\
\hline CHEMBL1814007 & 760264 & 4.8416 & 3.2823 & TRN \\
\hline CHEMBL1814251 & 760264 & 4.9031 & 5.0144 & TST \\
\hline CHEMBL1814376 & 760264 & 4.8013 & 5.0942 & TST \\
\hline CHEMBL1814220 & 760264 & 4.3778 & 4.0691 & TRN \\
\hline CHEMBL1814003 & 760264 & 3.5385 & 3.5913 & TRN \\
\hline CHEMBL1814029 & 760264 & 3.7169 & 3.7361 & TRN \\
\hline CHEMBL1814012 & 760264 & 2.0969 & 3.2823 & TRN \\
\hline CHEMBL1814260 & 760264 & 2.0969 & 4.9297 & TST \\
\hline CHEMBL1814374 & 760264 & 5.3565 & 4.8781 & TST \\
\hline CHEMBL1814021 & 760264 & 4.6946 & 3.6951 & TRN \\
\hline CHEMBL1814023 & 760264 & 2.0969 & 3.6951 & TRN \\
\hline CHEMBL1477268 & 688118 & 2.8239 & 3.3391 & TRN \\
\hline CHEMBL1443946 & 688118 & 4.6988 & 4.4275 & TRN \\
\hline CHEMBL1576087 & 688118 & 4.2018 & 4.4112 & TRN \\
\hline CHEMBL1495173 & 688118 & 4.3747 & 3.8777 & TRN \\
\hline CHEMBL1301299 & 688118 & 3.8591 & 3.7071 & TRN \\
\hline CHEMBL1405776 & 688118 & 4.0878 & 4.0332 & TST \\
\hline CHEMBL146525 & 688118 & 4.3627 & 4.0767 & TRN \\
\hline CHEMBL1309059 & 688118 & 4.4157 & 4.6074 & TRN \\
\hline CHEMBL3189193 & 688118 & 2.8239 & 3.6679 & TRN \\
\hline CHEMBL 3209306 & 688118 & 4.6733 & 4.615 & TRN \\
\hline CHEMBL1495504 & 688118 & 2.8239 & 3.8737 & TRN \\
\hline CHEMBL1577829 & 688118 & 3.9727 & 4.01 & TRN \\
\hline CHEMBL51931 & 688118 & 4.059 & 5.0311 & TRN \\
\hline CHEMBL1330113 & 688118 & 6.0 & 5.4966 & TRN \\
\hline CHEMBL1576581 & 688118 & 4.8173 & 4.7701 & TRN \\
\hline CHEMBL1093246 & 688118 & 4.1703 & 3.9553 & TRN \\
\hline CHEMBL1346468 & 688118 & 4.4343 & 4.4894 & TRN \\
\hline CHEMBL1448800 & 688118 & 4.8617 & 4.6771 & TRN \\
\hline CHEMBL140425 & 688118 & 5.2226 & 5.50299 & 9999999999 \\
\hline CHEMBL1971144 & 688118 & 4.4563 & 4.595 & TRN \\
\hline CHEMBL 3191273 & 688118 & 4.5369 & 4.5792 & TRN \\
\hline CHEMBL1490728 & 688118 & 4.0789 & 3.8895 & TRN \\
\hline CHEMBL1980226 & 688118 & 4.225 & 4.1962 & TRN \\
\hline CHEMBL1958251 & 688118 & 4.5065 & 4.5958 & TRN \\
\hline CHEMBL1327202 & 688118 & 5.0232 & 4.7881 & TRN \\
\hline CHEMBL1467720 & 688118 & 4.2289 & 4.3401 & TRN \\
\hline
\end{tabular}

Page 12246 


\begin{tabular}{|c|c|c|c|c|c|c|}
\hline & & \multicolumn{5}{|c|}{ Supplemental Table S2.txt } \\
\hline CHEMBL1459734 & 688118 & 3.8606 & 3.6489 & TST & & \\
\hline CHEMBL1608375 & 688118 & 4.077 & 4.0436 & TST & & \\
\hline CHEMBL1521960 & 688118 & 4.8502 & 4.6976 & TST & & \\
\hline CHEMBL1330307 & 688118 & 4.2577 & 4.6112 & TRN & & \\
\hline CHEMBL334707 & 688118 & 5.7077 & 5.8054 & TRN & & \\
\hline CHEMBL3192021 & 688118 & 4.1243 & 3.7357 & TRN & & \\
\hline CHEMBL1459764 & 688118 & 4.3453 & 4.1506 & TRN & & \\
\hline CHEMBL1483235 & 688118 & 4.545 & 4.5834 & TRN & & \\
\hline CHEMBL1597655 & 688118 & 4.5153 & 4.659 & TRN & & \\
\hline CHEMBL1594766 & 688118 & 3.8348 & 3.7465 & TRN & & \\
\hline CHEMBL199387 & 688118 & 3.9957 & 4.4797 & TRN & & \\
\hline CHEMBL1563323 & 688118 & 2.8239 & 3.6473 & TRN & & \\
\hline CHEMBL89445 & 688118 & 4.7846 & 4.6914 & TRN & & \\
\hline CHEMBL 3213876 & 688118 & 4.1653 & 4.29 & TRN & & \\
\hline CHEMBL573543 & 688118 & 4.6647 & 4.9572 & TRN & & \\
\hline CHEMBL1604947 & 688118 & 4.3371 & 4.3463 & TRN & & \\
\hline CHEMBL1454183 & 688118 & 2.8239 & 3.5729 & TST & & \\
\hline CHEMBL1353170 & 688118 & 4.6533 & 4.5967 & TRN & & \\
\hline CHEMBL1500249 & 688118 & 4.0805 & 3.7827 & TST & & \\
\hline CHEMBL1346640 & 688118 & 3.9043 & 3.8932 & TRN & & \\
\hline CHEMBL1448849 & 688118 & 2.8239 & 3.7206 & TRN & & \\
\hline CHEMBL1319488 & 688118 & 4.2423 & 4.2414 & TRN & & \\
\hline CHEMBL1509380 & 688118 & 4.5733 & 4.5177 & TRN & & \\
\hline CHEMBL1318861 & 688118 & 5.5186 & 5.8586 & TST & & \\
\hline CHEMBL1337033 & 688118 & 4.6486 & 4.5163 & TST & & \\
\hline CHEMBL1500265 & 688118 & 3.887 & 3.9708 & TRN & & \\
\hline CHEMBL1491847 & 688118 & 4.7071 & 4.4961 & TRN & & \\
\hline CHEMBL1983839 & 688118 & $4.3610 e$ & 0000000 & $\partial 1$ & 4.4213 & TRN \\
\hline CHEMBL1518625 & 688118 & 4.1043 & 4.2138 & TRN & & \\
\hline CHEMBL1323853 & 688118 & 3.9084 & 4.0829 & TRN & & \\
\hline CHEMBL1441196 & 688118 & 4.8465 & 4.7584 & TRN & & \\
\hline CHEMBL3197991 & 688118 & 4.069 & 3.8137 & TRN & & \\
\hline CHEMBL1416329 & 688118 & 4.0519 & 4.2077 & TRN & & \\
\hline CHEMBL1450615 & 688118 & 4.0964 & 3.9971 & TRN & & \\
\hline CHEMBL1600855 & 688118 & 4.421 & 4.3677 & TRN & & \\
\hline CHEMBL3189712 & 688118 & 4.1599 & 3.9766 & TRN & & \\
\hline CHEMBL1558725 & 688118 & 4.1397 & 4.1682 & TRN & & \\
\hline CHEMBL1461972 & 688118 & 4.2727 & 4.1555 & TRN & & \\
\hline CHEMBL 283849 & 688118 & 6.2924 & 6.1525 & TST & & \\
\hline CHEMBL3189460 & 688118 & 4.4356 & 4.2522 & TRN & & \\
\hline CHEMBL3189342 & 688118 & 4.8857 & 4.7305 & TRN & & \\
\hline CHEMBL1172192 & 688118 & 4.7135 & 4.4526 & TST & & \\
\hline CHEMBL1305997 & 688118 & 4.7307 & 4.4344 & TST & & \\
\hline CHEMBL1322395 & 688118 & 4.4722 & 4.3649 & TRN & & \\
\hline CHEMBL1410758 & 688118 & 4.6334 & 3.8588 & TRN & & \\
\hline CHEMBL1542886 & 688118 & 4.2628 & 4.3801 & TST & & \\
\hline CHEMBL1310009 & 688118 & 4.1029 & 4.0087 & TST & & \\
\hline CHEMBL1528900 & 688118 & 4.266 & 4.3103 & TRN & & \\
\hline
\end{tabular}


Supplemental Table S2.txt

\begin{tabular}{|c|c|c|c|c|}
\hline CHEMBL1200567 & 688118 & 5.8125 & 5.7406 & TST \\
\hline CHEMBL586602 & 688118 & 4.2695 & 4.168 & TRN \\
\hline CHEMBL1572266 & 688118 & 6.1427 & 6.5166 & TST \\
\hline CHEMBL1329197 & 688118 & 3.9607 & 3.9365 & TRN \\
\hline CHEMBL582444 & 688118 & 3.9166 & 3.9273 & TST \\
\hline CHEMBL1984324 & 688118 & 4.4256 & 4.1614 & TRN \\
\hline CHEMBL1572134 & 688118 & 4.4062 & 4.2254 & TRN \\
\hline CHEMBL1385206 & 688118 & 5.2125 & \multicolumn{2}{|c|}{5.1610000000000005} \\
\hline CHEMBL1414291 & 688118 & 2.8239 & 3.7157 & TRN \\
\hline CHEMBL123 & 688118 & 4.1565 & 4.6628 & TST \\
\hline CHEMBL1348582 & 688118 & 4.4495 & 4.6422 & TRN \\
\hline CHEMBL1593697 & 688118 & 6.0 & 6.2184 & TST \\
\hline CHEMBL1989897 & 688118 & 3.8713 & 3.8602 & TRN \\
\hline CHEMBL591834 & 688118 & 4.3016 & 4.2817 & TST \\
\hline CHEMBL1453970 & 688118 & 3.8764 & 4.0316 & TRN \\
\hline CHEMBL1419329 & 688118 & 2.8239 & 3.0724 & TRN \\
\hline CHEMBL3190268 & 688118 & 4.2922 & 3.8247 & TRN \\
\hline CHEMBL1351542 & 688118 & 4.5201 & 4.7678 & TRN \\
\hline CHEMBL 3191504 & 688118 & 3.8648 & 4.1326 & TRN \\
\hline CHEMBL1987685 & 688118 & 2.8239 & \multicolumn{2}{|c|}{3.5260000000000002} \\
\hline CHEMBL1596681 & 688118 & 4.0734 & 4.2677 & TRN \\
\hline CHEMBL592124 & 688118 & 3.8604 & 3.9761 & TRN \\
\hline CHEMBL428064 & 688118 & 5.5214 & 5.3242 & TRN \\
\hline CHEMBL1409001 & 688118 & 4.2172 & 3.5012 & TST \\
\hline CHEMBL 3191713 & 688118 & 4.5331 & 4.5854 & TRN \\
\hline CHEMBL1977877 & 688118 & 4.4921 & 4.7248 & TRN \\
\hline CHEMBL1974450 & 688118 & 4.2121 & 3.5514 & TRN \\
\hline CHEMBL1569989 & 688118 & 4.0078 & 4.027 & TRN \\
\hline CHEMBL1522007 & 688118 & 4.782 & 4.8045 & TRN \\
\hline CHEMBL 2373661 & 688118 & 4.9897 & 4.919 & TST \\
\hline CHEMBL1532668 & 688118 & 4.3998 & 4.1757 & TRN \\
\hline CHEMBL1524353 & 688118 & 3.8661 & 3.6435 & TST \\
\hline CHEMBL1309484 & 688118 & 4.0649 & 4.1687 & TRN \\
\hline CHEMBL1304363 & 688118 & 4.5558 & 4.5309 & TRN \\
\hline CHEMBL1990174 & 688118 & 4.4961 & 4.5457 & TRN \\
\hline CHEMBL1505275 & 688118 & 5.1255 & 4.8665 & TST \\
\hline CHEMBL1483252 & 688118 & 4.3862 & \multicolumn{2}{|c|}{ 4.678999999999999 } \\
\hline CHEMBL 3194133 & 688118 & 2.8239 & 3.4162 & TRN \\
\hline CHEMBL1360037 & 688118 & 4.2276 & 4.3305 & TRN \\
\hline CHEMBL1309890 & 688118 & 4.4209 & 4.694 & TRN \\
\hline CHEMBL1326083 & 688118 & 4.6194 & 4.8954 & TRN \\
\hline CHEMBL1481601 & 688118 & 4.2595 & 3.9879 & TST \\
\hline CHEMBL 3197372 & 688118 & 2.8239 & 3.5649 & TRN \\
\hline CHEMBL601768 & 688118 & 4.2057 & 4.0649 & TRN \\
\hline CHEMBL1456240 & 688118 & 3.8837 & 3.8992 & TRN \\
\hline CHEMBL1497597 & 688118 & 4.3062 & 4.2932 & TRN \\
\hline CHEMBL1348018 & 688118 & 3.9766 & 3.5537 & TRN \\
\hline CHEMBL1340176 & 688118 & 2.8239 & 2.8582 & TST \\
\hline
\end{tabular}

Page 12248 


\begin{tabular}{|c|c|c|c|c|c|c|}
\hline \multicolumn{6}{|c|}{ Supplemental Table S2.txt } & \\
\hline CHEMBL590186 & 688118 & 4.2259 & 4.1963 & TRN & & \\
\hline CHEMBL581880 & 688118 & 4.0797 & 3.7436 & TST & & \\
\hline CHEMBL3197599 & 688118 & 2.8239 & 3.5044 & TRN & & \\
\hline CHEMBL1492585 & 688118 & 4.0399 & 4.1686 & TRN & & \\
\hline CHEMBL1438881 & 688118 & 4.7109 & 4.609 & TRN & & \\
\hline CHEMBL1463614 & 688118 & 4.0224 & 3.9728 & TRN & & \\
\hline CHEMBL461579 & 688118 & 4.6621 & 4.1989 & TRN & & \\
\hline CHEMBL1385128 & 688118 & 3.957 & 3.6558 & TRN & & \\
\hline CHEMBL3194704 & 688118 & 4.3409 & 4.1952 & TRN & & \\
\hline CHEMBL1428562 & 688118 & 4.4064 & 4.0411 & TRN & & \\
\hline CHEMBL1323744 & 688118 & 4.1171 & 4.6064 & TRN & & \\
\hline CHEMBL1563898 & 688118 & 4.2474 & 4.1477 & TRN & & \\
\hline CHEMBL1507898 & 688118 & 4.061 & 4.2234 & TRN & & \\
\hline CHEMBL1587753 & 688118 & 5.5719 & 4.8977 & TST & & \\
\hline CHEMBL1329974 & 688118 & 4.1354 & 3.7919 & TRN & & \\
\hline CHEMBL1566068 & 688118 & 2.8239 & 3.7952 & TRN & & \\
\hline CHEMBL1431928 & 688118 & 3.9486 & 3.8735 & TRN & & \\
\hline CHEMBL1413908 & 688118 & 4.0642 & 3.5663 & TRN & & \\
\hline CHEMBL1330558 & 688118 & 4.8027 & 4.8022 & TRN & & \\
\hline CHEMBL1541834 & 688118 & 5.1331 & 4.7454 & TRN & & \\
\hline CHEMBL 3145303 & 688118 & 4.65600 & 0000000 & & 4.6930000000000005 & TRN \\
\hline CHEMBL1494444 & 688118 & 3.86800 & 3000000 & 203 & 3.7837 TRN & \\
\hline CHEMBL1198307 & 688118 & 4.0269 & 3.7998 & TRN & & \\
\hline CHEMBL1496705 & 688118 & 4.5882 & 4.6638 & TRN & & \\
\hline CHEMBL1470712 & 688118 & 3.8371 & 4.1085 & TRN & & \\
\hline CHEMBL1415720 & 688118 & 4.2311 & 3.7903 & TST & & \\
\hline CHEMBL1580989 & 688118 & 2.8239 & 3.6487 & TRN & & \\
\hline CHEMBL1388038 & 688118 & 3.8685 & 3.4472 & TRN & & \\
\hline CHEMBL1570835 & 688118 & 3.8366 & 3.8793 & TRN & & \\
\hline CHEMBL1606504 & 688118 & 4.1439 & 3.984 & TRN & & \\
\hline CHEMBL1514790 & 688118 & 4.3988 & 4.0868 & TRN & & \\
\hline CHEMBL1548492 & 688118 & 4.3064 & 3.9396 & TRN & & \\
\hline CHEMBL 2004417 & 688118 & 4.4885 & 4.4971 & TRN & & \\
\hline CHEMBL1501653 & 688118 & 4.3925 & 4.2773 & TST & & \\
\hline CHEMBL1466123 & 688118 & 4.4725 & 4.2762 & TRN & & \\
\hline CHEMBL 2000750 & 688118 & 4.3978 & 4.1958 & TRN & & \\
\hline CHEMBL1527341 & 688118 & 4.4313 & 4.6836 & TRN & & \\
\hline CHEMBL1393256 & 688118 & 4.519 & 3.9443 & TST & & \\
\hline CHEMBL19954 & 688118 & 4.0936 & 4.4034 & TST & & \\
\hline CHEMBL590408 & 688118 & 3.8678 & 3.8389 & TRN & & \\
\hline CHEMBL1588223 & 688118 & 4.4541 & 4.4399 & TST & & \\
\hline CHEMBL1527520 & 688118 & 4.1877 & 3.8771 & TST & & \\
\hline CHEMBL1612634 & 688118 & 4.6653 & 4.5499 & TRN & & \\
\hline CHEMBL1319643 & 688118 & 2.8239 & 3.9915 & TST & & \\
\hline CHEMBL1550897 & 688118 & 4.3079 & 4.1491 & TRN & & \\
\hline CHEMBL1588513 & 688118 & 4.2441 & 4.0812 & TRN & & \\
\hline CHEMBL580340 & 688118 & 4.4217 & 3.9126 & TRN & & \\
\hline CHEMBL1562066 & 688118 & 3.9757 & 4.0096 & TRN & & \\
\hline
\end{tabular}

Page 12249 


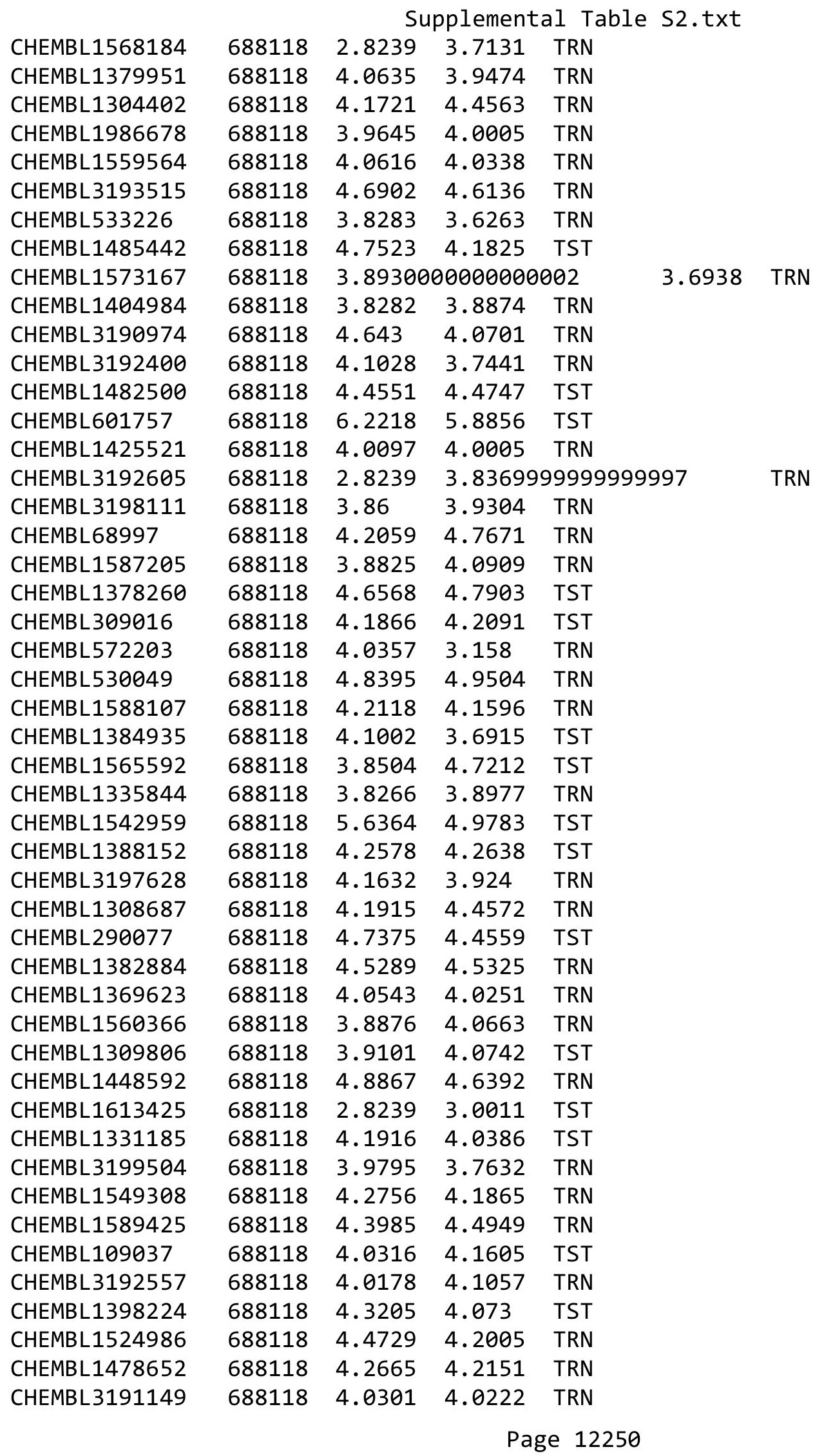


Supplemental Table S2.txt

\begin{tabular}{|c|c|c|c|c|c|}
\hline CHEMBL1986342 & 688118 & 4.1588 & 4.1264 & TST & \\
\hline CHEMBL1556805 & 688118 & 4.1307 & \multicolumn{2}{|c|}{3.9339999999999997} & TRN \\
\hline CHEMBL1479316 & 688118 & 4.3829 & 4.5176 & TRN & \\
\hline CHEMBL1870697 & 688118 & 3.9258 & 3.4932 & TRN & \\
\hline CHEMBL1557213 & 688118 & 3.8777 & 3.7937 & TST & \\
\hline CHEMBL1541468 & 688118 & 4.5363 & 4.1151 & TST & \\
\hline CHEMBL1562835 & 688118 & 2.8239 & 2.957 & TRN & \\
\hline CHEMBL1385808 & 688118 & 6.0 & 6.0876 & TST & \\
\hline CHEMBL3192181 & 688118 & 4.3987 & 4.2137 & TRN & \\
\hline CHEMBL1454171 & 688118 & 3.8674 & 3.8329 & TRN & \\
\hline CHEMBL1981464 & 688118 & 2.8239 & 3.8977 & TRN & \\
\hline CHEMBL1548109 & 688118 & 4.0828 & \multicolumn{2}{|c|}{4.031000000000001} & TRN \\
\hline CHEMBL429095 & 688118 & 4.1876 & 4.2143 & TRN & \\
\hline CHEMBL1418974 & 688118 & 3.8813 & 3.8531 & TRN & \\
\hline CHEMBL251670 & 688118 & 6.4685 & 5.9459 & TST & \\
\hline CHEMBL1995715 & 688118 & 4.2622 & 4.1926 & TRN & \\
\hline CHEMBL1387843 & 688118 & 4.5219 & 4.0186 & TST & \\
\hline CHEMBL1325192 & 688118 & 4.0682 & 4.021 & TRN & \\
\hline CHEMBL1973647 & 688118 & 4.1635 & 3.6981 & TRN & \\
\hline CHEMBL547285 & 688118 & 4.2623 & 4.003 & TRN & \\
\hline CHEMBL1594055 & 688118 & 6.0269 & 6.098 & TST & \\
\hline CHEMBL2369277 & 688118 & 4.2483 & 4.2803 & TRN & \\
\hline CHEMBL 3197896 & 688118 & 4.0894 & 4.1874 & TRN & \\
\hline CHEMBL139935 & 688118 & 5.0223 & 5.3313 & TRN & \\
\hline CHEMBL1333537 & 688118 & 5.3872 & 4.9919 & TST & \\
\hline CHEMBL1560982 & 688118 & 4.558 & 4.3978 & TST & \\
\hline CHEMBL1549646 & 688118 & 4.0632 & 3.5431 & TST & \\
\hline CHEMBL1412043 & 688118 & 4.0938 & 4.1196 & TRN & \\
\hline CHEMBL1519239 & 688118 & 4.4255 & 4.5633 & TRN & \\
\hline CHEMBL1084441 & 688118 & 4.099 & 4.0486 & TRN & \\
\hline CHEMBL1388845 & 688118 & 4.595 & 4.6116 & TST & \\
\hline CHEMBL3189791 & 688118 & 4.1647 & 4.2578 & TRN & \\
\hline CHEMBL1568848 & 688118 & 4.1475 & 4.1698 & TRN & \\
\hline CHEMBL3195409 & 688118 & 4.5418 & 4.2748 & TRN & \\
\hline CHEMBL1608143 & 688118 & 3.9655 & 3.8175 & TRN & \\
\hline CHEMBL1489407 & 688118 & 4.2506 & 4.4053 & TRN & \\
\hline CHEMBL1994463 & 688118 & 4.6278 & 4.6883 & TST & \\
\hline CHEMBL1401089 & 688118 & 4.0144 & 3.926 & TRN & \\
\hline CHEMBL3195334 & 688118 & 4.0336 & 3.7122 & TST & \\
\hline CHEMBL1419945 & 688118 & 4.1963 & 4.3124 & TST & \\
\hline CHEMBL587892 & 688118 & 4.1286 & 4.011 & TRN & \\
\hline CHEMBL1521705 & 688118 & 5.0701 & 5.0116 & TST & \\
\hline CHEMBL1964793 & 688118 & 4.4583 & 4.3485 & TRN & \\
\hline CHEMBL1352234 & 688118 & 4.2137 & 4.1331 & TST & \\
\hline CHEMBL 3197284 & 688118 & 3.9026 & 4.0279 & TST & \\
\hline CHEMBL1422161 & 688118 & 4.2537 & 3.9634 & TRN & \\
\hline CHEMBL1541657 & 688118 & 4.144 & 4.1608 & TST & \\
\hline CHEMBL1968732 & 688118 & 4.4366 & 4.3265 & TRN & \\
\hline
\end{tabular}

Page 12251 
Supplemental Table S2.txt

\begin{tabular}{|c|c|c|c|c|}
\hline CHEMBL1522486 & 688118 & 4.3983 & 4.8038 & TRN \\
\hline CHEMBL1996730 & 688118 & 4.9027 & 4.8947 & TRN \\
\hline CHEMBL602377 & 688118 & 4.1955 & 4.3711 & TRN \\
\hline CHEMBL 3144884 & 688118 & 2.8239 & 3.8438 & TRN \\
\hline CHEMBL1520777 & 688118 & 4.2593 & 3.967 & TRN \\
\hline CHEMBL1568414 & 688118 & 2.8239 & 3.6393 & TRN \\
\hline CHEMBL532641 & 688118 & 3.8293 & 3.6785 & TRN \\
\hline CHEMBL1457463 & 688118 & 3.9609 & 4.0604 & TST \\
\hline CHEMBL1425316 & 688118 & 4.1785 & 4.4394 & TST \\
\hline CHEMBL1426411 & 688118 & 3.8471 & 3.8672 & TRN \\
\hline CHEMBL3199539 & 688118 & 3.8933 & 3.9927 & TRN \\
\hline CHEMBL1501309 & 688118 & 4.5245 & 4.3304 & TST \\
\hline CHEMBL1502937 & 688118 & 3.9801 & 3.7766 & TRN \\
\hline CHEMBL520667 & 688118 & 4.0676 & 3.8095 & TRN \\
\hline CHEMBL1367776 & 688118 & 3.8988 & 3.5423 & TRN \\
\hline CHEMBL1998521 & 688118 & 4.4765 & 4.4283 & TRN \\
\hline CHEMBL414400 & 688118 & 5.0376 & 4.9586 & TRN \\
\hline CHEMBL600778 & 688118 & 4.3955 & 4.284 & TRN \\
\hline CHEMBL 2359911 & 688118 & 3.8399 & 4.3703 & TRN \\
\hline CHEMBL1339328 & 688118 & 3.8606 & 3.6734 & TST \\
\hline CHEMBL1329235 & 688118 & 4.0674 & 4.0494 & TRN \\
\hline CHEMBL1301480 & 688118 & 4.6265 & 4.4767 & TRN \\
\hline CHEMBL1567315 & 688118 & 4.2433 & 4.0587 & TRN \\
\hline CHEMBL 2006909 & 688118 & 2.8239 & 3.4693 & TRN \\
\hline CHEMBL1325945 & 688118 & 5.3526 & 5.2386 & TST \\
\hline CHEMBL3195484 & 688118 & 4.731 & 4.8787 & TST \\
\hline CHEMBL1332756 & 688118 & 4.1399 & 4.0773 & TRN \\
\hline CHEMBL1365456 & 688118 & 4.3398 & 4.4968 & TRN \\
\hline CHEMBL1373096 & 688118 & 4.3357 & 4.1224 & TRN \\
\hline CHEMBL1589298 & 688118 & 4.301 & \multicolumn{2}{|c|}{4.281000000000001} \\
\hline CHEMBL1309207 & 688118 & 4.3312 & 3.8114 & TST \\
\hline CHEMBL1485275 & 688118 & 6.0 & 6.2279 & TST \\
\hline CHEMBL1363249 & 688118 & 4.2084 & 4.251 & TRN \\
\hline CHEMBL1561153 & 688118 & 4.1389 & \multicolumn{2}{|c|}{4.2410000000000005} \\
\hline CHEMBL1585390 & 688118 & 3.9402 & 4.0791 & TRN \\
\hline CHEMBL530609 & 688118 & 3.9619 & 3.8703 & TRN \\
\hline CHEMBL1342852 & 688118 & 4.699 & 4.5184 & TRN \\
\hline CHEMBL1486366 & 688118 & 4.1165 & 4.2969 & TRN \\
\hline CHEMBL1583127 & 688118 & 4.379 & 4.0202 & TRN \\
\hline CHEMBL1427508 & 688118 & 3.9492 & 3.5054 & TRN \\
\hline CHEMBL1403380 & 688118 & 4.0165 & 3.4321 & TST \\
\hline CHEMBL3144874 & 688118 & 3.9621 & 3.9543 & TRN \\
\hline CHEMBL1378952 & 688118 & 4.4825 & 4.7672 & TRN \\
\hline CHEMBL1579686 & 688118 & 5.011 & 4.7119 & TRN \\
\hline CHEMBL1533590 & 688118 & 4.0481 & 3.9077 & TRN \\
\hline CHEMBL1327470 & 688118 & 4.3916 & 4.1698 & TRN \\
\hline CHEMBL351660 & 688118 & 6.0 & 5.8346 & TRN \\
\hline CHEMBL1470669 & 688118 & 4.4632 & 4.1026 & TRN \\
\hline
\end{tabular}

Page 12252 


\begin{tabular}{|c|c|c|c|c|c|}
\hline \multicolumn{6}{|c|}{ Supplemental Table S2.txt } \\
\hline CHEMBL1456244 & 688118 & 3.8742 & 3.0491 & TST & \\
\hline CHEMBL209101 & 688118 & 2.8239 & 4.1982 & TST & \\
\hline CHEMBL67311 & 688118 & 4.477 & 3.6722 & TST & \\
\hline CHEMBL104270 & 688118 & 6.2757 & 6.4879 & TST & \\
\hline CHEMBL586135 & 688118 & 4.9073 & 5.1723 & TRN & \\
\hline CHEMBL1601781 & 688118 & 4.3933 & 4.3695 & TRN & \\
\hline CHEMBL3208179 & 688118 & 4.2455 & 4.0957 & TRN & \\
\hline CHEMBL1491222 & 688118 & 4.4946 & 4.4596 & TRN & \\
\hline CHEMBL578294 & 688118 & 2.8239 & 3.6015 & TRN & \\
\hline CHEMBL1315061 & 688118 & 6.1739 & 5.9876 & TST & \\
\hline CHEMBL1534053 & 688118 & 4.4947 & 4.2682 & TST & \\
\hline CHEMBL1558625 & 688118 & 2.8239 & 3.9847 & TST & \\
\hline CHEMBL1413726 & 688118 & 4.0547 & 4.2507 & TRN & \\
\hline CHEMBL1237072 & 688118 & 4.6463 & 4.5485 & TST & \\
\hline CHEMBL3196837 & 688118 & 4.4277 & 4.5279 & TRN & \\
\hline CHEMBL570345 & 688118 & 4.8854 & 4.2361 & TRN & \\
\hline CHEMBL3191293 & 688118 & 4.3448 & 4.2419 & TRN & \\
\hline CHEMBL1387835 & 688118 & 4.4955 & 4.2745 & TST & \\
\hline CHEMBL1519379 & 688118 & 3.8365 & 3.62899 & 99999999996 & TRN \\
\hline CHEMBL1581682 & 688118 & 4.7357 & 4.5419 & TRN & \\
\hline CHEMBL1429849 & 688118 & 2.8239 & 3.3692 & TRN & \\
\hline CHEMBL1528425 & 688118 & 4.761 & 4.3915 & TRN & \\
\hline CHEMBL1598785 & 688118 & 4.4931 & 4.2252 & TRN & \\
\hline CHEMBL1530097 & 688118 & 3.9289 & 4.0372 & TRN & \\
\hline CHEMBL1375045 & 688118 & 4.6035 & 4.4652 & TRN & \\
\hline CHEMBL1562494 & 688118 & 2.8239 & 3.6275 & TRN & \\
\hline CHEMBL1454614 & 688118 & 4.1554 & 4.0964 & TRN & \\
\hline CHEMBL1609529 & 688118 & 4.1548 & 3.9678 & TRN & \\
\hline CHEMBL 2018847 & 688118 & 3.9593 & 3.8961 & TRN & \\
\hline CHEMBL1437516 & 688118 & 4.3513 & 4.3622 & TRN & \\
\hline CHEMBL3198912 & 688118 & 3.8692 & 3.6722 & TRN & \\
\hline CHEMBL1348852 & 688118 & 2.8239 & 3.60600 & 00000000003 & TRN \\
\hline CHEMBL1326371 & 688118 & 5.2692 & 4.4362 & TST & \\
\hline CHEMBL1487639 & 688118 & 5.1688 & 5.2677 & TRN & \\
\hline CHEMBL 1410641 & 688118 & 4.6264 & 4.3461 & TRN & \\
\hline CHEMBL1526539 & 688118 & 4.3832 & 4.1051 & TRN & \\
\hline CHEMBL1387381 & 688118 & 4.0985 & 4.1357 & TRN & \\
\hline CHEMBL1986183 & 688118 & 3.8552 & 3.7027 & TST & \\
\hline CHEMBL1428407 & 688118 & 4.442 & 4.5491 & TRN & \\
\hline CHEMBL1410381 & 688118 & 4.2432 & 4.4082 & TRN & \\
\hline CHEMBL1968085 & 688118 & 4.6117 & 4.4455 & TRN & \\
\hline CHEMBL1426059 & 688118 & 4.169 & 3.766 & TRN & \\
\hline CHEMBL1998606 & 688118 & 4.4592 & 3.7561 & TRN & \\
\hline CHEMBL1464731 & 688118 & 4.2725 & 4.3826 & TST & \\
\hline CHEMBL66953 & 688118 & 4.7395 & 4.461 & TST & \\
\hline CHEMBL1403156 & 688118 & 4.0865 & 3.9547 & TRN & \\
\hline CHEMBL1427717 & 688118 & 4.4451 & 4.0074 & TRN & \\
\hline CHEMBL1556917 & 688118 & 3.8926 & 3.5896 & TRN & \\
\hline
\end{tabular}

Page 12253 


\begin{tabular}{|c|c|c|c|c|c|c|}
\hline & & \multicolumn{5}{|c|}{ Supplemental Table S2.txt } \\
\hline CHEMBL1562824 & 688118 & 4.192 & 4.3778 & TRN & & \\
\hline CHEMBL1455650 & 688118 & 4.2862 & 4.1211 & TST & & \\
\hline CHEMBL1432427 & 688118 & 3.9836 & 4.3635 & TRN & & \\
\hline CHEMBL1546767 & 688118 & 4.5216 & 4.5454 & TRN & & \\
\hline CHEMBL1430611 & 688118 & 6.0655 & 5.8452 & TRN & & \\
\hline CHEMBL3190468 & 688118 & 4.0292 & 4.0632 & TRN & & \\
\hline CHEMBL417727 & 688118 & 4.9626 & 5.1401 & TRN & & \\
\hline CHEMBL1423463 & 688118 & 4.198 & 3.8581 & TST & & \\
\hline CHEMBL1337416 & 688118 & 4.3582 & 4.5723 & TRN & & \\
\hline CHEMBL1610525 & 688118 & 4.2449 & 4.1549 & TRN & & \\
\hline CHEMBL1242180 & 688118 & 4.5701 & 4.4198 & TRN & & \\
\hline CHEMBL1487183 & 688118 & \multicolumn{3}{|c|}{5.2620000000000005} & 4.6295 & TST \\
\hline CHEMBL1385616 & 688118 & 4.0795 & 4.0408 & TRN & & \\
\hline CHEMBL1366942 & 688118 & 4.7249 & 4.3603 & TRN & & \\
\hline CHEMBL1407234 & 688118 & 4.7409 & 3.8933 & TST & & \\
\hline CHEMBL1565537 & 688118 & 3.9502 & 3.8936 & TST & & \\
\hline CHEMBL3191443 & 688118 & 4.1511 & 4.0514 & TRN & & \\
\hline CHEMBL3189743 & 688118 & 3.8496 & 3.8275 & TRN & & \\
\hline CHEMBL81782 & 688118 & 4.4298 & 4.3526 & TRN & & \\
\hline CHEMBL3198095 & 688118 & 2.8239 & 2.9327 & TRN & & \\
\hline CHEMBL1321398 & 688118 & 4.4612 & 4.1445 & TST & & \\
\hline CHEMBL1487570 & 688118 & 2.8239 & 3.3569 & TRN & & \\
\hline CHEMBL1300831 & 688118 & 4.1805 & 4.1315 & TST & & \\
\hline CHEMBL1555739 & 688118 & 3.985 & 3.9994 & TRN & & \\
\hline CHEMBL3212972 & 688118 & 4.2513 & 3.8997 & TRN & & \\
\hline CHEMBL3190369 & 688118 & 4.6295 & 4.7904 & TST & & \\
\hline CHEMBL1496732 & 688118 & 4.0227 & 3.9348 & TRN & & \\
\hline CHEMBL1499792 & 688118 & 4.5143 & 4.2192 & TRN & & \\
\hline CHEMBL1462938 & 688118 & 4.8887 & 4.8937 & TRN & & \\
\hline CHEMBL1588476 & 688118 & 4.1774 & 3.8985 & TRN & & \\
\hline CHEMBL3192690 & 688118 & \multicolumn{3}{|c|}{3.9610000000000003} & 3.7252 & TRN \\
\hline CHEMBL1422849 & 688118 & 4.3366 & 4.2482 & TRN & & \\
\hline CHEMBL1928491 & 688118 & 4.1993 & 4.3405 & TRN & & \\
\hline CHEMBL1511879 & 688118 & 2.8239 & 3.1252 & TRN & & \\
\hline CHEMBL1513972 & 688118 & 4.5246 & 4.3562 & TRN & & \\
\hline CHEMBL1604283 & 688118 & 6.0 & 6.0791 & TST & & \\
\hline CHEMBL1386820 & 688118 & 3.8975 & 4.0379 & TRN & & \\
\hline CHEMBL1463272 & 688118 & 2.8239 & 3.6158 & TST & & \\
\hline CHEMBL32793 & 688118 & 4.09 & 4.1242 & TRN & & \\
\hline CHEMBL1310632 & 688118 & 4.8735 & 4.6822 & TST & & \\
\hline CHEMBL1460004 & 688118 & 3.9454 & 3.9737 & TRN & & \\
\hline CHEMBL1573630 & 688118 & 3.9321 & 3.7693 & TRN & & \\
\hline CHEMBL1503359 & 688118 & 5.1851 & 4.7324 & TRN & & \\
\hline CHEMBL1500500 & 688118 & 4.0723 & 4.0101 & TRN & & \\
\hline CHEMBL1983530 & 688118 & 3.8516 & 4.0424 & TRN & & \\
\hline CHEMBL584269 & 688118 & 4.4865 & 4.3985 & TRN & & \\
\hline CHEMBL601547 & 688118 & 3.9927 & 3.79699 & 99999 & 7 & TRN \\
\hline \multirow[t]{2}{*}{ CHEMBL3197141 } & 688118 & 4.5232 & 4.0465 & TRN & & \\
\hline & & \multicolumn{5}{|c|}{ Page 122} \\
\hline
\end{tabular}




\begin{tabular}{|c|c|c|c|c|c|}
\hline \multirow[b]{2}{*}{ CHEMBL1448161 } & \multicolumn{5}{|c|}{ Supplemental Table S2.txt } \\
\hline & 688118 & 4.2729 & 3.6516 & TRN & \\
\hline CHEMBL1980844 & 688118 & 4.7469 & 4.3412 & TST & \\
\hline CHEMBL1391048 & 688118 & 4.0784 & 4.327 & TST & \\
\hline CHEMBL142816 & 688118 & 4.1846 & 4.2195 & TST & \\
\hline CHEMBL1419557 & 688118 & 4.1662 & 4.1904 & TRN & \\
\hline CHEMBL69612 & 688118 & 4.5351 & 4.4605 & TRN & \\
\hline CHEMBL582980 & 688118 & 4.0714 & 4.0179 & TRN & \\
\hline CHEMBL609139 & 142909 & 4.6308 & 4.6167 & TRN & \\
\hline CHEMBL124471 & 142909 & 5.7447 & 5.8398 & TRN & \\
\hline CHEMBL435616 & 142909 & 4.9136 & 4.8188 & TRN & \\
\hline CHEMBL609143 & 142909 & 3.0 & 2.9929 & TRN & \\
\hline CHEMBL332008 & 142909 & 6.0 & 6.2115 & TRN & \\
\hline CHEMBL127640 & 142909 & 4.4908 & 4.0408 & TST & \\
\hline CHEMBL341099 & 142909 & 3.0 & 3.138 & TRN & \\
\hline CHEMBL127621 & 142909 & 3.0 & 3.0355 & TRN & \\
\hline CHEMBL340894 & 142909 & 4.3706 & 3.9742 & TRN & \\
\hline CHEMBL6623 & 142909 & 9.0969 & 5.0836 & TST & \\
\hline CHEMBL338558 & 142909 & 6.9208 & 6.7194 & TRN & \\
\hline CHEMBL1161007 & 142909 & 3.0 & 3.319 & TRN & \\
\hline CHEMBL340079 & 142909 & 3.0 & 4.3049 & TST & \\
\hline CHEMBL125917 & 142909 & 3.0 & 3.0703 & TRN & \\
\hline CHEMBL612086 & 142909 & 4.98300 & 20000000 & 005 & 5.0314 \\
\hline CHEMBL127945 & 142909 & 3.0 & 3.1227 & TRN & \\
\hline CHEMBL127580 & 142909 & 4.2262 & 4.2523 & TRN & \\
\hline CHEMBL123508 & 142909 & 4.1637 & 4.186 & TRN & \\
\hline CHEMBL609399 & 142909 & 4.2798 & 3.7947 & TRN & \\
\hline CHEMBL339474 & 142909 & 5.8239 & 5.7967 & TRN & \\
\hline CHEMBL126637 & 142909 & 3.0 & 3.5093 & TST & \\
\hline CHEMBL609402 & 142909 & 3.0 & 4.3668 & TST & \\
\hline CHEMBL609403 & 142909 & 3.0 & 3.2893 & TRN & \\
\hline CHEMBL609145 & 142909 & 6.0315 & 5.9242 & TRN & \\
\hline CHEMBL25619 & 142909 & 8.3468 & 5.6198 & TST & \\
\hline CHEMBL609400 & 142909 & 5.2226 & 5.1336 & TRN & \\
\hline CHEMBL612085 & 142909 & 3.0 & 3.3739 & TRN & \\
\hline CHEMBL122270 & 142909 & 7.0605 & 6.9464 & TRN & \\
\hline CHEMBL126015 & 142909 & 4.0315 & 5.3191 & TST & \\
\hline CHEMBL609395 & 142909 & 4.9031 & 4.6066 & TRN & \\
\hline CHEMBL127430 & 142909 & 3.0 & 2.8473 & TRN & \\
\hline CHEMBL332009 & 142909 & 5.1871 & 5.2301 & TRN & \\
\hline CHEMBL126222 & 142909 & 3.0 & 4.4818 & TST & \\
\hline CHEMBL609140 & 142909 & 5.4318 & 5.3408 & TRN & \\
\hline CHEMBL338316 & 142909 & 3.9586 & 3.917 & TRN & \\
\hline CHEMBL338898 & 142909 & 4.0506 & 3.8273 & TRN & \\
\hline CHEMBL612087 & 142909 & 3.0 & 2.8632 & TRN & \\
\hline CHEMBL126527 & 142909 & 3.0 & 4.5733 & TST & \\
\hline CHEMBL127620 & 142909 & 4.27 & 4.3469 & TRN & \\
\hline CHEMBL612094 & 142909 & 4.6968 & 5.3396 & TST & \\
\hline CHEMBL124568 & 142909 & 4.2034 & 3.9969 & TRN & \\
\hline
\end{tabular}




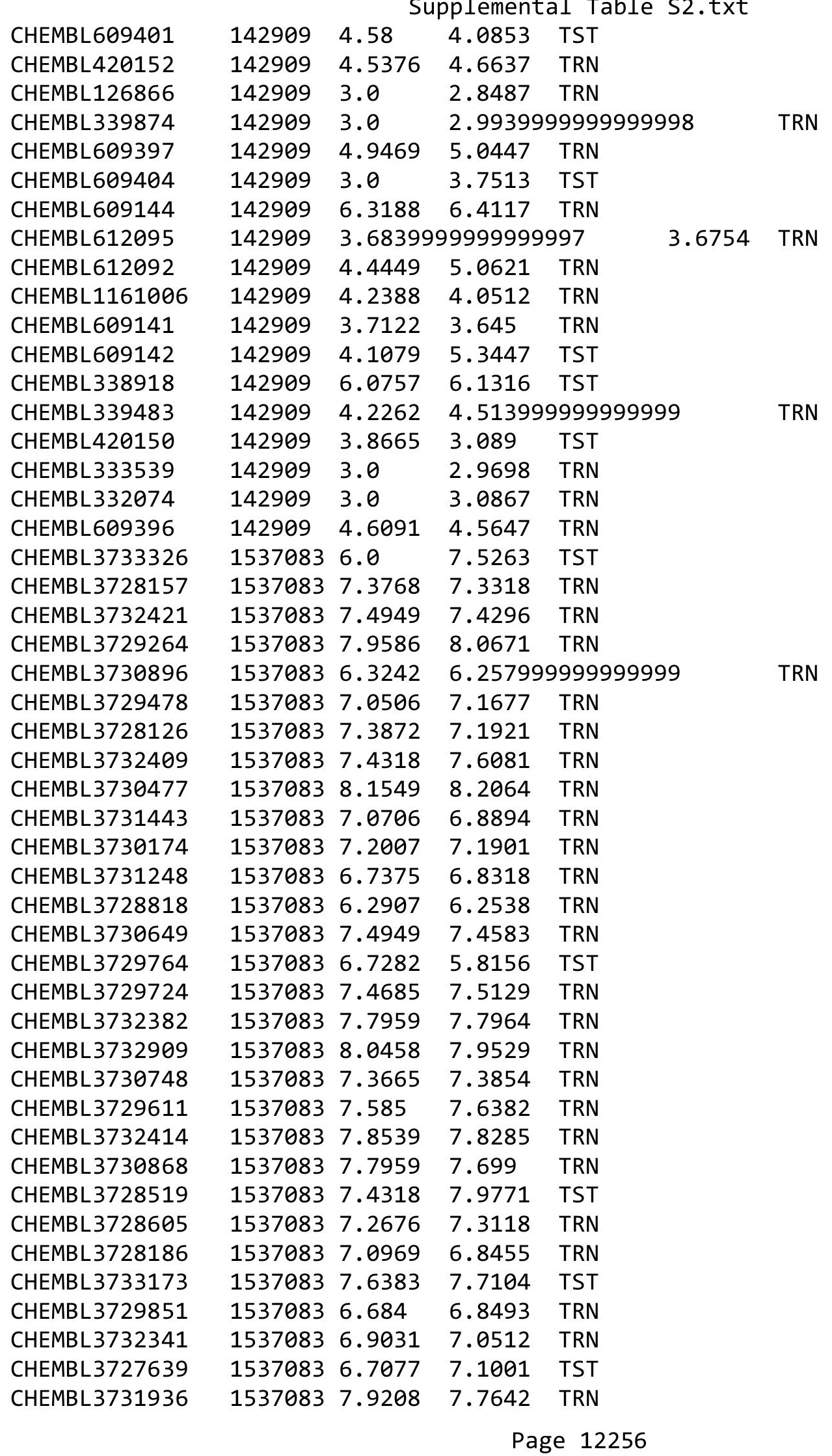


Supplemental Table S2.txt

\begin{tabular}{|c|c|c|c|c|c|}
\hline CHEMBL 3733102 & 1537083 & 7.5086 & 7.6269 & TRN & \\
\hline CHEMBL 3728501 & 1537083 & 7.3768 & 7.2621 & TRN & \\
\hline CHEMBL3729172 & 1537083 & 4.0 & 3.8895 & TRN & \\
\hline CHEMBL 3727749 & 1537083 & 6.6271 & 6.4117 & TST & \\
\hline CHEMBL 3731191 & 1537083 & 7.1079 & 7.1146 & TRN & \\
\hline CHEMBL 3729891 & 1537083 & 7.7212 & 7.4734 & TRN & \\
\hline CHEMBL 3729654 & 1537083 & 6.52 & 6.5812 & TRN & \\
\hline CHEMBL 3729871 & 1537083 & 7.3979 & 7.4009 & TRN & \\
\hline CHEMBL 3727954 & 1537083 & 7.8239 & 7.9309 & TRN & \\
\hline CHEMBL 3729135 & 1537083 & 7.2007 & 7.3428 & TRN & \\
\hline CHEMBL 3727897 & 1537083 & 7.2291 & 7.3939 & TRN & \\
\hline CHEMBL 3728853 & 1537083 & 7.7959 & 7.8181 & TRN & \\
\hline CHEMBL 3728949 & 1537083 & 7.8861 & 7.7271 & TRN & \\
\hline CHEMBL 3731465 & 1537083 & 6.0 & 6.7517 & TRN & \\
\hline CHEMBL 3730584 & 1537083 & 7.8239 & 7.6664 & TRN & \\
\hline CHEMBL 3728033 & 1537083 & 6.20200 & 00000000 & 1 & 6.3748 \\
\hline CHEMBL 3731731 & 1537083 & 7.0177 & 7.0718 & TRN & \\
\hline CHEMBL 3730212 & 1537083 & 7.6021 & 7.6045 & TRN & \\
\hline CHEMBL 3728207 & 1537083 & 6.0605 & 6.1278 & TRN & \\
\hline CHEMBL 3731729 & 1537083 & 6.0 & 7.2528 & TST & \\
\hline CHEMBL 3730253 & 1537083 & 6.9281 & 5.8234 & TST & \\
\hline CHEMBL 3731610 & 1537083 & 6.8861 & 6.8686 & TRN & \\
\hline CHEMBL 3731921 & 1537083 & 7.4685 & 7.3165 & TRN & \\
\hline CHEMBL 3731419 & 1537083 & 7.9208 & 7.8603 & TRN & \\
\hline CHEMBL 3731305 & 1537083 & 7.4202 & 7.4585 & TRN & \\
\hline CHEMBL 3731764 & 1537083 & 8.1549 & 8.3805 & TRN & \\
\hline CHEMBL 3730043 & 1537083 & 5.7352 & 5.9737 & TRN & \\
\hline CHEMBL 3732239 & 1537083 & 6.3737 & 6.0987 & TRN & \\
\hline CHEMBL 3730941 & 1537083 & 6.9957 & 6.9137 & TRN & \\
\hline CHEMBL 3730913 & 1537083 & 7.8539 & 7.6916 & TRN & \\
\hline CHEMBL 3731410 & 1537083 & 7.699 & 7.8531 & TRN & \\
\hline CHEMBL 3729325 & 1537083 & 7.4318 & 7.1268 & TRN & \\
\hline CHEMBL 3728833 & 1537083 & 7.3768 & 7.2772 & TRN & \\
\hline CHEMBL 3732185 & 1537083 & 7.6383 & 7.5075 & TRN & \\
\hline CHEMBL 3732671 & 1537083 & 7.1871 & 6.9765 & TRN & \\
\hline CHEMBL3731357 & 1537083 & 6.5467 & 6.7663 & TRN & \\
\hline CHEMBL 3727382 & 1537083 & 8.2218 & 8.1334 & TRN & \\
\hline CHEMBL 3732208 & 1537083 & 7.5528 & 7.5373 & TRN & \\
\hline CHEMBL 3732959 & 1537083 & 7.8861 & 7.9174 & TRN & \\
\hline CHEMBL 3728301 & 1537083 & 7.3872 & 7.81 & TST & \\
\hline CHEMBL 3732353 & 1537083 & 7.2518 & 7.397 & TRN & \\
\hline CHEMBL 3733189 & 1537083 & 7.6576 & 7.9667 & TST & \\
\hline CHEMBL3730205 & 1537083 & 7.6778 & 7.5781 & TRN & \\
\hline CHEMBL 3731231 & 1537083 & 7.6778 & 7.5692 & TST & \\
\hline CHEMBL 3728579 & 1537083 & 5.8604 & 6.1547 & TST & \\
\hline CHEMBL 3728453 & 1537083 & 6.8069 & 7.4313 & TST & \\
\hline CHEMBL 3732062 & 1537083 & 6.9136 & 7.0678 & TST & \\
\hline CHEMBL 3730650 & 1537083 & 7.041 & 6.2971 & TST & \\
\hline
\end{tabular}


Supplemental Table S2.txt

\begin{tabular}{|c|c|c|c|c|c|}
\hline CHEMBL3730186 & 1537083 & 6.0 & 7.5586 & TST & \\
\hline CHEMBL 3729987 & 1537083 & 7.8239 & 7.7795 & TST & \\
\hline CHEMBL 3727542 & 1537083 & 7.0458 & 6.7625 & TST & \\
\hline CHEMBL3729489 & 1537083 & 7.4815 & 7.16100 & 20000000005 & TST \\
\hline CHEMBL 3731366 & 1537083 & 7.7447 & 7.6831 & TST & \\
\hline CHEMBL3733209 & 1537083 & 7.5376 & 7.66700 & 0000000001 & \\
\hline CHEMBL1421321 & 809286 & 3.9224 & 4.6927 & TRN & \\
\hline CHEMBL1465978 & 809286 & 5.1986 & 4.3334 & TST & \\
\hline CHEMBL485636 & 809286 & 3.4452 & 4.6233 & TRN & \\
\hline CHEMBL1972216 & 809286 & 4.8895 & 4.7771 & TRN & \\
\hline CHEMBL1899898 & 809286 & 5.2031 & 4.4261 & TRN & \\
\hline CHEMBL 2000559 & 809286 & 4.9482 & 4.6354 & TST & \\
\hline CHEMBL1515941 & 809286 & 4.5939 & 4.6279 & TRN & \\
\hline CHEMBL1399858 & 809286 & 4.7034 & 4.5238 & TST & \\
\hline CHEMBL1540237 & 809286 & 4.7028 & 4.3202 & TRN & \\
\hline CHEMBL1974180 & 809286 & 4.9797 & 4.5293 & TRN & \\
\hline CHEMBL576412 & 809286 & 4.819 & 4.0747 & TRN & \\
\hline CHEMBL1719626 & 809286 & 5.0671 & 4.4431 & TST & \\
\hline CHEMBL1427335 & 809286 & 4.5955 & 4.6397 & TRN & \\
\hline CHEMBL 2000752 & 809286 & 4.7898 & 4.5559 & TRN & \\
\hline CHEMBL1903362 & 809286 & 4.8223 & 4.1584 & TST & \\
\hline CHEMBL1562983 & 809286 & 4.9724 & 4.0085 & TRN & \\
\hline CHEMBL1372947 & 809286 & 3.4453 & 3.9785 & TST & \\
\hline CHEMBL1387923 & 809286 & 5.0967 & 5.0545 & TRN & \\
\hline CHEMBL1717403 & 809286 & 4.963 & 4.6851 & TRN & \\
\hline CHEMBL1413178 & 809286 & 4.8768 & 5.1963 & TST & \\
\hline CHEMBL1418980 & 809286 & 5.5462 & 4.7831 & TRN & \\
\hline CHEMBL1368216 & 809286 & 3.4453 & 4.1635 & TRN & \\
\hline CHEMBL1461035 & 809286 & 5.2677 & 5.0382 & TRN & \\
\hline CHEMBL1412573 & 809286 & 4.8909 & 4.7041 & TRN & \\
\hline CHEMBL1400379 & 809286 & 3.4453 & 3.9624 & TRN & \\
\hline CHEMBL1564670 & 809286 & 5.4122 & 4.8035 & TRN & \\
\hline CHEMBL1528660 & 809286 & 5.0477 & 4.2557 & TRN & \\
\hline CHEMBL1323722 & 809286 & 3.9224 & 4.3743 & TRN & \\
\hline CHEMBL1563358 & 809286 & 3.4453 & 4.2051 & TRN & \\
\hline CHEMBL1544409 & 809286 & \multicolumn{2}{|c|}{5.0280000000000005} & 4.6438 & \\
\hline CHEMBL494325 & 809286 & 5.1682 & 5.2014 & TRN & \\
\hline CHEMBL1877372 & 809286 & 4.3675 & 4.117 & TRN & \\
\hline CHEMBL1976374 & 809286 & 3.4453 & 4.1188 & TRN & \\
\hline CHEMBL1516127 & 809286 & 4.6716 & 4.1081 & TRN & \\
\hline CHEMBL1375217 & 809286 & 4.9595 & 4.7161 & TRN & \\
\hline CHEMBL1504109 & 809286 & 3.4453 & 4.2112 & TRN & \\
\hline CHEMBL1487959 & 809286 & 4.8359 & 4.0825 & TRN & \\
\hline CHEMBL1490392 & 809286 & 4.5942 & 4.4075 & TRN & \\
\hline CHEMBL1480880 & 809286 & 4.9583 & 4.4695 & TRN & \\
\hline CHEMBL1972217 & 809286 & 4.9404 & 4.8709 & TRN & \\
\hline CHEMBL1517605 & 809286 & 4.5591 & 4.3028 & TRN & \\
\hline CHEMBL1413003 & 809286 & 4.7281 & 4.4966 & TRN & \\
\hline
\end{tabular}

Page 12258 
Supplemental Table S2.txt

\begin{tabular}{|c|c|c|c|c|}
\hline 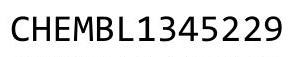 & & & & \\
\hline HEMBL1440409 & 09286 & 1521 & 7237 & \\
\hline & & & & \\
\hline FMRI 156 & 286 & & 4391 & \\
\hline IEMBL1967149 & 09286 & 689 & 1909 & \\
\hline AEMBL1549424 & 09286 & 4453 & 3163 & \\
\hline HEMBL1318140 & 09286 & & 9402 & \\
\hline IEMBL13 & 09286 & & & \\
\hline IEMBL132 & 286 & & 4.8988 & \\
\hline AEMBL1993555 & 09286 & 5625 & 4.2231 & \\
\hline HEMBL1406398 & 09286 & 52 & 9173 & \\
\hline AEMBL148 & 09286 & & 1009 & \\
\hline AEMBL14 & & & & \\
\hline HEMBL1€ & 86 & & & \\
\hline AEMBL158 & 09286 & & 5779 & \\
\hline AEMBL 2373711 & 86 & & 79 & \\
\hline AEMBL14 & 86 & & 19 & \\
\hline HEMBL1C & & & & \\
\hline HEMBL 1 & 86 & & & \\
\hline AEMBL15 & 86 & 97 & & RN \\
\hline EMABLI 10 & 86 & 34 & 5017 & NIV \\
\hline HEMBL19 & 86 & & 59 & 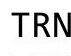 \\
\hline HEMBL17 & 36 & & 35 & \\
\hline HFMBI 1 & 36 & & 7185 & RN \\
\hline HEMBL956 & 36 & & 89 & II \\
\hline HEMBL19 & 36 & 1 & 5565 & RIN \\
\hline HEMBL15 & 86 & & 5453 & 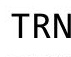 \\
\hline HEMBL13 & & & 931 & \\
\hline 48 & & & & RN \\
\hline L17 & 36 & & 76 & SI - ra \\
\hline HEMBL157 & 36 & & 211 & RN \\
\hline HEMBL138 & 86 & & 711 & KIV \\
\hline HFMBI 14 & & & 091 & RN \\
\hline & & & & RN \\
\hline IEMBL 14 & 36 & & 295 & RN \\
\hline EMBL56 & 36 & & 43 & \\
\hline HEMBL19 & 86 & & 379 & RN \\
\hline & & & & RN \\
\hline HEMBL143 & & & 376 & RN \\
\hline HEMBL13: & 86 & & 585 & RN \\
\hline HEMBL14 & & & 851 & \\
\hline HEMBL1866510 & & & & \\
\hline 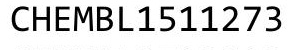 & & & & RN \\
\hline HEMBL17: & 86 & & 3242 & RN \\
\hline IEMBL13. & 09286 & 46 & 355 & \\
\hline & & & & \\
\hline HEM & 09286 & 3.4453 & 3.7368 & \\
\hline 50774 & 309286 & 3.4452 & 3.4373 & \\
\hline
\end{tabular}

Page 12259 
Supplemental Table S2.txt

\begin{tabular}{|c|c|c|c|c|}
\hline CHEMBL1875320 & 809286 & 4.7976 & 4.3399 & TRN \\
\hline CHEMBL1399772 & 809286 & 5.0016 & 5.3493 & TRN \\
\hline CHEMBL1882211 & 809286 & 5.0199 & 4.7086 & TRN \\
\hline CHEMBL1549657 & 809286 & 3.445 & 4.314 & TRN \\
\hline CHEMBL1996281 & 809286 & 5.2853 & 4.9503 & TRN \\
\hline CHEMBL1967019 & 809286 & 4.8994 & 4.6907 & TRN \\
\hline CHEMBL1400374 & 809286 & 4.7051 & 4.6305 & TRN \\
\hline CHEMBL1508267 & 809286 & 4.9564 & 4.6059 & TST \\
\hline CHEMBL1885633 & 809286 & 5.0205 & 4.5891 & TRN \\
\hline CHEMBL1397089 & 809286 & 5.3535 & 4.6545 & TST \\
\hline CHEMBL1378385 & 809286 & 4.9869 & 4.9597 & TRN \\
\hline CHEMBL1535999 & 809286 & 4.3992 & 4.1736 & TRN \\
\hline CHEMBL1469961 & 809286 & 5.1183 & 4.7417 & TRN \\
\hline CHEMBL533226 & 809286 & 5.2823 & 4.4769 & TRN \\
\hline CHEMBL1421781 & 809286 & 5.0307 & 4.859 & TRN \\
\hline CHEMBL1469670 & 809286 & 5.4722 & 5.1679 & TRN \\
\hline CHEMBL1491703 & 809286 & 3.4453 & 3.8797 & TRN \\
\hline CHEMBL1703566 & 809286 & 4.9566 & 4.7769 & TRN \\
\hline CHEMBL356169 & 809286 & 5.0882 & 4.8603 & TRN \\
\hline CHEMBL1736199 & 809286 & 3.4443 & 4.6261 & TRN \\
\hline CHEMBL1440892 & 809286 & 4.7843 & 4.5984 & TRN \\
\hline CHEMBL1480936 & 809286 & 4.8229 & 4.2955 & TRN \\
\hline CHEMBL1585209 & 809286 & 4.9489 & 4.49100 & 00000000005 \\
\hline CHEMBL1713127 & 809286 & 3.923 & 4.628 & TRN \\
\hline CHEMBL1995641 & 809286 & 3.4453 & 4.2137 & TRN \\
\hline CHEMBL1475299 & 809286 & 5.2216 & 4.8523 & TRN \\
\hline CHEMBL1605666 & 809286 & 4.9307 & 4.6769 & TRN \\
\hline CHEMBL1494091 & 809286 & 4.7577 & 4.7356 & TRN \\
\hline CHEMBL3195049 & 809286 & 4.7387 & 4.7132 & TRN \\
\hline CHEMBL1380143 & 809286 & 4.9925 & 4.6839 & TRN \\
\hline CHEMBL1612809 & 809286 & 3.4453 & 4.2395 & TRN \\
\hline CHEMBL1376974 & 809286 & 3.4451 & 3.487 & TST \\
\hline CHEMBL1706512 & 809286 & 3.4453 & 3.8195 & TRN \\
\hline CHEMBL1372451 & 809286 & 3.4456 & 4.3328 & TRN \\
\hline CHEMBL1985459 & 809286 & 4.9494 & 4.4539 & TRN \\
\hline CHEMBL1464490 & 809286 & 3.4452 & 3.8635 & TRN \\
\hline CHEMBL1310435 & 809286 & 3.4452 & 3.8166 & TRN \\
\hline CHEMBL1396943 & 809286 & 3.4452 & 3.2196 & TRN \\
\hline CHEMBL1705854 & 809286 & 5.4623 & 5.3134 & TRN \\
\hline CHEMBL1331226 & 809286 & 4.6745 & 4.5072 & TRN \\
\hline CHEMBL1370927 & 809286 & 5.1538 & 4.9498 & TRN \\
\hline CHEMBL1329069 & 809286 & 3.4453 & 4.386 & TRN \\
\hline CHEMBL1453780 & 809286 & 4.4473 & 4.1035 & TRN \\
\hline CHEMBL1724732 & 809286 & 4.6177 & 4.5594 & TRN \\
\hline CHEMBL1965433 & 809286 & 5.125 & 4.3816 & TRN \\
\hline CHEMBL1608402 & 809286 & 3.4452 & 4.2722 & TRN \\
\hline CHEMBL1309254 & 809286 & 4.6436 & 4.1508 & TRN \\
\hline CHEMBL1992109 & 809286 & 4.8365 & 4.1739 & TRN \\
\hline
\end{tabular}




\begin{tabular}{|c|c|c|c|c|c|c|}
\hline & & & & & . ts & \\
\hline CHEMBL1985010 & 809286 & 3.4456 & 3.3102 & TRN & & \\
\hline CHEMBL479368 & 809286 & 5.17200 & 00000000 & $\partial 1$ & 5.042 & TRN \\
\hline CHEMBL1409060 & 809286 & 4.9535 & 4.8089 & TRN & & \\
\hline CHEMBL1528507 & 809286 & 5.4009 & 5.2377 & TRN & & \\
\hline CHEMBL1557219 & 809286 & 4.7797 & 4.4791 & TRN & & \\
\hline CHEMBL1600535 & 809286 & 4.9265 & 4.7174 & TRN & & \\
\hline CHEMBL1350077 & 809286 & 3.4453 & 4.0733 & TST & & \\
\hline CHEMBL1339283 & 809286 & 3.4452 & 3.9489 & TRN & & \\
\hline CHEMBL1412284 & 809286 & 4.3995 & 4.8819 & TRN & & \\
\hline CHEMBL1995593 & 809286 & 5.0926 & 4.5268 & TRN & & \\
\hline CHEMBL1200512 & 809286 & 3.4453 & 3.7721 & TRN & & \\
\hline CHEMBL1479201 & 809286 & 3.4452 & 4.7272 & TST & & \\
\hline CHEMBL1372654 & 809286 & 3.4453 & 3.6244 & TRN & & \\
\hline CHEMBL1965654 & 809286 & 4.9707 & 4.9618 & TRN & & \\
\hline CHEMBL1965376 & 809286 & 5.0778 & 5.0094 & TRN & & \\
\hline CHEMBL1502254 & 809286 & 4.9408 & 4.6217 & TRN & & \\
\hline CHEMBL1552808 & 809286 & 3.4454 & 4.2693 & TRN & & \\
\hline CHEMBL1318520 & 809286 & 4.49100 & 00000000 & 205 & 4.2365 & TRN \\
\hline CHEMBL1595937 & 809286 & 5.0202 & 4.8011 & TRN & & \\
\hline CHEMBL1728248 & 809286 & 4.4855 & 4.1517 & TRN & & \\
\hline CHEMBL1987516 & 809286 & 3.9223 & 4.1007 & TRN & & \\
\hline CHEMBL1597286 & 809286 & 4.9258 & 5.0126 & TRN & & \\
\hline CHEMBL1373969 & 809286 & 5.1603 & 5.6752 & TRN & & \\
\hline CHEMBL1393412 & 809286 & 4.8872 & 4.2784 & TST & & \\
\hline CHEMBL1300713 & 809286 & 4.5031 & 4.1775 & TRN & & \\
\hline CHEMBL1996902 & 809286 & 5.1472 & 4.8123 & TRN & & \\
\hline CHEMBL1302818 & 809286 & 3.4452 & 4.1898 & TRN & & \\
\hline CHEMBL1339546 & 809286 & 4.9741 & 4.8854 & TRN & & \\
\hline CHEMBL1367428 & 809286 & 4.8349 & 4.5639 & TRN & & \\
\hline CHEMBL1412433 & 809286 & 4.9346 & 4.9438 & TST & & \\
\hline CHEMBL1327038 & 809286 & 4.7721 & 4.9525 & TRN & & \\
\hline CHEMBL1438559 & 809286 & 4.5893 & 4.6747 & TRN & & \\
\hline CHEMBL 2001316 & 809286 & 5.0767 & 4.7142 & TRN & & \\
\hline CHEMBL1992293 & 809286 & 4.9524 & 4.4413 & TRN & & \\
\hline CHEMBL 2004809 & 809286 & 4.9763 & 4.8835 & TRN & & \\
\hline CHEMBL1445386 & 809286 & 3.4454 & 3.4045 & TRN & & \\
\hline CHEMBL 2028187 & 809286 & 3.4452 & 3.5615 & TST & & \\
\hline CHEMBL1558455 & 809286 & 3.4452 & 3.7841 & TRN & & \\
\hline CHEMBL1306377 & 809286 & 5.2445 & 4.7539 & TRN & & \\
\hline CHEMBL1975487 & 809286 & 4.8333 & 4.4267 & TRN & & \\
\hline CHEMBL1366319 & 809286 & 4.6471 & 4.5382 & TRN & & \\
\hline CHEMBL1881832 & 809286 & 4.8576 & 4.4016 & TRN & & \\
\hline CHEMBL1494764 & 809286 & 4.5554 & 4.3132 & TRN & & \\
\hline CHEMBL1525654 & 809286 & 3.4455 & 4.515 & TRN & & \\
\hline CHEMBL1368708 & 809286 & 4.9694 & 4.5843 & TRN & & \\
\hline CHEMBL1597726 & 809286 & 4.6041 & 4.2679 & TRN & & \\
\hline CHEMBL1380630 & 809286 & 4.8344 & 4.8271 & TRN & & \\
\hline CHEMBL492267 & 809286 & 5.0126 & 4.9996 & TRN & & \\
\hline
\end{tabular}




\begin{tabular}{|c|c|c|c|c|c|c|}
\hline \multicolumn{7}{|c|}{ Supplemental Table S2.txt } \\
\hline CHEMBL1555905 & 809286 & 4.5457 & 4.4642 & TST & & \\
\hline CHEMBL1699187 & 809286 & 4.3991 & 5.3214 & TRN & & \\
\hline CHEMBL1612097 & 809286 & 4.8564 & 4.8352 & TRN & & \\
\hline CHEMBL1730950 & 809286 & 4.897 & 4.7374 & TRN & & \\
\hline CHEMBL1337807 & 809286 & 3.4452 & 3.5756 & TRN & & \\
\hline CHEMBL1486651 & 809286 & 3.4454 & 4.3913 & TRN & & \\
\hline CHEMBL1893675 & 809286 & 4.9542 & 4.573 & TRN & & \\
\hline CHEMBL1546346 & 809286 & 3.4449 & 4.0916 & TST & & \\
\hline CHEMBL1444434 & 809286 & \multicolumn{3}{|c|}{4.9030000000000005} & 4.96 & TST \\
\hline CHEMBL1481928 & 809286 & 3.4456 & 3.4767 & TRN & & \\
\hline CHEMBL2001670 & 809286 & 3.4448 & 3.1074 & TRN & & \\
\hline CHEMBL1466076 & 809286 & 4.7105 & 4.1109 & TRN & & \\
\hline CHEMBL1975006 & 809286 & 3.9225 & 4.8574 & TRN & & \\
\hline CHEMBL1305435 & 809286 & 3.4453 & 4.4534 & TRN & & \\
\hline CHEMBL1467678 & 809286 & 3.4453 & 4.4922 & TRN & & \\
\hline CHEMBL1348955 & 809286 & 4.8028 & 4.7161 & TST & & \\
\hline CHEMBL1340423 & 809286 & 4.9369 & 4.4401 & TRN & & \\
\hline CHEMBL1347672 & 809286 & 3.4452 & 4.4289 & TST & & \\
\hline CHEMBL1529280 & 809286 & 4.737 & 4.4932 & TST & & \\
\hline CHEMBL59530 & 809286 & 5.2132 & 4.3699 & TST & & \\
\hline CHEMBL1566908 & 809286 & 4.6643 & 4.2581 & TST & & \\
\hline CHEMBL1980684 & 809286 & 4.897 & 4.8658 & TST & & \\
\hline CHEMBL1511754 & 809286 & 3.4452 & 4.0416 & TST & & \\
\hline CHEMBL1355544 & 809286 & 4.5544 & 4.43 & TST & & \\
\hline CHEMBL1729353 & 809286 & 3.4452 & 4.5045 & TST & & \\
\hline CHEMBL1383315 & 809286 & 5.3176 & 4.8715 & TST & & \\
\hline CHEMBL1309164 & 809286 & 3.4454 & 4.352 & TST & & \\
\hline CHEMBL1708715 & 809286 & 4.7913 & 4.456 & TST & & \\
\hline CHEMBL3304020 & 809286 & 3.4449 & 4.8827 & TST & & \\
\hline CHEMBL1542260 & 809286 & 4.8015 & 4.9359 & TST & & \\
\hline CHEMBL1610875 & 809286 & 5.6123 & 5.1714 & TST & & \\
\hline CHEMBL1572233 & 809286 & 3.4449 & 4.8852 & TST & & \\
\hline CHEMBL428909 & 809286 & 4.8803 & 4.8405 & TST & & \\
\hline CHEMBL132431 & 809286 & 3.4448 & 4.4783 & TST & & \\
\hline CHEMBL1721357 & 809286 & 3.4454 & 4.2565 & TST & & \\
\hline CHEMBL1888871 & 809286 & 3.4449 & 4.9444 & TST & & \\
\hline CHEMBL1993707 & 809286 & 4.8248 & 4.2684 & TST & & \\
\hline CHEMBL1583698 & 809286 & 4.9223 & 4.4337 & TST & & \\
\hline CHEMBL587564 & 809286 & 3.4455 & 4.1562 & TST & & \\
\hline CHEMBL1312928 & 809286 & 3.4452 & 4.5723 & TST & & \\
\hline CHEMBL1307972 & 809286 & 5.371 & 4.95 & TST & & \\
\hline CHEMBL1456725 & 809286 & 5.157 & 4.958 & TST & & \\
\hline CHEMBL1508246 & 809286 & 3.4456 & 4.0731 & TST & & \\
\hline CHEMBL1994902 & 809286 & 4.7553 & 4.4956 & TST & & \\
\hline CHEMBL1471916 & 809286 & 5.2175 & 4.7219 & TST & & \\
\hline CHEMBL2007313 & 809286 & 4.9274 & 4.5617 & TST & & \\
\hline CHEMBL1487723 & 809286 & 4.5869 & 4.23300 & 00006 & & נد \\
\hline CHEMBL1969300 & 809286 & 5.2446 & 4.6438 & TST & & \\
\hline
\end{tabular}




\begin{tabular}{|c|c|c|c|c|c|c|}
\hline & & \multicolumn{5}{|c|}{ Supplemental Table S2.txt } \\
\hline CHEMBL1316462 & 809286 & 3.4453 & 4.1688 & TST & & \\
\hline CHEMBL1980848 & 809286 & 4.7761 & 4.7102 & TST & & \\
\hline CHEMBL1341317 & 809286 & 3.4452 & 4.7065 & TST & & \\
\hline CHEMBL3644416 & 1535850 & 6.0 & 5.8347 & TRN & & \\
\hline CHEMBL 3702406 & 1535850 & 5.3468 & 5.8714 & TST & & \\
\hline CHEMBL3702373 & 1535850 & 5.5528 & 5.50799 & 99999999 & & TRN \\
\hline CHEMBL3702365 & 1535850 & 6.1612 & 6.4256 & TRN & & \\
\hline CHEMBL3644372 & 1535850 & 5.8861 & 5.7786 & TRN & & \\
\hline CHEMBL3644375 & 1535850 & 4.0 & 4.0285 & TRN & & \\
\hline CHEMBL 3702434 & 1535850 & 5.2291 & 5.136 & TRN & & \\
\hline CHEMBL3702394 & 1535850 & 4.0 & 4.0768 & TRN & & \\
\hline CHEMBL3702410 & 1535850 & 5.7959 & 5.5187 & TRN & & \\
\hline CHEMBL3644429 & 1535850 & 5.8239 & 5.8601 & TRN & & \\
\hline CHEMBL3644379 & 1535850 & 4.0 & 4.6815 & TRN & & \\
\hline CHEMBL3702377 & 1535850 & 4.0 & 3.7223 & TST & & \\
\hline CHEMBL3702416 & 1535850 & 4.0 & 4.2408 & TST & & \\
\hline CHEMBL3702374 & 1535850 & 5.284 & 5.1827 & TRN & & \\
\hline CHEMBL 3644384 & 1535850 & 4.0 & 4.1362 & TRN & & \\
\hline CHEMBL3702438 & 1535850 & 4.699 & 5.0737 & TRN & & \\
\hline CHEMBL3644433 & 1535850 & 4.699 & 4.7455 & TRN & & \\
\hline CHEMBL3702401 & 1535850 & 4.0 & 5.6653 & TST & & \\
\hline CHEMBL 3702441 & 1535850 & 5.4111 & 4.9088 & TRN & & \\
\hline CHEMBL3702364 & 1535850 & 6.0269 & 5.6689 & TRN & & \\
\hline CHEMBL 3644382 & 1535850 & 4.0 & 3.8597 & TRN & & \\
\hline CHEMBL3644428 & 1535850 & 6.1475 & 6.2194 & TRN & & \\
\hline CHEMBL3702369 & 1535850 & 5.4559 & 5.4215 & TRN & & \\
\hline CHEMBL3644430 & 1535850 & 4.699 & 4.635 & TRN & & \\
\hline CHEMBL3644409 & 1535850 & 4.0 & 4.0393 & TRN & & \\
\hline CHEMBL 3702444 & 1535850 & 5.9776 & 6.4802 & TRN & & \\
\hline CHEMBL 3644371 & 1535850 & 4.0 & 4.3588 & TRN & & \\
\hline CHEMBL3702385 & 1535850 & 7.0315 & 6.6527 & TST & & \\
\hline CHEMBL3702465 & 1535850 & 6.16299 & 99999999 & 99 & 6.0525 & TRN \\
\hline CHEMBL3702431 & 1535850 & 4.0 & 4.8717 & TST & & \\
\hline CHEMBL3702429 & 1535850 & 4.0 & 3.6468 & TRN & & \\
\hline CHEMBL 3644378 & 1535850 & 4.0 & 4.7233 & TST & & \\
\hline CHEMBL3702397 & 1535850 & 5.6576 & 4.6503 & TST & & \\
\hline CHEMBL3702446 & 1535850 & 5.7312 & 5.949 & TRN & & \\
\hline CHEMBL3702376 & 1535850 & 4.0 & 4.0118 & TST & & \\
\hline CHEMBL 3702445 & 1535850 & 4.0 & 3.9306 & TRN & & \\
\hline CHEMBL 3702370 & 1535850 & 4.0 & 4.263 & TRN & & \\
\hline CHEMBL3644394 & 1535850 & 6.0506 & 6.0262 & TRN & & \\
\hline CHEMBL3702363 & 1535850 & 4.0 & 4.4805 & TRN & & \\
\hline CHEMBL3702400 & 1535850 & 4.0 & 3.6871 & TRN & & \\
\hline CHEMBL 3644401 & 1535850 & 6.2916 & 6.2999 & TRN & & \\
\hline CHEMBL 3702403 & 1535850 & 4.0 & 4.2776 & TRN & & \\
\hline CHEMBL3644419 & 1535850 & 4.0 & 4.5727 & TRN & & \\
\hline CHEMBL3644374 & 1535850 & 4.0 & 3.7911 & TST & & \\
\hline CHEMBL3644399 & 1535850 & 5.6304 & 5.6145 & TRN & & \\
\hline
\end{tabular}


Supplemental Table S2.txt

\begin{tabular}{|c|c|c|c|c|c|}
\hline CHEMBL3702424 & 1535850 & 5.3768 & 4.8325 & TRN & \\
\hline CHEMBL3913043 & 1535850 & 5.6821 & 5.6712 & TRN & \\
\hline CHEMBL3644406 & 1535850 & 7.3872 & 7.0564 & TRN & \\
\hline CHEMBL3702418 & 1535850 & 4.0 & 4.0675 & TRN & \\
\hline CHEMBL3702433 & 1535850 & 5.7959 & 5.9579 & TRN & \\
\hline CHEMBL3644390 & 1535850 & 4.0 & 4.02 & TRN & \\
\hline CHEMBL3702426 & 1535850 & 4.0 & 3.9959 & TRN & \\
\hline CHEMBL3702467 & 1535850 & 6.251 & 5.8858 & TRN & \\
\hline CHEMBL3702455 & 1535850 & 5.6198 & 5.5794 & TRN & \\
\hline CHEMBL3702382 & 1535850 & 5.8539 & 6.1185 & TRN & \\
\hline CHEMBL3702439 & 1535850 & 4.0 & 4.1004 & TRN & \\
\hline CHEMBL3702452 & 1535850 & 5.8239 & 6.0228 & TRN & \\
\hline CHEMBL3644413 & 1535850 & 5.8283 & 5.1409 & TRN & \\
\hline CHEMBL 3644402 & 1535850 & 5.7841 & 5.7763 & TRN & \\
\hline CHEMBL3644404 & 1535850 & 5.4815 & 5.6034 & TRN & \\
\hline CHEMBL3639432 & 1535850 & 6.1726 & 6.4903 & TRN & \\
\hline CHEMBL3644424 & 1535850 & 5.7447 & 5.739 & TRN & \\
\hline CHEMBL3644377 & 1535850 & 4.0 & 3.4435 & TRN & \\
\hline CHEMBL 3644368 & 1535850 & 4.0 & 3.91899 & & TRN \\
\hline CHEMBL3702415 & 1535850 & 5.8539 & 5.0638 & TST & \\
\hline CHEMBL3644403 & 1535850 & 4.699 & 4.3704 & TRN & \\
\hline CHEMBL3702359 & 1535850 & 6.8239 & 5.0262 & TST & \\
\hline CHEMBL 3644367 & 1535850 & 4.0 & 3.9502 & TRN & \\
\hline CHEMBL 3644364 & 1535850 & 4.0 & 3.4472 & TST & \\
\hline CHEMBL3644414 & 1535850 & 4.0 & 4.1456 & TRN & \\
\hline CHEMBL3644376 & 1535850 & 5.1347 & 4.8612 & TRN & \\
\hline CHEMBL3702423 & 1535850 & 6.7696 & 6.5866 & TRN & \\
\hline CHEMBL3702366 & 1535850 & 5.8861 & 5.8578 & TRN & \\
\hline CHEMBL 3644423 & 1535850 & 5.4815 & 5.4647 & TRN & \\
\hline CHEMBL3702432 & 1535850 & 4.0 & 4.3972 & TRN & \\
\hline CHEMBL3702419 & 1535850 & 5.1938 & 5.1884 & TRN & \\
\hline CHEMBL 3644407 & 1535850 & 5.4799 & 5.4008 & TRN & \\
\hline CHEMBL3702389 & 1535850 & 7.6576 & 5.4567 & TST & \\
\hline CHEMBL3702362 & 1535850 & 6.6778 & 6.5498 & TRN & \\
\hline CHEMBL3922521 & 1535850 & 4.0 & 4.1217 & TRN & \\
\hline CHEMBL3702412 & 1535850 & 4.0 & 4.0407 & TRN & \\
\hline CHEMBL3702386 & 1535850 & 7.8239 & 5.3805 & TST & \\
\hline CHEMBL3702453 & 1535850 & 4.0 & 3.7047 & TRN & \\
\hline CHEMBL 3644432 & 1535850 & 5.9574 & 5.6338 & TRN & \\
\hline CHEMBL 3644365 & 1535850 & 6.0894 & 6.0981 & TRN & \\
\hline CHEMBL3702462 & 1535850 & 4.9211 & 4.7892 & TRN & \\
\hline CHEMBL3644369 & 1535850 & 4.0 & 5.0072 & TRN & \\
\hline CHEMBL3702420 & 1535850 & 4.0 & 4.9481 & TST & \\
\hline CHEMBL 3644387 & 1535850 & 5.0315 & 5.7593 & TST & \\
\hline CHEMBL 3702427 & 1535850 & 4.0 & 4.3506 & TRN & \\
\hline CHEMBL3644417 & 1535850 & 5.4685 & 5.1259 & TRN & \\
\hline CHEMBL3644398 & 1535850 & 4.699 & 4.9193 & TRN & \\
\hline CHEMBL3702371 & 1535850 & 4.0 & 3.8292 & TRN & \\
\hline
\end{tabular}


Supplemental Table S2.txt

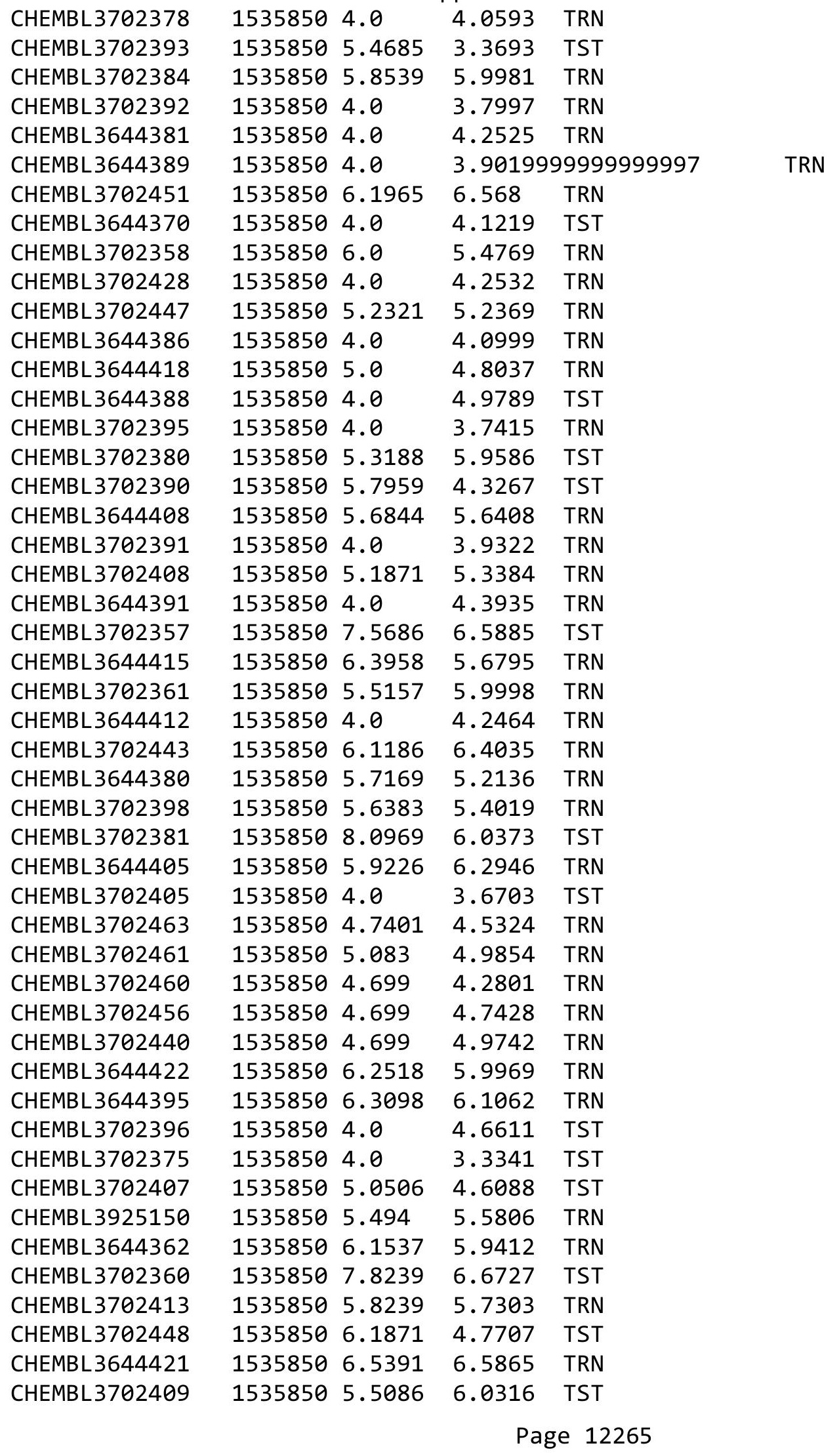




\begin{tabular}{|c|c|c|c|c|c|}
\hline \multirow{3}{*}{$\begin{array}{l}\text { CHEMBL } 3644410 \\
\text { CHEMBL } 3702404\end{array}$} & \multicolumn{5}{|c|}{ Supplemental Table s2.txt } \\
\hline & 1535850 & 4.0 & \multicolumn{2}{|c|}{3.8310000000000004} & TRN \\
\hline & 1535850 & 4.0 & 5.2677 & TST & \\
\hline CHEMBL3702442 & 1535850 & 5.7093 & 6.0634 & TRN & \\
\hline CHEMBL3702379 & 1535850 & 4.0 & 4.1056 & TST & \\
\hline CHEMBL3644383 & 1535850 & 4.699 & 4.4786 & TRN & \\
\hline CHEMBL3702459 & 1535850 & 4.0 & 4.2675 & TRN & \\
\hline CHEMBL3702411 & 1535850 & 5.4949 & 5.5936 & TRN & \\
\hline CHEMBL 3702421 & 1535850 & 4.0 & 4.1694 & TST & \\
\hline CHEMBL 3644411 & 1535850 & 4.699 & 4.8012 & TRN & \\
\hline CHEMBL3702402 & 1535850 & 4.0 & 5.3733 & TST & \\
\hline CHEMBL3644392 & 1535850 & 6.1805 & 6.0085 & TRN & \\
\hline CHEMBL 3644431 & 1535850 & 4.0 & 4.4145 & TRN & \\
\hline CHEMBL3644427 & 1535850 & 4.699 & 4.6098 & TRN & \\
\hline CHEMBL3702399 & 1535850 & 4.0 & 5.1373 & TST & \\
\hline CHEMBL3702457 & 1535850 & 4.0 & 4.5841 & TRN & \\
\hline CHEMBL3702372 & 1535850 & 6.0969 & 5.3398 & TST & \\
\hline CHEMBL3702449 & 1535850 & 5.8239 & 4.7779 & TST & \\
\hline CHEMBL3702367 & 1535850 & 6.2757 & 5.6449 & TST & \\
\hline CHEMBL 3702422 & 1535850 & 5.9208 & \multicolumn{2}{|c|}{5.763999999999999} & TRN \\
\hline CHEMBL3644400 & 1535850 & 6.6459 & 6.1842 & TRN & \\
\hline CHEMBL3702454 & 1535850 & 5.2291 & 5.1439 & TRN & \\
\hline CHEMBL3644366 & 1535850 & 4.2218 & \multicolumn{2}{|c|}{4.1419999999999995} & TRN \\
\hline CHEMBL 3644373 & 1535850 & 4.0 & 3.9693 & TRN & \\
\hline CHEMBL 3640012 & 1535850 & 4.0 & 3.8753 & TST & \\
\hline CHEMBL3702417 & 1535850 & 4.0 & 4.615 & TRN & \\
\hline CHEMBL3644425 & 1535850 & 5.6383 & 5.2613 & TRN & \\
\hline CHEMBL3702430 & 1535850 & 4.0 & 4.1026 & TRN & \\
\hline CHEMBL3702368 & 1535850 & 4.0 & 5.5179 & TST & \\
\hline CHEMBL 3702414 & 1535850 & 4.0 & 5.3777 & TST & \\
\hline CHEMBL3702450 & 1535850 & 6.6576 & 6.5054 & TRN & \\
\hline CHEMBL 3702458 & 1535850 & 4.0 & 4.6812 & TST & \\
\hline CHEMBL3702387 & 1535850 & 5.1612 & 4.9122 & TST & \\
\hline CHEMBL311564 & 66720 & 3.3468 & 2.3346 & TST & \\
\hline CHEMBL77381 & 66720 & 2.8665 & 2.9532 & TRN & \\
\hline CHEMBL308339 & 66720 & 2.8539 & 2.9782 & TST & \\
\hline CHEMBL307179 & 66720 & 3.7959 & 3.6445 & TRN & \\
\hline CHEMBL77778 & 66720 & 3.3468 & 2.6687 & TRN & \\
\hline CHEMBL310798 & 66720 & 5.5229 & 4.7874 & TRN & \\
\hline CHEMBL77197 & 66720 & 2.9586 & 3.4721 & TRN & \\
\hline CHEMBL 78302 & 66720 & 2.6021 & 3.8478 & TRN & \\
\hline CHEMBL 76985 & 66720 & 4.3279 & 3.1143 & TRN & \\
\hline CHEMBL 76589 & 66720 & 6.9031 & 5.0821 & TRN & \\
\hline CHEMBL 77243 & 66720 & 4.2596 & 4.4751 & TST & \\
\hline CHEMBL501368 & 66720 & 4.1249 & 4.0309 & TRN & \\
\hline CHEMBL77869 & 66720 & 3.699 & 3.8824 & TRN & \\
\hline CHEMBL 77387 & 66720 & 3.3468 & 4.2223 & TRN & \\
\hline CHEMBL 76904 & 66720 & 4.4559 & 4.6491 & TRN & \\
\hline CHEMBL296407 & 66720 & 5.0 & 5.0644 & TRN & \\
\hline
\end{tabular}




\begin{tabular}{|c|c|c|c|c|c|}
\hline \multicolumn{6}{|c|}{ Supplemental Table S2.txt } \\
\hline CHEMBL 308048 & 66720 & 3.0969 & 3.8635 & TRN & \\
\hline CHEMBL 76905 & 66720 & 4.4318 & 3.8997 & TRN & \\
\hline CHEMBL57712 & 66720 & 2.8861 & 2.9942 & TRN & \\
\hline CHEMBL 309598 & 66720 & 4.8697 & 4.4219 & TST & \\
\hline CHEMBL78150 & 66720 & 3.3372 & 4.072 & TRN & \\
\hline CHEMBL 305695 & 66720 & 3.2518 & 3.315 & TRN & \\
\hline CHEMBL77724 & 66720 & 1.9031 & 2.9264 & TRN & \\
\hline CHEMBL 78257 & 66720 & 6.0969 & 6.1612 & TRN & \\
\hline CHEMBL 308134 & 66720 & 3.9031 & 4.2138 & TRN & \\
\hline CHEMBL 79064 & 66720 & 3.6383 & 3.1689 & TST & \\
\hline CHEMBL420385 & 66720 & 2.2041 & 2.8802 & TRN & \\
\hline CHEMBL66879 & 66720 & 2.5229 & 2.7979 & TRN & \\
\hline CHEMBL310514 & 66720 & 3.585 & 2.9891 & TRN & \\
\hline CHEMBL 73820 & 66720 & 4.6021 & 4.6986 & TRN & \\
\hline CHEMBL310400 & 66720 & 3.426 & 3.3997 & TRN & \\
\hline CHEMBL 78184 & 66720 & 3.0794 & 2.9545 & TRN & \\
\hline CHEMBL77737 & 66720 & 3.6021 & 2.906 & TRN & \\
\hline CHEMBL 78005 & 66720 & 3.4559 & 3.2782 & TRN & \\
\hline CHEMBL 77280 & 66720 & 1.9031 & 3.3511 & TST & \\
\hline CHEMBL421877 & 66720 & 3.0706 & 3.5996 & TRN & \\
\hline CHEMBL3965817 & 66720 & 3.7825 & 3.4334 & TRN & \\
\hline CHEMBL78174 & 66720 & 3.3665 & 2.7514 & TRN & \\
\hline CHEMBL307248 & 66720 & 3.1938 & 2.8985 & TRN & \\
\hline CHEMBL 310958 & 66720 & 3.6478 & 3.3572 & TST & \\
\hline CHEMBL309866 & 66720 & 2.8861 & 3.0711 & TRN & \\
\hline CHEMBL77595 & 66720 & 3.0706 & 2.7406 & TRN & \\
\hline CHEMBL80155 & 66720 & 5.2218 & 4.38899 & 9999999999 & TRN \\
\hline CHEMBL77524 & 66720 & 3.0794 & 2.6028 & TRN & \\
\hline CHEMBL 75718 & 66720 & 2.6198 & 3.2364 & TRN & \\
\hline CHEMBL47986 & 66720 & 4.8539 & 3.8385 & TST & \\
\hline CHEMBL77803 & 66720 & 6.301 & 6.1885 & TRN & \\
\hline CHEMBL 76082 & 66720 & 3.2518 & 3.2697 & TRN & \\
\hline CHEMBL 145 & 66720 & 2.9208 & 3.9572 & TRN & \\
\hline CHEMBL77298 & 66720 & 3.8153 & 3.786 & TRN & \\
\hline CHEMBL77085 & 66720 & 4.0177 & 3.5128 & TRN & \\
\hline CHEMBL77456 & 66720 & 1.9031 & 2.444 & TRN & \\
\hline CHEMBL77825 & 66720 & 3.2218 & 2.5238 & TST & \\
\hline CHEMBL76587 & 66720 & 2.1871 & 3.3508 & TST & \\
\hline CHEMBL 76979 & 66720 & 3.5784 & 3.7234 & TRN & \\
\hline CHEMBL311119 & 66720 & 4.2218 & 2.9158 & TRN & \\
\hline CHEMBL 308133 & 66720 & 2.8239 & 2.9229 & TRN & \\
\hline CHEMBL309334 & 66720 & 5.6021 & 5.9342 & TRN & \\
\hline CHEMBL76983 & 66720 & 1.9031 & 2.8182 & TRN & \\
\hline CHEMBL 306988 & 66720 & 3.301 & 2.9516 & TST & \\
\hline CHEMBL 76557 & 66720 & 3.2041 & 3.7384 & TST & \\
\hline CHEMBL 307250 & 66720 & 3.4881 & 3.975 & TST & \\
\hline CHEMBL 80745 & 66720 & 5.9208 & 5.6564 & TST & \\
\hline CHEMBL77030 & 66720 & 5.6198 & 5.3907 & TST & \\
\hline
\end{tabular}




\begin{tabular}{|c|c|c|c|c|c|}
\hline \multicolumn{6}{|c|}{ Supplemental Table S2.txt } \\
\hline CHEMBL309625 & 66720 & 4.2218 & 5.4287 & TST & \\
\hline CHEMBL77814 & 66720 & 3.4559 & 3.2591 & TST & \\
\hline CHEMBL1687998 & 729459 & 3.6021 & 3.6409 & TRN & \\
\hline CHEMBL1687993 & 729459 & 3.6021 & 3.878 & TRN & \\
\hline CHEMBL1687989 & 729459 & 3.6021 & 3.571 & TRN & \\
\hline CHEMBL1688022 & 729459 & 3.6021 & 3.7785 & TRN & \\
\hline CHEMBL1687994 & 729459 & 4.7696 & 4.4287 & TRN & \\
\hline CHEMBL1688023 & 729459 & 3.6021 & 3.6288 & TRN & \\
\hline CHEMBL1687992 & 729459 & 3.6021 & 4.0298 & TRN & \\
\hline CHEMBL1688007 & 729459 & 3.6021 & 3.9439 & TRN & \\
\hline CHEMBL1688020 & 729459 & 3.6021 & 3.5494 & TRN & \\
\hline CHEMBL1687991 & 729459 & 3.6021 & 3.8158 & TRN & \\
\hline CHEMBL1688014 & 729459 & 3.6021 & 3.7041 & TRN & \\
\hline CHEMBL1688028 & 729459 & 3.6021 & 3.6759 & TRN & \\
\hline CHEMBL1688027 & 729459 & 3.6021 & 3.9138 & TST & \\
\hline CHEMBL1687945 & 729459 & 3.6021 & 3.4082 & TRN & \\
\hline CHEMBL1687990 & 729459 & 3.6021 & 3.7618 & TRN & \\
\hline CHEMBL1687995 & 729459 & 3.6021 & 4.2971 & TRN & \\
\hline CHEMBL1254783 & 729459 & 3.6021 & 3.4779 & TRN & \\
\hline CHEMBL1688010 & 729459 & 4.699 & 4.9618 & TRN & \\
\hline CHEMBL1688006 & 729459 & 3.6021 & 3.4726 & TRN & \\
\hline CHEMBL1688030 & 729459 & 3.6021 & 3.2387 & TST & \\
\hline CHEMBL1688019 & 729459 & 4.699 & 4.575 & TRN & \\
\hline CHEMBL1688025 & 729459 & 3.6021 & 3.6996 & TRN & \\
\hline CHEMBL1688004 & 729459 & 3.6021 & 3.4258 & TRN & \\
\hline CHEMBL1688012 & 729459 & 3.6021 & 3.7349 & TST & \\
\hline CHEMBL1688003 & 729459 & 4.6383 & 4.5667 & TRN & \\
\hline CHEMBL1688024 & 729459 & 3.6021 & 4.01399 & 9999999999 & TRN \\
\hline CHEMBL1687988 & 729459 & 4.7959 & 4.6581 & TRN & \\
\hline CHEMBL1687987 & 729459 & 4.7696 & 4.3314 & TRN & \\
\hline CHEMBL1688016 & 729459 & 3.6021 & 3.68899 & 99999999996 & TRN \\
\hline CHEMBL1687997 & 729459 & 3.6021 & 3.7903 & TRN & \\
\hline CHEMBL524922 & 729459 & 3.6021 & 3.4771 & TRN & \\
\hline CHEMBL439259 & 729459 & 3.6021 & 3.7918 & TRN & \\
\hline CHEMBL1688029 & 729459 & 3.6021 & 3.5155 & TST & \\
\hline CHEMBL1687996 & 729459 & 4.6778 & 4.3394 & TRN & \\
\hline CHEMBL1688002 & 729459 & 4.6778 & 4.6246 & TRN & \\
\hline CHEMBL1687999 & 729459 & 3.6021 & 3.8529 & TRN & \\
\hline CHEMBL1688026 & 729459 & 3.6021 & 3.7071 & TST & \\
\hline CHEMBL1688017 & 729459 & 4.7212 & 4.2524 & TRN & \\
\hline CHEMBL1688021 & 729459 & 3.6021 & 3.4757 & TRN & \\
\hline CHEMBL524969 & 729459 & 4.7959 & 4.5341 & TRN & \\
\hline CHEMBL1688011 & 729459 & 3.6021 & 3.5826 & TRN & \\
\hline CHEMBL1688005 & 729459 & 3.6021 & 3.5114 & TRN & \\
\hline CHEMBL548963 & 729459 & 3.6021 & 3.9912 & TRN & \\
\hline CHEMBL1687984 & 729459 & 4.7696 & 4.6267 & TRN & \\
\hline CHEMBL1687985 & 729459 & 3.6021 & 3.8104 & TRN & \\
\hline CHEMBL1688031 & 729459 & 3.6021 & 3.6121 & TST & \\
\hline
\end{tabular}




\begin{tabular}{|c|c|c|c|c|c|}
\hline & & & & & \\
\hline CHEMBL1688008 & 729459 & 4.8861 & 4.5467 & TRN & \\
\hline CHEMBL1688000 & 729459 & 3.6021 & 3.1958 & TRN & \\
\hline CHEMBL1688013 & 729459 & 3.6021 & 3.4277 & TRN & \\
\hline CHEMBL547264 & 729459 & 3.6021 & 3.3507 & TRN & \\
\hline CHEMBL1688015 & 729459 & 3.6021 & 3.5127 & TST & \\
\hline CHEMBL1688009 & 729459 & 3.6021 & 3.976006 & 00000000004 & TST \\
\hline CHEMBL1688018 & 729459 & 4.6383 & 4.09 & TST & \\
\hline CHEMBL1687983 & 729459 & 3.6021 & 4.064 & TST & \\
\hline CHEMBL587639 & 729459 & 4.7696 & 3.6031 & TST & \\
\hline CHEMBL1254870 & 729459 & 3.6021 & 3.9439 & TST & \\
\hline CHEMBL1254871 & 729459 & 4.8239 & 4.5875 & TST & \\
\hline CHEMBL1688001 & 729459 & 3.6021 & 3.4797 & TST & \\
\hline CHEMBL1687986 & 729459 & 4.7212 & 4.2824 & TST & \\
\hline CHEMBL3694396 & 1528035 & 8.0088 & 8.6066 & TRN & \\
\hline CHEMBL3694370 & 1528035 & 8.7959 & 9.1926 & TRN & \\
\hline CHEMBL3694391 & 1528035 & 7.6778 & 7.9721 & TRN & \\
\hline CHEMBL3694348 & 1528035 & 7.1675 & 7.4375 & TRN & \\
\hline CHEMBL3694357 & 1528035 & 7.9586 & 7.53299 & 99999999995 & TRN \\
\hline CHEMBL3694383 & 1528035 & 9.3468 & 9.4406 & TST & \\
\hline CHEMBL3694347 & 1528035 & 7.4318 & 7.7799 & TRN & \\
\hline CHEMBL3694350 & 1528035 & 7.8861 & 8.0588 & TRN & \\
\hline CHEMBL3694359 & 1528035 & 7.6778 & 7.4515 & TRN & \\
\hline CHEMBL3694346 & 1528035 & 7.9586 & 8.2362 & TRN & \\
\hline CHEMBL3694398 & 1528035 & 9.1367 & 9.4105 & TST & \\
\hline CHEMBL3694336 & 1528035 & 7.3565 & 7.3055 & TRN & \\
\hline CHEMBL3694393 & 1528035 & 8.7959 & 8.3891 & TRN & \\
\hline CHEMBL 3694397 & 1528035 & 10.5229 & 9.5392 & TST & \\
\hline CHEMBL3694364 & 1528035 & 8.5686 & 8.391 & TRN & \\
\hline CHEMBL3694388 & 1528035 & 9.3188 & 8.9611 & TRN & \\
\hline CHEMBL3694379 & 1528035 & 9.4949 & 9.4153 & TRN & \\
\hline CHEMBL3694340 & 1528035 & 7.585 & 7.1889 & TRN & \\
\hline CHEMBL3694372 & 1528035 & 7.9208 & 8.0501 & TST & \\
\hline CHEMBL3694343 & 1528035 & 8.699 & 7.6698 & TRN & \\
\hline CHEMBL3694368 & 1528035 & 8.8539 & 8.1963 & TST & \\
\hline CHEMBL3694361 & 1528035 & 7.3279 & 7.4762 & TRN & \\
\hline CHEMBL3694355 & 1528035 & 8.3872 & 8.3619 & TRN & \\
\hline CHEMBL3694385 & 1528035 & 9.8861 & 9.7086 & TST & \\
\hline CHEMBL3694392 & 1528035 & 7.8861 & 7.9046 & TRN & \\
\hline CHEMBL 3694367 & 1528035 & 7.1612 & 7.4615 & TRN & \\
\hline CHEMBL3694382 & 1528035 & 9.5528 & 9.4421 & TRN & \\
\hline CHEMBL3694360 & 1528035 & 7.4815 & 8.5962 & TST & \\
\hline CHEMBL3694386 & 1528035 & 9.2518 & 9.6306 & TST & \\
\hline CHEMBL3694366 & 1528035 & 8.5229 & 8.0932 & TRN & \\
\hline CHEMBL3694394 & 1528035 & 8.1249 & 8.1669 & TRN & \\
\hline CHEMBL3694338 & 1528035 & 7.8239 & 7.8062 & TRN & \\
\hline CHEMBL3694387 & 1528035 & 9.6383 & 9.6669 & TRN & \\
\hline CHEMBL3694345 & 1528035 & 6.8356 & 7.8136 & TST & \\
\hline CHEMBL3694378 & 1528035 & 8.9208 & 9.1151 & TRN & \\
\hline
\end{tabular}


Supplemental Table S2.txt

\begin{tabular}{|c|c|c|c|c|}
\hline HEMBL & 528035 & 8.1938 & 8.2483 & TF \\
\hline HFMRI 3694358 & 528035 & 7.7447 & 8.0813 & \\
\hline HFMRI & 28035 & 7212 & 9018 & \\
\hline HEMBL3694344 & 28035 & 7.2076 & & 2N1 \\
\hline HEMBL3694380 & 528035 & 9757 & 4949 & \\
\hline HEMBL3694349 & 528035 & 8.4559 & 8.414 & \\
\hline HEMBL3694369 & 528035 & 8.0 & 191 & \\
\hline IEMBL 369 & 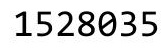 & 59 & & \\
\hline HEMBL3694351 & 528035 & 7.1079 & 7.1815 & \\
\hline HEMBL3694375 & 528035 & 9.3468 & 9.1473 & \\
\hline HEMBL3694395 & 528035 & 8.1079 & 8.0066 & \\
\hline AEMBL 369 & 528035 & 528 & 4844 & \\
\hline AEMBL369 & & & & RN \\
\hline HEMBL 369 & 528035 & 6.7471 & 7.1412 & \\
\hline AEMBL 369 & 528 & 8.1024 & 8208 & \\
\hline AEMBL369 & 528035 & 7.4202 & 7.4237 & \\
\hline HEMBL369 & $5<8$ & 41 & 1276 & וד \\
\hline HEMBL $36{ }^{\circ}$ & 528 & 528 & 973 & \\
\hline HEMBL369 & 528035 & 7.9586 & 7.8043 & \\
\hline AEMBL369. & 5 & & 38 & 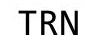 \\
\hline HEMBL3 & $528 t$ & 86 & 91 & SI \\
\hline HEMBL3 & 286 & 8 & 47 & RN \\
\hline HEMBL3 & I & 15 & 25 & \\
\hline HEMBL369 & 5200 & $\partial 6$ & 1309 & TST \\
\hline HEMBL 369 & & & & 15 \\
\hline HEMBL369 & 8035 & 7.0044 & 7.7947 & SI \\
\hline HEMBL & 2 & 57 & 94 & RN \\
\hline HEMBL 2 & 59 & 7. & 2386 & 「RN \\
\hline HEMBL194366 & & & 7.2829 & 15 \\
\hline HEMBL375 & 59 & & 388 & IRIN \\
\hline HEMBL3 & 99 & 458 & 9803 & $\mathrm{RN}$ \\
\hline HEMBL2 & 59 & 7 & 739 & TRN \\
\hline HEMBL370 & 59 & 28 & 319 & TST \\
\hline HEMBL 374752 & 22359 & 8.301 & 3366 & TRN \\
\hline HEMBL 223185 & 22359 & 4.9031 & 2249 & TST \\
\hline HEMBL1 & 2359 & 59 & 7966 & TRN \\
\hline HEMBL3 & 59 & 2 & 122 & $\Gamma \mathrm{RN}$ \\
\hline HEMBL 382 & 2359 & & 9937 & TRN \\
\hline HEMBL196615 & 22359 & 7.2676 & 9742 & TST \\
\hline IEMBL426e & 2359 & 58 & 1043 & TRN \\
\hline HEMBL 222 & 2359 & 31 & 9545 & (1) \\
\hline CHEMBL372174 & 522359 & 7.5376 & & TRN \\
\hline HEMBL223361 & 22359 & 6.8239 & 6.8651 & TRN \\
\hline HEMBL 2203 & 2359 & 4.9508 & 6.8473 & TS \\
\hline EMBL1 & 59 & & 3947 & I KIV \\
\hline CHEMBL369S & 2359 & 77 & .0437 & \\
\hline CHEMBL370325 & 22359 & 6.8539 & 6.9393 & \\
\hline CHEMBL424943 & 622359 & 7.3872 & 7.3237 & TRN \\
\hline
\end{tabular}

Page 12270 


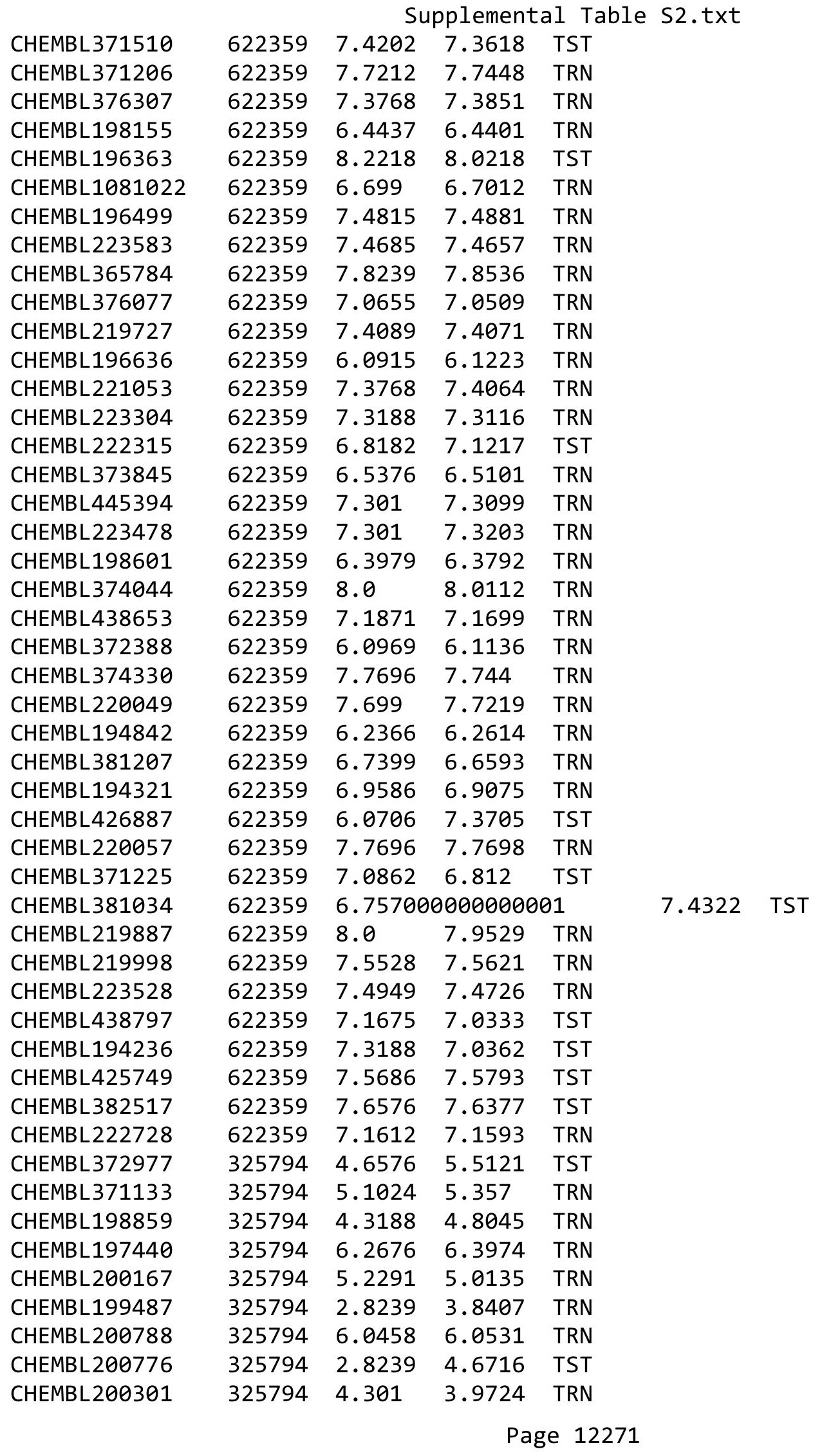




\begin{tabular}{|c|c|c|c|c|c|}
\hline \multicolumn{6}{|c|}{ oplemental Table S } \\
\hline CHEMBL200599 & 325794 & 4.7447 & 4.8039 & TRN & \\
\hline CHEMBL199488 & 325794 & 4.1487 & 4.8713 & TRN & \\
\hline CHEMBL372410 & 325794 & 5.041 & 5.6387 & TRN & \\
\hline CHEMBL200494 & 325794 & 4.7959 & 4.251 & TRN & \\
\hline CHEMBL200482 & 325794 & 5.1024 & 4.887 & TRN & \\
\hline CHEMBL435913 & 325794 & 5.6383 & 5.59 & TRN & \\
\hline CHEMBL199483 & 325794 & 2.8239 & 4.8449 & TST & \\
\hline CHEMBL370165 & 325794 & 6.3665 & 6.1607 & TRN & \\
\hline CHEMBL 200166 & 325794 & 5.1192 & 4.8673 & TRN & \\
\hline CHEMBL200744 & 325794 & 4.9586 & 5.461 & TST & \\
\hline CHEMBL199470 & 325794 & 4.9208 & 4.9017 & TRN & \\
\hline CHEMBL381026 & 325794 & 5.6576 & 4.794 & TRN & \\
\hline CHEMBL200619 & 325794 & 4.6383 & 5.2925 & TRN & \\
\hline CHEMBL200506 & 325794 & 4.7212 & 4.8724 & TRN & \\
\hline CHEMBL200543 & 325794 & 2.8239 & 4.1686 & TRN & \\
\hline CHEMBL 200708 & 325794 & 5.0555 & 4.8558 & TRN & \\
\hline CHEMBL200507 & 325794 & 5.1249 & 4.8682 & TRN & \\
\hline CHEMBL 372140 & 325794 & 2.8239 & 4.624 & TST & \\
\hline CHEMBL199358 & 325794 & 4.1308 & 4.2753 & TRN & \\
\hline CHEMBL200531 & 325794 & 4.4318 & 5.0846 & TST & \\
\hline CHEMBL199014 & 325794 & 6.3768 & 5.9096 & TRN & \\
\hline CHEMBL200151 & 325794 & 4.0223 & 4.68199 & 99999999995 & TST \\
\hline CHEMBL200672 & 325794 & 4.9586 & 5.2346 & TRN & \\
\hline CHEMBL 200954 & 325794 & 7.2676 & 5.0897 & TST & \\
\hline CHEMBL382971 & 325794 & 4.6021 & 4.8531 & TST & \\
\hline CHEMBL381190 & 325794 & 5.699 & 5.54 & TRN & \\
\hline CHEMBL371771 & 325794 & 2.8239 & 5.1748 & TST & \\
\hline CHEMBL 200289 & 325794 & 4.6576 & 5.0893 & TRN & \\
\hline CHEMBL 200596 & 325794 & 4.8239 & 4.9515 & TRN & \\
\hline CHEMBL426819 & 325794 & 5.2218 & 4.4718 & TRN & \\
\hline CHEMBL199214 & 325794 & 5.9208 & 5.655 & TRN & \\
\hline CHEMBL200203 & 325794 & 4.3468 & 4.7005 & TRN & \\
\hline CHEMBL372139 & 325794 & 2.8239 & 4.6464 & TST & \\
\hline CHEMBL414669 & 325794 & 5.0506 & 4.8359 & TRN & \\
\hline CHEMBL198802 & 325794 & 5.3979 & 5.6027 & TRN & \\
\hline CHEMBL370786 & 325794 & 4.7696 & 4.8614 & TRN & \\
\hline CHEMBL200287 & 325794 & 4.9208 & 4.7286 & TRN & \\
\hline CHEMBL198798 & 325794 & 5.0555 & 4.5966 & TRN & \\
\hline CHEMBL 200455 & 325794 & 4.8239 & 4.8102 & TRN & \\
\hline CHEMBL 200529 & 325794 & 4.6383 & 5.1647 & TST & \\
\hline CHEMBL200775 & 325794 & 4.0555 & 4.9516 & TST & \\
\hline CHEMBL 200602 & 325794 & 5.1938 & 4.8602 & TRN & \\
\hline CHEMBL383186 & 325794 & 5.4949 & 5.6113 & TRN & \\
\hline CHEMBL371059 & 325794 & 4.8539 & 4.7925 & TST & \\
\hline CHEMBL 200545 & 325794 & 2.8239 & 4.9573 & TST & \\
\hline CHEMBL200426 & 325794 & 5.2518 & 5.4865 & TRN & \\
\hline CHEMBL199163 & 325794 & 5.7959 & 5.3112 & TRN & \\
\hline CHEMBL440035 & 325794 & 5.0177 & 4.1022 & TRN & \\
\hline
\end{tabular}




\begin{tabular}{|c|c|c|c|c|c|}
\hline \multicolumn{6}{|c|}{ Supplemental Table S2.txt } \\
\hline CHEMBL193313 & 311816 & 4.1624 & 4.1597 & TRN & \\
\hline CHEMBL364272 & 311816 & 4.0 & 4.1058 & TST & \\
\hline CHEMBL427169 & 311816 & 4.3851 & 4.5288 & TST & \\
\hline CHEMBL191635 & 311816 & 6.2441 & 6.2535 & TRN & \\
\hline CHEMBL192145 & 311816 & 5.9586 & 5.96299 & 9999999999 & TRN \\
\hline CHEMBL190439 & 311816 & 3.9136 & 3.9193 & TRN & \\
\hline CHEMBL365159 & 311816 & 6.699 & 5.8154 & TST & \\
\hline CHEMBL191268 & 311816 & 4.8327 & 4.7549 & TRN & \\
\hline CHEMBL190518 & 311816 & 4.5654 & 4.4868 & TRN & \\
\hline CHEMBL192062 & 311816 & 5.4949 & 5.4717 & TRN & \\
\hline CHEMBL193892 & 311816 & 3.9666 & 3.9579 & TRN & \\
\hline CHEMBL371372 & 311816 & 4.0655 & 4.0628 & TRN & \\
\hline CHEMBL372013 & 311816 & 4.2426 & 4.6772 & TST & \\
\hline CHEMBL193672 & 311816 & 4.1979 & 4.1944 & TST & \\
\hline CHEMBL191668 & 311816 & 4.1759 & 4.1941 & TRN & \\
\hline CHEMBL193282 & 311816 & 5.7447 & 5.6802 & TRN & \\
\hline CHEMBL194716 & 311816 & 4.4437 & 3.79600 & 00000000003 & TST \\
\hline CHEMBL439852 & 311816 & 4.3851 & 4.3677 & TRN & \\
\hline CHEMBL364456 & 311816 & 4.6676 & 4.66 & TRN & \\
\hline CHEMBL352683 & 311816 & 4.1481 & 4.1452 & TRN & \\
\hline CHEMBL424824 & 311816 & 4.4976 & 4.4993 & TRN & \\
\hline CHEMBL365118 & 311816 & 2.301 & 2.2754 & TRN & \\
\hline CHEMBL364239 & 311816 & 3.3307 & 3.3319 & TRN & \\
\hline CHEMBL192013 & 311816 & 3.8416 & 3.8549 & TRN & \\
\hline CHEMBL 364730 & 311816 & 3.9172 & 3.9198 & TRN & \\
\hline CHEMBL371570 & 311816 & 2.8239 & 2.8294 & TRN & \\
\hline CHEMBL426086 & 311816 & 4.52 & 4.5081 & TRN & \\
\hline CHEMBL191641 & 311816 & 4.1844 & 4.2402 & TRN & \\
\hline CHEMBL192761 & 311816 & 4.3575 & 3.6851 & TST & \\
\hline CHEMBL189537 & 311816 & 4.5969 & 4.2448 & TST & \\
\hline CHEMBL191601 & 311816 & 4.3737 & 4.3737 & TRN & \\
\hline CHEMBL191835 & 311816 & 2.8239 & 2.8328 & TRN & \\
\hline CHEMBL363196 & 311816 & 4.7932 & 4.8045 & TRN & \\
\hline CHEMBL273986 & 311816 & 5.7212 & 5.7231 & TRN & \\
\hline CHEMBL191920 & 311816 & 4.684 & 4.7413 & TRN & \\
\hline CHEMBL193056 & 311816 & 3.1249 & 3.11899 & 99999999998 & TRN \\
\hline CHEMBL195869 & 311816 & 4.4237 & 4.3903 & TRN & \\
\hline CHEMBL415775 & 311816 & 3.8861 & 3.5101 & TST & \\
\hline CHEMBL192649 & 311816 & 4.2757 & 4.2068 & TST & \\
\hline CHEMBL349231 & 311816 & 4.7747 & 4.7856 & TRN & \\
\hline CHEMBL370286 & 311816 & 4.383 & 4.4043 & TRN & \\
\hline CHEMBL112953 & 311816 & 5.7447 & 5.7561 & TRN & \\
\hline CHEMBL191786 & 311816 & 5.4815 & 5.48 & TRN & \\
\hline CHEMBL192480 & 311816 & 4.3152 & 4.3085 & TRN & \\
\hline CHEMBL193310 & 311816 & 4.1649 & 4.7001 & TST & \\
\hline CHEMBL195096 & 311816 & 4.4634 & 4.4608 & TRN & \\
\hline CHEMBL191241 & 311816 & 4.4413 & 4.4608 & TRN & \\
\hline CHEMBL370092 & 311816 & 4.1791 & 3.9556 & TST & \\
\hline
\end{tabular}




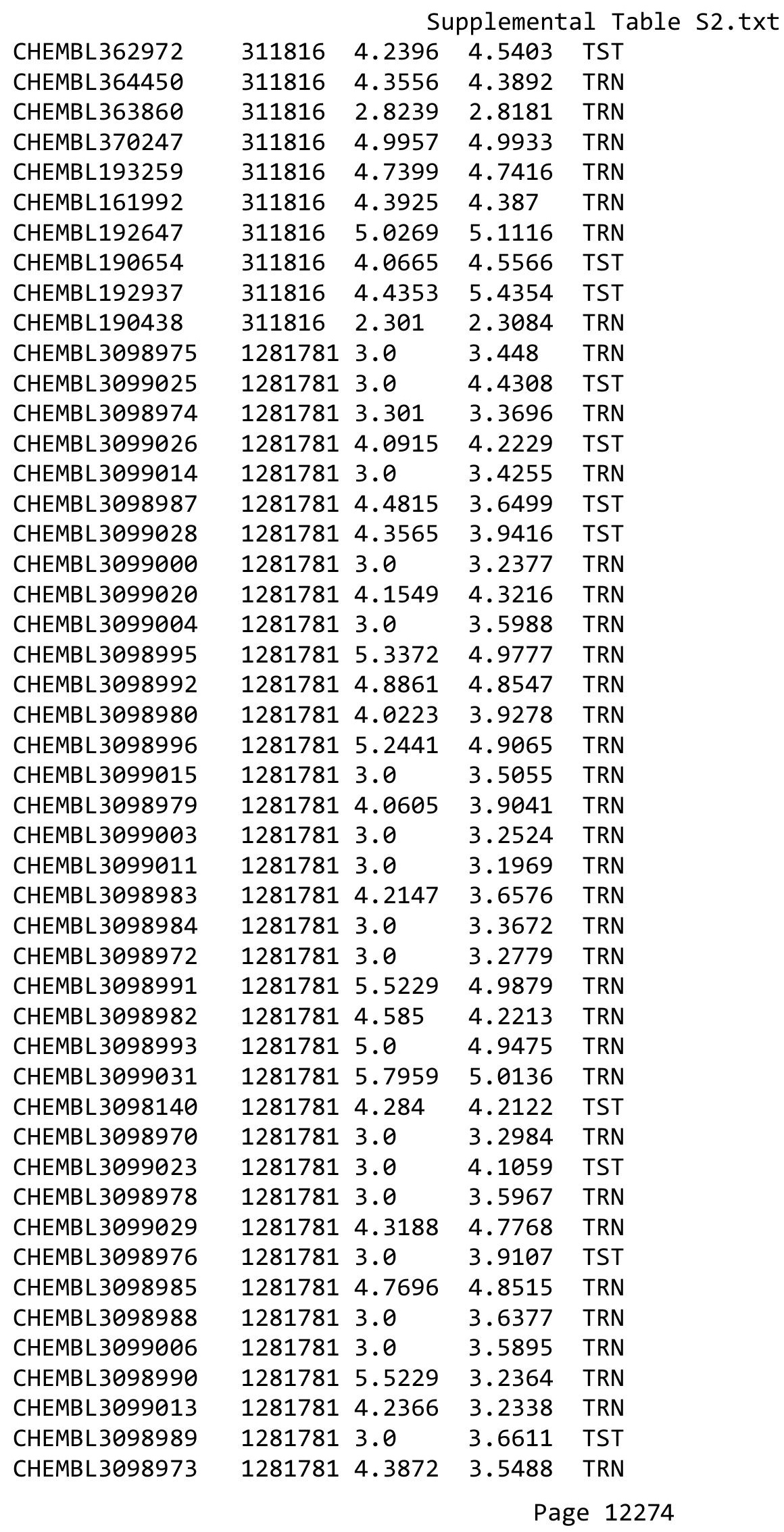


Supplemental Table S2.txt

\begin{tabular}{|c|c|c|c|c|}
\hline CHEMBL3098998 & 1281781 & 4.4815 & 4.8339 & TRN \\
\hline CHEMBL3099002 & 1281781 & 3.0 & 3.1215 & TRN \\
\hline CHEMBL3099010 & 1281781 & 3.0 & 3.2372 & TRN \\
\hline CHEMBL 3098997 & 1281781 & 4.6778 & 4.7452 & TRN \\
\hline CHEMBL3099001 & 1281781 & 3.0 & \multicolumn{2}{|c|}{3.3680000000000003} \\
\hline CHEMBL3099007 & 1281781 & 4.4202 & 3.8183 & TRN \\
\hline CHEMBL3098999 & 1281781 & 4.4437 & 4.8245 & TRN \\
\hline CHEMBL3099009 & 1281781 & 4.3372 & 3.7526 & TRN \\
\hline CHEMBL 3099005 & 1281781 & 3.0 & 3.6252 & TRN \\
\hline CHEMBL3099030 & 1281781 & 4.3665 & 4.9349 & TRN \\
\hline CHEMBL 3099021 & 1281781 & 4.1367 & 4.4351 & TRN \\
\hline CHEMBL3099012 & 1281781 & 4.1079 & 3.2477 & TRN \\
\hline CHEMBL3098977 & 1281781 & 4.1024 & 4.3025 & TRN \\
\hline CHEMBL 3098986 & 1281781 & 4.2596 & 3.6896 & TRN \\
\hline CHEMBL3098971 & 1281781 & 3.0 & 3.5872 & TRN \\
\hline CHEMBL3099008 & 1281781 & 3.0 & 3.5517 & TST \\
\hline CHEMBL87699 & 1281781 & 3.0 & 3.5781 & TST \\
\hline CHEMBL3099022 & 1281781 & 3.0 & 4.4835 & TST \\
\hline CHEMBL3098994 & 1281781 & 4.9586 & 4.9331 & TST \\
\hline CHEMBL3099027 & 1281781 & 4.0458 & 4.2131 & TST \\
\hline CHEMBL3098981 & 1281781 & 4.0809 & 3.9327 & TST \\
\hline CHEMBL3099024 & 1281781 & 3.0 & 4.4528 & TST \\
\hline CHEMBL1242476 & 654933 & 6.684 & 5.9481 & TRN \\
\hline CHEMBL1241945 & 654933 & 5.983 & 6.2713 & TRN \\
\hline CHEMBL1242754 & 654933 & 6.0 & 5.4336 & TRN \\
\hline CHEMBL1242028 & 654933 & 5.1612 & 5.9574 & TRN \\
\hline CHEMBL1234815 & 654933 & 6.4112 & 5.1242 & TRN \\
\hline CHEMBL1241680 & 654933 & 4.0 & 4.4537 & TRN \\
\hline CHEMBL1242852 & 654933 & 6.7471 & 6.3926 & TRN \\
\hline CHEMBL1241578 & 654933 & 6.2596 & 6.1809 & TRN \\
\hline CHEMBL1241487 & 654933 & 7.4815 & 6.4735 & TRN \\
\hline CHEMBL1242848 & 654933 & 5.6737 & 5.6918 & TRN \\
\hline CHEMBL1242200 & 654933 & 4.9586 & 5.3143 & TRN \\
\hline CHEMBL1242027 & 654933 & 4.9914 & 5.3818 & TRN \\
\hline CHEMBL1242750 & 654933 & 6.1107 & 5.8409 & TRN \\
\hline CHEMBL1240566 & 654933 & 5.5376 & 5.5822 & TRN \\
\hline CHEMBL1242115 & 654933 & 6.2373 & 5.0966 & TST \\
\hline CHEMBL1241677 & 654933 & 4.9066 & 5.6286 & TRN \\
\hline CHEMBL1242385 & 654933 & 6.2684 & 5.9661 & TRN \\
\hline CHEMBL1242029 & 654933 & 5.8539 & 5.4758 & TRN \\
\hline CHEMBL1241583 & 654933 & 4.7696 & 4.3146 & TRN \\
\hline CHEMBL1242660 & 654933 & 5.289 & 5.7688 & TRN \\
\hline CHEMBL1241859 & 654933 & 4.0 & 4.7466 & TRN \\
\hline CHEMBL1242657 & 654933 & 6.0 & 5.5692 & TRN \\
\hline CHEMBL1240553 & 654933 & 5.4815 & 5.9466 & TRN \\
\hline CHEMBL1242845 & 654933 & 4.0 & 4.9233 & TST \\
\hline CHEMBL1242755 & 654933 & 6.2676 & 5.6648 & TRN \\
\hline CHEMBL1240545 & 654933 & 4.8861 & 4.6064 & TRN \\
\hline
\end{tabular}


Supplemental Table S2.txt

\begin{tabular}{|c|c|c|c|c|c|}
\hline CHEMBL1242477 & 654933 & 5.6021 & 5.7811 & TRN & \\
\hline CHEMBL1242378 & 654933 & 6.0 & 5.6767 & TRN & \\
\hline CHEMBL1241684 & 654933 & 4.0 & \multicolumn{2}{|c|}{4.406000000000001} & TST \\
\hline CHEMBL1242109 & 654933 & 5.7773 & 5.9649 & TRN & \\
\hline CHEMBL1241301 & 654933 & 4.0 & 5.0317 & TRN & \\
\hline CHEMBL1242386 & 654933 & 5.9586 & 6.0064 & TRN & \\
\hline CHEMBL1241949 & 654933 & 4.9208 & 4.3746 & TRN & \\
\hline CHEMBL1242199 & 654933 & 6.1244 & 6.5202 & TRN & \\
\hline CHEMBL 1241587 & 654933 & 5.301 & 4.9685 & TST & \\
\hline CHEMBL1241491 & 654933 & 6.2403 & 5.8188 & TRN & \\
\hline CHEMBL1242573 & 654933 & 5.9208 & 5.6451 & TRN & \\
\hline CHEMBL1242207 & 654933 & 4.6021 & 4.2738 & TRN & \\
\hline CHEMBL1241948 & 654933 & 4.0 & 4.6477 & TRN & \\
\hline CHEMBL1241947 & 654933 & 5.0044 & 4.6367 & TST & \\
\hline CHEMBL1242758 & 654933 & 5.8539 & 6.4016 & TST & \\
\hline CHEMBL1242751 & 654933 & 5.4365 & 5.3344 & TRN & \\
\hline CHEMBL1242568 & 654933 & 6.4976 & 6.3887 & TRN & \\
\hline CHEMBL1242119 & 654933 & 4.0 & 5.0083 & TRN & \\
\hline CHEMBL1242031 & 654933 & 4.0 & 4.9734 & TRN & \\
\hline CHEMBL1242290 & 654933 & 5.52 & 5.294 & TRN & \\
\hline CHEMBL1241580 & 654933 & 5.9393 & \multicolumn{2}{|c|}{6.207000000000001} & TRN \\
\hline CHEMBL1242024 & 654933 & 6.0205 & 6.1042 & TRN & \\
\hline CHEMBL1241482 & 654933 & 4.0 & 4.6952 & TST & \\
\hline CHEMBL1241858 & 654933 & 5.5654 & 4.6533 & TRN & \\
\hline CHEMBL1242112 & 654933 & 6.0419 & 6.0638 & TRN & \\
\hline CHEMBL1242569 & 654933 & 5.2941 & 4.4156 & TRN & \\
\hline CHEMBL1240565 & 654933 & 4.8239 & 5.4104 & TRN & \\
\hline CHEMBL1242384 & 654933 & 6.02 & 5.2973 & TRN & \\
\hline CHEMBL1242209 & 654933 & 4.7447 & 4.6041 & TRN & \\
\hline CHEMBL1233881 & 654933 & 5.6383 & 5.9461 & TRN & \\
\hline CHEMBL1242110 & 654933 & 5.4295 & 5.8684 & TRN & \\
\hline CHEMBL1242475 & 654933 & 6.2434 & 6.4346 & TRN & \\
\hline CHEMBL1242034 & 654933 & 4.0 & 4.4357 & TRN & \\
\hline CHEMBL1241581 & 654933 & 7.0757 & 6.7287 & TRN & \\
\hline CHEMBL1242032 & 654933 & 4.0 & 4.6455 & TRN & \\
\hline CHEMBL1242285 & 654933 & 6.6038 & 6.3945 & TRN & \\
\hline CHEMBL1242033 & 654933 & 4.0 & 4.8514 & TRN & \\
\hline CHEMBL1242846 & 654933 & 4.0 & 4.8407 & TST & \\
\hline CHEMBL1242656 & 654933 & 6.4365 & 6.6373 & TRN & \\
\hline CHEMBL1241769 & 654933 & 5.0278 & 4.9155 & TRN & \\
\hline CHEMBL1242664 & 654933 & 7.0706 & 6.9247 & TRN & \\
\hline CHEMBL1241271 & 654933 & 4.7212 & 5.215 & TRN & \\
\hline CHEMBL1242665 & 654933 & 4.3468 & 4.001 & TST & \\
\hline CHEMBL1241582 & 654933 & 4.0 & 4.8851 & TRN & \\
\hline CHEMBL1081312 & 654933 & 6.585 & 6.6667 & TRN & \\
\hline CHEMBL1242293 & 654933 & 6.4202 & 6.1827 & TRN & \\
\hline CHEMBL1242757 & 654933 & 5.3372 & 5.8779 & TST & \\
\hline CHEMBL1241864 & 654933 & 5.8539 & 5.0814 & TRN & \\
\hline
\end{tabular}




\begin{tabular}{|c|c|c|c|c|c|c|}
\hline & & \multicolumn{5}{|c|}{ Supplemental Table S2.txt } \\
\hline CHEMBL1242118 & 654933 & 4.5376 & 4.8648 & TRN & & \\
\hline CHEMBL1241683 & 654933 & 4.0 & 4.9878 & TRN & & \\
\hline CHEMBL1242748 & 654933 & 6.0 & 5.6955 & TRN & & \\
\hline CHEMBL1241772 & 654933 & 4.0 & 4.1596 & TRN & & \\
\hline CHEMBL1241299 & 654933 & 4.0 & 5.1712 & TRN & & \\
\hline CHEMBL1241484 & 654933 & 6.8013 & 6.2488 & TRN & & \\
\hline CHEMBL1242030 & 654933 & 4.8928 & 4.6509 & TRN & & \\
\hline CHEMBL1242294 & 654933 & 6.7545 & 6.5933 & TRN & & \\
\hline CHEMBL1242202 & 654933 & 6.5686 & 6.5952 & TRN & & \\
\hline CHEMBL1241492 & 654933 & 5.0809 & 4.6237 & TRN & & \\
\hline CHEMBL1242847 & 654933 & 5.3665 & 5.1804 & TRN & & \\
\hline CHEMBL1241675 & 654933 & 4.9208 & 4.7222 & TST & & \\
\hline CHEMBL1241483 & 654933 & 5.4134 & 5.5979 & TRN & & \\
\hline CHEMBL1242566 & 654933 & 5.5376 & 5.721 & TRN & & \\
\hline CHEMBL1242381 & 654933 & 6.0 & 5.4125 & TST & & \\
\hline CHEMBL1242111 & 654933 & \multicolumn{3}{|c|}{5.752000000000001} & 6.1947 & TST \\
\hline CHEMBL1242756 & 654933 & 4.4685 & 4.7279 & TRN & & \\
\hline CHEMBL1242567 & 654933 & 5.5376 & 5.3526 & TRN & & \\
\hline CHEMBL1241682 & 654933 & 4.0 & 4.6996 & TRN & & \\
\hline CHEMBL1242117 & 654933 & 5.0 & 4.1239 & TRN & & \\
\hline CHEMBL1242201 & 654933 & 6.3595 & 6.5616 & TRN & & \\
\hline CHEMBL1242574 & 654933 & 6.6576 & 6.4037 & TRN & & \\
\hline CHEMBL1241481 & 654933 & 6.7696 & 6.6938 & TRN & & \\
\hline CHEMBL1242752 & 654933 & 4.266 & 5.0821 & TRN & & \\
\hline CHEMBL1233882 & 654933 & 6.2147 & 5.3301 & TRN & & \\
\hline CHEMBL1241676 & 654933 & 7.1739 & 6.8712 & TRN & & \\
\hline CHEMBL1242198 & 654933 & 6.2396 & 6.0931 & TRN & & \\
\hline CHEMBL1241775 & 654933 & 4.1549 & 4.0446 & TRN & & \\
\hline CHEMBL1241241 & 654933 & 6.0353 & 5.8566 & TRN & & \\
\hline CHEMBL1241946 & 654933 & 5.5528 & 4.7741 & TRN & & \\
\hline CHEMBL1242376 & 654933 & 6.6271 & 6.3467 & TRN & & \\
\hline CHEMBL1242663 & 654933 & 4.0 & 5.3994 & TST & & \\
\hline CHEMBL1242208 & 654933 & 4.0 & 4.3431 & TRN & & \\
\hline CHEMBL1241950 & 654933 & 5.1549 & 4.4456 & TRN & & \\
\hline CHEMBL1242470 & 654933 & 4.9586 & 4.6669 & TST & & \\
\hline CHEMBL1242286 & 654933 & 5.3645 & 5.2617 & TRN & & \\
\hline CHEMBL1241486 & 654933 & 5.2741 & 5.2069 & TRN & & \\
\hline CHEMBL1242853 & 654933 & 6.4078 & 6.4707 & TRN & & \\
\hline CHEMBL1242471 & 654933 & 4.0 & 4.2801 & TST & & \\
\hline CHEMBL1241767 & 654933 & 3.301 & 3.8379 & TST & & \\
\hline CHEMBL1241770 & 654933 & 5.6968 & 5.2443 & TRN & & \\
\hline CHEMBL1242377 & 654933 & 5.8539 & 6.3124 & TRN & & \\
\hline CHEMBL1241776 & 654933 & 5.1308 & 5.1951 & TRN & & \\
\hline CHEMBL1242844 & 654933 & 4.0 & 4.4827 & TRN & & \\
\hline CHEMBL1241391 & 654933 & 4.0 & 4.1883 & TRN & & \\
\hline CHEMBL1241679 & 654933 & 4.0 & 4.2999 & TRN & & \\
\hline CHEMBL1241863 & 654933 & 5.1739 & 5.0335 & TRN & & \\
\hline CHEMBL1242289 & 654933 & 6.1146 & 5.8322 & TRN & & \\
\hline
\end{tabular}

Page 12277 
Supplemental Table S2.txt

\begin{tabular}{|c|c|c|c|c|}
\hline CHEMBL1242114 & 654933 & 5.6596 & 6.0102 & TRN \\
\hline CHEMBL1230790 & 654933 & 6.0205 & 5.9836 & TRN \\
\hline CHEMBL1242379 & 654933 & 5.1979 & 5.142 & TRN \\
\hline CHEMBL1241270 & 654933 & 4.9066 & 5.1177 & TST \\
\hline CHEMBL1241588 & 654933 & 4.8239 & 5.1639 & TST \\
\hline CHEMBL1242572 & 654933 & 6.1192 & 6.3385 & TRN \\
\hline CHEMBL1241771 & 654933 & 5.0506 & 4.3993 & TRN \\
\hline CHEMBL1242113 & 654933 & 5.1904 & 5.2894 & TRN \\
\hline CHEMBL1242295 & 654933 & 6.1343 & 6.93 & TRN \\
\hline CHEMBL1242026 & 654933 & 6.1785 & 6.2995 & TRN \\
\hline CHEMBL1241860 & 654933 & 5.0458 & 4.6677 & TRN \\
\hline CHEMBL1241773 & 654933 & 4.9208 & 4.538 & TRN \\
\hline CHEMBL1242666 & 654933 & 6.1952 & 5.3506 & TRN \\
\hline CHEMBL1241862 & 654933 & 4.0 & 4.73600 & 000000001 \\
\hline CHEMBL1241674 & 654933 & 5.3565 & 5.5611 & TST \\
\hline CHEMBL1242472 & 654933 & 5.2255 & 4.90300 & 0000000005 \\
\hline CHEMBL1241390 & 654933 & 4.0 & 4.2101 & TST \\
\hline CHEMBL1242203 & 654933 & 4.7696 & 4.9169 & TST \\
\hline CHEMBL1240554 & 654933 & 5.8539 & 5.5404 & TST \\
\hline CHEMBL1242659 & 654933 & 5.9355 & 5.1132 & TST \\
\hline CHEMBL1241861 & 654933 & 5.0 & 5.1551 & TST \\
\hline CHEMBL1241944 & 654933 & 5.585 & 5.3114 & TST \\
\hline CHEMBL1241586 & 654933 & 6.0283 & 4.8777 & TST \\
\hline CHEMBL1241439 & 654933 & 5.2248 & 4.7461 & TST \\
\hline CHEMBL1242662 & 654933 & 7.0555 & 6.5049 & TST \\
\hline CHEMBL1241681 & 654933 & 5.6778 & 5.5318 & TST \\
\hline CHEMBL1242288 & 654933 & 4.8996 & 4.8588 & TST \\
\hline CHEMBL1242287 & 654933 & 6.4895 & 6.2541 & TST \\
\hline CHEMBL1241774 & 654933 & 4.7447 & 4.4083 & TST \\
\hline CHEMBL1241300 & 654933 & 4.0 & 4.8755 & TST \\
\hline CHEMBL1242661 & 654933 & 4.6778 & 4.9717 & TST \\
\hline CHEMBL1242469 & 654933 & 4.7447 & 4.6227 & TST \\
\hline CHEMBL1241943 & 654933 & 4.6882 & 4.9012 & TST \\
\hline CHEMBL1241490 & 654933 & 6.0159 & 5.3669 & TST \\
\hline CHEMBL1242753 & 654933 & 5.0964 & 4.5225 & TST \\
\hline CHEMBL1241485 & 654933 & 5.4145 & 5.8237 & TST \\
\hline CHEMBL68534 & 688184 & 4.45 & 4.7828 & TRN \\
\hline CHEMBL 280065 & 688184 & 4.95 & 4.8811 & TRN \\
\hline CHEMBL416657 & 688184 & 4.95 & 5.0669 & TRN \\
\hline CHEMBL539947 & 688184 & 6.15 & 4.8358 & TRN \\
\hline CHEMBL15192 & 688184 & 4.6 & 4.8964 & TRN \\
\hline CHEMBL1256814 & 688184 & 4.8 & 4.8949 & TRN \\
\hline CHEMBL604119 & 688184 & 4.65 & 5.0724 & TST \\
\hline CHEMBL1200567 & 688184 & 5.45 & 4.9314 & TRN \\
\hline CHEMBL65 & 688184 & 7.8013 & 6.3492 & TRN \\
\hline CHEMBL98350 & 688184 & 5.35 & 5.1892 & TRN \\
\hline CHEMBL1324022 & 688184 & 4.85 & 4.8181 & TRN \\
\hline CHEMBL543876 & 688184 & 4.75 & 4.7741 & TRN \\
\hline
\end{tabular}




\begin{tabular}{|c|c|c|c|c|}
\hline \multicolumn{5}{|c|}{ Supplemental Table S2.txt } \\
\hline CHEMBL182461 & 688184 & 4.55 & 4.9693 & TRN \\
\hline CHEMBL1255659 & 688184 & 4.6 & 4.8616 & TRN \\
\hline CHEMBL540848 & 688184 & 4.7 & 4.9351 & TRN \\
\hline CHEMBL313833 & 688184 & 4.45 & 4.8341 & TRN \\
\hline CHEMBL21260 & 688184 & 7.3002 & 6.3247 & TRN \\
\hline CHEMBL1316222 & 688184 & 4.8 & 4.9878 & TRN \\
\hline CHEMBL1255655 & 688184 & 6.1 & 5.0982 & TRN \\
\hline CHEMBL1330357 & 688184 & 4.85 & 5.3723 & TST \\
\hline CHEMBL310310 & 688184 & 4.65 & 4.8288 & TRN \\
\hline CHEMBL538595 & 688184 & 5.5 & 4.9392 & TRN \\
\hline CHEMBL22870 & 688184 & 4.8 & 4.8713 & TRN \\
\hline CHEMBL1257002 & 688184 & 4.45 & 4.8531 & TRN \\
\hline CHEMBL1256813 & 688184 & 6.1 & 5.3788 & TRN \\
\hline CHEMBL45245 & 688184 & 4.9 & 4.8183 & TRN \\
\hline CHEMBL 1257012 & 688184 & 4.7 & 4.9613 & TRN \\
\hline CHEMBL1256667 & 688184 & 5.4 & 5.1488 & TST \\
\hline CHEMBL24983 & 688184 & 4.45 & 4.6172 & TRN \\
\hline CHEMBL559612 & 688184 & 4.85 & 4.7974 & TST \\
\hline CHEMBL1526543 & 688184 & 6.25 & 5.16 & TRN \\
\hline CHEMBL34241 & 688184 & 4.8 & 5.1412 & TRN \\
\hline CHEMBL280998 & 688184 & 4.45 & 4.8453 & TRN \\
\hline CHEMBL78150 & 688184 & 4.45 & 5.1155 & TRN \\
\hline CHEMBL536950 & 688184 & 4.65 & 5.1408 & TRN \\
\hline CHEMBL60718 & 688184 & 4.85 & 4.8339 & TRN \\
\hline CHEMBL1563352 & 688184 & 5.3 & 5.0671 & TST \\
\hline CHEMBL28 & 688184 & 4.9 & 4.8239 & TRN \\
\hline CHEMBL1476762 & 688184 & 4.8 & 4.8747 & TRN \\
\hline CHEMBL274619 & 688184 & 7.5003 & 4.9742 & TRN \\
\hline CHEMBL1255866 & 688184 & 4.45 & 4.9411 & TRN \\
\hline CHEMBL1554717 & 688184 & 4.45 & 4.7405 & TRN \\
\hline CHEMBL1329033 & 688184 & 5.45 & 4.8971 & TRN \\
\hline CHEMBL1256024 & 688184 & 4.8 & 4.7981 & TRN \\
\hline CHEMBL188 & 688184 & 4.65 & 4.8611 & TRN \\
\hline CHEMBL428496 & 688184 & 4.45 & 5.1799 & TST \\
\hline CHEMBL110739 & 688184 & 4.6 & 4.8555 & TRN \\
\hline CHEMBL605003 & 688184 & 4.85 & 5.1306 & TRN \\
\hline CHEMBL295212 & 688184 & 4.6 & 4.9219 & TRN \\
\hline CHEMBL1315457 & 688184 & 4.9 & 5.1965 & TST \\
\hline CHEMBL1374843 & 688184 & 4.45 & 4.8538 & TRN \\
\hline CHEMBL1493117 & 688184 & 5.35 & 4.7964 & TRN \\
\hline CHEMBL328710 & 688184 & 4.95 & 4.9798 & TRN \\
\hline CHEMBL1256911 & 688184 & 5.25 & 4.812 & TRN \\
\hline CHEMBL282489 & 688184 & 4.7 & 4.7762 & TRN \\
\hline CHEMBL1380684 & 688184 & 4.65 & 4.73 & TRN \\
\hline CHEMBL1256943 & 688184 & 5.2 & 4.8686 & TRN \\
\hline CHEMBL1255733 & 688184 & 5.55 & 5.2412 & TRN \\
\hline CHEMBL153057 & 688184 & 4.9 & 4.9392 & TRN \\
\hline CHEMBL1255936 & 688184 & 5.95 & 4.7813 & TRN \\
\hline
\end{tabular}




\begin{tabular}{|c|c|c|c|c|c|}
\hline \multirow{3}{*}{$\begin{array}{l}\text { CHEMBL72365 } \\
\text { CHEMBL1256364 }\end{array}$} & & \multicolumn{4}{|c|}{ Supplemental Table S2.txt } \\
\hline & 688184 & 4.85 & 5.13200 & 0000000001 & TRN \\
\hline & 688184 & 5.3 & 5.1247 & TRN & \\
\hline CHEMBL1407012 & 688184 & 4.45 & 4.7558 & TRN & \\
\hline CHEMBL177820 & 688184 & 4.9 & 4.8874 & TST & \\
\hline CHEMBL303579 & 688184 & 5.4 & 5.1119 & TRN & \\
\hline CHEMBL1457622 & 688184 & 5.35 & 5.1486 & TRN & \\
\hline CHEMBL1710 & 688184 & 4.45 & 4.8502 & TRN & \\
\hline CHEMBL1256686 & 688184 & 5.55 & 5.4353 & TST & \\
\hline CHEMBL 8080 & 688184 & 5.0 & 4.8013 & TRN & \\
\hline CHEMBL1553428 & 688184 & 4.95 & 4.6743 & TRN & \\
\hline CHEMBL1256285 & 688184 & 4.45 & 4.8652 & TST & \\
\hline CHEMBL395915 & 688184 & 4.45 & 4.7816 & TRN & \\
\hline CHEMBL286722 & 688184 & 4.6 & 4.9572 & TRN & \\
\hline CHEMBL1478857 & 688184 & 4.7 & 4.9136 & TRN & \\
\hline CHEMBL402468 & 688184 & 5.3 & 4.8259 & TRN & \\
\hline CHEMBL1399702 & 688184 & 4.75 & 5.1508 & TRN & \\
\hline CHEMBL1256775 & 688184 & 5.0 & 4.9759 & TRN & \\
\hline CHEMBL336467 & 688184 & 4.7 & 4.9346 & TST & \\
\hline CHEMBL 2374058 & 688184 & 7.7496 & 4.8715 & TST & \\
\hline CHEMBL87285 & 688184 & 6.15 & 5.0982 & TRN & \\
\hline CHEMBL1256678 & 688184 & 5.0 & 5.2843 & TRN & \\
\hline CHEMBL 7917 & 688184 & 4.9 & 4.8621 & TRN & \\
\hline CHEMBL1559663 & 688184 & 6.5 & 5.5895 & TST & \\
\hline CHEMBL1523894 & 688184 & 4.75 & 5.024 & TST & \\
\hline CHEMBL1608159 & 688184 & 4.85 & 5.052 & TRN & \\
\hline CHEMBL596674 & 688184 & 5.0 & 4.8473 & TRN & \\
\hline CHEMBL44 & 688184 & 4.95 & 4.9056 & TRN & \\
\hline CHEMBL18686 & 688184 & 5.8 & 4.8925 & TST & \\
\hline CHEMBL1517187 & 688184 & 5.2 & 4.7879 & TRN & \\
\hline CHEMBL587714 & 688184 & 4.9 & 4.9657 & TRN & \\
\hline CHEMBL1323714 & 688184 & 4.9 & 4.9917 & TRN & \\
\hline CHEMBL1453208 & 688184 & 4.6 & 4.7933 & TRN & \\
\hline CHEMBL1372588 & 688184 & 4.9 & 4.9363 & TRN & \\
\hline CHEMBL1256749 & 688184 & 4.75 & 4.901 & TRN & \\
\hline CHEMBL1256656 & 688184 & 4.8 & 5.2035 & TRN & \\
\hline CHEMBL165 & 688184 & 4.9 & 4.6982 & TRN & \\
\hline CHEMBL1515334 & 688184 & 4.85 & 4.8183 & TRN & \\
\hline CHEMBL299052 & 688184 & 4.45 & 4.7704 & TRN & \\
\hline CHEMBL1256360 & 688184 & 4.45 & 4.7882 & TRN & \\
\hline CHEMBL1449651 & 688184 & 6.3 & 4.9762 & TST & \\
\hline CHEMBL1200450 & 688184 & 4.6 & 4.8779 & TRN & \\
\hline CHEMBL1440857 & 688184 & 4.95 & 5.5654 & TRN & \\
\hline CHEMBL1256995 & 688184 & 4.85 & 4.8738 & TRN & \\
\hline CHEMBL48449 & 688184 & 5.35 & 4.7286 & TRN & \\
\hline CHEMBL1442153 & 688184 & 4.7 & 5.0365 & TRN & \\
\hline CHEMBL1433897 & 688184 & 5.9 & 4.9034 & TRN & \\
\hline CHEMBL1395058 & 688184 & 4.7 & 4.7913 & TRN & \\
\hline CHEMBL76897 & 688184 & 4.45 & 5.2977 & TRN & \\
\hline
\end{tabular}




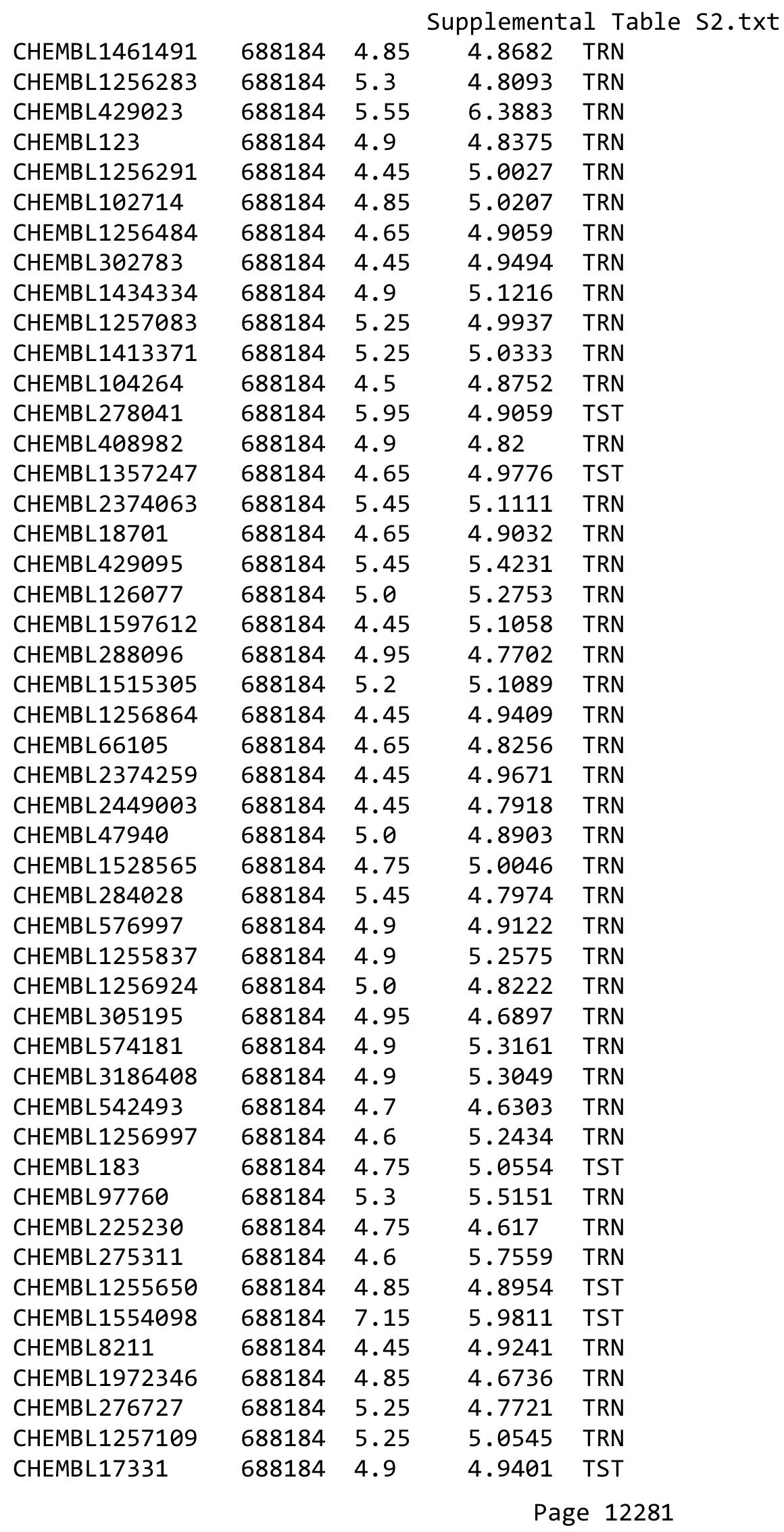




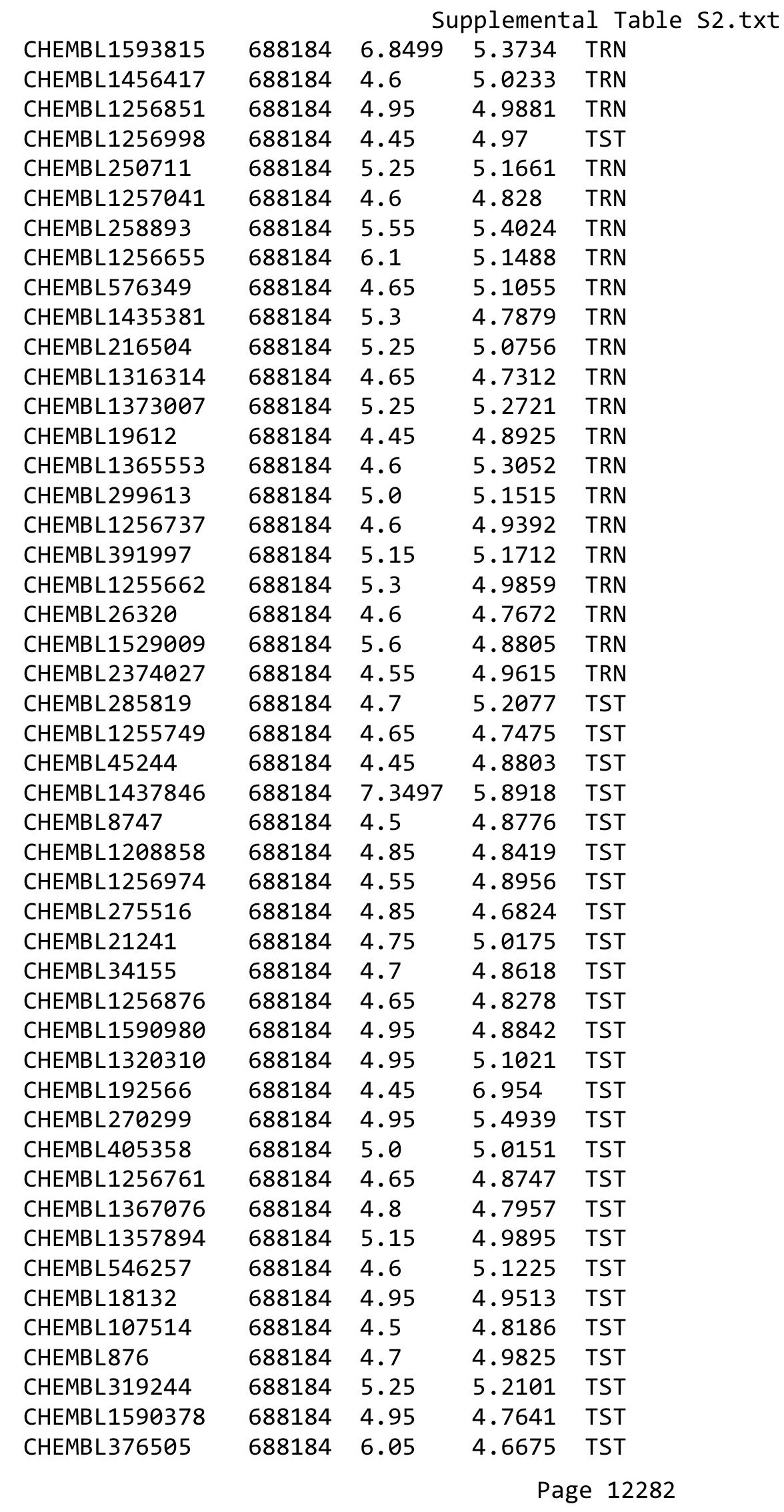




\begin{tabular}{|c|c|c|c|c|c|c|}
\hline \\
\hline CHEMBL1256869 & 688184 & 4.9 & 5.2016 & TST & & \\
\hline CHEMBL1237212 & 688184 & 4.7 & 4.8239 & TST & & \\
\hline CHEMBL355496 & 688184 & 4.65 & 5.2481 & TST & & \\
\hline CHEMBL212911 & 822292 & 5.083 & 4.9134 & TRN & & \\
\hline CHEMBL213315 & 822292 & 5.984 & 5.88399 & 99999 & 995 & \\
\hline CHEMBL214921 & 822292 & 6.0470 & 00000000 & 01 & 6.065 & \\
\hline CHEMBL213314 & 822292 & 5.854 & 6.0629 & TRN & & \\
\hline CHEMBL2037003 & 822292 & 5.8779 & 99999999 & 99 & 5.9111 & TRN \\
\hline CHEMBL 2036997 & 822292 & 4.963 & 4.9949 & TRN & & \\
\hline CHEMBL237519 & 822292 & 6.48 & 6.5242 & TRN & & \\
\hline CHEMBL237307 & 822292 & 6.726 & 6.7745 & TRN & & \\
\hline CHEMBL215245 & 822292 & 5.572 & 5.6201 & TRN & & \\
\hline CHEMBL 2037004 & 822292 & 5.05 & 4.9774 & TRN & & \\
\hline CHEMBL344282 & 822292 & 7.921 & 7.9598 & TRN & & \\
\hline CHEMBL149438 & 822292 & 6.602 & 6.5316 & TRN & & \\
\hline CHEMBL 237520 & 822292 & 6.416 & 6.4125 & TRN & & \\
\hline CHEMBL237305 & 822292 & 5.314 & 5.4194 & TRN & & \\
\hline CHEMBL149676 & 822292 & 7.796 & 7.7288 & TRN & & \\
\hline CHEMBL148639 & 822292 & 7.824 & 7.7546 & TRN & & \\
\hline CHEMBL215701 & 822292 & 5.159 & 5.17399 & 99999 & 995 & \\
\hline CHEMBL 377660 & 822292 & 5.425 & 5.4405 & TRN & & \\
\hline CHEMBL213361 & 822292 & 5.358 & 5.3294 & TRN & & \\
\hline CHEMBL214026 & 822292 & 5.275 & 5.3129 & TRN & & \\
\hline CHEMBL237306 & 822292 & 5.3770 & 00000000 & & 5.4456 & \\
\hline CHEMBL237277 & 822292 & 4.999 & 5.2456 & TST & & \\
\hline CHEMBL236877 & 822292 & 5.7979 & 99999999 & & 5.8554 & TRN \\
\hline CHEMBL237485 & 822292 & 5.1270 & 00000000 & & 5.2377 & TST \\
\hline CHEMBL392058 & 822292 & 5.4579 & 99999999 & & 5.3783 & TRN \\
\hline CHEMBL236875 & 822292 & 5.9479 & 99999999 & 995 & 5.9375 & TRN \\
\hline CHEMBL236664 & 822292 & 5.754 & 5.7489 & TRN & & \\
\hline CHEMBL232396 & 822292 & 6.5070 & 00000000 & & 5.9588 & TST \\
\hline CHEMBL234659 & 822292 & 8.328 & 6.1587 & TST & & \\
\hline CHEMBL234662 & 822292 & 5.305 & 5.5897 & TST & & \\
\hline CHEMBL 2037005 & 822292 & 5.734 & 6.9404 & TST & & \\
\hline CHEMBL264385 & 822292 & 7.745 & 6.7468 & TST & & \\
\hline CHEMBL2037006 & 822292 & 5.956 & 6.3182 & TST & & \\
\hline CHEMBL81592 & 822292 & 6.1670 & 00000000 & & 6.6201 & $\mathrm{~T}$ \\
\hline CHEMBL 2037007 & 822292 & 6.325 & 7.102 & TST & & \\
\hline CHEMBL345721 & 822292 & 7.721 & 7.7902 & TRN & & \\
\hline CHEMBL 2037008 & 822292 & 6.6579 & 99999999 & 995 & 6.6345 & TRN \\
\hline CHEMBL148774 & 822292 & 7.569 & 7.607 & TRN & & \\
\hline CHEMBL2037009 & 822292 & 6.4689 & 99999999 & 99 & 6.5486 & 1 \\
\hline CHEMBL202515 & 822292 & 5.348 & 5.5976 & TRN & & \\
\hline CHEMBL 201880 & 822292 & 6.947 & 6.4782 & TRN & & \\
\hline CHEMBL202140 & 822292 & 5.98 & 6.0158 & TRN & & \\
\hline CHEMBL 360246 & 822292 & 6.854 & 6.9062 & TRN & & \\
\hline CHEMBL 2037010 & 822292 & 7.022 & 6.9439 & TRN & & \\
\hline CHEMBL181656 & 822292 & 5.938 & 6.2047 & TST & & \\
\hline
\end{tabular}




\begin{tabular}{|c|c|c|c|c|c|c|}
\hline & & \multicolumn{5}{|c|}{ Supplemental Table S2.txt } \\
\hline CHEMBL182884 & 822292 & 6.246 & 6.8643 & TST & & \\
\hline CHEMBL367891 & 822292 & 7.398 & 7.3781 & TRN & & \\
\hline CHEMBL367549 & 822292 & 7.046 & 7.1343 & TRN & & \\
\hline CHEMBL 2037079 & 822292 & \multicolumn{3}{|c|}{6.0920000000000005} & 6.0797 & TRN \\
\hline CHEMBL363532 & 822292 & \multicolumn{3}{|c|}{6.327999999999999} & 6.683 & TST \\
\hline CHEMBL181644 & 822292 & 6.51 & 6.8361 & TST & & \\
\hline CHEMBL182230 & 822292 & 6.114 & 6.4734 & TST & & \\
\hline CHEMBL435343 & 822292 & 6.398 & 6.4342 & TRN & & \\
\hline CHEMBL180504 & 822292 & 5.87 & 6.517 & TST & & \\
\hline CHEMBL232395 & 822292 & 6.102 & 5.8788 & TST & & \\
\hline CHEMBL391479 & 822292 & 6.369 & 5.8893 & TST & & \\
\hline CHEMBL 2037080 & 822292 & 7.398 & 6.6429 & TST & & \\
\hline CHEMBL 2037078 & 822292 & \multicolumn{3}{|c|}{6.452999999999999} & 6.2196 & TST \\
\hline CHEMBL 360368 & 822292 & 5.773 & 6.5316 & TST & & \\
\hline CHEMBL391478 & 822292 & 6.893 & 6.2358 & TST & & \\
\hline CHEMBL 2037081 & 822292 & 7.215 & 6.3888 & TST & & \\
\hline CHEMBL425766 & 822292 & \multicolumn{3}{|c|}{6.327999999999999} & 6.495 & \\
\hline CHEMBL201581 & 822292 & 6.936 & 6.7334 & TRN & & \\
\hline CHEMBL 369725 & 822292 & 8.155 & 7.9689 & TRN & & \\
\hline CHEMBL201036 & 822292 & \multicolumn{3}{|c|}{6.2379999999999995} & 6.2443 & TRN \\
\hline CHEMBL180019 & 822292 & 7.796 & 7.7052 & TRN & & \\
\hline CHEMBL202617 & 822292 & 6.315 & 6.2634 & TRN & & \\
\hline CHEMBL 2037083 & 822292 & 6.903 & 6.0543 & TST & & \\
\hline CHEMBL201653 & 822292 & \multicolumn{3}{|c|}{6.382999999999999} & 6.3038 & TRN \\
\hline CHEMBL1783034 & 822292 & \multicolumn{3}{|c|}{7.327999999999999} & 7.523 & TRN \\
\hline CHEMBL202246 & 822292 & 5.348 & 5.6195 & TRN & & \\
\hline CHEMBL391084 & 822292 & 6.166 & 5.5283 & TST & & \\
\hline CHEMBL234589 & 822292 & 6.64 & 6.6586 & TST & & \\
\hline CHEMBL361424 & 822292 & 7.432 & 7.2192 & TRN & & \\
\hline CHEMBL391085 & 822292 & \multicolumn{3}{|c|}{6.507000000000001} & 5.4164 & TST \\
\hline CHEMBL234587 & 822292 & 5.33 & 5.9427 & TST & & \\
\hline CHEMBL 234588 & 822292 & 6.016 & 6.2153 & TST & & \\
\hline CHEMBL234799 & 822292 & 5.602 & 6.3779 & TST & & \\
\hline CHEMBL 38943 & 822292 & 5.7 & 5.3241 & TST & & \\
\hline CHEMBL278994 & 822292 & 7.268 & 7.2965 & TRN & & \\
\hline CHEMBL207103 & 822292 & 7.796 & 7.8244 & TRN & & \\
\hline CHEMBL427040 & 822292 & 6.06 & 5.9485 & TRN & & \\
\hline CHEMBL 383728 & 822292 & 6.398 & 6.3439 & TRN & & \\
\hline CHEMBL 209563 & 822292 & 6.222 & 6.1803 & TRN & & \\
\hline CHEMBL210768 & 822292 & 6.638 & 6.835 & TRN & & \\
\hline CHEMBL210973 & 822292 & 7.721 & 7.6576 & TRN & & \\
\hline CHEMBL207907 & 822292 & 6.347 & 6.2972 & TRN & & \\
\hline CHEMBL207442 & 822292 & 5.824 & 5.7254 & TRN & & \\
\hline CHEMBL207019 & 822292 & \multicolumn{3}{|c|}{6.5089999999999995} & 6.6684 & TRN \\
\hline CHEMBL241286 & 822292 & \multicolumn{3}{|c|}{5.3870000000000005} & 5.4827 & TRN \\
\hline CHEMBL241471 & 822292 & 5.081 & 4.9636 & TRN & & \\
\hline CHEMBL241479 & 822292 & \multicolumn{3}{|c|}{5.1339999999999995} & 4.9902 & $\mathrm{NI}$ \\
\hline CHEMBL241478 & 822292 & 5.231 & 5.2609 & TRN & & \\
\hline
\end{tabular}




\begin{tabular}{|c|c|c|c|c|c|c|}
\hline \multirow{2}{*}{ CHEMBL391470 } & \multicolumn{6}{|c|}{ Supplemental Table S2.txt } \\
\hline & 822292 & \multicolumn{3}{|c|}{4.9830000000000005} & 5.0271 & TRN \\
\hline CHEMBL 238970 & 822292 & 5.215 & 5.1824 & TRN & & \\
\hline CHEMBL391264 & 822292 & 5.347 & 5.3883 & TRN & & \\
\hline CHEMBL 241298 & 822292 & \multicolumn{3}{|c|}{5.3020000000000005} & 5.2379 & TRN \\
\hline CHEMBL 2037082 & 822292 & \multicolumn{3}{|c|}{5.577999999999999} & 5.6156 & TRN \\
\hline CHEMBL 206794 & 822292 & 7.523 & 7.3554 & TRN & & \\
\hline CHEMBL23296 & 822292 & 6.553 & 6.4746 & TRN & & \\
\hline CHEMBL 23670 & 822292 & \multicolumn{3}{|c|}{5.7620000000000005} & 5.7399 & I RIN \\
\hline CHEMBL 241078 & 822292 & 5.04 & 5.0181 & TRN & & \\
\hline CHEMBL392063 & 822292 & 5.225 & 5.3176 & TRN & & \\
\hline CHEMBL1783033 & 822292 & 7.0 & 7.1325 & TRN & & \\
\hline CHEMBL279053 & 822292 & 6.244 & 6.0727 & TRN & & \\
\hline CHEMBL 200495 & 822292 & 6.305 & 6.6366 & TRN & & \\
\hline CHEMBL 2037181 & 822292 & \multicolumn{3}{|c|}{7.377000000000001} & 7.4337 & 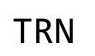 \\
\hline CHEMBL 2037182 & 822292 & 7.432 & 7.4594 & TRN & & \\
\hline CHEMBL 2037183 & 822292 & 7.046 & 7.0127 & TRN & & \\
\hline CHEMBL 2037184 & 822292 & \multicolumn{3}{|c|}{6.2010000000000005} & 6.1819 & TRN \\
\hline CHEMBL205665 & 822292 & \multicolumn{3}{|c|}{7.377000000000001} & 7.4518 & \\
\hline CHEMBL 23881 & 822292 & 5.131 & 5.2414 & TRN & & \\
\hline CHEMBL 25710 & 822292 & 6.222 & 6.2734 & TRN & & \\
\hline CHEMBL491039 & 822292 & 6.0 & 5.0817 & TST & & \\
\hline CHEMBL491237 & 822292 & 4.367 & 5.1531 & TST & & \\
\hline CHEMBL 235143 & 822292 & \multicolumn{3}{|c|}{5.6770000000000005} & 5.2799 & וכו \\
\hline CHEMBL393939 & 822292 & \multicolumn{3}{|c|}{5.757000000000001} & 5.6682 & \\
\hline CHEMBL 238357 & 822292 & 4.989 & 5.0031 & TST & & \\
\hline CHEMBL 237518 & 822292 & 6.504 & 6.5166 & TRN & & \\
\hline CHEMBL392717 & 822292 & 6.138 & 6.1766 & TRN & & \\
\hline CHEMBL237086 & 822292 & 5.145 & 5.2095 & TRN & & \\
\hline CHEMBL 237710 & 822292 & 5.829 & 5.7925 & TRN & & \\
\hline CHEMBL 236876 & 822292 & 6.194 & 6.0968 & TRN & & \\
\hline CHEMBL 237484 & 822292 & \multicolumn{3}{|c|}{5.946000000000001} & 4.9814 & TS \\
\hline CHEMBL393938 & 822292 & 5.91 & 5.9855 & TRN & & \\
\hline CHEMBL 237084 & 822292 & 4.987 & 4.9877 & TRN & & \\
\hline CHEMBL401236 & 822292 & 5.03 & 4.8284 & TST & & \\
\hline CHEMBL236218 & 822292 & 5.313 & 4.8735 & TST & & \\
\hline CHEMBL399217 & 822292 & \multicolumn{3}{|c|}{5.361000000000001} & 5.1663 & ביו \\
\hline CHEMBL 237085 & 822292 & 6.334 & 6.2984 & TRN & & \\
\hline CHEMBL485087 & 822292 & 5.0 & 4.9719 & TRN & & \\
\hline CHEMBL495904 & 822292 & 6.0 & 6.0349 & TRN & & \\
\hline CHEMBL495905 & 822292 & 5.9 & 5.8805 & TRN & & \\
\hline CHEMBL498172 & 822292 & 5.7 & 5.8752 & TRN & & \\
\hline CHEMBL525552 & 822292 & 5.1 & 5.1492 & TRN & & \\
\hline CHEMBL525366 & 822292 & 5.9 & 5.8739 & TRN & & \\
\hline CHEMBL498171 & 822292 & 6.0 & 5.8469 & TRN & & \\
\hline CHEMBL496733 & 822292 & 5.5 & 5.4975 & TRN & & \\
\hline CHEMBL522575 & 822292 & 5.6 & 5.6523 & TRN & & \\
\hline CHEMBL519345 & 822292 & 5.2 & 5.0876 & TRN & & \\
\hline CHEMBL522619 & 822292 & 5.8 & 5.6492 & TRN & & \\
\hline
\end{tabular}




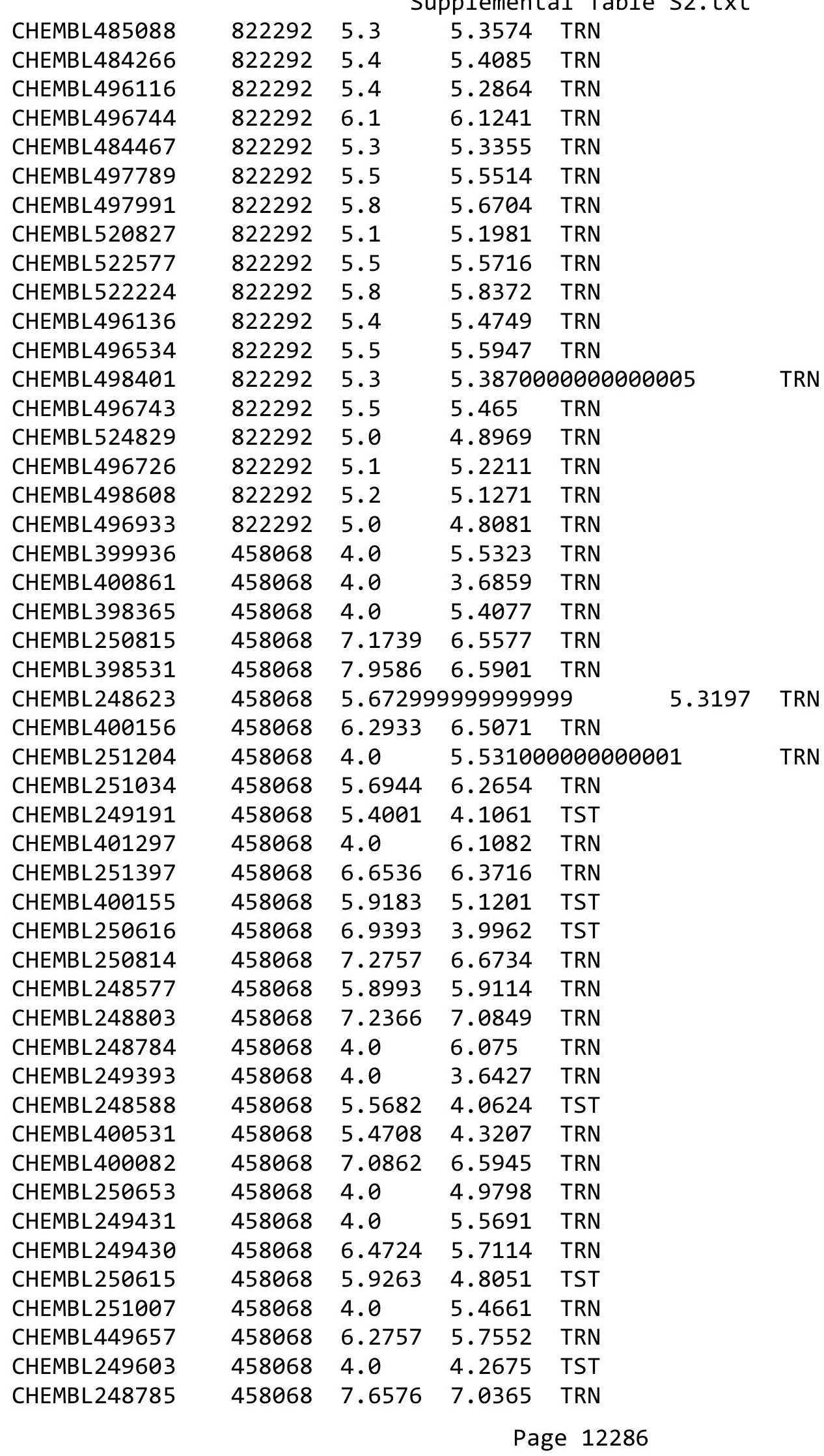




\begin{tabular}{|c|c|c|c|c|}
\hline \multicolumn{5}{|c|}{ Supplemental Table S2.txt } \\
\hline CHEMBL250280 & 458068 & 4.0 & 4.7608 & TST \\
\hline CHEMBL250618 & 458068 & 6.4157 & 5.6955 & TRN \\
\hline CHEMBL400952 & 458068 & 5.7612 & 5.6337 & TRN \\
\hline CHEMBL249798 & 458068 & 4.0 & 4.0709 & TST \\
\hline CHEMBL398300 & 458068 & 5.6242 & 5.0513 & TRN \\
\hline CHEMBL251006 & 458068 & 5.9147 & 6.0663 & TRN \\
\hline CHEMBL398843 & 458068 & 6.6696 & 6.5909 & TRN \\
\hline CHEMBL248996 & 458068 & 7.2924 & 6.7175 & TRN \\
\hline CHEMBL398425 & 458068 & 6.5751 & 6.5144 & TRN \\
\hline CHEMBL250614 & 458068 & 4.0 & 4.9166 & TRN \\
\hline CHEMBL398258 & 458068 & 7.5229 & 6.6695 & TRN \\
\hline CHEMBL402717 & 458068 & 6.341 & 6.6508 & TRN \\
\hline CHEMBL249392 & 458068 & 4.0 & 4.0334 & TST \\
\hline CHEMBL399746 & 458068 & 4.0 & 4.0456 & TST \\
\hline CHEMBL398842 & 458068 & 4.0 & 3.9204 & TRN \\
\hline CHEMBL400154 & 458068 & 6.1481 & 5.2212 & TST \\
\hline CHEMBL401327 & 458068 & 6.6003 & 5.768 & TRN \\
\hline CHEMBL251200 & 458068 & 7.6576 & 6.3173 & TRN \\
\hline CHEMBL401295 & 458068 & 6.3969 & 4.5945 & TRN \\
\hline CHEMBL249212 & 458068 & 5.9179 & 5.7314 & TRN \\
\hline CHEMBL250617 & 458068 & 7.2291 & 5.7268 & TRN \\
\hline CHEMBL249012 & 458068 & 5.329 & 5.7132 & TRN \\
\hline CHEMBL251199 & 458068 & 6.3605 & 6.8667 & TRN \\
\hline CHEMBL401137 & 458068 & 4.0 & 4.7386 & TST \\
\hline CHEMBL430019 & 458068 & 6.3261 & 6.9133 & TRN \\
\hline CHEMBL248816 & 458068 & 5.6137 & 5.6243 & TST \\
\hline CHEMBL249802 & 458068 & 4.0 & 4.1976 & TST \\
\hline CHEMBL248585 & 458068 & 5.8125 & 3.8693 & TST \\
\hline CHEMBL296021 & 688605 & 4.1 & 4.3847 & TRN \\
\hline CHEMBL1331245 & 688605 & 4.1 & 4.1994 & TRN \\
\hline CHEMBL1421613 & 688605 & 4.1 & 4.3802 & TST \\
\hline CHEMBL192627 & 688605 & 4.7 & 4.5538 & TRN \\
\hline CHEMBL1370662 & 688605 & 4.1 & 4.3681 & TRN \\
\hline CHEMBL346918 & 688605 & 4.1 & 4.4063 & TST \\
\hline CHEMBL1569226 & 688605 & 5.3 & 5.1105 & TRN \\
\hline CHEMBL538146 & 688605 & 4.1 & 4.6915 & TRN \\
\hline CHEMBL1495381 & 688605 & 6.0 & 4.9979 & TST \\
\hline CHEMBL1524617 & 688605 & 5.1 & 5.0769 & TRN \\
\hline CHEMBL1522486 & 688605 & 4.8 & 4.5888 & TRN \\
\hline CHEMBL1526319 & 688605 & 4.4 & 4.3075 & TRN \\
\hline CHEMBL1304981 & 688605 & 4.1 & 4.2078 & TST \\
\hline CHEMBL1447588 & 688605 & 4.8 & 4.9509 & TST \\
\hline CHEMBL8739 & 688605 & 4.3 & 4.1945 & TRN \\
\hline CHEMBL1492104 & 688605 & 4.8 & 4.7425 & TST \\
\hline CHEMBL1450607 & 688605 & 4.6 & 4.5552 & TST \\
\hline CHEMBL462576 & 688605 & 4.3 & 4.4663 & TST \\
\hline CHEMBL443949 & 688605 & 4.3 & 4.4107 & TRN \\
\hline CHEMBL1451833 & 688605 & 4.4 & 4.4188 & TRN \\
\hline
\end{tabular}




\begin{tabular}{|c|c|c|c|c|c|}
\hline \multicolumn{6}{|c|}{ Supplemental Table S2.txt } \\
\hline CHEMBL1559341 & 688605 & 4.5 & 4.3324 & TRN & \\
\hline CHEMBL1527567 & 688605 & 4.3 & 4.16 & TRN & \\
\hline CHEMBL486193 & 688605 & 4.3 & 4.62 & TST & \\
\hline CHEMBL1439332 & 688605 & 4.7 & 4.7888 & TST & \\
\hline CHEMBL 289277 & 688605 & 4.3 & 4.319 & TRN & \\
\hline CHEMBL1308088 & 688605 & 5.0 & 4.8061 & TRN & \\
\hline CHEMBL1409985 & 688605 & 5.3 & 5.1502 & TRN & \\
\hline CHEMBL1579130 & 688605 & 6.0 & 5.4623 & TST & \\
\hline CHEMBL1449018 & 688605 & 4.4 & 4.5739 & TRN & \\
\hline CHEMBL1612246 & 688605 & 4.4 & 4.583 & TRN & \\
\hline CHEMBL36296 & 688605 & 4.3 & 4.2871 & TRN & \\
\hline CHEMBL1530684 & 688605 & 4.3 & 4.3072 & TRN & \\
\hline CHEMBL1471289 & 688605 & 4.6 & 4.3818 & TRN & \\
\hline CHEMBL1330518 & 688605 & 4.1 & 4.2588 & TRN & \\
\hline CHEMBL1565705 & 688605 & 4.1 & 4.2612 & TRN & \\
\hline CHEMBL1492884 & 688605 & 4.4 & 4.3228 & TRN & \\
\hline CHEMBL1142 & 688605 & 4.4 & 4.2864 & TRN & \\
\hline CHEMBL1462419 & 688605 & 4.3 & 4.4166 & TRN & \\
\hline CHEMBL285235 & 688605 & 4.1 & 4.2822 & TRN & \\
\hline CHEMBL1414154 & 688605 & 4.4 & 4.1037 & TRN & \\
\hline CHEMBL1452158 & 688605 & 4.3 & 4.2801 & TRN & \\
\hline CHEMBL1485974 & 688605 & 4.5 & $4.2810 e$ & 0000000001 & TRN \\
\hline CHEMBL1545634 & 688605 & 6.6 & 6.5631 & TRN & \\
\hline CHEMBL1448387 & 688605 & 4.4 & 4.5012 & TRN & \\
\hline CHEMBL1407826 & 688605 & 4.8 & 4.7077 & TST & \\
\hline CHEMBL162598 & 688605 & 4.3 & 4.3388 & TST & \\
\hline CHEMBL1366408 & 688605 & 4.4 & 4.5635 & TRN & \\
\hline CHEMBL3391990 & 688605 & 4.3 & 4.3927 & TST & \\
\hline CHEMBL402063 & 688605 & 6.0 & 5.2138 & TST & \\
\hline CHEMBL 1485360 & 688605 & 4.3 & 4.5637 & TRN & \\
\hline CHEMBL935 & 688605 & 4.4 & 4.3256 & TRN & \\
\hline CHEMBL 280998 & 688605 & 4.4 & 4.4095 & TRN & \\
\hline CHEMBL230156 & 688605 & 4.1 & 4.208 & TRN & \\
\hline CHEMBL1489064 & 688605 & 4.3 & 4.1882 & TRN & \\
\hline CHEMBL140 & 688605 & 4.4 & 4.3003 & TRN & \\
\hline CHEMBL1609459 & 688605 & 5.1 & 5.0731 & TRN & \\
\hline CHEMBL334255 & 688605 & 4.9 & 4.9683 & TRN & \\
\hline CHEMBL144530 & 688605 & 4.3 & 4.2227 & TRN & \\
\hline CHEMBL1535689 & 688605 & 4.4 & 4.2622 & TRN & \\
\hline CHEMBL1365278 & 688605 & 4.4 & 4.6689 & TST & \\
\hline CHEMBL1499545 & 688605 & 5.2 & 5.2276 & TRN & \\
\hline CHEMBL1576086 & 688605 & 4.4 & 4.4003 & TRN & \\
\hline CHEMBL1496957 & 688605 & 4.7 & 4.5955 & TRN & \\
\hline CHEMBL1600998 & 688605 & 5.2 & 5.3564 & TRN & \\
\hline CHEMBL1562104 & 688605 & 5.0 & 5.3481 & TRN & \\
\hline CHEMBL195953 & 688605 & 4.3 & 4.2345 & TST & \\
\hline CHEMBL220845 & 688605 & 4.3 & 4.2313 & TRN & \\
\hline CHEMBL1517425 & 688605 & 4.1 & 4.08899 & 99999999995 & TRN \\
\hline & & & & 12288 & \\
\hline
\end{tabular}




\begin{tabular}{|c|c|c|c|c|}
\hline \multicolumn{5}{|c|}{ Supplemental Table S2.txt } \\
\hline CHEMBL1519327 & 688605 & 6.5 & 6.2475 & TRN \\
\hline CHEMBL1408847 & 688605 & 5.1 & 5.2286 & TRN \\
\hline CHEMBL1338613 & 688605 & 4.4 & 4.2808 & TST \\
\hline CHEMBL1602699 & 688605 & 5.3 & 5.1637 & TRN \\
\hline CHEMBL1393325 & 688605 & 4.1 & 4.4408 & TRN \\
\hline CHEMBL1303139 & 688605 & 5.2 & 5.0717 & TRN \\
\hline CHEMBL1566504 & 688605 & 4.3 & 4.3169 & TST \\
\hline CHEMBL242080 & 688605 & 6.0 & 4.4844 & TRN \\
\hline CHEMBL1569493 & 688605 & 5.6 & 5.8667 & TRN \\
\hline CHEMBL1430204 & 688605 & 4.3 & 4.3243 & TRN \\
\hline CHEMBL1236200 & 688605 & 4.1 & 4.3909 & TRN \\
\hline CHEMBL1526721 & 688605 & 5.1 & 4.9534 & TST \\
\hline CHEMBL1428964 & 688605 & 4.1 & 4.3019 & TRN \\
\hline CHEMBL1549844 & 688605 & 4.4 & 4.579 & TST \\
\hline CHEMBL1558796 & 688605 & 4.4 & 4.535 & TRN \\
\hline CHEMBL44072 & 688605 & 4.4 & 4.3378 & TST \\
\hline CHEMBL105712 & 688605 & 4.9 & 4.9935 & TRN \\
\hline CHEMBL1200471 & 688605 & 6.7001 & 6.601 & TRN \\
\hline CHEMBL440287 & 688605 & 4.4 & 4.4703 & TRN \\
\hline CHEMBL1418603 & 688605 & 4.0 & 4.1421 & TRN \\
\hline CHEMBL509531 & 688605 & 4.6 & 4.7801 & TST \\
\hline CHEMBL224282 & 688605 & 4.1 & 4.1555 & TRN \\
\hline CHEMBL1309179 & 688605 & 4.8 & 4.6859 & TRN \\
\hline CHEMBL 3899371 & 1617700 & 2.6021 & 2.602 & TRN \\
\hline CHEMBL3933283 & 1617700 & 2.6021 & 2.602 & TRN \\
\hline CHEMBL3894879 & 1617700 & 2.6021 & 2.6021 & TRN \\
\hline CHEMBL3970551 & 1617700 & 2.6021 & 2.6021 & TRN \\
\hline CHEMBL3954893 & 1617700 & 2.6021 & 2.6021 & TRN \\
\hline CHEMBL3915348 & 1617700 & 3.7144 & 3.7144 & TRN \\
\hline CHEMBL3928317 & 1617700 & 2.6021 & 2.602 & TRN \\
\hline CHEMBL3906378 & 1617700 & 2.6021 & 2.6021 & TRN \\
\hline CHEMBL3953543 & 1617700 & 2.6021 & 3.0039 & TST \\
\hline CHEMBL3904891 & 1617700 & 2.6021 & 2.6021 & TRN \\
\hline CHEMBL 3912547 & 1617700 & 3.8182 & 3.8182 & TRN \\
\hline CHEMBL3975683 & 1617700 & 2.6021 & 2.602 & TRN \\
\hline CHEMBL3980253 & 1617700 & 3.8962 & 3.8962 & TRN \\
\hline CHEMBL3910488 & 1617700 & 4.4815 & 4.4815 & TRN \\
\hline CHEMBL3942054 & 1617700 & 2.6021 & 2.6021 & TRN \\
\hline CHEMBL 3937258 & 1617700 & 2.6021 & 2.7058 & TST \\
\hline CHEMBL3934352 & 1617700 & 2.6021 & 2.602 & TRN \\
\hline CHEMBL3919412 & 1617700 & 2.6021 & 2.602 & TRN \\
\hline CHEMBL3919336 & 1617700 & 2.6021 & 2.3784 & TST \\
\hline CHEMBL3967047 & 1617700 & 3.7122 & 3.7122 & TRN \\
\hline CHEMBL 3924724 & 1617700 & 3.6968 & 3.6968 & TRN \\
\hline CHEMBL3955935 & 1617700 & 2.6021 & 2.6021 & TRN \\
\hline CHEMBL3983061 & 1617700 & 2.6021 & 2.6021 & TRN \\
\hline CHEMBL3960743 & 1617700 & 2.6021 & 2.6021 & TRN \\
\hline CHEMBL 3924343 & 1617700 & 2.6021 & 2.602 & TRN \\
\hline
\end{tabular}


Supplemental Table S2.txt

\begin{tabular}{|c|c|c|c|c|}
\hline CHEMBL3979736 & 1617700 & 2.6021 & 2.6021 & TRN \\
\hline CHEMBL3952406 & 1617700 & 3.8962 & 2.8654 & TST \\
\hline CHEMBL3040216 & 1617700 & 2.6021 & 2.7012 & TST \\
\hline CHEMBL3115908 & 1617700 & 2.9747 & 2.4874 & TST \\
\hline CHEMBL3943318 & 1617700 & 3.6498 & 3.6498 & TRN \\
\hline CHEMBL3947198 & 1617700 & 2.6021 & 2.6021 & TRN \\
\hline CHEMBL3966262 & 1617700 & 3.8962 & 3.8962 & TRN \\
\hline CHEMBL3952045 & 1617700 & 2.6021 & 2.6021 & TRN \\
\hline CHEMBL3907505 & 1617700 & 2.6021 & 2.6021 & TRN \\
\hline CHEMBL3986320 & 1617700 & 4.2291 & 4.2291 & TRN \\
\hline CHEMBL3978830 & 1617700 & 2.6021 & 2.602 & TRN \\
\hline CHEMBL3978029 & 1617700 & 2.6021 & 2.6021 & TRN \\
\hline CHEMBL3983712 & 1617700 & 2.6021 & 2.6021 & TRN \\
\hline CHEMBL 3947125 & 1617700 & 3.6737 & 3.6737 & TRN \\
\hline CHEMBL3938421 & 1617700 & 4.2147 & 4.2147 & TRN \\
\hline CHEMBL3903813 & 1617700 & 2.6021 & 2.6021 & TRN \\
\hline CHEMBL3951335 & 1617700 & 2.6021 & 2.602 & TRN \\
\hline CHEMBL3890411 & 1617700 & 2.6021 & 2.602 & TRN \\
\hline CHEMBL3922861 & 1617700 & 2.6021 & 2.7819 & TST \\
\hline CHEMBL 3894125 & 1617700 & 2.6021 & 2.9813 & TST \\
\hline CHEMBL3950773 & 1617700 & 2.6021 & 2.78 & TST \\
\hline CHEMBL3975456 & 1617700 & 2.6021 & 3.3397 & TST \\
\hline CHEMBL3908434 & 1617700 & 2.6021 & 2.5719 & TST \\
\hline CHEMBL3934460 & 1617700 & 3.8416 & 3.1058 & TST \\
\hline CHEMBL 3913878 & 1617700 & 2.6021 & 2.4376 & TST \\
\hline CHEMBL547269 & 817942 & 5.49200 & 00000000 & 5.4163 \\
\hline CHEMBL529385 & 817942 & 4.9163 & 5.3288 & TRN \\
\hline CHEMBL600030 & 817942 & 3.4948 & 4.0309 & TRN \\
\hline CHEMBL583555 & 817942 & 5.9237 & 5.5886 & TST \\
\hline CHEMBL581489 & 817942 & 3.4948 & 3.7739 & TRN \\
\hline CHEMBL580876 & 817942 & 3.4948 & 3.7223 & TRN \\
\hline CHEMBL527234 & 817942 & 5.5952 & 4.8452 & TRN \\
\hline CHEMBL 2021322 & 817942 & 5.3448 & 5.0463 & TRN \\
\hline CHEMBL578952 & 817942 & 3.4948 & 3.9209 & TRN \\
\hline CHEMBL547488 & 817942 & 4.7372 & 3.9324 & TRN \\
\hline CHEMBL600356 & 817942 & 5.3753 & 5.0999 & TST \\
\hline CHEMBL524973 & 817942 & 5.4481 & 5.69799 & 99999999995 \\
\hline CHEMBL1459149 & 817942 & 3.4948 & 4.0559 & TST \\
\hline CHEMBL 206540 & 817942 & 3.4948 & 3.8265 & TRN \\
\hline CHEMBL590675 & 817942 & 4.5594 & 4.1048 & TRN \\
\hline CHEMBL587083 & 817942 & 5.4073 & 5.6429 & TRN \\
\hline CHEMBL602234 & 817942 & 6.0061 & 6.3664 & TRN \\
\hline CHEMBL532560 & 817942 & 5.3949 & 5.1198 & TRN \\
\hline CHEMBL579300 & 817942 & 5.3886 & 5.1564 & TRN \\
\hline CHEMBL586178 & 817942 & 3.4948 & 3.8455 & TRN \\
\hline CHEMBL582180 & 817942 & 5.4138 & 5.1582 & TRN \\
\hline CHEMBL602940 & 817942 & 4.8576 & 4.9562 & TST \\
\hline CHEMBL600132 & 817942 & 5.178 & 5.0946 & TST \\
\hline
\end{tabular}




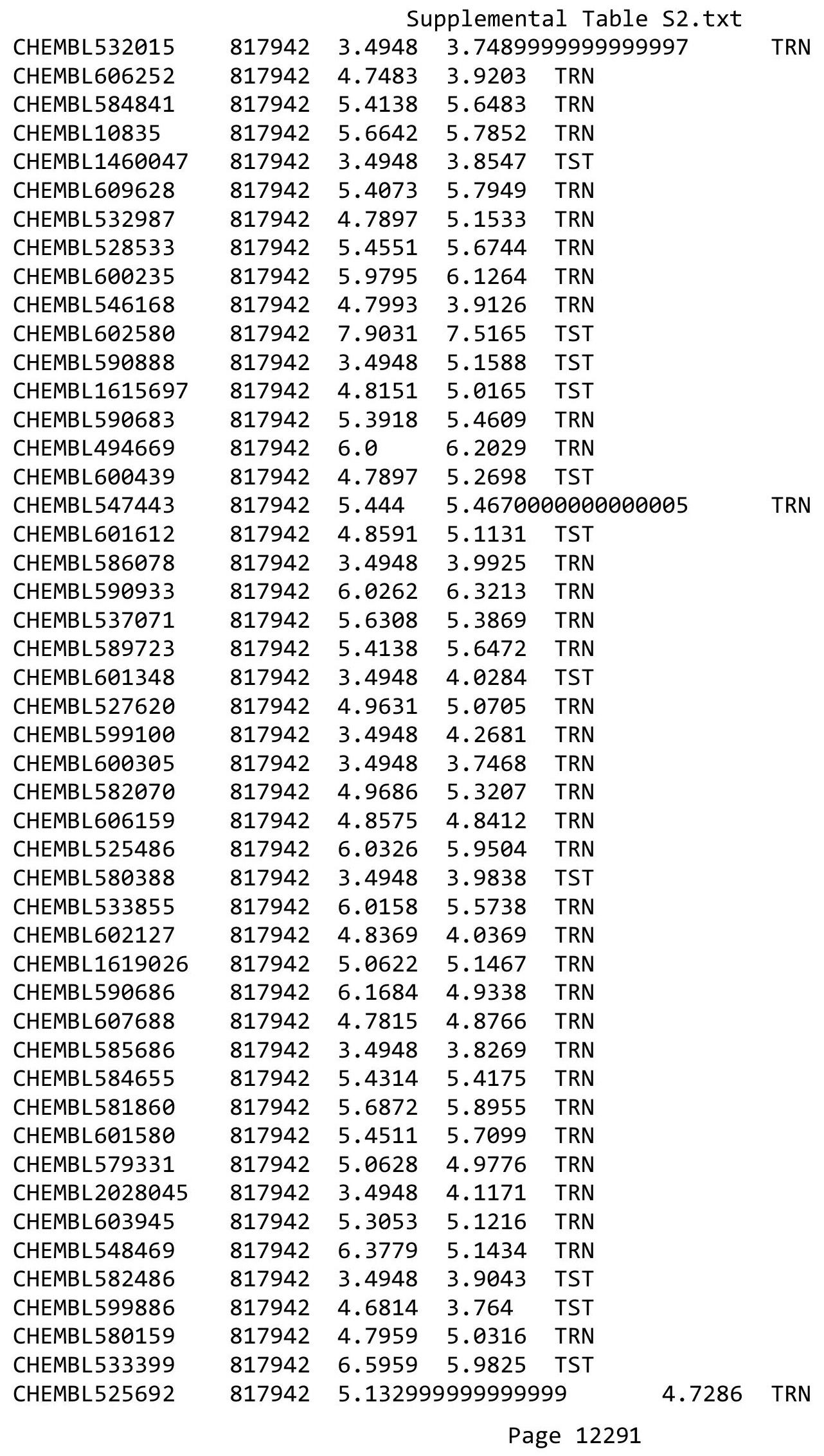


Supplemental Table S2.txt

\begin{tabular}{|c|c|c|c|c|}
\hline 0914 & 17942 & .3979 & 5.6254 & $\mathrm{TR}$ \\
\hline HEMBL533917 & 17942 & 7.9031 & 7.7232 & \\
\hline 933 & 7942 & & 5241 & \\
\hline HEMBL 202805 & 7942 & 4948 & & \\
\hline HEMBL525106 & 17942 & 939 & 8879 & \\
\hline HEMBL 530531 & 17942 & 9031 & 9129 & \\
\hline HEMBL587923 & .7942 & 128 & 5006 & \\
\hline AEMBL582767 & 7942 & & & \\
\hline HEMBL 1485159 & 17942 & 7959 & 1972 & \\
\hline HEMBL532155 & 17942 & .7587 & 0493 & \\
\hline HEMBL 587371 & 17942 & 5.0139 & .7792 & \\
\hline HEMBL580757 & 7942 & 48 & 8906 & \\
\hline HEMBL 600444 & 7942 & & & \\
\hline HEMBL 261693 & .7942 & 45 & 3.5788 & \\
\hline HEMBL605281 & 7942 & 45 & 5079 & \\
\hline AEMBL591393 & 17942 & 10 & .7625 & \\
\hline HEMBL531060 & 7942 & 56 & 658 & . \\
\hline HEMBL596643 & 942 & & 3.7723 & \\
\hline HEMBL 587410 & 7942 & 38 & 5.7716 & \\
\hline HEMBL 588481 & 942 & & & \\
\hline HEMBL581187 & 942 & 2 & 54 & - \\
\hline HEMBL527541 & 942 & & 219 & RN \\
\hline HEMBL1594640 & 942 & & 563 & \\
\hline HEMBL1740701 & 942 & & 4.2678 & \\
\hline HEMBL527131 & & & & $\Gamma \mathrm{RN}$ \\
\hline HEMBL 2028059 & 942 & & 98 & KIV \\
\hline HEMBL 5 & 942 & & 273 & RN \\
\hline HEMBL 5 & 942 & & 3.9673 & \\
\hline HEMBL2028047 & & & 5.5727 & 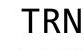 \\
\hline HEMBL588859 & 42 & & 552 & I RIV \\
\hline HEMBL549216 & 942 & & 735 & RN \\
\hline HEMBL2 & 942 & & 49 & RN \\
\hline HEMBL548374 & 942 & & 45 & $\Gamma \mathrm{RN}$ \\
\hline HEMBL528734 & 7942 & & 4.1578 & IRN \\
\hline HEMBL597262 & 7942 & & 3.7613 & TRN \\
\hline HEMBL581349 & 942 & & 3.9148 & I RN \\
\hline HFMBI 5 & 942 & 7 & 397 & $\Gamma \mathrm{RN}$ \\
\hline HEMBL587892 & 42 & & 5.7904 & TRN \\
\hline HEMBL 202805 & 7942 & & 5.4874 & TRN \\
\hline HEMBL 584240 & 7942 & & & TR \\
\hline CHEMBL123725 & 942 & & 091 & I RIV \\
\hline CHEMBL585622 & .7942 & 6 & 5.2209 & TRN \\
\hline CHEMBL582420 & 7942 & 48 & 3.6731 & TRN \\
\hline HEMBL601325 & 7942 & 5.3854 & 5.1587 & TS \\
\hline CHEMBL609036 & 7942 & 39 & 5.6827 & $T_{1}$ \\
\hline CHEMBL524784 & 7942 & & 3.9469 & \\
\hline CHEMBL601566 & 317942 & 4.8935 & 4.8924 & \\
\hline CHEMBL 202804 & 817942 & 3.4948 & 3.9447 & ГRN \\
\hline
\end{tabular}

Page 12292 


\begin{tabular}{|c|c|c|c|c|c|c|}
\hline & & \multicolumn{5}{|c|}{ Supplemental Table S2.txt } \\
\hline CHEMBL592550 & 817942 & 5.2976 & 5.2643 & TRN & & \\
\hline CHEMBL 2028067 & 817942 & 5.7436 & 5.4831 & TRN & & \\
\hline CHEMBL1616787 & 817942 & \multicolumn{3}{|c|}{5.957000000000001} & 5.6583 & TRN \\
\hline CHEMBL583682 & 817942 & 5.5372 & 5.23 & TRN & & \\
\hline CHEMBL530973 & 817942 & 3.4948 & 3.7718 & TRN & & \\
\hline CHEMBL586344 & 817942 & 3.4948 & 3.9329 & TST & & \\
\hline CHEMBL546799 & 817942 & 5.5462 & 5.4148 & TRN & & \\
\hline CHEMBL580819 & 817942 & 3.4948 & 3.8061 & TRN & & \\
\hline CHEMBL587989 & 817942 & 3.4948 & 3.9433 & TRN & & \\
\hline CHEMBL535730 & 817942 & \multicolumn{3}{|c|}{5.997000000000001} & 5.607 & TST \\
\hline CHEMBL588501 & 817942 & 7.9031 & 6.5223 & TRN & & \\
\hline CHEMBL591128 & 817942 & 4.5164 & 3.9075 & TRN & & \\
\hline CHEMBL1738986 & 817942 & 5.2134 & 5.6545 & TRN & & \\
\hline CHEMBL530308 & 817942 & 5.7644 & 5.3777 & TST & & \\
\hline CHEMBL533921 & 817942 & 4.7924 & 4.0983 & TRN & & \\
\hline CHEMBL603686 & 817942 & 5.3852 & 5.1764 & TRN & & \\
\hline CHEMBL125044 & 817942 & 3.4948 & 3.6357 & TRN & & \\
\hline CHEMBL601957 & 817942 & 4.7897 & 5.2764 & TRN & & \\
\hline CHEMBL527593 & 817942 & 3.4948 & 3.9733 & TST & & \\
\hline CHEMBL592786 & 817942 & 4.9163 & 4.9781 & TRN & & \\
\hline CHEMBL588516 & 817942 & 3.4948 & 3.6808 & TRN & & \\
\hline CHEMBL532879 & 817942 & 3.4948 & \multicolumn{3}{|c|}{3.8989999999999996} & TRN \\
\hline CHEMBL529640 & 817942 & 5.3949 & 5.51 & TRN & & \\
\hline CHEMBL586000 & 817942 & 5.1444 & 3.9025 & TRN & & \\
\hline CHEMBL605751 & 817942 & 6.6637 & 6.3882 & TRN & & \\
\hline CHEMBL577011 & 817942 & 3.4948 & 3.8643 & TRN & & \\
\hline CHEMBL527730 & 817942 & 6.447 & 6.39 & TRN & & \\
\hline CHEMBL532597 & 817942 & 3.4948 & 3.8427 & TRN & & \\
\hline CHEMBL580516 & 817942 & 6.6083 & 5.6648 & TRN & & \\
\hline CHEMBL602586 & 817942 & 5.4553 & 5.1506 & TST & & \\
\hline CHEMBL470514 & 817942 & 4.8293 & 5.3965 & TRN & & \\
\hline CHEMBL601743 & 817942 & 4.9016 & 5.4085 & TRN & & \\
\hline CHEMBL588155 & 817942 & 4.8665 & 5.066 & TRN & & \\
\hline CHEMBL586442 & 817942 & 3.4948 & 3.6904 & TRN & & \\
\hline CHEMBL124006 & 817942 & 7.9031 & 7.6526 & TRN & & \\
\hline CHEMBL607308 & 817942 & 5.1087 & 5.0233 & TRN & & \\
\hline CHEMBL601825 & 817942 & 3.4948 & 3.8328 & TRN & & \\
\hline CHEMBL598279 & 817942 & 5.3949 & 5.8522 & TRN & & \\
\hline CHEMBL529732 & 817942 & 3.4948 & 3.5728 & TRN & & \\
\hline CHEMBL577874 & 817942 & 5.4041 & 5.6017 & TRN & & \\
\hline CHEMBL589060 & 817942 & 3.4948 & 3.9008 & TRN & & \\
\hline CHEMBL601158 & 817942 & 3.4948 & 3.85 & TRN & & \\
\hline CHEMBL600374 & 817942 & 6.599 & 6.3655 & TRN & & \\
\hline CHEMBL589946 & 817942 & \multicolumn{3}{|c|}{5.997000000000001} & 5.9818 & TRN \\
\hline CHEMBL338094 & 817942 & 3.4948 & 3.6739 & TRN & & \\
\hline CHEMBL 2028057 & 817942 & 4.9865 & 4.9741 & TRN & & \\
\hline CHEMBL524930 & 817942 & 4.802 & 5.1112 & TRN & & \\
\hline CHEMBL459199 & 817942 & 5.5098 & 5.726 & TRN & & \\
\hline
\end{tabular}


Supplemental Table S2.txt

\begin{tabular}{|c|c|c|c|c|c|}
\hline CHEMBL 2028043 & 817942 & 6.0951 & 6.1229 & TRN & \\
\hline CHEMBL601122 & 817942 & 5.4751 & 5.7861 & TRN & \\
\hline CHEMBL611070 & 817942 & 4.789 & 3.7773 & TRN & \\
\hline CHEMBL591147 & 817942 & 4.8689 & 4.8889 & TRN & \\
\hline CHEMBL592808 & 817942 & 5.3645 & 5.7165 & TRN & \\
\hline CHEMBL589920 & 817942 & 4.7959 & 5.17399 & 99999999995 & TRN \\
\hline CHEMBL579760 & 817942 & 5.4042 & 5.5955 & TST & \\
\hline CHEMBL 548334 & 817942 & 3.4948 & 3.91899 & 99999999996 & TST \\
\hline CHEMBL591183 & 817942 & 6.4538 & 6.4795 & TRN & \\
\hline CHEMBL533563 & 817942 & 5.7729 & 5.3941 & TST & \\
\hline CHEMBL534288 & 817942 & 4.9046 & 5.0932 & TRN & \\
\hline CHEMBL606531 & 817942 & 5.9939 & 5.5544 & TRN & \\
\hline CHEMBL601156 & 817942 & 4.7959 & 4.9123 & TST & \\
\hline CHEMBL526587 & 817942 & 3.4948 & 3.8992 & TRN & \\
\hline CHEMBL578508 & 817942 & 3.4948 & 3.9899 & TRN & \\
\hline CHEMBL1623897 & 817942 & 4.7928 & 5.0981 & TRN & \\
\hline CHEMBL526800 & 817942 & 5.3821 & 4.9759 & TRN & \\
\hline CHEMBL584829 & 817942 & 5.3779 & 5.5385 & TRN & \\
\hline CHEMBL579443 & 817942 & 5.3645 & 5.092 & TRN & \\
\hline CHEMBL582495 & 817942 & 7.9031 & 5.0098 & TRN & \\
\hline CHEMBL602312 & 817942 & 6.6021 & 6.4916 & TRN & \\
\hline CHEMBL601814 & 817942 & 4.5107 & 4.2241 & TRN & \\
\hline CHEMBL601378 & 817942 & 5.5747 & 5.7568 & TRN & \\
\hline CHEMBL534190 & 817942 & 5.5137 & 3.7784 & TRN & \\
\hline CHEMBL590212 & 817942 & \multicolumn{3}{|c|}{5.997000000000001} & \\
\hline CHEMBL592344 & 817942 & 4.7928 & 4.7956 & TRN & \\
\hline CHEMBL602413 & 817942 & 5.4172 & 5.6693 & TRN & \\
\hline CHEMBL591637 & 817942 & 6.5649 & 6.1432 & TRN & \\
\hline CHEMBL602946 & 817942 & 5.9247 & 5.3482 & TRN & \\
\hline CHEMBL534319 & 817942 & 6.1003 & 6.5007 & TRN & \\
\hline CHEMBL578294 & 817942 & 5.4138 & 5.8896 & TRN & \\
\hline CHEMBL597444 & 817942 & 3.4948 & 4.2223 & TRN & \\
\hline CHEMBL548399 & 817942 & 3.4948 & 3.55 & TRN & \\
\hline CHEMBL529348 & 817942 & 5.4553 & 5.504 & TRN & \\
\hline CHEMBL582119 & 817942 & 4.6024 & 3.8454 & TST & \\
\hline CHEMBL529968 & 817942 & 3.4948 & 3.8415 & TRN & \\
\hline CHEMBL596852 & 817942 & 7.9031 & 6.9295 & TRN & \\
\hline CHEMBL530223 & 817942 & 5.9773 & 5.3317 & TRN & \\
\hline CHEMBL532079 & 817942 & 5.3979 & 5.5757 & TRN & \\
\hline CHEMBL 2028053 & 817942 & 3.4948 & 3.5502 & TRN & \\
\hline CHEMBL545880 & 817942 & \multicolumn{3}{|c|}{5.997000000000001} & TIV \\
\hline CHEMBL585839 & 817942 & 3.4948 & 3.7957 & TRN & \\
\hline CHEMBL596856 & 817942 & 4.5571 & 4.3086 & TRN & \\
\hline CHEMBL609156 & 817942 & 3.4948 & 3.7393 & TRN & \\
\hline CHEMBL585983 & 817942 & 4.7897 & 5.3147 & TRN & \\
\hline CHEMBL598881 & 817942 & 4.7897 & 4.8648 & TST & \\
\hline CHEMBL529603 & 817942 & 3.4948 & 4.0394 & TRN & \\
\hline CHEMBL590919 & 817942 & 5.9907 & 5.6673 & TRN & \\
\hline
\end{tabular}




\begin{tabular}{|c|c|c|c|c|c|}
\hline \\
\hline CHEMBL581225 & 817942 & 6.0 & 5.5673 & TST & \\
\hline CHEMBL578030 & 817942 & 5.4567 & 5.7244 & TRN & \\
\hline CHEMBL579294 & 817942 & 3.4948 & 4.1356 & TRN & \\
\hline CHEMBL536393 & 817942 & 3.4948 & 3.6678 & TRN & \\
\hline CHEMBL49055 & 817942 & 5.3949 & 5.914 & TRN & \\
\hline CHEMBL607975 & 817942 & 3.4948 & 3.6897 & TRN & \\
\hline CHEMBL580580 & 817942 & 4.9418 & 5.1468 & TRN & \\
\hline CHEMBL586962 & 817942 & 5.275 & 4.7444 & TRN & \\
\hline CHEMBL 2028042 & 817942 & 3.4948 & 3.6568 & TRN & \\
\hline CHEMBL586031 & 817942 & 6.5017 & 6.1485 & TST & \\
\hline CHEMBL547476 & 817942 & 3.4948 & 3.9396 & TRN & \\
\hline CHEMBL528245 & 817942 & 4.6476 & 4.1654 & TRN & \\
\hline CHEMBL600488 & 817942 & 3.4948 & 3.7359 & TRN & \\
\hline CHEMBL582552 & 817942 & 4.7437 & 5.2178 & TRN & \\
\hline CHEMBL534589 & 817942 & 3.4948 & 3.5918 & TRN & \\
\hline CHEMBL581240 & 817942 & 4.9441 & 5.0861 & TRN & \\
\hline CHEMBL 2028066 & 817942 & 4.9249 & 5.113 & TST & \\
\hline CHEMBL590680 & 817942 & 3.4948 & 3.8642 & TRN & \\
\hline CHEMBL532510 & 817942 & 4.7167 & 3.8882 & TRN & \\
\hline CHEMBL549210 & 817942 & 4.8575 & 5.0613 & TRN & \\
\hline CHEMBL601806 & 817942 & 5.3918 & 4.9764 & TST & \\
\hline CHEMBL535514 & 817942 & 4.8769 & 3.9159 & TRN & \\
\hline CHEMBL602179 & 817942 & 3.4948 & 3.8758 & TRN & \\
\hline CHEMBL600549 & 817942 & 3.4948 & 3.8267 & TRN & \\
\hline CHEMBL546994 & 817942 & 4.7563 & 3.7929 & TRN & \\
\hline CHEMBL586033 & 817942 & 6.0125 & 6.5473 & TRN & \\
\hline CHEMBL547266 & 817942 & 6.0 & 6.5146 & TRN & \\
\hline CHEMBL592305 & 817942 & 3.4948 & 3.9691 & TST & \\
\hline CHEMBL526981 & 817942 & 4.7928 & 4.7857 & TRN & \\
\hline CHEMBL530978 & 817942 & 4.7928 & 4.8208 & TRN & \\
\hline CHEMBL319952 & 817942 & 5.3278 & 5.021 & TRN & \\
\hline CHEMBL95606 & 817942 & 3.4948 & 4.0664 & TST & \\
\hline CHEMBL591887 & 817942 & 4.8155 & 4.9508 & TRN & \\
\hline CHEMBL531611 & 817942 & 5.1657 & 5.1185 & TRN & \\
\hline CHEMBL587485 & 817942 & 3.4948 & 3.7438 & TRN & \\
\hline CHEMBL599885 & 817942 & 3.4948 & 3.7769 & TRN & \\
\hline CHEMBL533017 & 817942 & 3.4948 & 3.7729 & TRN & \\
\hline CHEMBL1545915 & 817942 & 3.4948 & 4.0142 & TRN & \\
\hline CHEMBL 2028062 & 817942 & 4.7822 & 4.0558 & TRN & \\
\hline CHEMBL529874 & 817942 & 3.4948 & 3.7301 & TST & \\
\hline CHEMBL590182 & 817942 & 4.706 & 4.0346 & TRN & \\
\hline CHEMBL261095 & 817942 & 3.4948 & 3.7411 & TRN & \\
\hline CHEMBL 2028046 & 817942 & 5.3979 & 4.9467 & TRN & \\
\hline CHEMBL1437888 & 817942 & 6.6522 & 6.6704 & TRN & \\
\hline CHEMBL 1744512 & 817942 & 4.7882 & 3.8345 & TRN & \\
\hline CHEMBL531290 & 817942 & 4.883 & 5.0679 & TST & \\
\hline CHEMBL582072 & 817942 & 5.563 & 5.86299 & 99999999995 & TRN \\
\hline CHEMBL581175 & 817942 & 4.8099 & 4.1247 & TRN & \\
\hline
\end{tabular}




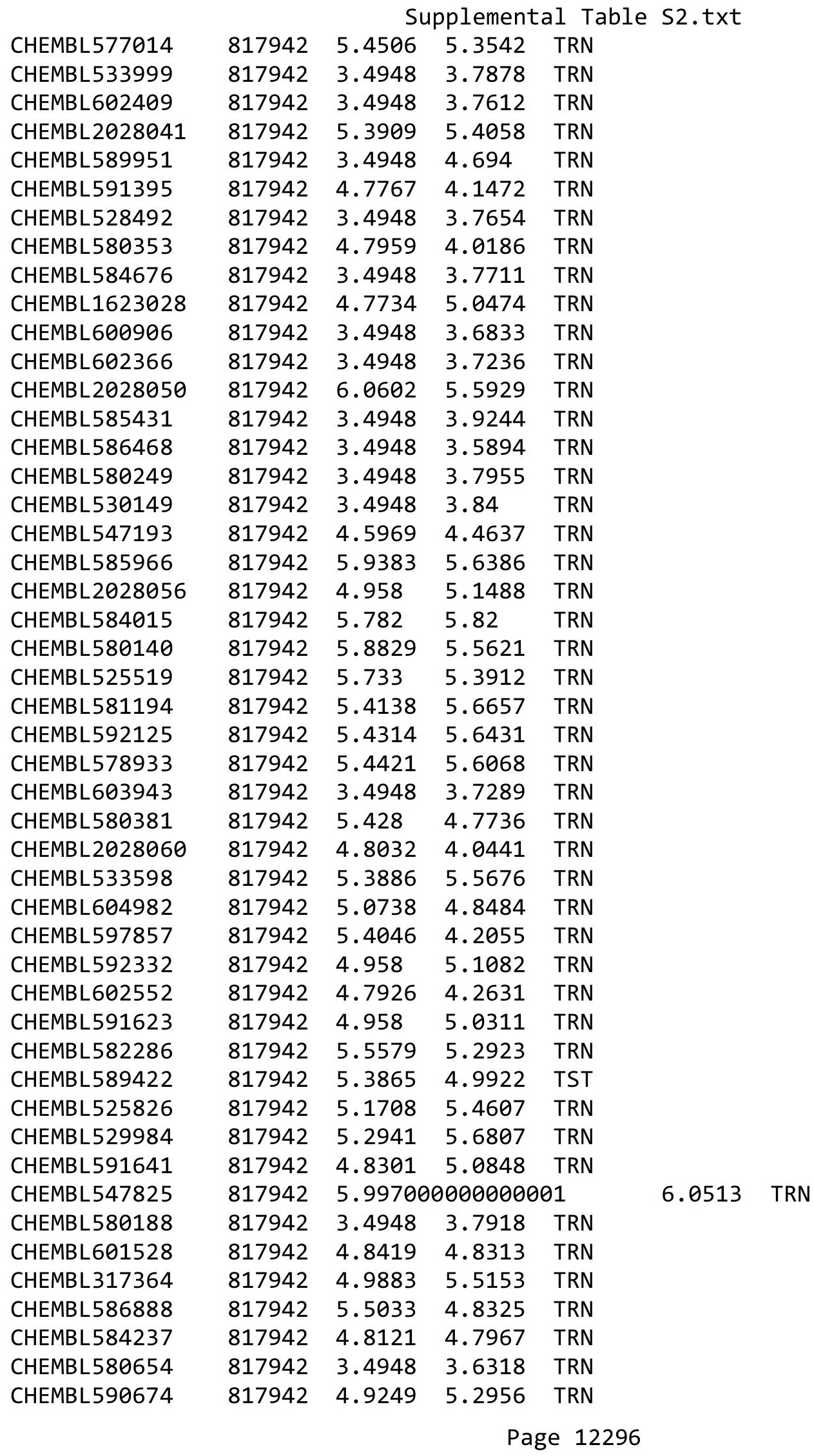


Supplemental Table S2.txt

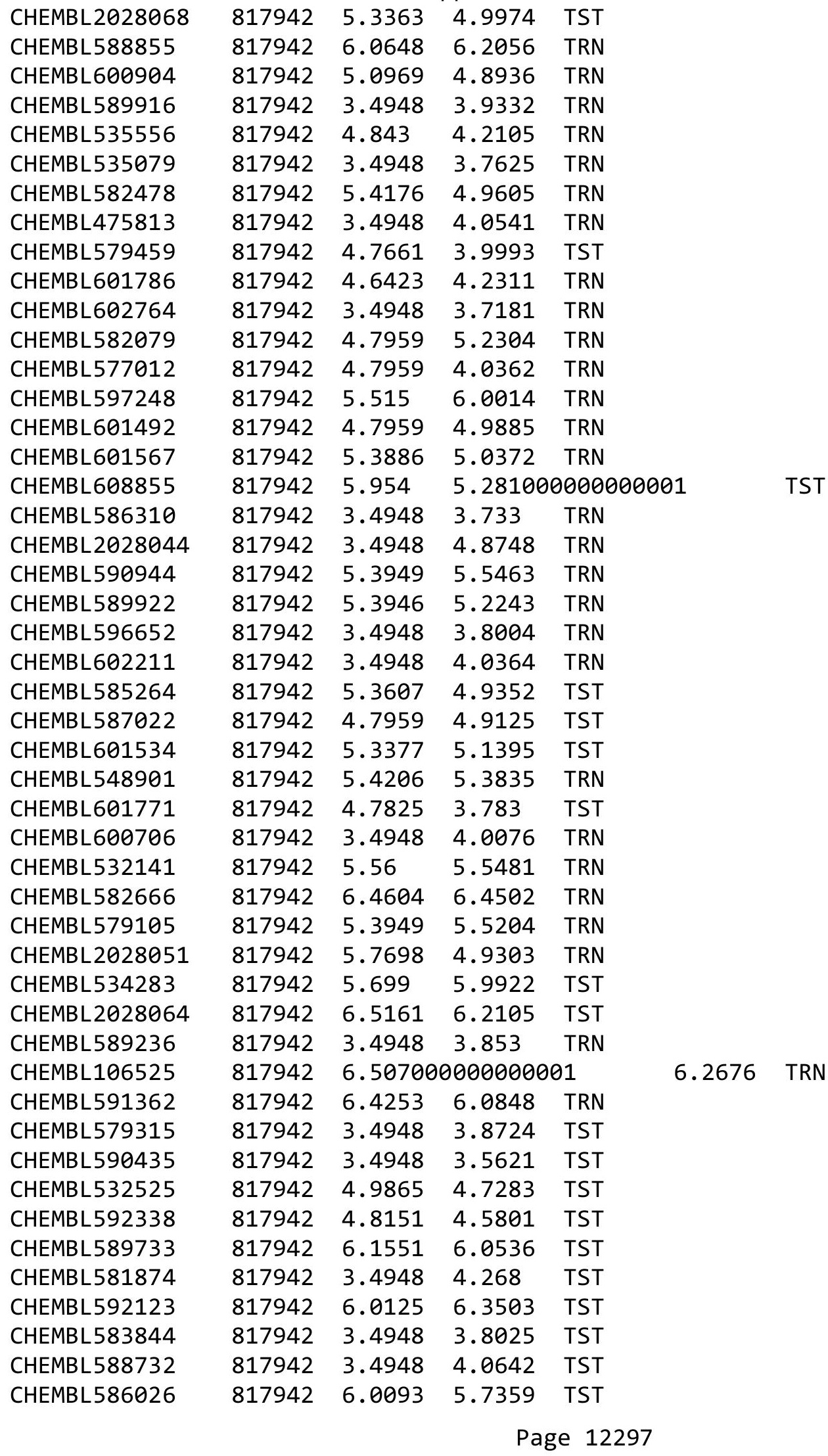




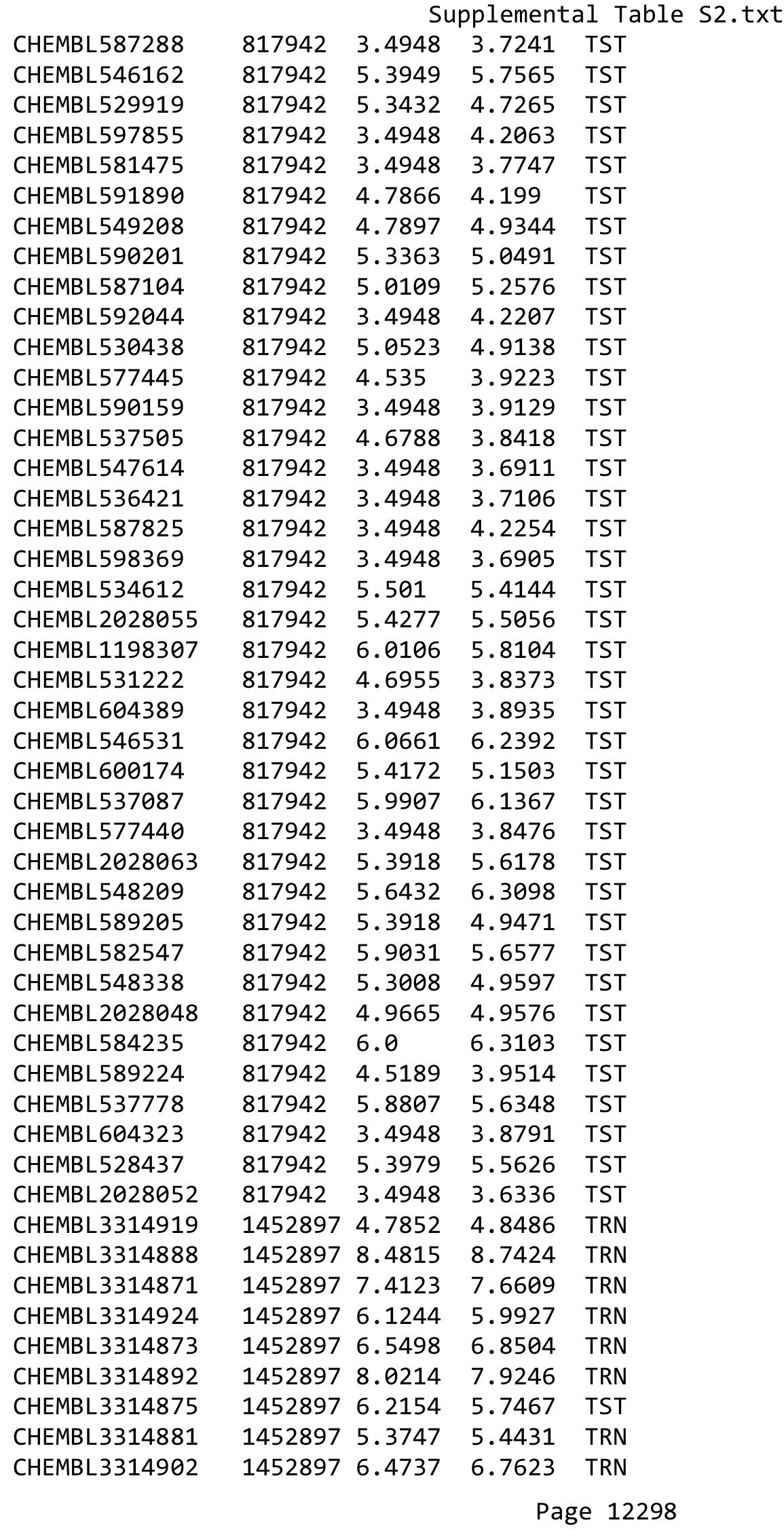


Supplemental Table S2.txt

\begin{tabular}{|c|c|c|c|c|c|}
\hline CHEMBL3314923 & 1452897 & 5.6517 & 6.2584 & TRN & \\
\hline CHEMBL3314906 & 1452897 & 6.0778 & 5.2512 & TST & \\
\hline CHEMBL3314887 & 1452897 & 8.383 & 7.9475 & TRN & \\
\hline CHEMBL3314903 & 1452897 & 7.9318 & 7.8407 & TRN & \\
\hline CHEMBL3314889 & 1452897 & 7.9469 & 7.6877 & TRN & \\
\hline CHEMBL3314908 & 1452897 & 6.9788 & 7.136 & TRN & \\
\hline CHEMBL136689 & 1452897 & 4.0 & 6.5417 & TST & \\
\hline CHEMBL3314920 & 1452897 & 6.7825 & 5.8575 & TST & \\
\hline CHEMBL3314928 & 1452897 & 4.7986 & 4.7043 & TRN & \\
\hline CHEMBL3314900 & 1452897 & 6.4908 & 6.8409 & TRN & \\
\hline CHEMBL3313941 & 1452897 & 6.8539 & 6.7685 & TRN & \\
\hline CHEMBL3314930 & 1452897 & 5.684 & 5.2962 & TRN & \\
\hline CHEMBL3314898 & 1452897 & 7.3344 & 7.1249 & TRN & \\
\hline CHEMBL3314911 & 1452897 & 6.8827 & 6.877000 & 2000000001 & TRN \\
\hline CHEMBL3314894 & 1452897 & 7.3851 & 7.4355 & TRN & \\
\hline CHEMBL324735 & 1452897 & 9.7959 & 5.2502 & TST & \\
\hline CHEMBL3314899 & 1452897 & 7.2457 & 7.1444 & TRN & \\
\hline CHEMBL3314905 & 1452897 & 6.2865 & 6.077000 & 0000000001 & TST \\
\hline CHEMBL3314915 & 1452897 & 4.7986 & 5.0067 & TRN & \\
\hline CHEMBL3314879 & 1452897 & 5.9245 & 5.5773 & TRN & \\
\hline CHEMBL3314886 & 1452897 & 4.2262 & 4.3414 & TST & \\
\hline CHEMBL3314874 & 1452897 & 7.057 & 7.2333 & TRN & \\
\hline CHEMBL3314901 & 1452897 & 6.058 & 5.8594 & TRN & \\
\hline CHEMBL3314897 & 1452897 & 7.2396 & 7.0061 & TRN & \\
\hline CHEMBL3314912 & 1452897 & 3.5229 & 3.4633 & TRN & \\
\hline CHEMBL3314883 & 1452897 & 6.4473 & 6.1795 & TRN & \\
\hline CHEMBL3314890 & 1452897 & 8.0241 & 7.5115 & TRN & \\
\hline CHEMBL3314917 & 1452897 & 4.58 & 5.1099 & TRN & \\
\hline CHEMBL3314926 & 1452897 & 4.8539 & 4.9376 & TRN & \\
\hline CHEMBL 3314872 & 1452897 & 6.7986 & 6.2847 & TRN & \\
\hline CHEMBL3314918 & 1452897 & 4.757 & 4.9651 & TRN & \\
\hline CHEMBL3314909 & 1452897 & 6.5607 & 6.6784 & TRN & \\
\hline CHEMBL3314895 & 1452897 & 8.0 & 7.7226 & TRN & \\
\hline CHEMBL3314925 & 1452897 & 5.2581 & 5.2917 & TRN & \\
\hline CHEMBL3314914 & 1452897 & 5.9245 & 6.335 & TRN & \\
\hline CHEMBL3314891 & 1452897 & 7.4056 & 7.1165 & TRN & \\
\hline CHEMBL 3314927 & 1452897 & 4.9355 & 4.8039 & TRN & \\
\hline CHEMBL3314916 & 1452897 & 6.3188 & 6.1088 & TRN & \\
\hline CHEMBL3314904 & 1452897 & 6.4935 & 6.877000 & 0000000001 & TRN \\
\hline CHEMBL3314913 & 1452897 & 7.6126 & 7.8101 & TRN & \\
\hline CHEMBL3314880 & 1452897 & 5.8697 & 5.9551 & TRN & \\
\hline CHEMBL3314884 & 1452897 & 5.6003 & 5.8487 & TST & \\
\hline CHEMBL3314878 & 1452897 & 4.7282 & 5.0259 & TST & \\
\hline CHEMBL3314885 & 1452897 & 5.5867 & 5.4826 & TRN & \\
\hline CHEMBL 3314882 & 1452897 & 6.2573 & 6.3712 & TRN & \\
\hline CHEMBL3314907 & 1452897 & 5.75200 & 000000000 & 4.9773 & TST \\
\hline CHEMBL3314929 & 1452897 & 4.5482 & 4.3158 & TRN & \\
\hline CHEMBL3314876 & 1452897 & 6.6234 & 6.7324 & TRN & \\
\hline
\end{tabular}


Supplemental Table S2.txt

\begin{tabular}{|c|c|c|c|c|}
\hline CHEMBL3314896 & 1452897 & 7.251 & 7.4746 & TRN \\
\hline CHEMBL3314877 & 1452897 & 6.1367 & 5.0314 & TST \\
\hline HEMBL 3314921 & 452897 & 4.752 & .2657 & ST \\
\hline HEMBL3314922 & 452897 & 4.8013 & .8053 & $\mathrm{ST}$ \\
\hline CHEMBL3314870 & 452897 & 5.5784 & .2397 & \\
\hline HEMBL3314910 & 452897 & 5.0605 & 3.5157 & ST \\
\hline HEMBL3314893 & 1452897 & 7.4559 & 7.5423 & \\
\hline CHEMBL72076 & 2506 & 7.4685 & 7.4934 & \\
\hline HEMBL307630 & 2506 & 7.3468 & 7.2717 & \\
\hline CHEMBL73794 & 2506 & 7.284 & 7.1789 & RN \\
\hline HEMBL441258 & 52506 & 7.3565 & 7.1516 & N \\
\hline HEMBL 76390 & 2506 & 7.5376 & 6.6386 & \\
\hline CHEMBL73772 & 2506 & 7.2518 & 7.0601 & \\
\hline HEMBL 308979 & 2506 & 7.4089 & 7.4736 & RN \\
\hline HEMBL308994 & 2506 & 7.0757 & 6.1064 & \\
\hline HEMBL 72069 & 52506 & 7.2676 & 7.2283 & N \\
\hline CHEMBL 306611 & 2506 & 7.2757 & 7.1917 & \\
\hline CHEMBL73485 & 2506 & 7.3768 & 7.3993 & RN \\
\hline HEMBL 72661 & 2506 & 6.4609 & 6.6805 & \\
\hline CHEMBL 73781 & 06 & 7.1427 & 7.1825 & RN \\
\hline HEMBL 306367 & 2506 & 7.0362 & 6.8162 & $2 \mathrm{~N}$ \\
\hline CHEMBL 308099 & 2506 & 7.4815 & 7.4261 & $\mathrm{~N}$ \\
\hline CHEMBL 72077 & 2506 & 7.1612 & 7.2057 & RI \\
\hline HEMBL72 & 06 & 7. & 7.0896 & RN \\
\hline HEMBL3E & 06 & 7.2676 & 7.2152 & RN \\
\hline HEMBL 388978 & 2506 & 7.2291 & 6.9273 & ST \\
\hline IHEMBL 73343 & 2506 & 7.2676 & 7.1917 & TRN \\
\hline LHEMBL 75952 & 2506 & 7.0757 & 7.1445 & RN \\
\hline HEMBL 30 & 06 & 4. & 6.3288 & RN \\
\hline CHEMBL 74883 & 2506 & 7.4949 & 7.2228 & TRN \\
\hline CHEMBL307219 & 2506 & 7.2076 & 7.0922 & TRN \\
\hline CHEMBL 76332 & 2506 & 7.0362 & 6.8307 & TRN \\
\hline HEMBL 763 & 2506 & 7.3979 & 7.4208 & RN \\
\hline HEMBL 74 & 06 & 7. & 7.4798 & ST \\
\hline CHEMBL 73080 & 2506 & 6.767 & 6.5982 & TRN \\
\hline HEMBL 73413 & 2506 & 6.7747 & 7.0466 & TRN \\
\hline CHEMBL 307152 & 52506 & 7.3098 & 7.3589 & TRN \\
\hline CHEMBL737 & & 6. & 6.9926 & ST \\
\hline CHEMBL430606 & 52506 & 7.3098 & 7.3302 & TRN \\
\hline CHEMBL 308252 & 52506 & 7.1739 & 7.0435 & TST \\
\hline CHEMBL307007 & 52506 & 7.2291 & 6.9456 & TRN \\
\hline CHEMBL73516 & 52506 & 4.699 & 6.7643 & RN \\
\hline CHEMBL306527 & & 6.2848 & 6.0138 & $\mathrm{RN}$ \\
\hline CHEMBL 76326 & 52506 & 7.4815 & 7.6471 & TRN \\
\hline CHEMBL310491 & 52506 & 7.0862 & 7.109 & RN \\
\hline CHEMBL307150 & 52506 & 7.5528 & 7.4083 & RN \\
\hline CHEMBL 73764 & 52506 & 7.2757 & 7.4812 & N \\
\hline CHEMBL308594 & 52506 & 7.0862 & 7.1087 & \\
\hline
\end{tabular}

Page 12300 


\begin{tabular}{|c|c|c|c|c|c|}
\hline & & \multicolumn{4}{|c|}{ Supplemental Table S2.txt } \\
\hline CHEMBL309343 & 52506 & 4.699 & 6.2604 & TRN & \\
\hline CHEMBL73832 & 52506 & 7.4202 & 6.5617 & TRN & \\
\hline CHEMBL306748 & 52506 & 7.1805 & 7.2414 & TST & \\
\hline CHEMBL75953 & 52506 & 6.9101 & 6.7722 & TRN & \\
\hline CHEMBL431181 & 52506 & 6.8097 & 6.153 & TRN & \\
\hline CHEMBL 75368 & 52506 & 7.3468 & 7.6648 & TRN & \\
\hline CHEMBL 73767 & 52506 & \multicolumn{3}{|c|}{6.172000000000001} & TST \\
\hline CHEMBL308479 & 52506 & 6.9957 & 7.0243 & TRN & \\
\hline CHEMBL 268368 & 52506 & 6.8539 & 7.0798 & TST & \\
\hline CHEMBL306034 & 52506 & 6.7212 & 7.1044 & TST & \\
\hline CHEMBL72808 & 52506 & 7.3279 & 6.76200 & 00000000005 & TRN \\
\hline CHEMBL 76499 & 52506 & 7.1192 & 6.54899 & 99999999995 & TRN \\
\hline CHEMBL 72754 & 52506 & 7.0177 & 7.0385 & TST & \\
\hline CHEMBL311851 & 52506 & 7.2007 & 7.2775 & TST & \\
\hline CHEMBL310260 & 52506 & 7.3279 & 7.0437 & TST & \\
\hline CHEMBL 308541 & 52506 & 7.301 & 7.391 & TRN & \\
\hline CHEMBL306501 & 52506 & 7.1135 & 7.2181 & TST & \\
\hline CHEMBL73499 & 52506 & 7.1487 & 6.3739 & TRN & \\
\hline CHEMBL306114 & 52506 & 7.3188 & 7.0322 & TRN & \\
\hline CHEMBL308116 & 52506 & 7.3279 & 7.0664 & TRN & \\
\hline CHEMBL263042 & 52506 & 4.699 & 6.4166 & TRN & \\
\hline CHEMBL73751 & 52506 & 7.4437 & 7.1091 & TST & \\
\hline CHEMBL306856 & 52506 & 7.3188 & 7.4341 & TST & \\
\hline CHEMBL 308542 & 52506 & 6.7282 & 6.2212 & TST & \\
\hline CHEMBL75984 & 52506 & 6.4056 & 6.4238 & TRN & \\
\hline CHEMBL312292 & 52506 & 7.2924 & 7.426 & TRN & \\
\hline CHEMBL 76464 & 52506 & 7.0223 & 7.4176 & TST & \\
\hline CHEMBL 75610 & 52506 & 6.8697 & 7.0501 & TST & \\
\hline CHEMBL 74289 & 52506 & 7.4202 & 7.4303 & TRN & \\
\hline CHEMBL306045 & 52506 & 7.0315 & 6.8227 & TRN & \\
\hline CHEMBL73718 & 52506 & 7.4559 & 7.2135 & TST & \\
\hline CHEMBL280605 & 155314 & 7.9208 & 7.9229 & TRN & \\
\hline CHEMBL 30617 & 155314 & 7.585 & 7.5926 & TRN & \\
\hline CHEMBL30331 & 155314 & 6.4949 & 8.6977 & TST & \\
\hline CHEMBL284192 & 155314 & 4.5086 & 7.1495 & TST & \\
\hline CHEMBL31154 & 155314 & 8.2218 & 8.2233 & TRN & \\
\hline CHEMBL286978 & 155314 & 8.699 & 8.6994 & TRN & \\
\hline CHEMBL 30425 & 155314 & 6.5376 & 6.5255 & TRN & \\
\hline CHEMBL 31922 & 155314 & 8.699 & 8.7766 & TRN & \\
\hline CHEMBL30928 & 155314 & 5.9718 & 5.9854 & TRN & \\
\hline CHEMBL 30832 & 155314 & 8.1549 & 8.1543 & TRN & \\
\hline CHEMBL281726 & 155314 & 7.9208 & 7.9176 & TRN & \\
\hline CHEMBL30845 & 155314 & 7.284 & 7.3014 & TRN & \\
\hline CHEMBL282186 & 155314 & 8.3979 & 8.4024 & TRN & \\
\hline CHEMBL283100 & 155314 & 8.1549 & 8.1748 & TRN & \\
\hline CHEMBL287068 & 155314 & 8.2218 & 8.2145 & TRN & \\
\hline CHEMBL 31043 & 155314 & 7.8539 & 7.8003 & TRN & \\
\hline CHEMBL418583 & 155314 & 8.0458 & 8.7716 & TST & \\
\hline
\end{tabular}




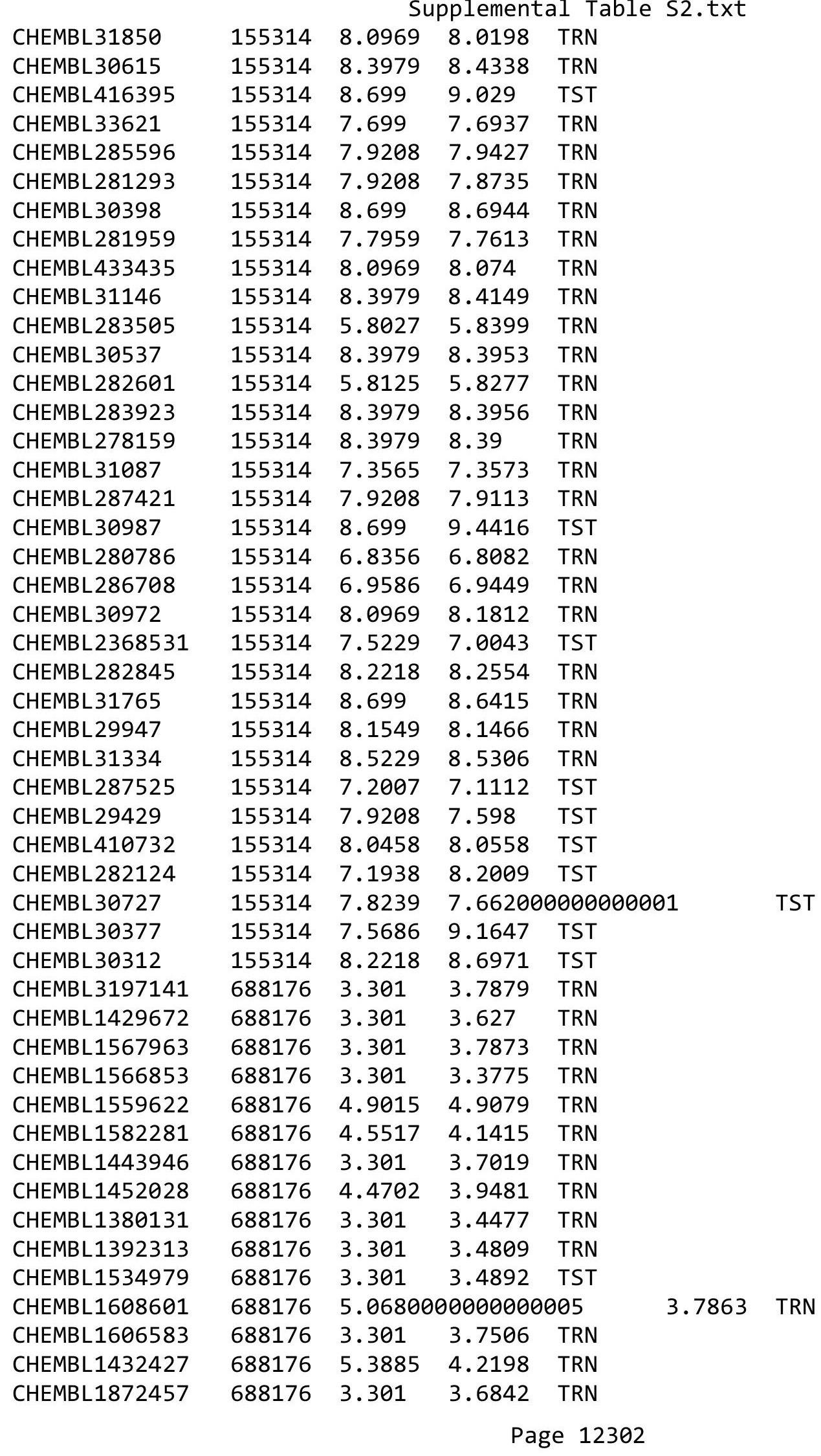




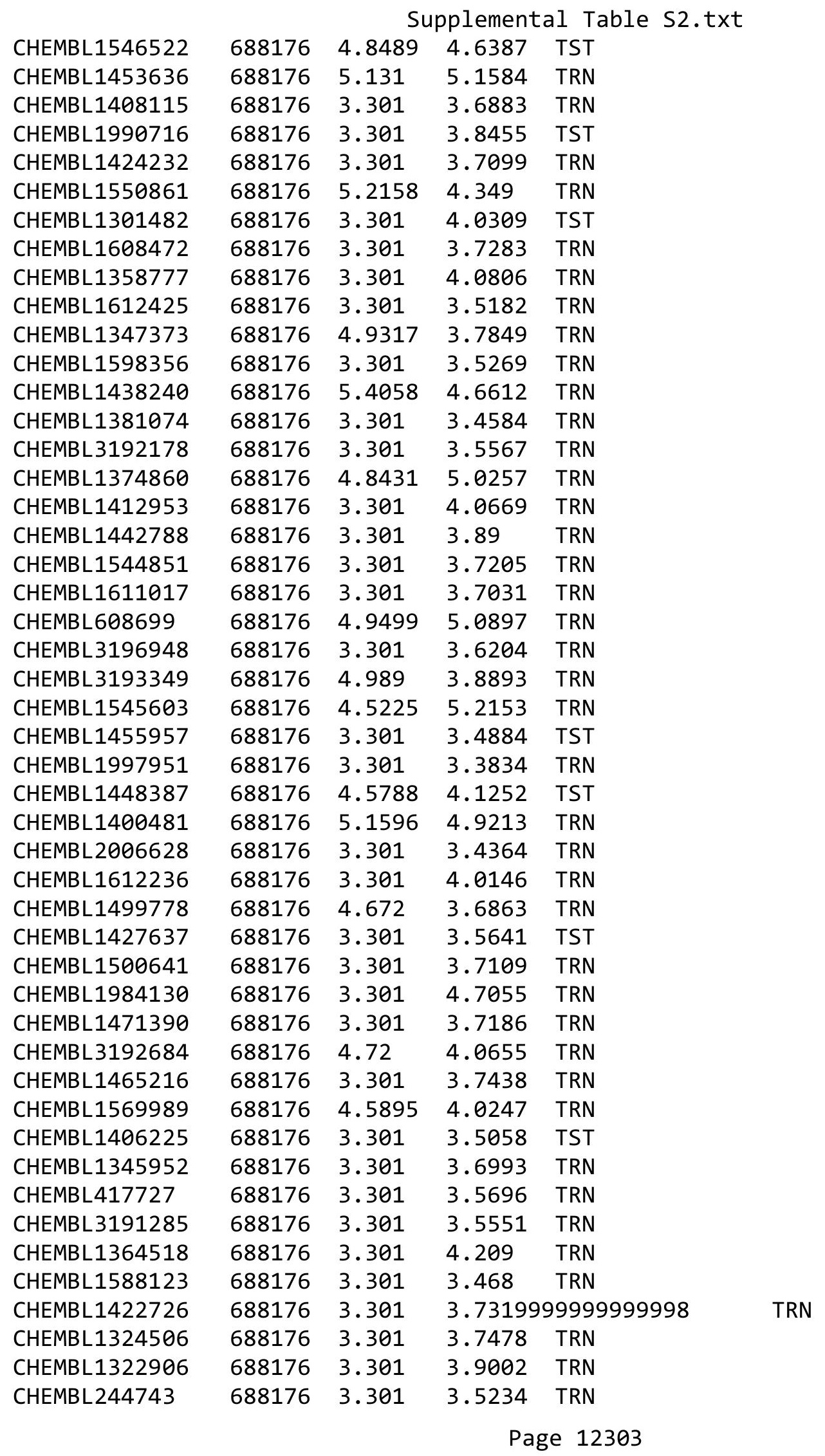




\begin{tabular}{|c|c|c|c|c|c|}
\hline & & \multicolumn{4}{|c|}{ Supplemental Table S2.txt } \\
\hline CHEMBL1503380 & 688176 & 3.301 & 4.1535 & TRN & \\
\hline CHEMBL3196067 & 688176 & 4.7365 & 3.9775 & TRN & \\
\hline CHEMBL1571704 & 688176 & 4.954 & 4.2052 & TRN & \\
\hline CHEMBL1499658 & 688176 & 4.8075 & 3.7527 & TRN & \\
\hline CHEMBL3194609 & 688176 & 4.573 & 4.5467 & TRN & \\
\hline CHEMBL3191714 & 688176 & 5.3467 & 4.2093 & TRN & \\
\hline CHEMBL1985664 & 688176 & 4.9204 & 4.0481 & TRN & \\
\hline CHEMBL1466570 & 688176 & 3.301 & 3.9542 & TRN & \\
\hline CHEMBL1451327 & 688176 & 4.4533 & 3.6355 & TST & \\
\hline CHEMBL1422255 & 688176 & 5.0263 & 3.5536 & TRN & \\
\hline CHEMBL1612805 & 688176 & 3.301 & 3.9054 & TRN & \\
\hline CHEMBL1557332 & 688176 & 3.301 & 3.7088 & TRN & \\
\hline CHEMBL1299907 & 688176 & 3.301 & 3.8693 & TRN & \\
\hline CHEMBL1478825 & 688176 & 3.301 & 3.4945 & TRN & \\
\hline CHEMBL1449112 & 688176 & 3.301 & 4.0588 & TRN & \\
\hline CHEMBL1510664 & 688176 & 3.301 & 4.0165 & TST & \\
\hline CHEMBL1543965 & 688176 & 3.301 & 3.5643 & TRN & \\
\hline CHEMBL1589626 & 688176 & 4.9613 & 3.9493 & TRN & \\
\hline CHEMBL1988401 & 688176 & 4.4385 & 4.1832 & TRN & \\
\hline CHEMBL1910223 & 688176 & 4.9579 & 4.4672 & TRN & \\
\hline CHEMBL3212461 & 688176 & 3.301 & 3.8063 & TST & \\
\hline CHEMBL1334768 & 688176 & 4.8389 & 3.7305 & TRN & \\
\hline CHEMBL3196407 & 688176 & 3.301 & 4.9441 & TRN & \\
\hline CHEMBL1423708 & 688176 & 3.301 & 3.7744 & TRN & \\
\hline CHEMBL1448001 & 688176 & 3.301 & 3.3668 & TRN & \\
\hline CHEMBL1496326 & 688176 & 4.8635 & 3.7377 & TRN & \\
\hline CHEMBL568739 & 688176 & 4.3036 & 3.64899 & 99999999996 & TRN \\
\hline CHEMBL1531298 & 688176 & 4.3647 & 3.4709 & TRN & \\
\hline CHEMBL1400479 & 688176 & 3.301 & 3.7259 & TST & \\
\hline CHEMBL1549128 & 688176 & 3.301 & 3.6956 & TST & \\
\hline CHEMBL1995112 & 688176 & 5.2707 & 5.2725 & TRN & \\
\hline CHEMBL1327721 & 688176 & 3.301 & 3.7707 & TRN & \\
\hline CHEMBL1368936 & 688176 & 3.301 & 3.6156 & TRN & \\
\hline CHEMBL1605045 & 688176 & 4.9515 & 3.8942 & TRN & \\
\hline CHEMBL1324805 & 688176 & 4.3176 & 3.8329 & TRN & \\
\hline CHEMBL1890161 & 688176 & 3.301 & 3.4621 & TRN & \\
\hline CHEMBL1557307 & 688176 & 3.301 & 3.5525 & TRN & \\
\hline CHEMBL175266 & 688176 & 5.4498 & 3.6121 & TRN & \\
\hline CHEMBL1373107 & 688176 & 3.301 & 3.4735 & TRN & \\
\hline CHEMBL1981992 & 688176 & 3.301 & 3.497 & TRN & \\
\hline CHEMBL1463647 & 688176 & 3.301 & 3.6245 & TST & \\
\hline CHEMBL1339149 & 688176 & 5.2798 & 5.1258 & TRN & \\
\hline CHEMBL1392552 & 688176 & 3.301 & 3.5502 & TRN & \\
\hline CHEMBL1392885 & 688176 & 4.3991 & 4.5639 & TST & \\
\hline CHEMBL1527416 & 688176 & 3.301 & 3.4845 & TRN & \\
\hline CHEMBL1602859 & 688176 & 5.0743 & 3.7966 & TRN & \\
\hline CHEMBL1518652 & 688176 & 3.301 & 3.6209 & TRN & \\
\hline CHEMBL1566632 & 688176 & 4.349 & 3.9462 & TRN & \\
\hline
\end{tabular}




\begin{tabular}{|c|c|c|c|c|c|}
\hline & & \multicolumn{4}{|c|}{ Supplemental Table S2.txt } \\
\hline CHEMBL1305427 & 688176 & 3.301 & 3.4778 & TRN & \\
\hline CHEMBL1466601 & 688176 & 3.301 & 3.6497 & TRN & \\
\hline CHEMBL1402454 & 688176 & 3.301 & 4.0449 & TRN & \\
\hline CHEMBL1527869 & 688176 & 5.0796 & 3.784 & TRN & \\
\hline CHEMBL1424358 & 688176 & 3.301 & 3.4404 & TRN & \\
\hline CHEMBL1973669 & 688176 & 3.301 & 3.6108 & TRN & \\
\hline CHEMBL 3208842 & 688176 & 3.301 & 3.9608 & TRN & \\
\hline CHEMBL3196976 & 688176 & 5.1796 & 5.7142 & TRN & \\
\hline CHEMBL244965 & 688176 & 4.4956 & 3.8266 & TRN & \\
\hline CHEMBL1478652 & 688176 & 4.7857 & 4.8809 & TRN & \\
\hline CHEMBL1463482 & 688176 & 3.301 & 3.4503 & TST & \\
\hline CHEMBL1302913 & 688176 & 3.301 & 3.6147 & TST & \\
\hline CHEMBL1329850 & 688176 & 4.7948 & 4.0463 & TRN & \\
\hline CHEMBL1391544 & 688176 & 3.301 & 3.88100 & 00000000002 & TRN \\
\hline CHEMBL1310318 & 688176 & 5.5368 & 5.1411 & TRN & \\
\hline CHEMBL1493396 & 688176 & 3.301 & 3.55 & TRN & \\
\hline CHEMBL1457747 & 688176 & 3.301 & 3.5517 & TRN & \\
\hline CHEMBL1991599 & 688176 & 4.9366 & 4.9814 & TRN & \\
\hline CHEMBL1487374 & 688176 & 3.301 & 3.8575 & TRN & \\
\hline CHEMBL1569541 & 688176 & 3.301 & 3.6429 & TST & \\
\hline CHEMBL1497287 & 688176 & 4.3203 & 4.5463 & TRN & \\
\hline CHEMBL 3197343 & 688176 & 3.301 & 3.7236 & TRN & \\
\hline CHEMBL1310221 & 688176 & 4.3721 & 3.7591 & TRN & \\
\hline CHEMBL1328836 & 688176 & 3.301 & 3.9641 & TRN & \\
\hline CHEMBL1598842 & 688176 & 3.301 & 3.6954 & TRN & \\
\hline CHEMBL1392651 & 688176 & 5.8952 & 5.6499 & TRN & \\
\hline CHEMBL1256360 & 688176 & 3.301 & 3.4873 & TRN & \\
\hline CHEMBL 3198618 & 688176 & 3.301 & 4.0095 & TRN & \\
\hline CHEMBL1489071 & 688176 & 5.4218 & 3.8853 & TRN & \\
\hline CHEMBL1324142 & 688176 & 3.301 & 3.4767 & TRN & \\
\hline CHEMBL3213857 & 688176 & 3.301 & 3.4892 & TRN & \\
\hline CHEMBL1539086 & 688176 & 3.301 & 3.4807 & TRN & \\
\hline CHEMBL1480798 & 688176 & 4.3133 & 3.9102 & TRN & \\
\hline CHEMBL1418971 & 688176 & 4.4406 & 3.7292 & TRN & \\
\hline CHEMBL 75913 & 688176 & 5.3227 & 4.5116 & TRN & \\
\hline CHEMBL1378546 & 688176 & 3.301 & 3.5748 & TRN & \\
\hline CHEMBL3198496 & 688176 & 4.8094 & 4.249 & TRN & \\
\hline CHEMBL 3109023 & 688176 & 3.301 & 4.3213 & TRN & \\
\hline CHEMBL1417290 & 688176 & 4.9993 & 4.7279 & TRN & \\
\hline CHEMBL1423690 & 688176 & 3.301 & 3.9382 & TRN & \\
\hline CHEMBL1390710 & 688176 & 5.3665 & 4.5093 & TRN & \\
\hline CHEMBL1541861 & 688176 & 3.301 & 3.9948 & TRN & \\
\hline CHEMBL1419335 & 688176 & 3.301 & 3.9275 & TRN & \\
\hline CHEMBL1382262 & 688176 & 3.301 & 3.6208 & TRN & \\
\hline CHEMBL1465693 & 688176 & 5.2904 & 5.0835 & TRN & \\
\hline CHEMBL1336959 & 688176 & 5.1689 & 4.9385 & TRN & \\
\hline CHEMBL1471698 & 688176 & 3.301 & 3.7648 & TRN & \\
\hline CHEMBL1369932 & 688176 & 4.9647 & 3.4593 & TRN & \\
\hline
\end{tabular}




\begin{tabular}{|c|c|c|c|c|c|}
\hline \multicolumn{6}{|c|}{ Supplemental Table S2.txt } \\
\hline CHEMBL3191022 & 688176 & 5.1537 & 4.8854 & TRN & \\
\hline CHEMBL1374511 & 688176 & 3.301 & 3.8296 & TRN & \\
\hline CHEMBL75412 & 688176 & 4.843 & 4.6982 & TST & \\
\hline CHEMBL1991234 & 688176 & 3.301 & 3.9741 & TST & \\
\hline CHEMBL1462570 & 688176 & 4.4036 & 3.8979 & TST & \\
\hline CHEMBL1453954 & 688176 & 3.301 & 3.4416 & TST & \\
\hline CHEMBL3198910 & 688176 & 3.301 & 3.6165 & TST & \\
\hline CHEMBL1535503 & 688176 & 3.301 & 3.3857 & TST & \\
\hline CHEMBL1605845 & 688176 & 4.4949 & 4.391999 & 99999999995 & TST \\
\hline CHEMBL3192031 & 688176 & 3.301 & 3.6593 & TST & \\
\hline CHEMBL339561 & 688176 & 3.301 & 3.5559 & TST & \\
\hline CHEMBL1581158 & 688176 & 4.6338 & 4.0133 & TST & \\
\hline CHEMBL1374283 & 688176 & 5.1372 & 3.9622 & TST & \\
\hline CHEMBL1452986 & 688176 & 3.301 & 3.88 & TST & \\
\hline CHEMBL1304194 & 688176 & 3.301 & 3.5492 & TST & \\
\hline CHEMBL1309195 & 688176 & 3.301 & 3.8753 & TST & \\
\hline CHEMBL1562260 & 688176 & 4.8973 & 3.8943 & TST & \\
\hline CHEMBL1550366 & 688176 & 4.7774 & 3.7964 & TST & \\
\hline CHEMBL1303585 & 688176 & 3.301 & 3.3775 & TST & \\
\hline CHEMBL1708832 & 688176 & 4.6331 & 5.01 & TST & \\
\hline CHEMBL3193519 & 688176 & 3.301 & 3.9074 & TST & \\
\hline CHEMBL1567974 & 688176 & 3.301 & 3.4752 & TST & \\
\hline CHEMBL3191780 & 688176 & 3.301 & 3.9066 & TST & \\
\hline CHEMBL1335505 & 688176 & 3.301 & 3.3854 & TST & \\
\hline CHEMBL1376590 & 688176 & 3.301 & 3.515 & TST & \\
\hline CHEMBL3197242 & 688176 & 4.7083 & 4.5489 & TST & \\
\hline CHEMBL1999046 & 688176 & 3.301 & 3.6147 & TST & \\
\hline CHEMBL1465769 & 688176 & 3.301 & 3.6082 & TST & \\
\hline CHEMBL1571309 & 688176 & 3.301 & 3.5392 & TST & \\
\hline CHEMBL 250450 & 688176 & 4.6716 & 4.5139 & TST & \\
\hline CHEMBL530049 & 688176 & 3.301 & 4.0978 & TST & \\
\hline CHEMBL1399191 & 688176 & 4.552 & 4.1829 & TST & \\
\hline CHEMBL 3686287 & 1528084 & 6.6819 & 6.6987 & TRN & \\
\hline CHEMBL3686343 & 1528084 & 8.3098 & 8.3977 & TRN & \\
\hline CHEMBL3686286 & 1528084 & 6.0 & 5.8812 & TRN & \\
\hline CHEMBL3686315 & 1528084 & 7.9586 & 7.9511 & TRN & \\
\hline CHEMBL 3686282 & 1528084 & 6.0 & 6.1358 & TRN & \\
\hline CHEMBL 3686308 & 1528084 & 8.0862 & 7.9758 & TRN & \\
\hline CHEMBL3686303 & 1528084 & 8.4318 & 8.9962 & TST & \\
\hline CHEMBL 3686304 & 1528084 & 9.3979 & 10.2117 & TST & \\
\hline CHEMBL 3686341 & 1528084 & 8.4437 & 8.6312 & TST & \\
\hline CHEMBL3686309 & 1528084 & 6.9914 & 7.1192 & TRN & \\
\hline CHEMBL 3686342 & 1528084 & 6.0 & 6.1312 & TRN & \\
\hline CHEMBL3234699 & 1528084 & 7.699 & 7.7235 & TRN & \\
\hline CHEMBL 3953556 & 1528084 & 8.3565 & 8.3615 & TRN & \\
\hline CHEMBL3686337 & 1528084 & 7.6021 & 7.7254 & TRN & \\
\hline CHEMBL 3686324 & 1528084 & 8.7447 & 8.818 & TRN & \\
\hline CHEMBL3686299 & 1528084 & 7.8539 & 7.8248 & TRN & \\
\hline
\end{tabular}


Supplemental Table S2.txt

\begin{tabular}{|c|c|c|c|c|}
\hline CHEMBL3686316 & 1528084 & 6.5391 & 7.5599 & TST \\
\hline CHEMBL3686291 & 1528084 & 7.8861 & 7.8459 & TRN \\
\hline CHEMBL3686300 & 1528084 & 8.2218 & 8.1559 & TRN \\
\hline CHEMBL3686319 & 1528084 & 7.6778 & 7.7563 & TRN \\
\hline CHEMBL3686333 & 1528084 & 8.4815 & 8.545 & TRN \\
\hline CHEMBL3686297 & 1528084 & 6.0 & 5.6373 & TRN \\
\hline CHEMBL3686329 & 1528084 & 9.5229 & 9.3731 & TRN \\
\hline CHEMBL3686318 & 1528084 & 7.3665 & \multicolumn{2}{|c|}{ 7.292999999999999 } \\
\hline CHEMBL3686338 & 1528084 & 6.9706 & 7.0846 & TRN \\
\hline CHEMBL3686327 & 1528084 & 7.0706 & 7.0867 & TRN \\
\hline CHEMBL3686313 & 1528084 & 7.4437 & 9.1629 & TST \\
\hline CHEMBL3686295 & 1528084 & 6.0 & 6.1168 & TRN \\
\hline CHEMBL3686331 & 1528084 & 8.9586 & 8.8257 & TRN \\
\hline CHEMBL3686288 & 1528084 & 6.0 & 6.2623 & TRN \\
\hline CHEMBL3686339 & 1528084 & 8.8861 & 8.9014 & TRN \\
\hline CHEMBL3686328 & 1528084 & 7.6576 & 7.5841 & TRN \\
\hline CHEMBL3686317 & 1528084 & 7.4685 & 7.3559 & TRN \\
\hline CHEMBL3686307 & 1528084 & 8.3372 & 8.2651 & TRN \\
\hline CHEMBL3686323 & 1528084 & 9.0458 & 9.112 & TRN \\
\hline CHEMBL3686325 & 1528084 & 7.4685 & 7.4883 & TRN \\
\hline CHEMBL3686284 & 1528084 & 6.0 & 6.0478 & TRN \\
\hline CHEMBL3686289 & 1528084 & 7.2757 & 7.2579 & TRN \\
\hline CHEMBL3686311 & 1528084 & 8.8861 & 8.8689 & TRN \\
\hline CHEMBL3686292 & 1528084 & 6.0 & 5.8659 & TRN \\
\hline CHEMBL3686306 & 1528084 & 7.2076 & 7.189 & TRN \\
\hline CHEMBL3686285 & 1528084 & 6.0 & 5.9601 & TRN \\
\hline CHEMBL3686290 & 1528084 & 8.301 & 8.3021 & TRN \\
\hline CHEMBL3686310 & 1528084 & 7.7959 & 7.7141 & TRN \\
\hline CHEMBL3686298 & 1528084 & 8.1308 & 8.2618 & TRN \\
\hline CHEMBL3686336 & 1528084 & 6.6799 & 6.4953 & TST \\
\hline CHEMBL3686326 & 1528084 & 8.9208 & 8.631 & TST \\
\hline CHEMBL3686332 & 1528084 & 9.301 & 9.1145 & TST \\
\hline CHEMBL 3686340 & 1528084 & 7.6021 & 8.1471 & TST \\
\hline CHEMBL3639852 & 1528084 & 7.6198 & 7.4206 & TST \\
\hline CHEMBL3686320 & 1528084 & 6.9393 & 7.0 & TST \\
\hline CHEMBL3686301 & 1528084 & 7.585 & 7.6106 & TST \\
\hline CHEMBL3686305 & 1528084 & 7.3468 & 7.9827 & TST \\
\hline CHEMBL3686302 & 1528084 & 8.2596 & 8.9634 & TST \\
\hline CHEMBL3908434 & 1617697 & 4.4559 & 4.475 & TRN \\
\hline CHEMBL3937258 & 1617697 & 3.0 & 4.1047 & TST \\
\hline CHEMBL3919412 & 1617697 & 4.3188 & 4.2516 & TRN \\
\hline CHEMBL3894125 & 1617697 & 3.0 & 4.0429 & TST \\
\hline CHEMBL3947125 & 1617697 & 4.4949 & 4.4804 & TRN \\
\hline CHEMBL3983061 & 1617697 & 4.2007 & 4.1353 & TRN \\
\hline CHEMBL3907505 & 1617697 & 4.2147 & 4.2406 & TRN \\
\hline CHEMBL3912547 & 1617697 & 4.6576 & 4.6591 & TRN \\
\hline CHEMBL3913878 & 1617697 & 5.4202 & 5.3949 & TRN \\
\hline CHEMBL3934460 & 1617697 & 4.6383 & 4.6976 & TRN \\
\hline
\end{tabular}


Supplemental Table S2.txt

\begin{tabular}{|c|c|c|c|c|}
\hline the & 617697 & & & \\
\hline & 617697 & 3.0 & 3.0055 & \\
\hline 371 & & 21 & & \\
\hline AEMBL3978029 & 7697 & & & \\
\hline AEMBL3980253 & 617697 & & 575 & \\
\hline HEMBL3904891 & 617697 & 4.7447 & 7084 & \\
\hline HEMBL3933283 & & & & \\
\hline IFMRI 39 & & & & \\
\hline AEMBL3952045 & 697 & 4.585 & 5757 & \\
\hline HEMBL3954893 & 617697 & 5.0 & 431 & \\
\hline HEMBL3928317 & 697 & 4.95 & & \\
\hline EMBL39 & 597 & & & \\
\hline AEMBL3S & & & & \\
\hline HEMBL 39 & & & & \\
\hline HEMBL396 & 97 & 28 & & \\
\hline IEMBL 394 & 597 & 4. & 41 & \\
\hline AEMBL3S & & & & \\
\hline HEMBL3S & & & & \\
\hline HEMBL39 & & & & \\
\hline AEMBL3S & & & & \\
\hline$F=M B$ & 97 & & & NIV \\
\hline AEMBL: & & & & RN \\
\hline HEMBL; & & & & \\
\hline 320 & & 6. & & \\
\hline AEMBL 3924 & & & & I RIV \\
\hline HEMBL3S & 997 & & & RN \\
\hline AEMBL & & & & No \\
\hline HFMBI 36 & 97 & & & \\
\hline HEMBL3943318 & & & & I \\
\hline HEMBL39797 & & & & IK \\
\hline HEMBL 389 & & & 977 & RN \\
\hline HEMBL & & & 25 & RN \\
\hline$\triangle 5 M P$ & & & 79 & 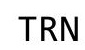 \\
\hline HEMBL3115908 & & & 65 & is \\
\hline HEMBL 3040216 & & & & TS \\
\hline HEMBL39 & & & & TST \\
\hline HFMRI & & & $\partial 9$ & ГST \\
\hline HEMBL3 & & & & TST \\
\hline HEMBL3947198 & 597 & 4. & 407 & TST \\
\hline HEMBL390 & 97 & & 101 & TST \\
\hline HEMBL37 & 29 & & 64 & \\
\hline HEMBL 2409208 & & 7.2 & & NIV \\
\hline HEMBL3704430 & 829 & 6.2 & 165 & RN \\
\hline HEMBL2409215 & 528829 & 6.5346 & 573 & TS \\
\hline $\mathrm{MBI} 3$ & & & & IRN \\
\hline HEMBL37 & & & & \\
\hline HEMBL 37 & 3829 & 5.7696 & .6984 & \\
\hline HEMBL3704425 & 1528829 & 6.0605 & 5.8544 & \\
\hline
\end{tabular}

Page 12308 
Supplemental Table S2.txt

\begin{tabular}{|c|c|c|c|c|c|}
\hline CHEMBL 3704411 & 1528829 & 6.2588 & 6.2236 & TRN & \\
\hline CHEMBL 3704421 & 1528829 & 5.2248 & 5.2401 & TRN & \\
\hline CHEMBL 3704444 & 1528829 & 5.7878 & 6.4446 & TST & \\
\hline CHEMBL 2409214 & 1528829 & 6.5143 & 6.4619 & TRN & \\
\hline CHEMBL3704409 & 1528829 & 5.4828 & 5.7224 & TST & \\
\hline CHEMBL 3704439 & 1528829 & 5.4191 & 5.6785 & TRN & \\
\hline CHEMBL 3704412 & 1528829 & 5.0405 & 4.9723 & TRN & \\
\hline CHEMBL3341979 & 1528829 & 7.426 & 7.6589 & TRN & \\
\hline CHEMBL 3704403 & 1528829 & 6.2741 & 6.3131 & TRN & \\
\hline CHEMBL3704442 & 1528829 & 5.0691 & 5.09 & TRN & \\
\hline CHEMBL 3704429 & 1528829 & 6.1785 & 6.1172 & TRN & \\
\hline CHEMBL 3704454 & 1528829 & 6.5702 & 6.5617 & TRN & \\
\hline CHEMBL 3704432 & 1528829 & 5.6364 & 5.5366 & TRN & \\
\hline CHEMBL 3704443 & 1528829 & 5.1463 & 5.1451 & TRN & \\
\hline CHEMBL3704436 & 1528829 & 5.2255 & 5.2535 & TST & \\
\hline CHEMBL 2409213 & 1528829 & 7.3716 & 7.3567 & TRN & \\
\hline CHEMBL3704422 & 1528829 & 5.8928 & 5.9512 & TRN & \\
\hline CHEMBL 3704402 & 1528829 & 6.4486 & 6.5712 & TRN & \\
\hline CHEMBL 3704400 & 1528829 & 5.7144 & 5.7666 & TRN & \\
\hline CHEMBL 3704417 & 1528829 & 5.1739 & 5.1805 & TRN & \\
\hline CHEMBL 3704426 & 1528829 & 5.699 & 5.8005 & TRN & \\
\hline CHEMBL 3704424 & 1528829 & 5.3307 & 5.5501 & TRN & \\
\hline CHEMBL 3704419 & 1528829 & 6.1713 & 6.1942 & TRN & \\
\hline CHEMBL 3704407 & 1528829 & 6.0783 & 6.1488 & TRN & \\
\hline CHEMBL 3704427 & 1528829 & 5.8097 & 5.6616 & TRN & \\
\hline CHEMBL 3704441 & 1528829 & 5.8601 & 5.8592 & TRN & \\
\hline CHEMBL 3704401 & 1528829 & 6.1403 & 6.1269 & TRN & \\
\hline CHEMBL 2409209 & 1528829 & 6.8327 & 6.5814 & TRN & \\
\hline CHEMBL 3704453 & 1528829 & 5.9469 & 5.3821 & TST & \\
\hline CHEMBL 2409210 & 1528829 & 7.301 & 7.3194 & TRN & \\
\hline CHEMBL 3704431 & 1528829 & 5.5784 & 5.6364 & TRN & \\
\hline CHEMBL 2409207 & 1528829 & 6.5969 & 6.6748 & TRN & \\
\hline CHEMBL 3704420 & 1528829 & 6.4711 & 6.3862 & TRN & \\
\hline CHEMBL 3704408 & 1528829 & 5.7305 & 5.7689 & TRN & \\
\hline CHEMBL 3704438 & 1528829 & 5.3768 & 5.3489 & TRN & \\
\hline CHEMBL 3704415 & 1528829 & 6.16299 & 999999999 & 99 & 6.1085 \\
\hline CHEMBL 3704435 & 1528829 & 5.2218 & 5.3383 & TRN & \\
\hline CHEMBL 3704413 & 1528829 & 6.58 & 7.2692 & TST & \\
\hline CHEMBL 3704410 & 1528829 & 5.8125 & 5.7563 & TRN & \\
\hline CHEMBL 3704440 & 1528829 & 5.3487 & 5.2085 & TRN & \\
\hline CHEMBL 3704433 & 1528829 & 5.5817 & 5.4787 & TST & \\
\hline CHEMBL 3704437 & 1528829 & 5.6289 & 5.7086 & TRN & \\
\hline CHEMBL 3704418 & 1528829 & 5.9914 & 5.5851 & TST & \\
\hline CHEMBL 3704406 & 1528829 & 5.4962 & 5.8288 & TST & \\
\hline CHEMBL 3704405 & 1528829 & 5.6716 & 6.4009 & TST & \\
\hline CHEMBL 3704434 & 1528829 & 5.4522 & 5.0014 & TST & \\
\hline CHEMBL 3704455 & 1528829 & 5.8508 & 7.0011 & TST & \\
\hline CHEMBL 3704428 & 1528829 & 6.0438 & 5.6615 & TST & \\
\hline
\end{tabular}




\begin{tabular}{|c|c|c|c|c|c|}
\hline \multirow[b]{2}{*}{ CHEMBL3704399 } & \multicolumn{5}{|c|}{ Supplemental Table S2.txt } \\
\hline & 1528829 & 6.3516 & 6.2277 & TST & \\
\hline CHEMBL1964290 & 809267 & 6.0 & 5.8944 & TRN & \\
\hline CHEMBL 2003768 & 809267 & 4.1 & 4.2039 & TRN & \\
\hline CHEMBL213505 & 809267 & 5.1 & 4.3859 & TRN & \\
\hline CHEMBL1982880 & 809267 & 4.1 & 4.7241 & TRN & \\
\hline CHEMBL1987034 & 809267 & 7.6 & 8.1224 & TRN & \\
\hline CHEMBL1993941 & 809267 & 4.1 & 4.1556 & TRN & \\
\hline CHEMBL 377383 & 809267 & 4.1 & 3.9581 & TRN & \\
\hline CHEMBL578061 & 809267 & 5.4 & 5.5599 & TRN & \\
\hline CHEMBL 2005886 & 809267 & 5.2 & 5.4799 & TRN & \\
\hline CHEMBL481491 & 809267 & 4.1 & 4.2705 & TST & \\
\hline CHEMBL1682345 & 809267 & 6.3 & 6.3559 & TRN & \\
\hline CHEMBL1973142 & 809267 & 6.1 & 5.4513 & TRN & \\
\hline CHEMBL1973145 & 809267 & 4.1 & 4.1006 & TRN & \\
\hline CHEMBL1982924 & 809267 & 5.2 & 5.0097 & TRN & \\
\hline CHEMBL 2005936 & 809267 & 6.7 & 6.789 & TRN & \\
\hline CHEMBL1807515 & 809267 & 8.2 & 7.6356 & TRN & \\
\hline CHEMBL1971141 & 809267 & 4.1 & 4.13899 & 9999999999 & TRN \\
\hline CHEMBL1995813 & 809267 & 6.8 & 7.6159 & TRN & \\
\hline CHEMBL1979718 & 809267 & 4.1 & 4.3335 & TRN & \\
\hline CHEMBL206236 & 809267 & 4.1 & 4.0658 & TRN & \\
\hline CHEMBL523823 & 809267 & 4.1 & 4.5395 & TST & \\
\hline CHEMBL 244378 & 809267 & 7.1 & 7.6914 & TRN & \\
\hline CHEMBL 2001957 & 809267 & 4.1 & 4.0121 & TRN & \\
\hline CHEMBL1969372 & 809267 & 4.1 & 4.1096 & TRN & \\
\hline CHEMBL1990583 & 809267 & 7.8 & 4.6729 & TRN & \\
\hline CHEMBL1986943 & 809267 & 7.4 & 7.9308 & TRN & \\
\hline CHEMBL 2006263 & 809267 & 4.1 & 4.8856 & TST & \\
\hline CHEMBL1993584 & 809267 & 5.1 & 4.133 & TRN & \\
\hline CHEMBL1986263 & 809267 & 7.7 & 7.019 & TRN & \\
\hline CHEMBL 2000114 & 809267 & 5.4 & 5.5964 & TRN & \\
\hline CHEMBL 210618 & 809267 & 4.1 & 4.3945 & TRN & \\
\hline CHEMBL1975647 & 809267 & 6.4 & 6.5382 & TRN & \\
\hline CHEMBL1968380 & 809267 & 4.1 & 4.1763 & TRN & \\
\hline CHEMBL1964644 & 809267 & 4.1 & 4.68 & TRN & \\
\hline CHEMBL1981782 & 809267 & 4.1 & 4.7524 & TRN & \\
\hline CHEMBL1977681 & 809267 & 5.7 & 5.3187 & TRN & \\
\hline CHEMBL1970142 & 809267 & 4.1 & 4.0235 & TRN & \\
\hline CHEMBL1990912 & 809267 & 6.3 & 5.8972 & TRN & \\
\hline CHEMBL1988163 & 809267 & 7.3 & 7.62299 & 9999999999 & TRN \\
\hline CHEMBL1995592 & 809267 & 6.2 & 5.3816 & TST & \\
\hline CHEMBL1975128 & 809267 & 7.5 & 7.1096 & TRN & \\
\hline CHEMBL 2006493 & 809267 & 4.1 & 4.1636 & TST & \\
\hline CHEMBL1982541 & 809267 & 4.1 & 4.228 & TRN & \\
\hline CHEMBL1996923 & 809267 & 6.5 & 4.2432 & TST & \\
\hline CHEMBL1983449 & 809267 & 4.1 & 4.0361 & TRN & \\
\hline CHEMBL1992323 & 809267 & 4.1 & 4.3608 & TRN & \\
\hline CHEMBL1969735 & 809267 & 4.1 & 4.0034 & TRN & \\
\hline
\end{tabular}




\begin{tabular}{|c|c|c|c|c|c|}
\hline \multirow[b]{2}{*}{ CHEMBL 2003524} & \multirow[b]{2}{*}{809267} & \\
\hline & & 5.5 & 5.8285 & TST & \\
\hline CHEMBL 2002649 & 809267 & 6.5 & 6.9877 & TRN & \\
\hline CHEMBL437747 & 809267 & 6.0 & 5.8056 & TRN & \\
\hline CHEMBL1995172 & 809267 & 4.1 & 4.3625 & TST & \\
\hline CHEMBL507936 & 809267 & 4.1 & 4.0755 & TRN & \\
\hline CHEMBL104264 & 809267 & 5.1 & 4.7398 & TST & \\
\hline CHEMBL1994321 & 809267 & 4.1 & 4.3113 & TRN & \\
\hline CHEMBL1997129 & 809267 & 6.6 & 6.2053 & TRN & \\
\hline CHEMBL229799 & 809267 & 7.4 & 7.5668 & TRN & \\
\hline CHEMBL1984788 & 809267 & 4.1 & 4.3354 & TRN & \\
\hline CHEMBL451964 & 809267 & 4.1 & 4.1196 & TRN & \\
\hline CHEMBL1964307 & 809267 & 5.2 & 5.1879 & TRN & \\
\hline CHEMBL2000508 & 809267 & 4.1 & 3.9727 & TRN & \\
\hline CHEMBL1971694 & 809267 & 4.1 & 4.3519 & TST & \\
\hline CHEMBL2001547 & 809267 & 4.1 & 3.9803 & TRN & \\
\hline CHEMBL 210928 & 809267 & 4.1 & 3.9608 & TRN & \\
\hline CHEMBL1994361 & 809267 & 4.1 & 4.2093 & TRN & \\
\hline CHEMBL1986603 & 809267 & 4.1 & 4.3979 & TST & \\
\hline CHEMBL1972840 & 809267 & 5.6 & 5.7954 & TRN & \\
\hline CHEMBL1977148 & 809267 & 4.1 & 4.1044 & TRN & \\
\hline CHEMBL2003286 & 809267 & 4.1 & $4.6530 e$ & 20000000005 & TRN \\
\hline CHEMBL1992306 & 809267 & 4.1 & 4.2794 & TRN & \\
\hline CHEMBL2002165 & 809267 & 4.1 & 4.3302 & TRN & \\
\hline CHEMBL2001668 & 809267 & 4.1 & 4.4124 & TST & \\
\hline CHEMBL1979318 & 809267 & 5.1 & 4.7714 & TRN & \\
\hline CHEMBL206382 & 809267 & 4.1 & 3.8555 & TRN & \\
\hline CHEMBL1998585 & 809267 & 5.2 & 4.7014 & TRN & \\
\hline CHEMBL127898 & 809267 & 4.1 & 4.6092 & TST & \\
\hline CHEMBL519697 & 809267 & 4.1 & 4.6713 & TST & \\
\hline CHEMBL2004934 & 809267 & 5.5 & 4.7177 & TRN & \\
\hline CHEMBL1970369 & 809267 & 4.1 & 4.1823 & TRN & \\
\hline CHEMBL2001485 & 809267 & 4.1 & 4.0553 & TRN & \\
\hline CHEMBL1966425 & 809267 & 4.1 & $5.2520 e$ & 0000000001 & TRN \\
\hline CHEMBL1984363 & 809267 & 5.4 & 5.1229 & TRN & \\
\hline CHEMBL1978099 & 809267 & 6.3 & 6.8761 & TRN & \\
\hline CHEMBL1968070 & 809267 & 5.8 & 5.7838 & TRN & \\
\hline CHEMBL1988608 & 809267 & 6.3 & 5.0086 & TRN & \\
\hline CHEMBL184847 & 809267 & 4.1 & 4.2733 & TRN & \\
\hline CHEMBL1984367 & 809267 & 4.1 & 4.3708 & TRN & \\
\hline CHEMBL178737 & 809267 & 6.0 & 5.3994 & TST & \\
\hline CHEMBL226898 & 809267 & 7.5 & 7.3723 & TRN & \\
\hline CHEMBL1982563 & 809267 & 4.1 & 4.038 & TRN & \\
\hline CHEMBL539474 & 809267 & 4.1 & 4.8291 & TST & \\
\hline CHEMBL575824 & 809267 & 4.1 & $5.3720 e$ & 0000000001 & TRN \\
\hline CHEMBL1988387 & 809267 & 4.1 & 4.771 & TRN & \\
\hline CHEMBL1997759 & 809267 & 4.1 & 4.2496 & TRN & \\
\hline CHEMBL1994968 & 809267 & 5.6 & 4.4842 & TRN & \\
\hline CHEMBL1989708 & 809267 & 4.1 & 4.3283 & TRN & \\
\hline & & & & 1231 & \\
\hline
\end{tabular}




\begin{tabular}{|c|c|c|c|c|}
\hline \multicolumn{5}{|c|}{ Supplemental Table S2.txt } \\
\hline CHEMBL1990288 & 809267 & 4.1 & 4.0679 & TRN \\
\hline CHEMBL1974803 & 809267 & 4.1 & 5.1047 & TST \\
\hline CHEMBL1970074 & 809267 & 4.1 & 4.6776 & TRN \\
\hline CHEMBL1986970 & 809267 & 6.3 & 6.0305 & TRN \\
\hline CHEMBL2005112 & 809267 & 4.1 & 4.5668 & TST \\
\hline CHEMBL1958401 & 809267 & 6.2 & 5.7262 & TRN \\
\hline CHEMBL1984044 & 809267 & 4.1 & 4.4144 & TRN \\
\hline CHEMBL 2003456 & 809267 & 5.3 & 5.1746 & TRN \\
\hline CHEMBL1966816 & 809267 & 6.9 & 6.2522 & TRN \\
\hline CHEMBL1972584 & 809267 & 5.8 & 4.3753 & TRN \\
\hline CHEMBL2002992 & 809267 & 6.2 & 4.8309 & TRN \\
\hline CHEMBL560813 & 809267 & 4.1 & 4.4666 & TRN \\
\hline CHEMBL 207253 & 809267 & 4.1 & 4.1344 & TST \\
\hline CHEMBL1890036 & 809267 & 4.1 & 4.3356 & TST \\
\hline CHEMBL1968791 & 809267 & 4.1 & 4.1174 & TRN \\
\hline CHEMBL326282 & 809267 & 4.1 & 4.2136 & TST \\
\hline CHEMBL2002682 & 809267 & 4.1 & 4.2509 & TST \\
\hline CHEMBL1992732 & 809267 & 4.1 & 4.1958 & TST \\
\hline CHEMBL1971186 & 809267 & 4.1 & 4.2005 & TRN \\
\hline CHEMBL 2003482 & 809267 & 6.0 & 4.9237 & TRN \\
\hline CHEMBL1973211 & 809267 & 4.1 & 4.3485 & TRN \\
\hline CHEMBL1984700 & 809267 & 4.1 & 3.9909 & TRN \\
\hline CHEMBL 2007151 & 809267 & 4.1 & 4.0175 & TRN \\
\hline CHEMBL1972125 & 809267 & 4.1 & 4.0885 & TRN \\
\hline CHEMBL1461728 & 809267 & 4.1 & 4.3398 & TRN \\
\hline CHEMBL1976134 & 809267 & 6.5 & 5.8029 & TRN \\
\hline CHEMBL1965131 & 809267 & 6.0 & 5.5009 & TRN \\
\hline CHEMBL1995448 & 809267 & 4.1 & 4.3598 & TRN \\
\hline CHEMBL1972158 & 809267 & 6.5 & 6.9866 & TRN \\
\hline CHEMBL1974457 & 809267 & 5.5 & 5.0064 & TRN \\
\hline CHEMBL2006580 & 809267 & 5.1 & 4.3476 & TRN \\
\hline CHEMBL 2006581 & 809267 & 4.1 & 4.043 & TRN \\
\hline CHEMBL 2006481 & 809267 & 4.1 & 4.1968 & TRN \\
\hline CHEMBL1979855 & 809267 & 4.1 & 4.2783 & TRN \\
\hline CHEMBL1970340 & 809267 & 4.1 & 4.3141 & TRN \\
\hline CHEMBL2005186 & 809267 & 4.1 & 4.6886 & TRN \\
\hline CHEMBL1995927 & 809267 & 4.1 & 4.3667 & TST \\
\hline CHEMBL1975534 & 809267 & 4.1 & 4.7781 & TRN \\
\hline CHEMBL1993424 & 809267 & 6.7 & 7.2223 & TRN \\
\hline CHEMBL1966703 & 809267 & 5.1 & 5.2578 & TST \\
\hline CHEMBL1969561 & 809267 & 7.0 & 6.0237 & TRN \\
\hline CHEMBL1972142 & 809267 & 5.7 & 4.4409 & TRN \\
\hline CHEMBL1997023 & 809267 & 4.1 & 4.16 & TST \\
\hline CHEMBL1964687 & 809267 & 4.1 & 4.8586 & TRN \\
\hline CHEMBL1971943 & 809267 & 5.2 & 5.0479 & TRN \\
\hline CHEMBL1999918 & 809267 & 6.6 & 6.7033 & TRN \\
\hline CHEMBL1974254 & 809267 & 4.1 & 4.1668 & TRN \\
\hline CHEMBL1988537 & 809267 & 6.1 & 5.499 & TST \\
\hline
\end{tabular}




\begin{tabular}{|c|c|c|c|c|}
\hline \multicolumn{5}{|c|}{ lemental } \\
\hline CHEMBL1969049 & 809267 & 4.1 & 4.3538 & TRN \\
\hline CHEMBL 2005828 & 809267 & 5.3 & 4.6447 & TRN \\
\hline CHEMBL 2002240 & 809267 & 4.1 & 4.1415 & TRN \\
\hline CHEMBL1991143 & 809267 & 4.1 & 4.0024 & TST \\
\hline CHEMBL1998611 & 809267 & 6.3 & 5.7255 & TRN \\
\hline CHEMBL485556 & 809267 & 4.1 & 4.5029 & TST \\
\hline CHEMBL1975900 & 809267 & 4.1 & 4.1601 & TRN \\
\hline CHEMBL255822 & 809267 & 5.4 & 4.7478 & TRN \\
\hline CHEMBL1972221 & 809267 & 6.8 & 6.3785 & TRN \\
\hline CHEMBL 2006778 & 809267 & 4.1 & 4.5696 & TRN \\
\hline CHEMBL 378627 & 809267 & 4.1 & 3.9347 & TRN \\
\hline CHEMBL1996979 & 809267 & 5.4 & 5.1788 & TRN \\
\hline CHEMBL1997025 & 809267 & 4.1 & 4.2727 & TRN \\
\hline CHEMBL1968406 & 809267 & 4.1 & 4.9388 & TRN \\
\hline CHEMBL1982476 & 809267 & 4.1 & 4.7326 & TRN \\
\hline CHEMBL1984274 & 809267 & 4.1 & 4.9228 & TST \\
\hline CHEMBL1998545 & 809267 & 4.1 & 4.0267 & TRN \\
\hline CHEMBL1986869 & 809267 & 4.1 & 4.1785 & TRN \\
\hline CHEMBL 2006010 & 809267 & 4.1 & 4.6266 & TRN \\
\hline CHEMBL1682558 & 809267 & 4.1 & 4.3495 & TRN \\
\hline CHEMBL1990496 & 809267 & 4.1 & 4.0045 & TRN \\
\hline CHEMBL1975937 & 809267 & 5.1 & 4.867 & TRN \\
\hline CHEMBL1997623 & 809267 & 4.1 & 4.49100 & 00000000005 \\
\hline CHEMBL 2002479 & 809267 & 5.3 & 5.2483 & TRN \\
\hline CHEMBL1980371 & 809267 & 5.1 & 5.0672 & TST \\
\hline CHEMBL1993166 & 809267 & 5.9 & 5.5214 & TRN \\
\hline CHEMBL1967094 & 809267 & 4.1 & 4.5153 & TRN \\
\hline CHEMBL1966035 & 809267 & 4.1 & 4.1522 & TRN \\
\hline CHEMBL 2003341 & 809267 & 4.1 & 4.0686 & TRN \\
\hline CHEMBL1992644 & 809267 & 5.0 & 4.3135 & TRN \\
\hline CHEMBL1992645 & 809267 & 4.1 & 4.3622 & TST \\
\hline CHEMBL1982992 & 809267 & 5.3 & 4.8238 & TRN \\
\hline CHEMBL1974363 & 809267 & 4.1 & 4.455 & TRN \\
\hline CHEMBL1999590 & 809267 & 4.1 & 4.4265 & TST \\
\hline CHEMBL1981079 & 809267 & 6.6 & 5.9499 & TRN \\
\hline CHEMBL1972276 & 809267 & 4.1 & 4.1844 & TRN \\
\hline CHEMBL1980489 & 809267 & 4.1 & 3.9141 & TRN \\
\hline CHEMBL 2000832 & 809267 & 7.1 & 6.6517 & TRN \\
\hline CHEMBL1967116 & 809267 & 4.1 & 4.282 & TRN \\
\hline CHEMBL1977814 & 809267 & 4.1 & 4.4224 & TST \\
\hline CHEMBL513846 & 809267 & 4.1 & 5.0596 & TRN \\
\hline CHEMBL1970709 & 809267 & 4.1 & 4.1543 & TRN \\
\hline CHEMBL1965660 & 809267 & 7.2 & 6.4096 & TRN \\
\hline CHEMBL1998112 & 809267 & 4.1 & 4.3011 & TRN \\
\hline CHEMBL1969126 & 809267 & 4.1 & 4.1333 & TRN \\
\hline CHEMBL1980896 & 809267 & 4.1 & 4.2839 & TRN \\
\hline CHEMBL1975208 & 809267 & 4.1 & 4.1214 & TST \\
\hline CHEMBL1970104 & 809267 & 6.4 & 6.3565 & TRN \\
\hline
\end{tabular}




\begin{tabular}{|c|c|c|c|c|c|}
\hline \multicolumn{6}{|c|}{ oplementa1 } \\
\hline CHEMBL1991429 & 809267 & 4.1 & 4.2482 & TRN & \\
\hline CHEMBL1964777 & 809267 & 5.5 & 5.7301 & TRN & \\
\hline CHEMBL1971149 & 809267 & 4.1 & 4.1145 & TRN & \\
\hline CHEMBL1999714 & 809267 & 4.1 & 4.3875 & TRN & \\
\hline CHEMBL1987533 & 809267 & 4.1 & 4.255 & TRN & \\
\hline CHEMBL1994040 & 809267 & 4.1 & 4.0027 & TRN & \\
\hline CHEMBL388978 & 809267 & 8.4 & 7.5185 & TST & \\
\hline CHEMBL579246 & 809267 & 5.3 & 5.6974 & TRN & \\
\hline CHEMBL1982506 & 809267 & 5.6 & 5.6252 & TST & \\
\hline CHEMBL 2004716 & 809267 & 4.1 & 4.6633 & TRN & \\
\hline CHEMBL1968127 & 809267 & 4.1 & 4.0344 & TRN & \\
\hline CHEMBL1975233 & 809267 & 4.1 & 4.3622 & TRN & \\
\hline CHEMBL1985406 & 809267 & 7.4 & 6.9373 & TRN & \\
\hline CHEMBL 207400 & 809267 & 4.1 & 4.0743 & TST & \\
\hline CHEMBL 2000894 & 809267 & 5.8 & 5.1803 & TST & \\
\hline CHEMBL 2002553 & 809267 & 4.1 & 4.3302 & TST & \\
\hline CHEMBL1982135 & 809267 & 4.1 & 4.4072 & TRN & \\
\hline CHEMBL1976090 & 809267 & 5.6 & 5.7124 & TRN & \\
\hline CHEMBL1993243 & 809267 & 4.1 & 4.3475 & TRN & \\
\hline CHEMBL1992922 & 809267 & 6.4 & 6.778 & TRN & \\
\hline CHEMBL 2004771 & 809267 & 4.1 & 4.7954 & TRN & \\
\hline CHEMBL399021 & 809267 & 4.1 & 4.0658 & TRN & \\
\hline CHEMBL1997597 & 809267 & 5.4 & 5.3475 & TRN & \\
\hline CHEMBL1969537 & 809267 & 4.1 & 4.8595 & TST & \\
\hline CHEMBL1976093 & 809267 & 4.1 & 4.2327 & TRN & \\
\hline CHEMBL 210032 & 809267 & 4.1 & 4.4445 & TRN & \\
\hline CHEMBL1975256 & 809267 & 5.5 & 4.8236 & TST & \\
\hline CHEMBL508928 & 809267 & 5.2 & 4.2194 & TRN & \\
\hline CHEMBL1991356 & 809267 & 4.1 & 4.5535 & TST & \\
\hline CHEMBL1983309 & 809267 & 4.1 & 4.7266 & TRN & \\
\hline CHEMBL 2004892 & 809267 & 5.6 & 5.3252 & TRN & \\
\hline CHEMBL1999126 & 809267 & 4.1 & 4.4366 & TST & \\
\hline CHEMBL1997503 & 809267 & 4.1 & 4.3954 & TST & \\
\hline CHEMBL116070 & 809267 & 5.8 & 5.5874 & TRN & \\
\hline CHEMBL1990821 & 809267 & 4.1 & $4.3180 e$ & 20000000005 & TST \\
\hline CHEMBL1970314 & 809267 & 4.1 & 4.4373 & TRN & \\
\hline CHEMBL 2004871 & 809267 & 4.1 & 4.0308 & TRN & \\
\hline CHEMBL 2004872 & 809267 & 4.1 & 4.0804 & TRN & \\
\hline CHEMBL1727312 & 809267 & 4.1 & 4.1157 & TRN & \\
\hline CHEMBL1969879 & 809267 & 4.1 & 4.41 & TRN & \\
\hline CHEMBL1981720 & 809267 & 7.1 & 6.38706 & 00000000005 & TRN \\
\hline CHEMBL419932 & 809267 & 4.1 & 4.1127 & TRN & \\
\hline CHEMBL262433 & 809267 & 4.1 & 4.2225 & TRN & \\
\hline CHEMBL 306380 & 809267 & 4.1 & 4.3296 & TRN & \\
\hline CHEMBL1966722 & 809267 & 4.1 & 5.8522 & TST & \\
\hline CHEMBL1975500 & 809267 & 6.6 & 6.4748 & TRN & \\
\hline CHEMBL1976328 & 809267 & 4.1 & 4.0874 & TRN & \\
\hline CHEMBL394619 & 809267 & 4.1 & 4.1245 & TRN & \\
\hline
\end{tabular}




\begin{tabular}{|c|c|c|c|c|c|}
\hline \\
\hline CHEMBL1964399 & 809267 & 6.6 & 6.2206 & TRN & \\
\hline CHEMBL1996831 & 809267 & 4.1 & 4.3692 & TST & \\
\hline CHEMBL411903 & 809267 & 5.6 & 4.8745 & TRN & \\
\hline CHEMBL1965988 & 809267 & 4.1 & 4.6604 & TRN & \\
\hline CHEMBL418203 & 809267 & 7.5 & 5.8853 & TST & \\
\hline CHEMBL1989646 & 809267 & 6.4 & 6.5708 & TRN & \\
\hline CHEMBL1682357 & 809267 & 5.6 & 5.7094 & TRN & \\
\hline CHEMBL225519 & 809267 & 6.2 & 5.7814 & TRN & \\
\hline CHEMBL 209534 & 809267 & 4.1 & 4.0061 & TRN & \\
\hline CHEMBL1978200 & 809267 & 4.1 & 4.0693 & TRN & \\
\hline CHEMBL2006631 & 809267 & 4.1 & 4.5446 & TRN & \\
\hline CHEMBL1970522 & 809267 & 5.2 & 4.6637 & TRN & \\
\hline CHEMBL402846 & 809267 & 4.1 & 4.2503 & TRN & \\
\hline CHEMBL1990415 & 809267 & 6.6 & 5.6361 & TRN & \\
\hline CHEMBL1964692 & 809267 & 4.1 & 4.478 & TRN & \\
\hline CHEMBL1996931 & 809267 & 4.1 & 4.04 & TRN & \\
\hline CHEMBL1964413 & 809267 & 4.1 & 4.6285 & TRN & \\
\hline CHEMBL1973483 & 809267 & 4.1 & 4.6861 & TRN & \\
\hline CHEMBL1984432 & 809267 & 5.1 & 5.0151 & TRN & \\
\hline CHEMBL1970735 & 809267 & 4.1 & 3.8846 & TRN & \\
\hline CHEMBL219722 & 809267 & 5.4 & 5.3087 & TRN & \\
\hline CHEMBL1997340 & 809267 & 4.1 & 4.1752 & TRN & \\
\hline CHEMBL 2004365 & 809267 & 4.1 & 5.0906 & TST & \\
\hline CHEMBL1522508 & 809267 & 4.1 & 4.4803 & TRN & \\
\hline CHEMBL1989474 & 809267 & 4.1 & 4.0949 & TRN & \\
\hline CHEMBL1090360 & 809267 & 4.1 & $3.9410 e$ & 00000000003 & TRN \\
\hline CHEMBL 210887 & 809267 & 5.1 & 4.7537 & TST & \\
\hline CHEMBL458997 & 809267 & 6.1 & 6.506 & TRN & \\
\hline CHEMBL1971021 & 809267 & 4.1 & 4.1468 & TRN & \\
\hline CHEMBL 227271 & 809267 & 7.0 & 7.3679 & TRN & \\
\hline CHEMBL583144 & 809267 & 5.1 & 4.9163 & TRN & \\
\hline CHEMBL1974310 & 809267 & 5.9 & 6.3733 & TRN & \\
\hline CHEMBL1982660 & 809267 & 6.2 & 5.8799 & TRN & \\
\hline CHEMBL1994693 & 809267 & 5.1 & 4.6607 & TRN & \\
\hline CHEMBL1982957 & 809267 & 7.2 & 6.8939 & TRN & \\
\hline CHEMBL1725279 & 809267 & 6.0 & 6.3537 & TST & \\
\hline CHEMBL1975138 & 809267 & 4.1 & 5.7201 & TST & \\
\hline CHEMBL424872 & 809267 & 4.1 & 3.8622 & TRN & \\
\hline CHEMBL 2006836 & 809267 & 4.1 & 4.3223 & TST & \\
\hline CHEMBL1971947 & 809267 & 4.1 & 4.1503 & TRN & \\
\hline CHEMBL412142 & 809267 & 4.1 & 4.7861 & TST & \\
\hline CHEMBL1980704 & 809267 & 4.1 & 4.4988 & TST & \\
\hline CHEMBL 2003271 & 809267 & 5.9 & $5.6620 e$ & 0000000001 & TRN \\
\hline CHEMBL1966808 & 809267 & 4.1 & 4.324 & TST & \\
\hline CHEMBL 2004447 & 809267 & 4.1 & 4.2081 & TRN & \\
\hline CHEMBL1983111 & 809267 & 7.4 & 7.7104 & TST & \\
\hline CHEMBL1973860 & 809267 & 5.4 & 4.5824 & TRN & \\
\hline CHEMBL1977713 & 809267 & 4.1 & 4.3354 & TRN & \\
\hline & & & & 12315 & \\
\hline
\end{tabular}




\begin{tabular}{|c|c|c|c|c|c|}
\hline \multicolumn{6}{|c|}{ Supplemental Table S2.txt } \\
\hline CHEMBL260135 & 809267 & 6.1 & 5.2693 & TRN & \\
\hline CHEMBL220241 & 809267 & 4.1 & 4.6049 & TRN & \\
\hline CHEMBL2004544 & 809267 & 4.1 & 4.6385 & TST & \\
\hline CHEMBL1982610 & 809267 & 4.1 & 4.5309 & TST & \\
\hline CHEMBL1999496 & 809267 & 4.1 & 4.0929 & TRN & \\
\hline CHEMBL2006933 & 809267 & 6.9 & 6.0924 & TST & \\
\hline CHEMBL1988300 & 809267 & 4.1 & 4.3582 & TRN & \\
\hline CHEMBL1991078 & 809267 & 7.4 & 8.1421 & TRN & \\
\hline CHEMBL1987359 & 809267 & 4.1 & 4.3275 & TST & \\
\hline CHEMBL 2000685 & 809267 & 6.8 & 6.1923 & TRN & \\
\hline CHEMBL1985311 & 809267 & 5.2 & 5.4658 & TRN & \\
\hline CHEMBL1989265 & 809267 & 4.1 & 4.2635 & TST & \\
\hline CHEMBL 2004647 & 809267 & 4.1 & 4.3012 & TST & \\
\hline CHEMBL1969502 & 809267 & 6.0 & 5.4773 & TRN & \\
\hline CHEMBL1965910 & 809267 & 4.1 & 4.09 & TRN & \\
\hline CHEMBL1682553 & 809267 & 6.0 & 5.8811 & TRN & \\
\hline CHEMBL1971430 & 809267 & 4.1 & 4.035 & TRN & \\
\hline CHEMBL1997764 & 809267 & 5.3 & 4.8974 & TRN & \\
\hline CHEMBL1983963 & 809267 & 4.1 & 4.2032 & TRN & \\
\hline CHEMBL 2000271 & 809267 & 6.5 & 6.6954 & TRN & \\
\hline CHEMBL1985092 & 809267 & 4.1 & 4.9008 & TST & \\
\hline CHEMBL2004692 & 809267 & 4.1 & 4.355 & TST & \\
\hline CHEMBL1981410 & 809267 & 4.1 & 4.4267 & TRN & \\
\hline CHEMBL1996234 & 809267 & 4.1 & 4.3643 & TRN & \\
\hline CHEMBL1991434 & 809267 & 4.1 & 4.5586 & TST & \\
\hline CHEMBL1967544 & 809267 & 4.1 & 4.9855 & TRN & \\
\hline CHEMBL223367 & 809267 & 4.1 & 4.6484 & TST & \\
\hline CHEMBL340384 & 809267 & 6.2 & 5.5953 & TST & \\
\hline CHEMBL1996587 & 809267 & 4.1 & 4.0881 & TRN & \\
\hline CHEMBL1964804 & 809267 & 6.3 & 5.5238 & TRN & \\
\hline CHEMBL443962 & 809267 & 6.6 & 5.80399 & 9999999999 & TST \\
\hline CHEMBL 2000354 & 809267 & 5.2 & 4.7642 & TRN & \\
\hline CHEMBL1965507 & 809267 & 7.5 & 4.4879 & TRN & \\
\hline CHEMBL1981107 & 809267 & 3.7 & 4.3426 & TST & \\
\hline CHEMBL 274064 & 809267 & 4.1 & 4.1387 & TRN & \\
\hline CHEMBL1967564 & 809267 & 6.0 & 5.7185 & TRN & \\
\hline CHEMBL592030 & 809267 & 7.5 & 6.7775 & TST & \\
\hline CHEMBL2000071 & 809267 & 6.0 & 6.5801 & TRN & \\
\hline CHEMBL1979176 & 809267 & 4.1 & 4.6771 & TRN & \\
\hline CHEMBL1970317 & 809267 & 4.1 & 4.0728 & TRN & \\
\hline CHEMBL2000408 & 809267 & 4.1 & 4.0152 & TRN & \\
\hline CHEMBL 248757 & 809267 & 4.1 & 4.6781 & TST & \\
\hline CHEMBL1978014 & 809267 & 4.1 & $4.6560 e$ & 2000000001 & TRN \\
\hline CHEMBL1994538 & 809267 & 5.8 & 5.9036 & TRN & \\
\hline CHEMBL1983195 & 809267 & 4.1 & 4.4108 & TST & \\
\hline CHEMBL1975490 & 809267 & 4.1 & 5.1134 & TRN & \\
\hline CHEMBL1964444 & 809267 & 6.3 & 5.8678 & TRN & \\
\hline CHEMBL1989957 & 809267 & 4.1 & 4.3967 & TRN & \\
\hline
\end{tabular}




\begin{tabular}{|c|c|c|c|c|}
\hline \multicolumn{5}{|c|}{ Supplemental Table S2.txt } \\
\hline CHEMBL 2006567 & 809267 & 4.1 & 4.3642 & TRN \\
\hline CHEMBL1986139 & 809267 & 4.1 & 4.3923 & TRN \\
\hline CHEMBL383527 & 809267 & 4.1 & 4.0682 & TRN \\
\hline CHEMBL1980540 & 809267 & 4.1 & 4.5298 & TRN \\
\hline CHEMBL1979883 & 809267 & 4.1 & 4.3321 & TRN \\
\hline CHEMBL1984162 & 809267 & 6.4 & 5.3604 & TRN \\
\hline CHEMBL491758 & 809267 & 6.2 & 6.0575 & TRN \\
\hline CHEMBL86066 & 809267 & 5.1 & 5.4895 & TST \\
\hline CHEMBL549730 & 809267 & 4.1 & 4.0783 & TRN \\
\hline CHEMBL1682360 & 809267 & 5.3 & 5.3973 & TRN \\
\hline CHEMBL1970189 & 809267 & 5.2 & 4.7742 & TRN \\
\hline CHEMBL1996791 & 809267 & 5.7 & 5.586 & TRN \\
\hline CHEMBL371206 & 809267 & 5.2 & 4.4699 & TRN \\
\hline CHEMBL1974664 & 809267 & 6.3 & 4.9967 & TST \\
\hline CHEMBL1974288 & 809267 & 5.3 & 4.7113 & TRN \\
\hline CHEMBL196363 & 809267 & 4.1 & 4.4718 & TRN \\
\hline CHEMBL1190711 & 809267 & 6.3 & 5.6644 & TRN \\
\hline CHEMBL1990346 & 809267 & 5.4 & 5.1717 & TRN \\
\hline CHEMBL1968705 & 809267 & 4.1 & 4.8522 & TRN \\
\hline CHEMBL404367 & 809267 & 4.1 & 4.251 & TRN \\
\hline CHEMBL1966343 & 809267 & 6.6 & 6.1894 & TRN \\
\hline CHEMBL1967887 & 809267 & 6.2 & 6.1734 & TRN \\
\hline CHEMBL 2000568 & 809267 & 5.4 & 5.1109 & TRN \\
\hline CHEMBL2000335 & 809267 & 6.5 & 5.2745 & TRN \\
\hline CHEMBL1977604 & 809267 & 4.1 & 4.2536 & TST \\
\hline CHEMBL1988717 & 809267 & 4.1 & 4.3341 & TRN \\
\hline CHEMBL1974328 & 809267 & 5.4 & 6.4673 & TRN \\
\hline CHEMBL509032 & 809267 & 6.5 & 7.3254 & TRN \\
\hline CHEMBL573339 & 809267 & 4.1 & 4.8563 & TRN \\
\hline CHEMBL1973808 & 809267 & 4.1 & 4.2645 & TRN \\
\hline CHEMBL 2000429 & 809267 & 4.1 & 3.9831 & TRN \\
\hline CHEMBL1972576 & 809267 & 6.2 & 4.5943 & TRN \\
\hline CHEMBL1992555 & 809267 & 4.1 & 4.2672 & TST \\
\hline CHEMBL1989069 & 809267 & 4.8 & 4.6731 & TST \\
\hline CHEMBL1992342 & 809267 & 5.7 & 5.3516 & TRN \\
\hline CHEMBL1988173 & 809267 & 4.1 & 6.1345 & TST \\
\hline CHEMBL535331 & 809267 & 4.1 & 4.3566 & TRN \\
\hline CHEMBL1989805 & 809267 & 4.1 & 5.1336 & TST \\
\hline CHEMBL1965423 & 809267 & 4.1 & 3.9643 & TRN \\
\hline CHEMBL1982980 & 809267 & 4.1 & 4.3647 & TST \\
\hline CHEMBL1983025 & 809267 & 4.1 & 4.6241 & TRN \\
\hline CHEMBL1977135 & 809267 & 4.1 & 3.9376 & TRN \\
\hline CHEMBL 2001920 & 809267 & 4.1 & 4.9502 & TRN \\
\hline CHEMBL2002322 & 809267 & 6.0 & 5.63899 & 9999999999 \\
\hline CHEMBL1241473 & 809267 & 7.7 & 7.8566 & TRN \\
\hline CHEMBL1978448 & 809267 & 4.1 & 4.6958 & TST \\
\hline CHEMBL 2004513 & 809267 & 4.1 & 4.8292 & TRN \\
\hline CHEMBL1972258 & 809267 & 4.1 & 3.8757 & TRN \\
\hline
\end{tabular}

TRN 


\begin{tabular}{|c|c|c|c|c|c|}
\hline CHEMBL 2001257 & 809267 & 4.1 & 4.2615 & TRN & \\
\hline CHEMBL 2005548 & 809267 & 4.1 & \multicolumn{2}{|c|}{4.071000000000001} & TRN \\
\hline CHEMBL1992536 & 809267 & 4.1 & 4.4148 & TRN & \\
\hline CHEMBL1987793 & 809267 & 4.1 & 4.4692 & TST & \\
\hline CHEMBL1992740 & 809267 & 5.9 & 5.8555 & TRN & \\
\hline CHEMBL 2002373 & 809267 & 4.1 & 4.1059 & TRN & \\
\hline CHEMBL439340 & 809267 & 4.1 & 3.938 & TRN & \\
\hline CHEMBL 2006188 & 809267 & 4.1 & 4.4547 & TRN & \\
\hline CHEMBL1967531 & 809267 & 4.1 & \multicolumn{2}{|c|}{4.696000000000001} & TRN \\
\hline CHEMBL1970913 & 809267 & 6.3 & 5.5473 & TRN & \\
\hline CHEMBL1973893 & 809267 & 6.4 & 6.2937 & TRN & \\
\hline CHEMBL1995736 & 809267 & 4.1 & \multicolumn{2}{|c|}{ 4. 343999999999999} & TRN \\
\hline CHEMBL1997534 & 809267 & 6.1 & 5.6421 & TRN & \\
\hline CHEMBL1996500 & 809267 & 4.1 & 4.037 & TRN & \\
\hline CHEMBL1985095 & 809267 & 5.8 & \multicolumn{2}{|c|}{6.382000000000001} & TST \\
\hline CHEMBL1998551 & 809267 & 4.1 & 4.0188 & TRN & \\
\hline CHEMBL1977374 & 809267 & 4.1 & \multicolumn{2}{|c|}{4.0569999999999995} & TRN \\
\hline CHEMBL1991180 & 809267 & 4.1 & 5.3058 & TST & \\
\hline CHEMBL1682540 & 809267 & 5.8 & 5.7772 & TRN & \\
\hline CHEMBL1978656 & 809267 & 4.1 & 4.2311 & TRN & \\
\hline CHEMBL1976420 & 809267 & 5.7 & 5.52 & TST & \\
\hline CHEMBL1994864 & 809267 & 4.1 & 3.844 & TRN & \\
\hline CHEMBL413779 & 809267 & 4.1 & 4.9348 & TST & \\
\hline CHEMBL 2002446 & 809267 & 4.1 & 4.541 & TST & \\
\hline CHEMBL497151 & 809267 & 5.2 & 4.9242 & TRN & \\
\hline CHEMBL246970 & 809267 & 6.0 & 5.6899 & TRN & \\
\hline CHEMBL1980497 & 809267 & 5.4 & 5.1459 & TRN & \\
\hline CHEMBL340921 & 809267 & 5.4 & 5.1762 & TST & \\
\hline CHEMBL373598 & 809267 & 4.1 & 4.5547 & TST & \\
\hline CHEMBL1999718 & 809267 & 4.1 & 4.4915 & TRN & \\
\hline CHEMBL1276446 & 809267 & 7.7 & 6.3543 & TST & \\
\hline CHEMBL1977346 & 809267 & 5.9 & 6.1143 & TRN & \\
\hline CHEMBL1971649 & 809267 & 5.9 & 4.2168 & TRN & \\
\hline CHEMBL 2003657 & 809267 & 4.1 & 4.0746 & TRN & \\
\hline CHEMBL1998435 & 809267 & 4.1 & 4.2817 & TRN & \\
\hline CHEMBL 2006439 & 809267 & 7.5 & 7.1349 & TRN & \\
\hline CHEMBL 2006156 & 809267 & 4.1 & 4.4898 & TST & \\
\hline CHEMBL1969190 & 809267 & 4.1 & 4.2934 & TRN & \\
\hline CHEMBL1973937 & 809267 & 4.1 & 4.5719 & TRN & \\
\hline CHEMBL1991674 & 809267 & 6.0 & 6.3205 & TRN & \\
\hline CHEMBL1982711 & 809267 & 7.4 & 6.2371 & TRN & \\
\hline CHEMBL1987982 & 809267 & 4.1 & 4.6718 & TST & \\
\hline CHEMBL1984842 & 809267 & 4.1 & 4.033 & TRN & \\
\hline CHEMBL1969102 & 809267 & 4.1 & 4.4021 & TRN & \\
\hline CHEMBL1682346 & 809267 & 6.5 & 6.6288 & TRN & \\
\hline CHEMBL 2007044 & 809267 & 4.1 & 4.6879 & TST & \\
\hline CHEMBL 2001998 & 809267 & 4.1 & 4.4237 & TST & \\
\hline CHEMBL1994241 & 809267 & 6.3 & 5.6321 & TRN & \\
\hline
\end{tabular}




\begin{tabular}{|c|c|c|c|c|c|}
\hline \multicolumn{6}{|c|}{ Supplemental Table S2.txt } \\
\hline CHEMBL223460 & 809267 & 4.1 & 4.3924 & TST & \\
\hline CHEMBL1998829 & 809267 & 4.1 & 4.2337 & TRN & \\
\hline CHEMBL50894 & 809267 & 7.5 & 6.6003 & TST & \\
\hline CHEMBL1988838 & 809267 & 6.1 & 7.045 & TRN & \\
\hline CHEMBL1981725 & 809267 & 4.1 & 4.3481 & TRN & \\
\hline CHEMBL375284 & 809267 & 4.1 & 4.0906 & TRN & \\
\hline CHEMBL1982866 & 809267 & 4.1 & 4.0531 & TRN & \\
\hline CHEMBL 2005792 & 809267 & 4.1 & 3.9925 & TRN & \\
\hline CHEMBL1968926 & 809267 & 4.1 & 4.1834 & TRN & \\
\hline CHEMBL1984206 & 809267 & 4.1 & 3.9177 & TRN & \\
\hline CHEMBL462120 & 809267 & 4.1 & 4.6307 & TST & \\
\hline CHEMBL1991577 & 809267 & 4.1 & 4.0648 & TRN & \\
\hline CHEMBL1965570 & 809267 & 4.1 & 4.4139 & TRN & \\
\hline CHEMBL 2007592 & 809267 & 4.1 & 4.1936 & TST & \\
\hline CHEMBL210963 & 809267 & 4.1 & 3.83600 & 00000000003 & TRN \\
\hline CHEMBL1082440 & 809267 & 5.5 & 5.3245 & TST & \\
\hline CHEMBL1614705 & 809267 & 4.1 & 4.09399 & 9999999999 & TRN \\
\hline CHEMBL1972362 & 809267 & 6.1 & 5.7943 & TRN & \\
\hline CHEMBL1984633 & 809267 & 4.1 & 4.2041 & TRN & \\
\hline CHEMBL 2007372 & 809267 & 4.1 & 4.0421 & TRN & \\
\hline CHEMBL1965845 & 809267 & 6.1 & 6.1976 & TRN & \\
\hline CHEMBL1982167 & 809267 & 4.1 & 4.3022 & TRN & \\
\hline CHEMBL 2006715 & 809267 & 4.1 & 4.3473 & TRN & \\
\hline CHEMBL1986597 & 809267 & 4.1 & 4.6664 & TRN & \\
\hline CHEMBL1971017 & 809267 & 6.7 & 6.7504 & TRN & \\
\hline CHEMBL1990482 & 809267 & 4.1 & 4.0331 & TRN & \\
\hline CHEMBL1990904 & 809267 & 4.1 & 4.0874 & TRN & \\
\hline CHEMBL 2005475 & 809267 & 5.3 & 4.9044 & TRN & \\
\hline CHEMBL1997349 & 809267 & 4.1 & 5.1502 & TST & \\
\hline CHEMBL183844 & 809267 & 4.1 & 4.135 & TRN & \\
\hline CHEMBL220057 & 809267 & 4.1 & 4.8795 & TRN & \\
\hline CHEMBL1682545 & 809267 & 4.1 & 4.7861 & TRN & \\
\hline CHEMBL383541 & 809267 & 4.1 & 4.297 & TRN & \\
\hline CHEMBL 2001224 & 809267 & 4.1 & 4.1333 & TRN & \\
\hline CHEMBL10 & 809267 & 4.1 & 4.2289 & TRN & \\
\hline CHEMBL1976732 & 809267 & 4.1 & 4.349 & TRN & \\
\hline CHEMBL1969506 & 809267 & 4.1 & 4.2668 & TRN & \\
\hline CHEMBL1964937 & 809267 & 5.7 & 6.105 & TRN & \\
\hline CHEMBL1980163 & 809267 & 4.1 & 4.2511 & TRN & \\
\hline CHEMBL590109 & 809267 & 6.5 & 6.6842 & TST & \\
\hline CHEMBL1970879 & 809267 & 4.1 & 4.2126 & TRN & \\
\hline CHEMBL1989856 & 809267 & 4.1 & 4.5189 & TST & \\
\hline CHEMBL1682552 & 809267 & 5.8 & 5.6839 & TRN & \\
\hline CHEMBL259850 & 809267 & 4.1 & 4.7323 & TRN & \\
\hline CHEMBL1972568 & 809267 & 4.1 & 4.022 & TRN & \\
\hline CHEMBL1996155 & 809267 & 4.1 & 4.3574 & TRN & \\
\hline CHEMBL1682359 & 809267 & 4.1 & 5.8063 & TRN & \\
\hline CHEMBL105739 & 809267 & 4.1 & 4.7259 & TRN & \\
\hline
\end{tabular}




\begin{tabular}{|c|c|c|c|c|c|}
\hline & & \multicolumn{4}{|c|}{ Supplemental Table S2.txt } \\
\hline CHEMBL379300 & 809267 & 7.3 & \multicolumn{2}{|c|}{7.138999999999999} & TRN \\
\hline CHEMBL203673 & 809267 & 4.1 & 3.9896 & TRN & \\
\hline CHEMBL1969523 & 809267 & 6.4 & 6.2776 & TRN & \\
\hline CHEMBL 2005214 & 809267 & 5.3 & 4.9212 & TRN & \\
\hline CHEMBL1988995 & 809267 & 4.1 & 4.0579 & TRN & \\
\hline CHEMBL1986781 & 809267 & 4.1 & 4.3444 & TRN & \\
\hline CHEMBL526133 & 809267 & 5.5 & 5.8947 & TRN & \\
\hline CHEMBL1979057 & 809267 & 4.1 & 4.5318 & TRN & \\
\hline CHEMBL1981045 & 809267 & 4.1 & 4.4012 & TRN & \\
\hline CHEMBL387971 & 809267 & 4.1 & 4.2688 & TST & \\
\hline CHEMBL1975418 & 809267 & 7.4 & 6.6325 & TRN & \\
\hline CHEMBL1992796 & 809267 & 4.1 & 4.3511 & TST & \\
\hline CHEMBL1999428 & 809267 & 5.3 & 4.2613 & TRN & \\
\hline CHEMBL223257 & 809267 & 4.1 & 4.5232 & TST & \\
\hline CHEMBL1967560 & 809267 & 4.1 & \multicolumn{2}{|c|}{ 4.2139999999999995 } & TRN \\
\hline CHEMBL1516890 & 809267 & 5.2 & 5.5397 & TRN & \\
\hline CHEMBL211378 & 809267 & 4.1 & 4.0834 & TRN & \\
\hline CHEMBL1982465 & 809267 & 4.1 & 4.1978 & TRN & \\
\hline CHEMBL 2001751 & 809267 & 6.6 & 6.9584 & TRN & \\
\hline CHEMBL 2003420 & 809267 & 4.1 & 4.5259 & TRN & \\
\hline CHEMBL1984586 & 809267 & 4.1 & 4.3521 & TRN & \\
\hline CHEMBL1972659 & 809267 & 4.1 & 4.0249 & TST & \\
\hline CHEMBL1973395 & 809267 & 6.5 & 6.4219 & TRN & \\
\hline CHEMBL272453 & 809267 & 4.1 & 4.1476 & TRN & \\
\hline CHEMBL1970217 & 809267 & 5.8 & \multicolumn{2}{|c|}{4.803999999999999} & TRN \\
\hline CHEMBL1971801 & 809267 & 4.1 & 5.2576 & TRN & \\
\hline CHEMBL1968850 & 809267 & 6.1 & 5.8912 & TRN & \\
\hline CHEMBL 2005528 & 809267 & 4.1 & 5.1928 & TST & \\
\hline CHEMBL185569 & 809267 & 4.1 & 4.0974 & TRN & \\
\hline CHEMBL1969843 & 809267 & 5.6 & 5.1972 & TRN & \\
\hline CHEMBL 2007002 & 809267 & 5.3 & 5.8625 & TRN & \\
\hline CHEMBL1987007 & 809267 & 4.1 & 4.4762 & TRN & \\
\hline CHEMBL1969588 & 809267 & 7.6 & 7.9645 & TRN & \\
\hline CHEMBL1984711 & 809267 & 5.4 & 4.8826 & TRN & \\
\hline CHEMBL1990212 & 809267 & 4.1 & 4.5245 & TRN & \\
\hline CHEMBL484390 & 809267 & 4.1 & 4.6792 & TST & \\
\hline CHEMBL1979252 & 809267 & 4.1 & 4.3192 & TRN & \\
\hline CHEMBL1682341 & 809267 & 6.2 & 5.8141 & TRN & \\
\hline CHEMBL 2004290 & 809267 & 4.1 & 4.2847 & TRN & \\
\hline CHEMBL1986499 & 809267 & 6.3 & 6.7228 & TRN & \\
\hline CHEMBL1972937 & 809267 & 4.1 & 4.5317 & TRN & \\
\hline CHEMBL1972250 & 809267 & 4.1 & 4.3869 & TST & \\
\hline CHEMBL 2000393 & 809267 & 5.6 & 6.1914 & TST & \\
\hline CHEMBL 2004072 & 809267 & 4.1 & 4.6429 & TRN & \\
\hline CHEMBL 2004311 & 809267 & 5.1 & 4.0732 & TRN & \\
\hline CHEMBL1992634 & 809267 & 6.4 & 6.6592 & TRN & \\
\hline CHEMBL1242373 & 809267 & 4.1 & 4.6621 & TRN & \\
\hline CHEMBL2000433 & 809267 & 4.1 & 4.3292 & TST & \\
\hline
\end{tabular}




\begin{tabular}{|c|c|c|c|c|}
\hline & & & pplement & al $\mathrm{Ta}$ \\
\hline CHEMBL56543 & 809267 & 4.1 & 4.3877 & TRN \\
\hline CHEMBL316264 & 809267 & 4.1 & 4.038 & TRN \\
\hline CHEMBL1988075 & 809267 & 4.1 & 4.3733 & TRN \\
\hline CHEMBL1991678 & 809267 & 4.1 & 4.0409 & TRN \\
\hline CHEMBL2001239 & 809267 & 4.1 & 5.2945 & TST \\
\hline CHEMBL1988594 & 809267 & 7.3 & 4.8515 & TRN \\
\hline CHEMBL 2001288 & 809267 & 5.2 & 5.3553 & TRN \\
\hline CHEMBL260092 & 809267 & 6.2 & 4.6277 & TRN \\
\hline CHEMBL1999811 & 809267 & 4.1 & 4.9479 & TST \\
\hline CHEMBL1965495 & 809267 & 6.3 & 5.4913 & TRN \\
\hline CHEMBL1985074 & 809267 & 5.1 & 4.9565 & TST \\
\hline CHEMBL1982874 & 809267 & 4.1 & 4.0955 & TRN \\
\hline CHEMBL 2000481 & 809267 & 4.1 & 4.479 & TRN \\
\hline CHEMBL1991725 & 809267 & 5.3 & 4.8715 & TRN \\
\hline CHEMBL1992242 & 809267 & 4.1 & 4.0209 & TRN \\
\hline CHEMBL 2007296 & 809267 & 4.1 & 4.7421 & TRN \\
\hline CHEMBL208637 & 809267 & 4.1 & 3.8459 & TRN \\
\hline CHEMBL 396523 & 809267 & 7.1 & 7.4616 & TRN \\
\hline CHEMBL2007138 & 809267 & 3.7 & 4.2755 & TRN \\
\hline CHEMBL1970203 & 809267 & 7.1 & 4.4892 & TRN \\
\hline CHEMBL1986530 & 809267 & 4.1 & 4.4851 & TST \\
\hline CHEMBL1965351 & 809267 & 4.1 & 4.9288 & TST \\
\hline CHEMBL1999321 & 809267 & 4.1 & 4.0851 & TRN \\
\hline CHEMBL1968590 & 809267 & 4.1 & 4.159 & TRN \\
\hline CHEMBL1999749 & 809267 & 4.1 & 4.1366 & TRN \\
\hline CHEMBL 2005375 & 809267 & 4.1 & 4.1577 & TRN \\
\hline CHEMBL1984191 & 809267 & 4.1 & 4.1949 & TRN \\
\hline CHEMBL1972183 & 809267 & 4.1 & 4.1667 & TRN \\
\hline CHEMBL1971029 & 809267 & 7.4 & 7.4499 & TRN \\
\hline CHEMBL1995391 & 809267 & 3.7 & 4.8316 & TRN \\
\hline CHEMBL394790 & 809267 & 4.1 & 4.2024 & TRN \\
\hline CHEMBL226471 & 809267 & 5.5 & 5.0209 & TRN \\
\hline CHEMBL1974702 & 809267 & 5.2 & 5.2036 & TRN \\
\hline CHEMBL1996111 & 809267 & 6.2 & 6.1686 & TRN \\
\hline CHEMBL1965589 & 809267 & 4.1 & 4.1062 & TRN \\
\hline CHEMBL1998193 & 809267 & 4.1 & 4.5025 & TRN \\
\hline CHEMBL474432 & 809267 & 5.4 & 5.4896 & TST \\
\hline CHEMBL1988153 & 809267 & 6.2 & 5.5443 & TRN \\
\hline CHEMBL1999556 & 809267 & 6.2 & 6.4864 & TRN \\
\hline CHEMBL1988437 & 809267 & 4.1 & 5.1746 & TST \\
\hline CHEMBL1998121 & 809267 & 5.2 & 5.7273 & TRN \\
\hline CHEMBL1979577 & 809267 & 4.1 & 4.3407 & TRN \\
\hline CHEMBL1991800 & 809267 & 4.1 & 3.9937 & TRN \\
\hline CHEMBL1985566 & 809267 & 4.1 & 4.6088 & TRN \\
\hline CHEMBL52387 & 809267 & 5.9 & 5.8538 & TST \\
\hline CHEMBL379835 & 809267 & 4.1 & 3.9704 & TST \\
\hline CHEMBL1979357 & 809267 & 4.1 & 4.1271 & TRN \\
\hline CHEMBL1980802 & 809267 & 4.1 & 4.2682 & TST \\
\hline
\end{tabular}




\begin{tabular}{|c|c|c|c|c|c|}
\hline & & \multicolumn{4}{|c|}{ Supplemental Table s2.txt } \\
\hline CHEMBL1979554 & 809267 & 4.1 & 4.5164 & TRN & \\
\hline CHEMBL1996817 & 809267 & 6.6 & 6.8305 & TRN & \\
\hline CHEMBL3197315 & 809267 & 4.1 & 4.3052 & TST & \\
\hline CHEMBL 2004355 & 809267 & 4.1 & 3.9044 & TRN & \\
\hline CHEMBL468280 & 809267 & 4.1 & 4.1249 & TST & \\
\hline CHEMBL1990884 & 809267 & 4.1 & 4.3464 & TRN & \\
\hline CHEMBL3109278 & 809267 & 4.1 & 5.2639 & TRN & \\
\hline CHEMBL 256835 & 809267 & 4.1 & 4.0541 & TRN & \\
\hline CHEMBL1970006 & 809267 & 4.1 & 4.9165 & TRN & \\
\hline CHEMBL1980142 & 809267 & 4.1 & 4.5108 & TRN & \\
\hline CHEMBL41783 & 809267 & 6.1 & 5.8595 & TRN & \\
\hline CHEMBL 2004438 & 809267 & 4.1 & 4.173 & TRN & \\
\hline CHEMBL 2006276 & 809267 & 6.2 & 4.7162 & TRN & \\
\hline CHEMBL 271381 & 809267 & 4.1 & 4.3002 & TRN & \\
\hline CHEMBL 2006785 & 809267 & 4.1 & 4.5191 & TRN & \\
\hline CHEMBL1982466 & 809267 & 4.1 & 4.1122 & TRN & \\
\hline CHEMBL249697 & 809267 & 5.4 & 5.1143 & TST & \\
\hline CHEMBL1995740 & 809267 & 8.2 & 6.4666 & TRN & \\
\hline CHEMBL1996390 & 809267 & 5.5 & 4.9625 & TRN & \\
\hline CHEMBL234085 & 809267 & 4.1 & 4.6204 & TRN & \\
\hline CHEMBL1995832 & 809267 & 4.1 & 3.9646 & TRN & \\
\hline CHEMBL1998414 & 809267 & 4.1 & 4.5197 & TRN & \\
\hline CHEMBL1969042 & 809267 & 5.7 & 5.1095 & TST & \\
\hline CHEMBL 2000345 & 809267 & 6.1 & 5.4544 & TRN & \\
\hline CHEMBL1999931 & 809267 & 8.3 & 8.3341 & TRN & \\
\hline CHEMBL1991640 & 809267 & 4.1 & 5.0549 & TST & \\
\hline CHEMBL1375418 & 809267 & 4.1 & 4.2438 & TRN & \\
\hline CHEMBL 302449 & 809267 & 7.8 & 7.1561 & TST & \\
\hline CHEMBL 2007064 & 809267 & 5.3 & 4.9722 & TRN & \\
\hline CHEMBL1981047 & 809267 & 5.5 & 6.0979 & TST & \\
\hline CHEMBL229968 & 809267 & 7.3 & 7.48799 & 99999999995 & TRN \\
\hline CHEMBL1976240 & 809267 & 5.1 & 4.8411 & TRN & \\
\hline CHEMBL1979093 & 809267 & 4.1 & 4.3039 & TRN & \\
\hline CHEMBL1968151 & 809267 & 4.1 & 4.3342 & TST & \\
\hline CHEMBL1381197 & 809267 & 4.1 & 4.0718 & TRN & \\
\hline CHEMBL1987009 & 809267 & 4.1 & 5.00899 & 99999999995 & TRN \\
\hline CHEMBL379218 & 809267 & 6.8 & 7.0871 & TRN & \\
\hline CHEMBL 2003817 & 809267 & 4.1 & 5.621 & TRN & \\
\hline CHEMBL1994830 & 809267 & 6.6 & 5.7806 & TRN & \\
\hline CHEMBL1987054 & 809267 & 5.9 & 5.2348 & TRN & \\
\hline CHEMBL1970083 & 809267 & 4.1 & 4.4658 & TRN & \\
\hline CHEMBL226403 & 809267 & 5.4 & 5.0782 & TRN & \\
\hline CHEMBL 2005631 & 809267 & 4.1 & 4.5079 & TRN & \\
\hline CHEMBL1994938 & 809267 & 4.1 & 4.4738 & TRN & \\
\hline CHEMBL1825138 & 809267 & 5.3 & 5.205 & TST & \\
\hline CHEMBL1977223 & 809267 & 8.4 & 7.9204 & TRN & \\
\hline CHEMBL1236126 & 809267 & 4.1 & 4.6115 & TST & \\
\hline CHEMBL1966279 & 809267 & 4.1 & 4.2107 & TRN & \\
\hline
\end{tabular}




\begin{tabular}{|c|c|c|c|c|}
\hline & & & pplement & al $\mathrm{Ta}$ \\
\hline CHEMBL1997846 & 809267 & 5.5 & 5.3193 & TRN \\
\hline CHEMBL 2004419 & 809267 & 4.1 & 4.0872 & TRN \\
\hline CHEMBL1991728 & 809267 & 6.2 & 5.6925 & TRN \\
\hline CHEMBL1975787 & 809267 & 6.5 & 6.4997 & TRN \\
\hline CHEMBL 2002407 & 809267 & 6.2 & 5.6249 & TRN \\
\hline CHEMBL1972489 & 809267 & 4.1 & 4.2183 & TRN \\
\hline CHEMBL1994074 & 809267 & 4.1 & 5.0143 & TRN \\
\hline CHEMBL1992937 & 809267 & 6.4 & 5.9168 & TST \\
\hline CHEMBL536151 & 809267 & 4.1 & 4.445 & TST \\
\hline CHEMBL1972119 & 809267 & 4.1 & 4.4119 & TRN \\
\hline CHEMBL1986328 & 809267 & 4.1 & 4.4416 & TST \\
\hline CHEMBL95692 & 809267 & 4.1 & 3.9503 & TRN \\
\hline CHEMBL1090356 & 809267 & 4.1 & 3.9158 & TRN \\
\hline CHEMBL1976455 & 809267 & 7.2 & 6.334 & TRN \\
\hline CHEMBL1983923 & 809267 & 4.1 & 5.1685 & TST \\
\hline CHEMBL1983534 & 809267 & 4.1 & 4.3285 & TRN \\
\hline CHEMBL1982361 & 809267 & 4.1 & 3.9836 & TRN \\
\hline CHEMBL1999112 & 809267 & 4.1 & 4.457 & TST \\
\hline CHEMBL1982122 & 809267 & 4.1 & 4.6407 & TRN \\
\hline CHEMBL 2000801 & 809267 & 4.1 & 4.1638 & TRN \\
\hline CHEMBL1682546 & 809267 & 4.1 & 4.7221 & TRN \\
\hline CHEMBL1991395 & 809267 & 4.1 & 3.971 & TRN \\
\hline CHEMBL1971245 & 809267 & 4.1 & 4.8316 & TRN \\
\hline CHEMBL1987648 & 809267 & 4.1 & 3.9715 & TRN \\
\hline CHEMBL1996780 & 809267 & 5.4 & 4.7811 & TST \\
\hline CHEMBL1966514 & 809267 & 4.1 & 4.2745 & TRN \\
\hline CHEMBL 2003638 & 809267 & 8.0 & 7.8896 & TRN \\
\hline CHEMBL1996066 & 809267 & 5.7 & 4.6602 & TST \\
\hline CHEMBL516429 & 809267 & 6.8 & 6.3848 & TRN \\
\hline CHEMBL1972152 & 809267 & 4.1 & 4.5129 & TST \\
\hline CHEMBL1993722 & 809267 & 5.4 & 5.516 & TRN \\
\hline CHEMBL1970806 & 809267 & 4.1 & 4.1953 & TST \\
\hline CHEMBL1375640 & 809267 & 4.1 & 4.6535 & TST \\
\hline CHEMBL 249282 & 809267 & 4.1 & 4.482 & TST \\
\hline CHEMBL1969264 & 809267 & 5.7 & 4.8901 & TRN \\
\hline CHEMBL1973711 & 809267 & 4.1 & 4.8437 & TRN \\
\hline CHEMBL 2006237 & 809267 & 4.1 & 4.3162 & TRN \\
\hline CHEMBL1967720 & 809267 & 4.1 & 4.3989 & TRN \\
\hline CHEMBL1572266 & 809267 & 4.1 & 4.3095 & TST \\
\hline CHEMBL1991138 & 809267 & 4.1 & 4.0439 & TRN \\
\hline CHEMBL1969755 & 809267 & 4.1 & 4.0091 & TRN \\
\hline CHEMBL1979516 & 809267 & 4.1 & 4.4431 & TRN \\
\hline CHEMBL1605605 & 809267 & 5.2 & 4.5135 & TRN \\
\hline CHEMBL1972820 & 809267 & 4.1 & 4.2899 & TST \\
\hline CHEMBL1996208 & 809267 & 4.1 & 4.6793 & TST \\
\hline CHEMBL1989029 & 809267 & 4.1 & 4.6215 & TRN \\
\hline CHEMBL392642 & 809267 & 6.6 & 5.8155 & TST \\
\hline CHEMBL514499 & 809267 & 4.1 & 4.5597 & TST \\
\hline
\end{tabular}




\begin{tabular}{|c|c|c|c|c|c|}
\hline \\
\hline CHEMBL1965631 & 809267 & 7.0 & 7.1745 & TST & \\
\hline CHEMBL1980144 & 809267 & 6.4 & 4.5169 & TST & \\
\hline CHEMBL1991188 & 809267 & 6.1 & 5.4098 & TST & \\
\hline CHEMBL1972849 & 809267 & 4.1 & 4.0308 & TST & \\
\hline CHEMBL377408 & 809267 & 4.1 & 3.9364 & TST & \\
\hline CHEMBL215152 & 809267 & 4.1 & 4.4101 & TST & \\
\hline CHEMBL231209 & 809267 & 4.1 & 4.2861 & TST & \\
\hline CHEMBL1975357 & 809267 & 4.1 & 4.4043 & TST & \\
\hline CHEMBL1976220 & 809267 & 4.1 & 4.1773 & TST & \\
\hline CHEMBL 259922 & 809267 & 4.1 & 4.1638 & TST & \\
\hline CHEMBL1997617 & 809267 & 4.1 & 4.3635 & TST & \\
\hline CHEMBL1982383 & 809267 & 4.1 & 3.9896 & TST & \\
\hline CHEMBL1969301 & 809267 & 4.1 & 4.706 & TST & \\
\hline CHEMBL17370 & 809267 & 4.1 & 4.1053 & TST & \\
\hline CHEMBL1987910 & 809267 & 4.1 & 4.2308 & TST & \\
\hline CHEMBL1983932 & 809267 & 4.1 & 5.7106 & TST & \\
\hline CHEMBL1966069 & 809267 & 5.6 & 5.5573 & TST & \\
\hline CHEMBL1997822 & 809267 & 4.1 & 4.3711 & TST & \\
\hline CHEMBL1991285 & 809267 & 4.1 & 4.1426 & TST & \\
\hline CHEMBL 243088 & 809267 & 6.3 & 6.888 & TST & \\
\hline CHEMBL1984038 & 809267 & 4.1 & 4.8953 & TST & \\
\hline CHEMBL1974416 & 809267 & 5.5 & 5.0199 & TST & \\
\hline CHEMBL 2004615 & 809267 & 4.1 & 4.9023 & TST & \\
\hline CHEMBL1984039 & 809267 & 4.1 & 4.3257 & TST & \\
\hline CHEMBL1997872 & 809267 & 4.1 & 4.4865 & TST & \\
\hline CHEMBL 2041454 & 824271 & 5.9747 & 6.0249 & TRN & \\
\hline CHEMBL 2041629 & 824271 & 4.6998 & 4.4273 & TRN & \\
\hline CHEMBL 2041445 & 824271 & 5.308 & 4.7824 & TST & \\
\hline CHEMBL 2041423 & 824271 & 3.6021 & 4.7683 & TRN & \\
\hline CHEMBL 2041661 & 824271 & 3.6021 & 5.0877 & TRN & \\
\hline CHEMBL3215664 & 824271 & 3.6021 & 4.4102 & TRN & \\
\hline CHEMBL 2041460 & 824271 & 6.0088 & 5.1887 & TRN & \\
\hline CHEMBL 2041430 & 824271 & 5.3893 & 4.6427 & TRN & \\
\hline CHEMBL 2041424 & 824271 & 5.2541 & 5.21399 & 99999999995 & TRN \\
\hline CHEMBL 2041630 & 824271 & 5.7878 & 4.7706 & TRN & \\
\hline CHEMBL 2041436 & 824271 & 5.71899 & 99999999 & 5.6305 & TRN \\
\hline CHEMBL 2041627 & 824271 & 5.5834 & 4.3164 & TRN & \\
\hline CHEMBL 2041651 & 824271 & 3.6021 & 3.9906 & TST & \\
\hline CHEMBL 2041665 & 824271 & 6.4685 & 6.3344 & TRN & \\
\hline CHEMBL 2041628 & 824271 & 3.6021 & 4.1489 & TRN & \\
\hline CHEMBL 2041439 & 824271 & 5.6216 & 5.3409 & TRN & \\
\hline CHEMBL 2041458 & 824271 & 5.4584 & 5.6729 & TRN & \\
\hline CHEMBL 2041444 & 824271 & 3.6021 & 4.1424 & TRN & \\
\hline CHEMBL 2041475 & 824271 & 3.6021 & 3.812 & TRN & \\
\hline CHEMBL 2041663 & 824271 & 7.2218 & 6.05399 & 9999999999 & TRN \\
\hline CHEMBL 2041662 & 824271 & 6.6021 & 6.025 & TRN & \\
\hline CHEMBL2041428 & 824271 & 5.4389 & 5.4468 & TST & \\
\hline CHEMBL 2041467 & 824271 & 5.9355 & 6.2022 & TRN & \\
\hline
\end{tabular}


Supplemental Table S2.txt

\begin{tabular}{|c|c|c|c|c|}
\hline CHEMBL2041471 & 824271 & 3.6021 & 3.627 & TRN \\
\hline CHEMBL 2041419 & 824271 & 4.9957 & 3.6625 & TST \\
\hline CHEMBL 2041440 & 824271 & 3.6021 & 3.7191 & TRN \\
\hline CHEMBL 2041434 & 824271 & 6.0809 & 5.9949 & TRN \\
\hline CHEMBL 2041640 & 824271 & 5.4855 & \multicolumn{2}{|c|}{6.122999999999999} \\
\hline CHEMBL 2041432 & 824271 & 3.6021 & 3.61 & TRN \\
\hline CHEMBL 2041634 & 824271 & 3.6021 & 3.7198 & TRN \\
\hline CHEMBL 2041647 & 824271 & 3.6021 & \multicolumn{2}{|c|}{ 3.6319999999999997 } \\
\hline CHEMBL 2041659 & 824271 & 3.6021 & 3.4218 & TRN \\
\hline CHEMBL2041643 & 824271 & 3.6021 & 3.5788 & TRN \\
\hline CHEMBL 2041470 & 824271 & 5.4868 & 5.9942 & TRN \\
\hline CHEMBL 2041425 & 824271 & 6.4559 & 5.9547 & TRN \\
\hline CHEMBL 2041654 & 824271 & 3.6021 & 4.1657 & TRN \\
\hline CHEMBL 2041473 & 824271 & 5.6925 & 4.73 & TRN \\
\hline CHEMBL 2041448 & 824271 & 6.0 & 6.569 & TRN \\
\hline CHEMBL 2041422 & 824271 & 5.1169 & 4.9127 & TRN \\
\hline CHEMBL2041464 & 824271 & 6.2076 & 5.7004 & TRN \\
\hline CHEMBL 2041667 & 824271 & 6.0044 & 5.9888 & TRN \\
\hline CHEMBL2041652 & 824271 & 3.6021 & 3.8557 & TST \\
\hline CHEMBL 2041469 & 824271 & 6.4815 & 7.0338 & TRN \\
\hline CHEMBL 2041435 & 824271 & 5.9957 & 5.8021 & TRN \\
\hline CHEMBL2041631 & 824271 & 6.0915 & 5.0236 & TRN \\
\hline CHEMBL 2041420 & 824271 & 3.6021 & 3.7404 & TRN \\
\hline CHEMBL 2041468 & 824271 & 5.6144 & 5.5382 & TRN \\
\hline CHEMBL 2041418 & 824271 & 3.6021 & 3.2872 & TST \\
\hline CHEMBL2041653 & 824271 & 3.6021 & 3.6211 & TST \\
\hline CHEMBL 2041660 & 824271 & 4.6108 & 4.3904 & TRN \\
\hline CHEMBL 2041646 & 824271 & 3.6021 & 3.3947 & TRN \\
\hline CHEMBL2041456 & 824271 & 5.1891 & 5.7994 & TRN \\
\hline CHEMBL 2041657 & 824271 & 6.7959 & 6.7635 & TRN \\
\hline CHEMBL 2041449 & 824271 & 5.7375 & 6.0775 & TRN \\
\hline CHEMBL 2041463 & 824271 & 5.6799 & 5.813 & TRN \\
\hline CHEMBL2041639 & 824271 & 3.6021 & 3.46 & TRN \\
\hline CHEMBL2041650 & 824271 & 3.6021 & \multicolumn{2}{|c|}{3.9730000000000003} \\
\hline CHEMBL 2041447 & 824271 & 6.1805 & 5.7954 & TRN \\
\hline CHEMBL2041453 & 824271 & 3.6021 & 4.331 & TRN \\
\hline CHEMBL 2041645 & 824271 & 3.6021 & \multicolumn{2}{|c|}{3.5180000000000002} \\
\hline CHEMBL 2041633 & 824271 & 3.6021 & \multicolumn{2}{|c|}{3.7710000000000004} \\
\hline CHEMBL 2041438 & 824271 & 5.3904 & 4.9775 & TRN \\
\hline CHEMBL 2041427 & 824271 & 3.6021 & 4.0137 & TRN \\
\hline CHEMBL 2041632 & 824271 & 3.6021 & 3.6929 & TRN \\
\hline CHEMBL 2041474 & 824271 & 3.6021 & 3.9124 & TRN \\
\hline CHEMBL2041451 & 824271 & 5.6038 & 5.849 & TRN \\
\hline CHEMBL 2041461 & 824271 & 3.6021 & 4.1159 & TRN \\
\hline CHEMBL 2041426 & 824271 & 5.8013 & 5.1168 & TRN \\
\hline CHEMBL2041635 & 824271 & 3.6021 & 3.7221 & TRN \\
\hline CHEMBL 2041656 & 824271 & 6.7696 & 6.2647 & TRN \\
\hline CHEMBL 2041668 & 824271 & 3.6021 & 4.7461 & TRN \\
\hline
\end{tabular}

Page 12325 


\begin{tabular}{|c|c|c|c|c|c|c|}
\hline & & \multicolumn{5}{|c|}{ Supplemental Table S2.txt } \\
\hline CHEMBL 2041441 & 824271 & 5.5654 & 5.1865 & TRN & & \\
\hline CHEMBL 2041625 & 824271 & 3.6021 & 3.69199 & \multicolumn{2}{|l|}{99999} & TRN \\
\hline CHEMBL2041655 & 824271 & 3.6021 & 4.0763 & TRN & & \\
\hline CHEMBL1421500 & 824271 & 3.6021 & 3.7398 & TRN & & \\
\hline CHEMBL2041437 & 824271 & 5.857 & 5.5884 & TRN & & \\
\hline CHEMBL 2041450 & 824271 & 5.7212 & 5.46 & TRN & & \\
\hline CHEMBL2041666 & 824271 & \multicolumn{3}{|c|}{5.757000000000001} & 5.6937 & TRN \\
\hline CHEMBL 2041433 & 824271 & 3.6021 & 3.6938 & TRN & & \\
\hline CHEMBL 2041465 & 824271 & 3.6021 & 3.3493 & TRN & & \\
\hline CHEMBL2041421 & 824271 & 3.6021 & 3.3929 & TRN & & \\
\hline CHEMBL 2041648 & 824271 & 3.6021 & 3.8816 & TST & & \\
\hline CHEMBL2041658 & 824271 & 6.0862 & 5.48 & TRN & & \\
\hline CHEMBL 2041457 & 824271 & 5.5436 & 4.6712 & TRN & & \\
\hline CHEMBL 2041641 & 824271 & 3.6021 & 5.2891 & TRN & & \\
\hline CHEMBL2041626 & 824271 & 3.6021 & 3.3914 & TRN & & \\
\hline CHEMBL 2041644 & 824271 & 3.6021 & 3.1371 & TRN & & \\
\hline CHEMBL2041459 & 824271 & 5.4056 & 6.0894 & TRN & & \\
\hline CHEMBL 2041455 & 824271 & 5.7375 & 5.7229 & TRN & & \\
\hline CHEMBL2041472 & 824271 & 5.7645 & 4.4433 & TST & & \\
\hline CHEMBL2041416 & 824271 & 6.6383 & 4.96 & TST & & \\
\hline CHEMBL 2041446 & 824271 & 5.7375 & 5.8417 & TST & & \\
\hline CHEMBL2041415 & 824271 & \multicolumn{3}{|c|}{5.718999999999999} & 4.5255 & TST \\
\hline CHEMBL 2041649 & 824271 & 3.6021 & 3.8571 & TST & & \\
\hline CHEMBL 2041417 & 824271 & 3.6021 & 3.2757 & TST & & \\
\hline CHEMBL2041638 & 824271 & 3.6021 & 3.5951 & TST & & \\
\hline CHEMBL 2041636 & 824271 & 3.6021 & 3.8243 & TST & & \\
\hline CHEMBL2041637 & 824271 & 4.7303 & 4.0751 & TST & & \\
\hline CHEMBL 2041431 & 824271 & 3.6021 & 3.2797 & TST & & \\
\hline CHEMBL2041442 & 824271 & 5.3556 & 5.4059 & TST & & \\
\hline CHEMBL 2041429 & 824271 & 3.6021 & 4.5635 & TST & & \\
\hline CHEMBL2041452 & 824271 & 5.6162 & 5.381 & TST & & \\
\hline CHEMBL2041466 & 824271 & 3.6021 & 3.51800 & 0000000000 & 02 & TST \\
\hline CHEMBL 2041664 & 824271 & 6.6383 & 6.1554 & TST & & \\
\hline CHEMBL2041642 & 824271 & 3.6021 & 4.2027 & TST & & \\
\hline CHEMBL 2041443 & 824271 & 3.6021 & 3.1454 & TST & & \\
\hline CHEMBL3674038 & 1535769 & 5.49 & 5.4329 & TRN & & \\
\hline CHEMBL3674107 & 1535769 & 6.0 & 6.005 & TRN & & \\
\hline CHEMBL 3674048 & 1535769 & 5.2 & 5.4453 & TST & & \\
\hline CHEMBL3674046 & 1535769 & 5.224 & 5.1943 & TRN & & \\
\hline CHEMBL3674091 & 1535769 & 6.0 & 6.0868 & TRN & & \\
\hline CHEMBL3674056 & 1535769 & 7.1681 & 6.6079 & TST & & \\
\hline CHEMBL 3674065 & 1535769 & \multicolumn{3}{|c|}{5.861000000000001} & 5.6353 & TST \\
\hline CHEMBL 3674142 & 1535769 & 4.0 & 4.029 & TRN & & \\
\hline CHEMBL3674060 & 1535769 & 5.3925 & 5.3413 & TRN & & \\
\hline CHEMBL 3674037 & 1535769 & 5.896 & 5.9924 & TRN & & \\
\hline CHEMBL 3674118 & 1535769 & 6.0 & 5.9877 & TRN & & \\
\hline CHEMBL 3674115 & 1535769 & 6.0 & 6.0195 & TRN & & \\
\hline CHEMBL3674071 & 1535769 & 5.0 & 4.8371 & TST & & \\
\hline
\end{tabular}


Supplemental Table S2.txt

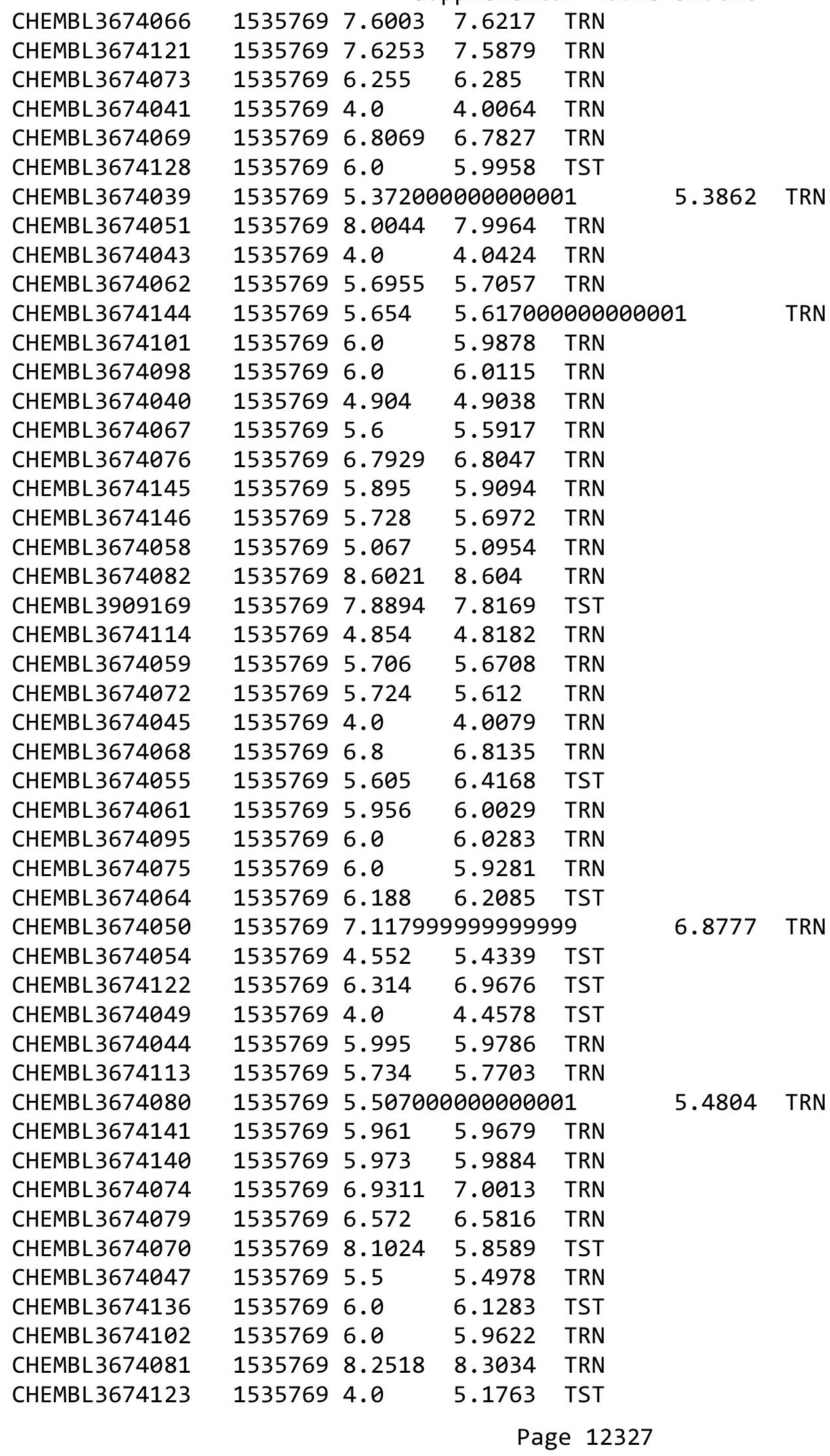




\begin{tabular}{|c|c|c|c|c|c|c|}
\hline \multicolumn{7}{|c|}{ Supplemental Table S2.txt } \\
\hline CHEMBL 3674143 & 1535769 & 5.145 & 5.1496 & TRN & & \\
\hline CHEMBL 3674124 & 1535769 & 6.093 & 6.1297 & TRN & & \\
\hline CHEMBL3674042 & 1535769 & 6.3103 & 6.3563 & TRN & & \\
\hline CHEMBL3674092 & 1535769 & 7.7496 & 6.8079 & TST & & \\
\hline CHEMBL3639729 & 1535769 & 6.5699 & 6.5708 & TRN & & \\
\hline CHEMBL 3674053 & 1535769 & 5.49299 & 99999999 & 99 & 5.5 & TRN \\
\hline CHEMBL 3674088 & 1535769 & 6.0 & 5.9484 & TST & & \\
\hline CHEMBL3674109 & 1535769 & 6.0 & 5.8917 & TST & & \\
\hline CHEMBL 3674052 & 1535769 & 6.471 & 6.511 & TRN & & \\
\hline CHEMBL3674057 & 1535769 & 5.34200 & 000000006 & 005 & 5.3772 & TRN \\
\hline CHEMBL 3674127 & 1535769 & 6.0 & 6.2646 & TST & & \\
\hline CHEMBL319791 & 207779 & 5.8861 & 5.8549 & TRN & & \\
\hline CHEMBL317733 & 207779 & 6.0 & 6.45299 & 9999999999 & & TRN \\
\hline CHEMBL 263019 & 207779 & 6.0 & 6.6959 & TST & & \\
\hline CHEMBL101870 & 207779 & 3.0 & 2.8159 & TRN & & \\
\hline CHEMBL 317322 & 207779 & 4.0 & 4.8122 & TST & & \\
\hline CHEMBL100755 & 207779 & 7.0862 & 7.0819 & TRN & & \\
\hline CHEMBL101841 & 207779 & 7.5528 & 7.5262 & TRN & & \\
\hline CHEMBL 330440 & 207779 & 7.1367 & 6.9841 & TRN & & \\
\hline CHEMBL98601 & 207779 & 6.0 & 6.6165 & TRN & & \\
\hline CHEMBL98141 & 207779 & 7.0 & 6.768 & TRN & & \\
\hline CHEMBL98941 & 207779 & 6.0 & 6.5489 & TRN & & \\
\hline CHEMBL99551 & 207779 & 7.1249 & 7.0055 & TRN & & \\
\hline CHEMBL99223 & 207779 & 7.284 & 7.0551 & TRN & & \\
\hline CHEMBL97891 & 207779 & 6.0 & 5.74 & TRN & & \\
\hline CHEMBL330614 & 207779 & 7.0 & 6.7772 & TRN & & \\
\hline CHEMBL101542 & 207779 & 6.0 & 6.5319 & TRN & & \\
\hline CHEMBL430495 & 207779 & 7.5376 & 7.1489 & TRN & & \\
\hline CHEMBL318459 & 207779 & 6.6021 & 6.4733 & TST & & \\
\hline CHEMBL101785 & 207779 & 7.0969 & 6.9974 & TRN & & \\
\hline CHEMBL 97917 & 207779 & 5.6576 & 5.8297 & TRN & & \\
\hline CHEMBL102200 & 207779 & 7.1871 & 7.1548 & TRN & & \\
\hline CHEMBL 98901 & 207779 & 7.3768 & 7.324 & TRN & & \\
\hline CHEMBL101098 & 207779 & 6.0 & 6.6165 & TRN & & \\
\hline CHEMBL330187 & 207779 & 7.2596 & 7.2243 & TRN & & \\
\hline CHEMBL328646 & 207779 & 6.0 & 5.9938 & TRN & & \\
\hline CHEMBL98439 & 207779 & 6.0 & 6.1259 & TRN & & \\
\hline CHEMBL 330442 & 207779 & 7.301 & 7.4805 & TRN & & \\
\hline CHEMBL 318048 & 207779 & 7.1871 & 7.231 & TRN & & \\
\hline CHEMBL98845 & 207779 & 7.2218 & 7.3992 & TST & & \\
\hline CHEMBL 98443 & 207779 & 7.5229 & 7.3033 & TRN & & \\
\hline CHEMBL98372 & 207779 & 6.2218 & 6.4899 & TRN & & \\
\hline CHEMBL317387 & 207779 & 6.8861 & 7.0948 & TRN & & \\
\hline CHEMBL321301 & 207779 & 5.5686 & 6.9508 & TST & & \\
\hline CHEMBL98085 & 207779 & 6.9586 & 7.3373 & TRN & & \\
\hline CHEMBL432014 & 207779 & 6.0 & 6.00299 & 9999999999 & & TRN \\
\hline CHEMBL329965 & 207779 & 7.3872 & 7.4655 & TRN & & \\
\hline CHEMBL98251 & 207779 & 7.0706 & 7.0211 & TRN & & \\
\hline
\end{tabular}




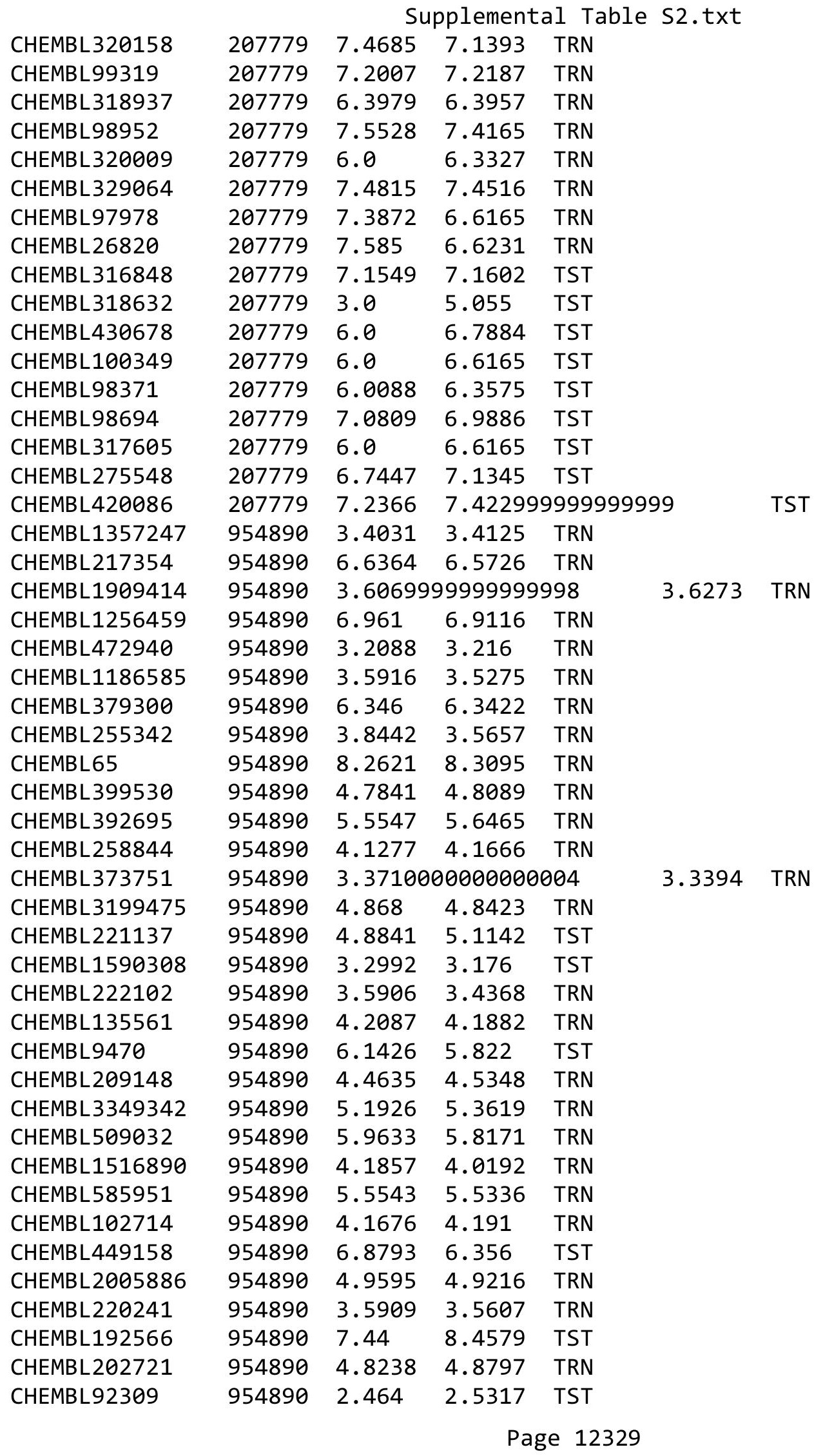


Supplemental Table S2.txt

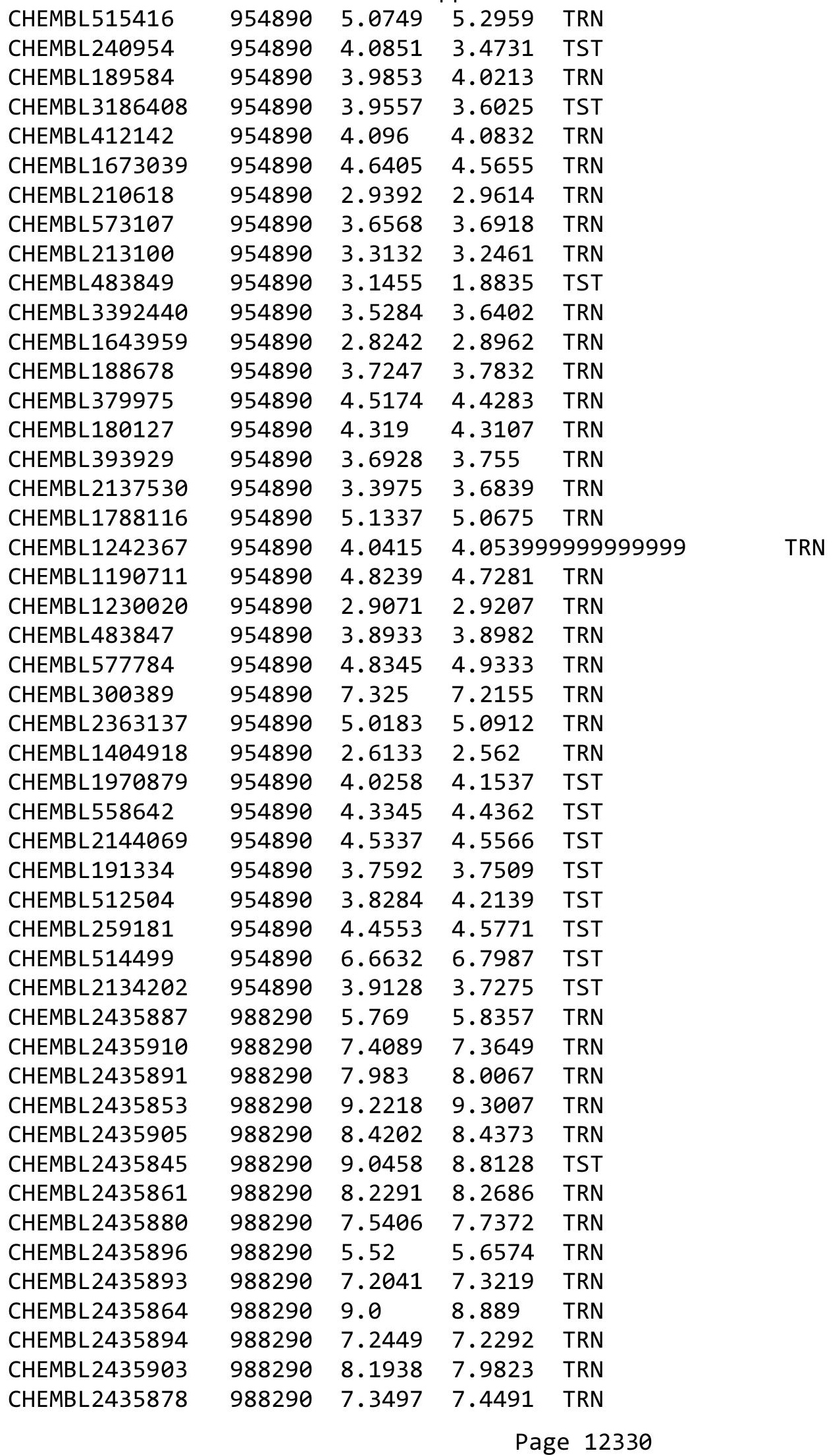




\begin{tabular}{|c|c|c|c|c|c|}
\hline & & \multicolumn{4}{|c|}{ Supplemental Table s2.txt } \\
\hline CHEMBL2435871 & 988290 & 6.2612 & 6.3418 & TRN & \\
\hline CHEMBL 2435897 & 988290 & 7.0991 & 7.3177 & TRN & \\
\hline CHEMBL2435892 & 988290 & 8.6021 & 8.4009 & TRN & \\
\hline CHEMBL 2435867 & 988290 & 6.3606 & 6.3343 & TRN & \\
\hline CHEMBL 2434978 & 988290 & 9.0458 & 7.9954 & TST & \\
\hline CHEMBL2435879 & 988290 & 7.2441 & 7.2737 & TRN & \\
\hline CHEMBL 2435868 & 988290 & 7.2958 & 7.3032 & TRN & \\
\hline CHEMBL2435899 & 988290 & 5.5319 & 5.5609 & TRN & \\
\hline CHEMBL 2435859 & 988290 & 9.0458 & 9.0428 & TRN & \\
\hline CHEMBL 2435848 & 988290 & 9.5229 & 8.4287 & TST & \\
\hline CHEMBL 2435856 & 988290 & 9.1549 & 9.2487 & TRN & \\
\hline CHEMBL 2435876 & 988290 & 7.2027 & 7.1218 & TRN & \\
\hline CHEMBL 2435865 & 988290 & 7.2518 & 7.13399 & 99999999995 & TRN \\
\hline CHEMBL2435869 & 988290 & 5.6904 & 5.6184 & TRN & \\
\hline CHEMBL2435873 & 988290 & 6.4734 & 6.4721 & TRN & \\
\hline CHEMBL 2435912 & 988290 & 9.0458 & 9.0595 & TRN & \\
\hline CHEMBL 2435863 & 988290 & 8.0315 & 8.2097 & TRN & \\
\hline CHEMBL2435858 & 988290 & 8.9586 & 8.66 & TRN & \\
\hline CHEMBL2435906 & 988290 & 8.7696 & 8.8438 & TRN & \\
\hline CHEMBL2435866 & 988290 & 9.0 & 9.0929 & TRN & \\
\hline CHEMBL 2435898 & 988290 & 7.7328 & 7.4906 & TRN & \\
\hline CHEMBL 2435877 & 988290 & 6.8668 & 6.7361 & TRN & \\
\hline CHEMBL 2435874 & 988290 & 6.6996 & 6.9851 & TST & \\
\hline CHEMBL2435908 & 988290 & 8.0655 & 8.2589 & TRN & \\
\hline CHEMBL2435904 & 988290 & 7.9508 & 7.9165 & TRN & \\
\hline CHEMBL 2435851 & 988290 & 8.8861 & 8.9139 & TRN & \\
\hline CHEMBL2435849 & 988290 & 7.8041 & 7.7563 & TRN & \\
\hline CHEMBL 2435844 & 988290 & 9.0458 & 8.7853 & TST & \\
\hline CHEMBL 2435847 & 988290 & 8.7696 & 7.0399 & TST & \\
\hline CHEMBL2435881 & 988290 & 7.8861 & 7.7609 & TST & \\
\hline CHEMBL2435855 & 988290 & 8.8239 & 8.6812 & TST & \\
\hline CHEMBL2435907 & 988290 & 9.0458 & 8.9356 & TRN & \\
\hline CHEMBL 2435901 & 988290 & 6.9314 & 6.9297 & TRN & \\
\hline CHEMBL 2435895 & 988290 & 6.4603 & 6.3698 & TRN & \\
\hline CHEMBL 2435862 & 988290 & 8.7696 & 8.7939 & TRN & \\
\hline CHEMBL 2435870 & 988290 & 6.6696 & 5.9864 & TST & \\
\hline CHEMBL2435889 & 988290 & $5.5020 e$ & 00000000 & 5.4446 & TRN \\
\hline CHEMBL 2435875 & 988290 & 5.0 & 5.6936 & TST & \\
\hline CHEMBL 2435900 & 988290 & 6.0415 & 6.0823 & TRN & \\
\hline CHEMBL 2435846 & 988290 & 7.0325 & 7.6122 & TST & \\
\hline CHEMBL 2435902 & 988290 & 7.2472 & 7.3593 & TRN & \\
\hline CHEMBL 2435890 & 988290 & 7.9318 & 8.0004 & TRN & \\
\hline CHEMBL 2435843 & 988290 & 8.8861 & 8.34700 & $\partial 000000001$ & TST \\
\hline CHEMBL 2435852 & 988290 & 8.8539 & 8.6774 & TST & \\
\hline CHEMBL 2435872 & 988290 & 6.5536 & 6.6829 & TST & \\
\hline CHEMBL 2435888 & 988290 & 6.466 & 6.3751 & TRN & \\
\hline CHEMBL2435909 & 988290 & 8.9586 & 8.8854 & TRN & \\
\hline CHEMBL2435857 & 988290 & 9.3979 & 8.3895 & TST & \\
\hline
\end{tabular}


Supplemental Table S2.txt

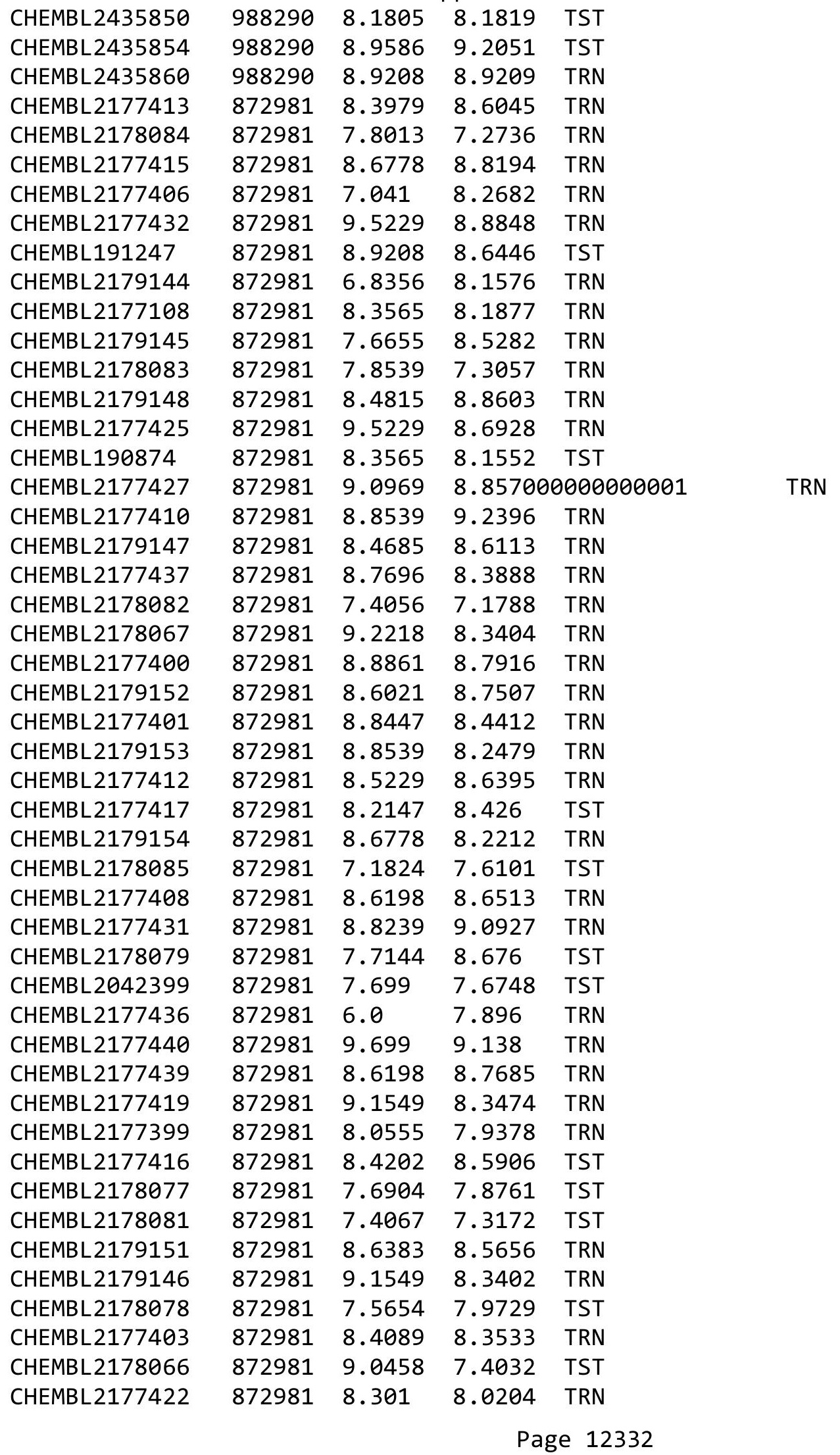




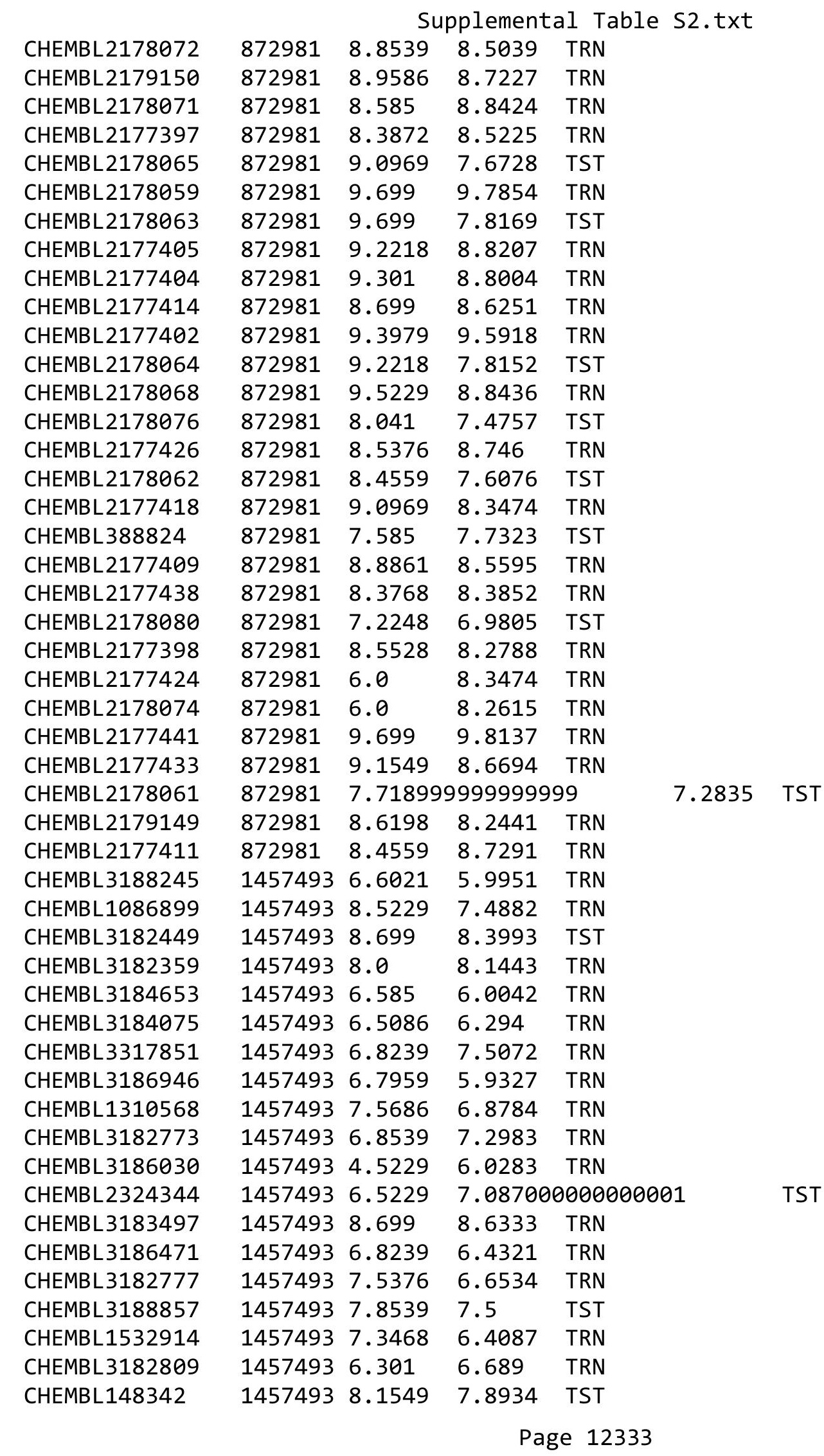


Supplemental Table S2.txt

\begin{tabular}{|c|c|c|c|c|c|}
\hline CHEMBL3317822 & 1457493 & 4.5229 & 5.8375 & TRN & \\
\hline CHEMBL3184966 & 1457493 & 7.284 & 6.5498 & TRN & \\
\hline CHEMBL3317853 & 1457493 & 4.5229 & 6.1524 & TRN & \\
\hline CHEMBL 3182370 & 1457493 & 7.0655 & 6.5505 & TRN & \\
\hline CHEMBL3186695 & 1457493 & 7.6383 & 7.5931 & TRN & \\
\hline CHEMBL3186207 & 1457493 & 7.0 & 7.0488 & TRN & \\
\hline CHEMBL3188024 & 1457493 & 6.0969 & 6.3471 & TRN & \\
\hline CHEMBL3187482 & 1457493 & 8.0458 & 8.2639 & TRN & \\
\hline CHEMBL3182091 & 1457493 & 8.301 & 7.539 & TRN & \\
\hline CHEMBL3317849 & 1457493 & 4.5229 & 5.5179 & TRN & \\
\hline CHEMBL3183773 & 1457493 & 8.0 & 6.9386 & TRN & \\
\hline CHEMBL3187764 & 1457493 & 8.1549 & 8.3974 & TRN & \\
\hline CHEMBL3181946 & 1457493 & 6.7212 & 6.1646 & TRN & \\
\hline CHEMBL1541525 & 1457493 & 5.8894 & 6.0994 & TRN & \\
\hline CHEMBL3185736 & 1457493 & 7.5229 & 7.3931 & TRN & \\
\hline CHEMBL 3317850 & 1457493 & 4.5229 & 5.8363 & TRN & \\
\hline CHEMBL3188671 & 1457493 & 5.8861 & 6.3136 & TRN & \\
\hline CHEMBL3182699 & 1457493 & 9.0 & 8.2879 & TRN & \\
\hline CHEMBL3188463 & 1457493 & 6.8239 & 6.5212 & TRN & \\
\hline CHEMBL3186489 & 1457493 & 7.6778 & 6.2292 & TRN & \\
\hline CHEMBL 3188343 & 1457493 & 6.6576 & 7.32 & TRN & \\
\hline CHEMBL 3182725 & 1457493 & 7.5376 & 7.85 & TRN & \\
\hline CHEMBL3182551 & 1457493 & 7.6021 & 7.5531 & TRN & \\
\hline CHEMBL3187891 & 1457493 & 7.0223 & \multicolumn{2}{|c|}{6.667999999999999} & TRN \\
\hline CHEMBL1480257 & 1457493 & 7.1367 & 8.3582 & TRN & \\
\hline CHEMBL3317852 & 1457493 & 6.6778 & 7.982 & TRN & \\
\hline CHEMBL3184095 & 1457493 & 7.1024 & 6.4889 & TST & \\
\hline CHEMBL1081188 & 1457493 & 8.3979 & 8.0162 & TRN & \\
\hline CHEMBL3183938 & 1457493 & 6.4815 & 6.4886 & TRN & \\
\hline CHEMBL3187806 & 1457493 & 7.5086 & 7.1903 & TST & \\
\hline CHEMBL1716797 & 1457493 & 7.4318 & 6.3544 & TST & \\
\hline CHEMBL 3188749 & 1457493 & 8.3979 & 8.2133 & TST & \\
\hline CHEMBL3186206 & 1457493 & 6.8861 & 6.657 & TST & \\
\hline CHEMBL3184438 & 1457493 & 6.4815 & 7.777 & TST & \\
\hline CHEMBL3317854 & 1457493 & 6.7447 & 7.3639 & TST & \\
\hline CHEMBL3186000 & 1457493 & 7.9586 & 8.2396 & TST & \\
\hline CHEMBL3181939 & 1457493 & 7.041 & 7.7048 & TST & \\
\hline CHEMBL3317848 & 1457493 & 4.5229 & 6.1495 & TST & \\
\hline CHEMBL3183945 & 1457493 & 6.7959 & 6.4412 & TST & \\
\hline CHEMBL3682837 & 1528918 & 6.585 & 6.2092 & TRN & \\
\hline CHEMBL3682714 & 1528918 & 7.3979 & 7.0942 & TRN & \\
\hline CHEMBL3682669 & 1528918 & 6.4815 & 7.0202 & TRN & \\
\hline CHEMBL3682681 & 1528918 & 6.0 & 6.5245 & TST & \\
\hline CHEMBL3682724 & 1528918 & 6.0605 & 5.4105 & TST & \\
\hline CHEMBL 3682748 & 1528918 & 6.6576 & 6.2838 & TRN & \\
\hline CHEMBL3682713 & 1528918 & 8.0 & 7.6369 & TRN & \\
\hline CHEMBL3687542 & 1528918 & 7.699 & 7.8572 & TRN & \\
\hline CHEMBL3692147 & 1528918 & 5.6021 & 6.2996 & TRN & \\
\hline
\end{tabular}

Page 12334 
Supplemental Table S2.txt

\begin{tabular}{|c|c|c|c|c|c|}
\hline CHEMBL3682702 & 1528918 & 6.8239 & \multicolumn{2}{|c|}{7.582000000000001} & TRN \\
\hline CHEMBL 3677852 & 1528918 & 6.0458 & 7.2739 & TRN & \\
\hline CHEMBL 3687577 & 1528918 & 4.0 & 5.2105 & TST & \\
\hline CHEMBL3682630 & 1528918 & 5.9281 & \multicolumn{2}{|c|}{6.196000000000001} & TST \\
\hline CHEMBL3682752 & 1528918 & 7.699 & 6.7491 & TRN & \\
\hline CHEMBL3677855 & 1528918 & 5.1101 & 6.8219 & TRN & \\
\hline CHEMBL 3682633 & 1528918 & 7.3979 & 7.2106 & TRN & \\
\hline CHEMBL3692143 & 1528918 & 7.3979 & 7.1369 & TRN & \\
\hline CHEMBL3682666 & 1528918 & 5.8069 & 7.1851 & TRN & \\
\hline CHEMBL3682779 & 1528918 & 6.699 & 6.0838 & TRN & \\
\hline CHEMBL 3682622 & 1528918 & 7.0969 & 7.1942 & TRN & \\
\hline CHEMBL3682813 & 1528918 & 6.9586 & 6.8055 & TRN & \\
\hline CHEMBL3682635 & 1528918 & 7.5229 & 7.4156 & TRN & \\
\hline CHEMBL3682652 & 1528918 & 6.5376 & 7.0672 & TST & \\
\hline CHEMBL3682659 & 1528918 & 5.3125 & 6.6508 & TRN & \\
\hline CHEMBL3682709 & 1528918 & 7.1549 & 7.0805 & TRN & \\
\hline CHEMBL3682745 & 1528918 & 7.699 & 6.8396 & TRN & \\
\hline CHEMBL 3687541 & 1528918 & 6.7696 & 6.4002 & TRN & \\
\hline CHEMBL3639816 & 1528918 & 6.1739 & 6.0867 & TRN & \\
\hline CHEMBL3682716 & 1528918 & 7.2218 & 7.0134 & TRN & \\
\hline CHEMBL3682733 & 1528918 & 5.6383 & 5.3166 & TRN & \\
\hline CHEMBL3682731 & 1528918 & 8.0 & 6.9626 & TRN & \\
\hline CHEMBL3687555 & 1528918 & 6.6576 & 6.7107 & TRN & \\
\hline CHEMBL3677850 & 1528918 & 7.5229 & 7.2626 & TRN & \\
\hline CHEMBL3682789 & 1528918 & 7.699 & 7.8699 & TRN & \\
\hline CHEMBL3682758 & 1528918 & 5.857 & 6.4537 & TRN & \\
\hline CHEMBL 3682792 & 1528918 & 6.9586 & 6.0255 & TRN & \\
\hline CHEMBL 3687544 & 1528918 & 8.0 & 7.6342 & TRN & \\
\hline CHEMBL3682794 & 1528918 & 5.6696 & 5.4896 & TST & \\
\hline CHEMBL 3682808 & 1528918 & 7.699 & 7.1537 & TRN & \\
\hline CHEMBL 3687574 & 1528918 & 4.0 & 5.3427 & TST & \\
\hline CHEMBL3682638 & 1528918 & 7.699 & 7.1204 & TRN & \\
\hline CHEMBL3682636 & 1528918 & 7.301 & 6.7743 & TRN & \\
\hline CHEMBL3682812 & 1528918 & 6.9586 & 6.5267 & TRN & \\
\hline CHEMBL3682685 & 1528918 & 6.5686 & 6.5244 & TST & \\
\hline CHEMBL3692134 & 1528918 & 7.5229 & 7.3119 & TRN & \\
\hline CHEMBL3682776 & 1528918 & 6.5686 & 6.2243 & TRN & \\
\hline CHEMBL 3682787 & 1528918 & 5.5331 & 6.6038 & TRN & \\
\hline CHEMBL3677856 & 1528918 & 6.699 & 6.8027 & TRN & \\
\hline CHEMBL 3682774 & 1528918 & 5.3706 & 5.7484 & TRN & \\
\hline CHEMBL3682662 & 1528918 & 7.2218 & 7.0733 & TRN & \\
\hline CHEMBL3682750 & 1528918 & 6.7447 & 5.9282 & TRN & \\
\hline CHEMBL3682678 & 1528918 & 7.1549 & 6.9599 & TRN & \\
\hline CHEMBL3682785 & 1528918 & 8.0 & 7.7898 & TRN & \\
\hline CHEMBL3682646 & 1528918 & 6.6778 & 7.2188 & TRN & \\
\hline CHEMBL3692138 & 1528918 & 6.9208 & 6.4553 & TRN & \\
\hline CHEMBL3687571 & 1528918 & 4.0 & 4.8474 & TST & \\
\hline CHEMBL3692142 & 1528918 & 7.1549 & 7.2869 & TRN & \\
\hline
\end{tabular}

Page 12335 


$$
\text { Supplemental Table S2.txt }
$$

\begin{tabular}{|c|c|c|c|c|}
\hline CHEMBL 3682723 & 1528918 & 6.0915 & 5.6688 & TST \\
\hline CHEMBL 3687553 & 1528918 & 7.301 & 7.3696 & TRN \\
\hline CHEMBL 3682642 & 1528918 & 6.9586 & 7.0047 & TRN \\
\hline CHEMBL 3687576 & 1528918 & 4.0 & 5.1567 & TST \\
\hline CHEMBL 3682688 & 1528918 & 8.0 & 8.1387 & TRN \\
\hline CHEMBL 3692136 & 1528918 & 7.1549 & 6.9931 & TRN \\
\hline CHEMBL 3682660 & 1528918 & 7.3979 & 6.6747 & TRN \\
\hline CHEMBL 3692132 & 1528918 & 7.699 & 7.2816 & TRN \\
\hline CHEMBL 3682775 & 1528918 & 6.4949 & 7.0517 & TRN \\
\hline CHEMBL 3687565 & 1528918 & 7.3979 & 7.2774 & TRN \\
\hline CHEMBL 3682701 & 1528918 & 6.7696 & 7.6739 & TRN \\
\hline CHEMBL 3692167 & 1528918 & 6.3372 & 6.2627 & TRN \\
\hline CHEMBL 3682668 & 1528918 & 7.0458 & 7.0026 & TRN \\
\hline CHEMBL 3687554 & 1528918 & 7.1549 & 7.2833 & TRN \\
\hline CHEMBL 3682703 & 1528918 & 7.3979 & 7.6719 & TRN \\
\hline CHEMBL 3682747 & 1528918 & 7.5229 & 6.4914 & TRN \\
\hline CHEMBL 3682679 & 1528918 & 8.0 & 6.4215 & TST \\
\hline CHEMBL 3682655 & 1528918 & 6.6478 & 6.75 & TRN \\
\hline CHEMBL 3687583 & 1528918 & 4.0 & 4.4787 & TRN \\
\hline CHEMBL 3682706 & 1528918 & 7.0969 & 8.0289 & TRN \\
\hline CHEMBL 3692133 & 1528918 & 7.3979 & 7.5822 & TRN \\
\hline CHEMBL 3682760 & 1528918 & 7.5229 & 6.4182 & TRN \\
\hline CHEMBL 3687581 & 1528918 & 4.0 & 5.2401 & TRN \\
\hline CHEMBL 3682804 & 1528918 & 7.1549 & 6.2861 & TRN \\
\hline CHEMBL 3687543 & 1528918 & 8.0 & 7.6669 & TRN \\
\hline CHEMBL 3682683 & 1528918 & 6.0 & 6.7675 & TST \\
\hline CHEMBL 3677857 & 1528918 & 6.3372 & 6.7495 & TRN \\
\hline CHEMBL 3682658 & 1528918 & 7.5229 & 7.3113 & TRN \\
\hline CHEMBL 3682744 & 1528918 & 5.1669 & 6.1023 & TRN \\
\hline CHEMBL 3682690 & 1528918 & 6.3372 & 6.3268 & TST \\
\hline CHEMBL 3682734 & 1528918 & 7.2218 & 6.5091 & TRN \\
\hline CHEMBL 3682825 & 1528918 & 6.6198 & 7.5135 & TRN \\
\hline CHEMBL 3682720 & 1528918 & 5.4023 & 4.7332 & TST \\
\hline CHEMBL 3682654 & 1528918 & 5.3107 & 6.7045 & TST \\
\hline CHEMBL 3677858 & 1528918 & 7.301 & 7.1827 & TRN \\
\hline CHEMBL 3687580 & 1528918 & 4.0 & 5.025 & TST \\
\hline CHEMBL 3682783 & 1528918 & 5.3028 & 5.6931 & TST \\
\hline CHEMBL 3692140 & 1528918 & 5.8182 & 6.4775 & TRN \\
\hline CHEMBL 3682648 & 1528918 & 6.3665 & 6.9955 & TRN \\
\hline CHEMBL 3682835 & 1528918 & 6.9208 & 6.7959 & TRN \\
\hline CHEMBL 3682680 & 1528918 & 6.9586 & 7.0695 & TRN \\
\hline CHEMBL 3682645 & 1528918 & 6.7212 & 6.8957 & TRN \\
\hline CHEMBL 3682632 & 1528918 & 7.699 & 7.3696 & TRN \\
\hline CHEMBL 3682707 & 1528918 & 6.0862 & 5.8919 & TST \\
\hline CHEMBL 3682732 & 1528918 & 7.0458 & \multicolumn{2}{|c|}{5.792000000000001} \\
\hline CHEMBL 3682700 & 1528918 & 6.4815 & 6.8765 & TRN \\
\hline CHEMBL 3687573 & 1528918 & 4.0 & 4.7031 & TST \\
\hline CHEMBL 3687593 & 1528918 & 4.0 & 5.6601 & TST \\
\hline
\end{tabular}


Supplemental Table S2.txt

\begin{tabular}{|c|c|c|c|c|c|}
\hline CHEMBL 3682743 & 1528918 & 7.5229 & 6.6692 & TRN & \\
\hline CHEMBL3687588 & 1528918 & 4.0 & 6.2302 & TRN & \\
\hline CHEMBL 3682801 & 1528918 & 7.699 & 8.1353 & TRN & \\
\hline CHEMBL 3682802 & 1528918 & 7.3979 & 7.0153 & TRN & \\
\hline CHEMBL 3682664 & 1528918 & 6.2218 & 6.8566 & TRN & \\
\hline CHEMBL 3682675 & 1528918 & 7.1549 & 7.0223 & TRN & \\
\hline CHEMBL 3682727 & 1528918 & 5.4815 & 5.0948 & TST & \\
\hline CHEMBL 3687575 & 1528918 & 4.0 & 5.2712 & TST & \\
\hline CHEMBL 3687578 & 1528918 & 4.0 & 5.1686 & TST & \\
\hline CHEMBL 3687589 & 1528918 & 4.0 & 6.3657 & TRN & \\
\hline CHEMBL 3682730 & 1528918 & 5.4023 & 5.4565 & TST & \\
\hline CHEMBL 3687551 & 1528918 & 7.5229 & 7.4501 & TRN & \\
\hline CHEMBL 3687552 & 1528918 & 7.3979 & 7.4101 & TRN & \\
\hline CHEMBL 3687539 & 1528918 & 7.3979 & 6.762006 & 00000000005 & TRN \\
\hline CHEMBL 3682673 & 1528918 & 7.0969 & 6.6686 & TRN & \\
\hline CHEMBL 3687587 & 1528918 & 4.0 & 5.6642 & TRN & \\
\hline CHEMBL 3682738 & 1528918 & 7.5229 & 6.5407 & TRN & \\
\hline CHEMBL 3639815 & 1528918 & 7.0458 & 6.98600 & 0000000001 & TRN \\
\hline CHEMBL3682836 & 1528918 & 7.699 & 7.4733 & TRN & \\
\hline CHEMBL3692130 & 1528918 & 6.5086 & 6.4586 & TRN & \\
\hline CHEMBL3919063 & 1528918 & 5.5129 & 4.1544 & TST & \\
\hline CHEMBL 3682777 & 1528918 & 5.6308 & 6.4515 & TRN & \\
\hline CHEMBL 3682840 & 1528918 & 6.585 & 7.0655 & TRN & \\
\hline CHEMBL3682749 & 1528918 & 5.1945 & 6.1516 & TRN & \\
\hline CHEMBL 3682691 & 1528918 & 5.6536 & 5.5756 & TST & \\
\hline CHEMBL 3682676 & 1528918 & 6.0458 & 7.0042 & TST & \\
\hline CHEMBL 3682711 & 1528918 & 7.5229 & 7.0355 & TRN & \\
\hline CHEMBL 3682653 & 1528918 & 7.301 & 6.8298 & TRN & \\
\hline CHEMBL 3682740 & 1528918 & 7.0969 & 6.5628 & TRN & \\
\hline CHEMBL 3682764 & 1528918 & 6.5686 & 5.8015 & TRN & \\
\hline CHEMBL 3682661 & 1528918 & 8.0 & 7.0912 & TRN & \\
\hline CHEMBL 3682751 & 1528918 & 5.3161 & 6.0267 & TRN & \\
\hline CHEMBL 3682753 & 1528918 & 7.699 & 7.0221 & TRN & \\
\hline CHEMBL3692137 & 1528918 & 6.4949 & 6.2616 & TRN & \\
\hline CHEMBL 3682746 & 1528918 & 7.3979 & 6.5077 & TRN & \\
\hline CHEMBL3682634 & 1528918 & 6.9586 & 7.3641 & TRN & \\
\hline CHEMBL 3682729 & 1528918 & 5.4078 & 4.1406 & TST & \\
\hline CHEMBL 3682826 & 1528918 & 6.1079 & 5.7263 & TST & \\
\hline CHEMBL 3692129 & 1528918 & 6.4685 & 7.5989 & TRN & \\
\hline CHEMBL3682694 & 1528918 & 5.9355 & 5.836 & TST & \\
\hline CHEMBL3682793 & 1528918 & 5.6778 & 5.8245 & TST & \\
\hline CHEMBL3682739 & 1528918 & 6.8861 & 5.9462 & TRN & \\
\hline CHEMBL 3682786 & 1528918 & 8.0 & 7.4457 & TRN & \\
\hline CHEMBL 3682765 & 1528918 & 6.3665 & 5.3269 & TRN & \\
\hline CHEMBL 3687538 & 1528918 & 8.0 & 7.6846 & TRN & \\
\hline CHEMBL 3682755 & 1528918 & 6.2441 & 5.8118 & TRN & \\
\hline CHEMBL 3682695 & 1528918 & 6.0 & 6.5917 & TST & \\
\hline CHEMBL 3682809 & 1528918 & 5.9586 & 6.4232 & TRN & \\
\hline
\end{tabular}


Supplemental Table S2.txt

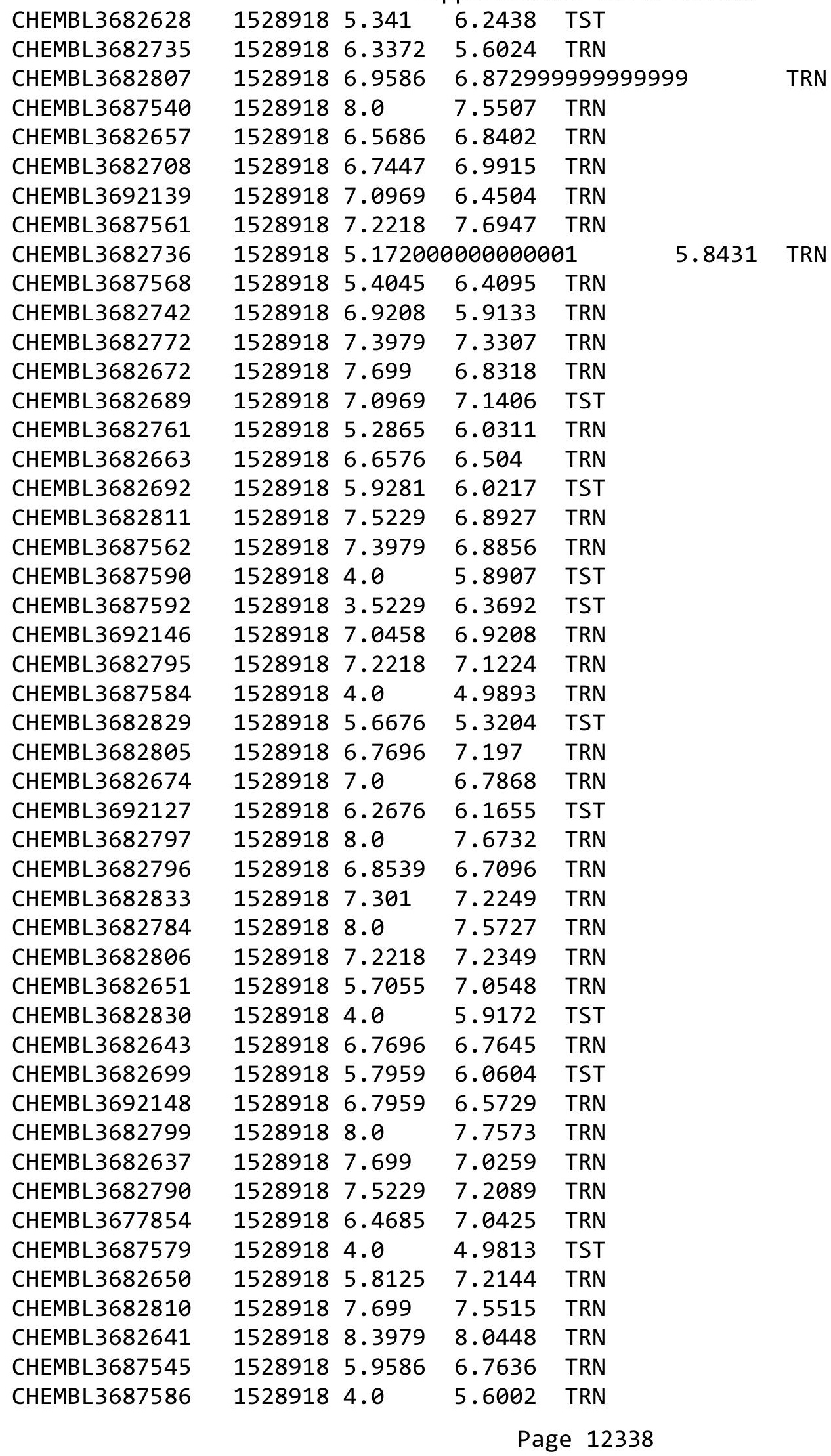


Supplemental Table S2.txt

\begin{tabular}{|c|c|c|c|c|c|}
\hline CHEMBL 3687570 & 1528918 & 4.0 & 5.0139 & TST & \\
\hline CHEMBL 3682756 & 1528918 & 5.1798 & 5.8011 & TRN & \\
\hline CHEMBL 3682728 & 1528918 & 5.4449 & 4.0257 & TST & \\
\hline CHEMBL 3682712 & 1528918 & 7.699 & 7.4144 & TRN & \\
\hline CHEMBL 3682820 & 1528918 & 6.8861 & 6.8853 & TST & \\
\hline CHEMBL3677849 & 1528918 & 7.5229 & 7.0242 & TRN & \\
\hline CHEMBL3692131 & 1528918 & 7.5229 & 6.9681 & TRN & \\
\hline CHEMBL 3682631 & 1528918 & 5.5031 & 6.21 & TST & \\
\hline CHEMBL 3682710 & 1528918 & 6.7447 & 6.4237 & TRN & \\
\hline CHEMBL3692141 & 1528918 & 7.2218 & 6.6502 & TST & \\
\hline CHEMBL3682828 & 1528918 & 5.6536 & 5.441 & TST & \\
\hline CHEMBL 3682629 & 1528918 & 6.1487 & 6.0832 & TST & \\
\hline CHEMBL 3682649 & 1528918 & 6.3098 & 7.0434 & TRN & \\
\hline CHEMBL 3682667 & 1528918 & 7.1549 & 6.9439 & TRN & \\
\hline CHEMBL3682686 & 1528918 & 5.4089 & 6.0163 & TST & \\
\hline CHEMBL3682778 & 1528918 & 6.4318 & 6.2036 & TRN & \\
\hline CHEMBL 3682821 & 1528918 & 6.0 & 6.4993 & TST & \\
\hline CHEMBL3692135 & 1528918 & 6.9586 & 6.9023 & TRN & \\
\hline CHEMBL 3677851 & 1528918 & 7.0458 & 7.17899 & 9999999999 & TRN \\
\hline CHEMBL 3682624 & 1528918 & 5.4486 & 6.3861 & TST & \\
\hline CHEMBL 3682644 & 1528918 & 6.7212 & 7.1144 & TRN & \\
\hline CHEMBL3682824 & 1528918 & 6.7212 & 7.4698 & TRN & \\
\hline CHEMBL 3682722 & 1528918 & 6.301 & 5.5373 & TST & \\
\hline CHEMBL3682693 & 1528918 & 6.5376 & 6.2772 & TST & \\
\hline CHEMBL 3687585 & 1528918 & 4.0 & 5.651 & TRN & \\
\hline CHEMBL 3682803 & 1528918 & 7.3979 & 7.0417 & TRN & \\
\hline CHEMBL 3682698 & 1528918 & 5.6055 & 5.7327 & TST & \\
\hline CHEMBL 3687546 & 1528918 & 7.699 & 7.3692 & TRN & \\
\hline CHEMBL 3682768 & 1528918 & 7.5229 & 7.1718 & TRN & \\
\hline CHEMBL 3682815 & 1528918 & 7.5229 & 6.8828 & TRN & \\
\hline CHEMBL 3682718 & 1528918 & 6.8861 & 6.6612 & TRN & \\
\hline CHEMBL 3682705 & 1528918 & 7.0 & 7.3902 & TRN & \\
\hline CHEMBL 3677853 & 1528918 & 6.7696 & 7.2422 & TRN & \\
\hline CHEMBL 3682677 & 1528918 & 5.9208 & 6.2869 & TST & \\
\hline CHEMBL 3687572 & 1528918 & 4.0 & 4.7991 & TST & \\
\hline CHEMBL 3682737 & 1528918 & 6.0362 & 5.5934 & TRN & \\
\hline CHEMBL 3687591 & 1528918 & 4.0 & 5.4395 & TST & \\
\hline CHEMBL 3682763 & 1528918 & 6.1367 & 5.4516 & TRN & \\
\hline CHEMBL 3682640 & 1528918 & 7.301 & 7.244 & TRN & \\
\hline CHEMBL 3682788 & 1528918 & 7.3979 & 7.2647 & TRN & \\
\hline CHEMBL 3682754 & 1528918 & 5.3851 & 5.9191 & TRN & \\
\hline CHEMBL 3682665 & 1528918 & 7.2218 & 7.693 & TRN & \\
\hline CHEMBL3682773 & 1528918 & 6.9586 & 6.3891 & TRN & \\
\hline CHEMBL 3682834 & 1528918 & 6.0 & 7.0708 & TRN & \\
\hline CHEMBL 3682627 & 1528918 & 5.6253 & 6.1843 & TST & \\
\hline CHEMBL 3687582 & 1528918 & 4.0 & 5.2698 & TRN & \\
\hline CHEMBL 3682725 & 1528918 & 5.7375 & 4.9981 & TST & \\
\hline CHEMBL 3682647 & 1528918 & 6.6778 & 7.2394 & TRN & \\
\hline
\end{tabular}

Page 12339 
Supplemental Table S2.txt

\begin{tabular}{|c|c|c|c|c|c|}
\hline CHEMBL 3682838 & 1528918 & 7.699 & 7.6965 & TRN & \\
\hline CHEMBL3682762 & 1528918 & 5.5768 & 5.9626 & TRN & \\
\hline CHEMBL3682827 & 1528918 & 5.9318 & 5.7317 & TST & \\
\hline CHEMBL 3682757 & 1528918 & 5.2652 & 4.1914 & TRN & \\
\hline CHEMBL3682819 & 1528918 & 7.301 & 7.4933 & TRN & \\
\hline CHEMBL3692128 & 1528918 & 7.5229 & 6.9288 & TRN & \\
\hline CHEMBL3682623 & 1528918 & 8.0 & \multicolumn{2}{|c|}{7.861000000000001} & TRN \\
\hline CHEMBL3682832 & 1528918 & 7.5229 & 7.5944 & TRN & \\
\hline CHEMBL3682639 & 1528918 & 7.301 & 7.1578 & TRN & \\
\hline CHEMBL3682759 & 1528918 & 7.301 & 6.4698 & TRN & \\
\hline CHEMBL3682814 & 1528918 & 8.0 & 7.1166 & TRN & \\
\hline CHEMBL3682656 & 1528918 & 7.4437 & 7.5081 & TRN & \\
\hline CHEMBL3682839 & 1528918 & 7.1549 & 7.2886 & TRN & \\
\hline CHEMBL3682741 & 1528918 & 7.2218 & 6.3091 & TRN & \\
\hline CHEMBL3682715 & 1528918 & 7.301 & 7.0917 & TRN & \\
\hline CHEMBL3682791 & 1528918 & 7.699 & 7.5499 & TRN & \\
\hline CHEMBL3687560 & 1528918 & 8.0 & 7.7313 & TRN & \\
\hline CHEMBL3687550 & 1528918 & 7.699 & 7.2184 & TRN & \\
\hline CHEMBL3682717 & 1528918 & 7.3979 & 6.9387 & TRN & \\
\hline CHEMBL3682626 & 1528918 & 5.8894 & 6.3646 & TST & \\
\hline CHEMBL3682798 & 1528918 & 7.5229 & 7.7176 & TST & \\
\hline CHEMBL3682766 & 1528918 & 6.1938 & 5.1413 & TST & \\
\hline CHEMBL3682687 & 1528918 & 5.0985 & 6.4729 & TST & \\
\hline CHEMBL3682800 & 1528918 & 7.699 & 7.7952 & TST & \\
\hline CHEMBL3682704 & 1528918 & 7.2218 & 7.4322 & TST & \\
\hline CHEMBL3682670 & 1528918 & 6.1135 & 6.407 & TST & \\
\hline CHEMBL135921 & 51212 & 7.5528 & \multicolumn{2}{|c|}{6.2860000000000005} & TRN \\
\hline CHEMBL137396 & 51212 & 7.301 & 7.835 & TRN & \\
\hline CHEMBL133262 & 51212 & 7.7696 & 7.8364 & TRN & \\
\hline CHEMBL336616 & 51212 & 7.0269 & 6.1757 & TRN & \\
\hline CHEMBL137589 & 51212 & 7.5229 & 6.2987 & TRN & \\
\hline CHEMBL132708 & 51212 & 7.7212 & \multicolumn{2}{|c|}{6.622999999999999} & TRN \\
\hline CHEMBL135849 & 51212 & 4.301 & 6.2098 & TST & \\
\hline CHEMBL137002 & 51212 & 7.1805 & 7.1265 & TRN & \\
\hline CHEMBL334958 & 51212 & 6.699 & 6.1737 & TRN & \\
\hline CHEMBL336708 & 51212 & 7.2147 & 7.8096 & TRN & \\
\hline CHEMBL341386 & 51212 & 8.0555 & 7.1973 & TRN & \\
\hline CHEMBL335252 & 51212 & 4.301 & \multicolumn{2}{|c|}{6.406000000000001} & TST \\
\hline CHEMBL135396 & 51212 & 5.3468 & 5.7945 & TRN & \\
\hline CHEMBL137604 & 51212 & 8.0269 & \multicolumn{2}{|c|}{7.792999999999999} & TRN \\
\hline CHEMBL138538 & 51212 & 6.6383 & 5.9845 & TRN & \\
\hline CHEMBL137757 & 51212 & 4.301 & 6.2907 & TST & \\
\hline CHEMBL335415 & 51212 & 4.699 & \multicolumn{2}{|c|}{5.992000000000001} & TRN \\
\hline CHEMBL137432 & 51212 & 4.699 & 5.4336 & TRN & \\
\hline CHEMBL343273 & 51212 & 5.7447 & 5.4449 & TRN & \\
\hline CHEMBL422093 & 51212 & 5.7144 & 6.5834 & TST & \\
\hline CHEMBL554619 & 51212 & 6.7959 & 6.7054 & TST & \\
\hline CHEMBL335436 & 51212 & 4.301 & 6.5542 & TRN & \\
\hline
\end{tabular}




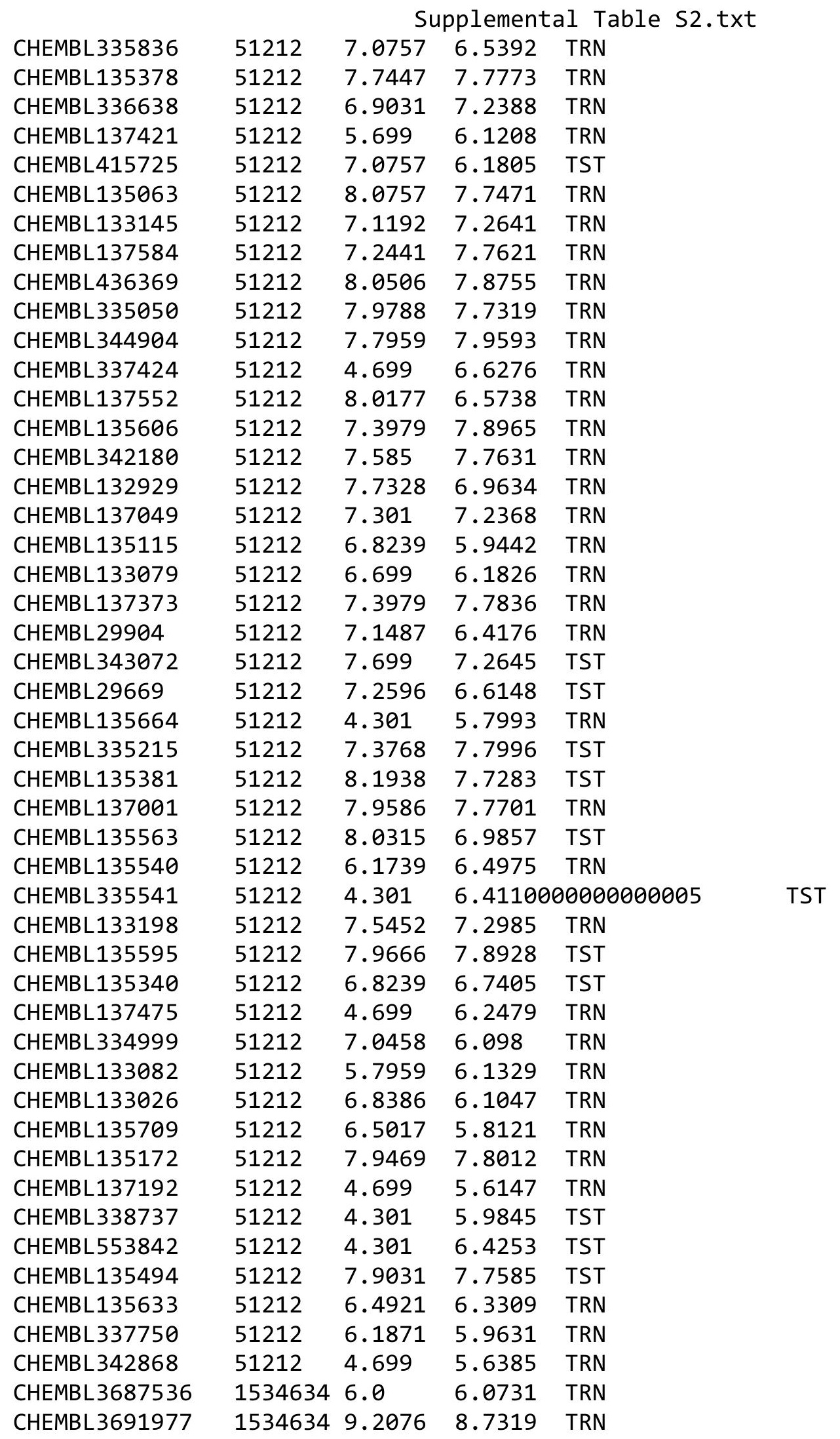

Page 12341 
Supplemental Table S2.txt

\begin{tabular}{|c|c|c|c|c|}
\hline CHEMBL3639863 & 1534634 & 8.5086 & 8.2571 & TRN \\
\hline CHEMBL 3687432 & 1534634 & 8.1688 & 8.2671 & TRN \\
\hline CHEMBL 3687422 & 1534634 & 7.7501 & 7.5278 & TRN \\
\hline CHEMBL 3687470 & 1534634 & 6.0 & 5.7601 & TRN \\
\hline CHEMBL3691975 & 1534634 & 8.0128 & 8.0519 & TRN \\
\hline CHEMBL 3687424 & 1534634 & 7.7086 & 7.655 & TST \\
\hline CHEMBL3687459 & 1534634 & 6.0 & 6.1827 & TST \\
\hline CHEMBL 3687414 & 1534634 & 8.5986 & 8.914 & TST \\
\hline CHEMBL 3687534 & 1534634 & 8.6216 & 8.4656 & TRN \\
\hline CHEMBL3639862 & 1534634 & 8.684 & 8.4712 & TRN \\
\hline CHEMBL3691966 & 1534634 & 7.5251 & 7.7644 & TRN \\
\hline CHEMBL 3691917 & 1534634 & 7.9788 & 7.7717 & TST \\
\hline CHEMBL 3687495 & 1534634 & 6.0 & 5.8173 & TRN \\
\hline CHEMBL 3639908 & 1534634 & 8.5157 & 8.4084 & TST \\
\hline CHEMBL 3687436 & 1534634 & 6.0 & 6.0259 & TRN \\
\hline CHEMBL 3691978 & 1534634 & 8.9318 & 9.0605 & TRN \\
\hline CHEMBL 3687423 & 1534634 & 6.0 & 6.3259 & TRN \\
\hline CHEMBL3691971 & 1534634 & 8.6925 & 8.6988 & TST \\
\hline CHEMBL 3687461 & 1534634 & 7.4462 & 7.1996 & TRN \\
\hline CHEMBL3691935 & 1534634 & 8.6615 & 8.3339 & TRN \\
\hline CHEMBL3691957 & 1534634 & 8.8794 & 8.673 & TRN \\
\hline CHEMBL3687446 & 1534634 & 6.0 & 5.7907 & TST \\
\hline CHEMBL3691986 & 1534634 & 8.8182 & 8.8001 & TRN \\
\hline CHEMBL 3691967 & 1534634 & 9.1249 & 8.9904 & TRN \\
\hline CHEMBL 3687519 & 1534634 & 7.9519 & 8.5563 & TST \\
\hline CHEMBL 3687427 & 1534634 & 8.9914 & 9.2072 & TRN \\
\hline CHEMBL3691926 & 1534634 & 6.0 & 6.25200 & 0000000001 \\
\hline CHEMBL 3687493 & 1534634 & 6.0 & 6.0419 & TRN \\
\hline CHEMBL 3687464 & 1534634 & 8.7595 & 8.5978 & TST \\
\hline CHEMBL 3687468 & 1534634 & 9.3098 & 8.9745 & TRN \\
\hline CHEMBL 3687524 & 1534634 & 8.7258 & 9.1666 & TRN \\
\hline CHEMBL3691919 & 1534634 & 9.585 & 9.0944 & TRN \\
\hline CHEMBL 3687512 & 1534634 & 6.0 & 5.9546 & TRN \\
\hline CHEMBL 3687416 & 1534634 & 7.5153 & 7.6547 & TRN \\
\hline CHEMBL 3687525 & 1534634 & 8.8416 & 8.656 & TRN \\
\hline CHEMBL 3691918 & 1534634 & 6.0 & 5.9817 & TST \\
\hline CHEMBL3691959 & 1534634 & 8.5986 & 9.0438 & TRN \\
\hline CHEMBL 3691914 & 1534634 & 8.7696 & 8.7824 & TRN \\
\hline CHEMBL 3687420 & 1534634 & 9.0655 & 9.2824 & TRN \\
\hline CHEMBL 3687507 & 1534634 & 8.6576 & 8.7272 & TRN \\
\hline CHEMBL3691960 & 1534634 & 9.0757 & 9.4747 & TST \\
\hline CHEMBL 3687466 & 1534634 & 9.2076 & 9.1432 & TRN \\
\hline CHEMBL 3687457 & 1534634 & 6.0 & 6.0708 & TRN \\
\hline CHEMBL 3691982 & 1534634 & 8.4486 & 8.3313 & TRN \\
\hline CHEMBL 3687518 & 1534634 & 8.2358 & 8.5079 & TRN \\
\hline CHEMBL 3687492 & 1534634 & 6.0 & 6.3109 & TRN \\
\hline CHEMBL 3687471 & 1534634 & 9.3098 & 9.0934 & TRN \\
\hline CHEMBL 3691928 & 1534634 & 8.9101 & 8.9895 & TRN \\
\hline
\end{tabular}

Page 12342 
Supplemental Table S2.txt

\begin{tabular}{|c|c|c|c|c|}
\hline 430 & & & & . \\
\hline & & 9.1675 & 9.4737 & \\
\hline HFMRI & 34 & 6.0 & & \\
\hline HEMBL3691980 & & 8.1612 & & \\
\hline HEMBL3687522 & 534634 & 8.382 & 3545 & \\
\hline HEMBL 3687474 & 534 & 6.0 & .379 & \\
\hline HEMBL: & 34 & 9.3665 & 2166 & \\
\hline HEMBL 368 & & & 3536 & ב \\
\hline HEMBL3691923 & 34 & 8.8097 & 8.925 & \\
\hline HEMBL3691915 & 534 & 8.8268 & 8.93 & \\
\hline HEMBL 368 & 53 & 6.0 & 7335 & \\
\hline HEMBL: & 34 & 8.2644 & 4804 & \\
\hline HEMBL3 & 34 & 6. & 1582 & \\
\hline HEMBL3687431 & 534 & 8.4935 & 8119 & \\
\hline HEMBL 368 & 34 & 8.2798 & 2605 & \\
\hline HEMBL3 & 4 & 49 & 7957 & RIV \\
\hline AEMBL & 4 & 77 & 9413 & 然 \\
\hline HEMBL; & 34 & 6. & 3177 & \\
\hline HEMBI 3 & 34 & 8.0985 & 9756 & \\
\hline HEMBL 368 & & 6.0 & 6601 & I KIV \\
\hline HEMBL & 4 & 8 . & 313 & ГRN \\
\hline HEM & 4 & & 825 & ונס \\
\hline HEMBL & 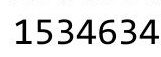 & 508 & 987 & \\
\hline HEMBL3 & & & 633 & TST \\
\hline HEMBL 368 & 53 & 6.0 & 1871 & ISI \\
\hline HEMBL3 & 2 & כ & 3678 & RN \\
\hline HEME & 4 & 3 & 45 & RN \\
\hline 74 & 4 & 6. & 9353 & RN \\
\hline AEMBL3 & & 9. & & IRN \\
\hline HEMBL 368 & 53 & 7.8035 & 7389 & TRN \\
\hline HEMBL & 53. & & 698 & ST \\
\hline$H E N$ & & & & RN \\
\hline נ & & 8 . & 907 & RN \\
\hline HEMBL3 & - & 5.9586 & 299 & 「RN \\
\hline HEMBL369 & 53 & 7.9007 & 9996 & ГRN \\
\hline JEMPI & 53 & 52 & 624 & TRN \\
\hline 0 & & 24 & 273 & ГRN \\
\hline HEMBL3 & & 7.9586 & 9368 & TST \\
\hline HEMBL3 & 53 & 8.8794 & 3001 & TRN \\
\hline TIDL & 4 & 7. & 079 & R \\
\hline HEMBL3 & - & 506 & 815 & TRN \\
\hline HEMBL3 & 4 & 9.1938 & 9.373 & RN \\
\hline HEMBL 368 & 52 & 8.7932 & 5436 & $T R$ \\
\hline HEMBL3 & 53 & 8.3862 & 303 & TS \\
\hline 8 & & 6 & & \\
\hline HEMBL3 & 1534 & 9.13 & 9.3485 & \\
\hline CHEMBL3 & 1534 & 6.0 & 6.2494 & IST \\
\hline CHEMBL3691955 & 153463 & 8.6003 & 8.3357 & TST \\
\hline
\end{tabular}

Page 12343 
Supplemental Table S2.txt

\begin{tabular}{|c|c|c|}
\hline 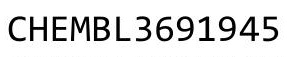 & & \\
\hline & & \\
\hline EMPI & & \\
\hline IEMBL 3691931 & & \\
\hline AEMBL3687417 & 34 & \\
\hline AEMBL3687450 & 534634 & 058 \\
\hline IEMBL368 & 34 & 6.0 \\
\hline IEMBL: & & 9.443 \\
\hline IEMBL3691970 & 534 & 8.542 \\
\hline HEMBL3691925 & 34 & 8.906 \\
\hline AEMBL3687520 & 34 & 746 \\
\hline IEMBL369 & 34 & 8.565 \\
\hline EMBL & & 266 \\
\hline AEMBL3687421 & 34 & $7.846 \varepsilon$ \\
\hline HEMBL368 & 34 & \\
\hline AEMBL368 & 153 & \\
\hline AEMBL368 & 34 & 8.4157 \\
\hline HEMBL; & 34 & 9.2596 \\
\hline AEMBL369 & 34 & $677 \varepsilon$ \\
\hline AEMBL369 & 34 & 8.2874 \\
\hline AEMBL. & 5 & 6.0 \\
\hline AEMBL & 34 & \\
\hline AEMBL & 34 & 8.8447 \\
\hline IEMBL36s & & 9.031 \\
\hline HEMBL368 & 34 & 8.759 \\
\hline AEMBL36؟ & 5 & 9.045 \\
\hline AEMBL & 34 & 8.6799 \\
\hline AEMBL & 34 & 8.3179 \\
\hline HEMBL369 & 34 & 7.652 \\
\hline AEMBL3687481 & 34 & 9.267 \\
\hline HEMBL 369 & 5 & 8.8239 \\
\hline IEMBL & 34 & 7.606 \\
\hline IEMB & 34 & 6.0 \\
\hline AEMBL3691979 & 53 & 7.846 \\
\hline HEMBL3691922 & 53 & 6.0 \\
\hline AEMBL & 34 & \\
\hline AEMBL & 34 & 8.0061 \\
\hline HEMBL3691961 & 34 & 8.5287 \\
\hline HEMBL3687529 & 532 & 7.170 \\
\hline AEMBL3691958 & 53 & 9.387 \\
\hline CHEMBL: & 15 & 9.4089 \\
\hline CHEMBL368 & $53 \Delta+2>$ & 7.9817 \\
\hline CHEMBL369 & 34 & 7.7062 \\
\hline AEMBL3691983 & 534 & 7.737 \\
\hline CHEMBL 3687514 & 53 & 6.703 \\
\hline CHEMBL3 & 15 & 9.130 \\
\hline CHEMBL369 & 534 & 8.838 \\
\hline CHFMBI 368 & & .0 \\
\hline
\end{tabular}

\begin{tabular}{ll}
9.195 & TRN \\
8.7263 & TRN \\
7.9611 & TRN \\
8.7699 & TRN \\
8.7264 & TRN \\
6.8891 & TRN \\
5.8638 & TRN \\
9.4508 & TRN \\
8.7817 & TST \\
8.8604 & TRN \\
7.8481 & TRN \\
8.6785 & TST \\
8.3362 & TRN \\
7.8823 & TRN \\
5.8542 & TRN \\
5.7412 & TRN \\
8.2448 & TRN \\
8.968 & TRN \\
8.2809 & TST \\
8.3982 & TST \\
6.2923 & TRN \\
6.0643 & TRN \\
8.474 & TRN \\
8.832 & TRN \\
8.8617 & TRN \\
8.6624 & TRN \\
8.3604 & TST \\
8.4287 & TST \\
7.9356 & TST \\
8.7503 & TRN \\
8.8497 & TRN \\
7.5151 & TRN \\
5.7884 & TRN \\
7.8775 & TST \\
6.228 & TRN \\
6.3029 & TRN \\
8.1797 & TRN \\
8.4412 & TRN \\
7.1183 & TST \\
9.3573 & TRN \\
9.5971 & TRN \\
8.2649 & TRN \\
7.8124 & TRN \\
8.1717 & TST \\
7.1706 & TRN \\
9.3866 & TST \\
8.7733 & TRN \\
\hline & TST
\end{tabular}

Page 12344 
Supplemental Table S2.txt

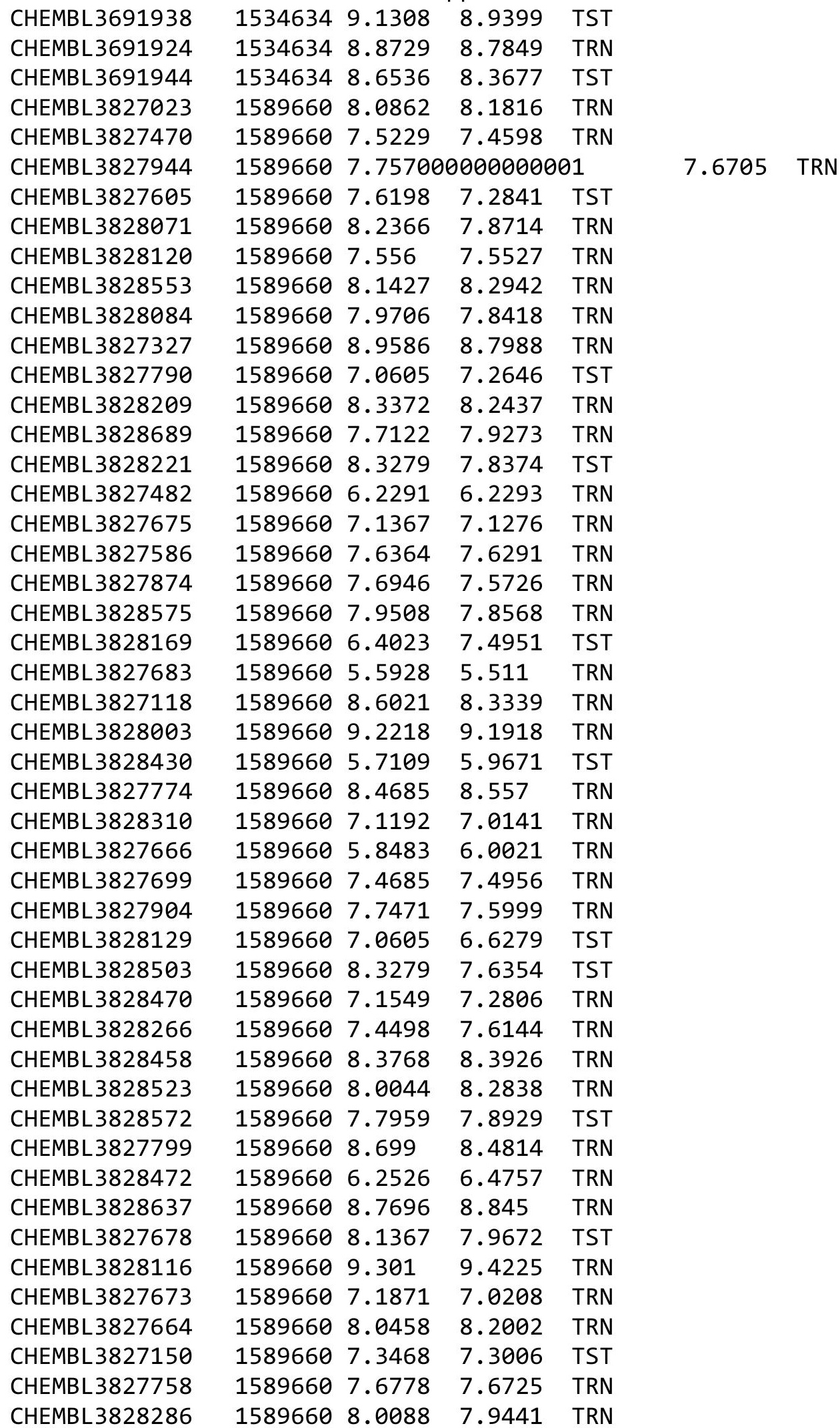

Page 12345 
Supplemental Table S2.txt

\begin{tabular}{|c|c|c|c|c|c|c|}
\hline CHEMBL3827333 & 1589660 & 7.3665 & 8.0342 & TST & & \\
\hline CHEMBL3827053 & 1589660 & 7.8996 & 8.0767 & TRN & & \\
\hline CHEMBL3827749 & 1589660 & 5.9094 & 5.886 & TST & & \\
\hline CHEMBL 3828370 & 1589660 & 7.7959 & 7.9459 & TRN & & \\
\hline CHEMBL 3827983 & 1589660 & 9.699 & 8.4106 & TST & & \\
\hline CHEMBL1552222 & 954363 & 4.8617 & 5.0893 & TRN & & \\
\hline CHEMBL1719064 & 954363 & 5.2027 & 5.4668 & TRN & & \\
\hline CHEMBL1475289 & 954363 & 5.2924 & 5.5963 & TRN & & \\
\hline CHEMBL3198899 & 954363 & 5.1884 & 5.1207 & TRN & & \\
\hline CHEMBL 2357474 & 954363 & 5.6676 & 5.6403 & TRN & & \\
\hline CHEMBL1570706 & 954363 & 5.1649 & 5.047 & TRN & & \\
\hline CHEMBL 2357620 & 954363 & 4.7254 & 5.2988 & TRN & & \\
\hline CHEMBL1873911 & 954363 & 4.9477 & 5.5871 & TRN & & \\
\hline CHEMBL 2357524 & 954363 & 4.9003 & 5.1683 & TRN & & \\
\hline CHEMBL1450615 & 954363 & 5.1549 & 5.0208 & TST & & \\
\hline CHEMBL1605642 & 954363 & 4.4575 & 4.8503 & TRN & & \\
\hline CHEMBL1905114 & 954363 & 4.6189 & 5.2694 & TRN & & \\
\hline CHEMBL1564133 & 954363 & 6.0269 & 5.0528 & TRN & & \\
\hline CHEMBL 2361956 & 954363 & 6.0 & 5.2862 & TRN & & \\
\hline CHEMBL 2360733 & 954363 & 5.3605 & 5.4756 & TRN & & \\
\hline CHEMBL1409445 & 954363 & 5.1113 & 4.9363 & TRN & & \\
\hline CHEMBL1705854 & 954363 & 5.7122 & 5.6717 & TST & & \\
\hline CHEMBL3126906 & 954363 & 5.7235 & 5.4208 & TRN & & \\
\hline CHEMBL1567488 & 954363 & 5.104 & 5.4253 & TRN & & \\
\hline CHEMBL1448198 & 954363 & 5.0883 & 5.2058 & TST & & \\
\hline CHEMBL1375563 & 954363 & 5.3206 & 4.9977 & TRN & & \\
\hline CHEMBL3193168 & 954363 & 5.0958 & 5.2564 & TST & & \\
\hline CHEMBL1432721 & 954363 & 5.3429 & 5.0443 & TRN & & \\
\hline CHEMBL 2357813 & 954363 & 5.3655 & 5.4969 & TRN & & \\
\hline CHEMBL1612755 & 954363 & 6.3757 & 4.9046 & TST & & \\
\hline CHEMBL1375740 & 954363 & 5.2097 & 5.2365 & TRN & & \\
\hline CHEMBL566283 & 954363 & 5.0716 & 4.7652 & TRN & & \\
\hline CHEMBL1380943 & 954363 & 4.7296 & 4.9546 & TRN & & \\
\hline CHEMBL 2362159 & 954363 & 5.5346 & 5.9308 & TRN & & \\
\hline CHEMBL1451112 & 954363 & 5.3251 & 5.0132 & TRN & & \\
\hline CHEMBL 2361057 & 954363 & 4.234 & 5.0213 & TRN & & \\
\hline CHEMBL1570537 & 954363 & 5.0255 & 5.154 & TRN & & \\
\hline CHEMBL1716486 & 954363 & 5.2118 & 5.1038 & TRN & & \\
\hline CHEMBL1418276 & 954363 & 4.9367 & 5.1996 & TRN & & \\
\hline CHEMBL1718302 & 954363 & 4.7959 & 4.9762 & TST & & \\
\hline CHEMBL 2362165 & 954363 & 6.0 & 5.7128 & TRN & & \\
\hline CHEMBL1576870 & 954363 & 7.585 & 6.3107 & TRN & & \\
\hline CHEMBL393287 & 954363 & 4.9834 & 4.8556 & TRN & & \\
\hline CHEMBL530499 & 954363 & $5.1720 e$ & 30000000 & 01 & 5.0332 & TS \\
\hline CHEMBL 1303750 & 954363 & 5.0083 & 4.9387 & TRN & & \\
\hline CHEMBL1460361 & 954363 & 5.3224 & 5.3313 & TRN & & \\
\hline CHEMBL 2135670 & 954363 & 5.3344 & 5.1911 & TRN & & \\
\hline CHEMBL2357823 & 954363 & 5.5969 & 5.7286 & TRN & & \\
\hline
\end{tabular}




\begin{tabular}{|c|c|c|c|c|c|c|}
\hline & & \multicolumn{5}{|c|}{ Supplemental Table S2.txt } \\
\hline CHEMBL1712998 & 954363 & 5.0991 & 5.2174 & TRN & & \\
\hline CHEMBL 2362845 & 954363 & 6.0 & 5.6756 & TRN & & \\
\hline CHEMBL1312397 & 954363 & 4.768 & 4.8795 & TRN & & \\
\hline CHEMBL 3196905 & 954363 & 4.7331 & 4.9195 & TST & & \\
\hline CHEMBL1486366 & 954363 & 5.0301 & 5.2237 & TRN & & \\
\hline CHEMBL 2355077 & 954363 & 6.0 & 5.5764 & TRN & & \\
\hline CHEMBL1418437 & 954363 & 5.1701 & 5.2586 & TST & & \\
\hline CHEMBL1459468 & 954363 & 5.8508 & 5.4437 & TRN & & \\
\hline CHEMBL1573963 & 954363 & 5.3778 & 5.3606 & TST & & \\
\hline CHEMBL1700596 & 954363 & 5.7375 & 5.1908 & TRN & & \\
\hline CHEMBL1459767 & 954363 & 5.1918 & 5.0756 & TST & & \\
\hline CHEMBL1610477 & 954363 & 4.9952 & 4.9993 & TRN & & \\
\hline CHEMBL 2361802 & 954363 & 5.51 & 5.346 & TRN & & \\
\hline CHEMBL1485372 & 954363 & 4.4249 & 5.0341 & TRN & & \\
\hline CHEMBL1508914 & 954363 & 5.4134 & 5.2613 & TRN & & \\
\hline CHEMBL1717252 & 954363 & 5.2328 & 4.9723 & TRN & & \\
\hline CHEMBL1422386 & 954363 & 4.4769 & 4.652 & TST & & \\
\hline CHEMBL1510639 & 954363 & 5.1891 & 5.2104 & TRN & & \\
\hline CHEMBL 2355208 & 954363 & 6.0 & 5.6335 & TRN & & \\
\hline CHEMBL1312953 & 954363 & 5.0496 & 4.7034 & TST & & \\
\hline CHEMBL 2354781 & 954363 & 5.4572 & 5.6382 & TRN & & \\
\hline CHEMBL1317554 & 954363 & 5.7258 & 5.9709 & TRN & & \\
\hline CHEMBL494325 & 954363 & 5.1898 & 4.8954 & TRN & & \\
\hline CHEMBL 2448464 & 954363 & 4.6851 & 5.1076 & TST & & \\
\hline CHEMBL1551207 & 954363 & 7.585 & 7.0934 & TRN & & \\
\hline CHEMBL 2354543 & 954363 & 5.9172 & 6.0615 & TRN & & \\
\hline CHEMBL1880486 & 954363 & 4.6494 & 5.1151 & TST & & \\
\hline CHEMBL1345115 & 954363 & 4.8742 & 5.1721 & TRN & & \\
\hline CHEMBL1432670 & 954363 & 5.6126 & 5.2366 & TRN & & \\
\hline CHEMBL1714018 & 954363 & 4.9859 & 5.3036 & TRN & & \\
\hline CHEMBL1384292 & 954363 & 5.9031 & 5.2891 & TRN & & \\
\hline CHEMBL2356590 & 954363 & 5.3458 & 5.6518 & TRN & & \\
\hline CHEMBL1721296 & 954363 & 5.3645 & 5.4591 & TRN & & \\
\hline CHEMBL1427279 & 954363 & 5.38299 & 99999999 & 99 & 5.1259 & TRN \\
\hline CHEMBL3183996 & 954363 & 6.0 & 5.5573 & TRN & & \\
\hline CHEMBL2356031 & 954363 & 6.0 & 5.6165 & TRN & & \\
\hline CHEMBL1349063 & 954363 & 6.056 & 5.5875 & TRN & & \\
\hline CHEMBL1522721 & 954363 & 4.6558 & 4.7149 & TRN & & \\
\hline CHEMBL 3560250 & 954363 & 5.4413 & 5.0212 & TRN & & \\
\hline CHEMBL1721373 & 954363 & 6.2154 & 5.8812 & TRN & & \\
\hline CHEMBL1469557 & 954363 & 4.7799 & 5.1105 & TST & & \\
\hline CHEMBL 2448504 & 954363 & 4.3674 & 5.0999 & TST & & \\
\hline CHEMBL 2355533 & 954363 & 6.0 & 5.5843 & TRN & & \\
\hline CHEMBL1314757 & 954363 & 5.6615 & 5.012 & TRN & & \\
\hline CHEMBL1411646 & 954363 & 4.9686 & 4.8634 & TST & & \\
\hline CHEMBL1607407 & 954363 & 5.1739 & 4.9898 & TRN & & \\
\hline CHEMBL1522937 & 954363 & 5.118 & 4.9741 & TRN & & \\
\hline CHEMBL1473718 & 954363 & 5.3468 & 5.2915 & TRN & & \\
\hline
\end{tabular}




\begin{tabular}{|c|c|c|c|c|c|}
\hline \multirow[b]{2}{*}{ CHEMBL1430935 } & \multicolumn{5}{|c|}{ Supplemental Table S2.txt } \\
\hline & 954363 & 5.2924 & 5.1812 & TST & \\
\hline CHEMBL1732521 & 954363 & 6.1555 & 6.04700 & 0000000001 & TRN \\
\hline CHEMBL1429793 & 954363 & 4.8814 & 5.3195 & TST & \\
\hline CHEMBL1535490 & 954363 & 6.4461 & 5.3365 & TRN & \\
\hline CHEMBL3210608 & 954363 & 5.0804 & 5.1627 & TRN & \\
\hline CHEMBL 2357719 & 954363 & 5.5114 & 5.5285 & TRN & \\
\hline CHEMBL1710114 & 954363 & 6.1726 & 6.12200 & 0000000001 & TRN \\
\hline CHEMBL1605033 & 954363 & 5.1427 & 5.0409 & TST & \\
\hline CHEMBL1353386 & 954363 & 4.3934 & 5.2727 & TRN & \\
\hline CHEMBL1466453 & 954363 & 5.1046 & 5.1469 & TRN & \\
\hline CHEMBL1436799 & 954363 & 6.5575 & 6.7251 & TRN & \\
\hline CHEMBL1562575 & 954363 & 7.585 & 6.4186 & TRN & \\
\hline CHEMBL3560793 & 954363 & 4.4532 & 5.4034 & TRN & \\
\hline CHEMBL1434227 & 954363 & 4.8837 & 4.7678 & TRN & \\
\hline CHEMBL 2362338 & 954363 & 6.3904 & 6.2267 & TRN & \\
\hline CHEMBL 2361973 & 954363 & 5.3215 & 5.3557 & TRN & \\
\hline CHEMBL 2136365 & 954363 & 4.7102 & 5.2572 & TRN & \\
\hline CHEMBL 2354897 & 954363 & 5.5935 & 5.7557 & TRN & \\
\hline CHEMBL 2356872 & 954363 & 4.7338 & 5.1496 & TRN & \\
\hline CHEMBL1703600 & 954363 & 6.4828 & 6.7613 & TRN & \\
\hline CHEMBL1730810 & 954363 & 4.4094 & 4.9759 & TRN & \\
\hline CHEMBL1382244 & 954363 & 4.9566 & 5.2401 & TRN & \\
\hline CHEMBL 2144271 & 954363 & 5.1079 & 5.183 & TRN & \\
\hline CHEMBL1506016 & 954363 & 5.3458 & 5.0077 & TST & \\
\hline CHEMBL1460595 & 954363 & 5.1972 & 4.9955 & TST & \\
\hline CHEMBL1346904 & 954363 & 4.5653 & 5.3497 & TRN & \\
\hline CHEMBL1594160 & 954363 & 4.5842 & 5.0723 & TRN & \\
\hline CHEMBL1385388 & 954363 & 6.2069 & 5.7986 & TRN & \\
\hline CHEMBL1521704 & 954363 & 4.9144 & 5.2225 & TRN & \\
\hline CHEMBL 2355836 & 954363 & 4.3051 & 5.1317 & TRN & \\
\hline CHEMBL1551228 & 954363 & 4.7488 & 5.1271 & TRN & \\
\hline CHEMBL1522458 & 954363 & 4.2681 & 4.7667 & TRN & \\
\hline CHEMBL3189913 & 954363 & 5.2487 & 5.03600 & 00000000005 & TST \\
\hline CHEMBL1541153 & 954363 & 5.6091 & 5.6394 & TST & \\
\hline CHEMBL1378490 & 954363 & 5.0721 & 5.0754 & TRN & \\
\hline CHEMBL1459657 & 954363 & 4.5613 & 4.9803 & TST & \\
\hline CHEMBL 2359156 & 954363 & 4.6236 & 5.2181 & TRN & \\
\hline CHEMBL 2362947 & 954363 & 6.0083 & 6.5926 & TRN & \\
\hline CHEMBL 2362599 & 954363 & 4.4334 & 5.1103 & TRN & \\
\hline CHEMBL 2360837 & 954363 & 4.4045 & 4.8319 & TRN & \\
\hline CHEMBL1323459 & 954363 & 5.2823 & 5.5239 & TRN & \\
\hline CHEMBL1528930 & 954363 & 5.0 & 5.1733 & TRN & \\
\hline CHEMBL 2361784 & 954363 & 6.0 & 6.0307 & TRN & \\
\hline CHEMBL1327046 & 954363 & 4.2518 & 4.5852 & TRN & \\
\hline CHEMBL 2357044 & 954363 & 4.6293 & 4.8873 & TRN & \\
\hline CHEMBL1868229 & 954363 & 5.5901 & 5.2144 & TRN & \\
\hline CHEMBL3187467 & 954363 & 5.062 & 5.2095 & TRN & \\
\hline CHEMBL 2356728 & 954363 & 4.6985 & 4.7547 & TRN & \\
\hline
\end{tabular}




\begin{tabular}{|c|c|c|c|c|c|c|}
\hline & & \multicolumn{5}{|c|}{ Supplemental Table S2.txt } \\
\hline CHEMBL1453285 & 954363 & 4.3594 & 5.0935 & TRN & & \\
\hline CHEMBL 2356874 & 954363 & 4.7841 & 5.1446 & TRN & & \\
\hline CHEMBL1327933 & 954363 & 4.2924 & 4.633 & TRN & & \\
\hline CHEMBL1557066 & 954363 & 4.9314 & \multicolumn{3}{|c|}{5.1770000000000005} & TRN \\
\hline CHEMBL1527251 & 954363 & 5.9508 & 4.9594 & TRN & & \\
\hline CHEMBL601933 & 954363 & 6.0716 & 5.1769 & TRN & & \\
\hline CHEMBL 2140727 & 954363 & 4.6447 & 4.692 & TRN & & \\
\hline CHEMBL 2448501 & 954363 & 5.1331 & 5.1178 & TST & & \\
\hline CHEMBL1698730 & 954363 & 5.1146 & 5.4766 & TRN & & \\
\hline CHEMBL1581005 & 954363 & 5.1403 & 5.1634 & TRN & & \\
\hline CHEMBL2362196 & 954363 & 6.0 & 5.7124 & TRN & & \\
\hline CHEMBL2357977 & 954363 & 4.7321 & 5.1232 & TRN & & \\
\hline CHEMBL1439783 & 954363 & 5.4214 & 5.0958 & TST & & \\
\hline CHEMBL1377607 & 954363 & 5.6162 & 5.3101 & TST & & \\
\hline CHEMBL2354439 & 954363 & 4.4133 & 5.0649 & TRN & & \\
\hline CHEMBL1379721 & 954363 & 4.8283 & 5.1833 & TRN & & \\
\hline CHEMBL1392086 & 954363 & 5.3063 & 5.1665 & TRN & & \\
\hline CHEMBL1601295 & 954363 & 4.7245 & 5.2221 & TST & & \\
\hline CHEMBL3197908 & 954363 & 4.8342 & 5.0595 & TST & & \\
\hline CHEMBL1388829 & 954363 & 5.3936 & 5.6139 & TST & & \\
\hline CHEMBL1867711 & 954363 & 5.3019 & 5.4193 & TRN & & \\
\hline CHEMBL1612156 & 954363 & 4.658 & 5.0077 & TRN & & \\
\hline CHEMBL1586355 & 954363 & 4.8611 & 5.1006 & TRN & & \\
\hline CHEMBL1329817 & 954363 & 4.2959 & 4.7272 & TRN & & \\
\hline CHEMBL1469715 & 954363 & 5.8097 & 5.6673 & TST & & \\
\hline CHEMBL 2136594 & 954363 & 6.0 & 5.4547 & TRN & & \\
\hline CHEMBL1577804 & 954363 & 5.098 & 5.2016 & TST & & \\
\hline CHEMBL 2359735 & 954363 & 4.5354 & 5.3259 & TRN & & \\
\hline CHEMBL1896918 & 954363 & 4.5754 & 5.1909 & TRN & & \\
\hline CHEMBL 2357950 & 954363 & 5.4342 & 5.2918 & TRN & & \\
\hline CHEMBL1585966 & 954363 & 5.4685 & 5.1232 & TRN & & \\
\hline CHEMBL1412473 & 954363 & 4.8579 & 4.7905 & TRN & & \\
\hline CHEMBL1709909 & 954363 & 5.556 & 6.1048 & TRN & & \\
\hline CHEMBL2356339 & 954363 & 5.1135 & 5.4094 & TRN & & \\
\hline CHEMBL 2358514 & 954363 & 4.5045 & 5.0215 & TST & & \\
\hline CHEMBL1610504 & 954363 & 5.1993 & 5.0849 & TST & & \\
\hline CHEMBL1344875 & 954363 & 4.9582 & 5.1717 & TRN & & \\
\hline CHEMBL2354821 & 954363 & 4.6496 & 5.0662 & TST & & \\
\hline CHEMBL2361017 & 954363 & 5.2692 & 5.266 & TRN & & \\
\hline CHEMBL1507890 & 954363 & 4.9263 & 4.8222 & TRN & & \\
\hline CHEMBL1436393 & 954363 & 5.1203 & 5.2494 & TRN & & \\
\hline CHEMBL1887450 & 954363 & 6.1662 & 5.2541 & TRN & & \\
\hline CHEMBL1322972 & 954363 & 4.3537 & 4.7904 & TRN & & \\
\hline CHEMBL1528004 & 954363 & 5.6882 & 4.7857 & TRN & & \\
\hline CHEMBL1439985 & 954363 & 5.2154 & 5.0181 & TRN & & \\
\hline CHEMBL1724034 & 954363 & 4.942 & 4.6325 & TRN & & \\
\hline CHEMBL1339433 & 954363 & \multicolumn{3}{|c|}{4.9830000000000005} & 5.9918 & RN \\
\hline CHEMBL3213599 & 954363 & 5.5229 & 5.1135 & TRN & & \\
\hline
\end{tabular}




\begin{tabular}{|c|c|c|c|c|c|c|}
\hline \multicolumn{7}{|c|}{ Supplemental Table S2.txt } \\
\hline CHEMBL2361455 & 954363 & 4.18 & 5.2719 & TRN & & \\
\hline CHEMBL1503659 & 954363 & 4.9382 & 4.9841 & TST & & \\
\hline CHEMBL1460011 & 954363 & 4.4959 & 5.0585 & TRN & & \\
\hline CHEMBL2359878 & 954363 & 5.3002 & 5.5441 & TRN & & \\
\hline CHEMBL2359517 & 954363 & 4.3468 & 5.0125 & TRN & & \\
\hline CHEMBL1482207 & 954363 & 4.5896 & 4.9718 & TRN & & \\
\hline CHEMBL1374384 & 954363 & 5.3979 & 5.2429 & TRN & & \\
\hline CHEMBL1425438 & 954363 & 5.2993 & 4.8447 & TRN & & \\
\hline CHEMBL1501091 & 954363 & 5.1675 & 5.0364 & TRN & & \\
\hline CHEMBL2362103 & 954363 & 5.5834 & 6.0635 & TRN & & \\
\hline CHEMBL2362398 & 954363 & 4.6121 & 4.7836 & TRN & & \\
\hline CHEMBL1394527 & 954363 & 5.1319 & 4.9587 & TST & & \\
\hline CHEMBL3195271 & 954363 & 5.4597 & 5.1509 & TRN & & \\
\hline CHEMBL1321083 & 954363 & 5.7773 & 4.8366 & TRN & & \\
\hline CHEMBL1409464 & 954363 & 4.99100 & 00000000 & 005 & 5.105 & TRN \\
\hline CHEMBL1423575 & 954363 & 4.4582 & 5.2945 & TRN & & \\
\hline CHEMBL1364572 & 954363 & 7.585 & 5.5955 & TST & & \\
\hline CHEMBL2354772 & 954363 & 5.5482 & 5.5537 & TRN & & \\
\hline CHEMBL1367217 & 954363 & 5.2434 & 5.3459 & TRN & & \\
\hline CHEMBL1863833 & 954363 & 5.5003 & 5.5736 & TRN & & \\
\hline CHEMBL1543358 & 954363 & 5.1068 & 5.1672 & TST & & \\
\hline CHEMBL1526750 & 954363 & 5.3655 & 5.3353 & TRN & & \\
\hline CHEMBL1610523 & 954363 & 5.0773 & 5.2226 & TRN & & \\
\hline CHEMBL1548549 & 954363 & 5.2055 & 4.9007 & TRN & & \\
\hline CHEMBL1489131 & 954363 & 4.6666 & 5.2357 & TRN & & \\
\hline CHEMBL1550670 & 954363 & 5.5421 & 4.8808 & TRN & & \\
\hline CHEMBL1301073 & 954363 & 5.0269 & 5.2412 & TRN & & \\
\hline CHEMBL1548205 & 954363 & 5.4921 & 5.0537 & TRN & & \\
\hline CHEMBL2139915 & 954363 & 6.3325 & 4.7406 & TRN & & \\
\hline CHEMBL1516583 & 954363 & 4.402 & 5.176 & TST & & \\
\hline CHEMBL1303580 & 954363 & 4.9197 & 5.0023 & TRN & & \\
\hline CHEMBL2360148 & 954363 & 5.4134 & 5.3034 & TRN & & \\
\hline CHEMBL1411872 & 954363 & 5.1284 & 4.8471 & TRN & & \\
\hline CHEMBL2359472 & 954363 & 6.0 & 5.5112 & TRN & & \\
\hline CHEMBL1869323 & 954363 & 5.8861 & 5.7701 & TRN & & \\
\hline CHEMBL2355709 & 954363 & 5.9172 & 5.2399 & TRN & & \\
\hline CHEMBL1490428 & 954363 & 5.4101 & 5.7658 & TRN & & \\
\hline CHEMBL1871362 & 954363 & 5.5171 & 5.7943 & TRN & & \\
\hline CHEMBL1299470 & 954363 & 4.7097 & 5.1855 & TRN & & \\
\hline CHEMBL2357287 & 954363 & 7.585 & 6.5087 & TRN & & \\
\hline CHEMBL1537158 & 954363 & 4.9944 & 5.0728 & TRN & & \\
\hline CHEMBL2361279 & 954363 & 5.0953 & 5.1367 & TRN & & \\
\hline CHEMBL1523841 & 954363 & 5.8962 & 5.5354 & TST & & \\
\hline CHEMBL1872984 & 954363 & 5.2765 & 5.2158 & TRN & & \\
\hline CHEMBL1420742 & 954363 & 5.15799 & 99999999 & 995 & 5.0697 & $\mathrm{TR}$ \\
\hline CHEMBL116919 & 954363 & 5.2807 & 4.5329 & TRN & & \\
\hline CHEMBL2360390 & 954363 & 4.4648 & 4.6516 & TRN & & \\
\hline CHEMBL1323505 & 954363 & 5.1878 & 5.0115 & TRN & & \\
\hline
\end{tabular}




\begin{tabular}{|c|c|c|c|c|c|}
\hline \multicolumn{6}{|c|}{ Supplemental Table S2.txt } \\
\hline CHEMBL1407998 & 954363 & 5.1124 & 5.1751 & TRN & \\
\hline CHEMBL1374693 & 954363 & 4.9066 & 4.8973 & TRN & \\
\hline CHEMBL2360847 & 954363 & 6.0 & 5.237 & TRN & \\
\hline CHEMBL1430290 & 954363 & 5.1871 & 5.0866 & TRN & \\
\hline CHEMBL1580426 & 954363 & 5.0329 & 4.84 & TRN & \\
\hline CHEMBL1415958 & 954363 & 6.2495 & 5.8773 & TRN & \\
\hline CHEMBL2360977 & 954363 & 4.2145 & 5.2775 & TRN & \\
\hline CHEMBL601146 & 954363 & 5.2644 & 5.0292 & TST & \\
\hline CHEMBL3211736 & 954363 & 4.8196 & 5.2422 & TRN & \\
\hline CHEMBL2358155 & 954363 & 6.5171 & 6.0556 & TRN & \\
\hline CHEMBL1371706 & 954363 & 5.7496 & 4.9204 & TRN & \\
\hline CHEMBL1375402 & 954363 & 5.1002 & 5.0307 & TRN & \\
\hline CHEMBL1519955 & 954363 & 7.585 & 4.8501 & TRN & \\
\hline CHEMBL1710095 & 954363 & 5.5986 & 5.4564 & TRN & \\
\hline CHEMBL1325003 & 954363 & 5.4949 & 6.1211 & TRN & \\
\hline CHEMBL2355244 & 954363 & 5.4547 & 5.6966 & TRN & \\
\hline CHEMBL585591 & 954363 & 5.5935 & 5.3107 & TST & \\
\hline CHEMBL1561002 & 954363 & 5.0757 & 4.7636 & TRN & \\
\hline CHEMBL1319304 & 954363 & 7.585 & 4.8515 & TRN & \\
\hline CHEMBL1315948 & 954363 & 5.2284 & 4.8393 & TST & \\
\hline CHEMBL1708919 & 954363 & 5.8794 & 5.8385 & TRN & \\
\hline CHEMBL 2448511 & 954363 & 4.8102 & 5.0121 & TST & \\
\hline CHEMBL2354652 & 954363 & 5.0227 & 5.2521 & TRN & \\
\hline CHEMBL2356600 & 954363 & 4.5879 & 5.3448 & TRN & \\
\hline CHEMBL1361461 & 954363 & 5.2757 & 5.0909 & TRN & \\
\hline CHEMBL1518765 & 954363 & 5.0357 & 4.9438 & TRN & \\
\hline CHEMBL1430094 & 954363 & 6.1778 & 5.562 & TRN & \\
\hline CHEMBL1724732 & 954363 & 5.2596 & 5.1055 & TRN & \\
\hline CHEMBL1419608 & 954363 & 5.3915 & 5.2548 & TRN & \\
\hline CHEMBL1520544 & 954363 & 4.8784 & 4.9949 & TRN & \\
\hline CHEMBL1582044 & 954363 & 5.71 & 5.3112 & TRN & \\
\hline CHEMBL37430 & 954363 & 5.5258 & 5.0729 & TRN & \\
\hline CHEMBL1551755 & 954363 & 5.8416 & 5.0828 & TRN & \\
\hline CHEMBL1432227 & 954363 & 6.2328 & 5.1129 & TRN & \\
\hline CHEMBL1329693 & 954363 & 5.2306 & 5.0545 & TRN & \\
\hline CHEMBL1375648 & 954363 & 5.4828 & 5.3412 & TRN & \\
\hline CHEMBL1597230 & 954363 & 5.0964 & 5.0131 & TRN & \\
\hline CHEMBL1324188 & 954363 & 5.1871 & 5.1004 & TRN & \\
\hline CHEMBL1437560 & 954363 & 5.2907 & 5.5773 & TRN & \\
\hline CHEMBL1324298 & 954363 & 5.6596 & 5.2724 & TRN & \\
\hline CHEMBL1412006 & 954363 & 6.5834 & 5.5972 & TRN & \\
\hline CHEMBL1595792 & 954363 & 5.5229 & 5.7893 & TRN & \\
\hline CHEMBL3195057 & 954363 & 5.4486 & 4.9804 & TRN & \\
\hline CHEMBL1529819 & 954363 & 5.4522 & 5.3078 & TRN & \\
\hline CHEMBL3184121 & 954363 & 5.0846 & 4.91 & TRN & \\
\hline CHEMBL1408140 & 954363 & 4.5424 & 5.1499 & TRN & \\
\hline CHEMBL1601830 & 954363 & 5.0521 & 4.5233 & TRN & \\
\hline CHEMBL2362263 & 954363 & 4.9961 & 5.07100 & 000000001 & TRN \\
\hline & & & & גנכ21 & \\
\hline
\end{tabular}




\begin{tabular}{|c|c|c|c|c|c|}
\hline & & \multicolumn{4}{|c|}{ Supplemental Table S2.txt } \\
\hline CHEMBL1561448 & 954363 & 5.9747 & 6.3434 & TRN & \\
\hline CHEMBL1510823 & 954363 & 5.0191 & 5.0061 & TST & \\
\hline CHEMBL1886120 & 954363 & 5.3288 & 5.5156 & TRN & \\
\hline CHEMBL 2356346 & 954363 & 4.4138 & 5.1895 & TRN & \\
\hline CHEMBL 2354895 & 954363 & 4.173 & 5.2747 & TRN & \\
\hline CHEMBL 2361274 & 954363 & 4.4084 & 5.2073 & TRN & \\
\hline CHEMBL1499450 & 954363 & 5.2708 & 5.2264 & TRN & \\
\hline CHEMBL1425552 & 954363 & 5.2314 & 5.2205 & TRN & \\
\hline CHEMBL1608942 & 954363 & 5.0975 & 5.2861 & TRN & \\
\hline CHEMBL1895135 & 954363 & 4.5319 & 4.9319 & TRN & \\
\hline CHEMBL 2362368 & 954363 & 5.5114 & 5.4491 & TRN & \\
\hline CHEMBL 2361075 & 954363 & 4.9889 & 5.6898 & TRN & \\
\hline CHEMBL1727847 & 954363 & 5.4622 & 5.685 & TRN & \\
\hline CHEMBL1347664 & 954363 & 4.7873 & 4.981 & TRN & \\
\hline CHEMBL1874105 & 954363 & 5.2549 & 5.5492 & TST & \\
\hline CHEMBL 2355211 & 954363 & 4.5461 & 5.0825 & TRN & \\
\hline CHEMBL1611723 & 954363 & 5.9281 & 5.5232 & TRN & \\
\hline CHEMBL1583846 & 954363 & 5.3335 & 5.3857 & TST & \\
\hline CHEMBL1349146 & 954363 & 5.1035 & 5.1616 & TST & \\
\hline CHEMBL1306267 & 954363 & 4.5284 & 5.1474 & TRN & \\
\hline CHEMBL 2141186 & 954363 & 5.0035 & 5.3271 & TST & \\
\hline CHEMBL1500480 & 954363 & 5.0074 & 5.147 & TRN & \\
\hline CHEMBL1310301 & 954363 & 5.6289 & 5.2808 & TRN & \\
\hline CHEMBL1902622 & 954363 & 5.1373 & 5.0736 & TRN & \\
\hline CHEMBL1597669 & 954363 & 5.6003 & 5.341 & TRN & \\
\hline CHEMBL1463225 & 954363 & 5.6271 & 6.3957 & TRN & \\
\hline CHEMBL1354040 & 954363 & 4.7169 & 5.1234 & TRN & \\
\hline CHEMBL 2136838 & 954363 & 5.0851 & 5.5576 & TRN & \\
\hline CHEMBL1497562 & 954363 & 5.8447 & 6.1014 & TST & \\
\hline CHEMBL1316921 & 954363 & 4.6411 & 5.2527 & TRN & \\
\hline CHEMBL1611601 & 954363 & 4.8931 & 5.2142 & TRN & \\
\hline CHEMBL 2356184 & 954363 & 5.4949 & 5.2517 & TRN & \\
\hline CHEMBL 282038 & 954363 & 4.3656 & 5.1317 & TST & \\
\hline CHEMBL 2361351 & 954363 & 5.3665 & 5.5056 & TRN & \\
\hline CHEMBL1345227 & 954363 & 4.5683 & 5.0781 & TRN & \\
\hline CHEMBL1455730 & 954363 & 4.8791 & 5.2117 & TRN & \\
\hline CHEMBL171699 & 954363 & 7.585 & 6.7533 & TRN & \\
\hline CHEMBL1347745 & 954363 & 4.8474 & 5.1767 & TRN & \\
\hline CHEMBL1373252 & 954363 & 5.4802 & 5.0688 & TRN & \\
\hline CHEMBL1501242 & 954363 & 5.3575 & 5.3944 & TST & \\
\hline CHEMBL1709276 & 954363 & 4.8333 & 5.2957 & TRN & \\
\hline CHEMBL1482680 & 954363 & 5.3298 & 5.38899 & 9999999999 & TRN \\
\hline CHEMBL1341816 & 954363 & 4.9234 & 5.0833 & TRN & \\
\hline CHEMBL1895081 & 954363 & 4.5099 & 5.0634 & TRN & \\
\hline CHEMBL 2141813 & 954363 & 4.7739 & 4.8945 & TST & \\
\hline CHEMBL 2355635 & 954363 & 5.0218 & 4.8479 & TRN & \\
\hline CHEMBL1359848 & 954363 & 5.0106 & 4.8332 & TRN & \\
\hline CHEMBL1597625 & 954363 & 5.3429 & 5.0214 & TRN & \\
\hline
\end{tabular}




\begin{tabular}{|c|c|c|c|c|c|c|}
\hline & & \multicolumn{5}{|c|}{ Supplemental Table S2.txt } \\
\hline CHEMBL1549444 & 954363 & 5.0119 & 5.1743 & TST & & \\
\hline CHEMBL 2358863 & 954363 & 4.7029 & 4.8147 & TRN & & \\
\hline CHEMBL 2355844 & 954363 & 6.0 & 6.1809 & TRN & & \\
\hline CHEMBL1499517 & 954363 & 5.4647 & 5.0753 & TRN & & \\
\hline CHEMBL1452157 & 954363 & 5.4353 & 4.7533 & TRN & & \\
\hline CHEMBL1309164 & 954363 & 4.9974 & 5.0781 & TST & & \\
\hline CHEMBL585656 & 954363 & 5.0846 & 5.2135 & TRN & & \\
\hline CHEMBL1385727 & 954363 & 4.4145 & 4.838 & TRN & & \\
\hline CHEMBL1366114 & 954363 & 4.671 & 4.9046 & TST & & \\
\hline CHEMBL1445386 & 954363 & 4.8356 & 6.0918 & TST & & \\
\hline CHEMBL1306402 & 954363 & 4.6164 & 4.8324 & TRN & & \\
\hline CHEMBL1531675 & 954363 & 5.5918 & 5.57600 & 20000 & 205 & TST \\
\hline CHEMBL1869587 & 954363 & 5.2832 & 5.3911 & TRN & & \\
\hline CHEMBL 2357481 & 954363 & 6.0 & 5.4287 & TRN & & \\
\hline CHEMBL290077 & 954363 & 5.7167 & 6.2619 & TRN & & \\
\hline CHEMBL1462457 & 954363 & 5.3958 & 5.1247 & TRN & & \\
\hline CHEMBL 2362950 & 954363 & 4.8901 & 5.0254 & TST & & \\
\hline CHEMBL 2360959 & 954363 & 4.4865 & 4.6436 & TRN & & \\
\hline CHEMBL1444764 & 954363 & 5.3089 & 4.8627 & TRN & & \\
\hline CHEMBL1884377 & 954363 & 5.6946 & 5.8483 & TRN & & \\
\hline CHEMBL1412298 & 954363 & 4.9326 & 4.9201 & TRN & & \\
\hline CHEMBL1974506 & 954363 & 5.3325 & 5.9404 & TRN & & \\
\hline CHEMBL1305455 & 954363 & 4.6293 & 4.7958 & TRN & & \\
\hline CHEMBL 2355856 & 954363 & 5.2557 & 5.2934 & TRN & & \\
\hline CHEMBL1423113 & 954363 & 5.17200 & 30000000 & $\partial 1$ & 5.3966 & TST \\
\hline CHEMBL1458306 & 954363 & 4.3763 & 4.8901 & TRN & & \\
\hline CHEMBL 2136129 & 954363 & 5.38399 & 99999999 & 995 & 5.6572 & TRN \\
\hline CHEMBL1349206 & 954363 & 5.6799 & 5.2864 & TST & & \\
\hline CHEMBL3185201 & 954363 & 6.0 & 5.4784 & TRN & & \\
\hline CHEMBL 2358730 & 954363 & 4.9638 & 5.1382 & TRN & & \\
\hline CHEMBL1582794 & 954363 & 5.6635 & 5.1159 & TRN & & \\
\hline CHEMBL1716038 & 954363 & 5.5017 & 5.2093 & TST & & \\
\hline CHEMBL1447442 & 954363 & 5.3098 & 5.5144 & TRN & & \\
\hline CHEMBL1890313 & 954363 & 5.0726 & 5.3876 & TRN & & \\
\hline CHEMBL1402422 & 954363 & 4.5984 & 5.2074 & TRN & & \\
\hline CHEMBL 2354403 & 954363 & 4.4417 & 5.1388 & TRN & & \\
\hline CHEMBL1731238 & 954363 & 5.3439 & 5.477 & TRN & & \\
\hline CHEMBL1594806 & 954363 & 4.5737 & 5.1572 & TRN & & \\
\hline CHEMBL1895783 & 954363 & 5.8477 & 5.1812 & TRN & & \\
\hline CHEMBL1373815 & 954363 & 4.5933 & 5.4236 & TST & & \\
\hline CHEMBL1420768 & 954363 & 5.0462 & 5.1218 & TST & & \\
\hline CHEMBL 2360102 & 954363 & 4.5494 & 4.8178 & TRN & & \\
\hline CHEMBL1388380 & 954363 & 5.0778 & 4.8829 & TRN & & \\
\hline CHEMBL1538246 & 954363 & 5.3883 & 5.1206 & TRN & & \\
\hline CHEMBL1459111 & 954363 & 5.3307 & 5.0769 & TRN & & \\
\hline CHEMBL1898104 & 954363 & 5.4078 & 5.1709 & TRN & & \\
\hline CHEMBL1390450 & 954363 & 6.1046 & 5.4004 & TRN & & \\
\hline CHEMBL1573351 & 954363 & 5.4597 & 4.9853 & TRN & & \\
\hline
\end{tabular}




\begin{tabular}{|c|c|c|c|c|c|}
\hline & & \multicolumn{4}{|c|}{ Supplemental Table s2.txt } \\
\hline CHEMBL1393891 & 954363 & 5.2628 & 5.6373 & TRN & \\
\hline CHEMBL 2357208 & 954363 & 5.4498 & 5.5424 & TRN & \\
\hline CHEMBL1401504 & 954363 & 5.2182 & 5.1062 & TST & \\
\hline CHEMBL1411209 & 954363 & 5.1543 & 5.1282 & TRN & \\
\hline CHEMBL2448508 & 954363 & 5.1379 & 5.2261 & TST & \\
\hline CHEMBL1471330 & 954363 & 5.0931 & 5.0169 & TRN & \\
\hline CHEMBL1436713 & 954363 & 4.9751 & 4.754 & TRN & \\
\hline CHEMBL193627 & 954363 & 5.9788 & 5.1994 & TST & \\
\hline CHEMBL2359661 & 954363 & 6.0942 & 5.2734 & TRN & \\
\hline CHEMBL3197091 & 954363 & 5.02 & 4.9967 & TST & \\
\hline CHEMBL2357436 & 954363 & 5.2581 & 5.2235 & TRN & \\
\hline CHEMBL1491601 & 954363 & 5.2588 & 5.1758 & TRN & \\
\hline CHEMBL1327034 & 954363 & 4.8983 & 5.0052 & TRN & \\
\hline CHEMBL1491453 & 954363 & 4.7844 & 5.19 & TRN & \\
\hline CHEMBL2359062 & 954363 & 6.0 & 5.3268 & TRN & \\
\hline CHEMBL2356909 & 954363 & 5.3904 & 4.712 & TRN & \\
\hline CHEMBL1401598 & 954363 & 4.3626 & 5.2368 & TRN & \\
\hline CHEMBL1424453 & 954363 & 4.6959 & 4.91100 & 00000000005 & TRN \\
\hline CHEMBL3191106 & 954363 & 4.7587 & 5.0145 & TRN & \\
\hline CHEMBL1320244 & 954363 & 5.2041 & 5.4393 & TRN & \\
\hline CHEMBL 2140736 & 954363 & 6.0 & 5.3995 & TRN & \\
\hline CHEMBL2358028 & 954363 & 4.6162 & 5.7705 & TRN & \\
\hline CHEMBL1477608 & 954363 & 4.4383 & 4.8128 & TST & \\
\hline CHEMBL2358124 & 954363 & 5.6799 & 5.0566 & TRN & \\
\hline CHEMBL536166 & 954363 & 5.585 & 5.2364 & TRN & \\
\hline CHEMBL1455644 & 954363 & 4.9237 & 4.9836 & TRN & \\
\hline CHEMBL1902683 & 954363 & 5.7721 & 5.4009 & TRN & \\
\hline CHEMBL1899185 & 954363 & 4.6451 & 5.1021 & TRN & \\
\hline CHEMBL1722184 & 954363 & 4.997 & 5.03600 & 00000000005 & TRN \\
\hline CHEMBL1712550 & 954363 & 4.9948 & 5.1816 & TRN & \\
\hline CHEMBL1332417 & 954363 & 5.0491 & 5.047 & TRN & \\
\hline CHEMBL1429129 & 954363 & 4.6625 & 4.998 & TST & \\
\hline CHEMBL1300237 & 954363 & 5.4437 & 5.1766 & TST & \\
\hline CHEMBL2361967 & 954363 & 6.1146 & 4.8422 & TRN & \\
\hline CHEMBL1442067 & 954363 & 4.2893 & 5.0884 & TST & \\
\hline CHEMBL2359142 & 954363 & 4.8386 & 5.6844 & TRN & \\
\hline CHEMBL1707564 & 954363 & 4.9348 & 5.7453 & TRN & \\
\hline CHEMBL1579968 & 954363 & 5.5528 & 5.7383 & TRN & \\
\hline CHEMBL1605919 & 954363 & 5.1952 & 5.28799 & 9999999999 & TST \\
\hline CHEMBL1420334 & 954363 & 6.4473 & 5.4154 & TRN & \\
\hline CHEMBL598679 & 954363 & 5.1226 & 5.1847 & TRN & \\
\hline CHEMBL1420247 & 954363 & 5.5784 & 5.0716 & TRN & \\
\hline CHEMBL2360646 & 954363 & 5.4672 & 5.1481 & TRN & \\
\hline CHEMBL1537739 & 954363 & 4.7129 & 5.0756 & TRN & \\
\hline CHEMBL1606066 & 954363 & 5.0022 & 5.1383 & TRN & \\
\hline CHEMBL1370423 & 954363 & 4.4571 & 4.7069 & TRN & \\
\hline CHEMBL577660 & 954363 & 5.3872 & 5.0365 & TRN & \\
\hline CHEMBL 2358725 & 954363 & 4.3674 & 5.244 & TRN & \\
\hline
\end{tabular}




\begin{tabular}{|c|c|c|c|c|c|c|}
\hline & & \multicolumn{5}{|c|}{ Supplemental Table S2.txt } \\
\hline CHEMBL1520831 & 954363 & 5.7721 & 6.0599 & TRN & & \\
\hline CHEMBL1976507 & 954363 & 5.6716 & 5.4172 & TRN & & \\
\hline CHEMBL1581829 & 954363 & 4.4227 & 5.065 & TRN & & \\
\hline CHEMBL1568152 & 954363 & \multicolumn{3}{|c|}{5.0569999999999995} & 5.0426 & TRN \\
\hline CHEMBL1351357 & 954363 & 5.9547 & 6.0333 & TRN & & \\
\hline CHEMBL1567308 & 954363 & 5.1649 & 5.0021 & TRN & & \\
\hline CHEMBL1403324 & 954363 & 5.4101 & 5.271 & TRN & & \\
\hline CHEMBL1875758 & 954363 & 5.317 & 5.5693 & TRN & & \\
\hline CHEMBL1349753 & 954363 & 5.1681 & 5.2237 & TRN & & \\
\hline CHEMBL1869505 & 954363 & 5.2924 & 5.7632 & TRN & & \\
\hline CHEMBL1376959 & 954363 & 4.8312 & 5.0295 & TRN & & \\
\hline CHEMBL1612194 & 954363 & 4.7734 & 5.1175 & TRN & & \\
\hline CHEMBL1436618 & 954363 & 5.2211 & 4.9207 & TRN & & \\
\hline CHEMBL1730354 & 954363 & 5.6655 & 5.6066 & TRN & & \\
\hline CHEMBL1568497 & 954363 & 5.2924 & 5.1072 & TST & & \\
\hline CHEMBL1505232 & 954363 & 4.4412 & 4.9734 & TRN & & \\
\hline CHEMBL2360779 & 954363 & 7.585 & 6.2649 & TRN & & \\
\hline CHEMBL1452729 & 954363 & 5.3019 & 5.0902 & TRN & & \\
\hline CHEMBL1350387 & 954363 & 5.3054 & 5.0212 & TRN & & \\
\hline CHEMBL2360410 & 954363 & 5.5482 & 4.9176 & TRN & & \\
\hline CHEMBL1583504 & 954363 & 4.5634 & 4.7565 & TRN & & \\
\hline CHEMBL 2134576 & 954363 & 6.0 & 5.5183 & TRN & & \\
\hline CHEMBL 2141861 & 954363 & \multicolumn{3}{|c|}{5.617999999999999} & 5.5291 & TRN \\
\hline CHEMBL102397 & 954363 & 6.2069 & 6.6702 & TRN & & \\
\hline CHEMBL2135379 & 954363 & 4.6635 & 4.9133 & TRN & & \\
\hline CHEMBL1573994 & 954363 & 6.4449 & 5.619 & TST & & \\
\hline CHEMBL3192760 & 954363 & 4.8142 & 5.023 & TRN & & \\
\hline CHEMBL2356526 & 954363 & 4.7595 & 4.7558 & TRN & & \\
\hline CHEMBL1469736 & 954363 & 5.1824 & 5.5333 & TRN & & \\
\hline CHEMBL2360820 & 954363 & 4.382 & 5.0496 & TRN & & \\
\hline CHEMBL1522315 & 954363 & 5.0645 & 4.9706 & TRN & & \\
\hline CHEMBL1866960 & 954363 & 5.5513 & 5.7737 & TRN & & \\
\hline CHEMBL1890660 & 954363 & 5.4179 & 5.5313 & TRN & & \\
\hline CHEMBL1335110 & 954363 & 4.5268 & 5.0536 & TST & & \\
\hline CHEMBL1342760 & 954363 & 5.2403 & 5.1625 & TRN & & \\
\hline CHEMBL1458905 & 954363 & 4.4765 & 4.9554 & TRN & & \\
\hline CHEMBL1905109 & 954363 & 5.4737 & 5.2948 & TRN & & \\
\hline CHEMBL1595687 & 954363 & \multicolumn{3}{|c|}{5.1579999999999995} & 5.008 & TST \\
\hline CHEMBL2359303 & 954363 & 4.6043 & 4.8239 & TRN & & \\
\hline CHEMBL1888955 & 954363 & 5.7375 & 5.881 & TRN & & \\
\hline CHEMBL1488923 & 954363 & 5.8356 & 5.4373 & TRN & & \\
\hline CHEMBL1698237 & 954363 & 5.0362 & 5.4216 & TRN & & \\
\hline CHEMBL1405122 & 954363 & 6.2676 & \multicolumn{3}{|c|}{5.917999999999999} & TST \\
\hline CHEMBL1587302 & 954363 & 5.0585 & 5.1676 & TRN & & \\
\hline CHEMBL 2138317 & 954363 & 5.8182 & 5.184 & TRN & & \\
\hline CHEMBL1475186 & 954363 & 4.5658 & 5.2123 & TST & & \\
\hline CHEMBL1904959 & 954363 & 5.8297 & 5.0662 & TRN & & \\
\hline CHEMBL1423706 & 954363 & 4.9473 & 5.1611 & TRN & & \\
\hline
\end{tabular}




\begin{tabular}{|c|c|c|c|c|c|c|}
\hline & & \multicolumn{5}{|c|}{ Supplemental Table S2.txt } \\
\hline CHEMBL1715769 & 954363 & 5.1361 & 5.5833 & TRN & & \\
\hline CHEMBL1338601 & 954363 & 4.9259 & 5.211 & TST & & \\
\hline CHEMBL1319336 & 954363 & 4.8425 & 5.6417 & TST & & \\
\hline CHEMBL 2358936 & 954363 & 5.585 & 5.3465 & TRN & & \\
\hline CHEMBL1515360 & 954363 & 4.6028 & 4.735 & TRN & & \\
\hline CHEMBL 2357708 & 954363 & 6.0 & 5.4982 & TRN & & \\
\hline CHEMBL1305638 & 954363 & 5.2197 & 5.3982 & TRN & & \\
\hline CHEMBL1470568 & 954363 & \multicolumn{3}{|c|}{5.162999999999999} & 5.0322 & TRN \\
\hline CHEMBL 2358405 & 954363 & 4.5931 & 4.9695 & TRN & & \\
\hline CHEMBL1387035 & 954363 & 4.7036 & 5.224 & TST & & \\
\hline CHEMBL1554917 & 954363 & 5.3757 & 5.3257 & TRN & & \\
\hline CHEMBL1516708 & 954363 & 5.3595 & 5.5511 & TST & & \\
\hline CHEMBL1871757 & 954363 & 4.87 & 5.1199 & TRN & & \\
\hline CHEMBL1488082 & 954363 & 4.2174 & 5.0581 & TST & & \\
\hline CHEMBL1715476 & 954363 & 4.2248 & 4.9813 & TRN & & \\
\hline CHEMBL1450612 & 954363 & 5.3391 & 5.192 & TRN & & \\
\hline CHEMBL2360924 & 954363 & 7.585 & 6.41200 & 0000000001 & & TRN \\
\hline CHEMBL1602454 & 954363 & 5.5918 & 5.5736 & TRN & & \\
\hline CHEMBL1884536 & 954363 & 5.3788 & 5.1751 & TRN & & \\
\hline CHEMBL1398919 & 954363 & 5.5436 & 4.9246 & TRN & & \\
\hline CHEMBL1605666 & 954363 & 5.5302 & 5.0956 & TST & & \\
\hline CHEMBL 2355112 & 954363 & 5.2328 & 4.931 & TRN & & \\
\hline CHEMBL 2361163 & 954363 & 6.0 & 5.8694 & TRN & & \\
\hline CHEMBL1870652 & 954363 & 5.4881 & 5.6324 & TRN & & \\
\hline CHEMBL543876 & 954363 & 4.9097 & 4.9816 & TRN & & \\
\hline CHEMBL1897053 & 954363 & 4.7387 & 5.1759 & TRN & & \\
\hline CHEMBL 2134677 & 954363 & 5.3585 & 5.4753 & TRN & & \\
\hline CHEMBL 2358093 & 954363 & 6.0 & 5.6811 & TRN & & \\
\hline CHEMBL1325192 & 954363 & 5.0655 & 5.0875 & TST & & \\
\hline CHEMBL1379480 & 954363 & 5.0329 & 5.4464 & TST & & \\
\hline CHEMBL1457403 & 954363 & 5.4157 & 5.3768 & TST & & \\
\hline CHEMBL1383228 & 954363 & 5.109 & 5.3295 & TRN & & \\
\hline CHEMBL1428293 & 954363 & 4.8359 & 5.0317 & TRN & & \\
\hline CHEMBL1447566 & 954363 & 4.5653 & 4.9857 & TRN & & \\
\hline CHEMBL 2139889 & 954363 & 5.6925 & 5.6738 & TRN & & \\
\hline CHEMBL530291 & 954363 & 5.4962 & 5.2664 & TRN & & \\
\hline CHEMBL1505743 & 954363 & 5.0752 & 5.1612 & TRN & & \\
\hline CHEMBL 2359880 & 954363 & 4.2996 & 4.9484 & TRN & & \\
\hline CHEMBL1370479 & 954363 & 5.3809 & 5.0485 & TRN & & \\
\hline CHEMBL 2362799 & 954363 & 6.0 & 5.2238 & TRN & & \\
\hline CHEMBL1440643 & 954363 & 5.0991 & 5.1321 & TRN & & \\
\hline CHEMBL 1600400 & 954363 & 4.8972 & 5.313 & TRN & & \\
\hline CHEMBL1545631 & 954363 & 5.3233 & 5.6642 & TRN & & \\
\hline CHEMBL1567814 & 954363 & 5.3478 & 5.3879 & TRN & & \\
\hline CHEMBL1370087 & 954363 & 6.3516 & 5.8413 & TRN & & \\
\hline CHEMBL1320042 & 954363 & 6.3439 & 4.7432 & TRN & & \\
\hline CHEMBL 2356473 & 954363 & 4.5484 & 4.9469 & TRN & & \\
\hline CHEMBL1541486 & 954363 & 4.2746 & 5.0067 & TRN & & \\
\hline
\end{tabular}




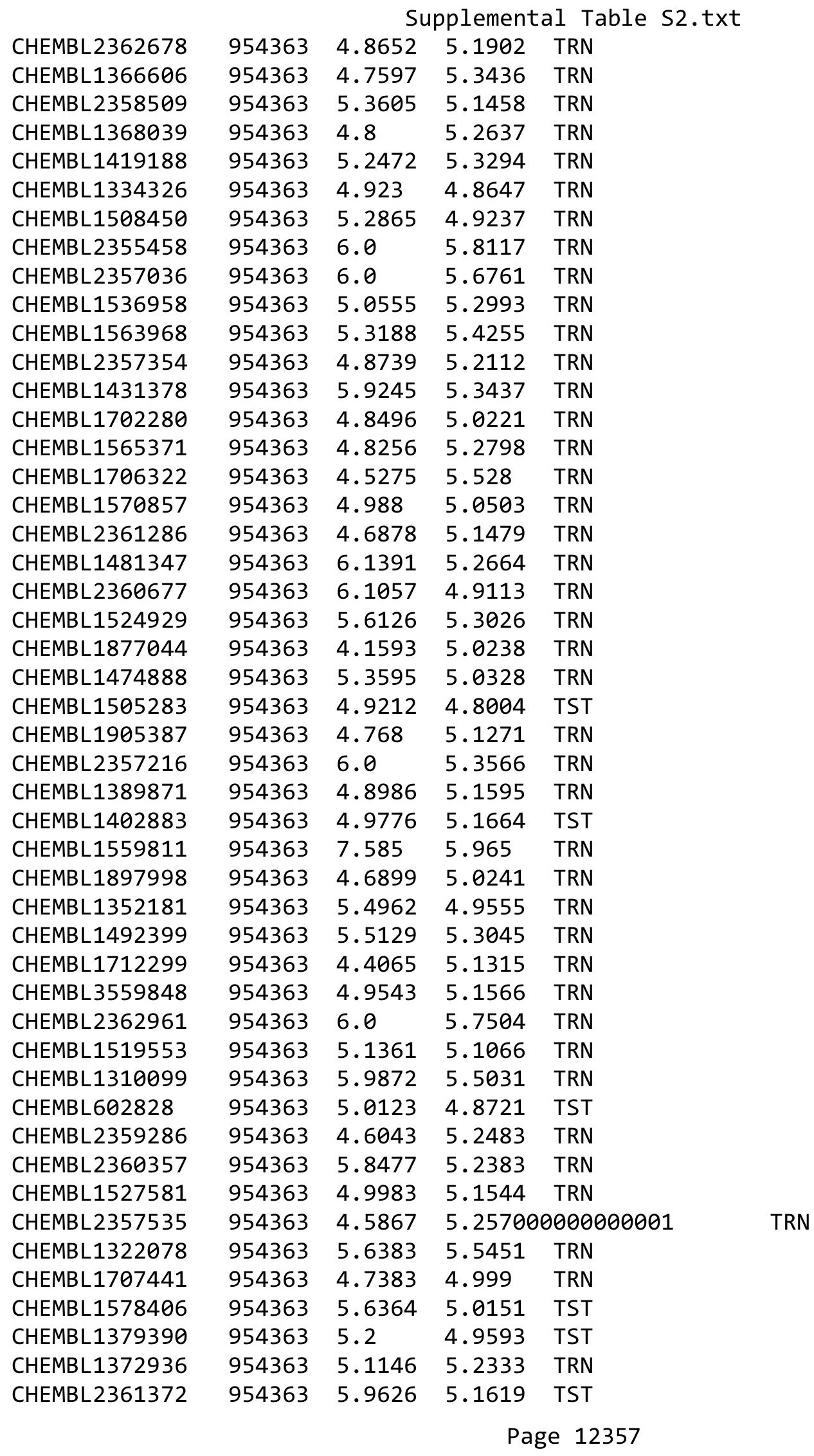




\begin{tabular}{|c|c|c|c|c|}
\hline & & & oplement & al $\mathrm{T}$ \\
\hline CHEMBL1714012 & 954363 & 5.1911 & 5.1107 & TST \\
\hline CHEMBL1442388 & 954363 & 5.1945 & 5.2439 & TST \\
\hline CHEMBL2139616 & 954363 & 6.0031 & 6.119 & TRN \\
\hline CHEMBL2358117 & 954363 & 4.5741 & 5.0398 & TRN \\
\hline CHEMBL1354163 & 954363 & 5.3947 & 5.848 & TRN \\
\hline CHEMBL1573112 & 954363 & 5.2125 & 5.1656 & TRN \\
\hline CHEMBL1594360 & 954363 & 4.4208 & 5.1489 & TRN \\
\hline CHEMBL1380482 & 954363 & 4.1617 & 5.1938 & TST \\
\hline CHEMBL1444205 & 954363 & 5.066 & 5.1944 & TRN \\
\hline CHEMBL1598066 & 954363 & 5.2857 & 5.2929 & TRN \\
\hline CHEMBL1599713 & 954363 & 4.8938 & 4.9869 & TRN \\
\hline CHEMBL1882531 & 954363 & 4.3413 & 4.8021 & TRN \\
\hline CHEMBL2133076 & 954363 & 6.0 & 5.5103 & TRN \\
\hline CHEMBL16288 & 954363 & 5.5436 & 5.9644 & TRN \\
\hline CHEMBL1394445 & 954363 & 4.8268 & 5.124 & TRN \\
\hline CHEMBL1468011 & 954363 & 5.7959 & 5.4216 & TRN \\
\hline CHEMBL 2358164 & 954363 & 4.5764 & 4.9076 & TRN \\
\hline CHEMBL1378226 & 954363 & 5.2255 & 5.718 & TRN \\
\hline CHEMBL1699402 & 954363 & 5.0752 & 5.414 & TRN \\
\hline CHEMBL1436659 & 954363 & 6.466 & 6.9718 & TRN \\
\hline CHEMBL2356196 & 954363 & 5.5272 & 5.0576 & TRN \\
\hline CHEMBL1733422 & 954363 & 4.9767 & 5.019 & TRN \\
\hline CHEMBL3561704 & 954363 & 5.3036 & 5.1293 & TRN \\
\hline CHEMBL 2354532 & 954363 & 5.0232 & 4.9716 & TRN \\
\hline CHEMBL464467 & 954363 & 5.3915 & 5.567 & TST \\
\hline CHEMBL1726645 & 954363 & 5.3507 & 5.4151 & TRN \\
\hline CHEMBL1541329 & 954363 & 4.8567 & 4.8592 & TRN \\
\hline CHEMBL1471810 & 954363 & 5.1451 & 5.0159 & TST \\
\hline CHEMBL2355499 & 954363 & 5.4609 & 5.3734 & TRN \\
\hline CHEMBL1392611 & 954363 & 6.3675 & 5.2863 & TRN \\
\hline CHEMBL1730853 & 954363 & 6.0991 & 5.8379 & TRN \\
\hline CHEMBL2354940 & 954363 & 5.3143 & 5.3598 & TRN \\
\hline CHEMBL1478769 & 954363 & 4.6476 & 4.9651 & TRN \\
\hline CHEMBL2357859 & 954363 & 5.3487 & 5.3369 & TRN \\
\hline CHEMBL 3194248 & 954363 & 5.5768 & 5.3455 & TRN \\
\hline CHEMBL2360990 & 954363 & 5.301 & 5.066 & TRN \\
\hline CHEMBL1342837 & 954363 & 5.51 & 5.1302 & TRN \\
\hline CHEMBL3212313 & 954363 & 5.1267 & 5.1772 & TRN \\
\hline CHEMBL2361624 & 954363 & 5.7696 & 5.1183 & TRN \\
\hline CHEMBL1487901 & 954363 & 4.9504 & 5.1936 & TST \\
\hline CHEMBL1543858 & 954363 & 4.9454 & 4.9706 & TRN \\
\hline CHEMBL1491097 & 954363 & 5.0985 & 4.9541 & TRN \\
\hline CHEMBL1487368 & 954363 & 5.4179 & 5.6613 & TST \\
\hline CHEMBL 2361197 & 954363 & 4.6469 & 5.1141 & TRN \\
\hline CHEMBL1529294 & 954363 & 4.367 & 5.0314 & TRN \\
\hline CHEMBL1578679 & 954363 & 4.5779 & 5.0939 & TST \\
\hline CHEMBL1524910 & 954363 & 4.7572 & 5.1019 & TRN \\
\hline CHEMBL1391059 & 954363 & 4.9763 & 5.2108 & TST \\
\hline
\end{tabular}


Supplemental Table S2.txt

\begin{tabular}{|c|c|c|c|c|}
\hline CHEMBL1366706 & 954363 & 5.8013 & 5.2056 & TRN \\
\hline CHEMBL 2359567 & 954363 & 5.7959 & 5.9731 & TRN \\
\hline CHEMBL1492073 & 954363 & 4.9905 & 4.9855 & TRN \\
\hline CHEMBL 2356856 & 954363 & 6.0 & 5.4713 & TRN \\
\hline CHEMBL 2136773 & 954363 & 5.4401 & 5.4619 & TRN \\
\hline CHEMBL1347246 & 954363 & 4.9523 & 5.0326 & TRN \\
\hline CHEMBL1562110 & 954363 & 4.9702 & 4.8694 & TRN \\
\hline CHEMBL1713983 & 954363 & 4.8821 & 5.2085 & TRN \\
\hline CHEMBL 2357014 & 954363 & 4.8959 & 4.8954 & TRN \\
\hline CHEMBL1605995 & 954363 & 4.8979 & 5.0191 & TST \\
\hline CHEMBL1389657 & 954363 & 4.7742 & 4.9197 & TRN \\
\hline CHEMBL 2360946 & 954363 & 6.0 & 5.5247 & TRN \\
\hline CHEMBL1524746 & 954363 & 5.2449 & 5.1613 & TRN \\
\hline CHEMBL 2142087 & 954363 & 4.7889 & 4.7181 & TRN \\
\hline CHEMBL1435670 & 954363 & 4.3663 & 4.5415 & TRN \\
\hline CHEMBL1580452 & 954363 & 5.4168 & 4.9396 & TRN \\
\hline CHEMBL 2357172 & 954363 & 5.7852 & 5.1853 & TRN \\
\hline CHEMBL 2359148 & 954363 & 4.5781 & 5.0603 & TRN \\
\hline CHEMBL1312619 & 954363 & 5.4895 & 5.2426 & TRN \\
\hline CHEMBL1440892 & 954363 & 4.7602 & 4.9003 & TRN \\
\hline CHEMBL1417294 & 954363 & 5.3449 & 5.7177 & TRN \\
\hline CHEMBL 2361564 & 954363 & 6.0 & 5.7013 & TRN \\
\hline CHEMBL1378564 & 954363 & 5.0825 & 5.0734 & TRN \\
\hline CHEMBL1468323 & 954363 & 5.8327 & 5.4014 & TRN \\
\hline CHEMBL1981570 & 954363 & 5.1904 & 5.0786 & TRN \\
\hline CHEMBL2356497 & 954363 & 4.8911 & 5.2517 & TRN \\
\hline CHEMBL 2357204 & 954363 & 5.1918 & 5.3479 & TRN \\
\hline CHEMBL1337961 & 954363 & 4.9923 & 5.0608 & TRN \\
\hline CHEMBL1536763 & 954363 & 5.5702 & 5.2043 & TRN \\
\hline CHEMBL 2133122 & 954363 & 5.4815 & 5.3319 & TRN \\
\hline CHEMBL65349 & 954363 & 6.0353 & 6.237 & TRN \\
\hline CHEMBL1380049 & 954363 & 4.5916 & 5.1457 & TRN \\
\hline CHEMBL1503131 & 954363 & 5.1445 & 4.9199 & TRN \\
\hline CHEMBL1536459 & 954363 & 4.8801 & 4.7948 & TRN \\
\hline CHEMBL1384874 & 954363 & 4.9772 & 5.1033 & TRN \\
\hline CHEMBL1321201 & 954363 & 5.6326 & 5.483 & TRN \\
\hline CHEMBL1314738 & 954363 & 6.2027 & 6.2987 & TRN \\
\hline CHEMBL 2355889 & 954363 & 6.0 & 5.3172 & TRN \\
\hline CHEMBL 2359218 & 954363 & 5.6345 & 6.1013 & TRN \\
\hline CHEMBL1368493 & 954363 & 5.3979 & 4.6486 & TRN \\
\hline CHEMBL1306071 & 954363 & 4.8492 & 5.0377 & TRN \\
\hline CHEMBL1887993 & 954363 & 5.3686 & 5.3122 & TRN \\
\hline CHEMBL1906549 & 954363 & 6.0799 & 6.2769 & TRN \\
\hline CHEMBL 2357938 & 954363 & 6.0 & 5.5591 & TRN \\
\hline CHEMBL 2359862 & 954363 & 6.3134 & \multicolumn{2}{|c|}{5.6979999999999995} \\
\hline CHEMBL1514666 & 954363 & 5.3354 & 5.1877 & TRN \\
\hline CHEMBL1512575 & 954363 & 4.6739 & 4.819 & TRN \\
\hline CHEMBL528181 & 954363 & 5.0706 & 5.2432 & TRN \\
\hline
\end{tabular}




\begin{tabular}{|c|c|c|c|c|c|}
\hline & & \multicolumn{4}{|c|}{ Supplemental Table S2.txt } \\
\hline CHEMBL1893761 & 954363 & 4.4744 & 5.353 & TRN & \\
\hline CHEMBL1496004 & 954363 & 5.3298 & 5.1044 & TRN & \\
\hline CHEMBL1710523 & 954363 & 5.4789 & 5.2666 & TRN & \\
\hline CHEMBL3209663 & 954363 & 5.4815 & 5.2654 & TST & \\
\hline CHEMBL1310995 & 954363 & 5.2218 & 5.1504 & TRN & \\
\hline CHEMBL1434237 & 954363 & 5.279 & 5.3923 & TRN & \\
\hline CHEMBL1321622 & 954363 & 5.3747 & 5.2543 & TRN & \\
\hline CHEMBL2356137 & 954363 & \multicolumn{3}{|c|}{5.757000000000001} & TRN \\
\hline CHEMBL2362067 & 954363 & 4.6396 & 5.4562 & TRN & \\
\hline CHEMBL1608402 & 954363 & 5.7852 & 5.1726 & TST & \\
\hline CHEMBL1458707 & 954363 & 4.9154 & 5.1908 & TRN & \\
\hline CHEMBL1736950 & 954363 & 4.9329 & 5.1652 & TRN & \\
\hline CHEMBL2354415 & 954363 & 6.129 & 5.9965 & TRN & \\
\hline CHEMBL1320353 & 954363 & 4.5207 & 5.0851 & TRN & \\
\hline CHEMBL 2361877 & 954363 & 4.585 & 4.7348 & TRN & \\
\hline CHEMBL1396779 & 954363 & 4.9731 & 4.7312 & TRN & \\
\hline CHEMBL2361367 & 954363 & 6.0 & 5.3899 & TRN & \\
\hline CHEMBL2356206 & 954363 & 5.5258 & 5.1776 & TRN & \\
\hline CHEMBL2355226 & 954363 & 6.0 & 5.7985 & TRN & \\
\hline CHEMBL2356987 & 954363 & 5.4841 & 5.7604 & TRN & \\
\hline CHEMBL1460004 & 954363 & 4.9586 & 4.8895 & TST & \\
\hline CHEMBL2355510 & 954363 & 4.9622 & 5.0997 & TRN & \\
\hline CHEMBL1395785 & 954363 & 5.0762 & 4.8735 & TRN & \\
\hline CHEMBL1540672 & 954363 & 4.7696 & 5.2072 & TRN & \\
\hline CHEMBL2357586 & 954363 & 6.0 & 5.8061 & TRN & \\
\hline CHEMBL1579153 & 954363 & 5.9136 & 5.3691 & TRN & \\
\hline CHEMBL1464930 & 954363 & 4.7575 & 5.0576 & TRN & \\
\hline CHEMBL1596891 & 954363 & 4.4487 & 4.9242 & TRN & \\
\hline CHEMBL1511219 & 954363 & 6.4962 & 5.7332 & TRN & \\
\hline CHEMBL3561832 & 954363 & 6.0 & 5.1834 & TRN & \\
\hline CHEMBL1502133 & 954363 & 5.3152 & 5.3506 & TRN & \\
\hline CHEMBL1889375 & 954363 & 4.5493 & 4.9419 & TRN & \\
\hline CHEMBL 2134222 & 954363 & 4.9965 & 4.9897 & TRN & \\
\hline CHEMBL1867339 & 954363 & 5.6655 & 5.6909 & TRN & \\
\hline CHEMBL2361012 & 954363 & 4.8986 & 5.6537 & TRN & \\
\hline CHEMBL3560302 & 954363 & 5.8239 & 5.5617 & TRN & \\
\hline CHEMBL 2360583 & 954363 & 5.0395 & 5.6366 & TRN & \\
\hline CHEMBL1410745 & 954363 & 4.7841 & 4.9177 & TST & \\
\hline CHEMBL1870719 & 954363 & 5.1073 & 5.21200 & 0000000001 & TRN \\
\hline CHEMBL1538392 & 954363 & 5.2062 & 5.1625 & TST & \\
\hline CHEMBL1303152 & 954363 & 5.8794 & 5.9205 & TST & \\
\hline CHEMBL1527341 & 954363 & 5.3958 & 5.073 & TST & \\
\hline CHEMBL1610579 & 954363 & 5.7545 & 5.6722 & TRN & \\
\hline CHEMBL1440258 & 954363 & 4.7474 & 4.8177 & TRN & \\
\hline CHEMBL1600736 & 954363 & 5.4078 & 5.0697 & TRN & \\
\hline CHEMBL1488010 & 954363 & 5.4134 & 5.09699 & 99999999995 & TST \\
\hline CHEMBL1718951 & 954363 & 4.776 & 5.1417 & TRN & \\
\hline CHEMBL1362520 & 954363 & 4.3513 & 4.99 & TRN & \\
\hline
\end{tabular}




\begin{tabular}{|c|c|c|c|c|c|c|}
\hline & & \multicolumn{5}{|c|}{ Supplemental Table S2.txt } \\
\hline CHEMBL 2136684 & 954363 & 5.6861 & 5.6009 & TRN & & \\
\hline CHEMBL1427272 & 954363 & 4.7416 & 4.9408 & TRN & & \\
\hline CHEMBL1562296 & 954363 & 5.063 & 5.0517 & TRN & & \\
\hline CHEMBL 2069955 & 954363 & 4.4621 & 5.2441 & TST & & \\
\hline CHEMBL1383873 & 954363 & 4.5918 & 4.7084 & TST & & \\
\hline CHEMBL1384853 & 954363 & 4.5776 & 5.1078 & TRN & & \\
\hline CHEMBL1415211 & 954363 & 5.15 & 5.1048 & TRN & & \\
\hline CHEMBL1896011 & 954363 & 5.9508 & 5.1235 & TRN & & \\
\hline CHEMBL1880788 & 954363 & 5.0119 & 4.99 & TST & & \\
\hline CHEMBL 2355906 & 954363 & 4.8303 & 5.2212 & TRN & & \\
\hline CHEMBL1721043 & 954363 & 4.978 & 5.0489 & TST & & \\
\hline CHEMBL1481301 & 954363 & 4.4049 & 4.4934 & TRN & & \\
\hline CHEMBL1369460 & 954363 & 4.6735 & 4.8412 & TRN & & \\
\hline CHEMBL1699099 & 954363 & 5.1469 & 5.0235 & TRN & & \\
\hline CHEMBL 2355314 & 954363 & 4.4984 & 5.4721 & TRN & & \\
\hline CHEMBL1522331 & 954363 & 5.4225 & 5.3351 & TRN & & \\
\hline CHEMBL1699733 & 954363 & 5.52 & 5.3582 & TRN & & \\
\hline CHEMBL1502434 & 954363 & 4.7212 & 5.3004 & TST & & \\
\hline CHEMBL389390 & 954363 & 5.38299 & 9999999 & 99 & 5.1029 & TST \\
\hline CHEMBL3194195 & 954363 & 4.6107 & 4.825 & TRN & & \\
\hline CHEMBL1557954 & 954363 & 5.8729 & 5.5266 & TRN & & \\
\hline CHEMBL1346449 & 954363 & 4.9602 & 4.8966 & TRN & & \\
\hline CHEMBL 2137652 & 954363 & 4.6794 & 5.1735 & TRN & & \\
\hline CHEMBL 2354969 & 954363 & 4.7124 & 5.0451 & TRN & & \\
\hline CHEMBL1383554 & 954363 & 5.5157 & 4.5211 & TRN & & \\
\hline CHEMBL 2362305 & 954363 & 4.9027 & 5.7295 & TRN & & \\
\hline CHEMBL 2362014 & 954363 & 4.6919 & 5.2706 & TRN & & \\
\hline CHEMBL1505224 & 954363 & 5.4112 & 5.0682 & TRN & & \\
\hline CHEMBL3194760 & 954363 & 5.7055 & 5.4196 & TST & & \\
\hline CHEMBL1420175 & 954363 & 4.3932 & 4.9937 & TRN & & \\
\hline CHEMBL1716540 & 954363 & 5.2 & 5.0435 & TST & & \\
\hline CHEMBL1576543 & 954363 & 5.8928 & 5.1132 & TRN & & \\
\hline CHEMBL 2144397 & 954363 & 5.0311 & 5.3696 & TRN & & \\
\hline CHEMBL1506451 & 954363 & 5.3298 & 5.3368 & TRN & & \\
\hline CHEMBL1891205 & 954363 & 5.5918 & 5.5419 & TRN & & \\
\hline CHEMBL3109486 & 954363 & 4.5258 & 5.1104 & TRN & & \\
\hline CHEMBL1604143 & 954363 & 5.9586 & 5.0737 & TRN & & \\
\hline CHEMBL1542055 & 954363 & 4.4839 & 4.9264 & TRN & & \\
\hline CHEMBL1344478 & 954363 & 4.8533 & 5.0617 & TRN & & \\
\hline CHEMBL1372292 & 954363 & 5.5654 & 5.65 & TRN & & \\
\hline CHEMBL1543215 & 954363 & 5.5952 & 5.3539 & TRN & & \\
\hline CHEMBL1496223 & 954363 & 4.4699 & 5.0336 & TRN & & \\
\hline CHEMBL 2358606 & 954363 & 4.533 & 5.0523 & TRN & & \\
\hline CHEMBL 2359534 & 954363 & 5.1649 & 5.1489 & TRN & & \\
\hline CHEMBL 2357917 & 954363 & 5.3565 & 5.0097 & TRN & & \\
\hline CHEMBL1428870 & 954363 & 5.3675 & 5.3743 & TRN & & \\
\hline CHEMBL1699398 & 954363 & 5.5622 & 5.2799 & TST & & \\
\hline CHEMBL1358887 & 954363 & 7.585 & 6.9624 & TRN & & \\
\hline
\end{tabular}




\begin{tabular}{|c|c|c|c|c|c|c|}
\hline & & \multicolumn{5}{|c|}{ Supplemental Table S2.txt } \\
\hline CHEMBL1462920 & 954363 & 5.6904 & 5.2852 & TST & & \\
\hline CHEMBL1877280 & 954363 & 4.7747 & 4.8297 & TRN & & \\
\hline CHEMBL1310739 & 954363 & 4.738 & 4.9398 & TRN & & \\
\hline CHEMBL1359616 & 954363 & 5.1785 & 5.1487 & TST & & \\
\hline CHEMBL2362396 & 954363 & 4.5608 & 4.9559 & TRN & & \\
\hline CHEMBL1344838 & 954363 & 5.24799 & 99999999 & 99 & 5.0615 & TRN \\
\hline CHEMBL1429297 & 954363 & 5.3675 & 4.9609 & TRN & & \\
\hline CHEMBL1546353 & 954363 & 5.0778 & 4.9447 & TRN & & \\
\hline CHEMBL 2355755 & 954363 & 5.3893 & 5.0792 & TRN & & \\
\hline CHEMBL1351347 & 954363 & 4.8013 & 5.4805 & TST & & \\
\hline CHEMBL1720969 & 954363 & 7.585 & 5.6968 & TRN & & \\
\hline CHEMBL1391167 & 954363 & 4.6347 & 4.9647 & TRN & & \\
\hline CHEMBL 2358039 & 954363 & 6.0 & 5.654 & TRN & & \\
\hline CHEMBL1299835 & 954363 & 5.567 & 5.6932 & TRN & & \\
\hline CHEMBL 2362148 & 954363 & 6.0 & 5.6302 & TRN & & \\
\hline CHEMBL1537098 & 954363 & 7.585 & 6.1557 & TRN & & \\
\hline CHEMBL1578547 & 954363 & 4.4831 & 5.0943 & TRN & & \\
\hline CHEMBL 2135705 & 954363 & 5.308 & 4.8541 & TRN & & \\
\hline CHEMBL1510946 & 954363 & 4.7557 & 5.2012 & TRN & & \\
\hline CHEMBL1305030 & 954363 & 5.4413 & 5.6411 & TST & & \\
\hline CHEMBL1999906 & 954363 & 6.3335 & 4.8532 & TST & & \\
\hline CHEMBL 2357126 & 954363 & 5.5952 & 5.4747 & TRN & & \\
\hline CHEMBL1892704 & 954363 & 4.6476 & 4.8771 & TRN & & \\
\hline CHEMBL1342825 & 954363 & 4.6602 & 4.9509 & TST & & \\
\hline CHEMBL 2361245 & 954363 & 4.5995 & 4.7526 & TRN & & \\
\hline CHEMBL1365949 & 954363 & 4.7719 & 4.9227 & TRN & & \\
\hline CHEMBL1717409 & 954363 & 5.71899 & 99999999 & 99 & 5.5861 & TRN \\
\hline CHEMBL1601532 & 954363 & 4.484 & 5.2082 & TST & & \\
\hline CHEMBL1539897 & 954363 & 5.2588 & 5.2564 & TST & & \\
\hline CHEMBL1371382 & 954363 & 5.0696 & 4.9958 & TRN & & \\
\hline CHEMBL1329535 & 954363 & 5.2097 & 5.1152 & TRN & & \\
\hline CHEMBL1357092 & 954363 & 4.988 & 4.7659 & TRN & & \\
\hline CHEMBL1333750 & 954363 & 4.9144 & 5.184 & TRN & & \\
\hline CHEMBL1474759 & 954363 & 4.7542 & 4.9834 & TST & & \\
\hline CHEMBL1440954 & 954363 & 6.4214 & 6.5996 & TRN & & \\
\hline CHEMBL 2355783 & 954363 & 4.4563 & 5.1531 & TRN & & \\
\hline CHEMBL1422378 & 954363 & 5.7447 & 4.7094 & TRN & & \\
\hline CHEMBL 2358614 & 954363 & 6.0 & 5.5538 & TRN & & \\
\hline CHEMBL1887850 & 954363 & 7.585 & 7.0034 & TRN & & \\
\hline CHEMBL 2361140 & 954363 & 4.3805 & 5.0704 & TRN & & \\
\hline CHEMBL1341124 & 954363 & 5.7375 & 5.4201 & TRN & & \\
\hline CHEMBL1727214 & 954363 & 5.2269 & 5.1391 & TRN & & \\
\hline CHEMBL1322589 & 954363 & 4.9108 & 4.8822 & TRN & & \\
\hline CHEMBL601970 & 954363 & 4.743 & 5.0624 & TRN & & \\
\hline CHEMBL 2362244 & 954363 & 5.0937 & 5.2318 & TRN & & \\
\hline CHEMBL 2359971 & 954363 & 6.0 & 5.5488 & TRN & & \\
\hline CHEMBL1458403 & 954363 & 4.7744 & 5.118 & TRN & & \\
\hline CHEMBL1525187 & 954363 & 5.2644 & 5.3079 & TRN & & \\
\hline
\end{tabular}




\begin{tabular}{|c|c|c|c|c|c|c|}
\hline \multicolumn{7}{|c|}{ Supplemental Table S2.txt } \\
\hline CHEMBL1887610 & 954363 & 5.6655 & 5.5373 & TRN & & \\
\hline CHEMBL1332776 & 954363 & 5.1851 & 5.1173 & TRN & & \\
\hline CHEMBL1867244 & 954363 & 6.1713 & 5.8135 & TRN & & \\
\hline CHEMBL1328306 & 954363 & 5.3363 & 5.4381 & TRN & & \\
\hline CHEMBL 2361471 & 954363 & 6.3862 & 6.1522 & TRN & & \\
\hline CHEMBL1519015 & 954363 & 5.0035 & 5.1798 & TRN & & \\
\hline CHEMBL1315617 & 954363 & 5.2823 & 4.9895 & TRN & & \\
\hline CHEMBL1387162 & 954363 & 5.2441 & 5.026 & TRN & & \\
\hline CHEMBL1579166 & 954363 & 5.3372 & 5.2286 & TRN & & \\
\hline CHEMBL2358408 & 954363 & 5.4949 & 5.2654 & TRN & & \\
\hline CHEMBL1385808 & 954363 & 7.585 & 6.63700 & 0000 & 005 & TST \\
\hline CHEMBL1715756 & 954363 & 6.21399 & 99999999 & 995 & 5.54 & TRN \\
\hline CHEMBL 2142640 & 954363 & 4.2228 & 4.9515 & TST & & \\
\hline CHEMBL1550584 & 954363 & 5.3458 & 5.1173 & TRN & & \\
\hline CHEMBL1451209 & 954363 & 5.9318 & 5.4913 & TRN & & \\
\hline CHEMBL1591875 & 954363 & 5.3019 & 5.5555 & TRN & & \\
\hline CHEMBL1486457 & 954363 & 4.3742 & 4.9288 & TRN & & \\
\hline CHEMBL 2360993 & 954363 & 6.0 & 5.6408 & TRN & & \\
\hline CHEMBL356169 & 954363 & 4.3962 & 4.8795 & TRN & & \\
\hline CHEMBL1442319 & 954363 & 5.9431 & 5.1866 & TRN & & \\
\hline CHEMBL 2360836 & 954363 & 6.0 & 4.8374 & TRN & & \\
\hline CHEMBL 2355447 & 954363 & 6.0 & 5.4277 & TRN & & \\
\hline CHEMBL1523019 & 954363 & 5.056 & 5.1059 & TRN & & \\
\hline CHEMBL1430416 & 954363 & 4.743 & 5.0794 & TRN & & \\
\hline CHEMBL 2361810 & 954363 & 5.6003 & 5.7943 & TRN & & \\
\hline CHEMBL1535257 & 954363 & 5.0491 & 5.0225 & TRN & & \\
\hline CHEMBL1606743 & 954363 & 4.8435 & 5.225 & TRN & & \\
\hline CHEMBL1592853 & 954363 & 5.51 & 5.6256 & TRN & & \\
\hline CHEMBL1460239 & 954363 & 5.1524 & 5.1791 & TRN & & \\
\hline CHEMBL1602800 & 954363 & 4.967 & 4.7133 & TRN & & \\
\hline CHEMBL1464202 & 954363 & 4.7706 & 5.0545 & TRN & & \\
\hline CHEMBL1345232 & 954363 & 5.0721 & 5.421 & TRN & & \\
\hline CHEMBL1388405 & 954363 & 4.5441 & 5.041 & TRN & & \\
\hline CHEMBL 2356833 & 954363 & 4.4454 & 5.1603 & TRN & & \\
\hline CHEMBL 2358636 & 954363 & 5.1759 & 5.9146 & TRN & & \\
\hline CHEMBL 2361521 & 954363 & 4.2555 & 5.1666 & TRN & & \\
\hline CHEMBL1451348 & 954363 & 5.1057 & 5.2355 & TRN & & \\
\hline CHEMBL1500372 & 954363 & 5.2055 & 5.0451 & TRN & & \\
\hline CHEMBL1428735 & 954363 & 5.3851 & 5.2377 & TRN & & \\
\hline CHEMBL1451002 & 954363 & 4.9289 & 5.2674 & TRN & & \\
\hline CHEMBL1712719 & 954363 & 4.9237 & 5.1604 & TRN & & \\
\hline CHEMBL1875522 & 954363 & 5.1469 & 4.9791 & TRN & & \\
\hline CHEMBL1367220 & 954363 & 5.1029 & 5.1819 & TRN & & \\
\hline CHEMBL1504776 & 954363 & 4.4916 & 5.2334 & TRN & & \\
\hline CHEMBL1448592 & 954363 & 5.279 & 4.8532 & TRN & & \\
\hline CHEMBL1700115 & 954363 & 5.7747 & 5.7207 & TRN & & \\
\hline CHEMBL1472420 & 954363 & 5.4486 & 5.2548 & TST & & \\
\hline CHEMBL 2358094 & 954363 & 5.3063 & 5.322 & TRN & & \\
\hline
\end{tabular}


Supplemental Table S2.txt

\begin{tabular}{|c|c|c|c|c|c|}
\hline CHEMBL1349832 & 954363 & 5.0013 & 4.8566 & TST & \\
\hline CHEMBL 2355909 & 954363 & 4.5746 & 5.4077 & TRN & \\
\hline CHEMBL 2357490 & 954363 & 4.5683 & 5.2354 & TRN & \\
\hline CHEMBL1607801 & 954363 & 7.585 & 6.0623 & TRN & \\
\hline CHEMBL1542076 & 954363 & 4.5476 & 4.7574 & TST & \\
\hline CHEMBL1569668 & 954363 & 4.4807 & 5.1579 & TRN & \\
\hline CHEMBL1894296 & 954363 & 4.8 & 5.1164 & TRN & \\
\hline CHEMBL1559529 & 954363 & 5.5622 & 5.4756 & TRN & \\
\hline CHEMBL1558826 & 954363 & 7.585 & 6.6831 & TST & \\
\hline CHEMBL1600371 & 954363 & 5.2277 & 5.2715 & TRN & \\
\hline CHEMBL 2361826 & 954363 & 5.9318 & 5.0277 & TRN & \\
\hline CHEMBL 3210088 & 954363 & 5.4802 & 5.2887 & TRN & \\
\hline CHEMBL 3192873 & 954363 & 5.8268 & 5.5311 & TRN & \\
\hline CHEMBL51931 & 954363 & 5.5751 & 5.2461 & TST & \\
\hline CHEMBL1374399 & 954363 & 4.9208 & 4.7176 & TRN & \\
\hline CHEMBL1435072 & 954363 & 5.1858 & 5.5707 & TRN & \\
\hline CHEMBL1424901 & 954363 & 5.0429 & 5.1907 & TST & \\
\hline CHEMBL1714479 & 954363 & 6.0 & 5.4077 & TRN & \\
\hline CHEMBL1436699 & 954363 & 5.2343 & 4.9626 & TRN & \\
\hline CHEMBL1360946 & 954363 & 6.1772 & 6.4902 & TRN & \\
\hline CHEMBL1497138 & 954363 & 4.7235 & 5.2348 & TST & \\
\hline CHEMBL1355253 & 954363 & 4.5643 & 4.8248 & TST & \\
\hline CHEMBL1448999 & 954363 & 5.2336 & 5.1709 & TST & \\
\hline CHEMBL1706712 & 954363 & 5.2652 & 5.42299 & 9999999999 & TS \\
\hline CHEMBL1550430 & 954363 & 4.7812 & 4.68 & TST & \\
\hline CHEMBL1348545 & 954363 & 5.2381 & 5.1636 & TST & \\
\hline CHEMBL1493367 & 954363 & 5.5346 & 5.0607 & TST & \\
\hline CHEMBL1328534 & 954363 & 5.2041 & 5.1248 & TST & \\
\hline CHEMBL2358913 & 954363 & 4.7156 & 5.3234 & TST & \\
\hline CHEMBL1333339 & 954363 & 5.1203 & 5.0088 & TST & \\
\hline CHEMBL1482541 & 954363 & 5.2403 & 5.1204 & TST & \\
\hline CHEMBL1376629 & 954363 & 5.8097 & 4.9527 & TST & \\
\hline CHEMBL1519965 & 954363 & \multicolumn{3}{|c|}{5.821000000000001} & TST \\
\hline CHEMBL1547483 & 954363 & 4.761 & 5.0568 & TST & \\
\hline CHEMBL1339696 & 954363 & 5.1249 & 5.0031 & TST & \\
\hline CHEMBL1711360 & 954363 & 5.7986 & 5.0917 & TST & \\
\hline CHEMBL 2359169 & 954363 & 5.4342 & 5.4546 & TST & \\
\hline CHEMBL 2356673 & 954363 & 7.585 & 6.3555 & TST & \\
\hline CHEMBL1569095 & 954363 & 5.2161 & 5.0785 & TST & \\
\hline CHEMBL1877605 & 954363 & 4.5452 & 4.9381 & TST & \\
\hline CHEMBL3184689 & 954363 & 4.4761 & 4.7875 & TST & \\
\hline CHEMBL1425718 & 954363 & 4.3339 & 5.3182 & TST & \\
\hline CHEMBL1576075 & 954363 & 4.3504 & 4.8584 & TST & \\
\hline CHEMBL2358923 & 954363 & 4.8758 & 5.4372 & TST & \\
\hline CHEMBL1428181 & 954363 & 5.1175 & 5.0848 & TST & \\
\hline CHEMBL1520051 & 954363 & 4.9983 & 5.1661 & TST & \\
\hline CHEMBL 2355186 & 954363 & 4.5574 & 5.1295 & TST & \\
\hline CHEMBL1372725 & 954363 & 4.5396 & 4.7451 & TST & \\
\hline
\end{tabular}




\begin{tabular}{|c|c|c|c|c|c|c|}
\hline & & \multicolumn{5}{|c|}{ Supplemental Table S2.txt } \\
\hline CHEMBL2360606 & 954363 & 4.4832 & 5.5289 & TST & & \\
\hline CHEMBL2360109 & 954363 & 5.5638 & 6.0407 & TST & & \\
\hline CHEMBL1535227 & 954363 & 5.767 & 4.8249 & TST & & \\
\hline CHEMBL2354668 & 954363 & 4.7303 & 5.2357 & TST & & \\
\hline CHEMBL1723968 & 954363 & 4.6659 & 5.1807 & TST & & \\
\hline CHEMBL1542018 & 954363 & 4.643 & 4.9432 & TST & & \\
\hline CHEMBL 2134088 & 954363 & 6.0 & 5.5651 & TST & & \\
\hline CHEMBL1998606 & 954363 & 5.1524 & 5.4456 & TST & & \\
\hline CHEMBL1706987 & 954363 & 4.452 & 5.0351 & TST & & \\
\hline CHEMBL1706371 & 954363 & 5.1427 & 5.4859 & TST & & \\
\hline CHEMBL1577938 & 954363 & 5.9586 & 5.5646 & TST & & \\
\hline CHEMBL274070 & 954363 & 6.0 & 5.6141 & TST & & \\
\hline CHEMBL3195410 & 954363 & 5.4535 & 5.1052 & TST & & \\
\hline CHEMBL 2355574 & 954363 & 5.5406 & 6.7143 & TST & & \\
\hline CHEMBL605708 & 954363 & 4.3944 & 4.9342 & TST & & \\
\hline CHEMBL2357825 & 954363 & 5.6144 & 5.5656 & TST & & \\
\hline CHEMBL2362298 & 954363 & 5.38299 & 99999999 & 99 & 5.2666 & IS \\
\hline CHEMBL1462900 & 954363 & 5.0035 & 4.8737 & TST & & \\
\hline CHEMBL1885590 & 954363 & 6.2118 & 6.061 & TST & & \\
\hline CHEMBL1894184 & 954363 & 5.4672 & 5.5899 & TST & & \\
\hline CHEMBL2362759 & 954363 & 4.3663 & 5.2889 & TST & & \\
\hline CHEMBL1446984 & 954363 & 4.4342 & 5.1083 & TST & & \\
\hline CHEMBL 2360927 & 954363 & 5.9245 & 5.6334 & TST & & \\
\hline CHEMBL1559187 & 954363 & 4.3995 & 5.188 & TST & & \\
\hline CHEMBL1703435 & 954363 & 4.8851 & 5.1458 & TST & & \\
\hline CHEMBL1434463 & 954363 & 6.2168 & 6.3936 & TST & & \\
\hline CHEMBL1308403 & 954363 & 5.3872 & 5.5101 & TST & & \\
\hline CHEMBL1609759 & 954363 & 5.0311 & 5.3767 & TST & & \\
\hline CHEMBL1360952 & 954363 & 4.5613 & 5.143 & TST & & \\
\hline CHEMBL1310617 & 954363 & 6.2449 & 6.0427 & TST & & \\
\hline CHEMBL1485417 & 954363 & 5.3363 & 5.1989 & TST & & \\
\hline CHEMBL1971142 & 954363 & 5.2807 & 5.2167 & TST & & \\
\hline CHEMBL1452795 & 954363 & 5.4737 & 5.224 & TST & & \\
\hline CHEMBL1491001 & 954363 & 4.9307 & 4.8708 & TST & & \\
\hline CHEMBL2359417 & 954363 & 6.0 & 5.6377 & TST & & \\
\hline CHEMBL1441491 & 954363 & 5.3696 & 5.456 & TST & & \\
\hline CHEMBL1328307 & 954363 & 4.3744 & 4.7852 & TST & & \\
\hline CHEMBL 2142138 & 954363 & 4.4803 & 5.3028 & TST & & \\
\hline CHEMBL 1710730 & 954363 & 5.1343 & 5.2339 & TST & & \\
\hline CHEMBL1603932 & 954363 & 4.5875 & 4.9484 & TST & & \\
\hline CHEMBL1501402 & 954363 & 5.399 & 4.8428 & TST & & \\
\hline CHEMBL1863841 & 954363 & 6.1409 & 5.5109 & TST & & \\
\hline CHEMBL1371507 & 954363 & 5.8962 & 5.5306 & TST & & \\
\hline CHEMBL1573548 & 954363 & 4.4429 & 5.1518 & TST & & \\
\hline CHEMBL1447479 & 954363 & 4.5334 & 5.3314 & TST & & \\
\hline CHEMBL1456751 & 954363 & 5.6108 & 5.2038 & TST & & \\
\hline CHEMBL1353797 & 954363 & 4.516 & 4.98600 & 0000000001 & & \\
\hline CHEMBL1319691 & 954363 & 5.8633 & 5.2592 & TST & & \\
\hline
\end{tabular}




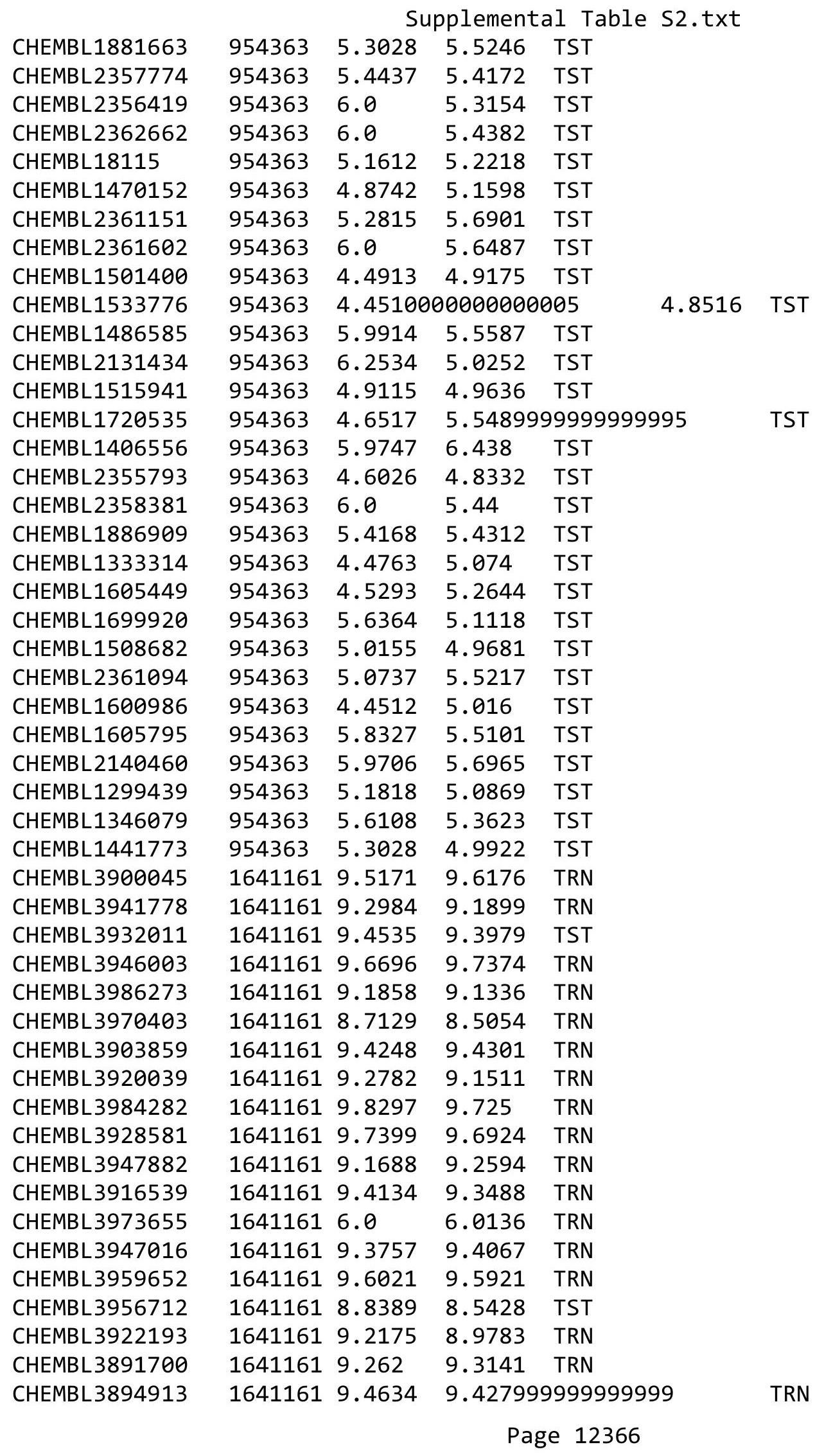


Supplemental Table S2.txt

\begin{tabular}{|c|c|c|c|c|}
\hline CHEMBL3890682 & 1641161 & 9.4056 & 9.4644 & TRN \\
\hline CHEMBL3966257 & 1641161 & 9.3635 & 9.4164 & TRN \\
\hline CHEMBL3987177 & 1641161 & 9.8794 & 9.81 & TRN \\
\hline CHEMBL3964522 & 1641161 & 9.0009 & 8.9991 & TST \\
\hline CHEMBL 3936964 & 1641161 & 9.6882 & 9.714 & TST \\
\hline CHEMBL 3942212 & 1641161 & 8.8459 & 8.9248 & TRN \\
\hline CHEMBL3980394 & 1641161 & 9.7011 & 9.5974 & TRN \\
\hline CHEMBL3952075 & 1641161 & 9.2874 & 9.2909 & TRN \\
\hline CHEMBL3952174 & 1641161 & 8.7009 & 8.7974 & TRN \\
\hline CHEMBL 3905047 & 1641161 & 9.3325 & 9.3743 & TRN \\
\hline CHEMBL 3907015 & 1641161 & 9.9066 & 9.7894 & TRN \\
\hline CHEMBL3889721 & 1641161 & 9.8069 & 9.7628 & TRN \\
\hline CHEMBL3929795 & 1641161 & 9.0434 & 8.9226 & TRN \\
\hline CHEMBL 3943351 & 1641161 & 9.1959 & 9.0824 & TRN \\
\hline CHEMBL 3968350 & 1641161 & 9.5243 & 9.3072 & TRN \\
\hline CHEMBL 3894542 & 1641161 & 9.6716 & 9.5901 & TRN \\
\hline CHEMBL3975841 & 1641161 & 8.5102 & 8.5956 & TRN \\
\hline CHEMBL3928316 & 1641161 & 9.109 & 8.9219 & TRN \\
\hline CHEMBL 3891340 & 1641161 & 9.1433 & 9.1037 & TRN \\
\hline CHEMBL 3893855 & 1641161 & 9.3401 & 9.4778 & TRN \\
\hline CHEMBL 3910040 & 1641161 & 8.6527 & 8.6865 & TRN \\
\hline CHEMBL3966297 & 1641161 & 8.2592 & 8.3921 & TRN \\
\hline CHEMBL3913923 & 1641161 & 9.301 & 9.4015 & TRN \\
\hline CHEMBL 3889893 & 1641161 & 9.3655 & 9.4536 & TRN \\
\hline CHEMBL 3940053 & 1641161 & 9.4449 & 9.5023 & TRN \\
\hline CHEMBL 3904596 & 1641161 & 9.059 & 9.1045 & TRN \\
\hline CHEMBL 3967893 & 1641161 & 9.9872 & 9.9119 & TRN \\
\hline CHEMBL 3905257 & 1641161 & 10.1871 & 10.0584 & TST \\
\hline CHEMBL3937081 & 1641161 & 9.2104 & 9.41 & TRN \\
\hline CHEMBL 3955103 & 1641161 & 9.5498 & 9.5975 & TRN \\
\hline CHEMBL 3982146 & 1641161 & 9.4112 & 9.5122 & TRN \\
\hline CHEMBL 3892757 & 1641161 & 8.6325 & 8.6036 & TRN \\
\hline CHEMBL3894928 & 1641161 & 9.4486 & 9.2857 & TRN \\
\hline CHEMBL 3933272 & 1641161 & 10.4089 & 10.1297 & TST \\
\hline CHEMBL 3968234 & 1641161 & 9.1772 & 9.1339 & TRN \\
\hline CHEMBL 3912148 & 1641161 & 9.7932 & 9.8025 & TRN \\
\hline CHEMBL 3903274 & 1641161 & 9.7471 & 9.7294 & TRN \\
\hline CHEMBL3951027 & 1641161 & 9.1051 & 9.0882 & TST \\
\hline CHEMBL 3910380 & 1641161 & 9.382 & 9.5569 & TRN \\
\hline CHEMBL 3917649 & 1641161 & 9.4365 & 9.3359 & TRN \\
\hline CHEMBL 3896593 & 1641161 & 8.7525 & 8.8341 & TRN \\
\hline CHEMBL 3975167 & 1641161 & 8.564 & 8.222000 & 0000000001 \\
\hline CHEMBL 3960378 & 1641161 & 9.2226 & 9.1953 & TRN \\
\hline CHEMBL3982235 & 1641161 & 9.266 & 9.4507 & TRN \\
\hline CHEMBL 3978705 & 1641161 & 9.5086 & 9.5945 & TRN \\
\hline CHEMBL 3977938 & 1641161 & 9.1979 & 9.059 & TRN \\
\hline CHEMBL 3918750 & 1641161 & 9.6676 & 9.6894 & TRN \\
\hline CHEMBL 3935937 & 1641161 & 8.6453 & 8.5897 & TRN \\
\hline
\end{tabular}

Page 12367 
Supplemental Table S2.txt

\begin{tabular}{|c|c|c|c|c|c|c|}
\hline CHEMBL3969209 & 1641161 & 8.6501 & 8.5419 & TRN & & \\
\hline CHEMBL3966766 & 1641161 & 9.9872 & 9.8652 & TRN & & \\
\hline CHEMBL3921105 & 1641161 & 8.997 & 8.6752 & TST & & \\
\hline CHEMBL 3924392 & 1641161 & 9.6596 & 9.7576 & TRN & & \\
\hline CHEMBL3972341 & 1641161 & 9.1163 & 9.0283 & TRN & & \\
\hline CHEMBL3903846 & 1641161 & 9.341000 & 000000000 & & 9.4544 & TRN \\
\hline CHEMBL 3975494 & 1641161 & 9.4001 & 9.3611 & TRN & & \\
\hline CHEMBL 3894464 & 1641161 & 7.9566 & 7.8871 & TRN & & \\
\hline CHEMBL 3944515 & 1641161 & 8.9606 & 9.0589 & TRN & & \\
\hline CHEMBL3966243 & 1641161 & 9.7033 & 9.7214 & TRN & & \\
\hline CHEMBL3940726 & 1641161 & 9.6108 & 9.4186 & TRN & & \\
\hline CHEMBL3925869 & 1641161 & 8.9872 & 8.9154 & TRN & & \\
\hline CHEMBL3935549 & 1641161 & 6.0 & 6.0898 & TRN & & \\
\hline CHEMBL 3933886 & 1641161 & 7.6198 & 7.6386 & TRN & & \\
\hline CHEMBL3930929 & 1641161 & 9.7447 & 9.8022 & TRN & & \\
\hline CHEMBL3951339 & 1641161 & 3.6021 & 3.9023 & TRN & & \\
\hline CHEMBL3902816 & 1641161 & 9.327 & 9.3683 & TRN & & \\
\hline CHEMBL3981117 & 1641161 & 9.3161 & 9.3232 & TRN & & \\
\hline CHEMBL 3896660 & 1641161 & 9.2924 & 9.2682 & TRN & & \\
\hline CHEMBL 3928661 & 1641161 & 8.195 & 8.4093 & TRN & & \\
\hline CHEMBL 3960436 & 1641161 & 9.7282 & 9.6387 & TRN & & \\
\hline CHEMBL 3946717 & 1641161 & 9.4413 & 9.1863 & TST & & \\
\hline CHEMBL3947696 & 1641161 & 9.6478 & 9.5108 & TST & & \\
\hline CHEMBL 3970281 & 1641161 & 8.115 & 8.048 & TRN & & \\
\hline CHEMBL3934972 & 1641161 & 9.4023 & 9.4516 & TRN & & \\
\hline CHEMBL 3890463 & 1641161 & 9.4425 & 9.4318 & TRN & & \\
\hline CHEMBL3966919 & 1641161 & 8.8254 & 8.5121 & TST & & \\
\hline CHEMBL3929643 & 1641161 & 9.0872 & 9.1084 & TRN & & \\
\hline CHEMBL 3917231 & 1641161 & 8.9978 & 9.0465 & TRN & & \\
\hline CHEMBL3933060 & 1641161 & 9.5452 & 9.4747 & TRN & & \\
\hline CHEMBL3919205 & 1641161 & 9.9318 & 9.5515 & TST & & \\
\hline CHEMBL3897441 & 1641161 & 8.5709 & 8.6411 & TRN & & \\
\hline CHEMBL3942721 & 1641161 & 9.8861 & 10.0182 & TRN & & \\
\hline CHEMBL 3951474 & 1641161 & 10.2518 & 10.2468 & TRN & & \\
\hline CHEMBL3938679 & 1641161 & 9.3809 & 9.5812 & TRN & & \\
\hline CHEMBL 3960775 & 1641161 & 9.6946 & 9.6336 & TRN & & \\
\hline CHEMBL3960706 & 1641161 & 9.1051 & 9.0186 & TRN & & \\
\hline CHEMBL3958636 & 1641161 & 9.289 & 9.4216 & TST & & \\
\hline CHEMBL 3924576 & 1641161 & 9.767000 & 000000000 & 01 & 9.3533 & TST \\
\hline CHEMBL3937040 & 1641161 & 9.3072 & 9.3936 & TRN & & \\
\hline CHEMBL 3937164 & 1641161 & 8.959 & 8.6709 & TST & & \\
\hline CHEMBL3943932 & 1641161 & 7.1084 & 6.8227 & TST & & \\
\hline CHEMBL3971983 & 1641161 & 8.7908 & 8.6168 & TST & & \\
\hline CHEMBL3970191 & 1641161 & 9.3242 & 9.3008 & TRN & & \\
\hline CHEMBL3921477 & 1641161 & 7.1079 & 7.1335 & TRN & & \\
\hline CHEMBL 3891470 & 1641161 & 8.7005 & 8.5011 & TST & & \\
\hline CHEMBL 3942103 & 1641161 & 9.0506 & 8.9908 & TRN & & \\
\hline CHEMBL3909155 & 1641161 & 8.9144 & 9.1136 & TRN & & \\
\hline
\end{tabular}


Supplemental Table S2.txt

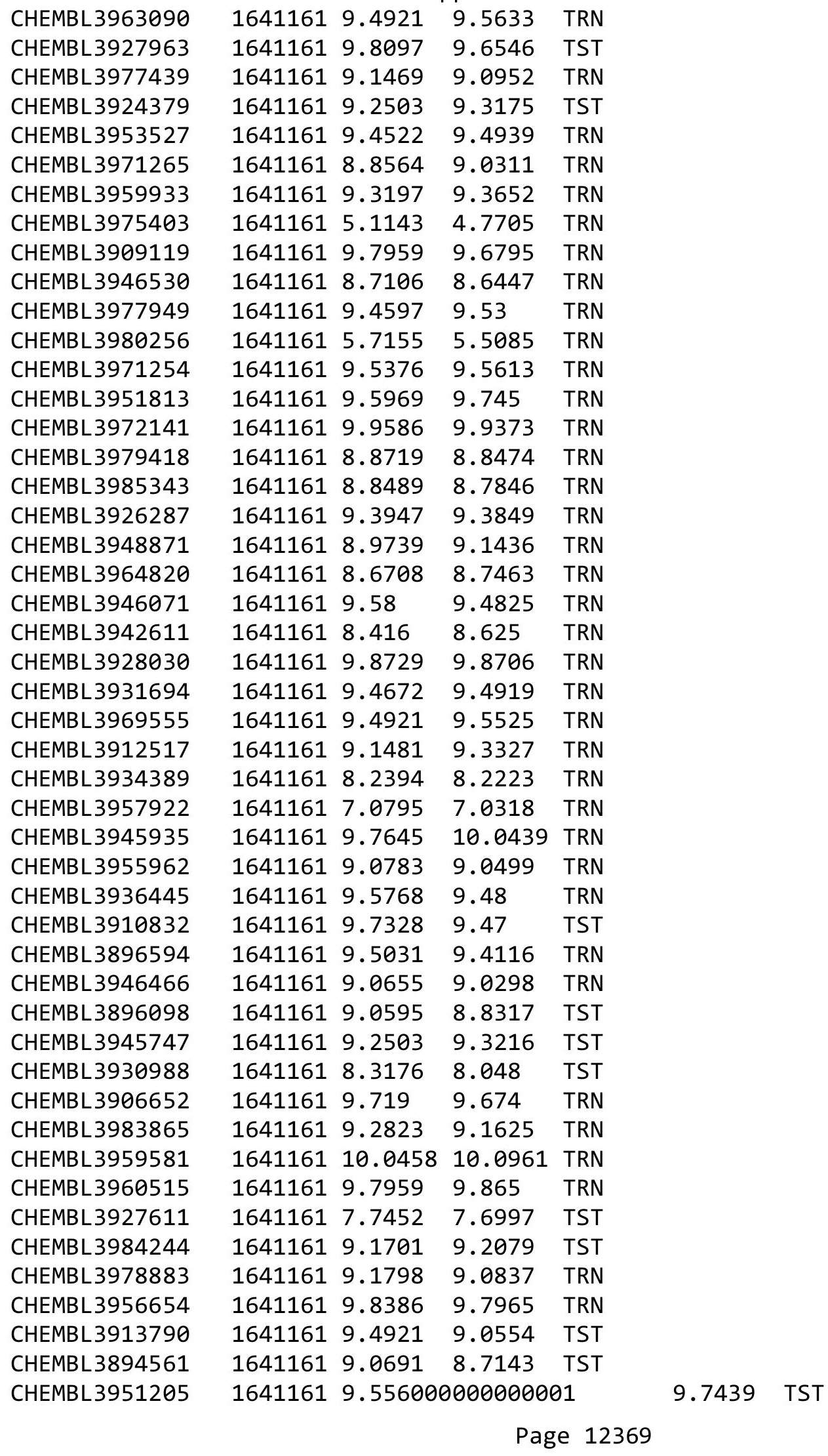


Supplemental Table S2.txt

\begin{tabular}{|c|c|c|c|c|c|c|}
\hline CHEMBL3940522 & 1641161 & 8.927 & 8.2684 & TRN & & \\
\hline CHEMBL3982101 & 1641161 & 9.3605 & 9.4552 & TRN & & \\
\hline CHEMBL3927672 & 1641161 & 9.5935 & $9.80600 t$ & 0000000001 & & TST \\
\hline CHEMBL3919411 & 1641161 & 9.4789 & 9.3161 & TRN & & \\
\hline CHEMBL3971301 & 1641161 & 9.7282 & 9.7313 & TST & & \\
\hline CHEMBL3975759 & 1641161 & 9.4841 & 9.5321 & TST & & \\
\hline CHEMBL3923479 & 1641161 & 9.5702 & 9.279 & TST & & \\
\hline CHEMBL3920610 & 1641161 & 9.1337 & 8.74 & TST & & \\
\hline CHEMBL3968536 & 1641161 & 9.059 & 8.7344 & TST & & \\
\hline CHEMBL3925508 & 1641161 & 8.6457 & 8.8096 & TST & & \\
\hline CHEMBL3897780 & 1641161 & 9.3645 & 8.9934 & TST & & \\
\hline CHEMBL3903630 & 1641161 & 9.3107 & 9.0934 & TST & & \\
\hline CHEMBL3918963 & 1641161 & 8.6008 & 8.5785 & TST & & \\
\hline CHEMBL3938806 & 1641161 & 9.1871 & 9.1934 & TRN & & \\
\hline CHEMBL 3949277 & 1641161 & 9.6021 & 9.5059 & TRN & & \\
\hline CHEMBL3955743 & 1641161 & 9.6778 & 9.6122 & TRN & & \\
\hline CHEMBL3911091 & 1641161 & 9.3089 & 9.43799 & 999999999 & & TST \\
\hline CHEMBL3962812 & 1641161 & 9.9245 & 10.1467 & TST & & \\
\hline CHEMBL3904667 & 1641161 & 9.6383 & 9.2639 & TST & & \\
\hline CHEMBL3976967 & 1641161 & 8.959 & 8.7661 & TST & & \\
\hline CHEMBL3956383 & 1641161 & 9.5243 & 9.6579 & TST & & \\
\hline CHEMBL3931624 & 1641161 & 8.7378 & 8.6747 & TRN & & \\
\hline CHEMBL3969121 & 1641161 & 6.0 & 6.6252 & TRN & & \\
\hline CHEMBL3981967 & 1641161 & 8.5381 & 8.5293 & TST & & \\
\hline CHEMBL 3976881 & 1641161 & 9.8633 & 9.5452 & TST & & \\
\hline CHEMBL 3914464 & 1641161 & 9.9136 & 10.0546 & TST & & \\
\hline CHEMBL3964430 & 1641161 & 9.4401 & 9.4457 & TRN & & \\
\hline CHEMBL398826 & 462459 & 1.8962 & 2.1045 & TRN & & \\
\hline CHEMBL252017 & 462459 & \multicolumn{3}{|c|}{0.6990000000000001} & 1.8395 & TRN \\
\hline CHEMBL429843 & 462459 & 2.0757 & 2.0404 & TRN & & \\
\hline CHEMBL253239 & 462459 & 1.8996 & 1.8434 & TRN & & \\
\hline CHEMBL252992 & 462459 & \multicolumn{3}{|c|}{0.6990000000000001} & 0.9677 & TRN \\
\hline CHEMBL399563 & 462459 & 2.0757 & 1.4915 & TST & & \\
\hline CHEMBL252387 & 462459 & 5.0 & 3.9993 & TRN & & \\
\hline CHEMBL252789 & 462459 & 1.8508 & 2.1753 & TST & & \\
\hline CHEMBL403564 & 462459 & \multicolumn{3}{|c|}{0.6990000000000001} & 0.4029 & TRN \\
\hline CHEMBL399759 & 462459 & 2.4948 & 2.1479 & TRN & & \\
\hline CHEMBL253240 & 462459 & 1.9957 & 2.4947 & TRN & & \\
\hline CHEMBL398825 & 462459 & 2.2757 & 1.6206 & TRN & & \\
\hline CHEMBL254917 & 462459 & 1.8729 & 1.7421 & TRN & & \\
\hline CHEMBL251815 & 462459 & 1.9508 & 1.7421 & TRN & & \\
\hline CHEMBL400444 & 462459 & 1.9245 & 1.2294 & TRN & & \\
\hline CHEMBL399561 & 462459 & 2.7696 & 2.8464 & TRN & & \\
\hline CHEMBL401061 & 462459 & 3.7986 & 3.3478 & TST & & \\
\hline CHEMBL252418 & 462459 & 1.8508 & 0.9688 & TRN & & \\
\hline CHEMBL253203 & 462459 & 1.8508 & 1.8165 & TRN & & \\
\hline CHEMBL252620 & 462459 & 2.1249 & 1.6714 & TRN & & \\
\hline CHEMBL401062 & 462459 & 1.8729 & 1.6153 & TRN & & \\
\hline
\end{tabular}




\begin{tabular}{|c|c|c|c|c|c|c|c|}
\hline \multirow[b]{2}{*}{ CHEMBL403566 } & \multicolumn{6}{|c|}{ Supplemental Ta } & \\
\hline & 462459 & 1.8508 & 1.2733 & TRN & & & \\
\hline CHEMBL 253238 & 462459 & 0.69900 & 00000000 & 001 & 0.5927 & TRN & \\
\hline CHEMBL 253445 & 462459 & 1.9245 & 1.9588 & TRN & & & \\
\hline CHEMBL 253643 & 462459 & 0.69900 & 00000000 & 001 & 0.7713 & TRN & \\
\hline CHEMBL 399884 & 462459 & 1.8729 & 1.5588 & TRN & & & \\
\hline CHEMBL 253427 & 462459 & 0.69900 & 00000000 & 001 & 1.454 & TRN & \\
\hline CHEMBL404633 & 462459 & 4.0511 & 3.7673 & TRN & & & \\
\hline CHEMBL 399240 & 462459 & 1.7055 & 1.3084 & TRN & & & \\
\hline CHEMBL 252787 & 462459 & 4.301 & 3.6185 & TST & & & \\
\hline CHEMBL 253644 & 462459 & 0.69900 & 00000000 & 001 & 0.3753 & TRN & \\
\hline CHEMBL399761 & 462459 & 2.0757 & 1.8926 & TST & & & \\
\hline CHEMBL401402 & 462459 & 1.8239 & 1.3084 & TRN & & & \\
\hline CHEMBL 253202 & 462459 & 2.0506 & 3.4941 & TST & & & \\
\hline CHEMBL400881 & 462459 & 1.8729 & 1.8856 & TRN & & & \\
\hline CHEMBL 253220 & 462459 & 0.69900 & 00000000 & 001 & 1.4807 & TRN & \\
\hline CHEMBL 253446 & 462459 & 2.1612 & 3.2665 & TRN & & & \\
\hline CHEMBL 251785 & 462459 & 4.3979 & 4.162 & TST & & & \\
\hline CHEMBL403565 & 462459 & 1.8508 & 2.8334 & TST & & & \\
\hline CHEMBL 253204 & 462459 & 0.69900 & 00000000 & 001 & 1.2608 & TRN & \\
\hline CHEMBL 254488 & 462459 & 1.8996 & 1.6582 & TRN & & & \\
\hline CHEMBL 253426 & 462459 & 0.69900 & 00000000 & 001 & 0.504 & TRN & \\
\hline CHEMBL 252788 & 462459 & 1.699 & 1.5897 & TRN & & & \\
\hline CHEMBL253642 & 462459 & 1.7077 & 1.2417 & TRN & & & \\
\hline CHEMBL 253408 & 462459 & 0.69900 & 00000000 & 001 & 0.8934 & TRN & \\
\hline CHEMBL 253221 & 462459 & 0.69900 & 00000000 & 001 & 1.1678 & TRN & \\
\hline CHEMBL 254916 & 462459 & 2.0969 & 2.5076 & TRN & & & \\
\hline CHEMBL 252217 & 462459 & 2.3468 & 1.9646 & TST & & & \\
\hline CHEMBL 252181 & 462459 & 3.9508 & 3.0918 & TST & & & \\
\hline CHEMBL251982 & 462459 & 3.8996 & 3.5749 & TRN & & & \\
\hline CHEMBL 253029 & 462459 & 0.69900 & 00000000 & 001 & 1.4606 & TRN & \\
\hline CHEMBL400856 & 462459 & 4.301 & 4.0048 & TRN & & & \\
\hline CHEMBL 252016 & 462459 & 0.69900 & 00000000 & 001 & $1.4880 €$ & 00000000002 & TST \\
\hline CHEMBL399562 & 462459 & 2.0223 & 1.9917 & TST & & & \\
\hline CHEMBL399350 & 462459 & 2.1739 & 2.8317 & TRN & & & \\
\hline CHEMBL 252215 & 462459 & 2.1249 & 3.4095 & TST & & & \\
\hline CHEMBL428947 & 462459 & 2.0458 & 3.5749 & TST & & & \\
\hline CHEMBL 252015 & 462459 & 1.8996 & 1.6967 & TST & & & \\
\hline CHEMBL 252420 & 462459 & 0.69900 & 00000000 & 001 & 0.9751 & TRN & \\
\hline CHEMBL399760 & 462459 & 1.8508 & 1.2767 & TRN & & & \\
\hline CHEMBL400443 & 462459 & 2.0506 & 2.1339 & TRN & & & \\
\hline CHEMBL 253030 & 462459 & 0.69900 & 00000000 & 001 & 0.8734 & TRN & \\
\hline CHEMBL 252994 & 462459 & 1.7077 & 2.1764 & TRN & & & \\
\hline CHEMBL251816 & 462459 & 0.69900 & 00000000 & 001 & 2.4638 & TST & \\
\hline CHEMBL 254275 & 462459 & 1.9208 & 2.2195 & TRN & & & \\
\hline CHEMBL 253425 & 462459 & 1.7055 & 1.5138 & TST & & & \\
\hline CHEMBL 252585 & 462459 & 3.752 & 3.9875 & TST & & & \\
\hline CHEMBL 399180 & 462459 & 0.69900 & 00000000 & 001 & 1.1464 & TRN & \\
\hline CHEMBL438337 & 462459 & 1.8729 & 1.7436 & TRN & & & \\
\hline
\end{tabular}




\begin{tabular}{|c|c|c|c|c|c|c|}
\hline \multirow[b]{2}{*}{ CHEMBL252586 } & \multirow[b]{2}{*}{462459} & \multicolumn{5}{|c|}{ Supplemental Table s2.txt } \\
\hline & & \multicolumn{2}{|c|}{$3.8508 \quad 4.3082$} & TST & & \\
\hline CHEMBL 253447 & 462459 & 2.2007 & 2.3869 & TRN & & \\
\hline CHEMBL252419 & 462459 & 1.8729 & 1.5519 & TRN & & \\
\hline CHEMBL254491 & 462459 & \multicolumn{3}{|c|}{0.6990000000000001} & 1.4561 & TRN \\
\hline CHEMBL399422 & 462459 & 4.1024 & 3.4859 & TRN & & \\
\hline CHEMBL399349 & 462459 & \multicolumn{3}{|c|}{0.6990000000000001} & 0.3465 & TRN \\
\hline CHEMBL 252621 & 462459 & \multicolumn{3}{|c|}{0.6990000000000001} & 1.1936 & TRN \\
\hline CHEMBL252216 & 462459 & 1.9031 & 2.3504 & TST & & \\
\hline CHEMBL 3137444 & 1301311 & 8.699 & 7.8542 & TRN & & \\
\hline CHEMBL3137468 & 1301311 & 7.7964 & 8.3092 & TRN & & \\
\hline CHEMBL 3104534 & 1301311 & 8.1549 & 7.7268 & TRN & & \\
\hline CHEMBL 3137451 & 1301311 & 7.3565 & 7.49200 & 20000 & & TRN \\
\hline CHEMBL3137448 & 1301311 & 7.4815 & 7.3314 & TRN & & \\
\hline CHEMBL 3104478 & 1301311 & 8.6289 & 8.5941 & TRN & & \\
\hline CHEMBL3104536 & 1301311 & 6.0 & 7.1887 & TRN & & \\
\hline CHEMBL3137445 & 1301311 & 7.8539 & 7.3214 & TRN & & \\
\hline CHEMBL3137471 & 1301311 & 7.8239 & 7.9409 & TST & & \\
\hline CHEMBL 3137474 & 1301311 & 8.301 & 8.2576 & TRN & & \\
\hline CHEMBL 3137447 & 1301311 & 7.1739 & 7.3144 & TRN & & \\
\hline CHEMBL3137460 & 1301311 & 7.9586 & 7.6013 & TRN & & \\
\hline CHEMBL3137478 & 1301311 & 8.699 & 8.5695 & TRN & & \\
\hline CHEMBL3104529 & 1301311 & 8.5746 & 7.9759 & TRN & & \\
\hline CHEMBL3104474 & 1301311 & 7.6198 & 7.2014 & TRN & & \\
\hline CHEMBL 3137483 & 1301311 & 6.0 & 7.50899 & 99999 & 995 & TST \\
\hline CHEMBL3104475 & 1301311 & 7.4089 & 7.0678 & TRN & & \\
\hline CHEMBL 3137464 & 1301311 & 8.0969 & 7.9458 & TST & & \\
\hline CHEMBL3137469 & 1301311 & 8.2909 & 8.1258 & TRN & & \\
\hline CHEMBL3104473 & 1301311 & 7.8239 & 7.3097 & TRN & & \\
\hline CHEMBL3104479 & 1301311 & 6.0 & 6.8988 & TRN & & \\
\hline CHEMBL3137475 & 1301311 & 8.1549 & 7.5018 & TST & & \\
\hline CHEMBL3137479 & 1301311 & 8.1549 & 7.1137 & TRN & & \\
\hline CHEMBL3137466 & 1301311 & 7.0269 & 7.8691 & TST & & \\
\hline CHEMBL3104535 & 1301311 & 7.8239 & 7.4933 & TRN & & \\
\hline CHEMBL3137456 & 1301311 & 7.7696 & 7.23799 & 99999 & 995 & TRN \\
\hline CHEMBL3137459 & 1301311 & 8.7447 & 8.5022 & TRN & & \\
\hline CHEMBL3104528 & 1301311 & 9.2255 & 8.3144 & TRN & & \\
\hline CHEMBL3104532 & 1301311 & 8.0458 & 7.5625 & TRN & & \\
\hline CHEMBL3137462 & 1301311 & 7.8239 & 7.6821 & TRN & & \\
\hline CHEMBL3137467 & 1301311 & 8.2354 & 8.1361 & TRN & & \\
\hline CHEMBL3104533 & 1301311 & 7.6778 & 7.5307 & TRN & & \\
\hline CHEMBL3137481 & 1301311 & 7.4437 & 7.7206 & TST & & \\
\hline CHEMBL3137472 & 1301311 & 6.0 & 7.6926 & TST & & \\
\hline CHEMBL3104531 & 1301311 & 9.209 & 8.2439 & TRN & & \\
\hline CHEMBL3137453 & 1301311 & 6.6778 & 7.26200 & 20000 & 005 & TRN \\
\hline CHEMBL3137452 & 1301311 & 7.7696 & 7.3345 & TRN & & \\
\hline CHEMBL 3137443 & 1301311 & 6.0 & 7.8513 & TRN & & \\
\hline CHEMBL3137458 & 1301311 & 8.0458 & 7.3425 & TRN & & \\
\hline CHEMBL3104527 & 1301311 & 6.2197 & 7.2604 & TRN & & \\
\hline
\end{tabular}


Supplemental Table S2.txt

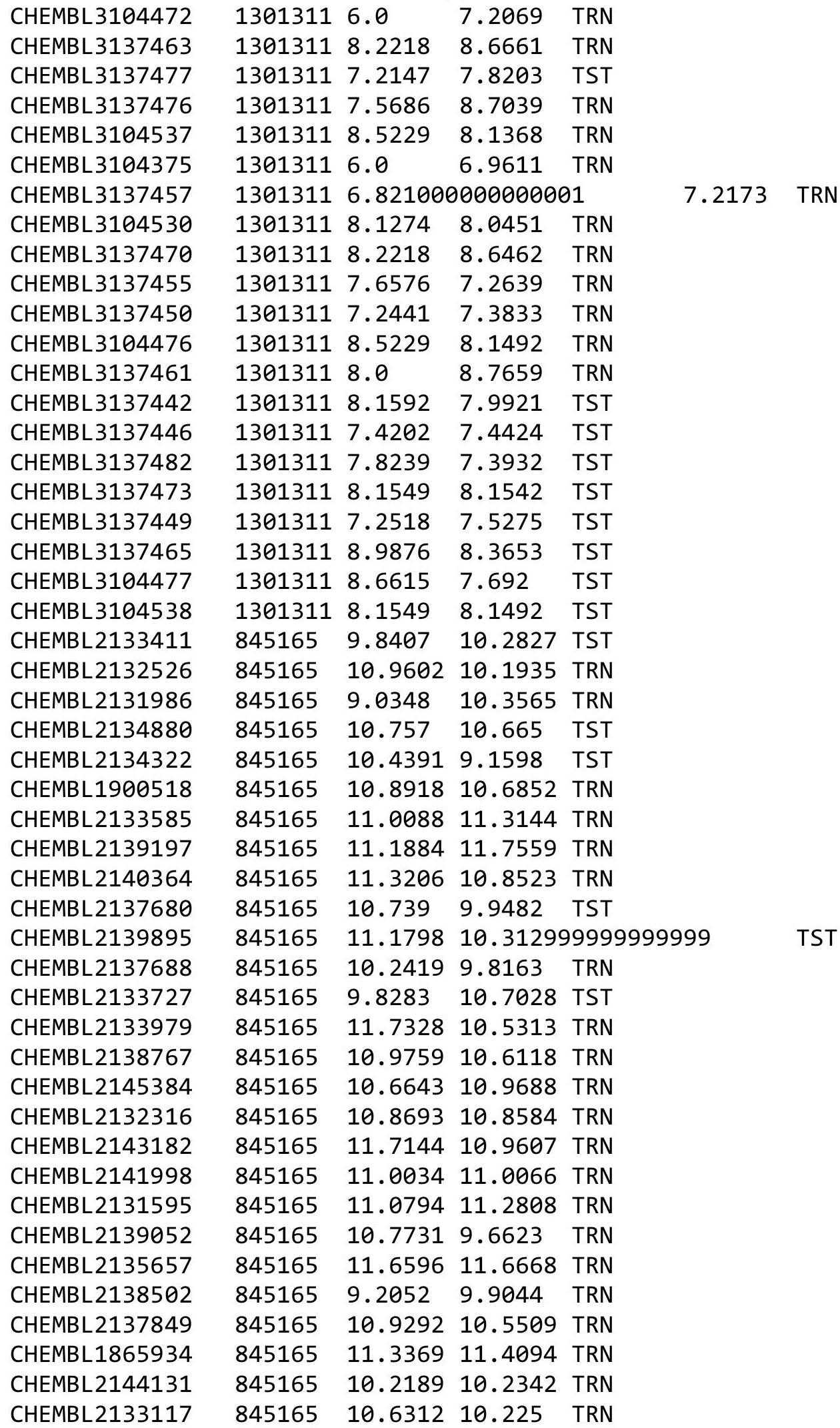

Page 12373 


\begin{tabular}{|c|c|c|c|c|c|}
\hline CHEMBL2139235 & 845165 & 10.2135 & 10.1077 & TST & \\
\hline CHEMBL 2138719 & 845165 & 10.5725 & 10.1979 & TRN & \\
\hline CHEMBL2136204 & 845165 & 8.3256 & 11.0435 & TRN & \\
\hline CHEMBL 2137928 & 845165 & 9.7371 & 10.2812 & TRN & \\
\hline CHEMBL 2143465 & 845165 & 11.2449 & 11.2596 & TRN & \\
\hline CHEMBL 2140595 & 845165 & 11.7352 & 11.3082 & TRN & \\
\hline CHEMBL 2132650 & 845165 & 10.9805 & 10.8053 & TRN & \\
\hline CHEMBL 2143184 & 845165 & 9.2589 & 11.0856 & TST & \\
\hline CHEMBL2142519 & 845165 & 10.8145 & 10.6993 & TRN & \\
\hline CHEMBL1884699 & 845165 & 10.7627 & 8.9755 & TST & \\
\hline CHEMBL 2140410 & 845165 & 10.4936 & 10.0404 & TRN & \\
\hline CHEMBL 2135201 & 845165 & 11.2882 & 10.9067 & TRN & \\
\hline CHEMBL 2138501 & 845165 & 7.0329 & 9.2819 & TRN & \\
\hline CHEMBL 2130929 & 845165 & 8.3013 & 10.1226 & TRN & \\
\hline CHEMBL 2138737 & 845165 & 7.8505 & 8.639 & TRN & \\
\hline CHEMBL 2141052 & 845165 & 11.4157 & 10.2235 & TRN & \\
\hline CHEMBL 2134144 & 845165 & 10.9935 & 10.6736 & TRN & \\
\hline CHEMBL 2137394 & 845165 & 6.8058 & 7.1004 & TRN & \\
\hline CHEMBL 2135979 & 845165 & 11.0691 & 11.2007 & TRN & \\
\hline CHEMBL 2142245 & 845165 & 10.1909 & 10.0427 & TST & \\
\hline CHEMBL 2142216 & 845165 & 9.817 & 10.335 & TRN & \\
\hline CHEMBL 2133181 & 845165 & 11.1506 & 10.335 & TRN & \\
\hline CHEMBL 2141666 & 845165 & 11.2644 & 10.243 & TRN & \\
\hline CHEMBL 2140567 & 845165 & 11.5186 & 11.0692 & TRN & \\
\hline CHEMBL 2141711 & 845165 & 10.8294 & 11.0905 & TRN & \\
\hline CHEMBL2137696 & 845165 & 10.7796 & 10.0964 & TRN & \\
\hline CHEMBL 2142496 & 845165 & 11.3134 & 10.5643 & TRN & \\
\hline CHEMBL 2132333 & 845165 & 10.7086 & 11.1111 & TRN & \\
\hline CHEMBL2138113 & 845165 & 11.4012 & 9.9468 & TRN & \\
\hline CHEMBL 2142058 & 845165 & 10.8008 & 11.2908 & TRN & \\
\hline CHEMBL 2135699 & 845165 & 10.7077 & 11.0519 & TRN & \\
\hline CHEMBL 2134695 & 845165 & 6.8542 & 10.3882 & TST & \\
\hline CHEMBL1971465 & 845165 & 11.1904 & 10.4849 & TRN & \\
\hline CHEMBL 2133477 & 845165 & 11.0615 & 10.9215 & TRN & \\
\hline CHEMBL 2136218 & 845165 & 10.80295 & 99999999 & 11.0907 & TRN \\
\hline CHEMBL 2138693 & 845165 & 11.6925 & 11.3645 & TRN & \\
\hline CHEMBL 2140166 & 845165 & 10.5403 & 10.2201 & TRN & \\
\hline CHEMBL 2133784 & 845165 & 11.3215 & 11.134 & TRN & \\
\hline CHEMBL2132529 & 845165 & 9.8441 & 10.4509 & 99999999999 & TRN \\
\hline CHEMBL 2132766 & 845165 & 9.6662 & 10.6081 & TRN & \\
\hline CHEMBL 2135890 & 845165 & 11.3893 & 11.005 & TRN & \\
\hline CHEMBL 2138028 & 845165 & 10.7455 & 11.3747 & TRN & \\
\hline CHEMBL 2130718 & 845165 & 9.8993 & 8.6567 & TST & \\
\hline CHEMBL 2135811 & 845165 & 10.87 & 10.5458 & TRN & \\
\hline CHEMBL 2136603 & 845165 & 10.9889 & 10.9832 & TRN & \\
\hline CHEMBL 2135227 & 845165 & 10.7409 & 10.1631 & TST & \\
\hline CHEMBL 2141371 & 845165 & 10.5608 & 11.2566 & TRN & \\
\hline CHEMBL 2136710 & 845165 & 10.9266 & 10.7894 & TRN & \\
\hline
\end{tabular}

Page 12374 


\begin{tabular}{|c|c|c|c|c|}
\hline & & & pplementa & \\
\hline CHEMBL 2142391 & 845165 & 11.4511 & 9.9348 & TST \\
\hline CHEMBL 2133413 & 845165 & 9.283 & 10.2646 & TST \\
\hline CHEMBL2134161 & 845165 & 11.6308 & 9.8609 & TST \\
\hline CHEMBL1867569 & 845165 & 11.6882 & 10.5458 & TST \\
\hline CHEMBL2139350 & 845165 & 9.5249 & 11.1954 & TST \\
\hline CHEMBL2139757 & 845165 & 8.8219 & 10.4218 & TST \\
\hline CHEMBL1325873 & 845165 & 9.1854 & 10.7709 & TST \\
\hline CHEMBL 2142712 & 845165 & 11.5272 & 9.7577 & TST \\
\hline CHEMBL 208283 & 364710 & 6.0 & 5.4505 & TRN \\
\hline CHEMBL207461 & 364710 & 8.1891 & 8.4029 & TST \\
\hline CHEMBL 379030 & 364710 & 8.4145 & 8.4314 & TRN \\
\hline CHEMBL379285 & 364710 & 8.1349 & 7.7026 & TRN \\
\hline CHEMBL207514 & 364710 & 6.0 & 6.5799 & TRN \\
\hline CHEMBL381797 & 364710 & 7.7375 & 7.7709 & TRN \\
\hline CHEMBL209965 & 364710 & 8.3354 & 8.2841 & TRN \\
\hline CHEMBL207116 & 364710 & 8.1952 & 8.0802 & TRN \\
\hline CHEMBL380666 & 364710 & 7.8069 & 7.7535 & TRN \\
\hline CHEMBL377095 & 364710 & 8.2464 & 8.0673 & TRN \\
\hline CHEMBL208579 & 364710 & 7.7627 & 7.6974 & TRN \\
\hline CHEMBL207245 & 364710 & 7.6358 & 7.7181 & TRN \\
\hline CHEMBL 210048 & 364710 & 8.2055 & 7.9413 & TST \\
\hline CHEMBL 377951 & 364710 & 8.699 & 8.7212 & TRN \\
\hline CHEMBL126377 & 364710 & 8.9957 & 9.0014 & TRN \\
\hline CHEMBL381954 & 364710 & 7.2531 & 7.2554 & TRN \\
\hline CHEMBL379843 & 364710 & 7.76 & 8.1062 & TST \\
\hline CHEMBL410089 & 364710 & 7.8871 & 8.0602 & TST \\
\hline CHEMBL208099 & 364710 & 7.0182 & 8.0706 & TST \\
\hline CHEMBL379739 & 364710 & 7.4447 & 7.409 & TRN \\
\hline CHEMBL207295 & 364710 & 8.2967 & 8.0584 & TRN \\
\hline CHEMBL210652 & 364710 & 8.757 & 8.5147 & TRN \\
\hline CHEMBL438809 & 364710 & 6.0 & 5.598 & TRN \\
\hline CHEMBL 210223 & 364710 & 6.0 & 8.4923 & TST \\
\hline CHEMBL382405 & 364710 & 8.2573 & 8.031 & TRN \\
\hline CHEMBL 380289 & 364710 & 6.0 & 7.5636 & TST \\
\hline CHEMBL109039 & 364710 & 7.8771 & 7.8718 & TRN \\
\hline CHEMBL206965 & 364710 & 7.6486 & 7.7246 & TRN \\
\hline CHEMBL 378844 & 364710 & 8.7496 & 8.7901 & TRN \\
\hline CHEMBL209660 & 364710 & 8.1463 & 8.0146 & TRN \\
\hline CHEMBL 376992 & 364710 & 8.0255 & 8.5141 & TST \\
\hline CHEMBL210289 & 364710 & 7.8303 & 7.4343 & TST \\
\hline CHEMBL207369 & 364710 & 7.9289 & 7.7846 & TRN \\
\hline CHEMBL383309 & 364710 & 8.0888 & 8.4512 & TRN \\
\hline CHEMBL383305 & 364710 & 6.0 & 5.7853 & TRN \\
\hline CHEMBL 378868 & 364710 & 6.0 & 6.1423 & TRN \\
\hline CHEMBL209026 & 364710 & 7.0145 & 8.6213 & TST \\
\hline CHEMBL382891 & 364710 & 8.7852 & 8.6534 & TRN \\
\hline CHEMBL 379475 & 364710 & 7.53 & 7.7016 & TST \\
\hline CHEMBL383621 & 364710 & 7.5719 & 7.6575 & TRN \\
\hline
\end{tabular}




\begin{tabular}{|c|c|c|c|c|c|c|}
\hline & & \multicolumn{5}{|c|}{ Supplemental Table S2.txt } \\
\hline CHEMBL 263215 & 364710 & 7.8765 & 8.1981 & TST & & \\
\hline CHEMBL 207789 & 364710 & 6.0 & 6.5463 & TRN & & \\
\hline CHEMBL208142 & 364710 & 7.5376 & 7.4447 & TRN & & \\
\hline CHEMBL 378263 & 364710 & \multicolumn{3}{|c|}{7.4510000000000005} & 7.7683 & TRN \\
\hline CHEMBL 377663 & 364710 & 7.1559 & 7.086 & TRN & & \\
\hline CHEMBL210912 & 364710 & 6.0 & 5.9854 & TRN & & \\
\hline CHEMBL 264835 & 364710 & 6.0 & 6.2663 & TRN & & \\
\hline CHEMBL210689 & 364710 & 6.0 & 6.3612 & TRN & & \\
\hline CHEMBL437318 & 364710 & 7.1385 & 7.1782 & TRN & & \\
\hline CHEMBL 207213 & 364710 & 7.1587 & 7.41 & TST & & \\
\hline CHEMBL379842 & 364710 & 7.5751 & 7.5563 & TRN & & \\
\hline CHEMBL 377121 & 364710 & 7.068 & 7.3402 & TRN & & \\
\hline CHEMBL207354 & 364710 & 8.7747 & 9.2992 & TRN & & \\
\hline CHEMBL 207306 & 364710 & 7.1162 & 8.3844 & TST & & \\
\hline CHEMBL377227 & 364710 & 7.2136 & 7.7162 & TRN & & \\
\hline CHEMBL 207443 & 364710 & 8.5969 & 8.3055 & TRN & & \\
\hline CHEMBL 209882 & 364710 & 6.0 & 6.2634 & TRN & & \\
\hline CHEMBL 207513 & 364710 & 8.5272 & 8.344 & TRN & & \\
\hline CHEMBL 245300 & 364710 & 7.7713 & 7.9159 & TST & & \\
\hline CHEMBL 209987 & 364710 & 7.6278 & 8.2127 & TST & & \\
\hline CHEMBL210704 & 364710 & 8.4559 & 8.4755 & TRN & & \\
\hline CHEMBL 208742 & 364710 & 8.3862 & 8.3498 & TRN & & \\
\hline CHEMBL 210496 & 364710 & 7.1579 & 8.0864 & TST & & \\
\hline CHEMBL377824 & 364710 & 8.0825 & 7.6727 & TRN & & \\
\hline CHEMBL 207227 & 364710 & 7.688 & 7.8005 & TRN & & \\
\hline CHEMBL208205 & 364710 & 7.8268 & 7.8435 & TRN & & \\
\hline CHEMBL 383040 & 364710 & 6.0 & 8.4062 & TST & & \\
\hline CHEMBL380472 & 364710 & 8.6308 & 8.4718 & TRN & & \\
\hline CHEMBL 207462 & 364710 & 7.7711 & 7.6571 & TRN & & \\
\hline CHEMBL 210238 & 364710 & 6.0 & 5.9537 & TRN & & \\
\hline CHEMBL210796 & 364710 & 8.2774 & 8.1298 & TRN & & \\
\hline CHEMBL 209508 & 364710 & 8.4724 & 8.5829 & TRN & & \\
\hline CHEMBL 3727766 & 1537619 & 4.6674 & 5.1479 & TRN & & \\
\hline CHEMBL3729796 & 1537619 & 5.3233 & 5.8403 & TRN & & \\
\hline CHEMBL 3731622 & 1537619 & 6.6383 & 5.945 & TRN & & \\
\hline CHEMBL 3729123 & 1537619 & 4.997 & 5.5306 & TRN & & \\
\hline CHEMBL602074 & 1537619 & 5.0851 & 5.5449 & TST & & \\
\hline CHEMBL 3727865 & 1537619 & 5.9872 & 5.351 & TRN & & \\
\hline CHEMBL 3730025 & 1537619 & 5.8761 & 5.7502 & TRN & & \\
\hline CHEMBL 3730703 & 1537619 & 5.1244 & 5.6337 & TRN & & \\
\hline CHEMBL3727775 & 1537619 & 5.2111 & 5.5565 & TRN & & \\
\hline CHEMBL3731152 & 1537619 & 5.7959 & 5.916 & TRN & & \\
\hline CHEMBL3729991 & 1537619 & 5.3556 & 5.6316 & TRN & & \\
\hline CHEMBL3728349 & 1537619 & 4.6631 & 5.6451 & TRN & & \\
\hline CHEMBL 3732376 & 1537619 & 5.5229 & 5.6437 & TRN & & \\
\hline CHEMBL 3729040 & 1537619 & 6.6383 & 5.6063 & TRN & & \\
\hline CHEMBL3732131 & 1537619 & 4.3818 & 5.31 & TRN & & \\
\hline CHEMBL 3727485 & 1537619 & 4.791 & 5.5268 & TRN & & \\
\hline
\end{tabular}


Supplemental Table S2.txt

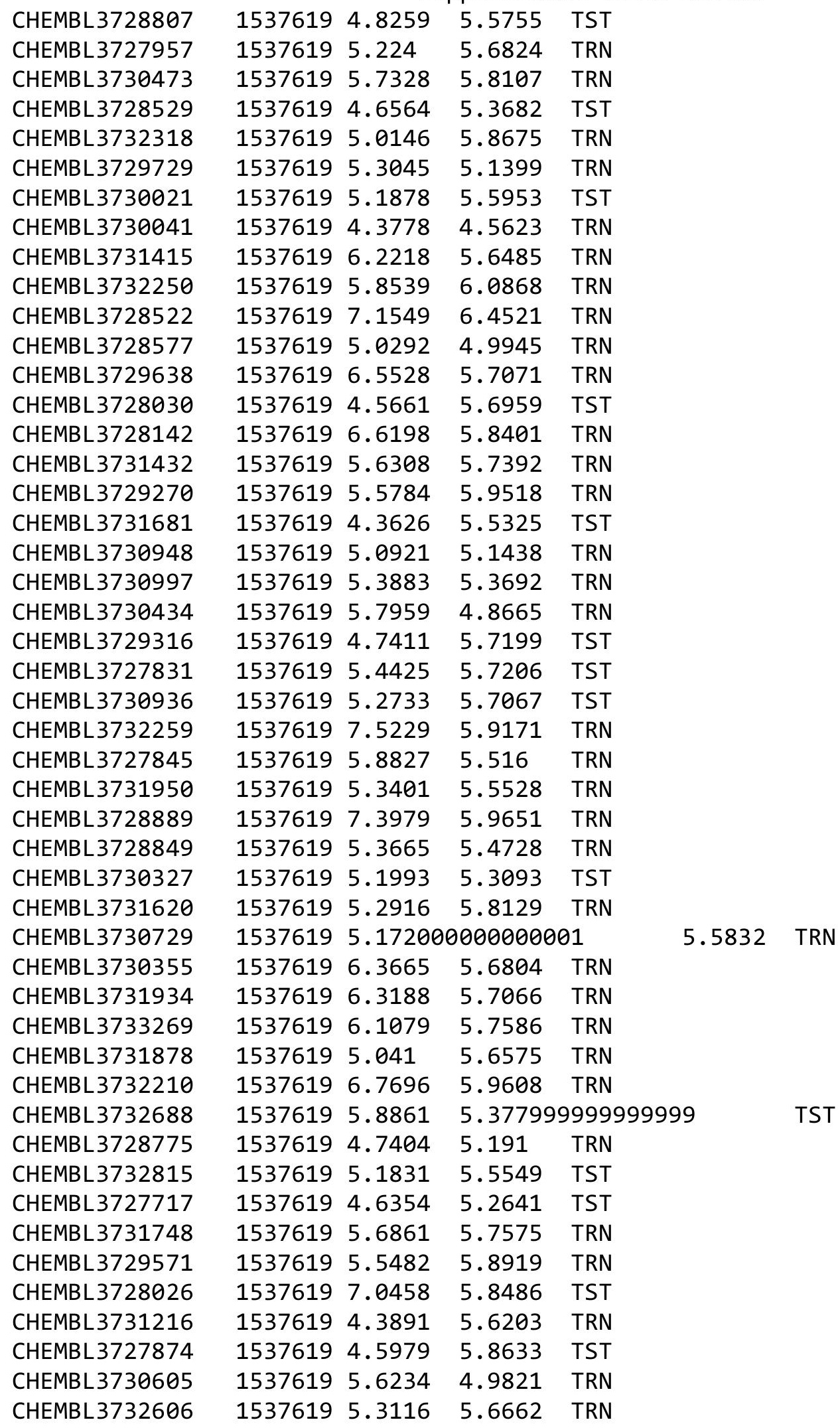

Page 12377 
Supplemental Table S2.txt

\begin{tabular}{|c|c|c|c|c|c|}
\hline CHEMBL3731098 & 1537619 & 5.5528 & 5.6398 & TRN & \\
\hline CHEMBL3730406 & 1537619 & 5.8356 & 5.5905 & TRN & \\
\hline CHEMBL3727725 & 1537619 & 4.4082 & 5.8415 & TRN & \\
\hline CHEMBL3732046 & 1537619 & 5.3478 & 5.3108 & TRN & \\
\hline CHEMBL 3728541 & 1537619 & 5.5129 & 5.5106 & TST & \\
\hline CHEMBL3730168 & 1537619 & 4.8407 & 5.3488 & TST & \\
\hline CHEMBL3730184 & 1537619 & 6.1192 & 5.6381 & TRN & \\
\hline CHEMBL3730642 & 1537619 & 6.5086 & 5.8034 & TRN & \\
\hline CHEMBL 3728723 & 1537619 & 6.9586 & 5.9661 & TRN & \\
\hline CHEMBL3729528 & 1537619 & 5.6021 & 5.6685 & TST & \\
\hline CHEMBL3729382 & 1537619 & 5.4584 & 5.5296 & TRN & \\
\hline CHEMBL3732119 & 1537619 & 4.7693 & 5.7982 & TST & \\
\hline CHEMBL3732893 & 1537619 & 5.1068 & 5.6782 & TRN & \\
\hline CHEMBL 3732211 & 1537619 & 6.6778 & 4.7555 & TST & \\
\hline CHEMBL3727746 & 1537619 & 6.6383 & 5.3133 & TRN & \\
\hline CHEMBL3727791 & 1537619 & 6.5086 & 5.3796 & TRN & \\
\hline CHEMBL3727947 & 1537619 & 7.2218 & 5.9838 & TRN & \\
\hline CHEMBL3731596 & 1537619 & 5.3251 & 5.4029 & TRN & \\
\hline CHEMBL3732687 & 1537619 & 7.0458 & 5.9725 & TRN & \\
\hline CHEMBL3732718 & 1537619 & 5.5986 & 5.8316 & TRN & \\
\hline CHEMBL3731842 & 1537619 & 5.7167 & 6.2976 & TRN & \\
\hline CHEMBL3728298 & 1537619 & 5.4685 & 5.8274 & TRN & \\
\hline CHEMBL3732420 & 1537619 & 4.8102 & 5.5721 & TRN & \\
\hline CHEMBL3727517 & 1537619 & 5.7852 & 5.5323 & TRN & \\
\hline CHEMBL3729928 & 1537619 & 4.9122 & 5.5258 & TST & \\
\hline CHEMBL3728396 & 1537619 & 5.8996 & 5.7128 & TRN & \\
\hline CHEMBL3731118 & 1537619 & 5.7033 & 5.5216 & TRN & \\
\hline CHEMBL3729941 & 1537619 & 4.6994 & 6.0437 & TRN & \\
\hline CHEMBL 3732545 & 1537619 & \multicolumn{2}{|c|}{5.2620000000000005} & 5.95 & TR \\
\hline CHEMBL 3733085 & 1537619 & 6.0 & 5.6425 & TST & \\
\hline CHEMBL3730889 & 1537619 & 5.8125 & 5.5212 & TRN & \\
\hline CHEMBL3729469 & 1537619 & 4.6123 & 5.8674 & TRN & \\
\hline CHEMBL3730883 & 1537619 & 4.808 & 5.4003 & TST & \\
\hline CHEMBL3730822 & 1537619 & 6.7959 & 6.0531 & TRN & \\
\hline CHEMBL3727757 & 1537619 & 4.5464 & 5.7076 & TRN & \\
\hline CHEMBL3728049 & 1537619 & 6.2218 & \multicolumn{2}{|c|}{5.718999999999999} & TRN \\
\hline CHEMBL3728312 & 1537619 & 5.4609 & 5.3372 & TRN & \\
\hline CHEMBL 3730280 & 1537619 & \multicolumn{3}{|c|}{4.428999999999999} & TRN \\
\hline CHEMBL3728101 & 1537619 & 6.7447 & 6.2014 & TRN & \\
\hline CHEMBL3728458 & 1537619 & 5.5901 & \multicolumn{2}{|c|}{5.212000000000001} & TRN \\
\hline CHEMBL3727534 & 1537619 & 4.5154 & 5.4957 & TRN & \\
\hline CHEMBL 3727973 & 1537619 & 5.5045 & 5.7047 & TRN & \\
\hline CHEMBL3727904 & 1537619 & 5.9355 & 5.2295 & TRN & \\
\hline CHEMBL3728091 & 1537619 & 5.1713 & 5.7144 & TRN & \\
\hline CHEMBL3733350 & 1537619 & 5.9508 & 5.8383 & TRN & \\
\hline CHEMBL3732023 & 1537619 & 5.4023 & 5.899 & TRN & \\
\hline CHEMBL 3728748 & 1537619 & 5.5376 & 5.6952 & TRN & \\
\hline CHEMBL3729419 & 1537619 & 5.8097 & 5.8483 & TST & \\
\hline
\end{tabular}


Supplemental Table S2.txt

\begin{tabular}{|c|c|c|c|c|c|}
\hline CHEMBL3728618 & 1537619 & 4.4082 & 5.2365 & TST & \\
\hline CHEMBL3730175 & 1537619 & 4.5594 & 5.2944 & TRN & \\
\hline CHEMBL3730165 & 1537619 & 5.8508 & 5.3386 & TRN & \\
\hline CHEMBL3732622 & 1537619 & 5.2976 & 5.5038 & TST & \\
\hline CHEMBL3728170 & 1537619 & 4.7249 & 5.8594 & TST & \\
\hline CHEMBL3732410 & 1537619 & 6.5686 & 5.6391 & TRN & \\
\hline CHEMBL3731995 & 1537619 & 4.4277 & 5.49799 & 9999999999 & TST \\
\hline CHEMBL3729090 & 1537619 & 5.6073 & 4.4468 & TRN & \\
\hline CHEMBL3732130 & 1537619 & 4.4728 & 4.4888 & TRN & \\
\hline CHEMBL3728951 & 1537619 & 5.9281 & 5.8537 & TRN & \\
\hline CHEMBL3727691 & 1537619 & 5.9172 & 5.3794 & TRN & \\
\hline CHEMBL3729236 & 1537619 & 4.9401 & 4.976 & TRN & \\
\hline CHEMBL3732169 & 1537619 & 5.2503 & 5.4288 & TRN & \\
\hline CHEMBL3731990 & 1537619 & 4.754 & 5.9059 & TRN & \\
\hline CHEMBL3729942 & 1537619 & 4.9226 & 5.4424 & TRN & \\
\hline CHEMBL3727974 & 1537619 & 4.8784 & 5.3904 & TRN & \\
\hline CHEMBL3728282 & 1537619 & 5.6635 & 5.7349 & TRN & \\
\hline CHEMBL3731605 & 1537619 & 6.6576 & 6.015 & TRN & \\
\hline CHEMBL3729337 & 1537619 & 4.8817 & 5.8649 & TST & \\
\hline CHEMBL3732697 & 1537619 & 4.8303 & 5.2283 & TRN & \\
\hline CHEMBL3729645 & 1537619 & 4.8499 & 5.49799 & 9999999999 & TRN \\
\hline CHEMBL3730368 & 1537619 & 5.4522 & 5.557 & TRN & \\
\hline CHEMBL3731129 & 1537619 & 5.5287 & 5.6168 & TST & \\
\hline CHEMBL3728299 & 1537619 & 5.5361 & 5.7717 & TRN & \\
\hline CHEMBL3728810 & 1537619 & 5.4437 & 5.6328 & TRN & \\
\hline CHEMBL 3732247 & 1537619 & 7.301 & 6.1895 & TRN & \\
\hline CHEMBL3731768 & 1537619 & 5.0555 & 5.7886 & TST & \\
\hline CHEMBL3730420 & 1537619 & 5.2882 & 5.7701 & TRN & \\
\hline CHEMBL3731881 & 1537619 & 5.0487 & 5.0281 & TRN & \\
\hline CHEMBL3730916 & 1537619 & 5.5243 & 5.434 & TRN & \\
\hline CHEMBL 3727498 & 1537619 & 4.9927 & 5.8179 & TRN & \\
\hline CHEMBL 3727894 & 1537619 & 5.3116 & 5.5806 & TRN & \\
\hline CHEMBL3731274 & 1537619 & 6.0809 & 5.6642 & TRN & \\
\hline CHEMBL3730972 & 1537619 & 4.3858 & 5.9262 & TST & \\
\hline CHEMBL3732898 & 1537619 & 5.9208 & 5.54799 & 9999999999 & TRN \\
\hline CHEMBL3730566 & 1537619 & 6.7959 & 6.32100 & 0000000001 & TRN \\
\hline CHEMBL3730376 & 1537619 & 5.3655 & 5.6691 & TRN & \\
\hline CHEMBL3732489 & 1537619 & 5.6498 & 5.9072 & TRN & \\
\hline CHEMBL 3727955 & 1537619 & 4.3168 & 4.7684 & TRN & \\
\hline CHEMBL3730878 & 1537619 & 4.6955 & 5.7433 & TST & \\
\hline CHEMBL3732268 & 1537619 & 5.3179 & 5.9134 & TST & \\
\hline CHEMBL3730782 & 1537619 & 6.6576 & 5.8097 & TST & \\
\hline CHEMBL 3729084 & 1537619 & 5.8827 & 5.5804 & TST & \\
\hline CHEMBL3732142 & 1537619 & 5.7825 & 6.1197 & TST & \\
\hline CHEMBL3732974 & 1537619 & 5.6576 & 5.5918 & TST & \\
\hline CHEMBL3727716 & 1537619 & 6.7212 & 6.04899 & 99999999995 & TST \\
\hline CHEMBL3728048 & 1537619 & 5.466 & 5.6496 & TST & \\
\hline CHEMBL 3764226 & 1556011 & 2.0 & 1.7753 & TRN & \\
\hline
\end{tabular}




\begin{tabular}{|c|c|c|c|c|c|}
\hline \multicolumn{6}{|c|}{ Supplemental Table S2.txt } \\
\hline CHEMBL3765531 & 1556011 & 2.0 & 1.829 & TRN & \\
\hline CHEMBL3763488 & 1556011 & 2.0 & 2.0356 & TRN & \\
\hline CHEMBL3765467 & 1556011 & 2.0 & 2.5609 & TST & \\
\hline CHEMBL3765212 & 1556011 & 2.0 & 2.4641 & TST & \\
\hline CHEMBL3763712 & 1556011 & 2.0 & 2.0581 & TRN & \\
\hline CHEMBL3763401 & 1556011 & 2.0 & 2.381 & TST & \\
\hline CHEMBL3765258 & 1556011 & 2.0 & 2.8026 & TRN & \\
\hline CHEMBL3763272 & 1556011 & 2.0 & 2.4227 & TST & \\
\hline CHEMBL3764520 & 1556011 & 4.4815 & 3.897 & TRN & \\
\hline CHEMBL3764111 & 1556011 & 2.0 & 2.6126 & TRN & \\
\hline CHEMBL3764356 & 1556011 & 2.0 & 3.0541 & TRN & \\
\hline CHEMBL3765656 & 1556011 & 2.0 & 2.4525 & TRN & \\
\hline CHEMBL3763525 & 1556011 & 2.0 & 2.4637 & TST & \\
\hline CHEMBL3765185 & 1556011 & 2.0 & 2.5626 & TRN & \\
\hline CHEMBL3764479 & 1556011 & 2.0 & 2.3418 & TST & \\
\hline CHEMBL3764521 & 1556011 & 2.0 & 1.8623 & TRN & \\
\hline CHEMBL3763916 & 1556011 & 2.0 & 1.9068 & TRN & \\
\hline CHEMBL3764299 & 1556011 & 2.0 & 2.9232 & TRN & \\
\hline CHEMBL3763512 & 1556011 & 4.1308 & 4.1142 & TRN & \\
\hline CHEMBL3765438 & 1556011 & 2.0 & 1.64699 & 99999999998 & TRN \\
\hline CHEMBL3763513 & 1556011 & 2.0 & 2.9113 & TRN & \\
\hline CHEMBL3765092 & 1556011 & 2.0 & 1.5238 & TRN & \\
\hline CHEMBL3763813 & 1556011 & 3.6108 & 3.0644 & TRN & \\
\hline CHEMBL3763945 & 1556011 & 2.0 & 1.7057 & TST & \\
\hline CHEMBL3765682 & 1556011 & 2.0 & 2.398 & TST & \\
\hline CHEMBL3763867 & 1556011 & 2.0 & 2.1254 & TRN & \\
\hline CHEMBL3764221 & 1556011 & 3.9136 & 3.3088 & TRN & \\
\hline CHEMBL3764932 & 1556011 & 2.0 & 2.06699 & 99999999997 & TST \\
\hline CHEMBL3764859 & 1556011 & 2.0 & 1.8062 & TST & \\
\hline CHEMBL3763187 & 1556011 & 4.7447 & 3.3285 & TRN & \\
\hline CHEMBL3764519 & 1556011 & 2.0 & 2.4294 & TRN & \\
\hline CHEMBL3765104 & 1556011 & 2.0 & 2.2052 & TST & \\
\hline CHEMBL3764965 & 1556011 & 2.0 & 2.9777 & TRN & \\
\hline CHEMBL3765321 & 1556011 & 4.0269 & 3.3739 & TRN & \\
\hline CHEMBL3765659 & 1556011 & 2.0 & 1.8286 & TST & \\
\hline CHEMBL3765723 & 1556011 & 2.0 & 2.3151 & TST & \\
\hline CHEMBL3764124 & 1556011 & 5.0969 & 3.167 & TRN & \\
\hline CHEMBL3763928 & 1556011 & 2.0 & 2.327 & TRN & \\
\hline CHEMBL3765130 & 1556011 & 2.0 & 2.2259 & TRN & \\
\hline CHEMBL3765260 & 1556011 & 2.0 & 1.4325 & TRN & \\
\hline CHEMBL3764551 & 1556011 & 2.0 & 2.4589 & TST & \\
\hline CHEMBL3763510 & 1556011 & 2.0 & 1.9974 & TRN & \\
\hline CHEMBL3765590 & 1556011 & 2.0 & 2.7472 & TRN & \\
\hline CHEMBL3763293 & 1556011 & 2.0 & 1.9146 & TRN & \\
\hline CHEMBL3765510 & 1556011 & 3.9172 & 3.4107 & TRN & \\
\hline CHEMBL3765140 & 1556011 & 4.0706 & 3.1942 & TRN & \\
\hline CHEMBL3764151 & 1556011 & 2.0 & 2.4899 & TRN & \\
\hline CHEMBL3765626 & 1556011 & 2.0 & 1.6401 & TRN & \\
\hline
\end{tabular}


Supplemental Table S2.txt

\begin{tabular}{|c|c|c|c|c|}
\hline HEMBL37 & & 3.4672 & 22 & \\
\hline HFMBI 3764924 & 556011 & 2.0 & 2.0677 & \\
\hline HEMBL3763959 & 56011 & 2.0 & 7525 & \\
\hline HEMBL3764064 & 56011 & 2.0 & 5198 & \\
\hline HEMBL3763445 & 556011 & 2.0 & .8657 & \\
\hline HEMBL3 & 56011 & 2.0 & .6465 & \\
\hline AEMBL3 & 6011 & 2.0 & .6937 & RN \\
\hline HEMBL3764012 & 556011 & 2.0 & .7505 & RN \\
\hline HEMBL3765443 & 556011 & 2.0 & .7965 & \\
\hline HEMBL3764563 & 556011 & 2.0 & 2.7528 & \\
\hline HEMBL37 & 56011 & 2.0 & .6353 & \\
\hline HEMBL1. & 268 & 587 & 5.5817 & RN \\
\hline HEMBL1: & 54268 & 5.8309 & 5.7659 & RN \\
\hline HEMBL14 & 68 & 4.9551 & 3598 & \\
\hline HEMBL1381679 & 68 & 5.2404 & 4.9897 & \\
\hline HEMBL1: & 58 & .755 & 34 & Niv \\
\hline HEMBL1 & & & & RN \\
\hline HEMBL1 & 68 & 5.3584 & 901 & RN \\
\hline HEMBL13 & 58 & 5.41 & & \\
\hline HEMBL3190811 & 58 & 4.0 & 024 & $\mathrm{~N} N \mathrm{~V}$ \\
\hline HEMBL2 & 58 & - & 05 & SI \\
\hline HEMBL1 & & & 89 & $\mathrm{RN}$ \\
\hline HEMBL1 & 68 & 5.1057 & 251 & ST \\
\hline HEMBL1 & & 36 & & $\mathrm{R}$ \\
\hline AEMBL1C & 58 & 4.0 & 24 & RN \\
\hline AEMBL4 & 58 & 5.97 & 69 & ST \\
\hline HEMBL 1 & & $\theta$ & & RN \\
\hline HEMBL1 & & 5.63 & & $\mathrm{RN}$ \\
\hline HEMBL13 & & & & RN \\
\hline AEMBL1583879 & 58 & 5.021 & 894 & 「RN \\
\hline HEMBL1 & 58 & 4 & 67 & 「RN \\
\hline AEMBL: & & 4 & & ГST \\
\hline HEMBL 2 & & 4.47 & & TST \\
\hline HEMBL3210814 & 8 & 4.4776 & 556 & TRN \\
\hline HEMBL1870076 & 58 & 4 & 101 & 「RN \\
\hline HEMBL1 & 58 & - & 07 & TRN \\
\hline נחביו & & 4. & & 「RN \\
\hline HEMBL1 & & 4.0 & & RN \\
\hline HEMBL1530410 & 58 & 4. & 819 & TRN \\
\hline IEMBL32 & 58 & 4 & 956 & TRN \\
\hline HEMBL31 & 68 & 5.6607 & 689 & TRN \\
\hline HEMBL14 & & 5.5923 & 5.5375 & 「RN \\
\hline HEMBL1608811 & & 5.8798 & 5.6447 & TRN \\
\hline AEMBL14 & 58 & 5.5516 & 38 & $\mathrm{R}$ \\
\hline MBL & & 4. & & $\mathrm{RN}$ \\
\hline CHEMBL1901265 & 54268 & 4.9543 & 5.4622 & \\
\hline CHEMBL1349788 & 54268 & 5.6334 & 5.555 & \\
\hline CHEMBL1465907 & 954268 & 5.3228 & 5.2511 & 3 \\
\hline
\end{tabular}

Page 12381 
Supplemental Table S2.txt

\begin{tabular}{ll} 
CHEMBL1431253 & 954268 \\
CHEMBL1892379 & 954268 \\
CHEMBL1312740 & 954268 \\
CHEMBL1312332 & 954268 \\
CHEMBL2356597 & 954268 \\
CHEMBL1331202 & 954268 \\
CHEMBL2141540 & 954268 \\
CHEMBL1595595 & 954268 \\
CHEMBL1709376 & 954268 \\
CHEMBL1385977 & 954268 \\
CHEMBL1416316 & 954268 \\
CHEMBL1561364 & 954268 \\
CHEMBL1396328 & 954268 \\
CHEMBL1425085 & 954268 \\
CHEMBL1431614 & 954268 \\
CHEMBL1403575 & 954268 \\
CHEMBL1330204 & 954268 \\
CHEMBL1319856 & 954268 \\
CHEMBL1327774 & 954268 \\
CHEMBL1362046 & 954268 \\
CHEMBL1471458 & 954268 \\
CHEMBL1348941 & 954268 \\
CHEMBL611941 & 954268 \\
CHEMBL1341468 & 954268 \\
CHEMBL1712808 & 954268 \\
CHEMBL1569740 & 954268 \\
CHEMBL510349 & 954268 \\
CHEMBL1880953 & 954268 \\
CHEMBL1417974 & 954268 \\
CHEMBL1530673 & 954268 \\
CHEMBL1726071 & 954268 \\
CHEMBL2144387 & 954268 \\
CHEMBL1611838 & 954268 \\
CHEMBLI1878419 & 954268 \\
CHEMBL1530961 & 954268 \\
CHEMBL587826 & 954268 \\
CHEMBL1571018 & 954268 \\
CHEMBL1377376 & 954268 \\
CHEMBL1419606 & 954268 \\
CHEMBL1608557 & 954268 \\
CHEMBL1460744 & 954268 \\
\hline
\end{tabular}

$\begin{array}{lll}4.4773 & 4.6928 \text { TRN }\end{array}$

5.53725 .4969 TRN

$\begin{array}{lll}4.0 & 3.9168 & \text { TST }\end{array}$

$\begin{array}{lll}5.3735 & 5.232 & \text { TRN }\end{array}$

$\begin{array}{llll}5.9215 & 5.8317 & \text { TRN }\end{array}$

$\begin{array}{llll}4.4773 & 4.7688 & \text { TRN }\end{array}$

$\begin{array}{lll}5.1504 & 5.0829 & \text { TRN }\end{array}$

$\begin{array}{llll}5.5387 & 4.6971 & \text { TRN }\end{array}$

$\begin{array}{llll}5.6098 & 5.4138 & \text { TRN }\end{array}$

$\begin{array}{lll}5.0309 & 5.0595 & \text { TST }\end{array}$

$\begin{array}{lll}5.8102 & 5.5857 & \text { TRN }\end{array}$

$\begin{array}{lll}5.2554 & 5.3628 & \text { TRN }\end{array}$

$5.6442 \quad 5.5523$ TRN

$\begin{array}{lll}5.5328 & 5.3401 & \text { TRN }\end{array}$

$\begin{array}{lll}5.4319 & 5.1524 & \text { TRN }\end{array}$

$5.7865 \quad 5.6461$ TRN

6.05615 .9354 TRN

5.30815 .2589 TRN

$\begin{array}{lll}4.0 & 4.0169 & \text { TRN }\end{array}$

$\begin{array}{lll}4.0 & 4.9082 \text { TRN }\end{array}$

$\begin{array}{lll}5.9614 & 5.7671 & \text { TRN }\end{array}$

5.49515 .2779 TRN

$\begin{array}{lll}5.7916 & 5.6038 \quad \text { TRN }\end{array}$

$5.3684 \quad 5.2591$ TRN

$\begin{array}{lll}4.0 & 4.0702 & \text { TRN }\end{array}$

$\begin{array}{lll}5.2551 & 5.197 \quad \text { TRN }\end{array}$

$\begin{array}{llll}5.2839 & 5.2075 & \text { TRN }\end{array}$

$\begin{array}{lll}5.4414 & 5.3488 & \text { TST }\end{array}$

$6.0209 \quad 5.8628$ TRN

$\begin{array}{lll}4.4779 & 4.7904 & \text { TRN }\end{array}$

$\begin{array}{lll}4.0 & 5.0888 \text { TRN }\end{array}$

$\begin{array}{llll}4.9543 & 5.1386 & \text { TRN }\end{array}$

$\begin{array}{llll}5.5387 & 5.4145 & \text { TRN }\end{array}$

4.95475 .5422 TRN

$\begin{array}{lll}5.2761 & 5.1415 & \text { TRN }\end{array}$

$\begin{array}{lll}5.5022 & 5.4358 \quad \text { TRN }\end{array}$

$\begin{array}{llll}5.5022 & 5.5497 & \text { TRN }\end{array}$

$\begin{array}{llll}5.5527 & 4.8928 & \text { TRN }\end{array}$

$\begin{array}{lll}4.9547 & 5.183 & \text { TRN }\end{array}$

$\begin{array}{lll}5.7277 & 5.6112 & \text { TRN }\end{array}$

$\begin{array}{lll}5.2476 & 4.7009 & \text { TRN }\end{array}$

$5.3483 \quad 5.3345$ TRN

$5.7886 \quad 5.6646 \quad$ TRN

$\begin{array}{llll}4.4774 & 4.6467 & \text { TRN }\end{array}$

$\begin{array}{lll}5.1742 & 5.1187 & \text { TRN }\end{array}$

$6.5452 \quad 6.0305$ TRN

5.47725 .4553 TRN

$\begin{array}{lll}5.4612 & 5.292999999999999 & \text { TRN }\end{array}$

Page 12382 


\begin{tabular}{|c|c|c|c|c|c|}
\hline \multirow[b]{2}{*}{ CHEMBL1537274 } & \multicolumn{5}{|c|}{ Supplemental Table S2.txt } \\
\hline & 954268 & 4.477 & 5.1231 & TRN & \\
\hline CHEMBL1895454 & 954268 & 5.2479 & 4.3717 & TRN & \\
\hline CHEMBL1431182 & 954268 & 5.2703 & 4.6463 & TRN & \\
\hline CHEMBL1527163 & 954268 & 4.0 & 4.9774 & TRN & \\
\hline CHEMBL1556319 & 954268 & 4.0 & 3.9103 & TRN & \\
\hline CHEMBL1474228 & 954268 & 5.1752 & 5.2988 & TRN & \\
\hline CHEMBL1711578 & 954268 & 5.263 & 5.2492 & TRN & \\
\hline CHEMBL1355971 & 954268 & 5.3065 & 5.2177 & TST & \\
\hline CHEMBL1383594 & 954268 & 5.5844 & 5.3896 & TRN & \\
\hline CHEMBL2361495 & 954268 & 4.0 & 4.6662 & TRN & \\
\hline CHEMBL1594993 & 954268 & 5.3174 & 5.2088 & TRN & \\
\hline CHEMBL1306548 & 954268 & 4.0 & 3.9803 & TRN & \\
\hline CHEMBL 3207326 & 954268 & 4.4776 & 4.2591 & TRN & \\
\hline CHEMBL1366544 & 954268 & 4.9547 & 5.5301 & TRN & \\
\hline CHEMBL1324794 & 954268 & 4.0 & 4.065 & TRN & \\
\hline CHEMBL1399123 & 954268 & 5.3616 & 5.1717 & TRN & \\
\hline CHEMBL1331272 & 954268 & 4.0 & 5.0378 & TRN & \\
\hline CHEMBL1339394 & 954268 & 4.0 & 5.4976 & TRN & \\
\hline CHEMBL1327350 & 954268 & 4.0 & 4.0579 & TRN & \\
\hline CHEMBL1332317 & 954268 & 4.0 & 3.9811 & TRN & \\
\hline CHEMBL1373487 & 954268 & 4.9547 & 5.4486 & TRN & \\
\hline CHEMBL1545432 & 954268 & 5.7469 & 5.3809 & TRN & \\
\hline CHEMBL1576309 & 954268 & 4.0 & 5.0524 & TST & \\
\hline CHEMBL1315419 & 954268 & 5.636 & 5.4526 & TRN & \\
\hline CHEMBL1322053 & 954268 & 4.0 & 3.98100 & 00000000003 & TRN \\
\hline CHEMBL1386332 & 954268 & 5.5669 & 5.4485 & TST & \\
\hline CHEMBL1468514 & 954268 & 4.477 & 4.8504 & TST & \\
\hline CHEMBL1468728 & 954268 & 5.8035 & 5.66299 & 9999999999 & TRN \\
\hline CHEMBL1876674 & 954268 & 5.9281 & 5.7254 & TRN & \\
\hline CHEMBL1369293 & 954268 & 4.0 & 4.91 & TRN & \\
\hline CHEMBL3196476 & 954268 & 4.0 & 4.135 & TRN & \\
\hline CHEMBL1464738 & 954268 & 6.3074 & 6.0935 & TRN & \\
\hline CHEMBL1566701 & 954268 & 5.336 & 5.2512 & TRN & \\
\hline CHEMBL1526920 & 954268 & 4.0 & 4.0428 & TRN & \\
\hline CHEMBL1866835 & 954268 & 5.564 & 5.584 & TRN & \\
\hline CHEMBL1560535 & 954268 & 4.0 & 3.8327 & TST & \\
\hline CHEMBL1300133 & 954268 & 5.8993 & 5.0327 & TRN & \\
\hline CHEMBL2362025 & 954268 & 5.5355 & 5.3401 & TRN & \\
\hline CHEMBL3211355 & 954268 & 5.032 & 4.3947 & TRN & \\
\hline CHEMBL1571914 & 954268 & 5.5837 & 5.3663 & TRN & \\
\hline CHEMBL1497742 & 954268 & 4.9547 & 5.5177 & TRN & \\
\hline CHEMBL1701673 & 954268 & 5.5239 & 5.5401 & TRN & \\
\hline CHEMBL1560398 & 954268 & 4.4777 & 5.3352 & TRN & \\
\hline CHEMBL1477902 & 954268 & 5.223 & 5.13899 & 9999999999 & TRN \\
\hline CHEMBL1583800 & 954268 & 5.6105 & 5.4034 & TRN & \\
\hline CHEMBL1596948 & 954268 & 5.0915 & 5.2344 & TRN & \\
\hline CHEMBL1885760 & 954268 & 4.0 & 4.0276 & TRN & \\
\hline CHEMBL1709293 & 954268 & 6.1122 & 5.7835 & TRN & \\
\hline
\end{tabular}

Page 12383 


\begin{tabular}{|c|c|c|c|c|}
\hline & & & oplement & al $\mathrm{Ta}$ \\
\hline CHEMBL1391949 & 954268 & 5.473 & 4.6251 & TRN \\
\hline CHEMBL1417696 & 954268 & 5.8996 & 5.8081 & TRN \\
\hline CHEMBL2358047 & 954268 & 5.5116 & 5.3505 & TRN \\
\hline CHEMBL1523271 & 954268 & 4.4772 & 5.401 & TRN \\
\hline CHEMBL1556733 & 954268 & 5.4449 & 5.3544 & TRN \\
\hline CHEMBL1404321 & 954268 & 5.5339 & 5.2578 & TRN \\
\hline CHEMBL1342859 & 954268 & 4.0 & 4.8327 & TRN \\
\hline CHEMBL1491357 & 954268 & 5.7203 & 5.4229 & TRN \\
\hline CHEMBL1504487 & 954268 & 5.7349 & 5.4803 & TST \\
\hline CHEMBL3190510 & 954268 & 4.9543 & 5.4985 & TRN \\
\hline CHEMBL1591599 & 954268 & 5.5444 & 5.4056 & TRN \\
\hline CHEMBL1877038 & 954268 & 4.0 & 3.8261 & TRN \\
\hline CHEMBL1451018 & 954268 & 5.7077 & 5.5667 & TRN \\
\hline CHEMBL1517767 & 954268 & 4.0 & 4.2719 & TRN \\
\hline CHEMBL1397449 & 954268 & 5.527 & 5.3929 & TST \\
\hline CHEMBL1566050 & 954268 & 5.6821 & 5.7063 & TST \\
\hline CHEMBL1420397 & 954268 & 5.3866 & 5.3677 & TST \\
\hline CHEMBL1573047 & 954268 & 5.8668 & 5.3704 & TST \\
\hline CHEMBL1429930 & 954268 & 6.0114 & 5.66 & TST \\
\hline CHEMBL1556516 & 954268 & 5.4063 & 5.3336 & TST \\
\hline CHEMBL1388022 & 954268 & 5.3459 & 5.4995 & TST \\
\hline CHEMBL2144855 & 954268 & 4.9547 & 5.4436 & TST \\
\hline CHEMBL1389755 & 954268 & 5.8918 & 5.3064 & TST \\
\hline CHEMBL1462925 & 954268 & 5.2422 & 5.3216 & TST \\
\hline CHEMBL2362078 & 954268 & 5.2953 & 5.3423 & TST \\
\hline CHEMBL1465048 & 954268 & 4.9555 & 5.5757 & TST \\
\hline CHEMBL1384403 & 954268 & 5.4746 & 5.3805 & TST \\
\hline CHEMBL1413355 & 954268 & 5.4147 & 5.3135 & TST \\
\hline CHEMBL1364365 & 954268 & 5.4782 & 4.6193 & TST \\
\hline CHEMBL1982831 & 954268 & 5.9834 & 5.7814 & TST \\
\hline CHEMBL2131581 & 954268 & 5.8716 & 5.6455 & TST \\
\hline CHEMBL1717732 & 954268 & 4.0 & 3.9517 & TST \\
\hline CHEMBL1305601 & 954268 & 4.9547 & 5.4895 & TST \\
\hline CHEMBL1889627 & 954268 & 4.4772 & 5.4058 & TST \\
\hline CHEMBL1492872 & 954268 & 6.0088 & 5.2286 & TST \\
\hline CHEMBL1517746 & 954268 & 5.5363 & 5.4743 & TST \\
\hline CHEMBL1716591 & 954268 & 5.3125 & 5.2043 & TST \\
\hline CHEMBL1332547 & 954268 & 5.6916 & 5.4452 & TST \\
\hline CHEMBL1490108 & 954268 & 5.3974 & 5.3077 & TST \\
\hline CHEMBL1881564 & 954268 & 5.2769 & 5.2118 & TST \\
\hline CHEMBL1875584 & 954268 & 4.0 & 4.1231 & TST \\
\hline CHEMBL300389 & 954436 & 5.6571 & 5.6609 & TRN \\
\hline CHEMBL393929 & 954436 & 5.1538 & 5.1692 & TRN \\
\hline CHEMBL191334 & 954436 & 3.4704 & 3.4714 & TRN \\
\hline CHEMBL1256459 & 954436 & 6.7723 & 6.7603 & TRN \\
\hline CHEMBL373751 & 954436 & 3.4428 & 3.4279 & TRN \\
\hline CHEMBL209148 & 954436 & 2.5141 & 2.4863 & TRN \\
\hline CHEMBL102714 & 954436 & 3.3459 & 3.3523 & TRN \\
\hline
\end{tabular}




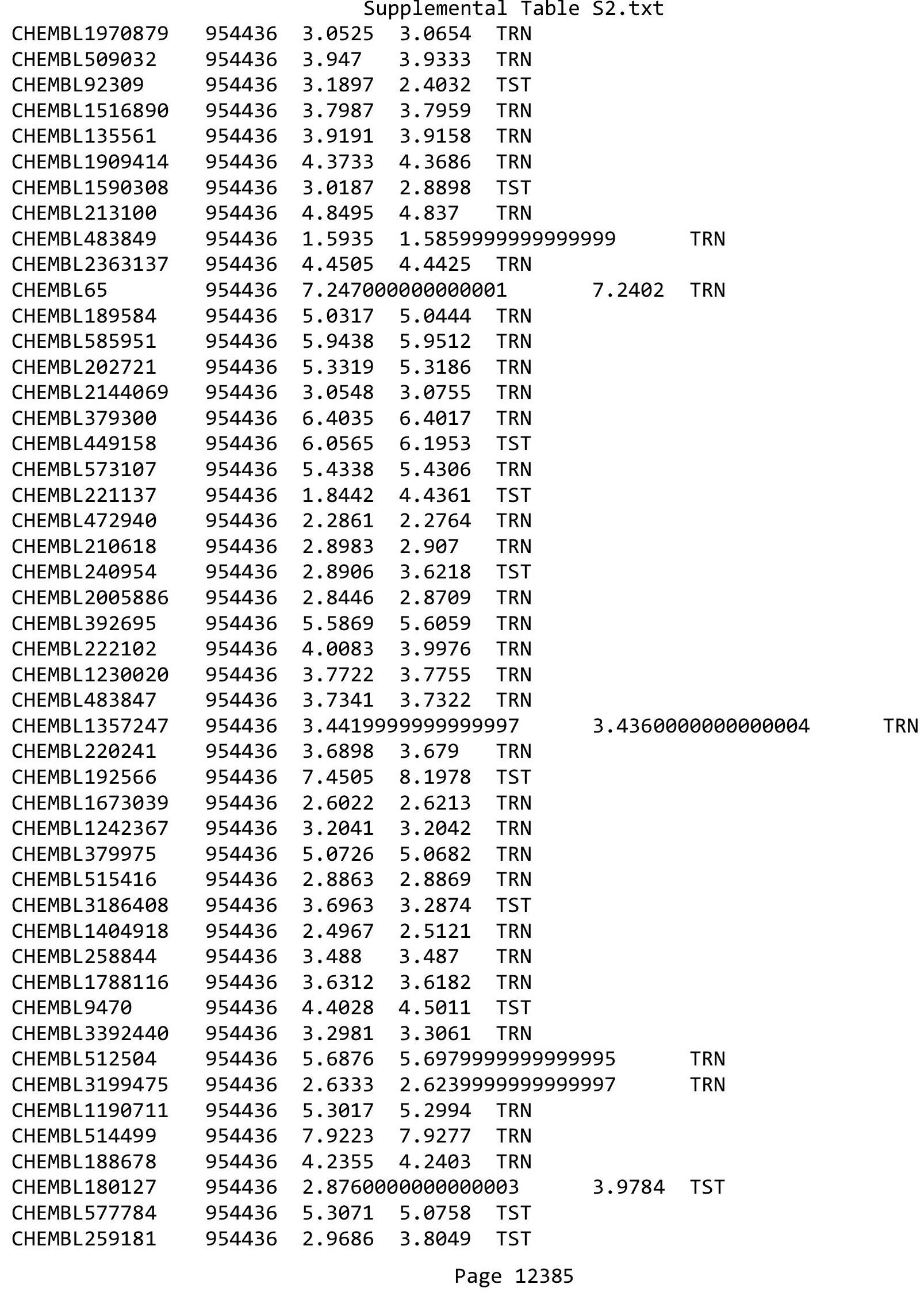




\begin{tabular}{|c|c|c|c|c|c|}
\hline \multicolumn{6}{|c|}{ Supplemental Table S2.txt } \\
\hline CHEMBL3349342 & 954436 & 3.5268 & 3.8704 & TST & \\
\hline CHEMBL412142 & 954436 & 3.3214 & 3.4082 & TST & \\
\hline CHEMBL558642 & 954436 & 3.8493 & 3.5133 & TST & \\
\hline CHEMBL1643959 & 954436 & 3.1092 & 3.2093 & TST & \\
\hline CHEMBL41748 & 305598 & 9.699 & 9.6995 & TRN & \\
\hline CHEMBL183902 & 305598 & 8.4559 & 8.4505 & TRN & \\
\hline CHEMBL368904 & 305598 & 8.699 & 8.0691 & TST & \\
\hline CHEMBL426961 & 305598 & 7.5376 & 7.6957 & TST & \\
\hline CHEMBL368218 & 305598 & 6.7959 & 8.951 & TST & \\
\hline CHEMBL362174 & 305598 & 7.7212 & 7.7078 & TRN & \\
\hline CHEMBL360525 & 305598 & 9.0969 & 9.1118 & TRN & \\
\hline CHEMBL183290 & 305598 & 8.0915 & 8.1026 & TRN & \\
\hline CHEMBL360574 & 305598 & 7.8239 & 7.8164 & TRN & \\
\hline CHEMBL 360084 & 305598 & 7.3188 & 7.3276 & TRN & \\
\hline CHEMBL183523 & 305598 & 8.4437 & 8.3795 & TST & \\
\hline CHEMBL182812 & 305598 & 8.2147 & 8.2154 & TRN & \\
\hline CHEMBL362044 & 305598 & 7.4949 & 7.4905 & TRN & \\
\hline CHEMBL262819 & 305598 & 7.9586 & 7.9537 & TRN & \\
\hline CHEMBL182512 & 305598 & 7.7212 & 7.7115 & TRN & \\
\hline CHEMBL183725 & 305598 & 8.2596 & 8.2506 & TRN & \\
\hline CHEMBL180139 & 305598 & 7.7959 & 7.7891 & TRN & \\
\hline CHEMBL369304 & 305598 & 7.5686 & 7.5974 & TRN & \\
\hline CHEMBL360694 & 305598 & 8.1135 & 8.639 & TST & \\
\hline CHEMBL180801 & 305598 & 7.0605 & 7.06 & TRN & \\
\hline CHEMBL183140 & 305598 & 7.9208 & 7.9093 & TRN & \\
\hline CHEMBL368903 & 305598 & 7.4815 & 7.4808 & TRN & \\
\hline CHEMBL183224 & 305598 & 8.585 & 7.99100 & 00000000005 & TST \\
\hline CHEMBL182347 & 305598 & 7.2147 & 7.2097 & TRN & \\
\hline CHEMBL182925 & 305598 & 8.2147 & 8.2271 & TRN & \\
\hline CHEMBL183759 & 305598 & 7.2291 & 7.2355 & TRN & \\
\hline CHEMBL183291 & 305598 & 7.8861 & 7.885 & TRN & \\
\hline CHEMBL183719 & 305598 & 8.8861 & 8.1998 & TST & \\
\hline CHEMBL183794 & 305598 & 7.1871 & 7.1853 & TRN & \\
\hline CHEMBL183356 & 305598 & 8.7447 & 8.2614 & TST & \\
\hline CHEMBL182180 & 305598 & 8.0 & 8.3938 & TST & \\
\hline CHEMBL181318 & 305598 & 8.5686 & 8.5786 & TRN & \\
\hline CHEMBL359540 & 305598 & 7.2076 & 7.2067 & TRN & \\
\hline CHEMBL181444 & 305598 & 7.2147 & 7.218 & TRN & \\
\hline CHEMBL180550 & 305598 & 8.0809 & 8.0832 & TRN & \\
\hline CHEMBL359950 & 305598 & 8.041 & 8.5785 & TST & \\
\hline CHEMBL361353 & 305598 & 8.7696 & 8.2635 & TST & \\
\hline CHEMBL361616 & 305598 & 7.8861 & 7.8923 & TRN & \\
\hline CHEMBL182944 & 305598 & 7.0915 & 7.1042 & TRN & \\
\hline CHEMBL362381 & 305598 & 7.8861 & 7.8842 & TRN & \\
\hline CHEMBL361734 & 305598 & 7.4202 & 7.4168 & TRN & \\
\hline CHEMBL183097 & 305598 & 8.7696 & 8.7352 & TRN & \\
\hline CHEMBL183548 & 305598 & 7.8539 & 7.8452 & TRN & \\
\hline CHEMBL183666 & 305598 & 8.1249 & 8.13600 & 0000000001 & KIN \\
\hline & & & & 12386 & \\
\hline
\end{tabular}




\begin{tabular}{|c|c|c|c|c|c|}
\hline & & & & & \\
\hline CHEMBL182679 & 305598 & 8.6778 & 8.6851 & TRN & \\
\hline CHEMBL361357 & 305598 & 8.3872 & 8.3957 & TRN & \\
\hline CHEMBL183372 & 305598 & 8.1249 & 8.5415 & TST & \\
\hline CHEMBL183832 & 305598 & 8.8861 & 8.084 & TST & \\
\hline CHEMBL180390 & 305598 & 7.4202 & 7.4117 & TRN & \\
\hline CHEMBL179857 & 305598 & 8.0458 & 8.0405 & TRN & \\
\hline CHEMBL182330 & 305598 & 8.7212 & 8.4249 & TST & \\
\hline CHEMBL425337 & 305598 & 7.1549 & 7.1611 & TRN & \\
\hline CHEMBL183246 & 305598 & 7.3279 & 7.3345 & TRN & \\
\hline CHEMBL180255 & 305598 & 7.2924 & 7.2967 & TRN & \\
\hline CHEMBL183276 & 305598 & 8.8239 & 8.83 & TRN & \\
\hline CHEMBL181901 & 305598 & 7.7447 & 7.7354 & TRN & \\
\hline CHEMBL 29982 & 305598 & 8.9586 & 7.3895 & TST & \\
\hline CHEMBL180754 & 305598 & 7.9208 & 7.92299 & 9999999999 & TRN \\
\hline CHEMBL179902 & 305598 & 8.8861 & 8.435 & TST & \\
\hline CHEMBL183480 & 305598 & 7.8861 & 7.88399 & 99999999995 & TRN \\
\hline CHEMBL180536 & 305598 & 7.699 & 7.6912 & TRN & \\
\hline CHEMBL180547 & 305598 & 7.2676 & 7.2616 & TRN & \\
\hline CHEMBL359959 & 305598 & 8.9208 & 8.2526 & TST & \\
\hline CHEMBL359517 & 305598 & 7.2291 & 7.2373 & TRN & \\
\hline CHEMBL 360229 & 305598 & 7.2676 & 7.2604 & TRN & \\
\hline CHEMBL182389 & 305598 & 7.7696 & 7.7683 & TRN & \\
\hline CHEMBL1321472 & 752386 & 4.6786 & 4.7534 & TRN & \\
\hline CHEMBL1323536 & 752386 & 2.4202 & 4.7358 & TRN & \\
\hline CHEMBL1497427 & 752386 & 2.4202 & 4.4488 & TST & \\
\hline CHEMBL1557253 & 752386 & 5.5859 & 5.6992 & TRN & \\
\hline CHEMBL1364896 & 752386 & 4.9813 & 5.0341 & TST & \\
\hline CHEMBL1542863 & 752386 & 4.7506 & 4.564 & TRN & \\
\hline CHEMBL1488412 & 752386 & 4.6269 & 4.9812 & TRN & \\
\hline CHEMBL1441739 & 752386 & 5.2128 & 5.0528 & TRN & \\
\hline CHEMBL 2006893 & 752386 & 4.8814 & 4.6823 & TRN & \\
\hline CHEMBL 3145200 & 752386 & 4.9727 & 5.0281 & TRN & \\
\hline CHEMBL1381436 & 752386 & 5.7918 & 4.6174 & TST & \\
\hline CHEMBL1982305 & 752386 & 6.28700 & 30000000 & 5.9738 & TRN \\
\hline CHEMBL1526076 & 752386 & 5.5926 & 4.8587 & TRN & \\
\hline CHEMBL1370838 & 752386 & 2.9208 & 5.5719 & TST & \\
\hline CHEMBL1445431 & 752386 & 5.3747 & 3.7648 & TRN & \\
\hline CHEMBL1197872 & 752386 & 5.2292 & 4.9603 & TRN & \\
\hline CHEMBL3210870 & 752386 & 5.1005 & 4.9389 & TRN & \\
\hline CHEMBL1432524 & 752386 & 4.8788 & 4.7644 & TRN & \\
\hline CHEMBL1538652 & 752386 & 2.4202 & 4.9633 & TST & \\
\hline CHEMBL1433113 & 752386 & 2.4202 & 3.5466 & TST & \\
\hline CHEMBL1992432 & 752386 & 2.4202 & 5.8771 & TST & \\
\hline CHEMBL 1303810 & 752386 & 5.6979 & 5.2646 & TRN & \\
\hline CHEMBL1384670 & 752386 & 6.3765 & 5.7409 & TRN & \\
\hline CHEMBL1395600 & 752386 & 6.4233 & 5.42 & TST & \\
\hline CHEMBL1470483 & 752386 & 4.9158 & 5.0616 & TRN & \\
\hline CHEMBL1410768 & 752386 & 2.4202 & 4.8081 & TRN & \\
\hline
\end{tabular}




\begin{tabular}{|c|c|c|c|c|c|}
\hline \multicolumn{6}{|c|}{ Supplemental Table S2.txt } \\
\hline CHEMBL1442136 & 752386 & 5.8256 & 6.0539 & TRN & \\
\hline CHEMBL1596076 & 752386 & 5.0241 & 4.6467 & TRN & \\
\hline CHEMBL1344292 & 752386 & 5.4044 & 5.3015 & TRN & \\
\hline CHEMBL 3145102 & 752386 & 4.7535 & 4.6616 & TRN & \\
\hline CHEMBL1575531 & 752386 & 5.501 & 4.9284 & TRN & \\
\hline CHEMBL1385073 & 752386 & 5.3617 & 5.0934 & TRN & \\
\hline CHEMBL1994973 & 752386 & 2.4202 & 3.9563 & TRN & \\
\hline CHEMBL 3144873 & 752386 & 5.2741 & 5.3189 & TRN & \\
\hline CHEMBL1309241 & 752386 & 3.7162 & 4.5829 & TRN & \\
\hline CHEMBL1303970 & 752386 & 4.9112 & 5.0424 & TRN & \\
\hline CHEMBL1497838 & 752386 & 2.4202 & 5.1283 & TRN & \\
\hline CHEMBL1453503 & 752386 & 2.9208 & 5.2033 & TRN & \\
\hline CHEMBL1560396 & 752386 & 5.8142 & 3.9694 & TRN & \\
\hline CHEMBL315362 & 752386 & 2.4202 & 3.5252 & TRN & \\
\hline CHEMBL1309763 & 752386 & 4.6949 & 4.8803 & TRN & \\
\hline CHEMBL1308667 & 752386 & 5.1643 & 4.7868 & TRN & \\
\hline CHEMBL1735239 & 752386 & 6.1216 & 5.71700 & 00000000005 & TRN \\
\hline CHEMBL1523567 & 752386 & 4.8468 & 5.3776 & TRN & \\
\hline CHEMBL1441329 & 752386 & 5.2724 & 4.8137 & TST & \\
\hline CHEMBL1384702 & 752386 & 6.7846 & 5.6438 & TRN & \\
\hline CHEMBL1302401 & 752386 & 5.2817 & 4.5154 & TRN & \\
\hline CHEMBL1416184 & 752386 & 5.9788 & 5.2667 & TRN & \\
\hline CHEMBL578512 & 752386 & 7.2441 & 6.8156 & TRN & \\
\hline CHEMBL1569134 & 752386 & 4.9654 & 4.3742 & TRN & \\
\hline CHEMBL1359240 & 752386 & 4.4299 & 4.2217 & TRN & \\
\hline CHEMBL1488429 & 752386 & 5.1713 & 5.1581 & TRN & \\
\hline CHEMBL1537149 & 752386 & 6.5519 & 5.7231 & TRN & \\
\hline CHEMBL1398450 & 752386 & 5.0365 & 4.1984 & TRN & \\
\hline CHEMBL1987742 & 752386 & 5.5845 & 5.1496 & TST & \\
\hline CHEMBL1465170 & 752386 & 4.6998 & 4.7482 & TRN & \\
\hline CHEMBL1429937 & 752386 & 4.613 & 4.2388 & TRN & \\
\hline CHEMBL1520740 & 752386 & 4.7781 & 4.2558 & TRN & \\
\hline CHEMBL1320429 & 752386 & 4.8111 & 4.7632 & TRN & \\
\hline CHEMBL1497287 & 752386 & 2.4202 & 4.7166 & TRN & \\
\hline CHEMBL1360322 & 752386 & 5.2699 & 4.7151 & TRN & \\
\hline CHEMBL1712155 & 752386 & 2.4202 & 3.6314 & TST & \\
\hline CHEMBL1980681 & 752386 & 2.4202 & 4.7042 & TRN & \\
\hline CHEMBL1508375 & 752386 & 6.0 & 4.6455 & TRN & \\
\hline CHEMBL1584739 & 752386 & 5.1489 & 5.186 & TRN & \\
\hline CHEMBL1347117 & 752386 & 4.3883 & 5.0995 & TST & \\
\hline CHEMBL1528243 & 752386 & 6.1327 & 5.1573 & TRN & \\
\hline CHEMBL1322313 & 752386 & 4.9586 & 4.4722 & TRN & \\
\hline CHEMBL1530209 & 752386 & 4.6702 & 4.3063 & TRN & \\
\hline CHEMBL1532174 & 752386 & 2.4202 & 4.5859 & TST & \\
\hline CHEMBL1361173 & 752386 & 4.9706 & 5.0911 & TRN & \\
\hline CHEMBL1391118 & 752386 & 5.2594 & 5.0337 & TRN & \\
\hline CHEMBL572189 & 752386 & 5.0605 & 4.9975 & TST & \\
\hline CHEMBL1453483 & 752386 & 4.6647 & 4.8782 & TRN & \\
\hline
\end{tabular}




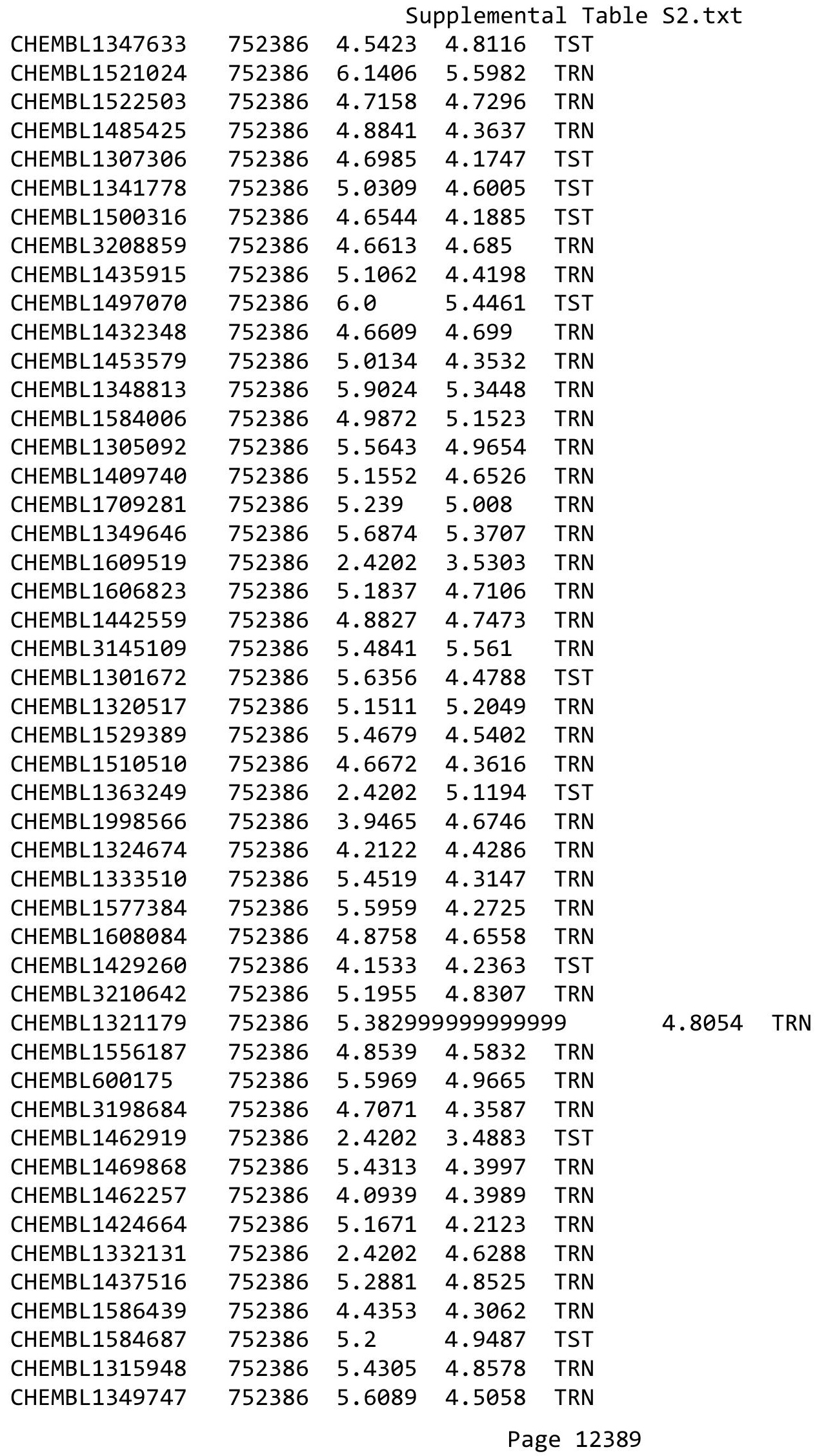


Supplemental Table S2.txt

\begin{tabular}{|c|c|c|c|c|c|}
\hline CHEMBL1600360 & 752386 & 4.8271 & 4.3864 & TRN & \\
\hline CHEMBL1421313 & 752386 & 5.4946 & 4.5168 & TST & \\
\hline CHEMBL1441170 & 752386 & 3.8339 & 4.4106 & TST & \\
\hline CHEMBL 3193450 & 752386 & 5.6598 & 4.9835 & TRN & \\
\hline CHEMBL1576666 & 752386 & 8.7447 & 4.8769 & TRN & \\
\hline CHEMBL1384771 & 752386 & 5.6923 & 4.8022 & TRN & \\
\hline CHEMBL1519846 & 752386 & 2.4202 & 4.1676 & TRN & \\
\hline CHEMBL1573427 & 752386 & 5.4291 & 5.1874 & TRN & \\
\hline CHEMBL1502004 & 752386 & 5.7033 & 4.7638 & TRN & \\
\hline CHEMBL1400437 & 752386 & 4.6592 & 4.5901 & TRN & \\
\hline CHEMBL1342141 & 752386 & 2.4202 & 4.4051 & TRN & \\
\hline CHEMBL1587473 & 752386 & 5.3518 & 5.6983 & TRN & \\
\hline CHEMBL1423410 & 752386 & 4.9539 & 4.488 & TRN & \\
\hline CHEMBL1345722 & 752386 & 4.852 & 4.4889 & TRN & \\
\hline CHEMBL1706657 & 752386 & 4.9686 & 4.5307 & TRN & \\
\hline CHEMBL1590615 & 752386 & 6.0 & 5.3907 & TRN & \\
\hline CHEMBL1987894 & 752386 & 6.3805 & 6.1286 & TRN & \\
\hline CHEMBL1611106 & 752386 & 4.0339 & \multicolumn{2}{|c|}{5.247000000000001} & TRN \\
\hline CHEMBL1496059 & 752386 & 4.5532 & 4.4276 & TRN & \\
\hline CHEMBL1531428 & 752386 & 2.4202 & 5.0332 & TRN & \\
\hline CHEMBL1400512 & 752386 & 5.4255 & 5.1237 & TST & \\
\hline CHEMBL1309059 & 752386 & 5.5154 & 4.8365 & TRN & \\
\hline CHEMBL1447341 & 752386 & 5.9087 & 5.609 & TRN & \\
\hline CHEMBL1548210 & 752386 & 4.0101 & 4.1177 & TRN & \\
\hline CHEMBL1330558 & 752386 & 5.1578 & 5.0821 & TRN & \\
\hline CHEMBL1587432 & 752386 & 5.3743 & 4.7839 & TST & \\
\hline CHEMBL1348289 & 752386 & 2.4202 & 3.498 & TRN & \\
\hline CHEMBL3193349 & 752386 & 2.4202 & 4.4536 & TRN & \\
\hline CHEMBL1428977 & 752386 & 2.4202 & 4.4528 & TRN & \\
\hline CHEMBL1465945 & 752386 & 5.0906 & 4.2141 & TRN & \\
\hline CHEMBL1322995 & 752386 & 5.2241 & 4.381 & TRN & \\
\hline CHEMBL1545902 & 752386 & 5.1244 & 4.8641 & TST & \\
\hline CHEMBL1366795 & 752386 & 4.2178 & 4.8206 & TRN & \\
\hline CHEMBL1333487 & 752386 & 3.8088 & 4.337 & TRN & \\
\hline CHEMBL1506031 & 752386 & 5.2895 & 5.0516 & TRN & \\
\hline CHEMBL1590402 & 752386 & 4.9788 & 5.1465 & TRN & \\
\hline CHEMBL183656 & 752386 & 4.1163 & 4.4005 & TRN & \\
\hline CHEMBL3196913 & 752386 & 5.7001 & 5.3503 & TRN & \\
\hline CHEMBL1389509 & 752386 & 5.6453 & 4.7421 & TST & \\
\hline CHEMBL1343101 & 752386 & 5.2275 & 4.975 & TST & \\
\hline CHEMBL1399100 & 752386 & 4.8821 & 4.6115 & TRN & \\
\hline CHEMBL3194941 & 752386 & 2.4202 & \multicolumn{2}{|c|}{4.7010000000000005} & TRN \\
\hline CHEMBL1432278 & 752386 & 5.261 & 4.7154 & TRN & \\
\hline CHEMBL1572001 & 752386 & 6.1274 & 4.9381 & TRN & \\
\hline CHEMBL1603753 & 752386 & 4.4264 & 4.3908 & TRN & \\
\hline CHEMBL3191597 & 752386 & 4.4618 & 4.0635 & TRN & \\
\hline CHEMBL1345195 & 752386 & 2.4202 & 4.6299 & TRN & \\
\hline CHEMBL1428823 & 752386 & 4.7897 & 4.5957 & TRN & \\
\hline
\end{tabular}

Page 12390 


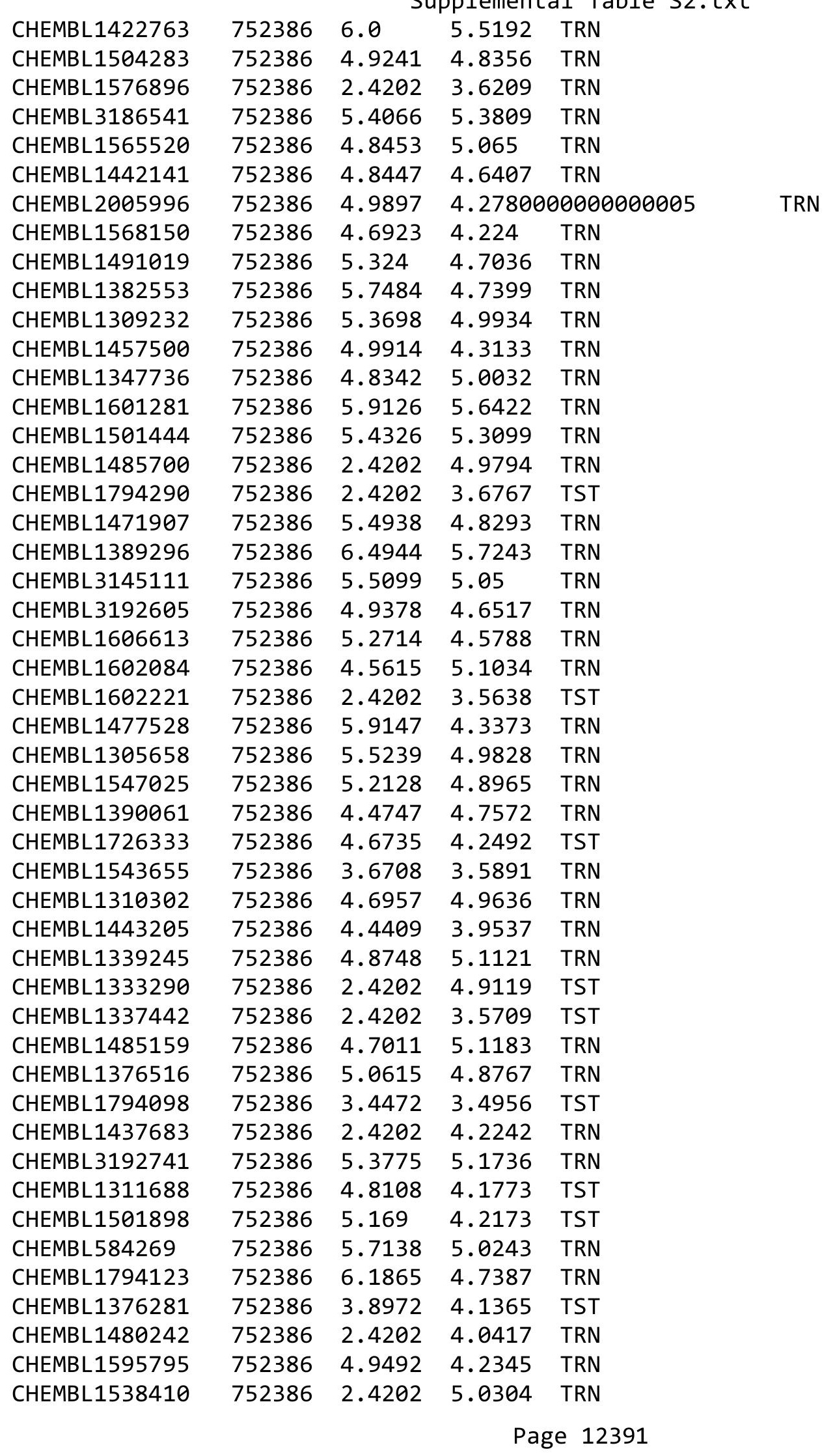




\begin{tabular}{|c|c|c|c|c|c|c|}
\hline & \\
\hline CHEMBL1462012 & 752386 & 4.3834 & 4.1957 & TRN & & \\
\hline CHEMBL1543601 & 752386 & 5.65799 & 99999999 & 995 & 5.4379 & TRN \\
\hline CHEMBL1981564 & 752386 & 3.8768 & 3.5484 & TRN & & \\
\hline CHEMBL3197978 & 752386 & 2.4202 & 4.1469 & TRN & & \\
\hline CHEMBL1432251 & 752386 & 5.4107 & 4.9281 & TRN & & \\
\hline CHEMBL1427272 & 752386 & 2.4202 & 4.4858 & TRN & & \\
\hline CHEMBL1582442 & 752386 & 4.8854 & 4.9801 & TST & & \\
\hline CHEMBL494083 & 752386 & 5.4968 & 4.5594 & TST & & \\
\hline CHEMBL1340601 & 752386 & 2.4202 & 3.5816 & TRN & & \\
\hline CHEMBL417727 & 752386 & 5.2743 & 5.0014 & TRN & & \\
\hline CHEMBL465226 & 752386 & 5.3405 & 4.5635 & TST & & \\
\hline CHEMBL1582351 & 752386 & 3.7685 & 3.5133 & TRN & & \\
\hline CHEMBL1494979 & 752386 & 5.4657 & 4.975 & TRN & & \\
\hline CHEMBL1586339 & 752386 & 3.9154 & 3.5837 & TRN & & \\
\hline CHEMBL1584201 & 752386 & 5.5406 & 4.783 & TRN & & \\
\hline CHEMBL1416543 & 752386 & 2.4202 & 5.21299 & 9999999999 & & TST \\
\hline CHEMBL1978855 & 752386 & 4.7001 & 4.1479 & TRN & & \\
\hline CHEMBL1424829 & 752386 & 4.7373 & 4.191 & TRN & & \\
\hline CHEMBL1507534 & 752386 & 4.2314 & 4.2161 & TRN & & \\
\hline CHEMBL1419788 & 752386 & 4.0981 & 4.6745 & TRN & & \\
\hline CHEMBL3210668 & 752386 & 4.9382 & 4.1546 & TRN & & \\
\hline CHEMBL3210913 & 752386 & 4.963 & 4.2861 & TRN & & \\
\hline CHEMBL1698464 & 752386 & 5.4509 & 4.8442 & TRN & & \\
\hline CHEMBL1430379 & 752386 & 4.2524 & 3.5182 & TRN & & \\
\hline CHEMBL1486359 & 752386 & 4.8735 & 4.8911 & TRN & & \\
\hline CHEMBL1464383 & 752386 & 5.8979 & 4.6004 & TRN & & \\
\hline CHEMBL1508129 & 752386 & 5.2073 & 5.0715 & TRN & & \\
\hline CHEMBL1563782 & 752386 & 5.4371 & 4.276 & TRN & & \\
\hline CHEMBL 3194842 & 752386 & 5.1319 & 4.3099 & TRN & & \\
\hline CHEMBL1484933 & 752386 & 4.6619 & 4.5383 & TRN & & \\
\hline CHEMBL3198685 & 752386 & 4.7696 & 4.0665 & TRN & & \\
\hline CHEMBL3199263 & 752386 & 2.4202 & 3.6169 & TST & & \\
\hline CHEMBL51931 & 752386 & 5.1888 & 5.0814 & TRN & & \\
\hline CHEMBL1536196 & 752386 & 2.9208 & 4.4953 & TST & & \\
\hline CHEMBL1556868 & 752386 & 5.534 & 4.437 & TST & & \\
\hline CHEMBL1557622 & 752386 & 4.7025 & 4.4112 & TRN & & \\
\hline CHEMBL3144974 & 752386 & 5.9045 & 5.6891 & TRN & & \\
\hline CHEMBL1306161 & 752386 & 4.4592 & 4.1647 & TRN & & \\
\hline CHEMBL571501 & 752386 & 5.2235 & 4.3893 & TRN & & \\
\hline CHEMBL1420007 & 752386 & 5.5117 & 4.7605 & TRN & & \\
\hline CHEMBL1330781 & 752386 & 4.9274 & 4.7651 & TST & & \\
\hline CHEMBL1549840 & 752386 & 5.528 & 4.3612 & TRN & & \\
\hline CHEMBL1398826 & 752386 & 4.8948 & 4.7023 & TRN & & \\
\hline CHEMBL166209 & 752386 & 5.39 & 5.2062 & TRN & & \\
\hline CHEMBL1467905 & 752386 & 4.8948 & 5.2938 & TRN & & \\
\hline CHEMBL1544793 & 752386 & 5.07 & 5.9681 & TRN & & \\
\hline CHEMBL1574879 & 752386 & 5.4747 & 4.5032 & TRN & & \\
\hline CHEMBL1439124 & 752386 & 6.3778 & 4.4923 & TRN & & \\
\hline
\end{tabular}


Supplemental Table S2.txt

\begin{tabular}{|c|c|c|c|c|c|c|}
\hline CHEMBL1478145 & 752386 & 5.1522 & 4.7627 & TST & & \\
\hline CHEMBL1428003 & 752386 & 4.9003 & 4.7238 & TRN & & \\
\hline CHEMBL1467422 & 752386 & 4.9179 & 4.5667 & TST & & \\
\hline CHEMBL1453212 & 752386 & 2.4202 & 4.6649 & TRN & & \\
\hline CHEMBL1602856 & 752386 & 5.1246 & 4.9713 & TRN & & \\
\hline CHEMBL1337591 & 752386 & 4.6548 & 4.8923 & TRN & & \\
\hline CHEMBL1428507 & 752386 & 5.2748 & 4.3261 & TRN & & \\
\hline CHEMBL1387378 & 752386 & 2.4202 & 4.0946 & TRN & & \\
\hline CHEMBL1351412 & 752386 & 2.4202 & 5.0549 & TRN & & \\
\hline CHEMBL1540603 & 752386 & \multicolumn{3}{|c|}{5.5120000000000005} & 4.6644 & TRN \\
\hline CHEMBL260148 & 752386 & 5.3101 & 4.2737 & TRN & & \\
\hline CHEMBL1407708 & 752386 & 4.4995 & 4.5897 & TRN & & \\
\hline CHEMBL1600684 & 752386 & 6.5163 & 6.3321 & TRN & & \\
\hline CHEMBL3189714 & 752386 & 2.9208 & 5.8564 & TRN & & \\
\hline CHEMBL1456937 & 752386 & 5.8471 & 4.8044 & TRN & & \\
\hline CHEMBL3188273 & 752386 & 4.9763 & 4.9647 & TRN & & \\
\hline CHEMBL1308358 & 752386 & 4.6117 & 4.1973 & TRN & & \\
\hline CHEMBL30095 & 752386 & 5.067 & 4.8103 & TRN & & \\
\hline CHEMBL1385214 & 752386 & 2.4202 & 3.8111 & TRN & & \\
\hline CHEMBL 3144856 & 752386 & 5.5235 & 5.3969 & TRN & & \\
\hline CHEMBL1496897 & 752386 & 5.1346 & 5.0996 & TRN & & \\
\hline CHEMBL1330160 & 752386 & 3.7115 & 3.5178 & TRN & & \\
\hline CHEMBL1465424 & 752386 & 4.2752 & 4.3368 & TRN & & \\
\hline CHEMBL1415772 & 752386 & 5.0957 & 5.0575 & TRN & & \\
\hline CHEMBL1546947 & 752386 & 5.2664 & 5.2365 & TRN & & \\
\hline CHEMBL505618 & 752386 & 4.6223 & 4.3118 & TST & & \\
\hline CHEMBL1606827 & 752386 & 4.8775 & 4.1789 & TRN & & \\
\hline CHEMBL1352564 & 752386 & 5.4874 & 4.9153 & TRN & & \\
\hline CHEMBL1611642 & 752386 & 5.3763 & 4.6993 & TRN & & \\
\hline CHEMBL1479725 & 752386 & 4.0341 & 4.5692 & TRN & & \\
\hline CHEMBL1466126 & 752386 & 5.0739 & 4.9817 & TRN & & \\
\hline CHEMBL1334552 & 752386 & 5.2777 & 4.413 & TRN & & \\
\hline CHEMBL1387900 & 752386 & 4.4322 & 4.1968 & TRN & & \\
\hline CHEMBL1576785 & 752386 & 4.9983 & 4.9229 & TST & & \\
\hline CHEMBL1583537 & 752386 & 5.1543 & 4.954 & TRN & & \\
\hline CHEMBL1504305 & 752386 & 4.272 & 4.6001 & TRN & & \\
\hline CHEMBL1371925 & 752386 & 2.4202 & 3.5675 & TRN & & \\
\hline CHEMBL1458949 & 752386 & 2.4202 & 3.5032 & TRN & & \\
\hline CHEMBL88811 & 752386 & 2.4202 & 4.3364 & TRN & & \\
\hline CHEMBL1595409 & 752386 & 4.5478 & 4.8383 & TRN & & \\
\hline CHEMBL1468635 & 752386 & 2.4202 & 4.5395 & TRN & & \\
\hline CHEMBL1386277 & 752386 & 4.9458 & 4.1986 & TRN & & \\
\hline CHEMBL1547143 & 752386 & 4.9458 & 4.8462 & TRN & & \\
\hline CHEMBL1528757 & 752386 & 5.1287 & 4.9137 & TST & & \\
\hline CHEMBL1346986 & 752386 & 2.4202 & 4.9795 & TRN & & \\
\hline CHEMBL 3194773 & 752386 & 4.8941 & 4.0745 & TRN & & \\
\hline CHEMBL1491275 & 752386 & 4.9296 & 4.2917 & TRN & & \\
\hline CHEMBL1368609 & 752386 & 5.1448 & 5.0436 & TST & & \\
\hline
\end{tabular}

Page 12393 


\begin{tabular}{|c|c|c|c|c|c|c|}
\hline & & \multicolumn{5}{|c|}{ Supplemental Table s2.txt } \\
\hline CHEMBL3190976 & 752386 & 4.5309 & 4.6743 & TRN & & \\
\hline CHEMBL1430266 & 752386 & 2.4202 & 4.8776 & TRN & & \\
\hline CHEMBL3193366 & 752386 & 4.4803 & 4.1962 & TRN & & \\
\hline CHEMBL1300552 & 752386 & 2.9208 & 4.9728 & TRN & & \\
\hline CHEMBL1491158 & 752386 & 2.4202 & 5.0309 & TRN & & \\
\hline CHEMBL1554411 & 752386 & 5.3675 & 5.0186 & TRN & & \\
\hline CHEMBL3197333 & 752386 & 5.5784 & 4.5107 & TRN & & \\
\hline CHEMBL1995112 & 752386 & 2.4202 & 5.1962 & TRN & & \\
\hline CHEMBL3199406 & 752386 & 4.2143 & \multicolumn{3}{|c|}{4.321000000000001} & TST \\
\hline CHEMBL566068 & 752386 & 5.697 & 5.5208 & TRN & & \\
\hline CHEMBL3189879 & 752386 & 4.7948 & 4.7831 & TRN & & \\
\hline CHEMBL1580896 & 752386 & 5.4443 & 5.4515 & TRN & & \\
\hline CHEMBL3191681 & 752386 & 5.5632 & 5.1676 & TRN & & \\
\hline CHEMBL1343343 & 752386 & 5.7479 & 5.5065 & TRN & & \\
\hline CHEMBL1570005 & 752386 & 4.8383 & 4.8227 & TRN & & \\
\hline CHEMBL3194086 & 752386 & 5.655 & \multicolumn{3}{|c|}{5.388999999999999} & TRN \\
\hline CHEMBL1485746 & 752386 & 5.5314 & 5.0004 & TRN & & \\
\hline CHEMBL1569238 & 752386 & 5.3693 & 4.6233 & TRN & & \\
\hline CHEMBL1603885 & 752386 & 5.3936 & 5.0597 & TRN & & \\
\hline CHEMBL1734820 & 752386 & 6.3279 & 5.6417 & TRN & & \\
\hline CHEMBL1311742 & 752386 & 5.3085 & 4.2782 & TST & & \\
\hline CHEMBL1555752 & 752386 & 5.3343 & 4.7757 & TST & & \\
\hline CHEMBL1349637 & 752386 & 6.4595 & 5.5964 & TRN & & \\
\hline CHEMBL1416421 & 752386 & 4.1269 & 4.8662 & TRN & & \\
\hline CHEMBL3145304 & 752386 & 4.3881 & 4.7954 & TRN & & \\
\hline CHEMBL1576509 & 752386 & 4.0149 & 5.2715 & TRN & & \\
\hline CHEMBL1596226 & 752386 & 5.1842 & 4.6436 & TST & & \\
\hline CHEMBL1588173 & 752386 & 5.8398 & 4.5475 & TRN & & \\
\hline CHEMBL 3144975 & 752386 & 4.7737 & 4.4251 & TRN & & \\
\hline CHEMBL1479534 & 752386 & 4.658 & 4.8483 & TRN & & \\
\hline CHEMBL1541950 & 752386 & 5.3866 & 4.48600 & 0000000001 & & TRN \\
\hline CHEMBL1610008 & 752386 & 4.2461 & 3.8973 & TRN & & \\
\hline CHEMBL1359736 & 752386 & 4.8645 & 4.87 & TRN & & \\
\hline CHEMBL1608041 & 752386 & 5.1757 & 4.2481 & TRN & & \\
\hline CHEMBL1463564 & 752386 & 4.6131 & 5.7147 & TRN & & \\
\hline CHEMBL1374108 & 752386 & 8.7447 & 4.7281 & TST & & \\
\hline CHEMBL1467745 & 752386 & 5.3882 & 4.9915 & TRN & & \\
\hline CHEMBL1519108 & 752386 & 5.3623 & 5.0963 & TRN & & \\
\hline CHEMBL460366 & 752386 & \multicolumn{3}{|c|}{4.6339999999999995} & 4.4544 & TRN \\
\hline CHEMBL1536606 & 752386 & 5.447 & 4.9993 & TRN & & \\
\hline CHEMBL1574219 & 752386 & 2.4202 & 3.475 & TRN & & \\
\hline CHEMBL3144999 & 752386 & 5.9055 & 5.6758 & TRN & & \\
\hline CHEMBL3145082 & 752386 & 5.528 & 5.3652 & TRN & & \\
\hline CHEMBL1608963 & 752386 & 2.4202 & 3.4391 & TST & & \\
\hline CHEMBL1577545 & 752386 & 5.3747 & 4.7123 & TRN & & \\
\hline CHEMBL1491865 & 752386 & 5.7476 & 5.4094 & TRN & & \\
\hline CHEMBL1568915 & 752386 & 5.6745 & 4.9556 & TST & & \\
\hline CHEMBL1428217 & 752386 & 4.1955 & 3.5881 & TRN & & \\
\hline
\end{tabular}




\begin{tabular}{|c|c|c|c|c|c|c|}
\hline & & & & & & \\
\hline CHEMBL1382562 & 752386 & 5.4655 & 5.0083 & TST & & \\
\hline CHEMBL1714915 & 752386 & 4.8821 & 4.9075 & TRN & & \\
\hline CHEMBL1547454 & 752386 & 5.3995 & 5.1898 & TRN & & \\
\hline CHEMBL1307050 & 752386 & 5.6426 & 4.4779 & TRN & & \\
\hline CHEMBL1440303 & 752386 & 4.3855 & 4.1212 & TRN & & \\
\hline CHEMBL1402422 & 752386 & 5.4477 & 5.138 & TST & & \\
\hline CHEMBL1311185 & 752386 & 5.8462 & 4.6214 & TRN & & \\
\hline CHEMBL1477488 & 752386 & 4.381 & 4.5772 & TRN & & \\
\hline CHEMBL3190880 & 752386 & 6.5583 & 6.1404 & TRN & & \\
\hline CHEMBL1306457 & 752386 & 4.3314 & 3.7806 & TRN & & \\
\hline CHEMBL1432870 & 752386 & 2.9208 & 4.4793 & TST & & \\
\hline CHEMBL1567226 & 752386 & 5.6207 & 5.3778 & TRN & & \\
\hline CHEMBL1365287 & 752386 & 2.4202 & 4.971 & TRN & & \\
\hline CHEMBL3193480 & 752386 & 4.5161 & 4.3528 & TRN & & \\
\hline CHEMBL1357976 & 752386 & 4.4065 & 4.3567 & TRN & & \\
\hline CHEMBL1479080 & 752386 & 4.4768 & 4.3125 & TRN & & \\
\hline CHEMBL1434250 & 752386 & 5.1862 & 4.831 & TRN & & \\
\hline CHEMBL3193655 & 752386 & 5.5972 & 5.2006 & TRN & & \\
\hline CHEMBL1300967 & 752386 & 4.702 & 4.7279 & TST & & \\
\hline CHEMBL1500359 & 752386 & 3.74300 & 30000000 & 203 & 3.5684 & TRN \\
\hline CHEMBL1508896 & 752386 & 4.7104 & 4.2538 & TRN & & \\
\hline CHEMBL1428758 & 752386 & 4.4034 & 4.9527 & TRN & & \\
\hline CHEMBL1406350 & 752386 & 4.8254 & 4.7223 & TRN & & \\
\hline CHEMBL1541405 & 752386 & 4.7135 & 4.3144 & TRN & & \\
\hline CHEMBL1480040 & 752386 & 3.9073 & 3.6065 & TRN & & \\
\hline CHEMBL1335426 & 752386 & 2.4202 & 3.4918 & TRN & & \\
\hline CHEMBL1557105 & 752386 & 5.3262 & 4.704 & TRN & & \\
\hline CHEMBL1392532 & 752386 & 5.33299 & 99999999 & 99 & 4.4767 & TRN \\
\hline CHEMBL1501597 & 752386 & 5.5141 & 5.5147 & TRN & & \\
\hline CHEMBL1567246 & 752386 & 6.3853 & 5.8283 & TRN & & \\
\hline CHEMBL1504194 & 752386 & 4.2775 & 3.5034 & TRN & & \\
\hline CHEMBL1794088 & 752386 & 5.1494 & 4.4878 & TRN & & \\
\hline CHEMBL1388639 & 752386 & 5.3956 & 4.8009 & TRN & & \\
\hline CHEMBL1402456 & 752386 & 2.4202 & 5.4873 & TRN & & \\
\hline CHEMBL1997668 & 752386 & 5.1162 & 4.8935 & TRN & & \\
\hline CHEMBL1989853 & 752386 & 5.2531 & 5.6316 & TRN & & \\
\hline CHEMBL 2006840 & 752386 & 4.5209 & 3.955 & TRN & & \\
\hline CHEMBL1516772 & 752386 & 5.2115 & 5.0754 & TST & & \\
\hline CHEMBL1440844 & 752386 & 5.4107 & 4.2946 & TST & & \\
\hline CHEMBL1407208 & 752386 & 2.4202 & 4.2182 & TRN & & \\
\hline CHEMBL1985649 & 752386 & 2.4202 & 4.0063 & TRN & & \\
\hline CHEMBL1794229 & 752386 & 2.4202 & 3.5221 & TST & & \\
\hline CHEMBL1543357 & 752386 & 2.4202 & 3.5002 & TST & & \\
\hline CHEMBL1304066 & 752386 & 5.2509 & 4.9835 & TRN & & \\
\hline CHEMBL1976304 & 752386 & 4.4712 & 4.4874 & TST & & \\
\hline CHEMBL1596056 & 752386 & 2.4202 & 4.3674 & TRN & & \\
\hline CHEMBL1386493 & 752386 & 4.7058 & 4.7665 & TRN & & \\
\hline CHEMBL1609807 & 752386 & 5.1782 & 4.6653 & TRN & & \\
\hline
\end{tabular}




\begin{tabular}{|c|c|c|c|c|c|}
\hline & & & & & \\
\hline CHEMBL1586425 & 752386 & 4.8147 & 4.1362 & TRN & \\
\hline CHEMBL1377533 & 752386 & 5.0271 & 4.8195 & TRN & \\
\hline CHEMBL1537961 & 752386 & 5.0877 & 4.9272 & TRN & \\
\hline CHEMBL1365249 & 752386 & 4.9423 & 4.7686 & TST & \\
\hline CHEMBL3192957 & 752386 & 6.0 & 5.6497 & TRN & \\
\hline CHEMBL1413252 & 752386 & 2.4202 & 4.5386 & TST & \\
\hline CHEMBL1384715 & 752386 & 4.9179 & 4.5755 & TRN & \\
\hline CHEMBL1508839 & 752386 & 6.4 & 5.7788 & TRN & \\
\hline CHEMBL1407193 & 752386 & 3.9311 & 4.0208 & TRN & \\
\hline CHEMBL1533236 & 752386 & 4.6763 & 4.8362 & TRN & \\
\hline CHEMBL3145176 & 752386 & 5.9735 & 5.5999 & TRN & \\
\hline CHEMBL1478235 & 752386 & 5.7525 & 5.052 & TRN & \\
\hline CHEMBL1480031 & 752386 & 5.604 & 4.5762 & TRN & \\
\hline CHEMBL1430882 & 752386 & 5.2333 & 5.0884 & TRN & \\
\hline CHEMBL1594685 & 752386 & 5.2853 & 4.8388 & TRN & \\
\hline CHEMBL1550425 & 752386 & 4.9935 & 4.5549 & TRN & \\
\hline CHEMBL1597827 & 752386 & 4.7484 & 4.8487 & TST & \\
\hline CHEMBL1463261 & 752386 & 3.7321 & 5.0162 & TRN & \\
\hline CHEMBL1417901 & 752386 & 5.4362 & 4.5221 & TRN & \\
\hline CHEMBL1506656 & 752386 & 2.4202 & 3.5464 & TRN & \\
\hline CHEMBL1302170 & 752386 & 4.9948 & 5.1664 & TRN & \\
\hline CHEMBL1567635 & 752386 & 4.7342 & 5.6597 & TRN & \\
\hline CHEMBL1572585 & 752386 & 3.9337 & 4.6957 & TRN & \\
\hline CHEMBL1794259 & 752386 & 3.9281 & 3.6494 & TRN & \\
\hline CHEMBL1970909 & 752386 & 4.5719 & 4.3421 & TRN & \\
\hline CHEMBL1472154 & 752386 & 5.3875 & 5.1784 & TRN & \\
\hline CHEMBL1380913 & 752386 & 4.7298 & 4.5905 & TRN & \\
\hline CHEMBL1492010 & 752386 & 5.6321 & 5.5197 & TRN & \\
\hline CHEMBL1541259 & 752386 & 4.9329 & 5.17399 & 99999999995 & TRN \\
\hline CHEMBL1313352 & 752386 & 5.1611 & 4.5033 & TRN & \\
\hline CHEMBL1585382 & 752386 & 4.311 & 4.1428 & TST & \\
\hline CHEMBL1587181 & 752386 & 5.6115 & 5.5758 & TRN & \\
\hline CHEMBL1364176 & 752386 & 6.0543 & 5.5303 & TRN & \\
\hline CHEMBL1568333 & 752386 & 4.6488 & 4.176 & TRN & \\
\hline CHEMBL1496231 & 752386 & 5.5137 & 4.40600 & 0000000001 & TRN \\
\hline CHEMBL1720482 & 752386 & 4.4652 & 4.8518 & TRN & \\
\hline CHEMBL1417099 & 752386 & 3.9165 & 4.949 & TST & \\
\hline CHEMBL1305275 & 752386 & 4.9223 & 5.0918 & TRN & \\
\hline CHEMBL3196684 & 752386 & 5.0892 & 4.902 & TRN & \\
\hline CHEMBL1448321 & 752386 & 4.9987 & 5.445 & TRN & \\
\hline CHEMBL601757 & 752386 & 7.0097 & 6.4426 & TRN & \\
\hline CHEMBL1721990 & 752386 & 5.5157 & 4.4921 & TST & \\
\hline CHEMBL1495048 & 752386 & 7.3143 & 4.5433 & TRN & \\
\hline CHEMBL1329297 & 752386 & 5.0242 & 4.5766 & TRN & \\
\hline CHEMBL1609318 & 752386 & 2.4202 & 4.8919 & TRN & \\
\hline CHEMBL1329532 & 752386 & 4.7113 & 4.6949 & TRN & \\
\hline CHEMBL1346302 & 752386 & 4.5817 & 4.7736 & TRN & \\
\hline CHEMBL1472344 & 752386 & 5.20200 & 30000000 & 4.82 & TRN \\
\hline
\end{tabular}




\begin{tabular}{|c|c|c|c|c|}
\hline & & & plemen & \\
\hline CHEMBL1421972 & 752386 & 4.6117 & 4.8192 & TST \\
\hline CHEMBL1476225 & 752386 & 2.4202 & 4.893 & TRN \\
\hline CHEMBL1425874 & 752386 & 4.3992 & 5.144 & TRN \\
\hline CHEMBL1321664 & 752386 & 5.6668 & 5.4603 & TRN \\
\hline CHEMBL1335223 & 752386 & 5.3079 & 4.9029 & TST \\
\hline CHEMBL1538796 & 752386 & 4.9465 & 4.2299 & TRN \\
\hline CHEMBL3209456 & 752386 & 5.2625 & 4.3511 & TRN \\
\hline CHEMBL1347586 & 752386 & 4.9991 & 5.0569 & TRN \\
\hline CHEMBL1331573 & 752386 & 4.5586 & 5.3545 & TRN \\
\hline CHEMBL1995641 & 752386 & 2.4202 & 4.1851 & TRN \\
\hline CHEMBL1414704 & 752386 & 3.7902 & 5.2123 & TRN \\
\hline CHEMBL1422689 & 752386 & 4.8333 & 5.1063 & TRN \\
\hline CHEMBL207931 & 752386 & 5.4484 & 4.0814 & TRN \\
\hline CHEMBL1459332 & 752386 & 4.8196 & 5.0671 & TRN \\
\hline CHEMBL1382518 & 752386 & 5.0384 & 4.9016 & TRN \\
\hline CHEMBL1562359 & 752386 & 4.5885 & 4.2731 & TRN \\
\hline CHEMBL1609672 & 752386 & 4.7053 & 5.1576 & TRN \\
\hline CHEMBL1405837 & 752386 & 4.4938 & 4.353 & TST \\
\hline CHEMBL1407401 & 752386 & 4.9274 & 4.7392 & TST \\
\hline CHEMBL3192509 & 752386 & 2.4202 & 3.695 & TST \\
\hline CHEMBL1367596 & 752386 & 5.5761 & 3.8542 & TST \\
\hline CHEMBL1420920 & 752386 & 5.0857 & 4.4718 & TRN \\
\hline CHEMBL1458321 & 752386 & 4.7627 & 4.8731 & TRN \\
\hline CHEMBL1576416 & 752386 & 2.4202 & 4.3261 & TST \\
\hline CHEMBL1613716 & 752386 & 5.4864 & 5.0037 & TRN \\
\hline CHEMBL1507162 & 752386 & 7.0841 & 6.4446 & TRN \\
\hline CHEMBL1541441 & 752386 & 2.9208 & 4.9598 & TRN \\
\hline CHEMBL1581727 & 752386 & 5.17 & 4.791 & TST \\
\hline CHEMBL1422754 & 752386 & 5.5547 & 5.0646 & TRN \\
\hline CHEMBL1510339 & 752386 & 6.4097 & 5.2039 & TRN \\
\hline CHEMBL1589428 & 752386 & 4.9821 & 4.4684 & TRN \\
\hline CHEMBL1573365 & 752386 & 2.9208 & 3.7005 & TST \\
\hline CHEMBL1320781 & 752386 & 4.4102 & 4.4455 & TRN \\
\hline CHEMBL1335893 & 752386 & 3.5566 & 3.6888 & TRN \\
\hline CHEMBL1465186 & 752386 & 5.3818 & 4.8511 & TRN \\
\hline CHEMBL1446060 & 752386 & 4.5672 & 4.5382 & TRN \\
\hline CHEMBL1558874 & 752386 & 4.8996 & 4.8765 & TST \\
\hline CHEMBL1335953 & 752386 & 5.4609 & 5.3008 & TRN \\
\hline CHEMBL1308867 & 752386 & 2.4202 & 3.5363 & TRN \\
\hline CHEMBL1385784 & 752386 & 5.8976 & 5.935 & TRN \\
\hline CHEMBL1467133 & 752386 & 5.436 & 5.2297 & TRN \\
\hline CHEMBL1510478 & 752386 & 2.4202 & 3.4882 & TRN \\
\hline CHEMBL1449794 & 752386 & 5.4548 & 4.1853 & TRN \\
\hline CHEMBL1416713 & 752386 & 5.3513 & 4.7693 & TRN \\
\hline CHEMBL1320799 & 752386 & 4.2743 & 4.9105 & TST \\
\hline CHEMBL1332682 & 752386 & 2.4202 & 3.9587 & TST \\
\hline CHEMBL1603581 & 752386 & 5.7192 & 5.0199 & TST \\
\hline CHEMBL1562304 & 752386 & 5.402 & 5.2993 & TST \\
\hline
\end{tabular}




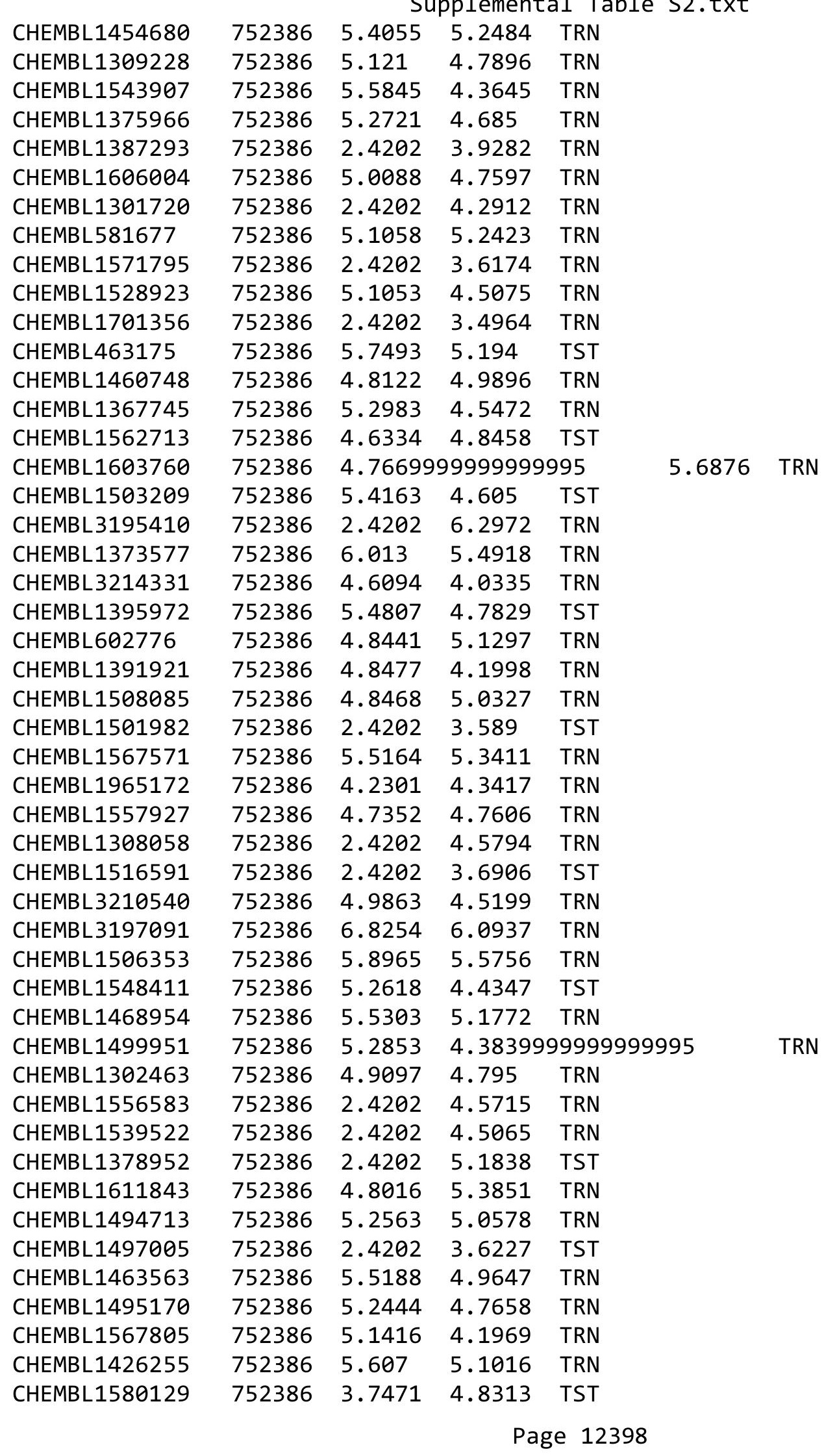


Supplemental Table S2.txt

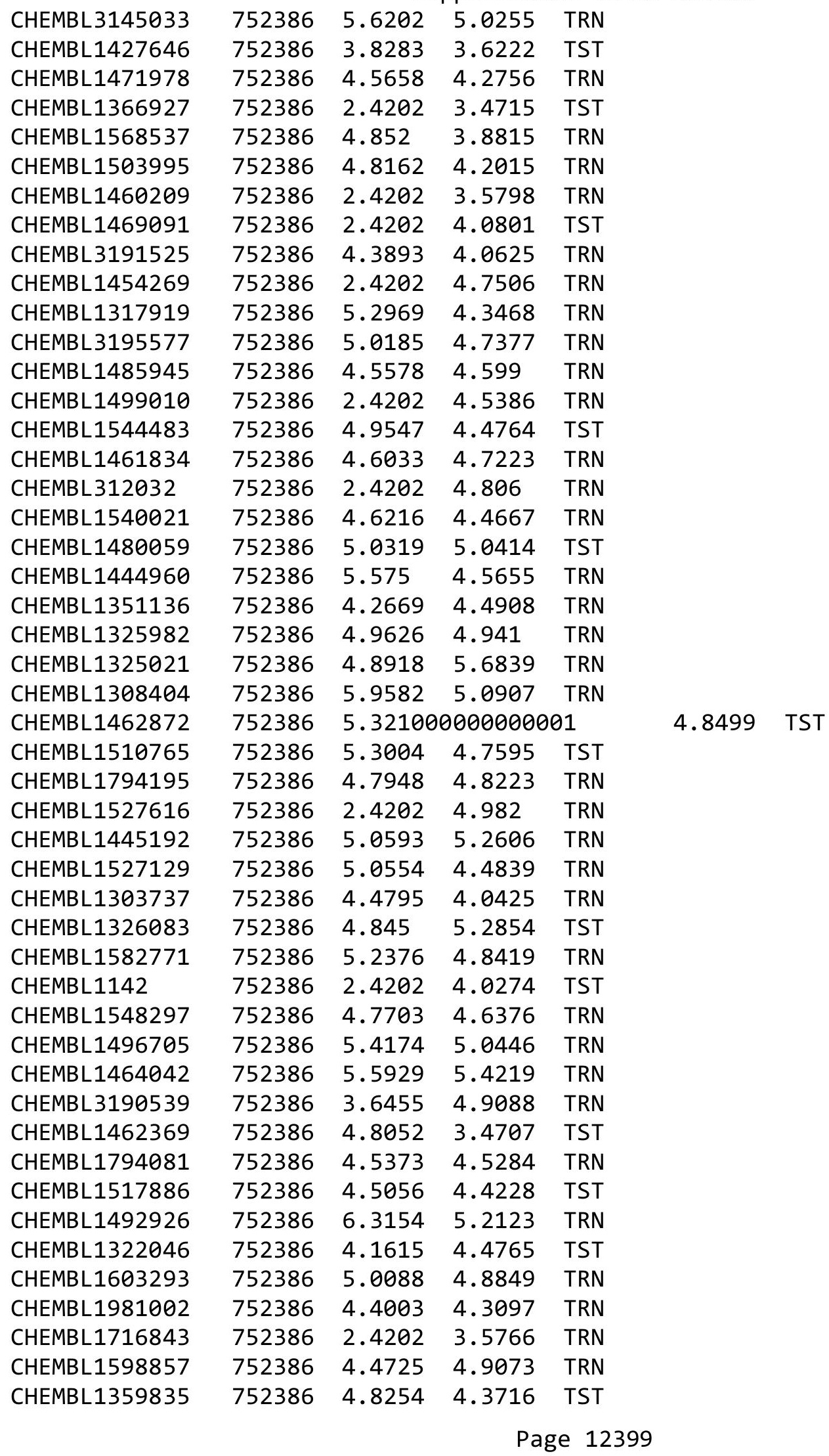


Supplemental Table S2.txt

\begin{tabular}{|c|c|}
\hline - & \\
\hline HEMBL1483870 & \\
\hline & \\
\hline FMRI 3 & 86 \\
\hline IEMBL1324556 & \\
\hline IEMBL1970242 & 5238 \\
\hline IEMBL14 & 52386 \\
\hline IEMBL136 & 52386 \\
\hline JEMBL15 & 752386 \\
\hline AEMBL1411044 & 75238 \\
\hline AEMBL1463885 & 52386 \\
\hline IEMBL1508040 & 52386 \\
\hline IEMBL1607263 & 52386 \\
\hline AEMBL1378118 & 752386 \\
\hline AEMBL1470321 & 5238 \\
\hline AEMBL 3193444 & $2<500$ \\
\hline AEMBL149 & 52386 \\
\hline HEMBL140 & 52386 \\
\hline AEMBL1346853 & 752386 \\
\hline AEMBL1450393 & 38 \\
\hline AEMBL1389505 & 152386 \\
\hline AEMBL1540053 & 52386 \\
\hline AEMBL1401582 & 52386 \\
\hline AEMBL1544548 & 752386 \\
\hline L150 & \\
\hline AEMBL1389508 & 752386 \\
\hline IEMBL3196831 & 752386 \\
\hline 111 & 752386 \\
\hline HEMBL1417290 & 75238 \\
\hline HEMBL12S & 52386 \\
\hline IEMBL1407961 & 752386 \\
\hline AFMB 138 & 52386 \\
\hline 92 & 52 \\
\hline AEMBL1477756 & 752386 \\
\hline AEMBL3198239 & 52386 \\
\hline IEMBL1451336 & 752386 \\
\hline IFMRI 32 & 86 \\
\hline HEMBL1326847 & 752386 \\
\hline AEMBL1510262 & 752386 \\
\hline AEMBL1520259 & 52386 \\
\hline HEMBL1567159 & 752386 \\
\hline CHEMBL1447473 & 752386 \\
\hline HEMBL1366252 & 752386 \\
\hline AEMBL1622566 & 75238 \\
\hline HEMBL1499903 & 5238 \\
\hline CHEMBL3145071 & 75238 \\
\hline CHEMBL1330489 & 75238 \\
\hline HEMBL 2003651 & 75238 \\
\hline
\end{tabular}

$\begin{array}{lll}5.2752 & 4.7989 & \text { TRN }\end{array}$

$\begin{array}{lll}5.1241 & 4.5559 & \text { TRN }\end{array}$

$\begin{array}{llll}5.1106 & 4.4749 & \text { TRN }\end{array}$

$\begin{array}{llll}4.3242 & 4.5416 & \text { TRN }\end{array}$

$\begin{array}{llll}5.0756 & 4.7249 & \text { TRN }\end{array}$

$\begin{array}{llll}5.358 & 4.9228 & \text { TRN }\end{array}$

$\begin{array}{lll}2.4202 & 3.7874 & \text { TST }\end{array}$

5.66415 .0116 TRN

$\begin{array}{lll}5.1668 & 5.399 & \text { TRN }\end{array}$

$\begin{array}{lll}6.471 & 5.8538 & \text { TRN }\end{array}$

$\begin{array}{lll}5.64 & 4.9685 & \text { TRN }\end{array}$

$\begin{array}{llll}4.2958 & 4.6173 & \text { TRN }\end{array}$

$6.1133 \quad 5.8332$ TRN

$\begin{array}{llll}4.6223 & 4.4237 & \text { TRN }\end{array}$

$\begin{array}{lll}5.572 & 4.311 & \text { TRN }\end{array}$

$\begin{array}{lll}5.4636 & 4.7065 & \text { TRN }\end{array}$

$\begin{array}{lll}5.7981 & 5.715 & \text { TRN }\end{array}$

$\begin{array}{llll}2.4202 & 4.0607 & \text { TRN }\end{array}$

$\begin{array}{llll}5.3744 & 5.0389 & \text { TST }\end{array}$

$\begin{array}{lll}5.7924 & 4.5447 & \text { TST }\end{array}$

$\begin{array}{llll}4.6988 & 4.7897 & \text { TRN }\end{array}$

$\begin{array}{lll}4.7031 & 4.2044 & \text { TST }\end{array}$

$\begin{array}{lll}4.6617 & 5.2569 & \text { TRN }\end{array}$

$\begin{array}{lll}2.4202 & 4.4528 & \text { TRN }\end{array}$

$\begin{array}{llll}6.3446 & 4.5789 & \text { TRN }\end{array}$

$\begin{array}{lll}4.9905 & 4.7503 & \text { TST }\end{array}$

$\begin{array}{llll}5.3424 & 5.3937 & \text { TRN }\end{array}$

$\begin{array}{llll}2.4202 & 3.7366 & \text { TRN }\end{array}$

$\begin{array}{lll}2.4202 & 4.7505 & \text { TST }\end{array}$

$\begin{array}{lll}4.575 & 4.748 & \text { TRN }\end{array}$

$\begin{array}{lll}5.845 & 4.8183 & \text { TRN }\end{array}$

$\begin{array}{lll}5.8438 & 5.522 & \text { TRN }\end{array}$

$\begin{array}{lll}4.9129 & 4.8864 & \text { TRN }\end{array}$

$\begin{array}{lll}5.1794 & 5.2259 & \text { TRN }\end{array}$

$\begin{array}{lll}2.4202 & 3.4867 & \text { TRN }\end{array}$

$\begin{array}{lll}4.7804 & 4.4495 & \text { TST }\end{array}$

$5.2152 \quad 5.153 \quad$ TRN

$\begin{array}{llll}2.4202 & 4.4848 & \text { TRN }\end{array}$

4.24354 .7838 TRN

$4.9727 \quad 4.093999999999999$

$\begin{array}{lll}5.8993 & 5.3094 & \text { TRN }\end{array}$

$\begin{array}{lll}5.8122 & 5.3038 & \text { TRN }\end{array}$

$5.4248 \quad 5.1325$ TRN

$6.2306 \quad 5.6793$ TRN

$\begin{array}{lll}5.1101 & 4.7233 & \text { TST }\end{array}$

$\begin{array}{lll}4.7817 & 5.1719 & \text { TRN }\end{array}$

$\begin{array}{lll}5.0381 & 4.9107 & \text { TST }\end{array}$

6.83626 .2482 TRN

Page 12400 
Supplemental Table S2.txt

\begin{tabular}{|c|c|c|c|c|c|}
\hline CHEMBL3197999 & 752386 & 4.5768 & 4.7196 & TRN & \\
\hline CHEMBL1520392 & 752386 & 2.4202 & 4.0546 & TRN & \\
\hline CHEMBL3192994 & 752386 & 5.5995 & 5.2018 & TRN & \\
\hline CHEMBL1383986 & 752386 & 6.3843 & 5.8955 & TRN & \\
\hline CHEMBL1375045 & 752386 & 5.3409 & 4.9248 & TST & \\
\hline CHEMBL1338987 & 752386 & 4.5447 & 5.226 & TST & \\
\hline CHEMBL1539943 & 752386 & 4.6453 & 4.7674 & TRN & \\
\hline CHEMBL1454770 & 752386 & 4.5485 & 4.2027 & TRN & \\
\hline CHEMBL1419822 & 752386 & 4.5824 & 4.2611 & TRN & \\
\hline CHEMBL1412588 & 752386 & 6.459 & 5.6711 & TRN & \\
\hline CHEMBL1597358 & 752386 & 5.9952 & 5.53700 & 000000001 & TRN \\
\hline CHEMBL1301125 & 752386 & 5.7373 & 5.1104 & TRN & \\
\hline CHEMBL1361500 & 752386 & 4.6739 & 4.5274 & TRN & \\
\hline CHEMBL 3191602 & 752386 & 4.9165 & 5.0972 & TRN & \\
\hline CHEMBL1719244 & 752386 & 2.9208 & 4.9944 & TRN & \\
\hline CHEMBL1549114 & 752386 & 4.624 & 4.453 & TRN & \\
\hline CHEMBL1326933 & 752386 & 4.2664 & 4.1476 & TRN & \\
\hline CHEMBL1560679 & 752386 & 4.9318 & 5.0135 & TRN & \\
\hline CHEMBL1326534 & 752386 & 5.6761 & 5.1876 & TRN & \\
\hline CHEMBL1410788 & 752386 & 5.1252 & 4.2263 & TRN & \\
\hline CHEMBL1497295 & 752386 & 5.6084 & 6.0461 & TRN & \\
\hline CHEMBL1301700 & 752386 & 5.8204 & 4.7633 & TRN & \\
\hline CHEMBL1463943 & 752386 & 4.7665 & 4.7397 & TRN & \\
\hline CHEMBL1988416 & 752386 & 5.3778 & 4.6374 & TRN & \\
\hline CHEMBL1339956 & 752386 & 5.3935 & 4.8043 & TRN & \\
\hline CHEMBL1542809 & 752386 & 5.8511 & 5.38399 & 9999999995 & TRN \\
\hline CHEMBL1391390 & 752386 & 4.4548 & 5.0718 & TRN & \\
\hline CHEMBL1302378 & 752386 & 5.6919 & 4.4395 & TST & \\
\hline CHEMBL1402986 & 752386 & 2.4202 & 3.4882 & TRN & \\
\hline CHEMBL1338246 & 752386 & 2.9208 & 3.4697 & TRN & \\
\hline CHEMBL1607648 & 752386 & 4.5068 & 4.3808 & TST & \\
\hline CHEMBL 3191474 & 752386 & 5.1536 & 4.9002 & TRN & \\
\hline CHEMBL1331912 & 752386 & 5.6629 & 4.81 & TRN & \\
\hline CHEMBL1344806 & 752386 & 5.659 & 4.887 & TRN & \\
\hline CHEMBL1497049 & 752386 & 5.136 & 4.6458 & TRN & \\
\hline CHEMBL1529127 & 752386 & 5.5216 & 4.6038 & TRN & \\
\hline CHEMBL1450139 & 752386 & 2.4202 & 3.4914 & TST & \\
\hline CHEMBL1494202 & 752386 & 4.3189 & 5.0941 & TRN & \\
\hline CHEMBL1301371 & 752386 & 4.6602 & 4.6772 & TRN & \\
\hline CHEMBL1471461 & 752386 & 2.4202 & 3.3906 & TST & \\
\hline CHEMBL1534678 & 752386 & 4.7268 & 4.3549 & TRN & \\
\hline CHEMBL1444859 & 752386 & 2.4202 & 3.5837 & TRN & \\
\hline CHEMBL1379048 & 752386 & 5.0505 & 5.2139 & TRN & \\
\hline CHEMBL1349651 & 752386 & 4.7438 & 5.0376 & TRN & \\
\hline CHEMBL1541973 & 752386 & 4.8526 & 5.0359 & TRN & \\
\hline CHEMBL1991885 & 752386 & 6.3979 & 5.4252 & TRN & \\
\hline CHEMBL1559655 & 752386 & 6.5516 & 5.8715 & TRN & \\
\hline CHEMBL333767 & 752386 & 4.6297 & 4.6934 & TRN & \\
\hline
\end{tabular}




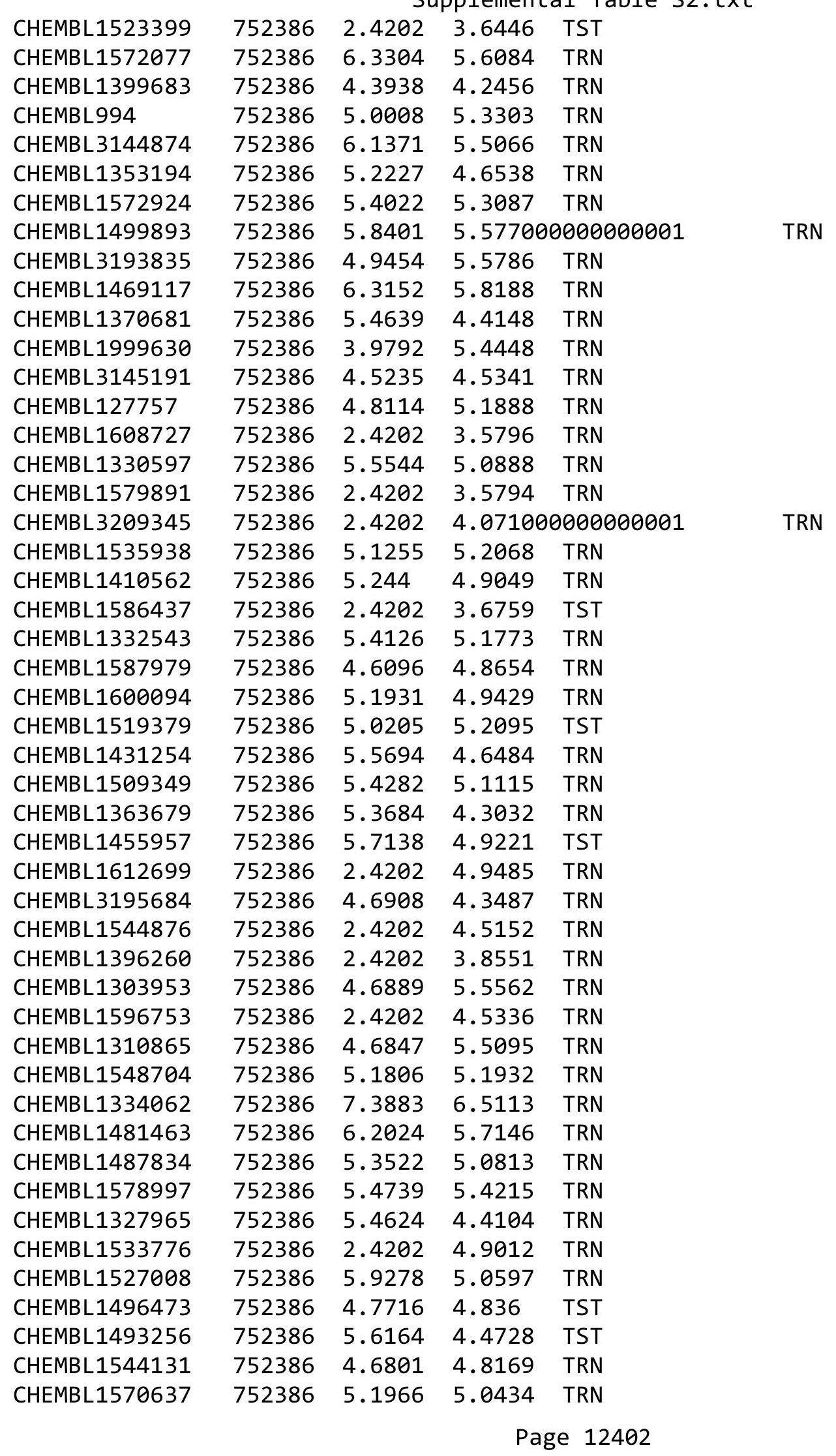




\begin{tabular}{|c|c|c|c|c|c|}
\hline \multicolumn{6}{|c|}{ semental } \\
\hline CHEMBL1483657 & 752386 & 4.8655 & 4.1256 & TRN & \\
\hline CHEMBL1482637 & 752386 & 3.4217 & 4.3844 & TST & \\
\hline CHEMBL1584428 & 752386 & 4.5056 & 4.3117 & TRN & \\
\hline CHEMBL1597039 & 752386 & 5.6385 & 5.7949 & TRN & \\
\hline CHEMBL1418568 & 752386 & 2.4202 & 5.3225 & TRN & \\
\hline CHEMBL1583807 & 752386 & 2.4202 & 4.2855 & TRN & \\
\hline CHEMBL1098875 & 752386 & 2.9208 & 3.5719 & TRN & \\
\hline CHEMBL1528469 & 752386 & 5.5948 & 5.0475 & TRN & \\
\hline CHEMBL3196407 & 752386 & 5.1448 & 4.9264 & TRN & \\
\hline CHEMBL3210545 & 752386 & 5.3011 & 4.832 & TRN & \\
\hline CHEMBL1430449 & 752386 & 4.8505 & 4.9007 & TRN & \\
\hline CHEMBL1359933 & 752386 & 6.4139 & 5.7978 & TRN & \\
\hline CHEMBL1794249 & 752386 & 4.8371 & 4.2806 & TRN & \\
\hline CHEMBL1409991 & 752386 & 4.9223 & 4.7393 & TRN & \\
\hline CHEMBL1390923 & 752386 & 5.2811 & 4.8367 & TRN & \\
\hline CHEMBL1731689 & 752386 & 6.2921 & 5.1637 & TRN & \\
\hline CHEMBL1719147 & 752386 & 2.4202 & 3.6654 & TRN & \\
\hline CHEMBL3210650 & 752386 & 4.6315 & 4.4603 & TRN & \\
\hline CHEMBL1501421 & 752386 & 2.4202 & 3.60699 & 99999999998 & TST \\
\hline CHEMBL 3145178 & 752386 & 5.6392 & 5.3794 & TRN & \\
\hline CHEMBL1479114 & 752386 & 4.6061 & 4.9711 & TRN & \\
\hline CHEMBL1389827 & 752386 & 4.9996 & 4.3719 & TST & \\
\hline CHEMBL1401841 & 752386 & 2.4202 & 4.7109 & TRN & \\
\hline CHEMBL1469676 & 752386 & 5.6251 & 5.7252 & TRN & \\
\hline CHEMBL1611041 & 752386 & 5.3201 & 5.1414 & TRN & \\
\hline CHEMBL1421441 & 752386 & 5.4578 & 4.3718 & TRN & \\
\hline CHEMBL1582076 & 752386 & 4.5714 & 4.7591 & TRN & \\
\hline CHEMBL1444473 & 752386 & 2.4202 & 5.2089 & TRN & \\
\hline CHEMBL1568113 & 752386 & 5.6981 & 5.4202 & TRN & \\
\hline CHEMBL1438646 & 752386 & 4.4921 & 4.207 & TRN & \\
\hline CHEMBL1533269 & 752386 & 5.0719 & 4.7186 & TRN & \\
\hline CHEMBL1568102 & 752386 & 4.4525 & 4.2264 & TST & \\
\hline CHEMBL1569877 & 752386 & 6.0417 & 4.149 & TRN & \\
\hline CHEMBL1490987 & 752386 & 2.4202 & 4.5895 & TRN & \\
\hline CHEMBL1486332 & 752386 & 5.2394 & 5.6655 & TRN & \\
\hline CHEMBL1718805 & 752386 & 4.9397 & 5.2774 & TRN & \\
\hline CHEMBL1373799 & 752386 & 4.0274 & 4.2419 & TRN & \\
\hline CHEMBL1331211 & 752386 & 6.0541 & 5.8337 & TRN & \\
\hline CHEMBL3183391 & 752386 & 5.5928 & 5.4736 & TRN & \\
\hline CHEMBL1415513 & 752386 & 6.494 & 5.74200 & 0000000001 & TRN \\
\hline CHEMBL1542804 & 752386 & 5.7565 & 5.2842 & TRN & \\
\hline CHEMBL1524916 & 752386 & 2.4202 & 5.0494 & TRN & \\
\hline CHEMBL1467294 & 752386 & 2.4202 & 5.13399 & 99999999995 & TRN \\
\hline CHEMBL1566889 & 752386 & 5.9706 & 5.4476 & TRN & \\
\hline CHEMBL1300242 & 752386 & 4.7891 & 5.1821 & TRN & \\
\hline CHEMBL1421882 & 752386 & 2.4202 & 3.6842 & TRN & \\
\hline CHEMBL1443497 & 752386 & 2.4202 & 4.1003 & TST & \\
\hline CHEMBL1535665 & 752386 & 5.295 & 4.8006 & TRN & \\
\hline
\end{tabular}




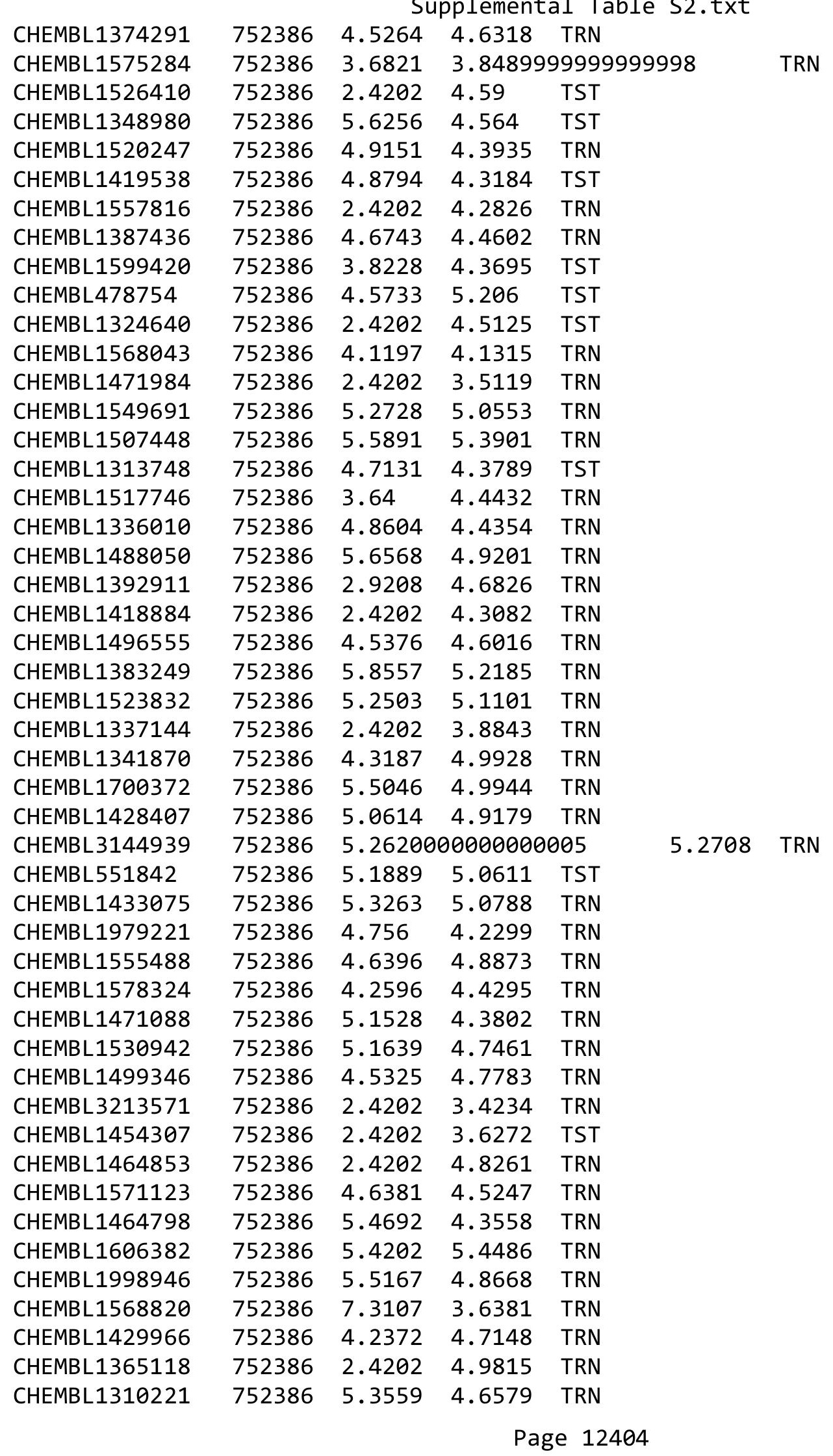




\begin{tabular}{|c|c|c|c|c|c|}
\hline \multirow[b]{2}{*}{ CHEMBL1525064 } & \multicolumn{5}{|c|}{ Supplemental Table S2.txt } \\
\hline & 752386 & 4.266 & 4.8647 & TST & \\
\hline CHEMBL1794130 & 752386 & 4.6562 & 4.6426 & TRN & \\
\hline CHEMBL3192555 & 752386 & 6.4703 & 6.122006 & 0000000001 & TRN \\
\hline CHEMBL1430074 & 752386 & 5.5081 & 5.5305 & TRN & \\
\hline CHEMBL1413355 & 752386 & 4.4176 & 4.6113 & TST & \\
\hline CHEMBL1487749 & 752386 & 3.8592 & 3.5106 & TST & \\
\hline CHEMBL3145051 & 752386 & 4.9602 & 4.278006 & 00000000005 & TRN \\
\hline CHEMBL600313 & 752386 & 4.61100 & 00000006 & 4.8028 & TRN \\
\hline CHEMBL1510156 & 752386 & 6.3558 & 5.4196 & TRN & \\
\hline CHEMBL1581795 & 752386 & 5.4406 & 5.1417 & TRN & \\
\hline CHEMBL1546205 & 752386 & 5.0014 & 5.011 & TRN & \\
\hline CHEMBL1432590 & 752386 & 5.6889 & 4.87 & TRN & \\
\hline CHEMBL17551 & 752386 & 3.4896 & 4.4281 & TRN & \\
\hline CHEMBL1345835 & 752386 & 2.4202 & 5.935 & TRN & \\
\hline CHEMBL1532323 & 752386 & 4.9446 & 4.8702 & TRN & \\
\hline CHEMBL1313900 & 752386 & 5.4131 & 5.1537 & TST & \\
\hline CHEMBL1537588 & 752386 & 5.3771 & 5.2923 & TRN & \\
\hline CHEMBL1576754 & 752386 & 5.0477 & 4.9884 & TRN & \\
\hline CHEMBL1399371 & 752386 & 6.8489 & 5.2272 & TRN & \\
\hline CHEMBL1365696 & 752386 & 5.6368 & 4.4125 & TRN & \\
\hline CHEMBL1445135 & 752386 & 4.1316 & 4.6036 & TRN & \\
\hline CHEMBL1326577 & 752386 & 4.6633 & 4.7568 & TST & \\
\hline CHEMBL1592492 & 752386 & 5.3187 & 5.1975 & TRN & \\
\hline CHEMBL1464832 & 752386 & 4.9983 & 4.7657 & TRN & \\
\hline CHEMBL1608787 & 752386 & 2.4202 & 4.266 & TST & \\
\hline CHEMBL1409606 & 752386 & 4.8077 & 5.1968 & TRN & \\
\hline CHEMBL1374351 & 752386 & 4.9662 & 4.4041 & TRN & \\
\hline CHEMBL1388469 & 752386 & 5.0741 & 5.3927 & TRN & \\
\hline CHEMBL1318742 & 752386 & 4.8658 & 4.1689 & TRN & \\
\hline CHEMBL1730123 & 752386 & 5.0419 & 5.3602 & TRN & \\
\hline CHEMBL1454882 & 752386 & 4.9948 & 4.2048 & TRN & \\
\hline CHEMBL1332048 & 752386 & 5.3 & 5.2454 & TRN & \\
\hline CHEMBL1403738 & 752386 & 2.9208 & 4.4664 & TRN & \\
\hline CHEMBL1519374 & 752386 & 5.7817 & 5.476 & TRN & \\
\hline CHEMBL586031 & 752386 & 4.7296 & 5.3544 & TRN & \\
\hline CHEMBL1587942 & 752386 & 5.4646 & 3.4741 & TRN & \\
\hline CHEMBL1465979 & 752386 & 5.3659 & 4.322 & TST & \\
\hline CHEMBL1411788 & 752386 & 5.2743 & 4.7098 & TRN & \\
\hline CHEMBL 1458840 & 752386 & 4.7001 & 4.7638 & TST & \\
\hline CHEMBL1430372 & 752386 & 2.4202 & 5.1001 & TRN & \\
\hline CHEMBL390559 & 752386 & 5.3075 & 4.8437 & TRN & \\
\hline CHEMBL1343352 & 752386 & 3.5812 & 4.8869 & TRN & \\
\hline CHEMBL1351750 & 752386 & 4.9842 & 5.0489 & TRN & \\
\hline CHEMBL1600855 & 752386 & 5.3203 & 4.8834 & TST & \\
\hline CHEMBL1540463 & 752386 & 5.6876 & 5.3607 & TRN & \\
\hline CHEMBL1300870 & 752386 & 2.4202 & 3.6488 & TST & \\
\hline CHEMBL1519313 & 752386 & 5.1757 & 4.7562 & TST & \\
\hline CHEMBL1462675 & 752386 & 5.1032 & 5.2832 & TRN & \\
\hline
\end{tabular}

Page 12405 


\begin{tabular}{|c|c|c|c|c|c|}
\hline & & & & & \\
\hline CHEMBL1306377 & 752386 & 2.4202 & 5.0426 & TRN & \\
\hline CHEMBL1321538 & 752386 & 5.8176 & 5.8082 & TRN & \\
\hline CHEMBL2001831 & 752386 & 3.9722 & 5.277 & TST & \\
\hline CHEMBL1309737 & 752386 & 5.4384 & 4.5023 & TST & \\
\hline CHEMBL1505548 & 752386 & 4.6633 & 4.92 & TRN & \\
\hline CHEMBL1569472 & 752386 & 5.0628 & 4.6614 & TRN & \\
\hline CHEMBL1599023 & 752386 & 2.4202 & 4.3534 & TST & \\
\hline CHEMBL1312285 & 752386 & 2.4202 & 4.9632 & TRN & \\
\hline CHEMBL1352082 & 752386 & 4.338999 & 79999999 & 4.2021 & TRN \\
\hline CHEMBL1388300 & 752386 & 6.4753 & 5.786006 & 00000000005 & TRN \\
\hline CHEMBL3198793 & 752386 & 2.4202 & 4.731 & TRN & \\
\hline CHEMBL1377692 & 752386 & 2.4202 & 3.4941 & TRN & \\
\hline CHEMBL1571318 & 752386 & 2.4202 & 3.5359 & TRN & \\
\hline CHEMBL3145143 & 752386 & 4.8752 & 4.971 & TRN & \\
\hline CHEMBL1601712 & 752386 & 5.3195 & 4.7429 & TRN & \\
\hline CHEMBL1581553 & 752386 & 2.4202 & 3.6434 & TRN & \\
\hline CHEMBL3145001 & 752386 & 6.0388 & 5.6507 & TRN & \\
\hline CHEMBL1484906 & 752386 & 5.247999 & 99999999 & 5.284 & TRN \\
\hline CHEMBL1964615 & 752386 & 2.4202 & 5.141 & TST & \\
\hline CHEMBL1578949 & 752386 & 3.7491 & 3.5168 & TRN & \\
\hline CHEMBL3191242 & 752386 & 2.4202 & 3.6426 & TRN & \\
\hline CHEMBL1406372 & 752386 & 4.8972 & 4.9583 & TRN & \\
\hline CHEMBL1430314 & 752386 & 5.6398 & 5.1378 & TRN & \\
\hline CHEMBL1349535 & 752386 & 5.2363 & 4.8963 & TRN & \\
\hline CHEMBL1452938 & 752386 & 4.4936 & 4.27800 & 00000000005 & TRN \\
\hline CHEMBL1493528 & 752386 & 2.4202 & 4.1131 & TRN & \\
\hline CHEMBL1585003 & 752386 & 5.3942 & 4.506 & TST & \\
\hline CHEMBL1449387 & 752386 & 4.6942 & 4.3005 & TRN & \\
\hline CHEMBL1372030 & 752386 & 2.4202 & 4.2039 & TST & \\
\hline CHEMBL1534860 & 752386 & 5.14 & 4.927 & TRN & \\
\hline CHEMBL1497597 & 752386 & 5.6012 & 4.0134 & TRN & \\
\hline CHEMBL1452937 & 752386 & 4.8156 & 4.7835 & TRN & \\
\hline CHEMBL1580684 & 752386 & 4.9073 & 4.625 & TRN & \\
\hline CHEMBL1717678 & 752386 & 4.9205 & 4.7645 & TRN & \\
\hline CHEMBL1344681 & 752386 & 2.4202 & 4.9447 & TRN & \\
\hline CHEMBL1733991 & 752386 & 4.914 & 5.2516 & TRN & \\
\hline CHEMBL1511042 & 752386 & 5.4607 & 4.8172 & TST & \\
\hline CHEMBL1396209 & 752386 & 5.442 & 4.92899 & 9999999999 & TST \\
\hline CHEMBL1367735 & 752386 & 2.4202 & 4.4712 & TST & \\
\hline CHEMBL1340016 & 752386 & 2.4202 & 3.6203 & TRN & \\
\hline CHEMBL1557820 & 752386 & 5.4247 & 4.8433 & TRN & \\
\hline CHEMBL599098 & 752386 & 5.246 & 5.0112 & TRN & \\
\hline CHEMBL1428450 & 752386 & 5.2741 & 4.9048 & TRN & \\
\hline CHEMBL1541821 & 752386 & 4.9961 & 4.4742 & TRN & \\
\hline CHEMBL1310969 & 752386 & 4.3548 & 4.3916 & TRN & \\
\hline CHEMBL1533867 & 752386 & 4.3764 & 4.2616 & TRN & \\
\hline CHEMBL1374083 & 752386 & 5.5967 & 5.3681 & TRN & \\
\hline CHEMBL1477097 & 752386 & 5.2309 & 5.0495 & TRN & \\
\hline
\end{tabular}




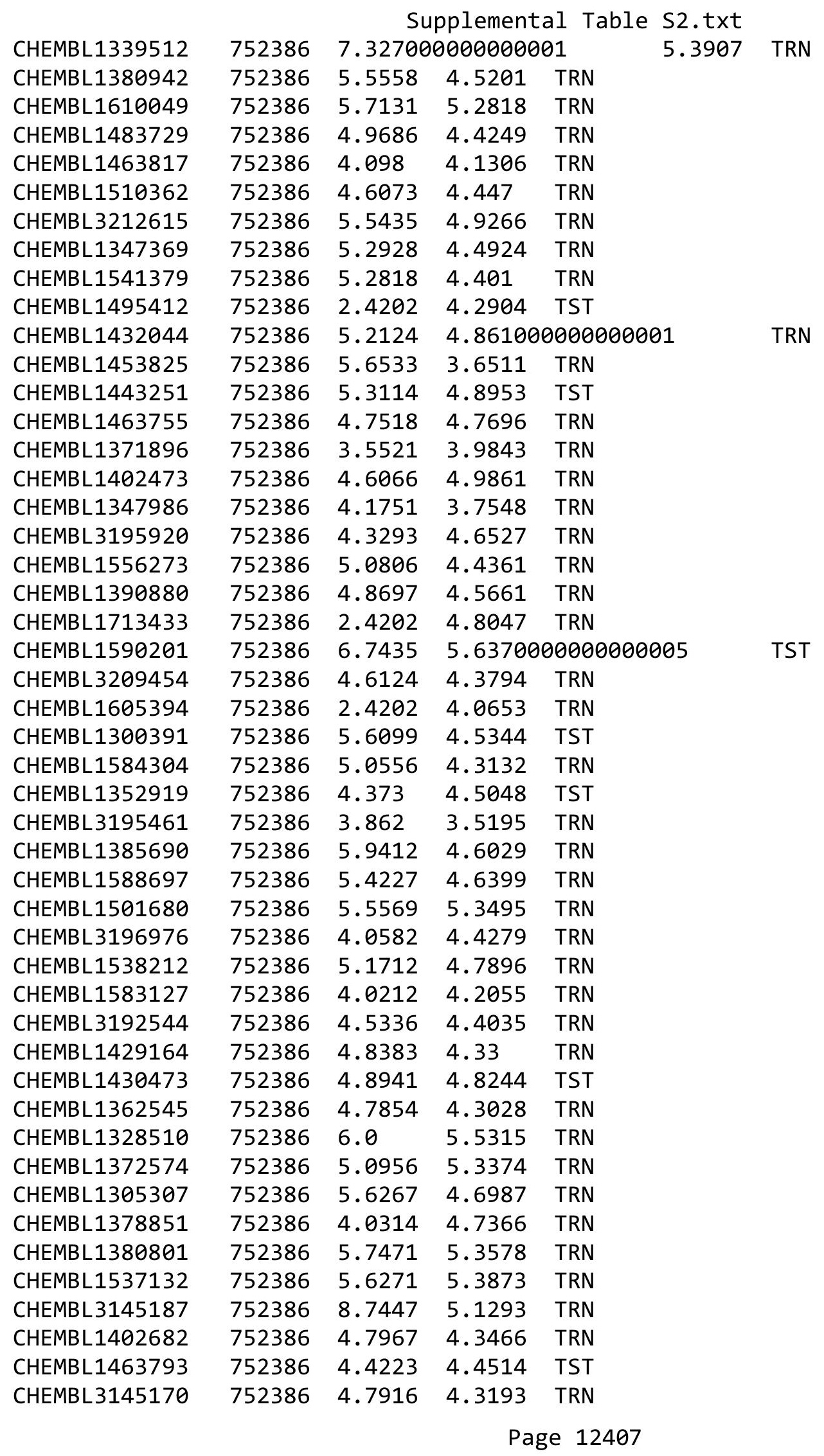




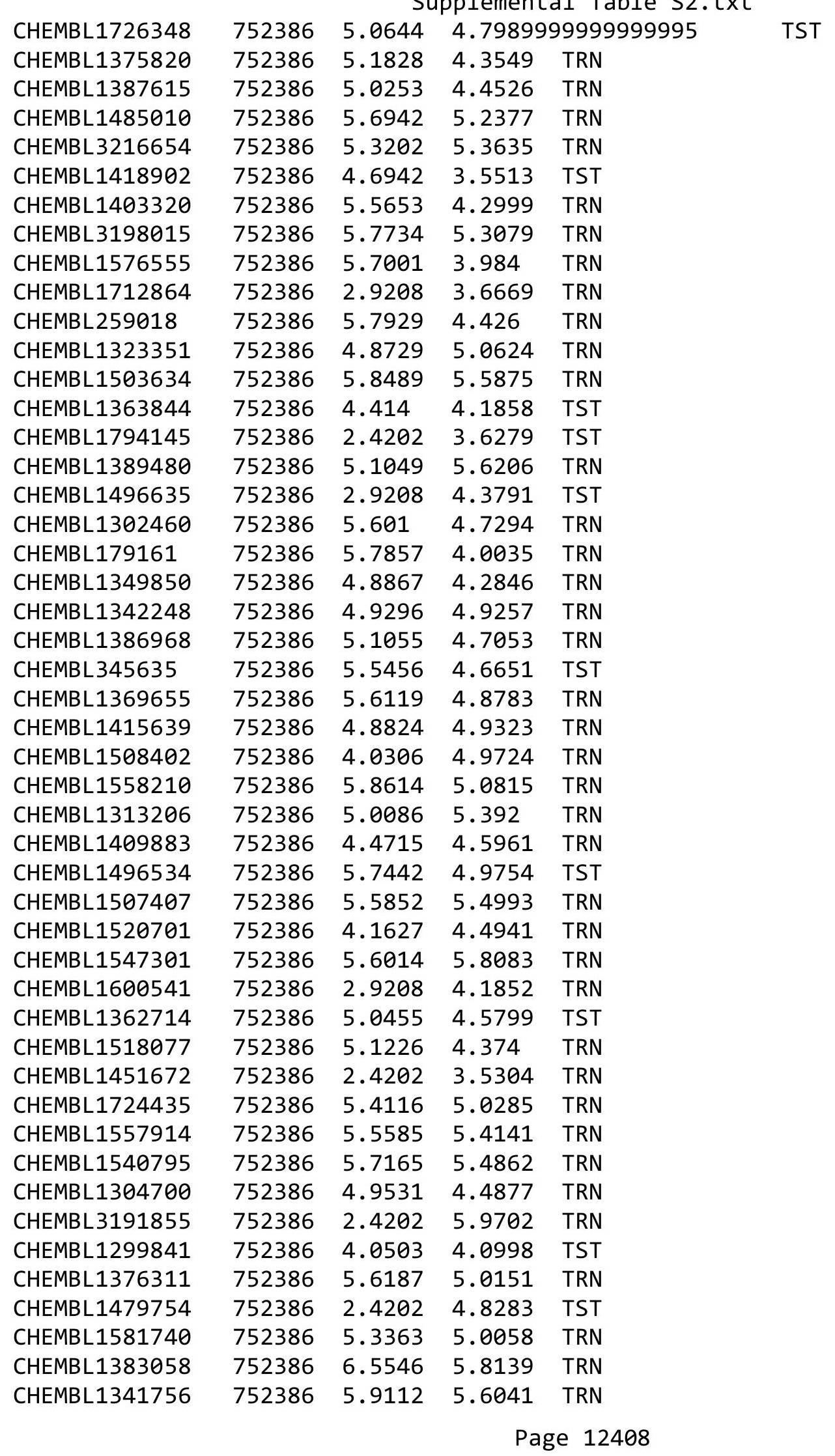


Supplemental Table S2.txt

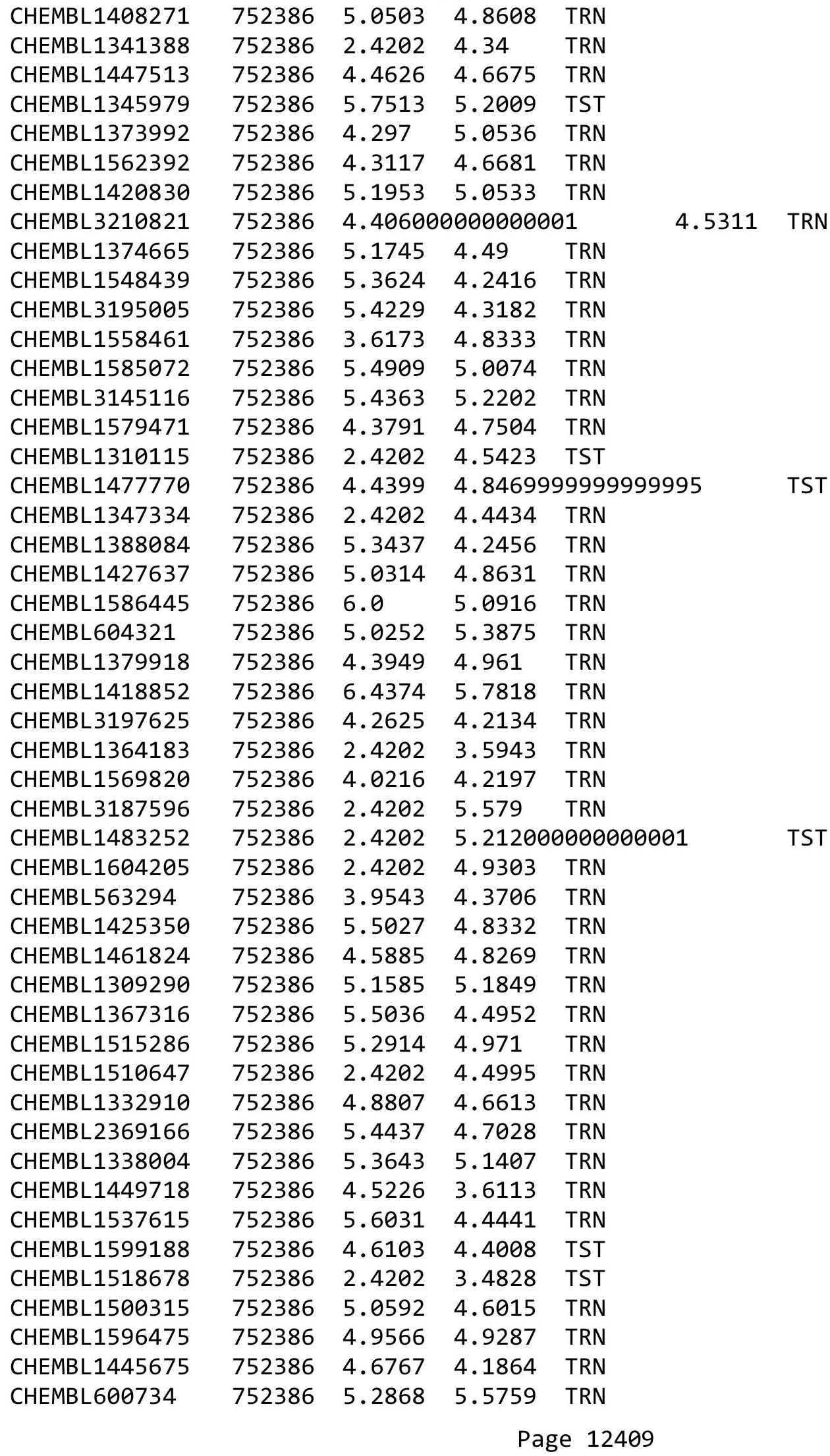




\begin{tabular}{|c|c|}
\hline CHEMBL1371873 & 752386 \\
\hline CHEMBL1490942 & 752386 \\
\hline CHEMBL 3144830 & 752386 \\
\hline CHEMBL1382853 & 752386 \\
\hline CHEMBL1525358 & 752386 \\
\hline CHEMBL1438154 & 752386 \\
\hline CHEMBL1304860 & 752386 \\
\hline CHEMBL1456821 & 752386 \\
\hline CHEMBL1453368 & 752386 \\
\hline CHEMBL3196451 & 752386 \\
\hline CHEMBL1539236 & 752386 \\
\hline CHEMBL1304902 & 752386 \\
\hline CHEMBL1526067 & 752386 \\
\hline CHEMBL1483112 & 752386 \\
\hline CHEMBL1458150 & 752386 \\
\hline CHEMBL517444 & 752386 \\
\hline CHEMBL1499567 & 752386 \\
\hline CHEMBL1503292 & 752386 \\
\hline CHEMBL1404492 & 752386 \\
\hline CHEMBL3191836 & 752386 \\
\hline CHEMBL1560220 & 752386 \\
\hline CHEMBL1568510 & 752386 \\
\hline CHEMBL1384581 & 752386 \\
\hline CHEMBL1331399 & 752386 \\
\hline CHEMBL 3198784 & 752386 \\
\hline CHEMBL1520989 & 752386 \\
\hline CHEMBL1567632 & 752386 \\
\hline CHEMBL1369862 & 752386 \\
\hline CHEMBL1583024 & 752386 \\
\hline CHEMBL1610747 & 752386 \\
\hline CHEMBL1456352 & 752386 \\
\hline CHEMBL1455522 & 752386 \\
\hline CHEMBL1427517 & 752386 \\
\hline CHEMBL171637 & 752386 \\
\hline CHEMBL1470357 & 752386 \\
\hline CHEMBL1574908 & 752386 \\
\hline CHEMBL1999049 & 752386 \\
\hline CHEMBL1392225 & 752386 \\
\hline CHEMBL1407253 & 752386 \\
\hline CHEMBL1548695 & 752386 \\
\hline CHEMBL1467760 & 752386 \\
\hline CHEMBL1606736 & 752386 \\
\hline CHEMBL3145026 & 752386 \\
\hline CHEMBL1572967 & 752386 \\
\hline CHEMBL1424562 & 752386 \\
\hline CHEMBL1928483 & 752386 \\
\hline CHEMBL579318 & 752386 \\
\hline CHEMBL1598561 & 752386 \\
\hline
\end{tabular}

Supplemental Table S2.txt

\begin{tabular}{lll}
5.2165 & 4.8659 & TST \\
5.4 & 5.5616 & TRN \\
5.4652 & 5.2744 & TRN \\
5.3471 & 5.3604 & TRN \\
5.4364 & 4.4541 & TRN \\
4.8428 & 4.9484 & TRN \\
\hline .6059 & 3.4941 & TST
\end{tabular}

$\begin{array}{llll}3.6059 & 3.4941 & \text { TST }\end{array}$

$\begin{array}{llll}4.9918 & 5.2162 & \text { TRN }\end{array}$

$\begin{array}{lll}4.8277 & 4.617 & \text { TRN }\end{array}$

$\begin{array}{llll}6.5211 & 5.8363 & \text { TRN }\end{array}$

$\begin{array}{lll}4.8327 & 4.5829 & \text { TST }\end{array}$

$\begin{array}{lll}5.6753 & 5.9712 & \text { TRN }\end{array}$

$\begin{array}{lll}2.4202 & 5.22 & \text { TRN }\end{array}$

$\begin{array}{llll}4.9041 & 4.8234 & \text { TRN }\end{array}$

$\begin{array}{llll}5.3458 & 4.4718 \text { TRN }\end{array}$

$\begin{array}{llll}4.806 & 5.0564 & \text { TRN }\end{array}$

$\begin{array}{lll}4.7528 & 4.8821 & \text { TRN }\end{array}$

$\begin{array}{llll}4.7359 & 4.4118 & \text { TRN }\end{array}$

$\begin{array}{llll}5.3877 & 4.1018 & \text { TRN }\end{array}$

$\begin{array}{llll}2.4202 & 3.5984 & \text { TRN }\end{array}$

$\begin{array}{llll}3.6258 & 4.6048 & \text { TRN }\end{array}$

$\begin{array}{lll}6.4433 & 5.7264 & \text { TRN }\end{array}$

$2.9208 \quad 4.5106$ TRN

$\begin{array}{lll}2.4202 & 4.7961 & \text { TRN }\end{array}$

$\begin{array}{lll}2.4202 & 5.34 & \text { TRN }\end{array}$

$\begin{array}{lll}5.0161 & 4.09 & \text { TRN }\end{array}$

$\begin{array}{llll}5.0689 & 4.8196 & \text { TRN }\end{array}$

$\begin{array}{llll}5.3436 & 5.0683 & \text { TRN }\end{array}$

$\begin{array}{lll}5.1472 & 4.5332 & \text { TST }\end{array}$

$\begin{array}{llll}5.2144 & 4.3752 & \text { TRN }\end{array}$

$\begin{array}{llll}4.3952 & 4.1306 & \text { TRN }\end{array}$

$5.6817 \quad 5.4456 \quad$ TRN

$\begin{array}{llll}4.3973 & 4.4859 & \text { TRN }\end{array}$

$\begin{array}{lll}5.6882 & 5.1405 & \text { TST }\end{array}$

$\begin{array}{lll}4.7249 & 4.698 \quad \text { TRN }\end{array}$

$\begin{array}{llll}5.4332 & 5.3504 & \text { TRN }\end{array}$

$\begin{array}{lll}4.7395 & 5.2185 & \text { TRN }\end{array}$

$\begin{array}{lll}3.8881 & 4.7498 & \text { TST }\end{array}$

$4.9454 \quad 4.7235$ TRN

$\begin{array}{llll}4.3799 & 4.3036 & \text { TRN }\end{array}$

$\begin{array}{llll}5.0603 & 5.0866 & \text { TRN }\end{array}$

$\begin{array}{llll}5.6183 & 5.3486 & \text { TRN }\end{array}$

$\begin{array}{llll}5.7217 & 5.4266 & \text { TRN }\end{array}$

$\begin{array}{lll}5.2946 & 5.2282 & \text { TRN }\end{array}$

$\begin{array}{llll}6.0157 & 4.2893 & \text { TRN }\end{array}$

$\begin{array}{llll}4.0893 & 3.9621 & \text { TRN }\end{array}$

6.35815 .7172 TRN

6.47475 .9474 TRN

Page 12410 


\begin{tabular}{|c|c|}
\hline CHEMBL594707 & 752386 \\
\hline CHEMBL1352695 & 752386 \\
\hline CHEMBL1481347 & 752386 \\
\hline CHEMBL1521393 & 752386 \\
\hline CHEMBL1551808 & 752386 \\
\hline CHEMBL1348057 & 752386 \\
\hline CHEMBL1420929 & 752386 \\
\hline CHEMBL1485134 & 752386 \\
\hline CHEMBL1465227 & 752386 \\
\hline CHEMBL1325970 & 752386 \\
\hline CHEMBL1362565 & 752386 \\
\hline CHEMBL1328712 & 752386 \\
\hline CHEMBL1365552 & 752386 \\
\hline CHEMBL1403089 & 752386 \\
\hline CHEMBL 3190845 & 752386 \\
\hline CHEMBL1483627 & 752386 \\
\hline CHEMBL1561089 & 752386 \\
\hline CHEMBL1338846 & 752386 \\
\hline CHEMBL1557932 & 752386 \\
\hline CHEMBL1523842 & 752386 \\
\hline CHEMBL3214593 & 752386 \\
\hline CHEMBL1564250 & 752386 \\
\hline CHEMBL1597736 & 752386 \\
\hline CHEMBL1525669 & 752386 \\
\hline CHEMBL1339869 & 752386 \\
\hline CHEMBL1301722 & 752386 \\
\hline CHEMBL1256974 & 752386 \\
\hline CHEMBL1581648 & 752386 \\
\hline CHEMBL1326349 & 752386 \\
\hline CHEMBL1402332 & 752386 \\
\hline CHEMBL1603886 & 752386 \\
\hline CHEMBL1559031 & 752386 \\
\hline CHEMBL1531656 & 752386 \\
\hline CHEMBL1374709 & 752386 \\
\hline CHEMBL1410897 & 752386 \\
\hline CHEMBL1330963 & 752386 \\
\hline CHEMBL1460225 & 752386 \\
\hline CHEMBL1517493 & 752386 \\
\hline CHEMBL1443679 & 752386 \\
\hline CHEMBL1447306 & 752386 \\
\hline CHEMBL1413374 & 752386 \\
\hline CHEMBL1588411 & 752386 \\
\hline CHEMBL1599965 & 752386 \\
\hline CHEMBL1399145 & 752386 \\
\hline CHEMBL1413380 & 752386 \\
\hline CHEMBL1531579 & 752386 \\
\hline CHEMBL1502410 & 752386 \\
\hline CHEMBL1445617 & 752386 \\
\hline
\end{tabular}

Supplemental Table S2.txt

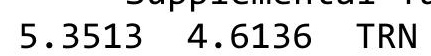

$3.7075 \quad 3.4442$ TRN

$\begin{array}{lll}5.5511 & 4.449 & \text { TST }\end{array}$

$\begin{array}{llll}5.1464 & 5.2747 & \text { TRN }\end{array}$

$\begin{array}{lll}5.0101 & 4.716 & \text { TRN }\end{array}$

$\begin{array}{llll}2.4202 & 4.6899 & \text { TRN }\end{array}$

$\begin{array}{lll}2.4202 & 4.7842 & \text { TRN }\end{array}$

$\begin{array}{llll}5.1322 & 4.9245 & \text { TRN }\end{array}$

$\begin{array}{lll}4.757 & 4.2204 & \text { TRN }\end{array}$

$\begin{array}{lll}4.6124 & 4.0453 & \text { TST }\end{array}$

$5.0242 \quad 5.4759$ TRN

$\begin{array}{lll}2.4202 & 4.9121 & \text { TRN }\end{array}$

$\begin{array}{lll}2.4202 & 4.8752 & \text { TRN }\end{array}$

$\begin{array}{lll}2.4202 & 3.5675 & \text { TST }\end{array}$

$\begin{array}{lll}5.7291 & 5.3093 & \text { TRN }\end{array}$

$\begin{array}{lll}5.6007 & 5.7285 & \text { TRN }\end{array}$

$\begin{array}{lll}5.0711 & 4.311 & \text { TST }\end{array}$

$\begin{array}{llll}5.1029 & 4.5929 & \text { TRN }\end{array}$

$\begin{array}{lll}2.4202 & 4.5127 & \text { TST }\end{array}$

$\begin{array}{lll}5.3216 & 4.9533 & \text { TST }\end{array}$

$\begin{array}{llll}4.4438 & 4.045 & \text { TRN }\end{array}$

$\begin{array}{lll}4.9722 & 4.3022 & \text { TST }\end{array}$

$\begin{array}{lll}2.4202 & 3.4744 & \text { TST }\end{array}$

$\begin{array}{lll}4.1868 & 4.9764 & \text { TRN }\end{array}$

$\begin{array}{llll}4.6295 & 4.2389 & \text { TRN }\end{array}$

$\begin{array}{lll}4.467 & 4.2323 & \text { TRN }\end{array}$

$\begin{array}{llll}2.9208 & 4.4343 & \text { TRN }\end{array}$

$\begin{array}{lll}4.9872 & 4.9083 & \text { TRN }\end{array}$

$\begin{array}{lll}5.4984 & 4.4486 & \text { TRN }\end{array}$

$\begin{array}{lll}5.3796 & 4.3464 & \text { TRN }\end{array}$

$5.0849 \quad 4.5794$ TRN

$2.4202 \quad 3.6209$ TRN

$5.9307 \quad 5.0686 \quad$ TRN

$2.4202 \quad 3.6535$ TST

$2.9208 \quad 4.1776$ TRN

$2.4202 \quad 5.1505$ TRN

$2.4202 \quad 4.4286$ TRN

$2.9208 \quad 4.8284$ TRN

$\begin{array}{lll}5.1886 & 5.1548 \quad \text { TRN }\end{array}$

$5.7176 \quad 5.4198 \quad$ TRN

$\begin{array}{lll}4.5384 & 4.2228 & \text { TRN }\end{array}$

$5.6844 \quad 4.7134$ TRN

$4.7135 \quad 5.4547$ TRN

$\begin{array}{lll}4.9714 & 4.7507 & \text { TRN }\end{array}$

$4.2725 \quad 3.4514$ TRN

$\begin{array}{lll}2.4202 & 4.4719999999999995 & \text { TST }\end{array}$

$\begin{array}{lll}5.0323 & 5.1537 & \text { TRN }\end{array}$

$6.6156 \quad 5.7657$ TRN 


\begin{tabular}{|c|c|c|c|c|c|c|}
\hline & & & & & & \\
\hline CHEMBL1643542 & 752386 & 4.694 & 4.9797 & TRN & & \\
\hline CHEMBL171632 & 752386 & 2.4202 & 5.3789 & TST & & \\
\hline CHEMBL1609405 & 752386 & 4.6876 & 4.4366 & TRN & & \\
\hline CHEMBL1325451 & 752386 & 5.2547 & 4.9367 & TRN & & \\
\hline CHEMBL1495610 & 752386 & 4.5919 & 4.8387 & TRN & & \\
\hline CHEMBL1794278 & 752386 & 4.051 & 4.3019 & TRN & & \\
\hline CHEMBL1460909 & 752386 & 4.7135 & 4.313 & TRN & & \\
\hline CHEMBL1467857 & 752386 & 5.3774 & 4.9075 & TRN & & \\
\hline CHEMBL1306254 & 752386 & 2.4202 & 4.1556 & TRN & & \\
\hline CHEMBL1440300 & 752386 & 5.569 & 5.038 & TRN & & \\
\hline CHEMBL1602314 & 752386 & 4.691 & 5.0794 & TRN & & \\
\hline CHEMBL1500035 & 752386 & 4.2912 & 4.9171 & TRN & & \\
\hline CHEMBL1508051 & 752386 & 4.40600 & 00000000 & 01 & 4.2728 & TST \\
\hline CHEMBL1432707 & 752386 & 5.8681 & 5.5412 & TRN & & \\
\hline CHEMBL3189264 & 752386 & 4.1061 & 4.6354 & TST & & \\
\hline CHEMBL1347107 & 752386 & 6.2255 & 5.7608 & TRN & & \\
\hline CHEMBL1351542 & 752386 & 4.9245 & 4.7905 & TST & & \\
\hline CHEMBL1547684 & 752386 & 5.16700 & 00000000 & & 4.968 & TRN \\
\hline CHEMBL1432432 & 752386 & 4.8147 & 4.5443 & TST & & \\
\hline CHEMBL1342337 & 752386 & 5.95700 & 30000000 & 01 & 5.7484 & TRN \\
\hline CHEMBL1453114 & 752386 & 4.5847 & 4.7963 & TST & & \\
\hline CHEMBL1969046 & 752386 & 4.5683 & 4.8135 & TRN & & \\
\hline CHEMBL1522100 & 752386 & 2.4202 & 4.0481 & TST & & \\
\hline CHEMBL3182716 & 752386 & 5.33 & 5.3728 & TRN & & \\
\hline CHEMBL1576130 & 752386 & 5.2634 & 4.6107 & TRN & & \\
\hline CHEMBL1573331 & 752386 & 6.5844 & 6.3305 & TRN & & \\
\hline CHEMBL1974348 & 752386 & 5.15600 & 30000000 & & 4.9141 & TRN \\
\hline CHEMBL1583996 & 752386 & 4.5547 & 4.801 & TRN & & \\
\hline CHEMBL1405221 & 752386 & 4.4212 & 4.3728 & TST & & \\
\hline CHEMBL1579903 & 752386 & 5.2355 & 4.4779 & TRN & & \\
\hline CHEMBL1483809 & 752386 & 4.4892 & 4.7989 & TST & & \\
\hline CHEMBL1496959 & 752386 & 2.4202 & 4.7803 & TST & & \\
\hline CHEMBL1519280 & 752386 & 4.6234 & 4.3831 & TRN & & \\
\hline CHEMBL1458294 & 752386 & 3.4279 & 3.4888 & TRN & & \\
\hline CHEMBL1308904 & 752386 & 5.8216 & 4.8089 & TRN & & \\
\hline CHEMBL 3144884 & 752386 & 5.8655 & 5.525 & TRN & & \\
\hline CHEMBL1472126 & 752386 & 5.5792 & 6.0193 & TRN & & \\
\hline CHEMBL1529781 & 752386 & 4.9097 & 4.7489 & TRN & & \\
\hline CHEMBL 327574 & 752386 & 2.4202 & 4.2666 & TRN & & \\
\hline CHEMBL1501990 & 752386 & 5.1123 & 4.9936 & TRN & & \\
\hline CHEMBL1378222 & 752386 & 4.8548 & 4.5421 & TRN & & \\
\hline CHEMBL1516834 & 752386 & 4.3779 & 5.6261 & TRN & & \\
\hline CHEMBL1567402 & 752386 & 2.4202 & 5.0391 & TRN & & \\
\hline CHEMBL1585380 & 752386 & 5.103 & 4.8656 & TRN & & \\
\hline CHEMBL1493700 & 752386 & 5.0409 & 4.8235 & TRN & & \\
\hline CHEMBL1606109 & 752386 & 2.4202 & 3.6503 & TRN & & \\
\hline CHEMBL1345991 & 752386 & 2.4202 & 3.4777 & TRN & & \\
\hline CHEMBL1300420 & 752386 & 5.1679 & 4.247 & TRN & & \\
\hline
\end{tabular}




\begin{tabular}{|c|c|c|c|c|c|c|}
\hline & & \multicolumn{5}{|c|}{ Supplemental Table S2.txt } \\
\hline CHEMBL3194896 & 752386 & 3.7238 & 3.6463 & TRN & & \\
\hline CHEMBL1556498 & 752386 & 4.8353 & 4.6154 & TRN & & \\
\hline CHEMBL1333634 & 752386 & 2.4202 & 4.3407 & TRN & & \\
\hline CHEMBL2004417 & 752386 & 5.3743 & 4.6732 & TRN & & \\
\hline CHEMBL1379902 & 752386 & \multicolumn{3}{|c|}{5.127000000000001} & 4.2084 & TRN \\
\hline CHEMBL1577151 & 752386 & 5.3513 & 5.1948 & TRN & & \\
\hline CHEMBL1305642 & 752386 & \multicolumn{3}{|c|}{5.678999999999999} & 5.0462 & TRN \\
\hline CHEMBL3199919 & 752386 & 5.0235 & 4.8586 & TST & & \\
\hline CHEMBL1471012 & 752386 & 5.4379 & 4.2676 & TRN & & \\
\hline CHEMBL1347560 & 752386 & 4.8156 & 4.1846 & TRN & & \\
\hline CHEMBL584626 & 752386 & 6.2407 & \multicolumn{3}{|c|}{5.502999999999999} & TRN \\
\hline CHEMBL1390013 & 752386 & 4.6923 & 4.2977 & TRN & & \\
\hline CHEMBL1488929 & 752386 & 5.2499 & 4.7014 & TRN & & \\
\hline CHEMBL1452061 & 752386 & 5.8735 & 5.4797 & TST & & \\
\hline CHEMBL3214116 & 752386 & 2.4202 & 3.5408 & TST & & \\
\hline CHEMBL1581233 & 752386 & 4.6686 & 4.8855 & TRN & & \\
\hline CHEMBL1974506 & 752386 & 5.4962 & 5.0299 & TST & & \\
\hline CHEMBL1442702 & 752386 & 5.3589 & 4.0061 & TRN & & \\
\hline CHEMBL1526855 & 752386 & 5.5252 & 5.4154 & TRN & & \\
\hline CHEMBL1451931 & 752386 & 2.4202 & 5.5255 & TRN & & \\
\hline CHEMBL1534947 & 752386 & 5.659 & 4.9972 & TRN & & \\
\hline CHEMBL1388764 & 752386 & 4.9255 & 5.2034 & TRN & & \\
\hline CHEMBL1313555 & 752386 & 5.4857 & 5.1841 & TRN & & \\
\hline CHEMBL3397122 & 752386 & 4.6347 & 4.2419 & TRN & & \\
\hline CHEMBL1727428 & 752386 & 6.3548 & 5.6408 & TRN & & \\
\hline CHEMBL1375884 & 752386 & 5.4878 & 4.4413 & TRN & & \\
\hline CHEMBL1405071 & 752386 & 4.4296 & 3.9757 & TRN & & \\
\hline CHEMBL1567670 & 752386 & 5.0322 & 4.8551 & TRN & & \\
\hline CHEMBL1546213 & 752386 & 4.7983 & 4.5582 & TRN & & \\
\hline CHEMBL1304384 & 752386 & 5.2393 & \multicolumn{3}{|c|}{4.6610000000000005} & TRN \\
\hline CHEMBL1485660 & 752386 & 4.3492 & 4.055 & TRN & & \\
\hline CHEMBL1371353 & 752386 & 4.8228 & 5.4455 & TRN & & \\
\hline CHEMBL1973501 & 752386 & 2.4202 & 3.8209 & TRN & & \\
\hline CHEMBL1441508 & 752386 & 2.4202 & 4.3964 & TST & & \\
\hline CHEMBL1596996 & 752386 & 5.0685 & 4.6835 & TRN & & \\
\hline CHEMBL1984648 & 752386 & 4.8598 & 4.1187 & TRN & & \\
\hline CHEMBL1734894 & 752386 & 4.0862 & 4.5368 & TRN & & \\
\hline CHEMBL1731632 & 752386 & 2.4202 & 3.5346 & TST & & \\
\hline CHEMBL1383283 & 752386 & 5.2298 & 4.6741 & TRN & & \\
\hline CHEMBL1322720 & 752386 & 5.0787 & 4.4238 & TRN & & \\
\hline CHEMBL3208288 & 752386 & 4.3506 & 4.0372 & TRN & & \\
\hline CHEMBL1372651 & 752386 & 4.7799 & 4.8794 & TRN & & \\
\hline CHEMBL1439983 & 752386 & 2.4202 & 4.5585 & TRN & & \\
\hline CHEMBL1502297 & 752386 & 4.4959 & 4.2094 & TRN & & \\
\hline CHEMBL1568897 & 752386 & 5.9223 & 5.5162 & TRN & & \\
\hline CHEMBL1537099 & 752386 & 6.2816 & 5.5798 & TRN & & \\
\hline CHEMBL1428683 & 752386 & 5.1737 & 4.3106 & TRN & & \\
\hline CHEMBL1325446 & 752386 & 4.7768 & 4.8937 & TRN & & \\
\hline
\end{tabular}

Page 12413 


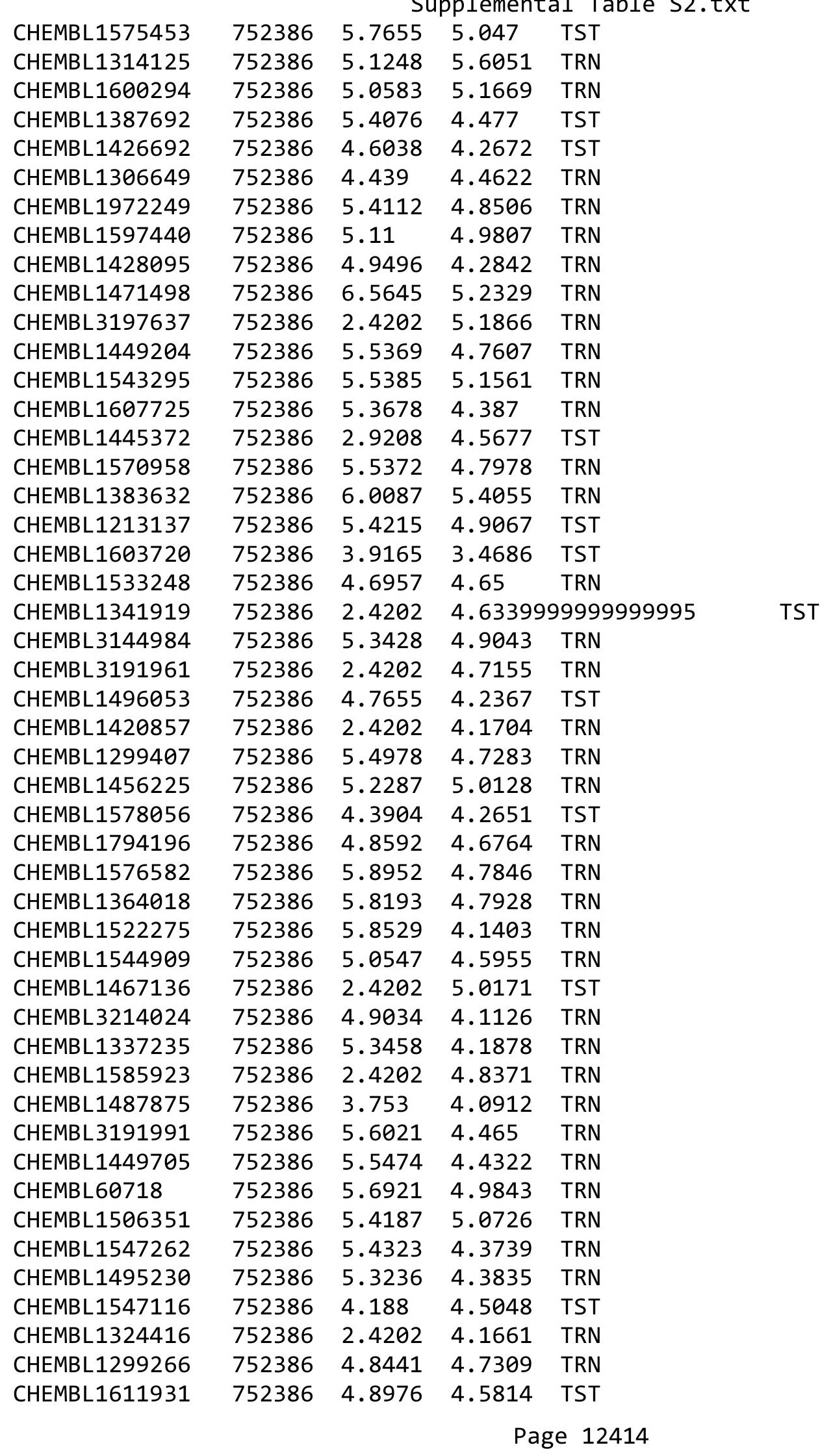




\begin{tabular}{|c|c|c|c|c|c|}
\hline & & & & & \\
\hline CHEMBL1400638 & 752386 & 5.5289 & 5.3678 & TST & \\
\hline CHEMBL1573586 & 752386 & 5.5086 & 4.9676 & TRN & \\
\hline CHEMBL1417929 & 752386 & 6.0883 & 5.8662 & TRN & \\
\hline CHEMBL1537553 & 752386 & 2.4202 & 5.5066 & TRN & \\
\hline CHEMBL1534503 & 752386 & 5.7064 & 4.4571 & TRN & \\
\hline CHEMBL1589309 & 752386 & 5.848 & 4.4984 & TRN & \\
\hline CHEMBL1559810 & 752386 & 5.4755 & 4.9181 & TRN & \\
\hline CHEMBL1339644 & 752386 & 5.244 & 4.5456 & TST & \\
\hline CHEMBL1301920 & 752386 & 4.9694 & 4.4627 & TST & \\
\hline CHEMBL3212479 & 752386 & 5.6983 & 4.3255 & TST & \\
\hline CHEMBL1458019 & 752386 & 2.4202 & 4.1202 & TRN & \\
\hline CHEMBL1536137 & 752386 & 4.8517 & 4.4975 & TRN & \\
\hline CHEMBL1305800 & 752386 & 5.3358 & 5.1961 & TRN & \\
\hline CHEMBL1586263 & 752386 & 2.4202 & 5.17700 & 00000000005 & TRN \\
\hline CHEMBL1461198 & 752386 & 2.4202 & 3.4682 & TRN & \\
\hline CHEMBL1370471 & 752386 & 5.5213 & 5.1161 & TRN & \\
\hline CHEMBL1996376 & 752386 & 4.5624 & 4.50899 & 99999999995 & TRN \\
\hline CHEMBL1471779 & 752386 & 5.3507 & 4.4614 & TRN & \\
\hline CHEMBL1978549 & 752386 & 4.7277 & 4.583 & TRN & \\
\hline CHEMBL3145155 & 752386 & 5.92700 & 00000000 & 5.6463 & TRN \\
\hline CHEMBL1576254 & 752386 & 3.5923 & 3.5078 & TST & \\
\hline CHEMBL1456115 & 752386 & 5.3515 & 4.8473 & TRN & \\
\hline CHEMBL 2006750 & 752386 & 5.3079 & 4.41 & TRN & \\
\hline CHEMBL1300695 & 752386 & 4.2502 & 4.3307 & TRN & \\
\hline CHEMBL1598985 & 752386 & 4.7335 & 4.8497 & TRN & \\
\hline CHEMBL1499544 & 752386 & 5.7387 & 6.0922 & TRN & \\
\hline CHEMBL1439672 & 752386 & 5.2454 & 4.3863 & TRN & \\
\hline CHEMBL1271764 & 752386 & 5.4256 & 5.0157 & TRN & \\
\hline CHEMBL1405577 & 752386 & 2.4202 & 4.0741 & TRN & \\
\hline CHEMBL1313412 & 752386 & 5.7003 & 5.4348 & TRN & \\
\hline CHEMBL3144828 & 752386 & 5.5605 & 5.318 & TRN & \\
\hline CHEMBL1420488 & 752386 & 4.7815 & 4.436 & TRN & \\
\hline CHEMBL1359931 & 752386 & 2.4202 & 5.0775 & TRN & \\
\hline CHEMBL1347984 & 752386 & 5.3155 & 5.0595 & TRN & \\
\hline CHEMBL1307792 & 752386 & 2.4202 & 3.5555 & TRN & \\
\hline CHEMBL1506210 & 752386 & 8.7447 & 5.1395 & TRN & \\
\hline CHEMBL1981667 & 752386 & 2.4202 & 4.6573 & TRN & \\
\hline CHEMBL1453311 & 752386 & 4.9622 & 4.8121 & TRN & \\
\hline CHEMBL1350396 & 752386 & 5.3821 & 4.9164 & TRN & \\
\hline CHEMBL1733076 & 752386 & 2.4202 & 3.4911 & TRN & \\
\hline CHEMBL1404559 & 752386 & 5.3114 & 4.8734 & TRN & \\
\hline CHEMBL1524399 & 752386 & 5.6341 & 5.25899 & 99999999995 & TRN \\
\hline CHEMBL1472108 & 752386 & 5.4168 & 4.4027 & TRN & \\
\hline CHEMBL1345808 & 752386 & 5.0963 & 4.5585 & TRN & \\
\hline CHEMBL1380020 & 752386 & 2.4202 & 4.0869 & TRN & \\
\hline CHEMBL1451917 & 752386 & 4.8016 & 4.1882 & TRN & \\
\hline CHEMBL1458858 & 752386 & 4.1883 & 4.9973 & TRN & \\
\hline CHEMBL1734499 & 752386 & 4.8462 & 4.7337 & TRN & \\
\hline
\end{tabular}

Page 12415 


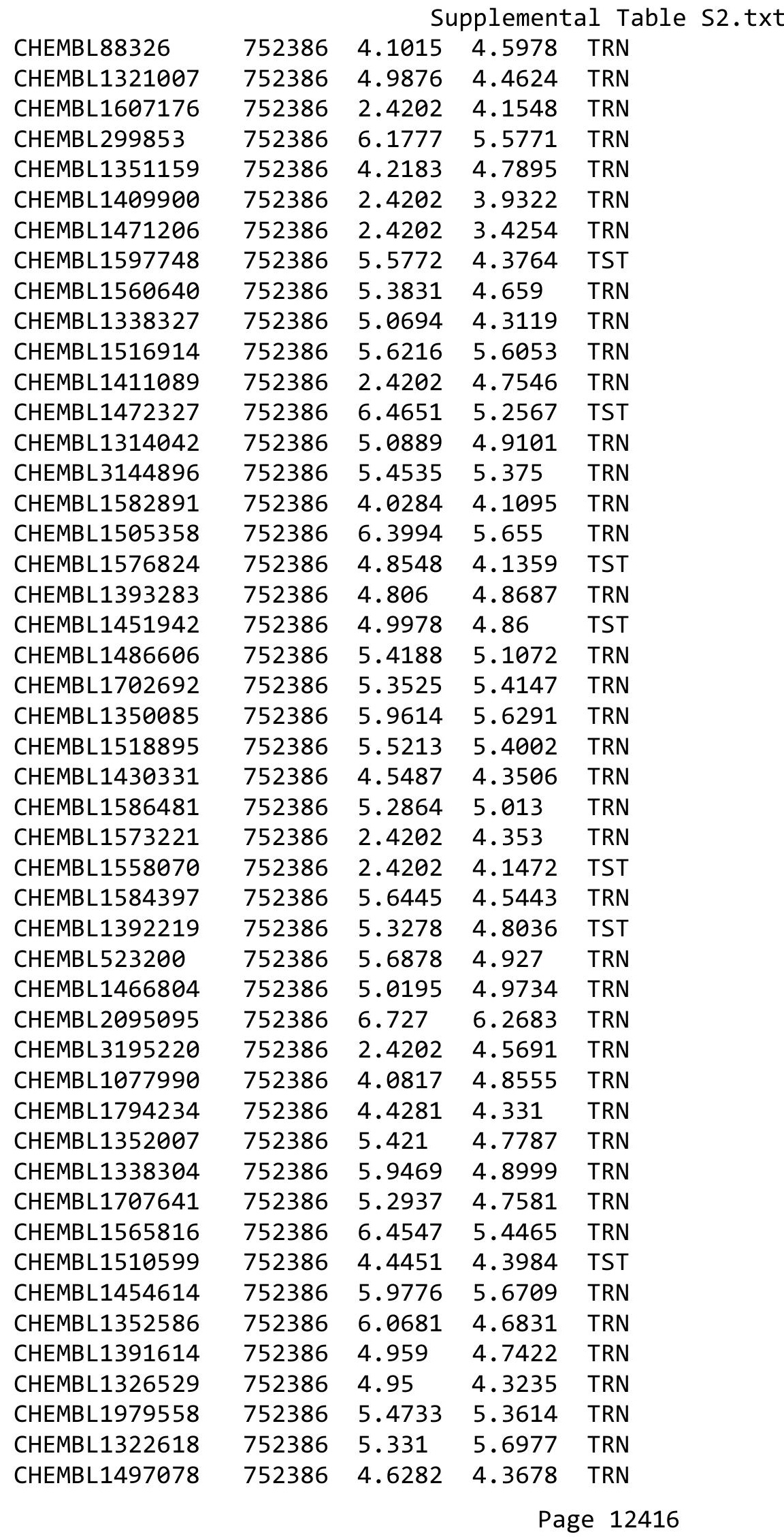




\begin{tabular}{|c|c|c|c|c|c|}
\hline & & & & & \\
\hline CHEMBL1521758 & 752386 & 6.416 & 6.1929 & TRN & \\
\hline CHEMBL1509317 & 752386 & 5.1848 & 4.34399 & 9999999999 & TRN \\
\hline CHEMBL1341835 & 752386 & 4.8359 & 4.8998 & TRN & \\
\hline CHEMBL1537363 & 752386 & 5.3715 & 4.4165 & TRN & \\
\hline CHEMBL1494507 & 752386 & 2.4202 & 3.6731 & TRN & \\
\hline CHEMBL1410350 & 752386 & 5.6737 & 5.3903 & TRN & \\
\hline CHEMBL1567760 & 752386 & 4.776 & 4.8888 & TRN & \\
\hline CHEMBL 2000517 & 752386 & 6.8935 & 6.3212 & TRN & \\
\hline CHEMBL1385433 & 752386 & 5.0595 & 4.7089 & TST & \\
\hline CHEMBL1489956 & 752386 & 4.4626 & 5.0745 & TRN & \\
\hline CHEMBL1532935 & 752386 & 4.7486 & 4.3079 & TST & \\
\hline CHEMBL504911 & 752386 & 4.8542 & 3.9792 & TRN & \\
\hline CHEMBL1403143 & 752386 & 4.6739 & 4.8476 & TST & \\
\hline CHEMBL1536119 & 752386 & 4.0016 & 3.6 & TST & \\
\hline CHEMBL1409588 & 752386 & 4.1773 & 4.237 & TRN & \\
\hline CHEMBL1402954 & 752386 & 5.4648 & 5.2165 & TRN & \\
\hline CHEMBL1566496 & 752386 & 5.1079 & 5.0354 & TRN & \\
\hline CHEMBL1413839 & 752386 & 2.4202 & 4.9164 & TRN & \\
\hline CHEMBL1359282 & 752386 & 6.2692 & 4.7544 & TRN & \\
\hline CHEMBL1401259 & 752386 & 5.5702 & 5.1183 & TRN & \\
\hline CHEMBL1568433 & 752386 & 5.1994 & 4.6073 & TRN & \\
\hline CHEMBL1405287 & 752386 & 4.0462 & 4.2751 & TRN & \\
\hline CHEMBL1510532 & 752386 & 2.4202 & 3.9861 & TRN & \\
\hline CHEMBL1607696 & 752386 & 4.783 & 4.3359 & TRN & \\
\hline CHEMBL1604490 & 752386 & 2.4202 & 3.5128 & TRN & \\
\hline CHEMBL1507657 & 752386 & 5.6284 & 4.5896 & TRN & \\
\hline CHEMBL1439030 & 752386 & 2.4202 & 4.7887 & TST & \\
\hline CHEMBL1389212 & 752386 & 5.105 & 4.9479 & TST & \\
\hline CHEMBL1444045 & 752386 & 5.2541 & 4.7059 & TRN & \\
\hline CHEMBL1493944 & 752386 & 5.5722 & 5.2948 & TRN & \\
\hline CHEMBL1454239 & 752386 & 5.5056 & 5.1443 & TRN & \\
\hline CHEMBL1794141 & 752386 & 5.2901 & 4.7822 & TRN & \\
\hline CHEMBL1383664 & 752386 & 4.9147 & 4.3966 & TRN & \\
\hline CHEMBL1343144 & 752386 & 5.5399 & 4.5842 & TRN & \\
\hline CHEMBL1430291 & 752386 & 5.4915 & 5.1546 & TRN & \\
\hline CHEMBL586029 & 752386 & 5.6859 & 5.1992 & TRN & \\
\hline CHEMBL1581601 & 752386 & 4.147 & 3.9805 & TRN & \\
\hline CHEMBL1426377 & 752386 & 2.4202 & 3.5221 & TST & \\
\hline CHEMBL1498136 & 752386 & 2.4202 & 5.0821 & TRN & \\
\hline CHEMBL1373049 & 752386 & 4.5306 & 4.1352 & TRN & \\
\hline CHEMBL1609009 & 752386 & 3.7778 & 5.1545 & TRN & \\
\hline CHEMBL1466445 & 752386 & 4.2418 & 5.0085 & TRN & \\
\hline CHEMBL1388358 & 752386 & 5.6386 & 5.9108 & TRN & \\
\hline CHEMBL1970867 & 752386 & 4.7997 & 4.5651 & TRN & \\
\hline CHEMBL1566989 & 752386 & 4.1278 & 4.2891 & TST & \\
\hline CHEMBL1502781 & 752386 & 6.3793 & 5.6873 & TRN & \\
\hline CHEMBL1486463 & 752386 & 2.4202 & 3.5748 & TRN & \\
\hline CHEMBL1610025 & 752386 & 5.6264 & 5.2242 & TRN & \\
\hline
\end{tabular}


Supplemental Table S2.txt

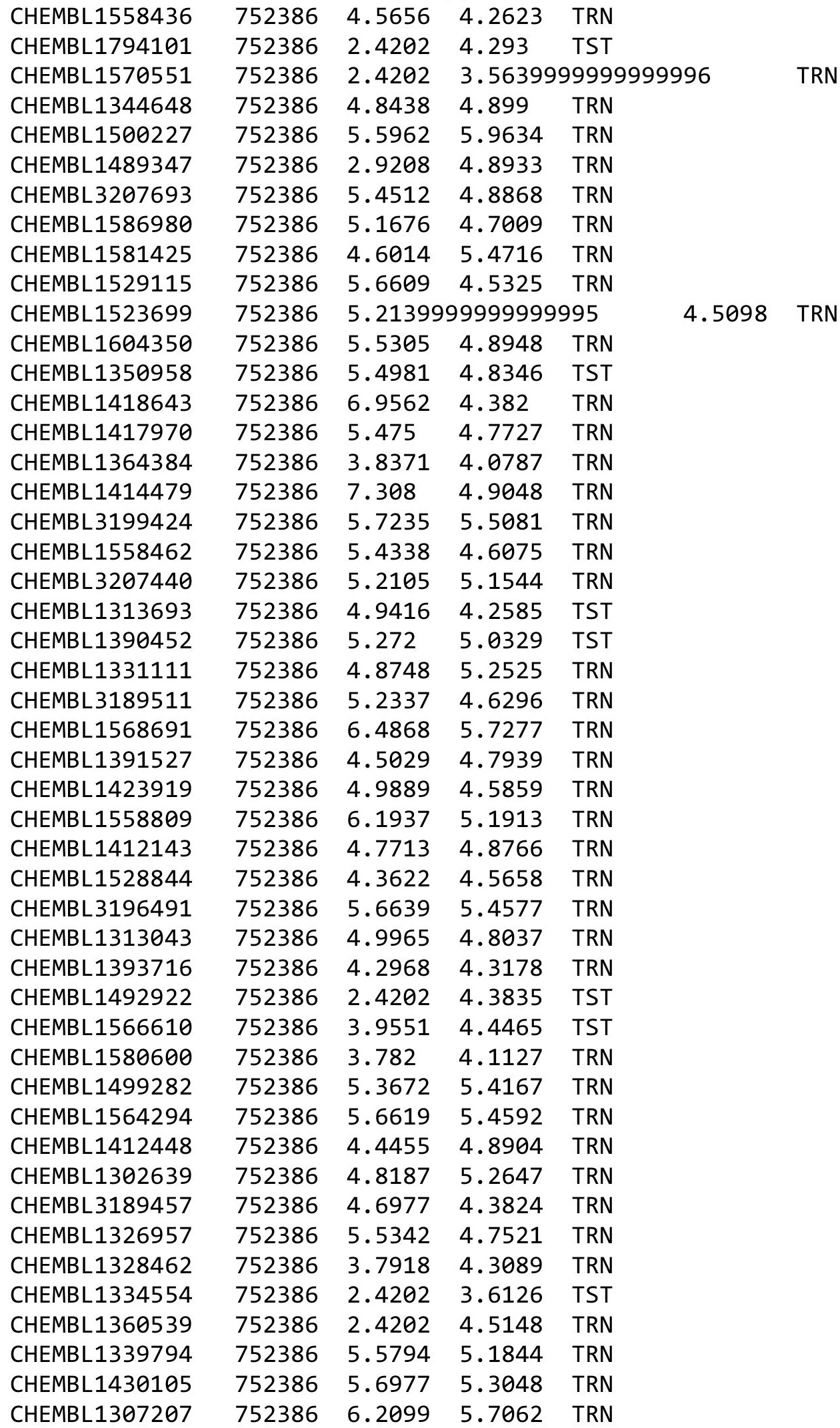

Page 12418 


\begin{tabular}{|c|c|c|c|c|c|}
\hline \multicolumn{6}{|c|}{ Supplemental Table S2.txt } \\
\hline CHEMBL 3212445 & 752386 & 4.2089 & 5.038 & TST & \\
\hline CHEMBL1505902 & 752386 & 4.763 & 4.3103 & TST & \\
\hline CHEMBL1428623 & 752386 & 4.277 & 3.946 & TST & \\
\hline CHEMBL602990 & 752386 & 5.2001 & 4.9154 & TRN & \\
\hline CHEMBL339561 & 752386 & 5.1646 & 5.3225 & TRN & \\
\hline CHEMBL1350983 & 752386 & 5.181 & 4.5802 & TRN & \\
\hline CHEMBL1546217 & 752386 & 4.734 & 4.4889 & TRN & \\
\hline CHEMBL1333617 & 752386 & 4.7354 & 4.9694 & TRN & \\
\hline CHEMBL1470101 & 752386 & 4.3331 & 4.89 & TST & \\
\hline CHEMBL1794153 & 752386 & 4.5504 & 4.3413 & TRN & \\
\hline CHEMBL1600712 & 752386 & 5.2797 & 4.4258 & TST & \\
\hline CHEMBL 2094422 & 752386 & 5.4991 & 5.1711 & TRN & \\
\hline CHEMBL1353155 & 752386 & 6.0 & 4.7478 & TRN & \\
\hline CHEMBL1565888 & 752386 & 5.3964 & 4.4533 & TRN & \\
\hline CHEMBL1301821 & 752386 & 2.9208 & 4.0381 & TST & \\
\hline CHEMBL1573265 & 752386 & 5.4171 & 4.4165 & TST & \\
\hline CHEMBL1401000 & 752386 & 5.4674 & 4.3725 & TRN & \\
\hline CHEMBL1353816 & 752386 & 5.3472 & 4.988 & TRN & \\
\hline CHEMBL1472280 & 752386 & 4.4841 & 4.5817 & TRN & \\
\hline CHEMBL1333637 & 752386 & 5.3361 & 4.6271 & TRN & \\
\hline CHEMBL1580910 & 752386 & 5.6256 & 5.1318 & TST & \\
\hline CHEMBL1374701 & 752386 & 4.8413 & 4.5947 & TRN & \\
\hline CHEMBL 3198718 & 752386 & 2.4202 & 3.6563 & TRN & \\
\hline CHEMBL1529238 & 752386 & 2.4202 & 4.551 & TRN & \\
\hline CHEMBL1473521 & 752386 & 5.2788 & 5.1193 & TST & \\
\hline CHEMBL1402496 & 752386 & 5.5129 & 4.4604 & TST & \\
\hline CHEMBL1308687 & 752386 & 5.4432 & 5.1556 & TRN & \\
\hline CHEMBL1498329 & 752386 & 5.7428 & 5.2974 & TRN & \\
\hline CHEMBL1579122 & 752386 & 5.4065 & 5.1482 & TRN & \\
\hline CHEMBL1368829 & 752386 & 5.4327 & 4.3213 & TRN & \\
\hline CHEMBL1529352 & 752386 & 5.3775 & 4.7549 & TRN & \\
\hline CHEMBL1361855 & 752386 & 5.2699 & 4.7033 & TST & \\
\hline CHEMBL1421433 & 752386 & 5.2911 & 4.7461 & TRN & \\
\hline CHEMBL1546134 & 752386 & 5.401 & 5.3114 & TRN & \\
\hline CHEMBL1496552 & 752386 & 5.3355 & 5.0751 & TRN & \\
\hline CHEMBL1420116 & 752386 & 2.4202 & 5.2522 & TRN & \\
\hline CHEMBL1492648 & 752386 & 5.3094 & 4.3645 & TRN & \\
\hline CHEMBL1308879 & 752386 & 5.437 & 4.9816 & TRN & \\
\hline CHEMBL1455110 & 752386 & 5.4038 & 4.9422 & TST & \\
\hline CHEMBL1594394 & 752386 & 4.3977 & 4.2079 & TRN & \\
\hline CHEMBL1341981 & 752386 & 4.0283 & 4.1507 & TRN & \\
\hline CHEMBL1431075 & 752386 & 5.4514 & 4.56800 & 00000000005 & TRN \\
\hline CHEMBL3191627 & 752386 & 5.9382 & 5.5494 & TRN & \\
\hline CHEMBL 3211966 & 752386 & 5.3548 & 4.4761 & TST & \\
\hline CHEMBL1093246 & 752386 & 4.9784 & 3.9282 & TRN & \\
\hline CHEMBL1308497 & 752386 & 4.8292 & 4.7609 & TRN & \\
\hline CHEMBL1323586 & 752386 & 4.377 & 4.9686 & TRN & \\
\hline CHEMBL1307882 & 752386 & 5.6866 & 4.8551 & TRN & \\
\hline
\end{tabular}




\begin{tabular}{|c|c|c|c|c|}
\hline & & & pplement & al $\mathrm{Ta}$ \\
\hline CHEMBL1525860 & 752386 & 5.3321 & 4.837 & TRN \\
\hline CHEMBL1505544 & 752386 & 2.4202 & 4.457 & TRN \\
\hline CHEMBL1399938 & 752386 & 5.1057 & 5.7522 & TRN \\
\hline CHEMBL1449008 & 752386 & 5.6596 & 4.9958 & TRN \\
\hline CHEMBL1384489 & 752386 & 5.4609 & 4.3207 & TRN \\
\hline CHEMBL1549657 & 752386 & 4.5995 & 5.2825 & TRN \\
\hline CHEMBL1465185 & 752386 & 3.862 & 4.4326 & TRN \\
\hline CHEMBL233549 & 752386 & 2.4202 & 3.5315 & TRN \\
\hline CHEMBL1414175 & 752386 & 5.4227 & 5.4246 & TRN \\
\hline CHEMBL3145078 & 752386 & 4.7185 & 4.5361 & TRN \\
\hline CHEMBL1352444 & 752386 & 5.3853 & 4.9897 & TRN \\
\hline CHEMBL3214581 & 752386 & 4.6194 & 4.0243 & TRN \\
\hline CHEMBL1519022 & 752386 & 5.7111 & 5.4578 & TRN \\
\hline CHEMBL175434 & 752386 & 5.7345 & 5.5231 & TRN \\
\hline CHEMBL1342385 & 752386 & 2.9208 & 4.0524 & TST \\
\hline CHEMBL1392791 & 752386 & 5.3962 & 5.2567 & TRN \\
\hline CHEMBL1459914 & 752386 & 5.0849 & 4.9041 & TRN \\
\hline CHEMBL3192493 & 752386 & 5.0526 & 4.8691 & TRN \\
\hline CHEMBL1466241 & 752386 & 4.5476 & 4.0519 & TRN \\
\hline CHEMBL1606280 & 752386 & 5.2416 & 4.2811 & TRN \\
\hline CHEMBL1322708 & 752386 & 4.7817 & 5.0913 & TST \\
\hline CHEMBL1368413 & 752386 & 2.4202 & 3.6254 & TRN \\
\hline CHEMBL1431612 & 752386 & 2.4202 & 4.494 & TRN \\
\hline CHEMBL1393568 & 752386 & 5.3014 & 4.2974 & TRN \\
\hline CHEMBL1405490 & 752386 & 4.5556 & 4.8113 & TRN \\
\hline CHEMBL1446211 & 752386 & 5.2251 & 4.5536 & TRN \\
\hline CHEMBL1698050 & 752386 & 5.4049 & 3.9303 & TRN \\
\hline CHEMBL1437741 & 752386 & 4.4186 & 4.1594 & TRN \\
\hline CHEMBL1403148 & 752386 & 5.1153 & 5.7903 & TRN \\
\hline CHEMBL1588306 & 752386 & 4.6275 & 4.1382 & TST \\
\hline CHEMBL1322557 & 752386 & 4.7176 & 4.4395 & TRN \\
\hline CHEMBL1611922 & 752386 & 4.5178 & 5.1169 & TRN \\
\hline CHEMBL1402869 & 752386 & 5.2956 & 5.1328 & TRN \\
\hline CHEMBL1480243 & 752386 & 4.1706 & 4.1735 & TRN \\
\hline CHEMBL1533676 & 752386 & 5.5424 & 4.7412 & TRN \\
\hline CHEMBL1605939 & 752386 & 5.3762 & 4.516 & TRN \\
\hline CHEMBL1310967 & 752386 & 5.4738 & 4.2948 & TRN \\
\hline CHEMBL3194415 & 752386 & 5.3031 & 4.9102 & TRN \\
\hline CHEMBL1403329 & 752386 & 5.0774 & 4.5053 & TRN \\
\hline CHEMBL1501755 & 752386 & 5.2422 & 4.9673 & TRN \\
\hline CHEMBL3145018 & 752386 & 5.4811 & 5.1187 & TRN \\
\hline CHEMBL1560379 & 752386 & 5.4911 & 5.0535 & TRN \\
\hline CHEMBL1581228 & 752386 & 2.4202 & 4.0455 & TRN \\
\hline CHEMBL1568009 & 752386 & 4.9014 & 4.9886 & TRN \\
\hline CHEMBL1327390 & 752386 & 5.2149 & 4.8181 & TRN \\
\hline CHEMBL1990545 & 752386 & 2.4202 & 3.9497 & TRN \\
\hline CHEMBL1425245 & 752386 & 2.4202 & 5.2095 & TRN \\
\hline CHEMBL1460524 & 752386 & 4.8438 & 5.0395 & TRN \\
\hline
\end{tabular}


Supplemental Table S2.txt

\begin{tabular}{|c|c|c|c|c|}
\hline 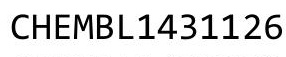 & & & 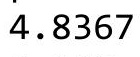 & \\
\hline HEMBL1436932 & 2386 & 2.4202 & 118 & \\
\hline HEMBL1543 & 2386 & 1793 & 231 & \\
\hline IEMBL14 & 2386 & 262 & 9352 & \\
\hline EMBL14 & 386 & & 2109 & \\
\hline HEMBL1455724 & 52386 & .9208 & 4533 & \\
\hline HEMBL1393098 & 52386 & 2.4202 & .5421 & \\
\hline HEMBL1381901 & 386 & & 7923 & \\
\hline 013 & 52386 & 8052 & .5298 & \\
\hline IEMBL15 & 52386 & & 1854 & \\
\hline HEMBL1466516 & 52386 & 2.4202 & 5787 & \\
\hline HEMBL1563469 & 52386 & 2.9208 & 5161 & \\
\hline HEMBL1577280 & 52386 & & 1022 & \\
\hline HEMBL: & 86 & & 81 & \\
\hline AEMBL14 & 86 & & 197 & \\
\hline HEMBL1505716 & 52386 & & 5002 & \\
\hline HEMBL1548898 & 386 & & & \\
\hline HEMBL146 & 86 & & 927 & \\
\hline 600 & 86 & & 505 & \\
\hline 495 & 86 & & 928 & \\
\hline HEMBL13 & 86 & & 542 & RN \\
\hline HEMBL1530927 & 86 & & & \\
\hline HEMBL37 & 86 & & 86 & \\
\hline HEME & & & 312 & \\
\hline HEMBL32 & 86 & & 31 & RN \\
\hline HEMBL 314 & & & & . \\
\hline HEMBL171 & 86 & & 188 & iv \\
\hline HEMBL17 & 86 & & 74 & RN \\
\hline HEM & 36 & & 95 & RN \\
\hline HEM & 86 & & 319 & ST \\
\hline HEMBL1479483 & 36 & & 001 & RN \\
\hline HEMBL1585742 & 86 & & 268 & RN \\
\hline HEMBL1C & 86 & & 991 & RN \\
\hline 8 & 36 & & 61 & RN \\
\hline HEMBL1535849 & 86 & & 091 & ST \\
\hline HEMBL1431334 & 52386 & & 536 & RN \\
\hline HEMBL1504810 & 52386 & & 509 & ST \\
\hline 6 & & & 847 & RN \\
\hline 1 & 36 & & & RN \\
\hline HEMBL153 & & & 416 & RN \\
\hline HEMBL1438890 & 52386 & & 658 & RN \\
\hline HEMBL13 & 86 & & 322 & TRN \\
\hline HEM & & & & \\
\hline LHEMBL14] & & & .001 & RN \\
\hline HEMBL1589625 & & & 5626 & RN \\
\hline HEMBL1409091 & 52386 & & 254 & RN \\
\hline HEMBL 1403154 & & & & \\
\hline HFMRI 13316 & & & & \\
\hline
\end{tabular}

Page 12421 


\begin{tabular}{|c|c|c|c|c|c|}
\hline & & & & & \\
\hline CHEMBL1508459 & 752386 & 3.7926 & 3.9968 & TRN & \\
\hline CHEMBL1608044 & 752386 & 4.5286 & 4.5205 & TRN & \\
\hline CHEMBL1379604 & 752386 & 5.1398 & 5.3967 & TRN & \\
\hline CHEMBL1572216 & 752386 & 2.4202 & 4.4958 & TRN & \\
\hline CHEMBL586135 & 752386 & 4.8674 & 4.7385 & TRN & \\
\hline CHEMBL1364145 & 752386 & 4.7201 & 4.254 & TRN & \\
\hline CHEMBL1389273 & 752386 & 4.5092 & 4.7701 & TRN & \\
\hline CHEMBL1364004 & 752386 & 4.2604 & 4.5601 & TRN & \\
\hline CHEMBL1565623 & 752386 & 5.1202 & 5.3967 & TRN & \\
\hline CHEMBL1376540 & 752386 & 5.2047 & 4.9673 & TRN & \\
\hline CHEMBL578905 & 752386 & 4.1642 & 5.3355 & TRN & \\
\hline CHEMBL3144906 & 752386 & 5.1219 & 5.2501 & TRN & \\
\hline CHEMBL1570673 & 752386 & 2.4202 & 4.9285 & TRN & \\
\hline CHEMBL1571825 & 752386 & 5.4726 & 5.0347 & TRN & \\
\hline CHEMBL3191754 & 752386 & 5.1357 & 4.849 & TRN & \\
\hline CHEMBL1429929 & 752386 & 5.3518 & 4.8267 & TRN & \\
\hline CHEMBL1484934 & 752386 & 5.9504 & 6.01 & TRN & \\
\hline CHEMBL1343329 & 752386 & 4.857 & 4.15300 & 00000000005 & TRN \\
\hline CHEMBL1305372 & 752386 & 4.7469 & 4.652 & TRN & \\
\hline CHEMBL1605867 & 752386 & 5.099 & 5.0689 & TRN & \\
\hline CHEMBL1372179 & 752386 & 4.98300 & 30000000 & 4.4145 & TST \\
\hline CHEMBL1383369 & 752386 & 4.8894 & 4.2169 & TRN & \\
\hline CHEMBL1506757 & 752386 & 4.7825 & 5.1318 & TRN & \\
\hline CHEMBL1364083 & 752386 & 5.6312 & 4.4252 & TRN & \\
\hline CHEMBL1321952 & 752386 & 5.3951 & 4.6427 & TRN & \\
\hline CHEMBL1430450 & 752386 & 5.263 & 5.0218 & TRN & \\
\hline CHEMBL1429537 & 752386 & 5.3793 & 4.4207 & TRN & \\
\hline CHEMBL1529482 & 752386 & 5.3593 & 5.0638 & TRN & \\
\hline CHEMBL505670 & 752386 & 5.2802 & 5.0401 & TRN & \\
\hline CHEMBL1320274 & 752386 & 5.6424 & 5.7475 & TRN & \\
\hline CHEMBL1557116 & 752386 & 5.2284 & 4.9705 & TRN & \\
\hline CHEMBL1569091 & 752386 & 2.4202 & 4.2844 & TRN & \\
\hline CHEMBL3196053 & 752386 & 4.9784 & 4.5042 & TRN & \\
\hline CHEMBL1414814 & 752386 & 4.2303 & 4.1384 & TRN & \\
\hline CHEMBL1459167 & 752386 & 5.155 & 5.1354 & TRN & \\
\hline CHEMBL1530161 & 752386 & 5.5131 & 5.1615 & TRN & \\
\hline CHEMBL1556185 & 752386 & 5.4699 & 5.0734 & TRN & \\
\hline CHEMBL1713763 & 752386 & 2.4202 & 4.4583 & TST & \\
\hline CHEMBL1546297 & 752386 & 6.1522 & 5.638 & TRN & \\
\hline CHEMBL1423138 & 752386 & 5.6321 & 5.2049 & TRN & \\
\hline CHEMBL1498517 & 752386 & 4.6349 & 4.9355 & TRN & \\
\hline CHEMBL582722 & 752386 & 4.7293 & 5.1835 & TRN & \\
\hline CHEMBL1345762 & 752386 & 5.3117 & 4.7815 & TRN & \\
\hline CHEMBL1384468 & 752386 & 5.5756 & 4.773 & TRN & \\
\hline CHEMBL1598272 & 752386 & 6.5038 & 5.7302 & TRN & \\
\hline CHEMBL 3145133 & 752386 & 5.29 & 4.8807 & TRN & \\
\hline CHEMBL1418601 & 752386 & 5.3373 & 4.6857 & TRN & \\
\hline CHEMBL1383240 & 752386 & 5.7249 & 5.4083 & TRN & \\
\hline
\end{tabular}




\begin{tabular}{|c|c|c|c|c|c|c|}
\hline CHEMBL1500823 & 752386 & 4.8245 & 4.573 & TRN & & \\
\hline CHEMBL1539293 & 752386 & 4.8077 & 4.7679 & TRN & & \\
\hline CHEMBL1365234 & 752386 & 6.524 & 5.65600 & 0000000001 & TRN & \\
\hline CHEMBL1491652 & 752386 & 3.9076 & 3.6271 & TST & & \\
\hline CHEMBL1577004 & 752386 & 2.4202 & 5.4145 & TRN & & \\
\hline CHEMBL1372597 & 752386 & 4.9147 & 4.4547 & TRN & & \\
\hline CHEMBL1393844 & 752386 & 2.4202 & 4.3173 & TST & & \\
\hline CHEMBL1706100 & 752386 & 5.0111 & 4.2553 & TRN & & \\
\hline CHEMBL1465144 & 752386 & 5.9289 & 4.5489 & TRN & & \\
\hline CHEMBL1531210 & 752386 & 4.9492 & 4.996 & TRN & & \\
\hline CHEMBL1567419 & 752386 & 4.8356 & 4.2586 & TRN & & \\
\hline CHEMBL1620590 & 752386 & 6.2585 & 5.5815 & TRN & & \\
\hline CHEMBL1700040 & 752386 & 2.4202 & 5.2559 & TRN & & \\
\hline CHEMBL1545792 & 752386 & 4.6523 & 4.7921 & TRN & & \\
\hline CHEMBL1520615 & 752386 & 2.4202 & 4.5791 & TST & & \\
\hline CHEMBL1564699 & 752386 & 5.53600 & 00000000 & 5.1 & 9999999999 & TRN \\
\hline CHEMBL1384253 & 752386 & 5.8726 & 5.2423 & TRN & & \\
\hline CHEMBL1427221 & 752386 & 4.2747 & 4.958 & TRN & & \\
\hline CHEMBL1377610 & 752386 & 4.8928 & 4.2702 & TRN & & \\
\hline CHEMBL1492668 & 752386 & 6.4117 & 3.4542 & TRN & & \\
\hline CHEMBL1525505 & 752386 & 4.6098 & 5.25299 & 9999999999 & TRN & \\
\hline CHEMBL1594740 & 752386 & 5.5105 & 4.5905 & TRN & & \\
\hline CHEMBL1489633 & 752386 & 6.0945 & 5.6902 & TRN & & \\
\hline CHEMBL1463659 & 752386 & 6.2415 & 6.4588 & TRN & & \\
\hline CHEMBL1419252 & 752386 & 4.5364 & 4.4149 & TRN & & \\
\hline CHEMBL1573118 & 752386 & 5.3572 & 4.5905 & TRN & & \\
\hline CHEMBL1535367 & 752386 & 2.4202 & 3.5847 & TRN & & \\
\hline CHEMBL1556750 & 752386 & 4.9161 & 5.3322 & TRN & & \\
\hline CHEMBL1388137 & 752386 & 5.6392 & 5.8844 & TRN & & \\
\hline CHEMBL1566134 & 752386 & 5.0175 & 4.4669 & TRN & & \\
\hline CHEMBL1734451 & 752386 & 5.8564 & 4.6313 & TRN & & \\
\hline CHEMBL1332955 & 752386 & 4.3942 & 4.3318 & TRN & & \\
\hline CHEMBL1442944 & 752386 & 5.8422 & 4.7371 & TRN & & \\
\hline CHEMBL1581068 & 752386 & 5.1819 & 5.0717 & TRN & & \\
\hline CHEMBL1519030 & 752386 & 4.7945 & 4.757 & TST & & \\
\hline CHEMBL1561505 & 752386 & 5.0987 & 4.8807 & TST & & \\
\hline CHEMBL1373969 & 752386 & 5.4907 & 5.8064 & TRN & & \\
\hline CHEMBL1405374 & 752386 & 5.3771 & 4.3888 & TRN & & \\
\hline CHEMBL1335254 & 752386 & 2.4202 & 3.2184 & TRN & & \\
\hline CHEMBL1420811 & 752386 & 5.4594 & 4.2219 & TRN & & \\
\hline CHEMBL1445962 & 752386 & 5.2777 & 5.6206 & TRN & & \\
\hline CHEMBL1733474 & 752386 & 6.6692 & 6.4009 & TRN & & \\
\hline CHEMBL1344426 & 752386 & 4.1057 & 5.04899 & & TRN & \\
\hline CHEMBL1523317 & 752386 & 2.4202 & 4.1065 & TRN & & \\
\hline CHEMBL1377938 & 752386 & 4.9069 & 4.2096 & TRN & & \\
\hline CHEMBL1330787 & 752386 & 2.9208 & 3.6166 & TRN & & \\
\hline CHEMBL1368065 & 752386 & 4.4564 & 4.9727 & TRN & & \\
\hline CHEMBL1381495 & 752386 & 5.6944 & 5.4332 & TST & & \\
\hline
\end{tabular}




\begin{tabular}{|c|c|c|c|c|c|}
\hline \multicolumn{6}{|c|}{ Supplemental Table S2.txt } \\
\hline CHEMBL533226 & 752386 & 5.0247 & 4.9158 & TRN & \\
\hline CHEMBL1300684 & 752386 & 4.9038 & 4.0158 & TRN & \\
\hline CHEMBL1572480 & 752386 & 5.3567 & 5.1292 & TRN & \\
\hline CHEMBL1555899 & 752386 & 4.1771 & 3.6175 & TST & \\
\hline CHEMBL1469314 & 752386 & 4.5299 & 3.96199 & 99999999997 & TRN \\
\hline CHEMBL441282 & 752386 & 5.5352 & 5.1236 & TST & \\
\hline CHEMBL1794266 & 752386 & 5.2687 & 4.6285 & TRN & \\
\hline CHEMBL1337500 & 752386 & 5.1442 & 4.8255 & TST & \\
\hline CHEMBL1392176 & 752386 & 2.4202 & 4.0421 & TRN & \\
\hline CHEMBL1351755 & 752386 & 6.1114 & 6.0349 & TRN & \\
\hline CHEMBL1507776 & 752386 & 5.6187 & 5.2988 & TRN & \\
\hline CHEMBL1535578 & 752386 & 2.9208 & 4.4692 & TST & \\
\hline CHEMBL3145174 & 752386 & 5.1744 & 5.2147 & TRN & \\
\hline CHEMBL1424118 & 752386 & 4.813 & 4.9029 & TRN & \\
\hline CHEMBL1556484 & 752386 & 2.4202 & 3.4737 & TST & \\
\hline CHEMBL3192031 & 752386 & 2.4202 & 5.0997 & TRN & \\
\hline CHEMBL1404013 & 752386 & 2.4202 & 4.0971 & TRN & \\
\hline CHEMBL3144926 & 752386 & 5.6878 & 5.4309 & TRN & \\
\hline CHEMBL1478578 & 752386 & 4.8642 & 5.5019 & TRN & \\
\hline CHEMBL3195106 & 752386 & 4.6068 & 4.8844 & TRN & \\
\hline CHEMBL1979747 & 752386 & 5.4183 & 4.8991 & TRN & \\
\hline CHEMBL1460342 & 752386 & 5.9119 & 5.2116 & TST & \\
\hline CHEMBL1330054 & 752386 & 5.0332 & 4.2141 & TRN & \\
\hline CHEMBL1428096 & 752386 & 3.5574 & 4.9555 & TRN & \\
\hline CHEMBL1495539 & 752386 & 2.4202 & 4.758 & TRN & \\
\hline CHEMBL1468055 & 752386 & 5.3955 & 4.7229 & TRN & \\
\hline CHEMBL1417919 & 752386 & 2.4202 & 3.5936 & TRN & \\
\hline CHEMBL1318943 & 752386 & 2.4202 & 4.9788 & TRN & \\
\hline CHEMBL3144936 & 752386 & 5.0099 & 4.32100 & 0000000001 & TRN \\
\hline CHEMBL3195749 & 752386 & 2.4202 & 5.9011 & TRN & \\
\hline CHEMBL1699978 & 752386 & 4.745 & 5.3219 & TRN & \\
\hline CHEMBL1409494 & 752386 & 4.4901 & 4.457 & TRN & \\
\hline CHEMBL1483235 & 752386 & 5.4959 & 5.045 & TRN & \\
\hline CHEMBL599924 & 752386 & 6.3122 & 6.1464 & TRN & \\
\hline CHEMBL1319867 & 752386 & 5.6588 & 5.1537 & TRN & \\
\hline CHEMBL1582246 & 752386 & 5.4012 & 4.1785 & TRN & \\
\hline CHEMBL1571290 & 752386 & 4.8626 & 4.7429 & TRN & \\
\hline CHEMBL1465938 & 752386 & 6.0529 & 5.8712 & TRN & \\
\hline CHEMBL1461680 & 752386 & 5.6799 & 4.6506 & TRN & \\
\hline CHEMBL1580990 & 752386 & 5.7469 & 5.456 & TRN & \\
\hline CHEMBL1329597 & 752386 & 6.5648 & 5.5349 & TST & \\
\hline CHEMBL1501843 & 752386 & 4.7739 & 4.3235 & TRN & \\
\hline CHEMBL1332119 & 752386 & 5.8837 & 4.4901 & TRN & \\
\hline CHEMBL1200938 & 752386 & 2.4202 & 3.7854 & TST & \\
\hline CHEMBL1341762 & 752386 & 5.3764 & 4.447 & TRN & \\
\hline CHEMBL1710140 & 752386 & 5.5077 & 4.5911 & TST & \\
\hline CHEMBL1549641 & 752386 & 5.6293 & 5.3266 & TRN & \\
\hline CHEMBL1727447 & 752386 & 5.5583 & 4.4501 & TRN & \\
\hline
\end{tabular}




\begin{tabular}{|c|c|c|c|c|c|c|}
\hline \multicolumn{7}{|c|}{ suppteilientas is } \\
\hline CHEMBL1364506 & 752386 & 6.8841 & 5.5995 & TRN & & \\
\hline CHEMBL1308783 & 752386 & 5.3232 & 5.1535 & TRN & & \\
\hline CHEMBL3145223 & 752386 & 5.5969 & 5.6284 & TRN & & \\
\hline CHEMBL3190218 & 752386 & 4.7423 & 4.3524 & TRN & & \\
\hline CHEMBL1583292 & 752386 & 2.4202 & 4.149 & TST & & \\
\hline CHEMBL1570760 & 752386 & 4.8097 & 4.8915 & TRN & & \\
\hline CHEMBL585656 & 752386 & 5.3071 & 5.4626 & TRN & & \\
\hline CHEMBL1980604 & 752386 & 6.6212 & 5.7726 & TRN & & \\
\hline CHEMBL99408 & 752386 & 5.1925 & 4.9152 & TRN & & \\
\hline CHEMBL1482281 & 752386 & 4.7406 & 4.1441 & TRN & & \\
\hline CHEMBL1533621 & 752386 & 2.4202 & 5.181 & TRN & & \\
\hline CHEMBL3194464 & 752386 & 5.01399 & 99999999 & 99 & 3.4789 & TRN \\
\hline CHEMBL1487851 & 752386 & 5.5694 & 5.2217 & TRN & & \\
\hline CHEMBL1415002 & 752386 & 4.6517 & 4.4233 & TST & & \\
\hline CHEMBL1522349 & 752386 & 2.9208 & 4.2445 & TRN & & \\
\hline CHEMBL1519642 & 752386 & 6.4978 & 5.7256 & TRN & & \\
\hline CHEMBL1327934 & 752386 & 2.4202 & 4.9495 & TRN & & \\
\hline CHEMBL1573722 & 752386 & 4.7518 & 4.2494 & TRN & & \\
\hline CHEMBL1542693 & 752386 & 5.769 & 5.7225 & TRN & & \\
\hline CHEMBL1347702 & 752386 & 3.7005 & 3.4302 & TRN & & \\
\hline CHEMBL3189876 & 752386 & 4.6906 & 4.3773 & TRN & & \\
\hline CHEMBL1452114 & 752386 & 5.0717 & 4.4213 & TST & & \\
\hline CHEMBL1605956 & 752386 & 4.8514 & 4.9586 & TRN & & \\
\hline CHEMBL1455639 & 752386 & 4.7865 & 4.2233 & TST & & \\
\hline CHEMBL1391217 & 752386 & 2.4202 & 4.4155 & TST & & \\
\hline CHEMBL1310030 & 752386 & 4.8398 & 4.5028 & TRN & & \\
\hline CHEMBL1453636 & 752386 & 5.2431 & 4.377 & TRN & & \\
\hline CHEMBL3193639 & 752386 & 5.7886 & 5.3297 & TRN & & \\
\hline CHEMBL1535577 & 752386 & 6.1396 & 4.0896 & TRN & & \\
\hline CHEMBL1325219 & 752386 & 5.945 & 5.5772 & TRN & & \\
\hline CHEMBL1520239 & 752386 & 2.4202 & 4.1984 & TRN & & \\
\hline CHEMBL1471341 & 752386 & 5.2552 & 4.3715 & TRN & & \\
\hline CHEMBL1369492 & 752386 & 5.50200 & 000000006 & $\partial 1$ & 4.8204 & TST \\
\hline CHEMBL1609951 & 752386 & 4.4191 & 4.1273 & TRN & & \\
\hline CHEMBL1346883 & 752386 & 5.5235 & 5.263 & TRN & & \\
\hline CHEMBL1565674 & 752386 & 5.358 & 5.1973 & TRN & & \\
\hline CHEMBL1451836 & 752386 & 6.5204 & 5.8134 & TRN & & \\
\hline CHEMBL1532588 & 752386 & 4.8069 & 5.0984 & TST & & \\
\hline CHEMBL1452136 & 752386 & 5.7747 & 4.3637 & TST & & \\
\hline CHEMBL1993627 & 752386 & 2.4202 & 5.2949 & TST & & \\
\hline CHEMBL1595403 & 752386 & 5.2627 & 5.0246 & TST & & \\
\hline CHEMBL1408577 & 752386 & 4.613 & 4.2529 & TST & & \\
\hline CHEMBL1449346 & 752386 & 4.8781 & 4.8122 & TST & & \\
\hline CHEMBL1451681 & 752386 & 5.2294 & 4.9351 & TST & & \\
\hline CHEMBL1335964 & 752386 & 5.0235 & 4.437 & TST & & \\
\hline CHEMBL1520852 & 752386 & 5.67299 & 99999999 & & 5.4913 & TST \\
\hline CHEMBL1545701 & 752386 & 4.2417 & 4.1418 & TST & & \\
\hline CHEMBL1483312 & 752386 & 5.3556 & 5.7037 & TST & & \\
\hline
\end{tabular}




\begin{tabular}{|c|c|c|c|c|c|c|}
\hline & & \\
\hline CHEMBL1332768 & 752386 & 4.6146 & 4.2706 & TST & & \\
\hline CHEMBL1527341 & 752386 & 5.407 & 5.0442 & TST & & \\
\hline CHEMBL1368727 & 752386 & 4.3991 & 4.7794 & TST & & \\
\hline CHEMBL580340 & 752386 & 5.24799 & 99999999 & 99 & 4.9976 & TST \\
\hline CHEMBL1337958 & 752386 & 2.4202 & 3.3437 & TST & & \\
\hline CHEMBL1521427 & 752386 & 5.4516 & 4.9724 & TST & & \\
\hline CHEMBL1444702 & 752386 & 4.1211 & 4.7702 & TST & & \\
\hline CHEMBL1165723 & 752386 & 5.3232 & 4.9721 & TST & & \\
\hline CHEMBL1502394 & 752386 & 5.2607 & 4.9842 & TST & & \\
\hline CHEMBL1321365 & 752386 & 4.9094 & 4.8553 & TST & & \\
\hline CHEMBL52347 & 752386 & 5.2357 & 5.0105 & TST & & \\
\hline CHEMBL3191989 & 752386 & 4.5656 & 5.0953 & TST & & \\
\hline CHEMBL1393004 & 752386 & 6.396 & 5.7796 & TST & & \\
\hline CHEMBL1450196 & 752386 & 5.3261 & 5.1714 & TST & & \\
\hline CHEMBL1706216 & 752386 & 6.3921 & 5.6084 & TST & & \\
\hline CHEMBL1390139 & 752386 & 5.5484 & 5.2394 & TST & & \\
\hline CHEMBL3192535 & 752386 & 2.9208 & 4.1335 & TST & & \\
\hline CHEMBL1445606 & 752386 & 5.1952 & 4.2373 & TST & & \\
\hline CHEMBL1487321 & 752386 & 4.9017 & 4.4109 & TST & & \\
\hline CHEMBL1421056 & 752386 & 3.4954 & 5.2343 & TST & & \\
\hline CHEMBL1577840 & 752386 & 2.4202 & 4.8322 & TST & & \\
\hline CHEMBL3213220 & 752386 & 4.4692 & 3.6012 & TST & & \\
\hline CHEMBL1612774 & 752386 & 4.9872 & 4.7343 & TST & & \\
\hline CHEMBL2000670 & 752386 & 2.4202 & 3.447 & TST & & \\
\hline CHEMBL3191438 & 752386 & 6.0 & 5.5897 & TST & & \\
\hline CHEMBL1369737 & 752386 & 5.2517 & 5.1613 & TST & & \\
\hline CHEMBL1529601 & 752386 & 5.0976 & 5.0003 & TST & & \\
\hline CHEMBL1536089 & 752386 & 5.0902 & 4.5319 & TST & & \\
\hline CHEMBL1567264 & 752386 & 4.5874 & 4.7386 & TST & & \\
\hline CHEMBL1305832 & 752386 & 5.1407 & 4.3934 & TST & & \\
\hline CHEMBL1343392 & 752386 & 5.4366 & 5.2948 & TST & & \\
\hline CHEMBL1545034 & 752386 & 5.5995 & 5.4913 & TST & & \\
\hline CHEMBL1719512 & 752386 & 2.4202 & 3.5302 & TST & & \\
\hline CHEMBL1462615 & 752386 & 5.022 & 4.9915 & TST & & \\
\hline CHEMBL576208 & 752386 & 4.1314 & 5.237 & TST & & \\
\hline CHEMBL1498127 & 752386 & 2.4202 & 4.3529 & TST & & \\
\hline CHEMBL306946 & 752386 & 5.9674 & 4.4736 & TST & & \\
\hline CHEMBL1400375 & 752386 & 6.0093 & 5.41 & TST & & \\
\hline CHEMBL3145089 & 752386 & 5.9133 & 5.7181 & TST & & \\
\hline CHEMBL1511238 & 752386 & 2.4202 & 3.7445 & TST & & \\
\hline CHEMBL1991373 & 752386 & 2.4202 & 3.6851 & TST & & \\
\hline CHEMBL3199015 & 752386 & 4.6745 & 4.8983 & TST & & \\
\hline CHEMBL1447796 & 752386 & 4.978 & 4.6705 & TST & & \\
\hline CHEMBL1486335 & 752386 & 4.2386 & 4.4397 & TST & & \\
\hline CHEMBL1366838 & 752386 & 5.5924 & 5.5369 & TST & & \\
\hline CHEMBL405110 & 752386 & 4.0245 & 4.7097 & TST & & \\
\hline CHEMBL57013 & 752386 & 2.4202 & 5.638 & TST & & \\
\hline CHEMBL1550490 & 752386 & 2.4202 & 4.7485 & TST & & \\
\hline
\end{tabular}




\begin{tabular}{|c|c|c|c|c|c|}
\hline & & \multicolumn{4}{|c|}{ Supplemental Table s2.txt } \\
\hline CHEMBL1390555 & 752386 & 5.4851 & 4.8867 & TST & \\
\hline CHEMBL1370899 & 752386 & 5.1701 & 4.4578 & TST & \\
\hline CHEMBL1719459 & 752386 & 5.0302 & 5.2612 & TST & \\
\hline CHEMBL1709150 & 752386 & 5.1133 & 4.7883 & TST & \\
\hline CHEMBL1309419 & 752386 & 4.6082 & 4.1124 & TST & \\
\hline CHEMBL1330184 & 752386 & 4.7503 & 4.7812 & TST & \\
\hline CHEMBL1449922 & 752386 & 2.4202 & 4.1304 & TST & \\
\hline CHEMBL456881 & 752386 & 4.8765 & 4.7761 & TST & \\
\hline CHEMBL1346860 & 752386 & 6.3813 & 5.4835 & TST & \\
\hline CHEMBL1534185 & 752386 & 4.8389 & 4.2571 & TST & \\
\hline CHEMBL1302625 & 752386 & 2.4202 & 4.1782 & TST & \\
\hline CHEMBL1307096 & 752386 & 5.1322 & 4.4939 & TST & \\
\hline CHEMBL1541219 & 752386 & 5.1399 & 4.7373 & TST & \\
\hline CHEMBL1579988 & 752386 & 4.2715 & 3.592 & TST & \\
\hline CHEMBL1348016 & 752386 & 5.4499 & 5.0506 & TST & \\
\hline CHEMBL1326624 & 752386 & 5.6821 & 4.9698 & TST & \\
\hline CHEMBL1565022 & 752386 & 3.9884 & 3.6439 & TST & \\
\hline CHEMBL590691 & 752386 & 4.7773 & 5.3211 & TST & \\
\hline CHEMBL1410091 & 752386 & 5.3852 & 4.572 & TST & \\
\hline CHEMBL1559156 & 752386 & 2.4202 & 4.7302 & TST & \\
\hline CHEMBL3192106 & 752386 & 5.6003 & 4.8273 & TST & \\
\hline CHEMBL577764 & 752386 & 4.4006 & 4.4315 & TST & \\
\hline CHEMBL3190263 & 752386 & 4.5136 & 4.8132 & TST & \\
\hline CHEMBL1456412 & 752386 & 4.3985 & 4.8366 & TST & \\
\hline CHEMBL3392069 & 752386 & 4.9458 & 4.9731 & TST & \\
\hline CHEMBL1516744 & 752386 & 2.4202 & 4.7359 & TST & \\
\hline CHEMBL1432126 & 752386 & 4.6205 & 4.8662 & TST & \\
\hline CHEMBL1542511 & 752386 & 5.3706 & 5.2612 & TST & \\
\hline CHEMBL1336261 & 752386 & 5.013 & 4.8975 & TST & \\
\hline CHEMBL1560229 & 752386 & 2.4202 & 5.0593 & TST & \\
\hline CHEMBL1707500 & 752386 & 2.4202 & 4.9284 & TST & \\
\hline CHEMBL1568257 & 752386 & 5.0652 & 4.667 & TST & \\
\hline CHEMBL1583184 & 752386 & 5.6178 & 3.9194 & TST & \\
\hline CHEMBL1481417 & 752386 & 4.7111 & 4.6801 & TST & \\
\hline CHEMBL1378877 & 752386 & 5.9359 & 4.5298 & TST & \\
\hline CHEMBL3211571 & 752386 & 5.6256 & 5.1294 & TST & \\
\hline CHEMBL1422056 & 752386 & 5.1955 & 4.9399 & TST & \\
\hline CHEMBL1391913 & 752386 & 4.6906 & 4.6028 & TST & \\
\hline CHEMBL1707033 & 752386 & 2.9208 & 5.4321 & TST & \\
\hline CHEMBL1460750 & 752386 & 4.9767 & 4.3805 & TST & \\
\hline CHEMBL1967862 & 752386 & 5.188 & 5.28700 & 0000000001 & TST \\
\hline CHEMBL1443601 & 752386 & 4.2891 & 4.9576 & TST & \\
\hline CHEMBL1364861 & 752386 & 4.4121 & 4.3519 & TST & \\
\hline CHEMBL1369671 & 752386 & 4.8821 & 5.2275 & TST & \\
\hline CHEMBL1421463 & 752386 & 5.5458 & 5.2562 & TST & \\
\hline CHEMBL600526 & 752386 & 4.6517 & 4.3924 & TST & \\
\hline CHEMBL1489430 & 752386 & 2.4202 & 5.2862 & TST & \\
\hline CHEMBL445304 & 752386 & 2.4202 & 4.9352 & TST & \\
\hline
\end{tabular}


Supplemental Table S2.txt

\begin{tabular}{|c|c|c|c|c|}
\hline CHEMBL3198175 & 752386 & 5.5106 & 4.8324 & TST \\
\hline CHEMBL1348529 & 752386 & 4.7031 & 4.2005 & TST \\
\hline CHEMBL1384089 & 752386 & 5.4479 & 5.0658 & TST \\
\hline CHEMBL1540330 & 752386 & 5.0764 & 5.2305 & TST \\
\hline CHEMBL1409997 & 752386 & 5.0067 & 5.026 & TST \\
\hline CHEMBL1377005 & 752386 & 5.2087 & 4.9479 & TST \\
\hline CHEMBL1433014 & 752386 & 2.4202 & 4.1725 & TST \\
\hline CHEMBL1555858 & 752386 & 5.2516 & 4.7566 & TST \\
\hline CHEMBL1380853 & 752386 & 4.3945 & 4.8122 & TST \\
\hline CHEMBL179794 & 752386 & 5.3267 & 4.5713 & TST \\
\hline CHEMBL1347897 & 752386 & 5.558 & 5.3638 & TST \\
\hline CHEMBL1605235 & 752386 & 5.5109 & 4.8699 & TST \\
\hline CHEMBL 3144932 & 752386 & 5.9389 & 5.6627 & TST \\
\hline CHEMBL1344573 & 752386 & 5.2708 & 4.8768 & TST \\
\hline CHEMBL1423623 & 752386 & 6.0118 & 5.2838 & TST \\
\hline CHEMBL1351794 & 752386 & 5.4468 & 4.3236 & TST \\
\hline CHEMBL1424773 & 752386 & 4.5464 & 3.9496 & TST \\
\hline CHEMBL1349727 & 752386 & 5.086 & 5.4562 & TST \\
\hline CHEMBL1478634 & 752386 & 4.6178 & 5.2716 & TST \\
\hline CHEMBL1503656 & 752386 & 6.3645 & 5.7387 & TST \\
\hline CHEMBL1481657 & 752386 & 5.2751 & 4.7912 & TST \\
\hline CHEMBL1386232 & 752386 & 4.9825 & 4.5451 & TST \\
\hline CHEMBL1526966 & 752386 & 5.4849 & 5.3788 & TST \\
\hline CHEMBL 3191689 & 752386 & 5.2155 & 5.1698 & TST \\
\hline CHEMBL1428166 & 752386 & 5.3606 & 5.1977 & TST \\
\hline CHEMBL1313973 & 752386 & 5.8011 & 5.5422 & TST \\
\hline CHEMBL1076559 & 752386 & 4.1702 & 4.375 & TST \\
\hline CHEMBL1542492 & 752386 & 2.9208 & 4.17 & TST \\
\hline CHEMBL1489005 & 752386 & 2.4202 & 5.1835 & TST \\
\hline CHEMBL1488395 & 752386 & 3.9516 & 4.0309 & TST \\
\hline CHEMBL1418676 & 752386 & 2.4202 & 4.1612 & TST \\
\hline CHEMBL1337382 & 752386 & 3.7883 & 3.6501 & TST \\
\hline CHEMBL1480387 & 752386 & 5.0895 & 5.0553 & TST \\
\hline CHEMBL1548086 & 752386 & 2.4202 & 5.1854 & TST \\
\hline CHEMBL1563903 & 752386 & 6.4896 & 5.6665 & TST \\
\hline CHEMBL592115 & 752386 & 5.3608 & 5.2596 & TST \\
\hline CHEMBL1393351 & 752386 & 5.2974 & 4.6443 & TST \\
\hline CHEMBL1407128 & 752386 & 4.2969 & 5.0917 & TST \\
\hline CHEMBL1464786 & 752386 & 2.9208 & 4.92899 & 9999999999 \\
\hline CHEMBL1449018 & 752386 & 3.8965 & 4.4814 & TST \\
\hline CHEMBL1309645 & 752386 & 2.4202 & 4.40600 & 0000000001 \\
\hline CHEMBL1579455 & 752386 & 3.6603 & 4.2589 & TST \\
\hline CHEMBL1383937 & 752386 & 5.3729 & 4.746 & TST \\
\hline CHEMBL1563864 & 752386 & 4.6478 & 4.8865 & TST \\
\hline CHEMBL1318998 & 752386 & 5.8219 & 5.4079 & TST \\
\hline CHEMBL1399536 & 752386 & 5.5296 & 4.7837 & TST \\
\hline CHEMBL1301509 & 752386 & 4.942 & 4.6252 & TST \\
\hline CHEMBL1333268 & 752386 & 4.7242 & 4.2903 & TST \\
\hline
\end{tabular}


Supplemental Table S2.txt

\begin{tabular}{|c|c|c|c|c|c|c|}
\hline CHEMBL1374511 & 752386 & 2.4202 & 4.3291 & TST & & \\
\hline CHEMBL1406341 & 752386 & 4.8962 & 4.5163 & TST & & \\
\hline CHEMBL1506201 & 752386 & 2.4202 & 3.5207 & TST & & \\
\hline CHEMBL1416089 & 752386 & 5.9416 & 5.2973 & TST & & \\
\hline CHEMBL1341867 & 752386 & 5.4597 & 5.2744 & TST & & \\
\hline CHEMBL1576520 & 752386 & 2.4202 & 4.1533 & TST & & \\
\hline CHEMBL1334903 & 752386 & 4.6672 & 5.2464 & TST & & \\
\hline CHEMBL1553074 & 752386 & 3.8719 & 3.6562 & TST & & \\
\hline CHEMBL1494762 & 752386 & 4.8851 & 4.1189 & TST & & \\
\hline CHEMBL1560706 & 752386 & 4.8726 & 4.6907 & TST & & \\
\hline CHEMBL1574609 & 752386 & 2.4202 & 4.9993 & TST & & \\
\hline CHEMBL1403980 & 752386 & 5.3673 & 5.5279 & TST & & \\
\hline CHEMBL1456285 & 752386 & 4.7854 & 4.3678 & TST & & \\
\hline CHEMBL1483562 & 752386 & 2.4202 & 5.3093 & TST & & \\
\hline CHEMBL1486196 & 752386 & 4.4234 & 3.9511 & TST & & \\
\hline CHEMBL527336 & 752386 & 5.1358 & 5.4647 & TST & & \\
\hline CHEMBL1430827 & 752386 & 5.38899 & 999999999 & 99 & 5.1354 & TST \\
\hline CHEMBL1406895 & 752386 & 2.4202 & 4.6111 & TST & & \\
\hline CHEMBL1586948 & 752386 & 5.5306 & 4.6547 & TST & & \\
\hline CHEMBL1585332 & 752386 & 5.51200 & 000000000 & 005 & 5.0708 & TST \\
\hline CHEMBL1587031 & 752386 & 5.1864 & 4.9181 & TST & & \\
\hline CHEMBL1359342 & 752386 & 2.4202 & 4.8306 & TST & & \\
\hline CHEMBL1989179 & 752386 & 5.63399 & 999999999 & 995 & 4.4818 & \\
\hline CHEMBL1388022 & 752386 & 4.6609 & 4.1667 & TST & & \\
\hline CHEMBL578502 & 752386 & 4.2902 & 4.8228 & TST & & \\
\hline CHEMBL1528476 & 752386 & 5.4885 & 5.0752 & TST & & \\
\hline CHEMBL1494363 & 752386 & 5.3392 & 5.1128 & TST & & \\
\hline CHEMBL1388180 & 752386 & 4.0378 & 3.536 & TST & & \\
\hline CHEMBL1386752 & 752386 & 4.5396 & 4.7856 & TST & & \\
\hline CHEMBL1370184 & 752386 & 2.4202 & 5.0129 & TST & & \\
\hline CHEMBL1400469 & 752386 & 4.9289 & 4.7895 & TST & & \\
\hline CHEMBL1359734 & 752386 & 4.1479 & 3.9399 & TST & & \\
\hline CHEMBL1550423 & 752386 & 2.4202 & 5.1855 & TST & & \\
\hline CHEMBL1512368 & 752386 & 5.6492 & 3.9556 & TST & & \\
\hline CHEMBL1595992 & 752386 & 5.4471 & 4.2253 & TST & & \\
\hline CHEMBL1570497 & 752386 & 2.4202 & 5.2405 & TST & & \\
\hline CHEMBL1352439 & 752386 & 4.2866 & 4.6828 & TST & & \\
\hline CHEMBL1735523 & 752386 & 2.4202 & 3.4172 & TST & & \\
\hline CHEMBL1499853 & 752386 & 5.4276 & 5.2057 & TST & & \\
\hline CHEMBL1312673 & 752386 & 2.4202 & 3.785 & TST & & \\
\hline CHEMBL1985131 & 752386 & 2.4202 & 4.3612 & TST & & \\
\hline CHEMBL1497120 & 752386 & 4.7312 & 4.2487 & TST & & \\
\hline CHEMBL3040442 & 1642210 & 4.6338 & 4.7003 & TRN & & \\
\hline CHEMBL3984792 & 1642210 & 4.575 & 4.6114 & TRN & & \\
\hline CHEMBL3931439 & 1642210 & 4.2753 & 4.4899 & TST & & \\
\hline CHEMBL3040527 & 1642210 & 4.5349 & 4.5459 & TRN & & \\
\hline CHEMBL3959682 & 1642210 & 3.2612 & 4.0109 & TST & & \\
\hline CHEMBL3892361 & 1642210 & 4.3886 & 4.3804 & TRN & & \\
\hline
\end{tabular}


Supplemental Table S2.txt

\begin{tabular}{|c|c|c|c|c|c|}
\hline CHEMBL 3913602 & 1642210 & 4.8111 & 4.8496 & TRN & \\
\hline CHEMBL 3934552 & 1642210 & 4.2988 & 4.2882 & TRN & \\
\hline CHEMBL 3941838 & 1642210 & 4.3415 & 4.3264 & TRN & \\
\hline CHEMBL 3040460 & 1642210 & 3.2612 & 4.1683 & TST & \\
\hline CHEMBL 3976627 & 1642210 & 4.5656 & 4.5427 & TRN & \\
\hline CHEMBL 3040443 & 1642210 & 4.5386 & 4.4936 & TRN & \\
\hline CHEMBL 3935189 & 1642210 & \multicolumn{2}{|c|}{4.821000000000001} & 4.8286 & TRN \\
\hline CHEMBL 3040491 & 1642210 & 3.2612 & 3.2664 & TRN & \\
\hline CHEMBL 3933238 & 1642210 & 3.2612 & 4.012 & TST & \\
\hline CHEMBL 3040493 & 1642210 & 3.2612 & 3.8161 & TST & \\
\hline CHEMBL 3040589 & 1642210 & 4.4592 & 4.5236 & TRN & \\
\hline CHEMBL 3963534 & 1642210 & 3.2612 & 4.248 & TST & \\
\hline CHEMBL 3960618 & 1642210 & 3.2612 & 4.3876 & TST & \\
\hline CHEMBL 3040528 & 1642210 & 4.6036 & 4.6135 & TRN & \\
\hline CHEMBL 3923222 & 1642210 & 3.2612 & 3.2778 & TRN & \\
\hline CHEMBL 3959167 & 1642210 & 4.8324 & 4.8127 & TRN & \\
\hline CHEMBL 3961346 & 1642210 & 3.2612 & 4.8416 & TST & \\
\hline CHEMBL 3962570 & 1642210 & 4.7742 & 4.7656 & TRN & \\
\hline CHEMBL 3040504 & 1642210 & 4.8901 & 4.8139 & TRN & \\
\hline CHEMBL 3940477 & 1642210 & 4.7857 & 5.1085 & TST & \\
\hline CHEMBL 3952658 & 1642210 & 3.2612 & 4.3308 & TST & \\
\hline CHEMBL 3976707 & 1642210 & 4.5005 & 4.4993 & TRN & \\
\hline CHEMBL 3933158 & 1642210 & 4.4309 & 4.4093 & TRN & \\
\hline CHEMBL 3970030 & 1642210 & 3.2612 & 4.4374 & TST & \\
\hline CHEMBL 3897050 & 1642210 & 4.6007 & 4.6049 & TRN & \\
\hline CHEMBL 3944632 & 1642210 & 4.4896 & 4.4712 & TRN & \\
\hline CHEMBL 3040594 & 1642210 & 3.2612 & 3.9609 & TST & \\
\hline CHEMBL 3929408 & 1642210 & 5.2577 & 5.2105 & TST & \\
\hline CHEMBL3985856 & 1642210 & 3.2612 & 3.2737 & TRN & \\
\hline CHEMBL 3950782 & 1642210 & 4.9682 & 4.989 & TRN & \\
\hline CHEMBL 3970731 & 1642210 & 4.5143 & 4.50899 & 99999999995 & Tास \\
\hline CHEMBL 3950467 & 1642210 & 3.2612 & 4.2028 & TST & \\
\hline CHEMBL 3957186 & 1642210 & 4.9154 & 4.9248 & TRN & \\
\hline CHEMBL 3908839 & 1642210 & 3.2612 & 3.2273 & TRN & \\
\hline CHEMBL 3890831 & 1642210 & 4.4263 & 4.42899 & 9999999999 & m \\
\hline CHEMBL 3939041 & 1642210 & 4.4654 & 4.4557 & TRN & \\
\hline CHEMBL3922751 & 1642210 & 4.8761 & 4.8893 & TRN & \\
\hline CHEMBL 3917787 & 1642210 & 4.7426 & 4.7159 & TRN & \\
\hline CHEMBL 3945572 & 1642210 & 4.4196 & 4.4058 & TRN & \\
\hline CHEMBL 3945201 & 1642210 & 4.7948 & 4.8112 & TRN & \\
\hline CHEMBL 3959594 & 1642210 & 4.7708 & 4.7723 & TRN & \\
\hline CHEMBL 3932171 & 1642210 & 3.2612 & 3.2854 & TRN & \\
\hline CHEMBL 3971427 & 1642210 & 4.9739 & 4.9754 & TRN & \\
\hline CHEMBL 3040492 & 1642210 & 3.2612 & 3.225 & TRN & \\
\hline CHEMBL 3984795 & 1642210 & 3.2612 & 3.3104 & TRN & \\
\hline CHEMBL 3911548 & 1642210 & 4.4683 & 4.4204 & TRN & \\
\hline CHEMBL 3902543 & 1642210 & 4.8374 & 4.8579 & TRN & \\
\hline CHEMBL 3953687 & 1642210 & 4.9076 & 4.8969 & TRN & \\
\hline
\end{tabular}

Page 12430 


\begin{tabular}{|c|c|c|c|c|c|}
\hline \multicolumn{6}{|c|}{ Supplemental Table S2 } \\
\hline CHEMBL189025 & 306447 & 6.9788 & 6.8319 & TRN & \\
\hline CHEMBL 365293 & 306447 & 6.1439 & 6.3546 & TRN & \\
\hline CHEMBL189080 & 306447 & 7.9208 & 8.19399 & 9999999999 & TRN \\
\hline CHEMBL 365625 & 306447 & 7.0177 & 7.2787 & TRN & \\
\hline CHEMBL183368 & 306447 & 8.2218 & 8.186 & TRN & \\
\hline CHEMBL189658 & 306447 & 8.6198 & 8.6075 & TRN & \\
\hline CHEMBL188619 & 306447 & 6.5952 & 6.8432 & TRN & \\
\hline CHEMBL187087 & 306447 & 8.5229 & 8.3391 & TRN & \\
\hline CHEMBL185837 & 306447 & 6.4168 & 6.8837 & TST & \\
\hline CHEMBL362355 & 306447 & 6.8729 & 7.282 & TRN & \\
\hline CHEMBL189024 & 306447 & 6.7423 & 6.8475 & TRN & \\
\hline CHEMBL188299 & 306447 & 6.9508 & 7.3052 & TRN & \\
\hline CHEMBL44 & 306447 & 8.0 & 7.3306 & TST & \\
\hline CHEMBL188458 & 306447 & 7.0605 & 7.5722 & TRN & \\
\hline CHEMBL187219 & 306447 & 7.699 & 8.1268 & TRN & \\
\hline CHEMBL187978 & 306447 & 7.0132 & 6.9505 & TST & \\
\hline CHEMBL188846 & 306447 & 8.7212 & 6.7985 & TRN & \\
\hline CHEMBL188528 & 306447 & 8.699 & 7.8294 & TRN & \\
\hline CHEMBL182751 & 306447 & 6.8097 & 7.0394 & TST & \\
\hline CHEMBL188189 & 306447 & 8.0969 & 8.1813 & TRN & \\
\hline CHEMBL187915 & 306447 & 8.8539 & 8.2002 & TRN & \\
\hline CHEMBL189706 & 306447 & 6.7212 & 6.451006 & 00000000005 & TST \\
\hline CHEMBL188516 & 306447 & 6.8697 & 6.8301 & TST & \\
\hline CHEMBL189556 & 306447 & 7.3372 & 7.6472 & TRN & \\
\hline CHEMBL186945 & 306447 & 7.5086 & 7.7798 & TRN & \\
\hline CHEMBL183367 & 306447 & 7.8239 & 7.9492 & TRN & \\
\hline CHEMBL426626 & 306447 & 6.7799 & 7.7757 & TRN & \\
\hline CHEMBL 361266 & 306447 & 6.4486 & 6.1428 & TST & \\
\hline CHEMBL361871 & 306447 & 7.6021 & 7.48799 & 99999999995 & TST \\
\hline CHEMBL188049 & 306447 & 7.8861 & 7.7807 & TRN & \\
\hline CHEMBL187069 & 306447 & 7.3372 & 7.3519 & TRN & \\
\hline CHEMBL 360817 & 306447 & 7.1805 & 7.0714 & TRN & \\
\hline CHEMBL187207 & 306447 & 8.5229 & 8.3812 & TRN & \\
\hline CHEMBL188246 & 306447 & 7.4815 & 7.7391 & TRN & \\
\hline CHEMBL 361078 & 306447 & 8.7447 & 9.0152 & TRN & \\
\hline CHEMBL362356 & 306447 & 7.7959 & 7.5066 & TRN & \\
\hline CHEMBL187671 & 306447 & 5.7959 & 5.9899 & TRN & \\
\hline CHEMBL189077 & 306447 & 8.5229 & 8.3817 & TRN & \\
\hline CHEMBL188230 & 306447 & 7.2291 & 7.2531 & TRN & \\
\hline CHEMBL 188410 & 306447 & 6.153 & 6.3157 & TRN & \\
\hline CHEMBL187392 & 306447 & 7.3098 & 7.0192 & TRN & \\
\hline CHEMBL 360189 & 306447 & 7.6021 & 8.0223 & TRN & \\
\hline CHEMBL189039 & 306447 & 7.3979 & 7.3069 & TRN & \\
\hline CHEMBL 364329 & 306447 & 7.8861 & 7.6893 & TRN & \\
\hline CHEMBL 364176 & 306447 & 7.585 & 7.9337 & TRN & \\
\hline CHEMBL 360651 & 306447 & 8.0 & 8.0796 & TRN & \\
\hline CHEMBL187473 & 306447 & 6.8601 & 6.9502 & TRN & \\
\hline CHEMBL186073 & 306447 & 6.0164 & 6.3171 & TRN & \\
\hline
\end{tabular}


Supplemental Table S2.txt

\begin{tabular}{|c|c|c|c|c|}
\hline CHEMBL365903 & 306447 & 7.0223 & 6.5992 & TST \\
\hline CHEMBL365016 & 306447 & 8.8477 & 7.1051 & TRN \\
\hline CHEMBL189002 & 306447 & 7.4089 & 7.2424 & TRN \\
\hline CHEMBL362307 & 306447 & 8.699 & 8.9064 & TRN \\
\hline CHEMBL188957 & 306447 & 7.9586 & 7.7727 & TRN \\
\hline CHEMBL365045 & 306447 & 6.5045 & 7.2522 & TST \\
\hline CHEMBL435090 & 306447 & 7.699 & 8.1435 & TRN \\
\hline CHEMBL186643 & 306447 & 8.4949 & 8.2894 & TRN \\
\hline CHEMBL189303 & 306447 & 7.8539 & 7.9453 & TRN \\
\hline CHEMBL189822 & 306447 & 7.4318 & 7.7112 & TRN \\
\hline CHEMBL185918 & 306447 & 8.301 & 7.9476 & TRN \\
\hline CHEMBL442037 & 306447 & 6.8041 & 6.9733 & TRN \\
\hline CHEMBL187105 & 306447 & 8.8539 & 8.6545 & TRN \\
\hline CHEMBL186513 & 306447 & 8.2218 & 8.1263 & TRN \\
\hline CHEMBL187673 & 306447 & 7.301 & 7.1566 & TRN \\
\hline CHEMBL188792 & 306447 & 7.2291 & 7.0792 & TST \\
\hline CHEMBL363017 & 306447 & 5.8153 & 6.2803 & TRN \\
\hline CHEMBL362507 & 306447 & 6.6968 & 6.8108 & TRN \\
\hline CHEMBL364333 & 306447 & 4.301 & 5.4208 & TST \\
\hline CHEMBL189073 & 306447 & 6.056 & 6.704 & TRN \\
\hline CHEMBL188951 & 306447 & 5.983 & 6.2405 & TRN \\
\hline CHEMBL187314 & 306447 & 6.2733 & 6.4788 & TRN \\
\hline CHEMBL363955 & 306447 & 8.4559 & 7.9635 & TRN \\
\hline CHEMBL189356 & 306447 & 8.5229 & 8.4012 & TRN \\
\hline CHEMBL188391 & 306447 & 7.2291 & 7.5097 & TST \\
\hline CHEMBL363902 & 306447 & 6.4365 & 6.569 & TST \\
\hline CHEMBL364551 & 306447 & 7.1938 & 7.273 & TST \\
\hline CHEMBL360410 & 306447 & 8.4559 & 7.6663 & TRN \\
\hline CHEMBL364110 & 306447 & 5.4365 & 5.6136 & TST \\
\hline CHEMBL188527 & 306447 & 5.9788 & 6.4345 & TST \\
\hline CHEMBL361063 & 306447 & 7.5686 & 7.6703 & TRN \\
\hline CHEMBL188900 & 306447 & 7.3468 & 7.274 & TRN \\
\hline CHEMBL185783 & 306447 & 6.6289 & 6.4218 & TST \\
\hline CHEMBL361272 & 306447 & 7.7959 & 7.7223 & TRN \\
\hline CHEMBL363963 & 306447 & 8.4318 & 8.2424 & TRN \\
\hline CHEMBL188051 & 306447 & 8.8239 & 8.747 & TRN \\
\hline CHEMBL187393 & 306447 & 7.7696 & 8.0742 & TRN \\
\hline CHEMBL188517 & 306447 & 8.6576 & 7.3007 & TRN \\
\hline CHEMBL189200 & 306447 & 8.5086 & 8.8662 & TRN \\
\hline CHEMBL362793 & 306447 & 7.1938 & 7.1679 & TST \\
\hline CHEMBL362349 & 306447 & 6.6216 & 6.5024 & TST \\
\hline CHEMBL188613 & 306447 & 7.1805 & 7.2158 & TRN \\
\hline CHEMBL186597 & 306447 & 8.301 & 8.5996 & TRN \\
\hline CHEMBL187663 & 306447 & 7.0862 & 7.19799 & 99995 \\
\hline CHEMBL361762 & 306447 & 7.284 & 7.2439 & TST \\
\hline CHEMBL187000 & 306447 & 7.6383 & 7.5453 & TRN \\
\hline CHEMBL363705 & 306447 & 7.3768 & 7.4254 & TST \\
\hline CHEMBL364345 & 306447 & 6.9914 & 7.0902 & TST \\
\hline
\end{tabular}

Page 12432 


\begin{tabular}{|c|c|c|c|c|}
\hline & & & oplement & al Ta \\
\hline CHEMBL188882 & 306447 & 7.2676 & 7.5734 & TRN \\
\hline CHEMBL187937 & 306447 & 7.8239 & 7.8071 & TRN \\
\hline CHEMBL187311 & 306447 & 8.8539 & 8.1439 & TRN \\
\hline CHEMBL187313 & 306447 & 6.2832 & 6.4011 & TST \\
\hline CHEMBL184003 & 306447 & 7.1024 & 7.1708 & TRN \\
\hline CHEMBL185890 & 306447 & 7.9208 & 8.0686 & TRN \\
\hline CHEMBL367588 & 306447 & 8.2218 & 7.3584 & TST \\
\hline CHEMBL188515 & 306447 & 5.8729 & 6.4124 & TRN \\
\hline CHEMBL189287 & 306447 & 7.6021 & 7.7828 & TST \\
\hline CHEMBL186598 & 306447 & 8.4437 & 8.9281 & TRN \\
\hline CHEMBL1257877 & 664906 & 8.4815 & 8.6481 & TRN \\
\hline CHEMBL1257756 & 664906 & 7.2596 & 7.2973 & TRN \\
\hline CHEMBL1258668 & 664906 & 4.301 & 4.0497 & TRN \\
\hline CHEMBL1257635 & 664906 & 9.1549 & 9.2694 & TRN \\
\hline CHEMBL1258447 & 664906 & 7.699 & 7.8995 & TRN \\
\hline CHEMBL1258904 & 664906 & 8.5528 & 8.3382 & TRN \\
\hline CHEMBL214943 & 664906 & 8.9208 & 7.9029 & TST \\
\hline CHEMBL1257879 & 664906 & 9.3979 & 9.0191 & TRN \\
\hline CHEMBL1257632 & 664906 & 9.0458 & 7.6815 & TST \\
\hline CHEMBL1257286 & 664906 & 7.7447 & 8.724 & TRN \\
\hline CHEMBL1258448 & 664906 & 6.1079 & 5.7583 & TRN \\
\hline CHEMBL1257755 & 664906 & 8.0605 & 7.8758 & TRN \\
\hline CHEMBL1258106 & 664906 & 7.0132 & 7.1698 & TRN \\
\hline CHEMBL1258903 & 664906 & 7.5528 & 7.5569 & TRN \\
\hline CHEMBL1257285 & 664906 & 8.301 & 8.3472 & TRN \\
\hline CHEMBL1258785 & 664906 & 9.1549 & 8.9387 & TRN \\
\hline CHEMBL1258784 & 664906 & 8.0555 & 8.3006 & TRN \\
\hline CHEMBL1257517 & 664906 & 9.3979 & 9.2893 & TRN \\
\hline CHEMBL1258220 & 664906 & 5.8539 & 6.2459 & TRN \\
\hline CHEMBL1258337 & 664906 & 8.8539 & 8.1218 & TRN \\
\hline CHEMBL1258449 & 664906 & 8.1805 & 8.6959 & TRN \\
\hline CHEMBL1258558 & 664906 & 9.0 & 9.0727 & TRN \\
\hline CHEMBL1258219 & 664906 & 6.0 & 6.0113 & TRN \\
\hline CHEMBL1258669 & 664906 & 8.6383 & 8.5224 & TRN \\
\hline CHEMBL1256163 & 664906 & 7.3098 & 7.0882 & TRN \\
\hline CHEMBL1257633 & 664906 & 4.301 & 5.1127 & TRN \\
\hline CHEMBL1258670 & 664906 & 8.1871 & 8.7429 & TRN \\
\hline CHEMBL1257989 & 664906 & 7.0 & 7.0615 & TST \\
\hline CHEMBL 1257518 & 664906 & 8.5686 & 8.849 & TRN \\
\hline CHEMBL1257515 & 664906 & 8.1308 & 7.7569 & TST \\
\hline CHEMBL1257759 & 664906 & 9.3979 & 9.3935 & TRN \\
\hline CHEMBL1258107 & 664906 & 7.1938 & 6.4659 & TRN \\
\hline CHEMBL1257758 & 664906 & 9.3979 & 9.0684 & TRN \\
\hline CHEMBL1257404 & 664906 & 8.9208 & 8.6426 & TRN \\
\hline CHEMBL1258557 & 664906 & 9.2218 & 8.8843 & TRN \\
\hline CHEMBL1257757 & 664906 & 8.8861 & 8.0646 & TRN \\
\hline CHEMBL1257170 & 664906 & 9.1549 & 9.1055 & TRN \\
\hline CHEMBL1257514 & 664906 & 9.3979 & 8.0462 & TST \\
\hline
\end{tabular}




\begin{tabular}{|c|c|c|c|c|c|}
\hline \multicolumn{6}{|c|}{ Supplemental Table S2.txt } \\
\hline CHEMBL1257990 & 664906 & 4.301 & 4.3151 & TRN & \\
\hline CHEMBL1258335 & 664906 & 7.6383 & 8.1794 & TRN & \\
\hline CHEMBL1257405 & 664906 & 9.3979 & 9.1086 & TRN & \\
\hline CHEMBL1258336 & 664906 & 7.8239 & 8.246 & TRN & \\
\hline CHEMBL1257169 & 664906 & 8.8861 & 8.9305 & TRN & \\
\hline CHEMBL1258221 & 664906 & 6.9586 & 7.2671 & TST & \\
\hline CHEMBL1257878 & 664906 & 8.0605 & 6.9347 & TST & \\
\hline CHEMBL1257516 & 664906 & 8.3768 & 8.8164 & TST & \\
\hline CHEMBL1257634 & 664906 & 8.699 & 8.7885 & TST & \\
\hline CHEMBL1258556 & 664906 & 5.5376 & 5.0938 & TST & \\
\hline CHEMBL1258105 & 664906 & 6.1871 & 5.8585 & TST & \\
\hline CHEMBL1256164 & 664906 & 8.4559 & 7.6815 & TST & \\
\hline CHEMBL1256165 & 664906 & 4.301 & 6.0364 & TST & \\
\hline CHEMBL 3663441 & 1642542 & 6.3716 & 5.7912 & TST & \\
\hline CHEMBL3663576 & 1642542 & 6.5901 & 6.9191 & TRN & \\
\hline CHEMBL3659189 & 1642542 & 6.4389 & 6.4735 & TRN & \\
\hline CHEMBL 3663406 & 1642542 & 5.5376 & 5.2683 & TRN & \\
\hline CHEMBL 3663432 & 1642542 & 5.0 & 4.9396 & TRN & \\
\hline CHEMBL 3663385 & 1642542 & 5.5086 & 4.6136 & TST & \\
\hline CHEMBL 3663386 & 1642542 & 5.0706 & 4.8239 & TST & \\
\hline CHEMBL 3663542 & 1642542 & 6.1612 & 6.1321 & TRN & \\
\hline CHEMBL 3663394 & 1642542 & 4.0 & 4.3088 & TRN & \\
\hline CHEMBL 3659237 & 1642542 & 6.7595 & 6.4552 & TRN & \\
\hline CHEMBL 3663425 & 1642542 & 6.4685 & 6.6876 & TRN & \\
\hline CHEMBL 3663573 & 1642542 & 4.0 & 3.9999 & TRN & \\
\hline CHEMBL 3659203 & 1642542 & 6.3307 & 6.4164 & TRN & \\
\hline CHEMBL 3663433 & 1642542 & 6.0 & 5.6962 & TRN & \\
\hline CHEMBL3663466 & 1642542 & 6.8239 & 5.9853 & TRN & \\
\hline CHEMBL 3663428 & 1642542 & 6.4498 & 6.3893 & TRN & \\
\hline CHEMBL 3663454 & 1642542 & 5.0 & 5.6626 & TRN & \\
\hline CHEMBL 3663506 & 1642542 & 5.3098 & 5.5147 & TRN & \\
\hline CHEMBL 3663553 & 1642542 & 5.7696 & 5.7123 & TRN & \\
\hline CHEMBL3663474 & 1642542 & 5.3979 & 5.5007 & TRN & \\
\hline CHEMBL 3663420 & 1642542 & 6.5017 & 6.36600 & 00000000005 & TRN \\
\hline CHEMBL3663392 & 1642542 & 4.0 & 3.8158 & TRN & \\
\hline CHEMBL 3659201 & 1642542 & 6.9101 & 7.0439 & TRN & \\
\hline CHEMBL 3663427 & 1642542 & 6.5436 & 6.5008 & TRN & \\
\hline CHEMBL3663476 & 1642542 & 7.4949 & 7.1382 & TRN & \\
\hline CHEMBL 3639623 & 1642542 & 6.2907 & 6.1722 & TST & \\
\hline CHEMBL 3659177 & 1642542 & 6.301 & 6.1293 & TRN & \\
\hline CHEMBL 3659221 & 1642542 & 4.0 & 5.012 & TRN & \\
\hline CHEMBL 3663502 & 1642542 & 7.0458 & 6.4644 & TRN & \\
\hline CHEMBL3663409 & 1642542 & 5.4437 & 5.4153 & TRN & \\
\hline CHEMBL 3663405 & 1642542 & 4.0 & 3.5273 & TRN & \\
\hline CHEMBL3663426 & 1642542 & 6.0 & 6.6096 & TRN & \\
\hline CHEMBL 3663481 & 1642542 & 6.2076 & 6.1453 & TRN & \\
\hline CHEMBL3659197 & 1642542 & 7.9586 & 7.5673 & TRN & \\
\hline CHEMBL3663455 & 1642542 & 5.2292 & 5.539 & TRN & \\
\hline
\end{tabular}


Supplemental Table S2.txt

\begin{tabular}{|c|c|c|c|c|c|}
\hline CHEMBL3659234 & 1642542 & 6.2076 & 6.1046 & TRN & \\
\hline CHEMBL3663461 & 1642542 & 5.7496 & 5.0524 & TRN & \\
\hline CHEMBL3663444 & 1642542 & 5.6383 & 5.7618 & TRN & \\
\hline CHEMBL3659193 & 1642542 & 6.7852 & 6.7723 & TRN & \\
\hline CHEMBL3663478 & 1642542 & 5.3872 & 5.2287 & TRN & \\
\hline CHEMBL3663480 & 1642542 & 5.9208 & 5.6851 & TRN & \\
\hline CHEMBL3663566 & 1642542 & 6.3799 & 6.355 & TRN & \\
\hline CHEMBL3659180 & 1642542 & 6.0 & 6.6024 & TRN & \\
\hline CHEMBL3659231 & 1642542 & 6.4698 & 6.7053 & TRN & \\
\hline CHEMBL3659205 & 1642542 & 6.9706 & 6.6108 & TRN & \\
\hline CHEMBL3663495 & 1642542 & 5.9586 & 5.2097 & TST & \\
\hline CHEMBL3663543 & 1642542 & 4.0 & 3.7444 & TST & \\
\hline CHEMBL3663508 & 1642542 & 5.5086 & 5.6484 & TRN & \\
\hline CHEMBL3659198 & 1642542 & 7.2218 & 6.1628 & TST & \\
\hline CHEMBL3663507 & 1642542 & 5.1249 & 5.0539 & TRN & \\
\hline CHEMBL3663554 & 1642542 & 6.8386 & 5.3689 & TST & \\
\hline CHEMBL3663431 & 1642542 & 5.9586 & 5.4816 & TST & \\
\hline CHEMBL3663527 & 1642542 & 6.1409 & 6.0567 & TRN & \\
\hline CHEMBL3659184 & 1642542 & 6.9208 & 6.8352 & TRN & \\
\hline CHEMBL 3663404 & 1642542 & 6.0757 & 5.9038 & TRN & \\
\hline CHEMBL3659196 & 1642542 & 6.4202 & 5.8444 & TST & \\
\hline CHEMBL3663562 & 1642542 & 6.0297 & 5.6034 & TST & \\
\hline CHEMBL3659212 & 1642542 & 7.0362 & 6.8857 & TRN & \\
\hline CHEMBL3659214 & 1642542 & 8.0 & 6.2549 & TST & \\
\hline CHEMBL3663485 & 1642542 & 5.0555 & 5.4164 & TRN & \\
\hline CHEMBL 3663424 & 1642542 & 6.9066 & 6.8413 & TRN & \\
\hline CHEMBL3663535 & 1642542 & 5.2757 & 5.061 & TST & \\
\hline CHEMBL3659181 & 1642542 & 6.0 & 5.9758 & TST & \\
\hline CHEMBL3663493 & 1642542 & 6.2573 & 5.485 & TST & \\
\hline CHEMBL 3659227 & 1642542 & 5.3098 & 5.5156 & TRN & \\
\hline CHEMBL3659224 & 1642542 & 4.0 & 3.9915 & TRN & \\
\hline CHEMBL3663469 & 1642542 & 5.5976 & 5.2714 & TRN & \\
\hline CHEMBL3639580 & 1642542 & 6.983 & 6.8838 & TRN & \\
\hline CHEMBL 3663489 & 1642542 & 6.4881 & 6.34399 & 9999999999 & TRN \\
\hline CHEMBL3659215 & 1642542 & 6.3788 & 6.0502 & TRN & \\
\hline CHEMBL3659183 & 1642542 & 7.1487 & 6.74700 & 0000000001 & TRN \\
\hline CHEMBL3659220 & 1642542 & 5.6383 & 5.6279 & TRN & \\
\hline CHEMBL3659243 & 1642542 & 6.6576 & 6.9099 & TRN & \\
\hline CHEMBL3663496 & 1642542 & 6.3526 & 6.0287 & TST & \\
\hline CHEMBL3663519 & 1642542 & 5.4815 & 5.5277 & TRN & \\
\hline CHEMBL3659240 & 1642542 & 5.6198 & 5.4472 & TST & \\
\hline CHEMBL 3663524 & 1642542 & 5.6778 & 5.38399 & 99999999995 & TRN \\
\hline CHEMBL3663556 & 1642542 & 6.1296 & 6.2967 & TRN & \\
\hline CHEMBL57712 & 1642542 & 6.5719 & 5.774 & TST & \\
\hline CHEMBL339286 & 1642542 & 6.3686 & 5.8158 & TST & \\
\hline CHEMBL3659217 & 1642542 & 6.7167 & 6.5366 & TRN & \\
\hline CHEMBL 3663383 & 1642542 & 4.0 & 3.7391 & TST & \\
\hline CHEMBL 3663416 & 1642542 & 6.0 & 5.7356 & TRN & \\
\hline
\end{tabular}


Supplemental Table S2.txt

\begin{tabular}{|c|c|c|c|c|c|}
\hline CHEMBL3663399 & 1642542 & 6.6615 & 6.0897 & TST & \\
\hline CHEMBL3663437 & 1642542 & 6.0223 & 5.8527 & TST & \\
\hline CHEMBL3663397 & 1642542 & 4.0 & 4.1927 & TRN & \\
\hline CHEMBL 3659187 & 1642542 & 7.3565 & 7.3846 & TRN & \\
\hline CHEMBL3663442 & 1642542 & 6.6021 & 6.2515 & TRN & \\
\hline CHEMBL3663477 & 1642542 & 5.9586 & 5.9315 & TRN & \\
\hline CHEMBL3931862 & 1642542 & 4.0 & 4.689 & TST & \\
\hline CHEMBL3663389 & 1642542 & 4.0 & 3.8471 & TST & \\
\hline CHEMBL3663401 & 1642542 & 5.6778 & 5.5893 & TRN & \\
\hline CHEMBL3663435 & 1642542 & 5.0 & 5.4976 & TRN & \\
\hline CHEMBL3659208 & 1642542 & 7.5686 & 7.1243 & TRN & \\
\hline CHEMBL3663468 & 1642542 & 5.1367 & 5.2557 & TRN & \\
\hline CHEMBL3663533 & 1642542 & 5.2518 & 5.5156 & TRN & \\
\hline CHEMBL3659213 & 1642542 & 7.2291 & 7.127999 & 9999999999 & TRN \\
\hline CHEMBL3659239 & 1642542 & 5.4318 & 4.9818 & TST & \\
\hline CHEMBL3663439 & 1642542 & 5.4089 & 5.4867 & TRN & \\
\hline CHEMBL3663472 & 1642542 & 6.0 & 6.0521 & TRN & \\
\hline CHEMBL3659232 & 1642542 & 7.0915 & 6.9899 & TRN & \\
\hline CHEMBL3659191 & 1642542 & 7.301 & 6.7552 & TRN & \\
\hline CHEMBL3663473 & 1642542 & 5.3979 & 5.5079 & TRN & \\
\hline CHEMBL3663572 & 1642542 & 6.3716 & 6.4754 & TRN & \\
\hline CHEMBL3663574 & 1642542 & 5.9586 & 5.5816 & TRN & \\
\hline CHEMBL3663530 & 1642542 & 5.9905 & 6.3956 & TRN & \\
\hline CHEMBL3663417 & 1642542 & 5.3188 & 5.4668 & TRN & \\
\hline CHEMBL 3663544 & 1642542 & 6.2848 & 6.1057 & TRN & \\
\hline CHEMBL3663510 & 1642542 & 6.3233 & 6.0699 & TST & \\
\hline CHEMBL3663515 & 1642542 & 5.4815 & 5.6147 & TRN & \\
\hline CHEMBL3663457 & 1642542 & 6.5229 & 6.7058 & TRN & \\
\hline CHEMBL3659209 & 1642542 & 5.9197 & 5.9901 & TST & \\
\hline CHEMBL3663526 & 1642542 & 6.6216 & 6.8046 & TRN & \\
\hline CHEMBL3663575 & 1642542 & 5.9208 & 6.3293 & TRN & \\
\hline CHEMBL3659236 & 1642542 & 6.2396 & 6.7309 & TRN & \\
\hline CHEMBL3663456 & 1642542 & 6.3565 & 6.095 & TST & \\
\hline CHEMBL 3663494 & 1642542 & 6.2581 & 5.6102 & TRN & \\
\hline CHEMBL3663503 & 1642542 & 6.1331 & 6.0609 & TRN & \\
\hline CHEMBL3659207 & 1642542 & 6.4168 & 6.6721 & TRN & \\
\hline CHEMBL 3663545 & 1642542 & 5.301 & 4.0986 & TST & \\
\hline CHEMBL3663411 & 1642542 & 6.8125 & 6.8286 & TRN & \\
\hline CHEMBL3663512 & 1642542 & 5.1739 & 4.5846 & TRN & \\
\hline CHEMBL3663509 & 1642542 & 5.0458 & 5.2415 & TRN & \\
\hline CHEMBL3663563 & 1642542 & 5.8861 & 5.9556 & TRN & \\
\hline CHEMBL3663538 & 1642542 & 6.4237 & 6.1161 & TRN & \\
\hline CHEMBL3663511 & 1642542 & 6.1135 & 6.5181 & TRN & \\
\hline CHEMBL 3663484 & 1642542 & 5.9208 & 5.222 & TRN & \\
\hline CHEMBL3659218 & 1642542 & 5.3566 & 5.722 & TST & \\
\hline CHEMBL3663463 & 1642542 & 4.0 & 4.4342 & TST & \\
\hline CHEMBL3663523 & 1642542 & 6.3098 & 6.984 & TRN & \\
\hline CHEMBL3663548 & 1642542 & 4.0 & 4.3875 & TRN & \\
\hline
\end{tabular}


Supplemental Table S2.txt

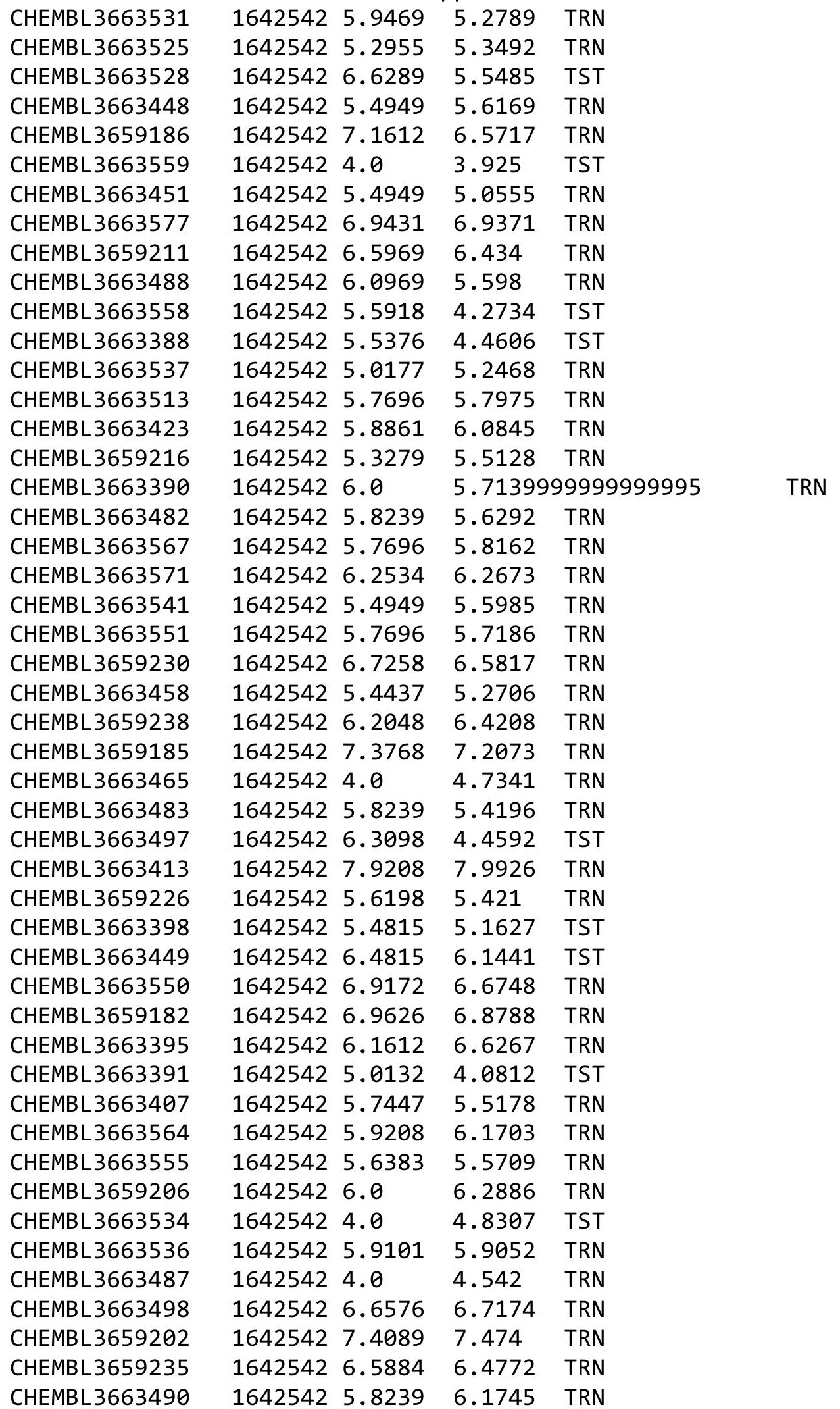

Page 12437 
Supplemental Table S2.txt

\begin{tabular}{|c|c|c|c|c|c|}
\hline CHEMBL3663521 & 1642542 & 4.0 & 3.9231 & TRN & \\
\hline CHEMBL3659233 & 1642542 & 5.2076 & 4.8722 & TRN & \\
\hline CHEMBL3663570 & 1642542 & 6.76200 & 00000000 & 6.5991 & TRN \\
\hline CHEMBL3663408 & 1642542 & 5.9208 & 5.6059 & TRN & \\
\hline CHEMBL 3663467 & 1642542 & 6.2596 & 6.2446 & TRN & \\
\hline CHEMBL 3663384 & 1642542 & 6.062 & 4.9147 & TST & \\
\hline CHEMBL 3659242 & 1642542 & 5.7696 & 5.7139 & TST & \\
\hline CHEMBL3659195 & 1642542 & 6.4045 & 6.3608 & TRN & \\
\hline CHEMBL3663492 & 1642542 & 6.1524 & 6.0136 & TST & \\
\hline CHEMBL3659192 & 1642542 & 5.8239 & 6.1803 & TRN & \\
\hline CHEMBL129596 & 1642542 & 4.0 & 5.1229 & TST & \\
\hline CHEMBL3663438 & 1642542 & 6.1612 & 6.3003 & TRN & \\
\hline CHEMBL 3663540 & 1642542 & 5.9586 & 5.9035 & TRN & \\
\hline CHEMBL 3663387 & 1642542 & 4.0 & 4.9752 & TST & \\
\hline CHEMBL 3663410 & 1642542 & 5.3372 & 5.4015 & TRN & \\
\hline CHEMBL 3663443 & 1642542 & 5.1871 & 5.8373 & TRN & \\
\hline CHEMBL 3659190 & 1642542 & 6.3125 & 6.7604 & TRN & \\
\hline CHEMBL 3663415 & 1642542 & 7.0269 & 7.1604 & TRN & \\
\hline CHEMBL3659176 & 1642542 & 6.5591 & 6.5778 & TRN & \\
\hline CHEMBL3659188 & 1642542 & 6.0 & 6.3126 & TRN & \\
\hline CHEMBL3663529 & 1642542 & 6.5406 & 6.6177 & TRN & \\
\hline CHEMBL 3663422 & 1642542 & 5.6576 & 6.0267 & TRN & \\
\hline CHEMBL 3663446 & 1642542 & 6.5229 & 6.5109 & TRN & \\
\hline CHEMBL 3663400 & 1642542 & 6.0778 & 5.86299 & 99999999995 & \\
\hline CHEMBL3663396 & 1642542 & 7.4202 & 7.4164 & TRN & \\
\hline CHEMBL 3659219 & 1642542 & 5.7447 & 5.9766 & TRN & \\
\hline CHEMBL 3663450 & 1642542 & 6.7077 & 6.3064 & TRN & \\
\hline CHEMBL3663532 & 1642542 & 4.0 & 5.1947 & TRN & \\
\hline CHEMBL 3659194 & 1642542 & 6.7959 & 6.7246 & TRN & \\
\hline CHEMBL3663505 & 1642542 & 5.7447 & \multicolumn{2}{|c|}{5.507000000000001} & \\
\hline CHEMBL 3663440 & 1642542 & 5.9208 & 5.3326 & TRN & \\
\hline CHEMBL 3659210 & 1642542 & 7.6576 & 7.6722 & TRN & \\
\hline CHEMBL 3663403 & 1642542 & 6.0223 & 5.7825 & TRN & \\
\hline CHEMBL3663552 & 1642542 & 5.4318 & 4.6897 & TRN & \\
\hline CHEMBL3663475 & 1642542 & 4.0 & 4.7938 & TRN & \\
\hline CHEMBL 3663520 & 1642542 & 4.0 & 4.5983 & TST & \\
\hline CHEMBL3663560 & 1642542 & 5.6021 & 5.4123 & TST & \\
\hline CHEMBL 3663434 & 1642542 & 5.1427 & 4.9538 & TRN & \\
\hline CHEMBL 3663557 & 1642542 & 6.4841 & 6.3026 & TST & \\
\hline CHEMBL3663436 & 1642542 & 5.1308 & 5.3623 & TRN & \\
\hline CHEMBL 3659241 & 1642542 & 5.1024 & 5.1409 & TRN & \\
\hline CHEMBL 3659228 & 1642542 & 4.0 & 4.4311 & TRN & \\
\hline CHEMBL3663479 & 1642542 & 5.5686 & 4.4722 & TST & \\
\hline CHEMBL 3663421 & 1642542 & 6.6108 & 6.647 & TRN & \\
\hline CHEMBL 3663429 & 1642542 & 6.8794 & 6.8548 & TRN & \\
\hline CHEMBL 3663414 & 1642542 & 7.0044 & 6.7382 & TRN & \\
\hline CHEMBL 3663460 & 1642542 & 6.27 & 5.7903 & TST & \\
\hline CHEMBL 3659222 & 1642542 & 5.6576 & 5.2961 & TRN & \\
\hline
\end{tabular}

Page 12438 
Supplemental Table S2.txt

\begin{tabular}{|c|c|c|c|c|c|}
\hline CHEMBL3663516 & 1642542 & 4.0 & 4.1545 & TST & \\
\hline CHEMBL3663514 & 1642542 & 5.9586 & 6.3606 & TST & \\
\hline CHEMBL3663459 & 1642542 & 4.0 & 3.8709 & TST & \\
\hline CHEMBL 3663547 & 1642542 & 5.9586 & 5.3594 & TST & \\
\hline CHEMBL3663539 & 1642542 & 6.5768 & 6.0067 & TST & \\
\hline CHEMBL3663491 & 1642542 & 6.0645 & 5.6413 & TST & \\
\hline CHEMBL3659199 & 1642542 & 6.8268 & 6.83 & TRN & \\
\hline CHEMBL3663546 & 1642542 & 5.3768 & 4.7962 & TST & \\
\hline CHEMBL3663464 & 1642542 & 5.8386 & \multicolumn{2}{|c|}{5.8260000000000005} & TRN \\
\hline CHEMBL3962823 & 1642542 & 7.1367 & 6.7233 & TRN & \\
\hline CHEMBL 3663452 & 1642542 & 5.699 & 5.6627 & TST & \\
\hline CHEMBL3659204 & 1642542 & 6.1593 & 6.645 & TRN & \\
\hline CHEMBL 3663462 & 1642542 & 6.1046 & 5.9714 & TRN & \\
\hline CHEMBL3663561 & 1642542 & 5.1308 & 4.993 & TST & \\
\hline CHEMBL 3663549 & 1642542 & 6.7258 & 5.294 & TST & \\
\hline CHEMBL3663569 & 1642542 & 5.7212 & 5.3681 & TST & \\
\hline CHEMBL 3663430 & 1642542 & 6.6364 & 7.0795 & TRN & \\
\hline CHEMBL 3659225 & 1642542 & 5.1367 & 5.2759 & TRN & \\
\hline CHEMBL 3659229 & 1642542 & 4.0 & \multicolumn{2}{|c|}{4.861000000000001} & TRN \\
\hline CHEMBL 3663565 & 1642542 & 4.0 & 5.2922 & TST & \\
\hline CHEMBL3663419 & 1642542 & 6.9666 & 7.0521 & TRN & \\
\hline CHEMBL 3663453 & 1642542 & 6.0044 & 6.2058 & TRN & \\
\hline CHEMBL 3663402 & 1642542 & 5.4318 & 5.5485 & TRN & \\
\hline CHEMBL 3639624 & 1642542 & 6.1152 & 5.3304 & TST & \\
\hline CHEMBL 3663447 & 1642542 & 5.3372 & 5.7259 & TRN & \\
\hline CHEMBL 3659200 & 1642542 & 6.9136 & 6.6776 & TRN & \\
\hline CHEMBL3659223 & 1642542 & 6.6946 & 5.8924 & TRN & \\
\hline CHEMBL 3663445 & 1642542 & 6.5229 & 6.1754 & TST & \\
\hline CHEMBL1967982 & 809294 & 3.1899 & 3.6558 & TRN & \\
\hline CHEMBL1378309 & 809294 & 4.5241 & 3.6476 & TRN & \\
\hline CHEMBL1971551 & 809294 & 4.1442 & 3.2737 & TST & \\
\hline CHEMBL1529827 & 809294 & 3.1899 & 3.5023 & TRN & \\
\hline CHEMBL1363112 & 809294 & 4.1441 & 3.3393 & TRN & \\
\hline CHEMBL1351081 & 809294 & 5.0742 & 4.0755 & TRN & \\
\hline CHEMBL1428363 & 809294 & 3.1898 & 3.7009 & TRN & \\
\hline CHEMBL1993189 & 809294 & 3.1898 & 3.3275 & TRN & \\
\hline CHEMBL1539782 & 809294 & 3.1898 & 3.7933 & TST & \\
\hline CHEMBL1452493 & 809294 & 3.1899 & 3.5583 & TRN & \\
\hline CHEMBL1589425 & 809294 & 4.5058 & 3.3744 & TST & \\
\hline CHEMBL1426792 & 809294 & 3.1899 & 3.2758 & TRN & \\
\hline CHEMBL1336032 & 809294 & 3.1901 & 3.3439 & TRN & \\
\hline CHEMBL1998496 & 809294 & 3.1898 & \multicolumn{2}{|c|}{3.4619999999999997} & TST \\
\hline CHEMBL1468519 & 809294 & 3.1899 & 4.016 & TRN & \\
\hline CHEMBL1413591 & 809294 & 3.1896 & 3.0734 & TRN & \\
\hline CHEMBL1422720 & 809294 & 3.1901 & 3.4343 & TRN & \\
\hline CHEMBL1595336 & 809294 & 4.9277 & \multicolumn{2}{|c|}{3.8480000000000003} & TRN \\
\hline CHEMBL1459132 & 809294 & 3.1899 & 3.7031 & TRN & \\
\hline CHEMBL1465836 & 809294 & 3.1901 & 3.5747 & TRN & \\
\hline
\end{tabular}

Page 12439 
Supplemental Table S2.txt

\begin{tabular}{|c|c|c|c|c|c|}
\hline CHEMBL1866397 & 809294 & 4.5796 & 3.3398 & TST & \\
\hline CHEMBL1313430 & 809294 & 3.1902 & 3.1559 & TRN & \\
\hline CHEMBL1565149 & 809294 & 3.1899 & 3.3263 & TRN & \\
\hline CHEMBL1996519 & 809294 & 4.513 & 3.7383 & TRN & \\
\hline CHEMBL1344943 & 809294 & 3.1898 & 3.2085 & TRN & \\
\hline CHEMBL1491086 & 809294 & 3.19 & 3.3421 & TRN & \\
\hline CHEMBL1519529 & 809294 & 3.1901 & 3.4021 & TRN & \\
\hline CHEMBL1731117 & 809294 & 4.9377 & 3.5756 & TRN & \\
\hline CHEMBL1490308 & 809294 & 5.2184 & 3.5764 & TST & \\
\hline CHEMBL1469994 & 809294 & 3.1902 & 3.7305 & TRN & \\
\hline CHEMBL1725374 & 809294 & 4.6372 & 4.2045 & TRN & \\
\hline CHEMBL1536422 & 809294 & 3.1898 & 3.4122 & TRN & \\
\hline CHEMBL1413988 & 809294 & 3.1902 & 3.5103 & TRN & \\
\hline CHEMBL1394750 & 809294 & 5.1165 & 3.9189 & TST & \\
\hline CHEMBL1494120 & 809294 & 5.0015 & 3.6299 & TRN & \\
\hline CHEMBL1536041 & 809294 & 3.1898 & 3.4037 & TRN & \\
\hline CHEMBL1899766 & 809294 & 3.1898 & 3.8865 & TRN & \\
\hline CHEMBL1498537 & 809294 & 3.1898 & 2.9963 & TRN & \\
\hline CHEMBL1533937 & 809294 & 3.1899 & 3.7679 & TST & \\
\hline CHEMBL 2002430 & 809294 & 4.8176 & 3.7131 & TST & \\
\hline CHEMBL1482436 & 809294 & 3.1901 & 3.497 & TRN & \\
\hline CHEMBL1338304 & 809294 & 3.1899 & 4.3216 & TRN & \\
\hline CHEMBL1883677 & 809294 & 3.1898 & 3.5824 & TST & \\
\hline CHEMBL1458873 & 809294 & 3.1898 & 3.3538 & TST & \\
\hline CHEMBL1977109 & 809294 & 3.1896 & 3.4608 & TRN & \\
\hline CHEMBL1717770 & 809294 & 4.8632 & 3.1679 & TST & \\
\hline CHEMBL 2004734 & 809294 & 4.6569 & 3.8358 & TST & \\
\hline CHEMBL1441940 & 809294 & 3.1898 & 3.36 & TST & \\
\hline CHEMBL1733168 & 809294 & 4.9974 & 3.72 & TRN & \\
\hline CHEMBL1574646 & 809294 & 3.1899 & 3.2455 & TRN & \\
\hline CHEMBL1321538 & 809294 & 3.19 & 3.1515 & TRN & \\
\hline CHEMBL1610049 & 809294 & 3.1898 & 3.8177 & TRN & \\
\hline CHEMBL1577986 & 809294 & 3.1898 & 3.7839 & TRN & \\
\hline CHEMBL1547736 & 809294 & 3.19 & 3.7361 & TST & \\
\hline CHEMBL1325640 & 809294 & 4.9165 & 3.1798 & TST & \\
\hline CHEMBL1343185 & 809294 & 3.1898 & 3.1814 & TRN & \\
\hline CHEMBL1372179 & 809294 & 4.8707 & 3.546999 & 99999999997 & TRN \\
\hline CHEMBL587849 & 809294 & 3.1899 & 3.2284 & TRN & \\
\hline CHEMBL1487300 & 809294 & 3.1903 & 2.9958 & TRN & \\
\hline CHEMBL1558038 & 809294 & 3.19 & 2.9864 & TRN & \\
\hline CHEMBL1529304 & 809294 & 3.1898 & 3.5789 & TRN & \\
\hline CHEMBL1702929 & 809294 & 3.1898 & 3.7493 & TST & \\
\hline CHEMBL1418869 & 809294 & 3.1899 & 3.4432 & TRN & \\
\hline CHEMBL1549067 & 809294 & 3.1901 & 3.7967 & TRN & \\
\hline CHEMBL1699592 & 809294 & 5.0567 & 3.3495 & TST & \\
\hline CHEMBL1459350 & 809294 & 3.1899 & 3.5315 & TRN & \\
\hline CHEMBL1441370 & 809294 & 3.1899 & 3.6627 & TRN & \\
\hline CHEMBL1863528 & 809294 & 3.1899 & 3.7235 & TRN & \\
\hline
\end{tabular}




\begin{tabular}{|c|c|c|c|c|c|}
\hline & & \multicolumn{4}{|c|}{ Supplemental Table s2.txt } \\
\hline CHEMBL1530780 & 809294 & 5.0746 & 3.7418 & TRN & \\
\hline CHEMBL1306085 & 809294 & 3.19 & 3.1462 & TRN & \\
\hline CHEMBL1497549 & 809294 & 3.1898 & 3.9139 & TRN & \\
\hline CHEMBL578716 & 809294 & 3.1899 & 3.9709 & TST & \\
\hline CHEMBL1352919 & 809294 & 3.1895 & 3.6484 & TRN & \\
\hline CHEMBL1532794 & 809294 & 4.2075 & 3.2501 & TST & \\
\hline CHEMBL1736185 & 809294 & 3.1898 & 3.4752 & TRN & \\
\hline CHEMBL1431891 & 809294 & 4.6855 & 3.589 & TRN & \\
\hline CHEMBL1602801 & 809294 & 3.1898 & 3.4681 & TRN & \\
\hline CHEMBL1535216 & 809294 & 3.6671 & 3.4931 & TST & \\
\hline CHEMBL1715357 & 809294 & 3.1899 & 3.6815 & TRN & \\
\hline CHEMBL1449374 & 809294 & 3.1896 & 3.2638 & TRN & \\
\hline CHEMBL1393597 & 809294 & 3.1899 & 3.1088 & TRN & \\
\hline CHEMBL1427945 & 809294 & 4.8415 & 3.2755 & TRN & \\
\hline CHEMBL1391094 & 809294 & 4.9242 & 4.11600 & 00000000005 & TRN \\
\hline CHEMBL1385784 & 809294 & 3.1902 & 3.0622 & TRN & \\
\hline CHEMBL1540781 & 809294 & 3.1899 & 3.6044 & TRN & \\
\hline CHEMBL1553553 & 809294 & 3.1901 & 3.8086 & TRN & \\
\hline CHEMBL1988829 & 809294 & 3.19 & 3.5581 & TRN & \\
\hline CHEMBL1566569 & 809294 & 3.1899 & 3.4776 & TRN & \\
\hline CHEMBL1409116 & 809294 & 3.6671 & 3.4094 & TRN & \\
\hline CHEMBL1440902 & 809294 & 3.19 & 3.7162 & TRN & \\
\hline CHEMBL1351102 & 809294 & 3.1895 & 3.2041 & TRN & \\
\hline CHEMBL1717996 & 809294 & 3.19 & 3.5033 & TRN & \\
\hline CHEMBL1503392 & 809294 & 4.7204 & 4.3492 & TRN & \\
\hline CHEMBL1423715 & 809294 & 3.1899 & 3.4056 & TST & \\
\hline CHEMBL1584382 & 809294 & 3.1901 & 3.6463 & TRN & \\
\hline CHEMBL1485617 & 809294 & 3.1896 & 3.4036 & TRN & \\
\hline CHEMBL1310276 & 809294 & 4.809 & 4.3386 & TRN & \\
\hline CHEMBL1499186 & 809294 & 3.19 & 3.3188 & TRN & \\
\hline CHEMBL1464024 & 809294 & 5.0984 & 4.3826 & TRN & \\
\hline CHEMBL1728670 & 809294 & 5.102 & 3.7729 & TST & \\
\hline CHEMBL1415885 & 809294 & 3.1899 & 3.6925 & TRN & \\
\hline CHEMBL1725591 & 809294 & 5.1454 & 3.8815 & TST & \\
\hline CHEMBL1514238 & 809294 & 3.1898 & $2.77100 t$ & 00000000004 & TRN \\
\hline CHEMBL1562233 & 809294 & 3.1899 & 3.5258 & TRN & \\
\hline CHEMBL1501376 & 809294 & 5.093999 & 79999999ऽ & 3.2289 & TST \\
\hline CHEMBL1429014 & 809294 & 3.19 & 3.0506 & TRN & \\
\hline CHEMBL1523206 & 809294 & 5.8914 & 3.7973 & TRN & \\
\hline CHEMBL1464798 & 809294 & 3.19 & 3.8792 & TRN & \\
\hline CHEMBL1887976 & 809294 & 4.938 & 4.0293 & TRN & \\
\hline CHEMBL1420129 & 809294 & 3.1899 & 3.3813 & TRN & \\
\hline CHEMBL1702964 & 809294 & 3.1901 & 3.4342 & TRN & \\
\hline CHEMBL1439680 & 809294 & 4.9535 & 3.771006 & 00000000004 & TRN \\
\hline CHEMBL1372951 & 809294 & 4.6216 & 3.685 & TRN & \\
\hline CHEMBL1880661 & 809294 & 3.1898 & 3.9955 & TRN & \\
\hline CHEMBL1397515 & 809294 & 3.1899 & 3.2953 & TRN & \\
\hline CHEMBL1698464 & 809294 & 5.0274 & 4.1189 & TRN & \\
\hline
\end{tabular}


Supplemental Table S2.txt

\begin{tabular}{|c|c|c|c|c|c|c|}
\hline CHEMBL1602948 & 809294 & 3.1899 & 3.3914 & TRN & & \\
\hline CHEMBL1709150 & 809294 & 3.1904 & 3.0342 & TRN & & \\
\hline CHEMBL1458479 & 809294 & 5.5995 & 3.9 & TRN & & \\
\hline CHEMBL1997928 & 809294 & 3.1899 & 3.59800 & $\partial 0000000$ & $\partial 03$ & $\mathrm{RN}$ \\
\hline CHEMBL1891068 & 809294 & 5.1396 & 3.5227 & TST & & \\
\hline CHEMBL1350706 & 809294 & 3.1899 & 3.9959 & TRN & & \\
\hline CHEMBL1576694 & 809294 & 4.6212 & 4.0443 & TRN & & \\
\hline CHEMBL1548184 & 809294 & 3.19 & 3.2679 & TRN & & \\
\hline CHEMBL1469171 & 809294 & 3.1896 & 3.3202 & TRN & & \\
\hline CHEMBL1372112 & 809294 & 3.1901 & 3.7304 & TRN & & \\
\hline CHEMBL1420519 & 809294 & 3.1898 & 4.0719 & TRN & & \\
\hline CHEMBL1384974 & 809294 & 3.19 & 2.8982 & TRN & & \\
\hline CHEMBL1534919 & 809294 & 4.9004 & 4.0788 & TRN & & \\
\hline CHEMBL1330113 & 809294 & 5.8105 & 3.2908 & TST & & \\
\hline CHEMBL1528149 & 809294 & 5.4167 & 3.2284 & TST & & \\
\hline CHEMBL1507872 & 809294 & 3.1899 & 3.5886 & TRN & & \\
\hline CHEMBL 2003819 & 809294 & 3.1898 & 3.9067 & TRN & & \\
\hline CHEMBL1417218 & 809294 & 3.6671 & 4.0298 & TRN & & \\
\hline CHEMBL1500227 & 809294 & 3.1898 & 3.2075 & TRN & & \\
\hline CHEMBL1587277 & 809294 & 3.19 & 3.4138 & TRN & & \\
\hline CHEMBL1548455 & 809294 & 3.1896 & 3.4106 & TRN & & \\
\hline CHEMBL1517438 & 809294 & 3.1899 & 3.4779 & TRN & & \\
\hline CHEMBL1609674 & 809294 & 3.1898 & 3.5781 & TRN & & \\
\hline CHEMBL355496 & 809294 & 5.1959 & 3.5497 & TST & & \\
\hline CHEMBL1380701 & 809294 & 3.1897 & 3.1028 & TRN & & \\
\hline CHEMBL1442788 & 809294 & 5.4265 & 3.0219 & TST & & \\
\hline CHEMBL1494017 & 809294 & 3.1899 & 3.9953 & TRN & & \\
\hline CHEMBL1530243 & 809294 & 3.1898 & 3.5644 & TRN & & \\
\hline CHEMBL1985344 & 809294 & 3.1901 & 3.792 & TRN & & \\
\hline CHEMBL1356930 & 809294 & 3.1899 & 3.2273 & TRN & & \\
\hline CHEMBL1967395 & 809294 & 4.1447 & 3.5059 & TRN & & \\
\hline CHEMBL1427185 & 809294 & 4.9117 & 3.7379 & TST & & \\
\hline CHEMBL1462900 & 809294 & 3.1898 & 3.8191 & TRN & & \\
\hline CHEMBL1880500 & 809294 & 3.667 & 3.3168 & TRN & & \\
\hline CHEMBL1519347 & 809294 & \multicolumn{3}{|c|}{5.127000000000001} & 3.5438 & 16 \\
\hline CHEMBL1703869 & 809294 & 4.7521 & 3.9347 & TST & & \\
\hline CHEMBL1612159 & 809294 & 3.19 & 3.3878 & TRN & & \\
\hline CHEMBL1701510 & 809294 & 3.1899 & 3.4325 & TRN & & \\
\hline CHEMBL1548086 & 809294 & 4.6141 & 3.3744 & TST & & \\
\hline CHEMBL1499544 & 809294 & 3.1899 & 3.3427 & TRN & & \\
\hline CHEMBL1431116 & 809294 & 3.1898 & 3.6872 & TRN & & \\
\hline CHEMBL1714457 & 809294 & 3.1899 & 3.5939 & TRN & & \\
\hline CHEMBL1537104 & 809294 & 4.1441 & 3.6586 & TRN & & \\
\hline CHEMBL 1447756 & 809294 & 4.1441 & 3.7507 & TRN & & \\
\hline CHEMBL171699 & 809294 & 3.1899 & 3.6486 & TST & & \\
\hline CHEMBL1560622 & 809294 & 3.1898 & 4.0453 & TRN & & \\
\hline CHEMBL1575552 & 809294 & 3.19 & 3.9638 & TRN & & \\
\hline CHEMBL1705379 & 809294 & 4.7399 & 3.3642 & TRN & & \\
\hline
\end{tabular}

Page 12442 


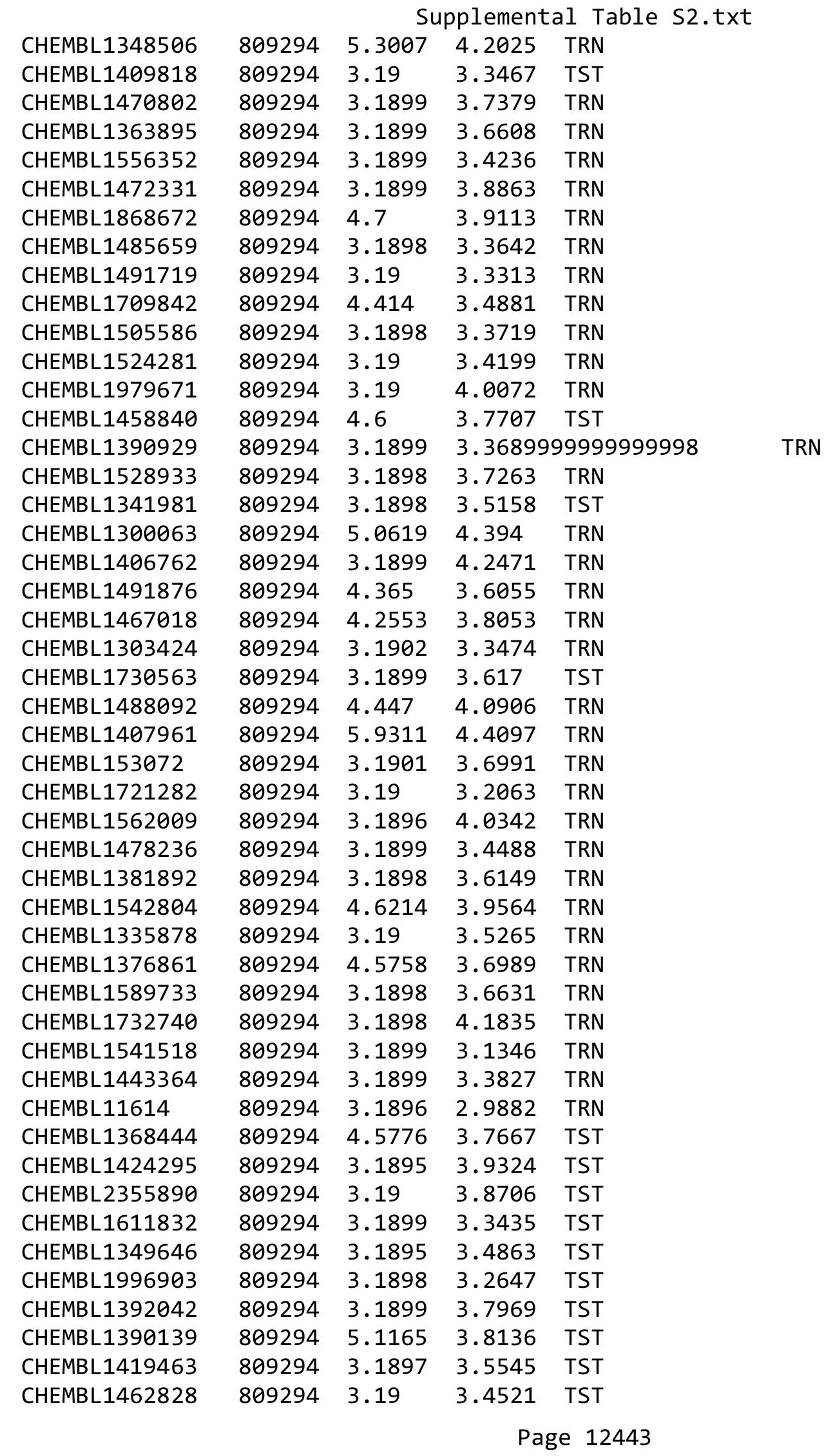




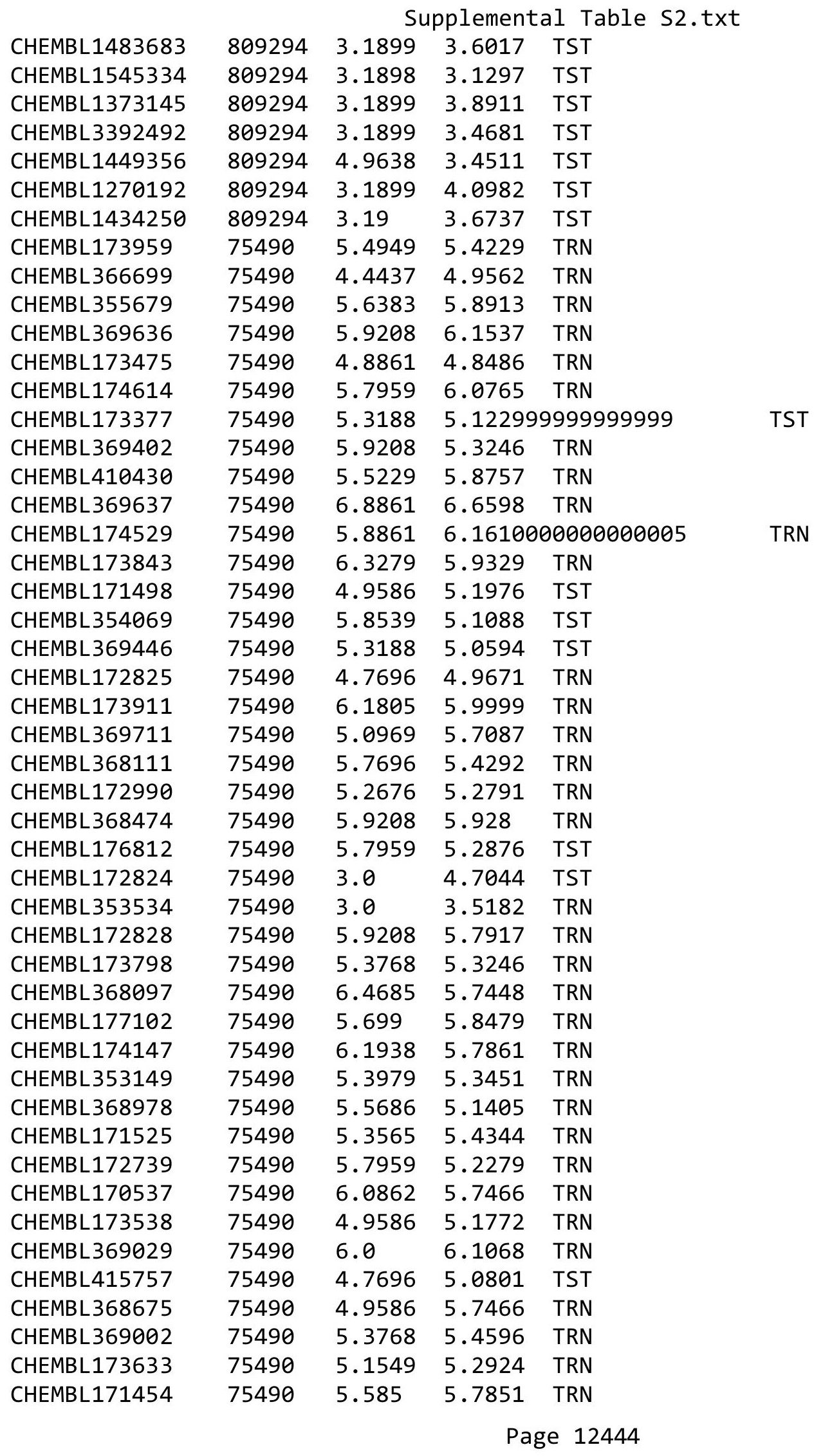




\begin{tabular}{|c|c|c|c|c|c|c|}
\hline & & \multicolumn{5}{|c|}{ Supplemental Table S2.txt } \\
\hline CHEMBL366895 & 75490 & 5.3979 & 5.2474 & TST & & \\
\hline CHEMBL171521 & 75490 & 3.0 & 4.6181 & TST & & \\
\hline CHEMBL174510 & 75490 & 5.4202 & 5.3494 & TRN & & \\
\hline CHEMBL171842 & 75490 & 5.8861 & 5.9637 & TRN & & \\
\hline CHEMBL367640 & 75490 & 5.2076 & 5.1483 & TRN & & \\
\hline CHEMBL173259 & 75490 & 5.0555 & 5.0044 & TRN & & \\
\hline CHEMBL172663 & 75490 & 5.2596 & 5.2101 & TRN & & \\
\hline CHEMBL173119 & 75490 & 5.0 & 5.1762 & TRN & & \\
\hline CHEMBL171363 & 75490 & 5.699 & 4.8352 & TRN & & \\
\hline CHEMBL368755 & 75490 & 6.1079 & 6.1095 & TRN & & \\
\hline CHEMBL368790 & 75490 & 5.1871 & 5.324 & TRN & & \\
\hline CHEMBL368767 & 75490 & 3.3872 & 4.8279 & TST & & \\
\hline CHEMBL174151 & 75490 & 5.8861 & 6.1236 & TRN & & \\
\hline CHEMBL173956 & 75490 & 5.3872 & 4.8152 & TST & & \\
\hline CHEMBL354844 & 75490 & 5.0605 & 5.1339 & TST & & \\
\hline CHEMBL352835 & 75490 & 6.1079 & 6.272 & TST & & \\
\hline CHEMBL176829 & 75490 & 4.8861 & 5.2687 & TST & & \\
\hline CHEMBL367669 & 75490 & 5.0 & 5.1169 & TST & & \\
\hline CHEMBL3912975 & 1642359 & 6.0 & 6.6267 & TRN & & \\
\hline CHEMBL3894497 & 1642359 & 7.2924 & 7.0158 & TRN & & \\
\hline CHEMBL3895121 & 1642359 & 6.1733 & 6.5851 & TRN & & \\
\hline CHEMBL3956033 & 1642359 & 7.0132 & 7.1191 & TRN & & \\
\hline CHEMBL3951946 & 1642359 & 6.8153 & 6.8737 & TST & & \\
\hline CHEMBL3973431 & 1642359 & 6.0 & 6.2064 & TRN & & \\
\hline CHEMBL3924875 & 1642359 & 6.0 & 6.4045 & TRN & & \\
\hline CHEMBL3895862 & 1642359 & 7.6383 & 6.9208 & TRN & & \\
\hline CHEMBL3971674 & 1642359 & 6.7212 & 6.7259 & TRN & & \\
\hline CHEMBL3903875 & 1642359 & 7.3468 & 7.1346 & TRN & & \\
\hline CHEMBL3966360 & 1642359 & 7.2676 & 6.621 & TST & & \\
\hline CHEMBL3920212 & 1642359 & $6.7570 e$ & 0000000 & $\partial 1$ & 5.9309 & TRN \\
\hline CHEMBL3907092 & 1642359 & 7.3665 & 7.4558 & TST & & \\
\hline CHEMBL3926538 & 1642359 & 7.3468 & 7.1228 & TRN & & \\
\hline CHEMBL3955523 & 1642359 & 6.0 & 6.586 & TRN & & \\
\hline CHEMBL3904609 & 1642359 & 7.4815 & 6.8157 & TRN & & \\
\hline CHEMBL3901864 & 1642359 & 6.3925 & 5.4381 & TRN & & \\
\hline CHEMBL3964290 & 1642359 & 6.8928 & 7.1622 & TRN & & \\
\hline CHEMBL3967084 & 1642359 & 7.2218 & 7.4296 & TRN & & \\
\hline CHEMBL3908969 & 1642359 & 6.9101 & 6.8541 & TRN & & \\
\hline CHEMBL 3974384 & 1642359 & 6.0 & 6.0995 & TRN & & \\
\hline CHEMBL3901258 & 1642359 & 6.9431 & 7.2137 & TRN & & \\
\hline CHEMBL3895914 & 1642359 & 6.0 & 7.3757 & TST & & \\
\hline CHEMBL3913635 & 1642359 & 6.0 & 6.3163 & TST & & \\
\hline CHEMBL3986526 & 1642359 & 7.284 & 6.999 & TRN & & \\
\hline CHEMBL3979786 & 1642359 & 8.7959 & 7.8622 & TRN & & \\
\hline CHEMBL3983576 & 1642359 & 6.0 & 6.1435 & TRN & & \\
\hline CHEMBL3964333 & 1642359 & 7.3979 & 7.2906 & TRN & & \\
\hline CHEMBL3902081 & 1642359 & 7.1457 & 7.4325 & TRN & & \\
\hline CHEMBL3978669 & 1642359 & 7.041 & 6.5158 & TST & & \\
\hline
\end{tabular}


Supplemental Table S2.txt

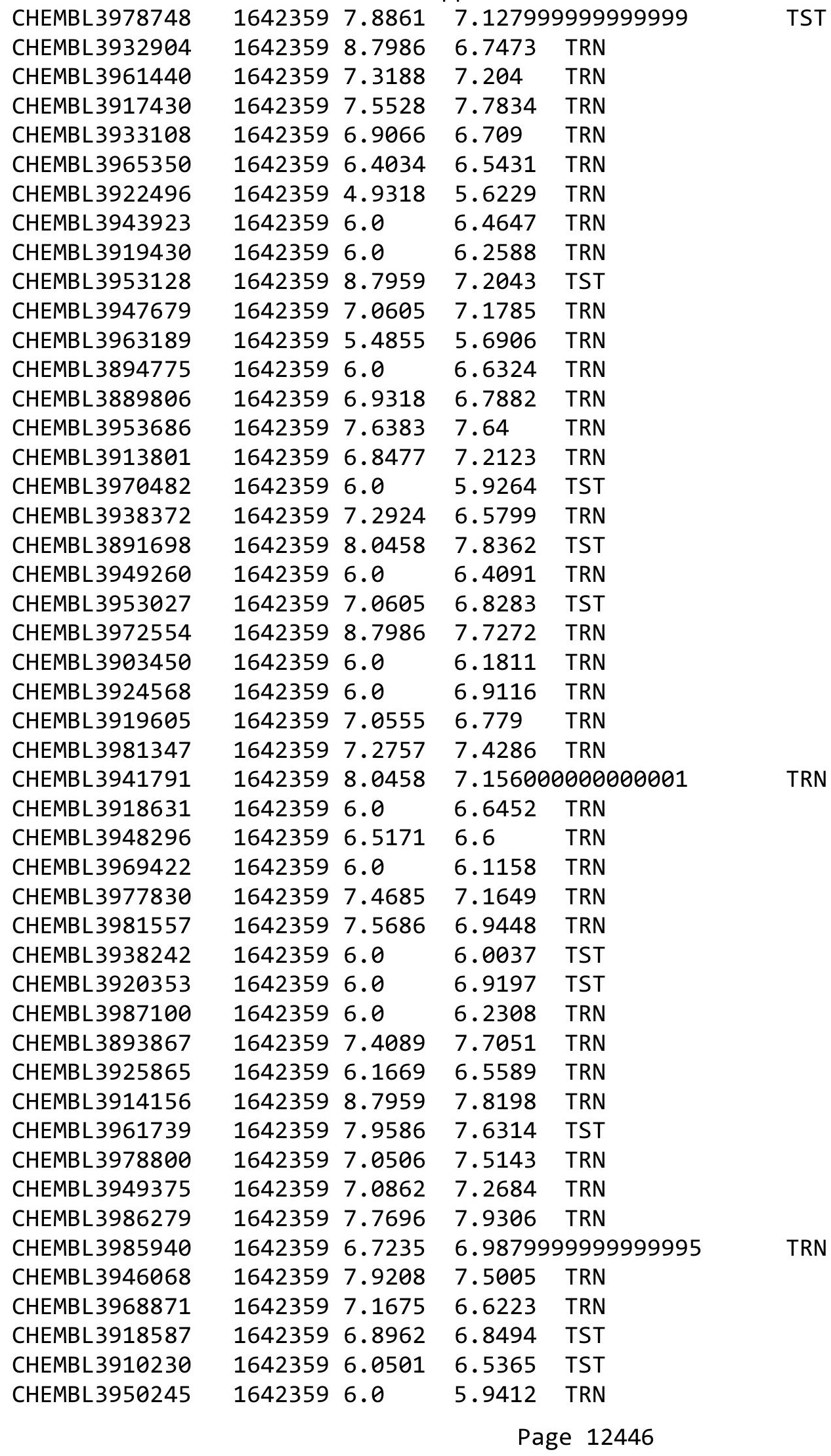


Supplemental Table S2.txt

\begin{tabular}{|c|c|c|c|c|c|}
\hline CHEMBL3957903 & 1642359 & 6.0 & 5.9947 & TRN & \\
\hline CHEMBL3903445 & 1642359 & 6.9208 & 6.8787 & TRN & \\
\hline CHEMBL3891227 & 1642359 & 7.1457 & 7.1715 & TRN & \\
\hline CHEMBL3930450 & 1642359 & 7.6478 & 7.4066 & TST & \\
\hline CHEMBL3898499 & 1642359 & 7.3279 & 6.5987 & TST & \\
\hline CHEMBL3954174 & 1642359 & 7.4437 & 7.421 & TRN & \\
\hline CHEMBL3965957 & 1642359 & 6.0 & 5.9811 & TRN & \\
\hline CHEMBL3959695 & 1642359 & 6.0 & 6.24200 & 0000000001 & TRN \\
\hline CHEMBL3985642 & 1642359 & 6.0 & 5.99799 & 9999999999 & TRN \\
\hline CHEMBL3902941 & 1642359 & 7.6198 & 7.2111 & TRN & \\
\hline CHEMBL3938657 & 1642359 & 7.7696 & 7.7445 & TRN & \\
\hline CHEMBL3940419 & 1642359 & 7.2007 & 6.9263 & TRN & \\
\hline CHEMBL3914536 & 1642359 & 6.4672 & 6.2423 & TRN & \\
\hline CHEMBL3909346 & 1642359 & 7.4949 & 8.0425 & TRN & \\
\hline CHEMBL 3910943 & 1642359 & 7.2924 & 7.2049 & TRN & \\
\hline CHEMBL3921957 & 1642359 & 5.8477 & 5.5697 & TRN & \\
\hline CHEMBL3915721 & 1642359 & 6.0 & 6.1863 & TRN & \\
\hline CHEMBL3972454 & 1642359 & 6.0 & 6.2439 & TRN & \\
\hline CHEMBL3890116 & 1642359 & 6.5229 & 6.8594 & TST & \\
\hline CHEMBL3890377 & 1642359 & 7.5331 & 7.3634 & TRN & \\
\hline CHEMBL 3897081 & 1642359 & 6.9031 & 7.178 & TRN & \\
\hline CHEMBL3903722 & 1642359 & 6.3439 & 6.3999 & TRN & \\
\hline CHEMBL3932885 & 1642359 & 6.7747 & 6.7675 & TRN & \\
\hline CHEMBL3920306 & 1642359 & 6.8508 & 6.7317 & TRN & \\
\hline CHEMBL3946446 & 1642359 & 6.0 & 6.1268 & TRN & \\
\hline CHEMBL3912459 & 1642359 & 7.2757 & 6.8145 & TRN & \\
\hline CHEMBL3899328 & 1642359 & 7.6308 & 7.1749 & TRN & \\
\hline CHEMBL3912765 & 1642359 & 6.0 & 6.4209 & TRN & \\
\hline CHEMBL3896022 & 1642359 & 6.3556 & 6.1601 & TST & \\
\hline CHEMBL3919564 & 1642359 & 6.0 & 6.644 & TRN & \\
\hline CHEMBL3955967 & 1642359 & 6.0 & 5.8927 & TRN & \\
\hline CHEMBL3894881 & 1642359 & 8.7959 & 7.9031 & TRN & \\
\hline CHEMBL3934745 & 1642359 & 7.6478 & 7.1362 & TRN & \\
\hline CHEMBL3960560 & 1642359 & 8.1549 & 8.2049 & TRN & \\
\hline CHEMBL3979270 & 1642359 & 6.4461 & 6.4665 & TRN & \\
\hline CHEMBL3903774 & 1642359 & 7.4089 & 7.1579 & TRN & \\
\hline CHEMBL 3971134 & 1642359 & 6.7595 & 6.3878 & TRN & \\
\hline CHEMBL3927323 & 1642359 & 6.7595 & 7.6582 & TRN & \\
\hline CHEMBL3954956 & 1642359 & 6.0 & 6.1017 & TRN & \\
\hline CHEMBL3979702 & 1642359 & 6.684 & 6.8192 & TST & \\
\hline CHEMBL3920067 & 1642359 & 7.2147 & 6.396 & TST & \\
\hline CHEMBL 3942030 & 1642359 & 7.3279 & 7.0401 & TST & \\
\hline CHEMBL3932931 & 1642359 & 5.6478 & 4.9708 & TRN & \\
\hline CHEMBL3957664 & 1642359 & 6.6003 & 6.5009 & TST & \\
\hline CHEMBL3970574 & 1642359 & 6.0 & 7.4102 & TST & \\
\hline CHEMBL3975109 & 1642359 & 6.2441 & 6.4609 & TRN & \\
\hline CHEMBL3908468 & 1642359 & 6.1135 & 6.6348 & TRN & \\
\hline CHEMBL3937890 & 1642359 & 7.1612 & 6.6219 & TRN & \\
\hline
\end{tabular}




\begin{tabular}{|c|c|c|c|c|}
\hline \multicolumn{5}{|c|}{ Supplemental Table S2.txt } \\
\hline CHEMBL 3916350 & 1642359 & 6.0 & 5.8582 & TRN \\
\hline CHEMBL 3961820 & 1642359 & 7.7212 & 7.9483 & TRN \\
\hline CHEMBL3965579 & 1642359 & 6.5969 & 6.3606 & TRN \\
\hline CHEMBL3970111 & 1642359 & 7.3768 & 6.9751 & TST \\
\hline CHEMBL 3900336 & 1642359 & 7.3279 & 6.9853 & TRN \\
\hline CHEMBL 3905391 & 1642359 & 6.0 & 7.1816 & TRN \\
\hline CHEMBL 3912716 & 1642359 & 7.1024 & 6.6504 & TRN \\
\hline CHEMBL3963465 & 1642359 & 6.7423 & 6.3088 & TST \\
\hline CHEMBL 3979363 & 1642359 & 6.3325 & 6.4673 & TRN \\
\hline CHEMBL3965898 & 1642359 & 6.9872 & 7.2396 & TRN \\
\hline CHEMBL 3897491 & 1642359 & 6.0 & 5.5622 & TST \\
\hline CHEMBL 3962229 & 1642359 & 8.3979 & 7.2477 & TST \\
\hline CHEMBL 3980514 & 1642359 & 6.0 & 6.1883 & TRN \\
\hline CHEMBL3961816 & 1642359 & 5.5302 & 5.4552 & TRN \\
\hline CHEMBL3925057 & 1642359 & 6.8182 & 6.523 & TRN \\
\hline CHEMBL 3927798 & 1642359 & 6.6308 & 6.5238 & TST \\
\hline CHEMBL3963135 & 1642359 & 5.5346 & 5.8196 & TRN \\
\hline CHEMBL 3943232 & 1642359 & 6.0 & 6.5313 & TRN \\
\hline CHEMBL 3955271 & 1642359 & 6.4012 & 6.2044 & TRN \\
\hline CHEMBL3901690 & 1642359 & 7.475 & 7.0162 & TST \\
\hline CHEMBL 3984786 & 1642359 & 6.0 & 6.7895 & TST \\
\hline CHEMBL3911629 & 1642359 & 7.1487 & 7.1336 & TST \\
\hline CHEMBL 3980822 & 1642359 & 6.0 & 6.643 & TST \\
\hline CHEMBL 3923174 & 1642359 & 8.0458 & 6.8018 & TST \\
\hline CHEMBL3939420 & 1642359 & 7.4949 & 7.3869 & TST \\
\hline CHEMBL 3986728 & 1642359 & 8.7986 & 7.8802 & TRN \\
\hline CHEMBL 3986787 & 1642359 & 7.3925 & 7.1014 & TRN \\
\hline CHEMBL3923366 & 1642359 & 7.7696 & 7.4992 & TRN \\
\hline CHEMBL 3960325 & 1642359 & 5.5157 & 5.2472 & TRN \\
\hline CHEMBL3981306 & 1642359 & 7.6778 & 7.4052 & TRN \\
\hline CHEMBL 3927020 & 1642359 & 6.0 & 6.8637 & TRN \\
\hline CHEMBL 3932532 & 1642359 & 5.8508 & 5.4543 & TRN \\
\hline CHEMBL 3896459 & 1642359 & 3.6021 & 6.6785 & TST \\
\hline CHEMBL3928533 & 1642359 & 5.5528 & 5.829 & TST \\
\hline CHEMBL3896034 & 1642359 & 7.8239 & 6.9342 & TRN \\
\hline CHEMBL3946170 & 1642359 & 7.7959 & 8.1368 & TRN \\
\hline CHEMBL 3924385 & 1642359 & 7.1938 & 7.0808 & TRN \\
\hline CHEMBL3916173 & 1642359 & 6.6968 & 6.7083 & TRN \\
\hline CHEMBL 3922864 & 1642359 & 7.301 & 7.223 & TRN \\
\hline CHEMBL3919446 & 1642359 & 6.5719 & 6.2451 & TRN \\
\hline CHEMBL 3953545 & 1642359 & 7.6383 & 6.984 & TST \\
\hline CHEMBL 3945074 & 1642359 & 6.7645 & 6.5765 & TRN \\
\hline CHEMBL3963405 & 1642359 & 8.7986 & 7.6304 & TRN \\
\hline CHEMBL3950734 & 1642359 & 7.5302 & 7.3593 & TRN \\
\hline CHEMBL 3940301 & 1642359 & 7.3615 & 7.1683 & TRN \\
\hline CHEMBL3959016 & 1642359 & 6.9666 & 6.7014 & TRN \\
\hline CHEMBL 3979210 & 1642359 & 6.4237 & 6.6837 & TST \\
\hline CHEMBL 3907620 & 1642359 & 7.1805 & 6.7166 & TRN \\
\hline
\end{tabular}


Supplemental Table S2.txt

\begin{tabular}{|c|c|c|c|c|c|}
\hline CHEMBL3937532 & 1642359 & 7.6576 & 7.9721 & TRN & \\
\hline CHEMBL3931829 & 1642359 & 7.1904 & 6.6541 & TRN & \\
\hline CHEMBL3918178 & 1642359 & 6.9393 & 7.5067 & TRN & \\
\hline CHEMBL3965934 & 1642359 & 6.0 & 6.4486 & TST & \\
\hline CHEMBL3922872 & 1642359 & 7.5272 & 7.2576 & TRN & \\
\hline CHEMBL3925469 & 1642359 & 6.0 & 6.7533 & TRN & \\
\hline CHEMBL3947095 & 1642359 & 7.8539 & 7.2252 & TST & \\
\hline CHEMBL3964688 & 1642359 & 4.7496 & 5.1836 & TRN & \\
\hline CHEMBL3977806 & 1642359 & 7.699 & 6.2852 & TRN & \\
\hline CHEMBL3918987 & 1642359 & 5.1518 & 6.3705 & TRN & \\
\hline CHEMBL3973540 & 1642359 & 5.9586 & 6.3317 & TRN & \\
\hline CHEMBL3943722 & 1642359 & 6.7852 & 7.2222 & TRN & \\
\hline CHEMBL3908054 & 1642359 & 5.8962 & 5.7966 & TRN & \\
\hline CHEMBL3941489 & 1642359 & 7.4318 & 7.3302 & TRN & \\
\hline CHEMBL3980075 & 1642359 & 6.8182 & 6.826000 & 0000000005 & TRN \\
\hline CHEMBL3891941 & 1642359 & 7.4815 & 7.6686 & TRN & \\
\hline CHEMBL3981136 & 1642359 & 6.025 & 6.2142 & TST & \\
\hline CHEMBL3951969 & 1642359 & 6.0 & 6.1235 & TRN & \\
\hline CHEMBL3960143 & 1642359 & 7.699 & 6.9881 & TRN & \\
\hline CHEMBL3953744 & 1642359 & 6.0 & 6.1524 & TRN & \\
\hline CHEMBL3966348 & 1642359 & 4.7508 & 6.0838 & TRN & \\
\hline CHEMBL3981282 & 1642359 & 6.6946 & 6.0364 & TRN & \\
\hline CHEMBL3940965 & 1642359 & 7.4202 & 7.7718 & TST & \\
\hline CHEMBL3895605 & 1642359 & 6.9508 & 7.0459 & TST & \\
\hline CHEMBL3974495 & 1642359 & 6.1972 & 7.7633 & TST & \\
\hline CHEMBL3909399 & 1642359 & 7.1367 & 6.8577 & TRN & \\
\hline CHEMBL3945750 & 1642359 & 5.9208 & 6.1969 & TRN & \\
\hline CHEMBL3938883 & 1642359 & 7.7696 & 7.5337 & TRN & \\
\hline CHEMBL3901219 & 1642359 & 7.585 & 7.1018 & TRN & \\
\hline CHEMBL3908513 & 1642359 & 7.4437 & 6.7376 & TRN & \\
\hline CHEMBL3956829 & 1642359 & 7.3372 & 6.6712 & TST & \\
\hline CHEMBL3980188 & 1642359 & 6.0 & 5.7938 & TRN & \\
\hline CHEMBL3929638 & 1642359 & 7.6091 & 7.609 & TRN & \\
\hline CHEMBL3929409 & 1642359 & 7.3872 & 7.1604 & TRN & \\
\hline CHEMBL3986808 & 1642359 & 6.0 & 6.0274 & TRN & \\
\hline CHEMBL3933711 & 1642359 & 6.7399 & 6.1278 & TRN & \\
\hline CHEMBL3904815 & 1642359 & 7.0177 & 7.2057 & TRN & \\
\hline CHEMBL3898756 & 1642359 & 6.6596 & 6.707999 & 999999999 & TRN \\
\hline CHEMBL3958585 & 1642359 & 6.0 & 7.2691 & TRN & \\
\hline CHEMBL3902255 & 1642359 & 7.1427 & 7.2949 & TRN & \\
\hline CHEMBL3897773 & 1642359 & 6.0 & 6.4152 & TRN & \\
\hline CHEMBL3963108 & 1642359 & 7.4559 & 7.0257 & TRN & \\
\hline CHEMBL3966557 & 1642359 & 5.6596 & 4.9214 & TST & \\
\hline CHEMBL3976299 & 1642359 & 6.5901 & 7.023 & TRN & \\
\hline CHEMBL3934735 & 1642359 & 7.1367 & 6.6687 & TST & \\
\hline CHEMBL3904836 & 1642359 & 6.821000 & 000000000 & 6.7461 & TST \\
\hline CHEMBL3905837 & 1642359 & 6.2857 & 6.3313 & TRN & \\
\hline CHEMBL3911490 & 1642359 & 3.6021 & 5.2136 & TRN & \\
\hline
\end{tabular}


Supplemental Table S2.txt

\begin{tabular}{|c|c|c|c|c|c|}
\hline CHEMBL 3979817 & 1642359 & 6.5751 & 6.2199 & TRN & \\
\hline CHEMBL 3946813 & 1642359 & 6.3344 & 6.4849 & TST & \\
\hline CHEMBL 3921440 & 1642359 & 5.8508 & 5.2064 & TRN & \\
\hline CHEMBL 3964390 & 1642359 & 6.0 & 6.6065 & TST & \\
\hline CHEMBL 3953091 & 1642359 & 6.0 & 5.9386 & TRN & \\
\hline CHEMBL3971609 & 1642359 & 7.4622 & 7.395 & TST & \\
\hline CHEMBL 3891217 & 1642359 & 5.6904 & 5.3425 & TRN & \\
\hline CHEMBL 3902907 & 1642359 & 6.0 & 6.4247 & TRN & \\
\hline CHEMBL 3945859 & 1642359 & 7.6882 & 8.2332 & TRN & \\
\hline CHEMBL 3892777 & 1642359 & 7.2798 & 6.1469 & TRN & \\
\hline CHEMBL 3944057 & 1642359 & 6.5045 & 6.5617 & TRN & \\
\hline CHEMBL 3890804 & 1642359 & 6.9626 & 7.3913 & TRN & \\
\hline CHEMBL 3921808 & 1642359 & 7.3279 & 7.8726 & TRN & \\
\hline CHEMBL 3906259 & 1642359 & 6.0 & 6.1621 & TRN & \\
\hline CHEMBL 3895367 & 1642359 & 7.3325 & 6.5033 & TRN & \\
\hline CHEMBL 3945313 & 1642359 & 8.7959 & 7.9305 & TRN & \\
\hline CHEMBL 3917057 & 1642359 & 6.6799 & 6.6823 & TRN & \\
\hline CHEMBL 3899137 & 1642359 & 6.3883 & 6.0449 & TRN & \\
\hline CHEMBL 3948226 & 1642359 & 7.5768 & 7.4222 & TRN & \\
\hline CHEMBL 3925345 & 1642359 & 6.9957 & 6.49 & TST & \\
\hline CHEMBL 3927758 & 1642359 & 7.699 & 7.0001 & TST & \\
\hline CHEMBL 3890742 & 1642359 & 7.4034 & 6.9547 & TRN & \\
\hline CHEMBL 3986591 & 1642359 & 6.0 & 6.2045 & TRN & \\
\hline CHEMBL 3978799 & 1642359 & 7.5376 & 7.5822 & TST & \\
\hline CHEMBL 3914286 & 1642359 & 6.3045 & 6.2227 & TST & \\
\hline CHEMBL 3949812 & 1642359 & 7.4559 & 7.5468 & TST & \\
\hline CHEMBL 3931951 & 1642359 & 6.7645 & 6.7548 & TST & \\
\hline CHEMBL 3928350 & 1642359 & 5.9914 & 6.0793 & TRN & \\
\hline CHEMBL 3962908 & 1642359 & 6.4067 & 7.0203 & TRN & \\
\hline CHEMBL 3984447 & 1642359 & 7.8539 & 7.1375 & TST & \\
\hline CHEMBL 3910527 & 1642359 & 6.0 & 6.0824 & TRN & \\
\hline CHEMBL 3925850 & 1642359 & 7.2596 & 6.294 & TST & \\
\hline CHEMBL 3947403 & 1642359 & 7.8539 & 7.1706 & TRN & \\
\hline CHEMBL 3943854 & 1642359 & 6.064 & 6.2399 & TRN & \\
\hline CHEMBL 3978764 & 1642359 & 6.0 & 6.2853 & TST & \\
\hline CHEMBL 3970058 & 1642359 & 6.5544 & 6.83 & TRN & \\
\hline CHEMBL 3985154 & 1642359 & 7.4437 & 6.5922 & TST & \\
\hline CHEMBL 3919048 & 1642359 & 5.7328 & 6.3943 & TRN & \\
\hline CHEMBL 3903325 & 1642359 & 6.3468 & 6.7257 & TRN & \\
\hline CHEMBL 3909040 & 1642359 & 6.0159 & 7.0384 & TST & \\
\hline CHEMBL 3933810 & 1642359 & 7.7696 & 8.1221 & TRN & \\
\hline CHEMBL 3950349 & 1642359 & 6.5638 & 7.3045 & TST & \\
\hline CHEMBL 3959538 & 1642359 & 7.5719 & 7.9185 & TRN & \\
\hline CHEMBL 3902677 & 1642359 & 6.0 & 6.3377 & TRN & \\
\hline CHEMBL 3895987 & 1642359 & 7.2596 & 6.9789 & TRN & \\
\hline CHEMBL 3947537 & 1642359 & 7.5935 & 7.4173 & TRN & \\
\hline CHEMBL 3972827 & 1642359 & 6.383999 & 999999999 & 995 & 6.9959 \\
\hline CHEMBL 3955826 & 1642359 & 7.2147 & 6.9124 & TRN & \\
\hline
\end{tabular}


Supplemental Table S2.txt

\begin{tabular}{|c|c|c|c|c|c|}
\hline CHEMBL3929833 & 1642359 & 7.4815 & 7.121 & TRN & \\
\hline CHEMBL3955964 & 1642359 & 6.7212 & 6.2354 & TRN & \\
\hline CHEMBL3904714 & 1642359 & 7.1427 & 6.4133 & TST & \\
\hline CHEMBL3956089 & 1642359 & 6.0 & 5.9039 & TRN & \\
\hline CHEMBL3904882 & 1642359 & 7.7696 & 6.9091 & TST & \\
\hline CHEMBL3948910 & 1642359 & 6.0 & 6.2953 & TRN & \\
\hline CHEMBL3904506 & 1642359 & 6.5045 & 6.95799 & 9999999999 & TST \\
\hline CHEMBL3898271 & 1642359 & 6.0 & 6.0055 & TRN & \\
\hline CHEMBL3891412 & 1642359 & 6.0 & 5.9105 & TRN & \\
\hline CHEMBL3926046 & 1642359 & 6.8633 & 6.5837 & TST & \\
\hline CHEMBL3920505 & 1642359 & 7.0155 & 7.4582 & TRN & \\
\hline CHEMBL3974345 & 1642359 & 6.6778 & 6.3428 & TRN & \\
\hline CHEMBL3938511 & 1642359 & 7.4949 & 7.1813 & TRN & \\
\hline CHEMBL3911852 & 1642359 & 6.6851 & 6.816 & TRN & \\
\hline CHEMBL3964301 & 1642359 & 6.0 & 6.6784 & TRN & \\
\hline CHEMBL3934588 & 1642359 & 7.5376 & 7.1997 & TRN & \\
\hline CHEMBL3976075 & 1642359 & 6.0 & 5.8493 & TRN & \\
\hline CHEMBL3905290 & 1642359 & 7.4318 & 5.6835 & TRN & \\
\hline CHEMBL3973362 & 1642359 & 6.857 & 7.2032 & TRN & \\
\hline CHEMBL3978877 & 1642359 & 6.0 & 6.271 & TRN & \\
\hline CHEMBL3970513 & 1642359 & 8.7959 & 7.4979 & TST & \\
\hline CHEMBL3969410 & 1642359 & 7.3098 & 7.0116 & TRN & \\
\hline CHEMBL3962307 & 1642359 & 6.767 & 6.9861 & TST & \\
\hline CHEMBL 3965474 & 1642359 & 7.0315 & 6.3547 & TST & \\
\hline CHEMBL3968221 & 1642359 & 7.5376 & 7.8679 & TRN & \\
\hline CHEMBL3973220 & 1642359 & 7.7212 & 7.4728 & TRN & \\
\hline CHEMBL3903388 & 1642359 & 6.6716 & 7.197999 & 99999999995 & TST \\
\hline CHEMBL3965354 & 1642359 & 3.6021 & 6.0425 & TRN & \\
\hline CHEMBL3959448 & 1642359 & 6.0 & 7.0705 & TRN & \\
\hline CHEMBL3917973 & 1642359 & 7.2716 & 7.7526 & TRN & \\
\hline CHEMBL3892513 & 1642359 & 7.5229 & 7.0084 & TRN & \\
\hline CHEMBL3904452 & 1642359 & 6.0 & 6.0571 & TST & \\
\hline CHEMBL3954948 & 1642359 & 6.4698 & 6.7444 & TRN & \\
\hline CHEMBL 3934884 & 1642359 & 6.6271 & 6.9245 & TRN & \\
\hline CHEMBL3963739 & 1642359 & 6.0 & 6.6113 & TST & \\
\hline CHEMBL3922430 & 1642359 & 6.945 & 6.9882 & TRN & \\
\hline CHEMBL3897899 & 1642359 & 6.2483 & 6.7867 & TRN & \\
\hline CHEMBL3940621 & 1642359 & 5.6576 & 5.2106 & TRN & \\
\hline CHEMBL3892805 & 1642359 & 7.1135 & 7.7178 & TST & \\
\hline CHEMBL3973284 & 1642359 & 6.9706 & 7.0546 & TST & \\
\hline CHEMBL3944541 & 1642359 & 6.4717 & 6.8231 & TRN & \\
\hline CHEMBL3920526 & 1642359 & 6.0123 & 6.483 & TST & \\
\hline CHEMBL3966163 & 1642359 & 6.0 & 6.4599 & TST & \\
\hline CHEMBL3977787 & 1642359 & 6.75200 & 000000000 & 7.0539 & TRN \\
\hline CHEMBL3889758 & 1642359 & 7.2518 & 7.1496 & TRN & \\
\hline CHEMBL3918872 & 1642359 & 6.51 & 6.2156 & TRN & \\
\hline CHEMBL3980106 & 1642359 & 7.8861 & 7.4307 & TRN & \\
\hline CHEMBL3906931 & 1642359 & 5.7447 & 6.2349 & TRN & \\
\hline
\end{tabular}




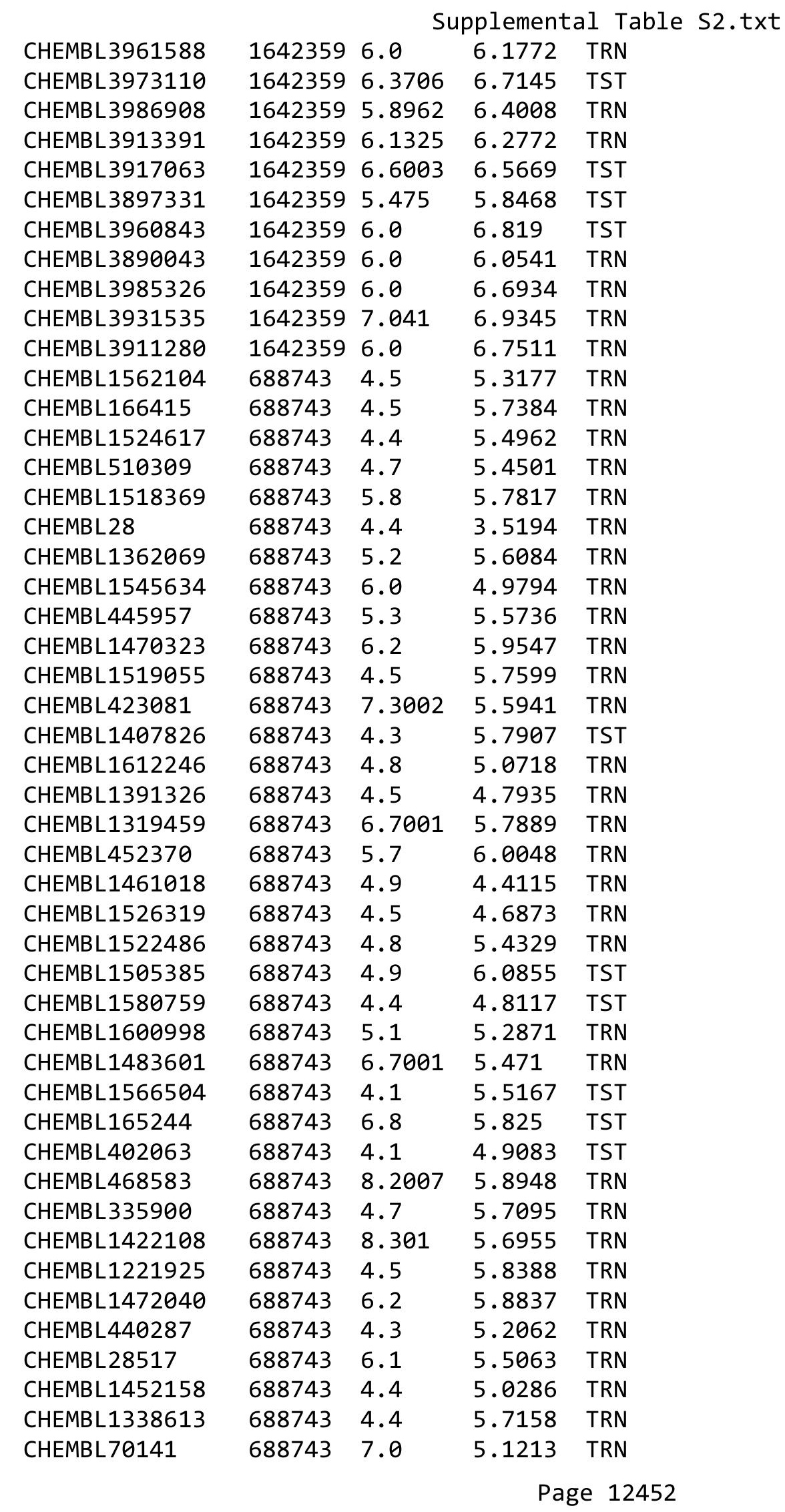




\begin{tabular}{|c|c|c|c|c|c|}
\hline \\
\hline CHEMBL1404017 & 688743 & 6.3 & 6.0311 & TRN & \\
\hline CHEMBL354663 & 688743 & 6.7001 & 5.8032 & TRN & \\
\hline CHEMBL1319813 & 688743 & 4.3 & 5.0697 & TRN & \\
\hline CHEMBL1305819 & 688743 & 4.5 & 6.2041 & TRN & \\
\hline CHEMBL327919 & 688743 & 4.6 & 4.7925 & TRN & \\
\hline CHEMBL1559341 & 688743 & 5.1 & 4.4126 & TRN & \\
\hline CHEMBL1416640 & 688743 & 6.1 & 6.011 & TRN & \\
\hline CHEMBL1531863 & 688743 & 6.2 & 5.5803 & TRN & \\
\hline CHEMBL1143 & 688743 & 8.1024 & 5.026 & TRN & \\
\hline CHEMBL1448387 & 688743 & 4.3 & 3.9415 & TRN & \\
\hline CHEMBL1496957 & 688743 & 4.5 & 5.8234 & TRN & \\
\hline CHEMBL89295 & 688743 & 6.3 & 6.0729 & TST & \\
\hline CHEMBL1414950 & 688743 & 4.9 & 5.1061 & TRN & \\
\hline CHEMBL1449018 & 688743 & 4.5 & 5.1454 & TRN & \\
\hline CHEMBL1313005 & 688743 & 7.0 & 5.6656 & TRN & \\
\hline CHEMBL1418603 & 688743 & 4.4 & 5.2734 & TRN & \\
\hline CHEMBL14092 & 688743 & 5.0 & 6.216 & TRN & \\
\hline CHEMBL115243 & 688743 & 6.9 & 6.1187 & TRN & \\
\hline CHEMBL46557 & 688743 & 6.2 & 5.7356 & TRN & \\
\hline CHEMBL1200471 & 688743 & 6.1 & 5.88399 & 99999999995 & TRN \\
\hline CHEMBL1579130 & 688743 & 6.0 & 5.3133 & TRN & \\
\hline CHEMBL1142 & 688743 & 4.2 & 4.2542 & TRN & \\
\hline CHEMBL334255 & 688743 & 4.7 & 5.36299 & 99999999995 & TRN \\
\hline CHEMBL1569493 & 688743 & 5.0 & 5.1948 & TRN & \\
\hline CHEMBL1585396 & 688743 & 4.6 & 5.7159 & TST & \\
\hline CHEMBL173521 & 688743 & 7.0 & 6.3987 & TRN & \\
\hline CHEMBL 261663 & 688743 & 5.8 & 5.9147 & TRN & \\
\hline CHEMBL329785 & 688743 & 4.4 & 4.9821 & TRN & \\
\hline CHEMBL1376677 & 688743 & 5.9 & 5.3897 & TRN & \\
\hline CHEMBL192627 & 688743 & 4.4 & 5.6624 & TST & \\
\hline CHEMBL230156 & 688743 & 5.9 & 5.596 & TRN & \\
\hline CHEMBL1328508 & 688743 & 5.4 & 5.5988 & TRN & \\
\hline CHEMBL156378 & 688743 & 4.5 & 5.9323 & TRN & \\
\hline CHEMBL1347061 & 688743 & 6.2 & 6.1658 & TST & \\
\hline CHEMBL 278980 & 688743 & 6.8 & 5.9919 & TRN & \\
\hline CHEMBL1489568 & 688743 & 6.1 & 5.5401 & TRN & \\
\hline CHEMBL1535371 & 688743 & 8.3979 & 5.6947 & TST & \\
\hline CHEMBL1602699 & 688743 & 5.2 & 5.5206 & TRN & \\
\hline CHEMBL157368 & 688743 & 7.0 & 5.9133 & TRN & \\
\hline CHEMBL1353833 & 688743 & 5.2 & 5.8573 & TRN & \\
\hline CHEMBL1542216 & 688743 & 4.5 & 5.6222 & TRN & \\
\hline CHEMBL16068 & 688743 & 8.2007 & 6.2239 & TRN & \\
\hline CHEMBL196590 & 688743 & 4.2 & 5.421 & TRN & \\
\hline CHEMBL1303139 & 688743 & 4.5 & 3.8671 & TRN & \\
\hline CHEMBL354676 & 688743 & 7.8996 & 6.6655 & TRN & \\
\hline CHEMBL1499545 & 688743 & 5.0 & 5.5303 & TRN & \\
\hline CHEMBL71460 & 688743 & 5.8 & 5.6352 & TRN & \\
\hline CHEMBL1408847 & 688743 & 4.7 & 5.3306 & TRN & \\
\hline
\end{tabular}




\begin{tabular}{|c|c|c|c|c|c|}
\hline \multicolumn{6}{|c|}{ Supplemental Table S2.txt } \\
\hline CHEMBL31970 & 688743 & 4.5 & 4.9015 & TRN & \\
\hline CHEMBL1535689 & 688743 & 4.3 & 4.46 & TRN & \\
\hline CHEMBL194400 & 688743 & 4.6 & 5.6329 & TST & \\
\hline CHEMBL1457966 & 688743 & 4.5 & 5.4311 & TRN & \\
\hline CHEMBL1492874 & 688743 & 6.4 & 6.0477 & TRN & \\
\hline CHEMBL1232240 & 688743 & 4.5 & 5.4958 & TRN & \\
\hline CHEMBL1569226 & 688743 & 4.9 & 5.495 & TRN & \\
\hline CHEMBL267476 & 688743 & 6.5 & 5.5129 & TRN & \\
\hline CHEMBL1348453 & 688743 & 6.0 & 6.1053 & TST & \\
\hline CHEMBL509531 & 688743 & 4.9 & 4.6916 & TST & \\
\hline CHEMBL1319452 & 688743 & 5.4 & 5.4403 & TRN & \\
\hline CHEMBL1496758 & 688743 & 4.6 & 5.2149 & TRN & \\
\hline CHEMBL388676 & 688743 & 4.9 & 5.3444 & TST & \\
\hline CHEMBL1334 & 688743 & 4.5 & 5.7556 & TRN & \\
\hline CHEMBL153062 & 688743 & 4.1 & 4.1009 & TRN & \\
\hline CHEMBL540 & 688743 & 6.7001 & 6.0661 & TST & \\
\hline CHEMBL1421613 & 688743 & 5.3 & 5.87299 & 9999999999 & TRN \\
\hline CHEMBL1164301 & 688743 & 6.5 & 5.4868 & TRN & \\
\hline CHEMBL1319213 & 688743 & 5.0 & 5.2079 & TRN & \\
\hline CHEMBL1558796 & 688743 & 4.3 & 4.9595 & TRN & \\
\hline CHEMBL1560250 & 688743 & 5.8 & 5.7296 & TRN & \\
\hline CHEMBL1328092 & 688743 & 5.5 & 5.92299 & 9999999999 & TRN \\
\hline CHEMBL1409985 & 688743 & 4.9 & 5.1238 & TRN & \\
\hline CHEMBL1560541 & 688743 & 7.2 & 5.4858 & TRN & \\
\hline CHEMBL1489064 & 688743 & 4.2 & 3.93899 & 99999999996 & TRN \\
\hline CHEMBL538965 & 688743 & 4.7 & 5.6344 & TRN & \\
\hline CHEMBL1609459 & 688743 & 4.8 & 5.1829 & TRN & \\
\hline CHEMBL1565705 & 688743 & 4.1 & 5.1425 & TRN & \\
\hline CHEMBL70582 & 688743 & 5.6 & 5.7966 & TRN & \\
\hline CHEMBL1409831 & 688743 & 7.1002 & 5.9589 & TRN & \\
\hline CHEMBL1578928 & 688743 & 4.4 & 5.6955 & TRN & \\
\hline CHEMBL1519327 & 688743 & 5.0 & 5.6445 & TRN & \\
\hline CHEMBL1568222 & 688743 & 6.5 & 6.2254 & TRN & \\
\hline CHEMBL194399 & 688743 & 4.4 & 5.5953 & TST & \\
\hline CHEMBL1411246 & 688743 & 4.4 & 5.5233 & TRN & \\
\hline CHEMBL1331312 & 688743 & 6.3 & 5.7415 & TRN & \\
\hline CHEMBL249120 & 688743 & 5.5 & 5.49 & TRN & \\
\hline CHEMBL1527339 & 688743 & 6.2 & 5.4948 & TRN & \\
\hline CHEMBL1603782 & 688743 & 4.4 & 5.375 & TRN & \\
\hline CHEMBL196537 & 688743 & 4.3 & 5.3903 & TST & \\
\hline CHEMBL1489547 & 688743 & 6.6 & 5.8559 & TRN & \\
\hline CHEMBL250969 & 688743 & 8.3979 & 5.9217 & TRN & \\
\hline CHEMBL105712 & 688743 & 4.5 & 5.7956 & TRN & \\
\hline CHEMBL1422466 & 688743 & 6.2 & 5.5202 & TRN & \\
\hline CHEMBL8739 & 688743 & 6.3 & 5.6189 & TST & \\
\hline CHEMBL1506537 & 688743 & 4.5 & 5.2895 & TST & \\
\hline CHEMBL363803 & 688743 & 4.3 & 5.407 & TST & \\
\hline CHEMBL1602127 & 688743 & 5.7 & 5.8142 & TST & \\
\hline
\end{tabular}




\begin{tabular}{|c|c|c|c|c|}
\hline \multicolumn{5}{|c|}{ Supplemen } \\
\hline CHEMBL1447588 & 688743 & 5.4 & 5.3655 & TST \\
\hline CHEMBL44201 & 688743 & 5.5 & 5.7168 & TST \\
\hline CHEMBL36296 & 688743 & 4.4 & 4.9823 & TST \\
\hline CHEMBL158237 & 688743 & 4.6 & 6.0501 & TST \\
\hline CHEMBL11860 & 688743 & 5.6 & 6.0053 & TST \\
\hline CHEMBL289277 & 688743 & 6.2 & 4.2665 & TST \\
\hline CHEMBL268291 & 688743 & 5.3 & 5.8171 & TST \\
\hline CHEMBL1369819 & 688743 & 6.2 & 5.6294 & TST \\
\hline CHEMBL466545 & 688743 & 6.3 & 5.7234 & TST \\
\hline CHEMBL1492884 & 688743 & 4.3 & 5.2575 & TST \\
\hline CHEMBL58835 & 688743 & 6.2 & 5.9906 & TST \\
\hline CHEMBL44072 & 688743 & 4.8 & 5.534 & TST \\
\hline CHEMBL1086446 & 688743 & 5.5 & \multicolumn{2}{|c|}{5.327999999999999} \\
\hline CHEMBL195953 & 688743 & 4.4 & 5.5185 & TST \\
\hline CHEMBL1530684 & 688743 & 4.4 & 5.5288 & TST \\
\hline CHEMBL195338 & 688743 & 6.0 & 5.5693 & TST \\
\hline CHEMBL46762 & 221704 & 4.8416 & 5.2581 & TRN \\
\hline CHEMBL290693 & 221704 & 5.3665 & 5.3398 & TRN \\
\hline CHEMBL46735 & 221704 & 6.3372 & 6.0489 & TRN \\
\hline CHEMBL13835 & 221704 & 5.4815 & 5.4612 & TRN \\
\hline CHEMBL296563 & 221704 & 3.4547 & 4.6265 & TRN \\
\hline CHEMBL45182 & 221704 & 6.8861 & 5.4505 & TRN \\
\hline CHEMBL263675 & 221704 & 4.71 & 5.4761 & TRN \\
\hline CHEMBL430741 & 221704 & 5.4078 & 4.7873 & TRN \\
\hline CHEMBL295916 & 221704 & 6.0555 & 6.1208 & TRN \\
\hline CHEMBL44740 & 221704 & 5.0044 & 5.8193 & TRN \\
\hline CHEMBL47159 & 221704 & 6.5229 & 6.193 & TRN \\
\hline CHEMBL295148 & 221704 & 5.7122 & 5.8318 & TRN \\
\hline CHEMBL46375 & 221704 & 5.0419 & 5.2138 & TRN \\
\hline CHEMBL46870 & 221704 & 5.8761 & 5.6792 & TRN \\
\hline CHEMBL47167 & 221704 & 5.1759 & 5.0934 & TRN \\
\hline CHEMBL43993 & 221704 & 5.699 & 5.8523 & TRN \\
\hline CHEMBL46616 & 221704 & 5.284 & 5.1523 & TRN \\
\hline CHEMBL44846 & 221704 & 6.1871 & 5.1674 & TRN \\
\hline CHEMBL296849 & 221704 & 5.1568 & 4.9727 & TRN \\
\hline CHEMBL297797 & 221704 & 5.5817 & 6.062 & TRN \\
\hline CHEMBL41988 & 221704 & 5.2924 & 5.5128 & TRN \\
\hline CHEMBL46972 & 221704 & 5.3925 & 5.3707 & TRN \\
\hline CHEMBL1160088 & 221704 & 4.8041 & 5.0076 & TST \\
\hline CHEMBL44060 & 221704 & 5.7932 & 5.0372 & TRN \\
\hline CHEMBL297778 & 221704 & 5.5452 & 5.0539 & TRN \\
\hline CHEMBL45092 & 221704 & 4.4559 & 5.1654 & TST \\
\hline CHEMBL440663 & 221704 & 4.9788 & 5.7472 & TRN \\
\hline CHEMBL 294983 & 221704 & 5.7471 & 5.4277 & TRN \\
\hline CHEMBL296785 & 221704 & 5.9172 & 4.9346 & TRN \\
\hline CHEMBL298209 & 221704 & 5.4698 & 5.5049 & TRN \\
\hline CHEMBL291177 & 221704 & 5.2111 & 5.0981 & TRN \\
\hline CHEMBL295379 & 221704 & 6.6778 & 5.86 & TRN \\
\hline
\end{tabular}




\begin{tabular}{|c|c|c|c|c|c|}
\hline \multicolumn{6}{|c|}{ зирргепеті } \\
\hline CHEMBL45073 & 221704 & 5.1965 & 5.3923 & TRN & \\
\hline CHEMBL297988 & 221704 & 5.5391 & 5.4277 & TRN & \\
\hline CHEMBL47843 & 221704 & 4.7375 & 5.4226 & TST & \\
\hline CHEMBL297147 & 221704 & 6.0458 & 5.7254 & TRN & \\
\hline CHEMBL288399 & 221704 & 6.1938 & 5.9447 & TRN & \\
\hline CHEMBL296973 & 221704 & 6.2676 & 6.2339 & TRN & \\
\hline CHEMBL46928 & 221704 & 5.1938 & 5.0661 & TRN & \\
\hline CHEMBL17997 & 221704 & 5.7905 & 5.2138 & TRN & \\
\hline CHEMBL296072 & 221704 & 5.0141 & 5.4848 & TRN & \\
\hline CHEMBL44281 & 221704 & 5.585 & 5.2138 & TRN & \\
\hline CHEMBL47199 & 221704 & 4.2676 & 4.9475 & TRN & \\
\hline CHEMBL47998 & 221704 & 5.0035 & 5.5485 & TRN & \\
\hline CHEMBL445355 & 221704 & 6.0915 & 5.8499 & TRN & \\
\hline CHEMBL47149 & 221704 & 5.6655 & 5.7629 & TRN & \\
\hline CHEMBL295434 & 221704 & 4.8665 & 4.9555 & TST & \\
\hline CHEMBL44434 & 221704 & 5.9393 & 5.7472 & TRN & \\
\hline CHEMBL296921 & 221704 & 6.1739 & 5.8334 & TRN & \\
\hline CHEMBL297375 & 221704 & 5.1858 & 6.0226 & TRN & \\
\hline CHEMBL44617 & 221704 & 6.6383 & 5.8231 & TRN & \\
\hline CHEMBL46615 & 221704 & 5.5229 & 5.487 & TST & \\
\hline CHEMBL296238 & 221704 & 6.699 & 5.8563 & TRN & \\
\hline CHEMBL47760 & 221704 & 5.7011 & 5.1822 & TRN & \\
\hline CHEMBL44540 & 221704 & 5.2757 & 5.0555 & TST & \\
\hline CHEMBL297298 & 221704 & 5.0414 & 5.25 & TRN & \\
\hline CHEMBL44597 & 221704 & 4.9281 & 5.7396 & TRN & \\
\hline CHEMBL418255 & 221704 & 3.2518 & 4.8875 & TRN & \\
\hline CHEMBL295205 & 221704 & 4.04 & 5.1493 & TRN & \\
\hline CHEMBL42725 & 221704 & 4.8268 & 4.7042 & TRN & \\
\hline CHEMBL47531 & 221704 & 5.4202 & 5.2738 & TRN & \\
\hline CHEMBL296432 & 221704 & 5.8268 & 5.4842 & TST & \\
\hline CHEMBL297974 & 221704 & 5.399 & 4.8425 & TRN & \\
\hline CHEMBL295639 & 221704 & 5.0306 & 4.8635 & TRN & \\
\hline CHEMBL47192 & 221704 & 4.2848 & 5.0981 & TRN & \\
\hline CHEMBL290038 & 221704 & 5.7352 & 5.83299 & 9999999999 & TRN \\
\hline CHEMBL 29665 & 221704 & 5.8041 & 5.6078 & TRN & \\
\hline CHEMBL263933 & 221704 & 5.0223 & 5.4634 & TRN & \\
\hline CHEMBL297825 & 221704 & 3.8041 & 5.1411 & TST & \\
\hline CHEMBL46752 & 221704 & 5.6799 & 6.2513 & TRN & \\
\hline CHEMBL296539 & 221704 & 4.6364 & 4.8592 & TRN & \\
\hline CHEMBL47073 & 221704 & 4.7825 & 4.9227 & TRN & \\
\hline CHEMBL44110 & 221704 & 5.8827 & 5.0603 & TRN & \\
\hline CHEMBL297458 & 221704 & 4.7645 & 5.3398 & TRN & \\
\hline CHEMBL44316 & 221704 & 4.5686 & 4.7731 & TST & \\
\hline CHEMBL45321 & 221704 & 4.1675 & 5.1766 & TRN & \\
\hline CHEMBL296668 & 221704 & 6.2147 & 5.6683 & TRN & \\
\hline CHEMBL297765 & 221704 & 5.6757 & 5.9499 & TRN & \\
\hline CHEMBL44975 & 221704 & 6.2441 & 5.7798 & TRN & \\
\hline CHEMBL417532 & 221704 & 5.2291 & 5.1257 & TRN & \\
\hline
\end{tabular}




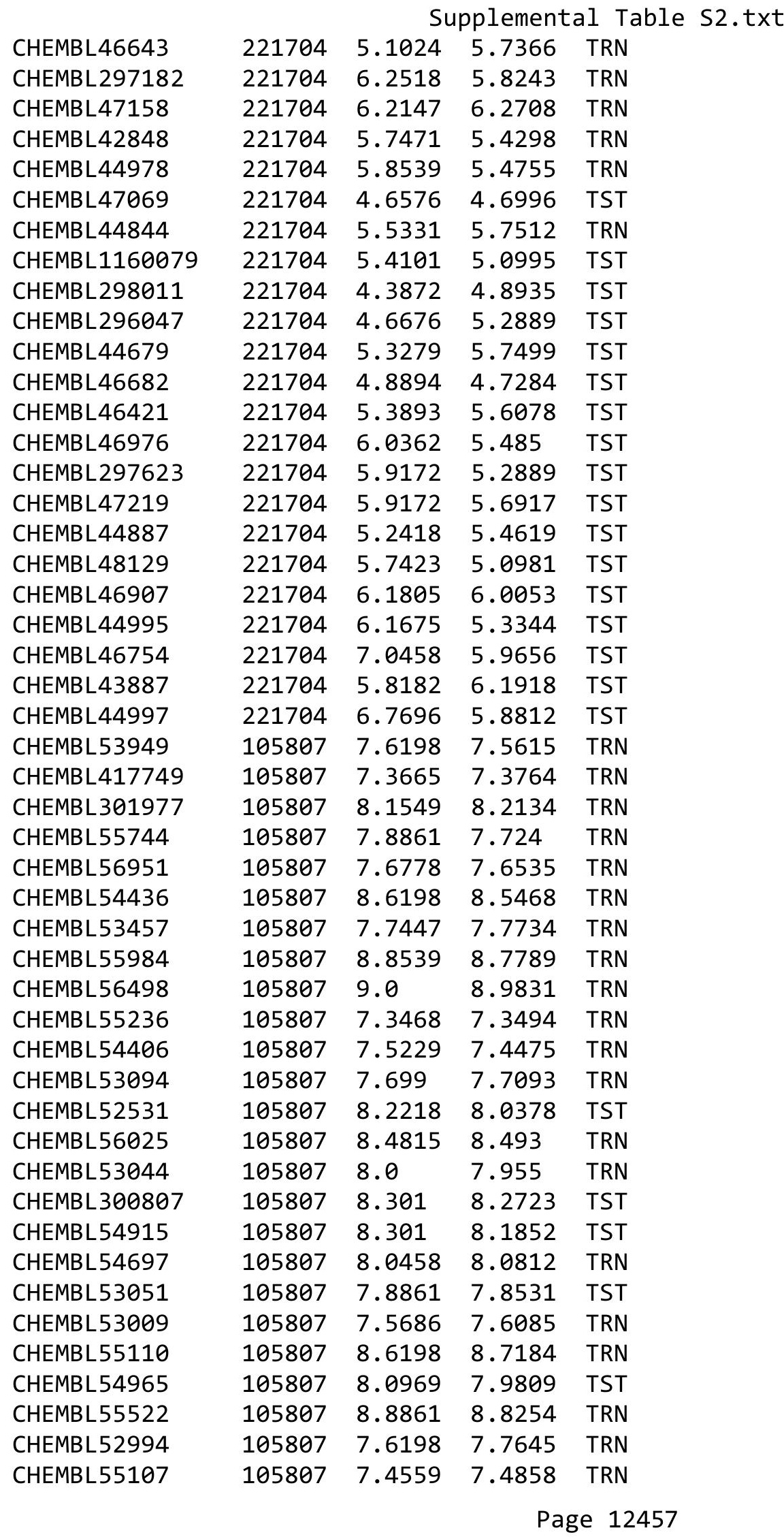




\begin{tabular}{|c|c|c|c|c|c|}
\hline \\
\hline CHEMBL293357 & 105807 & 9.301 & 9.1942 & TRN & \\
\hline CHEMBL53847 & 105807 & 8.6778 & 8.5799 & TRN & \\
\hline CHEMBL54566 & 105807 & 7.5086 & 7.5329 & TRN & \\
\hline CHEMBL54501 & 105807 & 7.4089 & 7.4166 & TST & \\
\hline CHEMBL52532 & 105807 & 7.6576 & 7.5934 & TRN & \\
\hline CHEMBL51862 & 105807 & 7.8239 & 7.9085 & TRN & \\
\hline CHEMBL 293504 & 105807 & 7.6198 & 7.7024 & TRN & \\
\hline CHEMBL417200 & 105807 & 8.0 & 8.1024 & TST & \\
\hline CHEMBL 300362 & 105807 & 8.3979 & 8.2991 & TST & \\
\hline CHEMBL55561 & 105807 & 7.4949 & 7.6109 & TRN & \\
\hline CHEMBL54617 & 105807 & 8.0 & 7.7906 & TST & \\
\hline CHEMBL280017 & 105807 & 7.8239 & 7.8689 & TRN & \\
\hline CHEMBL56065 & 105807 & 7.9208 & 7.7189 & TST & \\
\hline CHEMBL55154 & 105807 & 8.0458 & 7.6231 & TST & \\
\hline CHEMBL 299023 & 105807 & 7.8239 & 7.7701 & TRN & \\
\hline CHEMBL405600 & 105807 & 7.6198 & 7.5233 & TRN & \\
\hline CHEMBL 293774 & 105807 & 7.6778 & 7.6493 & TRN & \\
\hline CHEMBL 299600 & 105807 & 8.2218 & 8.2176 & TRN & \\
\hline CHEMBL 298822 & 105807 & 7.9208 & 7.7296 & TST & \\
\hline CHEMBL54483 & 105807 & 8.9586 & 9.0464 & TRN & \\
\hline CHEMBL292657 & 105807 & 7.2366 & 7.2801 & TRN & \\
\hline CHEMBL54904 & 105807 & 8.8861 & 8.90200 & 0000000001 & TRN \\
\hline CHEMBL55907 & 105807 & 7.7212 & 7.7149 & TRN & \\
\hline CHEMBL301177 & 105807 & 7.4685 & 7.6148 & TRN & \\
\hline CHEMBL54535 & 105807 & 8.8239 & 8.2689 & TST & \\
\hline CHEMBL54981 & 105807 & 7.7696 & 7.9577 & TRN & \\
\hline CHEMBL439931 & 105807 & 9.1549 & 9.1957 & TRN & \\
\hline CHEMBL417757 & 105807 & 7.6778 & 7.6473 & TRN & \\
\hline CHEMBL298606 & 105807 & 8.1549 & 7.945 & TRN & \\
\hline CHEMBL55521 & 105807 & 8.8239 & 8.84 & TRN & \\
\hline CHEMBL53116 & 105807 & 7.6383 & 7.669 & TRN & \\
\hline CHEMBL53091 & 105807 & 7.585 & 7.519 & TRN & \\
\hline CHEMBL54621 & 105807 & 8.3979 & 8.2811 & TST & \\
\hline CHEMBL416304 & 105807 & 7.5528 & 7.4613 & TRN & \\
\hline CHEMBL301786 & 105807 & 7.8861 & 7.9081 & TRN & \\
\hline CHEMBL 293503 & 105807 & 10.0 & 9.9133 & TRN & \\
\hline CHEMBL301085 & 105807 & 8.699 & 8.5562 & TRN & \\
\hline CHEMBL293305 & 105807 & 7.9586 & 7.9601 & TRN & \\
\hline CHEMBL54054 & 105807 & 9.1549 & 9.2343 & TRN & \\
\hline CHEMBL 293528 & 105807 & 8.9208 & 9.1024 & TRN & \\
\hline CHEMBL 299091 & 105807 & 7.5376 & 7.937 & TST & \\
\hline CHEMBL 292431 & 105807 & 8.0969 & 7.724 & TST & \\
\hline CHEMBL297488 & 105807 & 8.301 & 8.0247 & TST & \\
\hline CHEMBL 2179552 & 872709 & 7.3372 & 7.3667 & TRN & \\
\hline CHEMBL 2179560 & 872709 & 6.4685 & 7.1314 & TST & \\
\hline CHEMBL 2179517 & 872709 & 6.3098 & 6.3813 & TRN & \\
\hline CHEMBL 2179516 & 872709 & 8.0969 & 8.0586 & TRN & \\
\hline CHEMBL2179521 & 872709 & 7.7212 & 7.7248 & TRN & \\
\hline
\end{tabular}


Supplemental Table S2.txt

\begin{tabular}{|c|c|c|c|c|}
\hline CHEMBL2179961 & 872709 & 8.3979 & 8.4029 & TST \\
\hline CHEMBL2179531 & 872709 & 8.699 & 8.543 & TRN \\
\hline CHEMBL2179536 & 872709 & 7.5686 & 7.4216 & TRN \\
\hline CHEMBL 2179956 & 872709 & 7.3098 & 7.1792 & TRN \\
\hline CHEMBL 2179528 & 872709 & 7.6383 & 7.6637 & TRN \\
\hline CHEMBL 2179547 & 872709 & 8.5229 & 8.3279 & TRN \\
\hline CHEMBL 2179532 & 872709 & 7.1308 & 7.1576 & TRN \\
\hline CHEMBL2179549 & 872709 & 8.0969 & 7.7626 & TRN \\
\hline CHEMBL 2179525 & 872709 & 7.5229 & 7.5172 & TRN \\
\hline CHEMBL2179527 & 872709 & 7.4949 & 7.3531 & TRN \\
\hline CHEMBL 2179555 & 872709 & 7.7959 & 7.4593 & TRN \\
\hline CHEMBL 2179545 & 872709 & 7.8239 & 7.8199 & TRN \\
\hline CHEMBL2179535 & 872709 & 7.2757 & 7.5299 & TRN \\
\hline CHEMBL 2179530 & 872709 & 7.9586 & 7.9896 & TRN \\
\hline CHEMBL 2179957 & 872709 & 6.9586 & 7.4683 & TST \\
\hline CHEMBL 2179538 & 872709 & 7.3768 & 7.256 & TRN \\
\hline CHEMBL2179520 & 872709 & 7.585 & 7.6051 & TRN \\
\hline CHEMBL2179966 & 872709 & 7.4815 & 7.5441 & TRN \\
\hline CHEMBL 3094074 & 872709 & 6.0362 & 7.2035 & TST \\
\hline CHEMBL 2179558 & 872709 & 6.0 & 6.1203 & TRN \\
\hline CHEMBL 2179544 & 872709 & 8.301 & 8.29 & TRN \\
\hline CHEMBL2179546 & 872709 & 7.585 & 7.4672 & TRN \\
\hline CHEMBL 2179543 & 872709 & 8.301 & 8.7405 & TRN \\
\hline CHEMBL2179519 & 872709 & 6.699 & 7.8137 & TST \\
\hline CHEMBL 2179537 & 872709 & 7.8861 & 7.8396 & TRN \\
\hline CHEMBL 2179518 & 872709 & 6.6021 & 7.00899 & 79999999995 \\
\hline CHEMBL 2179524 & 872709 & 7.4318 & 8.2674 & TST \\
\hline CHEMBL 2179965 & 872709 & 6.0 & 6.9549 & TST \\
\hline CHEMBL2179533 & 872709 & 7.7959 & 8.0886 & TRN \\
\hline CHEMBL 2179534 & 872709 & 8.699 & 8.5043 & TRN \\
\hline CHEMBL2179971 & 872709 & 7.1739 & 8.4897 & TST \\
\hline CHEMBL2179559 & 872709 & 7.7212 & 7.8349 & TST \\
\hline CHEMBL2179539 & 872709 & 7.4949 & 7.527 & TRN \\
\hline CHEMBL2179551 & 872709 & 7.4089 & 7.4193 & TRN \\
\hline CHEMBL2179523 & 872709 & 7.2218 & 7.4518 & TST \\
\hline CHEMBL2179540 & 872709 & 8.5229 & 8.5244 & TRN \\
\hline CHEMBL 2179541 & 872709 & 7.6576 & 7.6399 & TRN \\
\hline CHEMBL 2179542 & 872709 & 7.301 & 7.3003 & TRN \\
\hline CHEMBL1876219 & 872709 & 7.9208 & 7.3397 & TST \\
\hline CHEMBL3094096 & 872709 & 7.699 & 7.6601 & TRN \\
\hline CHEMBL 2179526 & 872709 & 8.0969 & 8.1949 & TRN \\
\hline CHEMBL 2179550 & 872709 & 7.4815 & 7.6827 & TRN \\
\hline CHEMBL2179553 & 872709 & 6.7212 & 6.8841 & TRN \\
\hline CHEMBL2179962 & 872709 & 9.0 & 8.6343 & TST \\
\hline CHEMBL 2179548 & 872709 & 7.6383 & 7.7922 & TRN \\
\hline CHEMBL3191950 & 688680 & 5.3523 & 5.2008 & TRN \\
\hline CHEMBL1546228 & 688680 & 4.8986 & 5.0868 & TST \\
\hline CHEMBL 3197424 & 688680 & 5.3704 & 5.3436 & TRN \\
\hline
\end{tabular}

Page 12459 


\begin{tabular}{|c|c|c|c|c|c|}
\hline \multicolumn{6}{|c|}{ Supplemental Table S2.txt } \\
\hline CHEMBL599013 & 688680 & 5.1337 & 5.1232 & TRN & \\
\hline CHEMBL1489865 & 688680 & 5.2412 & 5.3526 & TRN & \\
\hline CHEMBL3198103 & 688680 & 3.4405 & 4.6048 & TRN & \\
\hline CHEMBL1351362 & 688680 & 4.6353 & 4.7664 & TRN & \\
\hline CHEMBL3196732 & 688680 & 5.1161 & 5.2595 & TST & \\
\hline CHEMBL1385808 & 688680 & 2.9634 & 5.1614 & TST & \\
\hline CHEMBL1323110 & 688680 & 5.3365 & 5.4934 & TRN & \\
\hline CHEMBL1600566 & 688680 & 5.6033 & 5.4904 & TRN & \\
\hline CHEMBL1299566 & 688680 & 5.4651 & 4.7056 & TRN & \\
\hline CHEMBL1337018 & 688680 & 4.9493 & 5.0421 & TRN & \\
\hline CHEMBL1971815 & 688680 & 4.6065 & 4.7563 & TRN & \\
\hline CHEMBL1587715 & 688680 & 5.29899 & 99999999 & 5.3768 & TRN \\
\hline CHEMBL3192400 & 688680 & 5.2752 & 5.2012 & TRN & \\
\hline CHEMBL1362157 & 688680 & 4.4522 & 4.7936 & TRN & \\
\hline CHEMBL1596969 & 688680 & 4.913 & 4.9401 & TRN & \\
\hline CHEMBL1343163 & 688680 & 4.7771 & 4.9349 & TRN & \\
\hline CHEMBL1333666 & 688680 & 5.4504 & 5.0987 & TRN & \\
\hline CHEMBL1458120 & 688680 & 5.4869 & 5.4693 & TRN & \\
\hline CHEMBL1336054 & 688680 & 5.5379 & 5.48799 & 99999999995 & TRN \\
\hline CHEMBL1595235 & 688680 & 4.957 & 4.71399 & 99999999995 & TRN \\
\hline CHEMBL1418430 & 688680 & 5.2665 & 5.2216 & TST & \\
\hline CHEMBL1299903 & 688680 & 5.5315 & 5.4779 & TRN & \\
\hline CHEMBL1562843 & 688680 & 5.5777 & 5.5827 & TRN & \\
\hline CHEMBL1374123 & 688680 & 5.76 & 5.7875 & TRN & \\
\hline CHEMBL1366482 & 688680 & 4.6546 & 5.1442 & TST & \\
\hline CHEMBL1576490 & 688680 & 4.6182 & 4.8084 & TRN & \\
\hline CHEMBL1587683 & 688680 & 5.2768 & 5.3822 & TRN & \\
\hline CHEMBL3195767 & 688680 & 5.1081 & 5.1551 & TRN & \\
\hline CHEMBL1449425 & 688680 & 5.1507 & 5.4184 & TRN & \\
\hline CHEMBL1324375 & 688680 & 2.9634 & 5.2345 & TST & \\
\hline CHEMBL1347122 & 688680 & 5.2507 & 4.5503 & TRN & \\
\hline CHEMBL1496459 & 688680 & 5.1969 & 5.1421 & TRN & \\
\hline CHEMBL1731995 & 688680 & 4.8999 & 4.7989 & TRN & \\
\hline CHEMBL1347385 & 688680 & 5.2559 & 5.0914 & TRN & \\
\hline CHEMBL1346055 & 688680 & 5.2171 & 5.2544 & TRN & \\
\hline CHEMBL1605561 & 688680 & 5.3026 & 5.2804 & TRN & \\
\hline CHEMBL1495335 & 688680 & 4.7629 & 5.0033 & TRN & \\
\hline CHEMBL1503034 & 688680 & 5.3476 & 5.4838 & TRN & \\
\hline CHEMBL1311288 & 688680 & 4.4949 & 4.3648 & TRN & \\
\hline CHEMBL1447158 & 688680 & 3.4405 & 4.0952 & TRN & \\
\hline CHEMBL1563898 & 688680 & 6.0044 & 5.669 & TST & \\
\hline CHEMBL1589514 & 688680 & 5.3362 & 4.9288 & TRN & \\
\hline CHEMBL1464595 & 688680 & 4.3037 & 4.8588 & TRN & \\
\hline CHEMBL1371074 & 688680 & 4.9096 & 5.2712 & TRN & \\
\hline CHEMBL 1425000 & 688680 & 4.4749 & 4.8645 & TRN & \\
\hline CHEMBL1504875 & 688680 & 5.0543 & 4.8641 & TST & \\
\hline CHEMBL1610160 & 688680 & 5.2049 & 5.2961 & TRN & \\
\hline CHEMBL1544885 & 688680 & 5.7102 & 5.6764 & TRN & \\
\hline
\end{tabular}




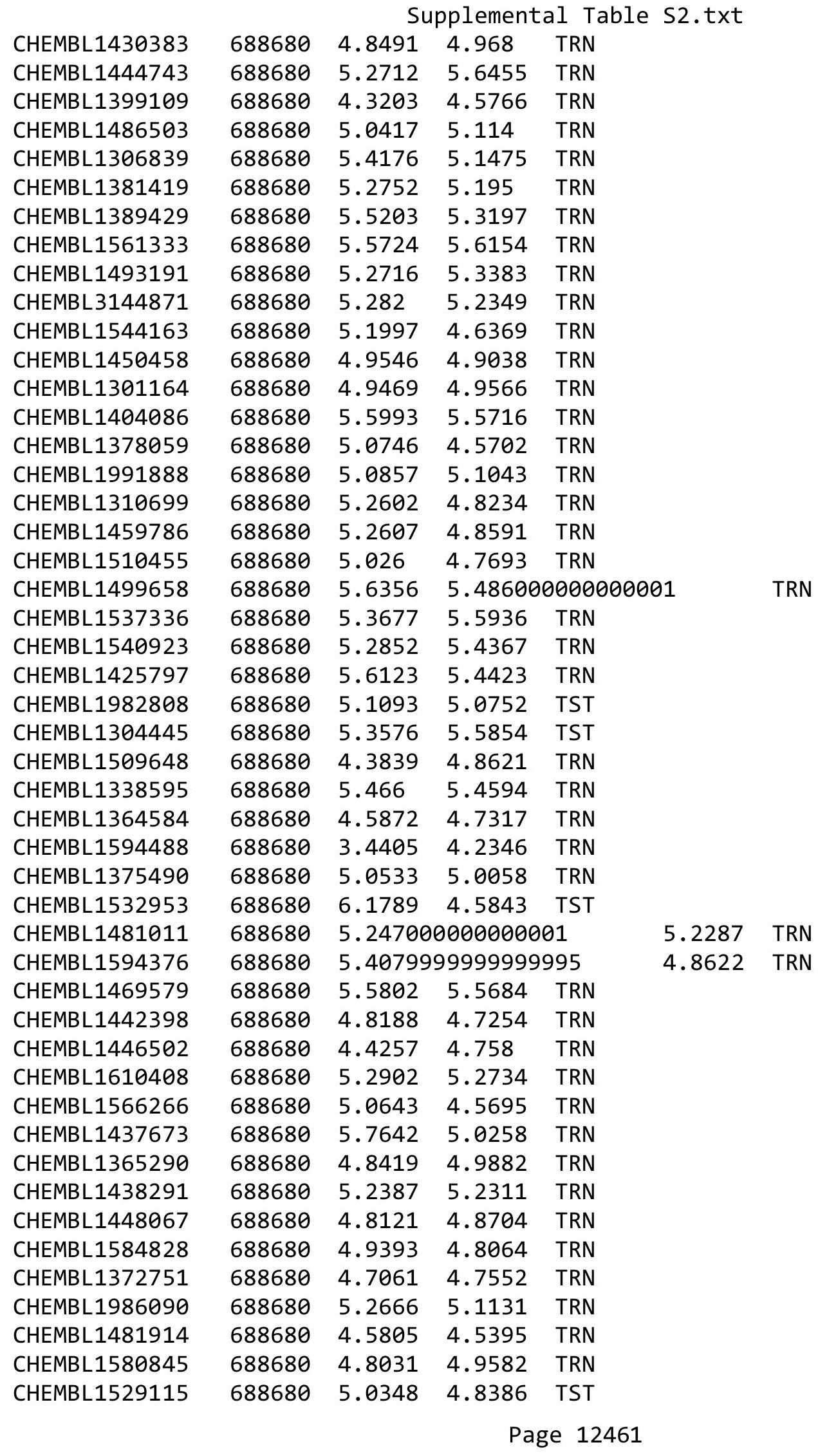




\begin{tabular}{|c|c|c|c|c|c|c|}
\hline \multirow[b]{2}{*}{ CHEMBL1543865 } & \multicolumn{6}{|c|}{ Supplemental Table S2.txt } \\
\hline & 688680 & 4.3947 & 5.0496 & TRN & & \\
\hline CHEMBL1500600 & 688680 & 5.2303 & 4.6939 & TRN & & \\
\hline CHEMBL1491676 & 688680 & 4.5914 & 4.7305 & TRN & & \\
\hline CHEMBL1373132 & 688680 & 5.5136 & 5.0166 & TRN & & \\
\hline CHEMBL1587849 & 688680 & 4.5174 & 4.5591 & TRN & & \\
\hline CHEMBL1605743 & 688680 & 5.1319 & 5.7051 & TST & & \\
\hline CHEMBL1416382 & 688680 & 5.0922 & 5.2073 & TRN & & \\
\hline CHEMBL3195976 & 688680 & 4.34 & 4.8712 & TST & & \\
\hline CHEMBL1549566 & 688680 & 5.039 & 5.3382 & TST & & \\
\hline CHEMBL1580969 & 688680 & 5.7042 & 4.5685 & TST & & \\
\hline CHEMBL1334412 & 688680 & 5.4349 & 4.8407 & TST & & \\
\hline CHEMBL1414563 & 688680 & 5.1692 & 4.9313 & TST & & \\
\hline CHEMBL602213 & 688680 & 5.1492 & 4.9643 & TST & & \\
\hline CHEMBL1592326 & 688680 & 5.2142 & 5.529 & TST & & \\
\hline CHEMBL1527520 & 688680 & 5.4645 & 5.3608 & TST & & \\
\hline CHEMBL1536896 & 688680 & 5.5879 & 4.9496 & TST & & \\
\hline CHEMBL1468444 & 688680 & 5.3123 & 5.2563 & TST & & \\
\hline CHEMBL1492622 & 688680 & \multicolumn{3}{|c|}{4.946000000000001} & 4.7377 & TST \\
\hline CHEMBL1581396 & 688680 & 5.0472 & 5.1362 & TST & & \\
\hline CHEMBL1611199 & 688680 & 5.2681 & 5.0753 & TST & & \\
\hline CHEMBL1494390 & 688680 & 5.362 & 5.2031 & TST & & \\
\hline CHEMBL1387835 & 688680 & 4.8255 & 5.2742 & TST & & \\
\hline CHEMBL1387693 & 688680 & 5.1083 & 5.20299 & 9999999999 & & TST \\
\hline CHEMBL1576217 & 688680 & 5.2308 & 5.267 & TST & & \\
\hline CHEMBL1546396 & 688680 & 5.2611 & 4.8307 & TST & & \\
\hline CHEMBL130290 & 58683 & 6.0381 & 6.00200 & 0000000001 & & TRN \\
\hline CHEMBL132783 & 58683 & 5.0575 & 5.3025 & TRN & & \\
\hline CHEMBL89934 & 58683 & 5.9172 & 6.465 & TRN & & \\
\hline CHEMBL128041 & 58683 & 5.6556 & 5.2629 & TRN & & \\
\hline CHEMBL336376 & 58683 & 6.8665 & 6.4254 & TST & & \\
\hline CHEMBL132901 & 58683 & 5.7352 & 5.5212 & TRN & & \\
\hline CHEMBL132333 & 58683 & \multicolumn{3}{|c|}{6.718999999999999} & 6.5887 & TRN \\
\hline CHEMBL128242 & 58683 & 6.0783 & 5.4342 & TRN & & \\
\hline CHEMBL131307 & 58683 & 5.6144 & 5.643 & TRN & & \\
\hline CHEMBL130035 & 58683 & 4.8996 & 5.2622 & TRN & & \\
\hline CHEMBL131261 & 58683 & 6.8239 & 6.5761 & TRN & & \\
\hline CHEMBL133671 & 58683 & 6.5436 & 6.0035 & TRN & & \\
\hline CHEMBL130388 & 58683 & 7.8539 & 6.4737 & TRN & & \\
\hline CHEMBL339926 & 58683 & 7.5376 & 6.3469 & TST & & \\
\hline CHEMBL132500 & 58683 & 6.289 & 6.2192 & TRN & & \\
\hline CHEMBL339852 & 58683 & 6.6498 & 6.0389 & TST & & \\
\hline CHEMBL424266 & 58683 & 5.5784 & 5.5986 & TRN & & \\
\hline CHEMBL130489 & 58683 & 5.0742 & 6.07600 & 0000000000 & & TST \\
\hline CHEMBL130894 & 58683 & 6.8827 & 6.7987 & TRN & & \\
\hline CHEMBL130036 & 58683 & \multicolumn{3}{|c|}{5.752000000000001} & 6.1416 & TRN \\
\hline CHEMBL131546 & 58683 & 6.3439 & 6.4342 & TST & & \\
\hline CHEMBL134027 & 58683 & 5.7852 & 5.9218 & TRN & & \\
\hline CHEMBL130788 & 58683 & 7.2596 & 6.3774 & TST & & \\
\hline
\end{tabular}




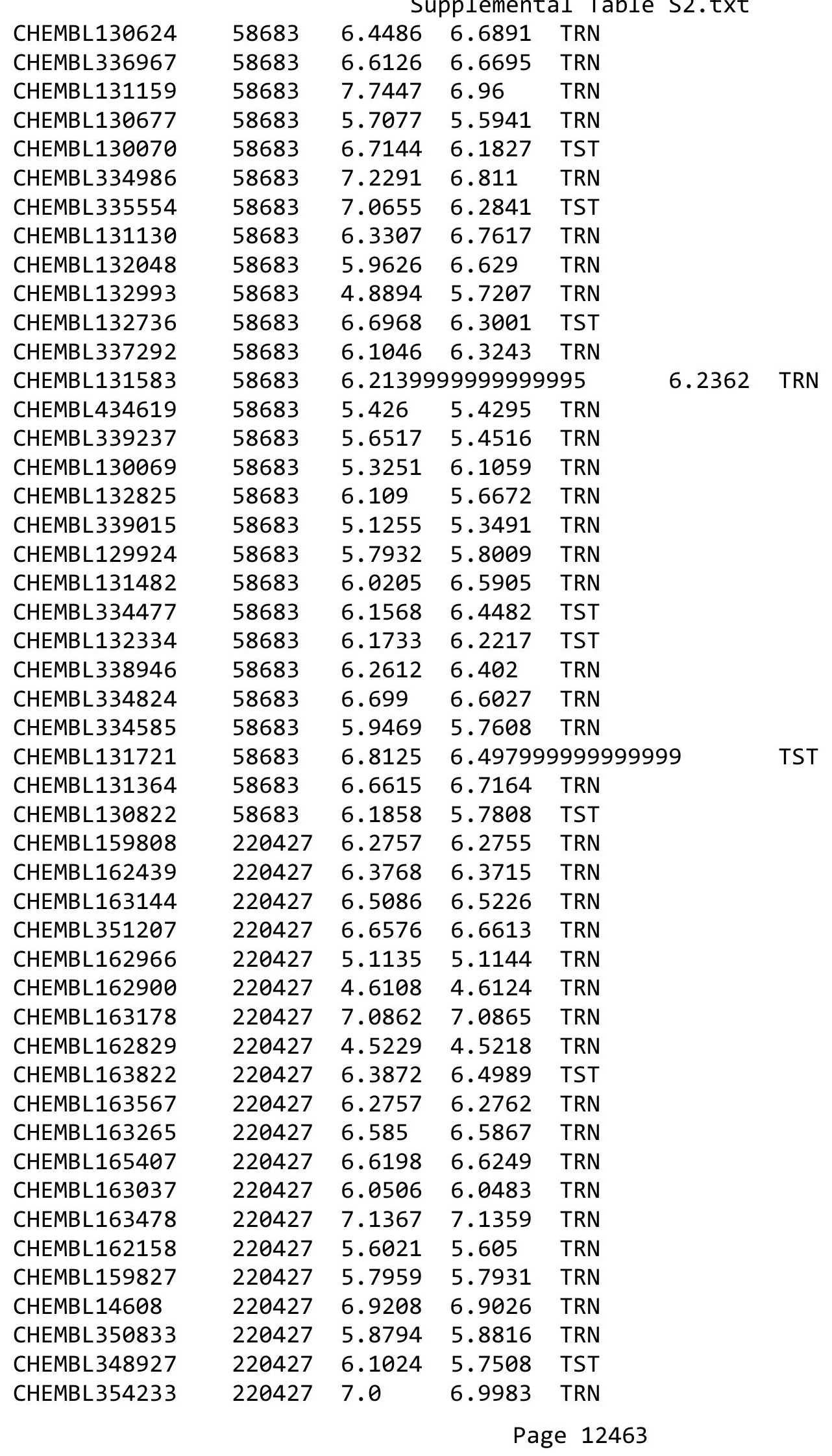


Supplemental Table S2.txt

\begin{tabular}{|c|c|c|c|c|}
\hline CHEMBL164353 & 7 & 5.6576 & 5.6564 & TRN \\
\hline HFMBI 163266 & 20427 & 6.2076 & 6.2043 & \\
\hline HEMBL163250 & 20427 & 8239 & 8267 & \\
\hline HEMBL 349672 & 20427 & 6576 & 6566 & \\
\hline HEMBL423811 & 20427 & 5.699 & .6985 & \\
\hline HEMBL3084969 & 20427 & .2924 & .9524 & \\
\hline HEMBL164168 & 20427 & .8539 & .8532 & RN \\
\hline HEMBL162156 & 220427 & .1249 & .1286 & PN \\
\hline HEMBL162865 & 20427 & .0269 & 6.026 & \\
\hline HEMBL162607 & 20427 & .6021 & 6.6025 & \\
\hline HEMBL163428 & 20427 & .7825 & .7805 & \\
\hline HEMBL 349 & & .8069 & 5.8079 & $\mathrm{RN}$ \\
\hline HEMBL 349189 & 20 & 7696 & 6.7688 & \\
\hline HEMBL 354015 & 27 & .8539 & 4.8541 & \\
\hline HEMBL 85320 & 20427 & 301 & 4.9617 & ST \\
\hline HEMBL119054 & 20 & 024 & 9938 & Niv \\
\hline HEMBL162 & 27 & & 33 & RN \\
\hline HEMBL162979 & 27 & 949 & 9688 & \\
\hline HEMBL163807 & 7 & 528 & 5553 & \\
\hline HEMBL163209 & 27 & 318 & 334 & RIN \\
\hline HEMBL162 & 7 & 861 & 859 & RN \\
\hline HEMBL16 & & 39 & & $\mathrm{RN}$ \\
\hline HEMBL162 & 27 & 372 & 332 & ГRN \\
\hline HEMBL112522 & & 696 & 776 & TRN \\
\hline HEMBL163179 & 27 & 862 & 848 & IRN \\
\hline HEMBL162180 & 7 & 239 & 219 & RN \\
\hline HEMBL16 & & & & 「RN \\
\hline HEMBL 352 & & & 546 & RN \\
\hline HEMBL 350586 & & & & ISI \\
\hline HEMBL162835 & 204 & 6.7212 & 149 & TRN \\
\hline HEMBL117 & 7 & 596 & 12 & TRN \\
\hline HEMBL16 & & & & ST \\
\hline HEMBL162 & & & 208 & TST \\
\hline HEMBL163630 & & 65 & 57 & TST \\
\hline HEMBL159263 & 0 & 6.9208 & 6.7776 & TST \\
\hline HEMBL351648 & 7 & & 605 & TST \\
\hline HEMBL16 & & 36 & & ST \\
\hline HEMBL164211 & & 458 & 7137 & TST \\
\hline HEMBL162424 & 20 & 7.1024 & 3847 & TST \\
\hline HEMBL162. & 7 & 596 & 826 & TST \\
\hline CHEMBL156864 & 1 & 702 & 4.5972 & TRN \\
\hline CHEMBL576208 & & 4.9914 & 4.6772 & TRN \\
\hline CHEMBL1510959 & 36971 & 4.684 & 4.6929 & TST \\
\hline HEMBL14901 & 36 & 4.5719 & 4.6766 & TST \\
\hline CHEMBL1389725 & & 576 & 4.7383 & $\mathrm{~K}$ \\
\hline CHEMBL381033 & 736971 & & 4.7951 & \\
\hline CHEMBL1611035 & 36971 & 4.7423 & 4.6279 & RN \\
\hline CHEMBL1365260 & 736971 & 4.4962 & 4.632 & TRN \\
\hline
\end{tabular}

Page 12464 
Supplemental Table S2.txt

\begin{tabular}{|c|c|c|c|c|c|}
\hline CHEMBL1504873 & 736971 & 4.5376 & 4.3654 & TRN & \\
\hline CHEMBL1313683 & 736971 & 5.1062 & 4.6719 & TRN & \\
\hline CHEMBL1507938 & 736971 & 4.8069 & 4.668 & TRN & \\
\hline CHEMBL1390831 & 736971 & 4.7595 & 4.7387 & TRN & \\
\hline CHEMBL 3197446 & 736971 & 4.1296 & 4.68 & TRN & \\
\hline CHEMBL1343309 & 736971 & 4.4145 & 4.2879 & TRN & \\
\hline CHEMBL442925 & 736971 & 5.2684 & 4.7539 & TRN & \\
\hline CHEMBL1467987 & 736971 & 4.45100 & 00000000 & 05 & 4.5824 \\
\hline CHEMBL1573586 & 736971 & 4.9547 & 4.6837 & TST & \\
\hline CHEMBL1427637 & 736971 & 4.0535 & 4.7974 & TST & \\
\hline CHEMBL1519862 & 736971 & 4.5498 & 4.3364 & TRN & \\
\hline CHEMBL1700085 & 736971 & 5.2211 & 4.7348 & TRN & \\
\hline CHEMBL1387749 & 736971 & 4.6289 & 4.6004 & TRN & \\
\hline CHEMBL1352220 & 736971 & 5.4498 & 4.8319 & TRN & \\
\hline CHEMBL1377488 & 736971 & 4.6459 & 4.6134 & TST & \\
\hline CHEMBL1398836 & 736971 & 4.8539 & 4.681 & TRN & \\
\hline CHEMBL1369984 & 736971 & 4.7328 & 4.853 & TST & \\
\hline CHEMBL1322261 & 736971 & 4.7986 & 4.6578 & TST & \\
\hline CHEMBL1504853 & 736971 & 5.0575 & 4.9279 & TRN & \\
\hline CHEMBL1511922 & 736971 & 5.4214 & 4.7148 & TRN & \\
\hline CHEMBL3199860 & 736971 & 4.5258 & 4.7787 & TRN & \\
\hline CHEMBL1392564 & 736971 & 4.2823 & 4.6198 & TRN & \\
\hline CHEMBL1349632 & 736971 & 4.3788 & 4.3216 & TRN & \\
\hline CHEMBL1397706 & 736971 & 3.0 & 4.5835 & TST & \\
\hline CHEMBL1477920 & 736971 & 4.4535 & 4.6533 & TRN & \\
\hline CHEMBL1560004 & 736971 & 4.7905 & 4.7077 & TRN & \\
\hline CHEMBL1449672 & 736971 & 4.6556 & 4.3103 & TRN & \\
\hline CHEMBL3196057 & 736971 & 5.5719 & 4.7386 & TST & \\
\hline CHEMBL1337752 & 736971 & 4.2823 & 4.6211 & TST & \\
\hline CHEMBL1472212 & 736971 & 4.3526 & 4.7703 & TRN & \\
\hline CHEMBL1712864 & 736971 & 5.7986 & 5.2063 & TRN & \\
\hline CHEMBL1324155 & 736971 & 5.5986 & 4.5257 & TRN & \\
\hline CHEMBL1328084 & 736971 & 4.8761 & 4.6704 & TRN & \\
\hline CHEMBL1732672 & 736971 & 4.0434 & 4.6292 & TRN & \\
\hline CHEMBL233119 & 736971 & 4.2604 & 4.4251 & TRN & \\
\hline CHEMBL1506796 & 736971 & 4.9626 & 4.9143 & TRN & \\
\hline CHEMBL1458444 & 736971 & 4.9914 & 4.9373 & TRN & \\
\hline CHEMBL1565609 & 736971 & 4.3872 & 4.6342 & TRN & \\
\hline CHEMBL3192666 & 736971 & 4.3188 & 4.4207 & TST & \\
\hline CHEMBL3199034 & 736971 & 4.5072 & 4.5353 & TRN & \\
\hline CHEMBL1559546 & 736971 & 4.757 & 4.5914 & TRN & \\
\hline CHEMBL1408715 & 736971 & 4.1707 & 4.588 & TRN & \\
\hline CHEMBL3197805 & 736971 & 4.556 & 4.7813 & TST & \\
\hline CHEMBL1999511 & 736971 & 4.8861 & 4.4784 & TRN & \\
\hline CHEMBL1609828 & 736971 & 5.2832 & 4.6262 & TRN & \\
\hline CHEMBL1504710 & 736971 & 4.9318 & 4.8598 & TST & \\
\hline CHEMBL1539876 & 736971 & 4.224 & 4.7663 & TRN & \\
\hline CHEMBL1504125 & 736971 & 5.7986 & 4.7976 & TST & \\
\hline
\end{tabular}


Supplemental Table S2.txt

\begin{tabular}{|c|c|c|c|c|}
\hline CHEMBL1556089 & 736971 & 4.6696 & 4.4627 & TRN \\
\hline CHEMBL1969046 & 736971 & 4.9508 & 4.8335 & TRN \\
\hline CHEMBL1528847 & 736971 & 4.5935 & 4.6853 & TRN \\
\hline CHEMBL1471498 & 736971 & 4.4962 & 4.949 & TRN \\
\hline CHEMBL1535503 & 736971 & 5.2358 & 4.805 & TRN \\
\hline CHEMBL3193011 & 736971 & 3.0 & 4.8558 & TRN \\
\hline CHEMBL3196248 & 736971 & 4.3072 & 4.6146 & TRN \\
\hline CHEMBL3210944 & 736971 & 4.6757 & 4.69600 & 0000000001 \\
\hline CHEMBL1505544 & 736971 & 5.5346 & 4.8826 & TRN \\
\hline CHEMBL1402456 & 736971 & 5.9914 & 5.239 & TRN \\
\hline CHEMBL1492590 & 736971 & 4.8665 & 4.8647 & TRN \\
\hline CHEMBL1301421 & 736971 & 4.2434 & 4.6458 & TRN \\
\hline CHEMBL 205040 & 736971 & 5.0857 & 4.9131 & TRN \\
\hline CHEMBL1378542 & 736971 & 4.5735 & 4.4278 & TRN \\
\hline CHEMBL1583785 & 736971 & 4.4437 & 4.7617 & TST \\
\hline CHEMBL1578879 & 736971 & 5.2549 & 4.3534 & TRN \\
\hline CHEMBL1602108 & 736971 & 4.7011 & 4.55 & TRN \\
\hline CHEMBL584668 & 736971 & 4.1163 & 4.6687 & TRN \\
\hline CHEMBL1413787 & 736971 & 4.9281 & 4.6985 & TRN \\
\hline CHEMBL1443965 & 736971 & 4.7932 & 4.7237 & TRN \\
\hline CHEMBL159895 & 736971 & 4.7645 & 4.681 & TRN \\
\hline CHEMBL1544497 & 736971 & 4.3468 & 4.5961 & TRN \\
\hline CHEMBL1428614 & 736971 & 4.5751 & 4.6409 & TRN \\
\hline CHEMBL1584073 & 736971 & 4.752 & 4.5487 & TRN \\
\hline CHEMBL3198259 & 736971 & 5.1952 & 4.7086 & TRN \\
\hline CHEMBL3208275 & 736971 & 4.7352 & 4.3638 & TRN \\
\hline CHEMBL1462691 & 736971 & 4.9508 & 4.7315 & TST \\
\hline CHEMBL1501990 & 736971 & 4.1555 & 4.813 & TRN \\
\hline CHEMBL3197065 & 736971 & 5.3716 & 4.6234 & TRN \\
\hline CHEMBL1573380 & 736971 & 4.6615 & 4.3008 & TRN \\
\hline CHEMBL1730590 & 736971 & 4.6345 & 4.6786 & TRN \\
\hline CHEMBL1521074 & 736971 & 4.7235 & 4.5943 & TRN \\
\hline CHEMBL1493528 & 736971 & 4.9666 & 4.7787 & TRN \\
\hline CHEMBL3190081 & 736971 & 4.4634 & 4.5188 & TRN \\
\hline CHEMBL1523828 & 736971 & 4.5302 & 4.6746 & TRN \\
\hline CHEMBL1452003 & 736971 & 4.9706 & 4.57100 & 0000000001 \\
\hline CHEMBL1428684 & 736971 & 4.5751 & 4.7329 & TRN \\
\hline CHEMBL1483847 & 736971 & 4.5654 & 4.6949 & TRN \\
\hline CHEMBL1462406 & 736971 & 4.466 & 4.6099 & TRN \\
\hline CHEMBL1501910 & 736971 & 4.7235 & 4.6111 & TRN \\
\hline CHEMBL1450897 & 736971 & 4.0367 & 4.867 & TST \\
\hline CHEMBL1376622 & 736971 & 4.8761 & 4.8468 & TRN \\
\hline CHEMBL1386967 & 736971 & 4.8153 & 4.7044 & TRN \\
\hline CHEMBL1480646 & 736971 & 4.7645 & 4.6934 & TRN \\
\hline CHEMBL1312888 & 736971 & 4.129 & 4.3311 & TRN \\
\hline CHEMBL1345096 & 736971 & 4.7399 & 4.5363 & TST \\
\hline CHEMBL1988699 & 736971 & 4.5058 & 4.4225 & TRN \\
\hline CHEMBL1537846 & 736971 & 4.6478 & 4.6051 & TRN \\
\hline
\end{tabular}


Supplemental Table S2.txt

\begin{tabular}{|c|c|c|c|c|c|}
\hline CHEMBL1569914 & 736971 & 4.6882 & 4.7073 & TRN & \\
\hline CHEMBL1492642 & 736971 & 4.8894 & 4.7743 & TRN & \\
\hline CHEMBL 3195897 & 736971 & 4.7258 & 4.561 & TST & \\
\hline CHEMBL1469807 & 736971 & 3.0 & 4.883 & TRN & \\
\hline CHEMBL1508306 & 736971 & 4.4034 & 4.4085 & TRN & \\
\hline CHEMBL1432218 & 736971 & 4.644 & 4.6363 & TRN & \\
\hline CHEMBL1488749 & 736971 & 4.8761 & 4.8965 & TRN & \\
\hline CHEMBL1405401 & 736971 & 4.2381 & 4.3451 & TRN & \\
\hline CHEMBL1405940 & 736971 & 4.5072 & 4.6408 & TRN & \\
\hline CHEMBL1412627 & 736971 & 4.7167 & 4.5483 & TRN & \\
\hline CHEMBL1698189 & 736971 & 4.0867 & 4.3447 & TRN & \\
\hline CHEMBL 3199870 & 736971 & 4.1838 & 4.6078 & TRN & \\
\hline CHEMBL1423071 & 736971 & 4.5591 & 4.7445 & TRN & \\
\hline CHEMBL1306211 & 736971 & 4.0227 & 4.6782 & TRN & \\
\hline CHEMBL 3196452 & 736971 & 4.7595 & 4.6205 & TRN & \\
\hline CHEMBL1354548 & 736971 & 4.4908 & 4.6476 & TRN & \\
\hline CHEMBL 3214026 & 736971 & 4.5045 & 4.5281 & TRN & \\
\hline CHEMBL1379026 & 736971 & 5.1586 & 4.6816 & TRN & \\
\hline CHEMBL1444349 & 736971 & 4.5591 & 4.6385 & TST & \\
\hline CHEMBL175434 & 736971 & 5.011 & 4.8786 & TRN & \\
\hline CHEMBL1364988 & 736971 & 5.4134 & 4.7869 & TRN & \\
\hline CHEMBL1422087 & 736971 & 4.8239 & 4.9121 & TST & \\
\hline CHEMBL1703849 & 736971 & 4.6925 & 4.4704 & TRN & \\
\hline CHEMBL1379048 & 736971 & 5.0434 & 4.7992 & TST & \\
\hline CHEMBL 3210723 & 736971 & 4.7932 & 4.7485 & TRN & \\
\hline CHEMBL1342287 & 736971 & 4.8665 & 4.5863 & TRN & \\
\hline CHEMBL510279 & 736971 & 3.0 & 4.5597 & TST & \\
\hline CHEMBL1463989 & 736971 & 4.7471 & 4.6007 & TRN & \\
\hline CHEMBL1440766 & 736971 & 4.6635 & 4.3506 & TRN & \\
\hline CHEMBL1461427 & 736971 & 4.5031 & \multicolumn{2}{|c|}{4.3660000000000005} & TRN \\
\hline CHEMBL1342873 & 736971 & 5.2321 & 4.6673 & TRN & \\
\hline CHEMBL1305329 & 736971 & 4.8182 & 4.894 & TST & \\
\hline CHEMBL1582309 & 736971 & 4.7878 & 4.6216 & TRN & \\
\hline CHEMBL 3209095 & 736971 & 4.8013 & 4.8068 & TRN & \\
\hline CHEMBL1565912 & 736971 & 5.1463 & 4.6936 & TRN & \\
\hline CHEMBL1724107 & 736971 & \multicolumn{3}{|c|}{5.3420000000000005} & TRN \\
\hline CHEMBL1457356 & 736971 & 4.8069 & 4.636 & TRN & \\
\hline CHEMBL1569920 & 736971 & 5.5045 & 4.6503 & TST & \\
\hline CHEMBL1408066 & 736971 & 4.4413 & 4.3998 & TRN & \\
\hline CHEMBL1465938 & 736971 & 4.9508 & 4.8234 & TRN & \\
\hline CHEMBL1491869 & 736971 & 4.6091 & 4.5854 & TRN & \\
\hline CHEMBL1518707 & 736971 & 4.4225 & 4.3682 & TRN & \\
\hline CHEMBL 3198813 & 736971 & 4.4559 & 4.2666 & TRN & \\
\hline CHEMBL1584930 & 736971 & 4.857 & 4.7511 & TRN & \\
\hline CHEMBL1447078 & 736971 & 4.6716 & 4.6709 & TST & \\
\hline CHEMBL1595804 & 736971 & 4.5768 & 4.6359 & TRN & \\
\hline CHEMBL1731096 & 736971 & 4.1244 & 4.5889 & TRN & \\
\hline CHEMBL 3199687 & 736971 & 4.4306 & 4.6129 & TST & \\
\hline
\end{tabular}




\begin{tabular}{|c|c|c|c|c|c|c|}
\hline & & \multicolumn{5}{|c|}{ Supplemental Table S2.txt } \\
\hline CHEMBL208926 & 736971 & 4.8665 & 4.6354 & TST & & \\
\hline CHEMBL1463363 & 736971 & 5.567 & 4.6797 & TRN & & \\
\hline CHEMBL1341119 & 736971 & 4.9066 & 4.7194 & TRN & & \\
\hline CHEMBL1361268 & 736971 & 4.6576 & 4.409 & TRN & & \\
\hline CHEMBL1539910 & 736971 & 4.7352 & 4.6488 & TRN & & \\
\hline CHEMBL1577291 & 736971 & 4.4622 & 4.4139 & TRN & & \\
\hline CHEMBL1518285 & 736971 & 4.2984 & 4.7035 & TST & & \\
\hline CHEMBL1483444 & 736971 & 4.6655 & 4.6358 & TST & & \\
\hline CHEMBL1381205 & 736971 & 5.4962 & 4.7972 & TRN & & \\
\hline CHEMBL1605599 & 736971 & 4.5901 & 4.6632 & TRN & & \\
\hline CHEMBL1564777 & 736971 & 4.426 & 4.7175 & TRN & & \\
\hline CHEMBL1479657 & 736971 & 4.6271 & 4.648 & TRN & & \\
\hline CHEMBL1497694 & 736971 & 4.8697 & 4.5927 & TRN & & \\
\hline CHEMBL1560993 & 736971 & 4.757 & 4.7088 & TST & & \\
\hline CHEMBL1394969 & 736971 & 5.1068 & 4.8823 & TST & & \\
\hline CHEMBL1407928 & 736971 & 4.6326 & 4.7715 & TST & & \\
\hline CHEMBL1482499 & 736971 & \multicolumn{3}{|c|}{5.162999999999999} & 4.7772 & TRN \\
\hline CHEMBL1413278 & 736971 & 4.4012 & 4.4108 & TRN & & \\
\hline CHEMBL1333044 & 736971 & 4.5391 & 4.574 & TRN & & \\
\hline CHEMBL1705186 & 736971 & 5.3316 & 4.3921 & TRN & & \\
\hline CHEMBL299853 & 736971 & 4.7305 & 4.8058 & TRN & & \\
\hline CHEMBL1591913 & 736971 & 4.8633 & 4.931 & TRN & & \\
\hline CHEMBL1336046 & 736971 & 5.0716 & 4.6782 & TRN & & \\
\hline CHEMBL1708850 & 736971 & 4.9393 & 4.7667 & TST & & \\
\hline CHEMBL1530147 & 736971 & 5.2518 & 4.9774 & TRN & & \\
\hline CHEMBL1464550 & 736971 & 4.4112 & 4.581 & TRN & & \\
\hline CHEMBL1426692 & 736971 & 4.4724 & 4.7019 & TST & & \\
\hline CHEMBL1384146 & 736971 & 4.752 & 4.7462 & TRN & & \\
\hline CHEMBL1405100 & 736971 & 4.7167 & 4.6386 & TRN & & \\
\hline CHEMBL1342938 & 736971 & 4.5784 & 4.3473 & TRN & & \\
\hline CHEMBL 3197545 & 736971 & 4.7328 & 4.6019 & TRN & & \\
\hline CHEMBL1351708 & 736971 & 4.4168 & 4.5432 & TST & & \\
\hline CHEMBL1432027 & 736971 & 4.7595 & 4.5362 & TRN & & \\
\hline CHEMBL3192913 & 736971 & 5.4295 & 4.76399 & 9999999999 & & TST \\
\hline CHEMBL3213606 & 736971 & 4.7545 & 4.5686 & TRN & & \\
\hline CHEMBL1478825 & 736971 & 4.5751 & 4.8647 & TRN & & \\
\hline CHEMBL3199331 & 736971 & 4.4828 & 4.7529 & TRN & & \\
\hline CHEMBL1424355 & 736971 & 4.3546 & 4.7337 & TRN & & \\
\hline CHEMBL1513162 & 736971 & 4.6676 & 4.7691 & TRN & & \\
\hline CHEMBL3193227 & 736971 & 3.0 & 4.2376 & TRN & & \\
\hline CHEMBL1532037 & 736971 & 4.7258 & 4.7343 & TRN & & \\
\hline CHEMBL1440488 & 736971 & 4.4949 & 4.5585 & TRN & & \\
\hline CHEMBL1354754 & 736971 & 4.76699 & 99999999 & 995 & 4.8559 & TRN \\
\hline CHEMBL1372677 & 736971 & 4.6091 & 4.5955 & TRN & & \\
\hline CHEMBL1460564 & 736971 & 5.0009 & 4.7224 & TST & & \\
\hline CHEMBL 3144856 & 736971 & 3.0 & 4.80399 & 9999999999 & & TST \\
\hline CHEMBL1391158 & 736971 & 5.3224 & 4.7828 & TRN & & \\
\hline CHEMBL1563187 & 736971 & 4.5528 & 4.3565 & TRN & & \\
\hline
\end{tabular}




\begin{tabular}{|c|c|c|c|c|c|c|}
\hline & & \multicolumn{5}{|c|}{ Supplemental Table S2.txt } \\
\hline CHEMBL1309678 & 736971 & 4.8827 & 4.5978 & TRN & & \\
\hline CHEMBL1349748 & 736971 & 5.4634 & 4.8335 & TST & & \\
\hline CHEMBL1585372 & 736971 & 4.6556 & 4.6355 & TRN & & \\
\hline CHEMBL1904348 & 736971 & 4.4815 & 4.7158 & TST & & \\
\hline CHEMBL1545955 & 736971 & 4.5031 & 4.2764 & TRN & & \\
\hline CHEMBL1379892 & 736971 & 5.1361 & 4.7136 & TRN & & \\
\hline CHEMBL1890591 & 736971 & 3.0 & 4.5592 & TRN & & \\
\hline CHEMBL551004 & 736971 & 4.7696 & 4.6276 & TRN & & \\
\hline CHEMBL1342723 & 736971 & 5.4895 & 4.9319 & TRN & & \\
\hline CHEMBL1376540 & 736971 & 3.0 & 4.7854 & TRN & & \\
\hline CHEMBL1466087 & 736971 & 4.5214 & 4.7135 & TST & & \\
\hline CHEMBL1501135 & 736971 & 4.7905 & 4.6536 & TST & & \\
\hline CHEMBL1566434 & 736971 & 4.7055 & 4.5333 & TRN & & \\
\hline CHEMBL1547222 & 736971 & 5.1325 & 4.798 & TRN & & \\
\hline CHEMBL1559362 & 736971 & 4.6635 & 4.6686 & TRN & & \\
\hline CHEMBL1462381 & 736971 & 4.383 & 4.7563 & TRN & & \\
\hline CHEMBL1532623 & 736971 & 4.76699 & 99999999 & 995 & 4.7316 & TRN \\
\hline CHEMBL88811 & 736971 & 5.3363 & 4.8328 & TRN & & \\
\hline CHEMBL1339228 & 736971 & 5.76200 & 30000000 & 005 & 4.8079 & TRN \\
\hline CHEMBL1365705 & 736971 & 4.6478 & 4.6745 & TRN & & \\
\hline CHEMBL1525316 & 736971 & 4.5272 & 4.5185 & TRN & & \\
\hline CHEMBL1569446 & 736971 & 4.5467 & 4.6019 & TRN & & \\
\hline CHEMBL1545215 & 736971 & 5.1681 & 4.4159 & TRN & & \\
\hline CHEMBL1585064 & 736971 & 4.5784 & 4.6926 & TRN & & \\
\hline CHEMBL1304247 & 736971 & 4.5498 & 4.6589 & TST & & \\
\hline CHEMBL3195061 & 736971 & 4.4802 & 4.5968 & TRN & & \\
\hline CHEMBL1530356 & 736971 & 4.7905 & 4.5366 & TRN & & \\
\hline CHEMBL 2000670 & 736971 & 4.8447 & 4.5383 & TRN & & \\
\hline CHEMBL1379920 & 736971 & 4.8125 & 4.695 & TRN & & \\
\hline CHEMBL1400093 & 736971 & 5.0685 & 4.6959 & TST & & \\
\hline CHEMBL1308385 & 736971 & 4.4157 & 4.5827 & TRN & & \\
\hline CHEMBL1601364 & 736971 & 4.8416 & 4.5383 & TRN & & \\
\hline CHEMBL1165723 & 736971 & 5.4413 & 4.7049 & TRN & & \\
\hline CHEMBL1598920 & 736971 & 4.7235 & 4.2935 & TRN & & \\
\hline CHEMBL1707247 & 736971 & 4.6778 & 4.7372 & TRN & & \\
\hline CHEMBL1609498 & 736971 & 4.6253 & 4.44300 & 00000 & 05 & n \\
\hline CHEMBL1477061 & 736971 & 3.0 & 4.8074 & TRN & & \\
\hline CHEMBL1568996 & 736971 & 4.3556 & 4.4617 & TST & & \\
\hline CHEMBL1356235 & 736971 & 4.6478 & 4.2524 & TRN & & \\
\hline CHEMBL1708975 & 736971 & 4.8729 & 4.7263 & TRN & & \\
\hline CHEMBL1563939 & 736971 & 4.6635 & 4.8501 & TST & & \\
\hline CHEMBL1489745 & 736971 & 4.9914 & 4.8837 & TRN & & \\
\hline CHEMBL3145370 & 736971 & 4.6596 & 4.6029 & TST & & \\
\hline CHEMBL573627 & 736971 & 4.5272 & 4.5709 & TRN & & \\
\hline CHEMBL1586985 & 736971 & 3.0 & 4.6349 & TRN & & \\
\hline CHEMBL1446989 & 736971 & 4.209 & 4.6143 & TRN & & \\
\hline CHEMBL1439396 & 736971 & 4.6925 & 4.3092 & TRN & & \\
\hline CHEMBL1371005 & 736971 & 4.757 & 4.7225 & TRN & & \\
\hline
\end{tabular}


Supplemental Table S2.txt

\begin{tabular}{|c|c|c|c|c|}
\hline 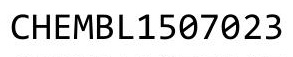 & & & & \\
\hline HEMBL1975547 & 36971 & 5.0195 & 7248 & \\
\hline HEMBL1719459 & 6971 & 16 & 158 & \\
\hline 51 & & & 881 & \\
\hline AEMBL13 & & & 5904 & \\
\hline AEMBL1409773 & 36971 & 22 & .7546 & \\
\hline HEMBL1491232 & 36971 & 4.5544 & 4.5848 & \\
\hline HEMBL161 & 1 & & 4.6025 & \\
\hline AEMBL34 & & 67 & 4.875 & \\
\hline AEMBL14 & & & .7552 & \\
\hline HEMBL1392754 & 36971 & 1949 & 4.7514 & \\
\hline HEMBL1470135 & 71 & 5331 & 4.613 & \\
\hline HEMBL153 & 1 & 86 & 4.6278 & \\
\hline HEMBL13 & & & 6538 & \\
\hline AEMBL14 & & & 746 & \\
\hline HEMBL1892270 & 71 & 841 & 4.4722 & \\
\hline HEMBL141 & & & 6373 & \\
\hline HEMBL 15 & 1 & & 4 & \\
\hline L14 & & & 1035 & \\
\hline HEMBL31 & & & 436 & \\
\hline HEMBL 130 & 71 & & 4.7138 & \\
\hline HEMBL602 & & 3 & 5223 & \\
\hline HEMBL19 & 1 & 86 & 4.6765 & \\
\hline L1: & & & 7337 & \\
\hline 17 & & & 309 & RN \\
\hline AEMBL13. & & & 4.5425 & not \\
\hline JEMBL14e & & & 5915 & TRN \\
\hline HEMBL 15 & 11 & & 594 & \\
\hline HEN & & & 886 & ST \\
\hline AEMBL1C & & & 888 & $\mathrm{RN}$ \\
\hline AEMBL31 & & & & RN \\
\hline HEMBL157 & & & 259 & RN \\
\hline HEMBL1C & & & 753 & RN \\
\hline 15 & & & 984 & RN \\
\hline L3. & & & 952 & ST \\
\hline HEMBL171 & & & 059 & RN \\
\hline AEMBL1608383 & 71 & 325 & 4.5692 & TST \\
\hline 153 & & & 454 & RN \\
\hline 2 & & & 375 & TRN \\
\hline AEMBL19 & & & 3989 & IST \\
\hline AEMBL1718 & 71 & 39 & 304 & RN \\
\hline IEMBL1: & & & 955 & is \\
\hline 121 & & & 4.6984 & \\
\hline HEMBL157 & & & 5839 & \\
\hline HEMBL1528059 & & 4.3391 & 4839 & RN \\
\hline AEMBL139 & 71 & 3. & 5414 & \\
\hline & & & & \\
\hline & 736971 & & & \\
\hline
\end{tabular}

Page 12470 


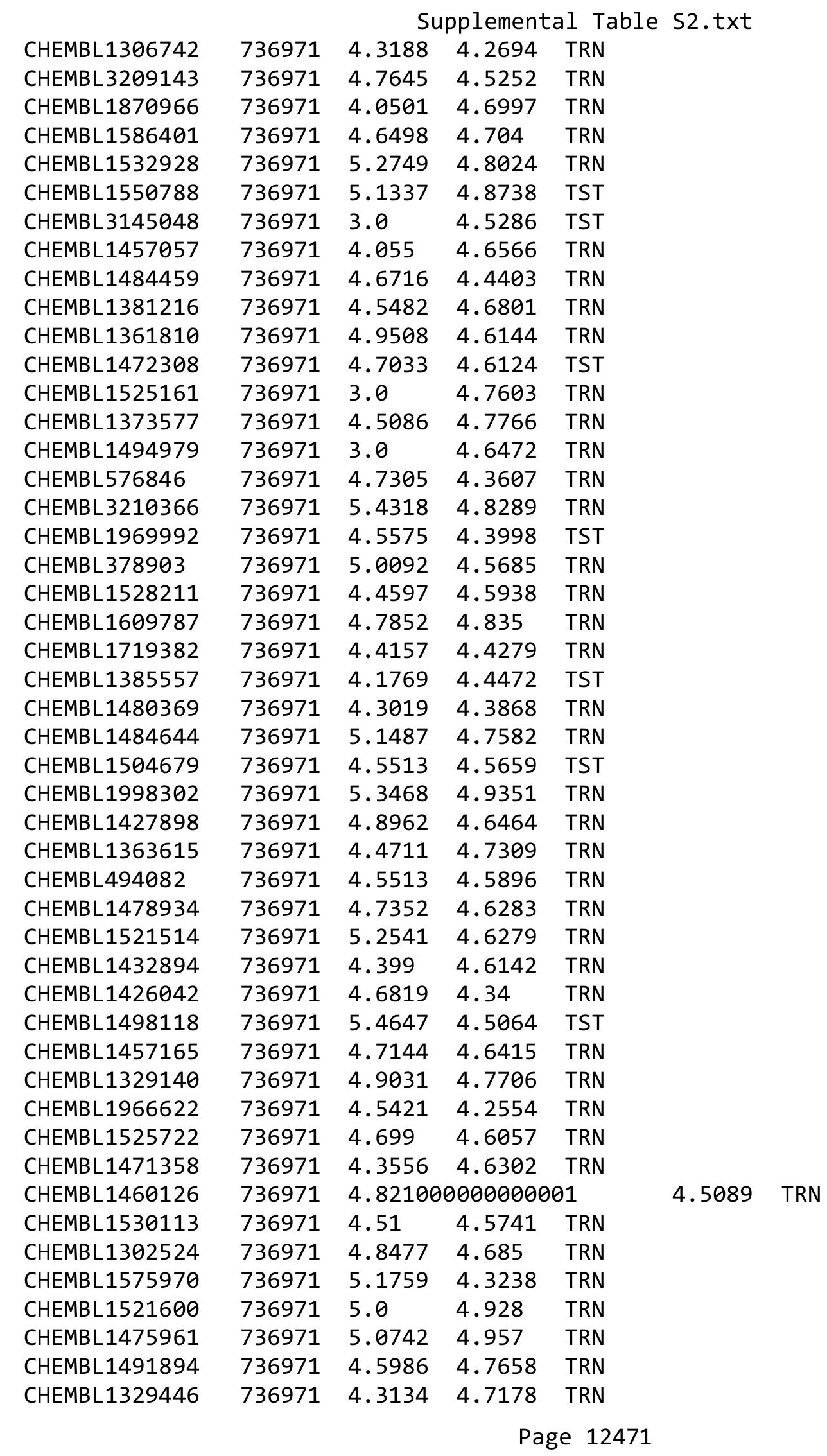




\begin{tabular}{|c|c|c|c|c|c|}
\hline \multirow{3}{*}{$\begin{array}{l}\text { CHEMBL1599965 } \\
\text { CHEMBL1604600 }\end{array}$} & \multicolumn{5}{|c|}{ Supplemental Table S2.txt } \\
\hline & 736971 & 4.8069 & 4.72199 & 99999999995 & TRN \\
\hline & 736971 & 4.6778 & 4.7257 & TST & \\
\hline CHEMBL1564821 & 736971 & 4.4377 & 4.6452 & TRN & \\
\hline CHEMBL1475973 & 736971 & 4.5186 & 4.5414 & TRN & \\
\hline CHEMBL3191871 & 736971 & 3.0 & 4.3344 & TRN & \\
\hline CHEMBL1560459 & 736971 & 4.7545 & 4.6717 & TST & \\
\hline CHEMBL3189672 & 736971 & 5.3915 & 4.5951 & TRN & \\
\hline CHEMBL1432131 & 736971 & 4.8069 & 4.393 & TRN & \\
\hline CHEMBL1469986 & 736971 & 4.6198 & 4.5745 & TST & \\
\hline CHEMBL1307406 & 736971 & 4.8182 & 4.7982 & TRN & \\
\hline CHEMBL1306782 & 736971 & 4.5361 & 4.6394 & TRN & \\
\hline CHEMBL3193997 & 736971 & 5.5017 & 4.7003 & TRN & \\
\hline CHEMBL1516968 & 736971 & 4.6925 & 4.5732 & TRN & \\
\hline CHEMBL1338489 & 736971 & 4.7595 & 4.7826 & TRN & \\
\hline CHEMBL1480814 & 736971 & 4.8827 & 4.8314 & TRN & \\
\hline CHEMBL1407802 & 736971 & 4.7122 & 4.8112 & TRN & \\
\hline CHEMBL3191759 & 736971 & 4.0223 & 4.1618 & TRN & \\
\hline CHEMBL1322521 & 736971 & 4.6655 & 4.6054 & TRN & \\
\hline CHEMBL392680 & 736971 & 4.7011 & 4.5608 & TRN & \\
\hline CHEMBL1573287 & 736971 & 4.3799 & 4.6994 & TRN & \\
\hline CHEMBL1370387 & 736971 & 4.0101 & 4.6655 & TRN & \\
\hline CHEMBL1405521 & 736971 & 4.6576 & 4.2482 & TRN & \\
\hline CHEMBL355496 & 736971 & 4.1918 & 4.3682 & TRN & \\
\hline CHEMBL1412738 & 736971 & 3.0 & 4.6448 & TRN & \\
\hline CHEMBL1341243 & 736971 & 4.7696 & 4.7173 & TRN & \\
\hline CHEMBL1318212 & 736971 & 4.644 & 4.5817 & TRN & \\
\hline CHEMBL3194086 & 736971 & 5.3188 & 4.8615 & TRN & \\
\hline CHEMBL1381587 & 736971 & 4.4935 & 4.6723 & TRN & \\
\hline CHEMBL1501843 & 736971 & 4.6696 & 4.5182 & TST & \\
\hline CHEMBL1372256 & 736971 & 4.6038 & 4.7297 & TRN & \\
\hline CHEMBL1515473 & 736971 & 4.5498 & 4.8557 & TRN & \\
\hline CHEMBL1486728 & 736971 & 5.2007 & 4.3182 & TRN & \\
\hline CHEMBL1449923 & 736971 & 5.0 & 4.9784 & TRN & \\
\hline CHEMBL1874620 & 736971 & 4.5482 & 4.6206 & TRN & \\
\hline CHEMBL3196451 & 736971 & 5.6778 & 4.9723 & TRN & \\
\hline CHEMBL1574587 & 736971 & 4.3936 & 4.497 & TRN & \\
\hline CHEMBL1322894 & 736971 & 4.9066 & 4.6761 & TRN & \\
\hline CHEMBL3197982 & 736971 & 5.6882 & 4.7554 & TRN & \\
\hline CHEMBL1414754 & 736971 & 4.6882 & 4.6879 & TRN & \\
\hline CHEMBL1398171 & 736971 & 4.6162 & 4.8031 & TST & \\
\hline CHEMBL1485847 & 736971 & 4.7033 & 4.3787 & TRN & \\
\hline CHEMBL1888528 & 736971 & 3.0 & 4.846 & TRN & \\
\hline CHEMBL1421377 & 736971 & 5.1007 & 4.7756 & TST & \\
\hline CHEMBL1500091 & 736971 & 4.4271 & 4.6785 & TST & \\
\hline CHEMBL63883 & 736971 & 4.684 & 4.5195 & TRN & \\
\hline CHEMBL1365257 & 736971 & 3.0 & 4.5182 & TRN & \\
\hline CHEMBL1353712 & 736971 & 4.4622 & 4.6465 & TRN & \\
\hline CHEMBL1610992 & 736971 & 4.9136 & 4.5184 & TRN & \\
\hline
\end{tabular}


Supplemental Table S2.txt

\begin{tabular}{|c|c|c|c|c|c|c|}
\hline CHEMBL600313 & 736971 & 5.1637 & 4.6744 & TRN & & \\
\hline CHEMBL595840 & 736971 & 5.6198 & 4.78 & TRN & & \\
\hline CHEMBL1613412 & 736971 & 4.8729 & 4.2854 & TRN & & \\
\hline CHEMBL1429870 & 736971 & 4.5719 & 4.7197 & TRN & & \\
\hline CHEMBL1449597 & 736971 & 4.5575 & 4.3244 & TRN & & \\
\hline CHEMBL1374950 & 736971 & 4.5287 & 4.5972 & TRN & & \\
\hline CHEMBL1434792 & 736971 & 5.2069 & 4.882 & TRN & & \\
\hline CHEMBL1427194 & 736971 & 4.3288 & 4.5624 & TRN & & \\
\hline CHEMBL1321156 & 736971 & 4.4949 & 4.624 & TRN & & \\
\hline CHEMBL 3193863 & 736971 & 4.4789 & 4.6245 & TRN & & \\
\hline CHEMBL1429243 & 736971 & 4.4283 & 4.6645 & TRN & & \\
\hline CHEMBL1300177 & 736971 & \multicolumn{3}{|c|}{4.1530000000000005} & 4.519 & TRN \\
\hline CHEMBL1560329 & 736971 & 4.3063 & 4.7415 & TRN & & \\
\hline CHEMBL1405247 & 736971 & 4.5072 & 4.6674 & TST & & \\
\hline CHEMBL1722874 & 736971 & 4.4353 & 4.3185 & TRN & & \\
\hline CHEMBL1463829 & 736971 & 4.8013 & 4.8742 & TRN & & \\
\hline CHEMBL1351535 & 736971 & 4.7167 & 4.356 & TRN & & \\
\hline CHEMBL1439751 & 736971 & 3.0 & 4.3433 & TRN & & \\
\hline CHEMBL1395615 & 736971 & 4.6108 & 4.658 & TRN & & \\
\hline CHEMBL1500164 & 736971 & 4.6271 & 4.5206 & TRN & & \\
\hline CHEMBL1445676 & 736971 & 5.0443 & 4.8665 & TST & & \\
\hline CHEMBL1578029 & 736971 & 5.0306 & 4.9264 & TRN & & \\
\hline CHEMBL1558497 & 736971 & 4.6144 & 4.5498 & TRN & & \\
\hline CHEMBL1375292 & 736971 & 5.0794 & 4.5686 & TRN & & \\
\hline CHEMBL 3211987 & 736971 & 4.3862 & 4.627 & TRN & & \\
\hline CHEMBL1596475 & 736971 & 5.0825 & 5.042 & TRN & & \\
\hline CHEMBL1371119 & 736971 & 4.3915 & 4.6652 & TST & & \\
\hline CHEMBL1340332 & 736971 & 4.4634 & 4.8131 & TRN & & \\
\hline CHEMBL236899 & 736971 & 4.3788 & 4.7871 & TRN & & \\
\hline CHEMBL3198635 & 736971 & 5.6517 & 4.8208 & TRN & & \\
\hline CHEMBL1594943 & 736971 & 4.5498 & 4.6905 & TRN & & \\
\hline CHEMBL1425406 & 736971 & 4.6696 & 4.6067 & TRN & & \\
\hline CHEMBL1545387 & 736971 & 4.6308 & 4.552 & TRN & & \\
\hline CHEMBL 3144898 & 736971 & 4.6946 & 4.3953 & TST & & \\
\hline CHEMBL1520808 & 736971 & 4.7258 & 4.6587 & TRN & & \\
\hline CHEMBL1093346 & 736971 & \multicolumn{3}{|c|}{4.821000000000001} & 4.6565 & TRN \\
\hline CHEMBL1502410 & 736971 & 4.1152 & 4.7209 & TRN & & \\
\hline CHEMBL1337075 & 736971 & 3.0 & 4.723 & TRN & & \\
\hline CHEMBL1504945 & 736971 & 4.8239 & 4.6564 & TRN & & \\
\hline CHEMBL1556284 & 736971 & 4.4647 & 4.5532 & TRN & & \\
\hline CHEMBL1548872 & 736971 & 5.0768 & 4.7523 & TST & & \\
\hline CHEMBL1380580 & 736971 & 5.1203 & 4.7782 & TRN & & \\
\hline CHEMBL484663 & 736971 & 4.7747 & 4.4177 & TRN & & \\
\hline CHEMBL1380030 & 736971 & 4.5638 & 4.584 & TRN & & \\
\hline CHEMBL3191962 & 736971 & 6.0259 & 4.698 & TST & & \\
\hline CHEMBL1430214 & 736971 & 4.4425 & 4.575 & TRN & & \\
\hline CHEMBL1701182 & 736971 & 5.1713 & 4.8381 & TRN & & \\
\hline CHEMBL2369298 & 736971 & 4.3344 & 4.4115 & TST & & \\
\hline
\end{tabular}




\begin{tabular}{|c|c|c|c|c|c|c|}
\hline \multirow[b]{2}{*}{ CHEMBL1361392 } & & \multicolumn{5}{|c|}{ Supplemental Table S2.txt } \\
\hline & 736971 & 4.9547 & 4.8217 & TRN & & \\
\hline CHEMBL1613323 & 736971 & 4.6216 & 4.805 & TRN & & \\
\hline CHEMBL3194958 & 736971 & 4.6198 & 4.565 & TST & & \\
\hline CHEMBL1600286 & 736971 & 4.3904 & 4.8406 & TRN & & \\
\hline CHEMBL1438627 & 736971 & 4.7696 & 4.6345 & TRN & & \\
\hline CHEMBL1348741 & 736971 & 4.7595 & 4.688 & TRN & & \\
\hline CHEMBL1542862 & 736971 & 4.5361 & 4.6191 & TRN & & \\
\hline CHEMBL1394975 & 736971 & 4.5317 & 4.6085 & TRN & & \\
\hline CHEMBL1315825 & 736971 & 4.8239 & 4.58 & TRN & & \\
\hline CHEMBL336718 & 736971 & 5.1656 & 4.8671 & TRN & & \\
\hline CHEMBL1500694 & 736971 & 4.6289 & 4.5454 & TRN & & \\
\hline CHEMBL1414729 & 736971 & 4.3605 & 4.4128 & TRN & & \\
\hline CHEMBL1711590 & 736971 & 4.7212 & 4.5823 & TST & & \\
\hline CHEMBL1582494 & 736971 & 4.5287 & 4.4032 & TRN & & \\
\hline CHEMBL1380540 & 736971 & 4.6234 & 4.4751 & TRN & & \\
\hline CHEMBL3194419 & 736971 & 3.0 & 4.2623 & TRN & & \\
\hline CHEMBL1707033 & 736971 & 5.7258 & 5.3129 & TRN & & \\
\hline CHEMBL1386457 & 736971 & 4.8125 & 4.5732 & TRN & & \\
\hline CHEMBL1453498 & 736971 & \multicolumn{3}{|c|}{4.9830000000000005} & 4.8795 & TST \\
\hline CHEMBL1499090 & 736971 & 5.1331 & 4.7665 & TRN & & \\
\hline CHEMBL1307513 & 736971 & 4.3947 & 4.5514 & TRN & & \\
\hline CHEMBL3193861 & 736971 & 4.4841 & 4.4271 & TRN & & \\
\hline CHEMBL1465850 & 736971 & 4.8761 & 4.7166 & TST & & \\
\hline CHEMBL1471717 & 736971 & 4.4737 & 4.6164 & TRN & & \\
\hline CHEMBL1475285 & 736971 & 4.4815 & 4.6817 & TRN & & \\
\hline CHEMBL1598139 & 736971 & 4.5498 & 4.6567 & TRN & & \\
\hline CHEMBL1322449 & 736971 & 4.6716 & 4.6353 & TRN & & \\
\hline CHEMBL1342479 & 736971 & \multicolumn{3}{|c|}{4.718999999999999} & 4.4842 & TRN \\
\hline CHEMBL1352443 & 736971 & 4.6253 & 4.638 & TRN & & \\
\hline CHEMBL1328930 & 736971 & 4.752 & 4.672 & TRN & & \\
\hline CHEMBL1342248 & 736971 & 4.7212 & 4.6359 & TRN & & \\
\hline CHEMBL1971324 & 736971 & 4.5214 & 4.4585 & TRN & & \\
\hline CHEMBL3210574 & 736971 & 5.4056 & 4.3286 & TST & & \\
\hline CHEMBL3209654 & 736971 & 4.7852 & 4.7834 & TST & & \\
\hline CHEMBL1606690 & 736971 & 4.618 & 4.5559 & TST & & \\
\hline CHEMBL1332928 & 736971 & 4.7595 & 4.7956 & TST & & \\
\hline CHEMBL1527802 & 736971 & 4.5607 & 4.6598 & TRN & & \\
\hline CHEMBL1531037 & 736971 & 4.5391 & 4.6433 & TRN & & \\
\hline CHEMBL3197063 & 736971 & 4.644 & 4.7081 & TRN & & \\
\hline CHEMBL1521051 & 736971 & \multicolumn{3}{|c|}{5.4510000000000005} & 4.7067 & IRIN \\
\hline CHEMBL1473955 & 736971 & 5.0731 & 4.9344 & TRN & & \\
\hline CHEMBL1469091 & 736971 & 5.0269 & 4.8209 & TST & & \\
\hline CHEMBL1425035 & 736971 & 4.7905 & 4.7738 & TRN & & \\
\hline CHEMBL1447460 & 736971 & 3.0 & 4.5293 & TRN & & \\
\hline CHEMBL1432044 & 736971 & 4.1549 & 4.3188 & TRN & & \\
\hline CHEMBL1546423 & 736971 & 4.3969 & 4.5987 & TRN & & \\
\hline CHEMBL1333579 & 736971 & 4.5317 & 4.4554 & TRN & & \\
\hline CHEMBL1418096 & 736971 & 6.0223 & 4.7987 & TRN & & \\
\hline
\end{tabular}

Page 12474 


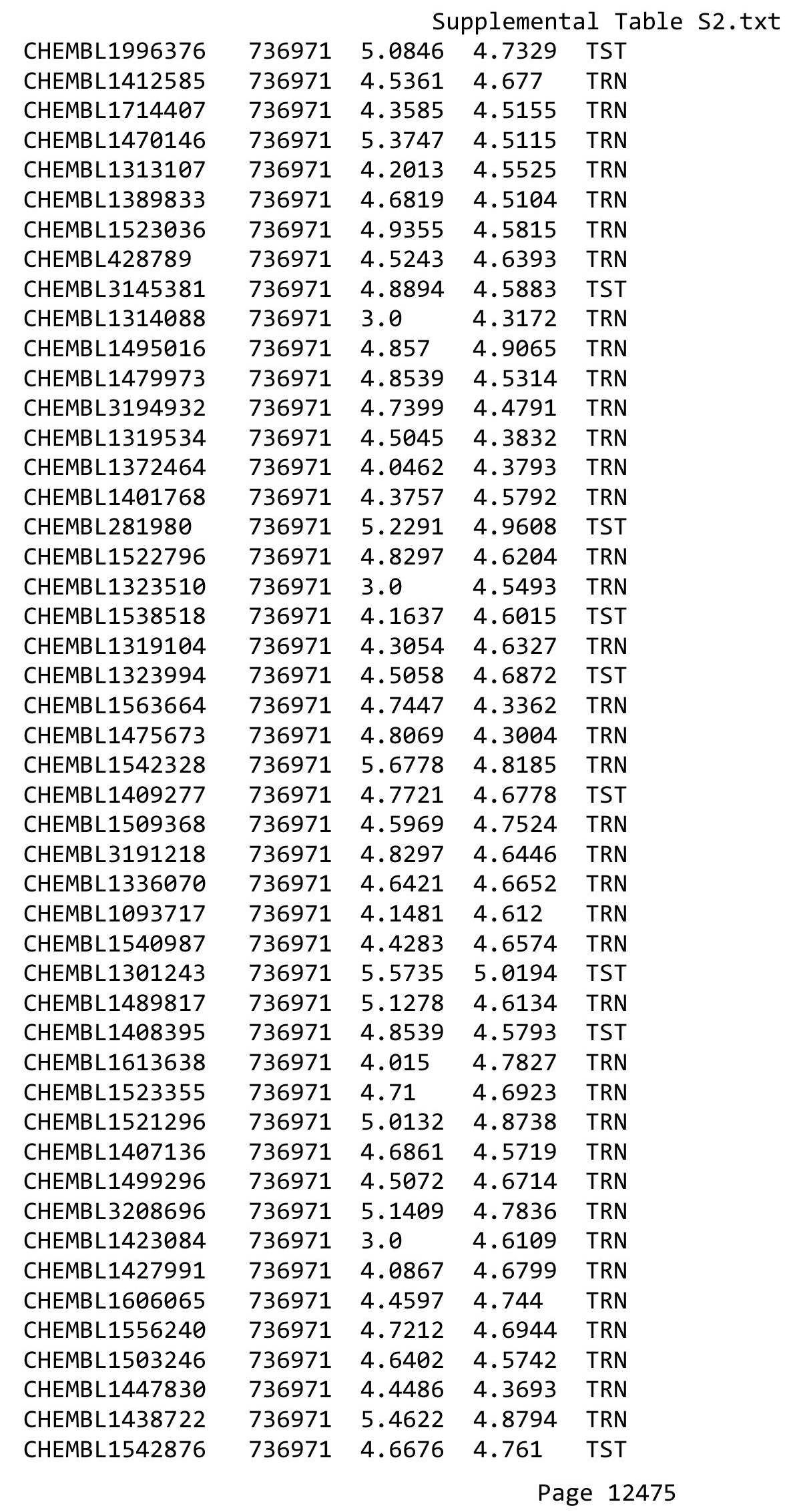




\begin{tabular}{|c|c|c|c|c|c|c|}
\hline \multicolumn{7}{|c|}{ Supplemental Table S2.txt } \\
\hline CHEMBL1379448 & 736971 & 3.0 & 4.7881 & TRN & & \\
\hline CHEMBL1421263 & 736971 & 5.4318 & 4.6927 & TST & & \\
\hline CHEMBL1588557 & 736971 & 4.3036 & 4.5449 & TRN & & \\
\hline CHEMBL1352627 & 736971 & 4.6289 & 4.8132 & TST & & \\
\hline CHEMBL3209723 & 736971 & 4.4202 & 4.659 & TRN & & \\
\hline CHEMBL1392911 & 736971 & 5.1226 & 4.8493 & TRN & & \\
\hline CHEMBL1475128 & 736971 & 5.9136 & 4.7907 & TRN & & \\
\hline CHEMBL1575869 & 736971 & 4.9136 & 4.9177 & TRN & & \\
\hline CHEMBL570468 & 736971 & 4.8508 & 4.6772 & TRN & & \\
\hline CHEMBL1343697 & 736971 & 5.05399 & 99999999 & 99 & 4.8135 & TST \\
\hline CHEMBL412603 & 736971 & 4.5918 & 4.6989 & TRN & & \\
\hline CHEMBL1536129 & 736971 & 4.2125 & 4.511 & TRN & & \\
\hline CHEMBL1503365 & 736971 & 3.0 & 4.484 & TRN & & \\
\hline CHEMBL1464949 & 736971 & 4.9393 & 4.9332 & TRN & & \\
\hline CHEMBL1569645 & 736971 & 4.9586 & 4.5972 & TRN & & \\
\hline CHEMBL3195102 & 736971 & 5.8996 & 4.8748 & TRN & & \\
\hline CHEMBL546865 & 736971 & 4.4921 & 4.387 & TRN & & \\
\hline CHEMBL1535900 & 736971 & 4.1518 & 4.4564 & TRN & & \\
\hline CHEMBL1342859 & 736971 & 4.8894 & 4.648 & TST & & \\
\hline CHEMBL1404207 & 736971 & 4.6308 & 4.85 & TRN & & \\
\hline CHEMBL3189585 & 736971 & 4.7721 & 4.3758 & TRN & & \\
\hline CHEMBL1534545 & 736971 & 5.1785 & 4.6725 & TRN & & \\
\hline CHEMBL1384143 & 736971 & 4.5258 & 4.4026 & TRN & & \\
\hline CHEMBL1718271 & 736971 & 4.3429 & 4.5685 & TRN & & \\
\hline CHEMBL1563249 & 736971 & 4.8894 & 4.7711 & TRN & & \\
\hline CHEMBL1344555 & 736971 & 4.6517 & 4.3644 & TRN & & \\
\hline CHEMBL1360419 & 736971 & 4.9706 & 4.6984 & TRN & & \\
\hline CHEMBL1378634 & 736971 & 4.0246 & 4.8075 & TRN & & \\
\hline CHEMBL1387142 & 736971 & 4.757 & 4.6851 & TRN & & \\
\hline CHEMBL3213561 & 736971 & 4.6091 & 4.5842 & TRN & & \\
\hline CHEMBL1319034 & 736971 & 4.4045 & 4.2451 & TRN & & \\
\hline CHEMBL1535290 & 736971 & 4.5638 & 4.6323 & TRN & & \\
\hline CHEMBL1379054 & 736971 & 4.8508 & 4.643 & TRN & & \\
\hline CHEMBL1519816 & 736971 & 4.3645 & 4.6027 & TRN & & \\
\hline CHEMBL1582178 & 736971 & 4.8447 & 4.794 & TST & & \\
\hline CHEMBL108660 & 736971 & 4.7825 & 4.5395 & TRN & & \\
\hline CHEMBL1424024 & 736971 & 4.9031 & 4.7211 & TRN & & \\
\hline CHEMBL1381872 & 736971 & 4.567 & 4.6834 & TRN & & \\
\hline CHEMBL1576896 & 736971 & 5.5702 & 5.0103 & TRN & & \\
\hline CHEMBL1522470 & 736971 & 4.6635 & 4.6721 & TRN & & \\
\hline CHEMBL1387710 & 736971 & 4.7235 & 4.655 & TST & & \\
\hline CHEMBL1332602 & 736971 & 4.6289 & 4.575 & TRN & & \\
\hline CHEMBL1507251 & 736971 & 4.6596 & 4.676 & TRN & & \\
\hline CHEMBL1564015 & 736971 & 4.6757 & 4.666 & TRN & & \\
\hline CHEMBL1613479 & 736971 & 4.585 & 4.8631 & TRN & & \\
\hline CHEMBL1605528 & 736971 & 4.6904 & 4.6552 & TRN & & \\
\hline CHEMBL1497617 & 736971 & 4.6716 & 4.4322 & TRN & & \\
\hline CHEMBL1586735 & 736971 & 4.5421 & 4.7158 & TRN & & \\
\hline
\end{tabular}


Supplemental Table S2.txt

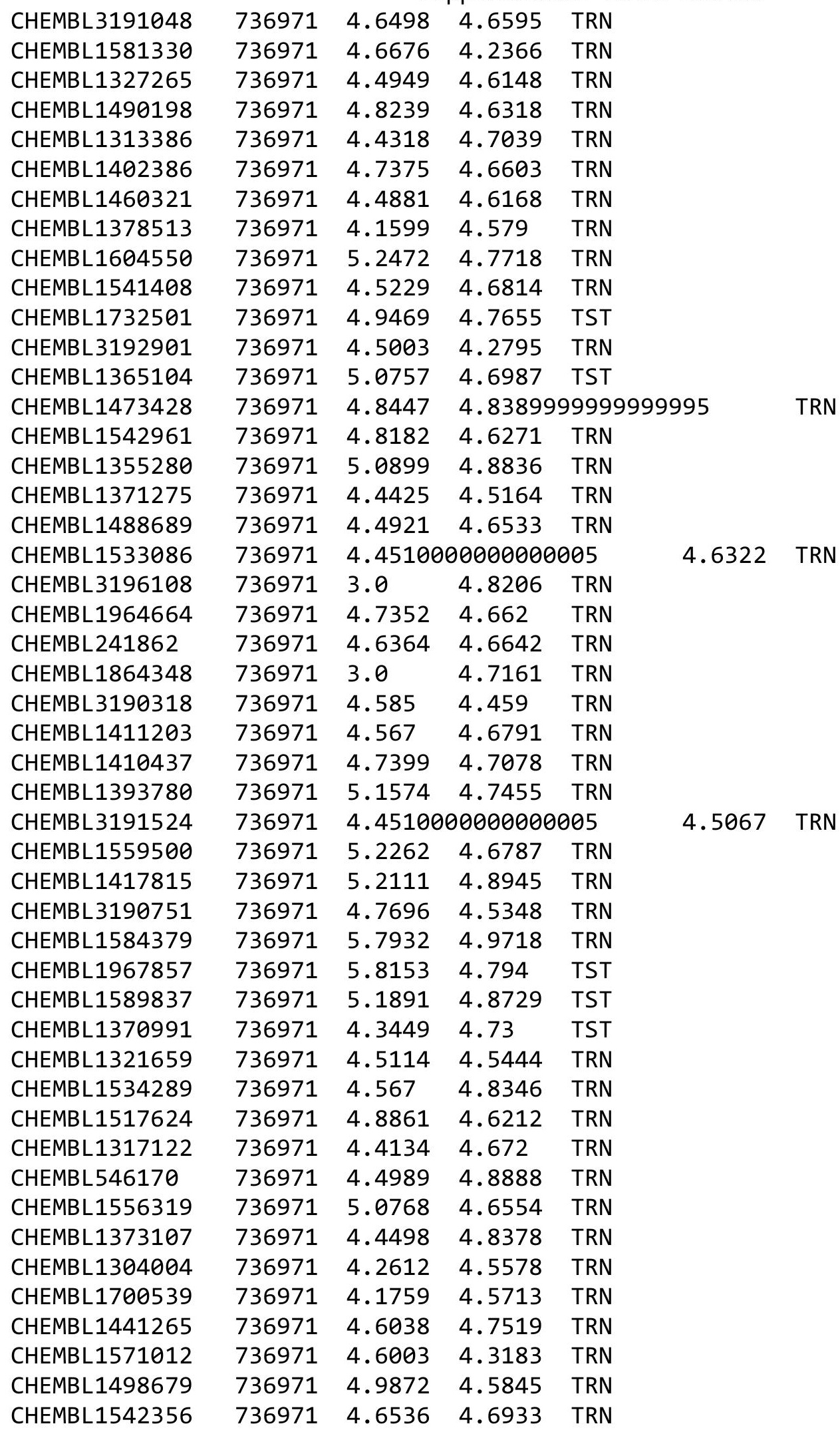

Page 12477 


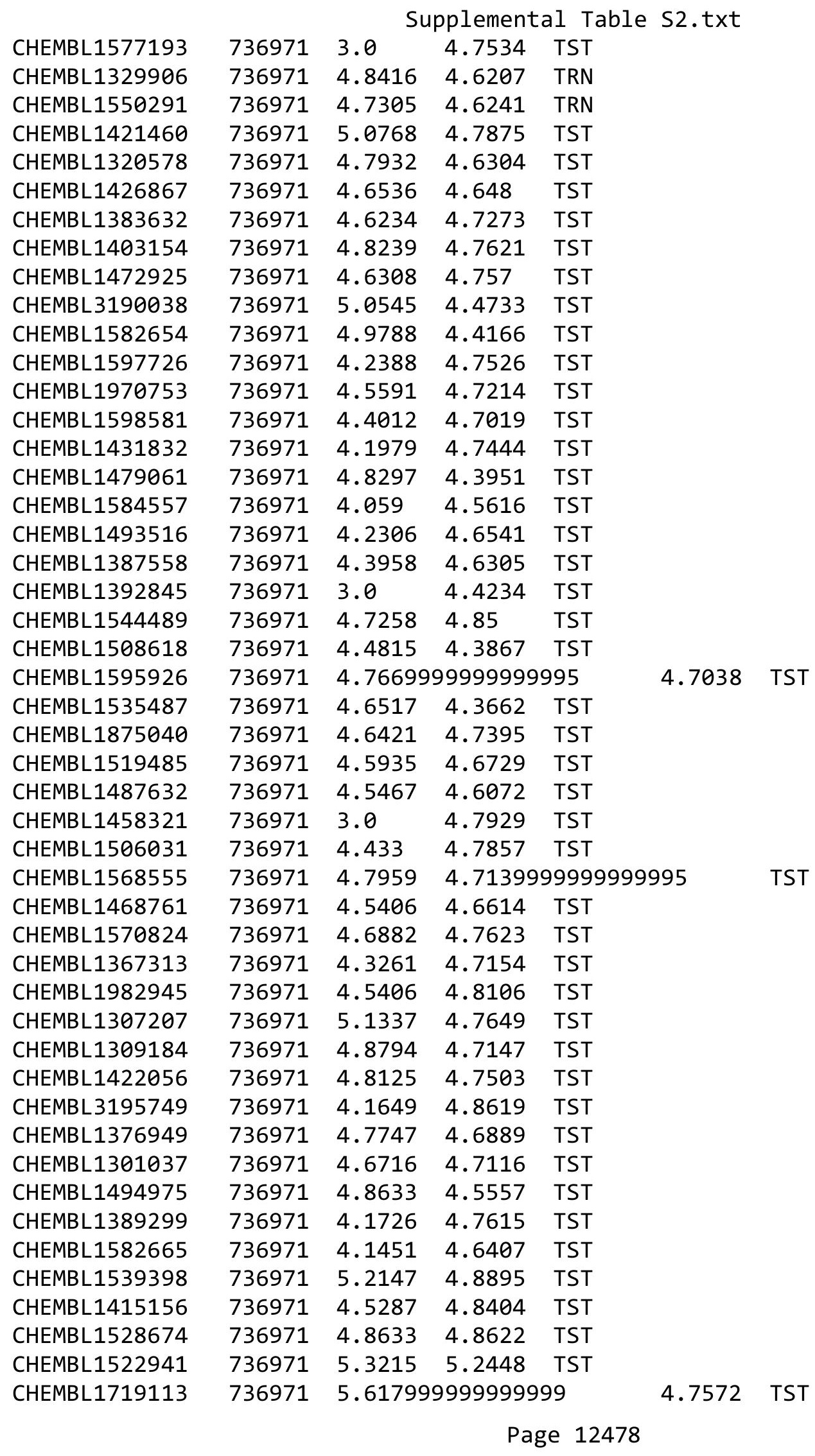


Supplemental Table S2.txt

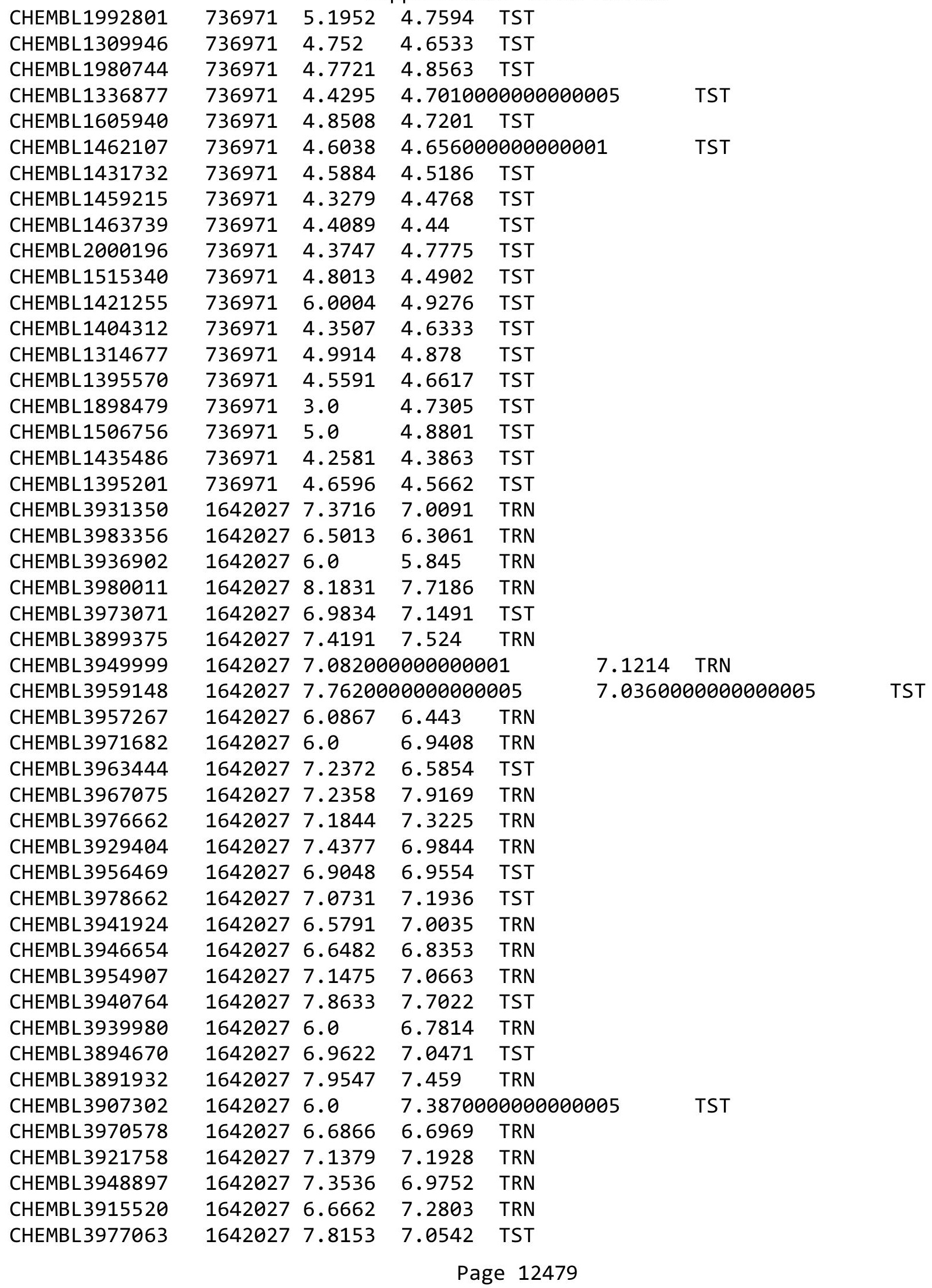


Supplemental Table S2.txt

\begin{tabular}{|c|c|c|c|c|c|c|}
\hline CHEMBL3934606 & 1642027 & 5.7001 & \multicolumn{3}{|c|}{7.5360000000000005} & TR \\
\hline CHEMBL3983491 & 1642027 & 7.2782 & 7.563 & TRN & & \\
\hline CHEMBL3968108 & 1642027 & 7.0496 & 7.0744 & TRN & & \\
\hline CHEMBL 3968160 & 1642027 & 6.1578 & 6.5458 & TRN & & \\
\hline CHEMBL 3983520 & 1642027 & 7.1555 & 7.3962 & TRN & & \\
\hline CHEMBL 3893471 & 1642027 & 7.1904 & 6.9908 & TST & & \\
\hline CHEMBL3949803 & 1642027 & 6.0 & 6.169 & TRN & & \\
\hline CHEMBL 3974541 & 1642027 & 7.4881 & 7.6918 & TRN & & \\
\hline CHEMBL 3960978 & 1642027 & 6.5669 & 7.0294 & TST & & \\
\hline CHEMBL 3931448 & 1642027 & 6.6059 & 6.5293 & TRN & & \\
\hline CHEMBL 3904166 & 1642027 & 7.7645 & 8.2029 & TST & & \\
\hline CHEMBL 3985144 & 1642027 & 7.7721 & 7.2746 & TRN & & \\
\hline CHEMBL 3942768 & 1642027 & 7.4145 & 7.2622 & TRN & & \\
\hline CHEMBL 3894523 & 1642027 & 8.1487 & 7.3447 & TRN & & \\
\hline CHEMBL 3897149 & 1642027 & 6.4165 & 7.3489 & TRN & & \\
\hline CHEMBL 3947378 & 1642027 & 7.4342 & 7.0529 & TRN & & \\
\hline CHEMBL3906998 & 1642027 & 6.9739 & 6.9605 & TRN & & \\
\hline CHEMBL3959536 & 1642027 & 6.8778 & 6.7331 & TRN & & \\
\hline CHEMBL 3931764 & 1642027 & 6.5981 & 6.7321 & TST & & \\
\hline CHEMBL 3959268 & 1642027 & 8.3665 & 8.0819 & TRN & & \\
\hline CHEMBL 3957809 & 1642027 & 7.3936 & 6.9016 & TRN & & \\
\hline CHEMBL3903116 & 1642027 & 7.7567 & 7.9436 & TRN & & \\
\hline CHEMBL3946470 & 1642027 & $7.7620 e$ & 00000000 & 205 & 7.9587 & \\
\hline CHEMBL 3958674 & 1642027 & 6.3163 & 6.8767 & TST & & \\
\hline CHEMBL 3978737 & 1642027 & 6.4628 & 7.233 & TST & & \\
\hline CHEMBL 3919304 & 1642027 & 7.1891 & 6.5912 & TRN & & \\
\hline CHEMBL3903483 & 1642027 & 6.9187 & 6.4875 & TST & & \\
\hline CHEMBL3985618 & 1642027 & 7.7033 & 7.1655 & TRN & & \\
\hline CHEMBL3946104 & 1642027 & 5.9809 & 6.2968 & TST & & \\
\hline CHEMBL3915611 & 1642027 & 8.1871 & 7.9833 & TRN & & \\
\hline CHEMBL 3986871 & 1642027 & 7.9318 & 7.0143 & TST & & \\
\hline CHEMBL3916127 & 1642027 & 7.0846 & 6.7459 & TRN & & \\
\hline CHEMBL 3893781 & 1642027 & 8.6198 & 8.2799 & TRN & & \\
\hline CHEMBL3931591 & 1642027 & 7.4527 & 6.831 & TRN & & \\
\hline CHEMBL 3900958 & 1642027 & 7.2055 & 7.4102 & TST & & \\
\hline CHEMBL3967654 & 1642027 & 7.2708 & 6.9015 & TST & & \\
\hline CHEMBL 3915364 & 1642027 & 7.7212 & 7.3397 & TRN & & \\
\hline CHEMBL 3983982 & 1642027 & 7.5513 & 6.8579 & TRN & & \\
\hline CHEMBL 3943480 & 1642027 & 6.7387 & 6.9655 & TRN & & \\
\hline CHEMBL3969335 & 1642027 & 6.4769 & 6.7739 & TRN & & \\
\hline CHEMBL 3969021 & 1642027 & 6.6908 & 6.892 & TRN & & \\
\hline CHEMBL 3946228 & 1642027 & 6.1731 & 6.2663 & TRN & & \\
\hline CHEMBL 3922660 & 1642027 & 7.2388 & 7.5937 & TRN & & \\
\hline CHEMBL 3978549 & 1642027 & 6.244 & 6.0747 & TRN & & \\
\hline CHEMBL 3917068 & 1642027 & 7.0691 & 6.638 & TRN & & \\
\hline CHEMBL 3905643 & 1642027 & 7.4473 & 7.3908 & TRN & & \\
\hline CHEMBL 3986249 & 1642027 & 9.301 & 8.1961 & TRN & & \\
\hline CHEMBL3950813 & 1642027 & 7.2358 & 7.7406 & TRN & & \\
\hline
\end{tabular}

Page 12480 
Supplemental Table S2.txt

\begin{tabular}{|c|c|c|c|c|c|}
\hline CHEMBL 3930006 & 1642027 & 7.9355 & 7.8883 & TRN & \\
\hline CHEMBL 3978055 & 1642027 & 6.1023 & 7.0917 & TST & \\
\hline CHEMBL3951995 & 1642027 & 7.0035 & 7.0442 & TRN & \\
\hline CHEMBL 3951382 & 1642027 & 6.7222 & 6.8832 & TRN & \\
\hline CHEMBL3904981 & 1642027 & 6.9983 & \multicolumn{2}{|c|}{6.922000000000001} & TRN \\
\hline CHEMBL3972626 & 1642027 & 7.5702 & 7.1767 & TST & \\
\hline CHEMBL 3940126 & 1642027 & 7.4056 & 6.921 & TRN & \\
\hline CHEMBL 3954929 & 1642027 & 7.1367 & 7.5641 & TRN & \\
\hline CHEMBL 3912567 & 1642027 & 7.4962 & 7.6194 & TRN & \\
\hline CHEMBL3913303 & 1642027 & 6.1994 & 6.5165 & TRN & \\
\hline CHEMBL3972362 & 1642027 & 6.6582 & 6.6595 & TRN & \\
\hline CHEMBL 3923669 & 1642027 & 8.7447 & 8.3357 & TRN & \\
\hline CHEMBL 3935032 & 1642027 & 6.8881 & \multicolumn{2}{|c|}{6.417999999999999} & TRN \\
\hline CHEMBL 3970427 & 1642027 & 6.364 & 6.6518 & TRN & \\
\hline CHEMBL3975761 & 1642027 & 6.0 & 7.1815 & TST & \\
\hline CHEMBL3949321 & 1642027 & 6.7167 & 6.8001 & TRN & \\
\hline CHEMBL 3898135 & 1642027 & 6.6799 & 6.7895 & TRN & \\
\hline CHEMBL 3980767 & 1642027 & 6.0807 & 6.5792 & TRN & \\
\hline CHEMBL 3928208 & 1642027 & 7.1487 & 7.2525 & TRN & \\
\hline CHEMBL3960572 & 1642027 & 6.4639 & 6.7105 & TRN & \\
\hline CHEMBL3927536 & 1642027 & 7.3206 & 7.0578 & TST & \\
\hline CHEMBL3979636 & 1642027 & 8.3665 & 8.0787 & TRN & \\
\hline CHEMBL 3918798 & 1642027 & 8.1612 & 7.3455 & TRN & \\
\hline CHEMBL 3891221 & 1642027 & 8.3768 & 7.6296 & TRN & \\
\hline CHEMBL 3900654 & 1642027 & 6.871 & 6.6961 & TRN & \\
\hline CHEMBL3895795 & 1642027 & 6.7711 & 6.8301 & TST & \\
\hline CHEMBL 3950160 & 1642027 & 6.6946 & 6.7032 & TRN & \\
\hline CHEMBL3915965 & 1642027 & 6.0857 & 7.2133 & TRN & \\
\hline CHEMBL 3937304 & 1642027 & 7.4776 & 6.9557 & TRN & \\
\hline CHEMBL 3896700 & 1642027 & 6.3386 & 7.1092 & TRN & \\
\hline CHEMBL 3953722 & 1642027 & 6.0 & 7.0359 & TRN & \\
\hline CHEMBL 3975682 & 1642027 & 5.8807 & 6.898 & TRN & \\
\hline CHEMBL 3980024 & 1642027 & 6.3848 & 6.6927 & TRN & \\
\hline CHEMBL3968100 & 1642027 & 6.7719 & \multicolumn{2}{|c|}{7.327999999999999} & TST \\
\hline CHEMBL 3894037 & 1642027 & 7.0278 & 6.9984 & TRN & \\
\hline CHEMBL 3960114 & 1642027 & 7.4724 & 7.2346 & TRN & \\
\hline CHEMBL3895195 & 1642027 & 7.3 & 7.5538 & TRN & \\
\hline CHEMBL 3927673 & 1642027 & 7.7471 & 7.1039 & TST & \\
\hline CHEMBL 3983545 & 1642027 & 7.3615 & 7.2814 & TRN & \\
\hline CHEMBL 3951962 & 1642027 & 6.9566 & 7.3976 & TRN & \\
\hline CHEMBL 3927465 & 1642027 & 7.4962 & 7.4572 & TRN & \\
\hline CHEMBL 3897545 & 1642027 & 6.2564 & 6.1461 & TRN & \\
\hline CHEMBL 3899409 & 1642027 & 6.75799 & 99999999 & 6.6596 & In \\
\hline CHEMBL 3925044 & 1642027 & 6.0 & 7.1967 & TRN & \\
\hline CHEMBL 3922257 & 1642027 & 3.301 & 8.3913 & TST & \\
\hline CHEMBL 3975172 & 1642027 & 6.7411 & 6.9883 & TRN & \\
\hline CHEMBL3950117 & 1642027 & 6.516 & 6.6553 & TRN & \\
\hline CHEMBL 3896030 & 1642027 & 7.0448 & 6.7963 & TRN & \\
\hline
\end{tabular}

Page 12481 
Supplemental Table S2.txt

\begin{tabular}{|c|c|c|c|c|c|}
\hline CHEMBL3961804 & 1642027 & 7.6676 & 7.6828 & TRN & \\
\hline CHEMBL3921896 & 1642027 & 7.7471 & 7.426 & TRN & \\
\hline CHEMBL3984291 & 1642027 & 7.7528 & 7.7025 & TRN & \\
\hline CHEMBL3900623 & 1642027 & 7.0706 & 6.4569 & TRN & \\
\hline CHEMBL3904292 & 1642027 & 6.9003 & 6.5577 & TRN & \\
\hline CHEMBL3903760 & 1642027 & 7.7959 & 7.5507 & TRN & \\
\hline CHEMBL3932978 & 1642027 & 6.7951 & 7.7367 & TST & \\
\hline CHEMBL3975011 & 1642027 & 8.7696 & 7.3998 & TRN & \\
\hline CHEMBL3936111 & 1642027 & 8.0809 & 7.7234 & TST & \\
\hline CHEMBL3976646 & 1642027 & 7.5686 & 7.4279 & TRN & \\
\hline CHEMBL 3898048 & 1642027 & 6.0 & 5.9641 & TRN & \\
\hline CHEMBL3891640 & 1642027 & 7.6615 & 7.2694 & TRN & \\
\hline CHEMBL3933251 & 1642027 & 7.114 & 7.0629 & TST & \\
\hline CHEMBL3910014 & 1642027 & 6.0 & 7.1685 & TST & \\
\hline CHEMBL3890545 & 1642027 & 7.3487 & 7.2938 & TRN & \\
\hline CHEMBL3916186 & 1642027 & 7.994 & 7.966 & TRN & \\
\hline CHEMBL3893888 & 1642027 & 6.0 & 5.717006 & 00000000005 & TRN \\
\hline CHEMBL3975968 & 1642027 & 7.1851 & 7.1227 & TRN & \\
\hline CHEMBL3945046 & 1642027 & 6.4169 & 6.4494 & TRN & \\
\hline CHEMBL3969396 & 1642027 & 7.025 & 7.2767 & TRN & \\
\hline CHEMBL3970868 & 1642027 & 6.0 & 6.171 & TRN & \\
\hline CHEMBL3922534 & 1642027 & 7.1296 & 7.2993 & TRN & \\
\hline CHEMBL3918226 & 1642027 & 7.433 & 7.896 & TRN & \\
\hline CHEMBL3945541 & 1642027 & 6.4327 & 6.8902 & TST & \\
\hline CHEMBL3945400 & 1642027 & 5.9678 & 6.8463 & TST & \\
\hline CHEMBL3901459 & 1642027 & 6.9126 & 6.6852 & TRN & \\
\hline CHEMBL3930689 & 1642027 & 6.9543 & 6.7048 & TST & \\
\hline CHEMBL3940125 & 1642027 & 6.7402 & 6.7519 & TRN & \\
\hline CHEMBL3948331 & 1642027 & 7.5229 & 7.317 & TRN & \\
\hline CHEMBL3917205 & 1642027 & 7.2118 & 7.4678 & TRN & \\
\hline CHEMBL3970555 & 1642027 & 6.4946 & 6.6912 & TRN & \\
\hline CHEMBL3962091 & 1642027 & 6.684 & 6.3916 & TRN & \\
\hline CHEMBL3960657 & 1642027 & 8.0177 & 7.2056 & TRN & \\
\hline CHEMBL3971513 & 1642027 & 7.1107 & 7.3878 & TRN & \\
\hline CHEMBL3894643 & 1642027 & 7.8539 & 6.6385 & TST & \\
\hline CHEMBL3938598 & 1642027 & 6.4291 & 7.4008 & TST & \\
\hline CHEMBL3909286 & 1642027 & 7.0292 & 7.4589 & TST & \\
\hline CHEMBL3908083 & 1642027 & 6.8861 & 7.1544 & TST & \\
\hline CHEMBL3924398 & 1642027 & 7.6576 & 7.6319 & TST & \\
\hline CHEMBL3926131 & 1642027 & 6.7678 & 6.7762 & TST & \\
\hline CHEMBL3956640 & 1642027 & 6.8761 & 6.9339 & TST & \\
\hline CHEMBL1404918 & 955008 & 3.0116 & 3.0115 & TRN & \\
\hline CHEMBL221137 & 955008 & 4.242 & 4.5962 & TST & \\
\hline CHEMBL300389 & 955008 & 6.5939 & \multicolumn{2}{|c|}{6.593999999999999} & TRN \\
\hline CHEMBL9470 & 955008 & 5.5611 & 5.3483 & TST & \\
\hline CHEMBL515416 & 955008 & 3.9058 & 3.9059 & TRN & \\
\hline CHEMBL1643959 & 955008 & 4.7713 & 4.7714 & TRN & \\
\hline CHEMBL 2137530 & 955008 & 3.9357 & 3.9356 & TRN & \\
\hline
\end{tabular}




\begin{tabular}{|c|c|c|c|c|}
\hline & & & oplement & al $\mathrm{Tc}$ \\
\hline CHEMBL 373751 & 955008 & 3.2408 & 3.2409 & TRN \\
\hline CHEMBL483849 & 955008 & 1.3581 & 2.1403 & TST \\
\hline CHEMBL135561 & 955008 & 4.0681 & 4.0681 & TRN \\
\hline CHEMBL 2144069 & 955008 & 4.615 & 4.615 & TRN \\
\hline CHEMBL220241 & 955008 & 3.4487 & 3.4487 & TRN \\
\hline CHEMBL 240954 & 955008 & 3.3234 & 3.4108 & TST \\
\hline CHEMBL189584 & 955008 & 4.0007 & 4.0006 & TRN \\
\hline CHEMBL188678 & 955008 & 3.9265 & 3.9265 & TRN \\
\hline CHEMBL1242367 & 955008 & 4.0097 & 4.0096 & TRN \\
\hline CHEMBL577784 & 955008 & 3.75 & 3.7499 & TRN \\
\hline CHEMBL 217354 & 955008 & 5.8651 & 5.8651 & TRN \\
\hline CHEMBL392695 & 955008 & 5.5563 & 5.5564 & TRN \\
\hline CHEMBL 379975 & 955008 & 4.0288 & 4.0288 & TRN \\
\hline CHEMBL558642 & 955008 & 4.5821 & 4.5821 & TRN \\
\hline CHEMBL1190711 & 955008 & 5.0853 & 5.0852 & TRN \\
\hline CHEMBL 3186408 & 955008 & 3.5028 & 3.3305 & TST \\
\hline CHEMBL 258844 & 955008 & 4.4385 & 4.4385 & TRN \\
\hline CHEMBL102714 & 955008 & 3.9086 & 3.9086 & TRN \\
\hline CHEMBL 259181 & 955008 & 4.1931 & 4.1932 & TRN \\
\hline CHEMBL202721 & 955008 & 4.1737 & 4.1737 & TRN \\
\hline CHEMBL472940 & 955008 & 3.1193 & 3.1193 & TRN \\
\hline CHEMBL1590308 & 955008 & 3.2998 & 2.9555 & TST \\
\hline CHEMBL585951 & 955008 & 5.7165 & 5.7165 & TRN \\
\hline CHEMBL180127 & 955008 & 3.8319 & 3.8318 & TRN \\
\hline CHEMBL514499 & 955008 & 7.2237 & 7.2237 & TRN \\
\hline CHEMBL3392440 & 955008 & 3.696 & 3.696 & TRN \\
\hline CHEMBL192566 & 955008 & 7.5379 & 7.8582 & TST \\
\hline CHEMBL 210618 & 955008 & 3.0804 & 3.0804 & TRN \\
\hline CHEMBL399530 & 955008 & 3.4397 & 3.4398 & TRN \\
\hline CHEMBL393929 & 955008 & 3.6479 & 3.6478 & TRN \\
\hline CHEMBL1256459 & 955008 & 6.439 & 6.439 & TRN \\
\hline CHEMBL509032 & 955008 & 6.1967 & 6.1966 & TRN \\
\hline CHEMBL412142 & 955008 & 3.6935 & 3.6934 & TRN \\
\hline CHEMBL1516890 & 955008 & 3.5695 & 3.5695 & TRN \\
\hline CHEMBL92309 & 955008 & 2.5895 & 2.7719 & TST \\
\hline CHEMBL 255342 & 955008 & 3.3346 & 3.3345 & TRN \\
\hline CHEMBL1673039 & 955008 & 4.5811 & 4.5811 & TRN \\
\hline CHEMBL1970879 & 955008 & 4.7799 & 4.7799 & TRN \\
\hline CHEMBL2363137 & 955008 & 5.2558 & 5.2557 & TRN \\
\hline CHEMBL1909414 & 955008 & 3.3866 & 3.3867 & TRN \\
\hline CHEMBL1357247 & 955008 & 3.0696 & 3.0695 & TRN \\
\hline CHEMBL 213100 & 955008 & 4.1086 & 4.1086 & TRN \\
\hline CHEMBL3349342 & 955008 & 5.7907 & 5.7907 & TRN \\
\hline CHEMBL573107 & 955008 & 3.9259 & 3.9259 & TRN \\
\hline CHEMBL 222102 & 955008 & 3.2471 & 3.2472 & TRN \\
\hline CHEMBL3199475 & 955008 & 4.873 & 4.873 & TRN \\
\hline CHEMBL483847 & 955008 & 4.1177 & 4.1178 & TRN \\
\hline CHEMBL512504 & 955008 & 4.3566 & 4.3567 & TRN \\
\hline
\end{tabular}


Supplemental Table S2.txt

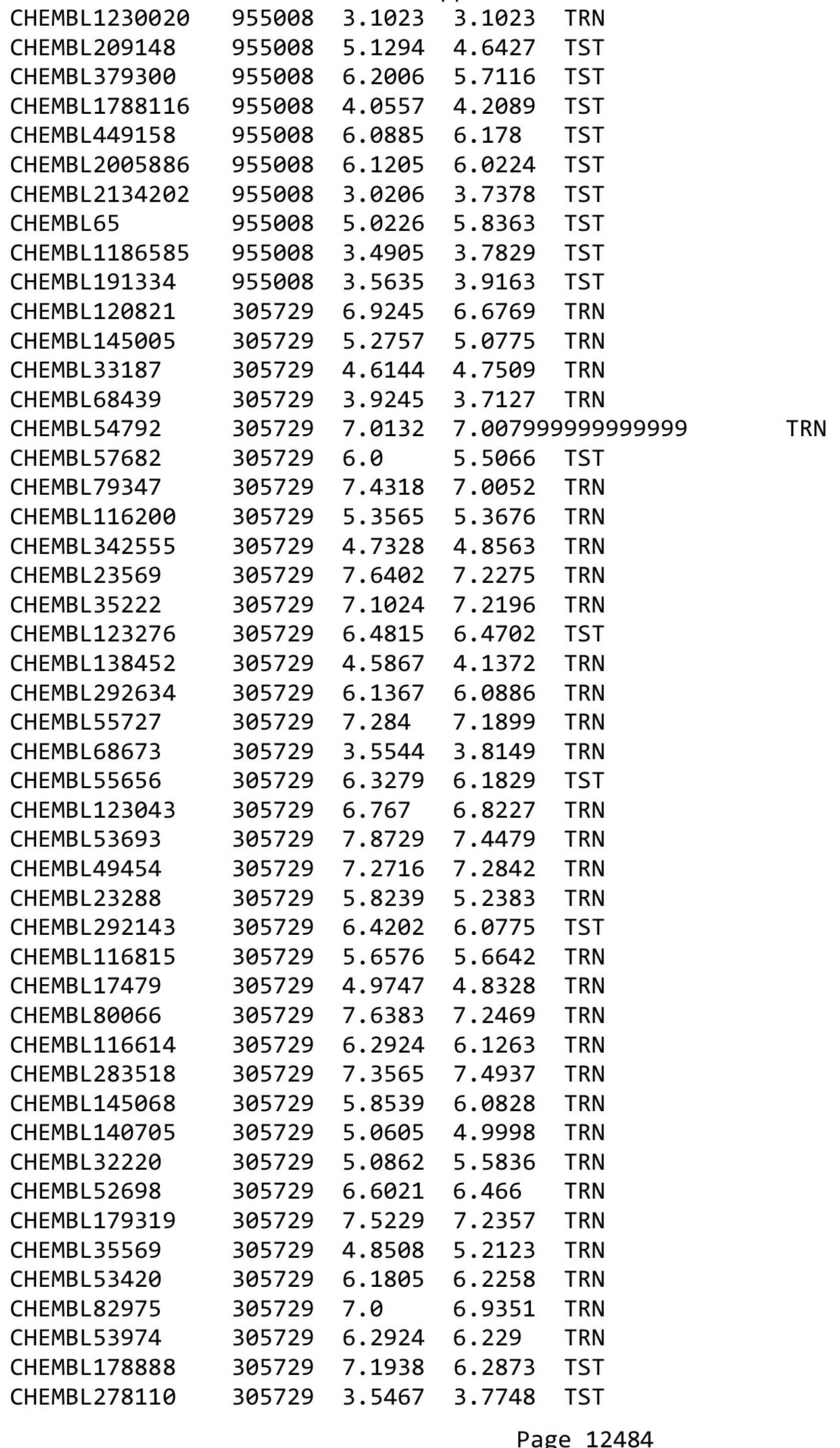




\begin{tabular}{|c|c|c|c|c|}
\hline \multicolumn{5}{|c|}{ Supplemental Table S2.txt } \\
\hline CHEMBL138252 & 305729 & 4.8356 & 4.6273 & TRN \\
\hline CHEMBL121264 & 305729 & 6.2865 & 6.3243 & TST \\
\hline CHEMBL52947 & 305729 & 5.3565 & 5.8178 & TRN \\
\hline CHEMBL52836 & 305729 & 5.7696 & 5.7208 & TRN \\
\hline CHEMBL 301105 & 305729 & 6.6778 & 6.4343 & TRN \\
\hline CHEMBL23867 & 305729 & 6.2418 & 7.1607 & TRN \\
\hline CHEMBL 278013 & 305729 & 4.5482 & 5.0538 & TST \\
\hline CHEMBL264548 & 305729 & 6.4962 & 6.6813 & TRN \\
\hline CHEMBL178512 & 305729 & 5.7447 & 5.4049 & TST \\
\hline CHEMBL 283515 & 305729 & 4.7212 & 3.8152 & TST \\
\hline CHEMBL 296382 & 305729 & 5.2596 & 5.6342 & TRN \\
\hline CHEMBL55928 & 305729 & 6.0458 & 5.9154 & TRN \\
\hline CHEMBL55179 & 305729 & 5.699 & 5.7381 & TRN \\
\hline CHEMBL51706 & 305729 & 5.699 & 5.8754 & TRN \\
\hline CHEMBL120939 & 305729 & 5.8041 & 5.8316 & TRN \\
\hline CHEMBL 283311 & 305729 & 6.1871 & 3.7361 & TST \\
\hline CHEMBL141260 & 305729 & 4.7932 & 4.7839 & TRN \\
\hline CHEMBL22561 & 305729 & 4.8297 & 3.784 & TST \\
\hline CHEMBL 337746 & 305729 & 5.4949 & 5.0794 & TST \\
\hline CHEMBL 279680 & 305729 & 6.4949 & 7.0518 & TRN \\
\hline CHEMBL17323 & 305729 & 4.3401 & 4.0969 & TRN \\
\hline CHEMBL137844 & 305729 & 6.1549 & 6.5682 & TST \\
\hline CHEMBL 23532 & 305729 & 7.0655 & 7.6715 & TRN \\
\hline CHEMBL121319 & 305729 & 6.3872 & 6.1822 & TST \\
\hline CHEMBL178904 & 305729 & 6.0269 & 6.4749 & TST \\
\hline CHEMBL 299174 & 305729 & 6.7959 & 6.8983 & TRN \\
\hline CHEMBL32583 & 305729 & 5.0362 & 4.9712 & TRN \\
\hline CHEMBL356490 & 305729 & 6.7212 & 6.2549 & TRN \\
\hline CHEMBL 333791 & 305729 & 6.2993 & 6.6528 & TST \\
\hline CHEMBL 284849 & 305729 & 5.2596 & 5.1617 & TRN \\
\hline CHEMBL23844 & 305729 & 5.5086 & 5.8084 & TRN \\
\hline CHEMBL415962 & 305729 & 6.6021 & 7.1119 & TRN \\
\hline CHEMBL 275893 & 305729 & 3.032 & 3.7903 & TRN \\
\hline CHEMBL 281803 & 305729 & 6.6655 & 6.2975 & TRN \\
\hline CHEMBL115788 & 305729 & 6.2596 & 6.4547 & TRN \\
\hline CHEMBL54618 & 305729 & 5.699 & 5.9403 & TRN \\
\hline CHEMBL142741 & 305729 & 6.6198 & 6.6602 & TRN \\
\hline CHEMBL123122 & 305729 & 7.0223 & 6.9069 & TST \\
\hline CHEMBL53903 & 305729 & 7.3872 & 6.8302 & TRN \\
\hline CHEMBL141218 & 305729 & 4.0438 & 4.2334 & TRN \\
\hline CHEMBL142081 & 305729 & 5.6576 & 6.1825 & TST \\
\hline CHEMBL55191 & 305729 & 6.8239 & 6.5896 & TRN \\
\hline CHEMBL52433 & 305729 & 6.3036 & 7.2654 & TRN \\
\hline CHEMBL23416 & 305729 & 7.2565 & 6.9359 & TRN \\
\hline CHEMBL32708 & 305729 & 5.4202 & 5.6799 & TRN \\
\hline CHEMBL121868 & 305729 & 6.5229 & 6.6341 & TST \\
\hline CHEMBL 367802 & 305729 & 7.7696 & 7.3022 & TRN \\
\hline CHEMBL22623 & 305729 & 6.8861 & 6.8839 & TRN \\
\hline
\end{tabular}




\begin{tabular}{|c|c|c|c|c|c|}
\hline \multicolumn{6}{|c|}{ Supplemental Table S2.txt } \\
\hline CHEMBL36245 & 305729 & 7.1192 & 7.1455 & TRN & \\
\hline CHEMBL116637 & 305729 & 5.3098 & 5.3032 & TRN & \\
\hline CHEMBL279914 & 305729 & 4.3872 & 3.1611 & TST & \\
\hline CHEMBL279983 & 305729 & 6.5003 & 6.5379 & TRN & \\
\hline CHEMBL 7488 & 305729 & 5.3372 & 6.0026 & TST & \\
\hline CHEMBL117750 & 305729 & 7.284 & 7.2419 & TRN & \\
\hline CHEMBL54523 & 305729 & 5.5686 & 5.4373 & TRN & \\
\hline CHEMBL 34337 & 305729 & 5.7447 & 5.8494 & TRN & \\
\hline CHEMBL423560 & 305729 & 6.3872 & 6.4492 & TST & \\
\hline CHEMBL33136 & 305729 & 5.7122 & 5.3157 & TRN & \\
\hline CHEMBL312348 & 305729 & 7.0205 & 7.1283 & TRN & \\
\hline CHEMBL 7263 & 305729 & 5.7773 & 5.8528 & TST & \\
\hline CHEMBL120994 & 305729 & 5.1675 & 6.3472 & TST & \\
\hline CHEMBL299927 & 305729 & 5.6576 & 5.1495 & TST & \\
\hline CHEMBL300603 & 305729 & 7.4202 & 6.9549 & TRN & \\
\hline CHEMBL33038 & 305729 & 7.1675 & 6.9352 & TRN & \\
\hline CHEMBL142624 & 305729 & 5.301 & 5.6835 & TRN & \\
\hline CHEMBL113816 & 305729 & 7.6234 & 7.6556 & TRN & \\
\hline CHEMBL 276734 & 305729 & 3.5129 & 4.2963 & TST & \\
\hline CHEMBL53165 & 305729 & 6.2757 & 5.9084 & TRN & \\
\hline CHEMBL32769 & 305729 & 5.3188 & 5.2048 & TRN & \\
\hline CHEMBL180476 & 305729 & 6.2076 & 6.2855 & TST & \\
\hline CHEMBL55063 & 305729 & 6.5376 & 7.0772 & TRN & \\
\hline CHEMBL179102 & 305729 & 6.1427 & 5.9825 & TRN & \\
\hline CHEMBL141585 & 305729 & 4.3936 & 4.6096 & TRN & \\
\hline CHEMBL300886 & 305729 & 5.699 & 5.5741 & TST & \\
\hline CHEMBL141708 & 305729 & 5.585 & 5.2579 & TRN & \\
\hline CHEMBL53318 & 305729 & 6.6778 & 6.4511 & TRN & \\
\hline CHEMBL 81820 & 305729 & 6.4949 & 7.0645 & TRN & \\
\hline CHEMBL292427 & 305729 & 6.3872 & 6.1627 & TRN & \\
\hline CHEMBL310880 & 305729 & 6.0 & 6.2408 & TRN & \\
\hline CHEMBL 32266 & 305729 & 5.2441 & 5.0148 & TRN & \\
\hline CHEMBL147886 & 305729 & 6.0706 & 6.5051 & TST & \\
\hline CHEMBL 32113 & 305729 & 7.0757 & 7.29299 & 9999999999 & TRN \\
\hline CHEMBL116816 & 305729 & 5.3372 & 5.4877 & TRN & \\
\hline CHEMBL121683 & 305729 & 6.9431 & 6.7687 & TST & \\
\hline CHEMBL17873 & 305729 & 4.4522 & 4.4086 & TRN & \\
\hline CHEMBL358297 & 305729 & 6.2441 & 6.7894 & TST & \\
\hline CHEMBL50514 & 305729 & 7.8794 & 7.7449 & TRN & \\
\hline CHEMBL 80065 & 305729 & 7.0926 & 7.2631 & TRN & \\
\hline CHEMBL54733 & 305729 & 5.7696 & 5.6964 & TRN & \\
\hline CHEMBL334271 & 305729 & 6.284 & 6.0064 & TRN & \\
\hline CHEMBL54913 & 305729 & 6.0 & 6.095 & TRN & \\
\hline CHEMBL 286700 & 305729 & 5.5686 & 5.1726 & TRN & \\
\hline CHEMBL23297 & 305729 & 5.0915 & 3.2981 & TST & \\
\hline CHEMBL52688 & 305729 & 6.9208 & 6.4745 & TRN & \\
\hline CHEMBL113999 & 305729 & 5.1675 & 5.3456 & TRN & \\
\hline CHEMBL 299140 & 305729 & 6.6383 & 6.4016 & TRN & \\
\hline
\end{tabular}




\begin{tabular}{|c|c|c|c|c|c|}
\hline \multirow[b]{2}{*}{ CHEMBL 264386} & \multicolumn{5}{|c|}{ Supplemental Table S2.txt } \\
\hline & 305729 & 7.4559 & 7.4095 & TRN & \\
\hline CHEMBL178119 & 305729 & 3.9355 & 5.1422 & TRN & \\
\hline CHEMBL368645 & 305729 & 5.3372 & 5.5964 & TST & \\
\hline CHEMBL292212 & 305729 & 5.7959 & 5.96399 & 99999999995 & TRN \\
\hline CHEMBL445359 & 305729 & 6.7696 & 6.6155 & TRN & \\
\hline CHEMBL145528 & 305729 & 6.5376 & 6.2281 & TRN & \\
\hline CHEMBL115474 & 305729 & 5.0605 & 5.609 & TRN & \\
\hline CHEMBL54732 & 305729 & 6.301 & 6.4084 & TRN & \\
\hline CHEMBL178684 & 305729 & 5.5086 & 5.9037 & TST & \\
\hline CHEMBL114833 & 305729 & 5.2676 & 5.245 & TRN & \\
\hline CHEMBL179131 & 305729 & 6.4559 & 6.2969 & TST & \\
\hline CHEMBL417746 & 305729 & 5.7959 & 5.4905 & TRN & \\
\hline CHEMBL139188 & 305729 & 5.0809 & 4.9542 & TRN & \\
\hline CHEMBL23021 & 305729 & 7.3372 & 6.984 & TRN & \\
\hline CHEMBL33208 & 305729 & 4.8508 & 4.9154 & TRN & \\
\hline CHEMBL54538 & 305729 & 7.3979 & 7.13700 & 00000000005 & TRN \\
\hline CHEMBL32754 & 305729 & 4.684 & 4.8348 & TRN & \\
\hline CHEMBL278261 & 305729 & 3.6799 & 4.823 & TST & \\
\hline CHEMBL 23960 & 305729 & 5.1135 & 3.1082 & TST & \\
\hline CHEMBL121433 & 305729 & 6.6091 & 7.1582 & TST & \\
\hline CHEMBL32635 & 305729 & 5.4089 & 5.6459 & TRN & \\
\hline CHEMBL23846 & 305729 & 4.8697 & 3.5931 & TST & \\
\hline CHEMBL325434 & 305729 & 7.0605 & 7.2455 & TRN & \\
\hline CHEMBL120826 & 305729 & 6.6778 & 6.7473 & TST & \\
\hline CHEMBL52777 & 305729 & 6.0706 & 6.0178 & TRN & \\
\hline CHEMBL32190 & 305729 & 7.2147 & 6.9644 & TRN & \\
\hline CHEMBL17430 & 305729 & 4.2328 & 4.3626 & TRN & \\
\hline CHEMBL420224 & 305729 & 7.2007 & 7.2199 & TRN & \\
\hline CHEMBL57624 & 305729 & 7.041 & 7.1122 & TRN & \\
\hline CHEMBL17431 & 305729 & 4.9547 & 4.3379 & TRN & \\
\hline CHEMBL115804 & 305729 & 7.0 & 6.996 & TRN & \\
\hline CHEMBL279679 & 305729 & 7.1152 & 7.3416 & TRN & \\
\hline CHEMBL137981 & 305729 & 7.0655 & 6.9319 & TST & \\
\hline CHEMBL121348 & 305729 & 7.0 & 6.9504 & TST & \\
\hline CHEMBL23705 & 305729 & 6.2924 & 6.38899 & 9999999999 & TRN \\
\hline CHEMBL81119 & 305729 & 7.3279 & 7.0618 & TRN & \\
\hline CHEMBL3137772 & 45264 & 6.0 & 5.7956 & TST & \\
\hline CHEMBL3137770 & 45264 & 6.4498 & 6.2783 & TRN & \\
\hline CHEMBL3138150 & 45264 & 7.0862 & 7.0944 & TRN & \\
\hline CHEMBL3138364 & 45264 & 6.011 & 5.8469 & TST & \\
\hline CHEMBL3137754 & 45264 & 6.0088 & 5.976 & TRN & \\
\hline CHEMBL 3137814 & 45264 & 8.0969 & 8.0335 & TRN & \\
\hline CHEMBL3138151 & 45264 & 7.0132 & 6.9785 & TRN & \\
\hline CHEMBL3137764 & 45264 & 7.9208 & 7.9796 & TRN & \\
\hline CHEMBL3137767 & 45264 & 6.0 & 6.0043 & TRN & \\
\hline CHEMBL 3137787 & 45264 & 6.6108 & 6.6753 & TRN & \\
\hline CHEMBL 3137751 & 45264 & 6.983 & 6.9617 & TRN & \\
\hline CHEMBL3137771 & 45264 & 7.5528 & 7.4813 & TST & \\
\hline
\end{tabular}




\begin{tabular}{|c|c|c|c|c|c|c|}
\hline & & \multicolumn{5}{|c|}{ Supplemental Table S2.txt } \\
\hline CHEMBL 3138158 & 45264 & 7.0605 & 7.1317 & TRN & & \\
\hline CHEMBL 3137785 & 45264 & 6.0 & 6.0344 & TRN & & \\
\hline CHEMBL 3137768 & 45264 & 6.0 & 5.858 & TRN & & \\
\hline CHEMBL 2113374 & 45264 & 7.6778 & 7.2725 & TST & & \\
\hline CHEMBL3138143 & 45264 & 5.9788 & 6.0046 & TRN & & \\
\hline CHEMBL 3137786 & 45264 & 7.0 & 6.9896 & TRN & & \\
\hline CHEMBL 3137802 & 45264 & 7.5086 & 7.6978 & TST & & \\
\hline CHEMBL 2113370 & 45264 & 7.2007 & 7.2989 & TST & & \\
\hline CHEMBL3137779 & 45264 & 6.5229 & 6.6178 & TRN & & \\
\hline CHEMBL3137799 & 45264 & 7.2218 & 7.0803 & TRN & & \\
\hline CHEMBL 3138182 & 45264 & 6.9393 & 7.0147 & TST & & \\
\hline CHEMBL3137762 & 45264 & 8.1549 & 8.5563 & TST & & \\
\hline CHEMBL3137793 & 45264 & 8.0458 & 8.4731 & TST & & \\
\hline CHEMBL3138183 & 45264 & 6.0 & 5.9386 & TRN & & \\
\hline CHEMBL3137811 & 45264 & 6.0 & 6.0941 & TRN & & \\
\hline CHEMBL 3138427 & 45264 & 6.0 & 5.9989 & TRN & & \\
\hline CHEMBL3137752 & 45264 & 6.9172 & 7.0157 & TRN & & \\
\hline CHEMBL 3138145 & 45264 & 6.8761 & 6.9097 & TRN & & \\
\hline CHEMBL3137750 & 45264 & 6.0 & 5.8785 & TRN & & \\
\hline CHEMBL 3138384 & 45264 & 6.5528 & 6.5149 & TRN & & \\
\hline CHEMBL 3138146 & 45264 & 8.0458 & 8.0559 & TRN & & \\
\hline CHEMBL3138161 & 45264 & 6.2596 & 6.2611 & TRN & & \\
\hline CHEMBL3138162 & 45264 & 7.2757 & 7.4452 & TRN & & \\
\hline CHEMBL3137805 & 45264 & 6.0 & 5.9275 & TRN & & \\
\hline CHEMBL 3137765 & 45264 & 6.0 & 6.1431 & TRN & & \\
\hline CHEMBL 3137796 & 45264 & 6.8861 & 7.2527 & TST & & \\
\hline CHEMBL3138434 & 45264 & 7.0809 & 7.0575 & TRN & & \\
\hline CHEMBL 3138410 & 45264 & \multicolumn{3}{|c|}{6.821000000000001} & 6.8636 & TRN \\
\hline CHEMBL 3137795 & 45264 & 8.0 & 7.9697 & TRN & & \\
\hline CHEMBL 3138171 & 45264 & 8.0458 & 8.0302 & TRN & & \\
\hline CHEMBL 3137808 & 45264 & 7.6198 & 7.5217 & TST & & \\
\hline CHEMBL 3137781 & 45264 & 6.4559 & 6.4384 & TRN & & \\
\hline CHEMBL 3138164 & 45264 & 7.7212 & 7.7007 & TRN & & \\
\hline CHEMBL3138178 & 45264 & 6.0 & 5.8594 & TRN & & \\
\hline CHEMBL3137789 & 45264 & 7.5229 & 7.7412 & TST & & \\
\hline CHEMBL3138167 & 45264 & 6.0 & 5.9943 & TRN & & \\
\hline CHEMBL3137806 & 45264 & 6.1871 & 6.1259 & TRN & & \\
\hline CHEMBL 3137792 & 45264 & 7.301 & 7.1686 & TRN & & \\
\hline CHEMBL3137756 & 45264 & 6.1249 & 6.1002 & TST & & \\
\hline CHEMBL3138166 & 45264 & 8.0 & 7.892 & TRN & & \\
\hline CHEMBL3138419 & 45264 & 8.0458 & 8.0944 & TRN & & \\
\hline CHEMBL 2113371 & 45264 & 8.0969 & 8.0861 & TST & & \\
\hline CHEMBL3137788 & 45264 & 6.8861 & 6.9653 & TRN & & \\
\hline CHEMBL3138169 & 45264 & 6.9101 & 6.8828 & TRN & & \\
\hline CHEMBL3137807 & 45264 & 7.301 & 7.5763 & TST & & \\
\hline CHEMBL 3138142 & 45264 & 7.5528 & 7.5493 & TRN & & \\
\hline CHEMBL3137753 & 45264 & 6.5229 & 6.6004 & TRN & & \\
\hline CHEMBL3138141 & 45264 & 6.3565 & 6.3813 & TRN & & \\
\hline
\end{tabular}




\begin{tabular}{|c|c|c|c|c|c|}
\hline & & \multicolumn{4}{|c|}{ Supplemental Table S2.txt } \\
\hline CHEMBL3138179 & 45264 & 7.5528 & 7.7023 & TRN & \\
\hline CHEMBL 3138160 & 45264 & 8.0458 & 7.9337 & TRN & \\
\hline CHEMBL3138165 & 45264 & 6.7747 & 6.8863 & TRN & \\
\hline CHEMBL3138159 & 45264 & 6.0362 & 5.9041 & TRN & \\
\hline CHEMBL3137782 & 45264 & 6.699 & 6.7525 & TRN & \\
\hline CHEMBL 3138153 & 45264 & 6.5952 & 6.6751 & TRN & \\
\hline CHEMBL3138176 & 45264 & 6.3665 & 6.3375 & TRN & \\
\hline CHEMBL3138487 & 45264 & 6.1308 & 6.1866 & TRN & \\
\hline CHEMBL 3138138 & 45264 & 6.6326 & 6.7571 & TRN & \\
\hline CHEMBL3138139 & 45264 & 6.8327 & 6.7981 & TRN & \\
\hline CHEMBL3138155 & 45264 & 6.5086 & 6.6749 & TRN & \\
\hline CHEMBL3137766 & 45264 & 5.8697 & 6.07299 & 99999999995 & TRN \\
\hline CHEMBL3138172 & 45264 & 7.0177 & 7.0048 & TRN & \\
\hline CHEMBL3138154 & 45264 & 7.5229 & 7.5963 & TRN & \\
\hline CHEMBL3138147 & 45264 & 6.0 & 6.0243 & TST & \\
\hline CHEMBL3138148 & 45264 & 6.9586 & 7.0208 & TRN & \\
\hline CHEMBL3137784 & 45264 & 6.0 & 5.8459 & TRN & \\
\hline CHEMBL3138157 & 45264 & 8.0969 & 8.0517 & TRN & \\
\hline CHEMBL3137797 & 45264 & 6.5528 & 6.63200 & 0000000001 & TRN \\
\hline CHEMBL3138149 & 45264 & 6.0 & 5.8667 & TST & \\
\hline CHEMBL 2113375 & 45264 & 6.0 & 5.86700 & 3000000001 & TST \\
\hline CHEMBL3137798 & 45264 & 5.9208 & 5.9815 & TST & \\
\hline CHEMBL3137791 & 45264 & 7.1612 & 7.2715 & TRN & \\
\hline CHEMBL3138367 & 45264 & 7.1549 & 6.9952 & TRN & \\
\hline CHEMBL3137777 & 45264 & 7.7212 & 7.74299 & 9999999999 & TST \\
\hline CHEMBL 3138373 & 45264 & 6.6576 & 6.6356 & TRN & \\
\hline CHEMBL3138168 & 45264 & 7.2676 & 7.0587 & TRN & \\
\hline CHEMBL3137759 & 45264 & 6.0 & 6.1803 & TRN & \\
\hline CHEMBL3138163 & 45264 & 6.5045 & 6.5567 & TRN & \\
\hline CHEMBL 3137780 & 45264 & 8.301 & 8.3472 & TST & \\
\hline CHEMBL3137775 & 45264 & 7.4437 & 7.2599 & TRN & \\
\hline CHEMBL 3138424 & 45264 & 8.1549 & 8.2626 & TST & \\
\hline CHEMBL 3137757 & 45264 & 7.5376 & 7.3874 & TRN & \\
\hline CHEMBL3138498 & 45264 & 6.0 & 6.1062 & TRN & \\
\hline CHEMBL3137761 & 45264 & 6.6882 & 7.1443 & TST & \\
\hline CHEMBL 3138174 & 45264 & 8.2218 & 8.2827 & TST & \\
\hline CHEMBL3138180 & 45264 & 6.2967 & 6.432 & TST & \\
\hline CHEMBL 3137755 & 45264 & 7.3979 & 7.3474 & TRN & \\
\hline CHEMBL564915 & 579310 & 5.7799 & 4.3088 & TST & \\
\hline CHEMBL560856 & 579310 & 5.6383 & 5.7621 & TRN & \\
\hline CHEMBL558116 & 579310 & 5.7066 & 6.1849 & TRN & \\
\hline CHEMBL557710 & 579310 & 2.5638 & 4.9599 & TST & \\
\hline CHEMBL556699 & 579310 & 4.9259 & 5.1924 & TRN & \\
\hline CHEMBL556417 & 579310 & 5.5686 & 6.2617 & TRN & \\
\hline CHEMBL562602 & 579310 & 2.566999 & و9999999 & 4.3336 & TRN \\
\hline CHEMBL549977 & 579310 & 3.6876 & 2.5875 & TRN & \\
\hline CHEMBL555876 & 579310 & 2.5686 & 4.1081 & TRN & \\
\hline CHEMBL550918 & 579310 & 5.3585 & 4.7987 & TRN & \\
\hline
\end{tabular}

Page 12489 


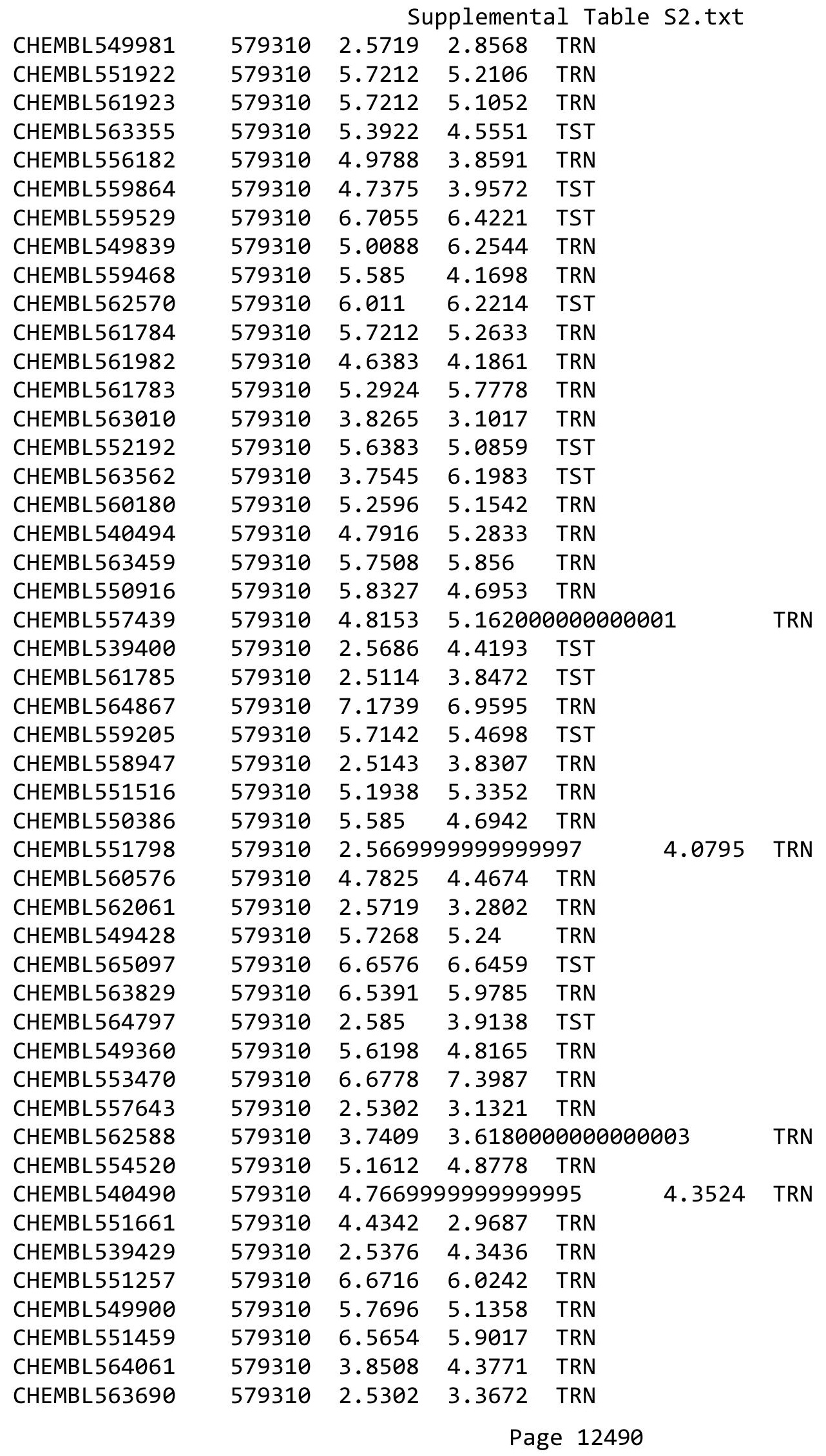




\begin{tabular}{|c|c|c|c|c|c|}
\hline & & & & & \\
\hline CHEMBL563418 & 579310 & 4.3161 & 4.4055 & TRN & \\
\hline CHEMBL551518 & 579310 & 5.9431 & 5.7996 & TRN & \\
\hline CHEMBL559924 & 579310 & 5.7959 & 6.1585 & TST & \\
\hline CHEMBL560259 & 579310 & 3.639 & 5.8424 & TST & \\
\hline CHEMBL558404 & 579310 & 5.6576 & 6.6211 & TST & \\
\hline CHEMBL564188 & 579310 & 2.5884 & 2.6005 & TRN & \\
\hline CHEMBL556483 & 579310 & 2.5686 & 3.16300 & 00000000003 & TRN \\
\hline CHEMBL550163 & 579310 & 5.8539 & 5.2724 & TST & \\
\hline CHEMBL560783 & 579310 & 6.5901 & 5.8468 & TRN & \\
\hline CHEMBL550992 & 579310 & 3.6064 & 5.8442 & TST & \\
\hline CHEMBL561859 & 579310 & 2.5346 & 3.0763 & TRN & \\
\hline CHEMBL550507 & 579310 & 4.1752 & 4.6211 & TST & \\
\hline CHEMBL562787 & 579310 & 2.585 & 2.9013 & TRN & \\
\hline CHEMBL557435 & 579310 & 3.8722 & 3.3197 & TRN & \\
\hline CHEMBL559788 & 579310 & 5.8239 & 5.7647 & TRN & \\
\hline CHEMBL562879 & 579310 & 5.7423 & 5.3906 & TRN & \\
\hline CHEMBL1491686 & 752448 & 5.4789 & 5.3477 & TRN & \\
\hline CHEMBL1406130 & 752448 & 4.6374 & 4.7262 & TRN & \\
\hline CHEMBL1500409 & 752448 & 5.4145 & 5.3421 & TRN & \\
\hline CHEMBL1492648 & 752448 & 4.5366 & 4.7143 & TRN & \\
\hline CHEMBL1315948 & 752448 & 5.5053 & 4.8611 & TRN & \\
\hline CHEMBL1701517 & 752448 & 3.3031 & 4.4287 & TRN & \\
\hline CHEMBL1704703 & 752448 & 4.6625 & 4.5092 & TRN & \\
\hline CHEMBL1611182 & 752448 & 4.9511 & 4.7248 & TRN & \\
\hline CHEMBL1415985 & 752448 & 5.4585 & 5.2097 & TRN & \\
\hline CHEMBL1319618 & 752448 & 3.3031 & 4.2738 & TRN & \\
\hline CHEMBL1487952 & 752448 & 5.0756 & 4.8591 & TRN & \\
\hline CHEMBL1699845 & 752448 & 4.9931 & 4.6564 & TRN & \\
\hline CHEMBL1462613 & 752448 & 5.3526 & 5.2851 & TRN & \\
\hline CHEMBL1711514 & 752448 & 4.6353 & 4.6417 & TRN & \\
\hline CHEMBL1728153 & 752448 & 4.7878 & 4.5476 & TRN & \\
\hline CHEMBL1554784 & 752448 & 5.5348 & 5.3967 & TST & \\
\hline CHEMBL1387110 & 752448 & 5.4052 & 5.3301 & TRN & \\
\hline CHEMBL1508875 & 752448 & 4.853 & 5.2527 & TRN & \\
\hline CHEMBL1460029 & 752448 & 5.2201 & 4.6533 & TRN & \\
\hline CHEMBL429095 & 752448 & 4.9155 & 4.7086 & TRN & \\
\hline CHEMBL1432251 & 752448 & 3.3033 & 4.7532 & TRN & \\
\hline CHEMBL1342053 & 752448 & 4.5432 & 4.4789 & TRN & \\
\hline CHEMBL1557820 & 752448 & 3.3033 & 4.6711 & TST & \\
\hline CHEMBL1555532 & 752448 & 4.9188 & 4.6171 & TRN & \\
\hline CHEMBL1473205 & 752448 & 5.0992 & 5.2603 & TST & \\
\hline CHEMBL1308255 & 752448 & 5.0785 & 5.278 & TRN & \\
\hline CHEMBL1472131 & 752448 & 5.5127 & 5.2512 & TRN & \\
\hline CHEMBL3197908 & 752448 & 5.6718 & 5.4276 & TRN & \\
\hline CHEMBL1532571 & 752448 & 5.2429 & 5.0296 & TRN & \\
\hline CHEMBL1712229 & 752448 & 5.141 & 5.3511 & TRN & \\
\hline CHEMBL1570323 & 752448 & 5.0527 & 5.3086 & TST & \\
\hline CHEMBL1303426 & 752448 & 5.2217 & 4.77800 & 00000000005 & TRN \\
\hline & & & & 2491 & \\
\hline
\end{tabular}




\begin{tabular}{|c|c|c|c|c|c|c|}
\hline \multicolumn{7}{|c|}{ Supplemental Table S2.txt } \\
\hline CHEMBL1405830 & 752448 & 4.9051 & 5.3387 & TRN & & \\
\hline CHEMBL1734763 & 752448 & 4.8651 & 4.5894 & TRN & & \\
\hline CHEMBL1375884 & 752448 & 5.0231 & 5.0468 & TRN & & \\
\hline CHEMBL1608392 & 752448 & 4.7297 & 5.0378 & TRN & & \\
\hline CHEMBL1340895 & 752448 & 5.4063 & 5.227 & TRN & & \\
\hline CHEMBL1589062 & 752448 & 5.2531 & 5.1001 & TRN & & \\
\hline CHEMBL1575428 & 752448 & 3.3031 & 4.6193 & TRN & & \\
\hline CHEMBL1449204 & 752448 & 4.7166 & 4.8279 & TRN & & \\
\hline CHEMBL1574879 & 752448 & 4.7959 & 4.5254 & TRN & & \\
\hline CHEMBL1583998 & 752448 & 5.3596 & 5.1789 & TRN & & \\
\hline CHEMBL1430995 & 752448 & 5.33799 & 999999999 & 5.2 & 0000000001 & TRN \\
\hline CHEMBL1301723 & 752448 & 4.7995 & 4.9706 & TST & & \\
\hline CHEMBL1609419 & 752448 & 4.9989 & 5.0666 & TRN & & \\
\hline CHEMBL1541918 & 752448 & 5.4283 & 5.2683 & TRN & & \\
\hline CHEMBL1534986 & 752448 & 5.1302 & 5.0829 & TRN & & \\
\hline CHEMBL1494120 & 752448 & 5.1063 & 4.4534 & TRN & & \\
\hline CHEMBL1790039 & 752448 & 5.3231 & 5.0063 & TRN & & \\
\hline CHEMBL1462078 & 752448 & 5.0046 & 5.1751 & TRN & & \\
\hline CHEMBL1713905 & 752448 & 5.2237 & 5.4051 & TRN & & \\
\hline CHEMBL1734268 & 752448 & 4.8391 & 4.8869 & TRN & & \\
\hline CHEMBL1527994 & 752448 & 5.4176 & 5.3506 & TRN & & \\
\hline CHEMBL131770 & 752448 & 5.2896 & 5.2471 & TRN & & \\
\hline CHEMBL1300370 & 752448 & 4.9282 & 4.7768 & TST & & \\
\hline CHEMBL1513846 & 752448 & 5.4364 & 5.3189 & TRN & & \\
\hline CHEMBL1362660 & 752448 & 3.3032 & 4.3431 & TRN & & \\
\hline CHEMBL1303810 & 752448 & 3.3031 & 4.1635 & TRN & & \\
\hline CHEMBL1327783 & 752448 & 4.5109 & 4.516999 & 99999999995 & TRN & \\
\hline CHEMBL1407961 & 752448 & 4.9561 & 4.7383 & TRN & & \\
\hline CHEMBL61559 & 752448 & 5.3268 & 5.4828 & TRN & & \\
\hline CHEMBL1535546 & 752448 & 5.2097 & 4.768 & TRN & & \\
\hline CHEMBL1727997 & 752448 & 3.3031 & 4.572 & TRN & & \\
\hline CHEMBL1607132 & 752448 & 5.2914 & 5.3461 & TRN & & \\
\hline CHEMBL1471341 & 752448 & 5.1165 & 4.9091 & TRN & & \\
\hline CHEMBL1723955 & 752448 & 4.7512 & 4.5644 & TRN & & \\
\hline CHEMBL1544093 & 752448 & 4.6506 & 4.3754 & TRN & & \\
\hline CHEMBL1458470 & 752448 & 5.4219 & 5.1662 & TRN & & \\
\hline CHEMBL1727091 & 752448 & 4.4885 & 4.8839 & TST & & \\
\hline CHEMBL1720248 & 752448 & 5.3464 & 5.3523 & TRN & & \\
\hline CHEMBL1585390 & 752448 & 5.3251 & 4.4327 & TRN & & \\
\hline CHEMBL1734503 & 752448 & 4.7577 & 4.6031 & TRN & & \\
\hline CHEMBL3207597 & 752448 & 4.9024 & 5.3765 & TRN & & \\
\hline CHEMBL1558462 & 752448 & 5.1775 & 4.8673 & TRN & & \\
\hline CHEMBL1608420 & 752448 & 5.0282 & 5.3094 & TRN & & \\
\hline CHEMBL1420325 & 752448 & 5.15 & 4.7367 & TST & & \\
\hline CHEMBL1736537 & 752448 & 5.1406 & 5.0499 & TRN & & \\
\hline CHEMBL1527042 & 752448 & 4.9859 & 4.9996 & TRN & & \\
\hline CHEMBL1338304 & 752448 & 5.0648 & 4.7485 & TRN & & \\
\hline CHEMBL1971127 & 752448 & 5.1486 & 5.2281 & TST & & \\
\hline
\end{tabular}


Supplemental Table S2.txt

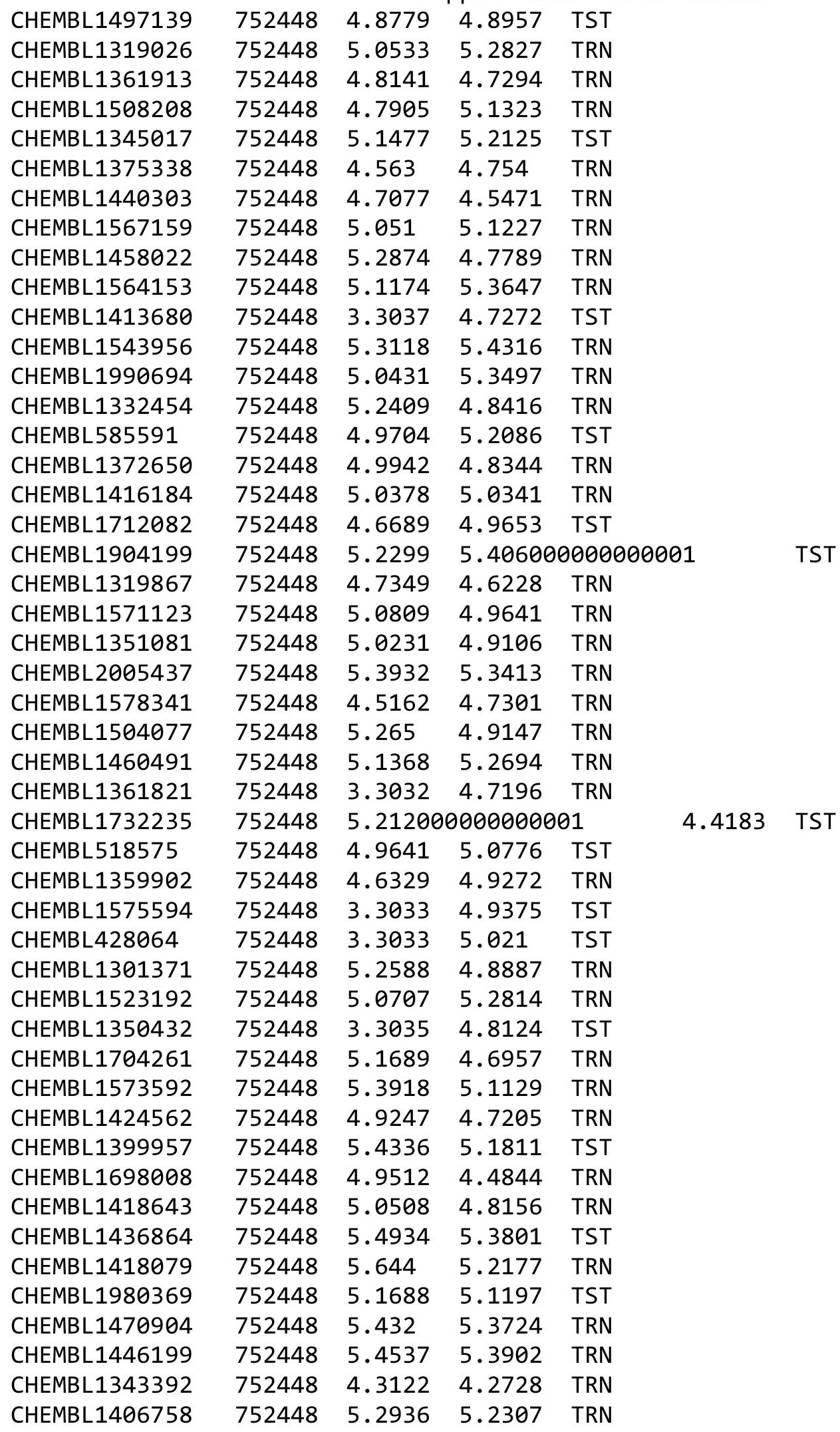

Page 12493 


\begin{tabular}{|c|c|c|c|c|c|c|}
\hline \multirow[b]{2}{*}{ CHEMBL1487183 } & \multirow[b]{2}{*}{752448} & \multicolumn{5}{|c|}{ Supplemental Table S2.txt } \\
\hline & & 5.2831 & 4.9102 & TST & & \\
\hline CHEMBL1539522 & 752448 & 4.9393 & 4.939 & TRN & & \\
\hline CHEMBL1370844 & 752448 & 5.1586 & 5.0595 & TRN & & \\
\hline CHEMBL1710816 & 752448 & 4.9594 & 4.7831 & TRN & & \\
\hline CHEMBL1573150 & 752448 & 4.927 & 4.9715 & TRN & & \\
\hline CHEMBL1301731 & 752448 & 5.3217 & 5.2121 & TRN & & \\
\hline CHEMBL1343705 & 752448 & 3.3033 & 4.9424 & TST & & \\
\hline CHEMBL1518077 & 752448 & 5.0257 & 5.0114 & TRN & & \\
\hline CHEMBL1418428 & 752448 & 5.4088 & 5.3159 & TRN & & \\
\hline CHEMBL1890919 & 752448 & 5.0866 & 5.26 & TRN & & \\
\hline CHEMBL1578982 & 752448 & 5.4281 & 5.3365 & TRN & & \\
\hline CHEMBL1453652 & 752448 & 5.1546 & 5.4402 & TRN & & \\
\hline CHEMBL1434843 & 752448 & 5.4117 & 5.3169 & TST & & \\
\hline CHEMBL1984584 & 752448 & 4.9901 & 5.2721 & TRN & & \\
\hline CHEMBL137913 & 752448 & 5.3215 & 5.6054 & TRN & & \\
\hline CHEMBL1429929 & 752448 & 4.5494 & 4.7767 & TRN & & \\
\hline CHEMBL1469035 & 752448 & 4.8633 & 4.8978 & TST & & \\
\hline CHEMBL505670 & 752448 & 5.1177 & 4.7389 & TRN & & \\
\hline CHEMBL1452132 & 752448 & 5.2521 & 5.3548 & TRN & & \\
\hline CHEMBL1524932 & 752448 & 5.1326 & 5.2106 & TRN & & \\
\hline CHEMBL1698608 & 752448 & 3.3029 & 4.9853 & TST & & \\
\hline CHEMBL1428415 & 752448 & 5.0991 & 4.8658 & TRN & & \\
\hline CHEMBL3195010 & 752448 & 4.9689 & 5.3257 & TRN & & \\
\hline CHEMBL1688693 & 752448 & 4.6806 & 5.1363 & TST & & \\
\hline CHEMBL1423626 & 752448 & 3.3028 & 4.7621 & TST & & \\
\hline CHEMBL1535665 & 752448 & 4.6734 & 4.5206 & TRN & & \\
\hline CHEMBL1534390 & 752448 & 5.3389 & 5.2152 & TRN & & \\
\hline CHEMBL1484327 & 752448 & 5.2816 & 5.3722 & TRN & & \\
\hline CHEMBL 3189224 & 752448 & 5.1293 & 5.2619 & TST & & \\
\hline CHEMBL1510339 & 752448 & 4.97199 & 99999999 & 995 & 4.9764 & TRN \\
\hline CHEMBL1492819 & 752448 & 5.2711 & 5.3513 & TRN & & \\
\hline CHEMBL1418162 & 752448 & 5.3471 & 5.0924 & TRN & & \\
\hline CHEMBL1307050 & 752448 & 4.9171 & 4.8692 & TRN & & \\
\hline CHEMBL1404578 & 752448 & 5.17299 & 9999999 & 99 & 4.798 & TRN \\
\hline CHEMBL1964993 & 752448 & 5.3782 & 5.2973 & TRN & & \\
\hline CHEMBL1538643 & 752448 & 5.1153 & 5.4313 & TRN & & \\
\hline CHEMBL432044 & 752448 & 5.4014 & 5.0823 & TRN & & \\
\hline CHEMBL1542492 & 752448 & 5.0844 & 4.976 & TRN & & \\
\hline CHEMBL1526855 & 752448 & 5.2756 & 4.8007 & TRN & & \\
\hline CHEMBL131037 & 752448 & 5.1701 & 4.4245 & TRN & & \\
\hline CHEMBL1984244 & 752448 & 5.4307 & 5.2931 & TST & & \\
\hline CHEMBL1386978 & 752448 & 5.2366 & 5.2873 & TRN & & \\
\hline CHEMBL1419822 & 752448 & 3.3028 & 4.5539 & TRN & & \\
\hline CHEMBL1417970 & 752448 & 4.8409 & 4.8671 & TRN & & \\
\hline CHEMBL1416020 & 752448 & 5.184 & 5.4129 & TRN & & \\
\hline CHEMBL1498308 & 752448 & 5.2766 & 5.3611 & TST & & \\
\hline CHEMBL1531308 & 752448 & 3.3031 & 4.7949 & TST & & \\
\hline CHEMBL1517505 & 752448 & 5.215 & 5.3095 & TRN & & \\
\hline
\end{tabular}




\begin{tabular}{|c|c|c|c|c|c|c|}
\hline & & \multicolumn{5}{|c|}{ Supplemental Table S2.txt } \\
\hline CHEMBL 1458548 & 752448 & 4.7882 & 4.4455 & TRN & & \\
\hline CHEMBL1899958 & 752448 & 5.5616 & 5.3342 & TRN & & \\
\hline CHEMBL1480031 & 752448 & 5.147 & 4.7538 & TRN & & \\
\hline CHEMBL 140 & 752448 & 5.1106 & 5.2185 & TRN & & \\
\hline CHEMBL1993431 & 752448 & 5.1146 & 5.2465 & TRN & & \\
\hline CHEMBL 1440300 & 752448 & 4.2576 & 4.5239 & TRN & & \\
\hline CHEMBL1319461 & 752448 & 5.1769 & 5.2213 & TRN & & \\
\hline CHEMBL1586067 & 752448 & 5.2808 & 5.3898 & TRN & & \\
\hline CHEMBL1476225 & 752448 & 5.2444 & 5.1994 & TRN & & \\
\hline CHEMBL1610025 & 752448 & 4.98 & 5.0467 & TRN & & \\
\hline CHEMBL1417212 & 752448 & 5.4418 & 5.2599 & TRN & & \\
\hline CHEMBL1971913 & 752448 & 5.3158 & 5.1362 & TST & & \\
\hline CHEMBL1865393 & 752448 & 5.2696 & 4.9218 & TRN & & \\
\hline CHEMBL116438 & 752448 & 4.9678 & 5.307 & TRN & & \\
\hline CHEMBL1532668 & 752448 & 3.3032 & 4.3837 & TRN & & \\
\hline CHEMBL1459316 & 752448 & 5.358 & 5.0946 & TST & & \\
\hline CHEMBL167542 & 752448 & 5.1961 & 5.0977 & TRN & & \\
\hline CHEMBL1520346 & 752448 & 5.5918 & 5.3678 & TRN & & \\
\hline CHEMBL1707429 & 752448 & \multicolumn{3}{|c|}{4.8660000000000005} & 4.555 & TRN \\
\hline CHEMBL1502104 & 752448 & 3.3031 & 4.9389 & TST & & \\
\hline CHEMBL1988416 & 752448 & 4.7091 & 4.5186 & TRN & & \\
\hline CHEMBL1999014 & 752448 & 5.3284 & 5.4884 & TRN & & \\
\hline CHEMBL1991303 & 752448 & 5.5236 & 5.2708 & TRN & & \\
\hline CHEMBL1316002 & 752448 & 5.2786 & 5.1694 & TRN & & \\
\hline CHEMBL1331822 & 752448 & 4.8321 & 4.6143 & TRN & & \\
\hline CHEMBL1726592 & 752448 & 3.3031 & 4.7545 & TRN & & \\
\hline CHEMBL 1477528 & 752448 & 5.2044 & 5.0362 & TRN & & \\
\hline CHEMBL1385690 & 752448 & 5.0805 & 4.9445 & TRN & & \\
\hline CHEMBL1526126 & 752448 & 5.5786 & 5.3149 & TRN & & \\
\hline CHEMBL1409883 & 752448 & 4.8068 & 4.5155 & TRN & & \\
\hline CHEMBL1711797 & 752448 & 4.6698 & 4.8922 & TRN & & \\
\hline CHEMBL1540557 & 752448 & 5.0378 & 5.3628 & TST & & \\
\hline CHEMBL1474143 & 752448 & 5.1786 & 4.9851 & TST & & \\
\hline CHEMBL1337235 & 752448 & 4.9899 & 4.9464 & TRN & & \\
\hline CHEMBL1731330 & 752448 & 5.2932 & 5.4358 & TRN & & \\
\hline CHEMBL1428095 & 752448 & 5.1186 & 4.9215 & TRN & & \\
\hline CHEMBL 1352586 & 752448 & 4.9606 & 5.0959 & TRN & & \\
\hline CHEMBL1499951 & 752448 & 4.7495 & 4.5692 & TRN & & \\
\hline CHEMBL1361740 & 752448 & 4.3368 & 4.8157 & TST & & \\
\hline CHEMBL1479144 & 752448 & 5.3246 & 5.2355 & TST & & \\
\hline CHEMBL1543839 & 752448 & 3.303 & 4.1827 & TST & & \\
\hline CHEMBL1566610 & 752448 & 4.7482 & 4.9456 & TST & & \\
\hline CHEMBL1308404 & 752448 & 5.1955 & 4.7375 & TST & & \\
\hline CHEMBL1725771 & 752448 & 5.3214 & 5.3119 & TST & & \\
\hline CHEMBL1705527 & 752448 & 5.4439 & 5.1066 & TST & & \\
\hline CHEMBL179512 & 752448 & 5.0918 & 5.4704 & TST & & \\
\hline CHEMBL1360031 & 752448 & 5.626 & 5.2274 & TST & & \\
\hline CHEMBL1999049 & 752448 & 4.9041 & 4.5626 & TST & & \\
\hline
\end{tabular}




\begin{tabular}{|c|c|c|c|c|c|}
\hline & & & & & \\
\hline CHEMBL1215650 & 752448 & 5.0457 & 5.675 & TST & \\
\hline CHEMBL1570958 & 752448 & 5.0807 & 4.9112 & TST & \\
\hline CHEMBL1703189 & 752448 & 3.3036 & 4.7232 & TST & \\
\hline CHEMBL1726287 & 752448 & 5.3565 & 5.4003 & TST & \\
\hline CHEMBL1427185 & 752448 & 5.1003 & 4.5524 & TST & \\
\hline CHEMBL3199893 & 752448 & 5.1084 & 5.023 & TST & \\
\hline CHEMBL1508593 & 752448 & 5.4357 & 5.1652 & TST & \\
\hline CHEMBL1588411 & 752448 & 4.9607 & 5.0066 & TST & \\
\hline CHEMBL1390797 & 752448 & 5.414 & 5.3347 & TST & \\
\hline CHEMBL1706548 & 752448 & 4.8417 & 4.9333 & TST & \\
\hline CHEMBL1904073 & 752558 & 3.0496 & 3.5321 & TRN & \\
\hline CHEMBL1314272 & 752558 & 3.0494 & 3.7043 & TRN & \\
\hline CHEMBL1401226 & 752558 & 4.3085 & 3.9238 & TRN & \\
\hline CHEMBL1733182 & 752558 & 3.0499 & 3.7588 & TST & \\
\hline CHEMBL1365476 & 752558 & 5.2493 & 3.7995 & TRN & \\
\hline CHEMBL1472131 & 752558 & 3.0499 & 3.5696 & TRN & \\
\hline CHEMBL1409608 & 752558 & 3.0497 & 3.6472 & TRN & \\
\hline CHEMBL1481849 & 752558 & 5.1974 & 5.1843 & TRN & \\
\hline CHEMBL1873186 & 752558 & 3.0497 & 4.003 & TRN & \\
\hline CHEMBL1713654 & 752558 & 3.0496 & 3.0391 & TST & \\
\hline CHEMBL1725771 & 752558 & 3.0493 & 3.3657 & TRN & \\
\hline CHEMBL1486690 & 752558 & 5.3429 & 3.1749 & TST & \\
\hline CHEMBL1549982 & 752558 & 3.0493 & 3.2546 & TST & \\
\hline CHEMBL1586096 & 752558 & 3.0496 & 3.4668 & TRN & \\
\hline CHEMBL1391773 & 752558 & 3.0496 & 2.6138 & TRN & \\
\hline CHEMBL1331010 & 752558 & 3.0497 & 3.6796 & TRN & \\
\hline CHEMBL1452571 & 752558 & 3.0497 & 3.4483 & TRN & \\
\hline CHEMBL1578670 & 752558 & 3.0493 & 2.8717 & TRN & \\
\hline CHEMBL1415720 & 752558 & 5.1243 & 4.4465 & TRN & \\
\hline CHEMBL1337599 & 752558 & 3.0496 & 3.2925 & TRN & \\
\hline CHEMBL1576059 & 752558 & 3.0496 & 3.9893 & TRN & \\
\hline CHEMBL1232381 & 752558 & 3.0498 & 3.1901 & TRN & \\
\hline CHEMBL1423359 & 752558 & 3.0501 & 3.6179 & TRN & \\
\hline CHEMBL1991601 & 752558 & 4.5615 & 4.4461 & TRN & \\
\hline CHEMBL1372920 & 752558 & 3.0498 & 3.08699 & 99999999997 & TRN \\
\hline CHEMBL1903746 & 752558 & 3.0496 & 2.6652 & TRN & \\
\hline CHEMBL1497642 & 752558 & 4.3331 & 4.342 & TRN & \\
\hline CHEMBL1721855 & 752558 & 3.0495 & 3.0433 & TST & \\
\hline CHEMBL1536835 & 752558 & 3.0499 & 3.6246 & TRN & \\
\hline CHEMBL1349596 & 752558 & 3.0499 & 2.8735 & TST & \\
\hline CHEMBL1489159 & 752558 & 3.0497 & 3.4127 & TST & \\
\hline CHEMBL1545021 & 752558 & 3.0499 & 3.7298 & TST & \\
\hline CHEMBL1504972 & 752558 & 4.5032 & 3.6727 & TRN & \\
\hline CHEMBL1568474 & 752558 & 3.0492 & 3.4582 & TRN & \\
\hline CHEMBL1605224 & 752558 & 4.9904 & 4.0591 & TRN & \\
\hline CHEMBL1500754 & 752558 & 3.0499 & 3.7653 & TRN & \\
\hline CHEMBL1429269 & 752558 & 3.0496 & 3.4814 & TRN & \\
\hline CHEMBL1703958 & 752558 & 3.0497 & 3.2826 & TRN & \\
\hline
\end{tabular}




\begin{tabular}{|c|c|c|c|c|}
\hline \multicolumn{5}{|c|}{ Supplemental Table S2.txt } \\
\hline CHEMBL1500686 & 752558 & 4.7319 & 4.5682 & TRN \\
\hline CHEMBL1527356 & 752558 & 3.0498 & 2.5437 & TRN \\
\hline CHEMBL1473205 & 752558 & 3.0503 & 3.3159 & TST \\
\hline CHEMBL1587031 & 752558 & 4.9916 & 4.3872 & TRN \\
\hline CHEMBL1360535 & 752558 & 4.6549 & 3.6392 & TST \\
\hline CHEMBL1707076 & 752558 & 3.0497 & 3.3111 & TRN \\
\hline CHEMBL1370322 & 752558 & 4.0039 & 2.9734 & TRN \\
\hline CHEMBL86464 & 752558 & 5.5794 & 3.7929 & TRN \\
\hline CHEMBL532160 & 752558 & 4.7975 & 4.5938 & TRN \\
\hline CHEMBL1367036 & 752558 & 3.0498 & 3.7018 & TST \\
\hline CHEMBL1353338 & 752558 & 4.6511 & 3.5666 & TRN \\
\hline CHEMBL1368701 & 752558 & 3.0496 & 3.5692 & TST \\
\hline CHEMBL1471509 & 752558 & 3.0496 & 3.3799 & TST \\
\hline CHEMBL1704902 & 752558 & 3.0498 & 3.0734 & TRN \\
\hline CHEMBL1510721 & 752558 & 3.0497 & 2.9763 & TRN \\
\hline CHEMBL1303641 & 752558 & 3.0497 & 3.6185 & TRN \\
\hline CHEMBL1318510 & 752558 & 3.0493 & 3.5891 & TRN \\
\hline CHEMBL1412077 & 752558 & 3.0499 & 3.3298 & TRN \\
\hline CHEMBL1312403 & 752558 & 3.0496 & 3.0419 & TRN \\
\hline CHEMBL1397114 & 752558 & 3.0494 & 3.5603 & TST \\
\hline CHEMBL1378294 & 752558 & 3.0496 & 3.2439 & TRN \\
\hline CHEMBL1527008 & 752558 & 3.0494 & 3.2139 & TRN \\
\hline CHEMBL1474602 & 752558 & 3.0496 & 3.2189 & TRN \\
\hline CHEMBL1448906 & 752558 & 3.0496 & 3.1506 & TRN \\
\hline CHEMBL1893003 & 752558 & 3.0501 & 2.9069 & TRN \\
\hline CHEMBL3196438 & 752558 & 3.0497 & 3.0664 & TRN \\
\hline CHEMBL589245 & 752558 & 4.2083 & 4.168 & TRN \\
\hline CHEMBL1971127 & 752558 & 5.3782 & 4.572 & TST \\
\hline CHEMBL1367989 & 752558 & 4.7445 & 3.9943 & TRN \\
\hline CHEMBL3192838 & 752558 & 4.5343 & 3.3531 & TRN \\
\hline CHEMBL1973159 & 752558 & 5.4019 & 4.77 & TST \\
\hline CHEMBL1485551 & 752558 & 4.595 & 4.3851 & TRN \\
\hline CHEMBL1713873 & 752558 & 3.05 & 3.3883 & TRN \\
\hline CHEMBL1331195 & 752558 & 3.0494 & 2.8269 & TRN \\
\hline CHEMBL1591708 & 752558 & 3.0494 & 3.5093 & TRN \\
\hline CHEMBL1418432 & 752558 & 3.0497 & 3.7451 & TRN \\
\hline CHEMBL1572055 & 752558 & 3.0497 & 3.1735 & TRN \\
\hline CHEMBL1880132 & 752558 & 3.0496 & 3.6111 & TRN \\
\hline CHEMBL1706025 & 752558 & 3.0496 & 3.9393 & TRN \\
\hline CHEMBL1390912 & 752558 & 3.0497 & 3.4573 & TRN \\
\hline CHEMBL1558968 & 752558 & 4.4527 & 4.1142 & TRN \\
\hline CHEMBL1565682 & 752558 & 3.0498 & 2.8575 & TRN \\
\hline CHEMBL1544339 & 752558 & 4.8986 & 3.3523 & TRN \\
\hline CHEMBL1392848 & 752558 & 3.0494 & 3.0434 & TRN \\
\hline CHEMBL1387366 & 752558 & 3.0492 & 2.7125 & TRN \\
\hline CHEMBL422692 & 752558 & 3.0496 & 3.1299 & TRN \\
\hline CHEMBL1528386 & 752558 & 3.0496 & 3.8526 & TRN \\
\hline CHEMBL1708021 & 752558 & 3.0497 & 3.7496 & TRN \\
\hline
\end{tabular}

Page 12497 


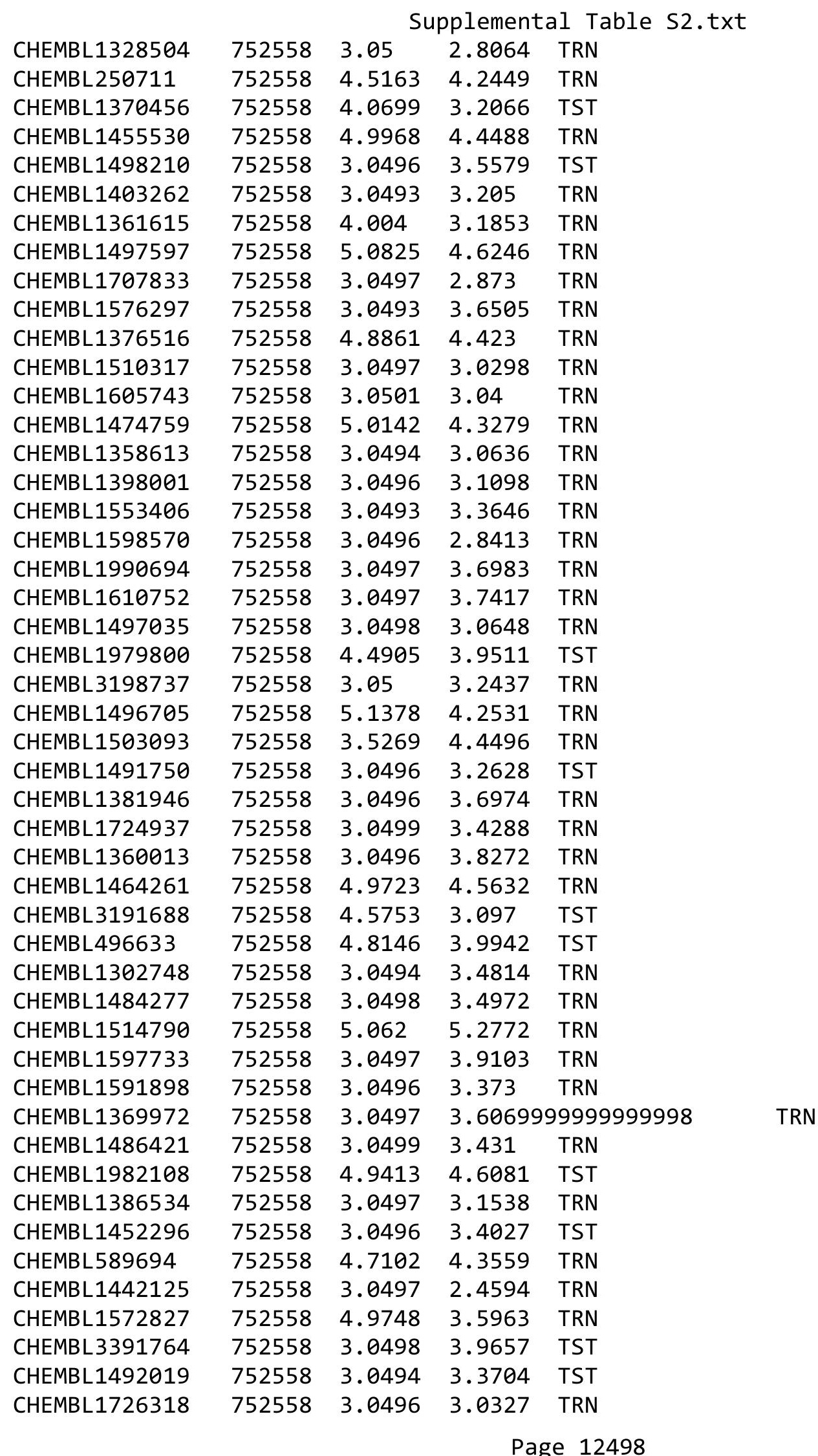


Supplemental Table S2.txt

\begin{tabular}{|c|c|c|c|c|}
\hline CHEMBL1611041 & 752558 & 5.0076 & 3.8262 & TST \\
\hline CHEMBL1321530 & 752558 & 3.0499 & 2.8912 & TRN \\
\hline CHEMBL1418754 & 752558 & 4.9694 & 3.5834 & TRN \\
\hline CHEMBL1562133 & 752558 & 3.0497 & 3.4456 & TRN \\
\hline CHEMBL1525340 & 752558 & 3.0494 & 3.1058 & TRN \\
\hline CHEMBL3193419 & 752558 & 3.0493 & 3.4242 & TRN \\
\hline CHEMBL1303339 & 752558 & 3.0498 & 3.7988 & TRN \\
\hline CHEMBL1984581 & 752558 & 5.7018 & 4.7242 & TST \\
\hline CHEMBL1729450 & 752558 & 3.0496 & 3.8643 & TRN \\
\hline CHEMBL1492044 & 752558 & 3.0496 & 2.9793 & TRN \\
\hline CHEMBL1332522 & 752558 & 3.0498 & 3.8015 & TST \\
\hline CHEMBL1989158 & 752558 & 5.3528 & 4.8414 & TST \\
\hline CHEMBL 3189224 & 752558 & 4.4735 & 4.7487 & TRN \\
\hline CHEMBL1359900 & 752558 & 3.0496 & 3.3811 & TRN \\
\hline CHEMBL1518886 & 752558 & 3.0499 & 3.2756 & TST \\
\hline CHEMBL1313831 & 752558 & 3.0496 & 3.0571 & TRN \\
\hline CHEMBL1602206 & 752558 & 5.0753 & 4.046 & TRN \\
\hline CHEMBL1454203 & 752558 & 3.0495 & 2.6729 & TRN \\
\hline CHEMBL1542526 & 752558 & 3.0496 & 4.3564 & TRN \\
\hline CHEMBL1208858 & 752558 & 5.6966 & 4.5054 & TST \\
\hline CHEMBL1986183 & 752558 & 5.6639 & 4.6452 & TST \\
\hline CHEMBL1584270 & 752558 & 4.4619 & 3.571 & TRN \\
\hline CHEMBL1462480 & 752558 & 3.0496 & 3.7312 & TRN \\
\hline CHEMBL1979061 & 752558 & 3.05 & 3.2861 & TRN \\
\hline CHEMBL1345866 & 752558 & 3.0497 & 3.7446 & TRN \\
\hline CHEMBL1369287 & 752558 & 4.9617 & 4.4101 & TRN \\
\hline CHEMBL1331762 & 752558 & 3.0496 & 3.4587 & TRN \\
\hline CHEMBL1361924 & 752558 & 4.8649 & 4.6826 & TRN \\
\hline CHEMBL1416701 & 752558 & 3.0493 & 2.7685 & TRN \\
\hline CHEMBL1491847 & 752558 & 5.472 & 4.513999 & 999999999 \\
\hline CHEMBL1730051 & 752558 & 3.0496 & 3.3433 & TST \\
\hline CHEMBL 3213565 & 752558 & 3.05 & 3.2618 & TRN \\
\hline CHEMBL1419164 & 752558 & 3.0498 & 3.3457 & TRN \\
\hline CHEMBL1578991 & 752558 & 3.0493 & 2.5752 & TRN \\
\hline CHEMBL1575701 & 752558 & 3.0493 & 3.2082 & TST \\
\hline CHEMBL1719363 & 752558 & 3.0496 & 3.529 & TRN \\
\hline CHEMBL1511114 & 752558 & 3.0498 & 3.568 & TRN \\
\hline CHEMBL1705738 & 752558 & 3.0497 & 2.6867 & TRN \\
\hline CHEMBL1995720 & 752558 & 5.0284 & 4.5697 & TST \\
\hline CHEMBL1355072 & 752558 & 4.8717 & 4.0327 & TRN \\
\hline CHEMBL1553368 & 752558 & 3.0496 & 3.1715 & TRN \\
\hline CHEMBL1974537 & 752558 & 5.0386 & 4.6883 & TST \\
\hline CHEMBL1604962 & 752558 & 3.05 & 3.0654 & TST \\
\hline CHEMBL1966241 & 752558 & 3.0497 & 3.3907 & TST \\
\hline CHEMBL1394552 & 752558 & 3.05 & 3.2842 & TST \\
\hline CHEMBL1522563 & 752558 & 3.0498 & 3.1809 & TST \\
\hline CHEMBL1378134 & 752558 & 3.0497 & 2.7895 & TRN \\
\hline CHEMBL1732485 & 752558 & 3.0497 & 2.7122 & TRN \\
\hline
\end{tabular}

Page 12499 


\begin{tabular}{|c|c|c|c|c|c|c|}
\hline & & \multicolumn{5}{|c|}{ Supplemental Table S2.txt } \\
\hline CHEMBL1547938 & 752558 & 3.0494 & 2.8984 & TRN & & \\
\hline CHEMBL1577275 & 752558 & 3.0499 & 3.5962 & TRN & & \\
\hline CHEMBL1513972 & 752558 & 5.0438 & 4.6688 & TRN & & \\
\hline CHEMBL1996133 & 752558 & 4.7487 & 4.6384 & TST & & \\
\hline CHEMBL1388543 & 752558 & 4.6953 & 4.1546 & TRN & & \\
\hline CHEMBL1574420 & 752558 & 3.05 & 2.5572 & TRN & & \\
\hline CHEMBL1709883 & 752558 & 3.0497 & 4.5331 & TST & & \\
\hline CHEMBL1527972 & 752558 & 3.0497 & 3.1164 & TRN & & \\
\hline CHEMBL1341102 & 752558 & 3.0496 & 3.0244 & TRN & & \\
\hline CHEMBL1410739 & 752558 & 4.7714 & 3.8362 & TRN & & \\
\hline CHEMBL1325192 & 752558 & \multicolumn{3}{|c|}{4.7589999999999995} & 4.0001 & TRN \\
\hline CHEMBL1731264 & 752558 & 3.0493 & 2.9465 & TRN & & \\
\hline CHEMBL1418096 & 752558 & 3.0493 & 3.1414 & TRN & & \\
\hline CHEMBL1528271 & 752558 & 3.0497 & 3.4298 & TST & & \\
\hline CHEMBL1309448 & 752558 & 4.6429 & 4.1264 & TST & & \\
\hline CHEMBL1322645 & 752558 & 4.9483 & 4.8177 & TRN & & \\
\hline CHEMBL1362746 & 752558 & 3.0497 & 3.4789 & TST & & \\
\hline CHEMBL1880442 & 752558 & 3.0496 & 4.1106 & TST & & \\
\hline CHEMBL601385 & 752558 & 3.0496 & 3.395 & TRN & & \\
\hline CHEMBL1723816 & 752558 & 3.0498 & 3.0532 & TRN & & \\
\hline CHEMBL1526165 & 752558 & 4.9164 & 4.5942 & TRN & & \\
\hline CHEMBL 3195513 & 752558 & 3.0497 & 3.7259 & TRN & & \\
\hline CHEMBL1992490 & 752558 & 5.0051 & 4.6248 & TST & & \\
\hline CHEMBL1458111 & 752558 & 3.0497 & 2.8705 & TRN & & \\
\hline CHEMBL1980281 & 752558 & 4.8397 & 4.5965 & TST & & \\
\hline CHEMBL1393633 & 752558 & 3.0501 & 3.3952 & TRN & & \\
\hline CHEMBL1389301 & 752558 & 3.0493 & 3.5492 & TRN & & \\
\hline CHEMBL1393761 & 752558 & 4.5478 & 4.3084 & TST & & \\
\hline CHEMBL1545734 & 752558 & 4.4695 & 4.0687 & TRN & & \\
\hline CHEMBL1571034 & 752558 & 3.0497 & 3.0587 & TRN & & \\
\hline CHEMBL1548876 & 752558 & 3.05 & 3.5723 & TST & & \\
\hline CHEMBL1530087 & 752558 & 4.9822 & 4.0881 & TST & & \\
\hline CHEMBL1484627 & 752558 & 4.5809 & 4.2868 & TST & & \\
\hline CHEMBL1460004 & 752558 & 4.7686 & 4.0494 & TST & & \\
\hline CHEMBL1557185 & 752558 & 3.05 & 3.2858 & TST & & \\
\hline CHEMBL 3087958 & 1274564 & 9.5 & 9.7622 & TRN & & \\
\hline CHEMBL 3087957 & 1274564 & 10.1 & 9.8558 & TRN & & \\
\hline CHEMBL3087956 & 1274564 & 7.6 & 8.4445 & TRN & & \\
\hline CHEMBL 3087955 & 1274564 & 9.4 & 9.4361 & TRN & & \\
\hline CHEMBL 3087954 & 1274564 & 9.6 & 9.1806 & TRN & & \\
\hline CHEMBL 3087953 & 1274564 & 9.8 & 9.6105 & TRN & & \\
\hline CHEMBL 3087952 & 1274564 & 10.0 & 9.7747 & TRN & & \\
\hline CHEMBL3087951 & 1274564 & 8.2 & 9.0772 & TRN & & \\
\hline CHEMBL 3087950 & 1274564 & 8.5 & 9.253 & TRN & & \\
\hline CHEMBL 3087949 & 1274564 & 10.0 & 9.4592 & TRN & & \\
\hline CHEMBL 3087948 & 1274564 & 9.2 & 9.457 & TRN & & \\
\hline CHEMBL 3087947 & 1274564 & 9.1 & 9.0561 & TRN & & \\
\hline CHEMBL 3087946 & 1274564 & 9.7 & 9.0829 & TRN & & \\
\hline
\end{tabular}




\begin{tabular}{|c|c|c|c|c|c|}
\hline \multicolumn{6}{|c|}{ plemental } \\
\hline CHEMBL3087945 & 1274564 & 8.6 & 8.7181 & TRN & \\
\hline CHEMBL3087379 & 1274564 & 9.1 & 9.3003 & TRN & \\
\hline CHEMBL 3087378 & 1274564 & 9.0 & 9.1992 & TRN & \\
\hline CHEMBL 3087377 & 1274564 & 9.4 & 9.2418 & TRN & \\
\hline CHEMBL 3087376 & 1274564 & 9.1 & 9.0653 & TRN & \\
\hline CHEMBL 3087375 & 1274564 & 9.6 & 8.9326 & TRN & \\
\hline CHEMBL 3087374 & 1274564 & 8.6 & 8.4872 & TRN & \\
\hline CHEMBL 3087373 & 1274564 & 9.1 & 9.5026 & TRN & \\
\hline CHEMBL 3087372 & 1274564 & 9.2 & 8.9256 & TRN & \\
\hline CHEMBL 3087371 & 1274564 & 9.3 & 9.4565 & TRN & \\
\hline CHEMBL 3087370 & 1274564 & 9.6 & 9.3587 & TRN & \\
\hline CHEMBL3087369 & 1274564 & 10.9 & 9.5692 & TRN & \\
\hline CHEMBL3087368 & 1274564 & 9.8 & 8.9226 & TRN & \\
\hline CHEMBL3087367 & 1274564 & 9.8 & 9.3019 & TRN & \\
\hline CHEMBL 3087366 & 1274564 & 9.2 & 9.258 & TRN & \\
\hline CHEMBL 3087365 & 1274564 & 8.6 & 9.2941 & TRN & \\
\hline CHEMBL3087364 & 1274564 & 9.7 & 9.2158 & TRN & \\
\hline CHEMBL 3087361 & 1274564 & 8.0 & 8.783 & TRN & \\
\hline CHEMBL 3087245 & 1274564 & 7.9 & 9.6392 & TRN & \\
\hline CHEMBL 3087244 & 1274564 & 9.4 & 9.562999 & 9999999999 & TRN \\
\hline CHEMBL 3087243 & 1274564 & 8.1 & 9.2363 & TRN & \\
\hline CHEMBL 3087242 & 1274564 & 10.0 & 9.5811 & TRN & \\
\hline CHEMBL 3087241 & 1274564 & 9.8 & 9.5016 & TRN & \\
\hline CHEMBL 3087240 & 1274564 & 11.2 & 9.8372 & TRN & \\
\hline CHEMBL 3087239 & 1274564 & 7.0 & 9.1424 & TST & \\
\hline CHEMBL 3087238 & 1274564 & 9.9 & 9.3728 & TRN & \\
\hline CHEMBL 3087237 & 1274564 & 9.6 & 9.4738 & TRN & \\
\hline CHEMBL3087236 & 1274564 & 9.7 & 9.7458 & TRN & \\
\hline CHEMBL 3087235 & 1274564 & 10.3 & 10.4326 & TRN & \\
\hline CHEMBL 3087234 & 1274564 & 9.3 & 9.3314 & TRN & \\
\hline CHEMBL 3087233 & 1274564 & 9.0 & 10.5539 & TRN & \\
\hline CHEMBL 3087232 & 1274564 & 9.8 & 10.4421 & TRN & \\
\hline CHEMBL 3087231 & 1274564 & 11.5 & 10.4349 & TRN & \\
\hline CHEMBL 3087230 & 1274564 & 10.3 & 10.1551 & TST & \\
\hline CHEMBL 3087229 & 1274564 & 11.4 & 10.5477 & TRN & \\
\hline CHEMBL3088086 & 1274564 & 10.2 & 10.7242 & TRN & \\
\hline CHEMBL3088085 & 1274564 & 9.9 & 10.3679 & TST & \\
\hline CHEMBL3088084 & 1274564 & 9.8 & 10.5727 & TST & \\
\hline CHEMBL 3088083 & 1274564 & 8.5 & 10.5488 & TST & \\
\hline CHEMBL 3088082 & 1274564 & 11.4 & 10.29099 & 99999999999 & TST \\
\hline CHEMBL 3088081 & 1274564 & 10.2 & 9.8647 & TST & \\
\hline CHEMBL 3088080 & 1274564 & 10.1 & 10.7409 & TST & \\
\hline CHEMBL3088079 & 1274564 & 8.5 & 9.9804 & TST & \\
\hline CHEMBL 3088078 & 1274564 & 7.4 & 9.5162 & TST & \\
\hline CHEMBL 3088077 & 1274564 & 7.4 & 9.6929 & TST & \\
\hline CHEMBL 3088076 & 1274564 & 8.6 & 10.3143 & TST & \\
\hline CHEMBL 3088075 & 1274564 & 10.1 & 9.1947 & TST & \\
\hline CHEMBL 3087961 & 1274564 & 10.2 & 9.736 & TST & \\
\hline
\end{tabular}




\begin{tabular}{|c|c|c|c|c|c|}
\hline CHEMBL 3087960 & 1274564 & 9.6 & 10.1826 & TST & \\
\hline CHEMBL 3087959 & 1274564 & 10.5 & 9.8271 & TST & \\
\hline CHEMBL3698785 & 1640309 & 6.3002 & 6.2455 & TRN & \\
\hline CHEMBL3698825 & 1640309 & 5.7555 & 6.1288 & TRN & \\
\hline CHEMBL3698906 & 1640309 & 6.8877 & 7.1348 & TRN & \\
\hline CHEMBL3695218 & 1640309 & 6.8125 & 6.6019 & TRN & \\
\hline CHEMBL3900892 & 1640309 & 6.0 & 6.4986 & TRN & \\
\hline CHEMBL3698821 & 1640309 & 6.2299 & 6.1329 & TRN & \\
\hline CHEMBL3698768 & 1640309 & 6.3788 & 6.4883 & TRN & \\
\hline CHEMBL3698787 & 1640309 & 6.1079 & 6.107 & TRN & \\
\hline CHEMBL3698907 & 1640309 & 7.3036 & 7.2068 & TRN & \\
\hline CHEMBL3698813 & 1640309 & 5.2879 & 5.46399 & 99999999995 & TRN \\
\hline CHEMBL3695265 & 1640309 & 6.3179 & 6.2416 & TRN & \\
\hline CHEMBL3698899 & 1640309 & 6.24799 & 99999999 & 6.3856 & TRN \\
\hline CHEMBL3695253 & 1640309 & 6.06 & 6.3531 & TRN & \\
\hline CHEMBL 3698820 & 1640309 & 6.2815 & 6.3525 & TRN & \\
\hline CHEMBL 3695254 & 1640309 & 7.1739 & 7.0429 & TST & \\
\hline CHEMBL3647960 & 1640309 & 6.1938 & 6.4478 & TRN & \\
\hline CHEMBL3944932 & 1640309 & 6.2314 & 6.3773 & TRN & \\
\hline CHEMBL3695251 & 1640309 & 6.4609 & 6.8097 & TRN & \\
\hline CHEMBL3698798 & 1640309 & 5.7645 & 6.0514 & TST & \\
\hline CHEMBL3698897 & 1640309 & 6.6509 & 6.6972 & TRN & \\
\hline CHEMBL3695257 & 1640309 & 6.4841 & 6.3028 & TRN & \\
\hline CHEMBL 3698848 & 1640309 & 6.5186 & 6.7576 & TRN & \\
\hline CHEMBL3698844 & 1640309 & 6.5482 & 6.5608 & TRN & \\
\hline CHEMBL3695256 & 1640309 & 6.6498 & 6.5518 & TRN & \\
\hline CHEMBL 3695273 & 1640309 & 6.0 & 6.5477 & TRN & \\
\hline CHEMBL3698861 & 1640309 & 7.5867 & 7.2428 & TRN & \\
\hline CHEMBL 3698872 & 1640309 & 6.3116 & 6.5374 & TRN & \\
\hline CHEMBL3698852 & 1640309 & 6.8508 & 6.8289 & TRN & \\
\hline CHEMBL3695283 & 1640309 & 6.0128 & 6.3501 & TRN & \\
\hline CHEMBL3698804 & 1640309 & 3.699 & 5.9356 & TST & \\
\hline CHEMBL3698902 & 1640309 & 6.3716 & 6.4478 & TRN & \\
\hline CHEMBL3698849 & 1640309 & 4.9393 & 5.7463 & TRN & \\
\hline CHEMBL3695219 & 1640309 & 6.1824 & 6.2189 & TRN & \\
\hline CHEMBL3695270 & 1640309 & 7.334 & 6.8269 & TST & \\
\hline CHEMBL3698900 & 1640309 & 6.426 & 6.3856 & TRN & \\
\hline CHEMBL3695220 & 1640309 & 6.0009 & 5.8156 & TRN & \\
\hline CHEMBL 3698862 & 1640309 & 6.064 & 6.3415 & TRN & \\
\hline CHEMBL3698870 & 1640309 & 6.1249 & 6.2863 & TRN & \\
\hline CHEMBL3698851 & 1640309 & 6.0 & 6.095 & TRN & \\
\hline CHEMBL3698775 & 1640309 & 6.6108 & 6.6579 & TRN & \\
\hline CHEMBL3698835 & 1640309 & 6.0516 & 5.7994 & TRN & \\
\hline CHEMBL 3698882 & 1640309 & 5.2218 & 5.4205 & TRN & \\
\hline CHEMBL3698890 & 1640309 & 5.9523 & 5.7199 & TRN & \\
\hline CHEMBL3698762 & 1640309 & 6.1765 & 5.9169 & TRN & \\
\hline CHEMBL3930169 & 1640309 & 6.1723 & 5.8605 & TRN & \\
\hline CHEMBL3698819 & 1640309 & 5.8008 & 6.0218 & TRN & \\
\hline
\end{tabular}


Supplemental Table S2.txt

\begin{tabular}{|c|c|c|c|c|c|}
\hline CHEMBL3695249 & 1640309 & 5.4789 & 5.9151 & TRN & \\
\hline CHEMBL3695217 & 1640309 & 6.0 & 6.0084 & TRN & \\
\hline CHEMBL3698864 & 1640309 & 5.7825 & 6.0563 & TRN & \\
\hline CHEMBL 3698847 & 1640309 & 6.2062 & 6.0485 & TRN & \\
\hline CHEMBL3698752 & 1640309 & 6.4214 & 6.7186 & TRN & \\
\hline CHEMBL3698877 & 1640309 & 7.3344 & 6.8902 & TRN & \\
\hline CHEMBL3698850 & 1640309 & 6.0696 & 6.4299 & TRN & \\
\hline CHEMBL3909917 & 1640309 & 5.3478 & 5.3925 & TST & \\
\hline CHEMBL 3695224 & 1640309 & 5.5467 & 5.6478 & TRN & \\
\hline CHEMBL3698857 & 1640309 & 7.0783 & 6.0524 & TST & \\
\hline CHEMBL3695272 & 1640309 & 6.426 & 6.2701 & TRN & \\
\hline CHEMBL3698753 & 1640309 & \multicolumn{3}{|c|}{6.757000000000001} & TRN \\
\hline CHEMBL3647958 & 1640309 & 6.0 & 5.7305 & TRN & \\
\hline CHEMBL3695229 & 1640309 & 5.9197 & 6.1035 & TRN & \\
\hline CHEMBL3695228 & 1640309 & 4.7156 & 4.815 & TRN & \\
\hline CHEMBL3698823 & 1640309 & 5.4099 & 5.2058 & TST & \\
\hline CHEMBL3698776 & 1640309 & 6.2708 & 6.2346 & TST & \\
\hline CHEMBL 3698778 & 1640309 & 6.0 & \multicolumn{2}{|c|}{6.082999999999999} & TRN \\
\hline CHEMBL3698866 & 1640309 & 6.0506 & 6.1036 & TRN & \\
\hline CHEMBL3698794 & 1640309 & 6.7645 & 6.8873 & TRN & \\
\hline CHEMBL3698884 & 1640309 & 7.1805 & 7.0991 & TRN & \\
\hline CHEMBL3695286 & 1640309 & 6.1475 & 6.0532 & TRN & \\
\hline CHEMBL3698796 & 1640309 & 6.0414 & 6.0558 & TRN & \\
\hline CHEMBL3698834 & 1640309 & 6.5901 & 6.4766 & TRN & \\
\hline CHEMBL3698863 & 1640309 & 6.5918 & 6.4737 & TRN & \\
\hline CHEMBL3698898 & 1640309 & 4.7757 & 5.94799 & 99999999995 & TST \\
\hline CHEMBL3695255 & 1640309 & 5.8259 & 5.8545 & TRN & \\
\hline CHEMBL 3698754 & 1640309 & 6.0 & 6.0386 & TRN & \\
\hline CHEMBL3695237 & 1640309 & 6.0 & 5.9912 & TRN & \\
\hline CHEMBL3698826 & 1640309 & 4.9897 & 5.0879 & TRN & \\
\hline CHEMBL3698790 & 1640309 & 6.8416 & 6.86799 & 9999999999 & TRN \\
\hline CHEMBL3698816 & 1640309 & 7.1979 & 7.2609 & TRN & \\
\hline CHEMBL3695221 & 1640309 & 7.8268 & 7.2266 & TRN & \\
\hline CHEMBL3695222 & 1640309 & 5.2716 & 5.5466 & TRN & \\
\hline CHEMBL3698843 & 1640309 & \multicolumn{3}{|c|}{7.821000000000001} & TRN \\
\hline CHEMBL3695262 & 1640309 & 6.7181 & 6.8271 & TRN & \\
\hline CHEMBL3695280 & 1640309 & \multicolumn{3}{|c|}{6.718999999999999} & TRN \\
\hline CHEMBL3639941 & 1640309 & 6.1506 & 5.816 & TRN & \\
\hline CHEMBL3698901 & 1640309 & 5.3497 & \multicolumn{2}{|c|}{5.4879999999999995} & TRN \\
\hline CHEMBL3698814 & 1640309 & 6.4377 & 6.1288 & TRN & \\
\hline CHEMBL3695243 & 1640309 & 6.6021 & 6.1304 & TST & \\
\hline CHEMBL3695279 & 1640309 & 6.0942 & 6.3011 & TRN & \\
\hline CHEMBL3984664 & 1640309 & 7.6861 & 6.3864 & TST & \\
\hline CHEMBL3695269 & 1640309 & 5.8919 & 5.9546 & TRN & \\
\hline CHEMBL3698896 & 1640309 & 7.1925 & 6.0796 & TST & \\
\hline CHEMBL3698763 & 1640309 & 6.0 & 5.9364 & TRN & \\
\hline CHEMBL 3698874 & 1640309 & 6.3675 & 6.501 & TRN & \\
\hline CHEMBL 3889570 & 1640309 & 5.6068 & 5.4421 & TRN & \\
\hline
\end{tabular}


Supplemental Table S2.txt

\begin{tabular}{|c|c|c|}
\hline CHEMBL3698868 & & \\
\hline CHEMBL3698894 & 1640309 & \\
\hline HEMBL3695244 & 640309 & \\
\hline HEMBL3695245 & 1640309 & 6.0 \\
\hline HEMBL 3698836 & 1640309 & \\
\hline SHEMBL 3695277 & 1640309 & \\
\hline HEMBL3695278 & 1640309 & \\
\hline HEMBL 3698755 & 1640309 & \\
\hline HEMBL 3698795 & 1640309 & \\
\hline HEMBL3695267 & 1640309 & \\
\hline CHEMBL 3698858 & 1640309 & \\
\hline HEMBL 3698792 & 1640309 & \\
\hline HEMBL3698879 & 1640309 & \\
\hline HEMBL3698856 & 1640309 & \\
\hline HEMBL3695235 & 1640309 & \\
\hline CHEMBL 3698788 & 1640309 & \\
\hline HEMBL3698773 & 1640309 & \\
\hline HEMBL 3698765 & 1640309 & \\
\hline HEMBL3647963 & 1640309 & \\
\hline HEMBL3698895 & 1640309 & \\
\hline CHEMBL3695238 & 1640309 & \\
\hline HEMBL 3698759 & 1640309 & \\
\hline CHEMBL 3647961 & 164 & \\
\hline CHEMBL 3939135 & 164 & \\
\hline HEMBL3698751 & 164 & \\
\hline CHEMBL3698791 & 164 & \\
\hline CHEMBL 3698854 & 1640309 & \\
\hline CHEMBL3698903 & 164 & \\
\hline CHEMBL 3698809 & 1640309 & \\
\hline CHEMBL3695240 & 1640309 & \\
\hline CHEMBL 3898898 & 1640309 & \\
\hline CHEMBL3698799 & 1640309 & \\
\hline CHEMBL 3698841 & 1640309 & \\
\hline CHEMBL 3698867 & 1640309 & \\
\hline CHEMBL3695216 & 1640309 & \\
\hline CHEMBL3698840 & 1640309 & \\
\hline CHEMBL 3698827 & 1640309 & 7.2 \\
\hline CHEMBL 3698842 & 1640309 & \\
\hline CHEMBL3695276 & 1640309 & \\
\hline CHEMBL3698756 & 1640309 & \\
\hline CHEMBL3698876 & 1640309 & \\
\hline CHEMBL 3698801 & 1640309 & 5.51 \\
\hline CHEMBL3695234 & 1640309 & 6.4 \\
\hline CHEMBL3698869 & 1640309 & \\
\hline CHEMBL3698889 & 1640309 & \\
\hline CHEMBL3698786 & 1640309 & \\
\hline CHEMBL3698817 & 1640309 & \\
\hline CHEMBL3698772 & 1640309 & 6 \\
\hline
\end{tabular}

$\begin{array}{ll}5.9885 & \text { TRN } \\ 5.454 & \text { TRN } \\ 6.5081 & \text { TRN } \\ 5.0764 & \text { TST } \\ 7.4594 & \text { TRN } \\ 5.972 & \text { TRN } \\ 6.2841 & \text { TRN } \\ 6.0724 & \text { TRN } \\ 7.2721 & \text { TRN } \\ 7.3539 & \text { TRN } \\ 7.2317 & \text { TRN } \\ 6.437 & \text { TRN } \\ 5.8075 & \text { TRN } \\ 6.1043 & \text { TST } \\ 6.8686 & \text { TST } \\ 6.2587 & \text { TRN } \\ 6.2581 & \text { TRN } \\ 6.4478 & \text { TRN } \\ 6.4478 & \text { TRN } \\ 6.0131 & \text { TRN } \\ 6.5714 & \text { TST } \\ 5.542000000000001 \\ 5.5984 & \text { TST } \\ 6.4899 & \text { TRN } \\ 5.9841 & \text { TRN } \\ 6.8283 & \text { TRN } \\ 7.2987 & \text { TRN } \\ 5.6774 & \text { TRN } \\ 6.8459 & \text { TRN } \\ 6.3792 & \text { TRN } \\ 6.5794 & \text { TST } \\ 6.0623 & \text { TRN } \\ 7.5121 & \text { TRN } \\ 5.6039 & \text { TRN } \\ 7.1743 & \text { TRN } \\ 6.7356 & \text { TRN } \\ 6.0692 & \text { TST } \\ 6.2449 & \text { TRN } \\ 5.891 & \text { TRN } \\ 6.3376 & \text { TST } \\ 5.5043 & \text { TST } \\ 5.102 & \text { TST } \\ 6.3777 & \text { TST } \\ 6.57 & \text { TRN } \\ 5.4579 & \text { TST } \\ 6.4647 & \text { TRN } \\ 6.6285 & \text { TRN } \\ 6.3412 & \text { TRN } \\ & \end{array}$


Supplemental Table S2.txt

\begin{tabular}{|c|c|c|c|c|c|}
\hline CHEMBL 3698878 & 1640309 & 6.3565 & 6.3856 & TRN & \\
\hline CHEMBL 3647959 & 1640309 & 6.0 & 5.7977 & TRN & \\
\hline CHEMBL 3695259 & 1640309 & \multicolumn{3}{|c|}{6.821000000000001} & TRN \\
\hline CHEMBL 3698793 & 1640309 & 7.3072 & 7.3761 & TRN & \\
\hline CHEMBL 3698818 & 1640309 & 7.0685 & 6.9452 & TRN & \\
\hline CHEMBL 3695268 & 1640309 & \multicolumn{3}{|c|}{6.4510000000000005} & TRN \\
\hline CHEMBL 3695242 & 1640309 & 6.3188 & 6.5474 & TRN & \\
\hline CHEMBL 3985983 & 1640309 & 5.9838 & 5.9159 & TRN & \\
\hline CHEMBL 3695281 & 1640309 & 6.1361 & 6.2482 & TRN & \\
\hline CHEMBL 3695263 & 1640309 & 6.2343 & 6.0914 & TRN & \\
\hline CHEMBL 3698853 & 1640309 & 5.9855 & 5.8368 & TRN & \\
\hline CHEMBL 3698904 & 1640309 & 6.3288 & 6.4478 & TRN & \\
\hline CHEMBL 3698865 & 1640309 & 6.1308 & 5.8765 & TST & \\
\hline CHEMBL 3695236 & 1640309 & 6.3372 & \multicolumn{2}{|c|}{6.742000000000001} & TST \\
\hline CHEMBL 3698789 & 1640309 & 6.3206 & 6.0404 & TST & \\
\hline CHEMBL 3698837 & 1640309 & 6.782 & 6.3888 & TST & \\
\hline CHEMBL 3695266 & 1640309 & 6.4225 & 6.3764 & TST & \\
\hline CHEMBL 3698774 & 1640309 & 6.2321 & 6.5899 & TST & \\
\hline CHEMBL 3695252 & 1640309 & 6.2725 & \multicolumn{2}{|c|}{6.707999999999999} & \\
\hline CHEMBL 3695260 & 1640309 & 7.5171 & 6.6534 & TST & \\
\hline CHEMBL 3698781 & 1640309 & 5.5642 & 6.0996 & TST & \\
\hline CHEMBL 3698838 & 1640309 & 6.5287 & 6.7882 & TST & \\
\hline CHEMBL 3698769 & 1640309 & 6.209 & 6.2985 & TST & \\
\hline CHEMBL 3698873 & 1640309 & 5.9382 & 6.0997 & TST & \\
\hline CHEMBL 3698760 & 1640309 & 5.9397 & 6.1594 & TST & \\
\hline CHEMBL 3698770 & 1640309 & 6.0026 & 6.1152 & TST & \\
\hline CHEMBL 3698846 & 1640309 & 7.032 & 6.358 & TST & \\
\hline CHEMBL 3698764 & 1640309 & 6.7932 & 7.0272 & TST & \\
\hline CHEMBL 3698828 & 1640309 & 6.3183 & 6.1606 & TST & \\
\hline CHEMBL 3695261 & 1640309 & 6.289 & 6.2158 & TST & \\
\hline CHEMBL 3698771 & 1640309 & 6.8794 & 6.9394 & TST & \\
\hline CHEMBL 3577539 & 1496998 & 4.1062 & 4.3263 & TRN & \\
\hline CHEMBL 3577527 & 1496998 & 4.5031 & 4.2022 & TRN & \\
\hline CHEMBL 3577522 & 1496998 & 4.2076 & 2.7973 & TRN & \\
\hline CHEMBL 3577547 & 1496998 & 3.451 & 2.7485 & TRN & \\
\hline CHEMBL 3577544 & 1496998 & 4.2168 & 4.1011 & TRN & \\
\hline CHEMBL 3577504 & 1496998 & 3.9682 & 3.8263 & TRN & \\
\hline CHEMBL 3577533 & 1496998 & 4.1124 & 4.3443 & TRN & \\
\hline CHEMBL 3577515 & 1496998 & 2.301 & 3.7808 & TRN & \\
\hline CHEMBL 3577537 & 1496998 & 4.1979 & 4.0686 & TRN & \\
\hline CHEMBL 3577536 & 1496998 & 4.0424 & 3.9314 & TST & \\
\hline CHEMBL 3577542 & 1496998 & 4.104 & 3.913000 & 00000000003 & 3 \\
\hline CHEMBL 3577546 & 1496998 & 2.301 & 2.9665 & TRN & \\
\hline CHEMBL 3577507 & 1496998 & 2.301 & 2.2524 & TST & \\
\hline CHEMBL 3577540 & 1496998 & 3.9634 & 3.0276 & TRN & \\
\hline CHEMBL 3577532 & 1496998 & 4.1226 & 4.1973 & TRN & \\
\hline CHEMBL 3577548 & 1496998 & 3.6198 & 3.0177 & TRN & \\
\hline CHEMBL55415 & 1496998 & 2.301 & 1.607 & TST & \\
\hline
\end{tabular}


Supplemental Table S2.txt

\begin{tabular}{|c|c|c|c|c|c|}
\hline CHEMBL 3577510 & 1496998 & 4.0168 & 3.8905 & TRN & \\
\hline CHEMBL 3577521 & 1496998 & 2.301 & 2.4565 & TRN & \\
\hline CHEMBL3577502 & 1496998 & 3.8674 & 3.6467 & TST & \\
\hline CHEMBL 3577523 & 1496998 & 2.301 & 2.4126 & TRN & \\
\hline CHEMBL3577545 & 1496998 & 4.3809 & 4.3085 & TRN & \\
\hline CHEMBL3577503 & 1496998 & 4.0899 & 3.7863 & TRN & \\
\hline CHEMBL 3577524 & 1496998 & 2.301 & 2.7293 & TRN & \\
\hline CHEMBL3577531 & 1496998 & 3.9948 & 4.0303 & TRN & \\
\hline CHEMBL3577511 & 1496998 & 4.1662 & 4.1233 & TRN & \\
\hline CHEMBL3577549 & 1496998 & 2.301 & 2.7663 & TRN & \\
\hline CHEMBL3577519 & 1496998 & 2.301 & 2.4125 & TRN & \\
\hline CHEMBL3577517 & 1496998 & 4.2132 & 4.035 & TRN & \\
\hline CHEMBL3577535 & 1496998 & 2.301 & 2.6524 & TRN & \\
\hline CHEMBL 3577526 & 1496998 & 4.0991 & 4.08899 & 99999999995 & TST \\
\hline CHEMBL3577530 & 1496998 & 3.9307 & 3.9069 & TST & \\
\hline CHEMBL3577550 & 1496998 & 2.301 & 3.0214 & TRN & \\
\hline CHEMBL3577506 & 1496998 & 2.301 & 2.8086 & TRN & \\
\hline CHEMBL3577552 & 1496998 & 3.3152 & 3.0635 & TRN & \\
\hline CHEMBL 3577529 & 1496998 & 2.301 & 2.5927 & TRN & \\
\hline CHEMBL3577514 & 1496998 & 4.0726 & 3.6317 & TST & \\
\hline CHEMBL 3577528 & 1496998 & 2.301 & 3.1212 & TRN & \\
\hline CHEMBL 3577541 & 1496998 & 2.301 & 2.7347 & TRN & \\
\hline CHEMBL3577534 & 1496998 & 3.8277 & 3.1783 & TRN & \\
\hline CHEMBL3577516 & 1496998 & 4.0173 & 3.8388 & TRN & \\
\hline CHEMBL3577538 & 1496998 & 4.0706 & 4.1159 & TRN & \\
\hline CHEMBL3577513 & 1496998 & 3.8353 & 2.2923 & TST & \\
\hline CHEMBL3577525 & 1496998 & 4.056 & 3.912 & TST & \\
\hline CHEMBL3577520 & 1496998 & 2.301 & 2.6958 & TRN & \\
\hline CHEMBL3577551 & 1496998 & 3.3936 & 2.7904 & TRN & \\
\hline CHEMBL3577508 & 1496998 & 4.066 & 3.677 & TST & \\
\hline CHEMBL 3577543 & 1496998 & 4.2832 & 4.0078 & TST & \\
\hline CHEMBL3577512 & 1496998 & 3.8834 & 2.7509 & TRN & \\
\hline CHEMBL3577505 & 1496998 & 4.1296 & 4.1089 & TRN & \\
\hline CHEMBL3577518 & 1496998 & 2.301 & 2.6548 & TRN & \\
\hline CHEMBL3577509 & 1496998 & 4.3893 & 3.8277 & TST & \\
\hline CHEMBL3646206 & 1528075 & 6.1284 & 6.315 & TRN & \\
\hline CHEMBL3649048 & 1528075 & 7.0088 & 6.9798 & TRN & \\
\hline CHEMBL3649097 & 1528075 & 6.983 & 6.5395 & TST & \\
\hline CHEMBL 3649100 & 1528075 & 7.2007 & 7.7764 & TST & \\
\hline CHEMBL3649038 & 1528075 & 6.9245 & 6.3093 & TRN & \\
\hline CHEMBL 3646178 & 1528075 & 6.1308 & 6.9315 & TRN & \\
\hline CHEMBL3649187 & 1528075 & 7.1675 & 6.8721 & TRN & \\
\hline CHEMBL3652523 & 1528075 & 6.7212 & 6.4433 & TST & \\
\hline CHEMBL 3649130 & 1528075 & 6.0246 & 6.6993 & TRN & \\
\hline CHEMBL3649109 & 1528075 & 6.8894 & 7.0712 & TRN & \\
\hline CHEMBL 3649025 & 1528075 & 7.3768 & 7.2412 & TRN & \\
\hline CHEMBL 3652467 & 1528075 & 8.3979 & 7.9085 & TST & \\
\hline CHEMBL3646193 & 1528075 & 6.2104 & 6.5892 & TRN & \\
\hline
\end{tabular}


Supplemental Table S2.txt

\begin{tabular}{|c|c|c|c|c|c|}
\hline CHEMBL3652472 & 1528075 & 7.7959 & 6.8763 & TRN & \\
\hline CHEMBL3646173 & 1528075 & 7.1549 & 7.421 & TRN & \\
\hline CHEMBL3649231 & 1528075 & 7.6383 & 6.9436 & TRN & \\
\hline CHEMBL3646204 & 1528075 & 5.301 & 6.2335 & TRN & \\
\hline CHEMBL3652508 & 1528075 & 6.9626 & 6.3657 & TRN & \\
\hline CHEMBL3649039 & 1528075 & 6.6253 & 6.2812 & TRN & \\
\hline CHEMBL 3652440 & 1528075 & 7.7212 & 6.852 & TRN & \\
\hline CHEMBL3652476 & 1528075 & 5.0 & 6.1982 & TRN & \\
\hline CHEMBL3649196 & 1528075 & 8.1549 & 7.308 & TRN & \\
\hline CHEMBL3639480 & 1528075 & 6.3215 & 6.3503 & TRN & \\
\hline CHEMBL3652498 & 1528075 & 5.0 & 6.2959 & TST & \\
\hline CHEMBL3649080 & 1528075 & 7.2924 & 6.6264 & TRN & \\
\hline CHEMBL3649088 & 1528075 & 7.2596 & 7.892 & TRN & \\
\hline CHEMBL3649031 & 1528075 & 7.8861 & 7.4153 & TRN & \\
\hline CHEMBL3649082 & 1528075 & 7.8239 & 7.9944 & TRN & \\
\hline CHEMBL3639479 & 1528075 & 6.61799 & 999999999 & 6.3288 & TRN \\
\hline CHEMBL3649179 & 1528075 & 6.4685 & 6.2652 & TRN & \\
\hline CHEMBL3649156 & 1528075 & 5.0 & 7.087000 & 0000000001 & TRN \\
\hline CHEMBL3652527 & 1528075 & 6.0809 & 6.3362 & TRN & \\
\hline CHEMBL3652455 & 1528075 & 7.585 & 6.8207 & TST & \\
\hline CHEMBL3649044 & 1528075 & 5.9126 & 6.409 & TRN & \\
\hline CHEMBL3652516 & 1528075 & 7.8239 & 6.8763 & TRN & \\
\hline CHEMBL3649166 & 1528075 & 5.8976 & 6.2346 & TRN & \\
\hline CHEMBL3649162 & 1528075 & 5.301 & 6.2389 & TRN & \\
\hline CHEMBL 3652451 & 1528075 & 5.5086 & 6.5522 & TRN & \\
\hline CHEMBL3646175 & 1528075 & 6.38200 & 000000000 & 7.0172 & TRN \\
\hline CHEMBL3646179 & 1528075 & 6.2403 & 6.8987 & TRN & \\
\hline CHEMBL3649212 & 1528075 & 8.0969 & 7.1184 & TRN & \\
\hline CHEMBL3649101 & 1528075 & 6.9245 & 6.9059 & TST & \\
\hline CHEMBL3646176 & 1528075 & 6.9586 & 7.6334 & TRN & \\
\hline CHEMBL 3652494 & 1528075 & 5.9208 & 6.1882 & TRN & \\
\hline CHEMBL 3649030 & 1528075 & 6.9245 & 6.2567 & TRN & \\
\hline CHEMBL3652530 & 1528075 & 7.7212 & 6.8371 & TRN & \\
\hline CHEMBL3652454 & 1528075 & 5.0 & 6.2923 & TRN & \\
\hline CHEMBL3646181 & 1528075 & 6.1024 & 6.8204 & TRN & \\
\hline CHEMBL3649138 & 1528075 & 6.9101 & 7.074 & TRN & \\
\hline CHEMBL 3649230 & 1528075 & 5.6432 & 6.3364 & TRN & \\
\hline CHEMBL3649056 & 1528075 & 7.1938 & 6.3703 & TRN & \\
\hline CHEMBL 3652443 & 1528075 & 8.0458 & 7.3289 & TRN & \\
\hline CHEMBL3652489 & 1528075 & 7.4437 & 6.6507 & TRN & \\
\hline CHEMBL3649046 & 1528075 & 7.9208 & 6.7 & TRN & \\
\hline CHEMBL 3652460 & 1528075 & 8.1549 & 7.6768 & TRN & \\
\hline CHEMBL3649133 & 1528075 & 6.0223 & 6.5837 & TRN & \\
\hline CHEMBL 3652518 & 1528075 & 7.3768 & 6.6536 & TRN & \\
\hline CHEMBL3649084 & 1528075 & 7.3565 & \multicolumn{2}{|c|}{6.297999999999999} & TRN \\
\hline CHEMBL3649032 & 1528075 & 7.7696 & 6.5446 & TRN & \\
\hline CHEMBL 3649173 & 1528075 & 7.2518 & 6.3504 & TRN & \\
\hline CHEMBL 3649122 & 1528075 & 7.3665 & 6.553 & TRN & \\
\hline
\end{tabular}


Supplemental Table S2.txt

\begin{tabular}{|c|c|c|c|c|}
\hline CHEMBL 3649060 & 1528075 & 7.5528 & 7.4737 & TRN \\
\hline CHEMBL3646188 & 1528075 & 6.7423 & 7.5803 & TRN \\
\hline CHEMBL 3649040 & 1528075 & 7.6021 & 6.9706 & TRN \\
\hline CHEMBL 3652512 & 1528075 & 7.7696 & 6.8359 & TRN \\
\hline CHEMBL3649170 & 1528075 & 5.5229 & 6.3726 & TRN \\
\hline CHEMBL 3646190 & 1528075 & 5.0458 & 6.2417 & TRN \\
\hline CHEMBL 3649177 & 1528075 & 5.6554 & 6.2038 & TRN \\
\hline CHEMBL 3649144 & 1528075 & 5.9842 & 7.0678 & TST \\
\hline CHEMBL 3649160 & 1528075 & 5.0 & 6.2152 & TRN \\
\hline CHEMBL3649108 & 1528075 & 7.0706 & 6.7396 & TST \\
\hline CHEMBL 3649104 & 1528075 & 7.0915 & 7.5927 & TRN \\
\hline CHEMBL 3649172 & 1528075 & 7.4815 & 6.5839 & TRN \\
\hline CHEMBL3649142 & 1528075 & 5.65799 & 99999999 & 6.2995 \\
\hline CHEMBL 3649146 & 1528075 & 5.0 & 6.3271 & TRN \\
\hline CHEMBL3649183 & 1528075 & 5.8321 & 6.2016 & TRN \\
\hline CHEMBL 3649168 & 1528075 & 5.6778 & 6.1972 & TRN \\
\hline CHEMBL3649204 & 1528075 & 6.7696 & 6.8314 & TRN \\
\hline CHEMBL3649239 & 1528075 & 5.8539 & 6.2299 & TRN \\
\hline CHEMBL 3649203 & 1528075 & 6.1871 & 6.6822 & TST \\
\hline CHEMBL3649207 & 1528075 & 5.301 & 6.2731 & TST \\
\hline CHEMBL3649197 & 1528075 & 7.7696 & 7.1154 & TRN \\
\hline CHEMBL3649169 & 1528075 & 5.0458 & 6.301 & TRN \\
\hline CHEMBL3649198 & 1528075 & 7.4089 & 7.143 & TST \\
\hline CHEMBL3649117 & 1528075 & 7.1612 & 6.5155 & TRN \\
\hline CHEMBL 3649215 & 1528075 & 5.0 & 6.3508 & TST \\
\hline CHEMBL 3649193 & 1528075 & 7.1612 & 6.32600 & 00000000005 \\
\hline CHEMBL 3646174 & 1528075 & 6.4389 & 7.1691 & TRN \\
\hline CHEMBL3649051 & 1528075 & 7.1249 & 6.2316 & TRN \\
\hline CHEMBL 3646163 & 1528075 & 7.3372 & 6.41799 & 9999999999 \\
\hline CHEMBL 3649065 & 1528075 & 7.4202 & 6.7317 & TRN \\
\hline CHEMBL 3649181 & 1528075 & 6.3737 & 6.2575 & TRN \\
\hline CHEMBL3649115 & 1528075 & 7.4815 & 6.3011 & TRN \\
\hline CHEMBL3649159 & 1528075 & 5.4229 & 6.3787 & TRN \\
\hline CHEMBL 3646183 & 1528075 & 7.3279 & 6.5001 & TRN \\
\hline CHEMBL 3652510 & 1528075 & 7.1367 & 6.8604 & TRN \\
\hline CHEMBL3649114 & 1528075 & 7.1249 & 6.8158 & TRN \\
\hline CHEMBL3652471 & 1528075 & 7.7959 & 7.3485 & TRN \\
\hline CHEMBL 3649069 & 1528075 & 7.2441 & 7.9655 & TRN \\
\hline CHEMBL 3652493 & 1528075 & 5.0 & 6.277 & TST \\
\hline CHEMBL 3649128 & 1528075 & 7.1805 & 7.0204 & TRN \\
\hline CHEMBL3649148 & 1528075 & 5.5837 & 6.8041 & TST \\
\hline CHEMBL 3649158 & 1528075 & 5.8821 & 6.902 & TRN \\
\hline CHEMBL 3649225 & 1528075 & 5.301 & 6.2047 & TRN \\
\hline CHEMBL3646152 & 1528075 & 7.4318 & 7.8237 & TRN \\
\hline CHEMBL 3649221 & 1528075 & 5.0 & 6.3472 & TST \\
\hline CHEMBL3649218 & 1528075 & 6.8962 & 6.3567 & TRN \\
\hline CHEMBL3649132 & 1528075 & 6.3468 & 6.4598 & TST \\
\hline CHEMBL3649057 & 1528075 & 6.2588 & 6.9978 & TRN \\
\hline
\end{tabular}


Supplemental Table S2.txt

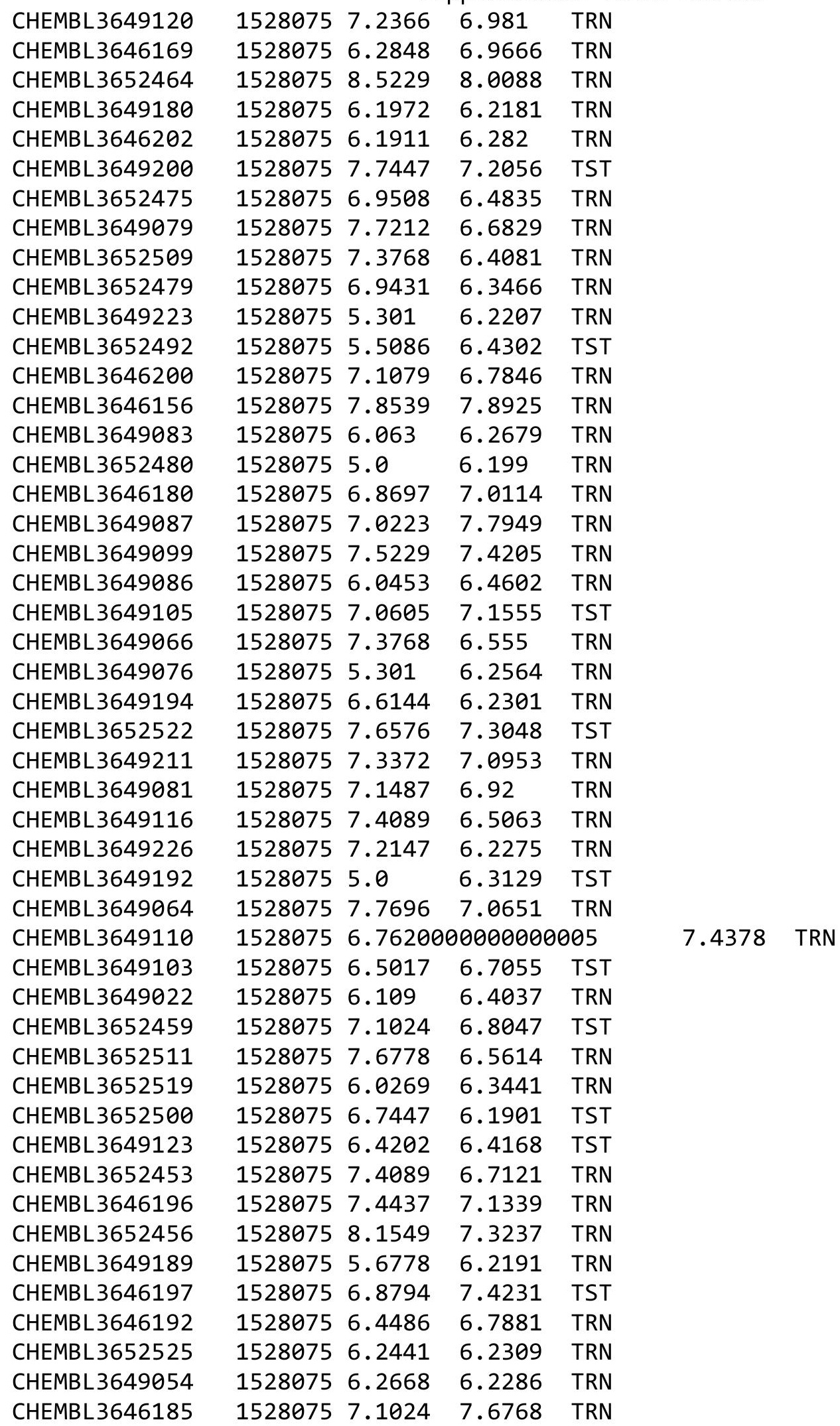

Page 12509 
Supplemental Table S2.txt

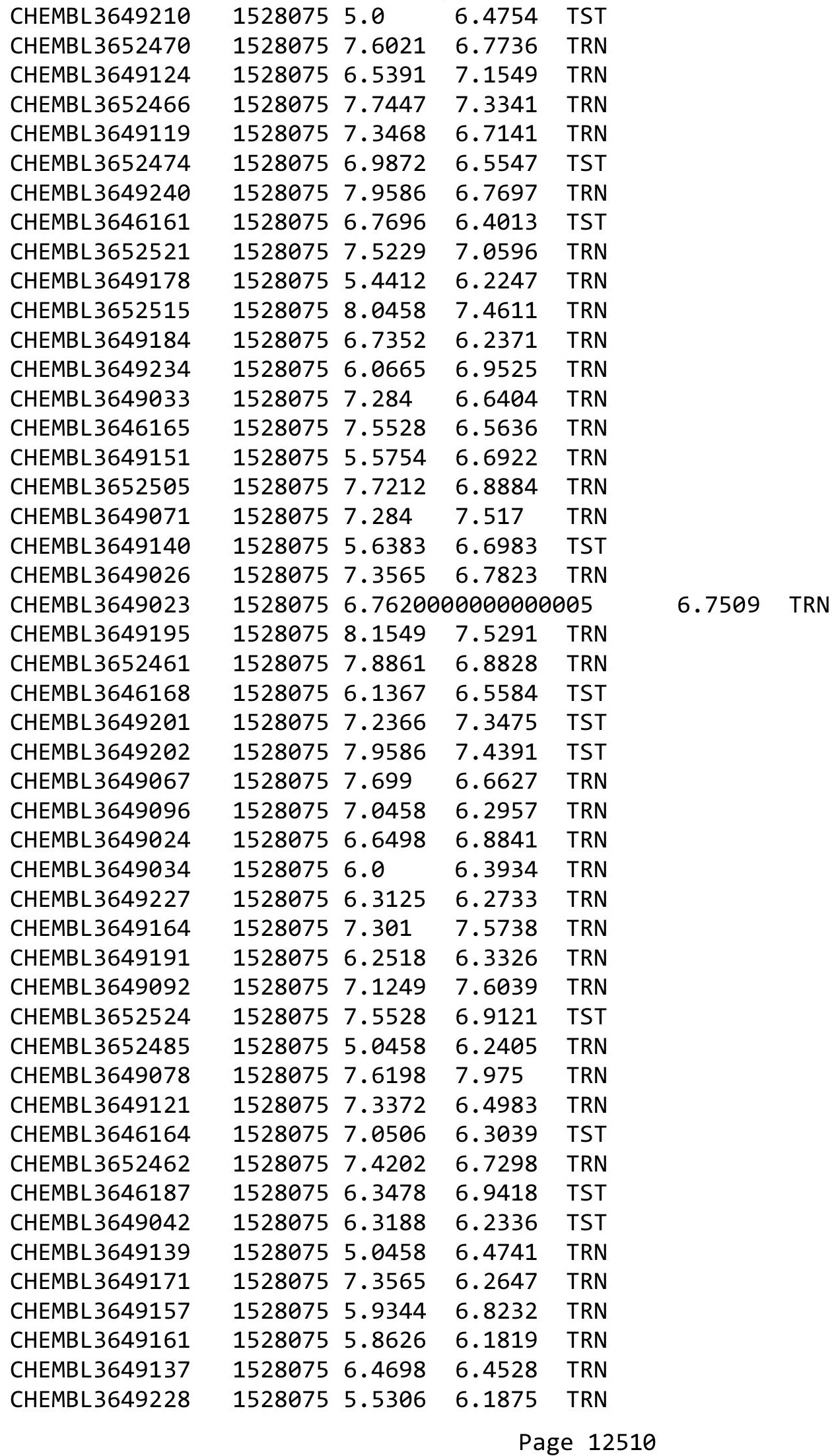


Supplemental Table S2.txt

\begin{tabular}{|c|c|c|c|c|}
\hline CHEMBL 3649127 & 1528075 & 6.3862 & 6.8036 & TRN \\
\hline CHEMBL3649111 & 1528075 & 7.0362 & 6.5137 & TRN \\
\hline CHEMBL3649126 & 1528075 & 6.3325 & 7.0903 & TRN \\
\hline CHEMBL 3652442 & 1528075 & 7.6198 & 6.9736 & TRN \\
\hline CHEMBL3652473 & 1528075 & 8.0969 & 7.2766 & TRN \\
\hline CHEMBL3646154 & 1528075 & 7.3768 & 7.6908 & TRN \\
\hline CHEMBL 3652457 & 1528075 & 7.1938 & 6.654 & TRN \\
\hline CHEMBL 3652441 & 1528075 & 8.3979 & 7.6199 & TRN \\
\hline CHEMBL 3652468 & 1528075 & 7.5376 & 7.1278 & TST \\
\hline CHEMBL3646184 & 1528075 & 6.6021 & 7.3175 & TRN \\
\hline CHEMBL3649062 & 1528075 & 6.6234 & 6.2763 & TRN \\
\hline CHEMBL3652452 & 1528075 & 8.1549 & 7.13 & TRN \\
\hline CHEMBL3649209 & 1528075 & 5.0 & 6.3198 & TST \\
\hline CHEMBL 3649085 & 1528075 & 6.3747 & 6.3062 & TRN \\
\hline CHEMBL3646203 & 1528075 & 7.1871 & 6.2618 & TRN \\
\hline CHEMBL3649113 & 1528075 & 6.9031 & 6.3592 & TST \\
\hline CHEMBL3649021 & 1528075 & 6.644 & 6.4893 & TRN \\
\hline CHEMBL3649152 & 1528075 & 5.9935 & 6.7074 & TST \\
\hline CHEMBL3652438 & 1528075 & 6.5751 & 6.4281 & TST \\
\hline CHEMBL3652487 & 1528075 & 5.0 & 6.1837 & TRN \\
\hline CHEMBL3649150 & 1528075 & 5.8861 & 6.6146 & TST \\
\hline CHEMBL3649058 & 1528075 & 6.6676 & 7.08299 & 9999999999 \\
\hline CHEMBL 3649233 & 1528075 & 5.0458 & 6.4051 & TST \\
\hline CHEMBL3652465 & 1528075 & 8.301 & 7.7491 & TRN \\
\hline CHEMBL 3649165 & 1528075 & 5.4963 & 6.19799 & 99999999995 \\
\hline CHEMBL3649107 & 1528075 & 7.5686 & 7.5071 & TST \\
\hline CHEMBL 3652529 & 1528075 & 6.7447 & 6.2753 & TRN \\
\hline CHEMBL 3649220 & 1528075 & 6.5768 & 6.4334 & TRN \\
\hline CHEMBL3652504 & 1528075 & 7.8239 & 6.8665 & TRN \\
\hline CHEMBL 3649094 & 1528075 & 6.5361 & 7.3461 & TRN \\
\hline CHEMBL 3649070 & 1528075 & 7.3372 & 7.9789 & TRN \\
\hline CHEMBL3649052 & 1528075 & 6.3449 & 6.2287 & TRN \\
\hline CHEMBL 3652469 & 1528075 & 8.0 & 7.396 & TST \\
\hline CHEMBL3646195 & 1528075 & 6.8477 & 6.2343 & TRN \\
\hline CHEMBL 3652528 & 1528075 & 6.9208 & 6.3186 & TRN \\
\hline CHEMBL 3652497 & 1528075 & 5.0 & 6.4326 & TST \\
\hline CHEMBL3649072 & 1528075 & 7.5528 & 7.7484 & TRN \\
\hline CHEMBL 3652448 & 1528075 & 7.4437 & 7.5401 & TRN \\
\hline CHEMBL3649153 & 1528075 & 5.937 & 7.0464 & TRN \\
\hline CHEMBL 3649129 & 1528075 & 6.2255 & 6.8677 & TST \\
\hline CHEMBL3652496 & 1528075 & 5.0 & 6.2895 & TST \\
\hline CHEMBL3646158 & 1528075 & 7.3768 & 7.7247 & TRN \\
\hline CHEMBL3649036 & 1528075 & 8.1549 & 7.6277 & TRN \\
\hline CHEMBL3649237 & 1528075 & 5.8239 & 6.2516 & TRN \\
\hline CHEMBL3649035 & 1528075 & 6.4976 & 6.4632 & TRN \\
\hline CHEMBL3652445 & 1528075 & 8.0458 & 7.4916 & TRN \\
\hline CHEMBL3646194 & 1528075 & 8.1549 & 7.1194 & TRN \\
\hline CHEMBL3649112 & 1528075 & 6.7352 & 7.2827 & TRN \\
\hline
\end{tabular}

Page 12511 
Supplemental Table S2.txt

\begin{tabular}{|c|c|c|c|c|c|}
\hline CHEMBL3652486 & 1528075 & 5.8179 & \multicolumn{2}{|c|}{6.247000000000001} & TRN \\
\hline CHEMBL3649217 & 1528075 & 5.0458 & 6.3986 & TRN & \\
\hline CHEMBL3652499 & 1528075 & 6.6383 & 6.2342 & TST & \\
\hline CHEMBL3649106 & 1528075 & 7.3468 & 7.6955 & TST & \\
\hline CHEMBL 3646205 & 1528075 & 6.1141 & 6.4796 & TRN & \\
\hline CHEMBL3649205 & 1528075 & 7.6021 & 6.9364 & TRN & \\
\hline CHEMBL3649135 & 1528075 & 6.1746 & 6.92899 & 9999999999 & TRN \\
\hline CHEMBL3649028 & 1528075 & 6.6421 & 7.4884 & TRN & \\
\hline CHEMBL3646162 & 1528075 & 5.8422 & 6.2144 & TRN & \\
\hline CHEMBL 3652507 & 1528075 & 5.4685 & 6.3742 & TRN & \\
\hline CHEMBL3649118 & 1528075 & 7.2596 & 6.4676 & TRN & \\
\hline CHEMBL3652491 & 1528075 & 7.6021 & 6.6962 & TRN & \\
\hline CHEMBL3652439 & 1528075 & 6.3686 & 6.4009 & TRN & \\
\hline CHEMBL 3649134 & 1528075 & 6.1373 & 6.3348 & TRN & \\
\hline CHEMBL 3652450 & 1528075 & 5.7696 & 6.4478 & TRN & \\
\hline CHEMBL3649154 & 1528075 & 5.0 & 6.9141 & TRN & \\
\hline CHEMBL3646167 & 1528075 & 6.5229 & 6.36700 & 0000000001 & TST \\
\hline CHEMBL3652437 & 1528075 & 7.7212 & 6.7579 & TRN & \\
\hline CHEMBL3652436 & 1528075 & 5.7447 & 6.2469 & TRN & \\
\hline CHEMBL 3649063 & 1528075 & 7.3188 & 6.5446 & TRN & \\
\hline CHEMBL3649174 & 1528075 & 5.9112 & 7.04299 & э999999999 & TRN \\
\hline CHEMBL3646170 & 1528075 & 7.6198 & 7.6715 & TRN & \\
\hline CHEMBL3646207 & 1528075 & 7.0969 & 7.0376 & TRN & \\
\hline CHEMBL3649208 & 1528075 & 5.6576 & 6.2367 & TST & \\
\hline CHEMBL 3649143 & 1528075 & 5.301 & 6.6885 & TST & \\
\hline CHEMBL3646201 & 1528075 & 6.6676 & 6.3667 & TRN & \\
\hline CHEMBL3646189 & 1528075 & 6.2882 & 7.2508 & TRN & \\
\hline CHEMBL3649216 & 1528075 & 5.0 & 6.2294 & TRN & \\
\hline CHEMBL3649229 & 1528075 & 6.1675 & 6.215 & TRN & \\
\hline CHEMBL3649073 & 1528075 & 7.0223 & 7.6947 & TRN & \\
\hline CHEMBL3916080 & 1528075 & 7.6021 & 7.3013 & TRN & \\
\hline CHEMBL3652506 & 1528075 & 7.0757 & 6.4188 & TRN & \\
\hline CHEMBL3646191 & 1528075 & 6.2526 & 7.0015 & TRN & \\
\hline CHEMBL3649027 & 1528075 & 6.2373 & 6.371 & TRN & \\
\hline CHEMBL3652501 & 1528075 & 5.3566 & 6.2271 & TST & \\
\hline CHEMBL3649049 & 1528075 & 6.5918 & 6.8542 & TST & \\
\hline CHEMBL 3652463 & 1528075 & 8.0 & 7.329 & TRN & \\
\hline CHEMBL3649155 & 1528075 & 5.959 & 7.2055 & TRN & \\
\hline CHEMBL3652503 & 1528075 & 7.6383 & 6.7867 & TRN & \\
\hline CHEMBL3649167 & 1528075 & 5.0458 & 6.3348 & TRN & \\
\hline CHEMBL3646199 & 1528075 & 6.1451 & 6.2638 & TRN & \\
\hline CHEMBL 3652483 & 1528075 & 6.2899 & 6.2554 & TRN & \\
\hline CHEMBL3649213 & 1528075 & 7.0458 & 6.3151 & TRN & \\
\hline CHEMBL3649199 & 1528075 & 7.7959 & 7.2969 & TST & \\
\hline CHEMBL3652481 & 1528075 & 7.2291 & 6.5769 & TRN & \\
\hline CHEMBL3649236 & 1528075 & 8.0969 & 7.0196 & TRN & \\
\hline CHEMBL 3646171 & 1528075 & 7.0362 & 7.3104 & TST & \\
\hline CHEMBL3649091 & 1528075 & 7.4949 & 6.5383 & TRN & \\
\hline
\end{tabular}


Supplemental Table S2.txt

\begin{tabular}{|c|c|c|c|c|}
\hline 041 & 528075 & 6.2596 & & \\
\hline & 528075 & & & \\
\hline & 3075 & & & \\
\hline 163 & 528075 & 301 & & \\
\hline AEMBL & 528075 & 716 & 2043 & \\
\hline AEMBL3649182 & 528075 & 6.0778 & 2179 & \\
\hline 343 & 528075 & 31 & & \\
\hline 82 & 528075 & & & \\
\hline AEMBL: & 528075 & 1739 & & RN \\
\hline AEMBL3649077 & 528075 & 7.6576 & 0384 & \\
\hline AEMBL 3652517 & 528075 & & 26 & \\
\hline IEMBL & 528075 & & & \\
\hline EMBL & 528075 & & & \\
\hline AEMBL. & 528075 & & 7208 & \\
\hline IEMBL & 528075 & 85 & 732 & \\
\hline IEMBL3652484 & 528075 & 9948 & 1854 & \\
\hline 074 & 528075 & & & \\
\hline IEMBL & 528075 & & & \\
\hline IEMBL & 528075 & & & \\
\hline IEMBL & 8075 & & & \\
\hline 166 & $80 / 5$ & 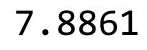 & 04 & \\
\hline 36 & 8075 & & & \\
\hline 45 & 28075 & & & \\
\hline 176 & 528075 & & & \\
\hline IEMBL: & 75 & & & RN \\
\hline IEMBL & 528075 & 2 & & \\
\hline 49 & 75 & & & \\
\hline 77 & 75 & & 89 & RN \\
\hline IEMBL & 528075 & & & \\
\hline IEMBL 3646172 & 528075 & & & ST \\
\hline IEMBL: & 28075 & & 08 & RN \\
\hline 2 & 75 & & 67 & RI \\
\hline & 75 & 5 & 31 & 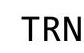 \\
\hline 552477 & 528075 & & & RI \\
\hline IEMBL3649235 & 528075 & & 533 & IRI \\
\hline 198 & 28075 & & 57 & 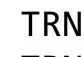 \\
\hline 5 & 75 & & & RN \\
\hline & 75 & & & RI \\
\hline IEMBL3652449 & 528075 & & 1227 & $\mathrm{RI}$ \\
\hline EMBL: & 528075 & & & TI \\
\hline 49055 & 28075 & & 59 & \\
\hline 49059 & & & & RN \\
\hline AEMBL3649222 & 28075 & & 6.2232 & $\mathrm{RI}$ \\
\hline IEMBL3649075 & 28075 & 498 & 6.9001 & R \\
\hline HEMBL36461 & 280 & & & $\kappa$ \\
\hline HEMBL3652478 & 528075 & .0915 & 6.5079 & \\
\hline CHEMBL 364 & 528075 & & 6.2461 & \\
\hline CHEMBL3649185 & 1528075 & 6.4962 & 6.2459 & 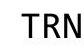 \\
\hline
\end{tabular}

Page 12513 
Supplemental Table S2.txt

\begin{tabular}{|c|c|c|}
\hline 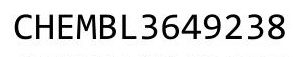 & & \\
\hline HEMBL 3649175 & 528075 & 6 \\
\hline AEMBL3649090 & 75 & \\
\hline & & \\
\hline IEMBL 3652444 & 75 & 8.22 \\
\hline AEMBL3649186 & 528075 & 6.5952 \\
\hline AEMBL3646153 & .528075 & 7.4815 \\
\hline AEMBL36 & 075 & 301 \\
\hline EMBL & 075 & 5.022 \\
\hline IEMBL & 075 & 6.9914 \\
\hline AEMBL3649098 & 1528075 & 7.301 \\
\hline AEMBL36 & 075 & 7.275 \\
\hline AEMBL3 & 075 & \\
\hline 053 & 975 & 7.420 \\
\hline IEMBL & 75 & 7.8239 \\
\hline AEMBL & 075 & 6.4214 \\
\hline AEMBL3 & 275 & 6.3478 \\
\hline IEMBL & 75 & 539 \\
\hline IEMBL & 75 & 447 \\
\hline 093 & 75 & 031 \\
\hline 155 & 75 & 7.1871 \\
\hline AEMBL: & & 7959 \\
\hline IEMBL & 75 & 079 \\
\hline 513 & 75 & 1696 \\
\hline 190 & 75 & 5.0 \\
\hline 495 & & 5.0 \\
\hline IEMBL36 & 75 & \\
\hline IEMBL3 & 12 & \\
\hline$A F M B$ & 36 & 566 \\
\hline HEME & 36 & 6.6556 \\
\hline AEMBL3 & 36 & 7.399 \\
\hline HEMBL3094057 & 36 & 5.4202 \\
\hline 9 & & \\
\hline 7 & 36 & 545 \\
\hline 59 & 136 & 6.699 \\
\hline HEMBL3094092 & 136 & 6.3422 \\
\hline AEMBL3094070 & 136 & 7.2984 \\
\hline & & \\
\hline$\theta$ & 36 & 4.301 \\
\hline HEMBL3094093 & 136 & 7.1355 \\
\hline AEMBL3094090 & 136 & 7.7986 \\
\hline HEMBL 3094068 & 128 & 8.3468 \\
\hline & & 7.6696 \\
\hline 3094061 & 136 & 4.301 \\
\hline HEMBL 3094083 & 1280136 & 4.0 \\
\hline AEMBL3094098 & 1280136 & 6.179 \\
\hline HEMBL 3094 & $12 \varepsilon$ & \\
\hline 8 & & \\
\hline
\end{tabular}

6.1919 TRN

6.1928 TRN

6.8148 TRN

7.2335 TRN

7.3928 TRN

6.265 TST

7.5801 TST

6.3658 TST

6.2764 TST

6.7514 TST

7.0541 TST

$6.821000000000001 \quad$ TST

6.4335 TST

6.6372 TST

7.4866 TST

6.1944 TST

7.1901 TST

6.5944 TST

6.6186 TST

6.362 TST

7.4524 TST

7.3783 TST

6.4309 TST

6.8553 TST

6.193 TST

6.4928 TST

6.2116 TST

6.8289 TRN

6.8234 TRN

6.8401 TRN

6.3283 TRN

6.3004 TRN

7.2455 TRN

6.7649 TRN

6.1234 TRN

7.0324 TRN

6.324 TRN

6.9235 TRN

5.7926 TRN

7.2175 TRN

6.9606 TRN

5.9758 TST

6.4479 TRN

5.6888 TST

6.1575 TRN

6.0716 TRN

6.7124 TRN

6.5849 TRN

Page 12514 


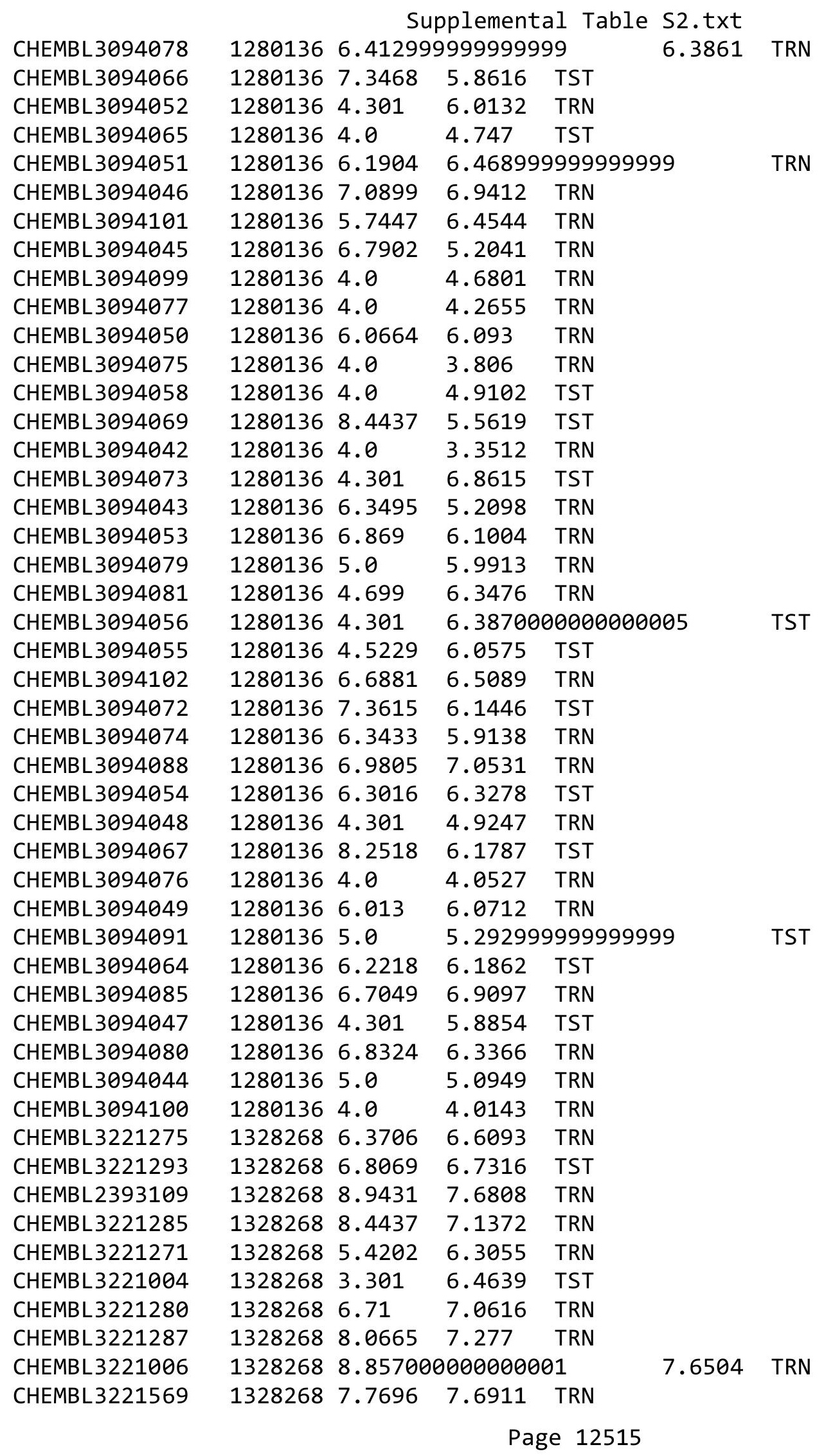


Supplemental Table S2.txt

\begin{tabular}{|c|c|c|c|c|}
\hline HEMBL32215 & & & 8.0747 & \\
\hline HEMRI 3221998 & 328268 & 8.8125 & 7.6504 & \\
\hline AEMBL & & & & \\
\hline AEMBL3221568 & 28268 & 375 & 6808 & \\
\hline HEMBL3221283 & 328268 & 7.857 & .277 & \\
\hline HEMBL3 & 28268 & 83 & .2366 & \\
\hline AEMBL & 268 & & & \\
\hline HEMBL3221288 & 268 & & 0616 & \\
\hline HEMBL3221277 & 328268 & 05 & 1372 & \\
\hline HEMBL3221276 & 328268 & 472 & .4333 & \\
\hline AEMBL3 & 328268 & 513 & & \\
\hline HEMBL; & & & & \\
\hline HEMBL3 & 8268 & & 7972 & \\
\hline AEMBL 2 & 268 & & 7813 & \\
\hline AEMBL2: & 328268 & & 7813 & \\
\hline AEMBL: & 68 & & 04 & \\
\hline AEMBL & & & & \\
\hline AEMBL 2 & 268 & & 11 & \\
\hline AEMBL3 & 68 & & & \\
\hline AEMBL2 & 268 & 7. & 72 & \\
\hline EMBL & 68 & & 72 & \\
\hline AEME & & & & \\
\hline HEMBL & 68 & & 77 & \\
\hline HEMBL & & & & \\
\hline AEMBL 3 & 68 & & 97 & TST \\
\hline EMBL & 68 & & & $R \Lambda$ \\
\hline 7 & & & & RN \\
\hline 91 & & & & \\
\hline IEMBL & & & & IRN \\
\hline AEMBL3 & 28268 & & & RN \\
\hline AEMBL & 68 & & & RN \\
\hline 1 & & & & $\mathrm{RN}$ \\
\hline & & & & RN \\
\hline AEMBL 2 & & & & ГRN \\
\hline AEMBL3 & 268 & & 504 & $\mathrm{RN}$ \\
\hline$A F M B I=$ & 58 & & 47 & ST \\
\hline & & & & \\
\hline AEMBL 3 & & & & S \\
\hline AEMBL2 & 328268 & & & $\Gamma R$ \\
\hline EMBL2 & 68 & & 13 & ГST \\
\hline HEMBL 2 & & & 972 & \\
\hline & & & & $\mathrm{RN}$ \\
\hline HEMBL3 & & & 7.1372 & TRN \\
\hline AEMBL3 & 268 & & 506 & TR \\
\hline 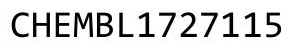 & & & & \\
\hline HEMBL1 & & & 2.8662 & \\
\hline HEMBL1 & & $2 . \varepsilon$ & 2.7663 & \\
\hline CHEMBL1428566 & 737458 & 7.8239 & 3.753 & ГST \\
\hline
\end{tabular}

Page 12516 


\begin{tabular}{|c|c|c|c|c|c|}
\hline & & \multicolumn{4}{|c|}{ Supplemental Table S2.txt } \\
\hline CHEMBL1727950 & 737458 & 2.8239 & 3.9202 & TRN & \\
\hline CHEMBL1729112 & 737458 & 2.8239 & 3.4218 & TRN & \\
\hline CHEMBL1562344 & 737458 & 7.8239 & 7.3689 & TRN & \\
\hline CHEMBL1574121 & 737458 & 7.8239 & 5.2696 & TST & \\
\hline CHEMBL1719058 & 737458 & 2.8239 & 2.9731 & TRN & \\
\hline CHEMBL1465152 & 737458 & 7.8239 & 8.1987 & TRN & \\
\hline CHEMBL1718814 & 737458 & 2.8239 & 2.8518 & TRN & \\
\hline CHEMBL1387835 & 737458 & 7.8239 & 7.3741 & TRN & \\
\hline CHEMBL1727455 & 737458 & 2.8239 & 2.5658 & TRN & \\
\hline CHEMBL1367940 & 737458 & 2.8239 & 2.68600 & 00000000004 & TRN \\
\hline CHEMBL606166 & 737458 & 7.8239 & 7.6301 & TRN & \\
\hline CHEMBL1725465 & 737458 & 2.8239 & 2.1937 & TRN & \\
\hline CHEMBL1702833 & 737458 & 2.8239 & 1.859 & TRN & \\
\hline CHEMBL1405964 & 737458 & 7.8239 & 5.6719 & TST & \\
\hline CHEMBL1722473 & 737458 & 2.8239 & 3.2123 & TRN & \\
\hline CHEMBL1388616 & 737458 & 7.8239 & 6.9228 & TST & \\
\hline CHEMBL1601270 & 737458 & 7.8239 & 6.0493 & TRN & \\
\hline CHEMBL1346881 & 737458 & 7.8239 & 7.7706 & TRN & \\
\hline CHEMBL1714744 & 737458 & 2.8239 & 3.0746 & TRN & \\
\hline CHEMBL600763 & 737458 & 2.8239 & 2.7626 & TRN & \\
\hline CHEMBL1718211 & 737458 & 2.8239 & 2.5736 & TRN & \\
\hline CHEMBL1349822 & 737458 & 7.8239 & 3.3994 & TST & \\
\hline CHEMBL1480287 & 737458 & 2.8239 & 3.6805 & TRN & \\
\hline CHEMBL1735921 & 737458 & 2.8239 & 2.9499 & TRN & \\
\hline CHEMBL1701218 & 737458 & 2.8239 & 2.4438 & TRN & \\
\hline CHEMBL1482740 & 737458 & 7.8239 & 7.4 & TST & \\
\hline CHEMBL1459191 & 737458 & 7.8239 & 8.0788 & TRN & \\
\hline CHEMBL1443573 & 737458 & 2.8239 & 3.5678 & TRN & \\
\hline CHEMBL1709870 & 737458 & 2.8239 & 2.6731 & TRN & \\
\hline CHEMBL1309702 & 737458 & 7.8239 & 7.6731 & TRN & \\
\hline CHEMBL1736049 & 737458 & 2.8239 & 3.2365 & TRN & \\
\hline CHEMBL1596605 & 737458 & 7.8239 & 8.0419 & TRN & \\
\hline CHEMBL1368987 & 737458 & 2.8239 & 3.4651 & TRN & \\
\hline CHEMBL1504766 & 737458 & 2.9031 & 2.5004 & TRN & \\
\hline CHEMBL1707553 & 737458 & 2.8239 & 2.9783 & TRN & \\
\hline CHEMBL1424833 & 737458 & 7.8239 & 2.5954 & TST & \\
\hline CHEMBL1731977 & 737458 & 2.8239 & 2.7348 & TRN & \\
\hline CHEMBL585828 & 737458 & 7.8239 & 8.1664 & TRN & \\
\hline CHEMBL1715644 & 737458 & 2.8239 & 3.0164 & TRN & \\
\hline CHEMBL1375539 & 737458 & 2.8239 & 2.4001 & TRN & \\
\hline CHEMBL1704831 & 737458 & 2.8239 & 2.517 & TRN & \\
\hline CHEMBL1472251 & 737458 & 7.8239 & 7.57700 & 0000000001 & TRN \\
\hline CHEMBL1729313 & 737458 & 2.8239 & 3.1002 & TRN & \\
\hline CHEMBL1575873 & 737458 & 2.8239 & 2.9007 & TRN & \\
\hline CHEMBL1389315 & 737458 & 7.8239 & 4.3218 & TST & \\
\hline CHEMBL606167 & 737458 & 7.8239 & 7.9647 & TRN & \\
\hline CHEMBL1703835 & 737458 & 2.8239 & 3.8056 & TST & \\
\hline CHEMBL1717959 & 737458 & 2.8239 & 1.2052 & TST & \\
\hline
\end{tabular}




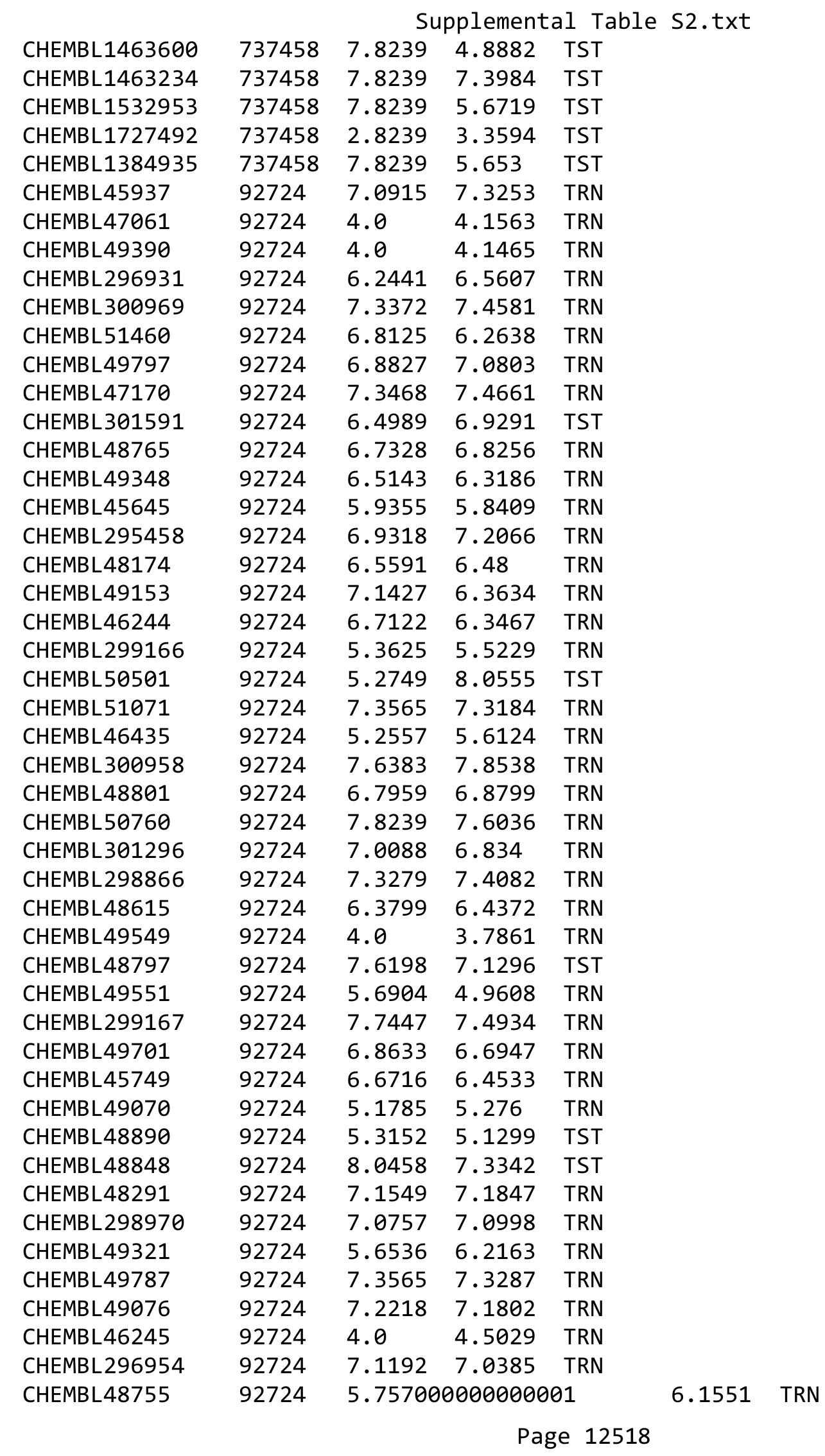




\begin{tabular}{|c|c|c|c|c|c|c|}
\hline & & \multicolumn{5}{|c|}{ Supplemental Table S2.txt } \\
\hline CHEMBL49806 & 92724 & 7.9208 & 6.8816 & TST & & \\
\hline CHEMBL 296879 & 92724 & 3.752 & 4.8022 & TST & & \\
\hline CHEMBL52283 & 92724 & 4.0 & 6.9479 & TST & & \\
\hline CHEMBL 298383 & 92724 & 7.0969 & 7.6055 & TST & & \\
\hline CHEMBL49116 & 92724 & 7.3098 & 5.6389 & TST & & \\
\hline CHEMBL 296840 & 92724 & 6.1244 & 6.9963 & TST & & \\
\hline CHEMBL49191 & 92724 & 6.3054 & 7.1082 & TST & & \\
\hline CHEMBL50374 & 92724 & 7.9208 & 7.4541 & TST & & \\
\hline CHEMBL92309 & 954650 & 3.2213 & 3.072 & TST & & \\
\hline CHEMBL 209148 & 954650 & 5.0218 & 4.6435 & TRN & & \\
\hline CHEMBL192566 & 954650 & 7.4943 & 8.3596 & TST & & \\
\hline CHEMBL 2144069 & 954650 & 3.5816 & 3.0856 & TRN & & \\
\hline CHEMBL240954 & 954650 & 3.7325 & 4.1597 & TST & & \\
\hline CHEMBL 379300 & 954650 & 5.716 & 6.6226 & TRN & & \\
\hline CHEMBL412142 & 954650 & 3.9288 & 3.6052 & TRN & & \\
\hline CHEMBL509032 & 954650 & 6.4775 & 5.9265 & TRN & & \\
\hline CHEMBL577784 & 954650 & 5.8627 & 5.5059 & TRN & & \\
\hline CHEMBL 2363137 & 954650 & 4.1846 & 4.2912 & TRN & & \\
\hline CHEMBL9470 & 954650 & \multicolumn{3}{|c|}{6.071000000000001} & 5.8281 & ה \\
\hline CHEMBL558642 & 954650 & 4.5622 & 4.3367 & TRN & & \\
\hline CHEMBL483849 & 954650 & 3.385 & 2.9491 & TRN & & \\
\hline CHEMBL 210618 & 954650 & 3.2725 & 3.5607 & TRN & & \\
\hline CHEMBL483847 & 954650 & 3.9972 & 3.8976 & TRN & & \\
\hline CHEMBL1909414 & 954650 & 3.8011 & 3.6499 & TRN & & \\
\hline CHEMBL514499 & 954650 & \multicolumn{3}{|c|}{7.617999999999999} & 7.6951 & TRN \\
\hline CHEMBL1643959 & 954650 & 2.955 & 3.4667 & TRN & & \\
\hline CHEMBL1516890 & 954650 & 4.2399 & 4.0595 & TRN & & \\
\hline CHEMBL191334 & 954650 & 3.3029 & 3.6819 & TRN & & \\
\hline CHEMBL573107 & 954650 & 5.3542 & 5.2411 & TRN & & \\
\hline CHEMBL180127 & 954650 & 4.92 & 4.5335 & TRN & & \\
\hline CHEMBL 373751 & 954650 & 3.3018 & 3.6467 & TRN & & \\
\hline CHEMBL392695 & 954650 & 6.0659 & 5.6389 & TRN & & \\
\hline CHEMBL102714 & 954650 & 3.6646 & 3.6239 & TRN & & \\
\hline CHEMBL1190711 & 954650 & 4.7038 & 5.3098 & TRN & & \\
\hline CHEMBL449158 & 954650 & 6.7797 & 6.5428 & TST & & \\
\hline CHEMBL 2005886 & 954650 & 6.602 & 5.5481 & TRN & & \\
\hline CHEMBL1590308 & 954650 & 4.5054 & 3.4492 & TST & & \\
\hline CHEMBL1673039 & 954650 & 4.7024 & 4.9361 & TRN & & \\
\hline CHEMBL515416 & 954650 & 4.1617 & 4.5165 & TRN & & \\
\hline CHEMBL585951 & 954650 & 6.2966 & 6.26200 & 00000 & 005 & TRN \\
\hline CHEMBL1256459 & 954650 & 7.5546 & 7.5601 & TRN & & \\
\hline CHEMBL65 & 954650 & 8.6897 & 8.6987 & TRN & & \\
\hline CHEMBL3349342 & 954650 & 3.2398 & 3.4367 & TRN & & \\
\hline CHEMBL188678 & 954650 & 4.1651 & 4.5458 & TRN & & \\
\hline CHEMBL213100 & 954650 & 4.5272 & 3.8962 & TRN & & \\
\hline CHEMBL3186408 & 954650 & 3.8126 & 3.8439 & TST & & \\
\hline CHEMBL 259181 & 954650 & 3.6388 & 4.5781 & TRN & & \\
\hline CHEMBL1404918 & 954650 & 3.0957 & 2.8639 & TRN & & \\
\hline
\end{tabular}

Page 12519 


\begin{tabular}{|c|c|c|c|c|}
\hline & & & oplement & al Ta \\
\hline CHEMBL1230020 & 954650 & 3.4352 & 3.5795 & TRN \\
\hline CHEMBL 221137 & 954650 & 4.2561 & 4.7551 & TST \\
\hline CHEMBL3392440 & 954650 & 3.9194 & 3.7656 & TRN \\
\hline CHEMBL 202721 & 954650 & 4.9471 & 5.1439 & TRN \\
\hline CHEMBL1242367 & 954650 & 4.6487 & 4.2768 & TRN \\
\hline CHEMBL379975 & 954650 & 6.4998 & 5.9489 & TRN \\
\hline CHEMBL 300389 & 954650 & 7.2662 & 7.1607 & TRN \\
\hline CHEMBL220241 & 954650 & 4.6063 & 4.3808 & TRN \\
\hline CHEMBL189584 & 954650 & 4.0767 & 4.7317 & TRN \\
\hline CHEMBL1788116 & 954650 & 3.3455 & 4.1501 & TRN \\
\hline CHEMBL472940 & 954650 & 4.1535 & 4.3799 & TRN \\
\hline CHEMBL 222102 & 954650 & 3.8336 & 3.9909 & TRN \\
\hline CHEMBL258844 & 954650 & 3.8924 & 4.4119 & TST \\
\hline CHEMBL512504 & 954650 & 6.3018 & 5.7327 & TST \\
\hline CHEMBL393929 & 954650 & 3.2458 & 4.1106 & TST \\
\hline CHEMBL135561 & 954650 & 3.887 & 4.1775 & TST \\
\hline CHEMBL1357247 & 954650 & 2.8494 & 3.0071 & TST \\
\hline CHEMBL3199475 & 954650 & 4.3738 & 4.8142 & TST \\
\hline CHEMBL1970879 & 954650 & 3.7458 & 4.2712 & TST \\
\hline CHEMBL 259181 & 954671 & 3.905 & 3.9049 & TRN \\
\hline CHEMBL399530 & 954671 & 5.0682 & 5.0682 & TRN \\
\hline CHEMBL483849 & 954671 & 1.864 & 2.1342 & TST \\
\hline CHEMBL221137 & 954671 & 4.453 & 4.6214 & TST \\
\hline CHEMBL191334 & 954671 & 3.1266 & 3.1266 & TRN \\
\hline CHEMBL 3186408 & 954671 & 3.0175 & 3.4189 & TST \\
\hline CHEMBL92309 & 954671 & 1.7181 & 3.0888 & TST \\
\hline CHEMBL 220241 & 954671 & 3.7859 & 3.786 & TRN \\
\hline CHEMBL1242367 & 954671 & 3.9373 & 3.9373 & TRN \\
\hline CHEMBL1357247 & 954671 & 3.2313 & 3.2313 & TRN \\
\hline CHEMBL412142 & 954671 & 3.4783 & 3.4783 & TRN \\
\hline CHEMBL1673039 & 954671 & 3.5841 & 3.5841 & TRN \\
\hline CHEMBL1256459 & 954671 & 6.5326 & 6.5326 & TRN \\
\hline CHEMBL1404918 & 954671 & 3.1866 & 3.1866 & TRN \\
\hline CHEMBL 213100 & 954671 & 3.9231 & 3.9231 & TRN \\
\hline CHEMBL 300389 & 954671 & 5.3673 & 5.3673 & TRN \\
\hline CHEMBL2363137 & 954671 & 5.3548 & 5.3548 & TRN \\
\hline CHEMBL512504 & 954671 & 6.8218 & 6.8218 & TRN \\
\hline CHEMBL 240954 & 954671 & 2.9659 & 3.7317 & TST \\
\hline CHEMBL392695 & 954671 & 4.6076 & 4.6076 & TRN \\
\hline CHEMBL515416 & 954671 & 3.2956 & 3.2955 & TRN \\
\hline CHEMBL1516890 & 954671 & 4.5417 & 4.5417 & TRN \\
\hline CHEMBL 2134202 & 954671 & 4.6448 & 4.6448 & TRN \\
\hline CHEMBL2144069 & 954671 & 3.8944 & 3.8944 & TRN \\
\hline CHEMBL1230020 & 954671 & 2.9378 & 2.9379 & TRN \\
\hline CHEMBL1590308 & 954671 & 2.8265 & 2.9309 & TST \\
\hline CHEMBL 2137530 & 954671 & 4.5215 & 4.5215 & TRN \\
\hline CHEMBL558642 & 954671 & 2.6097 & 2.6097 & TRN \\
\hline CHEMBL210618 & 954671 & 2.984 & 2.984 & TRN \\
\hline
\end{tabular}




\begin{tabular}{|c|c|c|c|c|c|c|}
\hline \multicolumn{6}{|c|}{ Supplemental Table S2.txt } & \\
\hline CHEMBL102714 & 954671 & 3.2607 & 3.2607 & TRN & & \\
\hline CHEMBL3199475 & 954671 & 4.6794 & 4.6794 & TRN & & \\
\hline CHEMBL1643959 & 954671 & 4.7022 & 4.7022 & TRN & & \\
\hline CHEMBL217354 & 954671 & 5.4126 & 5.4126 & TRN & & \\
\hline CHEMBL577784 & 954671 & 3.6664 & 3.6664 & TRN & & \\
\hline CHEMBL180127 & 954671 & 3.9431 & 3.9431 & TRN & & \\
\hline CHEMBL 202721 & 954671 & 3.6637 & 3.6637 & TRN & & \\
\hline CHEMBL258844 & 954671 & 4.9468 & 4.9467 & TRN & & \\
\hline CHEMBL209148 & 954671 & 3.10699 & 99999999 & 998 & 3.1069999999999998 & TRN \\
\hline CHEMBL1970879 & 954671 & 4.3755 & 4.3755 & TRN & & \\
\hline CHEMBL472940 & 954671 & 5.13 & 5.13 & TRN & & \\
\hline CHEMBL1788116 & 954671 & 4.9013 & 4.9013 & TRN & & \\
\hline CHEMBL483847 & 954671 & 3.6209 & 3.6209 & TRN & & \\
\hline CHEMBL573107 & 954671 & 5.0463 & 5.0463 & TRN & & \\
\hline CHEMBL65 & 954671 & 5.7021 & 5.7021 & TRN & & \\
\hline CHEMBL255342 & 954671 & 4.1432 & 4.1432 & TRN & & \\
\hline CHEMBL3392440 & 954671 & 3.5953 & 3.5953 & TRN & & \\
\hline CHEMBL1909414 & 954671 & 3.2609 & 3.2609 & TRN & & \\
\hline CHEMBL188678 & 954671 & 3.8915 & 3.8915 & TRN & & \\
\hline CHEMBL222102 & 954671 & 3.0253 & 3.0253 & TRN & & \\
\hline CHEMBL509032 & 954671 & 3.6942 & 3.6942 & TRN & & \\
\hline CHEMBL1190711 & 954671 & 4.98300 & 20000000 & 005 & 4.9830000000000005 & TRN \\
\hline CHEMBL514499 & 954671 & 5.5796 & 5.5796 & TRN & & \\
\hline CHEMBL449158 & 954671 & 5.8757 & 7.0154 & TST & & \\
\hline CHEMBL379300 & 954671 & 6.2333 & 6.2333 & TRN & & \\
\hline CHEMBL1186585 & 954671 & 4.5751 & 4.575 & TRN & & \\
\hline CHEMBL9470 & 954671 & 6.6812 & 5.7799 & TST & & \\
\hline CHEMBL3349342 & 954671 & 4.3789 & 3.7173 & TST & & \\
\hline CHEMBL585951 & 954671 & 5.9466 & 5.9889 & TST & & \\
\hline CHEMBL189584 & 954671 & 3.7795 & 3.8282 & TST & & \\
\hline CHEMBL192566 & 954671 & 6.678 & 7.1545 & TST & & \\
\hline CHEMBL393929 & 954671 & 3.4685 & 3.4191 & TST & & \\
\hline CHEMBL2005886 & 954671 & 3.5715 & 3.8238 & TST & & \\
\hline CHEMBL373751 & 954671 & 3.5197 & 3.739 & TST & & \\
\hline CHEMBL135561 & 954671 & 4.245 & 4.2031 & TST & & \\
\hline CHEMBL379975 & 954671 & 4.1093 & 4.5588 & TST & & \\
\hline CHEMBL194889 & 1640196 & 6.3565 & 6.4696 & TRN & & \\
\hline CHEMBL197377 & 1640196 & 9.266 & 9.139 & TRN & & \\
\hline CHEMBL196539 & 1640196 & 9.0841 & 9.2069 & TRN & & \\
\hline CHEMBL3957468 & 1640196 & 7.8962 & 7.9278 & TRN & & \\
\hline CHEMBL93087 & 1640196 & 7.2441 & 7.2376 & TST & & \\
\hline CHEMBL3960154 & 1640196 & 9.2226 & 9.1063 & TST & & \\
\hline CHEMBL557915 & 1640196 & 8.762 & 8.7299 & TRN & & \\
\hline CHEMBL48813 & 1640196 & 8.8125 & 8.8723 & TST & & \\
\hline CHEMBL198654 & 1640196 & 8.3575 & 8.481 & TRN & & \\
\hline CHEMBL196492 & 1640196 & 8.3215 & 8.1496 & TRN & & \\
\hline CHEMBL194186 & 1640196 & 9.0783 & 9.2646 & TRN & & \\
\hline CHEMBL194810 & 1640196 & 7.8633 & 7.982 & TRN & & \\
\hline
\end{tabular}


Supplemental Table S2.txt

\begin{tabular}{|c|c|c|c|c|}
\hline CHEMBL3966335 & 1640196 & 5.9872 & 5.9979 & TST \\
\hline CHEMBL3955803 & 1640196 & 8.7122 & 8.8088 & TRN \\
\hline CHEMBL372956 & 1640196 & 8.6925 & 8.4989 & TRN \\
\hline CHEMBL3972799 & 1640196 & 9.0899 & 9.1066 & TRN \\
\hline CHEMBL3912108 & 1640196 & 8.7986 & 8.5578 & TRN \\
\hline CHEMBL190142 & 1640196 & 8.7696 & 8.5911 & TRN \\
\hline CHEMBL 3986101 & 1640196 & 8.9355 & 9.1227 & TRN \\
\hline CHEMBL120413 & 1640196 & 7.2328 & 7.0604 & TST \\
\hline CHEMBL3958789 & 1640196 & 8.5719 & 8.5116 & TRN \\
\hline CHEMBL3979386 & 1640196 & 8.9355 & 9.0162 & TRN \\
\hline CHEMBL364284 & 1640196 & 9.6925 & 9.8238 & TRN \\
\hline CHEMBL381866 & 1640196 & 8.4353 & 8.4216 & TRN \\
\hline CHEMBL550453 & 1640196 & 8.2351 & 8.3197 & TRN \\
\hline CHEMBL3304291 & 1640196 & 8.2815 & 8.4697 & TRN \\
\hline CHEMBL3972969 & 1640196 & 8.2111 & 8.3013 & TRN \\
\hline CHEMBL196669 & 1640196 & 5.2104 & 5.2996 & TRN \\
\hline CHEMBL564248 & 1640196 & 8.8996 & 8.9854 & TRN \\
\hline CHEMBL3904655 & 1640196 & 8.7447 & 8.6659 & TRN \\
\hline CHEMBL3974641 & 1640196 & 7.7447 & 7.3565 & TST \\
\hline CHEMBL197547 & 1640196 & 7.4401 & 7.2743 & TRN \\
\hline CHEMBL198421 & 1640196 & 6.6021 & 6.8051 & TRN \\
\hline CHEMBL3907419 & 1640196 & 8.719 & 8.629 & TRN \\
\hline CHEMBL 3910588 & 1640196 & 9.0883 & 9.1174 & TRN \\
\hline CHEMBL370176 & 1640196 & 6.8182 & 6.9826 & TRN \\
\hline CHEMBL196162 & 1640196 & 8.4123 & 7.7241 & TRN \\
\hline CHEMBL3961484 & 1640196 & 9.1152 & 8.9686 & TRN \\
\hline CHEMBL1235423 & 1640196 & 7.6615 & 7.2646 & TST \\
\hline CHEMBL3959350 & 1640196 & 7.4145 & 7.3279 & TRN \\
\hline CHEMBL436293 & 1640196 & 7.0605 & 6.9089 & TRN \\
\hline CHEMBL197624 & 1640196 & 7.4191 & 7.485 & TRN \\
\hline CHEMBL 3968842 & 1640196 & 8.6635 & 8.7614 & TRN \\
\hline CHEMBL371106 & 1640196 & 7.4962 & 7.7902 & TRN \\
\hline CHEMBL3305961 & 1640196 & 7.7423 & 7.7691 & TRN \\
\hline CHEMBL370614 & 1640196 & 9.1506 & 8.9486 & TRN \\
\hline CHEMBL196589 & 1640196 & 6.9066 & 7.2637 & TST \\
\hline CHEMBL196551 & 1640196 & 8.1349 & 8.0925 & TST \\
\hline CHEMBL3956658 & 1640196 & 8.1838 & 8.3598 & TST \\
\hline CHEMBL383361 & 1640196 & 9.0691 & 9.2013 & TST \\
\hline CHEMBL316053 & 1640196 & 7.4895 & 7.2404 & TST \\
\hline CHEMBL3928201 & 1640196 & 7.4134 & 7.2914 & TST \\
\hline CHEMBL372568 & 1640196 & 6.4535 & 6.4681 & TST \\
\hline CHEMBL3941603 & 1641435 & 8.1549 & 8.2485 & TRN \\
\hline CHEMBL3897939 & 1641435 & 8.2218 & 7.9837 & TRN \\
\hline CHEMBL3968879 & 1641435 & 6.1002 & 6.34399 & 9999999999 \\
\hline CHEMBL3926924 & 1641435 & 8.9586 & 9.0028 & TRN \\
\hline CHEMBL3986096 & 1641435 & 6.5436 & 6.5059 & TST \\
\hline CHEMBL3932477 & 1641435 & 9.0 & 8.1471 & TRN \\
\hline CHEMBL3889575 & 1641435 & 6.2441 & 7.0172 & TST \\
\hline
\end{tabular}

Page 12522 
Supplemental Table S2.txt

\begin{tabular}{|c|c|c|c|c|c|}
\hline CHEMBL3981541 & 1641435 & 8.0969 & 8.8194 & TRN & \\
\hline CHEMBL3961864 & 1641435 & 6.6655 & 6.6762 & TST & \\
\hline CHEMBL3982506 & 1641435 & 8.1549 & 8.2873 & TRN & \\
\hline CHEMBL3944561 & 1641435 & 8.1549 & 7.3472 & TRN & \\
\hline CHEMBL3932307 & 1641435 & 8.0969 & 7.5072 & TRN & \\
\hline CHEMBL3983596 & 1641435 & 6.0645 & 6.5151 & TRN & \\
\hline CHEMBL3902962 & 1641435 & 6.4023 & 6.7651 & TST & \\
\hline CHEMBL 3947748 & 1641435 & 6.6861 & 6.4035 & TST & \\
\hline CHEMBL3899235 & 1641435 & 8.699 & 7.5627 & TST & \\
\hline CHEMBL3937668 & 1641435 & 7.0809 & 6.9495 & TRN & \\
\hline CHEMBL 3894113 & 1641435 & 7.0706 & 7.3178 & TRN & \\
\hline CHEMBL3898163 & 1641435 & 7.301 & 7.4753 & TST & \\
\hline CHEMBL 3908724 & 1641435 & 8.6198 & 8.4495 & TRN & \\
\hline CHEMBL3934902 & 1641435 & 9.0969 & 8.9951 & TRN & \\
\hline CHEMBL3908116 & 1641435 & 8.8861 & 8.8523 & TRN & \\
\hline CHEMBL3940682 & 1641435 & 6.9208 & 7.0157 & TRN & \\
\hline CHEMBL3922304 & 1641435 & 9.0 & 8.6478 & TRN & \\
\hline CHEMBL3909881 & 1641435 & 6.71899 & 99999999 & 99 & 6.7739 \\
\hline CHEMBL3971025 & 1641435 & 8.9586 & 8.9159 & TRN & \\
\hline CHEMBL3920506 & 1641435 & 8.699 & 7.1193 & TRN & \\
\hline CHEMBL3910314 & 1641435 & 6.0 & 7.2918 & TRN & \\
\hline CHEMBL3925004 & 1641435 & 7.5086 & 7.7212 & TRN & \\
\hline CHEMBL3917313 & 1641435 & 8.5229 & 8.5285 & TRN & \\
\hline CHEMBL3959275 & 1641435 & 9.2218 & 9.0161 & TRN & \\
\hline CHEMBL3953127 & 1641435 & 7.3279 & 7.159 & TST & \\
\hline CHEMBL3903271 & 1641435 & 6.475 & 5.8823 & TRN & \\
\hline CHEMBL3961101 & 1641435 & 7.7212 & 6.3219 & TRN & \\
\hline CHEMBL 3898776 & 1641435 & 8.9586 & 9.0024 & TRN & \\
\hline CHEMBL3943733 & 1641435 & 8.6198 & 8.6433 & TRN & \\
\hline CHEMBL3949287 & 1641435 & 8.6383 & 8.7155 & TRN & \\
\hline CHEMBL3914662 & 1641435 & 7.8539 & 7.1125 & TRN & \\
\hline CHEMBL3957687 & 1641435 & 8.7212 & 8.4858 & TRN & \\
\hline CHEMBL3958755 & 1641435 & 8.6778 & 8.4699 & TRN & \\
\hline CHEMBL3913106 & 1641435 & 7.0862 & 7.1648 & TRN & \\
\hline CHEMBL3965443 & 1641435 & 8.6021 & 8.7893 & TRN & \\
\hline CHEMBL3904765 & 1641435 & 8.8861 & 9.0387 & TRN & \\
\hline CHEMBL3913279 & 1641435 & 6.6517 & 6.8588 & TRN & \\
\hline CHEMBL3944418 & 1641435 & 7.284 & 7.1853 & TRN & \\
\hline CHEMBL3953086 & 1641435 & 7.3098 & 6.9777 & TRN & \\
\hline CHEMBL 3934540 & 1641435 & 6.3958 & 7.0144 & TRN & \\
\hline CHEMBL3977588 & 1641435 & 8.9208 & 9.2281 & TRN & \\
\hline CHEMBL3921594 & 1641435 & 6.6055 & 6.4236 & TRN & \\
\hline CHEMBL3971166 & 1641435 & 7.7959 & 8.1309 & TST & \\
\hline CHEMBL3923731 & 1641435 & 6.8665 & 7.7129 & TST & \\
\hline CHEMBL3969141 & 1641435 & 7.1487 & 6.9202 & TRN & \\
\hline CHEMBL3925288 & 1641435 & 8.5229 & 7.8603 & TRN & \\
\hline CHEMBL 3898782 & 1641435 & 6.5452 & 6.4042 & TRN & \\
\hline CHEMBL 3975785 & 1641435 & 9.2218 & 8.7967 & TRN & \\
\hline
\end{tabular}

Page 12523 


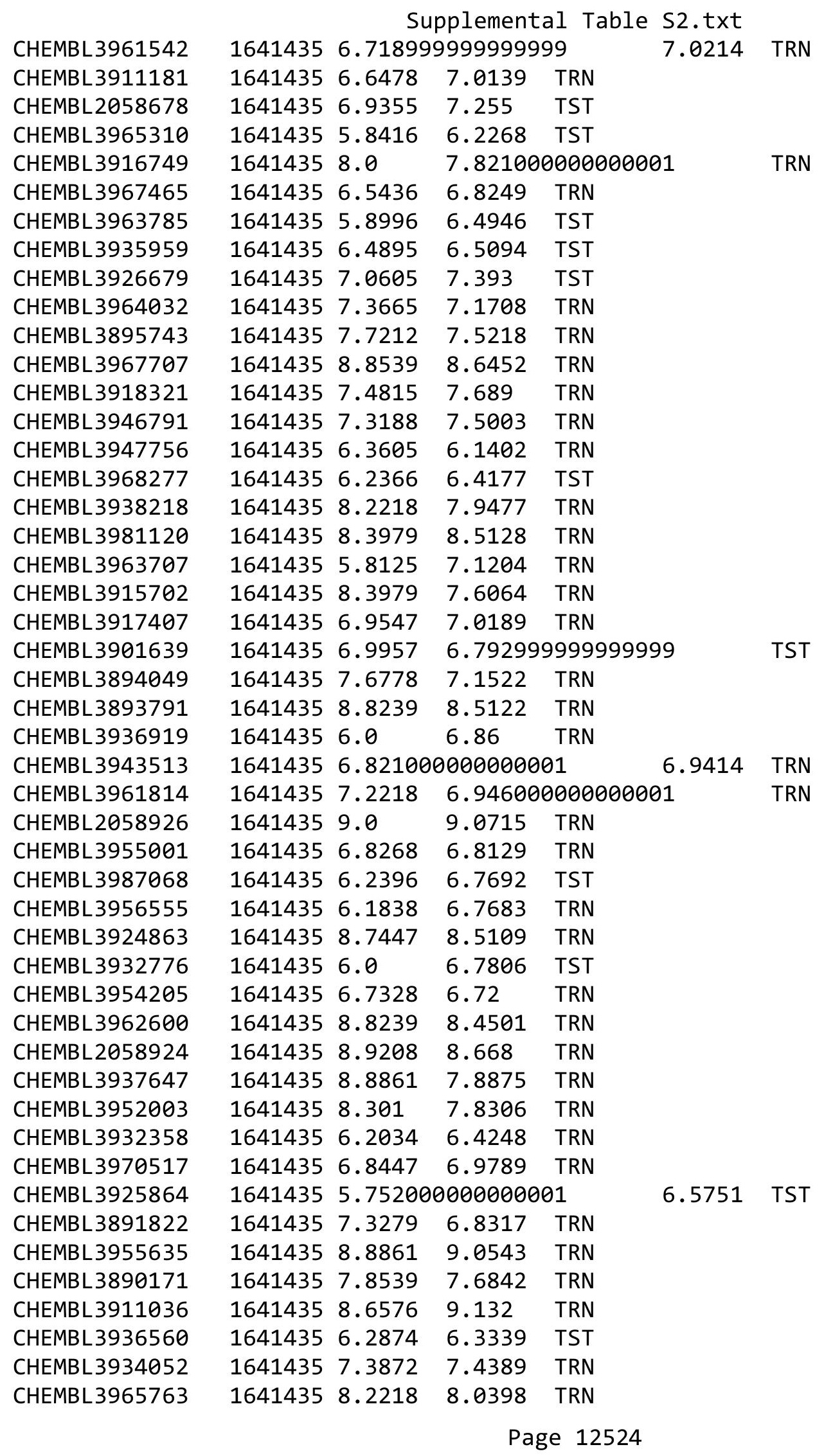


Supplemental Table S2.txt

\begin{tabular}{|c|c|c|c|c|c|}
\hline CHEMBL 2058685 & 1641435 & 7.9208 & 7.6928 & TST & \\
\hline CHEMBL3954734 & 1641435 & 6.9066 & 7.2743 & TST & \\
\hline CHEMBL3923821 & 1641435 & 6.71899 & 99999999 & 6.9414 & TST \\
\hline CHEMBL3911328 & 1641435 & 8.3979 & 8.1388 & TRN & \\
\hline CHEMBL3965627 & 1641435 & 7.5528 & 7.388 & TRN & \\
\hline CHEMBL3907393 & 1641435 & 9.0 & 8.789 & TRN & \\
\hline CHEMBL2058912 & 1641435 & 8.7696 & 8.9203 & TRN & \\
\hline CHEMBL3942177 & 1641435 & 7.6576 & 7.1398 & TRN & \\
\hline CHEMBL3986597 & 1641435 & 7.041 & 7.0123 & TST & \\
\hline CHEMBL3903509 & 1641435 & 7.2147 & 7.4266 & TRN & \\
\hline CHEMBL3986557 & 1641435 & 9.0 & 7.442 & TST & \\
\hline CHEMBL3985223 & 1641435 & 7.6778 & 7.4499 & TRN & \\
\hline CHEMBL3934995 & 1641435 & 5.8041 & 7.0966 & TST & \\
\hline CHEMBL3973010 & 1641435 & 5.7258 & 7.46399 & 99999999995 & TST \\
\hline CHEMBL3928128 & 1641435 & 8.3979 & 8.3732 & TRN & \\
\hline CHEMBL3933156 & 1641435 & 8.301 & 8.9484 & TRN & \\
\hline CHEMBL3917804 & 1641435 & 6.3251 & 7.2571 & TST & \\
\hline CHEMBL3912175 & 1641435 & 7.1871 & 6.7364 & TRN & \\
\hline CHEMBL3967582 & 1641435 & 7.8539 & 7.4959 & TRN & \\
\hline CHEMBL3964387 & 1641435 & 8.8239 & 9.0663 & TRN & \\
\hline CHEMBL3972338 & 1641435 & 7.2596 & 7.2585 & TRN & \\
\hline CHEMBL3898349 & 1641435 & 8.8239 & 8.6213 & TRN & \\
\hline CHEMBL3897400 & 1641435 & 8.2218 & 7.5835 & TST & \\
\hline CHEMBL3929947 & 1641435 & 6.6737 & 6.8198 & TRN & \\
\hline CHEMBL3926216 & 1641435 & 8.8239 & 8.5756 & TRN & \\
\hline CHEMBL3949222 & 1641435 & 6.1129 & 6.8463 & TRN & \\
\hline CHEMBL3937652 & 1641435 & 8.7447 & 8.8439 & TRN & \\
\hline CHEMBL3962419 & 1641435 & 5.6556 & 6.439 & TRN & \\
\hline CHEMBL3985126 & 1641435 & 8.699 & 7.4688 & TST & \\
\hline CHEMBL3974615 & 1641435 & 8.3979 & 8.0832 & TRN & \\
\hline CHEMBL3981021 & 1641435 & 6.6038 & 7.8347 & TRN & \\
\hline CHEMBL3974851 & 1641435 & 6.1662 & 6.2249 & TRN & \\
\hline CHEMBL3955786 & 1641435 & 7.2518 & 7.5865 & TRN & \\
\hline CHEMBL3981758 & 1641435 & 5.6716 & 6.3744 & TST & \\
\hline CHEMBL3924915 & 1641435 & 7.1871 & 7.6994 & TST & \\
\hline CHEMBL3960376 & 1641435 & 9.1549 & 7.5494 & TST & \\
\hline CHEMBL3893660 & 1641435 & 5.6038 & 6.5831 & TST & \\
\hline CHEMBL3917181 & 1641435 & 9.0969 & 7.6559 & TST & \\
\hline CHEMBL3912303 & 1641435 & 7.1871 & 7.1728 & TRN & \\
\hline CHEMBL3946304 & 1641435 & 6.4724 & 7.2431 & TST & \\
\hline CHEMBL3889630 & 1641435 & 10.0 & 8.9969 & TRN & \\
\hline CHEMBL3961821 & 1641435 & 6.5901 & 6.0435 & TST & \\
\hline CHEMBL3953479 & 1641435 & 9.2218 & 8.9206 & TRN & \\
\hline CHEMBL3957216 & 1641435 & 8.301 & 8.1042 & TRN & \\
\hline CHEMBL3980063 & 1641435 & 7.0 & 7.0516 & TRN & \\
\hline CHEMBL3899001 & 1641435 & 7.8539 & 8.6802 & TRN & \\
\hline CHEMBL3904695 & 1641435 & 7.2518 & 7.4003 & TRN & \\
\hline CHEMBL3907646 & 1641435 & 7.0706 & 7.2304 & TRN & \\
\hline
\end{tabular}


Supplemental Table S2.txt

\begin{tabular}{|c|c|c|c|c|c|c|}
\hline CHEMBL3925419 & 1641435 & 6.5186 & 6.6847 & TRN & & \\
\hline CHEMBL3961655 & 1641435 & 6.3188 & 6.9687 & TST & & \\
\hline CHEMBL3936448 & 1641435 & 6.757006 & 30000000 & $\partial 1$ & 6.8598 & TRN \\
\hline CHEMBL3962941 & 1641435 & 7.3279 & 7.5507 & TRN & & \\
\hline CHEMBL3951203 & 1641435 & 8.5229 & 8.7439 & TRN & & \\
\hline CHEMBL3910275 & 1641435 & 7.4815 & 7.5113 & TRN & & \\
\hline CHEMBL3927432 & 1641435 & 6.75200 & 0000000 & $\partial 1$ & 6.9518 & TRN \\
\hline CHEMBL3941627 & 1641435 & 7.6778 & 7.6208 & TST & & \\
\hline CHEMBL 3919281 & 1641435 & 5.9788 & 6.5383 & TRN & & \\
\hline CHEMBL3971128 & 1641435 & 7.1938 & 7.2817 & TRN & & \\
\hline CHEMBL 3897164 & 1641435 & 6.7773 & 6.9392 & TST & & \\
\hline CHEMBL 2058683 & 1641435 & 8.0458 & 7.5845 & TST & & \\
\hline CHEMBL3909079 & 1641435 & 6.8827 & 6.9628 & TRN & & \\
\hline CHEMBL3904019 & 1641435 & 6.2097 & 6.3675 & TST & & \\
\hline CHEMBL3979197 & 1641435 & 6.6904 & 6.2707 & TRN & & \\
\hline CHEMBL 2058679 & 1641435 & 8.301 & 7.5666 & TST & & \\
\hline CHEMBL2058929 & 1641435 & 8.9208 & 7.5266 & TST & & \\
\hline CHEMBL3890246 & 1641435 & 5.5834 & 6.526 & TST & & \\
\hline CHEMBL 3924725 & 1641435 & 6.2725 & 6.8464 & TRN & & \\
\hline CHEMBL3953380 & 1641435 & 8.8239 & 8.7491 & TRN & & \\
\hline CHEMBL3959183 & 1641435 & 6.5346 & 6.9604 & TRN & & \\
\hline CHEMBL3954947 & 1641435 & 8.8539 & 8.8871 & TRN & & \\
\hline CHEMBL3942474 & 1641435 & 6.1791 & 6.6067 & TRN & & \\
\hline CHEMBL3979859 & 1641435 & 6.4034 & 7.1864 & TST & & \\
\hline CHEMBL3946265 & 1641435 & 9.0458 & 8.5529 & TRN & & \\
\hline CHEMBL3984349 & 1641435 & 8.3979 & 8.3464 & TRN & & \\
\hline CHEMBL 3895879 & 1641435 & 6.2503 & 7.1212 & TST & & \\
\hline CHEMBL3935200 & 1641435 & 7.5528 & 6.8368 & TRN & & \\
\hline CHEMBL3975133 & 1641435 & 6.8013 & 6.6445 & TRN & & \\
\hline CHEMBL3901347 & 1641435 & 7.3872 & 7.0995 & TST & & \\
\hline CHEMBL3927932 & 1641435 & 6.0757 & 7.0791 & TST & & \\
\hline CHEMBL 3957031 & 1641435 & 7.2441 & 7.2474 & TRN & & \\
\hline CHEMBL3971705 & 1641435 & 7.5086 & 7.2514 & TRN & & \\
\hline CHEMBL3918759 & 1641435 & 6.0255 & 6.3103 & TRN & & \\
\hline CHEMBL3980391 & 1641435 & 6.6162 & 7.4216 & TRN & & \\
\hline CHEMBL3944563 & 1641435 & 7.6576 & 7.4578 & TRN & & \\
\hline CHEMBL3920261 & 1641435 & 8.0 & 7.7295 & TRN & & \\
\hline CHEMBL3912710 & 1641435 & 8.7447 & 8.1245 & TRN & & \\
\hline CHEMBL3957957 & 1641435 & 8.8861 & 8.7803 & TRN & & \\
\hline CHEMBL3890553 & 1641435 & 7.1487 & 7.494 & TRN & & \\
\hline CHEMBL3918492 & 1641435 & 7.0177 & 6.3658 & TST & & \\
\hline CHEMBL3980226 & 1641435 & 7.6021 & 7.3918 & TRN & & \\
\hline CHEMBL3892324 & 1641435 & 9.0458 & 8.7612 & TRN & & \\
\hline CHEMBL 2058930 & 1641435 & 8.699 & 9.0995 & TRN & & \\
\hline CHEMBL3947808 & 1641435 & 7.6198 & 7.7166 & TRN & & \\
\hline CHEMBL3954323 & 1641435 & 7.0809 & 7.4962 & TRN & & \\
\hline CHEMBL 2058927 & 1641435 & 9.3979 & 9.1336 & TRN & & \\
\hline CHEMBL3984604 & 1641435 & 7.9208 & 7.1308 & TRN & & \\
\hline
\end{tabular}


Supplemental Table S2.txt

\begin{tabular}{|c|c|c|c|c|c|}
\hline CHEMBL3968312 & 1641435 & 8.699 & 7.3731 & TST & \\
\hline CHEMBL3934924 & 1641435 & 6.1972 & 6.0556 & TRN & \\
\hline CHEMBL3950628 & 1641435 & 6.6021 & 6.6016 & TRN & \\
\hline CHEMBL 3902883 & 1641435 & 9.0 & 8.7777 & TRN & \\
\hline CHEMBL3985672 & 1641435 & 9.301 & 7.5946 & TST & \\
\hline CHEMBL3936400 & 1641435 & 8.5229 & 8.7813 & TRN & \\
\hline CHEMBL3979927 & 1641435 & 8.5528 & 8.5434 & TRN & \\
\hline CHEMBL 3986547 & 1641435 & 6.7033 & 6.888 & TRN & \\
\hline CHEMBL2058911 & 1641435 & 8.7212 & 8.9781 & TRN & \\
\hline CHEMBL3975402 & 1641435 & 7.284 & 7.6734 & TRN & \\
\hline CHEMBL3963055 & 1641435 & 7.699 & 7.8495 & TRN & \\
\hline CHEMBL3906065 & 1641435 & 6.1688 & 6.6307 & TRN & \\
\hline CHEMBL3902005 & 1641435 & 8.7696 & 8.8546 & TRN & \\
\hline CHEMBL3948205 & 1641435 & 8.3979 & 7.9734 & TRN & \\
\hline CHEMBL3949862 & 1641435 & 7.8539 & 6.76200 & 00000000005 & TST \\
\hline CHEMBL3940278 & 1641435 & 5.3851 & 5.8616 & TST & \\
\hline CHEMBL3940294 & 1641435 & 7.6576 & 7.4634 & TRN & \\
\hline CHEMBL3908235 & 1641435 & 8.5229 & 7.74100 & 00000000005 & TST \\
\hline CHEMBL3940452 & 1641435 & 6.8239 & 6.4835 & TRN & \\
\hline CHEMBL3943793 & 1641435 & 6.4089 & 6.5478 & TRN & \\
\hline CHEMBL3939921 & 1641435 & 7.5528 & 7.2278 & TRN & \\
\hline CHEMBL3927618 & 1641435 & 6.9066 & 6.9371 & TRN & \\
\hline CHEMBL 3958202 & 1641435 & 9.5229 & 9.2396 & TRN & \\
\hline CHEMBL3896377 & 1641435 & 8.6778 & 8.4623 & TRN & \\
\hline CHEMBL3929685 & 1641435 & 6.4547 & 6.2098 & TST & \\
\hline CHEMBL3891180 & 1641435 & 8.7212 & 8.9713 & TRN & \\
\hline CHEMBL 3927040 & 1641435 & 7.1675 & 7.0948 & TRN & \\
\hline CHEMBL3934967 & 1641435 & 5.7696 & 6.6978 & TRN & \\
\hline CHEMBL 3968732 & 1641435 & \multicolumn{3}{|c|}{6.7620000000000005} & - \\
\hline CHEMBL3986489 & 1641435 & 7.6383 & 7.5496 & TRN & \\
\hline CHEMBL3982693 & 1641435 & 8.8539 & 8.6814 & TRN & \\
\hline CHEMBL2058913 & 1641435 & 8.1549 & 8.272 & TRN & \\
\hline CHEMBL3961392 & 1641435 & 7.3565 & 7.5524 & TRN & \\
\hline CHEMBL3944750 & 1641435 & 9.0 & 8.5759 & TRN & \\
\hline CHEMBL3919399 & 1641435 & 7.6576 & 7.4282 & TRN & \\
\hline CHEMBL3983267 & 1641435 & 8.699 & 8.6603 & TRN & \\
\hline CHEMBL3943233 & 1641435 & 8.5229 & 8.4058 & TRN & \\
\hline CHEMBL 3954313 & 1641435 & 7.2676 & 7.0746 & TST & \\
\hline CHEMBL3949787 & 1641435 & 8.8861 & 8.867 & TRN & \\
\hline CHEMBL3934769 & 1641435 & 8.7959 & 8.8886 & TRN & \\
\hline CHEMBL3910835 & 1641435 & 7.8539 & 7.5442 & TRN & \\
\hline CHEMBL 2058688 & 1641435 & 8.8861 & 7.2995 & TST & \\
\hline CHEMBL3982881 & 1641435 & 7.1192 & 6.8408 & TRN & \\
\hline CHEMBL3897575 & 1641435 & 8.585 & 8.3257 & TRN & \\
\hline CHEMBL3925437 & 1641435 & 8.6383 & 8.6492 & TRN & \\
\hline CHEMBL3919967 & 1641435 & 6.7328 & 6.5844 & TRN & \\
\hline CHEMBL 2058917 & 1641435 & 8.8539 & 8.8661 & TRN & \\
\hline CHEMBL3982698 & 1641435 & 8.9208 & 8.7791 & TRN & \\
\hline
\end{tabular}

Page 12527 
Supplemental Table S2.txt

\begin{tabular}{|c|c|c|c|c|c|}
\hline CHEMBL3965502 & 1641435 & 8.6383 & 8.3759 & TRN & \\
\hline CHEMBL 2058922 & 1641435 & 9.0969 & 8.993 & TRN & \\
\hline CHEMBL3958994 & 1641435 & 6.0 & 7.6721 & TST & \\
\hline CHEMBL3954051 & 1641435 & 7.4685 & \multicolumn{2}{|c|}{7.492999999999999} & TRN \\
\hline CHEMBL3911833 & 1641435 & 6.3215 & 6.0965 & TRN & \\
\hline CHEMBL3981249 & 1641435 & 8.3768 & 8.6377 & TRN & \\
\hline CHEMBL3900920 & 1641435 & 8.5528 & 8.4476 & TRN & \\
\hline CHEMBL3965317 & 1641435 & 6.9172 & 6.4564 & TST & \\
\hline CHEMBL3949013 & 1641435 & 7.0223 & 7.565 & TRN & \\
\hline CHEMBL 3897941 & 1641435 & 8.7959 & 8.8339 & TRN & \\
\hline CHEMBL3920556 & 1641435 & 7.9586 & 7.2672 & TRN & \\
\hline CHEMBL3907837 & 1641435 & 8.5229 & \multicolumn{2}{|c|}{8.697000000000001} & TRN \\
\hline CHEMBL3935115 & 1641435 & 9.0 & 8.6513 & TRN & \\
\hline CHEMBL 3958634 & 1641435 & 6.8013 & 6.8813 & TRN & \\
\hline CHEMBL3956869 & 1641435 & 6.1101 & 6.5095 & TRN & \\
\hline CHEMBL3964165 & 1641435 & 6.8297 & 7.3342 & TST & \\
\hline CHEMBL3973398 & 1641435 & 7.2366 & 6.7374 & TRN & \\
\hline CHEMBL3962950 & 1641435 & 6.4295 & 7.0346 & TST & \\
\hline CHEMBL3953004 & 1641435 & 7.2518 & 7.176 & TST & \\
\hline CHEMBL3979551 & 1641435 & 7.2366 & 7.2308 & TRN & \\
\hline CHEMBL3927444 & 1641435 & 6.4089 & 7.1095 & TST & \\
\hline CHEMBL3900558 & 1641435 & 7.8539 & 7.7797 & TRN & \\
\hline CHEMBL3986629 & 1641435 & 6.9208 & 7.0301 & TRN & \\
\hline CHEMBL3935333 & 1641435 & 8.6021 & 8.3795 & TRN & \\
\hline CHEMBL 3935582 & 1641435 & 7.1739 & 7.3945 & TRN & \\
\hline CHEMBL3975795 & 1641435 & 7.8539 & 8.0482 & TRN & \\
\hline CHEMBL3919974 & 1641435 & 7.3665 & \multicolumn{2}{|c|}{7.0120000000000005} & TRN \\
\hline CHEMBL3925997 & 1641435 & 6.6778 & 7.181 & TRN & \\
\hline CHEMBL3916058 & 1641435 & 6.0 & 7.8007 & TRN & \\
\hline CHEMBL3966619 & 1641435 & 8.5229 & \multicolumn{2}{|c|}{8.777999999999999} & TRN \\
\hline CHEMBL3983119 & 1641435 & 6.2549 & 6.8464 & TST & \\
\hline CHEMBL3913157 & 1641435 & 6.0675 & 6.8968 & TST & \\
\hline CHEMBL3960942 & 1641435 & 8.9586 & 8.9917 & TRN & \\
\hline CHEMBL3959338 & 1641435 & 8.3979 & 8.5441 & TRN & \\
\hline CHEMBL3983709 & 1641435 & 8.699 & 8.941 & TRN & \\
\hline CHEMBL3901504 & 1641435 & 6.2612 & 6.7601 & TRN & \\
\hline CHEMBL3948359 & 1641435 & 7.1079 & 7.2722 & TRN & \\
\hline CHEMBL3908435 & 1641435 & 7.699 & 7.575 & TRN & \\
\hline CHEMBL3986054 & 1641435 & 5.0353 & 5.9824 & TST & \\
\hline CHEMBL3982178 & 1641435 & 7.3979 & 6.902 & TRN & \\
\hline CHEMBL3899855 & 1641435 & 6.9666 & 6.7707 & TRN & \\
\hline CHEMBL3984109 & 1641435 & 8.7696 & 8.7206 & TRN & \\
\hline CHEMBL3966513 & 1641435 & 6.6925 & 7.0292 & TRN & \\
\hline CHEMBL3911509 & 1641435 & 8.3979 & 8.6636 & TRN & \\
\hline CHEMBL3906980 & 1641435 & 8.7212 & 8.4678 & TRN & \\
\hline CHEMBL3958597 & 1641435 & 6.9208 & 7.1676 & TRN & \\
\hline CHEMBL3904319 & 1641435 & 6.4401 & 6.8008 & TRN & \\
\hline CHEMBL3972878 & 1641435 & 6.2154 & 6.6922 & TST & \\
\hline
\end{tabular}


Supplemental Table S2.txt

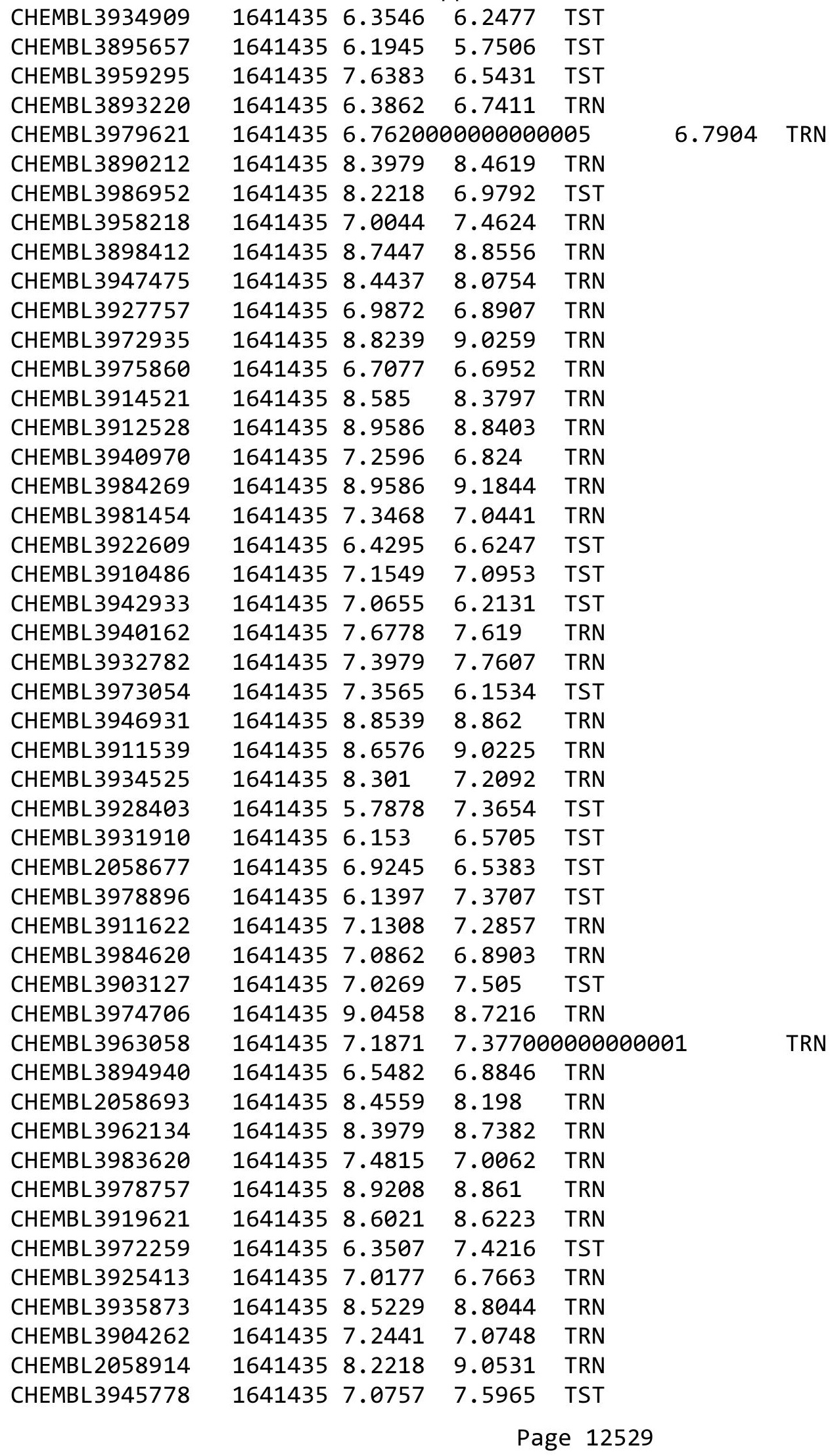


Supplemental Table S2.txt

\begin{tabular}{|c|c|c|c|c|}
\hline CHEMBL3977834 & 1641435 & 7.7696 & 7.1931 & TST \\
\hline CHEMBL3974898 & 1641435 & 6.8996 & 6.6509 & TST \\
\hline CHEMBL3911774 & 1641435 & 8.0 & 7.8539 & TRN \\
\hline CHEMBL 3954548 & 1641435 & 9.0969 & 8.5887 & TRN \\
\hline CHEMBL3984330 & 1641435 & 7.8861 & 7.5113 & TRN \\
\hline CHEMBL 3894120 & 1641435 & 7.0088 & 6.5372 & TRN \\
\hline CHEMBL3901816 & 1641435 & 6.0 & 6.9912 & TRN \\
\hline CHEMBL 2058684 & 1641435 & 7.7696 & 7.3489 & TST \\
\hline CHEMBL3957951 & 1641435 & 7.6383 & 7.4346 & TRN \\
\hline CHEMBL3956498 & 1641435 & 7.1024 & 7.0136 & TRN \\
\hline CHEMBL3927345 & 1641435 & 8.9208 & 9.0657 & TRN \\
\hline CHEMBL3973251 & 1641435 & 8.5686 & 8.6234 & TRN \\
\hline CHEMBL3906957 & 1641435 & 8.7212 & 8.5995 & TRN \\
\hline CHEMBL 3944277 & 1641435 & 6.0 & 7.6768 & TST \\
\hline CHEMBL3954828 & 1641435 & 8.301 & 7.9496 & TRN \\
\hline CHEMBL3904253 & 1641435 & 8.9586 & 8.8961 & TRN \\
\hline CHEMBL3918245 & 1641435 & 8.8539 & 8.8934 & TRN \\
\hline CHEMBL3971791 & 1641435 & 7.7447 & 7.0234 & TST \\
\hline CHEMBL3944818 & 1641435 & 9.0 & 8.7663 & TRN \\
\hline CHEMBL 3897811 & 1641435 & 6.8794 & 7.0596 & TRN \\
\hline CHEMBL3897004 & 1641435 & 8.2218 & 8.5625 & TRN \\
\hline CHEMBL 2058921 & 1641435 & 8.8861 & 8.8961 & TRN \\
\hline CHEMBL3972076 & 1641435 & 8.699 & 7.1634 & TST \\
\hline CHEMBL3983279 & 1641435 & 7.3565 & 6.9614 & TRN \\
\hline CHEMBL3949079 & 1641435 & 7.0862 & 6.9588 & TRN \\
\hline CHEMBL3945041 & 1641435 & 7.3565 & 7.7102 & TRN \\
\hline CHEMBL3959267 & 1641435 & 7.699 & 8.31899 & 9999999999 \\
\hline CHEMBL3926185 & 1641435 & 6.6882 & 6.9222 & TRN \\
\hline CHEMBL3929823 & 1641435 & 7.3279 & 6.5053 & TST \\
\hline CHEMBL 3917032 & 1641435 & 6.1586 & 7.4243 & TST \\
\hline CHEMBL3894180 & 1641435 & 7.6021 & 7.5809 & TRN \\
\hline CHEMBL3912084 & 1641435 & 7.0269 & 7.1225 & TRN \\
\hline CHEMBL3948838 & 1641435 & 7.2291 & 7.0123 & TRN \\
\hline CHEMBL3972718 & 1641435 & 7.3979 & 6.5569 & TST \\
\hline CHEMBL3927874 & 1641435 & 8.699 & 8.852 & TRN \\
\hline CHEMBL3967308 & 1641435 & 8.7447 & 8.7766 & TRN \\
\hline CHEMBL3912520 & 1641435 & 8.0969 & 7.7836 & TST \\
\hline CHEMBL3908043 & 1641435 & 8.0 & 7.9673 & TRN \\
\hline CHEMBL3890001 & 1641435 & 8.1549 & 7.9409 & TRN \\
\hline CHEMBL3910368 & 1641435 & 7.5229 & 7.8186 & TRN \\
\hline CHEMBL3930221 & 1641435 & 6.8356 & 7.2007 & TRN \\
\hline CHEMBL3898013 & 1641435 & 6.58 & 6.8233 & TRN \\
\hline CHEMBL 2058692 & 1641435 & 8.0458 & 7.89 & TRN \\
\hline CHEMBL3899070 & 1641435 & 8.3979 & 8.2226 & TRN \\
\hline CHEMBL3927151 & 1641435 & 6.9136 & 6.9512 & TRN \\
\hline CHEMBL3902713 & 1641435 & 7.2518 & 6.9025 & TST \\
\hline CHEMBL 3898234 & 1641435 & 7.4559 & 7.4915 & TRN \\
\hline CHEMBL3937891 & 1641435 & 7.0088 & 6.7561 & TRN \\
\hline
\end{tabular}


Supplemental Table S2.txt

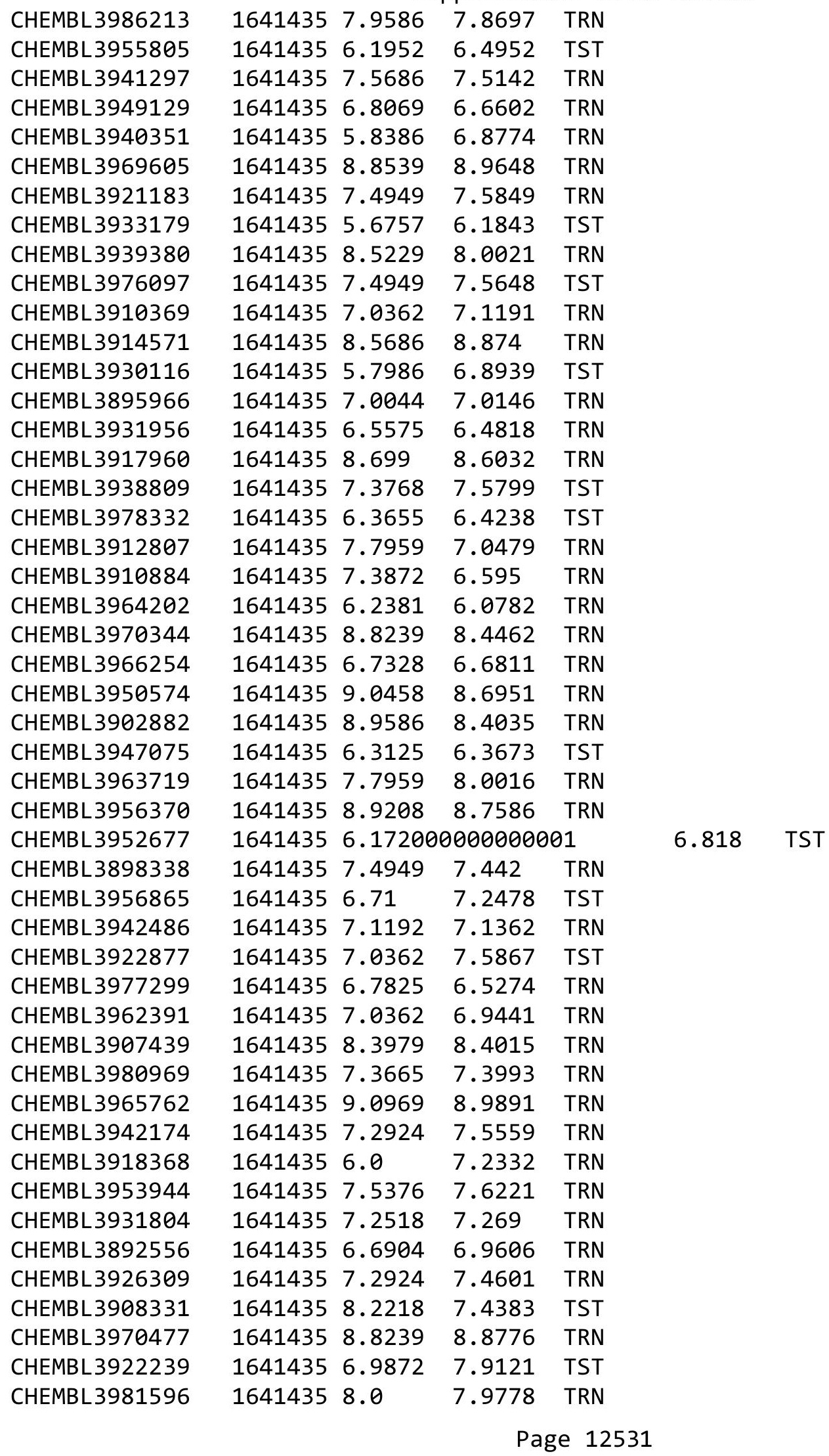


Supplemental Table S2.txt

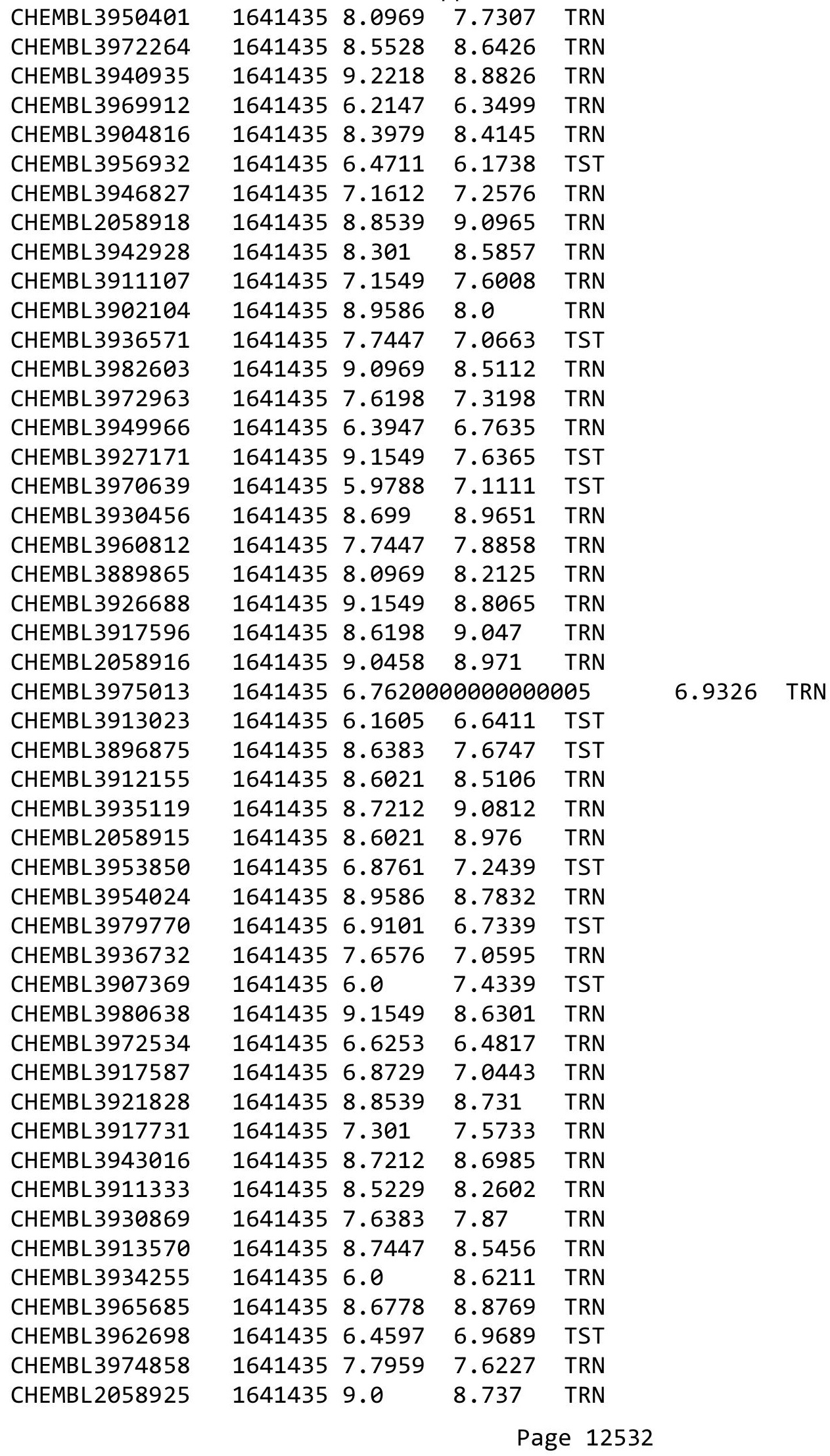


Supplemental Table S2.txt

\begin{tabular}{|c|c|c|c|c|}
\hline HEMBL & 541435 & & & \\
\hline & & 7.3872 & 7.4667 & \\
\hline 78 & & & & \\
\hline HEMBL 394 & & 96 & & \\
\hline AEMBL3906970 & 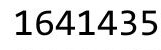 & 3979 & & \\
\hline HEMBL3890145 & 641435 & 5.8271 & 8706 & \\
\hline 202 & & & 711 & \\
\hline IFMRI 394 & & & 2448 & $\mathrm{RN}$ \\
\hline AEMBL3956979 & & & 6.7635 & \\
\hline HEMBL3932631 & 64 & 5.6925 & 5281 & \\
\hline HEMBL3903871 & $6+5+$ & 6.4089 & .7879 & \\
\hline IEMBL396 & & 212 & 173 & \\
\hline IEMBL38 & & & 4478 & \\
\hline HEMBL 395 & & 549 & 6.1012 & \\
\hline HEMBL397 & 62 & & 7686 & \\
\hline AEMBL392 & 64 & 47 & 6497 & \\
\hline AEMBL392 & 0 & 49 & 448 & \\
\hline HEMBL 392 & & & 3939 & \\
\hline HEMBL392 & & 7. & 7.2959 & \\
\hline HEMBL 394 & & & 221 & \\
\hline HEIMBLSS & 62 & 7 & 737 & NIV \\
\hline HEMBL39 & & & 917 & SI \\
\hline HEMBL39 & & 6. & 323 & \\
\hline HFMBI 392 & & 8 & 3682 & \\
\hline HEMBL390 & & & & TST \\
\hline HEMBL39 & 6 & & 004 & ГRN \\
\hline AEMBL3 & & & 466 & RN \\
\hline HFMBI $1 \mathrm{C}$ & & & 3926 & \\
\hline HEMBL 398 & & & 204 & I \\
\hline HEMBL3893072 & & & 027 & IK \\
\hline HEMBL3S & & & 048 & RN \\
\hline HEMBL3 & & & 3979 & RN \\
\hline HEMBL3 & & & 6.7799 & IN \\
\hline HEMBL3959274 & & & 1377 & IRN \\
\hline HEMBL3931503 & $6+2+$ & 208 & 5136 & TRN \\
\hline HEMBL39 & & & 4289 & \\
\hline HFMRI 3 & & & 185 & ST \\
\hline HEMBL3S & & & 8.0196 & TRN \\
\hline HEMBL3922478 & & 8.5229 & 4823 & TRN \\
\hline HEMBL395 & & & 653 & TRN \\
\hline HEMBL39 & 6 & & 9942 & \\
\hline CHEMBL 38 & & & 7.5043 & RN \\
\hline HEMBL3910994 & 16 & 8.699 & 8.7135 & TRN \\
\hline HEMBL3966627 & 16 & 6.2565 & .2101 & TRN \\
\hline MRI 3 & & & 677 & \\
\hline HEMBL 39 & & 14 & 6.8612 & \\
\hline CHEMBL 3896362 & & 969 & 8.8995 & \\
\hline HEMBL3942113 & 1641435 & 5.767 & 6.5767 & IST \\
\hline
\end{tabular}

Page 12533 
Supplemental Table S2.txt

\begin{tabular}{|c|c|c|c|c|c|}
\hline CHEMBL3982789 & 1641435 & 7.9586 & 8.3355 & TRN & \\
\hline CHEMBL3896329 & 1641435 & 6.1656 & 6.2637 & TST & \\
\hline CHEMBL3901029 & 1641435 & 8.1549 & 7.5727 & TST & \\
\hline CHEMBL3901842 & 1641435 & 9.1549 & 9.0179 & TRN & \\
\hline CHEMBL3941896 & 1641435 & 5.9031 & 6.1576 & TRN & \\
\hline CHEMBL3948066 & 1641435 & 8.301 & 8.5281 & TRN & \\
\hline CHEMBL3980444 & 1641435 & 8.9586 & 8.8734 & TRN & \\
\hline CHEMBL3948164 & 1641435 & 8.699 & 9.0702 & TRN & \\
\hline CHEMBL3925541 & 1641435 & 7.3188 & 8.1639 & TRN & \\
\hline CHEMBL3950585 & 1641435 & 8.5229 & 8.668 & TRN & \\
\hline CHEMBL3914434 & 1641435 & 6.3354 & 6.7325 & TRN & \\
\hline CHEMBL3956074 & 1641435 & 7.3188 & 7.6258 & TRN & \\
\hline CHEMBL3944026 & 1641435 & 6.4271 & 6.8903 & TRN & \\
\hline CHEMBL 2058680 & 1641435 & 8.5229 & 7.4004 & TST & \\
\hline CHEMBL3934312 & 1641435 & 6.6536 & 6.4802 & TST & \\
\hline CHEMBL3953611 & 1641435 & 5.9431 & 6.6373 & TST & \\
\hline CHEMBL3955369 & 1641435 & 7.0315 & 6.8826 & TRN & \\
\hline CHEMBL3965068 & 1641435 & 5.9957 & 6.9517 & TST & \\
\hline CHEMBL3923230 & 1641435 & 7.0555 & 7.0169 & TRN & \\
\hline CHEMBL3940801 & 1641435 & 6.0 & 6.6996 & TRN & \\
\hline CHEMBL 3894247 & 1641435 & 8.6383 & 8.7502 & TRN & \\
\hline CHEMBL 2058681 & 1641435 & 8.8539 & 7.6227 & TST & \\
\hline CHEMBL3898660 & 1641435 & 7.2218 & 7.6274 & TST & \\
\hline CHEMBL3924340 & 1641435 & 6.04 & 6.0678 & TST & \\
\hline CHEMBL3963977 & 1641435 & 7.3768 & 7.3176 & TRN & \\
\hline CHEMBL3967030 & 1641435 & 7.3768 & 7.73 & TRN & \\
\hline CHEMBL3904912 & 1641435 & 6.1403 & 7.6377 & TST & \\
\hline CHEMBL3937699 & 1641435 & 9.0 & 8.8385 & TRN & \\
\hline CHEMBL3923545 & 1641435 & 8.301 & 8.2155 & TRN & \\
\hline CHEMBL 3907189 & 1641435 & 8.2218 & 7.8204 & TRN & \\
\hline CHEMBL3928259 & 1641435 & 8.301 & 7.4967 & TST & \\
\hline CHEMBL3893711 & 1641435 & 7.5229 & 7.8812 & TRN & \\
\hline CHEMBL3976224 & 1641435 & 8.9586 & 8.7953 & TRN & \\
\hline CHEMBL3942650 & 1641435 & 7.7212 & 6.9577 & TST & \\
\hline CHEMBL3960351 & 1641435 & 8.3979 & 8.708 & TRN & \\
\hline CHEMBL3951368 & 1641435 & 6.9136 & 6.86700 & 0000000001 & TRN \\
\hline CHEMBL3914483 & 1641435 & 7.1612 & 7.6029 & TST & \\
\hline CHEMBL3949072 & 1641435 & 8.6198 & 8.7658 & TRN & \\
\hline CHEMBL3949763 & 1641435 & 7.9208 & 6.9636 & TRN & \\
\hline CHEMBL3903128 & 1641435 & 6.8665 & 6.6653 & TRN & \\
\hline CHEMBL3912900 & 1641435 & 8.7696 & 8.6283 & TRN & \\
\hline CHEMBL3898342 & 1641435 & 8.0458 & 6.8862 & TRN & \\
\hline CHEMBL3984521 & 1641435 & 7.6576 & 7.8488 & TRN & \\
\hline CHEMBL 2058690 & 1641435 & 7.7447 & 7.8631 & TRN & \\
\hline CHEMBL3901005 & 1641435 & 8.5229 & 8.2237 & TRN & \\
\hline CHEMBL3980127 & 1641435 & 8.699 & 7.7424 & TST & \\
\hline CHEMBL 2058920 & 1641435 & 9.0458 & 8.8679 & TRN & \\
\hline CHEMBL3931235 & 1641435 & 6.4609 & 5.9167 & TST & \\
\hline
\end{tabular}




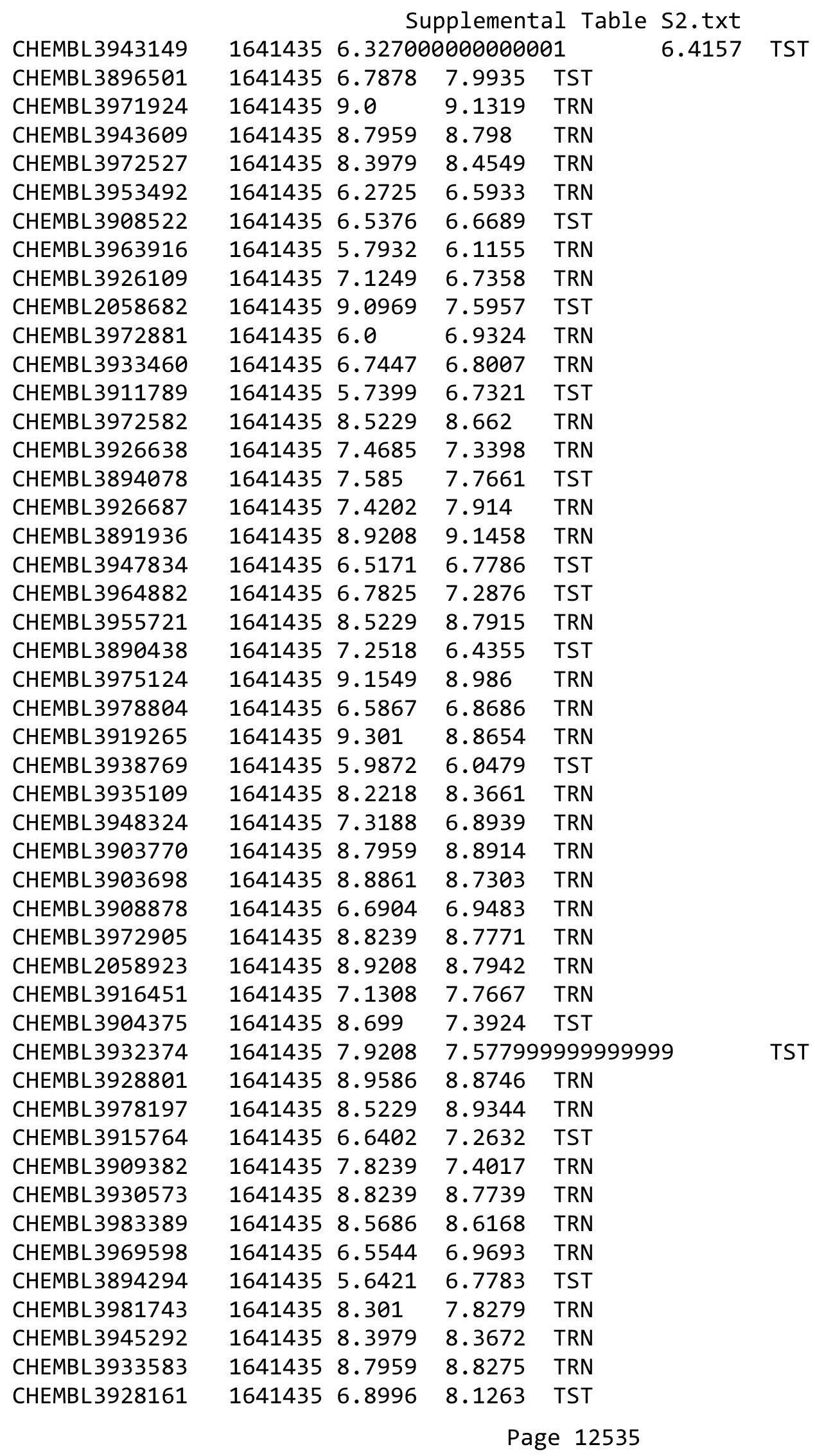


Supplemental Table S2.txt

\begin{tabular}{|c|c|c|c|c|}
\hline HEMB & S & 7.0862 & & \\
\hline HEMBL3941962 & & 6.0164 & 5.9556 & \\
\hline 426 & & 307 & & \\
\hline HEMBL3928664 & & 1158 & & \\
\hline HEMBL3968163 & 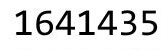 & 218 & & \\
\hline HEMBL3916714 & 641435 & 7.0655 & 8135 & \\
\hline+39 & & .8861 & & \\
\hline AEMBL396 & & & & \\
\hline HEMBL3900192 & & .5229 & 627 & \\
\hline HEMBL 389 & 64 & 3539 & 5848 & \\
\hline HEMBL3913258 & 62 & 9.0969 & 14 & \\
\hline AEMBL39: & 0 & 645 & & \\
\hline AEMBL39 & & & & \\
\hline HEMBL 393 & & 6.9031 & 7.0099 & \\
\hline HEMBL397 & 62 & 301 & 7498 & \\
\hline AEMBL393 & 0 & 6.7799 & 97 & \\
\hline HEMBL39 & 6 & 827 & 353 & \\
\hline HEMBL39 & & 576 & 554 & \\
\hline HEMBL 395 & & 7.8239 & 9587 & \\
\hline HEMBL393 & & 8. & & \\
\hline HEMBL3S & 64 & 29 & 282 & RIN \\
\hline HEMBL3S & & 03 & & 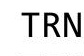 \\
\hline HEMBL39 & & 861 & & \\
\hline HFMRI 39 & & 229 & 206 & \\
\hline IEMBL 20 & & & & TST \\
\hline HEMBL3S & 6 & 64 & 38 & RIN \\
\hline HEMBL3S & & 34 & & ГRN \\
\hline HFMBI 30 & & 62 & 29 & \\
\hline HEMBL39८ & & & 3918 & RIV \\
\hline HEMBL 391 & & & 253 & I RIV \\
\hline HEMBL39 & & 5 & 916 & ST \\
\hline HEMBL3 & & & 63 & RN \\
\hline HEMBL3 & & 39 & 24 & $\mathrm{RN}$ \\
\hline HEMBL398 & & & 037 & is \\
\hline HEMBL3933200 & 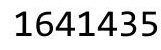 & 45 & 331 & TRN \\
\hline HEMBL397 & & & 638 & TRN \\
\hline HFMRI 3 & & & & RN \\
\hline HEMBL3 & & & 1783 & RN \\
\hline HEMBL3920833 & 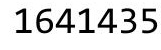 & 6.8962 & 7911 & TRN \\
\hline HEMBL 205 & & & 9947 & $\Gamma \mathrm{RN}$ \\
\hline HEMBL 395 & 6 & 29 & 171 & \\
\hline CHEMBL393 & & & 7.6259 & RN \\
\hline HEMBL393 & 16 & 8.0458 & & RN \\
\hline HEMBL 397 & 6 & 7.5086 & 5039 & TRN \\
\hline $\mathrm{MBI} 3$ & & & 728 & \\
\hline HEMBL 39 & & & 7325 & \\
\hline CHEMBL 394 & & & 8.4983 & \\
\hline CHEMBL3941306 & 1641435 & 6.0496 & 6.3523 & RN \\
\hline
\end{tabular}

Page 12536 


\begin{tabular}{|c|c|c|c|c|c|c|}
\hline \multicolumn{7}{|c|}{ Supplemental Table s2.txt } \\
\hline CHEMBL3983397 & 1641435 & 6.51 & 6.6931 & TRN & & \\
\hline CHEMBL3971091 & 1641435 & 8.8861 & 8.6488 & TRN & & \\
\hline CHEMBL3950202 & 1641435 & 8.7447 & 8.48 & TRN & & \\
\hline CHEMBL3903759 & 1641435 & 8.301 & 7.766 & TRN & & \\
\hline CHEMBL3895535 & 1641435 & 7.2924 & 6.985 & TRN & & \\
\hline CHEMBL3983746 & 1641435 & 8.301 & 7.57600 & 000000000 & TST & \\
\hline CHEMBL3934647 & 1641435 & 6.8041 & 6.4836 & TRN & & \\
\hline CHEMBL3983566 & 1641435 & 8.9586 & 8.9352 & TRN & & \\
\hline CHEMBL 3890231 & 1641435 & 7.3188 & 6.7135 & TST & & \\
\hline CHEMBL3919943 & 1641435 & 7.2924 & 7.4497 & TRN & & \\
\hline CHEMBL3961793 & 1641435 & 5.9101 & 7.535 & TST & & \\
\hline CHEMBL3923695 & 1641435 & 7.4949 & 7.5375 & TRN & & \\
\hline CHEMBL3986414 & 1641435 & 8.6576 & 8.3916 & TRN & & \\
\hline CHEMBL3960133 & 1641435 & 7.2757 & 7.4125 & TRN & & \\
\hline CHEMBL3952324 & 1641435 & 7.7212 & 7.6301 & TRN & & \\
\hline CHEMBL3932639 & 1641435 & 8.1549 & 7.9597 & TRN & & \\
\hline CHEMBL3973041 & 1641435 & 8.699 & 8.6339 & TRN & & \\
\hline CHEMBL3974297 & 1641435 & 7.9586 & 7.4171 & TRN & & \\
\hline CHEMBL 3964944 & 1641435 & 6.7986 & 6.9942 & TRN & & \\
\hline CHEMBL3892401 & 1641435 & 7.6021 & 8.0016 & TRN & & \\
\hline CHEMBL3973462 & 1641435 & 5.3757 & 6.9272 & TST & & \\
\hline CHEMBL3949296 & 1641435 & 7.2518 & 7.341 & TRN & & \\
\hline CHEMBL3949339 & 1641435 & 6.9788 & 7.0187 & TRN & & \\
\hline CHEMBL3966359 & 1641435 & 5.4949 & 7.593 & TST & & \\
\hline CHEMBL3958068 & 1641435 & 8.0458 & 8.6205 & TRN & & \\
\hline CHEMBL3961474 & 1641435 & 9.0458 & 8.831 & TRN & & \\
\hline CHEMBL3980930 & 1641435 & 7.3979 & 6.9348 & TRN & & \\
\hline CHEMBL3967416 & 1641435 & 6.8416 & 6.6559 & TST & & \\
\hline CHEMBL3937688 & 1641435 & 6.8125 & 7.0459 & TRN & & \\
\hline CHEMBL3971286 & 1641435 & 7.3565 & 7.8006 & TRN & & \\
\hline CHEMBL3890987 & 1641435 & 7.6576 & 7.6002 & TRN & & \\
\hline CHEMBL 3906574 & 1641435 & 7.1805 & 7.2236 & TRN & & \\
\hline CHEMBL 3974749 & 1641435 & 6.7959 & 6.6113 & TRN & & \\
\hline CHEMBL 2058686 & 1641435 & 8.3979 & 7.5289 & TST & & \\
\hline CHEMBL3942243 & 1641435 & 7.2518 & 7.2513 & TST & & \\
\hline CHEMBL3909439 & 1641435 & 9.1549 & 7.5356 & TST & & \\
\hline CHEMBL3933641 & 1641435 & 7.2366 & 6.6195 & TST & & \\
\hline CHEMBL3920013 & 1641435 & 6.0 & 7.7173 & TST & & \\
\hline CHEMBL 3939291 & 1641435 & 7.8861 & 8.8579 & TRN & & \\
\hline CHEMBL3972922 & 1641435 & 7.0655 & 7.3067 & TRN & & \\
\hline CHEMBL3954818 & 1637980 & 7.6778 & 7.7535 & TRN & & \\
\hline CHEMBL3972140 & 1637980 & 5.5229 & 5.6298 & TRN & & \\
\hline CHEMBL3959310 & 1637980 & 8.28399 & 99999999 & 99 & 8.062000000000001 & TRN \\
\hline CHEMBL 3975603 & 1637980 & 7.7212 & 7.6745 & TRN & & \\
\hline CHEMBL3965471 & 1637980 & 7.8239 & 7.9639 & TRN & & \\
\hline CHEMBL3911428 & 1637980 & 9.0 & 8.9123 & TRN & & \\
\hline CHEMBL3955019 & 1637980 & 8.6576 & 8.6444 & TRN & & \\
\hline CHEMBL3920315 & 1637980 & 7.0 & 6.9623 & TRN & & \\
\hline
\end{tabular}


Supplemental Table S2.txt

\begin{tabular}{|c|c|c|c|c|}
\hline CHEMBL3953227 & 1637980 & 7.8861 & 8.0097 & TRN \\
\hline CHEMBL3913600 & 1637980 & 7.0 & 9.0121 & TST \\
\hline CHEMBL3965277 & 1637980 & 8.7959 & 8.7958 & TRN \\
\hline CHEMBL3956824 & 1637980 & 7.7959 & 8.0833 & TRN \\
\hline CHEMBL3941907 & 1637980 & 7.5686 & 7.6918 & TRN \\
\hline CHEMBL3930485 & 1637980 & 8.5686 & 8.3613 & TRN \\
\hline CHEMBL3891951 & 1637980 & 7.3188 & 8.164 & TST \\
\hline CHEMBL3942640 & 1637980 & 7.699 & 7.5064 & TRN \\
\hline CHEMBL3932298 & 1637980 & 8.0 & 7.8997 & TRN \\
\hline CHEMBL3984641 & 1637980 & 8.3872 & 8.48200 & 0000000001 \\
\hline CHEMBL3931953 & 1637980 & 7.9586 & 7.776 & TRN \\
\hline CHEMBL3904637 & 1637980 & 7.9431 & 7.7947 & TST \\
\hline CHEMBL 3894732 & 1637980 & 8.1938 & 8.4409 & TRN \\
\hline CHEMBL 3985867 & 1637980 & 7.5528 & 7.414 & TRN \\
\hline CHEMBL 3944307 & 1637980 & 7.3565 & 7.3349 & TRN \\
\hline CHEMBL3903603 & 1637980 & 7.4559 & 7.5137 & TRN \\
\hline CHEMBL3899567 & 1637980 & 7.0223 & 7.6151 & TST \\
\hline CHEMBL 3980946 & 1637980 & 6.0 & 6.1141 & TRN \\
\hline CHEMBL 3928528 & 1637980 & 7.9208 & 7.9939 & TRN \\
\hline CHEMBL3959357 & 1637980 & 8.3468 & 8.288 & TRN \\
\hline CHEMBL3905305 & 1637980 & 8.5528 & 8.4928 & TRN \\
\hline CHEMBL3966821 & 1637980 & 7.699 & 7.2383 & TST \\
\hline CHEMBL3965764 & 1637980 & 6.5229 & 6.5088 & TRN \\
\hline CHEMBL3986713 & 1637980 & 7.6198 & 7.5905 & TRN \\
\hline CHEMBL3948411 & 1637980 & 7.4685 & 7.3717 & TRN \\
\hline CHEMBL3986951 & 1637980 & 8.2007 & 8.2739 & TRN \\
\hline CHEMBL3946759 & 1637980 & 7.9208 & 7.9655 & TRN \\
\hline CHEMBL3984370 & 1637980 & 7.8239 & 7.74100 & 00000000005 \\
\hline CHEMBL3956618 & 1637980 & 8.0088 & 8.1336 & TRN \\
\hline CHEMBL3965452 & 1637980 & 8.8239 & 8.6121 & TRN \\
\hline CHEMBL3971962 & 1637980 & 7.8239 & 7.8844 & TRN \\
\hline CHEMBL3925826 & 1637980 & 7.5376 & 7.6485 & TRN \\
\hline CHEMBL3914097 & 1637980 & 9.0 & 9.0424 & TRN \\
\hline CHEMBL3918357 & 1637980 & 7.6383 & 7.6746 & TRN \\
\hline CHEMBL3889841 & 1637980 & 6.9508 & 7.1969 & TST \\
\hline CHEMBL3981871 & 1637980 & 7.9393 & 7.7477 & TST \\
\hline CHEMBL3903553 & 1637980 & 8.0969 & 8.1956 & TRN \\
\hline CHEMBL3925855 & 1637980 & 8.2076 & 8.2894 & TRN \\
\hline CHEMBL3921873 & 1637980 & 8.0 & 7.8172 & TRN \\
\hline CHEMBL3951147 & 1637980 & 8.2366 & 8.265 & TRN \\
\hline CHEMBL3890452 & 1637980 & 7.5229 & 7.4447 & TRN \\
\hline CHEMBL3894668 & 1637980 & 6.0 & 5.9823 & TRN \\
\hline CHEMBL3909731 & 1637980 & 7.7447 & 7.6383 & TRN \\
\hline CHEMBL3952496 & 1637980 & 8.0969 & 8.0151 & TRN \\
\hline CHEMBL3984623 & 1637980 & 6.9747 & 6.9484 & TST \\
\hline CHEMBL 3907574 & 1637980 & 7.6778 & 7.5698 & TRN \\
\hline CHEMBL3947527 & 1637980 & 8.2518 & 8.2284 & TRN \\
\hline CHEMBL3896427 & 1637980 & 8.0969 & 8.2294 & TRN \\
\hline
\end{tabular}


Supplemental Table S2.txt

\begin{tabular}{|c|c|c|c|c|}
\hline CHEMBL3936736 & 1637980 & 8.4437 & 8.3117 & TRN \\
\hline CHEMBL3963901 & 1637980 & 8.0223 & 7.5838 & TRN \\
\hline CHEMBL3951790 & 1637980 & 6.8539 & 6.689 & TST \\
\hline CHEMBL3959522 & 1637980 & 7.6576 & 7.6854 & TRN \\
\hline CHEMBL3889849 & 1637980 & 7.3565 & 7.8219 & TST \\
\hline CHEMBL3958163 & 1637980 & 8.1249 & 8.0171 & TRN \\
\hline CHEMBL3958174 & 1637980 & 6.0 & 6.0438 & TRN \\
\hline CHEMBL3916334 & 1637980 & 7.9208 & 7.8117 & TRN \\
\hline CHEMBL3962576 & 1637980 & 8.6778 & 8.4848 & TRN \\
\hline CHEMBL3903680 & 1637980 & 6.0 & 5.9748 & TRN \\
\hline CHEMBL3900618 & 1637980 & 8.3979 & 8.679 & TRN \\
\hline CHEMBL3961315 & 1637980 & 7.5229 & 7.6511 & TRN \\
\hline CHEMBL3972427 & 1637980 & 7.7696 & 7.7764 & TRN \\
\hline CHEMBL3938388 & 1637980 & 7.2218 & 7.2534 & TST \\
\hline CHEMBL3908857 & 1637980 & 7.8416 & 7.5849 & TRN \\
\hline CHEMBL3907378 & 1637980 & 7.0269 & 7.0569 & TRN \\
\hline CHEMBL3891895 & 1637980 & 8.585 & 8.6278 & TRN \\
\hline CHEMBL3968859 & 1637980 & 7.301 & 6.8398 & TST \\
\hline CHEMBL3891979 & 1637980 & 8.2757 & 8.4183 & TRN \\
\hline CHEMBL3899112 & 1637980 & 8.5686 & 8.4647 & TRN \\
\hline CHEMBL3968184 & 1637980 & 6.5229 & 6.5571 & TRN \\
\hline CHEMBL3910043 & 1637980 & 9.0 & 8.0808 & TST \\
\hline CHEMBL3978265 & 1637980 & 7.6576 & 7.6737 & TRN \\
\hline CHEMBL3914819 & 1637980 & 8.4089 & 8.5407 & TRN \\
\hline CHEMBL3907423 & 1637980 & 8.301 & 8.3294 & TRN \\
\hline CHEMBL3900801 & 1637980 & 8.1549 & 8.0305 & TRN \\
\hline CHEMBL3947493 & 1637980 & 8.1135 & 8.1032 & TRN \\
\hline CHEMBL3974881 & 1637980 & 7.6021 & 7.8452 & TRN \\
\hline CHEMBL3912174 & 1637980 & 8.1024 & 8.2441 & TRN \\
\hline CHEMBL3969695 & 1637980 & 8.0 & 7.9683 & TRN \\
\hline CHEMBL3974908 & 1637980 & 8.0 & 7.9151 & TRN \\
\hline CHEMBL3904168 & 1637980 & 8.4202 & 8.3843 & TRN \\
\hline CHEMBL3945318 & 1637980 & 7.6383 & 7.6423 & TRN \\
\hline CHEMBL3901827 & 1637980 & 7.9586 & 7.9975 & TRN \\
\hline CHEMBL3918836 & 1637980 & 6.0 & 5.7964 & TRN \\
\hline CHEMBL3985150 & 1637980 & 8.5229 & 8.6676 & TRN \\
\hline CHEMBL3911423 & 1637980 & 8.3372 & 8.1066 & TRN \\
\hline CHEMBL3978730 & 1637980 & 7.699 & 7.3232 & TST \\
\hline CHEMBL3906315 & 1637980 & 8.699 & 8.7448 & TRN \\
\hline CHEMBL3933175 & 1637980 & 8.1487 & 8.0844 & TRN \\
\hline CHEMBL3891135 & 1637980 & 7.0 & 7.07799 & 9999999999 \\
\hline CHEMBL3965963 & 1637980 & 7.8861 & 8.0684 & TRN \\
\hline CHEMBL3963477 & 1637980 & 8.3188 & 8.2848 & TRN \\
\hline CHEMBL3899200 & 1637980 & 8.2518 & 8.1855 & TRN \\
\hline CHEMBL3920383 & 1637980 & 8.3279 & 7.6599 & TST \\
\hline CHEMBL3935569 & 1637980 & 7.5528 & 7.7802 & TRN \\
\hline CHEMBL3938361 & 1637980 & 7.9393 & 7.5302 & TST \\
\hline CHEMBL3927752 & 1637980 & 6.9747 & 7.2564 & TST \\
\hline
\end{tabular}


Supplemental Table S2.txt

\begin{tabular}{|c|c|c|c|c|}
\hline CHEMBL 3915544 & 1637980 & 7.4559 & 8.4574 & TST \\
\hline CHEMBL3915607 & 1637980 & 8.3565 & 8.4381 & TRN \\
\hline CHEMBL3967940 & 1637980 & 8.2366 & 7.9511 & TST \\
\hline CHEMBL3953173 & 1637980 & 7.7959 & 8.016 & TRN \\
\hline CHEMBL 3963146 & 1637980 & 8.5376 & 8.4351 & TST \\
\hline CHEMBL 3904608 & 1637980 & 8.3372 & 7.0106 & TST \\
\hline CHEMBL3967498 & 1637980 & 7.4559 & 8.2376 & TST \\
\hline CHEMBL 3942288 & 1637980 & 7.4815 & 7.4212 & TRN \\
\hline CHEMBL3954085 & 1637980 & 7.5376 & 7.6412 & TST \\
\hline CHEMBL 3982880 & 1637980 & 8.0555 & 8.0461 & TRN \\
\hline CHEMBL 3963347 & 1637980 & 8.1805 & 7.4462 & TST \\
\hline CHEMBL3922509 & 1637980 & 7.301 & 7.3361 & TRN \\
\hline CHEMBL3960830 & 1637980 & 8.6383 & 8.1025 & TST \\
\hline CHEMBL3979120 & 1637980 & 7.5229 & 7.6834 & TST \\
\hline CHEMBL 3912410 & 1637980 & 6.5229 & 7.8375 & TST \\
\hline CHEMBL3915626 & 1637980 & 7.5528 & 7.5533 & TRN \\
\hline CHEMBL3965725 & 1637980 & 7.6383 & 7.4756 & TRN \\
\hline CHEMBL 3899028 & 1637980 & 8.301 & 8.561 & TST \\
\hline CHEMBL 3973118 & 1637980 & 6.5229 & 6.8866 & TST \\
\hline CHEMBL 3949546 & 1637980 & 8.2518 & 7.9788 & TST \\
\hline CHEMBL 3977771 & 1637980 & 7.6778 & 7.6765 & TRN \\
\hline CHEMBL3953791 & 1637980 & 7.0605 & 6.6771 & TST \\
\hline CHEMBL3899609 & 1637980 & 8.4815 & 8.3867 & TRN \\
\hline CHEMBL 3897909 & 1637980 & 7.8239 & 7.7551 & TST \\
\hline CHEMBL 3892583 & 1637980 & 7.301 & 7.3234 & TRN \\
\hline CHEMBL 3925024 & 1637980 & 8.4202 & 8.2072 & TRN \\
\hline CHEMBL 3940103 & 1637980 & 6.0 & 6.4558 & TRN \\
\hline CHEMBL61154 & 214387 & 6.4437 & 6.6418 & TRN \\
\hline CHEMBL 302233 & 214387 & 5.5528 & 5.5935 & TRN \\
\hline CHEMBL 60726 & 214387 & 5.5086 & 5.3875 & TRN \\
\hline CHEMBL64520 & 214387 & 5.4318 & 5.4448 & TRN \\
\hline CHEMBL59699 & 214387 & 6.6021 & 6.5489 & TRN \\
\hline CHEMBL60323 & 214387 & 6.2076 & 6.0418 & TRN \\
\hline CHEMBL293922 & 214387 & 5.5086 & \multicolumn{2}{|c|}{5.507000000000001} \\
\hline CHEMBL 61578 & 214387 & 5.0757 & 5.2949 & TRN \\
\hline CHEMBL64332 & 214387 & 5.8539 & 5.5616 & TRN \\
\hline CHEMBL60054 & 214387 & 5.8861 & 5.3975 & TRN \\
\hline CHEMBL296908 & 214387 & 6.3565 & 6.5809 & TRN \\
\hline CHEMBL59754 & 214387 & 6.5229 & 6.6762 & TRN \\
\hline CHEMBL60096 & 214387 & 6.6778 & 6.6341 & TRN \\
\hline CHEMBL64319 & 214387 & 4.585 & 5.5384 & TST \\
\hline CHEMBL303111 & 214387 & 3.0 & 5.515 & TST \\
\hline CHEMBL293905 & 214387 & 7.0 & 6.5379 & TRN \\
\hline CHEMBL64811 & 214387 & 5.9208 & \multicolumn{2}{|c|}{5.513999999999999} \\
\hline CHEMBL59567 & 214387 & 3.0 & 5.3236 & TRN \\
\hline CHEMBL59896 & 214387 & 6.301 & 5.5861 & TRN \\
\hline CHEMBL64436 & 214387 & 6.1079 & 6.6532 & TRN \\
\hline CHEMBL304486 & 214387 & 6.1249 & 6.4552 & TRN \\
\hline
\end{tabular}

Page 12540 


\begin{tabular}{|c|c|c|c|c|}
\hline \multicolumn{5}{|c|}{ Supplemental Table S2.txt } \\
\hline CHEMBL62344 & 214387 & 5.4559 & 5.7678 & TRN \\
\hline CHEMBL61906 & 214387 & 6.3279 & 5.6182 & TRN \\
\hline CHEMBL60672 & 214387 & 6.6198 & 6.5259 & TRN \\
\hline CHEMBL304485 & 214387 & 6.4815 & 6.4975 & TRN \\
\hline CHEMBL59740 & 214387 & 6.4949 & 6.4835 & TRN \\
\hline CHEMBL60502 & 214387 & 5.8539 & 5.5251 & TRN \\
\hline CHEMBL59947 & 214387 & 5.7212 & 5.2856 & TRN \\
\hline CHEMBL416505 & 214387 & 4.4318 & 5.3406 & TRN \\
\hline CHEMBL293177 & 214387 & 5.0044 & 5.2886 & TRN \\
\hline CHEMBL294293 & 214387 & 4.9586 & 5.4204 & TST \\
\hline CHEMBL60905 & 214387 & 7.1675 & 6.5379 & TRN \\
\hline CHEMBL60736 & 214387 & 6.6778 & 6.3311 & TRN \\
\hline CHEMBL418692 & 214387 & 6.5528 & 6.5379 & TRN \\
\hline CHEMBL60312 & 214387 & 5.2007 & 5.38 & TRN \\
\hline CHEMBL60262 & 214387 & 5.8861 & 5.4737 & TRN \\
\hline CHEMBL64695 & 214387 & 6.3768 & 6.5982 & TRN \\
\hline CHEMBL431159 & 214387 & 6.301 & 5.4721 & TRN \\
\hline CHEMBL431723 & 214387 & 5.8239 & 6.7169 & TRN \\
\hline CHEMBL303134 & 214387 & 6.9208 & 6.6762 & TRN \\
\hline CHEMBL59397 & 214387 & 4.9586 & 5.4554 & TRN \\
\hline CHEMBL59900 & 214387 & 6.4559 & 6.0438 & TRN \\
\hline CHEMBL293184 & 214387 & 6.301 & 5.7966 & TRN \\
\hline CHEMBL64836 & 214387 & 5.4318 & 5.7325 & TRN \\
\hline CHEMBL64434 & 214387 & 5.3565 & 5.4196 & TRN \\
\hline CHEMBL293863 & 214387 & 6.4815 & 5.8915 & TST \\
\hline CHEMBL301850 & 214387 & 6.7959 & 6.6762 & TST \\
\hline CHEMBL302624 & 214387 & 6.2676 & 6.4959 & TST \\
\hline CHEMBL61688 & 214387 & 5.699 & 5.4406 & TST \\
\hline CHEMBL64375 & 214387 & 5.0757 & 5.4731 & TST \\
\hline CHEMBL 305588 & 214387 & 5.8239 & 5.3135 & TST \\
\hline CHEMBL60773 & 214387 & 4.9208 & 5.5152 & TST \\
\hline CHEMBL60954 & 214387 & 6.3768 & 6.4685 & TST \\
\hline CHEMBL61947 & 214387 & 5.699 & 6.3627 & TST \\
\hline CHEMBL304430 & 214387 & 5.6021 & 5.4496 & TST \\
\hline CHEMBL305309 & 214387 & 3.0 & 5.3966 & TST \\
\hline CHEMBL64046 & 214387 & 6.3098 & 5.9211 & TST \\
\hline CHEMBL577122 & 595939 & 4.0 & 3.6991 & TRN \\
\hline CHEMBL399873 & 595939 & 4.0 & 4.8262 & TST \\
\hline CHEMBL576519 & 595939 & 4.0 & 3.9329 & TRN \\
\hline CHEMBL464466 & 595939 & 4.0 & 5.2843 & TST \\
\hline CHEMBL1478 & 595939 & 5.2518 & 4.4837 & TST \\
\hline CHEMBL567770 & 595939 & 4.0 & 4.2135 & TRN \\
\hline CHEMBL571642 & 595939 & 4.0 & 4.084 & TRN \\
\hline CHEMBL571415 & 595939 & 4.0 & 3.9413 & TRN \\
\hline CHEMBL571478 & 595939 & 5.4989 & 5.5995 & TRN \\
\hline CHEMBL566930 & 595939 & 4.0 & 3.9452 & TRN \\
\hline CHEMBL446317 & 595939 & 4.0 & 3.8739 & TRN \\
\hline CHEMBL486393 & 595939 & 4.0 & 4.0648 & TRN \\
\hline
\end{tabular}




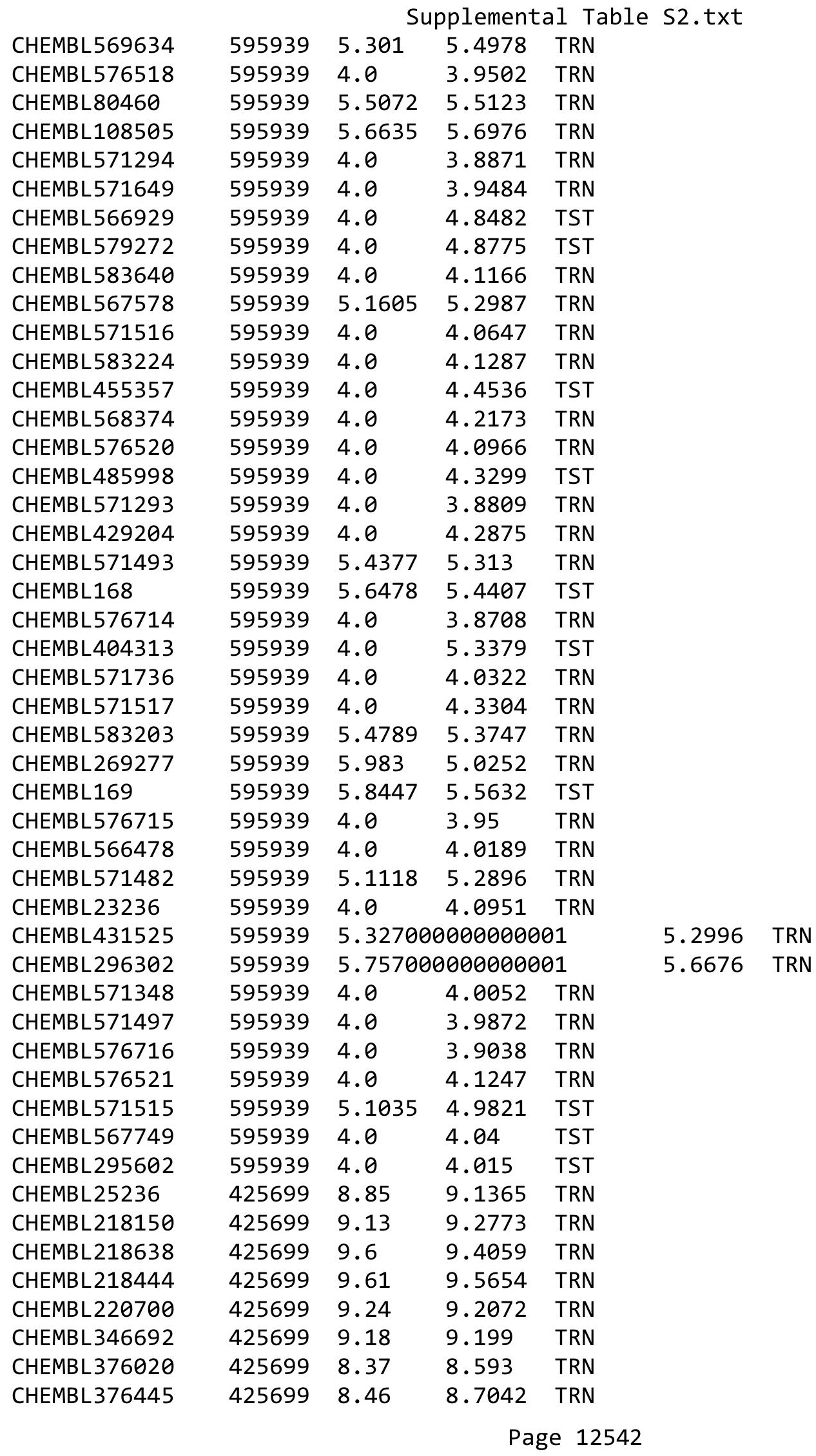




\begin{tabular}{|c|c|c|c|c|c|}
\hline \multicolumn{6}{|c|}{ Supplemental Table S2.txt } \\
\hline CHEMBL221681 & 425699 & 9.16 & 8.9965 & TRN & \\
\hline CHEMBL139926 & 425699 & 8.95 & 8.9746 & TRN & \\
\hline CHEMBL124444 & 425699 & 8.95 & 9.0212 & TRN & \\
\hline CHEMBL218368 & 425699 & 9.42 & 9.4191 & TRN & \\
\hline CHEMBL218318 & 425699 & 9.34 & 9.2841 & TRN & \\
\hline CHEMBL221397 & 425699 & 9.41 & 9.4587 & TRN & \\
\hline CHEMBL59725 & 425699 & 9.3 & 9.3648 & TRN & \\
\hline CHEMBL424294 & 425699 & 9.63 & 9.4526 & TRN & \\
\hline CHEMBL374749 & 425699 & 9.55 & 9.6772 & TRN & \\
\hline CHEMBL221549 & 425699 & 8.51 & 8.424 & TRN & \\
\hline CHEMBL219274 & 425699 & 8.77 & 8.8596 & TRN & \\
\hline CHEMBL218203 & 425699 & 9.0 & 8.8805 & TRN & \\
\hline CHEMBL210955 & 425699 & 5.72 & 5.7761 & TRN & \\
\hline CHEMBL210405 & 425699 & 6.85 & 5.9119 & TST & \\
\hline CHEMBL210404 & 425699 & 7.14 & 6.1878 & TST & \\
\hline CHEMBL425057 & 425699 & 6.8 & 6.1386 & TST & \\
\hline CHEMBL310843 & 425699 & 5.28 & 5.8513 & TST & \\
\hline CHEMBL160952 & 425699 & 5.34 & 6.1017 & TST & \\
\hline CHEMBL423247 & 425699 & 5.43 & 5.534 & TST & \\
\hline CHEMBL218787 & 425699 & 5.57 & 5.6951 & TST & \\
\hline CHEMBL345357 & 425699 & 5.59 & 5.7784 & TST & \\
\hline CHEMBL 7927 & 425699 & 5.41 & 5.5807 & TST & \\
\hline CHEMBL344677 & 425699 & 7.54 & 7.5925 & TRN & \\
\hline CHEMBL 342060 & 425699 & 8.55 & 8.7802 & TRN & \\
\hline CHEMBL143352 & 425699 & 7.7 & 7.8387 & TRN & \\
\hline CHEMBL139600 & 425699 & 7.19 & 7.41100 & 00000000005 & TRN \\
\hline CHEMBL141845 & 425699 & 6.44 & 6.3014 & TRN & \\
\hline CHEMBL140968 & 425699 & 7.29 & 7.5701 & TRN & \\
\hline CHEMBL142020 & 425699 & 8.37 & 7.5802 & TRN & \\
\hline CHEMBL357684 & 425699 & 6.19 & 6.5415 & TRN & \\
\hline CHEMBL139722 & 425699 & 6.6 & 6.4566 & TRN & \\
\hline CHEMBL218151 & 425699 & 9.45 & 9.2208 & TRN & \\
\hline CHEMBL221129 & 425699 & 8.13 & 8.0394 & TRN & \\
\hline CHEMBL386986 & 425699 & 8.46 & 8.0698 & TRN & \\
\hline CHEMBL217981 & 425699 & 7.82 & 7.5495 & TRN & \\
\hline CHEMBL385289 & 425699 & 7.49 & 7.5589 & TRN & \\
\hline CHEMBL218351 & 425699 & 7.89 & 7.8916 & TRN & \\
\hline CHEMBL220754 & 425699 & 7.06 & 7.41200 & 0000000001 & TRN \\
\hline CHEMBL221866 & 425699 & 7.47 & 7.4289 & TRN & \\
\hline CHEMBL437525 & 425699 & 7.54 & 7.4083 & TRN & \\
\hline CHEMBL218607 & 425699 & 7.96 & 8.0938 & TRN & \\
\hline CHEMBL425285 & 425699 & 8.62 & 8.615 & TRN & \\
\hline CHEMBL221587 & 425699 & 7.8 & 7.5642 & TRN & \\
\hline CHEMBL221897 & 425699 & 8.07 & 8.0794 & TRN & \\
\hline CHEMBL 221843 & 425699 & 7.17 & 7.5642 & TRN & \\
\hline CHEMBL 373873 & 425699 & 8.37 & 8.0746 & TRN & \\
\hline CHEMBL267014 & 425699 & 4.51 & 5.5942 & TST & \\
\hline CHEMBL221814 & 425699 & 7.03 & 5.7103 & TST & \\
\hline
\end{tabular}




\begin{tabular}{|c|c|c|c|c|c|}
\hline \multirow{2}{*}{ CHEMBL 221600} & \multirow{2}{*}{425699} & \\
\hline & & 7.48 & \multicolumn{2}{|c|}{5.752999999999999} & TST \\
\hline & 425699 & 6.49 & 5.8738 & TST & \\
\hline CHEMBL 208018 & 425699 & 6.44 & 6.1337 & TST & \\
\hline CHEMBL210717 & 425699 & 7.17 & 6.3449 & TST & \\
\hline CHEMBL437490 & 425699 & 6.27 & 6.2563 & TST & \\
\hline CHEMBL412204 & 103941 & 5.0 & 4.994 & TRN & \\
\hline CHEMBL 2370219 & 103941 & 3.0 & 2.9508 & TRN & \\
\hline CHEMBL415792 & 103941 & 4.3979 & 4.7377 & TRN & \\
\hline CHEMBL437840 & 103941 & 5.6778 & 5.5895 & TRN & \\
\hline CHEMBL 267368 & 103941 & 4.9208 & 4.9475 & TRN & \\
\hline CHEMBL3215342 & 103941 & 3.0 & 3.6013 & TST & \\
\hline CHEMBL 3215340 & 103941 & 3.0 & 3.0041 & TRN & \\
\hline CHEMBL429343 & 103941 & 5.0605 & 4.9525 & TRN & \\
\hline CHEMBL267410 & 103941 & 4.9586 & 5.0372 & TRN & \\
\hline CHEMBL 266527 & 103941 & 4.0862 & 4.11 & TRN & \\
\hline CHEMBL 2304060 & 103941 & 5.1135 & 3.8722 & TST & \\
\hline CHEMBL406690 & 103941 & 4.8539 & 4.8295 & TRN & \\
\hline CHEMBL440635 & 103941 & 5.7696 & \multicolumn{2}{|c|}{5.832999999999999} & TRN \\
\hline CHEMBL269379 & 103941 & 4.9586 & 5.0017 & TRN & \\
\hline CHEMBL 263998 & 103941 & 4.9586 & 4.8505 & TRN & \\
\hline CHEMBL 2304315 & 103941 & 5.0969 & 4.5922 & TST & \\
\hline CHEMBL384264 & 103941 & 4.9208 & 4.8334 & TRN & \\
\hline CHEMBL 2304149 & 103941 & 4.3979 & 5.0687 & TST & \\
\hline CHEMBL411769 & 103941 & 3.0 & 3.6624 & TST & \\
\hline CHEMBL405267 & 103941 & 4.3979 & 4.3801 & TRN & \\
\hline CHEMBL263485 & 103941 & 5.0757 & 4.8966 & TRN & \\
\hline CHEMBL415132 & 103941 & 4.3979 & 4.5033 & TRN & \\
\hline CHEMBL405708 & 103941 & 4.8539 & 4.5866 & TRN & \\
\hline CHEMBL405483 & 103941 & 5.1612 & 5.0316 & TRN & \\
\hline CHEMBL 217475 & 103941 & 4.3979 & \multicolumn{2}{|c|}{4.4110000000000005} & TRN \\
\hline CHEMBL267424 & 103941 & 5.0969 & 5.2118 & TST & \\
\hline CHEMBL 264310 & 103941 & 5.3565 & 5.3526 & TRN & \\
\hline CHEMBL411390 & 103941 & 4.3279 & 4.5239 & TRN & \\
\hline CHEMBL 2367780 & 103941 & 3.0 & 3.7452 & TST & \\
\hline CHEMBL444020 & 103941 & 4.0605 & 4.4683 & TST & \\
\hline CHEMBL410210 & 103941 & 5.1192 & 5.1871 & TRN & \\
\hline CHEMBL407397 & 103941 & 5.1249 & 4.9855 & TRN & \\
\hline CHEMBL428274 & 103941 & 4.3979 & \multicolumn{2}{|c|}{4.4110000000000005} & TRN \\
\hline CHEMBL415231 & 103941 & 3.699 & 3.4787 & TRN & \\
\hline CHEMBL 267982 & 103941 & 4.7212 & \multicolumn{2}{|c|}{4.656000000000001} & TRN \\
\hline CHEMBL387070 & 103941 & 4.8861 & 4.8956 & TRN & \\
\hline CHEMBL 217361 & 103941 & 5.4437 & \multicolumn{2}{|c|}{5.492000000000001} & TRN \\
\hline CHEMBL267216 & 103941 & 4.585 & 5.4591 & TST & \\
\hline CHEMBL384064 & 103941 & 4.5686 & 4.3403 & TST & \\
\hline CHEMBL 217364 & 103941 & 5.0088 & 5.1607 & TRN & \\
\hline CHEMBL412977 & 103941 & 4.3979 & \multicolumn{2}{|c|}{4.4239999999999995} & TRN \\
\hline CHEMBL414553 & 103941 & 5.1612 & 5.1174 & TRN & \\
\hline CHEMBL265142 & 103941 & 4.9208 & 4.9384 & TRN & \\
\hline
\end{tabular}




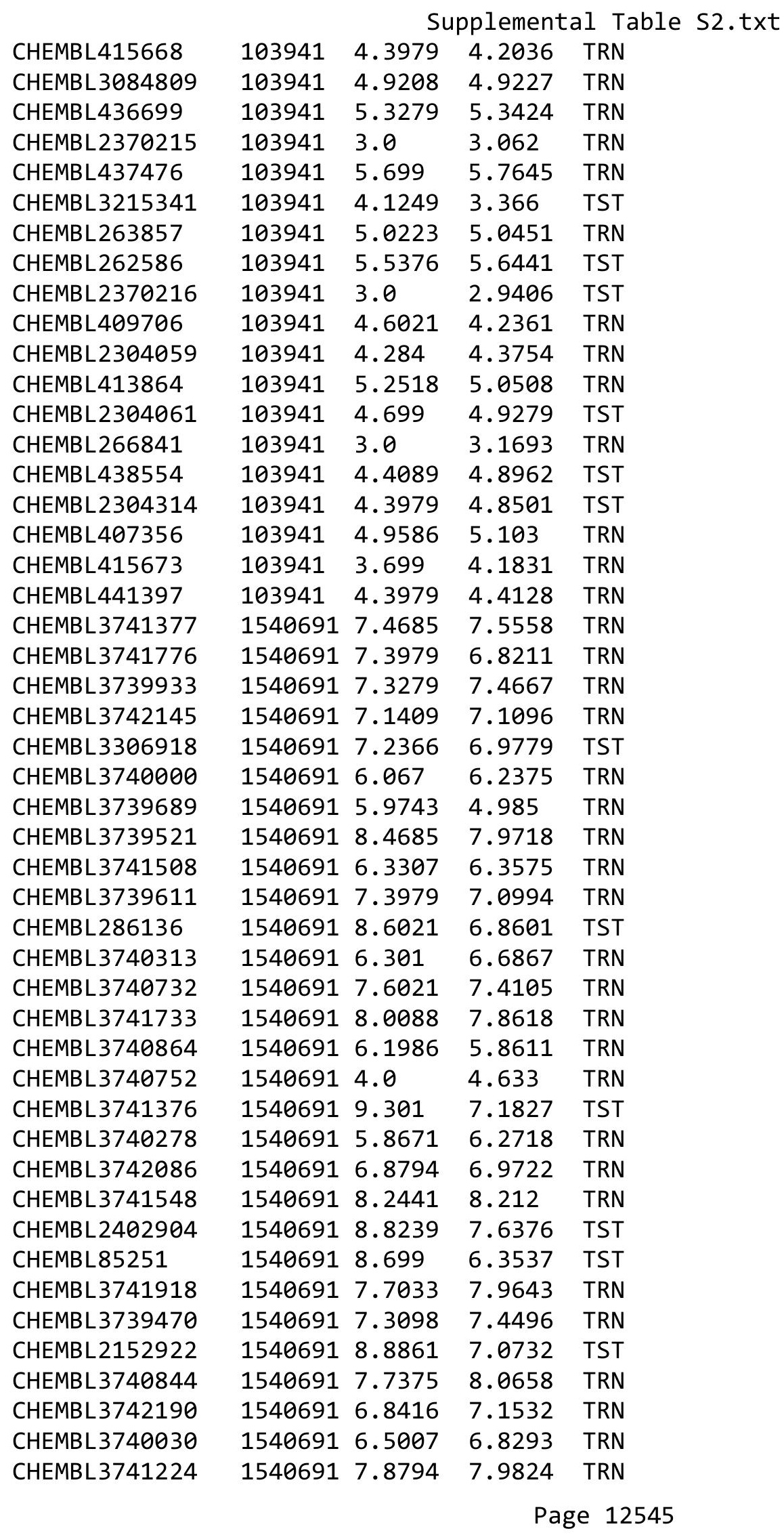


Supplemental Table S2.txt

\begin{tabular}{|c|c|c|c|c|c|}
\hline CHEMBL3739467 & 1540691 & 6.1331 & 5.9233 & TRN & \\
\hline CHEMBL3740400 & 1540691 & 7.301 & 7.261 & TRN & \\
\hline CHEMBL3739931 & 1540691 & 7.7447 & 7.8336 & TRN & \\
\hline CHEMBL3741199 & 1540691 & 6.0757 & 6.0112 & TRN & \\
\hline CHEMBL3741608 & 1540691 & 8.0 & 7.8578 & TRN & \\
\hline CHEMBL3741322 & 1540691 & 7.3098 & \multicolumn{2}{|c|}{7.242000000000001} & TRN \\
\hline CHEMBL3739455 & 1540691 & 6.284 & 6.1342 & TRN & \\
\hline CHEMBL 3742080 & 1540691 & 7.0555 & 6.7763 & TRN & \\
\hline CHEMBL 3741403 & 1540691 & 4.0 & 4.4014 & TRN & \\
\hline CHEMBL3740708 & 1540691 & 6.8416 & 7.2266 & TRN & \\
\hline CHEMBL3739647 & 1540691 & 7.5086 & 7.7712 & TRN & \\
\hline CHEMBL3739862 & 1540691 & 7.9586 & 7.8724 & TRN & \\
\hline CHEMBL3740472 & 1540691 & 7.6576 & 7.3047 & TRN & \\
\hline CHEMBL3740669 & 1540691 & 8.0605 & 8.1238 & TRN & \\
\hline CHEMBL3741703 & 1540691 & 6.7077 & 6.6651 & TRN & \\
\hline CHEMBL3739459 & 1540691 & 7.2464 & 7.2674 & TRN & \\
\hline CHEMBL3741787 & 1540691 & 8.0132 & 7.9151 & TRN & \\
\hline CHEMBL3741595 & 1540691 & 7.7447 & 7.4598 & TST & \\
\hline CHEMBL 3742300 & 1540691 & 5.6484 & \multicolumn{2}{|c|}{6.462000000000001} & TST \\
\hline CHEMBL3741826 & 1540691 & 7.8097 & 7.3297 & TST & \\
\hline CHEMBL3739826 & 1540691 & 7.4089 & 6.5166 & TST & \\
\hline CHEMBL3741062 & 1540691 & 7.2757 & 6.8429 & TST & \\
\hline CHEMBL3740612 & 1540691 & 7.684 & 7.8341 & TST & \\
\hline CHEMBL 3740908 & 1540691 & 8.4089 & 6.9401 & TST & \\
\hline CHEMBL3741821 & 1540691 & 8.3188 & 7.5786 & TST & \\
\hline CHEMBL3416915 & 1473384 & 4.301 & 4.3045 & TRN & \\
\hline CHEMBL3414596 & 1473384 & 4.4089 & 4.8998 & TRN & \\
\hline CHEMBL3416910 & 1473384 & 4.3098 & 4.8998 & TRN & \\
\hline CHEMBL3416934 & 1473384 & 6.8539 & 6.3382 & TRN & \\
\hline CHEMBL3416887 & 1473384 & 5.4089 & 7.4997 & TST & \\
\hline CHEMBL3417041 & 1473384 & 5.7212 & 5.7963 & TRN & \\
\hline CHEMBL3416899 & 1473384 & 5.5686 & 4.8998 & TRN & \\
\hline CHEMBL3416936 & 1473384 & 6.6198 & 6.3382 & TRN & \\
\hline CHEMBL 3416889 & 1473384 & 4.3188 & 4.3154 & TRN & \\
\hline CHEMBL3416929 & 1473384 & 5.9586 & 5.947 & TRN & \\
\hline CHEMBL3416895 & 1473384 & 4.3372 & 4.8998 & TRN & \\
\hline CHEMBL3416900 & 1473384 & 5.3279 & 4.8998 & TRN & \\
\hline CHEMBL3416938 & 1473384 & 5.585 & 5.5095 & TRN & \\
\hline CHEMBL3416931 & 1473384 & 7.1549 & 7.2156 & TRN & \\
\hline CHEMBL3416943 & 1473384 & 6.2757 & 6.6222 & TRN & \\
\hline CHEMBL3416941 & 1473384 & 5.2147 & 5.1062 & TRN & \\
\hline CHEMBL3417039 & 1473384 & 5.4815 & 5.6317 & TRN & \\
\hline CHEMBL3416925 & 1473384 & 5.3279 & 5.3553 & TRN & \\
\hline CHEMBL3416903 & 1473384 & 4.301 & 4.8998 & TRN & \\
\hline CHEMBL3416922 & 1473384 & 5.699 & 5.6655 & TRN & \\
\hline CHEMBL3416935 & 1473384 & 5.4685 & 6.3382 & TRN & \\
\hline CHEMBL3416902 & 1473384 & 5.8239 & 5.8647 & TRN & \\
\hline CHEMBL3416886 & 1473384 & 6.699 & 6.3144 & TRN & \\
\hline
\end{tabular}


Supplemental Table S2.txt

\begin{tabular}{|c|c|c|c|c|}
\hline HEM & & & & \\
\hline & & 5.5229 & & \\
\hline & & & & \\
\hline HEMBL3 & & & & \\
\hline AEMBL3416892 & 473384 & 949 & 51 & \\
\hline HEMBL3416916 & 473384 & 301 & 3045 & \\
\hline 035 & 384 & & & \\
\hline 5901 & & & & \\
\hline AEMBL3 3 & 384 & & 6222 & \\
\hline HEMBL3416920 & 3384 & & 7644 & \\
\hline HEMBL3416917 & 84 & 4. & 321 & \\
\hline IEMBL3 & 384 & & & \\
\hline AEMBL3 & & & & RN \\
\hline HEMBL3 & 384 & 4. & 0852 & \\
\hline AEMBL3 & & & & \\
\hline AEMBL3 3 & 44 & 44 & 62 & \\
\hline AEMBL3 & & & & \\
\hline HEMBL3 & & & & \\
\hline HEMBL3 & & 7. & 29 & \\
\hline AEMBL3 & & 4 & & \\
\hline HEMBL & & & 33 & I NIV \\
\hline AEMBL & & & & RN \\
\hline HEMBL; & & & & \\
\hline 6888 & & & & \\
\hline AEMBL3 & & & & I RIV \\
\hline HEMBL & & & & RIN \\
\hline HEMBL & & & & 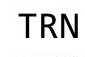 \\
\hline HFMBI : & & & & \\
\hline HEMBL3 & & & & 15 15 \\
\hline HEMBL3 & & & & $\mathrm{IR}$ \\
\hline HEMBL3 & & & 44 & RN \\
\hline HEMBL: & & & & RN \\
\hline HEMBL3 & & & 83 & - \\
\hline HEMBL34 & & & & is \\
\hline HEMBL3416926 & & 7.0 & & TST \\
\hline HEMBL3 & & & 52 & TST \\
\hline HFMRI & & & & ГST \\
\hline HEMBL3 & & & & TST \\
\hline HEMBL3 & & & 998 & TST \\
\hline AEMBL3 & & & & TST \\
\hline HEMBL3 & & & 98 & \\
\hline CHEMBL 3 & & & & TST \\
\hline HEMBL3 & 3384 & & 8912 & TST \\
\hline HEMBL33 & 7338 & 7. & 373 & TS \\
\hline MBL3 & & & & TS \\
\hline HEMBL3 & & & & \\
\hline HEMBL $3 \angle$ & & 4.3468 & 2.7427 & \\
\hline CHEMBL2426495 & 983410 & 7.0362 & 6.7397 & ГRN \\
\hline
\end{tabular}

Page 12547 
Supplemental Table S2.txt

\begin{tabular}{|c|c|c|c|c|c|}
\hline CHEMBL 2426465 & 983410 & 5.6576 & 5.6335 & TRN & \\
\hline CHEMBL 2426478 & 983410 & 6.6576 & 6.7264 & TRN & \\
\hline CHEMBL 2426365 & 983410 & 7.301 & 7.4156 & TRN & \\
\hline CHEMBL 2426474 & 983410 & 4.0 & 5.6735 & TRN & \\
\hline CHEMBL 2426498 & 983410 & 7.3188 & 6.96 & TRN & \\
\hline CHEMBL 2426361 & 983410 & 6.3468 & 6.436 & TRN & \\
\hline CHEMBL 2426494 & 983410 & 6.6021 & 6.5234 & TRN & \\
\hline CHEMBL2426489 & 983410 & 7.0915 & 7.0875 & TRN & \\
\hline CHEMBL 2426363 & 983410 & 7.1675 & 7.1629 & TRN & \\
\hline CHEMBL2426491 & 983410 & 6.0969 & 6.2275 & TRN & \\
\hline CHEMBL 2426469 & 983410 & 6.9586 & 7.0882 & TRN & \\
\hline CHEMBL 2426368 & 983410 & 7.2147 & 7.2739 & TRN & \\
\hline CHEMBL 2426482 & 983410 & 6.8239 & 6.7913 & TRN & \\
\hline CHEMBL 2426472 & 983410 & 6.0969 & 6.1515 & TRN & \\
\hline CHEMBL 2426366 & 983410 & 7.2924 & 7.4452 & TRN & \\
\hline CHEMBL 2426374 & 983410 & 6.8239 & 6.6768 & TST & \\
\hline CHEMBL 2426462 & 983410 & 6.6576 & 6.7354 & TRN & \\
\hline CHEMBL 2426471 & 983410 & 6.4559 & 6.6017 & TRN & \\
\hline CHEMBL 2426475 & 983410 & 5.0969 & 5.2981 & TRN & \\
\hline CHEMBL 2426487 & 983410 & 5.7959 & 5.7907 & TRN & \\
\hline CHEMBL 2426479 & 983410 & 6.4559 & 6.4925 & TRN & \\
\hline CHEMBL 2426497 & 983410 & 6.5376 & 6.484 & TRN & \\
\hline CHEMBL 2424677 & 983410 & 6.8539 & 6.8637 & TST & \\
\hline CHEMBL 2426376 & 983410 & 6.7959 & 6.6462 & TST & \\
\hline CHEMBL 2426484 & 983410 & 6.7959 & 5.6735 & TRN & \\
\hline CHEMBL 2426492 & 983410 & 5.4949 & 5.5687 & TRN & \\
\hline CHEMBL 2426470 & 983410 & 6.5528 & 6.5216 & TRN & \\
\hline CHEMBL 2426485 & 983410 & 6.6778 & 5.6735 & TRN & \\
\hline CHEMBL 2426461 & 983410 & 6.5229 & 6.5925 & TRN & \\
\hline CHEMBL 2426493 & 983410 & 6.1135 & 6.0559 & TRN & \\
\hline CHEMBL 2426473 & 983410 & 5.7212 & 5.9513 & TST & \\
\hline CHEMBL 2426468 & 983410 & 5.3468 & 5.249 & TST & \\
\hline CHEMBL 2426467 & 983410 & 5.4559 & 5.5771 & TRN & \\
\hline CHEMBL1235119 & 983410 & 5.3279 & 6.0168 & TST & \\
\hline CHEMBL 2426466 & 983410 & 6.2076 & 6.1605 & TRN & \\
\hline CHEMBL 2426486 & 983410 & 5.9586 & 6.0101 & TRN & \\
\hline CHEMBL 2426481 & 983410 & 7.0132 & 7.0953 & TRN & \\
\hline CHEMBL 2426373 & 983410 & 6.4559 & 6.5759 & TST & \\
\hline CHEMBL 2426360 & 983410 & 7.3665 & 7.3945 & TRN & \\
\hline CHEMBL 2426362 & 983410 & 6.5086 & 6.6701 & TRN & \\
\hline CHEMBL 2426490 & 983410 & 7.0362 & 6.8284 & TRN & \\
\hline CHEMBL 2426477 & 983410 & 7.0555 & 6.8937 & TRN & \\
\hline CHEMBL 2426488 & 983410 & 6.7447 & \multicolumn{2}{|c|}{6.837999999999999} & TRN \\
\hline CHEMBL 2426483 & 983410 & 6.8861 & 6.9251 & TRN & \\
\hline CHEMBL 2426367 & 983410 & 7.2757 & 7.246 & TRN & \\
\hline CHEMBL 2426496 & 983410 & 7.1308 & 7.0882 & TRN & \\
\hline CHEMBL 2424678 & 983410 & 7.2147 & 7.0504 & TRN & \\
\hline CHEMBL2426359 & 983410 & 6.6198 & 6.6922 & TRN & \\
\hline
\end{tabular}

Page 12548 
Supplemental Table S2.txt

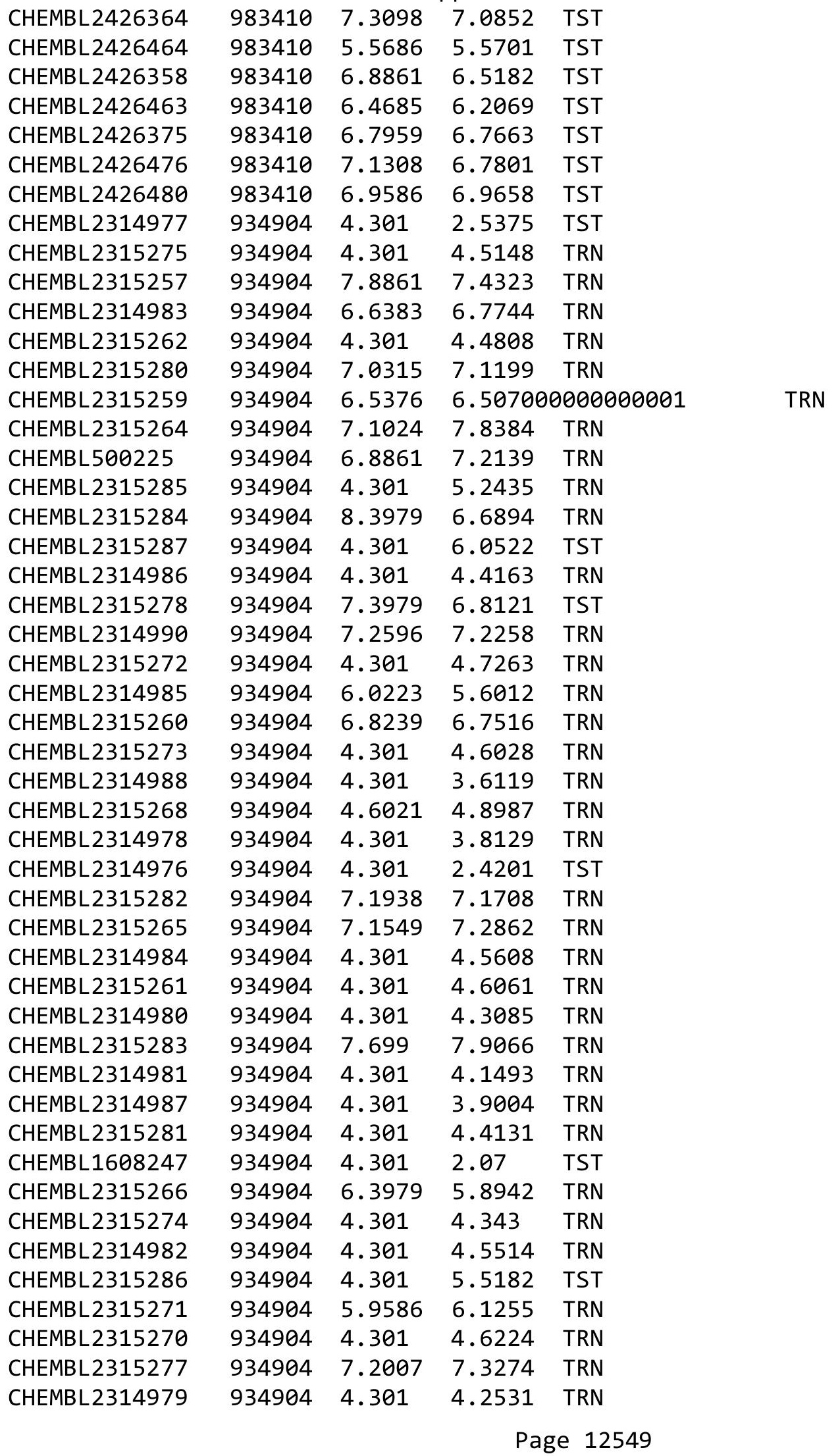




\begin{tabular}{|c|c|c|c|c|}
\hline \multicolumn{5}{|c|}{ Supplemental Table S2.txt } \\
\hline CHEMBL 2315267 & 934904 & 7.4815 & 7.0684 & TRN \\
\hline CHEMBL2315269 & 934904 & 4.301 & 4.2006 & TRN \\
\hline CHEMBL2314975 & 934904 & 6.0 & 5.8387 & TRN \\
\hline CHEMBL1313756 & 934904 & 4.301 & 4.306 & TRN \\
\hline CHEMBL2315258 & 934904 & 7.2676 & 5.2375 & TST \\
\hline CHEMBL2315279 & 934904 & 7.4949 & 6.1419 & TST \\
\hline CHEMBL 2315276 & 934904 & 4.301 & 4.6602 & TST \\
\hline CHEMBL2314991 & 934904 & 7.5229 & 7.9543 & TST \\
\hline CHEMBL 2315263 & 934904 & 6.699 & 7.9501 & TST \\
\hline CHEMBL2314989 & 934904 & 4.301 & 4.7163 & TST \\
\hline CHEMBL2314992 & 934904 & 7.6198 & 6.751 & TST \\
\hline CHEMBL36462 & 209194 & 8.5229 & 8.4921 & TRN \\
\hline CHEMBL32173 & 209194 & 8.0458 & 7.791 & TRN \\
\hline CHEMBL32477 & 209194 & 7.8539 & 7.8168 & TRN \\
\hline CHEMBL 33198 & 209194 & 7.6021 & 7.4068 & TRN \\
\hline CHEMBL32533 & 209194 & 7.8861 & 7.8252 & TST \\
\hline CHEMBL35891 & 209194 & 6.8861 & 7.3153 & TRN \\
\hline CHEMBL32201 & 209194 & 8.1549 & 7.7692 & TRN \\
\hline CHEMBL32197 & 209194 & 8.699 & 8.4892 & TRN \\
\hline CHEMBL 34167 & 209194 & 7.699 & 7.3548 & TRN \\
\hline CHEMBL32431 & 209194 & 7.4559 & 7.325 & TRN \\
\hline CHEMBL32309 & 209194 & 8.0458 & 7.8547 & TRN \\
\hline CHEMBL33479 & 209194 & 7.4202 & 7.7185 & TRN \\
\hline CHEMBL 286433 & 209194 & 6.9281 & 7.1803 & TRN \\
\hline CHEMBL 33302 & 209194 & 8.0969 & 7.7958 & TRN \\
\hline CHEMBL 32700 & 209194 & 6.8861 & 7.4997 & TRN \\
\hline CHEMBL 286901 & 209194 & 8.699 & 8.3457 & TRN \\
\hline CHEMBL 285986 & 209194 & 7.9586 & 7.6744 & TRN \\
\hline CHEMBL32717 & 209194 & 7.9208 & 7.7911 & TRN \\
\hline CHEMBL 33215 & 209194 & 8.2218 & 8.4973 & TRN \\
\hline CHEMBL284597 & 209194 & 7.699 & 7.2659 & TST \\
\hline CHEMBL32163 & 209194 & 8.3979 & 8.4465 & TRN \\
\hline CHEMBL 285475 & 209194 & 6.7773 & 7.6275 & TST \\
\hline CHEMBL 290786 & 209194 & 7.7696 & 7.7846 & TRN \\
\hline CHEMBL32124 & 209194 & 9.0 & 8.5196 & TRN \\
\hline CHEMBL 287523 & 209194 & 7.6576 & 7.4578 & TRN \\
\hline CHEMBL 286646 & 209194 & 8.2218 & 8.4061 & TRN \\
\hline CHEMBL33194 & 209194 & 6.5436 & 7.5345 & TRN \\
\hline CHEMBL417490 & 209194 & 6.8665 & 7.8034 & TRN \\
\hline CHEMBL 32279 & 209194 & 8.2218 & 7.7408 & TRN \\
\hline CHEMBL 33833 & 209194 & 7.3768 & 7.6098 & TRN \\
\hline CHEMBL 284396 & 209194 & 7.7447 & 7.8005 & TRN \\
\hline CHEMBL285476 & 209194 & 8.0 & 7.1635 & TRN \\
\hline CHEMBL32537 & 209194 & 8.699 & 8.4991 & TRN \\
\hline CHEMBL 286640 & 209194 & 7.2676 & 8.1838 & TRN \\
\hline CHEMBL284269 & 209194 & 7.5528 & 7.8097 & TRN \\
\hline CHEMBL32385 & 209194 & 7.8239 & 7.755 & TRN \\
\hline CHEMBL32430 & 209194 & 8.0969 & 7.6169 & TRN \\
\hline
\end{tabular}


Supplemental Table S2.txt

\begin{tabular}{|c|c|c|c|c|c|}
\hline CHEMBL285929 & 209194 & 7.6778 & 7.6621 & TRN & \\
\hline CHEMBL 284145 & 209194 & 8.3979 & 7.5025 & TRN & \\
\hline CHEMBL 274557 & 209194 & 6.4789 & 7.2489 & TRN & \\
\hline CHEMBL 284244 & 209194 & 6.8041 & 7.3304 & TST & \\
\hline CHEMBL418224 & 209194 & 8.3979 & 8.395 & TRN & \\
\hline CHEMBL160210 & 209194 & 8.1549 & 8.3869 & TRN & \\
\hline CHEMBL 32273 & 209194 & 8.3979 & 8.44 & TST & \\
\hline CHEMBL 34460 & 209194 & 7.3665 & 7.8053 & TST & \\
\hline CHEMBL 33243 & 209194 & 8.5229 & 8.4395 & TST & \\
\hline CHEMBL33106 & 209194 & 9.0 & 7.6178 & TST & \\
\hline CHEMBL 32215 & 209194 & 7.3979 & 7.7585 & TST & \\
\hline CHEMBL 286589 & 209194 & 7.0 & 7.2791 & TST & \\
\hline CHEMBL 285422 & 209194 & 8.0969 & 8.4745 & TST & \\
\hline CHEMBL33046 & 209194 & 7.6778 & 7.7791 & TST & \\
\hline CHEMBL 33249 & 209194 & 8.699 & 7.6386 & TST & \\
\hline CHEMBL1302528 & 809358 & 3.0044 & 4.5187 & TRN & \\
\hline CHEMBL1579066 & 809358 & 5.7212 & 5.3341 & TRN & \\
\hline CHEMBL1446430 & 809358 & 3.0044 & 3.7185 & TRN & \\
\hline CHEMBL1603637 & 809358 & 5.5436 & 5.5038 & TRN & \\
\hline CHEMBL104663 & 809358 & 5.1656 & 4.7654 & TRN & \\
\hline CHEMBL1508582 & 809358 & 4.6308 & 4.262 & TST & \\
\hline CHEMBL1341590 & 809358 & 5.062 & 4.7101 & TST & \\
\hline CHEMBL1322848 & 809358 & 4.9469 & 5.0909 & TRN & \\
\hline CHEMBL1485960 & 809358 & 5.3726 & 5.3422 & TRN & \\
\hline CHEMBL1607517 & 809358 & 4.3872 & 5.2398 & TRN & \\
\hline CHEMBL1521144 & 809358 & 5.04 & 4.7375 & TRN & \\
\hline CHEMBL1608654 & 809358 & 5.3516 & 5.25 & TRN & \\
\hline CHEMBL1523953 & 809358 & 5.2976 & 4.6545 & TST & \\
\hline CHEMBL1301673 & 809358 & 5.4881 & 5.49100 & 00000000005 & TRN \\
\hline CHEMBL1503050 & 809358 & 5.1713 & 5.1309 & TRN & \\
\hline CHEMBL1533230 & 809358 & 5.4437 & 4.8396 & TST & \\
\hline CHEMBL1313324 & 809358 & 5.3316 & 5.5038 & TRN & \\
\hline CHEMBL1434555 & 809358 & 5.0334 & 4.1175 & TRN & \\
\hline CHEMBL599013 & 809358 & 5.2676 & 5.6271 & TRN & \\
\hline CHEMBL1303651 & 809358 & 5.3893 & 5.7917 & TRN & \\
\hline CHEMBL1715550 & 809358 & 5.0851 & 5.4984 & TST & \\
\hline CHEMBL1558195 & 809358 & 5.0419 & 4.8598 & TRN & \\
\hline CHEMBL1522300 & 809358 & 5.0438 & 5.4303 & TRN & \\
\hline CHEMBL1310120 & 809358 & 5.3019 & 5.0584 & TST & \\
\hline CHEMBL1988862 & 809358 & 5.9914 & 5.5655 & TRN & \\
\hline CHEMBL1672291 & 809358 & 5.2652 & 4.9838 & TRN & \\
\hline CHEMBL1573309 & 809358 & 3.0044 & 3.7588 & TRN & \\
\hline CHEMBL1340117 & 809358 & 5.2248 & 5.3301 & TRN & \\
\hline CHEMBL1904582 & 809358 & 5.0155 & 4.558 & TST & \\
\hline CHEMBL 2007178 & 809358 & 5.3605 & 5.0027 & TRN & \\
\hline CHEMBL1509377 & 809358 & 5.2581 & 5.239 & TRN & \\
\hline CHEMBL1672292 & 809358 & 5.0747 & 4.8503 & TRN & \\
\hline CHEMBL1430983 & 809358 & 5.3372 & 5.1874 & TRN & \\
\hline
\end{tabular}




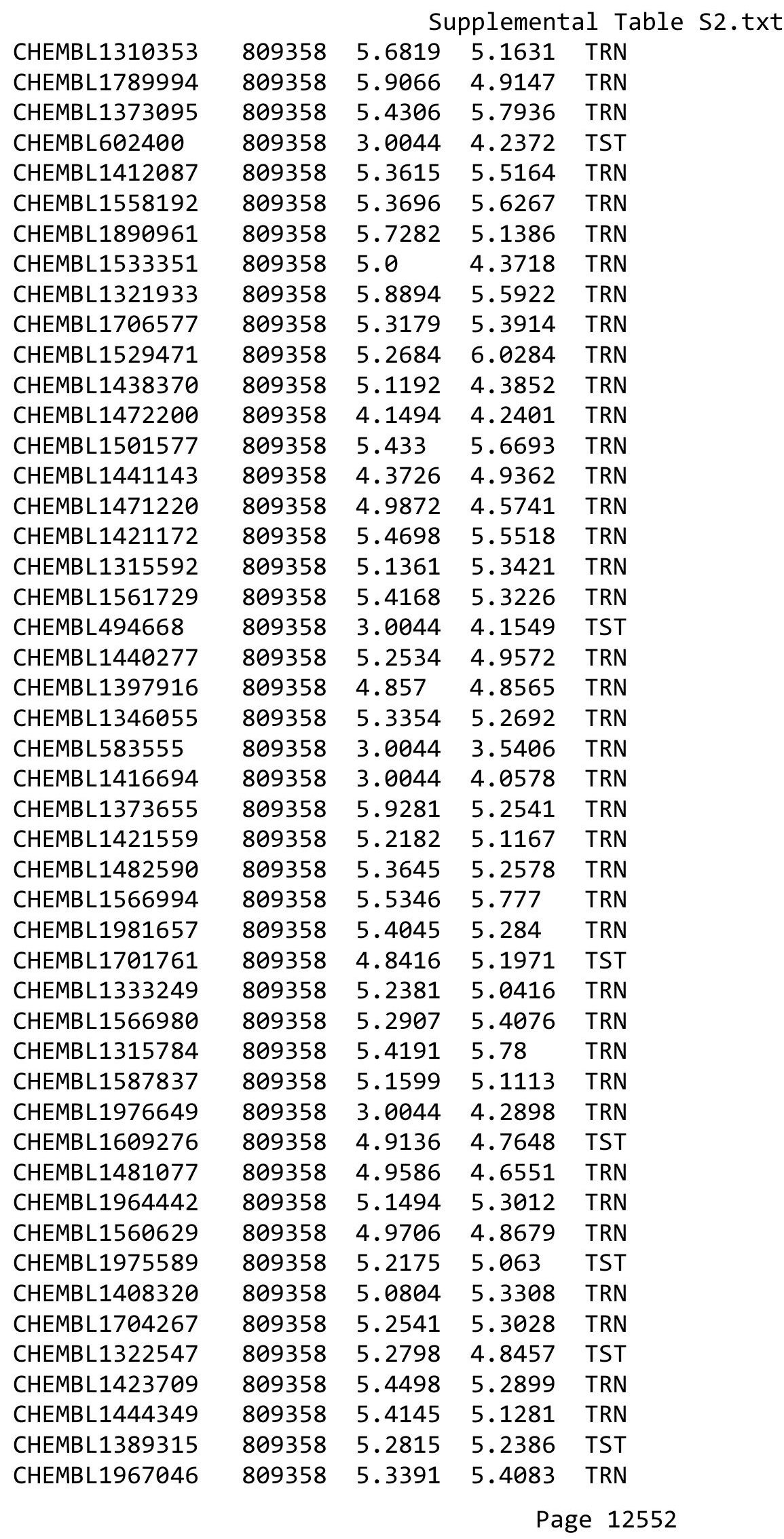




\begin{tabular}{|c|c|c|c|c|c|}
\hline \multicolumn{6}{|c|}{ Supplemental Table S2.txt } \\
\hline CHEMBL1358848 & 809358 & 5.4353 & 5.2526 & TRN & \\
\hline CHEMBL1707222 & 809358 & 5.059 & 5.1959 & TST & \\
\hline CHEMBL1440076 & 809358 & 5.2823 & 6.1463 & TRN & \\
\hline CHEMBL592316 & 809358 & 3.0044 & 4.2379 & TRN & \\
\hline CHEMBL1551448 & 809358 & 5.2048 & 5.2249 & TRN & \\
\hline CHEMBL1464280 & 809358 & 5.8386 & 5.4749 & TRN & \\
\hline CHEMBL1902527 & 809358 & 5.1427 & 5.0232 & TST & \\
\hline CHEMBL1372387 & 809358 & 4.8508 & 5.1588 & TRN & \\
\hline CHEMBL1462469 & 809358 & 4.8356 & 4.7529 & TRN & \\
\hline CHEMBL1434750 & 809358 & 5.1331 & 5.5797 & TRN & \\
\hline CHEMBL1397359 & 809358 & 5.3516 & 4.6159 & TRN & \\
\hline CHEMBL1423186 & 809358 & 5.0701 & 4.9442 & TRN & \\
\hline CHEMBL1408747 & 809358 & 5.4559 & 4.9459 & TRN & \\
\hline CHEMBL492418 & 809358 & 3.0044 & 4.3421 & TST & \\
\hline CHEMBL1464200 & 809358 & 5.4949 & 5.1846 & TRN & \\
\hline CHEMBL1439640 & 809358 & 5.3497 & 5.4847 & TRN & \\
\hline CHEMBL1435948 & 809358 & 5.2351 & 5.2729 & TRN & \\
\hline CHEMBL1356373 & 809358 & 4.9318 & 4.9587 & TRN & \\
\hline CHEMBL1181670 & 809358 & 5.0343 & 4.7053 & TRN & \\
\hline CHEMBL1360585 & 809358 & 5.7122 & 5.5858 & TRN & \\
\hline CHEMBL582503 & 809358 & 3.0044 & 4.3118 & TST & \\
\hline CHEMBL1380580 & 809358 & 4.7144 & 4.9283 & TRN & \\
\hline CHEMBL1897695 & 809358 & 5.0835 & 4.8483 & TST & \\
\hline CHEMBL1377441 & 809358 & 5.3429 & 5.4665 & TRN & \\
\hline CHEMBL1446088 & 809358 & 4.5622 & 4.1588 & TRN & \\
\hline CHEMBL1995706 & 809358 & 5.4698 & 5.5495 & TRN & \\
\hline CHEMBL1461389 & 809358 & 5.1135 & 4.4409 & TRN & \\
\hline CHEMBL1361703 & 809358 & 5.1481 & 5.0428 & TRN & \\
\hline CHEMBL1514259 & 809358 & 4.9957 & 5.2752 & TRN & \\
\hline CHEMBL1346592 & 809358 & 5.1959 & 4.4823 & TRN & \\
\hline CHEMBL1605668 & 809358 & 5.0088 & 5.0206 & TRN & \\
\hline CHEMBL1404761 & 809358 & 4.9355 & 5.3507 & TRN & \\
\hline CHEMBL1320799 & 809358 & 5.1163 & 5.8381 & TST & \\
\hline CHEMBL1464373 & 809358 & 5.0177 & 5.6214 & TRN & \\
\hline CHEMBL1443718 & 809358 & 5.1701 & 4.8826 & TRN & \\
\hline CHEMBL1983083 & 809358 & 5.0742 & 4.5342 & TRN & \\
\hline CHEMBL1985987 & 809358 & 5.3288 & 4.9917 & TRN & \\
\hline CHEMBL1507881 & 809358 & 4.7447 & 4.9616 & TRN & \\
\hline CHEMBL1371869 & 809358 & 5.9914 & 6.0145 & TRN & \\
\hline CHEMBL1490134 & 809358 & 5.2741 & 5.3984 & TRN & \\
\hline CHEMBL1548829 & 809358 & 5.0768 & 5.3074 & TST & \\
\hline CHEMBL1529334 & 809358 & 4.9547 & 4.3869 & TRN & \\
\hline CHEMBL1520297 & 809358 & 3.0044 & 3.4087 & TRN & \\
\hline CHEMBL1571682 & 809358 & 5.1637 & 4.688 & TRN & \\
\hline CHEMBL 374740 & 809358 & 4.9281 & 5.2164 & TST & \\
\hline CHEMBL1975801 & 809358 & 4.9914 & 4.7053 & TRN & \\
\hline CHEMBL1536569 & 809358 & 3.0044 & 5.16200 & 0000000001 & TST \\
\hline CHEMBL1713628 & 809358 & 5.1494 & 5.3301 & TRN & \\
\hline & & & & 12553 & \\
\hline
\end{tabular}




\begin{tabular}{|c|c|c|c|c|c|}
\hline & & \multicolumn{4}{|c|}{ Supplemental Table s2.txt } \\
\hline CHEMBL1453126 & 809358 & 3.0044 & 3.615 & TRN & \\
\hline CHEMBL1411673 & 809358 & 4.9101 & 5.745 & TRN & \\
\hline CHEMBL1704614 & 809358 & 5.8729 & 5.2498 & TRN & \\
\hline CHEMBL1490332 & 809358 & 4.9393 & 4.4433 & TRN & \\
\hline CHEMBL1381264 & 809358 & 5.2434 & 5.3986 & TRN & \\
\hline CHEMBL1433062 & 809358 & 5.3615 & 5.1745 & TRN & \\
\hline CHEMBL1893341 & 809358 & 5.0878 & 5.2616 & TRN & \\
\hline CHEMBL1368108 & 809358 & 5.3054 & 5.4966 & TRN & \\
\hline CHEMBL1369492 & 809358 & 5.2104 & 5.5068 & TRN & \\
\hline CHEMBL1519992 & 809358 & 4.7423 & 4.5756 & TRN & \\
\hline CHEMBL1320181 & 809358 & 5.2676 & 5.2515 & TRN & \\
\hline CHEMBL1361920 & 809358 & 5.475 & 5.1543 & TRN & \\
\hline CHEMBL1437464 & 809358 & 5.1925 & 4.7823 & TRN & \\
\hline CHEMBL1458444 & 809358 & 4.6003 & 5.0007 & TRN & \\
\hline CHEMBL1332506 & 809358 & 4.9914 & 5.1673 & TRN & \\
\hline CHEMBL1445488 & 809358 & 5.3851 & 4.9792 & TRN & \\
\hline CHEMBL1371301 & 809358 & 5.0635 & 4.6548 & TRN & \\
\hline CHEMBL1546750 & 809358 & 3.0044 & 3.8161 & TRN & \\
\hline CHEMBL1456035 & 809358 & 5.3605 & 5.3605 & TRN & \\
\hline CHEMBL1469245 & 809358 & 5.475 & 4.4114 & TRN & \\
\hline CHEMBL1702473 & 809358 & 5.3063 & 4.8019 & TST & \\
\hline CHEMBL1510676 & 809358 & 5.4271 & 5.2017 & TST & \\
\hline CHEMBL1429479 & 809358 & 5.3979 & 4.9267 & TRN & \\
\hline CHEMBL1485277 & 809358 & 5.2381 & 5.1791 & TRN & \\
\hline CHEMBL1729254 & 809358 & 5.4559 & 5.2924 & TRN & \\
\hline CHEMBL1972915 & 809358 & 5.3675 & 5.1439 & TRN & \\
\hline CHEMBL1875722 & 809358 & 4.9872 & 4.7877 & TRN & \\
\hline CHEMBL1308055 & 809358 & 5.1124 & 4.8428 & TRN & \\
\hline CHEMBL1317569 & 809358 & 5.2154 & 4.9218 & TRN & \\
\hline CHEMBL1978925 & 809358 & 5.2676 & 5.0594 & TRN & \\
\hline CHEMBL1411344 & 809358 & 5.317 & 5.8101 & TRN & \\
\hline CHEMBL1566530 & 809358 & 5.3279 & 5.3926 & TRN & \\
\hline CHEMBL1569215 & 809358 & 5.1314 & 5.0475 & TRN & \\
\hline CHEMBL1391256 & 809358 & 5.1791 & 5.1515 & TRN & \\
\hline CHEMBL1386849 & 809358 & 3.0044 & 3.7195 & TRN & \\
\hline CHEMBL1990599 & 809358 & 3.0044 & 3.8337 & TRN & \\
\hline CHEMBL1529522 & 809358 & 3.0044 & 3.83600 & 00000000003 & TRN \\
\hline CHEMBL1395998 & 809358 & 5.2041 & 5.1193 & TRN & \\
\hline CHEMBL1312212 & 809358 & 5.1002 & 5.4958 & TRN & \\
\hline CHEMBL256098 & 809358 & 5.0376 & 4.3416 & TRN & \\
\hline CHEMBL1403497 & 809358 & 5.8013 & 5.6379 & TRN & \\
\hline CHEMBL1863716 & 809358 & 5.3072 & 5.0544 & TRN & \\
\hline CHEMBL233896 & 809358 & 3.0044 & 4.551 & TST & \\
\hline CHEMBL1568915 & 809358 & 5.2269 & 4.9236 & TST & \\
\hline CHEMBL1571625 & 809358 & 5.0762 & 4.9776 & TST & \\
\hline CHEMBL1529285 & 809358 & 4.9957 & 5.3529 & TST & \\
\hline CHEMBL1328733 & 809358 & 6.091 & 5.9277 & TST & \\
\hline CHEMBL1730022 & 809358 & 3.0044 & 5.0248 & TST & \\
\hline
\end{tabular}




\begin{tabular}{|c|c|c|c|c|c|c|}
\hline \multirow[b]{2}{*}{ CHEMBL212414 } & & \multicolumn{5}{|c|}{ Supplemental T } \\
\hline & 809358 & 5.2182 & 4.6003 & TST & & \\
\hline CHEMBL1967028 & 809358 & 5.15799 & 99999999 & 995 & 4.9893 & TST \\
\hline CHEMBL1536256 & 809358 & 5.2958 & 5.265 & TST & & \\
\hline CHEMBL1981446 & 809358 & 5.6216 & 4.8627 & TST & & \\
\hline CHEMBL1348946 & 809358 & 5.082 & 5.4845 & TST & & \\
\hline CHEMBL1332402 & 809358 & 4.9469 & 4.3878 & TST & & \\
\hline CHEMBL1511981 & 809358 & 5.4868 & 5.4878 & TST & & \\
\hline CHEMBL1560128 & 809358 & 5.1555 & 4.1144 & TST & & \\
\hline CHEMBL1612983 & 809358 & 5.0214 & 4.6576 & TST & & \\
\hline CHEMBL1543134 & 809358 & 5.4881 & 5.2665 & TST & & \\
\hline CHEMBL1509648 & 809358 & 5.1439 & 4.7932 & TST & & \\
\hline CHEMBL1330058 & 809358 & 3.0044 & 4.9532 & TST & & \\
\hline CHEMBL1480378 & 809358 & 5.0381 & 5.5251 & TST & & \\
\hline CHEMBL580076 & 809358 & 4.9431 & 4.3637 & TST & & \\
\hline CHEMBL1539325 & 809358 & 5.5346 & 5.2108 & TST & & \\
\hline CHEMBL1347385 & 809358 & 5.1475 & 5.0652 & TST & & \\
\hline CHEMBL1606403 & 809358 & 5.301 & 4.8372 & TST & & \\
\hline CHEMBL1209491 & 809358 & 5.1215 & 5.1278 & TST & & \\
\hline CHEMBL306529 & 570538 & 8.022 & 7.9279 & TRN & & \\
\hline CHEMBL306764 & 570538 & 6.785 & 6.4682 & TRN & & \\
\hline CHEMBL561013 & 570538 & 8.045 & 8.172 & TRN & & \\
\hline CHEMBL558801 & 570538 & 6.46399 & 99999999 & 995 & 6.6069 & TRN \\
\hline CHEMBL564066 & 570538 & 7.97 & 8.0891 & TRN & & \\
\hline CHEMBL563390 & 570538 & 5.978 & 6.2607 & TRN & & \\
\hline CHEMBL551833 & 570538 & 6.669 & 6.3663 & TRN & & \\
\hline CHEMBL561349 & 570538 & 7.2 & 6.7708 & TST & & \\
\hline CHEMBL565042 & 570538 & 8.92 & 8.3518 & TST & & \\
\hline CHEMBL550949 & 570538 & 6.322 & 6.5969 & TRN & & \\
\hline CHEMBL564888 & 570538 & 8.346 & 8.1719 & TRN & & \\
\hline CHEMBL497811 & 570538 & 5.977 & 6.325 & TRN & & \\
\hline CHEMBL557004 & 570538 & 9.161 & 8.0415 & TST & & \\
\hline CHEMBL561089 & 570538 & 6.91 & 6.6353 & TRN & & \\
\hline CHEMBL561090 & 570538 & 8.301 & 8.1879 & TRN & & \\
\hline CHEMBL562895 & 570538 & 6.602 & 6.6399 & TRN & & \\
\hline CHEMBL551351 & 570538 & 7.346 & 7.4308 & TRN & & \\
\hline CHEMBL563670 & 570538 & 5.80399 & 9999999 & & 5.9173 & TRN \\
\hline CHEMBL552087 & 570538 & 5.62700 & $0000000 €$ & & 5.567 & \\
\hline CHEMBL552088 & 570538 & 8.18 & 8.1683 & TRN & & \\
\hline CHEMBL564407 & 570538 & 6.69 & 6.5113 & TRN & & \\
\hline CHEMBL563929 & 570538 & 7.356 & 7.3532 & TRN & & \\
\hline CHEMBL539479 & 570538 & 7.585 & 7.2079 & TST & & \\
\hline CHEMBL564901 & 570538 & 8.88600 & $0000000 €$ & & 8.8269 & I RIV \\
\hline CHEMBL564302 & 570538 & 9.18700 & 2000000e & & 8.9309 & TST \\
\hline CHEMBL565194 & 570538 & 7.28299 & 99999999 & 995 & 7.3214 & TR \\
\hline CHEMBL549603 & 570538 & 9.337 & 8.9045 & TST & & \\
\hline CHEMBL562350 & 570538 & 7.154 & 7.2015 & TRN & & \\
\hline CHEMBL557627 & 570538 & 7.481 & 7.1316 & TST & & \\
\hline CHEMBL564622 & 570538 & 8.823 & 8.8188 & TRN & & \\
\hline
\end{tabular}




\begin{tabular}{|c|c|c|c|c|c|c|c|}
\hline \multicolumn{8}{|c|}{ Sирргетіеті } \\
\hline CHEMBL539994 & 570538 & 8.075 & 8.0751 & TRN & & & \\
\hline CHEMBL561894 & 570538 & 6.471 & 6.3297 & TRN & & & \\
\hline CHEMBL564623 & 570538 & 5.869 & 6.0621 & TRN & & & \\
\hline CHEMBL552499 & 570538 & 6.465 & 6.5539 & TST & & & \\
\hline CHEMBL558474 & 570538 & 7.853 & 7.7121 & TST & & & \\
\hline CHEMBL552150 & 570538 & \multicolumn{3}{|c|}{6.832000000000001} & 6.6224 & TRN & \\
\hline CHEMBL540248 & 570538 & 7.376 & 7.5608 & TRN & & & \\
\hline CHEMBL540759 & 570538 & 8.337 & 7.9632 & TST & & & \\
\hline CHEMBL562704 & 570538 & 6.657 & 6.2956 & TST & & & \\
\hline CHEMBL562549 & 570538 & \multicolumn{3}{|c|}{7.537000000000001} & 7.5676 & TRN & \\
\hline CHEMBL550419 & 570538 & 6.115 & 6.0802 & TRN & & & \\
\hline CHEMBL562489 & 570538 & \multicolumn{3}{|c|}{7.5520000000000005} & 7.5688 & TRN & \\
\hline CHEMBL556101 & 570538 & 5.421 & 5.2095 & TST & & & \\
\hline CHEMBL564543 & 570538 & 6.419 & 6.825 & TST & & & \\
\hline CHEMBL524822 & 570538 & 5.86 & 5.7712 & TRN & & & \\
\hline CHEMBL365878 & 570538 & 7.045 & 7.0893 & TRN & & & \\
\hline CHEMBL188940 & 570538 & 5.973 & 6.1145 & TRN & & & \\
\hline CHEMBL364111 & 570538 & 5.775 & 5.5809 & TRN & & & \\
\hline CHEMBL189035 & 570538 & 8.096 & 8.1597 & TST & & & \\
\hline CHEMBL361032 & 570538 & 7.886 & 7.7467 & TRN & & & \\
\hline CHEMBL186525 & 570538 & \multicolumn{3}{|c|}{6.906000000000001} & 6.8234 & TRN & \\
\hline CHEMBL188819 & 570538 & 6.41 & 6.3087 & TRN & & & \\
\hline CHEMBL187813 & 570538 & 5.796 & 5.7809 & TRN & & & \\
\hline CHEMBL187354 & 570538 & \multicolumn{3}{|c|}{6.747000000000001} & 6.565 & TRN & \\
\hline CHEMBL187771 & 570538 & \multicolumn{3}{|c|}{6.127000000000001} & 6.3257 & TRN & \\
\hline CHEMBL188822 & 570538 & 7.42 & 7.4407 & TRN & & & \\
\hline CHEMBL190305 & 570538 & \multicolumn{3}{|c|}{5.9879999999999995} & 6.0487 & TRN & \\
\hline CHEMBL363471 & 570538 & 8.075 & 8.1603 & TST & & & \\
\hline CHEMBL188031 & 570538 & \multicolumn{3}{|c|}{7.957999999999999} & 8.1544 & TST & \\
\hline CHEMBL364820 & 570538 & \multicolumn{3}{|c|}{7.537000000000001} & 7.4651 & TST & \\
\hline CHEMBL188494 & 570538 & 7.638 & 7.5583 & TRN & & & \\
\hline CHEMBL188887 & 570538 & \multicolumn{3}{|c|}{7.207000000000001} & \multicolumn{2}{|c|}{ 7.212999999999999 } & TRN \\
\hline CHEMBL186674 & 570538 & 7.769 & 7.7616 & TRN & & & \\
\hline CHEMBL188910 & 570538 & 6.931 & 6.9773 & TRN & & & \\
\hline CHEMBL187559 & 570538 & \multicolumn{3}{|c|}{7.8229999999999995} & 7.9088 & TRN & \\
\hline CHEMBL361088 & 570538 & 7.602 & 7.6779 & TRN & & & \\
\hline CHEMBL187883 & 570538 & 7.638 & 7.8536 & TST & & & \\
\hline CHEMBL189545 & 570538 & 7.142 & 7.0575 & TRN & & & \\
\hline CHEMBL187412 & 570538 & 6.374 & 6.3648 & TRN & & & \\
\hline CHEMBL190469 & 570538 & \multicolumn{3}{|c|}{7.4079999999999995} & 7.4565 & TRN & \\
\hline CHEMBL427524 & 570538 & \multicolumn{3}{|c|}{6.3660000000000005} & 6.5571 & TRN & \\
\hline CHEMBL162432 & 96941 & 8.1805 & 7.5074 & TRN & & & \\
\hline CHEMBL163478 & 96941 & 8.2218 & 7.9403 & TRN & & & \\
\hline CHEMBL163428 & 96941 & 6.7212 & 6.8654 & TRN & & & \\
\hline CHEMBL351182 & 96941 & 3.6021 & 6.6001 & TRN & & & \\
\hline CHEMBL351207 & 96941 & 6.6576 & 7.2482 & TRN & & & \\
\hline CHEMBL162322 & 96941 & 6.2291 & 6.96399 & 99999 & 995 & TRN & \\
\hline CHEMBL163494 & 96941 & 4.5229 & 5.3984 & TRN & & & \\
\hline
\end{tabular}




\begin{tabular}{|c|c|c|c|c|}
\hline & & & oplement & al $\mathrm{Tc}$ \\
\hline CHEMBL423811 & 96941 & 5.9101 & 5.0465 & TRN \\
\hline CHEMBL162984 & 96941 & 3.6021 & 4.6205 & TRN \\
\hline CHEMBL163266 & 96941 & 7.1249 & 6.9703 & TRN \\
\hline CHEMBL162829 & 96941 & 4.5229 & 4.3322 & TRN \\
\hline CHEMBL163250 & 96941 & 5.8697 & 6.6232 & TRN \\
\hline CHEMBL349672 & 96941 & 7.1135 & 7.1027 & TRN \\
\hline CHEMBL162161 & 96941 & 7.0969 & 6.6798 & TRN \\
\hline CHEMBL350833 & 96941 & 6.6383 & 6.7624 & TRN \\
\hline CHEMBL159263 & 96941 & 7.4318 & 7.1049 & TRN \\
\hline CHEMBL163396 & 96941 & 5.7447 & 5.7882 & TRN \\
\hline CHEMBL164212 & 96941 & 3.0 & 3.9169 & TRN \\
\hline CHEMBL354015 & 96941 & 5.0132 & 5.0168 & TRN \\
\hline CHEMBL349189 & 96941 & 7.9586 & 6.9388 & TRN \\
\hline CHEMBL164168 & 96941 & 7.0 & 7.6296 & TRN \\
\hline CHEMBL159808 & 96941 & 7.3979 & 6.9924 & TRN \\
\hline CHEMBL117132 & 96941 & 7.3665 & 7.6834 & TRN \\
\hline CHEMBL162788 & 96941 & 7.699 & 7.5183 & TRN \\
\hline CHEMBL162091 & 96941 & 4.0 & 4.484 & TRN \\
\hline CHEMBL 3084970 & 96941 & 4.5229 & 5.6738 & TST \\
\hline CHEMBL163265 & 96941 & 7.0605 & 7.0343 & TRN \\
\hline CHEMBL165407 & 96941 & 6.7212 & 7.1476 & TRN \\
\hline CHEMBL112522 & 96941 & 7.2596 & 7.1049 & TRN \\
\hline CHEMBL162180 & 96941 & 7.5686 & 6.4222 & TRN \\
\hline CHEMBL354233 & 96941 & 7.4815 & 7.3551 & TRN \\
\hline CHEMBL350586 & 96941 & 7.0 & 7.439 & TST \\
\hline CHEMBL163807 & 96941 & 8.0458 & 8.2206 & TRN \\
\hline CHEMBL162347 & 96941 & 7.5229 & 7.1235 & TRN \\
\hline CHEMBL162966 & 96941 & 5.3979 & 6.0219 & TRN \\
\hline CHEMBL163630 & 96941 & 5.5376 & 5.6504 & TRN \\
\hline CHEMBL162156 & 96941 & 7.3279 & 7.3038 & TRN \\
\hline CHEMBL162835 & 96941 & 7.1739 & 7.0916 & TRN \\
\hline CHEMBL164211 & 96941 & 4.6073 & 3.6247 & TRN \\
\hline CHEMBL163872 & 96941 & 5.7447 & 5.9377 & TRN \\
\hline CHEMBL163178 & 96941 & 8.1549 & 6.1599 & TRN \\
\hline CHEMBL3084969 & 96941 & 6.4318 & 6.0783 & TST \\
\hline CHEMBL163037 & 96941 & 7.1549 & 6.3174 & TRN \\
\hline CHEMBL163623 & 96941 & 4.5229 & 5.5738 & TRN \\
\hline CHEMBL349368 & 96941 & 6.2007 & 7.1996 & TRN \\
\hline CHEMBL163179 & 96941 & 6.1549 & 5.5724 & TRN \\
\hline CHEMBL162668 & 96941 & 6.1739 & 6.1092 & TRN \\
\hline CHEMBL162607 & 96941 & 7.1135 & 7.3385 & TRN \\
\hline CHEMBL163822 & 96941 & 7.7696 & 7.4673 & TST \\
\hline CHEMBL119054 & 96941 & 6.699 & 7.0498 & TRN \\
\hline CHEMBL162424 & 96941 & 7.5229 & 7.3226 & TRN \\
\hline CHEMBL162439 & 96941 & 6.8239 & 6.2645 & TRN \\
\hline CHEMBL85320 & 96941 & 8.301 & 4.6627 & TST \\
\hline CHEMBL348927 & 96941 & 6.1549 & 6.153 & TST \\
\hline CHEMBL163567 & 96941 & 7.4437 & 6.0229 & TRN \\
\hline
\end{tabular}




\begin{tabular}{|c|c|c|c|c|c|}
\hline \multicolumn{6}{|c|}{ Supplemental Table S2.txt } \\
\hline CHEMBL162844 & 96941 & 5.7447 & 5.5432 & TRN & \\
\hline CHEMBL14608 & 96941 & 7.585 & 7.1225 & TRN & \\
\hline CHEMBL163144 & 96941 & 6.8239 & 6.792006 & 0000000001 & TST \\
\hline CHEMBL162158 & 96941 & 6.0757 & 5.6614 & TST & \\
\hline CHEMBL164353 & 96941 & 6.0458 & 6.5184 & TST & \\
\hline CHEMBL162624 & 96941 & 7.2218 & 5.5675 & TST & \\
\hline CHEMBL159827 & 96941 & 5.5528 & 6.0483 & TST & \\
\hline CHEMBL162865 & 96941 & 6.3188 & 6.1021 & TST & \\
\hline CHEMBL351648 & 96941 & 7.2218 & 7.2547 & TST & \\
\hline CHEMBL352092 & 96941 & 7.2757 & 5.7923 & TST & \\
\hline CHEMBL162979 & 96941 & 6.585 & 6.3242 & TST & \\
\hline CHEMBL349006 & 96941 & 4.5229 & 5.358 & TST & \\
\hline CHEMBL163209 & 96941 & 7.1612 & 7.3523 & TST & \\
\hline CHEMBL162900 & 96941 & 5.1249 & 5.5519 & TST & \\
\hline CHEMBL310523 & 28347 & 7.3768 & 7.3718 & TRN & \\
\hline CHEMBL 78773 & 28347 & 7.5686 & 7.1709 & TST & \\
\hline CHEMBL77842 & 28347 & 7.5229 & 7.5138 & TRN & \\
\hline CHEMBL76429 & 28347 & 5.0 & 4.9801 & TRN & \\
\hline CHEMBL420021 & 28347 & 7.6383 & 7.6275 & TRN & \\
\hline CHEMBL312095 & 28347 & 6.7447 & 6.7551 & TRN & \\
\hline CHEMBL 78597 & 28347 & 7.3279 & 7.32799 & 9999999999 & TRN \\
\hline CHEMBL311524 & 28347 & 7.7447 & 7.7327 & TRN & \\
\hline CHEMBL 79602 & 28347 & 7.9208 & 7.9164 & TRN & \\
\hline CHEMBL81707 & 28347 & 6.699 & 6.7113 & TRN & \\
\hline CHEMBL420577 & 28347 & 7.1871 & 7.2873 & TRN & \\
\hline CHEMBL 80288 & 28347 & 7.4202 & 7.419 & TRN & \\
\hline CHEMBL 25110 & 28347 & 5.3979 & 8.3438 & TST & \\
\hline CHEMBL 78387 & 28347 & 7.5376 & 7.5017 & TRN & \\
\hline CHEMBL80585 & 28347 & 7.5528 & 7.5061 & TRN & \\
\hline CHEMBL420574 & 28347 & 6.1249 & 7.4489 & TST & \\
\hline CHEMBL557744 & 28347 & 7.7212 & 7.7473 & TRN & \\
\hline CHEMBL 80229 & 28347 & 7.3565 & 7.3863 & TRN & \\
\hline CHEMBL 78737 & 28347 & 7.5686 & 7.625 & TRN & \\
\hline CHEMBL 80762 & 28347 & 7.3565 & 7.5131 & TST & \\
\hline CHEMBL277986 & 28347 & 7.4815 & 7.1335 & TST & \\
\hline CHEMBL311725 & 28347 & 7.0044 & 6.9696 & TRN & \\
\hline CHEMBL 78870 & 28347 & 7.8539 & 7.8922 & TRN & \\
\hline CHEMBL311193 & 28347 & 7.3565 & 7.3892 & TRN & \\
\hline CHEMBL 309757 & 28347 & 7.0 & 7.0183 & TRN & \\
\hline CHEMBL311285 & 28347 & 7.699 & 7.6503 & TRN & \\
\hline CHEMBL 78861 & 28347 & 7.2596 & 7.2673 & TRN & \\
\hline CHEMBL81392 & 28347 & 7.0 & 6.959 & TRN & \\
\hline CHEMBL312798 & 28347 & 7.1367 & 7.1524 & TRN & \\
\hline CHEMBL78869 & 28347 & 6.8861 & 6.8772 & TRN & \\
\hline CHEMBL 78144 & 28347 & 7.4559 & 7.4865 & TRN & \\
\hline CHEMBL80396 & 28347 & 7.6576 & 7.6847 & TRN & \\
\hline CHEMBL80763 & 28347 & 6.6021 & 6.6083 & TRN & \\
\hline CHEMBL 80742 & 28347 & 7.6198 & 7.5619 & TRN & \\
\hline
\end{tabular}




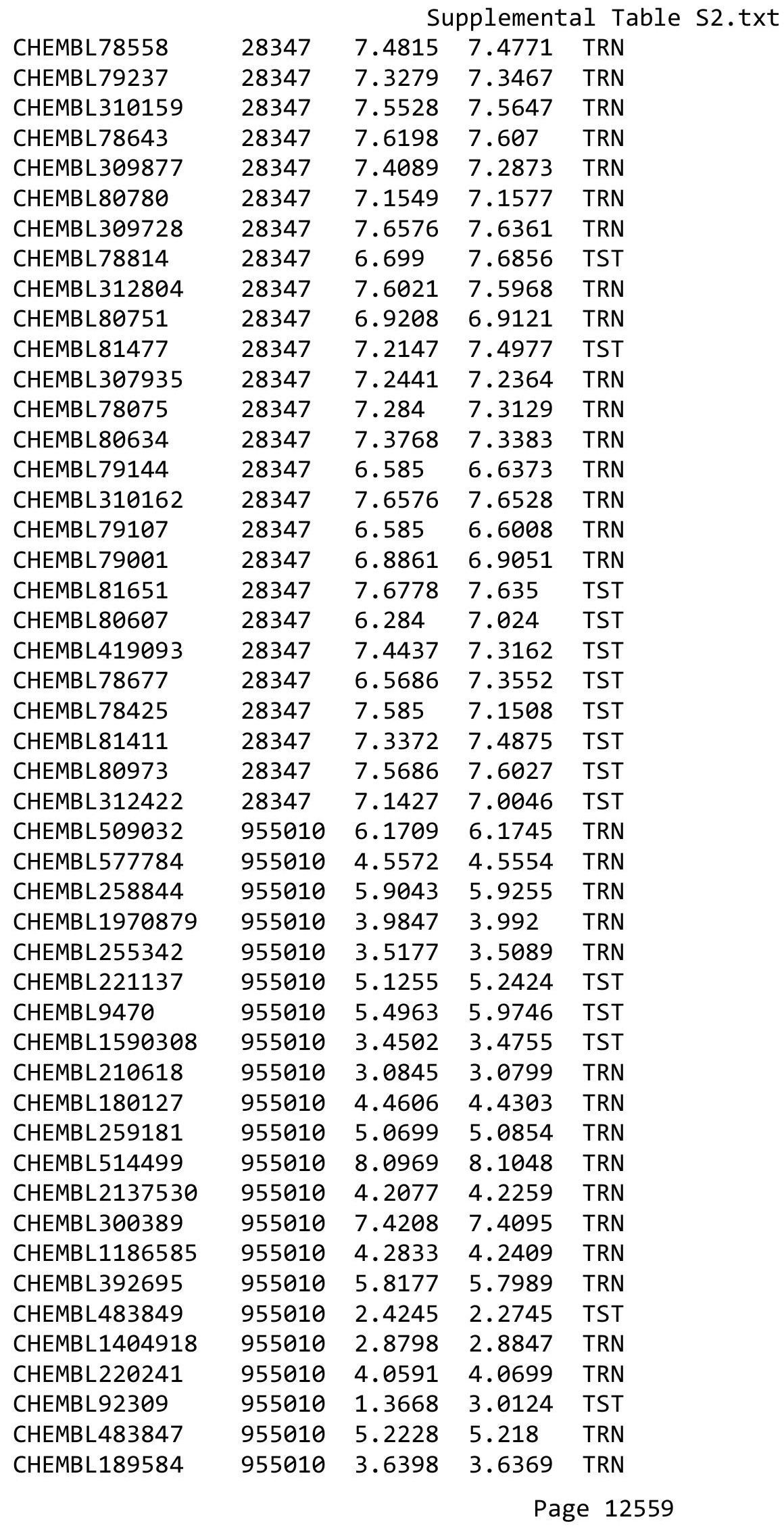




\begin{tabular}{|c|c|c|c|c|c|c|}
\hline & & \multicolumn{5}{|c|}{ Supplemental Table S2.txt } \\
\hline CHEMBL1357247 & 955010 & 3.3808 & 3.3562 & TRN & & \\
\hline CHEMBL3199475 & 955010 & 5.6813 & 5.6759 & TRN & & \\
\hline CHEMBL412142 & 955010 & 4.1293 & 4.1559 & TRN & & \\
\hline CHEMBL1673039 & 955010 & 5.1515 & 5.1515 & TRN & & \\
\hline CHEMBL515416 & 955010 & 4.8448 & 4.8444 & TRN & & \\
\hline CHEMBL 2005886 & 955010 & 6.3032 & 6.315 & TRN & & \\
\hline CHEMBL379975 & 955010 & 4.2532 & 4.2374 & TRN & & \\
\hline CHEMBL393929 & 955010 & 3.2645 & 3.2411 & TRN & & \\
\hline CHEMBL399530 & 955010 & 4.4187 & 4.4189 & TRN & & \\
\hline CHEMBL512504 & 955010 & 4.5178 & 4.5367 & TRN & & \\
\hline CHEMBL 373751 & 955010 & 3.8599 & 3.8551 & TRN & & \\
\hline CHEMBL472940 & 955010 & 2.7743 & 2.7633 & TRN & & \\
\hline CHEMBL1230020 & 955010 & 4.7665 & 4.7784 & TRN & & \\
\hline CHEMBL191334 & 955010 & 3.1135 & 3.1199 & TRN & & \\
\hline CHEMBL102714 & 955010 & 3.282 & 3.2748 & TRN & & \\
\hline CHEMBL1190711 & 955010 & 5.4227 & 5.40600 & 0000000001 & & TRN \\
\hline CHEMBL1256459 & 955010 & 7.8419 & 7.8546 & TRN & & \\
\hline CHEMBL2363137 & 955010 & 5.3444 & 5.347 & TRN & & \\
\hline CHEMBL3186408 & 955010 & 4.1371 & 3.8996 & TST & & \\
\hline CHEMBL 379300 & 955010 & 7.0582 & 7.0135 & TRN & & \\
\hline CHEMBL585951 & 955010 & 6.7023 & 6.6929 & TRN & & \\
\hline CHEMBL188678 & 955010 & 4.1938 & 4.2188 & TRN & & \\
\hline CHEMBL135561 & 955010 & 4.9346 & 4.9524 & TRN & & \\
\hline CHEMBL 202721 & 955010 & 3.4612 & 3.4861 & TRN & & \\
\hline CHEMBL192566 & 955010 & 7.8655 & 9.3083 & TST & & \\
\hline CHEMBL 2134202 & 955010 & 4.04899 & 99999999 & 995 & 4.1097 & TRN \\
\hline CHEMBL3349342 & 955010 & 6.3948 & 6.3905 & TRN & & \\
\hline CHEMBL558642 & 955010 & 4.9821 & 4.995 & TRN & & \\
\hline CHEMBL1516890 & 955010 & 3.8986 & 3.8886 & TRN & & \\
\hline CHEMBL 217354 & 955010 & 5.9051 & 5.9115 & TRN & & \\
\hline CHEMBL 222102 & 955010 & 3.3478 & 3.3293 & TRN & & \\
\hline CHEMBL 213100 & 955010 & 4.4103 & 4.4024 & TRN & & \\
\hline CHEMBL1909414 & 955010 & 4.5195 & 4.5212 & TRN & & \\
\hline CHEMBL449158 & 955010 & 6.3621 & 7.3327 & TST & & \\
\hline CHEMBL65 & 955010 & 7.23600 & 00000000 & 01 & 7.0203 & TST \\
\hline CHEMBL1788116 & 955010 & 4.6846 & 5.0524 & TST & & \\
\hline CHEMBL 3392440 & 955010 & 3.8932 & 4.3699 & TST & & \\
\hline CHEMBL1242367 & 955010 & 4.9484 & 4.6724 & TST & & \\
\hline CHEMBL2144069 & 955010 & 7.0381 & 6.1652 & TST & & \\
\hline CHEMBL 209148 & 955010 & 5.3624 & 5.0729 & TST & & \\
\hline CHEMBL573107 & 955010 & 4.6519 & 4.8043 & TST & & \\
\hline CHEMBL 240954 & 955010 & 3.2246 & 3.6496 & TST & & \\
\hline CHEMBL1643959 & 955010 & 3.1597 & 3.7089 & TST & & \\
\hline CHEMBL 2000167 & 737241 & 5.983 & 5.3142 & TRN & & \\
\hline CHEMBL1439815 & 737241 & 4.9706 & 4.7586 & TST & & \\
\hline CHEMBL1718472 & 737241 & 4.1261 & 3.9069 & TRN & & \\
\hline CHEMBL1407963 & 737241 & 3.0 & 2.737 & TRN & & \\
\hline CHEMBL1408081 & 737241 & 6.0857 & 6.2075 & TRN & & \\
\hline
\end{tabular}




\begin{tabular}{|c|c|c|c|c|c|}
\hline & & \multicolumn{4}{|c|}{ Supplemental Table S2.txt } \\
\hline CHEMBL1727280 & 737241 & 3.0 & 2.915 & TRN & \\
\hline CHEMBL 1706168 & 737241 & 4.0259 & 4.3007 & TRN & \\
\hline CHEMBL1574614 & 737241 & 3.0 & 2.9005 & TRN & \\
\hline CHEMBL1735637 & 737241 & 3.0 & 3.3242 & TST & \\
\hline CHEMBL1721385 & 737241 & 3.0 & 3.8616 & TST & \\
\hline CHEMBL1390354 & 737241 & 6.0339 & 5.9797 & TRN & \\
\hline CHEMBL601167 & 737241 & 5.4572 & 5.4467 & TRN & \\
\hline CHEMBL1704862 & 737241 & 5.5143 & 5.1501 & TRN & \\
\hline CHEMBL1526088 & 737241 & 4.9872 & \multicolumn{2}{|c|}{5.207999999999999} & TRN \\
\hline CHEMBL1732186 & 737241 & 3.0 & 2.9158 & TRN & \\
\hline CHEMBL1572439 & 737241 & 6.0146 & 5.6864 & TRN & \\
\hline CHEMBL1722719 & 737241 & 4.202 & 4.6317 & TRN & \\
\hline CHEMBL1411988 & 737241 & 3.0 & 2.6464 & TRN & \\
\hline CHEMBL1589694 & 737241 & 3.0 & 3.1556 & TRN & \\
\hline CHEMBL1560901 & 737241 & 3.0 & 3.3415 & TRN & \\
\hline CHEMBL 3193786 & 737241 & 5.2958 & 5.2397 & TRN & \\
\hline CHEMBL1715912 & 737241 & 3.0 & 3.1305 & TRN & \\
\hline CHEMBL1719458 & 737241 & 3.0 & 3.1899 & TRN & \\
\hline CHEMBL1730304 & 737241 & 4.6635 & 4.5079 & TRN & \\
\hline CHEMBL3194119 & 737241 & 4.3458 & 4.7578 & TRN & \\
\hline CHEMBL1672292 & 737241 & 5.4179 & \multicolumn{2}{|c|}{5.2589999999999995} & TRN \\
\hline CHEMBL1407368 & 737241 & \multicolumn{3}{|c|}{5.821000000000001} & TRN \\
\hline CHEMBL1323221 & 737241 & 3.0 & 3.9152 & TRN & \\
\hline CHEMBL1488869 & 737241 & 3.0 & 3.205 & TRN & \\
\hline CHEMBL1715328 & 737241 & 4.1107 & 3.6897 & TST & \\
\hline CHEMBL1732016 & 737241 & 4.8069 & 4.5378 & TRN & \\
\hline CHEMBL1327648 & 737241 & 4.3516 & 4.6429 & TRN & \\
\hline CHEMBL1719149 & 737241 & 5.8894 & 5.7887 & TRN & \\
\hline CHEMBL1562411 & 737241 & 5.2684 & 5.7285 & TRN & \\
\hline CHEMBL1478943 & 737241 & 3.0 & 2.8624 & TRN & \\
\hline CHEMBL1492305 & 737241 & 4.9508 & 4.8771 & TRN & \\
\hline CHEMBL1333032 & 737241 & 4.1415 & 3.8562 & TRN & \\
\hline CHEMBL1724547 & 737241 & 4.5157 & 4.2635 & TRN & \\
\hline CHEMBL1413629 & 737241 & 4.1146 & 4.0032 & TRN & \\
\hline CHEMBL1438889 & 737241 & 5.3883 & 5.0833 & TRN & \\
\hline CHEMBL1701224 & 737241 & 6.2034 & 6.0577 & TRN & \\
\hline CHEMBL1713374 & 737241 & 3.0 & 2.3445 & TST & \\
\hline CHEMBL1417070 & 737241 & 4.8013 & 4.0808 & TST & \\
\hline CHEMBL1721618 & 737241 & 5.3045 & 5.3372 & TRN & \\
\hline CHEMBL1714966 & 737241 & 4.0814 & 3.7932 & TRN & \\
\hline CHEMBL1371816 & 737241 & 5.3242 & 5.4635 & TRN & \\
\hline CHEMBL1487870 & 737241 & 4.4584 & 3.9431 & TRN & \\
\hline CHEMBL1710376 & 737241 & 3.0 & 3.4794 & TRN & \\
\hline CHEMBL1724311 & 737241 & 4.2472 & 4.3746 & TRN & \\
\hline CHEMBL3209371 & 737241 & 3.0 & 3.2067 & TRN & \\
\hline CHEMBL1708751 & 737241 & 3.0 & 2.7831 & TRN & \\
\hline CHEMBL1373132 & 737241 & 5.5406 & 4.7418 & TST & \\
\hline CHEMBL1734920 & 737241 & 3.0 & 2.7427 & TRN & \\
\hline
\end{tabular}




\begin{tabular}{|c|c|c|c|c|}
\hline \multicolumn{5}{|c|}{ Supplemental Table S2.txt } \\
\hline CHEMBL3210218 & 737241 & 3.0 & 3.0745 & TRN \\
\hline CHEMBL1550429 & 737241 & 5.585 & 5.4158 & TRN \\
\hline CHEMBL1320181 & 737241 & 6.1107 & 6.2224 & TRN \\
\hline CHEMBL1425801 & 737241 & 3.0 & 2.7538 & TRN \\
\hline CHEMBL1589711 & 737241 & 3.0 & 3.2051 & TRN \\
\hline CHEMBL1716861 & 737241 & 3.0 & 2.9338 & TRN \\
\hline CHEMBL1732934 & 737241 & 3.0 & 3.3855 & TRN \\
\hline CHEMBL1718018 & 737241 & 4.4609 & 4.2811 & TRN \\
\hline CHEMBL1409987 & 737241 & 3.0 & 2.8746 & TRN \\
\hline CHEMBL1672291 & 737241 & 5.3969 & 5.2148 & TRN \\
\hline CHEMBL1367928 & 737241 & 3.0 & 3.1245 & TRN \\
\hline CHEMBL1529781 & 737241 & 3.0 & 3.5173 & TRN \\
\hline CHEMBL1709810 & 737241 & 4.3507 & 4.1138 & TRN \\
\hline CHEMBL1443268 & 737241 & 4.6882 & 4.9174 & TRN \\
\hline CHEMBL1487024 & 737241 & 3.0 & 3.7785 & TST \\
\hline CHEMBL408702 & 737241 & 3.0 & 1.9609 & TST \\
\hline CHEMBL1729772 & 737241 & 3.0 & 4.5134 & TST \\
\hline CHEMBL1532025 & 737241 & 4.0391 & 3.7676 & TST \\
\hline CHEMBL1444708 & 737241 & 4.2147 & 3.6087 & TST \\
\hline CHEMBL1700415 & 737241 & 3.0 & 3.2596 & TST \\
\hline CHEMBL1721448 & 737241 & 3.0 & 3.3712 & TST \\
\hline CHEMBL1721258 & 737241 & 3.0 & 3.448 & TST \\
\hline CHEMBL1343331 & 737241 & 4.4989 & 4.9578 & TST \\
\hline CHEMBL1373210 & 737241 & 5.4034 & 5.2009 & TST \\
\hline CHEMBL1724482 & 737241 & 4.4318 & 4.7663 & TST \\
\hline CHEMBL1387413 & 737241 & 4.52 & 3.8699 & TST \\
\hline CHEMBL1552304 & 737241 & 3.0 & 3.8667 & TST \\
\hline CHEMBL1729688 & 737241 & 4.1624 & 4.3512 & TST \\
\hline CHEMBL 3728377 & 1537148 & 6.0 & 5.3167 & TRN \\
\hline CHEMBL3730299 & 1537148 & 6.0 & 6.5561 & TRN \\
\hline CHEMBL3729313 & 1537148 & 4.0 & 4.9094 & TRN \\
\hline CHEMBL3727996 & 1537148 & 6.0 & 5.5565 & TRN \\
\hline CHEMBL3731521 & 1537148 & 6.0 & 5.6824 & TRN \\
\hline CHEMBL3731051 & 1537148 & 4.0 & 4.5512 & TRN \\
\hline CHEMBL3727997 & 1537148 & 7.0 & 7.1173 & TRN \\
\hline CHEMBL3728684 & 1537148 & 7.0 & 7.6256 & TRN \\
\hline CHEMBL 3732740 & 1537148 & 4.0 & 5.7956 & TRN \\
\hline CHEMBL3727506 & 1537148 & 7.0 & 6.3354 & TRN \\
\hline CHEMBL3731647 & 1537148 & 6.0 & 5.2661 & TRN \\
\hline CHEMBL3732992 & 1537148 & 4.0 & 5.945 & TST \\
\hline CHEMBL3729682 & 1537148 & 7.0 & 6.8015 & TRN \\
\hline CHEMBL3727728 & 1537148 & 7.0 & 7.684 & TRN \\
\hline CHEMBL3733136 & 1537148 & 7.0 & 6.1828 & TRN \\
\hline CHEMBL3728959 & 1537148 & 7.0 & 7.4498 & TRN \\
\hline CHEMBL3196036 & 1537148 & 4.0 & 4.6206 & TRN \\
\hline CHEMBL3730062 & 1537148 & 7.0 & 6.3055 & TRN \\
\hline CHEMBL3731095 & 1537148 & 4.0 & 4.1873 & TRN \\
\hline CHEMBL3729052 & 1537148 & 6.0 & 6.1399 & TRN \\
\hline
\end{tabular}




\begin{tabular}{|c|c|c|c|c|c|}
\hline & & & & & \\
\hline CHEMBL3728599 & 1537148 & 4.0 & 3.8177 & TRN & \\
\hline CHEMBL3729359 & 1537148 & 6.0 & 6.3492 & TRN & \\
\hline CHEMBL3730555 & 1537148 & 7.0 & 7.2777 & TRN & \\
\hline CHEMBL3732611 & 1537148 & 6.0 & 5.4588 & TRN & \\
\hline CHEMBL 3728445 & 1537148 & 7.0 & 6.9404 & TRN & \\
\hline CHEMBL3728289 & 1537148 & 4.0 & 6.7746 & TST & \\
\hline CHEMBL 3729247 & 1537148 & 7.0 & 6.794 & TRN & \\
\hline CHEMBL3732076 & 1537148 & 6.0 & 6.0213 & TRN & \\
\hline CHEMBL 3733170 & 1537148 & 6.0 & 6.2626 & TRN & \\
\hline CHEMBL3728963 & 1537148 & 4.0 & 5.8373 & TST & \\
\hline CHEMBL3733295 & 1537148 & 4.0 & 3.8348 & TRN & \\
\hline CHEMBL3728666 & 1537148 & 6.0 & 4.8838 & TRN & \\
\hline CHEMBL3729126 & 1537148 & 4.0 & 6.2136 & TST & \\
\hline CHEMBL 3732134 & 1537148 & 4.0 & 3.7988 & TRN & \\
\hline CHEMBL3730611 & 1537148 & 6.0 & 5.0452 & TRN & \\
\hline CHEMBL 3727587 & 1537148 & 6.0 & 5.4542 & TRN & \\
\hline CHEMBL3728983 & 1537148 & 4.0 & 5.3145 & TRN & \\
\hline CHEMBL3728261 & 1537148 & 7.0 & 6.559 & TRN & \\
\hline CHEMBL 3728772 & 1537148 & 8.0 & 7.1596 & TRN & \\
\hline CHEMBL3732001 & 1537148 & 6.0 & 6.1512 & TRN & \\
\hline CHEMBL3730604 & 1537148 & 5.0 & 5.6043 & TRN & \\
\hline CHEMBL3727963 & 1537148 & 6.0 & 5.7822 & TRN & \\
\hline CHEMBL3728259 & 1537148 & 6.0 & 6.0884 & TRN & \\
\hline CHEMBL3729519 & 1537148 & 7.0 & $6.2860 e$ & 00000000005 & TRN \\
\hline CHEMBL 3729044 & 1537148 & 7.0 & 7.3104 & TST & \\
\hline CHEMBL3731114 & 1537148 & 7.0 & 7.2349 & TRN & \\
\hline CHEMBL 3728265 & 1537148 & 4.0 & 4.0446 & TRN & \\
\hline CHEMBL3732856 & 1537148 & 4.0 & 4.812 & TRN & \\
\hline CHEMBL3731262 & 1537148 & 7.0 & 6.9536 & TST & \\
\hline CHEMBL3727605 & 1537148 & 4.0 & 4.9987 & TRN & \\
\hline CHEMBL3728327 & 1537148 & 4.0 & 6.0197 & TST & \\
\hline CHEMBL 3732018 & 1537148 & 8.0 & 7.1786 & TRN & \\
\hline CHEMBL3731835 & 1537148 & 8.0 & 6.4855 & TRN & \\
\hline CHEMBL3731541 & 1537148 & 4.0 & 6.7726 & TST & \\
\hline CHEMBL 3730250 & 1537148 & 7.0 & 7.5191 & TRN & \\
\hline CHEMBL3729970 & 1537148 & 7.0 & 6.1242 & TRN & \\
\hline CHEMBL 3730779 & 1537148 & 4.0 & 4.7468 & TRN & \\
\hline CHEMBL3729974 & 1537148 & 4.0 & 7.5693 & TST & \\
\hline CHEMBL 3730425 & 1537148 & 7.0 & 7.2201 & TST & \\
\hline CHEMBL 3730286 & 1537148 & 6.0 & 4.8773 & TRN & \\
\hline CHEMBL3732370 & 1537148 & 4.0 & 6.0222 & TST & \\
\hline CHEMBL 3729597 & 1537148 & 7.0 & 7.2823 & TST & \\
\hline CHEMBL3728290 & 1537148 & 4.0 & 6.005 & TST & \\
\hline CHEMBL3729412 & 1537148 & 7.0 & 6.5817 & TRN & \\
\hline CHEMBL3728097 & 1537148 & 6.0 & 6.7927 & TRN & \\
\hline CHEMBL3728662 & 1537148 & 7.0 & 7.0022 & TRN & \\
\hline CHEMBL3727962 & 1537148 & 6.0 & 5.5476 & TRN & \\
\hline CHEMBL3732155 & 1537148 & 7.0 & 6.7443 & TST & \\
\hline & & & & 12563 & \\
\hline
\end{tabular}




\begin{tabular}{|c|c|c|c|c|}
\hline & & & pplement & \\
\hline CHEMBL3732468 & 1537148 & 8.0 & 7.1536 & TST \\
\hline CHEMBL3732030 & 1537148 & 4.0 & 5.5637 & TRN \\
\hline CHEMBL3728275 & 1537148 & 6.0 & 5.7808 & TRN \\
\hline CHEMBL3732113 & 1537148 & 4.0 & 4.8138 & TRN \\
\hline CHEMBL3728531 & 1537148 & 8.0 & 7.2031 & TRN \\
\hline CHEMBL3731691 & 1537148 & 4.0 & 4.5106 & TRN \\
\hline CHEMBL3732161 & 1537148 & 4.0 & 6.1287 & TST \\
\hline CHEMBL3730586 & 1537148 & 7.0 & 7.0748 & TRN \\
\hline CHEMBL 3731472 & 1537148 & 7.0 & 7.4587 & TRN \\
\hline CHEMBL3732726 & 1537148 & 8.0 & 7.521 & TRN \\
\hline CHEMBL3729453 & 1537148 & 8.0 & 7.35 & TRN \\
\hline CHEMBL3732762 & 1537148 & 4.0 & 3.0951 & TRN \\
\hline CHEMBL3730343 & 1537148 & 7.0 & 7.126 & TRN \\
\hline CHEMBL3731185 & 1537148 & 6.0 & 6.365 & TST \\
\hline CHEMBL3730059 & 1537148 & 4.0 & 3.911 & TRN \\
\hline CHEMBL3731966 & 1537148 & 4.0 & 5.9977 & TRN \\
\hline CHEMBL3728346 & 1537148 & 7.0 & 7.1474 & TRN \\
\hline CHEMBL3727590 & 1537148 & 4.0 & 4.1635 & TRN \\
\hline CHEMBL3732736 & 1537148 & 6.0 & 6.5881 & TRN \\
\hline CHEMBL 3732237 & 1537148 & 6.0 & 5.0947 & TRN \\
\hline CHEMBL3732073 & 1537148 & 7.0 & 6.6865 & TRN \\
\hline CHEMBL3731340 & 1537148 & 6.0 & 4.8502 & TST \\
\hline CHEMBL3730458 & 1537148 & 6.0 & 6.4946 & TST \\
\hline CHEMBL 3727573 & 1537148 & 6.0 & 5.6393 & TST \\
\hline CHEMBL3728217 & 1537148 & 4.0 & 6.0722 & TST \\
\hline CHEMBL3730001 & 1537148 & 4.0 & 5.1592 & TST \\
\hline CHEMBL3727632 & 1537148 & 7.0 & 7.6313 & TST \\
\hline CHEMBL3731839 & 1537148 & 6.0 & 7.051 & TST \\
\hline CHEMBL 3731537 & 1537148 & 6.0 & 6.4154 & TST \\
\hline CHEMBL1724238 & 752472 & 3.4559 & 4.4692 & TST \\
\hline CHEMBL155563 & 752472 & 5.3797 & 4.8759 & TRN \\
\hline CHEMBL1453126 & 752472 & 5.4694 & 4.3987 & TST \\
\hline CHEMBL1365476 & 752472 & 4.5811 & 4.0956 & TRN \\
\hline CHEMBL1450527 & 752472 & 4.319 & 3.7322 & TRN \\
\hline CHEMBL1710184 & 752472 & 4.6248 & 4.533 & TRN \\
\hline CHEMBL1578341 & 752472 & 3.4559 & 4.0875 & TRN \\
\hline CHEMBL373137 & 752472 & 3.4559 & 4.4082 & TST \\
\hline CHEMBL3191116 & 752472 & 4.7582 & 4.3714 & TRN \\
\hline CHEMBL1413633 & 752472 & 3.4559 & 4.0065 & TRN \\
\hline CHEMBL1715042 & 752472 & 3.4559 & 4.1107 & TST \\
\hline CHEMBL1462821 & 752472 & 3.4559 & 3.5958 & TRN \\
\hline CHEMBL1400379 & 752472 & 3.4559 & 3.5795 & TRN \\
\hline CHEMBL1531003 & 752472 & 4.423 & 4.4826 & TRN \\
\hline CHEMBL1331514 & 752472 & 4.4719 & 3.5578 & TRN \\
\hline CHEMBL3191640 & 752472 & 3.9586 & 3.9787 & TRN \\
\hline CHEMBL1430757 & 752472 & 4.3262 & 4.5652 & TRN \\
\hline CHEMBL1334040 & 752472 & 4.808 & 4.6388 & TRN \\
\hline CHEMBL1559741 & 752472 & 3.4559 & 3.9653 & TRN \\
\hline
\end{tabular}


Supplemental Table S2.txt

\begin{tabular}{|c|c|c|c|c|c|}
\hline CHEMBL1480031 & 752472 & 3.4559 & 3.7775 & TRN & \\
\hline CHEMBL1540446 & 752472 & 3.9586 & 4.4364 & TRN & \\
\hline CHEMBL1519289 & 752472 & 3.4559 & 3.8041 & TRN & \\
\hline CHEMBL 3213733 & 752472 & 3.4559 & 4.2415 & TRN & \\
\hline CHEMBL1583552 & 752472 & 4.6534 & 4.4554 & TRN & \\
\hline CHEMBL1427087 & 752472 & 4.5163 & 4.1733 & TRN & \\
\hline CHEMBL1586034 & 752472 & 3.4559 & 3.7789 & TRN & \\
\hline CHEMBL1570276 & 752472 & 3.4559 & 3.8253 & TRN & \\
\hline CHEMBL1572028 & 752472 & 3.9586 & 4.4991 & TRN & \\
\hline CHEMBL1361227 & 752472 & 4.4413 & 4.7615 & TRN & \\
\hline CHEMBL1573994 & 752472 & 4.5903 & 4.3594 & TRN & \\
\hline CHEMBL1450335 & 752472 & 3.4559 & 3.9212 & TRN & \\
\hline CHEMBL1451348 & 752472 & 5.17899 & 99999999 & 4.7391 & TRN \\
\hline CHEMBL1428758 & 752472 & 4.5109 & 4.3119 & TRN & \\
\hline CHEMBL1455230 & 752472 & 4.3104 & 4.0898 & TRN & \\
\hline CHEMBL1447697 & 752472 & 3.4559 & 4.0105 & TRN & \\
\hline CHEMBL1550485 & 752472 & 4.4738 & 4.2068 & TST & \\
\hline CHEMBL1714133 & 752472 & 4.7691 & 4.5115 & TRN & \\
\hline CHEMBL 3189770 & 752472 & 4.7345 & 4.406006 & 0000000001 & TRN \\
\hline CHEMBL 3196181 & 752472 & 4.3341 & 4.3506 & TRN & \\
\hline CHEMBL1419104 & 752472 & 4.4562 & 4.2622 & TRN & \\
\hline CHEMBL1369593 & 752472 & 4.7378 & 4.2768 & TRN & \\
\hline CHEMBL125044 & 752472 & 4.6936 & 4.0319 & TRN & \\
\hline CHEMBL1430520 & 752472 & 4.4364 & 4.6397 & TRN & \\
\hline CHEMBL1992138 & 752472 & 3.4559 & 3.7373 & TRN & \\
\hline CHEMBL1321756 & 752472 & 4.3844 & 4.1811 & TRN & \\
\hline CHEMBL1336277 & 752472 & 4.5595 & 4.216 & TRN & \\
\hline CHEMBL1573916 & 752472 & 3.4559 & 3.94 & TRN & \\
\hline CHEMBL1541828 & 752472 & 3.4559 & 4.2305 & TRN & \\
\hline CHEMBL1560590 & 752472 & 4.4061 & 4.0951 & TRN & \\
\hline CHEMBL1377376 & 752472 & 3.4559 & 4.378 & TST & \\
\hline CHEMBL1404138 & 752472 & 4.6941 & 4.7104 & TST & \\
\hline CHEMBL1450615 & 752472 & 4.7216 & 4.8311 & TRN & \\
\hline CHEMBL1562186 & 752472 & 4.6677 & 4.5193 & TRN & \\
\hline CHEMBL1452555 & 752472 & 3.9586 & 4.2309 & TRN & \\
\hline CHEMBL1518326 & 752472 & 4.8149 & 4.4285 & TRN & \\
\hline CHEMBL 591370 & 752472 & 4.419 & 4.4831 & TRN & \\
\hline CHEMBL1701600 & 752472 & 4.6293 & 4.503 & TST & \\
\hline CHEMBL1485562 & 752472 & 4.4253 & 4.3985 & TST & \\
\hline CHEMBL1468869 & 752472 & 3.4559 & 3.7688 & TST & \\
\hline CHEMBL3208179 & 752472 & 4.7445 & 4.4686 & TRN & \\
\hline CHEMBL1970537 & 752472 & 3.4559 & 4.0088 & TRN & \\
\hline CHEMBL1584006 & 752472 & 4.5675 & 4.1462 & TRN & \\
\hline CHEMBL1423463 & 752472 & 4.6398 & 4.8375 & TRN & \\
\hline CHEMBL1485890 & 752472 & 5.1146 & 4.7297 & TRN & \\
\hline CHEMBL1304623 & 752472 & 3.4559 & 3.9966 & TRN & \\
\hline CHEMBL 3190217 & 752472 & 3.4559 & 4.2041 & TRN & \\
\hline CHEMBL601351 & 752472 & 4.5254 & 4.9315 & TST & \\
\hline
\end{tabular}




\begin{tabular}{|c|c|c|c|c|c|c|}
\hline \multirow[b]{2}{*}{ CHEMBL1610029 } & \multirow[b]{2}{*}{752472} & \multicolumn{5}{|c|}{ Supplemental Table s2.txt } \\
\hline & & 4.6147 & 4.6095 & TST & & \\
\hline CHEMBL1420393 & 752472 & 4.5496 & 4.2 & TRN & & \\
\hline CHEMBL1377682 & 752472 & 4.4835 & 4.2766 & TRN & & \\
\hline CHEMBL1442783 & 752472 & 4.6835 & 4.8765 & TRN & & \\
\hline CHEMBL1378837 & 752472 & 3.4559 & 4.2098 & TST & & \\
\hline CHEMBL1305475 & 752472 & 4.6852 & 4.6725 & TRN & & \\
\hline CHEMBL1426177 & 752472 & 4.7257 & 4.5717 & TRN & & \\
\hline CHEMBL1572924 & 752472 & 4.4688 & 4.6147 & TRN & & \\
\hline CHEMBL578675 & 752472 & 4.4303 & 4.4953 & TRN & & \\
\hline CHEMBL1302639 & 752472 & 3.4559 & 3.9163 & TRN & & \\
\hline CHEMBL1443454 & 752472 & 4.5988 & 3.6855 & TRN & & \\
\hline CHEMBL1732062 & 752472 & 4.3853 & 4.3305 & TRN & & \\
\hline CHEMBL1328118 & 752472 & 4.7569 & 4.8449 & TRN & & \\
\hline CHEMBL1433859 & 752472 & 4.5206 & 4.2286 & TRN & & \\
\hline CHEMBL1512375 & 752472 & 4.6891 & 4.4199 & TRN & & \\
\hline CHEMBL1338805 & 752472 & 4.5439 & 4.249 & TRN & & \\
\hline CHEMBL1605163 & 752472 & 3.4559 & 3.4699 & TRN & & \\
\hline CHEMBL1501466 & 752472 & 4.6069 & 4.7714 & TRN & & \\
\hline CHEMBL582722 & 752472 & 4.3693 & 4.2067 & TRN & & \\
\hline CHEMBL1359715 & 752472 & 3.4559 & 3.1922 & TRN & & \\
\hline CHEMBL1970597 & 752472 & 3.9586 & 4.3351 & TRN & & \\
\hline CHEMBL95704 & 752472 & 4.3368 & 4.525 & TST & & \\
\hline CHEMBL1537553 & 752472 & 4.4229 & 4.8229 & TRN & & \\
\hline CHEMBL1301197 & 752472 & 3.9586 & 4.3201 & TRN & & \\
\hline CHEMBL1527537 & 752472 & 4.4852 & 3.952 & TRN & & \\
\hline CHEMBL3195196 & 752472 & 3.4559 & 3.6739 & TRN & & \\
\hline CHEMBL1550490 & 752472 & $5.1770 e$ & 30000000 & 205 & 4.6922 & TRN \\
\hline CHEMBL1352326 & 752472 & 3.4559 & 3.4004 & TRN & & \\
\hline CHEMBL1321427 & 752472 & 3.4559 & 3.5116 & TRN & & \\
\hline CHEMBL1585764 & 752472 & 3.9586 & 4.3497 & TRN & & \\
\hline CHEMBL1382429 & 752472 & 4.9013 & 4.8617 & TRN & & \\
\hline CHEMBL1513566 & 752472 & 3.4559 & 4.0015 & TRN & & \\
\hline CHEMBL1398224 & 752472 & 4.7021 & 4.5314 & TST & & \\
\hline CHEMBL1423040 & 752472 & 4.4585 & 4.5377 & TST & & \\
\hline CHEMBL1489022 & 752472 & 3.9586 & 4.4181 & TRN & & \\
\hline CHEMBL3196173 & 752472 & 3.4559 & 4.2631 & TRN & & \\
\hline CHEMBL1341008 & 752472 & 4.6769 & 4.4413 & TRN & & \\
\hline CHEMBL1489428 & 752472 & 3.4559 & 3.4805 & TRN & & \\
\hline CHEMBL1454102 & 752472 & 3.4559 & 4.1788 & TRN & & \\
\hline CHEMBL1377826 & 752472 & 3.4559 & 3.6844 & TRN & & \\
\hline CHEMBL1306583 & 752472 & 4.5189 & 4.6188 & TRN & & \\
\hline CHEMBL1455957 & 752472 & 4.4202 & 4.0838 & TST & & \\
\hline CHEMBL1424665 & 752472 & 4.3065 & 4.1188 & TRN & & \\
\hline CHEMBL1387688 & 752472 & 5.1229 & 4.4183 & TRN & & \\
\hline CHEMBL1589637 & 752472 & 4.5873 & 4.3301 & TRN & & \\
\hline CHEMBL1444690 & 752472 & 4.4962 & 4.5018 & TRN & & \\
\hline CHEMBL1554169 & 752472 & 4.456 & 3.8853 & TRN & & \\
\hline CHEMBL1979784 & 752472 & $4.3260 e$ & 30000000 & 205 & 4.1273 & TRN \\
\hline & & & & & & \\
\hline
\end{tabular}


Supplemental Table S2.txt

\begin{tabular}{|c|c|c|c|c|c|}
\hline CHEMBL1302028 & 752472 & 3.4559 & 3.5048 & TRN & \\
\hline CHEMBL1470617 & 752472 & 4.3452 & 4.0713 & TRN & \\
\hline CHEMBL1509812 & 752472 & 4.3644 & 4.3689 & TRN & \\
\hline CHEMBL1562684 & 752472 & 4.3689 & 3.97300 & 00000000003 & TRN \\
\hline CHEMBL1447872 & 752472 & 3.4559 & 3.7171 & TRN & \\
\hline CHEMBL1416660 & 752472 & 4.4674 & 4.6211 & TST & \\
\hline CHEMBL1406465 & 752472 & 3.9586 & 4.3186 & TRN & \\
\hline CHEMBL1337227 & 752472 & 3.4559 & 3.8953 & TRN & \\
\hline CHEMBL589715 & 752472 & 4.4755 & 4.4193 & TRN & \\
\hline CHEMBL1487635 & 752472 & 3.4559 & 4.3304 & TRN & \\
\hline CHEMBL1585409 & 752472 & 3.4559 & 3.6723 & TRN & \\
\hline CHEMBL1321668 & 752472 & 3.4559 & 3.2945 & TRN & \\
\hline CHEMBL1384006 & 752472 & 3.4559 & 3.8357 & TRN & \\
\hline CHEMBL1329140 & 752472 & \multicolumn{3}{|c|}{4.4510000000000005} & TST \\
\hline CHEMBL1379675 & 752472 & 4.4795 & 4.256 & TRN & \\
\hline CHEMBL1558863 & 752472 & 4.4699 & 4.3762 & TRN & \\
\hline CHEMBL1569824 & 752472 & 4.7014 & 4.5881 & TRN & \\
\hline CHEMBL1386881 & 752472 & 4.7884 & 4.2695 & TRN & \\
\hline CHEMBL1587205 & 752472 & 4.7065 & 4.3238 & TRN & \\
\hline CHEMBL 3207960 & 752472 & 3.4559 & 3.8807 & TRN & \\
\hline CHEMBL1501102 & 752472 & 4.6963 & 4.3184 & TRN & \\
\hline CHEMBL1385384 & 752472 & 4.4651 & 4.3575 & TRN & \\
\hline CHEMBL1459312 & 752472 & 3.4559 & 3.7428 & TRN & \\
\hline CHEMBL1556118 & 752472 & 4.6261 & 4.0703 & TRN & \\
\hline CHEMBL602990 & 752472 & 4.3778 & 4.1726 & TRN & \\
\hline CHEMBL1559811 & 752472 & 3.4559 & 3.7976 & TRN & \\
\hline CHEMBL1346027 & 752472 & 3.4559 & 3.5305 & TRN & \\
\hline CHEMBL1531245 & 752472 & 4.5386 & 4.8244 & TRN & \\
\hline CHEMBL1534959 & 752472 & 4.5141 & 4.2776 & TST & \\
\hline CHEMBL1416329 & 752472 & 4.7178 & 4.7391 & TRN & \\
\hline CHEMBL 3196351 & 752472 & 4.5408 & 4.0482 & TRN & \\
\hline CHEMBL1706149 & 752472 & 3.4559 & 3.6776 & TRN & \\
\hline CHEMBL1989225 & 752472 & 4.3144 & 4.0438 & TRN & \\
\hline CHEMBL1370991 & 752472 & 3.4559 & 3.60399 & 99999999996 & $\mathrm{TR}$ \\
\hline CHEMBL1576310 & 752472 & 4.5578 & 4.3933 & TRN & \\
\hline CHEMBL1373255 & 752472 & 4.6949 & 3.9377 & TRN & \\
\hline CHEMBL1601310 & 752472 & 4.742 & 4.6582 & TRN & \\
\hline CHEMBL 3189325 & 752472 & 4.3919 & 4.5201 & TRN & \\
\hline CHEMBL1315054 & 752472 & 4.4762 & 4.9686 & TRN & \\
\hline CHEMBL1529783 & 752472 & 3.4559 & 3.6241 & TRN & \\
\hline CHEMBL1354020 & 752472 & 4.5269 & 4.3709 & TRN & \\
\hline CHEMBL1323821 & 752472 & 3.9586 & 4.1558 & TRN & \\
\hline CHEMBL1456821 & 752472 & 4.5933 & 4.6124 & TST & \\
\hline CHEMBL1578593 & 752472 & 3.4559 & 4.2821 & TST & \\
\hline CHEMBL1429012 & 752472 & 3.4559 & 3.6078 & TRN & \\
\hline CHEMBL1417704 & 752472 & 3.4559 & 3.6738 & TRN & \\
\hline CHEMBL1543238 & 752472 & 4.3869 & 3.6805 & TRN & \\
\hline CHEMBL1385190 & 752472 & 4.4342 & 4.2566 & TRN & \\
\hline
\end{tabular}

Page 12567 


\begin{tabular}{|c|c|c|c|c|c|c|}
\hline & & \multicolumn{5}{|c|}{ Supplemental Table S2.txt } \\
\hline CHEMBL 2003819 & 752472 & 4.5117 & 4.1701 & TST & & \\
\hline CHEMBL1472327 & 752472 & 4.452 & 4.2836 & TST & & \\
\hline CHEMBL1347156 & 752472 & 4.3928 & 3.8107 & TRN & & \\
\hline CHEMBL1538643 & 752472 & 4.3886 & 4.846 & TRN & & \\
\hline CHEMBL610198 & 752472 & 4.6231 & 4.1728 & TRN & & \\
\hline CHEMBL1538410 & 752472 & 4.4314 & 4.5018 & TRN & & \\
\hline CHEMBL1350245 & 752472 & 4.434 & 4.7399 & TRN & & \\
\hline CHEMBL3208387 & 752472 & 3.4559 & 3.4415 & TRN & & \\
\hline CHEMBL1507990 & 752472 & 4.8559 & 4.4853 & TRN & & \\
\hline CHEMBL1336446 & 752472 & 4.4808 & 4.025 & TRN & & \\
\hline CHEMBL1363130 & 752472 & 3.9586 & 4.0208 & TRN & & \\
\hline CHEMBL3199673 & 752472 & 4.5246 & 4.1463 & TRN & & \\
\hline CHEMBL1494202 & 752472 & 3.4559 & 3.707 & TRN & & \\
\hline CHEMBL1308547 & 752472 & 4.6118 & 4.4564 & TRN & & \\
\hline CHEMBL3190786 & 752472 & 4.2818 & 4.3266 & TRN & & \\
\hline CHEMBL1413039 & 752472 & 3.9586 & 4.2621 & TRN & & \\
\hline CHEMBL1463626 & 752472 & 4.6671 & 3.8851 & TST & & \\
\hline CHEMBL1333929 & 752472 & 3.4559 & 4.5835 & TST & & \\
\hline CHEMBL3198812 & 752472 & 4.8297 & 5.1309 & TRN & & \\
\hline CHEMBL1424746 & 752472 & 4.665 & 4.283 & TST & & \\
\hline CHEMBL1487205 & 752472 & 3.4559 & 4.2775 & TST & & \\
\hline CHEMBL1729277 & 752472 & 4.3786 & 4.4015 & TRN & & \\
\hline CHEMBL602718 & 752472 & 4.4562 & 4.3224 & TRN & & \\
\hline CHEMBL1441491 & 752472 & 3.4559 & 3.6789 & TRN & & \\
\hline CHEMBL1405281 & 752472 & 4.7241 & 4.63899 & 999999999 & & TRN \\
\hline CHEMBL1514238 & 752472 & 4.5244 & 3.9847 & TRN & & \\
\hline CHEMBL1561133 & 752472 & 4.751 & 4.8107 & TRN & & \\
\hline CHEMBL1509854 & 752472 & 3.4559 & 3.8825 & TRN & & \\
\hline CHEMBL1403131 & 752472 & 4.7617 & 4.7194 & TRN & & \\
\hline CHEMBL1383386 & 752472 & 4.6766 & 4.3391 & TRN & & \\
\hline CHEMBL1503246 & 752472 & 3.4559 & 3.3807 & TRN & & \\
\hline CHEMBL1345067 & 752472 & 3.9586 & 3.6863 & TRN & & \\
\hline CHEMBL1480124 & 752472 & 3.4559 & 4.0574 & TRN & & \\
\hline CHEMBL1597245 & 752472 & 3.4559 & 3.8517 & TRN & & \\
\hline CHEMBL1488909 & 752472 & 3.4559 & 3.7861 & TRN & & \\
\hline CHEMBL1573697 & 752472 & 4.3917 & 4.2609 & TRN & & \\
\hline CHEMBL1416242 & 752472 & 3.9586 & 4.1642 & TRN & & \\
\hline CHEMBL1547092 & 752472 & 4.0401 & 4.1755 & TRN & & \\
\hline CHEMBL1329016 & 752472 & 4.7579 & 4.5944 & TRN & & \\
\hline CHEMBL1320886 & 752472 & 3.4559 & 3.4847 & TRN & & \\
\hline CHEMBL1418103 & 752472 & 3.4559 & 4.1813 & TST & & \\
\hline CHEMBL1447782 & 752472 & 4.7048 & 4.4636 & TRN & & \\
\hline CHEMBL1605224 & 752472 & 4.7373 & 4.6096 & TRN & & \\
\hline CHEMBL1716759 & 752472 & 4.5435 & 4.3088 & TRN & & \\
\hline CHEMBL1326819 & 752472 & 3.9586 & 4.3039 & TRN & & \\
\hline CHEMBL1458483 & 752472 & 4.67399 & 79999999 & 995 & 4.6798 & TST \\
\hline CHEMBL1565526 & 752472 & 4.2541 & 4.2323 & TRN & & \\
\hline CHEMBL1485551 & 752472 & 4.7311 & 4.5664 & TRN & & \\
\hline
\end{tabular}




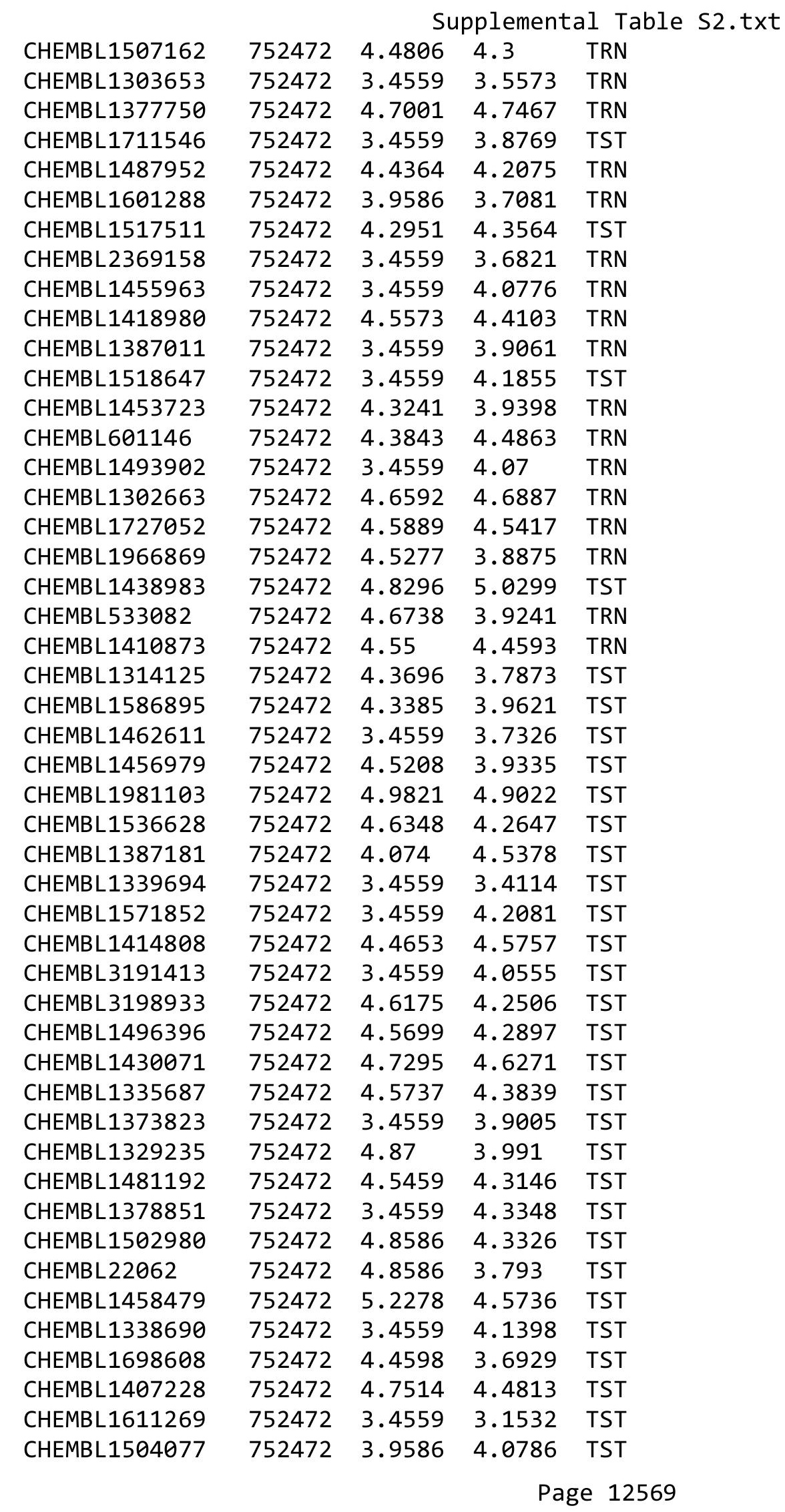


Supplemental Table S2.txt

\begin{tabular}{|c|c|c|c|c|c|c|}
\hline CHEMBL1504139 & 752472 & 4.662 & 4.3928 & TST & & \\
\hline CHEMBL1463529 & 752472 & 4.8302 & 4.062 & TST & & \\
\hline CHEMBL1545556 & 752472 & 4.7356 & 3.9521 & TST & & \\
\hline CHEMBL1521536 & 752472 & 3.4559 & 4.4772 & TST & & \\
\hline CHEMBL1411646 & 752472 & 4.5797 & 4.6429 & TST & & \\
\hline CHEMBL1491532 & 752472 & 3.4559 & 3.9575 & TST & & \\
\hline CHEMBL1544186 & 1301571 & 4.8911 & 4.5046 & TRN & & \\
\hline CHEMBL1428095 & 1301571 & 4.8972 & 4.4318 & TRN & & \\
\hline CHEMBL1321427 & 1301571 & 6.1649 & 6.1746 & TRN & & \\
\hline CHEMBL1617452 & 1301571 & 5.2472 & 5.2176 & TRN & & \\
\hline CHEMBL1568022 & 1301571 & 4.9165 & 4.2419 & TRN & & \\
\hline CHEMBL3184311 & 1301571 & 4.1718 & 4.6623 & TRN & & \\
\hline CHEMBL1597245 & 1301571 & 3.0 & 3.1089 & TRN & & \\
\hline CHEMBL2361346 & 1301571 & 4.4219 & 4.7918 & TRN & & \\
\hline CHEMBL1483562 & 1301571 & 5.0292 & 4.0235 & TRN & & \\
\hline CHEMBL1584985 & 1301571 & 5.8861 & 4.9265 & TST & & \\
\hline CHEMBL1345220 & 1301571 & 5.7471 & 5.5124 & TRN & & \\
\hline CHEMBL2359406 & 1301571 & 4.9481 & 5.1626 & TRN & & \\
\hline CHEMBL 2355724 & 1301571 & 6.7471 & 6.6125 & TRN & & \\
\hline CHEMBL2358863 & 1301571 & 3.1549 & 4.051 & TRN & & \\
\hline CHEMBL1451348 & 1301571 & 4.4531 & 3.9019 & TRN & & \\
\hline CHEMBL1405749 & 1301571 & 6.4828 & 5.7575 & TRN & & \\
\hline CHEMBL 2359612 & 1301571 & 4.5771 & 6.5307 & TRN & & \\
\hline CHEMBL3188935 & 1301571 & 4.4232 & 5.8682 & TRN & & \\
\hline CHEMBL2355735 & 1301571 & 4.4289 & 5.9955 & TRN & & \\
\hline CHEMBL257286 & 1301571 & 4.713999 & 99999999 & 995 & 4.1246 & TRN \\
\hline CHEMBL2362298 & 1301571 & 9.1701 & 5.8053 & TRN & & \\
\hline CHEMBL1396619 & 1301571 & 4.5315 & 4.6469 & TST & & \\
\hline CHEMBL2357535 & 1301571 & 10.0241 & 6.9924 & TRN & & \\
\hline CHEMBL1452421 & 1301571 & 5.1618 & 5.65 & TRN & & \\
\hline CHEMBL2354539 & 1301571 & 4.7144 & 5.3698 & TRN & & \\
\hline CHEMBL 3182148 & 1301571 & 4.4624 & 4.6194 & TRN & & \\
\hline CHEMBL 3187821 & 1301571 & 4.9626 & 4.4031 & TRN & & \\
\hline CHEMBL1344930 & 1301571 & 4.6394 & 3.9538 & TRN & & \\
\hline CHEMBL2357173 & 1301571 & 4.2586 & 5.9571 & TRN & & \\
\hline CHEMBL1559741 & 1301571 & 4.4521 & 5.5195 & TRN & & \\
\hline CHEMBL3182041 & 1301571 & 3.0 & 4.6484 & TRN & & \\
\hline CHEMBL1536108 & 1301571 & 4.5789 & 5.1081 & TRN & & \\
\hline CHEMBL1544797 & 1301571 & 5.3809 & 5.0864 & TRN & & \\
\hline CHEMBL585827 & 1301571 & 5.3809 & 4.6891 & TRN & & \\
\hline CHEMBL1578386 & 1301571 & 4.817 & 5.3239 & TRN & & \\
\hline CHEMBL1420472 & 1301571 & 4.5717 & 4.993 & TRN & & \\
\hline CHEMBL 2358940 & 1301571 & 4.4495 & 6.1139 & TRN & & \\
\hline CHEMBL1306900 & 1301571 & 4.8908 & 5.2973 & TRN & & \\
\hline CHEMBL1459394 & 1301571 & 4.4998 & 4.3637 & TRN & & \\
\hline CHEMBL3186226 & 1301571 & 3.1549 & 3.8078 & TRN & & \\
\hline CHEMBL1873627 & 1301571 & 9.6198 & 6.4465 & TRN & & \\
\hline CHEMBL 3186440 & 1301571 & 3.1549 & 4.6271 & TRN & & \\
\hline
\end{tabular}


Supplemental Table S2.txt

\begin{tabular}{|c|c|c|c|c|c|}
\hline CHEMBL2355506 & 1301571 & 6.0 & 5.9459 & TRN & \\
\hline CHEMBL1711200 & 1301571 & 4.3359 & 4.8986 & TRN & \\
\hline CHEMBL1560870 & 1301571 & 4.6696 & 4.6796 & TST & \\
\hline CHEMBL1392527 & 1301571 & 5.9706 & 4.9373 & TST & \\
\hline CHEMBL1543417 & 1301571 & 4.5262 & 4.058 & TRN & \\
\hline CHEMBL1579170 & 1301571 & 4.7254 & 4.2593 & TRN & \\
\hline CHEMBL2362650 & 1301571 & 5.1805 & 5.2372 & TRN & \\
\hline CHEMBL1551808 & 1301571 & 4.5538 & 3.4592 & TRN & \\
\hline CHEMBL1500469 & 1301571 & 4.9059 & 4.7145 & TRN & \\
\hline CHEMBL1337726 & 1301571 & 5.3335 & 5.7332 & TST & \\
\hline CHEMBL1305372 & 1301571 & 4.4166 & 4.4988 & TRN & \\
\hline CHEMBL3186267 & 1301571 & 8.0841 & 5.4348 & TRN & \\
\hline CHEMBL2361967 & 1301571 & 4.1853 & 4.6823 & TRN & \\
\hline CHEMBL1704298 & 1301571 & 4.5324 & 5.1417 & TST & \\
\hline CHEMBL1350915 & 1301571 & 4.3406 & 4.4408 & TRN & \\
\hline CHEMBL1347023 & 1301571 & 4.0963 & 3.9361 & TRN & \\
\hline CHEMBL1622981 & 1301571 & 4.3479 & 4.4081 & TRN & \\
\hline CHEMBL1602637 & 1301571 & 5.8153 & 5.3848 & TST & \\
\hline CHEMBL2361006 & 1301571 & 4.5596 & 5.8813 & TRN & \\
\hline CHEMBL2359622 & 1301571 & 8.6778 & 6.5442 & TRN & \\
\hline CHEMBL2356442 & 1301571 & 4.5577 & 6.1289 & TRN & \\
\hline CHEMBL1418341 & 1301571 & 5.0742 & 4.74100 & 00000000005 & TRN \\
\hline CHEMBL1487099 & 1301571 & 5.4622 & 6.0905 & TST & \\
\hline CHEMBL2355635 & 1301571 & 3.1549 & 5.3654 & TRN & \\
\hline CHEMBL1375289 & 1301571 & 5.0123 & 4.7703 & TRN & \\
\hline CHEMBL1564801 & 1301571 & 4.2505 & 4.3407 & TST & \\
\hline CHEMBL1904071 & 1301571 & 3.0 & 4.4735 & TST & \\
\hline CHEMBL 2356002 & 1301571 & 4.934 & 4.5625 & TRN & \\
\hline CHEMBL2138714 & 1301571 & 5.2865 & 5.2013 & TRN & \\
\hline CHEMBL1582221 & 1301571 & 3.0 & 3.3989 & TRN & \\
\hline CHEMBL3188673 & 1301571 & 4.4366 & 4.5363 & TRN & \\
\hline CHEMBL3182281 & 1301571 & 4.3033 & 3.74899 & 99999999997 & TRN \\
\hline CHEMBL1488060 & 1301571 & 4.0074 & 5.1301 & TST & \\
\hline CHEMBL1530866 & 1301571 & 5.1878 & 5.2085 & TRN & \\
\hline CHEMBL2359502 & 1301571 & 4.4636 & 6.1289 & TRN & \\
\hline CHEMBL1574530 & 1301571 & 7.1931 & 4.3192 & TST & \\
\hline CHEMBL1489779 & 1301571 & 6.0846 & 5.9471 & TRN & \\
\hline CHEMBL591363 & 1301571 & 5.2933 & 4.9076 & TRN & \\
\hline CHEMBL2354788 & 1301571 & 3.1549 & 5.1965 & TRN & \\
\hline CHEMBL2356728 & 1301571 & 8.3497 & 5.9263 & TRN & \\
\hline CHEMBL1321754 & 1301571 & 4.9702 & 4.2935 & TRN & \\
\hline CHEMBL1625031 & 1301571 & 4.6421 & 4.6915 & TRN & \\
\hline CHEMBL1375884 & 1301571 & 5.3862 & 5.1775 & TST & \\
\hline CHEMBL1445297 & 1301571 & 6.4724 & 6.6497 & TST & \\
\hline CHEMBL2354712 & 1301571 & 6.0 & 5.2274 & TST & \\
\hline CHEMBL1390112 & 1301571 & 4.8626 & 4.6888 & TST & \\
\hline CHEMBL 2362844 & 1301571 & 3.1549 & 5.0251 & TST & \\
\hline CHEMBL2358729 & 1301571 & 4.739 & 5.2358 & TST & \\
\hline
\end{tabular}


Supplemental Table S2.txt

\begin{tabular}{|c|c|c|c|c|c|}
\hline CHEMBL1580784 & 1301571 & 4.8633 & 5.261 & TST & \\
\hline CHEMBL1866791 & 1301571 & 5.0942 & 4.2381 & TST & \\
\hline CHEMBL1379675 & 1301571 & 4.8661 & 4.8784 & TST & \\
\hline CHEMBL1378851 & 1301571 & 4.4311 & 4.8381 & TST & \\
\hline CHEMBL2354497 & 1301571 & 6.0 & 5.6022 & TST & \\
\hline CHEMBL 3185444 & 1301571 & 4.5824 & 4.8465 & TST & \\
\hline CHEMBL 215118 & 398818 & 6.8601 & 6.898 & TRN & \\
\hline CHEMBL212756 & 398818 & 7.6198 & 7.6033 & TRN & \\
\hline CHEMBL 214750 & 398818 & 7.3665 & 7.3526 & TRN & \\
\hline CHEMBL379457 & 398818 & 6.71899 & 79999999 & 6.8636 & TRN \\
\hline CHEMBL 266840 & 398818 & 7.0757 & \multicolumn{2}{|c|}{7.917999999999999} & TST \\
\hline CHEMBL211984 & 398818 & 7.8239 & 7.8898 & TRN & \\
\hline CHEMBL386759 & 398818 & 7.2291 & 7.341 & TRN & \\
\hline CHEMBL 384163 & 398818 & 7.7959 & 7.9361 & TRN & \\
\hline CHEMBL384172 & 398818 & 7.4559 & 7.4666 & TRN & \\
\hline CHEMBL387025 & 398818 & 6.0975 & 7.1967 & TST & \\
\hline CHEMBL215259 & 398818 & 8.0 & 8.013 & TRN & \\
\hline CHEMBL214185 & 398818 & 6.0846 & 5.8623 & TRN & \\
\hline CHEMBL213946 & 398818 & 5.0 & 5.0005 & TRN & \\
\hline CHEMBL 212508 & 398818 & 7.6021 & 7.5978 & TRN & \\
\hline CHEMBL379201 & 398818 & 6.1439 & 5.9488 & TRN & \\
\hline CHEMBL215281 & 398818 & 5.0 & 4.9483 & TRN & \\
\hline CHEMBL 378428 & 398818 & 8.1675 & 8.1542 & TRN & \\
\hline CHEMBL215666 & 398818 & 7.6198 & 7.4848 & TRN & \\
\hline CHEMBL384738 & 398818 & 7.6383 & 7.6037 & TRN & \\
\hline CHEMBL 263771 & 398818 & 6.9666 & 7.021 & TRN & \\
\hline CHEMBL 212142 & 398818 & 6.9245 & 6.8543 & TRN & \\
\hline CHEMBL425434 & 398818 & 7.585 & 7.6489 & TRN & \\
\hline CHEMBL 385038 & 398818 & 6.8761 & 7.5341 & TST & \\
\hline CHEMBL379391 & 398818 & 8.1938 & 8.0543 & TRN & \\
\hline CHEMBL 215501 & 398818 & 7.4437 & 7.3404 & TST & \\
\hline CHEMBL386041 & 398818 & 7.6576 & 7.5571 & TRN & \\
\hline CHEMBL 379002 & 398818 & 8.1549 & 8.1375 & TRN & \\
\hline CHEMBL 213464 & 398818 & 7.2676 & 7.1582 & TRN & \\
\hline CHEMBL214979 & 398818 & 5.0 & 5.2023 & TRN & \\
\hline CHEMBL215567 & 398818 & 7.8239 & 7.83299 & 9999999999 & TRN \\
\hline CHEMBL386411 & 398818 & 7.8539 & 7.9141 & TRN & \\
\hline CHEMBL211964 & 398818 & 7.3872 & 7.3797 & TRN & \\
\hline CHEMBL 215728 & 398818 & 8.0315 & 8.0409 & TRN & \\
\hline CHEMBL377519 & 398818 & 7.9586 & 7.9337 & TRN & \\
\hline CHEMBL 217581 & 398818 & 7.8861 & 7.82799 & 9999999999 & TRN \\
\hline CHEMBL385947 & 398818 & 7.4559 & 7.5341 & TRN & \\
\hline CHEMBL384116 & 398818 & 7.0605 & 7.0569 & TRN & \\
\hline CHEMBL262175 & 398818 & 7.6198 & 7.6223 & TRN & \\
\hline CHEMBL212955 & 398818 & 7.4685 & 8.0731 & TST & \\
\hline CHEMBL212136 & 398818 & 6.8601 & 7.6411 & TST & \\
\hline CHEMBL384115 & 398818 & 7.7959 & 6.7662 & TST & \\
\hline CHEMBL211978 & 398818 & 7.7959 & 7.8523 & TST & \\
\hline
\end{tabular}




\begin{tabular}{|c|c|c|c|c|c|c|}
\hline & & \multicolumn{5}{|c|}{ Supplemental Table S2.tx } \\
\hline CHEMBL 213383 & 398818 & 6.7747 & 6.8094 & TRN & & \\
\hline CHEMBL 212230 & 398818 & 6.34200 & $\partial 000000 €$ & 005 & 6.3201 & TRN \\
\hline CHEMBL213491 & 398818 & 7.5376 & 7.145 & TST & & \\
\hline CHEMBL 383891 & 398818 & 5.0 & 5.1717 & TST & & \\
\hline CHEMBL 377251 & 398818 & 7.1135 & 7.1739 & TRN & & \\
\hline CHEMBL 215619 & 398818 & 7.2007 & 7.3491 & TST & & \\
\hline CHEMBL 386819 & 398818 & 7.4202 & 6.3949 & TST & & \\
\hline CHEMBL 215850 & 398818 & 6.0329 & 6.2296 & TRN & & \\
\hline CHEMBL425791 & 398818 & 6.9393 & 6.9132 & TRN & & \\
\hline CHEMBL 379940 & 398818 & 7.3372 & 6.92 & TST & & \\
\hline CHEMBL 379004 & 398818 & 7.0223 & 7.0072 & TRN & & \\
\hline CHEMBL 385218 & 398818 & 7.4202 & 7.0066 & TST & & \\
\hline CHEMBL408332 & 398818 & 8.0132 & 8.013 & TRN & & \\
\hline CHEMBL 212941 & 398818 & 7.9586 & 7.92299 & 9999999999 & & TRN \\
\hline CHEMBL 213050 & 398818 & 7.1367 & 7.1858 & TRN & & \\
\hline CHEMBL 210167 & 398818 & 7.1135 & 7.0848 & TRN & & \\
\hline CHEMBL263975 & 398818 & 7.3468 & 7.7706 & TST & & \\
\hline CHEMBL 86268 & 195670 & 5.3372 & 5.5556 & TRN & & \\
\hline CHEMBL 84705 & 195670 & 6.6576 & 4.7113 & TST & & \\
\hline CHEMBL 316043 & 195670 & 4.2924 & 4.1345 & TRN & & \\
\hline CHEMBL 85280 & 195670 & 5.2007 & 5.4242 & TRN & & \\
\hline CHEMBL 313729 & 195670 & 5.2147 & 4.3105 & TRN & & \\
\hline CHEMBL 84266 & 195670 & 5.0969 & 5.0572 & TRN & & \\
\hline CHEMBL84717 & 195670 & 5.7423 & 5.6604 & TRN & & \\
\hline CHEMBL 314054 & 195670 & 5.3979 & 5.3271 & TRN & & \\
\hline CHEMBL86039 & 195670 & 3.5229 & 4.2754 & TRN & & \\
\hline CHEMBL268871 & 195670 & 9.0 & 6.2102 & TST & & \\
\hline CHEMBL 313273 & 195670 & 6.0 & 5.6462 & TRN & & \\
\hline CHEMBL312160 & 195670 & 4.8962 & 5.4428 & TRN & & \\
\hline CHEMBL84743 & 195670 & 6.0 & 4.4285 & TST & & \\
\hline CHEMBL82803 & 195670 & 6.0 & 5.8803 & TRN & & \\
\hline CHEMBL 85270 & 195670 & 4.585 & 4.5765 & TRN & & \\
\hline CHEMBL 85697 & 195670 & 5.9586 & 5.8407 & TRN & & \\
\hline CHEMBL 82628 & 195670 & 5.0 & 4.8836 & TRN & & \\
\hline CHEMBL 314103 & 195670 & 5.3372 & 5.6097 & TRN & & \\
\hline CHEMBL 84260 & 195670 & 5.3979 & 5.7744 & TRN & & \\
\hline CHEMBL 84693 & 195670 & 3.0 & 4.4284 & TST & & \\
\hline CHEMBL 315488 & 195670 & 4.6198 & 5.7948 & TRN & & \\
\hline CHEMBL85446 & 195670 & 6.0 & 6.2155 & TRN & & \\
\hline CHEMBL 310421 & 195670 & 4.752 & 5.2101 & TRN & & \\
\hline CHEMBL 85500 & 195670 & 3.0 & 4.0936 & TRN & & \\
\hline CHEMBL 83362 & 195670 & 6.0458 & 5.4642 & TRN & & \\
\hline CHEMBL85459 & 195670 & 4.3979 & 4.3968 & TRN & & \\
\hline CHEMBL 315675 & 195670 & 4.0 & 4.0614 & TRN & & \\
\hline CHEMBL 313676 & 195670 & 5.4559 & 4.5019 & TRN & & \\
\hline CHEMBL262374 & 195670 & 6.0132 & 6.1904 & TRN & & \\
\hline CHEMBL315990 & 195670 & 6.4089 & 5.9945 & TRN & & \\
\hline CHEMBL 84430 & 195670 & 3.0 & 4.5462 & TRN & & \\
\hline
\end{tabular}




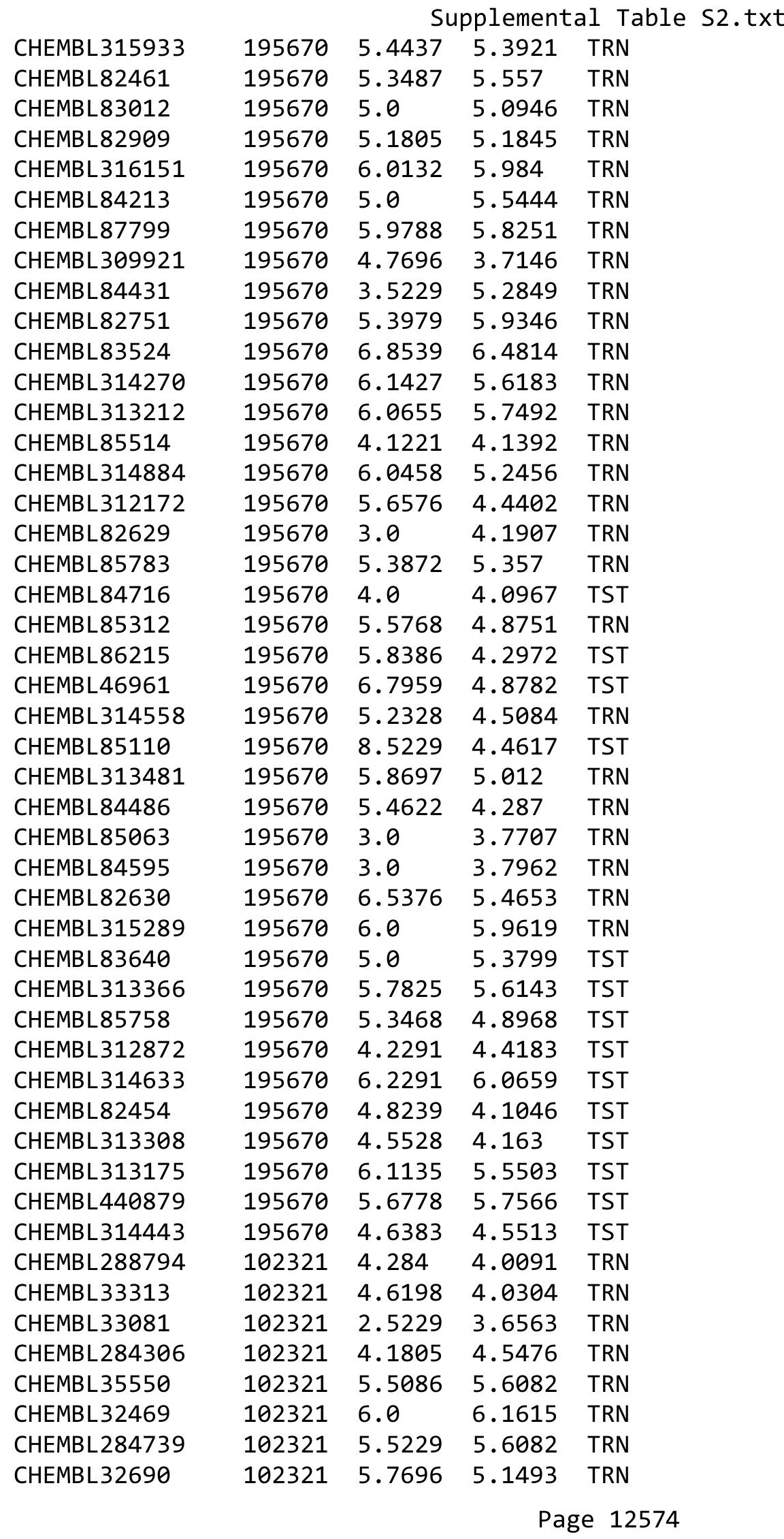




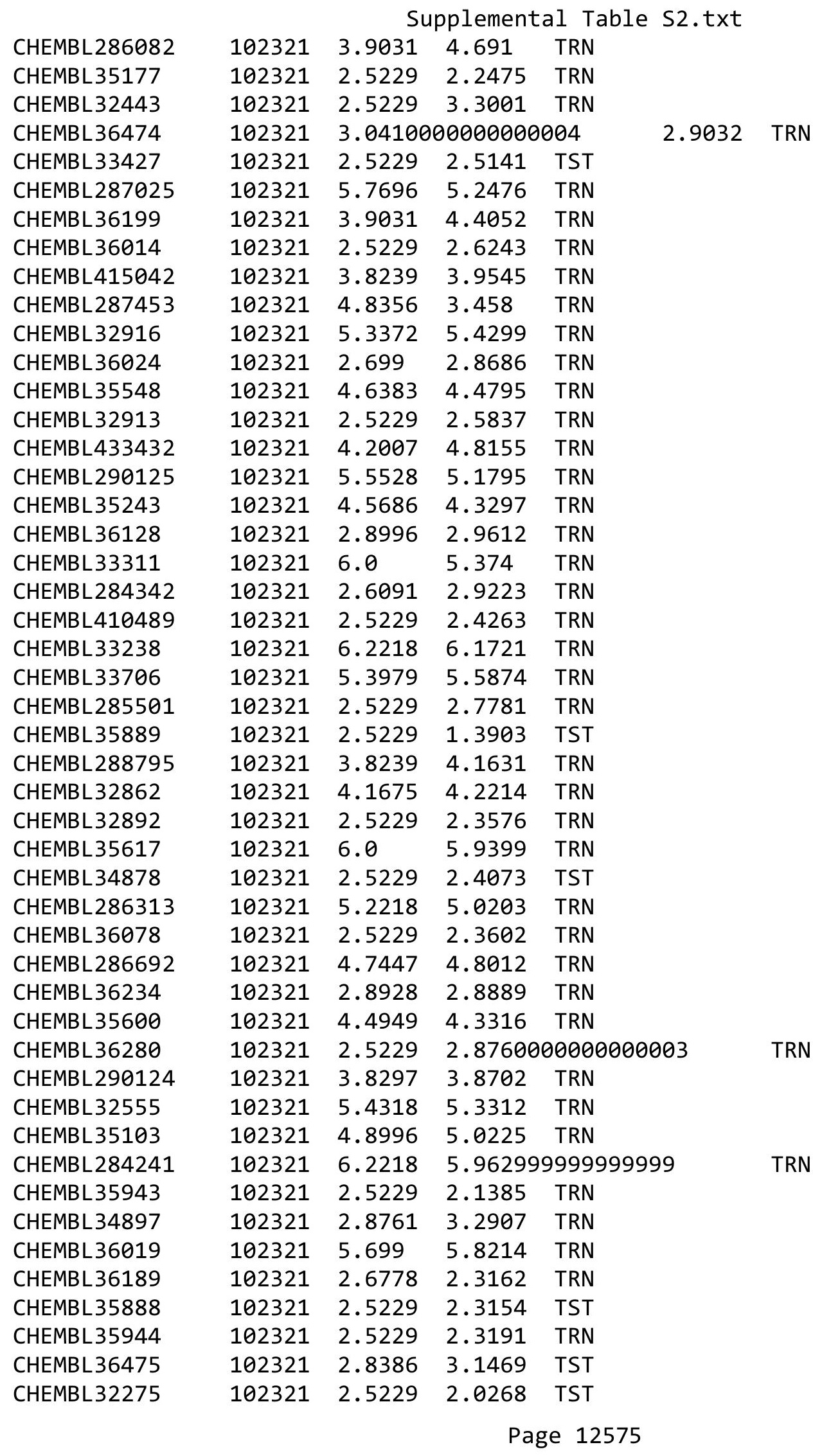




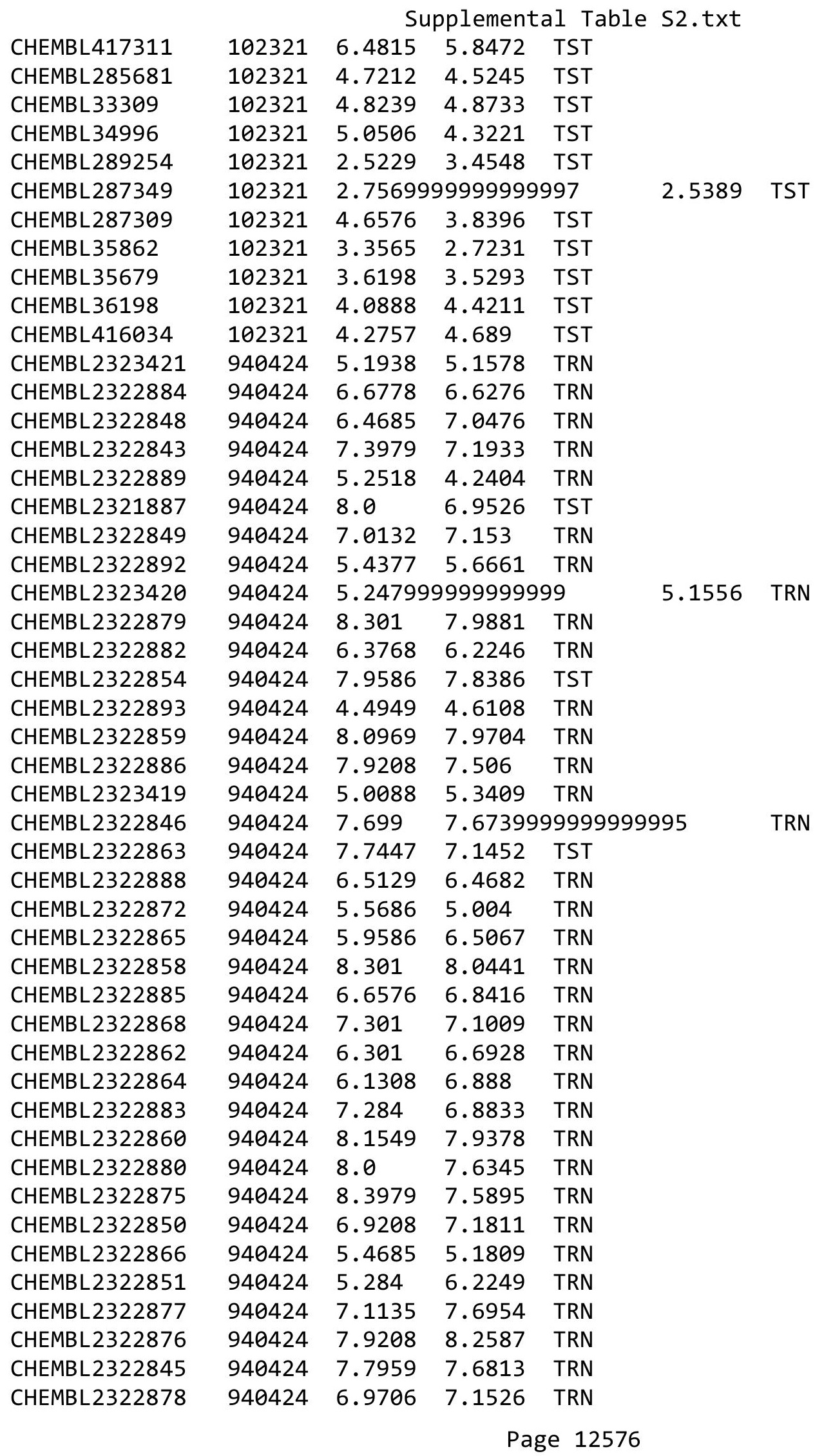




\begin{tabular}{|c|c|c|c|c|c|}
\hline \multicolumn{6}{|c|}{ Supplemental Table S2.txt } \\
\hline CHEMBL 2322844 & 940424 & 8.0969 & 7.455 & TRN & \\
\hline CHEMBL 2322873 & 940424 & 4.9586 & 5.5569 & TRN & \\
\hline CHEMBL2322874 & 940424 & 7.0 & 7.1726 & TRN & \\
\hline CHEMBL 2322869 & 940424 & 7.3279 & 7.0018 & TRN & \\
\hline CHEMBL 2323422 & 940424 & 5.4815 & 5.7854 & TRN & \\
\hline CHEMBL 2322867 & 940424 & 8.0 & 7.0126 & TST & \\
\hline CHEMBL 2322861 & 940424 & 8.2218 & 7.4931 & TST & \\
\hline CHEMBL 2322847 & 940424 & 8.0 & 7.1427 & TST & \\
\hline CHEMBL 2322890 & 940424 & 7.0088 & 5.8207 & TST & \\
\hline CHEMBL2322891 & 940424 & 6.7399 & 6.3417 & TST & \\
\hline CHEMBL 2322887 & 940424 & 7.7959 & 7.4722 & TST & \\
\hline CHEMBL 2322871 & 940424 & 6.9208 & 7.1442 & TST & \\
\hline CHEMBL 2322881 & 940424 & 7.8539 & 7.8768 & TST & \\
\hline CHEMBL 2322857 & 940424 & 7.7212 & 7.3856 & TST & \\
\hline CHEMBL2322870 & 940424 & 7.1675 & 6.7226 & TST & \\
\hline CHEMBL 3890675 & 1640600 & 7.0177 & 6.9075 & TRN & \\
\hline CHEMBL3936411 & 1640600 & 6.7959 & 6.5373 & TRN & \\
\hline CHEMBL 3923928 & 1640600 & 6.5768 & 6.1954 & TST & \\
\hline CHEMBL3946365 & 1640600 & 7.041 & 7.2128 & TRN & \\
\hline CHEMBL 3926984 & 1640600 & 5.5157 & 6.5196 & TST & \\
\hline CHEMBL 3946014 & 1640600 & 7.7447 & 7.7012 & TRN & \\
\hline CHEMBL3947662 & 1640600 & 8.3979 & 6.6911 & TST & \\
\hline CHEMBL 3977195 & 1640600 & 6.7825 & 7.019 & TRN & \\
\hline CHEMBL3909562 & 1640600 & 6.9355 & 7.00299 & 9999999999 & TRN \\
\hline CHEMBL3981011 & 1640600 & 6.8894 & 6.8859 & TRN & \\
\hline CHEMBL 3904246 & 1640600 & 6.9666 & 7.1419 & TRN & \\
\hline CHEMBL3982519 & 1640600 & 7.7696 & 7.7549 & TRN & \\
\hline CHEMBL3957034 & 1640600 & 7.0177 & 7.0193 & TRN & \\
\hline CHEMBL3900041 & 1640600 & 7.7696 & 7.6683 & TRN & \\
\hline CHEMBL3912590 & 1640600 & 6.4353 & 6.4603 & TST & \\
\hline CHEMBL 3894150 & 1640600 & 6.289 & 6.2962 & TRN & \\
\hline CHEMBL 3910610 & 1640600 & 6.0 & 6.7776 & TST & \\
\hline CHEMBL3931851 & 1640600 & 7.1805 & 7.0921 & TRN & \\
\hline CHEMBL3914904 & 1640600 & 7.0706 & 7.0091 & TRN & \\
\hline CHEMBL3902133 & 1640600 & 7.2218 & 7.2625 & TRN & \\
\hline CHEMBL3937024 & 1640600 & 7.5086 & 7.6286 & TRN & \\
\hline CHEMBL3953900 & 1640600 & 6.1858 & 6.2399 & TRN & \\
\hline CHEMBL3954551 & 1640600 & 5.9872 & 5.5789 & TRN & \\
\hline CHEMBL3985175 & 1640600 & 7.7696 & 6.9494 & TST & \\
\hline CHEMBL3903931 & 1640600 & 6.0223 & 6.21700 & 00000000005 & TRN \\
\hline CHEMBL3971583 & 1640600 & 7.0706 & 6.8282 & TRN & \\
\hline CHEMBL3907664 & 1640600 & 6.3401 & 6.629 & TST & \\
\hline CHEMBL3937009 & 1640600 & 6.6364 & 6.5669 & TRN & \\
\hline CHEMBL3940536 & 1640600 & 7.2757 & 7.3442 & TRN & \\
\hline CHEMBL3920300 & 1640600 & 8.0 & 7.0485 & TST & \\
\hline CHEMBL3961057 & 1640600 & 5.3224 & 5.4095 & TRN & \\
\hline CHEMBL3970269 & 1640600 & 6.3872 & 6.2894 & TST & \\
\hline CHEMBL 3904414 & 1640600 & 6.3307 & 6.4063 & TRN & \\
\hline
\end{tabular}


Supplemental Table S2.txt

\begin{tabular}{|c|c|c|c|c|c|}
\hline CHEMBL 3921654 & 1640600 & 7.3565 & 7.495 & TRN & \\
\hline CHEMBL 3935782 & 1640600 & 7.5528 & 7.467006 & 20000000005 & TRN \\
\hline CHEMBL3931924 & 1640600 & 6.0737 & 6.0604 & TRN & \\
\hline CHEMBL 3937502 & 1640600 & 6.8894 & 6.8414 & TRN & \\
\hline CHEMBL3936394 & 1640600 & 6.8633 & 6.9491 & TRN & \\
\hline CHEMBL3891945 & 1640600 & 7.5528 & 7.6663 & TRN & \\
\hline CHEMBL3921718 & 1640600 & 6.3979 & 6.3646 & TRN & \\
\hline CHEMBL3897193 & 1640600 & 6.7825 & 6.7681 & TRN & \\
\hline CHEMBL 3948126 & 1640600 & 6.0177 & 6.0676 & TRN & \\
\hline CHEMBL3976652 & 1640600 & 6.7595 & 6.9337 & TRN & \\
\hline CHEMBL 3947854 & 1640600 & 6.8297 & 6.7695 & TRN & \\
\hline CHEMBL3889495 & 1640600 & 5.8601 & 5.9384 & TRN & \\
\hline CHEMBL 3936488 & 1640600 & 6.5702 & 6.5271 & TRN & \\
\hline CHEMBL3916666 & 1640600 & 6.983 & 7.0162 & TRN & \\
\hline CHEMBL 3984402 & 1640600 & 7.0969 & 6.9148 & TRN & \\
\hline CHEMBL3909890 & 1640600 & 6.767 & 6.8951 & TRN & \\
\hline CHEMBL3961052 & 1640600 & 7.0506 & 7.1282 & TRN & \\
\hline CHEMBL3918039 & 1640600 & 5.0137 & 6.8147 & TST & \\
\hline CHEMBL 3948362 & 1640600 & 6.9706 & 6.9116 & TRN & \\
\hline CHEMBL 3946286 & 1640600 & 5.1549 & 6.4319 & TST & \\
\hline CHEMBL 3938554 & 1640600 & 6.7959 & 6.837006 & 0000000001 & TRN \\
\hline CHEMBL 3898087 & 1640600 & 6.6091 & 6.6896 & TRN & \\
\hline CHEMBL3972624 & 1640600 & 6.9355 & 7.0591 & TRN & \\
\hline CHEMBL 3913250 & 1640600 & 7.2518 & 7.1455 & TRN & \\
\hline CHEMBL 3932344 & 1640600 & 5.4535 & 5.5488 & TRN & \\
\hline CHEMBL 3894997 & 1640600 & 5.75700 & 00000000 & 5.7985 & TRN \\
\hline CHEMBL3895656 & 1640600 & 7.9208 & 7.7904 & TRN & \\
\hline CHEMBL3930978 & 1640600 & 7.4815 & 7.4754 & TST & \\
\hline CHEMBL 3907904 & 1640600 & 7.9586 & 7.7453 & TRN & \\
\hline CHEMBL3918909 & 1640600 & 6.5129 & 6.6574 & TRN & \\
\hline CHEMBL 3919805 & 1640600 & 6.9872 & 6.7922 & TRN & \\
\hline CHEMBL 3959687 & 1640600 & 6.7011 & 6.7202 & TRN & \\
\hline CHEMBL3951783 & 1640600 & 6.9066 & 6.9963 & TRN & \\
\hline CHEMBL3903583 & 1640600 & 6.5467 & 6.6624 & TST & \\
\hline CHEMBL3941398 & 1640600 & 6.3883 & 6.2846 & TRN & \\
\hline CHEMBL 3985694 & 1640600 & 6.9747 & 6.9466 & TST & \\
\hline CHEMBL 3940941 & 1640600 & 5.983 & 5.9128 & TRN & \\
\hline CHEMBL3977104 & 1640600 & 8.0969 & 7.9925 & TRN & \\
\hline CHEMBL 3968528 & 1640600 & 6.7825 & 6.8712 & TRN & \\
\hline CHEMBL3964930 & 1640600 & 6.8729 & 7.7533 & TST & \\
\hline CHEMBL 3959847 & 1640600 & 5.6536 & 5.7606 & TRN & \\
\hline CHEMBL 3966754 & 1640600 & 7.0506 & 7.1083 & TRN & \\
\hline CHEMBL3901611 & 1640600 & 7.7447 & 7.5703 & TRN & \\
\hline CHEMBL 3962676 & 1640600 & 6.4841 & 6.4814 & TST & \\
\hline CHEMBL3900910 & 1640600 & 7.2924 & 7.3351 & TRN & \\
\hline CHEMBL3956518 & 1640600 & 6.8327 & 6.959 & TRN & \\
\hline CHEMBL 3930877 & 1640600 & 6.3316 & 6.2101 & TST & \\
\hline CHEMBL3895510 & 1640600 & 7.284 & 7.4087 & TRN & \\
\hline
\end{tabular}


Supplemental Table S2.txt

\begin{tabular}{|c|c|c|c|c|}
\hline$\theta$ & 540600 & & & \\
\hline & 640600 & 7.284 & 7.2987 & \\
\hline 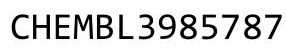 & 600 & & & \\
\hline IEMBL & 600 & +318 & & \\
\hline AEMBL3917525 & 640600 & 5.8928 & 7481 & \\
\hline HEMBL3 & 600 & 6.2291 & 1798 & \\
\hline 45 & 600 & & 8232 & \\
\hline AEMBL & 600 & 6.8539 & 8686 & \\
\hline HEMBL3898095 & 640600 & 8.0 & 7.8994 & \\
\hline HEMBL398 & 640600 & 6.4647 & .4466 & \\
\hline HEMBL; & 600 & 7. & .1315 & \\
\hline IEM & 600 & & 5291 & \\
\hline HEMBL; & 500 & & 3729 & \\
\hline HEMBL 390 & 600 & 366 & 5.3454 & \\
\hline HEMBL391 & 600 & & & \\
\hline AEMBL3 & $\partial 0$ & 7. & 652 & \\
\hline AEMBL & & & & \\
\hline HEMBL3 & 500 & 7. & 847 & \\
\hline HFMBI 3 & 600 & 7 & 7.2513 & \\
\hline AEMBL3 & 00 & 7 & & 151 \\
\hline HEMBL & 30 & & 87 & RN \\
\hline IEM & & & & 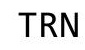 \\
\hline AEMBL & 00 & 78 & 581 & \\
\hline IFMD & 500 & & 308 & \\
\hline AEMBL3S & & & 735 & $S$ \\
\hline HEMBL & 00 & & 589 & ST \\
\hline HFM & & & 68 & RN \\
\hline 14 & 00 & & 308 & \\
\hline AEMBL3 & & & & IRN \\
\hline HEMBL 394 & 500 & 6. & 95 & ГST \\
\hline AEMBL & 00 & 7 & 353 & TRN \\
\hline HFM & 30 & & & 「RN \\
\hline us & & & 6.5596 & 「RN \\
\hline HEMBL3 & & & 226 & $\mathrm{~K}$ \\
\hline HEMBL393 & 600 & 6. & 973 & ST \\
\hline 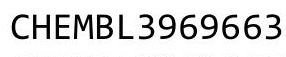 & 20 & & 957 & RN \\
\hline 5 & & & 76 & RN \\
\hline HEMBL3 & & & 6.0718 & TST \\
\hline HEMBL3 & 500 & & 419 & $\Gamma R$ \\
\hline 2 & 00 & & 861 & RN \\
\hline IFMD & $\partial 0$ & & 902 & ST \\
\hline & & & 6.9834 & 「RN \\
\hline HEMBL3 & 600 & 7.1871 & 7.0639 & $\Gamma R$ \\
\hline HEMBL3 & 600 & & 009 & TS \\
\hline С & & & & \\
\hline HEMBL3 & & & 6.6136 & \\
\hline HEMBL 3 & 600 & 7.8861 & 7.8372 & \\
\hline CHEMBL3984445 & 1640600 & 6.9281 & 6.7173 & \\
\hline
\end{tabular}

Page 12579 
Supplemental Table S2.txt

\begin{tabular}{|c|c|c|c|c|}
\hline CHEMBL3921281 & 1640600 & 6.3242 & 6.1719 & TST \\
\hline CHEMBL 3926017 & 1640600 & 7.2757 & 7.3738 & TRN \\
\hline CHEMBL3960402 & 1640600 & 6.9136 & 6.961 & TRN \\
\hline CHEMBL 3946210 & 1640600 & 7.2147 & 7.3672 & TRN \\
\hline CHEMBL 3970368 & 1640600 & 6.8069 & 6.7177 & TRN \\
\hline CHEMBL 3898114 & 1640600 & 5.6421 & 7.1144 & TST \\
\hline CHEMBL3986611 & 1640600 & 6.8097 & 6.7116 & TST \\
\hline CHEMBL3920533 & 1640600 & 6.9245 & 7.0558 & TRN \\
\hline CHEMBL 3944726 & 1640600 & 8.0969 & 7.9705 & TRN \\
\hline CHEMBL 3944544 & 1640600 & 6.7328 & 6.4565 & TRN \\
\hline CHEMBL 3986767 & 1640600 & 5.4486 & 5.5349 & TRN \\
\hline CHEMBL 3941265 & 1640600 & 7.7212 & 7.6829 & TRN \\
\hline CHEMBL3916226 & 1640600 & 7.8539 & 7.9323 & TRN \\
\hline CHEMBL 3974490 & 1640600 & 6.5817 & 6.8214 & TRN \\
\hline CHEMBL 3977362 & 1640600 & 6.0888 & 6.0036 & TST \\
\hline CHEMBL 3951633 & 1640600 & 6.4881 & 6.3702 & TRN \\
\hline CHEMBL 3908203 & 1640600 & 6.8861 & 6.8731 & TRN \\
\hline CHEMBL3919490 & 1640600 & 5.4078 & 5.6601 & TRN \\
\hline CHEMBL 3953818 & 1640600 & 6.9626 & 6.9061 & TRN \\
\hline CHEMBL 3932488 & 1640600 & 6.8327 & 6.6816 & TRN \\
\hline CHEMBL 3918551 & 1640600 & 6.8477 & 6.8008 & TST \\
\hline CHEMBL3903193 & 1640600 & 6.8827 & 6.8125 & TRN \\
\hline CHEMBL 3975529 & 1640600 & 8.1549 & 8.1859 & TRN \\
\hline CHEMBL3983446 & 1640600 & 7.4559 & 7.3737 & TRN \\
\hline CHEMBL 3900535 & 1640600 & 6.71 & 7.0651 & TRN \\
\hline CHEMBL 3940718 & 1640600 & 6.4724 & 6.5501 & TST \\
\hline CHEMBL 3927580 & 1640600 & 6.8633 & 6.8322 & TST \\
\hline CHEMBL3916443 & 1640600 & 5.9101 & 6.2153 & TST \\
\hline CHEMBL3976334 & 1640600 & 7.2147 & 7.2225 & TRN \\
\hline CHEMBL 3893164 & 1640600 & 7.6198 & 7.7779 & TRN \\
\hline CHEMBL 3919517 & 1640600 & 6.8729 & 6.5935 & TST \\
\hline CHEMBL 3947777 & 1640600 & 5.4089 & 5.4275 & TRN \\
\hline CHEMBL 3940777 & 1640600 & 6.1824 & 6.95700 & 0000000001 \\
\hline CHEMBL 3901562 & 1640600 & 6.8794 & 6.9018 & TRN \\
\hline CHEMBL 3963004 & 1640600 & 6.209 & 6.2821 & TST \\
\hline CHEMBL 3937834 & 1640600 & 6.8097 & 6.6927 & TRN \\
\hline CHEMBL 3948276 & 1640600 & 7.2757 & 7.3481 & TST \\
\hline CHEMBL 3962185 & 1640600 & 7.3872 & 7.2751 & TRN \\
\hline CHEMBL 3964057 & 1640600 & 7.0315 & 7.2723 & TRN \\
\hline CHEMBL 3957521 & 1640600 & 7.284 & 7.026 & TRN \\
\hline CHEMBL 3959487 & 1640600 & 8.301 & 8.0233 & TRN \\
\hline CHEMBL 3932420 & 1640600 & 6.2984 & 6.4252 & TRN \\
\hline CHEMBL 3915058 & 1640600 & 6.8327 & 6.8543 & TST \\
\hline CHEMBL 3985962 & 1640600 & 7.6021 & 7.6281 & TRN \\
\hline CHEMBL 3935277 & 1640600 & 5.8356 & 6.6935 & TST \\
\hline CHEMBL 3960561 & 1640600 & 6.6536 & 6.5225 & TST \\
\hline CHEMBL 3942847 & 1640600 & 7.7696 & 7.8363 & TRN \\
\hline CHEMBL 3956857 & 1640600 & 5.3757 & 6.4775 & TST \\
\hline
\end{tabular}


Supplemental Table S2.txt

\begin{tabular}{|c|c|c|c|c|c|}
\hline CHEMBL 3985437 & 1640600 & 7.7696 & 8.025 & TRN & \\
\hline CHEMBL 3893162 & 1640600 & 7.1871 & \multicolumn{2}{|c|}{7.196000000000001} & TRN \\
\hline CHEMBL3931996 & 1640600 & 7.4685 & 7.2955 & TRN & \\
\hline CHEMBL 3914576 & 1640600 & 7.1427 & 7.1821 & TRN & \\
\hline CHEMBL 3900996 & 1640600 & 8.301 & 8.3724 & TRN & \\
\hline CHEMBL 3964382 & 1640600 & 6.3507 & 6.3494 & TRN & \\
\hline CHEMBL3933069 & 1640600 & 6.7959 & 6.6282 & TRN & \\
\hline CHEMBL 3890014 & 1640600 & 5.3556 & 6.7664 & TST & \\
\hline CHEMBL 3889674 & 1640600 & 7.5376 & 7.5274 & TRN & \\
\hline CHEMBL 3910045 & 1640600 & 6.983 & 7.0278 & TRN & \\
\hline CHEMBL 3979075 & 1640600 & 7.4202 & 7.3366 & TRN & \\
\hline CHEMBL 3903568 & 1640600 & 5.9318 & 6.7513 & TST & \\
\hline CHEMBL 3926163 & 1640600 & 6.5607 & 6.5649 & TRN & \\
\hline CHEMBL3896890 & 1640600 & 7.0655 & 6.9636 & TST & \\
\hline CHEMBL 3964068 & 1640600 & 6.3449 & 5.9432 & TRN & \\
\hline CHEMBL3913129 & 1640600 & 8.699 & 8.7198 & TRN & \\
\hline CHEMBL3943021 & 1640600 & 6.9666 & 7.0008 & TST & \\
\hline CHEMBL 3914540 & 1640600 & 7.7959 & 7.6932 & TRN & \\
\hline CHEMBL3923969 & 1640600 & 5.1463 & 5.2415 & TRN & \\
\hline CHEMBL 3953436 & 1640600 & 7.6198 & \multicolumn{2}{|c|}{ 7.468999999999999 } & TRN \\
\hline CHEMBL 3946484 & 1640600 & 5.1506 & 5.301 & TRN & \\
\hline CHEMBL 3928014 & 1640600 & 7.3565 & 7.2241 & TRN & \\
\hline CHEMBL 3912787 & 1640600 & 6.2757 & 7.2175 & TST & \\
\hline CHEMBL3946511 & 1640600 & 6.8827 & 6.943 & TST & \\
\hline CHEMBL 3699251 & 1528853 & 8.8827 & \multicolumn{2}{|c|}{9.017999999999999} & TRN \\
\hline CHEMBL 3699296 & 1528853 & \multicolumn{3}{|c|}{8.857000000000001} & TRN \\
\hline CHEMBL 3699273 & 1528853 & 7.8582 & 7.7387 & TRN & \\
\hline CHEMBL 3699284 & 1528853 & 8.8477 & 8.7943 & TST & \\
\hline CHEMBL3699301 & 1528853 & 7.2213 & 6.9275 & TST & \\
\hline CHEMBL 3699264 & 1528853 & 8.8729 & 8.9806 & TRN & \\
\hline CHEMBL 3699243 & 1528853 & 7.5084 & 7.3654 & TRN & \\
\hline CHEMBL 3699294 & 1528853 & 9.6383 & 9.4692 & TRN & \\
\hline CHEMBL 3941038 & 1528853 & 8.8153 & 8.8255 & TRN & \\
\hline CHEMBL 3699244 & 1528853 & 9.6576 & 9.7609 & TRN & \\
\hline CHEMBL3916092 & 1528853 & 9.5686 & 9.1725 & TRN & \\
\hline CHEMBL 3699275 & 1528853 & 8.219 & 8.1675 & TRN & \\
\hline CHEMBL 3699245 & 1528853 & 8.8069 & 8.8812 & TRN & \\
\hline CHEMBL3699246 & 1528853 & 7.5245 & 7.3898 & TRN & \\
\hline CHEMBL 3699241 & 1528853 & 8.8416 & 8.6016 & TRN & \\
\hline CHEMBL 3699270 & 1528853 & 8.0173 & 8.0263 & TRN & \\
\hline CHEMBL 3699274 & 1528853 & 8.8477 & 8.7899 & TRN & \\
\hline CHEMBL 3699255 & 1528853 & 9.5229 & 9.5077 & TRN & \\
\hline CHEMBL 3699303 & 1528853 & \multicolumn{3}{|c|}{8.857000000000001} & TRN \\
\hline CHEMBL3699235 & 1528853 & 9.7696 & 9.986 & TRN & \\
\hline CHEMBL 3890962 & 1528853 & 9.5229 & 9.4323 & TRN & \\
\hline CHEMBL 3699283 & 1528853 & 6.7607 & 5.8024 & TST & \\
\hline CHEMBL 3699297 & 1528853 & 8.8794 & 8.8255 & TRN & \\
\hline CHEMBL3699304 & 1528853 & 7.6366 & 7.6719 & TST & \\
\hline
\end{tabular}


Supplemental Table S2.txt

\begin{tabular}{|c|c|c|c|c|}
\hline 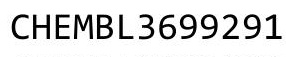 & & 6.0 & 6759 & \\
\hline HEMBL3699280 & 528853 & 9.5528 & 5152 & \\
\hline HEMBL3979154 & 528853 & 8.8665 & 9766 & \\
\hline 238 & & 9.5376 & & \\
\hline IEMBL3 & 3 & 8.4168 & 36 & \\
\hline HEMBL3699277 & 528853 & 9.8539 & 5671 & \\
\hline HEMBL3699299 & 528853 & 7.8841 & .1035 & \\
\hline HEMBL3699269 & & & & \\
\hline IEMBL: & $0<00$ & 8.8539 & & \\
\hline AEMBL 36 & 528853 & 8.0969 & & \\
\hline HEMBL3699240 & 528853 & 8.8697 & 216 & \\
\hline HEMBL3699302 & 528853 & 8.0088 & 8.1546 & \\
\hline HEMBL3923258 & $\int<00$ & 8.8633 & 8.7551 & \\
\hline HEMBL 36 & $p<c$ & 7.6803 & 89 & \\
\hline HEMBL: & $52 \varepsilon$ & 9.5086 & & \\
\hline HEMBL 369 & 528 & 7.5933 & & \\
\hline HEMBL3923466 & 5288 & 6.6574 & & \\
\hline HEMBL 36 & 92 & 9. & 92 & \\
\hline HEME & $52 \varepsilon$ & 8 . & 87 & \\
\hline HEMBI & 52 & 9 . & & \\
\hline HEMBL36 & 33 & 8.8697 & & \\
\hline HEMBL3699271 & 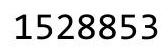 & 8.2104 & & \\
\hline HEMBL39 & $52 \varepsilon$ & 685 & & ונ \\
\hline HEMBL36 & & 539 & & RN \\
\hline HEME & 3 & 9.5229 & & RN \\
\hline HEMBL 369 & 3 & 198 & & RIN \\
\hline HEMBL3699248 & 2 & 7.0383 & & IRN \\
\hline HEMBL36 & 52 & 778 & & $R / N$ \\
\hline HEM & 3 & 59 & & RN \\
\hline HEM & 3 & 83 & 92 & RN \\
\hline HEMBL 369 & 528 & & & S \\
\hline HEMBL3699247 & -20 & 6.7486 & & TRN \\
\hline HEMBL3 & & & & Niv \\
\hline HEM & 3 & 8. & & ST \\
\hline HEMBL 39 & & 9.5686 & & ST \\
\hline HEMBL3699242 & 528 & 8.8633 & & RN \\
\hline HEMBL3699300 & 5288 & 8.0645 & 342 & ST \\
\hline HEMBL3 & & 7. & & TRN \\
\hline אב וסנזו & 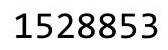 & 8. & 36 & I \\
\hline HEMBL 36 & & 9.8861 & & ST \\
\hline HEMBL395 & 528853 & 8.1226 & 198 & ST \\
\hline HEMBL369 & .528853 & 9 . & 31 & RN \\
\hline HEMBL 20 & & & & \\
\hline IHEMBL 200 & & 4.5086 & & ST \\
\hline HEMBL198802 & 25795 & & 9671 & RN \\
\hline HEMBL 200 & 25795 & 4.7696 & 9629 & N \\
\hline L199 & & & & \\
\hline UГM & & & & \\
\hline
\end{tabular}

Page 12582 


\begin{tabular}{|c|c|c|c|c|c|}
\hline & & & & & \\
\hline CHEMBL200287 & 325795 & 4.4815 & 4.82100 & 0000000001 & TRN \\
\hline CHEMBL372977 & 325795 & 6.3979 & 5.7701 & TST & \\
\hline CHEMBL200301 & 325795 & 4.3768 & 4.8919 & TRN & \\
\hline CHEMBL370786 & 325795 & 5.0 & 4.8799 & TRN & \\
\hline CHEMBL200954 & 325795 & 6.7447 & 5.7903 & TST & \\
\hline CHEMBL372410 & 325795 & 4.7959 & 5.1423 & TRN & \\
\hline CHEMBL199488 & 325795 & 3.9914 & 3.9502 & TRN & \\
\hline CHEMBL414669 & 325795 & 4.6778 & 4.5567 & TRN & \\
\hline CHEMBL200788 & 325795 & 5.1024 & 5.415 & TRN & \\
\hline CHEMBL381190 & 325795 & 5.0605 & 5.0191 & TRN & \\
\hline CHEMBL371059 & 325795 & 4.3768 & 5.3647 & TST & \\
\hline CHEMBL200506 & 325795 & 4.3768 & 4.7816 & TRN & \\
\hline CHEMBL370165 & 325795 & 5.041 & 5.05399 & & TRN \\
\hline CHEMBL200545 & 325795 & 5.3768 & 5.3023 & TST & \\
\hline CHEMBL200166 & 325795 & 4.5229 & 4.6394 & TRN & \\
\hline CHEMBL 200672 & 325795 & 5.1024 & 5.2032 & TRN & \\
\hline CHEMBL200529 & 325795 & 6.8239 & 5.5775 & TST & \\
\hline CHEMBL435913 & 325795 & 4.8861 & 4.9851 & TRN & \\
\hline CHEMBL200531 & 325795 & 6.0655 & 5.5547 & TST & \\
\hline CHEMBL200426 & 325795 & 4.9208 & 4.8684 & TRN & \\
\hline CHEMBL200494 & 325795 & 5.1938 & 5.1317 & TRN & \\
\hline CHEMBL200507 & 325795 & 5.3468 & 5.0056 & TRN & \\
\hline CHEMBL200776 & 325795 & 2.8239 & 5.2703 & TST & \\
\hline CHEMBL383186 & 325795 & 5.2441 & 5.2431 & TRN & \\
\hline CHEMBL371771 & 325795 & 5.3979 & 5.1259 & TST & \\
\hline CHEMBL426819 & 325795 & 4.3279 & 4.4125 & TRN & \\
\hline CHEMBL200203 & 325795 & 5.1871 & 4.8203 & TRN & \\
\hline CHEMBL200602 & 325795 & 4.699 & 4.7852 & TRN & \\
\hline CHEMBL199163 & 325795 & 5.4089 & 5.2409 & TRN & \\
\hline CHEMBL200167 & 325795 & 5.8539 & 5.3615 & TRN & \\
\hline CHEMBL200619 & 325795 & 5.0555 & 5.5453 & TRN & \\
\hline CHEMBL198859 & 325795 & 4.4559 & 4.6618 & TRN & \\
\hline CHEMBL200455 & 325795 & 4.699 & 4.6954 & TRN & \\
\hline CHEMBL200482 & 325795 & 5.2076 & 5.2108 & TRN & \\
\hline CHEMBL200744 & 325795 & 4.1675 & 5.2404 & TST & \\
\hline CHEMBL197440 & 325795 & 5.2596 & 5.2212 & TRN & \\
\hline CHEMBL199487 & 325795 & 3.9586 & 3.7576 & TRN & \\
\hline CHEMBL199483 & 325795 & 2.8239 & 5.3044 & TST & \\
\hline CHEMBL372139 & 325795 & 4.4685 & 5.1023 & TST & \\
\hline CHEMBL199470 & 325795 & 4.585 & 4.8763 & TRN & \\
\hline CHEMBL199358 & 325795 & 4.8861 & 5.1386 & TRN & \\
\hline CHEMBL382971 & 325795 & 4.8539 & 5.3862 & TST & \\
\hline CHEMBL199014 & 325795 & 5.6021 & 5.5034 & TRN & \\
\hline CHEMBL371133 & 325795 & 5.3098 & 5.2735 & TRN & \\
\hline CHEMBL200775 & 325795 & 5.4559 & 5.3505 & TST & \\
\hline CHEMBL440035 & 325795 & 4.7959 & 4.1838 & TRN & \\
\hline CHEMBL200289 & 325795 & 5.7212 & 5.6894 & TRN & \\
\hline CHEMBL200708 & 325795 & 4.7212 & 4.9053 & TRN & \\
\hline
\end{tabular}




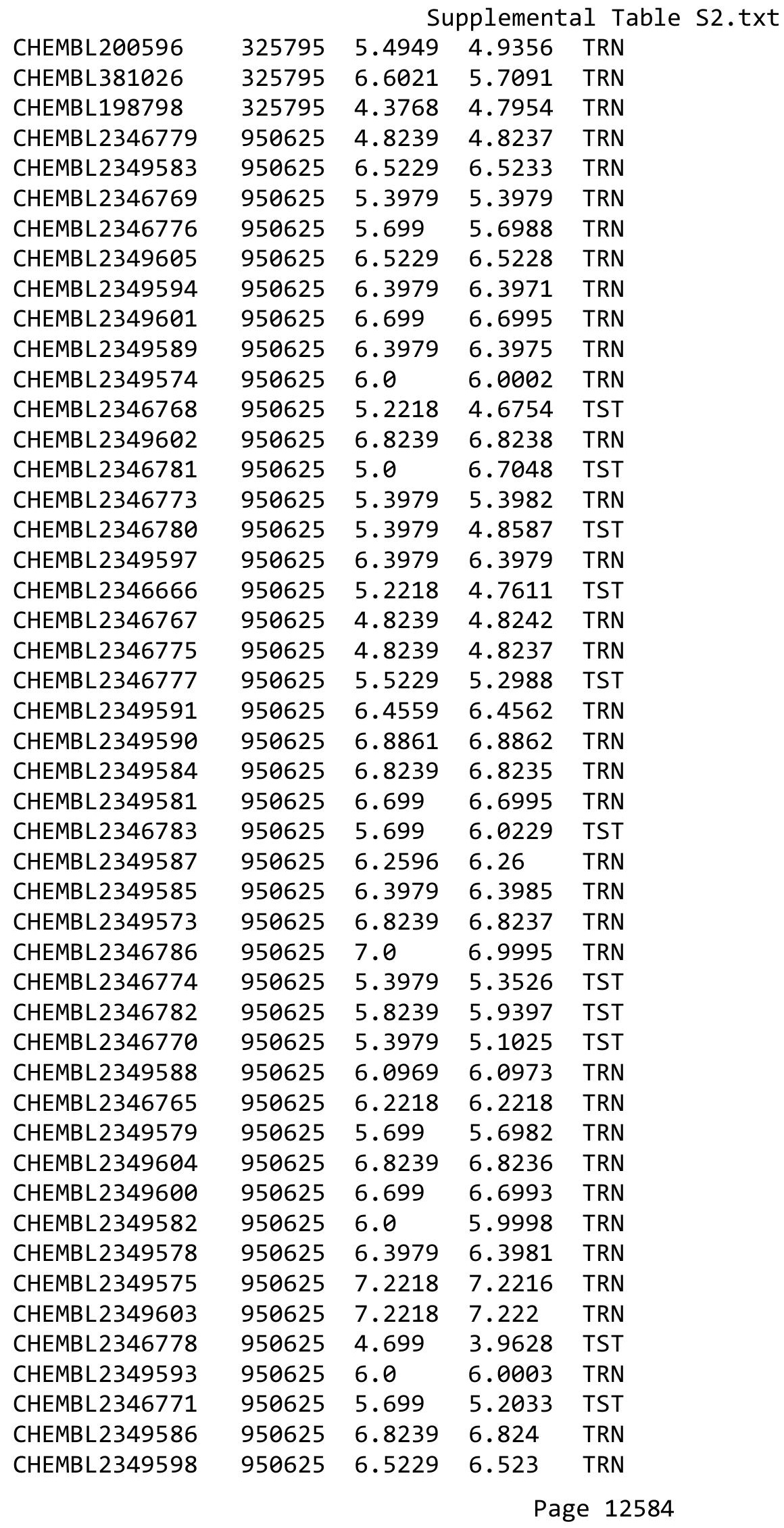




\begin{tabular}{|c|c|c|c|c|c|c|}
\hline \multirow[b]{2}{*}{ CHEMBL 2346772} & \multicolumn{6}{|c|}{ Supplemental Table S2.txt } \\
\hline & 950625 & 5.5229 & 5.7862 & TST & & \\
\hline CHEMBL2349576 & 950625 & 6.699 & 6.6988 & TRN & & \\
\hline CHEMBL2349580 & 950625 & 6.8239 & 6.8238 & TRN & & \\
\hline CHEMBL2346785 & 950625 & 5.0 & 6.2044 & TST & & \\
\hline CHEMBL2349592 & 950625 & 6.0969 & 6.0967 & TRN & & \\
\hline CHEMBL2346766 & 950625 & 5.0969 & 4.6998 & TST & & \\
\hline CHEMBL 2349596 & 950625 & 6.0969 & 6.0974 & TRN & & \\
\hline CHEMBL2346787 & 950625 & 6.8239 & 6.8239 & TRN & & \\
\hline CHEMBL 2346784 & 950625 & 6.0969 & 5.8328 & TST & & \\
\hline CHEMBL2349599 & 950625 & 6.5229 & 6.5226 & TRN & & \\
\hline CHEMBL2349595 & 950625 & 6.699 & 6.699 & TRN & & \\
\hline CHEMBL 2346788 & 950625 & 7.2218 & 7.2219 & TRN & & \\
\hline CHEMBL2349577 & 950625 & 7.0 & 7.0 & TRN & & \\
\hline CHEMBL 3909080 & 1641807 & 7.6091 & 7.7384 & TRN & & \\
\hline CHEMBL 3934841 & 1641807 & 7.8013 & 6.7054 & TST & & \\
\hline CHEMBL 3922452 & 1641807 & 6.5038 & 6.5502 & TRN & & \\
\hline CHEMBL3890291 & 1641807 & 7.0039 & 6.9839 & TRN & & \\
\hline CHEMBL 3972145 & 1641807 & 6.6238 & 6.4564 & TRN & & \\
\hline CHEMBL 3944143 & 1641807 & 7.4271 & 7.5271 & TRN & & \\
\hline CHEMBL3966519 & 1641807 & 5.1444 & 5.4635 & TRN & & \\
\hline CHEMBL 3934032 & 1641807 & 5.6284 & 5.4504 & TRN & & \\
\hline CHEMBL 3947020 & 1641807 & 7.6716 & 7.2483 & TST & & \\
\hline CHEMBL 3957002 & 1641807 & 6.6275 & 6.5354 & TRN & & \\
\hline CHEMBL3903310 & 1641807 & 6.2294 & 5.824 & TRN & & \\
\hline CHEMBL 3944968 & 1641807 & 5.2511 & 5.3315 & TRN & & \\
\hline CHEMBL 3942615 & 1641807 & 6.6735 & 7.2034 & TST & & \\
\hline CHEMBL3957488 & 1641807 & 6.4345 & 6.6541 & TRN & & \\
\hline CHEMBL 3946704 & 1641807 & 8.3188 & 8.1724 & TRN & & \\
\hline CHEMBL 3913236 & 1641807 & 7.098 & 6.3127 & TST & & \\
\hline CHEMBL 3902946 & 1641807 & 6.3452 & 6.5567 & TRN & & \\
\hline CHEMBL 3984566 & 1641807 & 6.7555 & 7.1503 & TRN & & \\
\hline CHEMBL 3898491 & 1641807 & 6.5706 & 6.8708 & TST & & \\
\hline CHEMBL 3898473 & 1641807 & 6.2022 & 5.8853 & TRN & & \\
\hline CHEMBL3934049 & 1641807 & 6.3146 & 6.4264 & TRN & & \\
\hline CHEMBL 3890776 & 1641807 & 6.36299 & 99999999 & 995 & 6.6685 & TST \\
\hline CHEMBL 3907961 & 1641807 & 6.6476 & 6.8906 & TRN & & \\
\hline CHEMBL 3977646 & 1641807 & 8.5528 & 8.2093 & TRN & & \\
\hline CHEMBL 3950541 & 1641807 & 5.7711 & 6.1332 & TST & & \\
\hline CHEMBL 3891791 & 1641807 & 7.5686 & 7.3624 & TRN & & \\
\hline CHEMBL 3949986 & 1641807 & 6.3725 & 6.3964 & TST & & \\
\hline CHEMBL 3943163 & 1641807 & 7.6655 & 7.7243 & TRN & & \\
\hline CHEMBL3902459 & 1641807 & 7.9666 & 8.0257 & TRN & & \\
\hline CHEMBL 3946554 & 1641807 & 8.3372 & 8.3292 & TRN & & \\
\hline CHEMBL 3926411 & 1641807 & 6.3161 & 6.4147 & TRN & & \\
\hline CHEMBL 3915195 & 1641807 & 7.1844 & 7.2521 & TRN & & \\
\hline CHEMBL 3935737 & 1641807 & 6.6002 & 5.6796 & TST & & \\
\hline CHEMBL3908532 & 1641807 & 7.9508 & 8.0823 & TRN & & \\
\hline CHEMBL 3981223 & 1641807 & 6.8526 & 6.5296 & TRN & & \\
\hline
\end{tabular}

Page 12585 
Supplemental Table S2.txt

\begin{tabular}{|c|c|c|c|c|c|}
\hline CHEMBL 3937770 & 1641807 & 6.8904 & \multicolumn{3}{|c|}{$6.4670000000000005 \quad$ TRN } \\
\hline CHEMBL 3974725 & 1641807 & 6.7224 & 6.3536 & TRN & \\
\hline CHEMBL 3917635 & 1641807 & 5.6735 & 5.6716 & TRN & \\
\hline CHEMBL 3983281 & 1641807 & 6.5902 & 6.8598 & TST & \\
\hline CHEMBL 3985762 & 1641807 & 7.6799 & 7.683 & TRN & \\
\hline CHEMBL 3964121 & 1641807 & 6.2771 & 6.5487 & TRN & \\
\hline CHEMBL 3966728 & 1641807 & 7.3675 & 7.1721 & TST & \\
\hline CHEMBL 3921552 & 1641807 & 8.1487 & 7.6779 & TRN & \\
\hline CHEMBL 3901180 & 1641807 & 5.7711 & 6.5479 & TST & \\
\hline CHEMBL 3912976 & 1641807 & 5.7095 & 5.5835 & TRN & \\
\hline CHEMBL 3907866 & 1641807 & 6.0723 & 6.4416 & TRN & \\
\hline CHEMBL 3907229 & 1641807 & 6.3211 & 6.2581 & TRN & \\
\hline CHEMBL 3930503 & 1641807 & 7.0424 & 6.891 & TRN & \\
\hline CHEMBL 3926360 & 1641807 & 5.7265 & 5.1078 & TST & \\
\hline CHEMBL 3939430 & 1641807 & 7.9393 & 7.5374 & TRN & \\
\hline CHEMBL 3964399 & 1641807 & 6.6351 & 5.8783 & TRN & \\
\hline CHEMBL 3943094 & 1641807 & 6.8327 & 6.6695 & TRN & \\
\hline CHEMBL 3966964 & 1641807 & \multicolumn{3}{|c|}{5.757000000000001} & \\
\hline CHEMBL 3977454 & 1641807 & 6.1669 & 6.3513 & TRN & \\
\hline CHEMBL 3930263 & 1641807 & 8.3372 & 8.1062 & TRN & \\
\hline CHEMBL 3961253 & 1641807 & 7.6676 & 7.5755 & TRN & \\
\hline CHEMBL 3928604 & 1641807 & 5.2238 & 5.0938 & TRN & \\
\hline CHEMBL 3935708 & 1641807 & 6.5327 & 6.585 & TST & \\
\hline CHEMBL 3964681 & 1641807 & 7.1904 & 6.9674 & TRN & \\
\hline CHEMBL 3980704 & 1641807 & 8.2007 & 7.8665 & TRN & \\
\hline CHEMBL 3972425 & 1641807 & 7.7235 & 5.9159 & TST & \\
\hline CHEMBL 3976570 & 1641807 & 6.0559 & 6.2868 & TST & \\
\hline CHEMBL 3944864 & 1641807 & 6.2732 & 6.5134 & TRN & \\
\hline CHEMBL 3951733 & 1641807 & 6.585 & 6.5772 & TRN & \\
\hline CHEMBL 3955808 & 1641807 & 7.0022 & 7.0983 & TRN & \\
\hline CHEMBL 3897099 & 1641807 & 6.0725 & 6.4618 & TST & \\
\hline CHEMBL 3928188 & 1641807 & 6.6231 & 6.9943 & TRN & \\
\hline CHEMBL 3962360 & 1641807 & 7.7959 & 8.0025 & TRN & \\
\hline CHEMBL 3922309 & 1641807 & 6.0773 & \multicolumn{2}{|c|}{6.8260000000000005} & \\
\hline CHEMBL 3969673 & 1641807 & 6.447 & 6.4626 & TRN & \\
\hline CHEMBL 3894083 & 1641807 & 7.6778 & 7.4957 & TRN & \\
\hline CHEMBL 3896028 & 1641807 & 7.8996 & 6.0664 & TST & \\
\hline CHEMBL 3932993 & 1641807 & 5.5784 & 6.0716 & TRN & \\
\hline CHEMBL 3966921 & 1641807 & 8.1938 & 8.2202 & TRN & \\
\hline CHEMBL 3972670 & 1641807 & 6.1792 & 6.6782 & TRN & \\
\hline CHEMBL 3912432 & 1641807 & 7.5575 & 7.2766 & TRN & \\
\hline CHEMBL 3976017 & 1641807 & 7.9469 & 8.3664 & TRN & \\
\hline CHEMBL 3984518 & 1641807 & 7.567 & 7.4469 & TRN & \\
\hline CHEMBL 3921632 & 1641807 & 6.8804 & 6.1816 & TST & \\
\hline CHEMBL 3907782 & 1641807 & 6.0891 & 6.6128 & TST & \\
\hline CHEMBL 3892269 & 1641807 & 6.3417 & 6.9866 & TRN & \\
\hline CHEMBL 3945311 & 1641807 & 6.5586 & 6.3519 & TRN & \\
\hline CHEMBL 3922820 & 1641807 & 7.3288 & 6.2421 & TST & \\
\hline
\end{tabular}


Supplemental Table S2.txt

\begin{tabular}{|c|c|c|c|c|}
\hline CHEMBL3927700 & 1641807 & 7.0128 & 6.6823 & TST \\
\hline CHEMBL3945522 & 1641807 & 5.6038 & 5.7938 & TRN \\
\hline CHEMBL3903538 & 1641807 & 7.6021 & 7.8502 & TRN \\
\hline CHEMBL 3972257 & 1641807 & 7.0762 & 6.9763 & TRN \\
\hline CHEMBL3905805 & 1641807 & 5.471 & 5.4882 & TRN \\
\hline CHEMBL3958141 & 1641807 & 7.8539 & 7.6553 & TRN \\
\hline CHEMBL3891651 & 1641807 & 5.0166 & 5.1638 & TRN \\
\hline CHEMBL3977895 & 1641807 & 8.0044 & 7.1961 & TST \\
\hline CHEMBL3974292 & 1641807 & 6.3003 & 6.6936 & TST \\
\hline CHEMBL3969731 & 1641807 & 7.5017 & 7.7498 & TRN \\
\hline CHEMBL3909781 & 1641807 & 7.5129 & 7.5491 & TST \\
\hline CHEMBL3960676 & 1641807 & 6.0649 & 5.8506 & TRN \\
\hline CHEMBL3937720 & 1641807 & 7.5157 & 7.9931 & TRN \\
\hline CHEMBL 3975451 & 1641807 & 8.4815 & 6.9258 & TST \\
\hline CHEMBL3949297 & 1641807 & 6.7508 & 7.0892 & TST \\
\hline CHEMBL3972602 & 1641807 & 5.4504 & 5.8391 & TRN \\
\hline CHEMBL3933644 & 1641807 & 8.2076 & 7.9961 & TRN \\
\hline CHEMBL3944094 & 1641807 & 5.3571 & 5.1189 & TRN \\
\hline CHEMBL3948425 & 1641807 & 7.3595 & 7.6421 & TST \\
\hline CHEMBL3942997 & 1641807 & 5.4912 & 5.4861 & TRN \\
\hline CHEMBL3949840 & 1641807 & 6.5714 & 5.9348 & TRN \\
\hline CHEMBL3974770 & 1641807 & 6.767 & 6.7134 & TRN \\
\hline CHEMBL3930445 & 1641807 & 7.4976 & 7.2295 & TRN \\
\hline CHEMBL3957919 & 1641807 & 6.0363 & 6.0186 & TRN \\
\hline CHEMBL3948799 & 1641807 & 6.8077 & 6.73799 & 99999999995 \\
\hline CHEMBL3921811 & 1641807 & 6.7535 & 6.1005 & TRN \\
\hline CHEMBL3950410 & 1641807 & 7.6345 & 7.2792 & TRN \\
\hline CHEMBL3890241 & 1641807 & 6.1904 & 6.8216 & TST \\
\hline CHEMBL3955161 & 1641807 & 5.6176 & 5.6139 & TRN \\
\hline CHEMBL 3924134 & 1641807 & 8.0706 & 7.744 & TRN \\
\hline CHEMBL3963224 & 1641807 & 7.8633 & 7.4737 & TRN \\
\hline CHEMBL3984214 & 1641807 & 8.0706 & 7.6781 & TRN \\
\hline CHEMBL3954764 & 1641807 & 5.2752 & 5.7512 & TRN \\
\hline CHEMBL3934349 & 1641807 & 7.7375 & 7.6932 & TRN \\
\hline CHEMBL3949586 & 1641807 & 6.44 & 6.0384 & TST \\
\hline CHEMBL3889891 & 1641807 & 5.7421 & 5.5284 & TRN \\
\hline CHEMBL3962706 & 1641807 & 7.1605 & 6.5445 & TST \\
\hline CHEMBL 3890644 & 1641807 & 8.1612 & 7.9144 & TRN \\
\hline CHEMBL3893534 & 1641807 & 8.1192 & 7.8063 & TRN \\
\hline CHEMBL3901229 & 1641807 & 7.9747 & 7.9063 & TRN \\
\hline CHEMBL3939657 & 1641807 & 8.0132 & 7.8714 & TRN \\
\hline CHEMBL3952430 & 1641807 & 5.7791 & 5.9866 & TRN \\
\hline CHEMBL3905831 & 1641807 & 5.9535 & 6.1558 & TRN \\
\hline CHEMBL3906044 & 1641807 & 6.4766 & 5.9155 & TST \\
\hline CHEMBL3977593 & 1641807 & 8.1805 & 8.208 & TRN \\
\hline CHEMBL3957849 & 1641807 & 6.7647 & 6.59 & TST \\
\hline CHEMBL3944801 & 1641807 & 7.1073 & 7.15799 & 99999999995 \\
\hline CHEMBL3979177 & 1641807 & 8.1871 & 6.6903 & TST \\
\hline
\end{tabular}


Supplemental Table S2.txt

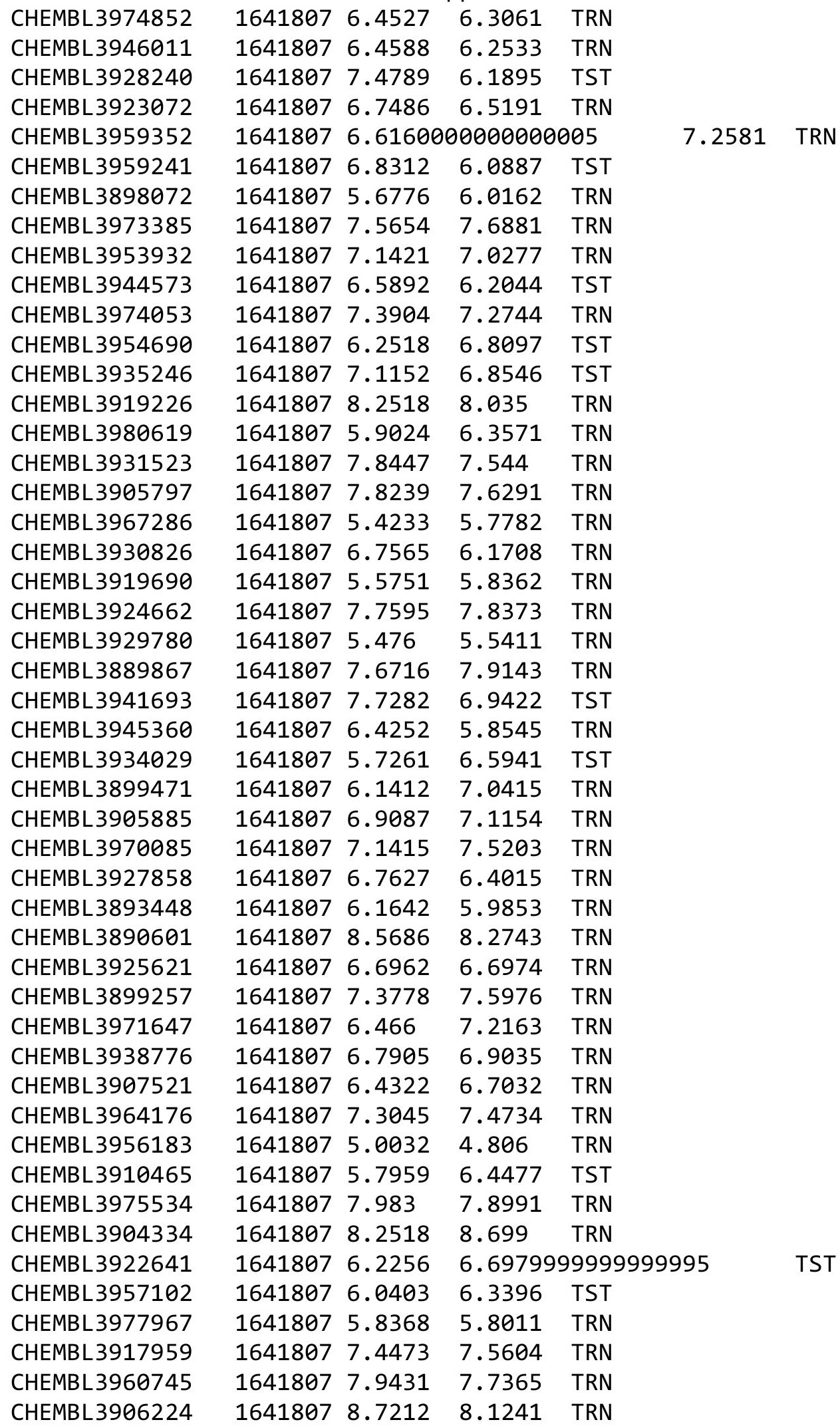

Page 12588 
Supplemental Table S2.txt

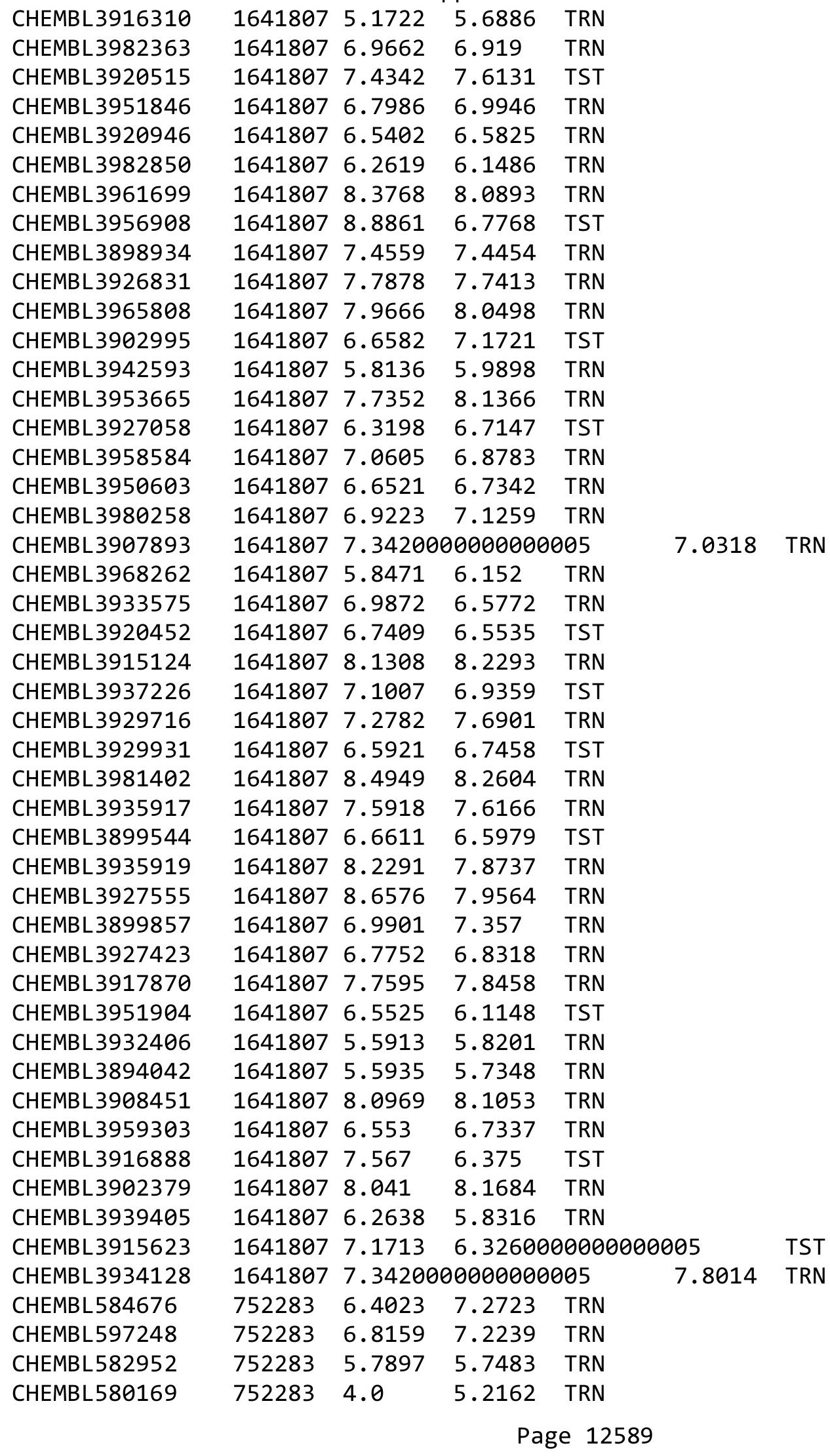




\begin{tabular}{|c|c|c|c|c|c|}
\hline \multicolumn{6}{|c|}{ Supplemental Table S2.txt } \\
\hline CHEMBL601394 & 752283 & 4.0 & 4.5627 & TRN & \\
\hline CHEMBL578058 & 752283 & 7.1261 & 7.0149 & TRN & \\
\hline CHEMBL582322 & 752283 & 4.3206 & 5.4578 & TRN & \\
\hline CHEMBL601598 & 752283 & 7.5331 & 6.8674 & TRN & \\
\hline CHEMBL600521 & 752283 & 7.5929 & 6.08200 & 0000000001 & TST \\
\hline CHEMBL604780 & 752283 & 4.0 & 4.9364 & TRN & \\
\hline CHEMBL578294 & 752283 & 6.1965 & 6.6994 & TRN & \\
\hline CHEMBL586668 & 752283 & 7.0438 & 6.995 & TRN & \\
\hline CHEMBL603018 & 752283 & 7.1643 & 6.5166 & TRN & \\
\hline CHEMBL584882 & 752283 & 4.0 & 4.1149 & TRN & \\
\hline CHEMBL524973 & 752283 & 7.0283 & 7.0202 & TRN & \\
\hline CHEMBL584442 & 752283 & 6.6114 & 6.9209 & TST & \\
\hline CHEMBL602585 & 752283 & 6.3188 & 6.5296 & TRN & \\
\hline CHEMBL601124 & 752283 & 7.0168 & 6.3367 & TST & \\
\hline CHEMBL601768 & 752283 & 6.7208 & 6.96899 & 9999999999 & TRN \\
\hline CHEMBL582099 & 752283 & 6.3478 & 6.2216 & TRN & \\
\hline CHEMBL 2368645 & 752283 & 7.475 & 6.6088 & TRN & \\
\hline CHEMBL596631 & 752283 & 6.0872 & 6.7799 & TRN & \\
\hline CHEMBL601179 & 752283 & 4.0114 & 5.1749 & TRN & \\
\hline CHEMBL599501 & 752283 & 6.2549 & 6.3378 & TRN & \\
\hline CHEMBL202969 & 752283 & 6.4535 & 6.6606 & TRN & \\
\hline CHEMBL600929 & 752283 & 6.3635 & 6.803 & TRN & \\
\hline CHEMBL306946 & 752283 & 6.6476 & 6.63700 & 00000000005 & TRN \\
\hline CHEMBL583599 & 752283 & 4.0 & 5.9084 & TST & \\
\hline CHEMBL602200 & 752283 & 6.308 & 5.7537 & TRN & \\
\hline CHEMBL602371 & 752283 & 7.4045 & 7.0169 & TRN & \\
\hline CHEMBL598884 & 752283 & 7.0395 & 6.2686 & TRN & \\
\hline CHEMBL530475 & 752283 & 6.1599 & 5.3954 & TRN & \\
\hline CHEMBL577850 & 752283 & 5.4191 & 5.4593 & TRN & \\
\hline CHEMBL576945 & 752283 & 6.0904 & 6.1676 & TRN & \\
\hline CHEMBL601377 & 752283 & 6.1537 & 4.4478 & TRN & \\
\hline CHEMBL602013 & 752283 & 5.2007 & 4.1833 & TRN & \\
\hline CHEMBL1567944 & 752283 & 7.0958 & 7.144 & TRN & \\
\hline CHEMBL600295 & 752283 & 7.7307 & 5.3335 & TST & \\
\hline CHEMBL530650 & 752283 & 5.8945 & 5.8717 & TRN & \\
\hline CHEMBL607519 & 752283 & 4.0 & 5.9487 & TST & \\
\hline CHEMBL597457 & 752283 & 5.1765 & 5.3521 & TRN & \\
\hline CHEMBL528471 & 752283 & 5.3354 & 4.3484 & TRN & \\
\hline CHEMBL590647 & 752283 & 4.0 & 4.9433 & TRN & \\
\hline CHEMBL579367 & 752283 & 7.3089 & 7.1677 & TST & \\
\hline CHEMBL582504 & 752283 & 6.5566 & 6.9853 & TRN & \\
\hline CHEMBL528165 & 752283 & 7.0074 & 6.9004 & TRN & \\
\hline CHEMBL602978 & 752283 & 7.9481 & 7.6126 & TST & \\
\hline CHEMBL604109 & 752283 & 4.0 & 5.3721 & TRN & \\
\hline CHEMBL535464 & 752283 & 6.1512 & 6.2407 & TRN & \\
\hline CHEMBL585828 & 752283 & 6.6509 & 6.1384 & TRN & \\
\hline CHEMBL602562 & 752283 & 7.9492 & 6.9496 & TST & \\
\hline CHEMBL598897 & 752283 & 6.4461 & 6.6251 & TRN & \\
\hline
\end{tabular}




\begin{tabular}{|c|c|c|c|c|c|}
\hline \multicolumn{6}{|c|}{ Supplemental Table S2.txt } \\
\hline CHEMBL604980 & 752283 & 7.015 & 6.5946 & TRN & \\
\hline CHEMBL601324 & 752283 & 6.3872 & 6.5713 & TRN & \\
\hline CHEMBL549275 & 752283 & 6.1101 & 6.2258 & TRN & \\
\hline CHEMBL597244 & 752283 & 5.5053 & 5.4248 & TRN & \\
\hline CHEMBL579615 & 752283 & 6.8652 & 6.8639 & TRN & \\
\hline CHEMBL578530 & 752283 & 6.9492 & 6.5796 & TST & \\
\hline CHEMBL581866 & 752283 & 6.8336 & 6.35 & TRN & \\
\hline CHEMBL600312 & 752283 & 4.0 & 5.9782 & TST & \\
\hline CHEMBL582107 & 752283 & 6.9259 & 7.1355 & TRN & \\
\hline CHEMBL578674 & 752283 & 4.0 & 4.702 & TRN & \\
\hline CHEMBL601113 & 752283 & 7.3197 & 6.1866 & TRN & \\
\hline CHEMBL580891 & 752283 & 4.0 & 4.9321 & TRN & \\
\hline CHEMBL609628 & 752283 & 6.6131 & 7.4729 & TRN & \\
\hline CHEMBL585022 & 752283 & 4.0501 & 5.0882 & TRN & \\
\hline CHEMBL602785 & 752283 & 6.0443 & 6.4617 & TRN & \\
\hline CHEMBL528586 & 752283 & 5.1427 & 5.7723 & TRN & \\
\hline CHEMBL531108 & 752283 & 5.6929 & 5.7829 & TRN & \\
\hline CHEMBL529858 & 752283 & 5.4622 & 4.079 & TRN & \\
\hline CHEMBL530445 & 752283 & 7.1891 & 6.9368 & TRN & \\
\hline CHEMBL1348555 & 752283 & 7.0405 & 7.7756 & TRN & \\
\hline CHEMBL583401 & 752283 & 7.2418 & 6.6509 & TRN & \\
\hline CHEMBL582456 & 752283 & 7.9385 & 6.4511 & TST & \\
\hline CHEMBL544227 & 752283 & 8.5918 & 8.1656 & TRN & \\
\hline CHEMBL580827 & 752283 & 6.9263 & 5.9531 & TRN & \\
\hline CHEMBL582072 & 752283 & 6.4962 & 4.7337 & TRN & \\
\hline CHEMBL600501 & 752283 & 4.0 & 4.4021 & TRN & \\
\hline CHEMBL585357 & 752283 & 5.4067 & 4.6103 & TRN & \\
\hline CHEMBL576410 & 752283 & 6.5857 & 6.4695 & TST & \\
\hline CHEMBL531760 & 752283 & 6.9435 & 7.1504 & TRN & \\
\hline CHEMBL530049 & 752283 & 6.8492 & 6.6529 & TRN & \\
\hline CHEMBL530973 & 752283 & 7.3757 & 6.8509 & TRN & \\
\hline CHEMBL528492 & 752283 & 7.3298 & 7.0798 & TRN & \\
\hline CHEMBL584444 & 752283 & 6.1057 & 6.0781 & TRN & \\
\hline CHEMBL531401 & 752283 & 6.8119 & 6.8096 & TRN & \\
\hline CHEMBL582532 & 752283 & 6.3019 & 6.23600 & 3000000001 & TRN \\
\hline CHEMBL582302 & 752283 & 4.0 & 4.9813 & TRN & \\
\hline CHEMBL606231 & 752283 & 6.2154 & 5.0522 & TRN & \\
\hline CHEMBL600906 & 752283 & 6.5541 & 7.0122 & TRN & \\
\hline CHEMBL604775 & 752283 & 6.6078 & 6.9925 & TST & \\
\hline CHEMBL578752 & 752283 & 6.0747 & 5.277 & TRN & \\
\hline CHEMBL597855 & 752283 & 7.699 & 6.5722 & TRN & \\
\hline CHEMBL601336 & 752283 & 5.9598 & 5.6445 & TRN & \\
\hline CHEMBL582277 & 752283 & 6.1085 & 5.1396 & TRN & \\
\hline CHEMBL610788 & 752283 & 6.7726 & 7.2289 & TRN & \\
\hline CHEMBL533105 & 752283 & 6.5524 & 6.3649 & TST & \\
\hline CHEMBL579485 & 752283 & 6.7233 & 7.1301 & TRN & \\
\hline CHEMBL609027 & 752283 & 6.7575 & 6.3882 & TST & \\
\hline CHEMBL531888 & 752283 & 5.1135 & 4.6366 & TRN & \\
\hline & & & & 12591 & \\
\hline
\end{tabular}




\begin{tabular}{|c|c|c|c|c|c|c|}
\hline \multirow[b]{2}{*}{ CHEMBL600320 } & \multicolumn{6}{|c|}{ Supplemental Table S2.txt } \\
\hline & 752283 & 6.3188 & 6.9762 & TRN & & \\
\hline CHEMBL599084 & 752283 & 6.4168 & 6.82 & TRN & & \\
\hline CHEMBL576992 & 752283 & 7.0857 & 6.6168 & TRN & & \\
\hline CHEMBL579749 & 752283 & 4.0 & 4.7925 & TRN & & \\
\hline CHEMBL585993 & 752283 & 6.5236 & 5.9713 & TRN & & \\
\hline CHEMBL577676 & 752283 & 5.3382 & 5.8335 & TRN & & \\
\hline CHEMBL602818 & 752283 & 5.96899 & 99999999 & 99 & 5.06 & TRN \\
\hline CHEMBL606167 & 752283 & 6.6221 & 6.3275 & TRN & & \\
\hline CHEMBL587633 & 752283 & 4.0 & 5.4757 & TST & & \\
\hline CHEMBL581257 & 752283 & 7.1367 & 7.8367 & TRN & & \\
\hline CHEMBL579105 & 752283 & 5.9551 & 6.9917 & TRN & & \\
\hline CHEMBL598883 & 752283 & 7.5305 & 7.8336 & TRN & & \\
\hline CHEMBL 2000517 & 752283 & 7.0675 & 7.6588 & TST & & \\
\hline CHEMBL578290 & 752283 & 4.0 & 5.7421 & TST & & \\
\hline CHEMBL535514 & 752283 & 5.6115 & 5.9082 & TRN & & \\
\hline CHEMBL601964 & 752283 & 4.4283 & 5.1619 & TRN & & \\
\hline CHEMBL584832 & 752283 & 4.1605 & 4.8172 & TRN & & \\
\hline CHEMBL584625 & 752283 & 6.9801 & 6.8417 & TRN & & \\
\hline CHEMBL603035 & 752283 & 6.3036 & 6.0297 & TRN & & \\
\hline CHEMBL602219 & 752283 & 6.475 & 5.7928 & TRN & & \\
\hline CHEMBL531543 & 752283 & 5.4949 & 4.993 & TRN & & \\
\hline CHEMBL581872 & 752283 & 6.8069 & 4.6019 & TST & & \\
\hline CHEMBL584290 & 752283 & 4.0 & 3.575 & TRN & & \\
\hline CHEMBL599917 & 752283 & 6.7314 & 6.8002 & TRN & & \\
\hline CHEMBL579373 & 752283 & 4.0 & 5.3951 & TRN & & \\
\hline CHEMBL600754 & 752283 & 8.6409 & 7.2726 & TRN & & \\
\hline CHEMBL586000 & 752283 & 6.7891 & 6.8101 & TRN & & \\
\hline CHEMBL546162 & 752283 & 5.4067 & 5.5047 & TRN & & \\
\hline CHEMBL527634 & 752283 & 5.5355 & 6.1588 & TRN & & \\
\hline CHEMBL581892 & 752283 & 6.067 & 5.7666 & TRN & & \\
\hline CHEMBL585583 & 752283 & 5.0269 & 5.199 & TRN & & \\
\hline CHEMBL579144 & 752283 & 5.4389 & 6.4682 & TST & & \\
\hline CHEMBL585627 & 752283 & 6.8636 & 7.2455 & TRN & & \\
\hline CHEMBL585956 & 752283 & 5.7533 & 6.0584 & TRN & & \\
\hline CHEMBL584637 & 752283 & 6.08200 & 00000000 & & 6.4561 & TRN \\
\hline CHEMBL606252 & 752283 & 6.4353 & 5.6522 & TRN & & \\
\hline CHEMBL584028 & 752283 & 6.0419 & 6.69 & TST & & \\
\hline CHEMBL578876 & 752283 & 6.7891 & 5.9542 & TRN & & \\
\hline CHEMBL605334 & 752283 & 6.9165 & 6.165 & TRN & & \\
\hline CHEMBL579316 & 752283 & 6.5224 & 5.54799 & 999999999 & & TRN \\
\hline CHEMBL585048 & 752283 & 7.0501 & 6.0091 & TRN & & \\
\hline CHEMBL580848 & 752283 & 7.9634 & 7.3948 & TST & & \\
\hline CHEMBL583351 & 752283 & 5.96299 & 79999999 & 99 & 6.3825 & TRN \\
\hline CHEMBL525826 & 752283 & 7.2055 & 7.0002 & TRN & & \\
\hline CHEMBL578061 & 752283 & 5.8309 & 5.6074 & TRN & & \\
\hline CHEMBL601378 & 752283 & 6.4855 & 6.5507 & TRN & & \\
\hline CHEMBL581691 & 752283 & 4.0 & 5.4625 & TST & & \\
\hline CHEMBL603024 & 752283 & 6.5068 & 5.2377 & TRN & & \\
\hline
\end{tabular}

Page 12592 


\begin{tabular}{|c|c|c|c|c|c|c|}
\hline & & \multicolumn{5}{|c|}{ Supplemental Table S2.txt } \\
\hline CHEMBL600319 & 752283 & 6.1284 & 6.8082 & TRN & & \\
\hline CHEMBL601318 & 752283 & 4.0 & 6.7997 & TST & & \\
\hline CHEMBL585325 & 752283 & 4.0 & 5.2674 & TRN & & \\
\hline CHEMBL578462 & 752283 & 6.7151 & 6.0025 & TRN & & \\
\hline CHEMBL599493 & 752283 & 4.0 & 5.072 & TRN & & \\
\hline CHEMBL586414 & 752283 & 4.0 & 2.7799 & TRN & & \\
\hline CHEMBL596638 & 752283 & 6.266 & 6.4814 & TRN & & \\
\hline CHEMBL580639 & 752283 & 7.0841 & 6.9311 & TRN & & \\
\hline CHEMBL602174 & 752283 & 7.9682 & 7.0712 & TRN & & \\
\hline CHEMBL599089 & 752283 & 4.0 & 4.8287 & TRN & & \\
\hline CHEMBL582102 & 752283 & 6.0835 & 6.1966 & TST & & \\
\hline CHEMBL585833 & 752283 & 4.0177 & 5.082 & TRN & & \\
\hline CHEMBL599497 & 752283 & 4.0 & 5.6858 & TRN & & \\
\hline CHEMBL587611 & 752283 & 7.3585 & 6.7629 & TRN & & \\
\hline CHEMBL580162 & 752283 & 5.3054 & 6.3195 & TRN & & \\
\hline CHEMBL578681 & 752283 & 7.8677 & 7.3276 & TRN & & \\
\hline CHEMBL579173 & 752283 & $5.9910 e$ & 00000000 & 205 & 5.0378 & TRN \\
\hline CHEMBL532641 & 752283 & 5.9825 & 6.474 & TRN & & \\
\hline CHEMBL611663 & 752283 & 7.8781 & 6.7577 & TST & & \\
\hline CHEMBL579074 & 752283 & 6.9446 & 6.9781 & TRN & & \\
\hline CHEMBL388886 & 752283 & 6.871 & 6.1576 & TRN & & \\
\hline CHEMBL587259 & 752283 & 7.9481 & 6.5147 & TRN & & \\
\hline CHEMBL587620 & 752283 & 5.4271 & 5.353 & TRN & & \\
\hline CHEMBL532671 & 752283 & 6.2441 & 5.8245 & TRN & & \\
\hline CHEMBL611070 & 752283 & 6.4237 & 6.317 & TRN & & \\
\hline CHEMBL601152 & 752283 & 7.1397 & 6.5545 & TRN & & \\
\hline CHEMBL596635 & 752283 & 4.0 & 5.3563 & TRN & & \\
\hline CHEMBL601580 & 752283 & 6.1512 & 6.1932 & TRN & & \\
\hline CHEMBL585288 & 752283 & 6.8196 & 5.9651 & TST & & \\
\hline CHEMBL585238 & 752283 & 6.8202 & 7.0874 & TRN & & \\
\hline CHEMBL598685 & 752283 & 5.5268 & 5.7356 & TRN & & \\
\hline CHEMBL461579 & 752283 & 7.8529 & 7.1486 & TRN & & \\
\hline CHEMBL531046 & 752283 & 4.0 & 5.6717 & TST & & \\
\hline CHEMBL603013 & 752283 & 6.8362 & 6.4195 & TRN & & \\
\hline CHEMBL602193 & 752283 & 8.2069 & 8.5166 & TST & & \\
\hline CHEMBL604979 & 752283 & 4.0 & 4.9519 & TRN & & \\
\hline CHEMBL576606 & 752283 & 4.0 & 6.3952 & TST & & \\
\hline CHEMBL599884 & 752283 & 6.2933 & 5.6588 & TRN & & \\
\hline CHEMBL579968 & 752283 & 6.3116 & 6.1749 & TRN & & \\
\hline CHEMBL582511 & 752283 & 4.0 & 4.484 & TST & & \\
\hline CHEMBL585772 & 752283 & 5.7841 & 5.1295 & TRN & & \\
\hline CHEMBL602833 & 752283 & 4.3665 & 5.8044 & TRN & & \\
\hline CHEMBL601766 & 752283 & 7.7231 & 7.0925 & TRN & & \\
\hline CHEMBL584269 & 752283 & 7.1255 & 6.1972 & TRN & & \\
\hline CHEMBL528712 & 752283 & 6.3585 & 6.6933 & TRN & & \\
\hline CHEMBL582483 & 752283 & 5.9041 & 7.2524 & TST & & \\
\hline CHEMBL609606 & 752283 & 6.7698 & 6.939 & TST & & \\
\hline CHEMBL586955 & 752283 & 8.3468 & 7.2254 & TST & & \\
\hline
\end{tabular}




\begin{tabular}{|c|c|c|c|c|c|c|}
\hline & & & -0 & & & \\
\hline CHEMBL545872 & 752283 & 6.3615 & 5.5222 & TRN & & \\
\hline CHEMBL584236 & 752283 & 6.4584 & 5.6235 & TRN & & \\
\hline CHEMBL601821 & 752283 & 6.65600 & 0000000 & 01 & 6.5499 & TRN \\
\hline CHEMBL525126 & 752283 & 6.3468 & 6.1801 & TRN & & \\
\hline CHEMBL586785 & 752283 & 5.6513 & 5.9634 & TRN & & \\
\hline CHEMBL600161 & 752283 & 7.1707 & 5.8751 & TST & & \\
\hline CHEMBL583359 & 752283 & 6.1612 & 6.9032 & TRN & & \\
\hline CHEMBL576403 & 752283 & 6.3958 & 6.8997 & TRN & & \\
\hline CHEMBL525128 & 752283 & 6.2644 & 6.2404 & TRN & & \\
\hline CHEMBL586001 & 752283 & 6.5507 & 6.9342 & TST & & \\
\hline CHEMBL600560 & 752283 & 5.8861 & 6.4064 & TRN & & \\
\hline CHEMBL600972 & 752283 & 7.0044 & 7.0011 & TRN & & \\
\hline CHEMBL579147 & 752283 & 5.1772 & $5.90600 t$ & 0000000001 & & TRN \\
\hline CHEMBL600296 & 752283 & 5.5379 & 6.8835 & TRN & & \\
\hline CHEMBL581476 & 752283 & 7.2526 & 7.1933 & TST & & \\
\hline CHEMBL578500 & 752283 & 7.0195 & 6.5578 & TRN & & \\
\hline CHEMBL602024 & 752283 & 7.5916 & 6.8383 & TST & & \\
\hline CHEMBL586184 & 752283 & 7.0195 & 7.2227 & TRN & & \\
\hline CHEMBL584454 & 752283 & 4.0395 & 5.1024 & TRN & & \\
\hline CHEMBL586697 & 752283 & 4.0 & 6.4794 & TST & & \\
\hline CHEMBL602593 & 752283 & 4.0 & 4.8987 & TRN & & \\
\hline CHEMBL598272 & 752283 & 6.3487 & 6.8358 & TRN & & \\
\hline CHEMBL578749 & 752283 & 6.05399 & 99999999 & 99 & 5.9155 & TRN \\
\hline CHEMBL6742 & 752283 & 7.0 & 7.8296 & TRN & & \\
\hline CHEMBL577662 & 752283 & 7.1163 & 7.4988 & TRN & & \\
\hline CHEMBL602612 & 752283 & 7.9702 & 6.5167 & TRN & & \\
\hline CHEMBL531222 & 752283 & 4.0017 & 4.1784 & TRN & & \\
\hline CHEMBL584827 & 752283 & 6.5137 & 6.5801 & TRN & & \\
\hline CHEMBL585414 & 752283 & 4.0 & 5.3471 & TST & & \\
\hline CHEMBL578950 & 752283 & 5.7361 & 5.5456 & TRN & & \\
\hline CHEMBL531777 & 752283 & 4.0 & 4.5719 & TRN & & \\
\hline CHEMBL610912 & 752283 & 7.2848 & 6.8163 & TST & & \\
\hline CHEMBL600108 & 752283 & 5.3449 & 6.37799 & 9999999999 & & TST \\
\hline CHEMBL547775 & 752283 & 6.1898 & 5.8108 & TRN & & \\
\hline CHEMBL604514 & 752283 & 5.7231 & 6.0038 & TRN & & \\
\hline CHEMBL578941 & 752283 & 6.7991 & 6.6251 & TRN & & \\
\hline CHEMBL587902 & 752283 & 7.6897 & 6.1775 & TRN & & \\
\hline CHEMBL587142 & 752283 & 6.5733 & 6.3884 & TRN & & \\
\hline CHEMBL598683 & 752283 & 6.5186 & 5.539 & TST & & \\
\hline CHEMBL598062 & 752283 & 6.8582 & 7.2826 & TRN & & \\
\hline CHEMBL579424 & 752283 & 6.3595 & 5.2134 & TRN & & \\
\hline CHEMBL588643 & 752283 & 6.475 & 5.2646 & TRN & & \\
\hline CHEMBL578334 & 752283 & 7.1637 & 6.1888 & TST & & \\
\hline CHEMBL600755 & 752283 & 7.4191 & 6.5569 & TRN & & \\
\hline CHEMBL379386 & 752283 & 6.78700 & 00000006 & $\partial 1$ & 6.5536 & TRN \\
\hline CHEMBL602164 & 752283 & 7.8225 & 6.5048 & TST & & \\
\hline CHEMBL601397 & 752283 & 7.2366 & 6.6311 & TRN & & \\
\hline CHEMBL486081 & 752283 & 7.1707 & 6.4805 & TRN & & \\
\hline
\end{tabular}




\begin{tabular}{|c|c|c|c|c|c|c|}
\hline & & & & & & \\
\hline CHEMBL582429 & 752283 & 6.6692 & 6.5469 & TRN & & \\
\hline CHEMBL548155 & 752283 & 8.0 & 7.6278 & TRN & & \\
\hline CHEMBL533670 & 752283 & 6.6123 & 6.7672 & TRN & & \\
\hline CHEMBL533376 & 752283 & 8.3072 & 6.4273 & TST & & \\
\hline CHEMBL584218 & 752283 & 4.0 & 4.26 & TRN & & \\
\hline CHEMBL527541 & 752283 & 6.8857 & 7.1763 & TRN & & \\
\hline CHEMBL584232 & 752283 & 4.0 & 5.1219 & TST & & \\
\hline CHEMBL494668 & 752283 & 6.4855 & 6.1908 & TRN & & \\
\hline CHEMBL582492 & 752283 & 5.6639 & 6.194 & TRN & & \\
\hline CHEMBL585651 & 752283 & 6.8526 & 6.6661 & TRN & & \\
\hline CHEMBL598476 & 752283 & 5.6 & 5.2317 & TRN & & \\
\hline CHEMBL582672 & 752283 & 7.6515 & 7.084 & TRN & & \\
\hline CHEMBL601952 & 752283 & 5.71 & 5.9997 & TST & & \\
\hline CHEMBL602178 & 752283 & 5.5569 & 6.4004 & TRN & & \\
\hline CHEMBL600766 & 752283 & 8.1701 & 7.4451 & TRN & & \\
\hline CHEMBL578967 & 752283 & 8.7328 & 7.2968 & TRN & & \\
\hline CHEMBL602423 & 752283 & 4.0 & 5.1798 & TRN & & \\
\hline CHEMBL606450 & 752283 & 5.4056 & 5.2988 & TST & & \\
\hline CHEMBL547770 & 752283 & 7.1029 & 7.5753 & TRN & & \\
\hline CHEMBL577000 & 752283 & 6.9801 & 6.4591 & TRN & & \\
\hline CHEMBL599496 & 752283 & 6.90799 & 79999999 & 995 & 6.5223 & TRN \\
\hline CHEMBL585035 & 752283 & 6.6202 & 5.6641 & TRN & & \\
\hline CHEMBL534001 & 752283 & 4.0 & 4.6904 & TRN & & \\
\hline CHEMBL600923 & 752283 & 6.7423 & 6.785 & TRN & & \\
\hline CHEMBL585136 & 752283 & 5.4214 & 6.8468 & TRN & & \\
\hline CHEMBL585443 & 752283 & 4.0353 & 5.5168 & TRN & & \\
\hline CHEMBL581700 & 752283 & 6.5699 & 6.3331 & TRN & & \\
\hline CHEMBL598053 & 752283 & 8.1469 & 6.4955 & TRN & & \\
\hline CHEMBL578700 & 752283 & 6.8887 & 6.6722 & TRN & & \\
\hline CHEMBL603000 & 752283 & 4.0 & 4.6993 & TRN & & \\
\hline CHEMBL578669 & 752283 & 6.5572 & 7.0857 & TRN & & \\
\hline CHEMBL401540 & 752283 & 6.9694 & 5.7972 & TST & & \\
\hline CHEMBL583165 & 752283 & 4.032 & 4.2643 & TRN & & \\
\hline CHEMBL579352 & 752283 & 7.7577 & 7.8366 & TRN & & \\
\hline CHEMBL584462 & 752283 & 6.3778 & 7.3754 & TRN & & \\
\hline CHEMBL577807 & 752283 & 4.0 & 5.0304 & TRN & & \\
\hline CHEMBL368715 & 752283 & 4.0 & 5.651 & TST & & \\
\hline CHEMBL578502 & 752283 & 6.64 & 6.45 & TRN & & \\
\hline CHEMBL609155 & 752283 & 4.0 & 5.9502 & TRN & & \\
\hline CHEMBL577011 & 752283 & 7.3251 & 6.6845 & TRN & & \\
\hline CHEMBL602366 & 752283 & 6.301 & 7.0247 & TRN & & \\
\hline CHEMBL584251 & 752283 & 6.8297 & 6.7825 & TRN & & \\
\hline CHEMBL599308 & 752283 & 4.0 & 4.9739 & TRN & & \\
\hline CHEMBL587249 & 752283 & 4.0 & 4.4595 & TRN & & \\
\hline CHEMBL599102 & 752283 & 6.2336 & 5.88 & TRN & & \\
\hline CHEMBL578512 & 752283 & 6.98799 & 99999999 & 995 & 5.6766 & TST \\
\hline CHEMBL577647 & 752283 & 4.0 & 4.4556 & TRN & & \\
\hline CHEMBL582807 & 752283 & 6.0044 & 6.5978 & TRN & & \\
\hline
\end{tabular}




\begin{tabular}{|c|c|c|c|c|c|c|}
\hline \multirow[b]{2}{*}{ CHEMBL601594 } & & \multicolumn{5}{|c|}{ Supplemental Table S2.txt } \\
\hline & 752283 & 7.6944 & 6.7345 & TRN & & \\
\hline CHEMBL602625 & 752283 & 4.0 & 4.9307 & TRN & & \\
\hline CHEMBL596640 & 752283 & 6.7426 & 6.7898 & TRN & & \\
\hline CHEMBL578109 & 752283 & 6.2993 & 6.1707 & TRN & & \\
\hline CHEMBL578944 & 752283 & 7.34200 & 30000000 & 005 & 7.0905 & TST \\
\hline CHEMBL578879 & 752283 & 6.8193 & 5.7519 & TRN & & \\
\hline CHEMBL524376 & 752283 & 7.3197 & 7.2465 & TRN & & \\
\hline CHEMBL7070 & 752283 & 8.3716 & 8.2516 & TRN & & \\
\hline CHEMBL533794 & 752283 & 6.7215 & 7.1102 & TRN & & \\
\hline CHEMBL601188 & 752283 & 5.7625 & 6.5113 & TST & & \\
\hline CHEMBL531190 & 752283 & 5.5211 & 6.0036 & TST & & \\
\hline CHEMBL576810 & 752283 & 7.76 & 7.439 & TST & & \\
\hline CHEMBL579150 & 752283 & 6.1385 & 7.0011 & TST & & \\
\hline CHEMBL581868 & 752283 & 7.4609 & 7.0449 & TST & & \\
\hline CHEMBL600753 & 752283 & 7.8392 & 5.358 & TST & & \\
\hline CHEMBL598478 & 752283 & 6.2204 & 6.6589 & TST & & \\
\hline CHEMBL585829 & 752283 & 5.9974 & 6.599 & TST & & \\
\hline CHEMBL580166 & 752283 & 7.3242 & 7.2292 & TST & & \\
\hline CHEMBL528486 & 752283 & 6.5977 & 6.3032 & TST & & \\
\hline CHEMBL598279 & 752283 & 6.5151 & 6.6642 & TST & & \\
\hline CHEMBL582508 & 752283 & 4.0 & 5.7826 & TST & & \\
\hline CHEMBL580381 & 752283 & 7.1232 & 6.4287 & TST & & \\
\hline CHEMBL582739 & 752283 & 4.0 & 5.3728 & TST & & \\
\hline CHEMBL597464 & 752283 & 5.7464 & 6.49299 & 9999999999 & & TST \\
\hline CHEMBL601158 & 752283 & 6.251 & 6.1647 & TST & & \\
\hline CHEMBL584520 & 752283 & 4.0 & 5.4578 & TST & & \\
\hline CHEMBL582454 & 752283 & 6.2526 & 6.1979 & TST & & \\
\hline CHEMBL106525 & 752283 & 6.26200 & 30000000 & 005 & 6.5825 & TST \\
\hline CHEMBL606166 & 752283 & 6.9465 & 6.2135 & TST & & \\
\hline CHEMBL588925 & 752283 & 6.1891 & 5.5955 & TST & & \\
\hline CHEMBL585453 & 752283 & 6.6356 & 5.9532 & TST & & \\
\hline CHEMBL600332 & 752283 & 4.0 & 5.5618 & TST & & \\
\hline CHEMBL599899 & 752283 & 7.3063 & 6.6699 & TST & & \\
\hline CHEMBL607255 & 752283 & 6.5366 & 5.8676 & TST & & \\
\hline CHEMBL604116 & 752283 & 4.0 & 5.0794 & TST & & \\
\hline CHEMBL535267 & 752283 & 8.0 & 7.6842 & TST & & \\
\hline CHEMBL528661 & 752283 & 6.63399 & 99999999 & 995 & 6.0328 & TST \\
\hline CHEMBL581449 & 752283 & 8.3788 & 6.869 & TST & & \\
\hline CHEMBL1256164 & 664904 & 7.9208 & 8.7095 & TST & & \\
\hline CHEMBL 214943 & 664904 & 8.5528 & 8.6913 & TST & & \\
\hline CHEMBL1257285 & 664904 & 8.5086 & 8.6337 & TRN & & \\
\hline CHEMBL1258336 & 664904 & 8.4437 & 8.2542 & TRN & & \\
\hline CHEMBL1258668 & 664904 & 4.301 & 4.3782 & TRN & & \\
\hline CHEMBL1257880 & 664904 & 9.0969 & 8.5983 & TST & & \\
\hline CHEMBL1258557 & 664904 & 8.4685 & 8.5462 & TRN & & \\
\hline CHEMBL1256165 & 664904 & 5.4202 & 5.2133 & TRN & & \\
\hline CHEMBL1257632 & 664904 & 8.4089 & 8.7095 & TST & & \\
\hline CHEMBL1257635 & 664904 & 9.3979 & 9.1664 & TRN & & \\
\hline
\end{tabular}




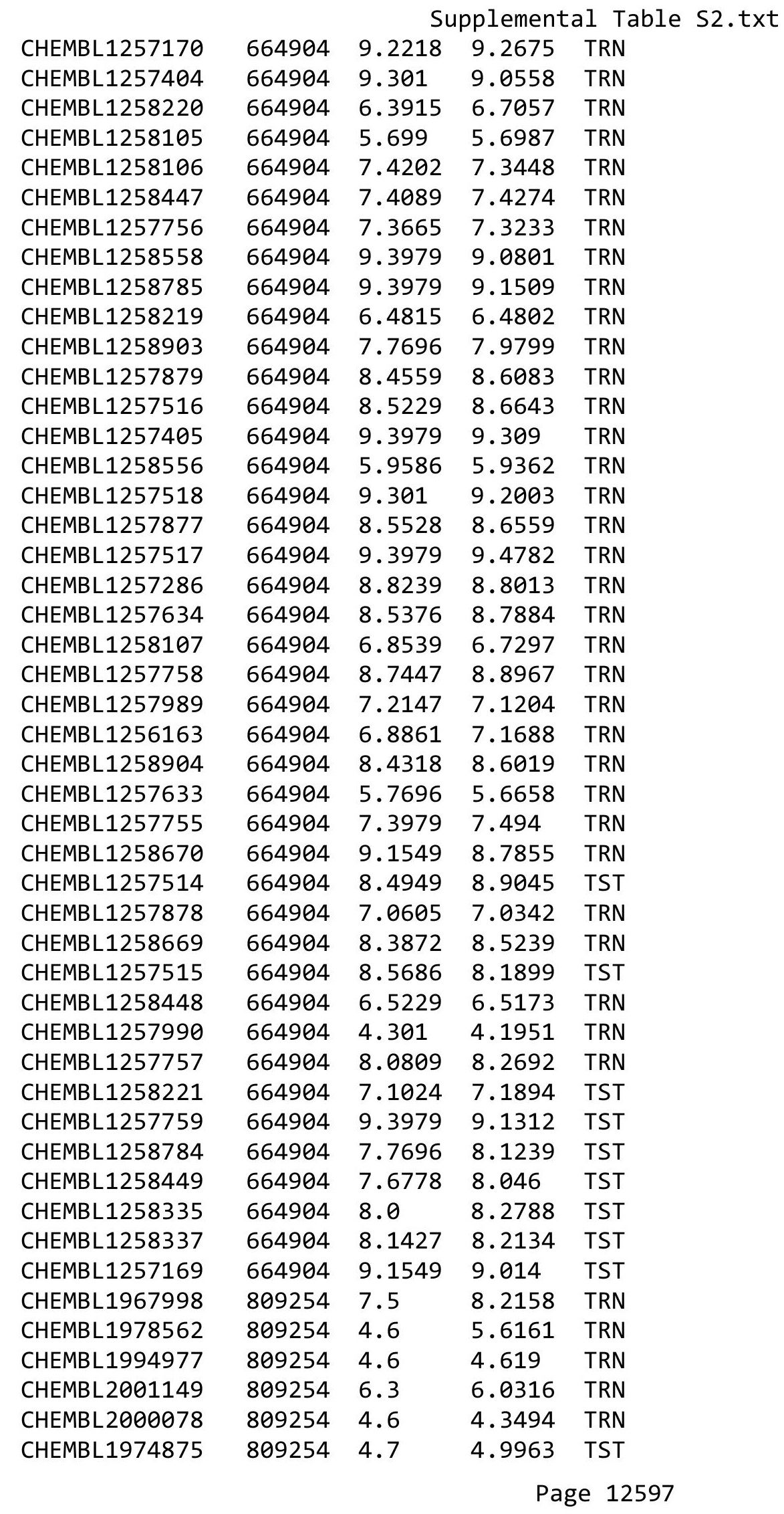




\begin{tabular}{|c|c|c|c|c|}
\hline & & & pplement & $\mathrm{a} \perp \mathrm{Ta}$ \\
\hline CHEMBL2005478 & 809254 & 6.0 & 5.5862 & TRN \\
\hline CHEMBL1996646 & 809254 & 5.9 & 6.019 & TRN \\
\hline CHEMBL1979773 & 809254 & 4.6 & 5.0186 & TRN \\
\hline CHEMBL1989471 & 809254 & 6.0 & 5.8369 & TST \\
\hline CHEMBL1996702 & 809254 & 5.7 & 6.1457 & TRN \\
\hline CHEMBL 2005482 & 809254 & 4.6 & 4.4361 & TRN \\
\hline CHEMBL1997909 & 809254 & 4.6 & 4.3086 & TRN \\
\hline CHEMBL 2007124 & 809254 & 4.6 & 4.6198 & TRN \\
\hline CHEMBL1978195 & 809254 & 6.7 & 6.0394 & TRN \\
\hline CHEMBL 2006439 & 809254 & 4.6 & 6.3282 & TRN \\
\hline CHEMBL1985681 & 809254 & 5.9 & 6.3839 & TRN \\
\hline CHEMBL1966842 & 809254 & 4.6 & 4.6436 & TRN \\
\hline CHEMBL1991674 & 809254 & 7.5 & 7.4508 & TRN \\
\hline CHEMBL1982711 & 809254 & 7.0 & 7.0207 & TRN \\
\hline CHEMBL 262623 & 809254 & 5.7 & 5.6912 & TRN \\
\hline CHEMBL1984842 & 809254 & 4.6 & 4.4028 & TRN \\
\hline CHEMBL2004118 & 809254 & 7.8 & 7.3111 & TRN \\
\hline CHEMBL1996345 & 809254 & 4.6 & 5.1103 & TRN \\
\hline CHEMBL 2004025 & 809254 & 4.6 & 5.4747 & TRN \\
\hline CHEMBL1996048 & 809254 & 6.8 & 6.5369 & TRN \\
\hline CHEMBL50894 & 809254 & 4.6 & 5.3424 & TRN \\
\hline CHEMBL1995211 & 809254 & 6.8 & 7.3063 & TRN \\
\hline CHEMBL1965033 & 809254 & 4.6 & 4.5713 & TRN \\
\hline CHEMBL461876 & 809254 & 8.1 & 7.4426 & TRN \\
\hline CHEMBL1982753 & 809254 & 7.0 & 6.5216 & TRN \\
\hline CHEMBL 2006299 & 809254 & 4.6 & 4.8949 & TRN \\
\hline CHEMBL1972346 & 809254 & 6.3 & 6.3926 & TST \\
\hline CHEMBL1971519 & 809254 & 5.9 & 5.6805 & TRN \\
\hline CHEMBL1997335 & 809254 & 6.6 & 6.5968 & TRN \\
\hline CHEMBL1965169 & 809254 & 4.6 & 5.3622 & TRN \\
\hline CHEMBL1081312 & 809254 & 7.2 & 8.0974 & TRN \\
\hline CHEMBL1965170 & 809254 & 4.6 & 5.7987 & TRN \\
\hline CHEMBL1994808 & 809254 & 4.1 & 4.7411 & TRN \\
\hline CHEMBL2005792 & 809254 & 4.6 & 4.4229 & TRN \\
\hline CHEMBL1991867 & 809254 & 4.8 & 5.1421 & TRN \\
\hline CHEMBL1972355 & 809254 & 6.1 & 6.1428 & TRN \\
\hline CHEMBL1997892 & 809254 & 4.6 & 4.2911 & TRN \\
\hline CHEMBL 2001641 & 809254 & 4.9 & 5.5089 & TRN \\
\hline CHEMBL1997193 & 809254 & 4.6 & 5.4906 & TST \\
\hline CHEMBL1964902 & 809254 & 4.6 & 4.2133 & TRN \\
\hline CHEMBL1973868 & 809254 & 6.0 & 5.2352 & TRN \\
\hline CHEMBL1983715 & 809254 & 7.7 & 7.6748 & TRN \\
\hline CHEMBL1984500 & 809254 & 4.5 & 4.4722 & TRN \\
\hline CHEMBL 2002992 & 809254 & 7.7 & 7.0612 & TRN \\
\hline CHEMBL1982700 & 809254 & 4.6 & 4.9717 & TRN \\
\hline CHEMBL1966799 & 809254 & 4.0 & 4.5785 & TRN \\
\hline CHEMBL10 & 809254 & 4.6 & 4.6263 & TRN \\
\hline CHEMBL1980763 & 809254 & 7.6 & 7.1212 & TRN \\
\hline
\end{tabular}




\begin{tabular}{|c|c|c|c|c|c|}
\hline \\
\hline CHEMBL1977634 & 809254 & 4.6 & 4.5595 & TRN & \\
\hline CHEMBL1977931 & 809254 & 4.9 & 5.7483 & TRN & \\
\hline CHEMBL1976872 & 809254 & 4.6 & 4.8928 & TRN & \\
\hline CHEMBL2007479 & 809254 & 4.6 & 4.8548 & TRN & \\
\hline CHEMBL1998953 & 809254 & 7.7 & 6.2131 & TRN & \\
\hline CHEMBL1971606 & 809254 & 4.6 & 5.0731 & TRN & \\
\hline CHEMBL1999120 & 809254 & 4.4 & 4.8853 & TST & \\
\hline CHEMBL1972220 & 809254 & 7.6 & 6.6072 & TRN & \\
\hline CHEMBL1981215 & 809254 & 4.6 & 4.6963 & TRN & \\
\hline CHEMBL 2003785 & 809254 & 5.7 & 5.3264 & TRN & \\
\hline CHEMBL1973720 & 809254 & 8.7 & 8.093 & TRN & \\
\hline CHEMBL1999414 & 809254 & 5.9 & 6.4758 & TRN & \\
\hline CHEMBL1967336 & 809254 & 4.6 & 4.5275 & TRN & \\
\hline CHEMBL 2001228 & 809254 & 4.6 & 4.3253 & TRN & \\
\hline CHEMBL 2001923 & 809254 & 4.6 & 4.4313 & TRN & \\
\hline CHEMBL1983070 & 809254 & 4.6 & 4.9439 & TRN & \\
\hline CHEMBL 2003514 & 809254 & 4.6 & 4.9525 & TRN & \\
\hline CHEMBL1970340 & 809254 & 5.5 & 5.4495 & TRN & \\
\hline CHEMBL1967992 & 809254 & 6.1 & 4.9041 & TRN & \\
\hline CHEMBL1989043 & 809254 & 4.6 & 5.3338 & TRN & \\
\hline CHEMBL2006450 & 809254 & 4.6 & 5.524 & TRN & \\
\hline CHEMBL2001987 & 809254 & 4.6 & 4.417 & TRN & \\
\hline CHEMBL1994555 & 809254 & 5.7 & 5.7445 & TRN & \\
\hline CHEMBL1164180 & 809254 & 5.7 & 6.4509 & TST & \\
\hline CHEMBL1975121 & 809254 & 4.6 & 4.9459 & TRN & \\
\hline CHEMBL1983640 & 809254 & 4.6 & 5.50899 & 99999999995 & TRN \\
\hline CHEMBL1997611 & 809254 & 5.7 & 5.2109 & TST & \\
\hline CHEMBL1971943 & 809254 & 4.6 & 5.6905 & TRN & \\
\hline CHEMBL1997924 & 809254 & 8.0 & 8.0272 & TRN & \\
\hline CHEMBL1984686 & 809254 & 4.6 & 4.9663 & TST & \\
\hline CHEMBL1978267 & 809254 & 4.6 & 4.4036 & TRN & \\
\hline CHEMBL1973793 & 809254 & 6.1 & 5.4025 & TRN & \\
\hline CHEMBL1992073 & 809254 & 7.0 & 7.0647 & TRN & \\
\hline CHEMBL1990254 & 809254 & 4.6 & 5.3561 & TRN & \\
\hline CHEMBL1986143 & 809254 & 4.6 & 5.0316 & TRN & \\
\hline CHEMBL1972934 & 809254 & 4.9 & 5.183 & TRN & \\
\hline CHEMBL 2007559 & 809254 & 7.4 & 6.131 & TRN & \\
\hline CHEMBL1992581 & 809254 & 5.8 & 5.3072 & TRN & \\
\hline CHEMBL2004290 & 809254 & 6.3 & 5.9948 & TRN & \\
\hline CHEMBL1975921 & 809254 & 5.4 & 5.2988 & TRN & \\
\hline CHEMBL2004033 & 809254 & 5.6 & 5.0381 & TST & \\
\hline CHEMBL1975923 & 809254 & 4.9 & 5.1568 & TST & \\
\hline CHEMBL1984847 & 809254 & 4.6 & 4.7527 & TRN & \\
\hline CHEMBL1984402 & 809254 & 4.1 & 4.6414 & TRN & \\
\hline CHEMBL2005449 & 809254 & 5.8 & 5.9615 & TRN & \\
\hline CHEMBL1996576 & 809254 & 4.6 & 4.6654 & TST & \\
\hline CHEMBL1988076 & 809254 & 5.6 & 4.3524 & TRN & \\
\hline CHEMBL1991678 & 809254 & 4.6 & 4.3821 & TRN & \\
\hline
\end{tabular}




\begin{tabular}{|c|c|c|c|c|}
\hline \multicolumn{5}{|c|}{ blemental T } \\
\hline CHEMBL1987998 & 809254 & 4.6 & 4.1813 & TRN \\
\hline CHEMBL1971534 & 809254 & 5.0 & 5.2042 & TRN \\
\hline CHEMBL1990496 & 809254 & 4.6 & 4.4938 & TRN \\
\hline CHEMBL 242865 & 809254 & 5.8 & 6.8372 & TRN \\
\hline CHEMBL235157 & 809254 & 7.2 & 5.2968 & TRN \\
\hline CHEMBL 2004159 & 809254 & 4.6 & 4.6181 & TRN \\
\hline CHEMBL1978371 & 809254 & 4.6 & 5.1477 & TST \\
\hline CHEMBL440084 & 809254 & 4.6 & 4.9597 & TRN \\
\hline CHEMBL1998110 & 809254 & 4.6 & 4.7424 & TRN \\
\hline CHEMBL1978166 & 809254 & 6.2 & 6.7226 & TRN \\
\hline CHEMBL1990590 & 809254 & 4.6 & 4.8204 & TRN \\
\hline CHEMBL1974617 & 809254 & 5.4 & 5.5817 & TRN \\
\hline CHEMBL1965660 & 809254 & 6.5 & 5.9554 & TRN \\
\hline CHEMBL1992125 & 809254 & 5.6 & 6.0654 & TRN \\
\hline CHEMBL1966175 & 809254 & 6.5 & 6.4468 & TRN \\
\hline CHEMBL 2007375 & 809254 & 4.6 & 4.6048 & TRN \\
\hline CHEMBL1178727 & 809254 & 4.5 & 4.7254 & TRN \\
\hline CHEMBL 379975 & 809254 & 7.0 & 6.1734 & TST \\
\hline CHEMBL1967612 & 809254 & 4.3 & 4.9749 & TST \\
\hline CHEMBL1965387 & 809254 & 4.6 & 4.3428 & TRN \\
\hline CHEMBL 388978 & 809254 & 9.4 & 9.6472 & TST \\
\hline CHEMBL1997041 & 809254 & 6.4 & 6.4132 & TRN \\
\hline CHEMBL550418 & 809254 & 5.8 & 5.3612 & TRN \\
\hline CHEMBL398951 & 809254 & 4.6 & 4.7897 & TST \\
\hline CHEMBL1971289 & 809254 & 6.3 & 5.0567 & TST \\
\hline CHEMBL1988437 & 809254 & 7.7 & 6.9797 & TRN \\
\hline CHEMBL 2007603 & 809254 & 4.6 & 4.5293 & TRN \\
\hline CHEMBL1421720 & 809254 & 6.1 & 5.5079 & TRN \\
\hline CHEMBL1233887 & 809254 & 6.3 & 4.9389 & TRN \\
\hline CHEMBL1968130 & 809254 & 4.3 & 4.8628 & TRN \\
\hline CHEMBL1992607 & 809254 & 4.5 & 5.2318 & TRN \\
\hline CHEMBL1996649 & 809254 & 6.0 & 6.0731 & TRN \\
\hline CHEMBL1986756 & 809254 & 4.6 & 4.6938 & TRN \\
\hline CHEMBL1949855 & 809254 & 5.8 & 5.0691 & TRN \\
\hline CHEMBL 3109278 & 809254 & 4.8 & 5.3519 & TRN \\
\hline CHEMBL1727312 & 809254 & 4.5 & 4.2683 & TRN \\
\hline CHEMBL1990223 & 809254 & 4.6 & 4.4153 & TRN \\
\hline CHEMBL 2004438 & 809254 & 4.6 & 4.2623 & TRN \\
\hline CHEMBL1964382 & 809254 & 5.6 & 5.351 & TST \\
\hline CHEMBL101311 & 809254 & 5.9 & 5.9482 & TRN \\
\hline CHEMBL191003 & 809254 & 7.1 & 6.9363 & TRN \\
\hline CHEMBL1973359 & 809254 & 6.9 & 6.5654 & TST \\
\hline CHEMBL1988581 & 809254 & 7.0 & 6.9292 & TST \\
\hline CHEMBL 2005699 & 809254 & 4.6 & 4.2868 & TRN \\
\hline CHEMBL 2006564 & 809254 & 8.9 & 8.3603 & TRN \\
\hline CHEMBL1986943 & 809254 & 8.1 & 7.9459 & TRN \\
\hline CHEMBL1979690 & 809254 & 7.8 & 8.3081 & TRN \\
\hline CHEMBL234085 & 809254 & 6.7 & 6.1996 & TRN \\
\hline
\end{tabular}




\begin{tabular}{|c|c|c|c|c|c|}
\hline & & & & & \\
\hline CHEMBL1978167 & 809254 & 5.9 & 5.6006 & TRN & \\
\hline CHEMBL418203 & 809254 & 6.0 & 5.3641 & TST & \\
\hline CHEMBL225519 & 809254 & 6.1 & 5.3972 & TST & \\
\hline CHEMBL1994159 & 809254 & 4.2 & 4.8532 & TRN & \\
\hline CHEMBL1976376 & 809254 & 4.6 & 4.9667 & TRN & \\
\hline CHEMBL1988622 & 809254 & 5.4 & 5.3764 & TRN & \\
\hline CHEMBL1983575 & 809254 & 7.2 & 7.28799 & 9999999999 & TRN \\
\hline CHEMBL1968868 & 809254 & 4.6 & 4.8042 & TRN & \\
\hline CHEMBL1981047 & 809254 & 6.1 & 7.1403 & TRN & \\
\hline CHEMBL1998470 & 809254 & 6.7 & 5.7041 & TRN & \\
\hline CHEMBL1976196 & 809254 & 4.6 & 5.0814 & TRN & \\
\hline CHEMBL1997197 & 809254 & 4.6 & 4.8143 & TRN & \\
\hline CHEMBL1975903 & 809254 & 6.2 & 4.96899 & 9999999999 & TRN \\
\hline CHEMBL1983630 & 809254 & 4.7 & 4.7007 & TRN & \\
\hline CHEMBL1522508 & 809254 & 5.1 & 4.5213 & TRN & \\
\hline CHEMBL1988805 & 809254 & 6.6 & 5.4098 & TRN & \\
\hline CHEMBL458997 & 809254 & 8.6 & 7.6773 & TRN & \\
\hline CHEMBL1969942 & 809254 & 4.6 & 4.9564 & TRN & \\
\hline CHEMBL1982660 & 809254 & 4.6 & 5.2061 & TRN & \\
\hline CHEMBL1978567 & 809254 & 4.6 & 4.7424 & TRN & \\
\hline CHEMBL1965838 & 809254 & 4.4 & 4.9944 & TST & \\
\hline CHEMBL1995765 & 809254 & 5.2 & 4.7448 & TST & \\
\hline CHEMBL1984760 & 809254 & 7.3 & 7.5212 & TRN & \\
\hline CHEMBL1997846 & 809254 & 5.6 & 6.5558 & TRN & \\
\hline CHEMBL424872 & 809254 & 4.6 & 4.2846 & TRN & \\
\hline CHEMBL360847 & 809254 & 4.6 & 5.5085 & TRN & \\
\hline CHEMBL1995811 & 809254 & 5.9 & 5.2913 & TRN & \\
\hline CHEMBL1983111 & 809254 & 9.2 & 8.5125 & TRN & \\
\hline CHEMBL1995916 & 809254 & 4.3 & $5.1160 e$ & 00000000005 & TRN \\
\hline CHEMBL1988141 & 809254 & 4.6 & 6.3289 & TST & \\
\hline CHEMBL1992937 & 809254 & 6.1 & 5.2675 & TRN & \\
\hline CHEMBL451401 & 809254 & 4.8 & 5.2328 & TRN & \\
\hline CHEMBL1977134 & 809254 & 4.6 & 4.1785 & TRN & \\
\hline CHEMBL1970873 & 809254 & 4.1 & 4.3347 & TRN & \\
\hline CHEMBL1985206 & 809254 & 6.0 & 4.8689 & TRN & \\
\hline CHEMBL1991078 & 809254 & 6.3 & 6.3771 & TRN & \\
\hline CHEMBL1977749 & 809254 & 6.8 & 5.7971 & TST & \\
\hline CHEMBL1975212 & 809254 & 5.2 & 5.1458 & TRN & \\
\hline CHEMBL2001613 & 809254 & 5.4 & 5.3025 & TRN & \\
\hline CHEMBL261849 & 809254 & 4.6 & 4.5882 & TRN & \\
\hline CHEMBL1983923 & 809254 & 6.7 & 6.1955 & TRN & \\
\hline CHEMBL1993904 & 809254 & 6.8 & 6.5859 & TRN & \\
\hline CHEMBL1997275 & 809254 & 4.6 & 5.704 & TRN & \\
\hline CHEMBL1967513 & 809254 & 4.6 & 4.3947 & TRN & \\
\hline CHEMBL1980376 & 809254 & 4.8 & 5.1622 & TRN & \\
\hline CHEMBL 2000724 & 809254 & 4.6 & 4.9736 & TRN & \\
\hline CHEMBL1982413 & 809254 & 4.6 & 5.2347 & TRN & \\
\hline CHEMBL2002182 & 809254 & 4.4 & 4.6535 & TRN & \\
\hline & & & & 12601 & \\
\hline
\end{tabular}




\begin{tabular}{|c|c|c|c|c|c|}
\hline & & & & & \\
\hline CHEMBL1985042 & 809254 & 4.4 & 4.8378 & TST & \\
\hline CHEMBL1987535 & 809254 & 6.2 & 6.3443 & TRN & \\
\hline CHEMBL1983393 & 809254 & 4.6 & 5.0512 & TRN & \\
\hline CHEMBL1981792 & 809254 & 4.6 & 4.5227 & TRN & \\
\hline CHEMBL 2002586 & 809254 & 7.5 & 6.6526 & TRN & \\
\hline CHEMBL 2006674 & 809254 & 4.6 & 5.0878 & TST & \\
\hline CHEMBL 383264 & 809254 & 6.0 & 6.4717 & TRN & \\
\hline CHEMBL1992371 & 809254 & 5.8 & 5.3678 & TRN & \\
\hline CHEMBL1984236 & 809254 & 4.6 & 4.9428 & TST & \\
\hline CHEMBL2007421 & 809254 & 6.0 & 6.1553 & TRN & \\
\hline CHEMBL1973138 & 809254 & 4.6 & 4.494 & TRN & \\
\hline CHEMBL 2002599 & 809254 & 4.6 & 4.9928 & TRN & \\
\hline CHEMBL1992673 & 809254 & 4.4 & 4.547 & TST & \\
\hline CHEMBL1969151 & 809254 & 7.8 & $7.6610 e$ & 00000000005 & TRN \\
\hline CHEMBL1967252 & 809254 & 6.4 & 5.7841 & TRN & \\
\hline CHEMBL1993335 & 809254 & 6.4 & 6.0676 & TRN & \\
\hline CHEMBL1981492 & 809254 & 5.6 & 4.7551 & TRN & \\
\hline CHEMBL 2007574 & 809254 & 7.1 & 6.9128 & TRN & \\
\hline CHEMBL1988692 & 809254 & 6.5 & 5.5383 & TST & \\
\hline CHEMBL1993374 & 809254 & 4.6 & 5.475 & TRN & \\
\hline CHEMBL1994318 & 809254 & 5.7 & 5.0485 & TRN & \\
\hline CHEMBL1998680 & 809254 & 4.6 & 4.4278 & TRN & \\
\hline CHEMBL592030 & 809254 & 6.6 & 6.2666 & TST & \\
\hline CHEMBL1970317 & 809254 & 6.5 & 6.1434 & TRN & \\
\hline CHEMBL1605605 & 809254 & 6.1 & 5.6485 & TRN & \\
\hline CHEMBL1997007 & 809254 & 7.5 & 7.5652 & TRN & \\
\hline CHEMBL1970352 & 809254 & 5.6 & 5.0104 & TST & \\
\hline CHEMBL1964444 & 809254 & 4.6 & 4.5921 & TRN & \\
\hline CHEMBL 2002690 & 809254 & 4.6 & 4.6239 & TRN & \\
\hline CHEMBL1980167 & 809254 & 4.6 & 4.9732 & TRN & \\
\hline CHEMBL1978713 & 809254 & 6.0 & 5.1473 & TRN & \\
\hline CHEMBL 377408 & 809254 & 4.6 & 4.6402 & TRN & \\
\hline CHEMBL 278041 & 809254 & 4.6 & 4.9617 & TRN & \\
\hline CHEMBL 215152 & 809254 & 4.6 & 4.6557 & TRN & \\
\hline CHEMBL1997051 & 809254 & 5.6 & 4.6622 & TRN & \\
\hline CHEMBL 2006765 & 809254 & 9.1 & 8.8311 & TRN & \\
\hline CHEMBL1986590 & 809254 & 6.2 & 6.2056 & TRN & \\
\hline CHEMBL1870106 & 809254 & 6.2 & 5.9483 & TST & \\
\hline CHEMBL406845 & 809254 & 4.6 & 4.878 & TRN & \\
\hline CHEMBL1980246 & 809254 & 4.6 & 4.6916 & TRN & \\
\hline CHEMBL1983980 & 809254 & 6.2 & 5.7695 & TRN & \\
\hline CHEMBL482538 & 809254 & 6.0 & 6.0649 & TRN & \\
\hline CHEMBL1999484 & 809254 & 7.3 & 7.8787 & TRN & \\
\hline CHEMBL1984296 & 809254 & 5.8 & 5.4103 & TRN & \\
\hline CHEMBL1986899 & 809254 & 4.6 & 4.8748 & TRN & \\
\hline CHEMBL1984038 & 809254 & 4.6 & 4.7281 & TRN & \\
\hline CHEMBL1964718 & 809254 & 4.5 & 4.8419 & TST & \\
\hline CHEMBL1993661 & 809254 & 9.5 & 9.0857 & TRN & \\
\hline & & & & 12602 & \\
\hline
\end{tabular}




\begin{tabular}{|c|c|c|c|c|}
\hline & & & upplement & al Table S \\
\hline CHEMBL1968705 & 809254 & 4.6 & 5.4029 & TRN \\
\hline CHEMBL1964441 & 809254 & 6.0 & 6.2191 & TRN \\
\hline CHEMBL1991410 & 809254 & 5.7 & 5.3691 & TRN \\
\hline CHEMBL546797 & 809254 & 4.6 & 5.2344 & TRN \\
\hline CHEMBL1978271 & 809254 & 4.6 & 4.7062 & TRN \\
\hline CHEMBL 2007266 & 809254 & 4.6 & 4.6294 & TRN \\
\hline CHEMBL202721 & 809254 & 4.6 & 4.8268 & TRN \\
\hline CHEMBL2000568 & 809254 & 6.8 & 6.3899 & TRN \\
\hline CHEMBL1974328 & 809254 & 7.9 & 7.8541 & TRN \\
\hline CHEMBL388311 & 809254 & 8.2 & 8.6567 & TST \\
\hline CHEMBL1964948 & 809254 & 6.3 & 4.5253 & TST \\
\hline CHEMBL1973013 & 809254 & 6.3 & 6.2995 & TST \\
\hline CHEMBL1987430 & 809254 & 4.6 & 4.4607 & TST \\
\hline CHEMBL1993413 & 809254 & 4.6 & 5.2387 & TST \\
\hline CHEMBL 205415 & 809254 & 4.6 & 5.8252 & TST \\
\hline CHEMBL1975927 & 809254 & 7.6 & 6.7135 & TST \\
\hline CHEMBL289959 & 809254 & 4.7 & 4.6563 & TST \\
\hline CHEMBL1997119 & 809254 & 4.5 & 4.5764 & TST \\
\hline CHEMBL1977138 & 809254 & 7.8 & 6.9448 & TST \\
\hline CHEMBL 2000879 & 809254 & 4.1 & 5.2413 & TST \\
\hline CHEMBL1978448 & 809254 & 4.6 & 4.5694 & TST \\
\hline CHEMBL1969483 & 809254 & 4.6 & 4.2782 & TST \\
\hline CHEMBL1980329 & 809254 & 8.1 & 7.2926 & TST \\
\hline CHEMBL 2004515 & 809254 & 6.4 & $6.7810 e$ & 0000000001 \\
\hline CHEMBL1992042 & 809254 & 4.6 & 5.2938 & TST \\
\hline CHEMBL1986265 & 809254 & 4.6 & 4.0785 & TST \\
\hline CHEMBL 2001704 & 809254 & 4.1 & 4.9461 & TST \\
\hline CHEMBL1991734 & 809254 & 6.6 & 6.3033 & TST \\
\hline CHEMBL 21156 & 809254 & 7.6 & 7.5696 & TST \\
\hline CHEMBL1994724 & 809254 & 4.6 & 5.4005 & TST \\
\hline CHEMBL1989267 & 809254 & 5.7 & 6.2896 & TST \\
\hline CHEMBL1991782 & 809254 & 3.3 & 3.9845 & TST \\
\hline CHEMBL 2002105 & 809254 & 5.5 & 5.4041 & TST \\
\hline CHEMBL1983348 & 809254 & 7.3 & 7.194 & TST \\
\hline CHEMBL1993877 & 809254 & 7.0 & 6.901 & TST \\
\hline CHEMBL 2000934 & 809254 & 4.6 & 4.4075 & TST \\
\hline CHEMBL1996500 & 809254 & 4.6 & 4.3686 & TST \\
\hline CHEMBL1986177 & 809254 & 4.6 & 4.7701 & TST \\
\hline CHEMBL1989708 & 809254 & 7.2 & 6.8101 & TST \\
\hline CHEMBL1976420 & 809254 & 6.2 & 5.7756 & TST \\
\hline CHEMBL1981744 & 809254 & 4.6 & 4.5846 & TST \\
\hline CHEMBL1989423 & 809254 & 5.0 & 4.7252 & TST \\
\hline CHEMBL1985367 & 809254 & 4.6 & 5.1098 & TST \\
\hline CHEMBL1996510 & 809254 & 6.4 & 6.1699 & TST \\
\hline CHEMBL 2000029 & 809254 & 7.4 & 6.6599 & TST \\
\hline CHEMBL1995172 & 809254 & 4.4 & 5.0527 & TST \\
\hline CHEMBL 2001584 & 809254 & 4.6 & 4.5941 & TST \\
\hline CHEMBL1973961 & 809254 & 4.6 & 5.7963 & TST \\
\hline
\end{tabular}


Supplemental Table S2.txt

\begin{tabular}{|c|c|c|c|c|c|c|}
\hline CHEMBL 3680995 & 1537555 & 4.9355 & 3.9005 & TRN & & \\
\hline CHEMBL 3685682 & 1537555 & 4.6091 & 4.7127 & TRN & & \\
\hline CHEMBL3685668 & 1537555 & \multicolumn{3}{|c|}{ 4.718999999999999 } & 4.3924 & TRN \\
\hline CHEMBL3639798 & 1537555 & 3.6021 & 3.6957 & TRN & & \\
\hline CHEMBL 3685656 & 1537555 & 4.757 & 4.3382 & TRN & & \\
\hline CHEMBL 3681022 & 1537555 & 3.6021 & 4.1761 & TRN & & \\
\hline CHEMBL 3685728 & 1537555 & 3.6021 & 3.7239 & TRN & & \\
\hline CHEMBL 3685727 & 1537555 & 3.6021 & 4.0122 & TRN & & \\
\hline CHEMBL 3681008 & 1537555 & 3.6021 & 3.7959 & TRN & & \\
\hline CHEMBL 3685715 & 1537555 & 3.6021 & 3.7389 & TRN & & \\
\hline CHEMBL 3681005 & 1537555 & 3.6021 & 3.5472 & TRN & & \\
\hline CHEMBL 3685717 & 1537555 & 5.0458 & 4.6333 & TRN & & \\
\hline CHEMBL 3681007 & 1537555 & \multicolumn{3}{|c|}{4.821000000000001} & 3.8311 & TRN \\
\hline CHEMBL 3685657 & 1537555 & 3.6021 & 4.8093 & TST & & \\
\hline CHEMBL 3685653 & 1537555 & 4.64199 & 99999999 & 995 & 4.0928 & TST \\
\hline CHEMBL 3685628 & 1537555 & 3.6021 & 3.85 & TRN & & \\
\hline CHEMBL 3685695 & 1537555 & 3.6021 & 5.2165 & TST & & \\
\hline CHEMBL 3685718 & 1537555 & 3.6021 & 4.0416 & TRN & & \\
\hline CHEMBL3685660 & 1537555 & 3.6021 & 3.7041 & TRN & & \\
\hline CHEMBL 3680988 & 1537555 & 3.6021 & 3.7617 & TRN & & \\
\hline CHEMBL 3685634 & 1537555 & 4.6968 & 4.3239 & TRN & & \\
\hline CHEMBL 3680992 & 1537555 & 3.6021 & 3.9393 & TST & & \\
\hline CHEMBL3680998 & 1537555 & 4.6383 & 3.9979 & TRN & & \\
\hline CHEMBL 3685683 & 1537555 & 4.6271 & 4.6076 & TRN & & \\
\hline CHEMBL 3685704 & 1537555 & 3.6021 & 3.9929 & TRN & & \\
\hline CHEMBL 3685692 & 1537555 & 4.6554 & 4.7615 & TRN & & \\
\hline CHEMBL 3685631 & 1537555 & 3.6021 & 4.8083 & TST & & \\
\hline CHEMBL3685673 & 1537555 & 4.6882 & 4.8095 & TRN & & \\
\hline CHEMBL3685684 & 1537555 & 4.6021 & 4.74100 & 0000000000 & & TRN \\
\hline CHEMBL3685712 & 1537555 & 4.6421 & 4.6621 & TRN & & \\
\hline CHEMBL 3681013 & 1537555 & 3.6021 & 3.9233 & TRN & & \\
\hline CHEMBL 3681010 & 1537555 & 3.6021 & 4.0273 & TRN & & \\
\hline CHEMBL3681012 & 1537555 & 3.6021 & 4.0099 & TRN & & \\
\hline CHEMBL3681024 & 1537555 & 4.6364 & 3.9787 & TRN & & \\
\hline CHEMBL3685659 & 1537555 & 3.6021 & 3.4256 & TRN & & \\
\hline CHEMBL3685713 & 1537555 & 4.6676 & 4.3839 & TST & & \\
\hline CHEMBL3685681 & 1537555 & 4.6021 & 4.5849 & TRN & & \\
\hline CHEMBL3680994 & 1537555 & 3.6021 & 3.699 & TRN & & \\
\hline CHEMBL3681006 & 1537555 & 3.6021 & 3.5812 & TRN & & \\
\hline CHEMBL3680993 & 1537555 & 4.9914 & 3.6262 & TST & & \\
\hline CHEMBL3681004 & 1537555 & 3.6021 & 3.8458 & TRN & & \\
\hline CHEMBL 3685636 & 1537555 & 3.6021 & 3.9274 & TRN & & \\
\hline CHEMBL3680986 & 1537555 & 3.6021 & 4.3894 & TST & & \\
\hline CHEMBL 3681009 & 1537555 & 4.8297 & 5.1805 & TRN & & \\
\hline CHEMBL3685661 & 1537555 & 4.6459 & 3.9691 & TRN & & \\
\hline CHEMBL3685658 & 1537555 & 3.6021 & 3.8456 & TRN & & \\
\hline CHEMBL 3681027 & 1537555 & 5.4202 & 5.2078 & TRN & & \\
\hline CHEMBL3681014 & 1537555 & 3.6021 & 3.859 & TRN & & \\
\hline
\end{tabular}


Supplemental Table S2.txt

\begin{tabular}{|c|c|c|c|c|}
\hline CHEMBL3685729 & 1537555 & 4.6021 & 3.7164 & TST \\
\hline CHEMBL3685666 & 1537555 & 3.6021 & 3.8359 & TST \\
\hline CHEMBL3685672 & 1537555 & 3.6021 & 4.3315 & TST \\
\hline CHEMBL 3685667 & 1537555 & 3.6021 & 3.9405 & TST \\
\hline CHEMBL3685722 & 1537555 & 3.6021 & 4.1314 & TST \\
\hline CHEMBL3685654 & 1537555 & 4.6108 & 3.8147 & TST \\
\hline CHEMBL3908907 & 1622037 & 5.8539 & 5.9588 & TRN \\
\hline CHEMBL3978895 & 1622037 & 5.8539 & 6.3473 & TST \\
\hline CHEMBL3938408 & 1622037 & 7.5229 & 7.5666 & TRN \\
\hline CHEMBL3985118 & 1622037 & 7.3979 & 7.185 & TST \\
\hline CHEMBL3891576 & 1622037 & 6.5086 & 6.595 & TRN \\
\hline CHEMBL3915331 & 1622037 & 7.3979 & 7.3088 & TST \\
\hline CHEMBL3893541 & 1622037 & 7.5229 & 7.7114 & TRN \\
\hline CHEMBL3911524 & 1622037 & 7.5229 & 7.4344 & TRN \\
\hline CHEMBL3972721 & 1622037 & 6.699 & 6.5287 & TRN \\
\hline CHEMBL3910675 & 1622037 & 7.0458 & 6.6151 & TRN \\
\hline CHEMBL3962542 & 1622037 & 7.699 & 7.6273 & TRN \\
\hline CHEMBL3907779 & 1622037 & 6.9586 & 6.3792 & TRN \\
\hline CHEMBL3909879 & 1622037 & 6.7447 & 6.8883 & TRN \\
\hline CHEMBL3943463 & 1622037 & 6.4437 & 7.273 & TRN \\
\hline CHEMBL3906525 & 1622037 & 7.3979 & 7.3187 & TRN \\
\hline CHEMBL3917803 & 1622037 & 5.3565 & 7.1569 & TRN \\
\hline CHEMBL3979220 & 1622037 & 4.301 & 5.9175 & TRN \\
\hline CHEMBL3898753 & 1622037 & 7.0 & 6.2252 & TRN \\
\hline CHEMBL3970636 & 1622037 & 6.4685 & 6.0718 & TRN \\
\hline CHEMBL3917504 & 1622037 & 7.699 & 7.636 & TRN \\
\hline CHEMBL3981511 & 1622037 & 7.699 & 7.6333 & TRN \\
\hline CHEMBL3943644 & 1622037 & 5.3665 & 5.86700 & 0000000001 \\
\hline CHEMBL3926801 & 1622037 & 6.8539 & 6.4166 & TRN \\
\hline CHEMBL 3897524 & 1622037 & 6.8539 & 6.7021 & TRN \\
\hline CHEMBL3908519 & 1622037 & 6.3665 & 6.2552 & TRN \\
\hline CHEMBL3916599 & 1622037 & 6.699 & 6.7322 & TRN \\
\hline CHEMBL3915504 & 1622037 & 7.1549 & 7.3149 & TRN \\
\hline CHEMBL3947092 & 1622037 & 6.041 & 6.2773 & TST \\
\hline CHEMBL3973151 & 1622037 & 5.3872 & 6.2205 & TST \\
\hline CHEMBL3920459 & 1622037 & 7.5229 & 7.5676 & TRN \\
\hline CHEMBL3917847 & 1622037 & 6.4685 & 6.3204 & TST \\
\hline CHEMBL3899464 & 1622037 & 6.5229 & 6.2657 & TST \\
\hline CHEMBL3900573 & 1622037 & 6.8239 & 6.7207 & TRN \\
\hline CHEMBL3928531 & 1622037 & 6.6576 & 6.6664 & TRN \\
\hline CHEMBL3959584 & 1622037 & 6.2076 & 6.4701 & TST \\
\hline CHEMBL3901643 & 1622037 & 4.301 & 6.05 & TST \\
\hline CHEMBL3919629 & 1622037 & 6.6383 & 6.5813 & TRN \\
\hline CHEMBL3892467 & 1622037 & 7.5229 & 7.4423 & TRN \\
\hline CHEMBL3889679 & 1622037 & 7.5229 & 7.3359 & TRN \\
\hline CHEMBL3973515 & 1622037 & 7.5229 & 7.5603 & TRN \\
\hline CHEMBL3963381 & 1622037 & 6.7212 & 6.4022 & TST \\
\hline CHEMBL3891644 & 1622037 & 6.7959 & 6.3115 & TST \\
\hline
\end{tabular}


Supplemental Table S2.txt

\begin{tabular}{|c|c|c|c|c|}
\hline CHEMBL3980755 & 1622037 & 7.1549 & 6.601 & TRN \\
\hline CHEMBL3963182 & 1622037 & 5.9208 & 6.3314 & TST \\
\hline CHEMBL3934488 & 1622037 & 7.5229 & 7.2548 & TRN \\
\hline CHEMBL3962757 & 1622037 & 7.2218 & 7.0064 & TRN \\
\hline CHEMBL3935734 & 1622037 & 6.6021 & 6.4398 & TST \\
\hline CHEMBL3902514 & 1622037 & 8.0 & 7.6058 & TRN \\
\hline CHEMBL3936675 & 1622037 & 7.0458 & 6.7191 & TRN \\
\hline CHEMBL3986361 & 1622037 & 6.8539 & 6.862 & TRN \\
\hline CHEMBL3985211 & 1642144 & 6.1024 & 5.9543 & TRN \\
\hline CHEMBL3893046 & 1642144 & 5.1421 & 5.0367 & TRN \\
\hline CHEMBL3957570 & 1642144 & 6.6383 & 6.2596 & TRN \\
\hline CHEMBL3928667 & 1642144 & 5.4855 & 5.655 & TRN \\
\hline CHEMBL3909167 & 1642144 & 5.1904 & 4.8177 & TST \\
\hline CHEMBL3978897 & 1642144 & 6.0 & 6.561 & TRN \\
\hline CHEMBL3935931 & 1642144 & 5.2596 & 5.2219 & TRN \\
\hline CHEMBL3960202 & 1642144 & 5.4815 & 5.5128 & TRN \\
\hline CHEMBL3935711 & 1642144 & 5.7471 & 5.6152 & TRN \\
\hline CHEMBL3949848 & 1642144 & 5.279 & 5.3013 & TRN \\
\hline CHEMBL3905572 & 1642144 & 5.8601 & 5.8177 & TRN \\
\hline CHEMBL3958511 & 1642144 & 4.6735 & 4.7146 & TRN \\
\hline CHEMBL3951398 & 1642144 & 5.5901 & 5.6606 & TRN \\
\hline CHEMBL3971267 & 1642144 & 5.8508 & 5.5524 & TST \\
\hline CHEMBL3930984 & 1642144 & 6.6576 & 6.6087 & TRN \\
\hline CHEMBL3909910 & 1642144 & 6.0 & 6.1756 & TRN \\
\hline CHEMBL3919071 & 1642144 & 5.3536 & 5.6123 & TRN \\
\hline CHEMBL3986270 & 1642144 & 5.2269 & 5.1173 & TRN \\
\hline CHEMBL3922989 & 1642144 & 5.8697 & 5.7214 & TRN \\
\hline CHEMBL3953733 & 1642144 & 4.6364 & 4.9955 & TRN \\
\hline CHEMBL3965644 & 1642144 & 5.0191 & 5.0592 & TRN \\
\hline CHEMBL3953309 & 1642144 & 6.2147 & 6.2008 & TRN \\
\hline CHEMBL3935577 & 1642144 & 5.1141 & 5.0959 & TRN \\
\hline CHEMBL3909836 & 1642144 & 5.6289 & 5.61600 & 00000000005 \\
\hline CHEMBL3905554 & 1642144 & 4.8514 & 5.052 & TST \\
\hline CHEMBL3971099 & 1642144 & 4.4689 & 4.6937 & TRN \\
\hline CHEMBL3915191 & 1642144 & 5.8268 & 5.5011 & TST \\
\hline CHEMBL3965983 & 1642144 & 4.5945 & 4.9365 & TST \\
\hline CHEMBL3957455 & 1642144 & 4.6251 & 4.6823 & TRN \\
\hline CHEMBL3911999 & 1642144 & 6.0223 & 5.9929 & TRN \\
\hline CHEMBL3924752 & 1642144 & 5.3401 & 5.7475 & TRN \\
\hline CHEMBL3969658 & 1642144 & 5.5229 & 5.3192 & TST \\
\hline CHEMBL3893917 & 1642144 & 6.8861 & 6.7645 & TRN \\
\hline CHEMBL3982051 & 1642144 & 5.9469 & 5.7989 & TRN \\
\hline CHEMBL3947346 & 1642144 & 5.7799 & 5.6875 & TRN \\
\hline CHEMBL3976287 & 1642144 & 5.3316 & 5.324 & TST \\
\hline CHEMBL3976225 & 1642144 & 6.5086 & 6.4417 & TRN \\
\hline CHEMBL3922095 & 1642144 & 5.5482 & 5.4467 & TRN \\
\hline CHEMBL3907495 & 1642144 & 5.5513 & 5.6499 & TST \\
\hline CHEMBL3964557 & 1642144 & 5.5575 & 5.7349 & TRN \\
\hline
\end{tabular}


Supplemental Table S2.txt

\begin{tabular}{|c|c|c|c|c|c|c|}
\hline CHEMBL3914422 & 1642144 & 5.6234 & 5.3717 & TST & & \\
\hline CHEMBL3942261 & 1642144 & 6.6198 & 6.4298 & TRN & & \\
\hline CHEMBL3927491 & 1642144 & 4.7729 & 4.7793 & TST & & \\
\hline CHEMBL3915731 & 1642144 & 4.731 & 5.1269 & TRN & & \\
\hline CHEMBL3978003 & 1642144 & 5.5498 & 5.4059 & TRN & & \\
\hline CHEMBL3985474 & 1642144 & 4.6247 & 4.7215 & TRN & & \\
\hline CHEMBL3925927 & 1642144 & 6.0 & 6.2333 & TRN & & \\
\hline CHEMBL3906123 & 1642144 & 4.6012 & 5.1458 & TST & & \\
\hline CHEMBL3981062 & 1642144 & \multicolumn{3}{|c|}{5.247999999999999} & 5.1997 & TST \\
\hline CHEMBL3889830 & 1642144 & \multicolumn{3}{|c|}{5.7620000000000005} & 5.5991 & TST \\
\hline CHEMBL3933571 & 1642144 & 5.4486 & 5.4945 & TRN & & \\
\hline CHEMBL3950407 & 1642144 & 6.5376 & 6.4055 & TRN & & \\
\hline CHEMBL3961958 & 1642144 & 6.0269 & 5.7905 & TRN & & \\
\hline CHEMBL3963476 & 1642144 & 5.1013 & 4.9724 & TRN & & \\
\hline CHEMBL3919954 & 1642144 & 5.3089 & 5.1972 & TST & & \\
\hline CHEMBL3931006 & 1642144 & 4.8693 & 5.2598 & TST & & \\
\hline CHEMBL3984344 & 1642144 & 4.901 & 5.1885 & TST & & \\
\hline CHEMBL3915762 & 1642144 & 5.7423 & 5.7748 & TRN & & \\
\hline CHEMBL3902157 & 1642144 & 4.6407 & 4.9488 & TRN & & \\
\hline CHEMBL3970759 & 1642144 & 6.3768 & 6.3566 & TRN & & \\
\hline CHEMBL3949428 & 1642144 & 5.5935 & 5.6326 & TRN & & \\
\hline CHEMBL3916427 & 1642144 & 6.3188 & 6.5275 & TRN & & \\
\hline CHEMBL3924386 & 1642144 & 6.5528 & 6.3912 & TRN & & \\
\hline CHEMBL3898845 & 1642144 & 5.4698 & 5.5243 & TRN & & \\
\hline CHEMBL3902198 & 1642144 & 6.1249 & 6.0492 & TRN & & \\
\hline CHEMBL3930135 & 1642144 & 4.7333 & 5.2019 & TST & & \\
\hline CHEMBL3933759 & 1642144 & 5.4401 & 5.3901 & TRN & & \\
\hline CHEMBL3939356 & 1642144 & 5.1938 & 5.364 & TRN & & \\
\hline CHEMBL3915310 & 1642144 & 5.9586 & 5.9805 & TRN & & \\
\hline CHEMBL3968328 & 1642144 & 5.6383 & 5.7158 & TRN & & \\
\hline CHEMBL3964092 & 1642144 & 6.2676 & 6.0006 & TRN & & \\
\hline CHEMBL3895011 & 1642144 & 4.3607 & 4.5249 & TRN & & \\
\hline CHEMBL3893705 & 1642144 & 6.5528 & 6.4212 & TRN & & \\
\hline CHEMBL3890493 & 1642144 & 4.5536 & 4.6296 & TST & & \\
\hline CHEMBL3919532 & 1642144 & 6.5686 & 6.3817 & TRN & & \\
\hline CHEMBL3935725 & 1642144 & 5.6364 & 5.4812 & TRN & & \\
\hline CHEMBL3950331 & 1642144 & 5.7423 & 6.0476 & TRN & & \\
\hline CHEMBL3932515 & 1642144 & 6.1308 & 6.3138 & TRN & & \\
\hline CHEMBL3943829 & 1642144 & 5.9318 & 5.7085 & TRN & & \\
\hline CHEMBL3979450 & 1642144 & 4.9363 & 5.09699 & 9999999999 & & TRN \\
\hline CHEMBL3971858 & 1642144 & 6.4685 & 6.50200 & 0000000001 & & TRN \\
\hline CHEMBL3904518 & 1642144 & 6.0 & 6.3958 & TRN & & \\
\hline CHEMBL3928851 & 1642144 & 5.0462 & 5.2168 & TRN & & \\
\hline CHEMBL3984981 & 1642144 & 5.2798 & 5.496 & TRN & & \\
\hline CHEMBL3942423 & 1642144 & 5.5003 & 5.0171 & TST & & \\
\hline CHEMBL3930848 & 1642144 & 5.9586 & 5.9462 & TRN & & \\
\hline CHEMBL3907840 & 1642144 & 5.6676 & 5.6219 & TST & & \\
\hline CHEMBL3975703 & 1642144 & 5.21399 & 99999999 & 95 & 5.1361 & TRN \\
\hline
\end{tabular}


Supplemental Table S2.txt

\begin{tabular}{|c|c|c|c|c|}
\hline CHEMBL3931611 & 1642144 & 5.0128 & 5.0612 & TST \\
\hline CHEMBL3919762 & 1642144 & 5.3401 & 5.1179 & TRN \\
\hline CHEMBL3909096 & 1642144 & 6.0 & 6.3955 & TRN \\
\hline CHEMBL 3894890 & 1642144 & 4.5372 & 4.9029 & TST \\
\hline CHEMBL3925417 & 1642144 & 5.983 & 6.3728 & TRN \\
\hline CHEMBL3900786 & 1642144 & 5.1938 & 5.2698 & TRN \\
\hline CHEMBL3985165 & 1642144 & 6.2596 & 6.2406 & TRN \\
\hline CHEMBL 3927164 & 1642144 & 6.0757 & 6.0261 & TRN \\
\hline CHEMBL3904114 & 1642144 & 6.2757 & 5.9779 & TRN \\
\hline CHEMBL3986190 & 1642144 & 4.4773 & 4.3189 & TRN \\
\hline CHEMBL3923592 & 1642144 & 5.8861 & 6.2198 & TRN \\
\hline CHEMBL3894195 & 1642144 & 6.8539 & 6.6912 & TRN \\
\hline CHEMBL3911949 & 1642144 & 6.4437 & 6.41700 & 0000000001 \\
\hline CHEMBL3933422 & 1642144 & 6.0315 & 6.0691 & TRN \\
\hline CHEMBL 3908087 & 1642144 & 4.8941 & 5.2323 & TST \\
\hline CHEMBL3914519 & 1642144 & 4.9055 & 4.7126 & TST \\
\hline CHEMBL 3985504 & 1642144 & 5.8386 & 5.7291 & TRN \\
\hline CHEMBL3923583 & 1642144 & 6.0 & 6.3216 & TRN \\
\hline CHEMBL3960753 & 1642144 & 4.978 & 5.1327 & TRN \\
\hline CHEMBL 3970083 & 1642144 & 4.9477 & 4.9168 & TST \\
\hline CHEMBL 3938773 & 1642144 & 5.1085 & 4.912 & TST \\
\hline CHEMBL 3901774 & 1642144 & 6.1367 & 6.0217 & TRN \\
\hline CHEMBL3898469 & 1642144 & 5.3851 & 5.2285 & TST \\
\hline CHEMBL3927195 & 1642144 & 5.8761 & 5.6774 & TRN \\
\hline CHEMBL3951332 & 1642144 & 5.5884 & 5.6457 & TRN \\
\hline CHEMBL 3960131 & 1642144 & 5.1355 & 4.9383 & TST \\
\hline CHEMBL3941206 & 1642144 & 6.3768 & 5.8926 & TRN \\
\hline CHEMBL3973992 & 1642144 & 6.041 & 5.7726 & TRN \\
\hline CHEMBL3914953 & 1642144 & 6.2757 & 6.5155 & TRN \\
\hline CHEMBL3926169 & 1642144 & 6.7696 & 6.1501 & TST \\
\hline CHEMBL 3962934 & 1642144 & 5.1759 & 4.8961 & TRN \\
\hline CHEMBL3936843 & 1642144 & 5.4012 & 5.513 & TRN \\
\hline CHEMBL 3928868 & 1642144 & 5.2581 & 5.1792 & TRN \\
\hline CHEMBL3942538 & 1642144 & 4.7187 & 5.4314 & TRN \\
\hline CHEMBL3934508 & 1642144 & 5.5591 & 5.4271 & TRN \\
\hline CHEMBL3985331 & 1642144 & 5.5436 & 5.9364 & TRN \\
\hline CHEMBL3983370 & 1642144 & 6.6198 & 6.4493 & TRN \\
\hline CHEMBL3904269 & 1642144 & 4.5976 & 4.75 & TRN \\
\hline CHEMBL 3927977 & 1642144 & 5.7235 & 5.6766 & TST \\
\hline CHEMBL3939572 & 1642144 & 5.9666 & 5.5564 & TRN \\
\hline CHEMBL 3894876 & 1642144 & 6.7447 & 6.6876 & TRN \\
\hline CHEMBL3905420 & 1642144 & 6.6198 & 6.0361 & TRN \\
\hline CHEMBL 3899677 & 1642144 & 4.8665 & 4.8738 & TST \\
\hline CHEMBL 3905274 & 1642144 & 6.0 & 6.1588 & TRN \\
\hline CHEMBL3939854 & 1642144 & 6.585 & 6.4611 & TRN \\
\hline CHEMBL3961990 & 1642144 & 6.3872 & 6.1378 & TRN \\
\hline CHEMBL 3924721 & 1642144 & 5.2933 & 5.2547 & TST \\
\hline CHEMBL3914279 & 1642144 & 6.4559 & 6.3645 & TRN \\
\hline
\end{tabular}

Page 12608 
Supplemental Table S2.txt

\begin{tabular}{|c|c|c|c|c|c|}
\hline CHEMBL3897397 & 1642144 & 4.9559 & 5.1643 & TRN & \\
\hline CHEMBL3904422 & 1642144 & 6.0362 & 5.6392 & TRN & \\
\hline CHEMBL3902935 & 1642144 & 6.5229 & 6.4385 & TRN & \\
\hline CHEMBL3944552 & 1642144 & \multicolumn{3}{|c|}{5.821000000000001} & TRN \\
\hline CHEMBL3958522 & 1642144 & 4.5759 & 4.7192 & TRN & \\
\hline CHEMBL3934104 & 1642144 & 5.4248 & 5.5013 & TST & \\
\hline CHEMBL3945129 & 1642144 & 6.3872 & 6.3364 & TRN & \\
\hline CHEMBL3900121 & 1642144 & 5.4763 & 5.3535 & TST & \\
\hline CHEMBL3900769 & 1642144 & 4.7597 & 5.0703 & TST & \\
\hline CHEMBL3958567 & 1642144 & 6.4559 & 5.8064 & TST & \\
\hline CHEMBL 3893184 & 1642144 & 5.5406 & 5.3788 & TST & \\
\hline CHEMBL3908079 & 1642144 & 6.6198 & 6.6048 & TRN & \\
\hline CHEMBL3979445 & 1642144 & 5.7878 & 5.9092 & TRN & \\
\hline CHEMBL 3942878 & 1642144 & 5.3615 & 5.3926 & TRN & \\
\hline CHEMBL3951211 & 1642144 & 6.0706 & 5.8465 & TST & \\
\hline CHEMBL3911115 & 1642144 & 5.6003 & 5.2044 & TRN & \\
\hline CHEMBL3984390 & 1642144 & 5.0867 & 4.921 & TST & \\
\hline CHEMBL3924186 & 1642144 & 5.7799 & \multicolumn{2}{|c|}{5.167000000000001} & TST \\
\hline CHEMBL3943957 & 1642144 & 6.1308 & 6.4641 & TRN & \\
\hline CHEMBL3932529 & 1642144 & 4.4695 & 4.1733 & TRN & \\
\hline CHEMBL3918140 & 1642144 & 5.5607 & 5.3463 & TRN & \\
\hline CHEMBL3930167 & 1642144 & 5.5768 & 5.603 & TRN & \\
\hline CHEMBL3897439 & 1642144 & 6.6198 & 6.468 & TRN & \\
\hline CHEMBL3919396 & 1642144 & 5.6253 & 5.4926 & TRN & \\
\hline CHEMBL3909207 & 1642144 & 5.52 & 5.3313 & TRN & \\
\hline CHEMBL393929 & 954799 & 3.512 & 3.5232 & TRN & \\
\hline CHEMBL512504 & 954799 & 3.8607 & 3.6786 & TRN & \\
\hline CHEMBL192566 & 954799 & 7.2617 & 6.7647 & TST & \\
\hline CHEMBL180127 & 954799 & 4.4514 & 4.2792 & TRN & \\
\hline CHEMBL3199475 & 954799 & 3.5992 & 3.8098 & TRN & \\
\hline CHEMBL472940 & 954799 & 2.7009 & 2.9212 & TRN & \\
\hline CHEMBL 202721 & 954799 & 4.3906 & 4.3301 & TRN & \\
\hline CHEMBL1590308 & 954799 & 4.2492 & 3.8637 & TST & \\
\hline CHEMBL2363137 & 954799 & 4.9787 & 5.0441 & TRN & \\
\hline CHEMBL135561 & 954799 & 4.2195 & 4.3753 & TRN & \\
\hline CHEMBL 217354 & 954799 & 6.284 & 6.5089 & TRN & \\
\hline CHEMBL2134202 & 954799 & 4.0463 & 3.8872 & TRN & \\
\hline CHEMBL3349342 & 954799 & 5.1028 & 5.2771 & TRN & \\
\hline CHEMBL399530 & 954799 & 4.9041 & 4.4198 & TRN & \\
\hline CHEMBL1970879 & 954799 & 3.2593 & 3.3902 & TRN & \\
\hline CHEMBL102714 & 954799 & 3.7513 & 3.6273 & TRN & \\
\hline CHEMBL392695 & 954799 & 5.0453 & 4.9986 & TRN & \\
\hline CHEMBL573107 & 954799 & 5.319 & 5.50799 & 9999999999 & TRN \\
\hline CHEMBL1909414 & 954799 & 3.8841 & 3.5388 & TRN & \\
\hline CHEMBL1256459 & 954799 & 5.2549 & 5.6634 & TRN & \\
\hline CHEMBL1516890 & 954799 & 3.6632 & 3.7413 & TRN & \\
\hline CHEMBL92309 & 954799 & 3.6674 & 3.3017 & TST & \\
\hline CHEMBL255342 & 954799 & 3.2628 & 3.3816 & TRN & \\
\hline
\end{tabular}




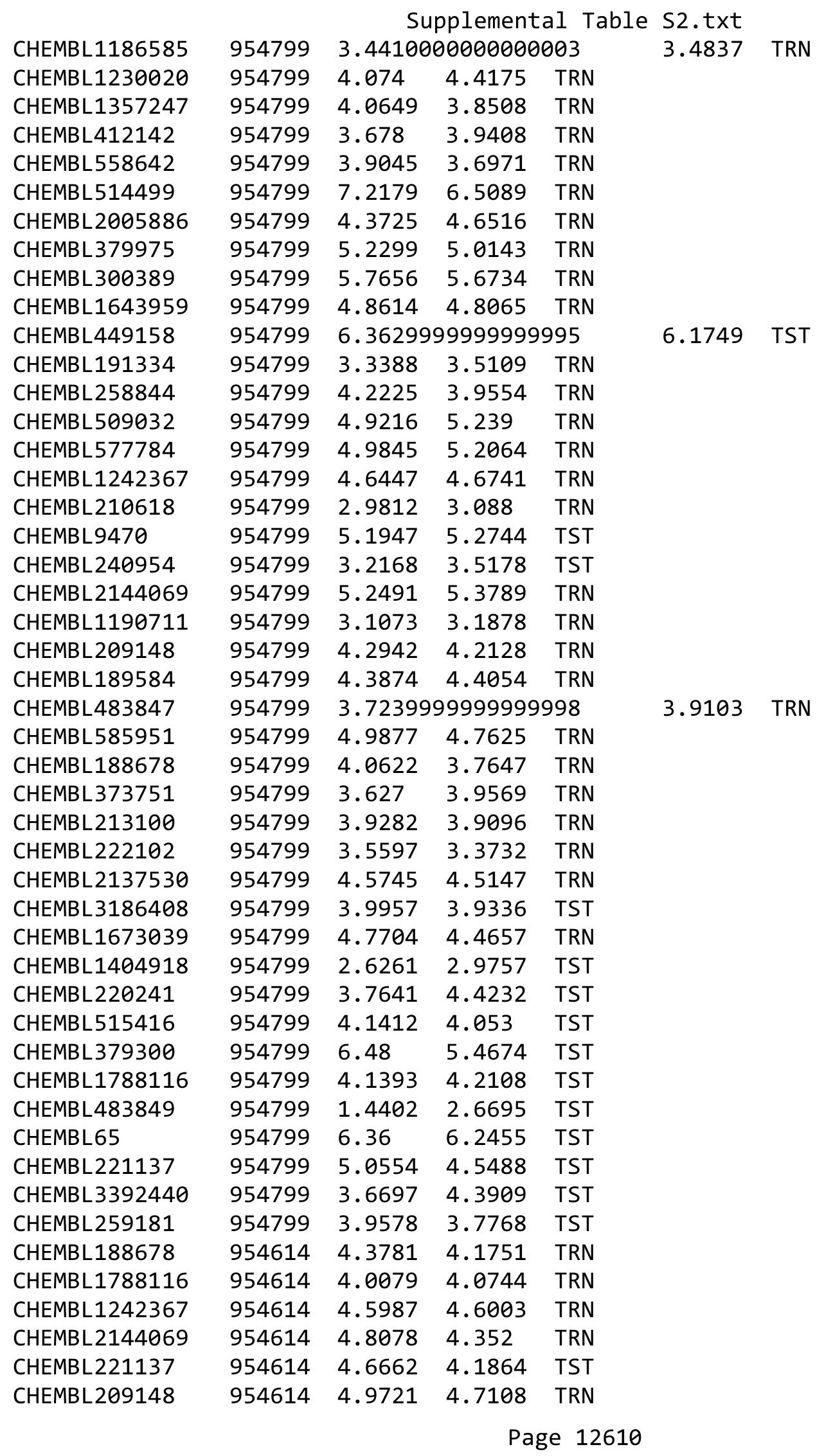


Supplemental Table S2.txt

\begin{tabular}{|c|c|c|c|c|c|}
\hline CHEMBL222102 & 954614 & 3.602 & 3.9102 & TRN & \\
\hline CHEMBL577784 & 954614 & 5.0053 & 5.1757 & TRN & \\
\hline CHEMBL65 & 954614 & 7.4546 & 6.9203 & TRN & \\
\hline CHEMBL255342 & 954614 & 3.6952 & 3.6599 & TRN & \\
\hline CHEMBL92309 & 954614 & 2.9967 & 2.4371 & TST & \\
\hline CHEMBL412142 & 954614 & 3.7072 & 3.47899 & 99999999996 & TRN \\
\hline CHEMBL379975 & 954614 & 5.4012 & 5.2115 & TRN & \\
\hline CHEMBL483847 & 954614 & 4.7264 & 4.7593 & TRN & \\
\hline CHEMBL509032 & 954614 & 6.1607 & 6.0693 & TRN & \\
\hline CHEMBL2137530 & 954614 & 4.2889 & 4.6308 & TRN & \\
\hline CHEMBL1970879 & 954614 & 5.6886 & 5.3505 & TRN & \\
\hline CHEMBL192566 & 954614 & 7.6578 & 7.3676 & TST & \\
\hline CHEMBL449158 & 954614 & 6.1709 & 6.8223 & TST & \\
\hline CHEMBL472940 & 954614 & 2.4831 & 2.35 & TRN & \\
\hline CHEMBL 3349342 & 954614 & 4.8349 & 4.8129 & TRN & \\
\hline CHEMBL1673039 & 954614 & 4.9621 & 4.8083 & TRN & \\
\hline CHEMBL258844 & 954614 & 4.4067 & 4.2464 & TRN & \\
\hline CHEMBL220241 & 954614 & 4.0407 & 4.106 & TRN & \\
\hline CHEMBL392695 & 954614 & 5.4439 & 5.4097 & TRN & \\
\hline CHEMBL483849 & 954614 & 3.6845 & 2.6408 & TST & \\
\hline CHEMBL1590308 & 954614 & 3.225 & 3.8839 & TST & \\
\hline CHEMBL210618 & 954614 & 3.7879 & 3.65 & TRN & \\
\hline CHEMBL102714 & 954614 & 3.4044 & 3.6269 & TRN & \\
\hline CHEMBL1230020 & 954614 & 3.7949 & 3.7749 & TRN & \\
\hline CHEMBL 2134202 & 954614 & 4.4017 & 4.5391 & TRN & \\
\hline CHEMBL213100 & 954614 & 5.1728 & 5.1529 & TRN & \\
\hline CHEMBL399530 & 954614 & 5.0214 & 4.7365 & TRN & \\
\hline CHEMBL585951 & 954614 & 4.5749 & 5.0426 & TRN & \\
\hline CHEMBL512504 & 954614 & 4.1602 & 4.1359 & TRN & \\
\hline CHEMBL191334 & 954614 & \multicolumn{3}{|c|}{2.9819999999999998} & TRI \\
\hline CHEMBL573107 & 954614 & 5.2979 & 5.3469 & TRN & \\
\hline CHEMBL 9470 & 954614 & 4.8014 & 4.7632 & TST & \\
\hline CHEMBL3199475 & 954614 & 3.6514 & 3.5583 & TRN & \\
\hline CHEMBL1516890 & 954614 & 4.8368 & 4.6439 & TRN & \\
\hline CHEMBL373751 & 954614 & 3.9023 & 4.4608 & TRN & \\
\hline CHEMBL3392440 & 954614 & 4.1049 & 4.4758 & TRN & \\
\hline CHEMBL515416 & 954614 & 4.6458 & 4.9259 & TRN & \\
\hline CHEMBL 3186408 & 954614 & 4.5399 & 3.7334 & TST & \\
\hline CHEMBL1643959 & 954614 & 4.8275 & 4.7264 & TRN & \\
\hline CHEMBL558642 & 954614 & 3.1858 & 3.5148 & TRN & \\
\hline CHEMBL217354 & 954614 & 6.0189 & 6.2617 & TRN & \\
\hline CHEMBL1357247 & 954614 & 3.4691 & 3.1665 & TRN & \\
\hline CHEMBL2363137 & 954614 & 5.1161 & 4.7081 & TRN & \\
\hline CHEMBL300389 & 954614 & 6.1299 & 6.3242 & TRN & \\
\hline CHEMBL189584 & 954614 & 3.7383 & 4.59699 & 99999999995 & $\mathrm{NI}$ \\
\hline CHEMBL393929 & 954614 & 5.1029 & 4.6596 & TRN & \\
\hline CHEMBL240954 & 954614 & 3.4444 & 3.8316 & TST & \\
\hline CHEMBL135561 & 954614 & 4.7778 & 4.2047 & TRN & \\
\hline
\end{tabular}

Page 12611 


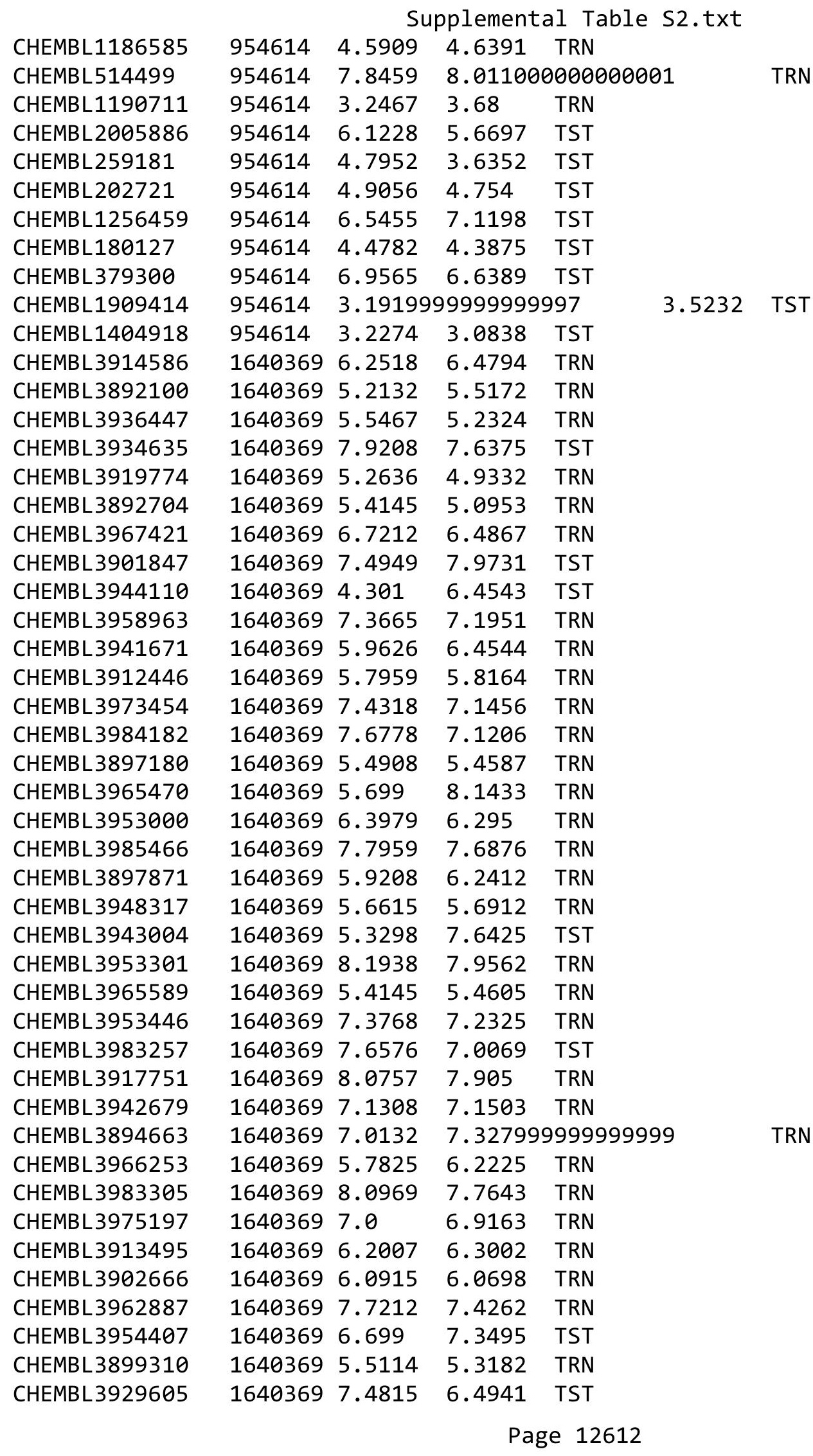


Supplemental Table S2.txt

\begin{tabular}{|c|c|c|c|c|c|c|}
\hline CHEMBL3957319 & 1640369 & 6.6198 & 6.7896 & TRN & & \\
\hline CHEMBL3958498 & 1640369 & 6.2518 & 6.362 & TRN & & \\
\hline CHEMBL3919758 & 1640369 & 7.1739 & 7.8611 & TRN & & \\
\hline CHEMBL3929161 & 1640369 & 6.3279 & 6.5668 & TRN & & \\
\hline CHEMBL3947561 & 1640369 & 5.5575 & 5.7596 & TRN & & \\
\hline CHEMBL3940564 & 1640369 & 6.0 & 6.193 & TRN & & \\
\hline CHEMBL3948782 & 1640369 & 6.0269 & 6.3707 & TRN & & \\
\hline CHEMBL3938852 & 1640369 & 5.71899 & 79999999 & 99 & 5.9734 & TRN \\
\hline CHEMBL 3922490 & 1640369 & 6.9208 & 6.0675 & TRN & & \\
\hline CHEMBL3903289 & 1640369 & 8.3979 & 8.1598 & TRN & & \\
\hline CHEMBL3958011 & 1640369 & 7.3279 & 7.101 & TRN & & \\
\hline CHEMBL3936071 & 1640369 & 5.9747 & 6.9492 & TST & & \\
\hline CHEMBL3958851 & 1640369 & 7.3188 & 7.6474 & TST & & \\
\hline CHEMBL3933418 & 1640369 & 6.5686 & 7.3491 & TST & & \\
\hline CHEMBL3975332 & 1640369 & 6.9208 & 7.2545 & TRN & & \\
\hline CHEMBL3964375 & 1640369 & 5.2596 & 5.3666 & TRN & & \\
\hline CHEMBL3947338 & 1640369 & 8.8539 & 8.1892 & TRN & & \\
\hline CHEMBL3973493 & 1640369 & 7.1367 & 6.9533 & TRN & & \\
\hline CHEMBL 3932132 & 1640369 & 7.8539 & 7.2283 & TRN & & \\
\hline CHEMBL3957169 & 1640369 & 6.0969 & 5.5626 & TST & & \\
\hline CHEMBL3941147 & 1640369 & 8.301 & 7.4048 & TST & & \\
\hline CHEMBL3970200 & 1640369 & 7.7696 & 7.1015 & TRN & & \\
\hline CHEMBL3967772 & 1640369 & 7.4559 & 7.1666 & TRN & & \\
\hline CHEMBL 3974747 & 1640369 & 6.1079 & 6.2451 & TRN & & \\
\hline CHEMBL 3984413 & 1640369 & 5.7055 & 6.1006 & TRN & & \\
\hline CHEMBL3959693 & 1640369 & 6.8239 & 7.3855 & TST & & \\
\hline CHEMBL3894215 & 1640369 & 8.699 & 8.3676 & TRN & & \\
\hline CHEMBL3956707 & 1640369 & 7.4685 & 7.4377 & TRN & & \\
\hline CHEMBL3954879 & 1640369 & 7.3768 & 7.2949 & TRN & & \\
\hline CHEMBL3911676 & 1640369 & 7.6021 & 7.8691 & TST & & \\
\hline CHEMBL3932753 & 1640369 & 7.4685 & 7.4324 & TST & & \\
\hline CHEMBL3978164 & 1640369 & 6.6198 & 6.4496 & TST & & \\
\hline CHEMBL3954217 & 1640369 & 5.9508 & 6.246 & TRN & & \\
\hline CHEMBL3890582 & 1640369 & 6.7212 & 6.8089 & TRN & & \\
\hline CHEMBL3970060 & 1640369 & 7.0655 & 7.1943 & TRN & & \\
\hline CHEMBL3965151 & 1640369 & 7.0 & 7.1445 & TST & & \\
\hline CHEMBL3970140 & 1640369 & 6.3279 & 7.8767 & TST & & \\
\hline CHEMBL3930120 & 1640369 & 7.5686 & 7.564 & TRN & & \\
\hline CHEMBL 3969651 & 1640369 & 6.3872 & 6.3793 & TRN & & \\
\hline CHEMBL3911675 & 1640369 & 6.1871 & 6.2258 & TST & & \\
\hline CHEMBL3902346 & 1640369 & 7.5376 & 7.296 & TRN & & \\
\hline CHEMBL3944249 & 1640369 & 6.2291 & 6.5612 & TST & & \\
\hline CHEMBL3909464 & 1640369 & 6.0 & 6.2366 & TRN & & \\
\hline CHEMBL 3936148 & 1640369 & 5.6144 & 5.7789 & TST & & \\
\hline CHEMBL 3898854 & 1640369 & 7.6778 & \multicolumn{3}{|c|}{7.297999999999999} & TRN \\
\hline CHEMBL3935069 & 1640369 & 6.4318 & 6.5158 & TRN & & \\
\hline CHEMBL3732761 & 1537410 & 6.2218 & 6.5245 & TRN & & \\
\hline CHEMBL3733254 & 1537410 & 7.2218 & 7.4145 & TRN & & \\
\hline
\end{tabular}

Page 12613 
Supplemental Table S2.txt

\begin{tabular}{|c|c|c|c|c|c|}
\hline CHEMBL3731651 & 1537410 & 7.2218 & 6.3462 & TST & \\
\hline CHEMBL3730656 & 1537410 & 6.2218 & 6.2633 & TRN & \\
\hline CHEMBL3733237 & 1537410 & 4.9208 & 5.2036 & TRN & \\
\hline CHEMBL3728931 & 1537410 & 4.9208 & 6.1169 & TRN & \\
\hline CHEMBL 3728218 & 1537410 & 4.9208 & 5.661006 & 00000000005 & TST \\
\hline CHEMBL3729551 & 1537410 & 6.2218 & 6.9165 & TRN & \\
\hline CHEMBL3728969 & 1537410 & 6.2218 & 6.8063 & TRN & \\
\hline CHEMBL3731876 & 1537410 & 7.2218 & 6.8662 & TRN & \\
\hline CHEMBL3727611 & 1537410 & 6.2218 & 6.0678 & TRN & \\
\hline CHEMBL 3728450 & 1537410 & 7.2218 & 6.8796 & TRN & \\
\hline CHEMBL 3732522 & 1537410 & 7.2218 & 6.7325 & TRN & \\
\hline CHEMBL3728468 & 1537410 & 6.2218 & 6.2366 & TRN & \\
\hline CHEMBL3732708 & 1537410 & 4.9208 & 6.7834 & TST & \\
\hline CHEMBL3732547 & 1537410 & 7.2218 & 6.5839 & TRN & \\
\hline CHEMBL3728855 & 1537410 & 7.2218 & 7.186 & TRN & \\
\hline CHEMBL3730339 & 1537410 & 7.2218 & 7.0712 & TRN & \\
\hline CHEMBL3730009 & 1537410 & 7.2218 & 6.1303 & TRN & \\
\hline CHEMBL3732630 & 1537410 & 7.2218 & 6.7157 & TRN & \\
\hline CHEMBL3729261 & 1537410 & 7.2218 & 6.6795 & TRN & \\
\hline CHEMBL3732779 & 1537410 & 4.9208 & 6.0621 & TST & \\
\hline CHEMBL3729739 & 1537410 & 7.2218 & 6.7741 & TRN & \\
\hline CHEMBL 3730293 & 1537410 & 7.2218 & \multicolumn{2}{|c|}{6.7410000000000005} & TRN \\
\hline CHEMBL3732999 & 1537410 & 7.2218 & 7.263 & TRN & \\
\hline CHEMBL3732620 & 1537410 & 7.2218 & 6.4239 & TST & \\
\hline CHEMBL 3732114 & 1537410 & 6.2218 & 6.7307 & TRN & \\
\hline CHEMBL3727989 & 1537410 & 6.2218 & 6.0999 & TRN & \\
\hline CHEMBL3732450 & 1537410 & 7.2218 & 7.1971 & TRN & \\
\hline CHEMBL3731488 & 1537410 & 6.2218 & 6.4161 & TRN & \\
\hline CHEMBL3729841 & 1537410 & 7.2218 & 7.0651 & TRN & \\
\hline CHEMBL3730598 & 1537410 & 7.2218 & 6.7176 & TRN & \\
\hline CHEMBL 3729900 & 1537410 & 7.2218 & 7.151 & TRN & \\
\hline CHEMBL 3731250 & 1537410 & 6.2218 & 7.2856 & TRN & \\
\hline CHEMBL3727938 & 1537410 & 7.2218 & 6.7547 & TRN & \\
\hline CHEMBL3728825 & 1537410 & 4.9208 & 6.4789 & TRN & \\
\hline CHEMBL 3732677 & 1537410 & 4.9208 & 6.903 & TST & \\
\hline CHEMBL3730254 & 1537410 & 4.9208 & 6.4442 & TST & \\
\hline CHEMBL3730176 & 1537410 & 4.9208 & 6.6716 & TST & \\
\hline CHEMBL3728875 & 1537410 & 7.2218 & 6.6582 & TRN & \\
\hline CHEMBL3727649 & 1537410 & 4.9208 & 6.7181 & TST & \\
\hline CHEMBL3731310 & 1537410 & 4.9208 & 5.8981 & TRN & \\
\hline CHEMBL3728232 & 1537410 & 6.2218 & 7.098 & TRN & \\
\hline CHEMBL 3731030 & 1537410 & 7.2218 & 7.0313 & TRN & \\
\hline CHEMBL3729059 & 1537410 & 7.2218 & 6.9665 & TRN & \\
\hline CHEMBL3729101 & 1537410 & 7.2218 & 6.7811 & TRN & \\
\hline CHEMBL3727480 & 1537410 & 4.9208 & 6.6483 & TST & \\
\hline CHEMBL3729771 & 1537410 & 7.2218 & 6.4758 & TST & \\
\hline CHEMBL 3727377 & 1537410 & 7.2218 & 6.3354 & TRN & \\
\hline CHEMBL3730952 & 1537410 & 7.2218 & 6.7143 & TRN & \\
\hline
\end{tabular}


Supplemental Table S2.txt

\begin{tabular}{|c|c|c|c|c|c|}
\hline CHEMBL 3727934 & 1537410 & 7.2218 & 6.4262 & TST & \\
\hline CHEMBL3730579 & 1537410 & 4.9208 & 6.1431 & TST & \\
\hline CHEMBL 3733040 & 1537410 & 7.2218 & 6.6088 & TRN & \\
\hline CHEMBL 3728704 & 1537410 & 7.2218 & 6.8489 & TST & \\
\hline CHEMBL 3730740 & 1537410 & 7.2218 & 6.3926 & TST & \\
\hline CHEMBL 3731485 & 1537410 & 6.2218 & 6.5701 & TRN & \\
\hline CHEMBL 3727600 & 1537410 & 7.2218 & 7.5011 & TRN & \\
\hline CHEMBL3731964 & 1537410 & 7.2218 & 7.1406 & TRN & \\
\hline CHEMBL 3729283 & 1537410 & 4.9208 & 6.3756 & TRN & \\
\hline CHEMBL3729158 & 1537410 & 7.2218 & 7.1251 & TRN & \\
\hline CHEMBL 3733059 & 1537410 & 7.2218 & 7.4091 & TRN & \\
\hline CHEMBL3729109 & 1537410 & 7.2218 & 6.0596 & TST & \\
\hline CHEMBL3730679 & 1537410 & 7.2218 & 6.7565 & TRN & \\
\hline CHEMBL3727381 & 1537410 & 7.2218 & 7.0278 & TRN & \\
\hline CHEMBL3733355 & 1537410 & 7.2218 & 6.6073 & TST & \\
\hline CHEMBL 3727447 & 1537410 & 6.2218 & \multicolumn{2}{|c|}{6.747999999999999} & TRN \\
\hline CHEMBL3732104 & 1537410 & 7.2218 & 7.1846 & TRN & \\
\hline CHEMBL3728323 & 1537410 & 6.2218 & 6.8752 & TST & \\
\hline CHEMBL3729995 & 1537410 & 7.2218 & 7.3051 & TRN & \\
\hline CHEMBL3731738 & 1537410 & 7.2218 & 6.7543 & TST & \\
\hline CHEMBL 3728485 & 1537410 & 7.2218 & 7.3396 & TRN & \\
\hline CHEMBL3732982 & 1537410 & 6.2218 & 6.0461 & TRN & \\
\hline CHEMBL 3731765 & 1537410 & 6.2218 & 5.7838 & TRN & \\
\hline CHEMBL 3941514 & 1640789 & 5.6267 & \multicolumn{2}{|c|}{6.0360000000000005} & TST \\
\hline CHEMBL3964308 & 1640789 & 7.2518 & 6.6968 & TRN & \\
\hline CHEMBL 3983399 & 1640789 & 8.2147 & 8.0923 & TRN & \\
\hline CHEMBL3936799 & 1640789 & 7.7375 & \multicolumn{2}{|c|}{7.047999999999999} & TRN \\
\hline CHEMBL 3899032 & 1640789 & 6.2306 & 5.6818 & TRN & \\
\hline CHEMBL3904537 & 1640789 & 6.3635 & 6.6892 & TRN & \\
\hline CHEMBL3980201 & 1640789 & 7.8861 & 8.137 & TRN & \\
\hline CHEMBL3926569 & 1640789 & 5.5832 & 5.7924 & TST & \\
\hline CHEMBL 3957887 & 1640789 & 6.0009 & 5.8684 & TRN & \\
\hline CHEMBL 3964692 & 1640789 & 7.6326 & 7.8468 & TRN & \\
\hline CHEMBL3922395 & 1640789 & 7.3188 & 7.1492 & TRN & \\
\hline CHEMBL3929668 & 1640789 & 5.0677 & 6.7669 & TST & \\
\hline CHEMBL3895258 & 1640789 & 8.0 & 6.8801 & TST & \\
\hline CHEMBL3935845 & 1640789 & 5.4991 & 5.91299 & 9999999999 & TRN \\
\hline CHEMBL 3982624 & 1640789 & 5.7111 & 6.3723 & TRN & \\
\hline CHEMBL 3893407 & 1640789 & 6.684 & \multicolumn{2}{|c|}{6.707000000000001} & TRN \\
\hline CHEMBL3941095 & 1640789 & 7.4572 & 7.3529 & TRN & \\
\hline CHEMBL3913400 & 1640789 & 6.2636 & 6.6985 & TRN & \\
\hline CHEMBL3975049 & 1640789 & 6.0 & 6.8152 & TRN & \\
\hline CHEMBL 3896318 & 1640789 & 6.0227 & 5.7097 & TRN & \\
\hline CHEMBL3892264 & 1640789 & 6.8356 & 6.3712 & TRN & \\
\hline CHEMBL3931727 & 1640789 & 7.4318 & 7.9967 & TRN & \\
\hline CHEMBL3938241 & 1640789 & 8.8861 & 8.6773 & TRN & \\
\hline CHEMBL3986687 & 1640789 & 5.5287 & 5.6805 & TRN & \\
\hline CHEMBL3958334 & 1640789 & 6.8861 & 6.8673 & TRN & \\
\hline
\end{tabular}


Supplemental Table S2.txt

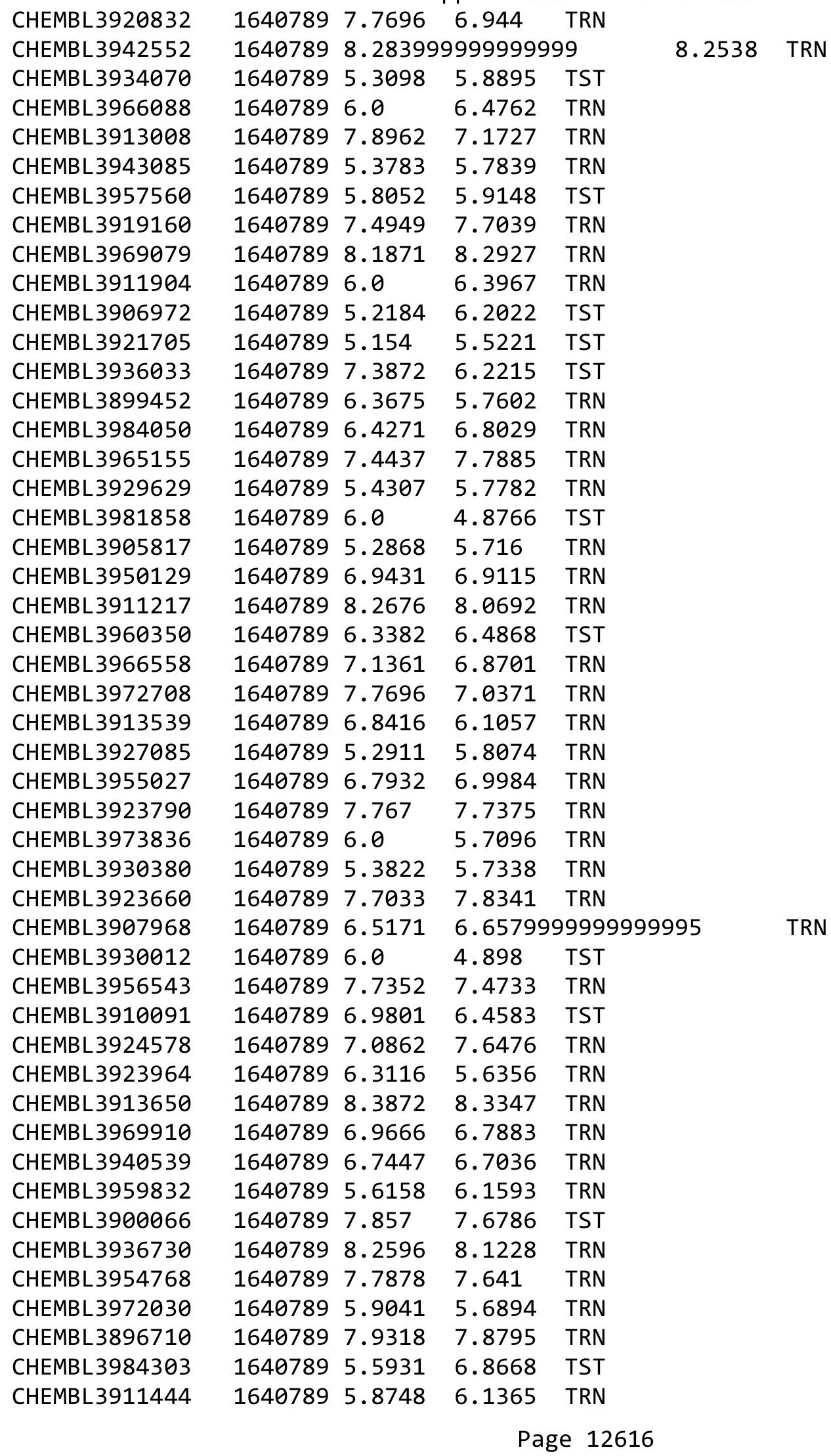


Supplemental Table S2.txt

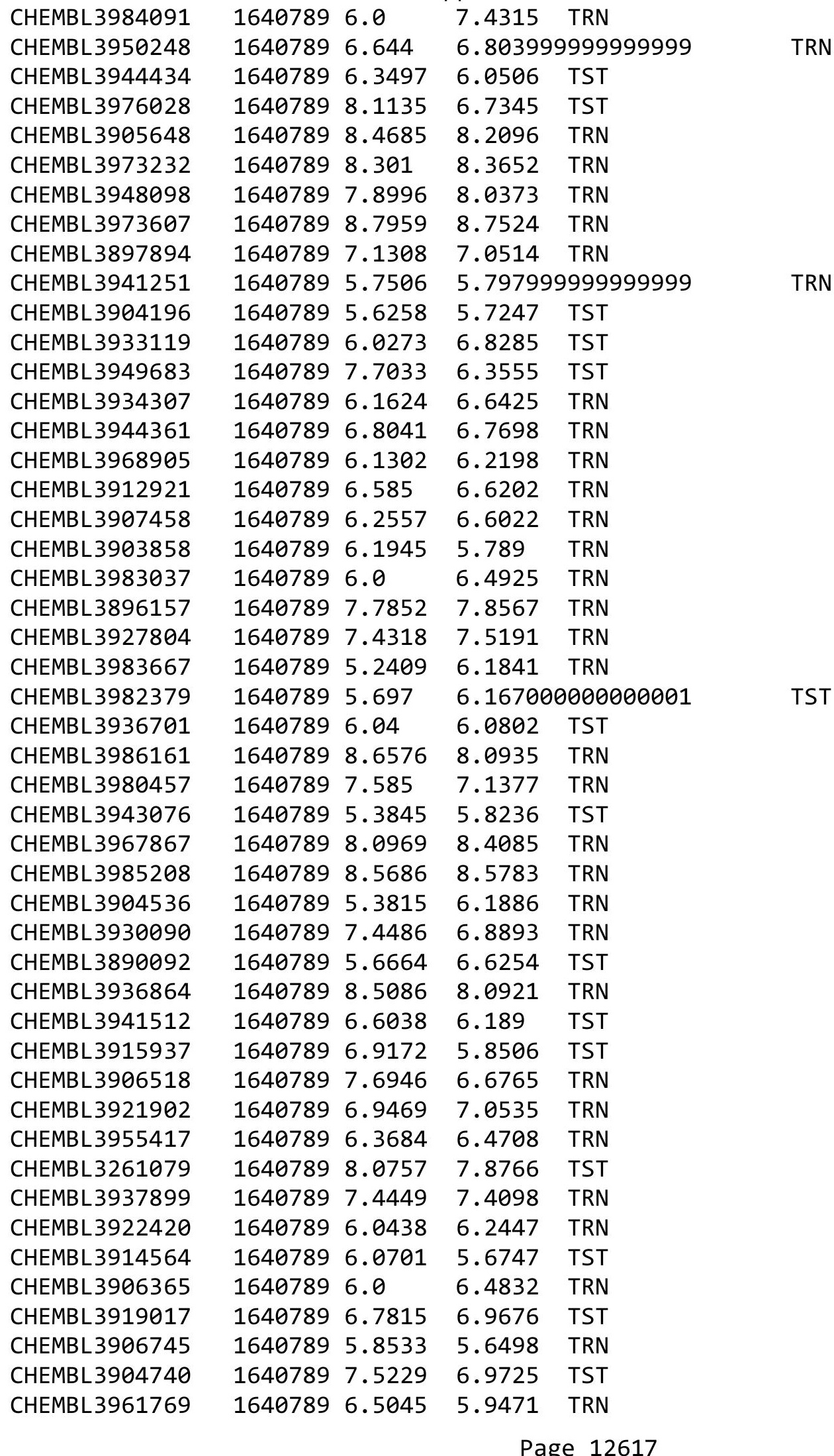


Supplemental Table S2.txt

\begin{tabular}{|c|c|c|c|c|}
\hline CHEMBL3909483 & 1640789 & 6.9666 & 7.6754 & TRN \\
\hline CHEMBL3952587 & 1640789 & 7.0555 & 6.7913 & TST \\
\hline CHEMBL3892339 & 1640789 & 5.6819 & 5.6443 & TRN \\
\hline CHEMBL3913185 & 1640789 & 6.0 & 6.4591 & TRN \\
\hline CHEMBL3910429 & 1640789 & 7.9747 & 8.4041 & TRN \\
\hline CHEMBL3958825 & 1640789 & 7.6946 & 6.5658 & TST \\
\hline CHEMBL3944871 & 1640789 & 5.8176 & 5.9477 & TRN \\
\hline CHEMBL3984945 & 1640789 & 5.4995 & 6.4699 & TRN \\
\hline CHEMBL3946832 & 1640789 & 6.959 & 6.8189 & TST \\
\hline CHEMBL3897396 & 1640789 & 6.0 & 6.3213 & TRN \\
\hline CHEMBL 3910252 & 1640789 & 7.3872 & 6.591 & TRN \\
\hline CHEMBL3912689 & 1640789 & 5.8887 & 6.8998 & TST \\
\hline CHEMBL3913922 & 1640789 & 5.4401 & 5.7223 & TST \\
\hline CHEMBL3905107 & 1640789 & 5.8775 & 6.4149 & TST \\
\hline CHEMBL3905319 & 1640789 & 7.9586 & 7.6902 & TRN \\
\hline CHEMBL3983432 & 1640789 & 8.3768 & 8.1341 & TRN \\
\hline CHEMBL3981231 & 1640789 & 7.9706 & 8.066 & TRN \\
\hline CHEMBL3897738 & 1640789 & 6.9666 & 6.9782 & TRN \\
\hline CHEMBL3980366 & 1640789 & 7.9626 & 7.6566 & TRN \\
\hline CHEMBL3971718 & 1640789 & 6.8327 & 6.8579 & TRN \\
\hline CHEMBL3945065 & 1640789 & 7.0862 & 6.1698 & TRN \\
\hline CHEMBL3948118 & 1640789 & 8.4437 & 8.0342 & TRN \\
\hline CHEMBL3921426 & 1640789 & 6.1445 & 6.4731 & TST \\
\hline CHEMBL3960661 & 1640789 & 5.633999 & 999999999 & 5.8234 \\
\hline CHEMBL3978379 & 1640789 & 8.2441 & 6.8871 & TRN \\
\hline CHEMBL3902972 & 1640789 & 7.7305 & 7.5143 & TRN \\
\hline CHEMBL3912550 & 1640789 & 6.5229 & 5.9013 & TRN \\
\hline CHEMBL3896325 & 1640789 & 6.0 & 6.5887 & TRN \\
\hline CHEMBL3914455 & 1640789 & 6.0 & 6.4357 & TRN \\
\hline CHEMBL3985039 & 1640789 & 7.3439 & 6.4559 & TRN \\
\hline CHEMBL 209094 & 355136 & 8.3768 & 8.0767 & TRN \\
\hline CHEMBL207407 & 355136 & 7.3768 & 7.9197 & TST \\
\hline CHEMBL207860 & 355136 & 8.699 & 8.0988 & TRN \\
\hline CHEMBL207374 & 355136 & 8.3188 & 8.0195 & TRN \\
\hline CHEMBL207635 & 355136 & 7.0182 & 8.015 & TRN \\
\hline CHEMBL379699 & 355136 & 8.2218 & 8.0112 & TST \\
\hline CHEMBL207719 & 355136 & 7.1079 & 7.9213 & TRN \\
\hline CHEMBL382248 & 355136 & 8.0809 & 7.6793 & TRN \\
\hline CHEMBL207480 & 355136 & 8.5086 & 8.0833 & TST \\
\hline CHEMBL207755 & 355136 & 8.2676 & 7.7382 & TRN \\
\hline CHEMBL207914 & 355136 & 8.1487 & 7.7181 & TRN \\
\hline CHEMBL377882 & 355136 & 8.2218 & 8.0605 & TRN \\
\hline CHEMBL208535 & 355136 & 8.2596 & 8.0591 & TRN \\
\hline CHEMBL207837 & 355136 & 7.041 & 7.9742 & TST \\
\hline CHEMBL380191 & 355136 & 7.1612 & 7.901 & TST \\
\hline CHEMBL208070 & 355136 & 8.0132 & 7.9699 & TRN \\
\hline CHEMBL378070 & 355136 & 5.9747 & 6.197999 & 99999999995 \\
\hline CHEMBL377574 & 355136 & 8.0177 & 7.9863 & TRN \\
\hline
\end{tabular}




\begin{tabular}{|c|c|c|c|c|c|c|}
\hline & & & oplement & al Table S & S2.txt & \\
\hline CHEMBL208067 & 355136 & 8.4815 & 8.0737 & TRN & & \\
\hline CHEMBL 208252 & 355136 & 8.4685 & 7.92200 & 0000000001 & & TRN \\
\hline CHEMBL 377678 & 355136 & 8.0088 & 8.1266 & TRN & & \\
\hline CHEMBL 207807 & 355136 & 7.699 & 8.2032 & TRN & & \\
\hline CHEMBL208121 & 355136 & 8.1871 & 8.0993 & TRN & & \\
\hline CHEMBL382554 & 355136 & 7.4815 & 8.0382 & TRN & & \\
\hline CHEMBL208191 & 355136 & 8.3872 & 8.05600 & 0000000001 & & TST \\
\hline CHEMBL 207810 & 355136 & 7.3757 & 7.0163 & TRN & & \\
\hline CHEMBL381056 & 355136 & 6.8239 & 7.8246 & TST & & \\
\hline CHEMBL206153 & 355136 & 7.8761 & 8.0537 & TRN & & \\
\hline CHEMBL 207854 & 355136 & 8.4437 & 8.1678 & TRN & & \\
\hline CHEMBL383734 & 355136 & 7.0655 & 8.1144 & TST & & \\
\hline CHEMBL 377057 & 355136 & 7.585 & 8.013 & TST & & \\
\hline CHEMBL381079 & 355136 & 7.7986 & 8.0705 & TRN & & \\
\hline CHEMBL 207023 & 355136 & 8.2924 & 8.083 & TRN & & \\
\hline CHEMBL 206152 & 355136 & 7.8761 & 8.0192 & TRN & & \\
\hline CHEMBL382001 & 355136 & 6.7212 & 7.6708 & TST & & \\
\hline CHEMBL438059 & 355136 & 8.4815 & 8.1097 & TRN & & \\
\hline CHEMBL 208444 & 355136 & 7.3665 & 7.9368 & TST & & \\
\hline CHEMBL207894 & 355136 & 7.2924 & 7.9172 & TRN & & \\
\hline CHEMBL 380890 & 355136 & 8.4949 & 8.0876 & TRN & & \\
\hline CHEMBL 208533 & 355136 & 6.3768 & 7.9369 & TRN & & \\
\hline CHEMBL383611 & 355136 & 7.6778 & 7.9884 & TRN & & \\
\hline CHEMBL 208178 & 355136 & 8.1675 & 7.6616 & TRN & & \\
\hline CHEMBL 208232 & 355136 & 8.6576 & 8.0867 & TRN & & \\
\hline CHEMBL208069 & 355136 & 7.2147 & 8.0574 & TRN & & \\
\hline CHEMBL 208251 & 355136 & 8.8539 & 8.0571 & TRN & & \\
\hline CHEMBL381373 & 355136 & 6.5935 & 7.8489 & TST & & \\
\hline CHEMBL378498 & 355136 & 8.2147 & 8.1303 & TRN & & \\
\hline CHEMBL378839 & 355136 & 6.75700 & 30000000 & & 7.9454 & TRN \\
\hline CHEMBL207634 & 355136 & 8.2076 & 8.1012 & TRN & & \\
\hline CHEMBL426316 & 355136 & 8.0809 & 8.1536 & TRN & & \\
\hline CHEMBL425589 & 355136 & 6.1612 & 7.6534 & TST & & \\
\hline CHEMBL208420 & 355136 & 8.5686 & 8.0899 & TRN & & \\
\hline CHEMBL441358 & 355136 & 8.7447 & 8.1344 & TRN & & \\
\hline CHEMBL206580 & 355136 & 6.5229 & 7.87 & TST & & \\
\hline CHEMBL207915 & 355136 & 6.8386 & 6.8881 & TRN & & \\
\hline CHEMBL207886 & 355136 & 7.8239 & 8.1871 & TRN & & \\
\hline CHEMBL1547641 & 752317 & 5.0814 & 5.0163 & TRN & & \\
\hline CHEMBL1500327 & 752317 & 5.0555 & 5.1883 & TRN & & \\
\hline CHEMBL1564057 & 752317 & 5.0575 & 4.8709 & TRN & & \\
\hline CHEMBL1346557 & 752317 & 5.0429 & 5.1623 & TRN & & \\
\hline CHEMBL1575468 & 752317 & 5.0168 & 5.0842 & TRN & & \\
\hline CHEMBL1601426 & 752317 & 4.6819 & 4.9603 & TRN & & \\
\hline CHEMBL1446422 & 752317 & 5.8861 & 5.2161 & TRN & & \\
\hline CHEMBL1454056 & 752317 & 4.1772 & 4.8304 & TRN & & \\
\hline CHEMBL1583918 & 752317 & 5.02 & 5.0308 & TRN & & \\
\hline CHEMBL1323406 & 752317 & 4.8894 & 4.9923 & TRN & & \\
\hline
\end{tabular}




\begin{tabular}{|c|c|c|c|c|c|c|}
\hline & & \multicolumn{5}{|c|}{ Supplemental Table S2.txt } \\
\hline CHEMBL1322001 & 752317 & 5.1124 & 4.9083 & TRN & & \\
\hline CHEMBL1566254 & 752317 & 4.9586 & 4.86 & TRN & & \\
\hline CHEMBL1701401 & 752317 & 5.1851 & 5.0173 & TST & & \\
\hline CHEMBL1441485 & 752317 & 5.1965 & 5.0463 & TST & & \\
\hline CHEMBL1402117 & 752317 & 4.5346 & 4.9994 & TST & & \\
\hline CHEMBL1331279 & 752317 & 4.9245 & 4.8672 & TRN & & \\
\hline CHEMBL3192732 & 752317 & 4.8125 & 5.0252 & TRN & & \\
\hline CHEMBL1405348 & 752317 & 4.9431 & 4.9765 & TRN & & \\
\hline CHEMBL1556345 & 752317 & 5.0191 & 4.8669 & TRN & & \\
\hline CHEMBL1385092 & 752317 & 5.0975 & 4.7881 & TST & & \\
\hline CHEMBL1601754 & 752317 & 5.0372 & 4.8704 & TRN & & \\
\hline CHEMBL1410494 & 752317 & 5.1232 & 5.1506 & TRN & & \\
\hline CHEMBL1972739 & 752317 & 4.9172 & 5.3056 & TRN & & \\
\hline CHEMBL201289 & 752317 & 5.0841 & 5.0317 & TRN & & \\
\hline CHEMBL1327389 & 752317 & 4.699 & 5.1276 & TST & & \\
\hline CHEMBL3199504 & 752317 & 4.7447 & 5.0921 & TRN & & \\
\hline CHEMBL1715183 & 752317 & 5.0414 & 5.1219 & TST & & \\
\hline CHEMBL1442995 & 752317 & 5.083 & 5.1227 & TRN & & \\
\hline CHEMBL1998302 & 752317 & 4.4597 & 3.6903 & TRN & & \\
\hline CHEMBL1374603 & 752317 & 5.16299 & 99999999 & 99 & 4.9635 & TRN \\
\hline CHEMBL1391013 & 752317 & 6.4473 & 5.0901 & TRN & & \\
\hline CHEMBL1484992 & 752317 & 4.9101 & 5.1147 & TRN & & \\
\hline CHEMBL1505219 & 752317 & 5.0 & 4.979 & TRN & & \\
\hline CHEMBL1315727 & 752317 & 4.9393 & 5.2224 & TRN & & \\
\hline CHEMBL1305800 & 752317 & 4.9318 & 4.6944 & TRN & & \\
\hline CHEMBL1573487 & 752317 & 5.025 & 5.2527 & TST & & \\
\hline CHEMBL1398617 & 752317 & 5.0757 & 4.9896 & TRN & & \\
\hline CHEMBL1200567 & 752317 & 4.3675 & 5.0431 & TST & & \\
\hline CHEMBL1459883 & 752317 & 5.1805 & 5.0223 & TRN & & \\
\hline CHEMBL1604142 & 752317 & 5.2373 & 5.1871 & TRN & & \\
\hline CHEMBL1974450 & 752317 & 4.8827 & 5.0944 & TRN & & \\
\hline CHEMBL1982888 & 752317 & 4.6596 & 5.1977 & TRN & & \\
\hline CHEMBL1302389 & 752317 & 5.1811 & 5.147 & TRN & & \\
\hline CHEMBL1439317 & 752317 & 5.0501 & 4.9787 & TRN & & \\
\hline CHEMBL417727 & 752317 & 4.3116 & 4.2917 & TRN & & \\
\hline CHEMBL1587708 & 752317 & 4.9318 & 5.1845 & TRN & & \\
\hline CHEMBL1424356 & 752317 & 5.1267 & 5.0701 & TRN & & \\
\hline CHEMBL1553969 & 752317 & 5.6459 & 4.9703 & TRN & & \\
\hline CHEMBL1429991 & 752317 & 5.0292 & 5.115 & TRN & & \\
\hline CHEMBL1353223 & 752317 & 5.4271 & 4.9591 & TST & & \\
\hline CHEMBL8739 & 752317 & 4.6517 & 4.9386 & TST & & \\
\hline CHEMBL1585162 & 752317 & 4.9547 & 5.0823 & TRN & & \\
\hline CHEMBL1349770 & 752317 & 5.5867 & 5.1532 & TRN & & \\
\hline CHEMBL1558180 & 752317 & 5.27 & 5.0916 & TRN & & \\
\hline CHEMBL1313760 & 752317 & 4.9172 & 5.1336 & TRN & & \\
\hline CHEMBL1480968 & 752317 & 5.2269 & 5.1965 & TRN & & \\
\hline CHEMBL1429460 & 752317 & 5.0159 & 5.0514 & TRN & & \\
\hline CHEMBL1312212 & 752317 & 4.9747 & 4.9933 & TRN & & \\
\hline
\end{tabular}




\begin{tabular}{|c|c|c|c|c|c|}
\hline & & \multicolumn{4}{|c|}{ Supplemental Table S2.txt } \\
\hline CHEMBL1500909 & 752317 & 5.71 & 5.0007 & TRN & \\
\hline CHEMBL1427943 & 752317 & 4.8794 & 4.9786 & TRN & \\
\hline CHEMBL3193932 & 752317 & 5.2907 & 4.9921 & TRN & \\
\hline CHEMBL1497387 & 752317 & 5.0991 & 5.0625 & TRN & \\
\hline CHEMBL1730686 & 752317 & 5.0996 & 4.9666 & TST & \\
\hline CHEMBL1310744 & 752317 & 5.6383 & 5.2257 & TRN & \\
\hline CHEMBL3189467 & 752317 & 4.9508 & 5.1582 & TRN & \\
\hline CHEMBL1305880 & 752317 & 5.0311 & 5.0138 & TRN & \\
\hline CHEMBL 3198285 & 752317 & 5.1314 & 5.1518 & TRN & \\
\hline CHEMBL1457118 & 752317 & 4.3969 & 4.9945 & TRN & \\
\hline CHEMBL1538079 & 752317 & 6.4935 & 5.1651 & TRN & \\
\hline CHEMBL1455066 & 752317 & 5.0083 & 4.9724 & TRN & \\
\hline CHEMBL1441848 & 752317 & 5.0395 & 5.1566 & TRN & \\
\hline CHEMBL1351532 & 752317 & 5.1593 & 5.3672 & TRN & \\
\hline CHEMBL1548451 & 752317 & 5.9245 & 5.1004 & TRN & \\
\hline CHEMBL1416439 & 752317 & 4.8861 & 5.0179 & TRN & \\
\hline CHEMBL1463659 & 752317 & 3.0969 & 3.4403 & TRN & \\
\hline CHEMBL1486491 & 752317 & 4.9547 & 5.2105 & TST & \\
\hline CHEMBL1566994 & 752317 & 3.0969 & 4.985 & TRN & \\
\hline CHEMBL1347385 & 752317 & 5.0926 & 5.1466 & TST & \\
\hline CHEMBL1699206 & 752317 & 4.6925 & 5.0505 & TRN & \\
\hline CHEMBL3192915 & 752317 & 5.3716 & 4.9787 & TRN & \\
\hline CHEMBL1303265 & 752317 & 5.4056 & 4.9425 & TRN & \\
\hline CHEMBL1328930 & 752317 & 5.1421 & 4.9912 & TRN & \\
\hline CHEMBL1373087 & 752317 & 5.0857 & 5.20100 & 00000000005 & TRN \\
\hline CHEMBL3212203 & 752317 & 5.5969 & 5.2673 & TRN & \\
\hline CHEMBL1560072 & 752317 & 5.1858 & 5.1834 & TRN & \\
\hline CHEMBL1367539 & 752317 & 5.3585 & 5.1655 & TRN & \\
\hline CHEMBL1564133 & 752317 & 4.9245 & 5.3076 & TRN & \\
\hline CHEMBL1598704 & 752317 & 5.3161 & 5.0018 & TRN & \\
\hline CHEMBL1443982 & 752317 & 5.0975 & 5.096 & TRN & \\
\hline CHEMBL1989234 & 752317 & $5.2620 e$ & 30000000 & 5.0927 & TRN \\
\hline CHEMBL1299634 & 752317 & 5.7258 & 5.0868 & TRN & \\
\hline CHEMBL1520133 & 752317 & 5.2749 & 4.9732 & TRN & \\
\hline CHEMBL3199268 & 752317 & 5.1146 & 5.2003 & TRN & \\
\hline CHEMBL3194663 & 752317 & 6.2993 & 5.0964 & TRN & \\
\hline CHEMBL1363151 & 752317 & 5.0711 & 5.3531 & TRN & \\
\hline CHEMBL1597967 & 752317 & 5.0278 & 4.945 & TRN & \\
\hline CHEMBL1341070 & 752317 & 5.056 & 5.0059 & TRN & \\
\hline CHEMBL1312400 & 752317 & 5.0241 & 5.0481 & TRN & \\
\hline CHEMBL523844 & 752317 & 5.2262 & 5.0759 & TRN & \\
\hline CHEMBL1583199 & 752317 & 4.9318 & 4.6095 & TST & \\
\hline CHEMBL1163377 & 752317 & 4.2299 & 4.1232 & TRN & \\
\hline CHEMBL1597430 & 752317 & 4.9136 & 5.0023 & TRN & \\
\hline CHEMBL1990772 & 752317 & 5.3125 & 4.824 & TRN & \\
\hline CHEMBL1562767 & 752317 & 3.0969 & 4.987 & TRN & \\
\hline CHEMBL1328505 & 752317 & 4.8827 & 5.1795 & TRN & \\
\hline CHEMBL1612983 & 752317 & 4.8508 & 5.151 & TRN & \\
\hline
\end{tabular}


Supplemental Table S2.txt

\begin{tabular}{|c|c|c|c|c|c|}
\hline CHEMBL1346724 & 752317 & 4.9208 & 5.09 & TRN & \\
\hline CHEMBL1390878 & 752317 & 4.9872 & 4.8948 & TRN & \\
\hline CHEMBL3194622 & 752317 & 4.4935 & 5.0921 & TRN & \\
\hline CHEMBL1338064 & 752317 & 5.0325 & 4.9564 & TRN & \\
\hline CHEMBL1493277 & 752317 & 5.3242 & 4.8129 & TRN & \\
\hline CHEMBL1471276 & 752317 & 4.9957 & 5.0997 & TRN & \\
\hline CHEMBL1351099 & 752317 & 5.05699 & 99999999 & 5.0132 & TST \\
\hline CHEMBL1332976 & 752317 & 5.0 & 5.0628 & TRN & \\
\hline CHEMBL1358863 & 752317 & 5.0655 & 4.9795 & TRN & \\
\hline CHEMBL3197857 & 752317 & 4.475 & 5.1222 & TRN & \\
\hline CHEMBL1377368 & 752317 & 4.8601 & 5.0071 & TRN & \\
\hline CHEMBL1510714 & 752317 & 5.3242 & 5.0203 & TRN & \\
\hline CHEMBL1726134 & 752317 & 4.2358 & 4.5047 & TRN & \\
\hline CHEMBL1377980 & 752317 & 4.9136 & 5.0278 & TRN & \\
\hline CHEMBL1700402 & 752317 & 5.1397 & 4.9974 & TRN & \\
\hline CHEMBL1537344 & 752317 & 5.2403 & 4.8265 & TST & \\
\hline CHEMBL3211199 & 752317 & 5.0975 & 5.1019 & TRN & \\
\hline CHEMBL429095 & 752317 & 4.2557 & 4.5899 & TRN & \\
\hline CHEMBL3211239 & 752317 & 4.8794 & 4.7832 & TRN & \\
\hline CHEMBL1569063 & 752317 & 5.0768 & 4.9856 & TRN & \\
\hline CHEMBL1540038 & 752317 & 5.1169 & 4.8045 & TRN & \\
\hline CHEMBL1422978 & 752317 & 4.8097 & 5.24799 & 9999999999 & TST \\
\hline CHEMBL1324710 & 752317 & 4.8761 & 4.9375 & TRN & \\
\hline CHEMBL3211859 & 752317 & 5.0052 & 5.0716 & TRN & \\
\hline CHEMBL1503793 & 752317 & 4.5751 & 5.0215 & TRN & \\
\hline CHEMBL1419772 & 752317 & 5.061 & 4.893 & TST & \\
\hline CHEMBL1376844 & 752317 & 4.8041 & 4.9916 & TRN & \\
\hline CHEMBL1523011 & 752317 & 4.4989 & 4.7621 & TRN & \\
\hline CHEMBL605084 & 752317 & 5.6882 & 4.999 & TRN & \\
\hline CHEMBL1533308 & 752317 & 5.0057 & 5.0941 & TRN & \\
\hline CHEMBL1389834 & 752317 & 5.1118 & 5.0584 & TRN & \\
\hline CHEMBL1711530 & 752317 & 5.1746 & 4.9973 & TRN & \\
\hline CHEMBL1431536 & 752317 & 5.0996 & 5.1285 & TST & \\
\hline CHEMBL1362499 & 752317 & 5.2757 & 5.1573 & TRN & \\
\hline CHEMBL1393740 & 752317 & 5.5072 & 5.1696 & TRN & \\
\hline CHEMBL1559660 & 752317 & 5.2518 & 4.8762 & TST & \\
\hline CHEMBL1393256 & 752317 & 4.9281 & 5.2998 & TST & \\
\hline CHEMBL1371777 & 752317 & 5.1232 & 5.1281 & TRN & \\
\hline CHEMBL1320533 & 752317 & 4.7799 & 5.0646 & TRN & \\
\hline CHEMBL1978651 & 752317 & 5.098 & 5.1265 & TRN & \\
\hline CHEMBL1501247 & 752317 & 4.9586 & 5.0825 & TRN & \\
\hline CHEMBL1502665 & 752317 & 4.8097 & 5.0347 & TRN & \\
\hline CHEMBL1601975 & 752317 & 4.7852 & 4.8569 & TRN & \\
\hline CHEMBL1448592 & 752317 & 5.2381 & 5.1695 & TST & \\
\hline CHEMBL1612433 & 752317 & 5.1409 & 5.0859 & TRN & \\
\hline CHEMBL1313603 & 752317 & 4.9172 & 5.1251 & TRN & \\
\hline CHEMBL1384734 & 752317 & 5.1163 & 4.7852 & TRN & \\
\hline CHEMBL1488830 & 752317 & 5.0799 & 5.0405 & TRN & \\
\hline
\end{tabular}




\begin{tabular}{|c|c|c|c|c|c|c|}
\hline & & \multicolumn{5}{|c|}{ Supplemental Table S2.txt } \\
\hline CHEMBL51931 & 752317 & 4.3686 & 4.3369 & TRN & & \\
\hline CHEMBL1571467 & 752317 & 4.9747 & 5.0246 & TRN & & \\
\hline CHEMBL1412001 & 752317 & 5.0947 & 5.1771 & TRN & & \\
\hline CHEMBL1583535 & 752317 & 5.1244 & 5.0806 & TRN & & \\
\hline CHEMBL1511348 & 752317 & 5.0092 & 5.1632 & TRN & & \\
\hline CHEMBL1573569 & 752317 & 5.3233 & 4.8349 & TRN & & \\
\hline CHEMBL1564502 & 752317 & 5.1163 & 5.0005 & TRN & & \\
\hline CHEMBL1479309 & 752317 & 5.1824 & 5.395 & TRN & & \\
\hline CHEMBL1521669 & 752317 & 5.2798 & 5.1664 & TRN & & \\
\hline CHEMBL1412087 & 752317 & 5.1568 & 5.0888 & TRN & & \\
\hline CHEMBL1328880 & 752317 & 5.4584 & 5.0355 & TRN & & \\
\hline CHEMBL1325945 & 752317 & 3.0969 & 3.556 & TRN & & \\
\hline CHEMBL1453871 & 752317 & 4.8761 & 5.2103 & TRN & & \\
\hline CHEMBL1364923 & 752317 & 4.9101 & 4.9796 & TRN & & \\
\hline CHEMBL601757 & 752317 & 3.0969 & 3.5611 & TRN & & \\
\hline CHEMBL1452232 & 752317 & 5.0269 & 4.9207 & TRN & & \\
\hline CHEMBL1576198 & 752317 & 4.8239 & 5.0493 & TRN & & \\
\hline CHEMBL1305716 & 752317 & 5.2291 & 5.0591 & TRN & & \\
\hline CHEMBL1556531 & 752317 & 4.7747 & 5.1129 & TRN & & \\
\hline CHEMBL1399663 & 752317 & 5.06 & 5.0529 & TST & & \\
\hline CHEMBL1190214 & 752317 & 5.0177 & 5.2565 & TST & & \\
\hline CHEMBL1426966 & 752317 & 4.6737 & 5.0288 & TRN & & \\
\hline CHEMBL3191531 & 752317 & 4.7905 & 5.0145 & TRN & & \\
\hline CHEMBL1700257 & 752317 & 5.1726 & 4.9494 & TRN & & \\
\hline CHEMBL3211474 & 752317 & 4.7905 & 5.1307 & TST & & \\
\hline CHEMBL1434175 & 752317 & 5.4737 & 5.1436 & TRN & & \\
\hline CHEMBL1986418 & 752317 & $5.8210 e$ & 00000000 & 01 & 1023 & TRN \\
\hline CHEMBL1347506 & 752317 & 5.064 & 4.8786 & TST & & \\
\hline CHEMBL1486981 & 752317 & 5.2774 & 5.1228 & TRN & & \\
\hline CHEMBL1328704 & 752317 & 5.1858 & 5.1119 & TRN & & \\
\hline CHEMBL1450458 & 752317 & 5.0804 & 5.1861 & TRN & & \\
\hline CHEMBL1518606 & 752317 & 5.0458 & 4.957 & TRN & & \\
\hline CHEMBL1496397 & 752317 & 6.7399 & 5.1454 & TRN & & \\
\hline CHEMBL1454614 & 752317 & 3.0969 & 3.9152 & TRN & & \\
\hline CHEMBL1569505 & 752317 & 5.1884 & 5.1 & TRN & & \\
\hline CHEMBL1477862 & 752317 & 5.2226 & 5.0233 & TRN & & \\
\hline CHEMBL1303261 & 752317 & 4.684 & 5.1692 & TRN & & \\
\hline CHEMBL1401522 & 752317 & 5.8239 & 5.0825 & TRN & & \\
\hline CHEMBL1326194 & 752317 & 4.857 & 4.8825 & TRN & & \\
\hline CHEMBL1568747 & 752317 & 5.0969 & 4.8822 & TRN & & \\
\hline CHEMBL1393131 & 752317 & 4.9136 & 5.1686 & TRN & & \\
\hline CHEMBL1381095 & 752317 & 4.3054 & 5.0984 & TRN & & \\
\hline CHEMBL1438166 & 752317 & 5.1469 & 4.8986 & TRN & & \\
\hline CHEMBL1511427 & 752317 & 4.9626 & 4.9936 & TRN & & \\
\hline CHEMBL1398275 & 752317 & 5.1475 & 4.9036 & TST & & \\
\hline CHEMBL1575914 & 752317 & 4.857 & 5.0067 & TRN & & \\
\hline CHEMBL1460470 & 752317 & 4.618 & 4.848 & TRN & & \\
\hline CHEMBL1329884 & 752317 & 5.2118 & 5.0918 & TRN & & \\
\hline
\end{tabular}


Supplemental Table S2.txt

\begin{tabular}{|c|c|c|c|c|c|c|}
\hline CHEMBL1498006 & 752317 & 5.1772 & 5.1052 & TRN & & \\
\hline CHEMBL1528102 & 752317 & 4.2541 & 5.1884 & TRN & & \\
\hline CHEMBL1600974 & 752317 & 5.0899 & 4.9907 & TRN & & \\
\hline CHEMBL1497428 & 752317 & 4.9318 & 5.3682 & TRN & & \\
\hline CHEMBL 3189968 & 752317 & 5.5482 & 4.8275 & TRN & & \\
\hline CHEMBL1999630 & 752317 & 4.8125 & 3.9983 & TRN & & \\
\hline CHEMBL1497153 & 752317 & 5.0438 & 4.7813 & TRN & & \\
\hline CHEMBL 3193909 & 752317 & 5.1096 & 4.8396 & TRN & & \\
\hline CHEMBL1506609 & 752317 & 4.3316 & 4.9705 & TRN & & \\
\hline CHEMBL1503919 & 752317 & 5.0186 & 4.9366 & TRN & & \\
\hline CHEMBL1720735 & 752317 & 4.8297 & 5.0604 & TRN & & \\
\hline CHEMBL1401747 & 752317 & 3.0969 & 5.1232 & TRN & & \\
\hline CHEMBL1428166 & 752317 & 4.2823 & 4.6999 & TST & & \\
\hline CHEMBL1378604 & 752317 & 5.098 & 5.0118 & TRN & & \\
\hline CHEMBL1432309 & 752317 & 6.011 & 5.1583 & TRN & & \\
\hline CHEMBL1518580 & 752317 & 5.0097 & 5.0293 & TST & & \\
\hline CHEMBL1410545 & 752317 & 4.9136 & 5.0581 & TRN & & \\
\hline CHEMBL1404040 & 752317 & 4.9245 & 5.2081 & TRN & & \\
\hline CHEMBL1505993 & 752317 & 4.9355 & 5.1139 & TRN & & \\
\hline CHEMBL1713454 & 752317 & 5.0888 & 4.962 & TST & & \\
\hline CHEMBL334255 & 752317 & 5.0788 & 5.1015 & TST & & \\
\hline CHEMBL1334010 & 752317 & 5.0329 & 4.7827 & TRN & & \\
\hline CHEMBL1481493 & 752317 & \multicolumn{3}{|c|}{5.752000000000001} & 5.2392 & TRN \\
\hline CHEMBL1576175 & 752317 & 4.7747 & 5.1056 & TRN & & \\
\hline CHEMBL473314 & 752317 & 3.0969 & 5.0872 & TST & & \\
\hline CHEMBL1377441 & 752317 & 4.7932 & 5.1997 & TRN & & \\
\hline CHEMBL1458390 & 752317 & 5.3915 & 5.0392 & TRN & & \\
\hline CHEMBL1736506 & 752317 & 5.1415 & 5.4643 & TRN & & \\
\hline CHEMBL1425421 & 752317 & 4.8697 & 5.1175 & TRN & & \\
\hline CHEMBL1526958 & 752317 & 5.0783 & 4.992 & TRN & & \\
\hline CHEMBL1346869 & 752317 & 5.3028 & 4.9774 & TRN & & \\
\hline CHEMBL193872 & 752317 & 5.1046 & 5.2135 & TST & & \\
\hline CHEMBL570399 & 752317 & \multicolumn{3}{|c|}{5.757000000000001} & 5.1802 & TRN \\
\hline CHEMBL 3208530 & 752317 & 5.0386 & 5.1121 & TRN & & \\
\hline CHEMBL1434750 & 752317 & 5.3298 & 5.0083 & TRN & & \\
\hline CHEMBL1468314 & 752317 & 4.9586 & 4.6721 & TST & & \\
\hline CHEMBL1490712 & 752317 & 4.9318 & 5.1112 & TST & & \\
\hline CHEMBL1994668 & 752317 & 5.7305 & 5.1618 & TRN & & \\
\hline CHEMBL1311869 & 752317 & 4.9914 & 4.9863 & TST & & \\
\hline CHEMBL1969593 & 752317 & 4.9431 & 5.1167 & TRN & & \\
\hline CHEMBL1996572 & 752317 & 4.52 & 5.0823 & TRN & & \\
\hline CHEMBL 30109 & 752317 & 4.2027 & 4.8823 & TRN & & \\
\hline CHEMBL1506013 & 752317 & 4.8633 & 4.8594 & TST & & \\
\hline CHEMBL1561248 & 752317 & \multicolumn{3}{|c|}{4.9830000000000005} & 4.9692 & TRN \\
\hline CHEMBL 3214630 & 752317 & 4.8794 & 4.9157 & TRN & & \\
\hline CHEMBL1380757 & 752317 & 4.9136 & 4.9848 & TRN & & \\
\hline CHEMBL 3189838 & 752317 & 5.0083 & 4.9951 & TRN & & \\
\hline CHEMBL1433039 & 752317 & 5.0453 & 4.9619 & TRN & & \\
\hline
\end{tabular}


Supplemental Table S2.txt

\begin{tabular}{|c|c|c|c|c|c|}
\hline CHEMBL1504918 & 752317 & 6.2182 & 5.1378 & TRN & \\
\hline CHEMBL1407766 & 752317 & 4.9245 & 4.803 & TRN & \\
\hline CHEMBL1583879 & 752317 & 4.766999 & 99999999 & 4.9722 & TRN \\
\hline CHEMBL1469715 & 752317 & 5.0768 & 5.0933 & TRN & \\
\hline CHEMBL1421142 & 752317 & 4.8729 & 4.7394 & TRN & \\
\hline CHEMBL1568915 & 752317 & 5.6904 & 4.8068 & TST & \\
\hline CHEMBL1599509 & 752317 & 5.0301 & 5.1316 & TRN & \\
\hline CHEMBL1412248 & 752317 & 5.0039 & 5.1236 & TRN & \\
\hline CHEMBL1337070 & 752317 & 4.9747 & 5.1002 & TRN & \\
\hline CHEMBL1487870 & 752317 & 5.2733 & 5.1944 & TRN & \\
\hline CHEMBL1731352 & 752317 & 5.2069 & 5.0666 & TRN & \\
\hline CHEMBL1452390 & 752317 & 5.1255 & 5.0367 & TRN & \\
\hline CHEMBL 3194834 & 752317 & 4.7471 & 5.0981 & TST & \\
\hline CHEMBL1312200 & 752317 & 4.9172 & 5.0317 & TRN & \\
\hline CHEMBL1613080 & 752317 & 5.0209 & 5.1642 & TST & \\
\hline CHEMBL1539918 & 752317 & 5.1221 & 5.0679 & TRN & \\
\hline CHEMBL1525161 & 752317 & 5.1898 & 4.5041 & TRN & \\
\hline CHEMBL1523577 & 752317 & 5.0 & 4.90300 & 00000000005 & \\
\hline CHEMBL 2369239 & 752317 & 5.2534 & 5.1808 & TST & \\
\hline CHEMBL1968273 & 752317 & 4.4342 & 5.1324 & TRN & \\
\hline CHEMBL1487183 & 752317 & 5.0218 & 5.0603 & TST & \\
\hline CHEMBL1305708 & 752317 & 4.7986 & 5.0359 & TRN & \\
\hline CHEMBL1714002 & 752317 & 3.0969 & 4.5981 & TRN & \\
\hline CHEMBL528181 & 752317 & 4.8125 & 4.8965 & TRN & \\
\hline CHEMBL1520654 & 752317 & 5.05399 & 79999999 & 5.0592 & \\
\hline CHEMBL1367816 & 752317 & 4.9431 & 5.1096 & TRN & \\
\hline CHEMBL1326881 & 752317 & 4.9318 & 4.9511 & TST & \\
\hline CHEMBL1301641 & 752317 & 4.8297 & 4.9604 & TST & \\
\hline CHEMBL1708195 & 752317 & 4.9101 & 4.9719 & TST & \\
\hline CHEMBL1709730 & 752317 & 5.0191 & 4.9912 & TST & \\
\hline CHEMBL1589556 & 752317 & 5.0773 & 5.0911 & TST & \\
\hline CHEMBL1363824 & 752317 & 5.0419 & 4.9906 & TST & \\
\hline CHEMBL1546793 & 752317 & 5.0301 & 5.1607 & TST & \\
\hline CHEMBL3199659 & 752317 & 5.9281 & 5.1759 & TST & \\
\hline CHEMBL1379347 & 752317 & 5.6073 & 5.2559 & TST & \\
\hline CHEMBL1333407 & 752317 & 4.9508 & 4.88899 & 9999999999 & \\
\hline CHEMBL1369003 & 752317 & 5.1343 & 5.3371 & TST & \\
\hline CHEMBL 1408678 & 752317 & 4.8996 & 4.9874 & TST & \\
\hline CHEMBL1485315 & 752317 & 4.4597 & 5.0885 & TST & \\
\hline CHEMBL381033 & 752317 & 5.0846 & 4.9933 & TST & \\
\hline CHEMBL1572028 & 752317 & 5.1574 & 4.9651 & TST & \\
\hline CHEMBL 1478848 & 752317 & 5.1605 & 5.0885 & TST & \\
\hline CHEMBL1385727 & 752317 & 5.4225 & 5.121 & TST & \\
\hline CHEMBL1523232 & 752317 & 4.7747 & 4.9905 & TST & \\
\hline CHEMBL1728280 & 752317 & 3.0969 & 4.3493 & TST & \\
\hline CHEMBL1494802 & 752317 & 6.0097 & 5.0168 & TST & \\
\hline CHEMBL1387693 & 752317 & 5.9626 & 5.1911 & TST & \\
\hline CHEMBL1460092 & 752317 & 4.9508 & 5.0775 & TST & \\
\hline
\end{tabular}


Supplemental Table S2.txt

\begin{tabular}{|c|c|c|c|c|c|}
\hline CHEMBL1402403 & 752317 & 4.9101 & 5.0622 & TST & \\
\hline CHEMBL1392232 & 752317 & 5.6234 & 5.1156 & TST & \\
\hline CHEMBL1327470 & 752317 & 4.9872 & 5.1294 & TST & \\
\hline CHEMBL599924 & 752317 & 3.0969 & 4.0244 & TST & \\
\hline CHEMBL1603896 & 752317 & 4.9706 & 4.9584 & TST & \\
\hline CHEMBL1402456 & 752317 & 3.0969 & 4.4789 & TST & \\
\hline CHEMBL1374864 & 752317 & 5.4895 & 5.1169 & TST & \\
\hline CHEMBL1730774 & 752317 & 5.9914 & 4.8919 & TST & \\
\hline CHEMBL1432707 & 752317 & 4.1831 & 4.0426 & TST & \\
\hline CHEMBL1521940 & 752317 & 5.1186 & 4.9881 & TST & \\
\hline CHEMBL1582301 & 752317 & 5.3799 & 5.0225 & TST & \\
\hline CHEMBL1427626 & 752317 & 6.5686 & 5.3255 & TST & \\
\hline CHEMBL1303760 & 752317 & 4.4672 & 4.8758 & TST & \\
\hline CHEMBL 2408363 & 972799 & 4.919 & 4.9071 & TRN & \\
\hline CHEMBL 2408548 & 972799 & 5.5331 & 5.5951 & TRN & \\
\hline CHEMBL 2408556 & 972799 & 3.3979 & 3.3193 & TST & \\
\hline CHEMBL 2408538 & 972799 & 4.8389 & 4.952 & TRN & \\
\hline CHEMBL 2408360 & 972799 & 4.5947 & 4.1393 & TST & \\
\hline CHEMBL 2408533 & 972799 & 4.8147 & 4.4002 & TST & \\
\hline CHEMBL 2408545 & 972799 & 5.4056 & 5.4025 & TRN & \\
\hline CHEMBL 2408541 & 972799 & 4.8844 & 4.8311 & TRN & \\
\hline CHEMBL 2408554 & 972799 & 5.4473 & 5.3088 & TRN & \\
\hline CHEMBL 2408520 & 972799 & 5.1938 & 5.3328 & TRN & \\
\hline CHEMBL 2408526 & 972799 & 4.6185 & 4.7265 & TRN & \\
\hline CHEMBL 2408522 & 972799 & 5.6676 & 5.8501 & TRN & \\
\hline CHEMBL 2408558 & 972799 & 3.3979 & 3.6194 & TST & \\
\hline CHEMBL 2408527 & 972799 & 5.5302 & 5.4798 & TRN & \\
\hline CHEMBL 2408553 & 972799 & 5.4737 & 5.4337 & TRN & \\
\hline CHEMBL 2408514 & 972799 & 5.1918 & 5.2269 & TRN & \\
\hline CHEMBL 2408359 & 972799 & 4.5198 & 4.2337 & TST & \\
\hline CHEMBL 2408361 & 972799 & 4.8486 & 4.8295 & TRN & \\
\hline CHEMBL 2408540 & 972799 & 5.4425 & 5.3685 & TRN & \\
\hline CHEMBL 2408529 & 972799 & 5.2 & 5.1755 & TRN & \\
\hline CHEMBL 2408551 & 972799 & 4.965 & 5.0896 & TRN & \\
\hline CHEMBL 2408513 & 972799 & 4.7567 & 4.6559 & TRN & \\
\hline CHEMBL2408531 & 972799 & 5.6498 & 5.5175 & TRN & \\
\hline CHEMBL 2408543 & 972799 & 5.0535 & 5.12200 & 0000000001 & TRN \\
\hline CHEMBL 2408521 & 972799 & 5.3279 & 5.2197 & TRN & \\
\hline CHEMBL 2408539 & 972799 & 5.6234 & 5.5474 & TRN & \\
\hline CHEMBL 2408524 & 972799 & 4.7349 & 4.541 & TST & \\
\hline CHEMBL 2408530 & 972799 & 5.2676 & 5.2279 & TRN & \\
\hline CHEMBL 2408517 & 972799 & 5.52 & 5.4812 & TRN & \\
\hline CHEMBL 2408550 & 972799 & 5.3363 & 5.2479 & TRN & \\
\hline CHEMBL 2408512 & 972799 & 4.9578 & 4.9269 & TRN & \\
\hline CHEMBL 2408362 & 972799 & 4.6482 & 3.9919 & TST & \\
\hline CHEMBL 2408523 & 972799 & 5.4225 & 5.4271 & TRN & \\
\hline CHEMBL 2408515 & 972799 & 5.098 & 5.1087 & TST & \\
\hline CHEMBL 2408519 & 972799 & 5.8447 & 5.8534 & TRN & \\
\hline
\end{tabular}




\begin{tabular}{|c|c|c|c|c|c|c|}
\hline & & \multicolumn{5}{|c|}{ Supplemental Table S2.txt } \\
\hline CHEMBL 2408544 & 972799 & 5.6819 & 5.7436 & TRN & & \\
\hline CHEMBL 2408542 & 972799 & 4.7328 & 4.2189 & TST & & \\
\hline CHEMBL 2408559 & 972799 & 4.4728 & 3.6884 & TST & & \\
\hline CHEMBL 2408364 & 972799 & 3.3979 & 3.4713 & TRN & & \\
\hline CHEMBL 2408525 & 972799 & 5.0701 & 5.1839 & TRN & & \\
\hline CHEMBL 2408516 & 972799 & 3.3979 & 3.9174 & TST & & \\
\hline CHEMBL 2408532 & 972799 & 5.0899 & 5.0856 & TST & & \\
\hline CHEMBL 2408518 & 972799 & 4.8752 & 4.782 & TRN & & \\
\hline CHEMBL 2408537 & 972799 & 4.9654 & 5.1845 & TRN & & \\
\hline CHEMBL 2408546 & 972799 & 5.3747 & 5.4409 & TRN & & \\
\hline CHEMBL 2408528 & 972799 & 5.5817 & 5.5004 & TRN & & \\
\hline CHEMBL2408547 & 972799 & 5.5901 & 5.6327 & TRN & & \\
\hline CHEMBL 2408557 & 972799 & 3.3979 & 4.3831 & TST & & \\
\hline CHEMBL 2408365 & 972799 & 5.0009 & 4.9727 & TRN & & \\
\hline CHEMBL 2408552 & 972799 & 5.6778 & 5.6062 & TRN & & \\
\hline CHEMBL 2408535 & 972799 & $5.2020 e$ & 00000000 & $\partial 1$ & 5.006 & TRN \\
\hline CHEMBL2408536 & 972799 & 5.2526 & 5.2722 & TRN & & \\
\hline CHEMBL 2408549 & 972799 & 4.8801 & 4.708 & TST & & \\
\hline CHEMBL 2408555 & 972799 & 5.5436 & 5.5757 & TRN & & \\
\hline CHEMBL 2408534 & 972799 & 4.9427 & 4.9686 & TRN & & \\
\hline CHEMBL1427379 & 688233 & 3.2218 & 3.5619 & TST & & \\
\hline CHEMBL1565991 & 688233 & 3.2218 & 3.9883 & TRN & & \\
\hline CHEMBL1605870 & 688233 & 3.5229 & 3.2261 & TRN & & \\
\hline CHEMBL1407452 & 688233 & 3.2218 & 3.3131 & TRN & & \\
\hline CHEMBL1480827 & 688233 & 3.2218 & 3.7463 & TRN & & \\
\hline CHEMBL1602449 & 688233 & 5.1713 & 4.2218 & TRN & & \\
\hline CHEMBL1419909 & 688233 & 3.5229 & 4.0056 & TRN & & \\
\hline CHEMBL1432514 & 688233 & 3.2218 & 3.5074 & TRN & & \\
\hline CHEMBL1382320 & 688233 & 5.1037 & 3.7273 & TRN & & \\
\hline CHEMBL1581079 & 688233 & 3.2218 & 3.2099 & TRN & & \\
\hline CHEMBL1608375 & 688233 & 3.2218 & 3.8327 & TST & & \\
\hline CHEMBL1606975 & 688233 & 3.2218 & 3.4161 & TRN & & \\
\hline CHEMBL 3196667 & 688233 & 3.2218 & 3.736 & TST & & \\
\hline CHEMBL1303118 & 688233 & 3.2218 & 3.1143 & TRN & & \\
\hline CHEMBL1458485 & 688233 & 3.2218 & 4.0773 & TRN & & \\
\hline CHEMBL1563484 & 688233 & 3.2218 & 3.2748 & TRN & & \\
\hline CHEMBL1485786 & 688233 & 3.2218 & 3.7981 & TRN & & \\
\hline CHEMBL1556974 & 688233 & 3.2218 & 3.3274 & TRN & & \\
\hline CHEMBL1421143 & 688233 & 3.5229 & 3.5976 & TRN & & \\
\hline CHEMBL1312606 & 688233 & 3.2218 & 3.6125 & TRN & & \\
\hline CHEMBL1464261 & 688233 & 5.0074 & 3.9633 & TRN & & \\
\hline CHEMBL1329678 & 688233 & 3.2218 & 3.4399 & TRN & & \\
\hline CHEMBL1388262 & 688233 & 3.2218 & 3.3842 & TRN & & \\
\hline CHEMBL1566203 & 688233 & 3.2218 & 3.8361 & TST & & \\
\hline CHEMBL1366168 & 688233 & 5.3797 & 4.2626 & TRN & & \\
\hline CHEMBL1603688 & 688233 & 3.2218 & 4.9314 & TST & & \\
\hline CHEMBL 3211050 & 688233 & 5.0475 & 4.4247 & TRN & & \\
\hline CHEMBL1342990 & 688233 & 3.2218 & 3.1254 & TRN & & \\
\hline
\end{tabular}


Supplemental Table S2.txt

\begin{tabular}{|c|c|c|c|c|}
\hline CHEMBL580609 & 688233 & 3.2218 & 3.2917 & TRN \\
\hline CHEMBL1492648 & 688233 & 5.5933 & 5.1301 & TRN \\
\hline CHEMBL1570435 & 688233 & 3.2218 & 3.3034 & TRN \\
\hline CHEMBL1562186 & 688233 & 3.2218 & 3.8275 & TRN \\
\hline CHEMBL1514530 & 688233 & 6.2097 & 6.2437 & TRN \\
\hline CHEMBL1458178 & 688233 & 5.4785 & 4.2621 & TST \\
\hline CHEMBL1430211 & 688233 & 3.2218 & 3.7562 & TRN \\
\hline CHEMBL1579548 & 688233 & 4.9644 & 3.9047 & TRN \\
\hline CHEMBL1509954 & 688233 & 3.2218 & 3.4488 & TRN \\
\hline CHEMBL1477501 & 688233 & 3.2218 & 3.2771 & TRN \\
\hline CHEMBL1613478 & 688233 & 3.2218 & 2.8561 & TRN \\
\hline CHEMBL1447988 & 688233 & 3.2218 & 3.3332 & TRN \\
\hline CHEMBL1417823 & 688233 & 3.2218 & 3.9366 & TRN \\
\hline CHEMBL1597523 & 688233 & 3.5229 & 3.4391 & TRN \\
\hline CHEMBL1522020 & 688233 & 3.2218 & 3.1409 & TST \\
\hline CHEMBL1518316 & 688233 & 3.2218 & 3.8265 & TRN \\
\hline CHEMBL1382160 & 688233 & 3.2218 & 3.4401 & TRN \\
\hline CHEMBL1312038 & 688233 & 3.2218 & 4.2785 & TRN \\
\hline CHEMBL1381121 & 688233 & 3.2218 & 3.4698 & TRN \\
\hline CHEMBL1584055 & 688233 & 3.2218 & 3.6805 & TRN \\
\hline CHEMBL3193305 & 688233 & 3.2218 & 3.3087 & TRN \\
\hline CHEMBL1555655 & 688233 & 3.2218 & 3.7519 & TST \\
\hline CHEMBL1349378 & 688233 & 3.5229 & 3.8349 & TRN \\
\hline CHEMBL3197064 & 688233 & 3.5229 & 3.3645 & TRN \\
\hline CHEMBL3212850 & 688233 & 3.2218 & 3.1603 & TRN \\
\hline CHEMBL1465342 & 688233 & 3.2218 & 3.5801 & TRN \\
\hline CHEMBL1540973 & 688233 & 3.2218 & 3.4842 & TRN \\
\hline CHEMBL1421010 & 688233 & 4.8672 & 3.3143 & TRN \\
\hline CHEMBL1532127 & 688233 & 3.2218 & 3.6868 & TRN \\
\hline CHEMBL3195405 & 688233 & 4.8605 & 3.7196 & TST \\
\hline CHEMBL1524986 & 688233 & 5.4069 & 4.6458 & TRN \\
\hline CHEMBL1382698 & 688233 & 3.2218 & 3.677 & TRN \\
\hline CHEMBL1471951 & 688233 & 3.2218 & 3.6051 & TRN \\
\hline CHEMBL1347055 & 688233 & 3.2218 & 3.7409 & TRN \\
\hline CHEMBL1967586 & 688233 & 3.5229 & 4.229 & TST \\
\hline CHEMBL1384286 & 688233 & 3.2218 & 3.4323 & TRN \\
\hline CHEMBL1599262 & 688233 & 4.4666 & 3.4582 & TRN \\
\hline CHEMBL1402909 & 688233 & 3.2218 & 4.0729 & TST \\
\hline CHEMBL3190825 & 688233 & 4.8953 & 3.6592 & TRN \\
\hline CHEMBL1483356 & 688233 & 3.2218 & 4.0208 & TRN \\
\hline CHEMBL1499275 & 688233 & 3.2218 & 3.5279 & TRN \\
\hline CHEMBL1423251 & 688233 & 3.5229 & 3.8569 & TRN \\
\hline CHEMBL3198513 & 688233 & 3.5229 & 3.8768 & TRN \\
\hline CHEMBL1592239 & 688233 & 3.2218 & 3.4473 & TRN \\
\hline CHEMBL1307602 & 688233 & 3.5229 & 3.6648 & TRN \\
\hline CHEMBL530291 & 688233 & 3.2218 & 4.5172 & TRN \\
\hline CHEMBL1532890 & 688233 & 3.2218 & \multicolumn{2}{|c|}{3.3310000000000004} \\
\hline CHEMBL1312371 & 688233 & 3.5229 & 3.6191 & TST \\
\hline
\end{tabular}


Supplemental Table S2.txt

\begin{tabular}{|c|c|c|c|c|c|}
\hline CHEMBL1370471 & 688233 & 3.2218 & 4.2298 & TRN & \\
\hline CHEMBL1502121 & 688233 & 4.7721 & 3.1992 & TRN & \\
\hline CHEMBL1421570 & 688233 & 3.2218 & 3.222 & TRN & \\
\hline CHEMBL 3199314 & 688233 & 4.3988 & 3.3633 & TST & \\
\hline CHEMBL1333262 & 688233 & 3.2218 & 3.8311 & TST & \\
\hline CHEMBL1582517 & 688233 & 3.5229 & 3.8735 & TRN & \\
\hline CHEMBL1558598 & 688233 & 3.2218 & 3.378 & TRN & \\
\hline CHEMBL1425367 & 688233 & 3.2218 & 3.2296 & TRN & \\
\hline CHEMBL1353925 & 688233 & 3.2218 & 3.5476 & TRN & \\
\hline CHEMBL1544065 & 688233 & 3.5229 & 3.4279 & TRN & \\
\hline CHEMBL1575043 & 688233 & 3.2218 & 3.097 & TRN & \\
\hline CHEMBL1578296 & 688233 & 3.2218 & 3.2597 & TRN & \\
\hline CHEMBL1388053 & 688233 & 3.2218 & 3.6856 & TRN & \\
\hline CHEMBL1594637 & 688233 & 3.2218 & 3.1823 & TST & \\
\hline CHEMBL1379493 & 688233 & 3.2218 & 3.0913 & TRN & \\
\hline CHEMBL1419859 & 688233 & 3.5229 & 3.1933 & TRN & \\
\hline CHEMBL1484139 & 688233 & 3.2218 & 3.1425 & TRN & \\
\hline CHEMBL1563748 & 688233 & 5.3061 & 4.1457 & TST & \\
\hline CHEMBL1594820 & 688233 & 3.2218 & 3.1163 & TRN & \\
\hline CHEMBL1580532 & 688233 & 3.2218 & 3.707 & TRN & \\
\hline CHEMBL1568298 & 688233 & 5.0991 & 3.4264 & TRN & \\
\hline CHEMBL1326939 & 688233 & 3.2218 & 3.5714 & TRN & \\
\hline CHEMBL1577917 & 688233 & 4.9801 & 3.8533 & TST & \\
\hline CHEMBL1444877 & 688233 & 4.9139 & 4.1673 & TRN & \\
\hline CHEMBL1305471 & 688233 & 3.5229 & 3.6181 & TRN & \\
\hline CHEMBL1491864 & 688233 & 3.2218 & 3.0047 & TRN & \\
\hline CHEMBL1497409 & 688233 & 4.8132 & 3.2454 & TRN & \\
\hline CHEMBL1456950 & 688233 & 3.2218 & 3.2881 & TRN & \\
\hline CHEMBL1341989 & 688233 & 3.2218 & 3.3631 & TRN & \\
\hline CHEMBL3192648 & 688233 & 3.2218 & 4.3662 & TRN & \\
\hline CHEMBL 3197248 & 688233 & 3.2218 & 3.6529 & TRN & \\
\hline CHEMBL1500194 & 688233 & 5.079 & 3.2481 & TRN & \\
\hline CHEMBL1339925 & 688233 & 4.9631 & 3.8613 & TRN & \\
\hline CHEMBL1452782 & 688233 & 3.2218 & 3.3777 & TRN & \\
\hline CHEMBL1337261 & 688233 & 3.2218 & 4.1957 & TRN & \\
\hline CHEMBL1566464 & 688233 & 3.2218 & 3.3265 & TRN & \\
\hline CHEMBL1338599 & 688233 & 3.2218 & 3.2448 & TRN & \\
\hline CHEMBL1363275 & 688233 & 3.2218 & 3.733 & TRN & \\
\hline CHEMBL1498307 & 688233 & 3.5229 & 3.9365 & TRN & \\
\hline CHEMBL1461417 & 688233 & 3.2218 & 3.8271 & TRN & \\
\hline CHEMBL1504841 & 688233 & 3.2218 & 3.81699 & 99999999997 & TRN \\
\hline CHEMBL1488107 & 688233 & 3.2218 & 3.3333 & TRN & \\
\hline CHEMBL1306287 & 688233 & 3.2218 & 3.2041 & TRN & \\
\hline CHEMBL1461175 & 688233 & 3.2218 & 2.6631 & TRN & \\
\hline CHEMBL577894 & 688233 & 3.5229 & 3.8031 & TRN & \\
\hline CHEMBL1423708 & 688233 & 3.2218 & 4.0722 & TST & \\
\hline CHEMBL1441595 & 688233 & 3.2218 & 3.6496 & TRN & \\
\hline CHEMBL1482363 & 688233 & 3.5229 & 4.0383 & TRN & \\
\hline
\end{tabular}

Page 12629 


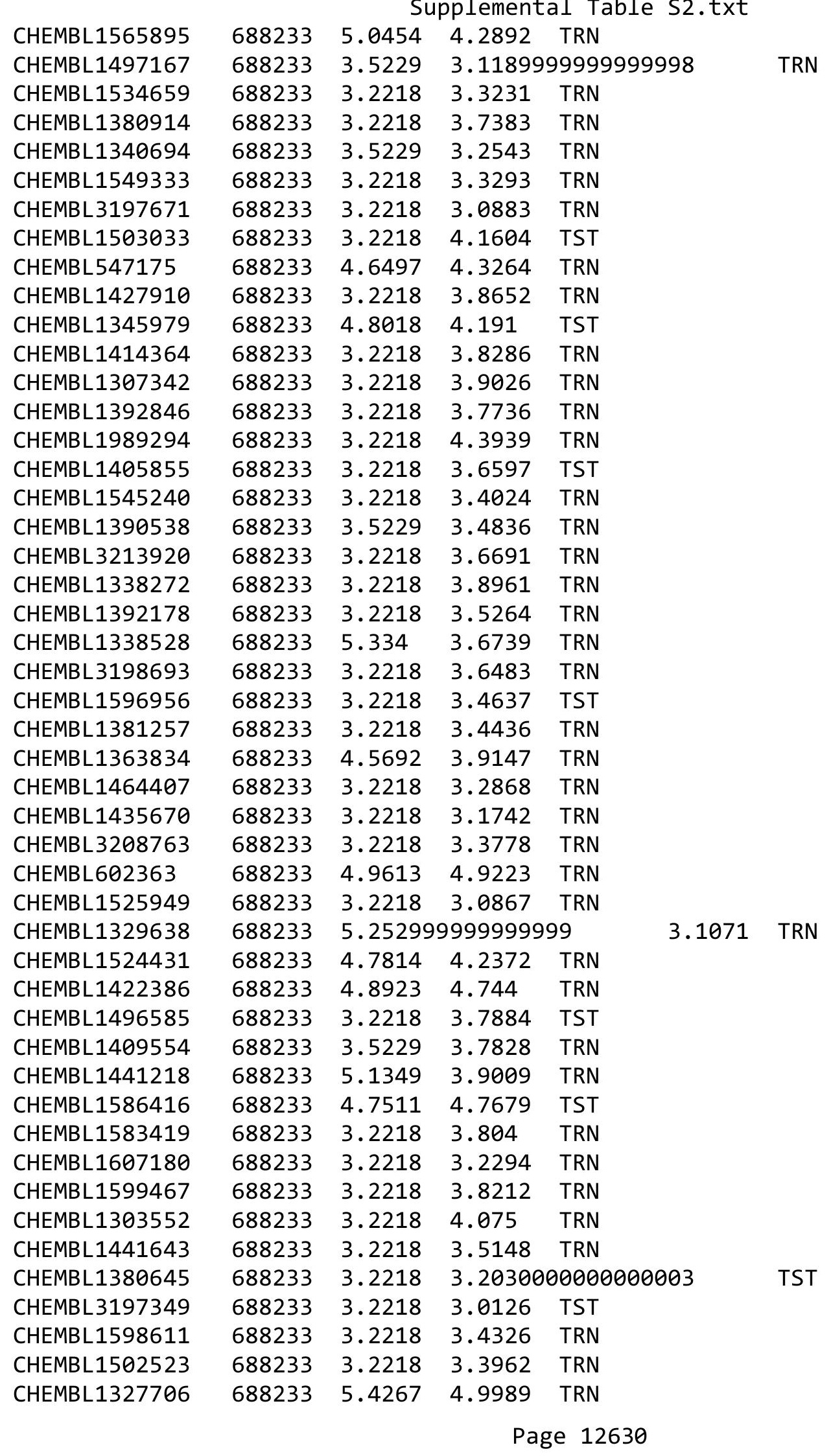




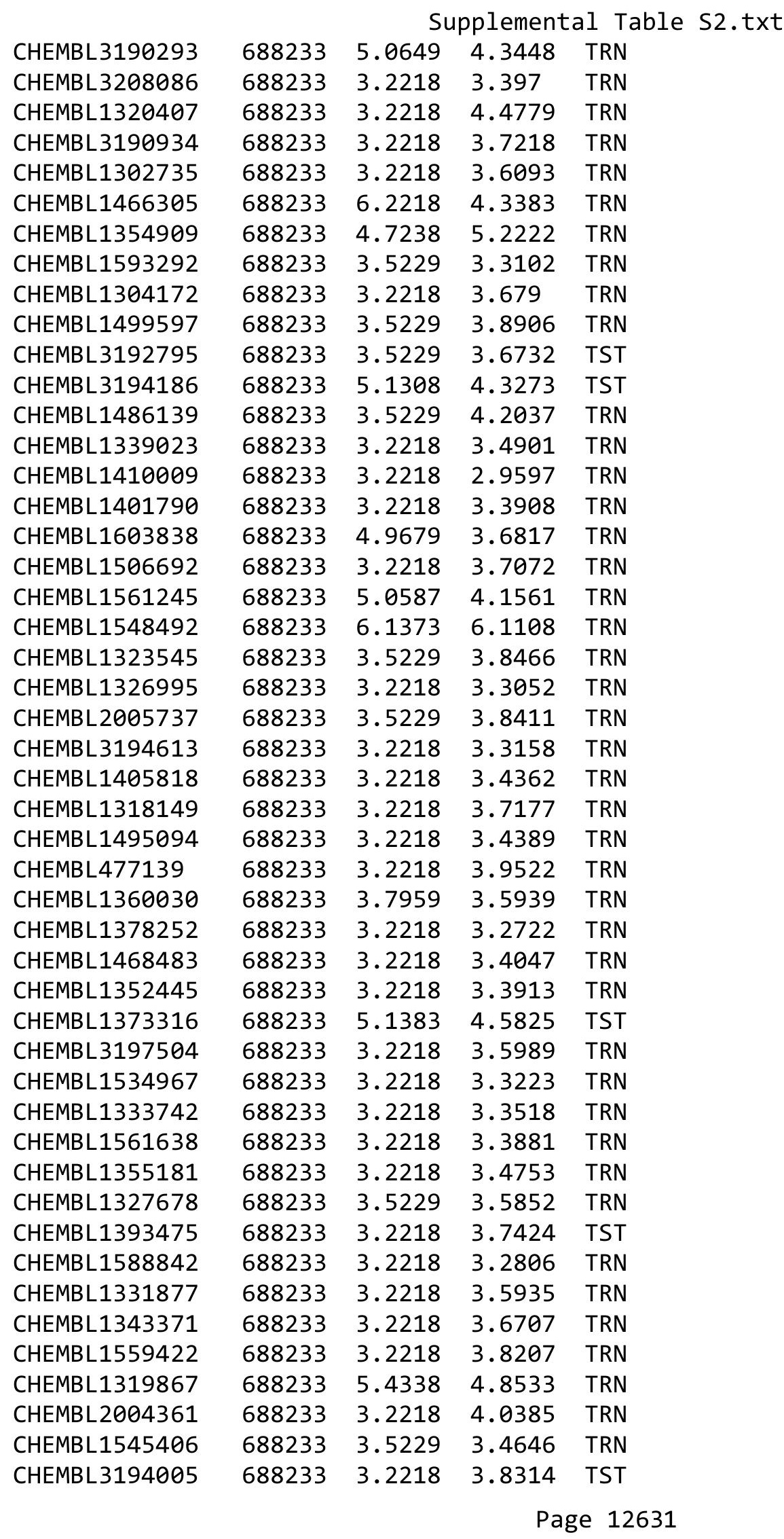


Supplemental Table S2.txt

\begin{tabular}{|c|c|c|c|c|}
\hline 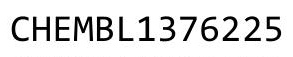 & & & & \\
\hline HEMBL3189959 & 88233 & 2218 & 2382 & \\
\hline & & & & \\
\hline FMBI $2=$ & 8233 & 7064 & 4377 & \\
\hline IEMBL1535817 & 38233 & 9846 & 7064 & \\
\hline AEMBL1326471 & 88233 & 5229 & 2693 & \\
\hline HEMBL 576200 & 88233 & 539 & 9857 & \\
\hline 721 & 3233 & 18 & 3831 & \\
\hline EMBL14 & 38233 & 2218 & . 4709 & \\
\hline AEMBL469036 & 88233 & 4369 & .1535 & \\
\hline HEMBL1382644 & 88233 & 2218 & 0659 & \\
\hline AEMBL1601802 & 88233 & 31 & .8588 & \\
\hline IEMBL1 & & & 51 & \\
\hline AEMBL14 & 88233 & & .8031 & \\
\hline AEMBL1327783 & 88233 & 706 & 2882 & \\
\hline AEMBL142 & 233 & 18 & & \\
\hline AEMBL14 & 88233 & 218 & 21 & \\
\hline HEMBL1S & 33 & & & \\
\hline HEMBL16 & 33 & 18 & & \\
\hline AEMBL13 & 88233 & 229 & 975 & RN \\
\hline ENMBL1611426 & 33 & 18 & 1343 & KIV \\
\hline HEMBL15 & 88233 & 8 & 4744 & $\mathrm{RN}$ \\
\hline HEMBL16 & 33 & 18 & & RN \\
\hline 33 & 33 & & & RN \\
\hline AEMBL13e & 33 & & & II \\
\hline HEMBL1609301 & 33 & 8 & 84 & RN \\
\hline HEMBL158 & 38233 & 8 & 6009 & RN \\
\hline HEMBL 15 & 33 & & 19 & RN \\
\hline HEM & & & & RN \\
\hline IEMBL14 & 33 & & 85 & RIN \\
\hline EMBL13 & 3 & 8 & 3698 & RN \\
\hline HEMBL14 & 33 & 18 & 093 & ST \\
\hline HEMBL13 & 3 & 18 & 522 & RN \\
\hline & & & & RN \\
\hline AEMBL147€ & 3 & 8 & 381 & RN \\
\hline EMBL15 & 3 & 8 & 88 & RN \\
\hline HEMBL16e & 33 & 18 & 74 & RIV \\
\hline & & & & RN \\
\hline HEMBL1465142 & & & 3.9207 & $\mathrm{RN}$ \\
\hline HEMBL1593843 & 88233 & 18 & 981 & RN \\
\hline HEMBL133 & 38233 & 59 & 938 & \\
\hline HEMBL1388545 & & & & \\
\hline 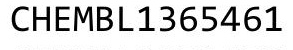 & & & & $\mathrm{RN}$ \\
\hline HEMBL1351458 & 38233 & 218 & 3.3364 & RN \\
\hline AEMBL3190520 & 8233 & 8 & .9816 & $F$ \\
\hline & & & & \\
\hline HEMBL13 & 88233 & .2218 & $2-e_{-1}$ & \\
\hline$\Pi \mathrm{LL}$ & $\$ 88233$ & 18 & 28 & \\
\hline
\end{tabular}

Page 12632 


\begin{tabular}{|c|c|c|c|c|c|}
\hline & & \multicolumn{4}{|c|}{ Supplemental Table s2.txt } \\
\hline CHEMBL463175 & 688233 & 5.0745 & 4.5315 & TST & \\
\hline CHEMBL1498822 & 688233 & 3.2218 & 3.4673 & TRN & \\
\hline CHEMBL1386387 & 688233 & 3.5229 & 3.1734 & TRN & \\
\hline CHEMBL1596245 & 688233 & 5.1299 & 3.3298 & TST & \\
\hline CHEMBL3191951 & 688233 & 3.2218 & 3.7871 & TRN & \\
\hline CHEMBL1460853 & 688233 & 3.2218 & 3.9239 & TRN & \\
\hline CHEMBL1324202 & 688233 & 3.5229 & 3.6271 & TRN & \\
\hline CHEMBL1567465 & 688233 & 3.2218 & 3.4645 & TRN & \\
\hline CHEMBL1383639 & 688233 & 3.2218 & 3.9763 & TST & \\
\hline CHEMBL1326561 & 688233 & 3.2218 & 3.5533 & TRN & \\
\hline CHEMBL1413509 & 688233 & 3.2218 & 3.5751 & TRN & \\
\hline CHEMBL596633 & 688233 & 5.0737 & 3.7847 & TRN & \\
\hline CHEMBL1528536 & 688233 & 5.2094 & 3.9928 & TST & \\
\hline CHEMBL1994815 & 688233 & 5.0762 & 3.8166 & TRN & \\
\hline CHEMBL1379112 & 688233 & 3.2218 & 2.74300 & 00000000003 & TRN \\
\hline CHEMBL1978733 & 688233 & 5.1189 & 4.3152 & TRN & \\
\hline CHEMBL1325969 & 688233 & 3.2218 & 3.5295 & TRN & \\
\hline CHEMBL1976317 & 688233 & 4.574 & 3.8631 & TRN & \\
\hline CHEMBL1467533 & 688233 & 6.9172 & 4.0578 & TRN & \\
\hline CHEMBL3196836 & 688233 & 3.5229 & 3.69 & TRN & \\
\hline CHEMBL3209411 & 688233 & 3.5229 & 3.9397 & TST & \\
\hline CHEMBL1534134 & 688233 & 3.2218 & 2.9269 & TRN & \\
\hline CHEMBL1580265 & 688233 & 5.005 & 3.9086 & TRN & \\
\hline CHEMBL1577446 & 688233 & 3.5229 & 3.5824 & TRN & \\
\hline CHEMBL1541331 & 688233 & 3.2218 & 3.4902 & TST & \\
\hline CHEMBL3197607 & 688233 & 3.2218 & 3.5028 & TRN & \\
\hline CHEMBL1516253 & 688233 & 4.5716 & 4.0081 & TRN & \\
\hline CHEMBL1340774 & 688233 & 3.2218 & 3.6723 & TRN & \\
\hline CHEMBL1599815 & 688233 & 5.2014 & 4.7132 & TRN & \\
\hline CHEMBL1467293 & 688233 & 4.673 & 3.7377 & TRN & \\
\hline CHEMBL1585288 & 688233 & 3.2218 & 3.201 & TRN & \\
\hline CHEMBL1545484 & 688233 & 3.2218 & 2.8626 & TRN & \\
\hline CHEMBL1604813 & 688233 & 3.2218 & 3.2123 & TRN & \\
\hline CHEMBL1353330 & 688233 & 4.6575 & 4.0001 & TRN & \\
\hline CHEMBL1585988 & 688233 & 3.2218 & 3.6999 & TRN & \\
\hline CHEMBL1599053 & 688233 & 3.2218 & 3.0556 & TRN & \\
\hline CHEMBL1534832 & 688233 & 3.5229 & 3.53899 & 99999999997 & TRN \\
\hline CHEMBL1402518 & 688233 & 3.2218 & 3.2412 & TRN & \\
\hline CHEMBL1500974 & 688233 & 3.2218 & 3.3469 & TRN & \\
\hline CHEMBL1427684 & 688233 & 3.2218 & 3.4467 & TST & \\
\hline CHEMBL365161 & 688233 & 5.133999 & 99999999 & 4.4109 & TST \\
\hline CHEMBL1159655 & 688233 & 3.2218 & 3.128 & TST & \\
\hline CHEMBL1321758 & 688233 & 3.2218 & 3.8795 & TST & \\
\hline CHEMBL1564442 & 688233 & 3.2218 & 2.9306 & TRN & \\
\hline CHEMBL3211539 & 688233 & 3.2218 & 3.9797 & TRN & \\
\hline CHEMBL1450189 & 688233 & 4.9995 & 3.6281 & TRN & \\
\hline CHEMBL1486391 & 688233 & 3.5229 & 3.4534 & TRN & \\
\hline CHEMBL1516772 & 688233 & 4.8693 & 3.958 & TRN & \\
\hline
\end{tabular}


Supplemental Table S2.txt

\begin{tabular}{|c|c|c|c|c|}
\hline 列 & & .5229 & & \\
\hline & & .5229 & 2.7829 & \\
\hline & & & & \\
\hline EMBL & & & & \\
\hline IEMBL3192922 & 88233 & 2218 & 5688 & $\mathrm{~T}$ \\
\hline HEMBL1528898 & 88233 & .2218 & 0571 & \\
\hline AEMBL: & & 899 & 619 & \\
\hline EMBL & & & & RN \\
\hline IEMBL1573622 & & 2218 & 3401 & \\
\hline AEMBL581257 & 33 & 3462 & .1729 & ST \\
\hline AEMBL321 & & .2218 & 3.2777 & \\
\hline EMBL & & 45 & 913 & \\
\hline EMBL: & & & & $\mathrm{RN}$ \\
\hline IEMBL1 & & .2218 & 3.7991 & PN \\
\hline IEMBL1 & & & 5127 & \\
\hline IEMBL1 & & 8 & 7151 & \\
\hline IEMBL & & 8 & 98 & $\mathrm{RN}$ \\
\hline IEMBL: & & & & \\
\hline IEMBL1 & & & & N \\
\hline EMBL1 & & & & N \\
\hline IEMBL & & 8 & 778 & RN \\
\hline EMBL & & & & RN \\
\hline EMBL & & & & \\
\hline 158 & & & & RN \\
\hline EMBL1 & & & & $\Gamma \mathrm{RN}$ \\
\hline EMBL & & & 88 & RN \\
\hline EMBL & & & & RN \\
\hline FMBI & & & 61 & RN \\
\hline EMBL1 & & & & IS \\
\hline HEMBL154 & & & & TRN \\
\hline IEMBL1 & & & 596 & RN \\
\hline EMBL & & & 42 & $\mathrm{RN}$ \\
\hline 59 & & & 81 & $\mathrm{RN}$ \\
\hline IEMBL1605374 & & & 58 & $\lceil\mathrm{RN}$ \\
\hline AEMBL1361509 & & & 596 & TRN \\
\hline IEMBL & & & 46 & TRN \\
\hline 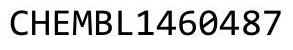 & & 8 & & $\Gamma \mathrm{RN}$ \\
\hline & & & & $\mathrm{RN}$ \\
\hline IEMBL3213664 & & 5229 & 3.7076 & TST \\
\hline EMBL14 & & & & TRN \\
\hline IEMBL & & & & $\lceil\mathrm{RN}$ \\
\hline & & & & RN \\
\hline HEMBL1545434 & & 3.2218 & 3.7976 & ГST \\
\hline EMBL1458736 & & 18 & 3.2292 & RN \\
\hline $\mathrm{MRI} 1$ & & & & RN \\
\hline HEMBL & & & & RIV \\
\hline HEMBL602828 & & & 3.7128 & SI \\
\hline CHEMBL148530 & 688233 & 3.2218 & 4.4498 & ST \\
\hline
\end{tabular}

Page 12634 
Supplemental Table S2.txt

\begin{tabular}{|c|c|c|c|c|c|}
\hline CHEMBL1557079 & 688233 & 3.5229 & 4.0694 & TRN & \\
\hline CHEMBL598679 & 688233 & 3.2218 & 3.9531 & TRN & \\
\hline CHEMBL1607349 & 688233 & 3.2218 & 2.8904 & TST & \\
\hline CHEMBL1345388 & 688233 & 5.2921 & 4.8002 & TRN & \\
\hline CHEMBL1997062 & 688233 & 3.5229 & 4.2362 & TRN & \\
\hline CHEMBL1419582 & 688233 & 3.2218 & 2.9552 & TRN & \\
\hline CHEMBL1982304 & 688233 & 5.2684 & 4.2726 & TRN & \\
\hline CHEMBL1417213 & 688233 & 3.2218 & 3.635 & TRN & \\
\hline CHEMBL1603578 & 688233 & 3.2218 & 3.8688 & TRN & \\
\hline CHEMBL1399938 & 688233 & 5.6218 & 5.2057 & TRN & \\
\hline CHEMBL1321953 & 688233 & 3.2218 & 3.1815 & TRN & \\
\hline CHEMBL1430107 & 688233 & 5.0896 & 3.7382 & TRN & \\
\hline CHEMBL1452116 & 688233 & 5.9751 & 4.1775 & TST & \\
\hline CHEMBL1510199 & 688233 & 3.2218 & 3.372 & TST & \\
\hline CHEMBL1337726 & 688233 & 5.9801 & 3.735 & TST & \\
\hline CHEMBL1578962 & 688233 & 5.1425 & 4.3579 & TST & \\
\hline CHEMBL1381724 & 688233 & 3.2218 & 3.39 & TST & \\
\hline CHEMBL1570765 & 688233 & 6.1675 & 4.5648 & TRN & \\
\hline CHEMBL1402511 & 688233 & 3.2218 & 3.2782 & TRN & \\
\hline CHEMBL1510244 & 688233 & 3.2218 & 3.3511 & TRN & \\
\hline CHEMBL3209165 & 688233 & 3.2218 & 3.1104 & TRN & \\
\hline CHEMBL1367691 & 688233 & 3.5229 & 3.7768 & TRN & \\
\hline CHEMBL1360870 & 688233 & 5.0525 & 3.813 & TRN & \\
\hline CHEMBL1423951 & 688233 & 3.2218 & 3.6866 & TRN & \\
\hline CHEMBL1439562 & 688233 & 3.2218 & 3.5464 & TRN & \\
\hline CHEMBL1334906 & 688233 & 3.2218 & 3.8043 & TRN & \\
\hline CHEMBL1973500 & 688233 & 3.2218 & 3.9643 & TST & \\
\hline CHEMBL1438803 & 688233 & 3.2218 & 3.7473 & TRN & \\
\hline CHEMBL1375462 & 688233 & 3.2218 & 3.4143 & TRN & \\
\hline CHEMBL1410560 & 688233 & 3.2218 & 3.4211 & TRN & \\
\hline CHEMBL1584815 & 688233 & 4.4969 & 3.6788 & TRN & \\
\hline CHEMBL1352607 & 688233 & 5.1258 & 3.4933 & TRN & \\
\hline CHEMBL1431331 & 688233 & 3.2218 & 3.8106 & TRN & \\
\hline CHEMBL1398183 & 688233 & 3.2218 & 3.5576 & TRN & \\
\hline CHEMBL1506281 & 688233 & 3.2218 & 3.6241 & TRN & \\
\hline CHEMBL1389131 & 688233 & 3.2218 & 3.3102 & TRN & \\
\hline CHEMBL 2094567 & 688233 & 6.1831 & 5.8848 & TRN & \\
\hline CHEMBL1392315 & 688233 & 3.5229 & 4.0524 & TRN & \\
\hline CHEMBL1356454 & 688233 & 5.1322 & 3.9467 & TRN & \\
\hline CHEMBL1329197 & 688233 & 3.5229 & 3.5672 & TRN & \\
\hline CHEMBL3193931 & 688233 & 3.2218 & 3.40199 & 99999999997 & TRN \\
\hline CHEMBL1563140 & 688233 & 3.2218 & 3.1011 & TRN & \\
\hline CHEMBL494668 & 688233 & 4.9208 & 4.2473 & TST & \\
\hline CHEMBL1579710 & 688233 & 3.2218 & 3.3015 & TRN & \\
\hline CHEMBL1564759 & 688233 & 3.2218 & 3.3285 & TRN & \\
\hline CHEMBL1379694 & 688233 & 3.2218 & 3.7683 & TRN & \\
\hline CHEMBL1410751 & 688233 & 3.2218 & 3.1003 & TRN & \\
\hline CHEMBL1306394 & 688233 & 3.2218 & 3.3121 & TRN & \\
\hline
\end{tabular}


Supplemental Table S2.txt

\begin{tabular}{|c|c|c|c|c|}
\hline CHEMBL1611583 & 688233 & 3.2218 & 3.3534 & TRN \\
\hline CHEMBL1445171 & 688233 & 6.2218 & 4.7518 & TRN \\
\hline CHEMBL1404766 & 688233 & 3.5229 & 3.3798 & TRN \\
\hline CHEMBL3209581 & 688233 & 3.2218 & 3.8809 & TST \\
\hline CHEMBL1578997 & 688233 & 5.3037 & 5.4028 & TRN \\
\hline CHEMBL1556420 & 688233 & 3.2218 & 3.8168 & TRN \\
\hline CHEMBL1339881 & 688233 & 3.2218 & 3.6272 & TST \\
\hline CHEMBL1461245 & 688233 & 3.2218 & 3.5559 & TRN \\
\hline CHEMBL1493415 & 688233 & 5.0246 & 3.8217 & TRN \\
\hline CHEMBL1340002 & 688233 & 4.7041 & 3.0706 & TRN \\
\hline CHEMBL 3197532 & 688233 & 3.2218 & 3.6129 & TRN \\
\hline CHEMBL1430621 & 688233 & 3.5229 & 2.9521 & TRN \\
\hline CHEMBL1398431 & 688233 & 5.1855 & 3.5247 & TRN \\
\hline CHEMBL1451015 & 688233 & 3.5229 & 3.7667 & TRN \\
\hline CHEMBL602954 & 688233 & 3.2218 & 3.1172 & TRN \\
\hline CHEMBL1390786 & 688233 & 3.2218 & 3.5552 & TRN \\
\hline CHEMBL3191334 & 688233 & 3.2218 & 4.7572 & TST \\
\hline CHEMBL1389316 & 688233 & 3.2218 & 3.8202 & TRN \\
\hline CHEMBL1491513 & 688233 & 3.2218 & 3.513 & TRN \\
\hline CHEMBL1478420 & 688233 & 3.2218 & 3.5551 & TRN \\
\hline CHEMBL1381159 & 688233 & 3.2218 & 4.0653 & TRN \\
\hline CHEMBL1535712 & 688233 & 3.2218 & 3.7508 & TRN \\
\hline CHEMBL1562159 & 688233 & 3.2218 & 3.9043 & TRN \\
\hline CHEMBL1427474 & 688233 & 3.2218 & 3.656 & TRN \\
\hline CHEMBL1299526 & 688233 & 5.4992 & 5.3169 & TRN \\
\hline CHEMBL 3194214 & 688233 & 5.4641 & 4.1598 & TST \\
\hline CHEMBL1565600 & 688233 & 4.8263 & 3.6311 & TRN \\
\hline CHEMBL3197910 & 688233 & 3.2218 & \multicolumn{2}{|c|}{3.1289999999999996} \\
\hline CHEMBL1507864 & 688233 & 5.0474 & 4.2588 & TRN \\
\hline CHEMBL1358038 & 688233 & 3.5229 & 3.7652 & TST \\
\hline CHEMBL1375155 & 688233 & 3.2218 & 3.3334 & TRN \\
\hline CHEMBL1479940 & 688233 & 3.2218 & 3.2403 & TRN \\
\hline CHEMBL 3213394 & 688233 & 3.5229 & 3.9239 & TRN \\
\hline CHEMBL1440904 & 688233 & 3.2218 & 3.4636 & TRN \\
\hline CHEMBL1462433 & 688233 & 5.5038 & 3.8641 & TST \\
\hline CHEMBL1373670 & 688233 & 3.2218 & 3.7274 & TRN \\
\hline CHEMBL1424665 & 688233 & 6.0921 & 4.7451 & TRN \\
\hline CHEMBL1336705 & 688233 & 3.2218 & 3.1496 & TRN \\
\hline CHEMBL1573374 & 688233 & 3.2218 & 3.5366 & TRN \\
\hline CHEMBL1533231 & 688233 & 3.5229 & 3.8562 & TRN \\
\hline CHEMBL1580381 & 688233 & 4.7224 & 3.7221 & TRN \\
\hline CHEMBL1343778 & 688233 & 5.016 & 3.8349 & TRN \\
\hline CHEMBL1303061 & 688233 & 3.2218 & 3.4994 & TRN \\
\hline CHEMBL3196619 & 688233 & 3.2218 & 3.5672 & TRN \\
\hline CHEMBL 3194943 & 688233 & 3.2218 & 3.4776 & TRN \\
\hline CHEMBL1495352 & 688233 & 3.2218 & 3.9044 & TRN \\
\hline CHEMBL1575766 & 688233 & 3.2218 & 3.2175 & TRN \\
\hline CHEMBL1485598 & 688233 & 3.2218 & 3.6398 & TRN \\
\hline
\end{tabular}

Page 12636 
Supplemental Table S2.txt

\begin{tabular}{|c|c|c|c|c|}
\hline CHEMBL1510749 & 688233 & 3.2218 & 3.3277 & TRN \\
\hline CHEMBL1497906 & 688233 & 3.2218 & 3.7786 & TRN \\
\hline CHEMBL1571801 & 688233 & 3.2218 & 4.5828 & TRN \\
\hline CHEMBL1424003 & 688233 & 4.9844 & 4.1756 & TRN \\
\hline CHEMBL1355541 & 688233 & 5.063 & 4.1071 & TST \\
\hline CHEMBL1416440 & 688233 & 3.2218 & 3.2789 & TST \\
\hline CHEMBL1305849 & 688233 & 5.0237 & 4.319 & TRN \\
\hline CHEMBL1375041 & 688233 & 3.2218 & 3.6027 & TRN \\
\hline CHEMBL1487578 & 688233 & 3.2218 & 4.0685 & TRN \\
\hline CHEMBL3192845 & 688233 & 3.2218 & 4.0444 & TST \\
\hline CHEMBL1420206 & 688233 & 3.2218 & 3.1633 & TRN \\
\hline CHEMBL1530144 & 688233 & 4.7409 & 3.2605 & TRN \\
\hline CHEMBL3196591 & 688233 & 3.2218 & 4.1728 & TRN \\
\hline CHEMBL1558865 & 688233 & 3.5229 & 2.9271 & TRN \\
\hline CHEMBL1353563 & 688233 & 3.2218 & 3.52399 & 799999999996 \\
\hline CHEMBL3195997 & 688233 & 5.1837 & 4.3671 & TRN \\
\hline CHEMBL1612977 & 688233 & 3.2218 & 3.1732 & TRN \\
\hline CHEMBL1489815 & 688233 & 3.2218 & 3.3753 & TRN \\
\hline CHEMBL1413584 & 688233 & 5.0282 & 3.7155 & TRN \\
\hline CHEMBL1570989 & 688233 & 4.7676 & 3.375 & TRN \\
\hline CHEMBL1599458 & 688233 & 5.5468 & 4.8415 & TRN \\
\hline CHEMBL3190292 & 688233 & 3.2218 & 3.8275 & TST \\
\hline CHEMBL1379600 & 688233 & 3.2218 & 3.6987 & TRN \\
\hline CHEMBL1437258 & 688233 & 3.2218 & 3.3135 & TRN \\
\hline CHEMBL1341097 & 688233 & 3.2218 & 3.4681 & TST \\
\hline CHEMBL1439642 & 688233 & 3.2218 & 3.3833 & TRN \\
\hline CHEMBL1451287 & 688233 & 3.2218 & 3.3461 & TRN \\
\hline CHEMBL1477243 & 688233 & 3.5229 & 3.7944 & TRN \\
\hline CHEMBL1467833 & 688233 & 3.2218 & 2.9526 & TRN \\
\hline CHEMBL1443747 & 688233 & 4.699 & 3.5244 & TRN \\
\hline CHEMBL1559098 & 688233 & 3.5229 & 3.0478 & TRN \\
\hline CHEMBL1373289 & 688233 & 3.2218 & 3.927 & TRN \\
\hline CHEMBL1477640 & 688233 & 5.3518 & 3.3936 & TST \\
\hline CHEMBL1347610 & 688233 & 4.7673 & 3.7491 & TST \\
\hline CHEMBL1449018 & 688233 & 3.2218 & 3.7968 & TRN \\
\hline CHEMBL1303810 & 688233 & 5.7258 & 5.8223 & TRN \\
\hline CHEMBL1499819 & 688233 & 3.5229 & 3.6834 & TRN \\
\hline CHEMBL1461679 & 688233 & 3.2218 & 3.5585 & TRN \\
\hline CHEMBL1538786 & 688233 & 3.2218 & 3.5357 & TRN \\
\hline CHEMBL1393032 & 688233 & 3.2218 & 3.8133 & TRN \\
\hline CHEMBL1376889 & 688233 & 3.2218 & 3.7038 & TRN \\
\hline CHEMBL1581166 & 688233 & 3.2218 & 3.5839 & TRN \\
\hline CHEMBL1330670 & 688233 & 4.6959 & 3.5816 & TRN \\
\hline CHEMBL1306232 & 688233 & 3.2218 & 3.8485 & TRN \\
\hline CHEMBL1322395 & 688233 & 3.2218 & 3.5864 & TRN \\
\hline CHEMBL1601853 & 688233 & 3.5229 & 3.4556 & TRN \\
\hline CHEMBL1404731 & 688233 & 3.5229 & 3.4542 & TRN \\
\hline CHEMBL1522648 & 688233 & 4.7176 & 3.4935 & TRN \\
\hline
\end{tabular}

Page 12637 


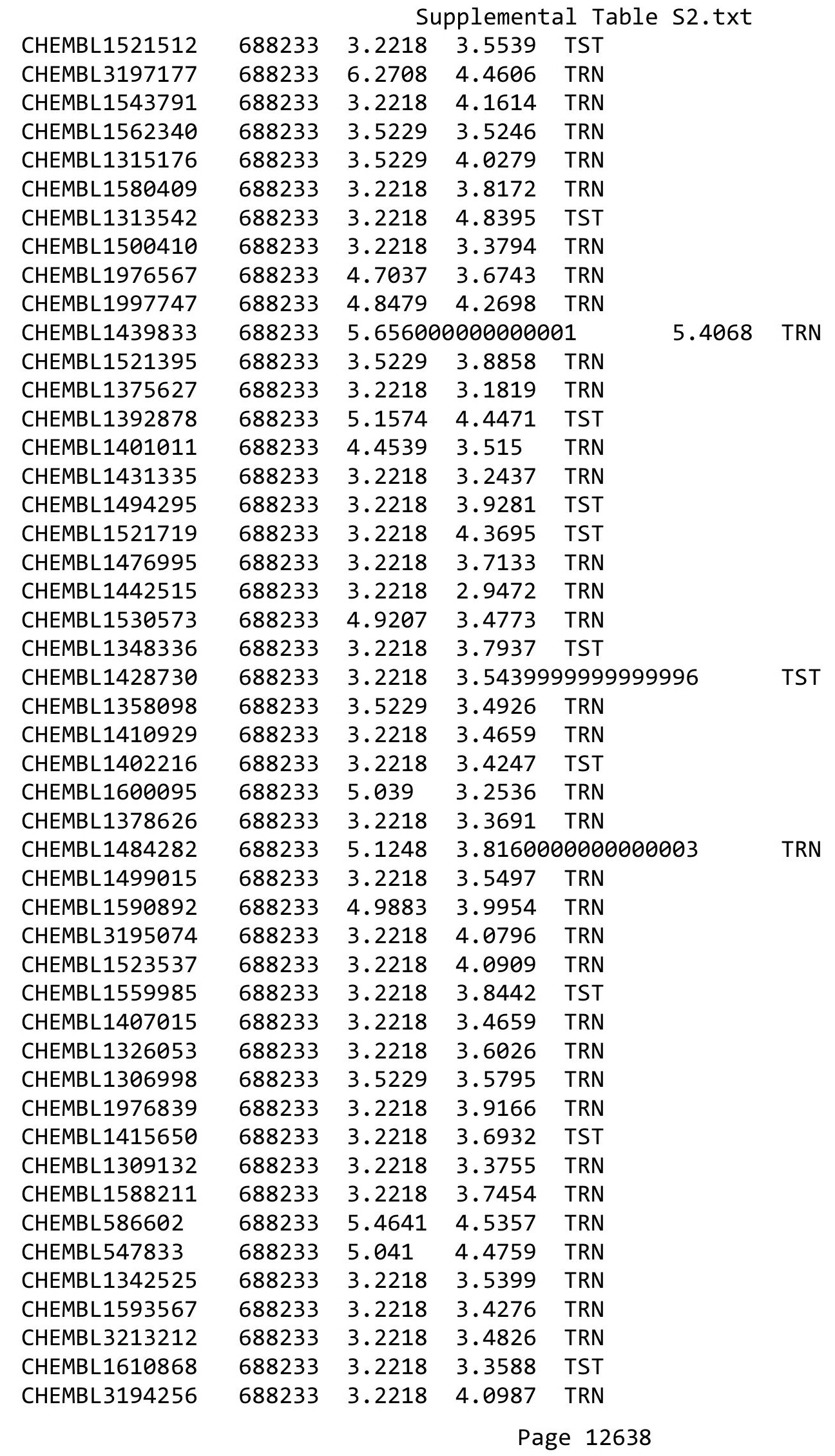




\begin{tabular}{|c|c|c|c|c|}
\hline & & & oplement & al $\mathrm{Tc}$ \\
\hline CHEMBL1323274 & 688233 & 3.2218 & 3.0526 & TRN \\
\hline CHEMBL3193095 & 688233 & 4.9418 & 3.6914 & TRN \\
\hline CHEMBL1462133 & 688233 & 3.5229 & 3.7001 & TRN \\
\hline CHEMBL3198142 & 688233 & 4.4838 & 3.6427 & TRN \\
\hline CHEMBL1506819 & 688233 & 3.5229 & 3.4094 & TRN \\
\hline CHEMBL1501995 & 688233 & 3.5229 & 3.7284 & TRN \\
\hline CHEMBL528564 & 688233 & 3.5229 & 4.1509 & TRN \\
\hline CHEMBL1389077 & 688233 & 3.5229 & 3.5441 & TRN \\
\hline CHEMBL1379563 & 688233 & 3.2218 & 3.2634 & TRN \\
\hline CHEMBL1403090 & 688233 & 3.2218 & 3.1092 & TRN \\
\hline CHEMBL1307207 & 688233 & 5.4832 & 5.0654 & TRN \\
\hline CHEMBL1351106 & 688233 & 3.2218 & 3.6235 & TRN \\
\hline CHEMBL1300193 & 688233 & 5.3512 & 3.8552 & TRN \\
\hline CHEMBL3192432 & 688233 & 5.9817 & 5.2534 & TRN \\
\hline CHEMBL1365885 & 688233 & 3.2218 & 3.3873 & TRN \\
\hline CHEMBL1358680 & 688233 & 3.2218 & 3.3878 & TRN \\
\hline CHEMBL1388583 & 688233 & 4.6564 & 3.5489 & TRN \\
\hline CHEMBL1452421 & 688233 & 5.8948 & 5.8367 & TRN \\
\hline CHEMBL1543347 & 688233 & 3.2218 & 3.602 & TRN \\
\hline CHEMBL1342070 & 688233 & 3.2218 & 4.4403 & TST \\
\hline CHEMBL1326851 & 688233 & 3.2218 & 2.9711 & TRN \\
\hline CHEMBL1456780 & 688233 & 5.5281 & 4.7818 & TRN \\
\hline CHEMBL1308088 & 688233 & 4.9764 & 4.0486 & TRN \\
\hline CHEMBL1513401 & 688233 & 3.2218 & 3.5126 & TRN \\
\hline CHEMBL1383987 & 688233 & 3.2218 & 3.779 & TRN \\
\hline CHEMBL1333096 & 688233 & 3.2218 & 3.2127 & TRN \\
\hline CHEMBL1583752 & 688233 & 5.3594 & 3.9044 & TRN \\
\hline CHEMBL2369168 & 688233 & 3.2218 & 4.1564 & TRN \\
\hline CHEMBL1385142 & 688233 & 5.149 & 4.1168 & TST \\
\hline CHEMBL1363966 & 688233 & 5.1699 & 4.0804 & TRN \\
\hline CHEMBL1605073 & 688233 & 3.2218 & 3.5758 & TRN \\
\hline CHEMBL1992689 & 688233 & 3.2218 & 3.7056 & TRN \\
\hline CHEMBL1502402 & 688233 & 3.2218 & 3.1077 & TRN \\
\hline CHEMBL580727 & 688233 & 5.1424 & 5.3066 & TRN \\
\hline CHEMBL1583892 & 688233 & 3.2218 & 3.4464 & TRN \\
\hline CHEMBL1995078 & 688233 & 3.2218 & 4.0615 & TRN \\
\hline CHEMBL1487013 & 688233 & 3.2218 & 2.963 & TRN \\
\hline CHEMBL1584684 & 688233 & 3.2218 & 3.6414 & TRN \\
\hline CHEMBL1501506 & 688233 & 5.0965 & 3.9054 & TST \\
\hline CHEMBL1370513 & 688233 & 5.8312 & 6.3983 & TRN \\
\hline CHEMBL1359186 & 688233 & 3.2218 & 3.3405 & TRN \\
\hline CHEMBL1518478 & 688233 & 4.5848 & 3.5296 & TRN \\
\hline CHEMBL482116 & 688233 & 3.5229 & 4.4399 & TRN \\
\hline CHEMBL1398709 & 688233 & 4.8946 & 3.8288 & TST \\
\hline CHEMBL1412708 & 688233 & 3.2218 & 3.6941 & TRN \\
\hline CHEMBL1424596 & 688233 & 5.1726 & 4.0658 & TST \\
\hline CHEMBL1303468 & 688233 & 3.2218 & 3.3517 & TRN \\
\hline CHEMBL1566354 & 688233 & 3.2218 & 3.7925 & TRN \\
\hline
\end{tabular}




\begin{tabular}{|c|c|c|c|c|c|}
\hline \multicolumn{6}{|c|}{ Supplemental Table S2.txt } \\
\hline CHEMBL1359321 & 688233 & 3.2218 & 4.2606 & TRN & \\
\hline CHEMBL1490602 & 688233 & 5.3243 & 3.707 & TST & \\
\hline CHEMBL1444886 & 688233 & 3.2218 & 3.4736 & TST & \\
\hline CHEMBL1986418 & 688233 & 6.2218 & 5.0093 & TRN & \\
\hline CHEMBL1383799 & 688233 & 3.2218 & 4.1114 & TRN & \\
\hline CHEMBL1507137 & 688233 & 4.9573 & 4.3876 & TRN & \\
\hline CHEMBL589694 & 688233 & 5.0721 & 4.0523 & TRN & \\
\hline CHEMBL1335986 & 688233 & 5.3371 & 4.4207 & TRN & \\
\hline CHEMBL1532372 & 688233 & 3.2218 & 3.0123 & TRN & \\
\hline CHEMBL1424032 & 688233 & 3.2218 & 3.418 & TRN & \\
\hline CHEMBL1542402 & 688233 & 3.5229 & 3.4692 & TRN & \\
\hline CHEMBL1506580 & 688233 & 5.1828 & 5.5386 & TRN & \\
\hline CHEMBL1460613 & 688233 & 3.2218 & 3.7642 & TRN & \\
\hline CHEMBL1309228 & 688233 & 5.205 & 4.4772 & TRN & \\
\hline CHEMBL3190827 & 688233 & 3.2218 & 4.3991 & TST & \\
\hline CHEMBL1381569 & 688233 & 3.5229 & 3.20899 & 99999999996 & TRN \\
\hline CHEMBL1573309 & 688233 & 5.0237 & 4.4645 & TST & \\
\hline CHEMBL1379252 & 688233 & 3.2218 & 3.6117 & TRN & \\
\hline CHEMBL1560092 & 688233 & 5.0728 & 4.7453 & TRN & \\
\hline CHEMBL1499684 & 688233 & 5.0857 & 3.7826 & TST & \\
\hline CHEMBL1507682 & 688233 & 3.2218 & 3.45300 & 00000000003 & TST \\
\hline CHEMBL1444212 & 688233 & 3.5229 & 3.8939 & TRN & \\
\hline CHEMBL1349058 & 688233 & 3.2218 & 3.5065 & TRN & \\
\hline CHEMBL1423935 & 688233 & 6.2218 & 4.8194 & TRN & \\
\hline CHEMBL1386066 & 688233 & 3.2218 & 3.036 & TRN & \\
\hline CHEMBL602730 & 688233 & 3.2218 & 3.9412 & TRN & \\
\hline CHEMBL 2006503 & 688233 & 5.4957 & 5.7994 & TST & \\
\hline CHEMBL1588899 & 688233 & 3.5229 & 3.87399 & 99999999997 & TRN \\
\hline CHEMBL1373678 & 688233 & 3.2218 & 3.8838 & TRN & \\
\hline CHEMBL1326180 & 688233 & 3.5229 & 4.2165 & TRN & \\
\hline CHEMBL1733454 & 688233 & 3.2218 & 3.5587 & TRN & \\
\hline CHEMBL1998592 & 688233 & 3.2218 & 3.2899 & TST & \\
\hline CHEMBL1446560 & 688233 & 3.2218 & 3.1974 & TRN & \\
\hline CHEMBL1529115 & 688233 & 5.6054 & 4.5405 & TRN & \\
\hline CHEMBL1495205 & 688233 & 3.5229 & 3.9402 & TST & \\
\hline CHEMBL1336959 & 688233 & 5.0128 & 4.3411 & TRN & \\
\hline CHEMBL1411488 & 688233 & 3.5229 & 3.7785 & TRN & \\
\hline CHEMBL1329742 & 688233 & 3.2218 & 3.4658 & TRN & \\
\hline CHEMBL1468055 & 688233 & 3.2218 & 3.6795 & TST & \\
\hline CHEMBL1350465 & 688233 & 3.2218 & 3.3473 & TRN & \\
\hline CHEMBL1499436 & 688233 & 4.9874 & 3.9613 & TST & \\
\hline CHEMBL1588034 & 688233 & 3.5229 & 3.635 & TRN & \\
\hline CHEMBL1569005 & 688233 & 3.5229 & 3.9031 & TRN & \\
\hline CHEMBL1332334 & 688233 & 3.2218 & 3.679 & TRN & \\
\hline CHEMBL1330830 & 688233 & 3.2218 & 3.2678 & TRN & \\
\hline CHEMBL1430772 & 688233 & 3.2218 & 4.2461 & TST & \\
\hline CHEMBL1583193 & 688233 & 3.2218 & 3.4645 & TRN & \\
\hline CHEMBL1490351 & 688233 & 3.2218 & 3.7665 & TRN & \\
\hline
\end{tabular}




\begin{tabular}{|c|c|c|c|c|}
\hline & & & pplement & al $\mathrm{T}$ \\
\hline CHEMBL1595820 & 688233 & 5.2353 & 5.8333 & TRN \\
\hline CHEMBL1371146 & 688233 & 4.9697 & 4.1626 & TRN \\
\hline CHEMBL64391 & 688233 & 3.2218 & 3.9232 & TST \\
\hline CHEMBL1555034 & 688233 & 3.2218 & 3.8956 & TRN \\
\hline CHEMBL1588889 & 688233 & 3.2218 & 3.6132 & TST \\
\hline CHEMBL1537588 & 688233 & 3.5229 & 4.3376 & TST \\
\hline CHEMBL1594460 & 688233 & 3.2218 & 3.2741 & TRN \\
\hline CHEMBL3207894 & 688233 & 3.2218 & 3.4007 & TST \\
\hline CHEMBL1313959 & 688233 & 3.2218 & 3.1928 & TRN \\
\hline CHEMBL1457321 & 688233 & 3.2218 & 3.3801 & TRN \\
\hline CHEMBL1422741 & 688233 & 3.2218 & 3.1885 & TRN \\
\hline CHEMBL1469224 & 688233 & 3.2218 & 3.8536 & TRN \\
\hline CHEMBL1401325 & 688233 & 3.2218 & 3.2522 & TRN \\
\hline CHEMBL1383777 & 688233 & 3.2218 & 3.2453 & TRN \\
\hline CHEMBL1599708 & 688233 & 5.2783 & 5.4475 & TRN \\
\hline CHEMBL1361962 & 688233 & 3.2218 & 3.7401 & TRN \\
\hline CHEMBL1479266 & 688233 & 3.2218 & 3.4983 & TRN \\
\hline CHEMBL1563818 & 688233 & 3.5229 & 3.3368 & TST \\
\hline CHEMBL1494154 & 688233 & 3.2218 & 3.8432 & TRN \\
\hline CHEMBL1517103 & 688233 & 4.6092 & 3.6413 & TRN \\
\hline CHEMBL1525808 & 688233 & 3.2218 & 4.1719 & TRN \\
\hline CHEMBL1427574 & 688233 & 3.2218 & 3.096 & TRN \\
\hline CHEMBL1440558 & 688233 & 3.2218 & 3.9439 & TRN \\
\hline CHEMBL1360505 & 688233 & 3.2218 & 3.5895 & TRN \\
\hline CHEMBL1486894 & 688233 & 3.2218 & 3.4576 & TRN \\
\hline CHEMBL1321070 & 688233 & 4.652 & 3.6455 & TST \\
\hline CHEMBL591370 & 688233 & 5.5363 & 4.721 & TRN \\
\hline CHEMBL1536422 & 688233 & 3.2218 & 3.5849 & TRN \\
\hline CHEMBL1437823 & 688233 & 4.7862 & 4.0511 & TRN \\
\hline CHEMBL1500059 & 688233 & 3.2218 & 3.7999 & TRN \\
\hline CHEMBL1495589 & 688233 & 3.2218 & 3.4973 & TRN \\
\hline CHEMBL1568848 & 688233 & 3.5229 & 3.6249 & TST \\
\hline CHEMBL1540613 & 688233 & 3.2218 & 3.2287 & TRN \\
\hline CHEMBL1518985 & 688233 & 3.2218 & 3.8043 & TRN \\
\hline CHEMBL1519411 & 688233 & 4.7538 & 3.8948 & TRN \\
\hline CHEMBL1463625 & 688233 & 3.2218 & 3.7351 & TRN \\
\hline CHEMBL1390221 & 688233 & 3.2218 & 3.8538 & TRN \\
\hline CHEMBL1490799 & 688233 & 3.2218 & 3.345 & TRN \\
\hline CHEMBL1999960 & 688233 & 5.2626 & 4.3168 & TRN \\
\hline CHEMBL1525167 & 688233 & 3.5229 & 3.7693 & TST \\
\hline CHEMBL1346447 & 688233 & 3.2218 & 3.0022 & TRN \\
\hline CHEMBL1305477 & 688233 & 3.2218 & 3.6775 & TRN \\
\hline CHEMBL1444905 & 688233 & 3.2218 & 3.2398 & TRN \\
\hline CHEMBL1996441 & 688233 & 3.5229 & 3.2507 & TRN \\
\hline CHEMBL1321140 & 688233 & 3.2218 & 2.4619 & TRN \\
\hline CHEMBL1990786 & 688233 & 3.2218 & 4.3491 & TRN \\
\hline CHEMBL1460077 & 688233 & 3.2218 & 3.4727 & TST \\
\hline CHEMBL609628 & 688233 & 3.2218 & 4.3489 & TRN \\
\hline
\end{tabular}




\begin{tabular}{|c|c|c|c|c|c|}
\hline \multicolumn{6}{|c|}{ Supplemental Table S2.txt } \\
\hline CHEMBL1561609 & 688233 & 3.2218 & 3.3538 & TRN & \\
\hline CHEMBL3191149 & 688233 & 3.2218 & 3.6477 & TRN & \\
\hline CHEMBL1473676 & 688233 & 6.767 & 4.288 & TST & \\
\hline CHEMBL1594274 & 688233 & 3.2218 & 3.6761 & TRN & \\
\hline CHEMBL1323615 & 688233 & 3.2218 & 3.6242 & TRN & \\
\hline CHEMBL1540625 & 688233 & 5.3218 & 3.6978 & TRN & \\
\hline CHEMBL1455508 & 688233 & 5.0306 & 4.1196 & TRN & \\
\hline CHEMBL1418200 & 688233 & 3.2218 & 3.4285 & TRN & \\
\hline CHEMBL1556382 & 688233 & 3.2218 & 3.1687 & TRN & \\
\hline CHEMBL1335443 & 688233 & 3.2218 & 3.6304 & TRN & \\
\hline CHEMBL 2005743 & 688233 & 3.2218 & 3.7613 & TRN & \\
\hline CHEMBL1491927 & 688233 & 6.2218 & 4.2281 & TRN & \\
\hline CHEMBL1990545 & 688233 & 5.0451 & 3.5345 & TRN & \\
\hline CHEMBL 2006221 & 688233 & 3.2218 & 3.9309 & TRN & \\
\hline CHEMBL1545598 & 688233 & 3.2218 & 3.8362 & TRN & \\
\hline CHEMBL1346887 & 688233 & 3.2218 & 3.66600 & 00000000004 & TRN \\
\hline CHEMBL1577558 & 688233 & 3.2218 & 3.7851 & TRN & \\
\hline CHEMBL3197024 & 688233 & 5.2642 & 4.1241 & TRN & \\
\hline CHEMBL1429288 & 688233 & 3.2218 & 3.3383 & TRN & \\
\hline CHEMBL1610821 & 688233 & 3.2218 & 3.8051 & TRN & \\
\hline CHEMBL1495283 & 688233 & 3.2218 & 4.2758 & TRN & \\
\hline CHEMBL1491816 & 688233 & 3.2218 & 3.8779 & TST & \\
\hline CHEMBL1609529 & 688233 & 3.2218 & 3.7243 & TRN & \\
\hline CHEMBL1494647 & 688233 & 3.5229 & 3.7374 & TRN & \\
\hline CHEMBL3210599 & 688233 & 3.2218 & 3.8116 & TST & \\
\hline CHEMBL1416323 & 688233 & 3.2218 & 3.5147 & TRN & \\
\hline CHEMBL1215474 & 688233 & 3.2218 & 3.5898 & TRN & \\
\hline CHEMBL1987108 & 688233 & 4.4753 & 3.5886 & TRN & \\
\hline CHEMBL1503479 & 688233 & 3.2218 & 4.0699 & TST & \\
\hline CHEMBL1376732 & 688233 & 5.1341 & 4.3505 & TRN & \\
\hline CHEMBL1445085 & 688233 & 3.2218 & 3.3539 & TRN & \\
\hline CHEMBL3193010 & 688233 & 5.3519 & 4.2775 & TRN & \\
\hline CHEMBL3194756 & 688233 & 3.5229 & 3.2783 & TRN & \\
\hline CHEMBL1504286 & 688233 & 5.1118 & 3.7359 & TRN & \\
\hline CHEMBL1519453 & 688233 & 3.2218 & 3.1151 & TRN & \\
\hline CHEMBL1517832 & 688233 & 3.2218 & 3.3997 & TRN & \\
\hline CHEMBL1311899 & 688233 & 5.3572 & 3.2651 & TST & \\
\hline CHEMBL1374620 & 688233 & 3.2218 & 3.76 & TRN & \\
\hline CHEMBL1381628 & 688233 & 5.0555 & 3.5816 & TRN & \\
\hline CHEMBL1460755 & 688233 & 4.982 & 3.5464 & TRN & \\
\hline CHEMBL1444044 & 688233 & 3.2218 & 3.2033 & TRN & \\
\hline CHEMBL1540239 & 688233 & 3.2218 & 3.1825 & TRN & \\
\hline CHEMBL1378097 & 688233 & 3.2218 & 3.1732 & TRN & \\
\hline CHEMBL1348093 & 688233 & 3.2218 & 3.4078 & TRN & \\
\hline CHEMBL1351519 & 688233 & 3.2218 & 3.85399 & 99999999996 & TRN \\
\hline CHEMBL1732085 & 688233 & 3.2218 & 3.3773 & TRN & \\
\hline CHEMBL1494100 & 688233 & 3.2218 & 3.8093 & TRN & \\
\hline CHEMBL53260 & 688233 & 3.2218 & 3.4537 & TRN & \\
\hline
\end{tabular}


Supplemental Table S2.txt

\begin{tabular}{|c|c|c|c|c|c|}
\hline CHEMBL504977 & 688233 & 3.5229 & 5.3896 & TST & \\
\hline CHEMBL1300244 & 688233 & 3.2218 & 3.9313 & TST & \\
\hline CHEMBL1316691 & 688233 & 5.0658 & \multicolumn{2}{|c|}{3.5060000000000002} & TRN \\
\hline CHEMBL1415154 & 688233 & 3.2218 & 3.5452 & TRN & \\
\hline CHEMBL1386112 & 688233 & 3.2218 & 3.7638 & TRN & \\
\hline CHEMBL1598391 & 688233 & 3.2218 & 3.3362 & TRN & \\
\hline CHEMBL1301490 & 688233 & 3.2218 & 3.4387 & TRN & \\
\hline CHEMBL1483235 & 688233 & 3.2218 & 4.4978 & TRN & \\
\hline CHEMBL1340602 & 688233 & 3.2218 & 3.4592 & TRN & \\
\hline CHEMBL1457240 & 688233 & 3.2218 & 3.5598 & TRN & \\
\hline CHEMBL1586531 & 688233 & 5.4836 & 3.9661 & TST & \\
\hline CHEMBL 3193178 & 688233 & 3.2218 & 3.7651 & TRN & \\
\hline CHEMBL1607901 & 688233 & 3.2218 & 3.6602 & TST & \\
\hline CHEMBL1568501 & 688233 & 5.0709 & 3.6547 & TST & \\
\hline CHEMBL1558021 & 688233 & 5.6866 & \multicolumn{2}{|c|}{5.422000000000001} & TRN \\
\hline CHEMBL1574894 & 688233 & 3.2218 & 3.8273 & TRN & \\
\hline CHEMBL1452258 & 688233 & 3.2218 & 3.1724 & TRN & \\
\hline CHEMBL1361404 & 688233 & 4.3247 & 3.554 & TRN & \\
\hline CHEMBL1576413 & 688233 & 3.2218 & 3.279 & TST & \\
\hline CHEMBL1321912 & 688233 & 3.2218 & 3.5316 & TRN & \\
\hline CHEMBL1461496 & 688233 & 3.2218 & 4.2005 & TRN & \\
\hline CHEMBL233895 & 688233 & 3.2218 & 4.2727 & TRN & \\
\hline CHEMBL1499346 & 688233 & 3.2218 & 3.5288 & TRN & \\
\hline CHEMBL1423390 & 688233 & 3.2218 & 3.9085 & TRN & \\
\hline CHEMBL1572982 & 688233 & 3.2218 & 3.5082 & TRN & \\
\hline CHEMBL1530308 & 688233 & 3.2218 & 3.0112 & TRN & \\
\hline CHEMBL1343347 & 688233 & 3.2218 & 3.3753 & TST & \\
\hline CHEMBL1336882 & 688233 & 3.2218 & 3.745 & TST & \\
\hline CHEMBL1346127 & 688233 & 3.5229 & 3.5734 & TRN & \\
\hline CHEMBL1466872 & 688233 & 3.2218 & 3.3988 & TRN & \\
\hline CHEMBL1573697 & 688233 & 3.5229 & 4.3399 & TRN & \\
\hline CHEMBL1372709 & 688233 & 3.2218 & 3.2119 & TRN & \\
\hline CHEMBL1602880 & 688233 & 3.2218 & 3.0386 & TRN & \\
\hline CHEMBL1405379 & 688233 & 3.2218 & 3.6453 & TRN & \\
\hline CHEMBL1606234 & 688233 & 3.2218 & 3.9613 & TRN & \\
\hline CHEMBL1311220 & 688233 & 3.2218 & \multicolumn{2}{|c|}{3.7289999999999996} & TRN \\
\hline CHEMBL1304177 & 688233 & 3.2218 & 3.7798 & TRN & \\
\hline CHEMBL1494987 & 688233 & 3.2218 & 3.7884 & TST & \\
\hline CHEMBL3211962 & 688233 & 3.5229 & \multicolumn{2}{|c|}{3.3289999999999997} & TRN \\
\hline CHEMBL1346272 & 688233 & 3.2218 & 3.3603 & TRN & \\
\hline CHEMBL1567752 & 688233 & 3.2218 & 3.4813 & TRN & \\
\hline CHEMBL1570555 & 688233 & 3.2218 & 3.4955 & TRN & \\
\hline CHEMBL1544998 & 688233 & 3.5229 & 3.4049 & TRN & \\
\hline CHEMBL1977995 & 688233 & 3.2218 & 4.2753 & TRN & \\
\hline CHEMBL1407068 & 688233 & 3.2218 & 3.5153 & TRN & \\
\hline CHEMBL1538014 & 688233 & 3.2218 & 3.3904 & TRN & \\
\hline CHEMBL1360206 & 688233 & 3.5229 & 3.7327 & TRN & \\
\hline CHEMBL1374222 & 688233 & 3.5229 & 3.195 & TRN & \\
\hline
\end{tabular}


Supplemental Table S2.txt

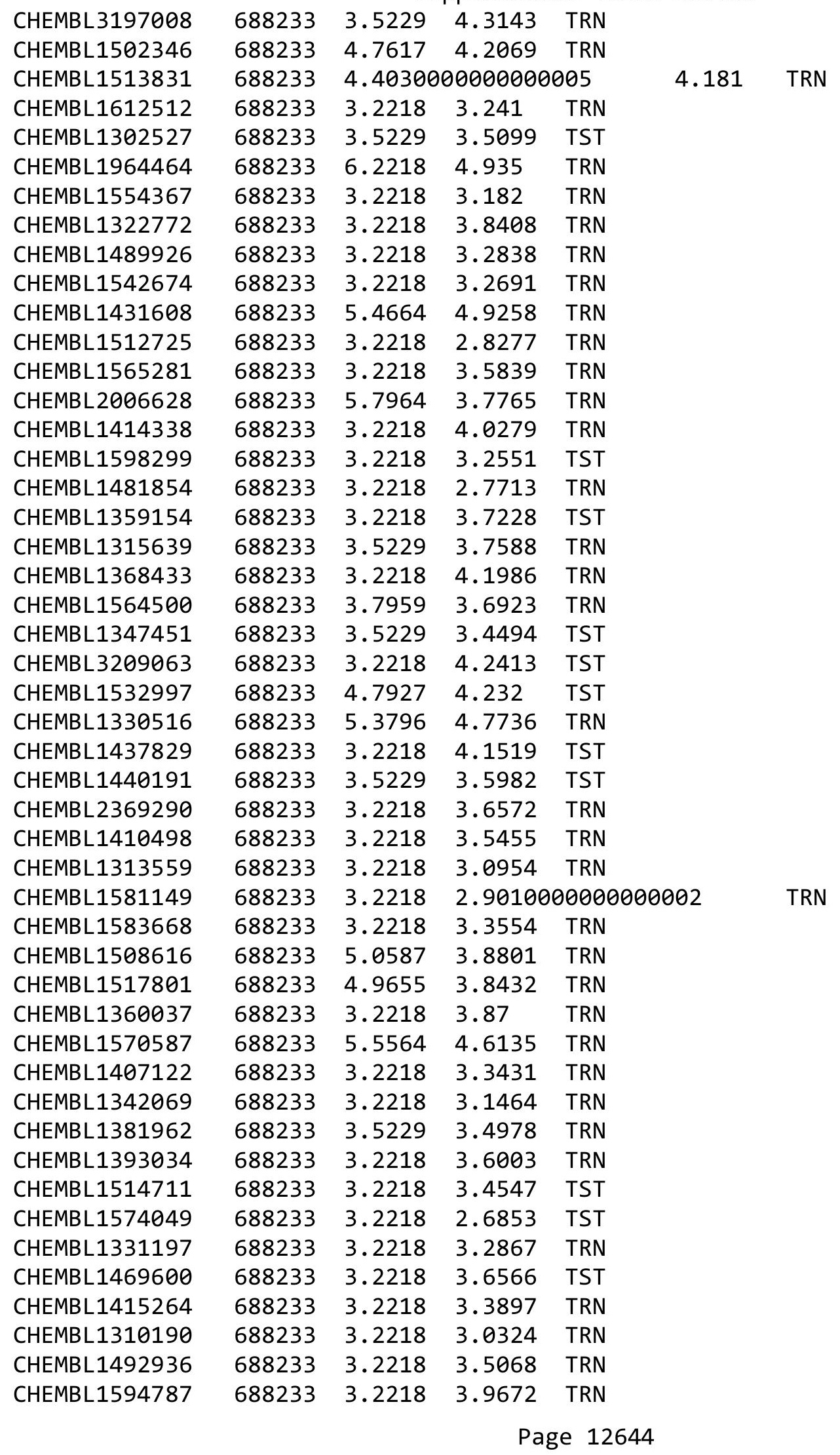




\begin{tabular}{|c|c|c|c|c|c|}
\hline & & \multicolumn{4}{|c|}{ Supplemental Table S2.txt } \\
\hline CHEMBL1729277 & 688233 & 3.2218 & 3.14 & TRN & \\
\hline CHEMBL1416921 & 688233 & 3.5229 & 3.0097 & TRN & \\
\hline CHEMBL1404130 & 688233 & 3.2218 & 3.7657 & TST & \\
\hline CHEMBL1595675 & 688233 & 3.2218 & 2.8503 & TRN & \\
\hline CHEMBL1575137 & 688233 & 3.2218 & 3.2838 & TRN & \\
\hline CHEMBL1459050 & 688233 & 3.5229 & 3.4694 & TRN & \\
\hline CHEMBL1500002 & 688233 & 4.9969 & 3.8557 & TRN & \\
\hline CHEMBL1330113 & 688233 & 5.1068 & 3.9123 & TST & \\
\hline CHEMBL3195621 & 688233 & 3.2218 & 3.7534 & TRN & \\
\hline CHEMBL3198253 & 688233 & 3.2218 & 3.2141 & TRN & \\
\hline CHEMBL1386511 & 688233 & 3.2218 & 3.5232 & TRN & \\
\hline CHEMBL1382838 & 688233 & 3.2218 & 3.8109 & TRN & \\
\hline CHEMBL1340022 & 688233 & 4.9747 & 3.8576 & TRN & \\
\hline CHEMBL 275097 & 688233 & 3.2218 & 3.6304 & TRN & \\
\hline CHEMBL1461084 & 688233 & 3.2218 & 3.5884 & TRN & \\
\hline CHEMBL1578482 & 688233 & 5.228 & 5.2237 & TRN & \\
\hline CHEMBL1323770 & 688233 & 3.2218 & 3.1976 & TRN & \\
\hline CHEMBL1610249 & 688233 & 3.5229 & 3.78899 & 99999999997 & TRN \\
\hline CHEMBL1500767 & 688233 & 3.2218 & 3.8237 & TRN & \\
\hline CHEMBL1603602 & 688233 & 3.2218 & 3.8566 & TRN & \\
\hline CHEMBL1310848 & 688233 & 3.2218 & 3.3438 & TRN & \\
\hline CHEMBL1401860 & 688233 & 3.2218 & 3.0657 & TRN & \\
\hline CHEMBL1408596 & 688233 & 3.2218 & 3.3721 & TRN & \\
\hline CHEMBL1383333 & 688233 & 5.4695 & 4.9851 & TRN & \\
\hline CHEMBL1413153 & 688233 & 4.4292 & 4.3174 & TRN & \\
\hline CHEMBL1430895 & 688233 & 5.4966 & 5.0282 & TRN & \\
\hline CHEMBL1469584 & 688233 & 3.2218 & 3.8117 & TST & \\
\hline CHEMBL1300695 & 688233 & 5.4317 & 4.5819 & TST & \\
\hline CHEMBL1443767 & 688233 & 4.6607 & 3.8676 & TRN & \\
\hline CHEMBL3213876 & 688233 & 3.2218 & 3.8652 & TRN & \\
\hline CHEMBL1493120 & 688233 & 4.927 & 3.576 & TST & \\
\hline CHEMBL1506369 & 688233 & 3.5229 & 3.5013 & TRN & \\
\hline CHEMBL1360865 & 688233 & 3.2218 & 3.5471 & TRN & \\
\hline CHEMBL1533447 & 688233 & 3.2218 & 2.8907 & TRN & \\
\hline CHEMBL1530525 & 688233 & 5.1632 & 3.9342 & TST & \\
\hline CHEMBL1312619 & 688233 & 3.5229 & 3.2986 & TRN & \\
\hline CHEMBL1986073 & 688233 & 5.5201 & 4.4419 & TRN & \\
\hline CHEMBL1547060 & 688233 & 3.2218 & 3.7164 & TRN & \\
\hline CHEMBL1361273 & 688233 & 3.2218 & 4.6865 & TST & \\
\hline CHEMBL1527580 & 688233 & 5.0326 & 4.0996 & TRN & \\
\hline CHEMBL1419659 & 688233 & 3.2218 & 3.4832 & TRN & \\
\hline CHEMBL1461748 & 688233 & 3.2218 & 3.7909 & TRN & \\
\hline CHEMBL1584573 & 688233 & 3.5229 & 3.5548 & TRN & \\
\hline CHEMBL3210267 & 688233 & 3.2218 & 4.046 & TRN & \\
\hline CHEMBL1386918 & 688233 & 3.2218 & 3.6068 & TRN & \\
\hline CHEMBL1508476 & 688233 & 3.2218 & 3.4799 & TRN & \\
\hline CHEMBL3199428 & 688233 & 4.9623 & 4.3412 & TRN & \\
\hline CHEMBL1460800 & 688233 & 3.2218 & 3.7157 & TRN & \\
\hline
\end{tabular}




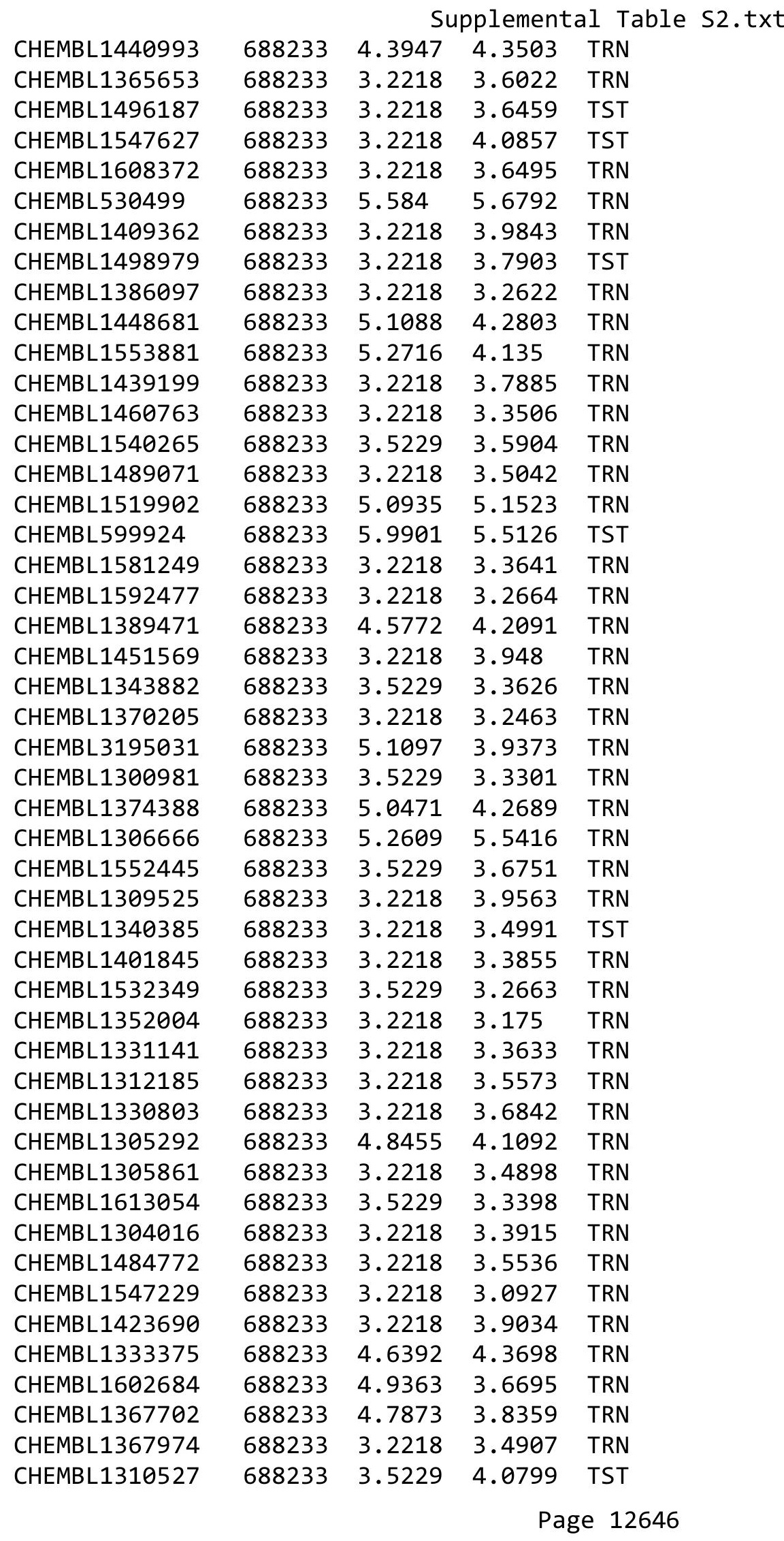


Supplemental Table S2.txt

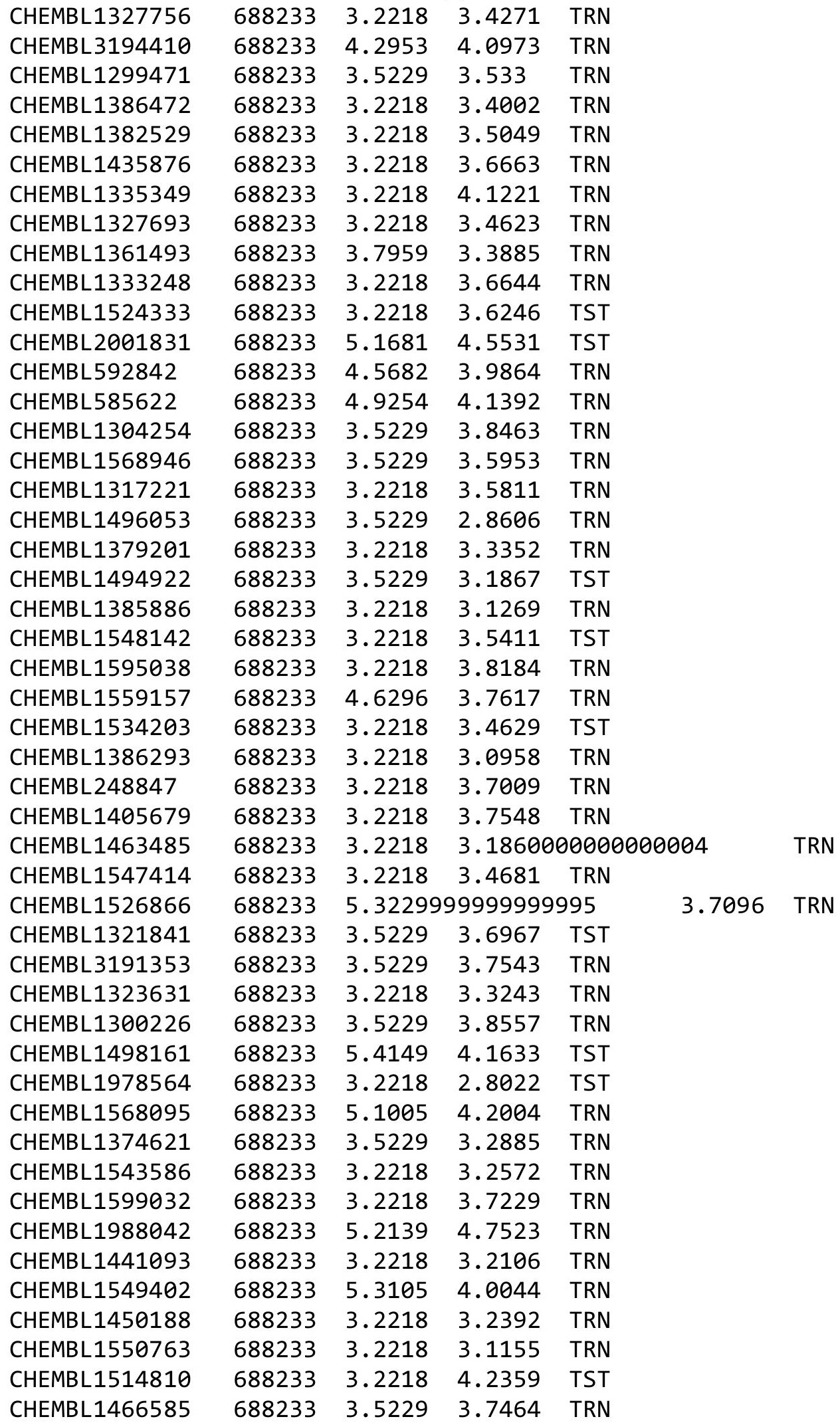

Page 12647 


\begin{tabular}{|c|c|c|c|c|}
\hline & & & oplement & al $\mathrm{Tc}$ \\
\hline CHEMBL1415035 & 688233 & 5.0281 & 3.9739 & TRN \\
\hline CHEMBL1602411 & 688233 & 3.2218 & 3.2613 & TRN \\
\hline CHEMBL1568316 & 688233 & 3.2218 & 3.4732 & TRN \\
\hline CHEMBL1324755 & 688233 & 3.2218 & 3.4945 & TRN \\
\hline CHEMBL1325957 & 688233 & 3.2218 & 3.5057 & TRN \\
\hline CHEMBL3195226 & 688233 & 5.1259 & 4.6078 & TRN \\
\hline CHEMBL1517374 & 688233 & 3.2218 & 4.0345 & TST \\
\hline CHEMBL1509629 & 688233 & 3.2218 & 3.3715 & TRN \\
\hline CHEMBL1453857 & 688233 & 5.1566 & 4.3031 & TRN \\
\hline CHEMBL3197275 & 688233 & 3.2218 & 3.786 & TRN \\
\hline CHEMBL1387729 & 688233 & 3.2218 & 3.8251 & TST \\
\hline CHEMBL1604735 & 688233 & 5.3628 & 4.7791 & TRN \\
\hline CHEMBL1326782 & 688233 & 3.2218 & 3.6525 & TRN \\
\hline CHEMBL1493194 & 688233 & 3.2218 & 3.8352 & TRN \\
\hline CHEMBL1555809 & 688233 & 3.2218 & 3.8118 & TST \\
\hline CHEMBL1347246 & 688233 & 3.2218 & 3.6852 & TRN \\
\hline CHEMBL1336066 & 688233 & 3.2218 & 3.5627 & TRN \\
\hline CHEMBL1612163 & 688233 & 4.9231 & 3.91 & TRN \\
\hline CHEMBL1414994 & 688233 & 4.7453 & 3.6557 & TST \\
\hline CHEMBL1308836 & 688233 & 3.5229 & 3.6716 & TRN \\
\hline CHEMBL1380091 & 688233 & 3.2218 & 4.1796 & TRN \\
\hline CHEMBL405857 & 688233 & 3.2218 & 3.7483 & TRN \\
\hline CHEMBL3195285 & 688233 & 3.2218 & 3.596 & TST \\
\hline CHEMBL1458403 & 688233 & 3.2218 & 3.2343 & TRN \\
\hline CHEMBL1389509 & 688233 & 3.2218 & 3.8281 & TRN \\
\hline CHEMBL1535252 & 688233 & 5.329 & 4.5838 & TRN \\
\hline CHEMBL1346955 & 688233 & 3.2218 & 3.9602 & TST \\
\hline CHEMBL1353998 & 688233 & 3.2218 & 3.4543 & TRN \\
\hline CHEMBL1482308 & 688233 & 3.5229 & 3.4888 & TRN \\
\hline CHEMBL1411474 & 688233 & 3.2218 & 3.5353 & TRN \\
\hline CHEMBL479107 & 688233 & 5.2002 & 3.7427 & TST \\
\hline CHEMBL1461792 & 688233 & 3.2218 & 3.1772 & TRN \\
\hline CHEMBL570399 & 688233 & 3.2218 & 3.9953 & TRN \\
\hline CHEMBL1489344 & 688233 & 5.311 & 4.0274 & TRN \\
\hline CHEMBL1455808 & 688233 & 3.2218 & 4.0928 & TST \\
\hline CHEMBL3196547 & 688233 & 3.2218 & 3.4406 & TRN \\
\hline CHEMBL171289 & 688233 & 3.2218 & 3.4401 & TRN \\
\hline CHEMBL1502222 & 688233 & 3.2218 & 3.4612 & TRN \\
\hline CHEMBL1538202 & 688233 & 3.2218 & 3.2933 & TRN \\
\hline CHEMBL1388509 & 688233 & 3.2218 & 3.8732 & TST \\
\hline CHEMBL1339071 & 688233 & 3.2218 & 3.4953 & TRN \\
\hline CHEMBL530049 & 688233 & 5.2216 & 4.8794 & TRN \\
\hline CHEMBL1565369 & 688233 & 5.2917 & 5.2667 & TRN \\
\hline CHEMBL1503962 & 688233 & 5.3286 & 3.9598 & TST \\
\hline CHEMBL1331050 & 688233 & 5.0422 & 3.7567 & TST \\
\hline CHEMBL1401989 & 688233 & 4.8182 & 4.831 & TRN \\
\hline CHEMBL3212517 & 688233 & 3.5229 & 3.9047 & TRN \\
\hline CHEMBL1609946 & 688233 & 5.407 & 5.3658 & TRN \\
\hline
\end{tabular}




\begin{tabular}{|c|c|c|c|c|c|}
\hline \multicolumn{6}{|c|}{ Supplemental Table S2.txt } \\
\hline CHEMBL1509840 & 688233 & 3.2218 & 3.5368 & TRN & \\
\hline CHEMBL1583080 & 688233 & 3.2218 & 3.287 & TRN & \\
\hline CHEMBL1540768 & 688233 & 3.2218 & 3.4016 & TRN & \\
\hline CHEMBL597251 & 688233 & 3.2218 & 3.5839 & TRN & \\
\hline CHEMBL565269 & 688233 & 5.2148 & 4.1052 & TRN & \\
\hline CHEMBL1373323 & 688233 & 3.2218 & 3.1894 & TRN & \\
\hline CHEMBL 3192084 & 688233 & 3.2218 & 3.9424 & TRN & \\
\hline CHEMBL1607875 & 688233 & 3.2218 & 3.3035 & TRN & \\
\hline CHEMBL1366588 & 688233 & 5.352 & 4.5004 & TRN & \\
\hline CHEMBL1602182 & 688233 & 3.5229 & 3.9971 & TRN & \\
\hline CHEMBL1502351 & 688233 & 5.0434 & 5.4797 & TRN & \\
\hline CHEMBL1361820 & 688233 & 3.2218 & 3.3854 & TRN & \\
\hline CHEMBL1519302 & 688233 & 3.2218 & 3.2364 & TRN & \\
\hline CHEMBL1420234 & 688233 & 3.5229 & 3.3964 & TRN & \\
\hline CHEMBL1515292 & 688233 & 3.5229 & 3.3827 & TRN & \\
\hline CHEMBL1600040 & 688233 & 3.2218 & 3.588 & TST & \\
\hline CHEMBL1302563 & 688233 & 3.2218 & 3.659 & TRN & \\
\hline CHEMBL1405018 & 688233 & 3.2218 & 3.1181 & TRN & \\
\hline CHEMBL1451494 & 688233 & 3.5229 & 3.5208 & TRN & \\
\hline CHEMBL1328686 & 688233 & 3.2218 & 3.885 & TST & \\
\hline CHEMBL1420321 & 688233 & 3.2218 & 3.7935 & TRN & \\
\hline CHEMBL1542594 & 688233 & 5.0065 & 3.9704 & TRN & \\
\hline CHEMBL1996749 & 688233 & 5.4246 & 5.2448 & TRN & \\
\hline CHEMBL1349870 & 688233 & 3.2218 & 3.1683 & TRN & \\
\hline CHEMBL1536360 & 688233 & 4.9127 & 4.3214 & TRN & \\
\hline CHEMBL1497561 & 688233 & 3.2218 & 2.9867 & TRN & \\
\hline CHEMBL1965403 & 688233 & 3.2218 & 3.6823 & TRN & \\
\hline CHEMBL1531172 & 688233 & 5.1214 & 4.0836 & TRN & \\
\hline CHEMBL1541107 & 688233 & 3.2218 & 3.7605 & TST & \\
\hline CHEMBL1522824 & 688233 & 3.2218 & 3.6321 & TRN & \\
\hline CHEMBL1584157 & 688233 & 4.2606 & 3.5236 & TRN & \\
\hline CHEMBL3196108 & 688233 & 5.0472 & 4.0739 & TRN & \\
\hline CHEMBL1372492 & 688233 & 5.9614 & 4.6919 & TRN & \\
\hline CHEMBL 3210057 & 688233 & 3.2218 & 4.2344 & TRN & \\
\hline CHEMBL1440902 & 688233 & 3.2218 & 3.6391 & TRN & \\
\hline CHEMBL1511464 & 688233 & 3.2218 & 2.9213 & TRN & \\
\hline CHEMBL1608985 & 688233 & 4.9628 & 3.7351 & TRN & \\
\hline CHEMBL1396327 & 688233 & 3.2218 & 3.4746 & TST & \\
\hline CHEMBL1442280 & 688233 & 5.1623 & 5.96700 & 00000000005 & TRN \\
\hline CHEMBL1974613 & 688233 & 4.9541 & 4.2581 & TRN & \\
\hline CHEMBL 3207674 & 688233 & 5.1959 & 4.0349 & TRN & \\
\hline CHEMBL 1459537 & 688233 & 3.2218 & 2.8641 & TST & \\
\hline CHEMBL1511748 & 688233 & 3.2218 & 3.8678 & TRN & \\
\hline CHEMBL601335 & 688233 & 3.2218 & 3.2396 & TRN & \\
\hline CHEMBL1443497 & 688233 & 3.5229 & 3.5665 & TRN & \\
\hline CHEMBL1563323 & 688233 & 3.2218 & 4.3398 & TRN & \\
\hline CHEMBL1573817 & 688233 & 3.2218 & 3.5275 & TRN & \\
\hline CHEMBL1402496 & 688233 & 3.2218 & 3.6528 & TRN & \\
\hline
\end{tabular}


Supplemental Table S2.txt

\begin{tabular}{|c|c|c|c|c|c|}
\hline CHEMBL1576431 & 688233 & 3.5229 & 4.006 & TRN & \\
\hline CHEMBL1406635 & 688233 & 3.2218 & 4.1271 & TST & \\
\hline CHEMBL1540313 & 688233 & 3.5229 & 3.2774 & TRN & \\
\hline CHEMBL1558058 & 688233 & 3.2218 & 3.56100 & 00000000004 & TRN \\
\hline CHEMBL 3192762 & 688233 & 3.2218 & 3.3571 & TST & \\
\hline CHEMBL3210051 & 688233 & 5.15600 & 000000006 & 4.0638 & TRN \\
\hline CHEMBL1505495 & 688233 & 3.2218 & 3.552 & TRN & \\
\hline CHEMBL1304312 & 688233 & 3.2218 & 3.2927 & TRN & \\
\hline CHEMBL1439734 & 688233 & 3.2218 & 3.763 & TRN & \\
\hline CHEMBL3196441 & 688233 & 4.7977 & 4.1347 & TRN & \\
\hline CHEMBL1588177 & 688233 & 3.2218 & 3.5738 & TRN & \\
\hline CHEMBL1599994 & 688233 & 3.2218 & 4.4189 & TRN & \\
\hline CHEMBL1340504 & 688233 & 3.2218 & 3.2249 & TRN & \\
\hline CHEMBL1367226 & 688233 & 5.0641 & 4.0284 & TRN & \\
\hline CHEMBL1454987 & 688233 & 3.2218 & 3.9065 & TRN & \\
\hline CHEMBL1589882 & 688233 & 3.2218 & 3.4436 & TST & \\
\hline CHEMBL1328878 & 688233 & 3.2218 & 3.3288 & TRN & \\
\hline CHEMBL1337500 & 688233 & 5.9846 & 4.9471 & TST & \\
\hline CHEMBL1608758 & 688233 & 4.5002 & 3.6638 & TRN & \\
\hline CHEMBL1557920 & 688233 & 3.2218 & 4.0392 & TRN & \\
\hline CHEMBL1303440 & 688233 & 3.2218 & 3.1331 & TRN & \\
\hline CHEMBL1971458 & 688233 & 3.2218 & 3.3959 & TRN & \\
\hline CHEMBL1499094 & 688233 & 3.2218 & 2.9507 & TRN & \\
\hline CHEMBL1714915 & 688233 & 3.2218 & 3.6449 & TST & \\
\hline CHEMBL1442155 & 688233 & 4.7721 & 3.4812 & TST & \\
\hline CHEMBL1606696 & 688233 & 3.2218 & 3.5418 & TRN & \\
\hline CHEMBL1300928 & 688233 & 3.2218 & 3.9071 & TRN & \\
\hline CHEMBL1437683 & 688233 & 5.6863 & 4.7306 & TRN & \\
\hline CHEMBL1300532 & 688233 & 4.7196 & 3.8628 & TRN & \\
\hline CHEMBL 2369200 & 688233 & 3.5229 & 4.2653 & TRN & \\
\hline CHEMBL1541113 & 688233 & 3.2218 & 3.1054 & TRN & \\
\hline CHEMBL1465422 & 688233 & 5.2328 & 4.6035 & TRN & \\
\hline CHEMBL1422456 & 688233 & 5.043 & 3.5471 & TRN & \\
\hline CHEMBL1304308 & 688233 & 3.5229 & 3.4725 & TRN & \\
\hline CHEMBL1416618 & 688233 & 3.2218 & 4.1837 & TST & \\
\hline CHEMBL1360539 & 688233 & 3.2218 & 5.1597 & TST & \\
\hline CHEMBL1404887 & 688233 & 3.2218 & 3.6626 & TRN & \\
\hline CHEMBL1581277 & 688233 & 3.2218 & 3.1306 & TRN & \\
\hline CHEMBL1969593 & 688233 & 3.2218 & 3.6303 & TRN & \\
\hline CHEMBL1304002 & 688233 & 3.2218 & 3.4155 & TRN & \\
\hline CHEMBL1330269 & 688233 & 4.7136 & 3.7942 & TRN & \\
\hline CHEMBL1390643 & 688233 & 3.2218 & 3.4175 & TRN & \\
\hline CHEMBL1359655 & 688233 & 5.4859 & 5.831 & TRN & \\
\hline CHEMBL1519771 & 688233 & 3.2218 & 3.7799 & TRN & \\
\hline CHEMBL1393788 & 688233 & 3.2218 & 3.1682 & TRN & \\
\hline CHEMBL22062 & 688233 & 6.2708 & 4.6003 & TRN & \\
\hline CHEMBL1183425 & 688233 & 3.2218 & 3.6268 & TRN & \\
\hline CHEMBL528165 & 688233 & 3.2218 & 3.5382 & TST & \\
\hline
\end{tabular}


Supplemental Table S2.txt

\begin{tabular}{|c|c|c|c|c|}
\hline W & & & & \\
\hline & & .2218 & & \\
\hline & & & & \\
\hline IEMBL1300 & & 2218 & & $\mathrm{MI}$ \\
\hline AEMBL1301172 & 8233 & 2218 & 369 & \\
\hline HEMBL1406934 & 88233 & .5229 & 4077 & \\
\hline HEMBL1303620 & & & & \\
\hline IEMBL1569552 & & & & \\
\hline AEMBL1460514 & 33 & 2218 & & \\
\hline HEMBL1541409 & 88233 & 2218 & 98 & \\
\hline HEMBL1419306 & 3 & 5229 & 19 & \\
\hline EMBL1 & & 18 & & \\
\hline IEMBL132e & & & & \\
\hline HEMBL1432082 & & 2218 & & \\
\hline IEMBL1462341 & & & & \\
\hline AEMBL1605977 & 3 & 22 & 53 & \\
\hline AEMBL1613375 & & & & \\
\hline HEMBL1489204 & & & & \\
\hline AEMBL1571445 & & & & \\
\hline AEMBL1422217 & & & & \\
\hline 化MBLI & & & & 19 \\
\hline AEMBL1C & & & & ודים \\
\hline HEMBL1C & & & & \\
\hline 715 & & & & \\
\hline AEMBL152 & & & & (2) \\
\hline AEMBL1 & & & & KIV \\
\hline HEMBL: & & & & RN \\
\hline HFMBI 1 & & & & \\
\hline AEMBL3 & & & & $T_{2}$ \\
\hline HEMBL1463257 & & & & (د) \\
\hline HEMBL3 & & & & ST \\
\hline HEMBL & & & & RN \\
\hline$\triangle 5 M P$ & & & & ג \\
\hline HEMBL1508560 & & & & IR \\
\hline HEMBL1564737 & & & & TRN \\
\hline HEMBLI & & & & $\mid$ \\
\hline HFMRI & & & & TRN \\
\hline HEMBL1554002 & & & & IST \\
\hline HEMBL1489240 & 3 & 9 & & TRN \\
\hline AEMBL1307 & & & & TRN \\
\hline HEMBL585594 & & & & TRN \\
\hline HEMBL1525481 & & & & TRN \\
\hline HEMBL1345336 & & & 792 & ST \\
\hline AEMBL1581020 & 33 & & 476 & TR \\
\hline MBL1 & & & & $\mathrm{N}$ \\
\hline LHEMBL1378644 & & & & \\
\hline CHEMBL1465458 & & & 3.444 & \\
\hline CHEMBL1545168 & 688233 & 3.2218 & 3.5469 & ГRN \\
\hline
\end{tabular}

Page 12651 
Supplemental Table S2.txt

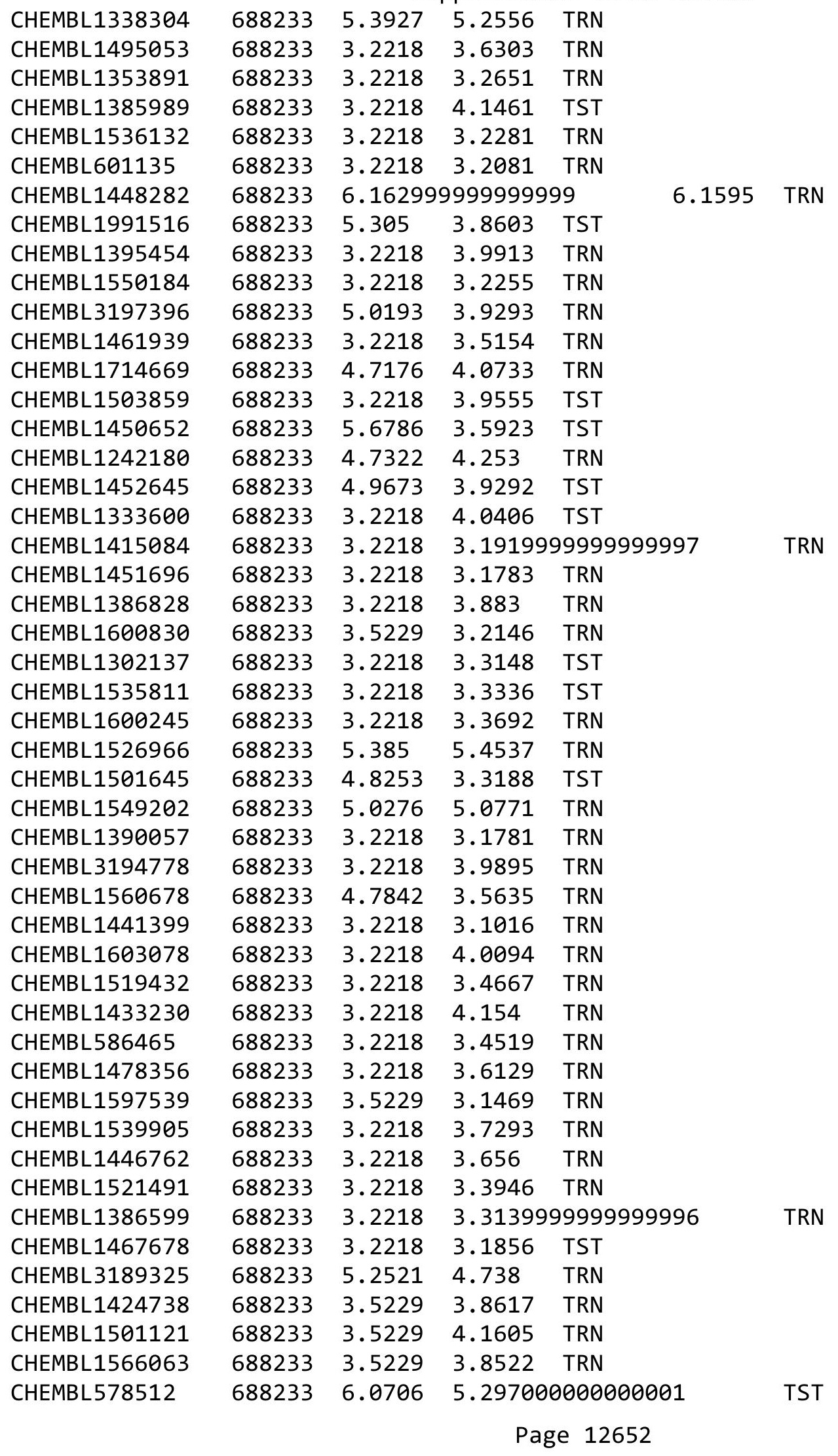


Supplemental Table S2.txt

\begin{tabular}{|c|c|c|c|c|c|}
\hline CHEMBL1456768 & 688233 & 3.2218 & 3.3363 & TRN & \\
\hline CHEMBL1343079 & 688233 & 3.2218 & 3.6628 & TRN & \\
\hline CHEMBL221190 & 688233 & 3.5229 & 4.0702 & TRN & \\
\hline CHEMBL1331384 & 688233 & 3.2218 & 3.2461 & TRN & \\
\hline CHEMBL1399995 & 688233 & 5.3224 & 3.5371 & TRN & \\
\hline CHEMBL3199822 & 688233 & 5.0039 & 4.1006 & TRN & \\
\hline CHEMBL1387474 & 688233 & 3.2218 & 4.0186 & TRN & \\
\hline CHEMBL1324135 & 688233 & 3.2218 & 3.6828 & TRN & \\
\hline CHEMBL1490409 & 688233 & 3.2218 & 3.8659 & TRN & \\
\hline CHEMBL3189428 & 688233 & 5.0966 & 4.2971 & TRN & \\
\hline CHEMBL3191106 & 688233 & 5.5124 & 4.5185 & TRN & \\
\hline CHEMBL1351508 & 688233 & 5.0433 & 3.6302 & TST & \\
\hline CHEMBL1596094 & 688233 & 4.9843 & 4.0091 & TRN & \\
\hline CHEMBL1457139 & 688233 & 5.0407 & 5.6999 & TRN & \\
\hline CHEMBL1535975 & 688233 & 3.2218 & 3.4599 & TRN & \\
\hline CHEMBL1544097 & 688233 & 3.2218 & 3.5492 & TRN & \\
\hline CHEMBL1352488 & 688233 & 5.0531 & 4.4215 & TRN & \\
\hline CHEMBL1592829 & 688233 & 3.2218 & 3.7919 & TST & \\
\hline CHEMBL1363376 & 688233 & 4.7469 & 3.8462 & TRN & \\
\hline CHEMBL1983418 & 688233 & 6.1249 & 5.1542 & TRN & \\
\hline CHEMBL1569272 & 688233 & 3.5229 & 3.5709 & TST & \\
\hline CHEMBL1409903 & 688233 & 3.2218 & 3.2813 & TRN & \\
\hline CHEMBL1487849 & 688233 & 5.0942 & 4.2736 & TRN & \\
\hline CHEMBL1375963 & 688233 & 3.2218 & 3.582 & TST & \\
\hline CHEMBL1461209 & 688233 & 4.82 & 3.731999 & Э999999999988 & TRN \\
\hline CHEMBL1338064 & 688233 & 4.7755 & 3.775 & TRN & \\
\hline CHEMBL1548862 & 688233 & 4.5383 & 3.6688 & TRN & \\
\hline CHEMBL1343069 & 688233 & 3.2218 & 3.5194 & TRN & \\
\hline CHEMBL1542798 & 688233 & 3.5229 & 3.342 & TRN & \\
\hline CHEMBL1513198 & 688233 & 4.9978 & 3.7826 & TRN & \\
\hline CHEMBL1416268 & 688233 & 3.2218 & 4.1105 & TST & \\
\hline CHEMBL578294 & 688233 & 3.2218 & 4.1379 & TRN & \\
\hline CHEMBL1603936 & 688233 & 3.2218 & 4.1337 & TST & \\
\hline CHEMBL1309290 & 688233 & 5.6133 & 5.2331 & TRN & \\
\hline CHEMBL1597262 & 688233 & 3.2218 & 2.9101 & TRN & \\
\hline CHEMBL1547350 & 688233 & 5.7667 & 4.3094 & TRN & \\
\hline CHEMBL1314125 & 688233 & 5.3701 & 5.383999 & 99999999995 & TRN \\
\hline CHEMBL1548535 & 688233 & 4.5101 & 3.3773 & TRN & \\
\hline CHEMBL1455794 & 688233 & 4.2659 & 3.6297 & TRN & \\
\hline CHEMBL1588104 & 688233 & 3.5229 & 3.9433 & TST & \\
\hline CHEMBL1599283 & 688233 & 5.2062 & 3.5939 & TST & \\
\hline CHEMBL3199850 & 688233 & 3.2218 & 3.8054 & TRN & \\
\hline CHEMBL1404493 & 688233 & 5.2462 & 4.8938 & TRN & \\
\hline CHEMBL1316717 & 688233 & 3.5229 & 3.4423 & TRN & \\
\hline CHEMBL1605960 & 688233 & 3.2218 & 3.6114 & TRN & \\
\hline CHEMBL1542029 & 688233 & 3.2218 & 3.2632 & TRN & \\
\hline CHEMBL1352261 & 688233 & 3.2218 & 3.4186 & TST & \\
\hline CHEMBL3195459 & 688233 & 3.2218 & 4.0604 & TRN & \\
\hline
\end{tabular}




\begin{tabular}{|c|c|c|c|c|}
\hline \multicolumn{5}{|c|}{ Supplemental Table s2.txt } \\
\hline CHEMBL1539600 & 688233 & 3.2218 & 3.6084 & TRN \\
\hline CHEMBL607140 & 688233 & 6.2652 & 6.1484 & TRN \\
\hline CHEMBL1427431 & 688233 & 3.5229 & 4.2143 & TRN \\
\hline CHEMBL1542506 & 688233 & 3.2218 & 3.0833 & TRN \\
\hline CHEMBL1440235 & 688233 & 3.2218 & 3.8775 & TRN \\
\hline CHEMBL1350342 & 688233 & 3.2218 & 3.5046 & TRN \\
\hline CHEMBL1989315 & 688233 & 3.2218 & 3.5358 & TRN \\
\hline CHEMBL1580434 & 688233 & 5.1733 & 4.6258 & TRN \\
\hline CHEMBL1561001 & 688233 & 3.5229 & 3.2361 & TST \\
\hline CHEMBL1463188 & 688233 & 3.2218 & 3.1907 & TRN \\
\hline CHEMBL1443205 & 688233 & 5.6492 & 4.8735 & TRN \\
\hline CHEMBL1593023 & 688233 & 3.2218 & 3.6328 & TST \\
\hline CHEMBL1595133 & 688233 & 3.2218 & 3.7955 & TST \\
\hline CHEMBL3192651 & 688233 & 3.2218 & 3.7163 & TRN \\
\hline CHEMBL1457884 & 688233 & 3.2218 & 3.5631 & TRN \\
\hline CHEMBL1304120 & 688233 & 3.2218 & 3.11 & TRN \\
\hline CHEMBL1609900 & 688233 & 3.2218 & 2.9556 & TRN \\
\hline CHEMBL1377730 & 688233 & 3.2218 & 3.1619 & TST \\
\hline CHEMBL1511950 & 688233 & 3.2218 & 3.6542 & TRN \\
\hline CHEMBL1555681 & 688233 & 3.2218 & 3.6684 & TRN \\
\hline CHEMBL1375345 & 688233 & 3.5229 & 3.3121 & TST \\
\hline CHEMBL1386607 & 688233 & 3.2218 & 3.3977 & TRN \\
\hline CHEMBL3199335 & 688233 & 5.0613 & 4.5276 & TRN \\
\hline CHEMBL1302055 & 688233 & 3.5229 & 3.7147 & TRN \\
\hline CHEMBL 234180 & 688233 & 3.2218 & 4.003 & TRN \\
\hline CHEMBL1304179 & 688233 & 3.2218 & 3.2068 & TRN \\
\hline CHEMBL3196736 & 688233 & 4.9651 & 3.9832 & TST \\
\hline CHEMBL 3189867 & 688233 & 3.2218 & 2.9598 & TRN \\
\hline CHEMBL1416569 & 688233 & 3.5229 & 3.4815 & TRN \\
\hline CHEMBL1399175 & 688233 & 3.5229 & 3.8948 & TST \\
\hline CHEMBL577662 & 688233 & 4.599 & 3.8387 & TRN \\
\hline CHEMBL1431408 & 688233 & 3.2218 & 3.2519 & TRN \\
\hline CHEMBL1520374 & 688233 & 3.2218 & 3.6267 & TRN \\
\hline CHEMBL1440037 & 688233 & 3.2218 & 4.1498 & TRN \\
\hline CHEMBL1498941 & 688233 & 5.2366 & 4.2356 & TRN \\
\hline CHEMBL1459296 & 688233 & 3.2218 & 3.6482 & TRN \\
\hline CHEMBL1444041 & 688233 & 4.5978 & 3.824 & TST \\
\hline CHEMBL1322673 & 688233 & 5.3019 & 3.6716 & TRN \\
\hline CHEMBL1513403 & 688233 & 3.2218 & 3.5145 & TRN \\
\hline CHEMBL349417 & 688233 & 3.2218 & 3.7507 & TRN \\
\hline CHEMBL1609264 & 688233 & 5.4698 & 5.1288 & TRN \\
\hline CHEMBL1403514 & 688233 & 3.2218 & 3.3408 & TRN \\
\hline CHEMBL1606330 & 688233 & 5.025 & 3.74 & TST \\
\hline CHEMBL1391835 & 688233 & 3.2218 & 3.3296 & TRN \\
\hline CHEMBL1398630 & 688233 & 4.6178 & 3.2488 & TRN \\
\hline CHEMBL1366055 & 688233 & 5.0971 & 4.7648 & TRN \\
\hline CHEMBL1376053 & 688233 & 3.2218 & 3.7274 & TST \\
\hline CHEMBL1452858 & 688233 & 3.2218 & 4.1465 & TRN \\
\hline
\end{tabular}


Supplemental Table S2.txt

\begin{tabular}{|c|c|c|c|c|c|}
\hline CHEMBL1458468 & 688233 & 5.3162 & 3.9167 & TST & \\
\hline CHEMBL1494201 & 688233 & 3.5229 & 3.2795 & TST & \\
\hline CHEMBL1382621 & 688233 & 3.2218 & 3.7674 & TRN & \\
\hline CHEMBL1333987 & 688233 & 5.1578 & 4.8108 & TRN & \\
\hline CHEMBL1377273 & 688233 & 3.2218 & 3.3531 & TRN & \\
\hline CHEMBL1485727 & 688233 & 3.2218 & 3.3433 & TST & \\
\hline CHEMBL1409883 & 688233 & \multicolumn{2}{|c|}{5.656000000000001} & 4.6613 & TST \\
\hline CHEMBL1453212 & 688233 & 5.3114 & 4.3221 & TST & \\
\hline CHEMBL1504569 & 688233 & 5.1271 & 5.6669 & TRN & \\
\hline CHEMBL1429263 & 688233 & 3.2218 & 2.8704 & TST & \\
\hline CHEMBL1550144 & 688233 & 3.5229 & 3.6497 & TRN & \\
\hline CHEMBL1342420 & 688233 & 3.2218 & 3.5162 & TRN & \\
\hline CHEMBL1517864 & 688233 & 3.5229 & 3.9663 & TRN & \\
\hline CHEMBL1470789 & 688233 & 3.2218 & 3.2301 & TRN & \\
\hline CHEMBL3199594 & 688233 & 3.5229 & 3.5491 & TRN & \\
\hline CHEMBL1489017 & 688233 & 3.2218 & 3.2918 & TRN & \\
\hline CHEMBL1446405 & 688233 & 5.2929 & 3.9742 & TRN & \\
\hline CHEMBL1374393 & 688233 & 5.0101 & 3.9566 & TRN & \\
\hline CHEMBL1586028 & 688233 & 3.2218 & 3.3277 & TST & \\
\hline CHEMBL1553215 & 688233 & 5.0383 & 3.8049 & TST & \\
\hline CHEMBL1563709 & 688233 & 3.5229 & 3.3839 & TRN & \\
\hline CHEMBL1607290 & 688233 & 3.2218 & 3.1914 & TRN & \\
\hline CHEMBL1574150 & 688233 & 3.5229 & 3.4507 & TRN & \\
\hline CHEMBL1509707 & 688233 & 4.8519 & 3.8268 & TRN & \\
\hline CHEMBL1563257 & 688233 & 5.229 & 4.0342 & TRN & \\
\hline CHEMBL1578834 & 688233 & 3.2218 & 3.4456 & TST & \\
\hline CHEMBL1576927 & 688233 & 3.2218 & 3.6711 & TRN & \\
\hline CHEMBL1500719 & 688233 & 3.5229 & 3.69100 & 30000000003 & \\
\hline CHEMBL1371343 & 688233 & 3.2218 & 3.3333 & TRN & \\
\hline CHEMBL1537553 & 688233 & 5.2751 & 4.4569 & TST & \\
\hline CHEMBL1304169 & 688233 & 3.5229 & 3.7003 & TRN & \\
\hline CHEMBL1399982 & 688233 & 5.3563 & 3.8844 & TRN & \\
\hline CHEMBL590665 & 688233 & 6.2441 & 6.0927 & TRN & \\
\hline CHEMBL1333111 & 688233 & 3.2218 & 3.4212 & TRN & \\
\hline CHEMBL1576905 & 688233 & 3.2218 & 3.3642 & TRN & \\
\hline CHEMBL1473233 & 688233 & 3.2218 & 3.4888 & TRN & \\
\hline CHEMBL1496972 & 688233 & 3.2218 & 3.48100 & 00000000003 & \\
\hline CHEMBL1480738 & 688233 & 4.9746 & 3.862 & TST & \\
\hline CHEMBL1519558 & 688233 & 3.2218 & 3.1755 & TRN & \\
\hline CHEMBL1304058 & 688233 & 3.2218 & 3.5035 & TRN & \\
\hline CHEMBL1359166 & 688233 & 3.2218 & 3.1889 & TRN & \\
\hline CHEMBL1309847 & 688233 & 5.2963 & 3.7565 & TST & \\
\hline CHEMBL1537990 & 688233 & 3.5229 & 3.5522 & TRN & \\
\hline CHEMBL1308823 & 688233 & 3.2218 & 3.54 & TRN & \\
\hline CHEMBL1418631 & 688233 & 3.2218 & 3.3419 & TRN & \\
\hline CHEMBL1338780 & 688233 & 3.5229 & 3.2937 & TRN & \\
\hline CHEMBL3211531 & 688233 & 3.2218 & 3.7837 & TRN & \\
\hline CHEMBL3194794 & 688233 & 3.2218 & 3.4626 & TRN & \\
\hline
\end{tabular}

Page 12655 
Supplemental Table S2.txt

$\begin{array}{lllll}\text { CHEMBL1482998 } & 688233 & 3.2218 & 4.0905 & \text { TST } \\ \text { CHEMBL1373654 } & 688233 & 3.2218 & 3.2106 & \text { TST } \\ \text { CHEMBL1580259 } & 688233 & 3.5229 & 3.5241 & \text { TST } \\ \text { CHEMBL1327264 } & 688233 & 3.2218 & 3.3171 & \text { TRN } \\ \text { CHEMBL1583911 } & 688233 & 3.2218 & 3.9402 & \text { TST } \\ \text { CHEMBL1350432 } & 688233 & 4.8431 & 3.8994 & \text { TST } \\ \text { CHEMBL1975652 } & 688233 & 3.2218 & 3.4289 & \text { TRN } \\ \text { CHEMBL1465021 } & 688233 & 3.2218 & 3.0587 & \text { TRN } \\ \text { CHEMBL1603615 } & 688233 & 6.2218 & 4.0892 & \text { TRN } \\ \text { CHEMBL1468556 } & 688233 & 3.2218 & 3.7401 & \text { TRN } \\ \text { CHEMBL1483481 } & 688233 & 3.2218 & 3.7897 & \text { TRN } \\ \text { CHEMBL1524605 } & 688233 & 3.2218 & 3.3025 & \text { TRN } \\ \text { CHEMBL1428768 } & 688233 & 3.2218 & 3.3798 & \text { TRN } \\ \text { CHEMBL1384438 } & 688233 & 3.2218 & 3.7712 & \text { TRN } \\ \text { CHEMBL3190712 } & 688233 & 3.2218 & 4.0531 & \text { TRN } \\ \text { CHEMBL1571635 } & 688233 & 3.5229 & 3.4017 & \text { TRN } \\ \text { CHEMBL1408058 } & 688233 & 3.2218 & 3.9094 & \text { TST } \\ \text { CHEMBL1606863 } & 688233 & 3.5229 & 4.3648 & \text { TRN } \\ \text { CHEMBL1415769 } & 688233 & 3.2218 & 3.6206 & \text { TRN } \\ \text { CHEMBL1343101 } & 688233 & 3.2218 & 4.2369 & \text { TST } \\ \text { CHEMBL1313522 } & 688233 & 4.6531 & 3.9364 & \text { TRN } \\ \text { CHEMBL1592705 } & 688233 & 3.2218 & 3.5725 & \text { TRN } \\ \text { CHEMBL1540089 } & 688233 & 3.2218 & 3.945 & \text { TST } \\ \text { CHEMBL516194 } & 688233 & 3.5229 & 4.3031 & \text { TRN } \\ \text { CHEMBL1343034 } & 688233 & 3.2218 & 3.8513 & \text { TRN } \\ \text { CHEMBL1365519 } & 688233 & 5.1281 & 4.1794 & \text { TST } \\ \text { CHEMBL2001950 } & 688233 & 3.2218 & 3.8331 & \text { TRN } \\ \text { CHEMBL1433185 } & 688233 & 4.9462 & 4.0797 & \text { TRN } \\ \text { CHEMBL1510342 } & 688233 & 3.2218 & 3.5979 & \text { TRN } \\ \text { CHEMBL1441481 } & 688233 & 3.2218 & 3.6145 & \text { TRN } \\ \text { CHEMBL1341810 } & 6888233 & 3.2218 & 3.7184 & \text { TRN } \\ \text { CHEMBL1588531 } & 688233 & 3.2218 & 3.4755 & \text { TRN } \\ \text { CHEMBL3212702 } & 688233 & 4.801 & 3.4823 & \text { TST } \\ \text { CHEMBL1602006 } & 688233 & 3.2218 & 3.1807 & \text { TRN } \\ \text { CHEMEMB } 1493027 & 6888233 & 3.2218 & 4.2325 & \text { TST }\end{array}$

Page 12656 
Supplemental Table S2.txt

\begin{tabular}{|c|c|c|c|c|}
\hline 21 & & 851 & & \\
\hline HГMD 119010 & & 3.2218 & 3.0193 & \\
\hline 589 & & & & \\
\hline AEMBL31S & & 2218 & & \\
\hline AEMBL1365247 & 8233 & 5229 & 9706 & \\
\hline HEMBL1340919 & 88233 & .2218 & 7848 & \\
\hline HEMBL14 & & & & \\
\hline IFMRI 13 & & & & $\mathrm{RN}$ \\
\hline HEMBL151 & 33 & 2218 & & \\
\hline HEMBL600100 & 88233 & 37 & 7244 & \\
\hline HEMBL1455181 & 3 & 18 & & \\
\hline IEMBL14 & & 29 & & \\
\hline IEMBL 14 & & & & \\
\hline HEMBL131 & & .2218 & & \\
\hline HEMBL133 & & & & \\
\hline AEMBL15 & 3 & 29 & & \\
\hline HEMBL14 & & & & \\
\hline HEMBL13 & & & & \\
\hline HEMBL16€ & & & & \\
\hline AEMBL 31 & & & & \\
\hline AEMBL14 & & & & \\
\hline HEMBL 32 & & & & . \\
\hline HEMBL 14 & & & & \\
\hline HEMBL146 & & & & \\
\hline HEMBL161 & & & & \\
\hline HEMBL13 & & & & $\cdot$ \\
\hline HEMBL15 & & & & RN \\
\hline HFMBI 19 & & 52 & & \\
\hline HEMBL131 & & & & 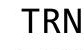 \\
\hline HEMBL132 & & & & ( \\
\hline HEMBL16 & & & & RN \\
\hline HEMBL: & & 3 & & KIV \\
\hline HFMRI 1 & & 9 & & \\
\hline HEMBL 321 & & & & is \\
\hline HEMBL1984190 & & 18 & & TRN \\
\hline HEMBL1 & & & & RN \\
\hline HEMDI 10 & & 8 & & \\
\hline HEMBL 13 & & & & TRN \\
\hline HEMBL1490222 & 88233 & 75 & & TRN \\
\hline AEMBL15 & & & & TST \\
\hline HEMBL14 & & & & IST \\
\hline CHEMBL14 & & 3.2218 & & TRN \\
\hline HEMBL14 & & & & RN \\
\hline HEMBL31906 & 33 & 18 & 18 & P \\
\hline HEMBL138 & & 2 & & \\
\hline CHEMBL 14 & & & & \\
\hline CHEMBL15234 & & 5.3665 & 3.8373 & \\
\hline HEMBL1323306 & 688233 & 3.2218 & 3.573 & \\
\hline
\end{tabular}

Page 12657 


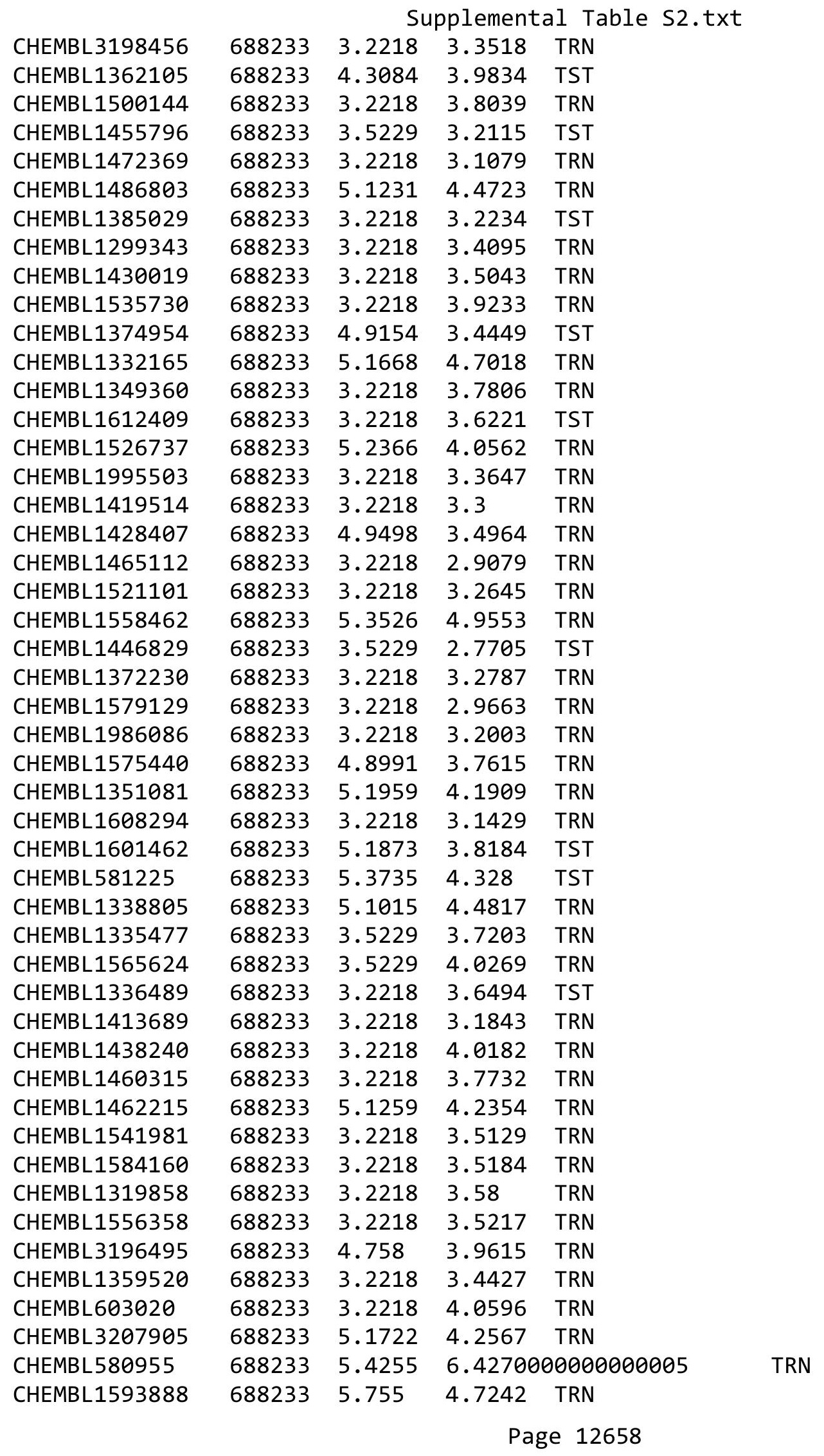




\begin{tabular}{|c|c|c|c|c|}
\hline \multicolumn{5}{|c|}{ Supplemental Table s2.txt } \\
\hline CHEMBL1970368 & 688233 & 3.2218 & 4.4425 & TRN \\
\hline CHEMBL1421670 & 688233 & 5.5751 & 3.8231 & TST \\
\hline CHEMBL1328240 & 688233 & 5.1941 & 4.004 & TRN \\
\hline CHEMBL3190901 & 688233 & 3.2218 & 3.7533 & TRN \\
\hline CHEMBL1332089 & 688233 & 3.2218 & 3.2937 & TRN \\
\hline CHEMBL1369125 & 688233 & 3.2218 & 3.6154 & TRN \\
\hline CHEMBL1609419 & 688233 & 5.4365 & 4.9081 & TRN \\
\hline CHEMBL1348135 & 688233 & 5.0918 & 3.5217 & TRN \\
\hline CHEMBL1527604 & 688233 & 3.2218 & 3.0524 & TRN \\
\hline CHEMBL1480313 & 688233 & 3.2218 & 4.0732 & TST \\
\hline CHEMBL1588345 & 688233 & 3.2218 & 3.8916 & TRN \\
\hline CHEMBL1531073 & 688233 & 5.8022 & 4.4127 & TST \\
\hline CHEMBL1580897 & 688233 & 3.5229 & 3.4643 & TRN \\
\hline CHEMBL3193077 & 688233 & 3.2218 & 3.4594 & TRN \\
\hline CHEMBL1446052 & 688233 & 4.6689 & 3.4096 & TST \\
\hline CHEMBL1367706 & 688233 & 5.3489 & 3.8047 & TRN \\
\hline CHEMBL1549732 & 688233 & 3.2218 & 2.9824 & TRN \\
\hline CHEMBL1526462 & 688233 & 3.2218 & 3.9195 & TRN \\
\hline CHEMBL 1458277 & 688233 & 3.2218 & 3.2167 & TST \\
\hline CHEMBL1429312 & 688233 & 3.2218 & 4.1896 & TRN \\
\hline CHEMBL1381355 & 688233 & 3.2218 & 3.1139 & TRN \\
\hline CHEMBL1506021 & 688233 & 3.2218 & 3.1766 & TST \\
\hline CHEMBL3207955 & 688233 & 3.2218 & 3.5663 & TRN \\
\hline CHEMBL1388405 & 688233 & 3.2218 & 3.9387 & TRN \\
\hline CHEMBL1509065 & 688233 & 5.3498 & 5.2611 & TRN \\
\hline CHEMBL1363108 & 688233 & 4.9845 & 3.6952 & TRN \\
\hline CHEMBL1532766 & 688233 & 3.5229 & 3.2397 & TRN \\
\hline CHEMBL1412271 & 688233 & 4.6661 & 3.7388 & TRN \\
\hline CHEMBL1543470 & 688233 & 5.0212 & 3.7229 & TRN \\
\hline CHEMBL1404976 & 688233 & 3.2218 & 3.9481 & TST \\
\hline CHEMBL1424546 & 688233 & 3.2218 & 3.1812 & TRN \\
\hline CHEMBL1377644 & 688233 & 4.6586 & 3.4256 & TRN \\
\hline CHEMBL 3194114 & 688233 & 3.2218 & 3.6182 & TRN \\
\hline CHEMBL1327702 & 688233 & 3.2218 & 3.8148 & TRN \\
\hline CHEMBL1586659 & 688233 & 4.9794 & 3.6637 & TRN \\
\hline CHEMBL1426831 & 688233 & 3.2218 & 3.8595 & TRN \\
\hline CHEMBL1493788 & 688233 & 3.2218 & 3.8162 & TRN \\
\hline CHEMBL1608531 & 688233 & 3.2218 & 3.4512 & TRN \\
\hline CHEMBL1403575 & 688233 & 5.0084 & 3.9447 & TRN \\
\hline CHEMBL1575081 & 688233 & 3.2218 & 3.8799 & TRN \\
\hline CHEMBL1387605 & 688233 & 5.8952 & 4.898 & TRN \\
\hline CHEMBL1365141 & 688233 & 3.2218 & 3.2928 & TRN \\
\hline CHEMBL1540122 & 688233 & 3.2218 & 4.2168 & TRN \\
\hline CHEMBL1581901 & 688233 & 3.5229 & 3.3137 & TRN \\
\hline CHEMBL1578702 & 688233 & 3.2218 & 3.5477 & TRN \\
\hline CHEMBL2369277 & 688233 & 3.2218 & 3.9182 & TRN \\
\hline CHEMBL1411104 & 688233 & 3.2218 & 3.5413 & TRN \\
\hline CHEMBL1580498 & 688233 & 3.5229 & 3.2059 & TRN \\
\hline
\end{tabular}


Supplemental Table S2.txt

\begin{tabular}{|c|c|c|c|c|c|}
\hline CHEMBL1369642 & 688233 & 3.2218 & 3.0046 & TRN & \\
\hline CHEMBL1343868 & 688233 & 3.2218 & 3.0639 & TST & \\
\hline CHEMBL1582357 & 688233 & 3.5229 & 3.6449 & TRN & \\
\hline CHEMBL355318 & 688233 & 3.2218 & 3.4619 & TRN & \\
\hline CHEMBL 1462240 & 688233 & 3.2218 & 3.8943 & TRN & \\
\hline CHEMBL1347533 & 688233 & 3.5229 & 4.0573 & TRN & \\
\hline CHEMBL1387962 & 688233 & 3.2218 & 3.3238 & TST & \\
\hline CHEMBL1537379 & 688233 & 3.2218 & 3.8107 & TRN & \\
\hline CHEMBL1347673 & 688233 & 3.2218 & 3.5376 & TST & \\
\hline CHEMBL1478087 & 688233 & 3.2218 & 3.75100 & 00000000003 & TRN \\
\hline CHEMBL1371831 & 688233 & 3.2218 & 3.4259 & TRN & \\
\hline CHEMBL1393267 & 688233 & 4.9752 & 3.8405 & TRN & \\
\hline CHEMBL1419329 & 688233 & 3.2218 & 3.5992 & TRN & \\
\hline CHEMBL532239 & 688233 & 3.5229 & 3.9163 & TRN & \\
\hline CHEMBL1375373 & 688233 & 3.2218 & 4.984 & TRN & \\
\hline CHEMBL1513196 & 688233 & 3.2218 & 3.2421 & TRN & \\
\hline CHEMBL1440247 & 688233 & 3.2218 & 3.4174 & TRN & \\
\hline CHEMBL1388072 & 688233 & 3.2218 & 4.0538 & TRN & \\
\hline CHEMBL3192460 & 688233 & 3.2218 & 3.3622 & TST & \\
\hline CHEMBL1538511 & 688233 & 3.2218 & 3.0658 & TRN & \\
\hline CHEMBL1386031 & 688233 & 3.2218 & 3.8891 & TRN & \\
\hline CHEMBL1495419 & 688233 & 3.2218 & 4.0081 & TRN & \\
\hline CHEMBL1542883 & 688233 & 4.9669 & 3.6135 & TRN & \\
\hline CHEMBL1497588 & 688233 & 3.2218 & 4.0411 & TST & \\
\hline CHEMBL 1424867 & 688233 & 3.2218 & 3.3722 & TRN & \\
\hline CHEMBL1443040 & 688233 & 3.2218 & 3.6788 & TRN & \\
\hline CHEMBL1335703 & 688233 & 5.0234 & 4.2882 & TRN & \\
\hline CHEMBL3212271 & 688233 & 5.1603 & 5.4395 & TRN & \\
\hline CHEMBL3189808 & 688233 & 3.2218 & 2.9326 & TST & \\
\hline CHEMBL1391672 & 688233 & 3.2218 & \multicolumn{2}{|c|}{3.6239999999999997} & TRN \\
\hline CHEMBL1408009 & 688233 & 3.2218 & 3.866 & TRN & \\
\hline CHEMBL1505781 & 688233 & 3.5229 & 3.0359 & TRN & \\
\hline CHEMBL1317657 & 688233 & 5.3646 & 4.6524 & TST & \\
\hline CHEMBL1570769 & 688233 & 4.5237 & 4.2799 & TRN & \\
\hline CHEMBL 1498473 & 688233 & 3.2218 & 3.7897 & TST & \\
\hline CHEMBL1504216 & 688233 & 3.2218 & 3.0975 & TRN & \\
\hline CHEMBL1529180 & 688233 & 3.2218 & 3.6912 & TRN & \\
\hline CHEMBL1469636 & 688233 & 3.2218 & 3.4846 & TRN & \\
\hline CHEMBL1452711 & 688233 & 5.0954 & 4.8888 & TRN & \\
\hline CHEMBL1402922 & 688233 & 3.2218 & 3.7191 & TRN & \\
\hline CHEMBL1326449 & 688233 & 3.2218 & 3.6006 & TRN & \\
\hline CHEMBL1303653 & 688233 & 4.9629 & 4.011 & TRN & \\
\hline CHEMBL1977424 & 688233 & 3.2218 & 4.6368 & TRN & \\
\hline CHEMBL1438971 & 688233 & 4.6223 & 3.1882 & TRN & \\
\hline CHEMBL1455877 & 688233 & 3.5229 & 3.4562 & TRN & \\
\hline CHEMBL1333271 & 688233 & 4.6948 & 4.3561 & TRN & \\
\hline CHEMBL 1428228 & 688233 & 3.2218 & 4.1779 & TRN & \\
\hline CHEMBL3189272 & 688233 & 3.2218 & 4.4074 & TST & \\
\hline
\end{tabular}


Supplemental Table S2.txt

\begin{tabular}{|c|c|c|c|c|}
\hline CHEMBL1390716 & 688233 & 5.2362 & 5.1832 & TST \\
\hline CHEMBL1367596 & 688233 & 3.2218 & 3.8364 & TRN \\
\hline CHEMBL1403654 & 688233 & 3.5229 & 4.1252 & TRN \\
\hline CHEMBL1391330 & 688233 & 3.2218 & 3.8176 & TST \\
\hline CHEMBL1360998 & 688233 & 5.2854 & 3.6524 & TST \\
\hline CHEMBL1406399 & 688233 & 3.2218 & 3.3124 & TRN \\
\hline CHEMBL1420664 & 688233 & 3.2218 & 3.1683 & TRN \\
\hline CHEMBL1454364 & 688233 & 3.2218 & 3.6805 & TRN \\
\hline CHEMBL1566084 & 688233 & 5.2556 & 4.7031 & TRN \\
\hline CHEMBL1573692 & 688233 & 3.2218 & 3.1226 & TRN \\
\hline CHEMBL3197928 & 688233 & 4.755 & 3.5992 & TRN \\
\hline CHEMBL1505746 & 688233 & 5.1041 & 3.7218 & TRN \\
\hline CHEMBL3191730 & 688233 & 5.4015 & 4.7241 & TRN \\
\hline CHEMBL1347339 & 688233 & 3.2218 & 3.7598 & TRN \\
\hline CHEMBL1348964 & 688233 & 3.5229 & 3.3189 & TST \\
\hline CHEMBL1405869 & 688233 & 3.5229 & 3.5382 & TRN \\
\hline CHEMBL1351445 & 688233 & 3.5229 & 3.554 & TRN \\
\hline CHEMBL1358406 & 688233 & 3.2218 & 3.108 & TST \\
\hline CHEMBL1598631 & 688233 & 3.2218 & 3.7028 & TST \\
\hline CHEMBL3195171 & 688233 & 5.1408 & 5.0329 & TRN \\
\hline CHEMBL1459626 & 688233 & 3.5229 & 3.4095 & TRN \\
\hline CHEMBL1484618 & 688233 & 3.2218 & 3.7672 & TRN \\
\hline CHEMBL1415061 & 688233 & 3.2218 & 3.6654 & TRN \\
\hline CHEMBL1386824 & 688233 & 3.2218 & 4.0923 & TST \\
\hline CHEMBL1994623 & 688233 & 3.5229 & 5.0514 & TRN \\
\hline CHEMBL1516456 & 688233 & 3.2218 & 3.2888 & TRN \\
\hline CHEMBL3209776 & 688233 & 5.0056 & 4.352 & TRN \\
\hline CHEMBL1445650 & 688233 & 5.8395 & 4.7506 & TRN \\
\hline CHEMBL1356472 & 688233 & 3.2218 & 3.6461 & TRN \\
\hline CHEMBL1384573 & 688233 & 3.2218 & 3.9373 & TRN \\
\hline CHEMBL1493490 & 688233 & 5.7815 & 4.4215 & TRN \\
\hline CHEMBL1427603 & 688233 & 3.2218 & 3.4053 & TRN \\
\hline CHEMBL1352375 & 688233 & 3.2218 & 3.4964 & TRN \\
\hline CHEMBL1574469 & 688233 & 3.2218 & 3.3825 & TRN \\
\hline CHEMBL1508826 & 688233 & 3.2218 & 4.2945 & TRN \\
\hline CHEMBL1471845 & 688233 & 5.1991 & 4.2294 & TRN \\
\hline CHEMBL1596097 & 688233 & 3.2218 & 3.3085 & TRN \\
\hline CHEMBL3208118 & 688233 & 3.5229 & 4.1241 & TRN \\
\hline CHEMBL 3213034 & 688233 & 5.2987 & 5.4507 & TRN \\
\hline CHEMBL1476215 & 688233 & 6.3645 & 4.0653 & TRN \\
\hline CHEMBL1485422 & 688233 & 3.2218 & 4.0006 & TST \\
\hline CHEMBL1339538 & 688233 & 5.0233 & 3.3359 & TST \\
\hline CHEMBL1499233 & 688233 & 5.4372 & 5.2044 & TRN \\
\hline CHEMBL1491724 & 688233 & 3.2218 & 4.13899 & 9999999999 \\
\hline CHEMBL1595207 & 688233 & 3.2218 & 3.3402 & TRN \\
\hline CHEMBL1301171 & 688233 & 3.2218 & 3.6696 & TRN \\
\hline CHEMBL1412300 & 688233 & 3.2218 & 3.7291 & TST \\
\hline CHEMBL1312953 & 688233 & 5.226 & 3.4271 & TST \\
\hline
\end{tabular}


Supplemental Table S2.txt

\begin{tabular}{|c|c|c|c|c|c|}
\hline CHEMBL1471737 & 688233 & 3.2218 & 3.2825 & TRN & \\
\hline CHEMBL1601100 & 688233 & 3.5229 & 3.1089 & TRN & \\
\hline CHEMBL1499652 & 688233 & 5.2947 & 3.6088 & TRN & \\
\hline CHEMBL 3195567 & 688233 & 5.0728 & 3.3679 & TRN & \\
\hline CHEMBL1531841 & 688233 & 5.2939 & 4.4317 & TRN & \\
\hline CHEMBL1492096 & 688233 & 3.2218 & 3.3277 & TRN & \\
\hline CHEMBL1351455 & 688233 & 3.2218 & 3.973999 & 99999999998 & TRN \\
\hline CHEMBL2369159 & 688233 & 3.2218 & 3.9487 & TRN & \\
\hline CHEMBL1453314 & 688233 & 3.2218 & 3.5204 & TRN & \\
\hline CHEMBL1584937 & 688233 & 4.3448 & 3.5922 & TRN & \\
\hline CHEMBL1484174 & 688233 & 3.5229 & 3.2317 & TRN & \\
\hline CHEMBL1366187 & 688233 & 3.5229 & 4.08 & TRN & \\
\hline CHEMBL1389053 & 688233 & 3.2218 & 3.3297 & TRN & \\
\hline CHEMBL1511522 & 688233 & 4.2473 & 3.8341 & TRN & \\
\hline CHEMBL1349747 & 688233 & 3.2218 & 3.7273 & TST & \\
\hline CHEMBL1492590 & 688233 & 3.2218 & 3.4756 & TRN & \\
\hline CHEMBL1457690 & 688233 & 3.2218 & 3.4916 & TRN & \\
\hline CHEMBL1391094 & 688233 & 5.2209 & 4.19 & TRN & \\
\hline CHEMBL1582535 & 688233 & 4.9043 & 3.6901 & TRN & \\
\hline CHEMBL1580116 & 688233 & 3.2218 & 3.4215 & TRN & \\
\hline CHEMBL1308687 & 688233 & 3.2218 & 4.3043 & TRN & \\
\hline CHEMBL1525672 & 688233 & 3.2218 & 3.7949 & TRN & \\
\hline CHEMBL1355284 & 688233 & 4.8361 & 3.7554 & TST & \\
\hline CHEMBL 3145019 & 688233 & 3.2218 & 3.9809 & TST & \\
\hline CHEMBL1391958 & 688233 & 4.916 & 4.5482 & TRN & \\
\hline CHEMBL1537810 & 688233 & 3.2218 & 4.1954 & TST & \\
\hline CHEMBL1368429 & 688233 & \multicolumn{3}{|c|}{5.1610000000000005} & TRIV \\
\hline CHEMBL1409950 & 688233 & 3.2218 & 3.1856 & TRN & \\
\hline CHEMBL1535032 & 688233 & 3.2218 & 3.4468 & TST & \\
\hline CHEMBL1542936 & 688233 & 3.2218 & 3.378999 & 99999999996 & m \\
\hline CHEMBL1595704 & 688233 & 3.2218 & 3.0497 & TRN & \\
\hline CHEMBL1515139 & 688233 & 3.2218 & 3.4511 & TRN & \\
\hline CHEMBL 249987 & 688233 & 4.8683 & 4.2602 & TRN & \\
\hline CHEMBL1415310 & 688233 & 3.2218 & 3.8093 & TRN & \\
\hline CHEMBL 3208866 & 688233 & 3.2218 & 3.1028 & TRN & \\
\hline CHEMBL1312654 & 688233 & 4.4848 & 4.7745 & TRN & \\
\hline CHEMBL1529190 & 688233 & 5.3732 & 5.8557 & TRN & \\
\hline CHEMBL1314461 & 688233 & 3.5229 & 3.7026 & TRN & \\
\hline CHEMBL1454557 & 688233 & 4.896 & 4.315 & TRN & \\
\hline CHEMBL1351388 & 688233 & 3.2218 & 3.7359 & TRN & \\
\hline CHEMBL 3199288 & 688233 & 3.2218 & 3.5484 & TRN & \\
\hline CHEMBL1391965 & 688233 & 5.4115 & 4.1275 & TRN & \\
\hline CHEMBL1346837 & 688233 & 3.2218 & 3.4459 & TRN & \\
\hline CHEMBL1430882 & 688233 & 3.2218 & 3.5146 & TRN & \\
\hline CHEMBL162347 & 688233 & 4.8824 & 4.0138 & TRN & \\
\hline CHEMBL1364978 & 688233 & 3.2218 & 4.2037 & TRN & \\
\hline CHEMBL1437673 & 688233 & 4.7507 & 3.2882 & TST & \\
\hline CHEMBL 3194060 & 688233 & 5.0479 & 4.0902 & TRN & \\
\hline
\end{tabular}

Page 12662 
Supplemental Table S2.txt

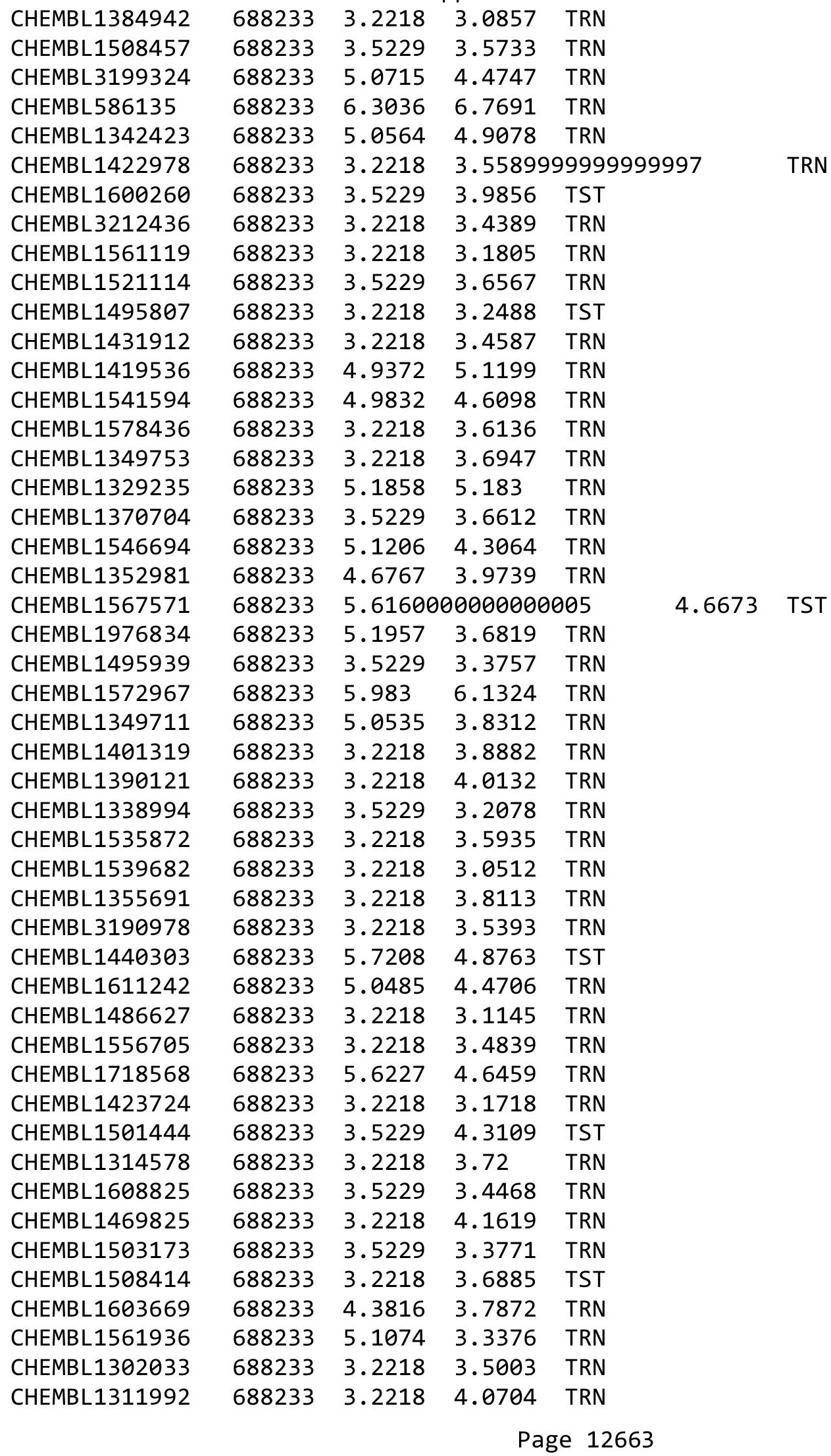




\begin{tabular}{|c|c|c|c|c|}
\hline \multicolumn{5}{|c|}{ Supplemental Table s2.txt } \\
\hline CHEMBL1449040 & 688233 & 5.4585 & 4.8191 & TRN \\
\hline CHEMBL1304427 & 688233 & 3.2218 & 3.3332 & TRN \\
\hline CHEMBL1447341 & 688233 & 5.7231 & 6.6558 & TRN \\
\hline CHEMBL1589770 & 688233 & 3.5229 & 3.5375 & TRN \\
\hline CHEMBL1497771 & 688233 & 3.5229 & 3.3956 & TRN \\
\hline CHEMBL1335899 & 688233 & 3.2218 & 3.4215 & TRN \\
\hline CHEMBL1370221 & 688233 & 5.0193 & 3.7458 & TRN \\
\hline CHEMBL1309980 & 688233 & 4.9423 & 3.6971 & TRN \\
\hline CHEMBL1321294 & 688233 & 5.0423 & 3.404 & TRN \\
\hline CHEMBL1445850 & 688233 & 3.5229 & 3.9285 & TRN \\
\hline CHEMBL1410618 & 688233 & 5.0819 & 4.7152 & TRN \\
\hline CHEMBL1509719 & 688233 & 3.2218 & 3.8421 & TRN \\
\hline CHEMBL1509365 & 688233 & 3.2218 & 3.2451 & TRN \\
\hline CHEMBL1427661 & 688233 & 3.2218 & 4.0201 & TRN \\
\hline CHEMBL1556468 & 688233 & 3.2218 & 3.4856 & TRN \\
\hline CHEMBL3195863 & 688233 & 3.5229 & 4.1831 & TRN \\
\hline CHEMBL1376864 & 688233 & 3.2218 & 3.4554 & TRN \\
\hline CHEMBL 3210550 & 688233 & 3.2218 & 3.068 & TRN \\
\hline CHEMBL1419572 & 688233 & 3.2218 & 3.6021 & TRN \\
\hline CHEMBL1520936 & 688233 & 4.3148 & 3.4396 & TRN \\
\hline CHEMBL1393059 & 688233 & 3.2218 & 3.4055 & TRN \\
\hline CHEMBL1393349 & 688233 & 3.2218 & 3.4381 & TRN \\
\hline CHEMBL1341145 & 688233 & 3.2218 & 3.1809 & TRN \\
\hline CHEMBL 229150 & 688233 & 3.2218 & 3.6712 & TRN \\
\hline CHEMBL1496534 & 688233 & 5.3227 & 4.2616 & TRN \\
\hline CHEMBL1580339 & 688233 & 4.9213 & 3.6997 & TRN \\
\hline CHEMBL1332396 & 688233 & 3.2218 & 3.7564 & TRN \\
\hline CHEMBL1557945 & 688233 & 3.2218 & 3.5489 & TRN \\
\hline CHEMBL1429418 & 688233 & 4.938 & 3.9958 & TRN \\
\hline CHEMBL1431917 & 688233 & 3.2218 & 2.835 & TRN \\
\hline CHEMBL1507774 & 688233 & 5.1608 & 4.2553 & TRN \\
\hline CHEMBL1351116 & 688233 & 3.5229 & 3.3677 & TRN \\
\hline CHEMBL1518678 & 688233 & 3.2218 & 3.12 & TRN \\
\hline CHEMBL1531615 & 688233 & 3.2218 & 3.6897 & TRN \\
\hline CHEMBL1413494 & 688233 & 3.2218 & 3.7188 & TRN \\
\hline CHEMBL1522083 & 688233 & 3.2218 & 3.3789 & TRN \\
\hline CHEMBL1557906 & 688233 & 3.2218 & 3.2128 & TRN \\
\hline CHEMBL1393490 & 688233 & 5.0344 & 3.8493 & TRN \\
\hline CHEMBL1424307 & 688233 & 5.0086 & 3.903 & TRN \\
\hline CHEMBL1347724 & 688233 & 3.5229 & 3.6385 & TRN \\
\hline CHEMBL1423941 & 688233 & 3.2218 & 2.8498 & TRN \\
\hline CHEMBL1505248 & 688233 & 3.2218 & 3.7774 & TST \\
\hline CHEMBL1477538 & 688233 & 4.9728 & 4.15 & TRN \\
\hline CHEMBL1399928 & 688233 & 3.2218 & 3.8886 & TST \\
\hline CHEMBL1414529 & 688233 & 3.2218 & 3.4982 & TRN \\
\hline CHEMBL1492769 & 688233 & 3.2218 & 3.2376 & TRN \\
\hline CHEMBL1506248 & 688233 & 3.2218 & 3.6957 & TRN \\
\hline CHEMBL1393813 & 688233 & 3.5229 & 4.7229 & TRN \\
\hline
\end{tabular}


Supplemental Table S2.txt

\begin{tabular}{|c|c|c|c|c|}
\hline CHEMBL1491932 & 688233 & 5.3488 & 3.9918 & TST \\
\hline CHEMBL1369226 & 688233 & 3.2218 & 4.2762 & TRN \\
\hline CHEMBL1423723 & 688233 & 3.2218 & 3.7124 & TST \\
\hline CHEMBL1405052 & 688233 & 3.2218 & 3.4303 & TRN \\
\hline CHEMBL 3190849 & 688233 & 5.1045 & 3.7805 & TRN \\
\hline CHEMBL1597693 & 688233 & 3.2218 & 3.2519 & TRN \\
\hline CHEMBL 3856089 & 688233 & 3.2218 & 3.9115 & TST \\
\hline CHEMBL1447188 & 688233 & 3.7959 & 3.5875 & TRN \\
\hline CHEMBL1340188 & 688233 & 3.2218 & 3.5961 & TRN \\
\hline CHEMBL602718 & 688233 & 5.7778 & 5.9003 & TRN \\
\hline CHEMBL1477071 & 688233 & 3.2218 & 3.6449 & TST \\
\hline CHEMBL1444246 & 688233 & 3.5229 & 3.6166 & TRN \\
\hline CHEMBL1519873 & 688233 & 3.2218 & 4.0145 & TRN \\
\hline CHEMBL1411665 & 688233 & 5.4123 & 4.1595 & TRN \\
\hline CHEMBL1586770 & 688233 & 3.2218 & 3.9189 & TST \\
\hline CHEMBL1465813 & 688233 & 3.2218 & 3.2908 & TRN \\
\hline CHEMBL1484987 & 688233 & 3.2218 & 3.1382 & TRN \\
\hline CHEMBL1348243 & 688233 & 3.5229 & 3.5055 & TRN \\
\hline CHEMBL1528103 & 688233 & 3.5229 & 3.5976 & TRN \\
\hline CHEMBL1351537 & 688233 & 3.5229 & 3.3041 & TRN \\
\hline CHEMBL1544409 & 688233 & 5.5278 & 3.955 & TRN \\
\hline CHEMBL1376605 & 688233 & 3.2218 & 4.1231 & TST \\
\hline CHEMBL1987472 & 688233 & 4.9888 & 5.1202 & TRN \\
\hline CHEMBL1527929 & 688233 & 5.0525 & 3.7245 & TST \\
\hline CHEMBL1609910 & 688233 & 3.2218 & 3.3877 & TRN \\
\hline CHEMBL1434502 & 688233 & 5.3744 & 3.8231 & TRN \\
\hline CHEMBL1525098 & 688233 & 5.153 & 4.1124 & TRN \\
\hline CHEMBL1395305 & 688233 & 3.2218 & 3.4709 & TRN \\
\hline CHEMBL1389078 & 688233 & 4.8004 & 3.4438 & TRN \\
\hline CHEMBL1337833 & 688233 & 3.2218 & 3.6041 & TRN \\
\hline CHEMBL1578651 & 688233 & 5.0222 & 3.7335 & TRN \\
\hline CHEMBL1612383 & 688233 & 3.2218 & 4.5075 & TRN \\
\hline CHEMBL1413334 & 688233 & 3.5229 & 3.5896 & TRN \\
\hline CHEMBL1300618 & 688233 & 3.2218 & 3.4339 & TRN \\
\hline CHEMBL1527336 & 688233 & 3.2218 & 3.3744 & TRN \\
\hline CHEMBL1426005 & 688233 & 3.2218 & 3.8234 & TRN \\
\hline CHEMBL1586230 & 688233 & 6.2218 & 3.9285 & TRN \\
\hline CHEMBL1343511 & 688233 & 3.2218 & 3.4368 & TST \\
\hline CHEMBL1604779 & 688233 & 3.2218 & 3.4935 & TRN \\
\hline CHEMBL1492280 & 688233 & 3.2218 & 3.7125 & TRN \\
\hline CHEMBL1300840 & 688233 & 3.2218 & 3.3442 & TRN \\
\hline CHEMBL1409364 & 688233 & 3.2218 & 3.8141 & TRN \\
\hline CHEMBL1526628 & 688233 & 3.2218 & 3.8903 & TRN \\
\hline CHEMBL1580066 & 688233 & 3.2218 & 3.8989 & TST \\
\hline CHEMBL1498488 & 688233 & 6.5969 & 5.008999 & 99999999995 \\
\hline CHEMBL1544640 & 688233 & 3.2218 & 3.2877 & TRN \\
\hline CHEMBL1430071 & 688233 & 3.2218 & 3.9257 & TRN \\
\hline CHEMBL1314709 & 688233 & 3.5229 & 3.1793 & TRN \\
\hline
\end{tabular}

Page 12665 


\begin{tabular}{|c|c|c|c|c|c|c|}
\hline CHEMBL1323553 & 688233 & \multicolumn{4}{|c|}{ Supplemental Table S2.txt } & TRN \\
\hline CHEMBL1491019 & 688233 & 5.278 & 5.1745 & TST & & \\
\hline CHEMBL1378814 & 688233 & 3.2218 & 3.221 & TRN & & \\
\hline CHEMBL3194618 & 688233 & 3.2218 & 4.1197 & TRN & & \\
\hline CHEMBL3192656 & 688233 & 5.1324 & 3.6536 & TRN & & \\
\hline CHEMBL1422199 & 688233 & 3.2218 & 3.6236 & TST & & \\
\hline CHEMBL1329502 & 688233 & 3.2218 & 3.2291 & TST & & \\
\hline CHEMBL1581208 & 688233 & 3.2218 & 3.6485 & TRN & & \\
\hline CHEMBL1424169 & 688233 & 5.1814 & 3.9009 & TST & & \\
\hline CHEMBL1325192 & 688233 & 3.2218 & 4.0348 & TRN & & \\
\hline CHEMBL1597604 & 688233 & 3.2218 & 3.8541 & TRN & & \\
\hline CHEMBL1583669 & 688233 & 3.2218 & 3.1681 & TRN & & \\
\hline CHEMBL1458338 & 688233 & 3.2218 & 3.9137 & TST & & \\
\hline CHEMBL1503772 & 688233 & 3.2218 & 3.0837 & TRN & & \\
\hline CHEMBL1583082 & 688233 & 5.1882 & 4.3682 & TRN & & \\
\hline CHEMBL1525720 & 688233 & 3.2218 & 3.4152 & TRN & & \\
\hline CHEMBL1508501 & 688233 & 3.2218 & 3.4136 & TRN & & \\
\hline CHEMBL1334247 & 688233 & 3.5229 & 3.3543 & TRN & & \\
\hline CHEMBL1505371 & 688233 & 3.5229 & 3.6628 & TRN & & \\
\hline CHEMBL1398888 & 688233 & 3.5229 & 3.7516 & TST & & \\
\hline CHEMBL1406270 & 688233 & 3.2218 & 3.4504 & TRN & & \\
\hline CHEMBL1343758 & 688233 & 4.4281 & 3.4206 & TRN & & \\
\hline CHEMBL1422433 & 688233 & 3.2218 & 3.3961 & TRN & & \\
\hline CHEMBL1604217 & 688233 & 5.7908 & 4.6833 & TRN & & \\
\hline CHEMBL1362499 & 688233 & 3.2218 & 3.5871 & TRN & & \\
\hline CHEMBL1387773 & 688233 & 3.5229 & 3.3723 & TRN & & \\
\hline CHEMBL1561080 & 688233 & 3.2218 & 3.3103 & TRN & & \\
\hline CHEMBL1324564 & 688233 & 3.2218 & 3.5502 & TRN & & \\
\hline CHEMBL1546987 & 688233 & 3.2218 & 3.7909 & TRN & & \\
\hline CHEMBL1410160 & 688233 & 3.5229 & 3.2873 & TRN & & \\
\hline CHEMBL1540705 & 688233 & 3.2218 & 3.5005 & TRN & & \\
\hline CHEMBL1531377 & 688233 & 4.4667 & 4.0273 & TRN & & \\
\hline CHEMBL1526855 & 688233 & 5.4872 & 5.0373 & TRN & & \\
\hline CHEMBL1578547 & 688233 & 3.2218 & 3.8985 & TRN & & \\
\hline CHEMBL1548234 & 688233 & 3.2218 & 4.2314 & TRN & & \\
\hline CHEMBL3198812 & 688233 & 5.6461 & 5.101 & TRN & & \\
\hline CHEMBL1399277 & 688233 & 3.2218 & 3.739 & TRN & & \\
\hline CHEMBL1380395 & 688233 & 3.2218 & 3.2134 & TRN & & \\
\hline CHEMBL1505040 & 688233 & 3.5229 & 3.6205 & TST & & \\
\hline CHEMBL1303567 & 688233 & 3.2218 & 3.4217 & TST & & \\
\hline CHEMBL1442145 & 688233 & 3.2218 & 3.3048 & TRN & & \\
\hline CHEMBL1501748 & 688233 & 3.2218 & 3.2046 & TRN & & \\
\hline CHEMBL3195273 & 688233 & 5.3764 & 4.521 & TRN & & \\
\hline CHEMBL1455107 & 688233 & 3.2218 & 3.4981 & TRN & & \\
\hline CHEMBL1354027 & 688233 & 3.2218 & 3.6721 & TST & & \\
\hline CHEMBL1991736 & 688233 & 3.2218 & 3.6702 & TRN & & \\
\hline CHEMBL547285 & 688233 & 6.2306 & 6.13399 & 99999999995 & & TRN \\
\hline CHEMBL1573175 & 688233 & 3.2218 & 3.1774 & TRN & & \\
\hline
\end{tabular}




\begin{tabular}{|c|c|c|c|c|c|}
\hline \multicolumn{6}{|c|}{ Supplemental Table S2.txt } \\
\hline CHEMBL1368909 & 688233 & 3.2218 & 3.6789 & TRN & \\
\hline CHEMBL1315433 & 688233 & 3.2218 & 3.614 & TRN & \\
\hline CHEMBL1424826 & 688233 & 3.2218 & 3.2689 & TRN & \\
\hline CHEMBL1498519 & 688233 & 3.2218 & 3.1437 & TRN & \\
\hline CHEMBL1510761 & 688233 & 5.3449 & 3.807 & TRN & \\
\hline CHEMBL1352127 & 688233 & 3.2218 & 4.0307 & TST & \\
\hline CHEMBL1550449 & 688233 & 4.9094 & 3.0982 & TST & \\
\hline CHEMBL1567646 & 688233 & 3.2218 & 3.3825 & TRN & \\
\hline CHEMBL1414078 & 688233 & 3.5229 & 3.16399 & 99999999997 & TRN \\
\hline CHEMBL1467233 & 688233 & 3.2218 & 3.8575 & TRN & \\
\hline CHEMBL1304951 & 688233 & 3.2218 & 3.036 & TRN & \\
\hline CHEMBL1598571 & 688233 & 3.2218 & 3.418 & TRN & \\
\hline CHEMBL1522064 & 688233 & 3.2218 & 3.3983 & TRN & \\
\hline CHEMBL1324005 & 688233 & 3.2218 & 4.032 & TST & \\
\hline CHEMBL1400809 & 688233 & 3.2218 & 4.0371 & TRN & \\
\hline CHEMBL1327470 & 688233 & 3.2218 & 3.6249 & TST & \\
\hline CHEMBL1378719 & 688233 & 3.2218 & 3.7869 & TRN & \\
\hline CHEMBL1382799 & 688233 & 3.5229 & 3.2295 & TRN & \\
\hline CHEMBL3189925 & 688233 & 3.5229 & 3.5611 & TRN & \\
\hline CHEMBL1532068 & 688233 & 6.3625 & 6.1653 & TRN & \\
\hline CHEMBL1385115 & 688233 & 3.2218 & 3.3877 & TST & \\
\hline CHEMBL1327455 & 688233 & 3.2218 & 3.2386 & TRN & \\
\hline CHEMBL1482740 & 688233 & 3.5229 & 3.6492 & TRN & \\
\hline CHEMBL1307861 & 688233 & 4.9358 & 4.5292 & TRN & \\
\hline CHEMBL3213112 & 688233 & 3.2218 & 3.805 & TST & \\
\hline CHEMBL1571301 & 688233 & 3.2218 & 3.4397 & TRN & \\
\hline CHEMBL3199347 & 688233 & 3.2218 & 3.1765 & TRN & \\
\hline CHEMBL1499282 & 688233 & 3.2218 & 4.8948 & TRN & \\
\hline CHEMBL 28324 & 688233 & 4.9495 & 3.62100 & 00000000004 & TST \\
\hline CHEMBL1348049 & 688233 & 3.5229 & 3.4501 & TST & \\
\hline CHEMBL1993291 & 688233 & 3.2218 & 3.4513 & TRN & \\
\hline CHEMBL1340458 & 688233 & 3.2218 & 3.3881 & TRN & \\
\hline CHEMBL1605660 & 688233 & 3.2218 & 3.6455 & TRN & \\
\hline CHEMBL1412143 & 688233 & 3.2218 & 3.9394 & TRN & \\
\hline CHEMBL1457083 & 688233 & 3.2218 & 3.5083 & TRN & \\
\hline CHEMBL1561313 & 688233 & 3.2218 & 3.9993 & TRN & \\
\hline CHEMBL1428004 & 688233 & 3.2218 & 3.4567 & TRN & \\
\hline CHEMBL1558075 & 688233 & 3.2218 & 3.9558 & TST & \\
\hline CHEMBL1562606 & 688233 & 3.2218 & 3.3033 & TRN & \\
\hline CHEMBL1457718 & 688233 & 3.2218 & 3.594 & TRN & \\
\hline CHEMBL1334036 & 688233 & 3.5229 & 3.4096 & TRN & \\
\hline CHEMBL1303201 & 688233 & 4.5805 & 3.5183 & TRN & \\
\hline CHEMBL3189599 & 688233 & 5.3061 & 4.6892 & TRN & \\
\hline CHEMBL1300857 & 688233 & 3.2218 & 3.6812 & TRN & \\
\hline CHEMBL1411889 & 688233 & 3.2218 & 3.7305 & TRN & \\
\hline CHEMBL1304704 & 688233 & 3.2218 & 4.0292 & TRN & \\
\hline CHEMBL 2094665 & 688233 & 3.2218 & 3.4238 & TRN & \\
\hline CHEMBL1337227 & 688233 & 5.3462 & 5.7067 & TRN & \\
\hline
\end{tabular}




\begin{tabular}{|c|c|c|c|c|c|}
\hline \multicolumn{6}{|c|}{ Supplemental Table S2.txt } \\
\hline CHEMBL1494677 & 688233 & 3.2218 & 3.3635 & TRN & \\
\hline CHEMBL1530499 & 688233 & 3.2218 & 3.2501 & TRN & \\
\hline CHEMBL1518868 & 688233 & 3.2218 & 3.9712 & TST & \\
\hline CHEMBL583351 & 688233 & 3.2218 & 3.3507 & TRN & \\
\hline CHEMBL 1400298 & 688233 & 5.468 & 5.02 & TRN & \\
\hline CHEMBL1354075 & 688233 & 3.2218 & 3.4192 & TRN & \\
\hline CHEMBL1562009 & 688233 & 3.2218 & 3.8667 & TRN & \\
\hline CHEMBL1423138 & 688233 & 5.0942 & 3.5235 & TRN & \\
\hline CHEMBL1364345 & 688233 & 3.2218 & 3.7034 & TST & \\
\hline CHEMBL1482046 & 688233 & 5.0452 & 3.4461 & TRN & \\
\hline CHEMBL579742 & 688233 & 5.0121 & 4.306999 & 99999999995 & TRN \\
\hline CHEMBL1527565 & 688233 & 5.38399 & 999999999 & 3.8811 & TST \\
\hline CHEMBL1512652 & 688233 & 3.2218 & 4.2951 & TRN & \\
\hline CHEMBL1458752 & 688233 & 3.5229 & 3.686000 & 00000000004 & TRN \\
\hline CHEMBL1399698 & 688233 & 5.1677 & 4.6587 & TST & \\
\hline CHEMBL1429930 & 688233 & 3.5229 & 4.07 & TRN & \\
\hline CHEMBL1318143 & 688233 & 3.2218 & 3.9508 & TRN & \\
\hline CHEMBL1607305 & 688233 & 3.5229 & 3.4459 & TRN & \\
\hline CHEMBL1594279 & 688233 & 3.2218 & 3.3976 & TRN & \\
\hline CHEMBL1310319 & 688233 & 4.6465 & 4.0724 & TST & \\
\hline CHEMBL1505727 & 688233 & 3.2218 & 3.9002 & TRN & \\
\hline CHEMBL1405150 & 688233 & 5.9485 & 5.6924 & TRN & \\
\hline CHEMBL3192555 & 688233 & 6.2218 & 6.1611 & TST & \\
\hline CHEMBL1520753 & 688233 & 5.6014 & 5.1396 & TRN & \\
\hline CHEMBL1532303 & 688233 & 4.8426 & 3.6608 & TRN & \\
\hline CHEMBL482687 & 688233 & 3.2218 & 3.4686 & TRN & \\
\hline CHEMBL1528186 & 688233 & 3.2218 & 3.4053 & TRN & \\
\hline CHEMBL3211295 & 688233 & 3.2218 & 3.2708 & TRN & \\
\hline CHEMBL 3211624 & 688233 & 3.5229 & 3.9853 & TRN & \\
\hline CHEMBL1588774 & 688233 & 3.2218 & 3.3904 & TRN & \\
\hline CHEMBL1413416 & 688233 & 3.2218 & 4.7495 & TRN & \\
\hline CHEMBL1506663 & 688233 & 3.2218 & 3.7173 & TRN & \\
\hline CHEMBL1426147 & 688233 & 4.9734 & 3.4617 & TRN & \\
\hline CHEMBL3197890 & 688233 & 3.2218 & 3.166000 & 30000000004 & TST \\
\hline CHEMBL1543203 & 688233 & 3.2218 & 3.1947 & TRN & \\
\hline CHEMBL1529399 & 688233 & 3.2218 & 3.9532 & TRN & \\
\hline CHEMBL1574497 & 688233 & 3.2218 & 3.6603 & TST & \\
\hline CHEMBL1576407 & 688233 & 3.2218 & 3.8955 & TRN & \\
\hline CHEMBL1528425 & 688233 & 4.994 & 4.7925 & TRN & \\
\hline CHEMBL1544663 & 688233 & 3.2218 & 3.2816 & TST & \\
\hline CHEMBL1432681 & 688233 & 5.0722 & 4.3383 & TRN & \\
\hline CHEMBL1612159 & 688233 & 3.2218 & 3.5665 & TST & \\
\hline CHEMBL1365622 & 688233 & 3.5229 & 3.4064 & TST & \\
\hline CHEMBL1337374 & 688233 & 3.2218 & 3.3942 & TRN & \\
\hline CHEMBL1311181 & 688233 & 3.2218 & 3.4661 & TRN & \\
\hline CHEMBL1430872 & 688233 & 5.1174 & 3.4054 & TRN & \\
\hline CHEMBL1299672 & 688233 & 3.5229 & 3.0116 & TRN & \\
\hline CHEMBL1405111 & 688233 & 3.5229 & 3.6567 & TRN & \\
\hline
\end{tabular}


Supplemental Table S2.txt

\begin{tabular}{|c|c|c|c|c|c|}
\hline CHEMBL584442 & 688233 & 3.2218 & 3.7872 & TRN & \\
\hline CHEMBL1326819 & 688233 & 3.2218 & 3.3649 & TRN & \\
\hline CHEMBL1379015 & 688233 & 3.2218 & 3.1555 & TRN & \\
\hline CHEMBL1347212 & 688233 & 3.2218 & 3.8198 & TST & \\
\hline CHEMBL585267 & 688233 & 3.2218 & 3.5618 & TST & \\
\hline CHEMBL1565362 & 688233 & 3.2218 & 3.4663 & TRN & \\
\hline CHEMBL1559713 & 688233 & 3.2218 & 3.2727 & TRN & \\
\hline CHEMBL3196941 & 688233 & 3.2218 & 3.6042 & TST & \\
\hline CHEMBL1505555 & 688233 & 5.0705 & 3.69 & TRN & \\
\hline CHEMBL1548058 & 688233 & 3.2218 & 3.3588 & TRN & \\
\hline CHEMBL1491222 & 688233 & 5.0861 & 5.0165 & TRN & \\
\hline CHEMBL1542041 & 688233 & 4.4228 & 3.6985 & TST & \\
\hline CHEMBL1375511 & 688233 & 3.2218 & 3.656 & TRN & \\
\hline CHEMBL1595226 & 688233 & 3.2218 & 3.4267 & TRN & \\
\hline CHEMBL1557973 & 688233 & 4.6645 & 4.1162 & TRN & \\
\hline CHEMBL1305357 & 688233 & 3.2218 & 3.8314 & TST & \\
\hline CHEMBL1479560 & 688233 & 3.2218 & 3.4607 & TRN & \\
\hline CHEMBL1432792 & 688233 & 3.5229 & 3.1472 & TRN & \\
\hline CHEMBL1351755 & 688233 & 5.9101 & 5.6548 & TRN & \\
\hline CHEMBL1518441 & 688233 & 3.2218 & 3.6505 & TRN & \\
\hline CHEMBL1471351 & 688233 & 3.2218 & 3.1211 & TRN & \\
\hline CHEMBL1421558 & 688233 & 3.2218 & 3.6341 & TST & \\
\hline CHEMBL3195168 & 688233 & 3.2218 & 3.5155 & TRN & \\
\hline CHEMBL1516792 & 688233 & 3.5229 & 3.57 & TRN & \\
\hline CHEMBL1582320 & 688233 & 3.2218 & 3.9313 & TRN & \\
\hline CHEMBL1340656 & 688233 & 5.4096 & 3.7688 & TRN & \\
\hline CHEMBL1442730 & 688233 & 3.2218 & 3.3369 & TRN & \\
\hline CHEMBL1544979 & 688233 & 3.2218 & 3.3774 & TRN & \\
\hline CHEMBL1324397 & 688233 & 5.0206 & 4.235 & TRN & \\
\hline CHEMBL1986090 & 688233 & 5.1366 & 3.6538 & TRN & \\
\hline CHEMBL1464161 & 688233 & 3.2218 & 3.32800 & 00000000003 & TRN \\
\hline CHEMBL1338669 & 688233 & 3.5229 & 3.8161 & TRN & \\
\hline CHEMBL1579831 & 688233 & 3.2218 & 3.7013 & TRN & \\
\hline CHEMBL3189237 & 688233 & 6.2218 & 5.166 & TRN & \\
\hline CHEMBL1459740 & 688233 & 3.2218 & 3.0866 & TRN & \\
\hline CHEMBL1558925 & 688233 & 3.2218 & 3.4897 & TRN & \\
\hline CHEMBL1594604 & 688233 & 3.2218 & 4.0019 & TRN & \\
\hline CHEMBL1406337 & 688233 & 4.8366 & 3.6953 & TRN & \\
\hline CHEMBL3197816 & 688233 & 3.2218 & 3.2226 & TRN & \\
\hline CHEMBL1438636 & 688233 & 6.0106 & 5.8316 & TRN & \\
\hline CHEMBL1329312 & 688233 & 3.2218 & 3.1602 & TRN & \\
\hline CHEMBL1511029 & 688233 & 3.2218 & 3.22899 & 99999999996 & TRN \\
\hline CHEMBL590927 & 688233 & 5.8533 & 6.2487 & TRN & \\
\hline CHEMBL1609009 & 688233 & 5.3177 & 5.0355 & TRN & \\
\hline CHEMBL1442542 & 688233 & 3.2218 & 3.657 & TRN & \\
\hline CHEMBL1506510 & 688233 & 3.2218 & 3.80800 & 00000000003 & TRN \\
\hline CHEMBL1344557 & 688233 & 3.2218 & 2.9884 & TRN & \\
\hline CHEMBL1521930 & 688233 & 3.2218 & 3.2413 & TRN & \\
\hline
\end{tabular}




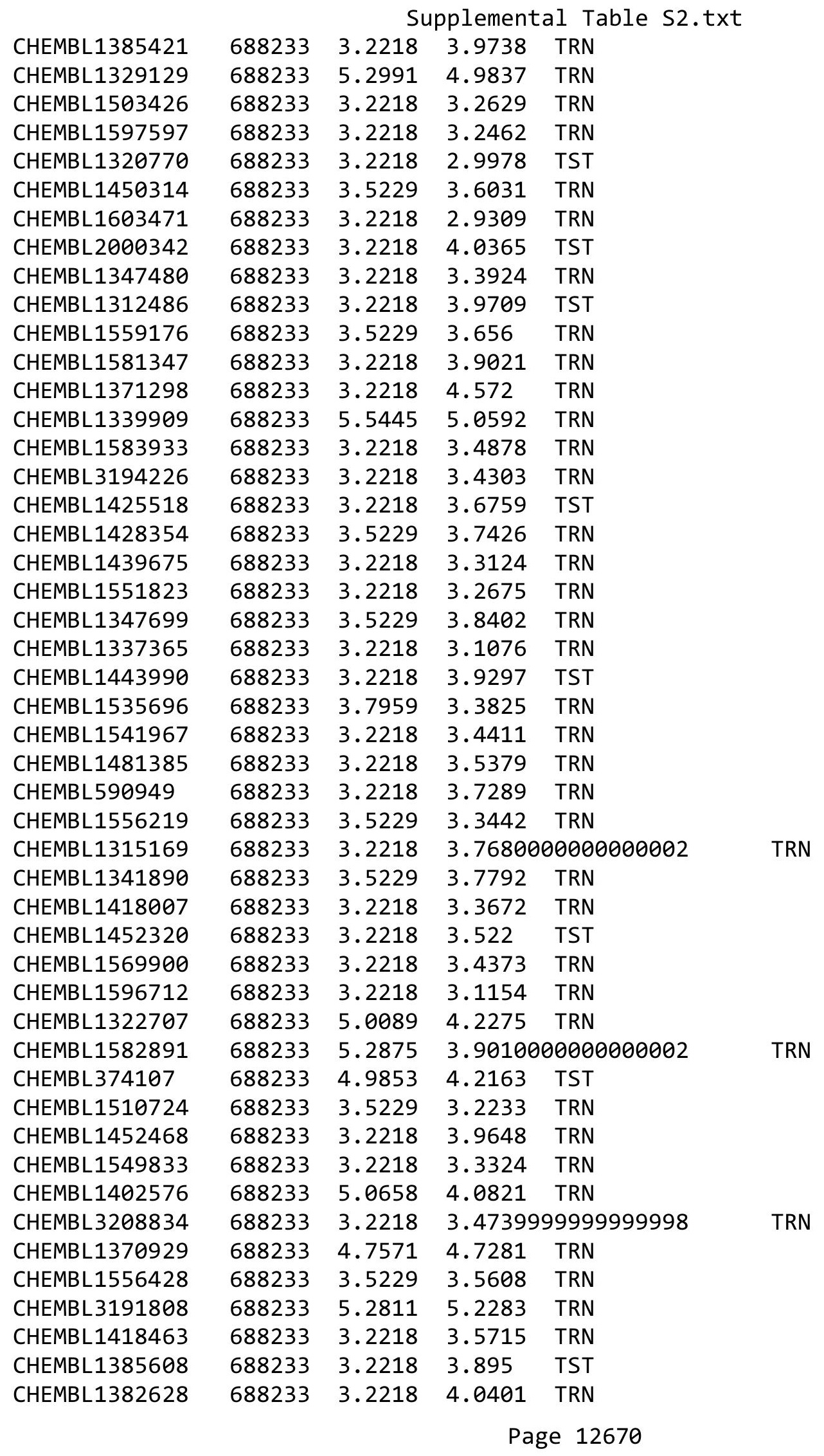




\begin{tabular}{|c|c|c|c|c|}
\hline & & & oplement & al $\mathrm{Tc}$ \\
\hline CHEMBL1574116 & 688233 & 3.2218 & 3.1746 & TRN \\
\hline CHEMBL1468147 & 688233 & 3.2218 & 3.7126 & TST \\
\hline CHEMBL1985759 & 688233 & 5.6611 & 4.6508 & TRN \\
\hline CHEMBL1608336 & 688233 & 3.2218 & 3.1437 & TRN \\
\hline CHEMBL1572896 & 688233 & 3.2218 & 3.8483 & TRN \\
\hline CHEMBL1393511 & 688233 & 3.2218 & 3.6912 & TRN \\
\hline CHEMBL1345399 & 688233 & 5.0115 & 3.7474 & TRN \\
\hline CHEMBL1431641 & 688233 & 3.2218 & 3.4828 & TRN \\
\hline CHEMBL2006909 & 688233 & 5.1863 & 3.7117 & TRN \\
\hline CHEMBL1504716 & 688233 & 3.2218 & 3.6407 & TRN \\
\hline CHEMBL1483355 & 688233 & 3.2218 & 4.2978 & TRN \\
\hline CHEMBL1497295 & 688233 & 6.2218 & 5.7941 & TST \\
\hline CHEMBL1316193 & 688233 & 3.2218 & 3.7629 & TRN \\
\hline CHEMBL1503091 & 688233 & 3.5229 & 3.5503 & TRN \\
\hline CHEMBL1336823 & 688233 & 3.5229 & 3.2734 & TST \\
\hline CHEMBL1414110 & 688233 & 3.5229 & 2.9351 & TRN \\
\hline CHEMBL1423649 & 688233 & 3.2218 & 3.0196 & TRN \\
\hline CHEMBL1501777 & 688233 & 3.2218 & 3.1955 & TRN \\
\hline CHEMBL1500417 & 688233 & 3.2218 & 3.4867 & TRN \\
\hline CHEMBL 2095095 & 688233 & 5.8884 & 6.7826 & TST \\
\hline CHEMBL1472012 & 688233 & 3.2218 & 3.4755 & TRN \\
\hline CHEMBL1522721 & 688233 & 3.5229 & 3.4142 & TRN \\
\hline CHEMBL452409 & 688233 & 3.2218 & 4.1682 & TRN \\
\hline CHEMBL3196365 & 688233 & 3.2218 & 3.3962 & TRN \\
\hline CHEMBL1361674 & 688233 & 3.5229 & 3.446 & TRN \\
\hline CHEMBL1323722 & 688233 & 3.2218 & 3.4305 & TRN \\
\hline CHEMBL1502375 & 688233 & 3.2218 & 3.7082 & TRN \\
\hline CHEMBL1579010 & 688233 & 3.2218 & 3.3839 & TST \\
\hline CHEMBL1386133 & 688233 & 3.2218 & 2.6447 & TRN \\
\hline CHEMBL1498801 & 688233 & 3.2218 & 3.8876 & TST \\
\hline CHEMBL1323541 & 688233 & 3.2218 & 3.7063 & TST \\
\hline CHEMBL1551385 & 688233 & 5.1444 & 3.9462 & TRN \\
\hline CHEMBL1540097 & 688233 & 3.5229 & 3.4623 & TRN \\
\hline CHEMBL1502723 & 688233 & 3.2218 & 3.2628 & TRN \\
\hline CHEMBL1503688 & 688233 & 3.2218 & 3.3596 & TRN \\
\hline CHEMBL1532028 & 688233 & 3.2218 & 3.8075 & TRN \\
\hline CHEMBL1988686 & 688233 & 3.2218 & 3.6156 & TST \\
\hline CHEMBL1580534 & 688233 & 3.2218 & 3.9236 & TST \\
\hline CHEMBL1406709 & 688233 & 3.2218 & 3.8201 & TRN \\
\hline CHEMBL1569267 & 688233 & 3.2218 & 3.3549 & TRN \\
\hline CHEMBL1555565 & 688233 & 3.2218 & 3.5076 & TRN \\
\hline CHEMBL1362490 & 688233 & 3.2218 & 3.3041 & TRN \\
\hline CHEMBL1426709 & 688233 & 3.5229 & 3.8853 & TRN \\
\hline CHEMBL585221 & 688233 & 3.2218 & 3.4061 & TRN \\
\hline CHEMBL3196728 & 688233 & 3.2218 & 3.6735 & TRN \\
\hline CHEMBL527336 & 688233 & 3.5229 & 4.6428 & TRN \\
\hline CHEMBL1454599 & 688233 & 3.5229 & 3.0849 & TRN \\
\hline CHEMBL1500199 & 688233 & 3.2218 & 3.3011 & TRN \\
\hline
\end{tabular}




\begin{tabular}{|c|c|c|c|c|c|c|}
\hline & & \multicolumn{5}{|c|}{ Supplemental Table S2.txt } \\
\hline CHEMBL1516976 & 688233 & 3.2218 & 3.4316 & TRN & & \\
\hline CHEMBL1325039 & 688233 & 3.2218 & 3.8504 & TRN & & \\
\hline CHEMBL1381780 & 688233 & 4.987 & 4.3334 & TRN & & \\
\hline CHEMBL1577081 & 688233 & 3.2218 & 3.9525 & TRN & & \\
\hline CHEMBL1367086 & 688233 & 5.1538 & 4.394 & TST & & \\
\hline CHEMBL1455396 & 688233 & 3.2218 & 3.5358 & TST & & \\
\hline CHEMBL1338638 & 688233 & 3.5229 & 3.2778 & TRN & & \\
\hline CHEMBL1375320 & 688233 & 3.2218 & 3.8059 & TST & & \\
\hline CHEMBL1458944 & 688233 & 3.2218 & 3.4604 & TST & & \\
\hline CHEMBL3191420 & 688233 & 3.2218 & 3.3377 & TRN & & \\
\hline CHEMBL1444859 & 688233 & 5.4286 & 4.6042 & TRN & & \\
\hline CHEMBL1447425 & 688233 & 3.2218 & 3.6129 & TST & & \\
\hline CHEMBL1540776 & 688233 & 3.2218 & 3.6003 & TRN & & \\
\hline CHEMBL3212126 & 688233 & 3.2218 & 3.2726 & TRN & & \\
\hline CHEMBL1546968 & 688233 & 3.2218 & 2.8888 & TRN & & \\
\hline CHEMBL 297304 & 688233 & 4.8039 & 4.3162 & TST & & \\
\hline CHEMBL1519697 & 688233 & 3.2218 & 3.9101 & TRN & & \\
\hline CHEMBL1534094 & 688233 & 3.2218 & 3.5033 & TRN & & \\
\hline CHEMBL1333006 & 688233 & 3.2218 & 3.4409 & TRN & & \\
\hline CHEMBL1511640 & 688233 & 3.2218 & 3.1511 & TRN & & \\
\hline CHEMBL1570706 & 688233 & 5.24200 & 30000000 & 01 & 4.3451 & TRN \\
\hline CHEMBL1312231 & 688233 & 5.7058 & 4.3646 & TRN & & \\
\hline CHEMBL1468779 & 688233 & 5.3499 & 4.2662 & TRN & & \\
\hline CHEMBL578675 & 688233 & 5.4233 & 4.1016 & TRN & & \\
\hline CHEMBL1436755 & 688233 & 3.2218 & 3.766 & TRN & & \\
\hline CHEMBL1518625 & 688233 & 5.0818 & 3.8387 & TRN & & \\
\hline CHEMBL1442300 & 688233 & 3.2218 & 3.2581 & TST & & \\
\hline CHEMBL581870 & 688233 & 3.2218 & 4.1944 & TRN & & \\
\hline CHEMBL1977568 & 688233 & 3.2218 & 3.6481 & TRN & & \\
\hline CHEMBL1988416 & 688233 & 5.5501 & 4.9842 & TST & & \\
\hline CHEMBL1562386 & 688233 & 3.2218 & 3.4178 & TRN & & \\
\hline CHEMBL1349635 & 688233 & 3.2218 & 3.7279 & TRN & & \\
\hline CHEMBL1340421 & 688233 & 3.2218 & 3.4834 & TRN & & \\
\hline CHEMBL1604690 & 688233 & 5.0666 & 3.9971 & TRN & & \\
\hline CHEMBL1440608 & 688233 & 3.5229 & 3.5718 & TRN & & \\
\hline CHEMBL1419867 & 688233 & 3.5229 & 3.7196 & TRN & & \\
\hline CHEMBL1311878 & 688233 & 3.2218 & 3.6585 & TRN & & \\
\hline CHEMBL1448157 & 688233 & 4.8426 & 3.7102 & TRN & & \\
\hline CHEMBL1542084 & 688233 & 3.5229 & 3.2876 & TST & & \\
\hline CHEMBL1579650 & 688233 & 5.0335 & 3.5698 & TRN & & \\
\hline CHEMBL1442412 & 688233 & 3.2218 & 3.2897 & TST & & \\
\hline CHEMBL1377682 & 688233 & 5.7138 & 5.3258 & TRN & & \\
\hline CHEMBL1979106 & 688233 & 5.0497 & 3.9911 & TRN & & \\
\hline CHEMBL1466926 & 688233 & 3.2218 & 3.1447 & TRN & & \\
\hline CHEMBL534353 & 688233 & 3.2218 & 3.5604 & TRN & & \\
\hline CHEMBL1527869 & 688233 & 3.2218 & 3.4518 & TRN & & \\
\hline CHEMBL1425204 & 688233 & 4.9872 & 3.5205 & TRN & & \\
\hline CHEMBL1427476 & 688233 & 3.5229 & 3.8106 & TRN & & \\
\hline
\end{tabular}


Supplemental Table S2.txt

\begin{tabular}{|c|c|c|c|c|}
\hline CHEMBL1538267 & 688233 & 3.2218 & 3.6005 & TRN \\
\hline CHEMBL1556670 & 688233 & 3.2218 & 3.7615 & TST \\
\hline CHEMBL3209453 & 688233 & 3.2218 & 3.51899 & 99999999997 \\
\hline CHEMBL1595498 & 688233 & 3.5229 & 3.2036 & TRN \\
\hline CHEMBL1407952 & 688233 & 5.2975 & 5.3606 & TRN \\
\hline CHEMBL1366389 & 688233 & 3.2218 & 4.2632 & TST \\
\hline CHEMBL1353913 & 688233 & 3.5229 & 3.4654 & TRN \\
\hline CHEMBL1455242 & 688233 & 3.2218 & 2.8535 & TRN \\
\hline CHEMBL1401231 & 688233 & 3.2218 & 3.1352 & TRN \\
\hline CHEMBL1341601 & 688233 & 3.2218 & 3.5621 & TRN \\
\hline CHEMBL1560331 & 688233 & 3.2218 & 3.5923 & TRN \\
\hline CHEMBL1408619 & 688233 & 3.2218 & 3.4492 & TST \\
\hline CHEMBL1364553 & 688233 & 3.2218 & 3.35 & TRN \\
\hline CHEMBL1510014 & 688233 & 3.5229 & 3.9062 & TRN \\
\hline CHEMBL1392079 & 688233 & 3.2218 & 3.2051 & TRN \\
\hline CHEMBL1528798 & 688233 & 3.2218 & 3.4973 & TRN \\
\hline CHEMBL1382744 & 688233 & 3.2218 & 3.4088 & TRN \\
\hline CHEMBL1428016 & 688233 & 3.2218 & 3.7469 & TRN \\
\hline CHEMBL1564144 & 688233 & 3.2218 & 3.2879 & TRN \\
\hline CHEMBL1441601 & 688233 & 3.5229 & 3.1009 & TST \\
\hline CHEMBL1550106 & 688233 & 3.2218 & 3.2991 & TRN \\
\hline CHEMBL3210428 & 688233 & 4.9049 & 3.9688 & TRN \\
\hline CHEMBL1403049 & 688233 & 4.4787 & 3.6387 & TRN \\
\hline CHEMBL1556978 & 688233 & 3.2218 & 4.5132 & TST \\
\hline CHEMBL1523126 & 688233 & 3.2218 & 3.7739 & TRN \\
\hline CHEMBL1576956 & 688233 & 3.2218 & 3.0334 & TST \\
\hline CHEMBL1312303 & 688233 & 5.3611 & 4.9115 & TRN \\
\hline CHEMBL3189416 & 688233 & 5.1304 & 4.7127 & TRN \\
\hline CHEMBL1455913 & 688233 & 3.2218 & 3.9964 & TRN \\
\hline CHEMBL1521617 & 688233 & 3.2218 & 3.5864 & TRN \\
\hline CHEMBL 3192725 & 688233 & 3.2218 & 4.1029 & TRN \\
\hline CHEMBL1421267 & 688233 & 3.2218 & 3.3138 & TRN \\
\hline CHEMBL1392171 & 688233 & 5.0667 & 4.2146 & TRN \\
\hline CHEMBL1981103 & 688233 & 5.3252 & 4.0387 & TST \\
\hline CHEMBL1460032 & 688233 & 3.2218 & 4.1763 & TST \\
\hline CHEMBL1504221 & 688233 & 3.2218 & 3.5703 & TST \\
\hline CHEMBL1340358 & 688233 & 3.5229 & 3.2161 & TRN \\
\hline CHEMBL1326032 & 688233 & 3.5229 & 3.5763 & TST \\
\hline CHEMBL1560506 & 688233 & 4.7877 & 4.1035 & TRN \\
\hline CHEMBL3193151 & 688233 & 4.921 & 3.7313 & TRN \\
\hline CHEMBL1344533 & 688233 & 3.5229 & 3.93 & TRN \\
\hline CHEMBL1600678 & 688233 & 3.2218 & 3.3262 & TST \\
\hline CHEMBL1482927 & 688233 & 3.2218 & 4.0084 & TST \\
\hline CHEMBL1490430 & 688233 & 3.2218 & 4.1424 & TRN \\
\hline CHEMBL1536803 & 688233 & 3.5229 & 3.4566 & TRN \\
\hline CHEMBL1312906 & 688233 & 3.2218 & 3.3459 & TRN \\
\hline CHEMBL142816 & 688233 & 4.8963 & 3.5829 & TST \\
\hline CHEMBL1364364 & 688233 & 3.2218 & 3.5743 & TRN \\
\hline
\end{tabular}


Supplemental Table S2.txt

\begin{tabular}{|c|c|c|c|c|c|}
\hline CHEMBL1417027 & 688233 & 3.5229 & 3.7686 & TRN & \\
\hline CHEMBL1572951 & 688233 & 3.5229 & 3.5317 & TST & \\
\hline CHEMBL1319618 & 688233 & 5.6008 & 5.8222 & TRN & \\
\hline CHEMBL1559371 & 688233 & 3.2218 & 3.3606 & TRN & \\
\hline CHEMBL1447783 & 688233 & 5.3369 & 4.3721 & TRN & \\
\hline CHEMBL1521990 & 688233 & 3.5229 & 4.4932 & TRN & \\
\hline CHEMBL1325549 & 688233 & 3.5229 & 3.5113 & TST & \\
\hline CHEMBL1522928 & 688233 & 3.5229 & 3.4199 & TRN & \\
\hline CHEMBL1607453 & 688233 & 3.2218 & 3.562 & TRN & \\
\hline CHEMBL1371754 & 688233 & 3.2218 & 3.8451 & TRN & \\
\hline CHEMBL1566671 & 688233 & 5.1061 & 3.7156 & TRN & \\
\hline CHEMBL1328118 & 688233 & 4.8605 & 3.8241 & TRN & \\
\hline CHEMBL1341209 & 688233 & 3.2218 & 3.1159 & TRN & \\
\hline CHEMBL1355120 & 688233 & 3.2218 & 3.5142 & TRN & \\
\hline CHEMBL1479432 & 688233 & 3.2218 & 3.6823 & TRN & \\
\hline CHEMBL1377193 & 688233 & 4.869 & 4.208 & TRN & \\
\hline CHEMBL3193284 & 688233 & 3.2218 & 3.4722 & TRN & \\
\hline CHEMBL1340890 & 688233 & 3.2218 & 3.5127 & TRN & \\
\hline CHEMBL1510148 & 688233 & 3.5229 & 3.4866 & TRN & \\
\hline CHEMBL1368748 & 688233 & 4.9632 & 4.0558 & TRN & \\
\hline CHEMBL1566345 & 688233 & 3.2218 & 4.0984 & TRN & \\
\hline CHEMBL1328004 & 688233 & 3.2218 & 2.8915 & TRN & \\
\hline CHEMBL1358906 & 688233 & 4.88899 & 79999999 & 3.7904 & TST \\
\hline CHEMBL1383709 & 688233 & 3.2218 & 2.7666 & TRN & \\
\hline CHEMBL1359318 & 688233 & 3.2218 & 3.4989 & TRN & \\
\hline CHEMBL1993103 & 688233 & 3.2218 & 3.2668 & TRN & \\
\hline CHEMBL1563478 & 688233 & 3.5229 & 3.8412 & TRN & \\
\hline CHEMBL1394145 & 688233 & 5.3558 & 4.4995 & TRN & \\
\hline CHEMBL1495072 & 688233 & 5.1178 & 5.3912 & TRN & \\
\hline CHEMBL1606396 & 688233 & 3.2218 & 3.84899 & 99999999998 & TST \\
\hline CHEMBL1478612 & 688233 & 3.2218 & 3.5951 & TRN & \\
\hline CHEMBL1465999 & 688233 & 3.2218 & 3.3299 & TRN & \\
\hline CHEMBL1494214 & 688233 & 3.2218 & 3.8021 & TRN & \\
\hline CHEMBL1377340 & 688233 & 3.5229 & 4.0991 & TST & \\
\hline CHEMBL1432870 & 688233 & 4.8209 & 3.8352 & TRN & \\
\hline CHEMBL1375232 & 688233 & 4.7164 & 4.3873 & TRN & \\
\hline CHEMBL1517609 & 688233 & 3.5229 & 3.3334 & TRN & \\
\hline CHEMBL1380449 & 688233 & 3.2218 & 3.5676 & TRN & \\
\hline CHEMBL1450762 & 688233 & 3.2218 & 4.3701 & TST & \\
\hline CHEMBL1411856 & 688233 & 3.2218 & 3.4163 & TRN & \\
\hline CHEMBL1575372 & 688233 & 3.2218 & 3.7079 & TRN & \\
\hline CHEMBL609438 & 688233 & 3.2218 & 3.4193 & TRN & \\
\hline CHEMBL1406953 & 688233 & 3.2218 & 3.6432 & TRN & \\
\hline CHEMBL1539970 & 688233 & 3.5229 & 3.6951 & TRN & \\
\hline CHEMBL1411210 & 688233 & 3.2218 & 4.09399 & 9999999999 & TST \\
\hline CHEMBL1406067 & 688233 & 3.5229 & 4.2388 & TRN & \\
\hline CHEMBL1485078 & 688233 & 5.1062 & 5.3033 & TRN & \\
\hline CHEMBL1542057 & 688233 & 3.2218 & 3.6878 & TRN & \\
\hline
\end{tabular}




\begin{tabular}{|c|c|c|c|c|c|}
\hline & & \multicolumn{4}{|c|}{ Supplemental Table S2.txt } \\
\hline CHEMBL1449142 & 688233 & 3.2218 & 3.6511 & TRN & \\
\hline CHEMBL1377889 & 688233 & 3.2218 & 3.4992 & TST & \\
\hline CHEMBL1312833 & 688233 & 3.2218 & 3.4543 & TRN & \\
\hline CHEMBL1414813 & 688233 & 3.2218 & 3.3834 & TRN & \\
\hline CHEMBL1557913 & 688233 & 3.5229 & 3.5143 & TRN & \\
\hline CHEMBL3198425 & 688233 & 5.091 & 4.2124 & TRN & \\
\hline CHEMBL1510550 & 688233 & 4.5266 & 3.7161 & TRN & \\
\hline CHEMBL1352195 & 688233 & 3.2218 & 3.6581 & TRN & \\
\hline CHEMBL1401821 & 688233 & 5.0519 & 4.1625 & TRN & \\
\hline CHEMBL1430098 & 688233 & 3.2218 & 3.3279 & TRN & \\
\hline CHEMBL1606232 & 688233 & 3.2218 & 3.9623 & TST & \\
\hline CHEMBL1329637 & 688233 & 3.2218 & 3.44100 & 00000000003 & TRN \\
\hline CHEMBL1343532 & 688233 & 3.2218 & 4.1255 & TST & \\
\hline CHEMBL1497463 & 688233 & 4.8026 & 3.9676 & TRN & \\
\hline CHEMBL523200 & 688233 & 5.7426 & 4.652 & TRN & \\
\hline CHEMBL1502115 & 688233 & 3.2218 & 3.4033 & TRN & \\
\hline CHEMBL1504859 & 688233 & 5.1049 & 3.5569 & TST & \\
\hline CHEMBL1590153 & 688233 & 3.2218 & 3.7159 & TRN & \\
\hline CHEMBL1523432 & 688233 & 3.5229 & 3.7234 & TRN & \\
\hline CHEMBL1606890 & 688233 & 4.9315 & 4.9175 & TRN & \\
\hline CHEMBL1415640 & 688233 & 3.5229 & 3.3905 & TRN & \\
\hline CHEMBL1579424 & 688233 & 3.5229 & 3.2264 & TRN & \\
\hline CHEMBL1322742 & 688233 & 3.2218 & 3.3516 & TRN & \\
\hline CHEMBL1435226 & 688233 & 3.2218 & 3.5815 & TRN & \\
\hline CHEMBL1359156 & 688233 & 3.5229 & 4.1877 & TRN & \\
\hline CHEMBL1507537 & 688233 & 5.6921 & 4.998 & TRN & \\
\hline CHEMBL1412792 & 688233 & 3.2218 & 3.5895 & TRN & \\
\hline CHEMBL3189460 & 688233 & 3.2218 & 4.0311 & TRN & \\
\hline CHEMBL1550370 & 688233 & 4.6779 & 4.0891 & TRN & \\
\hline CHEMBL1464024 & 688233 & 5.4588 & 5.1194 & TRN & \\
\hline CHEMBL1607722 & 688233 & 3.2218 & 3.5278 & TRN & \\
\hline CHEMBL1463351 & 688233 & 3.2218 & 3.7019 & TRN & \\
\hline CHEMBL1430328 & 688233 & 3.5229 & 3.5209 & TRN & \\
\hline CHEMBL3189613 & 688233 & 3.2218 & 4.6968 & TRN & \\
\hline CHEMBL1569013 & 688233 & 3.5229 & 3.8243 & TRN & \\
\hline CHEMBL1470502 & 688233 & 3.2218 & 3.889 & TRN & \\
\hline CHEMBL1599800 & 688233 & 3.2218 & 3.3531 & TRN & \\
\hline CHEMBL1457032 & 688233 & 4.8031 & 3.7062 & TRN & \\
\hline CHEMBL1340215 & 688233 & 3.2218 & 3.8923 & TRN & \\
\hline CHEMBL1445327 & 688233 & 3.2218 & 3.7391 & TRN & \\
\hline CHEMBL1532368 & 688233 & 3.2218 & 3.9909 & TRN & \\
\hline CHEMBL1420056 & 688233 & 3.5229 & 3.4408 & TST & \\
\hline CHEMBL1576718 & 688233 & 3.2218 & 3.2516 & TRN & \\
\hline CHEMBL1525666 & 688233 & 3.2218 & 3.2748 & TRN & \\
\hline CHEMBL3193259 & 688233 & 4.9646 & 4.4812 & TRN & \\
\hline CHEMBL3197447 & 688233 & 3.2218 & 3.8264 & TRN & \\
\hline CHEMBL1578107 & 688233 & 3.2218 & 3.4575 & TRN & \\
\hline CHEMBL1493012 & 688233 & 3.2218 & 3.7506 & TST & \\
\hline
\end{tabular}




\begin{tabular}{|c|c|c|c|c|c|c|}
\hline & & \multicolumn{5}{|c|}{ Supplemental Table S2.txt } \\
\hline CHEMBL1354447 & 688233 & 3.2218 & 3.6815 & TRN & & \\
\hline CHEMBL1389254 & 688233 & 3.2218 & 2.8842 & TRN & & \\
\hline CHEMBL1540057 & 688233 & 3.2218 & 3.2891 & TST & & \\
\hline CHEMBL1422398 & 688233 & 3.2218 & 3.2332 & TRN & & \\
\hline CHEMBL1407833 & 688233 & 3.2218 & 4.1528 & TRN & & \\
\hline CHEMBL1580655 & 688233 & 3.2218 & 4.0182 & TRN & & \\
\hline CHEMBL1579512 & 688233 & 3.2218 & 3.9214 & TRN & & \\
\hline CHEMBL 3210108 & 688233 & 3.2218 & 3.7504 & TRN & & \\
\hline CHEMBL1595114 & 688233 & 3.2218 & 3.4343 & TRN & & \\
\hline CHEMBL1474925 & 688233 & 3.5229 & 3.4751 & TRN & & \\
\hline CHEMBL1345564 & 688233 & 4.8052 & 4.2475 & TRN & & \\
\hline CHEMBL1391606 & 688233 & 3.2218 & 3.3135 & TRN & & \\
\hline CHEMBL1299962 & 688233 & 3.2218 & 3.7043 & TRN & & \\
\hline CHEMBL600968 & 688233 & 3.2218 & 3.3876 & TRN & & \\
\hline CHEMBL 3197290 & 688233 & 5.0706 & 3.8358 & TRN & & \\
\hline CHEMBL1403638 & 688233 & 3.5229 & 3.6772 & TRN & & \\
\hline CHEMBL1440668 & 688233 & 5.1061 & 3.9769 & TRN & & \\
\hline CHEMBL1534574 & 688233 & 3.5229 & 3.3986 & TRN & & \\
\hline CHEMBL1491334 & 688233 & 3.2218 & 3.655 & TRN & & \\
\hline CHEMBL1368752 & 688233 & 3.2218 & 3.1093 & TRN & & \\
\hline CHEMBL1494338 & 688233 & 3.2218 & 4.2707 & TRN & & \\
\hline CHEMBL1968356 & 688233 & 3.2218 & 4.0141 & TRN & & \\
\hline CHEMBL1415357 & 688233 & 3.2218 & 3.7277 & TRN & & \\
\hline CHEMBL1994402 & 688233 & 5.05699 & 99999999 & 995 & 4.148 & TRN \\
\hline CHEMBL1479393 & 688233 & 3.2218 & 3.6163 & TRN & & \\
\hline CHEMBL1513910 & 688233 & 3.5229 & 3.5412 & TST & & \\
\hline CHEMBL1536437 & 688233 & 5.3759 & 3.6014 & TST & & \\
\hline CHEMBL1502931 & 688233 & 4.6512 & 3.9998 & TRN & & \\
\hline CHEMBL1575023 & 688233 & 3.2218 & 3.4068 & TRN & & \\
\hline CHEMBL1486862 & 688233 & 3.2218 & 3.1099 & TRN & & \\
\hline CHEMBL1438205 & 688233 & 3.2218 & 3.7162 & TRN & & \\
\hline CHEMBL1397224 & 688233 & 3.5229 & 3.0891 & TRN & & \\
\hline CHEMBL1489229 & 688233 & 3.2218 & 3.4677 & TRN & & \\
\hline CHEMBL1586240 & 688233 & 3.2218 & 3.2447 & TRN & & \\
\hline CHEMBL1549657 & 688233 & 5.3079 & 5.1517 & TRN & & \\
\hline CHEMBL1501557 & 688233 & 3.2218 & 3.4276 & TRN & & \\
\hline CHEMBL 1444896 & 688233 & 5.1201 & 3.9726 & TRN & & \\
\hline CHEMBL1349976 & 688233 & 3.2218 & 3.2862 & TRN & & \\
\hline CHEMBL1437928 & 688233 & 3.2218 & 3.1895 & TRN & & \\
\hline CHEMBL1593551 & 688233 & 3.2218 & 3.6687 & TRN & & \\
\hline CHEMBL1501300 & 688233 & 3.2218 & 3.0774 & TRN & & \\
\hline CHEMBL1610530 & 688233 & 4.4422 & 3.5898 & TRN & & \\
\hline CHEMBL1464802 & 688233 & 3.2218 & 3.2971 & TRN & & \\
\hline CHEMBL1498044 & 688233 & 3.2218 & 3.3696 & TRN & & \\
\hline CHEMBL1336926 & 688233 & 3.2218 & 3.9778 & TRN & & \\
\hline CHEMBL1313191 & 688233 & 4.6871 & 3.6548 & TST & & \\
\hline CHEMBL1341407 & 688233 & 3.5229 & 4.1735 & TRN & & \\
\hline CHEMBL1427040 & 688233 & 3.2218 & 3.1358 & TRN & & \\
\hline
\end{tabular}


Supplemental Table S2.txt

\begin{tabular}{|c|c|c|c|c|c|}
\hline CHEMBL1432149 & 688233 & 3.5229 & 4.1272 & TRN & \\
\hline CHEMBL1496504 & 688233 & 3.2218 & 3.9066 & TRN & \\
\hline CHEMBL591412 & 688233 & 5.8099 & 5.9083 & TRN & \\
\hline CHEMBL1360013 & 688233 & 3.2218 & 3.9049 & TRN & \\
\hline CHEMBL1543982 & 688233 & 3.2218 & 3.0987 & TRN & \\
\hline CHEMBL1601769 & 688233 & 3.2218 & 3.7953 & TST & \\
\hline CHEMBL1419954 & 688233 & 3.5229 & 3.2841 & TRN & \\
\hline CHEMBL1545435 & 688233 & 3.2218 & 3.9749 & TRN & \\
\hline CHEMBL1566415 & 688233 & 5.2088 & 3.9335 & TRN & \\
\hline CHEMBL1969543 & 688233 & 3.2218 & 3.4886 & TRN & \\
\hline CHEMBL1468333 & 688233 & 3.5229 & 3.7309 & TST & \\
\hline CHEMBL1606969 & 688233 & 3.2218 & 3.0174 & TRN & \\
\hline CHEMBL1587027 & 688233 & 3.2218 & 3.6047 & TRN & \\
\hline CHEMBL2001433 & 688233 & 3.2218 & 2.7205 & TRN & \\
\hline CHEMBL536166 & 688233 & 3.2218 & 4.5357 & TRN & \\
\hline CHEMBL1546205 & 688233 & 5.6949 & 5.9236 & TRN & \\
\hline CHEMBL1349539 & 688233 & 5.0823 & 3.6367 & TST & \\
\hline CHEMBL1342523 & 688233 & 3.2218 & 3.5681 & TRN & \\
\hline CHEMBL1579498 & 688233 & 3.2218 & 3.4234 & TRN & \\
\hline CHEMBL1609819 & 688233 & 4.6202 & 4.2697 & TRN & \\
\hline CHEMBL1508726 & 688233 & 3.2218 & 3.8659 & TRN & \\
\hline CHEMBL1565189 & 688233 & 4.9251 & 3.6934 & TST & \\
\hline CHEMBL1372400 & 688233 & 3.2218 & 3.9892 & TRN & \\
\hline CHEMBL1306343 & 688233 & 5.1548 & 3.7337 & TRN & \\
\hline CHEMBL1607512 & 688233 & 3.5229 & 3.8744 & TRN & \\
\hline CHEMBL1536905 & 688233 & 3.2218 & 3.4029 & TRN & \\
\hline CHEMBL1372102 & 688233 & 3.2218 & 3.7403 & TRN & \\
\hline CHEMBL3199462 & 688233 & 3.2218 & 4.4658 & TST & \\
\hline CHEMBL1587218 & 688233 & 3.2218 & 3.6204 & TRN & \\
\hline CHEMBL1457644 & 688233 & 3.2218 & 4.4431 & TRN & \\
\hline CHEMBL1490311 & 688233 & 3.2218 & 3.5493 & TRN & \\
\hline CHEMBL1523254 & 688233 & 3.5229 & 3.5121 & TRN & \\
\hline CHEMBL1341301 & 688233 & 3.2218 & 3.2012 & TRN & \\
\hline CHEMBL1388777 & 688233 & 3.2218 & 3.2118 & TRN & \\
\hline CHEMBL1385581 & 688233 & 3.5229 & 3.5002 & TRN & \\
\hline CHEMBL1562557 & 688233 & 3.2218 & 3.8747 & TRN & \\
\hline CHEMBL2000517 & 688233 & 6.3134 & 6.6439 & TST & \\
\hline CHEMBL1476688 & 688233 & 3.2218 & 3.6106 & TRN & \\
\hline CHEMBL1575786 & 688233 & 3.5229 & 3.67199 & 99999999997 & TRN \\
\hline CHEMBL1429512 & 688233 & 3.5229 & 4.5163 & TRN & \\
\hline CHEMBL1546922 & 688233 & 3.2218 & 3.6665 & TRN & \\
\hline CHEMBL1359342 & 688233 & 3.2218 & 3.6896 & TST & \\
\hline CHEMBL1391551 & 688233 & 4.2253 & 4.3334 & TRN & \\
\hline CHEMBL1545271 & 688233 & 3.2218 & 3.3127 & TRN & \\
\hline CHEMBL3193093 & 688233 & 5.0138 & 4.2109 & TRN & \\
\hline CHEMBL1309890 & 688233 & 6.2218 & 5.2649 & TRN & \\
\hline CHEMBL1372058 & 688233 & 3.2218 & 3.4069 & TRN & \\
\hline CHEMBL1519338 & 688233 & 4.9434 & 4.2304 & TRN & \\
\hline
\end{tabular}


Supplemental Table S2.txt

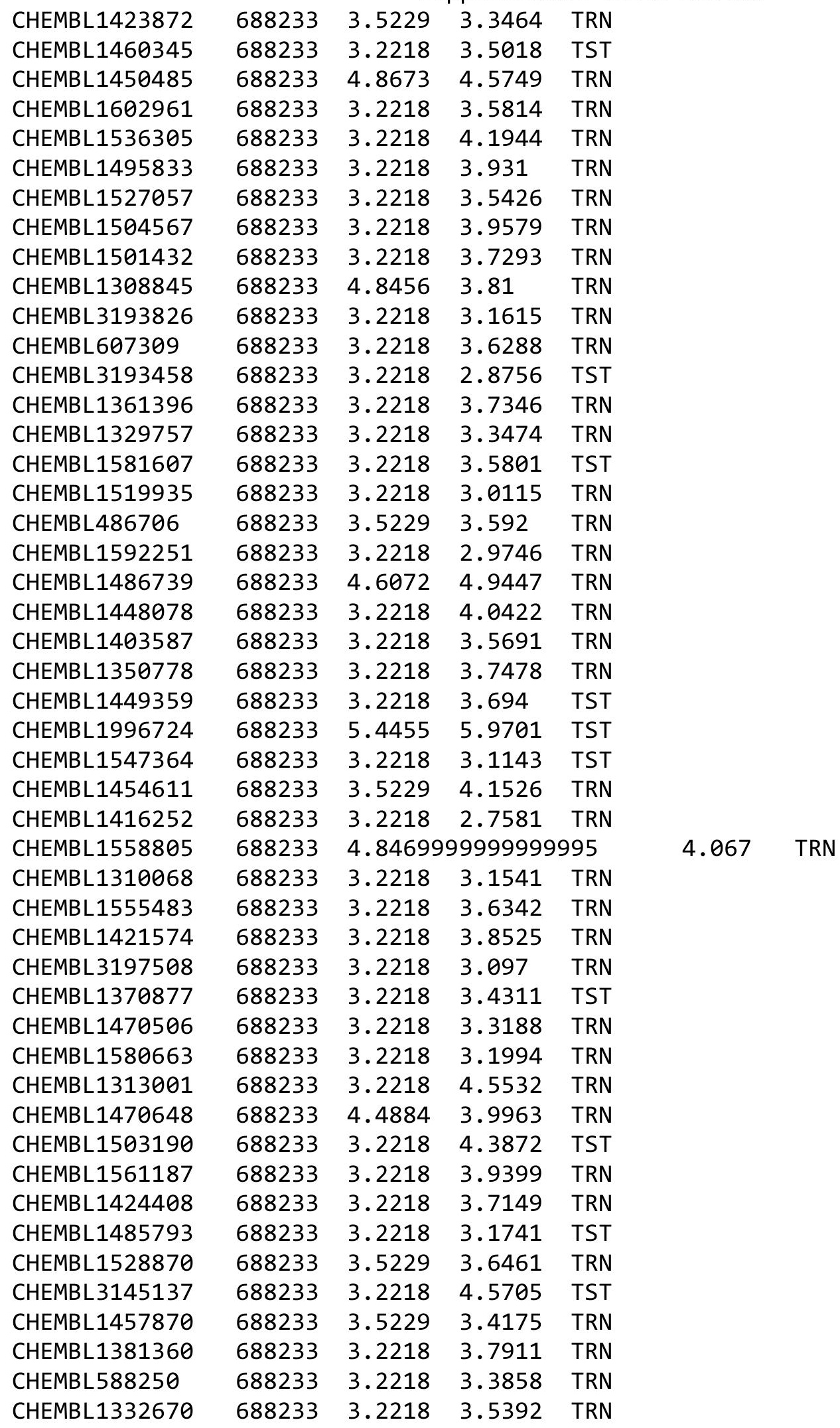

Page 12678 
Supplemental Table S2.txt

\begin{tabular}{|c|c|c|c|c|c|}
\hline CHEMBL600862 & 688233 & 6.0535 & 6.0982 & TRN & \\
\hline CHEMBL1342790 & 688233 & 4.6686 & 3.6378 & TRN & \\
\hline CHEMBL581152 & 688233 & 4.7766 & 4.4611 & TRN & \\
\hline CHEMBL1403005 & 688233 & 3.2218 & 3.4508 & TRN & \\
\hline CHEMBL1388988 & 688233 & 3.2218 & 3.4014 & TRN & \\
\hline CHEMBL1388616 & 688233 & 3.2218 & 3.4418 & TST & \\
\hline CHEMBL1609836 & 688233 & 3.2218 & 3.5867 & TST & \\
\hline CHEMBL1566928 & 688233 & 5.3113 & 4.4002 & TST & \\
\hline CHEMBL527586 & 688233 & 3.2218 & 3.5141 & TST & \\
\hline CHEMBL1521061 & 688233 & 3.2218 & 3.0648 & TRN & \\
\hline CHEMBL1353840 & 688233 & 3.2218 & 2.9133 & TST & \\
\hline CHEMBL1441527 & 688233 & 3.2218 & 3.8319 & TRN & \\
\hline CHEMBL1553717 & 688233 & 5.1586 & 3.69 & TRN & \\
\hline CHEMBL 2005117 & 688233 & 3.2218 & 3.8476 & TRN & \\
\hline CHEMBL1432611 & 688233 & 5.1049 & 3.8517 & TRN & \\
\hline CHEMBL1606575 & 688233 & 4.6953 & 4.0691 & TRN & \\
\hline CHEMBL1342293 & 688233 & 5.0361 & 4.4916 & TRN & \\
\hline CHEMBL3193276 & 688233 & 3.2218 & 3.6663 & TRN & \\
\hline CHEMBL1517879 & 688233 & 3.2218 & 3.5547 & TRN & \\
\hline CHEMBL1389268 & 688233 & 4.8152 & 3.6814 & TRN & \\
\hline CHEMBL1545863 & 688233 & 3.2218 & 3.1813 & TRN & \\
\hline CHEMBL1467937 & 688233 & 3.2218 & 3.6069 & TRN & \\
\hline CHEMBL1314809 & 688233 & 3.2218 & 3.5913 & TST & \\
\hline CHEMBL1406457 & 688233 & 3.2218 & 3.5674 & TST & \\
\hline CHEMBL1389740 & 688233 & 3.2218 & 3.9034 & TST & \\
\hline CHEMBL1335491 & 688233 & 5.1267 & 4.865 & TRN & \\
\hline CHEMBL1338802 & 688233 & 3.2218 & 2.9896 & TRN & \\
\hline CHEMBL1340282 & 688233 & 3.5229 & 3.3219 & TST & \\
\hline CHEMBL1542180 & 688233 & 3.2218 & \multicolumn{2}{|c|}{3.7739999999999996} & TRN \\
\hline CHEMBL1470008 & 688233 & 3.2218 & 3.3975 & TRN & \\
\hline CHEMBL1493425 & 688233 & 3.2218 & 3.4349 & TRN & \\
\hline CHEMBL1403946 & 688233 & 3.2218 & 3.5413 & TRN & \\
\hline CHEMBL1504127 & 688233 & 3.2218 & 3.7496 & TRN & \\
\hline CHEMBL1569989 & 688233 & 4.5523 & 5.26 & TRN & \\
\hline CHEMBL1581541 & 688233 & 3.2218 & 3.181 & TRN & \\
\hline CHEMBL1415090 & 688233 & 5.3098 & 3.9599 & TRN & \\
\hline CHEMBL1333527 & 688233 & 3.2218 & 3.6657 & TRN & \\
\hline CHEMBL1563777 & 688233 & 5.0516 & 3.8782 & TRN & \\
\hline CHEMBL1391048 & 688233 & 5.3043 & 4.8424 & TRN & \\
\hline CHEMBL1572723 & 688233 & 3.2218 & 3.3165 & TRN & \\
\hline CHEMBL1300339 & 688233 & 3.2218 & 3.2878 & TRN & \\
\hline CHEMBL3196726 & 688233 & 5.4633 & 4.3829 & TRN & \\
\hline CHEMBL1315217 & 688233 & 3.5229 & 3.3696 & TRN & \\
\hline CHEMBL394242 & 688233 & 3.2218 & 5.6976 & TRN & \\
\hline CHEMBL1344013 & 688233 & 3.2218 & 3.1591 & TRN & \\
\hline CHEMBL2094789 & 688233 & 5.3022 & 4.2797 & TST & \\
\hline CHEMBL1537043 & 688233 & 3.2218 & 3.3993 & TRN & \\
\hline CHEMBL1342145 & 688233 & 3.2218 & 3.3787 & TRN & \\
\hline
\end{tabular}

Page 12679 
Supplemental Table S2.txt

\begin{tabular}{|c|c|c|c|c|c|}
\hline CHEMBL1566533 & 688233 & 3.5229 & 3.3064 & TRN & \\
\hline CHEMBL3193266 & 688233 & 3.2218 & 3.0865 & TRN & \\
\hline CHEMBL1370879 & 688233 & 3.2218 & 3.6117 & TRN & \\
\hline CHEMBL1468874 & 688233 & 3.2218 & 3.3286 & TRN & \\
\hline CHEMBL1363887 & 688233 & 3.2218 & 3.3683 & TRN & \\
\hline CHEMBL1548005 & 688233 & 3.2218 & \multicolumn{2}{|c|}{3.1210000000000004} & TST \\
\hline CHEMBL1497838 & 688233 & 3.2218 & 4.1452 & TST & \\
\hline CHEMBL1557727 & 688233 & 5.1225 & 4.721 & TRN & \\
\hline CHEMBL1467958 & 688233 & 3.2218 & 3.0972 & TRN & \\
\hline CHEMBL1426138 & 688233 & 3.2218 & 3.4542 & TRN & \\
\hline CHEMBL3198074 & 688233 & 3.2218 & 3.4502 & TRN & \\
\hline CHEMBL1460273 & 688233 & 4.6559 & 4.1859 & TST & \\
\hline CHEMBL1497375 & 688233 & 3.2218 & 3.4928 & TRN & \\
\hline CHEMBL1864040 & 688233 & 5.1406 & 4.602 & TRN & \\
\hline CHEMBL1558327 & 688233 & 3.2218 & 3.7607 & TRN & \\
\hline CHEMBL1517571 & 688233 & 3.2218 & 3.861 & TRN & \\
\hline CHEMBL1320454 & 688233 & 3.2218 & 3.1223 & TRN & \\
\hline CHEMBL1361680 & 688233 & 3.2218 & 3.7725 & TRN & \\
\hline CHEMBL1523690 & 688233 & 4.4748 & 3.7005 & TRN & \\
\hline CHEMBL1312140 & 688233 & 3.5229 & 3.7174 & TST & \\
\hline CHEMBL3193676 & 688233 & 3.2218 & 3.4377 & TRN & \\
\hline CHEMBL1559953 & 688233 & 3.2218 & 3.7433 & TRN & \\
\hline CHEMBL1492754 & 688233 & 5.0185 & 3.5745 & TRN & \\
\hline CHEMBL1393049 & 688233 & 3.2218 & 3.1384 & TRN & \\
\hline CHEMBL1575105 & 688233 & 3.2218 & 3.5986 & TRN & \\
\hline CHEMBL1540341 & 688233 & 3.2218 & 2.8798 & TRN & \\
\hline CHEMBL1595850 & 688233 & 3.2218 & 3.6866 & TRN & \\
\hline CHEMBL1412700 & 688233 & 3.2218 & 3.423 & TRN & \\
\hline CHEMBL1547262 & 688233 & 5.037 & 3.7956 & TRN & \\
\hline CHEMBL1534270 & 688233 & 3.2218 & 3.5215 & TRN & \\
\hline CHEMBL1418230 & 688233 & 5.2338 & 4.3231 & TRN & \\
\hline CHEMBL1982308 & 688233 & 4.8105 & 3.5826 & TRN & \\
\hline CHEMBL1560008 & 688233 & 3.5229 & 3.967 & TST & \\
\hline CHEMBL1990036 & 688233 & 3.2218 & 3.3509 & TRN & \\
\hline CHEMBL1349899 & 688233 & 3.2218 & 3.45300 & 00000000003 & TRN \\
\hline CHEMBL1544054 & 688233 & 3.2218 & 3.8303 & TRN & \\
\hline CHEMBL1600372 & 688233 & 3.2218 & 3.7381 & TST & \\
\hline CHEMBL1468734 & 688233 & 3.2218 & 2.99899 & 99999999997 & TRN \\
\hline CHEMBL585112 & 688233 & 3.2218 & 3.2845 & TRN & \\
\hline CHEMBL1467655 & 688233 & 3.5229 & 3.8469 & TRN & \\
\hline CHEMBL1617452 & 688233 & 5.1912 & 4.6302 & TRN & \\
\hline CHEMBL1544131 & 688233 & 5.7055 & 5.2695 & TRN & \\
\hline CHEMBL1522224 & 688233 & 3.2218 & 4.0117 & TRN & \\
\hline CHEMBL1998516 & 688233 & 3.2218 & 3.5295 & TRN & \\
\hline CHEMBL1369986 & 688233 & 3.2218 & 3.0589 & TRN & \\
\hline CHEMBL1997413 & 688233 & 3.2218 & 3.9715 & TST & \\
\hline CHEMBL1392603 & 688233 & 3.2218 & 3.5388 & TRN & \\
\hline CHEMBL1550238 & 688233 & 4.9911 & 3.6271 & TRN & \\
\hline
\end{tabular}




\begin{tabular}{|c|c|c|c|c|c|}
\hline & & \multicolumn{4}{|c|}{ Supplemental Table s2.txt } \\
\hline CHEMBL3190547 & 688233 & 3.2218 & 3.6137 & TRN & \\
\hline CHEMBL1566645 & 688233 & 5.3481 & 3.4892 & TST & \\
\hline CHEMBL1380361 & 688233 & 3.2218 & 3.6578 & TST & \\
\hline CHEMBL 237424 & 688233 & 3.2218 & 3.3444 & TRN & \\
\hline CHEMBL1374947 & 688233 & 3.2218 & 4.1959 & TRN & \\
\hline CHEMBL3198627 & 688233 & 3.2218 & 3.1356 & TRN & \\
\hline CHEMBL1363712 & 688233 & 3.2218 & 3.1886 & TRN & \\
\hline CHEMBL1435292 & 688233 & 3.5229 & 3.3465 & TST & \\
\hline CHEMBL1335611 & 688233 & 3.2218 & 3.2712 & TRN & \\
\hline CHEMBL1569162 & 688233 & 6.2218 & 4.2957 & TRN & \\
\hline CHEMBL609027 & 688233 & 4.742 & 3.7615 & TRN & \\
\hline CHEMBL1522988 & 688233 & 3.5229 & 3.3368 & TRN & \\
\hline CHEMBL188 & 688233 & 4.2526 & 3.194 & TST & \\
\hline CHEMBL577709 & 688233 & 5.3974 & 4.2184 & TRN & \\
\hline CHEMBL1586139 & 688233 & 3.2218 & 3.38100 & 00000000002 & TRN \\
\hline CHEMBL1584308 & 688233 & 3.2218 & 3.40199 & 99999999997 & TRN \\
\hline CHEMBL1454385 & 688233 & 3.2218 & 3.7113 & TRN & \\
\hline CHEMBL1454384 & 688233 & 3.2218 & 4.3122 & TRN & \\
\hline CHEMBL1465450 & 688233 & 4.8933 & 3.3043 & TST & \\
\hline CHEMBL1529848 & 688233 & 3.2218 & 3.5045 & TST & \\
\hline CHEMBL1576004 & 688233 & 3.2218 & 3.6578 & TRN & \\
\hline CHEMBL1562367 & 688233 & 3.2218 & 3.4247 & TRN & \\
\hline CHEMBL1498173 & 688233 & 4.2527 & 3.5425 & TRN & \\
\hline CHEMBL1400523 & 688233 & 5.0023 & 4.1163 & TRN & \\
\hline CHEMBL1476181 & 688233 & 5.2018 & 4.0252 & TRN & \\
\hline CHEMBL1486095 & 688233 & 4.9031 & 3.1841 & TRN & \\
\hline CHEMBL3193914 & 688233 & 3.2218 & 3.7873 & TST & \\
\hline CHEMBL1309292 & 688233 & 3.2218 & 3.7858 & TRN & \\
\hline CHEMBL1368437 & 688233 & 3.2218 & 3.4704 & TRN & \\
\hline CHEMBL1459155 & 688233 & 3.2218 & 4.1489 & TRN & \\
\hline CHEMBL1377028 & 688233 & 3.5229 & 3.8404 & TRN & \\
\hline CHEMBL1376183 & 688233 & 3.2218 & 3.6545 & TST & \\
\hline CHEMBL1971154 & 688233 & 3.2218 & 4.1478 & TRN & \\
\hline CHEMBL1583479 & 688233 & 3.2218 & 3.6182 & TRN & \\
\hline CHEMBL1595988 & 688233 & 3.2218 & 3.2866 & TRN & \\
\hline CHEMBL1423197 & 688233 & 3.2218 & 3.6685 & TST & \\
\hline CHEMBL1299258 & 688233 & 3.5229 & 2.89399 & 99999999997 & TRN \\
\hline CHEMBL1455689 & 688233 & 5.0041 & 3.835 & TRN & \\
\hline CHEMBL1345510 & 688233 & 3.2218 & 4.0999 & TST & \\
\hline CHEMBL1565254 & 688233 & 3.2218 & 3.3208 & TRN & \\
\hline CHEMBL1575070 & 688233 & 3.2218 & 3.2863 & TRN & \\
\hline CHEMBL1891759 & 688233 & 3.2218 & 3.9621 & TST & \\
\hline CHEMBL1401984 & 688233 & 3.2218 & 3.0142 & TRN & \\
\hline CHEMBL1380844 & 688233 & 3.2218 & 3.7771 & TRN & \\
\hline CHEMBL1361202 & 688233 & 4.7586 & 4.4729 & TRN & \\
\hline CHEMBL1349314 & 688233 & 4.4502 & 3.9279 & TRN & \\
\hline CHEMBL1381574 & 688233 & 3.2218 & 3.6573 & TRN & \\
\hline CHEMBL 305686 & 688233 & 3.2218 & 4.2012 & TST & \\
\hline
\end{tabular}


Supplemental Table S2.txt

\begin{tabular}{|c|c|c|c|c|}
\hline CHEMBL1359097 & 688233 & 3.2218 & 2.7988 & TST \\
\hline CHEMBL1581819 & 688233 & 3.5229 & 3.4724 & TRN \\
\hline CHEMBL1586276 & 688233 & 3.2218 & 3.4084 & TRN \\
\hline CHEMBL1412548 & 688233 & 5.0807 & 3.7324 & TRN \\
\hline CHEMBL1362978 & 688233 & 3.5229 & 3.3768 & TRN \\
\hline CHEMBL1325077 & 688233 & 3.2218 & 4.2796 & TRN \\
\hline CHEMBL1366651 & 688233 & 3.5229 & 3.5087 & TRN \\
\hline CHEMBL1606886 & 688233 & 3.2218 & 3.8598 & TRN \\
\hline CHEMBL1409539 & 688233 & 3.2218 & 3.2774 & TRN \\
\hline CHEMBL1462421 & 688233 & 3.2218 & 3.3906 & TRN \\
\hline CHEMBL1369698 & 688233 & 3.5229 & 3.1126 & TRN \\
\hline CHEMBL1575901 & 688233 & 3.5229 & 3.0814 & TRN \\
\hline CHEMBL1558506 & 688233 & 3.2218 & 3.8942 & TST \\
\hline CHEMBL1558309 & 688233 & 3.5229 & 3.2675 & TRN \\
\hline CHEMBL3191763 & 688233 & 3.2218 & 4.5723 & TRN \\
\hline CHEMBL1345313 & 688233 & 3.2218 & 3.2235 & TRN \\
\hline CHEMBL1593516 & 688233 & 4.9663 & 3.6661 & TST \\
\hline CHEMBL1391923 & 688233 & 3.2218 & 4.1206 & TRN \\
\hline CHEMBL1385766 & 688233 & 3.5229 & 4.2016 & TST \\
\hline CHEMBL1576374 & 688233 & 3.2218 & 3.8759 & TRN \\
\hline CHEMBL1436964 & 688233 & 3.2218 & 3.0262 & TRN \\
\hline CHEMBL1607938 & 688233 & 3.2218 & 3.5949 & TRN \\
\hline CHEMBL1468684 & 688233 & 5.0573 & 3.8684 & TRN \\
\hline CHEMBL1984723 & 688233 & 3.2218 & 3.5289 & TRN \\
\hline CHEMBL1541215 & 688233 & 3.2218 & 2.77399 & 99999999996 \\
\hline CHEMBL1400048 & 688233 & 4.6238 & 4.3816 & TRN \\
\hline CHEMBL1414836 & 688233 & 3.2218 & 3.5622 & TRN \\
\hline CHEMBL1563291 & 688233 & 3.5229 & 4.2284 & TRN \\
\hline CHEMBL1380419 & 688233 & 3.2218 & 3.3166 & TST \\
\hline CHEMBL1404209 & 688233 & 5.0189 & 3.4991 & TRN \\
\hline CHEMBL1350765 & 688233 & 3.2218 & 3.9063 & TRN \\
\hline CHEMBL1383334 & 688233 & 6.2218 & 4.413 & TRN \\
\hline CHEMBL1583505 & 688233 & 3.2218 & 3.4755 & TRN \\
\hline CHEMBL1557674 & 688233 & 3.2218 & 3.5384 & TRN \\
\hline CHEMBL1468642 & 688233 & 3.2218 & 3.4608 & TRN \\
\hline CHEMBL1557316 & 688233 & 4.2323 & 3.6581 & TRN \\
\hline CHEMBL1315948 & 688233 & 5.2572 & 3.8972 & TST \\
\hline CHEMBL1593220 & 688233 & 3.2218 & 3.5385 & TRN \\
\hline CHEMBL1438500 & 688233 & 3.2218 & 3.4429 & TRN \\
\hline CHEMBL1521877 & 688233 & 3.2218 & 3.6144 & TRN \\
\hline CHEMBL3191812 & 688233 & 3.5229 & 4.2188 & TRN \\
\hline CHEMBL1401727 & 688233 & 3.2218 & 3.3744 & TRN \\
\hline CHEMBL1382038 & 688233 & 3.2218 & 3.5224 & TRN \\
\hline CHEMBL1475194 & 688233 & 3.2218 & 4.2989 & TRN \\
\hline CHEMBL1301355 & 688233 & 3.2218 & 3.7915 & TRN \\
\hline CHEMBL1332404 & 688233 & 5.9961 & 5.8236 & TRN \\
\hline CHEMBL1625031 & 688233 & 5.1445 & 4.1691 & TRN \\
\hline CHEMBL1404308 & 688233 & 3.2218 & 3.5009 & TRN \\
\hline
\end{tabular}

Page 12682 
Supplemental Table S2.txt

\begin{tabular}{|c|c|c|c|c|c|}
\hline CHEMBL1468750 & 688233 & 3.5229 & 3.2964 & TRN & \\
\hline CHEMBL1402502 & 688233 & 3.5229 & 3.5858 & TST & \\
\hline CHEMBL583305 & 688233 & 5.2313 & 4.0551 & TRN & \\
\hline CHEMBL1483975 & 688233 & 5.3481 & 4.5308 & TRN & \\
\hline CHEMBL1337675 & 688233 & 3.2218 & 3.1123 & TRN & \\
\hline CHEMBL1462795 & 688233 & 3.2218 & 3.6585 & TRN & \\
\hline CHEMBL3191452 & 688233 & 3.2218 & 3.6857 & TRN & \\
\hline CHEMBL1352651 & 688233 & 4.8902 & 4.0159 & TST & \\
\hline CHEMBL1500614 & 688233 & 4.6836 & 3.5886 & TRN & \\
\hline CHEMBL1327683 & 688233 & 3.2218 & 3.1909 & TRN & \\
\hline CHEMBL1343003 & 688233 & 3.2218 & 3.9934 & TRN & \\
\hline CHEMBL1558402 & 688233 & 3.5229 & 3.4595 & TST & \\
\hline CHEMBL1403185 & 688233 & 3.5229 & 3.5631 & TRN & \\
\hline CHEMBL1339150 & 688233 & 3.2218 & 3.4084 & TRN & \\
\hline CHEMBL1545797 & 688233 & 3.5229 & 3.513 & TRN & \\
\hline CHEMBL1409120 & 688233 & 3.5229 & 3.1954 & TST & \\
\hline CHEMBL1459681 & 688233 & 3.2218 & 4.0051 & TST & \\
\hline CHEMBL3190508 & 688233 & 3.2218 & 3.7036 & TRN & \\
\hline CHEMBL578719 & 688233 & 3.2218 & 3.3864 & TST & \\
\hline CHEMBL1366934 & 688233 & 3.2218 & 4.0326 & TRN & \\
\hline CHEMBL1459735 & 688233 & 3.2218 & 3.9746 & TST & \\
\hline CHEMBL1491888 & 688233 & 3.2218 & 3.0234 & TRN & \\
\hline CHEMBL1475884 & 688233 & 5.2031 & 4.087 & TST & \\
\hline CHEMBL1361462 & 688233 & 3.2218 & 3.5851 & TRN & \\
\hline CHEMBL3190702 & 688233 & 3.2218 & 3.5651 & TRN & \\
\hline CHEMBL1580926 & 688233 & 3.2218 & 4.1185 & TRN & \\
\hline CHEMBL1311109 & 688233 & 3.2218 & 3.8379 & TST & \\
\hline CHEMBL1567282 & 688233 & 3.2218 & 3.819 & TRN & \\
\hline CHEMBL162057 & 688233 & 3.5229 & 3.1842 & TRN & \\
\hline CHEMBL584444 & 688233 & 3.5229 & 3.058000 & 00000000003 & TRN \\
\hline CHEMBL1496327 & 688233 & 3.2218 & 3.4398 & TRN & \\
\hline CHEMBL1576088 & 688233 & 4.7197 & 3.5197 & TRN & \\
\hline CHEMBL1505189 & 688233 & 3.2218 & 3.3683 & TRN & \\
\hline CHEMBL1526654 & 688233 & 3.2218 & 4.0061 & TRN & \\
\hline CHEMBL1334574 & 688233 & 5.3029 & 3.9556 & TRN & \\
\hline CHEMBL1587013 & 688233 & 3.2218 & 3.0629 & TRN & \\
\hline CHEMBL1305636 & 688233 & 3.2218 & 3.3883 & TRN & \\
\hline CHEMBL1546159 & 688233 & 3.2218 & 3.8498 & TST & \\
\hline CHEMBL587801 & 688233 & 3.5229 & 3.9033 & TST & \\
\hline CHEMBL1332927 & 688233 & 3.2218 & 3.8594 & TRN & \\
\hline CHEMBL1399543 & 688233 & 4.9184 & 4.6977 & TST & \\
\hline CHEMBL1499059 & 688233 & 3.2218 & 3.4461 & TRN & \\
\hline CHEMBL1527528 & 688233 & 3.2218 & 3.2469 & TRN & \\
\hline CHEMBL1330307 & 688233 & 5.2317 & 5.4753 & TRN & \\
\hline CHEMBL1332873 & 688233 & \multicolumn{4}{|c|}{5.582000000000001} \\
\hline CHEMBL1482679 & 688233 & 4.9066 & 3.4641 & TRN & \\
\hline CHEMBL1373096 & 688233 & 6.2299 & 6.3244 & TRN & \\
\hline CHEMBL1454008 & 688233 & 3.2218 & 3.4112 & TRN & \\
\hline
\end{tabular}




\begin{tabular}{|c|c|c|c|c|c|}
\hline \multicolumn{6}{|c|}{ Supplemental Table S2.txt } \\
\hline CHEMBL3210126 & 688233 & 3.2218 & 3.6657 & TRN & \\
\hline CHEMBL1311115 & 688233 & 3.5229 & 3.7141 & TRN & \\
\hline CHEMBL1387790 & 688233 & 4.2616 & 4.3304 & TRN & \\
\hline CHEMBL1537056 & 688233 & 3.2218 & 3.4606 & TRN & \\
\hline CHEMBL1329918 & 688233 & 3.2218 & 3.7365 & TRN & \\
\hline CHEMBL1442500 & 688233 & 4.984 & 4.9517 & TRN & \\
\hline CHEMBL1501217 & 688233 & 4.8365 & 3.6669 & TRN & \\
\hline CHEMBL1415885 & 688233 & 5.1454 & 4.0395 & TRN & \\
\hline CHEMBL1433403 & 688233 & 3.2218 & 3.4987 & TRN & \\
\hline CHEMBL1468865 & 688233 & 3.5229 & 3.2805 & TRN & \\
\hline CHEMBL1361740 & 688233 & 5.5124 & 4.7072 & TST & \\
\hline CHEMBL1367639 & 688233 & 3.2218 & 3.4567 & TRN & \\
\hline CHEMBL1533902 & 688233 & 3.2218 & 3.3403 & TRN & \\
\hline CHEMBL1413513 & 688233 & 3.2218 & 3.2734 & TRN & \\
\hline CHEMBL1544525 & 688233 & 3.2218 & 3.3291 & TRN & \\
\hline CHEMBL3192284 & 688233 & 3.5229 & 3.7802 & TRN & \\
\hline CHEMBL1429091 & 688233 & 3.2218 & 3.16399 & 99999999997 & TRN \\
\hline CHEMBL1427859 & 688233 & 4.996 & 3.8115 & TRN & \\
\hline CHEMBL1426659 & 688233 & 3.2218 & 3.6253 & TRN & \\
\hline CHEMBL1540963 & 688233 & 5.0066 & 3.7561 & TRN & \\
\hline CHEMBL1570959 & 688233 & 3.5229 & 3.9334 & TRN & \\
\hline CHEMBL1557781 & 688233 & 3.2218 & 3.3845 & TRN & \\
\hline CHEMBL1348922 & 688233 & 3.5229 & 3.1625 & TRN & \\
\hline CHEMBL1479491 & 688233 & 3.2218 & 3.8067 & TRN & \\
\hline CHEMBL1515696 & 688233 & 5.2089 & 4.4242 & TRN & \\
\hline CHEMBL 2001139 & 688233 & 3.2218 & 3.5554 & TRN & \\
\hline CHEMBL1583226 & 688233 & 5.2798 & 3.5487 & TRN & \\
\hline CHEMBL1351290 & 688233 & 3.5229 & 3.9271 & TST & \\
\hline CHEMBL572994 & 688233 & 4.4264 & 4.1317 & TRN & \\
\hline CHEMBL1573977 & 688233 & 3.2218 & 3.5862 & TRN & \\
\hline CHEMBL1310479 & 688233 & 3.2218 & 3.7361 & TRN & \\
\hline CHEMBL1525103 & 688233 & 4.9931 & 3.6678 & TRN & \\
\hline CHEMBL1546166 & 688233 & 4.51 & 3.833 & TRN & \\
\hline CHEMBL1383654 & 688233 & 3.2218 & 3.4556 & TRN & \\
\hline CHEMBL1530259 & 688233 & 3.2218 & 3.3002 & TRN & \\
\hline CHEMBL1571734 & 688233 & 3.2218 & 3.6202 & TRN & \\
\hline CHEMBL583558 & 688233 & 3.2218 & 3.39300 & 00000000002 & TRN \\
\hline CHEMBL1383044 & 688233 & 3.2218 & 3.8098 & TRN & \\
\hline CHEMBL1428827 & 688233 & 3.5229 & 4.2604 & TST & \\
\hline CHEMBL1453552 & 688233 & 3.2218 & 3.8486 & TRN & \\
\hline CHEMBL1575946 & 688233 & 3.2218 & 3.3517 & TRN & \\
\hline CHEMBL1431496 & 688233 & 3.2218 & 3.6037 & TRN & \\
\hline CHEMBL 2365737 & 688233 & 4.7115 & 3.7338 & TRN & \\
\hline CHEMBL1310690 & 688233 & 3.5229 & 4.3437 & TRN & \\
\hline CHEMBL1313978 & 688233 & 3.2218 & 4.072 & TRN & \\
\hline CHEMBL1529783 & 688233 & 5.4159 & 4.3542 & TRN & \\
\hline CHEMBL1542356 & 688233 & 3.2218 & 3.1847 & TRN & \\
\hline CHEMBL1414681 & 688233 & 3.2218 & 3.4262 & TRN & \\
\hline
\end{tabular}


Supplemental Table S2.txt

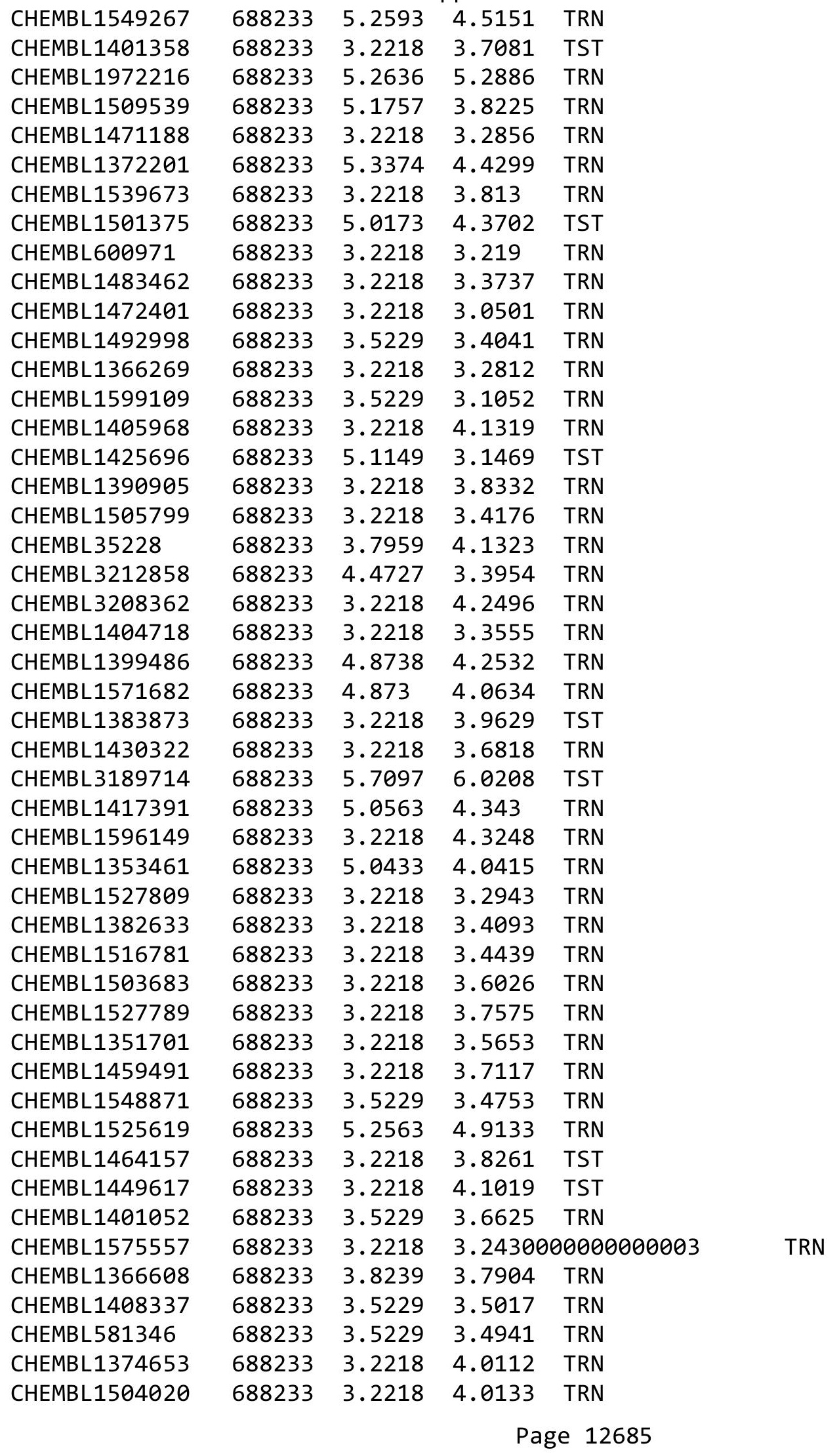


Supplemental Table S2.txt

\begin{tabular}{|c|c|c|c|c|c|}
\hline CHEMBL1458840 & 688233 & 5.3378 & 4.2311 & TRN & \\
\hline CHEMBL1468513 & 688233 & 4.9953 & 3.8837 & TRN & \\
\hline CHEMBL1526744 & 688233 & 3.2218 & 3.2031 & TRN & \\
\hline CHEMBL1342053 & 688233 & 4.8228 & 4.7789 & TRN & \\
\hline CHEMBL1527540 & 688233 & 3.5229 & 4.1438 & TST & \\
\hline CHEMBL1493211 & 688233 & 3.2218 & 2.9606 & TRN & \\
\hline CHEMBL3210984 & 688233 & 3.5229 & 3.6418 & TRN & \\
\hline CHEMBL1314691 & 688233 & 3.5229 & 3.5154 & TRN & \\
\hline CHEMBL1503034 & 688233 & 5.1961 & 4.4614 & TST & \\
\hline CHEMBL1462003 & 688233 & 3.2218 & 3.6709 & TRN & \\
\hline CHEMBL1596985 & 688233 & 5.3653 & 4.497 & TRN & \\
\hline CHEMBL1442253 & 688233 & 3.2218 & 3.7294 & TRN & \\
\hline CHEMBL1575868 & 688233 & 3.2218 & 3.4214 & TRN & \\
\hline CHEMBL1428809 & 688233 & 3.2218 & 4.1974 & TRN & \\
\hline CHEMBL1584579 & 688233 & 3.2218 & 3.4291 & TST & \\
\hline CHEMBL1377336 & 688233 & 3.2218 & 3.6223 & TRN & \\
\hline CHEMBL1448321 & 688233 & 3.5229 & 4.8965 & TRN & \\
\hline CHEMBL3199132 & 688233 & 3.2218 & 4.1758 & TRN & \\
\hline CHEMBL1529005 & 688233 & 3.2218 & 3.5868 & TRN & \\
\hline CHEMBL1536719 & 688233 & 3.2218 & 3.6112 & TRN & \\
\hline CHEMBL1353790 & 688233 & 3.2218 & 3.4193 & TRN & \\
\hline CHEMBL1548854 & 688233 & 5.0243 & 3.8898 & TRN & \\
\hline CHEMBL1471108 & 688233 & 3.2218 & 3.6926 & TST & \\
\hline CHEMBL1423920 & 688233 & 3.5229 & 3.0046 & TRN & \\
\hline CHEMBL1382801 & 688233 & 3.5229 & 3.5313 & TRN & \\
\hline CHEMBL1525538 & 688233 & 3.2218 & 3.4601 & TRN & \\
\hline CHEMBL1608065 & 688233 & 3.2218 & 3.7992 & TRN & \\
\hline CHEMBL3195036 & 688233 & 5.254 & 5.0593 & TRN & \\
\hline CHEMBL1411521 & 688233 & 3.5229 & 3.6651 & TRN & \\
\hline CHEMBL1388576 & 688233 & 3.2218 & 3.4233 & TRN & \\
\hline CHEMBL1589219 & 688233 & 3.2218 & 3.31699 & 99999999997 & TST \\
\hline CHEMBL1557849 & 688233 & 3.2218 & 4.4919 & TST & \\
\hline CHEMBL1571452 & 688233 & 3.2218 & 3.4501 & TST & \\
\hline CHEMBL1599379 & 688233 & 3.2218 & 3.5712 & TRN & \\
\hline CHEMBL409906 & 688233 & 3.2218 & 3.9014 & TRN & \\
\hline CHEMBL1548882 & 688233 & 3.2218 & 3.3146 & TST & \\
\hline CHEMBL3191962 & 688233 & 5.4453 & 4.9066 & TRN & \\
\hline CHEMBL1605568 & 688233 & 3.2218 & 3.1481 & TRN & \\
\hline CHEMBL1541426 & 688233 & 3.2218 & 3.7213 & TST & \\
\hline CHEMBL1453582 & 688233 & 3.5229 & 3.3541 & TRN & \\
\hline CHEMBL1999900 & 688233 & 3.5229 & 4.3923 & TRN & \\
\hline CHEMBL1391028 & 688233 & 3.2218 & 2.6515 & TRN & \\
\hline CHEMBL1503342 & 688233 & 3.5229 & 3.2513 & TRN & \\
\hline CHEMBL1479786 & 688233 & 5.3766 & 4.2978 & TRN & \\
\hline CHEMBL1306912 & 688233 & 4.623 & 3.6084 & TST & \\
\hline CHEMBL1365771 & 688233 & 3.2218 & 4.0917 & TST & \\
\hline CHEMBL1382191 & 688233 & 3.2218 & 3.8525 & TRN & \\
\hline CHEMBL1397537 & 688233 & 3.2218 & 3.4874 & TRN & \\
\hline
\end{tabular}


Supplemental Table S2.txt

\begin{tabular}{|c|c|c|c|c|}
\hline S & & & & \\
\hline & & .2218 & 3.3644 & \\
\hline$=0$ & & & & \\
\hline AEMBL13: & & & & $\mathrm{MI}$ \\
\hline AEMBL1515473 & 8233 & & 3939 & \\
\hline HEMBL1524531 & 88233 & 5229 & 9864 & \\
\hline HEMBL1 & & & & \\
\hline |FMRI & & & & \\
\hline AEMBL13 & & & 7416 & \\
\hline HEMBL1524865 & 88233 & & 5681 & \\
\hline AEMBL14 & 33 & & 508 & \\
\hline IEMBL3 & & & 214 & \\
\hline IEMBL: & & & & \\
\hline HEMBL1 & & & 3.2342 & \\
\hline AEMBL1 & & & 3674 & \\
\hline HEMBL1 & 3 & & 572 & \\
\hline HEMBL1 & & & 57 & \\
\hline HEMBLI & & & & \\
\hline HEMBL1 & & & .0159 & \\
\hline AEMBL1 & & & & \\
\hline AEIMBL. & & & 98 & Niv \\
\hline AEMBL & & & & RN \\
\hline HEMBL & & & 57 & \\
\hline 020 & & & & \\
\hline AEMBL13 & & & & 1د \\
\hline HEMBL: & & & 151 & SI \\
\hline HEMBL & & & 74 & RN \\
\hline HFMRI & & & 36 & \\
\hline JEMBL3 & & & & בידוt \\
\hline HEMBL1527622 & & & & $\ln$ \\
\hline HEMBL1 & & & 189 & SI \\
\hline HEMBL & & & 78 & RN \\
\hline HEMPI & & & 29 & 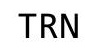 \\
\hline HEMBL1598069 & & & & IR \\
\hline HEMBL1476264 & & & 5.0357 & TRN \\
\hline HEMBL & & & 387 & RN \\
\hline HCMDI & & & & ST \\
\hline & & & & ГRN \\
\hline HEMBL1478510 & 3 & & 3.3059 & TRN \\
\hline AEMBL1 & & & 3.4179 & $\mathrm{RN}$ \\
\hline HEMBL1 & & & 3.1127 & \\
\hline CHEMBL 5 & & & 4.3759 & TRN \\
\hline HEMBL1: & & & 3.8459 & $\mathrm{R}$ \\
\hline AEMBL1 & 33 & & 1148 & TR \\
\hline HEMBL1 & & & 3.2 & \\
\hline CHEMBL1 & & & & \\
\hline HEMBL1 & & & 4.5619 & \\
\hline HEMBL1454957 & 688233 & 3.2218 & 3.2243 & ГRN \\
\hline
\end{tabular}

Page 12687 
Supplemental Table S2.txt

\begin{tabular}{|c|c|c|c|c|c|}
\hline CHEMBL1606583 & 688233 & 5.1356 & 4.8553 & TRN & \\
\hline CHEMBL1583262 & 688233 & 3.2218 & 3.7832 & TST & \\
\hline CHEMBL1421764 & 688233 & 3.2218 & 3.615 & TRN & \\
\hline CHEMBL1563835 & 688233 & 3.2218 & 3.8504 & TRN & \\
\hline CHEMBL1513753 & 688233 & 3.2218 & 3.663999 & 99999999997 & TRN \\
\hline CHEMBL1564542 & 688233 & 3.5229 & 3.8403 & TRN & \\
\hline CHEMBL1567438 & 688233 & 3.2218 & 3.8921 & TRN & \\
\hline CHEMBL1491626 & 688233 & 3.2218 & 4.0345 & TRN & \\
\hline CHEMBL1320638 & 688233 & 3.2218 & 4.0009 & TRN & \\
\hline CHEMBL1384550 & 688233 & 5.0157 & 3.6004 & TRN & \\
\hline CHEMBL1538216 & 688233 & 3.2218 & 3.4046 & TRN & \\
\hline CHEMBL1517625 & 688233 & 3.2218 & 3.1146 & TRN & \\
\hline CHEMBL1581902 & 688233 & 3.2218 & 3.3091 & TRN & \\
\hline CHEMBL1324917 & 688233 & 3.2218 & 3.447 & TRN & \\
\hline CHEMBL1538325 & 688233 & 3.2218 & 3.7905 & TST & \\
\hline CHEMBL1393563 & 688233 & 3.2218 & 3.4055 & TRN & \\
\hline CHEMBL1380330 & 688233 & 3.2218 & 3.4904 & TRN & \\
\hline CHEMBL1538919 & 688233 & 3.5229 & 3.2915 & TRN & \\
\hline CHEMBL1521989 & 688233 & 5.0421 & 3.8343 & TRN & \\
\hline CHEMBL1439532 & 688233 & 3.2218 & 3.2109 & TRN & \\
\hline CHEMBL1471189 & 688233 & 5.1267 & 3.8287 & TST & \\
\hline CHEMBL1547328 & 688233 & 3.2218 & 3.1111 & TRN & \\
\hline CHEMBL1353885 & 688233 & 3.5229 & 4.1128 & TRN & \\
\hline CHEMBL1454738 & 688233 & 3.2218 & 4.0861 & TRN & \\
\hline CHEMBL600734 & 688233 & 5.1264 & 5.0865 & TST & \\
\hline CHEMBL1369945 & 688233 & 5.3408 & 4.7271 & TRN & \\
\hline CHEMBL1532622 & 688233 & 4.5728 & 3.6432 & TRN & \\
\hline CHEMBL1517535 & 688233 & 3.2218 & 3.9056 & TRN & \\
\hline CHEMBL1320354 & 688233 & 3.2218 & 3.5241 & TRN & \\
\hline CHEMBL1332003 & 688233 & 3.2218 & 4.1192 & TRN & \\
\hline CHEMBL305469 & 688233 & 3.2218 & 3.9152 & TRN & \\
\hline CHEMBL1594475 & 688233 & \multicolumn{3}{|c|}{5.968999999999999} & TRN \\
\hline CHEMBL1441035 & 688233 & 3.2218 & 3.6048 & TRN & \\
\hline CHEMBL1532309 & 688233 & 3.2218 & 3.8593 & TRN & \\
\hline CHEMBL3197394 & 688233 & 3.2218 & 3.4544 & TST & \\
\hline CHEMBL3197856 & 688233 & 3.5229 & 3.5086 & TRN & \\
\hline CHEMBL 1472122 & 688233 & 3.5229 & 3.4352 & TRN & \\
\hline CHEMBL1314661 & 688233 & 3.2218 & 3.683999 & & TRN \\
\hline CHEMBL1539624 & 688233 & 5.3539 & 4.7999 & TRN & \\
\hline CHEMBL 1466735 & 688233 & 3.2218 & 4.2687 & TRN & \\
\hline CHEMBL1561229 & 688233 & 3.5229 & 3.5192 & TRN & \\
\hline CHEMBL1345355 & 688233 & 3.2218 & 3.6348 & TRN & \\
\hline CHEMBL1432378 & 688233 & 5.2331 & 4.3548 & TST & \\
\hline CHEMBL1600639 & 688233 & 5.0234 & 4.3243 & TRN & \\
\hline CHEMBL163428 & 688233 & 3.2218 & 3.9809 & TRN & \\
\hline CHEMBL1479681 & 688233 & 3.2218 & 3.5055 & TRN & \\
\hline CHEMBL1430889 & 688233 & 3.2218 & 3.3356 & TRN & \\
\hline CHEMBL1325994 & 688233 & 3.2218 & 3.3344 & TRN & \\
\hline
\end{tabular}


Supplemental Table S2.txt

\begin{tabular}{|c|c|c|c|c|}
\hline HEN & & 218 & 8824 & \\
\hline & & & & \\
\hline FMRI 31 & & & & \\
\hline IEMBL: & 8233 & 18 & & \\
\hline AEMBL1457549 & 88233 & 5229 & 8633 & \\
\hline HEMBL13 & 88233 & .8792 & 8391 & \\
\hline HEMBL1 & & .0225 & & \\
\hline AEMBL31 & & & & \\
\hline HEMBL1575414 & 88233 & 2218 & .6842 & \\
\hline HEMBL585827 & 88233 & 9863 & 9922 & \\
\hline HEMBL 31 & & & 26 & \\
\hline HEMBL1: & & 48 & .4912 & \\
\hline HEMBL15 & & & & \\
\hline HEMBL134 & 33 & .2218 & .227 & \\
\hline HEMBL 144 & & & & \\
\hline HEMBL16 & & 9 & 03 & \\
\hline HEMBL14 & & & & \\
\hline HEMBL12 & & & 338 & \\
\hline HFMBI 31 & & & 1999 & \\
\hline AEMBL13 & & & & \\
\hline HEMBL1 & & & 33 & וכ ד \\
\hline AEMBLI & & & & RN \\
\hline AEMBL1 & & & & \\
\hline HEMPI $2-$ & & & & \\
\hline AEMBL14 & & 9 & 37 & |SI \\
\hline HEMBL31 & & & 24 & ГR/ \\
\hline HEM & & & & ונס \\
\hline HEMPI 1 & & 9 & 14 & \\
\hline HEMBL14 & & & & IRN \\
\hline AEMBL135 & & 9 & 3.0936 & RN \\
\hline HEMBL1C & & & 282 & ST \\
\hline HFM & & & & RN \\
\hline 15נים & & & & 「RN \\
\hline HEMBL14 & & & & 「RN \\
\hline HEMBL19 & & & 739 & RN \\
\hline AEMR 1 & & & 49 & TRN \\
\hline 1 & & 9 & 13 & TRN \\
\hline HEMBL13 & & & & TRN \\
\hline HEMBL14 & & & & $\Gamma R$ \\
\hline EMBL & & & & ГST \\
\hline HEMBL13 & & & 22 & TRN \\
\hline & & 3. & 3.0898 & 「RN \\
\hline HEMBL133 & & 3.2218 & 3.4331 & $T R$ \\
\hline HEMBL13 & & & 96 & TS \\
\hline CHEMPI 152 & & & & \\
\hline HEMBL136 & & & & \\
\hline HEMBL150 & & 3.2218 & 3.9451 & \\
\hline CHEMBL1608757 & 688233 & 3.2218 & 3.6479 & כו \\
\hline
\end{tabular}

Page 12689 
Supplemental Table S2.txt

\begin{tabular}{|c|c|c|c|c|c|}
\hline CHEMBL1385128 & 688233 & 3.5229 & 4.5719 & TRN & \\
\hline CHEMBL1338677 & 688233 & 6.2218 & 5.5427 & TRN & \\
\hline CHEMBL1603307 & 688233 & 3.2218 & 3.9112 & TRN & \\
\hline CHEMBL1580286 & 688233 & 5.0939 & 4.3507 & TRN & \\
\hline CHEMBL1544063 & 688233 & 4.5035 & 3.6211 & TST & \\
\hline CHEMBL1361161 & 688233 & 3.5229 & 3.3683 & TST & \\
\hline CHEMBL 239275 & 688233 & 6.2218 & 5.5027 & TRN & \\
\hline CHEMBL1438681 & 688233 & 3.2218 & 3.5449 & TRN & \\
\hline CHEMBL591126 & 688233 & 5.1955 & 4.7163 & TRN & \\
\hline CHEMBL1452090 & 688233 & 5.2203 & 5.0972 & TRN & \\
\hline CHEMBL1478316 & 688233 & 3.2218 & 3.4827 & TRN & \\
\hline CHEMBL3191556 & 688233 & 5.0014 & 4.3054 & TST & \\
\hline CHEMBL1315704 & 688233 & 5.187 & 3.4769 & TST & \\
\hline CHEMBL1532320 & 688233 & 3.2218 & 3.4088 & TRN & \\
\hline CHEMBL1524297 & 688233 & 3.2218 & 2.9636 & TRN & \\
\hline CHEMBL1500696 & 688233 & 4.4453 & 3.8223 & TST & \\
\hline CHEMBL1501464 & 688233 & 5.3454 & 3.3842 & TST & \\
\hline CHEMBL1325631 & 688233 & 3.2218 & 3.6014 & TST & \\
\hline CHEMBL1515913 & 688233 & 3.5229 & 3.5548 & TRN & \\
\hline CHEMBL1519798 & 688233 & 4.8263 & 3.5059 & TRN & \\
\hline CHEMBL1496808 & 688233 & 4.3728 & 3.461999 & 9999999997 & TRN \\
\hline CHEMBL1299591 & 688233 & 3.2218 & 3.0979 & TST & \\
\hline CHEMBL3197098 & 688233 & 3.5229 & 4.04 & TRN & \\
\hline CHEMBL1550090 & 688233 & 5.0281 & 4.1256 & TRN & \\
\hline CHEMBL1535187 & 688233 & 3.2218 & 3.9148 & TST & \\
\hline CHEMBL1543188 & 688233 & 3.2218 & 3.2043 & TRN & \\
\hline CHEMBL1450105 & 688233 & 3.2218 & 3.5547 & TRN & \\
\hline CHEMBL1509857 & 688233 & 3.2218 & 3.0163 & TRN & \\
\hline CHEMBL1470840 & 688233 & 3.5229 & 3.435 & TRN & \\
\hline CHEMBL 3199025 & 688233 & 3.2218 & 3.8263 & TRN & \\
\hline CHEMBL1503375 & 688233 & 3.2218 & 3.8885 & TRN & \\
\hline CHEMBL1410957 & 688233 & 4.8793 & 3.2599 & TRN & \\
\hline CHEMBL1429497 & 688233 & 3.2218 & 3.248 & TRN & \\
\hline CHEMBL1525766 & 688233 & 3.2218 & 3.5643 & TRN & \\
\hline CHEMBL1468264 & 688233 & 3.2218 & 4.1081 & TST & \\
\hline CHEMBL3193701 & 688233 & 3.2218 & 4.0367 & TRN & \\
\hline CHEMBL1364729 & 688233 & 3.5229 & 3.9051 & TST & \\
\hline CHEMBL1318190 & 688233 & 3.2218 & 3.2722 & TRN & \\
\hline CHEMBL1408197 & 688233 & 3.2218 & 3.8769 & TRN & \\
\hline CHEMBL1431754 & 688233 & 3.2218 & 3.6811 & TRN & \\
\hline CHEMBL1452119 & 688233 & 3.2218 & 3.4176 & TRN & \\
\hline CHEMBL1399311 & 688233 & 4.5052 & 4.0913 & TRN & \\
\hline CHEMBL1525040 & 688233 & 4.9856 & 3.9273 & TRN & \\
\hline CHEMBL1370947 & 688233 & 3.2218 & 3.2199 & TRN & \\
\hline CHEMBL1351963 & 688233 & 3.2218 & 3.5507 & TRN & \\
\hline CHEMBL1489356 & 688233 & 3.2218 & 3.0287 & TRN & \\
\hline CHEMBL1329349 & 688233 & 5.4371 & 4.3628 & TRN & \\
\hline CHEMBL1440600 & 688233 & 3.2218 & 3.4891 & TRN & \\
\hline
\end{tabular}




\begin{tabular}{|c|c|c|c|c|c|}
\hline & & & oplement & al Table S2 & \\
\hline CHEMBL1557166 & 688233 & 5.2894 & 4.5628 & TST & \\
\hline CHEMBL1382389 & 688233 & 3.2218 & 3.70300 & 00000000003 & TRN \\
\hline CHEMBL1507231 & 688233 & 3.2218 & 3.9485 & TRN & \\
\hline CHEMBL1428905 & 688233 & 3.2218 & 3.1584 & TRN & \\
\hline CHEMBL1480424 & 688233 & 5.0173 & 3.6876 & TRN & \\
\hline CHEMBL1406312 & 688233 & 3.2218 & 3.218 & TRN & \\
\hline CHEMBL1426530 & 688233 & 3.2218 & 3.6936 & TRN & \\
\hline CHEMBL1559355 & 688233 & 5.3892 & 3.7603 & TRN & \\
\hline CHEMBL1521380 & 688233 & 3.2218 & 3.4663 & TST & \\
\hline CHEMBL1382265 & 688233 & 5.2657 & 4.2749 & TRN & \\
\hline CHEMBL3210588 & 688233 & 3.5229 & 3.27399 & 99999999996 & TST \\
\hline CHEMBL585481 & 688233 & 3.2218 & 4.1286 & TRN & \\
\hline CHEMBL1382687 & 688233 & 3.5229 & 3.8887 & TRN & \\
\hline CHEMBL3194048 & 688233 & 3.2218 & 3.5928 & TST & \\
\hline CHEMBL1346817 & 688233 & 3.2218 & 3.8157 & TRN & \\
\hline CHEMBL1469579 & 688233 & 4.7576 & 3.8604 & TST & \\
\hline CHEMBL1466481 & 688233 & 3.2218 & 3.7344 & TRN & \\
\hline CHEMBL1310098 & 688233 & 3.2218 & 3.4375 & TST & \\
\hline CHEMBL1465730 & 688233 & 3.2218 & 3.352 & TRN & \\
\hline CHEMBL3199937 & 688233 & 5.2858 & 4.748 & TRN & \\
\hline CHEMBL1576090 & 688233 & 3.2218 & 3.4459 & TRN & \\
\hline CHEMBL1455636 & 688233 & 3.2218 & 3.5176 & TRN & \\
\hline CHEMBL1399720 & 688233 & 3.2218 & 3.3502 & TRN & \\
\hline CHEMBL1389194 & 688233 & 3.2218 & 3.00399 & 99999999996 & TRN \\
\hline CHEMBL1452012 & 688233 & 3.2218 & 3.2809 & TRN & \\
\hline CHEMBL1338225 & 688233 & 3.2218 & 3.1955 & TRN & \\
\hline CHEMBL2369174 & 688233 & 3.2218 & 3.2759 & TRN & \\
\hline CHEMBL1538817 & 688233 & 3.2218 & 3.8093 & TRN & \\
\hline CHEMBL1535365 & 688233 & 3.2218 & 3.6307 & TRN & \\
\hline CHEMBL1589160 & 688233 & 3.5229 & 3.5938 & TRN & \\
\hline CHEMBL1324349 & 688233 & 3.2218 & 3.551 & TST & \\
\hline CHEMBL1464020 & 688233 & 3.2218 & 3.449 & TRN & \\
\hline CHEMBL1362366 & 688233 & 3.2218 & 3.6698 & TRN & \\
\hline CHEMBL1307435 & 688233 & 4.5175 & 3.4069 & TRN & \\
\hline CHEMBL1496236 & 688233 & 3.2218 & 3.5856 & TRN & \\
\hline CHEMBL1413459 & 688233 & 3.5229 & 3.5961 & TRN & \\
\hline CHEMBL1410902 & 688233 & 3.2218 & 3.22 & TRN & \\
\hline CHEMBL1605037 & 688233 & 3.2218 & 3.0769 & TRN & \\
\hline CHEMBL1388234 & 688233 & 3.2218 & 3.1101 & TRN & \\
\hline CHEMBL566064 & 688233 & 5.1799 & 3.9809 & TRN & \\
\hline CHEMBL1420524 & 688233 & 3.2218 & 4.1519 & TST & \\
\hline CHEMBL1594854 & 688233 & 3.2218 & 4.0878 & TRN & \\
\hline CHEMBL1513856 & 688233 & 5.2508 & 3.9381 & TRN & \\
\hline CHEMBL1518491 & 688233 & 3.2218 & 3.4781 & TRN & \\
\hline CHEMBL1439007 & 688233 & 3.5229 & 3.6236 & TRN & \\
\hline CHEMBL1322532 & 688233 & 3.5229 & 3.1056 & TST & \\
\hline CHEMBL1577085 & 688233 & 5.0725 & 4.0587 & TST & \\
\hline CHEMBL1394637 & 688233 & 3.2218 & 3.7236 & TRN & \\
\hline
\end{tabular}




\begin{tabular}{|c|c|c|c|c|c|c|}
\hline & & \multicolumn{5}{|c|}{ Supplemental Table S2.txt } \\
\hline CHEMBL1453771 & 688233 & 3.2218 & 3.5586 & TRN & & \\
\hline CHEMBL1347509 & 688233 & 5.0064 & 3.6662 & TRN & & \\
\hline CHEMBL1385771 & 688233 & 5.395 & 5.8405 & TRN & & \\
\hline CHEMBL1543822 & 688233 & 3.2218 & 3.6275 & TRN & & \\
\hline CHEMBL1509075 & 688233 & 4.4887 & 3.9544 & TRN & & \\
\hline CHEMBL601547 & 688233 & 3.5229 & 3.877 & TRN & & \\
\hline CHEMBL1496338 & 688233 & 3.2218 & 4.228 & TRN & & \\
\hline CHEMBL1343169 & 688233 & 3.2218 & 3.7147 & TRN & & \\
\hline CHEMBL1506210 & 688233 & 4.9234 & 4.6909 & TST & & \\
\hline CHEMBL1567824 & 688233 & 3.2218 & 3.7535 & TRN & & \\
\hline CHEMBL1580616 & 688233 & 3.2218 & 3.6467 & TRN & & \\
\hline CHEMBL1567619 & 688233 & 3.5229 & 3.8434 & TRN & & \\
\hline CHEMBL1383015 & 688233 & 3.2218 & 3.6352 & TST & & \\
\hline CHEMBL1491124 & 688233 & 3.2218 & 4.1843 & TRN & & \\
\hline CHEMBL1546120 & 688233 & 3.2218 & 3.6049 & TRN & & \\
\hline CHEMBL 270362 & 688233 & 5.3123 & 3.7744 & TST & & \\
\hline CHEMBL493691 & 688233 & 3.2218 & 3.6171 & TST & & \\
\hline CHEMBL1612647 & 688233 & 3.2218 & 4.0473 & TRN & & \\
\hline CHEMBL1472130 & 688233 & 3.2218 & 3.1161 & TRN & & \\
\hline CHEMBL1443775 & 688233 & 3.5229 & 4.3646 & TRN & & \\
\hline CHEMBL1320178 & 688233 & 3.2218 & 3.6485 & TRN & & \\
\hline CHEMBL1429837 & 688233 & 3.2218 & 4.1152 & TRN & & \\
\hline CHEMBL1506706 & 688233 & 3.2218 & 3.2467 & TRN & & \\
\hline CHEMBL1486546 & 688233 & 5.58299 & 99999999 & 99 & 5.7219 & TRN \\
\hline CHEMBL1522066 & 688233 & 3.2218 & 3.8343 & TRN & & \\
\hline CHEMBL1337204 & 688233 & 3.2218 & 3.6748 & TRN & & \\
\hline CHEMBL1440952 & 688233 & 5.0605 & 4.3991 & TRN & & \\
\hline CHEMBL1350245 & 688233 & 3.2218 & 3.2903 & TRN & & \\
\hline CHEMBL1404086 & 688233 & 5.0875 & 3.9346 & TST & & \\
\hline CHEMBL1587786 & 688233 & 3.2218 & 3.7217 & TRN & & \\
\hline CHEMBL1486146 & 688233 & 3.5229 & 3.3331 & TRN & & \\
\hline CHEMBL1440829 & 688233 & 4.7537 & 3.9373 & TRN & & \\
\hline CHEMBL1384414 & 688233 & 3.2218 & 3.2414 & TRN & & \\
\hline CHEMBL1349570 & 688233 & 3.2218 & 4.067 & TST & & \\
\hline CHEMBL1587493 & 688233 & 3.2218 & 3.8888 & TRN & & \\
\hline CHEMBL1437660 & 688233 & 5.256 & 4.1507 & TRN & & \\
\hline CHEMBL1364193 & 688233 & 4.9261 & 4.3914 & TRN & & \\
\hline CHEMBL1457560 & 688233 & 3.2218 & 3.9131 & TRN & & \\
\hline CHEMBL1484652 & 688233 & 3.2218 & 3.4325 & TRN & & \\
\hline CHEMBL1603270 & 688233 & 3.2218 & 3.6199 & TRN & & \\
\hline CHEMBL1358777 & 688233 & 3.2218 & 3.5988 & TST & & \\
\hline CHEMBL1339229 & 688233 & 5.0733 & 3.6094 & TST & & \\
\hline CHEMBL3190426 & 688233 & 3.5229 & 3.4131 & TST & & \\
\hline CHEMBL1351683 & 688233 & 3.2218 & 3.3385 & TRN & & \\
\hline CHEMBL1418742 & 688233 & 3.2218 & 3.5976 & TRN & & \\
\hline CHEMBL1312502 & 688233 & 5.0482 & 4.0117 & TRN & & \\
\hline CHEMBL548458 & 688233 & 3.2218 & 4.1476 & TRN & & \\
\hline CHEMBL1558531 & 688233 & 3.2218 & 3.4604 & TRN & & \\
\hline
\end{tabular}




\begin{tabular}{|c|c|c|c|c|c|}
\hline \multirow[b]{2}{*}{ CHEMBL1494462 } & \multicolumn{5}{|c|}{ Supplemental Table S2.txt } \\
\hline & 688233 & 3.2218 & 3.1566 & TRN & \\
\hline CHEMBL1389267 & 688233 & 3.2218 & 3.1228 & TRN & \\
\hline CHEMBL1533362 & 688233 & 5.0481 & 3.3683 & TRN & \\
\hline CHEMBL1486900 & 688233 & 3.2218 & 2.9873 & TRN & \\
\hline CHEMBL1445146 & 688233 & 3.2218 & 4.1839 & TRN & \\
\hline CHEMBL1563708 & 688233 & 3.2218 & 3.4283 & TRN & \\
\hline CHEMBL1520483 & 688233 & 3.2218 & 3.4378 & TRN & \\
\hline CHEMBL1505182 & 688233 & 3.2218 & 3.9477 & TRN & \\
\hline CHEMBL1542481 & 688233 & 5.1008 & 4.2951 & TRN & \\
\hline CHEMBL1545491 & 688233 & 3.2218 & 3.6794 & TST & \\
\hline CHEMBL1514590 & 688233 & 5.3188 & 3.7555 & TRN & \\
\hline CHEMBL1564972 & 688233 & 3.2218 & 2.9165 & TRN & \\
\hline CHEMBL1485958 & 688233 & 3.2218 & 3.1202 & TRN & \\
\hline CHEMBL 3189626 & 688233 & 3.2218 & 4.0213 & TRN & \\
\hline CHEMBL1598383 & 688233 & 4.9659 & 3.6741 & TRN & \\
\hline CHEMBL1523938 & 688233 & 5.4087 & 4.5978 & TST & \\
\hline CHEMBL1352295 & 688233 & 3.2218 & 3.2456 & TRN & \\
\hline CHEMBL1384193 & 688233 & 3.2218 & 4.0548 & TST & \\
\hline CHEMBL1490018 & 688233 & 3.2218 & 3.1472 & TRN & \\
\hline CHEMBL1462697 & 688233 & 3.2218 & 2.6217 & TRN & \\
\hline CHEMBL1410722 & 688233 & 3.2218 & 3.4078 & TRN & \\
\hline CHEMBL1388922 & 688233 & 5.3652 & 4.7477 & TRN & \\
\hline CHEMBL1497717 & 688233 & 4.7345 & 3.49600 & 00000000004 & TST \\
\hline CHEMBL1417223 & 688233 & 3.2218 & 3.6263 & TRN & \\
\hline CHEMBL1510627 & 688233 & 3.2218 & 3.6579 & TRN & \\
\hline CHEMBL1561591 & 688233 & 3.5229 & 3.5447 & TRN & \\
\hline CHEMBL1481335 & 688233 & 3.5229 & 3.77 & TRN & \\
\hline CHEMBL1600804 & 688233 & 3.2218 & 3.9886 & TRN & \\
\hline CHEMBL1353980 & 688233 & 3.2218 & 3.8146 & TST & \\
\hline CHEMBL1454346 & 688233 & 3.2218 & 3.39399 & 99999999997 & TRN \\
\hline CHEMBL1583585 & 688233 & 4.4904 & 3.8511 & TRN & \\
\hline CHEMBL587849 & 688233 & 3.2218 & 4.0573 & TST & \\
\hline CHEMBL1406194 & 688233 & 3.2218 & 3.1883 & TRN & \\
\hline CHEMBL1525567 & 688233 & 4.3688 & 3.8056 & TRN & \\
\hline CHEMBL1606040 & 688233 & 3.2218 & 3.7803 & TRN & \\
\hline CHEMBL1462872 & 688233 & 5.1215 & 3.792 & TST & \\
\hline CHEMBL 1470728 & 688233 & 5.2125 & 3.7909 & TST & \\
\hline CHEMBL1309183 & 688233 & 3.5229 & 3.3812 & TRN & \\
\hline CHEMBL3197597 & 688233 & 3.2218 & 3.3869 & TRN & \\
\hline CHEMBL1569409 & 688233 & 3.2218 & 3.8763 & TRN & \\
\hline CHEMBL1463131 & 688233 & 4.8027 & 3.6198 & TRN & \\
\hline CHEMBL1350442 & 688233 & 3.5229 & 3.31699 & 99999999997 & TRN \\
\hline CHEMBL1528519 & 688233 & 3.2218 & 3.23100 & 00000000003 & TRN \\
\hline CHEMBL1521418 & 688233 & 3.2218 & 3.6117 & TRN & \\
\hline CHEMBL3208191 & 688233 & 3.2218 & 3.8767 & TRN & \\
\hline CHEMBL1444729 & 688233 & 3.2218 & 3.2193 & TRN & \\
\hline CHEMBL1394270 & 688233 & 3.2218 & 3.8686 & TRN & \\
\hline CHEMBL1970082 & 688233 & 3.2218 & 3.3401 & TRN & \\
\hline
\end{tabular}

Page 12693 


\begin{tabular}{|c|c|c|c|c|}
\hline \multicolumn{5}{|c|}{ Supplemental Table s2.txt } \\
\hline CHEMBL1476738 & 688233 & 3.2218 & 3.825 & TRN \\
\hline CHEMBL1325564 & 688233 & 3.2218 & 3.5905 & TRN \\
\hline CHEMBL1464788 & 688233 & 3.2218 & 3.4704 & TRN \\
\hline CHEMBL1353285 & 688233 & 3.2218 & 3.8884 & TRN \\
\hline CHEMBL1483731 & 688233 & 3.2218 & 3.5602 & TRN \\
\hline CHEMBL1581410 & 688233 & 3.2218 & 3.7396 & TRN \\
\hline CHEMBL1511166 & 688233 & 3.2218 & 3.5089 & TRN \\
\hline CHEMBL1610386 & 688233 & 3.2218 & 3.2808 & TRN \\
\hline CHEMBL1568279 & 688233 & 4.7499 & 3.8803 & TRN \\
\hline CHEMBL1606239 & 688233 & 4.8808 & 3.5846 & TST \\
\hline CHEMBL1611658 & 688233 & 3.2218 & 3.1241 & TRN \\
\hline CHEMBL1537508 & 688233 & 3.2218 & 3.622 & TRN \\
\hline CHEMBL1321238 & 688233 & 4.9468 & 4.9392 & TRN \\
\hline CHEMBL1456276 & 688233 & 5.3218 & 4.1793 & TRN \\
\hline CHEMBL1520276 & 688233 & 5.3807 & 5.1015 & TRN \\
\hline CHEMBL1468682 & 688233 & 3.2218 & 4.0079 & TRN \\
\hline CHEMBL1344934 & 688233 & 3.2218 & 3.0508 & TRN \\
\hline CHEMBL1411787 & 688233 & 3.2218 & 3.5258 & TRN \\
\hline CHEMBL3198299 & 688233 & 3.2218 & 3.6013 & TRN \\
\hline CHEMBL1548998 & 688233 & 3.2218 & 3.6903 & TST \\
\hline CHEMBL1399502 & 688233 & 3.2218 & 3.3336 & TRN \\
\hline CHEMBL3197665 & 688233 & 3.2218 & 2.9276 & TRN \\
\hline CHEMBL534214 & 688233 & 4.6863 & 4.2616 & TRN \\
\hline CHEMBL1461290 & 688233 & 3.2218 & 3.9741 & TRN \\
\hline CHEMBL1584502 & 688233 & 3.5229 & 3.8704 & TRN \\
\hline CHEMBL1459266 & 688233 & 3.2218 & 3.4195 & TRN \\
\hline CHEMBL1583964 & 688233 & 4.9701 & 3.9406 & TST \\
\hline CHEMBL1364072 & 688233 & 3.2218 & 4.0475 & TRN \\
\hline CHEMBL3211430 & 688233 & 3.2218 & 3.3558 & TRN \\
\hline CHEMBL1311185 & 688233 & 5.6855 & 4.7908 & TRN \\
\hline CHEMBL1467492 & 688233 & 4.6429 & 4.4322 & TRN \\
\hline CHEMBL1468238 & 688233 & 3.2218 & 3.2292 & TRN \\
\hline CHEMBL1516689 & 688233 & 3.2218 & 4.3596 & TRN \\
\hline CHEMBL1883149 & 688233 & 3.2218 & 3.3904 & TRN \\
\hline CHEMBL1352337 & 688233 & 3.2218 & 3.5582 & TRN \\
\hline CHEMBL1547208 & 688233 & 3.2218 & 3.3724 & TRN \\
\hline CHEMBL1570958 & 688233 & 5.4409 & 5.3187 & TRN \\
\hline CHEMBL1524363 & 688233 & 3.2218 & 3.8992 & TST \\
\hline CHEMBL1511962 & 688233 & 3.2218 & 3.4336 & TRN \\
\hline CHEMBL1547860 & 688233 & 3.2218 & 3.7897 & TRN \\
\hline CHEMBL1499951 & 688233 & 5.401 & 4.8226 & TRN \\
\hline CHEMBL1498731 & 688233 & 4.7778 & 3.4551 & TRN \\
\hline CHEMBL1520962 & 688233 & 3.2218 & 3.8112 & TRN \\
\hline CHEMBL584840 & 688233 & 3.2218 & 3.0195 & TRN \\
\hline CHEMBL1319018 & 688233 & 3.2218 & 3.3 & TRN \\
\hline CHEMBL1438109 & 688233 & 5.2932 & 4.0377 & TRN \\
\hline CHEMBL1567410 & 688233 & 3.5229 & 3.2656 & TRN \\
\hline CHEMBL1468680 & 688233 & 3.2218 & 3.6692 & TRN \\
\hline
\end{tabular}


Supplemental Table S2.txt

\begin{tabular}{|c|c|c|c|c|}
\hline CHEMBL 3199944 & 688233 & 4.6193 & 4.0626 & TRN \\
\hline CHEMBL1426809 & 688233 & 3.2218 & 3.4478 & TRN \\
\hline CHEMBL 3190585 & 688233 & 3.2218 & 3.0884 & TRN \\
\hline CHEMBL1411156 & 688233 & 3.2218 & 4.1776 & TRN \\
\hline CHEMBL1422338 & 688233 & 3.5229 & 3.2597 & TRN \\
\hline CHEMBL1494867 & 688233 & 3.2218 & 3.1926 & TRN \\
\hline CHEMBL1611486 & 688233 & 3.2218 & 3.5946 & TRN \\
\hline CHEMBL1378654 & 688233 & 3.2218 & 3.6654 & TRN \\
\hline CHEMBL1612267 & 688233 & \multicolumn{2}{|c|}{5.3229999999999995} & 4.1008 \\
\hline CHEMBL 1464158 & 688233 & 4.875 & 4.1163 & TRN \\
\hline CHEMBL1384306 & 688233 & 3.5229 & 3.6104 & TRN \\
\hline CHEMBL1340965 & 688233 & 3.2218 & 3.7913 & TRN \\
\hline CHEMBL1335838 & 688233 & 3.2218 & 3.3246 & TRN \\
\hline CHEMBL1388469 & 688233 & 5.5784 & 5.1534 & TRN \\
\hline CHEMBL1519553 & 688233 & 3.2218 & 3.4856 & TRN \\
\hline CHEMBL1547129 & 688233 & 5.0137 & 3.9667 & TRN \\
\hline CHEMBL1550934 & 688233 & 3.2218 & 3.998 & TRN \\
\hline CHEMBL1572059 & 688233 & 3.2218 & 3.5824 & TRN \\
\hline CHEMBL1335254 & 688233 & 3.2218 & 3.2723 & TRN \\
\hline CHEMBL1348909 & 688233 & 3.2218 & 3.9274 & TRN \\
\hline CHEMBL1487443 & 688233 & 3.2218 & 3.7865 & TRN \\
\hline CHEMBL1492017 & 688233 & 5.311 & 4.7541 & TRN \\
\hline CHEMBL1999137 & 688233 & 3.2218 & 3.5951 & TRN \\
\hline CHEMBL1610565 & 688233 & 5.4124 & 3.5514 & TRN \\
\hline CHEMBL1334887 & 688233 & 3.2218 & 3.9997 & TRN \\
\hline CHEMBL1455046 & 688233 & 3.2218 & 3.5123 & TST \\
\hline CHEMBL1494718 & 688233 & 3.2218 & 2.9562 & TRN \\
\hline CHEMBL1319128 & 688233 & 3.5229 & 3.1961 & TRN \\
\hline CHEMBL1369547 & 688233 & 3.2218 & 3.8785 & TRN \\
\hline CHEMBL 1606342 & 688233 & 4.8587 & 3.3729 & TST \\
\hline CHEMBL1556555 & 688233 & 3.2218 & 3.2307 & TRN \\
\hline CHEMBL1965975 & 688233 & 3.2218 & 3.655 & TRN \\
\hline CHEMBL1425041 & 688233 & 3.2218 & 3.28899 & 99999999997 \\
\hline CHEMBL1506757 & 688233 & 3.2218 & 3.6963 & TST \\
\hline CHEMBL1571289 & 688233 & 3.5229 & 3.6343 & TRN \\
\hline CHEMBL1589432 & 688233 & 3.5229 & 3.5175 & TRN \\
\hline CHEMBL 1541490 & 688233 & 3.2218 & 3.8331 & TRN \\
\hline CHEMBL1421411 & 688233 & 3.2218 & 3.1692 & TST \\
\hline CHEMBL 2001712 & 688233 & 4.3769 & 4.1932 & TRN \\
\hline CHEMBL 3191810 & 688233 & 3.2218 & 3.4133 & TRN \\
\hline CHEMBL1569370 & 688233 & 3.2218 & 3.1559 & TRN \\
\hline CHEMBL1374973 & 688233 & 3.2218 & 3.1547 & TRN \\
\hline CHEMBL1319478 & 688233 & 3.2218 & 3.3889 & TRN \\
\hline CHEMBL1377937 & 688233 & 3.2218 & 3.4838 & TRN \\
\hline CHEMBL1423463 & 688233 & 4.706 & 3.6989 & TST \\
\hline CHEMBL1611777 & 688233 & 3.2218 & 3.155 & TRN \\
\hline CHEMBL1401402 & 688233 & 5.3644 & 4.0324 & TRN \\
\hline CHEMBL1326349 & 688233 & 3.2218 & 3.3146 & TST \\
\hline
\end{tabular}




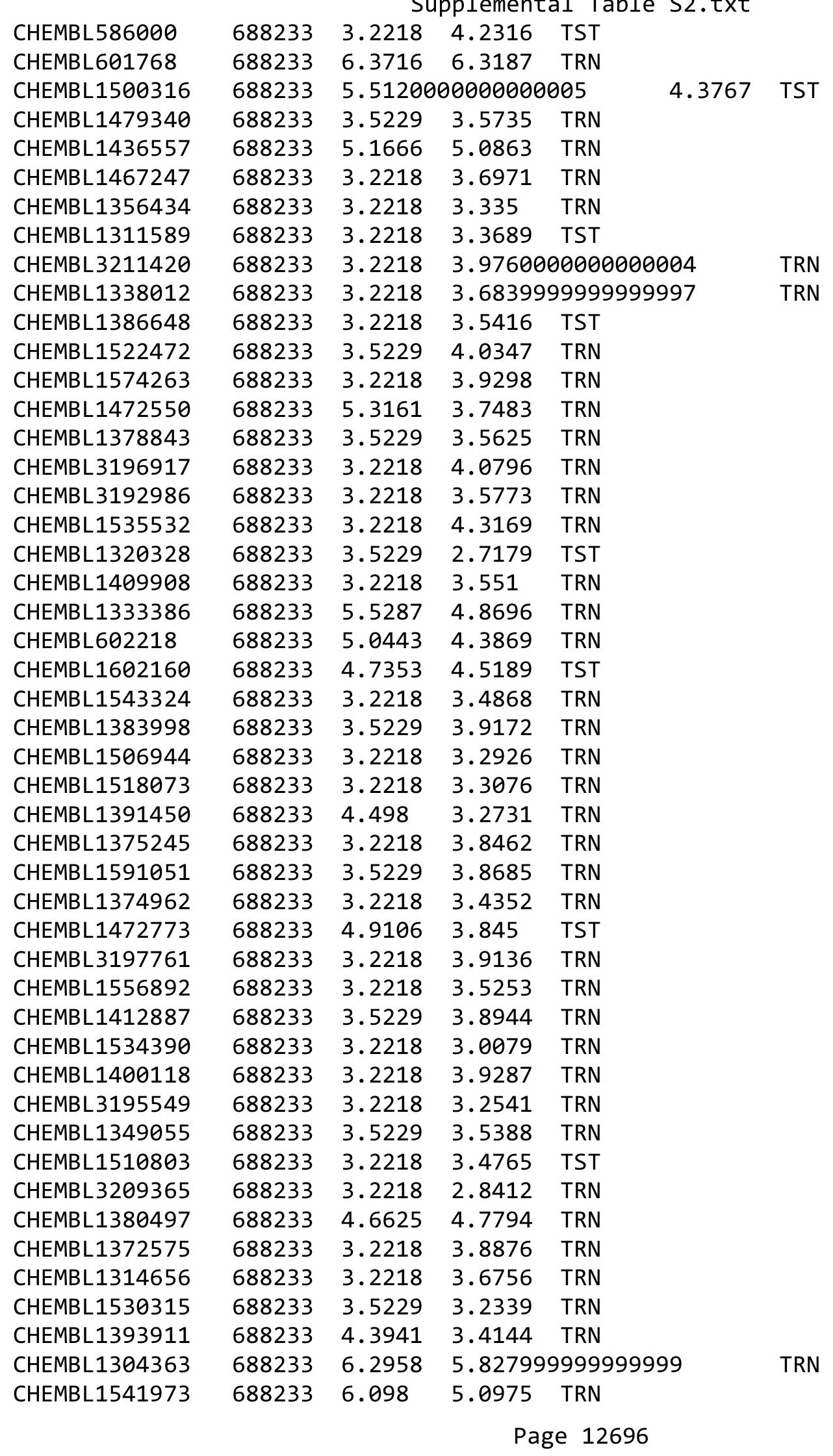


Supplemental Table S2.txt

\begin{tabular}{|c|c|c|c|c|}
\hline CHEMBL1600754 & 688233 & 3.2218 & 2.8644 & TRN \\
\hline CHEMBL1382833 & 688233 & 3.2218 & 3.4933 & TRN \\
\hline CHEMBL1349631 & 688233 & 4.4858 & 4.7049 & TRN \\
\hline CHEMBL3195599 & 688233 & 3.2218 & 3.6843 & TST \\
\hline CHEMBL1459090 & 688233 & 3.2218 & 3.6463 & TRN \\
\hline CHEMBL1450615 & 688233 & 3.2218 & 3.8019 & TRN \\
\hline CHEMBL1349441 & 688233 & 3.2218 & 3.7428 & TRN \\
\hline CHEMBL1361507 & 688233 & 5.0269 & 3.0245 & TST \\
\hline CHEMBL1546827 & 688233 & 3.5229 & 3.5195 & TRN \\
\hline CHEMBL1524234 & 688233 & 3.2218 & 3.5114 & TRN \\
\hline CHEMBL1596747 & 688233 & 3.2218 & 3.9442 & TST \\
\hline CHEMBL1610820 & 688233 & 3.2218 & 3.5991 & TRN \\
\hline CHEMBL1601578 & 688233 & 3.5229 & 3.3435 & TRN \\
\hline CHEMBL1522373 & 688233 & 3.5229 & 4.7756 & TRN \\
\hline CHEMBL1606254 & 688233 & 4.6172 & 4.2373 & TST \\
\hline CHEMBL1462449 & 688233 & 3.2218 & 3.2653 & TRN \\
\hline CHEMBL1596287 & 688233 & 3.2218 & 3.1453 & TRN \\
\hline CHEMBL1459313 & 688233 & 3.5229 & 3.9028 & TST \\
\hline CHEMBL1343971 & 688233 & 3.2218 & 3.8321 & TRN \\
\hline CHEMBL1377903 & 688233 & 4.7727 & 3.773999 & 9999999996 \\
\hline CHEMBL1481717 & 688233 & 3.2218 & 3.5557 & TRN \\
\hline CHEMBL3212029 & 688233 & 4.2607 & 4.8392 & TRN \\
\hline CHEMBL1390857 & 688233 & 3.2218 & 2.9932 & TRN \\
\hline CHEMBL1557917 & 688233 & 3.2218 & 3.7656 & TRN \\
\hline CHEMBL1570797 & 688233 & 5.38 & 4.4345 & TRN \\
\hline CHEMBL1444725 & 688233 & 3.2218 & 3.3045 & TRN \\
\hline CHEMBL1548699 & 688233 & 3.2218 & 3.3982 & TST \\
\hline CHEMBL1305827 & 688233 & 3.2218 & 3.3853 & TRN \\
\hline CHEMBL1430826 & 688233 & 3.2218 & 3.0811 & TRN \\
\hline CHEMBL1603313 & 688233 & 3.2218 & 3.6874 & TRN \\
\hline CHEMBL1461171 & 688233 & 5.0352 & 3.7505 & TRN \\
\hline CHEMBL1504429 & 688233 & 5.3222 & 5.2201 & TRN \\
\hline CHEMBL1606474 & 688233 & 3.2218 & 3.461006 & 0000000003 \\
\hline CHEMBL1612393 & 688233 & 3.2218 & 3.5954 & TRN \\
\hline CHEMBL1424231 & 688233 & 3.2218 & 3.6051 & TRN \\
\hline CHEMBL1581655 & 688233 & 3.2218 & 3.6373 & TST \\
\hline CHEMBL3195222 & 688233 & 3.2218 & 3.4244 & TRN \\
\hline CHEMBL1469791 & 688233 & 4.8277 & 4.4491 & TRN \\
\hline CHEMBL1326623 & 688233 & 3.2218 & 3.5329 & TRN \\
\hline CHEMBL1372156 & 688233 & 3.2218 & 3.7929 & TRN \\
\hline CHEMBL1501413 & 688233 & 3.2218 & 3.592 & TRN \\
\hline CHEMBL1467798 & 688233 & 3.2218 & 3.359 & TRN \\
\hline CHEMBL1406484 & 688233 & 3.2218 & 3.0807 & TRN \\
\hline CHEMBL1374678 & 688233 & 3.2218 & 3.5778 & TST \\
\hline CHEMBL605753 & 688233 & 4.6872 & 3.9005 & TRN \\
\hline CHEMBL1613629 & 688233 & 3.2218 & 3.3152 & TRN \\
\hline CHEMBL1414275 & 688233 & 3.2218 & 3.3284 & TRN \\
\hline CHEMBL1399269 & 688233 & 4.7983 & 4.2516 & TRN \\
\hline
\end{tabular}

Page 12697 


\begin{tabular}{|c|c|c|c|c|c|}
\hline & & \multicolumn{4}{|c|}{ Supplemental Table S2.txt } \\
\hline CHEMBL1458565 & 688233 & 3.2218 & 3.4667 & TRN & \\
\hline CHEMBL1396320 & 688233 & 3.2218 & 3.2126 & TRN & \\
\hline CHEMBL1594815 & 688233 & 3.5229 & 3.555 & TRN & \\
\hline CHEMBL1367933 & 688233 & 3.2218 & 3.8906 & TRN & \\
\hline CHEMBL1989760 & 688233 & 3.2218 & 3.5416 & TRN & \\
\hline CHEMBL1341008 & 688233 & 5.6959 & 4.0823 & TST & \\
\hline CHEMBL1473837 & 688233 & 4.8061 & 4.0245 & TST & \\
\hline CHEMBL586937 & 688233 & 5.2674 & 4.114 & TRN & \\
\hline CHEMBL3196370 & 688233 & 3.2218 & 3.4292 & TRN & \\
\hline CHEMBL1348534 & 688233 & 3.2218 & 3.3893 & TRN & \\
\hline CHEMBL1352919 & 688233 & 5.1804 & 4.6119 & TST & \\
\hline CHEMBL1375247 & 688233 & 3.2218 & 4.0358 & TRN & \\
\hline CHEMBL3196691 & 688233 & 3.2218 & 4.1243 & TRN & \\
\hline CHEMBL1346694 & 688233 & 3.5229 & 3.3885 & TRN & \\
\hline CHEMBL1358591 & 688233 & 3.2218 & 3.5745 & TST & \\
\hline CHEMBL1391128 & 688233 & 3.2218 & 3.7731 & TRN & \\
\hline CHEMBL578928 & 688233 & 5.0645 & 3.5407 & TRN & \\
\hline CHEMBL3191242 & 688233 & 5.0804 & 4.4983 & TRN & \\
\hline CHEMBL1530438 & 688233 & 3.2218 & 3.0792 & TRN & \\
\hline CHEMBL1566789 & 688233 & 3.5229 & 3.5813 & TRN & \\
\hline CHEMBL1608354 & 688233 & 3.2218 & 3.3461 & TRN & \\
\hline CHEMBL1419946 & 688233 & 5.0098 & 3.841 & TST & \\
\hline CHEMBL1302283 & 688233 & 3.2218 & 3.6874 & TRN & \\
\hline CHEMBL1369984 & 688233 & 3.2218 & 3.8231 & TRN & \\
\hline CHEMBL1343490 & 688233 & 3.2218 & 3.9671 & TRN & \\
\hline CHEMBL1450526 & 688233 & 5.7924 & 5.381 & TRN & \\
\hline CHEMBL1417605 & 688233 & 4.2933 & 3.3381 & TRN & \\
\hline CHEMBL1589364 & 688233 & 3.2218 & 3.0688 & TST & \\
\hline CHEMBL1593656 & 688233 & 3.5229 & 3.7317 & TRN & \\
\hline CHEMBL600778 & 688233 & 6.7167 & 6.2827 & TRN & \\
\hline CHEMBL1433286 & 688233 & 3.2218 & 3.0935 & TST & \\
\hline CHEMBL603522 & 688233 & 3.2218 & 3.7188 & TRN & \\
\hline CHEMBL1506837 & 688233 & 3.2218 & 3.5978 & TST & \\
\hline CHEMBL1533772 & 688233 & 4.734 & 3.3431 & TRN & \\
\hline CHEMBL1353697 & 688233 & 5.1725 & 3.5901 & TST & \\
\hline CHEMBL1334432 & 688233 & 3.2218 & 3.8236 & TRN & \\
\hline CHEMBL1316845 & 688233 & 3.5229 & 3.2095 & TRN & \\
\hline CHEMBL1364803 & 688233 & 3.2218 & 3.4765 & TRN & \\
\hline CHEMBL1347001 & 688233 & 3.2218 & 3.6359 & TRN & \\
\hline CHEMBL3207397 & 688233 & 3.2218 & 3.4095 & TRN & \\
\hline CHEMBL1325213 & 688233 & 3.2218 & 3.5357 & TRN & \\
\hline CHEMBL1342468 & 688233 & 3.2218 & 3.4881 & TRN & \\
\hline CHEMBL3213476 & 688233 & 3.2218 & 3.216 & TRN & \\
\hline CHEMBL1383625 & 688233 & 4.7213 & 3.99399 & 99999999998 & TST \\
\hline CHEMBL1581523 & 688233 & 4.3099 & 3.7292 & TRN & \\
\hline CHEMBL1348172 & 688233 & 3.2218 & 3.2726 & TRN & \\
\hline CHEMBL1576984 & 688233 & 3.2218 & 3.4252 & TRN & \\
\hline CHEMBL1567827 & 688233 & 5.6105 & 4.4833 & TRN & \\
\hline
\end{tabular}


Supplemental Table S2.txt

\begin{tabular}{|c|c|c|c|c|c|c|}
\hline CHEMBL1425921 & 688233 & 5.3268 & 4.4671 & TRN & & \\
\hline CHEMBL1558065 & 688233 & 5.2114 & 5.2293 & TRN & & \\
\hline CHEMBL1500801 & 688233 & 3.2218 & 3.4476 & TRN & & \\
\hline CHEMBL1344586 & 688233 & 3.2218 & 4.3901 & TST & & \\
\hline CHEMBL520275 & 688233 & 3.2218 & 3.67 & TST & & \\
\hline CHEMBL1580472 & 688233 & 5.5027 & 5.1249 & TRN & & \\
\hline CHEMBL1340257 & 688233 & 3.2218 & 3.8397 & TRN & & \\
\hline CHEMBL1541692 & 688233 & 3.2218 & 3.0896 & TRN & & \\
\hline CHEMBL1338825 & 688233 & 3.2218 & 3.2397 & TRN & & \\
\hline CHEMBL1997017 & 688233 & 3.2218 & 3.3828 & TRN & & \\
\hline CHEMBL602400 & 688233 & 3.5229 & 4.1488 & TST & & \\
\hline CHEMBL1313495 & 688233 & 3.2218 & 3.4396 & TRN & & \\
\hline CHEMBL1470634 & 688233 & 3.2218 & 3.3656 & TRN & & \\
\hline CHEMBL1374191 & 688233 & 3.2218 & 3.5335 & TST & & \\
\hline CHEMBL1446369 & 688233 & 3.5229 & 4.0523 & TRN & & \\
\hline CHEMBL 3195985 & 688233 & 3.2218 & 3.5963 & TRN & & \\
\hline CHEMBL1507840 & 688233 & 3.2218 & 4.2639 & TRN & & \\
\hline CHEMBL67212 & 688233 & 3.2218 & 3.533 & TRN & & \\
\hline CHEMBL1490953 & 688233 & 3.2218 & 3.9154 & TRN & & \\
\hline CHEMBL1508707 & 688233 & 3.2218 & 3.6933 & TRN & & \\
\hline CHEMBL1480626 & 688233 & 3.2218 & 3.3645 & TST & & \\
\hline CHEMBL1401096 & 688233 & 3.2218 & 3.4195 & TRN & & \\
\hline CHEMBL1330162 & 688233 & 3.2218 & 4.2211 & TST & & \\
\hline CHEMBL 3191879 & 688233 & 3.2218 & 3.6851 & TRN & & \\
\hline CHEMBL1549686 & 688233 & 4.9554 & 3.8455 & TRN & & \\
\hline CHEMBL1327278 & 688233 & 3.2218 & 3.2428 & TST & & \\
\hline CHEMBL1356254 & 688233 & 3.2218 & 3.8898 & TRN & & \\
\hline CHEMBL 3189165 & 688233 & 3.2218 & 3.5038 & TST & & \\
\hline CHEMBL1610102 & 688233 & 3.5229 & 3.0891 & TRN & & \\
\hline CHEMBL1538399 & 688233 & 4.9909 & 4.1615 & TRN & & \\
\hline CHEMBL1511171 & 688233 & 5.0036 & 3.4476 & TRN & & \\
\hline CHEMBL1583191 & 688233 & 3.2218 & 3.2827 & TRN & & \\
\hline CHEMBL1357288 & 688233 & 3.2218 & 3.3872 & TRN & & \\
\hline CHEMBL1478187 & 688233 & 3.2218 & 3.6272 & TRN & & \\
\hline CHEMBL1353293 & 688233 & 3.2218 & 4.0301 & TRN & & \\
\hline CHEMBL3194489 & 688233 & 4.7258 & 4.4163 & TRN & & \\
\hline CHEMBL1334351 & 688233 & 5.2971 & 3.949 & TRN & & \\
\hline CHEMBL1534781 & 688233 & \multicolumn{3}{|c|}{5.2379999999999995} & 4.1526 & TRN \\
\hline CHEMBL1550397 & 688233 & 3.2218 & 3.4126 & TRN & & \\
\hline CHEMBL1404657 & 688233 & 3.2218 & 3.9355 & TST & & \\
\hline CHEMBL1607015 & 688233 & 3.2218 & 3.8551 & TST & & \\
\hline CHEMBL1511893 & 688233 & 3.2218 & 4.064 & TRN & & \\
\hline CHEMBL1308225 & 688233 & 4.9953 & 3.8703 & TRN & & \\
\hline CHEMBL1439058 & 688233 & 3.2218 & 3.4774 & TRN & & \\
\hline CHEMBL1538061 & 688233 & 3.2218 & 3.1833 & TRN & & \\
\hline CHEMBL1569910 & 688233 & 3.2218 & 4.2844 & TRN & & \\
\hline CHEMBL1479642 & 688233 & 3.5229 & 3.1978 & TRN & & \\
\hline CHEMBL1366536 & 688233 & 3.2218 & 3.4707 & TRN & & \\
\hline
\end{tabular}

Page 12699 


\begin{tabular}{|c|c|c|c|c|c|}
\hline & & \multicolumn{4}{|c|}{ Supplemental Table s2.txt } \\
\hline CHEMBL1449336 & 688233 & 3.2218 & 3.417 & TST & \\
\hline CHEMBL1309888 & 688233 & 3.5229 & 3.588 & TRN & \\
\hline CHEMBL1400965 & 688233 & 5.0553 & 4.0421 & TST & \\
\hline CHEMBL1543839 & 688233 & 5.971 & 6.2411 & TRN & \\
\hline CHEMBL1451774 & 688233 & 3.2218 & 4.0033 & TRN & \\
\hline CHEMBL1492965 & 688233 & 3.2218 & 3.6042 & TRN & \\
\hline CHEMBL1398621 & 688233 & 5.1832 & 3.8124 & TRN & \\
\hline CHEMBL1488473 & 688233 & 3.2218 & 3.3478 & TRN & \\
\hline CHEMBL1471807 & 688233 & 3.2218 & 3.4458 & TRN & \\
\hline CHEMBL1470620 & 688233 & 3.2218 & 3.8803 & TRN & \\
\hline CHEMBL1375788 & 688233 & 3.2218 & 3.4351 & TRN & \\
\hline CHEMBL1348126 & 688233 & 3.2218 & 3.33600 & 00000000003 & TRN \\
\hline CHEMBL1407879 & 688233 & 3.2218 & 3.6456 & TRN & \\
\hline CHEMBL1488321 & 688233 & 5.0685 & 3.7692 & TRN & \\
\hline CHEMBL1477352 & 688233 & 3.2218 & 3.5898 & TRN & \\
\hline CHEMBL1390112 & 688233 & 5.4374 & 5.1514 & TRN & \\
\hline CHEMBL1559629 & 688233 & 4.4874 & 3.9734 & TST & \\
\hline CHEMBL1570465 & 688233 & 3.2218 & 3.4138 & TRN & \\
\hline CHEMBL1404397 & 688233 & 3.5229 & 3.385 & TRN & \\
\hline CHEMBL1443984 & 688233 & 3.2218 & 3.7119 & TST & \\
\hline CHEMBL1351105 & 688233 & 3.2218 & 3.3184 & TRN & \\
\hline CHEMBL1445324 & 688233 & 3.2218 & 3.8922 & TST & \\
\hline CHEMBL585213 & 688233 & 3.5229 & 3.2788 & TRN & \\
\hline CHEMBL1371250 & 688233 & 3.5229 & 3.7619 & TRN & \\
\hline CHEMBL1433858 & 688233 & 3.2218 & 3.9826 & TRN & \\
\hline CHEMBL1448733 & 688233 & 3.2218 & 3.6872 & TRN & \\
\hline CHEMBL1548869 & 688233 & 3.2218 & 3.4286 & TRN & \\
\hline CHEMBL1319510 & 688233 & 5.2033 & 3.0166 & TST & \\
\hline CHEMBL1974269 & 688233 & 4.8752 & 3.8549 & TRN & \\
\hline CHEMBL1326320 & 688233 & 3.5229 & 3.0509 & TRN & \\
\hline CHEMBL1563955 & 688233 & 3.5229 & 3.392 & TRN & \\
\hline CHEMBL1511143 & 688233 & 3.2218 & 3.2949 & TRN & \\
\hline CHEMBL1334937 & 688233 & 3.2218 & 3.5047 & TRN & \\
\hline CHEMBL1328537 & 688233 & 3.5229 & 3.1508 & TRN & \\
\hline CHEMBL1508753 & 688233 & 5.1105 & 4.0558 & TRN & \\
\hline CHEMBL1607320 & 688233 & 3.2218 & 3.3225 & TRN & \\
\hline CHEMBL1500172 & 688233 & 3.5229 & 3.0154 & TRN & \\
\hline CHEMBL1450341 & 688233 & 3.5229 & 3.2217 & TRN & \\
\hline CHEMBL1500469 & 688233 & 5.7402 & 5.3001 & TRN & \\
\hline CHEMBL1320243 & 688233 & 4.805 & 3.8142 & TRN & \\
\hline CHEMBL1599468 & 688233 & 3.2218 & 3.9465 & TRN & \\
\hline CHEMBL1538223 & 688233 & 3.2218 & 3.2625 & TRN & \\
\hline CHEMBL1439269 & 688233 & 3.5229 & 3.5772 & TST & \\
\hline CHEMBL1462321 & 688233 & 3.2218 & 3.7661 & TST & \\
\hline CHEMBL493863 & 688233 & 5.1882 & 4.0663 & TRN & \\
\hline CHEMBL1300881 & 688233 & 3.2218 & 4.2858 & TRN & \\
\hline CHEMBL1432642 & 688233 & 5.0657 & 3.1475 & TRN & \\
\hline CHEMBL1403999 & 688233 & 3.2218 & 2.8532 & TRN & \\
\hline
\end{tabular}

Page 12700 
Supplemental Table S2.txt

\begin{tabular}{|c|c|c|c|c|c|}
\hline CHEMBL1328653 & 688233 & 3.5229 & 4.306 & TRN & \\
\hline CHEMBL1435987 & 688233 & 3.2218 & 3.5513 & TRN & \\
\hline CHEMBL1588926 & 688233 & 5.1851 & 4.3716 & TRN & \\
\hline CHEMBL1409471 & 688233 & 3.2218 & 3.5603 & TRN & \\
\hline CHEMBL1494144 & 688233 & 4.5062 & 3.9139 & TRN & \\
\hline CHEMBL1599558 & 688233 & 3.2218 & 3.7894 & TRN & \\
\hline CHEMBL1508682 & 688233 & 3.2218 & 3.9233 & TRN & \\
\hline CHEMBL1487401 & 688233 & 5.431 & 5.1116 & TRN & \\
\hline CHEMBL1492024 & 688233 & 3.2218 & 3.5121 & TRN & \\
\hline CHEMBL3191683 & 688233 & 3.2218 & 3.8807 & TRN & \\
\hline CHEMBL1350062 & 688233 & 3.2218 & 3.7807 & TRN & \\
\hline CHEMBL1466191 & 688233 & 3.2218 & 4.332 & TRN & \\
\hline CHEMBL1391324 & 688233 & 3.2218 & 3.5702 & TRN & \\
\hline CHEMBL1542513 & 688233 & 3.2218 & 3.5489 & TST & \\
\hline CHEMBL1601701 & 688233 & 3.5229 & 3.3184 & TST & \\
\hline CHEMBL1498301 & 688233 & 3.2218 & 3.5667 & TRN & \\
\hline CHEMBL1417099 & 688233 & 3.2218 & 3.7908 & TST & \\
\hline CHEMBL1504978 & 688233 & 3.2218 & 3.6759 & TRN & \\
\hline CHEMBL1346437 & 688233 & 3.2218 & 3.3984 & TRN & \\
\hline CHEMBL1453673 & 688233 & 4.678 & 3.4871 & TST & \\
\hline CHEMBL1531919 & 688233 & 3.2218 & 3.8794 & TRN & \\
\hline CHEMBL1516586 & 688233 & 3.2218 & 3.2246 & TRN & \\
\hline CHEMBL1312586 & 688233 & 3.2218 & 3.3953 & TRN & \\
\hline CHEMBL1370630 & 688233 & 3.2218 & 3.373 & TRN & \\
\hline CHEMBL1477061 & 688233 & 3.5229 & 3.9718 & TRN & \\
\hline CHEMBL1320566 & 688233 & 3.2218 & 3.4159 & TRN & \\
\hline CHEMBL1344080 & 688233 & 3.2218 & 3.211999 & 99999999997 & TRN \\
\hline CHEMBL1404959 & 688233 & 3.2218 & 3.7183 & TRN & \\
\hline CHEMBL1488591 & 688233 & 5.1751 & 4.1182 & TST & \\
\hline CHEMBL1428840 & 688233 & 3.2218 & 3.8453 & TRN & \\
\hline CHEMBL1380129 & 688233 & 3.2218 & 3.5342 & TRN & \\
\hline CHEMBL1449930 & 688233 & 5.0283 & 3.5306 & TRN & \\
\hline CHEMBL3193741 & 688233 & 3.2218 & 4.0207 & TST & \\
\hline CHEMBL1544633 & 688233 & 6.2396 & 5.0665 & TRN & \\
\hline CHEMBL1399754 & 688233 & 3.2218 & 2.9369 & TRN & \\
\hline CHEMBL1598374 & 688233 & 3.2218 & 3.4481 & TRN & \\
\hline CHEMBL1500161 & 688233 & 3.2218 & 3.2235 & TRN & \\
\hline CHEMBL601957 & 688233 & 3.2218 & 4.2106 & TRN & \\
\hline CHEMBL1526016 & 688233 & 3.2218 & 3.1048 & TRN & \\
\hline CHEMBL1331573 & 688233 & 5.51399 & 999999999 & 4.7108 & TST \\
\hline CHEMBL1329950 & 688233 & 3.2218 & 3.5469 & TST & \\
\hline CHEMBL1483558 & 688233 & 3.5229 & 2.9192 & TRN & \\
\hline CHEMBL1606685 & 688233 & 5.0254 & 5.2056 & TRN & \\
\hline CHEMBL3193419 & 688233 & 5.1506 & 4.7817 & TRN & \\
\hline CHEMBL1385823 & 688233 & 3.5229 & 3.6779 & TRN & \\
\hline CHEMBL533542 & 688233 & 3.2218 & 3.0863 & TRN & \\
\hline CHEMBL1388543 & 688233 & 5.0731 & 4.1428 & TRN & \\
\hline CHEMBL1443656 & 688233 & 4.9305 & 3.8942 & TRN & \\
\hline
\end{tabular}


Supplemental Table S2.txt

\begin{tabular}{|c|c|c|c|c|c|}
\hline CHEMBL1999862 & 688233 & 3.2218 & 3.9046 & TRN & \\
\hline CHEMBL1380943 & 688233 & 3.2218 & 3.4622 & TRN & \\
\hline CHEMBL1432867 & 688233 & 5.5969 & 4.2573 & TRN & \\
\hline CHEMBL1506948 & 688233 & 3.2218 & 3.6192 & TRN & \\
\hline CHEMBL1342452 & 688233 & 3.2218 & 3.4296 & TRN & \\
\hline CHEMBL1467294 & 688233 & 3.5229 & 3.4093 & TRN & \\
\hline CHEMBL1577826 & 688233 & 3.2218 & \multicolumn{2}{|c|}{3.6919999999999997} & TST \\
\hline CHEMBL1485433 & 688233 & 3.5229 & \multicolumn{2}{|c|}{2.9960000000000004} & TRN \\
\hline CHEMBL1464304 & 688233 & 4.9813 & 3.9561 & TRN & \\
\hline CHEMBL1304963 & 688233 & 3.2218 & 4.1778 & TRN & \\
\hline CHEMBL 3198269 & 688233 & 3.5229 & 3.3273 & TRN & \\
\hline CHEMBL1307069 & 688233 & 3.2218 & 4.0769 & TRN & \\
\hline CHEMBL1462774 & 688233 & 3.5229 & 3.6644 & TRN & \\
\hline CHEMBL1424855 & 688233 & 3.2218 & 3.3202 & TRN & \\
\hline CHEMBL1360994 & 688233 & 4.4871 & 3.0194 & TRN & \\
\hline CHEMBL1326404 & 688233 & 3.5229 & 3.9119 & TRN & \\
\hline CHEMBL1307607 & 688233 & 3.2218 & 2.5007 & TRN & \\
\hline CHEMBL3192153 & 688233 & 3.2218 & 3.0217 & TRN & \\
\hline CHEMBL1458255 & 688233 & 3.2218 & 3.0078 & TRN & \\
\hline CHEMBL1540026 & 688233 & 3.2218 & 3.4838 & TRN & \\
\hline CHEMBL1589014 & 688233 & 5.0583 & 3.6643 & TRN & \\
\hline CHEMBL1382659 & 688233 & 3.2218 & 3.4267 & TRN & \\
\hline CHEMBL560579 & 688233 & 3.2218 & 3.1109 & TST & \\
\hline CHEMBL1424146 & 688233 & 3.5229 & 3.2413 & TRN & \\
\hline CHEMBL1523343 & 688233 & 3.2218 & 3.5275 & TRN & \\
\hline CHEMBL3198503 & 688233 & 3.2218 & 4.0834 & TRN & \\
\hline CHEMBL1467646 & 688233 & 3.2218 & 3.2839 & TRN & \\
\hline CHEMBL1402621 & 688233 & 3.2218 & 3.6126 & TRN & \\
\hline CHEMBL1414059 & 688233 & 3.2218 & 3.5514 & TRN & \\
\hline CHEMBL1588339 & 688233 & 3.2218 & 3.8568 & TRN & \\
\hline CHEMBL1565500 & 688233 & 3.2218 & 3.5703 & TST & \\
\hline CHEMBL1490247 & 688233 & 3.2218 & 3.8534 & TRN & \\
\hline CHEMBL1366850 & 688233 & 3.2218 & 3.174 & TRN & \\
\hline CHEMBL1558538 & 688233 & 3.2218 & 3.4232 & TRN & \\
\hline CHEMBL1559232 & 688233 & 3.2218 & 3.7189 & TRN & \\
\hline CHEMBL1556687 & 688233 & 3.2218 & 3.7793 & TRN & \\
\hline CHEMBL1451911 & 688233 & 3.2218 & 3.4729 & TRN & \\
\hline CHEMBL1411318 & 688233 & 4.9485 & 4.0193 & TRN & \\
\hline CHEMBL1392318 & 688233 & 4.231 & 3.6342 & TRN & \\
\hline CHEMBL1348403 & 688233 & 3.2218 & 3.1425 & TRN & \\
\hline CHEMBL1301226 & 688233 & 3.2218 & 3.5478 & TRN & \\
\hline CHEMBL1339973 & 688233 & 3.2218 & 3.1522 & TRN & \\
\hline CHEMBL1432747 & 688233 & 3.5229 & 3.6384 & TRN & \\
\hline CHEMBL1341517 & 688233 & 4.5776 & 3.8429 & TRN & \\
\hline CHEMBL1473119 & 688233 & 5.0672 & 3.4212 & TRN & \\
\hline CHEMBL1322516 & 688233 & 3.2218 & 3.2343 & TRN & \\
\hline CHEMBL1361797 & 688233 & 3.2218 & 3.5904 & TRN & \\
\hline CHEMBL1570521 & 688233 & 3.5229 & 4.7212 & TRN & \\
\hline
\end{tabular}

Page 12702 


\begin{tabular}{|c|c|c|c|c|c|}
\hline \multicolumn{6}{|c|}{ Supplemental Table s2.txt } \\
\hline CHEMBL1505041 & 688233 & 3.2218 & 3.4196 & TRN & \\
\hline CHEMBL391123 & 688233 & 5.2747 & 4.428 & TST & \\
\hline CHEMBL1464666 & 688233 & 3.2218 & 3.214 & TRN & \\
\hline CHEMBL 1488150 & 688233 & 3.2218 & 3.0075 & TRN & \\
\hline CHEMBL1324203 & 688233 & 3.2218 & 3.253 & TST & \\
\hline CHEMBL1516721 & 688233 & 3.5229 & 3.5167 & TRN & \\
\hline CHEMBL1517284 & 688233 & 5.0674 & 4.9637 & TRN & \\
\hline CHEMBL1546247 & 688233 & 3.2218 & 3.9088 & TRN & \\
\hline CHEMBL 3194441 & 688233 & 5.2482 & 4.146 & TRN & \\
\hline CHEMBL1331851 & 688233 & 4.2466 & 4.6402 & TRN & \\
\hline CHEMBL1353778 & 688233 & 3.2218 & 3.3671 & TRN & \\
\hline CHEMBL1546086 & 688233 & 3.2218 & 3.3237 & TRN & \\
\hline CHEMBL1596102 & 688233 & 3.5229 & \multicolumn{2}{|c|}{3.1260000000000003} & TST \\
\hline CHEMBL 3210310 & 688233 & 3.2218 & 3.9653 & TST & \\
\hline CHEMBL1421053 & 688233 & 3.2218 & 3.821 & TST & \\
\hline CHEMBL1480289 & 688233 & 3.2218 & 3.7314 & TST & \\
\hline CHEMBL1579895 & 688233 & 3.2218 & 3.4904 & TST & \\
\hline CHEMBL1307106 & 688233 & 4.4869 & 4.2728 & TST & \\
\hline CHEMBL1349490 & 688233 & 3.2218 & 3.3523 & TST & \\
\hline CHEMBL1982484 & 688233 & 3.2218 & 3.5073 & TST & \\
\hline CHEMBL1468786 & 688233 & 3.2218 & 3.4569 & TST & \\
\hline CHEMBL1377059 & 688233 & 3.2218 & 3.5409 & TST & \\
\hline CHEMBL1528097 & 688233 & 3.2218 & 4.1407 & TST & \\
\hline CHEMBL602135 & 688233 & 3.5229 & 3.8757 & TST & \\
\hline CHEMBL1519710 & 688233 & 3.2218 & 3.4223 & TST & \\
\hline CHEMBL1301150 & 688233 & 3.2218 & 3.0188 & TST & \\
\hline CHEMBL1612809 & 688233 & 3.2218 & 4.4161 & TST & \\
\hline CHEMBL1301480 & 688233 & 3.5229 & 3.7894 & TST & \\
\hline CHEMBL1459005 & 688233 & 3.2218 & 4.0827 & TST & \\
\hline CHEMBL1529212 & 688233 & 3.2218 & 3.8802 & TST & \\
\hline CHEMBL1405704 & 688233 & 5.0464 & 3.807 & TST & \\
\hline CHEMBL1500500 & 688233 & 3.2218 & 3.3969 & TST & \\
\hline CHEMBL1361046 & 688233 & 5.3251 & \multicolumn{2}{|c|}{5.502000000000001} & TST \\
\hline CHEMBL1363597 & 688233 & 3.2218 & 4.2589 & TST & \\
\hline CHEMBL1517422 & 688233 & 3.2218 & 3.0017 & TST & \\
\hline CHEMBL1585212 & 688233 & 3.2218 & 3.5726 & TST & \\
\hline CHEMBL1580683 & 688233 & 5.0262 & 3.1351 & TST & \\
\hline CHEMBL1587643 & 688233 & 3.2218 & 3.403 & TST & \\
\hline CHEMBL1458569 & 688233 & 3.2218 & 3.3112 & TST & \\
\hline CHEMBL1481836 & 688233 & 3.2218 & 3.7207 & TST & \\
\hline CHEMBL1312033 & 688233 & 3.5229 & 3.3919 & TST & \\
\hline CHEMBL1541441 & 688233 & 5.1633 & 4.6331 & TST & \\
\hline CHEMBL1407258 & 688233 & 5.2896 & 4.7522 & TST & \\
\hline CHEMBL1433248 & 688233 & 3.2218 & 4.6347 & TST & \\
\hline CHEMBL 3196538 & 688233 & 3.5229 & 3.3663 & TST & \\
\hline CHEMBL1365183 & 688233 & 3.5229 & 3.4511 & TST & \\
\hline CHEMBL1382693 & 688233 & 3.2218 & \multicolumn{2}{|c|}{4.3260000000000005} & TST \\
\hline CHEMBL1577829 & 688233 & 3.2218 & 3.3261 & TST & \\
\hline & & & & 12703 & \\
\hline
\end{tabular}




\begin{tabular}{|c|c|c|c|c|c|}
\hline \multirow[b]{2}{*}{ CHEMBL1409486 } & \multicolumn{5}{|c|}{ Supplemental Table S2.txt } \\
\hline & 688233 & 3.2218 & 4.1551 & TST & \\
\hline CHEMBL1456311 & 688233 & 3.2218 & 3.48199 & 99999999998 & TST \\
\hline CHEMBL1310876 & 688233 & 3.2218 & 3.8657 & TST & \\
\hline CHEMBL1340153 & 688233 & 3.2218 & 2.9402 & TST & \\
\hline CHEMBL1469281 & 688233 & 3.2218 & 4.0886 & TST & \\
\hline CHEMBL1344831 & 688233 & 3.2218 & 4.2445 & TST & \\
\hline CHEMBL1449965 & 688233 & 3.2218 & 2.7789 & TST & \\
\hline CHEMBL1446830 & 688233 & 3.2218 & 2.8796 & TST & \\
\hline CHEMBL1487681 & 688233 & 3.2218 & 3.09899 & 99999999998 & TST \\
\hline CHEMBL1422038 & 688233 & 4.9381 & 3.9816 & TST & \\
\hline CHEMBL1534096 & 688233 & 3.2218 & 3.2346 & TST & \\
\hline CHEMBL1368998 & 688233 & 3.2218 & 4.6215 & TST & \\
\hline CHEMBL1604326 & 688233 & 3.2218 & 3.5006 & TST & \\
\hline CHEMBL1302863 & 688233 & 3.2218 & 3.3852 & TST & \\
\hline CHEMBL1474782 & 688233 & 3.2218 & 3.208 & TST & \\
\hline CHEMBL1378502 & 688233 & 3.2218 & 4.0721 & TST & \\
\hline CHEMBL3213359 & 688233 & 3.2218 & 3.50600 & 00000000002 & TST \\
\hline CHEMBL1586169 & 688233 & 3.2218 & 4.3146 & TST & \\
\hline CHEMBL1306117 & 688233 & 3.5229 & 3.3332 & TST & \\
\hline CHEMBL1518506 & 688233 & 3.2218 & 3.9348 & TST & \\
\hline CHEMBL592600 & 688233 & 6.3726 & 6.4297 & TST & \\
\hline CHEMBL1323186 & 688233 & 5.2436 & 4.1006 & TST & \\
\hline CHEMBL1500188 & 688233 & 3.2218 & 3.718 & TST & \\
\hline CHEMBL1577399 & 688233 & 3.2218 & 3.2918 & TST & \\
\hline CHEMBL1533151 & 688233 & 3.2218 & 3.298 & TST & \\
\hline CHEMBL1402403 & 688233 & 3.5229 & 3.7379 & TST & \\
\hline CHEMBL1466404 & 688233 & 5.0419 & 3.9559 & TST & \\
\hline CHEMBL1498430 & 688233 & 3.2218 & 3.5155 & TST & \\
\hline CHEMBL582980 & 688233 & 4.95 & 3.7908 & TST & \\
\hline CHEMBL1509253 & 688233 & 4.8026 & 3.7765 & TST & \\
\hline CHEMBL1734063 & 688233 & 3.2218 & 3.7005 & TST & \\
\hline CHEMBL3195896 & 688233 & 3.2218 & 3.5737 & TST & \\
\hline CHEMBL1510455 & 688233 & 3.2218 & 3.4094 & TST & \\
\hline CHEMBL1465741 & 688233 & 3.2218 & 3.9733 & TST & \\
\hline CHEMBL1433394 & 688233 & 5.0304 & 3.4773 & TST & \\
\hline CHEMBL1392478 & 688233 & 5.1094 & 3.6364 & TST & \\
\hline CHEMBL1401114 & 688233 & 3.2218 & 4.4779 & TST & \\
\hline CHEMBL1542864 & 688233 & 3.2218 & 3.2695 & TST & \\
\hline CHEMBL1368428 & 688233 & 3.2218 & 3.3797 & TST & \\
\hline CHEMBL1359302 & 688233 & 3.2218 & 3.2621 & TST & \\
\hline CHEMBL1467164 & 688233 & 3.2218 & 3.8594 & TST & \\
\hline CHEMBL1424344 & 688233 & 4.2271 & 3.8575 & TST & \\
\hline CHEMBL1299566 & 688233 & 3.5229 & 4.4265 & TST & \\
\hline CHEMBL1424996 & 688233 & 3.2218 & 3.264 & TST & \\
\hline CHEMBL1588945 & 688233 & 4.2971 & 3.2434 & TST & \\
\hline CHEMBL1473001 & 688233 & 3.5229 & 3.3318 & TST & \\
\hline CHEMBL3198154 & 688233 & 3.2218 & 3.3819 & TST & \\
\hline CHEMBL1347793 & 688233 & 5.0372 & 3.5006 & TST & \\
\hline
\end{tabular}


Supplemental Table S2.txt

\begin{tabular}{|c|c|c|c|c|c|}
\hline CHEMBL3214537 & 688233 & 3.2218 & 3.0545 & TST & \\
\hline CHEMBL1586163 & 688233 & 3.2218 & 3.1536 & TST & \\
\hline CHEMBL1360154 & 688233 & 3.2218 & 3.5591 & TST & \\
\hline CHEMBL1978150 & 688233 & 3.2218 & 3.1871 & TST & \\
\hline CHEMBL3213787 & 688233 & 3.2218 & 3.7363 & TST & \\
\hline CHEMBL1352381 & 688233 & 3.2218 & 3.2568 & TST & \\
\hline CHEMBL1562771 & 688233 & 3.2218 & 3.7679 & TST & \\
\hline CHEMBL1521674 & 688233 & 3.5229 & 3.2639 & TST & \\
\hline CHEMBL1606726 & 688233 & 3.2218 & 3.5023 & TST & \\
\hline CHEMBL1540024 & 688233 & 4.9846 & 3.8172 & TST & \\
\hline CHEMBL1482730 & 688233 & 4.6817 & 3.8281 & TST & \\
\hline CHEMBL1496325 & 688233 & 3.2218 & 3.2248 & TST & \\
\hline CHEMBL1332667 & 688233 & 5.0027 & 3.5125 & TST & \\
\hline CHEMBL1521766 & 688233 & 3.2218 & 4.2 & TST & \\
\hline CHEMBL1387181 & 688233 & 3.2218 & 3.2941 & TST & \\
\hline CHEMBL1324481 & 688233 & 3.2218 & 3.4423 & TST & \\
\hline CHEMBL523375 & 688233 & 3.2218 & 3.5417 & TST & \\
\hline CHEMBL1420074 & 688233 & 3.2218 & 3.7372 & TST & \\
\hline CHEMBL1602962 & 688233 & 5.1535 & 3.7579 & TST & \\
\hline CHEMBL1302158 & 688233 & 5.1787 & 3.9872 & TST & \\
\hline CHEMBL1509653 & 688233 & 3.2218 & 3.35600 & 00000000003 & TST \\
\hline CHEMBL1419641 & 688233 & 3.2218 & 3.3753 & TST & \\
\hline CHEMBL1418062 & 688233 & 3.2218 & 3.47300 & 00000000003 & TST \\
\hline CHEMBL1330788 & 688233 & 3.2218 & 2.7759 & TST & \\
\hline CHEMBL1561133 & 688233 & 3.5229 & 3.6308 & TST & \\
\hline CHEMBL1552686 & 688233 & 3.5229 & 3.6539 & TST & \\
\hline CHEMBL1302488 & 688233 & 3.2218 & 3.1879 & TST & \\
\hline CHEMBL1608731 & 688233 & 3.2218 & 3.2974 & TST & \\
\hline CHEMBL1430378 & 688233 & 3.2218 & 3.7738 & TST & \\
\hline CHEMBL1572294 & 688233 & 5.3138 & 3.8523 & TST & \\
\hline CHEMBL1441053 & 688233 & 3.5229 & 3.0776 & TST & \\
\hline CHEMBL1433443 & 688233 & 3.2218 & 3.6904 & TST & \\
\hline CHEMBL1990071 & 688233 & 6.3716 & 3.3897 & TST & \\
\hline CHEMBL1510954 & 688233 & 3.2218 & 3.6286 & TST & \\
\hline CHEMBL1393625 & 688233 & 5.1246 & 4.0258 & TST & \\
\hline CHEMBL1477317 & 688233 & 3.2218 & 3.5878 & TST & \\
\hline CHEMBL1498645 & 688233 & 3.2218 & 3.0029 & TST & \\
\hline CHEMBL1339902 & 688233 & 3.2218 & 3.6071 & TST & \\
\hline CHEMBL1586170 & 688233 & 3.2218 & 3.5044 & TST & \\
\hline CHEMBL1366764 & 688233 & 3.5229 & 3.7532 & TST & \\
\hline CHEMBL1420768 & 688233 & 3.2218 & 3.75100 & 00000000003 & TST \\
\hline CHEMBL1469056 & 688233 & 3.2218 & 3.8311 & TST & \\
\hline CHEMBL1340381 & 688233 & 3.2218 & 3.7226 & TST & \\
\hline CHEMBL1415768 & 688233 & 3.5229 & 3.8673 & TST & \\
\hline CHEMBL1547139 & 688233 & 3.2218 & 3.5428 & TST & \\
\hline CHEMBL1380760 & 688233 & 3.5229 & 4.3997 & TST & \\
\hline CHEMBL1308218 & 688233 & 3.2218 & 3.2865 & TST & \\
\hline CHEMBL1417730 & 688233 & 3.2218 & 3.5331 & TST & \\
\hline
\end{tabular}




\begin{tabular}{|c|c|c|c|c|c|}
\hline \multirow[b]{2}{*}{ CHEMBL601137 } & & \multicolumn{4}{|c|}{ Supplemental Table S2.txt } \\
\hline & 688233 & 3.2218 & 3.5174 & TST & \\
\hline CHEMBL1415135 & 688233 & 3.2218 & 3.824 & TST & \\
\hline CHEMBL578515 & 688233 & 3.2218 & 3.6191 & TST & \\
\hline CHEMBL1600295 & 688233 & 3.2218 & 3.80899 & 99999999997 & TST \\
\hline CHEMBL585502 & 688233 & 5.2564 & 4.3158 & TST & \\
\hline CHEMBL1558458 & 688233 & 4.9728 & 3.5184 & TST & \\
\hline CHEMBL3194424 & 688233 & 3.2218 & 3.33 & TST & \\
\hline CHEMBL1425624 & 688233 & 4.9487 & 4.0104 & TST & \\
\hline CHEMBL1425849 & 688233 & $5.1270 e$ & 00000000 & 4.4348 & TST \\
\hline CHEMBL1410701 & 688233 & 3.2218 & 3.6915 & TST & \\
\hline CHEMBL1994963 & 688233 & 5.3187 & 4.4086 & TST & \\
\hline CHEMBL1563546 & 688233 & 3.2218 & 4.1981 & TST & \\
\hline CHEMBL1405075 & 688233 & 3.5229 & 3.4053 & TST & \\
\hline CHEMBL1452831 & 688233 & 3.5229 & 3.1665 & TST & \\
\hline CHEMBL1550290 & 688233 & 3.2218 & 4.0769 & TST & \\
\hline CHEMBL1406217 & 688233 & 3.5229 & 3.2489 & TST & \\
\hline CHEMBL3192732 & 688233 & 3.2218 & 3.6195 & TST & \\
\hline CHEMBL1421106 & 688233 & 3.2218 & 4.2321 & TST & \\
\hline CHEMBL1507510 & 688233 & 3.2218 & 3.4935 & TST & \\
\hline CHEMBL1818878 & 688233 & 3.2218 & 4.024 & TST & \\
\hline CHEMBL1418073 & 688233 & 3.2218 & 3.4198 & TST & \\
\hline CHEMBL1483740 & 688233 & 3.2218 & 3.80899 & 99999999997 & TST \\
\hline CHEMBL1341761 & 688233 & 3.2218 & 3.1181 & TST & \\
\hline CHEMBL1412322 & 688233 & 3.2218 & 2.6271 & TST & \\
\hline CHEMBL1488269 & 688233 & 3.2218 & 3.8569 & TST & \\
\hline CHEMBL1429755 & 688233 & 5.0405 & 3.9159 & TST & \\
\hline CHEMBL1449008 & 688233 & 3.2218 & 4.2097 & TST & \\
\hline CHEMBL1566514 & 688233 & 3.2218 & 3.7364 & TST & \\
\hline CHEMBL1530018 & 688233 & 3.2218 & 3.7581 & TST & \\
\hline CHEMBL1536074 & 688233 & 3.2218 & 3.9423 & TST & \\
\hline CHEMBL1481444 & 688233 & 3.2218 & 3.2765 & TST & \\
\hline CHEMBL1370172 & 688233 & 3.2218 & 3.2712 & TST & \\
\hline CHEMBL 2003973 & 688233 & 5.3299 & 3.7832 & TST & \\
\hline CHEMBL1351620 & 688233 & 3.2218 & 3.5918 & TST & \\
\hline CHEMBL3191989 & 688233 & 6.7167 & 4.9405 & TST & \\
\hline CHEMBL1426189 & 688233 & 3.2218 & 3.6545 & TST & \\
\hline CHEMBL600121 & 688233 & 3.2218 & 3.5224 & TST & \\
\hline CHEMBL1409104 & 688233 & 3.2218 & 3.9786 & TST & \\
\hline CHEMBL1477200 & 688233 & 3.2218 & 3.4083 & TST & \\
\hline CHEMBL3193604 & 688233 & 3.5229 & 3.6074 & TST & \\
\hline CHEMBL1543510 & 688233 & 3.2218 & 3.3515 & TST & \\
\hline CHEMBL1329490 & 688233 & 3.5229 & 3.7679 & TST & \\
\hline CHEMBL1440687 & 688233 & 3.2218 & 3.8518 & TST & \\
\hline CHEMBL3194760 & 688233 & 5.4874 & 3.3239 & TST & \\
\hline CHEMBL1366820 & 688233 & 3.2218 & 3.7835 & TST & \\
\hline CHEMBL1539286 & 688233 & 3.2218 & 3.7338 & TST & \\
\hline CHEMBL1484388 & 688233 & 3.2218 & 3.4772 & TST & \\
\hline CHEMBL1505548 & 688233 & 5.3547 & 4.0906 & TST & \\
\hline
\end{tabular}


Supplemental Table S2.txt

\begin{tabular}{|c|c|c|c|c|}
\hline CHEMBL1562359 & 688233 & 3.5229 & 3.9882 & TST \\
\hline CHEMBL1552537 & 688233 & 3.2218 & 3.2484 & TST \\
\hline CHEMBL1321181 & 688233 & 3.2218 & 3.612 & TST \\
\hline CHEMBL1385062 & 688233 & 3.5229 & 3.6763 & TST \\
\hline CHEMBL 272922 & 688233 & 3.5229 & 3.3313 & TST \\
\hline CHEMBL1605450 & 688233 & 3.2218 & 3.6787 & TST \\
\hline CHEMBL1608575 & 688233 & 3.2218 & 3.4148 & TST \\
\hline CHEMBL1578876 & 688233 & 3.2218 & 3.0824 & TST \\
\hline CHEMBL1306817 & 688233 & 4.7745 & 3.9278 & TST \\
\hline CHEMBL1340739 & 688233 & 3.5229 & 4.0146 & TST \\
\hline CHEMBL1381599 & 688233 & 3.2218 & 3.9651 & TST \\
\hline CHEMBL1332689 & 688233 & 3.2218 & 4.1303 & TST \\
\hline CHEMBL1426561 & 688233 & 3.2218 & 3.66600 & 00000000004 \\
\hline CHEMBL1523566 & 688233 & 4.5252 & 4.2077 & TST \\
\hline CHEMBL1347637 & 688233 & 4.4372 & 3.8731 & TST \\
\hline CHEMBL1386291 & 688233 & 3.2218 & 3.5966 & TST \\
\hline CHEMBL1605095 & 688233 & 3.2218 & 3.4033 & TST \\
\hline CHEMBL1366622 & 688233 & 4.6156 & 3.552 & TST \\
\hline CHEMBL1353899 & 688233 & 3.2218 & 3.458 & TST \\
\hline CHEMBL1524141 & 688233 & 3.2218 & 3.0567 & TST \\
\hline CHEMBL1537115 & 688233 & 4.9677 & 3.5613 & TST \\
\hline CHEMBL1546577 & 688233 & 3.2218 & 3.0253 & TST \\
\hline CHEMBL1390770 & 688233 & 3.8239 & 3.6097 & TST \\
\hline CHEMBL1556010 & 688233 & 3.2218 & 3.4315 & TST \\
\hline CHEMBL1403800 & 688233 & 3.2218 & 3.8101 & TST \\
\hline CHEMBL1524985 & 688233 & 3.2218 & 3.4636 & TST \\
\hline CHEMBL1497123 & 688233 & 3.2218 & 3.1908 & TST \\
\hline CHEMBL1372380 & 688233 & 4.9541 & 3.2276 & TST \\
\hline CHEMBL1383144 & 688233 & 3.2218 & 3.2048 & TST \\
\hline CHEMBL1329222 & 688233 & 3.2218 & 3.7839 & TST \\
\hline CHEMBL1468524 & 688233 & 3.5229 & 3.6302 & TST \\
\hline CHEMBL1431017 & 688233 & 3.2218 & 3.7414 & TST \\
\hline CHEMBL1355165 & 688233 & 5.016 & 3.54699 & 99999999997 \\
\hline CHEMBL1412488 & 688233 & 3.5229 & 3.6656 & TST \\
\hline CHEMBL1351542 & 688233 & 5.1844 & 6.1079 & TST \\
\hline CHEMBL3196241 & 688233 & 5.7027 & 4.3621 & TST \\
\hline CHEMBL1363249 & 688233 & 3.2218 & 5.0112 & TST \\
\hline CHEMBL1413445 & 688233 & 3.2218 & 3.2086 & TST \\
\hline CHEMBL1445206 & 688233 & 4.9076 & 3.6378 & TST \\
\hline CHEMBL1325908 & 688233 & 3.2218 & 2.9911 & TST \\
\hline CHEMBL1535416 & 688233 & 3.5229 & 3.7345 & TST \\
\hline CHEMBL333767 & 688233 & 3.2218 & 4.4403 & TST \\
\hline CHEMBL1995715 & 688233 & 3.2218 & 4.1929 & TST \\
\hline CHEMBL1530515 & 688233 & 3.2218 & 3.6749 & TST \\
\hline CHEMBL1335286 & 688233 & 3.2218 & 3.6815 & TST \\
\hline CHEMBL1496582 & 688233 & 3.2218 & 3.4917 & TST \\
\hline CHEMBL1529206 & 688233 & 3.2218 & 3.7154 & TST \\
\hline CHEMBL1530139 & 688233 & 3.2218 & 3.6956 & TST \\
\hline
\end{tabular}

Page 12707 
Supplemental Table S2.txt

\begin{tabular}{|c|c|c|c|c|c|}
\hline CHEMBL1427739 & 688233 & 4.9808 & 3.3641 & TST & \\
\hline CHEMBL1341771 & 688233 & 3.2218 & 3.3117 & TST & \\
\hline CHEMBL1314923 & 688233 & 3.2218 & 3.7215 & TST & \\
\hline CHEMBL1518850 & 688233 & 3.5229 & 3.141 & TST & \\
\hline CHEMBL1484893 & 688233 & 3.2218 & 3.5401 & TST & \\
\hline CHEMBL1421700 & 688233 & 4.8537 & 3.7221 & TST & \\
\hline CHEMBL581860 & 688233 & 3.5229 & 4.0495 & TST & \\
\hline CHEMBL1326728 & 688233 & 3.2218 & 3.2997 & TST & \\
\hline CHEMBL1508047 & 688233 & 3.2218 & 3.3506 & TST & \\
\hline CHEMBL3189322 & 688233 & 3.2218 & 3.8531 & TST & \\
\hline CHEMBL1371896 & 688233 & 3.2218 & 3.9294 & TST & \\
\hline CHEMBL1428409 & 688233 & 3.2218 & 3.3199 & TST & \\
\hline CHEMBL1349113 & 688233 & 3.2218 & 4.0762 & TST & \\
\hline CHEMBL1976225 & 688233 & 5.0419 & 4.4638 & TST & \\
\hline CHEMBL1386223 & 688233 & 3.2218 & 2.9619 & TST & \\
\hline CHEMBL1312040 & 688233 & 3.2218 & 2.9498 & TST & \\
\hline CHEMBL1378686 & 688233 & 4.7301 & 3.2266 & TST & \\
\hline CHEMBL3212652 & 688233 & 3.5229 & 3.3884 & TST & \\
\hline CHEMBL1428972 & 688233 & 4.9694 & 3.3786 & TST & \\
\hline CHEMBL1467366 & 688233 & 3.2218 & 3.5066 & TST & \\
\hline CHEMBL1351825 & 688233 & 3.2218 & 3.8332 & TST & \\
\hline CHEMBL1373415 & 688233 & 3.2218 & 3.3916 & TST & \\
\hline CHEMBL1543341 & 688233 & 3.2218 & 4.3784 & TST & \\
\hline CHEMBL1471341 & 688233 & 5.3094 & 5.1605 & TST & \\
\hline CHEMBL1506351 & 688233 & 5.0205 & 3.694 & TST & \\
\hline CHEMBL1430193 & 688233 & 3.5229 & 3.6177 & TST & \\
\hline CHEMBL1421724 & 688233 & 3.2218 & 3.3586 & TST & \\
\hline CHEMBL1492688 & 688233 & 3.5229 & 3.5946 & TST & \\
\hline CHEMBL1518337 & 688233 & 3.2218 & 4.0068 & TST & \\
\hline CHEMBL1485299 & 688233 & 3.2218 & 3.2532 & TST & \\
\hline CHEMBL1535991 & 688233 & 4.8203 & 4.1684 & TST & \\
\hline CHEMBL1332266 & 688233 & 3.5229 & 3.6087 & TST & \\
\hline CHEMBL1564403 & 688233 & 3.2218 & 4.3664 & TST & \\
\hline CHEMBL1377321 & 688233 & 3.2218 & 3.3205 & TST & \\
\hline CHEMBL1535558 & 688233 & 4.9096 & 3.4589 & TST & \\
\hline CHEMBL1371138 & 688233 & 3.2218 & 4.1322 & TST & \\
\hline CHEMBL1542066 & 688233 & 3.2218 & 3.6799 & TST & \\
\hline CHEMBL591137 & 688233 & \multicolumn{3}{|c|}{5.3020000000000005} & 3.9930000000000003 \\
\hline CHEMBL1317288 & 688233 & 3.2218 & 2.9709 & TST & \\
\hline CHEMBL1481521 & 688233 & 3.2218 & 3.3963 & TST & \\
\hline CHEMBL1599642 & 688233 & 3.2218 & 3.6491 & TST & \\
\hline CHEMBL1991388 & 688233 & 5.0499 & 3.7088 & TST & \\
\hline CHEMBL1341581 & 688233 & 3.2218 & 3.9081 & TST & \\
\hline CHEMBL1312788 & 688233 & 3.2218 & 4.1847 & TST & \\
\hline CHEMBL1549336 & 688233 & 3.5229 & 3.5371 & TST & \\
\hline CHEMBL1402679 & 688233 & 3.2218 & 2.9325 & TST & \\
\hline CHEMBL1578286 & 688233 & 3.2218 & 3.6053 & TST & \\
\hline CHEMBL511979 & 688233 & 4.8548 & 3.73 & TST & \\
\hline
\end{tabular}


Supplemental Table S2.txt

\begin{tabular}{|c|c|c|c|c|}
\hline CHEMBL1473337 & 688233 & 3.2218 & 3.3158 & TST \\
\hline CHEMBL1324831 & 688233 & 3.2218 & 3.3574 & TST \\
\hline CHEMBL1338004 & 688233 & 3.2218 & 4.1816 & TST \\
\hline CHEMBL1330524 & 688233 & 3.2218 & 3.5204 & TST \\
\hline CHEMBL1603515 & 688233 & 4.5392 & 3.5093 & TST \\
\hline CHEMBL1460030 & 688233 & 3.2218 & 3.5132 & TST \\
\hline CHEMBL1521122 & 688233 & 3.2218 & 3.9408 & TST \\
\hline CHEMBL312032 & 688233 & 3.2218 & 3.0621 & TST \\
\hline CHEMBL1327816 & 688233 & 5.0238 & 4.9554 & TST \\
\hline CHEMBL3194715 & 688233 & 3.2218 & 3.7359 & TST \\
\hline CHEMBL1386650 & 688233 & 3.2218 & 3.6239 & TST \\
\hline CHEMBL1336675 & 688233 & 4.7554 & 3.6024 & TST \\
\hline CHEMBL1347081 & 688233 & 3.2218 & 3.6763 & TST \\
\hline CHEMBL1585086 & 688233 & 3.2218 & 3.8243 & TST \\
\hline CHEMBL1545262 & 688233 & 3.2218 & 3.7329 & TST \\
\hline CHEMBL1577992 & 688233 & 3.2218 & 3.4895 & TST \\
\hline CHEMBL1544733 & 688233 & 3.2218 & 3.6598 & TST \\
\hline CHEMBL1543833 & 688233 & 3.5229 & 3.9475 & TST \\
\hline CHEMBL573226 & 688233 & 3.2218 & 4.2615 & TST \\
\hline CHEMBL 3197662 & 688233 & 4.9636 & 3.1537 & TST \\
\hline CHEMBL1464095 & 688233 & 3.2218 & 3.1992 & TST \\
\hline CHEMBL1460700 & 688233 & 3.2218 & 3.4075 & TST \\
\hline CHEMBL1597731 & 688233 & 3.2218 & 3.7545 & TST \\
\hline CHEMBL1582997 & 688233 & 5.2798 & 4.7737 & TST \\
\hline CHEMBL1477838 & 688233 & 3.2218 & 4.3296 & TST \\
\hline CHEMBL1611004 & 688233 & 4.5157 & 3.762 & TST \\
\hline CHEMBL3195308 & 688233 & 3.2218 & 3.74 & TST \\
\hline CHEMBL1393054 & 688233 & 3.2218 & 4.5998 & TST \\
\hline CHEMBL1452892 & 688233 & 3.2218 & 3.5973 & TST \\
\hline CHEMBL586031 & 688233 & 3.5229 & 4.7133 & TST \\
\hline CHEMBL1506283 & 688233 & 3.2218 & 3.5212 & TST \\
\hline CHEMBL1438437 & 688233 & 3.2218 & 3.7212 & TST \\
\hline CHEMBL1401767 & 688233 & 4.9605 & 3.8403 & TST \\
\hline CHEMBL1599954 & 688233 & 4.6085 & 3.3237 & TST \\
\hline CHEMBL 1453858 & 688233 & 3.5229 & 4.088 & TST \\
\hline CHEMBL1393829 & 688233 & 5.8303 & 6.1418 & TST \\
\hline CHEMBL1413835 & 688233 & 3.2218 & 3.9081 & TST \\
\hline CHEMBL1355046 & 688233 & 3.2218 & 3.7624 & TST \\
\hline CHEMBL1468847 & 688233 & 5.6185 & 6.0393 & TST \\
\hline CHEMBL1360033 & 688233 & 3.2218 & 3.5732 & TST \\
\hline CHEMBL1447166 & 688233 & 3.5229 & 2.96100 & 00000000003 \\
\hline CHEMBL1403351 & 688233 & 3.2218 & 4.1039 & TST \\
\hline CHEMBL1385806 & 688233 & 3.2218 & 4.1066 & TST \\
\hline CHEMBL3197603 & 688233 & 3.5229 & 4.1133 & TST \\
\hline CHEMBL1392785 & 688233 & 3.5229 & 3.5539 & TST \\
\hline CHEMBL1409381 & 688233 & 4.9375 & 3.5528 & TST \\
\hline CHEMBL1312160 & 688233 & 4.3076 & 3.6091 & TST \\
\hline CHEMBL1385263 & 688233 & 3.2218 & 3.0806 & TST \\
\hline
\end{tabular}


Supplemental Table S2.txt

\begin{tabular}{|c|c|c|c|c|}
\hline . & & & & \\
\hline & & .2218 & 2.965 & \\
\hline & & 586 & & \\
\hline AEMBL1 & & 522 & & \\
\hline AEMBL1328792 & & 3089 & & \\
\hline HEMBL1503689 & 88233 & 5229 & 0822 & \\
\hline HEMBL13 & & & 385 & \\
\hline IFMRI 1 & & & & \\
\hline AEMBL1359299 & & & & \\
\hline AEMBL1546468 & 8233 & 218 & 3958 & \\
\hline HEMBL1329473 & 33 & 18 & & \\
\hline IEMBL13 & & & 302 & \\
\hline AEMBL5 & & & & \\
\hline AEMBL1378467 & & & 3018 & \\
\hline IEMBL13 & & & 069 & \\
\hline AEMBL3190804 & 3 & 22 & 507 & \\
\hline HEMBL13 & & & 15 & \\
\hline HEMBL14 & & & & \\
\hline AEMBL15€ & & & & \\
\hline IEMBL15 & & & & \\
\hline AEMBLII & & & 23 & \\
\hline AEMBL14 & & & 46 & \\
\hline HEMBL14 & & & & \\
\hline AFMRI 13 & & & & \\
\hline HEMBL196 & & & & \\
\hline AEMBL1; & & 8 & & \\
\hline HEMBL1: & & & & \\
\hline AFMBI 31 & & & & \\
\hline HEMBL 14 & & & & \\
\hline HEMBL152: & & & 3.8552 & ГST \\
\hline HEMBL1. & & & 66 & ST \\
\hline HEMBL1 & & & 24 & \\
\hline 9 & & & 33 & \\
\hline HEMBL1299463 & & & 227 & \\
\hline HEMBL1443756 & & & 3.3472 & TST \\
\hline HEMBL13 & & & 383 & \\
\hline $45 M D^{\prime} 1$ & & & & \\
\hline HEMBL14 & & & 94 & ST \\
\hline HEMBL1309799 & 88233 & 8 & 394 & ГST \\
\hline IEMBL1602 & & & & IST \\
\hline HEMBL1336856 & & & 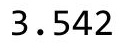 & \\
\hline HEMBL 14 & & & & S \\
\hline HEMBL150 & & & 3.681 & ST \\
\hline AEMBL1592881 & 33 & 29 & .3604 & S \\
\hline MBL3 & & & & \\
\hline CHEMBL3693269 & & 201 & & \\
\hline HEMBL3693361 & 528880 & & 6.8551 & \\
\hline CHEMBL369334 & 1528880 & 6.9872 & 7.0448 & \\
\hline
\end{tabular}

Page 12710 
Supplemental Table S2.txt

\begin{tabular}{|c|c|c|c|c|c|}
\hline CHEMBL3693288 & 1528880 & 8.0969 & 7.9225 & TRN & \\
\hline CHEMBL3693336 & 1528880 & 6.8416 & 7.7772 & TST & \\
\hline CHEMBL3693353 & 1528880 & 7.3665 & 7.4907 & TST & \\
\hline CHEMBL3693270 & 1528880 & 8.0458 & 7.8832 & TRN & \\
\hline CHEMBL3693349 & 1528880 & 8.699 & 8.5837 & TRN & \\
\hline CHEMBL3693323 & 1528880 & 8.5229 & 8.796 & TRN & \\
\hline CHEMBL3693366 & 1528880 & 7.0 & 6.7801 & TRN & \\
\hline CHEMBL3693364 & 1528880 & 6.9872 & 7.0152 & TRN & \\
\hline CHEMBL3693268 & 1528880 & 9.0 & 9.1634 & TRN & \\
\hline CHEMBL3693354 & 1528880 & 6.7011 & 6.9678 & TST & \\
\hline CHEMBL3693284 & 1528880 & 7.7447 & 7.8415 & TRN & \\
\hline CHEMBL3693334 & 1528880 & 8.3979 & 8.4746 & TRN & \\
\hline CHEMBL3693367 & 1528880 & 6.2062 & 6.2173 & TRN & \\
\hline CHEMBL 3693300 & 1528880 & 6.0 & 5.9953 & TRN & \\
\hline CHEMBL3693264 & 1528880 & 8.5229 & 8.7006 & TRN & \\
\hline CHEMBL3693358 & 1528880 & 6.0 & 6.8296 & TRN & \\
\hline CHEMBL3693360 & 1528880 & 6.0 & 7.4117 & TST & \\
\hline CHEMBL3693277 & 1528880 & 6.0 & 6.5406 & TRN & \\
\hline CHEMBL3693285 & 1528880 & 7.699 & 7.6235 & TRN & \\
\hline CHEMBL3693351 & 1528880 & 9.0 & 8.9558 & TRN & \\
\hline CHEMBL3693305 & 1528880 & 8.0969 & 8.1462 & TRN & \\
\hline CHEMBL3693357 & 1528880 & 8.3979 & 8.3397 & TRN & \\
\hline CHEMBL3693260 & 1528880 & 7.3872 & 7.3801 & TST & \\
\hline CHEMBL3693299 & 1528880 & 7.1135 & 7.2691 & TRN & \\
\hline CHEMBL3693279 & 1528880 & 7.1135 & 7.32700 & 0000000001 & TRN \\
\hline CHEMBL3693315 & 1528880 & 6.0 & 6.47 & TRN & \\
\hline CHEMBL3693303 & 1528880 & 8.301 & 8.4021 & TRN & \\
\hline CHEMBL 3693344 & 1528880 & 7.1308 & 7.0138 & TRN & \\
\hline CHEMBL 3693350 & 1528880 & 7.0655 & 6.9853 & TRN & \\
\hline CHEMBL3693359 & 1528880 & 9.699 & 8.9567 & TRN & \\
\hline CHEMBL3693365 & 1528880 & 8.5229 & 8.3679 & TRN & \\
\hline CHEMBL3693281 & 1528880 & 6.0 & 5.8897 & TRN & \\
\hline CHEMBL3693356 & 1528880 & 6.2284 & 6.3427 & TST & \\
\hline CHEMBL3693330 & 1528880 & 6.7235 & 6.4532 & TRN & \\
\hline CHEMBL3693346 & 1528880 & 7.7447 & 7.6639 & TRN & \\
\hline CHEMBL3693261 & 1528880 & 8.5229 & 8.0274 & TRN & \\
\hline CHEMBL3693308 & 1528880 & 6.7122 & 6.8224 & TRN & \\
\hline CHEMBL3693337 & 1528880 & 8.0 & 8.0756 & TRN & \\
\hline CHEMBL 3693282 & 1528880 & 7.4202 & 7.4793 & TRN & \\
\hline CHEMBL3693290 & 1528880 & 8.2218 & 7.8395 & TRN & \\
\hline CHEMBL3693263 & 1528880 & 6.9208 & 6.8051 & TST & \\
\hline CHEMBL3693339 & 1528880 & 6.7011 & 6.6993 & TST & \\
\hline CHEMBL3693274 & 1528880 & 6.9508 & 6.8921 & TRN & \\
\hline CHEMBL 3693287 & 1528880 & 7.699 & 7.7227 & TRN & \\
\hline CHEMBL3693310 & 1528880 & 7.9586 & 8.3112 & TST & \\
\hline CHEMBL3693348 & 1528880 & 9.0 & 9.106 & TRN & \\
\hline CHEMBL3693316 & 1528880 & 6.8447 & 6.2128 & TRN & \\
\hline CHEMBL3693321 & 1528880 & 7.3468 & 7.551 & TST & \\
\hline
\end{tabular}


Supplemental Table S2.txt

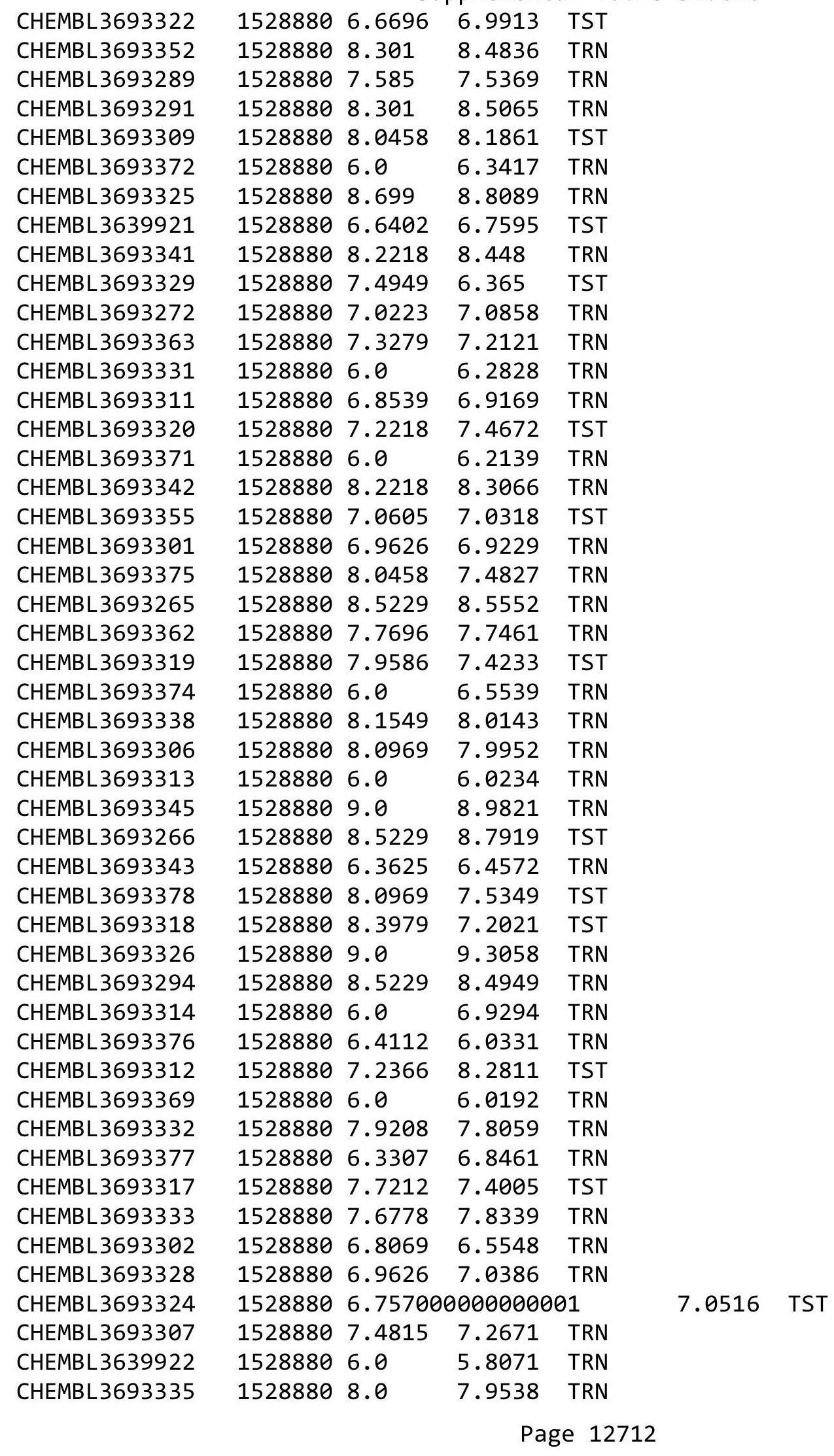


Supplemental Table S2.txt

\begin{tabular}{|c|c|c|c|c|c|c|}
\hline CHEMBL3693304 & 1528880 & 7.301 & 7.3 & TRN & & \\
\hline CHEMBL3693286 & 1528880 & 7.4318 & 7.5331 & TRN & & \\
\hline CHEMBL3693370 & 1528880 & 8.1549 & 6.8442 & TRN & & \\
\hline CHEMBL3693280 & 1528880 & 7.6576 & 7.5296 & TRN & & \\
\hline CHEMBL 3693340 & 1528880 & 8.3979 & 8.5104 & TRN & & \\
\hline CHEMBL3693327 & 1528880 & 6.7878 & 6.4194 & TST & & \\
\hline CHEMBL3693271 & 1528880 & 7.4437 & 7.3577 & TRN & & \\
\hline CHEMBL3693267 & 1528880 & 8.699 & 8.891 & TST & & \\
\hline CHEMBL135561 & 955080 & 4.7631 & 4.7604 & TRN & & \\
\hline CHEMBL65 & 955080 & 9.2446 & 9.2531 & TRN & & \\
\hline CHEMBL3349342 & 955080 & 6.2542 & 6.261 & TRN & & \\
\hline CHEMBL1242367 & 955080 & 3.1101 & 3.1178 & TRN & & \\
\hline CHEMBL1256459 & 955080 & 6.4923 & 6.4972 & TRN & & \\
\hline CHEMBL221137 & 955080 & 3.5767 & 4.6951 & TST & & \\
\hline CHEMBL3199475 & 955080 & 5.0326 & 5.0401 & TRN & & \\
\hline CHEMBL509032 & 955080 & 6.4978 & 6.4945 & TRN & & \\
\hline CHEMBL1190711 & 955080 & 4.9594 & 4.9554 & TRN & & \\
\hline CHEMBL1643959 & 955080 & 4.5686 & 4.5642 & TRN & & \\
\hline CHEMBL240954 & 955080 & 3.7772 & 3.8367 & TST & & \\
\hline CHEMBL393929 & 955080 & 3.3146 & 3.3076 & TRN & & \\
\hline CHEMBL92309 & 955080 & 3.6716 & 3.2328 & TST & & \\
\hline CHEMBL558642 & 955080 & 4.2847 & 4.2819 & TRN & & \\
\hline CHEMBL180127 & 955080 & 3.6684 & 3.6746 & TRN & & \\
\hline CHEMBL3186408 & 955080 & 3.1299 & 3.992 & TST & & \\
\hline CHEMBL1186585 & 955080 & 4.9142 & 4.9092 & TRN & & \\
\hline CHEMBL300389 & 955080 & 4.8304 & 4.8341 & TRN & & \\
\hline CHEMBL189584 & 955080 & 4.8543 & 4.8466 & TRN & & \\
\hline CHEMBL 9470 & 955080 & 6.6722 & 6.4383 & TST & & \\
\hline CHEMBL188678 & 955080 & 5.2737 & 5.2442 & TRN & & \\
\hline CHEMBL259181 & 955080 & 4.5004 & 4.5066 & TRN & & \\
\hline CHEMBL 2144069 & 955080 & 6.7183 & 6.7354 & TRN & & \\
\hline CHEMBL379975 & 955080 & 3.5729 & 3.5669 & TRN & & \\
\hline CHEMBL1909414 & 955080 & 3.6 & 3.6063 & TRN & & \\
\hline CHEMBL1970879 & 955080 & 5.4831 & 5.4824 & TRN & & \\
\hline CHEMBL514499 & 955080 & 5.6347 & 5.6359 & TRN & & \\
\hline CHEMBL 2137530 & 955080 & 5.3615 & 5.3692 & TRN & & \\
\hline CHEMBL373751 & 955080 & 3.0857 & 3.0851 & TRN & & \\
\hline CHEMBL512504 & 955080 & 6.1638 & 6.1552 & TRN & & \\
\hline CHEMBL220241 & 955080 & 4.2509 & 4.2482 & TRN & & \\
\hline CHEMBL1788116 & 955080 & \multicolumn{3}{|c|}{3.7039999999999997} & 3.7019 & TRN \\
\hline CHEMBL217354 & 955080 & 6.0571 & 6.0575 & TRN & & \\
\hline CHEMBL1357247 & 955080 & 3.9502 & 3.9631 & TRN & & \\
\hline CHEMBL222102 & 955080 & 3.4992 & 3.5253 & TRN & & \\
\hline CHEMBL483847 & 955080 & 3.8341 & 3.8417 & TRN & & \\
\hline CHEMBL202721 & 955080 & 5.4909 & 5.4797 & TRN & & \\
\hline CHEMBL515416 & 955080 & 3.2573 & 3.2618 & TRN & & \\
\hline CHEMBL209148 & 955080 & 5.1766 & 5.1625 & TRN & & \\
\hline CHEMBL483849 & 955080 & 3.0106 & 2.0224 & TST & & \\
\hline
\end{tabular}


Supplemental Table S2.txt

\begin{tabular}{|c|c|c|c|c|}
\hline CHEMBL192566 & 955080 & 9.0589 & 8.3804 & TST \\
\hline CHEMBL 2005886 & 955080 & 6.5335 & 6.5343 & TRN \\
\hline CHEMBL449158 & 955080 & 7.1207 & 7.3513 & TST \\
\hline CHEMBL1673039 & 955080 & 5.1052 & 5.1035 & TRN \\
\hline CHEMBL379300 & 955080 & 6.6446 & 6.6317 & TRN \\
\hline CHEMBL3392440 & 955080 & 3.3294 & 3.3252 & TRN \\
\hline CHEMBL585951 & 955080 & 5.8444 & 5.8421 & TRN \\
\hline CHEMBL213100 & 955080 & 4.5175 & 4.5194 & TRN \\
\hline CHEMBL573107 & 955080 & 4.8942 & 4.8861 & TRN \\
\hline CHEMBL399530 & 955080 & 3.9933 & 3.9866 & TRN \\
\hline CHEMBL577784 & 955080 & 5.936 & 5.9493 & TRN \\
\hline CHEMBL1516890 & 955080 & 4.3452 & 4.3604 & TRN \\
\hline CHEMBL 2134202 & 955080 & 4.6354 & 4.6205 & TRN \\
\hline CHEMBL210618 & 955080 & 3.3053 & 3.295 & TRN \\
\hline CHEMBL2363137 & 955080 & 4.5045 & 4.5111 & TRN \\
\hline CHEMBL1590308 & 955080 & 2.6753 & 3.2495 & TST \\
\hline CHEMBL191334 & 955080 & 5.5762 & 5.5767 & TRN \\
\hline CHEMBL412142 & 955080 & 3.5569 & 3.2528 & TST \\
\hline CHEMBL1230020 & 955080 & 2.9866 & 3.853 & TST \\
\hline CHEMBL472940 & 955080 & 5.1698 & 3.7515 & TST \\
\hline CHEMBL 258844 & 955080 & 4.0675 & 4.1626 & TST \\
\hline CHEMBL392695 & 955080 & 5.7539 & 4.8074 & TST \\
\hline CHEMBL102714 & 955080 & 4.5821 & 3.2506 & TST \\
\hline CHEMBL 255342 & 955080 & 4.4174 & 3.9019 & TST \\
\hline CHEMBL1404918 & 955080 & 3.0546 & 2.3059 & TST \\
\hline CHEMBL404573 & 469356 & 1.7696 & 2.1535 & TST \\
\hline CHEMBL404838 & 469356 & 1.585 & 2.48199 & 99999999998 \\
\hline CHEMBL 272726 & 469356 & 2.699 & 2.62 & TRN \\
\hline CHEMBL 272724 & 469356 & 3.699 & 2.7215 & TRN \\
\hline CHEMBL401755 & 469356 & 1.4202 & 2.4997 & TRN \\
\hline CHEMBL 255188 & 469356 & 1.0315 & 2.5206 & TRN \\
\hline CHEMBL 255187 & 469356 & 2.699 & 2.5153 & TRN \\
\hline CHEMBL404302 & 469356 & 0.08199 & 79999999 & 2.3226 \\
\hline CHEMBL 271465 & 469356 & 3.0969 & 2.4059 & TRN \\
\hline CHEMBL 271466 & 469356 & 2.5229 & 2.4529 & TRN \\
\hline CHEMBL 255425 & 469356 & 0.7651 & 2.3102 & TRN \\
\hline CHEMBL429573 & 469356 & 0.6459 & 2.293 & TRN \\
\hline CHEMBL255217 & 469356 & 1.8861 & 2.4844 & TRN \\
\hline CHEMBL 255332 & 469356 & 3.699 & 2.5531 & TRN \\
\hline CHEMBL404149 & 469356 & 3.2218 & 2.6843 & TRN \\
\hline CHEMBL 272055 & 469356 & 3.699 & 2.3172 & TRN \\
\hline CHEMBL 272056 & 469356 & 0.2692 & 2.3824 & TRN \\
\hline CHEMBL 270425 & 469356 & 2.0458 & 2.4809 & TRN \\
\hline CHEMBL429417 & 469356 & 3.699 & 2.8517 & TRN \\
\hline CHEMBL404617 & 469356 & 1.1438 & 2.5095 & TRN \\
\hline CHEMBL 255120 & 469356 & 3.699 & 2.6311 & TRN \\
\hline CHEMBL 258121 & 469356 & 3.699 & 2.2999 & TRN \\
\hline CHEMBL404712 & 469356 & 3.699 & 2.7818 & TRN \\
\hline
\end{tabular}




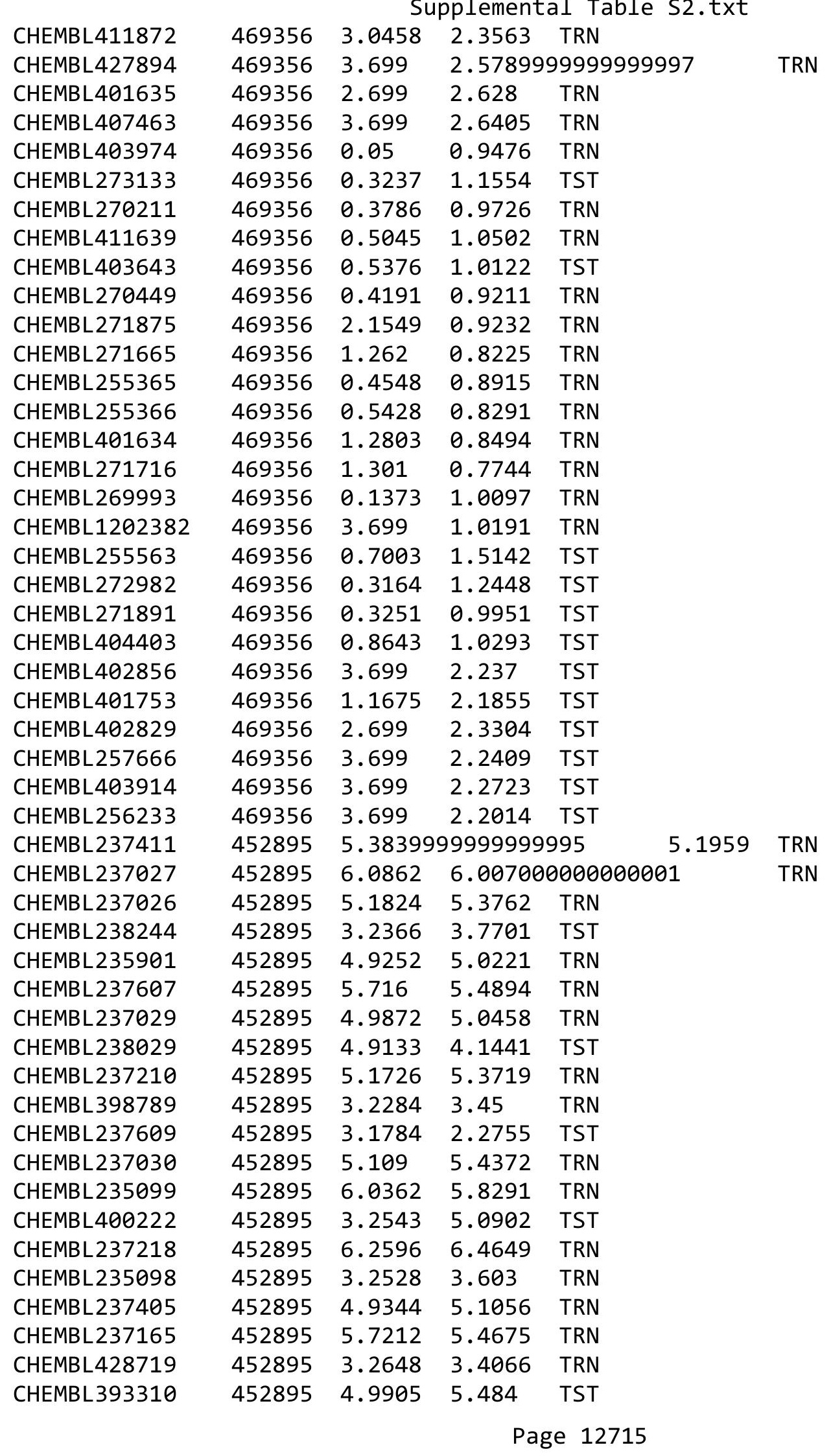




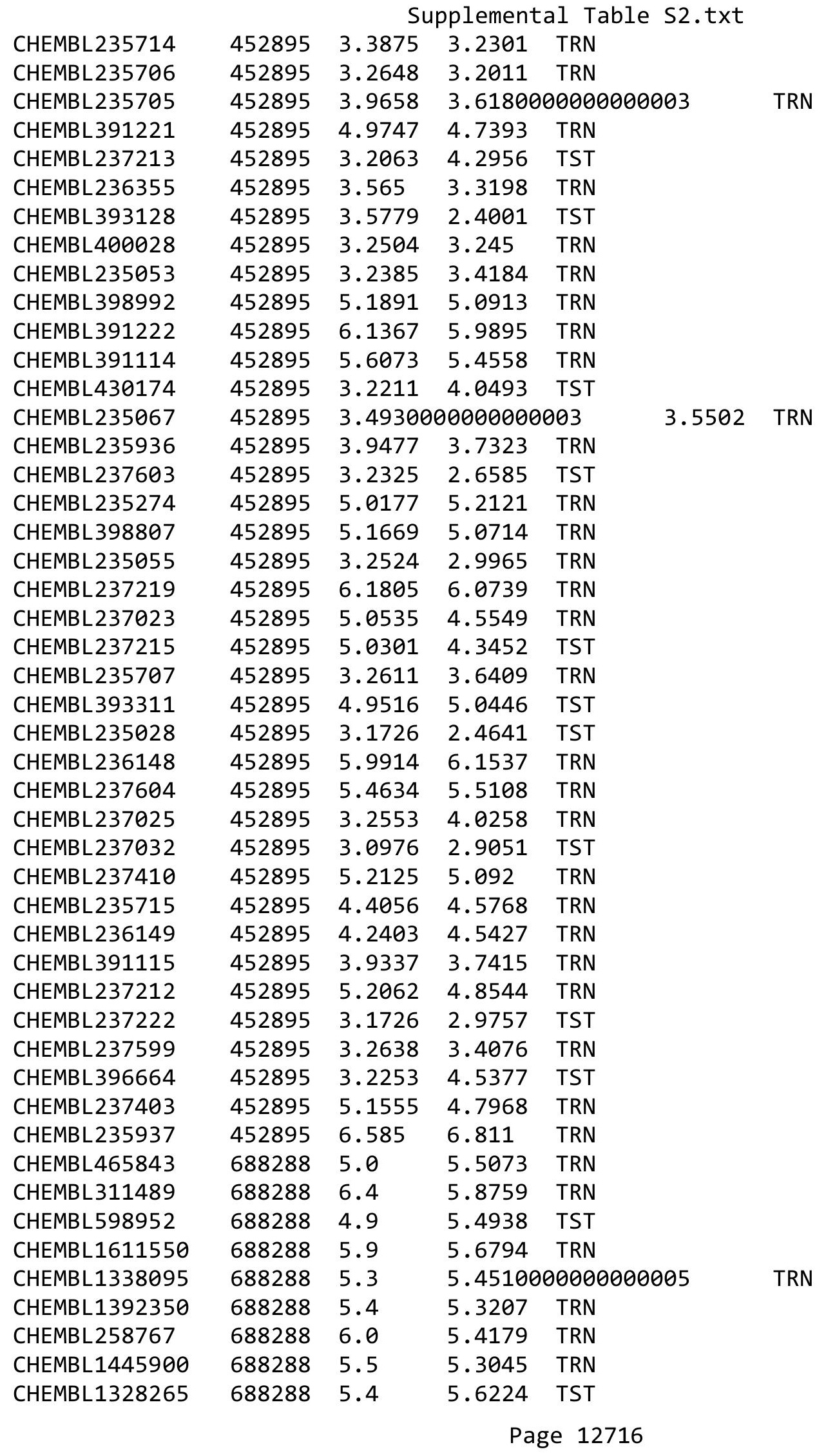




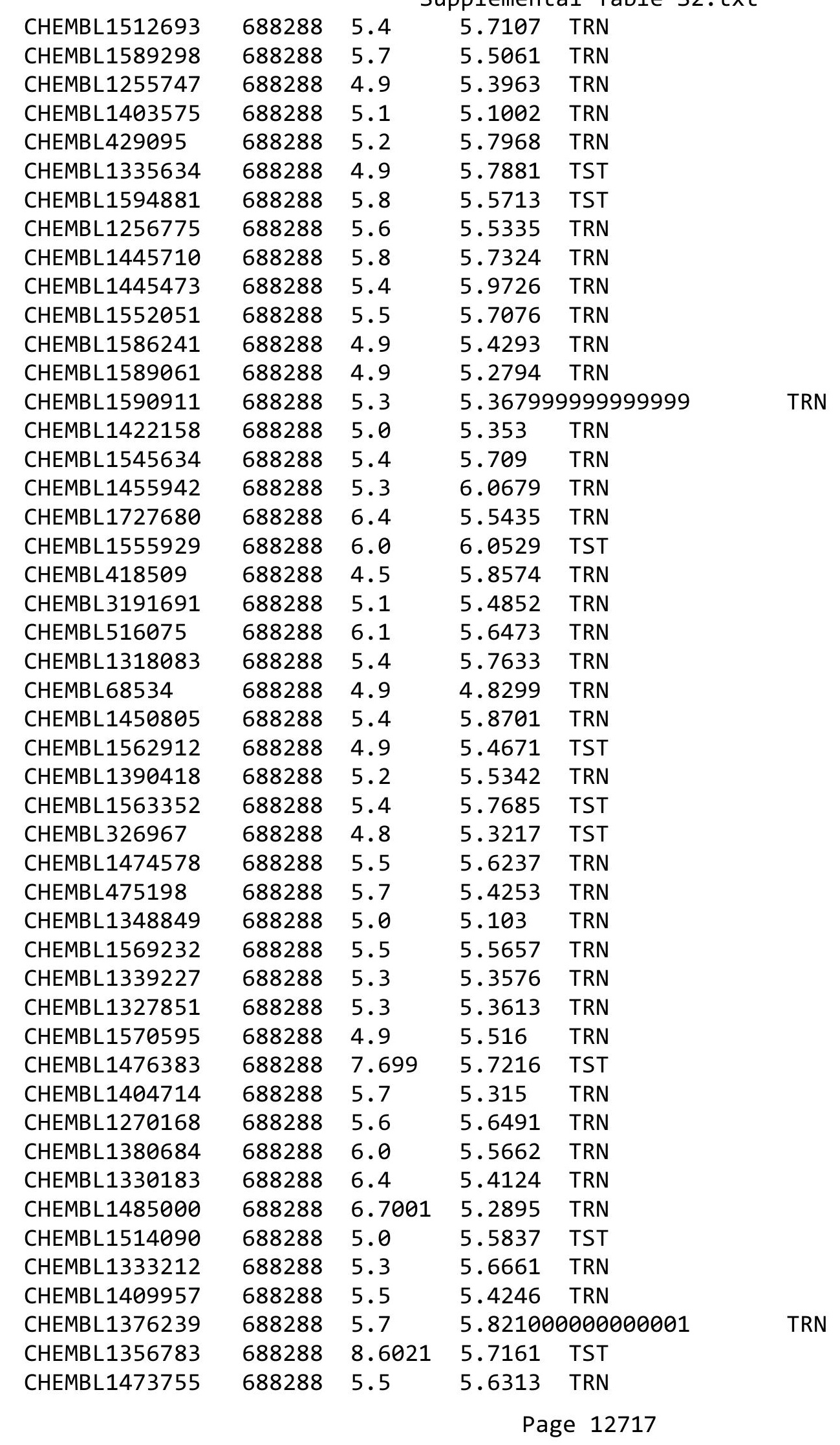




\begin{tabular}{|c|c|c|c|c|c|}
\hline & & & & & \\
\hline CHEMBL1412519 & 688288 & 5.7 & 5.4092 & TRN & \\
\hline CHEMBL1468261 & 688288 & 4.9 & 5.6269 & TRN & \\
\hline CHEMBL1436042 & 688288 & 5.3 & 5.4458 & TRN & \\
\hline CHEMBL1534566 & 688288 & 4.6 & 5.3937 & TRN & \\
\hline CHEMBL1504792 & 688288 & 5.0 & 5.2449 & TRN & \\
\hline CHEMBL1475191 & 688288 & 5.4 & 5.4433 & TRN & \\
\hline CHEMBL1288013 & 688288 & 5.5 & 5.70299 & 9999999999 & TST \\
\hline CHEMBL1366371 & 688288 & 5.5 & 5.6341 & TRN & \\
\hline CHEMBL1381989 & 688288 & 5.4 & 5.6005 & TST & \\
\hline CHEMBL1403102 & 688288 & 6.9 & 5.7065 & TRN & \\
\hline CHEMBL1592812 & 688288 & 6.3 & 6.05399 & & TRN \\
\hline CHEMBL2373615 & 688288 & 6.0 & 5.6768 & TRN & \\
\hline CHEMBL1497574 & 688288 & 5.4 & 5.5644 & TRN & \\
\hline CHEMBL1256869 & 688288 & 4.5 & 5.2889 & TST & \\
\hline CHEMBL1460595 & 688288 & 5.0 & 5.4461 & TST & \\
\hline CHEMBL1484120 & 688288 & 5.5 & 5.74299 & 9999999999 & TRN \\
\hline CHEMBL1590980 & 688288 & 4.8 & 5.5389 & TRN & \\
\hline CHEMBL1552957 & 688288 & 5.5 & 5.5839 & TRN & \\
\hline CHEMBL1482426 & 688288 & 5.5 & 5.6613 & TRN & \\
\hline CHEMBL1395009 & 688288 & 5.3 & 5.425 & TRN & \\
\hline CHEMBL 2028181 & 688288 & 6.5 & 5.5512 & TST & \\
\hline CHEMBL1315129 & 688288 & 5.8 & 5.7604 & TRN & \\
\hline CHEMBL1455548 & 688288 & 5.0 & 5.0877 & TRN & \\
\hline CHEMBL1421193 & 688288 & 5.5 & 5.4976 & TRN & \\
\hline CHEMBL1599337 & 688288 & 5.5 & 5.0974 & TRN & \\
\hline CHEMBL1386432 & 688288 & 5.8 & 5.7307 & TRN & \\
\hline CHEMBL1514958 & 688288 & 5.5 & 5.7346 & TRN & \\
\hline CHEMBL19980 & 688288 & 6.5 & 5.8956 & TST & \\
\hline CHEMBL149223 & 688288 & 5.1 & 5.4621 & TST & \\
\hline CHEMBL1434308 & 688288 & 7.0 & 5.776 & TRN & \\
\hline CHEMBL1565228 & 688288 & 6.8 & 5.9752 & TRN & \\
\hline CHEMBL1346785 & 688288 & 5.0 & 5.3553 & TRN & \\
\hline CHEMBL1304431 & 688288 & 5.0 & 5.3788 & TRN & \\
\hline CHEMBL1411278 & 688288 & 5.0 & 5.3023 & TRN & \\
\hline CHEMBL1419598 & 688288 & 5.4 & 5.0191 & TRN & \\
\hline CHEMBL1596971 & 688288 & 4.9 & 5.4094 & TRN & \\
\hline CHEMBL1523314 & 688288 & 5.3 & 5.6555 & TRN & \\
\hline CHEMBL1335967 & 688288 & 5.5 & 5.5306 & TRN & \\
\hline CHEMBL1408854 & 688288 & 6.2 & 6.0182 & TRN & \\
\hline CHEMBL1716992 & 688288 & 5.0 & 5.1115 & TRN & \\
\hline CHEMBL1533853 & 688288 & 5.2 & 5.8226 & TRN & \\
\hline CHEMBL1257078 & 688288 & 4.9 & 5.7541 & TST & \\
\hline CHEMBL1394095 & 688288 & 6.0 & 5.9344 & TRN & \\
\hline CHEMBL1457755 & 688288 & 5.7 & 5.1797 & TRN & \\
\hline CHEMBL3189836 & 688288 & 5.0 & 5.0626 & TRN & \\
\hline CHEMBL1593153 & 688288 & 5.5 & 5.8585 & TRN & \\
\hline CHEMBL67311 & 688288 & 4.6 & 5.6141 & TST & \\
\hline CHEMBL1591380 & 688288 & 5.6 & 5.545 & TRN & \\
\hline & & & & 12718 & \\
\hline
\end{tabular}




\begin{tabular}{|c|c|c|c|c|c|}
\hline & & & & & \\
\hline CHEMBL1357381 & 688288 & 6.4 & 5.4167 & TRN & \\
\hline CHEMBL165 & 688288 & 6.0 & 5.4781 & TRN & \\
\hline CHEMBL1534849 & 688288 & 5.5 & 5.5942 & TRN & \\
\hline CHEMBL1256835 & 688288 & 5.6 & 5.0211 & TST & \\
\hline CHEMBL1569307 & 688288 & 6.0 & 5.6253 & TRN & \\
\hline CHEMBL1789988 & 688288 & 5.6 & 5.48799 & 99999999995 & TRN \\
\hline CHEMBL1385840 & 688288 & 6.4 & 5.489 & TST & \\
\hline CHEMBL1468845 & 688288 & 5.1 & 5.1413 & TST & \\
\hline CHEMBL2373582 & 688288 & 6.5 & 5.6446 & TST & \\
\hline CHEMBL 7644 & 688288 & 5.4 & 5.3239 & TRN & \\
\hline CHEMBL1395402 & 688288 & 5.3 & 5.6117 & TRN & \\
\hline CHEMBL1590601 & 688288 & 7.0 & 5.7379 & TRN & \\
\hline CHEMBL1512122 & 688288 & 5.8 & 5.6299 & TRN & \\
\hline CHEMBL1256646 & 688288 & 5.1 & 5.1684 & TRN & \\
\hline CHEMBL1450716 & 688288 & 5.5 & 5.5437 & TRN & \\
\hline CHEMBL1609341 & 688288 & 5.0 & 5.6376 & TRN & \\
\hline CHEMBL1500533 & 688288 & 4.9 & 5.3546 & TST & \\
\hline CHEMBL1535431 & 688288 & 5.4 & 5.6999 & TRN & \\
\hline CHEMBL1415465 & 688288 & 5.5 & 5.56 & TRN & \\
\hline CHEMBL1551841 & 688288 & 5.3 & 5.7437 & TRN & \\
\hline CHEMBL1439007 & 688288 & 5.2 & 5.3962 & TRN & \\
\hline CHEMBL1424950 & 688288 & 5.3 & 5.4901 & TRN & \\
\hline CHEMBL1436865 & 688288 & 5.5 & 5.4255 & TRN & \\
\hline CHEMBL1543205 & 688288 & 5.0 & 5.1622 & TRN & \\
\hline CHEMBL1592470 & 688288 & 5.5 & 5.5633 & TRN & \\
\hline CHEMBL1474922 & 688288 & 7.5003 & 5.7583 & TST & \\
\hline CHEMBL1354256 & 688288 & 4.9 & 5.4237 & TST & \\
\hline CHEMBL1373998 & 688288 & 5.5 & 5.3859 & TRN & \\
\hline CHEMBL1316222 & 688288 & 5.3 & 5.4456 & TRN & \\
\hline CHEMBL1581127 & 688288 & 5.2 & 5.7006 & TRN & \\
\hline CHEMBL1396010 & 688288 & 5.4 & 5.9556 & TRN & \\
\hline CHEMBL1256667 & 688288 & 4.8 & 5.3169 & TRN & \\
\hline CHEMBL1394456 & 688288 & 6.9 & 5.9426 & TRN & \\
\hline CHEMBL1403333 & 688288 & 5.3 & 5.6853 & TRN & \\
\hline CHEMBL1311310 & 688288 & 5.3 & 5.5974 & TST & \\
\hline CHEMBL1316779 & 688288 & 5.5 & 5.5558 & TRN & \\
\hline CHEMBL1445121 & 688288 & 5.0 & 5.3373 & TRN & \\
\hline CHEMBL1388465 & 688288 & 5.0 & 5.371 & TRN & \\
\hline CHEMBL1257041 & 688288 & 5.6 & 5.4316 & TRN & \\
\hline CHEMBL1435259 & 688288 & 5.9 & 5.8935 & TRN & \\
\hline CHEMBL543467 & 688288 & 4.9 & 5.5558 & TST & \\
\hline CHEMBL1399656 & 688288 & 6.7001 & 5.7835 & TRN & \\
\hline CHEMBL164269 & 688288 & 5.5 & 5.6106 & TST & \\
\hline CHEMBL1515858 & 688288 & 5.4 & 5.4736 & TRN & \\
\hline CHEMBL1515635 & 688288 & 5.5 & 5.557 & TRN & \\
\hline CHEMBL1337691 & 688288 & 5.5 & 5.3948 & TRN & \\
\hline CHEMBL1503131 & 688288 & 5.1 & 5.2442 & TRN & \\
\hline CHEMBL1486465 & 688288 & 6.4 & 5.3865 & TST & \\
\hline & & & & 12719 & \\
\hline
\end{tabular}




\begin{tabular}{|c|c|c|c|c|c|}
\hline \\
\hline CHEMBL1395997 & 688288 & 5.3 & 5.8254 & TRN & \\
\hline CHEMBL319244 & 688288 & 5.3 & 5.1874 & TRN & \\
\hline CHEMBL1371152 & 688288 & 4.9 & 5.6556 & TRN & \\
\hline CHEMBL95431 & 688288 & 5.5 & 5.2437 & TST & \\
\hline CHEMBL1493014 & 688288 & 5.2 & 5.0666 & TRN & \\
\hline CHEMBL1399519 & 688288 & 5.3 & 5.0145 & TRN & \\
\hline CHEMBL876 & 688288 & 6.0 & 5.4908 & TST & \\
\hline CHEMBL1321005 & 688288 & 7.3002 & 6.0405 & TRN & \\
\hline CHEMBL1474016 & 688288 & 5.6 & 5.654 & TRN & \\
\hline CHEMBL1483855 & 688288 & 5.4 & 5.5336 & TRN & \\
\hline CHEMBL1440148 & 688288 & 5.4 & 5.2475 & TRN & \\
\hline CHEMBL 2374063 & 688288 & 4.8 & 5.6463 & TST & \\
\hline CHEMBL1372837 & 688288 & 5.3 & 5.3073 & TRN & \\
\hline CHEMBL1369601 & 688288 & 5.5 & 5.722 & TRN & \\
\hline CHEMBL1407114 & 688288 & 5.0 & 5.2439 & TRN & \\
\hline CHEMBL1600497 & 688288 & 5.4 & 5.1345 & TRN & \\
\hline CHEMBL1512744 & 688288 & 5.3 & 5.7552 & TRN & \\
\hline CHEMBL1512111 & 688288 & 5.9 & 5.8113 & TST & \\
\hline CHEMBL1422338 & 688288 & 4.9 & 5.2893 & TRN & \\
\hline CHEMBL1462487 & 688288 & 5.2 & 5.7091 & TRN & \\
\hline CHEMBL418068 & 688288 & 4.9 & 5.7063 & TRN & \\
\hline CHEMBL1487323 & 688288 & 4.9 & 4.9846 & TRN & \\
\hline CHEMBL1318114 & 688288 & 5.6 & 5.5879 & TRN & \\
\hline CHEMBL1529009 & 688288 & 5.0 & 5.2818 & TRN & \\
\hline CHEMBL 243664 & 688288 & 6.1 & 5.4872 & TRN & \\
\hline CHEMBL1487318 & 688288 & 5.8 & 5.76 & TRN & \\
\hline CHEMBL1591205 & 688288 & 6.6 & 5.9092 & TST & \\
\hline CHEMBL1598413 & 688288 & 6.5 & 5.3875 & TRN & \\
\hline CHEMBL1404884 & 688288 & 5.8 & 5.4031 & TRN & \\
\hline CHEMBL1590378 & 688288 & 6.0 & 5.5492 & TST & \\
\hline CHEMBL 2374058 & 688288 & 4.6 & 5.49200 & 0000000001 & TST \\
\hline CHEMBL1458327 & 688288 & 5.4 & 5.2638 & TRN & \\
\hline CHEMBL1354355 & 688288 & 5.3 & 5.6009 & TRN & \\
\hline CHEMBL1325765 & 688288 & 5.0 & 5.32700 & 0000000001 & TRN \\
\hline CHEMBL1585547 & 688288 & 6.5 & 5.3249 & TRN & \\
\hline CHEMBL1404093 & 688288 & 5.6 & 5.6165 & TRN & \\
\hline CHEMBL1470983 & 688288 & 5.4 & 5.3547 & TST & \\
\hline CHEMBL1467918 & 688288 & 5.6 & 5.5196 & TRN & \\
\hline CHEMBL1331383 & 688288 & 4.9 & 5.7418 & TRN & \\
\hline CHEMBL1593219 & 688288 & 5.5 & 5.6596 & TRN & \\
\hline CHEMBL1436272 & 688288 & 5.9 & 5.4645 & TRN & \\
\hline CHEMBL1318927 & 688288 & 5.6 & 5.1829 & TRN & \\
\hline CHEMBL1315725 & 688288 & 5.5 & 5.6354 & TST & \\
\hline CHEMBL1441920 & 688288 & 5.5 & 5.5835 & TST & \\
\hline CHEMBL 3716478 & 688288 & 5.1 & 5.501 & TST & \\
\hline CHEMBL1396595 & 688288 & 6.8 & 5.8367 & TRN & \\
\hline CHEMBL1475366 & 688288 & 5.6 & 5.5924 & TRN & \\
\hline CHEMBL1595142 & 688288 & 5.5 & 6.0159 & TRN & \\
\hline
\end{tabular}




\begin{tabular}{|c|c|c|c|c|}
\hline & & & & $a \perp 1 a$ \\
\hline CHEMBL1414943 & 688288 & 5.8 & 5.8416 & TRN \\
\hline CHEMBL1437054 & 688288 & 6.6 & 5.3617 & TST \\
\hline CHEMBL1511034 & 688288 & 5.6 & 6.1274 & TRN \\
\hline CHEMBL1369215 & 688288 & 5.6 & 5.6424 & TST \\
\hline CHEMBL1571006 & 688288 & 5.9 & 5.5059 & TRN \\
\hline CHEMBL1325511 & 688288 & 5.4 & 5.8183 & TRN \\
\hline CHEMBL1326152 & 688288 & 5.5 & 5.5092 & TRN \\
\hline CHEMBL1474522 & 688288 & 6.0 & 5.811 & TST \\
\hline CHEMBL1555037 & 688288 & 5.5 & 5.6638 & TRN \\
\hline CHEMBL1436195 & 688288 & 5.7 & 5.8104 & TRN \\
\hline CHEMBL1525813 & 688288 & 6.0 & 5.9554 & TRN \\
\hline CHEMBL1541618 & 688288 & 6.3 & 5.5887 & TRN \\
\hline CHEMBL1417140 & 688288 & 5.7 & 5.7273 & TRN \\
\hline CHEMBL1367281 & 688288 & 4.9 & 5.8838 & TST \\
\hline CHEMBL1495077 & 688288 & 5.5 & 5.9272 & TRN \\
\hline CHEMBL1558246 & 688288 & 5.0 & 5.3885 & TRN \\
\hline CHEMBL1442458 & 688288 & 5.5 & 5.5111 & TRN \\
\hline CHEMBL1433687 & 688288 & 6.0 & 5.6294 & TRN \\
\hline CHEMBL60518 & 688288 & 5.5 & 5.7885 & TRN \\
\hline CHEMBL1341213 & 688288 & 5.5 & 5.2533 & TRN \\
\hline CHEMBL1494893 & 688288 & 4.9 & 5.4145 & TRN \\
\hline CHEMBL1365898 & 688288 & 5.8 & 5.1883 & TRN \\
\hline CHEMBL1514280 & 688288 & 5.6 & 5.7808 & TRN \\
\hline CHEMBL 250711 & 688288 & 4.5 & 4.9991 & TRN \\
\hline CHEMBL1301935 & 688288 & 5.0 & 5.4391 & TRN \\
\hline CHEMBL495068 & 688288 & 5.6 & 5.6585 & TRN \\
\hline CHEMBL1499903 & 688288 & 4.9 & 5.4748 & TRN \\
\hline CHEMBL539027 & 688288 & 6.0 & 5.4913 & TRN \\
\hline CHEMBL566899 & 688288 & 6.4 & 5.7578 & TRN \\
\hline CHEMBL587849 & 688288 & 5.5 & 5.5467 & TRN \\
\hline CHEMBL1257081 & 688288 & 4.8 & 5.2241 & TRN \\
\hline CHEMBL1403982 & 688288 & 5.6 & 5.6921 & TRN \\
\hline CHEMBL1449350 & 688288 & 5.4 & 5.2015 & TRN \\
\hline CHEMBL1880070 & 688288 & 5.5 & 5.4411 & TST \\
\hline CHEMBL261131 & 688288 & 5.3 & 5.1586 & TRN \\
\hline CHEMBL1475750 & 688288 & 6.3 & 5.6653 & TRN \\
\hline CHEMBL1482155 & 688288 & 5.5 & 5.6556 & TRN \\
\hline CHEMBL1384200 & 688288 & 6.4 & 5.4387 & TRN \\
\hline CHEMBL1355909 & 688288 & 5.5 & 5.6239 & TRN \\
\hline CHEMBL3210598 & 688288 & 5.1 & 4.9998 & TRN \\
\hline CHEMBL442581 & 688288 & 7.0 & 5.4039 & TRN \\
\hline CHEMBL1572855 & 688288 & 5.5 & 5.6635 & TRN \\
\hline CHEMBL1397604 & 688288 & 5.5 & 5.3787 & TRN \\
\hline CHEMBL1417789 & 688288 & 5.5 & 5.7178 & TRN \\
\hline CHEMBL1551633 & 688288 & 6.0 & 5.4208 & TRN \\
\hline CHEMBL1324287 & 688288 & 5.4 & 5.5078 & TRN \\
\hline CHEMBL109037 & 688288 & 4.8 & 5.6755 & TRN \\
\hline CHEMBL1452316 & 688288 & 5.4 & 5.4744 & TST \\
\hline
\end{tabular}




\begin{tabular}{|c|c|c|c|c|c|}
\hline \\
\hline CHEMBL1569814 & 688288 & 4.9 & 5.2741 & TST & \\
\hline CHEMBL389390 & 688288 & 6.1 & 6.1729 & TRN & \\
\hline CHEMBL1444625 & 688288 & 5.4 & 5.5112 & TRN & \\
\hline CHEMBL1440617 & 688288 & 5.4 & 5.8998 & TRN & \\
\hline CHEMBL1405744 & 688288 & 6.2 & 5.6598 & TRN & \\
\hline CHEMBL1453641 & 688288 & 7.6003 & 5.9183 & TST & \\
\hline CHEMBL1318643 & 688288 & 5.0 & 5.7645 & TRN & \\
\hline CHEMBL1399590 & 688288 & 5.3 & 5.3677 & TRN & \\
\hline CHEMBL1354281 & 688288 & 5.4 & 5.4701 & TRN & \\
\hline CHEMBL1357186 & 688288 & 5.4 & 5.4974 & TRN & \\
\hline CHEMBL1344878 & 688288 & 5.0 & 5.1753 & TRN & \\
\hline CHEMBL1397079 & 688288 & 5.4 & 5.5537 & TRN & \\
\hline CHEMBL1316796 & 688288 & 5.5 & 5.7962 & TRN & \\
\hline CHEMBL1611820 & 688288 & 5.5 & 5.5574 & TRN & \\
\hline CHEMBL1315316 & 688288 & 5.9 & 5.6168 & TRN & \\
\hline CHEMBL1441843 & 688288 & 5.4 & 5.5321 & TRN & \\
\hline CHEMBL1310585 & 688288 & 5.9 & 5.4832 & TST & \\
\hline CHEMBL1492263 & 688288 & 5.8 & 5.2313 & TRN & \\
\hline CHEMBL1434739 & 688288 & 8.699 & 5.8779 & TST & \\
\hline CHEMBL1330020 & 688288 & 6.5 & 5.9018 & TRN & \\
\hline CHEMBL304291 & 688288 & 4.9 & 5.9625 & TST & \\
\hline CHEMBL1378043 & 688288 & 5.6 & 5.2995 & TRN & \\
\hline CHEMBL1340944 & 688288 & 5.0 & 5.2097 & TRN & \\
\hline CHEMBL1467091 & 688288 & 5.0 & 5.59399 & 9999999999 & TRN \\
\hline CHEMBL1357157 & 688288 & 7.8996 & 5.6095 & TRN & \\
\hline CHEMBL1489016 & 688288 & 5.8 & 5.6477 & TRN & \\
\hline CHEMBL1416814 & 688288 & 5.8 & 6.12299 & 7999999999 & TRN \\
\hline CHEMBL3197198 & 688288 & 5.2 & 5.5083 & TRN & \\
\hline CHEMBL572576 & 688288 & 4.9 & 5.3727 & TRN & \\
\hline CHEMBL1243269 & 688288 & 4.9 & 5.5093 & TST & \\
\hline CHEMBL1575588 & 688288 & 6.3 & 5.9934 & TRN & \\
\hline CHEMBL1426258 & 688288 & 4.9 & 5.3333 & TRN & \\
\hline CHEMBL1317916 & 688288 & 5.5 & 5.6467 & TRN & \\
\hline CHEMBL1553766 & 688288 & 6.9 & 5.6225 & TRN & \\
\hline CHEMBL1438928 & 688288 & 5.5 & 5.4846 & TRN & \\
\hline CHEMBL1491288 & 688288 & 5.2 & 5.4654 & TRN & \\
\hline CHEMBL1332463 & 688288 & 6.2 & 5.604 & TRN & \\
\hline CHEMBL1396282 & 688288 & 5.3 & 5.5414 & TST & \\
\hline CHEMBL1353133 & 688288 & 6.9 & 5.4506 & TRN & \\
\hline CHEMBL1319308 & 688288 & 5.6 & 5.6247 & TST & \\
\hline CHEMBL1363513 & 688288 & 5.9 & 5.6908 & TRN & \\
\hline CHEMBL1306312 & 688288 & 5.8 & 5.4317 & TRN & \\
\hline CHEMBL1377807 & 688288 & 6.2 & 5.7064 & TRN & \\
\hline CHEMBL1356463 & 688288 & 6.7001 & 5.5388 & TST & \\
\hline CHEMBL1397088 & 688288 & 5.5 & 5.614 & TRN & \\
\hline CHEMBL1462380 & 688288 & 5.0 & 5.4833 & TRN & \\
\hline CHEMBL1554763 & 688288 & 5.5 & 5.5811 & TRN & \\
\hline CHEMBL1514129 & 688288 & 5.4 & 5.4909 & TRN & \\
\hline
\end{tabular}




\begin{tabular}{|c|c|c|c|c|}
\hline \multicolumn{5}{|c|}{ Supplemental Table S2.txt } \\
\hline CHEMBL578943 & 688288 & 9.0969 & 5.5526 & TST \\
\hline CHEMBL1497991 & 688288 & 5.1 & 5.0221 & TRN \\
\hline CHEMBL1492102 & 688288 & 5.7 & 5.5347 & TRN \\
\hline CHEMBL1328690 & 688288 & 4.9 & 5.1596 & TRN \\
\hline CHEMBL1552562 & 688288 & 5.4 & 6.2552 & TRN \\
\hline CHEMBL1554721 & 688288 & 5.8 & 5.5846 & TRN \\
\hline CHEMBL1561363 & 688288 & 5.5 & 5.7023 & TRN \\
\hline CHEMBL76904 & 688288 & 5.0 & 5.1475 & TRN \\
\hline CHEMBL1320310 & 688288 & 4.6 & 5.7826 & TST \\
\hline CHEMBL1570532 & 688288 & 5.3 & 5.516 & TRN \\
\hline CHEMBL150 & 688288 & 5.8 & 5.5134 & TRN \\
\hline CHEMBL1417349 & 688288 & 5.5 & 5.6702 & TRN \\
\hline CHEMBL1435120 & 688288 & 4.8 & 6.063 & TRN \\
\hline CHEMBL1314324 & 688288 & 6.8 & 5.9791 & TRN \\
\hline CHEMBL1476274 & 688288 & 7.2 & 5.718 & TST \\
\hline CHEMBL1358402 & 688288 & 6.1 & 5.6909 & TST \\
\hline CHEMBL1564477 & 688288 & 5.5 & 5.5198 & TRN \\
\hline CHEMBL1491965 & 688288 & 5.5 & 5.6957 & TRN \\
\hline CHEMBL1996233 & 688288 & 5.0 & 5.1899 & TRN \\
\hline CHEMBL1564501 & 688288 & 5.9 & 5.5317 & TRN \\
\hline CHEMBL1355307 & 688288 & 5.3 & 5.5793 & TRN \\
\hline CHEMBL1559783 & 688288 & 5.4 & 5.4849 & TRN \\
\hline CHEMBL1488771 & 688288 & 5.4 & 5.2997 & TRN \\
\hline CHEMBL1331786 & 688288 & 4.9 & 5.4025 & TST \\
\hline CHEMBL1354119 & 688288 & 5.5 & 6.2897 & TRN \\
\hline CHEMBL469309 & 688288 & 5.4 & 5.61 & TRN \\
\hline CHEMBL1550296 & 688288 & 5.8 & 5.4673 & TRN \\
\hline CHEMBL1524001 & 688288 & 5.5 & 5.7 & TRN \\
\hline CHEMBL1515691 & 688288 & 6.3 & 5.8738 & TRN \\
\hline CHEMBL1256851 & 688288 & 4.6 & 5.2743 & TST \\
\hline CHEMBL1334327 & 688288 & 6.2 & 5.7027 & TRN \\
\hline CHEMBL172064 & 688288 & 5.9 & 5.636 & TRN \\
\hline CHEMBL1496617 & 688288 & 5.4 & 5.6556 & TRN \\
\hline CHEMBL1315141 & 688288 & 6.0 & 6.0514 & TRN \\
\hline CHEMBL1331248 & 688288 & 5.1 & 4.9369 & TRN \\
\hline CHEMBL1603418 & 688288 & 5.6 & 5.7329 & TRN \\
\hline CHEMBL1310378 & 688288 & 4.9 & 5.1504 & TRN \\
\hline CHEMBL3192314 & 688288 & 5.0 & 5.5507 & TRN \\
\hline CHEMBL1256360 & 688288 & 6.0 & 6.1434 & TRN \\
\hline CHEMBL1397427 & 688288 & 5.8 & 5.5879 & TRN \\
\hline CHEMBL29027 & 688288 & 4.8 & 5.4192 & TRN \\
\hline CHEMBL1575892 & 688288 & 6.1 & 5.6117 & TRN \\
\hline CHEMBL1359396 & 688288 & 5.2 & 5.5192 & TRN \\
\hline CHEMBL491578 & 688288 & 5.3 & 5.5155 & TRN \\
\hline CHEMBL1476521 & 688288 & 5.4 & 6.0849 & TRN \\
\hline CHEMBL1358092 & 688288 & 5.6 & 5.2704 & TRN \\
\hline CHEMBL1482649 & 688288 & 5.7 & 5.1962 & TRN \\
\hline CHEMBL1256697 & 688288 & 4.9 & 5.8407 & TRN \\
\hline
\end{tabular}




\begin{tabular}{|c|c|c|c|c|c|}
\hline CHEMBL1436037 & 688288 & 5.5 & \multicolumn{2}{|c|}{5.7829999999999995} & TRN \\
\hline CHEMBL1345005 & 688288 & 5.4 & 5.4872 & TRN & \\
\hline CHEMBL1420954 & 688288 & 5.3 & 5.8536 & TRN & \\
\hline CHEMBL1508914 & 688288 & 5.5 & 5.3865 & TRN & \\
\hline CHEMBL1409720 & 688288 & 6.6 & 5.5218 & TRN & \\
\hline CHEMBL1465739 & 688288 & 5.0 & \multicolumn{2}{|c|}{5.5360000000000005} & TRN \\
\hline CHEMBL428768 & 688288 & 6.0 & 5.351 & TRN & \\
\hline CHEMBL1317924 & 688288 & 5.4 & 5.6807 & TRN & \\
\hline CHEMBL1420011 & 688288 & 5.0 & 5.6187 & TST & \\
\hline CHEMBL1317986 & 688288 & 6.1 & 5.4364 & TRN & \\
\hline CHEMBL1520216 & 688288 & 5.9 & 5.6087 & TRN & \\
\hline CHEMBL1526697 & 688288 & 5.6 & 5.7081 & TRN & \\
\hline CHEMBL1502224 & 688288 & 6.5 & 5.6343 & TRN & \\
\hline CHEMBL1314956 & 688288 & 5.5 & 5.5387 & TRN & \\
\hline CHEMBL1342336 & 688288 & 7.0 & 5.8038 & TRN & \\
\hline CHEMBL1369825 & 688288 & 5.4 & 5.6383 & TST & \\
\hline CHEMBL1375753 & 688288 & 5.4 & 5.5594 & TRN & \\
\hline CHEMBL1513458 & 688288 & 5.3 & 5.8823 & TRN & \\
\hline CHEMBL1475617 & 688288 & 6.0 & 5.9712 & TRN & \\
\hline CHEMBL1563047 & 688288 & 5.4 & 5.8072 & TRN & \\
\hline CHEMBL1340201 & 688288 & 6.1 & 5.1814 & TRN & \\
\hline CHEMBL1444339 & 688288 & 4.9 & 5.3187 & TRN & \\
\hline CHEMBL1529543 & 688288 & 5.5 & 5.5929 & TRN & \\
\hline CHEMBL1256623 & 688288 & 4.8 & 5.5151 & TRN & \\
\hline CHEMBL1500231 & 688288 & 4.9 & 5.2004 & TRN & \\
\hline CHEMBL1351807 & 688288 & 5.4 & 5.2467 & TRN & \\
\hline CHEMBL1446139 & 688288 & 5.3 & 6.3149 & TRN & \\
\hline CHEMBL1607062 & 688288 & 8.4949 & 6.1032 & TRN & \\
\hline CHEMBL1523817 & 688288 & 5.4 & 5.2809 & TST & \\
\hline CHEMBL 265699 & 688288 & 5.7 & 5.7507 & TRN & \\
\hline CHEMBL1490528 & 688288 & 5.5 & 5.484 & TRN & \\
\hline CHEMBL1379801 & 688288 & 5.0 & 5.5826 & TRN & \\
\hline CHEMBL1417636 & 688288 & 6.0 & 5.4715 & TRN & \\
\hline CHEMBL1512023 & 688288 & 5.4 & 5.7634 & TRN & \\
\hline CHEMBL1534710 & 688288 & 5.4 & 5.3355 & TRN & \\
\hline CHEMBL1357130 & 688288 & 5.3 & 5.4793 & TST & \\
\hline CHEMBL565654 & 688288 & 5.7 & 5.5319 & TRN & \\
\hline CHEMBL1398538 & 688288 & 5.4 & 5.794 & TRN & \\
\hline CHEMBL1590886 & 688288 & 5.5 & 5.5287 & TRN & \\
\hline CHEMBL333985 & 688288 & 4.9 & 5.4069 & TST & \\
\hline CHEMBL25236 & 688288 & 6.0 & 5.1264 & TRN & \\
\hline CHEMBL1611413 & 688288 & 6.0 & 5.7761 & TRN & \\
\hline CHEMBL1350830 & 688288 & 5.0 & 5.1982 & TRN & \\
\hline CHEMBL1591533 & 688288 & 5.4 & 5.4872 & TRN & \\
\hline CHEMBL1495589 & 688288 & 4.9 & 5.4288 & TRN & \\
\hline CHEMBL39947 & 688288 & 5.5 & 5.4736 & TST & \\
\hline CHEMBL1441192 & 688288 & 5.5 & 5.647 & TRN & \\
\hline CHEMBL1473116 & 688288 & 5.3 & 5.7351 & TRN & \\
\hline
\end{tabular}




\begin{tabular}{|c|c|c|c|c|}
\hline \\
\hline CHEMBL1468976 & 688288 & 5.5 & 5.4096 & TRN \\
\hline CHEMBL1543216 & 688288 & 5.3 & 5.1261 & TRN \\
\hline CHEMBL1492017 & 688288 & 6.0 & 5.5287 & TRN \\
\hline CHEMBL1399394 & 688288 & 7.4001 & 5.9879 & TRN \\
\hline CHEMBL1531699 & 688288 & 6.9 & 6.1352 & TRN \\
\hline CHEMBL1357445 & 688288 & 5.3 & 5.4198 & TRN \\
\hline CHEMBL1360151 & 688288 & 7.699 & 5.641 & TRN \\
\hline CHEMBL1548425 & 688288 & 5.1 & 5.4901 & TRN \\
\hline CHEMBL 75967 & 688288 & 6.0 & 5.6326 & TST \\
\hline CHEMBL1395226 & 688288 & 5.4 & 5.5698 & TRN \\
\hline CHEMBL1327681 & 688288 & 5.5 & 5.2536 & TRN \\
\hline CHEMBL1328094 & 688288 & 5.1 & 5.6833 & TST \\
\hline CHEMBL492610 & 688288 & 5.7 & 5.6926 & TRN \\
\hline CHEMBL1572915 & 688288 & 5.6 & 5.8569 & TRN \\
\hline CHEMBL1255733 & 688288 & 5.9 & 5.8342 & TST \\
\hline CHEMBL1328339 & 688288 & 5.5 & 5.4605 & TRN \\
\hline CHEMBL189438 & 688288 & 6.0 & 5.3259 & TST \\
\hline CHEMBL1417135 & 688288 & 5.5 & 5.553 & TRN \\
\hline CHEMBL1357401 & 688288 & 8.0 & 6.1185 & TRN \\
\hline CHEMBL1376191 & 688288 & 5.5 & 5.6752 & TRN \\
\hline CHEMBL1355200 & 688288 & 5.9 & 5.8599 & TRN \\
\hline CHEMBL1521453 & 688288 & 5.1 & 5.6833 & TST \\
\hline CHEMBL1355263 & 688288 & 5.4 & 5.7519 & TRN \\
\hline CHEMBL1314414 & 688288 & 5.4 & 6.2006 & TRN \\
\hline CHEMBL1595377 & 688288 & 5.4 & 5.6124 & TRN \\
\hline CHEMBL1321338 & 688288 & 5.5 & 6.1284 & TRN \\
\hline CHEMBL1397548 & 688288 & 5.3 & 5.3575 & TRN \\
\hline CHEMBL1350047 & 688288 & 5.2 & 5.1906 & TRN \\
\hline CHEMBL1545211 & 688288 & 5.0 & 5.2386 & TRN \\
\hline CHEMBL1351918 & 688288 & 5.0 & 5.4722 & TRN \\
\hline CHEMBL1371947 & 688288 & 5.5 & 5.6953 & TST \\
\hline CHEMBL1372951 & 688288 & 6.0 & 5.6677 & TRN \\
\hline CHEMBL1493644 & 688288 & 5.5 & 5.6323 & TRN \\
\hline CHEMBL1491966 & 688288 & 5.6 & 5.6881 & TRN \\
\hline CHEMBL1496345 & 688288 & 5.3 & 5.5535 & TRN \\
\hline CHEMBL1516495 & 688288 & 4.9 & 5.5338 & TRN \\
\hline CHEMBL1450917 & 688288 & 5.4 & 5.1731 & TRN \\
\hline CHEMBL1590831 & 688288 & 5.6 & 5.7368 & TRN \\
\hline CHEMBL1473919 & 688288 & 5.4 & 5.7395 & TRN \\
\hline CHEMBL3211772 & 688288 & 5.0 & 4.9867 & TRN \\
\hline CHEMBL1160709 & 688288 & 6.0 & 6.2274 & TRN \\
\hline CHEMBL1435360 & 688288 & 5.5 & 6.0904 & TRN \\
\hline CHEMBL1408427 & 688288 & 6.0 & 5.7759 & TRN \\
\hline CHEMBL1449517 & 688288 & 5.5 & 5.6393 & TRN \\
\hline CHEMBL1403769 & 688288 & 5.5 & 5.5637 & TRN \\
\hline CHEMBL1435823 & 688288 & 5.5 & 6.0671 & TRN \\
\hline CHEMBL1440588 & 688288 & 5.0 & 5.4339 & TST \\
\hline CHEMBL1446539 & 688288 & 5.4 & 5.4252 & TRN \\
\hline
\end{tabular}




\begin{tabular}{|c|c|c|c|c|c|}
\hline CHEMBL407232 & 688288 & 4.6 & \multicolumn{2}{|c|}{5.4110000000000005} & \multirow[t]{2}{*}{ TRN } \\
\hline CHEMBL1596743 & 688288 & 5.4 & 5.73 & TRN & \\
\hline CHEMBL1200938 & 688288 & 6.0 & 5.5868 & TST & \\
\hline CHEMBL1325297 & 688288 & 5.9 & 5.7497 & TST & \\
\hline CHEMBL1574196 & 688288 & 5.3 & 5.6647 & TRN & \\
\hline CHEMBL1467629 & 688288 & 6.2 & 5.5338 & TRN & \\
\hline CHEMBL1467236 & 688288 & 5.5 & 5.5825 & TRN & \\
\hline CHEMBL1518705 & 688288 & 6.1 & 5.6744 & TRN & \\
\hline CHEMBL131921 & 688288 & 5.0 & 5.6615 & TRN & \\
\hline CHEMBL1552353 & 688288 & 5.6 & 5.5439 & TRN & \\
\hline CHEMBL471226 & 688288 & 5.4 & 5.431 & TST & \\
\hline CHEMBL1366433 & 688288 & 5.4 & 5.6995 & TRN & \\
\hline CHEMBL73310 & 688288 & 5.3 & 5.5264 & TRN & \\
\hline CHEMBL1600340 & 688288 & 5.6 & 5.6424 & TRN & \\
\hline CHEMBL3191152 & 688288 & 5.2 & 5.3288 & TST & \\
\hline CHEMBL1496315 & 688288 & 5.3 & 5.6862 & TRN & \\
\hline CHEMBL1366616 & 688288 & 4.8 & 5.6092 & TRN & \\
\hline CHEMBL1487503 & 688288 & 5.5 & 5.7902 & TST & \\
\hline CHEMBL1554158 & 688288 & 5.3 & 5.646 & TRN & \\
\hline CHEMBL1413497 & 688288 & 5.6 & 5.6824 & TRN & \\
\hline CHEMBL1495171 & 688288 & 5.7 & 5.5752 & TRN & \\
\hline CHEMBL1611654 & 688288 & 5.5 & 5.5532 & TST & \\
\hline CHEMBL1613349 & 688288 & 5.2 & 5.2751 & TRN & \\
\hline CHEMBL1328768 & 688288 & 9.2218 & 5.8177 & TST & \\
\hline CHEMBL1556733 & 688288 & 5.0 & 5.5844 & TRN & \\
\hline CHEMBL1591504 & 688288 & 5.3 & \multicolumn{2}{|c|}{6.218999999999999} & TRN \\
\hline CHEMBL1531863 & 688288 & 4.5 & 5.5028 & TRN & \\
\hline CHEMBL583849 & 688288 & 6.1 & 5.8277 & TRN & \\
\hline CHEMBL1433752 & 688288 & 5.7 & 5.6847 & TRN & \\
\hline CHEMBL1579891 & 688288 & 5.4 & 5.3442 & TRN & \\
\hline CHEMBL1353175 & 688288 & 5.0 & 5.2019 & TRN & \\
\hline CHEMBL1526212 & 688288 & 5.3 & 5.4742 & TRN & \\
\hline CHEMBL1530236 & 688288 & 5.0 & 5.5171 & TST & \\
\hline CHEMBL1497731 & 688288 & 4.9 & 5.4078 & TRN & \\
\hline CHEMBL1365983 & 688288 & 5.5 & 5.2856 & TRN & \\
\hline CHEMBL1256291 & 688288 & 5.3 & 5.3341 & TRN & \\
\hline CHEMBL1593374 & 688288 & 6.3 & 5.7402 & TRN & \\
\hline CHEMBL3351064 & 688288 & 6.0 & 5.5105 & TST & \\
\hline CHEMBL1592717 & 688288 & 6.6 & 5.7934 & TST & \\
\hline CHEMBL1317306 & 688288 & 6.2 & 5.7516 & TRN & \\
\hline CHEMBL391997 & 688288 & 5.3 & 5.3893 & TRN & \\
\hline CHEMBL85139 & 688288 & 4.8 & 5.1137 & TRN & \\
\hline CHEMBL1256836 & 688288 & 4.8 & 5.2402 & TRN & \\
\hline CHEMBL1607143 & 688288 & 5.1 & 5.5071 & TRN & \\
\hline CHEMBL1337820 & 688288 & 5.3 & 5.6676 & TRN & \\
\hline CHEMBL1454107 & 688288 & 5.3 & 5.2457 & TRN & \\
\hline CHEMBL1306749 & 688288 & 5.6 & 5.3664 & TRN & \\
\hline CHEMBL323356 & 688288 & 4.9 & 5.5082 & TRN & \\
\hline & & & & 12726 & \\
\hline
\end{tabular}




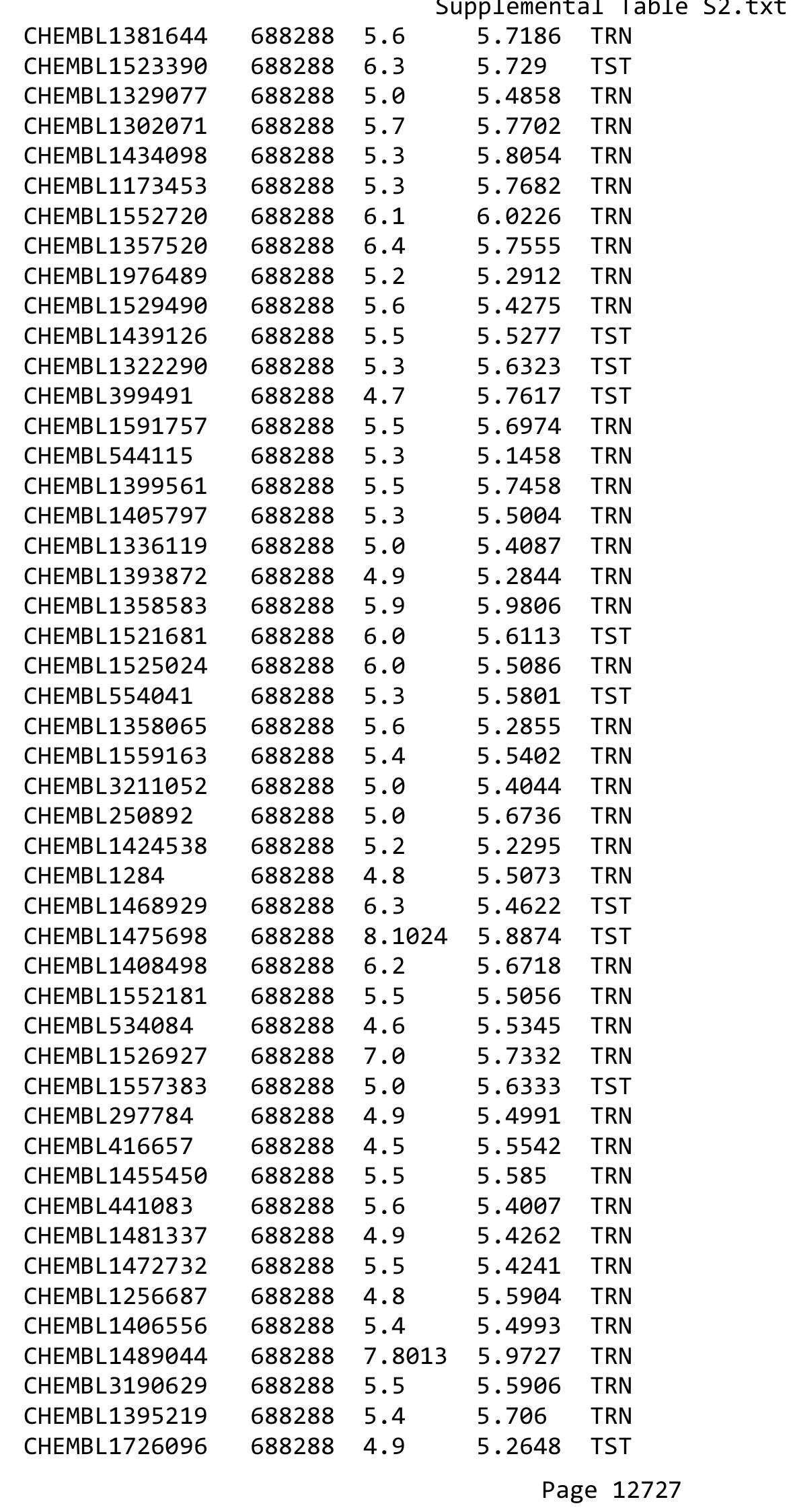




\begin{tabular}{|c|c|c|c|c|}
\hline \multicolumn{5}{|r|}{1 Table } \\
\hline CHEMBL1551925 & 688288 & 5.4 & 5.5134 & TRN \\
\hline CHEMBL1551834 & 688288 & 5.2 & 5.9933 & TRN \\
\hline CHEMBL1467406 & 688288 & 5.1 & 5.1385 & TRN \\
\hline CHEMBL1613194 & 688288 & 5.3 & 5.8715 & TRN \\
\hline CHEMBL1598394 & 688288 & 5.5 & 5.5789 & TRN \\
\hline CHEMBL1160706 & 688288 & 7.2 & 6.1253 & TRN \\
\hline CHEMBL1434022 & 688288 & 5.5 & 5.278 & TRN \\
\hline CHEMBL 76143 & 688288 & 6.8 & 5.9308 & TRN \\
\hline CHEMBL1306570 & 688288 & 5.8 & 5.2496 & TRN \\
\hline CHEMBL1591674 & 688288 & 5.5 & 5.6429 & TRN \\
\hline CHEMBL1366810 & 688288 & 5.0 & 5.0834 & TRN \\
\hline CHEMBL1236872 & 688288 & 6.0 & 6.0508 & TRN \\
\hline CHEMBL77030 & 688288 & 5.0 & 5.1196 & TRN \\
\hline CHEMBL1302135 & 688288 & 6.0 & 5.5009 & TST \\
\hline CHEMBL 267014 & 688288 & 4.9 & 5.6579 & TRN \\
\hline CHEMBL64391 & 688288 & 5.6 & 5.7696 & TST \\
\hline CHEMBL1547481 & 688288 & 5.2 & 5.3644 & TRN \\
\hline CHEMBL1451327 & 688288 & 5.2 & 5.4976 & TST \\
\hline CHEMBL1233274 & 688288 & 5.3 & 5.6208 & TST \\
\hline CHEMBL1335195 & 688288 & 5.3 & 5.9305 & TST \\
\hline CHEMBL1496363 & 688288 & 5.5 & 5.7588 & TST \\
\hline CHEMBL1513684 & 688288 & 8.8861 & 6.5067 & TRN \\
\hline CHEMBL1487735 & 688288 & 5.5 & 5.50799 & 9999999999 \\
\hline CHEMBL50378 & 688288 & 5.9 & 5.5709 & TRN \\
\hline CHEMBL1373796 & 688288 & 5.3 & 5.675 & TRN \\
\hline CHEMBL1442459 & 688288 & 6.7001 & 5.8301 & TST \\
\hline CHEMBL1591879 & 688288 & 5.5 & 5.7312 & TST \\
\hline CHEMBL1559829 & 688288 & 4.9 & 5.3406 & TRN \\
\hline CHEMBL1453673 & 688288 & 4.9 & 5.5143 & TST \\
\hline CHEMBL1591272 & 688288 & 5.5 & 5.7269 & TRN \\
\hline CHEMBL265177 & 688288 & 7.0 & 5.4024 & TST \\
\hline CHEMBL1410957 & 688288 & 5.0 & 5.2796 & TRN \\
\hline CHEMBL1358085 & 688288 & 5.5 & 5.7945 & TRN \\
\hline CHEMBL1533197 & 688288 & 5.5 & 5.4973 & TRN \\
\hline CHEMBL1376987 & 688288 & 5.9 & 5.7784 & TRN \\
\hline CHEMBL1595910 & 688288 & 5.4 & 5.6729 & TRN \\
\hline CHEMBL1333061 & 688288 & 5.6 & 5.5866 & TRN \\
\hline CHEMBL1323631 & 688288 & 5.1 & 5.5397 & TRN \\
\hline CHEMBL1335410 & 688288 & 5.0 & 5.5495 & TST \\
\hline CHEMBL476672 & 688288 & 5.3 & 5.7197 & TRN \\
\hline CHEMBL1327772 & 688288 & 6.9 & 5.6962 & TRN \\
\hline CHEMBL1488918 & 688288 & 5.4 & 5.3271 & TRN \\
\hline CHEMBL541585 & 688288 & 5.3 & 5.2657 & TRN \\
\hline CHEMBL507159 & 688288 & 7.0 & 5.6283 & TRN \\
\hline CHEMBL1506225 & 688288 & 5.0 & 5.8388 & TRN \\
\hline CHEMBL1408879 & 688288 & 6.7001 & 5.4484 & TST \\
\hline CHEMBL137267 & 688288 & 5.7 & 5.4022 & TRN \\
\hline CHEMBL1256186 & 688288 & 4.8 & 5.5336 & TST \\
\hline
\end{tabular}

TRN 


\begin{tabular}{|c|c|c|c|c|}
\hline \multicolumn{5}{|c|}{ Supplemental Table S2.txt } \\
\hline CHEMBL1571157 & 688288 & 6.4 & 5.8034 & TRN \\
\hline CHEMBL1558901 & 688288 & 5.2 & 5.4952 & TRN \\
\hline CHEMBL1356501 & 688288 & 5.4 & 5.5712 & TRN \\
\hline CHEMBL1525456 & 688288 & 5.5 & 5.768 & TRN \\
\hline CHEMBL1591487 & 688288 & 5.5 & 5.42200 & 0000000001 \\
\hline CHEMBL1404660 & 688288 & 5.5 & 5.8569 & TRN \\
\hline CHEMBL1366296 & 688288 & 5.5 & 5.4337 & TRN \\
\hline CHEMBL1582777 & 688288 & 4.9 & 5.1001 & TRN \\
\hline CHEMBL1455194 & 688288 & 5.2 & 5.2777 & TRN \\
\hline CHEMBL102714 & 688288 & 5.4 & 5.1929 & TRN \\
\hline CHEMBL1455097 & 688288 & 6.6 & 6.0115 & TRN \\
\hline CHEMBL1411808 & 688288 & 7.5003 & 6.1759 & TRN \\
\hline CHEMBL1321855 & 688288 & 5.9 & 6.2189 & TRN \\
\hline CHEMBL1607443 & 688288 & 5.5 & 5.401 & TRN \\
\hline CHEMBL1492000 & 688288 & 5.0 & 5.7875 & TRN \\
\hline CHEMBL1315609 & 688288 & 6.0 & 5.6689 & TRN \\
\hline CHEMBL1358137 & 688288 & 5.7 & 5.5472 & TRN \\
\hline CHEMBL1452454 & 688288 & 5.9 & 5.2448 & TRN \\
\hline CHEMBL1416389 & 688288 & 5.3 & 5.4913 & TRN \\
\hline CHEMBL1391184 & 688288 & 4.9 & 5.3621 & TRN \\
\hline CHEMBL1468658 & 688288 & 4.9 & 5.5296 & TRN \\
\hline CHEMBL1609790 & 688288 & 4.9 & 4.9623 & TRN \\
\hline CHEMBL3195914 & 688288 & 5.3 & 5.4146 & TRN \\
\hline CHEMBL1181366 & 688288 & 5.8 & 5.7491 & TST \\
\hline CHEMBL1399619 & 688288 & 5.4 & 5.6519 & TRN \\
\hline CHEMBL21241 & 688288 & 5.3 & 5.7015 & TST \\
\hline CHEMBL1566442 & 688288 & 5.8 & 5.6287 & TRN \\
\hline CHEMBL1437164 & 688288 & 5.5 & 5.6083 & TRN \\
\hline CHEMBL1318464 & 688288 & 6.6 & 5.9247 & TRN \\
\hline CHEMBL1532615 & 688288 & 5.1 & 5.7379 & TST \\
\hline CHEMBL1594030 & 688288 & 5.6 & 5.4613 & TRN \\
\hline CHEMBL 2374062 & 688288 & 4.6 & 5.9472 & TST \\
\hline CHEMBL1515305 & 688288 & 5.8 & 5.8446 & TRN \\
\hline CHEMBL1564461 & 688288 & 5.8 & 5.7515 & TRN \\
\hline CHEMBL1398713 & 688288 & 5.4 & 5.761 & TST \\
\hline CHEMBL1457014 & 688288 & 5.6 & 5.403 & TST \\
\hline CHEMBL1593867 & 688288 & 5.2 & 5.657 & TRN \\
\hline CHEMBL 388342 & 688288 & 6.0 & 5.5907 & TRN \\
\hline CHEMBL1377200 & 688288 & 5.0 & 5.3422 & TRN \\
\hline CHEMBL1552403 & 688288 & 6.8 & 5.6886 & TST \\
\hline CHEMBL1322584 & 688288 & 5.4 & 5.5886 & TRN \\
\hline CHEMBL542493 & 688288 & 5.6 & 5.3974 & TRN \\
\hline CHEMBL1570111 & 688288 & 5.3 & 5.3417 & TRN \\
\hline CHEMBL1437263 & 688288 & 5.3 & 5.6341 & TRN \\
\hline CHEMBL1310973 & 688288 & 5.2 & 5.1402 & TRN \\
\hline CHEMBL1565914 & 688288 & 5.8 & 5.8537 & TRN \\
\hline CHEMBL1508743 & 688288 & 5.0 & 5.1685 & TRN \\
\hline CHEMBL 285819 & 688288 & 6.0 & 5.7054 & TRN \\
\hline
\end{tabular}

TRN 


\begin{tabular}{|c|c|c|c|c|}
\hline & & & pplement & al $\mathrm{Ta}$ \\
\hline CHEMBL1394348 & 688288 & 5.5 & 5.5274 & TRN \\
\hline CHEMBL151 & 688288 & 6.4 & 5.4094 & TRN \\
\hline CHEMBL1442094 & 688288 & 7.0 & 5.5971 & TRN \\
\hline CHEMBL 76589 & 688288 & 4.8 & 5.278 & TRN \\
\hline CHEMBL1551051 & 688288 & 5.5 & 5.4534 & TRN \\
\hline CHEMBL1396310 & 688288 & 6.3 & 5.8663 & TRN \\
\hline CHEMBL1447590 & 688288 & 5.5 & 5.4349 & TST \\
\hline CHEMBL1328509 & 688288 & 5.3 & 5.2732 & TRN \\
\hline CHEMBL1566136 & 688288 & 5.6 & 5.652 & TST \\
\hline CHEMBL1600210 & 688288 & 5.5 & 5.726 & TRN \\
\hline CHEMBL1417771 & 688288 & 5.5 & 5.5678 & TRN \\
\hline CHEMBL1516232 & 688288 & 5.2 & 5.8426 & TRN \\
\hline CHEMBL18132 & 688288 & 4.5 & 5.4668 & TRN \\
\hline CHEMBL1357076 & 688288 & 5.5 & 5.4986 & TRN \\
\hline CHEMBL1386326 & 688288 & 5.6 & 5.865 & TRN \\
\hline CHEMBL1326723 & 688288 & 5.5 & 5.603 & TRN \\
\hline CHEMBL1577591 & 688288 & 4.9 & 5.7792 & TST \\
\hline CHEMBL3193689 & 688288 & 5.0 & 4.9848 & TRN \\
\hline CHEMBL596674 & 688288 & 4.5 & 5.6379 & TRN \\
\hline CHEMBL1349625 & 688288 & 5.0 & 4.999 & TST \\
\hline CHEMBL1400014 & 688288 & 6.8 & 5.7828 & TST \\
\hline CHEMBL1474475 & 688288 & 5.5 & 5.3107 & TRN \\
\hline CHEMBL1422178 & 688288 & 4.9 & 5.216 & TRN \\
\hline CHEMBL1415053 & 688288 & 5.5 & 5.7002 & TRN \\
\hline CHEMBL124267 & 688288 & 4.6 & 5.5001 & TRN \\
\hline CHEMBL1397438 & 688288 & 5.5 & 5.7717 & TRN \\
\hline CHEMBL1386915 & 688288 & 4.9 & 5.1359 & TRN \\
\hline CHEMBL1336793 & 688288 & 5.4 & 5.7216 & TRN \\
\hline CHEMBL1484944 & 688288 & 5.5 & 5.5057 & TRN \\
\hline CHEMBL1406307 & 688288 & 5.7 & 5.365 & TRN \\
\hline CHEMBL1256484 & 688288 & 5.2 & 5.4922 & TRN \\
\hline CHEMBL1313103 & 688288 & 6.9 & 5.6637 & TRN \\
\hline CHEMBL1517724 & 688288 & 6.4 & 6.1429 & TRN \\
\hline CHEMBL1488679 & 688288 & 5.7 & 5.4728 & TST \\
\hline CHEMBL1471867 & 688288 & 5.6 & 5.395 & TRN \\
\hline CHEMBL1552839 & 688288 & 6.3 & 5.5891 & TRN \\
\hline CHEMBL15192 & 688288 & 4.5 & 5.6379 & TRN \\
\hline CHEMBL 2374026 & 688288 & 6.6 & 5.7406 & TST \\
\hline CHEMBL1496664 & 688288 & 6.1 & 5.4682 & TRN \\
\hline CHEMBL1591712 & 688288 & 5.0 & 5.2857 & TST \\
\hline CHEMBL1331037 & 688288 & 5.4 & 5.4209 & TRN \\
\hline CHEMBL512908 & 688288 & 5.6 & 5.5187 & TRN \\
\hline CHEMBL1414867 & 688288 & 5.6 & 5.1363 & TRN \\
\hline CHEMBL1436151 & 688288 & 4.9 & 5.9569 & TST \\
\hline CHEMBL1356060 & 688288 & 5.7 & 5.6799 & TRN \\
\hline CHEMBL1397293 & 688288 & 5.9 & 5.6119 & TRN \\
\hline CHEMBL1437783 & 688288 & 5.5 & 5.5201 & TRN \\
\hline CHEMBL1452716 & 688288 & 5.0 & 5.5753 & TRN \\
\hline
\end{tabular}




\begin{tabular}{|c|c|c|c|c|}
\hline \multicolumn{5}{|c|}{ Supplement } \\
\hline CHEMBL1591673 & 688288 & 6.0 & 5.6918 & TRN \\
\hline CHEMBL1328480 & 688288 & 5.4 & 5.4412 & TRN \\
\hline CHEMBL1358252 & 688288 & 5.5 & 5.6821 & TRN \\
\hline CHEMBL1439673 & 688288 & 5.5 & 5.3265 & TRN \\
\hline CHEMBL1399699 & 688288 & 5.6 & 5.5441 & TRN \\
\hline CHEMBL1725507 & 688288 & 5.2 & 5.2068 & TRN \\
\hline CHEMBL1572051 & 688288 & 5.3 & 5.466 & TST \\
\hline CHEMBL1592227 & 688288 & 5.4 & 5.6649 & TRN \\
\hline CHEMBL1382813 & 688288 & 5.1 & 5.0213 & TRN \\
\hline CHEMBL1512802 & 688288 & 6.0 & 6.1304 & TRN \\
\hline CHEMBL1485579 & 688288 & 5.3 & 5.5709 & TRN \\
\hline CHEMBL1397466 & 688288 & 8.6021 & 5.6644 & TST \\
\hline CHEMBL1526543 & 688288 & 6.0 & 5.67200 & 0000000001 \\
\hline CHEMBL1475695 & 688288 & 5.8 & 5.8083 & TRN \\
\hline CHEMBL1383144 & 688288 & 5.5 & 5.2986 & TRN \\
\hline CHEMBL1501564 & 688288 & 5.4 & 5.4574 & TST \\
\hline CHEMBL1374335 & 688288 & 5.3 & 5.3118 & TRN \\
\hline CHEMBL1256659 & 688288 & 5.5 & 5.2203 & TRN \\
\hline CHEMBL1407527 & 688288 & 5.6 & 6.0316 & TRN \\
\hline CHEMBL1257123 & 688288 & 5.0 & 5.4137 & TRN \\
\hline CHEMBL1355879 & 688288 & 7.8013 & 5.8711 & TST \\
\hline CHEMBL1575721 & 688288 & 5.0 & 5.3191 & TRN \\
\hline CHEMBL1593661 & 688288 & 5.5 & 5.5765 & TRN \\
\hline CHEMBL 7917 & 688288 & 4.8 & 5.4243 & TRN \\
\hline CHEMBL1569583 & 688288 & 6.0 & 5.4466 & TST \\
\hline CHEMBL1469584 & 688288 & 5.8 & 5.3965 & TRN \\
\hline CHEMBL1497468 & 688288 & 5.2 & 5.2192 & TRN \\
\hline CHEMBL1604597 & 688288 & 5.5 & 5.2029 & TRN \\
\hline CHEMBL1404408 & 688288 & 5.3 & 5.2364 & TRN \\
\hline CHEMBL1406782 & 688288 & 5.5 & 5.5708 & TRN \\
\hline CHEMBL1572173 & 688288 & 5.9 & 5.7821 & TRN \\
\hline CHEMBL1330961 & 688288 & 5.9 & 5.6769 & TRN \\
\hline CHEMBL1435404 & 688288 & 6.2 & 6.0903 & TRN \\
\hline CHEMBL 3214579 & 688288 & 5.2 & 5.2425 & TRN \\
\hline CHEMBL1316808 & 688288 & 5.3 & 5.5873 & TRN \\
\hline CHEMBL1355970 & 688288 & 5.5 & 5.6698 & TRN \\
\hline CHEMBL1526043 & 688288 & 5.5 & 5.4513 & TRN \\
\hline CHEMBL1335406 & 688288 & 4.7 & 5.6688 & TRN \\
\hline CHEMBL1449856 & 688288 & 5.4 & 5.5521 & TRN \\
\hline CHEMBL183 & 688288 & 5.0 & 5.1776 & TST \\
\hline CHEMBL274189 & 688288 & 4.9 & 5.7572 & TRN \\
\hline CHEMBL1397406 & 688288 & 5.4 & 6.1322 & TRN \\
\hline CHEMBL1311072 & 688288 & 6.4 & 5.4748 & TRN \\
\hline CHEMBL546257 & 688288 & 6.0 & 5.5264 & TRN \\
\hline CHEMBL1334561 & 688288 & 4.9 & 5.4162 & TRN \\
\hline CHEMBL1512708 & 688288 & 5.5 & 5.7164 & TRN \\
\hline CHEMBL1452199 & 688288 & 5.6 & 5.301 & TRN \\
\hline CHEMBL1314906 & 688288 & 5.5 & 5.4137 & TRN \\
\hline
\end{tabular}




\begin{tabular}{|c|c|c|c|c|}
\hline \multicolumn{5}{|c|}{ Supplemental Table S2.txt } \\
\hline CHEMBL3193813 & 688288 & 5.2 & 5.1682 & TRN \\
\hline CHEMBL1612261 & 688288 & 5.7 & 5.5557 & TRN \\
\hline CHEMBL1596698 & 688288 & 6.0 & 5.2827 & TRN \\
\hline CHEMBL1408138 & 688288 & 5.3 & 5.6444 & TRN \\
\hline CHEMBL17551 & 688288 & 5.0 & 5.3815 & TST \\
\hline CHEMBL1417392 & 688288 & 5.1 & 5.6496 & TRN \\
\hline CHEMBL1514560 & 688288 & 5.5 & 5.7145 & TRN \\
\hline CHEMBL476135 & 688288 & 5.5 & 5.4048 & TST \\
\hline CHEMBL1317451 & 688288 & 5.5 & 5.6219 & TRN \\
\hline CHEMBL1318349 & 688288 & 5.4 & 6.0814 & TRN \\
\hline CHEMBL1391196 & 688288 & 5.4 & 5.435 & TRN \\
\hline CHEMBL1303113 & 688288 & 5.2 & 5.1444 & TRN \\
\hline CHEMBL1376572 & 688288 & 5.3 & 5.8117 & TRN \\
\hline CHEMBL1437213 & 688288 & 7.6003 & 5.9851 & TRN \\
\hline CHEMBL1396661 & 688288 & 5.0 & 5.5674 & TST \\
\hline CHEMBL1587764 & 688288 & 4.9 & 5.1614 & TRN \\
\hline CHEMBL1544947 & 688288 & 5.5 & 5.012 & TRN \\
\hline CHEMBL1703229 & 688288 & 6.3 & 5.683 & TRN \\
\hline CHEMBL1459956 & 688288 & 5.5 & 5.3988 & TRN \\
\hline CHEMBL1315527 & 688288 & 5.4 & 5.3609 & TRN \\
\hline CHEMBL340807 & 688288 & 5.0 & 5.2911 & TRN \\
\hline CHEMBL1310777 & 688288 & 5.0 & 5.2918 & TRN \\
\hline CHEMBL584759 & 688288 & 6.1 & 5.9545 & TRN \\
\hline CHEMBL1321846 & 688288 & 5.6 & 5.564 & TRN \\
\hline CHEMBL30707 & 688288 & 5.0 & 5.3437 & TRN \\
\hline CHEMBL3192605 & 688288 & 5.1 & 5.5587 & TRN \\
\hline CHEMBL1593511 & 688288 & 5.5 & 5.7426 & TRN \\
\hline CHEMBL1469355 & 688288 & 6.3 & 5.5105 & TRN \\
\hline CHEMBL1437139 & 688288 & 6.3 & 5.8451 & TST \\
\hline CHEMBL1481510 & 688288 & 5.5 & 5.5132 & TRN \\
\hline CHEMBL1255659 & 688288 & 4.6 & 5.3013 & TRN \\
\hline CHEMBL1573094 & 688288 & 5.0 & 5.319 & TRN \\
\hline CHEMBL105278 & 688288 & 4.8 & 5.6669 & TST \\
\hline CHEMBL45244 & 688288 & 5.3 & 5.1004 & TRN \\
\hline CHEMBL1417398 & 688288 & 4.9 & 5.3809 & TRN \\
\hline CHEMBL1301473 & 688288 & 5.4 & 5.4117 & TRN \\
\hline CHEMBL1484484 & 688288 & 5.1 & 5.4402 & TRN \\
\hline CHEMBL1366157 & 688288 & 5.4 & 5.6574 & TRN \\
\hline CHEMBL1334357 & 688288 & 5.3 & 5.5101 & TRN \\
\hline CHEMBL1569958 & 688288 & 6.4 & 5.8922 & TRN \\
\hline CHEMBL1334189 & 688288 & 5.0 & 5.3521 & TRN \\
\hline CHEMBL1512605 & 688288 & 5.2 & 5.2113 & TST \\
\hline CHEMBL374107 & 688288 & 5.1 & 5.7111 & TST \\
\hline CHEMBL1597506 & 688288 & 5.3 & 5.5149 & TST \\
\hline CHEMBL553751 & 688288 & 5.7 & 5.6176 & TRN \\
\hline CHEMBL1589897 & 688288 & 5.3 & 5.8052 & TRN \\
\hline CHEMBL1332120 & 688288 & 5.4 & 5.8282 & TRN \\
\hline CHEMBL1564476 & 688288 & 4.9 & 5.7154 & TRN \\
\hline
\end{tabular}




\begin{tabular}{|c|c|c|c|c|c|}
\hline \\
\hline CHEMBL1574715 & 688288 & 5.0 & 5.575 & TST & \\
\hline CHEMBL8747 & 688288 & 5.1 & 5.5899 & TRN & \\
\hline CHEMBL1470039 & 688288 & 5.0 & 5.2921 & TRN & \\
\hline CHEMBL1320129 & 688288 & 5.0 & 5.7973 & TST & \\
\hline CHEMBL1593774 & 688288 & 5.6 & 5.7074 & TRN & \\
\hline CHEMBL1593926 & 688288 & 5.5 & 5.4438 & TRN & \\
\hline CHEMBL1349507 & 688288 & 6.8 & 5.6704 & TRN & \\
\hline CHEMBL1436324 & 688288 & 6.2 & 5.6739 & TRN & \\
\hline CHEMBL408994 & 688288 & 5.5 & 5.4759 & TRN & \\
\hline CHEMBL1604925 & 688288 & 5.2 & 5.5448 & TRN & \\
\hline CHEMBL1355203 & 688288 & 5.5 & 5.7133 & TRN & \\
\hline CHEMBL1523959 & 688288 & 5.5 & 5.4566 & TRN & \\
\hline CHEMBL1572655 & 688288 & 4.6 & 5.5831 & TRN & \\
\hline CHEMBL1475999 & 688288 & 6.1 & 5.7731 & TST & \\
\hline CHEMBL1321223 & 688288 & 5.3 & 5.7532 & TST & \\
\hline CHEMBL1331657 & 688288 & 5.8 & 5.8551 & TRN & \\
\hline CHEMBL1312967 & 688288 & 4.8 & 5.0597 & TRN & \\
\hline CHEMBL1496863 & 688288 & 5.0 & 5.3297 & TRN & \\
\hline CHEMBL1224512 & 688288 & 4.8 & 5.1249 & TRN & \\
\hline CHEMBL1592556 & 688288 & 5.6 & 5.6272 & TRN & \\
\hline CHEMBL1446523 & 688288 & 6.5 & 5.6014 & TRN & \\
\hline CHEMBL 322970 & 688288 & 4.9 & 5.2985 & TRN & \\
\hline CHEMBL10284 & 688288 & 4.7 & 5.51 & TRN & \\
\hline CHEMBL56393 & 688288 & 5.1 & 4.82100 & 0000000001 & TRN \\
\hline CHEMBL1518164 & 688288 & 6.1 & 5.9593 & TRN & \\
\hline CHEMBL1256654 & 688288 & 5.4 & 5.7312 & TRN & \\
\hline CHEMBL1592371 & 688288 & 5.6 & 5.8156 & TRN & \\
\hline CHEMBL52 & 688288 & 6.0 & 5.6843 & TRN & \\
\hline CHEMBL1592186 & 688288 & 5.3 & 5.5458 & TRN & \\
\hline CHEMBL 28140 & 688288 & 8.301 & 6.1043 & TRN & \\
\hline CHEMBL1413343 & 688288 & 5.4 & 5.7924 & TRN & \\
\hline CHEMBL2373654 & 688288 & 6.0 & 5.7129 & TRN & \\
\hline CHEMBL1571851 & 688288 & 6.0 & 5.8108 & TST & \\
\hline CHEMBL1512701 & 688288 & 5.3 & 5.4696 & TRN & \\
\hline CHEMBL1610003 & 688288 & 5.5 & 5.5698 & TRN & \\
\hline CHEMBL1396109 & 688288 & 5.9 & 5.4671 & TRN & \\
\hline CHEMBL1358395 & 688288 & 6.8 & 5.6355 & TRN & \\
\hline CHEMBL1486659 & 688288 & 5.5 & 5.3124 & TST & \\
\hline CHEMBL1556023 & 688288 & 8.8861 & 5.9476 & TST & \\
\hline CHEMBL1736254 & 688288 & 6.8 & 5.7186 & TST & \\
\hline CHEMBL1343939 & 688288 & 5.0 & 5.3615 & TRN & \\
\hline CHEMBL1476129 & 688288 & 5.6 & 5.7943 & TRN & \\
\hline CHEMBL1429627 & 688288 & 5.3 & 5.2825 & TRN & \\
\hline CHEMBL1397151 & 688288 & 5.5 & 5.7513 & TRN & \\
\hline CHEMBL1546891 & 688288 & 5.0 & 5.0902 & TRN & \\
\hline CHEMBL275006 & 688288 & 4.9 & 5.3859 & TST & \\
\hline CHEMBL 2006590 & 688288 & 4.9 & 5.3038 & TRN & \\
\hline CHEMBL1465394 & 688288 & 5.0 & 5.2246 & TRN & \\
\hline
\end{tabular}




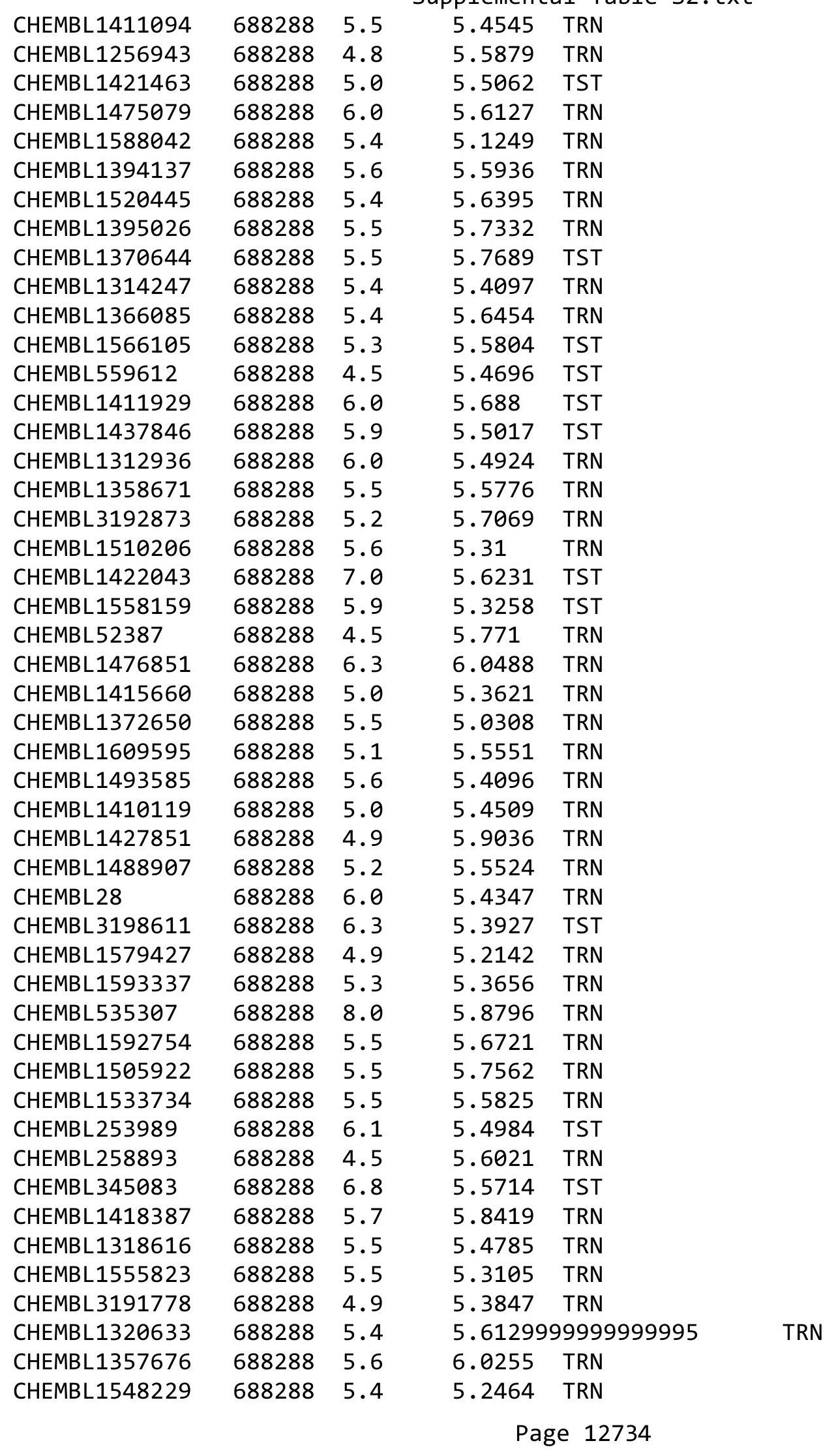




\begin{tabular}{|c|c|c|c|c|}
\hline \multicolumn{5}{|c|}{ lemental Table s } \\
\hline CHEMBL 2373676 & 688288 & 5.6 & 5.8079 & TST \\
\hline CHEMBL1552680 & 688288 & 5.3 & 5.5034 & TRN \\
\hline CHEMBL1318316 & 688288 & 6.0 & 5.29200 & 0000000001 \\
\hline CHEMBL1559279 & 688288 & 5.5 & 5.5796 & TRN \\
\hline CHEMBL1551557 & 688288 & 6.5 & 5.7148 & TRN \\
\hline CHEMBL1444935 & 688288 & 5.8 & 5.8749 & TRN \\
\hline CHEMBL1414842 & 688288 & 5.0 & 5.1979 & TRN \\
\hline CHEMBL1299369 & 688288 & 5.6 & 5.4191 & TRN \\
\hline CHEMBL553503 & 688288 & 5.4 & 5.1913 & TRN \\
\hline CHEMBL1502154 & 688288 & 5.0 & 5.2042 & TRN \\
\hline CHEMBL1603371 & 688288 & 5.3 & 5.5945 & TRN \\
\hline CHEMBL1524638 & 688288 & 5.3 & 5.2635 & TRN \\
\hline CHEMBL14276 & 688288 & 5.4 & 5.8515 & TRN \\
\hline CHEMBL1356041 & 688288 & 5.5 & 5.5063 & TRN \\
\hline CHEMBL1529011 & 688288 & 5.1 & 5.3186 & TRN \\
\hline CHEMBL 1409222 & 688288 & 4.9 & 5.3571 & TRN \\
\hline CHEMBL1547754 & 688288 & 5.6 & 5.1934 & TRN \\
\hline CHEMBL1465923 & 688288 & 5.1 & 5.5503 & TRN \\
\hline CHEMBL1545244 & 688288 & 5.0 & 5.3008 & TST \\
\hline CHEMBL1607167 & 688288 & 5.9 & 5.7636 & TST \\
\hline CHEMBL 1474479 & 688288 & 4.6 & 5.6122 & TRN \\
\hline CHEMBL1375094 & 688288 & 5.3 & 5.4452 & TRN \\
\hline CHEMBL72365 & 688288 & 4.6 & 5.3839 & TRN \\
\hline CHEMBL1376696 & 688288 & 5.0 & 5.17 & TRN \\
\hline CHEMBL1354913 & 688288 & 6.8 & 5.5822 & TRN \\
\hline CHEMBL10347 & 688288 & 4.8 & 5.4595 & TRN \\
\hline CHEMBL1256709 & 688288 & 4.9 & 5.1185 & TRN \\
\hline CHEMBL1393480 & 688288 & 6.5 & 5.657 & TRN \\
\hline CHEMBL1450521 & 688288 & 6.2 & 5.9473 & TRN \\
\hline CHEMBL1499884 & 688288 & 6.4 & 5.6755 & TRN \\
\hline CHEMBL1565485 & 688288 & 5.0 & 5.1259 & TRN \\
\hline CHEMBL1380644 & 688288 & 5.3 & 5.4424 & TRN \\
\hline CHEMBL1570500 & 688288 & 7.5003 & 5.9279 & TRN \\
\hline CHEMBL1593068 & 688288 & 5.8 & 5.4093 & TRN \\
\hline CHEMBL1256971 & 688288 & 4.6 & 5.7124 & TST \\
\hline CHEMBL 2004160 & 688288 & 6.2 & 5.2544 & TRN \\
\hline CHEMBL44 & 688288 & 5.3 & 5.6857 & TRN \\
\hline CHEMBL1374363 & 688288 & 5.3 & 5.3142 & TST \\
\hline CHEMBL1471643 & 688288 & 6.2 & 5.6904 & TRN \\
\hline CHEMBL1445386 & 688288 & 6.1 & 5.8854 & TST \\
\hline CHEMBL1606369 & 688288 & 6.3 & 5.6324 & TRN \\
\hline CHEMBL1361855 & 688288 & 5.5 & 5.5775 & TRN \\
\hline CHEMBL1583388 & 688288 & 4.9 & 5.5037 & TST \\
\hline CHEMBL1470336 & 688288 & 5.6 & 5.3135 & TRN \\
\hline CHEMBL1334162 & 688288 & 5.3 & 5.4397 & TST \\
\hline CHEMBL1555118 & 688288 & 6.1 & 5.5532 & TRN \\
\hline CHEMBL1344735 & 688288 & 5.3 & 5.2351 & TRN \\
\hline CHEMBL1560847 & 688288 & 4.9 & 5.0942 & TRN \\
\hline
\end{tabular}

TRN 


\begin{tabular}{|c|c|c|c|c|c|}
\hline \multicolumn{6}{|c|}{ oplemental lable S2.txt } \\
\hline CHEMBL1565060 & 688288 & 5.5 & 5.3728 & TRN & \\
\hline CHEMBL1450455 & 688288 & 5.5 & 5.3988 & TRN & \\
\hline CHEMBL1387556 & 688288 & 5.0 & 5.10800 & 00000000005 & TRN \\
\hline CHEMBL1474294 & 688288 & 6.0 & 5.8758 & TST & \\
\hline CHEMBL1538395 & 688288 & 5.1 & 5.5422 & TRN & \\
\hline CHEMBL1500323 & 688288 & 5.2 & 5.5662 & TST & \\
\hline CHEMBL1589923 & 688288 & 5.3 & 5.4801 & TRN & \\
\hline CHEMBL1499275 & 688288 & 6.7001 & 5.3388 & TRN & \\
\hline CHEMBL48449 & 688288 & 6.0 & 5.7662 & TST & \\
\hline CHEMBL576349 & 688288 & 7.3002 & 5.6636 & TRN & \\
\hline CHEMBL1483133 & 688288 & 5.5 & 5.7505 & TRN & \\
\hline CHEMBL568379 & 688288 & 5.4 & 5.4623 & TRN & \\
\hline CHEMBL1304237 & 688288 & 4.9 & 5.6233 & TRN & \\
\hline CHEMBL1358722 & 688288 & 7.2 & 6.1042 & TST & \\
\hline CHEMBL1367030 & 688288 & 5.6 & 5.2925 & TRN & \\
\hline CHEMBL1597390 & 688288 & 7.0 & 5.3043 & TRN & \\
\hline CHEMBL1519261 & 688288 & 5.9 & 5.3907 & TRN & \\
\hline CHEMBL1514307 & 688288 & 5.5 & 5.5548 & TRN & \\
\hline CHEMBL1405627 & 688288 & 5.6 & 5.8554 & TRN & \\
\hline CHEMBL1512222 & 688288 & 5.5 & 5.3569 & TRN & \\
\hline CHEMBL190259 & 688288 & 7.4001 & 5.9788 & TST & \\
\hline CHEMBL1449987 & 688288 & 5.0 & 5.4679 & TST & \\
\hline CHEMBL1458925 & 688288 & 5.3 & 5.2761 & TRN & \\
\hline CHEMBL1482759 & 688288 & 5.5 & 5.7125 & TRN & \\
\hline CHEMBL1358806 & 688288 & 6.3 & 5.6587 & TRN & \\
\hline CHEMBL487356 & 688288 & 7.699 & 5.6079 & TRN & \\
\hline CHEMBL239439 & 688288 & 5.5 & 5.62 & TRN & \\
\hline CHEMBL1566428 & 688288 & 5.4 & 5.6821 & TRN & \\
\hline CHEMBL1410416 & 688288 & 5.0 & 5.4655 & TRN & \\
\hline CHEMBL1513665 & 688288 & 5.3 & 5.6559 & TRN & \\
\hline CHEMBL1434164 & 688288 & 5.4 & 5.8986 & TRN & \\
\hline CHEMBL1355323 & 688288 & 5.0 & 6.0595 & TST & \\
\hline CHEMBL1461031 & 688288 & 4.9 & 5.9758 & TRN & \\
\hline CHEMBL1522486 & 688288 & 4.9 & 5.8346 & TRN & \\
\hline CHEMBL1316709 & 688288 & 6.1 & 5.7614 & TRN & \\
\hline CHEMBL1488167 & 688288 & 6.4 & 5.2791 & TRN & \\
\hline CHEMBL1493700 & 688288 & 4.9 & 5.0423 & TRN & \\
\hline CHEMBL1436059 & 688288 & 7.1002 & 5.8509 & TRN & \\
\hline CHEMBL1437142 & 688288 & 7.1002 & 5.7779 & TST & \\
\hline CHEMBL1516749 & 688288 & 5.1 & 5.2647 & TRN & \\
\hline CHEMBL1455570 & 688288 & 5.5 & 5.8205 & TRN & \\
\hline CHEMBL1327203 & 688288 & 5.4 & 5.4326 & TRN & \\
\hline CHEMBL475375 & 688288 & 5.5 & 5.6765 & TRN & \\
\hline CHEMBL1384211 & 688288 & 5.9 & 5.1894 & TRN & \\
\hline CHEMBL1501915 & 688288 & 5.0 & 5.2311 & TRN & \\
\hline CHEMBL1354563 & 688288 & 5.3 & 5.3543 & TRN & \\
\hline CHEMBL1400198 & 688288 & 6.6 & 5.3804 & TRN & \\
\hline CHEMBL1362287 & 688288 & 5.5 & 5.7601 & TRN & \\
\hline & & & & 12736 & \\
\hline
\end{tabular}




\begin{tabular}{|c|c|c|c|c|c|}
\hline & & & & & \\
\hline CHEMBL1402299 & 688288 & 5.6 & 5.7544 & TRN & \\
\hline CHEMBL1449838 & 688288 & 6.0 & 5.6661 & TRN & \\
\hline CHEMBL34730 & 688288 & 4.9 & 5.4351 & TRN & \\
\hline CHEMBL1358838 & 688288 & 6.2 & 5.691 & TRN & \\
\hline CHEMBL1551036 & 688288 & 6.5 & 5.9117 & TRN & \\
\hline CHEMBL1360725 & 688288 & 5.4 & 5.4072 & TRN & \\
\hline CHEMBL1593989 & 688288 & 5.5 & 5.7704 & TRN & \\
\hline CHEMBL1385808 & 688288 & 4.9 & 5.5909 & TST & \\
\hline CHEMBL1411314 & 688288 & 5.9 & 5.9009 & TRN & \\
\hline CHEMBL1355537 & 688288 & 6.2 & 5.6203 & TRN & \\
\hline CHEMBL225230 & 688288 & 5.6 & 5.3776 & TRN & \\
\hline CHEMBL1603692 & 688288 & 5.5 & 5.5305 & TRN & \\
\hline CHEMBL1269022 & 688288 & 5.6 & 5.6572 & TST & \\
\hline CHEMBL1401031 & 688288 & 6.5 & 5.7838 & TRN & \\
\hline CHEMBL1482342 & 688288 & 5.3 & 5.6362 & TRN & \\
\hline CHEMBL1425234 & 688288 & 6.0 & 5.4354 & TRN & \\
\hline CHEMBL1513030 & 688288 & 5.3 & 5.7226 & TRN & \\
\hline CHEMBL1476170 & 688288 & 6.0 & 5.3648 & TST & \\
\hline CHEMBL1475620 & 688288 & 6.2 & 6.0781 & TRN & \\
\hline CHEMBL1588305 & 688288 & 5.5 & 5.5084 & TRN & \\
\hline CHEMBL1613623 & 688288 & 5.2 & 5.4901 & TRN & \\
\hline CHEMBL1559618 & 688288 & 4.9 & 5.6783 & TRN & \\
\hline CHEMBL1508113 & 688288 & 5.0 & 5.3299 & TRN & \\
\hline CHEMBL1554791 & 688288 & 5.6 & 5.6271 & TRN & \\
\hline CHEMBL1593707 & 688288 & 5.5 & 5.4431 & TRN & \\
\hline CHEMBL21260 & 688288 & 6.0 & 5.8486 & TRN & \\
\hline CHEMBL1541211 & 688288 & 5.5 & 5.3929 & TRN & \\
\hline CHEMBL1552542 & 688288 & 5.5 & 5.5168 & TRN & \\
\hline CHEMBL1363920 & 688288 & 5.2 & 5.4408 & TRN & \\
\hline CHEMBL1417025 & 688288 & 5.8 & 5.4704 & TRN & \\
\hline CHEMBL1412511 & 688288 & 4.9 & 5.5432 & TRN & \\
\hline CHEMBL1404315 & 688288 & 5.9 & 5.6678 & TRN & \\
\hline CHEMBL1398321 & 688288 & 5.0 & 5.6484 & TRN & \\
\hline CHEMBL1522897 & 688288 & 5.4 & 5.7268 & TRN & \\
\hline CHEMBL539947 & 688288 & 6.2 & 5.5 & TRN & \\
\hline CHEMBL1487191 & 688288 & 5.4 & 5.61799 & 9999999999 & TRN \\
\hline CHEMBL30432 & 688288 & 6.1 & 5.4263 & TRN & \\
\hline CHEMBL598263 & 688288 & 5.8 & 5.8826 & TST & \\
\hline CHEMBL1325494 & 688288 & 4.9 & 5.0659 & TRN & \\
\hline CHEMBL164 & 688288 & 5.7 & 5.5814 & TRN & \\
\hline CHEMBL1391287 & 688288 & 6.5 & 5.92299 & 9999999999 & TRN \\
\hline CHEMBL1324032 & 688288 & 6.3 & 5.8483 & TST & \\
\hline CHEMBL1331927 & 688288 & 5.2 & 5.669 & TRN & \\
\hline CHEMBL1392030 & 688288 & 5.3 & 5.3015 & TRN & \\
\hline CHEMBL1497576 & 688288 & 5.9 & 5.5076 & TRN & \\
\hline CHEMBL1353983 & 688288 & 5.5 & 5.3892 & TRN & \\
\hline CHEMBL1363883 & 688288 & 6.0 & 5.7219 & TST & \\
\hline CHEMBL1304256 & 688288 & 8.0 & 5.4158 & TRN & \\
\hline & & & & 12737 & \\
\hline
\end{tabular}




\begin{tabular}{|c|c|c|c|c|}
\hline \multicolumn{5}{|c|}{ Supplemental Table s2.txt } \\
\hline CHEMBL1429345 & 688288 & 4.9 & 5.0421 & TRN \\
\hline CHEMBL1407586 & 688288 & 5.5 & 5.175 & TRN \\
\hline CHEMBL1536971 & 688288 & 4.9 & 5.5183 & TRN \\
\hline CHEMBL458765 & 688288 & 5.8 & 5.4616 & TRN \\
\hline CHEMBL1440145 & 688288 & 5.3 & 5.4039 & TRN \\
\hline CHEMBL1455073 & 688288 & 5.9 & 5.6162 & TST \\
\hline CHEMBL1567032 & 688288 & 5.7 & 5.5302 & TST \\
\hline CHEMBL1612410 & 688288 & 6.2 & 5.6585 & TRN \\
\hline CHEMBL1325419 & 688288 & 5.1 & 5.6001 & TRN \\
\hline CHEMBL1444522 & 688288 & 5.4 & 5.2285 & TRN \\
\hline CHEMBL1084478 & 688288 & 5.3 & 5.3882 & TRN \\
\hline CHEMBL1422573 & 688288 & 5.1 & 5.3415 & TRN \\
\hline CHEMBL1522370 & 688288 & 6.0 & 5.5522 & TRN \\
\hline CHEMBL3392050 & 688288 & 4.6 & 5.3895 & TST \\
\hline CHEMBL1398528 & 688288 & 5.8 & 5.4311 & TRN \\
\hline CHEMBL1593056 & 688288 & 5.5 & 5.4559 & TRN \\
\hline CHEMBL275938 & 688288 & 4.9 & 5.4966 & TST \\
\hline CHEMBL16671 & 688288 & 6.5 & 5.9625 & TRN \\
\hline CHEMBL1571692 & 688288 & 4.9 & 5.8186 & TST \\
\hline CHEMBL1330594 & 688288 & 6.0 & 5.7363 & TRN \\
\hline CHEMBL1414885 & 688288 & 8.1024 & 6.0262 & TST \\
\hline CHEMBL1516622 & 688288 & 6.5 & 5.8179 & TRN \\
\hline CHEMBL1370146 & 688288 & 4.9 & 5.2492 & TRN \\
\hline CHEMBL1314473 & 688288 & 5.9 & 5.6126 & TRN \\
\hline CHEMBL1387249 & 688288 & 5.8 & 5.4620 & 0000000001 \\
\hline CHEMBL1308455 & 688288 & 6.5 & 5.05 & TRN \\
\hline CHEMBL1591544 & 688288 & 5.5 & 5.6181 & TRN \\
\hline CHEMBL1406513 & 688288 & 4.9 & 5.7188 & TRN \\
\hline CHEMBL1443628 & 688288 & 5.5 & 5.6627 & TRN \\
\hline CHEMBL1413371 & 688288 & 4.6 & 5.419 & TST \\
\hline CHEMBL1398185 & 688288 & 5.6 & 5.5723 & TRN \\
\hline CHEMBL1253215 & 688288 & 7.0 & 5.7414 & TRN \\
\hline CHEMBL1559143 & 688288 & 5.3 & 5.5473 & TRN \\
\hline CHEMBL1408836 & 688288 & 5.5 & 5.4507 & TRN \\
\hline CHEMBL1460909 & 688288 & 5.0 & 5.1942 & TRN \\
\hline CHEMBL1472651 & 688288 & 5.5 & 5.6866 & TRN \\
\hline CHEMBL 269277 & 688288 & 4.9 & 5.8723 & TST \\
\hline CHEMBL1374426 & 688288 & 5.5 & 5.6126 & TST \\
\hline CHEMBL168279 & 688288 & 4.5 & 5.7558 & TRN \\
\hline CHEMBL1426207 & 688288 & 5.8 & 5.2613 & TRN \\
\hline CHEMBL1608159 & 688288 & 5.4 & 5.624 & TRN \\
\hline CHEMBL1301611 & 688288 & 5.3 & 5.0882 & TRN \\
\hline CHEMBL1526358 & 688288 & 5.5 & 5.7914 & TST \\
\hline CHEMBL1529365 & 688288 & 5.4 & 5.5604 & TRN \\
\hline CHEMBL1330951 & 688288 & 5.5 & 5.4424 & TRN \\
\hline CHEMBL1314182 & 688288 & 5.5 & 5.7294 & TRN \\
\hline CHEMBL1411543 & 688288 & 5.3 & 5.6448 & TRN \\
\hline CHEMBL110739 & 688288 & 6.0 & 5.829 & TST \\
\hline
\end{tabular}

TRN 


\begin{tabular}{|c|c|c|c|c|c|}
\hline \\
\hline CHEMBL1332182 & 688288 & 5.2 & 5.5251 & TRN & \\
\hline CHEMBL1499183 & 688288 & 6.1 & 5.3631 & TRN & \\
\hline CHEMBL1461491 & 688288 & 5.3 & 5.6416 & TRN & \\
\hline CHEMBL1551254 & 688288 & 5.5 & 5.49 & TRN & \\
\hline CHEMBL1556549 & 688288 & 5.1 & 5.1855 & TRN & \\
\hline CHEMBL1411609 & 688288 & 5.3 & 5.3562 & TST & \\
\hline CHEMBL1462791 & 688288 & 5.0 & 5.2216 & TRN & \\
\hline CHEMBL1437741 & 688288 & 5.3 & 5.4384 & TRN & \\
\hline CHEMBL1473331 & 688288 & 5.6 & 5.6674 & TRN & \\
\hline CHEMBL1440100 & 688288 & 5.0 & 5.2086 & TRN & \\
\hline CHEMBL1437522 & 688288 & 7.4001 & 5.7543 & TRN & \\
\hline CHEMBL1572807 & 688288 & 5.1 & 5.3314 & TRN & \\
\hline CHEMBL 3190482 & 688288 & 5.7 & 5.2348 & TST & \\
\hline CHEMBL1604377 & 688288 & 6.0 & 5.443 & TRN & \\
\hline CHEMBL1335944 & 688288 & 5.8 & 5.5558 & TRN & \\
\hline CHEMBL1358756 & 688288 & 5.5 & 5.3855 & TRN & \\
\hline CHEMBL1380403 & 688288 & 5.3 & 5.6633 & TRN & \\
\hline CHEMBL1495685 & 688288 & 5.6 & 5.1267 & TRN & \\
\hline CHEMBL1584264 & 688288 & 4.9 & 5.3069 & TRN & \\
\hline CHEMBL1598565 & 688288 & 5.6 & 5.4814 & TRN & \\
\hline CHEMBL1341461 & 688288 & 5.0 & 5.5103 & TRN & \\
\hline CHEMBL1537860 & 688288 & 5.1 & 5.1515 & TRN & \\
\hline CHEMBL1496666 & 688288 & 4.9 & 5.4106 & TRN & \\
\hline CHEMBL491960 & 688288 & 5.5 & 5.2005 & TRN & \\
\hline CHEMBL1316158 & 688288 & 6.2 & 5.7509 & TRN & \\
\hline CHEMBL475813 & 688288 & 5.4 & 5.6285 & TRN & \\
\hline CHEMBL1436526 & 688288 & 7.0 & 5.9727 & TRN & \\
\hline CHEMBL421215 & 688288 & 5.1 & 5.4965 & TST & \\
\hline CHEMBL1451357 & 688288 & 6.0 & 5.55399 & 9999999999 & TRN \\
\hline CHEMBL515505 & 688288 & 5.8 & 5.6585 & TRN & \\
\hline CHEMBL1518182 & 688288 & 6.3 & 5.6906 & TRN & \\
\hline CHEMBL1232207 & 688288 & 5.0 & 5.8159 & TRN & \\
\hline CHEMBL1514547 & 688288 & 5.4 & 5.3885 & TST & \\
\hline CHEMBL1458376 & 688288 & 6.1 & 5.4777 & TRN & \\
\hline CHEMBL1395974 & 688288 & 5.4 & 5.7035 & TRN & \\
\hline CHEMBL402468 & 688288 & 5.1 & 5.5952 & TRN & \\
\hline CHEMBL1367656 & 688288 & 6.8 & 5.796 & TRN & \\
\hline CHEMBL1435885 & 688288 & 5.3 & 5.7155 & TST & \\
\hline CHEMBL126077 & 688288 & 4.6 & 5.4056 & TRN & \\
\hline CHEMBL1356392 & 688288 & 7.1002 & 5.7127 & TRN & \\
\hline CHEMBL1602451 & 688288 & 5.1 & 5.255 & TRN & \\
\hline CHEMBL1406660 & 688288 & 4.9 & 5.2889 & TRN & \\
\hline CHEMBL1325701 & 688288 & 5.4 & 5.7181 & TRN & \\
\hline CHEMBL1383447 & 688288 & 5.9 & 5.3969 & TST & \\
\hline CHEMBL1379653 & 688288 & 4.9 & 5.2538 & TRN & \\
\hline CHEMBL1515526 & 688288 & 5.5 & 5.479 & TRN & \\
\hline CHEMBL293749 & 688288 & 5.0 & 5.0675 & TRN & \\
\hline CHEMBL1316831 & 688288 & 5.4 & 5.9438 & TRN & \\
\hline & & & & 273 & \\
\hline
\end{tabular}




\begin{tabular}{|c|c|c|c|c|c|}
\hline \\
\hline CHEMBL1521220 & 688288 & 5.3 & 5.3322 & TRN & \\
\hline CHEMBL1329454 & 688288 & 5.3 & 5.11 & TRN & \\
\hline CHEMBL1581690 & 688288 & 4.9 & 5.461 & TRN & \\
\hline CHEMBL1355217 & 688288 & 6.7001 & 5.6925 & TRN & \\
\hline CHEMBL52030 & 688288 & 5.0 & 5.4265 & TRN & \\
\hline CHEMBL1558165 & 688288 & 5.1 & 5.6017 & TRN & \\
\hline CHEMBL1570413 & 688288 & 5.8 & 5.8377 & TRN & \\
\hline CHEMBL1451733 & 688288 & 5.3 & 5.479 & TRN & \\
\hline CHEMBL47814 & 688288 & 4.9 & 5.942 & TRN & \\
\hline CHEMBL1606018 & 688288 & 6.1 & 6.0729 & TRN & \\
\hline CHEMBL1533263 & 688288 & 5.5 & 5.5091 & TRN & \\
\hline CHEMBL1479708 & 688288 & 5.3 & 5.3215 & TRN & \\
\hline CHEMBL145 & 688288 & 5.1 & 5.3177 & TRN & \\
\hline CHEMBL53898 & 688288 & 6.0 & 5.0021 & TRN & \\
\hline CHEMBL1256735 & 688288 & 4.9 & 5.5762 & TRN & \\
\hline CHEMBL1255866 & 688288 & 4.8 & 5.459 & TST & \\
\hline CHEMBL1315382 & 688288 & 5.6 & 5.646 & TRN & \\
\hline CHEMBL1397965 & 688288 & 5.5 & 5.8392 & TRN & \\
\hline CHEMBL1439882 & 688288 & 5.5 & 5.6829 & TRN & \\
\hline CHEMBL1326031 & 688288 & 5.5 & 5.4252 & TRN & \\
\hline CHEMBL1527317 & 688288 & 6.8 & 5.7864 & TRN & \\
\hline CHEMBL1420669 & 688288 & 5.3 & 5.3188 & TRN & \\
\hline CHEMBL1376253 & 688288 & 5.7 & 5.9167 & TRN & \\
\hline CHEMBL1435009 & 688288 & 5.6 & 5.8799 & TRN & \\
\hline CHEMBL 2062343 & 688288 & 6.5 & 5.9923 & TRN & \\
\hline CHEMBL1475257 & 688288 & 5.9 & 5.3978 & TRN & \\
\hline CHEMBL1523296 & 688288 & 5.0 & 5.0926 & TRN & \\
\hline CHEMBL1448712 & 688288 & 6.7001 & 5.5158 & TRN & \\
\hline CHEMBL1369009 & 688288 & 7.3002 & 5.9033 & TST & \\
\hline CHEMBL1380504 & 688288 & 4.9 & 5.9424 & TRN & \\
\hline CHEMBL1355708 & 688288 & 7.6003 & 6.152 & TRN & \\
\hline CHEMBL1452098 & 688288 & 5.5 & 5.2828 & TRN & \\
\hline CHEMBL1336166 & 688288 & 4.5 & 5.54899 & 99999999995 & TRN \\
\hline CHEMBL1463790 & 688288 & 5.0 & 5.4567 & TRN & \\
\hline CHEMBL1514719 & 688288 & 5.7 & 5.7508 & TRN & \\
\hline CHEMBL1437523 & 688288 & 5.7 & 5.8058 & TRN & \\
\hline CHEMBL1540350 & 688288 & 5.5 & 5.3313 & TRN & \\
\hline CHEMBL1309066 & 688288 & 5.2 & 5.7498 & TRN & \\
\hline CHEMBL 8618 & 688288 & 4.8 & 5.2129 & TRN & \\
\hline CHEMBL1461834 & 688288 & 4.9 & 5.2691 & TRN & \\
\hline CHEMBL1516006 & 688288 & 5.5 & 5.7887 & TRN & \\
\hline CHEMBL1371756 & 688288 & 5.1 & 5.2935 & TRN & \\
\hline CHEMBL1475562 & 688288 & 7.3002 & 5.4815 & TRN & \\
\hline CHEMBL1418094 & 688288 & 5.7 & 5.6886 & TST & \\
\hline CHEMBL1354363 & 688288 & 5.5 & 5.7478 & TRN & \\
\hline CHEMBL1331778 & 688288 & 6.4 & 5.7005 & TRN & \\
\hline CHEMBL1444371 & 688288 & 5.6 & 5.7286 & TRN & \\
\hline CHEMBL1399181 & 688288 & 5.5 & 5.5841 & TRN & \\
\hline
\end{tabular}




\begin{tabular}{|c|c|c|c|c|c|}
\hline \multirow{2}{*}{ CHEMBL1403112 } & \\
\hline & 688288 & 5.9 & 5.5403 & TRN & \\
\hline CHEMBL1397634 & 688288 & 5.4 & 5.6795 & TRN & \\
\hline CHEMBL8867 & 688288 & 4.5 & 5.5224 & TST & \\
\hline CHEMBL522121 & 688288 & 5.7 & 5.4417 & TRN & \\
\hline CHEMBL1527269 & 688288 & 5.5 & 5.4902 & TRN & \\
\hline CHEMBL444422 & 688288 & 4.6 & 5.6333 & TST & \\
\hline CHEMBL1611496 & 688288 & 6.0 & 5.685 & TRN & \\
\hline CHEMBL1390316 & 688288 & 5.5 & 5.5641 & TST & \\
\hline CHEMBL1352733 & 688288 & 5.2 & 5.05399 & 9999999999 & TRN \\
\hline CHEMBL1517852 & 688288 & 5.6 & 5.9423 & TRN & \\
\hline CHEMBL1536966 & 688288 & 5.7 & 5.4058 & TRN & \\
\hline CHEMBL1454730 & 688288 & 6.1 & 5.9812 & TRN & \\
\hline CHEMBL1455438 & 688288 & 5.5 & 5.6994 & TRN & \\
\hline CHEMBL1322702 & 688288 & 5.2 & 5.5088 & TST & \\
\hline CHEMBL1316463 & 688288 & 6.0 & 5.8895 & TRN & \\
\hline CHEMBL1173475 & 688288 & 6.0 & 5.5437 & TRN & \\
\hline CHEMBL1479767 & 688288 & 5.5 & 5.5041 & TRN & \\
\hline CHEMBL1571135 & 688288 & 5.9 & 5.5563 & TRN & \\
\hline CHEMBL491547 & 688288 & 5.7 & 5.7157 & TRN & \\
\hline CHEMBL1435654 & 688288 & 5.9 & 6.0197 & TRN & \\
\hline CHEMBL2373648 & 688288 & 5.4 & 5.6274 & TST & \\
\hline CHEMBL475376 & 688288 & 5.4 & 5.6469 & TRN & \\
\hline CHEMBL1376954 & 688288 & 6.4 & 5.7098 & TRN & \\
\hline CHEMBL1476139 & 688288 & 5.4 & 5.5154 & TRN & \\
\hline CHEMBL1593589 & 688288 & 6.1 & 6.0471 & TRN & \\
\hline CHEMBL1516351 & 688288 & 6.0 & 5.6869 & TST & \\
\hline CHEMBL3211562 & 688288 & 6.4 & 5.4763 & TST & \\
\hline CHEMBL1559628 & 688288 & 5.0 & 5.3049 & TRN & \\
\hline CHEMBL1604074 & 688288 & 5.3 & 5.4625 & TRN & \\
\hline CHEMBL1355262 & 688288 & 5.5 & 5.7483 & TRN & \\
\hline CHEMBL1411360 & 688288 & 5.8 & 5.5478 & TRN & \\
\hline CHEMBL26138 & 688288 & 4.6 & 5.29799 & 9999999999 & TRN \\
\hline CHEMBL1338950 & 688288 & 7.8013 & 6.0232 & TRN & \\
\hline CHEMBL1567944 & 688288 & 6.0 & 6.0527 & TRN & \\
\hline CHEMBL238624 & 688288 & 5.8 & 5.6146 & TRN & \\
\hline CHEMBL1544060 & 688288 & 4.9 & 5.2561 & TRN & \\
\hline CHEMBL1320460 & 688288 & 5.4 & 5.087 & TRN & \\
\hline CHEMBL1399058 & 688288 & 7.5003 & 5.8666 & TRN & \\
\hline CHEMBL1355762 & 688288 & 5.1 & 5.5189 & TRN & \\
\hline CHEMBL1324529 & 688288 & 5.6 & 5.7626 & TRN & \\
\hline CHEMBL1537294 & 688288 & 5.0 & 5.5596 & TRN & \\
\hline CHEMBL16687 & 688288 & 5.3 & 5.2516 & TRN & \\
\hline CHEMBL1412573 & 688288 & 5.0 & 5.4961 & TST & \\
\hline CHEMBL1475375 & 688288 & 5.5 & 5.6231 & TST & \\
\hline CHEMBL1562125 & 688288 & 5.1 & 5.0401 & TRN & \\
\hline CHEMBL1479202 & 688288 & 5.8 & 5.7637 & TRN & \\
\hline CHEMBL1611308 & 688288 & 5.5 & 5.8487 & TRN & \\
\hline CHEMBL1454153 & 688288 & 5.5 & 5.7235 & TRN & \\
\hline & & & & 127 & \\
\hline
\end{tabular}




\begin{tabular}{|c|c|c|c|c|c|}
\hline \\
\hline CHEMBL1547901 & 688288 & 5.0 & 5.1821 & TRN & \\
\hline CHEMBL1516211 & 688288 & 5.3 & 5.6676 & TRN & \\
\hline CHEMBL1516468 & 688288 & 5.6 & 5.4695 & TRN & \\
\hline CHEMBL1357553 & 688288 & 5.6 & 5.6063 & TRN & \\
\hline CHEMBL1473285 & 688288 & 5.4 & 6.0726 & TRN & \\
\hline CHEMBL1512838 & 688288 & 5.5 & 5.6742 & TRN & \\
\hline CHEMBL604119 & 688288 & 4.6 & 5.5315 & TST & \\
\hline CHEMBL1420053 & 688288 & 5.0 & 5.2479 & TST & \\
\hline CHEMBL1609406 & 688288 & 5.6 & 5.7698 & TRN & \\
\hline CHEMBL1435248 & 688288 & 5.8 & 5.5574 & TRN & \\
\hline CHEMBL1545288 & 688288 & 5.7 & 5.2098 & TRN & \\
\hline CHEMBL1574390 & 688288 & 5.5 & 5.5656 & TRN & \\
\hline CHEMBL1380237 & 688288 & 4.9 & 5.7183 & TST & \\
\hline CHEMBL1534297 & 688288 & 6.0 & 5.6764 & TRN & \\
\hline CHEMBL491555 & 688288 & 5.4 & 5.71299 & 9999999999 & TRN \\
\hline CHEMBL17468 & 688288 & 5.0 & 5.5153 & TRN & \\
\hline CHEMBL494887 & 688288 & 5.5 & 5.81 & TST & \\
\hline CHEMBL544713 & 688288 & 4.8 & 5.5346 & TST & \\
\hline CHEMBL1356497 & 688288 & 5.5 & 5.4856 & TRN & \\
\hline CHEMBL1420083 & 688288 & 5.0 & 5.1656 & TRN & \\
\hline CHEMBL1511046 & 688288 & 5.2 & 5.6018 & TRN & \\
\hline CHEMBL1435809 & 688288 & 5.4 & 5.6048 & TRN & \\
\hline CHEMBL441282 & 688288 & 5.5 & 5.6462 & TST & \\
\hline CHEMBL1590123 & 688288 & 6.6 & 5.2818 & TRN & \\
\hline CHEMBL1592560 & 688288 & 5.5 & 5.4662 & TRN & \\
\hline CHEMBL1430891 & 688288 & 4.9 & 5.2066 & TRN & \\
\hline CHEMBL1439172 & 688288 & 4.5 & 5.4677 & TRN & \\
\hline CHEMBL1407440 & 688288 & 5.5 & 5.7932 & TRN & \\
\hline CHEMBL1515804 & 688288 & 5.4 & 5.6375 & TRN & \\
\hline CHEMBL1320913 & 688288 & 5.3 & 5.7293 & TST & \\
\hline CHEMBL1079460 & 688288 & 4.6 & 5.6123 & TST & \\
\hline CHEMBL1476670 & 688288 & 6.4 & 5.8599 & TRN & \\
\hline CHEMBL1401859 & 688288 & 5.3 & 5.6885 & TRN & \\
\hline CHEMBL1592464 & 688288 & 5.7 & 5.4887 & TRN & \\
\hline CHEMBL1434411 & 688288 & 5.4 & 5.6999 & TRN & \\
\hline CHEMBL1398425 & 688288 & 5.3 & 5.6209 & TRN & \\
\hline CHEMBL1590242 & 688288 & 5.5 & 5.5871 & TRN & \\
\hline CHEMBL1438389 & 688288 & 6.4 & 5.4633 & TRN & \\
\hline CHEMBL1537507 & 688288 & 5.0 & 5.4922 & TRN & \\
\hline CHEMBL3207941 & 688288 & 5.0 & 5.8178 & TST & \\
\hline CHEMBL1588679 & 688288 & 5.3 & 5.5196 & TRN & \\
\hline CHEMBL1328240 & 688288 & 5.2 & 5.4114 & TRN & \\
\hline CHEMBL1434833 & 688288 & 5.5 & 5.6647 & TRN & \\
\hline CHEMBL1317302 & 688288 & 5.3 & 5.5811 & TRN & \\
\hline CHEMBL491748 & 688288 & 5.5 & 5.4614 & TRN & \\
\hline CHEMBL1315504 & 688288 & 5.3 & 5.3101 & TRN & \\
\hline CHEMBL605003 & 688288 & 4.7 & 5.6776 & TRN & \\
\hline CHEMBL1586681 & 688288 & 5.0 & 5.3492 & TRN & \\
\hline
\end{tabular}




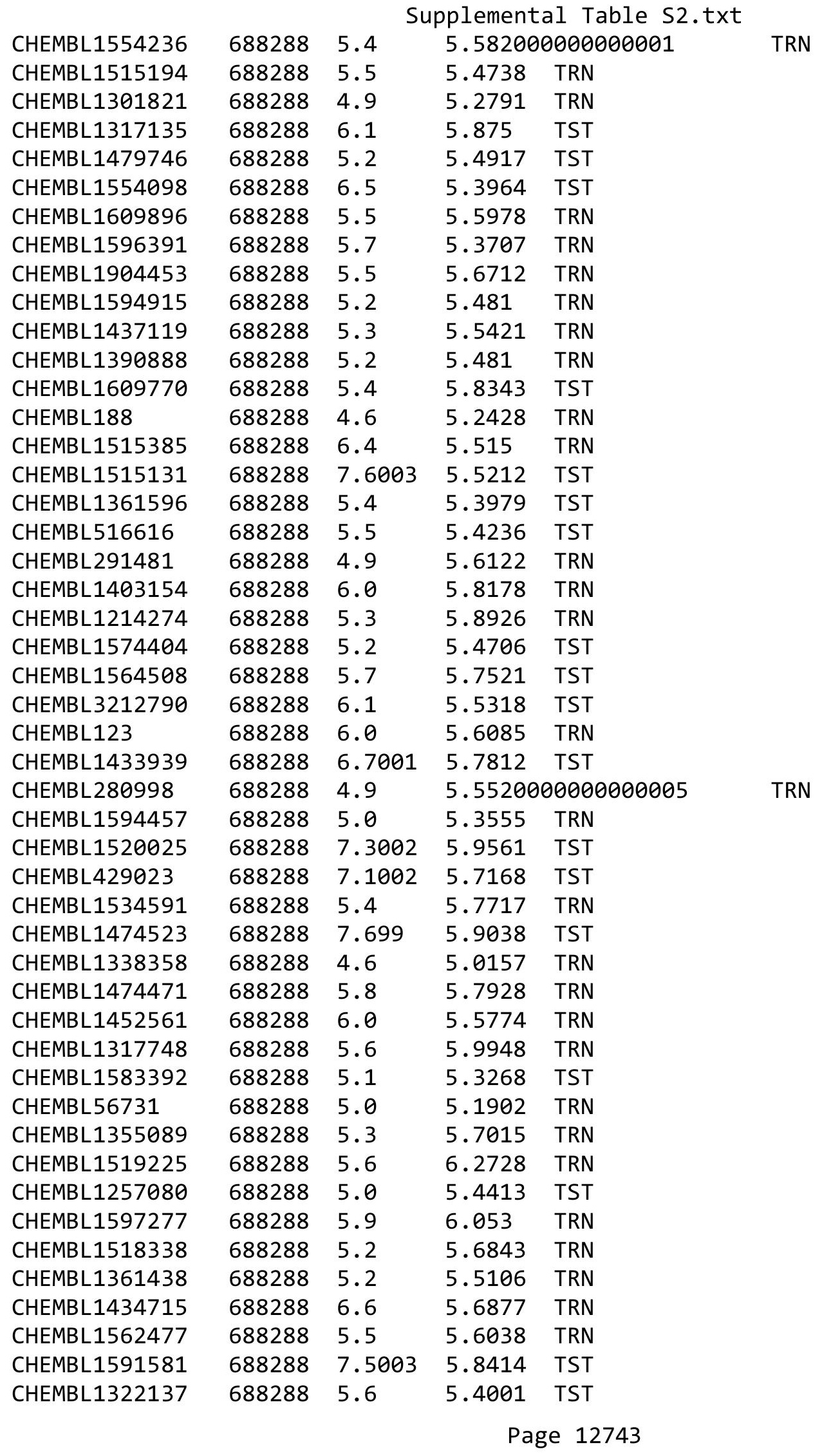




\begin{tabular}{|c|c|c|c|c|c|}
\hline \\
\hline CHEMBL1424148 & 688288 & 4.9 & 5.016 & TRN & \\
\hline CHEMBL268609 & 688288 & 6.0 & 5.4042 & TRN & \\
\hline CHEMBL1433760 & 688288 & 6.3 & 6.1803 & TRN & \\
\hline CHEMBL1447051 & 688288 & 5.2 & 5.7332 & TST & \\
\hline CHEMBL1316492 & 688288 & 5.4 & 5.5014 & TRN & \\
\hline CHEMBL1438041 & 688288 & 5.5 & 5.6246 & TRN & \\
\hline CHEMBL1496243 & 688288 & 5.5 & 5.399 & TRN & \\
\hline CHEMBL1438688 & 688288 & 5.7 & 5.5803 & TRN & \\
\hline CHEMBL1376430 & 688288 & 5.2 & 5.5267 & TRN & \\
\hline CHEMBL23327 & 688288 & 5.0 & 5.7962 & TRN & \\
\hline CHEMBL1607568 & 688288 & 6.2 & 5.9766 & TRN & \\
\hline CHEMBL1477182 & 688288 & 6.9 & 5.8611 & TST & \\
\hline CHEMBL1336469 & 688288 & 5.0 & 5.9801 & TRN & \\
\hline CHEMBL410873 & 688288 & 4.9 & 5.5252 & TRN & \\
\hline CHEMBL1371634 & 688288 & 5.5 & 5.2207 & TST & \\
\hline CHEMBL 1445135 & 688288 & 5.3 & 5.181 & TRN & \\
\hline CHEMBL1512210 & 688288 & 5.5 & 5.3458 & TRN & \\
\hline CHEMBL1570996 & 688288 & 7.699 & 6.0138 & TRN & \\
\hline CHEMBL1397532 & 688288 & 5.6 & 5.5918 & TRN & \\
\hline CHEMBL1417375 & 688288 & 7.0 & 5.9543 & TRN & \\
\hline CHEMBL1553863 & 688288 & 6.2 & 5.9275 & TRN & \\
\hline CHEMBL1554411 & 688288 & 5.5 & 5.6088 & TRN & \\
\hline CHEMBL1358654 & 688288 & 5.7 & 5.6285 & TRN & \\
\hline CHEMBL1515004 & 688288 & 5.6 & 5.3827 & TRN & \\
\hline CHEMBL1572770 & 688288 & 5.5 & 5.4712 & TST & \\
\hline CHEMBL1435374 & 688288 & 5.5 & 5.6223 & TRN & \\
\hline CHEMBL 3212171 & 688288 & 5.6 & 4.9519 & TST & \\
\hline CHEMBL1589998 & 688288 & 8.6021 & 6.1382 & TRN & \\
\hline CHEMBL1256885 & 688288 & 5.4 & 5.2968 & TRN & \\
\hline CHEMBL1551049 & 688288 & 5.4 & 5.6418 & TRN & \\
\hline CHEMBL1503627 & 688288 & 5.7 & 5.5274 & TRN & \\
\hline CHEMBL1573732 & 688288 & 5.7 & 5.3971 & TRN & \\
\hline CHEMBL1563566 & 688288 & 6.0 & 5.7904 & TRN & \\
\hline CHEMBL1316980 & 688288 & 5.9 & 6.0537 & TRN & \\
\hline CHEMBL1430695 & 688288 & 7.1002 & 5.3211 & TST & \\
\hline CHEMBL1084643 & 688288 & 5.6 & 5.5619 & TST & \\
\hline CHEMBL1433897 & 688288 & 6.0 & 5.8176 & TST & \\
\hline CHEMBL1408176 & 688288 & 5.4 & 5.75899 & 99999999995 & TRN \\
\hline CHEMBL1353094 & 688288 & 5.0 & 5.5649 & TRN & \\
\hline CHEMBL1564545 & 688288 & 5.3 & 5.7395 & TRN & \\
\hline CHEMBL1330357 & 688288 & 4.8 & 5.5342 & TST & \\
\hline CHEMBL1536379 & 688288 & 5.6 & 5.2728 & TRN & \\
\hline CHEMBL1718952 & 688288 & 5.5 & 5.5968 & TRN & \\
\hline CHEMBL1354069 & 688288 & 5.0 & 5.1113 & TRN & \\
\hline CHEMBL34704 & 688288 & 5.9 & 5.5611 & TST & \\
\hline CHEMBL192566 & 688288 & 4.5 & 5.6754 & TST & \\
\hline CHEMBL1341664 & 688288 & 5.2 & 5.1996 & TRN & \\
\hline CHEMBL1318708 & 688288 & 5.2 & 5.816 & TRN & \\
\hline
\end{tabular}




\begin{tabular}{|c|c|c|c|c|c|}
\hline \multicolumn{6}{|c|}{ olemental labıe S2. } \\
\hline CHEMBL1415545 & 688288 & 5.7 & 5.0925 & TRN & \\
\hline CHEMBL1160544 & 688288 & 6.0 & \multicolumn{2}{|c|}{6.3260000000000005} & TRN \\
\hline CHEMBL1554131 & 688288 & 6.0 & 5.9377 & TRN & \\
\hline CHEMBL 3193278 & 688288 & 5.0 & 5.2962 & TRN & \\
\hline CHEMBL1396898 & 688288 & 6.9 & 5.7561 & TRN & \\
\hline CHEMBL1506496 & 688288 & 5.3 & 5.2641 & TRN & \\
\hline CHEMBL1493388 & 688288 & 8.0 & 5.8552 & TRN & \\
\hline CHEMBL1396665 & 688288 & 4.9 & 5.3364 & TRN & \\
\hline CHEMBL1458643 & 688288 & 5.0 & 5.2808 & TRN & \\
\hline CHEMBL1498117 & 688288 & 5.3 & 5.4694 & TRN & \\
\hline CHEMBL1410826 & 688288 & 7.2 & 5.8957 & TRN & \\
\hline CHEMBL1356721 & 688288 & 5.3 & 5.6044 & TRN & \\
\hline CHEMBL1492922 & 688288 & 5.4 & 5.6438 & TST & \\
\hline CHEMBL1256698 & 688288 & 4.8 & 5.4011 & TRN & \\
\hline CHEMBL1437990 & 688288 & 7.0 & 5.7699 & TRN & \\
\hline CHEMBL1390 & 688288 & 7.1002 & 5.7278 & TST & \\
\hline CHEMBL3199921 & 688288 & 5.0 & 5.3855 & TRN & \\
\hline CHEMBL1355201 & 688288 & 5.6 & 5.6797 & TRN & \\
\hline CHEMBL1447428 & 688288 & 5.7 & 5.5396 & TRN & \\
\hline CHEMBL 2068684 & 688288 & 6.7001 & 5.733 & TRN & \\
\hline CHEMBL1487898 & 688288 & 5.3 & 6.3262 & TRN & \\
\hline CHEMBL1475487 & 688288 & 5.3 & 5.7541 & TRN & \\
\hline CHEMBL1536363 & 688288 & 5.3 & \multicolumn{2}{|c|}{5.242999999999999} & TRN \\
\hline CHEMBL1314975 & 688288 & 4.9 & 5.9689 & TRN & \\
\hline CHEMBL1375431 & 688288 & 5.3 & 5.6439 & TRN & \\
\hline CHEMBL1320485 & 688288 & 8.699 & 6.1144 & TRN & \\
\hline CHEMBL 275516 & 688288 & 4.9 & 5.7626 & TST & \\
\hline CHEMBL1502538 & 688288 & 5.6 & 5.3736 & TST & \\
\hline CHEMBL 291829 & 688288 & 6.0 & 5.5748 & TRN & \\
\hline CHEMBL24510 & 688288 & 6.0 & 5.6137 & TST & \\
\hline CHEMBL1306263 & 688288 & 6.7001 & 5.3982 & TRN & \\
\hline CHEMBL1097940 & 688288 & 4.6 & 5.8416 & TST & \\
\hline CHEMBL1592584 & 688288 & 5.6 & 5.609 & TRN & \\
\hline CHEMBL1339229 & 688288 & 5.0 & 5.8513 & TST & \\
\hline CHEMBL1256984 & 688288 & 4.6 & \multicolumn{2}{|c|}{5.462999999999999} & TST \\
\hline CHEMBL1256814 & 688288 & 4.9 & 5.3688 & TRN & \\
\hline CHEMBL1435381 & 688288 & 4.8 & 5.3096 & TST & \\
\hline CHEMBL282489 & 688288 & 4.6 & 5.5905 & TST & \\
\hline CHEMBL222993 & 688288 & 5.5 & 5.5773 & TRN & \\
\hline CHEMBL1335307 & 688288 & 5.4 & 5.3098 & TRN & \\
\hline CHEMBL1256718 & 688288 & 4.6 & 5.5969 & TST & \\
\hline CHEMBL1433593 & 688288 & 8.3979 & 5.9524 & TST & \\
\hline CHEMBL1553825 & 688288 & 5.9 & 5.9033 & TRN & \\
\hline CHEMBL1421938 & 688288 & 5.1 & 5.3556 & TRN & \\
\hline CHEMBL1319312 & 688288 & 6.1 & 5.8087 & TRN & \\
\hline CHEMBL1390014 & 688288 & 5.1 & 5.2276 & TRN & \\
\hline CHEMBL1394089 & 688288 & 5.0 & 5.6006 & TST & \\
\hline CHEMBL1421867 & 688288 & 5.1 & 5.1595 & TRN & \\
\hline
\end{tabular}




\begin{tabular}{|c|c|c|c|c|c|}
\hline \multirow[b]{2}{*}{ CHEMBL1325833 } & \\
\hline & 688288 & 5.3 & 5.6514 & TRN & \\
\hline CHEMBL1596347 & 688288 & 5.7 & 5.8074 & TST & \\
\hline CHEMBL309339 & 688288 & 5.4 & 5.4067 & TRN & \\
\hline CHEMBL1562786 & 688288 & 5.4 & 5.5152 & TRN & \\
\hline CHEMBL1327752 & 688288 & 6.4 & 5.86299 & 99999999995 & TRN \\
\hline CHEMBL1256910 & 688288 & 5.2 & 5.5355 & TST & \\
\hline CHEMBL1314172 & 688288 & 5.6 & 5.8284 & TRN & \\
\hline CHEMBL1437747 & 688288 & 5.5 & 5.865 & TRN & \\
\hline CHEMBL1410838 & 688288 & 5.2 & 5.2319 & TRN & \\
\hline CHEMBL3196589 & 688288 & 5.2 & 5.3274 & TRN & \\
\hline CHEMBL270299 & 688288 & 4.7 & 5.9218 & TST & \\
\hline CHEMBL491953 & 688288 & 5.7 & 5.6963 & TRN & \\
\hline CHEMBL1315530 & 688288 & 5.5 & 5.6673 & TRN & \\
\hline CHEMBL1556431 & 688288 & 5.4 & 5.5071 & TRN & \\
\hline CHEMBL1593815 & 688288 & 5.6 & 5.8173 & TRN & \\
\hline CHEMBL1376723 & 688288 & 5.1 & 5.2869 & TRN & \\
\hline CHEMBL1518237 & 688288 & 5.0 & 5.2294 & TRN & \\
\hline CHEMBL1395850 & 688288 & 5.4 & 5.4986 & TRN & \\
\hline CHEMBL1473793 & 688288 & 5.5 & 5.6409 & TRN & \\
\hline CHEMBL1442173 & 688288 & 5.5 & 5.5051 & TRN & \\
\hline CHEMBL1208858 & 688288 & 4.6 & 5.4077 & TRN & \\
\hline CHEMBL2374367 & 688288 & 5.6 & 5.8386 & TST & \\
\hline CHEMBL1329117 & 688288 & 6.2 & 5.8187 & TRN & \\
\hline CHEMBL1476939 & 688288 & 5.5 & 5.4853 & TRN & \\
\hline CHEMBL3195219 & 688288 & 5.0 & 5.3634 & TRN & \\
\hline CHEMBL1316219 & 688288 & 5.9 & 5.5787 & TRN & \\
\hline CHEMBL1538246 & 688288 & 6.0 & 5.5927 & TRN & \\
\hline CHEMBL1725279 & 688288 & 4.8 & 5.7252 & TST & \\
\hline CHEMBL1335455 & 688288 & 8.6021 & 5.7159 & TST & \\
\hline CHEMBL598270 & 688288 & 4.9 & 5.1198 & TST & \\
\hline CHEMBL1561148 & 688288 & 7.0 & 5.428 & TST & \\
\hline CHEMBL1435907 & 688288 & 5.5 & 5.2137 & TRN & \\
\hline CHEMBL1471010 & 688288 & 5.2 & 5.0701 & TRN & \\
\hline CHEMBL1515310 & 688288 & 4.5 & 5.7152 & TST & \\
\hline CHEMBL1479677 & 688288 & 6.0 & 5.6689 & TRN & \\
\hline CHEMBL1605510 & 688288 & 6.4 & 6.0434 & TRN & \\
\hline CHEMBL1320206 & 688288 & 6.4 & 5.5556 & TRN & \\
\hline CHEMBL1489424 & 688288 & 6.6 & 5.6233 & TRN & \\
\hline CHEMBL1512027 & 688288 & 5.4 & 5.8384 & TRN & \\
\hline CHEMBL1593545 & 688288 & 5.5 & 5.7749 & TRN & \\
\hline CHEMBL1407576 & 688288 & 7.4001 & 5.79799 & 9999999999 & TST \\
\hline CHEMBL1400543 & 688288 & 4.5 & 5.7504 & TST & \\
\hline CHEMBL1435899 & 688288 & 5.5 & 5.5168 & TRN & \\
\hline CHEMBL1539236 & 688288 & 5.3 & 5.4322 & TST & \\
\hline CHEMBL1355185 & 688288 & 5.8 & 5.687 & TRN & \\
\hline CHEMBL1971698 & 688288 & 5.0 & 5.0762 & TRN & \\
\hline CHEMBL1554910 & 688288 & 5.3 & 5.6398 & TRN & \\
\hline CHEMBL251647 & 688288 & 4.9 & 5.8861 & TST & \\
\hline & & & & 12746 & \\
\hline
\end{tabular}




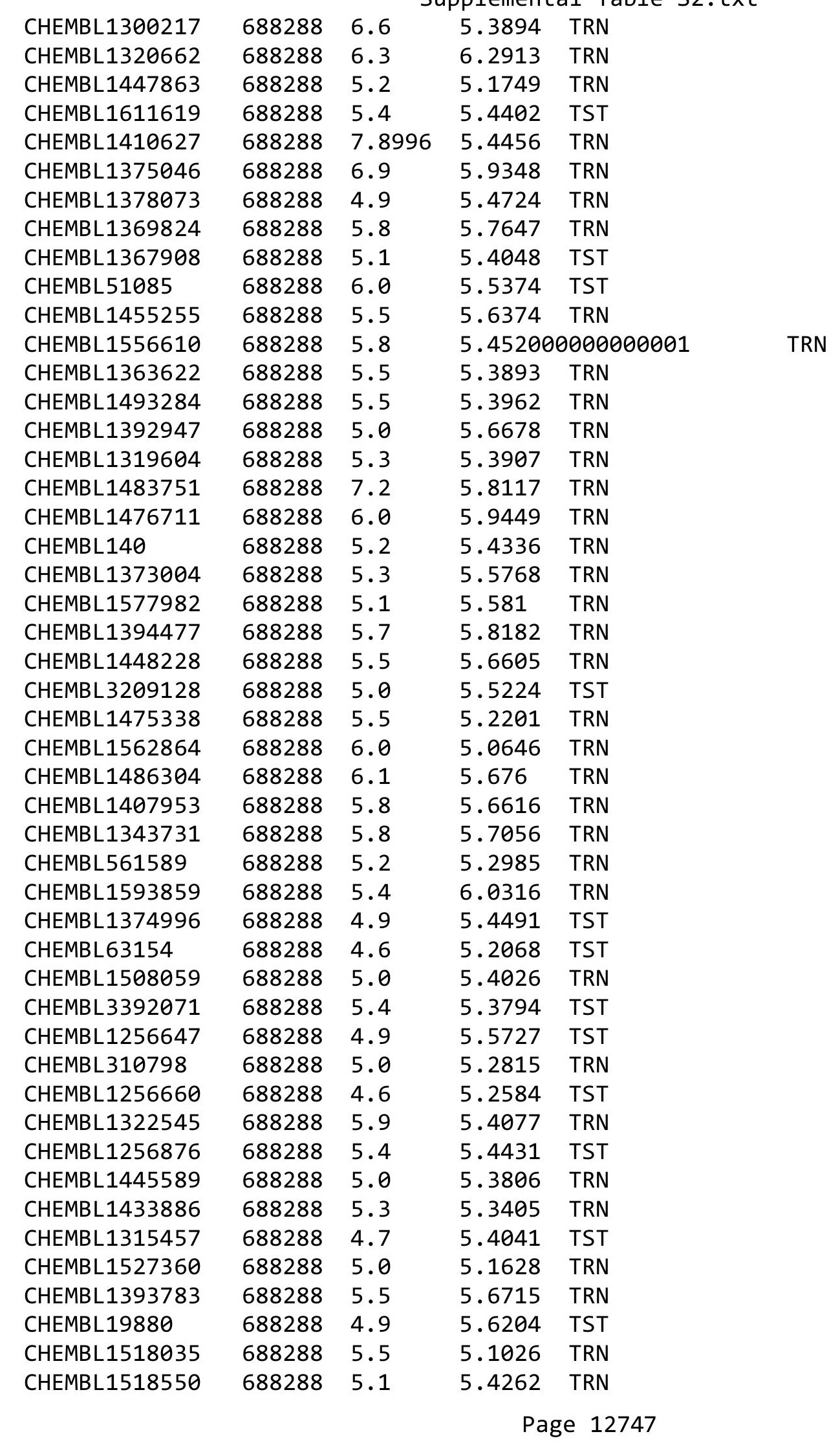




\begin{tabular}{|c|c|c|c|c|}
\hline & & & & \\
\hline CHEMBL288174 & 688288 & 4.5 & 5.1594 & TST \\
\hline CHEMBL1476021 & 688288 & 6.5 & 5.6863 & TRN \\
\hline CHEMBL1370296 & 688288 & 5.8 & 5.6275 & TRN \\
\hline CHEMBL1520199 & 688288 & 5.0 & 5.2268 & TRN \\
\hline CHEMBL1328369 & 688288 & 5.6 & 5.3323 & TST \\
\hline CHEMBL1593199 & 688288 & 5.5 & 5.6731 & TRN \\
\hline CHEMBL1302028 & 688288 & 4.9 & 5.4123 & TRN \\
\hline CHEMBL1336414 & 688288 & 4.9 & 5.1322 & TRN \\
\hline CHEMBL1565588 & 688288 & 4.9 & 5.9677 & TST \\
\hline CHEMBL1418583 & 688288 & 6.1 & 5.2371 & TRN \\
\hline CHEMBL105739 & 688288 & 6.8 & 5.6773 & TRN \\
\hline CHEMBL1515717 & 688288 & 5.2 & 5.4298 & TRN \\
\hline CHEMBL1518305 & 688288 & 5.6 & 5.6098 & TRN \\
\hline CHEMBL1344787 & 688288 & 5.5 & 5.5212 & TRN \\
\hline CHEMBL1378010 & 688288 & 5.5 & 5.5721 & TRN \\
\hline CHEMBL1355963 & 688288 & 6.0 & 5.9612 & TST \\
\hline CHEMBL1561474 & 688288 & 4.8 & 5.8244 & TRN \\
\hline CHEMBL1256751 & 688288 & 4.8 & 5.2265 & TRN \\
\hline CHEMBL1515410 & 688288 & 5.9 & 6.0723 & TRN \\
\hline CHEMBL1514604 & 688288 & 6.5 & 5.7208 & TST \\
\hline CHEMBL1402241 & 688288 & 5.8 & 5.9497 & TRN \\
\hline CHEMBL1327989 & 688288 & 5.5 & 5.5255 & TRN \\
\hline CHEMBL1574403 & 688288 & 5.4 & 5.6998 & TRN \\
\hline CHEMBL1328484 & 688288 & 5.6 & 5.892 & TST \\
\hline CHEMBL1085765 & 688288 & 4.9 & 5.3148 & TRN \\
\hline CHEMBL1387946 & 688288 & 5.3 & 5.3562 & TRN \\
\hline CHEMBL1552897 & 688288 & 5.2 & 5.9546 & TRN \\
\hline CHEMBL1435919 & 688288 & 6.0 & 5.7163 & TRN \\
\hline CHEMBL1966792 & 688288 & 5.3 & 5.4825 & TRN \\
\hline CHEMBL1318789 & 688288 & 8.0 & 5.5707 & TST \\
\hline CHEMBL2374259 & 688288 & 4.9 & 5.5468 & TRN \\
\hline CHEMBL1574693 & 688288 & 5.6 & 5.4025 & TRN \\
\hline CHEMBL1256663 & 688288 & 4.8 & 5.3155 & TRN \\
\hline CHEMBL432527 & 688288 & 5.5 & 5.9031 & TRN \\
\hline CHEMBL1518154 & 688288 & 7.2 & 5.6648 & TST \\
\hline CHEMBL1511379 & 688288 & 4.9 & 5.3739 & TST \\
\hline CHEMBL1395805 & 688288 & 6.1 & 5.7448 & TRN \\
\hline CHEMBL1558135 & 688288 & 5.5 & 5.8387 & TRN \\
\hline CHEMBL1391679 & 688288 & 5.6 & 5.4212 & TRN \\
\hline CHEMBL1401483 & 688288 & 5.5 & 5.934 & TRN \\
\hline CHEMBL1332162 & 688288 & 6.0 & 5.4985 & TST \\
\hline CHEMBL1384026 & 688288 & 5.9 & 5.3765 & TRN \\
\hline CHEMBL393136 & 688288 & 5.4 & $5.6220 e$ & 0000000001 \\
\hline CHEMBL1436438 & 688288 & 4.8 & 5.8949 & TRN \\
\hline CHEMBL1526964 & 688288 & 6.6 & 5.4414 & TST \\
\hline CHEMBL 71851 & 688288 & 4.9 & 5.3793 & TRN \\
\hline CHEMBL1496013 & 688288 & 6.6 & 5.6488 & TRN \\
\hline CHEMBL222334 & 688288 & 5.2 & 5.4572 & TRN \\
\hline
\end{tabular}




\begin{tabular}{|c|c|c|c|c|}
\hline & & & ent & al Table S \\
\hline CHEMBL1529346 & 688288 & 5.2 & 5.2223 & TRN \\
\hline CHEMBL1430325 & 688288 & 5.2 & 4.995 & TRN \\
\hline CHEMBL1612474 & 688288 & 5.0 & 5.8726 & TRN \\
\hline CHEMBL3304020 & 688288 & 6.1 & 5.8455 & TRN \\
\hline CHEMBL1395137 & 688288 & 5.5 & 5.47 & TRN \\
\hline CHEMBL1374585 & 688288 & 5.5 & 5.5259 & TRN \\
\hline CHEMBL1395196 & 688288 & 5.8 & 5.6225 & TST \\
\hline CHEMBL1327825 & 688288 & 5.0 & 5.2194 & TRN \\
\hline CHEMBL1429863 & 688288 & 6.4 & 5.6152 & TRN \\
\hline CHEMBL1516054 & 688288 & 5.3 & 5.4909 & TRN \\
\hline CHEMBL1569549 & 688288 & 6.4 & 5.5856 & TRN \\
\hline CHEMBL1396742 & 688288 & 5.7 & 5.7594 & TRN \\
\hline CHEMBL1441453 & 688288 & 5.4 & 5.4956 & TRN \\
\hline CHEMBL1256746 & 688288 & 5.2 & 5.7746 & TRN \\
\hline CHEMBL1435994 & 688288 & 5.8 & 5.8581 & TRN \\
\hline CHEMBL582444 & 688288 & 5.3 & 5.7224 & TRN \\
\hline CHEMBL1592580 & 688288 & 6.2 & 5.5871 & TRN \\
\hline CHEMBL1398260 & 688288 & 6.0 & 5.8247 & TST \\
\hline CHEMBL1375243 & 688288 & 6.3 & 5.6283 & TST \\
\hline CHEMBL1373007 & 688288 & 6.6 & 5.2713 & TST \\
\hline CHEMBL56543 & 688288 & 5.0 & 5.0498 & TRN \\
\hline CHEMBL1554577 & 688288 & 5.4 & 5.6298 & TRN \\
\hline CHEMBL1319303 & 688288 & 5.5 & 5.6143 & TRN \\
\hline CHEMBL1551016 & 688288 & 7.0 & 5.8719 & TRN \\
\hline CHEMBL1602568 & 688288 & 5.5 & 5.82799 & 9999999999 \\
\hline CHEMBL1432451 & 688288 & 5.0 & 5.4121 & TRN \\
\hline CHEMBL1470178 & 688288 & 5.0 & 5.2508 & TRN \\
\hline CHEMBL1532555 & 688288 & 5.6 & 5.8224 & TRN \\
\hline CHEMBL1377111 & 688288 & 5.4 & 5.3373 & TST \\
\hline CHEMBL1591556 & 688288 & 6.0 & 6.0092 & TST \\
\hline CHEMBL288096 & 688288 & 5.6 & 5.2889 & TRN \\
\hline CHEMBL1333454 & 688288 & 5.9 & 5.3818 & TRN \\
\hline CHEMBL1318276 & 688288 & 6.0 & 6.1623 & TRN \\
\hline CHEMBL1299407 & 688288 & 4.9 & 4.7571 & TRN \\
\hline CHEMBL1413630 & 688288 & 5.4 & 5.1627 & TRN \\
\hline CHEMBL1494883 & 688288 & 5.4 & 5.5442 & TRN \\
\hline CHEMBL1329033 & 688288 & 5.1 & 5.2006 & TRN \\
\hline CHEMBL1608337 & 688288 & 6.0 & 5.5873 & TRN \\
\hline CHEMBL1398518 & 688288 & 4.9 & 5.7523 & TST \\
\hline CHEMBL1325388 & 688288 & 6.9 & 5.6501 & TRN \\
\hline CHEMBL1490339 & 688288 & 6.5 & 5.7282 & TRN \\
\hline CHEMBL1434334 & 688288 & 6.0 & 5.6487 & TST \\
\hline CHEMBL1315690 & 688288 & 5.5 & 5.3012 & TRN \\
\hline CHEMBL1592966 & 688288 & 5.4 & 5.6001 & TRN \\
\hline CHEMBL47940 & 688288 & 4.5 & 5.7391 & TST \\
\hline CHEMBL1436179 & 688288 & 5.7 & 5.6675 & TRN \\
\hline CHEMBL405358 & 688288 & 4.9 & 5.4349 & TRN \\
\hline CHEMBL1345141 & 688288 & 5.4 & 5.466 & TRN \\
\hline
\end{tabular}

TRN 


\begin{tabular}{|c|c|c|c|c|}
\hline & & & pplement & $d \perp$ \\
\hline CHEMBL1599748 & 688288 & 6.6 & 6.1012 & TRN \\
\hline CHEMBL1476762 & 688288 & 4.6 & 5.4694 & TST \\
\hline CHEMBL1433105 & 688288 & 4.9 & 5.7254 & TRN \\
\hline CHEMBL1322719 & 688288 & 5.3 & 5.575 & TST \\
\hline CHEMBL1416946 & 688288 & 4.9 & 5.114 & TRN \\
\hline CHEMBL451226 & 688288 & 4.6 & 5.6566 & TST \\
\hline CHEMBL1502888 & 688288 & 5.0 & 5.1354 & TRN \\
\hline CHEMBL1594350 & 688288 & 6.6 & 5.811 & TRN \\
\hline CHEMBL1423437 & 688288 & 6.3 & 5.4436 & TRN \\
\hline CHEMBL1358012 & 688288 & 5.1 & 5.5691 & TST \\
\hline CHEMBL1589942 & 688288 & 5.6 & 5.8138 & TST \\
\hline CHEMBL1405546 & 688288 & 5.8 & 5.6401 & TRN \\
\hline CHEMBL1561888 & 688288 & 6.0 & 5.7243 & TRN \\
\hline CHEMBL1371355 & 688288 & 6.7001 & 5.7357 & TRN \\
\hline CHEMBL1552028 & 688288 & 5.5 & 5.6855 & TRN \\
\hline CHEMBL1565927 & 688288 & 6.1 & 5.6805 & TRN \\
\hline CHEMBL1597692 & 688288 & 4.8 & 5.4702 & TST \\
\hline CHEMBL1476511 & 688288 & 5.7 & 6.095 & TRN \\
\hline CHEMBL1257003 & 688288 & 5.0 & 4.9471 & TRN \\
\hline CHEMBL1408760 & 688288 & 6.0 & 5.9812 & TRN \\
\hline CHEMBL1473205 & 688288 & 5.0 & 5.3049 & TRN \\
\hline CHEMBL1354262 & 688288 & 5.5 & 5.5038 & TRN \\
\hline CHEMBL446315 & 688288 & 6.0 & 5.4361 & TST \\
\hline CHEMBL1448121 & 688288 & 5.4 & 5.4057 & TRN \\
\hline CHEMBL1475686 & 688288 & 6.1 & 5.9347 & TRN \\
\hline CHEMBL1365069 & 688288 & 5.5 & 5.6045 & TRN \\
\hline CHEMBL1494177 & 688288 & 5.5 & 5.4815 & TRN \\
\hline CHEMBL542700 & 688288 & 4.9 & 5.3772 & TRN \\
\hline CHEMBL1390770 & 688288 & 5.8 & 5.21 & TRN \\
\hline CHEMBL1481029 & 688288 & 5.3 & 5.7487 & TRN \\
\hline CHEMBL1315257 & 688288 & 5.6 & 5.8238 & TRN \\
\hline CHEMBL 244743 & 688288 & 5.0 & 5.2859 & TRN \\
\hline CHEMBL327708 & 688288 & 4.5 & 5.2276 & TST \\
\hline CHEMBL93655 & 688288 & 5.6 & 5.5332 & TRN \\
\hline CHEMBL1376212 & 688288 & 5.3 & 5.0769 & TRN \\
\hline CHEMBL1448044 & 688288 & 4.9 & 5.4104 & TRN \\
\hline CHEMBL 1324842 & 688288 & 6.3 & 5.7669 & TRN \\
\hline CHEMBL 296586 & 688288 & 5.5 & 5.1925 & TRN \\
\hline CHEMBL1403793 & 688288 & 5.4 & 5.5472 & TRN \\
\hline CHEMBL1481974 & 688288 & 5.5 & 5.4491 & TST \\
\hline CHEMBL1473498 & 688288 & 8.7959 & 6.0828 & TRN \\
\hline CHEMBL3207894 & 688288 & 5.4 & 5.4121 & TST \\
\hline CHEMBL1604036 & 688288 & 6.7001 & 5.7685 & TST \\
\hline CHEMBL1394945 & 688288 & 4.9 & 6.0873 & TRN \\
\hline CHEMBL1514416 & 688288 & 7.6003 & 5.8897 & TRN \\
\hline CHEMBL1530216 & 688288 & 5.4 & 5.3848 & TST \\
\hline CHEMBL 1255936 & 688288 & 4.6 & 5.4577 & TRN \\
\hline CHEMBL1539075 & 688288 & 5.0 & 5.1715 & TRN \\
\hline
\end{tabular}




\begin{tabular}{|c|c|c|c|c|c|}
\hline \multicolumn{6}{|c|}{ Supplemental Table S2.txt } \\
\hline CHEMBL1523150 & 688288 & 5.4 & 5.1067 & TRN & \\
\hline CHEMBL1396997 & 688288 & 5.6 & 5.6933 & TRN & \\
\hline CHEMBL3195118 & 688288 & 5.0 & 5.2522 & TST & \\
\hline CHEMBL1256878 & 688288 & 6.0 & 5.50200 & 2000000001 & TRN \\
\hline CHEMBL404613 & 688288 & 7.8013 & 5.4848 & TST & \\
\hline CHEMBL1588762 & 688288 & 5.6 & 5.4477 & TRN & \\
\hline CHEMBL3197899 & 688288 & 5.0 & 5.2337 & TRN & \\
\hline CHEMBL1455614 & 688288 & 6.2 & 5.4247 & TRN & \\
\hline CHEMBL1356134 & 688288 & 5.5 & 5.4519 & TRN & \\
\hline CHEMBL1593412 & 688288 & 6.0 & 5.6689 & TRN & \\
\hline CHEMBL1355220 & 688288 & 7.4001 & 5.8804 & TST & \\
\hline CHEMBL1407769 & 688288 & 5.0 & 5.6791 & TST & \\
\hline CHEMBL1357222 & 688288 & 5.4 & 6.1762 & TRN & \\
\hline CHEMBL1973435 & 688288 & 6.0 & 5.1401 & TRN & \\
\hline CHEMBL3198736 & 688288 & 5.0 & 5.5203 & TST & \\
\hline CHEMBL1354600 & 688288 & 5.5 & 5.5086 & TRN & \\
\hline CHEMBL1591294 & 688288 & 5.9 & 5.5292 & TST & \\
\hline CHEMBL1561738 & 688288 & 5.1 & 4.9951 & TRN & \\
\hline CHEMBL287689 & 688288 & 5.5 & 5.5373 & TRN & \\
\hline CHEMBL1315716 & 688288 & 5.5 & 5.3268 & TRN & \\
\hline CHEMBL471225 & 688288 & 6.2 & 5.8617 & TRN & \\
\hline CHEMBL1372723 & 688288 & 4.9 & 5.6019 & TRN & \\
\hline CHEMBL1590645 & 688288 & 5.5 & 5.5918 & TRN & \\
\hline CHEMBL1455263 & 688288 & 4.9 & 5.2576 & TRN & \\
\hline CHEMBL1437007 & 688288 & 5.5 & 5.6355 & TRN & \\
\hline CHEMBL517186 & 688288 & 5.6 & 5.6983 & TRN & \\
\hline CHEMBL1403305 & 688288 & 5.4 & 5.4092 & TRN & \\
\hline CHEMBL60718 & 688288 & 4.6 & 5.5573 & TRN & \\
\hline CHEMBL1456747 & 688288 & 5.4 & 5.8671 & TST & \\
\hline CHEMBL1300597 & 688288 & 5.9 & 5.5779 & TRN & \\
\hline CHEMBL1553218 & 688288 & 5.4 & 5.8131 & TRN & \\
\hline CHEMBL95606 & 688288 & 5.2 & 5.6564 & TRN & \\
\hline CHEMBL1356135 & 688288 & 5.9 & 5.6611 & TRN & \\
\hline CHEMBL1316647 & 688288 & 6.0 & 5.7595 & TRN & \\
\hline CHEMBL1481668 & 688288 & 5.5 & 5.3403 & TRN & \\
\hline CHEMBL1584312 & 688288 & 5.7 & 5.6094 & TST & \\
\hline CHEMBL1506173 & 688288 & 5.0 & 5.4712 & TRN & \\
\hline CHEMBL1594086 & 688288 & 5.4 & 5.7078 & TRN & \\
\hline CHEMBL1331122 & 688288 & 5.5 & 5.4834 & TRN & \\
\hline CHEMBL22075 & 688288 & 4.9 & 5.3451 & TRN & \\
\hline CHEMBL1515315 & 688288 & 6.2 & 5.6551 & TRN & \\
\hline CHEMBL1440857 & 688288 & 5.0 & 5.8491 & TRN & \\
\hline CHEMBL29711 & 688288 & 5.7 & 5.7159 & TST & \\
\hline CHEMBL1393548 & 688288 & 5.0 & 5.1943 & TRN & \\
\hline CHEMBL1410039 & 688288 & 5.5 & 5.42 & TRN & \\
\hline CHEMBL1598680 & 688288 & 4.9 & 5.4364 & TRN & \\
\hline CHEMBL1608811 & 688288 & 5.7 & 5.1148 & TRN & \\
\hline CHEMBL1342837 & 688288 & 5.4 & 5.2781 & TRN & \\
\hline
\end{tabular}




\begin{tabular}{|c|c|c|c|c|}
\hline \multicolumn{5}{|c|}{ Supplemental Table S2.txt } \\
\hline CHEMBL1255656 & 688288 & 5.2 & 5.5552 & TRN \\
\hline CHEMBL 86676 & 688288 & 4.6 & 5.7315 & TST \\
\hline CHEMBL98350 & 688288 & 5.1 & 5.3445 & TRN \\
\hline CHEMBL1395277 & 688288 & 5.3 & 5.9401 & TRN \\
\hline CHEMBL1566345 & 688288 & 5.0 & 5.3223 & TRN \\
\hline CHEMBL1394944 & 688288 & 5.5 & 5.7122 & TRN \\
\hline CHEMBL1489182 & 688288 & 5.8 & 5.6592 & TRN \\
\hline CHEMBL1488420 & 688288 & 5.7 & 5.1733 & TRN \\
\hline CHEMBL1446970 & 688288 & 5.0 & 5.8448 & TST \\
\hline CHEMBL1590855 & 688288 & 5.5 & 5.7057 & TRN \\
\hline CHEMBL1354693 & 688288 & 5.5 & 5.5946 & TRN \\
\hline CHEMBL1405001 & 688288 & 5.4 & 5.7581 & TRN \\
\hline CHEMBL1572167 & 688288 & 5.1 & 5.2139 & TST \\
\hline CHEMBL303579 & 688288 & 4.6 & 5.5573 & TRN \\
\hline CHEMBL1327187 & 688288 & 6.0 & 5.559 & TRN \\
\hline CHEMBL1480806 & 688288 & 5.3 & 5.5916 & TRN \\
\hline CHEMBL1484261 & 688288 & 6.6 & 5.6509 & TRN \\
\hline CHEMBL1350478 & 688288 & 5.0 & 4.9785 & TRN \\
\hline CHEMBL1357648 & 688288 & 5.3 & 5.3515 & TRN \\
\hline CHEMBL1515867 & 688288 & 5.5 & 5.6096 & TRN \\
\hline CHEMBL1458826 & 688288 & 5.0 & 5.6138 & TRN \\
\hline CHEMBL3209312 & 688288 & 6.2 & 5.4069 & TRN \\
\hline CHEMBL1338490 & 688288 & 5.1 & 5.494 & TST \\
\hline CHEMBL 228792 & 688288 & 4.9 & 5.7186 & TRN \\
\hline CHEMBL1790009 & 688288 & 7.4001 & 5.6659 & TRN \\
\hline CHEMBL1400411 & 688288 & 5.5 & 5.8052 & TST \\
\hline CHEMBL590670 & 688288 & 5.3 & 5.5136 & TRN \\
\hline CHEMBL1593547 & 688288 & 5.5 & 5.6787 & TRN \\
\hline CHEMBL10009 & 688288 & 5.0 & 5.3583 & TRN \\
\hline CHEMBL1569893 & 688288 & 6.2 & 5.4405 & TRN \\
\hline CHEMBL3210606 & 688288 & 4.9 & 5.675 & TRN \\
\hline CHEMBL581886 & 688288 & 7.3002 & 6.0902 & TRN \\
\hline CHEMBL1365701 & 688288 & 6.0 & 5.7111 & TRN \\
\hline CHEMBL521970 & 688288 & 5.4 & 5.6627 & TRN \\
\hline CHEMBL1255653 & 688288 & 5.0 & 5.9142 & TST \\
\hline CHEMBL1403488 & 688288 & 5.5 & 5.5191 & TRN \\
\hline CHEMBL1535395 & 688288 & 5.2 & 5.0767 & TRN \\
\hline CHEMBL1528005 & 688288 & 6.1 & 5.8839 & TST \\
\hline CHEMBL1336155 & 688288 & 6.3 & 5.8513 & TST \\
\hline CHEMBL1591600 & 688288 & 6.4 & 5.8924 & TRN \\
\hline CHEMBL443893 & 688288 & 6.0 & 6.0249 & TRN \\
\hline CHEMBL1406410 & 688288 & 5.5 & 5.6723 & TRN \\
\hline CHEMBL1477573 & 688288 & 5.1 & 5.2073 & TRN \\
\hline CHEMBL1472547 & 688288 & 6.0 & 5.705 & TST \\
\hline CHEMBL565856 & 688288 & 5.3 & 5.4263 & TRN \\
\hline CHEMBL1362157 & 688288 & 5.0 & 5.2799 & TRN \\
\hline CHEMBL1547696 & 688288 & 5.4 & 5.9769 & TRN \\
\hline CHEMBL491771 & 688288 & 5.7 & 5.6226 & TRN \\
\hline
\end{tabular}




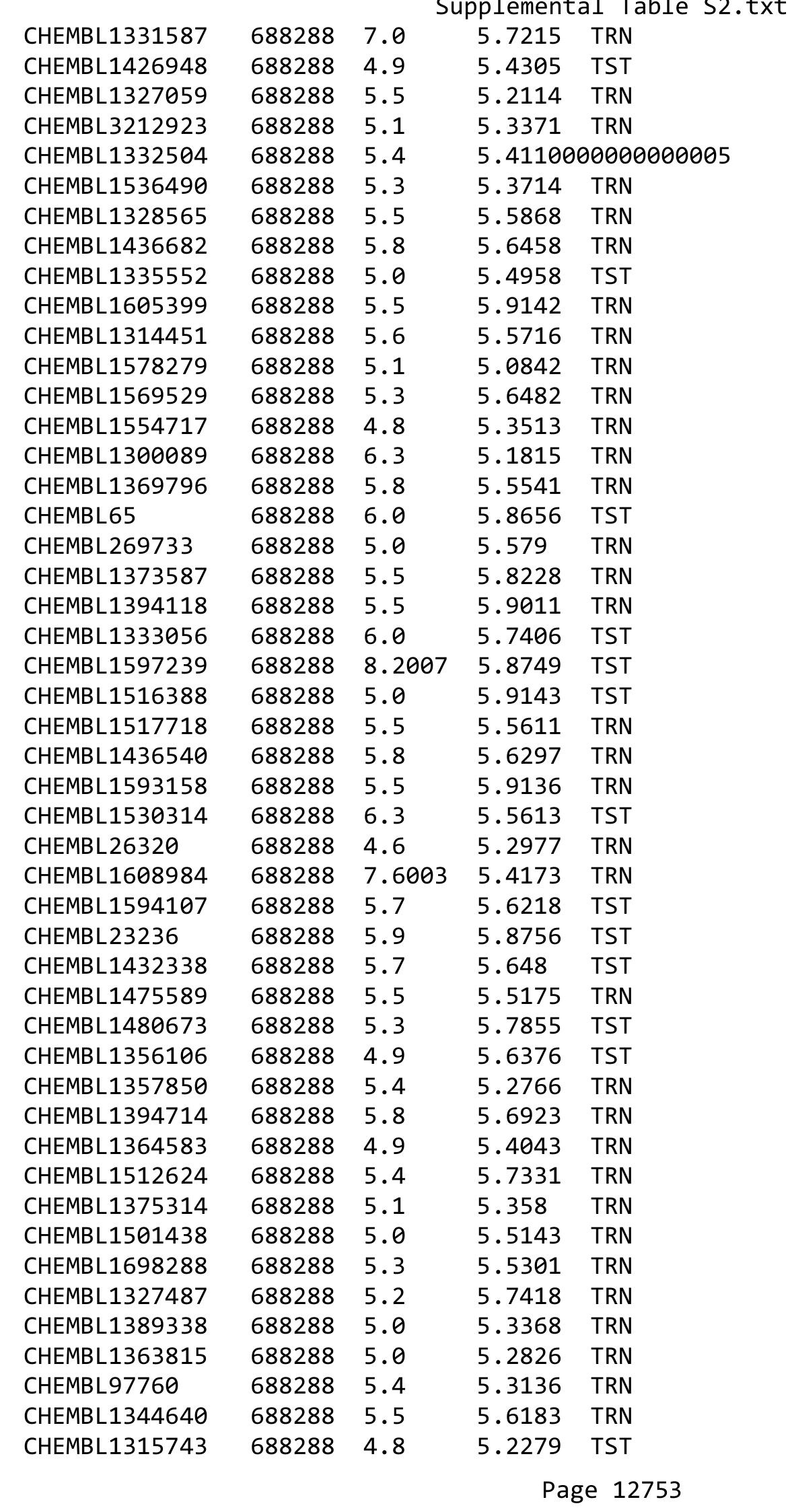




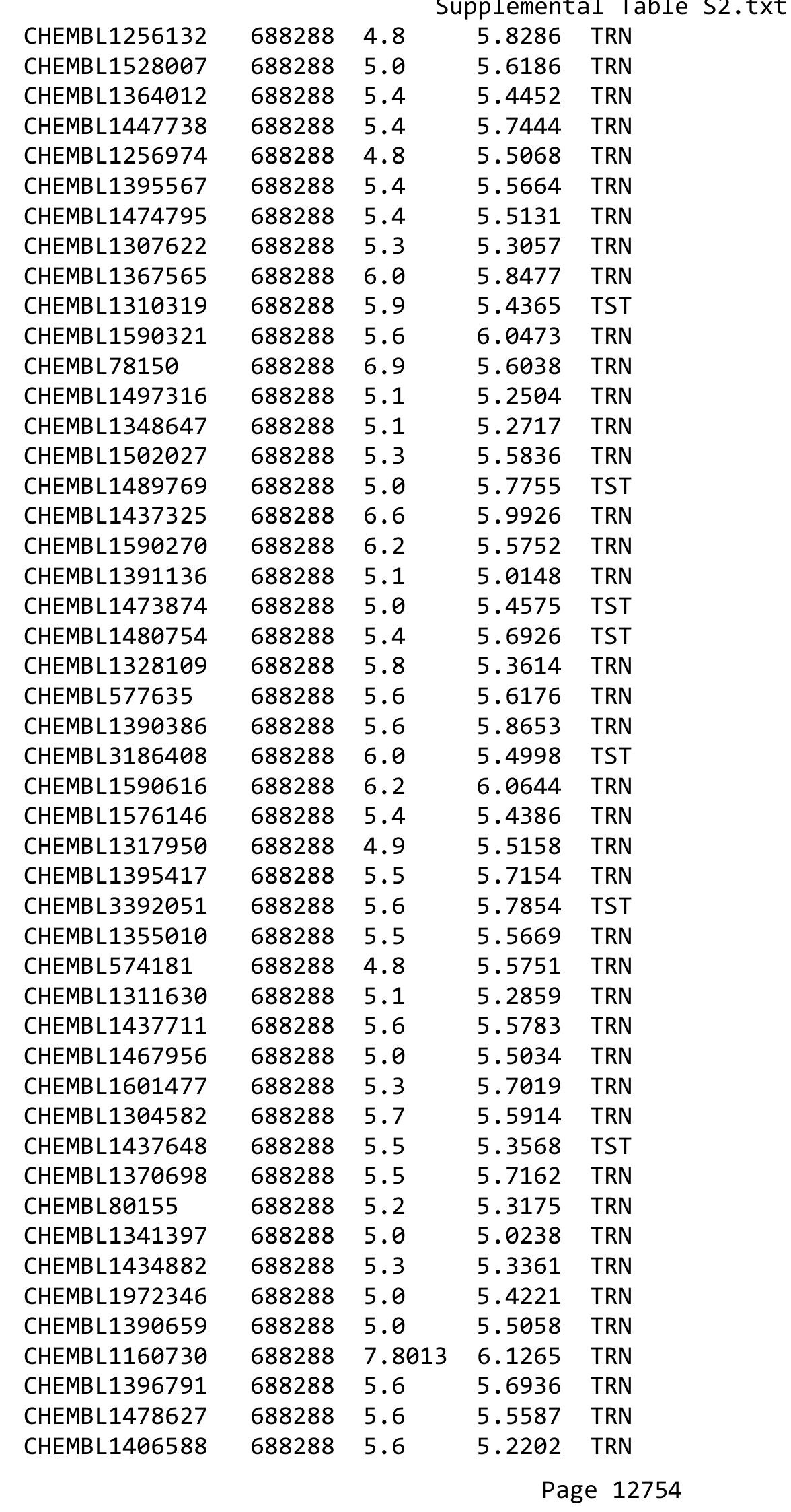




\begin{tabular}{|c|c|c|c|c|c|}
\hline \multirow[b]{2}{*}{ CHEMBL1591374 } & \multirow[b]{2}{*}{688288} & \\
\hline & & 7.0 & 5.9455 & TRN & \\
\hline CHEMBL1513490 & 688288 & 6.0 & 5.8821 & TST & \\
\hline CHEMBL1464723 & 688288 & 5.3 & 5.3819 & TRN & \\
\hline CHEMBL1306509 & 688288 & 4.9 & 5.3841 & TST & \\
\hline CHEMBL1395297 & 688288 & 5.5 & 5.5113 & TRN & \\
\hline CHEMBL1256283 & 688288 & 4.8 & 5.756 & TRN & \\
\hline CHEMBL1315072 & 688288 & 5.6 & 5.6193 & TRN & \\
\hline CHEMBL1519472 & 688288 & 6.4 & 5.5138 & TRN & \\
\hline CHEMBL1516068 & 688288 & 5.0 & 5.2228 & TRN & \\
\hline CHEMBL1531932 & 688288 & 6.4 & 5.1074 & TST & \\
\hline CHEMBL428496 & 688288 & 6.8 & 5.7093 & TST & \\
\hline CHEMBL1556447 & 688288 & 5.2 & 5.3554 & TRN & \\
\hline CHEMBL1545498 & 688288 & 5.3 & 5.7648 & TRN & \\
\hline CHEMBL24983 & 688288 & 4.5 & 5.2753 & TST & \\
\hline CHEMBL66 & 688288 & 4.6 & 5.51399 & 9999999999 & TRN \\
\hline CHEMBL1494897 & 688288 & 5.0 & 5.2664 & TST & \\
\hline CHEMBL399121 & 688288 & 5.3 & 5.75 & TRN & \\
\hline CHEMBL1326758 & 688288 & 5.0 & 5.2751 & TRN & \\
\hline CHEMBL1397877 & 688288 & 5.4 & 5.4981 & TRN & \\
\hline CHEMBL1362714 & 688288 & 5.1 & 5.7295 & TST & \\
\hline CHEMBL1553179 & 688288 & 5.5 & 5.559 & TRN & \\
\hline CHEMBL1397671 & 688288 & 5.3 & 5.8716 & TRN & \\
\hline CHEMBL104264 & 688288 & 4.8 & 5.5241 & TST & \\
\hline CHEMBL1318222 & 688288 & 5.5 & 5.6874 & TRN & \\
\hline CHEMBL1487340 & 688288 & 6.0 & 5.3325 & TRN & \\
\hline CHEMBL3207906 & 688288 & 6.1 & 5.7678 & TST & \\
\hline CHEMBL1471205 & 688288 & 5.5 & 5.2811 & TRN & \\
\hline CHEMBL1437488 & 688288 & 5.6 & 5.3982 & TRN & \\
\hline CHEMBL1553635 & 688288 & 8.1024 & 5.54299 & 9999999999 & TST \\
\hline CHEMBL1410841 & 688288 & 5.6 & 5.7921 & TST & \\
\hline CHEMBL1377507 & 688288 & 6.0 & 5.9371 & TST & \\
\hline CHEMBL1475207 & 688288 & 5.4 & 5.5055 & TRN & \\
\hline CHEMBL1384421 & 688288 & 5.5 & 5.2695 & TRN & \\
\hline CHEMBL1516163 & 688288 & 5.5 & 5.7774 & TRN & \\
\hline CHEMBL1316956 & 688288 & 5.5 & 5.6799 & TRN & \\
\hline CHEMBL1342353 & 688288 & 5.3 & 5.7368 & TRN & \\
\hline CHEMBL1480293 & 688288 & 5.7 & 5.33700 & 0000000001 & TRN \\
\hline CHEMBL1410859 & 688288 & 5.7 & 5.6026 & TRN & \\
\hline CHEMBL137743 & 688288 & 4.9 & 5.5314 & TRN & \\
\hline CHEMBL1551151 & 688288 & 5.6 & 5.9404 & TST & \\
\hline CHEMBL1473149 & 688288 & 5.5 & 5.5746 & TRN & \\
\hline CHEMBL1356391 & 688288 & 6.8 & 5.7112 & TRN & \\
\hline CHEMBL1350883 & 688288 & 5.2 & 5.8804 & TRN & \\
\hline CHEMBL1368286 & 688288 & 6.2 & 5.38700 & 00000000005 & TRN \\
\hline CHEMBL1386172 & 688288 & 6.8 & 5.664 & TRN & \\
\hline CHEMBL1528359 & 688288 & 5.3 & 5.4903 & TRN & \\
\hline CHEMBL1395431 & 688288 & 6.0 & 5.8225 & TRN & \\
\hline CHEMBL1487441 & 688288 & 5.9 & 5.6542 & TRN & \\
\hline & & & & 127 & \\
\hline
\end{tabular}




\begin{tabular}{|c|c|c|c|c|c|}
\hline \\
\hline CHEMBL1404954 & 688288 & 5.8 & 5.5331 & TRN & \\
\hline CHEMBL1502697 & 688288 & 5.3 & 5.6544 & TST & \\
\hline CHEMBL1563088 & 688288 & 5.3 & 5.5613 & TRN & \\
\hline CHEMBL1449938 & 688288 & 5.6 & 5.45100 & 00000000005 & TRN \\
\hline CHEMBL1514634 & 688288 & 4.9 & 5.4527 & TRN & \\
\hline CHEMBL1522752 & 688288 & 5.3 & 5.5704 & TRN & \\
\hline CHEMBL1435313 & 688288 & 6.0 & 5.8376 & TST & \\
\hline CHEMBL1459087 & 688288 & 5.3 & 5.3417 & TST & \\
\hline CHEMBL1524714 & 688288 & 4.9 & 5.3393 & TRN & \\
\hline CHEMBL1433464 & 688288 & 6.1 & 5.4688 & TRN & \\
\hline CHEMBL304621 & 688288 & 5.0 & 5.5122 & TRN & \\
\hline CHEMBL1476712 & 688288 & 5.9 & 5.6321 & TRN & \\
\hline CHEMBL1360778 & 688288 & 6.7001 & 5.8129 & TST & \\
\hline CHEMBL1421246 & 688288 & 6.6 & 5.2664 & TRN & \\
\hline CHEMBL1498734 & 688288 & 5.1 & 5.1328 & TRN & \\
\hline CHEMBL1463207 & 688288 & 4.9 & 5.2834 & TST & \\
\hline CHEMBL994 & 688288 & 5.0 & 5.9773 & TST & \\
\hline CHEMBL1596241 & 688288 & 5.9 & 5.5367 & TST & \\
\hline CHEMBL1372997 & 688288 & 5.0 & 5.3981 & TST & \\
\hline CHEMBL1515334 & 688288 & 4.6 & 5.6673 & TST & \\
\hline CHEMBL1456481 & 688288 & 5.5 & 5.4102 & TST & \\
\hline CHEMBL1367665 & 688288 & 4.9 & 5.5032 & TST & \\
\hline CHEMBL1449152 & 688288 & 5.6 & 5.4271 & TST & \\
\hline CHEMBL1525011 & 688288 & 5.1 & 5.7228 & TST & \\
\hline CHEMBL1368572 & 688288 & 5.5 & 5.5311 & TST & \\
\hline CHEMBL1541450 & 688288 & 5.2 & 5.2659 & TST & \\
\hline CHEMBL1594437 & 688288 & 5.0 & 5.2907 & TST & \\
\hline CHEMBL 290077 & 688288 & 5.2 & 5.9859 & TST & \\
\hline CHEMBL1269845 & 688288 & 5.5 & 5.575 & TST & \\
\hline CHEMBL1402856 & 688288 & 4.9 & 5.1606 & TST & \\
\hline CHEMBL1538257 & 688288 & 5.0 & 5.3193 & TST & \\
\hline CHEMBL1512049 & 688288 & 5.6 & 5.78100 & 0000000001 & TST \\
\hline CHEMBL372052 & 688288 & 4.8 & 5.9229 & TST & \\
\hline CHEMBL1329786 & 688288 & 5.7 & 5.4831 & TST & \\
\hline CHEMBL1314222 & 688288 & 5.5 & 5.6025 & TST & \\
\hline CHEMBL3195525 & 688288 & 5.5 & 5.315 & TST & \\
\hline CHEMBL1436075 & 688288 & 5.5 & 5.6132 & TST & \\
\hline CHEMBL1314286 & 688288 & 6.0 & 5.8195 & TST & \\
\hline CHEMBL1475008 & 688288 & 4.9 & 5.7552 & TST & \\
\hline CHEMBL1380755 & 688288 & 4.9 & 5.3294 & TST & \\
\hline CHEMBL3216363 & 688288 & 5.2 & 5.0971 & TST & \\
\hline CHEMBL1415165 & 688288 & 5.1 & 5.5583 & TST & \\
\hline CHEMBL1325335 & 688288 & 5.5 & 5.3241 & TST & \\
\hline CHEMBL1558184 & 688288 & 5.4 & 5.5786 & TST & \\
\hline CHEMBL 1257002 & 688288 & 5.9 & 5.4679 & TST & \\
\hline CHEMBL 2374368 & 688288 & 5.4 & 5.9293 & TST & \\
\hline CHEMBL128427 & 688288 & 5.1 & 5.7716 & TST & \\
\hline CHEMBL 271165 & 688288 & 5.5 & 5.5389 & TST & \\
\hline
\end{tabular}




\begin{tabular}{|c|c|c|c|c|}
\hline \multicolumn{5}{|c|}{ Supplemental Table s2.txt } \\
\hline CHEMBL1443125 & 688288 & 6.0 & 5.9368 & TST \\
\hline CHEMBL1430077 & 688288 & 4.9 & 5.1927 & TST \\
\hline CHEMBL117 & 688288 & 5.2 & 5.3836 & TST \\
\hline CHEMBL168276 & 688288 & 4.8 & 5.5194 & TST \\
\hline CHEMBL434063 & 688288 & 5.7 & 5.7402 & TST \\
\hline CHEMBL1375967 & 688288 & 5.5 & 5.528 & TST \\
\hline CHEMBL1469327 & 688288 & 5.3 & 5.1483 & TST \\
\hline CHEMBL3145312 & 688288 & 5.1 & 5.3134 & TST \\
\hline CHEMBL1473934 & 688288 & 5.5 & 5.5307 & TST \\
\hline CHEMBL1577300 & 688288 & 5.0 & 5.3038 & TST \\
\hline CHEMBL1476288 & 688288 & 5.5 & 5.5161 & TST \\
\hline CHEMBL1395415 & 688288 & 5.8 & 5.9563 & TST \\
\hline CHEMBL1358570 & 688288 & 5.9 & 5.6396 & TST \\
\hline CHEMBL1592452 & 688288 & 5.6 & 5.6948 & TST \\
\hline CHEMBL1565333 & 688288 & 5.4 & 5.7128 & TST \\
\hline CHEMBL1534248 & 688288 & 6.6 & 5.5276 & TST \\
\hline CHEMBL1527565 & 688288 & 5.4 & 5.6045 & TST \\
\hline CHEMBL1372282 & 688288 & 6.8 & 5.4867 & TST \\
\hline CHEMBL363332 & 688288 & 5.3 & 5.4582 & TST \\
\hline CHEMBL1528565 & 688288 & 4.5 & 5.375 & TST \\
\hline CHEMBL1585078 & 688288 & 5.1 & 5.3963 & TST \\
\hline CHEMBL1300512 & 688288 & 5.1 & 5.2475 & TST \\
\hline CHEMBL1200567 & 688288 & 6.0 & 5.8331 & TST \\
\hline CHEMBL1571264 & 688288 & 5.7 & 5.6262 & TST \\
\hline CHEMBL1377706 & 688288 & 5.6 & 5.9048 & TST \\
\hline CHEMBL1558569 & 688288 & 5.3 & 5.8947 & TST \\
\hline CHEMBL1591336 & 688288 & 5.4 & 5.3468 & TST \\
\hline CHEMBL1610945 & 688288 & 6.0 & 5.8776 & TST \\
\hline CHEMBL289277 & 688288 & 5.0 & 5.6382 & TST \\
\hline CHEMBL 330320 & 688288 & 6.7001 & 5.961 & TST \\
\hline CHEMBL1514143 & 688288 & 5.4 & 6.0543 & TST \\
\hline CHEMBL1325408 & 688288 & 6.0 & 5.6741 & TST \\
\hline CHEMBL1551548 & 688288 & 5.5 & 5.46 & TST \\
\hline CHEMBL1466877 & 688288 & 6.1 & 5.5653 & TST \\
\hline CHEMBL1486555 & 688288 & 7.0 & 5.7591 & TST \\
\hline CHEMBL1529147 & 688288 & 5.2 & 5.5148 & TST \\
\hline CHEMBL1446905 & 688288 & 5.4 & 5.794 & TST \\
\hline CHEMBL1304186 & 688288 & 5.4 & 5.3668 & TST \\
\hline CHEMBL1352377 & 688288 & 6.1 & 5.4572 & TST \\
\hline CHEMBL119171 & 688288 & 4.9 & 5.7996 & TST \\
\hline CHEMBL1358562 & 688288 & 5.6 & 6.0504 & TST \\
\hline CHEMBL1332450 & 688288 & 6.0 & 5.62299 & 9999999999 \\
\hline CHEMBL26915 & 688288 & 5.3 & 5.7671 & TST \\
\hline CHEMBL1464354 & 688288 & 5.4 & 5.5336 & TST \\
\hline CHEMBL1548769 & 688288 & 5.3 & 5.6005 & TST \\
\hline CHEMBL1605818 & 688288 & 5.5 & 5.9569 & TST \\
\hline CHEMBL 3192500 & 688288 & 5.0 & 5.5116 & TST \\
\hline CHEMBL1316285 & 688288 & 5.5 & 5.5343 & TST \\
\hline
\end{tabular}




\begin{tabular}{|c|c|c|c|c|c|}
\hline \\
\hline CHEMBL1473754 & 688288 & 5.9 & 5.9727 & TST & \\
\hline CHEMBL1162107 & 688288 & 5.8 & 5.5163 & TST & \\
\hline CHEMBL1496459 & 688288 & 5.5 & 5.2248 & TST & \\
\hline CHEMBL3216873 & 688288 & 5.0 & 5.4007 & TST & \\
\hline CHEMBL1440534 & 688288 & 5.3 & 5.3872 & TST & \\
\hline CHEMBL1373259 & 688288 & 5.3 & 5.7485 & TST & \\
\hline CHEMBL1513633 & 688288 & 5.6 & 5.5348 & TST & \\
\hline CHEMBL1409046 & 688288 & 4.9 & 5.7743 & TST & \\
\hline CHEMBL1593765 & 688288 & 6.0 & 5.6408 & TST & \\
\hline CHEMBL1256911 & 688288 & 5.2 & 5.5237 & TST & \\
\hline CHEMBL1688558 & 688288 & 6.4 & 6.0362 & TST & \\
\hline CHEMBL1448728 & 688288 & 5.5 & 5.6701 & TST & \\
\hline CHEMBL1409584 & 688288 & 5.0 & 5.9015 & TST & \\
\hline CHEMBL1363873 & 688288 & 5.5 & 5.4334 & TST & \\
\hline CHEMBL1437176 & 688288 & 5.5 & 5.8284 & TST & \\
\hline CHEMBL1311586 & 688288 & 6.3 & 5.3821 & TST & \\
\hline CHEMBL1317498 & 688288 & 5.4 & 5.5701 & TST & \\
\hline CHEMBL1555480 & 688288 & 5.9 & 6.1524 & TST & \\
\hline CHEMBL1408297 & 688288 & 4.9 & 5.5885 & TST & \\
\hline CHEMBL1527439 & 688288 & 6.7001 & 5.6986 & TST & \\
\hline CHEMBL1569552 & 688288 & 5.2 & 5.5399 & TST & \\
\hline CHEMBL1366745 & 688288 & 4.9 & 5.1538 & TST & \\
\hline CHEMBL1411844 & 688288 & 5.4 & 5.4131 & TST & \\
\hline CHEMBL1317647 & 688288 & 5.3 & 5.7186 & TST & \\
\hline CHEMBL585861 & 688288 & 5.5 & 5.6637 & TST & \\
\hline CHEMBL1490456 & 688288 & 4.9 & 5.3002 & TST & \\
\hline CHEMBL1436024 & 688288 & 6.0 & 5.8019 & TST & \\
\hline CHEMBL1478430 & 688288 & 5.5 & 5.4816 & TST & \\
\hline CHEMBL1558456 & 688288 & 6.8 & 6.1216 & TST & \\
\hline CHEMBL1440484 & 688288 & 5.3 & 5.4367 & TST & \\
\hline CHEMBL1516080 & 688288 & 7.8013 & 6.2094 & TST & \\
\hline CHEMBL1517187 & 688288 & 4.5 & 5.3096 & TST & \\
\hline CHEMBL1435477 & 688288 & 5.6 & 5.5704 & TST & \\
\hline CHEMBL1418227 & 688288 & 6.0 & 5.7319 & TST & \\
\hline CHEMBL1437709 & 688288 & 6.2 & 5.50899 & 99999999995 & TST \\
\hline CHEMBL1360942 & 688288 & 5.5 & 5.6392 & TST & \\
\hline CHEMBL1475146 & 688288 & 5.5 & 5.6278 & TST & \\
\hline CHEMBL1330459 & 688288 & 5.1 & 5.9847 & TST & \\
\hline CHEMBL1402957 & 688288 & 5.5 & 5.3226 & TST & \\
\hline CHEMBL1318495 & 688288 & 5.4 & 5.9107 & TST & \\
\hline CHEMBL1398137 & 688288 & 5.7 & 5.4734 & TST & \\
\hline CHEMBL1563501 & 688288 & 6.9 & 5.5206 & TST & \\
\hline CHEMBL362223 & 688288 & 4.9 & 5.586 & TST & \\
\hline CHEMBL1315965 & 688288 & 6.4 & 5.6514 & TST & \\
\hline CHEMBL1552708 & 688288 & 7.0 & 5.8793 & TST & \\
\hline CHEMBL1299470 & 688288 & 6.5 & 5.4938 & TST & \\
\hline CHEMBL1378742 & 688288 & 5.0 & 5.7684 & TST & \\
\hline CHEMBL420060 & 688288 & 4.8 & 5.3091 & TST & \\
\hline & & & & 12758 & \\
\hline
\end{tabular}




\begin{tabular}{|c|c|c|c|c|c|}
\hline \multicolumn{6}{|c|}{ Supplemental Table S2.txt } \\
\hline CHEMBL1338159 & 688288 & 5.5 & 5.8448 & TST & \\
\hline CHEMBL 2068217 & 688288 & 5.2 & 5.6555 & TST & \\
\hline CHEMBL1570993 & 688288 & 5.7 & 5.74700 & 0000000001 & TST \\
\hline CHEMBL1504180 & 688288 & 5.0 & 5.4345 & TST & \\
\hline CHEMBL3103646 & 1285138 & 5.9431 & 5.8929 & TRN & \\
\hline CHEMBL3104024 & 1285138 & 5.5186 & 6.1738 & TRN & \\
\hline CHEMBL3103645 & 1285138 & 5.7235 & 5.7081 & TRN & \\
\hline CHEMBL3104012 & 1285138 & 5.3382 & 5.5842 & TRN & \\
\hline CHEMBL3103906 & 1285138 & 5.5935 & 5.8594 & TRN & \\
\hline CHEMBL 3104232 & 1285138 & 5.1593 & 5.3537 & TRN & \\
\hline CHEMBL3103907 & 1285138 & 6.2924 & 5.716 & TRN & \\
\hline CHEMBL 3104020 & 1285138 & 5.7773 & 5.7466 & TRN & \\
\hline CHEMBL3103916 & 1285138 & 6.0315 & 6.2524 & TRN & \\
\hline CHEMBL3103905 & 1285138 & 5.6126 & 5.6266 & TRN & \\
\hline CHEMBL3104005 & 1285138 & 3.699 & 4.4535 & TRN & \\
\hline CHEMBL3103643 & 1285138 & 5.4935 & 5.5834 & TST & \\
\hline CHEMBL3104006 & 1285138 & 3.699 & 4.1537 & TRN & \\
\hline CHEMBL3103913 & 1285138 & 6.1079 & 5.6345 & TRN & \\
\hline CHEMBL3104023 & 1285138 & 5.8069 & 6.0546 & TRN & \\
\hline CHEMBL3104018 & 1285138 & 5.7721 & 5.4499 & TRN & \\
\hline CHEMBL3104230 & 1285138 & 4.9974 & 4.9974 & TRN & \\
\hline CHEMBL3103654 & 1285138 & 5.4634 & 5.1645 & TRN & \\
\hline CHEMBL3103915 & 1285138 & 5.8996 & 5.8855 & TRN & \\
\hline CHEMBL3104026 & 1285138 & 5.1135 & 5.0802 & TRN & \\
\hline CHEMBL3103650 & 1285138 & 5.2757 & 5.7822 & TST & \\
\hline CHEMBL3103917 & 1285138 & 6.2596 & 6.4549 & TRN & \\
\hline CHEMBL3104015 & 1285138 & 5.0141 & 4.9179 & TRN & \\
\hline CHEMBL3102870 & 1285138 & 6.1024 & 5.9344 & TRN & \\
\hline CHEMBL3104011 & 1285138 & 5.1746 & 5.086 & TRN & \\
\hline CHEMBL3104007 & 1285138 & 3.699 & 4.4373 & TST & \\
\hline CHEMBL3103644 & 1285138 & 5.8601 & 5.8377 & TRN & \\
\hline CHEMBL3103651 & 1285138 & 6.3979 & 6.0341 & TRN & \\
\hline CHEMBL3103652 & 1285138 & 5.5229 & 5.62799 & & TRN \\
\hline CHEMBL3103653 & 1285138 & 5.2557 & 5.5532 & TRN & \\
\hline CHEMBL3103900 & 1285138 & 5.8386 & 5.7381 & TST & \\
\hline CHEMBL3103647 & 1285138 & 6.1938 & 5.8372 & TRN & \\
\hline CHEMBL3103898 & 1285138 & 5.6021 & 5.7051 & TST & \\
\hline CHEMBL3104234 & 1285138 & 3.699 & 4.3191 & TRN & \\
\hline CHEMBL3103648 & 1285138 & 5.6326 & 5.4891 & TRN & \\
\hline CHEMBL3104233 & 1285138 & 3.699 & 5.027 & TST & \\
\hline CHEMBL3104003 & 1285138 & 3.699 & 4.7152 & TRN & \\
\hline CHEMBL3103897 & 1285138 & 5.8013 & 5.6479 & TST & \\
\hline CHEMBL3104009 & 1285138 & 5.2823 & 5.2012 & TRN & \\
\hline CHEMBL3103903 & 1285138 & 5.3615 & 5.352 & TRN & \\
\hline CHEMBL3104019 & 1285138 & 5.9393 & 5.3831 & TRN & \\
\hline CHEMBL3104025 & 1285138 & 4.8601 & 4.895 & TRN & \\
\hline CHEMBL3103904 & 1285138 & 5.1871 & 5.5265 & TRN & \\
\hline CHEMBL3103901 & 1285138 & 5.0899 & 4.1118 & TRN & \\
\hline
\end{tabular}


Supplemental Table S2.txt

\begin{tabular}{|c|c|c|c|c|c|}
\hline CHEMBL3104021 & 1285138 & 5.5171 & 5.6209 & TRN & \\
\hline CHEMBL3104008 & 1285138 & 5.1433 & 4.9365 & TRN & \\
\hline CHEMBL3104010 & 1285138 & 4.9678 & 4.8845 & TRN & \\
\hline CHEMBL3103902 & 1285138 & 5.4389 & 5.4801 & TRN & \\
\hline CHEMBL3103909 & 1285138 & 5.8182 & 5.5272 & TRN & \\
\hline CHEMBL3103910 & 1285138 & 5.9281 & 5.3557 & TRN & \\
\hline CHEMBL3103642 & 1285138 & 5.0491 & 4.4109 & TST & \\
\hline CHEMBL3103912 & 1285138 & 5.9318 & 5.9015 & TST & \\
\hline CHEMBL3104229 & 1285138 & 4.8897 & 4.4974 & TRN & \\
\hline CHEMBL3103899 & 1285138 & 5.7799 & 5.6795 & TST & \\
\hline CHEMBL3104013 & 1285138 & 5.2472 & 5.0026 & TRN & \\
\hline CHEMBL3103911 & 1285138 & 5.3546 & 5.8471 & TST & \\
\hline CHEMBL3103908 & 1285138 & 6.2218 & 5.6321 & TST & \\
\hline CHEMBL3104022 & 1285138 & 5.7905 & 5.8193 & TRN & \\
\hline CHEMBL3103914 & 1285138 & 6.2757 & 5.4497 & TST & \\
\hline CHEMBL3104014 & 1285138 & 5.3316 & 5.3505 & TRN & \\
\hline CHEMBL3103655 & 1285138 & 6.2007 & 5.647 & TST & \\
\hline CHEMBL3103649 & 1285138 & 5.3224 & 5.3803 & TST & \\
\hline CHEMBL3103641 & 1285138 & 5.5935 & 5.7994 & TST & \\
\hline CHEMBL3104016 & 1285138 & 5.1124 & 5.2983 & TRN & \\
\hline CHEMBL3104231 & 1285138 & 5.3439 & 5.7487 & TRN & \\
\hline CHEMBL3104004 & 1285138 & 4.9289 & 4.3651 & TST & \\
\hline CHEMBL3104017 & 1285138 & 5.51 & 5.5337 & TRN & \\
\hline CHEMBL3922625 & 1641766 & 6.7167 & \multicolumn{2}{|c|}{6.502000000000001} & TRN \\
\hline CHEMBL3955748 & 1641766 & 5.5867 & 5.2017 & TRN & \\
\hline CHEMBL3938138 & 1641766 & 5.7011 & 5.7902 & TRN & \\
\hline CHEMBL3916594 & 1641766 & 6.1118 & 6.3783 & TRN & \\
\hline CHEMBL3900718 & 1641766 & 4.8477 & 5.4084 & TRN & \\
\hline CHEMBL3979461 & 1641766 & 5.7033 & 5.4962 & TST & \\
\hline CHEMBL 3948091 & 1641766 & 4.7959 & 5.1145 & TST & \\
\hline CHEMBL3928121 & 1641766 & 6.3335 & 6.1996 & TRN & \\
\hline CHEMBL 3926642 & 1641766 & 6.4698 & 5.9444 & TRN & \\
\hline CHEMBL3896891 & 1641766 & 5.9136 & 6.1655 & TRN & \\
\hline CHEMBL3948444 & 1641766 & 6.2328 & 6.7367 & TRN & \\
\hline CHEMBL3898405 & 1641766 & 6.0969 & 5.9161 & TRN & \\
\hline CHEMBL3960584 & 1641766 & 6.011 & 6.3175 & TRN & \\
\hline CHEMBL3911479 & 1641766 & 6.1512 & 5.7705 & TRN & \\
\hline CHEMBL3948715 & 1641766 & 5.426 & 5.1771 & TRN & \\
\hline CHEMBL3982545 & 1641766 & 5.2351 & 5.7379 & TST & \\
\hline CHEMBL3920827 & 1641766 & 6.684 & 6.9925 & TRN & \\
\hline CHEMBL3912959 & 1641766 & 6.8729 & 6.8494 & TST & \\
\hline CHEMBL3904087 & 1641766 & 5.3002 & 5.5707 & TRN & \\
\hline CHEMBL3982796 & 1641766 & 6.5986 & 6.5296 & TRN & \\
\hline CHEMBL3939564 & 1641766 & 4.6326 & 5.0234 & TRN & \\
\hline CHEMBL3941069 & 1641766 & 6.3686 & 5.9557 & TRN & \\
\hline CHEMBL3907373 & 1641766 & 5.5702 & 6.0418 & TRN & \\
\hline CHEMBL3944229 & 1641766 & 6.0 & 6.0055 & TRN & \\
\hline CHEMBL3952945 & 1641766 & 6.9914 & 6.9458 & TST & \\
\hline
\end{tabular}


Supplemental Table S2.txt

\begin{tabular}{|c|c|c|c|c|c|c|}
\hline CHEMBL3969101 & 1641766 & 5.3904 & 5.19 & TRN & & \\
\hline CHEMBL 3891509 & 1641766 & 6.0241 & 5.5625 & TST & & \\
\hline CHEMBL3967377 & 1641766 & 5.3696 & 5.0843 & TRN & & \\
\hline CHEMBL 3906169 & 1641766 & 6.7144 & 6.5997 & TRN & & \\
\hline CHEMBL 3895556 & 1641766 & 6.8013 & 6.535 & TRN & & \\
\hline CHEMBL3968806 & 1641766 & 4.4737 & 5.6624 & TRN & & \\
\hline CHEMBL 3954678 & 1641766 & 4.76699 & 999999999 & 995 & 5.1563 & TRN \\
\hline CHEMBL 3982207 & 1641766 & 4.9245 & 5.0225 & TRN & & \\
\hline CHEMBL 3908279 & 1641766 & 4.9281 & 5.632000 & 0000000001 & & TRN \\
\hline CHEMBL 3958343 & 1641766 & 6.0 & 5.7719 & TRN & & \\
\hline CHEMBL 3981707 & 1641766 & 6.38200 & 000000000 & $\partial 1$ & 6.0924 & TRIV \\
\hline CHEMBL3909976 & 1641766 & 5.5452 & 5.2576 & TRN & & \\
\hline CHEMBL 3986073 & 1641766 & 4.8633 & 5.0896 & TRN & & \\
\hline CHEMBL 3975139 & 1641766 & 6.1308 & 6.2361 & TRN & & \\
\hline CHEMBL 3889949 & 1641766 & 5.8794 & 5.3865 & TRN & & \\
\hline CHEMBL 3954108 & 1641766 & 5.3107 & 5.3975 & TST & & \\
\hline CHEMBL 3906650 & 1641766 & 4.7033 & 5.5811 & TRN & & \\
\hline CHEMBL 3980393 & 1641766 & 5.6968 & 6.1211 & TRN & & \\
\hline CHEMBL 3974688 & 1641766 & 4.9547 & 5.428999 & 9999999999 & & . \\
\hline CHEMBL 3955295 & 1641766 & 6.1938 & 5.8435 & TRN & & \\
\hline CHEMBL 3915316 & 1641766 & 5.0958 & 5.4844 & TRN & & \\
\hline CHEMBL 3927450 & 1641766 & 6.8416 & 6.9445 & TRN & & \\
\hline CHEMBL 3972621 & 1641766 & 5.9547 & 5.8672 & TRN & & \\
\hline CHEMBL 3949565 & 1641766 & 6.4855 & 6.3843 & TRN & & \\
\hline CHEMBL 3914297 & 1641766 & 6.4067 & 6.2295 & TRN & & \\
\hline CHEMBL 3921824 & 1641766 & 5.6498 & 5.525 & TRN & & \\
\hline CHEMBL 3959387 & 1641766 & 6.5498 & 6.5472 & TRN & & \\
\hline CHEMBL 3977812 & 1641766 & 7.1701 & 6.6669 & TRN & & \\
\hline CHEMBL 3937678 & 1641766 & 5.3645 & 5.3692 & TRN & & \\
\hline CHEMBL 3944096 & 1641766 & 4.6635 & 4.9284 & TST & & \\
\hline CHEMBL 3910144 & 1641766 & 6.3893 & 5.9328 & TRN & & \\
\hline CHEMBL 3900428 & 1641766 & 6.5017 & 6.4731 & TRN & & \\
\hline CHEMBL3951692 & 1641766 & 4.9393 & 5.1565 & TRN & & \\
\hline CHEMBL 3902869 & 1641766 & 5.0888 & 5.2019 & TRN & & \\
\hline CHEMBL 3922565 & 1641766 & 6.34200 & 000000000 & 305 & 6.6257 & \\
\hline CHEMBL 3955931 & 1641766 & 5.8268 & 5.8757 & TRN & & \\
\hline CHEMBL3943111 & 1641766 & 6.7905 & 6.6235 & TST & & \\
\hline CHEMBL 3909713 & 1641766 & 6.5768 & 6.2879 & TRN & & \\
\hline CHEMBL 3970163 & 1641766 & 4.9706 & 5.2494 & TRN & & \\
\hline CHEMBL 3913493 & 1641766 & 5.6459 & 5.8035 & TRN & & \\
\hline CHEMBL 3932638 & 1641766 & 4.8601 & 5.0968 & TRN & & \\
\hline CHEMBL 3948638 & 1641766 & 5.7011 & 6.2636 & TRN & & \\
\hline CHEMBL 3917677 & 1641766 & 6.8239 & 6.1172 & TRN & & \\
\hline CHEMBL 3942240 & 1641766 & 5.6253 & 5.4641 & TRN & & \\
\hline CHEMBL 3933849 & 1641766 & 5.5086 & 5.6258 & TRN & & \\
\hline CHEMBL 3969238 & 1641766 & 6.0701 & 6.3192 & TRN & & \\
\hline CHEMBL 3896276 & 1641766 & 5.1993 & 5.2151 & TRN & & \\
\hline CHEMBL 3929582 & 1641766 & 7.1002 & 7.2651 & TRN & & \\
\hline
\end{tabular}

Page 12761 
Supplemental Table S2.txt

\begin{tabular}{|c|c|c|c|c|c|c|}
\hline CHEMBL3944754 & 1641766 & 6.8386 & 6.1473 & TST & & \\
\hline CHEMBL3944914 & 1641766 & 6.3546 & 5.7545 & TRN & & \\
\hline CHEMBL3949406 & 1641766 & 6.04 & 6.1461 & TRN & & \\
\hline CHEMBL3892907 & 1641766 & 5.475 & 6.3381 & TRN & & \\
\hline CHEMBL3889642 & 1641766 & 5.2874 & 5.1049 & TRN & & \\
\hline CHEMBL3983724 & 1641766 & 6.9066 & 6.4526 & TRN & & \\
\hline CHEMBL3918953 & 1641766 & 4.7011 & 4.916 & TRN & & \\
\hline CHEMBL3976155 & 1641766 & 6.4559 & 6.3466 & TRN & & \\
\hline CHEMBL3934234 & 1641766 & 4.7423 & 5.4804 & TRN & & \\
\hline CHEMBL3946878 & 1641766 & 5.4353 & 5.9951 & TRN & & \\
\hline CHEMBL3930854 & 1641766 & 5.1487 & 5.296 & TRN & & \\
\hline CHEMBL3909869 & 1641766 & 6.0 & 5.8722 & TST & & \\
\hline CHEMBL3986882 & 1641766 & 5.1925 & 5.2829 & TRN & & \\
\hline CHEMBL3930549 & 1641766 & 5.2741 & 5.3392 & TST & & \\
\hline CHEMBL3912648 & 1641766 & 5.7258 & 6.1065 & TRN & & \\
\hline CHEMBL3906360 & 1641766 & 5.5186 & 5.308 & TST & & \\
\hline CHEMBL3930997 & 1641766 & 6.4179 & 6.1827 & TRN & & \\
\hline CHEMBL3912549 & 1641766 & 5.2449 & 5.3024 & TST & & \\
\hline CHEMBL3893102 & 1641766 & 6.7595 & 6.5713 & TRN & & \\
\hline CHEMBL3929996 & 1641766 & 5.2765 & 5.3355 & TRN & & \\
\hline CHEMBL3952857 & 1641766 & 5.556 & 5.2861 & TRN & & \\
\hline CHEMBL3964740 & 1641766 & 6.75700 & 000000000 & 1 & 6.3253 & TST \\
\hline CHEMBL3919149 & 1641766 & 6.2874 & 6.6128 & TRN & & \\
\hline CHEMBL3905978 & 1641766 & 6.0477 & 6.03 & TRN & & \\
\hline CHEMBL3943304 & 1641766 & 6.5186 & 6.3453 & TRN & & \\
\hline CHEMBL3932071 & 1641766 & 6.4647 & 6.5504 & TRN & & \\
\hline CHEMBL3943018 & 1641766 & 5.5171 & 5.7587 & TRN & & \\
\hline CHEMBL3904587 & 1641766 & 6.011 & 5.5332 & TRN & & \\
\hline CHEMBL3954510 & 1641766 & 7.0391 & 6.7451 & TST & & \\
\hline CHEMBL3949355 & 1641766 & 6.6459 & 6.5328 & TRN & & \\
\hline CHEMBL3964144 & 1641766 & 5.9706 & 5.7571 & TST & & \\
\hline CHEMBL3920490 & 1641766 & 5.7399 & 5.7402 & TRN & & \\
\hline CHEMBL3980641 & 1641766 & 5.7825 & 5.5484 & TRN & & \\
\hline CHEMBL3899549 & 1641766 & 7.6126 & 7.0424 & TRN & & \\
\hline CHEMBL3918153 & 1641766 & 4.9136 & 5.1186 & TRN & & \\
\hline CHEMBL3939449 & 1641766 & 5.0348 & 5.4098 & TRN & & \\
\hline CHEMBL3948619 & 1641766 & 5.5817 & 5.5727 & TRN & & \\
\hline CHEMBL3919694 & 1641766 & 6.3947 & 6.1964 & TRN & & \\
\hline CHEMBL3923857 & 1641766 & 5.8633 & 5.9095 & TRN & & \\
\hline CHEMBL3952544 & 1641766 & 5.8386 & 6.4282 & TST & & \\
\hline CHEMBL3931583 & 1641766 & 6.1215 & 5.813 & TST & & \\
\hline CHEMBL3928011 & 1641766 & 7.16299 & 999999999 & 99 & 6.8525 & TRN \\
\hline CHEMBL3930401 & 1641766 & 6.2725 & 5.8594 & TRN & & \\
\hline CHEMBL3974790 & 1641766 & 5.7144 & 6.0758 & TST & & \\
\hline CHEMBL3922400 & 1641766 & 7.6253 & 7.5871 & TST & & \\
\hline CHEMBL3953829 & 1641766 & 6.2899 & 6.5339 & TST & & \\
\hline CHEMBL3978865 & 1641766 & 6.0706 & 6.1852 & TRN & & \\
\hline CHEMBL3922776 & 1641766 & 6.0173 & 5.782 & TRN & & \\
\hline
\end{tabular}

Page 12762 
Supplemental Table S2.txt

\begin{tabular}{|c|c|c|c|c|c|}
\hline CHEMBL 3974650 & 1641766 & 6.4921 & 5.9014 & TRN & \\
\hline CHEMBL 3934231 & 1641766 & 5.3036 & \multicolumn{2}{|c|}{5.428999999999999} & TRN \\
\hline CHEMBL3902642 & 1641766 & 5.5654 & 5.4593 & TRN & \\
\hline CHEMBL 3890100 & 1641766 & 5.9788 & 6.0131 & TRN & \\
\hline CHEMBL 3925263 & 1641766 & 5.3936 & 5.5928 & TRN & \\
\hline CHEMBL3919882 & 1641766 & 6.3747 & 6.1785 & TRN & \\
\hline CHEMBL 3904074 & 1641766 & 6.3288 & 5.9557 & TRN & \\
\hline CHEMBL3945942 & 1641766 & 5.4609 & 5.8839 & TST & \\
\hline CHEMBL3913628 & 1641766 & 5.4881 & 5.465 & TRN & \\
\hline CHEMBL3963974 & 1641766 & 5.2865 & \multicolumn{2}{|c|}{5.3870000000000005} & TRN \\
\hline CHEMBL3937046 & 1641766 & 5.5768 & 5.4799 & TRN & \\
\hline CHEMBL 3977404 & 1641766 & 6.8601 & 6.1826 & TST & \\
\hline CHEMBL3935306 & 1641766 & 5.3261 & 5.4149 & TRN & \\
\hline CHEMBL3900671 & 1641766 & 5.6576 & 5.7646 & TST & \\
\hline CHEMBL3921636 & 1641766 & 5.8729 & 5.8815 & TRN & \\
\hline CHEMBL3959065 & 1641766 & 7.1024 & \multicolumn{2}{|c|}{7.0489999999999995} & TST \\
\hline CHEMBL3950353 & 1641766 & 6.7375 & 6.9296 & TRN & \\
\hline CHEMBL3919513 & 1641766 & 7.2388 & 6.7674 & TST & \\
\hline CHEMBL3902690 & 1641766 & \multicolumn{3}{|c|}{5.757000000000001} & TST \\
\hline CHEMBL3907025 & 1641766 & 6.4283 & 6.8709 & TRN & \\
\hline CHEMBL3943116 & 1641766 & 6.1433 & 6.1661 & TST & \\
\hline CHEMBL3937896 & 1641766 & 5.7825 & 5.624 & TRN & \\
\hline CHEMBL3924938 & 1641766 & 5.1118 & 5.5639 & TRN & \\
\hline CHEMBL 3900228 & 1641766 & 5.5817 & \multicolumn{2}{|c|}{5.763999999999999} & TRN \\
\hline CHEMBL3944281 & 1641766 & 5.3468 & 5.5311 & TRN & \\
\hline CHEMBL3911405 & 1641766 & 6.1141 & 6.3184 & TRN & \\
\hline CHEMBL 3912845 & 1641766 & 5.5376 & 5.3478 & TRN & \\
\hline CHEMBL3982445 & 1641766 & 5.5376 & 5.4438 & TST & \\
\hline CHEMBL3927096 & 1641766 & 6.556 & 6.5021 & TRN & \\
\hline CHEMBL3985931 & 1641766 & 7.4498 & 7.3532 & TRN & \\
\hline CHEMBL3934299 & 1641766 & 6.1688 & 6.0785 & TRN & \\
\hline CHEMBL 3889675 & 1641766 & 6.4123 & 5.8785 & TRN & \\
\hline CHEMBL3939634 & 1641766 & 5.3054 & 5.3952 & TRN & \\
\hline CHEMBL3973123 & 1641766 & 4.8996 & \multicolumn{2}{|c|}{5.242999999999999} & TRN \\
\hline CHEMBL3948159 & 1641766 & 6.1649 & 6.331 & TRN & \\
\hline CHEMBL 3900187 & 1641766 & 6.0287 & 5.5139 & TRN & \\
\hline CHEMBL3975287 & 1641766 & 5.9245 & 6.0231 & TST & \\
\hline CHEMBL 3898020 & 1641766 & 6.2111 & 6.3063 & TST & \\
\hline CHEMBL3929862 & 1641766 & 6.4389 & 6.779 & TRN & \\
\hline CHEMBL3944898 & 1641766 & 5.857 & 5.7133 & TRN & \\
\hline CHEMBL3957373 & 1641766 & 5.8097 & 5.5879 & TRN & \\
\hline CHEMBL3963432 & 1641766 & \multicolumn{3}{|c|}{6.757000000000001} & TRN \\
\hline CHEMBL3937730 & 1641766 & 6.1811 & 6.6404 & TST & \\
\hline CHEMBL3926166 & 1641766 & 6.6615 & 6.5501 & TST & \\
\hline CHEMBL3934179 & 1641766 & 6.8697 & 7.0956 & TRN & \\
\hline CHEMBL3902709 & 1641766 & 7.2396 & 6.8133 & TST & \\
\hline CHEMBL3961261 & 1641766 & 4.8996 & 4.9562 & TRN & \\
\hline CHEMBL3915425 & 1641766 & 6.0 & 6.45100 & 00000000005 & TST \\
\hline
\end{tabular}


Supplemental Table S2.txt

\begin{tabular}{|c|c|c|c|c|c|}
\hline CHEMBL3966862 & 1641766 & 6.1325 & 6.487 & TST & \\
\hline CHEMBL 3952248 & 1641766 & 5.4437 & \multicolumn{2}{|c|}{6.047000000000001} & TRN \\
\hline CHEMBL3939863 & 1641766 & 5.4789 & 5.648 & TRN & \\
\hline CHEMBL 3946087 & 1641766 & 6.5143 & 6.4816 & TST & \\
\hline CHEMBL3906799 & 1641766 & 6.1249 & 6.0286 & TRN & \\
\hline CHEMBL3897092 & 1641766 & 4.9245 & 6.3462 & TST & \\
\hline CHEMBL3935356 & 1641766 & 6.2676 & 6.3381 & TST & \\
\hline CHEMBL3905397 & 1641766 & 6.8697 & 6.2524 & TST & \\
\hline CHEMBL 3958044 & 1641766 & 5.2396 & 5.0856 & TST & \\
\hline CHEMBL3983609 & 1641766 & 6.0851 & 5.6934 & TST & \\
\hline CHEMBL3928626 & 1641766 & 6.4685 & 5.9129 & TRN & \\
\hline CHEMBL3932586 & 1641766 & 5.6536 & 5.9073 & TRN & \\
\hline CHEMBL3956199 & 1641766 & 5.9281 & 5.7847 & TRN & \\
\hline CHEMBL3934058 & 1641766 & 5.6536 & 5.5278 & TRN & \\
\hline CHEMBL3983301 & 1641766 & 5.7959 & 5.7315 & TRN & \\
\hline CHEMBL3938755 & 1641766 & 5.5003 & 5.8384 & TRN & \\
\hline CHEMBL3972706 & 1641766 & 5.1152 & 5.1289 & TRN & \\
\hline CHEMBL3341981 & 1641766 & 7.4134 & 6.5384 & TRN & \\
\hline CHEMBL3911712 & 1641766 & 6.5186 & 6.3809 & TRN & \\
\hline CHEMBL3983923 & 1641766 & 5.8125 & 6.1762 & TRN & \\
\hline CHEMBL3967311 & 1641766 & 5.684 & 5.5017 & TRN & \\
\hline CHEMBL 3980561 & 1641766 & 5.4962 & 5.5948 & TRN & \\
\hline CHEMBL3960217 & 1641766 & 5.1707 & 5.0415 & TST & \\
\hline CHEMBL3939383 & 1641766 & 6.0106 & 5.8558 & TRN & \\
\hline CHEMBL 3928707 & 1641766 & 6.8356 & 7.1083 & TST & \\
\hline CHEMBL3943628 & 1641766 & 5.585 & 5.2543 & TRN & \\
\hline CHEMBL3945380 & 1641766 & 5.5935 & 5.7546 & TRN & \\
\hline CHEMBL3928200 & 1641766 & 6.3809 & 5.4576 & TRN & \\
\hline CHEMBL3978706 & 1641766 & 5.3251 & 5.5882 & TST & \\
\hline CHEMBL3961669 & 1641766 & 5.9666 & 5.7479 & TRN & \\
\hline CHEMBL3962721 & 1641766 & 7.2299 & 6.8038 & TST & \\
\hline CHEMBL3911657 & 1641766 & 5.2541 & 5.2767 & TRN & \\
\hline CHEMBL3898069 & 1641766 & 5.0424 & 4.8523 & TRN & \\
\hline CHEMBL3942456 & 1641766 & 5.2503 & 6.723 & TST & \\
\hline CHEMBL3946486 & 1641766 & 6.6402 & 6.9024 & TRN & \\
\hline CHEMBL3946933 & 1641766 & 5.5935 & 5.6071 & TRN & \\
\hline CHEMBL3929296 & 1641766 & 6.041 & 6.0753 & TST & \\
\hline CHEMBL3921625 & 1641766 & 6.3161 & 6.0958 & TST & \\
\hline CHEMBL3910221 & 1641766 & 6.1068 & 5.8418 & TRN & \\
\hline CHEMBL3909582 & 1641766 & 5.2111 & 5.4445 & TRN & \\
\hline CHEMBL3957302 & 1641766 & 4.7645 & 5.1184 & TST & \\
\hline CHEMBL3913715 & 1641766 & 6.0 & 5.86 & TST & \\
\hline CHEMBL3890316 & 1641766 & 5.6144 & 5.4745 & TRN & \\
\hline CHEMBL3909534 & 1641766 & 6.6925 & 6.79299 & 9999999999 & TRN \\
\hline CHEMBL3913179 & 1641766 & 5.0353 & 5.6839 & TST & \\
\hline CHEMBL3941557 & 1641766 & 5.8827 & 5.6709 & TRN & \\
\hline CHEMBL3930852 & 1641766 & 6.0 & 5.7621 & TRN & \\
\hline CHEMBL3919229 & 1641766 & 5.0357 & 5.07 & TRN & \\
\hline
\end{tabular}


Supplemental Table S2.txt

\begin{tabular}{|c|c|c|c|c|c|}
\hline CHEMBL3955581 & 1641766 & 5.6162 & 5.7753 & TRN & \\
\hline CHEMBL3940662 & 1641766 & 6.4191 & 6.7334 & TRN & \\
\hline CHEMBL3939862 & 1641766 & 5.3458 & 5.0627 & TRN & \\
\hline CHEMBL1363594 & 688624 & 4.75 & 4.6823 & TRN & \\
\hline CHEMBL1339209 & 688624 & 5.1 & 4.9105 & TRN & \\
\hline CHEMBL1475079 & 688624 & 4.9 & 4.9712 & TRN & \\
\hline CHEMBL1355139 & 688624 & 5.6 & 5.4509 & TRN & \\
\hline CHEMBL1446523 & 688624 & 7.0 & 7.0189 & TRN & \\
\hline CHEMBL1592464 & 688624 & 4.9 & 5.0853 & TRN & \\
\hline CHEMBL1438690 & 688624 & 4.7 & 4.6652 & TRN & \\
\hline CHEMBL1326341 & 688624 & 4.9 & 5.1362 & TRN & \\
\hline CHEMBL1435907 & 688624 & 5.5 & 5.0782 & TST & \\
\hline CHEMBL1551518 & 688624 & 4.8 & 5.0697 & TRN & \\
\hline CHEMBL1335654 & 688624 & 4.8 & 4.7609 & TRN & \\
\hline CHEMBL1472926 & 688624 & 6.9 & 6.6584 & TRN & \\
\hline CHEMBL1436682 & 688624 & 5.0 & 5.1037 & TRN & \\
\hline CHEMBL1354600 & 688624 & 4.9 & 4.8772 & TRN & \\
\hline CHEMBL1355881 & 688624 & 5.05 & 4.6964 & TST & \\
\hline CHEMBL1357293 & 688624 & 5.55 & 5.3777 & TRN & \\
\hline CHEMBL1417837 & 688624 & 6.25 & 6.0298 & TRN & \\
\hline CHEMBL1480806 & 688624 & 5.0 & 5.1641 & TRN & \\
\hline CHEMBL1433559 & 688624 & 5.85 & 5.8274 & TRN & \\
\hline CHEMBL1378755 & 688624 & 4.9 & 4.9361 & TST & \\
\hline CHEMBL1323759 & 688624 & 4.95 & 4.6881 & TST & \\
\hline CHEMBL1570633 & 688624 & 5.1 & 4.9793 & TRN & \\
\hline CHEMBL1495150 & 688624 & 4.9 & 4.8192 & TST & \\
\hline CHEMBL1475689 & 688624 & 4.85 & 4.8217 & TST & \\
\hline CHEMBL1595576 & 688624 & 5.45 & 5.5008 & TRN & \\
\hline CHEMBL1315373 & 688624 & 5.6 & 5.7321 & TRN & \\
\hline CHEMBL1314255 & 688624 & 4.9 & 4.7585 & TST & \\
\hline CHEMBL1561888 & 688624 & 5.0 & 5.15799 & 99999999995 & TRN \\
\hline CHEMBL1601477 & 688624 & 5.05 & 5.0386 & TRN & \\
\hline CHEMBL1568575 & 688624 & 5.1 & 4.8512 & TST & \\
\hline CHEMBL1403793 & 688624 & 6.8 & 6.7124 & TRN & \\
\hline CHEMBL1362079 & 688624 & 4.9 & 4.7315 & TRN & \\
\hline CHEMBL1554567 & 688624 & 5.1 & 5.0994 & TST & \\
\hline CHEMBL1397636 & 688624 & 4.85 & 5.0944 & TST & \\
\hline CHEMBL1396595 & 688624 & 5.1 & 5.6732 & TST & \\
\hline CHEMBL1439401 & 688624 & 4.85 & 5.0057 & TRN & \\
\hline CHEMBL1593134 & 688624 & 4.85 & 5.1628 & TRN & \\
\hline CHEMBL1474272 & 688624 & 4.9 & 4.8673 & TRN & \\
\hline CHEMBL1475428 & 688624 & 4.85 & 4.6913 & TST & \\
\hline CHEMBL1553322 & 688624 & 4.9 & 4.9548 & TST & \\
\hline CHEMBL1356135 & 688624 & 4.65 & 5.083 & TRN & \\
\hline CHEMBL1409689 & 688624 & 6.0 & 6.0006 & TST & \\
\hline CHEMBL1395431 & 688624 & 4.85 & 5.0655 & TRN & \\
\hline CHEMBL1568250 & 688624 & 5.05 & 5.256 & TRN & \\
\hline CHEMBL1373326 & 688624 & 4.85 & 5.0205 & TRN & \\
\hline
\end{tabular}




\begin{tabular}{|c|c|c|c|c|}
\hline \multicolumn{5}{|c|}{ Supplemental Table S2.txt } \\
\hline CHEMBL1316353 & 688624 & 5.5 & 5.2482 & TRN \\
\hline CHEMBL1358234 & 688624 & 5.0 & 5.0835 & TRN \\
\hline CHEMBL1475695 & 688624 & 5.15 & 5.2348 & TRN \\
\hline CHEMBL1473834 & 688624 & 5.35 & 5.2763 & TRN \\
\hline CHEMBL1318340 & 688624 & 6.5501 & 6.5838 & TRN \\
\hline CHEMBL1404501 & 688624 & 4.8 & 5.0935 & TRN \\
\hline CHEMBL1606727 & 688624 & 4.95 & 5.0229 & TRN \\
\hline CHEMBL1568854 & 688624 & 4.6 & 4.6306 & TRN \\
\hline CHEMBL1489182 & 688624 & 5.65 & 5.5567 & TRN \\
\hline CHEMBL566899 & 688624 & 5.8 & 5.8432 & TRN \\
\hline CHEMBL1570352 & 688624 & 4.8 & 4.6776 & TST \\
\hline CHEMBL585861 & 688624 & 6.1 & 6.1759 & TRN \\
\hline CHEMBL1322216 & 688624 & 6.2 & 6.0612 & TRN \\
\hline CHEMBL1474281 & 688624 & 4.95 & 4.9935 & TST \\
\hline CHEMBL1478772 & 688624 & 5.3 & 5.5157 & TRN \\
\hline CHEMBL1483855 & 688624 & 5.4 & 5.4062 & TRN \\
\hline CHEMBL568379 & 688624 & 6.8 & 6.3094 & TRN \\
\hline CHEMBL1394137 & 688624 & 5.3 & 5.3414 & TRN \\
\hline CHEMBL1433668 & 688624 & 4.75 & 5.1231 & TRN \\
\hline CHEMBL 259140 & 688624 & 5.45 & 5.3616 & TRN \\
\hline CHEMBL1407035 & 688624 & 7.3002 & 7.099 & TRN \\
\hline CHEMBL1475737 & 688624 & 4.9 & 4.9301 & TRN \\
\hline CHEMBL1357553 & 688624 & 5.5 & 5.4363 & TST \\
\hline CHEMBL1478761 & 688624 & 4.9 & 5.3427 & TRN \\
\hline CHEMBL1558843 & 688624 & 5.0 & 4.9698 & TRN \\
\hline CHEMBL1533572 & 688624 & 5.9 & 5.0296 & TRN \\
\hline CHEMBL1552922 & 688624 & 5.8 & 6.0188 & TST \\
\hline CHEMBL1491332 & 688624 & 4.9 & 5.0695 & TST \\
\hline CHEMBL1356439 & 688624 & 4.95 & 4.9109 & TRN \\
\hline CHEMBL1564845 & 688624 & 6.6499 & 6.4464 & TRN \\
\hline CHEMBL1601662 & 688624 & 4.85 & 4.8038 & TRN \\
\hline CHEMBL1361750 & 688624 & 5.05 & 4.7163 & TRN \\
\hline CHEMBL1559246 & 688624 & 4.95 & 4.7571 & TST \\
\hline CHEMBL1592571 & 688624 & 4.9 & 4.8718 & TST \\
\hline CHEMBL1396742 & 688624 & 5.35 & 4.6107 & TST \\
\hline CHEMBL1403562 & 688624 & 4.9 & 5.2612 & TRN \\
\hline CHEMBL1551919 & 688624 & 5.6 & 5.1912 & TRN \\
\hline CHEMBL1433596 & 688624 & 4.95 & 4.9208 & TRN \\
\hline CHEMBL541847 & 688624 & 5.7 & 5.8965 & TRN \\
\hline CHEMBL1480350 & 688624 & 6.5501 & 6.5178 & TRN \\
\hline CHEMBL1357551 & 688624 & 4.9 & 4.9227 & TST \\
\hline CHEMBL1590818 & 688624 & 5.15 & 4.7305 & TST \\
\hline CHEMBL1397427 & 688624 & 5.9 & 6.1622 & TST \\
\hline CHEMBL1355677 & 688624 & 6.45 & 6.4504 & TRN \\
\hline CHEMBL1551200 & 688624 & 5.5 & 5.1739 & TRN \\
\hline CHEMBL1496560 & 688624 & 4.9 & 4.8826 & TRN \\
\hline CHEMBL1437064 & 688624 & 4.9 & 4.8586 & TST \\
\hline CHEMBL1513077 & 688624 & 4.9 & 4.8023 & TRN \\
\hline
\end{tabular}




\begin{tabular}{|c|c|c|c|c|}
\hline \multicolumn{5}{|c|}{ Supplemental Table S2.txt } \\
\hline CHEMBL1403505 & 688624 & 4.9 & 5.1457 & TRN \\
\hline CHEMBL1395850 & 688624 & 5.15 & 4.9917 & TRN \\
\hline CHEMBL1490477 & 688624 & 4.9 & 5.2035 & TRN \\
\hline CHEMBL1601908 & 688624 & 4.65 & 5.0425 & TST \\
\hline CHEMBL1518067 & 688624 & 5.6 & 5.8183 & TST \\
\hline CHEMBL1314222 & 688624 & 5.3 & 5.1754 & TRN \\
\hline CHEMBL1551913 & 688624 & 5.0 & 5.1748 & TRN \\
\hline CHEMBL1320469 & 688624 & 5.0 & 5.3913 & TST \\
\hline CHEMBL495068 & 688624 & 5.15 & 4.9747 & TRN \\
\hline CHEMBL1552985 & 688624 & 4.85 & 4.615 & TRN \\
\hline CHEMBL1410859 & 688624 & 7.3002 & 6.7448 & TRN \\
\hline CHEMBL1555713 & 688624 & 5.25 & 4.8058 & TRN \\
\hline CHEMBL1475902 & 688624 & 5.1 & 5.3581 & TRN \\
\hline CHEMBL1377727 & 688624 & 4.85 & 4.7826 & TRN \\
\hline CHEMBL119841 & 688624 & 5.3 & 5.2862 & TRN \\
\hline CHEMBL490744 & 688624 & 4.9 & 4.9426 & TRN \\
\hline CHEMBL1482790 & 688624 & 4.7 & 4.7835 & TRN \\
\hline CHEMBL1554579 & 688624 & 5.7 & 5.9974 & TST \\
\hline CHEMBL1551503 & 688624 & 4.85 & 4.9327 & TST \\
\hline CHEMBL1409852 & 688624 & 6.15 & 6.3459 & TST \\
\hline CHEMBL1322756 & 688624 & 6.35 & 6.4598 & TRN \\
\hline CHEMBL1355256 & 688624 & 4.9 & 4.8607 & TRN \\
\hline CHEMBL1436045 & 688624 & 4.75 & 4.9408 & TRN \\
\hline CHEMBL1417771 & 688624 & 5.0 & 5.3245 & TRN \\
\hline CHEMBL1322584 & 688624 & 5.45 & 5.7104 & TRN \\
\hline CHEMBL1592376 & 688624 & 4.9 & 5.0393 & TRN \\
\hline CHEMBL1592327 & 688624 & 4.85 & 4.8165 & TRN \\
\hline CHEMBL1532720 & 688624 & 5.2 & 5.1595 & TST \\
\hline CHEMBL1475487 & 688624 & 4.9 & 5.1855 & TRN \\
\hline CHEMBL1474633 & 688624 & 4.7 & 4.8113 & TRN \\
\hline CHEMBL1437273 & 688624 & 5.55 & 5.7426 & TST \\
\hline CHEMBL1445893 & 688624 & 4.8 & 4.7988 & TRN \\
\hline CHEMBL1436715 & 688624 & 4.95 & 4.8134 & TRN \\
\hline CHEMBL1526043 & 688624 & 5.35 & 4.74 & TST \\
\hline CHEMBL1435032 & 688624 & 5.3 & 5.1893 & TRN \\
\hline CHEMBL1435077 & 688624 & 5.2 & 5.1732 & TRN \\
\hline CHEMBL1395417 & 688624 & 5.95 & 6.0295 & TRN \\
\hline CHEMBL1356029 & 688624 & 4.65 & 4.71 & TST \\
\hline CHEMBL1370622 & 688624 & 4.9 & 4.782 & TRN \\
\hline CHEMBL428814 & 688624 & 5.8 & 5.1596 & TRN \\
\hline CHEMBL1401682 & 688624 & 4.9 & 4.7971 & TRN \\
\hline CHEMBL1480219 & 688624 & 6.6499 & 6.9187 & TRN \\
\hline CHEMBL1359691 & 688624 & 4.75 & 4.8398 & TRN \\
\hline CHEMBL1449350 & 688624 & 4.9 & 5.2187 & TRN \\
\hline CHEMBL1552572 & 688624 & 4.9 & 5.225 & TST \\
\hline CHEMBL1318668 & 688624 & 4.6 & 4.96 & TST \\
\hline CHEMBL1316956 & 688624 & 4.95 & 4.9437 & TRN \\
\hline CHEMBL1472955 & 688624 & 4.95 & 5.1581 & TRN \\
\hline
\end{tabular}




\begin{tabular}{|c|c|c|c|c|c|}
\hline & & & & & \\
\hline CHEMBL1591107 & 688624 & 4.9 & 5.2553 & TRN & \\
\hline CHEMBL1590123 & 688624 & 5.75 & 5.6968 & TRN & \\
\hline CHEMBL1477982 & 688624 & 4.9 & 4.7898 & TRN & \\
\hline CHEMBL1565927 & 688624 & 6.8499 & 6.7931 & TRN & \\
\hline CHEMBL1528170 & 688624 & 4.95 & 4.8619 & TST & \\
\hline CHEMBL1515540 & 688624 & 4.85 & 4.9362 & TRN & \\
\hline CHEMBL1399528 & 688624 & 6.25 & 5.9655 & TRN & \\
\hline CHEMBL1527221 & 688624 & 4.8 & 4.7228 & TRN & \\
\hline CHEMBL1512988 & 688624 & 5.55 & 5.9984 & TST & \\
\hline CHEMBL1516054 & 688624 & 7.6003 & 7.2715 & TRN & \\
\hline CHEMBL1596170 & 688624 & 5.1 & 5.1907 & TRN & \\
\hline CHEMBL1396109 & 688624 & 4.85 & 4.6801 & TRN & \\
\hline CHEMBL1474402 & 688624 & 6.9 & 7.25200 & $\partial 000000001$ & TRN \\
\hline CHEMBL1357167 & 688624 & 6.5501 & 5.9842 & TRN & \\
\hline CHEMBL1486734 & 688624 & 4.95 & 5.1211 & TRN & \\
\hline CHEMBL1512250 & 688624 & 4.85 & 5.08899 & 99999999995 & TRN \\
\hline CHEMBL1438371 & 688624 & 4.95 & 4.7753 & TRN & \\
\hline CHEMBL1327681 & 688624 & 5.4 & 5.1431 & TRN & \\
\hline CHEMBL1331037 & 688624 & 4.9 & 5.2827 & TST & \\
\hline CHEMBL1513990 & 688624 & 5.55 & 5.5579 & TRN & \\
\hline CHEMBL1396611 & 688624 & 4.9 & 4.7873 & TST & \\
\hline CHEMBL1322233 & 688624 & 5.1 & 5.1818 & TRN & \\
\hline CHEMBL1523579 & 688624 & 4.8 & 4.7634 & TST & \\
\hline CHEMBL1373621 & 688624 & 5.05 & 5.1536 & TST & \\
\hline CHEMBL1317358 & 688624 & 4.9 & 5.0225 & TRN & \\
\hline CHEMBL1512708 & 688624 & 5.45 & 4.9256 & TRN & \\
\hline CHEMBL1437667 & 688624 & 4.9 & 4.6405 & TRN & \\
\hline CHEMBL1315083 & 688624 & 5.55 & 4.9561 & TRN & \\
\hline CHEMBL1409830 & 688624 & 4.85 & 4.6579 & TRN & \\
\hline CHEMBL1553902 & 688624 & 4.95 & 5.0227 & TRN & \\
\hline CHEMBL1357018 & 688624 & 7.3497 & 6.7663 & TRN & \\
\hline CHEMBL1472651 & 688624 & 4.8 & 4.8413 & TST & \\
\hline CHEMBL1514607 & 688624 & 4.95 & 5.1192 & TRN & \\
\hline CHEMBL1553694 & 688624 & 5.3 & 5.1317 & TRN & \\
\hline CHEMBL1357491 & 688624 & 6.15 & 6.1665 & TRN & \\
\hline CHEMBL1395915 & 688624 & 5.1 & 5.3859 & TRN & \\
\hline CHEMBL 1455570 & 688624 & 4.95 & 5.7303 & TST & \\
\hline CHEMBL1354563 & 688624 & 4.6 & 5.1972 & TRN & \\
\hline CHEMBL1591772 & 688624 & 5.35 & 5.6069 & TST & \\
\hline CHEMBL1472765 & 688624 & 6.7501 & 6.5761 & TRN & \\
\hline CHEMBL1515246 & 688624 & 5.7 & 6.1533 & TST & \\
\hline CHEMBL491547 & 688624 & 5.05 & 4.8299 & TRN & \\
\hline CHEMBL1435447 & 688624 & 4.9 & 4.7991 & TRN & \\
\hline CHEMBL1417025 & 688624 & 5.55 & 5.8276 & TST & \\
\hline CHEMBL1449458 & 688624 & 4.9 & 4.7945 & TRN & \\
\hline CHEMBL1434006 & 688624 & 4.9 & 4.9955 & TRN & \\
\hline CHEMBL1514149 & 688624 & 4.85 & 5.0123 & TRN & \\
\hline CHEMBL1316463 & 688624 & 4.85 & 5.0114 & TST & \\
\hline
\end{tabular}




\begin{tabular}{|c|c|c|c|c|c|}
\hline \multicolumn{6}{|c|}{ Supplemental Table S2.txt } \\
\hline CHEMBL447507 & 688624 & 4.75 & 4.6952 & TRN & \\
\hline CHEMBL1512833 & 688624 & 4.9 & 4.7989 & TRN & \\
\hline CHEMBL1596499 & 688624 & 5.4 & 4.9622 & TRN & \\
\hline CHEMBL1558184 & 688624 & 4.85 & 5.0716 & TRN & \\
\hline CHEMBL1356808 & 688624 & 6.3 & 6.2388 & TST & \\
\hline CHEMBL1447909 & 688624 & 4.9 & 5.2329 & TST & \\
\hline CHEMBL1473760 & 688624 & 5.4 & 5.434 & TRN & \\
\hline CHEMBL1535931 & 688624 & 5.3 & 5.0584 & TRN & \\
\hline CHEMBL1603418 & 688624 & 6.45 & 6.6226 & TRN & \\
\hline CHEMBL1531899 & 688624 & 4.95 & 5.0064 & TST & \\
\hline CHEMBL1418387 & 688624 & 6.7501 & 6.73600 & 0000000001 & TRN \\
\hline CHEMBL1315292 & 688624 & 4.85 & 5.104 & TST & \\
\hline CHEMBL1516530 & 688624 & 4.95 & 5.0775 & TRN & \\
\hline CHEMBL1356652 & 688624 & 7.15 & 7.1064 & TST & \\
\hline CHEMBL1375753 & 688624 & 6.3 & 6.4605 & TST & \\
\hline CHEMBL1336060 & 688624 & 4.95 & 5.0639 & TRN & \\
\hline CHEMBL1446539 & 688624 & 5.05 & 5.2742 & TRN & \\
\hline CHEMBL1475255 & 688624 & 4.9 & 5.1796 & TST & \\
\hline CHEMBL1435919 & 688624 & 4.8 & 4.9906 & TRN & \\
\hline CHEMBL1595002 & 688624 & 4.6 & 4.7713 & TRN & \\
\hline CHEMBL1553741 & 688624 & 4.85 & 4.7586 & TST & \\
\hline CHEMBL1406851 & 688624 & 5.0 & 4.6613 & TRN & \\
\hline CHEMBL1526697 & 688624 & 6.5501 & 6.4357 & TRN & \\
\hline CHEMBL1442458 & 688624 & 5.15 & 5.3965 & TRN & \\
\hline CHEMBL1517241 & 688624 & 4.75 & 4.6443 & TST & \\
\hline CHEMBL1366393 & 688624 & 5.65 & 5.3235 & TRN & \\
\hline CHEMBL1567472 & 688624 & 4.85 & 4.9403 & TST & \\
\hline CHEMBL1436355 & 688624 & 5.0 & 5.1138 & TRN & \\
\hline CHEMBL1513063 & 688624 & 5.1 & 5.1207 & TRN & \\
\hline CHEMBL1355896 & 688624 & 4.65 & 4.6268 & TRN & \\
\hline CHEMBL1437364 & 688624 & 7.0501 & 7.0626 & TST & \\
\hline CHEMBL1374585 & 688624 & 4.85 & 4.8519 & TRN & \\
\hline CHEMBL1592982 & 688624 & 7.15 & 6.8752 & TRN & \\
\hline CHEMBL1597037 & 688624 & 4.9 & 5.1374 & TRN & \\
\hline CHEMBL1395527 & 688624 & 4.9 & 4.9476 & TRN & \\
\hline CHEMBL1440157 & 688624 & 6.0 & 5.8063 & TRN & \\
\hline CHEMBL1473809 & 688624 & 5.0 & 5.3282 & TST & \\
\hline CHEMBL1418420 & 688624 & 4.9 & 4.7661 & TRN & \\
\hline CHEMBL1404954 & 688624 & 5.85 & 5.8563 & TRN & \\
\hline CHEMBL1438323 & 688624 & 5.5 & 5.6907 & TRN & \\
\hline CHEMBL1592209 & 688624 & 4.75 & 4.8042 & TRN & \\
\hline CHEMBL1437075 & 688624 & 4.85 & 4.9943 & TRN & \\
\hline CHEMBL545523 & 688624 & 4.95 & 5.2625 & TRN & \\
\hline CHEMBL1400043 & 688624 & 5.0 & 5.1342 & TST & \\
\hline CHEMBL1358796 & 688624 & 7.4498 & 7.2745 & TRN & \\
\hline CHEMBL1551979 & 688624 & 5.05 & 5.1615 & TRN & \\
\hline CHEMBL1484944 & 688624 & 6.1 & 6.0881 & TST & \\
\hline CHEMBL1433730 & 688624 & 4.65 & 4.6888 & TRN & \\
\hline
\end{tabular}




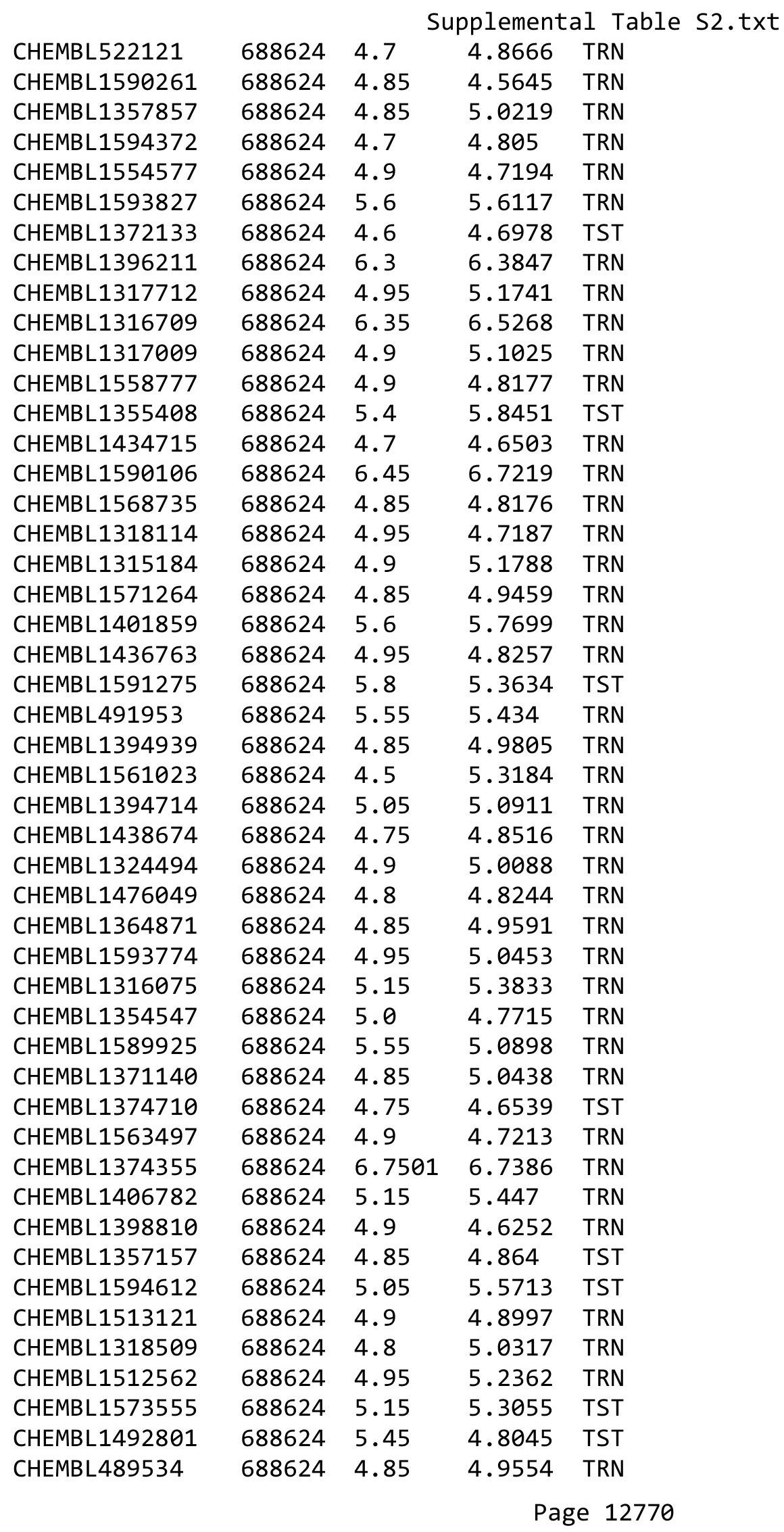




\begin{tabular}{|c|c|c|c|c|c|}
\hline \multicolumn{6}{|c|}{ Supplemental Table S2.txt } \\
\hline CHEMBL1514719 & 688624 & 4.9 & 4.8859 & TRN & \\
\hline CHEMBL1591543 & 688624 & 4.9 & 5.0572 & TRN & \\
\hline CHEMBL1357067 & 688624 & 4.9 & 5.6887 & TRN & \\
\hline CHEMBL1610375 & 688624 & 4.9 & 4.6937 & TST & \\
\hline CHEMBL1330317 & 688624 & 5.35 & 4.9926 & TRN & \\
\hline CHEMBL1513578 & 688624 & 5.55 & 4.8804 & TST & \\
\hline CHEMBL1442440 & 688624 & 5.3 & 5.0599 & TRN & \\
\hline CHEMBL1323385 & 688624 & 6.0 & 5.7832 & TST & \\
\hline CHEMBL1316656 & 688624 & 4.7 & 4.6887 & TST & \\
\hline CHEMBL1554158 & 688624 & 5.7 & 5.3993 & TST & \\
\hline CHEMBL1316056 & 688624 & 4.95 & 5.0972 & TRN & \\
\hline CHEMBL1332033 & 688624 & 7.3002 & 7.1829 & TRN & \\
\hline CHEMBL1554622 & 688624 & 4.7 & 4.734 & TRN & \\
\hline CHEMBL1334321 & 688624 & 6.45 & 6.4419 & TRN & \\
\hline CHEMBL1396407 & 688624 & 6.0 & 4.9877 & TRN & \\
\hline CHEMBL1446323 & 688624 & 4.95 & 5.0601 & TRN & \\
\hline CHEMBL1394520 & 688624 & 4.85 & 5.0997 & TST & \\
\hline CHEMBL1512919 & 688624 & 4.7 & 4.7816 & TRN & \\
\hline CHEMBL1315802 & 688624 & 4.95 & 5.1211 & TST & \\
\hline CHEMBL1436540 & 688624 & 5.65 & 5.7307 & TRN & \\
\hline CHEMBL1412390 & 688624 & 5.05 & 4.97 & TRN & \\
\hline CHEMBL1396377 & 688624 & 4.9 & 5.0652 & TRN & \\
\hline CHEMBL1602710 & 688624 & 4.95 & 4.7345 & TST & \\
\hline CHEMBL510009 & 688624 & 5.8 & 5.4469 & TRN & \\
\hline CHEMBL1610082 & 688624 & 4.9 & 4.97199 & 99999999995 & TRN \\
\hline CHEMBL1559654 & 688624 & 4.9 & 5.2924 & TST & \\
\hline CHEMBL1517718 & 688624 & 6.15 & 6.2277 & TST & \\
\hline CHEMBL1358983 & 688624 & 4.9 & 5.0006 & TST & \\
\hline CHEMBL1527332 & 688624 & 5.0 & 4.9291 & TRN & \\
\hline CHEMBL1591956 & 688624 & 4.7 & 4.9451 & TRN & \\
\hline CHEMBL1474195 & 688624 & 5.2 & 4.9348 & TRN & \\
\hline CHEMBL1606199 & 688624 & 5.05 & 4.9319 & TST & \\
\hline CHEMBL1403333 & 688624 & 5.1 & 5.2134 & TRN & \\
\hline CHEMBL1447959 & 688624 & 4.8 & 4.8516 & TRN & \\
\hline CHEMBL1534237 & 688624 & 4.45 & 4.5463 & TRN & \\
\hline CHEMBL475376 & 688624 & 5.8 & 5.4447 & TRN & \\
\hline CHEMBL1357294 & 688624 & 5.35 & 4.825 & TST & \\
\hline CHEMBL1488990 & 688624 & 4.9 & 4.7477 & TRN & \\
\hline CHEMBL1590458 & 688624 & 4.9 & 4.867 & TRN & \\
\hline CHEMBL1452413 & 688624 & 4.9 & 5.0187 & TRN & \\
\hline CHEMBL1594134 & 688624 & 4.7 & 4.7027 & TRN & \\
\hline CHEMBL1322545 & 688624 & 4.8 & 4.9106 & TRN & \\
\hline CHEMBL1592803 & 688624 & 6.4 & 6.4584 & TRN & \\
\hline CHEMBL1521490 & 688624 & 4.95 & 5.0362 & TRN & \\
\hline CHEMBL1437226 & 688624 & 5.35 & 5.0691 & TRN & \\
\hline CHEMBL1404451 & 688624 & 4.9 & 4.9065 & TRN & \\
\hline CHEMBL1329823 & 688624 & 4.9 & 4.8031 & TST & \\
\hline CHEMBL1394706 & 688624 & 4.75 & 4.7416 & TRN & \\
\hline
\end{tabular}




\begin{tabular}{|c|c|c|c|c|c|}
\hline \multicolumn{6}{|c|}{ Supplemental Table s2.txt } \\
\hline CHEMBL489935 & 688624 & 4.85 & 4.6797 & TRN & \\
\hline CHEMBL1475366 & 688624 & 6.2 & 5.5978 & TRN & \\
\hline CHEMBL1512023 & 688624 & 4.95 & 5.4148 & TST & \\
\hline CHEMBL1436272 & 688624 & 5.95 & \multicolumn{2}{|c|}{5.337000000000001} & TRN \\
\hline CHEMBL1473996 & 688624 & 4.9 & 4.9908 & TRN & \\
\hline CHEMBL1515366 & 688624 & 5.05 & 4.8958 & TRN & \\
\hline CHEMBL1401243 & 688624 & 4.85 & 4.9101 & TRN & \\
\hline CHEMBL1456015 & 688624 & 5.0 & 5.0686 & TRN & \\
\hline CHEMBL1436024 & 688624 & 4.9 & 4.8791 & TRN & \\
\hline CHEMBL1456454 & 688624 & 4.9 & 5.0184 & TRN & \\
\hline CHEMBL1563047 & 688624 & 4.95 & 5.0991 & TST & \\
\hline CHEMBL1590821 & 688624 & 4.9 & 4.838 & TST & \\
\hline CHEMBL1435409 & 688624 & 5.4 & 5.3052 & TST & \\
\hline CHEMBL1568086 & 688624 & 4.9 & 5.0857 & TRN & \\
\hline CHEMBL1433752 & 688624 & 6.25 & 6.4553 & TRN & \\
\hline CHEMBL1473430 & 688624 & 4.95 & 5.1152 & TRN & \\
\hline CHEMBL475198 & 688624 & 5.5 & 5.3358 & TRN & \\
\hline CHEMBL1515221 & 688624 & 4.9 & 4.9683 & TRN & \\
\hline CHEMBL1408427 & 688624 & 6.1 & 5.9156 & TRN & \\
\hline CHEMBL1591893 & 688624 & 5.7 & 5.6801 & TRN & \\
\hline CHEMBL1455926 & 688624 & 6.2 & 6.4459 & TRN & \\
\hline CHEMBL1396384 & 688624 & 4.95 & 4.7499 & TRN & \\
\hline CHEMBL1484253 & 688624 & 4.85 & 4.9884 & TST & \\
\hline CHEMBL1494452 & 688624 & 4.9 & 4.9645 & TRN & \\
\hline CHEMBL1355387 & 688624 & 4.9 & 4.9603 & TRN & \\
\hline CHEMBL1552519 & 688624 & 4.9 & \multicolumn{2}{|c|}{5.337000000000001} & TRN \\
\hline CHEMBL516075 & 688624 & 6.1 & 5.928 & TRN & \\
\hline CHEMBL1416207 & 688624 & 6.0 & 5.8975 & TRN & \\
\hline CHEMBL1315845 & 688624 & 4.95 & 4.8334 & TRN & \\
\hline CHEMBL1552277 & 688624 & 6.6499 & 6.9673 & TRN & \\
\hline CHEMBL1591140 & 688624 & 4.85 & 4.9467 & TRN & \\
\hline CHEMBL2325829 & 938986 & 5.4815 & 5.5277 & TRN & \\
\hline CHEMBL2325828 & 938986 & 5.4815 & 5.9112 & TRN & \\
\hline CHEMBL2325827 & 938986 & 5.4989 & 5.8791 & TRN & \\
\hline CHEMBL2325826 & 938986 & 5.5031 & 6.7149 & TST & \\
\hline CHEMBL2325825 & 938986 & 5.5031 & 5.2181 & TRN & \\
\hline CHEMBL2325824 & 938986 & 5.5072 & 5.8339 & TRN & \\
\hline CHEMBL2325823 & 938986 & 5.5072 & 5.6296 & TRN & \\
\hline CHEMBL2325822 & 938986 & 5.5086 & \multicolumn{2}{|c|}{5.452999999999999} & TRN \\
\hline CHEMBL2325821 & 938986 & 5.5086 & 5.2971 & TRN & \\
\hline CHEMBL2325820 & 938986 & 5.5114 & 6.4574 & TRN & \\
\hline CHEMBL2325819 & 938986 & 5.5143 & 5.9415 & TST & \\
\hline CHEMBL 2325818 & 938986 & 5.5229 & 4.4137 & TST & \\
\hline CHEMBL 2321877 & 938986 & 5.5229 & 4.6011 & TST & \\
\hline CHEMBL2326121 & 938986 & 5.5229 & 4.3263 & TST & \\
\hline CHEMBL 2326120 & 938986 & 5.5229 & 4.7002 & TST & \\
\hline CHEMBL2326119 & 938986 & 5.5229 & 4.6899 & TST & \\
\hline CHEMBL2326118 & 938986 & 5.5229 & 4.1516 & TST & \\
\hline
\end{tabular}


Supplemental Table S2.txt

\begin{tabular}{|c|c|c|c|c|c|}
\hline CHEMBL2326117 & 938986 & 5.5229 & 5.0533 & TRN & \\
\hline CHEMBL2326116 & 938986 & 5.5229 & 5.2197 & TRN & \\
\hline CHEMBL2326115 & 938986 & 5.5229 & 4.2435 & TST & \\
\hline CHEMBL2321919 & 938986 & 5.5229 & 5.3828 & TRN & \\
\hline CHEMBL 2325871 & 938986 & 5.5229 & 5.5769 & TST & \\
\hline CHEMBL 2325870 & 938986 & 5.5258 & 6.9673 & TST & \\
\hline CHEMBL2325869 & 938986 & 5.5302 & 5.5072 & TRN & \\
\hline CHEMBL2325868 & 938986 & 5.5376 & 5.9356 & TRN & \\
\hline CHEMBL 2325867 & 938986 & 5.5376 & 6.1187 & TST & \\
\hline CHEMBL2325866 & 938986 & 5.5376 & 6.0848 & TST & \\
\hline CHEMBL 2325865 & 938986 & 5.5376 & 5.7727 & TRN & \\
\hline CHEMBL 2325864 & 938986 & 5.5528 & 5.8216 & TRN & \\
\hline CHEMBL2325863 & 938986 & 5.5528 & 6.2244 & TRN & \\
\hline CHEMBL 2325862 & 938986 & 5.5528 & 6.1867 & TST & \\
\hline CHEMBL2325861 & 938986 & 5.5544 & 5.5761 & TST & \\
\hline CHEMBL 2325860 & 938986 & 5.556 & 4.647 & TST & \\
\hline CHEMBL2325859 & 938986 & 5.5686 & 5.8836 & TRN & \\
\hline CHEMBL2325858 & 938986 & 5.5686 & 5.3385 & TST & \\
\hline CHEMBL2325857 & 938986 & 5.5686 & 5.9062 & TRN & \\
\hline CHEMBL2325856 & 938986 & 5.5686 & 5.1667 & TRN & \\
\hline CHEMBL 2325855 & 938986 & 5.5686 & 5.7476 & TRN & \\
\hline CHEMBL2325854 & 938986 & 5.5735 & 5.4577 & TRN & \\
\hline CHEMBL 2325853 & 938986 & 5.5751 & 6.7402 & TST & \\
\hline CHEMBL2325852 & 938986 & 5.5817 & 6.0439 & TST & \\
\hline CHEMBL2325851 & 938986 & 5.585 & 6.1953 & TST & \\
\hline CHEMBL2325850 & 938986 & 5.585 & 5.5484 & TRN & \\
\hline CHEMBL2325849 & 938986 & 5.585 & 6.0633 & TRN & \\
\hline CHEMBL 2325848 & 938986 & 5.585 & 5.9881 & TRN & \\
\hline CHEMBL2326153 & 938986 & 5.5867 & 5.3788 & TST & \\
\hline CHEMBL2326152 & 938986 & 5.5952 & 5.4676 & TRN & \\
\hline CHEMBL2326151 & 938986 & 5.5969 & 5.9832 & TST & \\
\hline CHEMBL2326150 & 938986 & 5.6021 & 5.7388 & TRN & \\
\hline CHEMBL2326149 & 938986 & 5.6021 & 5.8201 & TRN & \\
\hline CHEMBL2326148 & 938986 & 5.6021 & 5.6285 & TRN & \\
\hline CHEMBL 2326147 & 938986 & 5.6021 & 5.7405 & TRN & \\
\hline CHEMBL2326146 & 938986 & 5.6021 & 5.8353 & TRN & \\
\hline CHEMBL 2326145 & 938986 & 5.6021 & 5.7278 & TRN & \\
\hline CHEMBL 2326144 & 938986 & 5.6073 & 6.0351 & TST & \\
\hline CHEMBL2326143 & 938986 & 5.6108 & \multicolumn{2}{|c|}{5.992000000000001} & TRN \\
\hline CHEMBL2326142 & 938986 & \multicolumn{3}{|c|}{$5.617999999999999 \quad 6.2873$} & TST \\
\hline CHEMBL2326141 & 938986 & 5.6198 & 5.2134 & TRN & \\
\hline CHEMBL 2326140 & 938986 & 5.6198 & 4.864 & TRN & \\
\hline CHEMBL2326139 & 938986 & 5.6198 & 6.3563 & TRN & \\
\hline CHEMBL2326138 & 938986 & 5.6234 & 5.3305 & TST & \\
\hline CHEMBL2326137 & 938986 & 5.6289 & 6.0952 & TRN & \\
\hline CHEMBL2326136 & 938986 & 5.6345 & 5.8535 & TRN & \\
\hline CHEMBL2326135 & 938986 & 5.6383 & 5.3885 & TRN & \\
\hline CHEMBL2326134 & 938986 & 5.6383 & 6.1471 & TRN & \\
\hline
\end{tabular}


Supplemental Table S2.txt

\begin{tabular}{|c|c|c|c|c|c|c|}
\hline CHEMBL2326133 & 938986 & 5.6383 & 4.8015 & TST & & \\
\hline CHEMBL 2326132 & 938986 & 5.6383 & 5.8173 & TRN & & \\
\hline CHEMBL2326131 & 938986 & 5.6421 & 6.6437 & TST & & \\
\hline CHEMBL2326130 & 938986 & 5.6478 & 5.6547 & TRN & & \\
\hline CHEMBL2326129 & 938986 & 5.6556 & 5.5936 & TRN & & \\
\hline CHEMBL2326128 & 938986 & 5.6576 & 6.3271 & TRN & & \\
\hline CHEMBL 2326127 & 938986 & 5.6576 & 5.9966 & TST & & \\
\hline CHEMBL2326126 & 938986 & 5.6576 & 5.7829 & TRN & & \\
\hline CHEMBL2326125 & 938986 & 5.6576 & 6.1106 & TST & & \\
\hline CHEMBL2326124 & 938986 & 5.6596 & 6.6572 & TRN & & \\
\hline CHEMBL2326123 & 938986 & 5.6615 & 6.1648 & TST & & \\
\hline CHEMBL 2326122 & 938986 & 5.6635 & 5.0922 & TRN & & \\
\hline CHEMBL 2326427 & 938986 & 5.6778 & 4.0972 & TST & & \\
\hline CHEMBL2326426 & 938986 & 5.6778 & 5.8854 & TRN & & \\
\hline CHEMBL2326425 & 938986 & 5.6778 & 5.8068 & TRN & & \\
\hline CHEMBL2326424 & 938986 & 5.6799 & 5.9569 & TRN & & \\
\hline CHEMBL2326423 & 938986 & 5.6882 & 7.0982 & TST & & \\
\hline CHEMBL 2326422 & 938986 & 5.6925 & 5.44600 & 00000000 & TRN & \\
\hline CHEMBL2326421 & 938986 & 5.6925 & 6.0877 & TRN & & \\
\hline CHEMBL 2326420 & 938986 & 5.699 & 6.8891 & TST & & \\
\hline CHEMBL2326419 & 938986 & 5.699 & 5.6661 & TRN & & \\
\hline CHEMBL 2326418 & 938986 & 5.699 & 5.5886 & TRN & & \\
\hline CHEMBL 2326417 & 938986 & 5.699 & 6.0304 & TRN & & \\
\hline CHEMBL 2326174 & 938986 & 5.699 & 5.8825 & TRN & & \\
\hline CHEMBL 2326173 & 938986 & 5.699 & 6.6065 & TST & & \\
\hline CHEMBL 2326172 & 938986 & 5.7033 & 5.2575 & TST & & \\
\hline CHEMBL 2326171 & 938986 & 5.7212 & 6.4175 & TRN & & \\
\hline CHEMBL 2326170 & 938986 & 5.7212 & 5.9486 & TRN & & \\
\hline CHEMBL2326169 & 938986 & 5.7212 & 6.0484 & TRN & & \\
\hline CHEMBL2326168 & 938986 & 5.7212 & 5.6336 & TRN & & \\
\hline CHEMBL 2326167 & 938986 & 5.7212 & 5.5718 & TRN & & \\
\hline CHEMBL 2326166 & 938986 & 5.7258 & 6.1599 & TRN & & \\
\hline CHEMBL2326165 & 938986 & 5.7282 & 5.9024 & TST & & \\
\hline CHEMBL 2326164 & 938986 & 5.7328 & 5.4861 & TRN & & \\
\hline CHEMBL 2326163 & 938986 & 5.7423 & 5.6505 & TRN & & \\
\hline CHEMBL 2326162 & 938986 & 5.7423 & 5.8216 & TST & & \\
\hline CHEMBL2326161 & 938986 & 5.7447 & 6.2661 & TRN & & \\
\hline CHEMBL 2326160 & 938986 & 5.7447 & 6.268 & TRN & & \\
\hline CHEMBL2326159 & 938986 & 5.7447 & 6.1399 & TRN & & \\
\hline CHEMBL2326158 & 938986 & 5.7447 & 5.7358 & TRN & & \\
\hline CHEMBL 2326157 & 938986 & 5.7447 & 5.3612 & TRN & & \\
\hline CHEMBL 2326156 & 938986 & 5.7471 & 5.3102 & TST & & \\
\hline CHEMBL2326155 & 938986 & \multicolumn{3}{|c|}{5.7620000000000005} & 5.178999999999999 & TRN \\
\hline CHEMBL 2326154 & 938986 & 5.767 & 6.2169 & TRN & & \\
\hline CHEMBL2326459 & 938986 & 5.7696 & 5.7603 & TRN & & \\
\hline CHEMBL 2326458 & 938986 & 5.7696 & 5.8271 & TRN & & \\
\hline CHEMBL2326457 & 938986 & 5.7696 & 5.9456 & TRN & & \\
\hline CHEMBL2326456 & 938986 & 5.7773 & 5.8407 & TRN & & \\
\hline
\end{tabular}

Page 12774 
Supplemental Table S2.txt

\begin{tabular}{|c|c|c|c|c|}
\hline CHEMBL 2326455 & 938986 & 5.7959 & 6.2329 & TST \\
\hline CHEMBL 2326454 & 938986 & 5.7959 & 5.8575 & TRN \\
\hline CHEMBL2326453 & 938986 & 5.7959 & 6.4407 & TRN \\
\hline CHEMBL 2326452 & 938986 & 5.7959 & 6.1083 & TRN \\
\hline CHEMBL 2326451 & 938986 & 5.7959 & 5.7531 & TRN \\
\hline CHEMBL 2326450 & 938986 & 5.7959 & 6.2071 & TRN \\
\hline CHEMBL 2326449 & 938986 & 5.7959 & 6.59 & TRN \\
\hline CHEMBL2326448 & 938986 & 5.7959 & 6.5707 & TST \\
\hline CHEMBL 2326447 & 938986 & 5.8013 & 5.6614 & TST \\
\hline CHEMBL 2326446 & 938986 & 5.8041 & 5.7026 & TST \\
\hline CHEMBL 2326445 & 938986 & 5.82100 & 0000000 & 6.114 \\
\hline CHEMBL 2326444 & 938986 & 5.82100 & $20000000 t$ & 6.0825 \\
\hline CHEMBL2326443 & 938986 & 5.8239 & 5.5314 & TRN \\
\hline CHEMBL 2326442 & 938986 & 5.8239 & 6.2583 & TRN \\
\hline CHEMBL 2326441 & 938986 & 5.8239 & 6.262006 & 30000000005 \\
\hline CHEMBL 2326440 & 938986 & 5.8327 & 5.2033 & TST \\
\hline CHEMBL2326439 & 938986 & 5.8416 & 5.8164 & TST \\
\hline CHEMBL 2326438 & 938986 & 5.8447 & 6.0846 & TRN \\
\hline CHEMBL 2326437 & 938986 & 5.857 & 6.3278 & TRN \\
\hline CHEMBL 2326436 & 938986 & 5.8633 & 6.5558 & TST \\
\hline CHEMBL 2326435 & 938986 & 5.8794 & 6.0992 & TRN \\
\hline CHEMBL 2326434 & 938986 & 5.8861 & 5.8522 & TRN \\
\hline CHEMBL 2326433 & 938986 & 5.8861 & 6.2867 & TRN \\
\hline CHEMBL 2326432 & 938986 & 5.8861 & 6.277 & TRN \\
\hline CHEMBL 2326431 & 938986 & 5.8861 & 5.9023 & TRN \\
\hline CHEMBL 2326430 & 938986 & 5.8861 & 6.6638 & TRN \\
\hline CHEMBL 2326429 & 938986 & 5.8861 & 5.2725 & TST \\
\hline CHEMBL 2326428 & 938986 & 5.8861 & 6.5467 & TRN \\
\hline CHEMBL 2326774 & 938986 & 5.8861 & 6.0417 & TRN \\
\hline CHEMBL 2326773 & 938986 & 5.8894 & 6.1567 & TRN \\
\hline CHEMBL 2326772 & 938986 & 5.9101 & 7.0398 & TST \\
\hline CHEMBL 2326771 & 938986 & 5.9101 & 6.8502 & TST \\
\hline CHEMBL 2326770 & 938986 & 5.9208 & 5.6027 & TST \\
\hline CHEMBL 2326769 & 938986 & 5.9208 & 6.1403 & TRN \\
\hline CHEMBL 2326768 & 938986 & 5.9208 & 6.1479 & TST \\
\hline CHEMBL 2326767 & 938986 & 5.9208 & 6.3418 & TRN \\
\hline CHEMBL 2326766 & 938986 & 5.9208 & 5.6705 & TRN \\
\hline CHEMBL 2326765 & 938986 & 5.9208 & 5.9421 & TRN \\
\hline CHEMBL 2326764 & 938986 & 5.9208 & 6.2651 & TRN \\
\hline CHEMBL 2326763 & 938986 & 5.9208 & 6.3039 & TRN \\
\hline CHEMBL 2326762 & 938986 & 5.9245 & 6.3063 & TST \\
\hline CHEMBL 2326761 & 938986 & 5.9393 & 5.7989 & TRN \\
\hline CHEMBL 2326760 & 938986 & 5.9469 & 5.4976 & TST \\
\hline CHEMBL 2326759 & 938986 & 5.9508 & 6.6608 & TRN \\
\hline CHEMBL 2326758 & 938986 & 5.9547 & 5.7777 & TRN \\
\hline CHEMBL 2326757 & 938986 & 5.9547 & 5.9369 & TST \\
\hline CHEMBL 2326756 & 938986 & 5.9586 & 6.1601 & TRN \\
\hline CHEMBL 2326755 & 938986 & 5.9586 & 6.3284 & TRN \\
\hline
\end{tabular}




\begin{tabular}{|c|c|c|c|c|c|}
\hline & & \multicolumn{4}{|c|}{ Supplemental Table S2.txt } \\
\hline CHEMBL 2326754 & 938986 & 5.9586 & 6.1858 & TST & \\
\hline CHEMBL 2326753 & 938986 & 5.9586 & 5.9959 & TRN & \\
\hline CHEMBL 2326752 & 938986 & 5.9586 & 6.5873 & TST & \\
\hline CHEMBL 2326751 & 938986 & 5.9586 & 5.8724 & TRN & \\
\hline CHEMBL 2326750 & 938986 & 5.9666 & 6.2544 & TST & \\
\hline CHEMBL 2326749 & 938986 & 5.9788 & 4.993 & TST & \\
\hline CHEMBL 2326748 & 938986 & 5.983 & 6.1407 & TRN & \\
\hline CHEMBL 2326467 & 938986 & 5.9872 & 5.8214 & TST & \\
\hline CHEMBL 2326466 & 938986 & 5.9914 & 6.2012 & TRN & \\
\hline CHEMBL 2326465 & 938986 & 6.0 & 6.1276 & TRN & \\
\hline CHEMBL 2326464 & 938986 & 6.0 & 6.7151 & TRN & \\
\hline CHEMBL 2326463 & 938986 & 6.0 & 5.9882 & TRN & \\
\hline CHEMBL 2326462 & 938986 & 6.0 & 5.8072 & TRN & \\
\hline CHEMBL 2326461 & 938986 & 6.0 & 5.8692 & TST & \\
\hline CHEMBL 2326460 & 938986 & 6.0 & 6.4583 & TRN & \\
\hline CHEMBL 2326803 & 938986 & 6.0 & 5.5497 & TRN & \\
\hline CHEMBL 2326802 & 938986 & 6.0 & 5.8173 & TRN & \\
\hline CHEMBL 2326801 & 938986 & 6.0 & 6.0055 & TRN & \\
\hline CHEMBL 2326800 & 938986 & 6.0 & 6.4656 & TST & \\
\hline CHEMBL 2326799 & 938986 & 6.0 & 5.2522 & TRN & \\
\hline CHEMBL 2326798 & 938986 & 6.0 & 5.6247 & TRN & \\
\hline CHEMBL 2326797 & 938986 & 6.0 & 5.8839 & TRN & \\
\hline CHEMBL 2326796 & 938986 & 6.0 & 5.2732 & TST & \\
\hline CHEMBL 2326795 & 938986 & 6.0 & 5.8551 & TST & \\
\hline CHEMBL 2326794 & 938986 & 6.0 & 6.6661 & TST & \\
\hline CHEMBL 2326793 & 938986 & 6.0 & 6.0036 & TRN & \\
\hline CHEMBL 2326792 & 938986 & 6.0 & 6.2838 & TRN & \\
\hline CHEMBL 2326791 & 938986 & 6.0 & 6.1325 & TRN & \\
\hline CHEMBL 2326790 & 938986 & 6.0 & 5.7909 & TRN & \\
\hline CHEMBL 2326789 & 938986 & 6.0 & 6.3148 & TRN & \\
\hline CHEMBL 2326788 & 938986 & 6.0 & 5.5228 & TRN & \\
\hline CHEMBL 2326787 & 938986 & 6.0 & 5.06800 & 00000000005 & TRN \\
\hline CHEMBL 2326786 & 938986 & 6.0 & 5.5414 & TRN & \\
\hline CHEMBL 2326785 & 938986 & 6.0 & 5.3165 & TST & \\
\hline CHEMBL 2326784 & 938986 & 6.0 & 5.68 & TRN & \\
\hline CHEMBL 2326783 & 938986 & 6.0 & 6.2547 & TRN & \\
\hline CHEMBL 2326782 & 938986 & 6.0 & 6.1485 & TRN & \\
\hline CHEMBL 2326781 & 938986 & 6.0 & 5.8432 & TRN & \\
\hline CHEMBL 2326780 & 938986 & 6.0 & 5.4378 & TRN & \\
\hline CHEMBL 2326779 & 938986 & 6.0 & 5.2557 & TRN & \\
\hline CHEMBL 2326778 & 938986 & 6.0 & 6.3511 & TRN & \\
\hline CHEMBL 2326777 & 938986 & 6.0 & 6.1578 & TRN & \\
\hline CHEMBL 2326776 & 938986 & 6.0 & 6.2261 & TRN & \\
\hline CHEMBL 2326775 & 938986 & 6.0 & 6.2322 & TRN & \\
\hline CHEMBL 2322087 & 938986 & 6.0 & 5.9092 & TRN & \\
\hline CHEMBL 2322086 & 938986 & 6.0 & 6.4751 & TRN & \\
\hline CHEMBL 2322085 & 938986 & 6.0 & 6.3862 & TRN & \\
\hline CHEMBL 2322084 & 938986 & 6.0 & 6.081 & TRN & \\
\hline
\end{tabular}




\begin{tabular}{|c|c|c|c|c|}
\hline & & & pplement & al $\mathrm{T}$ \\
\hline CHEMBL2322083 & 938986 & 6.0 & 6.3114 & TST \\
\hline CHEMBL 2322082 & 938986 & 6.0 & 6.5124 & TST \\
\hline CHEMBL2322081 & 938986 & 6.0 & 5.7433 & TRN \\
\hline CHEMBL 2322080 & 938986 & 6.0 & 5.8345 & TRN \\
\hline CHEMBL2322079 & 938986 & 6.0 & 5.6156 & TST \\
\hline CHEMBL2322078 & 938986 & 6.0 & 6.1323 & TST \\
\hline CHEMBL 2322077 & 938986 & 6.0 & 6.0648 & TST \\
\hline CHEMBL2322076 & 938986 & 6.0 & 6.2638 & TRN \\
\hline CHEMBL 2322075 & 938986 & 6.0 & 5.2866 & TST \\
\hline CHEMBL2322074 & 938986 & 6.0 & 5.092 & TRN \\
\hline CHEMBL2322073 & 938986 & 6.0 & 5.5825 & TRN \\
\hline CHEMBL2322072 & 938986 & 6.0 & 6.1074 & TST \\
\hline CHEMBL2322071 & 938986 & 6.0 & 5.4342 & TRN \\
\hline CHEMBL 2322070 & 938986 & 6.0 & 5.8751 & TRN \\
\hline CHEMBL2322069 & 938986 & 6.0044 & 6.9985 & TRN \\
\hline CHEMBL 2322068 & 938986 & 6.0044 & 6.3334 & TRN \\
\hline CHEMBL2322067 & 938986 & 6.0088 & 6.8698 & TRN \\
\hline CHEMBL2322066 & 938986 & 6.0132 & 6.6729 & TRN \\
\hline CHEMBL2322065 & 938986 & 6.0177 & 7.0064 & TST \\
\hline CHEMBL2322064 & 938986 & 6.0223 & 6.5395 & TRN \\
\hline CHEMBL 2322063 & 938986 & 6.0269 & 5.9868 & TRN \\
\hline CHEMBL2322062 & 938986 & 6.0315 & 6.0878 & TRN \\
\hline CHEMBL 2322061 & 938986 & 6.0315 & 6.249 & TRN \\
\hline CHEMBL2322060 & 938986 & 6.0362 & 6.2604 & TRN \\
\hline CHEMBL2326805 & 938986 & 6.0362 & 6.7266 & TRN \\
\hline CHEMBL 2326804 & 938986 & 6.0362 & 5.8268 & TRN \\
\hline CHEMBL2322378 & 938986 & 6.041 & 6.0509 & TRN \\
\hline CHEMBL 2322377 & 938986 & 6.0458 & 6.3291 & TRN \\
\hline CHEMBL2322113 & 938986 & 6.0458 & 6.4084 & TRN \\
\hline CHEMBL2322112 & 938986 & 6.0506 & 6.2837 & TRN \\
\hline CHEMBL 2322111 & 938986 & 6.0706 & 6.9255 & TRN \\
\hline CHEMBL2322110 & 938986 & 6.0757 & 5.6048 & TRN \\
\hline CHEMBL2322109 & 938986 & 6.0757 & 5.3311 & TRN \\
\hline CHEMBL2322108 & 938986 & 6.0757 & 6.1564 & TRN \\
\hline CHEMBL 2322107 & 938986 & 6.0862 & 6.784 & TST \\
\hline CHEMBL2322106 & 938986 & 6.0862 & 6.4576 & TRN \\
\hline CHEMBL2322105 & 938986 & 6.0862 & 6.9511 & TRN \\
\hline CHEMBL2322104 & 938986 & 6.0862 & 5.8293 & TRN \\
\hline CHEMBL2322103 & 938986 & 6.0915 & 5.7412 & TRN \\
\hline CHEMBL2322102 & 938986 & 6.0915 & 6.4968 & TRN \\
\hline CHEMBL 2322101 & 938986 & 6.0915 & 5.5454 & TST \\
\hline CHEMBL 2322100 & 938986 & 6.1079 & 6.1666 & TST \\
\hline CHEMBL2322099 & 938986 & 6.1079 & 5.6212 & TST \\
\hline CHEMBL2322098 & 938986 & 6.1079 & 6.6995 & TST \\
\hline CHEMBL2322097 & 938986 & 6.1079 & 5.8879 & TRN \\
\hline CHEMBL2322096 & 938986 & 6.1079 & 6.3542 & TRN \\
\hline CHEMBL 2322095 & 938986 & 6.1135 & 7.3144 & TST \\
\hline CHEMBL2322094 & 938986 & 6.1135 & 5.8105 & TRN \\
\hline
\end{tabular}




\begin{tabular}{|c|c|c|c|c|c|}
\hline & & \multicolumn{4}{|c|}{ Supplemental Table S2.txt } \\
\hline CHEMBL2322093 & 938986 & 6.1135 & 6.4591 & TRN & \\
\hline CHEMBL2322092 & 938986 & 6.1135 & 5.5963 & TRN & \\
\hline CHEMBL2322091 & 938986 & 6.1192 & 5.5823 & TRN & \\
\hline CHEMBL2322090 & 938986 & 6.1192 & 6.3007 & TRN & \\
\hline CHEMBL2322089 & 938986 & 6.1308 & 5.91299 & 9999999999 & TRN \\
\hline CHEMBL2322088 & 938986 & 6.1308 & 5.7896 & TRN & \\
\hline CHEMBL 2322410 & 938986 & 6.1308 & 6.0898 & TRN & \\
\hline CHEMBL2322409 & 938986 & 6.1308 & 4.4621 & TST & \\
\hline CHEMBL2322408 & 938986 & 6.1308 & 5.767 & TRN & \\
\hline CHEMBL 2322407 & 938986 & 6.1308 & 6.2277 & TRN & \\
\hline CHEMBL2322406 & 938986 & 6.1367 & 6.3148 & TRN & \\
\hline CHEMBL2322405 & 938986 & 6.1367 & 5.9099 & TRN & \\
\hline CHEMBL 2322404 & 938986 & 6.1427 & 5.7661 & TRN & \\
\hline CHEMBL2322403 & 938986 & 6.1427 & 5.8085 & TRN & \\
\hline CHEMBL 2322402 & 938986 & 6.1487 & 6.5427 & TRN & \\
\hline CHEMBL 2322401 & 938986 & 6.1487 & 6.7109 & TST & \\
\hline CHEMBL2322400 & 938986 & 6.1549 & 5.9669 & TST & \\
\hline CHEMBL2322399 & 938986 & 6.1612 & 6.8616 & TRN & \\
\hline CHEMBL2322398 & 938986 & 6.1675 & 6.4951 & TRN & \\
\hline CHEMBL 2322397 & 938986 & 6.1739 & 6.5995 & TRN & \\
\hline CHEMBL 2322396 & 938986 & 6.1739 & 5.9324 & TRN & \\
\hline CHEMBL2322395 & 938986 & 6.1805 & 6.7046 & TRN & \\
\hline CHEMBL 2322394 & 938986 & 6.1805 & 6.7069 & TRN & \\
\hline CHEMBL2322393 & 938986 & 6.1805 & 6.5296 & TRN & \\
\hline CHEMBL 2322392 & 938986 & 6.2007 & 5.8399 & TST & \\
\hline CHEMBL 2322391 & 938986 & 6.2007 & 6.5568 & TRN & \\
\hline CHEMBL 2322390 & 938986 & 6.2076 & 6.1681 & TRN & \\
\hline CHEMBL 2322389 & 938986 & 6.2218 & 5.7582 & TRN & \\
\hline CHEMBL 2322388 & 938986 & 6.2218 & 6.7271 & TST & \\
\hline CHEMBL 2322387 & 938986 & 6.2291 & 6.2365 & TST & \\
\hline CHEMBL 2322386 & 938986 & 6.2366 & 6.5607 & TRN & \\
\hline CHEMBL2322385 & 938986 & 6.2366 & 7.3641 & TST & \\
\hline CHEMBL 2322384 & 938986 & 6.2366 & 6.3949 & TRN & \\
\hline CHEMBL2322383 & 938986 & 6.2366 & 6.8272 & TRN & \\
\hline CHEMBL2322382 & 938986 & 6.2441 & 5.7134 & TST & \\
\hline CHEMBL2322381 & 938986 & 6.2518 & 7.4704 & TST & \\
\hline CHEMBL 2322380 & 938986 & 6.2596 & 6.4602 & TRN & \\
\hline CHEMBL2322379 & 938986 & 6.2596 & 5.6539 & TST & \\
\hline CHEMBL2322717 & 938986 & 6.2676 & 6.4305 & TRN & \\
\hline CHEMBL2322716 & 938986 & 6.2676 & 6.7939 & TRN & \\
\hline CHEMBL 2322715 & 938986 & 6.2676 & 6.2863 & TRN & \\
\hline CHEMBL 2322714 & 938986 & 6.2676 & 6.5101 & TRN & \\
\hline CHEMBL2322713 & 938986 & 6.2676 & 6.4865 & TRN & \\
\hline CHEMBL2322712 & 938986 & 6.2757 & 6.4458 & TRN & \\
\hline CHEMBL2322711 & 938986 & 6.2757 & 6.3722 & TRN & \\
\hline CHEMBL 2322436 & 938986 & 6.284 & 6.0945 & TRN & \\
\hline CHEMBL 2322435 & 938986 & 6.2924 & 6.7585 & TRN & \\
\hline CHEMBL 2322434 & 938986 & 6.2924 & 5.8788 & TRN & \\
\hline
\end{tabular}




\begin{tabular}{|c|c|c|c|c|c|}
\hline \multirow[b]{2}{*}{ CHEMBL2322433 } & \multicolumn{5}{|c|}{ Supplemental Table S2.txt } \\
\hline & 938986 & 6.2924 & 6.78299 & 99999999995 & TST \\
\hline CHEMBL 2322432 & 938986 & 6.301 & 6.8365 & TRN & \\
\hline CHEMBL2322431 & 938986 & 6.301 & 6.2568 & TST & \\
\hline CHEMBL2322430 & 938986 & 6.3098 & 6.7987 & TRN & \\
\hline CHEMBL 2322429 & 938986 & 6.3098 & 6.3914 & TRN & \\
\hline CHEMBL 2322428 & 938986 & 6.3098 & 6.9152 & TST & \\
\hline CHEMBL 2322427 & 938986 & 6.3188 & 5.9474 & TRN & \\
\hline CHEMBL2322426 & 938986 & 6.3188 & 6.4154 & TRN & \\
\hline CHEMBL 2322425 & 938986 & 6.3188 & 6.4951 & TRN & \\
\hline CHEMBL2322424 & 938986 & 6.3188 & 6.6217 & TST & \\
\hline CHEMBL 2322423 & 938986 & 6.3279 & 5.9726 & TRN & \\
\hline CHEMBL 2322422 & 938986 & 6.3279 & 6.2622 & TRN & \\
\hline CHEMBL 2322421 & 938986 & 6.3279 & 6.4783 & TRN & \\
\hline CHEMBL 2322420 & 938986 & 6.3279 & 6.2796 & TST & \\
\hline CHEMBL2322419 & 938986 & 6.3279 & 5.7967 & TST & \\
\hline CHEMBL 2322418 & 938986 & 6.3279 & 6.5392 & TRN & \\
\hline CHEMBL 2322417 & 938986 & 6.3468 & 5.8837 & TRN & \\
\hline CHEMBL2322416 & 938986 & 6.3468 & 6.6888 & TRN & \\
\hline CHEMBL2322415 & 938986 & 6.3468 & 6.2838 & TRN & \\
\hline CHEMBL 2322414 & 938986 & 6.3468 & 6.319 & TRN & \\
\hline CHEMBL 2322413 & 938986 & 6.3468 & 6.5118 & TST & \\
\hline CHEMBL 2322412 & 938986 & 6.3665 & 6.7395 & TRN & \\
\hline CHEMBL 2322411 & 938986 & 6.3665 & 6.9632 & TRN & \\
\hline CHEMBL 2321886 & 938986 & 6.3665 & 6.4161 & TRN & \\
\hline CHEMBL 2322748 & 938986 & 6.3665 & 6.0161 & TRN & \\
\hline CHEMBL 2322747 & 938986 & 6.3665 & 6.41299 & 9999999999 & TRN \\
\hline CHEMBL 2322746 & 938986 & 6.3768 & 6.6677 & TRN & \\
\hline CHEMBL 2322745 & 938986 & 6.3768 & 6.3533 & TRN & \\
\hline CHEMBL 2322744 & 938986 & 6.3768 & 6.2147 & TRN & \\
\hline CHEMBL 2322743 & 938986 & 6.3872 & 5.7261 & TRN & \\
\hline CHEMBL 2322742 & 938986 & 6.3872 & 6.2725 & TRN & \\
\hline CHEMBL 2322741 & 938986 & 6.3979 & 6.6955 & TST & \\
\hline CHEMBL 2322740 & 938986 & 6.3979 & 6.0344 & TRN & \\
\hline CHEMBL 2322739 & 938986 & 6.3979 & 7.5394 & TST & \\
\hline CHEMBL 2322738 & 938986 & 6.4089 & 7.3332 & TST & \\
\hline CHEMBL 2322737 & 938986 & 6.4089 & 7.8779 & TRN & \\
\hline CHEMBL 2322736 & 938986 & 6.4089 & 6.8129 & TRN & \\
\hline CHEMBL 2322735 & 938986 & 6.4202 & 5.9847 & TST & \\
\hline CHEMBL 2322734 & 938986 & 6.4202 & 6.186 & TRN & \\
\hline CHEMBL 2322733 & 938986 & 6.4202 & 6.3657 & TRN & \\
\hline CHEMBL 2322732 & 938986 & 6.4318 & 5.5865 & TRN & \\
\hline CHEMBL 2322731 & 938986 & 6.4318 & 6.2717 & TRN & \\
\hline CHEMBL 2322730 & 938986 & 6.4318 & 6.5648 & TRN & \\
\hline CHEMBL 2322729 & 938986 & 6.4437 & 6.6862 & TST & \\
\hline CHEMBL 2322728 & 938986 & 6.4437 & 6.513 & TRN & \\
\hline CHEMBL 2322727 & 938986 & 6.4437 & 6.6396 & TRN & \\
\hline CHEMBL2322726 & 938986 & 6.4559 & 6.0269 & TRN & \\
\hline CHEMBL 2322725 & 938986 & 6.4559 & 6.4517 & TRN & \\
\hline
\end{tabular}


Supplemental Table S2.txt

\begin{tabular}{|c|c|c|c|c|}
\hline CHEMBL 2322724 & 938986 & 6.4559 & 5.685 & TST \\
\hline CHEMBL 2322723 & 938986 & 6.4559 & 7.6201 & TST \\
\hline CHEMBL 2322722 & 938986 & 6.4685 & 6.806 & TST \\
\hline CHEMBL 2322721 & 938986 & 6.4685 & 6.0871 & TRN \\
\hline CHEMBL 2322720 & 938986 & 6.4685 & 6.0859 & TRN \\
\hline CHEMBL 2322719 & 938986 & 6.4685 & 6.7173 & TRN \\
\hline CHEMBL 2322718 & 938986 & 6.4685 & 6.4956 & TST \\
\hline CHEMBL 2323079 & 938986 & 6.4815 & 6.5357 & TRN \\
\hline CHEMBL 2323078 & 938986 & 6.4815 & 6.6934 & TST \\
\hline CHEMBL 2323077 & 938986 & 6.4815 & 6.4512 & TRN \\
\hline CHEMBL 2323076 & 938986 & 6.4815 & 6.53600 & 20000000005 \\
\hline CHEMBL 2323075 & 938986 & 6.4949 & 7.0203 & TRN \\
\hline CHEMBL 2323074 & 938986 & 6.4949 & 6.9408 & TRN \\
\hline CHEMBL 2323073 & 938986 & 6.4949 & 6.0531 & TRN \\
\hline CHEMBL 2323072 & 938986 & 6.5086 & 6.6789 & TRN \\
\hline CHEMBL 2323071 & 938986 & 6.5086 & 6.2416 & TRN \\
\hline CHEMBL 2323070 & 938986 & 6.5086 & 6.4135 & TRN \\
\hline CHEMBL 2323069 & 938986 & 6.5086 & 6.8655 & TRN \\
\hline CHEMBL 2323068 & 938986 & 6.5229 & 6.279 & TRN \\
\hline CHEMBL 2323067 & 938986 & 6.5229 & 6.6426 & TRN \\
\hline CHEMBL 2323066 & 938986 & 6.5229 & 5.959 & TRN \\
\hline CHEMBL 2323065 & 938986 & 6.5229 & 6.4395 & TRN \\
\hline CHEMBL 2323064 & 938986 & 6.5229 & 6.1731 & TRN \\
\hline CHEMBL 2323063 & 938986 & 6.5229 & 6.6992 & TRN \\
\hline CHEMBL 2323062 & 938986 & 6.5229 & 6.5045 & TRN \\
\hline CHEMBL 2323061 & 938986 & 6.5229 & 6.7674 & TST \\
\hline CHEMBL 2322762 & 938986 & 6.5229 & 6.7716 & TRN \\
\hline CHEMBL 2322761 & 938986 & 6.5229 & 6.3787 & TRN \\
\hline CHEMBL 2322760 & 938986 & 6.5229 & 6.7366 & TST \\
\hline CHEMBL 2322759 & 938986 & 6.5229 & 6.3019 & TST \\
\hline CHEMBL 2322758 & 938986 & 6.5229 & 6.9482 & TRN \\
\hline CHEMBL 2322757 & 938986 & 6.5229 & 6.4413 & TST \\
\hline CHEMBL 2322756 & 938986 & 6.5229 & 6.5945 & TST \\
\hline CHEMBL 2322755 & 938986 & 6.5528 & 6.8165 & TRN \\
\hline CHEMBL 2322754 & 938986 & 6.5528 & 7.3285 & TST \\
\hline CHEMBL 2322753 & 938986 & 6.5686 & 6.19 & TST \\
\hline CHEMBL 2322752 & 938986 & 6.5686 & 6.1952 & TST \\
\hline CHEMBL 2322751 & 938986 & 6.5686 & 7.3151 & TST \\
\hline CHEMBL 2322750 & 938986 & 6.5686 & 7.5829 & TRN \\
\hline CHEMBL 2322749 & 938986 & 6.585 & 6.5068 & TRN \\
\hline CHEMBL 2323108 & 938986 & 6.585 & 6.8431 & TRN \\
\hline CHEMBL 2323107 & 938986 & 6.585 & 7.1352 & TRN \\
\hline CHEMBL 2323106 & 938986 & 6.585 & 5.8014 & TRN \\
\hline CHEMBL 2323105 & 938986 & 6.585 & 6.4991 & TRN \\
\hline CHEMBL 2323104 & 938986 & 6.6021 & \multicolumn{2}{|c|}{6.8229999999999995} \\
\hline CHEMBL 2323103 & 938986 & 6.6021 & 6.7979 & TRN \\
\hline CHEMBL 2323102 & 938986 & 6.6021 & 6.3589 & TRN \\
\hline CHEMBL 2323101 & 938986 & 6.6198 & 6.5678 & TRN \\
\hline
\end{tabular}


Supplemental Table S2.txt

\begin{tabular}{|c|c|}
\hline CHEMBL 2323100 & 938986 \\
\hline CHEMBL2323099 & 938986 \\
\hline CHEMBL2323098 & 938986 \\
\hline CHEMBL2323097 & 938986 \\
\hline CHEMBL2323096 & 938986 \\
\hline CHEMBL2323095 & 938986 \\
\hline CHEMBL2323094 & 938986 \\
\hline CHEMBL 2323093 & 938986 \\
\hline CHEMBL2323092 & 938986 \\
\hline CHEMBL2323091 & 938986 \\
\hline CHEMBL 2323090 & 938986 \\
\hline CHEMBL2323089 & 938986 \\
\hline CHEMBL 2323088 & 938986 \\
\hline CHEMBL2323087 & 938986 \\
\hline CHEMBL2323086 & 938986 \\
\hline CHEMBL 2323085 & 938986 \\
\hline CHEMBL2323084 & 938986 \\
\hline CHEMBL 2323083 & 938986 \\
\hline CHEMBL2323082 & 938986 \\
\hline CHEMBL2323081 & 938986 \\
\hline CHEMBL 2323080 & 938986 \\
\hline CHEMBL2323322 & 938986 \\
\hline CHEMBL 2323321 & 938986 \\
\hline CHEMBL2323320 & 938986 \\
\hline CHEMBL2323319 & 938986 \\
\hline CHEMBL 2323318 & 938986 \\
\hline CHEMBL2323317 & 938986 \\
\hline CHEMBL 2323316 & 938986 \\
\hline CHEMBL2323315 & 938986 \\
\hline CHEMBL 2323314 & 938986 \\
\hline CHEMBL 2323313 & 938986 \\
\hline CHEMBL2323312 & 938986 \\
\hline CHEMBL 2323311 & 938986 \\
\hline CHEMBL2323310 & 938986 \\
\hline CHEMBL2323309 & 938986 \\
\hline CHEMBL2323308 & 938986 \\
\hline CHEMBL2323307 & 938986 \\
\hline CHEMBL2323306 & 938986 \\
\hline CHEMBL2323305 & 938986 \\
\hline CHEMBL 2323304 & 938986 \\
\hline CHEMBL 2323303 & 938986 \\
\hline CHEMBL 2323302 & 938986 \\
\hline CHEMBL2323301 & 938986 \\
\hline CHEMBL2323300 & 938986 \\
\hline CHEMBL2323299 & 938986 \\
\hline CHEMBL2323298 & 938986 \\
\hline CHEMBL 2323297 & 938986 \\
\hline CHEMBL2323296 & 938986 \\
\hline
\end{tabular}
$\begin{array}{lll}6.6198 & 6.4845 & \text { TRN }\end{array}$
$\begin{array}{lll}6.6198 & 7.1596 & \text { TRN }\end{array}$
$\begin{array}{lll}6.6198 & 6.7561 & \text { TRN }\end{array}$
$\begin{array}{llll}6.6198 & 6.8868 & \text { TRN }\end{array}$
$\begin{array}{lll}6.6198 & 7.1471 & \text { TRN }\end{array}$
$\begin{array}{lll}6.6198 & 6.3633 & \text { TRN }\end{array}$
$\begin{array}{lll}6.6383 & 7.2157 & \text { TRN }\end{array}$
$\begin{array}{lll}6.6383 & 6.6667 & \text { TRN }\end{array}$
$\begin{array}{lll}6.6383 & 6.4505 & \text { TRN }\end{array}$
$\begin{array}{lll}6.6383 & 5.6219 & \text { TST }\end{array}$
$\begin{array}{lll}6.6383 & 6.9374 & \text { TRN }\end{array}$
$\begin{array}{lll}6.6383 & 7.3977 \quad \text { TRN }\end{array}$
$\begin{array}{lll}6.6383 & 6.3438 \text { TRN }\end{array}$
$\begin{array}{lll}6.6383 & 6.5162 & \text { TRN }\end{array}$

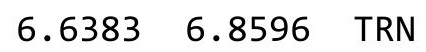
$\begin{array}{lll}6.6383 & 6.8986 & \text { TRN }\end{array}$
$\begin{array}{lll}6.6383 & 6.2539 & \text { TST }\end{array}$
$\begin{array}{lll}6.6576 & 6.7249 & \text { TRN }\end{array}$
$\begin{array}{lll}6.6576 & 6.6837 & \text { TRN }\end{array}$
$\begin{array}{lll}6.6576 & 6.7539 & \text { TST }\end{array}$
$\begin{array}{lll}6.6576 & 6.1618 \text { TRN }\end{array}$
$\begin{array}{lll}6.6778 & 7.1199 & \text { TRN }\end{array}$
$\begin{array}{lll}6.6778 & 6.1044 & \text { TRN }\end{array}$
$\begin{array}{lll}6.6778 & 6.3775 & \text { TRN }\end{array}$
$\begin{array}{lll}6.6778 & 6.6964 & \text { TRN }\end{array}$
6.67786 .3899 TRN
$\begin{array}{lll}6.699 & 6.7504 & \text { TRN }\end{array}$
$6.699 \quad 6.6116$ TRN
6.6996 .5008 TRN
$\begin{array}{ll}6.699 & 6.3481 \text { TRN }\end{array}$
$\begin{array}{lll}6.7212 & 6.9762 & \text { TRN }\end{array}$
$\begin{array}{lll}6.7212 & 6.5258 & \text { TRN }\end{array}$
$\begin{array}{lll}6.7212 & 6.3068 \text { TRN }\end{array}$
$\begin{array}{lll}6.7212 & 6.3859 & \text { TRN }\end{array}$
6.72126 .8316 TRN
$\begin{array}{lll}6.7212 & 6.9792 & \text { TRN }\end{array}$
$\begin{array}{lll}6.7212 & 7.0654 & \text { TRN }\end{array}$
$\begin{array}{llll}6.7212 & 7.4003 & \text { TRN }\end{array}$
$\begin{array}{lll}6.7212 & 7.159 & \text { TST }\end{array}$
$\begin{array}{llll}6.7212 & 6.7287 & \text { TRN }\end{array}$
$\begin{array}{llll}6.7447 & 7.2364 & \text { TRN }\end{array}$
$\begin{array}{lll}6.7447 & 7.0989 & \text { TRN }\end{array}$
$\begin{array}{llll}6.7447 & 7.1903 & \text { TRN }\end{array}$
$\begin{array}{llll}6.7447 & 6.3942 & \text { TRN }\end{array}$
$6.7696 \quad 6.6916$ TRN
$\begin{array}{lll}6.7696 & 7.0757 & \text { TST }\end{array}$
$6.7696 \quad 6.6616$ TRN
6.76966 .6793 TRN

Page 12781 


\begin{tabular}{|c|c|c|c|c|c|}
\hline \multicolumn{6}{|c|}{ Supplemental Table S2.txt } \\
\hline CHEMBL2323295 & 938986 & 6.7696 & 6.2474 & TRN & \\
\hline CHEMBL 2323110 & 938986 & 6.7696 & 7.0466 & TRN & \\
\hline CHEMBL2323109 & 938986 & 6.7696 & 7.3755 & TRN & \\
\hline CHEMBL2323639 & 938986 & 6.7959 & 6.931 & TRN & \\
\hline CHEMBL2323638 & 938986 & 6.7959 & 6.6945 & TRN & \\
\hline CHEMBL2323637 & 938986 & 6.7959 & 6.1724 & TRN & \\
\hline CHEMBL2323350 & 938986 & 6.7959 & 6.527 & TRN & \\
\hline CHEMBL2323349 & 938986 & 6.7959 & 6.9206 & TRN & \\
\hline CHEMBL 2323348 & 938986 & 6.7959 & 6.9147 & TRN & \\
\hline CHEMBL2323347 & 938986 & 6.7959 & 7.289 & TRN & \\
\hline CHEMBL2323346 & 938986 & 6.7959 & 6.8167 & TRN & \\
\hline CHEMBL2323345 & 938986 & 6.8239 & 7.0207 & TRN & \\
\hline CHEMBL2323344 & 938986 & 6.8539 & 6.4753 & TRN & \\
\hline CHEMBL 2323343 & 938986 & 6.8539 & 7.1653 & TRN & \\
\hline CHEMBL2321892 & 938986 & 6.8539 & 7.391 & TRN & \\
\hline CHEMBL 2323342 & 938986 & 6.8539 & 7.1117 & TRN & \\
\hline CHEMBL2323341 & 938986 & 6.8539 & 6.8966 & TRN & \\
\hline CHEMBL 2323340 & 938986 & 6.8539 & 6.7664 & TRN & \\
\hline CHEMBL2323339 & 938986 & 6.8539 & 6.928 & TRN & \\
\hline CHEMBL2323338 & 938986 & 6.8539 & 6.9189 & TRN & \\
\hline CHEMBL 2323337 & 938986 & 6.8539 & 6.2934 & TRN & \\
\hline CHEMBL2323336 & 938986 & 6.8539 & 7.3232 & TRN & \\
\hline CHEMBL 2323335 & 938986 & 6.8539 & 7.1277 & TRN & \\
\hline CHEMBL2323334 & 938986 & 6.8539 & 7.2436 & TRN & \\
\hline CHEMBL 2323333 & 938986 & 6.8861 & 7.0732 & TRN & \\
\hline CHEMBL 2323332 & 938986 & 6.8861 & 6.978 & TRN & \\
\hline CHEMBL2323331 & 938986 & 6.8861 & 6.9638 & TRN & \\
\hline CHEMBL 2323330 & 938986 & 6.8861 & 7.0268 & TRN & \\
\hline CHEMBL2323329 & 938986 & 6.8861 & 6.9401 & TRN & \\
\hline CHEMBL2323328 & 938986 & 6.8861 & 7.0867 & TRN & \\
\hline CHEMBL 2323327 & 938986 & 6.8861 & 7.0625 & TRN & \\
\hline CHEMBL2323326 & 938986 & 6.8861 & 6.33200 & 0000000001 & TRN \\
\hline CHEMBL2323325 & 938986 & 6.8861 & 7.2913 & TRN & \\
\hline CHEMBL2323324 & 938986 & 6.8861 & 6.9126 & TRN & \\
\hline CHEMBL2323323 & 938986 & 6.9208 & 6.6057 & TRN & \\
\hline CHEMBL2323668 & 938986 & 6.9208 & 7.1434 & TST & \\
\hline CHEMBL 2323667 & 938986 & 6.9208 & 6.605 & TST & \\
\hline CHEMBL2323666 & 938986 & 6.9208 & 7.0594 & TRN & \\
\hline CHEMBL2323665 & 938986 & 6.9208 & 6.4236 & TRN & \\
\hline CHEMBL2323664 & 938986 & 6.9208 & 7.3299 & TRN & \\
\hline CHEMBL 2323663 & 938986 & 6.9208 & 6.9842 & TRN & \\
\hline CHEMBL2323662 & 938986 & 6.9208 & 6.9278 & TRN & \\
\hline CHEMBL2323661 & 938986 & 6.9208 & 6.4145 & TRN & \\
\hline CHEMBL2323660 & 938986 & 6.9208 & 6.2495 & TRN & \\
\hline CHEMBL2323659 & 938986 & 6.9208 & 7.062 & TRN & \\
\hline CHEMBL 2323658 & 938986 & 6.9586 & 7.1165 & TRN & \\
\hline CHEMBL2323657 & 938986 & 6.9586 & 7.0716 & TRN & \\
\hline CHEMBL2323656 & 938986 & 6.9586 & 7.0679 & TRN & \\
\hline
\end{tabular}

Page 12782 


\begin{tabular}{|c|c|c|c|c|c|}
\hline & & \multicolumn{4}{|c|}{ Supplemental Table S2.txt } \\
\hline CHEMBL2323655 & 938986 & 6.9586 & 7.2567 & TST & \\
\hline CHEMBL 2323654 & 938986 & 6.9586 & 6.9276 & TST & \\
\hline CHEMBL 2323653 & 938986 & 6.9586 & 7.0167 & TRN & \\
\hline CHEMBL 2323652 & 938986 & 6.9586 & 6.6184 & TRN & \\
\hline CHEMBL 2323651 & 938986 & 6.9586 & 7.6735 & TRN & \\
\hline CHEMBL 2323650 & 938986 & 6.9586 & 6.6147 & TRN & \\
\hline CHEMBL 2323649 & 938986 & 6.9586 & 6.9043 & TRN & \\
\hline CHEMBL 2323648 & 938986 & 6.9586 & 6.4934 & TRN & \\
\hline CHEMBL 2323647 & 938986 & 6.9586 & 6.5062 & TRN & \\
\hline CHEMBL 2323646 & 938986 & 7.0 & 7.0064 & TRN & \\
\hline CHEMBL 2323645 & 938986 & 7.0 & 7.1714 & TRN & \\
\hline CHEMBL 2323644 & 938986 & 7.0 & 7.7181 & TRN & \\
\hline CHEMBL 2323643 & 938986 & 7.0 & 6.7428 & TRN & \\
\hline CHEMBL 2323642 & 938986 & 7.0 & 6.8057 & TRN & \\
\hline CHEMBL 2323641 & 938986 & 7.0 & 7.223 & TRN & \\
\hline CHEMBL 2323640 & 938986 & 7.0 & 7.0607 & TRN & \\
\hline CHEMBL 2321895 & 938986 & 7.0 & 6.7178 & TRN & \\
\hline CHEMBL 2323984 & 938986 & 7.0 & 7.3109 & TST & \\
\hline CHEMBL 2323983 & 938986 & 7.0 & 6.869 & TRN & \\
\hline CHEMBL 2323982 & 938986 & 7.0044 & 7.3935 & TRN & \\
\hline CHEMBL 2323981 & 938986 & 7.0132 & 7.6564 & TRN & \\
\hline CHEMBL 2323980 & 938986 & 7.0132 & 7.3763 & TRN & \\
\hline CHEMBL 2323979 & 938986 & 7.0132 & 7.221 & TRN & \\
\hline CHEMBL 2323978 & 938986 & 7.0177 & 6.4901 & TRN & \\
\hline CHEMBL 2323977 & 938986 & 7.0177 & 7.0668 & TRN & \\
\hline CHEMBL 2323976 & 938986 & 7.0223 & 7.0682 & TST & \\
\hline CHEMBL 2323975 & 938986 & 7.0315 & 6.6815 & TRN & \\
\hline CHEMBL 2323974 & 938986 & 7.041 & 6.8619 & TRN & \\
\hline CHEMBL 2323973 & 938986 & 7.041 & 7.4751 & TRN & \\
\hline CHEMBL 2323972 & 938986 & 7.0458 & 6.8082 & TRN & \\
\hline CHEMBL 2323971 & 938986 & 7.0458 & 6.8771 & TRN & \\
\hline CHEMBL 2323970 & 938986 & 7.0458 & 6.9732 & TRN & \\
\hline CHEMBL 2323969 & 938986 & 7.0458 & 6.5893 & TRN & \\
\hline CHEMBL 2323968 & 938986 & 7.0458 & 6.9045 & TRN & \\
\hline CHEMBL 2323682 & 938986 & 7.0555 & 7.6398 & TRN & \\
\hline CHEMBL 2323681 & 938986 & 7.0555 & 7.2626 & TRN & \\
\hline CHEMBL 2323680 & 938986 & 7.0555 & 7.0784 & TRN & \\
\hline CHEMBL 2323679 & 938986 & 7.0555 & 6.7795 & TRN & \\
\hline CHEMBL 2323678 & 938986 & 7.0555 & 6.7583 & TRN & \\
\hline CHEMBL 2323677 & 938986 & 7.0605 & 6.9833 & TRN & \\
\hline CHEMBL 2323676 & 938986 & 7.0809 & 6.9398 & TRN & \\
\hline CHEMBL 2323675 & 938986 & 7.0915 & 6.6403 & TRN & \\
\hline CHEMBL 2323674 & 938986 & 7.0915 & 7.2142 & TRN & \\
\hline CHEMBL 2323673 & 938986 & 7.0969 & 7.2747 & TRN & \\
\hline CHEMBL 2323672 & 938986 & 7.0969 & 6.9692 & TRN & \\
\hline CHEMBL 2323671 & 938986 & 7.0969 & 6.70799 & 9999999999 & TRN \\
\hline CHEMBL 2323670 & 938986 & 7.0969 & 6.9852 & TRN & \\
\hline CHEMBL 2323669 & 938986 & 7.1024 & 6.7479 & TRN & \\
\hline
\end{tabular}

Page 12783 
Supplemental Table S2.txt

\begin{tabular}{|c|c|c|c|c|c|}
\hline CHEMBL 2324014 & 938986 & 7.1079 & 7.9855 & TRN & \\
\hline CHEMBL 2324013 & 938986 & 7.1079 & 7.3102 & TST & \\
\hline CHEMBL2324012 & 938986 & 7.1135 & 7.0739 & TRN & \\
\hline CHEMBL2324011 & 938986 & 7.1135 & 7.3262 & TRN & \\
\hline CHEMBL2324010 & 938986 & 7.1135 & 7.0428 & TRN & \\
\hline CHEMBL2324009 & 938986 & 7.1192 & 6.443 & TRN & \\
\hline CHEMBL 2324008 & 938986 & 7.1249 & 7.9008 & TRN & \\
\hline CHEMBL2324007 & 938986 & 7.1249 & 7.6369 & TRN & \\
\hline CHEMBL 2324006 & 938986 & 7.1367 & 7.5725 & TRN & \\
\hline CHEMBL2324005 & 938986 & 7.1427 & 7.2096 & TRN & \\
\hline CHEMBL 2324004 & 938986 & 7.1427 & 6.9269 & TRN & \\
\hline CHEMBL2324003 & 938986 & 7.1487 & 6.7649 & TRN & \\
\hline CHEMBL 2324002 & 938986 & 7.1549 & 6.4932 & TRN & \\
\hline CHEMBL2324001 & 938986 & 7.1549 & 7.0563 & TRN & \\
\hline CHEMBL 2324000 & 938986 & 7.1549 & 7.1283 & TRN & \\
\hline CHEMBL2323999 & 938986 & 7.1549 & 6.7635 & TST & \\
\hline CHEMBL2323998 & 938986 & 7.1549 & 6.9802 & TRN & \\
\hline CHEMBL 2323997 & 938986 & 7.1549 & 6.7655 & TRN & \\
\hline CHEMBL2323996 & 938986 & 7.1612 & 7.5062 & TRN & \\
\hline CHEMBL2323995 & 938986 & 7.1739 & 7.1849 & TRN & \\
\hline CHEMBL2323994 & 938986 & 7.1739 & 7.3832 & TRN & \\
\hline CHEMBL 2323993 & 938986 & 7.1805 & 7.30399 & 9999999999 & TRN \\
\hline CHEMBL 2323992 & 938986 & 7.1805 & 6.6347 & TRN & \\
\hline CHEMBL2323991 & 938986 & 7.1938 & 7.3191 & TRN & \\
\hline CHEMBL2323990 & 938986 & 7.2007 & 7.5995 & TRN & \\
\hline CHEMBL2323989 & 938986 & 7.2218 & 7.3393 & TRN & \\
\hline CHEMBL2323988 & 938986 & 7.2218 & 7.1283 & TRN & \\
\hline CHEMBL 2323987 & 938986 & 7.2218 & 6.9372 & TRN & \\
\hline CHEMBL2323986 & 938986 & 7.2441 & 7.2093 & TRN & \\
\hline CHEMBL 2323985 & 938986 & 7.2441 & 7.3053 & TRN & \\
\hline CHEMBL 2324388 & 938986 & 7.2441 & 6.7007 & TRN & \\
\hline CHEMBL 2324387 & 938986 & 7.2518 & 7.169 & TRN & \\
\hline CHEMBL 2324386 & 938986 & 7.2518 & 7.5911 & TRN & \\
\hline CHEMBL2324385 & 938986 & 7.2518 & 5.8134 & TST & \\
\hline CHEMBL 2324384 & 938986 & 7.2757 & 6.8882 & TRN & \\
\hline CHEMBL2324383 & 938986 & 7.2757 & 7.0956 & TRN & \\
\hline CHEMBL 2324382 & 938986 & 7.2757 & 7.5321 & TRN & \\
\hline CHEMBL2324381 & 938986 & 7.2757 & 7.3695 & TRN & \\
\hline CHEMBL2324380 & 938986 & 7.284 & 6.7699 & TST & \\
\hline CHEMBL 2324379 & 938986 & 7.284 & 7.2802 & TRN & \\
\hline CHEMBL 2324378 & 938986 & 7.301 & 7.0157 & TRN & \\
\hline CHEMBL 2324377 & 938986 & 7.301 & 7.4711 & TRN & \\
\hline CHEMBL2324376 & 938986 & 7.301 & 6.6913 & TRN & \\
\hline CHEMBL 2324375 & 938986 & 7.301 & 6.9426 & TRN & \\
\hline CHEMBL 2324374 & 938986 & 7.301 & 6.6037 & TRN & \\
\hline CHEMBL2324030 & 938986 & 7.301 & 6.5014 & TRN & \\
\hline CHEMBL2324029 & 938986 & 7.301 & 7.362 & TRN & \\
\hline CHEMBL2324028 & 938986 & 7.3098 & 7.1955 & TST & \\
\hline
\end{tabular}


Supplemental Table S2.txt

\begin{tabular}{|c|c|c|c|c|c|}
\hline CHEMBL 2324027 & 938986 & 7.3188 & 7.0979 & TRN & \\
\hline CHEMBL 2324026 & 938986 & 7.3372 & 6.494 & TST & \\
\hline CHEMBL 2324025 & 938986 & 7.3468 & 7.0435 & TST & \\
\hline CHEMBL 2324024 & 938986 & 7.3468 & 8.035 & TRN & \\
\hline CHEMBL 2324023 & 938986 & 7.3565 & 7.4933 & TRN & \\
\hline CHEMBL 2324022 & 938986 & 7.3565 & 7.1066 & TRN & \\
\hline CHEMBL 2324021 & 938986 & 7.3565 & 6.7448 & TRN & \\
\hline CHEMBL 2324020 & 938986 & 7.3872 & 6.8559 & TRN & \\
\hline CHEMBL 2324019 & 938986 & 7.3979 & 7.0698 & TRN & \\
\hline CHEMBL 2324018 & 938986 & 7.3979 & 6.9745 & TRN & \\
\hline CHEMBL 2324017 & 938986 & 7.3979 & 7.8167 & TRN & \\
\hline CHEMBL 2324016 & 938986 & 7.3979 & 7.0302 & TRN & \\
\hline CHEMBL 2324015 & 938986 & 7.3979 & 7.3529 & TRN & \\
\hline CHEMBL 2324416 & 938986 & 7.3979 & 8.3069 & TRN & \\
\hline CHEMBL 2324415 & 938986 & 7.3979 & \multicolumn{2}{|c|}{7.321000000000001} & TRN \\
\hline CHEMBL 2324414 & 938986 & 7.4089 & 7.4608 & TRN & \\
\hline CHEMBL 2324413 & 938986 & 7.4089 & 7.3745 & TRN & \\
\hline CHEMBL 2324412 & 938986 & 7.4202 & 7.5988 & TRN & \\
\hline CHEMBL 2324411 & 938986 & 7.4437 & 7.3489 & TRN & \\
\hline CHEMBL 2324410 & 938986 & 7.4437 & 7.9572 & TRN & \\
\hline CHEMBL 2324409 & 938986 & 7.4559 & 7.0838 & TRN & \\
\hline CHEMBL 2324408 & 938986 & 7.4559 & 7.3085 & TRN & \\
\hline CHEMBL 2324407 & 938986 & 7.4685 & 7.4968 & TRN & \\
\hline CHEMBL 2324406 & 938986 & 7.4685 & 7.8901 & TRN & \\
\hline CHEMBL 2324405 & 938986 & 7.4685 & 7.2469 & TRN & \\
\hline CHEMBL 2324404 & 938986 & 7.4685 & 7.4692 & TRN & \\
\hline CHEMBL 2324403 & 938986 & 7.4685 & 6.8473 & TRN & \\
\hline CHEMBL 2324402 & 938986 & 7.4685 & 7.5266 & TRN & \\
\hline CHEMBL 2324401 & 938986 & 7.4685 & \multicolumn{2}{|c|}{7.162999999999999} & TRN \\
\hline CHEMBL 2324400 & 938986 & 7.4815 & 7.5694 & TRN & \\
\hline CHEMBL 2324399 & 938986 & 7.4815 & 7.6721 & TRN & \\
\hline CHEMBL 2324398 & 938986 & 7.4949 & 7.6786 & TRN & \\
\hline CHEMBL 2324397 & 938986 & 7.4949 & 7.1037 & TRN & \\
\hline CHEMBL 2324396 & 938986 & 7.4949 & 7.3105 & TRN & \\
\hline CHEMBL 2324395 & 938986 & 7.5086 & 7.6277 & TRN & \\
\hline CHEMBL 2324394 & 938986 & 7.5086 & 7.5133 & TRN & \\
\hline CHEMBL 2324393 & 938986 & 7.5086 & 7.6963 & TRN & \\
\hline CHEMBL 2324392 & 938986 & 7.5086 & 7.4177 & TRN & \\
\hline CHEMBL 2324391 & 938986 & 7.5229 & 7.4161 & TRN & \\
\hline CHEMBL 2324390 & 938986 & 7.5229 & 7.8239 & TRN & \\
\hline CHEMBL 2324389 & 938986 & 7.5229 & 7.8471 & TRN & \\
\hline CHEMBL 2324742 & 938986 & 7.5229 & 7.6304 & TRN & \\
\hline CHEMBL 2324741 & 938986 & 7.5229 & 7.7637 & TST & \\
\hline CHEMBL 2324740 & 938986 & 7.5229 & 7.2922 & TRN & \\
\hline CHEMBL 2324739 & 938986 & 7.5229 & 7.6757 & TRN & \\
\hline CHEMBL 2324738 & 938986 & 7.5229 & 6.4171 & TRN & \\
\hline CHEMBL 2324737 & 938986 & 7.5229 & 7.4739 & TRN & \\
\hline CHEMBL 2324736 & 938986 & 7.5376 & 8.3951 & TRN & \\
\hline
\end{tabular}

Page 12785 


\begin{tabular}{|c|c|c|c|c|}
\hline \multicolumn{5}{|c|}{ Supplemental Table S2.txt } \\
\hline CHEMBL2324735 & 938986 & 7.5376 & 7.1517 & TRN \\
\hline CHEMBL 2324734 & 938986 & 7.5376 & 7.7522 & TRN \\
\hline CHEMBL2324733 & 938986 & 7.5528 & 7.3494 & TRN \\
\hline CHEMBL2324732 & 938986 & 7.5686 & 7.9307 & TST \\
\hline CHEMBL2324731 & 938986 & 7.5686 & 6.5999 & TST \\
\hline CHEMBL2324730 & 938986 & 7.585 & 8.048 & TRN \\
\hline CHEMBL2324729 & 938986 & 7.6021 & 7.1348 & TRN \\
\hline CHEMBL2321906 & 938986 & 7.6021 & 7.6081 & TRN \\
\hline CHEMBL2324728 & 938986 & 7.6021 & 8.0779 & TRN \\
\hline CHEMBL2324727 & 938986 & 7.6021 & 7.4003 & TRN \\
\hline CHEMBL2324427 & 938986 & 7.6021 & 5.8667 & TST \\
\hline CHEMBL2324426 & 938986 & 7.6021 & 7.8339 & TRN \\
\hline CHEMBL 2324425 & 938986 & 7.6021 & 7.6082 & TRN \\
\hline CHEMBL 2324424 & 938986 & 7.6021 & 7.4322 & TRN \\
\hline CHEMBL 2324423 & 938986 & 7.6021 & 7.9113 & TRN \\
\hline CHEMBL 2324422 & 938986 & 7.6021 & 7.3665 & TRN \\
\hline CHEMBL2324421 & 938986 & 7.6198 & 7.5622 & TRN \\
\hline CHEMBL 2324420 & 938986 & 7.6383 & 8.2026 & TRN \\
\hline CHEMBL2324419 & 938986 & 7.6383 & 7.7302 & TRN \\
\hline CHEMBL 2324418 & 938986 & 7.6383 & 7.5546 & TRN \\
\hline CHEMBL 2324417 & 938986 & 7.6576 & 7.4322 & TRN \\
\hline CHEMBL 2324770 & 938986 & 7.6576 & 7.2163 & TRN \\
\hline CHEMBL 2324769 & 938986 & 7.6576 & 7.7289 & TRN \\
\hline CHEMBL2324768 & 938986 & 7.6576 & 6.9657 & TRN \\
\hline CHEMBL 2324767 & 938986 & 7.6576 & 7.7713 & TRN \\
\hline CHEMBL 2324766 & 938986 & 7.6576 & 7.5211 & TRN \\
\hline CHEMBL2324765 & 938986 & 7.6576 & 7.8976 & TRN \\
\hline CHEMBL 2324764 & 938986 & 7.6576 & 7.2784 & TRN \\
\hline CHEMBL 2324763 & 938986 & 7.6576 & 7.6603 & TRN \\
\hline CHEMBL 2324762 & 938986 & 7.6778 & 7.0137 & TST \\
\hline CHEMBL 2324761 & 938986 & 7.6778 & 7.1287 & TRN \\
\hline CHEMBL 2324760 & 938986 & 7.6778 & 7.8167 & TRN \\
\hline CHEMBL2324759 & 938986 & 7.699 & 8.1808 & TRN \\
\hline CHEMBL2324758 & 938986 & 7.699 & 8.0369 & TRN \\
\hline CHEMBL 2324757 & 938986 & 7.699 & 7.7849 & TRN \\
\hline CHEMBL2324756 & 938986 & 7.699 & 7.9418 & TRN \\
\hline CHEMBL 2324755 & 938986 & 7.699 & 7.3058 & TRN \\
\hline CHEMBL 2324754 & 938986 & 7.699 & 7.1741 & TRN \\
\hline CHEMBL2324753 & 938986 & 7.699 & 7.4316 & TRN \\
\hline CHEMBL2324752 & 938986 & 7.699 & 7.0946 & TRN \\
\hline CHEMBL 2324751 & 938986 & 7.699 & 7.3629 & TRN \\
\hline CHEMBL 2324750 & 938986 & 7.7212 & 7.9948 & TRN \\
\hline CHEMBL2324749 & 938986 & 7.7212 & 7.0497 & TRN \\
\hline CHEMBL 2324748 & 938986 & 7.7212 & 7.7965 & TRN \\
\hline CHEMBL2324747 & 938986 & 7.7212 & 8.0651 & TRN \\
\hline CHEMBL 2324746 & 938986 & 7.7212 & 7.9843 & TRN \\
\hline CHEMBL 2324745 & 938986 & 7.7447 & 7.2092 & TRN \\
\hline CHEMBL 2324744 & 938986 & 7.7447 & 7.544 & TRN \\
\hline
\end{tabular}




\begin{tabular}{|c|c|c|c|c|c|}
\hline \multicolumn{6}{|c|}{ Supplemental Table S2.txt } \\
\hline CHEMBL 2324743 & 938986 & 7.7447 & 7.5707 & TRN & \\
\hline CHEMBL 2325011 & 938986 & 7.7696 & 8.0133 & TRN & \\
\hline CHEMBL 2325010 & 938986 & 7.7696 & 7.2943 & TRN & \\
\hline CHEMBL 2325009 & 938986 & 7.7696 & 7.58299 & 9999999999 & TRN \\
\hline CHEMBL 2325008 & 938986 & 7.7696 & 7.5865 & TRN & \\
\hline CHEMBL 2325007 & 938986 & 7.7696 & 7.7646 & TRN & \\
\hline CHEMBL 2325006 & 938986 & 7.7696 & 7.7613 & TRN & \\
\hline CHEMBL 2325005 & 938986 & 7.7696 & 6.8282 & TST & \\
\hline CHEMBL 2325004 & 938986 & 7.7696 & 7.9627 & TST & \\
\hline CHEMBL 2325003 & 938986 & 7.7959 & 7.9106 & TRN & \\
\hline CHEMBL 2325002 & 938986 & 7.7959 & 7.87299 & 9999999999 & TRN \\
\hline CHEMBL 2325001 & 938986 & 7.8239 & 7.4047 & TRN & \\
\hline CHEMBL 2325000 & 938986 & 7.8239 & 7.8922 & TRN & \\
\hline CHEMBL 2324999 & 938986 & 7.8239 & 7.8434 & TRN & \\
\hline CHEMBL 2324998 & 938986 & 7.8239 & 6.8802 & TRN & \\
\hline CHEMBL 2324997 & 938986 & 7.8239 & 7.3062 & TRN & \\
\hline CHEMBL 2324996 & 938986 & 7.8239 & 7.7759 & TRN & \\
\hline CHEMBL2324995 & 938986 & 7.8539 & 7.3529 & TRN & \\
\hline CHEMBL 2324994 & 938986 & 7.8539 & 8.1962 & TRN & \\
\hline CHEMBL 2324993 & 938986 & 7.8539 & 7.4101 & TRN & \\
\hline CHEMBL 2324992 & 938986 & 7.8539 & 8.1564 & TRN & \\
\hline CHEMBL 2324991 & 938986 & 7.8539 & 7.4541 & TRN & \\
\hline CHEMBL 2324990 & 938986 & 7.8539 & 7.6931 & TRN & \\
\hline CHEMBL 2324779 & 938986 & 7.8861 & 7.8173 & TRN & \\
\hline CHEMBL 2324778 & 938986 & 7.8861 & 7.7294 & TRN & \\
\hline CHEMBL 2324777 & 938986 & 7.8861 & 7.2186 & TRN & \\
\hline CHEMBL 2324776 & 938986 & 7.8861 & 7.6349 & TRN & \\
\hline CHEMBL 2324775 & 938986 & 7.9208 & 8.0169 & TRN & \\
\hline CHEMBL 2324774 & 938986 & 7.9208 & 7.6555 & TRN & \\
\hline CHEMBL 2324773 & 938986 & 7.9208 & 8.0241 & TRN & \\
\hline CHEMBL 2324772 & 938986 & 7.9208 & 8.2247 & TRN & \\
\hline CHEMBL 2324771 & 938986 & 7.9208 & 7.6148 & TRN & \\
\hline CHEMBL 2325295 & 938986 & 7.9208 & 7.4919 & TRN & \\
\hline CHEMBL 2325294 & 938986 & 7.9208 & 7.521 & TST & \\
\hline CHEMBL2325293 & 938986 & 7.9586 & 7.9588 & TRN & \\
\hline CHEMBL 2325038 & 938986 & 7.9586 & 8.05 & TRN & \\
\hline CHEMBL 2325037 & 938986 & 7.9586 & 7.4969 & TRN & \\
\hline CHEMBL 2325036 & 938986 & 7.9586 & 7.8298 & TRN & \\
\hline CHEMBL 2325035 & 938986 & 7.9586 & 7.6426 & TRN & \\
\hline CHEMBL2325034 & 938986 & 7.9586 & 8.1562 & TRN & \\
\hline CHEMBL 2325033 & 938986 & 7.9586 & 7.3467 & TRN & \\
\hline CHEMBL 2325032 & 938986 & 7.9586 & 7.8134 & TRN & \\
\hline CHEMBL 2325031 & 938986 & 7.9586 & 7.5674 & TRN & \\
\hline CHEMBL 2325030 & 938986 & 7.9586 & 7.7643 & TRN & \\
\hline CHEMBL2325029 & 938986 & 7.9586 & 7.6201 & TRN & \\
\hline CHEMBL 2325028 & 938986 & 7.9586 & 8.2279 & TRN & \\
\hline CHEMBL 2325027 & 938986 & 8.0 & 7.7179 & TRN & \\
\hline CHEMBL 2325026 & 938986 & 8.0 & 7.6823 & TST & \\
\hline
\end{tabular}




\begin{tabular}{|c|c|c|c|c|c|}
\hline \multicolumn{6}{|c|}{ Supplemental Table S2.txt } \\
\hline CHEMBL2321909 & 938986 & 8.0 & 7.329 & TRN & \\
\hline CHEMBL 2325025 & 938986 & 8.0 & 7.2879 & TRN & \\
\hline CHEMBL2325024 & 938986 & 8.0 & 6.8056 & TRN & \\
\hline CHEMBL 2325023 & 938986 & 8.0044 & 7.8581 & TRN & \\
\hline CHEMBL2325022 & 938986 & 8.0044 & 7.9317 & TRN & \\
\hline CHEMBL 2325021 & 938986 & 8.0088 & 8.0058 & TRN & \\
\hline CHEMBL 2325020 & 938986 & 8.0132 & 7.9499 & TRN & \\
\hline CHEMBL2325019 & 938986 & 8.0177 & 8.0245 & TST & \\
\hline CHEMBL 2325018 & 938986 & 8.0269 & 7.8846 & TRN & \\
\hline CHEMBL2325017 & 938986 & 8.0362 & 7.5246 & TRN & \\
\hline CHEMBL2325016 & 938986 & 8.0458 & 7.706 & TRN & \\
\hline CHEMBL2325015 & 938986 & 8.0555 & 7.3555 & TRN & \\
\hline CHEMBL2325014 & 938986 & 8.0655 & 7.6526 & TRN & \\
\hline CHEMBL2325013 & 938986 & 8.0706 & 7.8174 & TRN & \\
\hline CHEMBL2325012 & 938986 & 8.0706 & 7.5778 & TRN & \\
\hline CHEMBL 2325326 & 938986 & 8.0757 & 7.7167 & TRN & \\
\hline CHEMBL2325325 & 938986 & 8.0757 & 8.275 & TRN & \\
\hline CHEMBL 2325324 & 938986 & 8.0969 & 7.9509 & TRN & \\
\hline CHEMBL2325323 & 938986 & 8.1024 & 7.6083 & TRN & \\
\hline CHEMBL2321912 & 938986 & 8.1079 & 8.3981 & TRN & \\
\hline CHEMBL 2325322 & 938986 & 8.1079 & 7.5933 & TRN & \\
\hline CHEMBL2325321 & 938986 & 8.1079 & 7.7478 & TRN & \\
\hline CHEMBL 2325320 & 938986 & 8.1192 & 7.5047 & TRN & \\
\hline CHEMBL2325319 & 938986 & 8.1249 & 8.0409 & TRN & \\
\hline CHEMBL 2325318 & 938986 & 8.1308 & 8.6578 & TRN & \\
\hline CHEMBL2325317 & 938986 & 8.1367 & 7.4553 & TRN & \\
\hline CHEMBL2325316 & 938986 & 8.1427 & 8.0344 & TRN & \\
\hline CHEMBL 2325315 & 938986 & 8.1549 & 7.7996 & TRN & \\
\hline CHEMBL 2325314 & 938986 & 8.1549 & 7.7963 & TRN & \\
\hline CHEMBL2325313 & 938986 & 8.1549 & 7.7933 & TRN & \\
\hline CHEMBL2325312 & 938986 & 8.1612 & 7.6758 & TRN & \\
\hline CHEMBL2325311 & 938986 & 8.1938 & 8.4149 & TRN & \\
\hline CHEMBL2325310 & 938986 & 8.2007 & 8.7528 & TRN & \\
\hline CHEMBL2325309 & 938986 & 8.2076 & 7.7582 & TRN & \\
\hline CHEMBL2325308 & 938986 & 8.2076 & 8.3402 & TRN & \\
\hline CHEMBL2325307 & 938986 & 8.2291 & 7.7734 & TRN & \\
\hline CHEMBL 2325306 & 938986 & 8.2291 & 8.3477 & TST & \\
\hline CHEMBL2325305 & 938986 & 8.2366 & 8.2499 & TRN & \\
\hline CHEMBL2325304 & 938986 & 8.2366 & 8.2377 & TRN & \\
\hline CHEMBL2325303 & 938986 & 8.2366 & 7.9576 & TRN & \\
\hline CHEMBL 2325302 & 938986 & 8.2366 & 7.7905 & TRN & \\
\hline CHEMBL2325301 & 938986 & 8.2676 & 8.4979 & TRN & \\
\hline CHEMBL 2325300 & 938986 & 8.2757 & 7.9845 & TRN & \\
\hline CHEMBL2325299 & 938986 & 8.28399 & 79999999 & 99 & 8.2096 \\
\hline CHEMBL2325298 & 938986 & 8.2924 & 8.0033 & TRN & \\
\hline CHEMBL 2325297 & 938986 & 8.2924 & 8.1555 & TRN & \\
\hline CHEMBL2325296 & 938986 & 8.2924 & 8.979 & TRN & \\
\hline CHEMBL 2325601 & 938986 & 8.301 & 8.3582 & TRN & \\
\hline
\end{tabular}




\begin{tabular}{|c|c|c|c|c|}
\hline \multicolumn{5}{|c|}{ Supplemental Tabl } \\
\hline CHEMBL 2325600 & 938986 & 8.3098 & 8.6376 & TRN \\
\hline CHEMBL 2325599 & 938986 & 8.3098 & 7.3488 & TRN \\
\hline CHEMBL 2325598 & 938986 & 8.3188 & 8.0007 & TRN \\
\hline CHEMBL 2325597 & 938986 & 8.3188 & 8.7657 & TRN \\
\hline CHEMBL 2325596 & 938986 & 8.3188 & 8.4256 & TRN \\
\hline CHEMBL 2325350 & 938986 & 8.3188 & 7.9193 & TRN \\
\hline CHEMBL 2325349 & 938986 & 8.3188 & 7.8746 & TRN \\
\hline CHEMBL 2325348 & 938986 & 8.3188 & 7.9703 & TRN \\
\hline CHEMBL 2325347 & 938986 & 8.3279 & 8.3817 & TRN \\
\hline CHEMBL 2325346 & 938986 & 8.3372 & 7.5637 & TRN \\
\hline CHEMBL 2325345 & 938986 & 8.3372 & 8.7618 & TRN \\
\hline CHEMBL 2325344 & 938986 & 8.3468 & 8.3406 & TRN \\
\hline CHEMBL 2325343 & 938986 & 8.3565 & 8.355 & TRN \\
\hline CHEMBL 2325342 & 938986 & 8.3565 & 7.9882 & TRN \\
\hline CHEMBL 2325341 & 938986 & 8.3565 & 7.8903 & TRN \\
\hline CHEMBL 2325340 & 938986 & 8.3768 & 8.1406 & TRN \\
\hline CHEMBL2325339 & 938986 & 8.3768 & 8.3051 & TRN \\
\hline CHEMBL 2325338 & 938986 & 8.3872 & 7.7921 & TRN \\
\hline CHEMBL 2325337 & 938986 & 8.3872 & 7.6444 & TRN \\
\hline CHEMBL 2325336 & 938986 & 8.3979 & 8.0326 & TRN \\
\hline CHEMBL 2325335 & 938986 & 8.3979 & 8.0778 & TRN \\
\hline CHEMBL 2325334 & 938986 & 8.4089 & 8.074 & TRN \\
\hline CHEMBL 2325333 & 938986 & 8.4202 & 8.7563 & TRN \\
\hline CHEMBL 2325332 & 938986 & 8.4202 & 8.0189 & TRN \\
\hline CHEMBL 2325331 & 938986 & 8.4202 & 8.4955 & TRN \\
\hline CHEMBL 2325330 & 938986 & 8.4318 & 7.807 & TRN \\
\hline CHEMBL 2325329 & 938986 & 8.4318 & 8.1907 & TST \\
\hline CHEMBL 2325328 & 938986 & 8.4437 & 8.672 & TRN \\
\hline CHEMBL 2325327 & 938986 & 8.4437 & 8.4524 & TRN \\
\hline CHEMBL 2325631 & 938986 & 8.4559 & 8.4879 & TRN \\
\hline CHEMBL 2325630 & 938986 & 8.4559 & 8.9211 & TRN \\
\hline CHEMBL 2325629 & 938986 & 8.4949 & 7.9671 & TRN \\
\hline CHEMBL 2325628 & 938986 & 8.5086 & 7.8049 & TRN \\
\hline CHEMBL 2325627 & 938986 & 8.5086 & 8.1517 & TRN \\
\hline CHEMBL 2325626 & 938986 & 8.5086 & 8.6174 & TRN \\
\hline CHEMBL 2325625 & 938986 & 8.5528 & 8.4332 & TRN \\
\hline CHEMBL 2325624 & 938986 & 8.5686 & 9.2771 & TRN \\
\hline CHEMBL 2325623 & 938986 & 8.5686 & 8.0918 & TRN \\
\hline CHEMBL 2325622 & 938986 & 8.585 & 8.5498 & TRN \\
\hline CHEMBL 2325621 & 938986 & 8.6021 & 8.4437 & TRN \\
\hline CHEMBL 2325620 & 938986 & 8.6021 & 7.688 & TRN \\
\hline CHEMBL 2321915 & 938986 & 8.6021 & 8.199 & TRN \\
\hline CHEMBL 2325619 & 938986 & 8.6198 & 8.3369 & TRN \\
\hline CHEMBL 2325618 & 938986 & 8.6198 & 8.0357 & TRN \\
\hline CHEMBL 2325617 & 938986 & 8.6198 & 7.6946 & TRN \\
\hline CHEMBL 2325616 & 938986 & 8.6198 & 8.6124 & TRN \\
\hline CHEMBL 2325615 & 938986 & 8.6383 & 8.6312 & TRN \\
\hline CHEMBL 2325614 & 938986 & 8.6383 & 8.4908 & TRN \\
\hline
\end{tabular}


Supplemental Table S2.txt

\begin{tabular}{|c|c|c|c|c|}
\hline HEM & & .6778 & 8.2174 & $\cdots$ \\
\hline & & .6778 & 8.4182 & \\
\hline 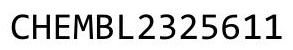 & & 5778 & 235 & \\
\hline IEMBL & 986 & 6778 & & \\
\hline AEMBL 2325609 & 38986 & 6778 & 6409 & \\
\hline HEMBL2325608 & 86 & .6778 & .3351 & \\
\hline HEMBL2325607 & & & 391 & \\
\hline AEMBL 2325606 & & & & \\
\hline HEMBL2325605 & 38986 & .7696 & 9847 & \\
\hline HEMBL2325604 & 86 & . 7959 & 0743 & \\
\hline HEMBL2325603 & & & & \\
\hline AEMBL2325602 & & 39 & & \\
\hline AEMBL 2325645 & & & & \\
\hline HEMBL2325644 & 986 & 8539 & 2659 & \\
\hline HEMBL 2325643 & & & & \\
\hline AEMBL2 & & 1 & 35 & \\
\hline HEMBL2 & & & & RN \\
\hline AEMBL 2325640 & & & & \\
\hline AEMBL2325639 & & & & \\
\hline AEMBL2325638 & & & & I nIV \\
\hline HEMBL 2 & & & & RN \\
\hline IEM & & & & No \\
\hline HEMBL & & & & BN \\
\hline 634 & & & & \\
\hline HEMBL 2325633 & & & & I RN \\
\hline HEMBL2325 & & & & 「RN \\
\hline HEMBL 2 & & & & ונס \\
\hline HEMP I: & & & & \\
\hline HEMBL2 & & & & 15 \\
\hline AEMBL 232523 & & & & TRN \\
\hline HEMBL 2 & & & & TRN \\
\hline 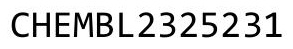 & & & & ST \\
\hline 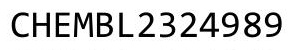 & & & & TST \\
\hline HEMBL 23249 & & & & TST \\
\hline HEMBL 232498 & & & & ГRN \\
\hline AEMRI 2 & & & & TRN \\
\hline 10 & & & & TRN \\
\hline HEMBL2324984 & & & & RN \\
\hline HEMBL2 & & & & TS \\
\hline EMBL2 & & & & TST \\
\hline HEMBL2 & & & & TRN \\
\hline & & & & TRN \\
\hline HEMBL2324979 & & & & TRN \\
\hline HEMBL2 & & & & TS \\
\hline CHEMPI 232107 & & & & 31 \\
\hline HEMBL2324976 & & & & \\
\hline HEMBL2325266 & & 29 & $L 19$ & $R N$ \\
\hline CHEMBL 2325265 & 938986 & 4.5901 & 6.9609 & - \\
\hline
\end{tabular}

Page 12790 


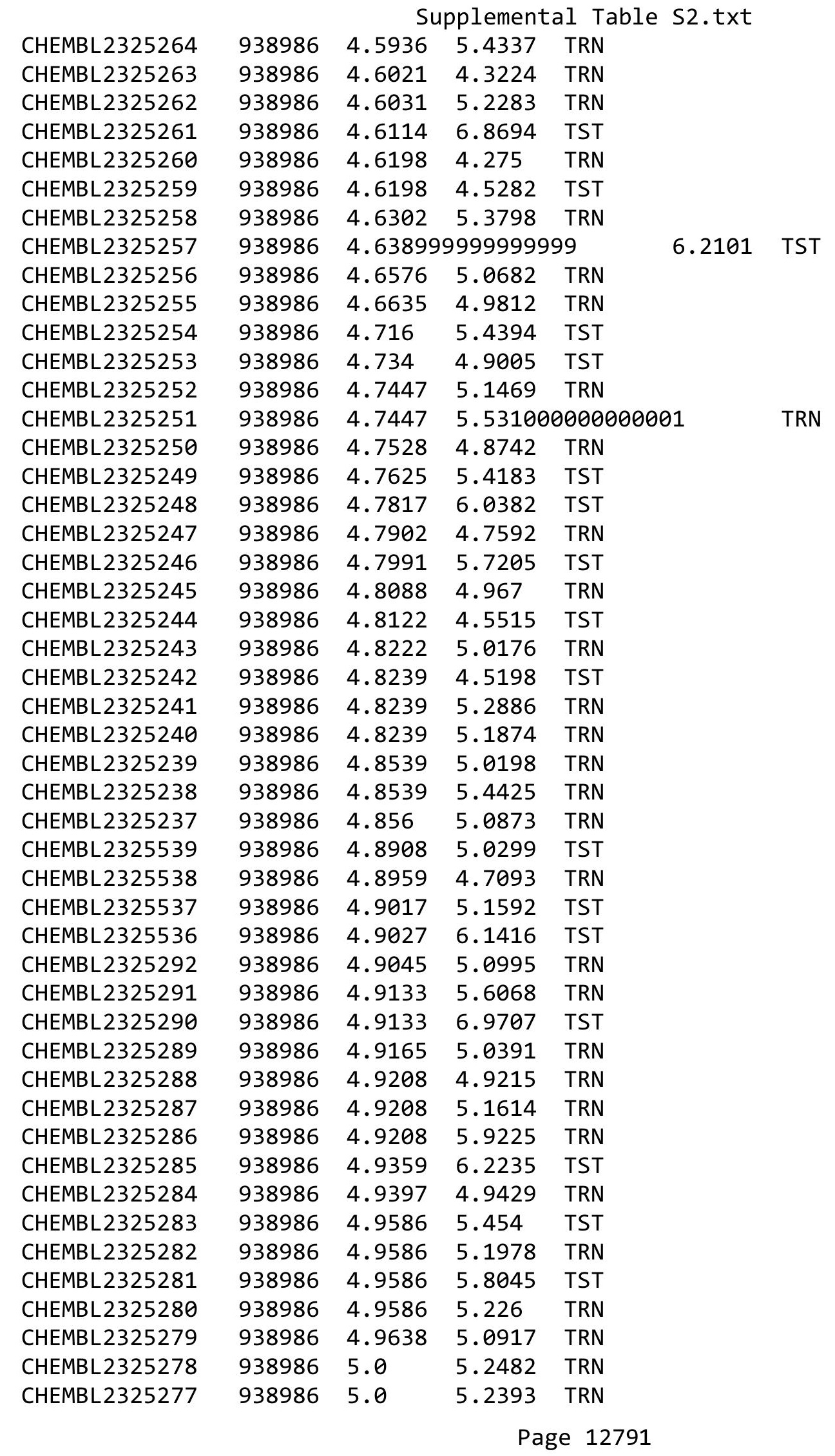




\begin{tabular}{|c|c|c|c|c|}
\hline \multicolumn{5}{|c|}{ splemental Table S } \\
\hline CHEMBL2325276 & 938986 & 5.0 & 4.6582 & TRN \\
\hline CHEMBL 2325275 & 938986 & 5.0 & 4.697 & TRN \\
\hline CHEMBL 2325274 & 938986 & 5.0 & 4.2926 & TST \\
\hline CHEMBL 2325273 & 938986 & 5.0 & 4.6838 & TRN \\
\hline CHEMBL 2325272 & 938986 & 5.0 & 6.1762 & TST \\
\hline CHEMBL2325271 & 938986 & 5.0 & 6.3306 & TST \\
\hline CHEMBL 2325270 & 938986 & 5.0 & 6.6134 & TST \\
\hline CHEMBL2325269 & 938986 & 5.0 & 5.8298 & TRN \\
\hline CHEMBL 2325268 & 938986 & 5.0 & 6.4408 & TST \\
\hline CHEMBL 2325267 & 938986 & 5.0 & 4.9972 & TRN \\
\hline CHEMBL 2325567 & 938986 & 5.0 & 5.1075 & TRN \\
\hline CHEMBL2325566 & 938986 & 5.0 & 4.4667 & TRN \\
\hline CHEMBL2325565 & 938986 & 5.0 & 5.6075 & TST \\
\hline CHEMBL 2325564 & 938986 & 5.0 & 5.2565 & TST \\
\hline CHEMBL 2325563 & 938986 & 5.0 & 5.2428 & TST \\
\hline CHEMBL 2325562 & 938986 & 5.0 & 6.0924 & TST \\
\hline CHEMBL2325561 & 938986 & 5.0 & 5.7851 & TST \\
\hline CHEMBL 2325560 & 938986 & 5.0 & 6.0311 & TST \\
\hline CHEMBL2325559 & 938986 & 5.0 & 6.0664 & TST \\
\hline CHEMBL 2325558 & 938986 & 5.0 & 5.6842 & TST \\
\hline CHEMBL2325557 & 938986 & 5.0 & 4.573 & TST \\
\hline CHEMBL2325556 & 938986 & 5.0 & 5.2066 & TST \\
\hline CHEMBL2325555 & 938986 & 5.0 & 5.7959 & TST \\
\hline CHEMBL 2325554 & 938986 & 5.0 & 4.9596 & TST \\
\hline CHEMBL 2325553 & 938986 & 5.0 & 5.3341 & TST \\
\hline CHEMBL2325552 & 938986 & 5.0 & 5.572 & TST \\
\hline CHEMBL 2325551 & 938986 & 5.0 & 5.6432 & TST \\
\hline CHEMBL 2325550 & 938986 & 5.0044 & 6.5376 & TST \\
\hline CHEMBL2325549 & 938986 & 5.0223 & 5.9312 & TST \\
\hline CHEMBL 2325548 & 938986 & 5.0259 & 5.7511 & TST \\
\hline CHEMBL2325547 & 938986 & 5.0362 & 4.9158 & TST \\
\hline CHEMBL 2325546 & 938986 & 5.0367 & 5.3895 & TST \\
\hline CHEMBL 2325545 & 938986 & 5.0376 & 5.1232 & TST \\
\hline CHEMBL 2325544 & 938986 & 5.0458 & 5.8229 & TST \\
\hline CHEMBL 2325543 & 938986 & 5.0521 & 5.4915 & TST \\
\hline CHEMBL2325542 & 938986 & 5.0605 & 4.1768 & TST \\
\hline CHEMBL2325541 & 938986 & 5.0655 & 5.0953 & TST \\
\hline CHEMBL 2325540 & 938986 & 5.1129 & 6.2944 & TST \\
\hline CHEMBL2325817 & 938986 & 5.1261 & 4.6702 & TST \\
\hline CHEMBL 2325816 & 938986 & 5.1367 & $4.4510 e$ & 00000000005 \\
\hline CHEMBL2325815 & 938986 & 5.1367 & 6.0608 & TST \\
\hline CHEMBL 2325814 & 938986 & 5.1487 & 5.0731 & TST \\
\hline CHEMBL2325595 & 938986 & 5.1612 & 6.0334 & TST \\
\hline CHEMBL 2325594 & 938986 & 5.1612 & 4.697 & TST \\
\hline CHEMBL 2325593 & 938986 & 5.1911 & 6.2554 & TST \\
\hline CHEMBL 2325592 & 938986 & 5.2007 & 5.7802 & TST \\
\hline CHEMBL2325591 & 938986 & 5.2076 & 6.3234 & TST \\
\hline CHEMBL2325590 & 938986 & 5.2218 & 5.3915 & TST \\
\hline
\end{tabular}


Supplemental Table S2.txt

\begin{tabular}{|c|c|c|c|c|c|}
\hline CHEMBL 2325589 & 938986 & 5.2269 & 5.2339 & TST & \\
\hline CHEMBL 2325588 & 938986 & 5.2411 & 5.28 & TST & \\
\hline CHEMBL2325587 & 938986 & 5.2457 & 5.6406 & TST & \\
\hline CHEMBL 2325586 & 938986 & 5.2596 & 4.5891 & TST & \\
\hline CHEMBL2325585 & 938986 & 5.2676 & 6.6922 & TST & \\
\hline CHEMBL 2325584 & 938986 & 5.2924 & 6.3608 & TST & \\
\hline CHEMBL 2325583 & 938986 & 5.301 & 6.2193 & TST & \\
\hline CHEMBL2325582 & 938986 & 5.3098 & 5.4307 & TST & \\
\hline CHEMBL 2325581 & 938986 & 5.3188 & 5.1811 & TST & \\
\hline CHEMBL2325580 & 938986 & 5.3372 & 5.8704 & TST & \\
\hline CHEMBL 2325579 & 938986 & 5.3429 & 5.0977 & TST & \\
\hline CHEMBL 2325578 & 938986 & 5.3665 & 5.1585 & TST & \\
\hline CHEMBL 2325577 & 938986 & 5.3665 & 6.6367 & TST & \\
\hline CHEMBL 2325576 & 938986 & 5.3696 & 5.5303 & TST & \\
\hline CHEMBL2325575 & 938986 & 5.3747 & 7.3167 & TST & \\
\hline CHEMBL 2325574 & 938986 & 5.3809 & 5.7332 & TST & \\
\hline CHEMBL2325573 & 938986 & 5.3979 & 6.1341 & TST & \\
\hline CHEMBL2325572 & 938986 & 5.4001 & 7.2223 & TST & \\
\hline CHEMBL 2325571 & 938986 & 5.4089 & 6.4201 & TST & \\
\hline CHEMBL 2325570 & 938986 & 5.4089 & 6.0087 & TST & \\
\hline CHEMBL 2325569 & 938986 & 5.4134 & 5.7393 & TST & \\
\hline CHEMBL2325568 & 938986 & 5.4202 & 5.7934 & TST & \\
\hline CHEMBL 2325847 & 938986 & 5.4202 & 5.6089 & TST & \\
\hline CHEMBL 2325846 & 938986 & 5.4237 & 5.4107 & TST & \\
\hline CHEMBL 2325845 & 938986 & 5.4248 & 5.3342 & TST & \\
\hline CHEMBL 2325844 & 938986 & 5.4437 & 5.6344 & TST & \\
\hline CHEMBL 2325843 & 938986 & 5.451000 & 00000000 & 205 & 6.5898 \\
\hline CHEMBL 2325842 & 938986 & 5.4559 & 6.4909 & TST & \\
\hline CHEMBL 2325841 & 938986 & 5.4572 & 5.4208 & TST & \\
\hline CHEMBL 2325840 & 938986 & 5.4672 & 6.9784 & TST & \\
\hline CHEMBL 2325839 & 938986 & 5.4685 & 6.4095 & TST & \\
\hline CHEMBL 2325838 & 938986 & 5.4685 & 5.8579 & TST & \\
\hline CHEMBL 2325837 & 938986 & 5.4685 & 5.9889 & TST & \\
\hline CHEMBL 2325836 & 938986 & 5.4685 & 6.7166 & TST & \\
\hline CHEMBL 2325835 & 938986 & 5.4685 & 5.7616 & TST & \\
\hline CHEMBL 2325834 & 938986 & 5.4711 & 5.2528 & TST & \\
\hline CHEMBL 2325833 & 938986 & 5.4763 & 5.8756 & TST & \\
\hline CHEMBL 2325832 & 938986 & 5.4815 & 5.388 & TST & \\
\hline CHEMBL 2325831 & 938986 & 5.4815 & 5.3119 & TST & \\
\hline CHEMBL 2325830 & 938986 & 5.4815 & 6.1042 & TST & \\
\hline CHEMBL3667907 & 1641082 & 8.4157 & 8.3789 & TRN & \\
\hline CHEMBL3951198 & 1641082 & 9.1612 & 8.8036 & TST & \\
\hline CHEMBL 3672878 & 1641082 & 8.8013 & 8.6854 & TRN & \\
\hline CHEMBL 3891548 & 1641082 & 8.4855 & 9.1234 & TST & \\
\hline CHEMBL 3672887 & 1641082 & 8.4295 & 8.5373 & TRN & \\
\hline CHEMBL 3667910 & 1641082 & 9.1549 & 9.2355 & TRN & \\
\hline CHEMBL 3672892 & 1641082 & 8.3307 & 8.4553 & TRN & \\
\hline CHEMBL 3667886 & 1641082 & 8.7721 & 8.5633 & TRN & \\
\hline
\end{tabular}

Page 12793 
Supplemental Table S2.txt

\begin{tabular}{|c|c|c|c|c|c|}
\hline CHEMBL3672868 & 1641082 & 8.4815 & 8.3774 & TRN & \\
\hline CHEMBL3672880 & 1641082 & 9.6778 & 9.6358 & TRN & \\
\hline CHEMBL3672889 & 1641082 & 8.8477 & 8.9749 & TRN & \\
\hline CHEMBL3667901 & 1641082 & 8.4989 & 8.6176 & TRN & \\
\hline CHEMBL3667894 & 1641082 & 8.0809 & 7.9847 & TRN & \\
\hline CHEMBL 3667898 & 1641082 & 8.1018 & 8.0444 & TRN & \\
\hline CHEMBL3959237 & 1641082 & 8.7033 & 8.7489 & TST & \\
\hline CHEMBL 3672853 & 1641082 & 8.3429 & 8.2625 & TRN & \\
\hline CHEMBL3667880 & 1641082 & 8.3872 & 8.648 & TST & \\
\hline CHEMBL3957967 & 1641082 & 8.7055 & 8.6987 & TRN & \\
\hline CHEMBL 3672860 & 1641082 & 9.0362 & 9.1076 & TRN & \\
\hline CHEMBL3672870 & 1641082 & 8.9957 & 9.0456 & TRN & \\
\hline CHEMBL 3667904 & 1641082 & 8.5086 & 8.3925 & TRN & \\
\hline CHEMBL3672852 & 1641082 & 8.4437 & 8.4574 & TRN & \\
\hline CHEMBL 3672865 & 1641082 & 8.2381 & 8.2826 & TRN & \\
\hline CHEMBL3672871 & 1641082 & 8.7986 & 8.7003 & TRN & \\
\hline CHEMBL3977688 & 1641082 & 8.4685 & 9.3591 & TST & \\
\hline CHEMBL 3672883 & 1641082 & 8.0964 & 8.1442 & TRN & \\
\hline CHEMBL3672866 & 1641082 & 8.0329 & 8.05299 & 9999999999 & TRN \\
\hline CHEMBL 3672884 & 1641082 & 8.7328 & 8.645 & TRN & \\
\hline CHEMBL3667902 & 1641082 & 6.0 & 6.0022 & TRN & \\
\hline CHEMBL3672893 & 1641082 & 8.451 & 8.4171 & TRN & \\
\hline CHEMBL3672864 & 1641082 & 8.7282 & 8.2972 & TST & \\
\hline CHEMBL3672891 & 1641082 & 8.6596 & 8.6497 & TRN & \\
\hline CHEMBL 3667879 & 1641082 & 9.2147 & 9.1068 & TST & \\
\hline CHEMBL3672857 & 1641082 & 8.7721 & 8.3989 & TRN & \\
\hline CHEMBL 3672888 & 1641082 & 8.6968 & 8.9573 & TRN & \\
\hline CHEMBL3672876 & 1641082 & 8.7959 & 8.8255 & TRN & \\
\hline CHEMBL3672872 & 1641082 & 9.3098 & 9.3539 & TRN & \\
\hline CHEMBL 3667908 & 1641082 & 8.5638 & 8.4842 & TRN & \\
\hline CHEMBL3667895 & 1641082 & 6.0 & 6.2417 & TRN & \\
\hline CHEMBL 3667906 & 1641082 & 8.7144 & 8.4502 & TRN & \\
\hline CHEMBL3667888 & 1641082 & 8.8239 & 8.8377 & TRN & \\
\hline CHEMBL3667885 & 1641082 & 8.8761 & 8.8966 & TRN & \\
\hline CHEMBL 3672873 & 1641082 & 8.9914 & 9.0515 & TRN & \\
\hline CHEMBL3672858 & 1641082 & 8.4737 & 8.2967 & TRN & \\
\hline CHEMBL 3639717 & 1641082 & 8.2865 & 8.3661 & TRN & \\
\hline CHEMBL3892801 & 1641082 & 8.2741 & 8.2789 & TRN & \\
\hline CHEMBL3667896 & 1641082 & 8.6038 & 8.6389 & TRN & \\
\hline CHEMBL3937222 & 1641082 & 9.0458 & 9.4054 & TRN & \\
\hline CHEMBL3949541 & 1641082 & 6.0 & 6.058 & TRN & \\
\hline CHEMBL3667883 & 1641082 & 9.301 & 9.1998 & TRN & \\
\hline CHEMBL3667884 & 1641082 & 9.0223 & 9.1508 & TRN & \\
\hline CHEMBL3667905 & 1641082 & 8.7773 & 8.815 & TRN & \\
\hline CHEMBL3903777 & 1641082 & 6.0 & 5.642 & TST & \\
\hline CHEMBL3672879 & 1641082 & 8.3565 & 8.3545 & TRN & \\
\hline CHEMBL3667913 & 1641082 & 6.0 & 6.0031 & TRN & \\
\hline CHEMBL 3667881 & 1641082 & 9.3768 & 9.4434 & TRN & \\
\hline
\end{tabular}


Supplemental Table S2.txt

\begin{tabular}{|c|c|c|c|c|}
\hline CHEMBL3959399 & 1641082 & 8.5421 & 8.5243 & TRN \\
\hline CHEMBL 3672855 & 1641082 & 8.4112 & 8.1099 & TRN \\
\hline CHEMBL3672885 & 1641082 & 8.4377 & 8.2645 & TRN \\
\hline CHEMBL3667909 & 1641082 & 8.5391 & 8.5994 & TRN \\
\hline CHEMBL 3897603 & 1641082 & 8.8861 & 9.1208 & TRN \\
\hline CHEMBL 3672861 & 1641082 & 8.475 & 8.354 & TRN \\
\hline CHEMBL3667912 & 1641082 & 8.5638 & 8.356 & TST \\
\hline CHEMBL3667893 & 1641082 & 8.7595 & 8.8281 & TRN \\
\hline CHEMBL3667882 & 1641082 & 9.1249 & 8.9816 & TRN \\
\hline CHEMBL 3672850 & 1641082 & 6.0 & 6.1871 & TRN \\
\hline CHEMBL3667891 & 1641082 & 8.2857 & 8.3575 & TRN \\
\hline CHEMBL3893916 & 1641082 & 8.9318 & 8.881 & TRN \\
\hline CHEMBL 3672875 & 1641082 & 8.4377 & 8.4628 & TRN \\
\hline CHEMBL3920800 & 1641082 & 8.8477 & 8.8959 & TST \\
\hline CHEMBL 3975448 & 1641082 & 8.7696 & 8.951 & TST \\
\hline CHEMBL3667897 & 1641082 & 6.0 & 5.6235 & TST \\
\hline CHEMBL 3672854 & 1641082 & 8.4112 & 8.4047 & TST \\
\hline CHEMBL 3667892 & 1641082 & 8.6021 & 8.3602 & TST \\
\hline CHEMBL 3667887 & 1641082 & 8.6946 & 8.4011 & TST \\
\hline CHEMBL 3667899 & 1641082 & 8.7545 & 8.6554 & TST \\
\hline CHEMBL 3672877 & 1641082 & 9.1249 & 9.0827 & TST \\
\hline CHEMBL3672863 & 1641082 & 8.4572 & 8.4881 & TST \\
\hline CHEMBL3672859 & 1641082 & 8.4101 & 8.4477 & TST \\
\hline CHEMBL3672869 & 1641082 & 8.8268 & 8.9752 & TST \\
\hline CHEMBL 3672882 & 1641082 & 6.0 & 5.7055 & TST \\
\hline CHEMBL213882 & 391331 & 8.1308 & 7.765 & TRN \\
\hline CHEMBL213443 & 391331 & 8.0 & 7.6331 & TRN \\
\hline CHEMBL212077 & 391331 & 7.9208 & 7.7265 & TRN \\
\hline CHEMBL383869 & 391331 & 6.3063 & 7.0376 & TRN \\
\hline CHEMBL386424 & 391331 & 6.9872 & 7.1446 & TST \\
\hline CHEMBL214142 & 391331 & 7.4559 & 7.5893 & TRN \\
\hline CHEMBL212597 & 391331 & 6.8125 & 6.8938 & TRN \\
\hline CHEMBL213444 & 391331 & 7.5528 & 7.6141 & TRN \\
\hline CHEMBL213795 & 391331 & 8.1135 & 7.9638 & TRN \\
\hline CHEMBL437112 & 391331 & 8.0 & 7.6594 & TRN \\
\hline CHEMBL212383 & 391331 & 8.1079 & 7.7186 & TRN \\
\hline CHEMBL213084 & 391331 & 8.3979 & 8.2826 & TRN \\
\hline CHEMBL378914 & 391331 & 7.5528 & 7.5598 & TST \\
\hline CHEMBL214407 & 391331 & 7.2924 & 7.5572 & TRN \\
\hline CHEMBL213336 & 391331 & 8.5229 & 8.5152 & TRN \\
\hline CHEMBL213477 & 391331 & 7.9208 & 7.7913 & TRN \\
\hline CHEMBL378669 & 391331 & 8.585 & 8.5252 & TRN \\
\hline CHEMBL215611 & 391331 & 7.1024 & 6.7938 & TRN \\
\hline CHEMBL425069 & 391331 & 8.7959 & 8.2695 & TRN \\
\hline CHEMBL378886 & 391331 & 7.1675 & 7.75299 & 9999999999 \\
\hline CHEMBL214016 & 391331 & 7.8861 & 8.2593 & TRN \\
\hline CHEMBL213492 & 391331 & 8.6021 & 8.6477 & TRN \\
\hline CHEMBL213372 & 391331 & 7.6576 & 7.5829 & TRN \\
\hline
\end{tabular}

Page 12795 
Supplemental Table S2.txt

\begin{tabular}{|c|c|c|c|c|}
\hline CHEMBL210016 & & 6.6253 & 5743 & TRN \\
\hline HFMRI 213278 & 91331 & 7.6383 & 7.5493 & \\
\hline HEMBL4 & & 8239 & 641 & \\
\hline HEMBL405751 & 91331 & 5229 & 6075 & וב \\
\hline HEMBL 213834 & 91331 & .4202 & .1364 & \\
\hline HEMBL 379757 & 91331 & .0088 & 91 & \\
\hline HEMBL 379874 & & .8539 & & 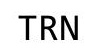 \\
\hline HEMBL 212912 & 91331 & 3979 & 7555 & DN \\
\hline HEMBL 377584 & 91331 & 4437 & 2324 & \\
\hline HEMBL 378512 & 91331 & .1871 & .6816 & \\
\hline HEMBL 384916 & 91331 & .4089 & .397 & \\
\hline HEMBL 2 & & & & RN \\
\hline HEMBL 2 & 31 & .5528 & & \\
\hline HEMBL 213793 & 31 & 229 & & \\
\hline HEMBL 377756 & 31 & 549 & .6788 & \\
\hline HEMBL 2 & 31 & 55 & 15 & \\
\hline HEMBL2 & 31 & & & $\mathrm{RN}$ \\
\hline HEMBL 2 & 31 & 949 & 63 & RN \\
\hline HEMBL21 & 31 & 539 & & \\
\hline HEMBL 376928 & 31 & 239 & 59 & RIN \\
\hline HEMBL 2 & 31 & 79 & 92 & $\mathrm{RN}$ \\
\hline HEMBL 2 & 31 & & & $\mathrm{RN}$ \\
\hline HEMBL 2 & 31 & 58 & 79 & CRN \\
\hline HEMBL2 & & 68 & & TST \\
\hline HEMBL2] & 31 & 47 & 58 & TST \\
\hline HEMBL3 & 31 & 85 & 47 & ST \\
\hline HEMBL & 31 & & & ST \\
\hline HEMBL & & & & TST \\
\hline HEMBL 2 & & & & TST \\
\hline HEMBL 212186 & 31 & 7.2076 & 69 & TST \\
\hline HEMBL 2 & 31 & 279 & & TST \\
\hline HEMBL & & 79 & & IST \\
\hline HEMBL3 & & & & TST \\
\hline HEMBL3216757 & & & & TRN \\
\hline HEMBL3216506 & 95 & 655 & 18 & 「RN \\
\hline HEMBL3 & 95 & 996 & & TST \\
\hline CHEMBL1 & & & & RN \\
\hline HEMBL1 & & 5.8989 & 3846 & TST \\
\hline HEMBL3217176 & 95 & .2218 & 32 & TRN \\
\hline HEMBL1 & 95 & 7.9914 & 51 & TRN \\
\hline CHEMBL3 & 95 & 8.2076 & 7.7364 & TRN \\
\hline CHEMBL 32 & & 6.71 & & RN \\
\hline CHEMBL1852359 & 6795 & 7.7696 & 8.0601 & TRN \\
\hline HEMBL3 & 95 & 8.5376 & 954 & $T R$ \\
\hline HEMBL3 & & 7. & & KIV \\
\hline CHEMBL 3216957 & 766795 & & & \\
\hline CHEMBL3215638 & 766795 & 6.7328 & 7.4361 & RN \\
\hline CHEMBL1852341 & 766795 & 7.9914 & 7.4712 & TRN \\
\hline
\end{tabular}

Page 12796 


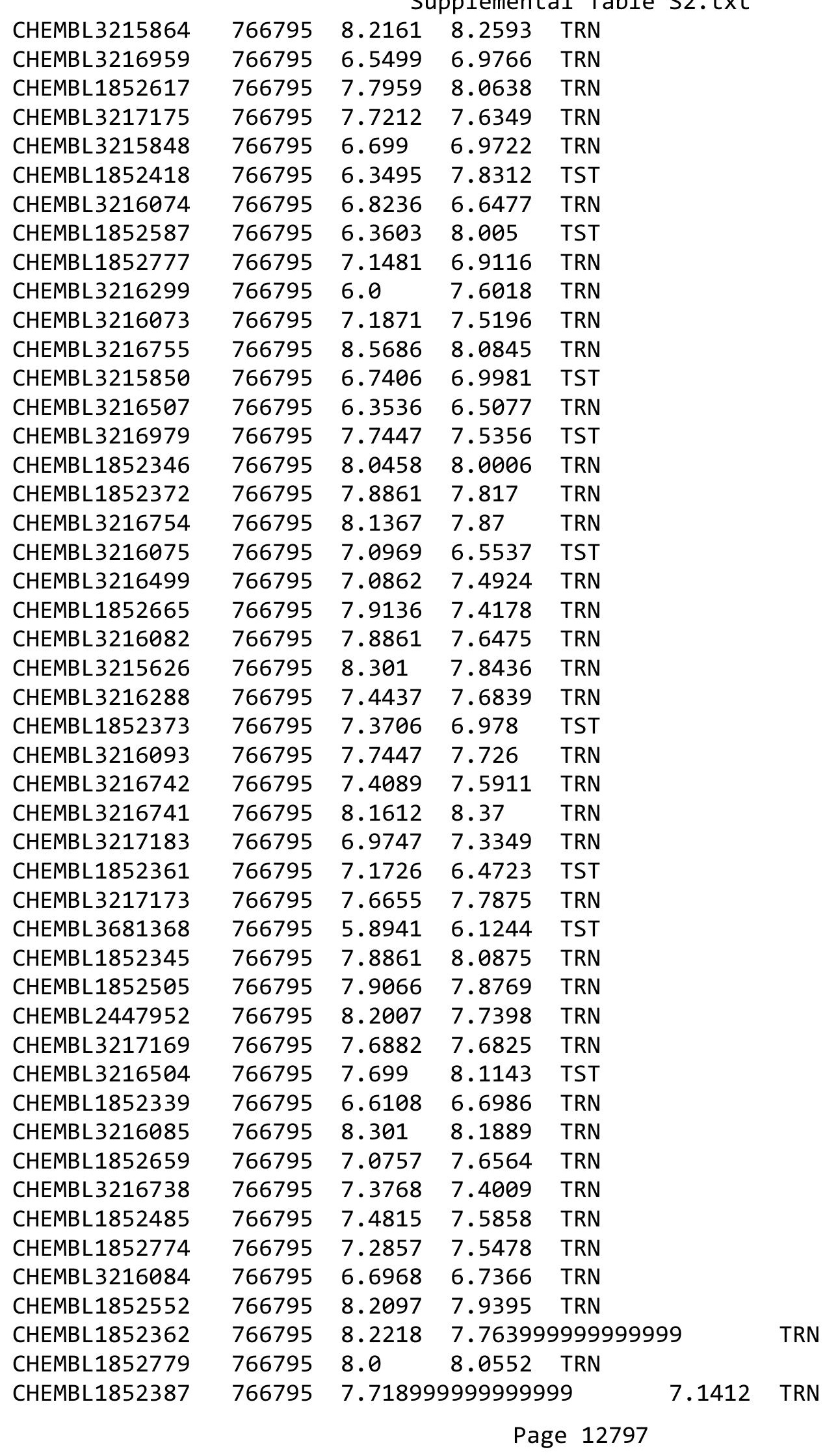




\begin{tabular}{|c|c|c|c|c|c|}
\hline \multicolumn{6}{|c|}{ Supplemental Table S2.txt } \\
\hline CHEMBL3216737 & 766795 & 6.8147 & 7.1132 & TRN & \\
\hline CHEMBL1852666 & 766795 & 7.9208 & 7.7441 & TST & \\
\hline CHEMBL3216290 & 766795 & 7.699 & 7.4039 & TRN & \\
\hline CHEMBL3216286 & 766795 & 7.2596 & 7.3683 & TRN & \\
\hline CHEMBL3215628 & 766795 & 7.5072 & 8.0613 & TRN & \\
\hline CHEMBL3215851 & 766795 & 8.0315 & 8.3427 & TST & \\
\hline CHEMBL3216965 & 766795 & 7.6198 & 7.4789 & TRN & \\
\hline CHEMBL3217170 & 766795 & 7.7496 & 7.5354 & TRN & \\
\hline CHEMBL 3215627 & 766795 & 7.153 & 7.4945 & TRN & \\
\hline CHEMBL1852422 & 766795 & 7.8013 & 7.3642 & TRN & \\
\hline CHEMBL3215622 & 766795 & 7.1192 & 6.9756 & TRN & \\
\hline CHEMBL3216518 & 766795 & 8.301 & 8.3412 & TRN & \\
\hline CHEMBL1852370 & 766795 & 7.8861 & 7.7184 & TRN & \\
\hline CHEMBL1852333 & 766795 & 7.7747 & 7.8345 & TST & \\
\hline CHEMBL3216961 & 766795 & 8.0209 & 7.7558 & TST & \\
\hline CHEMBL3217172 & 766795 & 7.8477 & 8.2802 & TRN & \\
\hline CHEMBL1852811 & 766795 & 7.5528 & 7.3212 & TRN & \\
\hline CHEMBL3216285 & 766795 & 7.7799 & 7.5952 & TRN & \\
\hline CHEMBL3216501 & 766795 & 7.2967 & 7.3 & TST & \\
\hline CHEMBL3215849 & 766795 & 6.1457 & 5.9658 & TST & \\
\hline CHEMBL3216508 & 766795 & 8.4089 & 8.0141 & TRN & \\
\hline CHEMBL3216284 & 766795 & 7.0757 & 7.0004 & TRN & \\
\hline CHEMBL3216964 & 766795 & 7.6021 & 7.2061 & TRN & \\
\hline CHEMBL1852472 & 766795 & 7.0862 & 7.2603 & TRN & \\
\hline CHEMBL3216956 & 766795 & 6.4597 & 6.8147 & TRN & \\
\hline CHEMBL3216966 & 766795 & 7.7696 & 7.5893 & TRN & \\
\hline CHEMBL1852420 & 766795 & 7.983 & 7.949 & TST & \\
\hline CHEMBL3215862 & 766795 & 7.3279 & 6.9648 & TRN & \\
\hline CHEMBL 3217171 & 766795 & 7.5528 & 7.4567 & TRN & \\
\hline CHEMBL3216498 & 766795 & 7.5528 & 7.70200 & 2000000001 & TRN \\
\hline CHEMBL3216505 & 766795 & 7.4078 & 7.7975 & TST & \\
\hline CHEMBL3215624 & 766795 & 7.4318 & 7.6078 & TRN & \\
\hline CHEMBL3216974 & 766795 & 8.3116 & 8.5305 & TRN & \\
\hline CHEMBL3215618 & 766795 & 8.1805 & 7.7984 & TRN & \\
\hline CHEMBL1852503 & 766795 & 8.0376 & 7.82299 & 99999999995 & TST \\
\hline CHEMBL1852466 & 766795 & 7.7747 & 7.7566 & TRN & \\
\hline CHEMBL3216078 & 766795 & 6.7258 & 7.4731 & TST & \\
\hline CHEMBL3216303 & 766795 & 7.4559 & 7.4966 & TST & \\
\hline CHEMBL3216975 & 766795 & 7.8539 & 8.208 & TST & \\
\hline CHEMBL 3216083 & 766795 & 7.3098 & 8.0068 & TST & \\
\hline CHEMBL97486 & 76934 & 5.7212 & 4.9526 & TRN & \\
\hline CHEMBL329409 & 76934 & 6.7447 & 5.5712 & TST & \\
\hline CHEMBL265277 & 76934 & 5.2924 & 5.3413 & TST & \\
\hline CHEMBL329700 & 76934 & 6.0 & 5.4843 & TRN & \\
\hline CHEMBL97230 & 76934 & 4.699 & 4.8518 & TRN & \\
\hline CHEMBL330273 & 76934 & 4.2007 & 4.6781 & TRN & \\
\hline CHEMBL97330 & 76934 & 5.7959 & 4.4894 & TST & \\
\hline CHEMBL97503 & 76934 & 5.2518 & 5.8871 & TRN & \\
\hline
\end{tabular}




\begin{tabular}{|c|c|c|c|c|}
\hline \multicolumn{5}{|c|}{ Supplemental Table s2.txt } \\
\hline CHEMBL1790765 & 76934 & 5.7447 & 5.3524 & TRN \\
\hline CHEMBL95145 & 76934 & 7.2518 & 7.5239 & TST \\
\hline CHEMBL94557 & 76934 & 5.6576 & 3.8867 & TST \\
\hline CHEMBL541463 & 76934 & 6.2596 & 5.3454 & TRN \\
\hline CHEMBL319934 & 76934 & 5.2218 & 4.6353 & TRN \\
\hline CHEMBL205747 & 76934 & 4.8539 & 4.2995 & TRN \\
\hline CHEMBL328871 & 76934 & 6.0 & 6.271 & TRN \\
\hline CHEMBL94057 & 76934 & 6.4202 & 5.68 & TRN \\
\hline CHEMBL95053 & 76934 & 5.7959 & 4.6377 & TRN \\
\hline CHEMBL98727 & 76934 & 6.2518 & 5.3184 & TRN \\
\hline CHEMBL95086 & 76934 & 5.0 & 4.3178 & TST \\
\hline CHEMBL94686 & 76934 & 4.4949 & 4.3417 & TST \\
\hline CHEMBL442961 & 76934 & 6.9208 & 6.4101 & TRN \\
\hline CHEMBL94804 & 76934 & 5.1192 & 5.5843 & TST \\
\hline CHEMBL94659 & 76934 & 5.4559 & 5.4912 & TRN \\
\hline CHEMBL 264488 & 76934 & 3.0 & 4.3741 & TRN \\
\hline CHEMBL94663 & 76934 & 5.284 & 5.5749 & TRN \\
\hline CHEMBL 318223 & 76934 & 5.699 & 5.7753 & TRN \\
\hline CHEMBL327395 & 76934 & 2.4948 & 3.8968 & TRN \\
\hline CHEMBL96534 & 76934 & 5.9586 & 5.4981 & TRN \\
\hline CHEMBL94405 & 76934 & 5.1487 & 5.4428 & TST \\
\hline CHEMBL94100 & 76934 & 4.2518 & 4.064 & TRN \\
\hline CHEMBL93924 & 76934 & 2.7212 & 4.0447 & TRN \\
\hline CHEMBL98560 & 76934 & 5.2676 & 4.4964 & TRN \\
\hline CHEMBL98400 & 76934 & 6.699 & 6.638 & TRN \\
\hline CHEMBL 329557 & 76934 & 6.1805 & 6.5307 & TRN \\
\hline CHEMBL96192 & 76934 & 5.8861 & 5.3023 & TRN \\
\hline CHEMBL 20668 & 76934 & 5.3979 & 4.6558 & TRN \\
\hline CHEMBL318130 & 76934 & 6.4949 & 6.5611 & TRN \\
\hline CHEMBL329254 & 76934 & 4.8539 & 4.8451 & TRN \\
\hline CHEMBL97036 & 76934 & 6.0 & 5.5209 & TRN \\
\hline CHEMBL98344 & 76934 & 6.6021 & 6.081 & TRN \\
\hline CHEMBL96994 & 76934 & 4.4089 & 5.3367 & TRN \\
\hline CHEMBL95015 & 76934 & 6.0 & 6.2325 & TRN \\
\hline CHEMBL95381 & 76934 & 5.7447 & 5.8 & TRN \\
\hline CHEMBL97696 & 76934 & 5.2291 & 5.7392 & TRN \\
\hline CHEMBL95300 & 76934 & 6.2007 & 6.341 & TRN \\
\hline CHEMBL420823 & 76934 & 5.0506 & 4.905 & TRN \\
\hline CHEMBL316456 & 76934 & 5.284 & 5.8049 & TRN \\
\hline CHEMBL95473 & 76934 & 5.8539 & 6.2047 & TRN \\
\hline CHEMBL59142 & 76934 & 3.0 & 4.2799 & TRN \\
\hline CHEMBL 330070 & 76934 & 4.7212 & 5.1009 & TRN \\
\hline CHEMBL95083 & 76934 & 4.5229 & 5.0276 & TRN \\
\hline CHEMBL94160 & 76934 & 5.2757 & 5.3914 & TRN \\
\hline CHEMBL317932 & 76934 & 6.1024 & 5.9017 & TRN \\
\hline CHEMBL317125 & 76934 & 5.0 & 4.9506 & TRN \\
\hline CHEMBL98620 & 76934 & 5.2518 & 5.228 & TRN \\
\hline CHEMBL264798 & 76934 & 6.7447 & 5.9838 & TRN \\
\hline
\end{tabular}




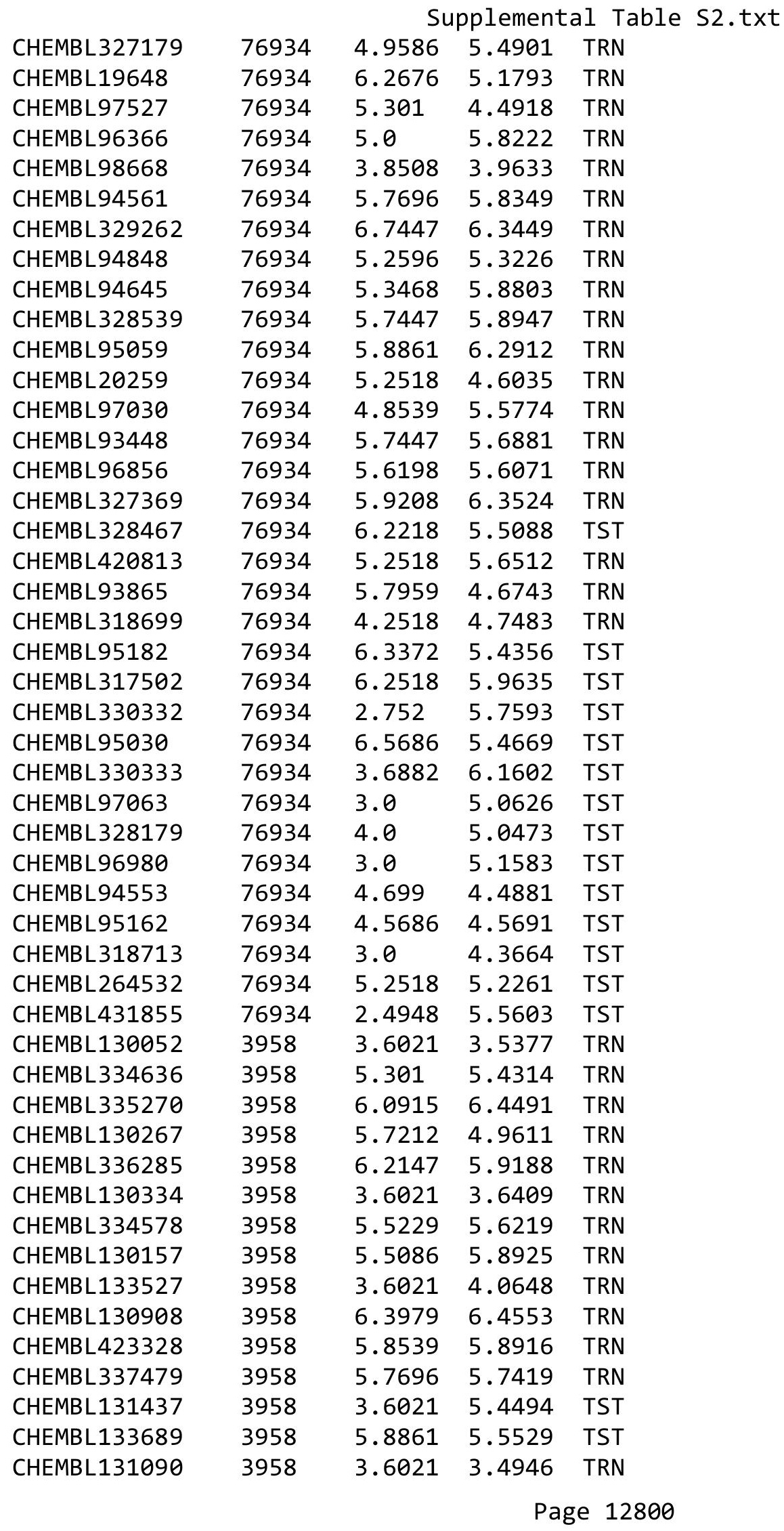




\begin{tabular}{|c|c|c|c|c|c|}
\hline \multicolumn{6}{|c|}{ Supplemental Table S2.txt } \\
\hline CHEMBL130726 & 3958 & 6.9208 & 6.1708 & TRN & \\
\hline CHEMBL 274373 & 3958 & 6.5686 & 6.1505 & TRN & \\
\hline CHEMBL130869 & 3958 & 3.6021 & 5.0103 & TST & \\
\hline CHEMBL131337 & 3958 & 5.6021 & 5.4086 & TRN & \\
\hline CHEMBL131438 & 3958 & 3.6021 & 4.904 & TST & \\
\hline CHEMBL130783 & 3958 & 5.585 & 6.4052 & TRN & \\
\hline CHEMBL 340654 & 3958 & 5.8239 & 5.8428 & TRN & \\
\hline CHEMBL11871 & 3958 & 6.6021 & 5.54299 & 9999999999 & TRN \\
\hline CHEMBL414432 & 3958 & 6.1249 & 5.8851 & TRN & \\
\hline CHEMBL131455 & 3958 & 3.6021 & 5.3561 & TRN & \\
\hline CHEMBL131595 & 3958 & 5.585 & 5.7413 & TRN & \\
\hline CHEMBL 334528 & 3958 & 3.6021 & 5.5451 & TST & \\
\hline CHEMBL130800 & 3958 & 3.6021 & 3.3459 & TRN & \\
\hline CHEMBL 337448 & 3958 & 3.6021 & 3.0967 & TRN & \\
\hline CHEMBL131886 & 3958 & 5.7959 & 6.4279 & TRN & \\
\hline CHEMBL11858 & 3958 & 3.6021 & 4.5027 & TRN & \\
\hline CHEMBL131267 & 3958 & 3.6021 & 3.73199 & 99999999998 & TRN \\
\hline CHEMBL131764 & 3958 & 5.699 & 5.8621 & TRN & \\
\hline CHEMBL130376 & 3958 & 3.6021 & 3.3448 & TRN & \\
\hline CHEMBL 340652 & 3958 & 6.041 & 5.4197 & TST & \\
\hline CHEMBL340554 & 3958 & 3.6021 & 4.2128 & TST & \\
\hline CHEMBL11541 & 3958 & 6.699 & 6.192 & TRN & \\
\hline CHEMBL131880 & 3958 & 3.6021 & 3.9596 & TRN & \\
\hline CHEMBL132228 & 3958 & 5.8239 & 6.4127 & TRN & \\
\hline CHEMBL11399 & 3958 & 5.301 & 5.8672 & TRN & \\
\hline CHEMBL11807 & 3958 & 3.6021 & 3.8622 & TRN & \\
\hline CHEMBL132854 & 3958 & 6.6021 & 5.9979 & TRN & \\
\hline CHEMBL131338 & 3958 & 5.2218 & 5.2536 & TRN & \\
\hline CHEMBL 334790 & 3958 & 3.6021 & 3.8461 & TRN & \\
\hline CHEMBL130273 & 3958 & 5.0 & 5.0106 & TRN & \\
\hline CHEMBL335671 & 3958 & 4.8861 & 5.4265 & TRN & \\
\hline CHEMBL11308 & 3958 & 6.8239 & 6.17299 & 9999999999 & TRN \\
\hline CHEMBL 274187 & 3958 & 7.2218 & 5.7539 & TRN & \\
\hline CHEMBL 334483 & 3958 & 5.3188 & 5.1959 & TRN & \\
\hline CHEMBL131359 & 3958 & 5.9208 & 6.0806 & TRN & \\
\hline CHEMBL130562 & 3958 & 5.9586 & 5.3446 & TRN & \\
\hline CHEMBL11309 & 3958 & 5.5229 & 6.1318 & TST & \\
\hline CHEMBL130479 & 3958 & 5.8239 & 5.0731 & TST & \\
\hline CHEMBL131279 & 3958 & 3.6021 & 5.671 & TST & \\
\hline CHEMBL131429 & 3958 & 3.6021 & 5.5135 & TST & \\
\hline CHEMBL130329 & 3958 & 5.0506 & 5.0555 & TST & \\
\hline CHEMBL129961 & 3958 & 6.6198 & 5.9294 & TST & \\
\hline CHEMBL130875 & 3958 & 5.7447 & 6.2166 & TST & \\
\hline CHEMBL131339 & 3958 & 6.2596 & 5.5306 & TST & \\
\hline CHEMBL 3215568 & 566777 & 5.0991 & 5.1616 & TRN & \\
\hline CHEMBL 3216890 & 566777 & 5.3507 & 5.3054 & TRN & \\
\hline CHEMBL 3216670 & 566777 & 3.7959 & 3.7292 & TRN & \\
\hline CHEMBL3217107 & 566777 & 7.3468 & 7.3275 & TRN & \\
\hline
\end{tabular}




\begin{tabular}{|c|c|c|c|c|c|}
\hline & & \multicolumn{4}{|c|}{ Supplemental Table S2.txt } \\
\hline CHEMBL3216216 & 566777 & 4.5513 & 5.8928 & TST & \\
\hline CHEMBL3215763 & 566777 & 4.8327 & 4.7727 & TRN & \\
\hline CHEMBL22998 & 566777 & 8.0 & 7.9018 & TRN & \\
\hline CHEMBL3216660 & 566777 & 7.6383 & 7.8067 & TRN & \\
\hline CHEMBL3216903 & 566777 & 6.2652 & 6.25700 & 0000000001 & TRN \\
\hline CHEMBL3216435 & 566777 & 8.0 & 7.8295 & TRN & \\
\hline CHEMBL3216901 & 566777 & 7.0088 & 7.0145 & TRN & \\
\hline CHEMBL3215567 & 566777 & 5.4318 & 5.4822 & TRN & \\
\hline CHEMBL3216214 & 566777 & 6.3809 & 6.4812 & TRN & \\
\hline CHEMBL 3216657 & 566777 & 6.058 & 6.0485 & TRN & \\
\hline CHEMBL522874 & 566777 & 3.7077 & 4.4631 & TST & \\
\hline CHEMBL3215765 & 566777 & 5.0146 & 4.9427 & TRN & \\
\hline CHEMBL3216658 & 566777 & 8.3979 & 8.3339 & TRN & \\
\hline CHEMBL3216889 & 566777 & 6.5884 & 6.4812 & TRN & \\
\hline CHEMBL3216030 & 566777 & 7.3979 & 7.2292 & TRN & \\
\hline CHEMBL3215566 & 566777 & 7.1871 & 7.2118 & TRN & \\
\hline CHEMBL3216427 & 566777 & 6.9586 & 6.8514 & TRN & \\
\hline CHEMBL3217106 & 566777 & 7.8861 & 7.82 & TRN & \\
\hline CHEMBL3216033 & 566777 & 4.9172 & 4.9857 & TRN & \\
\hline CHEMBL3216016 & 566777 & 5.8827 & 5.8253 & TRN & \\
\hline CHEMBL3216663 & 566777 & 7.1675 & 7.2178 & TRN & \\
\hline CHEMBL 3216891 & 566777 & 8.301 & 8.0224 & TST & \\
\hline CHEMBL 3216424 & 566777 & 2.6402 & 5.1632 & TST & \\
\hline CHEMBL494957 & 566777 & 7.301 & 7.3884 & TRN & \\
\hline CHEMBL3216217 & 566777 & 7.5686 & 7.3501 & TRN & \\
\hline CHEMBL3215782 & 566777 & 7.0458 & 7.2476 & TRN & \\
\hline CHEMBL 2360824 & 566777 & 7.7212 & 7.591 & TRN & \\
\hline CHEMBL3217109 & 566777 & 6.8327 & 5.516 & TST & \\
\hline CHEMBL 3215577 & 566777 & 5.3665 & 5.1904 & TRN & \\
\hline CHEMBL3216436 & 566777 & 7.2924 & 4.2367 & TST & \\
\hline CHEMBL495012 & 566777 & 2.5901 & 2.6027 & TRN & \\
\hline CHEMBL3216031 & 566777 & 6.6126 & 6.869 & TRN & \\
\hline CHEMBL3216032 & 566777 & 7.2518 & 7.1661 & TRN & \\
\hline CHEMBL3215565 & 566777 & 5.7122 & 5.6368 & TRN & \\
\hline CHEMBL3216228 & 566777 & 3.8153 & 3.866 & TRN & \\
\hline CHEMBL3217108 & 566777 & 7.6198 & 7.732 & TRN & \\
\hline CHEMBL3217116 & 566777 & 7.284 & 7.2742 & TRN & \\
\hline CHEMBL3216662 & 566777 & 6.7423 & 7.0356 & TST & \\
\hline CHEMBL3216017 & 566777 & 6.5391 & 6.5265 & TRN & \\
\hline CHEMBL 3216423 & 566777 & 6.5867 & 6.6546 & TRN & \\
\hline CHEMBL3216225 & 566777 & 7.3565 & 8.1966 & TST & \\
\hline CHEMBL3216013 & 566777 & 7.2441 & 7.1231 & TST & \\
\hline CHEMBL3216426 & 566777 & 8.1549 & 8.1947 & TRN & \\
\hline CHEMBL 3215578 & 566777 & 6.2083 & 6.2518 & TRN & \\
\hline CHEMBL935 & 566777 & 8.1549 & 7.9321 & TRN & \\
\hline CHEMBL3215766 & 566777 & 7.0315 & 7.1294 & TRN & \\
\hline CHEMBL3216902 & 566777 & 7.4437 & 7.9321 & TRN & \\
\hline CHEMBL3216229 & 566777 & 3.7375 & 4.2981 & TST & \\
\hline
\end{tabular}




\begin{tabular}{|c|c|c|c|c|c|}
\hline \multirow[b]{2}{*}{ CHEMBL494404 } & \multirow[b]{2}{*}{566777} & \multicolumn{4}{|c|}{ Supplemental Table S2.txt } \\
\hline & & 6.0899 & 6.0732 & TRN & \\
\hline CHEMBL494956 & 566777 & 7.2757 & 7.1555 & TRN & \\
\hline CHEMBL492579 & 566777 & 10.0 & 8.6591 & TST & \\
\hline CHEMBL3216425 & 566777 & 5.5171 & 6.6613 & TST & \\
\hline CHEMBL 3215570 & 566777 & 6.8069 & 7.5212 & TST & \\
\hline CHEMBL3216215 & 566777 & 7.1249 & 7.2118 & TRN & \\
\hline CHEMBL3216034 & 566777 & 7.3768 & 8.229 & TST & \\
\hline CHEMBL3215569 & 566777 & 6.7258 & 7.0309 & TST & \\
\hline CHEMBL3216434 & 566777 & 7.7447 & 7.6947 & TRN & \\
\hline CHEMBL3215764 & 566777 & 9.0 & 8.9073 & TRN & \\
\hline CHEMBL3217113 & 566777 & 7.9586 & 5.5587 & TST & \\
\hline CHEMBL3216894 & 566777 & 3.7747 & $3.80800 t$ & 00000000003 & TRN \\
\hline CHEMBL3217105 & 566777 & 5.8268 & 6.0485 & TRN & \\
\hline CHEMBL3215771 & 566777 & 6.5686 & 7.671 & TST & \\
\hline CHEMBL201637 & 327341 & 4.8256 & 4.7891 & TST & \\
\hline CHEMBL201078 & 327341 & 5.1831 & 5.3487 & TRN & \\
\hline CHEMBL200132 & 327341 & 6.1024 & 5.9771 & TRN & \\
\hline CHEMBL369978 & 327341 & 5.4486 & 5.4085 & TRN & \\
\hline CHEMBL380823 & 327341 & 5.9136 & 5.9927 & TRN & \\
\hline CHEMBL413570 & 327341 & 5.6655 & 5.6109 & TRN & \\
\hline CHEMBL201238 & 327341 & 5.8447 & 5.8983 & TRN & \\
\hline CHEMBL201734 & 327341 & 5.556 & 5.4193 & TRN & \\
\hline CHEMBL381737 & 327341 & 4.7003 & 4.9095 & TRN & \\
\hline CHEMBL380657 & 327341 & 5.767 & 5.6883 & TRN & \\
\hline CHEMBL382137 & 327341 & 5.6904 & 5.6892 & TRN & \\
\hline CHEMBL370376 & 327341 & 5.6216 & 5.3865 & TRN & \\
\hline CHEMBL440759 & 327341 & 5.6946 & 5.5982 & TRN & \\
\hline CHEMBL377948 & 327341 & 5.3372 & 5.36 & TRN & \\
\hline CHEMBL201123 & 327341 & 6.0 & 5.2151 & TST & \\
\hline CHEMBL201682 & 327341 & 5.0878 & 5.1497 & TRN & \\
\hline CHEMBL199332 & 327341 & 6.1249 & 6.1011 & TRN & \\
\hline CHEMBL383649 & 327341 & 5.8447 & 5.898 & TRN & \\
\hline CHEMBL381044 & 327341 & 5.4134 & 5.6498 & TRN & \\
\hline CHEMBL201579 & 327341 & 4.1967 & 4.275 & TRN & \\
\hline CHEMBL201545 & 327341 & 5.6003 & 5.6437 & TRN & \\
\hline CHEMBL202975 & 327341 & 5.5045 & 5.4802 & TRN & \\
\hline CHEMBL199604 & 327341 & 5.9788 & 6.0016 & TRN & \\
\hline CHEMBL202379 & 327341 & 5.4522 & 5.5205 & TRN & \\
\hline CHEMBL382849 & 327341 & 5.7852 & 5.5657 & TRN & \\
\hline CHEMBL383534 & 327341 & 4.6688 & 4.8354 & TRN & \\
\hline CHEMBL201380 & 327341 & 6.3665 & 6.2179 & TRN & \\
\hline CHEMBL 2448545 & 327341 & 5.7399 & 5.318 & TST & \\
\hline CHEMBL201345 & 327341 & 5.5003 & 5.7983 & TRN & \\
\hline CHEMBL202778 & 327341 & 5.2757 & 5.3222 & TRN & \\
\hline CHEMBL202976 & 327341 & 5.4672 & 5.4051 & TRN & \\
\hline CHEMBL381989 & 327341 & 5.45100 & 00000000 & 5.4005 & TRN \\
\hline CHEMBL199889 & 327341 & 5.4248 & 5.5203 & TRN & \\
\hline CHEMBL201704 & 327341 & 6.2007 & 5.906006 & $\partial 000000001$ & TRN \\
\hline & & & & 86 & \\
\hline
\end{tabular}




\begin{tabular}{|c|c|c|c|c|c|c|}
\hline & & \multicolumn{5}{|c|}{ Supplemental Table S2.txt } \\
\hline CHEMBL437138 & 327341 & 5.4685 & 5.4107 & TRN & & \\
\hline CHEMBL380413 & 327341 & 3.2411 & 4.0994 & TST & & \\
\hline CHEMBL197594 & 327341 & 5.0311 & 4.55 & TRN & & \\
\hline CHEMBL383608 & 327341 & 5.5719 & 5.768 & TRN & & \\
\hline CHEMBL202664 & 327341 & 5.5243 & 5.4972 & TRN & & \\
\hline CHEMBL380751 & 327341 & 5.1469 & 5.2616 & TRN & & \\
\hline CHEMBL202978 & 327341 & 6.0757 & 5.9478 & TRN & & \\
\hline CHEMBL201503 & 327341 & 3.2596 & 3.8346 & TST & & \\
\hline CHEMBL203140 & 327341 & 5.7399 & 5.0717 & TST & & \\
\hline CHEMBL199942 & 327341 & 5.4473 & 5.567 & TRN & & \\
\hline CHEMBL199953 & 327341 & \multicolumn{3}{|c|}{5.7620000000000005} & 5.7633 & TRN \\
\hline CHEMBL201356 & 327341 & 5.5072 & 5.6382 & TRN & & \\
\hline CHEMBL383494 & 327341 & 3.2291 & 3.8143 & TST & & \\
\hline CHEMBL199556 & 327341 & 5.3487 & 5.3717 & TRN & & \\
\hline CHEMBL382802 & 327341 & 5.2396 & 5.2378 & TRN & & \\
\hline CHEMBL201487 & 327341 & 5.3188 & 5.5902 & TST & & \\
\hline CHEMBL437511 & 327341 & 5.1273 & 4.7927 & TST & & \\
\hline CHEMBL201319 & 327341 & 5.2958 & 5.4007 & TST & & \\
\hline CHEMBL201134 & 327341 & 5.27 & 5.3836 & TST & & \\
\hline CHEMBL201590 & 327341 & 5.9431 & 5.7407 & TST & & \\
\hline CHEMBL198407 & 327341 & 5.5086 & 5.557 & TST & & \\
\hline CHEMBL199601 & 327341 & 5.9957 & 5.9613 & TST & & \\
\hline CHEMBL 2086531 & 841034 & 6.6576 & 6.6541 & TRN & & \\
\hline CHEMBL 2086518 & 841034 & 6.7447 & 6.746 & TRN & & \\
\hline CHEMBL2086501 & 841034 & 3.0969 & 3.0973 & TRN & & \\
\hline CHEMBL 2089387 & 841034 & 5.9586 & 5.9617 & TRN & & \\
\hline CHEMBL 2086543 & 841034 & 3.0969 & 3.0979 & TRN & & \\
\hline CHEMBL 2086498 & 841034 & 5.1675 & 3.6656 & TST & & \\
\hline CHEMBL 2089388 & 841034 & 6.3768 & 6.3738 & TRN & & \\
\hline CHEMBL 2086473 & 841034 & 6.1135 & 6.1141 & TRN & & \\
\hline CHEMBL 2086480 & 841034 & 6.5528 & 6.5547 & TRN & & \\
\hline CHEMBL 2367730 & 841034 & 6.699 & 6.7046 & TRN & & \\
\hline CHEMBL 2086519 & 841034 & 6.6198 & 6.6143 & TRN & & \\
\hline CHEMBL 2086526 & 841034 & 6.5086 & 6.5133 & TRN & & \\
\hline CHEMBL 2089396 & 841034 & 6.3565 & 6.3591 & TRN & & \\
\hline CHEMBL 2086503 & 841034 & 6.1308 & 6.1297 & TRN & & \\
\hline CHEMBL 2086530 & 841034 & 6.4685 & 6.4684 & TRN & & \\
\hline CHEMBL 2086505 & 841034 & 7.4089 & 7.4068 & TRN & & \\
\hline CHEMBL 2086504 & 841034 & 6.6778 & 6.6824 & TRN & & \\
\hline CHEMBL 2086523 & 841034 & 6.5528 & 6.55399 & 9999999999 & & TRN \\
\hline CHEMBL 2086506 & 841034 & 6.4949 & 6.4945 & TRN & & \\
\hline CHEMBL 2086538 & 841034 & 5.7959 & 5.7908 & TRN & & \\
\hline CHEMBL 2086510 & 841034 & 6.4685 & 6.4706 & TRN & & \\
\hline CHEMBL 2086502 & 841034 & 4.7959 & 4.7938 & TRN & & \\
\hline CHEMBL 2086537 & 841034 & 6.0088 & 6.0056 & TRN & & \\
\hline CHEMBL 2086544 & 841034 & 5.6021 & 5.6075 & TRN & & \\
\hline CHEMBL 2086511 & 841034 & 6.2007 & 6.2021 & TRN & & \\
\hline CHEMBL 2086528 & 841034 & 6.7447 & 6.7299 & TRN & & \\
\hline
\end{tabular}


Supplemental Table S2.txt

\begin{tabular}{|c|c|c|c|c|}
\hline CHEMBL 2086525 & 841034 & 6.5229 & 6.5217 & TRN \\
\hline CHEMBL 2086520 & 841034 & 6.1192 & 6.1177 & TRN \\
\hline CHEMBL 2086515 & 841034 & 6.1739 & 6.1711 & TRN \\
\hline CHEMBL2086482 & 841034 & 5.0506 & 5.0534 & TRN \\
\hline CHEMBL2089386 & 841034 & 6.3665 & 6.3709 & TRN \\
\hline CHEMBL 2086508 & 841034 & 6.301 & \multicolumn{2}{|c|}{6.3020000000000005} \\
\hline CHEMBL 2089395 & 841034 & 5.6778 & 5.6779 & TRN \\
\hline CHEMBL2086509 & 841034 & 6.6021 & 6.6035 & TRN \\
\hline CHEMBL 2086514 & 841034 & 6.1427 & 6.1456 & TRN \\
\hline CHEMBL 2086535 & 841034 & 5.8539 & 5.8538 & TRN \\
\hline CHEMBL 2086466 & 841034 & 5.1739 & 5.1747 & TRN \\
\hline CHEMBL 2086534 & 841034 & 6.4318 & 6.4328 & TRN \\
\hline CHEMBL 2086541 & 841034 & 5.6576 & 5.6659 & TRN \\
\hline CHEMBL 2089397 & 841034 & 6.284 & 6.2857 & TRN \\
\hline CHEMBL 2086517 & 841034 & 6.5086 & 6.5132 & TRN \\
\hline CHEMBL 2086512 & 841034 & 6.6383 & 6.6356 & TRN \\
\hline CHEMBL2086486 & 841034 & 3.0969 & 3.0938 & TRN \\
\hline CHEMBL 2086524 & 841034 & 6.4815 & 6.4809 & TRN \\
\hline CHEMBL 2086499 & 841034 & 4.3372 & 3.9425 & TST \\
\hline CHEMBL2086516 & 841034 & 6.3279 & 6.3288 & TRN \\
\hline CHEMBL2086513 & 841034 & 6.4202 & 6.4186 & TRN \\
\hline CHEMBL 2086533 & 841034 & 6.2441 & 6.2428 & TRN \\
\hline CHEMBL 2086527 & 841034 & 6.2441 & 6.2415 & TRN \\
\hline CHEMBL 2086540 & 841034 & 5.8239 & 5.8196 & TRN \\
\hline CHEMBL 2089400 & 841034 & 6.1739 & 6.1754 & TRN \\
\hline CHEMBL2086887 & 841034 & 3.585 & 3.1524 & TST \\
\hline CHEMBL 2086532 & 841034 & 6.6021 & 6.603 & TRN \\
\hline CHEMBL 2086542 & 841034 & 5.4815 & 5.4763 & TRN \\
\hline CHEMBL2089393 & 841034 & 6.2218 & 6.2212 & TRN \\
\hline CHEMBL 2089398 & 841034 & 6.5086 & \multicolumn{2}{|c|}{6.5089999999999995} \\
\hline CHEMBL2086522 & 841034 & 6.5086 & 6.529 & TST \\
\hline CHEMBL 2086496 & 841034 & 3.0969 & 3.8558 & TST \\
\hline CHEMBL 2086483 & 841034 & 3.0969 & 4.1481 & TST \\
\hline CHEMBL 2086507 & 841034 & 6.4815 & 6.353 & TST \\
\hline CHEMBL 2086890 & 841034 & 7.2924 & 6.8995 & TST \\
\hline CHEMBL2086529 & 841034 & 6.301 & 6.2302 & TST \\
\hline CHEMBL 2086539 & 841034 & 5.8861 & 4.5478 & TST \\
\hline CHEMBL 2086891 & 841034 & 7.1805 & 7.0674 & TST \\
\hline CHEMBL2089385 & 841034 & 3.0969 & 3.4507 & TST \\
\hline CHEMBL 2086489 & 841034 & 6.0605 & 5.5816 & TST \\
\hline CHEMBL1605548 & 841034 & 5.6198 & 5.3442 & TST \\
\hline CHEMBL2086479 & 841034 & 6.4559 & 5.643 & TST \\
\hline CHEMBL2089399 & 841034 & 6.3188 & 6.4381 & TST \\
\hline CHEMBL 2086536 & 841034 & 5.9208 & 6.0061 & TST \\
\hline CHEMBL 2089394 & 841034 & 6.0706 & 5.5829 & TST \\
\hline CHEMBL3663439 & 1642541 & 5.2676 & 5.2183 & TRN \\
\hline CHEMBL 3663515 & 1642541 & 6.699 & 6.7315 & TRN \\
\hline CHEMBL 3663442 & 1642541 & 6.2175 & 6.181 & TRN \\
\hline
\end{tabular}


Supplemental Table S2.txt

\begin{tabular}{|c|c|c|c|c|}
\hline HEN & 542541 & & 5.7586 & \\
\hline HEMBL3663547 & & 7.3872 & & \\
\hline & & & & \\
\hline AEMBL & 2541 & 5229 & 5005 & 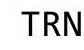 \\
\hline HEMBL & 642541 & 6.0 & 1606 & \\
\hline HEMBL3663414 & 642541 & 7.699 & 6879 & \\
\hline HEMBL & & & 3274 & \\
\hline AEMBL & & 686 & & \\
\hline HEMBL3 & 541 & 6.6021 & 7395 & \\
\hline HEMBL3663384 & 541 & 7.1805 & 1622 & \\
\hline HEMBL3659237 & 541 & 7.1938 & 1859 & \\
\hline IEMBL & 41 & 01 & 28 & \\
\hline HEMBL; & & & & \\
\hline HEMBL3 & 41 & 5.0 & 3436 & \\
\hline AEMBL3 & 41 & 8 & 664 & \\
\hline AEMBL366 & 6 & 8 . & 7.9735 & \\
\hline AEMBL3 & 41 & 86 & 584 & \\
\hline HEMBL & & & & \\
\hline HEMBL3 & & 39 & 1531 & \\
\hline AEMBL3 & 41 & 8 & & \\
\hline HEMBL & 6 & 7. & 74 & KIV \\
\hline AEMBL & & 47 & & 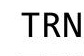 \\
\hline AEMBL & & & 59 & \\
\hline 99 & & & 517 & \\
\hline AEMBL36635 & & & & 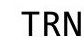 \\
\hline HEMBL; & 6 & & 54 & RN \\
\hline HEMBL & & & 61 & RN \\
\hline HFMRI & & 14 & 592 & \\
\hline HEMBL3 & & & .722 & in \\
\hline HEMBL36635 & & & & s \\
\hline HEMBL3 & 62 & 5 & 576 & SI \\
\hline HEMBL & & & 93 & RN \\
\hline HEMBL & & & 947 & Iv \\
\hline HEMBL3663538 & +1 & & 44 & IRN \\
\hline HEMBL3663470 & 62 & 5 . & 117 & TST \\
\hline HEMBL3 & 6 & 5 & 7.6172 & RN \\
\hline HEMRI & & 9 & 744 & RN \\
\hline HEMBL & & 7. & 585 & RN \\
\hline HEMBL3663443 & & 5.3566 & 3074 & $\Gamma \mathrm{RN}$ \\
\hline IEMBL: & & 49 & 5079 & IRN \\
\hline HEMBL3 & $\mathbf{r}$ & 08 & 109 & \\
\hline CHEMBL3 & & 7.0862 & .0562 & RN \\
\hline HEMBL3 & 16 & 5.0 & 0865 & RN \\
\hline HEMBL3659176 & 41 & 7.3872 & 5296 & TRN \\
\hline MPI & & & & $\mathrm{N}$ \\
\hline HEMBL3 & & 208 & 7.8504 & \\
\hline CHEMBL 366344 & 164 & .684 & .7514 & \\
\hline CHEMBL3663491 & 1642541 & 5.0458 & 4.8596 & ST \\
\hline
\end{tabular}

Page 12806 
Supplemental Table S2.txt

\begin{tabular}{|c|c|c|c|c|}
\hline CHEMBL3902222 & 1642541 & 7.5528 & 6.6493 & TST \\
\hline CHEMBL3659191 & 1642541 & 7.3279 & 7.2781 & TRN \\
\hline CHEMBL3659185 & 1642541 & 7.699 & 7.6868 & TRN \\
\hline CHEMBL 3663425 & 1642541 & 7.1675 & \multicolumn{2}{|c|}{6.912000000000001} \\
\hline CHEMBL3663456 & 1642541 & 5.9586 & 5.945 & TST \\
\hline CHEMBL3659209 & 1642541 & 5.301 & 5.4997 & TST \\
\hline CHEMBL339286 & 1642541 & 7.8239 & 6.8437 & TST \\
\hline CHEMBL3659189 & 1642541 & 6.5686 & 6.7085 & TRN \\
\hline CHEMBL3663523 & 1642541 & 7.7212 & 7.598 & TST \\
\hline CHEMBL3659196 & 1642541 & 6.1694 & 6.197 & TST \\
\hline CHEMBL3659194 & 1642541 & 7.1308 & 7.0533 & TRN \\
\hline CHEMBL3663542 & 1642541 & 7.3188 & 7.2947 & TRN \\
\hline CHEMBL3663510 & 1642541 & 7.1487 & 6.9939 & TST \\
\hline CHEMBL3663522 & 1642541 & 7.7959 & 7.7335 & TRN \\
\hline CHEMBL3659235 & 1642541 & 7.1612 & 7.3528 & TRN \\
\hline CHEMBL3663426 & 1642541 & 6.8125 & 7.0075 & TRN \\
\hline CHEMBL3659181 & 1642541 & 6.0 & 5.9732 & TST \\
\hline CHEMBL3663438 & 1642541 & 5.8239 & 5.8717 & TRN \\
\hline CHEMBL3663492 & 1642541 & 5.8505 & 5.4205 & TST \\
\hline CHEMBL3663451 & 1642541 & 5.2007 & 5.1628 & TRN \\
\hline CHEMBL3663572 & 1642541 & 7.4559 & 7.3553 & TST \\
\hline CHEMBL3659206 & 1642541 & 6.0 & 6.271 & TRN \\
\hline CHEMBL3663577 & 1642541 & 8.2218 & 8.2344 & TRN \\
\hline CHEMBL3663490 & 1642541 & 7.2147 & 7.2594 & TRN \\
\hline CHEMBL3663536 & 1642541 & 7.5686 & 7.585 & TRN \\
\hline CHEMBL3663563 & 1642541 & 7.4318 & 7.3018 & TRN \\
\hline CHEMBL3659188 & 1642541 & 6.0 & 5.9893 & TRN \\
\hline CHEMBL3663489 & 1642541 & 7.4318 & 7.5995 & TRN \\
\hline CHEMBL3663452 & 1642541 & 6.6576 & \multicolumn{2}{|c|}{6.3389999999999995} \\
\hline CHEMBL3663532 & 1642541 & 6.9245 & 6.7641 & TST \\
\hline CHEMBL3663556 & 1642541 & 7.585 & 7.5586 & TRN \\
\hline CHEMBL 3663450 & 1642541 & 6.7447 & 6.7624 & TRN \\
\hline CHEMBL3659232 & 1642541 & 7.6198 & 7.7196 & TRN \\
\hline CHEMBL3663511 & 1642541 & 7.3979 & 7.5732 & TRN \\
\hline CHEMBL3659243 & 1642541 & 8.1549 & 8.0281 & TRN \\
\hline CHEMBL3663528 & 1642541 & 7.3372 & 7.3185 & TST \\
\hline CHEMBL3659230 & 1642541 & 7.3372 & 7.2701 & TRN \\
\hline CHEMBL3663481 & 1642541 & 7.3188 & 7.3105 & TRN \\
\hline CHEMBL3659208 & 1642541 & 7.5376 & 7.4033 & TRN \\
\hline CHEMBL3663498 & 1642541 & 7.6021 & 7.45 & TRN \\
\hline CHEMBL3962823 & 1642541 & 7.3188 & 7.2136 & TRN \\
\hline CHEMBL3663441 & 1642541 & 6.0223 & 5.817 & TST \\
\hline CHEMBL 3663544 & 1642541 & 8.0 & 7.9999 & TRN \\
\hline CHEMBL3659212 & 1642541 & 6.6536 & 6.6269 & TRN \\
\hline CHEMBL3659178 & 1642541 & 6.0 & 6.2518 & TRN \\
\hline CHEMBL3663444 & 1642541 & 5.5086 & 5.5167 & TRN \\
\hline CHEMBL 3663564 & 1642541 & 7.7696 & 7.7652 & TRN \\
\hline CHEMBL3663399 & 1642541 & 7.9586 & 7.9518 & TST \\
\hline
\end{tabular}


Supplemental Table S2.txt

\begin{tabular}{|c|c|c|c|c|}
\hline CHEMBL 3659210 & 1642541 & 7.4559 & 7.2503 & TRN \\
\hline CHEMBL3663549 & 1642541 & 7.6383 & 7.6526 & TRN \\
\hline CHEMBL3663560 & 1642541 & 7.0132 & 7.0083 & TRN \\
\hline CHEMBL 3659203 & 1642541 & 7.2218 & 7.1313 & TRN \\
\hline CHEMBL3663424 & 1642541 & 7.8539 & 7.8565 & TRN \\
\hline CHEMBL3663501 & 1642541 & 7.0223 & 6.9588 & TRN \\
\hline CHEMBL3663433 & 1642541 & 6.7212 & 6.7226 & TRN \\
\hline CHEMBL 3663555 & 1642541 & 7.3768 & 7.4156 & TRN \\
\hline CHEMBL 3663557 & 1642541 & 7.9208 & 8.0199 & TRN \\
\hline CHEMBL3659200 & 1642541 & 7.4815 & 7.3692 & TRN \\
\hline CHEMBL3659182 & 1642541 & 6.9281 & 6.8434 & TRN \\
\hline CHEMBL3663429 & 1642541 & 7.5376 & 7.3565 & TRN \\
\hline CHEMBL3659190 & 1642541 & 6.5229 & 6.7419 & TRN \\
\hline CHEMBL3639623 & 1642541 & 5.7066 & 5.3982 & TST \\
\hline CHEMBL3659234 & 1642541 & 6.5331 & 6.6552 & TRN \\
\hline CHEMBL3663449 & 1642541 & 6.4685 & 6.3846 & TST \\
\hline CHEMBL3639580 & 1642541 & 6.3979 & 6.4294 & TRN \\
\hline CHEMBL3663505 & 1642541 & 7.2596 & 7.1846 & TRN \\
\hline CHEMBL3663530 & 1642541 & 7.7696 & 7.7307 & TST \\
\hline CHEMBL3663550 & 1642541 & 8.1549 & 8.2552 & TRN \\
\hline CHEMBL3663537 & 1642541 & 6.8182 & 6.7292 & TRN \\
\hline CHEMBL3659195 & 1642541 & 6.9318 & 6.9644 & TRN \\
\hline CHEMBL 3659223 & 1642541 & 6.8239 & 6.8868 & TRN \\
\hline CHEMBL3659179 & 1642541 & 6.0 & 6.1945 & TRN \\
\hline CHEMBL 3663571 & 1642541 & 7.7212 & 7.7701 & TRN \\
\hline CHEMBL3663570 & 1642541 & 7.4949 & 7.4834 & TST \\
\hline CHEMBL 3663540 & 1642541 & 7.2218 & 7.0351 & TST \\
\hline CHEMBL3659204 & 1642541 & 7.2366 & 7.1236 & TRN \\
\hline CHEMBL3659197 & 1642541 & 7.8539 & 7.6563 & TRN \\
\hline CHEMBL 3663471 & 1642541 & 6.1637 & 5.7853 & TST \\
\hline CHEMBL3659193 & 1642541 & 6.9136 & 6.9453 & TRN \\
\hline CHEMBL 3663576 & 1642541 & 8.0969 & 8.1763 & TST \\
\hline CHEMBL 3659211 & 1642541 & 5.8938 & 5.9554 & TRN \\
\hline CHEMBL3659226 & 1642541 & 6.9318 & 6.9432 & TRN \\
\hline CHEMBL 3663468 & 1642541 & 5.6383 & 5.3618 & TRN \\
\hline CHEMBL3663533 & 1642541 & 7.2676 & 7.2873 & TST \\
\hline CHEMBL3659198 & 1642541 & 7.9586 & 7.8253 & TST \\
\hline CHEMBL3659201 & 1642541 & 7.6778 & 7.8373 & TRN \\
\hline CHEMBL3659177 & 1642541 & 7.6383 & 6.7329 & TRN \\
\hline CHEMBL3663539 & 1642541 & 7.5376 & 7.3064 & TST \\
\hline CHEMBL3659213 & 1642541 & 7.1024 & 7.1737 & TRN \\
\hline CHEMBL3663467 & 1642541 & 6.3883 & 6.4259 & TRN \\
\hline CHEMBL 3663453 & 1642541 & 6.7447 & \multicolumn{2}{|c|}{6.672999999999999} \\
\hline CHEMBL3663478 & 1642541 & 6.4572 & 6.4261 & TST \\
\hline CHEMBL3663514 & 1642541 & 7.585 & 7.4698 & TST \\
\hline CHEMBL57712 & 1642541 & 7.7212 & 6.796 & TST \\
\hline CHEMBL3663525 & 1642541 & 6.7986 & 6.7261 & TST \\
\hline CHEMBL3659184 & 1642541 & 7.2518 & 7.1893 & TRN \\
\hline
\end{tabular}

Page 12808 
Supplemental Table S2.txt

\begin{tabular}{|c|c|c|c|c|}
\hline CHEMBL 3663401 & 1642541 & 6.699 & 6.8347 & TRN \\
\hline CHEMBL 3659205 & 1642541 & 7.1549 & 7.0289 & TRN \\
\hline CHEMBL3663436 & 1642541 & 5.0 & 5.0191 & TRN \\
\hline CHEMBL 3659214 & 1642541 & 7.0862 & 6.6239 & TST \\
\hline CHEMBL3663447 & 1642541 & 5.4089 & 5.379 & TRN \\
\hline CHEMBL 3663431 & 1642541 & 6.7212 & 6.4934 & TST \\
\hline CHEMBL 3663526 & 1642541 & 7.3872 & 7.2145 & TST \\
\hline CHEMBL3659183 & 1642541 & 7.301 & 7.1667 & TRN \\
\hline CHEMBL 3659202 & 1642541 & 8.0458 & 8.0282 & TRN \\
\hline CHEMBL3659192 & 1642541 & 6.4921 & 6.6061 & TRN \\
\hline CHEMBL 3663469 & 1642541 & 5.0458 & 5.0888 & TST \\
\hline CHEMBL 3663419 & 1642541 & 7.1079 & 7.1786 & TRN \\
\hline CHEMBL 3663432 & 1642541 & 5.2441 & 5.2176 & TRN \\
\hline CHEMBL 3663400 & 1642541 & 7.1367 & 7.1823 & TRN \\
\hline CHEMBL3663435 & 1642541 & 5.0 & 4.991000 & 00000000005 \\
\hline CHEMBL 3663546 & 1642541 & 6.75700 & 000000000 & 6.8797 \\
\hline CHEMBL3659186 & 1642541 & 7.3872 & 7.3965 & TRN \\
\hline CHEMBL 3663457 & 1642541 & 6.1612 & 6.2494 & TRN \\
\hline CHEMBL 3663403 & 1642541 & 7.1192 & 7.1609 & TRN \\
\hline CHEMBL 3663527 & 1642541 & 7.3468 & 7.2682 & TST \\
\hline CHEMBL 3663434 & 1642541 & 5.4318 & 5.459 & TRN \\
\hline CHEMBL 3659231 & 1642541 & 7.6021 & 7.4649 & TRN \\
\hline CHEMBL 3663493 & 1642541 & 5.7867 & 5.22 & TST \\
\hline CHEMBL 3663448 & 1642541 & 5.4437 & 5.4411 & TRN \\
\hline CHEMBL 3659238 & 1642541 & 7.2076 & 7.1119 & TRN \\
\hline CHEMBL1301313 & 752420 & 2.8752 & 3.8498 & TRN \\
\hline CHEMBL124006 & 752420 & 6.3429 & 6.3481 & TRN \\
\hline CHEMBL1424118 & 752420 & 5.3354 & 6.6037 & TRN \\
\hline CHEMBL 3199286 & 752420 & 6.7011 & 5.5236 & TRN \\
\hline CHEMBL1363614 & 752420 & 6.2441 & 4.9993 & TRN \\
\hline CHEMBL1592917 & 752420 & 6.2741 & 5.9407 & TST \\
\hline CHEMBL1517325 & 752420 & 6.2388 & 5.5397 & TRN \\
\hline CHEMBL267099 & 752420 & 7.983 & 6.4212 & TST \\
\hline CHEMBL1414112 & 752420 & 6.6021 & 7.7122 & TRN \\
\hline CHEMBL 3196518 & 752420 & 7.983 & 6.4138 & TRN \\
\hline CHEMBL1486214 & 752420 & 6.4841 & 4.5171 & TRN \\
\hline CHEMBL1601781 & 752420 & 2.8752 & 4.5701 & TST \\
\hline CHEMBL1481030 & 752420 & 6.6402 & 5.9572 & TRN \\
\hline CHEMBL1539678 & 752420 & 5.7167 & 5.3705 & TST \\
\hline CHEMBL1439210 & 752420 & 5.8697 & 5.5021 & TRN \\
\hline CHEMBL1341756 & 752420 & 5.5421 & 6.0192 & TRN \\
\hline CHEMBL1455468 & 752420 & 7.983 & 8.0189 & TRN \\
\hline CHEMBL1375740 & 752420 & 2.8752 & 4.3372 & TRN \\
\hline CHEMBL1535055 & 752420 & 2.8752 & 4.2276 & TRN \\
\hline CHEMBL1416406 & 752420 & 2.8752 & 3.6574 & TST \\
\hline CHEMBL1447563 & 752420 & 6.2984 & 5.5986 & TRN \\
\hline CHEMBL1310508 & 752420 & 5.2993 & 5.6436 & TRN \\
\hline CHEMBL193872 & 752420 & 5.7595 & 5.6834 & TRN \\
\hline
\end{tabular}


Supplemental Table S2.txt

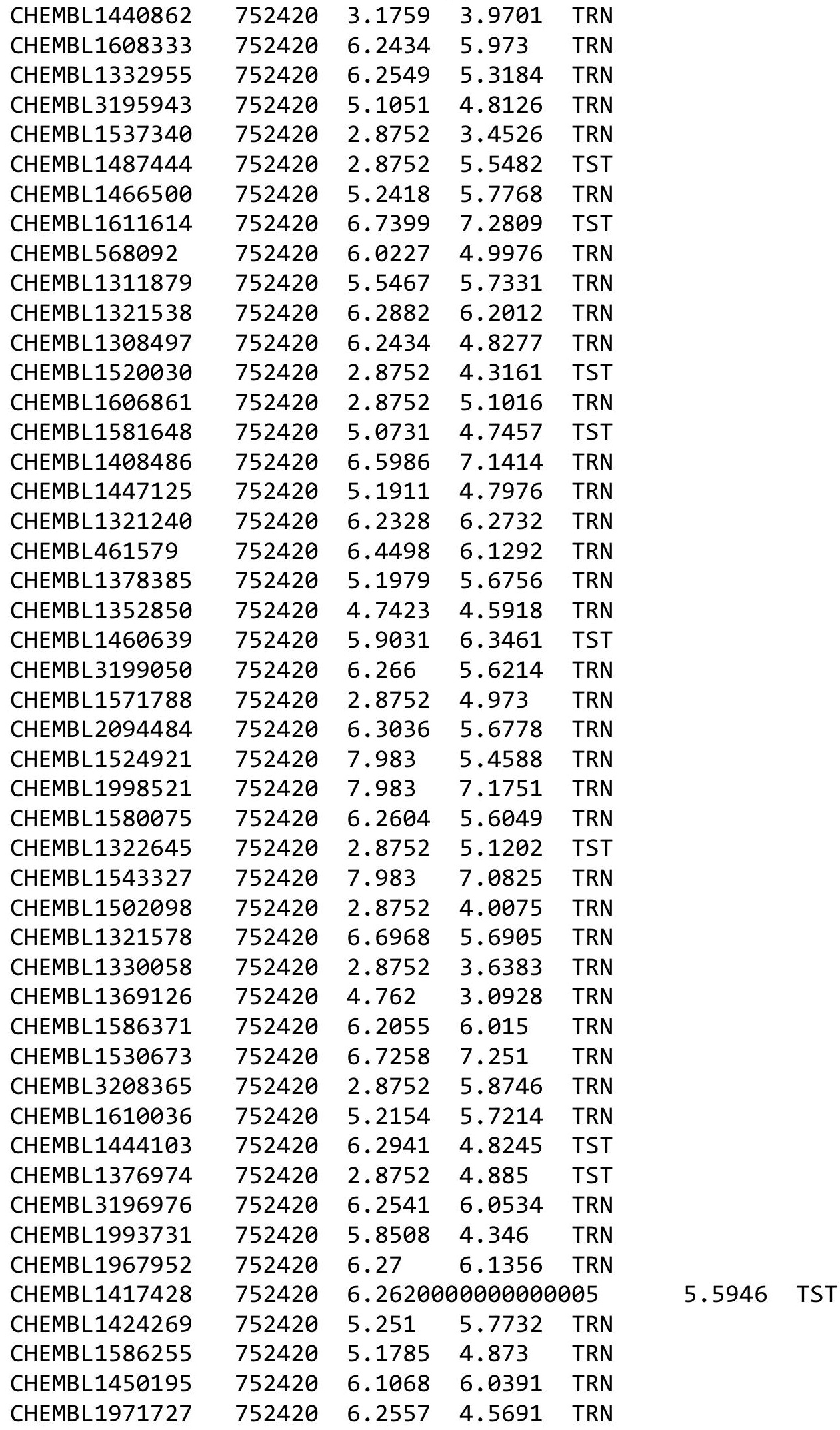

Page 12810 
Supplemental Table S2.txt

\begin{tabular}{|c|c|c|c|c|c|}
\hline CHEMBL1347192 & 752420 & 2.8752 & 5.6151 & TST & \\
\hline CHEMBL1472126 & 752420 & 5.5702 & 6.1299 & TRN & \\
\hline CHEMBL1405453 & 752420 & 7.983 & 8.1271 & TRN & \\
\hline CHEMBL1987938 & 752420 & 5.9101 & 6.1361 & TRN & \\
\hline CHEMBL1310221 & 752420 & 6.2182 & 5.2871 & TRN & \\
\hline CHEMBL1361550 & 752420 & 6.2636 & 5.3771 & TRN & \\
\hline CHEMBL1577044 & 752420 & 6.3536 & 6.013 & TRN & \\
\hline CHEMBL1342147 & 752420 & 2.8752 & 3.4484 & TRN & \\
\hline CHEMBL1328466 & 752420 & 6.7423 & 7.6103 & TRN & \\
\hline CHEMBL1372082 & 752420 & 7.983 & 7.3171 & TRN & \\
\hline CHEMBL1304902 & 752420 & 5.4034 & 5.88899 & 9999999999 & TRN \\
\hline CHEMBL1328069 & 752420 & 5.7375 & 6.0442 & TST & \\
\hline CHEMBL3196369 & 752420 & 2.8752 & 3.3433 & TRN & \\
\hline CHEMBL1411142 & 752420 & 2.8752 & 5.4466 & TRN & \\
\hline CHEMBL1422078 & 752420 & 6.1694 & 5.3075 & TRN & \\
\hline CHEMBL1303034 & 752420 & 6.209 & 6.5333 & TST & \\
\hline CHEMBL1342336 & 752420 & 7.983 & 6.8355 & TRN & \\
\hline CHEMBL65 & 752420 & 8.1152 & 6.0086 & TST & \\
\hline CHEMBL1491893 & 752420 & 5.3516 & 6.1126 & TRN & \\
\hline CHEMBL3197070 & 752420 & 6.3233 & 6.0087 & TRN & \\
\hline CHEMBL1460869 & 752420 & 2.8752 & 3.9359 & TRN & \\
\hline CHEMBL1403980 & 752420 & 5.8508 & 6.4861 & TRN & \\
\hline CHEMBL1340058 & 752420 & 7.983 & 7.261 & TRN & \\
\hline CHEMBL1491847 & 752420 & 6.2933 & 5.8869 & TST & \\
\hline CHEMBL1876078 & 752420 & 6.9101 & 5.8418 & TRN & \\
\hline CHEMBL1484547 & 752420 & 6.2503 & 7.0713 & TRN & \\
\hline CHEMBL1587117 & 752420 & 2.8752 & 4.0254 & TRN & \\
\hline CHEMBL1427287 & 752420 & 2.8752 & 4.5397 & TRN & \\
\hline CHEMBL1452795 & 752420 & 5.7305 & 6.5867 & TRN & \\
\hline CHEMBL1535665 & 752420 & 6.4976 & 5.9602 & TST & \\
\hline CHEMBL1544797 & 752420 & 6.3615 & 6.2772 & TRN & \\
\hline CHEMBL3145305 & 752420 & 2.8752 & 5.42399 & 99999999995 & TRN \\
\hline CHEMBL1486332 & 752420 & 6.2716 & 6.0171 & TRN & \\
\hline CHEMBL3199512 & 752420 & 2.8752 & 4.3688 & TRN & \\
\hline CHEMBL1606557 & 752420 & 4.9281 & 3.9917 & TRN & \\
\hline CHEMBL408850 & 752420 & 2.8752 & 3.1268 & TRN & \\
\hline CHEMBL1326110 & 752420 & 6.857 & 5.8094 & TRN & \\
\hline CHEMBL1611041 & 752420 & 2.8752 & 5.3526 & TRN & \\
\hline CHEMBL 1485865 & 752420 & 5.8861 & 6.0162 & TRN & \\
\hline CHEMBL463763 & 752420 & 7.983 & 6.4233 & TST & \\
\hline CHEMBL1302758 & 752420 & 2.8752 & 4.7469 & TRN & \\
\hline CHEMBL1550406 & 752420 & 5.6737 & 5.6587 & TRN & \\
\hline CHEMBL1578061 & 752420 & 5.4989 & 4.5051 & TRN & \\
\hline CHEMBL1567957 & 752420 & 3.9654 & 5.3103 & TRN & \\
\hline CHEMBL1300069 & 752420 & \multicolumn{3}{|c|}{6.247999999999999} & TRN \\
\hline CHEMBL1524734 & 752420 & 6.4089 & 5.6733 & TRN & \\
\hline CHEMBL405317 & 752420 & 2.8752 & 3.4978 & TRN & \\
\hline CHEMBL518292 & 752420 & 6.2403 & 5.5656 & TST & \\
\hline
\end{tabular}


Supplemental Table S2.txt

\begin{tabular}{|c|c|c|c|c|c|c|}
\hline CHEMBL3196139 & 752420 & 5.8386 & 5.3502 & TRN & & \\
\hline CHEMBL1610733 & 752420 & 5.7423 & 4.3236 & TRN & & \\
\hline CHEMBL1928491 & 752420 & 5.2132 & 4.52 & TRN & & \\
\hline CHEMBL1502738 & 752420 & 6.0022 & 5.5703 & TRN & & \\
\hline CHEMBL3199665 & 752420 & 5.9066 & 6.2646 & TRN & & \\
\hline CHEMBL1974506 & 752420 & 5.4237 & 4.5468 & TRN & & \\
\hline CHEMBL1528258 & 752420 & 4.6126 & 4.908 & TRN & & \\
\hline CHEMBL1360484 & 752420 & 7.983 & 7.6803 & TRN & & \\
\hline CHEMBL1558993 & 752420 & 2.8752 & 3.9215 & TRN & & \\
\hline CHEMBL1596798 & 752420 & 7.983 & 7.682 & TRN & & \\
\hline CHEMBL1487099 & 752420 & 6.4647 & 7.5495 & TST & & \\
\hline CHEMBL1547092 & 752420 & 5.8508 & 5.6733 & TRN & & \\
\hline CHEMBL1378118 & 752420 & 6.2924 & 5.8688 & TST & & \\
\hline CHEMBL1611182 & 752420 & 6.2328 & 5.9293 & TRN & & \\
\hline CHEMBL1522827 & 752420 & 6.284 & 6.5478 & TRN & & \\
\hline CHEMBL3193058 & 752420 & 6.4647 & 5.7767 & TST & & \\
\hline CHEMBL1967436 & 752420 & 6.1891 & 6.2868 & TST & & \\
\hline CHEMBL1324082 & 752420 & 5.6536 & 5.5099 & TRN & & \\
\hline CHEMBL1481538 & 752420 & 6.8761 & 6.4982 & TRN & & \\
\hline CHEMBL1400319 & 752420 & 2.8752 & 4.8847 & TRN & & \\
\hline CHEMBL1455137 & 752420 & 5.1512 & 5.7508 & TRN & & \\
\hline CHEMBL1414754 & 752420 & 4.8356 & 3.6509 & TRN & & \\
\hline CHEMBL1445386 & 752420 & 6.3788 & 5.9306 & TST & & \\
\hline CHEMBL1995692 & 752420 & 6.699 & 6.5347 & TRN & & \\
\hline CHEMBL1612556 & 752420 & 5.3686 & 3.5503 & TRN & & \\
\hline CHEMBL1448054 & 752420 & 6.5243 & 7.3634 & TRN & & \\
\hline CHEMBL 3198720 & 752420 & 6.098 & 5.3746 & TRN & & \\
\hline CHEMBL3191713 & 752420 & 7.983 & 6.1385 & TRN & & \\
\hline CHEMBL1197556 & 752420 & 5.7235 & 6.0502 & TRN & & \\
\hline CHEMBL1396099 & 752420 & 6.3883 & 5.6942 & TST & & \\
\hline CHEMBL 2000499 & 752420 & 4.6536 & 3.5603 & TRN & & \\
\hline CHEMBL1985575 & 752420 & 2.8752 & 3.7843 & TRN & & \\
\hline CHEMBL 3145303 & 752420 & \multicolumn{3}{|c|}{6.327000000000001} & 5.7725 & TRN \\
\hline CHEMBL1307663 & 752420 & 6.0283 & 5.8278 & TRN & & \\
\hline CHEMBL 82134 & 752420 & 6.0164 & 6.2368 & TRN & & \\
\hline CHEMBL3193510 & 752420 & 6.2111 & 5.1834 & TRN & & \\
\hline CHEMBL1414345 & 752420 & 5.3188 & 4.0689 & TRN & & \\
\hline CHEMBL1483768 & 752420 & 6.2343 & 6.1288 & TRN & & \\
\hline CHEMBL1544486 & 752420 & 6.4522 & 7.2094 & TRN & & \\
\hline CHEMBL1325021 & 752420 & 5.8182 & 4.4277 & TRN & & \\
\hline CHEMBL1469534 & 752420 & 2.8752 & 3.895 & TRN & & \\
\hline CHEMBL1416693 & 752420 & 2.8752 & 3.7557 & TRN & & \\
\hline CHEMBL1380801 & 752420 & 5.6144 & 5.8949 & TRN & & \\
\hline CHEMBL1371056 & 752420 & 7.983 & 9.0661 & TRN & & \\
\hline CHEMBL1560590 & 752420 & 3.9169 & 3.7901 & TRN & & \\
\hline CHEMBL492468 & 752420 & 5.6615 & 5.7566 & TRN & & \\
\hline CHEMBL3199311 & 752420 & 6.6198 & 5.8701 & TRN & & \\
\hline CHEMBL1329221 & 752420 & 6.5952 & 6.3072 & TRN & & \\
\hline
\end{tabular}

Page 12812 
Supplemental Table S2.txt

\begin{tabular}{|c|c|c|c|c|c|}
\hline CHEMBL1301094 & 752420 & 4.7235 & 4.2332 & TRN & \\
\hline CHEMBL1404448 & 752420 & 4.8041 & 5.6558 & TRN & \\
\hline CHEMBL1584364 & 752420 & 4.5918 & 4.1474 & TRN & \\
\hline CHEMBL1481139 & 752420 & 6.7721 & 4.8802 & TRN & \\
\hline CHEMBL1445297 & 752420 & 7.983 & 8.3657 & TRN & \\
\hline CHEMBL1363437 & 752420 & 7.983 & 7.7621 & TRN & \\
\hline CHEMBL1577495 & 752420 & 5.433 & 5.269 & TRN & \\
\hline CHEMBL1587031 & 752420 & 5.3605 & 5.7848 & TST & \\
\hline CHEMBL1565526 & 752420 & 5.7959 & 6.011 & TRN & \\
\hline CHEMBL585071 & 752420 & 6.5361 & 6.5069 & TRN & \\
\hline CHEMBL1339289 & 752420 & 6.9318 & \multicolumn{2}{|c|}{7.797000000000001} & TST \\
\hline CHEMBL1573720 & 752420 & 5.2426 & 4.9425 & TRN & \\
\hline CHEMBL86464 & 752420 & 6.1524 & 5.7029 & TRN & \\
\hline CHEMBL 260342 & 752420 & 2.8752 & 2.9932 & TRN & \\
\hline CHEMBL1523954 & 752420 & 3.1759 & 2.3762 & TRN & \\
\hline CHEMBL1373252 & 752420 & 5.7905 & 4.7548 & TRN & \\
\hline CHEMBL1352313 & 752420 & 5.8268 & 5.5967 & TRN & \\
\hline CHEMBL1332139 & 752420 & 6.9281 & 5.8259 & TRN & \\
\hline CHEMBL 257286 & 752420 & 6.2426 & 3.7647 & TRN & \\
\hline CHEMBL1487639 & 752420 & 6.5467 & 5.3612 & TRN & \\
\hline CHEMBL6742 & 752420 & 2.8752 & 3.7572 & TRN & \\
\hline CHEMBL3194563 & 752420 & 4.7122 & 4.9053 & TRN & \\
\hline CHEMBL1466997 & 752420 & 2.8752 & 3.6232 & TST & \\
\hline CHEMBL528791 & 752420 & 6.2351 & 6.081 & TST & \\
\hline CHEMBL570345 & 752420 & 5.4089 & 6.0268 & TST & \\
\hline CHEMBL1376166 & 752420 & 7.983 & 8.414 & TRN & \\
\hline CHEMBL1585706 & 752420 & 2.8752 & 2.9193 & TRN & \\
\hline CHEMBL1334307 & 752420 & 5.3862 & 5.8245 & TRN & \\
\hline CHEMBL1445372 & 752420 & 6.2411 & 5.8965 & TST & \\
\hline CHEMBL1308404 & 752420 & 6.3002 & 6.2917 & TRN & \\
\hline CHEMBL1444020 & 752420 & 5.0372 & 5.8137 & TRN & \\
\hline CHEMBL1522007 & 752420 & 7.1249 & 4.8406 & TRN & \\
\hline CHEMBL3198912 & 752420 & 4.6498 & 5.5586 & TRN & \\
\hline CHEMBL1567841 & 752420 & 7.983 & 7.0232 & TRN & \\
\hline CHEMBL1448503 & 752420 & 6.2351 & 5.5702 & TRN & \\
\hline CHEMBL1514187 & 752420 & 2.8752 & 3.867 & TRN & \\
\hline CHEMBL1342029 & 752420 & 7.983 & \multicolumn{2}{|c|}{7.132000000000001} & TRN \\
\hline CHEMBL1469676 & 752420 & 3.1759 & 4.8241 & TRN & \\
\hline CHEMBL1549418 & 752420 & 5.0665 & 4.6918 & TST & \\
\hline CHEMBL1499544 & 752420 & 6.7773 & 6.2118 & TRN & \\
\hline CHEMBL1374715 & 752420 & 7.983 & 7.697 & TRN & \\
\hline CHEMBL1397089 & 752420 & 6.3686 & 7.5279 & TRN & \\
\hline CHEMBL1362687 & 752420 & 6.8729 & 7.1219 & TRN & \\
\hline CHEMBL1993194 & 752420 & 6.2534 & 5.4302 & TRN & \\
\hline CHEMBL1518905 & 752420 & 6.5638 & 6.7224 & TRN & \\
\hline CHEMBL1462074 & 752420 & 6.5287 & 6.4291 & TRN & \\
\hline CHEMBL1481849 & 752420 & 5.7305 & 6.1768 & TST & \\
\hline CHEMBL1393820 & 752420 & 5.1878 & 5.7278 & TRN & \\
\hline
\end{tabular}

Page 12813 


\begin{tabular}{|c|c|c|c|c|c|c|}
\hline & & \multicolumn{5}{|c|}{ Supplemental Table S2.txt } \\
\hline CHEMBL1611922 & 752420 & 5.466 & 6.2063 & TRN & & \\
\hline CHEMBL513150 & 752420 & 6.6882 & 5.7614 & TRN & & \\
\hline CHEMBL1569698 & 752420 & 6.3768 & 5.6318 & TRN & & \\
\hline CHEMBL1497549 & 752420 & 5.9547 & 5.977 & TRN & & \\
\hline CHEMBL1404398 & 752420 & 2.8752 & 3.4453 & TRN & & \\
\hline CHEMBL1511219 & 752420 & 2.8752 & 4.4601 & TRN & & \\
\hline CHEMBL1503006 & 752420 & 5.0448 & 4.4314 & TRN & & \\
\hline CHEMBL1498509 & 752420 & 5.7959 & 5.9597 & TRN & & \\
\hline CHEMBL1482760 & 752420 & 2.8752 & 4.7412 & TRN & & \\
\hline CHEMBL1491358 & 752420 & 3.1759 & 3.3715 & TRN & & \\
\hline CHEMBL1505003 & 752420 & 4.065 & 3.8278 & TRN & & \\
\hline CHEMBL1602800 & 752420 & 2.8752 & 5.3377 & TRN & & \\
\hline CHEMBL1597628 & 752420 & 3.1759 & 3.6352 & TRN & & \\
\hline CHEMBL1451921 & 752420 & 7.983 & 7.9364 & TRN & & \\
\hline CHEMBL1348389 & 752420 & 6.5214 & 6.7031 & TRN & & \\
\hline CHEMBL1524484 & 752420 & 2.8752 & 4.3947 & TST & & \\
\hline CHEMBL1440293 & 752420 & 6.2226 & 6.2098 & TRN & & \\
\hline CHEMBL1395962 & 752420 & 2.8752 & 4.2816 & TRN & & \\
\hline CHEMBL1541324 & 752420 & 5.51 & 6.16700 & 00000 & 01 & TST \\
\hline CHEMBL1370884 & 752420 & 6.8861 & 5.50299 & 99999 & 99 & TRN \\
\hline CHEMBL1393664 & 752420 & 2.8752 & 4.958 & TRN & & \\
\hline CHEMBL1480701 & 752420 & 5.21899 & 99999999 & 99 & 3.8886 & TRN \\
\hline CHEMBL1598561 & 752420 & 5.4647 & 6.4274 & TRN & & \\
\hline CHEMBL1353341 & 752420 & 6.34200 & 00000000 & 205 & 6.1629 & TRN \\
\hline CHEMBL1522486 & 752420 & 5.2118 & 5.5829 & TRN & & \\
\hline CHEMBL388978 & 752420 & 10.3904 & 6.1631 & TST & & \\
\hline CHEMBL1444013 & 752420 & 2.8752 & 3.6574 & TRN & & \\
\hline CHEMBL1529978 & 752420 & 6.2434 & 6.0151 & TRN & & \\
\hline CHEMBL1995045 & 752420 & 6.4078 & 6.1363 & TST & & \\
\hline CHEMBL1572558 & 752420 & 6.2182 & 6.4665 & TRN & & \\
\hline CHEMBL1491711 & 752420 & 3.1759 & 3.5922 & TRN & & \\
\hline CHEMBL1319307 & 752420 & 4.0778 & 5.6466 & TRN & & \\
\hline CHEMBL 290077 & 752420 & 6.4584 & 6.7473 & TST & & \\
\hline CHEMBL1587181 & 752420 & 6.2306 & 6.4792 & TST & & \\
\hline CHEMBL 2006168 & 752420 & 6.2027 & 5.5516 & TRN & & \\
\hline CHEMBL1337416 & 752420 & 5.2269 & 5.2157 & TST & & \\
\hline CHEMBL 1484332 & 752420 & 5.5129 & 5.945 & TRN & & \\
\hline CHEMBL1348803 & 752420 & 6.4647 & 5.7681 & TRN & & \\
\hline CHEMBL3199198 & 752420 & 3.1759 & 3.5026 & TRN & & \\
\hline CHEMBL274070 & 752420 & 8.1439 & 5.599 & TST & & \\
\hline CHEMBL1303916 & 752420 & 2.8752 & 3.9304 & TRN & & \\
\hline CHEMBL1698464 & 752420 & 6.2211 & 6.2226 & TRN & & \\
\hline CHEMBL1410102 & 752420 & 6.6055 & 6.7104 & TRN & & \\
\hline CHEMBL199868 & 752420 & 6.015 & 5.4346 & TRN & & \\
\hline CHEMBL1327703 & 752420 & 6.7595 & 7.2347 & TRN & & \\
\hline CHEMBL1353737 & 752420 & 2.8752 & 3.4009 & TRN & & \\
\hline CHEMBL3192181 & 752420 & 6.2434 & 5.3345 & TRN & & \\
\hline CHEMBL1378489 & 752420 & 5.5186 & 5.7201 & TRN & & \\
\hline
\end{tabular}


Supplemental Table S2.txt

\begin{tabular}{|c|c|c|c|c|}
\hline CHEMBL1546722 & 752420 & 6.2381 & 7.5174 & TST \\
\hline CHEMBL1970422 & 752420 & 6.3468 & 6.6175 & TST \\
\hline CHEMBL 3195455 & 752420 & 5.9355 & 6.3229 & TRN \\
\hline CHEMBL1412002 & 752420 & 6.3325 & 6.9009 & TRN \\
\hline CHEMBL1462373 & 752420 & 2.8752 & 4.0842 & TRN \\
\hline CHEMBL1330793 & 752420 & 7.983 & 7.3467 & TRN \\
\hline CHEMBL528694 & 752420 & 6.1798 & $5.57600 e$ & 00000000005 \\
\hline CHEMBL1479010 & 752420 & 2.8752 & 3.3598 & TST \\
\hline CHEMBL37570 & 752420 & 7.983 & 5.483 & TST \\
\hline CHEMBL353764 & 752420 & 2.8752 & 4.0287 & TST \\
\hline CHEMBL1481347 & 752420 & 6.1512 & 5.9261 & TRN \\
\hline CHEMBL 3196853 & 752420 & 2.8752 & 2.8231 & TRN \\
\hline CHEMBL1457201 & 752420 & 6.2104 & 6.6676 & TRN \\
\hline CHEMBL1430094 & 752420 & 2.8752 & 3.4738 & TRN \\
\hline CHEMBL1373967 & 752420 & 4.8665 & 4.8852 & TRN \\
\hline CHEMBL1301278 & 752420 & 5.6716 & 6.0312 & TRN \\
\hline CHEMBL1301125 & 752420 & 5.9706 & 6.6151 & TRN \\
\hline CHEMBL 3189712 & 752420 & 5.3439 & 5.8649 & TRN \\
\hline CHEMBL1385690 & 752420 & 5.5498 & 5.6425 & TRN \\
\hline CHEMBL1993934 & 752420 & 6.5436 & 5.3039 & TRN \\
\hline CHEMBL1428662 & 752420 & 3.1759 & 3.4611 & TRN \\
\hline CHEMBL1335650 & 752420 & 2.8752 & 3.9735 & TST \\
\hline CHEMBL1337592 & 752420 & 6.9136 & 6.0694 & TRN \\
\hline CHEMBL 3197908 & 752420 & 6.4989 & 5.4495 & TRN \\
\hline CHEMBL1420037 & 752420 & 6.2284 & 6.3597 & TRN \\
\hline CHEMBL1541771 & 752420 & 4.2336 & 2.6887 & TRN \\
\hline CHEMBL1384253 & 752420 & 6.2565 & 6.3022 & TRN \\
\hline CHEMBL1459468 & 752420 & 2.8752 & 4.5636 & TRN \\
\hline CHEMBL1392025 & 752420 & 5.4498 & 5.1312 & TRN \\
\hline CHEMBL598883 & 752420 & 2.8752 & 3.7564 & TRN \\
\hline CHEMBL585591 & 752420 & 7.983 & 6.0411 & TRN \\
\hline CHEMBL 31840 & 752420 & 6.2565 & 7.2695 & TRN \\
\hline CHEMBL581251 & 752420 & 7.983 & 6.7703 & TRN \\
\hline CHEMBL1547706 & 752420 & 6.5784 & 6.7698 & TST \\
\hline CHEMBL1569585 & 752420 & 7.983 & 6.4053 & TST \\
\hline CHEMBL1343823 & 752420 & 6.2464 & 5.8204 & TRN \\
\hline CHEMBL1374860 & 752420 & 5.8697 & 5.5488 & TRN \\
\hline CHEMBL1386058 & 752420 & 5.6003 & 3.6218 & TRN \\
\hline CHEMBL1310861 & 752420 & 6.2899 & 5.2485 & TRN \\
\hline CHEMBL1545422 & 752420 & 2.8752 & 3.8733 & TRN \\
\hline CHEMBL1462938 & 752420 & 2.8752 & 4.4699 & TRN \\
\hline CHEMBL1505813 & 752420 & 6.5031 & 6.3143 & TRN \\
\hline CHEMBL1567944 & 752420 & 8.1175 & 6.9585 & TRN \\
\hline CHEMBL3199403 & 752420 & 6.0273 & 5.2984 & TRN \\
\hline CHEMBL1482663 & 752420 & 5.5346 & 4.9404 & TST \\
\hline CHEMBL589238 & 752420 & 6.2434 & \multicolumn{2}{|c|}{6.013999999999999} \\
\hline CHEMBL1994221 & 752420 & 2.8752 & 3.6431 & TRN \\
\hline CHEMBL1997659 & 752420 & 5.3344 & 5.3934 & TRN \\
\hline
\end{tabular}


Supplemental Table S2.txt

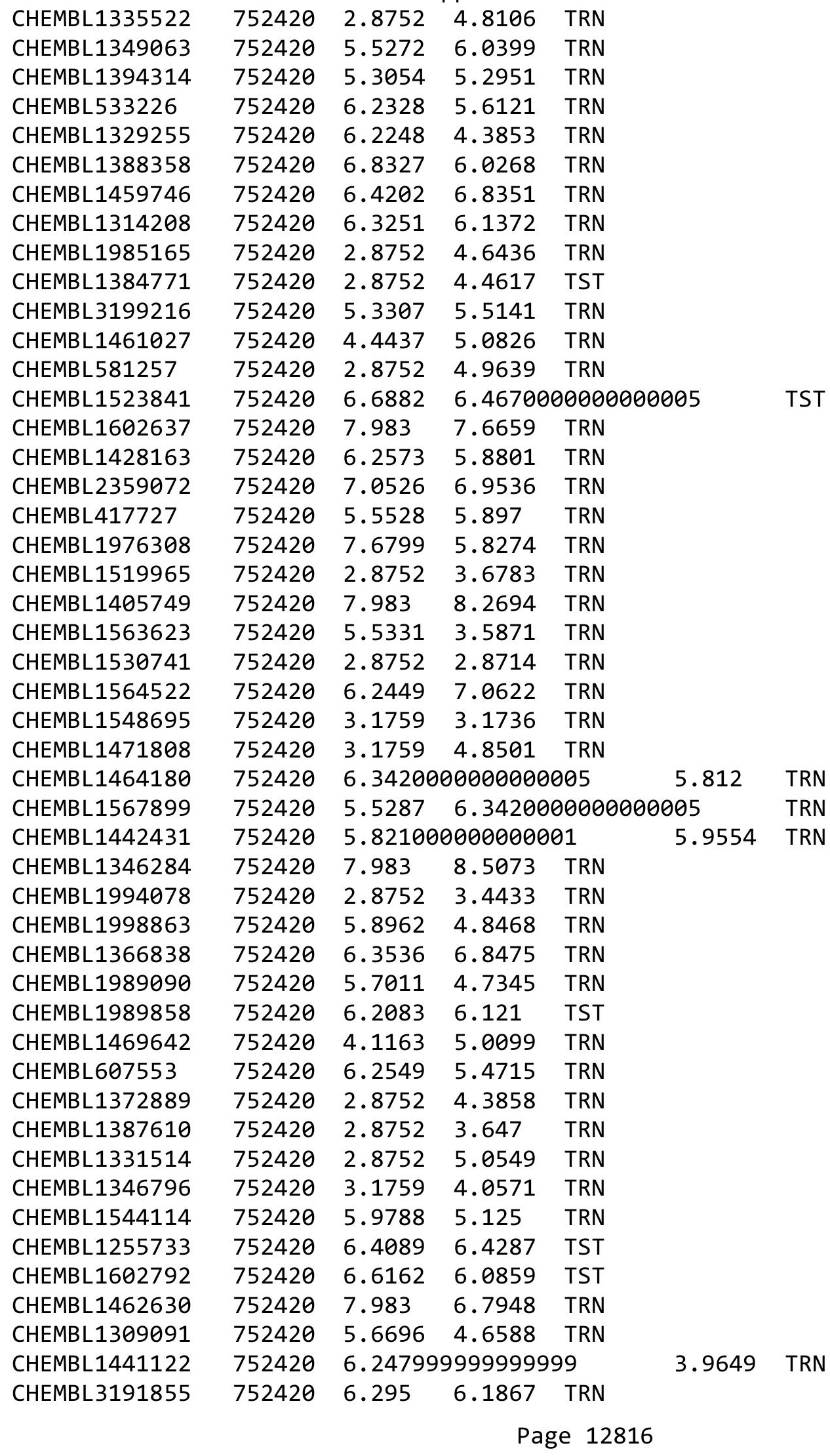


Supplemental Table S2.txt

\begin{tabular}{|c|c|c|c|c|}
\hline CHEMBL583584 & 752420 & 2.8752 & 3.1278 & TRN \\
\hline CHEMBL1321754 & 752420 & 5.2411 & 3.8723 & TRN \\
\hline CHEMBL1539486 & 752420 & 7.983 & 5.9478 & TRN \\
\hline CHEMBL1318350 & 752420 & 6.4318 & 6.1775 & TST \\
\hline CHEMBL1200512 & 752420 & 6.5467 & 6.1036 & TST \\
\hline CHEMBL1603040 & 752420 & 2.8752 & 4.9134 & TST \\
\hline CHEMBL1340089 & 752420 & 6.2749 & 5.2034 & TST \\
\hline CHEMBL578944 & 752420 & 5.6055 & 5.8266 & TST \\
\hline CHEMBL1605299 & 752420 & 3.1759 & 2.927 & TST \\
\hline CHEMBL51931 & 752420 & 5.5622 & 5.9537 & TST \\
\hline CHEMBL 1485562 & 752420 & 2.8752 & 3.7338 & TST \\
\hline CHEMBL1366987 & 752420 & 4.5143 & 4.6213 & TST \\
\hline CHEMBL1301700 & 752420 & 6.2161 & 7.3106 & TST \\
\hline CHEMBL1540682 & 752420 & 6.2495 & 6.86 & TST \\
\hline CHEMBL1345208 & 752420 & 3.1759 & 4.3056 & TST \\
\hline CHEMBL1349146 & 752420 & 5.4647 & 5.2467 & TST \\
\hline CHEMBL 3194449 & 752420 & 6.04 & 5.6036 & TST \\
\hline CHEMBL1492289 & 752420 & 6.2418 & 4.4384 & TST \\
\hline CHEMBL1504701 & 752420 & 6.1385 & 6.2867 & TST \\
\hline CHEMBL1537417 & 752420 & 6.2277 & 5.9577 & TST \\
\hline CHEMBL1383793 & 752420 & 2.8752 & 6.2451 & TST \\
\hline CHEMBL3193835 & 752420 & 5.6234 & 5.0231 & TST \\
\hline CHEMBL1612044 & 752420 & 2.8752 & 4.8123 & TST \\
\hline CHEMBL 3145285 & 752420 & 2.8752 & 5.0524 & TST \\
\hline CHEMBL1316978 & 752420 & 6.5391 & 7.4947 & TST \\
\hline CHEMBL131037 & 752420 & 5.3478 & 6.2998 & TST \\
\hline CHEMBL1330279 & 752420 & 5.6716 & 7.1374 & TST \\
\hline CHEMBL598263 & 752420 & 7.5114 & 6.7082 & TST \\
\hline CHEMBL599098 & 752420 & 5.8633 & 5.3691 & TST \\
\hline CHEMBL1520803 & 752420 & 2.8752 & 4.619 & TST \\
\hline CHEMBL1511371 & 752420 & 6.2441 & 6.2033 & TST \\
\hline CHEMBL1887153 & 752420 & 6.2733 & 4.7813 & TST \\
\hline CHEMBL1572001 & 752420 & 5.9469 & 5.4784 & TST \\
\hline CHEMBL309016 & 752420 & 5.3507 & 4.0568 & TST \\
\hline CHEMBL1514691 & 752420 & 4.8297 & 3.3903 & TST \\
\hline CHEMBL1987461 & 752420 & 6.025 & 4.98 & TST \\
\hline CHEMBL1407996 & 752420 & 2.8752 & 3.6629 & TST \\
\hline CHEMBL1380099 & 752420 & 2.8752 & 4.8352 & TST \\
\hline CHEMBL1566610 & 752420 & 7.2798 & 6.6708 & TST \\
\hline CHEMBL1437888 & 752420 & 5.5436 & 6.1077 & TST \\
\hline CHEMBL1568243 & 752420 & 2.8752 & 3.9853 & TST \\
\hline CHEMBL1322738 & 752420 & 7.983 & 5.3711 & TST \\
\hline CHEMBL1224755 & 752420 & 6.3242 & 6.1878 & TST \\
\hline CHEMBL1613578 & 752420 & 5.9788 & 4.90300 & 00000000005 \\
\hline CHEMBL1573883 & 752420 & 2.8752 & 1.6769 & TST \\
\hline CHEMBL1349455 & 752420 & 6.4214 & 5.8688 & TST \\
\hline CHEMBL1378769 & 752420 & 7.983 & 6.6895 & TST \\
\hline CHEMBL3644989 & 1535400 & 6.1512 & 6.2625 & TRN \\
\hline
\end{tabular}

Page 12817 
Supplemental Table S2.txt

\begin{tabular}{|c|c|c|c|c|}
\hline CHEMBL 3645039 & 1535400 & 6.8757 & 6.4872 & TRN \\
\hline CHEMBL 3639411 & 1535400 & 7.8297 & 7.5491 & TRN \\
\hline CHEMBL 3642403 & 1535400 & 7.421 & 7.4436 & TRN \\
\hline CHEMBL 3642330 & 1535400 & 5.0 & 4.9057 & TRN \\
\hline CHEMBL3642411 & 1535400 & 7.5634 & 7.548999 & 79999999995 \\
\hline CHEMBL 3642369 & 1535400 & 6.5426 & 6.3586 & TRN \\
\hline CHEMBL 3642270 & 1535400 & 6.7375 & 6.9443 & TRN \\
\hline CHEMBL 3642290 & 1535400 & 7.4776 & 7.2954 & TRN \\
\hline CHEMBL 3642335 & 1535400 & 5.0 & 5.5828 & TST \\
\hline CHEMBL 3645038 & 1535400 & 5.843 & 5.7327 & TRN \\
\hline CHEMBL 3642425 & 1535400 & 6.8318 & 7.2695 & TRN \\
\hline CHEMBL 3642373 & 1535400 & 6.46200 & 300000000 & 6.2416 \\
\hline CHEMBL 3642395 & 1535400 & 6.1679 & 6.0494 & TRN \\
\hline CHEMBL 3642261 & 1535400 & 6.3817 & 6.9041 & TRN \\
\hline CHEMBL 3645004 & 1535400 & 5.6287 & 5.8129 & TRN \\
\hline CHEMBL 3642352 & 1535400 & 6.675 & 6.7492 & TRN \\
\hline CHEMBL 3642361 & 1535400 & 7.0115 & 6.5671 & TRN \\
\hline CHEMBL2062806 & 1535400 & 6.8248 & 7.2351 & TRN \\
\hline CHEMBL 3642333 & 1535400 & 6.0302 & 6.1002 & TRN \\
\hline CHEMBL 3642398 & 1535400 & 6.5418 & 6.7658 & TRN \\
\hline CHEMBL 3642351 & 1535400 & 6.4938 & 6.5064 & TRN \\
\hline CHEMBL 3642393 & 1535400 & 5.4976 & 5.7449 & TRN \\
\hline CHEMBL 3645037 & 1535400 & 5.4705 & 6.0117 & TRN \\
\hline CHEMBL 2062811 & 1535400 & 6.6817 & 6.8629 & TRN \\
\hline CHEMBL 3642257 & 1535400 & 6.7587 & 6.7339 & TRN \\
\hline CHEMBL 3642259 & 1535400 & 6.9527 & 6.9588 & TRN \\
\hline CHEMBL 3644988 & 1535400 & 5.0 & 4.7595 & TRN \\
\hline CHEMBL 3642404 & 1535400 & 7.5436 & 7.5137 & TRN \\
\hline CHEMBL 3644986 & 1535400 & 6.376 & 6.2766 & TRN \\
\hline CHEMBL 3645047 & 1535400 & 6.9813 & 6.3969 & TRN \\
\hline CHEMBL 3644969 & 1535400 & 5.0 & 4.8294 & TST \\
\hline CHEMBL 3642386 & 1535400 & 6.0857 & 6.3057 & TRN \\
\hline CHEMBL 3642262 & 1535400 & 7.5719 & 7.5272 & TRN \\
\hline CHEMBL 3645061 & 1535400 & 6.5946 & 6.7832 & TRN \\
\hline CHEMBL 3642349 & 1535400 & 6.621 & 6.5093 & TRN \\
\hline CHEMBL 3642277 & 1535400 & 5.1872 & 5.7324 & TRN \\
\hline CHEMBL 3645022 & 1535400 & 5.0 & 5.2715 & TRN \\
\hline CHEMBL 3645019 & 1535400 & 5.0 & 5.3943 & TRN \\
\hline CHEMBL 2062805 & 1535400 & 7.5129 & 7.2677 & TRN \\
\hline CHEMBL 3645016 & 1535400 & 5.0 & 5.2906 & TRN \\
\hline CHEMBL 3642280 & 1535400 & 7.2495 & 6.8824 & TST \\
\hline CHEMBL 3645059 & 1535400 & 6.5984 & 6.7769 & TRN \\
\hline CHEMBL 3645014 & 1535400 & 6.9216 & 7.1138 & TRN \\
\hline CHEMBL 3644966 & 1535400 & 6.3227 & 6.8627 & TRN \\
\hline CHEMBL 3645042 & 1535400 & 7.4973 & 6.6558 & TRN \\
\hline CHEMBL 3645044 & 1535400 & 5.7897 & 5.6201 & TRN \\
\hline CHEMBL 3644958 & 1535400 & 5.0 & 5.5813 & TST \\
\hline CHEMBL 3645092 & 1535400 & 5.0 & 5.7153 & TRN \\
\hline
\end{tabular}


Supplemental Table S2.txt

\begin{tabular}{|c|c|c|c|c|c|c|}
\hline CHEMBL 3645072 & 1535400 & 6.8436 & 6.9612 & TRN & & \\
\hline CHEMBL 3642282 & 1535400 & 7.2321 & 7.269 & TRN & & \\
\hline CHEMBL 3644974 & 1535400 & 6.3867 & 6.3749 & TRN & & \\
\hline CHEMBL 3642390 & 1535400 & 5.4896 & 5.945 & TRN & & \\
\hline CHEMBL 3645017 & 1535400 & 6.4071 & 6.1075 & TST & & \\
\hline CHEMBL 3642310 & 1535400 & 6.7055 & 6.6049 & TST & & \\
\hline CHEMBL 2062807 & 1535400 & 7.4114 & 7.5417 & TRN & & \\
\hline CHEMBL 3645058 & 1535400 & 5.0 & 5.6435 & TRN & & \\
\hline CHEMBL 3642354 & 1535400 & 7.1028 & 6.5874 & TRN & & \\
\hline CHEMBL 3642384 & 1535400 & 5.4872 & 5.9024 & TST & & \\
\hline CHEMBL 2062797 & 1535400 & 5.0 & 5.3086 & TRN & & \\
\hline CHEMBL 2062800 & 1535400 & 6.2167 & 7.0213 & TRN & & \\
\hline CHEMBL 3642387 & 1535400 & 6.5138 & 6.5573 & TRN & & \\
\hline CHEMBL 3642348 & 1535400 & 6.8512 & 6.6303 & TRN & & \\
\hline CHEMBL 3645010 & 1535400 & 6.2408 & 5.9742 & TRN & & \\
\hline CHEMBL 3642424 & 1535400 & 6.8597 & 7.3082 & TRN & & \\
\hline CHEMBL 3644957 & 1535400 & 7.0003 & 7.1186 & TRN & & \\
\hline CHEMBL 3642368 & 1535400 & 7.3663 & 7.3099 & TRN & & \\
\hline CHEMBL 3644964 & 1535400 & 6.7125 & 6.7051 & TRN & & \\
\hline CHEMBL 3644984 & 1535400 & 6.6518 & 6.4115 & TST & & \\
\hline CHEMBL 3642346 & 1535400 & 6.07799 & 999999999 & 99 & 6.3421 & TRN \\
\hline CHEMBL 3645023 & 1535400 & 5.0 & 5.348 & TRN & & \\
\hline CHEMBL 3645091 & 1535400 & 5.0 & 5.8491 & TRN & & \\
\hline CHEMBL 3642392 & 1535400 & 6.2663 & 6.1205 & TRN & & \\
\hline CHEMBL 3642383 & 1535400 & 5.1872 & 5.614 & TRN & & \\
\hline CHEMBL 3645062 & 1535400 & 6.6602 & 6.7608 & TRN & & \\
\hline CHEMBL 3642300 & 1535400 & 6.2132 & 6.2412 & TRN & & \\
\hline CHEMBL 3642385 & 1535400 & \multicolumn{3}{|c|}{6.343999999999999} & 6.4303 & TRN \\
\hline CHEMBL 3642322 & 1535400 & 7.1555 & 7.2223 & TST & & \\
\hline CHEMBL 3645025 & 1535400 & 5.0 & 5.2026 & TRN & & \\
\hline CHEMBL 3645056 & 1535400 & 6.6951 & 6.204 & TRN & & \\
\hline CHEMBL 3642252 & 1535400 & 5.523 & 5.3561 & TST & & \\
\hline CHEMBL 3644990 & 1535400 & 5.9823 & 6.1421 & TST & & \\
\hline CHEMBL3642281 & 1535400 & 7.1701 & 7.3596 & TRN & & \\
\hline CHEMBL 3645079 & 1535400 & 6.0798 & 5.9384 & TRN & & \\
\hline CHEMBL 3642409 & 1535400 & 7.2252 & 7.3647 & TRN & & \\
\hline CHEMBL 3642309 & 1535400 & 7.279 & 7.046 & TST & & \\
\hline CHEMBL 3645052 & 1535400 & 6.3819 & 6.1355 & TRN & & \\
\hline CHEMBL3645024 & 1535400 & 6.4657 & 6.297000 & 0000000001 & & TRN \\
\hline CHEMBL 3644991 & 1535400 & 6.0937 & 6.0877 & TST & & \\
\hline CHEMBL 3642289 & 1535400 & 7.3726 & 7.221 & TRN & & \\
\hline CHEMBL 3645075 & 1535400 & 5.0 & 5.7841 & TRN & & \\
\hline CHEMBL 3642301 & 1535400 & 5.0 & 5.0345 & TRN & & \\
\hline CHEMBL 3642325 & 1535400 & 5.0 & 4.7117 & TST & & \\
\hline CHEMBL 3642405 & 1535400 & 7.6946 & 7.6635 & TRN & & \\
\hline CHEMBL 3642357 & 1535400 & 6.5623 & 6.4036 & TRN & & \\
\hline CHEMBL 3642394 & 1535400 & 5.9313 & 6.0082 & TRN & & \\
\hline CHEMBL 3642353 & 1535400 & 6.0809 & 5.6831 & TRN & & \\
\hline
\end{tabular}

Page 12819 


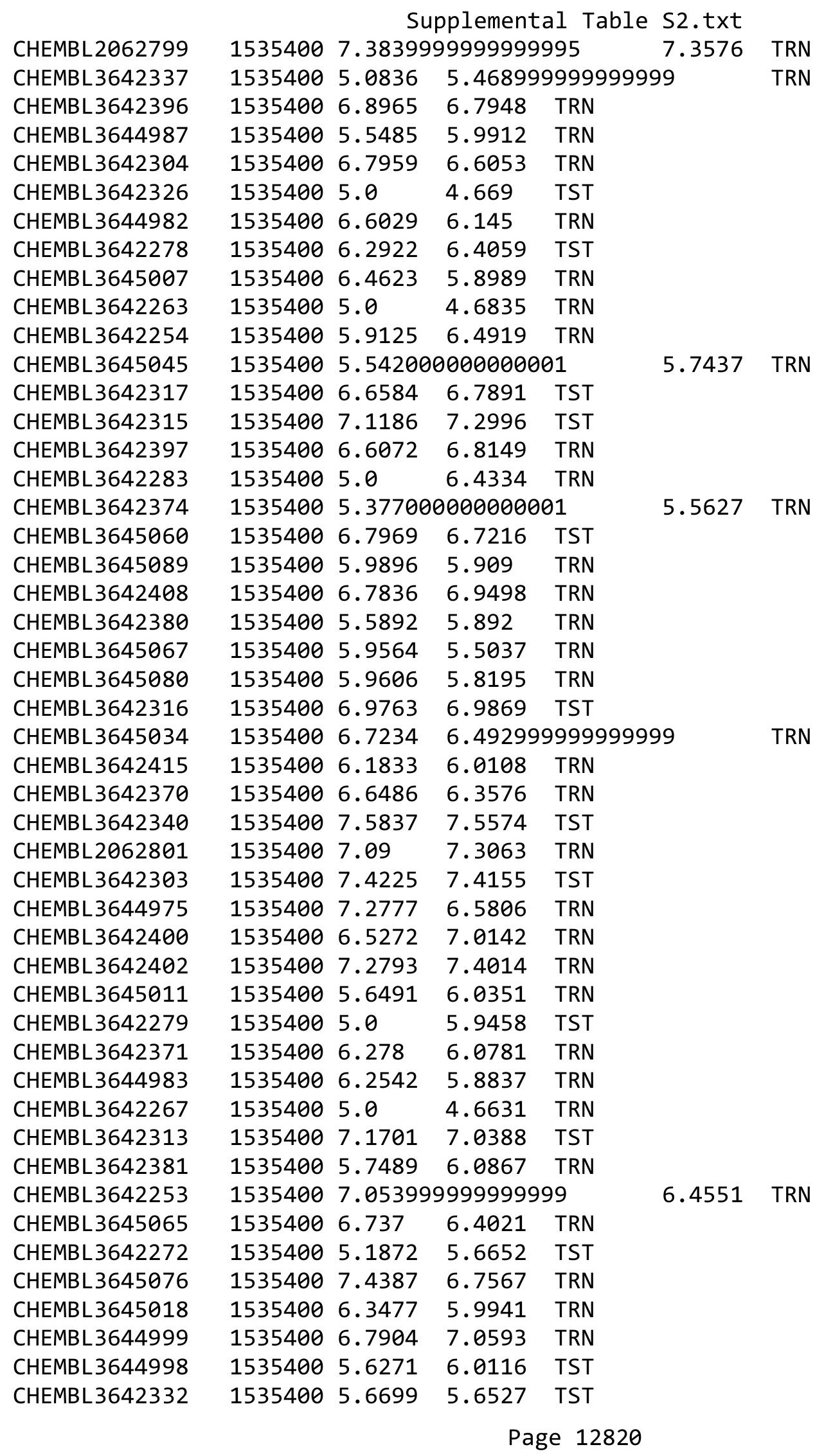


Supplemental Table S2.txt

\begin{tabular}{|c|c|c|c|c|c|}
\hline CHEMBL3645013 & 1535400 & 5.0 & 4.9548 & TST & \\
\hline CHEMBL3642251 & 1535400 & 5.0 & 5.0175 & TST & \\
\hline CHEMBL3644980 & 1535400 & 5.0 & 5.2557 & TST & \\
\hline CHEMBL 3642382 & 1535400 & 5.8401 & 6.0584 & TRN & \\
\hline CHEMBL3642388 & 1535400 & 6.9595 & 6.5664 & TRN & \\
\hline CHEMBL3645026 & 1535400 & 6.6442 & 6.4697 & TST & \\
\hline CHEMBL3644956 & 1535400 & 5.523 & 6.7999 & TRN & \\
\hline CHEMBL3644976 & 1535400 & 6.4657 & 6.2367 & TRN & \\
\hline CHEMBL 3645036 & 1535400 & 5.9529 & 5.8804 & TRN & \\
\hline CHEMBL3642379 & 1535400 & 6.2392 & 6.2928 & TRN & \\
\hline CHEMBL3645009 & 1535400 & 5.0 & 5.2449 & TRN & \\
\hline CHEMBL 3642323 & 1535400 & 6.1433 & \multicolumn{2}{|c|}{6.8839999999999995} & TST \\
\hline CHEMBL 3644971 & 1535400 & 6.7778 & \multicolumn{2}{|c|}{6.122000000000001} & TRN \\
\hline CHEMBL 3642269 & 1535400 & 5.0 & \multicolumn{2}{|c|}{6.742000000000001} & TRN \\
\hline CHEMBL3645055 & 1535400 & 6.2726 & 6.2115 & TRN & \\
\hline CHEMBL 2414545 & 1535400 & 6.8604 & 6.7432 & TST & \\
\hline CHEMBL3645053 & 1535400 & 5.1872 & 5.2961 & TRN & \\
\hline CHEMBL3642292 & 1535400 & 6.6582 & 6.3161 & TRN & \\
\hline CHEMBL 3642355 & 1535400 & 6.5736 & 6.3803 & TRN & \\
\hline CHEMBL3645070 & 1535400 & 5.523 & 6.0713 & TRN & \\
\hline CHEMBL3645054 & 1535400 & 6.1707 & 6.2454 & TRN & \\
\hline CHEMBL3645043 & 1535400 & 5.4884 & 5.4932 & TRN & \\
\hline CHEMBL3642341 & 1535400 & 7.2818 & 7.4617 & TST & \\
\hline CHEMBL 3644972 & 1535400 & 6.8751 & 6.3121 & TRN & \\
\hline CHEMBL3645064 & 1535400 & 5.7827 & 5.4044 & TRN & \\
\hline CHEMBL3642266 & 1535400 & 5.0 & 4.7055 & TRN & \\
\hline CHEMBL3642293 & 1535400 & 7.0487 & 6.99 & TRN & \\
\hline CHEMBL3642407 & 1535400 & 7.1479 & 7.294 & TRN & \\
\hline CHEMBL 2062798 & 1535400 & 7.2161 & 7.271 & TRN & \\
\hline CHEMBL 3642291 & 1535400 & 6.9978 & 6.3651 & TRN & \\
\hline CHEMBL3642339 & 1535400 & 7.519 & \multicolumn{2}{|c|}{7.553999999999999} & TRN \\
\hline CHEMBL3642389 & 1535400 & 7.1104 & 7.4312 & TRN & \\
\hline CHEMBL 2062809 & 1535400 & 7.2832 & 7.5211 & TRN & \\
\hline CHEMBL3644965 & 1535400 & 5.0 & 5.3103 & TRN & \\
\hline CHEMBL3642305 & 1535400 & 7.1487 & 7.1304 & TST & \\
\hline CHEMBL3645015 & 1535400 & 7.3368 & 7.1972 & TRN & \\
\hline CHEMBL 2062812 & 1535400 & 6.3062 & 6.5919 & TRN & \\
\hline CHEMBL3645069 & 1535400 & 6.9076 & 6.3148 & TRN & \\
\hline CHEMBL3642294 & 1535400 & 6.6847 & 6.9013 & TRN & \\
\hline CHEMBL 3642298 & 1535400 & 5.1872 & 5.5906 & TRN & \\
\hline CHEMBL3645040 & 1535400 & 6.8236 & 6.5142 & TRN & \\
\hline CHEMBL3645006 & 1535400 & 5.8709 & 5.8158 & TST & \\
\hline CHEMBL3645094 & 1535400 & 6.811 & 6.471 & TRN & \\
\hline CHEMBL 3645041 & 1535400 & 6.5342 & 6.3464 & TRN & \\
\hline CHEMBL 3642416 & 1535400 & 6.8704 & 6.4517 & TRN & \\
\hline CHEMBL3642273 & 1535400 & 5.822 & \multicolumn{2}{|c|}{6.117000000000001} & TST \\
\hline CHEMBL3645012 & 1535400 & 5.0 & 5.3873 & TRN & \\
\hline CHEMBL 2062804 & 1535400 & 7.0721 & 7.3425 & TRN & \\
\hline
\end{tabular}

Page 12821 
Supplemental Table S2.txt

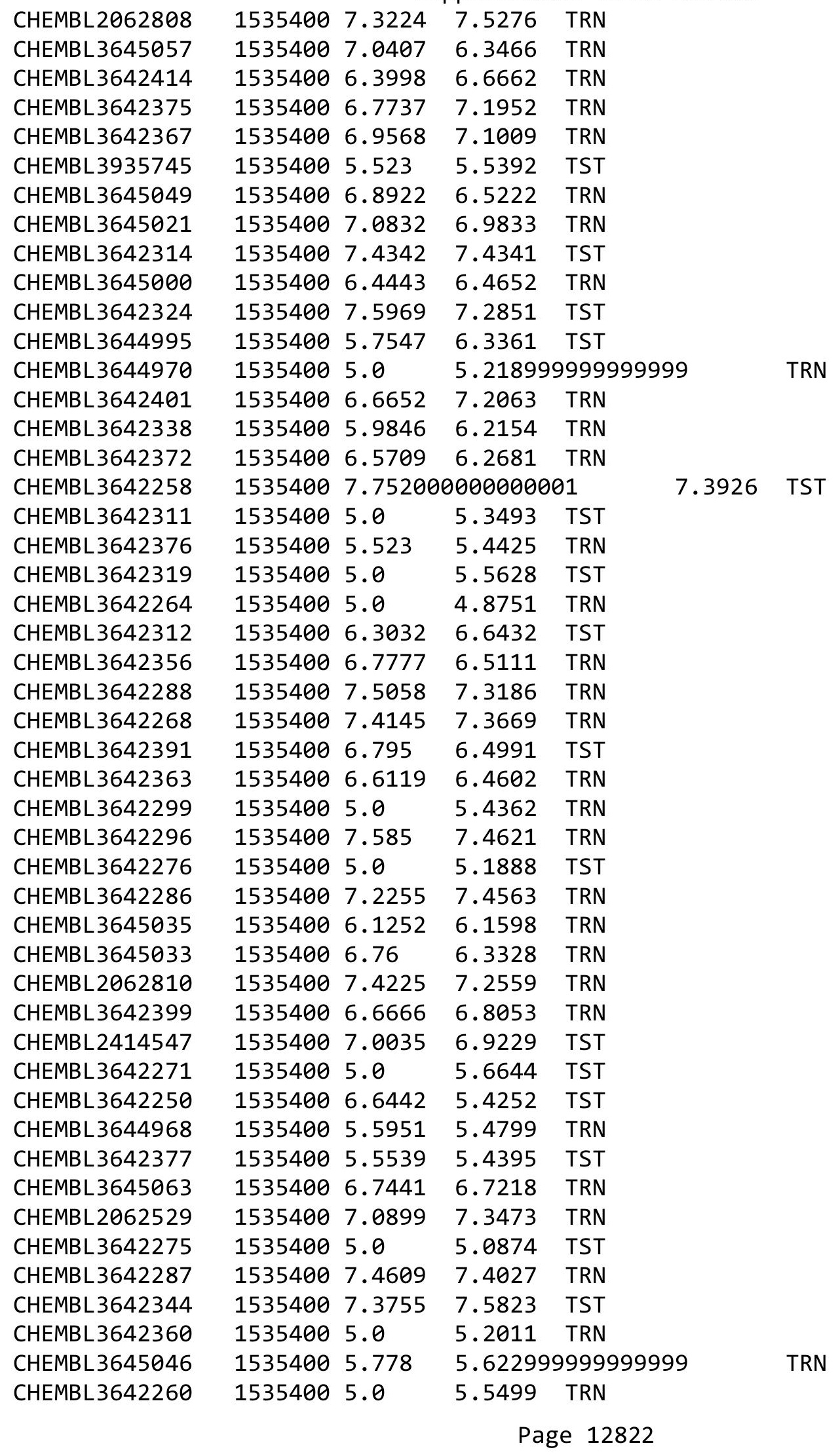


Supplemental Table S2.txt

\begin{tabular}{|c|c|c|c|c|}
\hline HEN & & 6.7127 & & \\
\hline & & 6.0363 & & \\
\hline$\partial 8$ & & & & \\
\hline AEMBL & & & 747 & \\
\hline AEMBL3 & 35400 & 6.7336 & 2754 & \\
\hline HEMBL3642412 & 535400 & 7.8784 & 6306 & \\
\hline 106 & & 636 & 319 & \\
\hline 336 & & & & \\
\hline HEMBL36 & 400 & & 8851 & \\
\hline HEMBL 364 & 535400 & 5.0 & 4257 & \\
\hline AEMBL364 & 535 & 7.08 & 365 & \\
\hline IEMBL3 & 0 & & & \\
\hline AEMBL & & & & \\
\hline HEMBL36 & 00 & 7. & 7873 & \\
\hline AEMBL36 & $\partial 0$ & 5 . & & \\
\hline AEMBL36 & 0 & 7. & 1916 & \\
\hline HEMBL36 & & 5. & 371 & \\
\hline HEMBL 3 & & & & \\
\hline HEMBL3E & & & 3303 & \\
\hline AEMBL2C & & & & \\
\hline HEMBL= & 30 & & & \\
\hline HEMBL3 & & & & וד \\
\hline HEMBL 2 & & & & \\
\hline 971 & & & & \\
\hline AEMBL36 & & & & I NIV \\
\hline HEMBL3 & $\theta$ & 7. & & | \\
\hline HEMBL; & & & & RN \\
\hline HFMBI : & & & & \\
\hline HEMBL36 & & & & 15 15 \\
\hline HEMBL 36 & & & & IK \\
\hline HEMBL3 & 30 & & 13 & RN \\
\hline AFMB : & 0 & & & RN \\
\hline HEMBL3 & 0 & 6 & & ST \\
\hline HEMBL36 & & 5 & 392 & IS \\
\hline HEMBL 364 & 0 & 7. & 569 & TR \\
\hline HEMBL3 & 5400 & & 54 & I NIV \\
\hline HFMRI & & 7. & & ST \\
\hline HEMBL & & 5 . & & IRN \\
\hline HEMBL 364 & 535400 & 6. & 961 & TST \\
\hline AEMBL36 & $\theta 0$ & & & TST \\
\hline HEMBL3 & $\partial 0$ & & 72 & \\
\hline CHEMBL 3 & & & & RIV \\
\hline HEMBL36 & 535400 & & 6.2841 & TST \\
\hline HEMBL 36 & 535400 & 6.2 & & TRN \\
\hline - & & & & RN \\
\hline HEMBL36 & & 27 & & \\
\hline HEMBL 36 & & .2882 & .4478 & \\
\hline HEMBL3642331 & 1535400 & 5.4634 & 5.2597 & ГRN \\
\hline
\end{tabular}

Page 12823 


$$
\text { Supplemental Table S2.txt }
$$

\begin{tabular}{|c|c|c|c|c|c|}
\hline CHEMBL 3642350 & 1535400 & 6.7618 & 6.6894 & TRN & \\
\hline CHEMBL3639439 & 1535400 & 5.523 & 5.2445 & TRN & \\
\hline CHEMBL3642307 & 1535400 & 5.0 & 5.2381 & TST & \\
\hline CHEMBL3642329 & 1535400 & 5.0 & 4.9041 & TRN & \\
\hline CHEMBL3644961 & 1535400 & 7.225 & 7.407999 & 99999999995 & TRN \\
\hline CHEMBL 3642284 & 1535400 & 6.9519 & 6.3132 & TRN & \\
\hline CHEMBL3644992 & 1535400 & 6.0986 & 6.1974 & TST & \\
\hline CHEMBL3639412 & 1535400 & 5.523 & 5.7552 & TRN & \\
\hline CHEMBL 2062803 & 1535400 & 7.6478 & 7.5077 & TRN & \\
\hline CHEMBL3642378 & 1535400 & 6.3905 & 6.362999 & 99999999995 & TRN \\
\hline CHEMBL3645078 & 1535400 & 7.0503 & 6.88 & TRN & \\
\hline CHEMBL3642343 & 1535400 & 7.9582 & 7.6481 & TRN & \\
\hline CHEMBL3644996 & 1535400 & 5.0 & 5.7142 & TST & \\
\hline CHEMBL3644959 & 1535400 & 5.523 & 5.3062 & TRN & \\
\hline CHEMBL3645048 & 1535400 & 7.0315 & 6.5262 & TRN & \\
\hline CHEMBL3642297 & 1535400 & 7.1555 & 6.9506 & TRN & \\
\hline CHEMBL3644985 & 1535400 & 6.4555 & 6.307 & TST & \\
\hline CHEMBL 3645118 & 1535400 & 7.2376 & 7.3002 & TST & \\
\hline CHEMBL3642334 & 1535400 & 5.0 & 5.9012 & TST & \\
\hline CHEMBL3644993 & 1535400 & 5.7754 & 6.0176 & TST & \\
\hline CHEMBL3642327 & 1535400 & 5.0 & 4.7924 & TST & \\
\hline CHEMBL 3645020 & 1535400 & 6.8155 & 6.8631 & TRN & \\
\hline CHEMBL3645074 & 1535400 & 7.2361 & 6.5994 & TST & \\
\hline CHEMBL3645005 & 1535400 & 5.7734 & 5.8621 & TST & \\
\hline CHEMBL3645001 & 1535400 & 5.0 & 5.3497 & TST & \\
\hline CHEMBL3642362 & 1535400 & 6.7335 & 6.2908 & TRN & \\
\hline CHEMBL3642413 & 1535400 & 6.2612 & 6.4884 & TRN & \\
\hline CHEMBL522262 & 563052 & 6.5086 & 6.3141 & TST & \\
\hline CHEMBL489450 & 563052 & 5.5086 & 6.1389 & TST & \\
\hline CHEMBL515641 & 563052 & 6.7696 & 5.8963 & TRN & \\
\hline CHEMBL514068 & 563052 & 7.7959 & 7.1145 & TRN & \\
\hline CHEMBL489645 & 563052 & 5.3279 & 6.2364 & TST & \\
\hline CHEMBL489031 & 563052 & 7.585 & 7.197 & TRN & \\
\hline CHEMBL489852 & 563052 & 6.5376 & 6.7877 & TST & \\
\hline CHEMBL477864 & 563052 & 5.1938 & 5.5526 & TRN & \\
\hline CHEMBL478696 & 563052 & 8.301 & 7.7371 & TRN & \\
\hline CHEMBL487708 & 563052 & 9.5229 & 8.5019 & TRN & \\
\hline CHEMBL520078 & 563052 & 6.699 & \multicolumn{2}{|c|}{8.283999999999999} & TRN \\
\hline CHEMBL517354 & 563052 & 5.0132 & 5.6516 & TRN & \\
\hline CHEMBL487912 & 563052 & 7.699 & 8.2913 & TRN & \\
\hline CHEMBL521596 & 563052 & 4.0 & 7.6385 & TST & \\
\hline CHEMBL489429 & 563052 & 6.3768 & 5.5948 & TRN & \\
\hline CHEMBL528997 & 563052 & 8.5229 & 8.4344 & TRN & \\
\hline CHEMBL490043 & 563052 & 6.699 & 6.1402 & TRN & \\
\hline CHEMBL485860 & 563052 & 8.699 & 8.3443 & TRN & \\
\hline CHEMBL522602 & 563052 & 6.6383 & 6.2827 & TST & \\
\hline CHEMBL476254 & 563052 & 8.2218 & 7.6874 & TRN & \\
\hline CHEMBL514697 & 563052 & 6.3279 & 6.751 & TRN & \\
\hline
\end{tabular}




\begin{tabular}{|c|c|c|c|c|c|}
\hline \multirow[b]{2}{*}{ CHEMBL488932 } & \multicolumn{5}{|c|}{ Supplemental Table S2.txt } \\
\hline & 563052 & 8.0969 & 8.2546 & TRN & \\
\hline CHEMBL488324 & 563052 & 6.3979 & 8.2499 & TRN & \\
\hline CHEMBL521163 & 563052 & 4.0 & 7.1842 & TST & \\
\hline CHEMBL529214 & 563052 & 8.0 & 8.2842 & TRN & \\
\hline CHEMBL477865 & 563052 & 5.0132 & 5.6665 & TRN & \\
\hline CHEMBL490023 & 563052 & 6.0969 & 5.6518 & TRN & \\
\hline CHEMBL516900 & 563052 & 8.9208 & 7.8209 & TRN & \\
\hline CHEMBL504182 & 563052 & 5.5528 & 6.1943 & TST & \\
\hline CHEMBL487090 & 563052 & 9.1549 & 8.2829 & TRN & \\
\hline CHEMBL487294 & 563052 & 8.1549 & 8.3704 & TRN & \\
\hline CHEMBL520543 & 563052 & 8.8239 & 8.2665 & TRN & \\
\hline CHEMBL478066 & 563052 & 5.0132 & 5.6257 & TRN & \\
\hline CHEMBL490859 & 563052 & 9.301 & 8.1479 & TRN & \\
\hline CHEMBL488731 & 563052 & 8.0969 & 8.3887 & TRN & \\
\hline CHEMBL487500 & 563052 & 9.5229 & 8.2686 & TRN & \\
\hline CHEMBL445204 & 563052 & 6.1079 & 5.5916 & TRN & \\
\hline CHEMBL522945 & 563052 & 4.0 & 7.6117 & TST & \\
\hline CHEMBL489425 & 563052 & 6.585 & 7.0916 & TRN & \\
\hline CHEMBL519389 & 563052 & 8.301 & 8.0963 & TRN & \\
\hline CHEMBL523100 & 563052 & 7.0223 & 5.9781 & TST & \\
\hline CHEMBL477964 & 563052 & 5.4559 & 5.569 & TST & \\
\hline CHEMBL477867 & 563052 & 5.3768 & 7.1614 & TST & \\
\hline CHEMBL523603 & 563052 & 5.0458 & 6.32100 & 0000000001 & TST \\
\hline CHEMBL490024 & 563052 & 6.6576 & 6.1264 & TST & \\
\hline CHEMBL477878 & 563052 & 5.5229 & 5.8961 & TRN & \\
\hline CHEMBL522930 & 563052 & 6.3979 & 5.9679 & TST & \\
\hline CHEMBL488109 & 563052 & 7.0 & 8.329 & TRN & \\
\hline CHEMBL529213 & 563052 & 9.699 & 8.3799 & TRN & \\
\hline CHEMBL477267 & 563052 & 6.8239 & 6.9277 & TRN & \\
\hline CHEMBL476253 & 563052 & 8.301 & 7.5721 & TRN & \\
\hline CHEMBL523300 & 563052 & 9.5229 & 8.3272 & TRN & \\
\hline CHEMBL522114 & 563052 & 7.2366 & 7.8271 & TRN & \\
\hline CHEMBL525204 & 563052 & 6.1549 & 6.4241 & TST & \\
\hline CHEMBL489438 & 563052 & 9.301 & 8.1581 & TRN & \\
\hline CHEMBL487091 & 563052 & 9.2218 & 8.2692 & TRN & \\
\hline CHEMBL490027 & 563052 & 8.0969 & 8.0934 & TRN & \\
\hline CHEMBL522115 & 563052 & 8.2218 & 8.1045 & TRN & \\
\hline CHEMBL490026 & 563052 & 8.3979 & 8.1284 & TRN & \\
\hline CHEMBL487499 & 563052 & 7.301 & 8.3682 & TRN & \\
\hline CHEMBL488535 & 563052 & 6.3979 & 8.1596 & TRN & \\
\hline CHEMBL484478 & 563052 & 4.0 & 6.2268 & TST & \\
\hline CHEMBL488730 & 563052 & 8.0 & 8.2312 & TRN & \\
\hline CHEMBL489644 & 563052 & 4.0 & 7.6756 & TRN & \\
\hline CHEMBL519252 & 563052 & 8.0458 & 8.421 & TRN & \\
\hline CHEMBL3959290 & 1642407 & 5.308 & 4.5395 & TST & \\
\hline CHEMBL3927229 & 1642407 & 4.0 & 4.4545 & TST & \\
\hline CHEMBL 3927803 & 1642407 & 5.6672 & 5.6203 & TRN & \\
\hline CHEMBL3921678 & 1642407 & 6.1805 & 6.1747 & TRN & \\
\hline
\end{tabular}

Page 12825 
Supplemental Table S2.txt

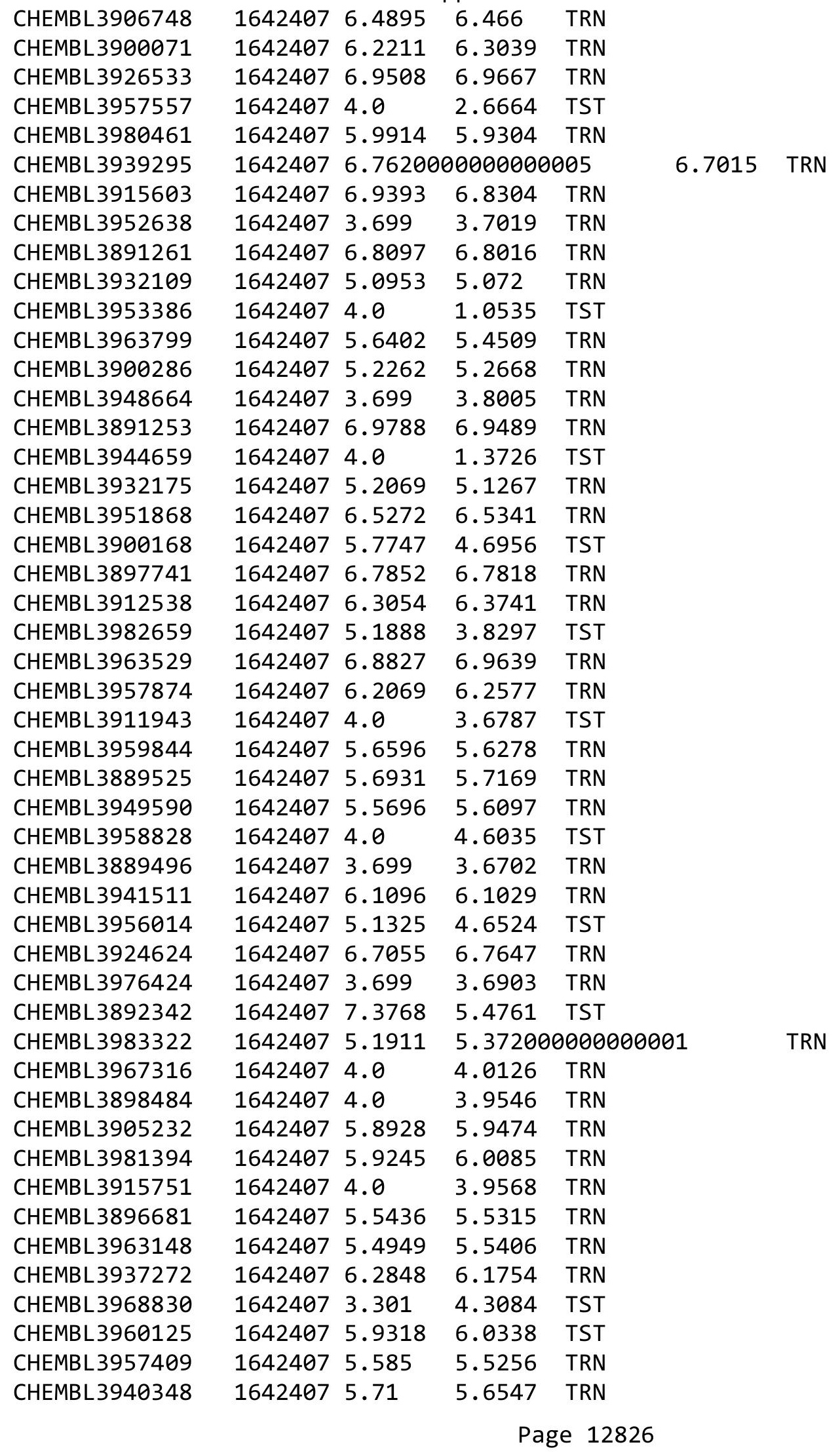


Supplemental Table S2.txt

\begin{tabular}{|c|c|c|c|c|c|c|}
\hline CHEMBL3967008 & 1642407 & 5.4547 & 5.4441 & TRN & & \\
\hline CHEMBL3913504 & 1642407 & 5.1135 & 5.1662 & TRN & & \\
\hline CHEMBL3948944 & 1642407 & 4.0 & 3.7184 & TST & & \\
\hline CHEMBL 3937344 & 1642407 & 5.9872 & 6.0858 & TRN & & \\
\hline CHEMBL3968033 & 1642407 & 5.4101 & 5.4097 & TRN & & \\
\hline CHEMBL3914013 & 1642407 & 4.0 & 4.0203 & TRN & & \\
\hline CHEMBL3910442 & 1642407 & 4.0 & 4.1563 & TST & & \\
\hline CHEMBL3953646 & 1642407 & 6.6498 & 6.5782 & TRN & & \\
\hline CHEMBL 3922336 & 1642407 & 6.1427 & 5.3131 & TST & & \\
\hline CHEMBL201734 & 327343 & 5.6091 & 5.5476 & TRN & & \\
\hline CHEMBL199556 & 327343 & 5.4855 & 5.5141 & TRN & & \\
\hline CHEMBL413570 & 327343 & 5.4815 & 5.4673 & TRN & & \\
\hline CHEMBL201345 & 327343 & 5.7282 & 5.7646 & TRN & & \\
\hline CHEMBL382849 & 327343 & 5.7496 & 5.6907 & TRN & & \\
\hline CHEMBL440759 & 327343 & 5.4976 & 5.54299 & 9999999999 & & TRN \\
\hline CHEMBL380657 & 327343 & 5.6253 & 5.7538 & TRN & & \\
\hline CHEMBL197594 & 327343 & 4.2855 & 4.2994 & TRN & & \\
\hline CHEMBL437511 & 327343 & 4.5588 & 4.6336 & TRN & & \\
\hline CHEMBL202664 & 327343 & 5.4895 & 5.5641 & TRN & & \\
\hline CHEMBL199889 & 327343 & 5.4023 & 5.3858 & TRN & & \\
\hline CHEMBL201487 & 327343 & 5.8665 & 5.8626 & TRN & & \\
\hline CHEMBL383534 & 327343 & 4.5293 & 4.5007 & TRN & & \\
\hline CHEMBL380413 & 327343 & 3.2411 & 4.1101 & TST & & \\
\hline CHEMBL201704 & 327343 & 5.7235 & 5.70299 & 9999999999 & & TRN \\
\hline CHEMBL202975 & 327343 & 5.4377 & 5.3989 & TRN & & \\
\hline CHEMBL 201380 & 327343 & 6.4437 & 6.4997 & TRN & & \\
\hline CHEMBL382137 & 327343 & 6.0269 & 6.0201 & TRN & & \\
\hline CHEMBL 202978 & 327343 & 5.9706 & 5.9413 & TRN & & \\
\hline CHEMBL202976 & 327343 & 5.4112 & 5.3883 & TRN & & \\
\hline CHEMBL381737 & 327343 & 5.213999 & 99999999 & 995 & 5.1909 & TRN \\
\hline CHEMBL 383494 & 327343 & 3.2291 & 4.4931 & TST & & \\
\hline CHEMBL 2448545 & 327343 & 5.617999 & 99999999 & 99 & 4.9011 & TST \\
\hline CHEMBL201579 & 327343 & 4.3627 & 4.3993 & TRN & & \\
\hline CHEMBL201637 & 327343 & 4.6207 & 4.9421 & TST & & \\
\hline CHEMBL201238 & 327343 & 5.9788 & 5.9829 & TRN & & \\
\hline CHEMBL201682 & 327343 & 4.2182 & 4.1834 & TRN & & \\
\hline CHEMBL437138 & 327343 & 5.3019 & 5.2363 & TRN & & \\
\hline CHEMBL380823 & 327343 & 6.3098 & 6.3701 & TRN & & \\
\hline CHEMBL 201590 & 327343 & 5.7986 & 5.6938 & TRN & & \\
\hline CHEMBL201545 & 327343 & 5.4737 & 5.4785 & TRN & & \\
\hline CHEMBL 203140 & 327343 & 5.762006 & 000000006 & 205 & 5.2366 & TST \\
\hline CHEMBL370376 & 327343 & 5.3645 & 5.4526 & TRN & & \\
\hline CHEMBL369978 & 327343 & 5.6003 & 5.5564 & TRN & & \\
\hline CHEMBL 201134 & 327343 & 5.5719 & 5.5246 & TRN & & \\
\hline CHEMBL202778 & 327343 & 5.5045 & 5.5202 & TRN & & \\
\hline CHEMBL198407 & 327343 & 5.5607 & 5.6737 & TRN & & \\
\hline CHEMBL199942 & 327343 & 5.4737 & 5.5267 & TRN & & \\
\hline CHEMBL 377948 & 327343 & 5.5498 & 5.4871 & TRN & & \\
\hline
\end{tabular}




\begin{tabular}{|c|c|c|c|c|c|c|}
\hline \multicolumn{7}{|c|}{ Supplemental Table S2.txt } \\
\hline CHEMBL199604 & 327343 & 6.0969 & 6.0836 & TRN & & \\
\hline CHEMBL383649 & 327343 & 5.7033 & 5.7097 & TRN & & \\
\hline CHEMBL 201356 & 327343 & 5.6234 & 5.6035 & TRN & & \\
\hline CHEMBL 201078 & 327343 & 5.45100 & 20000000 & 005 & 5.5419 & TRN \\
\hline CHEMBL199953 & 327343 & 5.9245 & 5.9204 & TRN & & \\
\hline CHEMBL 200132 & 327343 & 6.3468 & 6.1952 & TRN & & \\
\hline CHEMBL 382802 & 327343 & 5.4202 & 5.3615 & TRN & & \\
\hline CHEMBL381989 & 327343 & 5.4318 & 5.34 & TST & & \\
\hline CHEMBL 201319 & 327343 & 5.5157 & 5.4682 & TST & & \\
\hline CHEMBL199601 & 327343 & 6.1739 & 6.1026 & TST & & \\
\hline CHEMBL 201503 & 327343 & 3.2596 & 3.5149 & TST & & \\
\hline CHEMBL199332 & 327343 & 5.8827 & 5.7977 & TST & & \\
\hline CHEMBL 202379 & 327343 & 5.5072 & 5.4402 & TST & & \\
\hline CHEMBL 381044 & 327343 & 5.6383 & 5.5891 & TST & & \\
\hline CHEMBL380751 & 327343 & 5.6576 & 5.6408 & TST & & \\
\hline CHEMBL383608 & 327343 & 5.8125 & 5.739 & TST & & \\
\hline CHEMBL515416 & 954551 & 3.9776 & 3.8645 & TRN & & \\
\hline CHEMBL449158 & 954551 & 6.2813 & 5.7826 & TST & & \\
\hline CHEMBL1404918 & 954551 & 3.3489 & 3.0031 & TRN & & \\
\hline CHEMBL221137 & 954551 & 3.2905 & 3.7876 & TST & & \\
\hline CHEMBL 3186408 & 954551 & 3.2289 & 3.2225 & TST & & \\
\hline CHEMBL1357247 & 954551 & 2.4771 & 2.4089 & TRN & & \\
\hline CHEMBL512504 & 954551 & 5.5832 & 5.9979 & TRN & & \\
\hline CHEMBL 222102 & 954551 & 4.0825 & 3.8879 & TRN & & \\
\hline CHEMBL3349342 & 954551 & 3.9984 & 3.8165 & TRN & & \\
\hline CHEMBL472940 & 954551 & 2.4904 & 2.3959 & TRN & & \\
\hline CHEMBL 3392440 & 954551 & 3.7216 & 3.6974 & TRN & & \\
\hline CHEMBL102714 & 954551 & 4.4595 & 4.2653 & TRN & & \\
\hline CHEMBL191334 & 954551 & 4.6658 & 4.55399 & 9999 & 99 & TRN \\
\hline CHEMBL1643959 & 954551 & 3.21199 & 99999999 & 997 & 3.0728 & TRN \\
\hline CHEMBL 259181 & 954551 & 2.7653 & 2.9257 & TRN & & \\
\hline CHEMBL 3199475 & 954551 & 3.5051 & 3.4579 & TRN & & \\
\hline CHEMBL412142 & 954551 & 4.1203 & 4.2053 & TRN & & \\
\hline CHEMBL1590308 & 954551 & 3.8323 & 3.0836 & TST & & \\
\hline CHEMBL392695 & 954551 & 3.1461 & 3.139 & TRN & & \\
\hline CHEMBL189584 & 954551 & 4.7517 & 4.8437 & TRN & & \\
\hline CHEMBL1256459 & 954551 & 5.7828 & 5.8444 & TRN & & \\
\hline CHEMBL1190711 & 954551 & 4.7524 & 4.6598 & TRN & & \\
\hline CHEMBL 379300 & 954551 & 4.3829 & 4.6282 & TRN & & \\
\hline CHEMBL92309 & 954551 & 2.6246 & 2.1543 & TST & & \\
\hline CHEMBL1788116 & 954551 & 2.9485 & 2.9408 & TRN & & \\
\hline CHEMBL585951 & 954551 & 5.8758 & 5.5777 & TRN & & \\
\hline CHEMBL509032 & 954551 & 3.912 & 3.6408 & TRN & & \\
\hline CHEMBL 373751 & 954551 & 3.3883 & 3.7045 & TRN & & \\
\hline CHEMBL240954 & 954551 & 5.0434 & 4.1127 & TST & & \\
\hline CHEMBL483849 & 954551 & 1.4311 & 1.6578 & TRN & & \\
\hline CHEMBL180127 & 954551 & 2.8485 & 2.8604 & TRN & & \\
\hline CHEMBL483847 & 954551 & 3.8742 & 4.2739 & TRN & & \\
\hline
\end{tabular}




\begin{tabular}{|c|c|c|c|c|c|}
\hline & & \multicolumn{4}{|c|}{ Supplemental Table S2.txt } \\
\hline CHEMBL379975 & 954551 & 4.8476 & 4.8601 & TRN & \\
\hline CHEMBL135561 & 954551 & 3.8181 & 3.7257 & TRN & \\
\hline CHEMBL 213100 & 954551 & 3.7655 & 3.5461 & TRN & \\
\hline CHEMBL577784 & 954551 & 4.2794 & 4.0457 & TRN & \\
\hline CHEMBL9470 & 954551 & 3.8588 & 4.137 & TST & \\
\hline CHEMBL258844 & 954551 & 3.1642 & 3.2928 & TRN & \\
\hline CHEMBL210618 & 954551 & 4.3768 & 4.2569 & TRN & \\
\hline CHEMBL514499 & 954551 & 6.0798 & 6.183 & TRN & \\
\hline CHEMBL1242367 & 954551 & 4.4711 & 3.8597 & TRN & \\
\hline CHEMBL1230020 & 954551 & 3.7569 & 4.0746 & TRN & \\
\hline CHEMBL65 & 954551 & 7.29 & 7.0402 & TRN & \\
\hline CHEMBL1673039 & 954551 & 2.7724 & 3.2617 & TRN & \\
\hline CHEMBL 202721 & 954551 & 4.1319 & 4.224 & TRN & \\
\hline CHEMBL573107 & 954551 & 4.3948 & 4.3071 & TRN & \\
\hline CHEMBL220241 & 954551 & 4.0904 & 4.1013 & TRN & \\
\hline CHEMBL300389 & 954551 & 4.7107 & 4.928 & TRN & \\
\hline CHEMBL2144069 & 954551 & 6.4161 & 6.3122 & TRN & \\
\hline CHEMBL1516890 & 954551 & 4.0878 & 4.2831 & TRN & \\
\hline CHEMBL2363137 & 954551 & 3.6006 & 3.9298 & TRN & \\
\hline CHEMBL558642 & 954551 & 2.5804 & 3.0137 & TST & \\
\hline CHEMBL1909414 & 954551 & 4.2788 & 4.5103 & TST & \\
\hline CHEMBL188678 & 954551 & 5.746 & 4.3847 & TST & \\
\hline CHEMBL393929 & 954551 & 3.7053 & 4.2304 & TST & \\
\hline CHEMBL192566 & 954551 & 6.2587 & 6.0265 & TST & \\
\hline CHEMBL 2005886 & 954551 & 3.8575 & 4.0426 & TST & \\
\hline CHEMBL1970879 & 954551 & 3.8798 & 3.6836 & TST & \\
\hline CHEMBL209148 & 954551 & 2.7819 & 3.9088 & TST & \\
\hline CHEMBL 2313885 & 934299 & 5.5528 & 5.5133 & TRN & \\
\hline CHEMBL2313889 & 934299 & 4.0 & 3.9429 & TRN & \\
\hline CHEMBL 2314166 & 934299 & 4.0 & 3.9154 & TRN & \\
\hline CHEMBL2313914 & 934299 & 4.0 & 3.9985 & TRN & \\
\hline CHEMBL2313908 & 934299 & 6.0315 & 6.0347 & TRN & \\
\hline CHEMBL2313907 & 934299 & 5.1487 & 5.1428 & TRN & \\
\hline CHEMBL2313916 & 934299 & 4.0 & 3.9235 & TRN & \\
\hline CHEMBL2313892 & 934299 & 4.0 & 3.9645 & TRN & \\
\hline CHEMBL2313897 & 934299 & 4.0 & 3.9157 & TRN & \\
\hline CHEMBL2313920 & 934299 & 5.7959 & 5.8371 & TRN & \\
\hline CHEMBL2314169 & 934299 & 4.0 & 4.6735 & TST & \\
\hline CHEMBL2313923 & 934299 & 6.0315 & 6.1338 & TRN & \\
\hline CHEMBL 2313884 & 934299 & 6.1805 & 6.17700 & 00000000005 & TRN \\
\hline CHEMBL2313915 & 934299 & 4.0 & 4.0195 & TRN & \\
\hline CHEMBL 2313918 & 934299 & 5.699 & 5.7141 & TRN & \\
\hline CHEMBL2313925 & 934299 & 6.1487 & 6.02 & TRN & \\
\hline CHEMBL2313903 & 934299 & 4.0 & 6.365 & TST & \\
\hline CHEMBL 2314165 & 934299 & 4.0 & 3.9209 & TST & \\
\hline CHEMBL2313910 & 934299 & 4.0 & 3.9899 & TRN & \\
\hline CHEMBL2313906 & 934299 & 5.2147 & 5.2937 & TRN & \\
\hline CHEMBL2313890 & 934299 & 4.0 & 4.0655 & TRN & \\
\hline
\end{tabular}




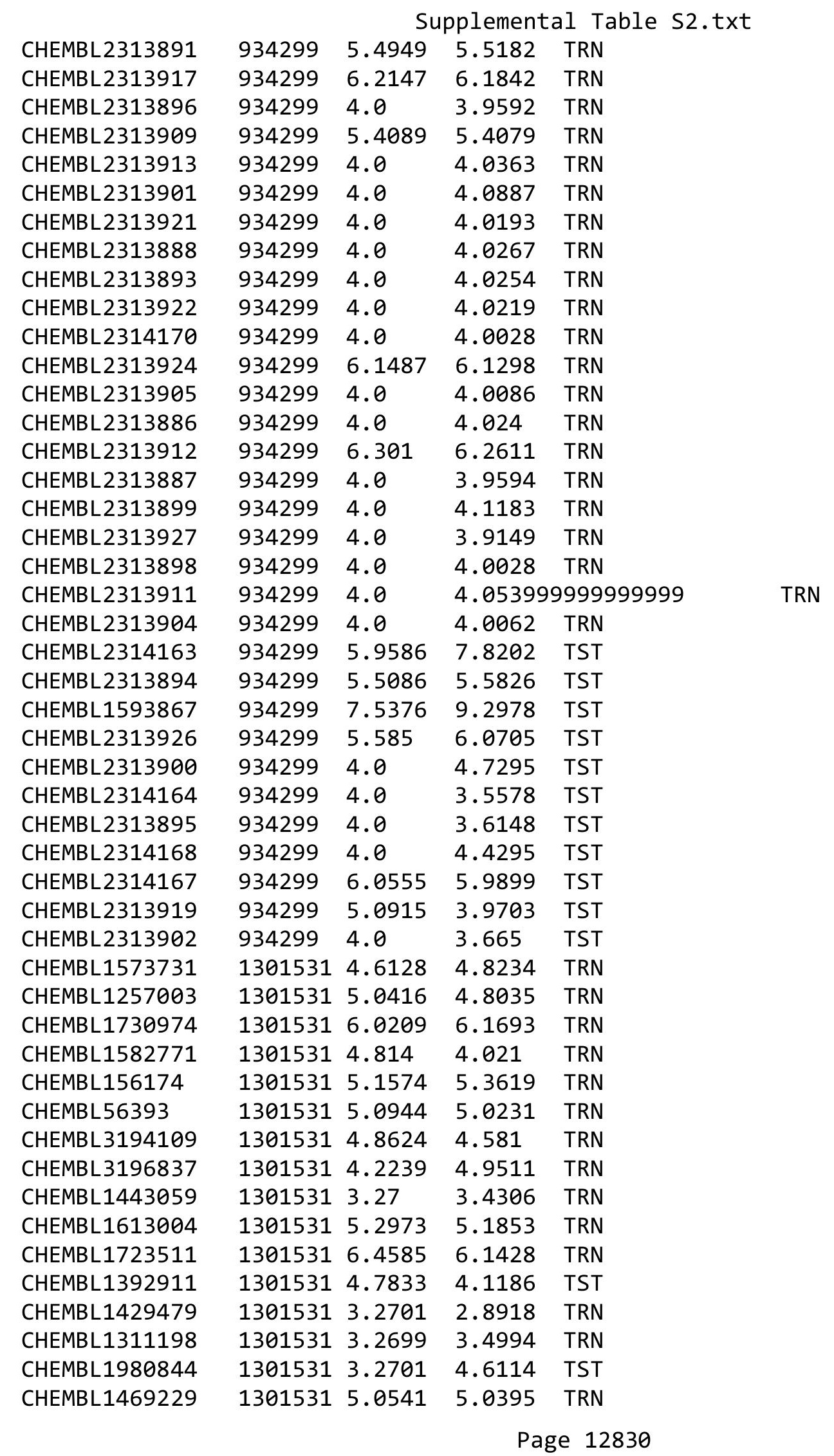


Supplemental Table S2.txt

\begin{tabular}{|c|c|c|c|c|}
\hline CHEMBL290914 & 1301531 & 5.3778 & 5.2657 & TRN \\
\hline CHEMBL1725798 & 1301531 & 3.2694 & 3.483 & TRN \\
\hline CHEMBL1721855 & 1301531 & 3.7467 & 4.5515 & TRN \\
\hline CHEMBL3193326 & 1301531 & 5.2445 & 5.7906 & TRN \\
\hline CHEMBL1533230 & 1301531 & 5.7165 & 5.1789 & TST \\
\hline CHEMBL156383 & 1301531 & 4.4925 & 4.721999 & 99999999995 \\
\hline CHEMBL1403497 & 1301531 & 3.27 & 3.7793 & TRN \\
\hline CHEMBL66966 & 1301531 & 5.1646 & 5.4217 & TRN \\
\hline CHEMBL1727349 & 1301531 & 5.806 & 5.3889 & TRN \\
\hline CHEMBL1967046 & 1301531 & 4.8247 & 3.9946 & TRN \\
\hline CHEMBL1574133 & 1301531 & 3.27 & 3.6124 & TRN \\
\hline CHEMBL1561729 & 1301531 & 3.2699 & 3.7535 & TRN \\
\hline CHEMBL1722566 & 1301531 & 4.34 & 4.4739 & TRN \\
\hline CHEMBL1413866 & 1301531 & 5.3231 & 5.2812 & TRN \\
\hline CHEMBL1323000 & 1301531 & 3.2699 & 3.7542 & TRN \\
\hline CHEMBL484640 & 1301531 & 4.877 & 4.7827 & TRN \\
\hline CHEMBL1877709 & 1301531 & 4.2871 & 4.5587 & TRN \\
\hline CHEMBL1429677 & 1301531 & 5.2832 & 5.6564 & TRN \\
\hline CHEMBL1560629 & 1301531 & 5.3726 & 5.0101 & TRN \\
\hline CHEMBL1374603 & 1301531 & 5.136 & 4.9723 & TRN \\
\hline CHEMBL151 & 1301531 & 4.8318 & 4.7414 & TRN \\
\hline CHEMBL3194385 & 1301531 & 4.5542 & 4.9668 & TRN \\
\hline CHEMBL1700996 & 1301531 & 5.8693 & 5.7417 & TRN \\
\hline CHEMBL1540637 & 1301531 & 5.1246 & 4.6618 & TRN \\
\hline CHEMBL222759 & 1301531 & 3.2699 & 3.1418 & TRN \\
\hline CHEMBL1336927 & 1301531 & 3.7471 & 3.5236 & TRN \\
\hline CHEMBL163316 & 1301531 & 4.348 & 4.7165 & TRN \\
\hline CHEMBL246446 & 1301531 & 5.3575 & 4.9742 & TRN \\
\hline CHEMBL1546656 & 1301531 & 3.27 & 3.3243 & TRN \\
\hline CHEMBL1598766 & 1301531 & 3.2699 & 4.088999 & 99999999995 \\
\hline CHEMBL1486827 & 1301531 & 4.6981 & 4.4801 & TRN \\
\hline CHEMBL1385808 & 1301531 & 5.5964 & 5.2218 & TST \\
\hline CHEMBL1709354 & 1301531 & 5.1321 & 5.3409 & TRN \\
\hline CHEMBL278037 & 1301531 & 4.7353 & 4.3196 & TRN \\
\hline CHEMBL1594376 & 1301531 & 4.8556 & 4.8403 & TRN \\
\hline CHEMBL405110 & 1301531 & 5.7082 & 5.0372 & TRN \\
\hline CHEMBL3195623 & 1301531 & 4.7851 & 4.4408 & TRN \\
\hline CHEMBL1701533 & 1301531 & 4.5704 & 4.1347 & TRN \\
\hline CHEMBL175266 & 1301531 & 5.8136 & 5.8475 & TRN \\
\hline CHEMBL1557426 & 1301531 & 3.27 & 3.4276 & TRN \\
\hline CHEMBL444478 & 1301531 & 4.4986 & 4.4233 & TRN \\
\hline CHEMBL1342436 & 1301531 & 3.2703 & 4.2821 & TST \\
\hline CHEMBL1706577 & 1301531 & 4.4579 & 4.6858 & TRN \\
\hline CHEMBL68096 & 1301531 & 4.4103 & 4.0141 & TST \\
\hline CHEMBL1301673 & 1301531 & 5.6716 & 4.6056 & TST \\
\hline CHEMBL1509648 & 1301531 & 3.2699 & 3.6544 & TRN \\
\hline CHEMBL1561877 & 1301531 & 3.2699 & 3.5808 & TRN \\
\hline CHEMBL3190268 & 1301531 & 3.2699 & 4.507 & TRN \\
\hline
\end{tabular}


Supplemental Table S2.txt

\begin{tabular}{|c|c|c|c|c|c|}
\hline CHEMBL1482554 & 1301531 & 3.2698 & 3.7369 & TRN & \\
\hline CHEMBL1984240 & 1301531 & 4.5289 & 4.5628 & TRN & \\
\hline CHEMBL3193134 & 1301531 & 5.0153 & 4.9851 & TRN & \\
\hline CHEMBL1732657 & 1301531 & 4.8733 & 5.0581 & TST & \\
\hline CHEMBL1509308 & 1301531 & 3.2696 & 3.0787 & TST & \\
\hline CHEMBL1374016 & 1301531 & 3.2699 & 4.0651 & TRN & \\
\hline CHEMBL224916 & 1301531 & 5.1468 & 5.2985 & TRN & \\
\hline CHEMBL1578953 & 1301531 & 4.5441 & 3.9844 & TRN & \\
\hline CHEMBL1704267 & 1301531 & 4.8238 & 4.5887 & TRN & \\
\hline CHEMBL1429070 & 1301531 & 5.3974 & 5.2871 & TRN & \\
\hline CHEMBL469424 & 1301531 & 5.3397 & 5.1743 & TRN & \\
\hline CHEMBL1408747 & 1301531 & 4.6862 & 4.4877 & TRN & \\
\hline CHEMBL1732315 & 1301531 & 3.2701 & 3.9317 & TRN & \\
\hline CHEMBL3199191 & 1301531 & 4.6311 & 4.2693 & TRN & \\
\hline CHEMBL1350188 & 1301531 & 5.0442 & 5.3988 & TRN & \\
\hline CHEMBL1893276 & 1301531 & 3.27 & 5.3915 & TST & \\
\hline CHEMBL1409344 & 1301531 & 3.2696 & 3.3806 & TRN & \\
\hline CHEMBL1576140 & 1301531 & 5.1194 & 5.0975 & TRN & \\
\hline CHEMBL1458486 & 1301531 & 3.27 & 3.7107 & TRN & \\
\hline CHEMBL3193581 & 1301531 & 4.8587 & 4.8177 & TRN & \\
\hline CHEMBL1493010 & 1301531 & 5.4383 & 5.401 & TRN & \\
\hline CHEMBL1407474 & 1301531 & 6.0607 & 6.0191 & TRN & \\
\hline CHEMBL1994094 & 1301531 & 4.8509 & 4.8259 & TRN & \\
\hline CHEMBL1375795 & 1301531 & 5.2793 & 5.4757 & TRN & \\
\hline CHEMBL1271266 & 1301531 & 5.4449 & 5.7243 & TRN & \\
\hline CHEMBL1986342 & 1301531 & 7.0708 & 7.0471 & TRN & \\
\hline CHEMBL1482883 & 1301531 & 3.27 & 3.4304 & TRN & \\
\hline CHEMBL1346055 & 1301531 & 4.9996 & 4.3796 & TRN & \\
\hline CHEMBL1408535 & 1301531 & 3.2701 & 3.4394 & TRN & \\
\hline CHEMBL3196993 & 1301531 & 5.4298 & 5.4924 & TRN & \\
\hline CHEMBL1401747 & 1301531 & 5.0026 & 4.556 & TRN & \\
\hline CHEMBL1866510 & 1301531 & 4.3129 & 4.506 & TRN & \\
\hline CHEMBL1715550 & 1301531 & 5.2065 & 4.8158 & TRN & \\
\hline CHEMBL1606907 & 1301531 & 4.3614 & 4.2391 & TRN & \\
\hline CHEMBL 2004928 & 1301531 & 4.3573 & 4.3872 & TRN & \\
\hline CHEMBL 82242 & 1301531 & 4.8558 & 4.9364 & TRN & \\
\hline CHEMBL1976219 & 1301531 & 3.2693 & 3.7901 & TRN & \\
\hline CHEMBL1728023 & 1301531 & 5.8389 & \multicolumn{2}{|c|}{5.292000000000001} & TRN \\
\hline CHEMBL1362935 & 1301531 & 6.079 & 6.6733 & TRN & \\
\hline CHEMBL1731349 & 1301531 & 5.2019 & 4.4979 & TST & \\
\hline CHEMBL463563 & 1301531 & 5.2821 & 5.3416 & TRN & \\
\hline CHEMBL1604163 & 1301531 & 3.2701 & 3.5533 & TRN & \\
\hline CHEMBL607979 & 1301531 & 5.3051 & 5.0759 & TRN & \\
\hline CHEMBL1335254 & 1301531 & 3.2699 & 2.7086 & TRN & \\
\hline CHEMBL1314787 & 1301531 & 4.3878 & 3.6948 & TRN & \\
\hline CHEMBL1503050 & 1301531 & 6.1696 & 4.8785 & TST & \\
\hline CHEMBL1461772 & 1301531 & 3.2699 & 3.9007 & TRN & \\
\hline CHEMBL1737002 & 1301531 & 5.334 & 5.3937 & TRN & \\
\hline
\end{tabular}

Page 12832 
Supplemental Table S2.txt

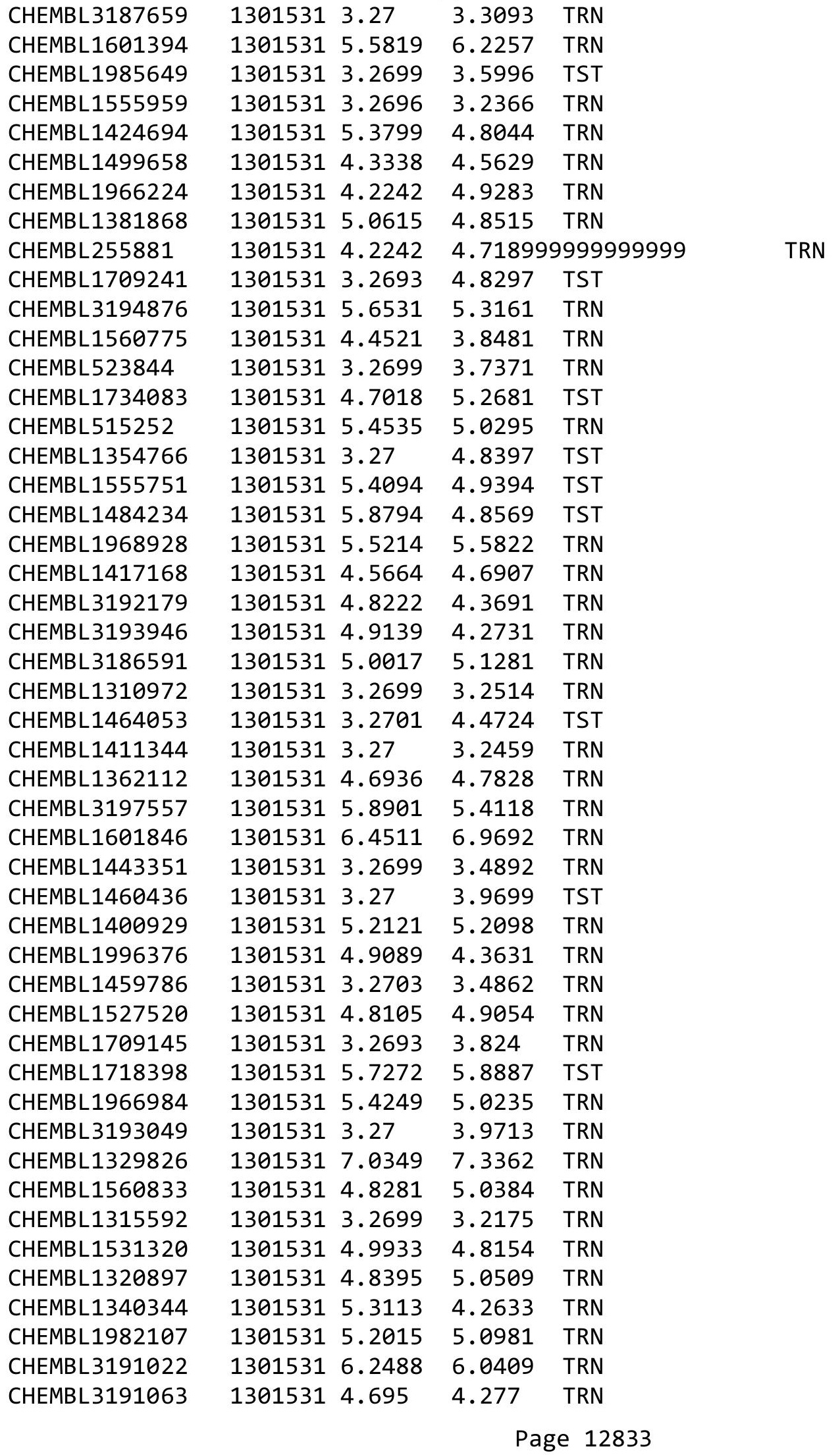


Supplemental Table S2.txt

\begin{tabular}{|c|c|c|c|c|}
\hline CHEMBL1985664 & 1301531 & 5.6026 & 5.5904 & TRN \\
\hline CHEMBL1424486 & 1301531 & 3.2699 & 3.4461 & TRN \\
\hline CHEMBL1325440 & 1301531 & 4.6393 & 4.7536 & TRN \\
\hline CHEMBL1315784 & 1301531 & 4.9731 & 4.7855 & TRN \\
\hline CHEMBL1373655 & 1301531 & 5.8496 & 4.9415 & TRN \\
\hline CHEMBL164 & 1301531 & 5.9431 & 6.022 & TRN \\
\hline CHEMBL1485960 & 1301531 & 3.27 & 3.6818 & TRN \\
\hline CHEMBL3192541 & 1301531 & 4.8287 & 4.7047 & TRN \\
\hline CHEMBL3195409 & 1301531 & 4.9103 & 4.7089 & TRN \\
\hline CHEMBL1481914 & 1301531 & 3.27 & 3.5412 & TRN \\
\hline CHEMBL1419228 & 1301531 & 5.4477 & 5.2694 & TRN \\
\hline CHEMBL1972037 & 1301531 & 5.4684 & 4.979 & TRN \\
\hline CHEMBL1731995 & 1301531 & 4.5826 & 4.5548 & TRN \\
\hline CHEMBL1488474 & 1301531 & 5.5761 & 5.5098 & TRN \\
\hline CHEMBL1321116 & 1301531 & 4.4444 & 4.0312 & TST \\
\hline CHEMBL1468796 & 1301531 & 6.6104 & 6.3573 & TRN \\
\hline CHEMBL3197564 & 1301531 & 3.2702 & 3.1771 & TRN \\
\hline CHEMBL1427047 & 1301531 & 3.2699 & 3.5593 & TRN \\
\hline CHEMBL136344 & 1301531 & 5.2874 & 5.1695 & TRN \\
\hline CHEMBL1399979 & 1301531 & 3.27 & 3.5162 & TRN \\
\hline CHEMBL1465049 & 1301531 & 3.27 & 3.7632 & TRN \\
\hline CHEMBL1349474 & 1301531 & 3.2699 & 2.9167 & TRN \\
\hline CHEMBL1447917 & 1301531 & 3.2694 & 3.4745 & TRN \\
\hline CHEMBL172350 & 1301531 & 5.005 & 4.9479 & TRN \\
\hline CHEMBL1302308 & 1301531 & 6.7061 & 6.7088 & TRN \\
\hline CHEMBL1706454 & 1301531 & 5.6385 & 5.5866 & TRN \\
\hline CHEMBL1575767 & 1301531 & 4.4306 & 4.1557 & TRN \\
\hline CHEMBL1964793 & 1301531 & 4.4891 & 3.9897 & TRN \\
\hline CHEMBL1173475 & 1301531 & 5.2721 & 5.1184 & TRN \\
\hline CHEMBL1981657 & 1301531 & 5.3426 & 4.8451 & TRN \\
\hline CHEMBL234338 & 1301531 & 3.2704 & 4.53100 & 0000000001 \\
\hline CHEMBL1501635 & 1301531 & 5.1479 & 4.9928 & TST \\
\hline CHEMBL1310907 & 1301531 & 3.2699 & 2.7681 & TRN \\
\hline CHEMBL483206 & 1301531 & 4.8781 & 5.2396 & TRN \\
\hline CHEMBL1368108 & 1301531 & 4.2242 & 4.652 & TST \\
\hline CHEMBL1727228 & 1301531 & 3.748 & 3.9758 & TST \\
\hline CHEMBL1508847 & 1301531 & 5.4803 & 5.2543 & TRN \\
\hline CHEMBL3192715 & 1301531 & 4.8353 & 4.6761 & TRN \\
\hline CHEMBL1333249 & 1301531 & 3.2701 & 3.4266 & TRN \\
\hline CHEMBL1323674 & 1301531 & 5.5659 & 5.12700 & 0000000001 \\
\hline CHEMBL1464280 & 1301531 & 5.1784 & 4.7069 & TST \\
\hline CHEMBL1715667 & 1301531 & 4.5673 & 4.6008 & TST \\
\hline CHEMBL1567396 & 1301531 & 5.5207 & 5.4297 & TST \\
\hline CHEMBL1997747 & 1301531 & 3.2699 & 3.7574 & TST \\
\hline CHEMBL1469743 & 1301531 & 3.27 & 5.05 & TST \\
\hline CHEMBL1730762 & 1301531 & 5.2948 & 4.5539 & TST \\
\hline CHEMBL3191780 & 1301531 & 5.4133 & 4.7701 & TST \\
\hline CHEMBL 3189823 & 1301531 & 5.0954 & 6.0217 & TST \\
\hline
\end{tabular}


Supplemental Table S2.txt

\begin{tabular}{|c|c|c|c|c|}
\hline CHEMBL1713097 & 1301531 & 5.5439 & 5.3017 & TST \\
\hline CHEMBL1409603 & 1301531 & 4.9776 & 4.6647 & TST \\
\hline CHEMBL1324051 & 1301531 & 3.2699 & 4.4121 & TST \\
\hline CHEMBL 3186253 & 1301531 & 5.3629 & 4.9856 & TST \\
\hline CHEMBL1459125 & 1301531 & 3.2699 & 4.0758 & TST \\
\hline CHEMBL3195177 & 1301531 & 4.8571 & 4.7657 & TST \\
\hline CHEMBL1360585 & 1301531 & 5.1785 & 4.5499 & TST \\
\hline CHEMBL1426749 & 1301531 & 3.27 & 4.1636 & TST \\
\hline CHEMBL1349475 & 1301531 & 3.2702 & 4.4521 & TST \\
\hline CHEMBL1320230 & 1301531 & 5.6101 & 4.0696 & TST \\
\hline CHEMBL1600440 & 1301531 & 4.7257 & 4.0403 & TST \\
\hline CHEMBL1501392 & 1301531 & 3.27 & 5.1414 & TST \\
\hline CHEMBL1463181 & 1301531 & 4.4891 & 4.7536 & TST \\
\hline CHEMBL1704223 & 1301531 & 4.9089 & 5.3139 & TST \\
\hline CHEMBL1522218 & 1301531 & 4.8412 & 3.8195 & TST \\
\hline CHEMBL1471337 & 1301531 & 4.9687 & 4.46 & TST \\
\hline CHEMBL1732979 & 1301531 & 4.7014 & 4.3064 & TST \\
\hline CHEMBL1700270 & 1301531 & 4.8086 & 5.29700 & 0000000001 \\
\hline CHEMBL1493191 & 1301531 & 4.3487 & 3.5047 & TST \\
\hline CHEMBL1373577 & 1301531 & 3.2702 & 4.3039 & TST \\
\hline CHEMBL1364584 & 1301531 & 3.27 & 3.2203 & TST \\
\hline CHEMBL1510349 & 1301531 & 4.2242 & 4.4156 & TST \\
\hline CHEMBL1735454 & 1301531 & 5.8047 & 4.6938 & TST \\
\hline CHEMBL2046928 & 828171 & 4.4949 & 4.109 & TRN \\
\hline CHEMBL2046923 & 828171 & 2.3063 & 2.8824 & TST \\
\hline CHEMBL 2013155 & 828171 & 2.6904 & 3.5144 & TRN \\
\hline CHEMBL 2046850 & 828171 & 3.7455 & 3.4014 & TRN \\
\hline CHEMBL 2013152 & 828171 & 3.7744 & 3.4004 & TRN \\
\hline CHEMBL2046856 & 828171 & 3.7335 & 4.4873 & TRN \\
\hline CHEMBL 2046932 & 828171 & 4.3307 & 4.1992 & TRN \\
\hline CHEMBL2046853 & 828171 & 4.7144 & 4.4102 & TRN \\
\hline CHEMBL 2046845 & 828171 & 2.4498 & 2.5377 & TRN \\
\hline CHEMBL2046847 & 828171 & 2.4535 & 2.4506 & TRN \\
\hline CHEMBL2046843 & 828171 & 2.4802 & 3.4399 & TRN \\
\hline CHEMBL2046849 & 828171 & 4.6576 & 3.38199 & 99999999997 \\
\hline CHEMBL2013146 & 828171 & 4.3625 & 4.4162 & TRN \\
\hline CHEMBL 2013145 & 828171 & 3.7812 & 4.1066 & TRN \\
\hline CHEMBL2046937 & 828171 & 2.5072 & 3.3307 & TST \\
\hline CHEMBL2046926 & 828171 & 3.8027 & 3.6922 & TRN \\
\hline CHEMBL2013154 & 828171 & 2.7747 & 3.5475 & TRN \\
\hline CHEMBL 2013151 & 828171 & 4.7033 & 3.3981 & TRN \\
\hline CHEMBL 2046927 & 828171 & 4.2396 & 4.4753 & TRN \\
\hline CHEMBL1969885 & 828171 & 2.4711 & 3.2619 & TRN \\
\hline CHEMBL1984585 & 828171 & 3.5429 & 3.2927 & TRN \\
\hline CHEMBL2046943 & 828171 & 4.3497 & 3.4637 & TRN \\
\hline CHEMBL 2046934 & 828171 & 4.0128 & 3.0093 & TST \\
\hline CHEMBL 2046924 & 828171 & 2.4179 & 2.5089 & TST \\
\hline CHEMBL1997945 & 828171 & 3.6533 & 3.3666 & TRN \\
\hline
\end{tabular}

Page 12835 


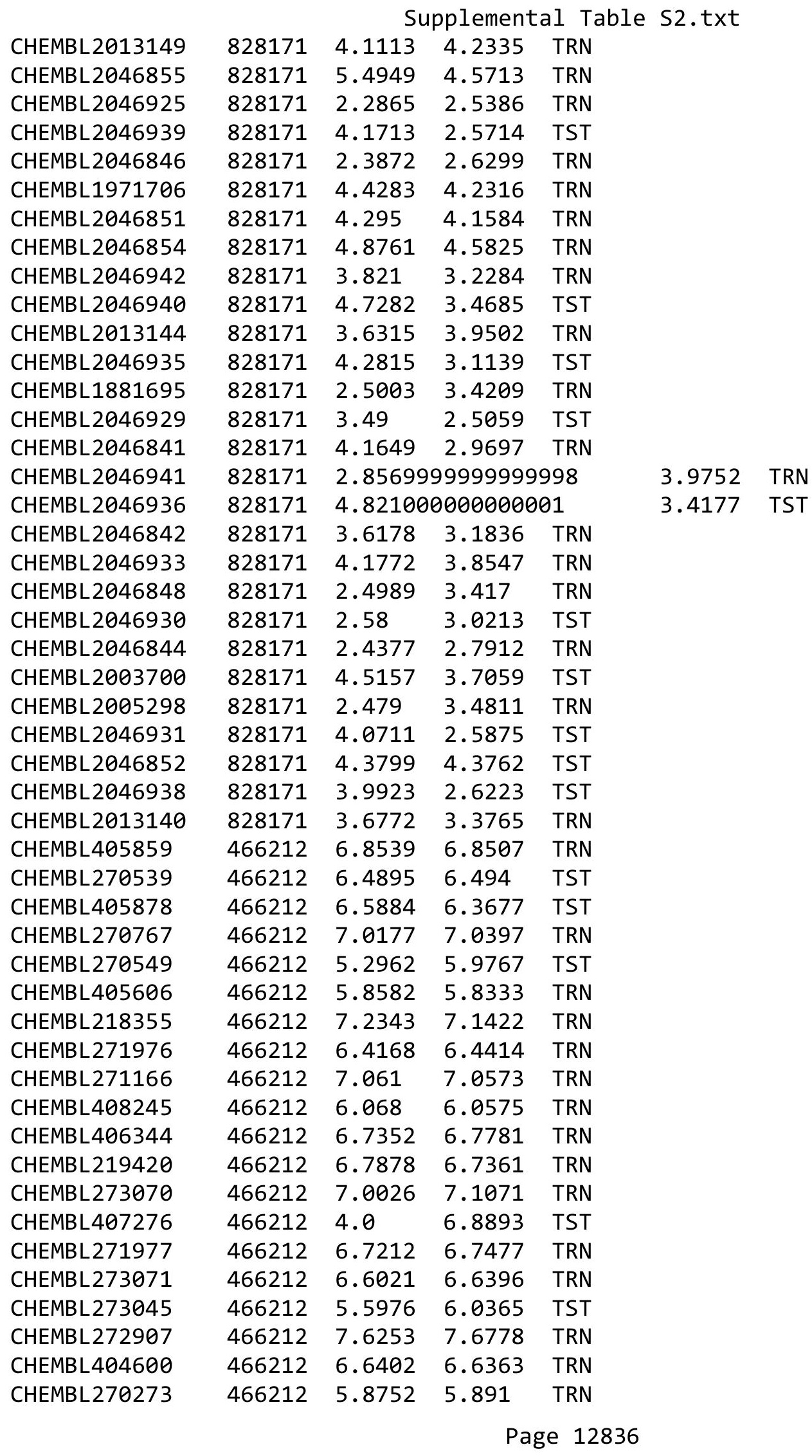


Supplemental Table S2.txt

\begin{tabular}{|c|c|c|c|c|c|}
\hline CHEMBL 270937 & 466212 & 6.2933 & 6.2271 & TRN & \\
\hline CHEMBL 273120 & 466212 & 6.6271 & 6.5582 & TRN & \\
\hline CHEMBL272879 & 466212 & 5.8336 & 5.8323 & TRN & \\
\hline CHEMBL 271415 & 466212 & 6.0348 & 6.0507 & TRN & \\
\hline CHEMBL259676 & 466212 & 5.6262 & 5.6735 & TRN & \\
\hline CHEMBL414194 & 466212 & 6.8239 & 6.7888 & TRN & \\
\hline CHEMBL 260304 & 466212 & 6.5918 & 6.59 & TRN & \\
\hline CHEMBL219708 & 466212 & 6.5952 & 6.5338 & TRN & \\
\hline CHEMBL408243 & 466212 & 7.5702 & 7.7304 & TST & \\
\hline CHEMBL219333 & 466212 & 7.5086 & 7.6377 & TST & \\
\hline CHEMBL438457 & 466212 & 6.8633 & 6.8492 & TRN & \\
\hline CHEMBL 219478 & 466212 & 7.1007 & 7.1342 & TRN & \\
\hline CHEMBL 271204 & 466212 & 6.7721 & 6.758999 & 99999999995 & TRN \\
\hline CHEMBL 270757 & 466212 & 4.0 & 6.2186 & TST & \\
\hline CHEMBL271153 & 466212 & 6.2027 & 6.2679 & TRN & \\
\hline CHEMBL 273085 & 466212 & 7.7235 & 7.7276 & TRN & \\
\hline CHEMBL408323 & 466212 & 6.6345 & 6.5959 & TRN & \\
\hline CHEMBL 270100 & 466212 & 6.8539 & 6.8255 & TRN & \\
\hline CHEMBL 277982 & 466212 & 6.6038 & 6.6288 & TRN & \\
\hline CHEMBL405475 & 466212 & 6.0443 & 6.1784 & TRN & \\
\hline CHEMBL1162972 & 466212 & 6.5513 & 6.559 & TRN & \\
\hline CHEMBL407590 & 466212 & 6.7799 & 6.7818 & TRN & \\
\hline CHEMBL409066 & 466212 & 6.6925 & 6.685 & TRN & \\
\hline CHEMBL 272451 & 466212 & 6.7055 & 6.7387 & TRN & \\
\hline CHEMBL218891 & 466212 & 6.8928 & 6.7773 & TRN & \\
\hline CHEMBL405857 & 466212 & 6.0894 & 6.1299 & TRN & \\
\hline CHEMBL270768 & 466212 & 6.7328 & 6.7035 & TRN & \\
\hline CHEMBL1162971 & 466212 & 5.8824 & 5.8189 & TRN & \\
\hline CHEMBL443575 & 466212 & 6.4486 & 6.2986 & TST & \\
\hline CHEMBL 270772 & 466212 & 7.2388 & 7.0083 & TST & \\
\hline CHEMBL 270259 & 466212 & 7.3325 & 7.2279 & TST & \\
\hline CHEMBL270538 & 466212 & 6.1018 & 6.3795 & TST & \\
\hline CHEMBL 271152 & 466212 & 6.1192 & 5.855 & TST & \\
\hline CHEMBL426525 & 466212 & 6.9872 & 6.6781 & TST & \\
\hline CHEMBL1272012 & 674305 & 4.2269 & 3.5752 & TRN & \\
\hline CHEMBL1271786 & 674305 & 2.301 & 2.4679 & TRN & \\
\hline CHEMBL1272173 & 674305 & 3.9586 & 3.7151 & TRN & \\
\hline CHEMBL1271625 & 674305 & 4.6198 & 4.0536 & TRN & \\
\hline CHEMBL1271624 & 674305 & 2.301 & 2.54 & TRN & \\
\hline CHEMBL1271674 & 674305 & 2.301 & 2.7303 & TST & \\
\hline CHEMBL1269515 & 674305 & 3.756999 & 99999999 & 3.9957 & TRN \\
\hline CHEMBL1272228 & 674305 & 3.8861 & 4.0163 & TRN & \\
\hline CHEMBL1272119 & 674305 & 3.4685 & 2.7396 & TRN & \\
\hline CHEMBL1271517 & 674305 & 3.6055 & 3.2958 & TRN & \\
\hline CHEMBL1272282 & 674305 & 3.6635 & 3.6835 & TRN & \\
\hline CHEMBL1271955 & 674305 & 3.6778 & 3.6851 & TRN & \\
\hline CHEMBL1271787 & 674305 & 3.5129 & 3.4896 & TRN & \\
\hline CHEMBL1269629 & 674305 & 2.301 & 2.5466 & TRN & \\
\hline
\end{tabular}

Page 12837 


\begin{tabular}{|c|c|c|c|c|c|}
\hline & & \multicolumn{4}{|c|}{ Supplemental Table s2.txt } \\
\hline CHEMBL1271673 & 674305 & 3.4437 & 3.449 & TRN & \\
\hline CHEMBL1272069 & 674305 & 3.5768 & 3.548 & TRN & \\
\hline CHEMBL1271568 & 674305 & 3.6144 & 3.5606 & TRN & \\
\hline CHEMBL1269513 & 674305 & 2.301 & 2.8155 & TST & \\
\hline CHEMBL1272067 & 674305 & 3.7144 & 3.7107 & TRN & \\
\hline CHEMBL1269627 & 674305 & 3.6478 & 3.5496 & TST & \\
\hline CHEMBL1271518 & 674305 & 2.301 & 2.6712 & TRN & \\
\hline CHEMBL1269710 & 674305 & 2.301 & 2.6481 & TRN & \\
\hline CHEMBL1269628 & 674305 & 3.8539 & 3.8495 & TST & \\
\hline CHEMBL1271727 & 674305 & 4.1549 & 3.7449 & TRN & \\
\hline CHEMBL1272068 & 674305 & 2.301 & 3.5479 & TRN & \\
\hline CHEMBL1271565 & 674305 & 3.6478 & 3.9957 & TST & \\
\hline CHEMBL1271956 & 674305 & 3.5143 & 3.4555 & TRN & \\
\hline CHEMBL1271728 & 674305 & 2.301 & 2.4568 & TRN & \\
\hline CHEMBL1272118 & 674305 & 2.301 & 2.6651 & TRN & \\
\hline CHEMBL1269731 & 674305 & 3.6021 & 3.5994 & TST & \\
\hline CHEMBL1272281 & 674305 & 3.6383 & 3.6633 & TRN & \\
\hline CHEMBL1237212 & 674305 & 4.2218 & 3.9111 & TST & \\
\hline CHEMBL1271901 & 674305 & 3.5528 & 3.6365 & TRN & \\
\hline CHEMBL1271900 & 674305 & 3.4685 & 2.7488 & TRN & \\
\hline CHEMBL1271785 & 674305 & 3.585 & 2.5559 & TRN & \\
\hline CHEMBL1271462 & 674305 & 3.7959 & 3.7426 & TRN & \\
\hline CHEMBL1269730 & 674305 & 2.301 & 2.77399 & 99999999996 & TRN \\
\hline CHEMBL1271844 & 674305 & 3.3925 & 2.7112 & TRN & \\
\hline CHEMBL1271463 & 674305 & 3.3565 & 3.6081 & TRN & \\
\hline CHEMBL48449 & 674305 & 5.0458 & 4.4417 & TST & \\
\hline CHEMBL1272117 & 674305 & 3.4145 & 3.4868 & TRN & \\
\hline CHEMBL1272172 & 674305 & 3.301 & 2.7574 & TRN & \\
\hline CHEMBL1271516 & 674305 & 3.3251 & 2.7327 & TRN & \\
\hline CHEMBL1271726 & 674305 & 2.301 & 3.7449 & TRN & \\
\hline CHEMBL1272280 & 674305 & 3.6021 & 3.7901 & TRN & \\
\hline CHEMBL1271672 & 674305 & 2.301 & 2.7897 & TRN & \\
\hline CHEMBL1269656 & 674305 & 2.301 & 2.5762 & TST & \\
\hline CHEMBL1269712 & 674305 & 5.5229 & 4.6131 & TRN & \\
\hline CHEMBL1271845 & 674305 & 3.585 & 3.6006 & TRN & \\
\hline CHEMBL1269514 & 674305 & 5.0506 & 4.4786 & TST & \\
\hline CHEMBL1269657 & 674305 & 2.301 & 2.6458 & TST & \\
\hline CHEMBL1269711 & 674305 & 2.301 & 2.7569 & TRN & \\
\hline CHEMBL1269655 & 674305 & 2.301 & 2.6477 & TST & \\
\hline CHEMBL1271567 & 674305 & 2.301 & 2.455 & TST & \\
\hline CHEMBL1269039 & 674305 & 3.5229 & 3.5524 & TRN & \\
\hline CHEMBL1271623 & 674305 & 2.301 & 2.68899 & 99999999996 & TST \\
\hline CHEMBL1271569 & 674305 & 3.4168 & 3.5968 & TRN & \\
\hline CHEMBL1271464 & 674305 & 3.5607 & 3.5627 & TRN & \\
\hline CHEMBL1271566 & 674305 & 3.426 & 3.9957 & TST & \\
\hline CHEMBL1269512 & 674305 & 2.301 & 2.65199 & 99999999997 & TST \\
\hline CHEMBL1272013 & 674305 & 4.3979 & 3.5208 & TRN & \\
\hline CHEMBL1272229 & 674305 & 2.301 & 3.54 & TRN & \\
\hline
\end{tabular}




\begin{tabular}{|c|c|c|c|c|c|}
\hline & & \multicolumn{4}{|c|}{ Supplemental Table S2.txt } \\
\hline CHEMBL1590308 & 954984 & 4.4983 & 3.4253 & TST & \\
\hline CHEMBL558642 & 954984 & 3.2358 & 3.5267 & TRN & \\
\hline CHEMBL449158 & 954984 & 6.9362 & 6.5147 & TST & \\
\hline CHEMBL102714 & 954984 & 3.5462 & 3.5377 & TRN & \\
\hline CHEMBL512504 & 954984 & 6.6753 & 6.6959 & TRN & \\
\hline CHEMBL573107 & 954984 & 5.2445 & 5.46700 & 00000000005 & TRN \\
\hline CHEMBL188678 & 954984 & 5.3214 & 5.2009 & TRN & \\
\hline CHEMBL393929 & 954984 & 4.21399 & 99999999 & 4.3745 & TRN \\
\hline CHEMBL515416 & 954984 & 4.936 & 4.6462 & TRN & \\
\hline CHEMBL192566 & 954984 & 9.0796 & 8.2236 & TST & \\
\hline CHEMBL514499 & 954984 & 7.0906 & 7.5091 & TRN & \\
\hline CHEMBL1643959 & 954984 & 2.7442 & 2.9029 & TRN & \\
\hline CHEMBL1673039 & 954984 & 5.0576 & 5.1553 & TRN & \\
\hline CHEMBL585951 & 954984 & 6.3516 & 6.2814 & TRN & \\
\hline CHEMBL1404918 & 954984 & 2.7654 & 2.9455 & TRN & \\
\hline CHEMBL1242367 & 954984 & 4.5942 & 4.3025 & TRN & \\
\hline CHEMBL213100 & 954984 & 3.3148 & 3.2102 & TRN & \\
\hline CHEMBL1256459 & 954984 & 8.5474 & 8.3362 & TRN & \\
\hline CHEMBL509032 & 954984 & 6.0842 & 6.17899 & 9999999999 & TRN \\
\hline CHEMBL3199475 & 954984 & 4.5111 & 4.5947 & TRN & \\
\hline CHEMBL 9470 & 954984 & 4.12 & 6.0759 & TST & \\
\hline CHEMBL 379975 & 954984 & 5.8149 & 6.0002 & TRN & \\
\hline CHEMBL379300 & 954984 & 6.815 & 6.805 & TRN & \\
\hline CHEMBL392695 & 954984 & 5.7627 & 5.8625 & TRN & \\
\hline CHEMBL135561 & 954984 & 3.8117 & 3.7239 & TRN & \\
\hline CHEMBL220241 & 954984 & 3.6727 & 3.6213 & TRN & \\
\hline CHEMBL180127 & 954984 & 4.8678 & 4.8232 & TRN & \\
\hline CHEMBL1190711 & 954984 & 5.5336 & 5.2963 & TRN & \\
\hline CHEMBL 3186408 & 954984 & 3.4354 & 3.8248 & TST & \\
\hline CHEMBL483849 & 954984 & 3.7472 & 3.8721 & TRN & \\
\hline CHEMBL259181 & 954984 & 5.1766 & 4.9342 & TRN & \\
\hline CHEMBL3392440 & 954984 & 3.3859 & 3.3216 & TRN & \\
\hline CHEMBL221137 & 954984 & 4.6177 & 4.8929 & TST & \\
\hline CHEMBL 258844 & 954984 & 4.1196 & 3.9538 & TRN & \\
\hline CHEMBL1516890 & 954984 & 4.2377 & 3.9366 & TRN & \\
\hline CHEMBL 2363137 & 954984 & 5.0675 & 4.5785 & TRN & \\
\hline CHEMBL 209148 & 954984 & 5.3066 & 5.3191 & TRN & \\
\hline CHEMBL92309 & 954984 & 3.8239 & 3.1608 & TST & \\
\hline CHEMBL189584 & 954984 & 5.3039 & 5.3734 & TRN & \\
\hline CHEMBL1230020 & 954984 & 4.4243 & 4.2297 & TRN & \\
\hline CHEMBL210618 & 954984 & 3.3919 & 3.4068 & TRN & \\
\hline CHEMBL65 & 954984 & 8.7284 & 8.8683 & TRN & \\
\hline CHEMBL 2144069 & 954984 & 3.7079 & 4.0306 & TRN & \\
\hline CHEMBL 2005886 & 954984 & 6.4838 & 6.4777 & TRN & \\
\hline CHEMBL191334 & 954984 & 3.5961 & 3.8436 & TRN & \\
\hline CHEMBL3349342 & 954984 & 3.8535 & 4.003 & TRN & \\
\hline CHEMBL 202721 & 954984 & 5.7097 & 5.3965 & TRN & \\
\hline CHEMBL222102 & 954984 & 4.1568 & 4.4204 & TRN & \\
\hline
\end{tabular}




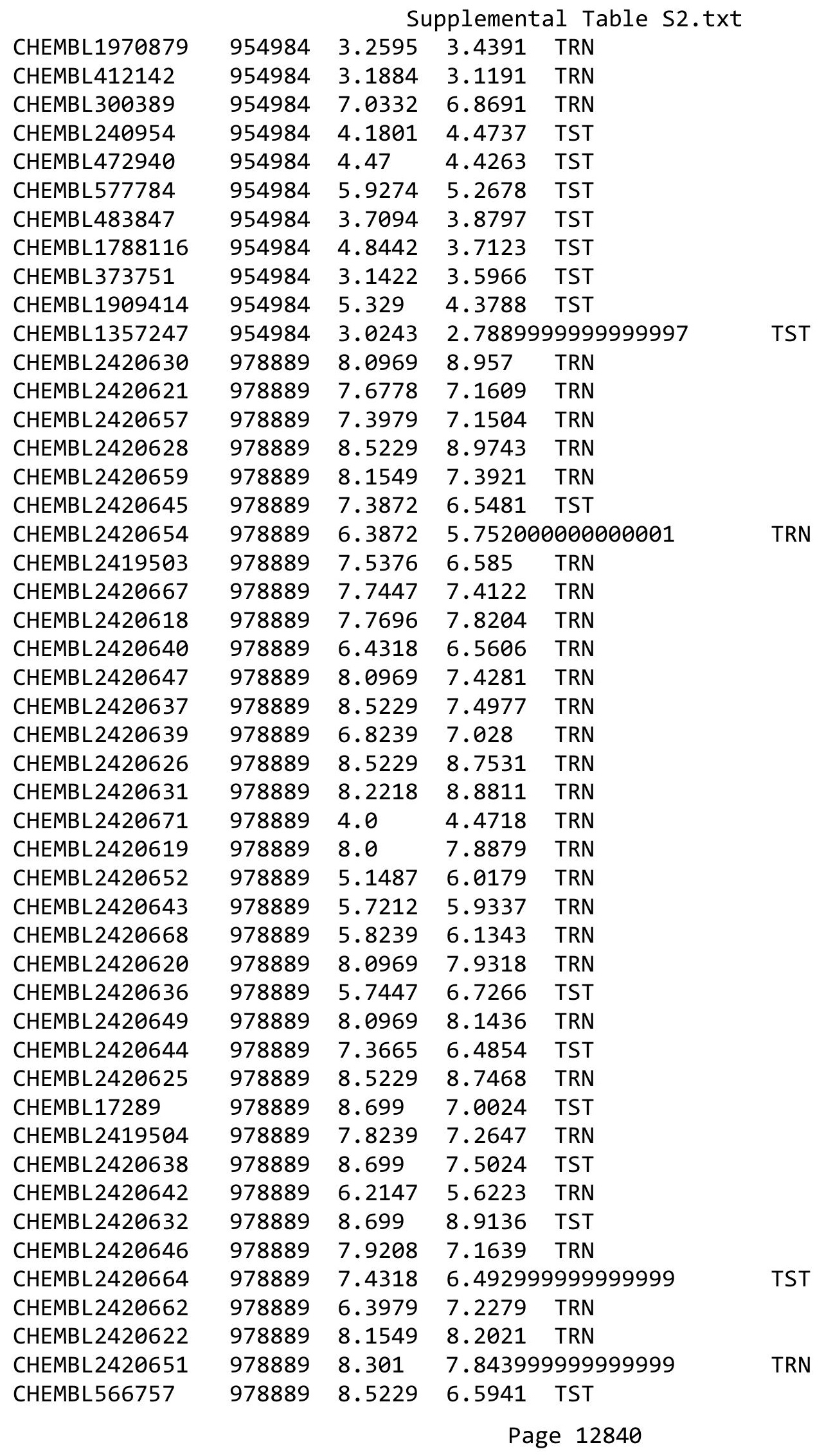




\begin{tabular}{|c|c|c|c|c|c|}
\hline \multirow[b]{2}{*}{ CHEMBL2420666 } & \multicolumn{5}{|c|}{ Supplemental Table S2.txt } \\
\hline & 978889 & 7.5528 & 7.4852 & TST & \\
\hline CHEMBL2420670 & 978889 & 8.0458 & 6.4446 & TRN & \\
\hline CHEMBL2420658 & 978889 & 7.9586 & 7.4569 & TRN & \\
\hline CHEMBL 2420633 & 978889 & 9.0 & 9.0973 & TST & \\
\hline CHEMBL2420672 & 978889 & 6.0132 & 5.8492 & TRN & \\
\hline CHEMBL2420627 & 978889 & 8.5229 & 8.9788 & TRN & \\
\hline CHEMBL2420669 & 978889 & 4.0 & 4.4691 & TRN & \\
\hline CHEMBL2420656 & 978889 & 6.8539 & 6.8485 & TRN & \\
\hline CHEMBL 2420629 & 978889 & 8.301 & 8.7828 & TST & \\
\hline CHEMBL2420665 & 978889 & 6.5086 & 6.0625 & TST & \\
\hline CHEMBL2420663 & 978889 & 6.6778 & 6.3769 & TRN & \\
\hline CHEMBL 2420641 & 978889 & 4.0 & 5.5905 & TRN & \\
\hline CHEMBL2420653 & 978889 & 4.0 & 5.6119 & TRN & \\
\hline CHEMBL 2420634 & 978889 & 9.0 & 8.9966 & TST & \\
\hline CHEMBL2420660 & 978889 & 6.8239 & 6.9839 & TRN & \\
\hline CHEMBL2420650 & 978889 & 7.7959 & 7.76 & TRN & \\
\hline CHEMBL2420635 & 978889 & 5.7696 & 6.2316 & TST & \\
\hline CHEMBL2420673 & 978889 & 6.0 & 6.2523 & TRN & \\
\hline CHEMBL 2420655 & 978889 & 5.7212 & 6.4065 & TST & \\
\hline CHEMBL2420648 & 978889 & 7.6198 & 7.8217 & TRN & \\
\hline CHEMBL2420661 & 978889 & 8.0969 & 7.0618 & TRN & \\
\hline CHEMBL2420623 & 978889 & 7.8539 & 8.4831 & TRN & \\
\hline CHEMBL2420624 & 978889 & 8.301 & 8.7622 & TRN & \\
\hline CHEMBL3687626 & 1528919 & 6.9586 & 6.86799 & 9999999999 & TRN \\
\hline CHEMBL3682776 & 1528919 & 5.5686 & 5.4813 & TRN & \\
\hline CHEMBL3682715 & 1528919 & 6.2874 & 6.1718 & TST & \\
\hline CHEMBL3682842 & 1528919 & 5.8962 & 5.7225 & TRN & \\
\hline CHEMBL3687698 & 1528919 & 6.9747 & 6.9221 & TRN & \\
\hline CHEMBL3687631 & 1528919 & 6.2899 & 6.0413 & TRN & \\
\hline CHEMBL3682788 & 1528919 & 6.3747 & 6.1498 & TRN & \\
\hline CHEMBL3682693 & 1528919 & 5.8356 & 4.997 & TST & \\
\hline CHEMBL3687544 & 1528919 & 6.5229 & 6.534 & TRN & \\
\hline CHEMBL3687743 & 1528919 & 5.9788 & 5.1108 & TST & \\
\hline CHEMBL3682741 & 1528919 & 5.6198 & 5.7176 & TRN & \\
\hline CHEMBL3687723 & 1528919 & 6.5421 & 6.4841 & TRN & \\
\hline CHEMBL3682704 & 1528919 & 6.4789 & 6.2318 & TST & \\
\hline CHEMBL3682719 & 1528919 & 5.6536 & 5.2743 & TRN & \\
\hline CHEMBL3687646 & 1528919 & 5.1733 & 5.3077 & TRN & \\
\hline CHEMBL 3687714 & 1528919 & 5.3936 & 5.5316 & TRN & \\
\hline CHEMBL3682785 & 1528919 & 6.8729 & 6.8451 & TRN & \\
\hline CHEMBL3682820 & 1528919 & 6.3665 & 5.7306 & TST & \\
\hline CHEMBL3687746 & 1528919 & 7.4685 & 7.1764 & TRN & \\
\hline CHEMBL3682793 & 1528919 & 5.1373 & 4.5595 & TST & \\
\hline CHEMBL3682828 & 1528919 & 4.5114 & 4.0822 & TST & \\
\hline CHEMBL3682837 & 1528919 & 5.279 & 5.6448 & TRN & \\
\hline CHEMBL3687711 & 1528919 & 5.5834 & 5.9719 & TRN & \\
\hline CHEMBL3687543 & 1528919 & 6.5528 & 6.4718 & TRN & \\
\hline CHEMBL3687640 & 1528919 & 6.0899 & 6.0321 & TRN & \\
\hline
\end{tabular}


Supplemental Table S2.txt

\begin{tabular}{|c|c|c|c|c|c|}
\hline CHEMBL 3687622 & 1528919 & 7.4202 & 7.4107 & TRN & \\
\hline CHEMBL 3687620 & 1528919 & 7.3979 & 7.2797 & TRN & \\
\hline CHEMBL3682836 & 1528919 & 6.4685 & 6.561 & TRN & \\
\hline CHEMBL 3682767 & 1528919 & 6.4056 & 6.3646 & TRN & \\
\hline CHEMBL3687697 & 1528919 & 6.2741 & 5.8933 & TRN & \\
\hline CHEMBL 3687538 & 1528919 & 6.699 & 6.3998 & TRN & \\
\hline CHEMBL 3687557 & 1528919 & 5.3516 & 5.4019 & TRN & \\
\hline CHEMBL 3682731 & 1528919 & 6.382000 & 000000000 & 6.2166 & TRN \\
\hline CHEMBL 3687664 & 1528919 & 5.9872 & 5.664 & TRN & \\
\hline CHEMBL3687669 & 1528919 & 5.9101 & 5.686 & TRN & \\
\hline CHEMBL 3687594 & 1528919 & 6.3904 & 5.8825 & TRN & \\
\hline CHEMBL3682806 & 1528919 & 6.3468 & 6.1255 & TRN & \\
\hline CHEMBL3687657 & 1528919 & 6.3546 & 6.032999 & 9999999995 & TRN \\
\hline CHEMBL 3682813 & 1528919 & 5.8182 & 5.7719 & TRN & \\
\hline CHEMBL 3692125 & 1528919 & 5.341 & 5.6332 & TRN & \\
\hline CHEMBL 3687604 & 1528919 & 7.6383 & 7.4658 & TRN & \\
\hline CHEMBL3682805 & 1528919 & 6.0991 & 6.0184 & TRN & \\
\hline CHEMBL 3687712 & 1528919 & 5.7258 & 6.1089 & TRN & \\
\hline CHEMBL 3687655 & 1528919 & 5.8761 & 6.1799 & TRN & \\
\hline CHEMBL3687692 & 1528919 & 6.5467 & 6.3532 & TRN & \\
\hline CHEMBL 3687603 & 1528919 & 6.9281 & 6.7561 & TRN & \\
\hline CHEMBL 3682841 & 1528919 & 6.4949 & 6.185 & TRN & \\
\hline CHEMBL3682771 & 1528919 & 5.8861 & 5.7628 & TRN & \\
\hline CHEMBL 3687680 & 1528919 & 3.5229 & 4.4481 & TST & \\
\hline CHEMBL3687623 & 1528919 & 6.7932 & 6.6468 & TRN & \\
\hline CHEMBL 3687541 & 1528919 & 5.7282 & 5.364 & TRN & \\
\hline CHEMBL 3687672 & 1528919 & 6.1046 & 6.0552 & TRN & \\
\hline CHEMBL3687734 & 1528919 & 6.752000 & 000000000 & 6.6329 & TRN \\
\hline CHEMBL 3687706 & 1528919 & 6.7696 & 6.5981 & TRN & \\
\hline CHEMBL3687679 & 1528919 & 5.3401 & 5.7965 & TRN & \\
\hline CHEMBL 3687633 & 1528919 & 6.2676 & 5.9999 & TRN & \\
\hline CHEMBL3682786 & 1528919 & 6.5258 & 6.5247 & TRN & \\
\hline CHEMBL3682748 & 1528919 & 5.5452 & 5.5737 & TRN & \\
\hline CHEMBL 3682772 & 1528919 & 6.3575 & 6.4394 & TRN & \\
\hline CHEMBL3687560 & 1528919 & 6.6778 & 6.5924 & TRN & \\
\hline CHEMBL 3687647 & 1528919 & 5.857 & 6.1745 & TRN & \\
\hline CHEMBL3687713 & 1528919 & 5.5391 & 5.5471 & TRN & \\
\hline CHEMBL3682698 & 1528919 & 5.1057 & 4.8331 & TST & \\
\hline CHEMBL 3682733 & 1528919 & 4.5287 & 4.6496 & TRN & \\
\hline CHEMBL3687674 & 1528919 & 5.8729 & 5.8032 & TRN & \\
\hline CHEMBL3682689 & 1528919 & 6.4908 & 5.5631 & TST & \\
\hline CHEMBL3687705 & 1528919 & 6.4449 & 6.2505 & TRN & \\
\hline CHEMBL3682817 & 1528919 & 6.2924 & 6.425 & TRN & \\
\hline CHEMBL 3687741 & 1528919 & 6.4168 & 6.3237 & TRN & \\
\hline CHEMBL3687551 & 1528919 & 6.3098 & 6.277 & TRN & \\
\hline CHEMBL 3687651 & 1528919 & 6.5171 & 6.8326 & TRN & \\
\hline CHEMBL 3687730 & 1528919 & 7.0223 & 6.9671 & TRN & \\
\hline CHEMBL 3682802 & 1528919 & 6.2526 & 6.1255 & TRN & \\
\hline
\end{tabular}


Supplemental Table S2.txt

\begin{tabular}{|c|c|c|c|c|c|}
\hline CHEMBL 3682808 & 1528919 & 6.0434 & 6.2298 & TRN & \\
\hline CHEMBL3919063 & 1528919 & 3.5229 & 4.6624 & TST & \\
\hline CHEMBL 3687750 & 1528919 & 7.2366 & 7.4208 & TRN & \\
\hline CHEMBL 3687654 & 1528919 & 5.983 & 5.926 & TRN & \\
\hline CHEMBL3687693 & 1528919 & 5.3116 & 5.6526 & TRN & \\
\hline CHEMBL3682690 & 1528919 & 5.6536 & 5.7905 & TST & \\
\hline CHEMBL 3682787 & 1528919 & 5.5143 & 5.6045 & TRN & \\
\hline CHEMBL 3687601 & 1528919 & 6.1805 & 5.8474 & TRN & \\
\hline CHEMBL 3687595 & 1528919 & 6.8097 & 6.5955 & TRN & \\
\hline CHEMBL3682795 & 1528919 & 6.4145 & 6.4764 & TRN & \\
\hline CHEMBL3692126 & 1528919 & 6.1494 & 6.0966 & TRN & \\
\hline CHEMBL 3687737 & 1528919 & 6.3335 & 6.1445 & TRN & \\
\hline CHEMBL 3687597 & 1528919 & 6.4776 & 6.6573 & TRN & \\
\hline CHEMBL 3639864 & 1528919 & 5.2865 & 5.5649 & TST & \\
\hline CHEMBL 3682814 & 1528919 & 6.3768 & 6.3327 & TRN & \\
\hline CHEMBL3682732 & 1528919 & 4.9706 & 5.4364 & TRN & \\
\hline CHEMBL 3682737 & 1528919 & 4.7852 & 4.728 & TRN & \\
\hline CHEMBL 3682717 & 1528919 & 6.2 & 6.3298 & TST & \\
\hline CHEMBL 3687704 & 1528919 & 6.6904 & 6.4272 & TRN & \\
\hline CHEMBL3682807 & 1528919 & 5.8153 & 5.9561 & TRN & \\
\hline CHEMBL 3687643 & 1528919 & 4.6108 & 4.8938 & TRN & \\
\hline CHEMBL 3687747 & 1528919 & 7.1871 & 7.1876 & TRN & \\
\hline CHEMBL3682798 & 1528919 & 6.5702 & 6.5787 & TRN & \\
\hline CHEMBL 3687648 & 1528919 & 5.75700 & 0000000 & 5.6908 & TRN \\
\hline CHEMBL 3687717 & 1528919 & 6.1035 & 6.1404 & TRN & \\
\hline CHEMBL 3687613 & 1528919 & 7.2518 & 7.2498 & TRN & \\
\hline CHEMBL 3687618 & 1528919 & 7.1249 & 7.1052 & TRN & \\
\hline CHEMBL3692165 & 1528919 & 6.5884 & 6.7955 & TRN & \\
\hline CHEMBL 3687716 & 1528919 & 5.5575 & 5.9459 & TRN & \\
\hline CHEMBL3687555 & 1528919 & 5.6946 & 5.8292 & TRN & \\
\hline CHEMBL 3687754 & 1528919 & 4.5331 & 4.9253 & TST & \\
\hline CHEMBL3687656 & 1528919 & 6.3686 & 6.5033 & TST & \\
\hline CHEMBL3682739 & 1528919 & 5.2351 & 5.2057 & TRN & \\
\hline CHEMBL 3687641 & 1528919 & 6.2636 & 6.394 & TRN & \\
\hline CHEMBL3682790 & 1528919 & 6.3726 & 6.6077 & TRN & \\
\hline CHEMBL3682816 & 1528919 & 6.4202 & 6.5016 & TRN & \\
\hline CHEMBL 3687548 & 1528919 & 6.3468 & 6.1662 & TRN & \\
\hline CHEMBL3692130 & 1528919 & 5.4828 & 5.662006 & 2000000001 & TRN \\
\hline CHEMBL 3682752 & 1528919 & 5.8761 & 6.1539 & TRN & \\
\hline CHEMBL3687673 & 1528919 & 6.0783 & 5.8709 & TRN & \\
\hline CHEMBL3687639 & 1528919 & 7.2366 & 7.2074 & TRN & \\
\hline CHEMBL 3682742 & 1528919 & 5.1433 & 5.1305 & TRN & \\
\hline CHEMBL3687550 & 1528919 & 6.301 & 6.2068 & TRN & \\
\hline CHEMBL 3687558 & 1528919 & 5.7144 & 5.5687 & TRN & \\
\hline CHEMBL3682755 & 1528919 & 4.9666 & 4.88899 & 9999999999 & TRN \\
\hline CHEMBL 3682702 & 1528919 & 6.5498 & 6.4611 & TST & \\
\hline CHEMBL 3682723 & 1528919 & 5.3778 & 5.7433 & TST & \\
\hline CHEMBL 3687625 & 1528919 & 5.7282 & 5.7273 & TRN & \\
\hline
\end{tabular}


Supplemental Table S2.txt

\begin{tabular}{|c|c|c|c|c|c|c|}
\hline CHEMBL3687752 & 1528919 & 6.6364 & 6.6668 & TRN & & \\
\hline CHEMBL3687617 & 1528919 & 7.4685 & 7.6912 & TRN & & \\
\hline CHEMBL3682735 & 1528919 & 4.7375 & 4.9991 & TRN & & \\
\hline CHEMBL3687694 & 1528919 & 6.0438 & 6.0347 & TRN & & \\
\hline CHEMBL3692128 & 1528919 & 6.0635 & 6.2489 & TST & & \\
\hline CHEMBL3692151 & 1528919 & 5.162999 & 99999999 & 99 & 5.4857 & TRN \\
\hline CHEMBL3682840 & 1528919 & 5.9788 & 6.0605 & TRN & & \\
\hline CHEMBL3687564 & 1528919 & 5.382006 & 00000000 & $\partial 1$ & 5.4104 & TRN \\
\hline CHEMBL3682791 & 1528919 & 6.5017 & 6.6005 & TRN & & \\
\hline CHEMBL3682764 & 1528919 & 4.7799 & 5.1701 & TRN & & \\
\hline CHEMBL3687677 & 1528919 & 5.6038 & 5.7372 & TRN & & \\
\hline CHEMBL3687719 & 1528919 & 5.8539 & 5.7112 & TRN & & \\
\hline CHEMBL3682710 & 1528919 & 5.5406 & 5.857 & TST & & \\
\hline CHEMBL3682835 & 1528919 & 5.7167 & 5.8409 & TRN & & \\
\hline CHEMBL3687689 & 1528919 & 7.4202 & 6.9446 & TRN & & \\
\hline CHEMBL3682728 & 1528919 & 3.5229 & 3.6857 & TST & & \\
\hline CHEMBL3682714 & 1528919 & 6.308 & 6.0726 & TST & & \\
\hline CHEMBL3682700 & 1528919 & 5.4789 & 6.3113 & TRN & & \\
\hline CHEMBL3682834 & 1528919 & 6.0 & 5.306 & TRN & & \\
\hline CHEMBL3687559 & 1528919 & 5.4828 & 5.8698 & TRN & & \\
\hline CHEMBL3682757 & 1528919 & 3.5229 & 3.6442 & TST & & \\
\hline CHEMBL3639816 & 1528919 & 5.2314 & 5.0577 & TRN & & \\
\hline CHEMBL3687740 & 1528919 & 6.1062 & 6.0966 & TST & & \\
\hline CHEMBL3687742 & 1528919 & 6.3206 & 6.2781 & TRN & & \\
\hline CHEMBL3687727 & 1528919 & 7.1612 & 7.3472 & TRN & & \\
\hline CHEMBL3682729 & 1528919 & 3.5229 & 4.1081 & TST & & \\
\hline CHEMBL3687627 & 1528919 & 7.3188 & 6.8024 & TRN & & \\
\hline CHEMBL3687596 & 1528919 & 6.6003 & 6.5261 & TRN & & \\
\hline CHEMBL3687545 & 1528919 & 5.5986 & 5.7484 & TRN & & \\
\hline CHEMBL3682768 & 1528919 & 6.295 & 6.4931 & TRN & & \\
\hline CHEMBL3692168 & 1528919 & 6.3344 & 6.3025 & TRN & & \\
\hline CHEMBL3687615 & 1528919 & 6.9136 & 6.9424 & TRN & & \\
\hline CHEMBL3687665 & 1528919 & 6.0809 & 6.0463 & TRN & & \\
\hline CHEMBL3687699 & 1528919 & 5.7496 & 5.7893 & TRN & & \\
\hline CHEMBL3682763 & 1528919 & 4.6383 & 4.6803 & TRN & & \\
\hline CHEMBL3687731 & 1528919 & 5.7986 & 6.0222 & TRN & & \\
\hline CHEMBL3687540 & 1528919 & 6.5528 & 6.4368 & TRN & & \\
\hline CHEMBL3682781 & 1528919 & 4.857 & 4.8688 & TRN & & \\
\hline CHEMBL3687562 & 1528919 & 6.2366 & 5.9998 & TRN & & \\
\hline CHEMBL3682773 & 1528919 & 5.8069 & 5.8804 & TRN & & \\
\hline CHEMBL3687666 & 1528919 & 5.1481 & 5.1434 & TRN & & \\
\hline CHEMBL3682809 & 1528919 & 5.1858 & 4.8389 & TRN & & \\
\hline CHEMBL3682821 & 1528919 & 6.0 & 4.9616 & TST & & \\
\hline CHEMBL3692147 & 1528919 & 5.4101 & 5.2486 & TRN & & \\
\hline CHEMBL3687614 & 1528919 & 7.1612 & 7.1676 & TRN & & \\
\hline CHEMBL3682713 & 1528919 & 6.9031 & 6.5707 & TST & & \\
\hline CHEMBL3687642 & 1528919 & 4.7799 & 5.6336 & TRN & & \\
\hline CHEMBL3682695 & 1528919 & 6.0 & 4.4879 & TST & & \\
\hline
\end{tabular}


Supplemental Table S2.txt

\begin{tabular}{|c|c|c|c|c|c|}
\hline CHEMBL 3687547 & 1528919 & 6.8239 & 6.7465 & TRN & \\
\hline CHEMBL3692146 & 1528919 & 6.2218 & 6.5886 & TRN & \\
\hline CHEMBL3687685 & 1528919 & 6.7328 & 6.5931 & TRN & \\
\hline CHEMBL3687611 & 1528919 & 7.5376 & 7.0073 & TRN & \\
\hline CHEMBL3687691 & 1528919 & 5.27 & 5.5065 & TRN & \\
\hline CHEMBL 3682750 & 1528919 & 5.2984 & 5.1415 & TRN & \\
\hline CHEMBL3687686 & 1528919 & 6.6615 & 6.6623 & TRN & \\
\hline CHEMBL3682830 & 1528919 & 4.9626 & 4.4218 & TST & \\
\hline CHEMBL 3687549 & 1528919 & 6.3372 & 5.9731 & TRN & \\
\hline CHEMBL3687696 & 1528919 & 6.08200 & 900000006 & 6.2821 & TRN \\
\hline CHEMBL 3692148 & 1528919 & 5.5969 & 5.5606 & TRN & \\
\hline CHEMBL3682812 & 1528919 & 5.644 & 5.8607 & TRN & \\
\hline CHEMBL3692160 & 1528919 & 5.6716 & 5.6792 & TRN & \\
\hline CHEMBL3682789 & 1528919 & 6.8069 & 6.8684 & TRN & \\
\hline CHEMBL 3682740 & 1528919 & 5.61799 & 99999999 & 5.6149 & TRN \\
\hline CHEMBL 3687552 & 1528919 & 6.3768 & 6.7238 & TRN & \\
\hline CHEMBL3687744 & 1528919 & 5.8928 & 5.741006 & 00000000005 & TRN \\
\hline CHEMBL3682831 & 1528919 & 6.041 & 5.683 & TST & \\
\hline CHEMBL 3687546 & 1528919 & 6.3279 & 5.8735 & TRN & \\
\hline CHEMBL3682716 & 1528919 & 6.2993 & 6.1386 & TST & \\
\hline CHEMBL3682760 & 1528919 & 5.7959 & 5.7906 & TRN & \\
\hline CHEMBL3687593 & 1528919 & 4.4271 & 4.5179 & TST & \\
\hline CHEMBL 3687703 & 1528919 & 6.644 & 6.5873 & TRN & \\
\hline CHEMBL 3687722 & 1528919 & 6.4711 & 6.6191 & TRN & \\
\hline CHEMBL3687726 & 1528919 & 6.9957 & 7.1416 & TRN & \\
\hline CHEMBL3692167 & 1528919 & 5.2248 & 5.1025 & TRN & \\
\hline CHEMBL 3682738 & 1528919 & 5.8633 & 6.0947 & TRN & \\
\hline CHEMBL 3687637 & 1528919 & 5.8477 & 6.1193 & TRN & \\
\hline CHEMBL3682815 & 1528919 & 6.2291 & 6.2868 & TRN & \\
\hline CHEMBL3687707 & 1528919 & 6.7447 & 6.5815 & TRN & \\
\hline CHEMBL 3682743 & 1528919 & 5.9914 & 5.904 & TRN & \\
\hline CHEMBL 3682680 & 1528919 & 6.2306 & 5.8158 & TST & \\
\hline CHEMBL 3687687 & 1528919 & 6.8182 & 6.6599 & TRN & \\
\hline CHEMBL 3687675 & 1528919 & 5.7799 & 5.8925 & TRN & \\
\hline CHEMBL3682753 & 1528919 & 6.4056 & 6.1399 & TRN & \\
\hline CHEMBL3682759 & 1528919 & 5.3706 & 5.6353 & TRN & \\
\hline CHEMBL3687732 & 1528919 & 6.5884 & 6.7312 & TRN & \\
\hline CHEMBL3687598 & 1528919 & 5.6383 & 5.734 & TRN & \\
\hline CHEMBL 3682725 & 1528919 & 4.4672 & 4.7933 & TST & \\
\hline CHEMBL3682685 & 1528919 & 5.8327 & 5.7289 & TST & \\
\hline CHEMBL 3687700 & 1528919 & 6.6925 & 6.2998 & TRN & \\
\hline CHEMBL3682799 & 1528919 & 6.4437 & 6.7002 & TRN & \\
\hline CHEMBL3687659 & 1528919 & 5.3036 & 5.388 & TRN & \\
\hline CHEMBL 3687599 & 1528919 & 6.1791 & 6.3302 & TRN & \\
\hline CHEMBL3682712 & 1528919 & 6.7471 & 6.0629 & TST & \\
\hline CHEMBL 3687684 & 1528919 & 6.5528 & 6.6475 & TRN & \\
\hline CHEMBL3687612 & 1528919 & 7.5086 & 7.5919 & TRN & \\
\hline CHEMBL 3687567 & 1528919 & 6.2218 & 6.0215 & TRN & \\
\hline
\end{tabular}


Supplemental Table S2.txt

\begin{tabular}{|c|c|c|c|c|c|c|}
\hline CHEMBL 3682721 & 1528919 & 5.0969 & 5.285 & TRN & & \\
\hline CHEMBL 3692129 & 1528919 & 6.2941 & 6.6555 & TRN & & \\
\hline CHEMBL 3687720 & 1528919 & 6.75200 & 000000006 & & 6.6885 & TRN \\
\hline CHEMBL 3682692 & 1528919 & 5.3516 & 5.0013 & TST & & \\
\hline CHEMBL 3687632 & 1528919 & 5.9706 & 5.8839 & TRN & & \\
\hline CHEMBL3687561 & 1528919 & 6.4949 & 6.6432 & TRN & & \\
\hline CHEMBL3341980 & 1528919 & 7.7212 & 7.7271 & TRN & & \\
\hline CHEMBL 3687709 & 1528919 & 7.2007 & 6.8875 & TRN & & \\
\hline CHEMBL 3687600 & 1528919 & 5.2916 & \multicolumn{3}{|c|}{5.882999999999999} & TRN \\
\hline CHEMBL 3682694 & 1528919 & 4.9281 & 5.3268 & TST & & \\
\hline CHEMBL 3687662 & 1528919 & 5.7773 & 5.8592 & TRN & & \\
\hline CHEMBL 3687629 & 1528919 & 6.4045 & 6.1335 & TRN & & \\
\hline CHEMBL 3687608 & 1528919 & 7.284 & 7.1442 & TRN & & \\
\hline CHEMBL 3687733 & 1528919 & 5.5229 & 5.8616 & TRN & & \\
\hline CHEMBL 3682770 & 1528919 & 5.7328 & 5.7348 & TRN & & \\
\hline CHEMBL 3687755 & 1528919 & 6.0128 & 5.9086 & TRN & & \\
\hline CHEMBL3682769 & 1528919 & 6.301 & \multicolumn{3}{|c|}{6.457000000000001} & TRN \\
\hline CHEMBL 3687635 & 1528919 & 7.3872 & 7.4558 & TRN & & \\
\hline CHEMBL3687721 & 1528919 & 6.8928 & 6.6636 & TRN & & \\
\hline CHEMBL 3687663 & 1528919 & 6.1643 & 5.9463 & TRN & & \\
\hline CHEMBL 3682800 & 1528919 & 6.6757 & 6.499 & TRN & & \\
\hline CHEMBL3682811 & 1528919 & 6.1302 & 6.4073 & TRN & & \\
\hline CHEMBL 3692158 & 1528919 & 6.1662 & 6.4129 & TRN & & \\
\hline CHEMBL3682829 & 1528919 & 4.5622 & 4.9513 & TST & & \\
\hline CHEMBL 3687749 & 1528919 & 5.6383 & 6.1598 & TRN & & \\
\hline CHEMBL 3687678 & 1528919 & 5.3546 & \multicolumn{3}{|c|}{5.547000000000001} & TRN \\
\hline CHEMBL3682691 & 1528919 & 4.8861 & \multicolumn{3}{|c|}{5.1160000000000005} & TST \\
\hline CHEMBL3687676 & 1528919 & 5.6556 & 6.2294 & TRN & & \\
\hline CHEMBL3682711 & 1528919 & 6.1858 & 6.3063 & TST & & \\
\hline CHEMBL 3682818 & 1528919 & 6.0088 & 6.2353 & TRN & & \\
\hline CHEMBL 3687542 & 1528919 & 6.8239 & 6.8783 & TRN & & \\
\hline CHEMBL 3687668 & 1528919 & 5.9136 & 5.9677 & TRN & & \\
\hline CHEMBL3687715 & 1528919 & 5.4389 & 6.0351 & TRN & & \\
\hline CHEMBL3692163 & 1528919 & 6.9066 & 6.4812 & TRN & & \\
\hline CHEMBL 3682703 & 1528919 & 6.8539 & 6.4347 & TST & & \\
\hline CHEMBL 3682779 & 1528919 & 5.45100 & \multicolumn{2}{|c|}{30000000005} & 5.7988 & TRN \\
\hline CHEMBL 3687729 & 1528919 & 7.1079 & 7.3352 & TRN & & \\
\hline CHEMBL 3682708 & 1528919 & 6.1599 & 6.7542 & TST & & \\
\hline CHEMBL3692150 & 1528919 & 5.6308 & 5.8006 & TRN & & \\
\hline CHEMBL 3692161 & 1528919 & 6.1046 & 5.7283 & TRN & & \\
\hline CHEMBL 3692157 & 1528919 & 6.7055 & 6.6245 & TRN & & \\
\hline CHEMBL 3692152 & 1528919 & 6.8153 & 6.4214 & TST & & \\
\hline CHEMBL3692159 & 1528919 & 5.3468 & 4.7385 & TRN & & \\
\hline CHEMBL3692132 & 1528919 & 6.3279 & 5.9485 & TRN & & \\
\hline CHEMBL3687569 & 1528919 & 5.6021 & 5.3366 & TRN & & \\
\hline CHEMBL 3682746 & 1528919 & 5.6615 & 5.865 & TRN & & \\
\hline CHEMBL 3682709 & 1528919 & 6.2055 & 6.42 & TST & & \\
\hline CHEMBL3687607 & 1528919 & 6.9626 & 6.9497 & TRN & & \\
\hline
\end{tabular}

Page 12846 
Supplemental Table S2.txt

\begin{tabular}{|c|c|c|c|c|}
\hline CHEMBL 3687630 & 1528919 & 5.6234 & 5.6216 & TRN \\
\hline CHEMBL 3682774 & 1528919 & 4.9318 & 5.1253 & TRN \\
\hline CHEMBL3687553 & 1528919 & 6.4559 & 6.4095 & TRN \\
\hline CHEMBL 3687644 & 1528919 & 5.6162 & 5.7302 & TRN \\
\hline CHEMBL 3687670 & 1528919 & 6.5654 & 6.3325 & TRN \\
\hline CHEMBL 3682784 & 1528919 & 6.5935 & 6.5588 & TRN \\
\hline CHEMBL 3682833 & 1528919 & 5.9393 & 6.0501 & TRN \\
\hline CHEMBL3692131 & 1528919 & 6.2118 & 6.0907 & TRN \\
\hline CHEMBL3687605 & 1528919 & 7.5528 & 7.3219 & TRN \\
\hline CHEMBL3682801 & 1528919 & 7.0655 & 6.8008 & TRN \\
\hline CHEMBL 3687724 & 1528919 & 7.0044 & 6.9119 & TRN \\
\hline CHEMBL 3687660 & 1528919 & 6.0061 & 6.2054 & TRN \\
\hline CHEMBL 3682724 & 1528919 & 5.1024 & 4.8036 & TST \\
\hline CHEMBL3692164 & 1528919 & 7.2366 & 7.476 & TRN \\
\hline CHEMBL 3687718 & 1528919 & 6.109 & 5.70299 & 9999999999 \\
\hline CHEMBL 3682722 & 1528919 & 5.3458 & 4.7016 & TST \\
\hline CHEMBL3687671 & 1528919 & 6.4353 & 6.4043 & TRN \\
\hline CHEMBL3682699 & 1528919 & 5.4157 & 4.4882 & TST \\
\hline CHEMBL3692133 & 1528919 & 6.5686 & 6.4709 & TRN \\
\hline CHEMBL 3687708 & 1528919 & 7.2518 & 6.9689 & TRN \\
\hline CHEMBL 3682734 & 1528919 & 5.7471 & 5.8474 & TRN \\
\hline CHEMBL 3682747 & 1528919 & 5.9469 & 5.9135 & TRN \\
\hline CHEMBL 3687650 & 1528919 & 6.9547 & 6.9819 & TRN \\
\hline CHEMBL 3687661 & 1528919 & 6.1612 & 6.3038 & TRN \\
\hline CHEMBL 3639865 & 1528919 & 5.7375 & 5.7633 & TRN \\
\hline CHEMBL 3682838 & 1528919 & 6.8239 & 6.7333 & TRN \\
\hline CHEMBL 3687610 & 1528919 & 6.4112 & \multicolumn{2}{|c|}{6.827000000000001} \\
\hline CHEMBL 3682810 & 1528919 & 6.5045 & 6.5396 & TRN \\
\hline CHEMBL3687539 & 1528919 & 6.0177 & 6.0366 & TRN \\
\hline CHEMBL 3682778 & 1528919 & 5.4012 & 5.5953 & TRN \\
\hline CHEMBL 3682707 & 1528919 & 4.9469 & 4.3934 & TST \\
\hline CHEMBL 3682686 & 1528919 & 4.9788 & 5.5041 & TST \\
\hline CHEMBL 3687725 & 1528919 & 7.2076 & 7.256 & TRN \\
\hline CHEMBL 3682701 & 1528919 & 6.6778 & 5.8524 & TST \\
\hline CHEMBL 3682827 & 1528919 & 4.9469 & 4.2068 & TST \\
\hline CHEMBL 3687556 & 1528919 & 6.2366 & 6.0135 & TRN \\
\hline CHEMBL 3687628 & 1528919 & 5.7328 & 5.4251 & TRN \\
\hline CHEMBL 3692155 & 1528919 & 5.5317 & 5.9558 & TST \\
\hline CHEMBL 3687645 & 1528919 & 5.2874 & 5.516 & TRN \\
\hline CHEMBL3692166 & 1528919 & 5.3883 & 5.7119 & TRN \\
\hline CHEMBL3692162 & 1528919 & 6.1192 & 6.8133 & TRN \\
\hline CHEMBL3687757 & 1528919 & 5.2993 & 5.4598 & TRN \\
\hline CHEMBL 3682782 & 1528919 & 6.4815 & 6.0997 & TRN \\
\hline CHEMBL3682796 & 1528919 & 6.0516 & 5.56 & TRN \\
\hline CHEMBL 3687756 & 1528919 & 5.7447 & 6.2231 & TRN \\
\hline CHEMBL 3687702 & 1528919 & 6.2464 & 6.1504 & TRN \\
\hline CHEMBL 3687701 & 1528919 & 6.4202 & 6.2381 & TRN \\
\hline CHEMBL3687649 & 1528919 & 5.5544 & 5.1533 & TRN \\
\hline
\end{tabular}

Page 12847 
Supplemental Table S2.txt

\begin{tabular}{|c|c|c|c|c|}
\hline CHEMBL 3687748 & 1528919 & 7.0 & 7.0223 & TRN \\
\hline CHEMBL 3682804 & 1528919 & 5.3344 & 5.7033 & TRN \\
\hline CHEMBL3682745 & 1528919 & 6.0391 & 5.9597 & TRN \\
\hline CHEMBL 3687636 & 1528919 & 7.3188 & 7.0784 & TRN \\
\hline CHEMBL 3682824 & 1528919 & 6.4089 & 6.2067 & TRN \\
\hline CHEMBL 3682797 & 1528919 & 6.6003 & 6.6046 & TRN \\
\hline CHEMBL3692153 & 1528919 & 6.51 & 6.6688 & TRN \\
\hline CHEMBL3682706 & 1528919 & 6.9281 & 6.4049 & TST \\
\hline CHEMBL 3682825 & 1528919 & 6.3188 & 6.2676 & TRN \\
\hline CHEMBL 3687736 & 1528919 & 6.6615 & 6.5284 & TRN \\
\hline CHEMBL 3682765 & 1528919 & 5.058 & 5.3505 & TRN \\
\hline CHEMBL 3687565 & 1528919 & 6.2218 & 6.2231 & TRN \\
\hline CHEMBL 3687563 & 1528919 & 5.3747 & 5.2674 & TRN \\
\hline CHEMBL 3682819 & 1528919 & 6.8239 & 5.8935 & TRN \\
\hline CHEMBL 3687735 & 1528919 & 5.8861 & 5.8949 & TST \\
\hline CHEMBL 3682780 & 1528919 & 4.8697 & 5.1017 & TRN \\
\hline CHEMBL 3687710 & 1528919 & 5.8665 & 5.4742 & TRN \\
\hline CHEMBL 3687621 & 1528919 & 6.9914 & 6.6813 & TRN \\
\hline CHEMBL3687606 & 1528919 & 7.1249 & 7.0947 & TRN \\
\hline CHEMBL 3682794 & 1528919 & 4.5607 & 4.6228 & TST \\
\hline CHEMBL 3687688 & 1528919 & 6.6253 & 6.2785 & TRN \\
\hline CHEMBL 3687695 & 1528919 & 5.3279 & 5.6159 & TRN \\
\hline CHEMBL 3687638 & 1528919 & 6.9136 & 6.87700 & 0000000001 \\
\hline CHEMBL3687682 & 1528919 & 7.1135 & 6.6615 & TST \\
\hline CHEMBL 3687667 & 1528919 & 5.9706 & 6.4304 & TST \\
\hline CHEMBL 3687753 & 1528919 & 6.0017 & 6.7901 & TST \\
\hline CHEMBL 3687745 & 1528919 & 5.585 & 5.7331 & TST \\
\hline CHEMBL 3687634 & 1528919 & 7.4437 & 6.9465 & TST \\
\hline CHEMBL3682766 & 1528919 & 4.5258 & 5.2384 & TST \\
\hline CHEMBL 3687653 & 1528919 & 6.1186 & 6.6202 & TST \\
\hline CHEMBL 3687690 & 1528919 & 7.4685 & 6.57100 & 3000000001 \\
\hline CHEMBL 3692156 & 1528919 & 5.4535 & 5.4493 & TST \\
\hline CHEMBL 3682683 & 1528919 & 6.0 & 5.4485 & TST \\
\hline CHEMBL 3687566 & 1528919 & 6.4685 & 5.9588 & TST \\
\hline CHEMBL 3687683 & 1528919 & 7.0605 & 6.8788 & TST \\
\hline CHEMBL 3682705 & 1528919 & 6.3382 & 6.21299 & э999999999 \\
\hline CHEMBL 3687728 & 1528919 & 7.0655 & 7.1477 & TST \\
\hline CHEMBL 3692149 & 1528919 & 6.8239 & 6.2196 & TST \\
\hline CHEMBL 3687554 & 1528919 & 6.4685 & 6.1867 & TST \\
\hline CHEMBL 3682826 & 1528919 & 4.9706 & 5.0246 & TST \\
\hline CHEMBL 3682688 & 1528919 & 7.2426 & 6.9054 & TST \\
\hline CHEMBL 3687681 & 1528919 & 5.3872 & 5.3794 & TST \\
\hline CHEMBL 3687652 & 1528919 & 6.4711 & 6.8872 & TST \\
\hline CHEMBL 3687624 & 1528919 & 7.1192 & 7.2561 & TST \\
\hline CHEMBL 3682803 & 1528919 & 6.1599 & 6.2366 & TST \\
\hline CHEMBL 3682832 & 1528919 & 6.5376 & 6.4483 & TST \\
\hline CHEMBL 3687619 & 1528919 & 6.8794 & 6.8349 & TST \\
\hline CHEMBL 3682792 & 1528919 & 5.3546 & 5.1838 & TST \\
\hline
\end{tabular}




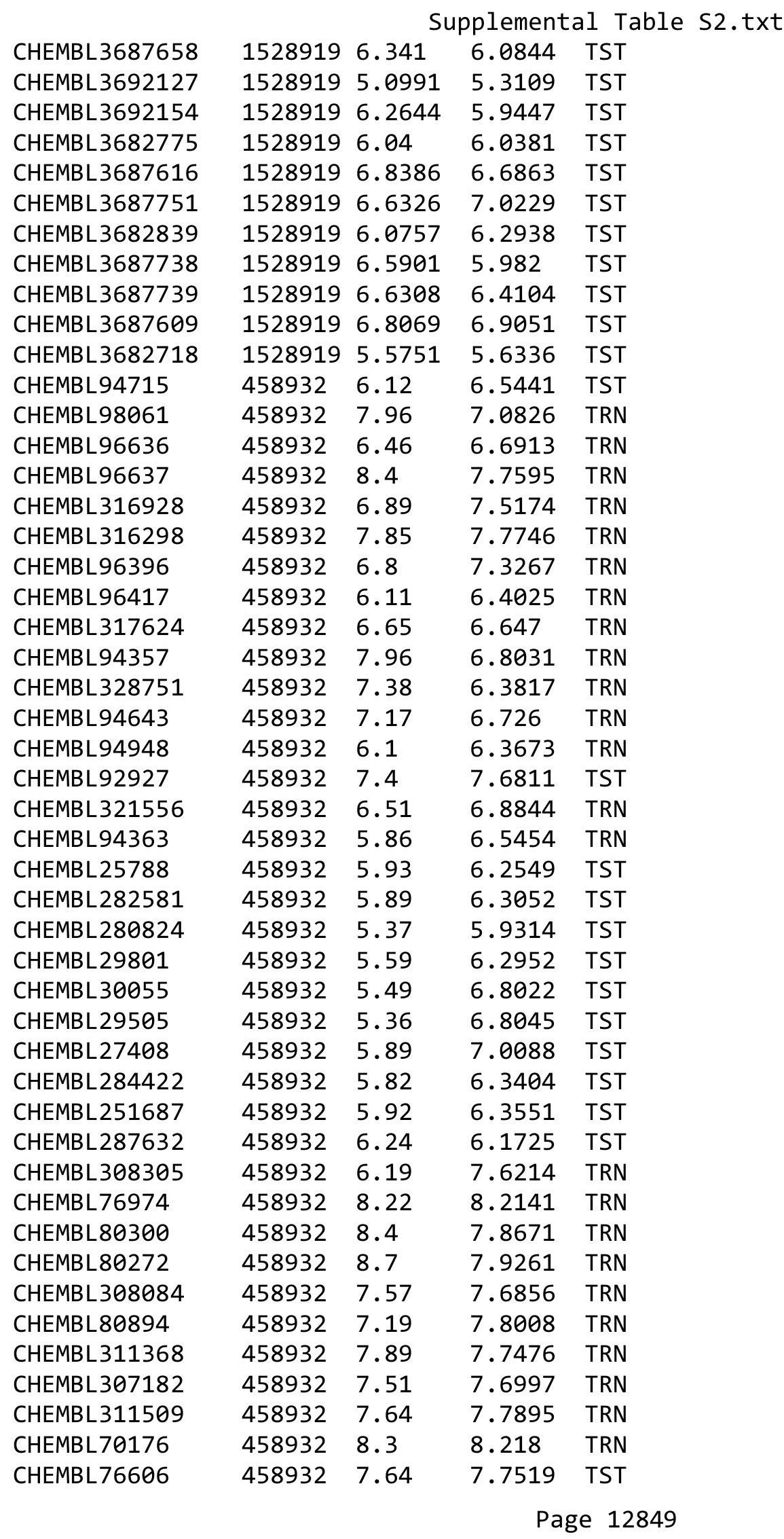




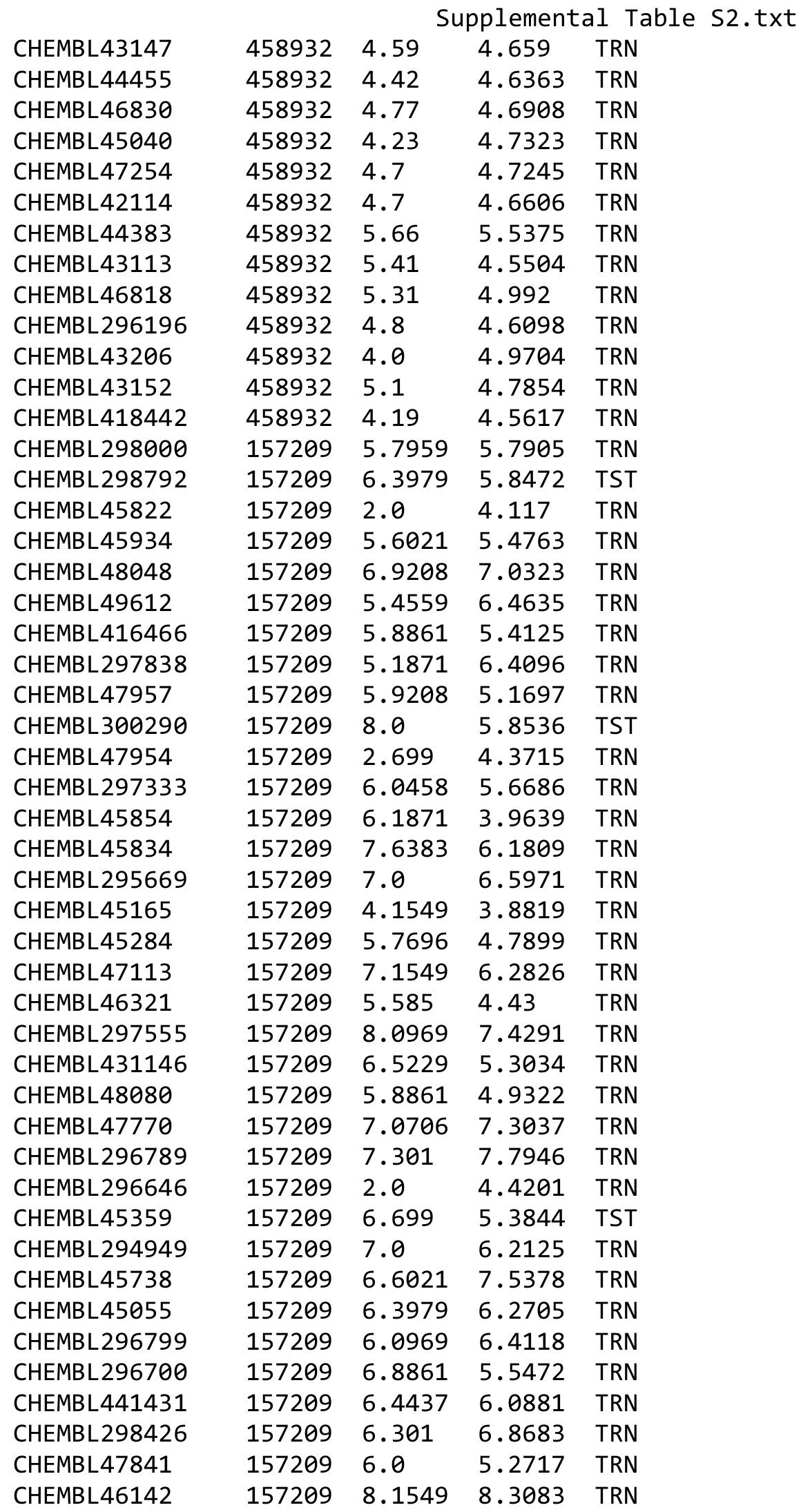

Page 12850 


\begin{tabular}{|c|c|c|c|c|}
\hline & & & pplement & al $\mathrm{T}$ \\
\hline CHEMBL44967 & 157209 & 2.699 & 4.9145 & TRN \\
\hline CHEMBL 289190 & 157209 & 6.7212 & 4.619 & TRN \\
\hline CHEMBL47288 & 157209 & 6.699 & 6.9039 & TRN \\
\hline CHEMBL 296477 & 157209 & 9.0 & 7.4742 & TST \\
\hline CHEMBL 296882 & 157209 & 6.2596 & 7.0461 & TRN \\
\hline CHEMBL 298262 & 157209 & 7.699 & 6.6124 & TRN \\
\hline CHEMBL 301813 & 157209 & 6.2596 & 7.4122 & TRN \\
\hline CHEMBL 276118 & 157209 & 2.0 & 5.2846 & TST \\
\hline CHEMBL 295976 & 157209 & 7.7959 & 7.3048 & TRN \\
\hline CHEMBL44673 & 157209 & 6.301 & 5.1851 & TRN \\
\hline CHEMBL48017 & 157209 & 7.0 & 7.2655 & TRN \\
\hline CHEMBL44109 & 157209 & 5.5086 & 4.8396 & TRN \\
\hline CHEMBL45231 & 157209 & 5.9208 & 5.0806 & TRN \\
\hline CHEMBL45855 & 157209 & 4.4318 & 5.7356 & TST \\
\hline CHEMBL46327 & 157209 & 2.0 & 3.397 & TRN \\
\hline CHEMBL 296626 & 157209 & 2.0 & 3.2677 & TRN \\
\hline CHEMBL47683 & 157209 & 4.9706 & 5.0149 & TRN \\
\hline CHEMBL291189 & 157209 & 2.0 & 4.4301 & TRN \\
\hline CHEMBL45128 & 157209 & 6.6198 & 5.8695 & TRN \\
\hline CHEMBL 296575 & 157209 & 6.0 & 6.1544 & TRN \\
\hline CHEMBL 300661 & 157209 & 7.1549 & 7.9275 & TRN \\
\hline CHEMBL46044 & 157209 & 6.3979 & 6.7887 & TRN \\
\hline CHEMBL44629 & 157209 & 6.5229 & 5.9335 & TST \\
\hline CHEMBL45395 & 157209 & 8.699 & 6.4173 & TST \\
\hline CHEMBL46066 & 157209 & 4.8239 & 6.3624 & TST \\
\hline CHEMBL50012 & 157209 & 6.3468 & 5.9103 & TST \\
\hline CHEMBL432500 & 157209 & 2.0 & 4.1107 & TST \\
\hline CHEMBL 297149 & 157209 & 6.301 & 6.9058 & TST \\
\hline CHEMBL44790 & 157209 & 7.4559 & 7.9893 & TST \\
\hline CHEMBL45687 & 157209 & 6.6021 & 5.7366 & TST \\
\hline CHEMBL47286 & 157209 & 7.0 & 6.6623 & TST \\
\hline CHEMBL 296138 & 157209 & 5.5086 & 6.7109 & TST \\
\hline CHEMBL416815 & 157209 & 5.5229 & 4.942 & TST \\
\hline CHEMBL3640613 & 1528915 & 5.8289 & 5.9743 & TRN \\
\hline CHEMBL3640578 & 1528915 & 5.0 & 5.1404 & TRN \\
\hline CHEMBL 3640575 & 1528915 & 7.8099 & 7.7473 & TRN \\
\hline CHEMBL 3640557 & 1528915 & 7.87 & 7.8187 & TRN \\
\hline CHEMBL3640560 & 1528915 & 6.1192 & 6.3031 & TRN \\
\hline CHEMBL 3640576 & 1528915 & 6.3872 & 6.4032 & TRN \\
\hline CHEMBL3640573 & 1528915 & 8.0511 & 8.0666 & TRN \\
\hline CHEMBL3640592 & 1528915 & 7.284 & 7.4481 & TST \\
\hline CHEMBL 3640569 & 1528915 & 7.5935 & 7.346 & TST \\
\hline CHEMBL3640586 & 1528915 & 5.6445 & 6.8051 & TST \\
\hline CHEMBL 3640558 & 1528915 & 7.301 & 8.0481 & TRN \\
\hline CHEMBL3640562 & 1528915 & 6.0 & 6.4474 & TRN \\
\hline CHEMBL3640610 & 1528915 & 6.8861 & 6.8981 & TRN \\
\hline CHEMBL3640600 & 1528915 & 6.5086 & 5.7784 & TST \\
\hline CHEMBL3640609 & 1528915 & 5.7696 & 7.4477 & TST \\
\hline
\end{tabular}


Supplemental Table S2.txt

\begin{tabular}{|c|c|c|c|c|}
\hline CHEMBL3640599 & 1528915 & 7.0956 & 6.907 & TRN \\
\hline CHEMBL3640577 & 1528915 & 6.8962 & 6.729 & TRN \\
\hline CHEMBL 3640583 & 1528915 & 6.1759 & 6.1363 & TRN \\
\hline CHEMBL3640597 & 1528915 & 6.8239 & 5.2227 & TST \\
\hline CHEMBL 3640585 & 1528915 & 5.0 & 5.0887 & TRN \\
\hline CHEMBL3640581 & 1528915 & 6.3429 & 6.2021 & TRN \\
\hline CHEMBL3640590 & 1528915 & 8.2628 & 7.6078 & TST \\
\hline CHEMBL 3640552 & 1528915 & 7.4701 & 7.4119 & TRN \\
\hline CHEMBL3640588 & 1528915 & 6.3279 & 6.3955 & TRN \\
\hline CHEMBL3640614 & 1528915 & 7.2291 & 7.5028 & TRN \\
\hline CHEMBL3640605 & 1528915 & 6.6778 & 6.7865 & TRN \\
\hline CHEMBL3640555 & 1528915 & 8.0862 & 7.7308 & TRN \\
\hline CHEMBL 3640587 & 1528915 & 6.7235 & 6.4193 & TRN \\
\hline CHEMBL3640568 & 1528915 & 6.5229 & 6.4121 & TRN \\
\hline CHEMBL 3640570 & 1528915 & 7.4604 & 7.6653 & TRN \\
\hline CHEMBL3640572 & 1528915 & 7.1739 & 7.0114 & TRN \\
\hline CHEMBL3640611 & 1528915 & 6.4202 & 6.5171 & TRN \\
\hline CHEMBL3639394 & 1528915 & 6.9208 & 6.7815 & TRN \\
\hline CHEMBL3640582 & 1528915 & 6.2798 & 6.3104 & TRN \\
\hline CHEMBL3640551 & 1528915 & 7.6778 & 7.4394 & TRN \\
\hline CHEMBL3640602 & 1528915 & 6.7447 & 6.8728 & TRN \\
\hline CHEMBL3640579 & 1528915 & 6.2941 & 6.3075 & TRN \\
\hline CHEMBL3640580 & 1528915 & 5.0 & 5.2841 & TRN \\
\hline CHEMBL3640556 & 1528915 & 8.0 & 7.905 & TRN \\
\hline CHEMBL3640550 & 1528915 & 8.4214 & 8.0113 & TRN \\
\hline CHEMBL3640606 & 1528915 & 6.4815 & 5.6556 & TST \\
\hline CHEMBL3640574 & 1528915 & 7.9792 & 8.0569 & TRN \\
\hline CHEMBL3640571 & 1528915 & 6.1238 & 5.7193 & TRN \\
\hline CHEMBL3640596 & 1528915 & 6.8861 & 6.32299 & 99999999995 \\
\hline CHEMBL3640591 & 1528915 & 7.7212 & 7.6055 & TST \\
\hline CHEMBL3640593 & 1528915 & 6.9318 & 6.4808 & TST \\
\hline CHEMBL3640607 & 1528915 & 6.5229 & 7.9272 & TST \\
\hline CHEMBL3640595 & 1528915 & 7.704 & 7.7588 & TST \\
\hline CHEMBL 3640564 & 1528915 & 6.9208 & 6.5102 & TRN \\
\hline CHEMBL3640598 & 1528915 & 6.9208 & 6.8778 & TRN \\
\hline CHEMBL3640559 & 1528915 & 6.9508 & 7.1986 & TRN \\
\hline CHEMBL3640561 & 1528915 & 6.1135 & 6.2409 & TRN \\
\hline CHEMBL3640584 & 1528915 & 6.1221 & 6.0476 & TRN \\
\hline CHEMBL 3640567 & 1528915 & 6.2733 & 6.0316 & TRN \\
\hline CHEMBL3640554 & 1528915 & 7.7212 & 7.7826 & TRN \\
\hline CHEMBL3640604 & 1528915 & 6.8096 & 6.2417 & TST \\
\hline CHEMBL 3640608 & 1528915 & 6.1367 & 6.7855 & TST \\
\hline CHEMBL3640565 & 1528915 & 6.9431 & 6.928 & TRN \\
\hline CHEMBL3640603 & 1528915 & 7.2523 & 7.3969 & TRN \\
\hline CHEMBL3640589 & 1528915 & 6.6778 & 6.7627 & TRN \\
\hline CHEMBL3640601 & 1528915 & 6.3665 & 5.6281 & TST \\
\hline CHEMBL3640566 & 1528915 & 8.3546 & 8.2695 & TRN \\
\hline CHEMBL3640553 & 1528915 & 7.9586 & 7.9705 & TRN \\
\hline
\end{tabular}


Supplemental Table S2.txt

\begin{tabular}{|c|c|c|c|c|c|}
\hline CHEMBL3640612 & 1528915 & 6.9208 & 6.8975 & TRN & \\
\hline CHEMBL3640594 & 1528915 & 8.09799 & 99999999 & 7.8619 & TST \\
\hline CHEMBL3640563 & 1528915 & 6.6021 & 6.6636 & TRN & \\
\hline CHEMBL338118 & 145030 & 7.2441 & 7.1776 & TRN & \\
\hline CHEMBL131551 & 145030 & 7.2757 & \multicolumn{2}{|c|}{7.087000000000001} & TR \\
\hline CHEMBL422080 & 145030 & 6.9586 & 6.7613 & TRN & \\
\hline CHEMBL341311 & 145030 & 7.3468 & 7.4766 & TRN & \\
\hline CHEMBL338636 & 145030 & 6.9208 & 6.8828 & TRN & \\
\hline CHEMBL337667 & 145030 & 6.7447 & 6.9212 & TRN & \\
\hline CHEMBL338951 & 145030 & 7.5229 & 7.7126 & TRN & \\
\hline CHEMBL131101 & 145030 & 5.0 & 6.3338 & TST & \\
\hline CHEMBL435613 & 145030 & 6.8539 & 6.7977 & TST & \\
\hline CHEMBL421090 & 145030 & 6.8539 & 6.7001 & TRN & \\
\hline CHEMBL129983 & 145030 & 7.6778 & 7.3365 & TRN & \\
\hline CHEMBL337519 & 145030 & 6.0 & 7.1 & TRN & \\
\hline CHEMBL338576 & 145030 & 7.7959 & 7.6746 & TRN & \\
\hline CHEMBL128327 & 145030 & 6.8239 & 6.6881 & TST & \\
\hline CHEMBL132165 & 145030 & 7.0969 & 7.1321 & TRN & \\
\hline CHEMBL336992 & 145030 & 6.9586 & 6.7895 & TRN & \\
\hline CHEMBL128423 & 145030 & 7.0915 & 7.2133 & TRN & \\
\hline CHEMBL130768 & 145030 & 7.0 & 6.8488 & TRN & \\
\hline CHEMBL341507 & 145030 & 6.699 & 6.9372 & TRN & \\
\hline CHEMBL421248 & 145030 & 7.1675 & 7.1076 & TRN & \\
\hline CHEMBL420144 & 145030 & 5.7447 & 6.1659 & TST & \\
\hline CHEMBL335634 & 145030 & 7.0223 & 6.8606 & TRN & \\
\hline CHEMBL131564 & 145030 & 6.8239 & 6.9335 & TRN & \\
\hline CHEMBL127445 & 145030 & 7.3665 & 7.45100 & 00000000005 & \\
\hline CHEMBL339497 & 145030 & 7.9586 & 7.7593 & TRN & \\
\hline CHEMBL 338490 & 145030 & 6.2441 & 6.2863 & TRN & \\
\hline CHEMBL 339768 & 145030 & 8.2291 & 7.6811 & TST & \\
\hline CHEMBL419973 & 145030 & 7.3098 & 7.5763 & TRN & \\
\hline CHEMBL339132 & 145030 & 7.8539 & 7.404 & TRN & \\
\hline CHEMBL338503 & 145030 & 7.3768 & 7.1162 & TRN & \\
\hline CHEMBL335886 & 145030 & 7.5686 & 7.0574 & TRN & \\
\hline CHEMBL 338921 & 145030 & 8.7696 & 8.4715 & TRN & \\
\hline CHEMBL335944 & 145030 & 7.5376 & 7.0453 & TRN & \\
\hline CHEMBL341338 & 145030 & 7.3188 & 7.0261 & TRN & \\
\hline CHEMBL338177 & 145030 & 6.7696 & 6.935 & TRN & \\
\hline CHEMBL128726 & 145030 & 7.0 & 7.0449 & TRN & \\
\hline CHEMBL 338548 & 145030 & 7.301 & 7.1186 & TRN & \\
\hline CHEMBL338711 & 145030 & 9.1549 & 8.7127 & TRN & \\
\hline CHEMBL131269 & 145030 & 6.9208 & 6.6228 & TRN & \\
\hline CHEMBL339783 & 145030 & 6.2076 & 6.138 & TRN & \\
\hline CHEMBL340964 & 145030 & 7.0132 & 6.9625 & TRN & \\
\hline CHEMBL340915 & 145030 & 7.2676 & 7.0723 & TRN & \\
\hline CHEMBL128163 & 145030 & 7.3188 & 7.1149 & TRN & \\
\hline CHEMBL132211 & 145030 & 7.2147 & 6.8939 & TRN & \\
\hline CHEMBL129971 & 145030 & 7.2218 & 7.2924 & TRN & \\
\hline
\end{tabular}




\begin{tabular}{|c|c|c|c|c|c|}
\hline \multirow[b]{2}{*}{ CHEMBL336082 } & \multicolumn{5}{|c|}{ Supplemental Table S2.txt } \\
\hline & 145030 & 8.6576 & 8.3841 & TRN & \\
\hline CHEMBL131613 & 145030 & 6.0 & 6.6342 & TRN & \\
\hline CHEMBL435409 & 145030 & 7.6383 & 7.2744 & TRN & \\
\hline CHEMBL340150 & 145030 & 6.3372 & 6.3975 & TRN & \\
\hline CHEMBL 2111851 & 145030 & 6.0 & 7.4451 & TRN & \\
\hline CHEMBL132157 & 145030 & 7.5229 & 7.2917 & TRN & \\
\hline CHEMBL449399 & 145030 & 7.3098 & 7.4095 & TRN & \\
\hline CHEMBL128712 & 145030 & 7.8539 & 7.2894 & TST & \\
\hline CHEMBL338984 & 145030 & 8.3768 & 7.4012 & TST & \\
\hline CHEMBL131538 & 145030 & 7.0458 & 6.75200 & 0000000001 & TST \\
\hline CHEMBL128680 & 145030 & 6.7696 & 6.6368 & TRN & \\
\hline CHEMBL132391 & 145030 & 7.0 & 7.1384 & TRN & \\
\hline CHEMBL339151 & 145030 & 6.8861 & 6.7005 & TRN & \\
\hline CHEMBL130770 & 145030 & 6.585 & 6.37799 & 9999999999 & TRN \\
\hline CHEMBL338383 & 145030 & 7.7447 & 7.2505 & TST & \\
\hline CHEMBL131477 & 145030 & 8.9208 & 8.7371 & TRN & \\
\hline CHEMBL423156 & 145030 & 6.7959 & 6.5078 & TRN & \\
\hline CHEMBL339155 & 145030 & 7.5229 & 7.0022 & TRN & \\
\hline CHEMBL341049 & 145030 & 7.9208 & 7.8245 & TST & \\
\hline CHEMBL128388 & 145030 & 6.6778 & 6.9132 & TST & \\
\hline CHEMBL337615 & 145030 & 7.1024 & 6.7028 & TRN & \\
\hline CHEMBL128328 & 145030 & 6.8539 & 6.74 & TRN & \\
\hline CHEMBL336742 & 145030 & 6.3872 & 6.472 & TRN & \\
\hline CHEMBL341339 & 145030 & 6.0969 & 6.171 & TRN & \\
\hline CHEMBL339433 & 145030 & 7.301 & 6.8288 & TRN & \\
\hline CHEMBL128652 & 145030 & 7.4949 & 8.0457 & TRN & \\
\hline CHEMBL131239 & 145030 & 6.8861 & 6.9547 & TRN & \\
\hline CHEMBL339096 & 145030 & 6.7447 & 6.916 & TST & \\
\hline CHEMBL339357 & 145030 & 6.8239 & 6.6808 & TST & \\
\hline CHEMBL131235 & 145030 & 6.8239 & 6.9262 & TRN & \\
\hline CHEMBL435019 & 145030 & 7.9586 & 7.1873 & TST & \\
\hline CHEMBL337889 & 145030 & 8.0809 & 8.3647 & TRN & \\
\hline CHEMBL433662 & 145030 & 8.4949 & 7.6295 & TST & \\
\hline CHEMBL337853 & 145030 & 7.301 & 7.2765 & TRN & \\
\hline CHEMBL339524 & 145030 & 8.1739 & 7.8366 & TST & \\
\hline CHEMBL334953 & 145030 & 6.0 & 6.5228 & TST & \\
\hline CHEMBL334610 & 145030 & 6.9586 & 7.0383 & TRN & \\
\hline CHEMBL336857 & 145030 & 6.2757 & 6.2588 & TRN & \\
\hline CHEMBL130905 & 145030 & 7.4559 & 7.3938 & TST & \\
\hline CHEMBL422612 & 145030 & 7.0458 & 7.1539 & TRN & \\
\hline CHEMBL339124 & 145030 & 7.3372 & 7.2219 & TRN & \\
\hline CHEMBL130803 & 145030 & 6.7696 & 6.5577 & TRN & \\
\hline CHEMBL265073 & 145030 & 7.4949 & 7.5837 & TST & \\
\hline CHEMBL340362 & 145030 & 7.0 & 6.8124 & TRN & \\
\hline CHEMBL132389 & 145030 & 7.3768 & 7.4355 & TRN & \\
\hline CHEMBL341470 & 145030 & 6.1871 & 6.4304 & TST & \\
\hline CHEMBL131388 & 145030 & 6.9586 & 7.36 & TRN & \\
\hline CHEMBL337212 & 145030 & 6.0 & 6.6018 & TRN & \\
\hline
\end{tabular}




\begin{tabular}{|c|c|c|c|c|}
\hline & \multicolumn{3}{|c|}{ Supplemental Tab } \\
\hline CHEMBL436189 & 145030 & 8.1192 & 8.5546 & TRN \\
\hline CHEMBL131499 & 145030 & 6.1135 & 6.2882 & TRN \\
\hline CHEMBL131581 & 145030 & 6.7696 & 7.4385 & TRN \\
\hline CHEMBL128258 & 145030 & 7.8861 & 7.6081 & TST \\
\hline CHEMBL434993 & 145030 & 6.7447 & 6.4618 & TRN \\
\hline CHEMBL338635 & 145030 & 6.7447 & 6.9912 & TST \\
\hline CHEMBL 276079 & 145030 & 6.7212 & 6.2686 & TRN \\
\hline CHEMBL336195 & 145030 & 7.2218 & 7.0163 & TST \\
\hline CHEMBL 2112663 & 145030 & 7.3979 & 7.3483 & TST \\
\hline CHEMBL338499 & 145030 & 7.3468 & 6.8828 & TRN \\
\hline CHEMBL276906 & 145030 & 6.6576 & 6.6022 & TRN \\
\hline CHEMBL128216 & 145030 & 6.9586 & 6.6792 & TRN \\
\hline CHEMBL335876 & 145030 & 7.0362 & 6.4953 & TRN \\
\hline CHEMBL 337842 & 145030 & 6.3468 & 6.6382 & TST \\
\hline CHEMBL128228 & 145030 & 7.2147 & 6.8476 & TRN \\
\hline CHEMBL130848 & 145030 & 7.0458 & 7.3527 & TRN \\
\hline CHEMBL405016 & 145030 & 7.8861 & 7.4804 & TST \\
\hline CHEMBL130891 & 145030 & 8.585 & 7.7348 & TST \\
\hline CHEMBL128383 & 145030 & 7.699 & 7.3196 & TST \\
\hline CHEMBL337888 & 145030 & 6.4815 & 7.181 & TRN \\
\hline CHEMBL339756 & 145030 & 8.2218 & 7.7748 & TST \\
\hline CHEMBL339366 & 145030 & 6.2366 & 6.7153 & TRN \\
\hline CHEMBL340016 & 145030 & 6.6198 & 6.5365 & TRN \\
\hline CHEMBL129234 & 145030 & 6.5086 & 6.7286 & TST \\
\hline CHEMBL128422 & 145030 & 7.0269 & 6.9752 & TRN \\
\hline CHEMBL339498 & 145030 & 8.3872 & 8.1865 & TRN \\
\hline CHEMBL435398 & 145030 & 6.1871 & 6.4555 & TRN \\
\hline CHEMBL128749 & 145030 & 8.3098 & 7.6236 & TRN \\
\hline CHEMBL130476 & 145030 & 7.4437 & 7.3837 & TST \\
\hline CHEMBL130887 & 145030 & 6.7447 & 7.1662 & TRN \\
\hline CHEMBL130993 & 145030 & 7.3098 & 7.2344 & TRN \\
\hline CHEMBL335182 & 145030 & 7.4559 & 7.0677 & TRN \\
\hline CHEMBL130742 & 145030 & 6.0 & 7.1739 & TRN \\
\hline CHEMBL339464 & 145030 & 6.3188 & 6.4633 & TRN \\
\hline CHEMBL128194 & 145030 & 6.7696 & 6.8073 & TST \\
\hline CHEMBL132210 & 145030 & 6.0 & 7.1801 & TRN \\
\hline CHEMBL131168 & 145030 & 6.9586 & 6.8993 & TRN \\
\hline CHEMBL339929 & 145030 & 8.6383 & 8.1286 & TRN \\
\hline CHEMBL340639 & 145030 & 7.4202 & 7.085 & TRN \\
\hline CHEMBL128219 & 145030 & 8.2007 & 7.97 & TRN \\
\hline CHEMBL128489 & 145030 & 7.0362 & 7.5044 & TST \\
\hline CHEMBL 340772 & 145030 & 6.0 & 6.1668 & TRN \\
\hline CHEMBL335170 & 145030 & 6.0 & 6.6517 & TST \\
\hline CHEMBL337221 & 145030 & 7.5229 & 7.1535 & TST \\
\hline CHEMBL128417 & 145030 & 7.3468 & 7.2284 & TRN \\
\hline CHEMBL340334 & 145030 & 6.6576 & 6.4932 & TRN \\
\hline CHEMBL128398 & 145030 & 6.9208 & 6.7369 & TRN \\
\hline CHEMBL435009 & 145030 & 6.8239 & 6.6651 & TRN \\
\hline
\end{tabular}




\begin{tabular}{|c|c|c|c|c|}
\hline & & & oplement & al Ta \\
\hline CHEMBL336362 & 145030 & 4.9208 & 6.234 & TRN \\
\hline CHEMBL334332 & 145030 & 6.5229 & 6.6299 & TRN \\
\hline CHEMBL340676 & 145030 & 7.301 & 7.7187 & TRN \\
\hline CHEMBL132496 & 145030 & 7.1871 & 7.1944 & TRN \\
\hline CHEMBL132064 & 145030 & 6.5686 & 6.5763 & TST \\
\hline CHEMBL340388 & 145030 & 7.7212 & 7.6904 & TST \\
\hline CHEMBL268567 & 199704 & 7.9208 & 7.2415 & TRN \\
\hline CHEMBL6442 & 199704 & 4.7696 & 5.0475 & TRN \\
\hline CHEMBL6517 & 199704 & 7.2218 & 6.8542 & TRN \\
\hline CHEMBL268099 & 199704 & 5.0 & 5.4832 & TRN \\
\hline CHEMBL6264 & 199704 & 6.699 & 5.8041 & TRN \\
\hline CHEMBL268070 & 199704 & 4.8239 & 5.0397 & TRN \\
\hline CHEMBL6229 & 199704 & 5.5229 & 4.9164 & TST \\
\hline CHEMBL6215 & 199704 & 3.0 & 2.8978 & TST \\
\hline CHEMBL6278 & 199704 & 7.2596 & 7.4157 & TRN \\
\hline CHEMBL6320 & 199704 & 4.3979 & 4.6554 & TST \\
\hline CHEMBL6316 & 199704 & 4.3979 & 4.7972 & TRN \\
\hline CHEMBL269570 & 199704 & 6.4685 & 5.6885 & TRN \\
\hline CHEMBL269497 & 199704 & 7.3468 & 7.1342 & TRN \\
\hline CHEMBL266572 & 199704 & 5.7696 & 6.1816 & TST \\
\hline CHEMBL262570 & 199704 & 7.2596 & 7.1311 & TRN \\
\hline CHEMBL269598 & 199704 & 7.4949 & 7.7453 & TRN \\
\hline CHEMBL6258 & 199704 & 5.8239 & 6.0319 & TRN \\
\hline CHEMBL263080 & 199704 & 6.1805 & 5.7783 & TRN \\
\hline CHEMBL6324 & 199704 & 4.3979 & 3.9811 & TRN \\
\hline CHEMBL266197 & 199704 & 5.7447 & 6.0607 & TRN \\
\hline CHEMBL267127 & 199704 & 5.3979 & 5.4567 & TST \\
\hline CHEMBL267914 & 199704 & 4.7959 & 4.7737 & TRN \\
\hline CHEMBL6369 & 199704 & 5.0757 & 5.2462 & TRN \\
\hline CHEMBL267678 & 199704 & 7.699 & 7.5065 & TRN \\
\hline CHEMBL269075 & 199704 & 7.0555 & 7.0152 & TRN \\
\hline CHEMBL266064 & 199704 & 4.0223 & 3.6416 & TST \\
\hline CHEMBL6371 & 199704 & 6.301 & 6.1333 & TRN \\
\hline CHEMBL266799 & 199704 & 5.6576 & 5.733 & TST \\
\hline CHEMBL6248 & 199704 & 7.301 & 6.7685 & TST \\
\hline CHEMBL6430 & 199704 & 4.3098 & 3.8848 & TST \\
\hline CHEMBL269056 & 199704 & 4.5686 & 3.1577 & TST \\
\hline CHEMBL 6275 & 199704 & 4.3979 & 4.6875 & TRN \\
\hline CHEMBL266198 & 199704 & 8.301 & 8.1885 & TRN \\
\hline CHEMBL6417 & 199704 & 3.0 & 3.0216 & TRN \\
\hline CHEMBL428508 & 199704 & 6.2076 & 6.733 & TRN \\
\hline CHEMBL269495 & 199704 & 4.3768 & 4.1256 & TST \\
\hline CHEMBL6612 & 199704 & 7.0 & 7.6767 & TRN \\
\hline CHEMBL266429 & 199704 & 6.8239 & 6.9866 & TRN \\
\hline CHEMBL6830 & 199704 & 7.3665 & 7.5636 & TRN \\
\hline CHEMBL263081 & 199704 & 6.8861 & 6.9856 & TRN \\
\hline CHEMBL267938 & 199704 & 6.2218 & 6.5854 & TRN \\
\hline CHEMBL6381 & 199704 & 6.1612 & 5.83 & TRN \\
\hline
\end{tabular}




\begin{tabular}{|c|c|c|c|c|c|}
\hline & & & च & & \\
\hline CHEMBL268667 & 199704 & 4.3979 & 4.3713 & TRN & \\
\hline CHEMBL 266460 & 199704 & 4.3979 & 4.7614 & TRN & \\
\hline CHEMBL6523 & 199704 & 4.6576 & 5.3016 & TST & \\
\hline CHEMBL6534 & 199704 & 5.0 & 5.1901 & TRN & \\
\hline CHEMBL6370 & 199704 & 5.4949 & 5.6036 & TRN & \\
\hline CHEMBL6542 & 199704 & 7.3565 & 7.535 & TRN & \\
\hline CHEMBL 6249 & 199704 & 4.3979 & 4.1949 & TRN & \\
\hline CHEMBL268530 & 199704 & 6.699 & 6.8877 & TRN & \\
\hline CHEMBL267456 & 199704 & 7.699 & 7.291 & TRN & \\
\hline CHEMBL266798 & 199704 & 4.3979 & 4.4021 & TRN & \\
\hline CHEMBL6257 & 199704 & 6.6021 & 6.2491 & TRN & \\
\hline CHEMBL 266708 & 199704 & 6.8539 & 6.7461 & TRN & \\
\hline CHEMBL267125 & 199704 & 7.8861 & 8.4089 & TST & \\
\hline CHEMBL6762 & 199704 & 4.3979 & 4.8846 & TST & \\
\hline CHEMBL1404918 & 954991 & 2.984 & 2.8682 & TRN & \\
\hline CHEMBL483849 & 954991 & 1.35 & 1.3598 & TST & \\
\hline CHEMBL180127 & 954991 & 5.0984 & 4.9523 & TRN & \\
\hline CHEMBL9470 & 954991 & 5.4837 & 6.20799 & 9999999999 & TST \\
\hline CHEMBL221137 & 954991 & 4.0531 & 5.08 & TST & \\
\hline CHEMBL191334 & 954991 & 4.4804 & 4.3559 & TRN & \\
\hline CHEMBL1242367 & 954991 & 3.9855 & 3.7433 & TRN & \\
\hline CHEMBL1970879 & 954991 & 3.9636 & 3.8405 & TRN & \\
\hline CHEMBL1357247 & 954991 & 3.2414 & 3.4375 & TRN & \\
\hline CHEMBL509032 & 954991 & 4.9323 & 4.9879 & TRN & \\
\hline CHEMBL 222102 & 954991 & 2.9933 & 3.1351 & TRN & \\
\hline CHEMBL573107 & 954991 & 4.2227 & 4.4388 & TRN & \\
\hline CHEMBL102714 & 954991 & 3.105 & 3.2045 & TRN & \\
\hline CHEMBL92309 & 954991 & 3.6298 & 3.1838 & TST & \\
\hline CHEMBL209148 & 954991 & 4.3412 & 4.4015 & TRN & \\
\hline CHEMBL 217354 & 954991 & 6.7508 & 7.04700 & $\partial 000000001$ & TRN \\
\hline CHEMBL 2144069 & 954991 & 8.3226 & 8.4002 & TRN & \\
\hline CHEMBL3186408 & 954991 & 4.1132 & 4.135 & TST & \\
\hline CHEMBL1516890 & 954991 & 3.6553 & 3.8992 & TRN & \\
\hline CHEMBL1590308 & 954991 & 3.9966 & 3.6126 & TST & \\
\hline CHEMBL577784 & 954991 & 3.5459 & 3.7217 & TRN & \\
\hline CHEMBL515416 & 954991 & 4.1585 & 4.0639 & TRN & \\
\hline CHEMBL472940 & 954991 & 3.2765 & 3.2864 & TRN & \\
\hline CHEMBL188678 & 954991 & 4.5076 & 4.2109 & TRN & \\
\hline CHEMBL 255342 & 954991 & 3.4039 & 3.2483 & TRN & \\
\hline CHEMBL 240954 & 954991 & 3.2524 & 3.0313 & TST & \\
\hline CHEMBL189584 & 954991 & 3.9431 & 3.9471 & TRN & \\
\hline CHEMBL 379300 & 954991 & 6.401 & 6.1139 & TRN & \\
\hline CHEMBL135561 & 954991 & 4.4069 & 4.4372 & TRN & \\
\hline CHEMBL 2137530 & 954991 & 3.9948 & 4.1962 & TRN & \\
\hline CHEMBL192566 & 954991 & 7.7615 & 8.004 & TST & \\
\hline CHEMBL512504 & 954991 & 4.0269 & 4.3067 & TRN & \\
\hline CHEMBL 373751 & 954991 & 3.5916 & 3.7786 & TRN & \\
\hline CHEMBL300389 & 954991 & 5.4828 & 5.4435 & TRN & \\
\hline
\end{tabular}


Supplemental Table S2.txt

\begin{tabular}{|c|c|c|c|c|}
\hline CHEMBL 2134202 & 954991 & 3.1248 & 3.1715 & TRN \\
\hline CHEMBL3349342 & 954991 & 7.1106 & 6.8266 & TRN \\
\hline CHEMBL1190711 & 954991 & 4.7408 & 4.5384 & TRN \\
\hline CHEMBL 259181 & 954991 & 4.9172 & \multicolumn{2}{|c|}{4.968999999999999} \\
\hline CHEMBL585951 & 954991 & 6.2675 & 6.2908 & TRN \\
\hline CHEMBL514499 & 954991 & 6.97 & 7.1038 & TRN \\
\hline CHEMBL1673039 & 954991 & 4.9111 & 4.9532 & TRN \\
\hline CHEMBL449158 & 954991 & 6.5325 & 7.3985 & TST \\
\hline CHEMBL3199475 & 954991 & 3.9352 & 3.9607 & TRN \\
\hline CHEMBL392695 & 954991 & 5.4312 & 5.5588 & TRN \\
\hline CHEMBL 213100 & 954991 & 7.331 & 7.3093 & TRN \\
\hline CHEMBL1186585 & 954991 & 3.3088 & 3.4726 & TRN \\
\hline CHEMBL1230020 & 954991 & 4.6263 & 4.6617 & TRN \\
\hline CHEMBL558642 & 954991 & 4.0349 & 4.1557 & TRN \\
\hline CHEMBL483847 & 954991 & 3.9384 & 4.4054 & TRN \\
\hline CHEMBL1256459 & 954991 & 7.0607 & 6.9209 & TRN \\
\hline CHEMBL1909414 & 954991 & 3.23 & 3.2977 & TRN \\
\hline CHEMBL379975 & 954991 & 5.1976 & 5.0236 & TRN \\
\hline CHEMBL 258844 & 954991 & 3.7586 & 3.628 & TRN \\
\hline CHEMBL1643959 & 954991 & 3.8745 & 3.4622 & TRN \\
\hline CHEMBL1788116 & 954991 & 4.6897 & 4.7173 & TRN \\
\hline CHEMBL412142 & 954991 & 5.2421 & 4.8995 & TRN \\
\hline CHEMBL393929 & 954991 & 3.4222 & 3.1459 & TRN \\
\hline CHEMBL65 & 954991 & 7.0592 & 7.6311 & TST \\
\hline CHEMBL220241 & 954991 & 5.7657 & 4.7987 & TST \\
\hline CHEMBL210618 & 954991 & 3.1374 & 3.1154 & TST \\
\hline CHEMBL 202721 & 954991 & 3.8614 & 4.4692 & TST \\
\hline CHEMBL3392440 & 954991 & 4.2427 & 3.5463 & TST \\
\hline CHEMBL2363137 & 954991 & 5.9361 & 5.7059 & TST \\
\hline CHEMBL2005886 & 954991 & 5.1355 & 5.5647 & TST \\
\hline CHEMBL 399530 & 954991 & 3.4531 & 4.0628 & TST \\
\hline CHEMBL3186408 & 954673 & 4.5508 & 4.1661 & TST \\
\hline CHEMBL 2144069 & 954673 & 6.1602 & 6.1254 & TRN \\
\hline CHEMBL 2005886 & 954673 & 4.753 & 4.6803 & TRN \\
\hline CHEMBL102714 & 954673 & 4.5119 & 4.6189 & TRN \\
\hline CHEMBL483847 & 954673 & 6.5443 & 6.4971 & TRN \\
\hline CHEMBL65 & 954673 & 8.6232 & 8.6721 & TRN \\
\hline CHEMBL259181 & 954673 & 4.3713 & 4.4283 & TRN \\
\hline CHEMBL189584 & 954673 & 6.0725 & 6.0045 & TRN \\
\hline CHEMBL558642 & 954673 & 3.6826 & 3.7039 & TRN \\
\hline CHEMBL 258844 & 954673 & 4.5456 & 4.5292 & TRN \\
\hline CHEMBL1970879 & 954673 & 6.4616 & 6.3698 & TRN \\
\hline CHEMBL449158 & 954673 & 6.2347 & 7.1269 & TST \\
\hline CHEMBL 240954 & 954673 & 5.5208 & 4.6907 & TST \\
\hline CHEMBL 209148 & 954673 & 4.2833 & 4.4334 & TRN \\
\hline CHEMBL1190711 & 954673 & 5.0621 & 5.0455 & TRN \\
\hline CHEMBL 220241 & 954673 & 4.7239 & 4.8514 & TRN \\
\hline CHEMBL1909414 & 954673 & 6.1132 & 6.0749 & TRN \\
\hline
\end{tabular}




\begin{tabular}{|c|c|c|c|c|c|}
\hline \multirow[b]{2}{*}{ CHEMBL1643959 } & \multicolumn{5}{|c|}{ Supplemental Table S2.txt } \\
\hline & 954673 & 4.0234 & 3.9374 & TRN & \\
\hline CHEMBL1230020 & 954673 & 6.0988 & 5.9986 & TRN & \\
\hline CHEMBL192566 & 954673 & 8.5518 & 6.9163 & TST & \\
\hline CHEMBL3199475 & 954673 & 3.7817 & 4.0706 & TRN & \\
\hline CHEMBL2363137 & 954673 & 3.4549 & 3.3882 & TRN & \\
\hline CHEMBL1357247 & 954673 & 3.2558 & 3.1048 & TRN & \\
\hline CHEMBL1516890 & 954673 & 4.7411 & 4.6923 & TRN & \\
\hline CHEMBL135561 & 954673 & 4.3714 & 4.5458 & TRN & \\
\hline CHEMBL9470 & 954673 & 6.3606 & 4.7861 & TST & \\
\hline CHEMBL300389 & 954673 & 6.8406 & 6.9551 & TRN & \\
\hline CHEMBL373751 & 954673 & 3.5545 & 3.4762 & TRN & \\
\hline CHEMBL202721 & 954673 & 5.7553 & 5.9172 & TRN & \\
\hline CHEMBL1590308 & 954673 & 3.9986 & 3.6647 & TST & \\
\hline CHEMBL573107 & 954673 & 5.7019 & 5.6797 & TRN & \\
\hline CHEMBL191334 & 954673 & 5.546 & 5.5883 & TRN & \\
\hline CHEMBL514499 & 954673 & 7.751 & 7.8332 & TRN & \\
\hline CHEMBL483849 & 954673 & 4.0276 & 3.9856 & TRN & \\
\hline CHEMBL1673039 & 954673 & 5.1291 & 5.1781 & TRN & \\
\hline CHEMBL1404918 & 954673 & 3.2033 & 3.4086 & TRN & \\
\hline CHEMBL221137 & 954673 & 3.1534 & 4.0771 & TST & \\
\hline CHEMBL512504 & 954673 & 4.3586 & 4.2314 & TRN & \\
\hline CHEMBL412142 & 954673 & 4.2402 & 4.3334 & TRN & \\
\hline CHEMBL213100 & 954673 & 9.2888 & 9.3463 & TRN & \\
\hline CHEMBL515416 & 954673 & 4.7773 & 4.7315 & TRN & \\
\hline CHEMBL3392440 & 954673 & 3.5385 & 3.5916 & TRN & \\
\hline CHEMBL585951 & 954673 & 6.1328 & $5.99200 t$ & 0000000001 & TRN \\
\hline CHEMBL1788116 & 954673 & 4.4721 & 4.6357 & TRN & \\
\hline CHEMBL180127 & 954673 & 4.9392 & 4.9825 & TRN & \\
\hline CHEMBL92309 & 954673 & 3.6304 & 2.8319 & TST & \\
\hline CHEMBL392695 & 954673 & 6.0046 & 5.7403 & TRN & \\
\hline CHEMBL1242367 & 954673 & 5.1987 & 5.0591 & TRN & \\
\hline CHEMBL472940 & 954673 & 3.2388 & 3.1801 & TRN & \\
\hline CHEMBL3349342 & 954673 & 5.62299 & 99999999 & 5.3395 & TRN \\
\hline CHEMBL379975 & 954673 & 6.3623 & 5.6433 & TST & \\
\hline CHEMBL 379300 & 954673 & 6.5706 & 6.6506 & TST & \\
\hline CHEMBL393929 & 954673 & 4.2227 & 4.2946 & TST & \\
\hline CHEMBL1256459 & 954673 & 7.657 & 7.626 & TST & \\
\hline CHEMBL210618 & 954673 & 4.8523 & 3.8909 & TST & \\
\hline CHEMBL509032 & 954673 & 5.4388 & 5.2839 & TST & \\
\hline CHEMBL195022 & 321621 & 5.9788 & 6.0002 & TRN & \\
\hline CHEMBL194408 & 321621 & 8.0269 & 6.8381 & TST & \\
\hline CHEMBL195351 & 321621 & 7.1871 & 7.2293 & TRN & \\
\hline CHEMBL427540 & 321621 & 8.0132 & 8.0143 & TRN & \\
\hline CHEMBL 373084 & 321621 & 8.1612 & 7.3218 & TST & \\
\hline CHEMBL196360 & 321621 & 5.9642 & 5.9687 & TRN & \\
\hline CHEMBL194946 & 321621 & 7.0223 & 7.0413 & TRN & \\
\hline CHEMBL198361 & 321621 & 7.0862 & 7.1183 & TRN & \\
\hline CHEMBL196196 & 321621 & 7.8861 & 7.8948 & TRN & \\
\hline
\end{tabular}




\begin{tabular}{|c|c|c|c|c|c|c|}
\hline & & \multicolumn{5}{|c|}{ Supplemental Table s2.txt } \\
\hline CHEMBL193473 & 321621 & 7.6383 & 7.6503 & TRN & & \\
\hline CHEMBL195250 & 321621 & 6.3883 & 6.3923 & TRN & & \\
\hline CHEMBL194691 & 321621 & 7.6778 & 9.2284 & TST & & \\
\hline CHEMBL365374 & 321621 & 5.58 & 5.5832 & TRN & & \\
\hline CHEMBL187756 & 321621 & 7.6198 & 7.6457 & TRN & & \\
\hline CHEMBL194459 & 321621 & 7.7959 & 7.7437 & TRN & & \\
\hline CHEMBL194530 & 321621 & 4.6055 & 6.1743 & TST & & \\
\hline CHEMBL194484 & 321621 & 4.0 & 4.01 & TRN & & \\
\hline CHEMBL195635 & 321621 & 8.1487 & 8.1687 & TRN & & \\
\hline CHEMBL426648 & 321621 & 6.3546 & 6.3606 & TRN & & \\
\hline CHEMBL197245 & 321621 & 7.3665 & 7.3053 & TST & & \\
\hline CHEMBL197050 & 321621 & 7.3872 & 7.347 & TRN & & \\
\hline CHEMBL382755 & 321621 & \multicolumn{3}{|c|}{6.617999999999999} & 6.6203 & TRN \\
\hline CHEMBL371576 & 321621 & 6.6498 & 6.805 & TST & & \\
\hline CHEMBL370820 & 321621 & 6.3809 & 6.376 & TRN & & \\
\hline CHEMBL193768 & 321621 & 3.1385 & 3.1442 & TRN & & \\
\hline CHEMBL195350 & 321621 & 6.9431 & 6.9655 & TRN & & \\
\hline CHEMBL370120 & 321621 & 7.0132 & 6.9978 & TRN & & \\
\hline CHEMBL196091 & 321621 & 7.2291 & 7.2345 & TRN & & \\
\hline CHEMBL197026 & 321621 & 8.4559 & 8.4612 & TRN & & \\
\hline CHEMBL366180 & 321621 & 7.0862 & 7.0657 & TRN & & \\
\hline CHEMBL194046 & 321621 & 7.6576 & 6.7907 & TST & & \\
\hline CHEMBL184717 & 321621 & 7.2366 & 7.2675 & TRN & & \\
\hline CHEMBL194253 & 321621 & 7.3468 & 7.3555 & TRN & & \\
\hline CHEMBL435494 & 321621 & 6.4609 & 6.4505 & TRN & & \\
\hline CHEMBL196567 & 321621 & 7.5376 & 7.2329 & TST & & \\
\hline CHEMBL198823 & 321621 & 5.7447 & 5.7364 & TRN & & \\
\hline CHEMBL194477 & 321621 & 6.0947 & 6.0585 & TST & & \\
\hline CHEMBL196573 & 321621 & 7.7959 & 7.8665 & TRN & & \\
\hline CHEMBL194417 & 321621 & 6.4855 & 6.4731 & TRN & & \\
\hline CHEMBL194997 & 321621 & 6.3585 & 6.3569 & TRN & & \\
\hline CHEMBL196667 & 321621 & 7.7959 & 7.7866 & TRN & & \\
\hline CHEMBL197145 & 321621 & 6.7595 & 5.818 & TST & & \\
\hline CHEMBL186077 & 321621 & 6.6003 & 6.5667 & TRN & & \\
\hline CHEMBL185997 & 321621 & 7.6576 & 7.6123 & TRN & & \\
\hline CHEMBL189118 & 321621 & 7.7212 & 6.8102 & TST & & \\
\hline CHEMBL196627 & 321621 & 6.3224 & 6.3074 & TRN & & \\
\hline CHEMBL184084 & 321621 & 7.5376 & 7.5131 & TRN & & \\
\hline CHEMBL196581 & 321621 & 8.4202 & 7.7899 & TST & & \\
\hline CHEMBL194468 & 321621 & 7.2518 & 7.1841 & TRN & & \\
\hline CHEMBL194837 & 321621 & 6.7447 & 6.2112 & TST & & \\
\hline CHEMBL1964290 & 809234 & 6.7 & 6.5546 & TRN & & \\
\hline CHEMBL2003768 & 809234 & 4.0 & 4.9519 & TRN & & \\
\hline CHEMBL213505 & 809234 & 6.2 & 6.3729 & TRN & & \\
\hline CHEMBL1987034 & 809234 & 7.0 & 6.3156 & TRN & & \\
\hline CHEMBL1993941 & 809234 & 5.7 & 5.8058 & TRN & & \\
\hline CHEMBL377383 & 809234 & 4.0 & 3.8094 & TRN & & \\
\hline CHEMBL 2005886 & 809234 & 4.0 & 4.2032 & TRN & & \\
\hline
\end{tabular}




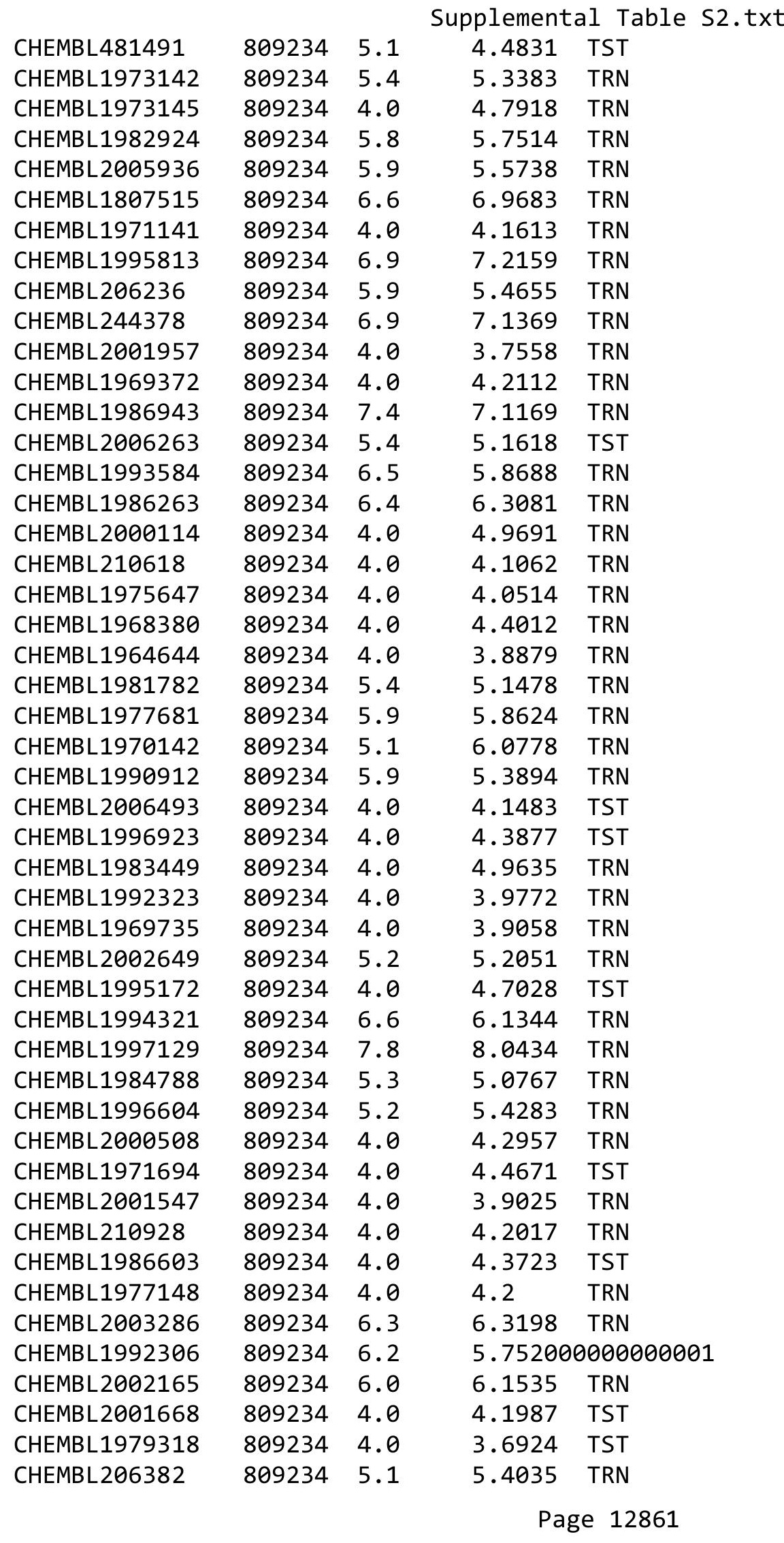

TRN 


\begin{tabular}{|c|c|c|c|c|c|}
\hline \multirow[b]{2}{*}{ CHEMBL1998585 } & \multirow[b]{2}{*}{809234} & \\
\hline & & 6.4 & 6.3476 & TRN & \\
\hline CHEMBL127898 & 809234 & 4.0 & 4.2497 & TST & \\
\hline CHEMBL519697 & 809234 & 4.0 & 5.2618 & TST & \\
\hline CHEMBL 2004934 & 809234 & 4.0 & 3.7393 & TRN & \\
\hline CHEMBL1981947 & 809234 & 5.4 & 4.258 & TST & \\
\hline CHEMBL1968459 & 809234 & 7.2 & 6.8786 & TRN & \\
\hline CHEMBL1975128 & 809234 & 6.8 & 7.0518 & TRN & \\
\hline CHEMBL1970369 & 809234 & 4.0 & \multicolumn{2}{|c|}{ 4. 343999999999999} & TRN \\
\hline CHEMBL2001485 & 809234 & 6.6 & 6.2115 & TRN & \\
\hline CHEMBL1966425 & 809234 & 5.2 & 5.1072 & TRN & \\
\hline CHEMBL1984363 & 809234 & 6.2 & 5.2161 & TRN & \\
\hline CHEMBL1978099 & 809234 & 6.0 & 5.1594 & TRN & \\
\hline CHEMBL1988608 & 809234 & 5.3 & 5.7386 & TRN & \\
\hline CHEMBL184847 & 809234 & 7.1 & 5.1483 & TRN & \\
\hline CHEMBL1984367 & 809234 & 4.0 & 5.5805 & TRN & \\
\hline CHEMBL226898 & 809234 & 6.2 & \multicolumn{2}{|c|}{5.917000000000001} & TRN \\
\hline CHEMBL1982563 & 809234 & 4.0 & 3.9456 & TRN & \\
\hline CHEMBL539474 & 809234 & 5.4 & 4.7133 & TST & \\
\hline CHEMBL575824 & 809234 & 4.1 & 4.6782 & TRN & \\
\hline CHEMBL1988387 & 809234 & 6.8 & \multicolumn{2}{|c|}{6.212999999999999} & TRN \\
\hline CHEMBL1990288 & 809234 & 4.0 & 3.9774 & TRN & \\
\hline CHEMBL1974803 & 809234 & 5.8 & 5.4414 & TST & \\
\hline CHEMBL1970074 & 809234 & 5.5 & 5.1613 & TRN & \\
\hline CHEMBL1986970 & 809234 & 5.2 & 5.1183 & TRN & \\
\hline CHEMBL2005112 & 809234 & 5.3 & 4.1601 & TST & \\
\hline CHEMBL1958401 & 809234 & 5.6 & 5.7802 & TRN & \\
\hline CHEMBL1984044 & 809234 & 4.0 & 4.9886 & TRN & \\
\hline CHEMBL 2003456 & 809234 & 6.4 & 5.6426 & TRN & \\
\hline CHEMBL1966816 & 809234 & 4.0 & 3.8023 & TRN & \\
\hline CHEMBL1972584 & 809234 & 4.0 & 4.476 & TRN & \\
\hline CHEMBL 2002992 & 809234 & 5.7 & \multicolumn{2}{|c|}{5.468999999999999} & TRN \\
\hline CHEMBL560813 & 809234 & 6.4 & 5.4575 & TRN & \\
\hline CHEMBL207253 & 809234 & 4.0 & 3.8015 & TST & \\
\hline CHEMBL1968791 & 809234 & 6.3 & 4.9145 & TRN & \\
\hline CHEMBL1971186 & 809234 & 4.0 & 3.9562 & TRN & \\
\hline CHEMBL2003482 & 809234 & 4.0 & 3.6407 & TRN & \\
\hline CHEMBL1973211 & 809234 & 6.0 & 6.2163 & TRN & \\
\hline CHEMBL1984700 & 809234 & 4.0 & 4.169 & TRN & \\
\hline CHEMBL1972125 & 809234 & 4.0 & 3.8402 & TRN & \\
\hline CHEMBL1461728 & 809234 & 5.1 & 4.5972 & TRN & \\
\hline CHEMBL1976134 & 809234 & 6.6 & 6.1715 & TRN & \\
\hline CHEMBL1965131 & 809234 & 5.6 & \multicolumn{2}{|c|}{5.0089999999999995} & TRN \\
\hline CHEMBL1999279 & 809234 & 7.6 & 7.3254 & TRN & \\
\hline CHEMBL1972158 & 809234 & 6.6 & 6.9716 & TRN & \\
\hline CHEMBL 2006580 & 809234 & 6.5 & 5.5549 & TRN & \\
\hline CHEMBL 2006481 & 809234 & 4.0 & 4.3339 & TRN & \\
\hline CHEMBL1979855 & 809234 & 4.0 & 3.3396 & TRN & \\
\hline \multirow[t]{2}{*}{ CHEMBL1970340 } & 809234 & 6.0 & 5.2018 & TRN & \\
\hline & & & \multicolumn{2}{|c|}{ Page 12862} & \\
\hline
\end{tabular}




\begin{tabular}{|c|c|c|c|c|c|}
\hline & & & Supplementa & Table S & \\
\hline CHEMBL 2005186 & 809234 & 4.0 & 4.4023 & TRN & \\
\hline CHEMBL1995927 & 809234 & 4.0 & 4.5059 & TST & \\
\hline CHEMBL1975534 & 809234 & 5.3 & 5.1353 & TRN & \\
\hline CHEMBL1966703 & 809234 & 4.0 & 3.0712 & TST & \\
\hline CHEMBL 243518 & 809234 & 6.6 & 6.1339 & TRN & \\
\hline CHEMBL1969561 & 809234 & 5.3 & 5.4788 & TRN & \\
\hline CHEMBL1997023 & 809234 & 4.0 & 4.9817 & TST & \\
\hline CHEMBL1964687 & 809234 & 6.5 & 6.8788 & TRN & \\
\hline CHEMBL1971943 & 809234 & 4.0 & 5.6916 & TST & \\
\hline CHEMBL1974254 & 809234 & 5.3 & 5.9161 & TRN & \\
\hline CHEMBL1988537 & 809234 & 4.0 & 4.6429 & TST & \\
\hline CHEMBL1969049 & 809234 & 4.0 & 3.5862 & TRN & \\
\hline CHEMBL 2005828 & 809234 & 6.5 & 6.6149 & TRN & \\
\hline CHEMBL 2002240 & 809234 & 4.0 & 4.0682 & TRN & \\
\hline CHEMBL1991143 & 809234 & 4.0 & 3.2582 & TST & \\
\hline CHEMBL1998611 & 809234 & 4.0 & 4.6518 & TRN & \\
\hline CHEMBL1975900 & 809234 & 6.3 & 5.7834 & TRN & \\
\hline CHEMBL 255822 & 809234 & 6.4 & 6.597 & TRN & \\
\hline CHEMBL1972221 & 809234 & 4.0 & 3.9559 & TRN & \\
\hline CHEMBL 2006778 & 809234 & 5.6 & 5.5423 & TRN & \\
\hline CHEMBL1981511 & 809234 & 6.5 & 4.9777 & TRN & \\
\hline CHEMBL378627 & 809234 & 4.0 & 4.3301 & TRN & \\
\hline CHEMBL1996979 & 809234 & 6.1 & 5.7647 & TRN & \\
\hline CHEMBL1997025 & 809234 & 4.0 & 5.0419 & TRN & \\
\hline CHEMBL1968406 & 809234 & 6.9 & 6.9717 & TRN & \\
\hline CHEMBL1984274 & 809234 & 5.0 & 4.678 & TST & \\
\hline CHEMBL1998545 & 809234 & 4.0 & 3.9536 & TRN & \\
\hline CHEMBL1986869 & 809234 & 4.0 & 4.2464 & TRN & \\
\hline CHEMBL 2006010 & 809234 & 4.0 & 3.3588 & TRN & \\
\hline CHEMBL1682558 & 809234 & 4.0 & 4.1208 & TRN & \\
\hline CHEMBL1990496 & 809234 & 4.0 & 4.138999 & 9999999999 & TRN \\
\hline CHEMBL 2002479 & 809234 & 5.4 & 5.4167 & TRN & \\
\hline CHEMBL1967094 & 809234 & 6.5 & 6.0462 & TRN & \\
\hline CHEMBL1966035 & 809234 & 4.0 & 4.7475 & TRN & \\
\hline CHEMBL 2003341 & 809234 & 4.0 & 4.093 & TRN & \\
\hline CHEMBL1982992 & 809234 & 4.0 & 5.4688 & TRN & \\
\hline CHEMBL1999590 & 809234 & 4.0 & 4.1139 & TST & \\
\hline CHEMBL1981079 & 809234 & 7.2 & 6.7507 & TRN & \\
\hline CHEMBL1972276 & 809234 & 5.6 & 4.0946 & TRN & \\
\hline CHEMBL1980489 & 809234 & 5.6 & 5.1601 & TRN & \\
\hline CHEMBL1967116 & 809234 & 7.0 & 6.4367 & TRN & \\
\hline CHEMBL 2000832 & 809234 & 6.2 & 5.8275 & TRN & \\
\hline CHEMBL513846 & 809234 & 4.0 & 4.5098 & TRN & \\
\hline CHEMBL1970709 & 809234 & 4.0 & 4.6506 & TRN & \\
\hline CHEMBL1965660 & 809234 & 7.1 & 7.3134 & TRN & \\
\hline CHEMBL1985309 & 809234 & 5.6 & 4.8154 & TRN & \\
\hline CHEMBL1998112 & 809234 & 4.0 & 4.8673 & TRN & \\
\hline CHEMBL1969126 & 809234 & 4.0 & 4.1867 & TRN & \\
\hline
\end{tabular}




\begin{tabular}{|c|c|c|c|c|c|}
\hline CHEMBL1980896 & 809234 & 5.4 & 5.2425 & TRN & \\
\hline CHEMBL1975208 & 809234 & 4.0 & $4.0680 e$ & 00000000005 & TST \\
\hline CHEMBL1970104 & 809234 & 5.5 & 5.4421 & TRN & \\
\hline CHEMBL1964777 & 809234 & 5.4 & 4.9393 & TST & \\
\hline CHEMBL1971149 & 809234 & 5.2 & 3.9255 & TRN & \\
\hline CHEMBL1999714 & 809234 & 4.0 & 3.5998 & TRN & \\
\hline CHEMBL1987533 & 809234 & 4.0 & 4.668 & TRN & \\
\hline CHEMBL1994040 & 809234 & 4.0 & 4.0993 & TRN & \\
\hline CHEMBL579246 & 809234 & 5.2 & 4.7194 & TRN & \\
\hline CHEMBL398951 & 809234 & 4.0 & 4.5908 & TRN & \\
\hline CHEMBL1982506 & 809234 & 4.0 & 4.5876 & TST & \\
\hline CHEMBL 2004716 & 809234 & 6.9 & 6.2623 & TRN & \\
\hline CHEMBL1968127 & 809234 & 4.0 & 4.1275 & TRN & \\
\hline CHEMBL1975233 & 809234 & 4.0 & 4.3232 & TRN & \\
\hline CHEMBL1985406 & 809234 & 4.0 & 4.0356 & TRN & \\
\hline CHEMBL 207400 & 809234 & 4.0 & 3.5556 & TST & \\
\hline CHEMBL 2000894 & 809234 & 4.0 & 4.3371 & TRN & \\
\hline CHEMBL 2002553 & 809234 & 4.0 & 4.4844 & TST & \\
\hline CHEMBL1982135 & 809234 & 7.0 & 6.5583 & TRN & \\
\hline CHEMBL1976090 & 809234 & 6.2 & 6.3358 & TRN & \\
\hline CHEMBL1993243 & 809234 & 5.6 & 5.3744 & TRN & \\
\hline CHEMBL1992922 & 809234 & 5.3 & 5.7797 & TRN & \\
\hline CHEMBL 2004771 & 809234 & 4.0 & 5.0135 & TRN & \\
\hline CHEMBL1997597 & 809234 & 5.4 & 5.2245 & TRN & \\
\hline CHEMBL1969537 & 809234 & 5.9 & 4.8191 & TST & \\
\hline CHEMBL1976093 & 809234 & 4.0 & 4.1425 & TRN & \\
\hline CHEMBL 210032 & 809234 & 4.0 & 4.4506 & TRN & \\
\hline CHEMBL1975256 & 809234 & 4.0 & 4.1393 & TRN & \\
\hline CHEMBL508928 & 809234 & 6.0 & 5.4931 & TRN & \\
\hline CHEMBL1991356 & 809234 & 5.4 & 4.2534 & TRN & \\
\hline CHEMBL1983309 & 809234 & 4.0 & 4.5201 & TRN & \\
\hline CHEMBL 2004892 & 809234 & 4.0 & 5.0984 & TRN & \\
\hline CHEMBL1999126 & 809234 & 5.5 & 4.1768 & TST & \\
\hline CHEMBL1997503 & 809234 & 4.0 & 4.4302 & TST & \\
\hline CHEMBL116070 & 809234 & 4.0 & 4.8832 & TST & \\
\hline CHEMBL1990821 & 809234 & 5.5 & 4.6604 & TST & \\
\hline CHEMBL1970314 & 809234 & 6.2 & 5.3121 & TRN & \\
\hline CHEMBL 2004871 & 809234 & 4.0 & 3.9042 & TRN & \\
\hline CHEMBL 2004872 & 809234 & 4.0 & 3.3959 & TRN & \\
\hline CHEMBL1727312 & 809234 & 4.0 & 3.8268 & TRN & \\
\hline CHEMBL1969879 & 809234 & 4.0 & 4.2223 & TRN & \\
\hline CHEMBL1995932 & 809234 & 6.8 & 6.864 & TRN & \\
\hline CHEMBL1981720 & 809234 & 6.0 & 4.9109 & TRN & \\
\hline CHEMBL419932 & 809234 & 6.1 & 5.5662 & TRN & \\
\hline CHEMBL 262433 & 809234 & 6.1 & 5.5521 & TRN & \\
\hline CHEMBL 306380 & 809234 & 4.0 & 3.85699 & 99999999998 & TRN \\
\hline CHEMBL1966722 & 809234 & 4.0 & 5.3621 & TST & \\
\hline CHEMBL1975500 & 809234 & 6.3 & 5.8025 & TRN & \\
\hline
\end{tabular}




\begin{tabular}{|c|c|c|c|c|c|}
\hline & & & & & \\
\hline CHEMBL394619 & 809234 & 5.9 & 5.8859 & TRN & \\
\hline CHEMBL1996831 & 809234 & 4.0 & 4.4554 & TST & \\
\hline CHEMBL411903 & 809234 & 7.6 & 7.2017 & TRN & \\
\hline CHEMBL1965988 & 809234 & 6.2 & 6.1253 & TRN & \\
\hline CHEMBL418203 & 809234 & 5.3 & 4.878 & TST & \\
\hline CHEMBL1989646 & 809234 & 6.2 & 6.2523 & TRN & \\
\hline CHEMBL 225519 & 809234 & 6.4 & 6.9686 & TRN & \\
\hline CHEMBL1978200 & 809234 & 4.0 & 3.9973 & TRN & \\
\hline CHEMBL 2006631 & 809234 & 4.0 & 4.5553 & TRN & \\
\hline CHEMBL1970522 & 809234 & 5.8 & 6.3705 & TRN & \\
\hline CHEMBL1990415 & 809234 & 4.0 & 4.1525 & TRN & \\
\hline CHEMBL1966087 & 809234 & 4.0 & 5.1901 & TRN & \\
\hline CHEMBL1964692 & 809234 & 6.5 & 5.9689 & TRN & \\
\hline CHEMBL1996931 & 809234 & 4.0 & 3.8239 & TRN & \\
\hline CHEMBL1964413 & 809234 & 4.0 & 4.1946 & TRN & \\
\hline CHEMBL1973483 & 809234 & 4.0 & 3.8296 & TRN & \\
\hline CHEMBL1970735 & 809234 & 4.0 & 4.4516 & TRN & \\
\hline CHEMBL1997340 & 809234 & 5.1 & 4.282 & TRN & \\
\hline CHEMBL 2004365 & 809234 & 5.5 & 4.717 & TST & \\
\hline CHEMBL1522508 & 809234 & 4.0 & 4.3316 & TRN & \\
\hline CHEMBL1989474 & 809234 & 4.0 & 4.06 & TRN & \\
\hline CHEMBL 210887 & 809234 & 4.0 & 4.2148 & TST & \\
\hline CHEMBL458997 & 809234 & 5.9 & 5.6879 & TRN & \\
\hline CHEMBL 227271 & 809234 & 5.6 & 5.928 & TRN & \\
\hline CHEMBL1971021 & 809234 & 4.0 & 4.6911 & TRN & \\
\hline CHEMBL583144 & 809234 & 5.2 & 4.9071 & TRN & \\
\hline CHEMBL1974310 & 809234 & 6.0 & 5.0582 & TST & \\
\hline CHEMBL1982660 & 809234 & 4.0 & 4.4216 & TRN & \\
\hline CHEMBL1994693 & 809234 & 6.8 & 7.5274 & TRN & \\
\hline CHEMBL1982957 & 809234 & 4.0 & 5.2736 & TRN & \\
\hline CHEMBL1725279 & 809234 & 6.5 & 5.0977 & TST & \\
\hline CHEMBL1975138 & 809234 & 4.0 & 5.5009 & TST & \\
\hline CHEMBL424872 & 809234 & 4.0 & 3.7937 & TRN & \\
\hline CHEMBL 2006836 & 809234 & 4.0 & 3.7211 & TST & \\
\hline CHEMBL412142 & 809234 & 4.0 & 4.1576 & TST & \\
\hline CHEMBL1985153 & 809234 & 4.0 & 4.9755 & TRN & \\
\hline CHEMBL1980704 & 809234 & 4.0 & 3.6397 & TST & \\
\hline CHEMBL 2003271 & 809234 & 5.9 & 5.3561 & TRN & \\
\hline CHEMBL1966808 & 809234 & 4.0 & 4.6631 & TST & \\
\hline CHEMBL 2004447 & 809234 & 4.0 & $3.9330 e$ & 00000000003 & TST \\
\hline CHEMBL1983111 & 809234 & 6.7 & 5.5229 & TST & \\
\hline CHEMBL1973860 & 809234 & 5.4 & 5.072 & TRN & \\
\hline CHEMBL1977713 & 809234 & 4.0 & 4.0022 & TRN & \\
\hline CHEMBL260135 & 809234 & 4.0 & 4.3651 & TRN & \\
\hline CHEMBL220241 & 809234 & 6.2 & 5.9595 & TRN & \\
\hline CHEMBL 2004544 & 809234 & 4.0 & 4.8488 & TST & \\
\hline CHEMBL1982610 & 809234 & 4.0 & 3.94199 & 99999999997 & TST \\
\hline CHEMBL1966040 & 809234 & 6.0 & 6.9199 & TRN & \\
\hline & & & & 12865 & \\
\hline
\end{tabular}




\begin{tabular}{|c|c|c|c|c|c|}
\hline \multirow[b]{2}{*}{ CHEMBL1989569 } & \multirow[b]{2}{*}{809234} & \\
\hline & & 5.7 & 5.3786 & TRN & \\
\hline CHEMBL1999496 & 809234 & 4.0 & 3.9653 & TRN & \\
\hline CHEMBL1988300 & 809234 & 6.6 & 5.6577 & TRN & \\
\hline CHEMBL1991078 & 809234 & 5.5 & 5.7649 & TRN & \\
\hline CHEMBL1987359 & 809234 & 4.0 & 3.622 & TST & \\
\hline CHEMBL1989265 & 809234 & 4.0 & 3.71 & TST & \\
\hline CHEMBL 2004647 & 809234 & 4.0 & 4.1325 & TST & \\
\hline CHEMBL1969502 & 809234 & 6.0 & 5.8509 & TRN & \\
\hline CHEMBL1682553 & 809234 & 4.0 & 4.655 & TRN & \\
\hline CHEMBL1971430 & 809234 & 4.0 & 4.03600 & 00000000005 & TRN \\
\hline CHEMBL1997764 & 809234 & 5.7 & 5.7268 & TRN & \\
\hline CHEMBL1983963 & 809234 & 6.6 & 6.245 & TRN & \\
\hline CHEMBL1985092 & 809234 & 5.9 & 5.9178 & TST & \\
\hline CHEMBL 2004692 & 809234 & 4.0 & 4.1886 & TRN & \\
\hline CHEMBL1981410 & 809234 & 6.2 & 6.1679 & TRN & \\
\hline CHEMBL1996234 & 809234 & 4.0 & 4.471 & TRN & \\
\hline CHEMBL1991434 & 809234 & 4.0 & 4.4113 & TRN & \\
\hline CHEMBL1967544 & 809234 & 4.0 & 4.9159 & TRN & \\
\hline CHEMBL223367 & 809234 & 4.0 & 4.6758 & TST & \\
\hline CHEMBL340384 & 809234 & 5.2 & 5.1286 & TRN & \\
\hline CHEMBL1996587 & 809234 & 4.0 & 4.1613 & TRN & \\
\hline CHEMBL1964804 & 809234 & 6.2 & 5.5105 & TRN & \\
\hline CHEMBL443962 & 809234 & 5.1 & 4.7142 & TST & \\
\hline CHEMBL 2000354 & 809234 & 6.9 & 6.465 & TRN & \\
\hline CHEMBL1965507 & 809234 & 7.2 & 7.4837 & TRN & \\
\hline CHEMBL274064 & 809234 & 4.0 & 4.5495 & TRN & \\
\hline CHEMBL1967564 & 809234 & 4.0 & 3.4179 & TRN & \\
\hline CHEMBL592030 & 809234 & 7.6 & 6.3461 & TST & \\
\hline CHEMBL 2000071 & 809234 & 5.8 & 5.9564 & TRN & \\
\hline CHEMBL1979176 & 809234 & 5.5 & 4.64199 & 99999999995 & TRN \\
\hline CHEMBL2000408 & 809234 & 4.0 & 4.1642 & TRN & \\
\hline CHEMBL 248757 & 809234 & 4.0 & 5.2821 & TST & \\
\hline CHEMBL1978014 & 809234 & 4.0 & 4.2024 & TRN & \\
\hline CHEMBL1994538 & 809234 & 4.0 & 3.7428 & TRN & \\
\hline CHEMBL1983195 & 809234 & 5.2 & 4.8067 & TST & \\
\hline CHEMBL1975490 & 809234 & 4.0 & 4.857 & TRN & \\
\hline CHEMBL1964444 & 809234 & 4.0 & 3.7575 & TRN & \\
\hline CHEMBL1989957 & 809234 & 4.0 & 4.843 & TRN & \\
\hline CHEMBL1986139 & 809234 & 6.0 & 5.489 & TRN & \\
\hline CHEMBL1980540 & 809234 & 4.0 & 3.6859 & TRN & \\
\hline CHEMBL2003229 & 809234 & 6.9 & 6.2162 & TRN & \\
\hline CHEMBL1979883 & 809234 & 6.4 & 6.1495 & TRN & \\
\hline CHEMBL1984162 & 809234 & 4.0 & 4.1955 & TRN & \\
\hline CHEMBL491758 & 809234 & 5.5 & 5.5999 & TRN & \\
\hline CHEMBL549730 & 809234 & 6.3 & 5.6516 & TRN & \\
\hline CHEMBL1970189 & 809234 & 4.0 & 3.8849 & TST & \\
\hline CHEMBL1996791 & 809234 & 5.0 & 4.6065 & TRN & \\
\hline CHEMBL371206 & 809234 & 6.8 & 6.4318 & TRN & \\
\hline & & & & 1286 & \\
\hline
\end{tabular}




\begin{tabular}{|c|c|c|c|c|}
\hline & & & pplement & al $\mathrm{Ta}$ \\
\hline CHEMBL1974664 & 809234 & 4.0 & 4.1775 & TRN \\
\hline CHEMBL1974288 & 809234 & 4.0 & 3.9788 & TRN \\
\hline CHEMBL 213207 & 809234 & 7.1 & 7.0262 & TRN \\
\hline CHEMBL196363 & 809234 & 6.2 & 6.0358 & TRN \\
\hline CHEMBL1190711 & 809234 & 6.0 & 5.6788 & TRN \\
\hline CHEMBL1968705 & 809234 & 5.1 & 5.1928 & TRN \\
\hline CHEMBL404367 & 809234 & 5.8 & 5.5164 & TRN \\
\hline CHEMBL1966343 & 809234 & 5.8 & 5.8777 & TRN \\
\hline CHEMBL1967887 & 809234 & 4.0 & 5.3445 & TRN \\
\hline CHEMBL 2000568 & 809234 & 5.8 & 5.6348 & TRN \\
\hline CHEMBL 2000335 & 809234 & 7.1 & 6.6454 & TRN \\
\hline CHEMBL1977604 & 809234 & 4.0 & 3.8987 & TST \\
\hline CHEMBL1988717 & 809234 & 5.2 & 5.0943 & TRN \\
\hline CHEMBL1974328 & 809234 & 6.4 & 5.5205 & TRN \\
\hline CHEMBL509032 & 809234 & 6.0 & 5.7724 & TRN \\
\hline CHEMBL573339 & 809234 & 4.0 & 4.8874 & TST \\
\hline CHEMBL1973808 & 809234 & 4.0 & 4.6464 & TRN \\
\hline CHEMBL 2000429 & 809234 & 4.0 & 4.3166 & TRN \\
\hline CHEMBL1972576 & 809234 & 7.7 & 7.1741 & TRN \\
\hline CHEMBL1990254 & 809234 & 5.4 & 4.1641 & TRN \\
\hline CHEMBL1992555 & 809234 & 4.0 & 3.9932 & TST \\
\hline CHEMBL1992342 & 809234 & 5.5 & 5.2437 & TRN \\
\hline CHEMBL 2003682 & 809234 & 6.4 & 5.6985 & TRN \\
\hline CHEMBL1988173 & 809234 & 6.7 & 5.5502 & TST \\
\hline CHEMBL535331 & 809234 & 4.0 & 4.7689 & TRN \\
\hline CHEMBL1989805 & 809234 & 4.0 & 4.8308 & TST \\
\hline CHEMBL1965423 & 809234 & 5.4 & 4.9222 & TRN \\
\hline CHEMBL1983025 & 809234 & 5.8 & 6.0456 & TRN \\
\hline CHEMBL 205415 & 809234 & 5.5 & 5.5023 & TRN \\
\hline CHEMBL1999153 & 809234 & 8.0 & 7.1237 & TRN \\
\hline CHEMBL1969473 & 809234 & 7.4 & 6.1388 & TRN \\
\hline CHEMBL1977135 & 809234 & 4.0 & 4.385 & TRN \\
\hline CHEMBL 2001920 & 809234 & 6.1 & 5.294 & TRN \\
\hline CHEMBL1241473 & 809234 & 4.0 & 5.6899 & TRN \\
\hline CHEMBL1978448 & 809234 & 6.1 & 4.7971 & TST \\
\hline CHEMBL 2004513 & 809234 & 4.0 & 3.9348 & TRN \\
\hline CHEMBL1972258 & 809234 & 5.1 & 5.3641 & TRN \\
\hline CHEMBL 2001257 & 809234 & 5.6 & 5.7505 & TRN \\
\hline CHEMBL1992536 & 809234 & 4.0 & 4.3749 & TRN \\
\hline CHEMBL1987793 & 809234 & 5.7 & 4.4932 & TST \\
\hline CHEMBL1992740 & 809234 & 4.0 & 3.4916 & TRN \\
\hline CHEMBL439340 & 809234 & 4.0 & 3.5592 & TRN \\
\hline CHEMBL 2002373 & 809234 & 4.0 & 4.105 & TRN \\
\hline CHEMBL 2006188 & 809234 & 4.0 & 3.7564 & TRN \\
\hline CHEMBL1967531 & 809234 & 6.5 & 6.9924 & TRN \\
\hline CHEMBL1970913 & 809234 & 4.0 & 3.3003 & TRN \\
\hline CHEMBL1973893 & 809234 & 4.0 & 4.2755 & TRN \\
\hline CHEMBL 2004631 & 809234 & 6.4 & 6.5143 & TRN \\
\hline
\end{tabular}




\begin{tabular}{|c|c|c|c|c|c|}
\hline \\
\hline CHEMBL1995736 & 809234 & 4.0 & 4.4685 & TRN & \\
\hline CHEMBL1997534 & 809234 & 4.0 & 4.3149 & TRN & \\
\hline CHEMBL1996500 & 809234 & 4.0 & 4.09699 & 99999999995 & TRN \\
\hline CHEMBL1985095 & 809234 & 7.0 & 6.2955 & TST & \\
\hline CHEMBL1998551 & 809234 & 4.0 & 4.1755 & TRN & \\
\hline CHEMBL1977374 & 809234 & 4.0 & 4.3506 & TRN & \\
\hline CHEMBL1682540 & 809234 & 4.0 & 4.7134 & TRN & \\
\hline CHEMBL1983315 & 809234 & 6.8 & 6.0116 & TRN & \\
\hline CHEMBL1976420 & 809234 & 4.0 & 5.1198 & TST & \\
\hline CHEMBL1994864 & 809234 & 5.1 & 4.7706 & TRN & \\
\hline CHEMBL 2002446 & 809234 & 5.2 & 4.9599 & TRN & \\
\hline CHEMBL497151 & 809234 & 6.2 & 6.30200 & 00000000005 & TST \\
\hline CHEMBL246970 & 809234 & 5.8 & 4.3014 & TRN & \\
\hline CHEMBL340921 & 809234 & 4.0 & 4.3239 & TRN & \\
\hline CHEMBL1999718 & 809234 & 4.0 & 4.1331 & TRN & \\
\hline CHEMBL1276446 & 809234 & 6.9 & 6.13299 & 9999999999 & TST \\
\hline CHEMBL1977346 & 809234 & 4.0 & 4.3006 & TRN & \\
\hline CHEMBL1971649 & 809234 & 4.0 & 5.226 & TRN & \\
\hline CHEMBL1998435 & 809234 & 4.0 & 4.8365 & TRN & \\
\hline CHEMBL 2006439 & 809234 & 7.1 & 6.9851 & TRN & \\
\hline CHEMBL 2006156 & 809234 & 5.6 & 5.2073 & TST & \\
\hline CHEMBL1969190 & 809234 & 5.9 & 6.4374 & TRN & \\
\hline CHEMBL1973937 & 809234 & 5.5 & 5.7746 & TRN & \\
\hline CHEMBL1991674 & 809234 & 6.2 & 6.6785 & TRN & \\
\hline CHEMBL1982711 & 809234 & 7.0 & 6.5405 & TRN & \\
\hline CHEMBL1987982 & 809234 & 4.0 & 4.4945 & TST & \\
\hline CHEMBL 2007044 & 809234 & 4.0 & 4.6002 & TRN & \\
\hline CHEMBL1994241 & 809234 & 5.6 & 6.8367 & TST & \\
\hline CHEMBL223460 & 809234 & 4.0 & 4.6358 & TST & \\
\hline CHEMBL1998829 & 809234 & 5.7 & 5.4896 & TRN & \\
\hline CHEMBL50894 & 809234 & 4.0 & 4.4542 & TST & \\
\hline CHEMBL1988838 & 809234 & 6.0 & 5.5187 & TRN & \\
\hline CHEMBL1981725 & 809234 & 5.3 & 4.9933 & TRN & \\
\hline CHEMBL1982866 & 809234 & 4.0 & 3.8318 & TRN & \\
\hline CHEMBL1968926 & 809234 & 4.0 & 4.794 & TRN & \\
\hline CHEMBL462120 & 809234 & 4.0 & 4.3911 & TST & \\
\hline CHEMBL1965570 & 809234 & 6.3 & 6.1667 & TRN & \\
\hline CHEMBL 2007592 & 809234 & 5.2 & 4.5229 & TST & \\
\hline CHEMBL210963 & 809234 & 4.0 & 4.2107 & TRN & \\
\hline CHEMBL 1082440 & 809234 & 5.5 & 5.2795 & TST & \\
\hline CHEMBL1614705 & 809234 & 4.0 & 4.0896 & TRN & \\
\hline CHEMBL1982400 & 809234 & 6.7 & 6.1862 & TRN & \\
\hline CHEMBL1984633 & 809234 & 4.0 & 4.136 & TRN & \\
\hline CHEMBL 2007372 & 809234 & 4.0 & 3.7466 & TRN & \\
\hline CHEMBL1965845 & 809234 & 6.2 & 6.3195 & TRN & \\
\hline CHEMBL1986597 & 809234 & 5.3 & 5.0527 & TRN & \\
\hline CHEMBL1990482 & 809234 & 6.8 & 5.2957 & TRN & \\
\hline CHEMBL1990904 & 809234 & 4.0 & 4.2767 & TRN & \\
\hline
\end{tabular}




\begin{tabular}{|c|c|c|c|c|}
\hline & & & ient & al Ta \\
\hline CHEMBL 2005475 & 809234 & 6.5 & 6.0752 & TRN \\
\hline CHEMBL402846 & 809234 & 5.7 & 5.1465 & TRN \\
\hline CHEMBL183844 & 809234 & 4.0 & 4.1496 & TRN \\
\hline CHEMBL1997349 & 809234 & 5.5 & 4.4927 & TST \\
\hline CHEMBL220057 & 809234 & 5.7 & 5.5727 & TRN \\
\hline CHEMBL1682545 & 809234 & 6.1 & 5.228 & TRN \\
\hline CHEMBL383541 & 809234 & 5.9 & 5.7307 & TRN \\
\hline CHEMBL 2001224 & 809234 & 4.0 & 4.0757 & TRN \\
\hline CHEMBL10 & 809234 & 4.0 & 3.9387 & TRN \\
\hline CHEMBL1982982 & 809234 & 4.0 & 4.7538 & TRN \\
\hline CHEMBL1976732 & 809234 & 4.0 & 4.2027 & TRN \\
\hline CHEMBL1964937 & 809234 & 5.7 & 6.1212 & TRN \\
\hline CHEMBL1969506 & 809234 & 4.0 & 4.7034 & TRN \\
\hline CHEMBL1980163 & 809234 & 5.4 & 4.8046 & TRN \\
\hline CHEMBL2005899 & 809234 & 6.3 & 5.4508 & TRN \\
\hline CHEMBL1682552 & 809234 & 4.0 & 4.4869 & TRN \\
\hline CHEMBL1972568 & 809234 & 5.7 & 5.0237 & TRN \\
\hline CHEMBL1987745 & 809234 & 6.7 & 5.2626 & TRN \\
\hline CHEMBL229799 & 809234 & 6.5 & 5.9678 & TRN \\
\hline CHEMBL105739 & 809234 & 4.0 & 4.7724 & TRN \\
\hline CHEMBL 379300 & 809234 & 5.4 & 5.6747 & TRN \\
\hline CHEMBL1969523 & 809234 & 7.6 & 6.7402 & TRN \\
\hline CHEMBL1988995 & 809234 & 4.0 & 4.1153 & TRN \\
\hline CHEMBL1986781 & 809234 & 4.0 & 3.645 & TRN \\
\hline CHEMBL526133 & 809234 & 5.4 & 5.3694 & TRN \\
\hline CHEMBL387971 & 809234 & 4.0 & 4.5984 & TRN \\
\hline CHEMBL1979057 & 809234 & 5.6 & 5.8863 & TRN \\
\hline CHEMBL1999428 & 809234 & 4.0 & 3.8743 & TRN \\
\hline CHEMBL1967560 & 809234 & 4.0 & 3.9945 & TRN \\
\hline CHEMBL 211378 & 809234 & 5.2 & 5.5013 & TRN \\
\hline CHEMBL1682358 & 809234 & 6.0 & 6.2768 & TRN \\
\hline CHEMBL1982465 & 809234 & 6.0 & 5.8524 & TRN \\
\hline CHEMBL 2001751 & 809234 & 6.5 & 6.2762 & TRN \\
\hline CHEMBL 2003420 & 809234 & 4.0 & 4.2107 & TRN \\
\hline CHEMBL1984586 & 809234 & 6.5 & 6.2805 & TRN \\
\hline CHEMBL1972659 & 809234 & 4.0 & 4.1622 & TST \\
\hline CHEMBL272453 & 809234 & 5.8 & 5.5699 & TRN \\
\hline CHEMBL1970217 & 809234 & 4.0 & 3.5976 & TRN \\
\hline CHEMBL 2005528 & 809234 & 4.0 & 4.8937 & TST \\
\hline CHEMBL185569 & 809234 & 6.3 & 5.1359 & TRN \\
\hline CHEMBL1969843 & 809234 & 4.0 & 4.3868 & TRN \\
\hline CHEMBL 2007002 & 809234 & 7.3 & 6.4121 & TRN \\
\hline CHEMBL1987007 & 809234 & 4.0 & 4.8236 & TRN \\
\hline CHEMBL1969588 & 809234 & 6.8 & 7.3705 & TRN \\
\hline CHEMBL1984711 & 809234 & 5.2 & 5.0202 & TRN \\
\hline CHEMBL484390 & 809234 & 4.0 & 5.0419 & TST \\
\hline CHEMBL1979252 & 809234 & 6.2 & 5.416 & TRN \\
\hline CHEMBL1986499 & 809234 & 6.4 & 6.6849 & TRN \\
\hline
\end{tabular}




\begin{tabular}{|c|c|c|c|c|c|}
\hline \multirow[b]{2}{*}{ CHEMBL 2004290} & \multirow{2}{*}{809234} & \\
\hline & & 5.1 & 5.4624 & TRN & \\
\hline CHEMBL1972937 & 809234 & 4.0 & 4.6448 & TRN & \\
\hline CHEMBL 2000393 & 809234 & 6.3 & 4.8199 & TST & \\
\hline CHEMBL2001477 & 809234 & 5.2 & 5.0151 & TRN & \\
\hline CHEMBL 2004311 & 809234 & 5.9 & 5.1551 & TRN & \\
\hline CHEMBL1992634 & 809234 & 6.3 & 6.6903 & TRN & \\
\hline CHEMBL1242373 & 809234 & 7.1 & 6.8719 & TRN & \\
\hline CHEMBL56543 & 809234 & 5.5 & 5.6666 & TRN & \\
\hline CHEMBL1988075 & 809234 & 5.3 & 6.4006 & TRN & \\
\hline CHEMBL316264 & 809234 & 4.0 & 4.2526 & TRN & \\
\hline CHEMBL1991678 & 809234 & 4.0 & 4.0837 & TRN & \\
\hline CHEMBL2001239 & 809234 & 4.0 & 5.7119 & TST & \\
\hline CHEMBL1988594 & 809234 & 7.6 & 7.9616 & TRN & \\
\hline CHEMBL 2001288 & 809234 & 4.0 & 4.3242 & TRN & \\
\hline CHEMBL1999811 & 809234 & 6.0 & 5.71700 & 00000000005 & TST \\
\hline CHEMBL1985074 & 809234 & 4.0 & 4.7223 & TST & \\
\hline CHEMBL1982874 & 809234 & 4.0 & 5.0507 & TRN & \\
\hline CHEMBL 2000481 & 809234 & 4.0 & 4.5569 & TRN & \\
\hline CHEMBL1991725 & 809234 & 6.7 & 5.4152 & TRN & \\
\hline CHEMBL1992242 & 809234 & 4.0 & 3.9527 & TRN & \\
\hline CHEMBL 2007296 & 809234 & 4.0 & 4.0004 & TRN & \\
\hline CHEMBL396523 & 809234 & 6.7 & 6.9751 & TRN & \\
\hline CHEMBL 208637 & 809234 & 4.0 & 4.3871 & TRN & \\
\hline CHEMBL1970203 & 809234 & 7.0 & 7.4614 & TRN & \\
\hline CHEMBL1986530 & 809234 & 4.0 & 4.9689 & TST & \\
\hline CHEMBL1965351 & 809234 & 4.0 & 4.9724 & TST & \\
\hline CHEMBL1999321 & 809234 & 4.0 & 4.569 & TRN & \\
\hline CHEMBL385478 & 809234 & 7.6 & 6.9989 & TRN & \\
\hline CHEMBL1968590 & 809234 & 4.0 & 4.7428 & TRN & \\
\hline CHEMBL 2007336 & 809234 & 5.2 & 4.8428 & TRN & \\
\hline CHEMBL 2005375 & 809234 & 4.0 & 4.3654 & TRN & \\
\hline CHEMBL1984191 & 809234 & 4.0 & 4.8476 & TRN & \\
\hline CHEMBL1972183 & 809234 & 4.0 & 4.44300 & 00000000005 & TST \\
\hline CHEMBL1971029 & 809234 & 6.4 & 6.0634 & TRN & \\
\hline CHEMBL394790 & 809234 & 5.9 & 6.1074 & TRN & \\
\hline CHEMBL1980592 & 809234 & 4.0 & 4.5559 & TST & \\
\hline CHEMBL226471 & 809234 & 5.8 & 6.8198 & TRN & \\
\hline CHEMBL1996111 & 809234 & 5.3 & 5.4608 & TRN & \\
\hline CHEMBL1974702 & 809234 & 4.0 & 4.1339 & TRN & \\
\hline CHEMBL1965589 & 809234 & 4.1 & 4.2218 & TRN & \\
\hline CHEMBL1998193 & 809234 & 4.0 & 4.4538 & TRN & \\
\hline CHEMBL474432 & 809234 & 4.0 & 4.7991 & TST & \\
\hline CHEMBL1988153 & 809234 & 4.0 & 4.9133 & TST & \\
\hline CHEMBL1988437 & 809234 & 5.2 & 5.4719 & TST & \\
\hline CHEMBL1998121 & 809234 & 6.2 & 5.8321 & TRN & \\
\hline CHEMBL1979577 & 809234 & 6.1 & 6.4351 & TRN & \\
\hline CHEMBL1991800 & 809234 & 4.0 & 4.0941 & TRN & \\
\hline CHEMBL52387 & 809234 & 4.0 & 4.414 & TST & \\
\hline & & & & 12870 & \\
\hline
\end{tabular}




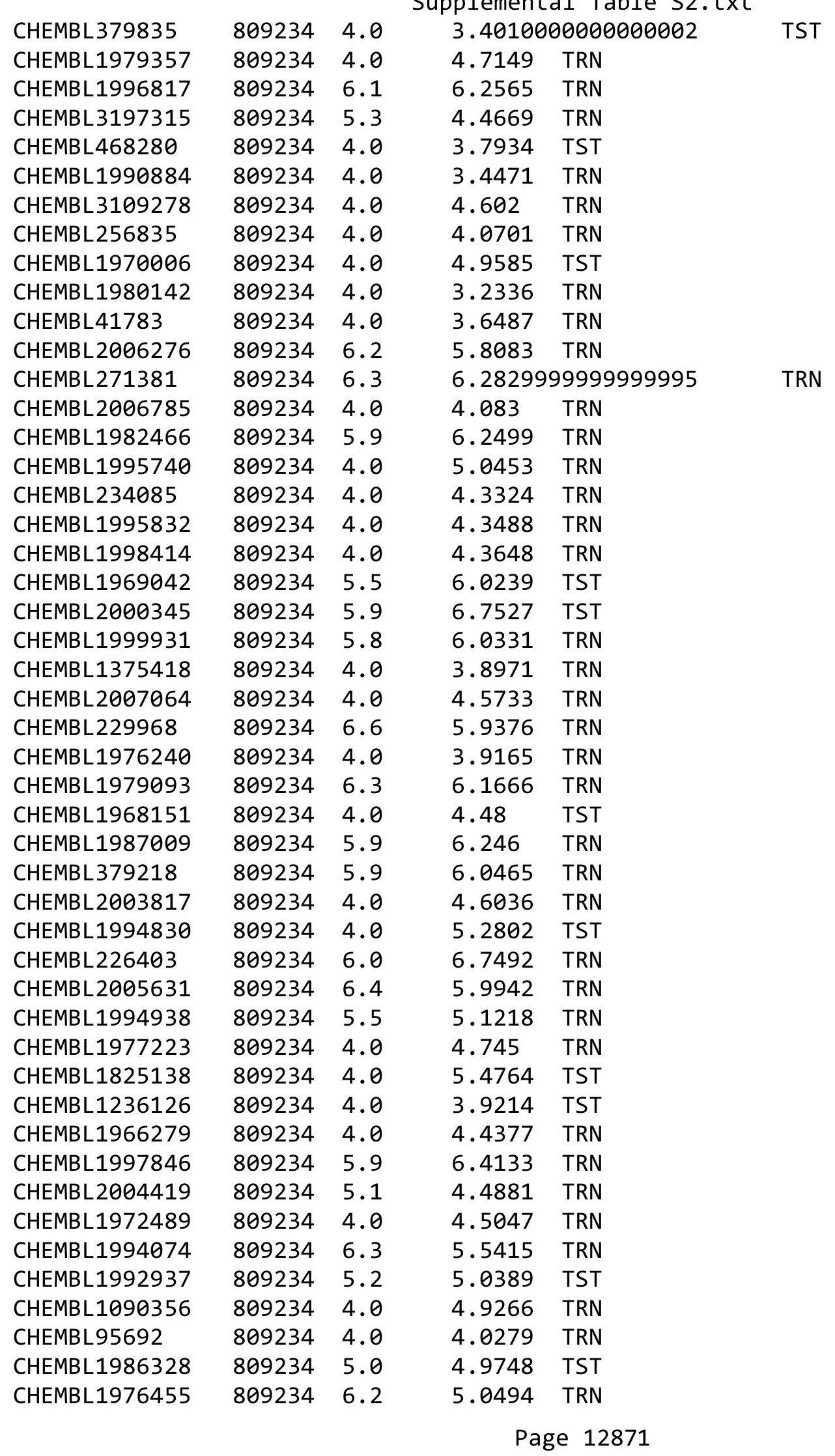




\begin{tabular}{|c|c|c|c|c|}
\hline \multicolumn{5}{|c|}{ Supplemental Table S2.txt } \\
\hline CHEMBL1983923 & 809234 & 4.0 & 4.9941 & TST \\
\hline CHEMBL1982361 & 809234 & 6.3 & 5.2049 & TRN \\
\hline CHEMBL1970950 & 809234 & 4.0 & 5.6344 & TRN \\
\hline CHEMBL1983534 & 809234 & 5.6 & 5.5997 & TRN \\
\hline CHEMBL1982122 & 809234 & 5.2 & 5.0401 & TRN \\
\hline CHEMBL 2000801 & 809234 & 4.0 & 3.9872 & TRN \\
\hline CHEMBL1999112 & 809234 & 5.2 & 4.6891 & TST \\
\hline CHEMBL1682546 & 809234 & 5.7 & 5.1549 & TRN \\
\hline CHEMBL1991395 & 809234 & 4.0 & 4.1384 & TRN \\
\hline CHEMBL1971245 & 809234 & 4.0 & 4.5924 & TRN \\
\hline CHEMBL1972142 & 809234 & 6.8 & 6.3499 & TRN \\
\hline CHEMBL1966514 & 809234 & 5.7 & 6.3111 & TRN \\
\hline CHEMBL2003638 & 809234 & 5.4 & 5.6068 & TRN \\
\hline CHEMBL1996066 & 809234 & 5.6 & 5.6805 & TST \\
\hline CHEMBL1972152 & 809234 & 4.0 & 4.6983 & TST \\
\hline CHEMBL1993722 & 809234 & 5.2 & 5.64 & TRN \\
\hline CHEMBL1970806 & 809234 & 4.0 & 4.3545 & TST \\
\hline CHEMBL1375640 & 809234 & 5.7 & 6.415 & TST \\
\hline CHEMBL1979970 & 809234 & 4.0 & 3.2363 & TRN \\
\hline CHEMBL 249282 & 809234 & 4.0 & 4.6735 & TST \\
\hline CHEMBL 2006237 & 809234 & 5.2 & 4.2941 & TST \\
\hline CHEMBL1967720 & 809234 & 5.9 & 6.1266 & TST \\
\hline CHEMBL1572266 & 809234 & 4.0 & 3.6269 & TST \\
\hline CHEMBL1991138 & 809234 & 5.2 & 4.5526 & TST \\
\hline CHEMBL1969755 & 809234 & 4.0 & 4.1177 & TST \\
\hline CHEMBL1979516 & 809234 & 4.1 & 5.6178 & TST \\
\hline CHEMBL1605605 & 809234 & 4.0 & 4.9186 & TST \\
\hline CHEMBL1972820 & 809234 & 4.0 & 4.1463 & TST \\
\hline CHEMBL1996208 & 809234 & 4.0 & 4.9193 & TST \\
\hline CHEMBL1989029 & 809234 & 5.5 & 4.8142 & TST \\
\hline CHEMBL514499 & 809234 & 4.0 & 4.4212 & TST \\
\hline CHEMBL1965631 & 809234 & 4.0 & 4.6825 & TST \\
\hline CHEMBL1980144 & 809234 & 6.6 & 7.1529 & TST \\
\hline CHEMBL1991188 & 809234 & 4.0 & 4.0328 & TST \\
\hline CHEMBL1972849 & 809234 & 4.0 & 4.0 & TST \\
\hline CHEMBL 377408 & 809234 & 4.0 & 4.4413 & TST \\
\hline CHEMBL231209 & 809234 & 5.7 & 6.2964 & TST \\
\hline CHEMBL1975357 & 809234 & 4.0 & 4.0049 & TST \\
\hline CHEMBL1976220 & 809234 & 6.2 & 6.3261 & TST \\
\hline CHEMBL 259922 & 809234 & 4.0 & 3.3034 & TST \\
\hline CHEMBL1997617 & 809234 & 5.6 & 4.4775 & TST \\
\hline CHEMBL1982383 & 809234 & 4.0 & 4.0978 & TST \\
\hline CHEMBL1969301 & 809234 & 4.0 & 4.9705 & TST \\
\hline CHEMBL17370 & 809234 & 4.0 & 4.0732 & TST \\
\hline CHEMBL1987910 & 809234 & 4.0 & 5.5237 & TST \\
\hline CHEMBL1983932 & 809234 & 4.0 & 5.3456 & TST \\
\hline CHEMBL1997822 & 809234 & 5.4 & $5.2810 e$ & 0000000001 \\
\hline CHEMBL1991285 & 809234 & 4.0 & 4.4682 & TST \\
\hline
\end{tabular}




\begin{tabular}{|c|c|c|c|c|c|}
\hline \multicolumn{6}{|c|}{ Supplemental Table S2.txt } \\
\hline CHEMBL1984038 & 809234 & 4.0 & 4.1309 & TST & \\
\hline CHEMBL243088 & 809234 & 6.1 & 6.6818 & TST & \\
\hline CHEMBL1993661 & 809234 & 6.6 & 6.19 & TST & \\
\hline CHEMBL1974416 & 809234 & 5.8 & 5.5074 & TST & \\
\hline CHEMBL2004615 & 809234 & 5.6 & 4.5649 & TST & \\
\hline CHEMBL1984039 & 809234 & 5.1 & 4.148 & TST & \\
\hline CHEMBL1997872 & 809234 & 4.0 & 5.3745 & TST & \\
\hline CHEMBL1407771 & 688257 & 5.0282 & 4.6842 & TRN & \\
\hline CHEMBL1583227 & 688257 & 5.0259 & 4.3384 & TST & \\
\hline CHEMBL3199283 & 688257 & 4.6765 & 4.4664 & TST & \\
\hline CHEMBL1419066 & 688257 & 4.3422 & 4.585 & TRN & \\
\hline CHEMBL1336680 & 688257 & 4.7574 & 5.0035 & TRN & \\
\hline CHEMBL1423440 & 688257 & 4.44 & 4.9649 & TRN & \\
\hline CHEMBL1543494 & 688257 & 4.5547 & 4.6524 & TRN & \\
\hline CHEMBL1508148 & 688257 & 4.633 & 4.5534 & TRN & \\
\hline CHEMBL1310721 & 688257 & 4.3407 & 4.2703 & TRN & \\
\hline CHEMBL1506708 & 688257 & 4.6856 & 4.4344 & TRN & \\
\hline CHEMBL1342234 & 688257 & 4.4512 & 4.9579 & TRN & \\
\hline CHEMBL1585563 & 688257 & 4.8415 & 4.5277 & TRN & \\
\hline CHEMBL1461513 & 688257 & 4.5673 & 4.566 & TRN & \\
\hline CHEMBL1547896 & 688257 & 4.9551 & 4.8141 & TRN & \\
\hline CHEMBL1465297 & 688257 & 4.4725 & 4.2829 & TRN & \\
\hline CHEMBL1606599 & 688257 & 4.4355 & 4.7889 & TRN & \\
\hline CHEMBL1300822 & 688257 & 4.0784 & 4.5554 & TRN & \\
\hline CHEMBL1545760 & 688257 & 3.0 & 4.3638 & TRN & \\
\hline CHEMBL1507013 & 688257 & 5.8539 & 5.0586 & TRN & \\
\hline CHEMBL1341124 & 688257 & 4.6468 & 4.6574 & TST & \\
\hline CHEMBL 3210280 & 688257 & 4.4232 & 4.7134 & TRN & \\
\hline CHEMBL1545848 & 688257 & 5.2937 & 4.5595 & TRN & \\
\hline CHEMBL1361887 & 688257 & 4.3901 & 4.4097 & TST & \\
\hline CHEMBL1304974 & 688257 & 4.8505 & 4.9002 & TRN & \\
\hline CHEMBL1313759 & 688257 & 4.6198 & 5.0277 & TRN & \\
\hline CHEMBL1493606 & 688257 & 4.6199 & 5.0334 & TRN & \\
\hline CHEMBL1494942 & 688257 & 4.5468 & 5.0714 & TRN & \\
\hline CHEMBL3197909 & 688257 & 4.4635 & 4.4855 & TRN & \\
\hline CHEMBL1417376 & 688257 & 5.6415 & 4.6271 & TRN & \\
\hline CHEMBL1557474 & 688257 & 4.5469 & 4.86600 & 00000000005 & TRN \\
\hline CHEMBL1606809 & 688257 & 4.7697 & 4.9978 & TRN & \\
\hline CHEMBL1376421 & 688257 & 4.4938 & 4.5393 & TRN & \\
\hline CHEMBL1449820 & 688257 & 3.0 & 3.9355 & TRN & \\
\hline CHEMBL1448568 & 688257 & 4.7024 & 4.7671 & TRN & \\
\hline CHEMBL1462011 & 688257 & 4.9968 & 4.9437 & TRN & \\
\hline CHEMBL1510060 & 688257 & 4.7083 & 4.8045 & TST & \\
\hline CHEMBL1373855 & 688257 & 4.8079 & 4.8009 & TRN & \\
\hline CHEMBL1341932 & 688257 & 4.4154 & 4.4562 & TRN & \\
\hline CHEMBL1378419 & 688257 & 4.5741 & 4.58899 & 99999999995 & TST \\
\hline CHEMBL1470463 & 688257 & 4.4282 & 4.5999 & TRN & \\
\hline CHEMBL1364290 & 688257 & 5.1172 & 4.3992 & TRN & \\
\hline
\end{tabular}

Page 12873 
Supplemental Table S2.txt

\begin{tabular}{|c|c|c|c|c|c|}
\hline CHEMBL1464631 & 688257 & 4.6887 & 4.7701 & TST & \\
\hline CHEMBL1465240 & 688257 & 4.5037 & 5.0292 & TRN & \\
\hline CHEMBL1305050 & 688257 & 4.63899 & 99999999 & 99 & 5.0117 \\
\hline CHEMBL1376664 & 688257 & 4.6065 & 4.6951 & TRN & \\
\hline CHEMBL1453654 & 688257 & 4.4976 & 4.5768 & TRN & \\
\hline CHEMBL1406094 & 688257 & 4.5381 & 4.689 & TRN & \\
\hline CHEMBL1506603 & 688257 & 4.4048 & 4.7858 & TRN & \\
\hline CHEMBL1990571 & 688257 & 4.6724 & 4.735 & TRN & \\
\hline CHEMBL1496707 & 688257 & 4.6182 & 4.4685 & TRN & \\
\hline CHEMBL1505572 & 688257 & 5.2275 & 4.2508 & TST & \\
\hline CHEMBL1420606 & 688257 & 4.9562 & 4.9691 & TRN & \\
\hline CHEMBL1422748 & 688257 & 5.0495 & 4.7864 & TRN & \\
\hline CHEMBL1533746 & 688257 & 4.5244 & 4.8653 & TRN & \\
\hline CHEMBL1468795 & 688257 & 4.4174 & 4.7644 & TST & \\
\hline CHEMBL1499652 & 688257 & 6.3809 & 4.5168 & TST & \\
\hline CHEMBL1510885 & 688257 & 4.3667 & 4.5316 & TRN & \\
\hline CHEMBL1369254 & 688257 & 5.3097 & 4.7934 & TRN & \\
\hline CHEMBL1500832 & 688257 & 3.0 & 4.4147 & TRN & \\
\hline CHEMBL1523836 & 688257 & 4.5672 & 4.6768 & TRN & \\
\hline CHEMBL1603085 & 688257 & 4.4864 & 4.4407 & TRN & \\
\hline CHEMBL3213254 & 688257 & 6.9666 & 4.7205 & TST & \\
\hline CHEMBL1499296 & 688257 & 4.7149 & 4.4905 & TRN & \\
\hline CHEMBL1391672 & 688257 & 5.3974 & 4.7178 & TRN & \\
\hline CHEMBL530280 & 688257 & 4.6816 & 4.7531 & TST & \\
\hline CHEMBL1391665 & 688257 & 4.4903 & 4.8927 & TRN & \\
\hline CHEMBL3199860 & 688257 & 4.8092 & 4.7644 & TRN & \\
\hline CHEMBL1533248 & 688257 & 4.8084 & 4.8261 & TRN & \\
\hline CHEMBL1304998 & 688257 & 4.4202 & 4.7118 & TRN & \\
\hline CHEMBL1490229 & 688257 & 4.5407 & 4.7966 & TRN & \\
\hline CHEMBL1576945 & 688257 & 4.4541 & 4.4276 & TRN & \\
\hline CHEMBL1429270 & 688257 & 5.8398 & 5.0623 & TRN & \\
\hline CHEMBL1585086 & 688257 & 4.6811 & 4.5655 & TST & \\
\hline CHEMBL1336922 & 688257 & 4.6115 & 4.2179 & TRN & \\
\hline CHEMBL1562136 & 688257 & 5.0143 & 4.753 & TRN & \\
\hline CHEMBL1388081 & 688257 & 4.9583 & 4.6438 & TRN & \\
\hline CHEMBL1542128 & 688257 & 4.226 & 4.4349 & TRN & \\
\hline CHEMBL1578500 & 688257 & 4.6337 & 4.9265 & TRN & \\
\hline CHEMBL1547893 & 688257 & 4.4774 & 4.5806 & TRN & \\
\hline CHEMBL1528840 & 688257 & 6.7496 & 5.0668 & TRN & \\
\hline CHEMBL1408788 & 688257 & 4.3241 & 4.7856 & TRN & \\
\hline CHEMBL1309994 & 688257 & 4.4691 & 4.4164 & TRN & \\
\hline CHEMBL1999046 & 688257 & 4.497 & 4.1744 & TST & \\
\hline CHEMBL1470905 & 688257 & 4.7571 & 4.2359 & TRN & \\
\hline CHEMBL1468100 & 688257 & 4.7368 & 4.4513 & TRN & \\
\hline CHEMBL1543922 & 688257 & 4.5353 & 4.5968 & TST & \\
\hline CHEMBL1468998 & 688257 & 4.6856 & 4.9629 & TRN & \\
\hline CHEMBL1322666 & 688257 & 4.4814 & 4.5594 & TRN & \\
\hline CHEMBL1606823 & 688257 & 3.0 & 4.8182 & TST & \\
\hline
\end{tabular}




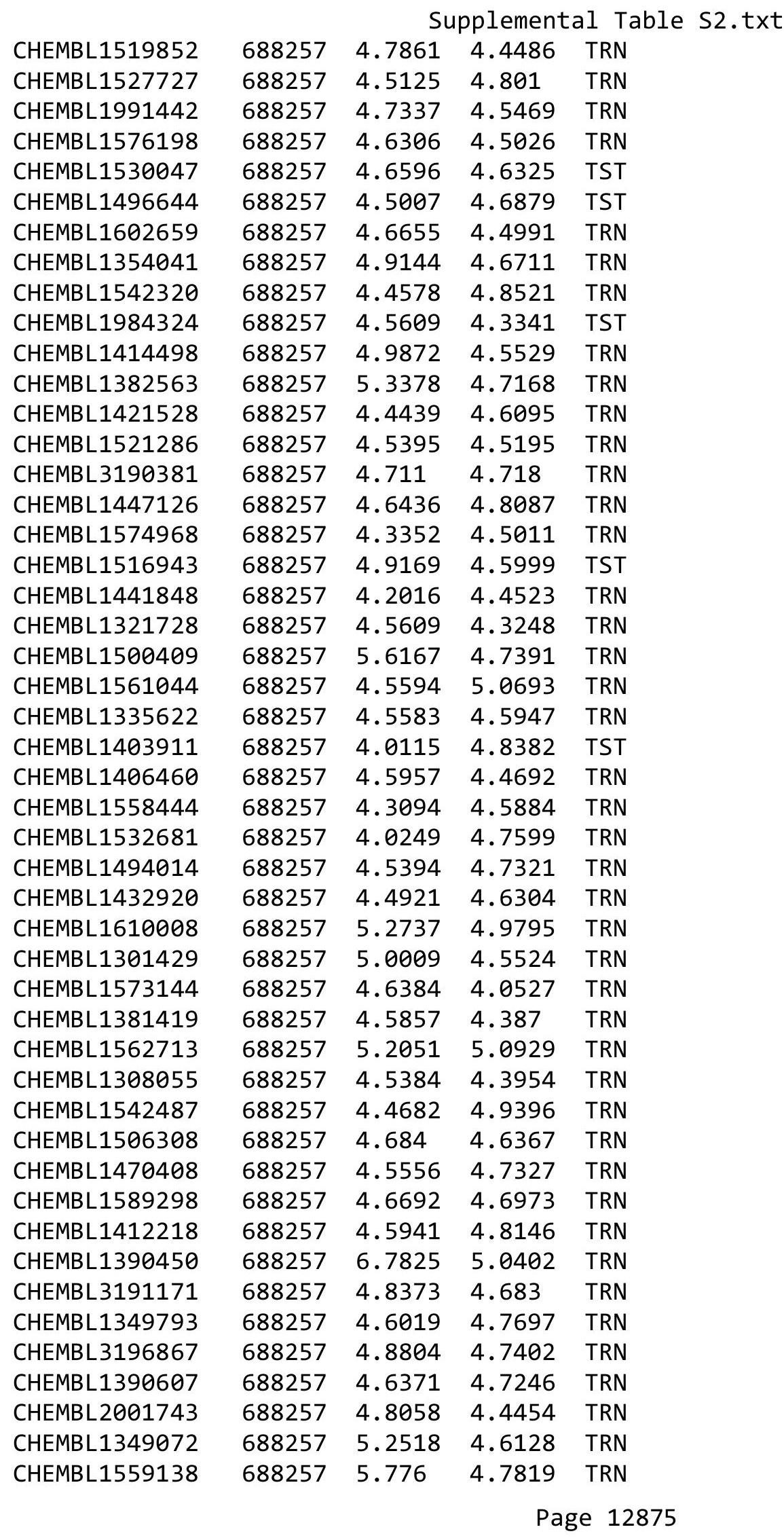




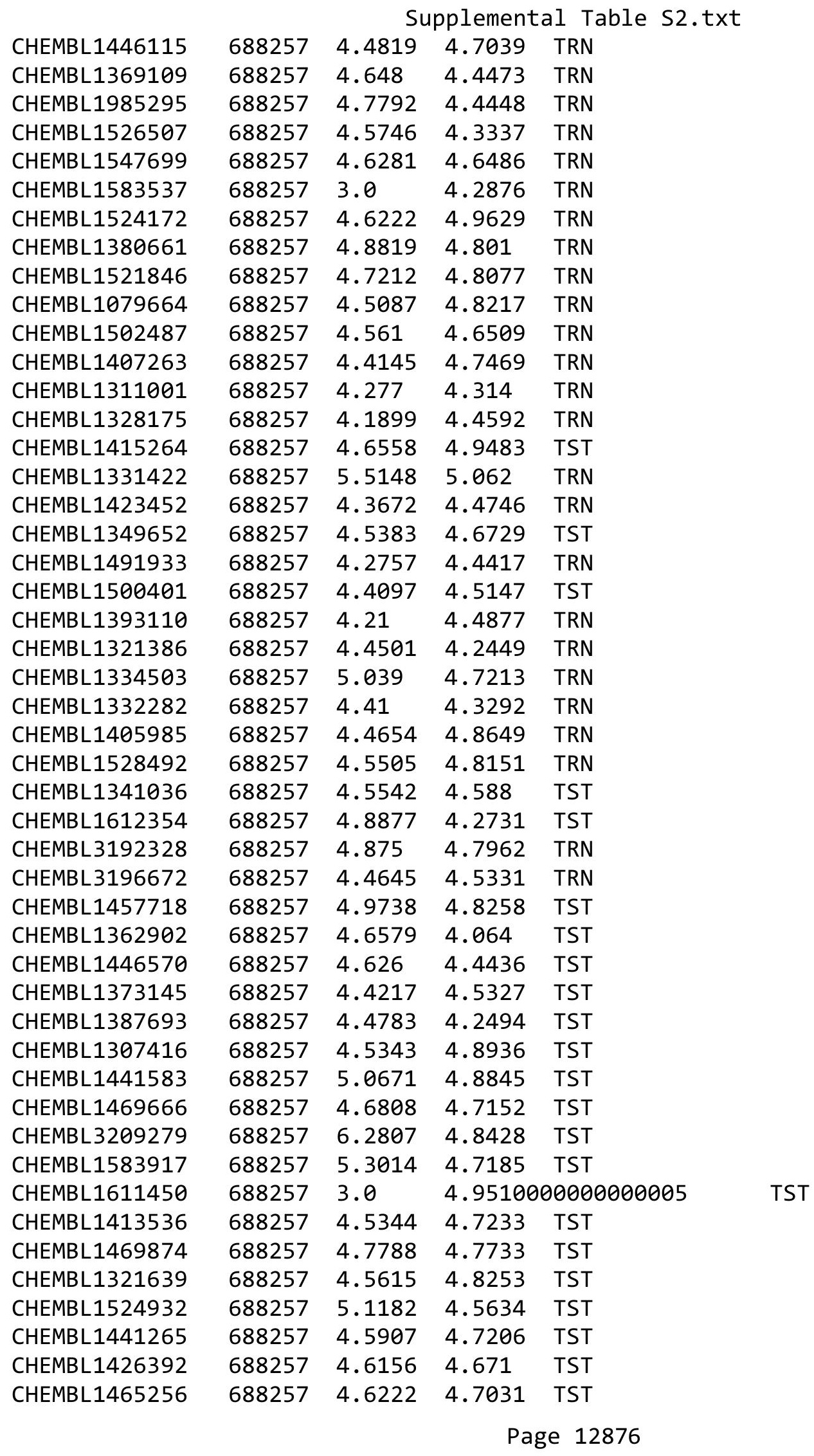




\begin{tabular}{|c|c|c|c|c|c|c|}
\hline & & \multicolumn{5}{|c|}{ Supplemental Table S2.txt } \\
\hline CHEMBL1517829 & 688257 & 4.3554 & 4.9901 & TST & & \\
\hline CHEMBL3191954 & 688257 & 4.5876 & 4.7879 & TST & & \\
\hline CHEMBL1455846 & 688257 & 4.4454 & 4.3675 & TST & & \\
\hline CHEMBL299194 & 217000 & 6.8239 & 6.8555 & TRN & & \\
\hline CHEMBL297523 & 217000 & 8.0458 & 8.0326 & TST & & \\
\hline CHEMBL320339 & 217000 & 7.8239 & 7.7956 & TRN & & \\
\hline CHEMBL111339 & 217000 & 7.301 & 7.3401 & TRN & & \\
\hline CHEMBL 301612 & 217000 & 7.699 & 7.5546 & TRN & & \\
\hline CHEMBL112706 & 217000 & 8.0969 & 8.1078 & TRN & & \\
\hline CHEMBL112080 & 217000 & 8.0458 & 8.0787 & TRN & & \\
\hline CHEMBL113356 & 217000 & \multicolumn{3}{|c|}{4.9830000000000005} & 5.0375 & TRN \\
\hline CHEMBL321193 & 217000 & 7.699 & 7.6721 & TRN & & \\
\hline CHEMBL332269 & 217000 & 5.6383 & 5.6397 & TRN & & \\
\hline CHEMBL50647 & 217000 & 8.0 & 8.0019 & TRN & & \\
\hline CHEMBL111913 & 217000 & 5.3768 & 5.3913 & TRN & & \\
\hline CHEMBL51573 & 217000 & 3.301 & 4.8199 & TST & & \\
\hline CHEMBL48172 & 217000 & 6.2757 & 6.3341 & TRN & & \\
\hline CHEMBL109296 & 217000 & 6.2291 & 6.2345 & TRN & & \\
\hline CHEMBL109525 & 217000 & 7.0969 & 7.1893 & TRN & & \\
\hline CHEMBL324926 & 217000 & 7.699 & 7.6142 & TRN & & \\
\hline CHEMBL323699 & 217000 & 5.7959 & 5.8226 & TRN & & \\
\hline CHEMBL 326041 & 217000 & 6.0915 & 6.0361 & TRN & & \\
\hline CHEMBL448154 & 217000 & 7.9208 & 7.8622 & TRN & & \\
\hline CHEMBL 324543 & 217000 & 7.9586 & 7.9925 & TRN & & \\
\hline CHEMBL107472 & 217000 & 6.1249 & 6.0662 & TRN & & \\
\hline CHEMBL320705 & 217000 & 5.9208 & 5.9627 & TRN & & \\
\hline CHEMBL50470 & 217000 & 6.0177 & 5.9958 & TRN & & \\
\hline CHEMBL109759 & 217000 & 5.7959 & 5.7964 & TRN & & \\
\hline CHEMBL111365 & 217000 & 7.1135 & 7.0909 & TRN & & \\
\hline CHEMBL109631 & 217000 & 8.0458 & 8.1101 & TRN & & \\
\hline CHEMBL327127 & 217000 & 8.2218 & 8.2581 & TRN & & \\
\hline CHEMBL 325589 & 217000 & 7.4202 & 7.4299 & TRN & & \\
\hline CHEMBL111618 & 217000 & 6.4815 & 6.4908 & TRN & & \\
\hline CHEMBL109725 & 217000 & 3.301 & 4.5955 & TST & & \\
\hline CHEMBL113128 & 217000 & 5.7959 & 5.711 & TST & & \\
\hline CHEMBL49596 & 217000 & 6.585 & 5.4146 & TST & & \\
\hline CHEMBL104779 & 217000 & 8.0 & 8.0605 & TRN & & \\
\hline CHEMBL111434 & 217000 & 7.2218 & 7.1491 & TRN & & \\
\hline CHEMBL322298 & 217000 & 7.2757 & 7.2915 & TRN & & \\
\hline CHEMBL113863 & 217000 & 6.4318 & 6.4402 & TRN & & \\
\hline CHEMBL111197 & 217000 & 7.301 & 7.4023 & TRN & & \\
\hline CHEMBL110905 & 217000 & 7.8861 & 7.8721 & TRN & & \\
\hline CHEMBL106232 & 217000 & 7.2218 & 7.16 & TRN & & \\
\hline CHEMBL110034 & 217000 & 5.4949 & 5.4478 & TRN & & \\
\hline CHEMBL331366 & 217000 & 7.8861 & 7.8161 & TRN & & \\
\hline CHEMBL 323775 & 217000 & 8.0969 & 8.0827 & TRN & & \\
\hline CHEMBL113521 & 217000 & 7.8239 & 7.8627 & TRN & & \\
\hline CHEMBL113070 & 217000 & 7.4949 & 7.4449 & TRN & & \\
\hline
\end{tabular}




\begin{tabular}{|c|c|c|c|c|c|}
\hline & & \multicolumn{4}{|c|}{ Supplemental Table S2.txt } \\
\hline CHEMBL109547 & 217000 & 7.8539 & 7.8946 & TRN & \\
\hline CHEMBL112914 & 217000 & 7.7696 & 7.6403 & TST & \\
\hline CHEMBL104153 & 217000 & 7.699 & 7.3722 & TST & \\
\hline CHEMBL51283 & 217000 & 8.0 & 8.4288 & TST & \\
\hline CHEMBL104244 & 217000 & 7.1549 & 7.0617 & TST & \\
\hline CHEMBL299347 & 217000 & 3.301 & 4.6504 & TST & \\
\hline CHEMBL111247 & 217000 & 6.8539 & 7.2348 & TST & \\
\hline CHEMBL113023 & 217000 & 7.301 & 7.1948 & TST & \\
\hline CHEMBL323405 & 217000 & 7.3979 & 7.5613 & TST & \\
\hline CHEMBL419022 & 217000 & 6.5229 & 6.9628 & TST & \\
\hline CHEMBL346742 & 36941 & 5.284 & 5.2233 & TRN & \\
\hline CHEMBL157565 & 36941 & 7.0269 & 7.2151 & TRN & \\
\hline CHEMBL157577 & 36941 & 8.8239 & 8.3591 & TRN & \\
\hline CHEMBL157203 & 36941 & 6.5086 & 6.5085 & TRN & \\
\hline CHEMBL345696 & 36941 & 7.1249 & 7.0836 & TRN & \\
\hline CHEMBL156243 & 36941 & 7.0269 & 6.8358 & TRN & \\
\hline CHEMBL155035 & 36941 & 7.4559 & 7.3672 & TRN & \\
\hline CHEMBL422333 & 36941 & 7.7696 & 7.8508 & TRN & \\
\hline CHEMBL157620 & 36941 & 7.585 & 7.5566 & TRN & \\
\hline CHEMBL156449 & 36941 & 5.7959 & 5.9707 & TRN & \\
\hline CHEMBL345127 & 36941 & 6.2676 & 6.2445 & TRN & \\
\hline CHEMBL348606 & 36941 & 7.5086 & 7.7178 & TRN & \\
\hline CHEMBL154975 & 36941 & 6.9208 & 7.1763 & TRN & \\
\hline CHEMBL346745 & 36941 & 6.0 & 5.8666 & TRN & \\
\hline CHEMBL156934 & 36941 & 8.3872 & 8.166 & TRN & \\
\hline CHEMBL154531 & 36941 & 7.0458 & 7.3606 & TRN & \\
\hline CHEMBL347513 & 36941 & 6.4202 & 6.4387 & TRN & \\
\hline CHEMBL155724 & 36941 & 6.1079 & 6.312 & TRN & \\
\hline CHEMBL347234 & 36941 & 6.3188 & 6.2652 & TRN & \\
\hline CHEMBL158257 & 36941 & 7.5229 & 6.3388 & TST & \\
\hline CHEMBL157980 & 36941 & 7.8861 & 6.6669 & TST & \\
\hline CHEMBL157690 & 36941 & 7.699 & 7.9752 & TRN & \\
\hline CHEMBL157524 & 36941 & 7.6778 & 7.535 & TRN & \\
\hline CHEMBL158196 & 36941 & 6.1135 & 6.0107 & TRN & \\
\hline CHEMBL345894 & 36941 & 5.7696 & 5.9123 & TST & \\
\hline CHEMBL 7641 & 36941 & 7.0177 & 6.7053 & TST & \\
\hline CHEMBL154315 & 36941 & 7.2007 & 7.0163 & TRN & \\
\hline CHEMBL346773 & 36941 & 6.4318 & 6.6764 & TRN & \\
\hline CHEMBL157185 & 36941 & 7.3768 & 7.5837 & TRN & \\
\hline CHEMBL345139 & 36941 & 8.1192 & 8.1058 & TRN & \\
\hline CHEMBL157512 & 36941 & 7.2441 & 7.11600 & 00000000005 & TRN \\
\hline CHEMBL345570 & 36941 & 8.4815 & 8.7115 & TRN & \\
\hline CHEMBL156408 & 36941 & 6.0655 & 6.0141 & TST & \\
\hline CHEMBL345826 & 36941 & 7.301 & 7.2847 & TRN & \\
\hline CHEMBL158133 & 36941 & 8.1308 & 8.1662 & TRN & \\
\hline CHEMBL347050 & 36941 & 5.8539 & 5.7508 & TST & \\
\hline CHEMBL348149 & 36941 & 5.6778 & 5.6548 & TRN & \\
\hline CHEMBL154949 & 36941 & 6.9586 & 7.2534 & TRN & \\
\hline
\end{tabular}




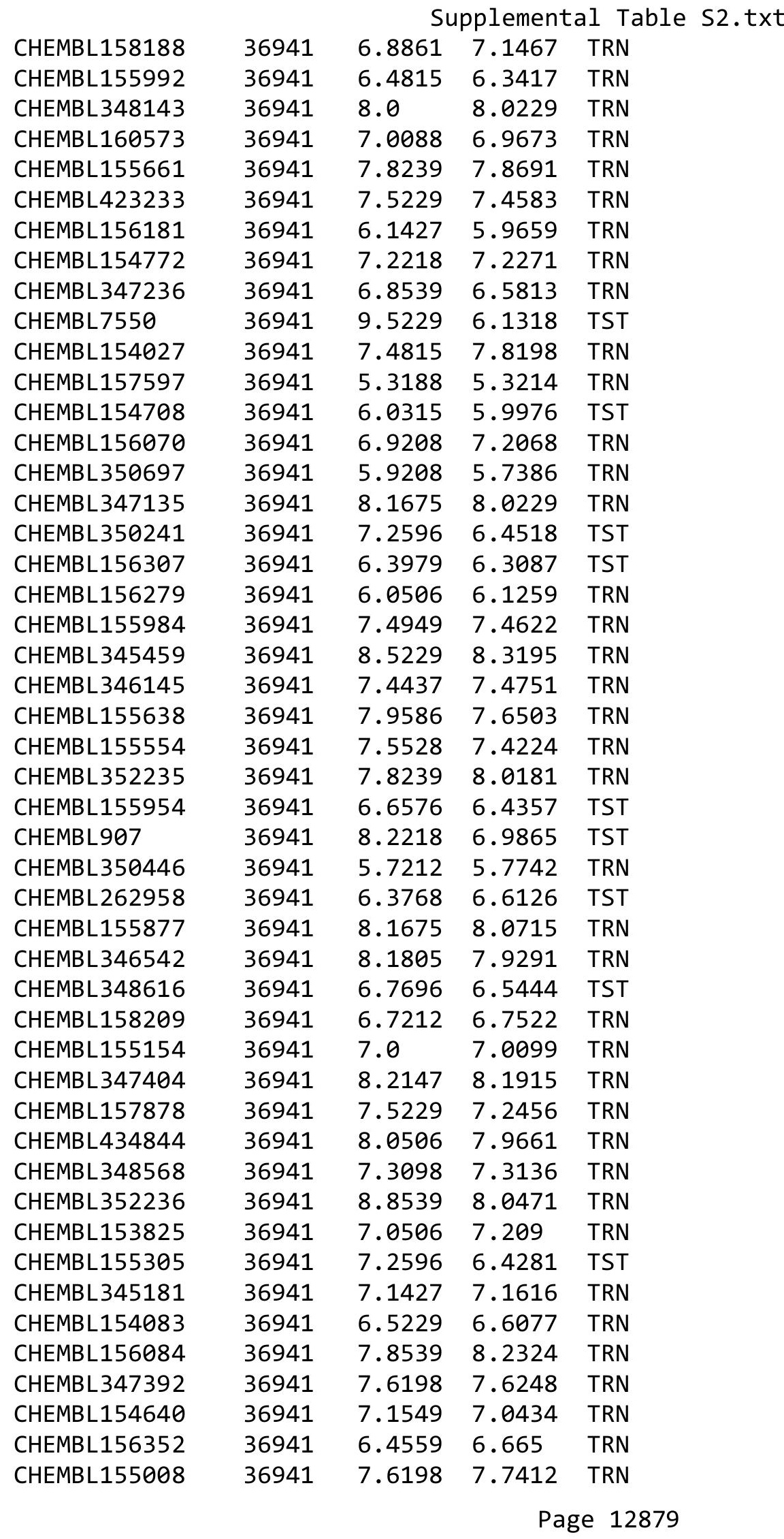




\begin{tabular}{|c|}
\hline CHEMBL158267 \\
\hline CHEMBL423418 \\
\hline CHEMBL274447 \\
\hline CHEMBL347630 \\
\hline CHEMBL345404 \\
\hline CHEMBL153968 \\
\hline CHEMBL156396 \\
\hline CHEMBL345717 \\
\hline CHEMBL158115 \\
\hline CHEMBL157779 \\
\hline CHEMBL155948 \\
\hline CHEMBL 236347 \\
\hline CHEMBL409750 \\
\hline CHEMBL 235927 \\
\hline CHEMBL235477 \\
\hline CHEMBL 236155 \\
\hline CHEMBL393826 \\
\hline CHEMBL237231 \\
\hline CHEMBL 237443 \\
\hline CHEMBL237616 \\
\hline CHEMBL 235080 \\
\hline CHEMBL 235683 \\
\hline CHEMBL236141 \\
\hline CHEMBL 235260 \\
\hline CHEMBL237192 \\
\hline CHEMBL235297 \\
\hline CHEMBL 236554 \\
\hline CHEMBL396324 \\
\hline CHEMBL 235898 \\
\hline CHEMBL444366 \\
\hline CHEMBL 237442 \\
\hline CHEMBL236553 \\
\hline CHEMBL392978 \\
\hline CHEMBL393759 \\
\hline CHEMBL394751 \\
\hline CHEMBL394939 \\
\hline CHEMBL 237230 \\
\hline CHEMBL393883 \\
\hline CHEMBL 235037 \\
\hline CHEMBL393271 \\
\hline CHEMBL237816 \\
\hline CHEMBL395169 \\
\hline CHEMBL235104 \\
\hline CHEMBL413237 \\
\hline CHEMBL235467 \\
\hline CHEMBL237833 \\
\hline CHEMBL 235468 \\
\hline CHEMBL395399 \\
\hline
\end{tabular}

Supplemental Table S2.txt

$\begin{array}{llll}36941 & 7.4437 & 7.6386 & \text { TRN } \\ 36941 & 6.0 & 6.0241 & \text { TST } \\ 36941 & 6.6383 & 6.7402 & \text { TST } \\ 36941 & 7.3188 & 6.5987 & \text { TST } \\ 36941 & 8.1079 & 6.3715 & \text { TST } \\ 36941 & 7.2218 & 6.8636 & \text { TST } \\ 36941 & 6.4949 & 6.7906 & \text { TST } \\ 36941 & 8.1487 & 7.943 & \text { TST } \\ 36941 & 7.3979 & 7.242000000000001 \\ 36941 & 7.5528 & 6.9078 & \text { TST } \\ 36941 & 7.8539 & 7.9208 & \text { TST } \\ 452413 & 1.4318 & 2.42 & \text { TST } \\ 452413 & 1.301 & 3.2033 & \text { TRN } \\ 452413 & 2.0 & 3.0541 & \text { TRN } \\ 452413 & 3.2581 & 2.1893 & \text { TRN } \\ 452413 & 1.301 & 1.8896 & \text { TRN } \\ 452413 & 1.3979 & 0.4962 & \text { TRN } \\ 452413 & 5.5528 & 3.775 & \text { TST } \\ 452413 & 3.3468 & 2.9717 & \text { TRN } \\ 452413 & 1.9876 & 2.6762 & \text { TRN } \\ 452413 & 1.301 & 2.1613 & \text { TST } \\ 452413 & 3.7773 & 3.3738 & \text { TRN } \\ 452413 & 1.9119 & 2.7644 & \text { TRN } \\ 452413 & 1.3979 & 0.3877 & \text { TST } \\ 452413 & 3.3439 & 3.747 & \text { TRN } \\ 452413 & 1.8239 & 1.4112 & \text { TRN } \\ 452413 & 1.4318 & 1.8703 & \text { TST } \\ 452413 & 1.4318 & 2.8803 & \text { TRN } \\ 452413 & 1.5229 & 1.1937 & \text { TST } \\ 452413 & 3.5243 & 3.2203 & \text { TRN } \\ 452413 & 3.4473 & 3.3156 & \text { TRN } \\ 452413 & 3.2396 & 1.9669 & \text { TRN } \\ 452413 & 1.5229 & 1.0123 & \text { TST } \\ 452413 & 1.3979 & 1.0314 & \text { TST } \\ 452413 & 3.8097 & 3.3515 & \text { TRN } \\ 452413 & 3.1221 & 2.9487 & \text { TRN } \\ 452413 & 3.2381 & 3.5828 & \text { TRN } \\ 452413 & 1.6021 & 1.5654 & \text { TRN } \\ 452413 & 4.0 & 3.5777 & \text { TRN } \\ 452413 & 3.4962 & 3.2147 & \text { TRN } \\ 452413 & 1.8539 & 2.6646 & \text { TRN } \\ 452413 & 3.5421 & 2.5116 & \text { TRN } \\ 452413 & 5.2518 & 2.4292 & \text { TST } \\ 452413 & 1.8239 & 1.0066 & \text { TST } \\ 452413 & 3.1221 & 2.6594 & \text { TRN } \\ 452413 & 1.3979 & 1.1105 & \text { TST } \\ 452413 & 3.6364 & 2.8501 & \text { TRN } \\ 452413 & 3.7282 & 2.7903 & \text { TRN }\end{array}$




\begin{tabular}{|c|c|c|c|c|}
\hline & & & oplement & al $\mathrm{T}$ \\
\hline CHEMBL438505 & 452413 & 1.6198 & 2.4232 & TRN \\
\hline CHEMBL392086 & 452413 & 1.301 & 1.092 & TRN \\
\hline CHEMBL237845 & 452413 & 1.3979 & 1.0602 & TST \\
\hline CHEMBL235298 & 452413 & 1.6021 & 0.983 & TRN \\
\hline CHEMBL236353 & 452413 & 3.2396 & 2.5186 & TRN \\
\hline CHEMBL396887 & 452413 & 3.8697 & 2.8563 & TRN \\
\hline CHEMBL394982 & 452413 & 1.9876 & 2.9161 & TRN \\
\hline CHEMBL391600 & 452413 & 3.1221 & 2.7961 & TRN \\
\hline CHEMBL428722 & 452413 & 3.2396 & 2.7709 & TRN \\
\hline CHEMBL391601 & 452413 & 3.1221 & 3.0216 & TRN \\
\hline CHEMBL235928 & 452413 & 3.2396 & 3.2459 & TRN \\
\hline CHEMBL236971 & 452413 & 4.8153 & 3.5599 & TRN \\
\hline CHEMBL393825 & 452413 & 1.5229 & 1.3794 & TST \\
\hline CHEMBL235038 & 452413 & 3.4473 & 2.4097 & TRN \\
\hline CHEMBL236352 & 452413 & 1.301 & 2.338 & TRN \\
\hline CHEMBL237444 & 452413 & 1.8239 & 1.659 & TRN \\
\hline CHEMBL235103 & 452413 & 3.3706 & 3.5494 & TST \\
\hline CHEMBL235469 & 452413 & 1.8239 & 2.5653 & TRN \\
\hline CHEMBL395400 & 452413 & 1.301 & 1.3476 & TRN \\
\hline CHEMBL237232 & 452413 & 1.3979 & 0.7021 & TST \\
\hline CHEMBL236367 & 452413 & 3.2967 & 2.9559 & TST \\
\hline CHEMBL235114 & 452413 & 2.8911 & 2.5205 & TST \\
\hline CHEMBL393678 & 452413 & 1.8539 & 2.4542 & TRN \\
\hline CHEMBL235681 & 452413 & 3.9101 & 3.537 & TRN \\
\hline CHEMBL235914 & 452413 & 3.5391 & 2.7938 & TRN \\
\hline CHEMBL396323 & 452413 & 4.8239 & 4.2846 & TRN \\
\hline CHEMBL325170 & 452413 & 5.5229 & 2.1073 & TST \\
\hline CHEMBL235944 & 452413 & 3.2396 & 3.1231 & TRN \\
\hline CHEMBL236136 & 452413 & 1.7305 & 2.6843 & TRN \\
\hline CHEMBL236818 & 452413 & 3.6904 & 4.081 & TRN \\
\hline CHEMBL237253 & 452413 & 4.0088 & 1.4724 & TST \\
\hline CHEMBL235078 & 452413 & 1.8539 & 3.3136 & TRN \\
\hline CHEMBL237815 & 452413 & 4.4089 & 1.9002 & TST \\
\hline CHEMBL237633 & 452413 & 2.0 & 2.5886 & TRN \\
\hline CHEMBL235713 & 452413 & 2.0 & 2.3575 & TRN \\
\hline CHEMBL236140 & 452413 & 1.6021 & 2.2469 & TRN \\
\hline CHEMBL237614 & 452413 & 3.1391 & 2.431 & TRN \\
\hline CHEMBL236388 & 452413 & 4.8239 & 3.6551 & TRN \\
\hline CHEMBL235039 & 452413 & 3.2396 & 3.3794 & TRN \\
\hline CHEMBL396886 & 452413 & 1.3979 & 3.5081 & TST \\
\hline CHEMBL 236346 & 452413 & 1.4318 & 2.7997 & TRN \\
\hline CHEMBL237005 & 452413 & 3.7212 & 3.0497 & TST \\
\hline CHEMBL235929 & 452413 & 2.0 & 2.4191 & TRN \\
\hline CHEMBL429802 & 452413 & 5.6383 & 4.4031 & TRN \\
\hline CHEMBL396885 & 452413 & 1.301 & 1.4845 & TRN \\
\hline CHEMBL235926 & 452413 & 1.8239 & 2.2935 & TRN \\
\hline CHEMBL235945 & 452413 & 1.301 & 1.7154 & TRN \\
\hline CHEMBL237615 & 452413 & 1.3979 & 2.5727 & TRN \\
\hline
\end{tabular}

Page 12881 


\begin{tabular}{|c|c|c|c|c|c|}
\hline \multicolumn{6}{|c|}{ Supplemental Table S2.txt } \\
\hline CHEMBL235036 & 452413 & 3.6364 & 2.7436 & TRN & \\
\hline CHEMBL394091 & 452413 & 2.0 & 2.3335 & TRN & \\
\hline CHEMBL 3704846 & 1528344 & 5.0605 & 4.9494 & TRN & \\
\hline CHEMBL 3704852 & 1528344 & 3.0 & 3.1564 & TRN & \\
\hline CHEMBL 3640037 & 1528344 & 3.0 & 2.7548 & TRN & \\
\hline CHEMBL 3704872 & 1528344 & 4.2007 & 3.7023 & TRN & \\
\hline CHEMBL 3704840 & 1528344 & 4.7959 & 4.7324 & TRN & \\
\hline CHEMBL 3704887 & 1528344 & 3.8794 & 4.4326 & TRN & \\
\hline CHEMBL 3704866 & 1528344 & 4.3224 & 4.1012 & TRN & \\
\hline CHEMBL3704838 & 1528344 & 4.8539 & 4.6839 & TRN & \\
\hline CHEMBL 3704881 & 1528344 & 4.1367 & 4.0324 & TST & \\
\hline CHEMBL 3704890 & 1528344 & 5.8539 & 4.2717 & TST & \\
\hline CHEMBL 3704875 & 1528344 & 2.699 & 2.8088 & TRN & \\
\hline CHEMBL3704893 & 1528344 & 4.0 & 4.9324 & TST & \\
\hline CHEMBL3704869 & 1528344 & 4.7375 & 4.6124 & TRN & \\
\hline CHEMBL 3704841 & 1528344 & 4.6778 & 4.2851 & TRN & \\
\hline CHEMBL3704871 & 1528344 & 2.699 & 3.2673 & TRN & \\
\hline CHEMBL3704839 & 1528344 & 4.5686 & 4.7787 & TRN & \\
\hline CHEMBL 3704854 & 1528344 & 4.0 & 3.7259 & TRN & \\
\hline CHEMBL3704859 & 1528344 & 3.0 & 2.8378 & TRN & \\
\hline CHEMBL3704878 & 1528344 & 3.9788 & 3.75600 & 00000000002 & TRN \\
\hline CHEMBL 3704851 & 1528344 & 3.0 & 3.1489 & TRN & \\
\hline CHEMBL 3704849 & 1528344 & 3.0 & 3.0335 & TRN & \\
\hline CHEMBL 3704842 & 1528344 & 4.7447 & 4.6862 & TRN & \\
\hline CHEMBL 3704843 & 1528344 & 4.6326 & 5.0457 & TRN & \\
\hline CHEMBL 3704885 & 1528344 & 3.9208 & 3.8106 & TRN & \\
\hline CHEMBL3704853 & 1528344 & 4.0 & 3.2428 & TRN & \\
\hline CHEMBL 3704884 & 1528344 & 4.7959 & 4.3473 & TRN & \\
\hline CHEMBL 3704889 & 1528344 & 5.1308 & 3.5474 & TST & \\
\hline CHEMBL3704863 & 1528344 & 3.8153 & 4.2991 & TRN & \\
\hline CHEMBL 3704847 & 1528344 & 4.8069 & 5.0261 & TRN & \\
\hline CHEMBL 3704850 & 1528344 & 3.0 & 2.6819 & TRN & \\
\hline CHEMBL471118 & 1528344 & 4.2676 & 4.2852 & TRN & \\
\hline CHEMBL3704879 & 1528344 & 3.7328 & 3.6337 & TST & \\
\hline CHEMBL3704895 & 1528344 & 5.0458 & 4.3768 & TST & \\
\hline CHEMBL3704855 & 1528344 & 2.699 & 2.3529 & TRN & \\
\hline CHEMBL3704864 & 1528344 & 4.9172 & 4.8148 & TRN & \\
\hline CHEMBL3704865 & 1528344 & 5.71 & 5.4986 & TRN & \\
\hline CHEMBL3704877 & 1528344 & 3.7696 & 3.70399 & 99999999997 & TRN \\
\hline CHEMBL3704891 & 1528344 & 4.1549 & 4.5373 & TST & \\
\hline CHEMBL471117 & 1528344 & 2.5229 & 2.5198 & TRN & \\
\hline CHEMBL 3704874 & 1528344 & 2.699 & 3.0074 & TRN & \\
\hline CHEMBL3704888 & 1528344 & 3.8371 & 2.9233 & TST & \\
\hline CHEMBL3704862 & 1528344 & 3.0 & 3.0756 & TRN & \\
\hline CHEMBL3704867 & 1528344 & 4.4535 & 4.7172 & TRN & \\
\hline CHEMBL 3704892 & 1528344 & 4.2083 & 5.0315 & TST & \\
\hline CHEMBL 3704870 & 1528344 & 4.2874 & 3.8305 & TRN & \\
\hline CHEMBL 3704883 & 1528344 & 4.5686 & 3.9801 & TST & \\
\hline
\end{tabular}




\begin{tabular}{|c|c|c|c|c|c|}
\hline \multirow{3}{*}{$\begin{array}{l}\text { CHEMBL } 3704860 \\
\text { CHEMBL } 3704880\end{array}$} & \multicolumn{5}{|c|}{ Supplemental Table S2.txt } \\
\hline & 1528344 & 3.0 & 3.46199 & 99999999997 & TRN \\
\hline & 1528344 & 4.1249 & 3.0961 & TST & \\
\hline CHEMBL513572 & 1528344 & 5.1871 & 4.8791 & TRN & \\
\hline CHEMBL3704876 & 1528344 & 4.0706 & 3.2492 & TST & \\
\hline CHEMBL 3704858 & 1528344 & 2.699 & 2.8509 & TRN & \\
\hline CHEMBL3704886 & 1528344 & 3.7167 & 4.2066 & TST & \\
\hline CHEMBL3704882 & 1528344 & 2.699 & 3.5567 & TST & \\
\hline CHEMBL3704873 & 1528344 & 4.6021 & 3.6924 & TST & \\
\hline CHEMBL3704837 & 1528344 & 5.0655 & 4.3867 & TRN & \\
\hline CHEMBL 3704857 & 1528344 & 2.699 & 3.3433 & TRN & \\
\hline CHEMBL3704861 & 1528344 & 3.0 & 3.9579 & TRN & \\
\hline CHEMBL3704848 & 1528344 & 5.301 & 5.4218 & TRN & \\
\hline CHEMBL3704894 & 1528344 & 4.8356 & 4.9347 & TST & \\
\hline CHEMBL3704844 & 1528344 & 4.5686 & 4.8361 & TRN & \\
\hline CHEMBL3704845 & 1528344 & 4.7212 & 4.5367 & TRN & \\
\hline CHEMBL3704868 & 1528344 & 4.7905 & 4.7079 & TRN & \\
\hline CHEMBL3704856 & 1528344 & 2.699 & 3.1512 & TRN & \\
\hline CHEMBL483728 & 556876 & 3.301 & 3.2956 & TRN & \\
\hline CHEMBL487326 & 556876 & 3.301 & 3.3029 & TRN & \\
\hline CHEMBL486284 & 556876 & 3.5686 & 3.6036 & TRN & \\
\hline CHEMBL482679 & 556876 & 3.5376 & 3.5335 & TRN & \\
\hline CHEMBL477077 & 556876 & 3.301 & 3.2956 & TRN & \\
\hline CHEMBL486712 & 556876 & 3.301 & 3.3088 & TRN & \\
\hline CHEMBL483535 & 556876 & 4.8013 & 4.7975 & TRN & \\
\hline CHEMBL488128 & 556876 & 3.301 & 3.1041 & TST & \\
\hline CHEMBL486302 & 556876 & 3.301 & 3.2458 & TRN & \\
\hline CHEMBL487521 & 556876 & 3.301 & 3.3089 & TRN & \\
\hline CHEMBL487327 & 556876 & 3.301 & 3.3122 & TRN & \\
\hline CHEMBL486301 & 556876 & 3.301 & 3.3136 & TRN & \\
\hline CHEMBL520864 & 556876 & 3.301 & 3.2839 & TRN & \\
\hline CHEMBL486497 & 556876 & 3.301 & 3.3018 & TRN & \\
\hline CHEMBL 260864 & 556876 & 3.301 & 3.3091 & TRN & \\
\hline CHEMBL486286 & 556876 & 3.301 & 3.3178 & TRN & \\
\hline CHEMBL486091 & 556876 & 3.301 & 3.2627 & TRN & \\
\hline CHEMBL487526 & 556876 & 3.301 & 3.766 & TST & \\
\hline CHEMBL486487 & 556876 & 3.301 & 2.7359 & TST & \\
\hline CHEMBL488548 & 556876 & 3.301 & 3.3168 & TRN & \\
\hline CHEMBL483514 & 556876 & 3.301 & 3.3026 & TRN & \\
\hline CHEMBL487328 & 556876 & 3.301 & 3.3017 & TRN & \\
\hline CHEMBL485892 & 556876 & 3.301 & 3.29 & TRN & \\
\hline CHEMBL482918 & 556876 & 3.301 & 3.3145 & TRN & \\
\hline CHEMBL530335 & 556876 & 4.6073 & 4.6177 & TRN & \\
\hline CHEMBL488342 & 556876 & 5.1427 & 3.3324 & TST & \\
\hline CHEMBL407095 & 556876 & 3.301 & 3.2839 & TRN & \\
\hline CHEMBL487731 & 556876 & 4.8601 & 4.8572 & TRN & \\
\hline CHEMBL476907 & 556876 & 3.301 & 3.3068 & TRN & \\
\hline CHEMBL515949 & 556876 & 3.301 & 3.2938 & TRN & \\
\hline CHEMBL485877 & 556876 & 3.301 & 3.2988 & TRN & \\
\hline
\end{tabular}




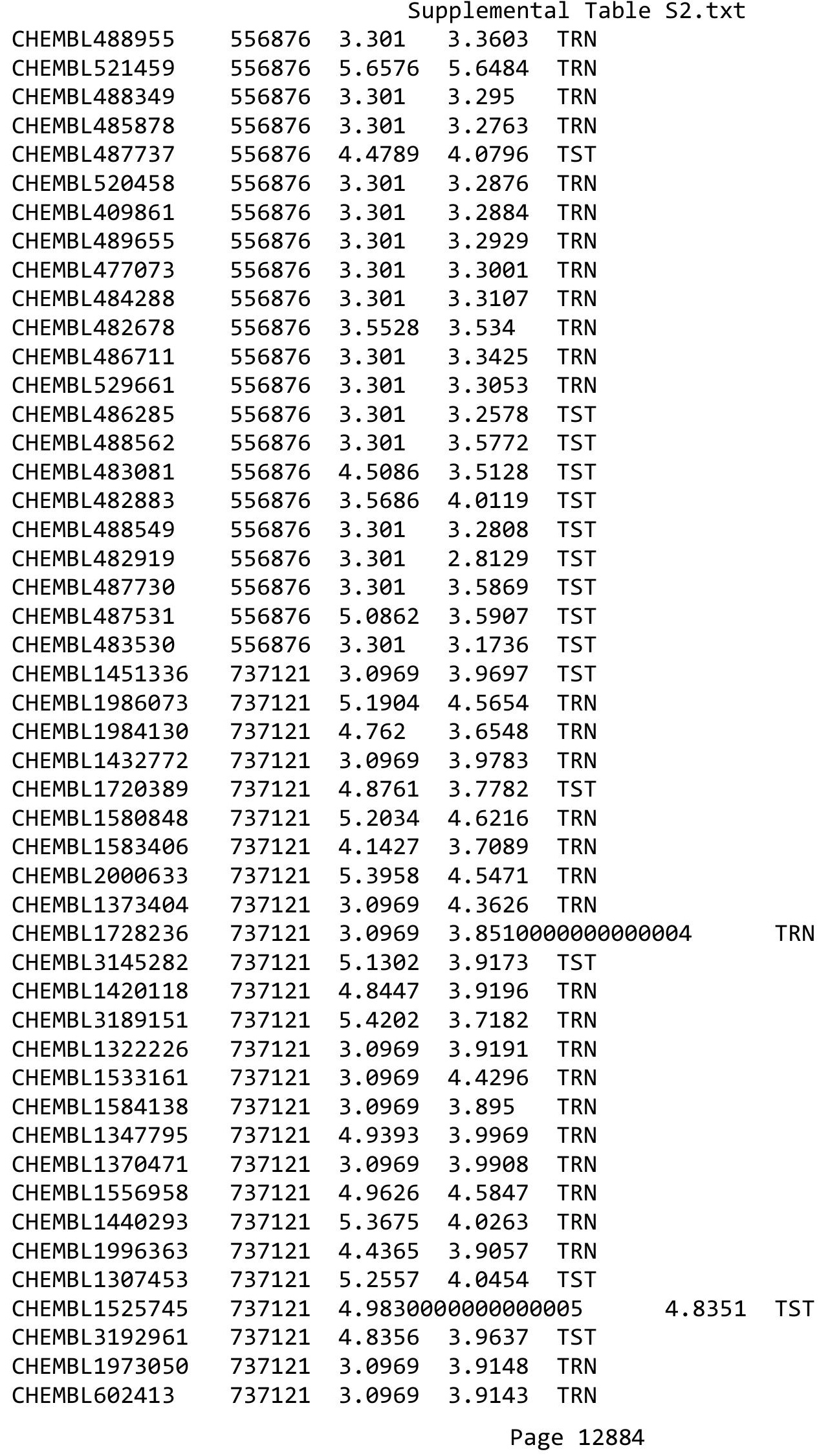


Supplemental Table S2.txt

\begin{tabular}{|c|c|c|c|c|}
\hline 15) & & & & \\
\hline 268 & 7121 & 4318 & 697 & \\
\hline AEMBL1350245 & 37121 & 9626 & 778 & \\
\hline HEMBL19 & 37121 & .1805 & 366 & \\
\hline 508 & 21 & 969 & & \\
\hline AEMBL1986183 & 121 & 969 & 085 & \\
\hline AEMBL1316090 & 37121 & 9969 & 5307 & \\
\hline HEMBL1973127 & 37121 & 2104 & 8309 & \\
\hline HEMBL1335 & 37121 & 969 & 3768 & \\
\hline IEMBL141 & 37121 & 66 & 3639 & \\
\hline HEMBL160 & 37121 & 969 & 338 & \\
\hline HEMBL1518054 & 37121 & 9857 & 5718 & \\
\hline HEMBL156 & 37121 & 969 & 9018 & \\
\hline AEMBL326 & 21 & 78 & 49 & \\
\hline IEMBL138 & 121 & 969 & 239 & \\
\hline AEMBL137 & 121 & 969 & & \\
\hline JEMBL154 & 37121 & 969 & 9035 & RN \\
\hline HEMBL171 & & 969 & 3739 & \\
\hline HEML $20 t$ & 21 & 91 & 891 & \\
\hline L161 & 21 & 969 & 9083 & \\
\hline L136 & 21 & 969 & 3767 & RN \\
\hline L145 & 37121 & 969 & 8887 & RN \\
\hline HEMBL 236 & & & 3076 & $2 \mathrm{~N}$ \\
\hline AEMBL15 & 21 & 56 & 3871 & \\
\hline L15 & 21 & 69 & 315 & RN \\
\hline 43 & 21 & 297 & 9652 & RN \\
\hline L496 & & 361 & 3855 & ST \\
\hline AEMBL141 & & & & RN \\
\hline IEMBL32e & 21 & 969 & 289 & RN \\
\hline 06 & 21 & 69 & 57 & ST \\
\hline 97 & 21 & 69 & 501 & RN \\
\hline AEMBL142 & & & 077 & RN \\
\hline AEMBL1561111 & & & & RN \\
\hline AEMBL13 & 21 & 601 & 348 & RN \\
\hline 10 & 21 & 69 & 89 & RN \\
\hline & 1 & 96 & 88 & RN \\
\hline HEMBL1587900 & 37121 & & 9004 & TRN \\
\hline HEMBL197 & & 041 & 245 & RN \\
\hline HEMBL 14 & 1 & 277 & 106 & RN \\
\hline 53 & & $\partial 1$ & 803 & RIV \\
\hline 02 & & & 3307 & RN \\
\hline HEMBL1623028 & 37121 & 1609 & 3652 & TRN \\
\hline IEMBL13 & 21 & 69 & 675 & S \\
\hline HEMBL1 14 & & & & 31 \\
\hline & & & 4688 & Tro \\
\hline HEMBL 14 & 21 & 834 & 8637 & RN \\
\hline 1367772 & 37121 & 3.0969 & .3253 & TRN \\
\hline CHEMBL1736624 & 737121 & 4.3107 & 3.8717 & $T C$ \\
\hline
\end{tabular}

Page 12885 
Supplemental Table S2.txt

\begin{tabular}{|c|c|c|c|c|c|}
\hline CHEMBL1386537 & 737121 & 3.0969 & 3.852 & TRN & \\
\hline CHEMBL1320095 & 737121 & 3.0969 & 3.8275 & TRN & \\
\hline CHEMBL3214200 & 737121 & 4.8239 & 4.0426 & TRN & \\
\hline CHEMBL1717612 & 737121 & 4.752 & 3.7718 & TST & \\
\hline CHEMBL559384 & 737121 & 3.0969 & 3.8134 & TRN & \\
\hline CHEMBL1400548 & 737121 & 4.8761 & 3.9495 & TRN & \\
\hline CHEMBL1377750 & 737121 & 3.0969 & 3.8741 & TRN & \\
\hline CHEMBL1485665 & 737121 & 3.0969 & 4.6064 & TRN & \\
\hline CHEMBL1517686 & 737121 & 3.0969 & 3.6629 & TRN & \\
\hline CHEMBL1525100 & 737121 & 3.0969 & 3.7676 & TRN & \\
\hline CHEMBL1576310 & 737121 & 4.9281 & 4.5268 & TST & \\
\hline CHEMBL1990659 & 737121 & 5.6326 & 4.4274 & TRN & \\
\hline CHEMBL1352760 & 737121 & 3.0969 & 4.5441 & TRN & \\
\hline CHEMBL117515 & 737121 & 4.2907 & 4.4553 & TRN & \\
\hline CHEMBL1400243 & 737121 & 5.056 & 4.4813 & TRN & \\
\hline CHEMBL1704624 & 737121 & 4.7423 & 4.5763 & TST & \\
\hline CHEMBL1337990 & 737121 & 4.4647 & 4.5541 & TRN & \\
\hline CHEMBL1523563 & 737121 & 3.0969 & 3.8057 & TRN & \\
\hline CHEMBL1459102 & 737121 & 4.4763 & 4.4449 & TRN & \\
\hline CHEMBL1420423 & 737121 & 3.0969 & 3.9935 & TRN & \\
\hline CHEMBL1520830 & 737121 & 4.8182 & 3.9408 & TRN & \\
\hline CHEMBL1500190 & 737121 & 4.5436 & 4.3565 & TRN & \\
\hline CHEMBL3213030 & 737121 & 4.7077 & 4.345 & TRN & \\
\hline CHEMBL1563339 & 737121 & 3.0969 & 3.8755 & TRN & \\
\hline CHEMBL1385898 & 737121 & 4.2175 & 3.7728 & TRN & \\
\hline CHEMBL1703331 & 737121 & 4.2328 & 4.4455 & TST & \\
\hline CHEMBL1453825 & 737121 & 4.8894 & $3.79100 e$ & 00000000004 & TRN \\
\hline CHEMBL1388960 & 737121 & 3.0969 & 3.9805 & TRN & \\
\hline CHEMBL1597580 & 737121 & 5.4237 & 3.9863 & TRN & \\
\hline CHEMBL1981677 & 737121 & 4.4855 & 4.7185 & TRN & \\
\hline CHEMBL1352381 & 737121 & 3.0969 & 4.0354 & TRN & \\
\hline CHEMBL1517553 & 737121 & 3.0969 & 3.7823 & TRN & \\
\hline CHEMBL 2002248 & 737121 & 3.0969 & 4.3186 & TRN & \\
\hline CHEMBL1471741 & 737121 & 3.0969 & 4.4809 & TRN & \\
\hline CHEMBL1545927 & 737121 & 4.567 & 4.5165 & TRN & \\
\hline CHEMBL1497982 & 737121 & 4.9706 & 4.6602 & TST & \\
\hline CHEMBL1545430 & 737121 & 3.0969 & 3.8505 & TST & \\
\hline CHEMBL1358906 & 737121 & 3.0969 & 3.7784 & TST & \\
\hline CHEMBL1542833 & 737121 & 4.4737 & 4.4809 & TRN & \\
\hline CHEMBL1553183 & 737121 & \multicolumn{3}{|c|}{4.7669999999999995} & TST \\
\hline CHEMBL1329069 & 737121 & 5.3979 & 4.5603 & TRN & \\
\hline CHEMBL1985582 & 737121 & 4.5591 & 3.9406 & TRN & \\
\hline CHEMBL1489785 & 737121 & 3.0969 & 3.8547 & TRN & \\
\hline CHEMBL1509380 & 737121 & 3.0969 & 3.8256 & TRN & \\
\hline CHEMBL1736101 & 737121 & 4.6498 & 3.9078 & TST & \\
\hline CHEMBL1506832 & 737121 & 4.6421 & 3.8898 & TRN & \\
\hline CHEMBL1549738 & 737121 & 4.9208 & 4.6074 & TRN & \\
\hline CHEMBL1996189 & 737121 & 4.58 & 4.3415 & TRN & \\
\hline
\end{tabular}


Supplemental Table S2.txt

\begin{tabular}{|c|c|c|c|c|c|}
\hline CHEMBL1337074 & 737121 & 3.0969 & 3.8774 & TRN & \\
\hline CHEMBL3209368 & 737121 & 5.1818 & 3.9689 & TST & \\
\hline CHEMBL1527739 & 737121 & 3.0969 & 4.4555 & TRN & \\
\hline CHEMBL1432711 & 737121 & 3.0969 & 4.5129 & TRN & \\
\hline CHEMBL1481347 & 737121 & 4.8697 & 4.4914 & TST & \\
\hline CHEMBL1971913 & 737121 & 4.8996 & 4.5008 & TST & \\
\hline CHEMBL1613318 & 737121 & 3.0969 & 4.5918 & TRN & \\
\hline CHEMBL3208237 & 737121 & 4.8665 & 4.046 & TRN & \\
\hline CHEMBL3191688 & 737121 & 4.7375 & 4.3754 & TRN & \\
\hline CHEMBL1377712 & 737121 & 3.0969 & 4.0065 & TRN & \\
\hline CHEMBL1495189 & 737121 & 3.0969 & 3.8805 & TRN & \\
\hline CHEMBL1729823 & 737121 & 4.5331 & 4.4749 & TRN & \\
\hline CHEMBL1377370 & 737121 & 3.0969 & 3.9422 & TRN & \\
\hline CHEMBL1376872 & 737121 & 4.2381 & 4.454 & TRN & \\
\hline CHEMBL3145321 & 737121 & 4.7595 & 3.9356 & TST & \\
\hline CHEMBL1983311 & 737121 & 3.0969 & 3.8371 & TRN & \\
\hline CHEMBL1392765 & 737121 & 4.6144 & 4.6127 & TRN & \\
\hline CHEMBL1966869 & 737121 & 3.0969 & 4.4024 & TRN & \\
\hline CHEMBL1607877 & 737121 & 4.9172 & 3.8555 & TRN & \\
\hline CHEMBL1328510 & 737121 & 4.7258 & 3.8551 & TRN & \\
\hline CHEMBL1308573 & 737121 & 4.699 & 4.441 & TRN & \\
\hline CHEMBL2006338 & 737121 & 4.8041 & 4.0172 & TRN & \\
\hline CHEMBL3197744 & 737121 & 3.0969 & 3.9042 & TRN & \\
\hline CHEMBL1709333 & 737121 & 4.8962 & 4.8435 & TRN & \\
\hline CHEMBL1722190 & 737121 & 4.7545 & 4.444 & TRN & \\
\hline CHEMBL3213948 & 737121 & 4.8761 & 4.4063 & TRN & \\
\hline CHEMBL1385436 & 737121 & 4.3507 & 3.9375 & TRN & \\
\hline CHEMBL1527341 & 737121 & 4.8928 & 4.3722 & TRN & \\
\hline CHEMBL2369162 & 737121 & 3.0969 & 4.4443 & TRN & \\
\hline CHEMBL1411646 & 737121 & 4.8729 & 3.7785 & TRN & \\
\hline CHEMBL1538162 & 737121 & 3.0969 & 3.8613 & TST & \\
\hline CHEMBL1532880 & 737121 & 3.0969 & 3.6743 & TRN & \\
\hline CHEMBL1989673 & 737121 & 4.3179 & 4.0705 & TRN & \\
\hline CHEMBL1341741 & 737121 & 3.0969 & 3.6542 & TRN & \\
\hline CHEMBL1580604 & 737121 & 3.0969 & 3.8922 & TRN & \\
\hline CHEMBL1304831 & 737121 & 4.9469 & 4.5374 & TRN & \\
\hline CHEMBL1481948 & 737121 & 4.8013 & 3.8576 & TRN & \\
\hline CHEMBL3195813 & 737121 & 4.8125 & 4.6244 & TRN & \\
\hline CHEMBL1701004 & 737121 & 4.7696 & 3.7813 & TST & \\
\hline CHEMBL1414837 & 737121 & 3.0969 & 4.4373 & TRN & \\
\hline CHEMBL1375847 & 737121 & 4.3595 & 4.4764 & TRN & \\
\hline CHEMBL1379511 & 737121 & 4.9586 & 3.9483 & TRN & \\
\hline CHEMBL1968356 & 737121 & 5.433 & 4.0353 & TRN & \\
\hline CHEMBL1581022 & 737121 & 4.21399 & 999999999 & 995 & 3.9207 \\
\hline CHEMBL3212008 & 737121 & 4.6234 & 3.8616 & TRN & \\
\hline CHEMBL3196698 & 737121 & 3.0969 & 3.8457 & TRN & \\
\hline CHEMBL3208577 & 737121 & 4.6615 & 3.9349 & TST & \\
\hline CHEMBL1502980 & 737121 & 4.6576 & 3.9978 & TST & \\
\hline
\end{tabular}


Supplemental Table S2.txt

\begin{tabular}{|c|c|c|c|c|c|c|}
\hline CHEMBL1343952 & 737121 & 5.1798 & 4.0068 & TST & & \\
\hline CHEMBL1563898 & 737121 & 3.0969 & 3.9215 & TRN & & \\
\hline CHEMBL1543384 & 737121 & 3.0969 & 4.5886 & TRN & & \\
\hline CHEMBL1351309 & 737121 & 3.0969 & 3.8765 & TST & & \\
\hline CHEMBL1353750 & 737121 & 4.8356 & 3.8278 & TST & & \\
\hline CHEMBL1324290 & 737121 & 4.7055 & 4.5243 & TRN & & \\
\hline CHEMBL1541452 & 737121 & 3.0969 & 3.8614 & TRN & & \\
\hline CHEMBL1411629 & 737121 & 4.7328 & 4.4453 & TRN & & \\
\hline CHEMBL1718736 & 737121 & 4.1096 & 3.9896 & TRN & & \\
\hline CHEMBL1580664 & 737121 & 5.1035 & 4.7303 & TRN & & \\
\hline CHEMBL1336428 & 737121 & 3.0969 & 3.9719 & TRN & & \\
\hline CHEMBL1444979 & 737121 & 3.0969 & 3.8859 & TRN & & \\
\hline CHEMBL1986591 & 737121 & 4.6596 & 4.5651 & TRN & & \\
\hline CHEMBL1731177 & 737121 & 4.4342 & 4.2759 & TRN & & \\
\hline CHEMBL1585763 & 737121 & 4.8962 & 3.8563 & TRN & & \\
\hline CHEMBL1379991 & 737121 & 4.7305 & 3.9924 & TST & & \\
\hline CHEMBL1607272 & 737121 & 3.0969 & 3.8996 & TRN & & \\
\hline CHEMBL 3208355 & 737121 & 4.5544 & 3.8762 & TRN & & \\
\hline CHEMBL1504510 & 737121 & 4.8962 & 4.8155 & TRN & & \\
\hline CHEMBL1535457 & 737121 & 4.9172 & 4.5646 & TRN & & \\
\hline CHEMBL1455619 & 737121 & 4.8477 & 3.8278 & TRN & & \\
\hline CHEMBL1518926 & 737121 & 4.752 & 4.474 & TRN & & \\
\hline CHEMBL1459240 & 737121 & 4.5031 & 4.3108 & TRN & & \\
\hline CHEMBL1339676 & 737121 & 3.0969 & 3.7449 & TST & & \\
\hline CHEMBL1319009 & 737121 & 3.0969 & 3.8918 & TRN & & \\
\hline CHEMBL1365006 & 737121 & 5.1107 & 3.94 & TST & & \\
\hline CHEMBL1332050 & 737121 & 5.2132 & 4.6392 & TST & & \\
\hline CHEMBL1508334 & 737121 & 3.0969 & 4.8204 & TRN & & \\
\hline CHEMBL1487444 & 737121 & 4.8827 & 3.9809 & TRN & & \\
\hline CHEMBL1735678 & 737121 & 3.0969 & 3.802 & TRN & & \\
\hline CHEMBL1490379 & 737121 & 5.0605 & 4.4884 & TRN & & \\
\hline CHEMBL 3195564 & 737121 & \multicolumn{3}{|c|}{4.9830000000000005} & 4.5105 & TRN \\
\hline CHEMBL1517763 & 737121 & 5.129 & 4.8567 & TRN & & \\
\hline CHEMBL1538986 & 737121 & 4.5784 & 4.4413 & TRN & & \\
\hline CHEMBL1346233 & 737121 & 3.0969 & 3.7079 & TRN & & \\
\hline CHEMBL1588339 & 737121 & 3.0969 & 4.4689 & TRN & & \\
\hline CHEMBL1979106 & 737121 & 5.0052 & 3.9928 & TRN & & \\
\hline CHEMBL1575194 & 737121 & 4.6716 & 3.9201 & TRN & & \\
\hline CHEMBL1576754 & 737121 & \multicolumn{3}{|c|}{5.172000000000001} & 4.6593 & TRN \\
\hline CHEMBL1300069 & 737121 & 5.3307 & 4.0198 & TRN & & \\
\hline CHEMBL1309018 & 737121 & 4.9469 & 4.7575 & TRN & & \\
\hline CHEMBL1984454 & 737121 & 3.0969 & 3.865 & TRN & & \\
\hline CHEMBL1324894 & 737121 & 4.9355 & 4.5002 & TRN & & \\
\hline CHEMBL1709936 & 737121 & 3.0969 & 4.3708 & TST & & \\
\hline CHEMBL1716112 & 737121 & 5.1107 & 4.6779 & TST & & \\
\hline CHEMBL1497100 & 737121 & 3.0969 & 3.8622 & TST & & \\
\hline CHEMBL1370810 & 737121 & 4.9208 & 4.7119 & TRN & & \\
\hline CHEMBL1588661 & 737121 & 4.2366 & 4.3557 & TST & & \\
\hline
\end{tabular}


Supplemental Table S2.txt

\begin{tabular}{|c|c|c|c|c|c|}
\hline CHEMBL1312115 & 737121 & 3.0969 & 3.9694 & TST & \\
\hline CHEMBL1986475 & 737121 & 4.4401 & 3.906 & TRN & \\
\hline CHEMBL1459757 & 737121 & 3.0969 & 3.8428 & TRN & \\
\hline CHEMBL3212519 & 737121 & 5.1141 & 4.1303 & TRN & \\
\hline CHEMBL1454693 & 737121 & 4.6904 & 4.5697 & TRN & \\
\hline CHEMBL3210329 & 737121 & 5.2815 & 4.7559 & TRN & \\
\hline CHEMBL1401001 & 737121 & 3.0969 & 4.3494 & TRN & \\
\hline CHEMBL1307769 & 737121 & 4.4067 & 4.0163 & TRN & \\
\hline CHEMBL3189689 & 737121 & 3.0969 & 3.9383 & TRN & \\
\hline CHEMBL1393287 & 737121 & 4.699 & 4.5356 & TRN & \\
\hline CHEMBL1428012 & 737121 & 5.0942 & 4.5684 & TRN & \\
\hline CHEMBL1525559 & 737121 & 4.8097 & 4.4341 & TST & \\
\hline CHEMBL3214431 & 737121 & 4.4437 & 3.8761 & TRN & \\
\hline CHEMBL1568754 & 737121 & 3.0969 & 3.9823 & TRN & \\
\hline CHEMBL584269 & 737121 & 3.0969 & 4.1168 & TRN & \\
\hline CHEMBL1733950 & 737121 & 3.0969 & 3.86899 & 99999999998 & TRN \\
\hline CHEMBL1444877 & 737121 & 3.0969 & 3.9011 & TRN & \\
\hline CHEMBL1468543 & 737121 & 3.0969 & 3.9299 & TRN & \\
\hline CHEMBL1509824 & 737121 & 3.0969 & 3.9643 & TRN & \\
\hline CHEMBL1986765 & 737121 & 5.0097 & 3.9418 & TRN & \\
\hline CHEMBL586602 & 737121 & 5.0458 & 4.6436 & TST & \\
\hline CHEMBL1401373 & 737121 & 4.1118 & 4.1823 & TRN & \\
\hline CHEMBL1992719 & 737121 & 3.0969 & 3.9736 & TRN & \\
\hline CHEMBL1702699 & 737121 & 4.4101 & 3.9871 & TST & \\
\hline CHEMBL1576784 & 737121 & 4.3737 & 4.3253 & TRN & \\
\hline CHEMBL3210395 & 737121 & 4.699 & 4.1962 & TRN & \\
\hline CHEMBL1438033 & 737121 & 3.0969 & 4.0124 & TRN & \\
\hline CHEMBL1369749 & 737121 & 4.6882 & 4.5149 & TRN & \\
\hline CHEMBL1450105 & 737121 & 3.0969 & 3.9641 & TRN & \\
\hline CHEMBL1460004 & 737121 & 3.0969 & 3.7951 & TRN & \\
\hline CHEMBL1305307 & 737121 & 4.8447 & 3.7193 & TRN & \\
\hline CHEMBL1976046 & 737121 & 3.0969 & 3.9458 & TRN & \\
\hline CHEMBL1312085 & 737121 & 4.7595 & 4.4476 & TRN & \\
\hline CHEMBL1538399 & 737121 & 5.0209 & 3.8962 & TRN & \\
\hline CHEMBL1572119 & 737121 & 4.8153 & 3.9525 & TRN & \\
\hline CHEMBL3191269 & 737121 & 3.0969 & 3.8962 & TST & \\
\hline CHEMBL1395615 & 737121 & 4.9586 & 3.9965 & TST & \\
\hline CHEMBL3197076 & 737121 & 4.9172 & 4.0485 & TRN & \\
\hline CHEMBL1431988 & 737121 & 5.1549 & 4.3041 & TRN & \\
\hline CHEMBL1471146 & 737121 & 3.0969 & 3.8611 & TRN & \\
\hline CHEMBL1366271 & 737121 & 4.7852 & 4.0063 & TRN & \\
\hline CHEMBL1574585 & 737121 & 5.157999 & 99999999 & 3.8869 & TST \\
\hline CHEMBL3193428 & 737121 & 5.0931 & 4.0093 & TRN & \\
\hline CHEMBL1442176 & 737121 & 3.0969 & 3.8346 & TRN & \\
\hline CHEMBL1536981 & 737121 & 3.0969 & 3.92100 & 00000000003 & this \\
\hline CHEMBL1497403 & 737121 & 4.8827 & 4.2825 & TRN & \\
\hline CHEMBL3190102 & 737121 & 5.1778 & $3.93600 t$ & 00000000004 & $\mathrm{NI}$ \\
\hline CHEMBL1581013 & 737121 & 4.7282 & 3.7817 & TRN & \\
\hline
\end{tabular}

Page 12889 
Supplemental Table S2.txt

\begin{tabular}{|c|c|c|c|c|}
\hline CHEMBL 2007390 & 737121 & 5.118 & 4.6938 & TRN \\
\hline CHEMBL1569496 & 737121 & 4.3788 & 3.932 & TRN \\
\hline CHEMBL1460440 & 737121 & 4.5391 & 3.9505 & TRN \\
\hline CHEMBL1450948 & 737121 & 3.0969 & 3.819 & TRN \\
\hline CHEMBL1709004 & 737121 & 5.0443 & 4.4325 & TRN \\
\hline CHEMBL1412385 & 737121 & 4.7747 & 4.0304 & TRN \\
\hline CHEMBL238188 & 737121 & 4.7799 & 3.9275 & TST \\
\hline CHEMBL3210428 & 737121 & 3.0969 & 3.7708 & TRN \\
\hline CHEMBL1503152 & 737121 & 4.8665 & 4.8674 & TST \\
\hline CHEMBL1290401 & 737121 & 4.248 & 4.3105 & TRN \\
\hline CHEMBL1383793 & 737121 & 5.1379 & 4.6677 & TRN \\
\hline CHEMBL1998521 & 737121 & 5.585 & 4.0443 & TST \\
\hline CHEMBL1573661 & 737121 & 4.7595 & 3.9163 & TRN \\
\hline CHEMBL1322082 & 737121 & 3.0969 & 3.9706 & TRN \\
\hline CHEMBL1438402 & 737121 & 3.0969 & 3.9856 & TRN \\
\hline CHEMBL1427492 & 737121 & 4.8996 & 3.9802 & TRN \\
\hline CHEMBL1531529 & 737121 & 4.4045 & 3.9465 & TRN \\
\hline CHEMBL1380296 & 737121 & 3.0969 & 3.9079 & TST \\
\hline CHEMBL503363 & 737121 & 5.1018 & 3.8009 & TST \\
\hline CHEMBL1573496 & 737121 & 5.1457 & 3.9022 & TRN \\
\hline CHEMBL1701527 & 737121 & 4.8416 & 4.5607 & TST \\
\hline CHEMBL1443859 & 737121 & 3.0969 & 3.8534 & TRN \\
\hline CHEMBL1534436 & 737121 & 3.0969 & 3.9399 & TRN \\
\hline CHEMBL1446641 & 737121 & 4.3615 & 3.9782 & TRN \\
\hline CHEMBL3209159 & 737121 & 4.7595 & 4.3149 & TRN \\
\hline CHEMBL3195562 & 737121 & 4.3497 & 4.4248 & TRN \\
\hline CHEMBL1312672 & 737121 & 4.7144 & 3.64300 & 00000000002 \\
\hline CHEMBL1419117 & 737121 & 3.0969 & 4.2937 & TRN \\
\hline CHEMBL1543331 & 737121 & 4.6536 & 4.4004 & TST \\
\hline CHEMBL1348169 & 737121 & 5.3615 & 4.8817 & TST \\
\hline CHEMBL1610943 & 737121 & 4.7773 & 3.8529 & TRN \\
\hline CHEMBL1578255 & 737121 & 3.0969 & 3.6282 & TRN \\
\hline CHEMBL1342782 & 737121 & 3.0969 & 3.802 & TRN \\
\hline CHEMBL1381837 & 737121 & 4.2226 & 4.5448 & TRN \\
\hline CHEMBL1330510 & 737121 & 4.9586 & 4.7475 & TRN \\
\hline CHEMBL1549574 & 737121 & 4.7375 & 3.9793 & TRN \\
\hline CHEMBL1377849 & 737121 & 5.0942 & 4.6934 & TRN \\
\hline CHEMBL1973341 & 737121 & 4.433 & 4.4797 & TRN \\
\hline CHEMBL1445171 & 737121 & 3.0969 & 4.5804 & TRN \\
\hline CHEMBL 1347600 & 737121 & 5.0438 & 4.041 & TRN \\
\hline CHEMBL1433088 & 737121 & 5.0 & 4.6001 & TRN \\
\hline CHEMBL1528822 & 737121 & 3.0969 & 3.9121 & TRN \\
\hline CHEMBL1608375 & 737121 & 4.7471 & 3.9114 & TST \\
\hline CHEMBL1549450 & 737121 & 3.0969 & 4.0114 & TST \\
\hline CHEMBL1704344 & 737121 & 3.0969 & \multicolumn{2}{|c|}{3.9730000000000003} \\
\hline CHEMBL1531500 & 737121 & 3.0969 & 3.985 & TST \\
\hline CHEMBL1964776 & 737121 & 3.0969 & 3.8856 & TRN \\
\hline CHEMBL1720448 & 737121 & 5.3307 & 5.0174 & TRN \\
\hline
\end{tabular}


Supplemental Table S2.txt

\begin{tabular}{|c|c|c|c|c|}
\hline CHEMBL 3189322 & 737121 & 4.9031 & 3.8915 & TRN \\
\hline CHEMBL1362441 & 737121 & 4.341 & 3.8466 & TRN \\
\hline CHEMBL3212870 & 737121 & 4.2765 & 3.889 & TRN \\
\hline CHEMBL598663 & 737121 & 4.7905 & 3.9798 & TRN \\
\hline CHEMBL1510228 & 737121 & 3.0969 & 3.8468 & TRN \\
\hline CHEMBL1446421 & 737121 & 3.0969 & 3.9086 & TRN \\
\hline CHEMBL296527 & 737121 & 4.5969 & 4.5411 & TRN \\
\hline CHEMBL1536646 & 737121 & 4.5901 & 4.4584 & TRN \\
\hline CHEMBL1717333 & 737121 & 4.8996 & 3.8026 & TST \\
\hline CHEMBL1569836 & 737121 & 3.0969 & 3.9456 & TRN \\
\hline CHEMBL1361507 & 737121 & 3.0969 & 3.927 & TRN \\
\hline CHEMBL1422635 & 737121 & 4.3316 & 3.833 & TST \\
\hline CHEMBL1718409 & 737121 & 4.5544 & 3.9016 & TST \\
\hline CHEMBL532239 & 737121 & 5.2351 & 3.9691 & TRN \\
\hline CHEMBL1488591 & 737121 & 3.0969 & 3.6136 & TST \\
\hline CHEMBL1303719 & 737121 & 5.3575 & 4.3865 & TRN \\
\hline CHEMBL3208631 & 737121 & 5.0429 & 4.8858 & TRN \\
\hline CHEMBL1720691 & 737121 & 4.5751 & 4.6661 & TRN \\
\hline CHEMBL1339322 & 737121 & 3.0969 & 3.8817 & TRN \\
\hline CHEMBL1978120 & 737121 & 4.8069 & 4.2585 & TRN \\
\hline CHEMBL1898721 & 737121 & 3.0969 & 3.92 & TRN \\
\hline CHEMBL1539808 & 737121 & 5.2757 & 4.7189 & TRN \\
\hline CHEMBL1407529 & 737121 & 3.0969 & 3.993999 & 99999999998 \\
\hline CHEMBL1486066 & 737121 & 4.7905 & 4.4262 & TRN \\
\hline CHEMBL3193533 & 737121 & 4.9872 & 4.7651 & TRN \\
\hline CHEMBL1381088 & 737121 & 4.2541 & 4.418 & TRN \\
\hline CHEMBL1718432 & 737121 & 4.8861 & 4.5404 & TRN \\
\hline CHEMBL3191811 & 737121 & 5.1433 & 4.485 & TRN \\
\hline CHEMBL1563861 & 737121 & 5.6402 & 4.0954 & TRN \\
\hline CHEMBL1988829 & 737121 & 3.0969 & 4.5429 & TRN \\
\hline CHEMBL1305641 & 737121 & 4.6216 & 4.4372 & TST \\
\hline CHEMBL1535134 & 737121 & 5.1385 & 4.614 & TRN \\
\hline CHEMBL1715154 & 737121 & 3.0969 & 3.7706 & TRN \\
\hline CHEMBL1386738 & 737121 & 4.8928 & 3.8718 & TST \\
\hline CHEMBL1301278 & 737121 & 5.2175 & 3.9559 & TST \\
\hline CHEMBL1603960 & 737121 & 4.3063 & 4.2593 & TRN \\
\hline CHEMBL1417867 & 737121 & 4.7747 & 4.3762 & TRN \\
\hline CHEMBL1986090 & 737121 & 4.8601 & 4.4176 & TRN \\
\hline CHEMBL3197754 & 737121 & 4.6383 & 3.881999 & 99999999997 \\
\hline CHEMBL1460676 & 737121 & 4.9626 & 3.8613 & TRN \\
\hline CHEMBL1581674 & 737121 & 5.0862 & 3.8411 & TRN \\
\hline CHEMBL1368384 & 737121 & 3.0969 & 3.8916 & TRN \\
\hline CHEMBL1472426 & 737121 & 3.0969 & 3.6119 & TRN \\
\hline CHEMBL1986505 & 737121 & 3.0969 & 4.3356 & TRN \\
\hline CHEMBL1458178 & 737121 & 3.0969 & 4.331 & TRN \\
\hline CHEMBL1369287 & 737121 & 3.0969 & 3.9713 & TST \\
\hline CHEMBL1499436 & 737121 & 4.9245 & 3.888 & TRN \\
\hline CHEMBL1613445 & 737121 & 4.8962 & 3.9146 & TRN \\
\hline
\end{tabular}




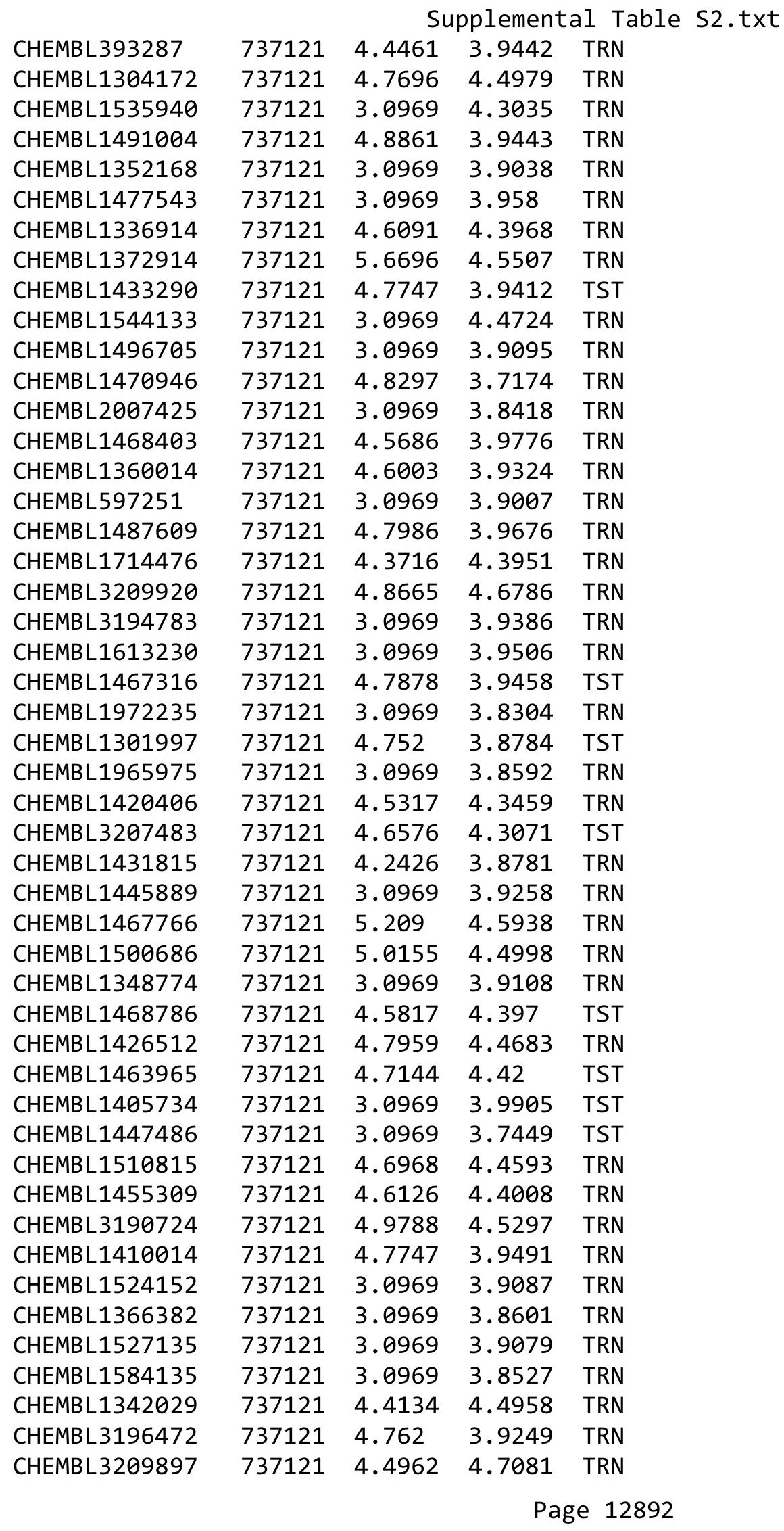




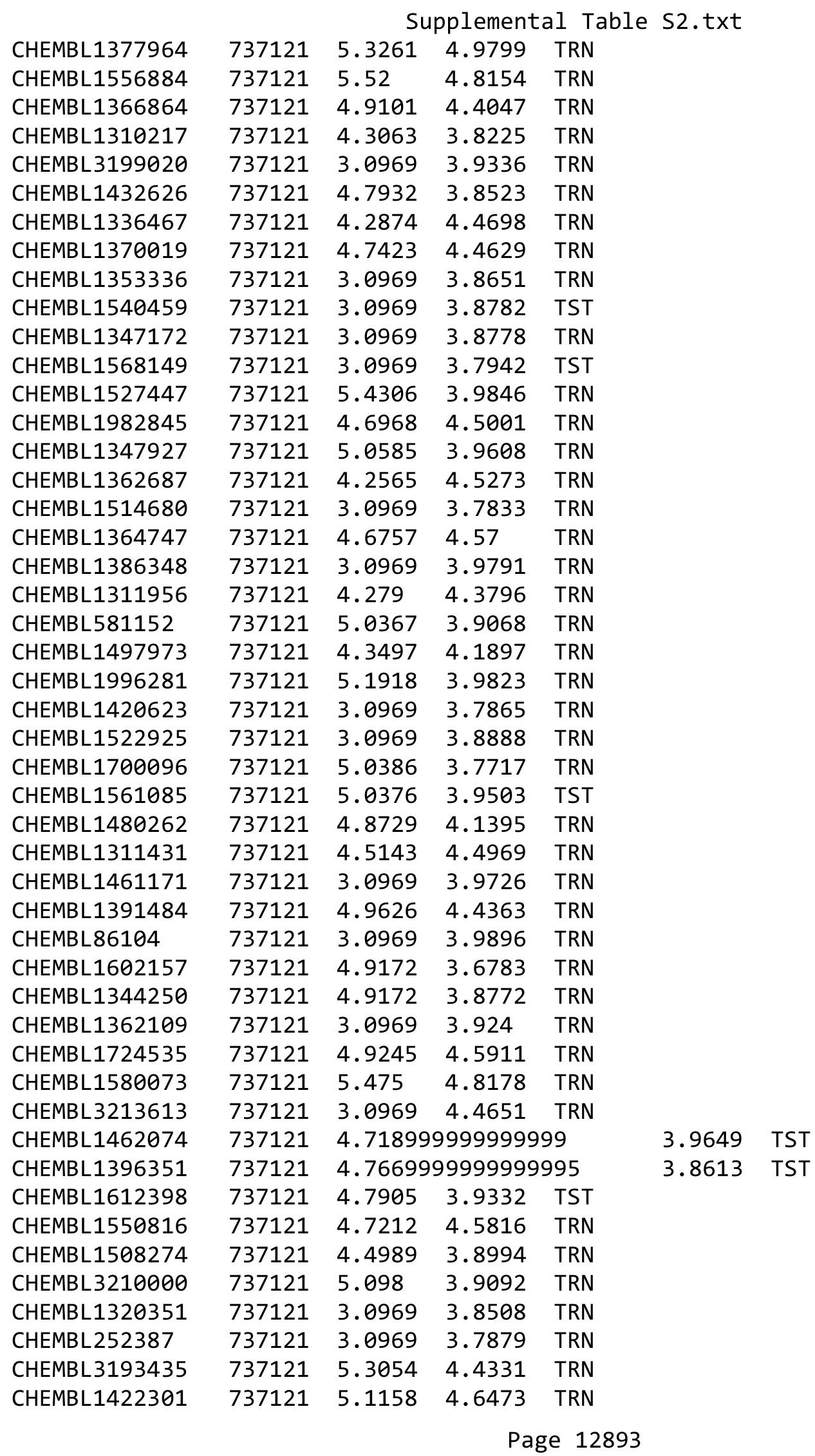




$$
\text { Supplemental Table S2.txt }
$$

\begin{tabular}{|c|c|c|c|c|c|}
\hline CHEMBL 2005296 & 737121 & 4.8069 & 4.4834 & TRN & \\
\hline CHEMBL1610463 & 737121 & 4.4737 & 3.8217 & TRN & \\
\hline CHEMBL1583552 & 737121 & 5.104 & 3.9011 & TRN & \\
\hline CHEMBL1331011 & 737121 & 3.0969 & 3.8867 & TST & \\
\hline CHEMBL1500059 & 737121 & 3.0969 & 4.4203 & TRN & \\
\hline CHEMBL3209308 & 737121 & 4.5654 & 4.5189 & TRN & \\
\hline CHEMBL3208014 & 737121 & 5.091 & 4.8947 & TRN & \\
\hline CHEMBL1511063 & 737121 & 5.032 & 3.6942 & TRN & \\
\hline CHEMBL1489685 & 737121 & 4.284 & 4.2776 & TRN & \\
\hline CHEMBL3197092 & 737121 & 5.1238 & 4.9237 & TRN & \\
\hline CHEMBL1555488 & 737121 & 5.2366 & 4.2016 & TRN & \\
\hline CHEMBL1382870 & 737121 & 4.1261 & 3.8958 & TRN & \\
\hline CHEMBL1593896 & 737121 & 4.6819 & 4.4641 & TRN & \\
\hline CHEMBL1465832 & 737121 & 3.0969 & 3.9056 & TRN & \\
\hline CHEMBL1468368 & 737121 & 4.7328 & 4.3622 & TRN & \\
\hline CHEMBL1421010 & 737121 & 4.8447 & 3.8529 & TST & \\
\hline CHEMBL1526117 & 737121 & 4.6882 & 4.3548 & TRN & \\
\hline CHEMBL1488408 & 737121 & 4.9872 & 3.9421 & TST & \\
\hline CHEMBL1301480 & 737121 & 3.0969 & 4.4811 & TRN & \\
\hline CHEMBL3193507 & 737121 & 3.0969 & 3.8968 & TRN & \\
\hline CHEMBL1609564 & 737121 & 4.8041 & 4.5439 & TRN & \\
\hline CHEMBL1509317 & 737121 & 3.0969 & 3.9019 & TST & \\
\hline CHEMBL1714915 & 737121 & 4.6596 & 3.8668 & TRN & \\
\hline CHEMBL1522369 & 737121 & 4.6055 & 3.9176 & TRN & \\
\hline CHEMBL1462378 & 737121 & 4.4067 & 3.8766 & TRN & \\
\hline CHEMBL1594756 & 737121 & 3.0969 & 3.9051 & TRN & \\
\hline CHEMBL1502739 & 737121 & 4.5331 & 3.8577 & TRN & \\
\hline CHEMBL1560628 & 737121 & 4.7447 & 4.5184 & TST & \\
\hline CHEMBL1493290 & 737121 & 3.0969 & 3.9202 & TRN & \\
\hline CHEMBL3211497 & 737121 & 4.5784 & 3.9465 & TRN & \\
\hline CHEMBL1509120 & 737121 & 3.0969 & 3.6476 & TRN & \\
\hline CHEMBL581860 & 737121 & 4.9666 & 3.9521 & TRN & \\
\hline CHEMBL1735616 & 737121 & 3.0969 & 4.444 & TST & \\
\hline CHEMBL1523175 & 737121 & 3.0969 & 4.7027 & TRN & \\
\hline CHEMBL1450040 & 737121 & 3.0969 & 3.8373 & TRN & \\
\hline CHEMBL1595841 & 737121 & 4.7471 & 3.9084 & TRN & \\
\hline CHEMBL1496189 & 737121 & 4.9355 & 4.5646 & TRN & \\
\hline CHEMBL1717433 & 737121 & 3.0969 & 3.7949 & TRN & \\
\hline CHEMBL1526421 & 737121 & 3.0969 & \multicolumn{2}{|c|}{3.7430000000000003} & TRN \\
\hline CHEMBL1526636 & 737121 & 3.0969 & 3.9552 & TRN & \\
\hline CHEMBL1493254 & 737121 & 4.9031 & 4.5479 & TST & \\
\hline CHEMBL1488623 & 737121 & 3.0969 & 4.0377 & TRN & \\
\hline CHEMBL1503673 & 737121 & 4.8069 & 3.845 & TRN & \\
\hline CHEMBL1389616 & 737121 & 4.6345 & 3.8419 & TRN & \\
\hline CHEMBL1421583 & 737121 & 3.0969 & 3.8672 & TRN & \\
\hline CHEMBL1462576 & 737121 & 3.0969 & 3.9811 & TRN & \\
\hline CHEMBL3197305 & 737121 & 5.8508 & 4.5258 & TRN & \\
\hline CHEMBL1398765 & 737121 & 4.15 & 4.3795 & TST & \\
\hline
\end{tabular}


Supplemental Table S2.txt

\begin{tabular}{|c|c|c|c|c|}
\hline 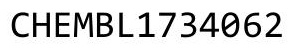 & & & & \\
\hline IEM & 7121 & 3675 & & \\
\hline HEMBL1379816 & 37121 & 3429 & 3722 & \\
\hline HEMBL1437888 & 37121 & .0835 & 9157 & \\
\hline & 21 & & & \\
\hline AEMBL155 & 121 & 308 & 3568 & \\
\hline AEMBL1481264 & 37121 & 5452 & .5274 & \\
\hline HEMBL1504679 & 37121 & 4.8633 & .9812 & \\
\hline HEMBL1518501 & 37121 & .4815 & 3512 & \\
\hline IEMBL319 & 121 & 969 & 359 & \\
\hline AEMBL1370719 & 121 & & 3.9396 & 3. \\
\hline HEMBL1310132 & 37121 & 3794 & 3.8266 & DMe \\
\hline HEMBL1547873 & 37121 & 969 & 87 & $\Delta \mid$ \\
\hline AEMBL134 & 21 & 69 & 39 & \\
\hline IEMBL155 & 121 & 212 & & \\
\hline AEMBL169 & 121 & 969 & & \\
\hline AEMBL3198149 & 37121 & 969 & 8318 & ST \\
\hline HEMBL 319 & & 82 & & RN \\
\hline EEMBLI/. & 21 & 28 & 23 & \\
\hline L15 & 21 & 62 & & \\
\hline L31C & 21 & 67 & & RN \\
\hline L156 & 37121 & 969 & & RN \\
\hline HEMBL150 & & & & RN \\
\hline AEMBL32e & 21 & 97 & & \\
\hline L154 & 21 & 95 & & \\
\hline 1310 & 21 & 34 & & RN \\
\hline L132 & & & & RN \\
\hline HEMBL196 & & & & RN \\
\hline HEMBL132 & 21 & & 81 & RN \\
\hline L13 & 21 & & & RN \\
\hline 03 & 21 & 56 & & RN \\
\hline HEMBL131 & & & & RN \\
\hline AEMBL1995692 & & & & RN \\
\hline AEMBL15 & 21 & 69 & & RN \\
\hline L15 & 21 & & 21 & ST \\
\hline 58 & 1 & & & ST \\
\hline HEMBL1991601 & 37121 & & 3881 & ST \\
\hline AEMBL1532878 & & & & RN \\
\hline HEMBL 321 & 21 & & & ST \\
\hline 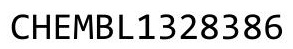 & & & 49 & RIN \\
\hline L17 & & & & RN \\
\hline HEMBL1481903 & 37121 & 1976 & 19 & TRN \\
\hline IEMBL19 & 21 & & & ST \\
\hline HEMBL17 & & & & TRN \\
\hline HEMBL31C & & & & RIV \\
\hline HEMBL 201986 & 737121 & & 3.9389 & RN \\
\hline 3L3209000 & 37121 & 4.1186 & 3.6233 & RN \\
\hline CHEMBL1410063 & 737121 & 3.0969 & 4.305 & TRN \\
\hline
\end{tabular}

Page 12895 
Supplemental Table S2.txt

\begin{tabular}{|c|c|c|c|c|c|}
\hline CHEMBL1389886 & 737121 & 4.8356 & 3.946 & TRN & \\
\hline CHEMBL1417168 & 737121 & 4.9914 & 3.8737 & TRN & \\
\hline CHEMBL1567008 & 737121 & 3.0969 & \multicolumn{2}{|c|}{3.8960000000000004} & TRN \\
\hline CHEMBL1700686 & 737121 & 4.15 & 4.3933 & TST & \\
\hline CHEMBL1335223 & 737121 & 4.4672 & 3.9123 & TST & \\
\hline CHEMBL1698340 & 737121 & 4.1945 & 4.3965 & TST & \\
\hline CHEMBL1415447 & 737121 & 4.5214 & 4.4074 & TST & \\
\hline CHEMBL1466329 & 737121 & 4.4012 & 3.8654 & TST & \\
\hline CHEMBL1570774 & 737121 & 4.129 & 3.8055 & TRN & \\
\hline CHEMBL1458403 & 737121 & 3.0969 & 3.8904 & TST & \\
\hline CHEMBL1410068 & 737121 & 4.8827 & 3.9334 & TST & \\
\hline CHEMBL1329781 & 737121 & 3.0969 & 3.9802 & TRN & \\
\hline CHEMBL1727260 & 737121 & 4.6737 & 4.2417 & TST & \\
\hline CHEMBL1517752 & 737121 & 5.4353 & 4.0637 & TRN & \\
\hline CHEMBL1418750 & 737121 & 3.0969 & 4.3639 & TRN & \\
\hline CHEMBL1342448 & 737121 & 4.9547 & 4.0164 & TST & \\
\hline CHEMBL3212452 & 737121 & 4.5918 & \multicolumn{2}{|c|}{3.9010000000000002} & TST \\
\hline CHEMBL1525833 & 737121 & 4.3969 & 3.9052 & TRN & \\
\hline CHEMBL1538775 & 737121 & 4.3054 & 3.9803 & TRN & \\
\hline CHEMBL1362998 & 737121 & 4.4776 & 3.9228 & TRN & \\
\hline CHEMBL32147 & 737121 & 4.8794 & 3.9892 & TRN & \\
\hline CHEMBL1502873 & 737121 & 4.3979 & 3.8427 & TRN & \\
\hline CHEMBL1381296 & 737121 & 4.6676 & 3.8724 & TRN & \\
\hline CHEMBL1431385 & 737121 & 3.0969 & 3.9293 & TRN & \\
\hline CHEMBL1738986 & 737121 & 3.0969 & 3.8687 & TRN & \\
\hline CHEMBL1532675 & 737121 & 3.0969 & 3.9497 & TRN & \\
\hline CHEMBL 2001794 & 737121 & 5.1343 & 3.7876 & TRN & \\
\hline CHEMBL1319467 & 737121 & 5.1952 & 4.0174 & TST & \\
\hline CHEMBL498436 & 737121 & 4.7077 & 3.8644 & TST & \\
\hline CHEMBL1607280 & 737121 & 5.0585 & 3.8432 & TST & \\
\hline CHEMBL1722421 & 737121 & 3.0969 & 3.9562 & TST & \\
\hline CHEMBL 2000338 & 737121 & 5.1681 & 4.6643 & TST & \\
\hline CHEMBL1995254 & 737121 & 4.4157 & 4.3593 & TST & \\
\hline CHEMBL1597446 & 737121 & 4.5607 & 3.6554 & TST & \\
\hline CHEMBL1341399 & 737121 & 4.8827 & 4.617 & TST & \\
\hline CHEMBL1441619 & 737121 & 5.2967 & 4.8991 & TST & \\
\hline CHEMBL1732128 & 737121 & 4.6946 & 4.4782 & TST & \\
\hline CHEMBL1464261 & 737121 & 3.0969 & 3.9805 & TST & \\
\hline CHEMBL1515023 & 737121 & 3.0969 & 3.9013 & TST & \\
\hline CHEMBL1457782 & 737121 & 3.0969 & 3.8803 & TST & \\
\hline CHEMBL3193227 & 737121 & 5.0348 & 4.8174 & TST & \\
\hline CHEMBL1709275 & 737121 & 3.0969 & 3.8113 & TST & \\
\hline CHEMBL1373688 & 737121 & 4.8928 & 3.9921 & TST & \\
\hline CHEMBL1319510 & 737121 & 3.0969 & 3.9467 & TST & \\
\hline CHEMBL1707764 & 737121 & 3.0969 & 4.5283 & TST & \\
\hline CHEMBL1983745 & 737121 & 5.1555 & 3.6199 & TST & \\
\hline CHEMBL1359006 & 737121 & 4.8861 & 3.8727 & TST & \\
\hline CHEMBL3199191 & 737121 & 4.3307 & 4.0115 & TST & \\
\hline
\end{tabular}




\begin{tabular}{|c|c|c|c|c|c|}
\hline \multirow{3}{*}{$\begin{array}{l}\text { CHEMBL } 3212447 \\
\text { CHEMBL1458390 }\end{array}$} & \multicolumn{5}{|c|}{ Supplemental Table S2.txt } \\
\hline & 737121 & 4.2526 & 3.91600 & 00000000004 & TST \\
\hline & 737121 & 3.0969 & 3.8875 & TST & \\
\hline CHEMBL391533 & 737121 & 3.0969 & 3.8909 & TST & \\
\hline CHEMBL3197214 & 737121 & 4.857 & 4.4689 & TST & \\
\hline CHEMBL1326333 & 737121 & 4.3429 & 4.3344 & TST & \\
\hline CHEMBL3198659 & 737121 & 4.8239 & 3.853 & TST & \\
\hline CHEMBL1576489 & 737121 & 3.0969 & 3.8701 & TST & \\
\hline CHEMBL1496182 & 737121 & 4.3536 & 3.9336 & TST & \\
\hline CHEMBL3211221 & 737121 & 4.4737 & 3.9375 & TST & \\
\hline CHEMBL1572058 & 737121 & 3.0969 & 3.7862 & TST & \\
\hline CHEMBL1324224 & 737121 & 4.644 & 3.9165 & TST & \\
\hline CHEMBL1453583 & 737121 & 3.0969 & 3.9127 & TST & \\
\hline CHEMBL1966612 & 737121 & 3.0969 & 3.7488 & TST & \\
\hline CHEMBL1482389 & 737121 & 4.8153 & 3.8083 & TST & \\
\hline CHEMBL1728032 & 737121 & 5.1403 & 4.4629 & TST & \\
\hline CHEMBL1351044 & 737121 & 4.3179 & 4.6193 & TST & \\
\hline CHEMBL1493178 & 737121 & 4.4935 & 3.9013 & TST & \\
\hline CHEMBL1340032 & 737121 & 4.4342 & 4.4273 & TST & \\
\hline CHEMBL1324397 & 737121 & 4.9431 & 4.0128 & TST & \\
\hline CHEMBL1351099 & 737121 & 3.0969 & 3.8709 & TST & \\
\hline CHEMBL1278035 & 737121 & 4.8665 & 3.9251 & TST & \\
\hline CHEMBL1715461 & 737121 & 3.0969 & 3.8668 & TST & \\
\hline CHEMBL1502574 & 737121 & 4.5784 & 3.9147 & TST & \\
\hline CHEMBL3209140 & 737121 & 4.1778 & 4.6094 & TST & \\
\hline CHEMBL3912108 & 1640197 & 8.7932 & 8.7381 & TRN & \\
\hline CHEMBL198654 & 1640197 & 8.5017 & 8.6789 & TRN & \\
\hline CHEMBL3305961 & 1640197 & 7.7167 & 7.6697 & TRN & \\
\hline CHEMBL48813 & 1640197 & 8.9101 & 8.826 & TST & \\
\hline CHEMBL550453 & 1640197 & 8.1457 & 8.1605 & TRN & \\
\hline CHEMBL383361 & 1640197 & 9.1284 & 9.1129 & TRN & \\
\hline CHEMBL197547 & 1640197 & 7.4045 & 7.4181 & TRN & \\
\hline CHEMBL3966335 & 1640197 & 5.8239 & 5.9598 & TST & \\
\hline CHEMBL194810 & 1640197 & 7.8633 & 7.7517 & TRN & \\
\hline CHEMBL364284 & 1640197 & 9.8097 & 9.5305 & TRN & \\
\hline CHEMBL3959350 & 1640197 & 7.3233 & 7.3337 & TRN & \\
\hline CHEMBL3304291 & 1640197 & 8.4377 & 8.4888 & TRN & \\
\hline CHEMBL196492 & 1640197 & 8.342 & 8.3534 & TRN & \\
\hline CHEMBL197377 & 1640197 & 9.2549 & 9.4109 & TRN & \\
\hline CHEMBL381866 & 1640197 & 8.5406 & 8.4907 & TRN & \\
\hline CHEMBL196551 & 1640197 & 8.1141 & 7.765 & TRN & \\
\hline CHEMBL3972799 & 1640197 & 9.0438 & 9.0191 & TRN & \\
\hline CHEMBL370176 & 1640197 & 6.8097 & 6.7698 & TRN & \\
\hline CHEMBL3974641 & 1640197 & 7.5391 & 7.6614 & TST & \\
\hline CHEMBL3955803 & 1640197 & 8.7986 & 8.7784 & TRN & \\
\hline CHEMBL196162 & 1640197 & 7.3686 & 7.7642 & TRN & \\
\hline CHEMBL3979386 & 1640197 & 8.9431 & 8.9449 & TRN & \\
\hline CHEMBL3961484 & 1640197 & 9.1215 & 9.0897 & TRN & \\
\hline CHEMBL197624 & 1640197 & 7.3947 & 7.3217 & TRN & \\
\hline
\end{tabular}


Supplemental Table S2.txt

\begin{tabular}{|c|c|c|c|c|}
\hline HEMBL & 540197 & 7.9747 & 7.9814 & . \\
\hline & 640197 & 8.7011 & 8.7331 & \\
\hline IFMR & 197 & 7.4763 & & \\
\hline AEMBL: & 197 & 7375 & 7379 & \\
\hline HEMBL93087 & 640197 & 7.2418 & 2902 & \\
\hline HEMBL39 & 197 & 7.4101 & 7.3527 & \\
\hline AEMBL & 97 & & 1628 & \\
\hline AEMBL3 & & & 2097 & DM \\
\hline HEMBL 372568 & 640197 & 6.4737 & 6.4888 & \\
\hline HEMBL196 & 640197 & 9.1296 & 9.1593 & \\
\hline HEMBL1 & 197 & & 6.2796 & \\
\hline HEMBL4 & 97 & & .016 & \\
\hline HEMBL3 & 97 & & 3.5248 & \\
\hline HEMBL 391 & 640197 & 9.0991 & 9.0905 & \\
\hline HEMBL194 & 197 & & 9.0724 & \\
\hline HEMBL3 & 97 & 8 . & 8.9005 & \\
\hline HEMBL3 & 97 & & 833 & ST \\
\hline HEMBL1 & 97 & & 3694 & RN \\
\hline HEMBL3 & 97 & 8. & 5421 & KIV \\
\hline HEMBL 397 & 97 & & 522 & IRIV \\
\hline HEMBL & 64 & & 1795 & SI \\
\hline HEME & 1 & & 29 & RN \\
\hline HEMBL & 97 & & 9.2495 & ST \\
\hline HEMBL1 & 97 & & 476 & $\mathrm{RN}$ \\
\hline AEMBL1 & & & & TST \\
\hline HEMBL5 & 97 & & 91 & ST \\
\hline HEMBL. & 97 & & 85 & ST \\
\hline HFM & 97 & & 7.3801 & ST \\
\hline HEMBL1 & & & 624 & SI \\
\hline AEMBL37 & 197 & 8. & 8.3674 & TST \\
\hline HEMBL: & 9 & & 731 & RN \\
\hline HFM & & & 77 & RN \\
\hline HEMBL4 & & & 02 & RN \\
\hline HEMBL12 & & & 029 & TRN \\
\hline HEMBL319 & 9 & & 8709 & RN \\
\hline AFMRI 1 & 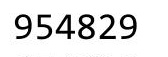 & & 124 & $\mathrm{RN}$ \\
\hline 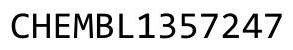 & 9 & & & RN \\
\hline HEMBL18 & & 4. & 4.8726 & TRN \\
\hline HEMBL2 & 9 & 974 & 13.2888 & TRN \\
\hline Th & & & 003 & RN \\
\hline HEMBL 5 & 9 & & & RN \\
\hline HEMBL1 & 29 & 2 . & 3.8534 & ST \\
\hline HEMBL2 & 29 & 282 & 6173 & TRN \\
\hline HEMBL 1 & 9 & & 48 & TR \\
\hline CHEMBL15 & & & & \\
\hline HEMBL3 & & & 36 & \\
\hline CHEMBL 379300 & 54829 & 6.2341 & 6.4075 & $\mathrm{~N}$ \\
\hline CHEMBL 258844 & 954829 & 4.0904 & 4.1267 & $\Gamma R$ \\
\hline
\end{tabular}

Page 12898 
Supplemental Table S2.txt

\begin{tabular}{|c|c|c|c|c|c|}
\hline CHEMBL1404918 & 954829 & 2.5927 & 2.6631 & TRN & \\
\hline CHEMBL135561 & 954829 & 4.1035 & 3.8742 & TRN & \\
\hline CHEMBL412142 & 954829 & 4.7299 & 5.1472 & TRN & \\
\hline CHEMBL3392440 & 954829 & 3.7865 & 3.9963 & TRN & \\
\hline CHEMBL1788116 & 954829 & 4.8497 & 4.6122 & TRN & \\
\hline CHEMBL1230020 & 954829 & 4.473 & 4.5909 & TRN & \\
\hline CHEMBL259181 & 954829 & 3.8598 & 4.0314 & TRN & \\
\hline CHEMBL202721 & 954829 & 5.8486 & 5.9724 & TRN & \\
\hline CHEMBL483849 & 954829 & 3.6388 & 3.7501 & TRN & \\
\hline CHEMBL 2363137 & 954829 & 4.7871 & 4.5392 & TRN & \\
\hline CHEMBL189584 & 954829 & 4.994 & 4.9644 & TRN & \\
\hline CHEMBL222102 & 954829 & 4.4999 & 4.6296 & TRN & \\
\hline CHEMBL1190711 & 954829 & 4.9783 & 5.2417 & TRN & \\
\hline CHEMBL373751 & 954829 & 3.3439 & 3.0566 & TRN & \\
\hline CHEMBL 9470 & 954829 & 6.0101 & 4.8354 & TST & \\
\hline CHEMBL221137 & 954829 & 4.4421 & 3.8048 & TST & \\
\hline CHEMBL1909414 & 954829 & 4.1565 & 3.7842 & TRN & \\
\hline CHEMBL1673039 & 954829 & 4.2918 & 4.4559 & TRN & \\
\hline CHEMBL220241 & 954829 & 5.6098 & 5.3459 & TRN & \\
\hline CHEMBL1643959 & 954829 & 3.0917 & 3.2744 & TRN & \\
\hline CHEMBL 2144069 & 954829 & 6.7079 & 6.65799 & 99999999995 & TRN \\
\hline CHEMBL3349342 & 954829 & 5.2675 & 5.4752 & TRN & \\
\hline CHEMBL472940 & 954829 & 2.5043 & 2.4325 & TRN & \\
\hline CHEMBL210618 & 954829 & 4.3242 & 4.123 & TRN & \\
\hline CHEMBL573107 & 954829 & 5.5343 & 5.3578 & TRN & \\
\hline CHEMBL577784 & 954829 & 5.6283 & 5.4064 & TRN & \\
\hline CHEMBL180127 & 954829 & 4.6886 & 4.8393 & TRN & \\
\hline CHEMBL102714 & 954829 & 4.6446 & 4.397 & TRN & \\
\hline CHEMBL515416 & 954829 & 4.6206 & 4.6697 & TRN & \\
\hline CHEMBL379975 & 954829 & 5.8776 & 4.7664 & TST & \\
\hline CHEMBL240954 & 954829 & 4.8929 & 3.9378 & TST & \\
\hline CHEMBL449158 & 954829 & 6.4116 & 7.6013 & TST & \\
\hline CHEMBL585951 & 954829 & 5.9406 & 5.9139 & TST & \\
\hline CHEMBL300389 & 954829 & 6.7533 & 6.6395 & TST & \\
\hline CHEMBL 92309 & 954829 & \multicolumn{3}{|c|}{3.6310000000000002} & TST \\
\hline CHEMBL514499 & 954829 & 6.9562 & 7.5065 & TST & \\
\hline CHEMBL 3186408 & 954829 & 4.3255 & 3.4126 & TST & \\
\hline CHEMBL 2005886 & 954829 & 4.4991 & 5.4668 & TST & \\
\hline CHEMBL192566 & 954829 & 7.2566 & 6.8569 & TST & \\
\hline CHEMBL65 & 954829 & 8.3893 & 7.8739 & TST & \\
\hline CHEMBL392695 & 954829 & 4.8452 & 4.9518 & TST & \\
\hline CHEMBL1532234 & 688307 & 4.3262 & 4.1777 & TRN & \\
\hline CHEMBL1377527 & 688307 & 3.301 & 4.1019 & TRN & \\
\hline CHEMBL1485005 & 688307 & 4.6255 & 4.1835 & TRN & \\
\hline CHEMBL1402732 & 688307 & 3.301 & 4.3244 & TRN & \\
\hline CHEMBL3198515 & 688307 & 4.4292 & 4.4645 & TRN & \\
\hline CHEMBL1531512 & 688307 & 4.4566 & 4.31 & TRN & \\
\hline CHEMBL1589718 & 688307 & 3.301 & 4.1988 & TRN & \\
\hline
\end{tabular}


Supplemental Table S2.txt

\begin{tabular}{|c|c|c|c|c|c|}
\hline CHEMBL1509453 & 688307 & 5.0737 & 4.4761 & TRN & \\
\hline CHEMBL3189442 & 688307 & 4.5224 & 4.4646 & TRN & \\
\hline CHEMBL1491936 & 688307 & 4.8565 & 4.5061 & TRN & \\
\hline CHEMBL1447311 & 688307 & 4.6036 & 4.2425 & TRN & \\
\hline CHEMBL1577757 & 688307 & 4.9875 & 4.2458 & TRN & \\
\hline CHEMBL1461574 & 688307 & 5.0611 & 4.0341 & TST & \\
\hline CHEMBL1438401 & 688307 & 3.301 & 4.0153 & TRN & \\
\hline CHEMBL1334452 & 688307 & 3.301 & 4.2116 & TRN & \\
\hline CHEMBL1585431 & 688307 & 4.3966 & 4.2679 & TRN & \\
\hline CHEMBL1449807 & 688307 & 3.301 & 4.0531 & TRN & \\
\hline CHEMBL1582458 & 688307 & 3.301 & 4.1485 & TRN & \\
\hline CHEMBL1455258 & 688307 & 5.0226 & 4.6102 & TRN & \\
\hline CHEMBL1499638 & 688307 & 4.739 & 4.1152 & TRN & \\
\hline CHEMBL1516948 & 688307 & 4.4828 & 4.2191 & TST & \\
\hline CHEMBL1334162 & 688307 & 3.301 & 4.2682 & TRN & \\
\hline CHEMBL1386105 & 688307 & 4.4147 & 4.3108 & TRN & \\
\hline CHEMBL1322601 & 688307 & 4.724 & 4.1392 & TRN & \\
\hline CHEMBL1498999 & 688307 & 4.5186 & 3.9657 & TRN & \\
\hline CHEMBL1496978 & 688307 & 4.7559 & 4.0655 & TRN & \\
\hline CHEMBL1342429 & 688307 & 3.301 & 3.9775 & TRN & \\
\hline CHEMBL1492422 & 688307 & 3.301 & 4.2016 & TST & \\
\hline CHEMBL1429150 & 688307 & 5.2033 & 4.3123 & TRN & \\
\hline CHEMBL1587920 & 688307 & 4.5258 & 4.2995 & TRN & \\
\hline CHEMBL1417890 & 688307 & 5.1492 & 3.9598 & TRN & \\
\hline CHEMBL1412224 & 688307 & 3.301 & 4.0474 & TST & \\
\hline CHEMBL1426947 & 688307 & 4.9214 & 4.5372 & TRN & \\
\hline CHEMBL1393131 & 688307 & 4.322 & 4.5302 & TRN & \\
\hline CHEMBL1519846 & 688307 & 3.301 & 4.0007 & TRN & \\
\hline CHEMBL1559976 & 688307 & 3.301 & 4.1781 & TRN & \\
\hline CHEMBL1428161 & 688307 & 4.4535 & 4.2524 & TRN & \\
\hline CHEMBL1510990 & 688307 & 3.301 & 4.2771 & TRN & \\
\hline CHEMBL1505040 & 688307 & 3.301 & 4.2945 & TST & \\
\hline CHEMBL1342736 & 688307 & 3.301 & 4.18 & TRN & \\
\hline CHEMBL1491627 & 688307 & 3.301 & 4.0739 & TRN & \\
\hline CHEMBL1302802 & 688307 & 4.9962 & 4.43199 & 99999999995 & TRN \\
\hline CHEMBL1427643 & 688307 & 4.5818 & 4.3884 & TRN & \\
\hline CHEMBL1583911 & 688307 & 3.301 & 3.9866 & TRN & \\
\hline CHEMBL1433062 & 688307 & 5.0094 & 4.5285 & TST & \\
\hline CHEMBL1564026 & 688307 & 3.301 & 4.1659 & TRN & \\
\hline CHEMBL1522300 & 688307 & 5.00899 & 99999999 & 4.5746 & TRN \\
\hline CHEMBL1495194 & 688307 & 4.5571 & 4.125 & TRN & \\
\hline CHEMBL1509933 & 688307 & 4.7623 & 4.4794 & TRN & \\
\hline CHEMBL1454402 & 688307 & 4.468 & 4.2823 & TST & \\
\hline CHEMBL1548231 & 688307 & 5.0186 & 4.0564 & TRN & \\
\hline CHEMBL1401227 & 688307 & 4.8733 & 4.2615 & TST & \\
\hline CHEMBL1586766 & 688307 & 3.301 & 4.3484 & TRN & \\
\hline CHEMBL150924 & 688307 & 4.6303 & 4.6751 & TRN & \\
\hline CHEMBL1393628 & 688307 & 3.301 & 4.3075 & TRN & \\
\hline
\end{tabular}




\begin{tabular}{|c|c|c|c|c|c|}
\hline \multicolumn{6}{|c|}{ Supplemental Table S2.txt } \\
\hline CHEMBL1466928 & 688307 & 4.4742 & 4.0375 & TRN & \\
\hline CHEMBL1476347 & 688307 & 4.8247 & 3.885 & TRN & \\
\hline CHEMBL1453264 & 688307 & 4.9272 & 4.1537 & TST & \\
\hline CHEMBL1603599 & 688307 & 4.8655 & 4.3483 & TRN & \\
\hline CHEMBL1587260 & 688307 & 5.0233 & 4.4516 & TRN & \\
\hline CHEMBL1424468 & 688307 & 4.5186 & 4.08 & TRN & \\
\hline CHEMBL1388431 & 688307 & 5.1483 & 4.2964 & TRN & \\
\hline CHEMBL1531555 & 688307 & 4.7208 & 4.1271 & TRN & \\
\hline CHEMBL1387920 & 688307 & 3.301 & 4.2457 & TRN & \\
\hline CHEMBL1374573 & 688307 & 4.521 & 4.35800 & 00000000005 & TRN \\
\hline CHEMBL3207314 & 688307 & 4.4995 & 4.1474 & TRN & \\
\hline CHEMBL3196534 & 688307 & 4.5677 & 4.2663 & TST & \\
\hline CHEMBL1448272 & 688307 & 4.5545 & 4.269 & TRN & \\
\hline CHEMBL1575187 & 688307 & 5.0109 & 4.226 & TRN & \\
\hline CHEMBL1303886 & 688307 & 4.6058 & 4.2206 & TRN & \\
\hline CHEMBL1433155 & 688307 & 3.301 & 4.2682 & TRN & \\
\hline CHEMBL1392188 & 688307 & 4.5142 & 4.2188 & TRN & \\
\hline CHEMBL1330161 & 688307 & 5.4499 & 4.1178 & TRN & \\
\hline CHEMBL1337538 & 688307 & 3.301 & 3.9107 & TRN & \\
\hline CHEMBL1340515 & 688307 & 3.301 & 4.2123 & TRN & \\
\hline CHEMBL1541552 & 688307 & 4.3736 & 4.1041 & TRN & \\
\hline CHEMBL1320937 & 688307 & 5.1564 & 4.1616 & TRN & \\
\hline CHEMBL1484998 & 688307 & 4.7519 & 4.0162 & TRN & \\
\hline CHEMBL1572403 & 688307 & 4.4773 & 4.3 & TRN & \\
\hline CHEMBL3196436 & 688307 & 3.301 & 4.1456 & TRN & \\
\hline CHEMBL1485768 & 688307 & 3.301 & 4.1067 & TRN & \\
\hline CHEMBL1340716 & 688307 & 3.301 & 4.2494 & TRN & \\
\hline CHEMBL1441655 & 688307 & 3.301 & 4.2332 & TRN & \\
\hline CHEMBL3199523 & 688307 & 4.9878 & 4.5253 & TST & \\
\hline CHEMBL1484399 & 688307 & 3.301 & 4.1826 & TRN & \\
\hline CHEMBL1349347 & 688307 & 4.6325 & 4.2615 & TRN & \\
\hline CHEMBL1352844 & 688307 & 3.301 & 4.2265 & TRN & \\
\hline CHEMBL1455614 & 688307 & 3.301 & 4.3513 & TRN & \\
\hline CHEMBL1389780 & 688307 & 4.7436 & 4.2649 & TRN & \\
\hline CHEMBL1410824 & 688307 & 4.3696 & 4.3653 & TRN & \\
\hline CHEMBL1566820 & 688307 & 6.8062 & 4.4197 & TRN & \\
\hline CHEMBL1411687 & 688307 & 4.8095 & 4.1469 & TRN & \\
\hline CHEMBL1996233 & 688307 & 4.3585 & 4.2688 & TRN & \\
\hline CHEMBL1495161 & 688307 & 3.301 & 3.9332 & TRN & \\
\hline CHEMBL1333846 & 688307 & 3.301 & 4.1029 & TRN & \\
\hline CHEMBL1505283 & 688307 & 4.7162 & 4.2719 & TRN & \\
\hline CHEMBL1575022 & 688307 & 3.301 & 3.9284 & TRN & \\
\hline CHEMBL1965461 & 688307 & 3.301 & 3.9966 & TST & \\
\hline CHEMBL1329411 & 688307 & 3.301 & 4.2248 & TST & \\
\hline CHEMBL1519669 & 688307 & 4.317 & 4.2019 & TRN & \\
\hline CHEMBL1521111 & 688307 & 4.6789 & 4.0811 & TRN & \\
\hline CHEMBL 1350947 & 688307 & 3.301 & 4.1143 & TRN & \\
\hline CHEMBL57978 & 688307 & 3.301 & 4.2767 & TRN & \\
\hline
\end{tabular}




\begin{tabular}{|c|c|c|c|c|c|}
\hline & & \multicolumn{4}{|c|}{ Supplemental Table S2.txt } \\
\hline CHEMBL1496108 & 688307 & 3.301 & 4.0715 & TRN & \\
\hline CHEMBL1431555 & 688307 & 5.2994 & 4.5688 & TRN & \\
\hline CHEMBL1502446 & 688307 & 3.301 & 4.235 & TRN & \\
\hline CHEMBL1584299 & 688307 & 4.4459 & 4.21899 & 9999999999 & TRN \\
\hline CHEMBL1393976 & 688307 & 4.3107 & 4.271 & TRN & \\
\hline CHEMBL1441028 & 688307 & 3.301 & 4.2687 & TRN & \\
\hline CHEMBL 3213380 & 688307 & 5.0088 & 3.8838 & TRN & \\
\hline CHEMBL1467399 & 688307 & 4.5341 & 4.5318 & TRN & \\
\hline CHEMBL1326483 & 688307 & 4.5239 & 4.2446 & TRN & \\
\hline CHEMBL3195623 & 688307 & 4.5173 & 4.4083 & TST & \\
\hline CHEMBL1353787 & 688307 & 3.301 & 4.0809 & TRN & \\
\hline CHEMBL1370120 & 688307 & 4.7461 & 4.0391 & TRN & \\
\hline CHEMBL1971815 & 688307 & 3.301 & 4.0629 & TRN & \\
\hline CHEMBL1507788 & 688307 & 4.3665 & 4.503 & TRN & \\
\hline CHEMBL1439181 & 688307 & 4.5901 & 4.2456 & TRN & \\
\hline CHEMBL1599210 & 688307 & 3.301 & 4.1904 & TRN & \\
\hline CHEMBL1520373 & 688307 & 5.1609 & 4.4269 & TRN & \\
\hline CHEMBL 85826 & 688307 & 4.7649 & 4.1882 & TRN & \\
\hline CHEMBL1329686 & 688307 & 4.4685 & 4.5828 & TRN & \\
\hline CHEMBL3190827 & 688307 & 5.2881 & 4.2912 & TST & \\
\hline CHEMBL1539136 & 688307 & 3.301 & 4.1826 & TRN & \\
\hline CHEMBL1349449 & 688307 & 3.301 & 4.382 & TRN & \\
\hline CHEMBL1421887 & 688307 & 5.3287 & 4.3001 & TRN & \\
\hline CHEMBL1531320 & 688307 & 4.8447 & 4.5636 & TRN & \\
\hline CHEMBL1344624 & 688307 & 3.301 & 4.0993 & TST & \\
\hline CHEMBL1482201 & 688307 & 4.7077 & 4.2036 & TRN & \\
\hline CHEMBL1501269 & 688307 & 4.6247 & 4.3635 & TRN & \\
\hline CHEMBL1613068 & 688307 & 5.1791 & 4.1483 & TST & \\
\hline CHEMBL1343011 & 688307 & 5.1051 & 4.166 & TRN & \\
\hline CHEMBL1312859 & 688307 & 5.0805 & 4.0778 & TRN & \\
\hline CHEMBL482116 & 688307 & 4.6748 & 4.2079 & TRN & \\
\hline CHEMBL1559731 & 688307 & 5.1229 & 4.3034 & TRN & \\
\hline CHEMBL1528804 & 688307 & 3.301 & 4.17899 & 9999999999 & TRN \\
\hline CHEMBL1573688 & 688307 & 3.301 & 4.3278 & TRN & \\
\hline CHEMBL1548186 & 688307 & 4.4132 & 4.1022 & TRN & \\
\hline CHEMBL1432915 & 688307 & 3.301 & 3.9155 & TRN & \\
\hline CHEMBL1304094 & 688307 & 3.301 & 4.2545 & TRN & \\
\hline CHEMBL1403448 & 688307 & 5.0479 & 3.9504 & TRN & \\
\hline CHEMBL1453259 & 688307 & 4.5793 & 4.1625 & TST & \\
\hline CHEMBL1331872 & 688307 & 4.9715 & 4.1607 & TRN & \\
\hline CHEMBL1299346 & 688307 & 3.301 & 3.9921 & TRN & \\
\hline CHEMBL1505467 & 688307 & 4.5612 & 4.4735 & TRN & \\
\hline CHEMBL1984703 & 688307 & 4.7568 & 4.166 & TRN & \\
\hline CHEMBL1526157 & 688307 & 5.0718 & 4.1853 & TRN & \\
\hline CHEMBL1341487 & 688307 & 3.301 & 3.903 & TRN & \\
\hline CHEMBL1480378 & 688307 & 4.9134 & 4.7615 & TRN & \\
\hline CHEMBL1565187 & 688307 & 4.8817 & 4.2771 & TRN & \\
\hline CHEMBL1324290 & 688307 & 5.1649 & 4.2544 & TRN & \\
\hline
\end{tabular}




\begin{tabular}{|c|c|c|c|c|c|c|}
\hline & & \multicolumn{5}{|c|}{ Supplemental Table S2.txt } \\
\hline CHEMBL1331278 & 688307 & 3.301 & 4.2434 & TRN & & \\
\hline CHEMBL 1483760 & 688307 & 3.301 & 4.1329 & TRN & & \\
\hline CHEMBL1373202 & 688307 & 3.301 & 4.2285 & TRN & & \\
\hline CHEMBL1386091 & 688307 & 4.7308 & 4.2948 & TRN & & \\
\hline CHEMBL1464837 & 688307 & 4.3924 & 4.1228 & TRN & & \\
\hline CHEMBL1388271 & 688307 & 5.1268 & 4.4437 & TRN & & \\
\hline CHEMBL1608989 & 688307 & \multicolumn{3}{|c|}{4.5569999999999995} & 4.274 & TRN \\
\hline CHEMBL1334570 & 688307 & 3.301 & 4.2285 & TRN & & \\
\hline CHEMBL1386676 & 688307 & 4.9391 & 4.3695 & TRN & & \\
\hline CHEMBL1362841 & 688307 & 4.872 & 4.5185 & TRN & & \\
\hline CHEMBL1478743 & 688307 & 3.301 & 4.4221 & TRN & & \\
\hline CHEMBL1442697 & 688307 & 5.2845 & 4.4868 & TRN & & \\
\hline CHEMBL1367559 & 688307 & 3.301 & 4.0896 & TRN & & \\
\hline CHEMBL1430316 & 688307 & 4.4289 & 4.8206 & TRN & & \\
\hline CHEMBL1351935 & 688307 & 3.301 & 4.1045 & TRN & & \\
\hline CHEMBL1493034 & 688307 & 5.3163 & 4.6307 & TRN & & \\
\hline CHEMBL1348377 & 688307 & 5.0572 & 4.0975 & TRN & & \\
\hline CHEMBL1466913 & 688307 & 4.4772 & 4.3379 & TRN & & \\
\hline CHEMBL1419810 & 688307 & 4.706 & 4.0487 & TRN & & \\
\hline CHEMBL1383468 & 688307 & 3.301 & 4.1184 & TRN & & \\
\hline CHEMBL1521414 & 688307 & 4.762 & 4.1338 & TRN & & \\
\hline CHEMBL3208438 & 688307 & 4.7984 & 4.103 & TRN & & \\
\hline CHEMBL1393680 & 688307 & 3.301 & 4.257 & TST & & \\
\hline CHEMBL1306474 & 688307 & 3.301 & 4.2149 & TRN & & \\
\hline CHEMBL1377973 & 688307 & 4.7469 & 4.6694 & TRN & & \\
\hline CHEMBL1539865 & 688307 & 4.427 & 4.1649 & TRN & & \\
\hline CHEMBL1323006 & 688307 & 5.0587 & 4.5446 & TRN & & \\
\hline CHEMBL1486906 & 688307 & 3.301 & 4.3957 & TRN & & \\
\hline CHEMBL1576748 & 688307 & 4.4425 & 4.4172 & TRN & & \\
\hline CHEMBL52 & 688307 & 4.6538 & 4.3469 & TST & & \\
\hline CHEMBL1307842 & 688307 & 3.301 & 4.1754 & TRN & & \\
\hline CHEMBL1501342 & 688307 & 4.4321 & 4.3623 & TRN & & \\
\hline CHEMBL1579100 & 688307 & 3.301 & 4.2916 & TST & & \\
\hline CHEMBL1506716 & 688307 & 5.5205 & 4.8525 & TST & & \\
\hline CHEMBL1330656 & 688307 & 3.301 & 4.2624 & TRN & & \\
\hline CHEMBL1299808 & 688307 & 3.301 & 4.0641 & TRN & & \\
\hline CHEMBL1491602 & 688307 & 4.6824 & 4.1887 & TRN & & \\
\hline CHEMBL3193600 & 688307 & 4.5351 & 4.1975 & TRN & & \\
\hline CHEMBL1421864 & 688307 & 4.3947 & 4.0039 & TST & & \\
\hline CHEMBL1612880 & 688307 & 4.8321 & 4.5781 & TRN & & \\
\hline CHEMBL3191473 & 688307 & 3.301 & 4.2155 & TRN & & \\
\hline CHEMBL1507012 & 688307 & 5.2007 & 4.0889 & TRN & & \\
\hline CHEMBL1372307 & 688307 & 5.4181 & 3.9549 & TRN & & \\
\hline CHEMBL1468708 & 688307 & 5.0263 & 4.4754 & TRN & & \\
\hline CHEMBL1407483 & 688307 & $5.2920 e$ & 20000000 & 01 & 3.9279 & TST \\
\hline CHEMBL1999723 & 688307 & 4.9913 & 4.1488 & TST & & \\
\hline CHEMBL1320651 & 688307 & 4.8298 & 4.072 & TRN & & \\
\hline CHEMBL1566266 & 688307 & 4.8273 & 4.1719 & TRN & & \\
\hline
\end{tabular}


Supplemental Table S2.txt

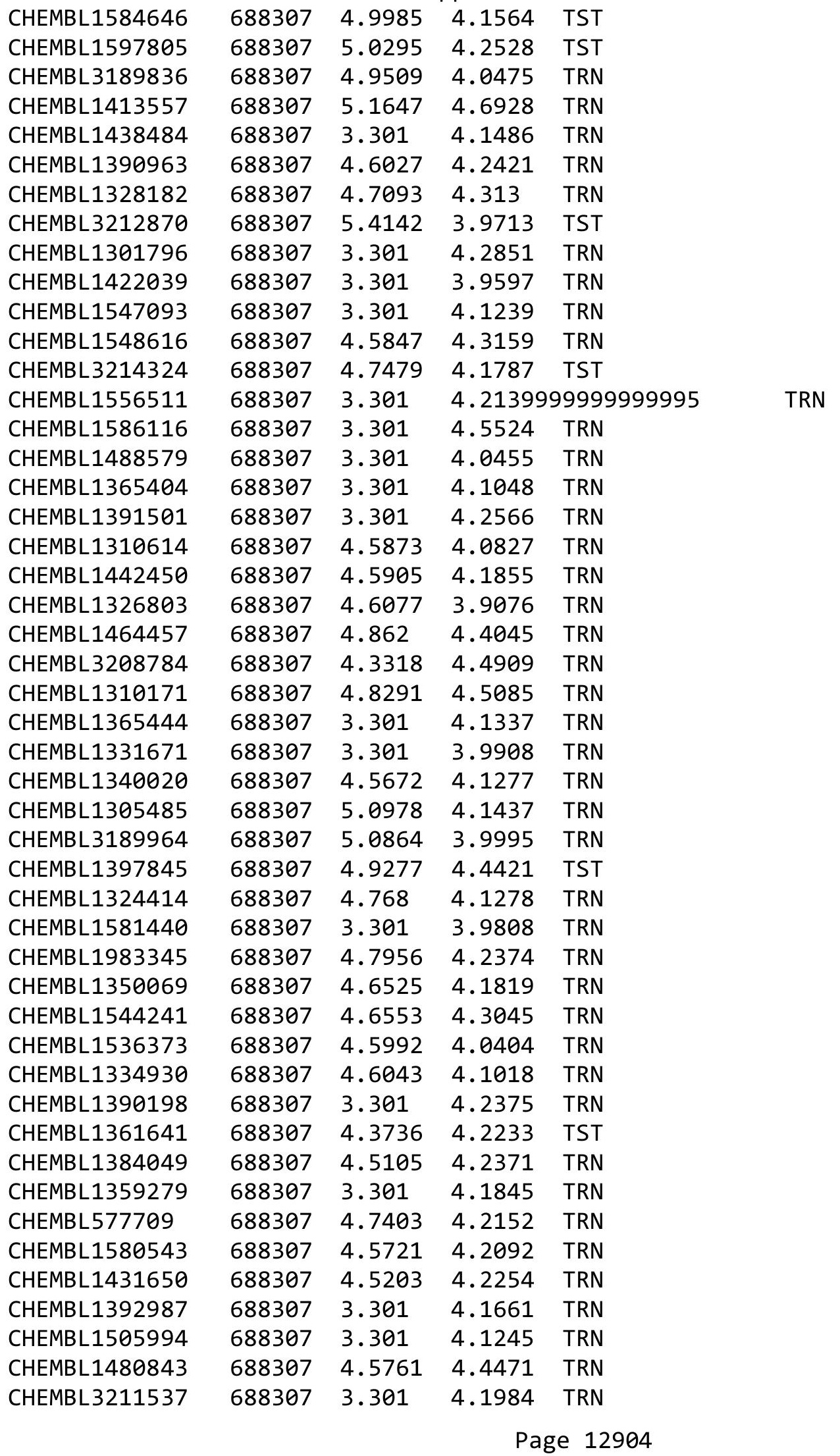




\begin{tabular}{|c|c|c|c|c|}
\hline \multicolumn{5}{|c|}{ Supplemental Table S2.txt } \\
\hline CHEMBL1610665 & 688307 & 3.301 & 4.3415 & TRN \\
\hline CHEMBL1407108 & 688307 & 3.301 & 4.2316 & TRN \\
\hline CHEMBL1548361 & 688307 & 4.4767 & 4.4633 & TRN \\
\hline CHEMBL1459339 & 688307 & 3.301 & 4.3674 & TST \\
\hline CHEMBL1582133 & 688307 & 3.301 & 4.4335 & TRN \\
\hline CHEMBL1366918 & 688307 & 3.301 & 4.16 & TST \\
\hline CHEMBL1304227 & 688307 & 4.6005 & 4.2336 & TRN \\
\hline CHEMBL447111 & 688307 & 4.5945 & 4.4825 & TRN \\
\hline CHEMBL1325233 & 688307 & 4.7473 & 4.5086 & TRN \\
\hline CHEMBL1300662 & 688307 & 4.3498 & 4.3185 & TRN \\
\hline CHEMBL1538223 & 688307 & 5.3732 & 4.2851 & TST \\
\hline CHEMBL1539548 & 688307 & 3.301 & 4.1785 & TRN \\
\hline CHEMBL1570659 & 688307 & 4.7991 & 4.3431 & TST \\
\hline CHEMBL 3856091 & 688307 & 4.9578 & 4.2362 & TST \\
\hline CHEMBL1407054 & 688307 & 4.8263 & 4.2144 & TRN \\
\hline CHEMBL1452952 & 688307 & 5.5576 & 4.2227 & TRN \\
\hline CHEMBL1579818 & 688307 & 3.301 & 4.4231 & TRN \\
\hline CHEMBL1565048 & 688307 & 3.301 & 4.3474 & TRN \\
\hline CHEMBL1458486 & 688307 & 4.9233 & 4.1438 & TRN \\
\hline CHEMBL1450059 & 688307 & 3.301 & 4.1572 & TRN \\
\hline CHEMBL1545617 & 688307 & 3.301 & 4.2349 & TRN \\
\hline CHEMBL1481853 & 688307 & 3.301 & 4.3664 & TRN \\
\hline CHEMBL1516388 & 688307 & 5.5932 & 4.2504 & TST \\
\hline CHEMBL1465900 & 688307 & 3.301 & 3.8996 & TRN \\
\hline CHEMBL1464700 & 688307 & 3.301 & 4.0959 & TST \\
\hline CHEMBL1359354 & 688307 & 4.488 & 3.9725 & TRN \\
\hline CHEMBL1606939 & 688307 & 3.301 & 4.0841 & TST \\
\hline CHEMBL1450825 & 688307 & 3.301 & 4.2508 & TRN \\
\hline CHEMBL1327977 & 688307 & 4.6526 & 4.2558 & TRN \\
\hline CHEMBL577938 & 688307 & 4.4756 & 4.2233 & TRN \\
\hline CHEMBL1572214 & 688307 & 3.301 & 4.2829 & TST \\
\hline CHEMBL1391679 & 688307 & 3.301 & 4.2924 & TRN \\
\hline CHEMBL3208616 & 688307 & 3.301 & 3.9865 & TRN \\
\hline CHEMBL1532515 & 688307 & 6.8062 & 4.0681 & TRN \\
\hline CHEMBL1572777 & 688307 & 4.7318 & 4.5048 & TRN \\
\hline CHEMBL1450791 & 688307 & 4.4412 & 4.3093 & TRN \\
\hline CHEMBL1491959 & 688307 & 4.5818 & 4.2681 & TRN \\
\hline CHEMBL1482875 & 688307 & 4.5231 & 4.1323 & TST \\
\hline CHEMBL1408468 & 688307 & 3.301 & 4.2356 & TST \\
\hline CHEMBL1406018 & 688307 & 5.033 & 4.4846 & TRN \\
\hline CHEMBL1577661 & 688307 & 5.5305 & 4.6354 & TRN \\
\hline CHEMBL1300008 & 688307 & 5.1404 & 4.462 & TRN \\
\hline CHEMBL1570364 & 688307 & 5.5077 & 4.2574 & TST \\
\hline CHEMBL1404523 & 688307 & 5.0204 & 4.1427 & TRN \\
\hline CHEMBL1596554 & 688307 & 4.9126 & 4.0946 & TRN \\
\hline CHEMBL1707275 & 688307 & 3.301 & 4.1381 & TRN \\
\hline CHEMBL1468795 & 688307 & 3.301 & 4.1948 & TRN \\
\hline CHEMBL1528600 & 688307 & 3.301 & 4.1071 & TRN \\
\hline
\end{tabular}




\begin{tabular}{|c|c|c|c|c|}
\hline & & & oplement & al $\mathrm{Ta}$ \\
\hline CHEMBL1557815 & 688307 & 3.301 & 4.2385 & TRN \\
\hline CHEMBL1299357 & 688307 & 4.6315 & 4.0625 & TRN \\
\hline CHEMBL1500059 & 688307 & 3.301 & 4.1525 & TRN \\
\hline CHEMBL1449885 & 688307 & 4.4211 & 4.216 & TRN \\
\hline CHEMBL125596 & 688307 & 3.301 & 4.0758 & TST \\
\hline CHEMBL1548834 & 688307 & 4.7468 & 4.4018 & TRN \\
\hline CHEMBL1381495 & 688307 & 4.9 & 4.0118 & TST \\
\hline CHEMBL1460126 & 688307 & 4.6293 & 3.9917 & TRN \\
\hline CHEMBL577758 & 688307 & 5.1433 & 4.55 & TRN \\
\hline CHEMBL1343134 & 688307 & 3.301 & 4.2177 & TRN \\
\hline CHEMBL1606765 & 688307 & 4.7006 & 4.2951 & TST \\
\hline CHEMBL1405097 & 688307 & 3.301 & 4.431 & TRN \\
\hline CHEMBL1414254 & 688307 & 4.9563 & 4.2477 & TRN \\
\hline CHEMBL1580036 & 688307 & 4.7418 & 4.5472 & TRN \\
\hline CHEMBL1471823 & 688307 & 4.3254 & 4.1487 & TRN \\
\hline CHEMBL1405411 & 688307 & 3.301 & 4.1728 & TRN \\
\hline CHEMBL1367590 & 688307 & 4.6027 & 3.9401 & TRN \\
\hline CHEMBL1585598 & 688307 & 3.301 & 4.3424 & TRN \\
\hline CHEMBL1484547 & 688307 & 5.052 & 4.1759 & TRN \\
\hline CHEMBL1332402 & 688307 & 4.7403 & 4.2271 & TRN \\
\hline CHEMBL1583952 & 688307 & 3.301 & 4.2027 & TRN \\
\hline CHEMBL3189821 & 688307 & 4.7884 & 4.4923 & TRN \\
\hline CHEMBL1341814 & 688307 & 4.6665 & 4.3064 & TRN \\
\hline CHEMBL1465370 & 688307 & 4.4943 & 4.4147 & TRN \\
\hline CHEMBL1504315 & 688307 & 4.5411 & 4.4846 & TRN \\
\hline CHEMBL1448466 & 688307 & 5.1002 & 4.5531 & TRN \\
\hline CHEMBL1541779 & 688307 & 4.4931 & 4.0936 & TRN \\
\hline CHEMBL1469865 & 688307 & 4.6466 & 3.9419 & TRN \\
\hline CHEMBL1522044 & 688307 & 4.6073 & 4.1001 & TST \\
\hline CHEMBL1345810 & 688307 & 4.6591 & 4.3162 & TRN \\
\hline CHEMBL1492286 & 688307 & 3.301 & 4.0799 & TRN \\
\hline CHEMBL1577029 & 688307 & 5.1756 & 4.1344 & TRN \\
\hline CHEMBL377295 & 688307 & 5.2419 & 4.8557 & TRN \\
\hline CHEMBL1379474 & 688307 & 3.301 & 4.1254 & TRN \\
\hline CHEMBL1509842 & 688307 & 3.301 & 4.2469 & TRN \\
\hline CHEMBL1565196 & 688307 & 3.301 & 4.4332 & TRN \\
\hline CHEMBL1313979 & 688307 & 4.8384 & 4.3639 & TRN \\
\hline CHEMBL1341057 & 688307 & 4.7784 & 4.5012 & TRN \\
\hline CHEMBL1333501 & 688307 & 3.301 & 4.1758 & TRN \\
\hline CHEMBL1594663 & 688307 & 3.301 & 4.1409 & TRN \\
\hline CHEMBL1337826 & 688307 & 4.8075 & 4.0904 & TRN \\
\hline CHEMBL1521410 & 688307 & 4.8756 & 4.2242 & TRN \\
\hline CHEMBL1307301 & 688307 & 4.8842 & 4.4506 & TRN \\
\hline CHEMBL1580991 & 688307 & 4.5409 & 4.1834 & TRN \\
\hline CHEMBL1485581 & 688307 & 3.301 & 4.277 & TRN \\
\hline CHEMBL1565816 & 688307 & 3.301 & 4.2852 & TRN \\
\hline CHEMBL1403999 & 688307 & 5.1526 & 4.2377 & TRN \\
\hline CHEMBL1377389 & 688307 & 4.3255 & 4.2376 & TRN \\
\hline
\end{tabular}




\begin{tabular}{|c|c|c|c|c|c|}
\hline \multicolumn{6}{|c|}{ Supplemental Table S2.txt } \\
\hline CHEMBL1481770 & 688307 & 5.02 & 4.0333 & TRN & \\
\hline CHEMBL1469743 & 688307 & 4.7496 & 3.9539 & TRN & \\
\hline CHEMBL1461750 & 688307 & 3.301 & 4.2053 & TRN & \\
\hline CHEMBL1564209 & 688307 & 4.3978 & 4.1981 & TRN & \\
\hline CHEMBL1581690 & 688307 & 5.3859 & 4.1472 & TST & \\
\hline CHEMBL1420411 & 688307 & 4.9052 & 4.3324 & TRN & \\
\hline CHEMBL1489063 & 688307 & 4.3767 & 4.0897 & TRN & \\
\hline CHEMBL1443090 & 688307 & 5.0846 & 4.2719 & TRN & \\
\hline CHEMBL1466882 & 688307 & 4.7203 & 4.6605 & TRN & \\
\hline CHEMBL1538325 & 688307 & 4.4226 & 4.2925 & TST & \\
\hline CHEMBL1603680 & 688307 & 3.301 & 3.972 & TRN & \\
\hline CHEMBL1976499 & 688307 & 4.8576 & 4.0754 & TRN & \\
\hline CHEMBL1595235 & 688307 & 3.301 & 4.4932 & TRN & \\
\hline CHEMBL1604500 & 688307 & 4.7073 & 4.2316 & TRN & \\
\hline CHEMBL1525824 & 688307 & 4.374 & 4.1808 & TRN & \\
\hline CHEMBL1331084 & 688307 & 5.4389 & 4.0152 & TRN & \\
\hline CHEMBL1604803 & 688307 & 4.673 & 4.5905 & TRN & \\
\hline CHEMBL522990 & 688307 & 4.7285 & 4.51399 & 9999999999 & TST \\
\hline CHEMBL 3207950 & 688307 & 3.301 & 4.3598 & TRN & \\
\hline CHEMBL1328083 & 688307 & 4.7024 & 4.0803 & TRN & \\
\hline CHEMBL1429596 & 688307 & 4.7259 & 3.9478 & TRN & \\
\hline CHEMBL1605393 & 688307 & 4.9484 & 4.3605 & TRN & \\
\hline CHEMBL1539668 & 688307 & 3.301 & 4.2492 & TRN & \\
\hline CHEMBL1462307 & 688307 & 5.2416 & 4.0157 & TRN & \\
\hline CHEMBL1353351 & 688307 & 3.301 & 4.0974 & TRN & \\
\hline CHEMBL1381306 & 688307 & 4.9326 & 4.533 & TRN & \\
\hline CHEMBL1359893 & 688307 & 4.6029 & 4.4083 & TRN & \\
\hline CHEMBL1385373 & 688307 & 4.9027 & 4.3167 & TRN & \\
\hline CHEMBL1349227 & 688307 & 3.301 & 4.2127 & TRN & \\
\hline CHEMBL1543038 & 688307 & 3.301 & 4.1711 & TRN & \\
\hline CHEMBL1350028 & 688307 & 4.7097 & 4.0451 & TRN & \\
\hline CHEMBL1606174 & 688307 & 3.301 & 4.2627 & TST & \\
\hline CHEMBL1582403 & 688307 & 4.6775 & 4.5608 & TST & \\
\hline CHEMBL1303477 & 688307 & 4.9357 & 4.4537 & TST & \\
\hline CHEMBL1500073 & 688307 & 3.301 & 4.1963 & TST & \\
\hline CHEMBL1390728 & 688307 & 3.301 & 4.2456 & TST & \\
\hline CHEMBL1305162 & 688307 & 3.301 & 4.0033 & TST & \\
\hline CHEMBL1519384 & 688307 & 4.4876 & 4.2522 & TST & \\
\hline CHEMBL1972915 & 688307 & 5.1652 & 4.4726 & TST & \\
\hline CHEMBL3208853 & 688307 & 3.301 & 4.0459 & TST & \\
\hline CHEMBL1301994 & 688307 & 4.931 & 4.2141 & TST & \\
\hline CHEMBL1442416 & 688307 & 5.0331 & 4.2915 & TST & \\
\hline CHEMBL1331281 & 688307 & 3.301 & 4.1234 & TST & \\
\hline CHEMBL1525366 & 688307 & 4.6844 & 4.3043 & TST & \\
\hline CHEMBL1322881 & 688307 & 3.301 & 4.175 & TST & \\
\hline CHEMBL1300705 & 688307 & 3.301 & 4.0585 & TST & \\
\hline CHEMBL1404155 & 688307 & 4.7668 & 4.0709 & TST & \\
\hline CHEMBL1333664 & 688307 & 3.301 & 4.1084 & TST & \\
\hline
\end{tabular}




\begin{tabular}{|c|c|c|c|c|}
\hline & & & oplement & al Ta \\
\hline CHEMBL1472407 & 688307 & 4.315 & 4.0654 & TST \\
\hline CHEMBL1431081 & 688307 & 5.0786 & 4.6237 & TST \\
\hline CHEMBL1500491 & 688307 & 3.301 & 3.9521 & TST \\
\hline CHEMBL1399039 & 688307 & 4.433 & 4.194 & TST \\
\hline CHEMBL1560367 & 688307 & 4.6517 & 4.0785 & TST \\
\hline CHEMBL1449110 & 688307 & 4.7195 & 4.6877 & TST \\
\hline CHEMBL1368345 & 688307 & 4.7795 & 4.305 & TST \\
\hline CHEMBL1535728 & 688307 & 4.5803 & 4.0551 & TST \\
\hline CHEMBL1533166 & 688307 & 4.6391 & 4.2758 & TST \\
\hline CHEMBL1427879 & 688307 & 5.5139 & 4.158 & TST \\
\hline CHEMBL1463596 & 688307 & 3.301 & 4.024 & TST \\
\hline CHEMBL1299324 & 688307 & 3.301 & 4.1611 & TST \\
\hline CHEMBL1487772 & 688307 & 4.6781 & 4.3219 & TST \\
\hline CHEMBL1423880 & 688307 & 4.4113 & 4.132 & TST \\
\hline CHEMBL1309506 & 688307 & 4.8305 & 4.0197 & TST \\
\hline CHEMBL294209 & 688307 & 3.301 & 3.9301 & TST \\
\hline CHEMBL1402012 & 688307 & 3.301 & 4.2344 & TST \\
\hline CHEMBL1504200 & 688307 & 3.301 & 4.1073 & TST \\
\hline CHEMBL1597933 & 688307 & 4.5494 & 3.9192 & TST \\
\hline CHEMBL3213194 & 688307 & 3.301 & 4.2067 & TST \\
\hline CHEMBL1532659 & 688307 & 4.4525 & 4.3025 & TST \\
\hline CHEMBL1468124 & 688307 & 4.3726 & 4.3207 & TST \\
\hline CHEMBL1391547 & 688307 & 5.0208 & 4.3092 & TST \\
\hline CHEMBL1606490 & 688307 & 4.3567 & 4.2634 & TST \\
\hline CHEMBL1511067 & 688307 & 4.9943 & 4.3106 & TST \\
\hline CHEMBL1312693 & 688307 & 4.8112 & 4.2792 & TST \\
\hline CHEMBL 2000120 & 688307 & 3.301 & 4.1814 & TST \\
\hline CHEMBL1528123 & 688307 & 4.426 & 4.2944 & TST \\
\hline CHEMBL1494151 & 688307 & 3.301 & 4.1749 & TST \\
\hline CHEMBL1326210 & 688307 & 5.3025 & 4.4851 & TST \\
\hline CHEMBL1386537 & 688307 & 5.1192 & 4.1882 & TST \\
\hline CHEMBL1442547 & 688307 & 3.301 & 4.4888 & TST \\
\hline CHEMBL3208556 & 688307 & 5.1357 & 4.1813 & TST \\
\hline CHEMBL1732228 & 688307 & 4.5551 & 4.2457 & TST \\
\hline CHEMBL1573735 & 688307 & 4.712 & 3.9334 & TST \\
\hline CHEMBL1321083 & 688307 & 3.301 & 4.2272 & TST \\
\hline CHEMBL1411209 & 688307 & 4.8994 & 4.0014 & TST \\
\hline CHEMBL1383151 & 688307 & 4.6599 & 4.1996 & TST \\
\hline CHEMBL1574512 & 688307 & 4.6981 & 4.2729 & TST \\
\hline CHEMBL1985765 & 688307 & 3.301 & 4.2519 & TST \\
\hline CHEMBL1470395 & 688307 & 4.6554 & 4.4216 & TST \\
\hline CHEMBL1347829 & 688307 & 4.3917 & 4.2581 & TST \\
\hline CHEMBL 255342 & 954995 & 3.1023 & 3.0583 & TRN \\
\hline CHEMBL1516890 & 954995 & 4.3406 & 4.2354 & TRN \\
\hline CHEMBL222102 & 954995 & 3.7857 & 3.6571 & TRN \\
\hline CHEMBL1186585 & 954995 & 3.7064 & 3.5663 & TRN \\
\hline CHEMBL1788116 & 954995 & 5.2448 & 5.3688 & TRN \\
\hline CHEMBL412142 & 954995 & 4.3595 & 4.5841 & TRN \\
\hline
\end{tabular}




\begin{tabular}{|c|c|c|c|c|c|c|}
\hline & & \multicolumn{5}{|c|}{ Supplemental Table S2.txt } \\
\hline CHEMBL191334 & 954995 & 3.0653 & 3.2249 & TRN & & \\
\hline CHEMBL1242367 & 954995 & 5.1281 & 4.8361 & TRN & & \\
\hline CHEMBL220241 & 954995 & 4.9518 & 4.8154 & TRN & & \\
\hline CHEMBL210618 & 954995 & 3.3416 & 3.4919 & TRN & & \\
\hline CHEMBL514499 & 954995 & 6.6991 & 6.6499 & TRN & & \\
\hline CHEMBL 373751 & 954995 & 3.4289 & 3.8301 & TRN & & \\
\hline CHEMBL1643959 & 954995 & 5.5303 & 5.3079 & TRN & & \\
\hline CHEMBL2363137 & 954995 & 5.6781 & 5.4655 & TRN & & \\
\hline CHEMBL 2137530 & 954995 & 4.7402 & 4.9411 & TRN & & \\
\hline CHEMBL1404918 & 954995 & 2.7383 & 2.6767 & TRN & & \\
\hline CHEMBL3392440 & 954995 & 4.0381 & 4.1209 & TRN & & \\
\hline CHEMBL392695 & 954995 & 4.7519 & 4.5238 & TRN & & \\
\hline CHEMBL192566 & 954995 & 8.404 & 8.6585 & TST & & \\
\hline CHEMBL483849 & 954995 & 2.2023 & 1.5777 & TST & & \\
\hline CHEMBL509032 & 954995 & 6.2595 & 6.0163 & TRN & & \\
\hline CHEMBL102714 & 954995 & 3.3467 & 3.4566 & TRN & & \\
\hline CHEMBL393929 & 954995 & 4.7647 & 4.47199 & 99999 & 995 & TRN \\
\hline CHEMBL 379300 & 954995 & 6.71200 & 30000000 & $\partial 1$ & 6.8993 & TRN \\
\hline CHEMBL9470 & 954995 & 5.7174 & 5.6526 & TST & & \\
\hline CHEMBL1673039 & 954995 & 4.2754 & 4.5158 & TRN & & \\
\hline CHEMBL1357247 & 954995 & 3.1909 & 3.2874 & TRN & & \\
\hline CHEMBL379975 & 954995 & 4.563 & 4.5045 & TRN & & \\
\hline CHEMBL585951 & 954995 & 6.3772 & 6.3381 & TRN & & \\
\hline CHEMBL573107 & 954995 & 5.45100 & 30000000 & 205 & 5.4792 & TRN \\
\hline CHEMBL221137 & 954995 & 4.9013 & 4.6693 & TST & & \\
\hline CHEMBL188678 & 954995 & 3.9143 & 3.93600 & 00000 & 004 & TRN \\
\hline CHEMBL515416 & 954995 & 3.9448 & 4.1638 & TRN & & \\
\hline CHEMBL 2134202 & 954995 & 4.1174 & 3.6616 & TRN & & \\
\hline CHEMBL3186408 & 954995 & 3.5427 & 3.1745 & TST & & \\
\hline CHEMBL 258844 & 954995 & 4.7494 & 4.7898 & TRN & & \\
\hline CHEMBL1230020 & 954995 & 3.6668 & 3.5554 & TRN & & \\
\hline CHEMBL3349342 & 954995 & 4.8922 & 4.9254 & TRN & & \\
\hline CHEMBL 2144069 & 954995 & 3.8504 & 3.9304 & TRN & & \\
\hline CHEMBL92309 & 954995 & 3.0405 & 2.6887 & TST & & \\
\hline CHEMBL1970879 & 954995 & 6.2268 & 6.1922 & TRN & & \\
\hline CHEMBL 213100 & 954995 & 6.8957 & 6.8476 & TRN & & \\
\hline CHEMBL449158 & 954995 & 6.8479 & 7.3975 & TST & & \\
\hline CHEMBL399530 & 954995 & 4.0321 & 4.3137 & TRN & & \\
\hline CHEMBL512504 & 954995 & 4.0796 & 3.9428 & TRN & & \\
\hline CHEMBL180127 & 954995 & 4.2287 & 3.9674 & TRN & & \\
\hline CHEMBL 300389 & 954995 & 7.4885 & 7.4386 & TRN & & \\
\hline CHEMBL577784 & 954995 & 5.0803 & 5.5989 & TRN & & \\
\hline CHEMBL65 & 954995 & 7.7359 & 7.7693 & TRN & & \\
\hline CHEMBL483847 & 954995 & 4.66100 & 00000000 & 205 & 4.876 & TRN \\
\hline CHEMBL3199475 & 954995 & 3.645 & 3.5198 & TRN & & \\
\hline CHEMBL 2005886 & 954995 & 5.8234 & 5.6336 & TRN & & \\
\hline CHEMBL558642 & 954995 & 4.0423 & 3.7932 & TRN & & \\
\hline CHEMBL259181 & 954995 & 3.2374 & 3.4698 & TRN & & \\
\hline
\end{tabular}




\begin{tabular}{|c|c|c|c|c|c|c|}
\hline \multirow[b]{2}{*}{ CHEMBL189584 } & \multicolumn{6}{|c|}{ Supplemental Table S2.txt } \\
\hline & 954995 & 4.2127 & 4.4473 & TRN & & \\
\hline CHEMBL472940 & 954995 & 3.7607 & 2.7836 & TST & & \\
\hline CHEMBL202721 & 954995 & 4.4624 & 4.79899 & 9999 & 995 & TST \\
\hline CHEMBL135561 & 954995 & 5.3226 & 4.6563 & TST & & \\
\hline CHEMBL1190711 & 954995 & 5.9912 & 4.7533 & TST & & \\
\hline CHEMBL 217354 & 954995 & 6.12799 & 99999999 & 99 & 6.909 & TST \\
\hline CHEMBL1909414 & 954995 & 3.1699 & 3.0073 & TST & & \\
\hline CHEMBL1590308 & 954995 & 3.0099 & 3.542 & TST & & \\
\hline CHEMBL 240954 & 954995 & 3.29399 & 99999999 & 996 & 3.2023 & \\
\hline CHEMBL1256459 & 954995 & 6.7938 & 7.1559 & TST & & \\
\hline CHEMBL209148 & 954995 & 5.2107 & 4.3819 & TST & & \\
\hline CHEMBL1360011 & 688564 & 4.45 & 5.1192 & TRN & & \\
\hline CHEMBL1364051 & 688564 & 4.6 & 4.6023 & TRN & & \\
\hline CHEMBL1588086 & 688564 & 4.85 & 4.7522 & TRN & & \\
\hline CHEMBL1571352 & 688564 & 5.15 & 5.0331 & TRN & & \\
\hline CHEMBL1361294 & 688564 & 4.6 & 4.6505 & TRN & & \\
\hline CHEMBL1520818 & 688564 & 5.8 & 5.7402 & TRN & & \\
\hline CHEMBL1549476 & 688564 & 5.0 & 4.8763 & TRN & & \\
\hline CHEMBL1546674 & 688564 & 6.6 & 5.8021 & TRN & & \\
\hline CHEMBL1588368 & 688564 & 4.95 & 5.2437 & TST & & \\
\hline CHEMBL1421442 & 688564 & 4.9 & 4.7585 & TRN & & \\
\hline CHEMBL1485809 & 688564 & 4.8 & 4.8421 & TRN & & \\
\hline CHEMBL491771 & 688564 & 4.75 & 5.2104 & TRN & & \\
\hline CHEMBL1984523 & 688564 & 5.5 & 4.9785 & TRN & & \\
\hline CHEMBL1411002 & 688564 & 5.1 & 4.8297 & TRN & & \\
\hline CHEMBL3209866 & 688564 & 5.05 & 5.0952 & TRN & & \\
\hline CHEMBL1421029 & 688564 & 4.5 & 4.8889 & TRN & & \\
\hline CHEMBL1328771 & 688564 & 4.9 & 5.0353 & TRN & & \\
\hline CHEMBL1482542 & 688564 & 4.8 & 4.7257 & TRN & & \\
\hline CHEMBL1329961 & 688564 & 5.8 & 5.53600 & 0000 & & \\
\hline CHEMBL1356041 & 688564 & 4.5 & 4.7496 & TRN & & \\
\hline CHEMBL1400950 & 688564 & 4.75 & 5.1643 & TRN & & \\
\hline CHEMBL570345 & 688564 & 5.7 & 5.046 & TRN & & \\
\hline CHEMBL1347487 & 688564 & 5.2 & 5.1085 & TRN & & \\
\hline CHEMBL 3208674 & 688564 & 5.3 & 4.8251 & TRN & & \\
\hline CHEMBL1467999 & 688564 & 5.35 & 5.0368 & TRN & & \\
\hline CHEMBL3196256 & 688564 & 4.8 & 5.0618 & TRN & & \\
\hline CHEMBL 2000619 & 688564 & 4.85 & 4.6424 & TRN & & \\
\hline CHEMBL1332293 & 688564 & 5.05 & 4.9518 & TRN & & \\
\hline CHEMBL1499910 & 688564 & 4.8 & 4.9891 & TST & & \\
\hline CHEMBL1494196 & 688564 & 4.9 & 5.3004 & TRN & & \\
\hline CHEMBL 7463 & 688564 & 5.9 & 5.197 & TRN & & \\
\hline CHEMBL1453443 & 688564 & 4.4 & 4.7623 & TRN & & \\
\hline CHEMBL1364131 & 688564 & 5.4 & 5.5799 & TRN & & \\
\hline CHEMBL484662 & 688564 & 4.4 & 4.9462 & TRN & & \\
\hline CHEMBL1397636 & 688564 & 5.7 & 6.0033 & TRN & & \\
\hline CHEMBL251785 & 688564 & 5.65 & 5.6225 & TRN & & \\
\hline CHEMBL1366433 & 688564 & 6.5501 & 5.6995 & TRN & & \\
\hline
\end{tabular}

Page 12910 


\begin{tabular}{|c|c|c|c|c|c|}
\hline \multirow{3}{*}{$\begin{array}{l}\text { CHEMBL1473123 } \\
\text { CHEMBL } 1428935\end{array}$} & \multirow{3}{*}{$\begin{array}{l}688564 \\
688564\end{array}$} & \multicolumn{4}{|c|}{ Supplemental Table s2.txt } \\
\hline & & 4.5 & 5.16100 & 00000000005 & TRN \\
\hline & & 4.95 & 5.1089 & TRN & \\
\hline CHEMBL1540513 & 688564 & 4.9 & 5.1947 & TRN & \\
\hline CHEMBL35482 & 688564 & 5.5 & 5.4798 & TRN & \\
\hline CHEMBL1492716 & 688564 & 4.85 & 4.8628 & TST & \\
\hline CHEMBL1497139 & 688564 & 4.95 & 5.0385 & TRN & \\
\hline CHEMBL1370390 & 688564 & 4.85 & 5.375 & TRN & \\
\hline CHEMBL1516882 & 688564 & 4.85 & 4.8293 & TRN & \\
\hline CHEMBL1424968 & 688564 & 5.1 & 4.9384 & TRN & \\
\hline CHEMBL1390986 & 688564 & 5.05 & 4.6411 & TRN & \\
\hline CHEMBL1454183 & 688564 & 5.15 & 5.0254 & TST & \\
\hline CHEMBL1319221 & 688564 & 4.85 & 5.1295 & TRN & \\
\hline CHEMBL1445388 & 688564 & 4.4 & 4.6229 & TRN & \\
\hline CHEMBL1564737 & 688564 & 5.15 & 4.69 & TRN & \\
\hline CHEMBL1521269 & 688564 & 5.25 & 5.0277 & TRN & \\
\hline CHEMBL468167 & 688564 & 5.65 & 5.2945 & TST & \\
\hline CHEMBL1728023 & 688564 & 5.1 & 5.0255 & TRN & \\
\hline CHEMBL1418759 & 688564 & 5.7 & 5.6845 & TRN & \\
\hline CHEMBL3209992 & 688564 & 5.75 & 5.4178 & TRN & \\
\hline CHEMBL1438323 & 688564 & 4.9 & 5.2239 & TRN & \\
\hline CHEMBL1591731 & 688564 & 6.5501 & 4.6903 & TST & \\
\hline CHEMBL1353216 & 688564 & 4.9 & 4.72 & TRN & \\
\hline CHEMBL1318789 & 688564 & 6.5 & 4.8671 & TST & \\
\hline CHEMBL1373004 & 688564 & 5.45 & 5.641 & TRN & \\
\hline CHEMBL581872 & 688564 & 4.65 & 4.852 & TRN & \\
\hline CHEMBL1967031 & 688564 & 5.25 & 5.1203 & TRN & \\
\hline CHEMBL1332463 & 688564 & 4.9 & 5.2507 & TRN & \\
\hline CHEMBL492610 & 688564 & 4.8 & 5.0266 & TRN & \\
\hline CHEMBL1312502 & 688564 & 5.1 & 4.9773 & TRN & \\
\hline CHEMBL491547 & 688564 & 4.8 & 5.3809 & TST & \\
\hline CHEMBL1324266 & 688564 & 4.85 & 5.1573 & TST & \\
\hline CHEMBL3211517 & 688564 & 5.55 & 5.1456 & TST & \\
\hline CHEMBL1384845 & 688564 & 4.9 & 4.9076 & TST & \\
\hline CHEMBL1565522 & 688564 & 6.4 & 4.8076 & TST & \\
\hline CHEMBL34704 & 688564 & 6.3 & 5.1371 & TST & \\
\hline CHEMBL1534591 & 688564 & 4.9 & 5.4394 & TST & \\
\hline CHEMBL3192140 & 688564 & 5.25 & 4.8238 & TST & \\
\hline CHEMBL1433464 & 688564 & 4.6 & 5.1124 & TST & \\
\hline CHEMBL1497853 & 688564 & 4.9 & 4.9372 & TST & \\
\hline CHEMBL1557669 & 688564 & 6.15 & 5.6291 & TST & \\
\hline CHEMBL1570159 & 688564 & 5.3 & 5.0763 & TST & \\
\hline CHEMBL 1350753 & 688564 & 5.05 & 5.3702 & TST & \\
\hline CHEMBL 2324900 & 941911 & 5.3372 & 5.5805 & TRN & \\
\hline CHEMBL 2324882 & 941911 & 3.0 & 3.1621 & TRN & \\
\hline CHEMBL 2324886 & 941911 & 3.0 & 2.7561 & TRN & \\
\hline CHEMBL 2324586 & 941911 & 4.5591 & 4.5599 & TRN & \\
\hline CHEMBL 2324574 & 941911 & 3.0 & 3.3487 & TRN & \\
\hline CHEMBL 2324891 & 941911 & 3.0 & 2.9652 & TST & \\
\hline
\end{tabular}




\begin{tabular}{|c|c|c|c|c|c|c|}
\hline \multicolumn{7}{|c|}{ Supplemental Table S2.txt } \\
\hline CHEMBL 2324892 & 941911 & 3.0 & 3.2207 & TRN & & \\
\hline CHEMBL 2324568 & 941911 & 6.4976 & 6.6323 & TRN & & \\
\hline CHEMBL 2324904 & 941911 & 5.0969 & 4.8861 & TRN & & \\
\hline CHEMBL 2324584 & 941911 & 4.5361 & 5.1647 & TST & & \\
\hline CHEMBL 2324572 & 941911 & 6.0453 & 6.2693 & TRN & & \\
\hline CHEMBL 2324895 & 941911 & 5.1871 & 4.30399 & 999999999 & TRN & \\
\hline CHEMBL 2324877 & 941911 & 5.067 & 4.7842 & TRN & & \\
\hline CHEMBL 2324888 & 941911 & 3.0 & 3.1139 & TRN & & \\
\hline CHEMBL2324545 & 941911 & 6.0 & 6.2905 & TRN & & \\
\hline CHEMBL 2324569 & 941911 & 6.1543 & 6.5282 & TRN & & \\
\hline CHEMBL 2324587 & 941911 & 3.7932 & 3.945 & TST & & \\
\hline CHEMBL 2324564 & 941911 & 5.1752 & 5.5856 & TRN & & \\
\hline CHEMBL 2324588 & 941911 & 3.0 & 3.1424 & TRN & & \\
\hline CHEMBL 2324585 & 941911 & 4.0101 & 3.9084 & TRN & & \\
\hline CHEMBL 2324903 & 941911 & 5.7235 & 6.0189 & TRN & & \\
\hline CHEMBL 2324561 & 941911 & 4.7055 & 5.1664 & TRN & & \\
\hline CHEMBL 2324540 & 941911 & 4.2366 & 3.7388 & TST & & \\
\hline CHEMBL 2324885 & 941911 & 3.0 & 3.2025 & TRN & & \\
\hline CHEMBL 2324894 & 941911 & 5.8416 & 5.5544 & TRN & & \\
\hline CHEMBL 2324547 & 941911 & 4.3019 & 4.1768 & TRN & & \\
\hline CHEMBL 2324542 & 941911 & 5.3768 & 5.6154 & TRN & & \\
\hline CHEMBL 2324580 & 941911 & 5.2924 & 4.9077 & TST & & \\
\hline CHEMBL 2324898 & 941911 & 5.4318 & 5.5256 & TRN & & \\
\hline CHEMBL 2324546 & 941911 & 5.2147 & 5.9957 & TRN & & \\
\hline CHEMBL 2324559 & 941911 & 5.4437 & 5.3576 & TRN & & \\
\hline CHEMBL 2324578 & 941911 & 4.5544 & 4.4477 & TRN & & \\
\hline CHEMBL 2324570 & 941911 & 6.5784 & 6.5142 & TRN & & \\
\hline CHEMBL 2324883 & 941911 & 3.301 & 3.7363 & TRN & & \\
\hline CHEMBL 2324577 & 941911 & 4.8665 & 4.9642 & TRN & & \\
\hline CHEMBL 2324897 & 941911 & 5.4318 & 5.3014 & TRN & & \\
\hline CHEMBL 2324881 & 941911 & 3.0 & 3.4553 & TRN & & \\
\hline CHEMBL 2324558 & 941911 & 7.71899 & 99999999 & 99 & 7. 3389999999999995 & TRN \\
\hline CHEMBL 2324583 & 941911 & 5.2204 & 4.9186 & TRN & & \\
\hline CHEMBL 2324890 & 941911 & 2.301 & 2.4051 & TRN & & \\
\hline CHEMBL 2324544 & 941911 & 6.4202 & 6.3437 & TRN & & \\
\hline CHEMBL 2324566 & 941911 & 5.5952 & 5.4457 & TRN & & \\
\hline CHEMBL 2324565 & 941911 & 4.7167 & 4.4023 & TRN & & \\
\hline CHEMBL 2324555 & 941911 & 5.2676 & 5.6829 & TRN & & \\
\hline CHEMBL 2324879 & 941911 & 3.301 & 3.3688 & TRN & & \\
\hline CHEMBL 2324880 & 941911 & 3.301 & 3.1315 & TRN & & \\
\hline CHEMBL 2324543 & 941911 & 6.8861 & 7.1238 & TRN & & \\
\hline CHEMBL 2324579 & 941911 & 3.0 & 4.5041 & TST & & \\
\hline CHEMBL 2324573 & 941911 & 6.4202 & 6.0482 & TRN & & \\
\hline CHEMBL2324875 & 941911 & 3.0 & 3.327 & TST & & \\
\hline CHEMBL 2324874 & 941911 & 4.7747 & 4.6167 & TRN & & \\
\hline CHEMBL 2324887 & 941911 & 3.0 & 3.11 & TRN & & \\
\hline CHEMBL1233436 & 941911 & 5.4271 & 5.3321 & TRN & & \\
\hline CHEMBL 2324905 & 941911 & 6.0521 & 5.9647 & TRN & & \\
\hline
\end{tabular}

Page 12912 


\begin{tabular}{|c|c|c|c|c|c|}
\hline \multicolumn{6}{|c|}{ Supplemental Table S2.txt } \\
\hline CHEMBL2324541 & 941911 & 3.0 & 2.9806 & TRN & \\
\hline CHEMBL2324550 & 941911 & 5.4908 & 5.3774 & TRN & \\
\hline CHEMBL2324893 & 941911 & 5.1308 & 5.0852 & TRN & \\
\hline CHEMBL2324901 & 941911 & 6.0209 & 6.0543 & TRN & \\
\hline CHEMBL2324556 & 941911 & 5.2366 & 4.9557 & TRN & \\
\hline CHEMBL2324562 & 941911 & 3.301 & 2.6932 & TRN & \\
\hline CHEMBL2324539 & 941911 & 3.0 & 3.72899 & 99999999996 & TST \\
\hline CHEMBL 2324581 & 941911 & 4.7328 & 4.4478 & TST & \\
\hline CHEMBL2324902 & 941911 & 6.2518 & 5.3952 & TRN & \\
\hline CHEMBL2324560 & 941911 & 5.4559 & 5.7248 & TRN & \\
\hline CHEMBL2324551 & 941911 & 3.301 & 3.4183 & TRN & \\
\hline CHEMBL2324557 & 941911 & 6.8729 & 6.6114 & TRN & \\
\hline CHEMBL 2324552 & 941911 & 3.301 & 3.4183 & TRN & \\
\hline CHEMBL 2324876 & 941911 & 4.4389 & 4.4268 & TRN & \\
\hline CHEMBL2324899 & 941911 & 3.0 & 3.1489 & TRN & \\
\hline CHEMBL 2324896 & 941911 & 5.1152 & 4.9687 & TRN & \\
\hline CHEMBL 2324554 & 941911 & 6.7282 & 6.3968 & TRN & \\
\hline CHEMBL 2324907 & 941911 & 5.3893 & 5.3444 & TRN & \\
\hline CHEMBL 2324908 & 941911 & 5.7696 & 5.3285 & TST & \\
\hline CHEMBL2324567 & 941911 & 5.585 & 6.1863 & TST & \\
\hline CHEMBL 2324563 & 941911 & 4.71 & 5.1435 & TST & \\
\hline CHEMBL2324884 & 941911 & 3.0 & 3.9139 & TST & \\
\hline CHEMBL 2324889 & 941911 & 2.301 & 2.5987 & TST & \\
\hline CHEMBL2324575 & 941911 & 5.5376 & 5.5026 & TST & \\
\hline CHEMBL2324906 & 941911 & 6.6946 & 6.9087 & TST & \\
\hline CHEMBL 2324571 & 941911 & 4.7747 & 5.4423 & TST & \\
\hline CHEMBL2324548 & 941911 & 6.3054 & 5.7294 & TST & \\
\hline CHEMBL2324576 & 941911 & 4.6478 & 4.3087 & TST & \\
\hline CHEMBL2324549 & 941911 & 6.7496 & 5.7477 & TST & \\
\hline CHEMBL 2324878 & 941911 & 3.301 & 4.0594 & TST & \\
\hline CHEMBL 2324582 & 941911 & 5.5229 & 4.473 & TST & \\
\hline CHEMBL166958 & 140229 & 5.2924 & 5.1492 & TST & \\
\hline CHEMBL167124 & 140229 & 5.9208 & 5.9661 & TRN & \\
\hline CHEMBL352183 & 140229 & 6.4949 & 6.5759 & TRN & \\
\hline CHEMBL355876 & 140229 & 6.2147 & 6.1872 & TRN & \\
\hline CHEMBL354058 & 140229 & 6.7595 & 6.6267 & TRN & \\
\hline CHEMBL354987 & 140229 & 6.4089 & 6.3971 & TRN & \\
\hline CHEMBL167496 & 140229 & 6.5575 & 6.5481 & TRN & \\
\hline CHEMBL351961 & 140229 & 4.7212 & 5.5129 & TST & \\
\hline CHEMBL353462 & 140229 & 7.5086 & 7.3802 & TRN & \\
\hline CHEMBL167096 & 140229 & 6.0 & 4.8861 & TST & \\
\hline CHEMBL355035 & 140229 & 3.5376 & 4.5313 & TST & \\
\hline CHEMBL167014 & 140229 & 7.9586 & 7.96299 & 9999999999 & TRN \\
\hline CHEMBL352729 & 140229 & 7.1308 & 7.4758 & TRN & \\
\hline CHEMBL167178 & 140229 & 5.9031 & 5.8767 & TRN & \\
\hline CHEMBL352344 & 140229 & 7.4685 & 7.4962 & TRN & \\
\hline CHEMBL167212 & 140229 & 6.7959 & 6.9947 & TRN & \\
\hline CHEMBL352858 & 140229 & 3.0458 & 3.2662 & TRN & \\
\hline
\end{tabular}

Page 12913 


\begin{tabular}{|c|c|c|c|c|c|}
\hline \multicolumn{6}{|c|}{ Supplemental Table s2.txt } \\
\hline CHEMBL353286 & 140229 & 6.9586 & 7.1255 & TRN & \\
\hline CHEMBL166231 & 140229 & 4.2757 & 4.3947 & TRN & \\
\hline CHEMBL166714 & 140229 & 4.1487 & 4.8059 & TST & \\
\hline CHEMBL354561 & 140229 & 6.7447 & 6.1555 & TRN & \\
\hline CHEMBL166169 & 140229 & 7.1135 & 7.0895 & TRN & \\
\hline CHEMBL 273886 & 140229 & 6.4559 & 6.4823 & TRN & \\
\hline CHEMBL353144 & 140229 & 7.6383 & 7.4305 & TRN & \\
\hline CHEMBL354975 & 140229 & 3.5528 & 3.1918 & TRN & \\
\hline CHEMBL167259 & 140229 & 2.0 & 2.0311 & TRN & \\
\hline CHEMBL166341 & 140229 & 7.4815 & 7.2847 & TRN & \\
\hline CHEMBL167185 & 140229 & 6.0315 & 6.0568 & TRN & \\
\hline CHEMBL352798 & 140229 & 2.7959 & 2.8079 & TRN & \\
\hline CHEMBL167909 & 140229 & 6.2596 & 6.1137 & TRN & \\
\hline CHEMBL11068 & 140229 & 5.0655 & 4.8311 & TRN & \\
\hline CHEMBL166409 & 140229 & 4.7696 & 4.7365 & TRN & \\
\hline CHEMBL10656 & 140229 & 4.6459 & 5.0268 & TST & \\
\hline CHEMBL355707 & 140229 & 6.0 & 6.5525 & TRN & \\
\hline CHEMBL355078 & 140229 & 6.2147 & 6.2033 & TRN & \\
\hline CHEMBL354387 & 140229 & 4.6198 & 4.1125 & TST & \\
\hline CHEMBL352728 & 140229 & 6.585 & 6.7431 & TRN & \\
\hline CHEMBL354864 & 140229 & 5.4437 & 5.5982 & TRN & \\
\hline CHEMBL269213 & 140229 & 7.3468 & 7.3234 & TRN & \\
\hline CHEMBL167947 & 140229 & 6.0 & 6.3353 & TRN & \\
\hline CHEMBL 355012 & 140229 & 3.0 & 3.6401 & TST & \\
\hline CHEMBL353587 & 140229 & 6.5528 & 6.103 & TRN & \\
\hline CHEMBL353519 & 140229 & 6.1487 & 5.3873 & TST & \\
\hline CHEMBL355013 & 140229 & 5.585 & 3.9897 & TST & \\
\hline CHEMBL349865 & 140229 & 1.3468 & 1.5341 & TRN & \\
\hline CHEMBL355658 & 140229 & 5.0555 & 5.3446 & TST & \\
\hline CHEMBL355243 & 140229 & 7.9586 & 6.3686 & TST & \\
\hline CHEMBL354865 & 140229 & 6.9208 & 7.0171 & TRN & \\
\hline CHEMBL167999 & 140229 & 5.0605 & 5.4241 & TST & \\
\hline CHEMBL167545 & 140229 & 1.3468 & 1.4586 & TRN & \\
\hline CHEMBL167556 & 140229 & 6.8539 & 6.8973 & TRN & \\
\hline CHEMBL352856 & 140229 & 6.8633 & 6.79799 & 9999999999 & TRN \\
\hline CHEMBL166962 & 140229 & 4.2441 & 4.1837 & TRN & \\
\hline CHEMBL352201 & 140229 & 6.0 & 6.3589 & TRN & \\
\hline CHEMBL165764 & 140229 & 7.5686 & 7.6467 & TRN & \\
\hline CHEMBL349956 & 140229 & 7.9586 & 7.9124 & TRN & \\
\hline CHEMBL166384 & 140229 & 4.9208 & 4.3188 & TST & \\
\hline CHEMBL167183 & 140229 & 7.5229 & 7.659 & TRN & \\
\hline CHEMBL165993 & 140229 & 5.6904 & 5.4319 & TST & \\
\hline CHEMBL353864 & 140229 & 4.2441 & 4.7056 & TST & \\
\hline CHEMBL167184 & 140229 & 7.0605 & 7.0628 & TRN & \\
\hline CHEMBL 3085017 & 140229 & 6.857 & 6.7913 & TRN & \\
\hline CHEMBL167642 & 140229 & 4.0 & 6.0211 & TST & \\
\hline CHEMBL167435 & 140229 & 5.1938 & 4.9137 & TRN & \\
\hline CHEMBL353142 & 140229 & 4.1367 & 4.10800 & 00000000005 & TRN \\
\hline & & & & 12914 & \\
\hline
\end{tabular}




\begin{tabular}{|c|c|c|c|c|c|}
\hline \multicolumn{6}{|c|}{ Supplemental Table S2 } \\
\hline CHEMBL167910 & 140229 & 7.3372 & 6.9982 & TRN & \\
\hline CHEMBL168116 & 140229 & 7.4949 & 7.6108 & TRN & \\
\hline CHEMBL353267 & 140229 & 7.7447 & 7.6094 & TRN & \\
\hline CHEMBL1687997 & 729458 & 3.6021 & 3.5001 & TRN & \\
\hline CHEMBL1688025 & 729458 & 3.6021 & 3.5499 & TRN & \\
\hline CHEMBL1688017 & 729458 & 3.6021 & 4.0271 & TRN & \\
\hline CHEMBL1687993 & 729458 & 3.6021 & 3.5323 & TRN & \\
\hline CHEMBL1688010 & 729458 & 4.8861 & 4.6403 & TRN & \\
\hline CHEMBL1688003 & 729458 & 4.6021 & 4.4563 & TRN & \\
\hline CHEMBL1688030 & 729458 & 3.6021 & 3.7588 & TST & \\
\hline CHEMBL1688014 & 729458 & 3.6021 & 3.5016 & TRN & \\
\hline CHEMBL1688029 & 729458 & 3.6021 & 3.6163 & TST & \\
\hline CHEMBL1687984 & 729458 & 4.7959 & 4.7306 & TRN & \\
\hline CHEMBL1688005 & 729458 & 3.6021 & 3.4672 & TRN & \\
\hline CHEMBL1688031 & 729458 & 3.6021 & 3.6487 & TST & \\
\hline CHEMBL1687989 & 729458 & 3.6021 & 3.8475 & TRN & \\
\hline CHEMBL1687992 & 729458 & 3.6021 & 3.781 & TRN & \\
\hline CHEMBL439259 & 729458 & 3.6021 & 3.9701 & TRN & \\
\hline CHEMBL1688008 & 729458 & 4.6576 & 4.7129 & TRN & \\
\hline CHEMBL1687988 & 729458 & 5.0 & 4.4793 & TRN & \\
\hline CHEMBL1688016 & 729458 & 3.6021 & 3.4973 & TRN & \\
\hline CHEMBL1688023 & 729458 & 3.6021 & 3.5366 & TRN & \\
\hline CHEMBL1688019 & 729458 & 4.8239 & 4.5636 & TRN & \\
\hline CHEMBL587639 & 729458 & 3.6021 & 4.1708 & TRN & \\
\hline CHEMBL1687999 & 729458 & 3.6021 & 3.6711 & TRN & \\
\hline CHEMBL1688004 & 729458 & 3.6021 & 3.6424 & TRN & \\
\hline CHEMBL1688015 & 729458 & 3.6021 & 3.35699 & 99999999998 & TRN \\
\hline CHEMBL1688002 & 729458 & 4.7959 & 4.5946 & TRN & \\
\hline CHEMBL1687987 & 729458 & 3.6021 & 4.2277 & TRN & \\
\hline CHEMBL1687986 & 729458 & 4.6778 & 4.5842 & TRN & \\
\hline CHEMBL1687996 & 729458 & 3.6021 & 4.2021 & TRN & \\
\hline CHEMBL547264 & 729458 & 3.6021 & 3.7906 & TRN & \\
\hline CHEMBL1687985 & 729458 & 3.6021 & 3.5802 & TRN & \\
\hline CHEMBL1688001 & 729458 & 3.6021 & 3.5307 & TRN & \\
\hline CHEMBL1688009 & 729458 & 3.6021 & 3.6805 & TRN & \\
\hline CHEMBL1687983 & 729458 & 3.6021 & 3.7947 & TRN & \\
\hline CHEMBL1688026 & 729458 & 3.6021 & 3.6066 & TRN & \\
\hline CHEMBL548963 & 729458 & 4.585 & 3.8894 & TRN & \\
\hline CHEMBL1688022 & 729458 & 3.6021 & 3.5936 & TRN & \\
\hline CHEMBL1254871 & 729458 & 4.8539 & 4.7667 & TRN & \\
\hline CHEMBL1688021 & 729458 & 3.6021 & 3.613 & TRN & \\
\hline CHEMBL1687990 & 729458 & 3.6021 & 3.8809 & TRN & \\
\hline CHEMBL1688018 & 729458 & 4.585 & 4.5836 & TRN & \\
\hline CHEMBL1688011 & 729458 & 3.6021 & 3.5637 & TRN & \\
\hline CHEMBL1688020 & 729458 & 3.6021 & 3.3819 & TRN & \\
\hline CHEMBL524969 & 729458 & 4.6198 & 4.4069 & TRN & \\
\hline CHEMBL1688000 & 729458 & 3.6021 & 3.4316 & TRN & \\
\hline CHEMBL1687991 & 729458 & 3.6021 & 3.5138 & TRN & \\
\hline
\end{tabular}




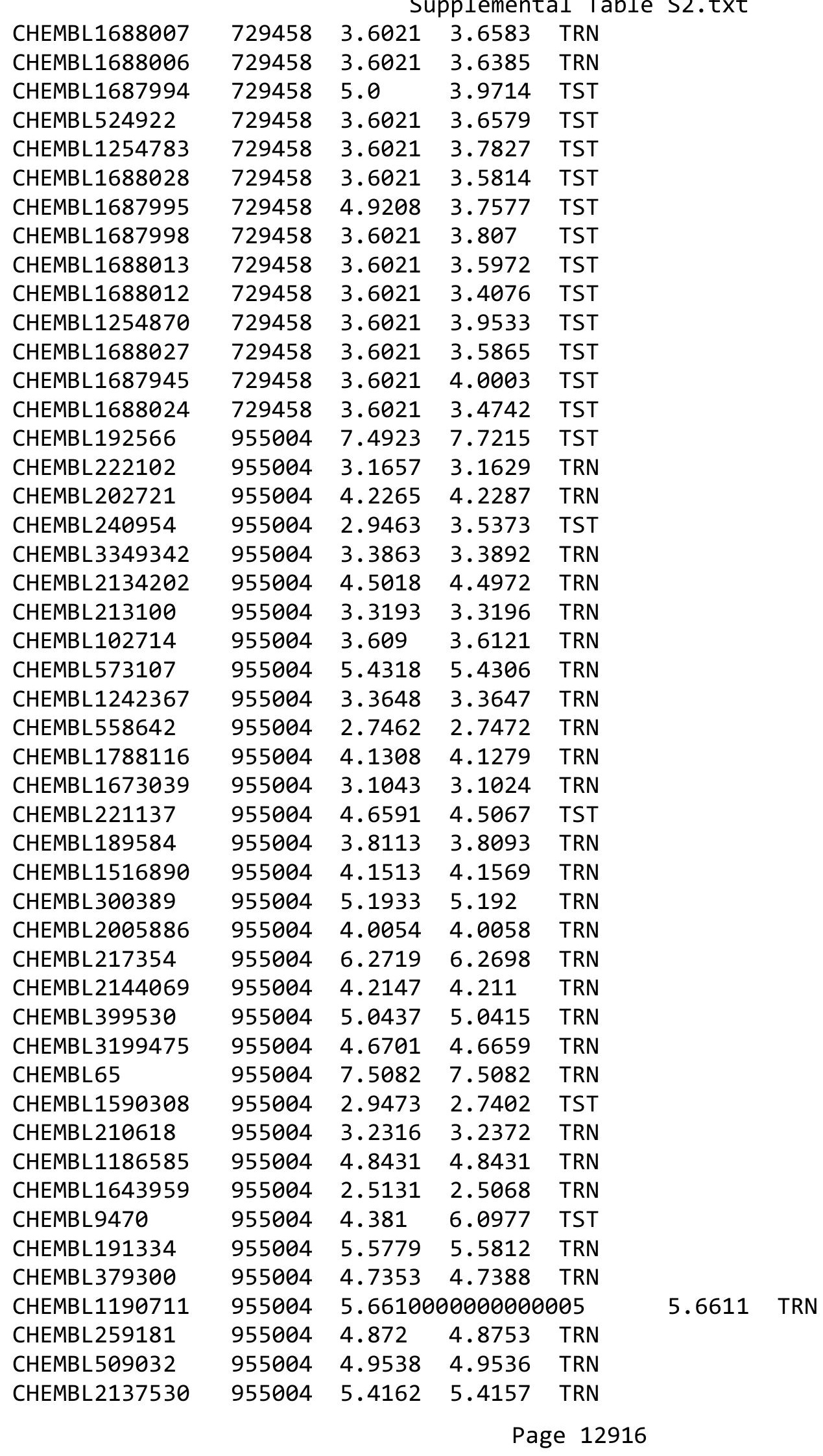




\begin{tabular}{|c|c|c|c|c|c|}
\hline & & \multicolumn{4}{|c|}{ Supplemental Table S2.txt } \\
\hline CHEMBL3186408 & 955004 & 3.0141 & 4.1353 & TST & \\
\hline CHEMBL1256459 & 955004 & 4.9442 & 4.9431 & TRN & \\
\hline CHEMBL258844 & 955004 & 4.9804 & 4.9825 & TRN & \\
\hline CHEMBL449158 & 955004 & 6.6793 & 6.3508 & TST & \\
\hline CHEMBL577784 & 955004 & 4.5143 & 4.5117 & TRN & \\
\hline CHEMBL585951 & 955004 & 6.0442 & 6.0447 & TRN & \\
\hline CHEMBL483849 & 955004 & 2.0804 & 2.0929 & TST & \\
\hline CHEMBL1909414 & 955004 & 3.4933 & 3.4934 & TRN & \\
\hline CHEMBL1404918 & 955004 & 2.7849 & 2.7832 & TRN & \\
\hline CHEMBL512504 & 955004 & 6.2619 & 6.2612 & TRN & \\
\hline CHEMBL514499 & 955004 & 4.3999 & 4.40300 & 00000000005 & TRN \\
\hline CHEMBL209148 & 955004 & 3.8575 & 3.8567 & TRN & \\
\hline CHEMBL1357247 & 955004 & 3.7483 & 3.7489 & TRN & \\
\hline CHEMBL412142 & 955004 & 3.7548 & 3.7561 & TRN & \\
\hline CHEMBL92309 & 955004 & 2.4939 & 2.7225 & TST & \\
\hline CHEMBL483847 & 955004 & 3.4246 & 3.4335 & TRN & \\
\hline CHEMBL135561 & 955004 & 4.1945 & 4.1921 & TRN & \\
\hline CHEMBL393929 & 955004 & 3.891 & 3.8864 & TRN & \\
\hline CHEMBL180127 & 955004 & 3.2247 & 3.2257 & TRN & \\
\hline CHEMBL515416 & 955004 & 3.1134 & 3.1132 & TRN & \\
\hline CHEMBL373751 & 955004 & 3.3675 & 3.3625 & TRN & \\
\hline CHEMBL472940 & 955004 & 4.3244 & 4.329 & TRN & \\
\hline CHEMBL 1230020 & 955004 & 2.9303 & 2.9316 & TRN & \\
\hline CHEMBL 220241 & 955004 & 3.488 & 3.8917 & TST & \\
\hline CHEMBL1970879 & 955004 & 4.0454 & 3.4665 & TST & \\
\hline CHEMBL 255342 & 955004 & 3.0584 & 3.6679 & TST & \\
\hline CHEMBL 2363137 & 955004 & 4.6662 & 4.5094 & TST & \\
\hline CHEMBL379975 & 955004 & 4.6837 & 4.8411 & TST & \\
\hline CHEMBL188678 & 955004 & 4.7565 & 3.6214 & TST & \\
\hline CHEMBL3392440 & 955004 & 3.8439 & 3.6087 & TST & \\
\hline CHEMBL392695 & 955004 & 3.1877 & 3.8586 & TST & \\
\hline CHEMBL3604738 & 1509931 & 5.4437 & 5.4383 & TRN & \\
\hline CHEMBL3604723 & 1509931 & 3.5229 & 3.5876 & TRN & \\
\hline CHEMBL 3604713 & 1509931 & 5.4815 & 5.6102 & TRN & \\
\hline CHEMBL3604717 & 1509931 & 6.2076 & 5.6865 & TRN & \\
\hline CHEMBL3604722 & 1509931 & 6.0044 & 5.9398 & TRN & \\
\hline CHEMBL3604716 & 1509931 & 4.7447 & 2.4871 & TST & \\
\hline CHEMBL3604746 & 1509931 & 3.5229 & 3.4831 & TRN & \\
\hline CHEMBL 3604757 & 1509931 & 3.5229 & 4.9183 & TST & \\
\hline CHEMBL3604708 & 1509931 & 4.7212 & 4.4331 & TRN & \\
\hline CHEMBL 3604720 & 1509931 & 3.5229 & 3.7527 & TRN & \\
\hline CHEMBL3604703 & 1509931 & 4.6576 & 4.40600 & 0000000001 & TRN \\
\hline CHEMBL3604754 & 1509931 & 3.5229 & 5.0537 & TST & \\
\hline CHEMBL3604719 & 1509931 & 5.3468 & 5.1303 & TRN & \\
\hline CHEMBL3604741 & 1509931 & 5.0706 & 5.28299 & 99999999995 & TRN \\
\hline CHEMBL3604724 & 1509931 & 4.8239 & 4.6324 & TRN & \\
\hline CHEMBL3604758 & 1509931 & 7.1192 & 7.1111 & TRN & \\
\hline CHEMBL3604740 & 1509931 & 6.5528 & 6.6466 & TRN & \\
\hline
\end{tabular}


Supplemental Table S2.txt

\begin{tabular}{|c|c|c|c|c|c|}
\hline CHEMBL 3604769 & 1509931 & 3.5229 & 3.7266 & TRN & \\
\hline CHEMBL 3604765 & 1509931 & 3.5229 & 3.6948 & TRN & \\
\hline CHEMBL3604726 & 1509931 & 3.5229 & 3.9982 & TRN & \\
\hline CHEMBL 3604739 & 1509931 & 6.8861 & \multicolumn{2}{|c|}{6.992999999999999} & TRN \\
\hline CHEMBL3604731 & 1509931 & 5.2076 & 5.2217 & TRN & \\
\hline CHEMBL3604742 & 1509931 & 5.1367 & 4.9037 & TRN & \\
\hline CHEMBL 3604718 & 1509931 & 3.5229 & 3.7945 & TRN & \\
\hline CHEMBL 3604735 & 1509931 & 6.8239 & 6.7781 & TRN & \\
\hline CHEMBL 3604736 & 1509931 & 5.3279 & 5.4035 & TRN & \\
\hline CHEMBL3603850 & 1509931 & 4.6198 & 4.5678 & TRN & \\
\hline CHEMBL3604762 & 1509931 & 3.5229 & 3.2746 & TRN & \\
\hline CHEMBL 3604744 & 1509931 & 5.6778 & 5.7989 & TRN & \\
\hline CHEMBL3604709 & 1509931 & 3.5229 & 3.5878 & TRN & \\
\hline CHEMBL3604759 & 1509931 & 4.0 & 4.095 & TRN & \\
\hline CHEMBL3604729 & 1509931 & 5.0177 & 4.8749 & TRN & \\
\hline CHEMBL3604715 & 1509931 & 3.5229 & 4.1408 & TRN & \\
\hline CHEMBL3604721 & 1509931 & 4.9586 & 5.1048 & TRN & \\
\hline CHEMBL 3604764 & 1509931 & 3.5229 & 3.4934 & TRN & \\
\hline CHEMBL3604743 & 1509931 & 3.5229 & 3.6955 & TRN & \\
\hline CHEMBL3604734 & 1509931 & 6.2924 & 6.2483 & TRN & \\
\hline CHEMBL3604767 & 1509931 & 3.5229 & 3.3909 & TRN & \\
\hline CHEMBL3604706 & 1509931 & 3.5229 & 3.2898 & TRN & \\
\hline CHEMBL 3604750 & 1509931 & 3.5229 & 3.8825 & TST & \\
\hline CHEMBL3604768 & 1509931 & 3.5229 & 3.8636 & TRN & \\
\hline CHEMBL 3604707 & 1509931 & 3.5229 & 3.5028 & TRN & \\
\hline CHEMBL3604748 & 1509931 & 3.5229 & 4.0164 & TST & \\
\hline CHEMBL3604756 & 1509931 & 3.5229 & 4.6022 & TST & \\
\hline CHEMBL 3604747 & 1509931 & 4.9586 & 4.3802 & TST & \\
\hline CHEMBL3604751 & 1509931 & 3.5229 & 4.0249 & TST & \\
\hline CHEMBL 3604712 & 1509931 & 4.6021 & 4.4342 & TRN & \\
\hline CHEMBL 3604701 & 1509931 & 5.1427 & 5.078 & TRN & \\
\hline CHEMBL 3604727 & 1509931 & 4.7959 & 4.6579 & TRN & \\
\hline CHEMBL 3604761 & 1509931 & 3.5229 & \multicolumn{2}{|c|}{ 3. 3989999999999996} & TRN \\
\hline CHEMBL3604733 & 1509931 & 5.9208 & 6.2748 & TRN & \\
\hline CHEMBL 3604725 & 1509931 & 3.5229 & 3.4235 & TRN & \\
\hline CHEMBL 3604755 & 1509931 & 3.5229 & 3.2762 & TRN & \\
\hline CHEMBL3604745 & 1509931 & 5.3098 & 5.3405 & TRN & \\
\hline CHEMBL 3604730 & 1509931 & 4.6198 & 4.4449 & TRN & \\
\hline CHEMBL3604770 & 1509931 & 5.0362 & 5.2866 & TRN & \\
\hline CHEMBL 3604704 & 1509931 & 4.6576 & 4.4518 & TRN & \\
\hline CHEMBL3604737 & 1509931 & 6.7696 & 6.5589 & TRN & \\
\hline CHEMBL3604749 & 1509931 & 3.5229 & 4.0357 & TST & \\
\hline CHEMBL3604728 & 1509931 & 5.3979 & 5.3548 & TRN & \\
\hline CHEMBL3604732 & 1509931 & 6.1079 & 6.3698 & TST & \\
\hline CHEMBL 3604763 & 1509931 & 3.5229 & 4.1444 & TST & \\
\hline CHEMBL3604760 & 1509931 & 3.5229 & 4.7649 & TST & \\
\hline CHEMBL3604711 & 1509931 & 4.7696 & 4.9359 & TST & \\
\hline CHEMBL3604702 & 1509931 & 3.5229 & 3.3433 & TST & \\
\hline
\end{tabular}

Page 12918 
Supplemental Table S2.txt

\begin{tabular}{|c|c|c|c|c|c|c|}
\hline CHEMBL 3604766 & 1509931 & 3.5229 & 4.4674 & TST & & \\
\hline CHEMBL 3604714 & 1509931 & 5.6383 & 4.2203 & TST & & \\
\hline CHEMBL 3604705 & 1509931 & 5.4815 & 5.0309 & TST & & \\
\hline CHEMBL 3604710 & 1509931 & 3.5229 & 3.6905 & TST & & \\
\hline CHEMBL342555 & 307259 & 5.1308 & 5.2751 & TRN & & \\
\hline CHEMBL68673 & 307259 & 4.2007 & 3.2362 & TST & & \\
\hline CHEMBL17323 & 307259 & 3.8069 & 3.2293 & TST & & \\
\hline CHEMBL17873 & 307259 & 4.842 & 3.9303 & TST & & \\
\hline CHEMBL 276734 & 307259 & 4.2269 & 3.4123 & TST & & \\
\hline CHEMBL68439 & 307259 & 3.9355 & 3.1023 & TST & & \\
\hline CHEMBL283515 & 307259 & 4.6383 & 4.0322 & TST & & \\
\hline CHEMBL23846 & 307259 & 4.9208 & 4.1102 & TST & & \\
\hline CHEMBL 279914 & 307259 & 4.4377 & 3.8385 & TST & & \\
\hline CHEMBL23960 & 307259 & 3.8633 & 3.4115 & TST & & \\
\hline CHEMBL23297 & 307259 & 4.7905 & 4.2094 & TST & & \\
\hline CHEMBL 22561 & 307259 & 4.8356 & 4.2197 & TST & & \\
\hline CHEMBL283311 & 307259 & 4.9101 & 4.1836 & TST & & \\
\hline CHEMBL 278110 & 307259 & 4.4647 & 4.0565 & TST & & \\
\hline CHEMBL 292427 & 307259 & 7.2676 & 7.2917 & TRN & & \\
\hline CHEMBL417746 & 307259 & 6.6778 & 6.7602 & TRN & & \\
\hline CHEMBL55928 & 307259 & 7.2218 & 7.1154 & TRN & & \\
\hline CHEMBL54618 & 307259 & 6.854 & 6.9127 & TRN & & \\
\hline CHEMBL52836 & 307259 & 6.699 & 6.6695 & TRN & & \\
\hline CHEMBL54523 & 307259 & 6.3768 & 6.3758 & TRN & & \\
\hline CHEMBL53165 & 307259 & 6.854 & 6.9539 & TRN & & \\
\hline CHEMBL55179 & 307259 & 6.699 & 6.7387 & TRN & & \\
\hline CHEMBL415962 & 307259 & 7.7447 & 7.4973 & TRN & & \\
\hline CHEMBL54733 & 307259 & 6.585 & 6.8053 & TRN & & \\
\hline CHEMBL53420 & 307259 & 7.3565 & 7.3571 & TRN & & \\
\hline CHEMBL23532 & 307259 & 8.6778 & 8.4594 & TRN & & \\
\hline CHEMBL50514 & 307259 & \multicolumn{3}{|c|}{8.142000000000001} & 7.9196 & TRN \\
\hline CHEMBL115788 & 307259 & 6.959 & 7.1081 & TRN & & \\
\hline CHEMBL81820 & 307259 & 7.276 & 7.3426 & TRN & & \\
\hline CHEMBL116614 & 307259 & 6.854 & 6.6908 & TRN & & \\
\hline CHEMBL 82975 & 307259 & 7.3768 & 7.1424 & TRN & & \\
\hline CHEMBL420224 & 307259 & 7.482 & 7.5754 & TRN & & \\
\hline CHEMBL334271 & 307259 & 6.602 & 6.6033 & TRN & & \\
\hline CHEMBL23867 & 307259 & 7.5287 & 7.3676 & TRN & & \\
\hline CHEMBL 23021 & 307259 & 6.893 & 7.1102 & TRN & & \\
\hline CHEMBL281803 & 307259 & 6.3904 & 6.3188 & TRN & & \\
\hline CHEMBL279679 & 307259 & 7.7595 & 7.8801 & TRN & & \\
\hline CHEMBL 23844 & 307259 & 5.523 & 5.8864 & TRN & & \\
\hline CHEMBL 23705 & 307259 & 6.482 & 6.3922 & TRN & & \\
\hline CHEMBL 279680 & 307259 & 7.3565 & 7.2274 & TRN & & \\
\hline CHEMBL 283518 & 307259 & 8.119 & 8.0008 & TRN & & \\
\hline CHEMBL279983 & 307259 & 6.6696 & 6.735 & TRN & & \\
\hline CHEMBL23569 & 307259 & \multicolumn{3}{|c|}{7.372000000000001} & 7.3659 & TRN \\
\hline CHEMBL 22623 & 307259 & 6.77 & 6.7413 & TRN & & \\
\hline
\end{tabular}




\begin{tabular}{|c|c|c|c|c|c|c|}
\hline \multirow[b]{2}{*}{ CHEMBL53903 } & & \multicolumn{5}{|c|}{ Supplemental Table S2.txt } \\
\hline & 307259 & 7.2676 & 7.2135 & TRN & & \\
\hline CHEMBL49454 & 307259 & 7.9281 & 7.9976 & TRN & & \\
\hline CHEMBL53693 & 307259 & $7.7570 e$ & 000000000 & & 7.8151 & TRN \\
\hline CHEMBL52433 & 307259 & 7.979 & 8.0067 & TRN & & \\
\hline CHEMBL 23288 & 307259 & 5.721 & 5.6803 & TRN & & \\
\hline CHEMBL142741 & 307259 & 6.5528 & 6.575 & TRN & & \\
\hline CHEMBL356490 & 307259 & 6.9208 & 6.7787 & TRN & & \\
\hline CHEMBL141708 & 307259 & 5.6778 & 5.4431 & TRN & & \\
\hline CHEMBL145005 & 307259 & 4.9281 & 5.0332 & TRN & & \\
\hline CHEMBL142624 & 307259 & 5.9431 & 6.0448 & TRN & & \\
\hline CHEMBL145068 & 307259 & 6.2147 & 6.2223 & TRN & & \\
\hline CHEMBL145528 & 307259 & 6.585 & 6.4459 & TRN & & \\
\hline CHEMBL179131 & 307259 & 6.6383 & 6.2807 & TST & & \\
\hline CHEMBL178512 & 307259 & 5.4559 & 5.6764 & TST & & \\
\hline CHEMBL180476 & 307259 & 6.77 & 6.4793 & TST & & \\
\hline CHEMBL178888 & 307259 & 6.3565 & 6.6011 & TST & & \\
\hline CHEMBL368645 & 307259 & 6.32799 & 999999999 & 99 & 6.3521 & TST \\
\hline CHEMBL299927 & 307259 & 6.7959 & 6.69 & TST & & \\
\hline CHEMBL121264 & 307259 & 6.857 & 6.9413 & TST & & \\
\hline CHEMBL121348 & 307259 & 6.7959 & 7.2239 & TRN & & \\
\hline CHEMBL123122 & 307259 & 7.4202 & 7.2686 & TRN & & \\
\hline CHEMBL120994 & 307259 & 6.824 & 6.8599 & TST & & \\
\hline CHEMBL121433 & 307259 & 7.4685 & 7.3288 & TRN & & \\
\hline CHEMBL 7488 & 307259 & 6.5376 & 6.6226 & TRN & & \\
\hline CHEMBL123276 & 307259 & 6.644 & 6.7457 & TST & & \\
\hline CHEMBL333791 & 307259 & 6.9626 & 6.9996 & TST & & \\
\hline CHEMBL 264548 & 307259 & 6.9355 & 6.7723 & TRN & & \\
\hline CHEMBL 7263 & 307259 & 6.2518 & 6.276 & TRN & & \\
\hline CHEMBL120939 & 307259 & 5.8327 & 6.1626 & TRN & & \\
\hline CHEMBL121319 & 307259 & 6.6198 & 6.6999 & TST & & \\
\hline CHEMBL178904 & 307259 & 6.893 & 6.9398 & TST & & \\
\hline CHEMBL120826 & 307259 & 6.7959 & 6.9914 & TST & & \\
\hline CHEMBL178684 & 307259 & 5.7878 & 5.7671 & TRN & & \\
\hline CHEMBL121868 & 307259 & 6.585 & 6.6886 & TRN & & \\
\hline CHEMBL123043 & 307259 & 7.1739 & 7.147 & TRN & & \\
\hline CHEMBL121683 & 307259 & 7.1487 & 7.149 & TRN & & \\
\hline CHEMBL120821 & 307259 & 7.1308 & 7.2519 & TRN & & \\
\hline CHEMBL54913 & 307259 & 7.086 & 6.9675 & TRN & & \\
\hline CHEMBL52777 & 307259 & 7.1367 & 7.0693 & TRN & & \\
\hline CHEMBL301105 & 307259 & 7.301 & 7.2907 & TRN & & \\
\hline CHEMBL52947 & 307259 & 6.5528 & 6.4429 & TRN & & \\
\hline CHEMBL51706 & 307259 & 6.2441 & 6.358 & TRN & & \\
\hline CHEMBL57624 & 307259 & 6.5686 & 8.2203 & TRN & & \\
\hline CHEMBL142081 & 307259 & 6.6383 & 6.7928 & TST & & \\
\hline CHEMBL137844 & 307259 & 7.125 & 7.0938 & TST & & \\
\hline CHEMBL137981 & 307259 & 7.7447 & 7.5008 & TST & & \\
\hline CHEMBL337746 & 307259 & 5.854 & 5.8816 & TST & & \\
\hline CHEMBL140705 & 307259 & 6.585 & 6.3748 & TRN & & \\
\hline
\end{tabular}




\begin{tabular}{|c|c|c|c|c|c|c|}
\hline & & \multicolumn{5}{|c|}{ Supplemental Table S2.txt } \\
\hline CHEMBL299174 & 307259 & 7.7959 & 7.6138 & TRN & & \\
\hline CHEMBL54792 & 307259 & 7.4559 & 7.4879 & TRN & & \\
\hline CHEMBL55727 & 307259 & 8.1427 & 7.9835 & TRN & & \\
\hline CHEMBL54538 & 307259 & 8.137 & 7.9259 & TRN & & \\
\hline CHEMBL53974 & 307259 & 6.9208 & 6.9815 & TRN & & \\
\hline CHEMBL141218 & 307259 & 5.4202 & 5.5018 & TRN & & \\
\hline CHEMBL141585 & 307259 & 5.959 & 5.8698 & TRN & & \\
\hline CHEMBL141260 & 307259 & 5.444 & 5.409 & TRN & & \\
\hline CHEMBL138452 & 307259 & 5.4949 & 5.4849 & TRN & & \\
\hline CHEMBL139188 & 307259 & \multicolumn{3}{|c|}{6.3660000000000005} & 6.4934 & TRN \\
\hline CHEMBL300603 & 307259 & 7.77 & 7.6758 & TRN & & \\
\hline CHEMBL55063 & 307259 & 7.6198 & 7.6778 & TRN & & \\
\hline CHEMBL52698 & 307259 & 7.06 & 7.1286 & TRN & & \\
\hline CHEMBL54732 & 307259 & 7.237 & 7.1802 & TRN & & \\
\hline CHEMBL292212 & 307259 & 6.699 & 6.7504 & TRN & & \\
\hline CHEMBL55191 & 307259 & \multicolumn{3}{|c|}{7.327999999999999} & 7.2263 & TRN \\
\hline CHEMBL138252 & 307259 & 6.086 & 6.2702 & TRN & & \\
\hline CHEMBL33038 & 307259 & 6.854 & 6.7686 & TRN & & \\
\hline CHEMBL34337 & 307259 & 5.854 & 5.9726 & TRN & & \\
\hline CHEMBL32113 & 307259 & 7.2441 & 7.2662 & TRN & & \\
\hline CHEMBL35569 & 307259 & 5.482 & 5.6343 & TRN & & \\
\hline CHEMBL53318 & 307259 & 6.9208 & 6.95200 & 0000000001 & & TRN \\
\hline CHEMBL445359 & 307259 & 7.3188 & 7.2141 & TRN & & \\
\hline CHEMBL52688 & 307259 & 7.284 & 7.3051 & TRN & & \\
\hline CHEMBL300886 & 307259 & 6.284 & 6.3768 & TST & & \\
\hline CHEMBL292634 & 307259 & 7.055 & 6.9831 & TRN & & \\
\hline CHEMBL284849 & 307259 & 5.959 & 5.8657 & TRN & & \\
\hline CHEMBL33208 & 307259 & 5.482 & 5.4754 & TRN & & \\
\hline CHEMBL32190 & 307259 & 7.482 & 7.4017 & TRN & & \\
\hline CHEMBL32708 & 307259 & 6.4559 & 6.359 & TRN & & \\
\hline CHEMBL 32754 & 307259 & 5.9208 & 5.4673 & TRN & & \\
\hline CHEMBL33187 & 307259 & 5.5376 & 5.5979 & TRN & & \\
\hline CHEMBL55656 & 307259 & 6.598 & 6.7977 & TST & & \\
\hline CHEMBL292143 & 307259 & 7.065 & 6.8933 & TST & & \\
\hline CHEMBL299140 & 307259 & 7.398 & 7.3234 & TRN & & \\
\hline CHEMBL 296382 & 307259 & 6.4949 & 6.357 & TRN & & \\
\hline CHEMBL278013 & 307259 & 5.523 & 4.8584 & TST & & \\
\hline CHEMBL278261 & 307259 & 5.086 & 4.2975 & TST & & \\
\hline CHEMBL35222 & 307259 & 7.523 & 7.5755 & TRN & & \\
\hline CHEMBL32769 & 307259 & 5.824 & 5.7605 & TRN & & \\
\hline CHEMBL 36245 & 307259 & 7.1427 & 7.1148 & TRN & & \\
\hline CHEMBL32266 & 307259 & 5.4685 & 5.4171 & TRN & & \\
\hline CHEMBL32635 & 307259 & 6.6198 & 6.5995 & TRN & & \\
\hline CHEMBL17430 & 307259 & 5.276 & 4.3322 & TST & & \\
\hline CHEMBL17431 & 307259 & 4.7773 & 3.8621 & TST & & \\
\hline CHEMBL17479 & 307259 & 5.523 & 4.4947 & TST & & \\
\hline CHEMBL275893 & 307259 & 4.0814 & 3.4176 & TST & & \\
\hline CHEMBL113999 & 307259 & 6.0458 & 5.9447 & TRN & & \\
\hline
\end{tabular}




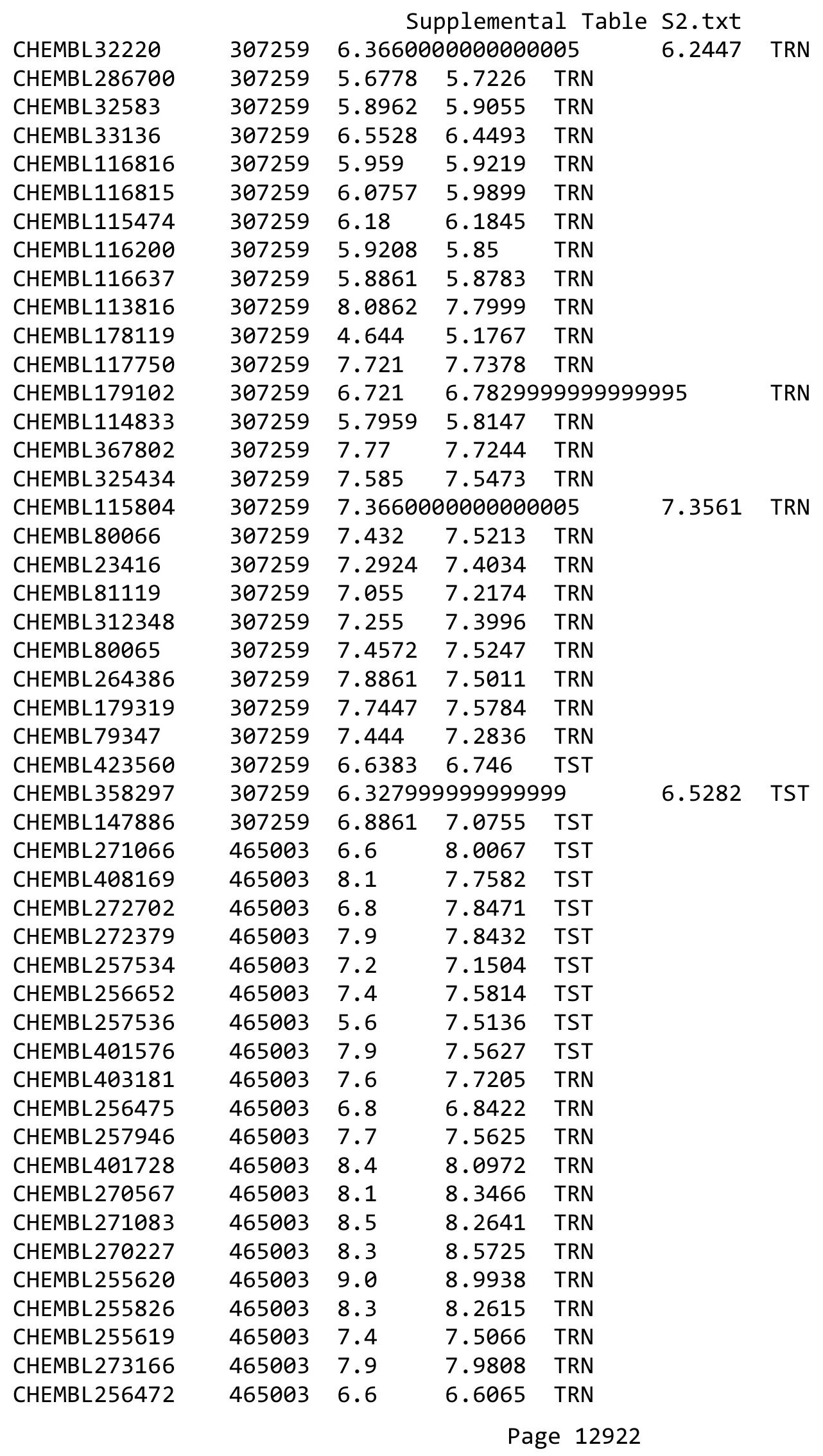




\begin{tabular}{|c|c|c|c|c|}
\hline & & & & $a \perp$ la \\
\hline CHEMBL256474 & 465003 & 7.7 & 7.8199 & TRN \\
\hline CHEMBL256473 & 465003 & 8.2 & 8.1218 & TRN \\
\hline CHEMBL258090 & 465003 & 7.4 & 7.351 & TRN \\
\hline CHEMBL402016 & 465003 & 7.3 & 7.6106 & TRN \\
\hline CHEMBL256651 & 465003 & 7.6 & 7.53 & TRN \\
\hline CHEMBL271096 & 465003 & 8.1 & 8.0959 & TRN \\
\hline CHEMBL272302 & 465003 & 7.0 & 7.8917 & TST \\
\hline CHEMBL270209 & 465003 & 7.0 & 6.8585 & TST \\
\hline CHEMBL269995 & 465003 & 7.5 & 6.8272 & TST \\
\hline CHEMBL439065 & 465003 & 7.6 & 7.3705 & TST \\
\hline CHEMBL256653 & 465003 & 6.9 & 7.3 & TST \\
\hline CHEMBL429132 & 465003 & 9.1 & 8.7388 & TRN \\
\hline CHEMBL271280 & 465003 & 6.7 & 6.6304 & TRN \\
\hline CHEMBL272695 & 465003 & 7.3 & 7.3388 & TRN \\
\hline CHEMBL256016 & 465003 & 8.0 & 7.9527 & TRN \\
\hline CHEMBL256015 & 465003 & 8.5 & 8.4553 & TRN \\
\hline CHEMBL402826 & 465003 & 8.4 & 8.5093 & TRN \\
\hline CHEMBL272546 & 465003 & 7.5 & 7.4397 & TRN \\
\hline CHEMBL272545 & 465003 & 7.9 & 7.84399 & 9999999999 \\
\hline CHEMBL271844 & 465003 & 7.3 & 7.2866 & TRN \\
\hline CHEMBL255621 & 465003 & 6.7 & 6.8204 & TRN \\
\hline CHEMBL255827 & 465003 & 6.8 & 6.7142 & TRN \\
\hline CHEMBL269959 & 465003 & 7.2 & 7.2097 & TRN \\
\hline CHEMBL255806 & 465003 & 7.6 & 7.0662 & TRN \\
\hline CHEMBL255618 & 465003 & 7.0 & 6.8716 & TRN \\
\hline CHEMBL255417 & 465003 & 7.0 & 6.9157 & TRN \\
\hline CHEMBL273165 & 465003 & 7.3 & 7.0744 & TRN \\
\hline CHEMBL257525 & 465003 & 7.1 & 6.9003 & TRN \\
\hline CHEMBL257524 & 465003 & 6.9 & 6.9561 & TRN \\
\hline CHEMBL270239 & 465003 & 6.6 & 7.0755 & TRN \\
\hline CHEMBL257900 & 465003 & 6.9 & 6.6898 & TRN \\
\hline CHEMBL401777 & 465003 & 6.6 & 6.7105 & TRN \\
\hline CHEMBL257901 & 465003 & 6.5 & 6.8046 & TRN \\
\hline CHEMBL408208 & 465003 & 6.5 & 6.6115 & TRN \\
\hline CHEMBL272378 & 465003 & 6.7 & 6.6077 & TRN \\
\hline CHEMBL402015 & 465003 & 6.5 & 6.7772 & TRN \\
\hline CHEMBL 256650 & 465003 & 7.5 & 6.9904 & TRN \\
\hline CHEMBL271097 & 465003 & 7.2 & 7.5046 & TRN \\
\hline CHEMBL269994 & 465003 & 7.6 & 7.5906 & TRN \\
\hline CHEMBL256481 & 465003 & 8.2 & 7.7521 & TRN \\
\hline CHEMBL257369 & 465003 & 7.7 & 7.4458 & TRN \\
\hline CHEMBL 256482 & 465003 & 7.4 & 7.4428 & TRN \\
\hline CHEMBL271072 & 465003 & 7.4 & 7.6068 & TRN \\
\hline CHEMBL271073 & 465003 & 6.5 & 6.9144 & TRN \\
\hline CHEMBL402087 & 465003 & 7.4 & 7.9489 & TRN \\
\hline CHEMBL401752 & 465003 & 7.5 & 7.0644 & TRN \\
\hline CHEMBL 272694 & 465003 & 7.4 & 7.13 & TRN \\
\hline CHEMBL255566 & 465003 & 7.9 & 7.8283 & TRN \\
\hline
\end{tabular}




\begin{tabular}{|c|c|c|c|c|}
\hline \multicolumn{5}{|c|}{ Supplemental Table S2.txt } \\
\hline CHEMBL 255778 & 465003 & 6.2 & 6.8789 & TRN \\
\hline CHEMBL255567 & 465003 & 8.4 & 8.4146 & TRN \\
\hline CHEMBL271631 & 465003 & 8.6 & 8.8345 & TRN \\
\hline CHEMBL 256471 & 465003 & 7.1 & 7.1244 & TRN \\
\hline CHEMBL271632 & 465003 & 7.7 & 7.557 & TRN \\
\hline CHEMBL 256477 & 465003 & 8.6 & 8.4863 & TRN \\
\hline CHEMBL272086 & 465003 & 6.9 & 7.7139 & TST \\
\hline CHEMBL 272300 & 465003 & 5.3 & 7.4918 & TST \\
\hline CHEMBL 270852 & 465003 & 7.4 & 8.5844 & TST \\
\hline CHEMBL270853 & 465003 & 6.6 & 7.9582 & TST \\
\hline CHEMBL 272478 & 465003 & 7.6 & 8.0928 & TST \\
\hline CHEMBL 272480 & 465003 & 6.2 & 7.4813 & TST \\
\hline CHEMBL273199 & 465003 & 8.8 & 8.1143 & TST \\
\hline CHEMBL85606 & 465003 & 8.4 & 7.5377 & TST \\
\hline CHEMBL1935060 & 794419 & 3.0 & 2.9579 & TST \\
\hline CHEMBL1935064 & 794419 & 3.0 & 2.9341 & TST \\
\hline CHEMBL1935033 & 794419 & 4.0592 & 3.6708 & TRN \\
\hline CHEMBL1935018 & 794419 & 3.0 & 3.4277 & TST \\
\hline CHEMBL1935034 & 794419 & 4.3929 & 4.0513 & TST \\
\hline CHEMBL1935039 & 794419 & 3.0 & 3.4648 & TRN \\
\hline CHEMBL1935172 & 794419 & 5.3045 & 2.9957 & TST \\
\hline CHEMBL1935059 & 794419 & 3.0 & 3.023 & TRN \\
\hline CHEMBL1935069 & 794419 & 5.1255 & 3.1759 & TST \\
\hline CHEMBL1935055 & 794419 & 3.0 & 3.1044 & TRN \\
\hline CHEMBL1935061 & 794419 & 3.0 & 2.9372 & TRN \\
\hline CHEMBL1935035 & 794419 & 3.0 & 3.9994 & TRN \\
\hline CHEMBL1935042 & 794419 & 4.5046 & 3.4142 & TRN \\
\hline CHEMBL1935067 & 794419 & 4.1605 & 3.366 & TRN \\
\hline CHEMBL1935170 & 794419 & 3.0 & 2.9943 & TST \\
\hline CHEMBL1935048 & 794419 & 3.0 & 3.1073 & TRN \\
\hline CHEMBL1935043 & 794419 & 3.0 & 3.4012 & TRN \\
\hline CHEMBL1935053 & 794419 & 3.0 & 2.9872 & TRN \\
\hline CHEMBL1935050 & 794419 & 3.0 & 3.0136 & TRN \\
\hline CHEMBL1935066 & 794419 & 3.0 & 3.2006 & TRN \\
\hline CHEMBL1935063 & 794419 & 3.0 & 2.9254 & TRN \\
\hline CHEMBL1935046 & 794419 & 3.0 & 2.9579 & TRN \\
\hline CHEMBL1935052 & 794419 & 4.3651 & 3.1411 & TRN \\
\hline CHEMBL1935026 & 794419 & 4.2067 & 4.1808 & TRN \\
\hline CHEMBL1933087 & 794419 & 4.1702 & 4.0521 & TRN \\
\hline CHEMBL1935037 & 794419 & 3.0 & 3.9877 & TRN \\
\hline CHEMBL1935028 & 794419 & 4.2893 & 4.0959 & TRN \\
\hline CHEMBL1935038 & 794419 & 3.0 & 4.0068 & TST \\
\hline CHEMBL1935036 & 794419 & 3.0 & 3.9733 & TRN \\
\hline CHEMBL1935171 & 794419 & 4.9594 & 3.4922 & TST \\
\hline CHEMBL1935068 & 794419 & 3.0 & 3.2841 & TRN \\
\hline CHEMBL1935062 & 794419 & 3.0 & 2.9304 & TRN \\
\hline CHEMBL1935021 & 794419 & 4.3303 & 4.0361 & TRN \\
\hline CHEMBL1935072 & 794419 & 4.7459 & 2.9213 & TST \\
\hline
\end{tabular}




\begin{tabular}{|c|c|c|c|c|c|}
\hline & & \multicolumn{4}{|c|}{ Supplemental Table S2.txt } \\
\hline CHEMBL1935022 & 794419 & 4.2484 & 4.0513 & TRN & \\
\hline CHEMBL1935056 & 794419 & 3.0 & 3.5925 & TRN & \\
\hline CHEMBL1935029 & 794419 & 4.4326 & 4.1028 & TRN & \\
\hline CHEMBL1935040 & 794419 & 3.0 & 3.2649 & TRN & \\
\hline CHEMBL1935041 & 794419 & 3.0 & 3.4731 & TRN & \\
\hline CHEMBL1935049 & 794419 & 3.0 & 3.0194 & TRN & \\
\hline CHEMBL1935030 & 794419 & 4.5278 & 4.1261 & TRN & \\
\hline CHEMBL1935032 & 794419 & 4.2233 & 4.1132 & TRN & \\
\hline CHEMBL1935025 & 794419 & 4.2106 & 3.8642 & TRN & \\
\hline CHEMBL1935065 & 794419 & 3.0 & 3.1744 & TRN & \\
\hline CHEMBL1935057 & 794419 & 3.0 & 3.2387 & TRN & \\
\hline CHEMBL1935023 & 794419 & 4.228 & 4.1452 & TRN & \\
\hline CHEMBL1935020 & 794419 & 3.0 & 3.1187 & TRN & \\
\hline CHEMBL1935044 & 794419 & 3.0 & 3.39399 & 99999999997 & TRN \\
\hline CHEMBL1935019 & 794419 & 3.0 & 2.8931 & TRN & \\
\hline CHEMBL1935070 & 794419 & 3.0 & 3.1574 & TRN & \\
\hline CHEMBL1935031 & 794419 & 4.4553 & 4.0286 & TRN & \\
\hline CHEMBL1935024 & 794419 & 4.2772 & 3.7089 & TRN & \\
\hline CHEMBL1935054 & 794419 & 3.0 & 3.2341 & TRN & \\
\hline CHEMBL1935051 & 794419 & 3.0 & 2.9838 & TRN & \\
\hline CHEMBL1935027 & 794419 & 4.0589 & 3.7639 & TRN & \\
\hline CHEMBL1935168 & 794419 & 3.0 & 2.9807 & TST & \\
\hline CHEMBL1935047 & 794419 & 3.0 & 3.0454 & TRN & \\
\hline CHEMBL1935169 & 794419 & 3.0 & 2.9695 & TST & \\
\hline CHEMBL1935071 & 794419 & 4.628 & 3.0301 & TST & \\
\hline CHEMBL1935045 & 794419 & 3.0 & 3.4159 & TST & \\
\hline CHEMBL1935017 & 794419 & 3.0 & 4.0159 & TST & \\
\hline CHEMBL1935058 & 794419 & 3.0 & 3.3765 & TST & \\
\hline CHEMBL1984190 & 688574 & 2.4559 & 4.1664 & TRN & \\
\hline CHEMBL1458107 & 688574 & 2.4559 & 2.4993 & TRN & \\
\hline CHEMBL1394571 & 688574 & 2.4559 & 2.5087 & TRN & \\
\hline CHEMBL1463312 & 688574 & 2.4559 & 2.628 & TRN & \\
\hline CHEMBL1382425 & 688574 & 2.4559 & 2.3666 & TRN & \\
\hline CHEMBL1485516 & 688574 & 2.4559 & 3.0533 & TRN & \\
\hline CHEMBL1452116 & 688574 & 4.7755 & 3.2888 & TST & \\
\hline CHEMBL1383180 & 688574 & 3.9461 & 2.5996 & TRN & \\
\hline CHEMBL1520745 & 688574 & 2.4559 & 2.4545 & TST & \\
\hline CHEMBL1585040 & 688574 & 2.4559 & 2.5393 & TRN & \\
\hline CHEMBL 3198754 & 688574 & 5.0077 & 4.146 & TRN & \\
\hline CHEMBL1565392 & 688574 & 2.4559 & 2.9047 & TRN & \\
\hline CHEMBL1578413 & 688574 & 2.4559 & 2.7536 & TRN & \\
\hline CHEMBL1417696 & 688574 & 2.4559 & 2.6744 & TRN & \\
\hline CHEMBL1497494 & 688574 & 2.4559 & 2.5471 & TRN & \\
\hline CHEMBL1349631 & 688574 & 5.0136 & 4.6679 & TRN & \\
\hline CHEMBL1448106 & 688574 & 2.4559 & 2.3105 & TST & \\
\hline CHEMBL1415705 & 688574 & 2.4559 & 2.5051 & TST & \\
\hline CHEMBL1331866 & 688574 & 2.4559 & 2.6252 & TST & \\
\hline CHEMBL1550039 & 688574 & 2.4559 & 2.4915 & TRN & \\
\hline
\end{tabular}




\begin{tabular}{|c|c|c|c|c|}
\hline & & & oplement & al $\mathrm{T}$ \\
\hline CHEMBL1409593 & 688574 & 2.4559 & 2.5826 & TRN \\
\hline CHEMBL1466643 & 688574 & 2.4559 & 2.4891 & TRN \\
\hline CHEMBL1306948 & 688574 & 2.4559 & 2.2489 & TRN \\
\hline CHEMBL1486691 & 688574 & 2.4559 & 2.3114 & TST \\
\hline CHEMBL1303082 & 688574 & 2.4559 & 2.7278 & TRN \\
\hline CHEMBL1352148 & 688574 & 2.4559 & 2.5951 & TRN \\
\hline CHEMBL1465665 & 688574 & 2.4559 & 2.5707 & TST \\
\hline CHEMBL1448964 & 688574 & 2.4559 & 2.8617 & TRN \\
\hline CHEMBL1323557 & 688574 & 2.4559 & 2.3708 & TRN \\
\hline CHEMBL1983939 & 688574 & 2.4559 & 4.3624 & TRN \\
\hline CHEMBL1440167 & 688574 & 2.4559 & 2.4161 & TRN \\
\hline CHEMBL1431458 & 688574 & 2.4559 & 2.4747 & TRN \\
\hline CHEMBL1612424 & 688574 & 2.4559 & 2.4638 & TRN \\
\hline CHEMBL1320983 & 688574 & 2.4559 & 2.3132 & TRN \\
\hline CHEMBL3190986 & 688574 & 5.047 & 4.1882 & TRN \\
\hline CHEMBL3193766 & 688574 & 2.4559 & 2.9632 & TRN \\
\hline CHEMBL1332165 & 688574 & 4.0343 & 3.5958 & TRN \\
\hline CHEMBL2004809 & 688574 & 4.2978 & 4.2997 & TRN \\
\hline CHEMBL1597454 & 688574 & 2.4559 & 3.0552 & TST \\
\hline CHEMBL1536005 & 688574 & 2.4559 & 2.5471 & TRN \\
\hline CHEMBL1463885 & 688574 & 2.4559 & 2.5877 & TRN \\
\hline CHEMBL1958251 & 688574 & 4.7425 & 4.2683 & TRN \\
\hline CHEMBL1449664 & 688574 & 2.4559 & 2.7093 & TRN \\
\hline CHEMBL1323804 & 688574 & 2.4559 & 2.7666 & TST \\
\hline CHEMBL1506697 & 688574 & 2.4559 & 2.707 & TRN \\
\hline CHEMBL1556822 & 688574 & 2.4559 & 2.9081 & TRN \\
\hline CHEMBL3197126 & 688574 & 5.0916 & 3.4771 & TRN \\
\hline CHEMBL3194900 & 688574 & 5.1161 & 4.1429 & TRN \\
\hline CHEMBL1495747 & 688574 & 2.4559 & 2.2744 & TRN \\
\hline CHEMBL 2359467 & 688574 & 5.171 & 3.5839 & TRN \\
\hline CHEMBL1443610 & 688574 & 2.4559 & 2.3236 & TRN \\
\hline CHEMBL 3192648 & 688574 & 3.8603 & 3.892 & TRN \\
\hline CHEMBL1559980 & 688574 & 2.4559 & 2.6261 & TST \\
\hline CHEMBL1376732 & 688574 & 2.4559 & 3.3155 & TRN \\
\hline CHEMBL1507678 & 688574 & 2.4559 & 2.3008 & TRN \\
\hline CHEMBL3194562 & 688574 & 4.003 & 4.1562 & TRN \\
\hline CHEMBL1987461 & 688574 & 5.0764 & 4.6823 & TRN \\
\hline CHEMBL1319311 & 688574 & 2.4559 & 2.3845 & TRN \\
\hline CHEMBL1520101 & 688574 & 2.4559 & 2.5443 & TRN \\
\hline CHEMBL 3199428 & 688574 & 5.1595 & 4.4358 & TRN \\
\hline CHEMBL1987472 & 688574 & 3.7179 & 4.5446 & TRN \\
\hline CHEMBL1983839 & 688574 & 3.7828 & 4.4604 & TRN \\
\hline CHEMBL1413464 & 688574 & 2.4559 & 2.4643 & TRN \\
\hline CHEMBL1304504 & 688574 & 2.4559 & 2.2817 & TRN \\
\hline CHEMBL1468065 & 688574 & 2.4559 & 3.0345 & TRN \\
\hline CHEMBL1468264 & 688574 & 2.4559 & 3.1179 & TST \\
\hline CHEMBL3191443 & 688574 & 5.0769 & 4.1096 & TRN \\
\hline CHEMBL3145060 & 688574 & 2.4559 & 2.6233 & TRN \\
\hline
\end{tabular}




\begin{tabular}{|c|c|c|c|c|c|}
\hline \multirow[b]{2}{*}{ CHEMBL590665 } & \multicolumn{5}{|c|}{ Supplemental Table S2.txt } \\
\hline & 688574 & 5.069 & 5.7857 & TRN & \\
\hline CHEMBL3194477 & 688574 & 4.3599 & 3.54600 & 00000000003 & TRN \\
\hline CHEMBL3199020 & 688574 & 2.4559 & 4.0014 & TRN & \\
\hline CHEMBL1477905 & 688574 & 2.4559 & 2.5149 & TRN & \\
\hline CHEMBL1309345 & 688574 & 2.4559 & 2.5041 & TRN & \\
\hline CHEMBL1442191 & 688574 & 2.4559 & 2.3959 & TRN & \\
\hline CHEMBL3214310 & 688574 & 4.1077 & 3.7789 & TRN & \\
\hline CHEMBL1493298 & 688574 & 2.4559 & 2.4688 & TRN & \\
\hline CHEMBL1331523 & 688574 & 2.4559 & 2.5643 & TRN & \\
\hline CHEMBL1329235 & 688574 & 5.1178 & 4.8372 & TRN & \\
\hline CHEMBL585622 & 688574 & 2.4559 & 3.4128 & TRN & \\
\hline CHEMBL1460882 & 688574 & 2.4559 & 2.7645 & TRN & \\
\hline CHEMBL1373763 & 688574 & 2.4559 & 2.6231 & TRN & \\
\hline CHEMBL1607964 & 688574 & 2.4559 & 2.8271 & TST & \\
\hline CHEMBL1414814 & 688574 & 2.4559 & 2.8768 & TRN & \\
\hline CHEMBL1462710 & 688574 & 2.4559 & 2.4877 & TRN & \\
\hline CHEMBL1977570 & 688574 & 2.4559 & 3.3217 & TRN & \\
\hline CHEMBL1600203 & 688574 & 3.9356 & 4.5799 & TRN & \\
\hline CHEMBL1577243 & 688574 & 2.4559 & 2.6655 & TST & \\
\hline CHEMBL1434720 & 688574 & 2.4559 & 2.7444 & TRN & \\
\hline CHEMBL3196282 & 688574 & 3.543 & 4.1084 & TRN & \\
\hline CHEMBL3194899 & 688574 & 2.4559 & 3.3685 & TRN & \\
\hline CHEMBL1569142 & 688574 & 2.4559 & 2.9339 & TST & \\
\hline CHEMBL3189323 & 688574 & 4.0354 & 3.0986 & TRN & \\
\hline CHEMBL1348683 & 688574 & 2.4559 & 2.6185 & TRN & \\
\hline CHEMBL1577246 & 688574 & 2.4559 & 2.4248 & TRN & \\
\hline CHEMBL1472807 & 688574 & 4.3924 & 3.2369 & TRN & \\
\hline CHEMBL1389940 & 688574 & 2.4559 & 2.3371 & TRN & \\
\hline CHEMBL1548156 & 688574 & 2.4559 & 2.309 & TRN & \\
\hline CHEMBL1379537 & 688574 & 2.4559 & 2.5974 & TRN & \\
\hline CHEMBL3191713 & 688574 & 5.22 & 4.7432 & TRN & \\
\hline CHEMBL 1305313 & 688574 & 2.4559 & 2.8226 & TST & \\
\hline CHEMBL1465294 & 688574 & 2.4559 & 2.4564 & TRN & \\
\hline CHEMBL3198227 & 688574 & 2.4559 & 3.7024 & TRN & \\
\hline CHEMBL1424516 & 688574 & 2.4559 & 2.5435 & TRN & \\
\hline CHEMBL1522631 & 688574 & 2.4559 & 3.0683 & TRN & \\
\hline CHEMBL 1354757 & 688574 & 2.4559 & 2.8678 & TST & \\
\hline CHEMBL1458150 & 688574 & 2.4559 & 2.6109 & TST & \\
\hline CHEMBL1387060 & 688574 & 2.4559 & 2.5027 & TRN & \\
\hline CHEMBL579045 & 688574 & 2.4559 & 2.2851 & TRN & \\
\hline CHEMBL3212362 & 688574 & 4.9681 & 4.1688 & TRN & \\
\hline CHEMBL1384672 & 688574 & 2.4559 & 2.6412 & TST & \\
\hline CHEMBL1366319 & 688574 & 2.4559 & 3.8191 & TRN & \\
\hline CHEMBL1304509 & 688574 & 2.4559 & 2.4146 & TRN & \\
\hline CHEMBL1332873 & 688574 & 4.9221 & 4.095 & TRN & \\
\hline CHEMBL1300421 & 688574 & 2.4559 & 2.4273 & TRN & \\
\hline CHEMBL1561112 & 688574 & 2.4559 & 2.3908 & TST & \\
\hline CHEMBL1564837 & 688574 & 2.4559 & 2.4253 & TRN & \\
\hline
\end{tabular}




\begin{tabular}{|c|c|c|c|c|}
\hline & & & oplemen & al $\mathrm{T}$ \\
\hline CHEMBL1568712 & 688574 & 2.4559 & 2.501 & TRN \\
\hline CHEMBL1351950 & 688574 & 2.4559 & 2.5565 & TST \\
\hline CHEMBL1964389 & 688574 & 4.5362 & 4.3003 & TRN \\
\hline CHEMBL1335107 & 688574 & 2.4559 & 2.4469 & TRN \\
\hline CHEMBL3191106 & 688574 & 4.9373 & 4.0984 & TRN \\
\hline CHEMBL1992872 & 688574 & 2.4559 & 3.2094 & TRN \\
\hline CHEMBL3190125 & 688574 & 4.2797 & 3.5195 & TRN \\
\hline CHEMBL1306283 & 688574 & 5.2865 & 4.9992 & TRN \\
\hline CHEMBL1372698 & 688574 & 4.808 & 2.8224 & TRN \\
\hline CHEMBL2007422 & 688574 & 5.1921 & 4.1482 & TRN \\
\hline CHEMBL1538041 & 688574 & 2.4559 & 2.7654 & TRN \\
\hline CHEMBL1308352 & 688574 & 2.4559 & 2.6592 & TRN \\
\hline CHEMBL3190974 & 688574 & 4.936 & 3.9811 & TRN \\
\hline CHEMBL1511179 & 688574 & 4.3931 & 4.2403 & TRN \\
\hline CHEMBL1453041 & 688574 & 2.4559 & 2.3737 & TRN \\
\hline CHEMBL1549286 & 688574 & 2.4559 & 2.6323 & TRN \\
\hline CHEMBL1527696 & 688574 & 2.4559 & 2.6425 & TST \\
\hline CHEMBL1340698 & 688574 & 2.4559 & 3.3999 & TRN \\
\hline CHEMBL1414754 & 688574 & 2.4559 & 2.7701 & TRN \\
\hline CHEMBL1564943 & 688574 & 2.4559 & 2.6667 & TRN \\
\hline CHEMBL1586385 & 688574 & 2.4559 & 2.6435 & TRN \\
\hline CHEMBL1370513 & 688574 & 5.096 & 5.5767 & TRN \\
\hline CHEMBL1595676 & 688574 & 2.4559 & 2.4196 & TRN \\
\hline CHEMBL1575502 & 688574 & 2.4559 & 4.6126 & TST \\
\hline CHEMBL3195273 & 688574 & 4.1766 & 4.5235 & TRN \\
\hline CHEMBL1996451 & 688574 & 2.4559 & 3.6627 & TRN \\
\hline CHEMBL1448563 & 688574 & 2.4559 & 2.7568 & TRN \\
\hline CHEMBL1410758 & 688574 & 5.1685 & 5.3457 & TRN \\
\hline CHEMBL3190293 & 688574 & 4.9613 & 4.3668 & TRN \\
\hline CHEMBL1307273 & 688574 & 2.4559 & 2.4695 & TRN \\
\hline CHEMBL1432028 & 688574 & 2.4559 & 2.5202 & TST \\
\hline CHEMBL1391619 & 688574 & 2.4559 & 2.6635 & TRN \\
\hline CHEMBL592068 & 688574 & 4.0997 & 3.6458 & TRN \\
\hline CHEMBL1538667 & 688574 & 2.4559 & 2.3958 & TRN \\
\hline CHEMBL3191770 & 688574 & 5.0368 & 3.9928 & TRN \\
\hline CHEMBL1312668 & 688574 & 2.4559 & 2.4472 & TRN \\
\hline CHEMBL1607403 & 688574 & 2.4559 & 2.5291 & TRN \\
\hline CHEMBL455284 & 688574 & 5.0074 & 5.3182 & TRN \\
\hline CHEMBL581452 & 688574 & 4.5169 & 3.7988 & TRN \\
\hline CHEMBL1564742 & 688574 & 2.4559 & 2.8012 & TRN \\
\hline CHEMBL1404027 & 688574 & 2.4559 & 3.0502 & TRN \\
\hline CHEMBL1388922 & 688574 & 4.9734 & 3.967 & TRN \\
\hline CHEMBL1424535 & 688574 & 2.4559 & 2.5924 & TRN \\
\hline CHEMBL1592550 & 688574 & 4.1387 & 3.4611 & TRN \\
\hline CHEMBL1338764 & 688574 & 2.4559 & 2.3729 & TRN \\
\hline CHEMBL1481220 & 688574 & 2.4559 & 2.5725 & TRN \\
\hline CHEMBL1550542 & 688574 & 2.4559 & 2.4957 & TRN \\
\hline CHEMBL1429929 & 688574 & 2.4559 & 2.8086 & TRN \\
\hline
\end{tabular}

Page 12928 


\begin{tabular}{|c|c|c|c|c|c|}
\hline \multicolumn{6}{|c|}{ Supplemental Table S2.txt } \\
\hline CHEMBL3195036 & 688574 & 4.9686 & 4.4108 & TRN & \\
\hline CHEMBL1989294 & 688574 & 2.4559 & 4.2042 & TRN & \\
\hline CHEMBL1976225 & 688574 & 4.8895 & 4.0548 & TRN & \\
\hline CHEMBL1584327 & 688574 & 2.4559 & 2.6259 & TRN & \\
\hline CHEMBL1541716 & 688574 & 2.4559 & 2.7446 & TST & \\
\hline CHEMBL1566300 & 688574 & 2.4559 & 2.1959 & TRN & \\
\hline CHEMBL533226 & 688574 & 4.4874 & 3.5199 & TRN & \\
\hline CHEMBL1314042 & 688574 & 2.4559 & 2.6932 & TRN & \\
\hline CHEMBL3208894 & 688574 & 2.4559 & 2.9245 & TRN & \\
\hline CHEMBL1401911 & 688574 & 2.4559 & 2.5576 & TRN & \\
\hline CHEMBL1979784 & 688574 & 5.5444 & 4.2135 & TRN & \\
\hline CHEMBL1581217 & 688574 & 2.4559 & 2.32099 & 99999999997 & TRN \\
\hline CHEMBL1505546 & 688574 & 4.9386 & 2.69199 & 99999999997 & TRN \\
\hline CHEMBL1571002 & 688574 & 2.4559 & 2.4381 & TRN & \\
\hline CHEMBL1424634 & 688574 & 2.4559 & 2.6483 & TRN & \\
\hline CHEMBL3197594 & 688574 & 4.811 & 4.2459 & TRN & \\
\hline CHEMBL1990091 & 688574 & 5.1991 & 4.2421 & TRN & \\
\hline CHEMBL1472304 & 688574 & 2.4559 & 3.2413 & TRN & \\
\hline CHEMBL3196181 & 688574 & 3.5773 & 4.0471 & TRN & \\
\hline CHEMBL3196124 & 688574 & 5.5397 & 4.3058 & TRN & \\
\hline CHEMBL1439833 & 688574 & 4.3212 & 5.0245 & TRN & \\
\hline CHEMBL1579666 & 688574 & 2.4559 & 2.8023 & TRN & \\
\hline CHEMBL3210297 & 688574 & 2.4559 & 3.5288 & TRN & \\
\hline CHEMBL1446069 & 688574 & 2.4559 & 2.8305 & TST & \\
\hline CHEMBL1519450 & 688574 & 5.239 & 5.3999 & TRN & \\
\hline CHEMBL1385369 & 688574 & 2.4559 & 2.4551 & TRN & \\
\hline CHEMBL3198368 & 688574 & 4.5148 & 3.7789 & TRN & \\
\hline CHEMBL1413863 & 688574 & 2.4559 & 2.4214 & TRN & \\
\hline CHEMBL1444021 & 688574 & 2.4559 & 2.3789 & TRN & \\
\hline CHEMBL1985330 & 688574 & 4.9759 & 4.6471 & TRN & \\
\hline CHEMBL1519644 & 688574 & 2.4559 & 3.1024 & TRN & \\
\hline CHEMBL3196163 & 688574 & 5.0092 & 3.9178 & TRN & \\
\hline CHEMBL1320702 & 688574 & 2.4559 & 2.8341 & TRN & \\
\hline CHEMBL1333738 & 688574 & 3.8437 & 2.6592 & TRN & \\
\hline CHEMBL3197761 & 688574 & 5.1337 & 3.8585 & TRN & \\
\hline CHEMBL1449796 & 688574 & 2.4559 & 3.0232 & TRN & \\
\hline CHEMBL1565084 & 688574 & 2.4559 & 2.117 & TRN & \\
\hline CHEMBL1519928 & 688574 & 2.4559 & 2.1653 & TRN & \\
\hline CHEMBL1979455 & 688574 & 5.1234 & 4.2438 & TRN & \\
\hline CHEMBL1610242 & 688574 & 2.4559 & 2.3738 & TRN & \\
\hline CHEMBL1380245 & 688574 & 2.4559 & 2.9434 & TST & \\
\hline CHEMBL1603384 & 688574 & 2.4559 & 3.1658 & TRN & \\
\hline CHEMBL1409066 & 688574 & 2.4559 & 2.4205 & TRN & \\
\hline CHEMBL1469884 & 688574 & 2.4559 & 2.6655 & TRN & \\
\hline CHEMBL1562276 & 688574 & 2.4559 & 2.8861 & TRN & \\
\hline CHEMBL1578009 & 688574 & 2.4559 & 2.1227 & TRN & \\
\hline CHEMBL1579064 & 688574 & 2.4559 & 2.3064 & TRN & \\
\hline CHEMBL1968859 & 688574 & 4.988 & 4.5278 & TRN & \\
\hline
\end{tabular}




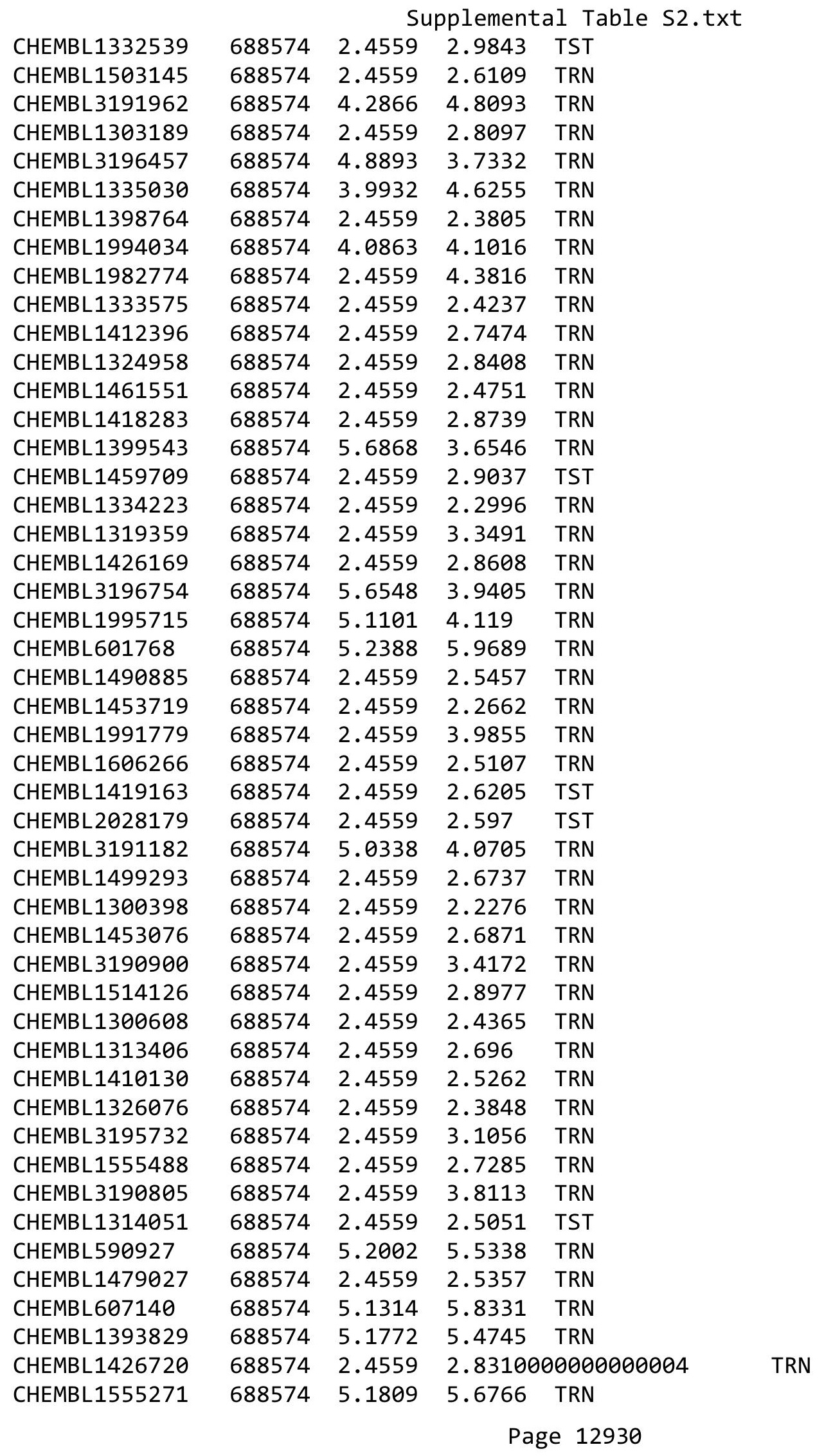




\begin{tabular}{|c|c|c|c|c|c|}
\hline \multirow[b]{2}{*}{ CHEMBL3194883 } & \multicolumn{5}{|c|}{ Supplemental Table s2.txt } \\
\hline & 688574 & 2.4559 & 3.803 & TRN & \\
\hline CHEMBL1964480 & 688574 & 2.4559 & 3.13100 & 00000000002 & TRN \\
\hline CHEMBL1457950 & 688574 & 2.4559 & 2.6461 & TST & \\
\hline CHEMBL1579122 & 688574 & 2.4559 & 3.0454 & TRN & \\
\hline CHEMBL1333791 & 688574 & 2.4559 & 2.6429 & TRN & \\
\hline CHEMBL1481509 & 688574 & 2.4559 & 2.577 & TST & \\
\hline CHEMBL3199034 & 688574 & 2.4559 & 3.8294 & TRN & \\
\hline CHEMBL1381322 & 688574 & 2.4559 & 2.6585 & TRN & \\
\hline CHEMBL1556390 & 688574 & 2.4559 & 2.7546 & TRN & \\
\hline CHEMBL1538056 & 688574 & 2.4559 & 2.5697 & TRN & \\
\hline CHEMBL1573309 & 688574 & 2.4559 & 3.2257 & TRN & \\
\hline CHEMBL1533431 & 688574 & 3.7948 & 2.967 & TRN & \\
\hline CHEMBL1518335 & 688574 & 2.4559 & 2.6348 & TRN & \\
\hline CHEMBL1399991 & 688574 & 2.4559 & 2.6384 & TRN & \\
\hline CHEMBL1329750 & 688574 & 2.4559 & 2.6059 & TST & \\
\hline CHEMBL1321916 & 688574 & 2.4559 & 2.4735 & TRN & \\
\hline CHEMBL1402200 & 688574 & 2.4559 & 2.4869 & TRN & \\
\hline CHEMBL274070 & 688574 & 2.4559 & 3.3607 & TST & \\
\hline CHEMBL 257781 & 688574 & 2.4559 & 2.4154 & TRN & \\
\hline CHEMBL1417577 & 688574 & 2.4559 & 2.6157 & TRN & \\
\hline CHEMBL1458498 & 688574 & 2.4559 & 2.5856 & TRN & \\
\hline CHEMBL1547771 & 688574 & 2.4559 & 2.7497 & TRN & \\
\hline CHEMBL1523550 & 688574 & 2.4559 & 2.5747 & TRN & \\
\hline CHEMBL1577274 & 688574 & 2.4559 & 2.5162 & TRN & \\
\hline CHEMBL1601572 & 688574 & 2.4559 & 2.5828 & TRN & \\
\hline CHEMBL1535361 & 688574 & 5.0304 & 4.8964 & TRN & \\
\hline CHEMBL1488885 & 688574 & 2.4559 & 2.8662 & TST & \\
\hline CHEMBL1478708 & 688574 & 2.4559 & 2.6831 & TRN & \\
\hline CHEMBL1305609 & 688574 & 2.4559 & 2.3242 & TRN & \\
\hline CHEMBL1396523 & 688574 & 2.4559 & 2.4353 & TRN & \\
\hline CHEMBL1564136 & 688574 & 2.4559 & 3.5719 & TST & \\
\hline CHEMBL1381449 & 688574 & 2.4559 & 2.6221 & TRN & \\
\hline CHEMBL1542554 & 688574 & 2.4559 & 3.3946 & TRN & \\
\hline CHEMBL1351924 & 688574 & 2.4559 & 2.5196 & TRN & \\
\hline CHEMBL3212085 & 688574 & 2.4559 & 2.83600 & 00000000003 & TRN \\
\hline CHEMBL3195409 & 688574 & 4.8676 & 4.229 & TRN & \\
\hline CHEMBL1969300 & 688574 & 4.0325 & 3.824 & TRN & \\
\hline CHEMBL1594475 & 688574 & 5.1269 & 5.6583 & TRN & \\
\hline CHEMBL1428702 & 688574 & 2.4559 & 2.4094 & TRN & \\
\hline CHEMBL1487598 & 688574 & 2.4559 & 2.7238 & TST & \\
\hline CHEMBL1606525 & 688574 & 2.4559 & 2.6187 & TST & \\
\hline CHEMBL3196304 & 688574 & 2.4559 & 3.6576 & TRN & \\
\hline CHEMBL1493541 & 688574 & 2.4559 & 2.51800 & 00000000002 & TRN \\
\hline CHEMBL3197978 & 688574 & 5.1599 & 4.5043 & TRN & \\
\hline CHEMBL1352764 & 688574 & 2.4559 & 2.4362 & TST & \\
\hline CHEMBL1577759 & 688574 & 2.4559 & 2.3543 & TRN & \\
\hline CHEMBL1536148 & 688574 & 2.4559 & 2.4618 & TRN & \\
\hline CHEMBL1424966 & 688574 & 2.4559 & 2.6785 & TRN & \\
\hline
\end{tabular}




\begin{tabular}{|c|c|c|c|c|}
\hline & & & oplement & al $\mathrm{T}$ \\
\hline CHEMBL1484572 & 688574 & 2.4559 & 2.6226 & TST \\
\hline CHEMBL1368242 & 688574 & 2.4559 & 2.5795 & TRN \\
\hline CHEMBL1419631 & 688574 & 2.4559 & 2.69 & TRN \\
\hline CHEMBL1475059 & 688574 & 2.4559 & 2.3531 & TRN \\
\hline CHEMBL1531184 & 688574 & 2.4559 & 2.5418 & TRN \\
\hline CHEMBL1996730 & 688574 & 2.4559 & 4.8022 & TRN \\
\hline CHEMBL1973629 & 688574 & 2.4559 & 3.0134 & TRN \\
\hline CHEMBL1446962 & 688574 & 2.4559 & 2.4906 & TRN \\
\hline CHEMBL 2002465 & 688574 & 4.6059 & 4.135 & TRN \\
\hline CHEMBL1464109 & 688574 & 2.4559 & 2.5426 & TRN \\
\hline CHEMBL1570835 & 688574 & 2.4559 & 2.9862 & TRN \\
\hline CHEMBL 3194563 & 688574 & 4.1285 & 4.3334 & TRN \\
\hline CHEMBL1371386 & 688574 & 2.4559 & 2.4735 & TRN \\
\hline CHEMBL1612686 & 688574 & 2.4559 & 2.6857 & TST \\
\hline CHEMBL1443775 & 688574 & 4.9023 & 3.2417 & TRN \\
\hline CHEMBL1610062 & 688574 & 2.4559 & 2.4888 & TST \\
\hline CHEMBL1466933 & 688574 & 2.4559 & 2.7401 & TRN \\
\hline CHEMBL1972216 & 688574 & 4.9169 & 4.5113 & TRN \\
\hline CHEMBL 3213645 & 688574 & 2.4559 & 3.0697 & TRN \\
\hline CHEMBL588804 & 688574 & 5.1904 & 5.4377 & TRN \\
\hline CHEMBL1405150 & 688574 & 4.2127 & 5.0581 & TRN \\
\hline CHEMBL1308035 & 688574 & 2.4559 & 2.6552 & TRN \\
\hline CHEMBL1540630 & 688574 & 2.4559 & 2.4047 & TRN \\
\hline CHEMBL1311358 & 688574 & 2.4559 & 2.2499 & TRN \\
\hline CHEMBL1306267 & 688574 & 4.9184 & 4.4919 & TRN \\
\hline CHEMBL1386118 & 688574 & 2.4559 & 2.7763 & TRN \\
\hline CHEMBL1382583 & 688574 & 2.4559 & 2.8357 & TRN \\
\hline CHEMBL2359911 & 688574 & 4.8991 & 4.7994 & TRN \\
\hline CHEMBL1381603 & 688574 & 2.4559 & 2.4225 & TRN \\
\hline CHEMBL1305428 & 688574 & 2.4559 & 2.2174 & TRN \\
\hline CHEMBL1560590 & 688574 & 5.1271 & 3.4674 & TRN \\
\hline CHEMBL1368262 & 688574 & 2.4559 & 2.3634 & TST \\
\hline CHEMBL1384998 & 688574 & 2.4559 & 2.8287 & TRN \\
\hline CHEMBL1506679 & 688574 & 4.973 & 2.5378 & TST \\
\hline CHEMBL1613483 & 688574 & 3.4813 & 2.8334 & TRN \\
\hline CHEMBL1445048 & 688574 & 2.4559 & 2.2843 & TRN \\
\hline CHEMBL1528138 & 688574 & 2.4559 & 2.2598 & TRN \\
\hline CHEMBL3197906 & 688574 & 5.0608 & 4.114 & TRN \\
\hline CHEMBL592600 & 688574 & 5.4387 & 6.057 & TRN \\
\hline CHEMBL1973855 & 688574 & 2.4559 & 3.2952 & TRN \\
\hline CHEMBL1965132 & 688574 & 5.0517 & 3.7509 & TRN \\
\hline CHEMBL3196355 & 688574 & 2.4559 & 3.2954 & TRN \\
\hline CHEMBL199405 & 688574 & 4.7526 & 4.3864 & TRN \\
\hline CHEMBL1406249 & 688574 & 2.4559 & 2.8668 & TRN \\
\hline CHEMBL3195142 & 688574 & 5.0141 & 3.6797 & TRN \\
\hline CHEMBL1343630 & 688574 & 2.4559 & 2.3045 & TRN \\
\hline CHEMBL1480006 & 688574 & 2.4559 & 2.5567 & TRN \\
\hline CHEMBL1993190 & 688574 & 4.0852 & 4.2589 & TRN \\
\hline
\end{tabular}




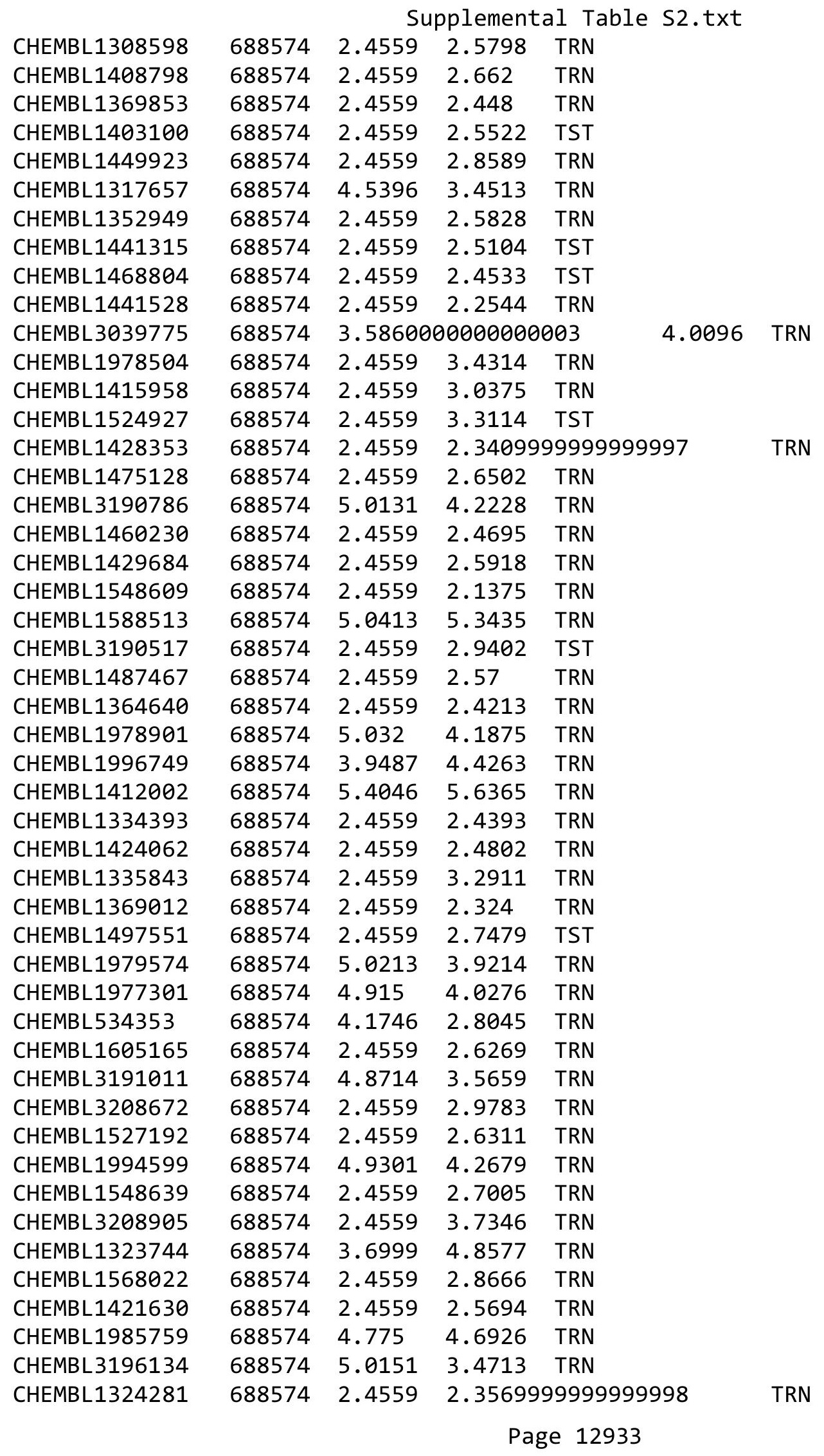


Supplemental Table S2.txt

\begin{tabular}{|c|c|c|c|c|}
\hline CHEMBL1426212 & 688574 & 2.4559 & 3.4622 & TRN \\
\hline CHEMBL1431432 & 688574 & 2.4559 & 2.5309 & TST \\
\hline CHEMBL1606589 & 688574 & 2.4559 & 2.4764 & TRN \\
\hline CHEMBL1379519 & 688574 & 4.3053 & 2.9128 & TST \\
\hline CHEMBL1427622 & 688574 & 2.4559 & 2.4979 & TRN \\
\hline CHEMBL1339870 & 688574 & 2.4559 & \multicolumn{2}{|c|}{2.9560000000000004} \\
\hline CHEMBL1419228 & 688574 & 2.4559 & 3.5198 & TST \\
\hline CHEMBL3198603 & 688574 & 3.9923 & 4.4162 & TRN \\
\hline CHEMBL1980322 & 688574 & 5.1695 & 4.2097 & TRN \\
\hline CHEMBL1574512 & 688574 & 2.4559 & \multicolumn{2}{|c|}{2.7769999999999997} \\
\hline CHEMBL1523867 & 688574 & 2.4559 & 2.6692 & TRN \\
\hline CHEMBL1421807 & 688574 & 2.4559 & 2.4571 & TRN \\
\hline CHEMBL1448284 & 688574 & 3.8237 & 2.7774 & TRN \\
\hline CHEMBL1472175 & 688574 & 2.4559 & 2.3848 & TRN \\
\hline CHEMBL1411247 & 688574 & 2.4559 & 2.5474 & TRN \\
\hline CHEMBL1500469 & 688574 & 4.3791 & 4.0268 & TRN \\
\hline CHEMBL3197187 & 688574 & 2.4559 & 2.608 & TRN \\
\hline CHEMBL1482988 & 688574 & 2.4559 & 2.5876 & TRN \\
\hline CHEMBL1378531 & 688574 & 2.4559 & 2.289 & TRN \\
\hline CHEMBL1520294 & 688574 & 2.4559 & 2.5356 & TRN \\
\hline CHEMBL1552813 & 688574 & 2.4559 & 2.7394 & TST \\
\hline CHEMBL1425140 & 688574 & 2.4559 & 2.4426 & TST \\
\hline CHEMBL1353839 & 688574 & 2.4559 & 2.627 & TRN \\
\hline CHEMBL1988042 & 688574 & 5.0843 & 4.6567 & TRN \\
\hline CHEMBL 3211277 & 688574 & 2.4559 & 2.804 & TST \\
\hline CHEMBL1453214 & 688574 & 2.4559 & 2.8319 & TRN \\
\hline CHEMBL1430905 & 688574 & 2.4559 & 2.372 & TRN \\
\hline CHEMBL1331881 & 688574 & 2.4559 & 2.6903 & TRN \\
\hline CHEMBL1997797 & 688574 & 2.4559 & 3.159 & TST \\
\hline CHEMBL3198332 & 688574 & 5.0765 & 4.6811 & TRN \\
\hline CHEMBL1964464 & 688574 & 4.2602 & 4.715 & TRN \\
\hline CHEMBL1374937 & 688574 & 2.4559 & 2.4229 & TRN \\
\hline CHEMBL3191025 & 688574 & 4.9648 & 4.0354 & TRN \\
\hline CHEMBL1449883 & 688574 & 4.721 & 4.8841 & TRN \\
\hline CHEMBL1576248 & 688574 & 2.4559 & 2.9795 & TST \\
\hline CHEMBL1493563 & 688574 & 2.4559 & 2.6089 & TST \\
\hline CHEMBL3192181 & 688574 & 5.5914 & 4.6046 & TRN \\
\hline CHEMBL3212629 & 688574 & 2.4559 & \multicolumn{2}{|c|}{2.7239999999999998} \\
\hline CHEMBL 3210587 & 688574 & 2.4559 & 3.2427 & TRN \\
\hline CHEMBL1419234 & 688574 & 2.4559 & 2.4389 & TRN \\
\hline CHEMBL1580892 & 688574 & 2.4559 & 2.5587 & TST \\
\hline CHEMBL1413505 & 688574 & 2.4559 & 2.7102 & TRN \\
\hline CHEMBL1563702 & 688574 & 2.4559 & 3.2813 & TRN \\
\hline CHEMBL1318750 & 688574 & 2.4559 & 2.5703 & TRN \\
\hline CHEMBL1548492 & 688574 & 5.3224 & 5.7344 & TRN \\
\hline CHEMBL1593768 & 688574 & 2.4559 & 2.5226 & TST \\
\hline CHEMBL1416745 & 688574 & 4.6318 & 3.3694 & TRN \\
\hline CHEMBL1527214 & 688574 & 2.4559 & 3.1979 & TRN \\
\hline
\end{tabular}

Page 12934 


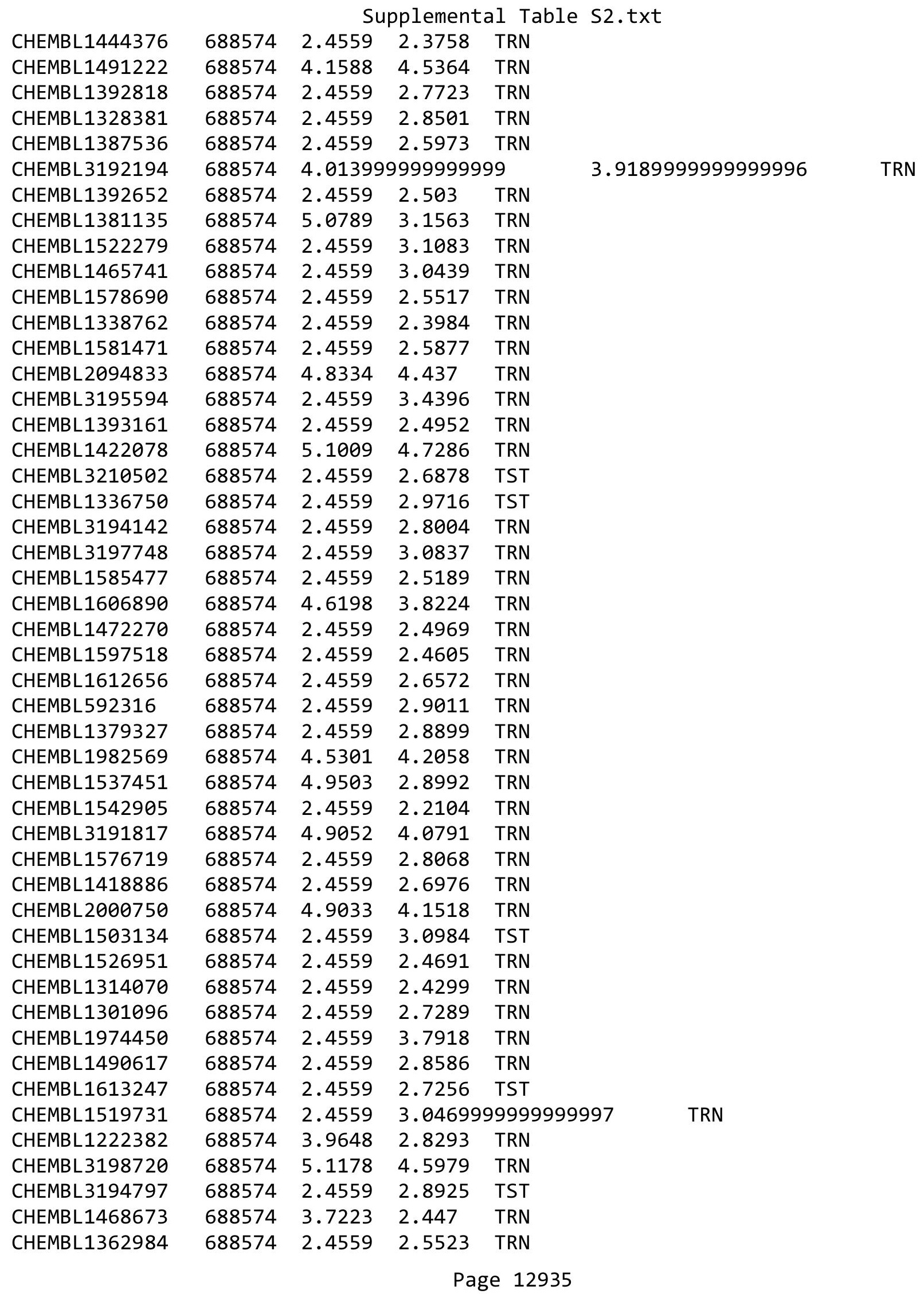




\begin{tabular}{|c|c|c|c|c|c|}
\hline & & \multicolumn{4}{|c|}{ Supplemental Table S2.txt } \\
\hline CHEMBL3193510 & 688574 & 5.4638 & 4.1517 & TRN & \\
\hline CHEMBL3198576 & 688574 & 5.3334 & 4.2876 & TRN & \\
\hline CHEMBL1550931 & 688574 & 2.4559 & 2.9165 & TRN & \\
\hline CHEMBL1395615 & 688574 & 2.4559 & 2.8571 & TRN & \\
\hline CHEMBL3189613 & 688574 & 4.872 & 3.904 & TRN & \\
\hline CHEMBL1426556 & 688574 & 2.4559 & 2.6799 & TRN & \\
\hline CHEMBL1524692 & 688574 & 4.553 & 2.9432 & TRN & \\
\hline CHEMBL1505090 & 688574 & 2.4559 & 2.4836 & TRN & \\
\hline CHEMBL1461115 & 688574 & 2.4559 & $2.6260 e$ & 00000000003 & TRN \\
\hline CHEMBL1964614 & 688574 & 5.0067 & 4.3989 & TRN & \\
\hline CHEMBL1498475 & 688574 & 2.4559 & 2.8005 & TRN & \\
\hline CHEMBL1490332 & 688574 & 4.3867 & 2.8222 & TRN & \\
\hline CHEMBL1371879 & 688574 & 2.4559 & 2.6387 & TRN & \\
\hline CHEMBL1431477 & 688574 & 2.4559 & 2.8208 & TRN & \\
\hline CHEMBL1423208 & 688574 & 2.4559 & 2.4061 & TRN & \\
\hline CHEMBL 3192547 & 688574 & 4.1609 & 4.3577 & TRN & \\
\hline CHEMBL1493439 & 688574 & 2.4559 & 2.4009 & TRN & \\
\hline CHEMBL1980848 & 688574 & 2.4559 & 3.9113 & TRN & \\
\hline CHEMBL1421524 & 688574 & 2.4559 & 2.6716 & TST & \\
\hline CHEMBL3196139 & 688574 & 5.0134 & 4.6428 & TRN & \\
\hline CHEMBL1543279 & 688574 & 2.4559 & 2.6849 & TST & \\
\hline CHEMBL1584183 & 688574 & 2.4559 & 2.6641 & TST & \\
\hline CHEMBL1546726 & 688574 & 2.4559 & 2.6109 & TRN & \\
\hline CHEMBL1418230 & 688574 & 4.7306 & 3.6054 & TRN & \\
\hline CHEMBL1575087 & 688574 & 2.4559 & 2.4956 & TRN & \\
\hline CHEMBL3189416 & 688574 & 5.1179 & 4.6636 & TRN & \\
\hline CHEMBL1462882 & 688574 & 2.4559 & 2.4591 & TRN & \\
\hline CHEMBL1305748 & 688574 & 2.4559 & 2.4071 & TRN & \\
\hline CHEMBL1569989 & 688574 & 5.1984 & 4.6728 & TRN & \\
\hline CHEMBL1452421 & 688574 & 5.2011 & 5.2825 & TRN & \\
\hline CHEMBL1348053 & 688574 & 2.4559 & 2.8868 & TST & \\
\hline CHEMBL1594833 & 688574 & 2.4559 & 2.5989 & TRN & \\
\hline CHEMBL1991242 & 688574 & 5.2272 & 4.3618 & TRN & \\
\hline CHEMBL 3194407 & 688574 & 3.6104 & 3.7625 & TRN & \\
\hline CHEMBL450802 & 688574 & 2.4559 & 2.4106 & TRN & \\
\hline CHEMBL494838 & 688574 & 2.4559 & 2.6988 & TRN & \\
\hline CHEMBL1986418 & 688574 & 4.0817 & 5.0084 & TRN & \\
\hline CHEMBL1447821 & 688574 & 2.4559 & 2.9748 & TRN & \\
\hline CHEMBL1467587 & 688574 & 2.4559 & 2.5402 & TST & \\
\hline CHEMBL1330501 & 688574 & 2.4559 & 2.5953 & TRN & \\
\hline CHEMBL1479134 & 688574 & 2.4559 & 2.3515 & TRN & \\
\hline CHEMBL1533210 & 688574 & 2.4559 & 2.5932 & TST & \\
\hline CHEMBL1485833 & 688574 & 2.4559 & 2.5399 & TST & \\
\hline CHEMBL 3199736 & 688574 & 2.4559 & 2.926 & TRN & \\
\hline CHEMBL1331702 & 688574 & 4.4914 & 2.8414 & TRN & \\
\hline CHEMBL1982662 & 688574 & 2.4559 & 3.0262 & TRN & \\
\hline CHEMBL1603584 & 688574 & 2.4559 & 2.8035 & TRN & \\
\hline CHEMBL1383131 & 688574 & 2.4559 & 2.7672 & TRN & \\
\hline
\end{tabular}




\begin{tabular}{|c|c|c|c|c|c|}
\hline \multicolumn{6}{|c|}{ Supplemental Table S2.txt } \\
\hline CHEMBL1454436 & 688574 & 2.4559 & 2.6107 & TRN & \\
\hline CHEMBL606532 & 688574 & 4.8491 & 4.7812 & TRN & \\
\hline CHEMBL1381206 & 688574 & 2.4559 & 2.8927 & TRN & \\
\hline CHEMBL1502020 & 688574 & 5.1201 & 4.038 & TRN & \\
\hline CHEMBL 1437483 & 688574 & 2.4559 & 2.4802 & TRN & \\
\hline CHEMBL1581517 & 688574 & 2.4559 & 2.5851 & TRN & \\
\hline CHEMBL1323011 & 688574 & 2.4559 & 2.2706 & TRN & \\
\hline CHEMBL1544598 & 688574 & 2.4559 & 2.6575 & TRN & \\
\hline CHEMBL1548606 & 688574 & 2.4559 & 2.9147 & TST & \\
\hline CHEMBL1400842 & 688574 & 2.4559 & 2.2917 & TRN & \\
\hline CHEMBL1303844 & 688574 & 2.4559 & 2.7639 & TRN & \\
\hline CHEMBL3193419 & 688574 & 4.9886 & 4.6764 & TRN & \\
\hline CHEMBL1601275 & 688574 & 2.4559 & 2.241 & TRN & \\
\hline CHEMBL1973139 & 688574 & 4.9293 & 4.2389 & TRN & \\
\hline CHEMBL1389020 & 688574 & 2.4559 & 2.8244 & TRN & \\
\hline CHEMBL1499324 & 688574 & 2.4559 & 2.65 & TRN & \\
\hline CHEMBL1302327 & 688574 & 2.4559 & 2.53800 & 00000000003 & TRN \\
\hline CHEMBL1332450 & 688574 & 4.2031 & 4.501 & TRN & \\
\hline CHEMBL1569162 & 688574 & 4.9484 & 3.5876 & TRN & \\
\hline CHEMBL3193902 & 688574 & 2.4559 & 2.8449 & TRN & \\
\hline CHEMBL1533459 & 688574 & 5.0752 & 3.9729 & TRN & \\
\hline CHEMBL1556113 & 688574 & 4.7656 & 2.5728 & TRN & \\
\hline CHEMBL1350543 & 688574 & 2.4559 & 2.8827 & TST & \\
\hline CHEMBL1345388 & 688574 & 5.1468 & 3.6148 & TRN & \\
\hline CHEMBL3209846 & 688574 & 2.4559 & 2.5763 & TRN & \\
\hline CHEMBL1598010 & 688574 & 2.4559 & 2.9311 & TST & \\
\hline CHEMBL3195682 & 688574 & 2.4559 & 3.2487 & TRN & \\
\hline CHEMBL1573589 & 688574 & 2.4559 & 2.3227 & TRN & \\
\hline CHEMBL1307453 & 688574 & 5.1612 & 4.0379 & TRN & \\
\hline CHEMBL3194211 & 688574 & 4.4595 & 4.2551 & TRN & \\
\hline CHEMBL1407259 & 688574 & 2.4559 & 2.4713 & TRN & \\
\hline CHEMBL 210145 & 688574 & 2.4559 & 2.4843 & TRN & \\
\hline CHEMBL3199599 & 688574 & 2.4559 & 2.6429 & TRN & \\
\hline CHEMBL1547884 & 688574 & 2.4559 & 2.6084 & TRN & \\
\hline CHEMBL1600390 & 688574 & 2.4559 & 2.3055 & TRN & \\
\hline CHEMBL1413610 & 688574 & 2.4559 & 2.7136 & TRN & \\
\hline CHEMBL1987820 & 688574 & 4.1794 & 4.4192 & TRN & \\
\hline CHEMBL1537759 & 688574 & 2.4559 & 2.86800 & 00000000003 & TRN \\
\hline CHEMBL1327067 & 688574 & 2.4559 & 2.4423 & TRN & \\
\hline CHEMBL1369945 & 688574 & 5.3286 & 3.5106 & TRN & \\
\hline CHEMBL1337202 & 688574 & 2.4559 & 2.4161 & TST & \\
\hline CHEMBL1535919 & 688574 & 2.4559 & 3.1357 & TRN & \\
\hline CHEMBL1386014 & 688574 & 2.4559 & 2.3759 & TST & \\
\hline CHEMBL1611843 & 688574 & 2.4559 & 2.9709 & TRN & \\
\hline CHEMBL1354350 & 688574 & 2.4559 & 2.4727 & TRN & \\
\hline CHEMBL1411930 & 688574 & 2.4559 & 2.6249 & TRN & \\
\hline CHEMBL1986316 & 688574 & 2.4559 & 3.2215 & TRN & \\
\hline CHEMBL1463491 & 688574 & 2.4559 & 2.5908 & TST & \\
\hline
\end{tabular}


Supplemental Table S2.txt

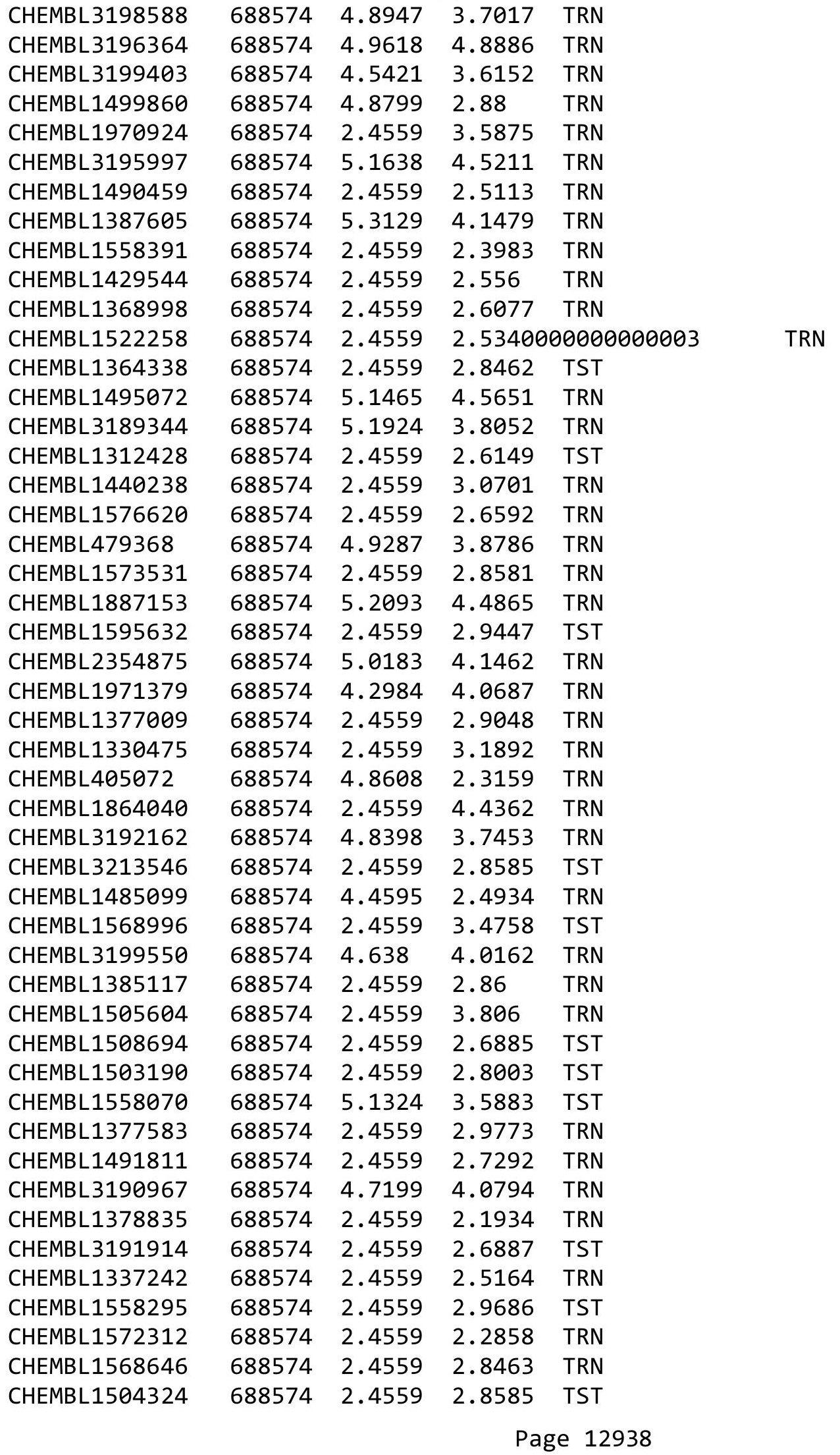




\begin{tabular}{|c|c|c|c|c|}
\hline & & & oplement & al $\mathrm{T}$ \\
\hline CHEMBL1439222 & 688574 & 2.4559 & 2.7538 & TST \\
\hline CHEMBL1454142 & 688574 & 2.4559 & 2.7546 & TRN \\
\hline CHEMBL1438833 & 688574 & 2.4559 & 2.8725 & TST \\
\hline CHEMBL1604463 & 688574 & 2.4559 & 2.3876 & TRN \\
\hline CHEMBL1548660 & 688574 & 2.4559 & 2.9853 & TRN \\
\hline CHEMBL1300235 & 688574 & 2.4559 & 2.8094 & TST \\
\hline CHEMBL1513500 & 688574 & 2.4559 & 2.3844 & TRN \\
\hline CHEMBL1502859 & 688574 & 2.4559 & 2.7164 & TRN \\
\hline CHEMBL1578386 & 688574 & 2.4559 & 2.7281 & TRN \\
\hline CHEMBL1388351 & 688574 & 2.4559 & 2.6675 & TRN \\
\hline CHEMBL1969992 & 688574 & 5.1099 & 4.5892 & TRN \\
\hline CHEMBL1534801 & 688574 & 2.4559 & 2.7076 & TRN \\
\hline CHEMBL1330370 & 688574 & 2.4559 & 2.6063 & TST \\
\hline CHEMBL1400058 & 688574 & 2.4559 & 2.6398 & TST \\
\hline CHEMBL1332804 & 688574 & 2.4559 & 2.3386 & TRN \\
\hline CHEMBL1422822 & 688574 & 2.4559 & 2.5558 & TRN \\
\hline CHEMBL1384178 & 688574 & 2.4559 & 2.44 & TRN \\
\hline CHEMBL3209306 & 688574 & 5.1405 & 4.5399 & TRN \\
\hline CHEMBL1409965 & 688574 & 4.6776 & 3.2016 & TRN \\
\hline CHEMBL 3208685 & 688574 & 2.4559 & 2.5937 & TRN \\
\hline CHEMBL1351522 & 688574 & 2.4559 & 2.5439 & TRN \\
\hline CHEMBL3189791 & 688574 & 4.7924 & 4.5778 & TRN \\
\hline CHEMBL3195241 & 688574 & 4.5093 & 4.3479 & TRN \\
\hline CHEMBL1972347 & 688574 & 4.6982 & 3.6415 & TRN \\
\hline CHEMBL1454395 & 688574 & 2.4559 & 2.8633 & TRN \\
\hline CHEMBL1578975 & 688574 & 2.4559 & 3.1435 & TRN \\
\hline CHEMBL1491721 & 688574 & 2.4559 & 2.8627 & TRN \\
\hline CHEMBL1548689 & 688574 & 2.4559 & 2.7847 & TRN \\
\hline CHEMBL1352206 & 688574 & 2.4559 & 2.6639 & TST \\
\hline CHEMBL1565915 & 688574 & 2.4559 & 3.1177 & TST \\
\hline CHEMBL3191445 & 688574 & 4.7998 & 3.5512 & TRN \\
\hline CHEMBL1310347 & 688574 & 2.4559 & 2.4093 & TRN \\
\hline CHEMBL1558065 & 688574 & 5.0899 & 4.4507 & TRN \\
\hline CHEMBL1487964 & 688574 & 2.4559 & 2.4865 & TRN \\
\hline CHEMBL1390112 & 688574 & 4.8696 & 3.8808 & TRN \\
\hline CHEMBL1440352 & 688574 & 2.4559 & 2.5029 & TRN \\
\hline CHEMBL1385316 & 688574 & 2.4559 & 2.9154 & TRN \\
\hline CHEMBL1585329 & 688574 & 2.4559 & 2.3693 & TRN \\
\hline CHEMBL1989897 & 688574 & 5.0665 & 4.3447 & TRN \\
\hline CHEMBL1462727 & 688574 & 2.4559 & 2.4346 & TRN \\
\hline CHEMBL1391799 & 688574 & 2.4559 & 2.6946 & TRN \\
\hline CHEMBL1391746 & 688574 & 2.4559 & 2.4873 & TRN \\
\hline CHEMBL1590254 & 688574 & 2.4559 & 2.39 & TRN \\
\hline CHEMBL1567827 & 688574 & 2.4559 & 3.8015 & TRN \\
\hline CHEMBL2005895 & 688574 & 3.9944 & 4.1165 & TRN \\
\hline CHEMBL1332664 & 688574 & 2.4559 & 2.6283 & TRN \\
\hline CHEMBL1577613 & 688574 & 2.4559 & 2.863 & TRN \\
\hline CHEMBL3189549 & 688574 & 2.4559 & 3.6394 & TRN \\
\hline
\end{tabular}


Supplemental Table S2.txt

\begin{tabular}{|c|c|c|c|c|}
\hline CHEMBL1303891 & 688574 & 2.4559 & 2.4283 & TRN \\
\hline CHEMBL1432177 & 688574 & 2.4559 & 2.5911 & TRN \\
\hline CHEMBL1607681 & 688574 & 2.4559 & 2.4408 & TRN \\
\hline CHEMBL1373215 & 688574 & 2.4559 & 2.2581 & TRN \\
\hline CHEMBL1423601 & 688574 & 2.4559 & 2.2396 & TRN \\
\hline CHEMBL1347533 & 688574 & 4.0677 & 3.2055 & TRN \\
\hline CHEMBL1327569 & 688574 & 2.4559 & 2.4782 & TRN \\
\hline CHEMBL1442358 & 688574 & 2.4559 & 2.6759 & TRN \\
\hline CHEMBL1364572 & 688574 & 2.4559 & 2.667 & TRN \\
\hline CHEMBL1508925 & 688574 & 2.4559 & 2.7769 & TST \\
\hline CHEMBL1446224 & 688574 & 2.4559 & 2.5242 & TST \\
\hline CHEMBL1457254 & 688574 & 2.4559 & 2.2393 & TRN \\
\hline CHEMBL1302963 & 688574 & 2.4559 & 2.4385 & TRN \\
\hline CHEMBL1471382 & 688574 & 2.4559 & 2.4877 & TRN \\
\hline CHEMBL1462446 & 688574 & 2.4559 & 2.431 & TRN \\
\hline CHEMBL1606613 & 688574 & 2.4559 & 2.9643 & TRN \\
\hline CHEMBL1597530 & 688574 & 2.4559 & 3.0662 & TST \\
\hline CHEMBL1579360 & 688574 & 2.4559 & 2.9035 & TRN \\
\hline CHEMBL1457139 & 688574 & 4.9015 & 5.3962 & TRN \\
\hline CHEMBL1451959 & 688574 & 2.4559 & 2.5929 & TRN \\
\hline CHEMBL1352843 & 688574 & 2.4559 & 2.9281 & TRN \\
\hline CHEMBL1583414 & 688574 & 2.4559 & 2.6463 & TRN \\
\hline CHEMBL1502412 & 688574 & 2.4559 & 2.7257 & TST \\
\hline CHEMBL1348582 & 688574 & 4.2885 & 4.6383 & TRN \\
\hline CHEMBL1445189 & 688574 & 2.4559 & 2.5571 & TST \\
\hline CHEMBL1477835 & 688574 & 2.4559 & 2.3724 & TRN \\
\hline CHEMBL1988121 & 688574 & 3.5067 & 4.2245 & TRN \\
\hline CHEMBL1418534 & 688574 & 2.4559 & 2.461 & TRN \\
\hline CHEMBL577928 & 688574 & 2.4559 & 2.7759 & TRN \\
\hline CHEMBL1313892 & 688574 & 2.4559 & 2.4687 & TRN \\
\hline CHEMBL1350460 & 688574 & 2.4559 & 3.2043 & TRN \\
\hline CHEMBL1308089 & 688574 & 2.4559 & 2.2064 & TRN \\
\hline CHEMBL583603 & 688574 & 2.4559 & 2.3014 & TRN \\
\hline CHEMBL1555900 & 688574 & 2.4559 & 2.4425 & TST \\
\hline CHEMBL1542994 & 688574 & 2.4559 & 2.5275 & TRN \\
\hline CHEMBL1469499 & 688574 & 2.4559 & 2.5695 & TRN \\
\hline CHEMBL1471741 & 688574 & 2.4559 & 3.7961 & TRN \\
\hline CHEMBL1536861 & 688574 & 2.4559 & 2.7771 & TRN \\
\hline CHEMBL1347723 & 688574 & 2.4559 & 2.3819 & TRN \\
\hline CHEMBL1557443 & 688574 & 2.4559 & 2.5615 & TRN \\
\hline CHEMBL1348966 & 688574 & 2.4559 & 2.7238 & TRN \\
\hline CHEMBL580955 & 688574 & 5.4203 & 5.8451 & TRN \\
\hline CHEMBL1521019 & 688574 & 2.4559 & 2.6006 & TRN \\
\hline CHEMBL1409266 & 688574 & 2.4559 & 2.4412 & TRN \\
\hline CHEMBL1342148 & 688574 & 5.053 & 2.75699 & 99999999997 \\
\hline CHEMBL3191242 & 688574 & 4.9176 & 4.4059 & TRN \\
\hline CHEMBL1541582 & 688574 & 2.4559 & 2.5441 & TRN \\
\hline CHEMBL1410860 & 688574 & 2.4559 & 2.6096 & TRN \\
\hline
\end{tabular}

Page 12940 


\begin{tabular}{|c|c|c|c|c|c|}
\hline & & \multicolumn{4}{|c|}{ Supplemental Table S2.txt } \\
\hline CHEMBL1321065 & 688574 & 2.4559 & 2.4233 & TST & \\
\hline CHEMBL1597633 & 688574 & 2.4559 & 2.5144 & TRN & \\
\hline CHEMBL1594367 & 688574 & 2.4559 & 2.3843 & TRN & \\
\hline CHEMBL1458314 & 688574 & 5.0619 & 2.8505 & TRN & \\
\hline CHEMBL1466064 & 688574 & 2.4559 & 2.4099 & TRN & \\
\hline CHEMBL3196374 & 688574 & 2.4559 & 3.1187 & TRN & \\
\hline CHEMBL1541658 & 688574 & 2.4559 & 2.1956 & TST & \\
\hline CHEMBL1491192 & 688574 & 2.4559 & 2.7672 & TST & \\
\hline CHEMBL1321526 & 688574 & 2.4559 & 2.4834 & TRN & \\
\hline CHEMBL1345825 & 688574 & 2.4559 & 2.733 & TRN & \\
\hline CHEMBL1990959 & 688574 & 3.7796 & 4.1072 & TRN & \\
\hline CHEMBL1519141 & 688574 & 2.4559 & 2.5759 & TRN & \\
\hline CHEMBL3196499 & 688574 & 3.5203 & 4.2443 & TRN & \\
\hline CHEMBL1606291 & 688574 & 5.0644 & 5.3887 & TRN & \\
\hline CHEMBL3198765 & 688574 & 4.7568 & 4.0958 & TRN & \\
\hline CHEMBL1458299 & 688574 & 2.4559 & 2.4563 & TST & \\
\hline CHEMBL1326664 & 688574 & 2.4559 & 2.4111 & TRN & \\
\hline CHEMBL1488450 & 688574 & 5.0942 & 4.0889 & TRN & \\
\hline CHEMBL1609234 & 688574 & 2.4559 & 2.4702 & TRN & \\
\hline CHEMBL1480983 & 688574 & 4.9993 & 2.7536 & TRN & \\
\hline CHEMBL3145071 & 688574 & 2.4559 & 2.6129 & TRN & \\
\hline CHEMBL1532722 & 688574 & 2.4559 & 2.5247 & TRN & \\
\hline CHEMBL1558381 & 688574 & 2.4559 & 2.5317 & TRN & \\
\hline CHEMBL3197396 & 688574 & 2.4559 & 4.1339 & TRN & \\
\hline CHEMBL1323688 & 688574 & 2.4559 & 2.5641 & TRN & \\
\hline CHEMBL1326294 & 688574 & 2.4559 & 3.4763 & TRN & \\
\hline CHEMBL1516347 & 688574 & 2.4559 & 2.4831 & TST & \\
\hline CHEMBL1520050 & 688574 & 2.4559 & 2.7573 & TST & \\
\hline CHEMBL1381877 & 688574 & 2.4559 & 2.4265 & TRN & \\
\hline CHEMBL1524026 & 688574 & 2.4559 & 2.6664 & TRN & \\
\hline CHEMBL1563339 & 688574 & 2.4559 & 2.4203 & TRN & \\
\hline CHEMBL3194213 & 688574 & 4.0372 & 3.7626 & TRN & \\
\hline CHEMBL3192306 & 688574 & 2.4559 & 3.3571 & TRN & \\
\hline CHEMBL3193308 & 688574 & 2.4559 & 2.8601 & TRN & \\
\hline CHEMBL1322059 & 688574 & 2.4559 & 2.3984 & TRN & \\
\hline CHEMBL1348657 & 688574 & 2.4559 & 2.5103 & TRN & \\
\hline CHEMBL1526751 & 688574 & 2.4559 & 2.8906 & TRN & \\
\hline CHEMBL1366987 & 688574 & 2.4559 & 3.2223 & TST & \\
\hline CHEMBL1307871 & 688574 & 2.4559 & 2.4389 & TRN & \\
\hline CHEMBL578467 & 688574 & 2.4559 & 2.2936 & TRN & \\
\hline CHEMBL1543723 & 688574 & 2.4559 & 2.5374 & TRN & \\
\hline CHEMBL1411600 & 688574 & 2.4559 & 2.5705 & TST & \\
\hline CHEMBL3199483 & 688574 & 2.4559 & 3.4818 & TRN & \\
\hline CHEMBL1487460 & 688574 & 2.4559 & 2.64899 & 99999999996 & TRN \\
\hline CHEMBL1563912 & 688574 & 2.4559 & 2.5317 & TRN & \\
\hline CHEMBL1455216 & 688574 & 2.4559 & 2.3685 & TRN & \\
\hline CHEMBL1367353 & 688574 & 2.4559 & 2.5319 & TRN & \\
\hline CHEMBL3195531 & 688574 & 4.6141 & 3.9284 & TRN & \\
\hline
\end{tabular}




\begin{tabular}{|c|c|c|c|c|c|c|}
\hline & & \multicolumn{5}{|c|}{ Supplemental Table S2.txt } \\
\hline CHEMBL1606682 & 688574 & 2.4559 & 2.6526 & TRN & & \\
\hline CHEMBL1330307 & 688574 & 5.0043 & 5.2225 & TRN & & \\
\hline CHEMBL1598785 & 688574 & 5.1691 & 5.70799 & 9999999 & 99 & TRN \\
\hline CHEMBL1570765 & 688574 & 2.4559 & 3.5209 & TRN & & \\
\hline CHEMBL1376176 & 688574 & 2.4559 & 2.3359 & TRN & & \\
\hline CHEMBL3199286 & 688574 & 5.2689 & 4.7669 & TRN & & \\
\hline CHEMBL3210442 & 688574 & 2.4559 & 2.5646 & TST & & \\
\hline CHEMBL1492717 & 688574 & 2.4559 & 2.3893 & TST & & \\
\hline CHEMBL1485106 & 688574 & 2.4559 & 2.3116 & TRN & & \\
\hline CHEMBL1338677 & 688574 & 5.1509 & 4.3527 & TRN & & \\
\hline CHEMBL3192035 & 688574 & $5.1270 e$ & 00000000 & & 4.115 & TRN \\
\hline CHEMBL1382534 & 688574 & 2.4559 & 2.3292 & TST & & \\
\hline CHEMBL1581904 & 688574 & 2.4559 & 2.4074 & TRN & & \\
\hline CHEMBL1612663 & 688574 & 2.4559 & 2.6116 & TST & & \\
\hline CHEMBL1384437 & 688574 & 2.4559 & 3.3417 & TRN & & \\
\hline CHEMBL1351145 & 688574 & 2.4559 & 2.8923 & TRN & & \\
\hline CHEMBL546170 & 688574 & 4.1904 & 3.9402 & TRN & & \\
\hline CHEMBL1454825 & 688574 & 2.4559 & 2.6314 & TRN & & \\
\hline CHEMBL1585920 & 688574 & 2.4559 & 2.3816 & TRN & & \\
\hline CHEMBL1314676 & 688574 & 2.4559 & 2.3672 & TRN & & \\
\hline CHEMBL585827 & 688574 & 5.1106 & 5.6409 & TRN & & \\
\hline CHEMBL1443339 & 688574 & 2.4559 & 2.2856 & TRN & & \\
\hline CHEMBL199868 & 688574 & 4.9861 & 4.5691 & TRN & & \\
\hline CHEMBL1359577 & 688574 & 2.4559 & 2.9356 & TRN & & \\
\hline CHEMBL3189519 & 688574 & 5.1928 & 4.4757 & TRN & & \\
\hline CHEMBL600862 & 688574 & $5.5120 e$ & 00000000 & 205 & 5.73 & TRN \\
\hline CHEMBL1526469 & 688574 & 2.4559 & 2.8552 & TRN & & \\
\hline CHEMBL1373096 & 688574 & 5.1465 & 6.0316 & TRN & & \\
\hline CHEMBL1389695 & 688574 & 2.4559 & 2.5223 & TRN & & \\
\hline CHEMBL1990786 & 688574 & 4.9479 & 4.0798 & TRN & & \\
\hline CHEMBL400912 & 688574 & 4.8171 & 4.0111 & TRN & & \\
\hline CHEMBL 2006168 & 688574 & 5.0897 & 3.8753 & TRN & & \\
\hline CHEMBL1332756 & 688574 & 5.3063 & 5.5687 & TRN & & \\
\hline CHEMBL1573551 & 688574 & 2.4559 & 2.2631 & TRN & & \\
\hline CHEMBL3191831 & 688574 & 4.939 & 4.2227 & TRN & & \\
\hline CHEMBL591412 & 688574 & 5.1046 & 5.306 & TRN & & \\
\hline CHEMBL3197343 & 688574 & 2.4559 & 3.8943 & TRN & & \\
\hline CHEMBL1993194 & 688574 & 5.2434 & 4.6914 & TRN & & \\
\hline CHEMBL3210964 & 688574 & 2.4559 & 2.8937 & TRN & & \\
\hline CHEMBL1456267 & 688574 & 2.4559 & 2.5832 & TRN & & \\
\hline CHEMBL1511713 & 688574 & 2.4559 & 2.9377 & TRN & & \\
\hline CHEMBL1533979 & 688574 & 2.4559 & 2.4759 & TRN & & \\
\hline CHEMBL3208249 & 688574 & 4.944 & 3.5174 & TRN & & \\
\hline CHEMBL1432409 & 688574 & 2.4559 & 2.784 & TRN & & \\
\hline CHEMBL1451278 & 688574 & 2.4559 & 2.6577 & TRN & & \\
\hline CHEMBL1583715 & 688574 & 2.4559 & 2.8455 & TRN & & \\
\hline CHEMBL1536986 & 688574 & 2.4559 & 2.4405 & TRN & & \\
\hline CHEMBL1514530 & 688574 & 5.4186 & 5.8727 & TRN & & \\
\hline
\end{tabular}


Supplemental Table S2.txt

\begin{tabular}{|c|c|c|c|c|}
\hline . & & & & \\
\hline HEMBL1451784 & 88574 & .4559 & 2.5367 & \\
\hline & 574 & & & \\
\hline FMRI 14 & 8574 & & 52 & \\
\hline AEMBL3189342 & 88574 & & 5191 & \\
\hline AEMBL1350475 & 88574 & 559 & .5056 & \\
\hline HEMBL14 & 88574 & & 6904 & \\
\hline AEMBL15 & 3574 & & 2973 & \\
\hline IEMBL 14 & 88574 & & .7188 & \\
\hline HEMBL1366411 & 88574 & & .48 & \\
\hline HEMBL146 & 88574 & & 2591 & \\
\hline IEMBL136 & 88574 & & .7918 & \\
\hline AEMBL13 & & & & \\
\hline HEMBL 31 & 88574 & & 4.0333 & \\
\hline IEMBL14] & 88574 & & & \\
\hline AEMBL137 & 88574 & & & \\
\hline HEMBL 31 & 38574 & & 72 & \\
\hline HEMBL 54 & 8574 & & & \\
\hline HEMBL15 & 88574 & & & \\
\hline AEMBL14 & 38574 & & & RN \\
\hline 化IBLL 19 & 88574 & & 58 & MIV \\
\hline HEMBL14 & 38574 & & & \\
\hline HEMBL15 & 8574 & & & RN \\
\hline 37 & 38574 & & & RN \\
\hline AEMBL157 & 8574 & & & RIV \\
\hline AEMBL13 & 38574 & & 3 . & RN \\
\hline AEM & 8574 & & 49 & - \\
\hline 3 & 74 & & & RN \\
\hline AEMBL13 & 38574 & & & RIN \\
\hline JEMBL15 & 38574 & & 08 & RIN \\
\hline AEMBL13 & 38574 & & 158 & RN \\
\hline AFMRI 17 & 8574 & & 48 & RN \\
\hline 5 & & & & RN \\
\hline HEMBL159 & & & & RN \\
\hline HEMBL158 & 88574 & & 2. & RN \\
\hline HEMBL1C & 88574 & & 2. & \\
\hline HEMDI 1 & 74 & & & RN \\
\hline 39 & 74 & & & IRN \\
\hline HEMBL3198554 & 88574 & & 3.9042 & TRN \\
\hline HEMBL15 & 88574 & & 2.4 & RN \\
\hline HEMBL14 & 88574 & & 2.3366 & 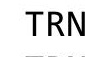 \\
\hline HEMBL13 & & & & RN \\
\hline HEMBL15 & 88574 & & 4.4964 & TRN \\
\hline HEMBL1600263 & 88574 & & 2.505 & TST \\
\hline L13 & 88574 & & 2.2462 & In \\
\hline HEMBL15 & 688574 & & 2.6687 & \\
\hline CHEMBL135 & 688574 & & 2.2245 & \\
\hline CHEMBL600778 & 688574 & 5.3374 & 6.0805 & \\
\hline
\end{tabular}

Page 12943 


\begin{tabular}{|c|c|c|c|c|c|}
\hline \multicolumn{6}{|c|}{ Supplemental Table S2.txt } \\
\hline CHEMBL1547019 & 688574 & 2.4559 & 2.7791 & TRN & \\
\hline CHEMBL1549214 & 688574 & 3.8435 & 2.3356 & TRN & \\
\hline CHEMBL528694 & 688574 & 5.5043 & 4.1561 & TRN & \\
\hline CHEMBL1570492 & 688574 & 2.4559 & 1.9686 & TRN & \\
\hline CHEMBL3190720 & 688574 & 4.8919 & 3.9667 & TRN & \\
\hline CHEMBL1581367 & 688574 & 2.4559 & 2.8012 & TRN & \\
\hline CHEMBL1580858 & 688574 & 2.4559 & 2.3406 & TRN & \\
\hline CHEMBL3192021 & 688574 & 3.7645 & 3.7974 & TRN & \\
\hline CHEMBL1534503 & 688574 & 2.4559 & 2.6488 & TRN & \\
\hline CHEMBL1309127 & 688574 & 5.0141 & 4.1443 & TRN & \\
\hline CHEMBL1342139 & 688574 & 2.4559 & 2.6695 & TRN & \\
\hline CHEMBL1548290 & 688574 & 2.4559 & 2.5703 & TST & \\
\hline CHEMBL530499 & 688574 & 4.6132 & 5.06 & TRN & \\
\hline CHEMBL1543918 & 688574 & 4.1135 & 2.7233 & TRN & \\
\hline CHEMBL1527311 & 688574 & 2.4559 & 2.4886 & TRN & \\
\hline CHEMBL1411542 & 688574 & 4.9285 & 2.6861 & TRN & \\
\hline CHEMBL1570335 & 688574 & 2.4559 & 2.46599 & 99999999997 & TST \\
\hline CHEMBL1456520 & 688574 & 2.4559 & 2.7247 & TRN & \\
\hline CHEMBL1500552 & 688574 & 2.4559 & 2.1976 & TRN & \\
\hline CHEMBL1329160 & 688574 & 2.4559 & 2.6062 & TST & \\
\hline CHEMBL1333939 & 688574 & 2.4559 & 2.8147 & TRN & \\
\hline CHEMBL1327979 & 688574 & 2.4559 & 2.7006 & TST & \\
\hline CHEMBL1516498 & 688574 & 2.4559 & 2.7677 & TRN & \\
\hline CHEMBL1520801 & 688574 & 2.4559 & 2.4264 & TRN & \\
\hline CHEMBL1993522 & 688574 & 5.0322 & 3.3592 & TRN & \\
\hline CHEMBL1091556 & 688574 & 3.9859 & 4.4142 & TRN & \\
\hline CHEMBL1571994 & 688574 & 2.4559 & 2.5783 & TRN & \\
\hline CHEMBL1502992 & 688574 & 2.4559 & 2.5086 & TST & \\
\hline CHEMBL3207319 & 688574 & 2.4559 & 2.6416 & TRN & \\
\hline CHEMBL1359902 & 688574 & 2.4559 & 3.0893 & TRN & \\
\hline CHEMBL578675 & 688574 & 4.7059 & 3.5221 & TRN & \\
\hline CHEMBL1489081 & 688574 & 4.8717 & 3.7266 & TRN & \\
\hline CHEMBL3212954 & 688574 & 2.4559 & 2.924 & TST & \\
\hline CHEMBL3197127 & 688574 & 4.9948 & 4.1832 & TRN & \\
\hline CHEMBL1329129 & 688574 & 4.9793 & 4.03100 & 0000000001 & TRN \\
\hline CHEMBL1299877 & 688574 & 2.4559 & 2.5862 & TST & \\
\hline CHEMBL1430971 & 688574 & 2.4559 & 2.3032 & TRN & \\
\hline CHEMBL1582437 & 688574 & 2.4559 & 2.6436 & TRN & \\
\hline CHEMBL1307630 & 688574 & 2.4559 & 2.5811 & TRN & \\
\hline CHEMBL1304318 & 688574 & 2.4559 & 2.4804 & TST & \\
\hline CHEMBL1587868 & 688574 & 2.4559 & 2.5669 & TRN & \\
\hline CHEMBL602218 & 688574 & 5.0679 & 4.5659 & TRN & \\
\hline CHEMBL1443662 & 688574 & 2.4559 & 2.2659 & TRN & \\
\hline CHEMBL1601133 & 688574 & 4.7817 & 5.4018 & TRN & \\
\hline CHEMBL3195688 & 688574 & 5.3361 & 4.3616 & TRN & \\
\hline CHEMBL1341116 & 688574 & 2.4559 & 2.6349 & TRN & \\
\hline CHEMBL1575152 & 688574 & 2.4559 & 2.6382 & TRN & \\
\hline CHEMBL1400933 & 688574 & 2.4559 & 2.5215 & TRN & \\
\hline
\end{tabular}




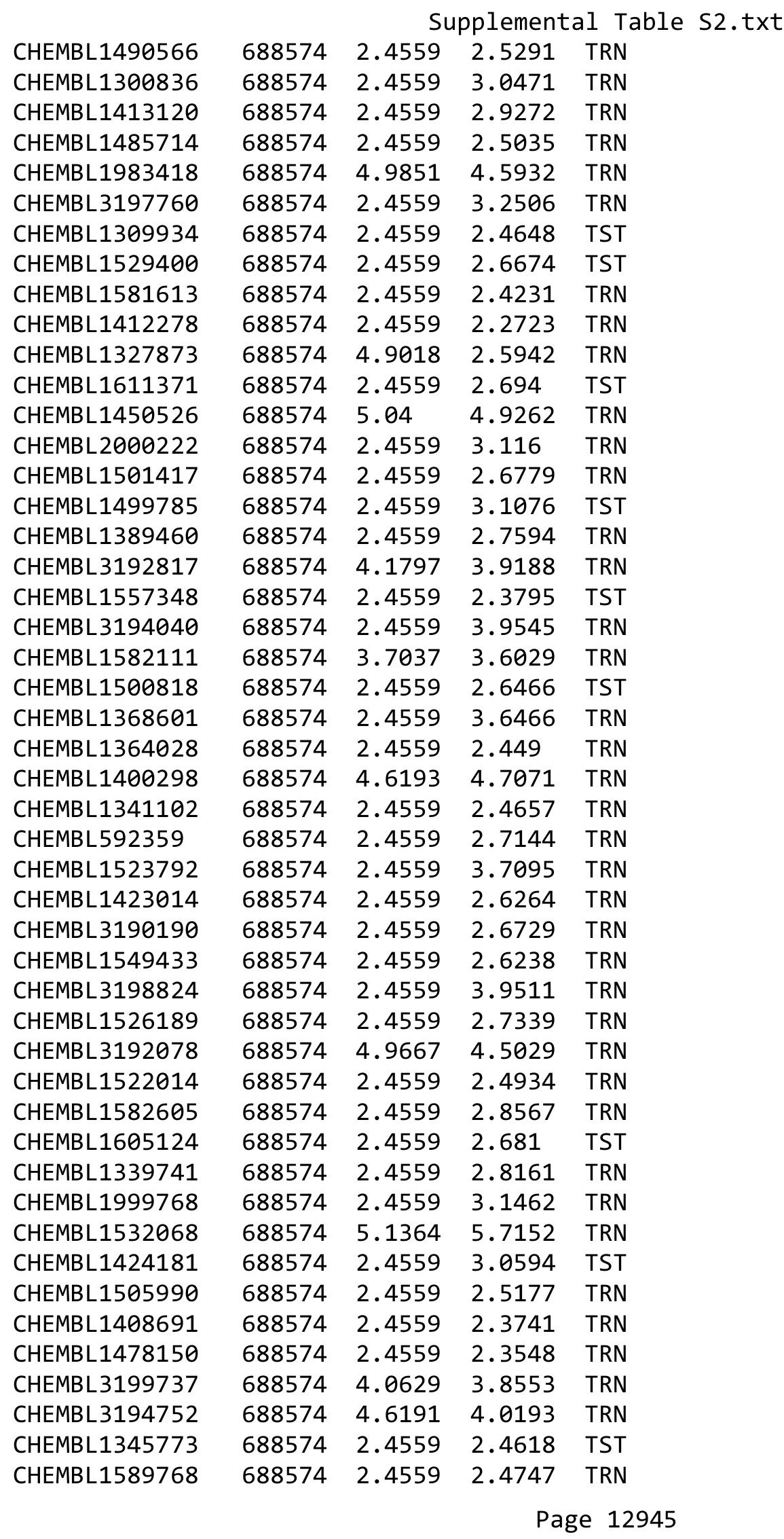




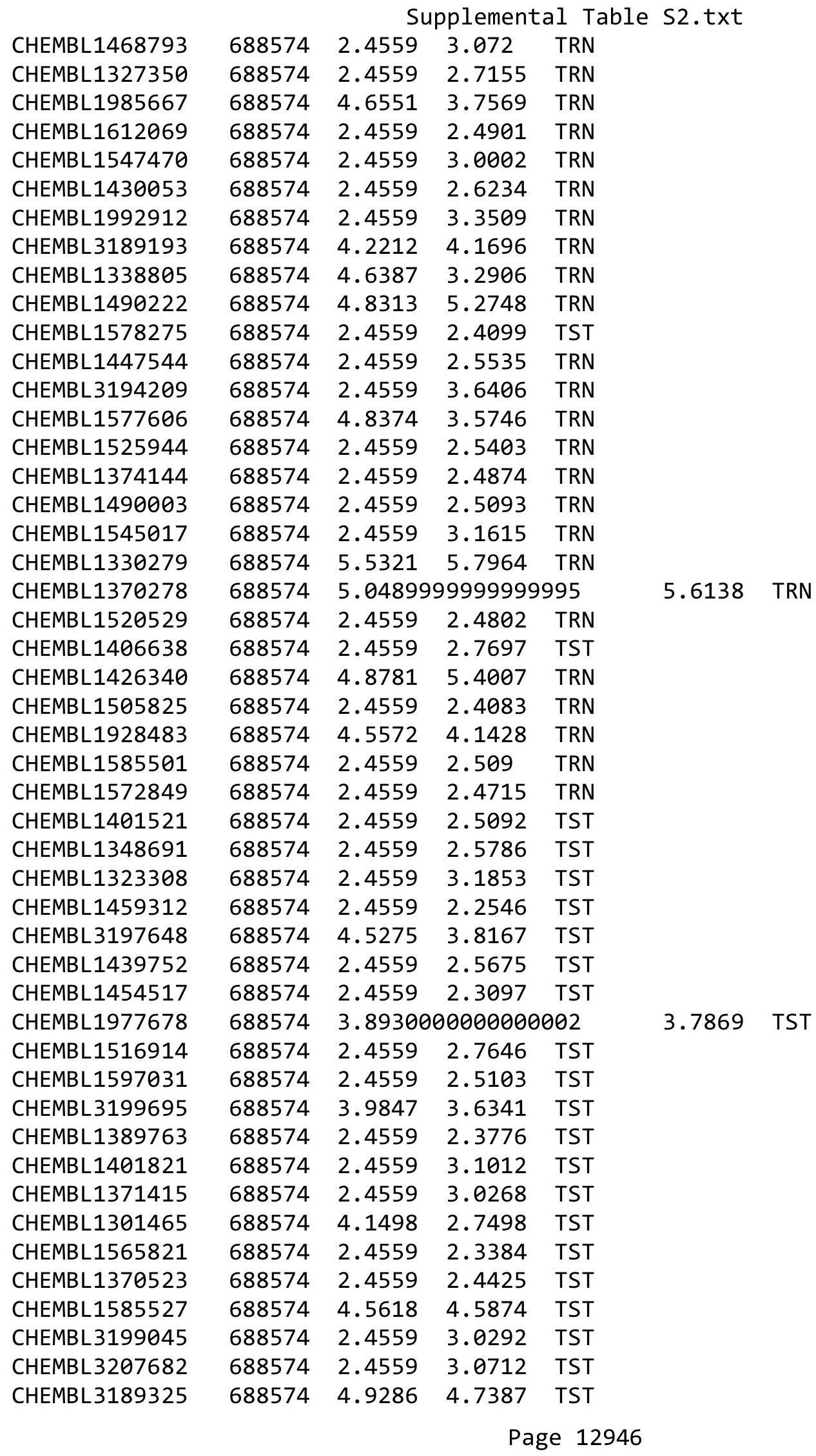


Supplemental Table S2.txt

\begin{tabular}{|c|c|c|c|c|}
\hline CHEMBL1588691 & 688574 & 2.4559 & 2.5353 & TST \\
\hline CHEMBL1453106 & 688574 & 2.4559 & 2.309 & TST \\
\hline CHEMBL1416015 & 688574 & 2.4559 & 2.3157 & TST \\
\hline CHEMBL1299757 & 688574 & 4.8564 & 3.7192 & TST \\
\hline CHEMBL1583292 & 688574 & 3.8646 & 3.6204 & TST \\
\hline CHEMBL 3198618 & 688574 & 4.9637 & 4.1792 & TST \\
\hline CHEMBL1703678 & 688574 & 2.4559 & 3.207 & TST \\
\hline CHEMBL1372201 & 688574 & 2.4559 & 2.802 & TST \\
\hline CHEMBL1579117 & 688574 & 2.4559 & 2.8731 & TST \\
\hline CHEMBL1573077 & 688574 & 2.4559 & 2.4563 & TST \\
\hline CHEMBL1511422 & 688574 & 2.4559 & $2.45300 e$ & 0000000003 \\
\hline CHEMBL1603830 & 688574 & 3.6553 & 3.4731 & TST \\
\hline CHEMBL1508033 & 688574 & 2.4559 & 2.9631 & TST \\
\hline CHEMBL1448282 & 688574 & 5.3664 & $5.65600 e$ & 000000001 \\
\hline CHEMBL1534781 & 688574 & 5.0835 & 3.3958 & TST \\
\hline CHEMBL1513446 & 688574 & 2.4559 & 2.4708 & TST \\
\hline CHEMBL1321544 & 688574 & 2.4559 & 2.4343 & TST \\
\hline CHEMBL1994963 & 688574 & 2.4559 & 4.439 & TST \\
\hline CHEMBL1507897 & 688574 & 2.4559 & 2.8106 & TST \\
\hline CHEMBL1387740 & 688574 & 2.4559 & 2.5236 & TST \\
\hline CHEMBL3196191 & 688574 & 2.4559 & 4.3783 & TST \\
\hline CHEMBL 3189827 & 688574 & 2.4559 & 3.5841 & TST \\
\hline CHEMBL104732 & 688574 & 2.4559 & 2.2808 & TST \\
\hline CHEMBL1496452 & 688574 & 2.4559 & 2.7148 & TST \\
\hline CHEMBL1995169 & 688574 & 2.4559 & 3.1995 & TST \\
\hline CHEMBL1996068 & 688574 & 2.4559 & 3.6982 & TST \\
\hline CHEMBL1381193 & 688574 & 2.4559 & 2.5026 & TST \\
\hline CHEMBL1489617 & 688574 & 2.4559 & 2.3794 & TST \\
\hline CHEMBL1588483 & 688574 & 2.4559 & 3.046999 & 9999999997 \\
\hline CHEMBL1386026 & 688574 & 2.4559 & 2.4287 & TST \\
\hline CHEMBL1471510 & 688574 & 2.4559 & 2.3144 & TST \\
\hline CHEMBL1444563 & 688574 & 2.4559 & 2.4836 & TST \\
\hline CHEMBL1571031 & 688574 & 2.4559 & 2.4884 & TST \\
\hline CHEMBL1559183 & 688574 & 2.4559 & 2.3734 & TST \\
\hline CHEMBL1559260 & 688574 & 2.4559 & 2.904 & TST \\
\hline CHEMBL1399035 & 688574 & 4.8942 & 3.5524 & TST \\
\hline CHEMBL1527460 & 688574 & 2.4559 & 2.8347 & TST \\
\hline CHEMBL1344700 & 688574 & 2.4559 & 2.4341 & TST \\
\hline CHEMBL1598129 & 688574 & 2.4559 & 2.4099 & TST \\
\hline CHEMBL1344163 & 688574 & 2.4559 & 2.4196 & TST \\
\hline CHEMBL1334272 & 688574 & 2.4559 & 2.72 & TST \\
\hline CHEMBL1420020 & 688574 & 2.4559 & 2.396 & TST \\
\hline CHEMBL1506745 & 688574 & 2.4559 & 2.1897 & TST \\
\hline CHEMBL1514091 & 688574 & 2.4559 & 2.6486 & TST \\
\hline CHEMBL1483037 & 688574 & 2.4559 & 3.0618 & TST \\
\hline CHEMBL1500265 & 688574 & 4.9262 & 4.9609 & TST \\
\hline CHEMBL1522584 & 688574 & 2.4559 & 2.2435 & TST \\
\hline CHEMBL1503200 & 688574 & 2.4559 & 2.758 & TST \\
\hline
\end{tabular}


Supplemental Table S2.txt

\begin{tabular}{|c|c|c|c|c|c|}
\hline CHEMBL1531992 & 688574 & 2.4559 & 2.675 & TST & \\
\hline CHEMBL1377376 & 688574 & 2.4559 & 3.1735 & TST & \\
\hline CHEMBL1878966 & 688574 & 2.4559 & 3.1239 & TST & \\
\hline CHEMBL1557680 & 688574 & 2.4559 & 2.4874 & TST & \\
\hline CHEMBL1431944 & 688574 & 2.4559 & 2.8937 & TST & \\
\hline CHEMBL1478971 & 688574 & 2.4559 & 2.7412 & TST & \\
\hline CHEMBL86104 & 688574 & 5.1654 & 4.7793 & TST & \\
\hline CHEMBL3193596 & 688574 & 2.4559 & 2.9871 & TST & \\
\hline CHEMBL1428692 & 688574 & 2.4559 & 2.6111 & TST & \\
\hline CHEMBL3194449 & 688574 & 5.1555 & 4.2901 & TST & \\
\hline CHEMBL1601296 & 688574 & 2.4559 & 2.5756 & TST & \\
\hline CHEMBL591876 & 688574 & 5.1258 & 5.6955 & TST & \\
\hline CHEMBL3194061 & 688574 & 2.4559 & 3.3997 & TST & \\
\hline CHEMBL1421893 & 688574 & 2.4559 & 2.6644 & TST & \\
\hline CHEMBL1352060 & 688574 & 2.4559 & 2.6136 & TST & \\
\hline CHEMBL1326110 & 688574 & 2.4559 & 2.6175 & TST & \\
\hline CHEMBL1305094 & 688574 & 2.4559 & 2.5008 & TST & \\
\hline CHEMBL1597655 & 688574 & 5.3347 & 4.5093 & TST & \\
\hline CHEMBL1326504 & 688574 & 2.4559 & 2.3376 & TST & \\
\hline CHEMBL1533242 & 688574 & 2.4559 & 2.8687 & TST & \\
\hline CHEMBL3191874 & 688574 & 2.4559 & 3.4131 & TST & \\
\hline CHEMBL1390364 & 688574 & 2.4559 & 2.8809 & TST & \\
\hline CHEMBL1382596 & 688574 & 2.4559 & 2.6017 & TST & \\
\hline CHEMBL534244 & 688574 & 2.4559 & 2.8568 & TST & \\
\hline CHEMBL1402114 & 688574 & 2.4559 & 2.2158 & TST & \\
\hline CHEMBL1501587 & 688574 & 2.4559 & 2.3713 & TST & \\
\hline CHEMBL1433072 & 688574 & 2.4559 & 2.72 & TST & \\
\hline CHEMBL1580671 & 688574 & 2.4559 & 3.3347 & TST & \\
\hline CHEMBL1585206 & 688574 & 2.4559 & 2.5995 & TST & \\
\hline CHEMBL1318882 & 688574 & 2.4559 & 2.7259 & TST & \\
\hline CHEMBL1574317 & 688574 & 2.4559 & 2.6553 & TST & \\
\hline CHEMBL1979295 & 688574 & 2.4559 & 2.9075 & TST & \\
\hline CHEMBL1466751 & 688574 & 2.4559 & 2.9082 & TST & \\
\hline CHEMBL1330077 & 688574 & 2.4559 & 2.60399 & 99999999996 & TST \\
\hline CHEMBL1596072 & 688574 & 4.0036 & 3.2853 & TST & \\
\hline CHEMBL3211923 & 688574 & 2.4559 & 3.5523 & TST & \\
\hline CHEMBL1434383 & 688574 & 2.4559 & 2.79600 & 00000000003 & TST \\
\hline CHEMBL1493490 & 688574 & 4.5565 & 3.7312 & TST & \\
\hline CHEMBL1423935 & 688574 & 4.8964 & 3.8158 & TST & \\
\hline CHEMBL3194301 & 688574 & 2.4559 & 3.0783 & TST & \\
\hline CHEMBL1484284 & 688574 & 2.4559 & 2.6307 & TST & \\
\hline CHEMBL1967081 & 688574 & 2.4559 & 4.0605 & TST & \\
\hline CHEMBL1442895 & 688574 & 2.4559 & 2.4551 & TST & \\
\hline CHEMBL 2002849 & 688574 & 4.5905 & 4.0485 & TST & \\
\hline CHEMBL1613672 & 688574 & 2.4559 & 2.3871 & TST & \\
\hline CHEMBL1489177 & 688574 & 2.4559 & 2.4281 & TST & \\
\hline CHEMBL1309853 & 688574 & 2.4559 & 2.5416 & TST & \\
\hline CHEMBL1330749 & 688574 & 2.4559 & 3.1525 & TST & \\
\hline
\end{tabular}


Supplemental Table S2.txt

\begin{tabular}{|c|c|c|c|c|}
\hline CHEMBL1584074 & 688574 & 2.4559 & 2.3151 & TST \\
\hline CHEMBL1446214 & 688574 & 2.4559 & 2.5701 & TST \\
\hline CHEMBL1368680 & 688574 & 2.4559 & 2.6463 & TST \\
\hline CHEMBL3193847 & 688574 & 2.4559 & 3.125 & TST \\
\hline CHEMBL1392959 & 688574 & 2.4559 & 2.5552 & TST \\
\hline CHEMBL1405454 & 688574 & 2.4559 & 2.7414 & TST \\
\hline CHEMBL3194964 & 688574 & 2.4559 & 4.28 & TST \\
\hline CHEMBL1473419 & 688574 & 2.4559 & 3.0107 & TST \\
\hline CHEMBL1536972 & 688574 & 2.4559 & 2.6078 & TST \\
\hline CHEMBL1602826 & 688574 & 2.4559 & 2.4622 & TST \\
\hline CHEMBL1582999 & 688574 & 2.4559 & 3.1518 & TST \\
\hline CHEMBL1987419 & 688574 & 2.4559 & 3.983 & TST \\
\hline CHEMBL1333685 & 688574 & 2.4559 & 2.8147 & TST \\
\hline CHEMBL1435474 & 688574 & 2.4559 & 2.6651 & TST \\
\hline CHEMBL1454024 & 688574 & 2.4559 & 2.4622 & TST \\
\hline CHEMBL1300409 & 688574 & 2.4559 & 2.1311 & TST \\
\hline CHEMBL1462239 & 688574 & 2.4559 & 2.8448 & TST \\
\hline CHEMBL1569147 & 688574 & 2.4559 & 2.3406 & TST \\
\hline CHEMBL1311879 & 688574 & 2.4559 & 4.6215 & TST \\
\hline CHEMBL1582032 & 688574 & 2.4559 & 2.8318 & TST \\
\hline CHEMBL1372800 & 688574 & 2.4559 & 2.6706 & TST \\
\hline CHEMBL547285 & 688574 & 5.1978 & 5.7666 & TST \\
\hline CHEMBL3208038 & 688574 & 2.4559 & 2.75699 & 99999999997 \\
\hline CHEMBL1401323 & 688574 & 2.4559 & 2.3389 & TST \\
\hline CHEMBL1405823 & 688574 & 2.4559 & 2.4682 & TST \\
\hline CHEMBL1509929 & 688574 & 2.4559 & 2.4244 & TST \\
\hline CHEMBL1337611 & 688574 & 2.4559 & 2.1895 & TST \\
\hline CHEMBL3210267 & 688574 & 4.6916 & 3.9944 & TST \\
\hline CHEMBL1568114 & 688574 & 2.4559 & 2.3767 & TST \\
\hline CHEMBL3199539 & 688574 & 4.3859 & 4.3295 & TST \\
\hline CHEMBL3196949 & 688574 & 4.4807 & 4.3958 & TST \\
\hline CHEMBL1446484 & 688574 & 2.4559 & 2.8846 & TST \\
\hline CHEMBL3214539 & 688574 & 2.4559 & 3.0726 & TST \\
\hline CHEMBL1405471 & 688574 & 2.4559 & 2.2861 & TST \\
\hline CHEMBL602718 & 688574 & 5.1408 & 5.2142 & TST \\
\hline CHEMBL3194778 & 688574 & 4.2918 & 3.7358 & TST \\
\hline CHEMBL1340821 & 688574 & 2.4559 & 2.4657 & TST \\
\hline CHEMBL1612985 & 688574 & 2.4559 & 2.2985 & TST \\
\hline CHEMBL3931533 & 1637324 & 8.73 & 8.6732 & TRN \\
\hline CHEMBL3947740 & 1637324 & 8.66 & 8.3815 & TRN \\
\hline CHEMBL3963816 & 1637324 & 7.32 & 7.6183 & TRN \\
\hline CHEMBL3909951 & 1637324 & 8.15 & 7.86600 & 00000000005 \\
\hline CHEMBL3912630 & 1637324 & 7.75 & 7.7978 & TRN \\
\hline CHEMBL3933449 & 1637324 & 8.47 & 8.3596 & TRN \\
\hline CHEMBL3898908 & 1637324 & 9.0 & 8.8638 & TST \\
\hline CHEMBL3986163 & 1637324 & 8.52 & 8.5021 & TRN \\
\hline CHEMBL 3898120 & 1637324 & 8.64 & 8.6341 & TRN \\
\hline CHEMBL3955288 & 1637324 & 8.55 & 8.6108 & TRN \\
\hline
\end{tabular}




\begin{tabular}{|c|c|c|c|c|c|}
\hline \multicolumn{6}{|c|}{ Supplemental Table s2.txt } \\
\hline CHEMBL 3957914 & 1637324 & 7.26 & 7.4651 & TRN & \\
\hline CHEMBL 3908978 & 1637324 & 6.22 & 6.0078 & TRN & \\
\hline CHEMBL3906155 & 1637324 & 8.45 & 8.4459 & TRN & \\
\hline CHEMBL 3940334 & 1637324 & 8.13 & 8.2455 & TRN & \\
\hline CHEMBL 3958153 & 1637324 & 8.95 & 8.9911 & TRN & \\
\hline CHEMBL 3925254 & 1637324 & 8.86 & 8.7145 & TRN & \\
\hline CHEMBL 3907600 & 1637324 & 8.55 & 8.6734 & TRN & \\
\hline CHEMBL3954368 & 1637324 & 7.39 & 7.4011 & TRN & \\
\hline CHEMBL 3951714 & 1637324 & 8.58 & 8.5676 & TRN & \\
\hline CHEMBL3965364 & 1637324 & 6.12 & 5.8979 & TRN & \\
\hline CHEMBL 3969446 & 1637324 & 9.01 & 8.8939 & TRN & \\
\hline CHEMBL 3951126 & 1637324 & 9.1 & 9.1446 & TRN & \\
\hline CHEMBL3933015 & 1637324 & 6.78 & 6.6302 & TRN & \\
\hline CHEMBL 3898881 & 1637324 & 8.97 & 8.9603 & TRN & \\
\hline CHEMBL3901644 & 1637324 & 8.29 & 8.469 & TRN & \\
\hline CHEMBL3944665 & 1637324 & 7.23 & 7.0486 & TST & \\
\hline CHEMBL3947293 & 1637324 & 7.53 & 7.5269 & TRN & \\
\hline CHEMBL3947826 & 1637324 & 7.08 & 6.665 & TST & \\
\hline CHEMBL 3985692 & 1637324 & 9.04 & 8.8432 & TST & \\
\hline CHEMBL3947990 & 1637324 & 8.2 & 8.2145 & TST & \\
\hline CHEMBL3925306 & 1637324 & 9.06 & 8.8473 & TRN & \\
\hline CHEMBL 3951245 & 1637324 & 9.15 & 8.8936 & TST & \\
\hline CHEMBL3948623 & 1637324 & 8.69 & 8.4525 & TRN & \\
\hline CHEMBL 3892018 & 1637324 & 8.49 & 8.4896 & TRN & \\
\hline CHEMBL 3987037 & 1637324 & 8.62 & 8.46600 & 0000000001 & TRN \\
\hline CHEMBL3921313 & 1637324 & 8.35 & 8.4423 & TRN & \\
\hline CHEMBL 3927327 & 1637324 & 8.95 & 8.7315 & TRN & \\
\hline CHEMBL3976280 & 1637324 & 8.64 & 8.8705 & TRN & \\
\hline CHEMBL 3973820 & 1637324 & 8.45 & 8.4831 & TRN & \\
\hline CHEMBL3918011 & 1637324 & 8.07 & 8.1644 & TRN & \\
\hline CHEMBL 3915235 & 1637324 & 8.21 & 8.2942 & TRN & \\
\hline CHEMBL 3965673 & 1637324 & 6.17 & 5.8767 & TRN & \\
\hline CHEMBL3968094 & 1637324 & 7.29 & 7.6554 & TRN & \\
\hline CHEMBL 3918751 & 1637324 & 8.93 & 8.988 & TRN & \\
\hline CHEMBL3956164 & 1637324 & 8.17 & 8.2246 & TRN & \\
\hline CHEMBL 3908829 & 1637324 & 8.54 & 8.6314 & TRN & \\
\hline CHEMBL3911573 & 1637324 & 8.68 & 8.7689 & TRN & \\
\hline CHEMBL3969879 & 1637324 & 7.77 & 7.8075 & TRN & \\
\hline CHEMBL 3972564 & 1637324 & 7.35 & 7.1223 & TRN & \\
\hline CHEMBL3927875 & 1637324 & 8.88 & 8.9031 & TRN & \\
\hline CHEMBL 3930634 & 1637324 & 7.22 & 7.3084 & TRN & \\
\hline CHEMBL3901627 & 1637324 & 8.79 & 8.6965 & TST & \\
\hline CHEMBL3904329 & 1637324 & 8.71 & 8.638 & TRN & \\
\hline CHEMBL3969408 & 1637324 & 6.06 & 5.6668 & TRN & \\
\hline CHEMBL3985853 & 1637324 & 8.76 & 8.702 & TRN & \\
\hline CHEMBL 3908326 & 1637324 & 8.75 & 8.5307 & TRN & \\
\hline CHEMBL3918092 & 1637324 & 8.73 & 8.8839 & TRN & \\
\hline CHEMBL3964675 & 1637324 & 8.75 & 8.5338 & TRN & \\
\hline
\end{tabular}




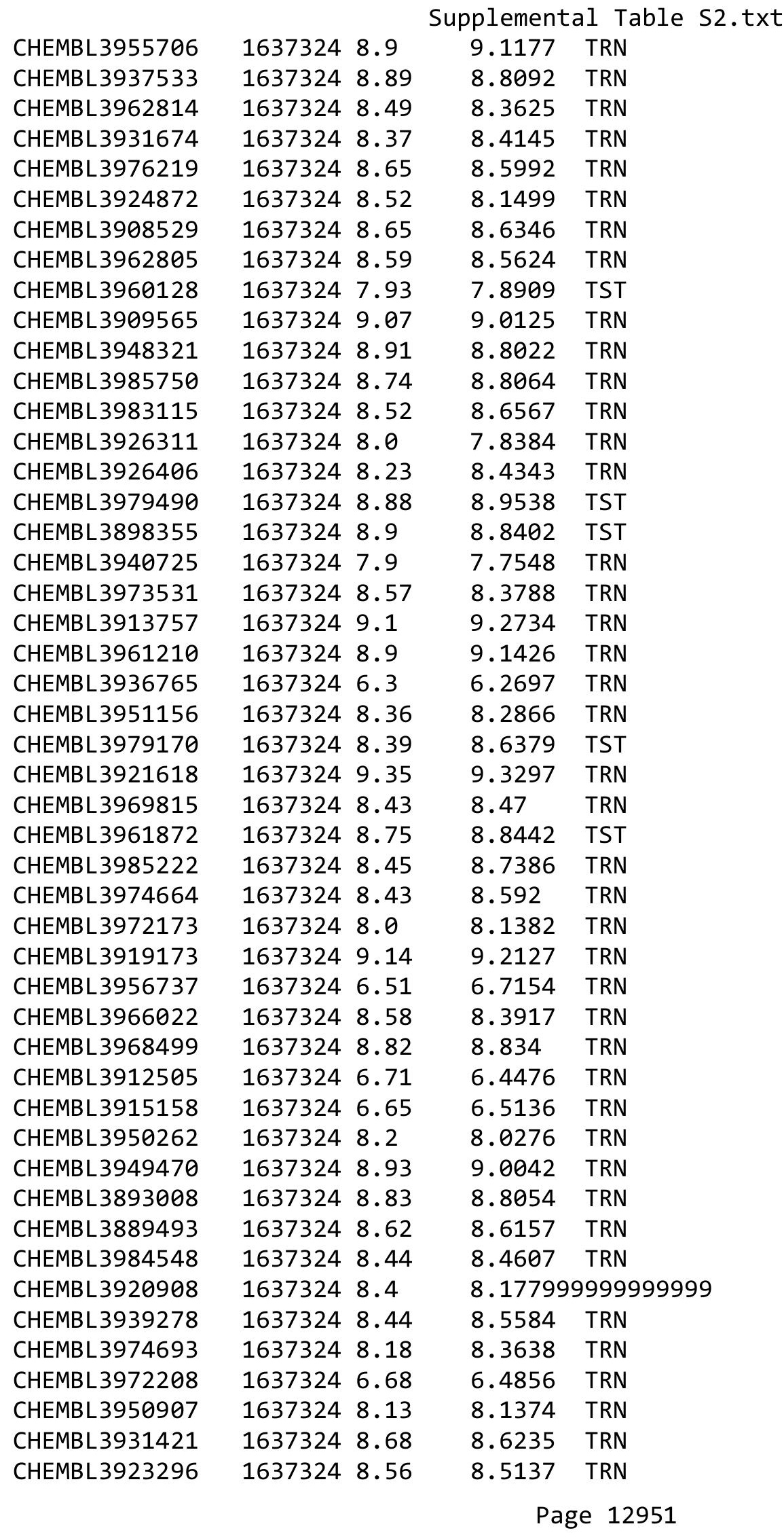




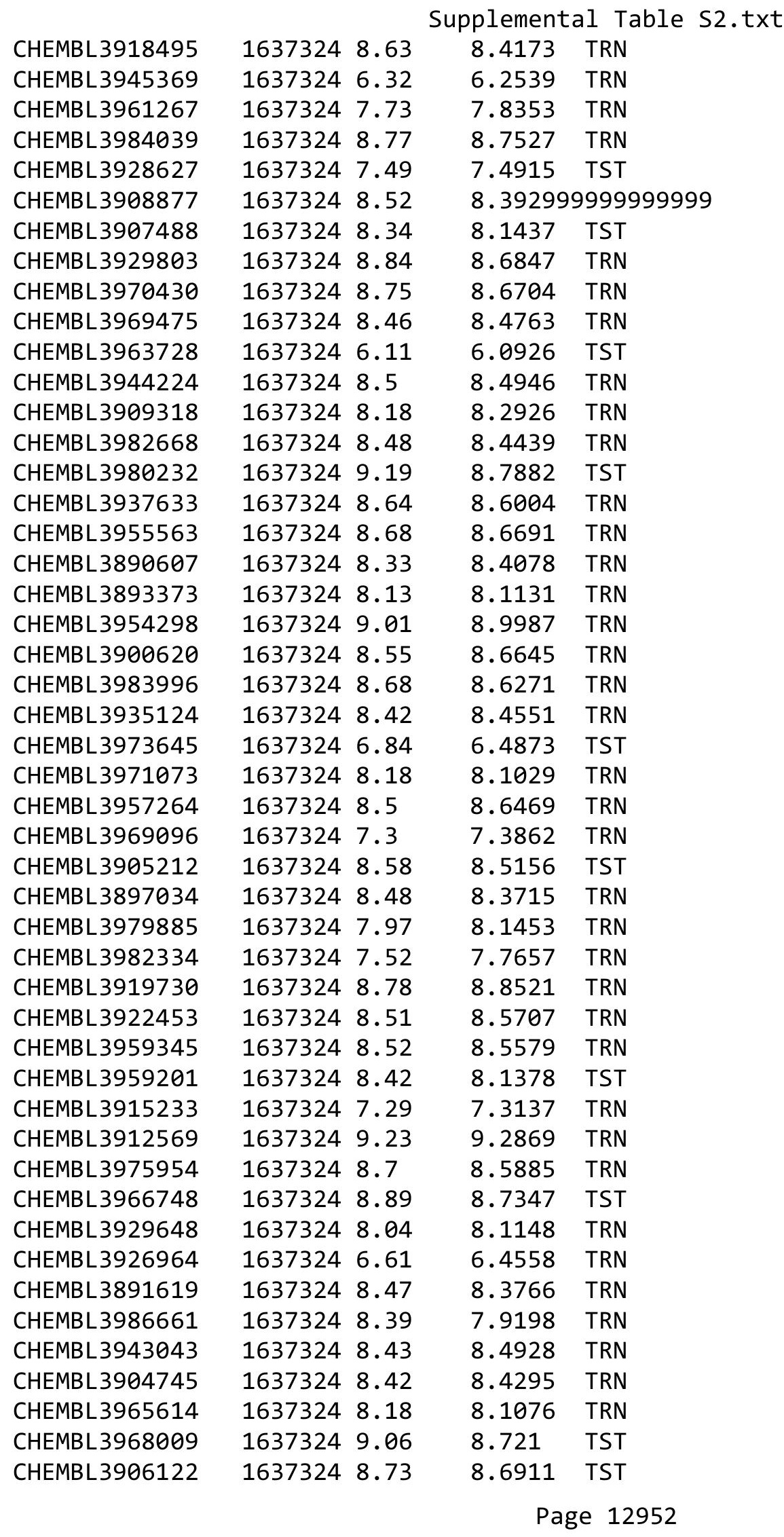




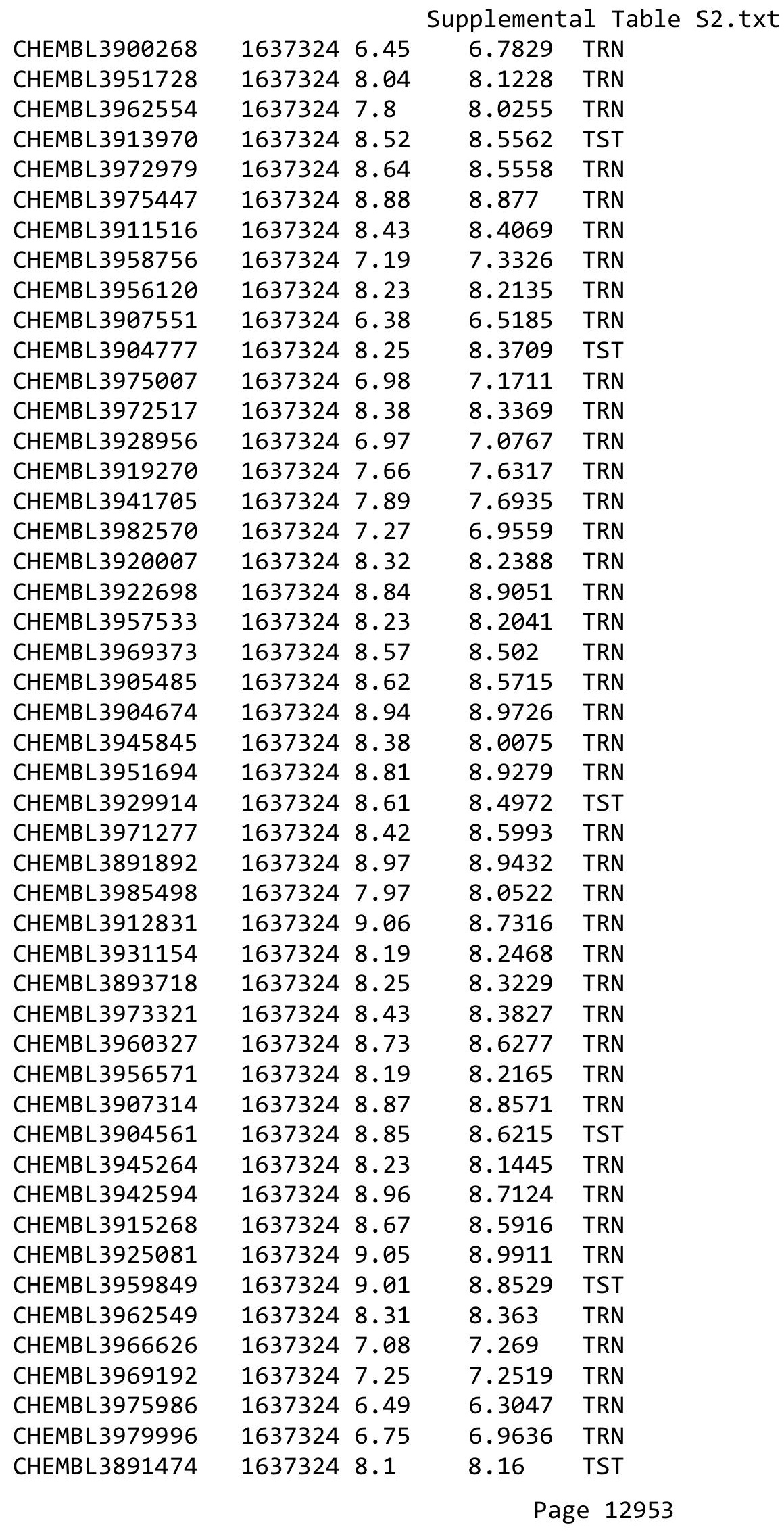


Supplemental Table S2.txt

\begin{tabular}{|c|c|c|c|c|}
\hline CHEMBL3892135 & 1637324 & 8.37 & 8.2958 & TRN \\
\hline CHEMBL3969824 & 1637324 & 8.27 & 8.2305 & TRN \\
\hline CHEMBL3932285 & 1637324 & 8.74 & 8.7459 & TRN \\
\hline CHEMBL3922586 & 1637324 & 8.81 & 8.8241 & TRN \\
\hline CHEMBL3901682 & 1637324 & 6.69 & 6.4693 & TRN \\
\hline CHEMBL3927733 & 1637324 & 8.38 & 8.4236 & TRN \\
\hline CHEMBL3976053 & 1637324 & 8.54 & 8.5277 & TST \\
\hline CHEMBL3973587 & 1637324 & 8.32 & 8.3278 & TRN \\
\hline CHEMBL3936828 & 1637324 & 8.5 & 8.5225 & TRN \\
\hline CHEMBL3934039 & 1637324 & 8.01 & 7.9989 & TRN \\
\hline CHEMBL3981418 & 1637324 & 8.52 & 8.55299 & \\
\hline CHEMBL3972694 & 1637324 & 7.99 & 7.9965 & TST \\
\hline CHEMBL3921457 & 1637324 & 8.94 & 8.7107 & TST \\
\hline CHEMBL3918739 & 1637324 & 8.71 & 8.5997 & TRN \\
\hline CHEMBL3968793 & 1637324 & 8.08 & 7.9674 & TRN \\
\hline CHEMBL3966305 & 1637324 & 8.88 & 8.72299 & 9999999999 \\
\hline CHEMBL3891115 & 1637324 & 6.8 & 6.2116 & TST \\
\hline CHEMBL3979662 & 1637324 & 6.4 & 6.13899 & 7999999999 \\
\hline CHEMBL 3983387 & 1637324 & 8.07 & 7.9878 & TST \\
\hline CHEMBL3986068 & 1637324 & 8.31 & 8.3046 & TRN \\
\hline CHEMBL3916975 & 1637324 & 8.41 & 8.6354 & TRN \\
\hline CHEMBL3919709 & 1637324 & 8.54 & 8.1184 & TRN \\
\hline CHEMBL3975791 & 1637324 & 8.56 & 8.1184 & TRN \\
\hline CHEMBL3963323 & 1637324 & 8.8 & 8.582 & TRN \\
\hline CHEMBL3945373 & 1637324 & 8.92 & 8.7305 & TRN \\
\hline CHEMBL3893344 & 1637324 & 8.37 & 8.4139 & TRN \\
\hline CHEMBL3896052 & 1637324 & 8.53 & 8.5889 & TRN \\
\hline CHEMBL3947361 & 1637324 & 7.9 & 8.0792 & TRN \\
\hline CHEMBL3944739 & 1637324 & 8.0 & 7.9615 & TST \\
\hline CHEMBL3909551 & 1637324 & 8.31 & 8.547 & TRN \\
\hline CHEMBL3899692 & 1637324 & 8.67 & 8.6883 & TRN \\
\hline CHEMBL3961400 & 1637324 & 8.28 & 8.3469 & TRN \\
\hline CHEMBL3958708 & 1637324 & 8.5 & 8.4706 & TRN \\
\hline CHEMBL 3974080 & 1637324 & 7.51 & 7.732 & TRN \\
\hline CHEMBL3921197 & 1637324 & 8.85 & 8.7983 & TST \\
\hline CHEMBL3898568 & 1637324 & 8.55 & 8.5395 & TRN \\
\hline CHEMBL3924422 & 1637324 & 8.18 & 8.1867 & TRN \\
\hline CHEMBL3959193 & 1637324 & 8.17 & 8.1461 & TRN \\
\hline CHEMBL3961923 & 1637324 & 8.54 & 8.6218 & TRN \\
\hline CHEMBL3936087 & 1637324 & 8.57 & 8.5491 & TRN \\
\hline CHEMBL3893070 & 1637324 & 8.38 & 8.23 & TRN \\
\hline CHEMBL3977904 & 1637324 & 7.72 & 8.3156 & TST \\
\hline CHEMBL3904441 & 1637324 & 8.37 & 8.1475 & TRN \\
\hline CHEMBL3945159 & 1637324 & 8.86 & 8.8084 & TRN \\
\hline CHEMBL3915021 & 1637324 & 8.35 & 7.9774 & TST \\
\hline CHEMBL3892776 & 1637324 & 9.15 & 9.0388 & TRN \\
\hline CHEMBL3981077 & 1637324 & 8.39 & 8.4539 & TST \\
\hline CHEMBL3930819 & 1637324 & 8.06 & 7.9813 & TRN \\
\hline
\end{tabular}




\begin{tabular}{|c|c|c|c|c|c|}
\hline \\
\hline CHEMBL3926082 & 1637324 & 8.64 & 8.6372 & TRN & \\
\hline CHEMBL3970423 & 1637324 & 8.68 & 8.6752 & TRN & \\
\hline CHEMBL3950089 & 1637324 & 8.79 & 8.7567 & TRN & \\
\hline CHEMBL3959573 & 1637324 & 8.88 & 8.8573 & TRN & \\
\hline CHEMBL3912310 & 1637324 & 7.97 & 8.1874 & TRN & \\
\hline CHEMBL3914955 & 1637324 & 8.38 & 8.3861 & TRN & \\
\hline CHEMBL3973263 & 1637324 & 8.29 & 8.3468 & TRN & \\
\hline CHEMBL3975714 & 1637324 & 8.01 & 7.9776 & TRN & \\
\hline CHEMBL3933707 & 1637324 & 8.79 & 8.6789 & TRN & \\
\hline CHEMBL3950069 & 1637324 & 8.57 & 8.5476 & TRN & \\
\hline CHEMBL3979013 & 1637324 & 8.99 & 8.9109 & TRN & \\
\hline CHEMBL3942811 & 1637324 & 8.24 & 8.4832 & TRN & \\
\hline CHEMBL3940175 & 1637324 & 8.37 & 8.55299 & 9999999999 & TST \\
\hline CHEMBL3968038 & 1637324 & 7.64 & 7.683 & TRN & \\
\hline CHEMBL3965640 & 1637324 & 8.42 & 8.3715 & TRN & \\
\hline CHEMBL3928393 & 1637324 & 9.09 & 8.758 & TST & \\
\hline CHEMBL3918704 & 1637324 & 8.52 & 8.5328 & TRN & \\
\hline CHEMBL3947189 & 1637324 & 8.56 & 8.588 & TRN & \\
\hline CHEMBL 3944438 & 1637324 & 8.58 & 8.7486 & TRN & \\
\hline CHEMBL3964574 & 1637324 & 8.96 & 9.0377 & TRN & \\
\hline CHEMBL3942328 & 1637324 & 8.83 & 8.8405 & TRN & \\
\hline CHEMBL 3951847 & 1637324 & 8.5 & $8.5910 e$ & 0000000001 & TRN \\
\hline CHEMBL 3930298 & 1637324 & 7.96 & 8.0265 & TST & \\
\hline CHEMBL3933000 & 1637324 & 8.57 & 8.2518 & TST & \\
\hline CHEMBL 3891464 & 1637324 & 8.1 & 8.1974 & TRN & \\
\hline CHEMBL3950910 & 1637324 & 8.92 & 8.8637 & TRN & \\
\hline CHEMBL3901420 & 1637324 & 8.0 & 8.1873 & TRN & \\
\hline CHEMBL 3905866 & 1637324 & 9.08 & 8.80299 & 9999999999 & TRN \\
\hline CHEMBL3903198 & 1637324 & 8.45 & 8.6466 & TRN & \\
\hline CHEMBL 3943933 & 1637324 & 7.47 & 7.7595 & TRN & \\
\hline CHEMBL3925077 & 1637324 & 8.32 & 8.2541 & TRN & \\
\hline CHEMBL 3946674 & 1637324 & 8.2 & 8.0894 & TRN & \\
\hline CHEMBL3931790 & 1637324 & 8.62 & 8.52 & TRN & \\
\hline CHEMBL3934487 & 1637324 & 8.52 & 8.4477 & TRN & \\
\hline CHEMBL 3893786 & 1637324 & 8.56 & 8.7267 & TRN & \\
\hline CHEMBL3917141 & 1637324 & 8.51 & 8.5268 & TRN & \\
\hline CHEMBL 3941700 & 1637324 & 8.71 & 8.7591 & TRN & \\
\hline CHEMBL3969665 & 1637324 & 8.42 & 8.0787 & TST & \\
\hline CHEMBL3981076 & 1637324 & 7.95 & 8.1439 & TRN & \\
\hline CHEMBL 3983529 & 1637324 & 8.24 & 8.58 & TRN & \\
\hline CHEMBL3935457 & 1637324 & 8.47 & 8.5766 & TRN & \\
\hline CHEMBL 3905048 & 1637324 & 8.43 & 8.4217 & TRN & \\
\hline CHEMBL3925610 & 1637324 & 8.21 & 7.8523 & TST & \\
\hline CHEMBL3928261 & 1637324 & 8.65 & 8.7171 & TRN & \\
\hline CHEMBL 3985259 & 1637324 & 8.66 & 8.3532 & TST & \\
\hline CHEMBL3890205 & 1637324 & 7.22 & 7.2761 & TST & \\
\hline CHEMBL 3944610 & 1637324 & 8.49 & 8.7429 & TRN & \\
\hline CHEMBL3944320 & 1637324 & 8.46 & 8.4826 & TRN & \\
\hline
\end{tabular}




\begin{tabular}{|c|c|c|c|c|c|}
\hline \multicolumn{6}{|c|}{ Supplemental Table S2.txt } \\
\hline CHEMBL3979908 & 1637324 & 7.8 & 7.7467 & TRN & \\
\hline CHEMBL3934355 & 1637324 & 8.41 & 8.203 & TRN & \\
\hline CHEMBL3919750 & 1637324 & 7.79 & 7.64 & TRN & \\
\hline CHEMBL 3969112 & 1637324 & 8.22 & 8.3693 & TRN & \\
\hline CHEMBL 3966560 & 1637324 & 8.35 & 8.5638 & TRN & \\
\hline CHEMBL3910444 & 1637324 & 8.66 & 8.5839 & TRN & \\
\hline CHEMBL3907642 & 1637324 & 8.59 & 8.3435 & TRN & \\
\hline CHEMBL3973929 & 1637324 & 8.39 & 8.5603 & TRN & \\
\hline CHEMBL 3972617 & 1637324 & 7.71 & 8.0511 & TRN & \\
\hline CHEMBL3908149 & 1637324 & 8.83 & 8.7078 & TRN & \\
\hline CHEMBL 3943080 & 1637324 & 7.86 & 7.7694 & TRN & \\
\hline CHEMBL 3904294 & 1637324 & 8.6 & 8.5201 & TRN & \\
\hline CHEMBL3907063 & 1637324 & 8.01 & 8.067 & TRN & \\
\hline CHEMBL 3896623 & 1637324 & 8.27 & 8.2049 & TRN & \\
\hline CHEMBL 3893950 & 1637324 & 8.22 & 8.2482 & TRN & \\
\hline CHEMBL 3955745 & 1637324 & 8.01 & 7.9776 & TRN & \\
\hline CHEMBL3953117 & 1637324 & 8.01 & 8.0288 & TST & \\
\hline CHEMBL3951360 & 1637324 & 8.32 & 8.4584 & TRN & \\
\hline CHEMBL 3930158 & 1637324 & 8.05 & 8.0718 & TRN & \\
\hline CHEMBL3911746 & 1637324 & 8.11 & 8.0229 & TST & \\
\hline CHEMBL3917295 & 1637324 & 8.26 & 8.4148 & TRN & \\
\hline CHEMBL3902110 & 1637324 & 8.47 & 8.55600 & 0000000001 & TRN \\
\hline CHEMBL 3904814 & 1637324 & 7.27 & 7.1498 & TST & \\
\hline CHEMBL 3911948 & 1637324 & 7.32 & 7.3417 & TST & \\
\hline CHEMBL3928239 & 1637324 & 8.9 & 8.6684 & TRN & \\
\hline CHEMBL 3979028 & 1637324 & 7.78 & 8.0025 & TRN & \\
\hline CHEMBL 3890378 & 1637324 & 8.78 & 8.661 & TRN & \\
\hline CHEMBL3932363 & 1637324 & 8.2 & 8.2164 & TRN & \\
\hline CHEMBL3932756 & 1637324 & 8.18 & 8.2583 & TRN & \\
\hline CHEMBL3919479 & 1637324 & 8.6 & 8.6799 & TRN & \\
\hline CHEMBL3968818 & 1637324 & 8.28 & 8.5006 & TRN & \\
\hline CHEMBL3966316 & 1637324 & 7.72 & 7.6731 & TRN & \\
\hline CHEMBL3943610 & 1637324 & 7.97 & 7.9288 & TRN & \\
\hline CHEMBL 3940940 & 1637324 & 8.05 & 7.9193 & TST & \\
\hline CHEMBL 3982107 & 1637324 & 8.15 & 8.2342 & TRN & \\
\hline CHEMBL3979670 & 1637324 & 8.65 & 8.5004 & TRN & \\
\hline CHEMBL3911738 & 1637324 & 8.28 & 8.1136 & TRN & \\
\hline CHEMBL3951090 & 1637324 & 8.04 & 8.1511 & TRN & \\
\hline CHEMBL 3960571 & 1637324 & 8.42 & 8.493 & TRN & \\
\hline CHEMBL 3949508 & 1637324 & 7.99 & 8.111 & TRN & \\
\hline CHEMBL3901612 & 1637324 & 8.4 & 8.6537 & TRN & \\
\hline CHEMBL 3974206 & 1637324 & 8.49 & 8.6451 & TST & \\
\hline CHEMBL3889711 & 1637324 & 8.43 & 8.4526 & TRN & \\
\hline CHEMBL 3927585 & 1637324 & 8.05 & 8.0043 & TRN & \\
\hline CHEMBL 3946103 & 1637324 & 8.8 & 8.8896 & TRN & \\
\hline CHEMBL3936421 & 1637324 & 7.66 & 7.7243 & TRN & \\
\hline CHEMBL3901119 & 1637324 & 8.51 & 8.9168 & TST & \\
\hline CHEMBL3919884 & 1637324 & 8.4 & 8.8651 & TST & \\
\hline
\end{tabular}




\begin{tabular}{|c|c|c|c|c|c|}
\hline \multicolumn{6}{|c|}{ Supplemental Table S2.txt } \\
\hline CHEMBL3942606 & 1637324 & 8.28 & 8.4471 & TST & \\
\hline CHEMBL3945277 & 1637324 & 8.42 & 8.6877 & TRN & \\
\hline CHEMBL3897523 & 1637324 & 8.32 & 8.1502 & TRN & \\
\hline CHEMBL 3907327 & 1637324 & 8.42 & 8.3355 & TRN & \\
\hline CHEMBL3956579 & 1637324 & 7.84 & 7.9678 & TST & \\
\hline CHEMBL3959260 & 1637324 & 8.28 & 8.2551 & TRN & \\
\hline CHEMBL3890852 & 1637324 & 8.61 & 8.4157 & TST & \\
\hline CHEMBL3893642 & 1637324 & 8.66 & 8.5588 & TRN & \\
\hline CHEMBL3950156 & 1637324 & 8.59 & 8.2154 & TRN & \\
\hline CHEMBL3952866 & 1637324 & 8.28 & 7.8892 & TST & \\
\hline CHEMBL3925114 & 1637324 & 8.66 & 8.5898 & TRN & \\
\hline CHEMBL3897155 & 1637324 & 8.91 & 8.8688 & TST & \\
\hline CHEMBL3937972 & 1637324 & 9.31 & 8.9641 & TRN & \\
\hline CHEMBL3935177 & 1637324 & 8.05 & 8.1237 & TRN & \\
\hline CHEMBL3962492 & 1637324 & 9.08 & 9.0055 & TRN & \\
\hline CHEMBL3903823 & 1637324 & 8.23 & 8.15899 & 9999999999 & TRN \\
\hline CHEMBL3964096 & 1637324 & 8.92 & 8.7675 & TST & \\
\hline CHEMBL3948755 & 1637324 & 7.94 & 8.0853 & TST & \\
\hline CHEMBL3892155 & 1637324 & 8.42 & 8.2215 & TRN & \\
\hline CHEMBL3987162 & 1637324 & 7.65 & 7.559 & TRN & \\
\hline CHEMBL3921441 & 1637324 & 9.02 & 8.9603 & TRN & \\
\hline CHEMBL3905015 & 1637324 & 7.69 & 7.8905 & TRN & \\
\hline CHEMBL3921817 & 1637324 & 8.14 & 8.3669 & TRN & \\
\hline CHEMBL3927219 & 1637324 & 8.12 & 7.9674 & TRN & \\
\hline CHEMBL3902434 & 1637324 & 7.91 & 8.058 & TRN & \\
\hline CHEMBL3927158 & 1637324 & 7.18 & 7.4861 & TRN & \\
\hline CHEMBL3985182 & 1637324 & 7.97 & 7.7657 & TRN & \\
\hline CHEMBL3933442 & 1637324 & 7.82 & 8.0007 & TRN & \\
\hline CHEMBL3934080 & 1637324 & 8.76 & 8.7766 & TRN & \\
\hline CHEMBL3895443 & 1637324 & 8.19 & 8.3129 & TRN & \\
\hline CHEMBL3904736 & 1637324 & 6.6 & 6.6035 & TRN & \\
\hline CHEMBL3914473 & 1637324 & 6.65 & 6.5822 & TRN & \\
\hline CHEMBL3898926 & 1637324 & 7.54 & 7.7317 & TRN & \\
\hline CHEMBL3952277 & 1637324 & 8.49 & 8.4711 & TRN & \\
\hline CHEMBL3926245 & 1637324 & 7.7 & 7.8957 & TST & \\
\hline CHEMBL3978617 & 1637324 & 8.73 & 8.4918 & TRN & \\
\hline CHEMBL3966071 & 1637324 & 8.29 & 8.355 & TST & \\
\hline CHEMBL3966200 & 1637324 & 8.49 & 8.3686 & TRN & \\
\hline CHEMBL3940672 & 1637324 & 8.25 & 8.0882 & TST & \\
\hline CHEMBL3979328 & 1637324 & 8.01 & 8.1188 & TRN & \\
\hline CHEMBL3983918 & 1637324 & 9.11 & 8.8914 & TST & \\
\hline CHEMBL3975193 & 1637324 & 8.03 & 7.96299 & 9999999999 & TRN \\
\hline CHEMBL3924172 & 1637324 & 8.92 & 8.5595 & TRN & \\
\hline CHEMBL3921469 & 1637324 & 8.7 & 8.7295 & TRN & \\
\hline CHEMBL3900551 & 1637324 & 6.46 & 6.7136 & TRN & \\
\hline CHEMBL3897783 & 1637324 & 8.78 & 8.6758 & TRN & \\
\hline CHEMBL3891525 & 1637324 & 8.92 & 8.5625 & TRN & \\
\hline CHEMBL3935838 & 1637324 & 8.48 & 8.2298 & TST & \\
\hline
\end{tabular}




\begin{tabular}{|c|c|c|c|c|c|}
\hline \multicolumn{6}{|c|}{ Supplemental Table S2.txt } \\
\hline CHEMBL 3977010 & 1637324 & 8.85 & 8.6687 & TRN & \\
\hline CHEMBL 3967761 & 1637324 & 8.85 & 8.7045 & TRN & \\
\hline CHEMBL 3893556 & 1637324 & 7.46 & 7.3335 & TRN & \\
\hline CHEMBL 3896249 & 1637324 & 8.5 & 8.6338 & TRN & \\
\hline CHEMBL 3952789 & 1637324 & 7.96 & 8.0886 & TRN & \\
\hline CHEMBL 3955385 & 1637324 & 7.6 & 7.6531 & TRN & \\
\hline CHEMBL3977708 & 1637324 & 8.1 & 8.1294 & TRN & \\
\hline CHEMBL 3980069 & 1637324 & 8.47 & 8.6102 & TRN & \\
\hline CHEMBL 3946938 & 1637324 & 8.82 & 8.9911 & TRN & \\
\hline CHEMBL3941337 & 1637324 & 6.77 & 6.6521 & TRN & \\
\hline CHEMBL 3983585 & 1637324 & 6.7 & 6.5354 & TRN & \\
\hline CHEMBL 3918638 & 1637324 & 8.55 & 8.1184 & TRN & \\
\hline CHEMBL3920637 & 1637324 & 8.56 & 8.2597 & TRN & \\
\hline CHEMBL 3917908 & 1637324 & 8.34 & 8.4007 & TRN & \\
\hline CHEMBL3980712 & 1637324 & 6.54 & 6.6311 & TRN & \\
\hline CHEMBL3978349 & 1637324 & 8.35 & 8.3519 & TST & \\
\hline CHEMBL3976721 & 1637324 & 7.32 & 7.6237 & TRN & \\
\hline CHEMBL3974273 & 1637324 & 7.24 & 7.4148 & TRN & \\
\hline CHEMBL 3898255 & 1637324 & 7.46 & 7.5494 & TST & \\
\hline CHEMBL3927794 & 1637324 & 7.42 & 7.4582 & TST & \\
\hline CHEMBL3953833 & 1637324 & 7.9 & 7.9206 & TRN & \\
\hline CHEMBL 3964043 & 1637324 & 8.3 & 8.2377 & TRN & \\
\hline CHEMBL 3945658 & 1637324 & 6.79 & 7.11299 & 99999999995 & TRN \\
\hline CHEMBL 3948306 & 1637324 & 6.6 & 6.7025 & TRN & \\
\hline CHEMBL 3984035 & 1637324 & 7.99 & 8.1708 & TST & \\
\hline CHEMBL 3986725 & 1637324 & 8.07 & 8.1189 & TST & \\
\hline CHEMBL 3896142 & 1637324 & 8.37 & 8.2072 & TST & \\
\hline CHEMBL3908707 & 1637324 & 8.3 & 8.5996 & TRN & \\
\hline CHEMBL 3941227 & 1637324 & 7.75 & 8.1149 & TST & \\
\hline CHEMBL3943917 & 1637324 & 7.96 & 8.1812 & TRN & \\
\hline CHEMBL 3979972 & 1637324 & 7.86 & 7.9864 & TRN & \\
\hline CHEMBL3982399 & 1637324 & 8.25 & 7.9104 & TRN & \\
\hline CHEMBL3932817 & 1637324 & 7.5 & 7.7128 & TST & \\
\hline CHEMBL 3930088 & 1637324 & 7.9 & 7.7227 & TST & \\
\hline CHEMBL 3972445 & 1637324 & 6.66 & 6.7878 & TRN & \\
\hline CHEMBL 3969747 & 1637324 & 7.62 & 7.4003 & TST & \\
\hline CHEMBL3918426 & 1637324 & 8.15 & 8.1211 & TST & \\
\hline CHEMBL3906938 & 1637324 & 8.19 & 8.0176 & TRN & \\
\hline CHEMBL 3956028 & 1637324 & 6.71 & 6.782 & TRN & \\
\hline CHEMBL3964762 & 1637324 & 7.89 & 7.8171 & TRN & \\
\hline CHEMBL 3948234 & 1637324 & 8.0 & 7.7515 & TST & \\
\hline CHEMBL 3932022 & 1637324 & 7.98 & 8.4156 & TST & \\
\hline CHEMBL3957473 & 1637324 & 8.62 & 8.236 & TRN & \\
\hline CHEMBL3950496 & 1637324 & 7.95 & 8.0139 & TRN & \\
\hline CHEMBL3902961 & 1637324 & 8.48 & 8.5074 & TRN & \\
\hline CHEMBL 3905633 & 1637324 & 8.11 & 8.2304 & TST & \\
\hline CHEMBL3937212 & 1637324 & 7.18 & 7.5573 & TST & \\
\hline CHEMBL3966929 & 1637324 & 8.04 & 7.9674 & TRN & \\
\hline
\end{tabular}




\begin{tabular}{|c|c|c|c|c|c|}
\hline \multicolumn{6}{|c|}{ Supplemental Table S2.txt } \\
\hline CHEMBL3922100 & 1637324 & 8.21 & 8.3548 & TST & \\
\hline CHEMBL3906284 & 1637324 & 8.69 & 8.9603 & TRN & \\
\hline CHEMBL3921787 & 1637324 & 7.55 & 7.3173 & TRN & \\
\hline CHEMBL3951171 & 1637324 & 8.13 & 8.3028 & TRN & \\
\hline CHEMBL3983694 & 1637324 & 7.75 & 7.79299 & 9999999999 & TRN \\
\hline CHEMBL3981207 & 1637324 & 7.81 & 7.8563 & TRN & \\
\hline CHEMBL3986631 & 1637324 & 7.21 & 7.3694 & TRN & \\
\hline CHEMBL3969667 & 1637324 & 7.84 & 7.9492 & TRN & \\
\hline CHEMBL3933908 & 1637324 & 7.89 & 7.6707 & TRN & \\
\hline CHEMBL3936673 & 1637324 & 7.48 & 7.50899 & 99999999995 & TRN \\
\hline CHEMBL3980417 & 1637324 & 8.28 & 8.2995 & TRN & \\
\hline CHEMBL3921190 & 1637324 & 8.33 & 8.4482 & TRN & \\
\hline CHEMBL3920274 & 1637324 & 6.53 & 6.4656 & TST & \\
\hline CHEMBL3953771 & 1637324 & 7.68 & 7.6436 & TST & \\
\hline CHEMBL 3950292 & 1637324 & 7.73 & 7.7863 & TRN & \\
\hline CHEMBL3959787 & 1637324 & 6.92 & 7.0023 & TRN & \\
\hline CHEMBL3986861 & 1637324 & 7.53 & 7.6727 & TST & \\
\hline CHEMBL3891816 & 1637324 & 7.48 & 8.0071 & TST & \\
\hline CHEMBL3927140 & 1637324 & 8.18 & 8.2515 & TRN & \\
\hline CHEMBL3929849 & 1637324 & 7.12 & 7.2678 & TRN & \\
\hline CHEMBL3966941 & 1637324 & 7.72 & 7.7584 & TST & \\
\hline CHEMBL3939018 & 1637324 & 8.59 & 8.4612 & TRN & \\
\hline CHEMBL3912757 & 1637324 & 7.63 & 7.5523 & TRN & \\
\hline CHEMBL3915450 & 1637324 & 7.57 & 7.3872 & TRN & \\
\hline CHEMBL3956493 & 1637324 & 8.53 & 8.5908 & TRN & \\
\hline CHEMBL3964931 & 1637324 & 7.74 & 7.6773 & TRN & \\
\hline CHEMBL3918956 & 1637324 & 7.65 & 7.7139 & TRN & \\
\hline CHEMBL3894754 & 1637324 & 7.72 & 7.8964 & TRN & \\
\hline CHEMBL3963296 & 1637324 & 7.59 & 7.6113 & TRN & \\
\hline CHEMBL 3890187 & 1637324 & 6.75 & 6.7584 & TST & \\
\hline CHEMBL3978313 & 1637324 & 7.73 & 7.6204 & TRN & \\
\hline CHEMBL3889604 & 1637324 & 7.88 & 7.8058 & TRN & \\
\hline CHEMBL3939332 & 1637324 & 7.94 & 7.8915 & TRN & \\
\hline CHEMBL3912250 & 1637324 & 7.6 & 7.474 & TRN & \\
\hline CHEMBL3901265 & 1637324 & 8.03 & 8.1422 & TRN & \\
\hline CHEMBL3903973 & 1637324 & 8.8 & 9.0327 & TRN & \\
\hline CHEMBL3957928 & 1637324 & 7.56 & 7.5543 & TRN & \\
\hline CHEMBL3960591 & 1637324 & 7.82 & 7.5543 & TST & \\
\hline CHEMBL3899721 & 1637324 & 7.29 & 7.273 & TRN & \\
\hline CHEMBL3934772 & 1637324 & 7.77 & 7.6751 & TRN & \\
\hline CHEMBL3909752 & 1637324 & 7.72 & 7.775 & TRN & \\
\hline CHEMBL3906945 & 1637324 & 7.93 & 7.9175 & TRN & \\
\hline CHEMBL3954396 & 1637324 & 8.31 & 8.4209 & TRN & \\
\hline CHEMBL3944937 & 1637324 & 7.04 & 6.9224 & TRN & \\
\hline CHEMBL 3895267 & 1637324 & 8.92 & 8.8301 & TRN & \\
\hline CHEMBL3892529 & 1637324 & 8.68 & 8.2925 & TRN & \\
\hline CHEMBL3935597 & 1637324 & 9.1 & 8.979 & TRN & \\
\hline CHEMBL3932893 & 1637324 & 7.08 & 7.1066 & TST & \\
\hline
\end{tabular}


Supplemental Table S2.txt

\begin{tabular}{|c|c|c|c|c|c|}
\hline CHEMBL3952706 & 1637324 & 7.57 & 7.6397 & TST & \\
\hline CHEMBL3939860 & 1637324 & 8.47 & 8.1015 & TST & \\
\hline CHEMBL3976275 & 1637324 & 8.62 & 8.6541 & TRN & \\
\hline CHEMBL3978754 & 1637324 & 8.64 & 8.4295 & TST & \\
\hline CHEMBL3942716 & 1637324 & 8.8 & 8.6193 & TRN & \\
\hline CHEMBL3982718 & 1637324 & 7.54 & 7.4699 & TRN & \\
\hline CHEMBL3892005 & 1637324 & 7.62 & 7.4047 & TST & \\
\hline CHEMBL3894762 & 1637324 & 8.95 & 8.6393 & TST & \\
\hline CHEMBL3896514 & 1637324 & 7.98 & 7.9949 & TST & \\
\hline CHEMBL3906253 & 1637324 & 7.75 & 7.8053 & TRN & \\
\hline CHEMBL3946877 & 1637324 & 6.43 & 6.5385 & TST & \\
\hline CHEMBL3944241 & 1637324 & 7.4 & 7.5117 & TST & \\
\hline CHEMBL3947664 & 1637324 & 8.48 & 8.3217 & TRN & \\
\hline CHEMBL3899151 & 1637324 & 8.6 & 8.85 & TRN & \\
\hline CHEMBL3960877 & 1637324 & 8.92 & 8.9618 & TRN & \\
\hline CHEMBL3958209 & 1637324 & 8.77 & 8.9392 & TRN & \\
\hline CHEMBL3951253 & 1637324 & 8.6 & 8.6198 & TRN & \\
\hline CHEMBL 3948629 & 1637324 & 5.0 & 7.2255 & TST & \\
\hline CHEMBL3913492 & 1637324 & 8.51 & 8.5697 & TRN & \\
\hline CHEMBL3933492 & 1637324 & 4.0 & 4.8416 & TRN & \\
\hline CHEMBL3982416 & 1637324 & 5.4 & 5.66200 & 0000000001 & TRN \\
\hline CHEMBL3984969 & 1637324 & 5.7 & 5.7548 & TRN & \\
\hline CHEMBL3953206 & 1637324 & 6.1 & 6.8049 & TST & \\
\hline CHEMBL3946591 & 1637324 & 7.33 & 6.9247 & TST & \\
\hline CHEMBL3942179 & 1637324 & 7.75 & 7.843 & TST & \\
\hline CHEMBL3930685 & 1637324 & 6.74 & 6.7716 & TST & \\
\hline CHEMBL3910555 & 1637324 & 8.39 & 8.6448 & TST & \\
\hline CHEMBL3918036 & 1637324 & 6.42 & 6.4067 & TST & \\
\hline CHEMBL3926088 & 1637324 & 6.34 & 5.9669 & TST & \\
\hline CHEMBL3948043 & 1637324 & 6.55 & 8.1184 & TST & \\
\hline CHEMBL3972657 & 1637324 & 7.49 & 7.2498 & TST & \\
\hline CHEMBL3918892 & 1637324 & 6.45 & 6.4498 & TST & \\
\hline CHEMBL3966660 & 1637324 & 6.76 & 7.0295 & TST & \\
\hline CHEMBL3899891 & 1637324 & 7.54 & 7.6308 & TST & \\
\hline CHEMBL3890118 & 1637324 & 8.27 & 8.0394 & TST & \\
\hline CHEMBL3950169 & 1637324 & 8.81 & 8.8171 & TST & \\
\hline CHEMBL 3952885 & 1637324 & 7.19 & 7.04899 & 99999999995 & TST \\
\hline CHEMBL 3890870 & 1637324 & 7.59 & 7.4914 & TST & \\
\hline CHEMBL3893659 & 1637324 & 5.0 & 5.4396 & TST & \\
\hline CHEMBL3928923 & 1637324 & 7.35 & 7.3984 & TST & \\
\hline CHEMBL3938712 & 1637324 & 6.91 & 6.8779 & TST & \\
\hline CHEMBL3975295 & 1637324 & 6.83 & 6.9816 & TST & \\
\hline CHEMBL3977791 & 1637324 & 6.84 & 6.9675 & TST & \\
\hline CHEMBL3916904 & 1637324 & 6.33 & 6.8872 & TST & \\
\hline CHEMBL3974131 & 1637324 & 6.56 & 7.0085 & TST & \\
\hline CHEMBL3925322 & 1637324 & 7.29 & 6.6233 & TST & \\
\hline CHEMBL3922592 & 1637324 & 5.0 & 5.8585 & TST & \\
\hline CHEMBL3985007 & 1637324 & 6.21 & 6.8857 & TST & \\
\hline
\end{tabular}




\begin{tabular}{|c|c|c|c|c|c|}
\hline \multicolumn{6}{|c|}{ Supplemental Table s2.txt } \\
\hline CHEMBL3982466 & 1637324 & 5.0 & 5.0927 & TST & \\
\hline CHEMBL3910921 & 1637324 & 7.86 & 7.3909 & TST & \\
\hline CHEMBL3908141 & 1637324 & 5.0 & 5.4543 & TST & \\
\hline CHEMBL 3971947 & 1637324 & 7.21 & 7.0408 & TST & \\
\hline CHEMBL3960102 & 1637324 & 6.91 & 6.5382 & TST & \\
\hline CHEMBL3932123 & 1637324 & 6.55 & 6.9307 & TST & \\
\hline CHEMBL 3952488 & 1637324 & 7.5 & 7.7704 & TST & \\
\hline CHEMBL3656171 & 1640955 & 6.296 & 6.2297 & TRN & \\
\hline CHEMBL3954507 & 1640955 & 6.4552 & 6.6964 & TRN & \\
\hline CHEMBL3922583 & 1640955 & 5.2875 & 5.2347 & TRN & \\
\hline CHEMBL3656164 & 1640955 & 5.7314 & 6.5821 & TRN & \\
\hline CHEMBL3901821 & 1640955 & 9.0969 & 8.7273 & TRN & \\
\hline CHEMBL3911980 & 1640955 & 8.0506 & 8.2634 & TRN & \\
\hline CHEMBL 3656154 & 1640955 & 6.9805 & 6.3444 & TRN & \\
\hline CHEMBL3985866 & 1640955 & 8.8539 & 8.4073 & TRN & \\
\hline CHEMBL3961810 & 1640955 & 6.1591 & 6.3019 & TRN & \\
\hline CHEMBL3933430 & 1640955 & 8.9586 & 9.2396 & TRN & \\
\hline CHEMBL3985554 & 1640955 & 6.6844 & 7.0243 & TRN & \\
\hline CHEMBL3656146 & 1640955 & 7.4168 & 7.1068 & TRN & \\
\hline CHEMBL3656138 & 1640955 & 7.9172 & 7.8645 & TRN & \\
\hline CHEMBL3656136 & 1640955 & 7.9508 & 8.0687 & TRN & \\
\hline CHEMBL3908165 & 1640955 & 8.0132 & 8.1307 & TRN & \\
\hline CHEMBL3921357 & 1640955 & 8.6576 & 8.3165 & TRN & \\
\hline CHEMBL3935629 & 1640955 & 6.5933 & 7.0345 & TRN & \\
\hline CHEMBL3656156 & 1640955 & 6.901 & 6.6368 & TRN & \\
\hline CHEMBL3656182 & 1640955 & 6.0 & 5.7656 & TRN & \\
\hline CHEMBL3656162 & 1640955 & 6.7486 & 6.71399 & 99999999995 & TRN \\
\hline CHEMBL3656167 & 1640955 & 6.4222 & 6.3311 & TRN & \\
\hline CHEMBL3894111 & 1640955 & 7.3799 & 7.33200 & 2000000001 & TRN \\
\hline CHEMBL3970029 & 1640955 & 7.4225 & 7.8797 & TRN & \\
\hline CHEMBL 3942260 & 1640955 & 7.5346 & 7.3173 & TST & \\
\hline CHEMBL3656169 & 1640955 & 6.3534 & 6.2076 & TRN & \\
\hline CHEMBL 3947870 & 1640955 & 8.5528 & 8.2177 & TRN & \\
\hline CHEMBL3952092 & 1640955 & 7.3716 & 7.2935 & TRN & \\
\hline CHEMBL3914405 & 1640955 & 8.0915 & 8.457 & TRN & \\
\hline CHEMBL3974239 & 1640955 & 6.6533 & 7.4727 & TST & \\
\hline CHEMBL3656184 & 1640955 & 8.6778 & 7.50700 & 0000000001 & TST \\
\hline CHEMBL3656166 & 1640955 & 6.0 & 6.1862 & TST & \\
\hline CHEMBL3898249 & 1640955 & 7.5482 & 6.4985 & TST & \\
\hline CHEMBL3656158 & 1640955 & 6.8024 & 6.9737 & TRN & \\
\hline CHEMBL3947739 & 1640955 & 8.2076 & 7.4761 & TRN & \\
\hline CHEMBL3656159 & 1640955 & 6.79700 & $\partial 0000000$ & 6.4209 & TRN \\
\hline CHEMBL3926119 & 1640955 & 7.3036 & 7.1019 & TRN & \\
\hline CHEMBL3983916 & 1640955 & 8.9586 & 8.5152 & TRN & \\
\hline CHEMBL3975565 & 1640955 & 8.585 & 8.4578 & TRN & \\
\hline CHEMBL 3944485 & 1640955 & 7.8665 & 8.2018 & TRN & \\
\hline CHEMBL3656161 & 1640955 & 6.7627 & 6.9654 & TST & \\
\hline CHEMBL3656177 & 1640955 & 5.8083 & 6.4325 & TST & \\
\hline
\end{tabular}


Supplemental Table S2.txt

\begin{tabular}{|c|c|c|c|c|}
\hline CHEMBL3899749 & 1640955 & 6.8639 & 6.7942 & TRN \\
\hline CHEMBL3915398 & 1640955 & 8.0458 & 7.3242 & TST \\
\hline CHEMBL3974349 & 1640955 & 8.1079 & 7.5297 & TST \\
\hline CHEMBL 3656140 & 1640955 & 7.8356 & 7.7166 & TRN \\
\hline CHEMBL3656130 & 1640955 & 8.1549 & 8.2387 & TRN \\
\hline CHEMBL3972883 & 1640955 & 9.0177 & 8.949 & TRN \\
\hline CHEMBL3656183 & 1640955 & 5.3277 & 5.2122 & TST \\
\hline CHEMBL3955907 & 1640955 & 7.8794 & 8.3819 & TRN \\
\hline CHEMBL 3949520 & 1640955 & 8.3468 & 6.9097 & TST \\
\hline CHEMBL3892793 & 1640955 & 5.0085 & 6.6226 & TST \\
\hline CHEMBL3905425 & 1640955 & 6.7027 & 7.6331 & TRN \\
\hline CHEMBL3968267 & 1640955 & 6.0 & 6.0869 & TST \\
\hline CHEMBL3939631 & 1640955 & 6.0607 & 6.4222 & TST \\
\hline CHEMBL 3944327 & 1640955 & 7.5287 & 7.619 & TRN \\
\hline CHEMBL3894514 & 1640955 & 8.1549 & 7.9434 & TRN \\
\hline CHEMBL3928831 & 1640955 & 7.7595 & 7.6114 & TRN \\
\hline CHEMBL3937984 & 1640955 & 7.7595 & 7.7185 & TRN \\
\hline CHEMBL 3951272 & 1640955 & 7.8416 & 7.3017 & TRN \\
\hline CHEMBL3961222 & 1640955 & 7.7773 & 8.2572 & TRN \\
\hline CHEMBL3936117 & 1640955 & 7.6091 & 8.0597 & TRN \\
\hline CHEMBL3977126 & 1640955 & 8.4815 & 8.2327 & TRN \\
\hline CHEMBL3902558 & 1640955 & 7.2434 & 7.9485 & TRN \\
\hline CHEMBL3972700 & 1640955 & 7.7773 & 7.4239 & TRN \\
\hline CHEMBL 3656175 & 1640955 & 6.0 & \multicolumn{2}{|c|}{6.162000000000001} \\
\hline CHEMBL3656150 & 1640955 & 6.0 & 6.5984 & TRN \\
\hline CHEMBL3962707 & 1640955 & 8.6198 & 8.4512 & TRN \\
\hline CHEMBL 3656260 & 1640955 & 5.8693 & 7.3137 & TST \\
\hline CHEMBL3652434 & 1640955 & 8.3468 & 8.1311 & TRN \\
\hline CHEMBL 3982658 & 1640955 & 6.806 & 7.1274 & TRN \\
\hline CHEMBL3656143 & 1640955 & 7.7144 & 7.1466 & TRN \\
\hline CHEMBL3984225 & 1640955 & 8.1367 & \multicolumn{2}{|c|}{7.962000000000001} \\
\hline CHEMBL3900416 & 1640955 & 8.2757 & 8.112 & TRN \\
\hline CHEMBL3656163 & 1640955 & 6.7233 & 6.6606 & TRN \\
\hline CHEMBL 3656129 & 1640955 & 8.2291 & 8.7108 & TRN \\
\hline CHEMBL 3973282 & 1640955 & 5.3638 & 6.7531 & TST \\
\hline CHEMBL3656133 & 1640955 & 8.1024 & 8.309 & TRN \\
\hline CHEMBL 3983157 & 1640955 & 7.699 & 7.6634 & TRN \\
\hline CHEMBL 3896388 & 1640955 & 7.5751 & 7.0757 & TST \\
\hline CHEMBL 3910991 & 1640955 & 9.0 & 8.3328 & TRN \\
\hline CHEMBL 3934108 & 1640955 & 5.4865 & 5.8768 & TRN \\
\hline CHEMBL3656131 & 1640955 & 8.1308 & 8.247 & TRN \\
\hline CHEMBL 3956487 & 1640955 & 6.7106 & 6.6196 & TRN \\
\hline CHEMBL 3656170 & 1640955 & 6.3318 & 6.0824 & TRN \\
\hline CHEMBL 3914462 & 1640955 & 6.3072 & 6.1876 & TRN \\
\hline CHEMBL3930955 & 1640955 & 7.7905 & 7.6654 & TRN \\
\hline CHEMBL3980807 & 1640955 & 7.9547 & 7.5611 & TST \\
\hline CHEMBL3913966 & 1640955 & 7.6271 & 7.3267 & TRN \\
\hline CHEMBL 3977008 & 1640955 & 6.8918 & 7.0477 & TRN \\
\hline
\end{tabular}

Page 12962 
Supplemental Table S2.txt

\begin{tabular}{|c|c|c|c|c|}
\hline CHEMBL3928953 & 1640955 & 8.4318 & 8.2809 & TRN \\
\hline CHEMBL3890041 & 1640955 & 6.0 & 6.895 & TRN \\
\hline CHEMBL3656152 & 1640955 & 7.0506 & 6.6697 & TRN \\
\hline CHEMBL3968202 & 1640955 & 9.2218 & 8.6203 & TRN \\
\hline CHEMBL3893517 & 1640955 & 6.9927 & \multicolumn{2}{|c|}{7.002000000000001} \\
\hline CHEMBL3898229 & 1640955 & 6.1737 & 6.1738 & TRN \\
\hline CHEMBL3975328 & 1640955 & 7.2464 & 8.3168 & TST \\
\hline CHEMBL3927880 & 1640955 & 7.2503 & 6.9392 & TRN \\
\hline CHEMBL3922032 & 1640955 & 8.699 & 7.9258 & TRN \\
\hline CHEMBL3970197 & 1640955 & 7.3799 & 7.2214 & TRN \\
\hline CHEMBL3916393 & 1640955 & 7.9393 & 7.6911 & TRN \\
\hline CHEMBL3898481 & 1640955 & 8.1024 & 8.2665 & TRN \\
\hline CHEMBL3956333 & 1640955 & 7.5214 & 7.5103 & TRN \\
\hline CHEMBL3891377 & 1640955 & 7.0947 & 7.4037 & TRN \\
\hline CHEMBL 3904483 & 1640955 & 7.8327 & 7.4637 & TST \\
\hline CHEMBL 3897179 & 1640955 & 5.2964 & 5.5055 & TRN \\
\hline CHEMBL3922947 & 1640955 & 6.7084 & 6.6046 & TRN \\
\hline CHEMBL3985071 & 1640955 & 5.4315 & 6.2604 & TST \\
\hline CHEMBL 3980027 & 1640955 & 8.3098 & 8.4882 & TRN \\
\hline CHEMBL3652430 & 1640955 & 8.585 & 8.4695 & TRN \\
\hline CHEMBL3656155 & 1640955 & 6.9147 & 6.9463 & TRN \\
\hline CHEMBL3902664 & 1640955 & 6.2091 & 6.4081 & TRN \\
\hline CHEMBL3897052 & 1640955 & 8.585 & 8.5651 & TRN \\
\hline CHEMBL 3656185 & 1640955 & 6.3642 & 6.8068 & TRN \\
\hline CHEMBL3652435 & 1640955 & 8.3188 & \multicolumn{2}{|c|}{7.9910000000000005} \\
\hline CHEMBL3919005 & 1640955 & 7.2321 & 7.8347 & TRN \\
\hline CHEMBL3639550 & 1640955 & 7.684 & 7.9937 & TRN \\
\hline CHEMBL3656141 & 1640955 & 7.7282 & 7.3449 & TST \\
\hline CHEMBL3656144 & 1640955 & 7.6778 & 7.3381 & TST \\
\hline CHEMBL3656142 & 1640955 & 7.7235 & 7.5629 & TST \\
\hline CHEMBL3656153 & 1640955 & 7.0301 & 6.7662 & TST \\
\hline CHEMBL3965611 & 1640955 & 7.9208 & 7.9979 & TRN \\
\hline CHEMBL 3978600 & 1640955 & 8.3979 & 6.7864 & TST \\
\hline CHEMBL3656157 & 1640955 & 6.8847 & 7.8183 & TST \\
\hline CHEMBL3656128 & 1640955 & 8.2291 & 7.6349 & TST \\
\hline CHEMBL3938174 & 1640955 & 8.7212 & 8.7508 & TRN \\
\hline CHEMBL3918966 & 1640955 & 6.0 & 8.0691 & TST \\
\hline CHEMBL 3656151 & 1640955 & 7.1302 & 7.8021 & TST \\
\hline CHEMBL3976796 & 1640955 & 6.7932 & 6.8467 & TRN \\
\hline CHEMBL3916104 & 1640955 & 8.1739 & 8.3405 & TRN \\
\hline CHEMBL3947373 & 1640955 & 6.0 & 5.3864 & TRN \\
\hline CHEMBL3977679 & 1640955 & 6.0569 & 6.4073 & TRN \\
\hline CHEMBL3656145 & 1640955 & 7.5817 & 7.2593 & TST \\
\hline CHEMBL3968709 & 1640955 & 8.5376 & 8.3243 & TRN \\
\hline CHEMBL3983783 & 1640955 & 7.8356 & 7.7882 & TRN \\
\hline CHEMBL3928355 & 1640955 & 8.0757 & 7.8198 & TRN \\
\hline CHEMBL3947174 & 1640955 & 8.1024 & 8.2446 & TRN \\
\hline CHEMBL3656134 & 1640955 & 8.0555 & 8.4099 & TST \\
\hline
\end{tabular}


Supplemental Table S2.txt

\begin{tabular}{|c|c|c|c|c|}
\hline 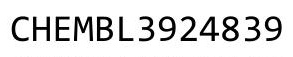 & & & 285 & \\
\hline & & 6.7929 & 5634 & \\
\hline & & & & \\
\hline AEMBL & & & & \\
\hline AEMBL3656139 & נבנשל40 & & 8431 & \\
\hline HEMBL3656149 & 640955 & 7.2104 & 693 & \\
\hline 104 & & & $\partial 199$ & \\
\hline JEMBL3921080 & & & & \\
\hline AEMBL3946731 & 64 & & 1904 & \\
\hline HEMBL3909292 & $64 e$ & & 7786 & \\
\hline HEMBL3913489 & 64 & & 4766 & \\
\hline IEMBL389 & 62 & & 571 & \\
\hline AEMBL39 & & & & \\
\hline HEMBL3652431 & 64 & & 5667 & \\
\hline AEMBL3906436 & 64 & & & \\
\hline AEMBL3956888 & 04 & & 53 & \\
\hline AEMBL3S & o & & 19 & \\
\hline HEMBL36 & & & & \\
\hline HEMBL3682602 & $5 ?$ & & & \\
\hline HEMBL 368 & 52 & & & \\
\hline HEIMBL3t & 52 & & & KIV \\
\hline HEMBL: & 2 & & 169 & 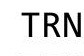 \\
\hline HEMBL & 2 & & & \\
\hline 565 & & & & \\
\hline HEMBL 368 & & & & ( \\
\hline HEMBL36 & 528 & & 899 & r \\
\hline HEMBL3 & 2 & & 09 & ST \\
\hline$H F M B I=$ & 2 & & 63 & \\
\hline HEMBL 36 & & & & iv \\
\hline HEMBL 3687 & 52 & & & 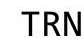 \\
\hline HEMBL 368 & 528 & & 968 & RN \\
\hline HEMBL; & 2 & & 23 & KIN \\
\hline HEMBL. & 2 & & 24 & N \\
\hline HEMBL3687324 & 52 & & 662 & IRN \\
\hline HEMBL3687343 & 528 & & 097 & TRN \\
\hline HEMBL36 & 52 & & & RN \\
\hline HFMRI 3 & 2 & & 04 & $\Gamma \mathrm{RN}$ \\
\hline HEMBL3 & 2 & & 333 & IRN \\
\hline HEMBL3687336 & 528612 & & 522 & TRN \\
\hline IEMBL368 & 528 & & 635 & TST \\
\hline HEMBL3687366 & 12 & & & \\
\hline CHEMBL36 & 1528612 & & 426 & IST \\
\hline HEMBL368 & 528612 & & 1408 & TST \\
\hline HEMBL3682549 & 528612 & 447 & 139 & TRN \\
\hline$M B L 3$ & 12 & & 093 & \\
\hline HEMBL36 & 2 & & 1986 & \\
\hline CHEMBL 3687372 & 528612 & .2218 & .7075 & \\
\hline CHEMBL3682539 & 1528612 & 8.5686 & 7.6994 & RN \\
\hline
\end{tabular}

Page 12964 
Supplemental Table S2.txt

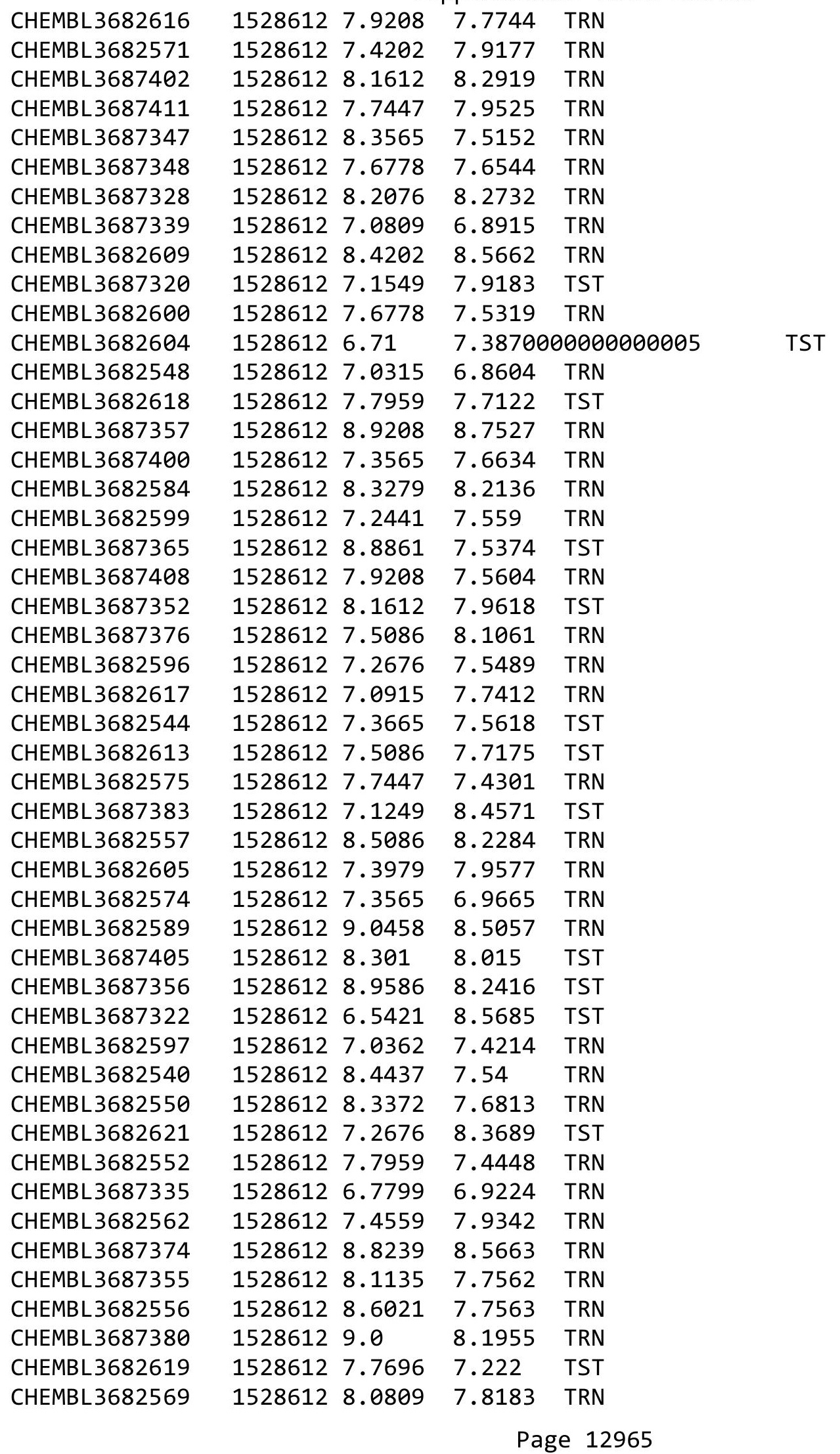


Supplemental Table S2.txt

\begin{tabular}{|c|c|c|c|c|}
\hline CHEMBL3682615 & 1528612 & 7.9586 & 7.6622 & TST \\
\hline CHEMBL3682588 & 1528612 & 6.9393 & 8.4302 & TST \\
\hline CHEMBL 3682568 & 1528612 & 8.8861 & 7.8591 & TRN \\
\hline CHEMBL 3687337 & 1528612 & 7.6778 & 7.0509 & TRN \\
\hline CHEMBL 3687378 & 1528612 & 7.9586 & 8.4302 & TRN \\
\hline CHEMBL3682582 & 1528612 & 8.1192 & 7.7437 & TRN \\
\hline CHEMBL 3687360 & 1528612 & 8.7696 & 8.3248 & TRN \\
\hline CHEMBL 3682567 & 1528612 & 8.0915 & 7.8082 & TRN \\
\hline CHEMBL 3682566 & 1528612 & 8.3279 & 7.809 & TRN \\
\hline CHEMBL3687363 & 1528612 & 8.0555 & 7.7751 & TRN \\
\hline CHEMBL 3687410 & 1528612 & 7.8539 & 8.1434 & TRN \\
\hline CHEMBL3682595 & 1528612 & 7.0132 & 7.7647 & TRN \\
\hline CHEMBL 3687371 & 1528612 & 8.2676 & 7.4953 & TST \\
\hline CHEMBL 3682551 & 1528612 & 7.585 & 7.2148 & TRN \\
\hline CHEMBL3682614 & 1528612 & 8.5086 & \multicolumn{2}{|c|}{ 7.877999999999999 } \\
\hline CHEMBL 3687407 & 1528612 & 6.2823 & 7.2526 & TRN \\
\hline CHEMBL3687373 & 1528612 & 8.8539 & 8.8569 & TRN \\
\hline CHEMBL 3687392 & 1528612 & 8.7696 & 8.1697 & TRN \\
\hline CHEMBL 3687370 & 1528612 & 8.4089 & 7.3768 & TST \\
\hline CHEMBL3687382 & 1528612 & 6.0057 & 8.039 & TST \\
\hline CHEMBL3682603 & 1528612 & 7.284 & 7.1262 & TRN \\
\hline CHEMBL 3687412 & 1528612 & 8.0706 & 8.1648 & TRN \\
\hline CHEMBL3687334 & 1528612 & 7.1487 & 7.3052 & TRN \\
\hline CHEMBL 3682578 & 1528612 & 8.5086 & 6.8151 & TST \\
\hline CHEMBL 3682570 & 1528612 & 7.9586 & 7.5352 & TST \\
\hline CHEMBL3687389 & 1528612 & 7.6778 & 7.6698 & TRN \\
\hline CHEMBL3687369 & 1528612 & 7.9586 & 7.4337 & TST \\
\hline CHEMBL3687396 & 1528612 & 8.5528 & 7.7798 & TRN \\
\hline CHEMBL 3687397 & 1528612 & 8.0362 & 8.3215 & TRN \\
\hline CHEMBL3687353 & 1528612 & 9.0 & 8.8273 & TRN \\
\hline CHEMBL3682593 & 1528612 & 7.8539 & \multicolumn{2}{|c|}{ 8.062999999999999 } \\
\hline CHEMBL 3682610 & 1528612 & 8.3665 & 8.1262 & TST \\
\hline CHEMBL3682580 & 1528612 & 8.0 & 7.3862 & TRN \\
\hline CHEMBL 3682573 & 1528612 & 7.0223 & 7.3627 & TRN \\
\hline CHEMBL 3687342 & 1528612 & 8.5376 & 7.9742 & TRN \\
\hline CHEMBL3687346 & 1528612 & 7.4559 & 8.015 & TRN \\
\hline CHEMBL 3682560 & 1528612 & 7.4318 & 7.4793 & TRN \\
\hline CHEMBL3687330 & 1528612 & 6.5214 & 6.7835 & TRN \\
\hline CHEMBL 3687349 & 1528612 & 7.5229 & 8.2612 & TRN \\
\hline CHEMBL 3682598 & 1528612 & 7.8239 & 7.3929 & TRN \\
\hline CHEMBL3682564 & 1528612 & 7.585 & 7.6738 & TRN \\
\hline CHEMBL 3682554 & 1528612 & 7.1871 & 6.9672 & TRN \\
\hline CHEMBL 3682558 & 1528612 & 7.9208 & 7.9863 & TRN \\
\hline CHEMBL 3687386 & 1528612 & 8.0862 & 8.0052 & TRN \\
\hline CHEMBL 3687387 & 1528612 & 7.1805 & 8.6899 & TST \\
\hline CHEMBL 3687351 & 1528612 & 8.6778 & 7.8431 & TST \\
\hline CHEMBL 3687381 & 1528612 & 9.0969 & 8.6263 & TRN \\
\hline CHEMBL 3687323 & 1528612 & 8.4089 & 8.1749 & TRN \\
\hline
\end{tabular}

Page 12966 
Supplemental Table S2.txt

\begin{tabular}{|c|c|c|c|c|c|}
\hline CHEMBL 3687329 & 1528612 & 6.4698 & 7.1489 & TRN & \\
\hline CHEMBL3682607 & 1528612 & 7.0269 & 8.3876 & TST & \\
\hline CHEMBL3682576 & 1528612 & 7.2366 & 7.5589 & TRN & \\
\hline CHEMBL 3687388 & 1528612 & 6.6216 & 8.7184 & TST & \\
\hline CHEMBL3682559 & 1528612 & 7.5229 & 7.4502 & TRN & \\
\hline CHEMBL 3682612 & 1528612 & 6.8665 & 7.9234 & TST & \\
\hline CHEMBL 3687404 & 1528612 & 9.0458 & 9.0183 & TRN & \\
\hline CHEMBL 3687395 & 1528612 & 8.2291 & 8.2071 & TRN & \\
\hline CHEMBL 3682591 & 1528612 & 7.6778 & 8.0818 & TRN & \\
\hline CHEMBL3682543 & 1528612 & 8.7212 & 8.0751 & TRN & \\
\hline CHEMBL 3687406 & 1528612 & 8.7959 & 8.9339 & TRN & \\
\hline CHEMBL 3687362 & 1528612 & 8.3372 & 8.3464 & TRN & \\
\hline CHEMBL 3682547 & 1528612 & 7.9208 & 8.1805 & TRN & \\
\hline CHEMBL 3687333 & 1528612 & 6.9788 & 7.2174 & TRN & \\
\hline CHEMBL3682608 & 1528612 & 6.9626 & 7.8248 & TST & \\
\hline CHEMBL 3687385 & 1528612 & 8.0915 & 7.9272 & TRN & \\
\hline CHEMBL3682611 & 1528612 & 6.15799 & 79999999 & 995 & 8.1044 \\
\hline CHEMBL 3687368 & 1528612 & 8.3372 & 7.5242 & TST & \\
\hline CHEMBL 3687331 & 1528612 & 7.4949 & 6.671 & TST & \\
\hline CHEMBL3682542 & 1528612 & 7.585 & 7.2867 & TRN & \\
\hline CHEMBL3682579 & 1528612 & 7.1024 & 7.6714 & TST & \\
\hline CHEMBL 3682585 & 1528612 & 7.9586 & 8.1517 & TRN & \\
\hline CHEMBL3682592 & 1528612 & 8.1308 & 8.2054 & TRN & \\
\hline CHEMBL3687325 & 1528612 & 8.6576 & 8.2724 & TRN & \\
\hline CHEMBL 3682553 & 1528612 & 8.3098 & 7.8639 & TRN & \\
\hline CHEMBL3687345 & 1528612 & 7.1079 & 8.1145 & TRN & \\
\hline CHEMBL 3639861 & 1528612 & 7.6383 & 8.5207 & TST & \\
\hline CHEMBL 3682587 & 1528612 & 7.6778 & 7.9144 & TRN & \\
\hline CHEMBL 3687409 & 1528612 & 6.9872 & 7.5765 & TRN & \\
\hline CHEMBL 3682583 & 1528612 & 7.041 & 7.6987 & TRN & \\
\hline CHEMBL 3687377 & 1528612 & 7.6778 & 8.22 & TRN & \\
\hline CHEMBL 3687393 & 1528612 & 8.7959 & 8.3052 & TRN & \\
\hline CHEMBL 3682545 & 1528612 & 8.3279 & 7.8266 & TRN & \\
\hline CHEMBL 3687327 & 1528612 & 8.6383 & 8.2825 & TRN & \\
\hline CHEMBL 3682541 & 1528612 & 7.6576 & 7.7956 & TST & \\
\hline CHEMBL3687319 & 1528612 & 7.041 & 7.6526 & TST & \\
\hline CHEMBL 3682563 & 1528612 & 7.7696 & 7.9481 & TRN & \\
\hline CHEMBL 3682586 & 1528612 & 7.5376 & 8.2125 & TRN & \\
\hline CHEMBL 3687341 & 1528612 & 7.2596 & 8.2533 & TRN & \\
\hline CHEMBL 3682590 & 1528612 & 8.699 & 8.461 & TRN & \\
\hline CHEMBL 3687379 & 1528612 & 8.0177 & 8.5271 & TRN & \\
\hline CHEMBL 3687332 & 1528612 & 7.4202 & 6.9607 & TST & \\
\hline CHEMBL 3687338 & 1528612 & 7.9208 & 6.9337 & TST & \\
\hline CHEMBL 3687375 & 1528612 & 8.5086 & 8.6627 & TRN & \\
\hline CHEMBL3682606 & 1528612 & 7.8239 & 7.9279 & TRN & \\
\hline CHEMBL 3687361 & 1528612 & 6.8297 & 7.1026 & TRN & \\
\hline CHEMBL 3687403 & 1528612 & 8.0 & 8.4342 & TRN & \\
\hline CHEMBL 3682594 & 1528612 & 7.6021 & 8.0269 & TRN & \\
\hline
\end{tabular}

Page 12967 
Supplemental Table S2.txt

\begin{tabular}{|c|c|c|c|c|}
\hline 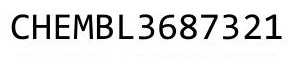 & & 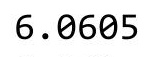 & & \\
\hline HEMBL3687391 & 528612 & 8.301 & 2409 & \\
\hline HEMBL3682555 & 528612 & 8.0655 & 5757 & \\
\hline 399 & 612 & & & \\
\hline EMBL1 & 38205 & 7696 & 824 & \\
\hline HEMBL1590058 & 88205 & .7696 & 7276 & \\
\hline HEMBL1593278 & 88205 & 3.7696 & .6201 & \\
\hline HEMBL1433287 & & & & \\
\hline 860 & 38205 & 384 & 984 & \\
\hline EMBL58 & 05 & 866 & & \\
\hline HEMBL1413226 & 88205 & 7696 & $\partial 151$ & \\
\hline HEMBL1472573 & 88205 & 6.7523 & .9739 & \\
\hline HEMBL1433416 & 88205 & 7696 & 6664 & \\
\hline HEMBL 2 & 05 & 696 & & \\
\hline AEMBL22 & 05 & 696 & & \\
\hline AEMBL34173 & $\partial 5$ & 3.7696 & 39 & \\
\hline HEMBL1314149 & 25 & 696 & & \\
\hline HEMBL13 & 95 & 95 & 66 & \\
\hline 503 & 5 & & 52 & \\
\hline 937 & 5 & & 778 & \\
\hline HEMBL 143 & 5 & 696 & & \\
\hline HEMBL1511928 & 5 & & & \\
\hline HEMBL15 & 5 & 96 & & \\
\hline HEMBL14 & & & 36 & \\
\hline 474 & & 596 & 18 & RN \\
\hline HEMBL 28 & 5 & 696 & & 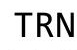 \\
\hline AEMBL413 & 5 & & & Iv \\
\hline HEMBL15 & 15 & & & RN \\
\hline 99 & 5 & & & RN \\
\hline 17 & & 96 & & RN \\
\hline HEMBL133 & 5 & & & 1 \\
\hline HEMBL1394054 & 35 & 596 & & RN \\
\hline HEMBL1: & & & & I \\
\hline 8 & 5 & & & RN \\
\hline HEMBL15 & & 96 & & RN \\
\hline HEMBL1554785 & 5 & 96 & & IRN \\
\hline HEMBL1552619 & 35 & 696 & & ST \\
\hline 872 & & & 61 & RN \\
\hline 44 & & & & RN \\
\hline HEMBL1553680 & & & & ST \\
\hline HEMBL 224501 & 88205 & 696 & 67 & RN \\
\hline HEMBL1433288 & 35 & 696 & 63 & RN \\
\hline 4013 & & & & \\
\hline CHEMBL 390793 & & 696 & 3969 & RN \\
\hline HEMBL1318391 & & 3.7696 & & RN \\
\hline HEMBL131 & 95 & 3.7696 & 269 & RN \\
\hline L224 & & & & \\
\hline סר רחנזו & & & & \\
\hline
\end{tabular}

Page 12968 


\begin{tabular}{|c|c|c|c|c|}
\hline \multicolumn{5}{|c|}{ Supplemental Table S2.txt } \\
\hline CHEMBL1589765 & 688205 & 3.7696 & 4.0955 & TRN \\
\hline CHEMBL407734 & 688205 & 6.8908 & 4.1699 & TST \\
\hline CHEMBL1568527 & 688205 & 3.7696 & 3.9104 & TRN \\
\hline CHEMBL224702 & 688205 & 3.7696 & 3.8986 & TRN \\
\hline CHEMBL1511878 & 688205 & 3.7696 & 3.718 & TRN \\
\hline CHEMBL1530026 & 688205 & 3.7696 & 3.8325 & TRN \\
\hline CHEMBL1354183 & 688205 & 5.9378 & 5.8541 & TRN \\
\hline CHEMBL1354497 & 688205 & 3.7696 & 3.6775 & TRN \\
\hline CHEMBL1433973 & 688205 & 3.7696 & 3.923 & TRN \\
\hline CHEMBL1473057 & 688205 & 3.7696 & 3.718 & TRN \\
\hline CHEMBL1516467 & 688205 & 3.7696 & 3.8237 & TRN \\
\hline CHEMBL1589730 & 688205 & 3.7696 & 3.7926 & TRN \\
\hline CHEMBL1472463 & 688205 & 5.8514 & 3.5621 & TST \\
\hline CHEMBL1551000 & 688205 & 3.7696 & 3.5806 & TRN \\
\hline CHEMBL1314074 & 688205 & 3.7696 & 4.1593 & TST \\
\hline CHEMBL1434483 & 688205 & 3.7696 & 3.7302 & TRN \\
\hline CHEMBL1550992 & 688205 & 3.7696 & 3.4793 & TST \\
\hline CHEMBL 390388 & 688205 & 3.7696 & 4.2901 & TRN \\
\hline CHEMBL1568616 & 688205 & 5.0453 & 4.7965 & TRN \\
\hline CHEMBL1354164 & 688205 & 3.7696 & 3.7519 & TRN \\
\hline CHEMBL1396694 & 688205 & 3.7696 & 3.6842 & TRN \\
\hline CHEMBL278262 & 688205 & 3.7696 & 3.537 & TRN \\
\hline CHEMBL1394104 & 688205 & 7.1098 & 6.9119 & TRN \\
\hline CHEMBL1398496 & 688205 & 3.7696 & 3.6133 & TRN \\
\hline CHEMBL1325140 & 688205 & 3.7696 & 3.9479 & TRN \\
\hline CHEMBL1589696 & 688205 & 3.7696 & 3.1594 & TST \\
\hline CHEMBL1355341 & 688205 & 3.7696 & 3.9696 & TRN \\
\hline CHEMBL1395784 & 688205 & 3.7696 & 3.6494 & TRN \\
\hline CHEMBL1554930 & 688205 & 3.7696 & 3.9233 & TRN \\
\hline CHEMBL1528228 & 688205 & 3.7696 & 3.6661 & TRN \\
\hline CHEMBL1397941 & 688205 & 6.6284 & 6.5819 & TRN \\
\hline CHEMBL1354204 & 688205 & 3.7696 & 3.7514 & TRN \\
\hline CHEMBL1314554 & 688205 & 3.7696 & 3.3477 & TST \\
\hline CHEMBL358678 & 688205 & 3.7696 & 4.1284 & TST \\
\hline CHEMBL1594059 & 688205 & 3.7696 & 3.6242 & TRN \\
\hline CHEMBL1472557 & 688205 & 3.7696 & 3.7088 & TRN \\
\hline CHEMBL64404 & 688205 & 6.0397 & 4.419 & TST \\
\hline CHEMBL1433381 & 688205 & 3.7696 & 3.6355 & TRN \\
\hline CHEMBL376139 & 688205 & 3.7696 & 3.562 & TRN \\
\hline CHEMBL355832 & 688205 & 3.7696 & 3.8749 & TST \\
\hline CHEMBL1433366 & 688205 & 5.2796 & 3.4193 & TST \\
\hline CHEMBL1592130 & 688205 & 3.7696 & 3.7373 & TST \\
\hline CHEMBL1513460 & 688205 & 3.7696 & 3.7478 & TRN \\
\hline CHEMBL225083 & 688205 & 5.0997 & 5.5488 & TRN \\
\hline CHEMBL1316039 & 688205 & 4.8844 & 4.7048 & TST \\
\hline CHEMBL1348462 & 688205 & 3.7696 & 3.8184 & TRN \\
\hline CHEMBL1511947 & 688205 & 5.3518 & 4.0215 & TST \\
\hline CHEMBL1449547 & 688205 & 6.3645 & 6.3502 & TRN \\
\hline
\end{tabular}




\begin{tabular}{|c|c|c|c|c|c|}
\hline \multicolumn{6}{|c|}{ Supplemental Table S2.txt } \\
\hline CHEMBL389656 & 688205 & 3.7696 & 3.7799 & TRN & \\
\hline CHEMBL1551006 & 688205 & 3.7696 & 3.8114 & TST & \\
\hline CHEMBL427244 & 688205 & 3.7696 & 3.593 & TRN & \\
\hline CHEMBL434759 & 688205 & 3.7696 & 3.6447 & TRN & \\
\hline CHEMBL1314026 & 688205 & 3.7696 & 3.6983 & TST & \\
\hline CHEMBL1355822 & 688205 & 3.7696 & 4.0654 & TST & \\
\hline CHEMBL1080375 & 616299 & 6.1871 & 5.0649 & TST & \\
\hline CHEMBL1081432 & 616299 & 7.6383 & 7.4644 & TRN & \\
\hline CHEMBL1082009 & 616299 & 8.3979 & 8.3716 & TRN & \\
\hline CHEMBL1079968 & 616299 & 8.0969 & 8.2626 & TRN & \\
\hline CHEMBL1081447 & 616299 & 7.301 & 7.455 & TRN & \\
\hline CHEMBL1081071 & 616299 & 7.7959 & 7.6549 & TRN & \\
\hline CHEMBL1086735 & 616299 & 8.5229 & 8.4963 & TRN & \\
\hline CHEMBL1081431 & 616299 & 6.9208 & 7.5478 & TRN & \\
\hline CHEMBL1076755 & 616299 & 8.4318 & 8.3778 & TRN & \\
\hline CHEMBL1081430 & 616299 & 7.0044 & 7.0928 & TRN & \\
\hline CHEMBL1079967 & 616299 & 7.4089 & 7.6738 & TRN & \\
\hline CHEMBL 388978 & 616299 & 7.6576 & 6.0948 & TST & \\
\hline CHEMBL1080849 & 616299 & 8.699 & 8.7156 & TRN & \\
\hline CHEMBL1076682 & 616299 & 7.699 & 7.5804 & TRN & \\
\hline CHEMBL1081429 & 616299 & 7.3565 & 7.473 & TRN & \\
\hline CHEMBL1082176 & 616299 & 7.6383 & 7.8082 & TRN & \\
\hline CHEMBL1076552 & 616299 & 7.7959 & 7.9756 & TRN & \\
\hline CHEMBL1081632 & 616299 & 7.7447 & 8.0003 & TRN & \\
\hline CHEMBL1081630 & 616299 & 7.699 & 7.7938 & TRN & \\
\hline CHEMBL1086601 & 616299 & 7.0605 & 8.1322 & TRN & \\
\hline CHEMBL1080848 & 616299 & 7.2291 & 7.28700 & 0000000001 & TRN \\
\hline CHEMBL 1081454 & 616299 & 6.1938 & 6.7748 & TRN & \\
\hline CHEMBL1076619 & 616299 & 6.3372 & 5.7017 & TST & \\
\hline CHEMBL1076695 & 616299 & 8.0458 & 8.2067 & TRN & \\
\hline CHEMBL1082157 & 616299 & 8.0458 & 8.4244 & TRN & \\
\hline CHEMBL1081102 & 616299 & 8.0809 & 8.5034 & TRN & \\
\hline CHEMBL1081069 & 616299 & 7.8539 & 8.2966 & TRN & \\
\hline CHEMBL1087244 & 616299 & 9.699 & 9.6217 & TRN & \\
\hline CHEMBL1080868 & 616299 & 5.8268 & 5.5855 & TST & \\
\hline CHEMBL1076721 & 616299 & 8.699 & 8.4279 & TRN & \\
\hline CHEMBL1076701 & 616299 & 8.7212 & 8.7425 & TRN & \\
\hline CHEMBL1081446 & 616299 & 8.1135 & 8.1258 & TRN & \\
\hline CHEMBL1088011 & 616299 & 9.3979 & 9.3286 & TRN & \\
\hline CHEMBL1081833 & 616299 & 8.301 & 8.1797 & TRN & \\
\hline CHEMBL1088725 & 616299 & 8.0969 & 7.7163 & TRN & \\
\hline CHEMBL1080902 & 616299 & 9.0969 & 8.6803 & TRN & \\
\hline CHEMBL1081070 & 616299 & 6.9586 & 7.2982 & TRN & \\
\hline CHEMBL1080377 & 616299 & 6.6021 & 5.8427 & TRN & \\
\hline CHEMBL1081631 & 616299 & 7.5229 & 7.9593 & TRN & \\
\hline CHEMBL1086602 & 616299 & 8.699 & 8.4661 & TRN & \\
\hline CHEMBL1081277 & 616299 & 4.3979 & 7.3493 & TST & \\
\hline CHEMBL1088021 & 616299 & 8.5229 & 8.2896 & TRN & \\
\hline
\end{tabular}

Page 12970 


$$
\text { Supplemental Table S2.txt }
$$

\begin{tabular}{|c|c|c|c|c|c|}
\hline CHEMBL1082156 & 616299 & 9.699 & 9.3551 & TRN & \\
\hline CHEMBL1082188 & 616299 & 8.1871 & 7.9896 & TRN & \\
\hline CHEMBL1081063 & 616299 & 6.0706 & 6.3515 & TRN & \\
\hline CHEMBL1082011 & 616299 & 7.5229 & 8.0495 & TRN & \\
\hline CHEMBL1082010 & 616299 & 8.0969 & 7.2534 & TRN & \\
\hline CHEMBL1088726 & 616299 & 9.4559 & 8.8455 & TRN & \\
\hline CHEMBL1081103 & 616299 & 7.6383 & 8.1033 & TRN & \\
\hline CHEMBL1088012 & 616299 & 9.699 & 9.5128 & TRN & \\
\hline CHEMBL1080847 & 616299 & 8.0458 & 6.8644 & TRN & \\
\hline CHEMBL1079966 & 616299 & 8.699 & 8.1925 & TRN & \\
\hline CHEMBL1087246 & 616299 & 9.4559 & 9.0969 & TRN & \\
\hline CHEMBL1081633 & 616299 & 8.699 & 8.4078 & TST & \\
\hline CHEMBL1080376 & 616299 & 6.699 & 5.8385 & TST & \\
\hline CHEMBL322970 & 616299 & 7.6198 & 6.9257 & TST & \\
\hline CHEMBL1080544 & 616299 & 6.1427 & 5.7634 & TST & \\
\hline CHEMBL1080374 & 616299 & 4.4318 & 5.7465 & TST & \\
\hline CHEMBL1087245 & 616299 & 9.4559 & 9.1862 & TST & \\
\hline CHEMBL1081068 & 616299 & 9.699 & 8.8361 & TST & \\
\hline CHEMBL1081278 & 616299 & 7.4559 & 7.8662 & TST & \\
\hline CHEMBL1088154 & 616299 & 6.5686 & 7.3444 & TST & \\
\hline CHEMBL1086736 & 616299 & 8.3468 & 7.7369 & TST & \\
\hline CHEMBL1088145 & 616299 & 9.3979 & 9.332 & TST & \\
\hline CHEMBL1973211 & 809197 & 5.6 & 5.2602 & TRN & \\
\hline CHEMBL1984700 & 809197 & 5.6 & 4.886 & TRN & \\
\hline CHEMBL 2007151 & 809197 & 5.9 & 5.0516 & TRN & \\
\hline CHEMBL1972125 & 809197 & 4.0 & 4.7151 & TRN & \\
\hline CHEMBL1461728 & 809197 & 4.0 & 4.2905 & TRN & \\
\hline CHEMBL1999120 & 809197 & 5.4 & 4.7206 & TST & \\
\hline CHEMBL1976134 & 809197 & 5.2 & 5.5869 & TRN & \\
\hline CHEMBL1965131 & 809197 & 5.6 & 5.3779 & TRN & \\
\hline CHEMBL1995448 & 809197 & 4.0 & 4.6022 & TRN & \\
\hline CHEMBL1972158 & 809197 & 6.3 & 5.2348 & TRN & \\
\hline CHEMBL1981215 & 809197 & 4.5 & 4.9596 & TRN & \\
\hline CHEMBL1974457 & 809197 & 4.0 & 4.6042 & TRN & \\
\hline CHEMBL 2006580 & 809197 & 4.0 & 4.4382 & TRN & \\
\hline CHEMBL 2006581 & 809197 & 4.0 & 4.1794 & TRN & \\
\hline CHEMBL1970340 & 809197 & 5.6 & 4.65600 & 0000000001 & TRN \\
\hline CHEMBL1967992 & 809197 & 4.5 & 4.6094 & TRN & \\
\hline CHEMBL1975534 & 809197 & 4.0 & 4.8283 & TRN & \\
\hline CHEMBL1966703 & 809197 & 4.0 & 4.5855 & TRN & \\
\hline CHEMBL1969561 & 809197 & 5.4 & 5.0781 & TRN & \\
\hline CHEMBL1994555 & 809197 & 5.5 & 5.4214 & TRN & \\
\hline CHEMBL1983640 & 809197 & 4.5 & 4.8637 & TRN & \\
\hline CHEMBL1997023 & 809197 & 4.0 & 4.2523 & TST & \\
\hline CHEMBL1980003 & 809197 & 4.1 & 4.6083 & TRN & \\
\hline CHEMBL1964687 & 809197 & 4.0 & 4.8996 & TRN & \\
\hline CHEMBL1999918 & 809197 & 5.6 & 5.9924 & TRN & \\
\hline CHEMBL1974254 & 809197 & 5.0 & 5.4981 & TRN & \\
\hline
\end{tabular}




\begin{tabular}{|c|c|c|c|c|c|}
\hline & & & & & \\
\hline CHEMBL1988537 & 809197 & 5.2 & 5.0652 & TST & \\
\hline CHEMBL 2005828 & 809197 & 5.5 & 5.0888 & TRN & \\
\hline CHEMBL 2002240 & 809197 & 4.0 & 3.9416 & TRN & \\
\hline CHEMBL1998611 & 809197 & 5.8 & 5.4317 & TRN & \\
\hline CHEMBL485556 & 809197 & 4.0 & 4.4495 & TST & \\
\hline CHEMBL1975900 & 809197 & 4.0 & 4.3563 & TRN & \\
\hline CHEMBL 255822 & 809197 & 4.0 & 4.3524 & TRN & \\
\hline CHEMBL1972221 & 809197 & 5.2 & 4.9541 & TRN & \\
\hline CHEMBL 2006778 & 809197 & 7.1 & 6.9284 & TRN & \\
\hline CHEMBL378627 & 809197 & 4.0 & $4.0280 e$ & 00000000005 & TRN \\
\hline CHEMBL1996979 & 809197 & 4.2 & 4.6733 & TRN & \\
\hline CHEMBL1997025 & 809197 & 4.0 & 3.8827 & TRN & \\
\hline CHEMBL1968406 & 809197 & 5.2 & 4.7392 & TRN & \\
\hline CHEMBL1982476 & 809197 & 6.7 & 6.9956 & TRN & \\
\hline CHEMBL1984274 & 809197 & 4.0 & 4.351 & TRN & \\
\hline CHEMBL1998545 & 809197 & 4.0 & 4.1878 & TRN & \\
\hline CHEMBL1975923 & 809197 & 6.7 & 5.0431 & TST & \\
\hline CHEMBL2005449 & 809197 & 5.6 & 5.4744 & TRN & \\
\hline CHEMBL1987998 & 809197 & 4.5 & 4.4311 & TRN & \\
\hline CHEMBL1682558 & 809197 & 4.0 & 4.4282 & TRN & \\
\hline CHEMBL1971534 & 809197 & 4.8 & 4.8732 & TRN & \\
\hline CHEMBL1990496 & 809197 & 4.2 & $4.6960 e$ & 0000000001 & TRN \\
\hline CHEMBL242865 & 809197 & 5.6 & 6.6496 & TRN & \\
\hline CHEMBL1997623 & 809197 & 4.0 & 4.5952 & TRN & \\
\hline CHEMBL1983884 & 809197 & 4.2 & 4.3071 & TST & \\
\hline CHEMBL1993166 & 809197 & 5.8 & 5.1481 & TRN & \\
\hline CHEMBL1967094 & 809197 & 5.5 & 5.0335 & TRN & \\
\hline CHEMBL 2003341 & 809197 & 4.0 & 4.2437 & TRN & \\
\hline CHEMBL1992645 & 809197 & 4.0 & 4.4316 & TST & \\
\hline CHEMBL550275 & 809197 & 6.2 & 5.1361 & TST & \\
\hline CHEMBL1974363 & 809197 & 4.0 & 4.3285 & TRN & \\
\hline CHEMBL1998110 & 809197 & 4.5 & 4.7454 & TRN & \\
\hline CHEMBL1999590 & 809197 & 5.1 & 4.3485 & TST & \\
\hline CHEMBL1978166 & 809197 & 4.5 & 5.5968 & TRN & \\
\hline CHEMBL1999632 & 809197 & 5.7 & 4.6181 & TST & \\
\hline CHEMBL1982993 & 809197 & 6.0 & 4.8667 & TRN & \\
\hline CHEMBL1972276 & 809197 & 4.0 & 4.3669 & TRN & \\
\hline CHEMBL1980489 & 809197 & 4.0 & 4.2855 & TRN & \\
\hline CHEMBL1967116 & 809197 & 6.9 & 6.4008 & TRN & \\
\hline CHEMBL 2000832 & 809197 & 4.0 & 5.5338 & TRN & \\
\hline CHEMBL1972454 & 809197 & 5.5 & 4.5659 & TRN & \\
\hline CHEMBL1977814 & 809197 & 4.2 & 3.8287 & TST & \\
\hline CHEMBL1970709 & 809197 & 4.0 & 4.3361 & TRN & \\
\hline CHEMBL1985309 & 809197 & 4.0 & 4.5635 & TRN & \\
\hline CHEMBL1980896 & 809197 & 6.0 & 5.5329 & TRN & \\
\hline CHEMBL1975208 & 809197 & 4.0 & 4.0541 & TRN & \\
\hline CHEMBL1178727 & 809197 & 4.3 & 4.5395 & TST & \\
\hline CHEMBL1970104 & 809197 & 5.7 & 5.9771 & TRN & \\
\hline & & & & 12972 & \\
\hline
\end{tabular}




\begin{tabular}{|c|c|c|c|c|c|}
\hline \multirow{2}{*}{ CHEMBL1967612 } & \multirow{2}{*}{809197} & \\
\hline & & 4.6 & 4.52 & TRN & \\
\hline CHEMBL1964777 & 809197 & 4.0 & 4.4629 & TRN & \\
\hline CHEMBL1999714 & 809197 & 4.0 & 4.1261 & TRN & \\
\hline CHEMBL1987533 & 809197 & 4.0 & 4.2671 & TRN & \\
\hline CHEMBL388978 & 809197 & 7.0 & 6.968 & TST & \\
\hline CHEMBL579246 & 809197 & 4.0 & 5.107 & TRN & \\
\hline CHEMBL1971150 & 809197 & 5.7 & 4.3793 & TST & \\
\hline CHEMBL398951 & 809197 & 4.0 & 3.8646 & TRN & \\
\hline CHEMBL1982506 & 809197 & 4.0 & 4.7444 & TST & \\
\hline CHEMBL1975233 & 809197 & 4.0 & 3.9351 & TRN & \\
\hline CHEMBL1985406 & 809197 & 4.0 & 4.6326 & TRN & \\
\hline CHEMBL207400 & 809197 & 4.0 & 3.9082 & TST & \\
\hline CHEMBL 2000894 & 809197 & 5.3 & 4.7571 & TST & \\
\hline CHEMBL1421720 & 809197 & 6.8 & 5.6914 & TRN & \\
\hline CHEMBL1968130 & 809197 & 5.7 & 4.9887 & TST & \\
\hline CHEMBL 2002553 & 809197 & 4.0 & 4.2578 & TRN & \\
\hline CHEMBL1982135 & 809197 & 5.9 & 5.2061 & TRN & \\
\hline CHEMBL1976090 & 809197 & 5.4 & 5.7788 & TRN & \\
\hline CHEMBL1993243 & 809197 & 6.6 & 6.4259 & TRN & \\
\hline CHEMBL1992922 & 809197 & 5.7 & 5.2926 & TRN & \\
\hline CHEMBL399021 & 809197 & 5.4 & 5.3253 & TRN & \\
\hline CHEMBL1997597 & 809197 & 5.2 & 4.9146 & TRN & \\
\hline CHEMBL1969537 & 809197 & 4.0 & 4.8703 & TST & \\
\hline CHEMBL576113 & 809197 & 6.1 & 4.3747 & TST & \\
\hline CHEMBL210032 & 809197 & 4.0 & 3.8408 & TRN & \\
\hline CHEMBL1996543 & 809197 & 5.0 & 4.3948 & TRN & \\
\hline CHEMBL1975256 & 809197 & 4.0 & 4.3791 & TST & \\
\hline CHEMBL508928 & 809197 & 6.8 & 5.28606 & 00000000005 & TRN \\
\hline CHEMBL 2004892 & 809197 & 4.0 & 4.9247 & TRN & \\
\hline CHEMBL1999126 & 809197 & 4.0 & 4.377 & TST & \\
\hline CHEMBL116070 & 809197 & 4.0 & 4.462 & TRN & \\
\hline CHEMBL1970314 & 809197 & 4.0 & 4.3924 & TRN & \\
\hline CHEMBL 2004871 & 809197 & 4.0 & 4.4814 & TRN & \\
\hline CHEMBL1727312 & 809197 & 4.0 & 3.9578 & TRN & \\
\hline CHEMBL1990223 & 809197 & 4.5 & 4.2853 & TRN & \\
\hline CHEMBL 2006149 & 809197 & 6.3 & 4.8231 & TST & \\
\hline CHEMBL1964382 & 809197 & 5.6 & 4.3672 & TST & \\
\hline CHEMBL101311 & 809197 & 5.8 & 5.5937 & TRN & \\
\hline CHEMBL1981720 & 809197 & 6.0 & 5.3631 & TRN & \\
\hline CHEMBL419932 & 809197 & 4.0 & 4.3637 & TRN & \\
\hline CHEMBL262433 & 809197 & 4.0 & 5.2203 & TRN & \\
\hline CHEMBL306380 & 809197 & 6.4 & 5.7901 & TRN & \\
\hline CHEMBL1966722 & 809197 & 4.0 & 5.2047 & TRN & \\
\hline CHEMBL1988581 & 809197 & 7.0 & 5.9909 & TST & \\
\hline CHEMBL2005699 & 809197 & 4.5 & 4.69 & TST & \\
\hline CHEMBL1976328 & 809197 & 4.0 & 4.3721 & TRN & \\
\hline CHEMBL1975500 & 809197 & 5.3 & 4.7314 & TRN & \\
\hline CHEMBL394619 & 809197 & 4.0 & 5.144 & TRN & \\
\hline & & & & 12973 & \\
\hline
\end{tabular}




\begin{tabular}{|c|c|c|c|c|c|}
\hline \multicolumn{6}{|c|}{ lable s2. } \\
\hline CHEMBL1964399 & 809197 & 6.5 & 6.0075 & TRN & \\
\hline CHEMBL1996831 & 809197 & 4.0 & 4.4376 & TST & \\
\hline CHEMBL411903 & 809197 & 5.9 & 5.54799 & 9999999999 & TRN \\
\hline CHEMBL1991008 & 809197 & 4.2 & 4.5646 & TRN & \\
\hline CHEMBL1978167 & 809197 & 5.7 & 5.4423 & TST & \\
\hline CHEMBL1965988 & 809197 & 5.6 & 5.3435 & TRN & \\
\hline CHEMBL418203 & 809197 & 4.5 & 4.9264 & TST & \\
\hline CHEMBL1682357 & 809197 & 4.0 & 5.3345 & TRN & \\
\hline CHEMBL225519 & 809197 & 4.5 & 5.3268 & TRN & \\
\hline CHEMBL209534 & 809197 & 4.0 & 4.0045 & TRN & \\
\hline CHEMBL1994159 & 809197 & 4.4 & 4.6279 & TRN & \\
\hline CHEMBL1970522 & 809197 & 4.0 & 4.4897 & TRN & \\
\hline CHEMBL402846 & 809197 & 5.1 & 4.2036 & TRN & \\
\hline CHEMBL1990415 & 809197 & 4.0 & 4.212 & TRN & \\
\hline CHEMBL1966087 & 809197 & 4.0 & 4.187 & TRN & \\
\hline CHEMBL1964692 & 809197 & 4.0 & 4.6677 & TRN & \\
\hline CHEMBL1996931 & 809197 & 5.5 & 4.2577 & TRN & \\
\hline CHEMBL1964413 & 809197 & 4.0 & 4.4017 & TRN & \\
\hline CHEMBL1984432 & 809197 & 4.0 & 4.529 & TRN & \\
\hline CHEMBL1970735 & 809197 & 4.0 & 3.7595 & TRN & \\
\hline CHEMBL219722 & 809197 & 5.6 & 5.3975 & TRN & \\
\hline CHEMBL1975903 & 809197 & 4.5 & 5.7705 & TRN & \\
\hline CHEMBL1997340 & 809197 & 4.0 & 4.3682 & TRN & \\
\hline CHEMBL 2004365 & 809197 & 4.0 & 4.3751 & TST & \\
\hline CHEMBL1522508 & 809197 & 4.6 & 4.6106 & TRN & \\
\hline CHEMBL1989474 & 809197 & 4.0 & 4.0484 & TRN & \\
\hline CHEMBL1988805 & 809197 & 6.7 & 4.8208 & TST & \\
\hline CHEMBL458997 & 809197 & 5.9 & 5.44600 & 0000000001 & TRN \\
\hline CHEMBL583144 & 809197 & 4.0 & 4.4874 & TRN & \\
\hline CHEMBL1974310 & 809197 & 5.6 & 5.4011 & TRN & \\
\hline CHEMBL1969942 & 809197 & 4.5 & 4.7799 & TRN & \\
\hline CHEMBL1978567 & 809197 & 4.5 & 4.7454 & TRN & \\
\hline CHEMBL1994693 & 809197 & 5.8 & 5.2099 & TRN & \\
\hline CHEMBL1982957 & 809197 & 6.3 & 6.2295 & TRN & \\
\hline CHEMBL 86755 & 809197 & 4.5 & 4.5647 & TRN & \\
\hline CHEMBL1975138 & 809197 & 4.0 & 4.7147 & TRN & \\
\hline CHEMBL424872 & 809197 & 4.0 & 4.0619 & TRN & \\
\hline CHEMBL 2006836 & 809197 & 5.6 & 4.30699 & 99999999995 & TST \\
\hline CHEMBL1971947 & 809197 & 6.1 & 5.2934 & TRN & \\
\hline CHEMBL412142 & 809197 & 5.2 & 4.0384 & TST & \\
\hline CHEMBL 2002802 & 809197 & 4.1 & 4.7202 & TRN & \\
\hline CHEMBL1980704 & 809197 & 4.0 & 4.4807 & TST & \\
\hline CHEMBL 2003271 & 809197 & 5.9 & 5.3833 & TRN & \\
\hline CHEMBL 2004447 & 809197 & 4.0 & 3.9375 & TRN & \\
\hline CHEMBL1983111 & 809197 & 6.9 & 6.4496 & TRN & \\
\hline CHEMBL1973860 & 809197 & 4.0 & 4.3921 & TRN & \\
\hline CHEMBL1977713 & 809197 & 4.0 & 4.3409 & TRN & \\
\hline CHEMBL260135 & 809197 & 4.0 & 4.5762 & TRN & \\
\hline
\end{tabular}




\begin{tabular}{|c|c|c|c|c|}
\hline \multicolumn{5}{|c|}{ ipplemental T } \\
\hline CHEMBL 2004544 & 809197 & 4.1 & 4.5093 & TST \\
\hline CHEMBL1988141 & 809197 & 6.3 & 5.7386 & TST \\
\hline CHEMBL1982610 & 809197 & 4.0 & 4.7203 & TST \\
\hline CHEMBL1977134 & 809197 & 4.5 & 4.6357 & TRN \\
\hline CHEMBL1999496 & 809197 & 4.1 & 4.0984 & TRN \\
\hline CHEMBL 2006933 & 809197 & 5.5 & 5.2887 & TST \\
\hline CHEMBL1985206 & 809197 & 4.5 & 4.6011 & TRN \\
\hline CHEMBL1988300 & 809197 & 5.7 & 5.4991 & TRN \\
\hline CHEMBL1977749 & 809197 & 4.5 & 4.6761 & TST \\
\hline CHEMBL 2001613 & 809197 & 5.5 & 4.742 & TRN \\
\hline CHEMBL 2000685 & 809197 & 6.3 & 6.0458 & TRN \\
\hline CHEMBL1993904 & 809197 & 4.5 & 5.6793 & TRN \\
\hline CHEMBL1980376 & 809197 & 4.7 & 4.4553 & TRN \\
\hline CHEMBL1985311 & 809197 & 5.3 & 5.401 & TRN \\
\hline CHEMBL1989265 & 809197 & 4.0 & 4.1867 & TST \\
\hline CHEMBL1982413 & 809197 & 7.0 & 5.1552 & TST \\
\hline CHEMBL 2004647 & 809197 & 4.0 & 4.2635 & TRN \\
\hline CHEMBL1969502 & 809197 & 7.5 & 6.024 & TRN \\
\hline CHEMBL1965910 & 809197 & 6.1 & 5.3853 & TRN \\
\hline CHEMBL1682553 & 809197 & 4.0 & 4.959 & TRN \\
\hline CHEMBL1971430 & 809197 & 4.0 & 4.5933 & TRN \\
\hline CHEMBL 2000271 & 809197 & 6.7 & 6.0718 & TRN \\
\hline CHEMBL1983963 & 809197 & 5.4 & 5.6806 & TRN \\
\hline CHEMBL1985042 & 809197 & 4.9 & 4.7249 & TST \\
\hline CHEMBL1987535 & 809197 & 4.5 & 5.1375 & TST \\
\hline CHEMBL1985092 & 809197 & 5.4 & 4.4896 & TRN \\
\hline CHEMBL 2004692 & 809197 & 4.0 & 4.0824 & TST \\
\hline CHEMBL 2002586 & 809197 & 4.5 & 4.7022 & TRN \\
\hline CHEMBL1981410 & 809197 & 4.0 & 4.7834 & TRN \\
\hline CHEMBL1991434 & 809197 & 4.0 & 3.8891 & TRN \\
\hline CHEMBL1973138 & 809197 & 4.5 & 4.73 & TRN \\
\hline CHEMBL223367 & 809197 & 4.0 & 4.1847 & TST \\
\hline CHEMBL340384 & 809197 & 6.3 & 5.3681 & TST \\
\hline CHEMBL1993335 & 809197 & 4.5 & 5.7627 & TST \\
\hline CHEMBL1988692 & 809197 & 5.9 & 4.832 & TRN \\
\hline CHEMBL1964804 & 809197 & 4.0 & 4.8307 & TRN \\
\hline CHEMBL443962 & 809197 & 4.0 & 4.6273 & TST \\
\hline CHEMBL 2000354 & 809197 & 5.1 & 4.3402 & TRN \\
\hline CHEMBL1965507 & 809197 & 6.0 & 4.7264 & TRN \\
\hline CHEMBL 274064 & 809197 & 6.1 & 4.6151 & TRN \\
\hline CHEMBL1998680 & 809197 & 4.5 & 4.8365 & TST \\
\hline CHEMBL1967564 & 809197 & 5.3 & 4.2807 & TRN \\
\hline CHEMBL592030 & 809197 & 5.9 & 5.3415 & TST \\
\hline CHEMBL 2000071 & 809197 & 5.8 & 5.3759 & TRN \\
\hline CHEMBL1970317 & 809197 & 6.9 & 6.3266 & TRN \\
\hline CHEMBL 2000408 & 809197 & 5.7 & 4.8803 & TRN \\
\hline CHEMBL248757 & 809197 & 4.0 & 3.9985 & TST \\
\hline CHEMBL1978014 & 809197 & 4.0 & 4.4468 & TRN \\
\hline
\end{tabular}




\begin{tabular}{|c|c|c|c|c|c|}
\hline \\
\hline CHEMBL1997007 & 809197 & 4.5 & 5.1022 & TRN & \\
\hline CHEMBL1994538 & 809197 & 5.8 & 5.0124 & TRN & \\
\hline CHEMBL1983195 & 809197 & 4.0 & 4.3118 & TRN & \\
\hline CHEMBL 2002690 & 809197 & 4.5 & 4.5901 & TRN & \\
\hline CHEMBL2006567 & 809197 & 4.0 & 3.8127 & TRN & \\
\hline CHEMBL1986139 & 809197 & 4.0 & 4.30399 & 9999999999 & TRN \\
\hline CHEMBL1975503 & 809197 & 4.5 & 4.5813 & TRN & \\
\hline CHEMBL383527 & 809197 & 5.7 & 4.4539 & TRN & \\
\hline CHEMBL 278041 & 809197 & 4.5 & 4.5856 & TRN & \\
\hline CHEMBL1979883 & 809197 & 5.7 & 5.1027 & TRN & \\
\hline CHEMBL1984162 & 809197 & 6.3 & 7.1866 & TRN & \\
\hline CHEMBL491758 & 809197 & 7.0 & 6.0515 & TRN & \\
\hline CHEMBL1986590 & 809197 & 5.8 & 4.8141 & TRN & \\
\hline CHEMBL549730 & 809197 & 4.0 & 4.2298 & TRN & \\
\hline CHEMBL1682360 & 809197 & 6.1 & 4.5905 & TRN & \\
\hline CHEMBL1970189 & 809197 & 5.1 & 4.231 & TRN & \\
\hline CHEMBL1996791 & 809197 & 5.0 & 5.4325 & TRN & \\
\hline CHEMBL371206 & 809197 & 5.9 & 6.0089 & TRN & \\
\hline CHEMBL1974664 & 809197 & 7.1 & 5.2764 & TRN & \\
\hline CHEMBL406845 & 809197 & 4.5 & 5.5604 & TRN & \\
\hline CHEMBL1984296 & 809197 & 6.5 & 5.6818 & TRN & \\
\hline CHEMBL196363 & 809197 & 5.4 & 5.4569 & TRN & \\
\hline CHEMBL1964718 & 809197 & 4.9 & 4.4069 & TST & \\
\hline CHEMBL1964441 & 809197 & 4.5 & 5.1734 & TRN & \\
\hline CHEMBL546797 & 809197 & 6.3 & 5.1148 & TRN & \\
\hline CHEMBL404367 & 809197 & 5.7 & 4.7287 & TRN & \\
\hline CHEMBL1966343 & 809197 & 5.3 & 5.3322 & TRN & \\
\hline CHEMBL 2007266 & 809197 & 4.5 & 4.2946 & TRN & \\
\hline CHEMBL 2000568 & 809197 & 4.5 & 4.6399 & TRN & \\
\hline CHEMBL 2000335 & 809197 & 6.1 & 5.9556 & TRN & \\
\hline CHEMBL1994308 & 809197 & 4.5 & 4.5061 & TRN & \\
\hline CHEMBL1977604 & 809197 & 4.0 & 4.2365 & TST & \\
\hline CHEMBL 2007097 & 809197 & 4.5 & 4.525 & TRN & \\
\hline CHEMBL1988717 & 809197 & 5.1 & 5.1415 & TRN & \\
\hline CHEMBL1974328 & 809197 & 4.5 & 5.1778 & TRN & \\
\hline CHEMBL509032 & 809197 & 6.6 & 6.7195 & TRN & \\
\hline CHEMBL1973808 & 809197 & 4.0 & 4.2114 & TRN & \\
\hline CHEMBL 2000429 & 809197 & 4.0 & 5.13899 & 9999999999 & TRN \\
\hline CHEMBL1972576 & 809197 & 5.3 & 5.0202 & TRN & \\
\hline CHEMBL1992342 & 809197 & 5.1 & 5.1632 & TRN & \\
\hline CHEMBL1988173 & 809197 & 5.5 & 5.0357 & TRN & \\
\hline CHEMBL1973013 & 809197 & 5.6 & 5.20299 & 9999999999 & TRN \\
\hline CHEMBL1989805 & 809197 & 4.0 & 4.5408 & TST & \\
\hline CHEMBL1965423 & 809197 & 5.2 & 4.6615 & TRN & \\
\hline CHEMBL1983025 & 809197 & 5.5 & 5.0339 & TRN & \\
\hline CHEMBL 205415 & 809197 & 4.7 & 4.8457 & TRN & \\
\hline CHEMBL1977135 & 809197 & 4.0 & 4.144 & TRN & \\
\hline CHEMBL 2001920 & 809197 & 5.4 & 4.6573 & TRN & \\
\hline
\end{tabular}




\begin{tabular}{|c|c|c|c|c|}
\hline \multicolumn{5}{|c|}{ oplemental lable s2.tx } \\
\hline CHEMBL 2002322 & 809197 & 4.0 & 4.4657 & TRN \\
\hline CHEMBL1977138 & 809197 & 6.3 & 5.1481 & TST \\
\hline CHEMBL1241473 & 809197 & 5.9 & 7.0903 & TRN \\
\hline CHEMBL 2002323 & 809197 & 4.0 & 4.1759 & TRN \\
\hline CHEMBL 2000879 & 809197 & 4.0 & 5.051 & TST \\
\hline CHEMBL1978448 & 809197 & 4.5 & 4.7236 & TST \\
\hline CHEMBL1972258 & 809197 & 4.0 & 4.1544 & TRN \\
\hline CHEMBL2001257 & 809197 & 5.1 & 4.7065 & TRN \\
\hline CHEMBL 2004515 & 809197 & 5.7 & 5.0685 & TRN \\
\hline CHEMBL1980329 & 809197 & 5.6 & 4.646 & TRN \\
\hline CHEMBL1992042 & 809197 & 6.7 & 5.6354 & TRN \\
\hline CHEMBL 2005548 & 809197 & 4.0 & 3.9316 & TRN \\
\hline CHEMBL1992536 & 809197 & 4.0 & 4.2898 & TRN \\
\hline CHEMBL21156 & 809197 & 4.5 & 4.7223 & TST \\
\hline CHEMBL1380050 & 809197 & 5.0 & 4.4037 & TST \\
\hline CHEMBL1992740 & 809197 & 4.0 & 4.4354 & TRN \\
\hline CHEMBL1994724 & 809197 & 4.5 & 5.1336 & TRN \\
\hline CHEMBL1989267 & 809197 & 7.2 & 6.4567 & TRN \\
\hline CHEMBL 2002373 & 809197 & 4.0 & 4.4823 & TRN \\
\hline CHEMBL439340 & 809197 & 5.7 & 4.378 & TRN \\
\hline CHEMBL1974574 & 809197 & 6.1 & 5.0754 & TST \\
\hline CHEMBL1967531 & 809197 & 5.9 & 5.7578 & TRN \\
\hline CHEMBL1970913 & 809197 & 5.5 & 4.3209 & TRN \\
\hline CHEMBL1973893 & 809197 & 5.3 & 5.005 & TRN \\
\hline CHEMBL1995736 & 809197 & 4.0 & 4.3917 & TRN \\
\hline CHEMBL1993877 & 809197 & 6.1 & 5.1697 & TRN \\
\hline CHEMBL1996500 & 809197 & 4.3 & 4.7777 & TRN \\
\hline CHEMBL1985095 & 809197 & 5.4 & 5.3335 & TST \\
\hline CHEMBL1973363 & 809197 & 6.0 & 5.0622 & TRN \\
\hline CHEMBL 2005352 & 809197 & 5.5 & 5.0368 & TRN \\
\hline CHEMBL1991180 & 809197 & 5.9 & 4.9588 & TST \\
\hline CHEMBL1682540 & 809197 & 4.0 & 4.9713 & TRN \\
\hline CHEMBL1978656 & 809197 & 4.0 & 4.1337 & TRN \\
\hline CHEMBL1998253 & 809197 & 6.3 & 4.7271 & TST \\
\hline CHEMBL1994864 & 809197 & 4.4 & 4.2942 & TRN \\
\hline CHEMBL413779 & 809197 & 4.0 & 4.2642 & TST \\
\hline CHEMBL 2002446 & 809197 & 5.1 & 4.1467 & TRN \\
\hline CHEMBL497151 & 809197 & 5.4 & 4.4772 & TRN \\
\hline CHEMBL 2000029 & 809197 & 4.5 & 5.5465 & TRN \\
\hline CHEMBL1973961 & 809197 & 4.5 & 4.63 & TRN \\
\hline CHEMBL 340921 & 809197 & 5.1 & 4.7192 & TST \\
\hline CHEMBL373598 & 809197 & 4.0 & 4.0631 & TST \\
\hline CHEMBL2001149 & 809197 & 6.5 & 5.21700 & 00000000005 \\
\hline CHEMBL 2005478 & 809197 & 5.6 & 5.4411 & TST \\
\hline CHEMBL1996646 & 809197 & 4.5 & 5.1757 & TRN \\
\hline CHEMBL1977346 & 809197 & 5.0 & 5.2845 & TRN \\
\hline CHEMBL1971649 & 809197 & 4.0 & 3.7957 & TRN \\
\hline CHEMBL 2003657 & 809197 & 5.3 & 4.8747 & TRN \\
\hline
\end{tabular}

TRN 


\begin{tabular}{|c|c|c|c|c|c|}
\hline \\
\hline CHEMBL1996702 & 809197 & 4.5 & 4.8484 & TRN & \\
\hline CHEMBL 2007124 & 809197 & 4.5 & 4.463 & TRN & \\
\hline CHEMBL2006156 & 809197 & 4.0 & 4.3779 & TRN & \\
\hline CHEMBL1985681 & 809197 & 4.5 & 4.8909 & TST & \\
\hline CHEMBL1969190 & 809197 & 5.0 & 5.0088 & TRN & \\
\hline CHEMBL1973937 & 809197 & 5.4 & 4.7062 & TRN & \\
\hline CHEMBL1982711 & 809197 & 4.2 & 5.4377 & TRN & \\
\hline CHEMBL262623 & 809197 & 4.9 & 4.9239 & TRN & \\
\hline CHEMBL1984842 & 809197 & 6.1 & 4.9654 & TRN & \\
\hline CHEMBL1969102 & 809197 & 6.3 & 6.3649 & TRN & \\
\hline CHEMBL 2004118 & 809197 & 4.5 & 4.9151 & TRN & \\
\hline CHEMBL1682346 & 809197 & 5.8 & 5.5241 & TRN & \\
\hline CHEMBL1996795 & 809197 & 5.7 & 4.9275 & TST & \\
\hline CHEMBL 2007044 & 809197 & 4.0 & 3.9307 & TRN & \\
\hline CHEMBL 2001998 & 809197 & 4.0 & 4.2283 & TRN & \\
\hline CHEMBL1994241 & 809197 & 4.0 & 4.5753 & TRN & \\
\hline CHEMBL223460 & 809197 & 4.0 & 3.9388 & TST & \\
\hline CHEMBL1998829 & 809197 & 4.2 & 3.9346 & TRN & \\
\hline CHEMBL50894 & 809197 & 4.3 & 5.3932 & TRN & \\
\hline CHEMBL375284 & 809197 & 4.0 & 4.5658 & TRN & \\
\hline CHEMBL 2006299 & 809197 & 4.5 & 4.4661 & TRN & \\
\hline CHEMBL1965169 & 809197 & 4.5 & 5.12799 & 9999999999 & TST \\
\hline CHEMBL1081312 & 809197 & 6.8 & 5.893 & TRN & \\
\hline CHEMBL1965170 & 809197 & 4.5 & 4.9104 & TRN & \\
\hline CHEMBL 2005792 & 809197 & 6.0 & 5.0448 & TRN & \\
\hline CHEMBL1968926 & 809197 & 4.0 & 4.2289 & TRN & \\
\hline CHEMBL462120 & 809197 & 5.8 & 4.2065 & TRN & \\
\hline CHEMBL1984206 & 809197 & 4.0 & 3.8727 & TRN & \\
\hline CHEMBL1991577 & 809197 & 4.0 & 4.1349 & TRN & \\
\hline CHEMBL1991867 & 809197 & 4.9 & 4.7423 & TRN & \\
\hline CHEMBL1986503 & 809197 & 5.8 & 4.2832 & TST & \\
\hline CHEMBL1965570 & 809197 & 6.2 & 6.00700 & 0000000001 & TRN \\
\hline CHEMBL 2007592 & 809197 & 4.0 & 4.1334 & TST & \\
\hline CHEMBL1972355 & 809197 & 7.5 & 5.8397 & TRN & \\
\hline CHEMBL1997892 & 809197 & 4.5 & 4.1546 & TRN & \\
\hline CHEMBL 2001641 & 809197 & 4.8 & 4.7087 & TRN & \\
\hline CHEMBL1997193 & 809197 & 4.5 & 5.1092 & TST & \\
\hline CHEMBL210963 & 809197 & 4.0 & 3.8077 & TRN & \\
\hline CHEMBL1964902 & 809197 & 4.5 & 4.7641 & TST & \\
\hline CHEMBL1082440 & 809197 & 6.6 & 5.4226 & TST & \\
\hline CHEMBL1614705 & 809197 & 4.0 & 4.1367 & TRN & \\
\hline CHEMBL1972362 & 809197 & 5.8 & 5.2667 & TRN & \\
\hline CHEMBL 2007372 & 809197 & 4.0 & 4.7674 & TRN & \\
\hline CHEMBL1983715 & 809197 & 8.0 & 6.9081 & TRN & \\
\hline CHEMBL1982167 & 809197 & 4.0 & 4.1559 & TRN & \\
\hline CHEMBL1971017 & 809197 & 5.8 & 5.8208 & TRN & \\
\hline CHEMBL1990482 & 809197 & 4.0 & 4.6947 & TRN & \\
\hline CHEMBL 2005475 & 809197 & 4.1 & 4.9892 & TRN & \\
\hline
\end{tabular}




\begin{tabular}{|c|c|c|c|c|}
\hline & & & pplement & al $\mathrm{Ta}$ \\
\hline CHEMBL 2000104 & 809197 & 5.6 & 5.056 & TRN \\
\hline CHEMBL1997349 & 809197 & 4.0 & 4.7887 & TST \\
\hline CHEMBL183844 & 809197 & 4.0 & 4.2981 & TRN \\
\hline CHEMBL220057 & 809197 & 5.4 & 4.9334 & TRN \\
\hline CHEMBL1682545 & 809197 & 5.1 & 4.6313 & TRN \\
\hline CHEMBL383541 & 809197 & 4.0 & 4.7717 & TRN \\
\hline CHEMBL2001224 & 809197 & 4.0 & 3.8686 & TRN \\
\hline CHEMBL10 & 809197 & 4.2 & 4.2923 & TRN \\
\hline CHEMBL1966799 & 809197 & 4.2 & 4.7483 & TST \\
\hline CHEMBL1969506 & 809197 & 4.0 & 4.333 & TRN \\
\hline CHEMBL1980763 & 809197 & 4.5 & 4.7587 & TRN \\
\hline CHEMBL1980163 & 809197 & 4.0 & 4.4696 & TRN \\
\hline CHEMBL590109 & 809197 & 5.3 & 5.3631 & TST \\
\hline CHEMBL1970879 & 809197 & 7.5 & 6.3689 & TRN \\
\hline CHEMBL1989856 & 809197 & 5.5 & 4.6866 & TST \\
\hline CHEMBL 2005899 & 809197 & 4.0 & 4.4291 & TRN \\
\hline CHEMBL1682552 & 809197 & 4.0 & 4.9979 & TRN \\
\hline CHEMBL 259850 & 809197 & 4.0 & 3.9937 & TRN \\
\hline CHEMBL1972568 & 809197 & 4.0 & 3.9928 & TRN \\
\hline CHEMBL 2007479 & 809197 & 5.5 & 4.7056 & TRN \\
\hline CHEMBL1996155 & 809197 & 5.3 & 4.4211 & TRN \\
\hline CHEMBL1682359 & 809197 & 5.2 & 4.8866 & TRN \\
\hline CHEMBL105739 & 809197 & 4.0 & 5.1371 & TRN \\
\hline CHEMBL1972220 & 809197 & 4.5 & 5.3637 & TRN \\
\hline CHEMBL379300 & 809197 & 6.1 & 5.8497 & TRN \\
\hline CHEMBL 203673 & 809197 & 4.0 & 4.3584 & TRN \\
\hline CHEMBL1969523 & 809197 & 6.3 & 5.9647 & TRN \\
\hline CHEMBL 207995 & 809197 & 4.0 & 4.1556 & TRN \\
\hline CHEMBL 2001923 & 809197 & 4.0 & 4.0057 & TRN \\
\hline CHEMBL 2003514 & 809197 & 4.5 & 4.5279 & TRN \\
\hline CHEMBL1989043 & 809197 & 5.6 & 5.2832 & TRN \\
\hline CHEMBL1979057 & 809197 & 4.0 & 4.9289 & TRN \\
\hline CHEMBL1981045 & 809197 & 4.0 & 4.1581 & TRN \\
\hline CHEMBL 387971 & 809197 & 4.0 & 4.1263 & TRN \\
\hline CHEMBL1975418 & 809197 & 5.7 & 5.8362 & TRN \\
\hline CHEMBL1992796 & 809197 & 5.1 & 4.1915 & TRN \\
\hline CHEMBL1164180 & 809197 & 5.7 & 4.9114 & TST \\
\hline CHEMBL1999428 & 809197 & 5.1 & 4.397 & TRN \\
\hline CHEMBL 223257 & 809197 & 4.0 & 4.0432 & TST \\
\hline CHEMBL1967560 & 809197 & 4.0 & 3.9674 & TRN \\
\hline CHEMBL1997611 & 809197 & 5.6 & 5.1204 & TST \\
\hline CHEMBL 211378 & 809197 & 4.0 & 4.757 & TRN \\
\hline CHEMBL1982465 & 809197 & 6.1 & 5.2703 & TRN \\
\hline CHEMBL 2001751 & 809197 & 6.1 & 6.0507 & TRN \\
\hline CHEMBL1984586 & 809197 & 5.5 & 5.449 & TRN \\
\hline CHEMBL1999774 & 809197 & 4.0 & 3.9003 & TRN \\
\hline CHEMBL1972659 & 809197 & 4.0 & 4.2215 & TST \\
\hline CHEMBL 2002723 & 809197 & 5.9 & 4.9715 & TST \\
\hline
\end{tabular}




\begin{tabular}{|c|c|c|c|c|}
\hline & & & pplement & al $\mathrm{Ta}$ \\
\hline CHEMBL1973395 & 809197 & 6.2 & 5.7212 & TRN \\
\hline CHEMBL 272453 & 809197 & 4.0 & 4.8536 & TRN \\
\hline CHEMBL1971801 & 809197 & 4.0 & 4.6312 & TRN \\
\hline CHEMBL1968850 & 809197 & 4.0 & 4.8967 & TRN \\
\hline CHEMBL2005528 & 809197 & 4.0 & 4.7858 & TST \\
\hline CHEMBL1984686 & 809197 & 4.5 & 4.6526 & TRN \\
\hline CHEMBL185569 & 809197 & 4.0 & 4.8552 & TRN \\
\hline CHEMBL1969843 & 809197 & 4.0 & 4.5504 & TRN \\
\hline CHEMBL1973793 & 809197 & 4.5 & 4.7179 & TST \\
\hline CHEMBL1984711 & 809197 & 6.2 & 5.5647 & TRN \\
\hline CHEMBL1990212 & 809197 & 4.0 & 4.3875 & TRN \\
\hline CHEMBL1990254 & 809197 & 4.7 & 4.5606 & TRN \\
\hline CHEMBL484390 & 809197 & 4.0 & 4.2018 & TST \\
\hline CHEMBL1986143 & 809197 & 4.5 & 4.5776 & TRN \\
\hline CHEMBL1979252 & 809197 & 4.0 & 4.4748 & TRN \\
\hline CHEMBL1972934 & 809197 & 5.4 & 4.738 & TRN \\
\hline CHEMBL2007559 & 809197 & 4.5 & 4.7922 & TRN \\
\hline CHEMBL1992581 & 809197 & 4.5 & 4.8548 & TRN \\
\hline CHEMBL1682341 & 809197 & 4.0 & 5.1339 & TRN \\
\hline CHEMBL2004290 & 809197 & 4.4 & 4.852 & TRN \\
\hline CHEMBL1972937 & 809197 & 4.0 & 4.1388 & TRN \\
\hline CHEMBL1972250 & 809197 & 4.0 & 4.1579 & TRN \\
\hline CHEMBL 2004072 & 809197 & 4.0 & 4.4679 & TRN \\
\hline CHEMBL1983573 & 809197 & 4.1 & 4.8732 & TST \\
\hline CHEMBL1992634 & 809197 & 5.5 & 5.0952 & TRN \\
\hline CHEMBL1242373 & 809197 & 6.2 & 4.8646 & TRN \\
\hline CHEMBL1984869 & 809197 & 5.5 & 4.2813 & TRN \\
\hline CHEMBL 2000433 & 809197 & 4.0 & 4.2923 & TST \\
\hline CHEMBL56543 & 809197 & 4.0 & 4.3678 & TRN \\
\hline CHEMBL1988075 & 809197 & 5.7 & 5.4774 & TRN \\
\hline CHEMBL1996576 & 809197 & 4.5 & 4.6515 & TST \\
\hline CHEMBL1991678 & 809197 & 4.5 & 5.0259 & TRN \\
\hline CHEMBL 2001239 & 809197 & 5.5 & 5.1327 & TST \\
\hline CHEMBL1988594 & 809197 & 5.7 & 4.963 & TRN \\
\hline CHEMBL 260092 & 809197 & 6.0 & 5.5525 & TRN \\
\hline CHEMBL1999811 & 809197 & 4.0 & 5.0234 & TRN \\
\hline CHEMBL1965495 & 809197 & 6.0 & 5.5189 & TRN \\
\hline CHEMBL1985074 & 809197 & 4.0 & 4.4424 & TST \\
\hline CHEMBL1982874 & 809197 & 5.2 & 4.8807 & TRN \\
\hline CHEMBL1991725 & 809197 & 6.4 & 5.0526 & TRN \\
\hline CHEMBL1992242 & 809197 & 4.0 & 3.9587 & TRN \\
\hline CHEMBL2004159 & 809197 & 4.5 & 4.4756 & TRN \\
\hline CHEMBL208637 & 809197 & 4.0 & 3.654 & TRN \\
\hline CHEMBL1978371 & 809197 & 6.8 & 5.4651 & TST \\
\hline CHEMBL1970203 & 809197 & 4.0 & 4.9908 & TRN \\
\hline CHEMBL1968590 & 809197 & 6.0 & 6.1135 & TRN \\
\hline CHEMBL1999749 & 809197 & 4.0 & 4.2982 & TRN \\
\hline CHEMBL 2005375 & 809197 & 4.0 & 3.8272 & TRN \\
\hline
\end{tabular}




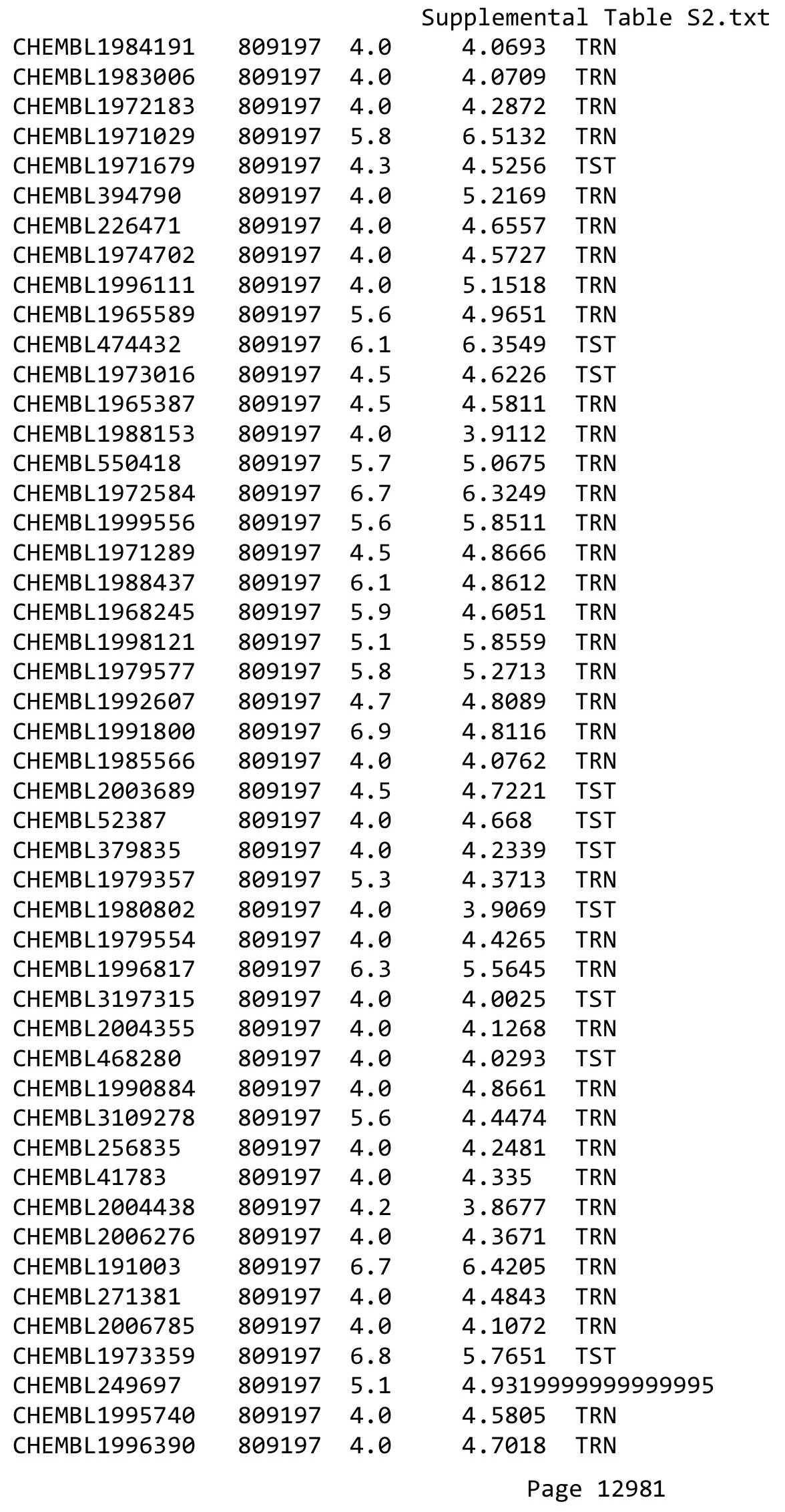




\begin{tabular}{|c|c|c|c|c|c|}
\hline & & & & & \\
\hline CHEMBL1979690 & 809197 & 6.5 & 6.6963 & TRN & \\
\hline CHEMBL 234085 & 809197 & 4.5 & 4.7063 & TRN & \\
\hline CHEMBL1995832 & 809197 & 6.0 & 5.1763 & TRN & \\
\hline CHEMBL1969042 & 809197 & 5.2 & 4.7555 & TRN & \\
\hline CHEMBL 2000345 & 809197 & 4.0 & 4.4543 & TRN & \\
\hline CHEMBL1976376 & 809197 & 4.5 & 4.9363 & TRN & \\
\hline CHEMBL1991640 & 809197 & 4.0 & 4.997 & TST & \\
\hline CHEMBL1983575 & 809197 & 7.1 & 5.5116 & TRN & \\
\hline CHEMBL1375418 & 809197 & 4.0 & 4.3115 & TRN & \\
\hline CHEMBL302449 & 809197 & 7.3 & 6.0066 & TST & \\
\hline CHEMBL 2007064 & 809197 & 5.8 & 5.5889 & TRN & \\
\hline CHEMBL1981047 & 809197 & 7.0 & 6.5371 & TRN & \\
\hline CHEMBL1976196 & 809197 & 4.5 & 5.3412 & TST & \\
\hline CHEMBL1997197 & 809197 & 4.5 & $5.1610 e$ & 00000000005 & TRN \\
\hline CHEMBL1983630 & 809197 & 4.2 & 4.6456 & TRN & \\
\hline CHEMBL1979093 & 809197 & 4.0 & 5.0314 & TRN & \\
\hline CHEMBL1381197 & 809197 & 4.0 & 4.2624 & TRN & \\
\hline CHEMBL1987009 & 809197 & 5.5 & 5.3161 & TRN & \\
\hline CHEMBL 379218 & 809197 & 6.0 & 5.7393 & TRN & \\
\hline CHEMBL 2003817 & 809197 & 5.4 & 4.9337 & TRN & \\
\hline CHEMBL336961 & 809197 & 4.0 & 4.1503 & TRN & \\
\hline CHEMBL1994830 & 809197 & 4.0 & 4.0472 & TRN & \\
\hline CHEMBL1987054 & 809197 & 5.5 & 7.1016 & TRN & \\
\hline CHEMBL1970083 & 809197 & 6.0 & 6.3042 & TRN & \\
\hline CHEMBL 226403 & 809197 & 4.0 & 5.0897 & TRN & \\
\hline CHEMBL 2005631 & 809197 & 6.0 & 6.6001 & TRN & \\
\hline CHEMBL1994938 & 809197 & 7.2 & 6.2947 & TRN & \\
\hline CHEMBL1825138 & 809197 & 7.0 & 4.9165 & TST & \\
\hline CHEMBL1977223 & 809197 & 4.0 & 5.2681 & TRN & \\
\hline CHEMBL1995765 & 809197 & 5.8 & 4.7913 & TST & \\
\hline CHEMBL1236126 & 809197 & 4.0 & 4.4971 & TST & \\
\hline CHEMBL1984760 & 809197 & 4.5 & 5.0945 & TRN & \\
\hline CHEMBL 2004419 & 809197 & 4.0 & 4.6542 & TRN & \\
\hline CHEMBL1991728 & 809197 & 5.9 & 5.3168 & TRN & \\
\hline CHEMBL360847 & 809197 & 4.5 & 4.5284 & TST & \\
\hline CHEMBL1995811 & 809197 & 4.5 & 5.3216 & TRN & \\
\hline CHEMBL1975787 & 809197 & 5.5 & 5.7423 & TRN & \\
\hline CHEMBL1995916 & 809197 & 4.0 & 4.4006 & TRN & \\
\hline CHEMBL 2002407 & 809197 & 5.9 & 4.4468 & TRN & \\
\hline CHEMBL1972489 & 809197 & 4.0 & 4.0999 & TRN & \\
\hline CHEMBL1992937 & 809197 & 4.5 & 4.9373 & TRN & \\
\hline CHEMBL536151 & 809197 & 4.0 & 4.29899 & 99999999995 & TRN \\
\hline CHEMBL1986328 & 809197 & 4.0 & 4.2426 & TRN & \\
\hline CHEMBL 95692 & 809197 & 4.0 & 4.346 & TRN & \\
\hline CHEMBL1090356 & 809197 & 6.3 & 5.8268 & TRN & \\
\hline CHEMBL 2002450 & 809197 & 5.4 & 4.3197 & TRN & \\
\hline CHEMBL1976455 & 809197 & 5.8 & 5.3938 & TRN & \\
\hline CHEMBL1983923 & 809197 & 6.5 & 5.6751 & TRN & \\
\hline & & & & 12982 & \\
\hline
\end{tabular}




\begin{tabular}{|c|c|c|c|c|c|}
\hline \\
\hline CHEMBL1982361 & 809197 & 4.3 & 4.3891 & TRN & \\
\hline CHEMBL1999112 & 809197 & 6.7 & 4.387 & TST & \\
\hline CHEMBL 2000801 & 809197 & 4.0 & 4.2466 & TRN & \\
\hline CHEMBL1682546 & 809197 & 4.0 & 4.7164 & TRN & \\
\hline CHEMBL1991395 & 809197 & 5.7 & 4.9445 & TRN & \\
\hline CHEMBL1988872 & 809197 & 6.3 & 5.0084 & TRN & \\
\hline CHEMBL 2003545 & 809197 & 4.8 & 4.5519 & TST & \\
\hline CHEMBL1987648 & 809197 & 6.7 & 4.8791 & TRN & \\
\hline CHEMBL1996780 & 809197 & 4.0 & 4.3923 & TST & \\
\hline CHEMBL1972142 & 809197 & 5.3 & 4.2438 & TRN & \\
\hline CHEMBL1966514 & 809197 & 6.4 & 5.8994 & TRN & \\
\hline CHEMBL296586 & 809197 & 5.1 & 5.0542 & TRN & \\
\hline CHEMBL1983393 & 809197 & 4.5 & 4.7393 & TRN & \\
\hline CHEMBL516429 & 809197 & 6.1 & 5.706 & TRN & \\
\hline CHEMBL1972152 & 809197 & 4.0 & 4.7719 & TST & \\
\hline CHEMBL1993722 & 809197 & 5.1 & 5.1951 & TRN & \\
\hline CHEMBL1970806 & 809197 & 4.0 & 4.1902 & TST & \\
\hline CHEMBL 2006674 & 809197 & 4.5 & 5.0889 & TST & \\
\hline CHEMBL1984236 & 809197 & 4.5 & 4.4243 & TST & \\
\hline CHEMBL1992371 & 809197 & 6.9 & 5.3228 & TRN & \\
\hline CHEMBL202635 & 809197 & 4.0 & 3.97399 & 99999999998 & TRN \\
\hline CHEMBL1375640 & 809197 & 5.7 & 5.098 & TST & \\
\hline CHEMBL1979970 & 809197 & 5.0 & 4.4921 & TRN & \\
\hline CHEMBL249282 & 809197 & 4.0 & 3.7861 & TRN & \\
\hline CHEMBL 2006771 & 809197 & 5.6 & 4.1184 & TRN & \\
\hline CHEMBL1967252 & 809197 & 4.1 & 5.0953 & TRN & \\
\hline CHEMBL1993374 & 809197 & 4.5 & 4.7963 & TRN & \\
\hline CHEMBL1969264 & 809197 & 4.0 & 4.5883 & TRN & \\
\hline CHEMBL1973711 & 809197 & 4.0 & 4.4045 & TRN & \\
\hline CHEMBL 2006237 & 809197 & 4.0 & 4.5722 & TRN & \\
\hline CHEMBL1967719 & 809197 & 5.5 & 4.8794 & TRN & \\
\hline CHEMBL1967720 & 809197 & 5.6 & $6.1720 e$ & 0000000001 & TRN \\
\hline CHEMBL1991138 & 809197 & 4.0 & 4.8124 & TRN & \\
\hline CHEMBL1969755 & 809197 & 5.3 & 4.1815 & TRN & \\
\hline CHEMBL1979516 & 809197 & 4.0 & 5.8851 & TRN & \\
\hline CHEMBL1605605 & 809197 & 4.5 & 4.8938 & TRN & \\
\hline CHEMBL1972820 & 809197 & 4.0 & 4.3165 & TST & \\
\hline CHEMBL1989029 & 809197 & 5.6 & 4.5891 & TRN & \\
\hline CHEMBL514499 & 809197 & 5.1 & 5.2807 & TST & \\
\hline CHEMBL1970352 & 809197 & 6.5 & 5.2875 & TST & \\
\hline CHEMBL1965631 & 809197 & 4.0 & 4.8126 & TRN & \\
\hline CHEMBL1980144 & 809197 & 5.1 & $5.0760 e$ & 00000000005 & TRN \\
\hline CHEMBL1980167 & 809197 & 6.6 & 5.3183 & TRN & \\
\hline CHEMBL377408 & 809197 & 4.0 & 4.1436 & TRN & \\
\hline CHEMBL215152 & 809197 & 4.2 & 4.2958 & TRN & \\
\hline CHEMBL231209 & 809197 & 5.1 & 5.0535 & TRN & \\
\hline CHEMBL 2006765 & 809197 & 4.5 & 5.3859 & TRN & \\
\hline CHEMBL1976220 & 809197 & 4.0 & 5.1948 & TRN & \\
\hline & & & & 298 & \\
\hline
\end{tabular}




\begin{tabular}{|c|c|c|c|c|}
\hline \multicolumn{5}{|c|}{ Supplemental Table S2.txt } \\
\hline CHEMBL259922 & 809197 & 4.0 & 4.1144 & TRN \\
\hline CHEMBL1997617 & 809197 & 6.3 & 6.3632 & TRN \\
\hline CHEMBL1982383 & 809197 & 4.0 & 4.9426 & TRN \\
\hline CHEMBL1969301 & 809197 & 4.0 & 4.2841 & TST \\
\hline CHEMBL1980246 & 809197 & 4.5 & 5.1874 & TST \\
\hline CHEMBL1983980 & 809197 & 6.7 & 5.9005 & TRN \\
\hline CHEMBL1999484 & 809197 & 6.8 & 7.0835 & TRN \\
\hline CHEMBL1973399 & 809197 & 4.1 & 4.5186 & TST \\
\hline CHEMBL1966069 & 809197 & 5.1 & 4.8958 & TRN \\
\hline CHEMBL1986899 & 809197 & 4.5 & 4.6653 & TRN \\
\hline CHEMBL1997822 & 809197 & 5.6 & 5.8846 & TRN \\
\hline CHEMBL1991285 & 809197 & 4.0 & 4.085 & TRN \\
\hline CHEMBL1984038 & 809197 & 4.5 & 4.1993 & TRN \\
\hline CHEMBL1993661 & 809197 & 7.7 & 7.0488 & TRN \\
\hline CHEMBL 2004615 & 809197 & 4.0 & 4.6967 & TST \\
\hline CHEMBL1997872 & 809197 & 4.0 & 4.4429 & TRN \\
\hline CHEMBL 213505 & 809197 & 5.0 & 5.0264 & TRN \\
\hline CHEMBL202721 & 809197 & 4.5 & 4.5466 & TRN \\
\hline CHEMBL1982880 & 809197 & 4.0 & 4.558 & TRN \\
\hline CHEMBL1993941 & 809197 & 5.8 & 5.7357 & TRN \\
\hline CHEMBL 377383 & 809197 & 4.0 & 4.1495 & TRN \\
\hline CHEMBL 2005886 & 809197 & 6.7 & 6.3719 & TRN \\
\hline CHEMBL481491 & 809197 & 5.1 & 4.8854 & TST \\
\hline CHEMBL1682345 & 809197 & 4.1 & 5.4734 & TRN \\
\hline CHEMBL1973142 & 809197 & 5.5 & 5.36799 & 9999999999 \\
\hline CHEMBL 388311 & 809197 & 6.3 & 6.1983 & TRN \\
\hline CHEMBL1973145 & 809197 & 4.0 & 4.4603 & TRN \\
\hline CHEMBL1979718 & 809197 & 4.0 & 4.3194 & TRN \\
\hline CHEMBL 206236 & 809197 & 4.0 & 4.3634 & TRN \\
\hline CHEMBL1989834 & 809197 & 5.1 & 4.4869 & TRN \\
\hline CHEMBL1562756 & 809197 & 4.0 & 4.2065 & TST \\
\hline CHEMBL1987430 & 809197 & 4.5 & 4.7192 & TRN \\
\hline CHEMBL 2001957 & 809197 & 6.1 & 5.2734 & TRN \\
\hline CHEMBL1990583 & 809197 & 4.0 & 5.5303 & TRN \\
\hline CHEMBL 289959 & 809197 & 4.6 & 4.2934 & TRN \\
\hline CHEMBL2006263 & 809197 & 4.0 & 4.8115 & TRN \\
\hline CHEMBL1993584 & 809197 & 4.2 & 4.4243 & TRN \\
\hline CHEMBL1986263 & 809197 & 6.0 & 6.6519 & TRN \\
\hline CHEMBL210618 & 809197 & 4.0 & 3.6099 & TRN \\
\hline CHEMBL1986265 & 809197 & 4.5 & 4.2308 & TRN \\
\hline CHEMBL1968380 & 809197 & 4.0 & 3.9766 & TRN \\
\hline CHEMBL1967211 & 809197 & 5.0 & 4.4668 & TRN \\
\hline CHEMBL1964644 & 809197 & 4.0 & 4.0686 & TRN \\
\hline CHEMBL1991734 & 809197 & 7.6 & 5.5064 & TST \\
\hline CHEMBL1981782 & 809197 & 5.0 & 4.9735 & TRN \\
\hline CHEMBL1977681 & 809197 & 4.0 & 4.4937 & TRN \\
\hline CHEMBL1990912 & 809197 & 5.1 & 4.8058 & TRN \\
\hline CHEMBL1991782 & 809197 & 3.2 & 3.7446 & TRN \\
\hline
\end{tabular}

TRN 


\begin{tabular}{|c|c|c|c|c|}
\hline & & & plem & \\
\hline CHEMBL 2002105 & 809197 & 4.5 & 4.9897 & TRN \\
\hline CHEMBL1983348 & 809197 & 4.5 & 5.4386 & TRN \\
\hline CHEMBL1995592 & 809197 & 5.7 & 5.4564 & TST \\
\hline CHEMBL 2006493 & 809197 & 4.0 & 3.9947 & TST \\
\hline CHEMBL1986177 & 809197 & 4.5 & 4.9284 & TRN \\
\hline CHEMBL1996923 & 809197 & 4.0 & 4.0897 & TST \\
\hline CHEMBL1983449 & 809197 & 4.4 & 4.227 & TRN \\
\hline CHEMBL1992323 & 809197 & 4.0 & 4.0999 & TRN \\
\hline CHEMBL1969735 & 809197 & 4.0 & 4.987 & TRN \\
\hline CHEMBL 2003524 & 809197 & 4.0 & 4.988 & TST \\
\hline CHEMBL1985367 & 809197 & 4.5 & 4.6994 & TST \\
\hline CHEMBL437747 & 809197 & 6.2 & 5.4224 & TRN \\
\hline CHEMBL1995172 & 809197 & 4.1 & 4.3154 & TST \\
\hline CHEMBL 2001584 & 809197 & 4.5 & 4.7865 & TRN \\
\hline CHEMBL507936 & 809197 & 4.0 & 3.8975 & TRN \\
\hline CHEMBL1971227 & 809197 & 6.1 & 4.9472 & TST \\
\hline CHEMBL104264 & 809197 & 6.1 & 4.7865 & TRN \\
\hline CHEMBL1994321 & 809197 & 6.2 & 5.5013 & TRN \\
\hline CHEMBL1978562 & 809197 & 4.5 & 5.4067 & TST \\
\hline CHEMBL1997129 & 809197 & 5.9 & 6.5312 & TRN \\
\hline CHEMBL1984788 & 809197 & 4.0 & 3.8075 & TRN \\
\hline CHEMBL451964 & 809197 & 4.0 & 4.042 & TRN \\
\hline CHEMBL1974875 & 809197 & 5.0 & 4.6133 & TST \\
\hline CHEMBL1996604 & 809197 & 4.0 & 4.1764 & TRN \\
\hline CHEMBL1964307 & 809197 & 5.3 & 5.2789 & TRN \\
\hline CHEMBL1989471 & 809197 & 5.9 & 5.2936 & TST \\
\hline CHEMBL1971694 & 809197 & 4.0 & 4.2641 & TST \\
\hline CHEMBL210928 & 809197 & 4.0 & 3.9317 & TRN \\
\hline CHEMBL1978195 & 809197 & 5.5 & 5.5053 & TRN \\
\hline CHEMBL1994361 & 809197 & 5.8 & 4.6507 & TRN \\
\hline CHEMBL1972840 & 809197 & 5.8 & 5.3285 & TRN \\
\hline CHEMBL1977148 & 809197 & 4.0 & 4.4357 & TRN \\
\hline CHEMBL1968025 & 809197 & 5.6 & 4.7654 & TST \\
\hline CHEMBL 2003286 & 809197 & 4.0 & 4.1348 & TRN \\
\hline CHEMBL 2002165 & 809197 & 5.8 & 6.0586 & TRN \\
\hline CHEMBL 2001668 & 809197 & 4.0 & 4.7236 & TST \\
\hline CHEMBL1979318 & 809197 & 4.0 & 4.3128 & TRN \\
\hline CHEMBL206382 & 809197 & 4.0 & 4.1267 & TRN \\
\hline CHEMBL1998585 & 809197 & 5.4 & 5.7734 & TRN \\
\hline CHEMBL519697 & 809197 & 4.0 & 4.223 & TST \\
\hline CHEMBL1996345 & 809197 & 4.5 & 4.7583 & TST \\
\hline CHEMBL1975128 & 809197 & 6.8 & 6.1274 & TST \\
\hline CHEMBL 2004025 & 809197 & 6.7 & 5.2937 & TST \\
\hline CHEMBL1996048 & 809197 & 4.5 & 4.4915 & TST \\
\hline CHEMBL1970369 & 809197 & 4.0 & 4.4532 & TST \\
\hline CHEMBL1976158 & 809197 & 6.2 & 5.0009 & TST \\
\hline CHEMBL461876 & 809197 & 4.5 & 4.6639 & TST \\
\hline CHEMBL1965033 & 809197 & 4.5 & 4.2519 & TST \\
\hline
\end{tabular}




\begin{tabular}{|c|c|c|c|c|c|}
\hline \multicolumn{6}{|c|}{ Supplemental Table S2.txt } \\
\hline CHEMBL504950 & 809197 & 5.5 & 5.4115 & TST & \\
\hline CHEMBL1997335 & 809197 & 7.5 & 5.147 & TST & \\
\hline CHEMBL1984363 & 809197 & 4.0 & 5.2068 & TST & \\
\hline CHEMBL1977041 & 809197 & 6.5 & 6.4517 & TST & \\
\hline CHEMBL1968070 & 809197 & 5.3 & 5.3648 & TST & \\
\hline CHEMBL1988608 & 809197 & 4.0 & 5.1868 & TST & \\
\hline CHEMBL184847 & 809197 & 4.0 & 4.5189 & TST & \\
\hline CHEMBL1994808 & 809197 & 4.7 & 4.5457 & TST & \\
\hline CHEMBL1982563 & 809197 & 4.0 & 4.8724 & TST & \\
\hline CHEMBL575824 & 809197 & 4.0 & 5.1469 & TST & \\
\hline CHEMBL1973868 & 809197 & 4.5 & 4.6569 & TST & \\
\hline CHEMBL1972462 & 809197 & 4.5 & 4.3408 & TST & \\
\hline CHEMBL1997759 & 809197 & 4.0 & 4.0936 & TST & \\
\hline CHEMBL1974803 & 809197 & 4.0 & 4.2735 & TST & \\
\hline CHEMBL1970074 & 809197 & 4.0 & 4.6026 & TST & \\
\hline CHEMBL1984500 & 809197 & 3.2 & 3.8759 & TST & \\
\hline CHEMBL1986970 & 809197 & 4.0 & 5.1175 & TST & \\
\hline CHEMBL 2005112 & 809197 & 4.0 & 4.3603 & TST & \\
\hline CHEMBL1984044 & 809197 & 4.0 & 4.0359 & TST & \\
\hline CHEMBL 2003456 & 809197 & 5.5 & 4.5903 & TST & \\
\hline CHEMBL 2002992 & 809197 & 6.0 & 5.1702 & TST & \\
\hline CHEMBL560813 & 809197 & 4.0 & 3.824 & TST & \\
\hline CHEMBL207253 & 809197 & 4.0 & 3.6739 & TST & \\
\hline CHEMBL1890036 & 809197 & 4.0 & 4.5516 & TST & \\
\hline CHEMBL1982700 & 809197 & 4.5 & 4.7777 & TST & \\
\hline CHEMBL1968791 & 809197 & 5.4 & 5.1849 & TST & \\
\hline CHEMBL326282 & 809197 & 4.0 & 4.0277 & TST & \\
\hline CHEMBL1977634 & 809197 & 4.5 & 4.8989 & TST & \\
\hline CHEMBL1992732 & 809197 & 4.0 & 3.8736 & TST & \\
\hline CHEMBL 2003482 & 809197 & 4.1 & 4.1568 & TST & \\
\hline CHEMBL1969156 & 809197 & 4.0 & 4.6577 & TST & \\
\hline CHEMBL325481 & 87956 & 3.0 & 3.0165 & TRN & \\
\hline CHEMBL117812 & 87956 & 3.0 & 2.8591 & TRN & \\
\hline CHEMBL435968 & 87956 & 3.0 & 3.9953 & TRN & \\
\hline CHEMBL117244 & 87956 & 3.0 & 3.2145 & TRN & \\
\hline CHEMBL117307 & 87956 & 3.0 & 3.838 & TRN & \\
\hline CHEMBL117186 & 87956 & 3.0 & 3.7131 & TRN & \\
\hline CHEMBL117969 & 87956 & 5.8861 & 4.1872 & TST & \\
\hline CHEMBL 330831 & 87956 & 3.0 & 3.18300 & 20000000003 & TRN \\
\hline CHEMBL419412 & 87956 & 3.0 & 3.2313 & TRN & \\
\hline CHEMBL334041 & 87956 & 3.0 & 4.0608 & TRN & \\
\hline CHEMBL324582 & 87956 & 4.699 & 3.8299 & TRN & \\
\hline CHEMBL325472 & 87956 & 3.0 & 2.6817 & TST & \\
\hline CHEMBL117384 & 87956 & 5.1427 & 4.2907 & TRN & \\
\hline CHEMBL115689 & 87956 & 3.0 & 3.6994 & TST & \\
\hline CHEMBL424068 & 87956 & 3.0 & 2.9246 & TRN & \\
\hline CHEMBL116075 & 87956 & 3.0 & 2.7605 & TRN & \\
\hline CHEMBL326265 & 87956 & 3.0 & 2.7738 & TST & \\
\hline
\end{tabular}




\begin{tabular}{|c|c|c|c|c|c|}
\hline \multicolumn{6}{|c|}{ Supplemental Table S2.txt } \\
\hline CHEMBL326970 & 87956 & 3.0 & 4.2659 & TST & \\
\hline CHEMBL117245 & 87956 & 3.0 & 3.0504 & TRN & \\
\hline CHEMBL117084 & 87956 & 3.0 & 2.94 & TRN & \\
\hline CHEMBL 325251 & 87956 & 3.0 & 4.4894 & TST & \\
\hline CHEMBL 324801 & 87956 & 5.301 & 4.0539 & TST & \\
\hline CHEMBL115575 & 87956 & 3.0 & 3.3244 & TRN & \\
\hline CHEMBL331660 & 87956 & 3.0 & 2.8935 & TRN & \\
\hline CHEMBL119691 & 87956 & 5.5528 & 4.4268 & TST & \\
\hline CHEMBL332925 & 87956 & 4.7959 & 4.3871 & TST & \\
\hline CHEMBL331604 & 87956 & 4.699 & 3.7071 & TRN & \\
\hline CHEMBL324910 & 87956 & 4.7959 & 4.5633 & TST & \\
\hline CHEMBL116778 & 87956 & 3.0 & 2.8955 & TRN & \\
\hline CHEMBL119741 & 87956 & 3.0 & 2.7989 & TRN & \\
\hline CHEMBL 326170 & 87956 & 3.0 & 4.0106 & TST & \\
\hline CHEMBL115417 & 87956 & 3.0 & 3.1243 & TRN & \\
\hline CHEMBL331499 & 87956 & 3.0 & 3.2339 & TRN & \\
\hline CHEMBL324995 & 87956 & 3.0 & 2.6797 & TRN & \\
\hline CHEMBL442756 & 87956 & 3.0 & 3.0593 & TRN & \\
\hline CHEMBL119356 & 87956 & 3.0 & 2.9888 & TRN & \\
\hline CHEMBL117758 & 87956 & 3.0 & 2.958 & TRN & \\
\hline CHEMBL326411 & 87956 & 3.0 & 2.9102 & TRN & \\
\hline CHEMBL333549 & 87956 & 3.0 & 3.0092 & TRN & \\
\hline CHEMBL 325243 & 87956 & 3.0 & 3.4329 & TRN & \\
\hline CHEMBL117854 & 87956 & 3.0 & 3.0173 & TRN & \\
\hline CHEMBL119141 & 87956 & 3.0 & 3.1102 & TRN & \\
\hline CHEMBL116145 & 87956 & 3.0 & 4.3596 & TST & \\
\hline CHEMBL116254 & 87956 & 3.0 & 3.0817 & TRN & \\
\hline CHEMBL116338 & 87956 & 5.301 & 3.7975 & TST & \\
\hline CHEMBL 332252 & 87956 & 3.0 & 3.3433 & TRN & \\
\hline CHEMBL117022 & 87956 & 3.0 & 2.8529 & TRN & \\
\hline CHEMBL117107 & 87956 & 3.0 & 2.8021 & TRN & \\
\hline CHEMBL446672 & 87956 & 5.0862 & 4.1496 & TST & \\
\hline CHEMBL116194 & 87956 & 5.5686 & 4.3692 & TRN & \\
\hline CHEMBL442397 & 87956 & 3.0 & 2.89399 & 99999999997 & TRN \\
\hline CHEMBL115708 & 87956 & 4.0458 & 3.8763 & TRN & \\
\hline CHEMBL116134 & 87956 & 3.0 & 2.8846 & TRN & \\
\hline CHEMBL 3423166 & 1474900 & 4.3585 & 3.7098 & TST & \\
\hline CHEMBL 3423170 & 1474900 & 3.0 & 3.5243 & TRN & \\
\hline CHEMBL 3423151 & 1474900 & 4.3947 & 4.2353 & TRN & \\
\hline CHEMBL 3423135 & 1474900 & 4.6478 & 4.48 & TRN & \\
\hline CHEMBL 3423157 & 1474900 & 3.0 & 3.5431 & TRN & \\
\hline CHEMBL 3423184 & 1474900 & 4.342 & 4.3338 & TRN & \\
\hline CHEMBL3423190 & 1474900 & 4.8297 & 4.6368 & TRN & \\
\hline CHEMBL 3423169 & 1474900 & 3.0 & 3.6908 & TST & \\
\hline CHEMBL3423182 & 1474900 & 4.1549 & 4.561 & TRN & \\
\hline CHEMBL 3087847 & 1474900 & 6.0 & 6.2511 & TRN & \\
\hline CHEMBL 3423174 & 1474900 & 4.2069 & 3.483 & TRN & \\
\hline CHEMBL3423176 & 1474900 & 4.1325 & 4.3335 & TRN & \\
\hline
\end{tabular}


Supplemental Table S2.txt

\begin{tabular}{|c|c|c|c|c|c|}
\hline CHEMBL3423156 & 1474900 & 4.0953 & 3.6659 & TRN & \\
\hline CHEMBL3423189 & 1474900 & 4.8861 & 4.6777 & TRN & \\
\hline CHEMBL 3423165 & 1474900 & 4.6799 & 5.2848 & TST & \\
\hline CHEMBL 3423155 & 1474900 & 4.1568 & 4.1216 & TRN & \\
\hline CHEMBL 3423139 & 1474900 & 3.0 & 3.2064 & TRN & \\
\hline CHEMBL 3423140 & 1474900 & 3.0 & 3.4725 & TST & \\
\hline CHEMBL3423171 & 1474900 & 4.4828 & 4.3417 & TRN & \\
\hline CHEMBL3423147 & 1474900 & 4.0655 & 3.4359 & TRN & \\
\hline CHEMBL 3423143 & 1474900 & 3.0 & 2.9196 & TST & \\
\hline CHEMBL 3423185 & 1474900 & 4.6716 & 4.7011 & TRN & \\
\hline CHEMBL 3423186 & 1474900 & 4.3615 & 3.7976 & TRN & \\
\hline CHEMBL 3423154 & 1474900 & 4.4895 & 4.7365 & TST & \\
\hline CHEMBL 3423158 & 1474900 & 3.0 & 3.3282 & TRN & \\
\hline CHEMBL 3423148 & 1474900 & 4.1599 & 3.8822 & TRN & \\
\hline CHEMBL 3423178 & 1474900 & 4.5157 & 4.2484 & TRN & \\
\hline CHEMBL 3423175 & 1474900 & 4.172 & 4.2393 & TRN & \\
\hline CHEMBL3423138 & 1474900 & 3.0 & 3.5756 & TST & \\
\hline CHEMBL 3423188 & 1474900 & 4.6234 & 4.7742 & TRN & \\
\hline CHEMBL3423141 & 1474900 & 4.0458 & 3.514 & TST & \\
\hline CHEMBL 3423167 & 1474900 & 4.6402 & 3.7409 & TST & \\
\hline CHEMBL3423181 & 1474900 & 4.1013 & 4.4842 & TRN & \\
\hline CHEMBL3423172 & 1474900 & 4.4535 & 4.276 & TRN & \\
\hline CHEMBL 3423144 & 1474900 & 3.0 & 2.7082 & TST & \\
\hline CHEMBL3423161 & 1474900 & 3.0 & 2.8556 & TRN & \\
\hline CHEMBL3423191 & 1474900 & 4.4935 & 4.5184 & TRN & \\
\hline CHEMBL3423173 & 1474900 & 3.0 & 3.3495 & TRN & \\
\hline CHEMBL3423168 & 1474900 & 4.3526 & \multicolumn{2}{|c|}{4.5760000000000005} & TST \\
\hline CHEMBL 3423145 & 1474900 & 3.0 & \multicolumn{2}{|c|}{3.3569999999999998} & TRN \\
\hline CHEMBL3423152 & 1474900 & 4.0376 & 4.3134 & TRN & \\
\hline CHEMBL 3423164 & 1474900 & 3.0 & 4.4234 & TST & \\
\hline CHEMBL3423183 & 1474900 & 3.0 & 3.1318 & TRN & \\
\hline CHEMBL 3423146 & 1474900 & 3.0 & 3.2874 & TRN & \\
\hline CHEMBL3423153 & 1474900 & 4.1355 & 3.9013 & TRN & \\
\hline CHEMBL3423149 & 1474900 & 3.0 & \multicolumn{2}{|c|}{3.3480000000000003} & TRN \\
\hline CHEMBL3423180 & 1474900 & 4.7545 & 4.6397 & TRN & \\
\hline CHEMBL3423142 & 1474900 & 4.4437 & 3.385 & TST & \\
\hline CHEMBL 3423160 & 1474900 & 3.0 & 3.3295 & TRN & \\
\hline CHEMBL 3421648 & 1474900 & 4.2358 & 3.8761 & TRN & \\
\hline CHEMBL3423150 & 1474900 & 4.0088 & 3.3138 & TST & \\
\hline CHEMBL3423187 & 1474900 & 4.1765 & 4.5667 & TRN & \\
\hline CHEMBL3423159 & 1474900 & 3.0 & 3.0296 & TRN & \\
\hline CHEMBL 3423162 & 1474900 & 4.6576 & 4.8623 & TRN & \\
\hline CHEMBL3423163 & 1474900 & 4.1543 & 4.2947 & TST & \\
\hline CHEMBL3423179 & 1474900 & 4.5452 & 4.1072 & TRN & \\
\hline CHEMBL3423177 & 1474900 & 4.8041 & 4.2585 & TRN & \\
\hline CHEMBL1964290 & 809204 & 6.0 & 5.3336 & TRN & \\
\hline CHEMBL 2003768 & 809204 & 4.2 & 4.0692 & TRN & \\
\hline CHEMBL 213505 & 809204 & 5.4 & 5.0488 & TRN & \\
\hline
\end{tabular}




\begin{tabular}{|c|c|c|c|c|}
\hline & & & pplement & al $\mathrm{Ta}$ \\
\hline CHEMBL202721 & 809204 & 4.3 & 4.532 & TRN \\
\hline CHEMBL1982880 & 809204 & 4.2 & 4.2913 & TRN \\
\hline CHEMBL1987034 & 809204 & 7.5 & 7.8515 & TRN \\
\hline CHEMBL1993941 & 809204 & 5.9 & 5.6136 & TRN \\
\hline CHEMBL377383 & 809204 & 4.2 & 4.3208 & TRN \\
\hline CHEMBL578061 & 809204 & 5.6 & 5.4049 & TRN \\
\hline CHEMBL 2005886 & 809204 & 7.0 & 6.955 & TRN \\
\hline CHEMBL481491 & 809204 & 4.2 & 3.9308 & TST \\
\hline CHEMBL1682345 & 809204 & 6.1 & 5.6996 & TRN \\
\hline CHEMBL1973142 & 809204 & 4.2 & 4.7206 & TST \\
\hline CHEMBL1973145 & 809204 & 4.2 & 4.3779 & TRN \\
\hline CHEMBL1982924 & 809204 & 5.9 & 5.7276 & TRN \\
\hline CHEMBL 2005936 & 809204 & 6.1 & 5.3494 & TRN \\
\hline CHEMBL1807515 & 809204 & 7.3 & 6.8476 & TRN \\
\hline CHEMBL1964948 & 809204 & 4.3 & 4.4519 & TRN \\
\hline CHEMBL1971141 & 809204 & 4.2 & 4.301 & TRN \\
\hline CHEMBL1995813 & 809204 & 6.8 & 6.5837 & TRN \\
\hline CHEMBL1979718 & 809204 & 4.2 & 4.3753 & TRN \\
\hline CHEMBL206236 & 809204 & 4.2 & 4.1792 & TRN \\
\hline CHEMBL523823 & 809204 & 4.2 & 4.6918 & TST \\
\hline CHEMBL1562756 & 809204 & 4.2 & 4.5236 & TST \\
\hline CHEMBL244378 & 809204 & 6.7 & 6.3697 & TRN \\
\hline CHEMBL 2001957 & 809204 & 4.2 & 4.4663 & TRN \\
\hline CHEMBL1969372 & 809204 & 4.2 & 4.3002 & TRN \\
\hline CHEMBL1990583 & 809204 & 7.0 & 6.3127 & TRN \\
\hline CHEMBL1986943 & 809204 & 7.3 & 6.8773 & TRN \\
\hline CHEMBL 2006263 & 809204 & 4.2 & 4.4387 & TST \\
\hline CHEMBL2001646 & 809204 & 5.5 & 5.7437 & TRN \\
\hline CHEMBL1993584 & 809204 & 4.2 & 4.2501 & TRN \\
\hline CHEMBL1986263 & 809204 & 6.1 & 6.2721 & TRN \\
\hline CHEMBL 2000114 & 809204 & 5.8 & 5.2515 & TRN \\
\hline CHEMBL210618 & 809204 & 4.2 & 4.0409 & TRN \\
\hline CHEMBL1975647 & 809204 & 4.2 & 4.8092 & TRN \\
\hline CHEMBL1968380 & 809204 & 4.2 & 4.257 & TRN \\
\hline CHEMBL1964644 & 809204 & 4.2 & 4.0569 & TRN \\
\hline CHEMBL1981782 & 809204 & 5.2 & 4.7536 & TRN \\
\hline CHEMBL1977681 & 809204 & 5.7 & 5.6776 & TRN \\
\hline CHEMBL1970142 & 809204 & 4.2 & 4.1479 & TRN \\
\hline CHEMBL1990912 & 809204 & 4.2 & 4.8086 & TRN \\
\hline CHEMBL1988163 & 809204 & 6.5 & 6.6531 & TRN \\
\hline CHEMBL1995592 & 809204 & 5.7 & 5.4728 & TST \\
\hline CHEMBL 2000934 & 809204 & 4.3 & 4.4628 & TRN \\
\hline CHEMBL 2006493 & 809204 & 4.2 & 4.5277 & TST \\
\hline CHEMBL1982541 & 809204 & 4.2 & 4.3551 & TRN \\
\hline CHEMBL1996923 & 809204 & 4.2 & 4.4418 & TST \\
\hline CHEMBL1983449 & 809204 & 4.2 & 4.1992 & TRN \\
\hline CHEMBL1992323 & 809204 & 4.2 & 4.587 & TST \\
\hline CHEMBL1969735 & 809204 & 4.2 & 4.3396 & TRN \\
\hline
\end{tabular}




\begin{tabular}{|c|c|c|c|c|}
\hline & & & & \\
\hline CHEMBL 2003524 & 809204 & 5.5 & 4.4993 & TST \\
\hline CHEMBL2002649 & 809204 & 6.2 & 6.3985 & TRN \\
\hline CHEMBL1996510 & 809204 & 6.4 & 5.7653 & TST \\
\hline CHEMBL437747 & 809204 & 5.5 & 4.8498 & TRN \\
\hline CHEMBL1995172 & 809204 & 5.3 & 4.2909 & TST \\
\hline CHEMBL507936 & 809204 & 4.2 & 3.9557 & TRN \\
\hline CHEMBL104264 & 809204 & 5.5 & 5.2895 & TST \\
\hline CHEMBL1994321 & 809204 & 6.0 & 5.6813 & TRN \\
\hline CHEMBL1997129 & 809204 & 7.3 & 6.9753 & TRN \\
\hline CHEMBL1984788 & 809204 & 4.2 & 4.2858 & TRN \\
\hline CHEMBL451964 & 809204 & 4.2 & 4.2554 & TRN \\
\hline CHEMBL1964307 & 809204 & 5.9 & 5.6733 & TRN \\
\hline CHEMBL 2000508 & 809204 & 4.2 & 4.2667 & TRN \\
\hline CHEMBL1971694 & 809204 & 4.2 & 4.5006 & TST \\
\hline CHEMBL2001547 & 809204 & 4.2 & 4.3143 & TRN \\
\hline CHEMBL 210928 & 809204 & 4.2 & 4.1428 & TRN \\
\hline CHEMBL1994361 & 809204 & 4.2 & 4.3513 & TRN \\
\hline CHEMBL1986603 & 809204 & 4.2 & 4.4339 & TST \\
\hline CHEMBL1972840 & 809204 & 5.8 & 5.6727 & TRN \\
\hline CHEMBL1977148 & 809204 & 4.2 & 3.8784 & TRN \\
\hline CHEMBL 2003286 & 809204 & 4.2 & 4.1868 & TRN \\
\hline CHEMBL1992306 & 809204 & 4.2 & 4.2655 & TRN \\
\hline CHEMBL 2002165 & 809204 & 6.2 & 5.7949 & TRN \\
\hline CHEMBL 2001668 & 809204 & 4.2 & 4.6077 & TST \\
\hline CHEMBL1979318 & 809204 & 5.5 & 4.8568 & TRN \\
\hline CHEMBL 206382 & 809204 & 4.2 & 4.1148 & TRN \\
\hline CHEMBL1998585 & 809204 & 7.0 & 6.2189 & TRN \\
\hline CHEMBL127898 & 809204 & 6.1 & 4.4198 & TST \\
\hline CHEMBL519697 & 809204 & 5.2 & 4.4715 & TST \\
\hline CHEMBL 2004934 & 809204 & 4.2 & 4.34 & TRN \\
\hline CHEMBL1981947 & 809204 & 5.2 & 4.9501 & TST \\
\hline CHEMBL1975128 & 809204 & 6.2 & 6.5506 & TRN \\
\hline CHEMBL1970369 & 809204 & 4.2 & 4.0321 & TRN \\
\hline CHEMBL 2001485 & 809204 & 4.2 & 4.7923 & TRN \\
\hline CHEMBL504950 & 809204 & 5.5 & 5.2212 & TRN \\
\hline CHEMBL1966425 & 809204 & 4.2 & 5.0333 & TRN \\
\hline CHEMBL1984363 & 809204 & 5.5 & 5.5403 & TRN \\
\hline CHEMBL1978099 & 809204 & 6.0 & 6.035 & TRN \\
\hline CHEMBL1977041 & 809204 & 5.9 & 5.7686 & TRN \\
\hline CHEMBL1968070 & 809204 & 4.2 & 4.7421 & TRN \\
\hline CHEMBL1988608 & 809204 & 4.2 & 4.9223 & TRN \\
\hline CHEMBL184847 & 809204 & 4.2 & 4.2132 & TRN \\
\hline CHEMBL1984367 & 809204 & 4.2 & 4.6862 & TRN \\
\hline CHEMBL178737 & 809204 & 4.2 & 4.6026 & TST \\
\hline CHEMBL226898 & 809204 & 7.2 & 7.0196 & TRN \\
\hline CHEMBL1982563 & 809204 & 4.2 & 4.2219 & TRN \\
\hline CHEMBL539474 & 809204 & 4.2 & 5.0067 & TST \\
\hline CHEMBL575824 & 809204 & 4.2 & 4.2945 & TRN \\
\hline
\end{tabular}




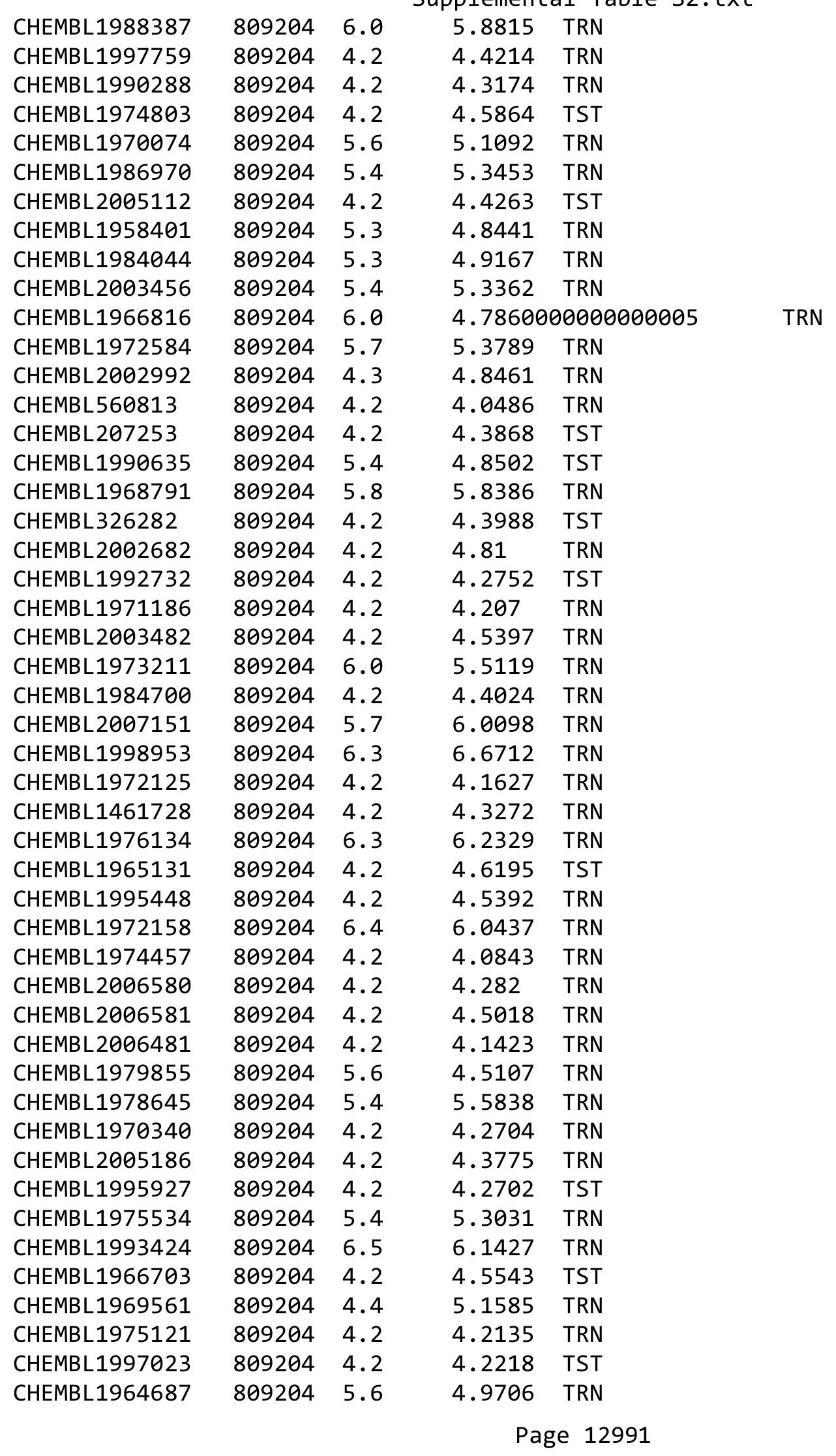




\begin{tabular}{|c|c|c|c|c|}
\hline & & & ipplement & al Table S \\
\hline CHEMBL1971943 & 809204 & 4.6 & 5.0514 & TRN \\
\hline CHEMBL1999918 & 809204 & 5.5 & 5.4992 & TRN \\
\hline CHEMBL1974254 & 809204 & 4.2 & 4.8247 & TRN \\
\hline CHEMBL1988537 & 809204 & 5.2 & 4.9499 & TST \\
\hline CHEMBL1969049 & 809204 & 4.2 & 4.3689 & TRN \\
\hline CHEMBL2005828 & 809204 & 4.2 & 4.0945 & TRN \\
\hline CHEMBL 2002240 & 809204 & 4.2 & 3.8837 & TRN \\
\hline CHEMBL1991143 & 809204 & 4.2 & 4.7504 & TST \\
\hline CHEMBL1998611 & 809204 & 4.3 & 4.798 & TST \\
\hline CHEMBL485556 & 809204 & 4.2 & 4.1445 & TST \\
\hline CHEMBL1975900 & 809204 & 4.2 & 4.1652 & TRN \\
\hline CHEMBL255822 & 809204 & 4.2 & 4.1109 & TRN \\
\hline CHEMBL1972221 & 809204 & 4.2 & 4.2781 & TRN \\
\hline CHEMBL 2006778 & 809204 & 5.8 & 5.653 & TRN \\
\hline CHEMBL378627 & 809204 & 4.2 & 4.2372 & TRN \\
\hline CHEMBL1996979 & 809204 & 6.1 & 5.5581 & TRN \\
\hline CHEMBL1997025 & 809204 & 4.2 & 4.0931 & TRN \\
\hline CHEMBL1968406 & 809204 & 5.7 & 5.5213 & TRN \\
\hline CHEMBL1982476 & 809204 & 6.0 & 5.8959 & TRN \\
\hline CHEMBL1984274 & 809204 & 5.3 & 5.2174 & TST \\
\hline CHEMBL1998545 & 809204 & 4.2 & 4.1084 & TRN \\
\hline CHEMBL1986869 & 809204 & 4.2 & 4.36100 & 0000000001 \\
\hline CHEMBL 2006010 & 809204 & 4.2 & 4.345 & TRN \\
\hline CHEMBL1682558 & 809204 & 4.2 & 4.3485 & TRN \\
\hline CHEMBL1990496 & 809204 & 4.2 & 4.2914 & TRN \\
\hline CHEMBL1997623 & 809204 & 4.2 & 4.8492 & TRN \\
\hline CHEMBL2002479 & 809204 & 6.4 & 5.353 & TRN \\
\hline CHEMBL1993166 & 809204 & 4.2 & 4.8831 & TRN \\
\hline CHEMBL1967094 & 809204 & 5.8 & 5.5787 & TRN \\
\hline CHEMBL1966035 & 809204 & 4.2 & 4.1595 & TRN \\
\hline CHEMBL2003341 & 809204 & 4.2 & 4.1482 & TRN \\
\hline CHEMBL1992644 & 809204 & 5.1 & 4.7911 & TRN \\
\hline CHEMBL1992645 & 809204 & 4.2 & 4.6765 & TST \\
\hline CHEMBL1982992 & 809204 & 4.2 & 3.9776 & TRN \\
\hline CHEMBL1999590 & 809204 & 4.2 & 4.2099 & TST \\
\hline CHEMBL1981079 & 809204 & 5.2 & 5.0578 & TRN \\
\hline CHEMBL1978166 & 809204 & 4.3 & 5.7559 & TRN \\
\hline CHEMBL1972276 & 809204 & 4.2 & 4.3335 & TRN \\
\hline CHEMBL1980489 & 809204 & 4.2 & 4.2241 & TRN \\
\hline CHEMBL 2000832 & 809204 & 5.6 & 4.8629 & TRN \\
\hline CHEMBL1967116 & 809204 & 6.3 & 6.2828 & TRN \\
\hline CHEMBL1990590 & 809204 & 4.3 & 5.0768 & TRN \\
\hline CHEMBL1977814 & 809204 & 4.2 & 4.2475 & TST \\
\hline CHEMBL513846 & 809204 & 4.2 & 4.3622 & TRN \\
\hline CHEMBL1970709 & 809204 & 4.2 & 4.2082 & TRN \\
\hline CHEMBL1965660 & 809204 & 6.3 & 5.3056 & TRN \\
\hline CHEMBL1998112 & 809204 & 4.2 & 4.3055 & TRN \\
\hline CHEMBL1969126 & 809204 & 4.2 & 4.3108 & TRN \\
\hline
\end{tabular}




\begin{tabular}{|c|c|c|c|c|c|}
\hline & & & & & \\
\hline CHEMBL1980896 & 809204 & 4.2 & 4.3036 & TRN & \\
\hline CHEMBL1975208 & 809204 & 4.2 & 4.5145 & TST & \\
\hline CHEMBL1970104 & 809204 & 6.0 & 6.4744 & TRN & \\
\hline CHEMBL1991429 & 809204 & 4.2 & 4.3164 & TRN & \\
\hline CHEMBL1964777 & 809204 & 4.2 & 4.4884 & TRN & \\
\hline CHEMBL1971149 & 809204 & 4.2 & 4.42399 & 99999999995 & TRN \\
\hline CHEMBL1999714 & 809204 & 4.2 & 4.3653 & TRN & \\
\hline CHEMBL1987533 & 809204 & 4.2 & 4.0864 & TRN & \\
\hline CHEMBL1994040 & 809204 & 4.2 & 4.2866 & TRN & \\
\hline CHEMBL388978 & 809204 & 9.4 & 8.5522 & TST & \\
\hline CHEMBL579246 & 809204 & 5.6 & 5.3862 & TRN & \\
\hline CHEMBL398951 & 809204 & 6.2 & 6.0245 & TST & \\
\hline CHEMBL1982506 & 809204 & 4.4 & 4.7556 & TST & \\
\hline CHEMBL 2004716 & 809204 & 6.3 & 6.0464 & TRN & \\
\hline CHEMBL1968127 & 809204 & 4.2 & 4.2494 & TRN & \\
\hline CHEMBL1975233 & 809204 & 4.3 & 4.3093 & TRN & \\
\hline CHEMBL1985406 & 809204 & 5.3 & 5.0919 & TRN & \\
\hline CHEMBL 2007603 & 809204 & 4.3 & 4.4242 & TRN & \\
\hline CHEMBL 207400 & 809204 & 4.2 & 4.2668 & TST & \\
\hline CHEMBL2000894 & 809204 & 4.2 & 4.6826 & TST & \\
\hline CHEMBL1982135 & 809204 & 4.2 & 4.5625 & TRN & \\
\hline CHEMBL1976090 & 809204 & 5.4 & 5.4084 & TRN & \\
\hline CHEMBL1993243 & 809204 & 5.8 & 5.1224 & TRN & \\
\hline CHEMBL1992922 & 809204 & 6.7 & 6.7575 & TRN & \\
\hline CHEMBL2004771 & 809204 & 6.2 & 4.534 & TRN & \\
\hline CHEMBL399021 & 809204 & 5.8 & 5.7498 & TRN & \\
\hline CHEMBL1997597 & 809204 & 5.4 & 5.0075 & TRN & \\
\hline CHEMBL1969537 & 809204 & 4.2 & 4.5538 & TST & \\
\hline CHEMBL1976093 & 809204 & 4.2 & 4.1523 & TRN & \\
\hline CHEMBL210032 & 809204 & 4.2 & 4.0132 & TRN & \\
\hline CHEMBL1996543 & 809204 & 4.2 & 4.2888 & TRN & \\
\hline CHEMBL1975256 & 809204 & 4.2 & 4.3301 & TST & \\
\hline CHEMBL508928 & 809204 & 4.2 & 3.7758 & TRN & \\
\hline CHEMBL1991356 & 809204 & 4.2 & 4.3342 & TST & \\
\hline CHEMBL1983309 & 809204 & 4.2 & 3.9385 & TRN & \\
\hline CHEMBL2004892 & 809204 & 5.6 & 5.2835 & TRN & \\
\hline CHEMBL1999126 & 809204 & 4.2 & 4.7242 & TST & \\
\hline CHEMBL1997503 & 809204 & 5.2 & 4.7125 & TST & \\
\hline CHEMBL116070 & 809204 & 4.2 & 4.1906 & TRN & \\
\hline CHEMBL1990821 & 809204 & 5.5 & 5.3088 & TRN & \\
\hline CHEMBL1970314 & 809204 & 4.2 & 4.3293 & TRN & \\
\hline CHEMBL2004871 & 809204 & 4.2 & 4.1615 & TRN & \\
\hline CHEMBL 2004872 & 809204 & 4.2 & $4.2860 e$ & 00000000005 & TRN \\
\hline CHEMBL1727312 & 809204 & 4.2 & 4.2851 & TRN & \\
\hline CHEMBL1969879 & 809204 & 4.2 & 4.8882 & TRN & \\
\hline CHEMBL1981720 & 809204 & 4.2 & 4.4414 & TRN & \\
\hline CHEMBL419932 & 809204 & 5.3 & 4.9388 & TRN & \\
\hline CHEMBL262433 & 809204 & 4.2 & 5.00899 & 99999999995 & TRN \\
\hline & & & & 12993 & \\
\hline
\end{tabular}




\begin{tabular}{|c|c|c|c|c|}
\hline & & & pplement & al $\mathrm{Ta}$ \\
\hline CHEMBL 306380 & 809204 & 4.3 & 5.2299 & TRN \\
\hline CHEMBL1966722 & 809204 & 5.3 & 4.9709 & TST \\
\hline CHEMBL1975500 & 809204 & 5.4 & 5.3506 & TRN \\
\hline CHEMBL1976328 & 809204 & 4.2 & 4.2401 & TRN \\
\hline CHEMBL394619 & 809204 & 4.2 & 5.0045 & TRN \\
\hline CHEMBL1964399 & 809204 & 6.7 & 6.5015 & TRN \\
\hline CHEMBL1996831 & 809204 & 4.2 & 4.3648 & TST \\
\hline CHEMBL411903 & 809204 & 5.3 & 5.7415 & TRN \\
\hline CHEMBL1965988 & 809204 & 6.0 & 5.7972 & TRN \\
\hline CHEMBL418203 & 809204 & 4.2 & 4.4508 & TST \\
\hline CHEMBL1989646 & 809204 & 5.9 & 5.8864 & TRN \\
\hline CHEMBL1682357 & 809204 & 5.4 & 4.706 & TRN \\
\hline CHEMBL225519 & 809204 & 4.3 & 5.1667 & TRN \\
\hline CHEMBL 209534 & 809204 & 4.2 & 4.3522 & TRN \\
\hline CHEMBL1978200 & 809204 & 4.2 & 4.3553 & TRN \\
\hline CHEMBL 2006631 & 809204 & 5.8 & 4.637 & TRN \\
\hline CHEMBL1970522 & 809204 & 4.2 & 4.1002 & TRN \\
\hline CHEMBL1990415 & 809204 & 4.2 & 4.3943 & TRN \\
\hline CHEMBL1966087 & 809204 & 4.2 & 4.2682 & TRN \\
\hline CHEMBL1964692 & 809204 & 4.2 & 5.0492 & TRN \\
\hline CHEMBL1996931 & 809204 & 4.2 & 3.9057 & TRN \\
\hline CHEMBL1964413 & 809204 & 4.2 & 4.0723 & TRN \\
\hline CHEMBL1973483 & 809204 & 5.2 & 4.4476 & TRN \\
\hline CHEMBL1984432 & 809204 & 4.2 & 4.3251 & TRN \\
\hline CHEMBL1970735 & 809204 & 4.2 & 4.1532 & TRN \\
\hline CHEMBL 219722 & 809204 & 5.4 & 5.8176 & TRN \\
\hline CHEMBL1997340 & 809204 & 4.2 & 4.0764 & TRN \\
\hline CHEMBL 2004365 & 809204 & 5.2 & 4.7327 & TST \\
\hline CHEMBL1522508 & 809204 & 4.2 & 3.9448 & TRN \\
\hline CHEMBL1989474 & 809204 & 4.2 & 4.1893 & TRN \\
\hline CHEMBL1090360 & 809204 & 4.2 & 4.0826 & TRN \\
\hline CHEMBL210887 & 809204 & 5.5 & 4.6648 & TST \\
\hline CHEMBL458997 & 809204 & 5.8 & 6.0326 & TRN \\
\hline CHEMBL1971021 & 809204 & 4.2 & 4.1795 & TRN \\
\hline CHEMBL 227271 & 809204 & 6.2 & 6.7702 & TRN \\
\hline CHEMBL583144 & 809204 & 4.2 & 4.4691 & TST \\
\hline CHEMBL1974310 & 809204 & 4.2 & 4.7106 & TRN \\
\hline CHEMBL1982660 & 809204 & 4.2 & 4.4547 & TRN \\
\hline CHEMBL1994693 & 809204 & 5.4 & 5.3871 & TRN \\
\hline CHEMBL1982957 & 809204 & 7.0 & 7.1174 & TRN \\
\hline CHEMBL1725279 & 809204 & 8.4 & 5.5284 & TST \\
\hline CHEMBL1975138 & 809204 & 4.2 & 4.4639 & TST \\
\hline CHEMBL424872 & 809204 & 4.3 & 4.4215 & TRN \\
\hline CHEMBL 2006836 & 809204 & 4.2 & 4.379 & TST \\
\hline CHEMBL1971947 & 809204 & 4.2 & 4.5726 & TRN \\
\hline CHEMBL412142 & 809204 & 4.2 & 4.0593 & TST \\
\hline CHEMBL1980704 & 809204 & 4.2 & 4.2298 & TST \\
\hline CHEMBL 2003271 & 809204 & 4.2 & 5.0044 & TST \\
\hline
\end{tabular}




\begin{tabular}{|c|c|c|c|c|}
\hline & & & & al Table S2 \\
\hline CHEMBL1966808 & 809204 & 4.2 & 4.5816 & TST \\
\hline CHEMBL 2004447 & 809204 & 4.2 & 4.4542 & TRN \\
\hline CHEMBL1983111 & 809204 & 7.8 & 6.65799 & 99999999995 \\
\hline CHEMBL1973860 & 809204 & 4.2 & 4.2512 & TRN \\
\hline CHEMBL260135 & 809204 & 4.2 & 4.8862 & TRN \\
\hline CHEMBL220241 & 809204 & 5.8 & 5.2422 & TRN \\
\hline CHEMBL 2004544 & 809204 & 4.2 & 4.5309 & TST \\
\hline CHEMBL1982610 & 809204 & 4.2 & 4.6141 & TST \\
\hline CHEMBL1986996 & 809204 & 5.4 & 5.3481 & TST \\
\hline CHEMBL1999496 & 809204 & 4.2 & 4.2242 & TRN \\
\hline CHEMBL 2006933 & 809204 & 5.8 & 5.3338 & TST \\
\hline CHEMBL1988300 & 809204 & 4.2 & 4.1238 & TRN \\
\hline CHEMBL1991078 & 809204 & 7.2 & 7.0315 & TRN \\
\hline CHEMBL1987359 & 809204 & 4.2 & 4.6193 & TST \\
\hline CHEMBL 2000685 & 809204 & 6.5 & 5.945 & TRN \\
\hline CHEMBL 2000724 & 809204 & 9.0 & 5.1352 & TRN \\
\hline CHEMBL1985311 & 809204 & 5.9 & 5.5323 & TRN \\
\hline CHEMBL1989265 & 809204 & 4.2 & 4.468 & TST \\
\hline CHEMBL1969502 & 809204 & 5.4 & 5.5506 & TRN \\
\hline CHEMBL1965910 & 809204 & 5.7 & 5.9604 & TRN \\
\hline CHEMBL1682553 & 809204 & 4.2 & 4.5619 & TRN \\
\hline CHEMBL1971430 & 809204 & 4.2 & 4.2939 & TRN \\
\hline CHEMBL1997764 & 809204 & 5.9 & 5.517 & TRN \\
\hline CHEMBL1983963 & 809204 & 4.3 & 5.0499 & TRN \\
\hline CHEMBL 2000271 & 809204 & 6.1 & 6.4408 & TRN \\
\hline CHEMBL1985092 & 809204 & 5.5 & 5.1379 & TRN \\
\hline CHEMBL 2004692 & 809204 & 4.2 & 4.2165 & TST \\
\hline CHEMBL1981410 & 809204 & 4.2 & 5.2499 & TRN \\
\hline CHEMBL1996234 & 809204 & 5.5 & 5.1016 & TRN \\
\hline CHEMBL1991434 & 809204 & 4.2 & 4.3422 & TST \\
\hline CHEMBL1967544 & 809204 & 4.2 & 4.4128 & TRN \\
\hline CHEMBL223367 & 809204 & 4.4 & 5.4491 & TST \\
\hline CHEMBL407391 & 809204 & 5.3 & 5.1169 & TST \\
\hline CHEMBL340384 & 809204 & 5.9 & 5.404 & TST \\
\hline CHEMBL1996587 & 809204 & 4.2 & 4.49 & TRN \\
\hline CHEMBL1964804 & 809204 & 4.2 & 4.1278 & TRN \\
\hline CHEMBL443962 & 809204 & 5.6 & 5.0609 & TST \\
\hline CHEMBL 2000354 & 809204 & 4.2 & 4.4531 & TRN \\
\hline CHEMBL1965507 & 809204 & 6.4 & 6.5506 & TRN \\
\hline CHEMBL 274064 & 809204 & 4.2 & 4.3416 & TRN \\
\hline CHEMBL 1967564 & 809204 & 4.2 & 4.1052 & TRN \\
\hline CHEMBL592030 & 809204 & 7.2 & 7.6156 & TST \\
\hline CHEMBL 2000071 & 809204 & 6.2 & 6.3232 & TRN \\
\hline CHEMBL1979176 & 809204 & 4.2 & 4.1675 & TRN \\
\hline CHEMBL1970317 & 809204 & 4.3 & 6.1804 & TRN \\
\hline CHEMBL 2000408 & 809204 & 4.2 & 4.2505 & TRN \\
\hline CHEMBL 248757 & 809204 & 4.2 & 5.1758 & TST \\
\hline CHEMBL1978014 & 809204 & 4.2 & 4.58 & TRN \\
\hline
\end{tabular}




\begin{tabular}{|c|c|c|c|c|}
\hline \multicolumn{5}{|c|}{ Supplemental Ta } \\
\hline CHEMBL1994538 & 809204 & 4.2 & 4.3297 & TRN \\
\hline CHEMBL1983195 & 809204 & 4.2 & 4.5256 & TST \\
\hline CHEMBL1975490 & 809204 & 4.2 & 5.0541 & TRN \\
\hline CHEMBL1964444 & 809204 & 4.2 & 4.2358 & TRN \\
\hline CHEMBL 2006567 & 809204 & 4.2 & 4.0052 & TRN \\
\hline CHEMBL1986139 & 809204 & 4.2 & 4.0174 & TRN \\
\hline CHEMBL383527 & 809204 & 4.2 & 4.379 & TRN \\
\hline CHEMBL1980540 & 809204 & 4.2 & 4.2487 & TRN \\
\hline CHEMBL 278041 & 809204 & 4.3 & 4.4681 & TRN \\
\hline CHEMBL1979883 & 809204 & 6.0 & 5.4908 & TRN \\
\hline CHEMBL1984162 & 809204 & 6.8 & 7.6648 & TRN \\
\hline CHEMBL491758 & 809204 & 5.7 & 5.4441 & TRN \\
\hline CHEMBL549730 & 809204 & 4.2 & 4.4227 & TRN \\
\hline CHEMBL1682360 & 809204 & 5.3 & 4.4763 & TRN \\
\hline CHEMBL1970189 & 809204 & 5.5 & 4.6677 & TRN \\
\hline CHEMBL 1870106 & 809204 & 5.7 & 5.3615 & TRN \\
\hline CHEMBL1996791 & 809204 & 5.7 & 4.9254 & TRN \\
\hline CHEMBL371206 & 809204 & 4.2 & 5.059 & TRN \\
\hline CHEMBL1974664 & 809204 & 4.2 & 4.1332 & TST \\
\hline CHEMBL406845 & 809204 & 4.3 & 5.0175 & TRN \\
\hline CHEMBL 1974288 & 809204 & 4.2 & 4.3563 & TRN \\
\hline CHEMBL196363 & 809204 & 5.4 & 5.3648 & TRN \\
\hline CHEMBL1190711 & 809204 & 4.2 & 5.045 & TRN \\
\hline CHEMBL1990346 & 809204 & 5.6 & 5.6442 & TRN \\
\hline CHEMBL1968705 & 809204 & 4.3 & 4.6208 & TRN \\
\hline CHEMBL404367 & 809204 & 4.2 & 4.2759 & TRN \\
\hline CHEMBL1966343 & 809204 & 6.1 & 5.8508 & TRN \\
\hline CHEMBL1967887 & 809204 & 5.2 & 5.4396 & TRN \\
\hline CHEMBL 2000568 & 809204 & 5.7 & 5.3298 & TRN \\
\hline CHEMBL 2000335 & 809204 & 6.0 & 6.1388 & TRN \\
\hline CHEMBL1977604 & 809204 & 4.2 & 4.4979 & TST \\
\hline CHEMBL1988717 & 809204 & 4.2 & 4.1766 & TRN \\
\hline CHEMBL1974328 & 809204 & 6.6 & 5.1881 & TST \\
\hline CHEMBL509032 & 809204 & 7.8 & 6.5074 & TRN \\
\hline CHEMBL1973808 & 809204 & 4.2 & 4.1609 & TRN \\
\hline CHEMBL 2000429 & 809204 & 4.2 & 4.3982 & TRN \\
\hline CHEMBL1972576 & 809204 & 6.0 & 5.9882 & TRN \\
\hline CHEMBL1992555 & 809204 & 4.2 & 4.5106 & TST \\
\hline CHEMBL1989069 & 809204 & 4.9 & 5.2139 & TST \\
\hline CHEMBL1992342 & 809204 & 5.3 & 5.0502 & TRN \\
\hline CHEMBL1988173 & 809204 & 5.4 & 5.0966 & TST \\
\hline CHEMBL535331 & 809204 & 4.2 & 4.2746 & TRN \\
\hline CHEMBL1989805 & 809204 & 4.3 & 4.6767 & TST \\
\hline CHEMBL1982980 & 809204 & 5.5 & 5.2978 & TRN \\
\hline CHEMBL1965423 & 809204 & 4.2 & 4.0933 & TRN \\
\hline CHEMBL1983025 & 809204 & 6.0 & 5.8408 & TRN \\
\hline CHEMBL205415 & 809204 & 4.3 & 5.0467 & TRN \\
\hline CHEMBL1977135 & 809204 & 4.2 & 4.2276 & TRN \\
\hline
\end{tabular}




\begin{tabular}{|c|c|c|c|c|}
\hline & & & ient & al T \\
\hline CHEMBL 2001920 & 809204 & 5.6 & 5.3217 & TST \\
\hline CHEMBL 2002322 & 809204 & 4.2 & 4.2675 & TRN \\
\hline CHEMBL 2002323 & 809204 & 4.2 & 4.1752 & TST \\
\hline CHEMBL1241473 & 809204 & 8.1 & 8.0189 & TRN \\
\hline CHEMBL1978448 & 809204 & 4.2 & 4.829 & TST \\
\hline CHEMBL1972258 & 809204 & 4.2 & 4.0693 & TRN \\
\hline CHEMBL 2001257 & 809204 & 5.9 & 5.1676 & TRN \\
\hline CHEMBL 2005548 & 809204 & 4.2 & 4.5079 & TRN \\
\hline CHEMBL1987793 & 809204 & 5.6 & 5.5566 & TRN \\
\hline CHEMBL1992536 & 809204 & 4.2 & 4.3197 & TRN \\
\hline CHEMBL1992740 & 809204 & 4.2 & 4.4964 & TRN \\
\hline CHEMBL 2002373 & 809204 & 4.2 & 4.2913 & TRN \\
\hline CHEMBL439340 & 809204 & 4.2 & 4.3124 & TRN \\
\hline CHEMBL 2006188 & 809204 & 5.3 & 4.1728 & TRN \\
\hline CHEMBL1967531 & 809204 & 5.9 & 5.4064 & TRN \\
\hline CHEMBL1970913 & 809204 & 4.2 & 4.3051 & TRN \\
\hline CHEMBL1973893 & 809204 & 4.2 & 4.166 & TRN \\
\hline CHEMBL1995736 & 809204 & 4.2 & 4.1858 & TRN \\
\hline CHEMBL1997534 & 809204 & 4.2 & 4.7551 & TRN \\
\hline CHEMBL1996500 & 809204 & 4.2 & 4.3106 & TRN \\
\hline CHEMBL1985095 & 809204 & 6.4 & 6.7799 & TST \\
\hline CHEMBL1998551 & 809204 & 4.2 & 4.3533 & TRN \\
\hline CHEMBL1977374 & 809204 & 4.2 & 4.4298 & TRN \\
\hline CHEMBL1991180 & 809204 & 6.4 & 5.7536 & TST \\
\hline CHEMBL1682540 & 809204 & 4.2 & 4.6619 & TRN \\
\hline CHEMBL1978656 & 809204 & 4.2 & 4.5289 & TRN \\
\hline CHEMBL1976420 & 809204 & 6.2 & 5.1495 & TST \\
\hline CHEMBL1994864 & 809204 & 4.2 & 4.1348 & TRN \\
\hline CHEMBL413779 & 809204 & 6.5 & 5.8143 & TST \\
\hline CHEMBL 2002446 & 809204 & 4.4 & 4.7553 & TST \\
\hline CHEMBL497151 & 809204 & 5.3 & 4.8961 & TRN \\
\hline CHEMBL 246970 & 809204 & 4.2 & 4.6498 & TRN \\
\hline CHEMBL340921 & 809204 & 4.2 & 4.4234 & TST \\
\hline CHEMBL373598 & 809204 & 6.8 & 5.1625 & TST \\
\hline CHEMBL1999718 & 809204 & 4.2 & 4.4106 & TRN \\
\hline CHEMBL1276446 & 809204 & 7.4 & 7.1713 & TST \\
\hline CHEMBL1979773 & 809204 & 4.3 & 4.3097 & TRN \\
\hline CHEMBL1977346 & 809204 & 5.2 & 4.8303 & TRN \\
\hline CHEMBL1971649 & 809204 & 4.2 & 3.9716 & TRN \\
\hline CHEMBL 2003657 & 809204 & 4.2 & 3.9774 & TRN \\
\hline CHEMBL1998435 & 809204 & 4.2 & 4.1246 & TRN \\
\hline CHEMBL 2006439 & 809204 & 6.8 & 6.481 & TRN \\
\hline CHEMBL2006156 & 809204 & 4.2 & 4.6199 & TST \\
\hline CHEMBL1969190 & 809204 & 5.7 & 5.4254 & TRN \\
\hline CHEMBL 2002660 & 809204 & 4.3 & 4.3949 & TRN \\
\hline CHEMBL1973937 & 809204 & 5.4 & 5.2779 & TRN \\
\hline CHEMBL1991674 & 809204 & 6.4 & 6.5936 & TRN \\
\hline CHEMBL1982711 & 809204 & 6.4 & 6.496 & TRN \\
\hline
\end{tabular}




\begin{tabular}{|c|c|c|c|c|c|}
\hline & & & & & \\
\hline CHEMBL1987982 & 809204 & 6.2 & 5.2618 & TST & \\
\hline CHEMBL1984842 & 809204 & 4.2 & 4.3628 & TRN & \\
\hline CHEMBL1969102 & 809204 & 5.9 & 5.74700 & 0000000001 & TRN \\
\hline CHEMBL1682346 & 809204 & 5.8 & 5.9944 & TRN & \\
\hline CHEMBL 2007044 & 809204 & 5.5 & 5.3827 & TST & \\
\hline CHEMBL2001998 & 809204 & 6.4 & 6.1698 & TST & \\
\hline CHEMBL1994241 & 809204 & 4.2 & 5.1909 & TRN & \\
\hline CHEMBL 223460 & 809204 & 4.2 & 4.9081 & TST & \\
\hline CHEMBL1998829 & 809204 & 4.2 & 4.808 & TRN & \\
\hline CHEMBL50894 & 809204 & 6.2 & 5.9983 & TRN & \\
\hline CHEMBL1988838 & 809204 & 6.2 & 6.7456 & TRN & \\
\hline CHEMBL1981725 & 809204 & 6.1 & 5.1131 & TRN & \\
\hline CHEMBL1982753 & 809204 & 5.6 & 4.9997 & TST & \\
\hline CHEMBL 375284 & 809204 & 4.2 & 4.2944 & TRN & \\
\hline CHEMBL1972346 & 809204 & 6.6 & 5.397 & TST & \\
\hline CHEMBL1081312 & 809204 & 6.1 & 5.82700 & 3000000001 & TRN \\
\hline CHEMBL1982866 & 809204 & 4.2 & 4.1271 & TRN & \\
\hline CHEMBL2005792 & 809204 & 4.2 & 4.3396 & TRN & \\
\hline CHEMBL1968926 & 809204 & 4.2 & 4.1833 & TRN & \\
\hline CHEMBL1984206 & 809204 & 4.2 & 4.2521 & TRN & \\
\hline CHEMBL462120 & 809204 & 4.2 & 4.3907 & TST & \\
\hline CHEMBL1991577 & 809204 & 4.2 & 4.1394 & TRN & \\
\hline CHEMBL1965570 & 809204 & 5.5 & 5.22 & TRN & \\
\hline CHEMBL 2007592 & 809204 & 4.2 & 4.4448 & TST & \\
\hline CHEMBL210963 & 809204 & 4.2 & 4.187 & TRN & \\
\hline CHEMBL1082440 & 809204 & 6.5 & 5.9659 & TST & \\
\hline CHEMBL1614705 & 809204 & 4.2 & 4.2892 & TRN & \\
\hline CHEMBL1972362 & 809204 & 4.2 & 4.3088 & TRN & \\
\hline CHEMBL1984633 & 809204 & 4.2 & 4.4997 & TRN & \\
\hline CHEMBL 2007372 & 809204 & 4.2 & 4.3403 & TRN & \\
\hline CHEMBL1965845 & 809204 & 6.0 & 6.1323 & TRN & \\
\hline CHEMBL1982167 & 809204 & 4.2 & 4.248 & TRN & \\
\hline CHEMBL 2006715 & 809204 & 4.2 & 4.7723 & TRN & \\
\hline CHEMBL1986597 & 809204 & 4.2 & 4.6271 & TRN & \\
\hline CHEMBL1971017 & 809204 & 5.5 & 5.3755 & TRN & \\
\hline CHEMBL1990482 & 809204 & 4.2 & 4.1349 & TRN & \\
\hline CHEMBL1990904 & 809204 & 4.2 & 4.2447 & TRN & \\
\hline CHEMBL 2005475 & 809204 & 6.2 & 5.6342 & TRN & \\
\hline CHEMBL 2000104 & 809204 & 4.2 & 4.4578 & TRN & \\
\hline CHEMBL402846 & 809204 & 4.2 & 4.1132 & TRN & \\
\hline CHEMBL1997349 & 809204 & 4.2 & 5.0148 & TST & \\
\hline CHEMBL183844 & 809204 & 4.2 & 4.0581 & TRN & \\
\hline CHEMBL220057 & 809204 & 5.5 & 5.54200 & 0000000001 & TRN \\
\hline CHEMBL1682545 & 809204 & 4.2 & 4.1573 & TRN & \\
\hline CHEMBL 383541 & 809204 & 4.2 & 4.6328 & TRN & \\
\hline CHEMBL 2001224 & 809204 & 4.2 & 4.465 & TRN & \\
\hline CHEMBL10 & 809204 & 4.2 & 4.2908 & TRN & \\
\hline CHEMBL1976732 & 809204 & 6.9 & 4.6606 & TRN & \\
\hline & & & & 12998 & \\
\hline
\end{tabular}




\begin{tabular}{|c|c|c|c|c|c|}
\hline \\
\hline CHEMBL1969506 & 809204 & 4.3 & 4.2271 & TRN & \\
\hline CHEMBL1964937 & 809204 & 5.5 & 5.8501 & TRN & \\
\hline CHEMBL1980163 & 809204 & 4.2 & 4.3134 & TRN & \\
\hline CHEMBL590109 & 809204 & 6.9 & 7.3287 & TST & \\
\hline CHEMBL1970879 & 809204 & 4.2 & 4.5595 & TRN & \\
\hline CHEMBL1989856 & 809204 & 4.2 & 4.2432 & TST & \\
\hline CHEMBL2005899 & 809204 & 4.2 & 4.5171 & TRN & \\
\hline CHEMBL1682552 & 809204 & 4.2 & 4.5481 & TRN & \\
\hline CHEMBL259850 & 809204 & 4.2 & 3.7755 & TRN & \\
\hline CHEMBL1972568 & 809204 & 4.2 & 4.1196 & TRN & \\
\hline CHEMBL1996155 & 809204 & 4.2 & 4.3749 & TRN & \\
\hline CHEMBL229799 & 809204 & 6.6 & 7.2857 & TRN & \\
\hline CHEMBL1682359 & 809204 & 5.4 & 4.2667 & TRN & \\
\hline CHEMBL105739 & 809204 & 5.7 & 5.66799 & 9999999999 & TRN \\
\hline CHEMBL 379300 & 809204 & 6.4 & 6.6983 & TRN & \\
\hline CHEMBL 203673 & 809204 & 4.2 & 4.0739 & TRN & \\
\hline CHEMBL1969523 & 809204 & 6.6 & 6.49200 & 0000000001 & TRN \\
\hline CHEMBL2005214 & 809204 & 5.7 & 5.1598 & TRN & \\
\hline CHEMBL207995 & 809204 & 4.2 & 4.3167 & TRN & \\
\hline CHEMBL1988995 & 809204 & 4.2 & 4.3977 & TRN & \\
\hline CHEMBL2001923 & 809204 & 4.2 & 4.9204 & TRN & \\
\hline CHEMBL1986781 & 809204 & 4.2 & 4.2193 & TRN & \\
\hline CHEMBL526133 & 809204 & 4.2 & 4.809 & TRN & \\
\hline CHEMBL1979057 & 809204 & 4.2 & 5.1098 & TRN & \\
\hline CHEMBL1981045 & 809204 & 5.4 & 5.0506 & TRN & \\
\hline CHEMBL387971 & 809204 & 4.2 & 4.5346 & TST & \\
\hline CHEMBL1975418 & 809204 & 6.3 & 5.671 & TRN & \\
\hline CHEMBL1992796 & 809204 & 4.2 & 4.6509 & TST & \\
\hline CHEMBL223257 & 809204 & 5.4 & 4.9337 & TST & \\
\hline CHEMBL1999428 & 809204 & 4.2 & 4.2674 & TRN & \\
\hline CHEMBL1967560 & 809204 & 4.2 & 4.0465 & TRN & \\
\hline CHEMBL1516890 & 809204 & 5.9 & 5.1397 & TRN & \\
\hline CHEMBL211378 & 809204 & 4.2 & 4.3718 & TRN & \\
\hline CHEMBL1982465 & 809204 & 5.6 & 5.6471 & TRN & \\
\hline CHEMBL 2001751 & 809204 & 7.4 & 7.0187 & TRN & \\
\hline CHEMBL2003420 & 809204 & 7.1 & 4.3449 & TRN & \\
\hline CHEMBL1984586 & 809204 & 4.2 & 4.5165 & TRN & \\
\hline CHEMBL1999774 & 809204 & 4.2 & 4.4643 & TST & \\
\hline CHEMBL1972659 & 809204 & 4.2 & 4.3032 & TST & \\
\hline CHEMBL1973395 & 809204 & 6.9 & 7.2108 & TRN & \\
\hline CHEMBL272453 & 809204 & 4.2 & 4.3305 & TRN & \\
\hline CHEMBL1970217 & 809204 & 4.2 & 4.3136 & TRN & \\
\hline CHEMBL1971801 & 809204 & 4.2 & 4.2799 & TRN & \\
\hline CHEMBL1968850 & 809204 & 4.2 & 4.4956 & TRN & \\
\hline CHEMBL2005528 & 809204 & 4.2 & 4.2726 & TST & \\
\hline CHEMBL185569 & 809204 & 4.2 & 4.4087 & TRN & \\
\hline CHEMBL1969843 & 809204 & 4.2 & 4.3448 & TRN & \\
\hline CHEMBL2007002 & 809204 & 5.4 & 5.2285 & TRN & \\
\hline & & & & 1299 & \\
\hline
\end{tabular}




\begin{tabular}{|c|c|c|c|c|}
\hline & & & IETIS & al Ta \\
\hline CHEMBL1987007 & 809204 & 4.2 & 4.6521 & TRN \\
\hline CHEMBL1969588 & 809204 & 6.8 & 6.3474 & TRN \\
\hline CHEMBL1984711 & 809204 & 5.4 & 5.4898 & TRN \\
\hline CHEMBL1992073 & 809204 & 6.8 & 5.8373 & TST \\
\hline CHEMBL1990212 & 809204 & 4.2 & 4.2072 & TRN \\
\hline CHEMBL484390 & 809204 & 5.2 & 4.1483 & TST \\
\hline CHEMBL1979252 & 809204 & 4.2 & 4.2165 & TRN \\
\hline CHEMBL1682341 & 809204 & 5.6 & 5.0546 & TRN \\
\hline CHEMBL 2004290 & 809204 & 4.2 & 3.9992 & TRN \\
\hline CHEMBL1986499 & 809204 & 6.1 & 6.0254 & TRN \\
\hline CHEMBL1972937 & 809204 & 4.2 & 4.1546 & TRN \\
\hline CHEMBL1972250 & 809204 & 5.3 & 4.8351 & TST \\
\hline CHEMBL 2000393 & 809204 & 6.7 & 6.3925 & TST \\
\hline CHEMBL 2004072 & 809204 & 4.2 & 3.9897 & TRN \\
\hline CHEMBL2004311 & 809204 & 4.2 & 4.3462 & TRN \\
\hline CHEMBL1992634 & 809204 & 6.4 & 6.0948 & TRN \\
\hline CHEMBL1242373 & 809204 & 5.5 & 5.2928 & TRN \\
\hline CHEMBL56543 & 809204 & 4.2 & 5.3326 & TST \\
\hline CHEMBL1984847 & 809204 & 4.3 & 5.2059 & TST \\
\hline CHEMBL316264 & 809204 & 4.2 & 4.2095 & TRN \\
\hline CHEMBL1988075 & 809204 & 5.4 & 5.1224 & TRN \\
\hline CHEMBL1991678 & 809204 & 4.2 & 4.3539 & TRN \\
\hline CHEMBL 2001239 & 809204 & 5.6 & 5.4464 & TST \\
\hline CHEMBL1988594 & 809204 & 6.2 & 6.5987 & TRN \\
\hline CHEMBL2001288 & 809204 & 4.2 & 4.5186 & TRN \\
\hline CHEMBL 260092 & 809204 & 6.5 & 5.7489 & TRN \\
\hline CHEMBL1999811 & 809204 & 5.8 & 4.9963 & TST \\
\hline CHEMBL1965495 & 809204 & 5.8 & 5.9851 & TRN \\
\hline CHEMBL1985074 & 809204 & 4.2 & 4.4223 & TST \\
\hline CHEMBL1982874 & 809204 & 4.2 & 4.3407 & TRN \\
\hline CHEMBL2000481 & 809204 & 4.2 & 4.5652 & TRN \\
\hline CHEMBL1991725 & 809204 & 4.2 & 4.3908 & TRN \\
\hline CHEMBL1992242 & 809204 & 4.2 & 4.1502 & TRN \\
\hline CHEMBL 2007296 & 809204 & 4.2 & 4.176 & TRN \\
\hline CHEMBL 208637 & 809204 & 4.2 & 4.0652 & TRN \\
\hline CHEMBL396523 & 809204 & 6.3 & 6.1555 & TRN \\
\hline CHEMBL 2007138 & 809204 & 3.8 & 4.1838 & TRN \\
\hline CHEMBL1970203 & 809204 & 5.6 & 5.3866 & TRN \\
\hline CHEMBL1986530 & 809204 & 4.2 & 4.5722 & TST \\
\hline CHEMBL440084 & 809204 & 4.3 & 4.769 & TRN \\
\hline CHEMBL1999321 & 809204 & 4.2 & 4.6301 & TRN \\
\hline CHEMBL1968590 & 809204 & 4.2 & 4.8435 & TRN \\
\hline CHEMBL1999749 & 809204 & 4.2 & 3.9193 & TRN \\
\hline CHEMBL 2005375 & 809204 & 4.2 & 4.1641 & TRN \\
\hline CHEMBL1984191 & 809204 & 4.2 & 4.2269 & TRN \\
\hline CHEMBL1983006 & 809204 & 4.2 & 4.3788 & TRN \\
\hline CHEMBL1972183 & 809204 & 4.2 & 4.4914 & TRN \\
\hline CHEMBL1971029 & 809204 & 7.5 & 7.812 & TRN \\
\hline
\end{tabular}




\begin{tabular}{|c|c|c|c|c|c|}
\hline \\
\hline CHEMBL1995391 & 809204 & 3.8 & 3.997 & TRN & \\
\hline CHEMBL 394790 & 809204 & 4.2 & 4.8434 & TRN & \\
\hline CHEMBL226471 & 809204 & 4.2 & 4.4563 & TRN & \\
\hline CHEMBL1974702 & 809204 & 4.2 & 4.4773 & TST & \\
\hline CHEMBL1996111 & 809204 & 6.0 & 5.3856 & TRN & \\
\hline CHEMBL1965589 & 809204 & 4.2 & 4.3274 & TRN & \\
\hline CHEMBL1998193 & 809204 & 4.2 & 4.3229 & TRN & \\
\hline CHEMBL474432 & 809204 & 5.7 & 5.4243 & TST & \\
\hline CHEMBL1988153 & 809204 & 4.2 & 3.8637 & TRN & \\
\hline CHEMBL1999556 & 809204 & 5.5 & 5.4139 & TRN & \\
\hline CHEMBL1988437 & 809204 & 6.0 & 5.4068 & TST & \\
\hline CHEMBL1968245 & 809204 & 4.2 & 4.1548 & TRN & \\
\hline CHEMBL1998121 & 809204 & 7.3 & 6.3686 & TRN & \\
\hline CHEMBL1979577 & 809204 & 6.3 & 5.7529 & TRN & \\
\hline CHEMBL1991800 & 809204 & 4.2 & 4.1348 & TRN & \\
\hline CHEMBL52387 & 809204 & 4.2 & 4.6539 & TST & \\
\hline CHEMBL379835 & 809204 & 4.2 & 4.2964 & TST & \\
\hline CHEMBL1979357 & 809204 & 4.2 & 4.0507 & TRN & \\
\hline CHEMBL1980802 & 809204 & 4.2 & 4.9089 & TST & \\
\hline CHEMBL1979554 & 809204 & 4.2 & 4.7048 & TRN & \\
\hline CHEMBL1996817 & 809204 & 6.7 & 7.1617 & TRN & \\
\hline CHEMBL3197315 & 809204 & 4.2 & 4.1308 & TST & \\
\hline CHEMBL 2004355 & 809204 & 4.2 & 4.4555 & TRN & \\
\hline CHEMBL468280 & 809204 & 4.2 & 4.5546 & TST & \\
\hline CHEMBL1990884 & 809204 & 4.2 & 4.289 & TRN & \\
\hline CHEMBL3109278 & 809204 & 6.7 & 6.1397 & TRN & \\
\hline CHEMBL256835 & 809204 & 4.2 & 4.1321 & TRN & \\
\hline CHEMBL1980142 & 809204 & 4.2 & 4.4298 & TRN & \\
\hline CHEMBL41783 & 809204 & 4.2 & 4.29899 & 79999999995 & TRN \\
\hline CHEMBL 2004438 & 809204 & 4.2 & 3.9559 & TRN & \\
\hline CHEMBL 2006276 & 809204 & 4.2 & 4.6998 & TRN & \\
\hline CHEMBL191003 & 809204 & 6.1 & 5.8932 & TRN & \\
\hline CHEMBL271381 & 809204 & 5.6 & 5.6181 & TRN & \\
\hline CHEMBL 2006785 & 809204 & 4.2 & 4.0118 & TST & \\
\hline CHEMBL1982466 & 809204 & 4.2 & 4.4134 & TRN & \\
\hline CHEMBL1995740 & 809204 & 4.2 & 4.4691 & TRN & \\
\hline CHEMBL1996390 & 809204 & 4.2 & 4.1487 & TRN & \\
\hline CHEMBL234085 & 809204 & 6.2 & 5.8558 & TRN & \\
\hline CHEMBL1995832 & 809204 & 4.2 & 4.4623 & TRN & \\
\hline CHEMBL1998414 & 809204 & 4.2 & 4.7285 & TRN & \\
\hline CHEMBL1969042 & 809204 & 5.3 & 5.5228 & TRN & \\
\hline CHEMBL 2000345 & 809204 & 5.3 & 5.375 & TRN & \\
\hline CHEMBL1999931 & 809204 & 7.1 & 7.379 & TRN & \\
\hline CHEMBL1991640 & 809204 & 5.6 & 5.0284 & TST & \\
\hline CHEMBL1375418 & 809204 & 5.3 & 4.2212 & TRN & \\
\hline CHEMBL302449 & 809204 & 7.7 & 7.3383 & TST & \\
\hline CHEMBL 2007064 & 809204 & 5.8 & 6.1137 & TRN & \\
\hline CHEMBL1981047 & 809204 & 7.3 & 6.2285 & TST & \\
\hline
\end{tabular}




\begin{tabular}{|c|c|c|c|c|c|}
\hline \multicolumn{6}{|c|}{ Supplemental Table S2.txt } \\
\hline CHEMBL229968 & 809204 & 6.5 & 6.8726 & TRN & \\
\hline CHEMBL1976240 & 809204 & 4.2 & 4.3113 & TRN & \\
\hline CHEMBL1979093 & 809204 & 5.6 & 5.3007 & TRN & \\
\hline CHEMBL1968151 & 809204 & 4.2 & 4.6568 & TST & \\
\hline CHEMBL1381197 & 809204 & 4.2 & 4.0524 & TRN & \\
\hline CHEMBL1987009 & 809204 & 5.7 & 5.71299 & 9999999999 & TRN \\
\hline CHEMBL379218 & 809204 & 5.7 & 6.1822 & TRN & \\
\hline CHEMBL 2003817 & 809204 & 4.2 & 4.3358 & TRN & \\
\hline CHEMBL336961 & 809204 & 4.2 & 4.3715 & TRN & \\
\hline CHEMBL1994830 & 809204 & 4.2 & 3.9527 & TRN & \\
\hline CHEMBL1987054 & 809204 & 6.9 & 7.3252 & TRN & \\
\hline CHEMBL1970083 & 809204 & 6.6 & 5.9428 & TRN & \\
\hline CHEMBL226403 & 809204 & 4.2 & 4.1899 & TRN & \\
\hline CHEMBL2005631 & 809204 & 6.1 & 5.9199 & TRN & \\
\hline CHEMBL1994938 & 809204 & 5.5 & 4.7983 & TRN & \\
\hline CHEMBL1825138 & 809204 & 5.3 & 5.6785 & TST & \\
\hline CHEMBL1977223 & 809204 & 5.9 & 5.8065 & TRN & \\
\hline CHEMBL1236126 & 809204 & 4.2 & 4.088 & TST & \\
\hline CHEMBL1966279 & 809204 & 4.2 & 4.3162 & TRN & \\
\hline CHEMBL1997846 & 809204 & 6.1 & 6.2126 & TRN & \\
\hline CHEMBL 2004419 & 809204 & 4.2 & 4.3294 & TRN & \\
\hline CHEMBL1991728 & 809204 & 5.7 & 5.0668 & TRN & \\
\hline CHEMBL1975787 & 809204 & 5.9 & 5.42399 & 99999999995 & TRN \\
\hline CHEMBL 2002407 & 809204 & 4.2 & 4.2939 & TRN & \\
\hline CHEMBL1972489 & 809204 & 4.2 & 4.1131 & TRN & \\
\hline CHEMBL1994074 & 809204 & 5.2 & 5.3024 & TRN & \\
\hline CHEMBL1992937 & 809204 & 5.8 & 4.9221 & TST & \\
\hline CHEMBL1985566 & 809204 & 4.2 & 4.5239 & TRN & \\
\hline CHEMBL1972119 & 809204 & 4.2 & 4.2716 & TRN & \\
\hline CHEMBL1986328 & 809204 & 4.2 & 4.7976 & TST & \\
\hline CHEMBL95692 & 809204 & 4.2 & 4.1767 & TRN & \\
\hline CHEMBL1090356 & 809204 & 4.2 & 4.0409 & TRN & \\
\hline CHEMBL1976455 & 809204 & 4.2 & 4.849 & TRN & \\
\hline CHEMBL1983923 & 809204 & 5.5 & 5.4168 & TST & \\
\hline CHEMBL1983534 & 809204 & 4.2 & 3.8512 & TRN & \\
\hline CHEMBL1982361 & 809204 & 4.2 & 4.5022 & TRN & \\
\hline CHEMBL1999112 & 809204 & 4.2 & 4.3073 & TST & \\
\hline CHEMBL1982122 & 809204 & 4.2 & 4.1397 & TRN & \\
\hline CHEMBL 2000801 & 809204 & 4.2 & 4.2205 & TRN & \\
\hline CHEMBL1682546 & 809204 & 4.2 & 4.1313 & TRN & \\
\hline CHEMBL1991395 & 809204 & 4.2 & 4.1035 & TRN & \\
\hline CHEMBL1971245 & 809204 & 5.3 & 5.0137 & TRN & \\
\hline CHEMBL1987648 & 809204 & 4.2 & 4.2 & TRN & \\
\hline CHEMBL1996780 & 809204 & 4.2 & 4.692 & TST & \\
\hline CHEMBL1972142 & 809204 & 4.2 & 5.4294 & TRN & \\
\hline CHEMBL1966514 & 809204 & 5.6 & 5.5154 & TRN & \\
\hline CHEMBL 2003638 & 809204 & 6.7 & 6.8777 & TRN & \\
\hline CHEMBL296586 & 809204 & 6.2 & 5.6635 & TRN & \\
\hline
\end{tabular}




\begin{tabular}{|c|c|c|c|c|}
\hline & & & pplement & al $\mathrm{Ta}$ \\
\hline CHEMBL1996066 & 809204 & 4.2 & 4.5599 & TST \\
\hline CHEMBL516429 & 809204 & 6.4 & 6.3929 & TRN \\
\hline CHEMBL1993722 & 809204 & 5.6 & 5.4328 & TRN \\
\hline CHEMBL1970806 & 809204 & 4.2 & 4.5074 & TST \\
\hline CHEMBL1375640 & 809204 & 5.2 & 4.5969 & TST \\
\hline CHEMBL1979970 & 809204 & 4.2 & 4.4307 & TRN \\
\hline CHEMBL249282 & 809204 & 5.6 & 5.5688 & TST \\
\hline CHEMBL1969264 & 809204 & 4.2 & 4.3795 & TRN \\
\hline CHEMBL1973711 & 809204 & 4.2 & 4.4411 & TST \\
\hline CHEMBL2006237 & 809204 & 4.2 & 4.2483 & TRN \\
\hline CHEMBL1967720 & 809204 & 6.3 & 6.021 & TRN \\
\hline CHEMBL1572266 & 809204 & 4.2 & 4.6658 & TST \\
\hline CHEMBL1991138 & 809204 & 4.2 & 4.7101 & TRN \\
\hline CHEMBL1969755 & 809204 & 4.2 & 4.1561 & TRN \\
\hline CHEMBL1979516 & 809204 & 5.4 & 5.4444 & TRN \\
\hline CHEMBL1605605 & 809204 & 4.2 & 4.235 & TRN \\
\hline CHEMBL1972820 & 809204 & 4.2 & 4.6079 & TST \\
\hline CHEMBL1989029 & 809204 & 4.2 & 4.3969 & TRN \\
\hline CHEMBL392642 & 809204 & 4.2 & 4.4433 & TST \\
\hline CHEMBL514499 & 809204 & 4.2 & 4.6227 & TST \\
\hline CHEMBL1965631 & 809204 & 4.2 & 4.9903 & TST \\
\hline CHEMBL1980144 & 809204 & 5.2 & 5.8061 & TST \\
\hline CHEMBL1991188 & 809204 & 5.5 & 4.1932 & TST \\
\hline CHEMBL1972849 & 809204 & 4.2 & 4.5761 & TST \\
\hline CHEMBL377408 & 809204 & 4.3 & 5.0333 & TST \\
\hline CHEMBL 215152 & 809204 & 4.2 & 4.4903 & TST \\
\hline CHEMBL231209 & 809204 & 4.2 & 4.2564 & TST \\
\hline CHEMBL1975357 & 809204 & 5.2 & 4.6678 & TST \\
\hline CHEMBL1976220 & 809204 & 4.2 & 4.8453 & TST \\
\hline CHEMBL259922 & 809204 & 4.2 & 4.1601 & TST \\
\hline CHEMBL1997617 & 809204 & 6.3 & 6.5014 & TST \\
\hline CHEMBL1982383 & 809204 & 4.2 & 4.0511 & TST \\
\hline CHEMBL1969301 & 809204 & 5.6 & 4.5125 & TST \\
\hline CHEMBL17370 & 809204 & 4.2 & 4.1738 & TST \\
\hline CHEMBL1987910 & 809204 & 4.2 & 4.4113 & TST \\
\hline CHEMBL1983932 & 809204 & 4.2 & 4.0859 & TST \\
\hline CHEMBL1966069 & 809204 & 5.3 & 4.9761 & TST \\
\hline CHEMBL1991285 & 809204 & 4.2 & 4.524 & TST \\
\hline CHEMBL1997822 & 809204 & 4.2 & 4.4065 & TST \\
\hline CHEMBL243088 & 809204 & 6.0 & 6.1314 & TST \\
\hline CHEMBL1984038 & 809204 & 4.2 & 4.5583 & TST \\
\hline CHEMBL1993661 & 809204 & 8.2 & 7.4554 & TST \\
\hline CHEMBL1974416 & 809204 & 6.0 & 5.6696 & TST \\
\hline CHEMBL 2004615 & 809204 & 4.2 & 4.3451 & TST \\
\hline CHEMBL1984039 & 809204 & 5.5 & 5.4883 & TST \\
\hline CHEMBL1997872 & 809204 & 5.5 & 4.7524 & TST \\
\hline CHEMBL1594186 & 688766 & 4.45 & 4.6356 & TST \\
\hline CHEMBL1357071 & 688766 & 5.05 & 5.07 & TRN \\
\hline
\end{tabular}




\begin{tabular}{|c|c|c|c|c|}
\hline \multicolumn{5}{|r|}{ al Ta } \\
\hline CHEMBL1396660 & 688766 & 4.6 & 4.834 & TRN \\
\hline CHEMBL1563669 & 688766 & 4.4 & 4.7599 & TRN \\
\hline CHEMBL1435975 & 688766 & 4.55 & 4.5892 & TRN \\
\hline CHEMBL1473939 & 688766 & 4.75 & 5.0512 & TRN \\
\hline CHEMBL1324817 & 688766 & 6.0 & 4.6053 & TST \\
\hline CHEMBL1555290 & 688766 & 7.5003 & 4.7471 & TST \\
\hline CHEMBL1332208 & 688766 & 6.0 & 5.1317 & TRN \\
\hline CHEMBL1571865 & 688766 & 4.4 & 5.0607 & TRN \\
\hline CHEMBL1434117 & 688766 & 4.8 & 4.5872 & TRN \\
\hline CHEMBL1319753 & 688766 & 5.1 & 4.9257 & TRN \\
\hline CHEMBL1394316 & 688766 & 4.75 & 4.8665 & TRN \\
\hline CHEMBL1395824 & 688766 & 5.05 & 4.8691 & TRN \\
\hline CHEMBL1553612 & 688766 & 4.9 & 4.9683 & TRN \\
\hline CHEMBL1433477 & 688766 & 4.65 & 4.9679 & TRN \\
\hline CHEMBL 1604841 & 688766 & 4.85 & 5.1136 & TRN \\
\hline CHEMBL1512036 & 688766 & 4.9 & 4.9725 & TRN \\
\hline CHEMBL1589735 & 688766 & 5.1 & 5.0608 & TRN \\
\hline CHEMBL1357440 & 688766 & 5.05 & 4.8202 & TRN \\
\hline CHEMBL1613138 & 688766 & 4.6 & 4.686 & TRN \\
\hline CHEMBL1336044 & 688766 & 6.0 & 4.6907 & TST \\
\hline CHEMBL1561604 & 688766 & 4.35 & 4.7417 & TST \\
\hline CHEMBL1335690 & 688766 & 4.4 & 4.9737 & TRN \\
\hline CHEMBL1396918 & 688766 & 4.8 & 4.8996 & TRN \\
\hline CHEMBL1472683 & 688766 & 4.45 & 5.0335 & TRN \\
\hline CHEMBL1318471 & 688766 & 4.65 & 4.9671 & TRN \\
\hline CHEMBL1317619 & 688766 & 4.8 & 4.6522 & TRN \\
\hline CHEMBL1490276 & 688766 & 4.35 & 4.66100 & 00000000005 \\
\hline CHEMBL1437903 & 688766 & 5.25 & 5.1332 & TRN \\
\hline CHEMBL1515891 & 688766 & 5.1 & 5.0132 & TRN \\
\hline CHEMBL1407467 & 688766 & 5.65 & 5.1265 & TRN \\
\hline CHEMBL1515072 & 688766 & 4.85 & 4.8139 & TRN \\
\hline CHEMBL1424954 & 688766 & 4.35 & 4.7973 & TST \\
\hline CHEMBL1509814 & 688766 & 4.7 & 4.6955 & TRN \\
\hline CHEMBL1552082 & 688766 & 4.55 & 4.3665 & TRN \\
\hline CHEMBL1366377 & 688766 & 4.5 & 5.0785 & TRN \\
\hline CHEMBL1372515 & 688766 & 4.45 & 4.511 & TST \\
\hline CHEMBL1395757 & 688766 & 4.8 & 4.8876 & TRN \\
\hline CHEMBL1610313 & 688766 & 4.5 & 4.5506 & TST \\
\hline CHEMBL1404328 & 688766 & 6.3 & 5.0865 & TRN \\
\hline CHEMBL1564635 & 688766 & 6.0 & 4.7052 & TST \\
\hline CHEMBL1572240 & 688766 & 4.8 & 5.0732 & TRN \\
\hline CHEMBL1356330 & 688766 & 6.5 & 4.7809 & TRN \\
\hline CHEMBL1414002 & 688766 & 4.9 & 4.6367 & TRN \\
\hline CHEMBL1368459 & 688766 & 5.2 & 5.1448 & TRN \\
\hline CHEMBL1514222 & 688766 & 4.6 & 4.5482 & TRN \\
\hline CHEMBL1358042 & 688766 & 4.45 & 4.8298 & TRN \\
\hline CHEMBL1317753 & 688766 & 4.5 & 4.5549 & TRN \\
\hline CHEMBL 1448146 & 688766 & 4.1 & 4.6658 & TST \\
\hline
\end{tabular}

TRN 


\begin{tabular}{|c|c|c|c|c|}
\hline \multicolumn{5}{|c|}{ Supplemental Table s2.txt } \\
\hline CHEMBL1591574 & 688766 & 5.25 & 5.1906 & TRN \\
\hline CHEMBL1552200 & 688766 & 5.5 & 5.1568 & TRN \\
\hline CHEMBL1479922 & 688766 & 4.8 & 4.8798 & TRN \\
\hline CHEMBL1610447 & 688766 & 4.9 & 4.8846 & TRN \\
\hline CHEMBL1552898 & 688766 & 5.35 & 5.2043 & TRN \\
\hline CHEMBL1394447 & 688766 & 4.45 & 4.628 & TST \\
\hline CHEMBL1370580 & 688766 & 4.75 & 4.8567 & TRN \\
\hline CHEMBL1592066 & 688766 & 4.5 & 4.4325 & TRN \\
\hline CHEMBL1315387 & 688766 & 4.7 & 5.0892 & TRN \\
\hline CHEMBL1563670 & 688766 & 5.4 & 4.9725 & TRN \\
\hline CHEMBL1357731 & 688766 & 4.5 & 4.6212 & TRN \\
\hline CHEMBL1422817 & 688766 & 4.45 & 4.657 & TST \\
\hline CHEMBL1552422 & 688766 & 5.55 & 5.1804 & TRN \\
\hline CHEMBL 3210295 & 688766 & 4.3 & 4.6357 & TST \\
\hline CHEMBL1423149 & 688766 & 4.45 & 4.7345 & TRN \\
\hline CHEMBL1531055 & 688766 & 4.4 & 4.6476 & TRN \\
\hline CHEMBL1396901 & 688766 & 5.0 & 4.6756 & TRN \\
\hline CHEMBL1514668 & 688766 & 5.1 & 5.0065 & TRN \\
\hline CHEMBL1433567 & 688766 & 4.6 & 4.7717 & TRN \\
\hline CHEMBL1534642 & 688766 & 4.4 & 5.0337 & TRN \\
\hline CHEMBL1613663 & 688766 & 5.5 & 5.1196 & TRN \\
\hline CHEMBL1485678 & 688766 & 5.1 & 5.1965 & TRN \\
\hline CHEMBL1513755 & 688766 & 5.0 & 5.0144 & TRN \\
\hline CHEMBL1554414 & 688766 & 4.85 & 4.6652 & TRN \\
\hline CHEMBL1314413 & 688766 & 4.3 & 4.8746 & TRN \\
\hline CHEMBL1372669 & 688766 & 5.55 & 5.1137 & TST \\
\hline CHEMBL1526314 & 688766 & 4.35 & 4.8783 & TST \\
\hline CHEMBL1354371 & 688766 & 4.55 & 4.8529 & TST \\
\hline CHEMBL1483242 & 688766 & 4.4 & 4.4772 & TST \\
\hline CHEMBL1376856 & 688766 & 4.6 & 4.8617 & TST \\
\hline CHEMBL1495371 & 688766 & 5.2 & 5.08 & TST \\
\hline CHEMBL1477190 & 688766 & 4.85 & 4.9436 & TST \\
\hline CHEMBL1454569 & 688766 & 6.0 & 4.6225 & TST \\
\hline CHEMBL1485549 & 752518 & 3.1705 & 3.185 & TRN \\
\hline CHEMBL1545169 & 752518 & 3.1705 & 3.4773 & TRN \\
\hline CHEMBL1488450 & 752518 & 6.1578 & 5.6791 & TRN \\
\hline CHEMBL1539517 & 752518 & 3.1706 & 3.6141 & TRN \\
\hline CHEMBL1345376 & 752518 & 3.1705 & 3.6275 & TRN \\
\hline CHEMBL 3210214 & 752518 & 3.1704 & 3.2803 & TRN \\
\hline CHEMBL1359915 & 752518 & 3.1708 & 3.2693 & TRN \\
\hline CHEMBL1392037 & 752518 & 3.1705 & 2.8643 & TRN \\
\hline CHEMBL1884239 & 752518 & 3.1704 & 3.2909 & TRN \\
\hline CHEMBL1497784 & 752518 & 3.1708 & 3.0842 & TRN \\
\hline CHEMBL1594939 & 752518 & 3.1705 & 3.3134 & TRN \\
\hline CHEMBL1883870 & 752518 & 3.1708 & 3.3342 & TST \\
\hline CHEMBL1580007 & 752518 & 3.1707 & 3.1371 & TRN \\
\hline CHEMBL1300613 & 752518 & 3.1703 & 3.085 & TRN \\
\hline CHEMBL1471683 & 752518 & 3.1705 & 3.1646 & TRN \\
\hline
\end{tabular}

Page 13005 
Supplemental Table S2.txt

\begin{tabular}{|c|c|c|c|c|}
\hline CHEMBL1544827 & 752518 & 3.1703 & 3.1739 & TRN \\
\hline CHEMBL1382538 & 752518 & 3.1701 & 3.49399 & 999 \\
\hline CHEMBL 70501 & 752518 & 3.1704 & 3.258 & TRN \\
\hline CHEMBL 3190073 & 752518 & 3.1705 & 3.0279 & TRN \\
\hline CHEMBL1461403 & 752518 & 3.1702 & 3.5401 & TRN \\
\hline CHEMBL1899639 & 752518 & 3.1708 & 3.4242 & TRN \\
\hline CHEMBL1303248 & 752518 & 3.1702 & 3.1688 & TRN \\
\hline CHEMBL3195906 & 752518 & 3.1703 & 3.5365 & TRN \\
\hline CHEMBL1310006 & 752518 & 3.1708 & 3.4403 & TRN \\
\hline CHEMBL1532144 & 752518 & 3.1705 & 3.2678 & TRN \\
\hline CHEMBL1500509 & 752518 & 3.1706 & 2.931 & TST \\
\hline CHEMBL1446542 & 752518 & 3.1705 & 3.5961 & TRN \\
\hline CHEMBL1426902 & 752518 & 3.1703 & 3.0097 & TST \\
\hline CHEMBL138649 & 752518 & 3.1702 & 3.0922 & TRN \\
\hline CHEMBL1303845 & 752518 & 3.1707 & 2.9449 & TRN \\
\hline CHEMBL1520379 & 752518 & 3.1705 & 3.4913 & TRN \\
\hline CHEMBL1365809 & 752518 & 3.1703 & 3.3003 & TRN \\
\hline CHEMBL1530924 & 752518 & 3.1707 & 3.2151 & TST \\
\hline CHEMBL1299628 & 752518 & 3.1707 & 3.7589 & TRN \\
\hline CHEMBL1724048 & 752518 & 3.1705 & 3.2625 & TRN \\
\hline CHEMBL1734782 & 752518 & 3.1718 & 3.155 & TRN \\
\hline CHEMBL1582247 & 752518 & 3.1705 & 3.07 & TRN \\
\hline CHEMBL1587035 & 752518 & 3.1702 & 3.5031 & TRN \\
\hline CHEMBL1604446 & 752518 & 3.1703 & 3.0948 & TRN \\
\hline CHEMBL3145118 & 752518 & 3.1708 & 2.7751 & TRN \\
\hline CHEMBL1305833 & 752518 & 3.1706 & 2.9284 & TRN \\
\hline CHEMBL1449236 & 752518 & 3.1706 & 2.9456 & TRN \\
\hline CHEMBL1526696 & 752518 & 3.1704 & 3.2229 & TRN \\
\hline CHEMBL 2369297 & 752518 & 5.5562 & 4.5539 & TRN \\
\hline CHEMBL1462180 & 752518 & 3.1708 & 3.4756 & TRN \\
\hline CHEMBL 2369211 & 752518 & 5.0792 & 4.6696 & TRN \\
\hline CHEMBL1413278 & 752518 & 3.1707 & 3.6868 & TST \\
\hline CHEMBL1570117 & 752518 & 3.1704 & 3.3101 & TRN \\
\hline CHEMBL1497851 & 752518 & 3.1709 & 3.0386 & TRN \\
\hline CHEMBL1458790 & 752518 & 3.1707 & 3.2583 & TRN \\
\hline CHEMBL1440824 & 752518 & 3.1705 & 3.3959 & TRN \\
\hline CHEMBL1526666 & 752518 & 3.17 & 2.6458 & TRN \\
\hline CHEMBL1556370 & 752518 & 4.609 & 3.6527 & TRN \\
\hline CHEMBL1558649 & 752518 & 3.1703 & 3.2114 & TRN \\
\hline CHEMBL1730712 & 752518 & 3.1703 & 3.3787 & TRN \\
\hline CHEMBL1364407 & 752518 & 3.1703 & 3.1995 & TST \\
\hline CHEMBL1374578 & 752518 & 3.1705 & 3.2585 & TST \\
\hline CHEMBL1489399 & 752518 & 3.1702 & 3.3576 & TRN \\
\hline CHEMBL1439578 & 752518 & 3.1702 & 3.1631 & TRN \\
\hline CHEMBL1604097 & 752518 & 3.1703 & 3.1536 & TRN \\
\hline CHEMBL1333979 & 752518 & 3.1707 & 3.178 & TRN \\
\hline CHEMBL1538311 & 752518 & 3.1708 & 3.2105 & TRN \\
\hline CHEMBL3196497 & 752518 & 3.1708 & 3.1389 & TRN \\
\hline
\end{tabular}

Page 13006 


\begin{tabular}{|c|c|c|c|c|c|}
\hline & & \multicolumn{4}{|c|}{ Supplemental Table S2.txt } \\
\hline CHEMBL1610197 & 752518 & 3.1701 & 3.1447 & TRN & \\
\hline CHEMBL 3193848 & 752518 & 3.17 & 3.1256 & TRN & \\
\hline CHEMBL579624 & 752518 & 3.1705 & 3.3599 & TRN & \\
\hline CHEMBL300685 & 752518 & 3.1705 & 3.2991 & TRN & \\
\hline CHEMBL1476987 & 752518 & 3.1705 & 2.9275 & TRN & \\
\hline CHEMBL1479907 & 752518 & 3.1705 & 3.4151 & TRN & \\
\hline CHEMBL1613366 & 752518 & 3.1703 & 3.2745 & TST & \\
\hline CHEMBL1558980 & 752518 & 3.1707 & 3.0642 & TST & \\
\hline CHEMBL1969590 & 752518 & 3.1704 & 3.7291 & TST & \\
\hline CHEMBL3194242 & 752518 & 3.1705 & 3.4618 & TRN & \\
\hline CHEMBL1589466 & 752518 & 3.1703 & 3.0349 & TRN & \\
\hline CHEMBL 9568 & 752518 & 4.6008 & 3.4541 & TST & \\
\hline CHEMBL1517210 & 752518 & 3.1702 & 3.2575 & TRN & \\
\hline CHEMBL1399882 & 752518 & 3.1705 & 3.3504 & TRN & \\
\hline CHEMBL1452854 & 752518 & 3.1705 & 3.1634 & TRN & \\
\hline CHEMBL1373715 & 752518 & 3.1705 & 2.9227 & TRN & \\
\hline CHEMBL3197401 & 752518 & 3.1707 & 3.1493 & TRN & \\
\hline CHEMBL1592178 & 752518 & 3.1705 & 3.4111 & TRN & \\
\hline CHEMBL1536643 & 752518 & \multicolumn{2}{|c|}{3.1710000000000003} & 2.9013 & TRN \\
\hline CHEMBL530664 & 752518 & 3.1704 & 3.0925 & TST & \\
\hline CHEMBL1522804 & 752518 & 3.1705 & 3.4359 & TRN & \\
\hline CHEMBL1300752 & 752518 & 3.1707 & 3.1432 & TRN & \\
\hline CHEMBL1598619 & 752518 & 3.1703 & 2.9963 & TRN & \\
\hline CHEMBL1730053 & 752518 & 3.1708 & 2.9186 & TST & \\
\hline CHEMBL1588641 & 752518 & 3.1704 & 3.7777 & TRN & \\
\hline CHEMBL1323335 & 752518 & 3.1705 & 2.903 & TRN & \\
\hline CHEMBL1878128 & 752518 & 3.1704 & 3.327 & TRN & \\
\hline CHEMBL1712486 & 752518 & 3.1704 & 3.3979 & TRN & \\
\hline CHEMBL1530257 & 752518 & 3.6479 & 3.3043 & TRN & \\
\hline CHEMBL1503720 & 752518 & 3.1704 & 3.35100 & 00000000004 & TRN \\
\hline CHEMBL3199082 & 752518 & 3.1708 & 3.5888 & TRN & \\
\hline CHEMBL 1608540 & 752518 & 3.1704 & 3.4233 & TRN & \\
\hline CHEMBL1711109 & 752518 & 3.1706 & 3.1393 & TRN & \\
\hline CHEMBL1364730 & 752518 & 3.1708 & 3.1414 & TRN & \\
\hline CHEMBL1510116 & 752518 & 3.1709 & 3.2049 & TRN & \\
\hline CHEMBL3194767 & 752518 & 3.1703 & 3.0386 & TRN & \\
\hline CHEMBL1568270 & 752518 & 3.1705 & 2.4998 & TST & \\
\hline CHEMBL1319472 & 752518 & 3.1704 & 2.65 & TRN & \\
\hline CHEMBL1302935 & 752518 & 3.1705 & 3.2201 & TRN & \\
\hline CHEMBL1483695 & 752518 & 3.1705 & 3.3891 & TRN & \\
\hline CHEMBL1530910 & 752518 & 3.1705 & 3.5737 & TRN & \\
\hline CHEMBL1532005 & 752518 & 3.17 & 3.2325 & TST & \\
\hline CHEMBL1967184 & 752518 & 4.6017 & 3.6234 & TRN & \\
\hline CHEMBL1449562 & 752518 & 4.6015 & 3.9894 & TRN & \\
\hline CHEMBL1969515 & 752518 & 3.1703 & 3.3697 & TRN & \\
\hline CHEMBL1611142 & 752518 & 3.1707 & 2.9643 & TRN & \\
\hline CHEMBL1383516 & 752518 & 3.1709 & 3.141 & TRN & \\
\hline CHEMBL377172 & 752518 & 3.1704 & 2.8205 & TRN & \\
\hline
\end{tabular}

Page 13007 


\begin{tabular}{|c|c|c|c|c|c|}
\hline & & \multicolumn{4}{|c|}{ Supplemental Table S2.txt } \\
\hline CHEMBL1879191 & 752518 & 3.1705 & 3.1399 & TRN & \\
\hline CHEMBL1714336 & 752518 & 3.1706 & 3.1827 & TST & \\
\hline CHEMBL1577922 & 752518 & 3.1704 & 3.0965 & TRN & \\
\hline CHEMBL1866840 & 752518 & 3.1704 & 3.3061 & TST & \\
\hline CHEMBL1870805 & 752518 & 3.1702 & 3.20600 & 00000000004 & TRN \\
\hline CHEMBL1341509 & 752518 & 3.1708 & 2.9082 & TRN & \\
\hline CHEMBL1546003 & 752518 & 3.1705 & 3.23100 & 00000000003 & TRN \\
\hline CHEMBL1892666 & 752518 & 3.1706 & 3.1098 & TRN & \\
\hline CHEMBL1891752 & 752518 & 3.1705 & 3.5763 & TRN & \\
\hline CHEMBL3199580 & 752518 & 3.1708 & 3.3475 & TRN & \\
\hline CHEMBL1400583 & 752518 & 3.1703 & 3.0572 & TRN & \\
\hline CHEMBL1728743 & 752518 & 3.1705 & 3.1199 & TRN & \\
\hline CHEMBL1892757 & 752518 & 3.1703 & 3.1971 & TRN & \\
\hline CHEMBL1885439 & 752518 & 3.1707 & 3.2348 & TRN & \\
\hline CHEMBL1349701 & 752518 & 3.1709 & 3.139 & TRN & \\
\hline CHEMBL1347069 & 752518 & 3.1704 & 3.0846 & TRN & \\
\hline CHEMBL1463368 & 752518 & 3.1704 & 3.2268 & TRN & \\
\hline CHEMBL1876779 & 752518 & 3.1703 & 2.9276 & TRN & \\
\hline CHEMBL1864101 & 752518 & 3.1705 & 3.3076 & TST & \\
\hline CHEMBL3211813 & 752518 & 3.17 & 3.1422 & TRN & \\
\hline CHEMBL1902831 & 752518 & 3.1704 & 3.0661 & TRN & \\
\hline CHEMBL1570589 & 752518 & 3.17 & 3.0854 & TRN & \\
\hline CHEMBL1469346 & 752518 & 3.1704 & 3.1485 & TRN & \\
\hline CHEMBL1717104 & 752518 & 3.1707 & 3.0561 & TRN & \\
\hline CHEMBL1350621 & 752518 & 3.1702 & 2.5106 & TRN & \\
\hline CHEMBL1403604 & 752518 & 3.1705 & 3.1584 & TRN & \\
\hline CHEMBL1352575 & 752518 & 3.1702 & 3.6934 & TST & \\
\hline CHEMBL1872370 & 752518 & 3.1709 & 3.5844 & TRN & \\
\hline CHEMBL1458054 & 752518 & 3.1698 & 3.3599 & TRN & \\
\hline CHEMBL3194003 & 752518 & 3.1707 & 3.1849 & TRN & \\
\hline CHEMBL3196941 & 752518 & 3.1705 & 3.4316 & TRN & \\
\hline CHEMBL3199849 & 752518 & 3.1704 & 4.0913 & TRN & \\
\hline CHEMBL1379985 & 752518 & 3.1704 & 3.2627 & TST & \\
\hline CHEMBL1387024 & 752518 & 3.1705 & 3.1331 & TRN & \\
\hline CHEMBL1906480 & 752518 & 3.1705 & 3.3237 & TRN & \\
\hline CHEMBL1388057 & 752518 & 3.1706 & 2.9693 & TST & \\
\hline CHEMBL291829 & 752518 & 3.17 & 3.10100 & 00000000004 & TRN \\
\hline CHEMBL1325231 & 752518 & 3.1705 & 2.9159 & TRN & \\
\hline CHEMBL1368025 & 752518 & 3.1705 & 3.5022 & TRN & \\
\hline CHEMBL1531147 & 752518 & 3.1705 & 3.2609 & TRN & \\
\hline CHEMBL1470718 & 752518 & 4.6073 & 3.7211 & TRN & \\
\hline CHEMBL1507935 & 752518 & 3.17 & 3.6405 & TST & \\
\hline CHEMBL1433231 & 752518 & 4.1854 & 4.2203 & TRN & \\
\hline CHEMBL1371859 & 752518 & 3.1701 & 3.21100 & 00000000003 & TRN \\
\hline CHEMBL1596663 & 752518 & 3.1705 & 3.1859 & TRN & \\
\hline CHEMBL1557898 & 752518 & 5.7997 & 5.2931 & TRN & \\
\hline CHEMBL1724888 & 752518 & 3.1704 & 3.4448 & TRN & \\
\hline CHEMBL1470160 & 752518 & 3.1704 & 3.1561 & TRN & \\
\hline
\end{tabular}


Supplemental Table S2.txt

\begin{tabular}{|c|c|c|c|c|c|c|}
\hline CHEMBL1701183 & 752518 & 3.1708 & 3.0282 & TRN & & \\
\hline CHEMBL1440318 & 752518 & 3.1707 & 2.7193 & TRN & & \\
\hline CHEMBL1353978 & 752518 & 3.1706 & 2.9585 & TRN & & \\
\hline CHEMBL1609967 & 752518 & 3.1708 & 3.3658 & TRN & & \\
\hline CHEMBL1303246 & 752518 & 3.1703 & 2.8865 & TST & & \\
\hline CHEMBL1370549 & 752518 & 3.1704 & 3.2034 & TRN & & \\
\hline CHEMBL1497670 & 752518 & 3.1707 & 3.4017 & TRN & & \\
\hline CHEMBL1413454 & 752518 & 3.1706 & 3.0598 & TRN & & \\
\hline CHEMBL1594810 & 752518 & 3.17 & 3.1447 & TRN & & \\
\hline CHEMBL1361605 & 752518 & 3.1706 & 3.1548 & TRN & & \\
\hline CHEMBL1509697 & 752518 & 3.1705 & 3.1354 & TRN & & \\
\hline CHEMBL1526530 & 752518 & 3.1704 & 3.0782 & TRN & & \\
\hline CHEMBL1711986 & 752518 & 3.1703 & 3.1079 & TRN & & \\
\hline CHEMBL1320101 & 752518 & 3.1703 & 3.0462 & TRN & & \\
\hline CHEMBL1332441 & 752518 & 3.1707 & 3.6211 & TRN & & \\
\hline CHEMBL1443120 & 752518 & 3.1702 & 3.0449 & TST & & \\
\hline CHEMBL605752 & 752518 & 3.1704 & 3.4267 & TRN & & \\
\hline CHEMBL1326671 & 752518 & 3.1705 & 3.3579 & TRN & & \\
\hline CHEMBL1419219 & 752518 & \multicolumn{3}{|c|}{3.1710000000000003} & 3.5052 & TRN \\
\hline CHEMBL1714938 & 752518 & 3.1704 & 3.197 & TRN & & \\
\hline CHEMBL1455166 & 752518 & 3.1713 & 3.2291 & TRN & & \\
\hline CHEMBL1703402 & 752518 & 3.1707 & 3.1848 & TRN & & \\
\hline CHEMBL1540407 & 752518 & 3.1708 & 2.8391 & TST & & \\
\hline CHEMBL1334807 & 752518 & 3.1704 & 3.6541 & TRN & & \\
\hline CHEMBL1699649 & 752518 & 3.1707 & 3.33 & TRN & & \\
\hline CHEMBL1597768 & 752518 & 3.17 & 3.5168 & TRN & & \\
\hline CHEMBL1305117 & 752518 & 3.1706 & 3.2475 & TRN & & \\
\hline CHEMBL1531268 & 752518 & 3.1706 & 3.2052 & TRN & & \\
\hline CHEMBL1558211 & 752518 & 3.1705 & 3.1667 & TRN & & \\
\hline CHEMBL3197189 & 752518 & 3.1702 & 3.2751 & TRN & & \\
\hline CHEMBL1345416 & 752518 & 3.1706 & 3.5647 & TRN & & \\
\hline CHEMBL1372065 & 752518 & 3.17 & 3.1963 & TST & & \\
\hline CHEMBL1348721 & 752518 & 3.1706 & 2.915 & TRN & & \\
\hline CHEMBL1577636 & 752518 & 3.1707 & 3.0909 & TRN & & \\
\hline CHEMBL1592550 & 752518 & 5.9846 & 5.2694 & TRN & & \\
\hline CHEMBL1586769 & 752518 & 3.1703 & 3.2145 & TRN & & \\
\hline CHEMBL1533576 & 752518 & 3.1703 & 2.9544 & TRN & & \\
\hline CHEMBL1480989 & 752518 & 3.1704 & 3.2357 & TRN & & \\
\hline CHEMBL1486187 & 752518 & 4.2978 & 3.3443 & TST & & \\
\hline CHEMBL1584747 & 752518 & 3.1704 & 3.0678 & TRN & & \\
\hline CHEMBL1406761 & 752518 & 3.1707 & 3.1591 & TRN & & \\
\hline CHEMBL1424754 & 752518 & 3.1704 & 3.5006 & TRN & & \\
\hline CHEMBL1375631 & 752518 & 3.1704 & 3.0916 & TRN & & \\
\hline CHEMBL1485099 & 752518 & 5.4593 & 4.2123 & TRN & & \\
\hline CHEMBL1711590 & 752518 & 3.1706 & 3.0393 & TRN & & \\
\hline CHEMBL1471057 & 752518 & 3.1707 & 3.21 & TRN & & \\
\hline CHEMBL1730826 & 752518 & 3.1704 & 2.8488 & TRN & & \\
\hline CHEMBL1885548 & 752518 & 3.1701 & 3.1719 & TRN & & \\
\hline
\end{tabular}

Page 13009 


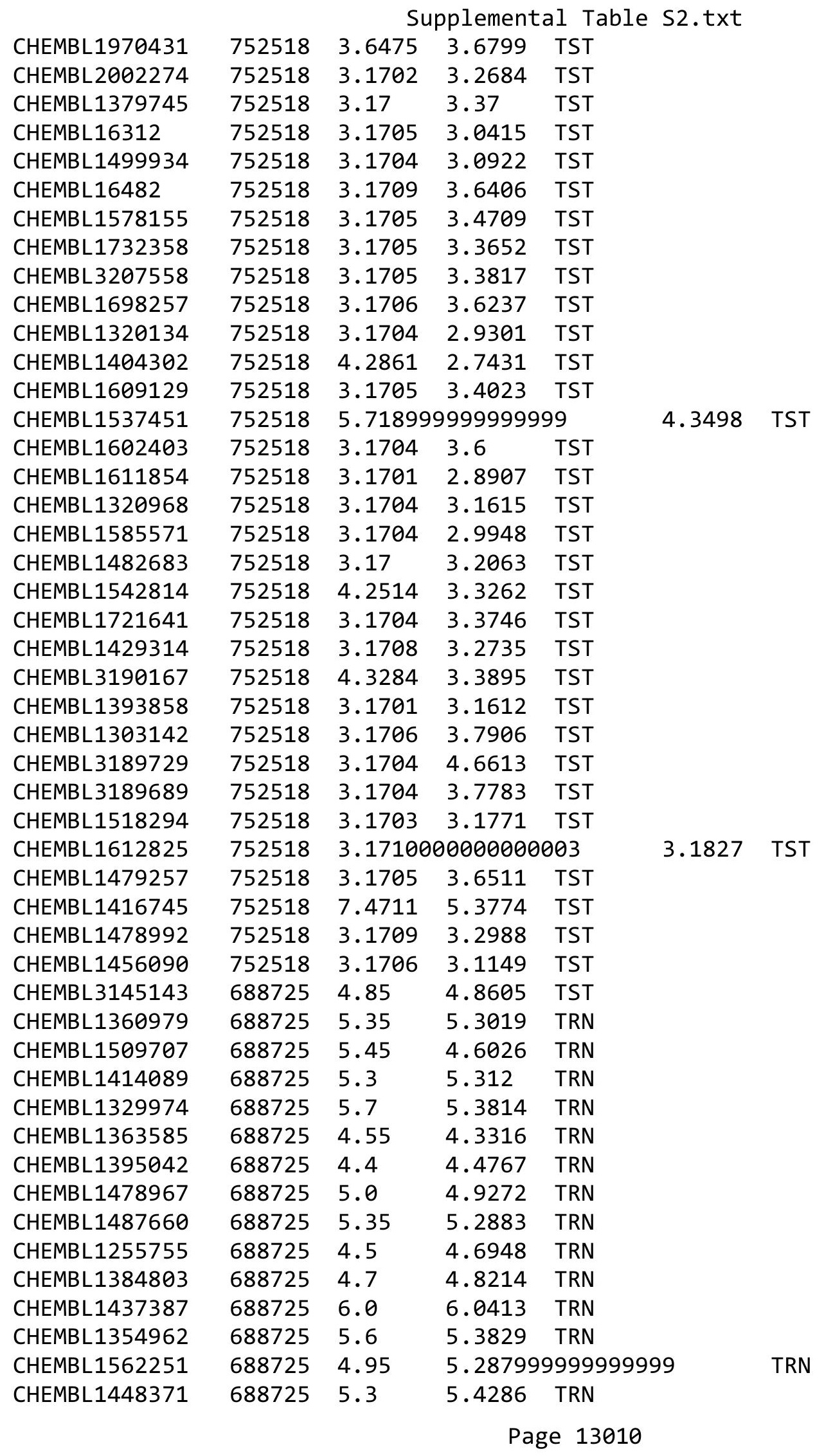




\begin{tabular}{|c|c|c|c|c|c|}
\hline & & \multicolumn{4}{|c|}{ Supplemental Table s2.txt } \\
\hline CHEMBL3197999 & 688725 & 4.35 & 4.8461 & TRN & \\
\hline CHEMBL1363633 & 688725 & 5.1 & 5.4485 & TRN & \\
\hline CHEMBL1417290 & 688725 & 5.0 & 4.7271 & TST & \\
\hline CHEMBL1579435 & 688725 & 5.1 & 4.8538 & TRN & \\
\hline CHEMBL1589350 & 688725 & 4.6 & 4.402 & TRN & \\
\hline CHEMBL3191602 & 688725 & 4.95 & 5.0299 & TRN & \\
\hline CHEMBL1339433 & 688725 & 4.45 & 5.0938 & TRN & \\
\hline CHEMBL525953 & 688725 & 6.0 & 5.5768 & TRN & \\
\hline CHEMBL1098087 & 688725 & 5.65 & 5.7699 & TRN & \\
\hline CHEMBL1540929 & 688725 & 5.55 & 5.1359 & TRN & \\
\hline CHEMBL1367795 & 688725 & 4.65 & 4.5833 & TRN & \\
\hline CHEMBL1467317 & 688725 & 5.55 & 5.0193 & TRN & \\
\hline CHEMBL1523308 & 688725 & 6.0 & 5.5854 & TRN & \\
\hline CHEMBL1575084 & 688725 & 4.4 & 4.5895 & TST & \\
\hline CHEMBL1473083 & 688725 & 4.7 & 5.035 & TRN & \\
\hline CHEMBL3192031 & 688725 & 5.8 & 5.9368 & TRN & \\
\hline CHEMBL1487571 & 688725 & 5.75 & 5.6224 & TRN & \\
\hline CHEMBL1395110 & 688725 & 4.45 & 4.8546 & TRN & \\
\hline CHEMBL461622 & 688725 & 5.2 & 5.3293 & TRN & \\
\hline CHEMBL1313356 & 688725 & 4.95 & 4.9131 & TRN & \\
\hline CHEMBL1397200 & 688725 & 4.8 & 4.5785 & TRN & \\
\hline CHEMBL1605269 & 688725 & 5.05 & 5.1223 & TRN & \\
\hline CHEMBL1315022 & 688725 & 5.45 & 5.7345 & TRN & \\
\hline CHEMBL1374242 & 688725 & 5.5 & 5.0424 & TRN & \\
\hline CHEMBL1572845 & 688725 & 4.3 & 4.5001 & TRN & \\
\hline CHEMBL1406350 & 688725 & 5.3 & 5.0728 & TRN & \\
\hline CHEMBL1643542 & 688725 & 5.95 & 5.3481 & TST & \\
\hline CHEMBL1338115 & 688725 & 4.35 & 4.9792 & TRN & \\
\hline CHEMBL1360508 & 688725 & 5.0 & 4.8255 & TRN & \\
\hline CHEMBL1370182 & 688725 & 4.35 & 4.7074 & TRN & \\
\hline CHEMBL1513778 & 688725 & 6.0 & 5.9762 & TRN & \\
\hline CHEMBL1576392 & 688725 & 5.6 & 5.6581 & TRN & \\
\hline CHEMBL1475181 & 688725 & 4.45 & 4.9327 & TRN & \\
\hline CHEMBL1323951 & 688725 & 4.55 & 4.8408 & TRN & \\
\hline CHEMBL1592419 & 688725 & 5.4 & 5.3348 & TRN & \\
\hline CHEMBL1338049 & 688725 & 5.1 & 5.1724 & TRN & \\
\hline CHEMBL1324177 & 688725 & 4.65 & 5.0466 & TRN & \\
\hline CHEMBL1593876 & 688725 & 5.05 & 4.8798 & TRN & \\
\hline CHEMBL1512538 & 688725 & 5.8 & 4.8134 & TRN & \\
\hline CHEMBL1318757 & 688725 & 5.5 & 5.3695 & TRN & \\
\hline CHEMBL1530782 & 688725 & 5.4 & 5.4268 & TRN & \\
\hline CHEMBL1607032 & 688725 & 4.3 & 4.3836 & TRN & \\
\hline CHEMBL1331665 & 688725 & 5.05 & 5.1358 & TRN & \\
\hline CHEMBL1525233 & 688725 & 4.45 & 4.5989 & TRN & \\
\hline CHEMBL1607263 & 688725 & 5.25 & 5.1878 & TRN & \\
\hline CHEMBL1555483 & 688725 & 5.95 & 6.0325 & TRN & \\
\hline CHEMBL1320902 & 688725 & 5.1 & 4.9251 & TST & \\
\hline CHEMBL1584975 & 688725 & 4.25 & $4.6530 e$ & 0000000 & TRN \\
\hline & & & & 13011 & \\
\hline
\end{tabular}




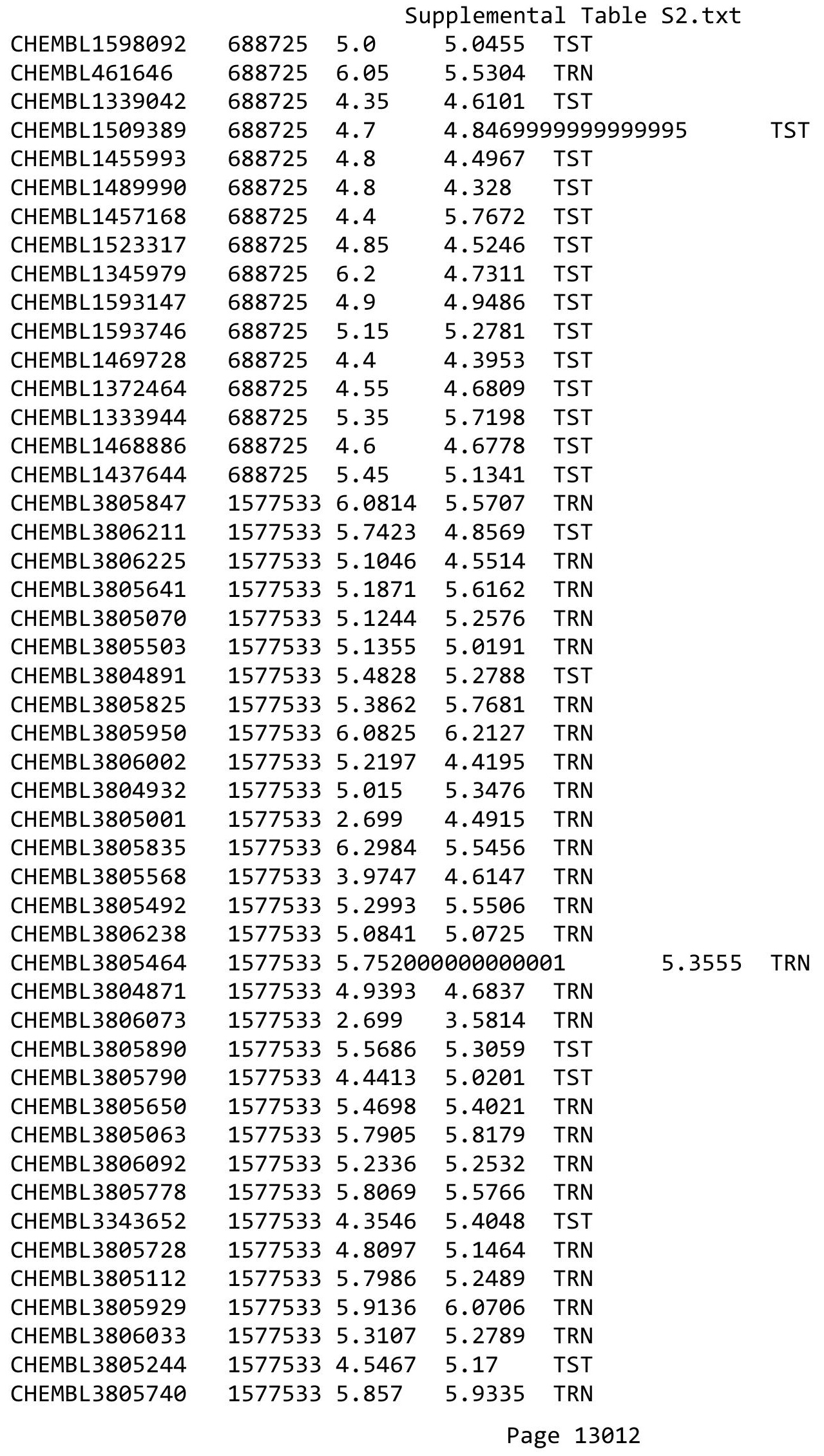


Supplemental Table S2.txt

\begin{tabular}{|c|c|c|c|c|}
\hline CHEMBL 3805107 & 1577533 & 5.2526 & 5.483 & TRN \\
\hline CHEMBL3804896 & 1577533 & 5.5317 & 4.9133 & TRN \\
\hline CHEMBL 3805692 & 1577533 & 5.7282 & 5.9975 & TRN \\
\hline CHEMBL 3805923 & 1577533 & 4.6517 & 4.6167 & TRN \\
\hline CHEMBL3805277 & 1577533 & 5.567 & 5.1917 & TRN \\
\hline CHEMBL3805578 & 1577533 & 2.699 & 4.1632 & TRN \\
\hline CHEMBL 3804901 & 1577533 & 4.0665 & 3.4714 & TRN \\
\hline CHEMBL 3805331 & 1577533 & 5.0438 & 5.176 & TRN \\
\hline CHEMBL 3805035 & 1577533 & 6.041 & 6.0063 & TRN \\
\hline CHEMBL3805574 & 1577533 & 5.2503 & 5.4359 & TRN \\
\hline CHEMBL3805632 & 1577533 & 5.4776 & 5.9608 & TRN \\
\hline CHEMBL3804923 & 1577533 & 4.7328 & 4.5966 & TST \\
\hline CHEMBL 3805072 & 1577533 & 5.5784 & 5.505 & TRN \\
\hline CHEMBL 3805130 & 1577533 & 5.6253 & 5.29 & TRN \\
\hline CHEMBL3805709 & 1577533 & 4.7471 & 5.1801 & TST \\
\hline CHEMBL3805538 & 1577533 & 6.2366 & 6.2283 & TRN \\
\hline CHEMBL3805724 & 1577533 & 5.2534 & 5.3245 & TRN \\
\hline CHEMBL3805630 & 1577533 & 5.3788 & 5.801 & TRN \\
\hline CHEMBL3806063 & 1577533 & 4.8729 & 5.3527 & TRN \\
\hline CHEMBL3805478 & 1577533 & 5.1945 & 5.1299 & TST \\
\hline CHEMBL3806268 & 1577533 & 6.1568 & 5.5124 & TRN \\
\hline CHEMBL3804850 & 1577533 & 5.5901 & 5.4879 & TRN \\
\hline CHEMBL 3804834 & 1577533 & 6.0742 & 6.0768 & TRN \\
\hline CHEMBL3805694 & 1577533 & 5.2328 & 4.4855 & TRN \\
\hline CHEMBL 3806001 & 1577533 & 5.0429 & 5.2637 & TRN \\
\hline CHEMBL3805304 & 1577533 & 5.1337 & 5.41799 & 9999999999 \\
\hline CHEMBL3805426 & 1577533 & 5.8069 & 5.4734 & TRN \\
\hline CHEMBL 3805427 & 1577533 & 5.7258 & 5.4919 & TRN \\
\hline CHEMBL3804859 & 1577533 & 5.1637 & 5.4489 & TRN \\
\hline CHEMBL 3806274 & 1577533 & 2.699 & 4.4717 & TST \\
\hline CHEMBL 3805267 & 1577533 & 5.0506 & 5.2815 & TRN \\
\hline CHEMBL3805306 & 1577533 & 5.4559 & 5.1571 & TRN \\
\hline CHEMBL 3805934 & 1577533 & 6.1101 & 5.6043 & TRN \\
\hline CHEMBL3806221 & 1577533 & 5.3893 & 4.5226 & TRN \\
\hline CHEMBL 3805448 & 1577533 & 5.0867 & 5.2861 & TRN \\
\hline CHEMBL 3805586 & 1577533 & 4.9431 & 4.4706 & TRN \\
\hline CHEMBL3805479 & 1577533 & 4.1778 & 4.1828 & TRN \\
\hline CHEMBL 3805547 & 1577533 & 6.1409 & 5.3147 & TST \\
\hline CHEMBL3805381 & 1577533 & 5.9666 & 4.9617 & TST \\
\hline CHEMBL 3805224 & 1577533 & 5.6021 & 5.2249 & TST \\
\hline CHEMBL3805997 & 1577533 & 4.71 & 4.6257 & TST \\
\hline CHEMBL3805831 & 1577533 & 5.4949 & 5.295 & TST \\
\hline CHEMBL3805639 & 1577533 & 5.1475 & 5.2081 & TST \\
\hline CHEMBL3806257 & 1577533 & 5.6198 & 5.3819 & TST \\
\hline CHEMBL 3805687 & 1577533 & 4.752 & 5.1795 & TST \\
\hline CHEMBL 3805022 & 1577533 & 5.3197 & 5.2018 & TST \\
\hline CHEMBL3804908 & 1577533 & 5.0888 & 4.8215 & TST \\
\hline CHEMBL3943985 & 1536181 & 6.4847 & 6.5877 & TRN \\
\hline
\end{tabular}

Page 13013 
Supplemental Table S2.txt

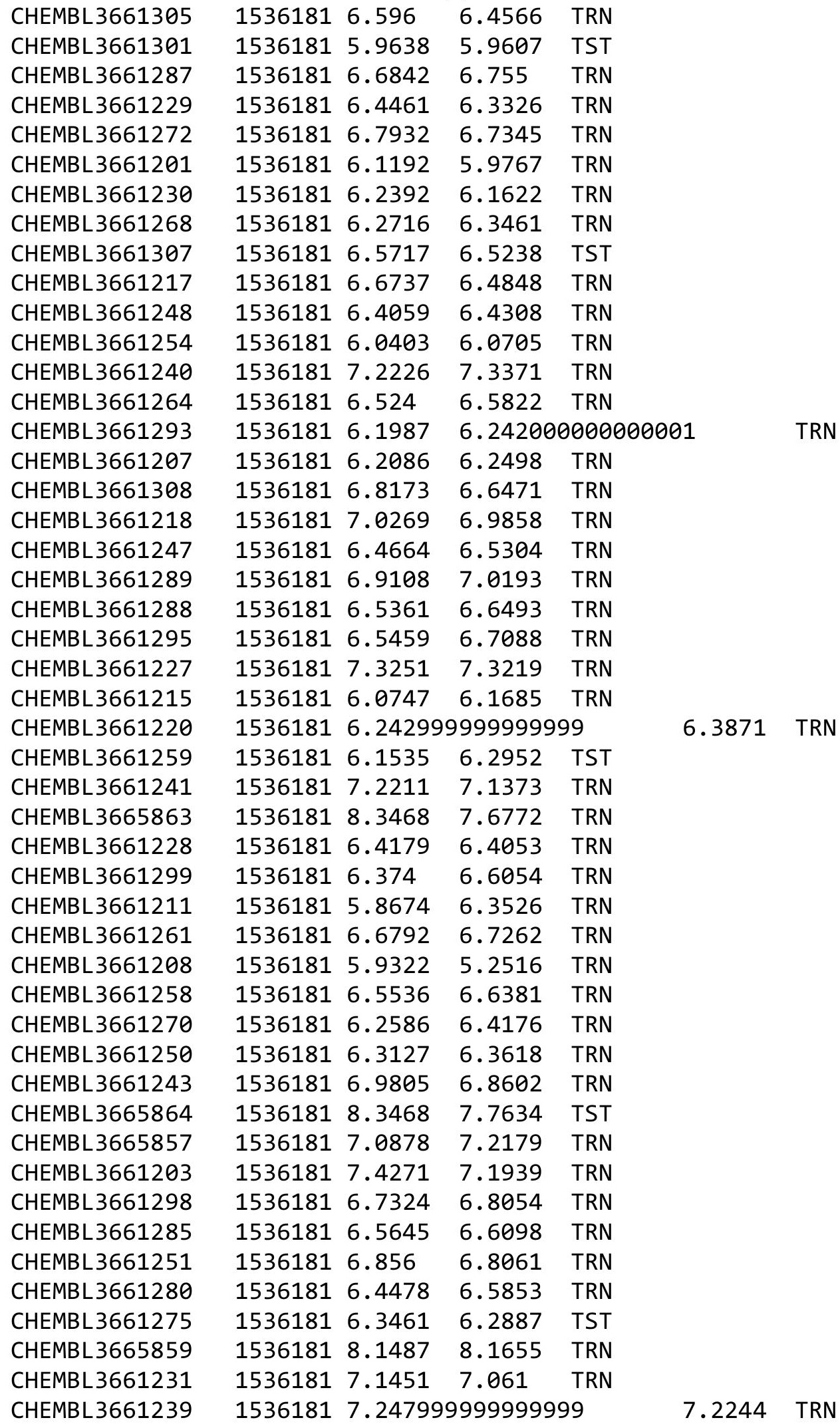

Page 13014 
Supplemental Table S2.txt

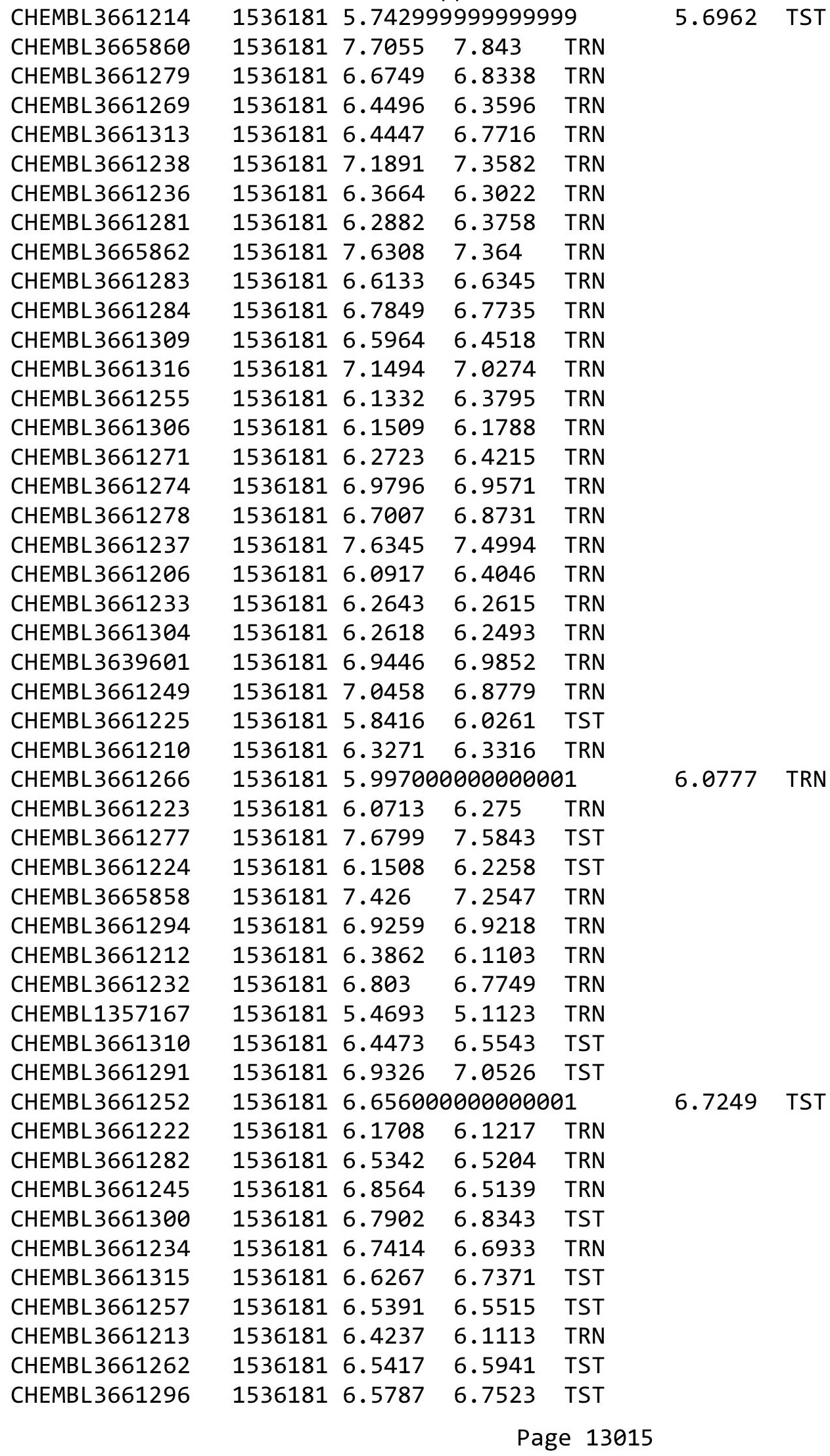


Supplemental Table S2.txt

\begin{tabular}{|c|c|c|c|c|c|}
\hline CHEMBL 3661276 & 1536181 & 7.6383 & 7.5724 & TST & \\
\hline CHEMBL3665865 & 1536181 & 6.6645 & 6.8416 & TST & \\
\hline CHEMBL3661246 & 1536181 & 7.1158 & 7.0369 & TRN & \\
\hline CHEMBL 3661256 & 1536181 & 6.2542 & 6.4242 & TST & \\
\hline CHEMBL3661312 & 1536181 & 6.0715 & 6.1116 & TST & \\
\hline CHEMBL3665861 & 1536181 & 7.7212 & 7.8801 & TST & \\
\hline CHEMBL3661260 & 1536181 & 6.7104 & 6.7017 & TST & \\
\hline CHEMBL 3661267 & 1536181 & 6.5929 & 6.6795 & TST & \\
\hline CHEMBL 3661292 & 1536181 & 6.2795 & 6.2612 & TRN & \\
\hline CHEMBL3661205 & 1536181 & 5.9897 & 6.1162 & TRN & \\
\hline CHEMBL3661219 & 1536181 & 5.63 & 5.8047 & TRN & \\
\hline CHEMBL 3661209 & 1536181 & 6.2823 & 6.4105 & TRN & \\
\hline CHEMBL3661314 & 1536181 & 6.704 & 6.5747 & TST & \\
\hline CHEMBL 3661202 & 1536181 & 5.3125 & 5.5554 & TRN & \\
\hline CHEMBL3661221 & 1536181 & 6.5369 & 6.4708 & TRN & \\
\hline CHEMBL3661216 & 1536181 & 6.3439 & 6.3592 & TRN & \\
\hline CHEMBL3661204 & 1536181 & 5.9634 & 6.2687 & TRN & \\
\hline CHEMBL3661303 & 1536181 & 6.5682 & 6.5141 & TRN & \\
\hline CHEMBL3661311 & 1536181 & 6.3263 & 6.1096 & TST & \\
\hline CHEMBL3661226 & 1536181 & 6.4577 & 5.9471 & TRN & \\
\hline CHEMBL3661263 & 1536181 & 6.4309 & 6.3229 & TST & \\
\hline CHEMBL3661286 & 1536181 & 7.0004 & 7.0264 & TST & \\
\hline CHEMBL 3661253 & 1536181 & 6.6196 & 6.624 & TST & \\
\hline CHEMBL3661242 & 1536181 & 7.2865 & 7.2498 & TRN & \\
\hline CHEMBL 3661235 & 1536181 & 6.1984 & 6.1192 & TRN & \\
\hline CHEMBL3661273 & 1536181 & 6.8222 & 6.7845 & TST & \\
\hline CHEMBL3661302 & 1536181 & 5.3682 & 5.9074 & TRN & \\
\hline CHEMBL 3661290 & 1536181 & 6.5553 & 6.6631 & TST & \\
\hline CHEMBL3661265 & 1536181 & 6.5872 & 6.6152 & TST & \\
\hline CHEMBL3965914 & 1640867 & 5.0 & 5.5546 & TRN & \\
\hline CHEMBL3943046 & 1640867 & 5.699 & 5.3974 & TRN & \\
\hline CHEMBL3934262 & 1640867 & 8.5229 & 8.7567 & TRN & \\
\hline CHEMBL 3955087 & 1640867 & 5.2218 & 5.2748 & TRN & \\
\hline CHEMBL3898026 & 1640867 & 8.8861 & 9.0214 & TRN & \\
\hline CHEMBL 3953222 & 1640867 & 8.3468 & 7.9328 & TRN & \\
\hline CHEMBL3933202 & 1640867 & 9.1549 & 9.1407 & TRN & \\
\hline CHEMBL3912895 & 1640867 & 4.8539 & 4.7129 & TRN & \\
\hline CHEMBL3968676 & 1640867 & 9.3979 & 9.495 & TRN & \\
\hline CHEMBL3984903 & 1640867 & 8.1549 & 8.5423 & TRN & \\
\hline CHEMBL3977757 & 1640867 & 8.5229 & 8.5643 & TRN & \\
\hline CHEMBL3977177 & 1640867 & 8.1675 & 7.78600 & 00000000005 & TRN \\
\hline CHEMBL3982546 & 1640867 & 8.2218 & 7.7323 & TRN & \\
\hline CHEMBL3929426 & 1640867 & 9.0915 & 6.3739 & TST & \\
\hline CHEMBL3891313 & 1640867 & 5.0969 & 5.6158 & TRN & \\
\hline CHEMBL3983735 & 1640867 & 6.1549 & 7.2262 & TST & \\
\hline CHEMBL3907610 & 1640867 & 8.7447 & 8.7148 & TRN & \\
\hline CHEMBL3927092 & 1640867 & 4.5229 & 5.375 & TRN & \\
\hline CHEMBL3932541 & 1640867 & 5.3979 & 6.1837 & TRN & \\
\hline
\end{tabular}

Page 13016 
Supplemental Table S2.txt

\begin{tabular}{|c|c|c|c|c|}
\hline 184 & 640867 & & & בני \\
\hline & 867 & & & \\
\hline HFMRI & 367 & & & \\
\hline AEMBL. & 867 & 3861 & & \\
\hline AEMBL3952138 & 640867 & 586 & 0371 & \\
\hline HEMBL3 & 867 & 8.6021 & 47 & \\
\hline HEMBL3 & 867 & 21 & & \\
\hline AEMBL3 & 867 & & & \\
\hline HEMBL3889782 & 640867 & 5 . & 516 & \\
\hline HEMBL 393 & 640867 & & 86 & \\
\hline HEMBL & 867 & & 2342 & \\
\hline IEMBL & 367 & & 741 & \\
\hline HEMBL3 & 367 & & & \\
\hline HEMBL 391 & 867 & 458 & & \\
\hline HEMBL 395 & 867 & & & \\
\hline HEMBL3 & 6 & 4. & & \\
\hline HEMBL3 & $6 /$ & & & ונ \\
\hline HEMBL3 & 367 & & & \\
\hline HFMBL 3 & 367 & & & \\
\hline AEMBL3 & & & 84 & \\
\hline HEMBL & 64 & 9 & 43 & $R / N$ \\
\hline HEM & & & & MIV \\
\hline HEMBL & 67 & & & \\
\hline HEMBL3 & 67 & & & \\
\hline AEMBL3 & & & & IRN \\
\hline HEMBL3 & 67 & & & SI \\
\hline HEMBL & & & & RN \\
\hline 55 & & & & $\mathrm{RN}$ \\
\hline HEMBL3 & & & & IRN \\
\hline HEMBL393 & 367 & 8. & 55 & RN \\
\hline AEMBL3 & 67 & 59 & 24 & ST \\
\hline HFM & 57 & 6 & & \\
\hline - - נסבז & & & & ST \\
\hline HEMBL3S & & & & $\mathrm{RN}$ \\
\hline HEMBL 392 & 867 & 9. & & RN \\
\hline 2 & 367 & 8. & & TRN \\
\hline 8 & & & & ГRN \\
\hline HEMBL3S & & & & TRN \\
\hline HEMBL3 & 67 & & & $\Gamma R$ \\
\hline 2 & 67 & & & RN \\
\hline HEMBL3 & 67 & 8 . & 77 & TRN \\
\hline HEMBL 39 & & 9.30 & 34 & 「RN \\
\hline HEMBL3 & 640867 & 4.36 & 7073 & $T R$ \\
\hline HEMBL3 & 867 & 9. & 53 & $\pi s^{2}$ \\
\hline CHEMPI 390 & & & & \\
\hline HEMBL391 & & & & \\
\hline CHEMBL 391 & 367 & 5.8539 & 5.1295 & \\
\hline CHEMBL3970683 & 1640867 & 8.2441 & 8.4647 & ГRN \\
\hline
\end{tabular}

Page 13017 
Supplemental Table S2.txt

\begin{tabular}{|c|c|c|c|c|c|}
\hline CHEMBL3923605 & 1640867 & 8.7447 & 6.5198 & TST & \\
\hline CHEMBL3978874 & 1640867 & 4.9208 & 4.1279 & TST & \\
\hline CHEMBL3915456 & 1640867 & 5.6021 & 5.8693 & TRN & \\
\hline CHEMBL3959640 & 1640867 & 8.6383 & 8.7309 & TRN & \\
\hline CHEMBL3897358 & 1640867 & 9.3468 & 8.9664 & TRN & \\
\hline CHEMBL3941845 & 1640867 & 5.7447 & 5.9245 & TRN & \\
\hline CHEMBL3985795 & 1640867 & 8.5229 & 9.0188 & TRN & \\
\hline CHEMBL 3912867 & 1640867 & 7.0 & 5.4639 & TST & \\
\hline CHEMBL 3947835 & 1640867 & 8.1739 & 8.2275 & TRN & \\
\hline CHEMBL3896783 & 1640867 & 5.6383 & 5.4416 & TRN & \\
\hline CHEMBL3927813 & 1640867 & 9.8239 & 9.4286 & TRN & \\
\hline CHEMBL 3970740 & 1640867 & 8.8239 & 7.664 & TRN & \\
\hline CHEMBL2314891 & 936907 & 5.0 & \multicolumn{2}{|c|}{5.577999999999999} & TRN \\
\hline CHEMBL1199533 & 936907 & 4.8097 & 4.5574 & TRN & \\
\hline CHEMBL2314906 & 936907 & 4.6819 & 4.4095 & TRN & \\
\hline CHEMBL2314903 & 936907 & 5.4202 & 5.5365 & TRN & \\
\hline CHEMBL1199576 & 936907 & 4.52 & 4.4198 & TRN & \\
\hline CHEMBL1164885 & 936907 & 5.7447 & 5.5838 & TRN & \\
\hline CHEMBL1593867 & 936907 & 4.3372 & 4.2725 & TST & \\
\hline CHEMBL2314909 & 936907 & 4.9431 & 4.6277 & TRN & \\
\hline CHEMBL1164796 & 936907 & 5.7959 & 5.436 & TRN & \\
\hline CHEMBL1164886 & 936907 & 5.7212 & 5.5704 & TRN & \\
\hline CHEMBL2314898 & 936907 & 5.2441 & 5.5885 & TRN & \\
\hline CHEMBL1199528 & 936907 & 4.6536 & 4.678 & TRN & \\
\hline CHEMBL2314897 & 936907 & 5.5686 & 5.5591 & TRN & \\
\hline CHEMBL2314908 & 936907 & 3.0 & 4.1119 & TRN & \\
\hline CHEMBL2314896 & 936907 & 5.5686 & 5.5119 & TRN & \\
\hline CHEMBL2314907 & 936907 & 4.8508 & 4.1889 & TRN & \\
\hline CHEMBL2314885 & 936907 & 4.5575 & 4.6278 & TRN & \\
\hline CHEMBL2314671 & 936907 & 4.8665 & 4.1235 & TRN & \\
\hline CHEMBL1199577 & 936907 & 3.0 & 4.1882 & TRN & \\
\hline CHEMBL2314668 & 936907 & 3.0 & 4.3283 & TST & \\
\hline CHEMBL2314895 & 936907 & 5.3768 & 5.5599 & TST & \\
\hline CHEMBL2314889 & 936907 & 4.6757 & 4.5802 & TST & \\
\hline CHEMBL1199826 & 936907 & 3.0 & 4.5051 & TRN & \\
\hline CHEMBL1199575 & 936907 & 4.3635 & 4.3666 & TRN & \\
\hline CHEMBL 2314888 & 936907 & 5.1367 & 4.697 & TRN & \\
\hline CHEMBL2314902 & 936907 & 5.5086 & 5.6852 & TST & \\
\hline CHEMBL2314900 & 936907 & 5.3979 & 5.5781 & TST & \\
\hline CHEMBL2314893 & 936907 & 4.3019 & 5.528 & TST & \\
\hline CHEMBL1165622 & 936907 & 4.8447 & 5.5582 & TST & \\
\hline CHEMBL1178003 & 936907 & 4.9172 & 4.4075 & TRN & \\
\hline CHEMBL2314670 & 936907 & 4.7496 & 4.6131 & TRN & \\
\hline CHEMBL2314886 & 936907 & 4.9066 & 4.5994 & TRN & \\
\hline CHEMBL2314667 & 936907 & 4.8069 & 4.4562 & TRN & \\
\hline CHEMBL2314899 & 936907 & 5.6198 & 5.5202 & TST & \\
\hline CHEMBL1200104 & 936907 & 3.0 & 4.5159 & TRN & \\
\hline CHEMBL1199961 & 936907 & 4.8097 & 4.3493 & TRN & \\
\hline
\end{tabular}

Page 13018 


\begin{tabular}{|c|c|c|c|c|c|}
\hline \multicolumn{6}{|c|}{ Supplemental Table s2.txt } \\
\hline CHEMBL1165565 & 936907 & 5.4089 & 5.4772 & TST & \\
\hline CHEMBL 2314901 & 936907 & 5.3872 & 5.5423 & TST & \\
\hline CHEMBL1199825 & 936907 & 4.8041 & 4.6159 & TRN & \\
\hline CHEMBL1199532 & 936907 & 4.1618 & 4.3597 & TRN & \\
\hline CHEMBL1199529 & 936907 & 4.8356 & 4.6621 & TRN & \\
\hline CHEMBL 2314894 & 936907 & 5.1192 & 5.5716 & TST & \\
\hline CHEMBL 2314892 & 936907 & 5.0177 & 5.5733 & TST & \\
\hline CHEMBL 2314883 & 936907 & 4.4342 & 4.3844 & TRN & \\
\hline CHEMBL 2314666 & 936907 & 4.8153 & 4.3911 & TRN & \\
\hline CHEMBL 2314904 & 936907 & 4.279 & 4.3788 & TRN & \\
\hline CHEMBL 2314672 & 936907 & 4.8069 & 4.5972 & TRN & \\
\hline CHEMBL 2314669 & 936907 & 4.8665 & 4.1882 & TRN & \\
\hline CHEMBL 2314905 & 936907 & 4.7878 & 4.3496 & TRN & \\
\hline CHEMBL 2314884 & 936907 & 3.0 & 4.2829 & TRN & \\
\hline CHEMBL 2314887 & 936907 & 4.8894 & 4.5679 & TRN & \\
\hline CHEMBL 2314890 & 936907 & 4.7773 & 4.51 & TRN & \\
\hline CHEMBL3314807 & 1451942 & 5.5331 & 5.5168 & TRN & \\
\hline CHEMBL 3314847 & 1451942 & 3.5229 & 4.8 & TST & \\
\hline CHEMBL3314844 & 1451942 & 3.5229 & 3.4446 & TRN & \\
\hline CHEMBL3314834 & 1451942 & 4.0 & 4.2538 & TRN & \\
\hline CHEMBL3314813 & 1451942 & 5.289 & 5.25 & TRN & \\
\hline CHEMBL3314856 & 1451942 & 3.5229 & 3.4626 & TRN & \\
\hline CHEMBL 3314804 & 1451942 & 6.0026 & 6.0445 & TRN & \\
\hline CHEMBL3314820 & 1451942 & 6.7011 & 6.6369 & TRN & \\
\hline CHEMBL3314811 & 1451942 & 6.9355 & 7.1034 & TRN & \\
\hline CHEMBL3314839 & 1451942 & 4.0 & 4.6419 & TST & \\
\hline CHEMBL3314824 & 1451942 & 3.5229 & 3.5121 & TRN & \\
\hline CHEMBL3314819 & 1451942 & 5.4179 & 5.4103 & TRN & \\
\hline CHEMBL3314815 & 1451942 & 6.1494 & 6.0527 & TRN & \\
\hline CHEMBL3314855 & 1451942 & 3.5229 & 3.9197 & TRN & \\
\hline CHEMBL3314818 & 1451942 & 5.063 & 5.0286 & TRN & \\
\hline CHEMBL3314817 & 1451942 & 6.9281 & 6.9916 & TRN & \\
\hline CHEMBL3314858 & 1451942 & 6.9547 & 6.9557 & TRN & \\
\hline CHEMBL3314821 & 1451942 & 6.1791 & 5.9713 & TRN & \\
\hline CHEMBL3314806 & 1451942 & 6.4449 & 6.5106 & TRN & \\
\hline CHEMBL3314848 & 1451942 & 3.5229 & 3.0026 & TRN & \\
\hline CHEMBL3314809 & 1451942 & 6.8894 & 6.7763 & TRN & \\
\hline CHEMBL3314833 & 1451942 & 4.0 & 4.3318 & TST & \\
\hline CHEMBL3314814 & 1451942 & 6.6737 & 6.67899 & 9999999999 & TRN \\
\hline CHEMBL3314826 & 1451942 & 4.0 & 3.7753 & TRN & \\
\hline CHEMBL3314842 & 1451942 & 3.5229 & 3.7029 & TRN & \\
\hline CHEMBL3314850 & 1451942 & 7.2048 & 7.0848 & TRN & \\
\hline CHEMBL3314836 & 1451942 & 5.1959 & 5.2555 & TST & \\
\hline CHEMBL3314823 & 1451942 & 4.0 & 3.9619 & TRN & \\
\hline CHEMBL3314816 & 1451942 & 5.3862 & 5.3989 & TRN & \\
\hline CHEMBL3314841 & 1451942 & 4.0 & 4.1064 & TRN & \\
\hline CHEMBL3314808 & 1451942 & 6.3947 & 5.435 & TST & \\
\hline CHEMBL3314851 & 1451942 & 7.0 & 7.0823 & TRN & \\
\hline
\end{tabular}


Supplemental Table S2.txt

\begin{tabular}{|c|c|c|c|c|}
\hline HEM & & & 5.3037 & Th \\
\hline & 451942 & & 5.2307 & \\
\hline 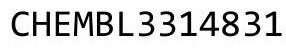 & & & & \\
\hline HEMBL331 & & & & $\mathrm{MI}$ \\
\hline HEMBL3314805 & 1942 & & 1982 & \\
\hline HEMBL3314827 & 451942 & 6.0487 & 0587 & \\
\hline HEMBL 331 & 942 & & 941 & \\
\hline AEMBL 331 & 451942 & & 0309 & \\
\hline HEMBL3314832 & 1942 & 29 & 6267 & \\
\hline HEMBL3314840 & 451942 & 5. & & \\
\hline HEMBL3314852 & 451942 & 6. & 285 & \\
\hline AEMBL24 & 942 & 67 & 4446 & \\
\hline AEMBL3: & & & 3.6856 & \\
\hline HEMBL331 & 942 & & 0974 & \\
\hline AEMBL33 & 942 & 4 & 9959 & \\
\hline AEMBL33 & 12 & 3. & 5151 & \\
\hline HEMBL3 & +2 & . & 838 & KIV \\
\hline HEMBL3 & & & & \\
\hline HEMBL3 & 942 & 35 & 4.3756 & \\
\hline AEMBL3 & & & & 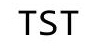 \\
\hline HEMBL3 & & & 414 & | IS \\
\hline HEMBL & & & 76 & ST \\
\hline HEMBL; & & & 12 & \\
\hline HEMBL & 942 & & 5727 & TST \\
\hline HEMBL 213 & & 4 & 55 & I RIV \\
\hline HEMBL 2 & & & 5236 & $2 \mathrm{~N}$ \\
\hline HEMBLI & & & 834 & ST \\
\hline HEMBL 1 & & 4 & 779 & RN \\
\hline HEMBL92 & & & 3.3111 & TST \\
\hline HEMBL167 & & 4. & 387 & IRIN \\
\hline HEMBL1 & & & & RN \\
\hline HEMBL2 & & & 84 & RN \\
\hline HEMBL2 & & & 18 & RN \\
\hline HEMBL191334 & & & 48 & IRN \\
\hline HEMBL2005886 & & & 5.5998 & TRN \\
\hline HEMBL1. & & 38 & 838 & RN \\
\hline HFMRI? & & 5 & 05 & $\Gamma \mathrm{RN}$ \\
\hline HEMBL4 & & & 112 & TRN \\
\hline HEMBL 217354 & & 52 & 5.1462 & TRN \\
\hline IEMBL: & & & 5.2102 & IRN \\
\hline HEMBL2 & & 504 & 1.5504 & DN \\
\hline CHEMBL31 & & & 4.6571 & TRN \\
\hline HEMBL483849 & & 2.5858 & 2.5858 & TRN \\
\hline HEMBL 220 & & 9999 & 3.9999 & TR \\
\hline MPI 3 & & & 3.8018 & RN \\
\hline HEMBL3 & & & 3.5317 & \\
\hline CHEMBL140 & & 2.7335 & 2.7335 & \\
\hline HEMBL190941 & 954828 & 3.3447 & 3.3447 & ГRN \\
\hline
\end{tabular}

Page 13020 


\begin{tabular}{|c|c|c|c|c|c|c|c|}
\hline \multicolumn{7}{|c|}{ Supplemental Table S2.txt } & \\
\hline CHEMBL180127 & 954828 & 4.4165 & 4.4165 & TRN & & & \\
\hline CHEMBL 399530 & 954828 & 4.5581 & 4.5581 & TRN & & & \\
\hline CHEMBL221137 & 954828 & 4.3289 & 4.3521 & TST & & & \\
\hline CHEMBL514499 & 954828 & 5.2127 & 5.2127 & TRN & & & \\
\hline CHEMBL 240954 & 954828 & 3.3702 & 4.0102 & TST & & & \\
\hline CHEMBL9470 & 954828 & 5.4349 & 5.2709 & TST & & & \\
\hline CHEMBL192566 & 954828 & 6.6012 & 6.6815 & TST & & & \\
\hline CHEMBL135561 & 954828 & 4.4007 & 4.4007 & TRN & & & \\
\hline CHEMBL509032 & 954828 & 5.0721 & 5.0721 & TRN & & & \\
\hline CHEMBL577784 & 954828 & 5.0432 & 5.0432 & TRN & & & \\
\hline CHEMBL1516890 & 954828 & 4.627 & 4.627 & TRN & & & \\
\hline CHEMBL512504 & 954828 & 4.3729 & 4.8924 & TST & & & \\
\hline CHEMBL65 & 954828 & 6.3601 & 6.3601 & TRN & & & \\
\hline CHEMBL 2363137 & 954828 & 5.1214 & 5.1214 & TRN & & & \\
\hline CHEMBL1186585 & 954828 & 3.9901 & 3.9901 & TRN & & & \\
\hline CHEMBL573107 & 954828 & 4.1664 & 4.1664 & TRN & & & \\
\hline CHEMBL393929 & 954828 & 3.7829 & 3.7829 & TRN & & & \\
\hline CHEMBL585951 & 954828 & 5.546 & 5.546 & TRN & & & \\
\hline CHEMBL1242367 & 954828 & 3.6436 & 3.6436 & TRN & & & \\
\hline CHEMBL102714 & 954828 & 3.2134 & 3.2134 & TRN & & & \\
\hline CHEMBL515416 & 954828 & 4.1168 & 4.1168 & TRN & & & \\
\hline CHEMBL1256459 & 954828 & 6.352 & 6.352 & TRN & & & \\
\hline CHEMBL 2134202 & 954828 & 3.4003 & 3.4003 & TRN & & & \\
\hline CHEMBL472940 & 954828 & 3.1259 & 3.1259 & TRN & & & \\
\hline CHEMBL 259181 & 954828 & 4.2908 & 4.2908 & TRN & & & \\
\hline CHEMBL 255342 & 954828 & 3.69199 & 99999999 & 997 & 3.69199 & 99999999997 & TRN \\
\hline CHEMBL3392440 & 954828 & 3.9329 & 3.9329 & TRN & & & \\
\hline CHEMBL449158 & 954828 & 7.3415 & 5.9609 & TST & & & \\
\hline CHEMBL1230020 & 954828 & 3.4605 & 3.4605 & TRN & & & \\
\hline CHEMBL209148 & 954828 & 3.8175 & 3.8175 & TRN & & & \\
\hline CHEMBL 379300 & 954828 & 5.5908 & 5.5908 & TRN & & & \\
\hline CHEMBL3349342 & 954828 & 5.3001 & 5.3001 & TRN & & & \\
\hline CHEMBL1190711 & 954828 & 4.433 & 4.6384 & TST & & & \\
\hline CHEMBL558642 & 954828 & 2.8643 & 4.58 & TST & & & \\
\hline CHEMBL1970879 & 954828 & 4.4091 & 4.4758 & TST & & & \\
\hline CHEMBL189584 & 954828 & 4.1386 & 3.8518 & TST & & & \\
\hline CHEMBL188678 & 954828 & 5.3741 & 4.6634 & TST & & & \\
\hline CHEMBL483847 & 954828 & 4.2146 & 3.7929 & TST & & & \\
\hline CHEMBL 258844 & 954828 & 5.1386 & 4.1766 & TST & & & \\
\hline CHEMBL3186408 & 954828 & 3.97300 & 00000000 & 203 & 3.9768 & TST & \\
\hline CHEMBL3560904 & 1495275 & 3.4089 & 5.0875 & TRN & & & \\
\hline CHEMBL3559894 & 1495275 & 4.9252 & 5.6681 & TRN & & & \\
\hline CHEMBL3561094 & 1495275 & 5.8013 & 5.9314 & TST & & & \\
\hline CHEMBL 3560282 & 1495275 & 5.1844 & 5.4656 & TRN & & & \\
\hline CHEMBL3559945 & 1495275 & 5.5735 & 5.6733 & TRN & & & \\
\hline CHEMBL3560840 & 1495275 & 5.466 & 5.2878 & TRN & & & \\
\hline CHEMBL3561676 & 1495275 & 4.6942 & 5.45200 & 0000000001 & & TST & \\
\hline CHEMBL 2360122 & 1495275 & 5.0391 & 5.0188 & TRN & & & \\
\hline
\end{tabular}


Supplemental Table S2.txt

\begin{tabular}{|c|c|c|c|c|c|c|}
\hline CHEMBL 3560847 & 1495275 & 4.4928 & 5.7251 & TST & & \\
\hline CHEMBL 3560093 & 1495275 & 4.9151 & 5.3891 & TRN & & \\
\hline CHEMBL3561893 & 1495275 & 5.0752 & 5.6394 & TRN & & \\
\hline CHEMBL2358899 & 1495275 & 6.5331 & 5.8387 & TRN & & \\
\hline CHEMBL 3559882 & 1495275 & 6.0 & 5.9153 & TRN & & \\
\hline CHEMBL3561385 & 1495275 & 6.4498 & 5.5874 & TRN & & \\
\hline CHEMBL3561099 & 1495275 & 6.0097 & 6.249 & TRN & & \\
\hline CHEMBL3561709 & 1495275 & 6.5702 & 5.9102 & TRN & & \\
\hline CHEMBL3559926 & 1495275 & 4.8162 & 5.4083 & TST & & \\
\hline CHEMBL3560490 & 1495275 & 4.8901 & 5.0399 & TRN & & \\
\hline CHEMBL3560666 & 1495275 & 6.7423 & 6.0832 & TRN & & \\
\hline CHEMBL3561915 & 1495275 & 5.8827 & 5.6653 & TST & & \\
\hline CHEMBL3560649 & 1495275 & 6.3089 & 5.2998 & TRN & & \\
\hline CHEMBL3559819 & 1495275 & 5.1681 & 5.6877 & TST & & \\
\hline CHEMBL 3559984 & 1495275 & 5.5229 & 5.7956 & TST & & \\
\hline CHEMBL3560151 & 1495275 & 6.2612 & 5.8655 & TST & & \\
\hline CHEMBL3559773 & 1495275 & 6.4225 & 5.9684 & TRN & & \\
\hline CHEMBL 2357286 & 1495275 & 5.2741 & 6.0193 & TRN & & \\
\hline CHEMBL 3189104 & 1495275 & 5.2373 & 5.3351 & TRN & & \\
\hline CHEMBL3561861 & 1495275 & 5.7423 & 5.7287 & TRN & & \\
\hline CHEMBL2362538 & 1495275 & 6.1296 & 6.1318 & TRN & & \\
\hline CHEMBL2359612 & 1495275 & 5.433 & 6.2134 & TRN & & \\
\hline CHEMBL 3560104 & 1495275 & \multicolumn{3}{|c|}{5.327000000000001} & 5.8651 & TRN \\
\hline CHEMBL 3560793 & 1495275 & 6.0 & 5.7615 & TRN & & \\
\hline CHEMBL3561612 & 1495275 & \multicolumn{3}{|c|}{5.7620000000000005} & 6.1512 & TRN \\
\hline CHEMBL 3560264 & 1495275 & 6.0 & 6.2488 & TRN & & \\
\hline CHEMBL3560006 & 1495275 & 7.0862 & 5.9077 & TRN & & \\
\hline CHEMBL 3560581 & 1495275 & 4.8422 & 5.4243 & TRN & & \\
\hline CHEMBL3559979 & 1495275 & 6.251 & 5.8774 & TST & & \\
\hline CHEMBL3560427 & 1495275 & 4.9578 & 5.3905 & TST & & \\
\hline CHEMBL3559843 & 1495275 & 4.9739 & 5.7612 & TRN & & \\
\hline CHEMBL 3559982 & 1495275 & 6.0975 & 6.1096 & TRN & & \\
\hline CHEMBL 3560210 & 1495275 & 4.6398 & 5.1977 & TRN & & \\
\hline CHEMBL3560565 & 1495275 & 6.1713 & 6.1853 & TRN & & \\
\hline CHEMBL3560073 & 1495275 & 5.4045 & 5.8269 & TRN & & \\
\hline CHEMBL3188484 & 1495275 & 6.0 & 6.1285 & TRN & & \\
\hline CHEMBL2360842 & 1495275 & 5.8125 & 5.9897 & TRN & & \\
\hline CHEMBL 3561148 & 1495275 & \multicolumn{3}{|c|}{6.4510000000000005} & 5.4207 & TRN \\
\hline CHEMBL 3560811 & 1495275 & 4.5224 & 5.3083 & TST & & \\
\hline CHEMBL 3560743 & 1495275 & 6.5129 & 6.2547 & TRN & & \\
\hline CHEMBL 3561218 & 1495275 & 4.95 & 5.004 & TRN & & \\
\hline CHEMBL3560346 & 1495275 & 5.1349 & 5.5007 & TST & & \\
\hline CHEMBL2359034 & 1495275 & 7.2403 & 5.71299 & 9999999999 & & TRN \\
\hline CHEMBL3186317 & 1495275 & 4.8834 & 5.018 & TRN & & \\
\hline CHEMBL 3560461 & 1495275 & 5.0904 & 5.8509 & TRN & & \\
\hline CHEMBL2360276 & 1495275 & 6.0 & 5.7594 & TRN & & \\
\hline CHEMBL 3560202 & 1495275 & 6.0 & 6.0562 & TRN & & \\
\hline CHEMBL 3560860 & 1495275 & 5.3507 & 5.5143 & TRN & & \\
\hline
\end{tabular}

Page 13022 
Supplemental Table S2.txt

\begin{tabular}{|c|c|c|c|c|c|}
\hline CHEMBL 3560474 & 1495275 & 6.8386 & 5.8308 & TST & \\
\hline CHEMBL 3187793 & 1495275 & 4.4992 & 6.0442 & TRN & \\
\hline CHEMBL 2362816 & 1495275 & 6.0 & 5.4167 & TRN & \\
\hline CHEMBL 3561243 & 1495275 & 4.6598 & 5.5602 & TRN & \\
\hline CHEMBL 3561593 & 1495275 & 6.0 & 5.9218 & TST & \\
\hline CHEMBL3561049 & 1495275 & 5.0773 & 5.0809 & TRN & \\
\hline CHEMBL 3561566 & 1495275 & 7.5157 & 6.3759 & TRN & \\
\hline CHEMBL 2359510 & 1495275 & 6.0 & 6.2466 & TRN & \\
\hline CHEMBL 3187916 & 1495275 & 5.7055 & 6.0815 & TRN & \\
\hline CHEMBL 3561956 & 1495275 & 6.3497 & 5.818 & TST & \\
\hline CHEMBL 3559805 & 1495275 & 5.1512 & 5.484 & TRN & \\
\hline CHEMBL 3560476 & 1495275 & 6.3536 & 6.0323 & TRN & \\
\hline CHEMBL 3560729 & 1495275 & 6.0 & 5.7012 & TRN & \\
\hline CHEMBL 3560333 & 1495275 & 4.8851 & 5.6486 & TST & \\
\hline CHEMBL 3560964 & 1495275 & 5.5884 & 5.5413 & TRN & \\
\hline CHEMBL 3560703 & 1495275 & 5.3778 & 5.3734 & TRN & \\
\hline CHEMBL 3561479 & 1495275 & 3.4089 & 5.3869 & TST & \\
\hline CHEMBL 3561955 & 1495275 & 5.45100 & 00000006 & 5.7606 & TRN \\
\hline CHEMBL 3559898 & 1495275 & 5.5346 & 5.6015 & TRN & \\
\hline CHEMBL 2356052 & 1495275 & 5.5591 & 6.0198 & TRN & \\
\hline CHEMBL 3561126 & 1495275 & 6.0 & 5.513999 & 7999999999 & TST \\
\hline CHEMBL 2361207 & 1495275 & 5.8697 & 5.843 & TRN & \\
\hline CHEMBL 3559992 & 1495275 & 4.8623 & 5.5425 & TRN & \\
\hline CHEMBL 3559849 & 1495275 & 6.0 & 5.7341 & TRN & \\
\hline CHEMBL 3561936 & 1495275 & 4.9974 & 5.4169 & TRN & \\
\hline CHEMBL 3561923 & 1495275 & 5.7932 & 6.1629 & TST & \\
\hline CHEMBL 3559968 & 1495275 & 6.0141 & 5.4516 & TRN & \\
\hline CHEMBL 3561384 & 1495275 & 4.6426 & 5.9793 & TST & \\
\hline CHEMBL 2355635 & 1495275 & 6.3072 & 5.6227 & TRN & \\
\hline CHEMBL 3183001 & 1495275 & 5.9318 & 5.6276 & TRN & \\
\hline CHEMBL 2358405 & 1495275 & 6.767 & 5.8438 & TRN & \\
\hline CHEMBL 1881588 & 1495275 & 5.2013 & 5.5877 & TST & \\
\hline CHEMBL 3186259 & 1495275 & 5.3372 & 5.1319 & TRN & \\
\hline CHEMBL 2355407 & 1495275 & 6.0809 & 5.1054 & TRN & \\
\hline CHEMBL 3560530 & 1495275 & 4.9104 & 5.5058 & TRN & \\
\hline CHEMBL 3560640 & 1495275 & 6.4089 & 6.4373 & TRN & \\
\hline CHEMBL 3185076 & 1495275 & 5.6576 & 5.762000 & 00000000005 & 13 \\
\hline CHEMBL 3560374 & 1495275 & 4.5074 & 5.3123 & TST & \\
\hline CHEMBL 3560625 & 1495275 & 6.0 & 5.5936 & TRN & \\
\hline CHEMBL 3560245 & 1495275 & 6.0 & 5.5487 & TRN & \\
\hline CHEMBL 3561177 & 1495275 & 6.8297 & 5.641 & TRN & \\
\hline CHEMBL 3186350 & 1495275 & 6.0 & 6.1168 & TRN & \\
\hline CHEMBL3561776 & 1495275 & 6.0565 & 5.2547 & TRN & \\
\hline CHEMBL 2139303 & 1495275 & 6.0 & 5.9692 & TST & \\
\hline CHEMBL 2362001 & 1495275 & 5.1643 & 5.5246 & TST & \\
\hline CHEMBL 2358924 & 1495275 & 5.118 & 5.7165 & TRN & \\
\hline CHEMBL 3559932 & 1495275 & 6.3072 & 6.2455 & TST & \\
\hline CHEMBL 3561847 & 1495275 & 4.8 & 5.3198 & TRN & \\
\hline
\end{tabular}


Supplemental Table S2.txt

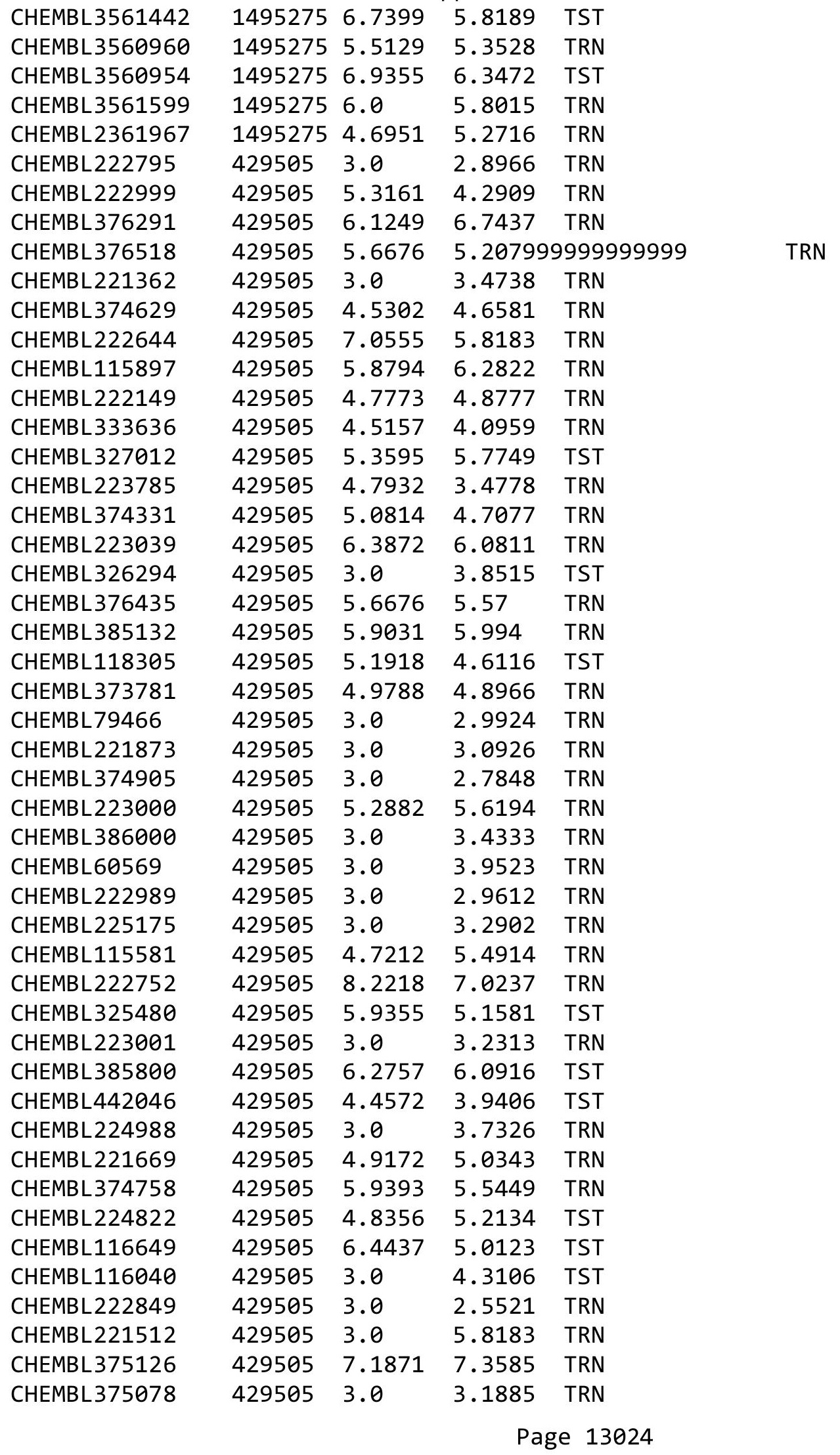




\begin{tabular}{|c|c|c|c|c|c|}
\hline & & & & & \\
\hline CHEMBL376228 & 429505 & 5.4828 & 5.4412 & TST & \\
\hline CHEMBL385799 & 429505 & 6.3872 & 6.1576 & TST & \\
\hline CHEMBL222711 & 429505 & 3.0 & 3.2889 & TRN & \\
\hline CHEMBL 222712 & 429505 & 5.9508 & 5.2011 & TRN & \\
\hline CHEMBL225169 & 429505 & 6.8861 & 6.2036 & TST & \\
\hline CHEMBL426562 & 429505 & 5.3936 & 5.2135 & TRN & \\
\hline CHEMBL 222292 & 429505 & 5.8477 & 5.7149 & TRN & \\
\hline CHEMBL222190 & 429505 & 5.3458 & 5.5496 & TRN & \\
\hline CHEMBL118883 & 429505 & 4.5817 & 4.273 & TST & \\
\hline CHEMBL221830 & 429505 & 6.3768 & 5.3851 & TST & \\
\hline CHEMBL373715 & 429505 & 4.7773 & 4.9488 & TRN & \\
\hline CHEMBL222891 & 429505 & 3.0 & 3.0615 & TRN & \\
\hline CHEMBL376290 & 429505 & 4.8508 & 4.8246 & TRN & \\
\hline CHEMBL 222851 & 429505 & 5.1308 & 4.5547 & TRN & \\
\hline CHEMBL 222660 & 429505 & 4.5735 & 3.5595 & TST & \\
\hline CHEMBL223254 & 429505 & 3.0 & 3.7215 & TRN & \\
\hline CHEMBL 374970 & 429505 & 4.5622 & 3.68600 & 00000000004 & TRN \\
\hline CHEMBL375304 & 429505 & 5.3098 & 4.7446 & TRN & \\
\hline CHEMBL117447 & 429505 & 6.2147 & 4.9545 & TST & \\
\hline CHEMBL 374740 & 429505 & 6.1192 & 5.95799 & 9999999999 & TRN \\
\hline CHEMBL222988 & 429505 & 6.3098 & 5.6293 & TST & \\
\hline CHEMBL 224884 & 429505 & 3.0 & 3.5992 & TRN & \\
\hline CHEMBL3650799 & 1641173 & 6.5086 & 6.3999 & TRN & \\
\hline CHEMBL3650835 & 1641173 & 3.5229 & 3.1711 & TRN & \\
\hline CHEMBL 3650774 & 1641173 & 6.8239 & 6.6203 & TRN & \\
\hline CHEMBL3650772 & 1641173 & 6.3872 & 6.4132 & TRN & \\
\hline CHEMBL3703305 & 1641173 & 6.3279 & 6.3369 & TRN & \\
\hline CHEMBL3703220 & 1641173 & 6.0 & 4.9149 & TST & \\
\hline CHEMBL 3650757 & 1641173 & 6.2366 & 6.0405 & TRN & \\
\hline CHEMBL3703247 & 1641173 & 5.8539 & 5.9242 & TST & \\
\hline CHEMBL 3650780 & 1641173 & 6.3188 & 6.2856 & TRN & \\
\hline CHEMBL3703225 & 1641173 & 6.2366 & 6.1857 & TST & \\
\hline CHEMBL3703272 & 1641173 & 7.1549 & 6.86 & TRN & \\
\hline CHEMBL3703289 & 1641173 & 7.4318 & 6.6986 & TST & \\
\hline CHEMBL3650804 & 1641173 & 7.1367 & 7.1512 & TRN & \\
\hline CHEMBL3703285 & 1641173 & 7.2366 & 7.0394 & TST & \\
\hline CHEMBL3650833 & 1641173 & 6.0 & 6.4611 & TST & \\
\hline CHEMBL3650851 & 1641173 & 9.2007 & 9.497 & TRN & \\
\hline CHEMBL 3703301 & 1641173 & 6.3372 & 6.5986 & TRN & \\
\hline CHEMBL3703226 & 1641173 & 6.3872 & 5.6217 & TST & \\
\hline CHEMBL3650764 & 1641173 & 5.9208 & 5.9166 & TRN & \\
\hline CHEMBL3703233 & 1641173 & 7.7212 & 7.572 & TRN & \\
\hline CHEMBL3650788 & 1641173 & 6.7447 & 6.8048 & TRN & \\
\hline CHEMBL3650771 & 1641173 & 6.8539 & 6.941 & TRN & \\
\hline CHEMBL3703259 & 1641173 & 6.7447 & 6.6584 & TRN & \\
\hline CHEMBL 3703231 & 1641173 & 7.1612 & 5.7276 & TST & \\
\hline CHEMBL3703232 & 1641173 & 6.0 & 7.3991 & TRN & \\
\hline CHEMBL3703256 & 1641173 & 7.1024 & 7.146 & TRN & \\
\hline
\end{tabular}


Supplemental Table S2.txt

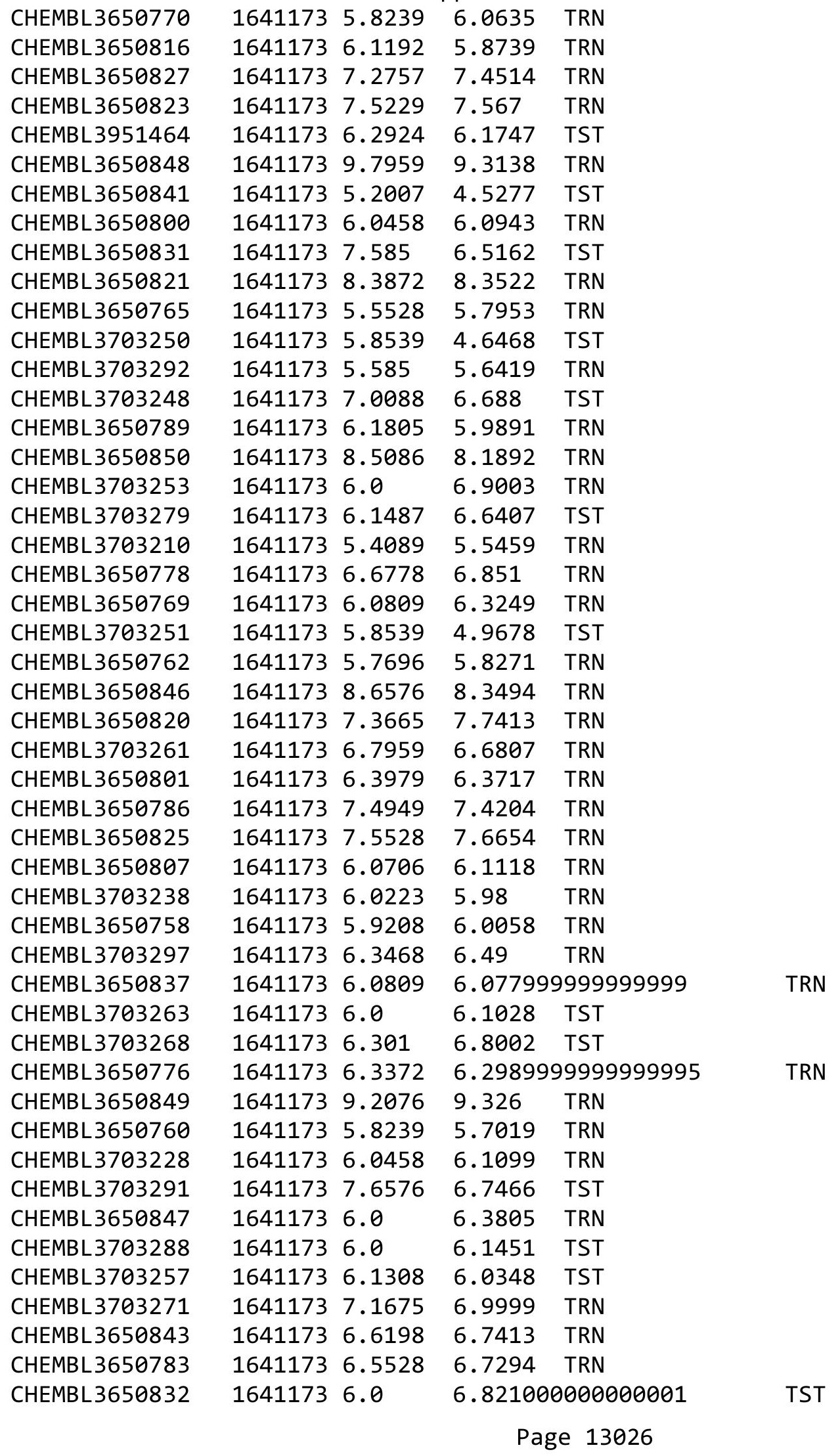


Supplemental Table S2.txt

\begin{tabular}{|c|c|c|c|c|}
\hline CHEMBL3703310 & 1641173 & 6.0044 & 5.8137 & TRN \\
\hline CHEMBL3703312 & 1641173 & 5.6383 & 5.8941 & TRN \\
\hline CHEMBL3650826 & 1641173 & 8.4949 & 8.1634 & TRN \\
\hline CHEMBL3703296 & 1641173 & 6.6198 & 6.4018 & TRN \\
\hline CHEMBL3703252 & 1641173 & 6.1612 & 6.0389 & TRN \\
\hline CHEMBL3703249 & 1641173 & 7.2441 & 6.4643 & TST \\
\hline CHEMBL3650767 & 1641173 & 5.7447 & 5.7455 & TST \\
\hline CHEMBL 3703270 & 1641173 & 6.9586 & 6.7924 & TRN \\
\hline CHEMBL3703294 & 1641173 & 6.6021 & 6.2385 & TRN \\
\hline CHEMBL 3703246 & 1641173 & 5.2291 & 5.412999 & 999999999 \\
\hline CHEMBL 3650805 & 1641173 & 5.4685 & 5.4229 & TRN \\
\hline CHEMBL 3650828 & 1641173 & 8.2441 & 7.8237 & TRN \\
\hline CHEMBL3703245 & 1641173 & 3.5229 & 4.6643 & TST \\
\hline CHEMBL 3650768 & 1641173 & 6.1805 & 6.3636 & TRN \\
\hline CHEMBL 3650808 & 1641173 & 5.8239 & 5.7781 & TRN \\
\hline CHEMBL 3650811 & 1641173 & 6.3098 & 6.3989 & TRN \\
\hline CHEMBL3703264 & 1641173 & 5.4815 & 5.4504 & TRN \\
\hline CHEMBL3954909 & 1641173 & 6.0362 & 5.9098 & TST \\
\hline CHEMBL3703307 & 1641173 & 5.9586 & 5.8961 & TRN \\
\hline CHEMBL3650761 & 1641173 & 5.1367 & 5.1663 & TRN \\
\hline CHEMBL3703265 & 1641173 & 5.6383 & 5.7186 & TRN \\
\hline CHEMBL3703237 & 1641173 & 7.6576 & 7.0135 & TRN \\
\hline CHEMBL3703298 & 1641173 & 6.5229 & 6.7308 & TRN \\
\hline CHEMBL3703236 & 1641173 & 7.2147 & 6.9543 & TRN \\
\hline CHEMBL 3703266 & 1641173 & 7.3098 & 7.2052 & TRN \\
\hline CHEMBL 3650836 & 1641173 & 5.2147 & 5.1259 & TRN \\
\hline CHEMBL3703224 & 1641173 & 6.3665 & 6.3574 & TRN \\
\hline CHEMBL3703269 & 1641173 & 6.0177 & 6.1446 & TRN \\
\hline CHEMBL3703208 & 1641173 & 5.1427 & 4.5476 & TST \\
\hline CHEMBL3703300 & 1641173 & 6.7959 & 6.6634 & TRN \\
\hline CHEMBL 3703227 & 1641173 & 5.5376 & 5.5252 & TST \\
\hline CHEMBL3650779 & 1641173 & 6.7696 & 6.2949 & TRN \\
\hline CHEMBL3703209 & 1641173 & 6.2291 & 6.456 & TRN \\
\hline CHEMBL 3650784 & 1641173 & 6.9586 & 7.1151 & TRN \\
\hline CHEMBL 3703284 & 1641173 & 7.1135 & 6.9196 & TRN \\
\hline CHEMBL 3703234 & 1641173 & 7.6576 & 7.8427 & TRN \\
\hline CHEMBL3650822 & 1641173 & 7.5686 & 7.4852 & TRN \\
\hline CHEMBL3703241 & 1641173 & 6.0915 & 6.059 & TRN \\
\hline CHEMBL 3650830 & 1641173 & 6.6198 & 5.9693 & TST \\
\hline CHEMBL 3703304 & 1641173 & 6.1805 & 6.4485 & TRN \\
\hline CHEMBL3703308 & 1641173 & 6.1549 & 6.0981 & TRN \\
\hline CHEMBL3650809 & 1641173 & 6.0915 & 6.0746 & TRN \\
\hline CHEMBL3703309 & 1641173 & 5.5229 & \multicolumn{2}{|c|}{5.672000000000001} \\
\hline CHEMBL 3703287 & 1641173 & 6.0 & 6.2919 & TST \\
\hline CHEMBL 3650773 & 1641173 & 5.8861 & 5.9161 & TRN \\
\hline CHEMBL 3703274 & 1641173 & 5.9586 & 5.9917 & TRN \\
\hline CHEMBL3650759 & 1641173 & 5.7447 & 5.5941 & TRN \\
\hline CHEMBL3703235 & 1641173 & 8.6383 & 8.3769 & TRN \\
\hline
\end{tabular}

Page 13027 
Supplemental Table S2.txt

\begin{tabular}{|c|c|c|c|c|c|}
\hline CHEMBL3650790 & 1641173 & 6.4318 & 6.4602 & TRN & \\
\hline CHEMBL3650763 & 1641173 & 5.4949 & 5.6455 & TRN & \\
\hline CHEMBL3650834 & 1641173 & 7.6576 & 6.935 & TST & \\
\hline CHEMBL3703239 & 1641173 & 6.585 & 6.4576 & TRN & \\
\hline CHEMBL 3703221 & 1641173 & 5.3188 & 4.8642 & TST & \\
\hline CHEMBL3703302 & 1641173 & 7.3188 & 6.9371 & TRN & \\
\hline CHEMBL3703303 & 1641173 & 8.0362 & 7.5612 & TRN & \\
\hline CHEMBL3650802 & 1641173 & 5.5086 & 5.391 & TRN & \\
\hline CHEMBL 3650824 & 1641173 & 7.0915 & 5.8996 & TST & \\
\hline CHEMBL3650813 & 1641173 & 5.6021 & 5.3515 & TRN & \\
\hline CHEMBL3703278 & 1641173 & 6.3468 & 6.9024 & TST & \\
\hline CHEMBL3650785 & 1641173 & 6.8861 & 6.9128 & TRN & \\
\hline CHEMBL3650781 & 1641173 & 5.9586 & 6.2176 & TRN & \\
\hline CHEMBL3650782 & 1641173 & 6.3468 & 6.4908 & TRN & \\
\hline CHEMBL 3703281 & 1641173 & 7.4437 & 7.2656 & TRN & \\
\hline CHEMBL3703314 & 1641173 & 5.9586 & 5.82799 & 9999999999 & TRN \\
\hline CHEMBL3924870 & 1641173 & 6.3872 & 5.5044 & TST & \\
\hline CHEMBL3703260 & 1641173 & 7.1192 & 7.0099 & TRN & \\
\hline CHEMBL3703282 & 1641173 & 7.3279 & 7.4449 & TRN & \\
\hline CHEMBL 3650810 & 1641173 & 5.8539 & 5.8773 & TRN & \\
\hline CHEMBL3703286 & 1641173 & 5.8539 & 6.2631 & TST & \\
\hline CHEMBL3953424 & 1641173 & 5.8861 & 5.6021 & TST & \\
\hline CHEMBL3703254 & 1641173 & 6.0 & 6.6747 & TRN & \\
\hline CHEMBL3703299 & 1641173 & 6.4685 & 6.8392 & TRN & \\
\hline CHEMBL3703262 & 1641173 & 6.4559 & 5.9264 & TST & \\
\hline CHEMBL3703293 & 1641173 & 5.7212 & 5.6009 & TRN & \\
\hline CHEMBL3703258 & 1641173 & 6.2147 & 6.13899 & 9999999999 & TRN \\
\hline CHEMBL3650812 & 1641173 & 6.0862 & 5.1516 & TST & \\
\hline CHEMBL 3650787 & 1641173 & 6.2007 & 6.1381 & TRN & \\
\hline CHEMBL1241492 & 654921 & 5.4685 & 5.3973 & TRN & \\
\hline CHEMBL1242756 & 654921 & 7.4559 & 6.6913 & TRN & \\
\hline CHEMBL1241583 & 654921 & 5.5376 & 5.345 & TRN & \\
\hline CHEMBL1241674 & 654921 & 5.699 & 6.1703 & TST & \\
\hline CHEMBL1242574 & 654921 & 5.585 & 6.0607 & TRN & \\
\hline CHEMBL1241142 & 654921 & 5.0706 & 4.3418 & TST & \\
\hline CHEMBL1240545 & 654921 & 5.0 & 5.018 & TRN & \\
\hline CHEMBL1241483 & 654921 & 6.2652 & 5.9569 & TRN & \\
\hline CHEMBL1241587 & 654921 & 5.71 & 5.6303 & TST & \\
\hline CHEMBL1241356 & 654921 & 4.8539 & 4.2261 & TST & \\
\hline CHEMBL1241858 & 654921 & 4.0 & 4.993 & TRN & \\
\hline CHEMBL1242573 & 654921 & 6.8416 & 6.1162 & TRN & \\
\hline CHEMBL1242295 & 654921 & 6.2749 & 6.1666 & TRN & \\
\hline CHEMBL1241586 & 654921 & 5.6576 & 5.3979 & TRN & \\
\hline CHEMBL1242115 & 654921 & 5.5229 & 5.6942 & TST & \\
\hline CHEMBL1242754 & 654921 & 5.5528 & 5.6609 & TRN & \\
\hline CHEMBL1241680 & 654921 & 4.3279 & 4.8876 & TRN & \\
\hline CHEMBL1242477 & 654921 & 7.1612 & 6.4883 & TRN & \\
\hline CHEMBL1242853 & 654921 & 4.0 & 5.4656 & TRN & \\
\hline
\end{tabular}




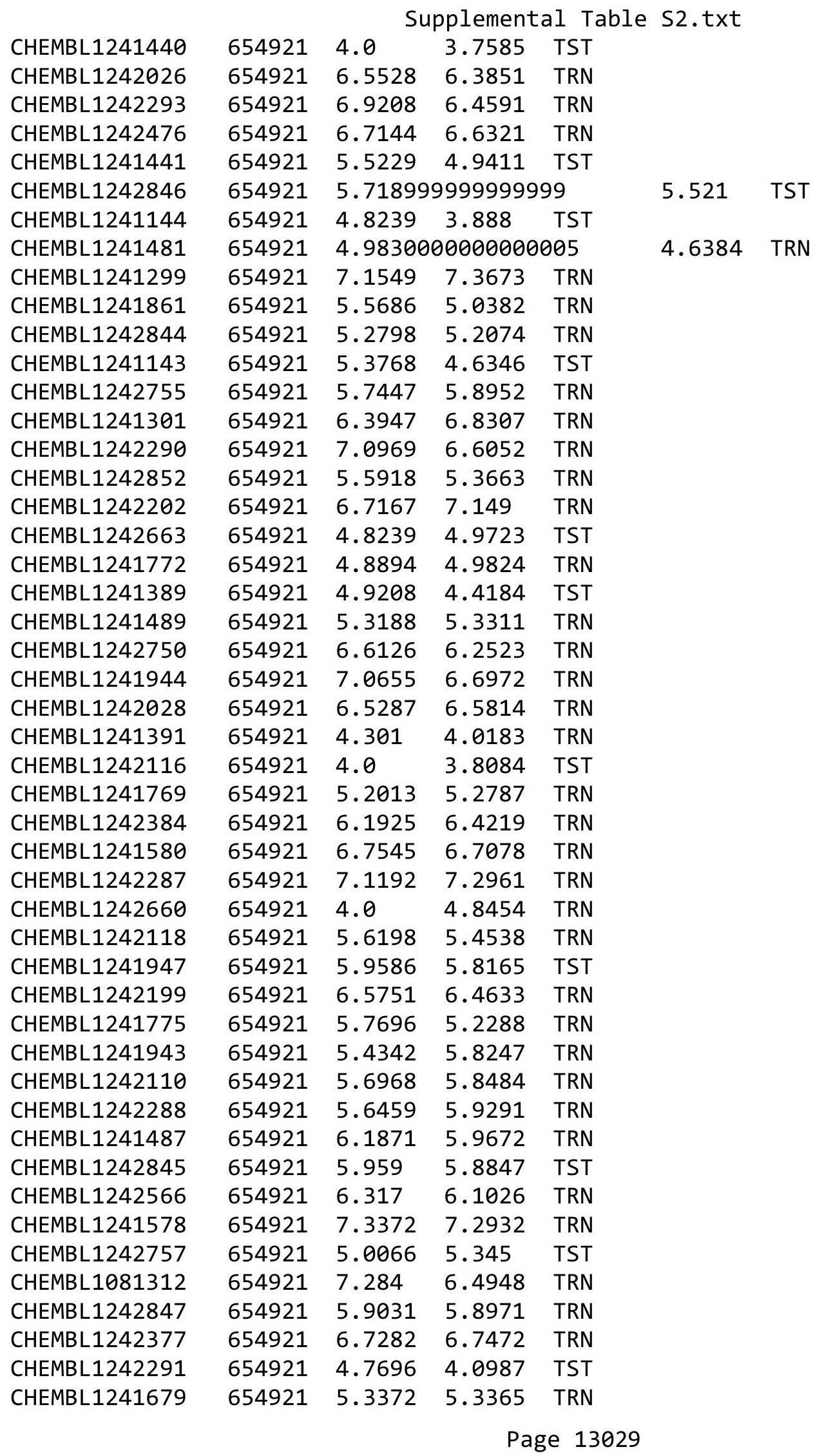




\begin{tabular}{|c|c|c|c|c|c|c|}
\hline & & \multicolumn{5}{|c|}{ Supplemental Table S2.txt } \\
\hline CHEMBL1242382 & 654921 & 4.4815 & 4.3792 & TRN & & \\
\hline CHEMBL1241773 & 654921 & 5.8539 & 5.6761 & TRN & & \\
\hline CHEMBL1231371 & 654921 & 4.0 & 4.0385 & TRN & & \\
\hline CHEMBL1234815 & 654921 & 5.9586 & 5.4564 & TRN & & \\
\hline CHEMBL1242748 & 654921 & 6.0 & 5.8317 & TRN & & \\
\hline CHEMBL1242029 & 654921 & 5.4949 & 5.3963 & TRN & & \\
\hline CHEMBL1241681 & 654921 & 7.1549 & 6.5399 & TRN & & \\
\hline CHEMBL1241439 & 654921 & 5.7959 & 5.5388 & TST & & \\
\hline CHEMBL1242109 & 654921 & 6.1249 & 6.0993 & TRN & & \\
\hline CHEMBL1240565 & 654921 & 7.041 & 6.2425 & TRN & & \\
\hline CHEMBL1242666 & 654921 & 6.3468 & 6.4421 & TRN & & \\
\hline CHEMBL1242656 & 654921 & 6.4597 & 6.7136 & TRN & & \\
\hline CHEMBL1242294 & 654921 & 6.1858 & 6.3387 & TRN & & \\
\hline CHEMBL1241676 & 654921 & 6.6478 & 6.814 & TRN & & \\
\hline CHEMBL1241145 & 654921 & 5.0458 & 4.1838 & TST & & \\
\hline CHEMBL1242662 & 654921 & 5.8861 & 6.4735 & TRN & & \\
\hline CHEMBL1242657 & 654921 & 6.0 & 5.8264 & TRN & & \\
\hline CHEMBL1241270 & 654921 & 5.8239 & 5.388 & TST & & \\
\hline CHEMBL1242376 & 654921 & 6.8477 & 7.1528 & TRN & & \\
\hline CHEMBL1242848 & 654921 & 5.4271 & 5.7749 & TRN & & \\
\hline CHEMBL1241675 & 654921 & 5.2007 & 5.3661 & TST & & \\
\hline CHEMBL1242850 & 654921 & 4.0 & 3.4649 & TST & & \\
\hline CHEMBL1242568 & 654921 & 6.2798 & 6.45 & TRN & & \\
\hline CHEMBL1241269 & 654921 & 5.4202 & 5.0735 & TST & & \\
\hline CHEMBL1242753 & 654921 & 5.8633 & 5.2358 & TRN & & \\
\hline CHEMBL1242114 & 654921 & 6.7852 & 6.7881 & TRN & & \\
\hline CHEMBL1242204 & 654921 & 4.9208 & 3.7609 & TST & & \\
\hline CHEMBL1242207 & 654921 & 4.4949 & 4.9214 & TRN & & \\
\hline CHEMBL1241582 & 654921 & 5.5086 & 5.523 & TRN & & \\
\hline CHEMBL1241684 & 654921 & 5.4685 & 5.4017 & TST & & \\
\hline CHEMBL1242659 & 654921 & 6.2111 & 6.4073 & TRN & & \\
\hline CHEMBL1242472 & 654921 & 6.2076 & 6.2696 & TRN & & \\
\hline CHEMBL1242752 & 654921 & 6.3635 & 6.2829 & TRN & & \\
\hline CHEMBL1242198 & 654921 & 6.75700 & 00000000 & $\partial 1$ & 6.5476 & TRN \\
\hline CHEMBL1241950 & 654921 & 6.3307 & 5.9038 & TRN & & \\
\hline CHEMBL1241770 & 654921 & 5.4145 & 5.8919 & TRN & & \\
\hline CHEMBL1241864 & 654921 & 4.0 & 3.835 & TRN & & \\
\hline CHEMBL1241488 & 654921 & 5.2518 & 4.9368 & TRN & & \\
\hline CHEMBL1242758 & 654921 & 5.5171 & 5.6615 & TST & & \\
\hline CHEMBL1242473 & 654921 & 5.301 & 4.9427 & TRN & & \\
\hline CHEMBL1241774 & 654921 & 6.6861 & 6.5526 & TRN & & \\
\hline CHEMBL1240566 & 654921 & 5.7447 & 5.7846 & TRN & & \\
\hline CHEMBL1241677 & 654921 & 6.064 & 6.3618 & TRN & & \\
\hline CHEMBL1233882 & 654921 & 7.7696 & 7.4024 & TRN & & \\
\hline CHEMBL1241585 & 654921 & 4.0 & 4.3154 & TRN & & \\
\hline CHEMBL1242469 & 654921 & 6.1593 & 5.9899 & TST & & \\
\hline CHEMBL1241581 & 654921 & 6.284 & 6.4735 & TRN & & \\
\hline CHEMBL1240594 & 654921 & 5.8861 & 5.4378 & TST & & \\
\hline
\end{tabular}


Supplemental Table S2.txt

\begin{tabular}{|c|c|c|c|c|c|}
\hline CHEMBL1241104 & 654921 & 5.0655 & 3.9728 & TST & \\
\hline CHEMBL1241767 & 654921 & 5.0177 & 6.3806 & TST & \\
\hline CHEMBL1242379 & 654921 & 6.3335 & $5.95100 e$ & 0000000005 & TRN \\
\hline CHEMBL1241860 & 654921 & 5.8539 & 5.9146 & TRN & \\
\hline CHEMBL1241776 & 654921 & 7.0969 & 6.7523 & TRN & \\
\hline CHEMBL1242569 & 654921 & 5.7212 & 6.0591 & TRN & \\
\hline CHEMBL1242285 & 654921 & 6.0958 & 6.3615 & TRN & \\
\hline CHEMBL1242209 & 654921 & 6.1238 & 6.4073 & TRN & \\
\hline CHEMBL1242030 & 654921 & 4.8633 & 5.2982 & TRN & \\
\hline CHEMBL1241300 & 654921 & 6.1518 & 5.9457 & TST & \\
\hline CHEMBL1241355 & 654921 & 4.0 & 3.694 & TST & \\
\hline CHEMBL1241949 & 654921 & 6.6108 & 6.6177 & TRN & \\
\hline CHEMBL1242470 & 654921 & 6.4045 & 6.124 & TST & \\
\hline CHEMBL1240567 & 654921 & 5.3098 & 4.6261 & TST & \\
\hline CHEMBL1241390 & 654921 & 5.1192 & 5.0232 & TRN & \\
\hline CHEMBL1241682 & 654921 & 6.3354 & 6.6719 & TRN & \\
\hline CHEMBL1242111 & 654921 & 5.8962 & 6.026 & TST & \\
\hline CHEMBL1242203 & 654921 & 5.6536 & 6.2966 & TRN & \\
\hline CHEMBL1241357 & 654921 & 4.7696 & 4.0412 & TST & \\
\hline CHEMBL1242205 & 654921 & 4.0 & 3.4428 & TST & \\
\hline CHEMBL1241588 & 654921 & 5.6576 & 5.6315 & TST & \\
\hline CHEMBL1242024 & 654921 & 6.3188 & 6.0014 & TRN & \\
\hline CHEMBL1240553 & 654921 & 6.5391 & 7.048999 & 9999999995 & TRN \\
\hline CHEMBL1242751 & 654921 & 4.0 & 4.3543 & TRN & \\
\hline CHEMBL1242117 & 654921 & 5.1675 & 5.2094 & TRN & \\
\hline CHEMBL1241358 & 654921 & 4.0 & 3.4886 & TST & \\
\hline CHEMBL1242567 & 654921 & 5.7878 & 6.1607 & TRN & \\
\hline CHEMBL 1240554 & 654921 & 6.8697 & 6.9498 & TRN & \\
\hline CHEMBL1242381 & 654921 & 6.0 & 5.8523 & TRN & \\
\hline CHEMBL1241486 & 654921 & 5.4685 & 4.9268 & TRN & \\
\hline CHEMBL1242385 & 654921 & 6.0804 & 5.841 & TRN & \\
\hline CHEMBL1242025 & 654921 & 4.8327 & 4.5025 & TST & \\
\hline CHEMBL1233881 & 654921 & 7.7696 & 7.5406 & TRN & \\
\hline CHEMBL1242383 & 654921 & 5.0315 & 4.8782 & TRN & \\
\hline CHEMBL1242292 & 654921 & 4.0 & 3.4672 & TST & \\
\hline CHEMBL1241859 & 654921 & 5.5751 & 5.8865 & TRN & \\
\hline CHEMBL1241485 & 654921 & 5.8239 & 5.9719 & TRN & \\
\hline CHEMBL1242112 & 654921 & 6.585 & 6.5937 & TRN & \\
\hline CHEMBL1242661 & 654921 & 4.0 & 5.2003 & TRN & \\
\hline CHEMBL1242113 & 654921 & 6.5591 & 6.7298 & TRN & \\
\hline CHEMBL1242201 & 654921 & 7.1675 & 7.2505 & TRN & \\
\hline CHEMBL1241863 & 654921 & 4.0 & 3.8779 & TRN & \\
\hline CHEMBL1242032 & 654921 & 5.6021 & 5.7155 & TRN & \\
\hline CHEMBL1242471 & 654921 & 5.4559 & 5.3673 & TST & \\
\hline CHEMBL1242286 & 654921 & 5.7696 & 6.0563 & TRN & \\
\hline CHEMBL1241862 & 654921 & 5.585 & 5.8722 & TRN & \\
\hline CHEMBL1242200 & 654921 & 5.2 & 5.176 & TRN & \\
\hline CHEMBL1241945 & 654921 & 7.0362 & 6.6696 & TRN & \\
\hline
\end{tabular}

Page 13031 
Supplemental Table S2.txt

\begin{tabular}{|c|c|c|c|c|}
\hline HEMBL 12 & 54921 & 212 & 4.0635 & (1) \\
\hline HEMBL1242849 & 54921 & 4.0 & 4.095 & \\
\hline 78 & & 0 & & \\
\hline HEMBL124 & 921 & 9208 & & \\
\hline AEMBL1242034 & 54921 & .2924 & 2544 & \\
\hline HEMBL1242208 & 54921 & .3536 & .1821 & \\
\hline HEMBL 124 & & .0 & 3204 & \\
\hline AEMBL12 & & 79 & & \\
\hline HEMBL1242572 & 21 & 0862 & 6.2941 & RN \\
\hline HEMBL1242475 & 21 & . 6799 & 5442 & \\
\hline HEMBL124 & 21 & .0899 & 4348 & \\
\hline AEMBL124 & 21 & 747 & 852 & \\
\hline IEMBL 12 & & & & \\
\hline HEMBL 124 & & .2924 & 938 & \\
\hline HEMBL124 & 21 & & 76 & \\
\hline HEMBL12 & 1 & 1634 & 4976 & \\
\hline HEMBL12 & & 29 & 28 & \\
\hline HEMBL12 & & 38 & & \\
\hline HEMBL12 12 & & 969 & 1985 & \\
\hline HEMBL124 & & 697 & & \\
\hline HEMBL12 & 1 & 872 & 97 & 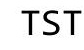 \\
\hline HEMBL12 & & 188 & 47 & $\mathrm{RN}$ \\
\hline HEMBL 12 & & 685 & 06 & \\
\hline HEMBL 12 & & 9959 & & \\
\hline AEMBL12 & & 76 & & N \\
\hline HEMBL12 & & & & SI \\
\hline HEMBL12 & & & 25 & RN \\
\hline HFMBI 12 & & 28 & 44 & RN \\
\hline HEMBL124 & & 386 & & וכו \\
\hline HEMBL191 & & 941 & & 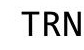 \\
\hline HEMBL4 & & 175 & 032 & SI \\
\hline HEMBL1 & & 236 & & RN \\
\hline HEMBL4 & & 765 & 775 & RN \\
\hline HEMBL180 & & 655 & 5646 & IRN \\
\hline HEMBL472 & & 3979 & 3962 & TRN \\
\hline HEMBL 30 & & 54 & .76 & \\
\hline HEMRI 2 & & 24 & 43 & ST \\
\hline HEMBL947 & & & 609 & IST \\
\hline HEMBL 258 & & 193 & 195 & TRN \\
\hline HEMBL 202 & & 7771 & & RN \\
\hline HEMBL 259 & & 5944 & 956 & \\
\hline CHEMBL483 & & & 1897 & TRN \\
\hline HEMBL151 & & 4.2496 & & RN \\
\hline HEMBL164 & 73 & 4.1657 & 1652 & TRN \\
\hline MBL1 & & 31 & 937 & \\
\hline HEMBL 57 & & 3396 & 5.8396 & \\
\hline CHEMBL125 & & .6531 & 6.654 & \\
\hline HEMBL 213100 & 954773 & 4.2541 & 4.2539 & RN \\
\hline
\end{tabular}

Page 13032 


\begin{tabular}{|c|c|c|c|c|c|c|}
\hline & & \multicolumn{5}{|c|}{ Supplemental Table S2.txt } \\
\hline CHEMBL1190711 & 954773 & 5.084 & 5.0841 & TRN & & \\
\hline CHEMBL 2144069 & 954773 & 4.4964 & 4.496 & TRN & & \\
\hline CHEMBL1590308 & 954773 & 3.5687 & 3.9168 & TST & & \\
\hline CHEMBL393929 & 954773 & 4.2509 & 4.2504 & TRN & & \\
\hline CHEMBL222102 & 954773 & 4.7638 & 4.7655 & TRN & & \\
\hline CHEMBL585951 & 954773 & 5.9561 & 5.9565 & TRN & & \\
\hline CHEMBL192566 & 954773 & 7.7703 & 7.6223 & TST & & \\
\hline CHEMBL373751 & 954773 & 4.0665 & 4.0665 & TRN & & \\
\hline CHEMBL3199475 & 954773 & 5.8426 & 5.8418 & TRN & & \\
\hline CHEMBL514499 & 954773 & 6.4428 & 6.4422 & TRN & & \\
\hline CHEMBL 2005886 & 954773 & 4.6319 & 4.6318 & TRN & & \\
\hline CHEMBL188678 & 954773 & 5.9525 & \multicolumn{3}{|c|}{5.952000000000001} & TRN \\
\hline CHEMBL379975 & 954773 & \multicolumn{3}{|c|}{6.6160000000000005} & 6.6152 & TRN \\
\hline CHEMBL509032 & 954773 & 5.303 & 5.3026 & TRN & & \\
\hline CHEMBL379300 & 954773 & 6.2936 & 6.2913 & TRN & & \\
\hline CHEMBL1909414 & 954773 & 4.6385 & 4.6376 & TRN & & \\
\hline CHEMBL220241 & 954773 & 4.2498 & 4.2493 & TRN & & \\
\hline CHEMBL240954 & 954773 & 5.1354 & 4.8316 & TST & & \\
\hline CHEMBL1788116 & 954773 & 4.3925 & 4.3929 & TRN & & \\
\hline CHEMBL65 & 954773 & 9.3673 & 9.3669 & TRN & & \\
\hline CHEMBL512504 & 954773 & 3.8295 & 3.8299 & TRN & & \\
\hline CHEMBL1970879 & 954773 & 4.1277 & 4.1279 & TRN & & \\
\hline CHEMBL558642 & 954773 & 4.3986 & 4.3993 & TRN & & \\
\hline CHEMBL1230020 & 954773 & 5.4683 & 5.4702 & TRN & & \\
\hline CHEMBL 2363137 & 954773 & 4.515 & 4.5146 & TRN & & \\
\hline CHEMBL3186408 & 954773 & 5.4142 & 4.1957 & TST & & \\
\hline CHEMBL392695 & 954773 & 5.4947 & 5.4952 & TRN & & \\
\hline CHEMBL3392440 & 954773 & 3.6616 & 3.6599 & TRN & & \\
\hline CHEMBL515416 & 954773 & 5.7904 & 5.7914 & TRN & & \\
\hline CHEMBL1404918 & 954773 & 3.7664 & 3.7655 & TRN & & \\
\hline CHEMBL1357247 & 954773 & 3.4182 & 3.4185 & TRN & & \\
\hline CHEMBL92309 & 954773 & 4.0657 & 3.7912 & TST & & \\
\hline CHEMBL1242367 & 954773 & 4.4152 & 4.4147 & TRN & & \\
\hline CHEMBL209148 & 954773 & 4.6963 & 4.6202 & TST & & \\
\hline CHEMBL210618 & 954773 & 4.1055 & 4.0702 & TST & & \\
\hline CHEMBL577784 & 954773 & 5.6202 & 5.8591 & TST & & \\
\hline CHEMBL3349342 & 954773 & 3.7161 & 5.0913 & TST & & \\
\hline CHEMBL102714 & 954773 & 3.5702 & 4.2608 & TST & & \\
\hline CHEMBL483847 & 954773 & 3.8824 & 4.4449 & TST & & \\
\hline CHEMBL189584 & 954773 & 5.4202 & 5.3752 & TST & & \\
\hline CHEMBL 2398249 & 967619 & 7.3098 & 7.3159 & TRN & & \\
\hline CHEMBL 2398272 & 967619 & 5.3979 & 5.3754 & TRN & & \\
\hline CHEMBL 2398278 & 967619 & 3.0 & 3.0958 & TRN & & \\
\hline CHEMBL 2398253 & 967619 & 7.2596 & 7.2338 & TRN & & \\
\hline CHEMBL 2398254 & 967619 & 7.8539 & 7.8353 & TRN & & \\
\hline CHEMBL371861 & 967619 & 5.6576 & 1.8059 & TST & & \\
\hline CHEMBL 2398258 & 967619 & 7.2924 & 7.2502 & TRN & & \\
\hline CHEMBL376408 & 967619 & 9.301 & 2.8972 & TST & & \\
\hline
\end{tabular}




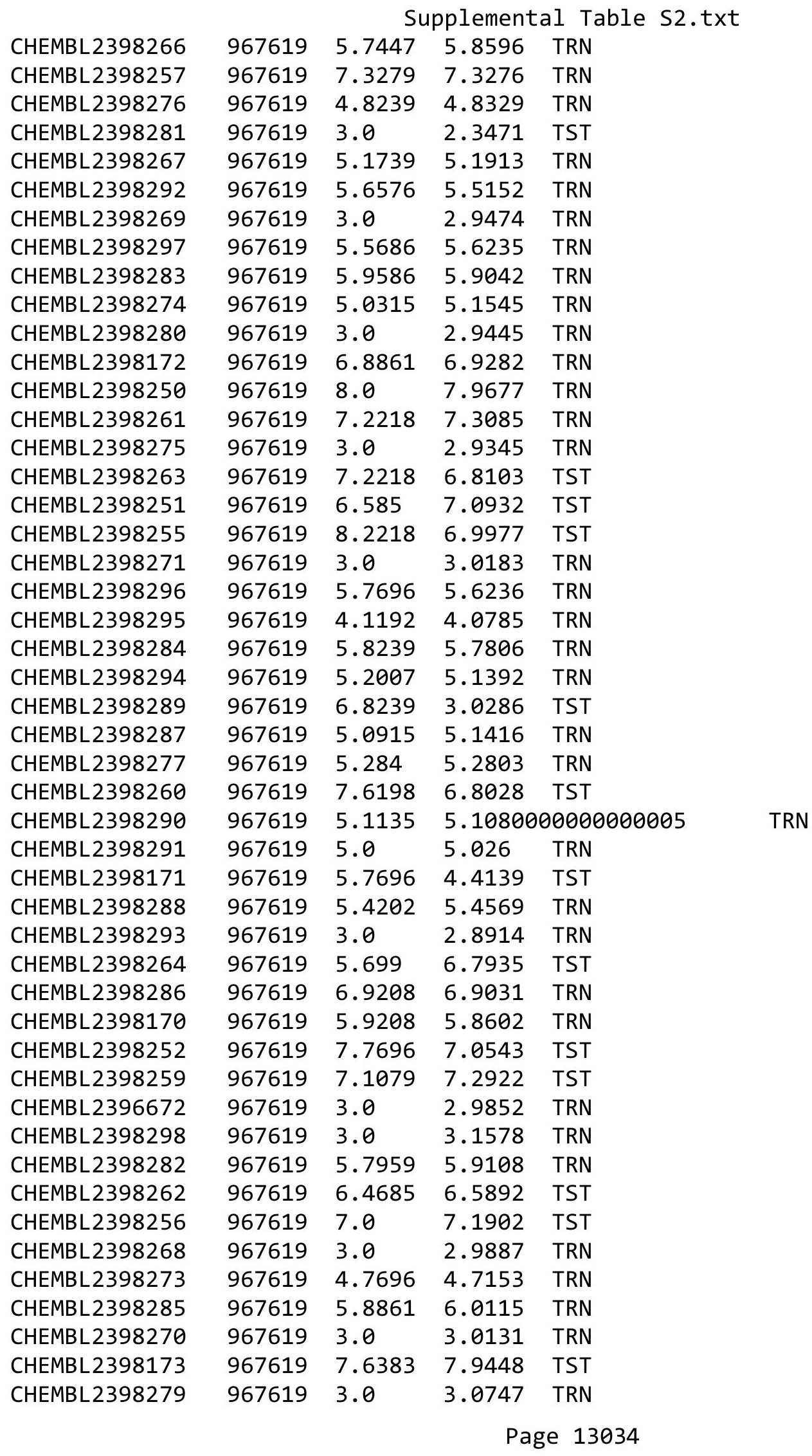


Supplemental Table S2.txt

\begin{tabular}{|c|c|c|c|c|c|}
\hline CHEMBL2398265 & 967619 & 5.8239 & 5.7373 & TRN & \\
\hline CHEMBL3894170 & 1642122 & 8.6576 & 8.6337 & TRN & \\
\hline CHEMBL3903034 & 1642122 & 7.2565 & 6.6257 & TRN & \\
\hline CHEMBL3933185 & 1642122 & 7.0186 & 6.7781 & TRN & \\
\hline CHEMBL3966168 & 1642122 & 6.8259 & 6.4071 & TRN & \\
\hline CHEMBL3966730 & 1642122 & 7.1367 & 7.3636 & TRN & \\
\hline CHEMBL3978125 & 1642122 & 8.9208 & 8.6119 & TRN & \\
\hline CHEMBL 3986765 & 1642122 & 6.0011 & 6.6658 & TRN & \\
\hline CHEMBL3956205 & 1642122 & 6.7486 & 7.4088 & TRN & \\
\hline CHEMBL3972174 & 1642122 & 8.7959 & 7.4671 & TRN & \\
\hline CHEMBL 3893742 & 1642122 & 6.945 & 7.1688 & TRN & \\
\hline CHEMBL3966887 & 1642122 & 6.0 & 6.6292 & TRN & \\
\hline CHEMBL3914194 & 1642122 & 6.0 & 6.3697 & TRN & \\
\hline CHEMBL 3934378 & 1642122 & 7.9281 & 7.2624 & TRN & \\
\hline CHEMBL3958413 & 1642122 & 8.2676 & 7.8726 & TRN & \\
\hline CHEMBL3985919 & 1642122 & 6.0 & 6.3359 & TRN & \\
\hline CHEMBL3942402 & 1642122 & 6.0 & 6.5764 & TST & \\
\hline CHEMBL 3899824 & 1642122 & 6.0 & 6.2854 & TRN & \\
\hline CHEMBL 3894408 & 1642122 & 7.7423 & 6.5475 & TST & \\
\hline CHEMBL3976062 & 1642122 & 6.0 & 6.5744 & TRN & \\
\hline CHEMBL3979919 & 1642122 & 7.2865 & 6.4623 & TST & \\
\hline CHEMBL3945608 & 1642122 & 9.1549 & 6.3306 & TRN & \\
\hline CHEMBL3942709 & 1642122 & 6.8362 & 6.5634 & TRN & \\
\hline CHEMBL3898300 & 1642122 & 6.0 & \multicolumn{2}{|c|}{6.4910000000000005} & TRN \\
\hline CHEMBL 3947665 & 1642122 & 6.0386 & 7.0465 & TRN & \\
\hline CHEMBL3942094 & 1642122 & 8.2757 & 6.6158 & TRN & \\
\hline CHEMBL3966810 & 1642122 & 6.6893 & 7.6295 & TRN & \\
\hline CHEMBL3913128 & 1642122 & 7.1898 & 7.7919 & TRN & \\
\hline CHEMBL3918371 & 1642122 & 6.0 & 6.4052 & TRN & \\
\hline CHEMBL3978186 & 1642122 & 6.0 & 6.5492 & TRN & \\
\hline CHEMBL 3890097 & 1642122 & 5.9994 & 7.9147 & TST & \\
\hline CHEMBL 3945464 & 1642122 & 6.0 & 6.5358 & TRN & \\
\hline CHEMBL 3925284 & 1642122 & 7.0164 & 8.2184 & TST & \\
\hline CHEMBL3977146 & 1642122 & 6.0 & 6.8392 & TST & \\
\hline CHEMBL3939925 & 1642122 & 7.1445 & 6.5968 & TRN & \\
\hline CHEMBL3919727 & 1642122 & 8.2441 & 6.5884 & TST & \\
\hline CHEMBL3915510 & 1642122 & 6.0 & 6.2879 & TRN & \\
\hline CHEMBL3926154 & 1642122 & 6.0 & 6.4747 & TRN & \\
\hline CHEMBL3986505 & 1642122 & 8.699 & 7.3662 & TRN & \\
\hline CHEMBL3976801 & 1642122 & 7.7696 & 6.5819 & TRN & \\
\hline CHEMBL3924010 & 1642122 & 5.9606 & 6.4364 & TRN & \\
\hline CHEMBL3909578 & 1642122 & 7.7696 & 6.6269 & TST & \\
\hline CHEMBL3923684 & 1642122 & 8.0223 & 7.8285 & TST & \\
\hline CHEMBL3960124 & 1642122 & 7.0851 & 7.7296 & TST & \\
\hline CHEMBL3914653 & 1642122 & 7.3605 & 6.0274 & TRN & \\
\hline CHEMBL3948314 & 1642122 & 6.0 & \multicolumn{2}{|c|}{6.547000000000001} & TRN \\
\hline CHEMBL 3973847 & 1642122 & 6.0 & 6.8494 & TRN & \\
\hline CHEMBL3933997 & 1642122 & 6.6594 & 6.6007 & TRN & \\
\hline
\end{tabular}

Page 13035 
Supplemental Table S2.txt

\begin{tabular}{|c|c|c|c|c|c|c|}
\hline CHEMBL 3957631 & 1642122 & 8.2924 & 8.0012 & TRN & & \\
\hline CHEMBL3933315 & 1642122 & 6.0 & 6.2699 & TRN & & \\
\hline CHEMBL 3968694 & 1642122 & 6.3423 & 6.4827 & TST & & \\
\hline CHEMBL 3940136 & 1642122 & 6.0 & 6.2843 & TRN & & \\
\hline CHEMBL3918150 & 1642122 & 6.0 & 6.3072 & TRN & & \\
\hline CHEMBL3958336 & 1642122 & 7.6021 & 6.3466 & TRN & & \\
\hline CHEMBL 3982308 & 1642122 & 7.0883 & 6.6003 & TRN & & \\
\hline CHEMBL 3921745 & 1642122 & 7.82100 & 0000000 & 01 & 6.5118 & TRN \\
\hline CHEMBL 3890329 & 1642122 & 6.0 & 6.4515 & TRN & & \\
\hline CHEMBL 3982907 & 1642122 & 8.1739 & 6.4114 & TST & & \\
\hline CHEMBL3982567 & 1642122 & 7.6364 & 7.4445 & TRN & & \\
\hline CHEMBL 3904968 & 1642122 & 6.0 & 6.3653 & TRN & & \\
\hline CHEMBL3959920 & 1642122 & 7.8041 & 6.5384 & TST & & \\
\hline CHEMBL 3980858 & 1642122 & 6.6893 & 6.5175 & TST & & \\
\hline CHEMBL 3907210 & 1642122 & 8.0088 & 6.6947 & TRN & & \\
\hline CHEMBL3917714 & 1642122 & 8.4949 & 6.7766 & TST & & \\
\hline CHEMBL3977194 & 1642122 & 6.934 & 7.0119 & TRN & & \\
\hline CHEMBL 3982644 & 1642122 & 6.1505 & 6.8179 & TRN & & \\
\hline CHEMBL 3940187 & 1642122 & 8.301 & 6.3131 & TST & & \\
\hline CHEMBL 3963165 & 1642122 & 7.1898 & 6.5769 & TRN & & \\
\hline CHEMBL 3950692 & 1642122 & 6.0 & 6.8321 & TRN & & \\
\hline CHEMBL 3943211 & 1642122 & 6.0 & 6.5214 & TRN & & \\
\hline CHEMBL3955970 & 1642122 & 6.0 & 6.6187 & TRN & & \\
\hline CHEMBL 3940691 & 1642122 & 7.3382 & 7.1194 & TRN & & \\
\hline CHEMBL 3916573 & 1642122 & 8.1192 & 8.0166 & TRN & & \\
\hline CHEMBL 3916285 & 1642122 & 6.9404 & 7.5346 & TRN & & \\
\hline CHEMBL3892096 & 1642122 & 6.0 & 6.5693 & TRN & & \\
\hline CHEMBL3907596 & 1642122 & 8.4685 & 7.7966 & TRN & & \\
\hline CHEMBL3941953 & 1642122 & 6.0 & 6.7502 & TRN & & \\
\hline CHEMBL 3894051 & 1642122 & 8.585 & 6.9166 & TRN & & \\
\hline CHEMBL 3893170 & 1642122 & 8.4685 & 6.6126 & TRN & & \\
\hline CHEMBL 3968008 & 1642122 & 6.4415 & 7.4198 & TST & & \\
\hline CHEMBL3918476 & 1642122 & 6.0 & 6.7742 & TRN & & \\
\hline CHEMBL3936627 & 1642122 & 8.1871 & 6.6858 & TRN & & \\
\hline CHEMBL3966311 & 1642122 & 7.3429 & 7.6874 & TRN & & \\
\hline CHEMBL3914922 & 1642122 & 8.5086 & 6.3459 & TST & & \\
\hline CHEMBL 3961882 & 1642122 & 6.0294 & 6.4332 & TRN & & \\
\hline CHEMBL3903056 & 1642122 & 7.4389 & 7.8052 & TRN & & \\
\hline CHEMBL 3962514 & 1642122 & 6.8395 & 7.6801 & TST & & \\
\hline CHEMBL 3945954 & 1642122 & 6.0 & 7.4135 & TRN & & \\
\hline CHEMBL3958638 & 1642122 & 6.7303 & 6.8166 & TRN & & \\
\hline CHEMBL3965091 & 1642122 & 6.4642 & 6.518 & TRN & & \\
\hline CHEMBL3962778 & 1642122 & 6.7991 & 6.4253 & TRN & & \\
\hline CHEMBL 3946121 & 1642122 & 6.0 & 6.6749 & TRN & & \\
\hline CHEMBL3908871 & 1642122 & 6.3179 & 6.5293 & TRN & & \\
\hline CHEMBL 3898725 & 1642122 & 6.0 & 6.8845 & TRN & & \\
\hline CHEMBL 3904362 & 1642122 & 8.2924 & 7.3394 & TRN & & \\
\hline CHEMBL3911558 & 1642122 & 6.0 & 6.3532 & TRN & & \\
\hline
\end{tabular}


Supplemental Table S2.txt

\begin{tabular}{|c|c|c|c|c|c|}
\hline CHEMBL3890458 & 1642122 & 8.2366 & 8.2169 & TST & \\
\hline CHEMBL3932973 & 1642122 & 8.2366 & 6.6693 & TST & \\
\hline CHEMBL3920942 & 1642122 & 7.7328 & 6.6751 & TRN & \\
\hline CHEMBL3908763 & 1642122 & 8.4815 & 8.0073 & TST & \\
\hline CHEMBL3930775 & 1642122 & 7.4828 & 6.8496 & TRN & \\
\hline CHEMBL3893838 & 1642122 & 6.0 & 6.9273 & TRN & \\
\hline CHEMBL3981993 & 1642122 & 6.0 & 6.3958 & TRN & \\
\hline CHEMBL3912664 & 1642122 & 6.181 & 7.2929 & TRN & \\
\hline CHEMBL3890455 & 1642122 & 6.0 & 6.5207 & TRN & \\
\hline CHEMBL3962970 & 1642122 & 6.8639 & 6.4767 & TRN & \\
\hline CHEMBL3978407 & 1642122 & 6.0 & 6.3165 & TRN & \\
\hline CHEMBL3941673 & 1642122 & 6.5339 & 6.3574 & TRN & \\
\hline CHEMBL3891677 & 1642122 & 7.3936 & 6.6738 & TST & \\
\hline CHEMBL3983255 & 1642122 & 7.1959 & 6.8296 & TRN & \\
\hline CHEMBL3950162 & 1642122 & 6.0 & 6.6738 & TRN & \\
\hline CHEMBL3943185 & 1642122 & 7.2907 & 6.5681 & TRN & \\
\hline CHEMBL3943441 & 1642122 & 8.6198 & 7.8042 & TRN & \\
\hline CHEMBL3927770 & 1642122 & 6.9363 & 6.6795 & TRN & \\
\hline CHEMBL3927530 & 1642122 & 7.109 & 6.9359 & TRN & \\
\hline CHEMBL3923434 & 1642122 & 7.2815 & 6.6615 & TST & \\
\hline CHEMBL3979781 & 1642122 & 6.7768 & 8.0142 & TST & \\
\hline CHEMBL3954854 & 1642122 & 6.0 & 6.6758 & TRN & \\
\hline CHEMBL3922110 & 1642122 & 6.6087 & \multicolumn{2}{|c|}{6.5760000000000005} & TRN \\
\hline CHEMBL3932300 & 1642122 & 8.0506 & 6.7986 & TRN & \\
\hline CHEMBL3936122 & 1642122 & 6.0 & 6.4875 & TRN & \\
\hline CHEMBL3918285 & 1642122 & 6.0 & 6.6555 & TRN & \\
\hline CHEMBL3897142 & 1642122 & 7.2111 & 7.0853 & TST & \\
\hline CHEMBL3945888 & 1642122 & 7.2807 & 6.4597 & TST & \\
\hline CHEMBL3925710 & 1642122 & 7.4828 & 7.0218 & TRN & \\
\hline CHEMBL3971550 & 1642122 & 7.9281 & 6.9845 & TRN & \\
\hline CHEMBL3943239 & 1642122 & 6.0 & 6.4933 & TRN & \\
\hline CHEMBL3967345 & 1642122 & 6.8921 & 6.4925 & TST & \\
\hline CHEMBL3955968 & 1642122 & 6.2323 & 7.8725 & TST & \\
\hline CHEMBL3974913 & 1642122 & 7.0942 & 6.8506 & TRN & \\
\hline CHEMBL3949331 & 1642122 & 6.0 & 6.4711 & TRN & \\
\hline CHEMBL3933180 & 1642122 & 7.9355 & 6.5645 & TST & \\
\hline CHEMBL3889656 & 1642122 & 6.0 & 6.7177 & TRN & \\
\hline CHEMBL 3937227 & 1642122 & 6.0 & 6.4509 & TRN & \\
\hline CHEMBL3925111 & 1642122 & 7.1851 & 6.3792 & TRN & \\
\hline CHEMBL3940907 & 1642122 & 7.02 & 6.8299 & TRN & \\
\hline CHEMBL3905942 & 1642122 & 6.8265 & 6.5996 & TST & \\
\hline CHEMBL3937055 & 1642122 & 7.9957 & 7.5286 & TRN & \\
\hline CHEMBL3904541 & 1642122 & 6.9931 & 7.2786 & TRN & \\
\hline CHEMBL3903776 & 1642122 & 6.0 & 6.5951 & TRN & \\
\hline CHEMBL3953854 & 1642122 & 6.0 & 6.5077 & TRN & \\
\hline CHEMBL3975079 & 1642122 & 6.0 & 6.8252 & TRN & \\
\hline CHEMBL3978856 & 1642122 & 6.7812 & 6.8995 & TRN & \\
\hline CHEMBL3958269 & 1642122 & 7.1273 & 6.5093 & TST & \\
\hline
\end{tabular}


Supplemental Table S2.txt

\begin{tabular}{|c|c|c|c|c|c|}
\hline CHEMBL3897056 & 1642122 & 7.7077 & 6.1341 & TRN & \\
\hline CHEMBL 3896366 & 1642122 & 6.0 & 6.6654 & TRN & \\
\hline CHEMBL3890622 & 1642122 & 7.3893 & 6.6018 & TST & \\
\hline CHEMBL3926699 & 1642122 & 7.2565 & 6.5752 & TRN & \\
\hline CHEMBL3939531 & 1642122 & 6.0 & 6.3609 & TRN & \\
\hline CHEMBL3906084 & 1642122 & 6.0 & 6.7714 & TRN & \\
\hline CHEMBL3919449 & 1642122 & 7.983 & 6.9256 & TRN & \\
\hline CHEMBL3935162 & 1642122 & 7.3251 & 6.5042 & TST & \\
\hline CHEMBL3945306 & 1642122 & 7.1391 & 6.6007 & TRN & \\
\hline CHEMBL 3970243 & 1642122 & 5.8413 & 7.28 & TRN & \\
\hline CHEMBL3966218 & 1642122 & 6.0 & 6.76200 & 00000000005 & TST \\
\hline CHEMBL3932963 & 1642122 & 7.5686 & 6.66700 & 0000000001 & TRN \\
\hline CHEMBL3906536 & 1642122 & 6.2618 & 6.7659 & TRN & \\
\hline CHEMBL3950922 & 1642122 & 8.8539 & 6.6903 & TRN & \\
\hline CHEMBL3969693 & 1642122 & 6.9626 & 6.479 & TRN & \\
\hline CHEMBL 3922649 & 1642122 & 6.0 & 6.545 & TRN & \\
\hline CHEMBL3980218 & 1642122 & 6.0 & 6.6937 & TRN & \\
\hline CHEMBL3966413 & 1642122 & 6.0136 & 6.3743 & TRN & \\
\hline CHEMBL3916408 & 1642122 & 6.3541 & 7.0059 & TRN & \\
\hline CHEMBL3898241 & 1642122 & 7.3307 & 6.8982 & TRN & \\
\hline CHEMBL 3957242 & 1642122 & 8.699 & 7.2386 & TRN & \\
\hline CHEMBL3897115 & 1642122 & 6.0 & 6.5716 & TRN & \\
\hline CHEMBL3943882 & 1642122 & 6.0 & 6.6308 & TRN & \\
\hline CHEMBL3944402 & 1642122 & 7.51 & \multicolumn{2}{|c|}{6.4110000000000005} & TST \\
\hline CHEMBL3900539 & 1642122 & 7.6345 & 6.3586 & TST & \\
\hline CHEMBL 3971251 & 1642122 & 6.2527 & 6.9847 & TRN & \\
\hline CHEMBL3966304 & 1642122 & 6.0 & 6.2842 & TRN & \\
\hline CHEMBL3955149 & 1642122 & 7.9136 & 6.4093 & TST & \\
\hline CHEMBL3918459 & 1642122 & 6.001 & 6.409 & TRN & \\
\hline CHEMBL3910524 & 1642122 & 6.0 & 6.5407 & TRN & \\
\hline CHEMBL3903761 & 1642122 & 7.9066 & 6.2948 & TRN & \\
\hline CHEMBL3893161 & 1642122 & 6.0 & 7.8607 & TST & \\
\hline CHEMBL3953148 & 1642122 & 6.0 & 6.8038 & TST & \\
\hline CHEMBL3986075 & 1642122 & 6.0 & 6.4014 & TRN & \\
\hline CHEMBL3901550 & 1642122 & 6.0 & 6.3742 & TRN & \\
\hline CHEMBL3909299 & 1642122 & 6.0 & 6.7986 & TRN & \\
\hline CHEMBL3977794 & 1642122 & 6.0374 & 6.5994 & TRN & \\
\hline CHEMBL3941805 & 1642122 & 6.0516 & 6.6489 & TRN & \\
\hline CHEMBL3952061 & 1642122 & 8.0362 & 6.64 & TST & \\
\hline CHEMBL3895595 & 1642122 & 7.9788 & 7.4421 & TRN & \\
\hline CHEMBL 3918794 & 1642122 & 6.5328 & 6.9964 & TST & \\
\hline CHEMBL3920679 & 1642122 & 8.0223 & 7.6009 & TST & \\
\hline CHEMBL3940771 & 1642122 & 6.3313 & 8.4043 & TST & \\
\hline CHEMBL3940981 & 1642122 & 6.0 & 6.6463 & TRN & \\
\hline CHEMBL3892349 & 1642122 & 7.8861 & 6.5567 & TST & \\
\hline CHEMBL3952968 & 1642122 & 7.4486 & 7.9457 & TST & \\
\hline CHEMBL3911641 & 1642122 & 6.0 & 6.2987 & TST & \\
\hline CHEMBL3918005 & 1642122 & 6.971 & 6.5118 & TST & \\
\hline
\end{tabular}


Supplemental Table S2.txt

\begin{tabular}{|c|c|c|c|c|}
\hline CHEMBL3 & 1642122 & 6.0 & 6.7144 & 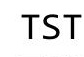 \\
\hline CHEMBL 3975486 & 1642122 & 6.0 & 6.6834 & TRN \\
\hline HEMBL189200 & 30438 & 8.5086 & 8.6775 & \\
\hline HEMBL 361063 & 30438 & 7.5686 & 6142 & \\
\hline HEMBL 363963 & 30438 & 8.4318 & 7.9344 & PN \\
\hline HEMBL 364345 & 30438 & 6.9914 & 6.9857 & 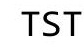 \\
\hline HEMBL510754 & 30438 & 8.8539 & 8.3288 & \\
\hline HEMBL187105 & 30438 & 8.8539 & 8.6464 & \\
\hline HEMBL 363705 & 30438 & 7.3768 & 7.1587 & \\
\hline HEMBL 364333 & 30438 & 5.301 & 4.9753 & \\
\hline HEMBL189706 & 30438 & 6.7212 & 6.0606 & ST \\
\hline HEMBL187473 & 30438 & 6.8601 & 6.8319 & \\
\hline HEMBL361762 & 30438 & 7.284 & 6.9221 & \\
\hline HEMBL188516 & 30438 & 6.8697 & 6.8262 & \\
\hline HEMBL187937 & 30438 & 7.8239 & 7.5326 & \\
\hline HEMBL364329 & 30438 & 7.8861 & 7.353 & \\
\hline HEMBL187069 & 304 & 7.3372 & 7.1427 & \\
\hline LHEMBL 36 & 304 & 7.6021 & 7.2404 & ST \\
\hline HEMBL36 & 38 & 6.6968 & 6.2846 & RN \\
\hline HEMBL1\& & 30 & 6.4168 & 6.904 & \\
\hline HEMBL188049 & 304 & 7.8861 & 7.4311 & \\
\hline CHEMBL182751 & $30<$ & 6.8097 & 6.9672 & $\mathrm{~T}$ \\
\hline CHEMBL 36 & 30 & 8.7447 & 8.6596 & $\mathrm{RN}$ \\
\hline HEMBL 36 & 8 & 6.6216 & 6.3702 & RN \\
\hline HEMBL18 & 38 & 8.6198 & 8.2961 & $\mathrm{RN}$ \\
\hline HEMBL188189 & 304 & 8.0969 & 7.9825 & RN \\
\hline CHEMBL185783 & 30438 & 6.6289 & 6.6127 & TST \\
\hline HEMBL18 & 30 & 7.9208 & 7.8831 & ГRN \\
\hline HEMBL18 & 8 & 7.7696 & 7.977 & RN \\
\hline CHEMBL 36 & 30 & 7.7959 & 7.8295 & RN \\
\hline CHEMBL 360817 & 30 & 7.1805 & 6.9054 & TRN \\
\hline CHEMBL365293 & 30438 & 6.1439 & 6.4455 & TRN \\
\hline HEMBL18 & 8 & 8.2218 & 7.9335 & TRN \\
\hline HEMBL1 & 8 & 6.056 & 7415 & TRN \\
\hline CHEMBL18 & 30 & 7.9208 & 7.9183 & TRN \\
\hline CHEMBL 363017 & 30438 & 5.8153 & 6.5453 & TRN \\
\hline CHEMBL187219 & 30438 & 7.699 & 8.1731 & TRN \\
\hline CHEMBL 36 & 8 & 7.6021 & 7.8592 & TRN \\
\hline CHEMBL18 & 38 & 5.983 & 5.9529 & TRN \\
\hline CHEMBL188527 & 30 & 5.9788 & 6.6087 & TRN \\
\hline CHEMBL188619 & 30438 & 6.5952 & 6.8634 & TRN \\
\hline CHEMBL189002 & 30 & 7.4089 & 6.7426 & TRN \\
\hline CHEMBL18 & & 6.0164 & 6.2778 & TRN \\
\hline CHEMBL189287 & 30438 & 7.6021 & 7.5845 & TRN \\
\hline CHEMBL189025 & 30438 & 6.9788 & 6.5546 & TRN \\
\hline CHEMBL 365625 & 530438 & 7.0177 & 7.2439 & IRN \\
\hline CHEMBL18664 & 530438 & 8.4949 & 7.7772 & \\
\hline CHEMBL 364551 & 530438 & 7.1938 & 7.1295 & \\
\hline
\end{tabular}

Page 13039 
Supplemental Table S2.txt

\begin{tabular}{|c|c|c|c|c|c|}
\hline CHEMBL188882 & 530438 & 7.2676 & 7.4612 & TRN & \\
\hline CHEMBL361266 & 530438 & 6.4486 & 5.6923 & TST & \\
\hline CHEMBL188515 & 530438 & 5.8729 & 6.4255 & TRN & \\
\hline CHEMBL189024 & 530438 & 6.7423 & 6.7028 & TRN & \\
\hline CHEMBL189077 & 530438 & 8.5229 & 8.1441 & TRN & \\
\hline CHEMBL186598 & 530438 & 8.4437 & 8.7432 & TRN & \\
\hline CHEMBL187087 & 530438 & 8.5229 & 8.0694 & TRN & \\
\hline CHEMBL 188230 & 530438 & 7.2291 & \multicolumn{2}{|c|}{6.992999999999999} & TRN \\
\hline CHEMBL365016 & 530438 & 6.8477 & 7.8246 & TRN & \\
\hline CHEMBL187313 & 530438 & 6.2832 & 6.3285 & TRN & \\
\hline CHEMBL188957 & 530438 & 7.9586 & 7.5348 & TRN & \\
\hline CHEMBL188613 & 530438 & 7.1805 & 7.0674 & TRN & \\
\hline CHEMBL189822 & 530438 & 7.4318 & 7.6086 & TRN & \\
\hline CHEMBL189303 & 530438 & 7.8539 & 7.4108 & TRN & \\
\hline CHEMBL183367 & 530438 & 7.8239 & 7.8018 & TRN & \\
\hline CHEMBL186597 & 530438 & 8.301 & 8.3138 & TRN & \\
\hline CHEMBL509360 & 530438 & 6.5045 & 7.0104 & TST & \\
\hline CHEMBL187673 & 530438 & 7.301 & 7.0215 & TRN & \\
\hline CHEMBL187314 & 530438 & 6.2733 & 6.4868 & TRN & \\
\hline CHEMBL435090 & 530438 & 7.699 & 8.1025 & TRN & \\
\hline CHEMBL186945 & 530438 & 7.5086 & 7.5936 & TRN & \\
\hline CHEMBL509026 & 530438 & 6.7799 & 8.1973 & TST & \\
\hline CHEMBL 188410 & 530438 & 6.153 & 6.1542 & TRN & \\
\hline CHEMBL362356 & 530438 & 7.7959 & 7.2862 & TRN & \\
\hline CHEMBL442037 & 530438 & 6.8041 & 6.7502 & TRN & \\
\hline CHEMBL365903 & 530438 & 7.0223 & 6.0876 & TST & \\
\hline CHEMBL189039 & 530438 & 7.3979 & 6.9517 & TRN & \\
\hline CHEMBL 362355 & 530438 & 6.8729 & 7.274 & TRN & \\
\hline CHEMBL187207 & 530438 & 8.5229 & 8.023 & TRN & \\
\hline CHEMBL364110 & 530438 & 5.4365 & 5.7966 & TST & \\
\hline CHEMBL187671 & 530438 & 5.7959 & 6.0042 & TRN & \\
\hline CHEMBL187663 & 530438 & 7.0862 & 6.9841 & TST & \\
\hline CHEMBL 364176 & 530438 & 7.585 & 7.3681 & TRN & \\
\hline CHEMBL187978 & 530438 & 7.0132 & 6.8509 & TST & \\
\hline CHEMBL188846 & 530438 & 6.0 & 8.2346 & TRN & \\
\hline CHEMBL188900 & 530438 & 7.3468 & 7.0184 & TST & \\
\hline CHEMBL189356 & 530438 & 8.5229 & 8.3472 & TST & \\
\hline CHEMBL 188246 & 530438 & 7.4815 & 7.5999 & TRN & \\
\hline CHEMBL188051 & 530438 & 8.8239 & 8.6175 & TRN & \\
\hline CHEMBL 188458 & 530438 & 7.0605 & 7.4991 & TRN & \\
\hline CHEMBL362307 & 530438 & 8.699 & 8.6341 & TRN & \\
\hline CHEMBL188792 & 530438 & 7.2291 & 6.8423 & TST & \\
\hline CHEMBL360651 & 530438 & 8.0 & 7.8965 & TRN & \\
\hline CHEMBL188391 & 530438 & 7.2291 & 7.4797 & TRN & \\
\hline CHEMBL188299 & 530438 & 6.9508 & 7.2527 & TRN & \\
\hline CHEMBL189556 & 530438 & 7.3372 & 7.49100 & 00000000005 & TRN \\
\hline CHEMBL186513 & 530438 & 8.2218 & 7.6719 & TST & \\
\hline CHEMBL362793 & 530438 & 7.1938 & 6.8967 & TRN & \\
\hline
\end{tabular}

Page 13040 


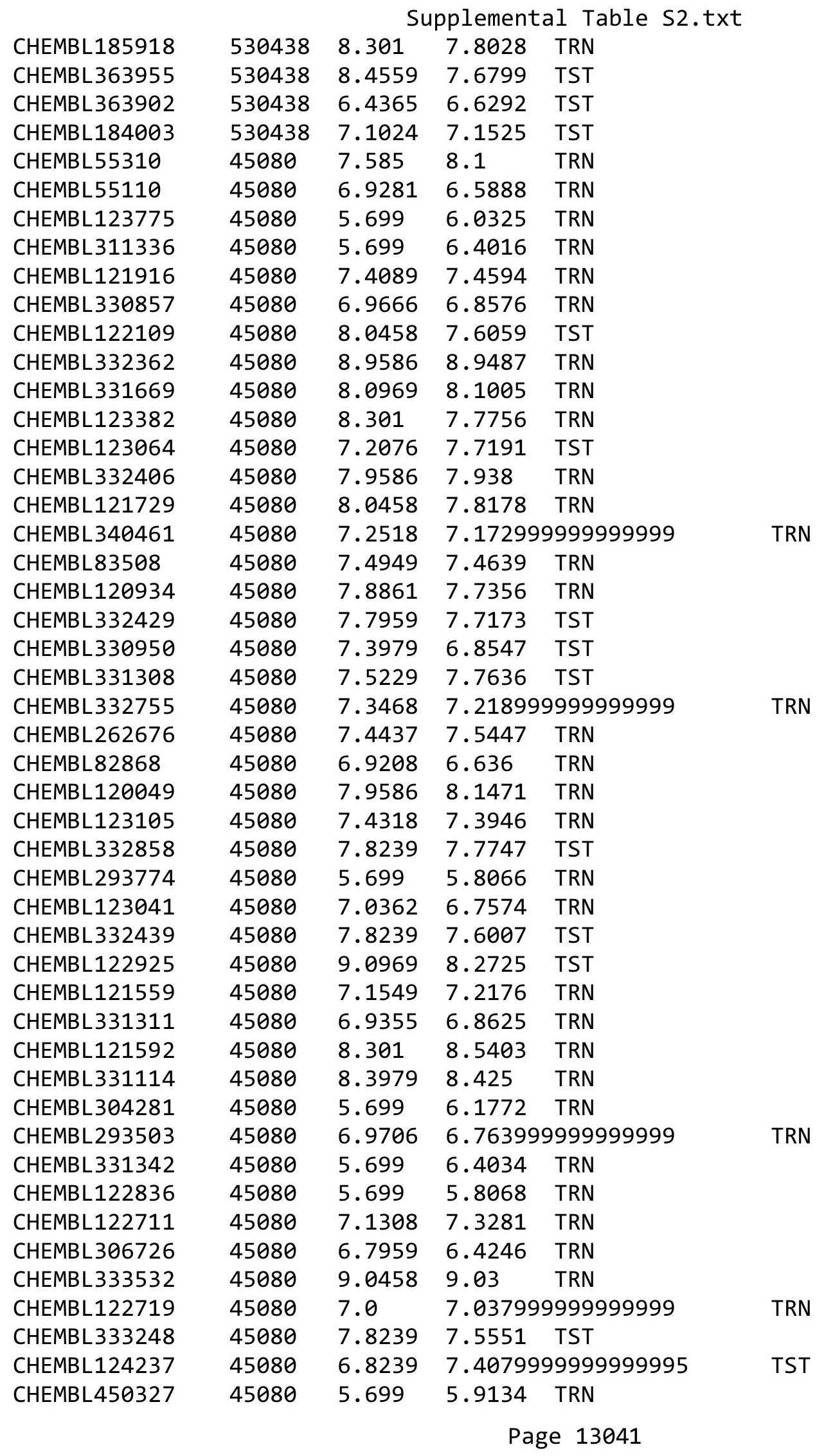




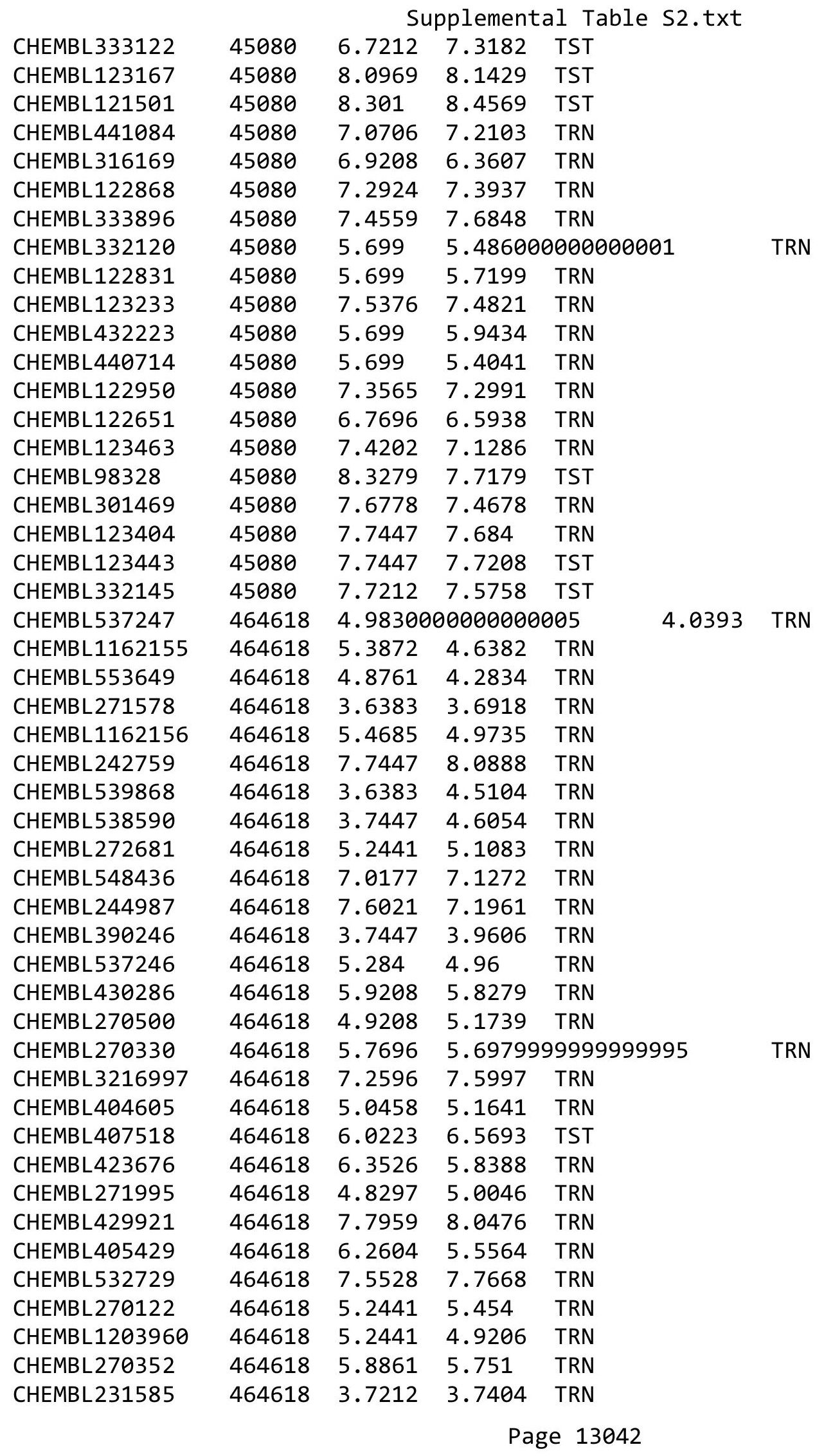




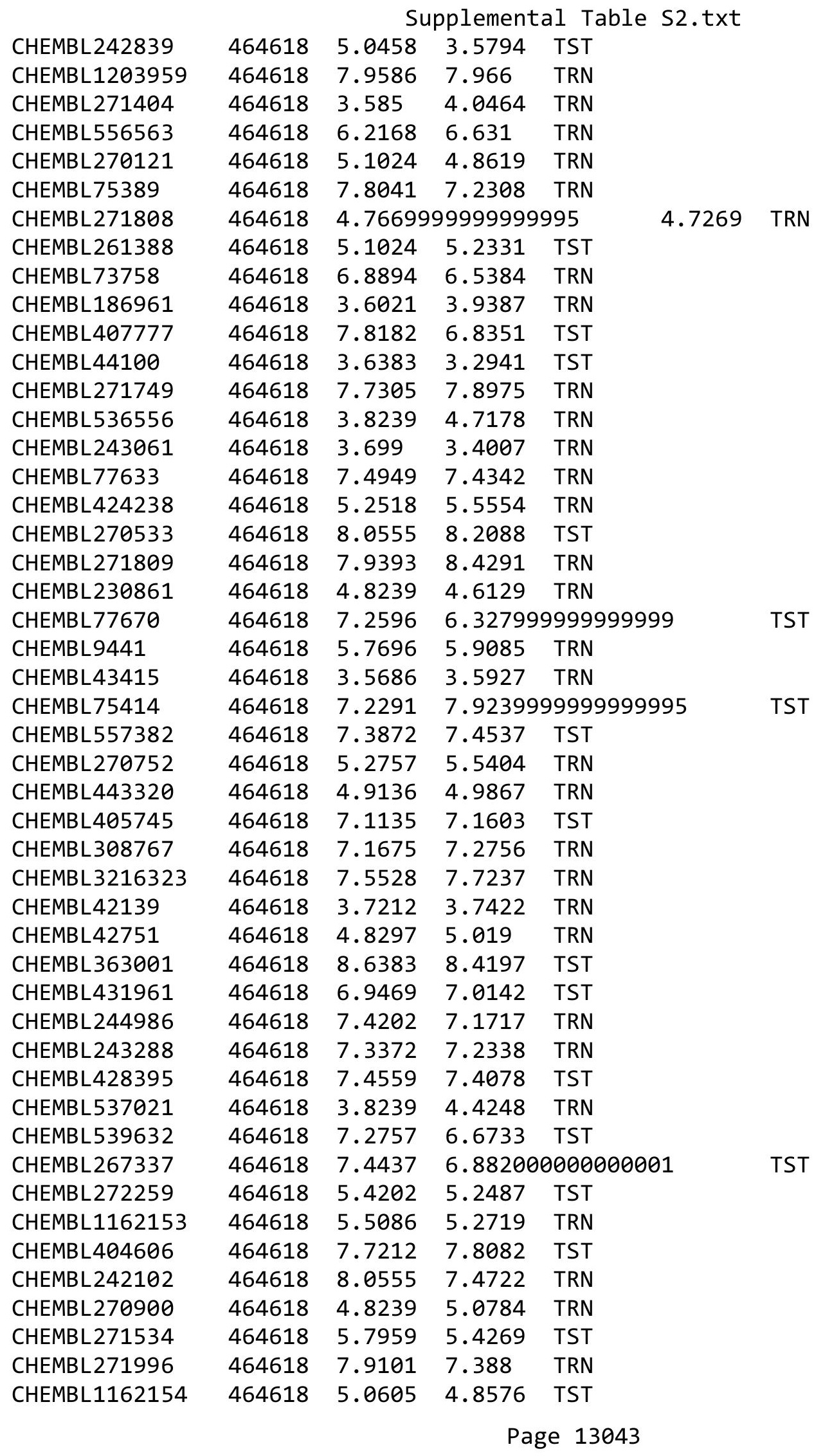


Supplemental Table S2.txt

\begin{tabular}{|c|c|c|c|c|c|}
\hline CHEMBL 3914035 & 1640733 & 7.6383 & 7.0117 & TRN & \\
\hline CHEMBL 3903750 & 1640733 & 6.6737 & 6.8638 & TRN & \\
\hline CHEMBL 3968904 & 1640733 & 7.2076 & 7.0329 & TRN & \\
\hline CHEMBL 3961113 & 1640733 & 7.3565 & 6.4235 & TST & \\
\hline CHEMBL3971234 & 1640733 & 6.7471 & 7.0138 & TRN & \\
\hline CHEMBL3958437 & 1640733 & 6.8794 & 7.2158 & TRN & \\
\hline CHEMBL 3902745 & 1640733 & 6.3188 & 6.7297 & TRN & \\
\hline CHEMBL 3904621 & 1640733 & 6.7496 & 6.575 & TST & \\
\hline CHEMBL 3980199 & 1640733 & 6.9469 & 7.1175 & TRN & \\
\hline CHEMBL3959231 & 1640733 & 7.6778 & 7.2423 & TRN & \\
\hline CHEMBL 3899818 & 1640733 & 7.1938 & 7.0273 & TRN & \\
\hline CHEMBL 3924085 & 1640733 & 6.8125 & 6.949 & TRN & \\
\hline CHEMBL 3908618 & 1640733 & 6.6716 & 6.9814 & TST & \\
\hline CHEMBL3932711 & 1640733 & \multicolumn{2}{|c|}{6.617999999999999} & 6.4371 & TST \\
\hline CHEMBL3909441 & 1640733 & 7.8539 & 7.0753 & TRN & \\
\hline CHEMBL3907199 & 1640733 & 6.5935 & 6.8709 & TRN & \\
\hline CHEMBL3955080 & 1640733 & 7.301 & 7.015 & TST & \\
\hline CHEMBL 3936140 & 1640733 & 6.9318 & 7.1134 & TRN & \\
\hline CHEMBL 3935943 & 1640733 & 6.8962 & 7.1279 & TRN & \\
\hline CHEMBL3965387 & 1640733 & 6.58 & 6.398 & TST & \\
\hline CHEMBL3948594 & 1640733 & 7.0706 & 6.4147 & TST & \\
\hline CHEMBL 3930724 & 1640733 & 6.3215 & 6.3897 & TRN & \\
\hline CHEMBL 3985133 & 1640733 & 6.767 & 6.8802 & TRN & \\
\hline CHEMBL 3945703 & 1640733 & 7.8239 & 6.9387 & TRN & \\
\hline CHEMBL 3956540 & 1640733 & 7.6576 & 7.2157 & TRN & \\
\hline CHEMBL3917938 & 1640733 & 6.7375 & 7.0074 & TST & \\
\hline CHEMBL 3954090 & 1640733 & 6.4437 & 6.3735 & TRN & \\
\hline CHEMBL 3919146 & 1640733 & 6.4023 & 7.1737 & TRN & \\
\hline CHEMBL3891716 & 1640733 & 7.6576 & 7.0311 & TST & \\
\hline CHEMBL 3903873 & 1640733 & 6.5143 & $6.71200 t$ & 0000000001 & TRN \\
\hline CHEMBL 3955616 & 1640733 & 7.0315 & 7.0429 & TRN & \\
\hline CHEMBL 3921374 & 1640733 & 6.8356 & 6.997006 & 0000000001 & TRA \\
\hline CHEMBL 3954292 & 1640733 & 6.6925 & 7.1925 & TRN & \\
\hline CHEMBL3977400 & 1640733 & 6.8601 & 7.1648 & TRN & \\
\hline CHEMBL 3969551 & 1640733 & 7.1308 & 7.0562 & TRN & \\
\hline CHEMBL 3943375 & 1640733 & 6.9355 & 7.2197 & TRN & \\
\hline CHEMBL3980402 & 1640733 & 7.0706 & 7.039 & TRN & \\
\hline CHEMBL 3977961 & 1640733 & 6.8239 & 7.0487 & TST & \\
\hline CHEMBL 3973025 & 1640733 & 6.4855 & 6.9195 & TRN & \\
\hline CHEMBL 3939837 & 1640733 & 6.4237 & 6.3915 & TST & \\
\hline CHEMBL3953166 & 1640733 & 6.0 & 6.9646 & TRN & \\
\hline CHEMBL3895962 & 1640733 & 6.8356 & 6.9916 & TRN & \\
\hline CHEMBL3906760 & 1640733 & 7.585 & 7.0783 & TRN & \\
\hline CHEMBL 3926453 & 1640733 & 6.4202 & 6.7111 & TST & \\
\hline CHEMBL 3980607 & 1640733 & 7.1805 & 7.0075 & TRN & \\
\hline CHEMBL 3892600 & 1640733 & 6.8508 & 7.1335 & TRN & \\
\hline CHEMBL3899906 & 1640733 & 6.0 & 6.8256 & TRN & \\
\hline CHEMBL3914023 & 1640733 & 6.8069 & 7.0149 & TRN & \\
\hline
\end{tabular}

Page 13044 
Supplemental Table S2.txt

\begin{tabular}{|c|c|c|c|c|c|}
\hline CHEMBL 3933500 & 1640733 & 8.5229 & 7.2716 & TRN & \\
\hline CHEMBL 3922124 & 1640733 & 7.6778 & 7.0291 & TRN & \\
\hline CHEMBL3917497 & 1640733 & 6.5498 & 7.0616 & TRN & \\
\hline CHEMBL3930771 & 1640733 & 6.8069 & 6.603 & TRN & \\
\hline CHEMBL3949790 & 1640733 & 7.301 & 6.4012 & TST & \\
\hline CHEMBL3923974 & 1640733 & 6.0 & 6.9887 & TRN & \\
\hline CHEMBL3969550 & 1640733 & 6.4949 & 6.62 & TST & \\
\hline CHEMBL3916596 & 1640733 & 7.0605 & 6.9525 & TRN & \\
\hline CHEMBL 3979430 & 1640733 & 6.7282 & 6.9309 & TRN & \\
\hline CHEMBL3938537 & 1640733 & 6.58 & 6.8607 & TRN & \\
\hline CHEMBL3963670 & 1640733 & 7.6198 & 6.7978 & TST & \\
\hline CHEMBL 3900082 & 1640733 & 6.718999 & 999999999 & 7.0565 & TST \\
\hline CHEMBL3950796 & 1640733 & 6.0 & 7.1414 & TRN & \\
\hline CHEMBL 3943427 & 1640733 & 7.4318 & 6.9305 & TRN & \\
\hline CHEMBL3969488 & 1640733 & 6.2692 & 7.1901 & TRN & \\
\hline CHEMBL3924276 & 1640733 & 6.4935 & 6.342000 & 0000000005 & TRN \\
\hline CHEMBL3946199 & 1640733 & 7.1367 & 6.9894 & TRN & \\
\hline CHEMBL3891671 & 1640733 & 6.567 & 6.7829 & TRN & \\
\hline CHEMBL 3986193 & 1640733 & 6.6819 & 7.069 & TST & \\
\hline CHEMBL3931868 & 1640733 & 6.5086 & 6.5751 & TST & \\
\hline CHEMBL3969369 & 1640733 & 7.0809 & 7.2589 & TRN & \\
\hline CHEMBL 3947153 & 1640733 & 7.6198 & 7.0775 & TRN & \\
\hline CHEMBL3894402 & 1640733 & 6.7033 & 7.0537 & TRN & \\
\hline CHEMBL 3915088 & 1640733 & 7.1308 & 6.9817 & TRN & \\
\hline CHEMBL3945852 & 1640733 & 6.7645 & 7.0518 & TRN & \\
\hline CHEMBL3960248 & 1640733 & 7.7212 & 7.0958 & TRN & \\
\hline CHEMBL 3954812 & 1640733 & 7.6576 & 7.1387 & TRN & \\
\hline CHEMBL3901149 & 1640733 & 6.718999 & 999999999 & 7.0807 & TRN \\
\hline CHEMBL 3917170 & 1640733 & 6.5575 & 6.3811 & TRN & \\
\hline CHEMBL 3970722 & 1640733 & 8.0458 & 6.7208 & TRN & \\
\hline CHEMBL3976845 & 1640733 & 6.4584 & 6.9426 & TRN & \\
\hline CHEMBL 3896333 & 1640733 & 7.5086 & 6.9769 & TRN & \\
\hline CHEMBL3963456 & 1640733 & 6.7282 & 7.0199 & TST & \\
\hline CHEMBL 3982527 & 1640733 & 7.0458 & 7.2282 & TRN & \\
\hline CHEMBL 3916384 & 1640733 & 8.3979 & 7.0206 & TST & \\
\hline CHEMBL3983073 & 1640733 & 7.9586 & 7.1848 & TRN & \\
\hline CHEMBL 3921845 & 1640733 & 7.4949 & 6.9939 & TRN & \\
\hline CHEMBL3894896 & 1640733 & 6.8761 & 7.1416 & TRN & \\
\hline CHEMBL 3919080 & 1640733 & 7.3768 & 7.0734 & TRN & \\
\hline CHEMBL 3983848 & 1640733 & 6.8601 & 6.7949 & TRN & \\
\hline CHEMBL3953010 & 1640733 & 7.699 & 7.1665 & TRN & \\
\hline CHEMBL 3956755 & 1640733 & 6.6696 & 6.4744 & TRN & \\
\hline CHEMBL3939762 & 1640733 & 6.5817 & 7.1461 & TRN & \\
\hline CHEMBL 3925397 & 1640733 & 7.1249 & 6.3235 & TRN & \\
\hline CHEMBL3985359 & 1640733 & 7.4685 & 7.0392 & TRN & \\
\hline CHEMBL3938770 & 1640733 & 6.8477 & 7.0072 & TRN & \\
\hline CHEMBL 3916434 & 1640733 & 6.4123 & 7.0002 & TRN & \\
\hline CHEMBL 3912844 & 1640733 & 7.9208 & 7.0547 & TRN & \\
\hline
\end{tabular}

Page 13045 
Supplemental Table S2.txt

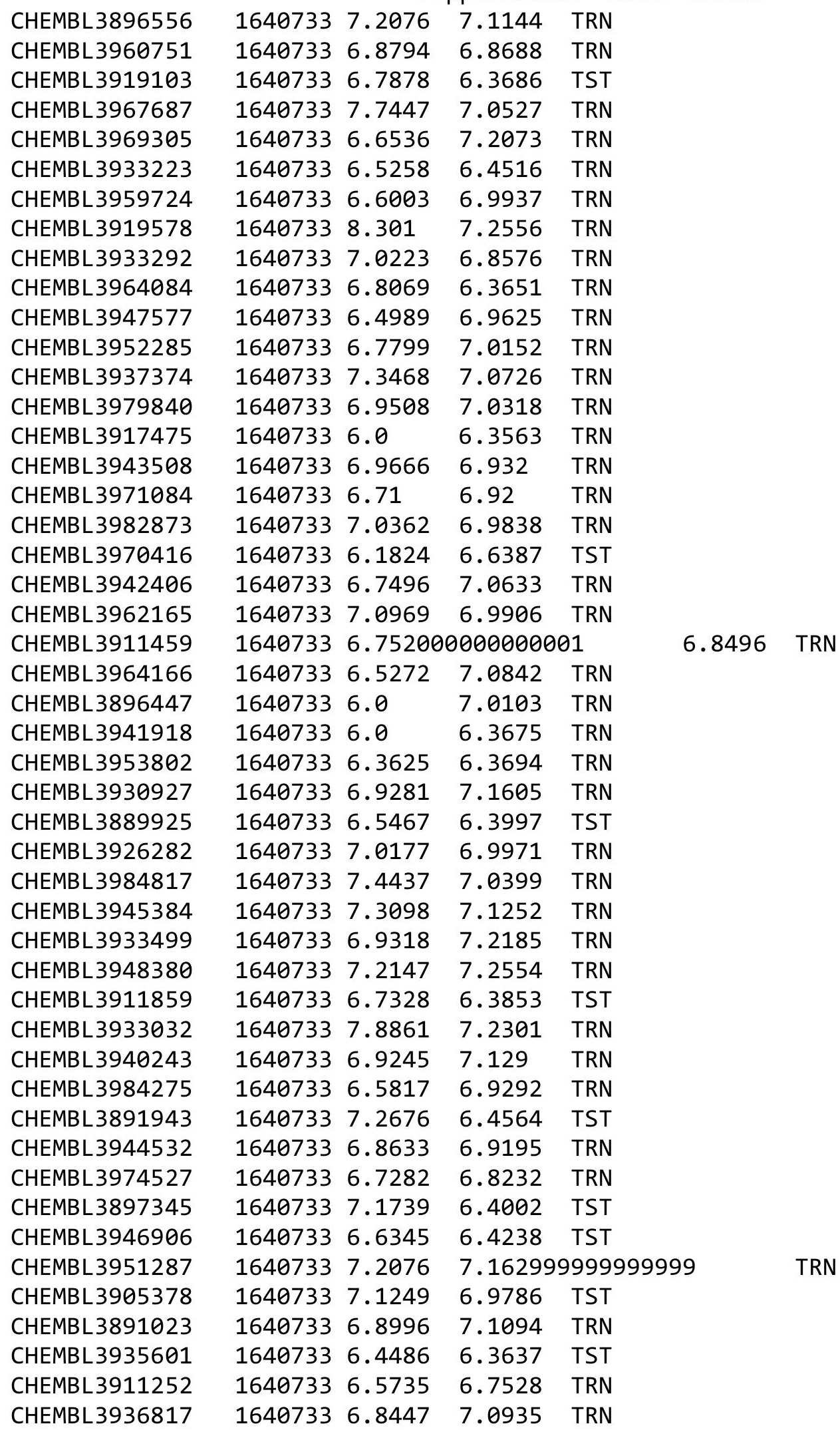

Page 13046 
Supplemental Table S2.txt

\begin{tabular}{|c|c|c|c|c|c|}
\hline CHEMBL3960494 & 1640733 & 7.1427 & \multicolumn{2}{|c|}{ 7.162999999999999 } & TST \\
\hline CHEMBL3910188 & 1640733 & 6.5784 & 6.6456 & TST & \\
\hline CHEMBL3890087 & 1640733 & 7.2518 & 7.0702 & TRN & \\
\hline CHEMBL3892358 & 1640733 & 6.6716 & 7.0514 & TRN & \\
\hline CHEMBL 3896494 & 1640733 & 7.0915 & 6.9878 & TRN & \\
\hline CHEMBL3940761 & 1640733 & 7.3188 & 6.3864 & TST & \\
\hline CHEMBL3933427 & 1640733 & 6.7375 & 7.0033 & TRN & \\
\hline CHEMBL3893865 & 1640733 & 6.8386 & 7.2366 & TST & \\
\hline CHEMBL3961342 & 1640733 & 6.8182 & 6.979 & TST & \\
\hline CHEMBL3962827 & 1640733 & 6.3872 & 6.6498 & TST & \\
\hline CHEMBL3923682 & 1640733 & 7.0044 & 6.9356 & TRN & \\
\hline CHEMBL3924100 & 1640733 & 6.699 & 7.0668 & TST & \\
\hline CHEMBL3948592 & 1640733 & 7.1549 & 6.4013 & TST & \\
\hline CHEMBL3981037 & 1640733 & 6.2798 & 7.0026 & TRN & \\
\hline CHEMBL 3941587 & 1640733 & 6.8827 & 6.693 & TST & \\
\hline CHEMBL 3914320 & 1640733 & 6.7545 & 6.9924 & TST & \\
\hline CHEMBL3918537 & 1640733 & 7.4089 & 6.9651 & TST & \\
\hline CHEMBL3909115 & 1640733 & 7.2518 & 7.2242 & TRN & \\
\hline CHEMBL3944940 & 1640733 & 6.0 & 7.0559 & TST & \\
\hline CHEMBL3916671 & 1640733 & 8.0969 & 7.0676 & TRN & \\
\hline CHEMBL3943300 & 1640733 & 6.9547 & 6.4275 & TST & \\
\hline CHEMBL3932616 & 1640733 & 6.5058 & 6.5474 & TST & \\
\hline CHEMBL3961650 & 1640733 & 6.4237 & 6.8311 & TRN & \\
\hline CHEMBL3983254 & 1640733 & 6.6904 & 6.7105 & TRN & \\
\hline CHEMBL 3940886 & 1640733 & 6.0742 & 6.6454 & TST & \\
\hline CHEMBL3979802 & 1640733 & 6.8761 & 7.0036 & TST & \\
\hline CHEMBL3930749 & 1640733 & 6.8601 & 7.2494 & TRN & \\
\hline CHEMBL3984888 & 1640733 & 6.9872 & 7.1436 & TST & \\
\hline CHEMBL3950460 & 1640733 & 7.0506 & 7.0923 & TRN & \\
\hline CHEMBL 3939741 & 1640733 & 7.1192 & 7.1633 & TRN & \\
\hline CHEMBL3917984 & 1640733 & 7.3468 & 6.9232 & TRN & \\
\hline CHEMBL3916170 & 1640733 & 6.9066 & 6.7866 & TRN & \\
\hline CHEMBL3951395 & 1640733 & 6.8416 & 6.93 & TRN & \\
\hline CHEMBL3973195 & 1640733 & 7.1308 & 7.0845 & TRN & \\
\hline CHEMBL3905423 & 1640733 & 7.1367 & 6.855 & TRN & \\
\hline CHEMBL3948063 & 1640733 & 6.7305 & 6.9309 & TRN & \\
\hline CHEMBL3925321 & 1640733 & 7.1805 & 7.2086 & TRN & \\
\hline CHEMBL3945619 & 1640733 & 6.5834 & 6.891 & TRN & \\
\hline CHEMBL3929603 & 1640733 & 6.5867 & 6.4968 & TST & \\
\hline CHEMBL3978142 & 1640733 & 7.7959 & 7.1022 & TRN & \\
\hline CHEMBL3904881 & 1640733 & 7.7212 & 7.0935 & TRN & \\
\hline CHEMBL3924026 & 1640733 & 6.0 & 7.0725 & TST & \\
\hline CHEMBL3940413 & 1640733 & 8.699 & 7.0191 & TRN & \\
\hline CHEMBL3930089 & 1640733 & 6.9431 & 7.178 & TRN & \\
\hline CHEMBL3957602 & 1640733 & 6.7595 & 7.1723 & TRN & \\
\hline CHEMBL 3908551 & 1640733 & 7.4202 & 7.07799 & 9999999999 & TRN \\
\hline CHEMBL3899269 & 1640733 & 7.4685 & 7.3003 & TRN & \\
\hline CHEMBL3929503 & 1640733 & 6.7399 & 6.8532 & TRN & \\
\hline
\end{tabular}


Supplemental Table S2.txt

\begin{tabular}{|c|c|c|c|c|}
\hline CHEMBL3939696 & 1640733 & 6.8386 & 6.7705 & TRN \\
\hline CHEMBL 3925675 & 1640733 & 7.1249 & 7.1371 & TRN \\
\hline CHEMBL3971865 & 1640733 & 6.9914 & 7.0703 & TRN \\
\hline CHEMBL3956759 & 1640733 & 6.4295 & 6.9164 & TRN \\
\hline CHEMBL 3949021 & 1640733 & 7.5376 & 7.2564 & TRN \\
\hline CHEMBL 3973640 & 1640733 & 7.7447 & 6.9714 & TST \\
\hline CHEMBL3910191 & 1640733 & 6.5918 & 7.15600 & 0000000001 \\
\hline CHEMBL 3934292 & 1640733 & 6.3354 & 6.3868 & TST \\
\hline CHEMBL3955679 & 1640733 & 7.4685 & 7.0745 & TRN \\
\hline CHEMBL 3947914 & 1640733 & 6.6108 & 6.3658 & TST \\
\hline CHEMBL 3937219 & 1640733 & 6.0 & 7.0478 & TRN \\
\hline CHEMBL 3985421 & 1640733 & 7.585 & 7.1901 & TRN \\
\hline CHEMBL 3909663 & 1640733 & 7.0223 & 7.0727 & TRN \\
\hline CHEMBL3901545 & 1640733 & 6.5072 & 6.7527 & TRN \\
\hline CHEMBL 3936275 & 1640733 & 7.2441 & 7.0955 & TRN \\
\hline CHEMBL 3903486 & 1640733 & 7.1192 & 6.999 & TST \\
\hline CHEMBL3977785 & 1640733 & 6.5017 & 6.76 & TRN \\
\hline CHEMBL 3908865 & 1640733 & 7.3468 & 7.028 & TRN \\
\hline CHEMBL3914794 & 1640733 & 6.9626 & 6.7552 & TRN \\
\hline CHEMBL 3906255 & 1640733 & 6.5406 & 6.5961 & TST \\
\hline CHEMBL3916302 & 1640733 & 7.5086 & 7.0231 & TRN \\
\hline CHEMBL 3904330 & 1640733 & 6.5017 & 6.3551 & TST \\
\hline CHEMBL3909166 & 1640733 & 6.75700 & 00000000 & 6.9311 \\
\hline CHEMBL3938135 & 1640733 & 6.4711 & 6.7899 & TRN \\
\hline CHEMBL 3986136 & 1640733 & 8.301 & 7.075 & TST \\
\hline CHEMBL 3975803 & 1640733 & 7.6198 & 7.1155 & TRN \\
\hline CHEMBL369550 & 303283 & 7.7447 & 7.7593 & TRN \\
\hline CHEMBL176071 & 303283 & 8.3979 & 8.2824 & TRN \\
\hline CHEMBL173672 & 303283 & 8.3979 & 8.1394 & TRN \\
\hline CHEMBL425685 & 303283 & 6.8239 & 6.7953 & TRN \\
\hline CHEMBL 360729 & 303283 & 5.0 & 5.9487 & TRN \\
\hline CHEMBL368382 & 303283 & 7.5229 & 8.0764 & TRN \\
\hline CHEMBL113142 & 303283 & 9.0458 & 6.9631 & TST \\
\hline CHEMBL177654 & 303283 & 7.1024 & 6.4821 & TRN \\
\hline CHEMBL175568 & 303283 & 5.301 & 6.3106 & TRN \\
\hline CHEMBL367593 & 303283 & 8.0969 & 8.2732 & TRN \\
\hline CHEMBL175927 & 303283 & 6.7447 & 5.8369 & TRN \\
\hline CHEMBL368092 & 303283 & 6.5686 & 6.2548 & TRN \\
\hline CHEMBL426782 & 303283 & 7.4318 & 7.7298 & TRN \\
\hline CHEMBL 177449 & 303283 & 6.8861 & 6.1169 & TRN \\
\hline CHEMBL177711 & 303283 & 6.7447 & 6.6774 & TRN \\
\hline CHEMBL17127 & 303283 & 7.4318 & 6.722 & TST \\
\hline CHEMBL368488 & 303283 & 5.9208 & 6.5313 & TRN \\
\hline CHEMBL174628 & 303283 & 8.3979 & 7.7407 & TRN \\
\hline CHEMBL 368070 & 303283 & 7.9586 & 7.9135 & TRN \\
\hline CHEMBL 368201 & 303283 & 8.301 & 8.2791 & TRN \\
\hline CHEMBL177539 & 303283 & 7.9208 & 7.7219 & TRN \\
\hline CHEMBL177943 & 303283 & 7.8539 & 8.1194 & TRN \\
\hline
\end{tabular}




\begin{tabular}{|c|c|c|c|c|c|}
\hline \multicolumn{6}{|c|}{ Supplemental Table S2.txt } \\
\hline CHEMBL369373 & 303283 & 8.1549 & 7.7417 & TRN & \\
\hline CHEMBL177386 & 303283 & 7.6576 & 7.8922 & TRN & \\
\hline CHEMBL361229 & 303283 & 6.2874 & 7.3574 & TRN & \\
\hline CHEMBL177859 & 303283 & 8.0969 & 8.0208 & TRN & \\
\hline CHEMBL177609 & 303283 & 7.6021 & 7.9568 & TRN & \\
\hline CHEMBL366472 & 303283 & 7.8539 & 6.6434 & TST & \\
\hline CHEMBL368983 & 303283 & 6.2518 & 6.5157 & TST & \\
\hline CHEMBL359641 & 303283 & 7.4089 & 7.8849 & TRN & \\
\hline CHEMBL173993 & 303283 & 8.1549 & 8.1458 & TRN & \\
\hline CHEMBL27508 & 303283 & 7.3768 & 6.5515 & TST & \\
\hline CHEMBL177441 & 303283 & 5.0 & 6.37299 & 9999999999 & TST \\
\hline CHEMBL178639 & 303283 & 5.0 & 6.3873 & TST & \\
\hline CHEMBL368619 & 303283 & 7.7447 & 6.1289 & TST & \\
\hline CHEMBL177710 & 303283 & 6.1675 & 6.5242 & TST & \\
\hline CHEMBL173941 & 303283 & 8.5229 & 6.8554 & TST & \\
\hline CHEMBL175569 & 303283 & 7.284 & 6.0409 & TST & \\
\hline CHEMBL177446 & 303283 & 8.3979 & 8.1218 & TRN & \\
\hline CHEMBL175818 & 303283 & 7.5229 & 7.4093 & TRN & \\
\hline CHEMBL 368827 & 303283 & 7.2441 & 7.7099 & TRN & \\
\hline CHEMBL175645 & 303283 & 7.8539 & 7.7479 & TRN & \\
\hline CHEMBL175564 & 303283 & 7.8239 & 7.6183 & TRN & \\
\hline CHEMBL177532 & 303283 & 8.301 & 8.158 & TRN & \\
\hline CHEMBL179478 & 303283 & 8.5229 & 7.8736 & TRN & \\
\hline CHEMBL175713 & 303283 & 6.699 & 6.3767 & TST & \\
\hline CHEMBL368620 & 303283 & 7.4437 & 7.8874 & TRN & \\
\hline CHEMBL177676 & 303283 & 5.0 & 6.4598 & TST & \\
\hline CHEMBL175298 & 303283 & 7.4089 & 7.8616 & TRN & \\
\hline CHEMBL 369070 & 303283 & 8.1549 & 7.7927 & TRN & \\
\hline CHEMBL 353323 & 303283 & 7.9208 & 6.6039 & TST & \\
\hline CHEMBL177615 & 303283 & 8.3979 & 8.1774 & TRN & \\
\hline CHEMBL177229 & 303283 & 7.7696 & 7.6315 & TRN & \\
\hline CHEMBL176039 & 303283 & 8.699 & 8.0422 & TRN & \\
\hline CHEMBL3653939 & 1528550 & 6.301 & 6.5101 & TRN & \\
\hline CHEMBL3653951 & 1528550 & 6.7959 & 6.725 & TRN & \\
\hline CHEMBL3653906 & 1528550 & 6.7447 & 6.6323 & TRN & \\
\hline CHEMBL3653912 & 1528550 & 6.5086 & 5.5613 & TST & \\
\hline CHEMBL 3653918 & 1528550 & 6.6383 & 6.6064 & TRN & \\
\hline CHEMBL3653944 & 1528550 & 6.6021 & 6.5984 & TRN & \\
\hline CHEMBL3653920 & 1528550 & 7.0 & 6.902 & TRN & \\
\hline CHEMBL 3653851 & 1528550 & 6.7212 & 7.001 & TRN & \\
\hline CHEMBL3653894 & 1528550 & 6.8239 & 6.8465 & TRN & \\
\hline CHEMBL 3653932 & 1528550 & 6.3979 & 6.6237 & TRN & \\
\hline CHEMBL3653943 & 1528550 & 6.5376 & 6.6687 & TRN & \\
\hline CHEMBL3653901 & 1528550 & 6.7212 & 6.3646 & TST & \\
\hline CHEMBL3653934 & 1528550 & 5.4698 & 5.4948 & TRN & \\
\hline CHEMBL3653954 & 1528550 & 6.5086 & 6.604 & TRN & \\
\hline CHEMBL 3653853 & 1528550 & 5.8416 & 6.0393 & TST & \\
\hline CHEMBL 3653889 & 1528550 & 6.7212 & 6.5967 & TRN & \\
\hline
\end{tabular}

Page 13049 
Supplemental Table S2.txt

\begin{tabular}{|c|c|c|c|c|c|}
\hline CHEMBL 3653867 & 1528550 & 6.6383 & 6.6264 & TRN & \\
\hline CHEMBL3653904 & 1528550 & 6.699 & 6.5967 & TRN & \\
\hline CHEMBL 3653907 & 1528550 & 6.4949 & \multicolumn{2}{|c|}{6.582000000000001} & TRN \\
\hline CHEMBL 3653877 & 1528550 & 6.4089 & 6.3377 & TRN & \\
\hline CHEMBL 3653892 & 1528550 & 6.7696 & 6.595 & TRN & \\
\hline CHEMBL 3653921 & 1528550 & 6.301 & 5.7493 & TST & \\
\hline CHEMBL 3653876 & 1528550 & 6.8239 & 6.8103 & TRN & \\
\hline CHEMBL 3653927 & 1528550 & 6.4685 & 5.8229 & TST & \\
\hline CHEMBL3653936 & 1528550 & 5.3605 & 5.3855 & TRN & \\
\hline CHEMBL 3653938 & 1528550 & 6.0757 & 6.0025 & TST & \\
\hline CHEMBL 3653854 & 1528550 & 6.7696 & 6.233 & TRN & \\
\hline CHEMBL 3653930 & 1528550 & 6.9208 & 6.8526 & TRN & \\
\hline CHEMBL 3653935 & 1528550 & 5.426 & 5.5024 & TRN & \\
\hline CHEMBL3653850 & 1528550 & 7.2218 & 7.38 & TRN & \\
\hline CHEMBL3653905 & 1528550 & 6.7696 & 6.7419 & TRN & \\
\hline CHEMBL 3653866 & 1528550 & 6.8861 & 6.8349 & TRN & \\
\hline CHEMBL3653886 & 1528550 & 6.6021 & 6.473 & TRN & \\
\hline CHEMBL 3653959 & 1528550 & 6.0757 & 6.6474 & TST & \\
\hline CHEMBL3653953 & 1528550 & 6.6778 & 6.6827 & TRN & \\
\hline CHEMBL 3653925 & 1528550 & 7.0969 & 6.9443 & TRN & \\
\hline CHEMBL 3653958 & 1528550 & 6.4949 & \multicolumn{2}{|c|}{6.757000000000001} & TRN \\
\hline CHEMBL3653899 & 1528550 & 6.7696 & 6.8743 & TRN & \\
\hline CHEMBL3653909 & 1528550 & 6.0605 & 5.9811 & TRN & \\
\hline CHEMBL3653960 & 1528550 & 3.0 & 3.3923 & TRN & \\
\hline CHEMBL 3653885 & 1528550 & 6.4318 & 5.5106 & TST & \\
\hline CHEMBL3653961 & 1528550 & 3.0 & 2.8272 & TRN & \\
\hline CHEMBL3653941 & 1528550 & 7.1549 & 7.314 & TRN & \\
\hline CHEMBL 3653875 & 1528550 & 6.8861 & 6.8103 & TRN & \\
\hline CHEMBL3653852 & 1528550 & 6.4685 & 6.477 & TRN & \\
\hline CHEMBL 3653896 & 1528550 & 6.7212 & 6.8027 & TRN & \\
\hline CHEMBL 3653956 & 1528550 & 6.9586 & 6.7635 & TRN & \\
\hline CHEMBL 3653945 & 1528550 & 6.0809 & 6.1002 & TRN & \\
\hline CHEMBL 3653849 & 1528550 & 6.7212 & 6.7662 & TRN & \\
\hline CHEMBL3653900 & 1528550 & 6.1308 & 6.0616 & TRN & \\
\hline CHEMBL 3653870 & 1528550 & 6.3468 & 6.3419 & TRN & \\
\hline CHEMBL3653919 & 1528550 & 6.1024 & 6.2449 & TRN & \\
\hline CHEMBL 3653962 & 1528550 & 3.0 & 3.0372 & TRN & \\
\hline CHEMBL 3653931 & 1528550 & 7.2218 & 7.1216 & TRN & \\
\hline CHEMBL3653915 & 1528550 & 6.4559 & 6.4957 & TRN & \\
\hline CHEMBL3653933 & 1528550 & 7.0 & 6.8413 & TRN & \\
\hline CHEMBL 3653893 & 1528550 & 6.6576 & 6.5834 & TRN & \\
\hline CHEMBL 3653884 & 1528550 & 6.3279 & 6.2292 & TRN & \\
\hline CHEMBL3653859 & 1528550 & 7.1549 & \multicolumn{2}{|c|}{7.2010000000000005} & TRN \\
\hline CHEMBL3653856 & 1528550 & 7.0 & 7.0092 & TRN & \\
\hline CHEMBL3653910 & 1528550 & 6.6778 & 6.5992 & TRN & \\
\hline CHEMBL 3653898 & 1528550 & 6.6778 & 6.7952 & TRN & \\
\hline CHEMBL 3653862 & 1528550 & 6.8539 & 6.5634 & TRN & \\
\hline CHEMBL3653858 & 1528550 & 6.3188 & 6.2954 & TRN & \\
\hline
\end{tabular}


Supplemental Table S2.txt

\begin{tabular}{|c|c|c|}
\hline AEMBL3653937 & & \\
\hline & & \\
\hline $\mathrm{C}$ & & \\
\hline IEMBL & & 95 \\
\hline AEMBL3 & & \\
\hline AEMBL3653914 & 528550 & 552 \\
\hline IEMBL: & $52 \varepsilon$ & 346 \\
\hline EMBL & C? & \\
\hline AEMBL3653864 & 528550 & 570 \\
\hline IEMBL 36 & 528550 & $56 \varepsilon$ \\
\hline AEMBL3653913 & 528550 & \\
\hline IEMBL3 & 528550 & 96 \\
\hline IEMBL & 50 & \\
\hline AEMBL3 & 528550 & 008 \\
\hline IEMBL36 & 50 & 397 \\
\hline IEMBL3 & .528 & נת \\
\hline AEMBL: & 528 & 6.677 \\
\hline AEMBL & 50 & 815 \\
\hline IEMBL & 50 & 187 \\
\hline IEMBL & & 853 \\
\hline AEMBL. & 528 & . \\
\hline IEMBL & 528 & 502 \\
\hline IEMBL & 528 & 3539 \\
\hline IEMBL: & 50 & 7.045 \\
\hline IEMBL36 & & 6.568 \\
\hline IEMBL36 & .528 & 6.431 \\
\hline IEMBL & 0 & 3268 \\
\hline IEMB & 528 & 208 \\
\hline IEMBL & 50 & 6.677 \\
\hline AEMBL3653880 & 50 & 7.154 \\
\hline AEMBL3 & 528 & 323 \\
\hline IEMBL & 5285 & 52 \\
\hline 71 & 50 & 6.8539 \\
\hline JEMBL 36 & 528550 & 7.0 \\
\hline HEMBL3639527 & 528550 & 6.823 \\
\hline IEMBL & 855 & 6.744 \\
\hline IEMBL & 0 & 6.657 \\
\hline HEMBL & 50 & 6.7959 \\
\hline HEMBL3653881 & 528550 & 5.806 \\
\hline AEMBL3653888 & 52855 & 6.769 \\
\hline CHEMBL & 15285 & 6.886 \\
\hline CHEMBL: & 528550 & 7.045 \\
\hline CHEMBL 3 & 528550 & 6.161 \\
\hline AEMBL3653879 & 528550 & 6.657 \\
\hline CHEMBL 3653911 & 52855 & 6.657 \\
\hline CHEMBL: & $152855 e$ & 6.920 \\
\hline CHEMBL & ז & 5.823 \\
\hline CHEMBL3 & & 7.0 \\
\hline
\end{tabular}

6.2333 TST

6.8916 TRN

6.5475 TRN

6.693 TRN

6.1935 TRN

6.2339 TST

6.3025 TRN

5.747999999999999

TST

7.8826 TST

5.7772 TST

6.8258 TRN

7.3386 TRN

6.6462 TST

6.9353 TST

5.6499 TST

6.9753 TRN

5.7758 TST

5.4916 TST

6.2097 TRN

7.0171 TST

6.8413 TRN

5.8682 TST

6.7142 TRN

7.1228 TRN

6.6424 TRN

7.2331 TST

5.7914 TRN

7.1508 TRN

6.9047 TRN

6.9782 TRN

7.0076 TST

6.5218 TRN

6.9034 TRN

6.223 TST

6.9503 TRN

5.6862 TST

6.6838 TRN

6.8185 TRN

5.9707 TST

6.7183 TRN

6.8947 TRN

7.0027 TRN

6.2658 TRN

6.1082 TST

6.2192 TST

6.9137 TRN

6.8084 TST

7.0189 TRN

Page 13051 
Supplemental Table S2.txt

\begin{tabular}{|c|c|c|c|c|c|}
\hline CHEMBL3653946 & 1528550 & 6.7212 & 5.9744 & TST & \\
\hline CHEMBL3653895 & 1528550 & 6.6778 & 6.7579 & TRN & \\
\hline CHEMBL3653891 & 1528550 & 6.5686 & 6.6083 & TRN & \\
\hline CHEMBL389491 & 440136 & 8.7447 & 8.5574 & TRN & \\
\hline CHEMBL226903 & 440136 & 7.7696 & 7.9 & TRN & \\
\hline CHEMBL226778 & 440136 & 6.4895 & 7.0434 & TRN & \\
\hline CHEMBL439012 & 440136 & 8.1549 & 7.7971 & TRN & \\
\hline CHEMBL376115 & 440136 & 7.8539 & \multicolumn{2}{|c|}{7.672000000000001} & TRN \\
\hline CHEMBL447539 & 440136 & 7.7696 & 7.5673 & TRN & \\
\hline CHEMBL227102 & 440136 & 6.9706 & 7.4145 & TRN & \\
\hline CHEMBL229759 & 440136 & 7.5376 & 7.5891 & TRN & \\
\hline CHEMBL 229380 & 440136 & 7.6778 & 7.7111 & TRN & \\
\hline CHEMBL437488 & 440136 & 8.2218 & 7.9538 & TRN & \\
\hline CHEMBL226958 & 440136 & 7.5686 & 7.7722 & TRN & \\
\hline CHEMBL226840 & 440136 & 8.5229 & 8.2347 & TRN & \\
\hline CHEMBL 226748 & 440136 & 8.699 & 7.8303 & TRN & \\
\hline CHEMBL226777 & 440136 & 8.5229 & 7.7427 & TRN & \\
\hline CHEMBL226890 & 440136 & 7.7696 & 7.9032 & TRN & \\
\hline CHEMBL427427 & 440136 & 7.585 & 8.0055 & TRN & \\
\hline CHEMBL3827377 & 440136 & 5.0572 & 6.938 & TST & \\
\hline CHEMBL427430 & 440136 & 7.699 & 7.9105 & TRN & \\
\hline CHEMBL226853 & 440136 & 8.2218 & 7.4769 & TRN & \\
\hline CHEMBL 229324 & 440136 & 7.5528 & 7.8006 & TRN & \\
\hline CHEMBL 226851 & 440136 & 7.4089 & 7.4272 & TRN & \\
\hline CHEMBL373953 & 440136 & 8.2218 & 7.6128 & TST & \\
\hline CHEMBL 227048 & 440136 & 7.0088 & \multicolumn{2}{|c|}{7.0520000000000005} & TRN \\
\hline CHEMBL387988 & 440136 & 6.8125 & 6.6474 & TRN & \\
\hline CHEMBL 226747 & 440136 & 7.6021 & 7.4976 & TRN & \\
\hline CHEMBL 229375 & 440136 & 5.1805 & 6.9761 & TST & \\
\hline CHEMBL389021 & 440136 & 7.585 & 7.4461 & TRN & \\
\hline CHEMBL 375963 & 440136 & 7.3372 & \multicolumn{2}{|c|}{7.4110000000000005} & TRN \\
\hline CHEMBL 276128 & 440136 & 7.6198 & 7.8876 & TRN & \\
\hline CHEMBL437924 & 440136 & 6.7352 & 7.0856 & TRN & \\
\hline CHEMBL 227049 & 440136 & 7.4202 & \multicolumn{2}{|c|}{7.827999999999999} & TRN \\
\hline CHEMBL226800 & 440136 & 7.8539 & 7.9235 & TRN & \\
\hline CHEMBL 226746 & 440136 & 8.2218 & 7.8263 & TRN & \\
\hline CHEMBL 3828305 & 440136 & 6.0862 & 7.1559 & TST & \\
\hline CHEMBL 226902 & 440136 & 7.5229 & 7.5509 & TRN & \\
\hline CHEMBL 229325 & 440136 & 6.9136 & 7.1167 & TRN & \\
\hline CHEMBL 226696 & 440136 & 7.1249 & 7.4067 & TRN & \\
\hline CHEMBL388198 & 440136 & 7.6383 & 7.942 & TRN & \\
\hline CHEMBL373951 & 440136 & 7.8861 & 7.8525 & TRN & \\
\hline CHEMBL 227153 & 440136 & 7.8239 & 7.9225 & TRN & \\
\hline CHEMBL 226956 & 440136 & 7.7447 & 7.1191 & TRN & \\
\hline CHEMBL 229866 & 440136 & 8.0969 & 7.8186 & TRN & \\
\hline CHEMBL374399 & 440136 & 7.6383 & 7.7704 & TRN & \\
\hline CHEMBL 226957 & 440136 & 8.0969 & 8.3101 & TST & \\
\hline CHEMBL374840 & 440136 & 7.4437 & 7.0135 & TRN & \\
\hline
\end{tabular}




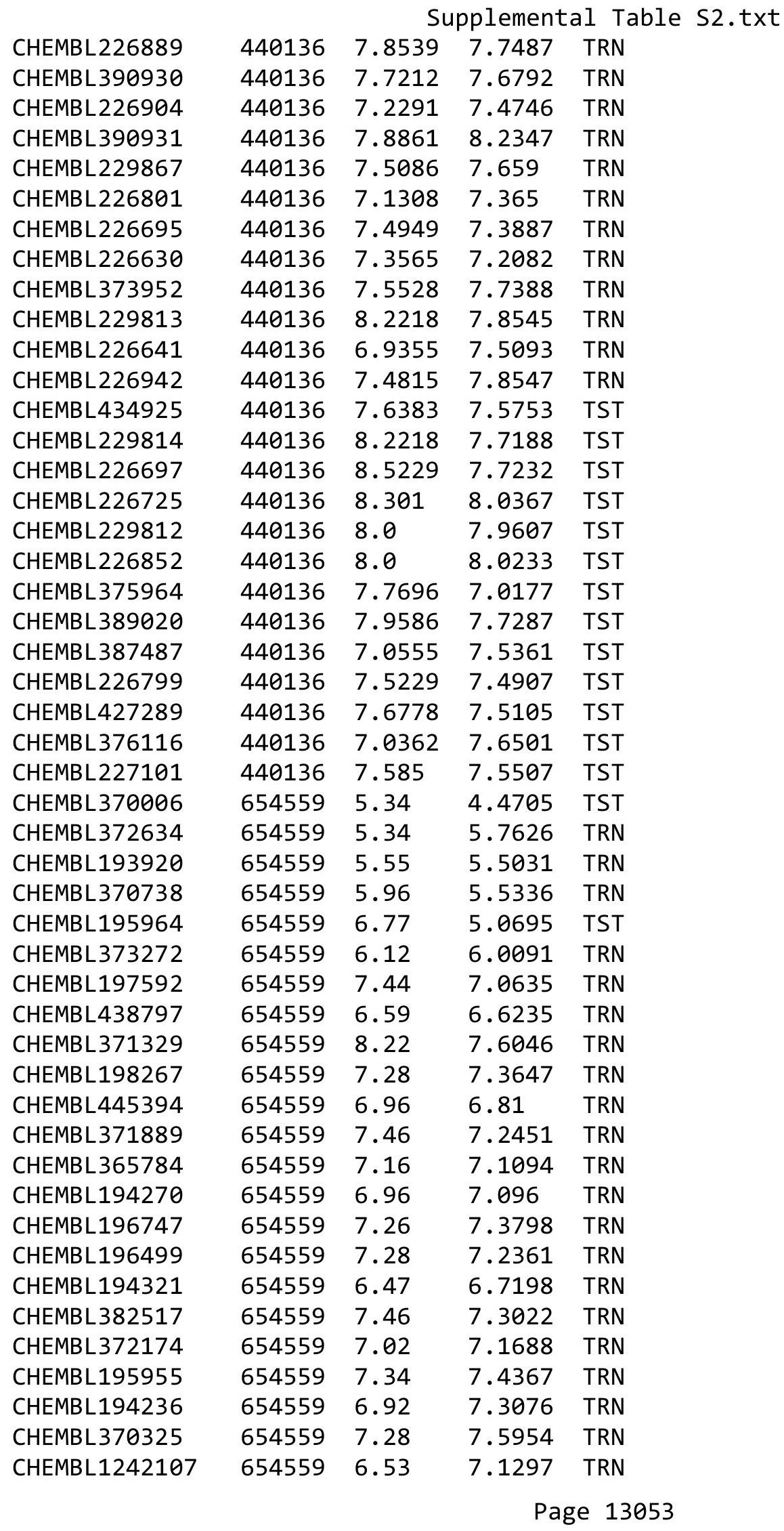




\begin{tabular}{|c|c|c|c|c|}
\hline \multicolumn{5}{|c|}{ Supplemental Table S2.txt } \\
\hline CHEMBL371206 & 654559 & 7.92 & 7.6973 & TRN \\
\hline CHEMBL381034 & 654559 & 6.8 & 7.1704 & TRN \\
\hline CHEMBL381207 & 654559 & 7.34 & 7.5873 & TRN \\
\hline CHEMBL199031 & 654559 & 7.21 & 7.1765 & TRN \\
\hline CHEMBL372744 & 654559 & 7.47 & 7.597 & TRN \\
\hline CHEMBL197635 & 654559 & 7.77 & 7.0066 & TRN \\
\hline CHEMBL198601 & 654559 & 6.48 & 6.9576 & TRN \\
\hline CHEMBL382112 & 654559 & 6.68 & 6.8768 & TRN \\
\hline CHEMBL194842 & 654559 & 6.68 & 6.8845 & TRN \\
\hline CHEMBL372388 & 654559 & 6.23 & 6.8738 & TRN \\
\hline CHEMBL425387 & 654559 & 6.74 & 7.1293 & TRN \\
\hline CHEMBL366241 & 654559 & 7.58 & 7.1594 & TRN \\
\hline CHEMBL196363 & 654559 & 8.52 & 8.7402 & TRN \\
\hline CHEMBL371225 & 654559 & 7.58 & 7.1211 & TRN \\
\hline CHEMBL 371890 & 654559 & 6.89 & 7.3002 & TRN \\
\hline CHEMBL372755 & 654559 & 6.55 & 6.9284 & TRN \\
\hline CHEMBL371379 & 654559 & 7.47 & 6.9451 & TRN \\
\hline CHEMBL369908 & 654559 & 7.28 & 6.8204 & TRN \\
\hline CHEMBL197353 & 654559 & 7.72 & 7.2856 & TRN \\
\hline CHEMBL198155 & 654559 & 7.19 & 6.9394 & TRN \\
\hline CHEMBL198297 & 654559 & 7.82 & 7.2027 & TRN \\
\hline CHEMBL196636 & 654559 & 6.64 & 6.9915 & TRN \\
\hline CHEMBL425749 & 654559 & 7.96 & 7.5047 & TRN \\
\hline CHEMBL 371332 & 654559 & 7.0 & 7.1959 & TRN \\
\hline CHEMBL194366 & 654559 & 7.0 & 7.1669 & TRN \\
\hline CHEMBL 371510 & 654559 & 7.72 & 7.7056 & TRN \\
\hline CHEMBL196615 & 654559 & 7.08 & 7.4753 & TRN \\
\hline CHEMBL 370545 & 654559 & 7.89 & 7.5065 & TRN \\
\hline CHEMBL197828 & 654559 & 7.3 & 7.3368 & TRN \\
\hline CHEMBL382979 & 654559 & 8.52 & 8.2563 & TRN \\
\hline CHEMBL 372765 & 654559 & 6.48 & 6.2437 & TRN \\
\hline CHEMBL197847 & 654559 & 6.1 & 6.426 & TRN \\
\hline CHEMBL196020 & 654559 & 7.26 & 5.8015 & TST \\
\hline CHEMBL198036 & 654559 & 5.72 & 6.0769 & TST \\
\hline CHEMBL 372960 & 654559 & 6.77 & 6.2677 & TST \\
\hline CHEMBL 363393 & 654559 & 6.74 & 7.4477 & TST \\
\hline CHEMBL196396 & 654559 & 5.77 & 7.4667 & TST \\
\hline CHEMBL1242373 & 654559 & 6.82 & 7.1711 & TST \\
\hline CHEMBL196021 & 654559 & 5.95 & 4.3276 & TST \\
\hline CHEMBL194057 & 654559 & 6.46 & 4.3367 & TST \\
\hline CHEMBL363389 & 654559 & 6.74 & 4.6384 & TST \\
\hline CHEMBL194150 & 654559 & 7.19 & 4.8176 & TST \\
\hline CHEMBL196022 & 654559 & 5.26 & 4.7213 & TST \\
\hline CHEMBL196841 & 654559 & 7.44 & 4.6891 & TST \\
\hline CHEMBL194149 & 654559 & 7.21 & 6.6252 & TST \\
\hline CHEMBL194911 & 654559 & 8.52 & 7.1963 & TST \\
\hline CHEMBL195567 & 654559 & 6.73 & 6.0935 & TST \\
\hline CHEMBL193752 & 654559 & 7.24 & 5.5427 & TST \\
\hline
\end{tabular}


Supplemental Table S2.txt

\begin{tabular}{|c|c|c|c|c|c|}
\hline CHEMBL 3103279 & 1560921 & 6.1024 & 5.9984 & TRN & \\
\hline CHEMBL 3103272 & 1560921 & 6.0706 & 6.3551 & TRN & \\
\hline CHEMBL 3103295 & 1560921 & 5.6498 & 5.7701 & TRN & \\
\hline CHEMBL 3103267 & 1560921 & 7.0969 & 7.2408 & TRN & \\
\hline CHEMBL 3103300 & 1560921 & 5.2321 & 4.9215 & TRN & \\
\hline CHEMBL327012 & 1560921 & 4.0 & 2.4055 & TST & \\
\hline CHEMBL 3103274 & 1560921 & 6.9208 & 6.9494 & TRN & \\
\hline CHEMBL 3103270 & 1560921 & 7.5229 & 7.5476 & TRN & \\
\hline CHEMBL 3103287 & 1560921 & 5.983 & 5.6213 & TRN & \\
\hline CHEMBL 3103297 & 1560921 & 7.5229 & 7.0088 & TRN & \\
\hline CHEMBL 3103285 & 1560921 & 6.1549 & 6.0725 & TRN & \\
\hline CHEMBL 3103263 & 1560921 & 6.6021 & 6.2746 & TRN & \\
\hline CHEMBL 3103275 & 1560921 & 6.0969 & 6.3618 & TRN & \\
\hline CHEMBL 3103268 & 1560921 & 6.4437 & 6.4709 & TRN & \\
\hline CHEMBL115897 & 1560921 & 4.0 & 2.8672 & TST & \\
\hline CHEMBL 3103283 & 1560921 & 7.1549 & 6.9238 & TRN & \\
\hline CHEMBL 3103289 & 1560921 & 6.3979 & 6.3305 & TRN & \\
\hline CHEMBL65 & 1560921 & 7.0706 & 5.6501 & TST & \\
\hline CHEMBL 3103304 & 1560921 & 4.0 & 4.0278 & TRN & \\
\hline CHEMBL 3103265 & 1560921 & 7.1549 & 6.7847 & TRN & \\
\hline CHEMBL 3103292 & 1560921 & 5.6308 & 5.6146 & TRN & \\
\hline CHEMBL 3103284 & 1560921 & 6.6576 & 6.7093 & TRN & \\
\hline CHEMBL116040 & 1560921 & 4.0 & 2.5003 & TST & \\
\hline CHEMBL 3103266 & 1560921 & 6.4202 & 6.4971 & TRN & \\
\hline CHEMBL 3103277 & 1560921 & 6.699 & 6.8484 & TRN & \\
\hline CHEMBL 3103271 & 1560921 & 6.585 & 6.64 & TRN & \\
\hline CHEMBL118883 & 1560921 & 4.0 & 2.7501 & TST & \\
\hline CHEMBL 3103262 & 1560921 & 6.699 & 5.496 & TST & \\
\hline CHEMBL 3103276 & 1560921 & 6.1938 & 6.3288 & TRN & \\
\hline CHEMBL 3103296 & 1560921 & 5.4962 & 5.2482 & TRN & \\
\hline CHEMBL 3103273 & 1560921 & 7.2218 & 7.1979 & TRN & \\
\hline CHEMBL 3103280 & 1560921 & 5.5072 & 5.3906 & TRN & \\
\hline CHEMBL 3103261 & 1560921 & 4.0 & 2.8273 & TST & \\
\hline CHEMBL 3103286 & 1560921 & 6.5086 & 6.2148 & TRN & \\
\hline CHEMBL 3103303 & 1560921 & 4.0 & 3.9846 & TRN & \\
\hline CHEMBL 3103282 & 1560921 & 7.5229 & 7.5813 & TRN & \\
\hline CHEMBL 3103299 & 1560921 & 5.0405 & 5.2065 & TRN & \\
\hline CHEMBL 3103298 & 1560921 & 5.9101 & 6.2327 & TRN & \\
\hline CHEMBL 222660 & 1560921 & 4.0 & 3.2489 & TST & \\
\hline CHEMBL 3103288 & 1560921 & 6.301 & 6.5363 & TRN & \\
\hline CHEMBL 326294 & 1560921 & 4.0 & 3.1266 & TST & \\
\hline CHEMBL 3103278 & 1560921 & 6.2076 & 6.6061 & TRN & \\
\hline CHEMBL 3103293 & 1560921 & 5.34200 & 000000000 & 205 & 5.4427 \\
\hline CHEMBL 3103264 & 1560921 & 6.699 & 6.3887 & TRN & \\
\hline CHEMBL 3103290 & 1560921 & 4.0 & 3.7462 & TRN & \\
\hline CHEMBL 3103291 & 1560921 & 5.7932 & 5.9252 & TRN & \\
\hline CHEMBL 3103301 & 1560921 & 4.0 & 4.8433 & TRN & \\
\hline CHEMBL 3103294 & 1560921 & 5.8447 & 4.9472 & TST & \\
\hline
\end{tabular}




\begin{tabular}{|c|c|c|c|c|}
\hline \multicolumn{5}{|c|}{ Supplemental Table S2.txt } \\
\hline CHEMBL3103302 & 1560921 & 4.0 & 4.4514 & TST \\
\hline CHEMBL3103281 & 1560921 & 4.0 & 5.118 & TST \\
\hline CHEMBL3103269 & 1560921 & 7.301 & 6.6487 & TST \\
\hline CHEMBL304154 & 49438 & 5.2291 & 5.1505 & TRN \\
\hline CHEMBL68431 & 49438 & 4.4559 & 5.3601 & TST \\
\hline CHEMBL67947 & 49438 & 5.585 & 6.1105 & TRN \\
\hline CHEMBL273334 & 49438 & 6.1549 & 5.6476 & TRN \\
\hline CHEMBL68585 & 49438 & 5.2076 & 5.9773 & TRN \\
\hline CHEMBL439755 & 49438 & 6.7696 & 7.7022 & TRN \\
\hline CHEMBL308215 & 49438 & 7.5229 & 7.7449 & TRN \\
\hline CHEMBL69090 & 49438 & 3.0 & 5.1884 & TST \\
\hline CHEMBL69564 & 49438 & 6.0969 & 6.2969 & TRN \\
\hline CHEMBL69611 & 49438 & 6.6576 & 6.1944 & TRN \\
\hline CHEMBL304544 & 49438 & 3.0 & 4.9607 & TST \\
\hline CHEMBL69849 & 49438 & 4.1871 & 4.769 & TRN \\
\hline CHEMBL304729 & 49438 & 7.7447 & 7.5758 & TRN \\
\hline CHEMBL305066 & 49438 & 6.7696 & 6.4992 & TRN \\
\hline CHEMBL69677 & 49438 & 7.5376 & 6.8218 & TRN \\
\hline CHEMBL 70061 & 49438 & 5.4815 & 5.5653 & TRN \\
\hline CHEMBL 71362 & 49438 & 6.4318 & 6.1243 & TRN \\
\hline CHEMBL 304838 & 49438 & 7.0862 & 7.4262 & TRN \\
\hline CHEMBL431187 & 49438 & 7.1675 & 7.4273 & TRN \\
\hline CHEMBL71757 & 49438 & 3.0 & 5.1774 & TST \\
\hline CHEMBL412582 & 49438 & 4.699 & 5.6151 & TST \\
\hline CHEMBL69009 & 49438 & 6.1549 & 6.1056 & TRN \\
\hline CHEMBL67334 & 49438 & 3.0 & 3.0837 & TRN \\
\hline CHEMBL 303871 & 49438 & 6.8861 & 6.6242 & TRN \\
\hline CHEMBL303194 & 49438 & 4.8539 & 5.4776 & TRN \\
\hline CHEMBL69553 & 49438 & 5.3372 & 4.9595 & TRN \\
\hline CHEMBL442366 & 49438 & 7.699 & 8.1599 & TRN \\
\hline CHEMBL68162 & 49438 & 4.5686 & 4.664 & TRN \\
\hline CHEMBL67054 & 49438 & 5.7447 & 6.0507 & TRN \\
\hline CHEMBL305175 & 49438 & 6.5229 & 6.0022 & TRN \\
\hline CHEMBL68428 & 49438 & 6.0458 & 6.4438 & TRN \\
\hline CHEMBL68946 & 49438 & 7.3979 & 6.8224 & TRN \\
\hline CHEMBL69991 & 49438 & 6.4202 & 5.8955 & TRN \\
\hline CHEMBL69969 & 49438 & 7.1805 & 6.8601 & TRN \\
\hline CHEMBL69714 & 49438 & 7.2218 & 7.651 & TRN \\
\hline CHEMBL302046 & 49438 & 4.0 & 4.095 & TRN \\
\hline CHEMBL68915 & 49438 & 7.6576 & 6.9084 & TRN \\
\hline CHEMBL68637 & 49438 & 4.7447 & 5.0587 & TRN \\
\hline CHEMBL305296 & 49438 & 3.0 & 5.1152 & TST \\
\hline CHEMBL 305800 & 49438 & 7.6383 & 6.8625 & TRN \\
\hline CHEMBL 70068 & 49438 & 6.2596 & 6.0324 & TRN \\
\hline CHEMBL65936 & 49438 & 6.2366 & 6.5101 & TRN \\
\hline CHEMBL443008 & 49438 & 7.4559 & 7.0872 & TRN \\
\hline CHEMBL412452 & 49438 & 5.9586 & 6.2268 & TRN \\
\hline CHEMBL69096 & 49438 & 4.5528 & 5.0872 & TST \\
\hline
\end{tabular}




\begin{tabular}{|c|c|c|c|c|c|}
\hline \multicolumn{6}{|c|}{ Supplemental Table s2.txt } \\
\hline CHEMBL66504 & 49438 & 6.0655 & 5.9853 & TST & \\
\hline CHEMBL 304785 & 49438 & 5.301 & 5.4421 & TST & \\
\hline CHEMBL303431 & 49438 & 6.9586 & 6.399 & TST & \\
\hline CHEMBL 304338 & 49438 & 6.301 & 6.1216 & TST & \\
\hline CHEMBL67393 & 49438 & 4.4815 & 5.0946 & TST & \\
\hline CHEMBL 303908 & 49438 & 5.4815 & 4.57600 & 00000000005 & TST \\
\hline CHEMBL3670982 & 1528434 & 4.6254 & 4.4543 & TRN & \\
\hline CHEMBL3670977 & 1528434 & 5.3625 & 5.3368 & TRN & \\
\hline CHEMBL3670987 & 1528434 & 4.6251 & 4.7707 & TRN & \\
\hline CHEMBL3671000 & 1528434 & 5.8041 & 5.7882 & TRN & \\
\hline CHEMBL3671009 & 1528434 & 4.9303 & 5.0509 & TRN & \\
\hline CHEMBL 3670988 & 1528434 & 5.6596 & 5.7902 & TRN & \\
\hline CHEMBL3670974 & 1528434 & 5.1079 & 5.093 & TRN & \\
\hline CHEMBL3670979 & 1528434 & 4.3987 & 4.5025 & TRN & \\
\hline CHEMBL3671010 & 1528434 & 5.0937 & 4.8897 & TRN & \\
\hline CHEMBL3670980 & 1528434 & 5.0343 & 5.0825 & TRN & \\
\hline CHEMBL3670986 & 1528434 & 5.3224 & 5.1992 & TRN & \\
\hline CHEMBL3670950 & 1528434 & 4.2681 & 5.2551 & TST & \\
\hline CHEMBL 3671014 & 1528434 & 4.8642 & 4.933 & TRN & \\
\hline CHEMBL3670951 & 1528434 & 4.4592 & 4.5041 & TRN & \\
\hline CHEMBL3670947 & 1528434 & 5.1798 & 5.0026 & TRN & \\
\hline CHEMBL3671007 & 1528434 & 5.2291 & 5.4943 & TRN & \\
\hline CHEMBL3671004 & 1528434 & 4.1959 & 4.1317 & TRN & \\
\hline CHEMBL 3670967 & 1528434 & 4.2496 & 4.2771 & TRN & \\
\hline CHEMBL3670976 & 1528434 & 4.2535 & 4.4932 & TRN & \\
\hline CHEMBL3671002 & 1528434 & 7.0 & 7.101 & TRN & \\
\hline CHEMBL3670948 & 1528434 & 4.2574 & 5.0708 & TST & \\
\hline CHEMBL3671001 & 1528434 & 5.3468 & 5.2504 & TRN & \\
\hline CHEMBL 3671015 & 1528434 & 6.4318 & 5.3269 & TST & \\
\hline CHEMBL3671013 & 1528434 & 6.3665 & 6.23799 & 99999999995 & TRN \\
\hline CHEMBL3670989 & 1528434 & 4.1287 & 5.06800 & 00000000005 & TRN \\
\hline CHEMBL 3670984 & 1528434 & 5.1778 & 4.996 & TRN & \\
\hline CHEMBL3670960 & 1528434 & 6.1079 & 5.1847 & TRN & \\
\hline CHEMBL 3670964 & 1528434 & 5.4949 & 5.5049 & TRN & \\
\hline CHEMBL3670997 & 1528434 & 4.8758 & 4.9572 & TRN & \\
\hline CHEMBL3670991 & 1528434 & 4.6682 & 4.6193 & TRN & \\
\hline CHEMBL3670983 & 1528434 & 4.3079 & 4.3863 & TRN & \\
\hline CHEMBL3670998 & 1528434 & 4.751 & 4.7991 & TRN & \\
\hline CHEMBL3670955 & 1528434 & 5.9547 & 5.9891 & TRN & \\
\hline CHEMBL3670972 & 1528434 & 5.3429 & 5.4227 & TRN & \\
\hline CHEMBL3639698 & 1528434 & 4.0868 & 4.1746 & TRN & \\
\hline CHEMBL3670949 & 1528434 & 4.1915 & 5.3235 & TST & \\
\hline CHEMBL3670981 & 1528434 & 4.7433 & 4.692 & TRN & \\
\hline CHEMBL3670978 & 1528434 & 4.2846 & 4.3445 & TRN & \\
\hline CHEMBL3670970 & 1528434 & 4.3188 & 4.2179 & TRN & \\
\hline CHEMBL3670975 & 1528434 & 4.0752 & 4.2387 & TRN & \\
\hline CHEMBL3670961 & 1528434 & 4.6312 & 4.6358 & TRN & \\
\hline CHEMBL3670990 & 1528434 & 5.8633 & 5.551 & TRN & \\
\hline
\end{tabular}


Supplemental Table S2.txt

\begin{tabular}{|c|c|c|c|c|}
\hline CHEMBL3671012 & 1528434 & 5.4634 & 5.5128 & TRN \\
\hline CHEMBL3670994 & 1528434 & 4.2246 & 4.1564 & TRN \\
\hline CHEMBL3670995 & 1528434 & 4.5784 & 4.5367 & TRN \\
\hline CHEMBL3670953 & 1528434 & 5.1669 & 5.2071 & TRN \\
\hline CHEMBL3670968 & 1528434 & 5.5452 & 5.5741 & TRN \\
\hline CHEMBL3671003 & 1528434 & 5.5229 & 5.4125 & TRN \\
\hline CHEMBL3670996 & 1528434 & 4.871 & 4.7529 & TRN \\
\hline CHEMBL3671008 & 1528434 & 7.0 & 4.6937 & TST \\
\hline CHEMBL3670963 & 1528434 & 5.5654 & 5.6049 & TRN \\
\hline CHEMBL3671011 & 1528434 & 4.0969 & 5.6768 & TST \\
\hline CHEMBL3670993 & 1528434 & 5.0904 & 4.9758 & TRN \\
\hline CHEMBL3670952 & 1528434 & 5.3487 & 5.3054 & TRN \\
\hline CHEMBL3670954 & 1528434 & 5.3655 & 5.4162 & TRN \\
\hline CHEMBL3670999 & 1528434 & 7.2565 & 7.3007 & TRN \\
\hline CHEMBL3671005 & 1528434 & 7.301 & 4.86600 & 00000000005 \\
\hline CHEMBL3670966 & 1528434 & 4.1135 & 5.5959 & TST \\
\hline CHEMBL3670992 & 1528434 & 4.36 & 5.0241 & TST \\
\hline CHEMBL3670959 & 1528434 & 6.2076 & 5.1189 & TST \\
\hline CHEMBL3670969 & 1528434 & 4.9454 & 6.152 & TST \\
\hline CHEMBL3670973 & 1528434 & 4.3502 & 5.5468 & TST \\
\hline CHEMBL3671006 & 1528434 & 5.9172 & 4.6171 & TST \\
\hline CHEMBL3670962 & 1528434 & 5.5751 & 5.2757 & TST \\
\hline CHEMBL3670965 & 1528434 & 4.3869 & 5.5009 & TST \\
\hline CHEMBL3670971 & 1528434 & 4.5147 & 4.4306 & TST \\
\hline CHEMBL3670985 & 1528434 & 4.5287 & 4.9502 & TST \\
\hline CHEMBL 75386 & 49485 & 5.4685 & 5.3882 & TRN \\
\hline CHEMBL75338 & 49485 & 4.9586 & 5.0114 & TRN \\
\hline CHEMBL 73183 & 49485 & 7.1549 & 7.58299 & 9999999999 \\
\hline CHEMBL 72485 & 49485 & 8.1549 & 8.0958 & TRN \\
\hline CHEMBL 72267 & 49485 & 8.0458 & 7.8432 & TRN \\
\hline CHEMBL 72623 & 49485 & 5.2218 & 5.4123 & TST \\
\hline CHEMBL308562 & 49485 & 5.5686 & 5.5147 & TRN \\
\hline CHEMBL310932 & 49485 & 5.1675 & 5.2573 & TRN \\
\hline CHEMBL307394 & 49485 & 6.3979 & 5.9753 & TRN \\
\hline CHEMBL 306581 & 49485 & 5.6021 & 5.7442 & TRN \\
\hline CHEMBL 73512 & 49485 & 8.0458 & 7.9165 & TST \\
\hline CHEMBL72619 & 49485 & 7.7212 & 7.746 & TRN \\
\hline CHEMBL 72264 & 49485 & 5.7959 & 5.8816 & TRN \\
\hline CHEMBL306717 & 49485 & 7.7696 & 7.8371 & TRN \\
\hline CHEMBL418895 & 49485 & 7.8861 & 7.4951 & TST \\
\hline CHEMBL419445 & 49485 & 8.0969 & 8.1359 & TST \\
\hline CHEMBL422234 & 49485 & 8.0458 & 8.4297 & TST \\
\hline CHEMBL306350 & 49485 & 5.2076 & 4.8202 & TST \\
\hline CHEMBL 72845 & 49485 & 8.0 & 7.7879 & TRN \\
\hline CHEMBL 74951 & 49485 & 7.9208 & 7.8895 & TRN \\
\hline CHEMBL 74054 & 49485 & 7.9208 & 7.3873 & TST \\
\hline CHEMBL 73778 & 49485 & 8.0969 & 7.8963 & TRN \\
\hline CHEMBL450327 & 49485 & 7.7212 & 7.69 & TRN \\
\hline
\end{tabular}




\begin{tabular}{|c|c|c|c|c|c|}
\hline \multicolumn{6}{|c|}{ Supplemental Table S2.txt } \\
\hline CHEMBL 309020 & 49485 & 5.5086 & 5.5047 & TRN & \\
\hline CHEMBL72471 & 49485 & 8.0 & 8.2327 & TST & \\
\hline CHEMBL73573 & 49485 & 8.301 & 8.36399 & 9999999999 & TRN \\
\hline CHEMBL72952 & 49485 & 7.2596 & 7.2462 & TST & \\
\hline CHEMBL308567 & 49485 & 7.4685 & 7.4825 & TRN & \\
\hline CHEMBL307579 & 49485 & 5.7447 & 5.7443 & TRN & \\
\hline CHEMBL307673 & 49485 & 5.301 & 5.2251 & TRN & \\
\hline CHEMBL303388 & 49485 & 8.0969 & 8.1168 & TRN & \\
\hline CHEMBL308526 & 49485 & 5.284 & 5.2089 & TST & \\
\hline CHEMBL72583 & 49485 & 5.5686 & 5.6345 & TRN & \\
\hline CHEMBL 75765 & 49485 & 5.5086 & 5.4139 & TRN & \\
\hline CHEMBL75151 & 49485 & 5.7696 & 5.75899 & 99999999995 & TRN \\
\hline CHEMBL304622 & 49485 & 7.6778 & 7.8632 & TST & \\
\hline CHEMBL309171 & 49485 & 7.3872 & 7.444 & TRN & \\
\hline CHEMBL306841 & 49485 & 5.7212 & 5.7708 & TRN & \\
\hline CHEMBL75292 & 49485 & 8.1549 & 8.1224 & TRN & \\
\hline CHEMBL72089 & 49485 & 4.7447 & 4.8636 & TST & \\
\hline CHEMBL 75039 & 49485 & 7.8539 & 7.7723 & TRN & \\
\hline CHEMBL 73306 & 49485 & 5.4437 & 5.4821 & TRN & \\
\hline CHEMBL 70591 & 49485 & 7.1938 & 7.4406 & TRN & \\
\hline CHEMBL 76177 & 49485 & 7.9208 & 7.8364 & TRN & \\
\hline CHEMBL72810 & 49485 & 8.0458 & 8.0974 & TRN & \\
\hline CHEMBL 307809 & 49485 & 4.7696 & 4.93199 & 99999999995 & TRN \\
\hline CHEMBL 74172 & 49485 & 8.0969 & 8.1634 & TRN & \\
\hline CHEMBL305964 & 49485 & 5.301 & 5.7572 & TST & \\
\hline CHEMBL306736 & 49485 & 7.1024 & 6.944 & TRN & \\
\hline CHEMBL72058 & 49485 & 5.5229 & 5.6006 & TRN & \\
\hline CHEMBL 75940 & 49485 & 8.0458 & 7.9297 & TRN & \\
\hline CHEMBL 305700 & 49485 & 5.2218 & 4.9977 & TST & \\
\hline CHEMBL72671 & 49485 & 5.6778 & 5.7844 & TRN & \\
\hline CHEMBL 73498 & 49485 & 6.5229 & 6.1412 & TRN & \\
\hline CHEMBL 73379 & 49485 & 7.4949 & 7.5626 & TRN & \\
\hline CHEMBL306820 & 49485 & 5.585 & 5.7353 & TRN & \\
\hline CHEMBL72948 & 49485 & 4.3665 & 4.3821 & TRN & \\
\hline CHEMBL 72064 & 49485 & 8.0969 & 8.0281 & TRN & \\
\hline CHEMBL423310 & 49485 & 8.0 & 7.7588 & TST & \\
\hline CHEMBL70254 & 49485 & 5.2076 & 5.1919 & TRN & \\
\hline CHEMBL73260 & 49485 & 8.2218 & 8.3056 & TRN & \\
\hline CHEMBL 305802 & 49485 & 7.2291 & 7.3002 & TRN & \\
\hline CHEMBL72612 & 49485 & 8.0 & 8.0007 & TRN & \\
\hline CHEMBL421307 & 49485 & 7.9208 & 7.8536 & TST & \\
\hline CHEMBL72079 & 49485 & 4.9208 & 5.0211 & TRN & \\
\hline CHEMBL420193 & 49485 & 5.3565 & 5.3258 & TRN & \\
\hline CHEMBL308565 & 49485 & 5.2441 & 5.2617 & TRN & \\
\hline CHEMBL72152 & 49485 & 8.0458 & 8.0823 & TRN & \\
\hline CHEMBL306388 & 49485 & 7.8861 & 7.7417 & TRN & \\
\hline CHEMBL75381 & 49485 & 6.1549 & 5.7295 & TST & \\
\hline CHEMBL305953 & 49485 & 7.0655 & 7.17 & TRN & \\
\hline
\end{tabular}




\begin{tabular}{|c|c|c|c|c|c|}
\hline \multicolumn{6}{|c|}{ Supplemental Table S2.txt } \\
\hline CHEMBL 309010 & 49485 & 5.6778 & 5.731 & TRN & \\
\hline CHEMBL306789 & 49485 & 5.699 & 5.7107 & TRN & \\
\hline CHEMBL72221 & 49485 & 4.5686 & 4.8593 & TRN & \\
\hline CHEMBL73650 & 49485 & 7.8539 & 7.8116 & TRN & \\
\hline CHEMBL70476 & 49485 & 7.9586 & 7.8027 & TRN & \\
\hline CHEMBL431196 & 49485 & 5.0 & 5.1432 & TRN & \\
\hline CHEMBL73427 & 49485 & 5.2757 & 5.3747 & TST & \\
\hline CHEMBL73798 & 49485 & 7.8239 & 7.6959 & TST & \\
\hline CHEMBL419450 & 49485 & 5.5229 & 5.5453 & TRN & \\
\hline CHEMBL72909 & 49485 & 4.6576 & 4.5885 & TRN & \\
\hline CHEMBL304281 & 49485 & 8.0 & 8.1055 & TRN & \\
\hline CHEMBL306093 & 49485 & 5.6778 & 5.6906 & TRN & \\
\hline CHEMBL306500 & 49485 & 5.699 & 6.0599 & TST & \\
\hline CHEMBL308709 & 49485 & 4.9586 & 5.0862 & TRN & \\
\hline CHEMBL306726 & 49485 & 8.301 & 8.5659 & TRN & \\
\hline CHEMBL72729 & 49485 & 5.1805 & 5.3803 & TST & \\
\hline CHEMBL73776 & 49485 & 5.301 & 4.8828 & TRN & \\
\hline CHEMBL 308852 & 49485 & 8.0 & 7.8878 & TRN & \\
\hline CHEMBL73615 & 49485 & 8.0458 & 7.6553 & TST & \\
\hline CHEMBL73951 & 49485 & 5.699 & 5.3341 & TST & \\
\hline CHEMBL310489 & 49485 & 7.5229 & 7.527 & TRN & \\
\hline CHEMBL72063 & 49485 & 5.6021 & 5.8091 & TST & \\
\hline CHEMBL420749 & 49485 & 5.4815 & 5.54200 & 0000000001 & TRN \\
\hline CHEMBL73357 & 49485 & 5.284 & 5.3106 & TRN & \\
\hline CHEMBL305658 & 49485 & 7.4815 & 7.2333 & TRN & \\
\hline CHEMBL308406 & 49485 & 5.2924 & 5.0533 & TRN & \\
\hline CHEMBL422950 & 49485 & 8.0969 & 8.1106 & TRN & \\
\hline CHEMBL423855 & 49485 & 8.0 & 8.1837 & TRN & \\
\hline CHEMBL72730 & 49485 & 5.1871 & 5.4415 & TST & \\
\hline CHEMBL240064 & 452746 & 5.041 & 5.6268 & TRN & \\
\hline CHEMBL241763 & 452746 & 3.699 & 5.7559 & TST & \\
\hline CHEMBL238113 & 452746 & 6.5229 & 6.2563 & TRN & \\
\hline CHEMBL240477 & 452746 & 5.3372 & 5.0586 & TRN & \\
\hline CHEMBL 238103 & 452746 & 7.585 & 6.0919 & TST & \\
\hline CHEMBL238108 & 452746 & 6.699 & 6.5961 & TRN & \\
\hline CHEMBL237858 & 452746 & 6.1938 & 6.0447 & TRN & \\
\hline CHEMBL238107 & 452746 & 5.0 & 4.5673 & TRN & \\
\hline CHEMBL237676 & 452746 & 6.0655 & 6.1571 & TRN & \\
\hline CHEMBL 239423 & 452746 & 7.0969 & 6.8927 & TRN & \\
\hline CHEMBL236780 & 452746 & 6.2366 & 6.6796 & TRN & \\
\hline CHEMBL239424 & 452746 & 8.1549 & 7.6667 & TRN & \\
\hline CHEMBL393719 & 452746 & 6.284 & 6.0246 & TST & \\
\hline CHEMBL239204 & 452746 & 5.4815 & 5.8498 & TRN & \\
\hline CHEMBL235969 & 452746 & 4.9586 & 4.846 & TRN & \\
\hline CHEMBL238574 & 452746 & 4.7959 & 5.6261 & TST & \\
\hline CHEMBL391846 & 452746 & 6.699 & 6.8977 & TRN & \\
\hline CHEMBL393332 & 452746 & 5.9066 & 5.8658 & TRN & \\
\hline CHEMBL393400 & 452746 & 5.2676 & 5.5456 & TRN & \\
\hline
\end{tabular}




\begin{tabular}{|c|c|c|c|c|c|}
\hline \multirow{2}{*}{ CHEMBL429809 } & \multicolumn{5}{|c|}{ Ello. } \\
\hline & 452746 & 5.7212 & 5.2696 & TRN & \\
\hline CHEMBL 240688 & 452746 & 5.3372 & 5.7447 & TRN & \\
\hline CHEMBL235966 & 452746 & 6.8239 & 7.1687 & TRN & \\
\hline CHEMBL236995 & 452746 & 9.301 & 7.9939 & TST & \\
\hline CHEMBL 393331 & 452746 & 6.301 & 6.3316 & TRN & \\
\hline CHEMBL238265 & 452746 & 6.2076 & 6.9687 & TRN & \\
\hline CHEMBL 238990 & 452746 & 5.5229 & 5.2947 & TRN & \\
\hline CHEMBL391499 & 452746 & 6.3768 & 5.7965 & TRN & \\
\hline CHEMBL 237675 & 452746 & 5.9586 & 6.0928 & TRN & \\
\hline CHEMBL337301 & 452746 & 8.0969 & 6.2178 & TST & \\
\hline CHEMBL 236603 & 452746 & 6.6021 & 6.2672 & TRN & \\
\hline CHEMBL 392490 & 452746 & 4.8996 & 5.0006 & TRN & \\
\hline CHEMBL237859 & 452746 & 6.301 & 6.1153 & TRN & \\
\hline CHEMBL399421 & 452746 & 8.301 & 6.1125 & TST & \\
\hline CHEMBL391847 & 452746 & 6.4318 & 6.4477 & TRN & \\
\hline CHEMBL393585 & 452746 & 5.4437 & 5.4861 & TRN & \\
\hline CHEMBL237677 & 452746 & 6.8539 & 6.20200 & 0000000001 & TRN \\
\hline CHEMBL238073 & 452746 & 3.699 & 5.6096 & TST & \\
\hline CHEMBL 238100 & 452746 & 6.3665 & 5.7342 & TRN & \\
\hline CHEMBL392147 & 452746 & 5.0 & 5.0844 & TRN & \\
\hline CHEMBL428725 & 452746 & 6.6198 & 6.46299 & 9999999999 & TRN \\
\hline CHEMBL442078 & 452746 & 7.5229 & 5.9339 & TST & \\
\hline CHEMBL238109 & 452746 & 6.301 & 6.4668 & TRN & \\
\hline CHEMBL392575 & 452746 & 3.3979 & 3.6933 & TRN & \\
\hline CHEMBL 394005 & 452746 & 6.6198 & 6.1435 & TRN & \\
\hline CHEMBL393768 & 452746 & 3.699 & 3.8576 & TRN & \\
\hline CHEMBL392491 & 452746 & 4.6576 & 5.6698 & TST & \\
\hline CHEMBL 235964 & 452746 & 5.3768 & 5.8957 & TRN & \\
\hline CHEMBL235971 & 452746 & 6.0 & 6.1359 & TRN & \\
\hline CHEMBL240476 & 452746 & 5.6383 & 5.7702 & TRN & \\
\hline CHEMBL 392342 & 452746 & 5.3279 & 5.9723 & TRN & \\
\hline CHEMBL238266 & 452746 & 7.4437 & 7.2789 & TRN & \\
\hline CHEMBL 240063 & 452746 & 5.0757 & 4.194 & TST & \\
\hline CHEMBL392281 & 452746 & 4.9066 & 5.4368 & TST & \\
\hline CHEMBL 240049 & 452746 & 6.284 & 5.8576 & TST & \\
\hline CHEMBL439564 & 452746 & 5.6198 & 5.9186 & TST & \\
\hline CHEMBL3087337 & 1276471 & 7.699 & 7.4272 & TRN & \\
\hline CHEMBL 3087334 & 1276471 & 3.301 & 4.02800 & 00000000005 & TRN \\
\hline CHEMBL 3087622 & 1276471 & 6.699 & 6.4943 & TRN & \\
\hline CHEMBL48573 & 1276471 & 6.2007 & 5.8186 & TRN & \\
\hline CHEMBL 3087623 & 1276471 & 5.699 & 5.3068 & TRN & \\
\hline CHEMBL3087630 & 1276471 & 6.4559 & 6.4137 & TST & \\
\hline CHEMBL 3087785 & 1276471 & 5.1487 & 4.6313 & TRN & \\
\hline CHEMBL3087635 & 1276471 & 4.7696 & 5.8632 & TST & \\
\hline CHEMBL 299873 & 1276471 & 3.301 & 3.5685 & TRN & \\
\hline CHEMBL 3087626 & 1276471 & 5.6021 & 5.2886 & TRN & \\
\hline CHEMBL3087330 & 1276471 & 5.8539 & 4.6974 & TST & \\
\hline CHEMBL 3087333 & 1276471 & 3.301 & 5.2541 & TST & \\
\hline
\end{tabular}


Supplemental Table S2.txt

\begin{tabular}{|c|c|c|c|c|}
\hline (2) & 6471 & 301 & 3.7902 & . \\
\hline HEMBL 3087616 & 276471 & 6.284 & 3794 & \\
\hline & & 301 & 5145 & \\
\hline EMBL & 76471 & 4318 & 3815 & \\
\hline AEMBL3087335 & 276471 & 3.301 & 5939 & \\
\hline AEMBL49363 & 276471 & 301 & 4646 & \\
\hline HEMBL3E & 276471 & .6198 & .5049 & \\
\hline AEMBL3 & 276471 & 599 & 2122 & \\
\hline HEMBL 308 & & 301 & .3625 & \\
\hline HEMBL3087632 & 276471 & 6.5086 & .0541 & \\
\hline HEMBL417356 & 276471 & 4.58 & .1789 & \\
\hline HEMBL3E & 71 & 2924 & .7337 & \\
\hline HEMBL36 & & 601 & & \\
\hline HEMBL4S & 71 & .301 & .3859 & \\
\hline HEMBL 308 & 71 & 1024 & .05 & RN \\
\hline HEMBL 308 & 11 & .7212 & 5.0629 & MIV \\
\hline HEMBL3e & 71 & 218 & 1975 & \\
\hline HEMBL3e & & 088 & 88 & \\
\hline HEMBL3e & 71 & 6021 & 234 & \\
\hline HEMBL 308 & 71 & 3.301 & 52 & $\operatorname{IN}$ \\
\hline HEMBL4C & 1 & 1559 & 224 & IRN \\
\hline HEMBL3C & 1 & 089 & 696 & \\
\hline HEMBL4 & & 595 & & \\
\hline HEMBL4\& & & 6.6021 & 5.8216 & RN \\
\hline HEMBL3e & 1 & 229 & 15 & RIN \\
\hline AEMBL3E & 71 & 696 & 56 & TRN \\
\hline HEMBL36 & 1 & 99 & $\partial 66$ & RN \\
\hline HEN & & & & ST \\
\hline HEMBL3C & & 01 & 17 & RN \\
\hline HEMBL308 & 1 & 915 & 6. & RN \\
\hline HEMBL45 & 71 & 599 & 6.2705 & RN \\
\hline HEMBL3 & & 595 & 66 & RN \\
\hline HEM & & 539 & & RN \\
\hline HEMBL 308 & & 99 & & IRN \\
\hline HEMBL 308 & 27 & 3. & 286 & TST \\
\hline HEMBL 308 & 1 & 576 & 984 & IST \\
\hline HEMBL3 & & & 99 & ST \\
\hline HEMBL308 & 276471 & 4.7905 & 3.4621 & TST \\
\hline HEMBL359638 & 3036 & 5.301 & 5.4284 & TRN \\
\hline HEMBL180 & 03 & 5383 & 6 . & TST \\
\hline HEMBL17 & 303 & 6.7447 & 406 & IRN \\
\hline HEMBL18 & & & & RN \\
\hline HEMBL427313 & 3036 & 6.9208 & 7.046 & TRN \\
\hline HEMBL 361754 & 303657 & 5.301 & 5.1871 & TRN \\
\hline IFMP 170 & & 192 & & \\
\hline CHEMBL360912 & 303 & 7.6778 & 7.5579 & RIV \\
\hline CHEMBL17 & 303657 & 7.4559 & 7.225 & \\
\hline CHEMBL 359545 & 303657 & 7.6778 & 7.8242 & ГRN \\
\hline
\end{tabular}

Page 13062 


\begin{tabular}{|c|c|c|c|c|}
\hline & & & pplement & al $\mathrm{T}$ \\
\hline CHEMBL360733 & 303657 & 7.7212 & 7.5424 & TRN \\
\hline CHEMBL361561 & 303657 & 6.8861 & 6.7915 & TRN \\
\hline CHEMBL361786 & 303657 & 8.3979 & 8.3165 & TRN \\
\hline CHEMBL178188 & 303657 & 6.699 & 6.9237 & TRN \\
\hline CHEMBL359650 & 303657 & 7.6021 & 7.441 & TRN \\
\hline CHEMBL178710 & 303657 & 7.7696 & 7.7157 & TRN \\
\hline CHEMBL361129 & 303657 & 8.6021 & 8.6294 & TRN \\
\hline CHEMBL362409 & 303657 & 7.3768 & 7.6235 & TRN \\
\hline CHEMBL178303 & 303657 & 6.7959 & 6.78 & TST \\
\hline CHEMBL440558 & 303657 & 7.2291 & 7.6212 & TRN \\
\hline CHEMBL369035 & 303657 & 8.0605 & 8.0921 & TRN \\
\hline CHEMBL359474 & 303657 & 5.301 & 5.2701 & TRN \\
\hline CHEMBL179700 & 303657 & 7.0862 & 7.035 & TRN \\
\hline CHEMBL179558 & 303657 & 8.2518 & 8.2878 & TRN \\
\hline CHEMBL180464 & 303657 & 7.3665 & 7.7365 & TRN \\
\hline CHEMBL360262 & 303657 & 5.301 & 5.4341 & TRN \\
\hline CHEMBL361114 & 303657 & 8.7696 & 8.5792 & TRN \\
\hline CHEMBL178831 & 303657 & 7.7959 & 7.4205 & TRN \\
\hline CHEMBL359613 & 303657 & 7.1427 & 7.2082 & TST \\
\hline CHEMBL178783 & 303657 & 8.1249 & 8.0298 & TRN \\
\hline CHEMBL360113 & 303657 & 6.9586 & 6.6747 & TRN \\
\hline CHEMBL178830 & 303657 & 7.1308 & 6.9878 & TRN \\
\hline CHEMBL175929 & 303657 & 7.2441 & 7.3353 & TRN \\
\hline CHEMBL178956 & 303657 & 8.1871 & 7.9713 & TRN \\
\hline CHEMBL178632 & 303657 & 6.3279 & 7.055 & TRN \\
\hline CHEMBL178242 & 303657 & 7.3979 & 7.2196 & TRN \\
\hline CHEMBL180215 & 303657 & 6.585 & 6.0847 & TST \\
\hline CHEMBL360311 & 303657 & 7.0 & 7.3464 & TRN \\
\hline CHEMBL360036 & 303657 & 6.7959 & 6.9134 & TST \\
\hline CHEMBL426234 & 303657 & 6.9586 & 6.7344 & TRN \\
\hline CHEMBL175475 & 303657 & 8.0088 & 8.2353 & TRN \\
\hline CHEMBL179810 & 303657 & 6.5686 & 6.5678 & TRN \\
\hline CHEMBL178837 & 303657 & 6.6021 & 6.8835 & TRN \\
\hline CHEMBL179430 & 303657 & 6.8539 & 6.2976 & TRN \\
\hline CHEMBL179777 & 303657 & 8.0915 & 8.0226 & TRN \\
\hline CHEMBL178508 & 303657 & 6.5528 & 6.3249 & TRN \\
\hline CHEMBL362282 & 303657 & 8.1249 & 7.9443 & TST \\
\hline CHEMBL179769 & 303657 & 6.9586 & 6.6585 & TRN \\
\hline CHEMBL179545 & 303657 & 6.5086 & 6.5565 & TRN \\
\hline CHEMBL178677 & 303657 & 8.4685 & 8.6384 & TRN \\
\hline CHEMBL360966 & 303657 & 7.284 & 6.8831 & TRN \\
\hline CHEMBL179513 & 303657 & 6.9586 & 6.9264 & TRN \\
\hline CHEMBL361105 & 303657 & 7.2676 & 7.24 & TRN \\
\hline CHEMBL179474 & 303657 & 8.699 & 8.4439 & TRN \\
\hline CHEMBL362869 & 303657 & 7.1024 & 7.1249 & TRN \\
\hline CHEMBL362421 & 303657 & 7.1675 & 7.0579 & TRN \\
\hline CHEMBL178633 & 303657 & 5.0 & 5.7579 & TRN \\
\hline CHEMBL361597 & 303657 & 7.1675 & 7.2483 & TRN \\
\hline
\end{tabular}




\begin{tabular}{|c|c|c|c|c|c|}
\hline \multicolumn{6}{|c|}{ Supplemental Table S2.txt } \\
\hline CHEMBL179654 & 303657 & 5.301 & 5.2717 & TRN & \\
\hline CHEMBL180575 & 303657 & 5.0 & 5.1726 & TST & \\
\hline CHEMBL359853 & 303657 & 5.301 & 5.2907 & TRN & \\
\hline CHEMBL 362485 & 303657 & 8.0044 & 8.2561 & TRN & \\
\hline CHEMBL359906 & 303657 & 7.5229 & 7.8071 & TRN & \\
\hline CHEMBL178992 & 303657 & 7.4685 & 7.0368 & TRN & \\
\hline CHEMBL179000 & 303657 & 6.6778 & 6.837999 & 9999999999 & TRN \\
\hline CHEMBL68712 & 303657 & 7.4437 & 7.4032 & TRN & \\
\hline CHEMBL179555 & 303657 & 5.0 & 5.0212 & TST & \\
\hline CHEMBL 361340 & 303657 & 7.7447 & 7.7397 & TRN & \\
\hline CHEMBL 366537 & 303657 & 8.1487 & 8.2238 & TRN & \\
\hline CHEMBL 366468 & 303657 & 7.7959 & 7.6141 & TRN & \\
\hline CHEMBL434138 & 303657 & 6.7447 & 6.3029 & TRN & \\
\hline CHEMBL180417 & 303657 & 6.7212 & 6.7777 & TRN & \\
\hline CHEMBL175886 & 303657 & 7.6576 & 7.6793 & TRN & \\
\hline CHEMBL179414 & 303657 & 8.5528 & 8.6558 & TRN & \\
\hline CHEMBL361015 & 303657 & 7.8239 & 7.6369 & TRN & \\
\hline CHEMBL361200 & 303657 & 7.4685 & 7.3552 & TRN & \\
\hline CHEMBL13662 & 303657 & 6.1427 & 5.9084 & TST & \\
\hline CHEMBL179509 & 303657 & 7.0809 & 7.2139 & TRN & \\
\hline CHEMBL 362620 & 303657 & 7.5528 & 7.4253 & TRN & \\
\hline CHEMBL360122 & 303657 & 8.6383 & 8.7095 & TRN & \\
\hline CHEMBL179664 & 303657 & 5.0 & 6.2135 & TRN & \\
\hline CHEMBL178942 & 303657 & 7.585 & 7.502000 & 0000000001 & TST \\
\hline CHEMBL368905 & 303657 & 6.4949 & 6.562 & TST & \\
\hline CHEMBL 366471 & 303657 & 7.4559 & 7.5161 & TST & \\
\hline CHEMBL 360345 & 303657 & 6.5376 & 5.8332 & TST & \\
\hline CHEMBL362014 & 303657 & 6.3188 & 6.3288 & TST & \\
\hline CHEMBL179475 & 303657 & 8.2291 & 8.254 & TST & \\
\hline CHEMBL178856 & 303657 & 7.3665 & 7.3775 & TST & \\
\hline CHEMBL359616 & 303657 & 6.4089 & 5.8864 & TST & \\
\hline CHEMBL180416 & 303657 & 8.041 & 8.2018 & TST & \\
\hline CHEMBL 360562 & 303657 & 5.0 & 5.6288 & TST & \\
\hline CHEMBL178738 & 303657 & 7.6198 & 7.1413 & TST & \\
\hline CHEMBL369093 & 303657 & 5.0 & 5.0923 & TST & \\
\hline CHEMBL179924 & 303657 & 7.301 & 7.3834 & TST & \\
\hline CHEMBL179712 & 303657 & 8.28399 & 999999999 & 8.3129 & VST \\
\hline CHEMBL178840 & 303657 & 7.3872 & 6.9385 & TST & \\
\hline CHEMBL178670 & 303657 & 7.1938 & 6.9112 & TST & \\
\hline CHEMBL 3978729 & 1642117 & 4.0 & 4.1511 & TRN & \\
\hline CHEMBL 3898171 & 1642117 & 5.8908 & 4.4341 & TRN & \\
\hline CHEMBL 3946399 & 1642117 & 4.0 & 3.9574 & TRN & \\
\hline CHEMBL 3964278 & 1642117 & 4.0 & 4.3456 & TRN & \\
\hline CHEMBL 3985937 & 1642117 & 6.0496 & 5.1133 & TST & \\
\hline CHEMBL 3986841 & 1642117 & 4.0 & 4.2782 & TRN & \\
\hline CHEMBL 3899901 & 1642117 & 4.0 & 4.0904 & TRN & \\
\hline CHEMBL3919391 & 1642117 & 4.0 & 3.8217 & TRN & \\
\hline CHEMBL 3952854 & 1642117 & 5.8042 & 4.2634 & TRN & \\
\hline
\end{tabular}


Supplemental Table S2.txt

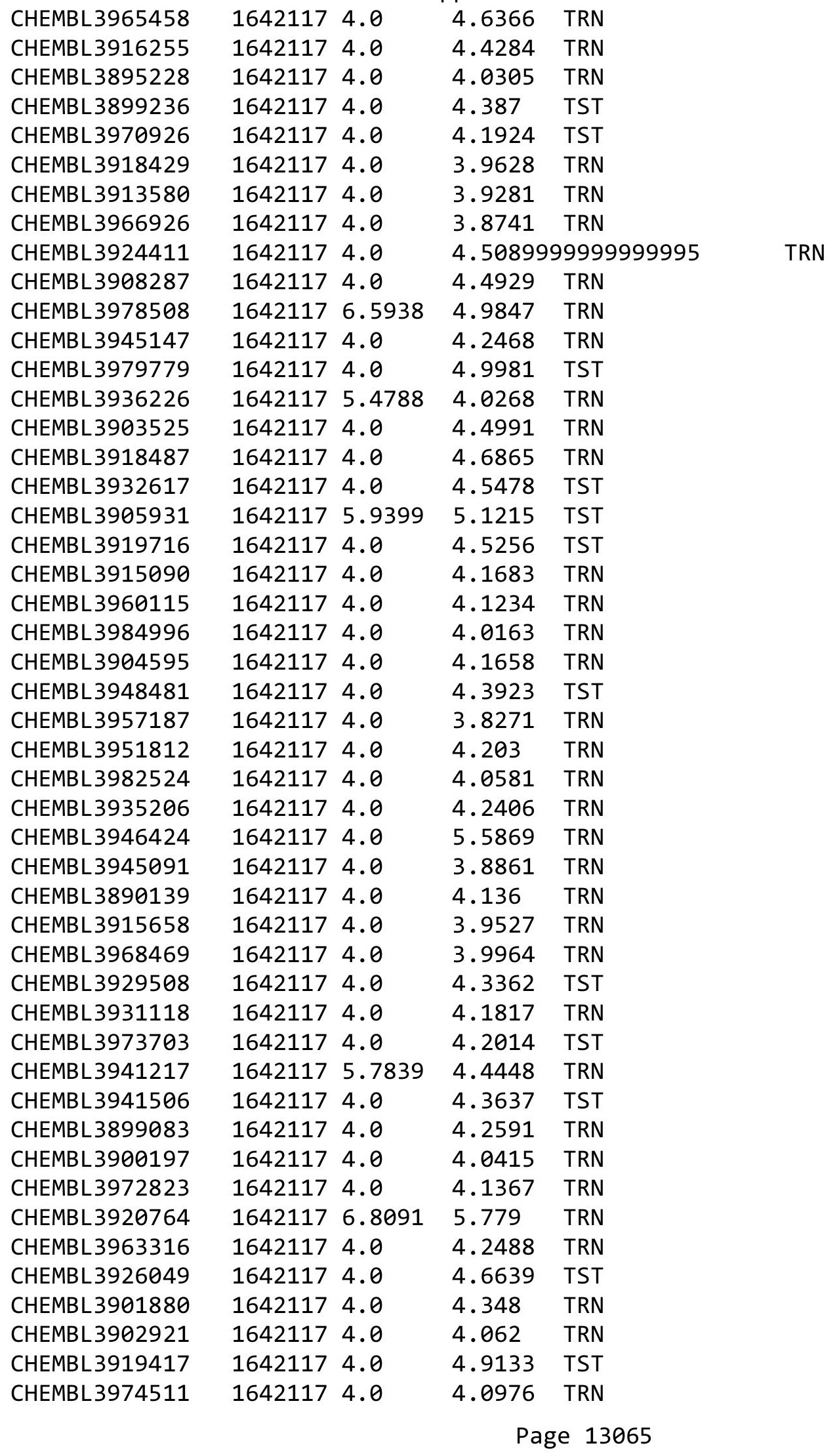




\begin{tabular}{|c|c|c|c|c|}
\hline \multicolumn{5}{|c|}{ Supplemental Table S2.txt } \\
\hline CHEMBL3969306 & 1642117 & 4.0 & 4.5778 & TRN \\
\hline CHEMBL3957074 & 1642117 & 4.0 & 4.1948 & TRN \\
\hline CHEMBL3946983 & 1642117 & 4.0 & 4.0944 & TRN \\
\hline CHEMBL3902735 & 1642117 & 4.0 & 4.1131 & TRN \\
\hline CHEMBL3969957 & 1642117 & 4.0 & 4.2902 & TRN \\
\hline CHEMBL3973657 & 1642117 & 4.0 & 4.151 & TRN \\
\hline CHEMBL3972177 & 1642117 & 4.0 & 4.0398 & TRN \\
\hline CHEMBL3896990 & 1642117 & 4.0 & 4.7762 & TST \\
\hline CHEMBL3920453 & 1642117 & 5.7829 & 4.598 & TST \\
\hline CHEMBL3920295 & 1642117 & 4.0 & 4.1849 & TRN \\
\hline CHEMBL3937051 & 1642117 & 4.0 & 4.007 & TRN \\
\hline CHEMBL3940625 & 1642117 & 4.0 & 4.4635 & TRN \\
\hline CHEMBL3930807 & 1642117 & 4.0 & 4.0078 & TRN \\
\hline CHEMBL 3968098 & 1642117 & 4.0 & 4.2789 & TRN \\
\hline CHEMBL3959188 & 1642117 & 4.0 & 3.9982 & TRN \\
\hline CHEMBL3968149 & 1642117 & 4.0 & 4.9157 & TST \\
\hline CHEMBL3936193 & 1642117 & 4.0 & 4.6049 & TST \\
\hline CHEMBL3905510 & 1642117 & 4.0 & 5.043 & TST \\
\hline CHEMBL3975413 & 1642117 & 6.803 & 5.5926 & TRN \\
\hline CHEMBL3898913 & 1642117 & 4.0 & 4.2574 & TST \\
\hline CHEMBL3900364 & 1642117 & 4.0 & 4.3249 & TST \\
\hline CHEMBL3936028 & 1642117 & 4.0 & 5.2556 & TRN \\
\hline CHEMBL 3986907 & 1642117 & 6.0585 & 4.3644 & TRN \\
\hline CHEMBL3186072 & 1301432 & 4.5691 & 4.5663 & TRN \\
\hline CHEMBL3182296 & 1301432 & 4.7755 & 4.7967 & TRN \\
\hline CHEMBL3187706 & 1301432 & 4.3063 & 4.3041 & TRN \\
\hline CHEMBL3185661 & 1301432 & 3.1549 & 3.1421 & TRN \\
\hline CHEMBL3184991 & 1301432 & 4.9241 & 4.9372 & TRN \\
\hline CHEMBL572318 & 1301432 & 3.1549 & 3.2964 & TST \\
\hline CHEMBL3184233 & 1301432 & 4.4055 & 4.3896 & TRN \\
\hline CHEMBL3189083 & 1301432 & 3.1549 & 3.1619 & TRN \\
\hline CHEMBL3186937 & 1301432 & 4.6519 & 4.6189 & TRN \\
\hline CHEMBL84014 & 1301432 & 3.1549 & 3.1865 & TRN \\
\hline CHEMBL 3185841 & 1301432 & 3.1549 & 3.1555 & TRN \\
\hline CHEMBL3188555 & 1301432 & 4.3002 & 4.1415 & TRN \\
\hline CHEMBL3187292 & 1301432 & 4.2621 & 4.2537 & TRN \\
\hline CHEMBL3188948 & 1301432 & 3.1549 & 3.1661 & TRN \\
\hline CHEMBL3183728 & 1301432 & 3.1549 & 3.1568 & TRN \\
\hline CHEMBL 3186880 & 1301432 & 4.7133 & 4.73 & TRN \\
\hline CHEMBL3182129 & 1301432 & 3.1549 & 5.8911 & TST \\
\hline CHEMBL3185242 & 1301432 & 4.3821 & 4.3084 & TRN \\
\hline CHEMBL3185596 & 1301432 & 4.3142 & 4.3116 & TRN \\
\hline CHEMBL3186663 & 1301432 & 3.1549 & 3.1395 & TRN \\
\hline CHEMBL3181966 & 1301432 & 3.1549 & 2.9792 & TST \\
\hline CHEMBL3187093 & 1301432 & 4.5854 & 4.6348 & TRN \\
\hline CHEMBL3183427 & 1301432 & 5.0942 & 5.0593 & TRN \\
\hline CHEMBL601071 & 1301432 & 3.1549 & 3.1091 & TRN \\
\hline CHEMBL 3185050 & 1301432 & 4.3463 & 4.3468 & TRN \\
\hline
\end{tabular}


Supplemental Table S2.txt

\begin{tabular}{|c|c|c|c|c|c|}
\hline CHEMBL 3188789 & 1301432 & 3.1549 & 3.2079 & TRN & \\
\hline CHEMBL 3184036 & 1301432 & 3.1549 & 3.1205 & TRN & \\
\hline CHEMBL 3187258 & 1301432 & 4.4995 & 4.4742 & TRN & \\
\hline CHEMBL 3188390 & 1301432 & 3.1549 & 3.183000 & 00000000003 & TST \\
\hline CHEMBL 312487 & 1301432 & 4.7899 & 5.1823 & TST & \\
\hline CHEMBL 3188071 & 1301432 & 3.1549 & 3.1404 & TRN & \\
\hline CHEMBL 3185393 & 1301432 & 4.5123 & 4.5688 & TRN & \\
\hline CHEMBL 3182144 & 1301432 & 4.3261 & 4.3397 & TRN & \\
\hline CHEMBL 2334467 & 1301432 & 3.1549 & 2.1253 & TST & \\
\hline CHEMBL 3188422 & 1301432 & 4.4053 & 4.4069 & TRN & \\
\hline CHEMBL 2414130 & 1301432 & 3.1549 & 3.1921 & TRN & \\
\hline CHEMBL600461 & 1301432 & 3.1549 & 3.2759 & TRN & \\
\hline CHEMBL 3187262 & 1301432 & 4.62 & 4.2737 & TST & \\
\hline CHEMBL 2334461 & 1301432 & 3.1549 & 2.8627 & TST & \\
\hline CHEMBL 1631460 & 1301432 & 3.1549 & 3.8342 & TST & \\
\hline CHEMBL 3187435 & 1301432 & 4.522 & 4.5186 & TRN & \\
\hline CHEMBL597649 & 1301432 & 4.2394 & 4.1938 & TRN & \\
\hline CHEMBL1631464 & 1301432 & 3.1549 & 2.8334 & TST & \\
\hline CHEMBL 3187855 & 1301432 & 3.1549 & 2.3364 & TST & \\
\hline CHEMBL 3185552 & 1301432 & 3.1549 & 4.178 & TST & \\
\hline CHEMBL 3182636 & 1301432 & 4.555 & 4.5004 & TRN & \\
\hline CHEMBL 3182615 & 1301432 & 4.5815 & 4.6194 & TRN & \\
\hline CHEMBL597469 & 1301432 & 3.1549 & 2.5165 & TST & \\
\hline CHEMBL 3186413 & 1301432 & 3.1549 & 3.645 & TST & \\
\hline CHEMBL 3185435 & 1301432 & 3.1549 & 4.0723 & TST & \\
\hline CHEMBL 3186593 & 1301432 & 3.1549 & 3.1263 & TRN & \\
\hline CHEMBL597060 & 1301432 & 4.5724 & 4.6882 & TRN & \\
\hline CHEMBL 3188163 & 1301432 & 3.1549 & 3.0174 & TRN & \\
\hline CHEMBL 3187950 & 1301432 & 4.6749 & 4.6593 & TRN & \\
\hline CHEMBL 3185103 & 1301432 & 3.1549 & 3.1922 & TRN & \\
\hline CHEMBL583997 & 1301432 & 3.1549 & 3.1263 & TRN & \\
\hline CHEMBL 3186241 & 1301432 & 3.1549 & 3.3173 & TRN & \\
\hline CHEMBL 3182425 & 1301432 & 4.6621 & 4.7027 & TRN & \\
\hline CHEMBL 3183472 & 1301432 & 3.1549 & 3.7633 & TST & \\
\hline CHEMBL 3187431 & 1301432 & 4.5336 & 4.5222 & TRN & \\
\hline CHEMBL 3185479 & 1301432 & 4.4704 & 4.4459 & TRN & \\
\hline CHEMBL 3894119 & 1642543 & 8.0132 & 8.263 & TRN & \\
\hline CHEMBL 3934724 & 1642543 & 7.3072 & 8.0727 & TRN & \\
\hline CHEMBL 3939115 & 1642543 & 9.8861 & 7.807 & TRN & \\
\hline CHEMBL 3919285 & 1642543 & 9.2366 & 8.4473 & TRN & \\
\hline CHEMBL 3905877 & 1642543 & 7.0783 & 8.3916 & TRN & \\
\hline CHEMBL 3916040 & 1642543 & 8.28399 & 999999999 & 9.1099 & TRN \\
\hline CHEMBL 3975273 & 1642543 & 9.2596 & 9.077 & TRN & \\
\hline CHEMBL 3984279 & 1642543 & 6.8687 & 8.5012 & TRN & \\
\hline CHEMBL 3907567 & 1642543 & 9.5528 & 7.9946 & TRN & \\
\hline CHEMBL 3925560 & 1642543 & 8.1079 & 8.8643 & TRN & \\
\hline CHEMBL 3984257 & 1642543 & 9.2676 & 8.6906 & TRN & \\
\hline CHEMBL 3940883 & 1642543 & 6.0 & 7.8382 & TRN & \\
\hline
\end{tabular}


Supplemental Table S2.txt

\begin{tabular}{|c|c|c|c|c|}
\hline CHEMBL3922530 & 1642543 & 8.4815 & 8.2891 & TST \\
\hline CHEMBL3960948 & 1642543 & 9.1308 & 8.8561 & TST \\
\hline CHEMBL3941345 & 1642543 & 9.1739 & 9.1908 & TST \\
\hline CHEMBL3968330 & 1642543 & 8.8239 & 8.9093 & TRN \\
\hline CHEMBL 3925458 & 1642543 & 8.1805 & 8.8238 & TRN \\
\hline CHEMBL3964336 & 1642543 & 9.1938 & 8.5707 & TST \\
\hline CHEMBL 3893524 & 1642543 & 8.7696 & 9.3266 & TRN \\
\hline CHEMBL 3914931 & 1642543 & 9.2366 & 9.3654 & TRN \\
\hline CHEMBL3965564 & 1642543 & 8.5086 & 8.9928 & TST \\
\hline CHEMBL3972611 & 1642543 & 9.5376 & 7.9459 & TRN \\
\hline CHEMBL3939476 & 1642543 & 8.7959 & 9.2795 & TRN \\
\hline CHEMBL3967616 & 1642543 & 9.8861 & 7.8396 & TRN \\
\hline CHEMBL3951827 & 1642543 & 9.3872 & 8.1619 & TRN \\
\hline CHEMBL3906582 & 1642543 & 8.8239 & 8.4218 & TRN \\
\hline CHEMBL3934038 & 1642543 & 9.5686 & 8.0649 & TRN \\
\hline CHEMBL 3891952 & 1642543 & 8.9208 & 9.0485 & TRN \\
\hline CHEMBL3908685 & 1642543 & 8.6576 & 8.3345 & TST \\
\hline CHEMBL3974536 & 1642543 & 8.6021 & 8.8658 & TRN \\
\hline CHEMBL3923388 & 1642543 & 9.301 & 8.9087 & TRN \\
\hline CHEMBL 3963441 & 1642543 & 6.8088 & 8.294 & TST \\
\hline CHEMBL 3890786 & 1642543 & 6.6187 & 8.3417 & TST \\
\hline CHEMBL 3924207 & 1642543 & 6.0 & 7.7891 & TRN \\
\hline CHEMBL3951925 & 1642543 & 7.75200 & 000000000 & 8.0829 \\
\hline CHEMBL3939071 & 1642543 & 9.2007 & \multicolumn{2}{|c|}{9.152999999999999} \\
\hline CHEMBL3934932 & 1642543 & 8.1367 & 8.1911 & TST \\
\hline CHEMBL3931065 & 1642543 & 8.9586 & 9.0607 & TRN \\
\hline CHEMBL3914081 & 1642543 & 9.6778 & 8.8399 & TRN \\
\hline CHEMBL3900933 & 1642543 & 9.5528 & 8.8409 & TRN \\
\hline CHEMBL 3971562 & 1642543 & 9.8861 & 8.5642 & TRN \\
\hline CHEMBL 3973970 & 1642543 & 8.7212 & 9.0535 & TRN \\
\hline CHEMBL3946686 & 1642543 & 9.1249 & 8.8862 & TRN \\
\hline CHEMBL 3902500 & 1642543 & 8.9208 & 9.0022 & TST \\
\hline CHEMBL 3972680 & 1642543 & 7.2175 & 8.2619 & TRN \\
\hline CHEMBL 3978712 & 1642543 & 8.1427 & 7.8597 & TRN \\
\hline CHEMBL 3918172 & 1642543 & 9.3565 & 8.9527 & TST \\
\hline CHEMBL3978721 & 1642543 & 9.3468 & 8.0285 & TRN \\
\hline CHEMBL3903624 & 1642543 & 7.0904 & 8.3408 & TRN \\
\hline CHEMBL3960685 & 1642543 & 8.4089 & 8.6024 & TRN \\
\hline CHEMBL3952052 & 1642543 & 8.6576 & 8.5932 & TRN \\
\hline CHEMBL 3945425 & 1642543 & 6.0 & 8.3494 & TRN \\
\hline CHEMBL3906891 & 1642543 & 8.8861 & 8.9831 & TRN \\
\hline CHEMBL3951661 & 1642543 & 8.8539 & 9.3404 & TRN \\
\hline CHEMBL3959583 & 1642543 & 9.5528 & 8.7932 & TRN \\
\hline CHEMBL3928617 & 1642543 & 6.841 & 8.0682 & TST \\
\hline CHEMBL3931157 & 1642543 & 8.1612 & 8.4742 & TST \\
\hline CHEMBL 3965867 & 1642543 & 9.6778 & 7.9136 & TRN \\
\hline CHEMBL3923666 & 1642543 & 9.0315 & 8.5443 & TST \\
\hline CHEMBL 3894136 & 1642543 & 8.6021 & 8.887 & TRN \\
\hline
\end{tabular}

Page 13068 
Supplemental Table S2.txt

\begin{tabular}{|c|c|c|c|c|}
\hline CHEMBL3931446 & 1642543 & 8.6778 & 8.387 & TST \\
\hline CHEMBL3924272 & 1642543 & 9.3468 & 9.3657 & TRN \\
\hline CHEMBL3933076 & 1642543 & 9.4685 & 8.5792 & TRN \\
\hline CHEMBL3924315 & 1642543 & 8.1871 & 8.5648 & TST \\
\hline CHEMBL3946939 & 1642543 & 9.6383 & 9.071 & TST \\
\hline CHEMBL3982138 & 1642543 & 7.5591 & 8.6098 & TST \\
\hline CHEMBL3951598 & 1642543 & 9.9208 & 8.4002 & TRN \\
\hline CHEMBL3920644 & 1642543 & 7.433 & 8.3678 & TST \\
\hline CHEMBL 3925545 & 1642543 & 8.3372 & 8.53 & TRN \\
\hline CHEMBL3923953 & 1642543 & 9.3872 & 9.2533 & TRN \\
\hline CHEMBL3899763 & 1642543 & 6.0 & 8.3357 & TRN \\
\hline CHEMBL3951792 & 1642543 & 8.5686 & 8.8146 & TRN \\
\hline CHEMBL3983216 & 1642543 & 7.295 & 8.2977 & TST \\
\hline CHEMBL3973666 & 1642543 & 8.6576 & 8.0612 & TRN \\
\hline CHEMBL3941391 & 1642543 & 9.3372 & 8.0912 & TRN \\
\hline CHEMBL 3925440 & 1642543 & 9.7447 & 8.2736 & TRN \\
\hline CHEMBL3898547 & 1642543 & 9.9208 & 8.8508 & TRN \\
\hline CHEMBL3968737 & 1642543 & 8.8861 & 7.832999 & 9999999999 \\
\hline CHEMBL 3970412 & 1642543 & 9.6198 & 8.3335 & TRN \\
\hline CHEMBL3906813 & 1642543 & 6.0 & 7.7388 & TRN \\
\hline CHEMBL3908107 & 1642543 & 8.7447 & 9.0679 & TST \\
\hline CHEMBL3896643 & 1642543 & 9.6576 & 8.0288 & TRN \\
\hline CHEMBL3924979 & 1642543 & 6.0 & 8.434 & TRN \\
\hline CHEMBL3909930 & 1642543 & 9.0915 & 8.5593 & TST \\
\hline CHEMBL3902575 & 1642543 & 9.5686 & 8.9747 & TRN \\
\hline CHEMBL3905726 & 1642543 & 6.0 & 7.8981 & TRN \\
\hline CHEMBL3968957 & 1642543 & 9.28399 & 999999999 & 8.5981 \\
\hline CHEMBL3969330 & 1642543 & 7.0146 & 8.7041 & TST \\
\hline CHEMBL 3969445 & 1642543 & 8.0458 & 8.644 & TRN \\
\hline CHEMBL3939969 & 1642543 & 8.3372 & 8.6941 & TRN \\
\hline CHEMBL3985796 & 1642543 & 8.4949 & 8.7266 & TRN \\
\hline CHEMBL3899492 & 1642543 & 8.8239 & 8.4192 & TRN \\
\hline CHEMBL3946831 & 1642543 & 8.3188 & 7.9768 & TRN \\
\hline CHEMBL3982759 & 1642543 & 9.0044 & 8.891 & TRN \\
\hline CHEMBL3921156 & 1642543 & 9.6576 & 8.9349 & TRN \\
\hline CHEMBL3927983 & 1642543 & 6.459 & 8.4884 & TRN \\
\hline CHEMBL3979354 & 1642543 & 9.9586 & 8.4613 & TRN \\
\hline CHEMBL3954845 & 1642543 & 6.0 & 8.7067 & TRN \\
\hline CHEMBL3969596 & 1642543 & 8.6383 & 8.5941 & TRN \\
\hline CHEMBL3971395 & 1642543 & 6.0 & 8.7533 & TRN \\
\hline CHEMBL3970935 & 1642543 & 9.3372 & 7.8554 & TRN \\
\hline CHEMBL3963277 & 1642543 & 8.4318 & 8.9957 & TRN \\
\hline CHEMBL3942777 & 1642543 & 6.0 & 7.7391 & TRN \\
\hline CHEMBL 3935982 & 1642543 & 9.3979 & 8.3911 & TRN \\
\hline CHEMBL3956271 & 1642543 & 9.6778 & 8.6231 & TRN \\
\hline CHEMBL3919827 & 1642543 & 9.6383 & 7.9453 & TRN \\
\hline CHEMBL3899541 & 1642543 & 9.0088 & 8.544 & TRN \\
\hline CHEMBL3903534 & 1642543 & 6.0 & 8.656 & TRN \\
\hline
\end{tabular}


Supplemental Table S2.txt

\begin{tabular}{|c|c|c|c|c|c|c|}
\hline CHEMBL3913366 & 1642543 & 9.3872 & 8.3237 & TST & & \\
\hline CHEMBL3936769 & 1642543 & 8.3565 & 8.4185 & TST & & \\
\hline CHEMBL3924671 & 1642543 & 9.3188 & 8.5933 & TRN & & \\
\hline CHEMBL3915287 & 1642543 & 8.8861 & 9.0098 & TST & & \\
\hline CHEMBL3971481 & 1642543 & 7.1618 & 8.5266 & TST & & \\
\hline CHEMBL3930082 & 1642543 & 9.7959 & 8.7436 & TRN & & \\
\hline CHEMBL 3942808 & 1642543 & 8.7447 & 9.0122 & TRN & & \\
\hline CHEMBL 3897279 & 1642543 & 9.7212 & 8.1599 & TRN & & \\
\hline CHEMBL3917607 & 1642543 & 6.0 & 7.7366 & TRN & & \\
\hline CHEMBL3971349 & 1642543 & \multicolumn{3}{|c|}{7.757000000000001} & 8.6363 & TRN \\
\hline CHEMBL3920716 & 1642543 & 9.699 & 8.7013 & TRN & & \\
\hline CHEMBL3921620 & 1642543 & 9.585 & 7.8496 & TRN & & \\
\hline CHEMBL3930491 & 1642543 & 9.1427 & 8.855 & TRN & & \\
\hline CHEMBL3939414 & 1642543 & 6.0 & 7.83 & TRN & & \\
\hline CHEMBL3960460 & 1642543 & 9.1739 & 7.7812 & TRN & & \\
\hline CHEMBL3961043 & 1642543 & 7.9706 & 8.6624 & TRN & & \\
\hline CHEMBL3983895 & 1642543 & 9.699 & 8.868 & TRN & & \\
\hline CHEMBL 3942823 & 1642543 & 6.0805 & 8.4258 & TRN & & \\
\hline CHEMBL3958058 & 1642543 & 8.9208 & 8.2236 & TST & & \\
\hline CHEMBL3956218 & 1642543 & 8.7212 & 8.6619 & TST & & \\
\hline CHEMBL3960401 & 1642543 & 8.6576 & 8.6635 & TST & & \\
\hline CHEMBL3912165 & 1642543 & 9.7447 & 8.6091 & TRN & & \\
\hline CHEMBL 3925134 & 1642543 & 6.5555 & 7.9458 & TRN & & \\
\hline CHEMBL3914958 & 1642543 & 6.6245 & 8.4209 & TST & & \\
\hline CHEMBL3932158 & 1642543 & 8.9586 & 8.6169 & TRN & & \\
\hline CHEMBL3964611 & 1642543 & 6.5653 & 8.5592 & TST & & \\
\hline CHEMBL3945683 & 1642543 & 9.2676 & 8.6987 & TRN & & \\
\hline CHEMBL3912887 & 1642543 & 8.8861 & 8.851 & TRN & & \\
\hline CHEMBL3949398 & 1642543 & 9.7212 & 8.2183 & TRN & & \\
\hline CHEMBL3936816 & 1642543 & 9.7696 & 9.0606 & TRN & & \\
\hline CHEMBL3902975 & 1642543 & 8.8239 & 9.1311 & TRN & & \\
\hline CHEMBL3911454 & 1642543 & 9.2366 & 8.5785 & TRN & & \\
\hline CHEMBL3968630 & 1642543 & 7.6038 & 7.7585 & TRN & & \\
\hline CHEMBL3979477 & 1642543 & 8.8539 & 8.9948 & TRN & & \\
\hline CHEMBL3951715 & 1642543 & 8.9586 & 8.9229 & TRN & & \\
\hline CHEMBL3916919 & 1642543 & 6.0 & 7.8308 & TRN & & \\
\hline CHEMBL3911994 & 1642543 & 9.4089 & 8.6762 & TRN & & \\
\hline CHEMBL 3897085 & 1642543 & 6.1158 & 7.8873 & TRN & & \\
\hline CHEMBL3924437 & 1642543 & 7.6091 & 8.9308 & TST & & \\
\hline CHEMBL3935573 & 1642543 & 9.1249 & 9.218 & TRN & & \\
\hline CHEMBL3951180 & 1642543 & 7.8268 & 8.5608 & TST & & \\
\hline CHEMBL3953056 & 1642543 & 6.0 & 7.7259 & TRN & & \\
\hline CHEMBL3909315 & 1642543 & 9.3468 & 8.5315 & TRN & & \\
\hline CHEMBL3980598 & 1642543 & 9.1938 & 8.5735 & TRN & & \\
\hline CHEMBL3968485 & 1642543 & 9.7959 & 8.3827 & TRN & & \\
\hline CHEMBL3914921 & 1642543 & 6.0 & 7.7349 & TRN & & \\
\hline CHEMBL3929374 & 1642543 & 8.8239 & 9.0354 & TST & & \\
\hline CHEMBL3925051 & 1642543 & 9.1249 & 8.667 & TRN & & \\
\hline
\end{tabular}

Page 13070 
Supplemental Table S2.txt

\begin{tabular}{|c|c|c|c|c|c|}
\hline CHEMBL3910576 & 1642543 & 9.8861 & 7.9998 & TRN & \\
\hline CHEMBL3909137 & 1642543 & 8.2007 & 8.2605 & TST & \\
\hline CHEMBL3964389 & 1642543 & 8.699 & 9.2655 & TRN & \\
\hline CHEMBL3946081 & 1642543 & 6.5352 & 8.6207 & TST & \\
\hline CHEMBL3940172 & 1642543 & \multicolumn{2}{|c|}{9.283999999999999} & 8.6946 & TRN \\
\hline CHEMBL3899641 & 1642543 & 6.0 & 8.1354 & TRN & \\
\hline CHEMBL3929022 & 1642543 & 6.0 & 7.8161 & TRN & \\
\hline CHEMBL3976232 & 1642543 & 9.1079 & 9.4509 & TRN & \\
\hline CHEMBL3922371 & 1642543 & 6.6101 & \multicolumn{2}{|c|}{8.238999999999999} & TST \\
\hline CHEMBL3903705 & 1642543 & 7.6253 & 8.5131 & TRN & \\
\hline CHEMBL3897468 & 1642543 & 8.2441 & 8.6165 & TRN & \\
\hline CHEMBL3936538 & 1642543 & 8.7212 & 8.208 & TST & \\
\hline CHEMBL3908593 & 1642543 & 9.0706 & 8.0136 & TRN & \\
\hline CHEMBL3948747 & 1642543 & 8.7212 & 8.8004 & TST & \\
\hline CHEMBL3913070 & 1642543 & 9.0506 & 8.7154 & TRN & \\
\hline CHEMBL3953126 & 1642543 & 8.3979 & 8.949 & TST & \\
\hline CHEMBL3929625 & 1642543 & 7.8962 & 7.9552 & TRN & \\
\hline CHEMBL3893689 & 1642543 & 9.2291 & 8.7262 & TST & \\
\hline CHEMBL3914239 & 1642543 & 8.5686 & 8.8163 & TST & \\
\hline CHEMBL3932075 & 1642543 & 9.3979 & 8.9539 & TRN & \\
\hline CHEMBL3961178 & 1642543 & 9.2441 & 8.5363 & TRN & \\
\hline CHEMBL 3937867 & 1642543 & 9.7959 & 8.0788 & TST & \\
\hline CHEMBL3966120 & 1642543 & 9.301 & 8.8131 & TRN & \\
\hline CHEMBL3981439 & 1642543 & 7.9066 & 8.1229 & TST & \\
\hline CHEMBL3949069 & 1642543 & 8.4202 & 8.7864 & TRN & \\
\hline CHEMBL3983507 & 1642543 & 9.2007 & 8.9973 & TRN & \\
\hline CHEMBL3930433 & 1642543 & 9.8861 & 8.8965 & TRN & \\
\hline CHEMBL3900863 & 1642543 & 9.5086 & 8.262 & TST & \\
\hline CHEMBL 3893734 & 1642543 & 8.7212 & 9.2673 & TRN & \\
\hline CHEMBL3911500 & 1642543 & 6.5453 & 8.2715 & TST & \\
\hline CHEMBL 3897476 & 1642543 & 8.0862 & 8.67 & TRN & \\
\hline CHEMBL3973275 & 1642277 & 6.1152 & 6.0564 & TRN & \\
\hline CHEMBL3926727 & 1642277 & 6.6162 & 6.7951 & TRN & \\
\hline CHEMBL3913456 & 1642277 & 6.4895 & 6.0591 & TRN & \\
\hline CHEMBL3932535 & 1642277 & 6.8239 & 6.2438 & TRN & \\
\hline CHEMBL3983275 & 1642277 & 4.6234 & 5.2313 & TRN & \\
\hline CHEMBL3907998 & 1642277 & 4.6234 & 5.4626 & TST & \\
\hline CHEMBL3975290 & 1642277 & 6.0039 & 5.95200 & 2000000001 & TST \\
\hline CHEMBL3983754 & 1642277 & 6.4802 & 6.754 & TRN & \\
\hline CHEMBL3916289 & 1642277 & 6.8633 & 6.8559 & TRN & \\
\hline CHEMBL 3893378 & 1642277 & 6.5406 & 6.71899 & 9999999999 & TRN \\
\hline CHEMBL 3982253 & 1642277 & 4.6234 & 5.4375 & TST & \\
\hline CHEMBL3958010 & 1642277 & 4.6234 & 6.6897 & TST & \\
\hline CHEMBL3933335 & 1642277 & 4.6234 & 5.4357 & TST & \\
\hline CHEMBL3950098 & 1642277 & 6.4535 & 6.0059 & TST & \\
\hline CHEMBL3959335 & 1642277 & 7.1439 & 6.4325 & TRN & \\
\hline CHEMBL 3894687 & 1642277 & 6.9393 & 6.8227 & TRN & \\
\hline CHEMBL3921387 & 1642277 & 6.5528 & 6.79 & TRN & \\
\hline
\end{tabular}


Supplemental Table S2.txt

\begin{tabular}{|c|c|c|c|c|c|}
\hline CHEMBL3978823 & 1642277 & 4.6234 & 6.2961 & TRN & \\
\hline CHEMBL3970167 & 1642277 & 6.9547 & 6.8375 & TRN & \\
\hline CHEMBL3928315 & 1642277 & 6.6055 & 6.5278 & TRN & \\
\hline CHEMBL3904538 & 1642277 & 6.6073 & 5.9781 & TST & \\
\hline CHEMBL3889469 & 1642277 & 5.9872 & 5.5787 & TRN & \\
\hline CHEMBL3896677 & 1642277 & 6.2403 & 6.3882 & TRN & \\
\hline CHEMBL3891867 & 1642277 & 6.4828 & 6.3638 & TRN & \\
\hline CHEMBL3960107 & 1642277 & 6.5171 & 6.4962 & TRN & \\
\hline CHEMBL3986608 & 1642277 & 6.6459 & 6.8219 & TRN & \\
\hline CHEMBL3958787 & 1642277 & 5.6596 & 5.5027 & TST & \\
\hline CHEMBL3889747 & 1642277 & 4.6234 & 5.5765 & TST & \\
\hline CHEMBL3915556 & 1642277 & 6.4698 & 6.6871 & TRN & \\
\hline CHEMBL3940775 & 1642277 & 5.7721 & 6.0752 & TRN & \\
\hline CHEMBL3895771 & 1642277 & 5.6345 & 6.0594 & TRN & \\
\hline CHEMBL 3923520 & 1642277 & 6.6498 & 6.7962 & TRN & \\
\hline CHEMBL 3904841 & 1642277 & 6.8827 & 6.5508 & TRN & \\
\hline CHEMBL3943520 & 1642277 & 6.567 & 6.4636 & TRN & \\
\hline CHEMBL3904925 & 1642277 & 6.1397 & 6.0442 & TRN & \\
\hline CHEMBL3975712 & 1642277 & 6.2976 & 6.4356 & TRN & \\
\hline CHEMBL3981925 & 1642277 & 6.7258 & 6.5553 & TRN & \\
\hline CHEMBL3952227 & 1642277 & 6.6126 & 6.6441 & TRN & \\
\hline CHEMBL3922908 & 1642277 & 6.8069 & 6.9269 & TRN & \\
\hline CHEMBL3950632 & 1642277 & 7.0742 & 6.6932 & TRN & \\
\hline CHEMBL3928182 & 1642277 & 4.6234 & 4.9104 & TRN & \\
\hline CHEMBL 3922445 & 1642277 & 4.6234 & 5.90799 & & TST \\
\hline CHEMBL3965144 & 1642277 & 6.5935 & 5.6451 & TRN & \\
\hline CHEMBL3926440 & 1642277 & 6.426 & 6.1694 & TST & \\
\hline CHEMBL3919279 & 1642277 & 6.1451 & 5.9054 & TRN & \\
\hline CHEMBL 3889934 & 1642277 & 6.5467 & 6.7747 & TRN & \\
\hline CHEMBL 3916873 & 1642277 & 7.0482 & 6.8723 & TRN & \\
\hline CHEMBL3935928 & 1642277 & 6.0405 & 6.4402 & TRN & \\
\hline CHEMBL3898375 & 1642277 & 6.4949 & 6.1003 & TST & \\
\hline CHEMBL3891194 & 1642277 & 5.8928 & 5.8267 & TRN & \\
\hline CHEMBL3967046 & 1642277 & 6.8539 & 6.8397 & TRN & \\
\hline CHEMBL3962469 & 1642277 & 7.1643 & 6.7693 & TRN & \\
\hline CHEMBL3964429 & 1642277 & 6.6055 & 6.0938 & TST & \\
\hline CHEMBL3898964 & 1642277 & 6.9355 & 6.7362 & TRN & \\
\hline CHEMBL3897197 & 1642277 & 6.2161 & 5.8519 & TST & \\
\hline CHEMBL3692852 & 1528679 & 8.301 & 8.2208 & TRN & \\
\hline CHEMBL3692995 & 1528679 & \multicolumn{3}{|c|}{10.300999999999998} & TRN \\
\hline CHEMBL 3692988 & 1528679 & 9.7959 & 9.8219 & TRN & \\
\hline CHEMBL3696982 & 1528679 & 6.0 & 9.6886 & TST & \\
\hline CHEMBL3692906 & 1528679 & 8.1249 & 8.8163 & TST & \\
\hline CHEMBL3696962 & 1528679 & 9.3979 & 9.406 & TRN & \\
\hline CHEMBL3692937 & 1528679 & 8.5229 & 8.5188 & TRN & \\
\hline CHEMBL3696978 & 1528679 & 7.2218 & 8.4694 & TST & \\
\hline CHEMBL3692901 & 1528679 & 9.6021 & $9.64200 t$ & 0000000001 & $\mid \mathrm{IRT}$ \\
\hline CHEMBL3692889 & 1528679 & 7.5528 & 8.4474 & TST & \\
\hline
\end{tabular}


Supplemental Table S2.txt

\begin{tabular}{|c|c|c|c|c|}
\hline 6 & & 9208 & 8874 & . \\
\hline & 528679 & 8.4815 & & \\
\hline EN & 28679 & & & \\
\hline EMBL & 8679 & & & \\
\hline AEMBL3696954 & 528679 & 229 & 6121 & \\
\hline HEMBL369 & 528679 & 08 & 2546 & \\
\hline 843 & 28679 & & 575 & \\
\hline IEMBL & & & & \\
\hline HEMBL3692846 & 528679 & 7.0 & 9559 & \\
\hline HEMBL3692968 & 528679 & 586 & 133 & \\
\hline HEMBL3692914 & 528679 & & 643 & \\
\hline 51 & 679 & & 93 & \\
\hline AEMBL & & & & \\
\hline HEMBL3696979 & 528679 & 7.3279 & 53 & \\
\hline AEMBL3696951 & 528679 & & & \\
\hline AEMBL3 & 79 & & 06 & \\
\hline AEMBL & 79 & & & \\
\hline AEMBL. & 79 & & & \\
\hline HEMBL3 & 528679 & 8.0 & 21 & \\
\hline HEMBL3692879 & & & & I \\
\hline HEMBL & 99 & & & RN \\
\hline IEM & & & & 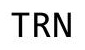 \\
\hline AEMBL & 79 & & 98 & ST \\
\hline AEMPI & & & & KIV \\
\hline AEMBL3 & & & & 31 \\
\hline HEMBL; & 79 & & 174 & RN \\
\hline 40 & & & & KIV \\
\hline 53 & & & & \\
\hline HEMBL & & & & IRN \\
\hline HEMBL3692920 & 528679 & & 03 & RN \\
\hline EMB & 79 & & 16 & קו \\
\hline 4 & & & & KIV \\
\hline וסMFנI & & & & RN \\
\hline HEMBL3 & & & & ST \\
\hline HEMBL3692899 & 28679 & & & ST \\
\hline 91 & 679 & & & RN \\
\hline 3 & & & & RN \\
\hline HEMBL3 & & & & TRN \\
\hline HEMBL3692865 & 579 & & & TRN \\
\hline 33 & 79 & & & ST \\
\hline HEMBL3 & 79 & & 19 & 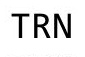 \\
\hline & 679 & 9.1024 & & RN \\
\hline HEMBL3 & 579 & 9. & & RN \\
\hline HEMBL 369 & 79 & & & TR \\
\hline CHEMBL3692907 & & & & \\
\hline HEMBL3692999 & $.5286 / 9$ & $9.4 \ell$ & 9.3947 & \\
\hline HEMBL 3692893 & 528679 & 6.0 & 8.7856 & \\
\hline CHEMBL3696952 & 1528679 & 9.301 & 9.4716 & $\mathrm{RN}$ \\
\hline
\end{tabular}

Page 13073 
Supplemental Table S2.txt

\begin{tabular}{|c|c|c|c|c|}
\hline CHEMBL3692869 & 1528679 & 7.5086 & \multicolumn{2}{|c|}{7.928999999999999} \\
\hline CHEMBL3696970 & 1528679 & 8.1135 & 8.1489 & TRN \\
\hline CHEMBL3696949 & 1528679 & 8.8861 & 8.6928 & TRN \\
\hline CHEMBL3692967 & 1528679 & 8.8239 & 8.8728 & TRN \\
\hline CHEMBL3696977 & 1528679 & 6.9747 & 7.4057 & TST \\
\hline CHEMBL3692845 & 1528679 & 7.4202 & 7.5824 & TRN \\
\hline CHEMBL3696984 & 1528679 & 9.2291 & 7.6684 & TST \\
\hline CHEMBL3696953 & 1528679 & 9.6576 & 9.6308 & TRN \\
\hline CHEMBL3692966 & 1528679 & 9.3188 & 9.3292 & TRN \\
\hline CHEMBL3692882 & 1528679 & 10.0809 & 10.1716 & TRN \\
\hline CHEMBL3692959 & 1528679 & 8.7696 & 8.795 & TRN \\
\hline CHEMBL3692930 & 1528679 & 7.5376 & 7.5768 & TRN \\
\hline CHEMBL3692847 & 1528679 & 5.8794 & 5.7563 & TRN \\
\hline CHEMBL3693000 & 1528679 & 9.5528 & 9.5971 & TRN \\
\hline CHEMBL3692963 & 1528679 & 6.7773 & 6.848 & TRN \\
\hline CHEMBL3692891 & 1528679 & 8.3665 & 8.382 & TRN \\
\hline CHEMBL3692986 & 1528679 & 6.0 & 6.5866 & TRN \\
\hline CHEMBL3696950 & 1528679 & 8.9208 & 8.9517 & TRN \\
\hline CHEMBL3696976 & 1528679 & 7.9586 & 9.3189 & TST \\
\hline CHEMBL3692965 & 1528679 & 9.1805 & 9.1841 & TRN \\
\hline CHEMBL3696959 & 1528679 & 7.301 & 7.4124 & TRN \\
\hline CHEMBL3692851 & 1528679 & 7.7696 & 7.5436 & TRN \\
\hline CHEMBL3692956 & 1528679 & 7.3468 & 7.1911 & TRN \\
\hline CHEMBL3696963 & 1528679 & 8.0555 & 7.9219 & TRN \\
\hline CHEMBL3696974 & 1528679 & 5.9547 & 5.932 & TRN \\
\hline CHEMBL3692980 & 1528679 & 6.0 & 6.0746 & TRN \\
\hline CHEMBL3692975 & 1528679 & 9.7212 & 9.754 & TRN \\
\hline CHEMBL3696972 & 1528679 & 8.2441 & 8.3176 & TRN \\
\hline CHEMBL3692862 & 1528679 & 8.7212 & 8.5277 & TRN \\
\hline CHEMBL3692848 & 1528679 & 7.4202 & 7.5279 & TRN \\
\hline CHEMBL3692908 & 1528679 & 6.0 & 7.6424 & TST \\
\hline CHEMBL3692894 & 1528679 & 6.0 & 8.3888 & TST \\
\hline CHEMBL3692984 & 1528679 & 9.4559 & 9.2463 & TRN \\
\hline CHEMBL3696985 & 1528679 & 8.0223 & 8.0438 & TRN \\
\hline CHEMBL3692911 & 1528679 & 8.4815 & 8.4839 & TRN \\
\hline CHEMBL3692976 & 1528679 & 9.1249 & 9.3152 & TRN \\
\hline CHEMBL3692969 & 1528679 & 9.4949 & 9.3895 & TRN \\
\hline CHEMBL3692857 & 1528679 & 9.2596 & 9.4111 & TRN \\
\hline CHEMBL3696966 & 1528679 & 9.9586 & 9.9707 & TRN \\
\hline CHEMBL3692944 & 1528679 & 7.699 & 7.5627 & TRN \\
\hline CHEMBL3692997 & 1528679 & 9.7696 & 9.7973 & TRN \\
\hline CHEMBL3692996 & 1528679 & 9.6383 & 9.7336 & TRN \\
\hline CHEMBL3692897 & 1528679 & 6.2823 & 8.4067 & TST \\
\hline CHEMBL3692860 & 1528679 & 9.4089 & 9.3957 & TRN \\
\hline CHEMBL3692854 & 1528679 & 9.2366 & 7.5744 & TST \\
\hline CHEMBL3692877 & 1528679 & 6.8125 & 8.2176 & TST \\
\hline CHEMBL3692904 & 1528679 & 6.0 & 8.7443 & TST \\
\hline CHEMBL3692856 & 1528679 & 9.3768 & 7.7883 & TST \\
\hline
\end{tabular}


Supplemental Table S2.txt

\begin{tabular}{|c|c|c|c|c|}
\hline ב & 528679 & & & \\
\hline & 528679 & 9.699 & & \\
\hline & 3679 & & & \\
\hline IEMBL: & 528679 & 9208 & & \\
\hline AEMBL & 528679 & 7959 & 8846 & \\
\hline AEMBL3692878 & 528679 & 6.2733 & 5153 & \\
\hline AEMBL & 528679 & 3861 & & \\
\hline EMB & 528679 & & 205 & \\
\hline IEMBL 36 & 528679 & 7.8861 & 3986 & \\
\hline HEMBL3692 & 528679 & 8.2147 & 2881 & \\
\hline IEMBL369 & 528679 & 7.585 & 102 & \\
\hline IEMBL & 528679 & 7.9208 & 026 & \\
\hline EMBL & 528679 & & 471 & \\
\hline AEMBL. & 528679 & 6.0 & 999 & \\
\hline IEMBL & 528679 & 208 & 981 & \\
\hline EMBL: & 528679 & 768 & 1789 & \\
\hline IEMBL & 528679 & 596 & 243 & \\
\hline IEMBL & 79 & 212 & 113 & \\
\hline IEMBL & 528679 & 8.1192 & 631 & \\
\hline IEMBL & 79 & 686 & & \\
\hline IEMB & 8679 & 86 & 14 & RI \\
\hline EMB & 79 & 598 & 06 & ( \\
\hline EMB & 79 & 39 & 24 & \\
\hline $5 M D$ & 528679 & 10.0 & 0061 & 7 \\
\hline IEMBL: & & 135 & & RN \\
\hline IEMBL & $286 / 9$ & 51 & 858 & KI \\
\hline EMB & 9 & 6 & 617 & 年 \\
\hline EME & 79 & 383 & & \\
\hline IEMBL & 528679 & 192 & 397 & RN \\
\hline IEMBL369 & 79 & 39 & 236 & ГRN \\
\hline IEMBL: & 8679 & 778 & 878 & 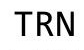 \\
\hline $\mathrm{FME}$ & & 18 & 751 & TII \\
\hline 0 & 79 & 361 & 289 & 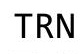 \\
\hline IEMBL3 & 28679 & 576 & 212 & $\mathrm{RN}$ \\
\hline AEMBL 369 & 528679 & 6.308 & 6.3969 & RI \\
\hline IEMBL & 36 & 212 & 828 & RI \\
\hline 4 & & & & niv \\
\hline & & & 316 & RI \\
\hline IEMBL369 & 528679 & 9.4949 & & $\mathrm{RI}$ \\
\hline EMBL & 28679 & 596 & 101 & RI \\
\hline IEMBL & 8679 & 979 & 344 & TRN \\
\hline - & & & & RI \\
\hline HEMBL & 528679 & 7.7696 & 3084 & ST \\
\hline IEMBL369 & 28679 & 8.7959 & 893 & $R$ \\
\hline$M B L$ & 8679 & 355 & 7.8731 & 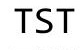 \\
\hline CHEMBL3 & 528679 & & 7.7716 & RI \\
\hline CHEMBL3 & 528679 & 3.3979 & 9.7296 & S \\
\hline CHEMBL3692903 & 152867 & 6.1904 & 10.4747 & S \\
\hline
\end{tabular}

Page 13075 
Supplemental Table S2.txt

\begin{tabular}{|c|c|c|c|c|}
\hline HEM & 528679 & 9.4559 & 9.4577 & \\
\hline & 528679 & & 7.8386 & \\
\hline AEM & 28679 & & & \\
\hline IEMBL & 28679 & 959 & & \\
\hline AEMBL3692849 & 528679 & 79 & 4975 & \\
\hline HEMBL3692970 & 528679 & 98 & 181 & \\
\hline 2880 & 28679 & & & \\
\hline AEMBL & 8679 & & & \\
\hline HEMBL3692934 & 528679 & 8.6383 & 5696 & \\
\hline HEMBL3692912 & 528679 & 8.6576 & 394 & \\
\hline HEMBL3692858 & 528679 & & & \\
\hline HEMBL & 8679 & 78 & & \\
\hline AEMBL: & & & & \\
\hline HEMBL3696960 & 528679 & 7.7447 & 5852 & \\
\hline AEMBL3693001 & 528679 & 86 & & \\
\hline HEMBL3696983 & 79 & 7. & & \\
\hline HEMBL & 79 & & & 年 \\
\hline HEMBL; & 79 & & & \\
\hline 92842 & 528679 & & & \\
\hline HEMBL3692874 & & & & niv \\
\hline HEMBL & 99 & & 72 & RN \\
\hline 921 & 9 & & & NIV \\
\hline HEMBL & 79 & 12 & 67 & \\
\hline HEMBL & 79 & & & $\mathrm{IRIV}$ \\
\hline AEMBL & 79 & & 03 & |S| \\
\hline HEMBL & 79 & & 37 & 「RN \\
\hline 861 & 79 & & 91 & NIV \\
\hline 900 & & & 31 & \\
\hline HEMBL & & & & $S$ \\
\hline HEMBL3692888 & 528679 & 8. & & TST \\
\hline HEMBL & 79 & 9. & 79 & TRN \\
\hline 58 & & & & \\
\hline 955 & & & & $\pi$ \\
\hline HEMBL3692866 & 9 & & & TST \\
\hline HEMBL3692887 & 528679 & 666 & 003 & ГST \\
\hline 969 & 9 & & & TST \\
\hline 70 & 79 & & & IST \\
\hline HEMBL1 & & & 6.7357 & TST \\
\hline HEMBL1 & +1 & & 79 & TRN \\
\hline$T M$ & & & & $\mathrm{R}$ \\
\hline HEMBL1 & & & 48 & TRN \\
\hline HEMBL 2 & & & 9861 & 「RN \\
\hline HEMBL343625 & 95521 & & 1612 & TST \\
\hline HEMBL1 & 5521 & & 975 & TS \\
\hline CHEMBL146169 & & & & \\
\hline HEMBL355918 & 95521 & 6.8239 & 6.7903 & \\
\hline CHEMBL 343883 & 95521 & 7.1549 & 7.4261 & \\
\hline CHEMBL422659 & 195521 & 7.0458 & 6.8758 & $\mathrm{~K}$ \\
\hline
\end{tabular}

Page 13076 


\begin{tabular}{|c|c|c|c|c|c|}
\hline & & \multicolumn{4}{|c|}{ Supplemental Table S2.txt } \\
\hline CHEMBL142853 & 195521 & 7.2218 & 7.2821 & TRN & \\
\hline CHEMBL145199 & 195521 & 7.699 & 7.7838 & TRN & \\
\hline CHEMBL345006 & 195521 & 6.4089 & 6.9112 & TRN & \\
\hline CHEMBL145295 & 195521 & 6.3979 & 6.3146 & TRN & \\
\hline CHEMBL142664 & 195521 & 5.9586 & 6.5985 & TRN & \\
\hline CHEMBL356998 & 195521 & 6.9586 & 6.9191 & TRN & \\
\hline CHEMBL143107 & 195521 & 6.9208 & 6.4163 & TST & \\
\hline CHEMBL144561 & 195521 & 6.4089 & 7.011 & TRN & \\
\hline CHEMBL358947 & 195521 & 7.0458 & 6.8999 & TRN & \\
\hline CHEMBL144326 & 195521 & 7.699 & 6.8804 & TRN & \\
\hline CHEMBL 37343 & 195521 & 6.8861 & 7.032 & TRN & \\
\hline CHEMBL145004 & 195521 & 6.0862 & 6.2882 & TRN & \\
\hline CHEMBL144866 & 195521 & 6.5086 & 7.0026 & TRN & \\
\hline CHEMBL344288 & 195521 & 6.8539 & 6.8869 & TRN & \\
\hline CHEMBL343007 & 195521 & 7.699 & 6.9032 & TST & \\
\hline CHEMBL144035 & 195521 & 7.1549 & 6.6165 & TRN & \\
\hline CHEMBL144851 & 195521 & 7.3979 & 6.9006 & TST & \\
\hline CHEMBL344289 & 195521 & 7.3979 & 6.7672 & TRN & \\
\hline CHEMBL342103 & 195521 & 7.699 & 6.8657 & TST & \\
\hline CHEMBL356779 & 195521 & 6.8861 & 6.7932 & TRN & \\
\hline CHEMBL144949 & 195521 & 6.0 & 7.0789 & TST & \\
\hline CHEMBL145237 & 195521 & 7.699 & 7.3789 & TRN & \\
\hline CHEMBL144378 & 195521 & 6.6383 & 7.1753 & TRN & \\
\hline CHEMBL359187 & 195521 & 6.6383 & 6.7381 & TRN & \\
\hline CHEMBL144852 & 195521 & 7.5229 & 6.8917 & TRN & \\
\hline CHEMBL144794 & 195521 & 5.8539 & 6.5095 & TRN & \\
\hline CHEMBL356314 & 195521 & 5.0 & 6.5234 & TRN & \\
\hline CHEMBL344134 & 195521 & 5.0 & 8.2195 & TST & \\
\hline CHEMBL 356744 & 195521 & 7.699 & 7.6223 & TST & \\
\hline CHEMBL15411 & 195521 & 7.1549 & 6.7318 & TST & \\
\hline CHEMBL342068 & 195521 & 6.7212 & 7.019 & TRN & \\
\hline CHEMBL358564 & 195521 & 6.4202 & 6.8018 & TRN & \\
\hline CHEMBL288336 & 195521 & 7.0969 & 6.8852 & TRN & \\
\hline CHEMBL341847 & 195521 & 7.0458 & 7.2058 & TST & \\
\hline CHEMBL422123 & 195521 & 7.301 & 6.6438 & TRN & \\
\hline CHEMBL342056 & 195521 & 6.6576 & 6.7491 & TRN & \\
\hline CHEMBL81319 & 195521 & 7.5229 & 6.7932 & TRN & \\
\hline CHEMBL357411 & 195521 & 6.5229 & 6.8804 & TRN & \\
\hline CHEMBL342771 & 195521 & 7.7447 & 6.84399 & 9999999999 & TRN \\
\hline CHEMBL144744 & 195521 & 8.0 & 7.2754 & TST & \\
\hline CHEMBL435030 & 195521 & 6.8239 & 6.9797 & TST & \\
\hline CHEMBL144653 & 195521 & 7.0 & 7.0468 & TRN & \\
\hline CHEMBL145322 & 195521 & 7.1549 & 7.0834 & TRN & \\
\hline CHEMBL144522 & 195521 & 7.5229 & 5.28299 & 99999999995 & TST \\
\hline CHEMBL142837 & 195521 & 8.0 & 7.0191 & TST & \\
\hline CHEMBL144290 & 195521 & 6.8239 & 7.1105 & TRN & \\
\hline CHEMBL146550 & 195521 & 7.0 & 6.7932 & TRN & \\
\hline CHEMBL358555 & 195521 & 5.4318 & 6.8018 & TRN & \\
\hline
\end{tabular}




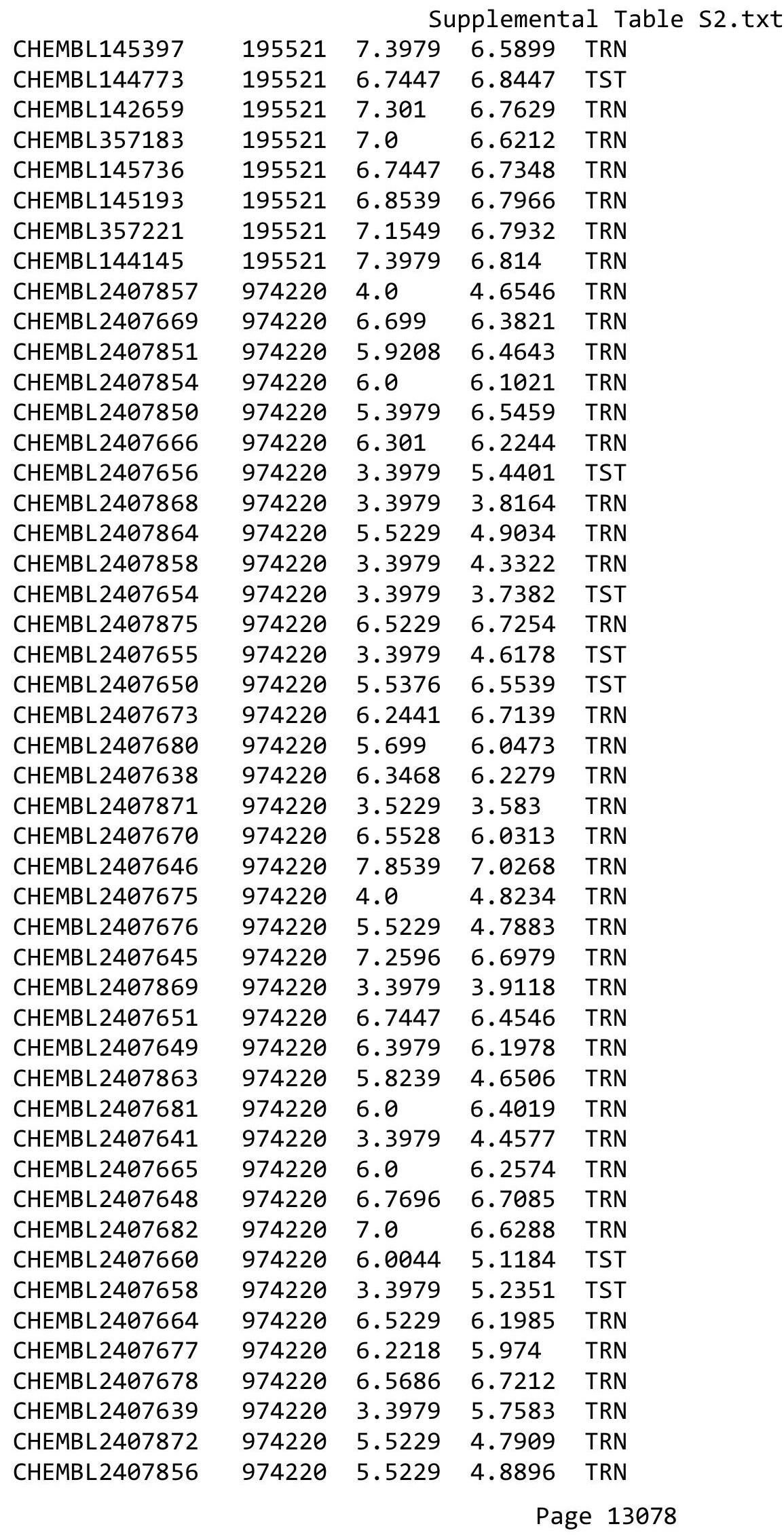




\begin{tabular}{|c|c|c|c|c|c|}
\hline & & \multicolumn{4}{|c|}{ Supplemental Table S2.txt } \\
\hline CHEMBL2407674 & 974220 & 6.301 & 6.5691 & TRN & \\
\hline CHEMBL 2407866 & 974220 & 5.3979 & 3.7785 & TRN & \\
\hline CHEMBL 2407683 & 974220 & 6.5229 & 6.5881 & TRN & \\
\hline CHEMBL 2407644 & 974220 & 7.4318 & 6.7125 & TRN & \\
\hline CHEMBL2407862 & 974220 & 5.6021 & 4.7835 & TRN & \\
\hline CHEMBL2407663 & 974220 & 6.0 & 5.2423 & TRN & \\
\hline CHEMBL 2407870 & 974220 & 3.3979 & 4.7828 & TST & \\
\hline CHEMBL 2407684 & 974220 & 7.0 & 6.2041 & TRN & \\
\hline CHEMBL 2407874 & 974220 & 6.5528 & 6.5663 & TRN & \\
\hline CHEMBL 2407637 & 974220 & 6.1249 & 6.0096 & TRN & \\
\hline CHEMBL2407679 & 974220 & 6.7447 & 7.0155 & TRN & \\
\hline CHEMBL 2407852 & 974220 & 5.699 & 6.4482 & TRN & \\
\hline CHEMBL 2407657 & 974220 & 4.0 & 5.45 & TST & \\
\hline CHEMBL 2407873 & 974220 & 6.699 & 6.524 & TRN & \\
\hline CHEMBL2407659 & 974220 & 6.4685 & 6.2372 & TST & \\
\hline CHEMBL 2407653 & 974220 & 3.3979 & 3.4643 & TRN & \\
\hline CHEMBL 2407861 & 974220 & 3.3979 & 3.9529 & TST & \\
\hline CHEMBL 2407860 & 974220 & 4.7959 & 4.885 & TRN & \\
\hline CHEMBL 2407640 & 974220 & 3.3979 & 4.231 & TRN & \\
\hline CHEMBL 2407652 & 974220 & 3.3979 & 3.7151 & TRN & \\
\hline CHEMBL 2407867 & 974220 & 4.8239 & 4.5122 & TRN & \\
\hline CHEMBL 2407855 & 974220 & 6.6021 & 6.2986 & TST & \\
\hline CHEMBL 2407642 & 974220 & 6.301 & 6.1516 & TST & \\
\hline CHEMBL 2407636 & 974220 & 3.3979 & 6.4898 & TST & \\
\hline CHEMBL2407647 & 974220 & 7.4815 & 6.6187 & TST & \\
\hline CHEMBL 2407859 & 974220 & 4.8861 & 5.06 & TST & \\
\hline CHEMBL 2407667 & 974220 & 5.5229 & 5.311 & TST & \\
\hline CHEMBL 2407865 & 974220 & 6.5229 & 5.2293 & TST & \\
\hline CHEMBL2349464 & 954243 & 5.2336 & 4.5726 & TST & \\
\hline CHEMBL 2349490 & 954243 & 7.4089 & 7.5575 & TRN & \\
\hline CHEMBL2349495 & 954243 & 6.4634 & 6.4364 & TRN & \\
\hline CHEMBL2349617 & 954243 & 7.5528 & 7.5088 & TRN & \\
\hline CHEMBL2349482 & 954243 & 5.8259 & 7.1181 & TST & \\
\hline CHEMBL2349619 & 954243 & 7.2218 & 7.24100 & 00000000005 & TRN \\
\hline CHEMBL2349615 & 954243 & 5.7693 & 5.7343 & TRN & \\
\hline CHEMBL2349473 & 954243 & 7.6198 & 7.4685 & TRN & \\
\hline CHEMBL 2349507 & 954243 & 6.8861 & 6.7442 & TRN & \\
\hline CHEMBL2349610 & 954243 & 4.4338 & 4.3996 & TRN & \\
\hline CHEMBL 2349501 & 954243 & 6.9469 & 6.9372 & TRN & \\
\hline CHEMBL 2349463 & 954243 & 4.4833 & 4.4986 & TRN & \\
\hline CHEMBL2349608 & 954243 & 6.3002 & 6.3138 & TRN & \\
\hline CHEMBL 2349606 & 954243 & 6.8386 & 6.8784 & TRN & \\
\hline CHEMBL2349493 & 954243 & 7.1549 & 7.1984 & TRN & \\
\hline CHEMBL 2349481 & 954243 & 6.153 & 7.1193 & TST & \\
\hline CHEMBL 2349607 & 954243 & $6.8210 €$ & 30000000 & 6.8387 & TRN \\
\hline CHEMBL2349613 & 954243 & 7.0269 & 6.9851 & TRN & \\
\hline CHEMBL2349609 & 954243 & 6.6383 & 4.2555 & TST & \\
\hline CHEMBL2349472 & 954243 & 7.6383 & 7.5971 & TRN & \\
\hline
\end{tabular}


Supplemental Table S2.txt

\begin{tabular}{|c|c|c|c|c|c|c|}
\hline CHEMBL 2349488 & 954243 & 5.7003 & 5.2426 & TST & & \\
\hline CHEMBL 2349479 & 954243 & 6.8697 & 6.8444 & TRN & & \\
\hline CHEMBL 2349478 & 954243 & 7.5229 & 7.5216 & TRN & & \\
\hline CHEMBL 2349485 & 954243 & 6.9101 & 6.9039 & TRN & & \\
\hline CHEMBL2349616 & 954243 & 5.1428 & 5.0694 & TRN & & \\
\hline CHEMBL 2349469 & 954243 & 6.0 & 6.1571 & TRN & & \\
\hline CHEMBL 2349465 & 954243 & 5.7194 & 4.1076 & TST & & \\
\hline CHEMBL 2349497 & 954243 & 7.0044 & 7.02 & TRN & & \\
\hline CHEMBL 2349614 & 954243 & 7.1675 & 7.1928 & TRN & & \\
\hline CHEMBL 2349471 & 954243 & 6.0 & 4.6029 & TST & & \\
\hline CHEMBL 2349506 & 954243 & 8.0 & 7.9838 & TRN & & \\
\hline CHEMBL 2349487 & 954243 & 6.1029 & 5.2484 & TST & & \\
\hline CHEMBL 2349477 & 954243 & 7.6576 & 7.6867 & TRN & & \\
\hline CHEMBL 2349618 & 954243 & 7.2147 & 7.2692 & TRN & & \\
\hline CHEMBL 2349498 & 954243 & 6.556 & 6.6055 & TRN & & \\
\hline CHEMBL 2349503 & 954243 & 5.2027 & 5.2253 & TRN & & \\
\hline CHEMBL2349489 & 954243 & 5.2412 & 5.1472 & TST & & \\
\hline CHEMBL 2349491 & 954243 & 7.4437 & 7.4468 & TRN & & \\
\hline CHEMBL 2349494 & 954243 & 7.1308 & 7.0979 & TRN & & \\
\hline CHEMBL 2349483 & 954243 & 6.585 & 6.6128 & TRN & & \\
\hline CHEMBL 2349505 & 954243 & 7.2007 & 7.1763 & TRN & & \\
\hline CHEMBL2349499 & 954243 & 6.3655 & 4.7418 & TST & & \\
\hline CHEMBL 2349492 & 954243 & 5.54299 & 99999999 & & 5.5515 & \\
\hline CHEMBL2349611 & 954243 & 6.34200 & j00000006 & 205 & 6.3325 & \\
\hline CHEMBL 2349486 & 954243 & 7.6576 & 7.6692 & TRN & & \\
\hline CHEMBL2349484 & 954243 & 6.21899 & 99999999 & 99 & 6.2217 & $\cdots$ \\
\hline CHEMBL 2349500 & 954243 & 5.0624 & 5.0873 & TRN & & \\
\hline CHEMBL 2349612 & 954243 & 7.6198 & 7.5985 & TRN & & \\
\hline CHEMBL 2349502 & 954243 & 5.6265 & 5.63299 & 9999999999 & & TRN \\
\hline CHEMBL2349474 & 954243 & 7.3279 & 6.9749 & TST & & \\
\hline CHEMBL2349496 & 954243 & 7.5528 & 6.4815 & TST & & \\
\hline CHEMBL 2349468 & 954243 & 6.0 & 6.7555 & TST & & \\
\hline CHEMBL239944 & 452327 & 8.6576 & 8.4355 & TRN & & \\
\hline CHEMBL237157 & 452327 & 9.301 & 9.2811 & TRN & & \\
\hline CHEMBL 236740 & 452327 & 9.301 & 8.8738 & TRN & & \\
\hline CHEMBL3217097 & 452327 & 8.3098 & 8.4965 & TRN & & \\
\hline CHEMBL536528 & 452327 & 7.9101 & 7.9133 & TRN & & \\
\hline CHEMBL 3216420 & 452327 & 7.3665 & 7.3581 & TRN & & \\
\hline CHEMBL 3216647 & 452327 & 8.2007 & 8.2197 & TRN & & \\
\hline CHEMBL535630 & 452327 & 6.585 & 6.59399 & 9999999999 & & r \\
\hline CHEMBL536755 & 452327 & 5.0888 & 5.087 & TRN & & \\
\hline CHEMBL396435 & 452327 & 8.699 & 8.5554 & TRN & & \\
\hline CHEMBL535403 & 452327 & 6.0969 & 6.0856 & TRN & & \\
\hline CHEMBL236949 & 452327 & 8.4202 & 8.8738 & TRN & & \\
\hline CHEMBL236569 & 452327 & 7.8861 & 9.0798 & TST & & \\
\hline CHEMBL535183 & 452327 & 9.301 & 9.1857 & TRN & & \\
\hline CHEMBL 236741 & 452327 & 8.7447 & 8.246 & TST & & \\
\hline CHEMBL237012 & 452327 & 7.1871 & 7.1874 & TRN & & \\
\hline
\end{tabular}


Supplemental Table S2.txt

\begin{tabular}{|c|c|c|c|c|c|}
\hline CHEMBL395841 & 452327 & 6.9208 & 6.5069 & TST & \\
\hline CHEMBL535406 & 452327 & 5.0706 & 5.0835 & TRN & \\
\hline CHEMBL558378 & 452327 & 6.1192 & 6.1356 & TRN & \\
\hline CHEMBL239726 & 452327 & 8.4202 & 8.4186 & TRN & \\
\hline CHEMBL395842 & 452327 & 8.5376 & 8.1595 & TST & \\
\hline CHEMBL236739 & 452327 & 8.1427 & 8.8738 & TST & \\
\hline CHEMBL239942 & 452327 & 8.5229 & 8.7546 & TRN & \\
\hline CHEMBL3216419 & 452327 & 7.0 & 8.2547 & TRN & \\
\hline CHEMBL239293 & 452327 & 5.7825 & 8.1304 & TST & \\
\hline CHEMBL393695 & 452327 & 8.3979 & 8.3924 & TRN & \\
\hline CHEMBL239298 & 452327 & 5.7447 & 8.0826 & TST & \\
\hline CHEMBL 236825 & 452327 & 5.3979 & 5.3881 & TRN & \\
\hline CHEMBL3215561 & 452327 & 9.0 & 8.9984 & TRN & \\
\hline CHEMBL236531 & 452327 & 5.8097 & 7.8755 & TST & \\
\hline CHEMBL 235534 & 452327 & 8.8539 & 8.7762 & TST & \\
\hline CHEMBL556764 & 452327 & 7.301 & 7.28299 & 99999999995 & TRN \\
\hline CHEMBL 76504 & 452327 & 8.7696 & 8.8902 & TRN & \\
\hline CHEMBL 3216264 & 452327 & 7.6778 & 8.2464 & TST & \\
\hline CHEMBL3217096 & 452327 & 9.0969 & 8.9335 & TRN & \\
\hline CHEMBL 237428 & 452327 & 5.2676 & 5.2533 & TRN & \\
\hline CHEMBL236530 & 452327 & 8.4815 & 6.0858 & TST & \\
\hline CHEMBL235896 & 452327 & 6.2676 & 7.584 & TST & \\
\hline CHEMBL 73627 & 452327 & 9.4559 & 9.4314 & TRN & \\
\hline CHEMBL239303 & 452327 & 5.699 & 5.7003 & TRN & \\
\hline CHEMBL235737 & 452327 & 6.3468 & 6.352 & TRN & \\
\hline CHEMBL578572 & 452327 & 9.5229 & 8.2547 & TRN & \\
\hline CHEMBL539858 & 452327 & 4.7328 & 4.7436 & TRN & \\
\hline CHEMBL236528 & 452327 & 6.7959 & 6.8048 & TRN & \\
\hline CHEMBL236321 & 452327 & 6.9586 & 7.584 & TST & \\
\hline CHEMBL536548 & 452327 & 6.8386 & 6.8521 & TRN & \\
\hline CHEMBL536300 & 452327 & 5.2518 & 5.2297 & TRN & \\
\hline CHEMBL 74288 & 452327 & 8.6383 & 9.3353 & TST & \\
\hline CHEMBL3216648 & 452327 & 8.6383 & 8.7855 & TRN & \\
\hline CHEMBL1203947 & 452327 & 4.284 & 4.2789 & TRN & \\
\hline CHEMBL396902 & 452327 & 6.5686 & 6.5699 & TRN & \\
\hline CHEMBL535404 & 452327 & 9.2218 & 9.1974 & TRN & \\
\hline CHEMBL393561 & 452327 & 8.3468 & 8.1544 & TST & \\
\hline CHEMBL236529 & 452327 & 8.8239 & 8.8118 & TRN & \\
\hline CHEMBL537662 & 452327 & 8.7959 & 8.8051 & TRN & \\
\hline CHEMBL3216002 & 452327 & 8.5229 & 8.5113 & TRN & \\
\hline CHEMBL236323 & 452327 & 6.9586 & 6.95299 & 9999999999 & TRN \\
\hline CHEMBL 237429 & 452327 & 7.5376 & 7.5507 & TRN & \\
\hline CHEMBL 3215562 & 452327 & 9.0 & 9.0184 & TRN & \\
\hline CHEMBL 245042 & 452327 & 8.699 & 8.6997 & TRN & \\
\hline CHEMBL 2172415 & 864364 & 5.3979 & 6.2295 & TRN & \\
\hline CHEMBL539985 & 864364 & 3.6198 & 4.5526 & TRN & \\
\hline CHEMBL538668 & 864364 & 3.6198 & 4.5526 & TRN & \\
\hline CHEMBL2172535 & 864364 & 5.6383 & 4.6055 & TRN & \\
\hline
\end{tabular}

Page 13081 
Supplemental Table S2.txt

\begin{tabular}{|c|c|c|c|c|}
\hline 23 & 364 & 301 & 5.2292 & \\
\hline CHEMBL532047 & 364364 & 5.3768 & 4.4771 & \\
\hline HEMBL555939 & 54364 & 6198 & 4.5038 & \\
\hline IEMBL2: & 4364 & 2366 & & \\
\hline EMBL2172398 & 4364 & 9101 & & \\
\hline HEMBL540167 & 54364 & 1024 & 5571 & \\
\hline HEMBL 2172400 & 64364 & 3.0 & 3.9877 & \\
\hline HEMBL 264380 & 364 & 8539 & & \\
\hline AEMBL 2 & 364 & .301 & & \\
\hline AEMBL2172420 & 364 & .0088 & & \\
\hline HEMBL1173475 & 64364 & 3.0 & 4.8862 & \\
\hline AEMBL553207 & 364 & 3665 & 26 & \\
\hline HEMBL 267353 & 64 & .7447 & 368 & \\
\hline AEMBL 2 & & 1612 & & \\
\hline HEMBL 2 & & .2596 & & \\
\hline AEMBL 2172405 & 64 & 3.0 & 614 & \\
\hline HEMBL2172397 & 64 & .7959 & 4. & \\
\hline HEMBL538670 & 64 & .3188 & 808 & \\
\hline HEMBL 2: & & .301 & & \\
\hline AEMBL & & 5.6021 & & \\
\hline IEMBL5 & & 2757 & & \\
\hline AEMBL539148 & 64 & .3372 & 4. & \\
\hline HEMBL558751 & 64 & 28 & 4. & \\
\hline AEMBL & & & & \\
\hline 399 & & 3.0 & & 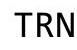 \\
\hline IEMBL53 & & 8 & & \\
\hline HEMBL 2172414 & 64 & 65 & 33 & RI \\
\hline HEMBL559143 & & 58 & & \\
\hline IEMB & & & & \\
\hline AEMB & & & & 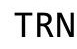 \\
\hline IEMBL539147 & & & & $\mathrm{RN}$ \\
\hline HEMBL2172403 & 64 & 3. & 12 & ST \\
\hline AEMBL2 & & & 48 & \\
\hline $15 M$ & & & & \\
\hline AEMBL2: & & & & \\
\hline AEMBL 2172530 & & 3.6198 & & \\
\hline HEMBL2: & 64 & 3.7212 & 71 & ST \\
\hline 735 & & .6198 & 71 & \\
\hline 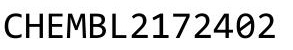 & & & & \\
\hline AEMBL: & & & & \\
\hline AEMBL5 & & .0862 & & $\mathrm{RI}$ \\
\hline AEMBL & & 5.1427 & & $\mathrm{RI}$ \\
\hline 734 & & & & \\
\hline CHEMBL2172531 & & 3.6198 & & \\
\hline HEMBL5 & & 3665 & & RI \\
\hline HEMBL2172406 & & .7352 & 985 & \\
\hline CHEMBL & & & 5 . & \\
\hline CHEMBL 217241 & & & 5.7681 & \\
\hline
\end{tabular}

Page 13082 


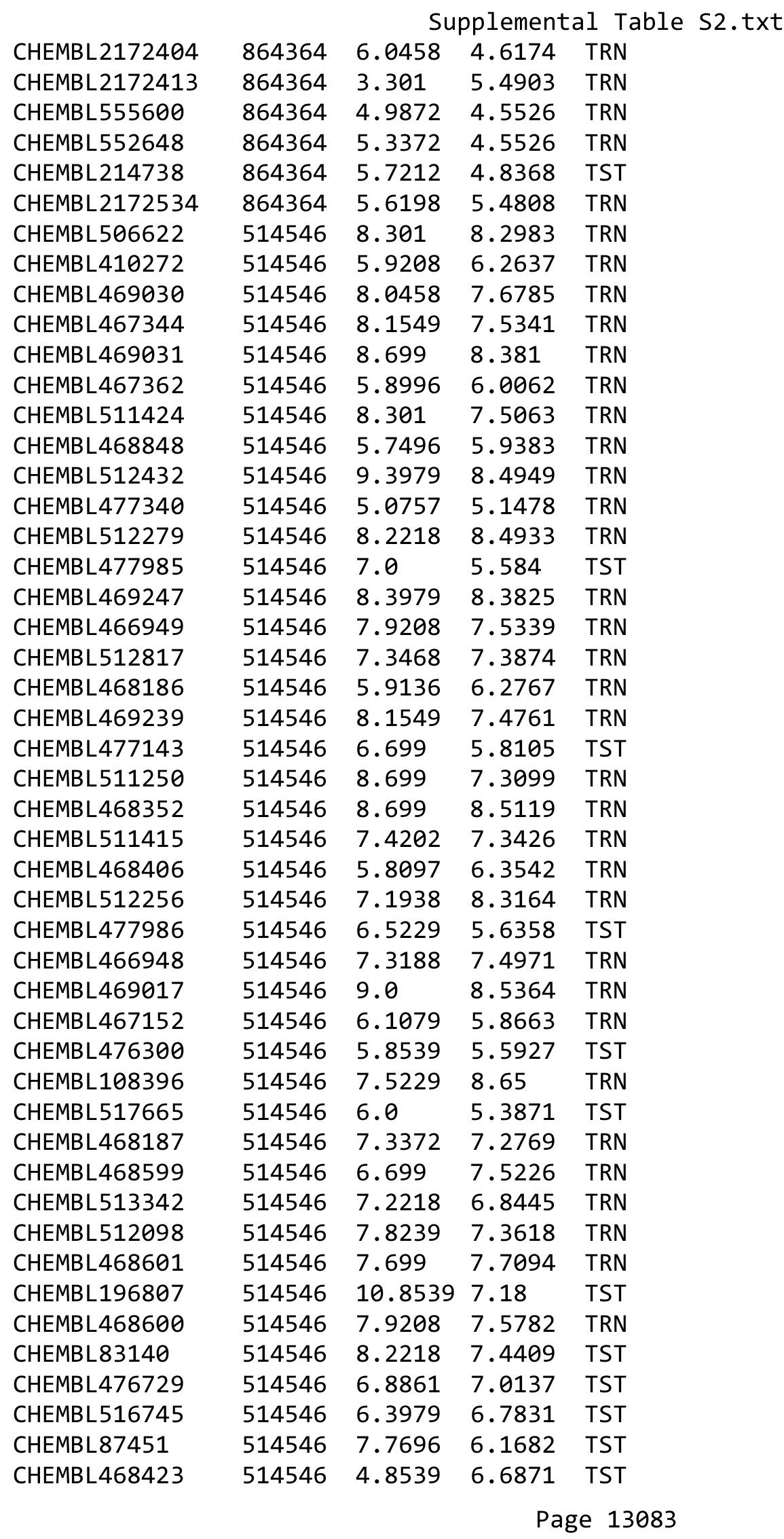




\begin{tabular}{|c|c|c|c|c|c|}
\hline & & \multicolumn{4}{|c|}{ Supplemental Table s2.txt } \\
\hline CHEMBL512788 & 514546 & 7.7212 & 7.4563 & TRN & \\
\hline CHEMBL469240 & 514546 & 5.4815 & 7.6524 & TRN & \\
\hline CHEMBL476524 & 514546 & 6.0 & 5.8652 & TRN & \\
\hline CHEMBL469016 & 514546 & 8.3979 & 8.3389 & TRN & \\
\hline CHEMBL469015 & 514546 & 8.301 & 8.4141 & TRN & \\
\hline CHEMBL199234 & 514546 & 8.1549 & 7.1113 & TST & \\
\hline CHEMBL476728 & 514546 & 5.0088 & 5.5512 & TRN & \\
\hline CHEMBL468424 & 514546 & 5.2291 & 6.9252 & TST & \\
\hline CHEMBL455752 & 514546 & 5.5086 & 5.7692 & TRN & \\
\hline CHEMBL450588 & 514546 & 4.9957 & 6.8817 & TST & \\
\hline CHEMBL467810 & 514546 & 7.6021 & 7.2717 & TRN & \\
\hline CHEMBL468360 & 514546 & 7.7696 & 8.3052 & TRN & \\
\hline CHEMBL259493 & 514546 & 7.1739 & 7.4646 & TRN & \\
\hline CHEMBL467363 & 514546 & 6.5376 & 5.9107 & TRN & \\
\hline CHEMBL1813919 & 762464 & 3.0 & 4.5971 & TST & \\
\hline CHEMBL1814137 & 762464 & 5.9586 & 5.9552 & TRN & \\
\hline CHEMBL1814133 & 762464 & 4.6383 & 4.7921 & TRN & \\
\hline CHEMBL1814117 & 762464 & 4.699 & 4.7344 & TRN & \\
\hline CHEMBL1814124 & 762464 & 6.1675 & 6.2377 & TRN & \\
\hline CHEMBL1814122 & 762464 & 5.9586 & 5.9027 & TRN & \\
\hline CHEMBL1813914 & 762464 & 5.3768 & 5.4046 & TRN & \\
\hline CHEMBL1814123 & 762464 & 5.6021 & 5.5026 & TRN & \\
\hline CHEMBL1813913 & 762464 & 3.301 & 3.2949 & TRN & \\
\hline CHEMBL1814141 & 762464 & 5.4437 & 5.4772 & TRN & \\
\hline CHEMBL1814118 & 762464 & 4.7959 & 5.794 & TST & \\
\hline CHEMBL1814131 & 762464 & 5.7212 & 5.7314 & TRN & \\
\hline CHEMBL1813917 & 762464 & 5.2518 & 5.0253 & TRN & \\
\hline CHEMBL49128 & 762464 & 6.2757 & 6.2663 & TRN & \\
\hline CHEMBL1814140 & 762464 & 6.0862 & 6.2144 & TRN & \\
\hline CHEMBL1275764 & 762464 & 6.301 & 6.5316 & TRN & \\
\hline CHEMBL1814113 & 762464 & 5.8539 & 5.8381 & TRN & \\
\hline CHEMBL1814119 & 762464 & 3.0 & 5.85 & TST & \\
\hline CHEMBL1814136 & 762464 & 4.3872 & 4.4756 & TRN & \\
\hline CHEMBL1614813 & 762464 & 4.2291 & 5.8971 & TST & \\
\hline CHEMBL1814132 & 762464 & 5.3468 & 5.3436 & TRN & \\
\hline CHEMBL1814130 & 762464 & 5.9586 & 5.76399 & 9999999999 & TRN \\
\hline CHEMBL1814110 & 762464 & 6.4318 & 6.8923 & TST & \\
\hline CHEMBL1814129 & 762464 & 3.0 & 3.0396 & TRN & \\
\hline CHEMBL1813918 & 762464 & 4.8539 & 4.6563 & TRN & \\
\hline CHEMBL1814111 & 762464 & 6.2596 & 6.3702 & TRN & \\
\hline CHEMBL1814121 & 762464 & 3.0 & 4.3236 & TST & \\
\hline CHEMBL48856 & 762464 & 5.699 & 5.7102 & TRN & \\
\hline CHEMBL1814134 & 762464 & 3.301 & 3.4149 & TRN & \\
\hline CHEMBL1814143 & 762464 & 5.2924 & 5.1845 & TRN & \\
\hline CHEMBL1813920 & 762464 & 5.8239 & 5.8408 & TRN & \\
\hline CHEMBL1814116 & 762464 & 5.8239 & 5.6815 & TRN & \\
\hline CHEMBL1814126 & 762464 & 4.5528 & 4.4184 & TRN & \\
\hline CHEMBL1813916 & 762464 & 6.0 & 6.0169 & TRN & \\
\hline
\end{tabular}




\begin{tabular}{|c|c|c|c|c|}
\hline \multicolumn{5}{|c|}{ Supplemental Table s2.txt } \\
\hline CHEMBL1814114 & 762464 & 3.301 & 5.795 & TST \\
\hline CHEMBL1814142 & 762464 & 5.8861 & 6.0152 & TRN \\
\hline CHEMBL1814139 & 762464 & 3.0 & 2.9542 & TRN \\
\hline CHEMBL1814115 & 762464 & 5.8539 & 5.8186 & TRN \\
\hline CHEMBL1814128 & 762464 & 3.0 & 3.2157 & TRN \\
\hline CHEMBL49894 & 762464 & 6.0757 & 6.0241 & TRN \\
\hline CHEMBL1814135 & 762464 & 5.6198 & 5.5241 & TRN \\
\hline CHEMBL1814145 & 762464 & 5.1024 & 5.2137 & TRN \\
\hline CHEMBL1814127 & 762464 & 4.5528 & 4.5995 & TRN \\
\hline CHEMBL1813921 & 762464 & 5.3468 & 5.3047 & TRN \\
\hline CHEMBL1813922 & 762464 & 5.9208 & 6.0223 & TRN \\
\hline CHEMBL1814120 & 762464 & 3.0 & 6.4791 & TST \\
\hline CHEMBL52210 & 762464 & 5.7959 & 6.4253 & TST \\
\hline CHEMBL1814138 & 762464 & 4.6778 & 4.5985 & TRN \\
\hline CHEMBL416108 & 762464 & 6.1739 & 6.1268 & TRN \\
\hline CHEMBL1813915 & 762464 & 5.2366 & 5.1386 & TRN \\
\hline CHEMBL1276549 & 762464 & 6.301 & 6.1025 & TST \\
\hline CHEMBL1814144 & 762464 & 4.5528 & 5.5041 & TST \\
\hline CHEMBL1814112 & 762464 & 4.5086 & 5.5218 & TST \\
\hline CHEMBL450746 & 762464 & 5.7696 & 6.2835 & TST \\
\hline CHEMBL1814125 & 762464 & 6.0 & 6.2169 & TST \\
\hline CHEMBL 71204 & 156010 & 8.1549 & 8.4551 & TRN \\
\hline CHEMBL71768 & 156010 & 6.6882 & 6.5459 & TRN \\
\hline CHEMBL71874 & 156010 & 6.7959 & 7.0675 & TRN \\
\hline CHEMBL 303010 & 156010 & 6.7212 & 6.6179 & TRN \\
\hline CHEMBL 303154 & 156010 & 8.2218 & 8.3439 & TRN \\
\hline CHEMBL303917 & 156010 & 5.8861 & 6.9292 & TRN \\
\hline CHEMBL 306426 & 156010 & 6.6778 & 6.4316 & TRN \\
\hline CHEMBL308747 & 156010 & 4.699 & 5.018 & TRN \\
\hline CHEMBL 307379 & 156010 & 7.2596 & 7.2184 & TRN \\
\hline CHEMBL71300 & 156010 & 5.5229 & 5.4147 & TST \\
\hline CHEMBL306417 & 156010 & 5.3279 & 5.4203 & TRN \\
\hline CHEMBL 306666 & 156010 & 7.7447 & 7.6762 & TRN \\
\hline CHEMBL71824 & 156010 & 5.9586 & 5.8898 & TRN \\
\hline CHEMBL18744 & 156010 & 7.8239 & 6.1889 & TST \\
\hline CHEMBL18745 & 156010 & 7.4437 & 7.0514 & TST \\
\hline CHEMBL305237 & 156010 & 8.699 & 8.4945 & TRN \\
\hline CHEMBL68152 & 156010 & 7.0 & 7.5554 & TRN \\
\hline CHEMBL 303385 & 156010 & 7.0 & 7.1947 & TRN \\
\hline CHEMBL 278644 & 156010 & 5.9031 & 5.3452 & TRN \\
\hline CHEMBL70569 & 156010 & 3.0 & 6.1173 & TST \\
\hline CHEMBL308828 & 156010 & 7.585 & 7.2928 & TRN \\
\hline CHEMBL70951 & 156010 & 5.0 & 5.3633 & TRN \\
\hline CHEMBL308973 & 156010 & 4.0 & 5.2725 & TST \\
\hline CHEMBL 305618 & 156010 & 7.6778 & 8.2222 & TRN \\
\hline CHEMBL 307640 & 156010 & 7.1549 & 7.006 & TRN \\
\hline CHEMBL72812 & 156010 & 7.7447 & 7.401 & TRN \\
\hline CHEMBL422235 & 156010 & 5.301 & 5.0075 & TRN \\
\hline
\end{tabular}




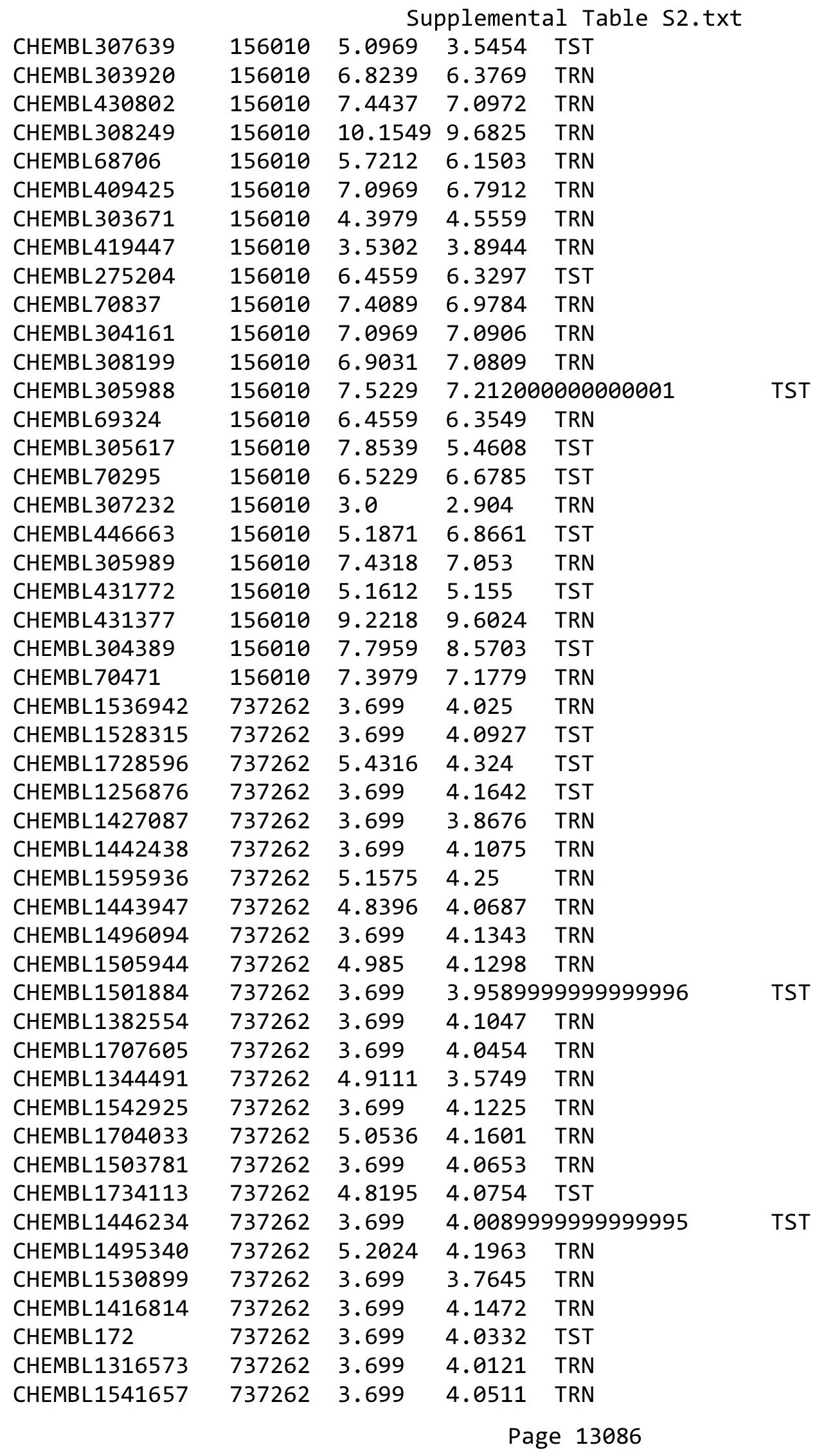


Supplemental Table S2.txt

\begin{tabular}{|c|c|c|c|c|}
\hline & 37262 & & 82 & \\
\hline CHEMBL1706319 & 37262 & 3.699 & 009 & \\
\hline HEMBL 584269 & 37262 & & & \\
\hline EMBL] & 7262 & & 306 & \\
\hline 020 & 37262 & 364 & 925 & \\
\hline AEMBL1306824 & 37262 & 4.78 & 45 & \\
\hline AEMBL2369209 & 37262 & 4.8516 & 162 & \\
\hline HEMBL1412214 & 37262 & 99 & & \\
\hline 129 & 37262 & 094 & 476 & \\
\hline 183598 & 37262 & 601 & 865 & \\
\hline AEMBL1710302 & 37262 & 3.699 & 747 & \\
\hline AEMBL1717286 & 37262 & & 083 & \\
\hline AEIMLL 1485 & 737262 & & & \\
\hline IEME & 37262 & & & \\
\hline 437888 & 37262 & & & \\
\hline AEMBL149 & 37262 & & 88 & \\
\hline 58 & 37262 & & & \\
\hline AEMB & 2 & 49 & & \\
\hline 42 & 52 & & & \\
\hline IEMBI 157 & 737262 & & & \\
\hline IEMBL1435657 & 37262 & & & \\
\hline 36 & 52 & 16 & & \\
\hline 9 & 2 & & & \\
\hline 0 & 62 & & & \\
\hline 27 & 737262 & & & \\
\hline 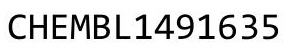 & & & & \\
\hline 4 & 62 & & & \\
\hline 4 & 737262 & 4. & & \\
\hline 8 & 62 & & & \\
\hline 85 & 62 & 387 & & \\
\hline & & & & \\
\hline AEMBL1382884 & 37262 & & & \\
\hline & 52 & & & \\
\hline 0 & 2 & & & \\
\hline HEMBL1540486 & 737262 & & & \\
\hline AEMBL1410233 & 737262 & & & \\
\hline 50197 & 37262 & & & \\
\hline & 37262 & & & \\
\hline $\mathrm{CH}$ & 2 & & & \\
\hline CHEMBL1398447 & 737262 & & & $\Gamma R$ \\
\hline AEMBL1595474 & 737262 & & 83 & \\
\hline & 737 & & & \\
\hline & 737262 & & & \\
\hline 51 & 737262 & & 109 & \\
\hline MBL1600624 & 737262 & 3.699 & 612 & 1 \\
\hline AEMBL1344485 & 737262 & 3.699 & 4 . & \\
\hline & 737 & 4. & & \\
\hline & 737262 & סרות & 4.1805 & \\
\hline
\end{tabular}

Page 13087 
Supplemental Table S2.txt

\begin{tabular}{|c|c|c|c|c|}
\hline CHEMBL552134 & 737262 & 3.699 & 4.086 & TRN \\
\hline CHEMBL1573976 & 737262 & 3.699 & 4.3682 & TRN \\
\hline CHEMBL1388021 & 737262 & 3.699 & 4.0025 & TST \\
\hline CHEMBL1323371 & 737262 & 3.699 & 3.9814 & TRN \\
\hline CHEMBL1393283 & 737262 & 3.699 & 4.04899 & 99999999995 \\
\hline CHEMBL1588889 & 737262 & 3.699 & 4.1873 & TST \\
\hline CHEMBL1499792 & 737262 & 3.699 & 4.0884 & TST \\
\hline CHEMBL3189275 & 737262 & 3.699 & 4.051 & TRN \\
\hline CHEMBL1503520 & 737262 & 5.0795 & 4.1715 & TRN \\
\hline CHEMBL1375947 & 737262 & 3.699 & 4.1919 & TRN \\
\hline CHEMBL1363123 & 737262 & 3.699 & 4.038 & TRN \\
\hline CHEMBL532452 & 737262 & 4.7688 & 3.6655 & TRN \\
\hline CHEMBL1358628 & 737262 & 3.699 & 4.0173 & TST \\
\hline CHEMBL1503253 & 737262 & 4.9275 & 3.6741 & TRN \\
\hline CHEMBL1555646 & 737262 & 3.699 & 4.1161 & TRN \\
\hline CHEMBL1547025 & 737262 & 4.7073 & 4.0253 & TRN \\
\hline CHEMBL1524733 & 737262 & 3.699 & 4.1931 & TRN \\
\hline CHEMBL3194432 & 737262 & 5.8755 & 4.5866 & TRN \\
\hline CHEMBL1305066 & 737262 & 4.8643 & 4.2555 & TRN \\
\hline CHEMBL3213394 & 737262 & 4.8804 & 4.113 & TRN \\
\hline CHEMBL1512116 & 737262 & 3.699 & 4.0794 & TST \\
\hline CHEMBL1518206 & 737262 & 3.699 & 4.0002 & TRN \\
\hline CHEMBL1723763 & 737262 & 3.699 & 4.0999 & TRN \\
\hline CHEMBL1738986 & 737262 & 3.699 & 4.1376 & TRN \\
\hline CHEMBL1570017 & 737262 & 3.699 & 4.2004 & TRN \\
\hline CHEMBL1550540 & 737262 & 4.7149 & 4.0342 & TRN \\
\hline CHEMBL1427545 & 737262 & 5.0045 & 4.2137 & TRN \\
\hline CHEMBL1201074 & 737262 & 3.699 & 4.0326 & TRN \\
\hline CHEMBL1380502 & 737262 & 3.699 & 4.0312 & TRN \\
\hline CHEMBL1575085 & 737262 & 3.699 & 4.0232 & TRN \\
\hline CHEMBL1384172 & 737262 & 5.4216 & 4.1648 & TST \\
\hline CHEMBL1569634 & 737262 & 3.699 & 4.144 & TST \\
\hline CHEMBL1315186 & 737262 & 3.699 & 4.1163 & TRN \\
\hline CHEMBL3196742 & 737262 & 3.699 & 4.0605 & TRN \\
\hline CHEMBL1700004 & 737262 & 3.699 & 4.0364 & TRN \\
\hline CHEMBL1484204 & 737262 & 3.699 & 3.878 & TRN \\
\hline CHEMBL1513694 & 737262 & 3.699 & 4.1594 & TRN \\
\hline CHEMBL1421212 & 737262 & 3.699 & 4.0536 & TST \\
\hline CHEMBL1434677 & 737262 & 3.699 & 3.9574 & TRN \\
\hline CHEMBL1537640 & 737262 & 3.699 & 4.0473 & TST \\
\hline CHEMBL3197963 & 737262 & 3.699 & 4.0811 & TST \\
\hline CHEMBL1386349 & 737262 & 3.699 & 3.9449 & TRN \\
\hline CHEMBL1613666 & 737262 & 3.699 & 4.0104 & TRN \\
\hline CHEMBL1531169 & 737262 & 3.699 & 4.0139 & TRN \\
\hline CHEMBL1532960 & 737262 & 5.1071 & 4.2663 & TRN \\
\hline CHEMBL1436134 & 737262 & 3.699 & 4.0536 & TST \\
\hline CHEMBL1591212 & 737262 & 3.699 & 4.0384 & TRN \\
\hline CHEMBL1322645 & 737262 & 3.699 & 3.9342 & TRN \\
\hline
\end{tabular}


Supplemental Table S2.txt

\begin{tabular}{|c|c|c|c|c|c|}
\hline CHEMBL1720341 & 737262 & 3.699 & 4.1067 & TST & \\
\hline CHEMBL1319541 & 737262 & 3.699 & 4.0122 & TRN & \\
\hline CHEMBL1466441 & 737262 & 5.2114 & 4.5017 & TRN & \\
\hline CHEMBL1995720 & 737262 & 5.3743 & 4.3917 & TST & \\
\hline CHEMBL1593484 & 737262 & 5.0271 & 4.1175 & TRN & \\
\hline CHEMBL1576958 & 737262 & 3.699 & 4.1386 & TRN & \\
\hline CHEMBL1450522 & 737262 & 4.9795 & 3.6713 & TST & \\
\hline CHEMBL1325958 & 737262 & 3.699 & 4.0299 & TRN & \\
\hline CHEMBL1531565 & 737262 & 3.699 & 3.8286 & TRN & \\
\hline CHEMBL1495682 & 737262 & 4.7429 & 4.0053 & TRN & \\
\hline CHEMBL1465573 & 737262 & 3.699 & 4.0542 & TRN & \\
\hline CHEMBL1488321 & 737262 & 3.699 & 4.1478 & TRN & \\
\hline CHEMBL1548213 & 737262 & 3.699 & 4.1336 & TRN & \\
\hline CHEMBL1726210 & 737262 & 3.699 & 4.1905 & TST & \\
\hline CHEMBL253239 & 737262 & 3.699 & 4.1169 & TST & \\
\hline CHEMBL1731879 & 737262 & 3.699 & 4.1803 & TST & \\
\hline CHEMBL1337517 & 737262 & 3.699 & 4.1766 & TRN & \\
\hline CHEMBL1731981 & 737262 & 3.699 & 4.0018 & TRN & \\
\hline CHEMBL1385940 & 737262 & 3.699 & 4.0707 & TRN & \\
\hline CHEMBL1406627 & 737262 & 3.699 & 4.1745 & TST & \\
\hline CHEMBL1527341 & 737262 & 4.8059 & 4.0189 & TRN & \\
\hline CHEMBL1388543 & 737262 & 3.699 & 3.947 & TRN & \\
\hline CHEMBL1729974 & 737262 & 5.2709 & 4.2498 & TST & \\
\hline CHEMBL1433248 & 737262 & 4.7534 & 4.1886 & TRN & \\
\hline CHEMBL1594906 & 737262 & 3.699 & 3.9424 & TRN & \\
\hline CHEMBL1724118 & 737262 & 3.699 & 4.0345 & TRN & \\
\hline CHEMBL1526165 & 737262 & 3.699 & 4.055 & TRN & \\
\hline CHEMBL1518357 & 737262 & 3.699 & 4.0759 & TST & \\
\hline CHEMBL 3212675 & 737262 & 3.699 & 4.0488 & TRN & \\
\hline CHEMBL1729269 & 737262 & 3.699 & 4.0822 & TRN & \\
\hline CHEMBL1494987 & 737262 & 4.7697 & 4.113 & TRN & \\
\hline CHEMBL1454967 & 737262 & 4.9041 & 4.02 & TRN & \\
\hline CHEMBL1341999 & 737262 & 3.699 & \multicolumn{2}{|c|}{4.0969999999999995} & TRN \\
\hline CHEMBL1594305 & 737262 & 3.699 & 3.9677 & TRN & \\
\hline CHEMBL1469216 & 737262 & 3.699 & 4.0246 & TRN & \\
\hline CHEMBL1707355 & 737262 & 3.699 & 4.0587 & TST & \\
\hline CHEMBL1419625 & 737262 & 3.699 & 3.8549 & TRN & \\
\hline CHEMBL1454903 & 737262 & 3.699 & 3.9498 & TST & \\
\hline CHEMBL1727624 & 737262 & 3.699 & 4.0974 & TRN & \\
\hline CHEMBL1409110 & 737262 & 3.699 & \multicolumn{2}{|c|}{3.9760000000000004} & TRN \\
\hline CHEMBL1711656 & 737262 & 3.699 & 4.0497 & TRN & \\
\hline CHEMBL1310009 & 737262 & 3.699 & 4.0115 & TRN & \\
\hline CHEMBL1509485 & 737262 & 3.699 & 3.7996 & TRN & \\
\hline CHEMBL1981290 & 737262 & 5.2559 & 4.4006 & TST & \\
\hline CHEMBL1594756 & 737262 & 3.699 & 3.9883 & TRN & \\
\hline CHEMBL503363 & 737262 & 4.7972 & 4.0524 & TST & \\
\hline CHEMBL1478931 & 737262 & 5.0622 & 4.0398 & TRN & \\
\hline CHEMBL1582369 & 737262 & 5.2113 & 4.117 & TST & \\
\hline
\end{tabular}




\begin{tabular}{|c|c|c|c|c|c|}
\hline & & \multicolumn{4}{|c|}{ Supplemental Table S2.txt } \\
\hline CHEMBL3197908 & 737262 & 4.9275 & 4.1418 & TRN & \\
\hline CHEMBL1361924 & 737262 & 3.699 & 3.9165 & TRN & \\
\hline CHEMBL1513768 & 737262 & 3.699 & 3.9823 & TRN & \\
\hline CHEMBL388087 & 737262 & 3.699 & 4.0729 & TRN & \\
\hline CHEMBL1543903 & 737262 & 4.8381 & 3.6459 & TRN & \\
\hline CHEMBL1363238 & 737262 & 3.699 & 4.0114 & TRN & \\
\hline CHEMBL1710358 & 737262 & 3.699 & 4.0153 & TRN & \\
\hline CHEMBL1543668 & 737262 & 3.699 & 4.04 & TST & \\
\hline CHEMBL1574828 & 737262 & 3.699 & 3.987 & TRN & \\
\hline CHEMBL1581013 & 737262 & 3.699 & 3.9208 & TRN & \\
\hline CHEMBL1586023 & 737262 & 3.699 & 3.9647 & TST & \\
\hline CHEMBL1699341 & 737262 & 3.699 & 4.0671 & TRN & \\
\hline CHEMBL1607918 & 737262 & 3.699 & 3.9798 & TRN & \\
\hline CHEMBL1471929 & 737262 & 3.699 & 4.09399 & 9999999999 & TRN \\
\hline CHEMBL1699246 & 737262 & 3.699 & 4.1554 & TRN & \\
\hline CHEMBL1527414 & 737262 & 3.699 & 4.0907 & TRN & \\
\hline CHEMBL1477355 & 737262 & 4.9647 & 4.0244 & TRN & \\
\hline CHEMBL1345981 & 737262 & 3.699 & 3.9084 & TRN & \\
\hline CHEMBL1719629 & 737262 & 3.699 & 4.1605 & TRN & \\
\hline CHEMBL 235843 & 737262 & 3.699 & 4.0189 & TRN & \\
\hline CHEMBL496324 & 737262 & 3.699 & 4.0609 & TRN & \\
\hline CHEMBL1492455 & 737262 & 3.699 & 4.1097 & TRN & \\
\hline CHEMBL1365734 & 737262 & 3.699 & 4.147 & TST & \\
\hline CHEMBL1711879 & 737262 & 3.699 & 4.1034 & TST & \\
\hline CHEMBL1499578 & 737262 & 5.3631 & 4.2808 & TRN & \\
\hline CHEMBL1348428 & 737262 & 4.9838 & 4.1513 & TRN & \\
\hline CHEMBL1507704 & 737262 & 3.699 & 3.9708 & TRN & \\
\hline CHEMBL1330234 & 737262 & 3.699 & 4.2553 & TRN & \\
\hline CHEMBL1448027 & 737262 & 4.945 & 4.2858 & TRN & \\
\hline CHEMBL1410019 & 737262 & 4.7765 & 3.56699 & 99999999997 & TRN \\
\hline CHEMBL 374350 & 737262 & 3.699 & 4.0582 & TST & \\
\hline CHEMBL23194 & 737262 & 4.8446 & 4.0514 & TST & \\
\hline CHEMBL1479236 & 737262 & 3.699 & 3.9858 & TRN & \\
\hline CHEMBL1733353 & 737262 & 3.699 & 3.9809 & TRN & \\
\hline CHEMBL1460871 & 737262 & 3.699 & 4.0711 & TRN & \\
\hline CHEMBL1423463 & 737262 & 4.7715 & 3.9026 & TST & \\
\hline CHEMBL87385 & 737262 & 3.699 & 4.2268 & TRN & \\
\hline CHEMBL1717153 & 737262 & 3.699 & 3.9267 & TRN & \\
\hline CHEMBL1318210 & 737262 & 4.7235 & 3.6511 & TRN & \\
\hline CHEMBL1435164 & 737262 & 4.7135 & 3.6332 & TRN & \\
\hline CHEMBL1608028 & 737262 & 3.699 & 3.8612 & TRN & \\
\hline CHEMBL1443133 & 737262 & 3.699 & 3.6852 & TST & \\
\hline CHEMBL1725631 & 737262 & 5.0536 & 4.1785 & TRN & \\
\hline CHEMBL1423507 & 737262 & 3.699 & 3.9154 & TRN & \\
\hline CHEMBL530361 & 737262 & 3.699 & 4.04 & TRN & \\
\hline CHEMBL1603662 & 737262 & 4.7132 & 3.6624 & TRN & \\
\hline CHEMBL1702693 & 737262 & 4.8746 & 3.6401 & TST & \\
\hline CHEMBL1331011 & 737262 & 3.699 & 4.1407 & TRN & \\
\hline
\end{tabular}


Supplemental Table S2.txt

\begin{tabular}{|c|c|c|c|c|}
\hline CHEMBL1698733 & 737262 & 3.699 & 4.0538 & TRN \\
\hline CHEMBL1321828 & 737262 & 3.699 & 4.0852 & TST \\
\hline CHEMBL1385384 & 737262 & 3.699 & 3.7894 & TRN \\
\hline CHEMBL1980281 & 737262 & 5.1814 & 4.3034 & TST \\
\hline CHEMBL1380274 & 737262 & 3.699 & 4.0659 & TST \\
\hline CHEMBL1590386 & 737262 & 3.699 & 3.9775 & TRN \\
\hline CHEMBL1430772 & 737262 & 3.699 & 4.1477 & TST \\
\hline CHEMBL1549341 & 737262 & 3.699 & 4.0795 & TRN \\
\hline CHEMBL1407169 & 737262 & 3.699 & 4.1113 & TST \\
\hline CHEMBL1978733 & 737262 & 5.0408 & 4.1997 & TRN \\
\hline CHEMBL1358310 & 737262 & 3.699 & 3.9964 & TRN \\
\hline CHEMBL1361159 & 737262 & 3.699 & 3.8847 & TRN \\
\hline CHEMBL1557121 & 737262 & 3.699 & 4.1493 & TST \\
\hline CHEMBL1302100 & 737262 & 3.699 & 3.8065 & TRN \\
\hline CHEMBL1542113 & 737262 & 5.1218 & 4.149 & TRN \\
\hline CHEMBL1377932 & 737262 & 3.699 & 4.0662 & TRN \\
\hline CHEMBL1428166 & 737262 & 4.9077 & 4.2077 & TST \\
\hline CHEMBL1468776 & 737262 & 5.1191 & 4.221 & TRN \\
\hline CHEMBL1334793 & 737262 & 3.699 & 3.9693 & TRN \\
\hline CHEMBL1542212 & 737262 & 3.699 & 4.1884 & TRN \\
\hline CHEMBL1726032 & 737262 & 3.699 & 4.1064 & TRN \\
\hline CHEMBL1471839 & 737262 & 3.699 & 4.0798 & TST \\
\hline CHEMBL1533483 & 737262 & 3.699 & 3.9997 & TRN \\
\hline CHEMBL1373533 & 737262 & 3.699 & 4.1039 & TRN \\
\hline CHEMBL1516044 & 737262 & 3.699 & 4.0387 & TRN \\
\hline CHEMBL1726756 & 737262 & 3.699 & 4.101 & TRN \\
\hline CHEMBL1585763 & 737262 & 4.8725 & 4.1053 & TRN \\
\hline CHEMBL1596383 & 737262 & 3.699 & 4.0032 & TRN \\
\hline CHEMBL1556027 & 737262 & 3.699 & 4.0838 & TRN \\
\hline CHEMBL1705481 & 737262 & 4.9068 & 3.9849 & TRN \\
\hline CHEMBL1543529 & 737262 & 4.8458 & 3.7011 & TST \\
\hline CHEMBL1370471 & 737262 & 3.699 & 4.0522 & TRN \\
\hline CHEMBL 226876 & 737262 & 3.699 & 3.8478 & TRN \\
\hline CHEMBL1409219 & 737262 & 4.9438 & 4.1228 & TRN \\
\hline CHEMBL1733544 & 737262 & 3.699 & 4.0094 & TRN \\
\hline CHEMBL1474443 & 737262 & 3.699 & 3.9653 & TRN \\
\hline CHEMBL1510761 & 737262 & 5.2531 & 4.0989 & TRN \\
\hline CHEMBL1508170 & 737262 & 3.699 & 3.9874 & TRN \\
\hline CHEMBL1366044 & 737262 & 3.699 & 4.069 & TRN \\
\hline CHEMBL1301680 & 737262 & 3.699 & 3.9804 & TST \\
\hline CHEMBL1450086 & 737262 & 3.699 & 4.0116 & TST \\
\hline CHEMBL1422966 & 737262 & 3.699 & 3.6594 & TRN \\
\hline CHEMBL1453809 & 737262 & 3.699 & \multicolumn{2}{|c|}{3.9530000000000003} \\
\hline CHEMBL1502199 & 737262 & 3.699 & 3.9882 & TRN \\
\hline CHEMBL1398224 & 737262 & 3.699 & 4.1182 & TST \\
\hline CHEMBL1458805 & 737262 & 3.699 & 4.035 & TRN \\
\hline CHEMBL2369228 & 737262 & 5.1985 & 4.2577 & TRN \\
\hline CHEMBL1300583 & 737262 & 5.0121 & 4.0529 & TRN \\
\hline
\end{tabular}

Page 13091 
Supplemental Table S2.txt

\begin{tabular}{|c|c|c|c|c|}
\hline CHEMBL3191116 & 737262 & 3.699 & 4.0819 & TRN \\
\hline CHEMBL1586169 & 737262 & 3.699 & 3.9788 & TRN \\
\hline CHEMBL2369277 & 737262 & 4.8867 & 4.1339 & TRN \\
\hline CHEMBL1318143 & 737262 & 3.699 & 4.2407 & TRN \\
\hline CHEMBL1730785 & 737262 & 3.699 & 4.0416 & TRN \\
\hline CHEMBL1493031 & 737262 & 3.699 & 4.1482 & TRN \\
\hline CHEMBL1713079 & 737262 & 3.699 & 4.2294 & TRN \\
\hline CHEMBL1967497 & 737262 & 3.699 & 4.1692 & TRN \\
\hline CHEMBL3195312 & 737262 & 3.699 & 4.14199 & 99999999995 \\
\hline CHEMBL1734888 & 737262 & 3.699 & 4.1844 & TST \\
\hline CHEMBL1701759 & 737262 & 3.699 & 4.0788 & TST \\
\hline CHEMBL1429982 & 737262 & 3.699 & 4.092 & TRN \\
\hline CHEMBL1483235 & 737262 & 3.699 & 4.0429 & TRN \\
\hline CHEMBL1726408 & 737262 & 3.699 & 4.0488 & TRN \\
\hline CHEMBL1701486 & 737262 & 3.699 & 4.0914 & TRN \\
\hline CHEMBL1389370 & 737262 & 3.699 & 4.0235 & TRN \\
\hline CHEMBL3212106 & 737262 & 3.699 & 4.5552 & TRN \\
\hline CHEMBL1714451 & 737262 & 3.699 & 4.0792 & TRN \\
\hline CHEMBL1563713 & 737262 & 3.699 & 4.0074 & TRN \\
\hline CHEMBL1340965 & 737262 & 3.699 & 4.0617 & TRN \\
\hline CHEMBL1386435 & 737262 & 3.699 & 4.2008 & TRN \\
\hline CHEMBL1374714 & 737262 & 3.699 & 4.0013 & TRN \\
\hline CHEMBL1519654 & 737262 & 3.699 & 4.0669 & TRN \\
\hline CHEMBL1734393 & 737262 & 3.699 & 4.0523 & TRN \\
\hline CHEMBL1394750 & 737262 & 4.9025 & 4.0704 & TRN \\
\hline CHEMBL1965403 & 737262 & 3.699 & 4.1699 & TRN \\
\hline CHEMBL587475 & 737262 & 3.699 & 3.8352 & TRN \\
\hline CHEMBL1452154 & 737262 & 4.7154 & 3.6402 & TRN \\
\hline CHEMBL1707800 & 737262 & 3.699 & 4.2565 & TRN \\
\hline CHEMBL461579 & 737262 & 5.0074 & 4.1152 & TST \\
\hline CHEMBL1500879 & 737262 & 3.699 & 4.2269 & TRN \\
\hline CHEMBL1437516 & 737262 & 3.699 & 4.1544 & TRN \\
\hline CHEMBL1724952 & 737262 & 3.699 & 4.1143 & TRN \\
\hline CHEMBL1706626 & 737262 & 4.8215 & 3.6601 & TRN \\
\hline CHEMBL1730189 & 737262 & 4.7349 & 4.1106 & TRN \\
\hline CHEMBL1394022 & 737262 & 3.699 & 4.1564 & TRN \\
\hline CHEMBL1365006 & 737262 & 3.699 & 4.0785 & TRN \\
\hline CHEMBL1423020 & 737262 & 3.699 & 4.2062 & TRN \\
\hline CHEMBL1516412 & 737262 & 4.9061 & 3.6702 & TRN \\
\hline CHEMBL1536597 & 737262 & 3.699 & 4.1393 & TRN \\
\hline CHEMBL1485626 & 737262 & 3.699 & 3.9336 & TRN \\
\hline CHEMBL1324397 & 737262 & 3.699 & 4.2678 & TRN \\
\hline CHEMBL1391380 & 737262 & 3.699 & 4.1577 & TRN \\
\hline CHEMBL1338004 & 737262 & 3.699 & 4.0976 & TRN \\
\hline CHEMBL1698534 & 737262 & 3.699 & 4.0593 & TRN \\
\hline CHEMBL1331847 & 737262 & 3.699 & 3.9258 & TRN \\
\hline CHEMBL1502692 & 737262 & 3.699 & 3.7807 & TRN \\
\hline CHEMBL1989158 & 737262 & 5.2351 & 4.3523 & TST \\
\hline
\end{tabular}


Supplemental Table S2.txt

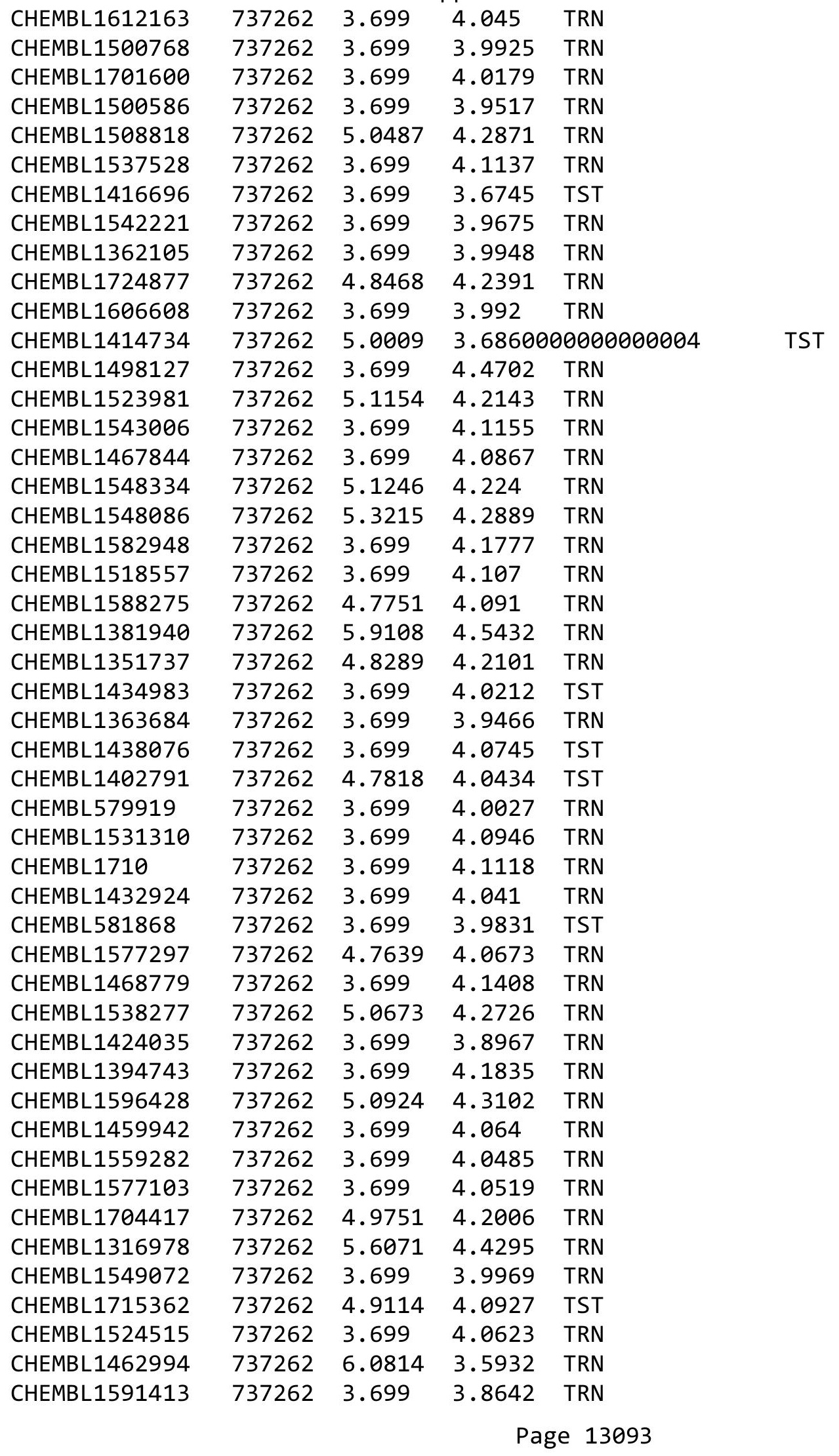


Supplemental Table S2.txt

\begin{tabular}{|c|c|c|c|c|}
\hline CHEMBL1382720 & 737262 & 3.699 & 4.0163 & TRN \\
\hline CHEMBL1413902 & 737262 & 4.862 & 4.1668 & TRN \\
\hline CHEMBL1421091 & 737262 & 3.699 & 4.1026 & TRN \\
\hline CHEMBL3213331 & 737262 & 3.699 & 4.1212 & TRN \\
\hline CHEMBL1542406 & 737262 & 3.699 & 4.2714 & TRN \\
\hline CHEMBL1348824 & 737262 & 3.699 & 3.8197 & TRN \\
\hline CHEMBL1479288 & 737262 & 3.699 & \multicolumn{2}{|c|}{3.9760000000000004} \\
\hline CHEMBL1481849 & 737262 & 3.699 & 3.9724 & TRN \\
\hline CHEMBL1488628 & 737262 & 3.699 & 4.1362 & TRN \\
\hline CHEMBL1462872 & 737262 & 3.699 & 3.9839 & TRN \\
\hline CHEMBL1315006 & 737262 & 3.699 & 3.9388 & TRN \\
\hline CHEMBL1534689 & 737262 & 3.699 & 3.8445 & TRN \\
\hline CHEMBL1299925 & 737262 & 4.9062 & 4.369 & TRN \\
\hline CHEMBL1498844 & 737262 & 3.699 & 3.9472 & TST \\
\hline CHEMBL1342070 & 737262 & 3.699 & 4.0941 & TRN \\
\hline CHEMBL3392037 & 737262 & 3.699 & 3.9988 & TST \\
\hline CHEMBL1507137 & 737262 & 4.7159 & 4.3795 & TRN \\
\hline CHEMBL1578679 & 737262 & 3.699 & 4.1137 & TRN \\
\hline CHEMBL3199272 & 737262 & 4.7608 & 3.7225 & TRN \\
\hline CHEMBL1427763 & 737262 & 5.4247 & 4.3348 & TRN \\
\hline CHEMBL1579326 & 737262 & 3.699 & 4.2387 & TRN \\
\hline CHEMBL1505192 & 737262 & 3.699 & 3.9954 & TST \\
\hline CHEMBL1513654 & 737262 & 3.699 & 4.0365 & TST \\
\hline CHEMBL1732411 & 737262 & 5.1868 & 4.2316 & TRN \\
\hline CHEMBL1337235 & 737262 & 4.8266 & 3.5355 & TRN \\
\hline CHEMBL1573851 & 737262 & 3.699 & 4.0794 & TRN \\
\hline CHEMBL1366581 & 737262 & 3.699 & 4.0636 & TRN \\
\hline CHEMBL1342353 & 737262 & 3.699 & 3.9698 & TRN \\
\hline CHEMBL1504870 & 737262 & 3.699 & 4.1346 & TRN \\
\hline CHEMBL489 & 737262 & 3.699 & 4.0388 & TRN \\
\hline CHEMBL1729720 & 737262 & 3.699 & 3.8302 & TST \\
\hline CHEMBL587856 & 737262 & 3.699 & 4.1039 & TRN \\
\hline CHEMBL197014 & 737262 & 3.699 & 3.7355 & TRN \\
\hline CHEMBL1339850 & 737262 & 3.699 & 4.0126 & TST \\
\hline CHEMBL1588541 & 737262 & 3.699 & 4.1323 & TST \\
\hline CHEMBL3197529 & 737262 & 5.1636 & 4.2236 & TRN \\
\hline CHEMBL1498329 & 737262 & 3.699 & 4.2447 & TRN \\
\hline CHEMBL1407381 & 737262 & 4.9212 & 4.1832 & TRN \\
\hline CHEMBL1735971 & 737262 & 3.699 & 3.8867 & TRN \\
\hline CHEMBL1574705 & 737262 & 3.699 & 4.1073 & TST \\
\hline CHEMBL1334731 & 737262 & 3.699 & 4.0942 & TST \\
\hline CHEMBL1200847 & 737262 & 5.4424 & 4.3051 & TST \\
\hline CHEMBL1358557 & 737262 & 3.699 & 4.0447 & TST \\
\hline CHEMBL1717221 & 737262 & 3.699 & 4.0247 & TRN \\
\hline CHEMBL1340439 & 737262 & 3.699 & 4.2902 & TRN \\
\hline CHEMBL1449653 & 737262 & 3.699 & 3.9474 & TRN \\
\hline CHEMBL1539253 & 737262 & 3.699 & 3.9699 & TST \\
\hline CHEMBL1535363 & 737262 & 4.8114 & 4.0724 & TRN \\
\hline
\end{tabular}


Supplemental Table S2.txt

\begin{tabular}{|c|c|c|c|c|c|}
\hline CHEMBL1475191 & 737262 & 3.699 & 4.1617 & TST & \\
\hline CHEMBL119345 & 737262 & 3.699 & 4.4838 & TRN & \\
\hline CHEMBL3211086 & 737262 & 4.7097 & 4.11 & TST & \\
\hline CHEMBL1329725 & 737262 & 3.699 & 4.0304 & TRN & \\
\hline CHEMBL1612267 & 737262 & 3.699 & 4.0752 & TST & \\
\hline CHEMBL1722206 & 737262 & 3.699 & 3.9977 & TRN & \\
\hline CHEMBL1434852 & 737262 & 3.699 & 4.1101 & TRN & \\
\hline CHEMBL1571189 & 737262 & 3.699 & 4.3404 & TRN & \\
\hline CHEMBL1458722 & 737262 & 3.699 & 4.0031 & TRN & \\
\hline CHEMBL1554781 & 737262 & 4.901 & 4.0461 & TRN & \\
\hline CHEMBL3191507 & 737262 & 6.0155 & 4.6352 & TRN & \\
\hline CHEMBL1996133 & 737262 & 4.9699 & 4.2384 & TST & \\
\hline CHEMBL1574856 & 737262 & 3.699 & 4.09 & TRN & \\
\hline CHEMBL1464556 & 737262 & 3.699 & 4.0906 & TRN & \\
\hline CHEMBL1346794 & 737262 & 3.699 & 4.1206 & TRN & \\
\hline CHEMBL1972638 & 737262 & 3.699 & 4.0366 & TRN & \\
\hline CHEMBL1226 & 737262 & 5.8251 & 4.5136 & TRN & \\
\hline CHEMBL1394557 & 737262 & 3.699 & 4.1179 & TRN & \\
\hline CHEMBL3211947 & 737262 & 4.979 & 4.027 & TRN & \\
\hline CHEMBL1490887 & 737262 & 3.699 & 4.0381 & TST & \\
\hline CHEMBL1561727 & 737262 & 5.0928 & 4.2272 & TRN & \\
\hline CHEMBL1471924 & 737262 & 3.699 & 4.0078 & TST & \\
\hline CHEMBL1732292 & 737262 & 3.699 & 4.0902 & TRN & \\
\hline CHEMBL1565800 & 737262 & 3.699 & 3.9527 & TRN & \\
\hline CHEMBL1403380 & 737262 & 3.699 & 3.9206 & TST & \\
\hline CHEMBL1710079 & 737262 & 5.3476 & 4.3034 & TST & \\
\hline CHEMBL1432498 & 737262 & 3.699 & 4.0227 & TRN & \\
\hline CHEMBL1350245 & 737262 & 3.699 & 3.9472 & TRN & \\
\hline CHEMBL1547321 & 737262 & 3.699 & 4.0195 & TRN & \\
\hline CHEMBL1528346 & 737262 & 3.699 & 4.0086 & TRN & \\
\hline CHEMBL1333191 & 737262 & 3.699 & 4.0018 & TRN & \\
\hline CHEMBL1580343 & 737262 & 3.699 & 3.8463 & TRN & \\
\hline CHEMBL1587829 & 737262 & 4.8789 & 3.7198 & TRN & \\
\hline CHEMBL1314963 & 737262 & 3.699 & 3.9375 & TST & \\
\hline CHEMBL1478673 & 737262 & 4.9406 & $4.19300 t$ & 00000000005 & TRN \\
\hline CHEMBL1599339 & 737262 & 4.7025 & 3.7154 & TRN & \\
\hline CHEMBL3209319 & 737262 & 4.8526 & 4.0663 & TRN & \\
\hline CHEMBL 2005247 & 737262 & 3.699 & 4.1357 & TRN & \\
\hline CHEMBL1534440 & 737262 & 3.699 & 4.0957 & TRN & \\
\hline CHEMBL1734073 & 737262 & 4.7658 & 4.0544 & TRN & \\
\hline CHEMBL157351 & 737262 & 5.2276 & 4.2422 & TST & \\
\hline CHEMBL1475584 & 737262 & 3.699 & 4.1934 & TST & \\
\hline CHEMBL1586238 & 737262 & 3.699 & 4.1166 & TRN & \\
\hline CHEMBL1304547 & 737262 & 3.699 & 3.9853 & TRN & \\
\hline CHEMBL3192624 & 737262 & 3.699 & 4.2616 & TRN & \\
\hline CHEMBL1361102 & 737262 & 3.699 & 4.1384 & TRN & \\
\hline CHEMBL1502340 & 737262 & 3.699 & 4.0029 & TRN & \\
\hline CHEMBL1524932 & 737262 & 3.699 & 3.8812 & TRN & \\
\hline
\end{tabular}




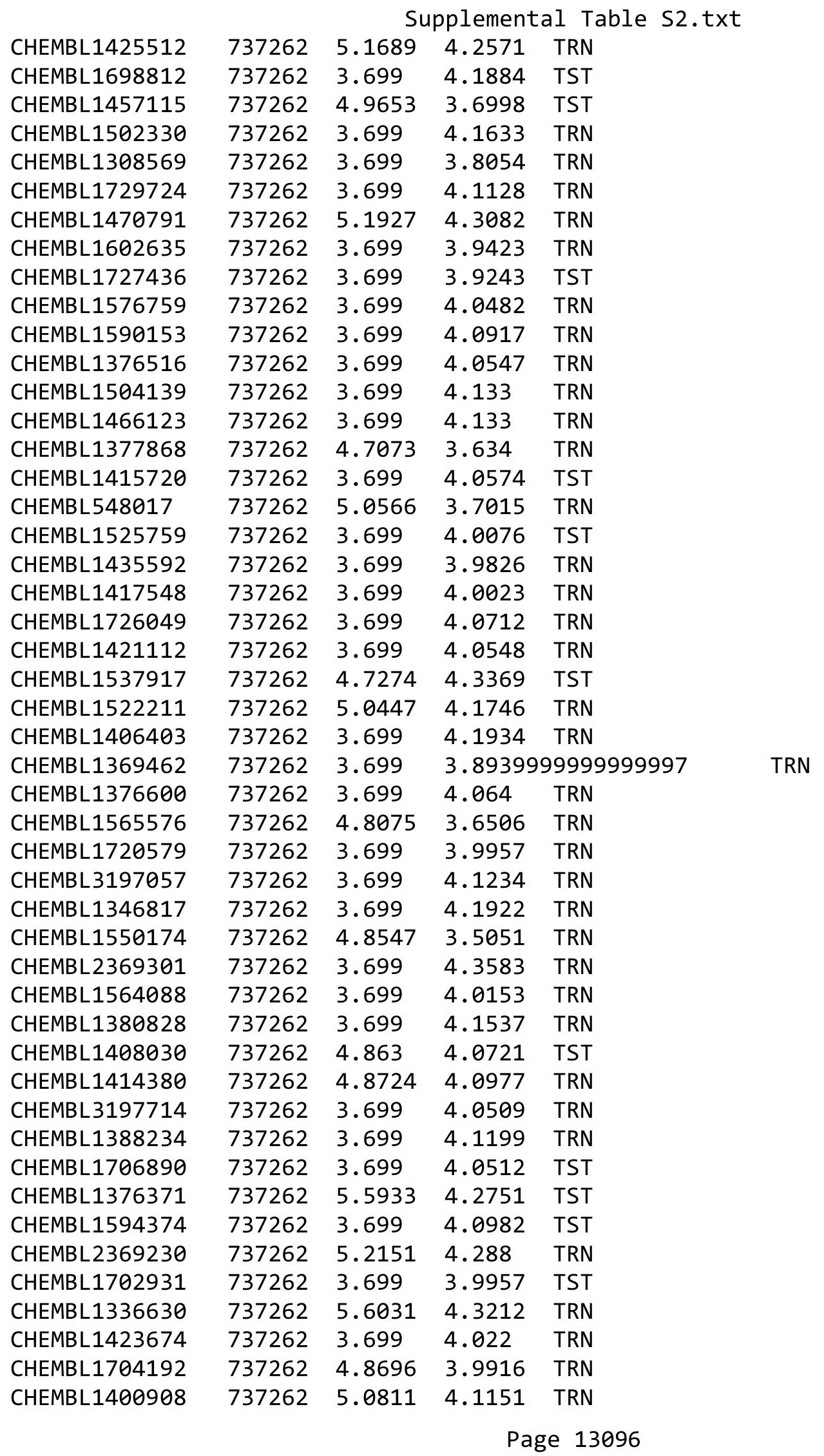


Supplemental Table S2.txt

\begin{tabular}{|c|c|c|c|c|}
\hline HEMBL1. & 2 & 599 & 24 & TRI \\
\hline HEMRI 1475416 & 37262 & & 4.0337 & \\
\hline HEMBL17203 & 7262 & & 8265 & \\
\hline AEMBL2369275 & 37262 & & 0711 & \\
\hline HEMBL1483161 & 37262 & 699 & .0279 & \\
\hline HEMBL13 & 7262 & 3078 & 1435 & \\
\hline IEMBL14 & 262 & 3563 & & \\
\hline HEMBL1304 & 37262 & 599 & 2281 & \\
\hline HEMBL1335707 & 37262 & 599 & 9534 & \\
\hline HEMBL1701367 & 37262 & 699 & .1204 & \\
\hline HEMBL 14 & 37262 & 699 & 1074 & \\
\hline HEMBL17 & 262 & & & RN \\
\hline HEMBL13 & 37262 & 99 & & \\
\hline HEMBL172 & 37262 & 599 & 399 & \\
\hline HEMBL159 & 7262 & 99 & & \\
\hline AEMBL17 & 62 & 99 & & \\
\hline AEMBL1 & 62 & & & RN \\
\hline HEMBL 15 & 37262 & 599 & 42 & \\
\hline HEMBL 31 & 262 & & & \\
\hline HEMBL160 & 62 & 99 & 3627 & KIV \\
\hline HEMBL6 & 62 & & 389 & $\mathrm{RN}$ \\
\hline HEMBL: & 62 & 49 & & RN \\
\hline HEMBL1 & 262 & 99 & & RN \\
\hline HEMBL13 & & & & \\
\hline AEMBL15 & 62 & 99 & 22 & RN \\
\hline AEMBL17 & 62 & 99 & 554 & RN \\
\hline AEMBL & 62 & & & ST \\
\hline$A$ IEPI- & & & & $\mathrm{RN}$ \\
\hline AEMBL1: & & & & IRN \\
\hline AEMBL15e & 62 & 99 & 8888 & ГST \\
\hline IEMBL14 & 62 & 99 & 172 & 「RN \\
\hline AFM & 52 & 73 & & ГRN \\
\hline & & & & $\mathrm{RN}$ \\
\hline AEMBL13 & & & & 「RN \\
\hline IEMBL169 & 7262 & & 938 & IST \\
\hline AEMB 13 & 52 & & 63 & 「RN \\
\hline & & & & ST \\
\hline HEMBL15 & & & & RN \\
\hline HEMBL157 & 62 & & & $\Gamma R$ \\
\hline EMBL1: & 62 & & 597 & RN \\
\hline HEMBL14 & 62 & & 528 & \\
\hline & & 737 & & RN \\
\hline HEMBL14 & 37262 & 3.699 & 4.0628 & IST \\
\hline AEMBL15 & 37262 & 695 & 964 & TRN \\
\hline (10 & 52 & & & 15 \\
\hline HEMBL1€ & 52 & & 7089 & \\
\hline CHEMBL1518062 & 37262 & 3.699 & 4.1529 & \\
\hline CHEMBL1610017 & 737262 & 3.699 & 4.0527 & ГRN \\
\hline
\end{tabular}

Page 13097 


\begin{tabular}{|c|c|c|c|c|c|}
\hline & & \multicolumn{4}{|c|}{ Supplemental Table S2.txt } \\
\hline CHEMBL1443214 & 737262 & 4.9448 & 4.2299 & TRN & \\
\hline CHEMBL1736898 & 737262 & 3.699 & 4.003 & TRN & \\
\hline CHEMBL1540231 & 737262 & 3.699 & 4.07600 & 00000000005 & TRN \\
\hline CHEMBL1390705 & 737262 & 4.9147 & 4.1153 & TRN & \\
\hline CHEMBL448741 & 737262 & 4.81 & 4.1213 & TST & \\
\hline CHEMBL595700 & 737262 & 3.699 & 4.0052 & TRN & \\
\hline CHEMBL1716119 & 737262 & 3.699 & 4.0539 & TRN & \\
\hline CHEMBL1715913 & 737262 & 3.699 & 4.1427 & TRN & \\
\hline CHEMBL1325858 & 737262 & 5.3958 & 4.2573 & TST & \\
\hline CHEMBL1540688 & 737262 & 3.699 & 4.0378 & TRN & \\
\hline CHEMBL1412497 & 737262 & 3.699 & 3.9592 & TRN & \\
\hline CHEMBL1573386 & 737262 & 3.699 & 4.1637 & TST & \\
\hline CHEMBL1414751 & 737262 & 3.699 & 4.0874 & TST & \\
\hline CHEMBL1430210 & 737262 & 3.699 & 4.0825 & TRN & \\
\hline CHEMBL1448789 & 737262 & 3.699 & 4.0035 & TRN & \\
\hline CHEMBL1548292 & 737262 & 3.699 & 3.9697 & TRN & \\
\hline CHEMBL1452610 & 737262 & 3.699 & 4.1039 & TRN & \\
\hline CHEMBL1402899 & 737262 & 3.699 & 3.9386 & TRN & \\
\hline CHEMBL1553787 & 737262 & 3.699 & 4.0337 & TST & \\
\hline CHEMBL1726061 & 737262 & 3.699 & 4.1011 & TRN & \\
\hline CHEMBL1608143 & 737262 & 3.699 & 4.0708 & TST & \\
\hline CHEMBL1981002 & 737262 & 5.0518 & 4.0933 & TST & \\
\hline CHEMBL1304286 & 737262 & 3.699 & 4.1101 & TRN & \\
\hline CHEMBL1299242 & 737262 & 3.699 & 4.1738 & TRN & \\
\hline CHEMBL1583849 & 737262 & 3.699 & 4.1451 & TRN & \\
\hline CHEMBL1306207 & 737262 & 3.699 & 3.9925 & TRN & \\
\hline CHEMBL492468 & 737262 & 3.699 & 4.0714 & TRN & \\
\hline CHEMBL1443346 & 737262 & 3.699 & 4.2515 & TRN & \\
\hline CHEMBL3392024 & 737262 & 3.699 & 4.0359 & TST & \\
\hline CHEMBL1728310 & 737262 & 3.699 & 4.1648 & TRN & \\
\hline CHEMBL1467492 & 737262 & 3.699 & 4.0443 & TRN & \\
\hline CHEMBL1461171 & 737262 & 3.699 & 4.0355 & TRN & \\
\hline CHEMBL1378944 & 737262 & 3.699 & 4.0186 & TRN & \\
\hline CHEMBL1471732 & 737262 & 3.699 & 4.046 & TRN & \\
\hline CHEMBL1478145 & 737262 & 3.699 & 4.331 & TRN & \\
\hline CHEMBL517186 & 737262 & 3.699 & 4.0599 & TST & \\
\hline CHEMBL1335384 & 737262 & 3.699 & 4.1555 & TRN & \\
\hline CHEMBL1713870 & 737262 & 3.699 & 3.94199 & 99999999997 & TST \\
\hline CHEMBL1367633 & 737262 & 3.699 & 4.0224 & TRN & \\
\hline CHEMBL591404 & 737262 & 5.1394 & 4.2111 & TRN & \\
\hline CHEMBL1705612 & 737262 & 5.0964 & 4.1789 & TST & \\
\hline CHEMBL1418656 & 737262 & 3.699 & 4.172 & TRN & \\
\hline CHEMBL3195381 & 737262 & 3.699 & 4.1647 & TRN & \\
\hline CHEMBL1549841 & 737262 & 3.699 & 4.025 & TRN & \\
\hline CHEMBL1506165 & 737262 & 3.699 & 3.83699 & 99999999997 & TST \\
\hline CHEMBL1496572 & 737262 & 4.762 & 4.0524 & TRN & \\
\hline CHEMBL1086026 & 737262 & 3.699 & 4.0768 & TST & \\
\hline CHEMBL1384903 & 737262 & 3.699 & 4.1335 & TRN & \\
\hline
\end{tabular}




\begin{tabular}{|c|c|c|c|c|c|}
\hline & & \multicolumn{4}{|c|}{ Supplemental Table S2.txt } \\
\hline CHEMBL598679 & 737262 & 3.699 & 4.0259 & TRN & \\
\hline CHEMBL1728060 & 737262 & 5.035 & 4.0312 & TRN & \\
\hline CHEMBL1557646 & 737262 & 3.699 & 4.115 & TRN & \\
\hline CHEMBL1604861 & 737262 & 4.8951 & 3.7334 & TRN & \\
\hline CHEMBL1713397 & 737262 & 3.699 & 3.9868 & TRN & \\
\hline CHEMBL1726914 & 737262 & 3.699 & 4.0319 & TRN & \\
\hline CHEMBL530682 & 737262 & 3.699 & 4.1924 & TST & \\
\hline CHEMBL1511432 & 737262 & 6.0079 & 4.4558 & TRN & \\
\hline CHEMBL1518668 & 737262 & 4.825 & 4.1486 & TRN & \\
\hline CHEMBL1530087 & 737262 & 4.885 & 4.129 & TRN & \\
\hline CHEMBL1533968 & 737262 & 5.0187 & 4.0647 & TRN & \\
\hline CHEMBL1703869 & 737262 & 3.699 & 4.0659 & TRN & \\
\hline CHEMBL1550943 & 737262 & 3.699 & 4.2633 & TRN & \\
\hline CHEMBL1721988 & 737262 & 3.699 & 4.1976 & TST & \\
\hline CHEMBL1590547 & 737262 & 3.699 & 4.0403 & TRN & \\
\hline CHEMBL1255944 & 737262 & 3.699 & 4.0764 & TST & \\
\hline CHEMBL1732792 & 737262 & 3.699 & 4.1563 & TST & \\
\hline CHEMBL1595575 & 737262 & 4.7245 & 4.05399 & 7999999999 & TRN \\
\hline CHEMBL3192124 & 737262 & 6.295 & 4.7087 & TRN & \\
\hline CHEMBL1406738 & 737262 & 4.787 & 3.702 & TRN & \\
\hline CHEMBL1330455 & 737262 & 3.699 & 3.8867 & TRN & \\
\hline CHEMBL1735976 & 737262 & 5.3432 & 4.1433 & TRN & \\
\hline CHEMBL1564990 & 737262 & 4.9326 & 4.1177 & TRN & \\
\hline CHEMBL1591732 & 737262 & 5.3218 & 4.3535 & TRN & \\
\hline CHEMBL1563079 & 737262 & 3.699 & 3.9331 & TRN & \\
\hline CHEMBL1588937 & 737262 & 3.699 & 4.1175 & TRN & \\
\hline CHEMBL1457602 & 737262 & 5.4121 & 4.3754 & TRN & \\
\hline CHEMBL1339463 & 737262 & 3.699 & 4.0386 & TRN & \\
\hline CHEMBL1366082 & 737262 & 4.7956 & 4.2103 & TRN & \\
\hline CHEMBL1305880 & 737262 & 3.699 & 3.9921 & TRN & \\
\hline CHEMBL1444436 & 737262 & 3.699 & 4.0764 & TRN & \\
\hline CHEMBL1487183 & 737262 & 5.704 & 4.3985 & TST & \\
\hline CHEMBL1504703 & 737262 & 3.699 & 4.3678 & TRN & \\
\hline CHEMBL1387761 & 737262 & 3.699 & 3.9171 & TST & \\
\hline CHEMBL1332530 & 737262 & 3.699 & 3.9875 & TRN & \\
\hline CHEMBL1721882 & 737262 & 3.699 & 4.1173 & TRN & \\
\hline CHEMBL1548109 & 737262 & 3.699 & 4.03 & TST & \\
\hline CHEMBL1966798 & 737262 & 3.699 & 4.122 & TRN & \\
\hline CHEMBL1387500 & 737262 & 3.699 & 4.1513 & TRN & \\
\hline CHEMBL1612978 & 737262 & 3.699 & 4.1123 & TRN & \\
\hline CHEMBL494668 & 737262 & 3.699 & 4.1651 & TRN & \\
\hline CHEMBL1501066 & 737262 & 3.699 & 4.0599 & TRN & \\
\hline CHEMBL1415882 & 737262 & 3.699 & 3.9718 & TRN & \\
\hline CHEMBL1345405 & 737262 & 3.699 & 3.9611 & TRN & \\
\hline CHEMBL1584720 & 737262 & 3.699 & 4.0717 & TST & \\
\hline CHEMBL1319081 & 737262 & 3.699 & 4.1871 & TRN & \\
\hline CHEMBL1304930 & 737262 & 3.699 & 4.0681 & TRN & \\
\hline CHEMBL1702299 & 737262 & 3.699 & 3.8923 & TRN & \\
\hline
\end{tabular}




\begin{tabular}{|c|c|c|c|c|c|c|}
\hline \multirow[b]{2}{*}{ CHEMBL1541209 } & \multicolumn{6}{|c|}{ Supplemental Table S2.txt } \\
\hline & 737262 & 3.699 & 4.0318 & TRN & & \\
\hline CHEMBL1208858 & 737262 & 4.96399 & 99999999 & 995 & 4.1672 & TST \\
\hline CHEMBL1440558 & 737262 & 4.8096 & 4.0985 & TRN & & \\
\hline CHEMBL581860 & 737262 & 3.699 & 4.0154 & TRN & & \\
\hline CHEMBL1474755 & 737262 & 3.699 & 4.0147 & TRN & & \\
\hline CHEMBL1519697 & 737262 & 3.699 & 4.5891 & TRN & & \\
\hline CHEMBL1417619 & 737262 & 3.699 & 4.2046 & TRN & & \\
\hline CHEMBL1729577 & 737262 & 3.699 & 3.8042 & TRN & & \\
\hline CHEMBL1467505 & 737262 & 4.7456 & 4.1274 & TRN & & \\
\hline CHEMBL1560273 & 737262 & 3.699 & 4.1268 & TST & & \\
\hline CHEMBL1581789 & 737262 & 4.7623 & 4.1997 & TRN & & \\
\hline CHEMBL1365226 & 737262 & 3.699 & 4.1484 & TST & & \\
\hline CHEMBL1347600 & 737262 & 4.7739 & 3.6797 & TRN & & \\
\hline CHEMBL1735839 & 737262 & 3.699 & 4.1012 & TRN & & \\
\hline CHEMBL1542538 & 737262 & 3.699 & 4.0671 & TRN & & \\
\hline CHEMBL1393812 & 737262 & 5.0685 & 4.1816 & TRN & & \\
\hline CHEMBL1510942 & 737262 & 3.699 & 4.1147 & TRN & & \\
\hline CHEMBL1986183 & 737262 & 5.6979 & 4.4877 & TST & & \\
\hline CHEMBL1604350 & 737262 & 4.96899 & 99999999 & 99 & 3.5615 & TRN \\
\hline CHEMBL1438860 & 737262 & 3.699 & 4.0687 & TRN & & \\
\hline CHEMBL1982108 & 737262 & 4.9562 & 4.2418 & TST & & \\
\hline CHEMBL1418004 & 737262 & 5.6643 & 4.5925 & TRN & & \\
\hline CHEMBL1731213 & 737262 & 3.699 & 4.1002 & TRN & & \\
\hline CHEMBL24759 & 737262 & 3.699 & 4.146 & TRN & & \\
\hline CHEMBL1487368 & 737262 & 3.699 & 3.9234 & TRN & & \\
\hline CHEMBL1351158 & 737262 & 3.699 & 4.0489 & TRN & & \\
\hline CHEMBL1428563 & 737262 & 3.699 & 3.9504 & TST & & \\
\hline CHEMBL1583807 & 737262 & 5.1471 & 4.162 & TRN & & \\
\hline CHEMBL1720169 & 737262 & 3.699 & 4.0889 & TRN & & \\
\hline CHEMBL1565508 & 737262 & 3.699 & 4.0757 & TRN & & \\
\hline CHEMBL1340520 & 737262 & 3.699 & 4.1054 & TRN & & \\
\hline CHEMBL1315701 & 737262 & 4.8794 & 4.1694 & TRN & & \\
\hline CHEMBL1318088 & 737262 & 5.0001 & 4.3135 & TRN & & \\
\hline CHEMBL1559298 & 737262 & 3.699 & 3.9085 & TRN & & \\
\hline CHEMBL1468219 & 737262 & 3.699 & 4.0073 & TRN & & \\
\hline CHEMBL1516672 & 737262 & 3.699 & 4.0358 & TRN & & \\
\hline CHEMBL3212803 & 737262 & 4.6991 & 4.0631 & TRN & & \\
\hline CHEMBL1378124 & 737262 & 3.699 & 4.1445 & TRN & & \\
\hline CHEMBL1709204 & 737262 & 3.699 & 4.1559 & TST & & \\
\hline CHEMBL1500268 & 737262 & 3.699 & 4.0927 & TRN & & \\
\hline CHEMBL1467095 & 737262 & 4.7218 & 3.6541 & TST & & \\
\hline CHEMBL1213137 & 737262 & 3.699 & 4.1256 & TRN & & \\
\hline CHEMBL1520667 & 737262 & 5.0458 & 4.1718 & TST & & \\
\hline CHEMBL1732259 & 737262 & 3.699 & 4.0672 & TRN & & \\
\hline CHEMBL1300497 & 737262 & 3.699 & 4.5219 & TRN & & \\
\hline CHEMBL1550448 & 737262 & 3.699 & 4.1568 & TRN & & \\
\hline CHEMBL1519670 & 737262 & 3.699 & 4.1271 & TRN & & \\
\hline CHEMBL1564542 & 737262 & 3.699 & 4.1098 & TRN & & \\
\hline
\end{tabular}


Supplemental Table S2.txt

\begin{tabular}{|c|c|c|c|c|c|c|}
\hline CHEMBL1411217 & 737262 & 3.699 & 4.0315 & TRN & & \\
\hline CHEMBL1354582 & 737262 & 3.699 & 4.1213 & TST & & \\
\hline CHEMBL1602189 & 737262 & 3.699 & 3.7176 & TRN & & \\
\hline CHEMBL1720696 & 737262 & 3.699 & 4.0806 & TRN & & \\
\hline CHEMBL3213571 & 737262 & 5.0832 & 4.0697 & TRN & & \\
\hline CHEMBL1725691 & 737262 & 3.699 & 4.0566 & TRN & & \\
\hline CHEMBL1979106 & 737262 & 3.699 & 4.0966 & TRN & & \\
\hline CHEMBL1377398 & 737262 & 3.699 & 4.4514 & TRN & & \\
\hline CHEMBL3198118 & 737262 & 5.7755 & 4.5485 & TRN & & \\
\hline CHEMBL1394121 & 737262 & 3.699 & 4.0291 & TRN & & \\
\hline CHEMBL1563862 & 737262 & 3.699 & 4.1151 & TRN & & \\
\hline CHEMBL1546433 & 737262 & 3.699 & 3.9232 & TRN & & \\
\hline CHEMBL1408841 & 737262 & 4.8255 & 3.6483 & TRN & & \\
\hline CHEMBL1588509 & 737262 & 3.699 & 4.037 & TRN & & \\
\hline CHEMBL3192765 & 737262 & 5.3411 & 4.1762 & TRN & & \\
\hline CHEMBL1331801 & 737262 & 3.699 & 4.2407 & TRN & & \\
\hline CHEMBL 1256740 & 737262 & 3.699 & 4.0667 & TRN & & \\
\hline CHEMBL1532679 & 737262 & 4.8094 & 3.6519 & TRN & & \\
\hline CHEMBL1732621 & 737262 & 3.699 & 4.0118 & TST & & \\
\hline CHEMBL1418255 & 737262 & 5.0182 & 4.0928 & TST & & \\
\hline CHEMBL1971151 & 737262 & 3.699 & 4.1513 & TRN & & \\
\hline CHEMBL1477643 & 737262 & 3.699 & 4.0955 & TRN & & \\
\hline CHEMBL1482840 & 737262 & 3.699 & 4.2765 & TRN & & \\
\hline CHEMBL1540419 & 737262 & 5.0756 & 4.1679 & TST & & \\
\hline CHEMBL1407747 & 737262 & 4.7812 & 4.1353 & TST & & \\
\hline CHEMBL578944 & 737262 & 3.699 & 3.9532 & TST & & \\
\hline CHEMBL1314825 & 737262 & 3.699 & 4.0531 & TST & & \\
\hline CHEMBL1534034 & 737262 & 5.5077 & 4.3629 & TRN & & \\
\hline CHEMBL1600400 & 737262 & 3.699 & 4.0782 & TRN & & \\
\hline CHEMBL1334739 & 737262 & 4.9838 & 4.0751 & TRN & & \\
\hline CHEMBL1382265 & 737262 & 3.699 & 4.0289 & TRN & & \\
\hline CHEMBL1312973 & 737262 & 3.699 & 4.0144 & TRN & & \\
\hline CHEMBL1360037 & 737262 & 3.699 & 4.1358 & TRN & & \\
\hline CHEMBL3198863 & 737262 & 3.699 & 4.1173 & TST & & \\
\hline CHEMBL77064 & 737262 & 3.699 & 3.9647 & TST & & \\
\hline CHEMBL1489969 & 737262 & 3.699 & 4.0012 & TRN & & \\
\hline CHEMBL1729758 & 737262 & 4.9643 & 4.136 & TRN & & \\
\hline CHEMBL1316090 & 737262 & 3.699 & 3.9797 & TST & & \\
\hline CHEMBL1731513 & 737262 & 3.699 & 4.0234 & TST & & \\
\hline CHEMBL1707551 & 737262 & 3.699 & 4.1245 & TRN & & \\
\hline CHEMBL1312050 & 737262 & 3.699 & 3.9593 & TRN & & \\
\hline CHEMBL1549666 & 737262 & 5.15799 & 99999999 & 995 & 4.2193 & TRN \\
\hline CHEMBL1428095 & 737262 & 4.9641 & 3.4763 & TRN & & \\
\hline CHEMBL1401107 & 737262 & 3.699 & 4.0643 & TRN & & \\
\hline CHEMBL1328510 & 737262 & 4.9022 & 4.1187 & TRN & & \\
\hline CHEMBL1330103 & 737262 & 4.90300 & 00000006 & 305 & 4.2471 & TRN \\
\hline CHEMBL2001936 & 737262 & 3.699 & 4.0947 & TST & & \\
\hline CHEMBL1464838 & 737262 & 4.855 & 3.7085 & TST & & \\
\hline
\end{tabular}


Supplemental Table S2.txt

\begin{tabular}{|c|c|c|c|c|}
\hline HEMBL13 & & 699 & 06 & TRI \\
\hline HEMRI 1488135 & 37262 & & 4.1528 & \\
\hline HEMBL1447 & 7262 & & & \\
\hline HEMBL1524052 & 3262 & & 345 & \\
\hline HEMBL1734265 & 37262 & 699 & 1494 & \\
\hline HEMBL17 & 7262 & 599 & & \\
\hline HEMBL236 & 262 & 111 & & \\
\hline HEMBL153. & 37262 & 599 & 9056 & \\
\hline HEMBL1387 & 37262 & 599 & 9252 & \\
\hline HEMBL1717 & 37262 & 9882 & .6491 & \\
\hline HEMBL14 & 37262 & .699 & 9412 & \\
\hline HEMBL18 & 262 & 613 & & \\
\hline HEMBL15 & 37262 & 3605 & 7279 & \\
\hline HEMBL142. & 262 & 599 & 2095 & \\
\hline HEMBL $132 \varepsilon$ & 7262 & 057 & 1185 & \\
\hline AEMBL13 & 262 & 208 & 868 & \\
\hline AEMBL1S & 62 & & & RN \\
\hline HEMBL13 & 37262 & 599 & 1323 & RN \\
\hline HEMBL13 & 262 & 325 & 2932 & \\
\hline HEMBL134 & 62 & 99 & 558 & SI \\
\hline AEMBL13 & 62 & 961 & 41 & $R N$ \\
\hline AEMBL1 & 62 & & & $\mathrm{RN}$ \\
\hline HEMBL5 & 262 & & 398 & \\
\hline HEMBL17 & & & & \\
\hline AEMBL17 & 62 & 99 & 74 & | \\
\hline IEMBL14 & 62 & & 69 & ST \\
\hline AEMBL1 & 62 & 96 & & ST \\
\hline 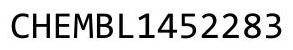 & & & & RN \\
\hline AEMBL1C & & & & IRN \\
\hline AEMBL158 & 62 & & 53 & RN \\
\hline AEMBL1 & 52 & & 09 & $\mathrm{RN}$ \\
\hline$I 5 M$ & 52 & & & RN \\
\hline & & & & RN \\
\hline AEMBL133 & & 4ד & & ST \\
\hline HEMBL13. & 62 & 1998 & & 「RN \\
\hline AFMR 1 & 52 & 12 & & 「RN \\
\hline & & & & ST \\
\hline HEMBL13 & & & & TST \\
\hline HEMBL13 & 62 & & 837 & 「RN \\
\hline EMBL1 & 62 & & 3687 & RN \\
\hline HEMBL1C & & 707 & 825 & TRN \\
\hline & & & 4.0063 & ST \\
\hline HEMBL 15 & 37262 & & 3933 & 「RN \\
\hline AEMBL17 & 62 & & 136 & TR \\
\hline HEMP 12 & & & 11 & 15 \\
\hline CHEMBL154 & 37262 & & & \\
\hline CHEMBL157 & 37262 & 4.7435 & 3.6333 & \\
\hline CHEMBL1609937 & 737262 & 3.699 & 4.0031 & RN \\
\hline
\end{tabular}

Page 13102 


\begin{tabular}{|c|c|c|c|c|c|c|}
\hline & & \multicolumn{4}{|c|}{ Supplemental Table S2.txt } & \\
\hline CHEMBL1576266 & 737262 & \multicolumn{3}{|c|}{4.8069999999999995} & 4.0293 & TRN \\
\hline CHEMBL1477085 & 737262 & 3.699 & 4.2059 & TST & & \\
\hline CHEMBL2369162 & 737262 & 3.699 & 4.1374 & TRN & & \\
\hline CHEMBL1719643 & 737262 & 3.699 & 3.892 & TRN & & \\
\hline CHEMBL1418661 & 737262 & 3.699 & 4.0715 & TRN & & \\
\hline CHEMBL1723205 & 737262 & 3.699 & 4.093 & TRN & & \\
\hline CHEMBL1343853 & 737262 & 5.1975 & 4.2368 & TRN & & \\
\hline CHEMBL1705791 & 737262 & 3.699 & 4.0799 & TRN & & \\
\hline CHEMBL3391727 & 737262 & 4.8696 & 4.0738 & TST & & \\
\hline CHEMBL1713976 & 737262 & 3.699 & 3.9985 & TRN & & \\
\hline CHEMBL 3213514 & 737262 & 3.699 & 4.1852 & TRN & & \\
\hline CHEMBL1509316 & 737262 & 4.7192 & 4.0706 & TRN & & \\
\hline CHEMBL1301480 & 737262 & 3.699 & 3.9955 & TRN & & \\
\hline CHEMBL1520122 & 737262 & 3.699 & 4.1792 & TRN & & \\
\hline CHEMBL1735343 & 737262 & 3.699 & 4.0281 & TRN & & \\
\hline CHEMBL1432123 & 737262 & 4.9547 & 4.1824 & TRN & & \\
\hline CHEMBL1377750 & 737262 & 3.699 & 3.9759 & TRN & & \\
\hline CHEMBL1338254 & 737262 & 3.699 & 4.011 & TRN & & \\
\hline CHEMBL1317759 & 737262 & 3.699 & 4.0682 & TRN & & \\
\hline CHEMBL1389427 & 737262 & 3.699 & 4.1309 & TRN & & \\
\hline CHEMBL1613445 & 737262 & \multicolumn{3}{|c|}{5.3389999999999995} & 4.2761 & TRN \\
\hline CHEMBL1415447 & 737262 & 3.699 & 4.1115 & TST & & \\
\hline CHEMBL1336154 & 737262 & 5.8111 & 4.3955 & TRN & & \\
\hline CHEMBL1406465 & 737262 & 3.699 & 3.8967 & TRN & & \\
\hline CHEMBL3193637 & 737262 & 3.699 & 3.9497 & TRN & & \\
\hline CHEMBL1571934 & 737262 & 4.9066 & 4.1596 & TRN & & \\
\hline CHEMBL1570672 & 737262 & 3.699 & 3.9189 & TRN & & \\
\hline CHEMBL1403421 & 737262 & 3.699 & 4.2111 & TRN & & \\
\hline CHEMBL1703098 & 737262 & 5.5447 & 4.333 & TST & & \\
\hline CHEMBL1612743 & 737262 & 3.699 & 4.1056 & TRN & & \\
\hline CHEMBL1356525 & 737262 & 5.1033 & 4.1163 & TRN & & \\
\hline CHEMBL1367989 & 737262 & 3.699 & 4.0499 & TRN & & \\
\hline CHEMBL1345666 & 737262 & 3.699 & 3.9721 & TRN & & \\
\hline CHEMBL1352867 & 737262 & 3.699 & 4.3446 & TRN & & \\
\hline CHEMBL1462898 & 737262 & 3.699 & 4.118 & TRN & & \\
\hline CHEMBL1256660 & 737262 & 3.699 & 4.1034 & TRN & & \\
\hline CHEMBL1335850 & 737262 & 3.699 & 4.1661 & TST & & \\
\hline CHEMBL2369258 & 737262 & 4.7039 & 4.2981 & TRN & & \\
\hline CHEMBL1720998 & 737262 & 3.699 & 3.9146 & TRN & & \\
\hline CHEMBL584444 & 737262 & 4.8984 & 4.0974 & TRN & & \\
\hline CHEMBL1716796 & 737262 & 3.699 & 4.0972 & TRN & & \\
\hline CHEMBL1304925 & 737262 & 3.699 & 4.0841 & TRN & & \\
\hline CHEMBL2369290 & 737262 & 3.699 & 4.2125 & TRN & & \\
\hline CHEMBL1549086 & 737262 & 3.699 & 3.9803 & TRN & & \\
\hline CHEMBL3212707 & 737262 & 5.4554 & 4.3454 & TST & & \\
\hline CHEMBL1602636 & 737262 & 3.699 & 4.044 & TRN & & \\
\hline CHEMBL1345687 & 737262 & 3.699 & 3.9713 & TRN & & \\
\hline CHEMBL1463926 & 737262 & 3.699 & 4.0315 & TRN & & \\
\hline
\end{tabular}


Supplemental Table S2.txt

\begin{tabular}{|c|c|c|c|c|c|}
\hline CHEMBL1705302 & 737262 & 3.699 & 4.0764 & TRN & \\
\hline CHEMBL1594055 & 737262 & 3.699 & 4.0179 & TST & \\
\hline CHEMBL1455947 & 737262 & 3.699 & 4.0941 & TRN & \\
\hline CHEMBL1532262 & 737262 & 4.9273 & 4.0517 & TRN & \\
\hline CHEMBL1532649 & 737262 & 3.699 & 4.0288 & TRN & \\
\hline CHEMBL1356454 & 737262 & 3.699 & 4.0485 & TRN & \\
\hline CHEMBL1200792 & 737262 & 4.7561 & 4.0853 & TRN & \\
\hline CHEMBL1715631 & 737262 & 4.8017 & 4.0573 & TST & \\
\hline CHEMBL1592636 & 737262 & 3.699 & 3.965 & TRN & \\
\hline CHEMBL1553855 & 737262 & 3.699 & 3.9222 & TRN & \\
\hline CHEMBL1724950 & 737262 & 4.9173 & 4.1651 & TST & \\
\hline CHEMBL1257078 & 737262 & 3.699 & 4.072 & TST & \\
\hline CHEMBL1349635 & 737262 & 3.699 & 4.0222 & TRN & \\
\hline CHEMBL1310325 & 737262 & 5.4276 & 4.3194 & TRN & \\
\hline CHEMBL1514283 & 737262 & 3.699 & 4.0474 & TRN & \\
\hline CHEMBL1550511 & 737262 & 3.699 & 4.1883 & TRN & \\
\hline CHEMBL1431228 & 737262 & 3.699 & 4.1219 & TRN & \\
\hline CHEMBL1589425 & 737262 & 5.3359 & 4.2889 & TRN & \\
\hline CHEMBL1413258 & 737262 & 3.699 & 4.0502 & TST & \\
\hline CHEMBL1494737 & 737262 & 5.8351 & 4.442 & TRN & \\
\hline CHEMBL1551138 & 737262 & 3.699 & 3.943 & TRN & \\
\hline CHEMBL1448793 & 737262 & 5.4782 & 4.4363 & TRN & \\
\hline CHEMBL1370042 & 737262 & 4.7318 & 4.2534 & TRN & \\
\hline CHEMBL1342376 & 737262 & 3.699 & 4.2491 & TRN & \\
\hline CHEMBL1704219 & 737262 & 3.699 & 4.171 & TRN & \\
\hline CHEMBL460273 & 737262 & 3.699 & 4.0463 & TRN & \\
\hline CHEMBL1882125 & 737262 & 3.699 & 4.0205 & TRN & \\
\hline CHEMBL1721366 & 737262 & 3.699 & 4.1371 & TST & \\
\hline CHEMBL1508847 & 737262 & 3.699 & 3.9869 & TST & \\
\hline CHEMBL1507187 & 737262 & 4.8397 & 4.01 & TRN & \\
\hline CHEMBL1461797 & 737262 & 3.699 & 3.7394 & TRN & \\
\hline CHEMBL1701840 & 737262 & 4.7112 & 3.6411 & TRN & \\
\hline CHEMBL1421282 & 737262 & 4.8492 & 3.6405 & TST & \\
\hline CHEMBL1474617 & 737262 & 3.699 & 4.0648 & TST & \\
\hline CHEMBL1716817 & 737262 & 3.699 & 4.0717 & TRN & \\
\hline CHEMBL1588552 & 737262 & 3.699 & 4.0482 & TRN & \\
\hline CHEMBL1383386 & 737262 & 3.699 & 3.9415 & TRN & \\
\hline CHEMBL1722909 & 737262 & 3.699 & 4.0849 & TRN & \\
\hline CHEMBL1440827 & 737262 & 5.1737 & 4.4208 & TRN & \\
\hline CHEMBL1387554 & 737262 & 4.702 & 4.1241 & TRN & \\
\hline CHEMBL1409350 & 737262 & 5.7627 & 4.6299 & TRN & \\
\hline CHEMBL1428623 & 737262 & 3.699 & \multicolumn{2}{|c|}{4.446000000000001} & TRN \\
\hline CHEMBL1304615 & 737262 & 4.8996 & 4.0767 & TRN & \\
\hline CHEMBL1450615 & 737262 & 3.699 & 4.0155 & TRN & \\
\hline CHEMBL1531357 & 737262 & 3.699 & 4.095 & TRN & \\
\hline CHEMBL1497342 & 737262 & 3.699 & 3.986 & TRN & \\
\hline CHEMBL1974537 & 737262 & 4.976 & 4.287 & TST & \\
\hline CHEMBL1368012 & 737262 & 5.6761 & 4.4645 & TRN & \\
\hline
\end{tabular}

Page 13104 


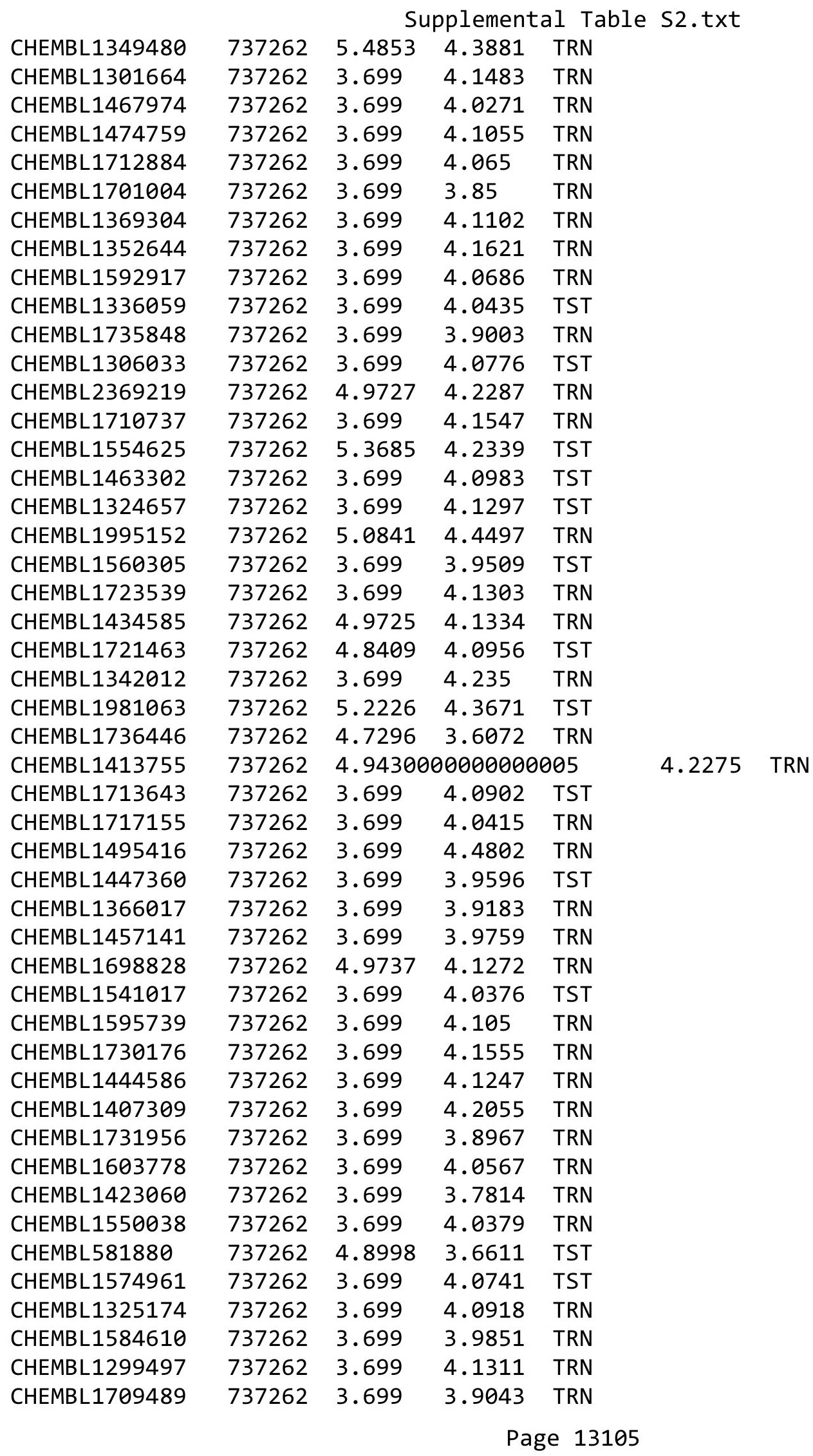


Supplemental Table S2.txt

\begin{tabular}{|c|c|c|c|c|c|}
\hline CHEMBL1562738 & 737262 & 3.699 & 4.1207 & TRN & \\
\hline CHEMBL1708466 & 737262 & 3.699 & 4.0588 & TRN & \\
\hline CHEMBL1349892 & 737262 & 4.8279 & 4.0216 & TRN & \\
\hline CHEMBL1434938 & 737262 & 3.699 & 4.0476 & TRN & \\
\hline CHEMBL1351099 & 737262 & 3.699 & 4.0723 & TRN & \\
\hline CHEMBL1734750 & 737262 & 3.699 & 3.7647 & TRN & \\
\hline CHEMBL1351668 & 737262 & 3.699 & 3.7168 & TRN & \\
\hline CHEMBL1490267 & 737262 & 3.699 & 4.0888 & TST & \\
\hline CHEMBL306783 & 737262 & 3.699 & 4.0568 & TST & \\
\hline CHEMBL1503928 & 737262 & 4.7128 & 3.6276 & TRN & \\
\hline CHEMBL1323696 & 737262 & 3.699 & 4.1068 & TRN & \\
\hline CHEMBL1967436 & 737262 & 3.699 & 4.032 & TRN & \\
\hline CHEMBL1403603 & 737262 & 3.699 & 4.0078 & TRN & \\
\hline CHEMBL1503689 & 737262 & 3.699 & 3.9643 & TRN & \\
\hline CHEMBL1474135 & 737262 & 3.699 & 4.1548 & TRN & \\
\hline CHEMBL1720642 & 737262 & 3.699 & 4.066 & TST & \\
\hline CHEMBL1463901 & 737262 & 3.699 & 4.1698 & TRN & \\
\hline CHEMBL1316324 & 737262 & 3.699 & 4.0556 & TST & \\
\hline CHEMBL1540237 & 737262 & 3.699 & 4.0428 & TRN & \\
\hline CHEMBL1545131 & 737262 & 3.699 & 4.0585 & TRN & \\
\hline CHEMBL1595020 & 737262 & 4.8763 & 4.1561 & TRN & \\
\hline CHEMBL1308879 & 737262 & 3.699 & 3.9683 & TRN & \\
\hline CHEMBL1575956 & 737262 & 3.699 & 3.976006 & 00000000004 & TRN \\
\hline CHEMBL1524151 & 737262 & 3.699 & 4.0199 & TRN & \\
\hline CHEMBL1368514 & 737262 & 5.0654 & 4.3566 & TRN & \\
\hline CHEMBL1527170 & 737262 & 3.699 & 4.0241 & TRN & \\
\hline CHEMBL1502559 & 737262 & 3.699 & 4.1325 & TST & \\
\hline CHEMBL1609296 & 737262 & 4.7889 & 4.1642 & TRN & \\
\hline CHEMBL1319248 & 737262 & 5.4628 & 4.3427 & TRN & \\
\hline CHEMBL1613394 & 737262 & 5.0684 & 4.1903 & TRN & \\
\hline CHEMBL1509380 & 737262 & 5.1852 & 4.1746 & TRN & \\
\hline CHEMBL1512652 & 737262 & 5.0808 & 4.197 & TRN & \\
\hline CHEMBL 2369200 & 737262 & 3.699 & 4.1171 & TRN & \\
\hline CHEMBL1718129 & 737262 & 3.699 & 4.0895 & TST & \\
\hline CHEMBL1330626 & 737262 & 3.699 & 4.1414 & TRN & \\
\hline CHEMBL1896042 & 737262 & 3.699 & 4.0902 & TRN & \\
\hline CHEMBL1977653 & 737262 & 3.699 & 4.1727 & TRN & \\
\hline CHEMBL1324195 & 737262 & 3.699 & 4.0204 & TRN & \\
\hline CHEMBL1730952 & 737262 & 5.3691 & 4.4316 & TRN & \\
\hline CHEMBL1436792 & 737262 & 5.4429 & 4.3182 & TRN & \\
\hline CHEMBL1558306 & 737262 & 4.825 & 4.6446 & TRN & \\
\hline CHEMBL1466029 & 737262 & 3.699 & 4.0378 & TRN & \\
\hline CHEMBL1708596 & 737262 & 4.919 & 4.1954 & TST & \\
\hline CHEMBL1709546 & 737262 & 3.699 & 4.0638 & TRN & \\
\hline CHEMBL1724587 & 737262 & 3.699 & 4.0503 & TRN & \\
\hline CHEMBL3192949 & 737262 & 6.3215 & 4.7733 & TRN & \\
\hline CHEMBL1352234 & 737262 & 3.699 & 4.0469 & TRN & \\
\hline CHEMBL1726406 & 737262 & 4.8166 & 3.7447 & TST & \\
\hline
\end{tabular}




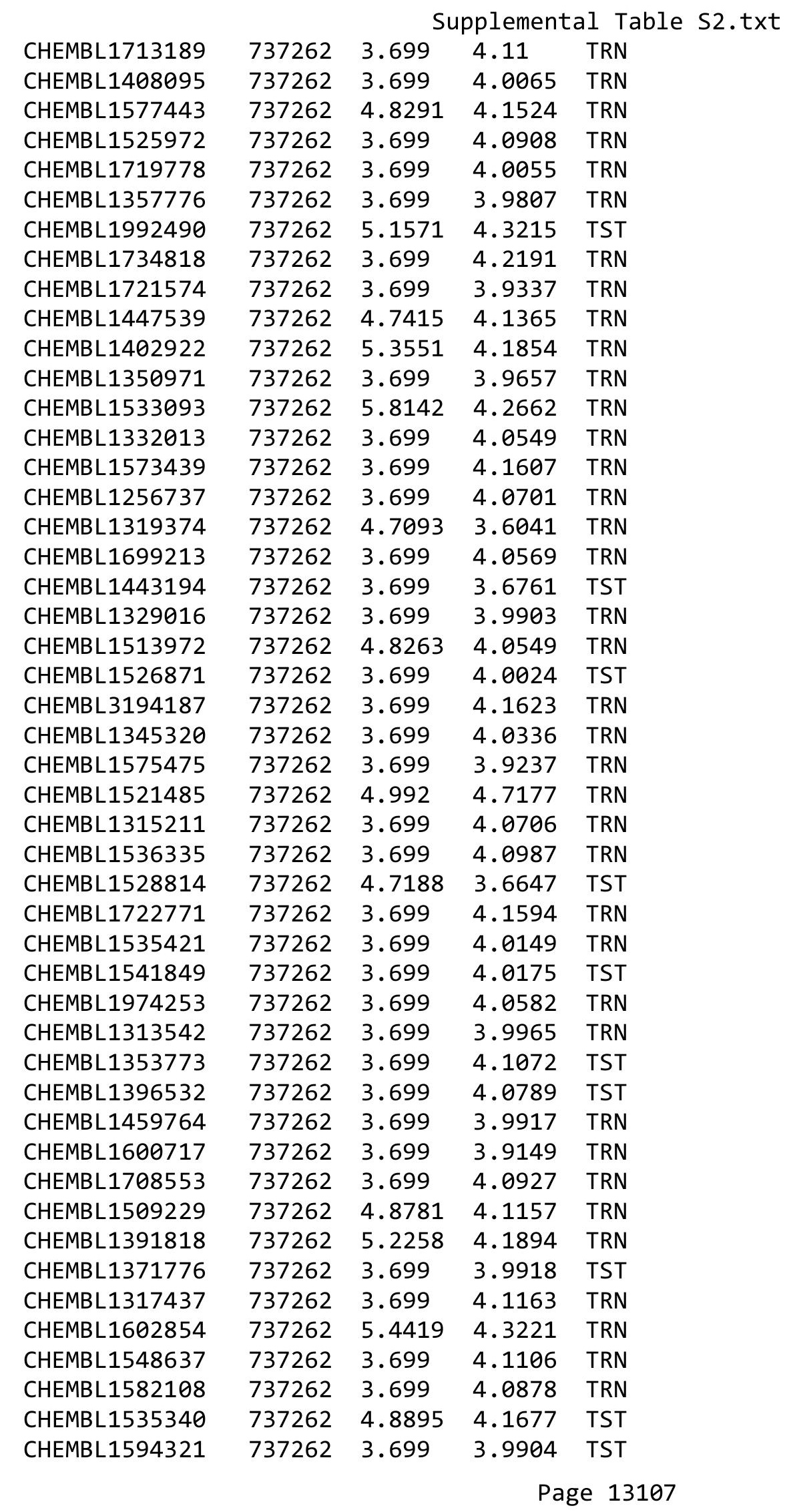




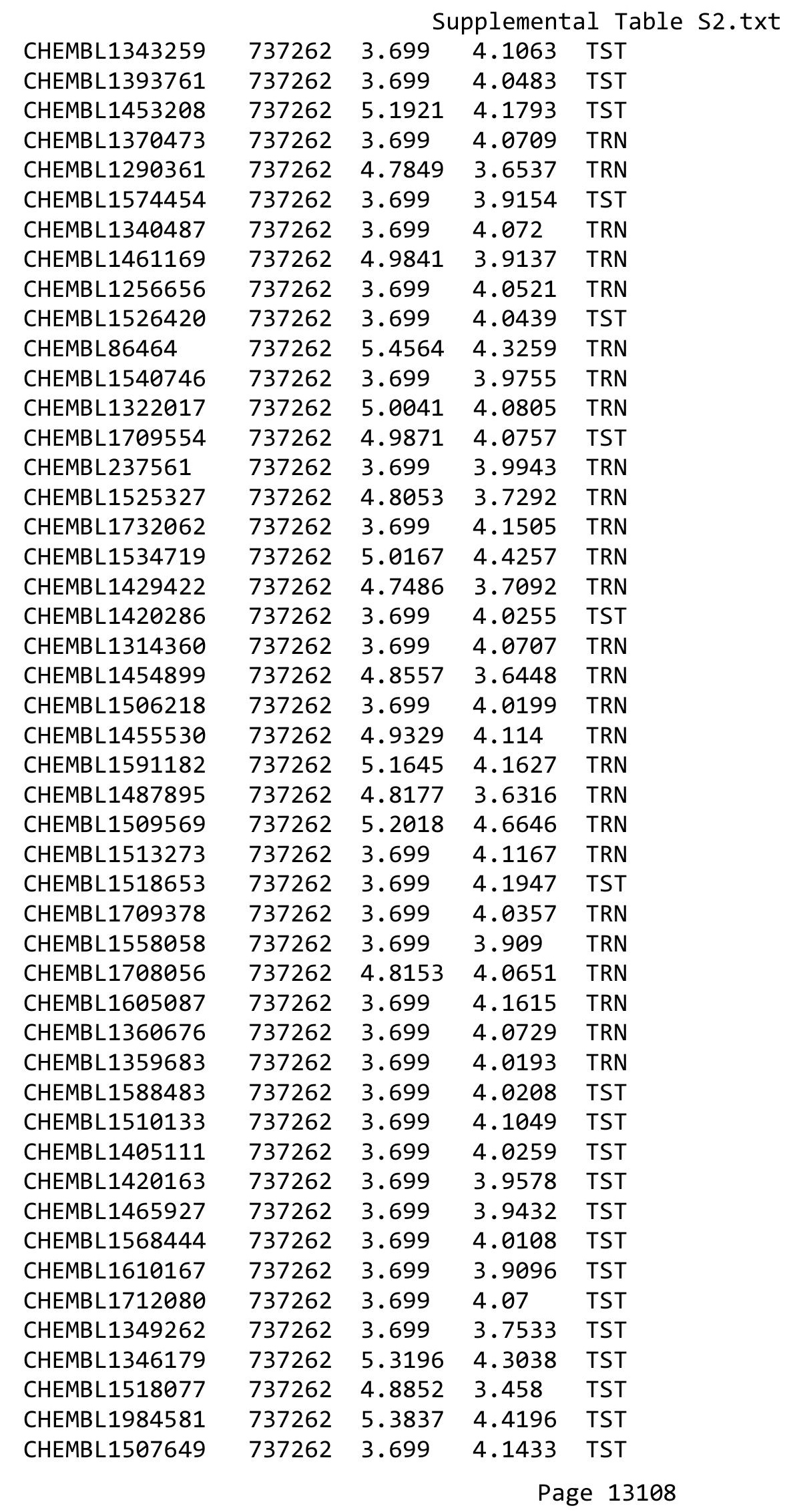


Supplemental Table S2.txt

\begin{tabular}{|c|c|c|c|c|c|}
\hline CHEMBL579837 & 737262 & 3.699 & 3.9617 & TST & \\
\hline CHEMBL1383214 & 737262 & 4.9185 & 4.1073 & TST & \\
\hline CHEMBL1380969 & 737262 & 4.8243 & 4.2142 & TST & \\
\hline CHEMBL1515128 & 737262 & 3.699 & 4.0884 & TST & \\
\hline CHEMBL1256995 & 737262 & 3.699 & 4.1526 & TST & \\
\hline CHEMBL1346693 & 737262 & 5.1015 & 4.3896 & TST & \\
\hline CHEMBL1325605 & 737262 & 3.699 & 4.0652 & TST & \\
\hline CHEMBL1549267 & 737262 & 3.699 & 4.0156 & TST & \\
\hline CHEMBL1706262 & 737262 & 3.699 & 4.0133 & TST & \\
\hline CHEMBL1310346 & 737262 & 3.699 & 4.1226 & TST & \\
\hline CHEMBL1577511 & 737262 & 3.699 & 4.0468 & TST & \\
\hline CHEMBL1336697 & 737262 & 3.699 & 4.1337 & TST & \\
\hline CHEMBL1600855 & 737262 & 3.699 & 4.1628 & TST & \\
\hline CHEMBL1473346 & 737262 & 3.699 & 4.0969 & TST & \\
\hline CHEMBL1592706 & 737262 & 5.4102 & 4.3244 & TST & \\
\hline CHEMBL 2004487 & 737262 & 4.9424 & 4.3444 & TST & \\
\hline CHEMBL1449029 & 737262 & 3.699 & 3.9094 & TST & \\
\hline CHEMBL1487035 & 737262 & 4.7578 & 3.9545 & TST & \\
\hline CHEMBL1321737 & 737262 & 3.699 & 4.026 & TST & \\
\hline CHEMBL1410483 & 737262 & 5.3422 & 4.294 & TST & \\
\hline CHEMBL1700422 & 737262 & 3.699 & 4.0533 & TST & \\
\hline CHEMBL1458254 & 737262 & 3.699 & 4.0685 & TST & \\
\hline CHEMBL1342266 & 737262 & 3.699 & 4.1062 & TST & \\
\hline CHEMBL1729624 & 737262 & 4.7629 & 4.0802 & TST & \\
\hline CHEMBL1454777 & 737262 & 5.0894 & 4.1993 & TST & \\
\hline CHEMBL1528914 & 737262 & 3.699 & 3.8937 & TST & \\
\hline CHEMBL528181 & 737262 & 3.699 & 4.0536 & TST & \\
\hline CHEMBL1574499 & 737262 & 3.699 & 3.99899 & 99999999997 & TST \\
\hline CHEMBL1460676 & 737262 & 4.9593 & 4.2128 & TST & \\
\hline CHEMBL1492017 & 737262 & 3.699 & 4.0824 & TST & \\
\hline CHEMBL1366934 & 737262 & 3.699 & 4.2031 & TST & \\
\hline CHEMBL1433859 & 737262 & 3.699 & 4.0999 & TST & \\
\hline CHEMBL1383807 & 737262 & 3.699 & 4.0613 & TST & \\
\hline CHEMBL1538399 & 737262 & 3.699 & 4.0822 & TST & \\
\hline CHEMBL3190721 & 737262 & 3.699 & 4.17899 & 9999999999 & TST \\
\hline CHEMBL1550225 & 737262 & 5.2783 & 4.2482 & TST & \\
\hline CHEMBL397761 & 443966 & 5.3407 & 5.7675 & TST & \\
\hline CHEMBL232075 & 443966 & 6.5834 & 6.4539 & TRN & \\
\hline CHEMBL232074 & 443966 & 6.4815 & 6.5711 & TRN & \\
\hline CHEMBL233750 & 443966 & 6.1267 & 6.5022 & TRN & \\
\hline CHEMBL232286 & 443966 & 6.7305 & 6.6798 & TRN & \\
\hline CHEMBL398794 & 443966 & 6.3716 & 6.4235 & TRN & \\
\hline CHEMBL441914 & 443966 & 7.5229 & 7.6757 & TRN & \\
\hline CHEMBL 232285 & 443966 & 6.8356 & 6.7568 & TRN & \\
\hline CHEMBL437380 & 443966 & 5.9389 & 5.9544 & TRN & \\
\hline CHEMBL233502 & 443966 & 5.5577 & 5.6043 & TRN & \\
\hline CHEMBL393971 & 443966 & 4.8801 & 4.84699 & 99999999995 & TRN \\
\hline \multirow[t]{2}{*}{ CHEMBL393985 } & 443966 & 5.3921 & 5.49200 & 0000000001 & TRN \\
\hline & & \multicolumn{4}{|c|}{ Page 13109} \\
\hline
\end{tabular}




\begin{tabular}{|c|c|c|c|c|c|c|}
\hline & & & oplement & & $2 . t x$ & \\
\hline CHEMBL233535 & 443966 & 6.1778 & 5.8508 & TST & & \\
\hline CHEMBL233323 & 443966 & 5.46700 & 00000000 & 205 & 5.4232 & TRN \\
\hline CHEMBL233327 & 443966 & 6.1397 & 6.3246 & TRN & & \\
\hline CHEMBL233536 & 443966 & 6.5544 & 6.528 & TRN & & \\
\hline CHEMBL 233748 & 443966 & 5.9763 & 5.7466 & TRN & & \\
\hline CHEMBL 233721 & 443966 & 5.1314 & 5.0351 & TST & & \\
\hline CHEMBL 233493 & 443966 & 5.3809 & 5.401 & TRN & & \\
\hline CHEMBL395838 & 443966 & 5.7003 & 5.8647 & TRN & & \\
\hline CHEMBL 232478 & 443966 & 6.9136 & 6.8758 & TRN & & \\
\hline CHEMBL401234 & 443966 & 4.9872 & 4.9893 & TRN & & \\
\hline CHEMBL393675 & 443966 & 4.7056 & 4.6936 & TRN & & \\
\hline CHEMBL393356 & 443966 & 5.5894 & 5.7248 & TST & & \\
\hline CHEMBL394695 & 443966 & 6.4123 & 5.3154 & TST & & \\
\hline CHEMBL 233503 & 443966 & 5.7804 & 5.7816 & TRN & & \\
\hline CHEMBL231866 & 443966 & 6.6676 & 6.6319 & TRN & & \\
\hline CHEMBL232067 & 443966 & 5.58299 & 99999999 & 99 & 5.5964 & TRN \\
\hline CHEMBL233955 & 443966 & 6.9355 & 6.8039 & TRN & & \\
\hline CHEMBL233749 & 443966 & 5.6794 & 5.7193 & TRN & & \\
\hline CHEMBL 234773 & 443966 & 5.0352 & 5.6271 & TST & & \\
\hline CHEMBL398039 & 443966 & 4.5783 & 4.9256 & TST & & \\
\hline CHEMBL437177 & 443966 & 6.7595 & 6.7906 & TRN & & \\
\hline CHEMBL392753 & 443966 & 5.769 & 5.7338 & TRN & & \\
\hline CHEMBL394222 & 443966 & 6.4908 & 6.4817 & TRN & & \\
\hline CHEMBL 231874 & 443966 & 5.0157 & 4.9931 & TRN & & \\
\hline CHEMBL232476 & 443966 & 5.76 & 5.8755 & TRN & & \\
\hline CHEMBL 232273 & 443966 & 6.0872 & 5.944 & TRN & & \\
\hline CHEMBL231664 & 443966 & 5.7445 & 4.7578 & TST & & \\
\hline CHEMBL233956 & 443966 & 6.556 & 6.5529 & TRN & & \\
\hline CHEMBL 233501 & 443966 & 4.2143 & 4.2885 & TRN & & \\
\hline CHEMBL400035 & 443966 & 6.3468 & 6.3792 & TRN & & \\
\hline CHEMBL400036 & 443966 & 6.1129 & 6.1344 & TRN & & \\
\hline CHEMBL233326 & 443966 & 7.8239 & 7.5832 & TRN & & \\
\hline CHEMBL 234771 & 443966 & 5.9694 & 5.2463 & TST & & \\
\hline CHEMBL 234543 & 443966 & 4.9448 & 4.7987 & TRN & & \\
\hline CHEMBL 232477 & 443966 & 6.5935 & 6.5348 & TRN & & \\
\hline CHEMBL233494 & 443966 & 5.4356 & 5.3712 & TRN & & \\
\hline CHEMBL231661 & 443966 & 5.8422 & 4.5326 & TST & & \\
\hline CHEMBL232076 & 443966 & 6.857 & 6.5551 & TST & & \\
\hline CHEMBL 233957 & 443966 & 5.8684 & 6.0651 & TST & & \\
\hline CHEMBL 228690 & 443966 & 6.4389 & 5.5967 & TST & & \\
\hline CHEMBL 232066 & 443966 & 6.1198 & 5.6296 & TST & & \\
\hline CHEMBL1716797 & 1457494 & 5.2291 & 5.398 & TRN & & \\
\hline CHEMBL3183773 & 1457494 & 5.2596 & 5.0022 & TRN & & \\
\hline CHEMBL 3182359 & 1457494 & 5.7258 & 6.1585 & TRN & & \\
\hline CHEMBL 3188343 & 1457494 & 5.8239 & 5.1875 & TRN & & \\
\hline CHEMBL 3186946 & 1457494 & 3.5229 & 4.2001 & TRN & & \\
\hline CHEMBL 3182370 & 1457494 & 5.6021 & 5.195 & TRN & & \\
\hline CHEMBL3184438 & 1457494 & 5.7696 & 6.0229 & TRN & & \\
\hline
\end{tabular}


Supplemental Table S2.txt

\begin{tabular}{|c|c|c|c|c|}
\hline CHEMBL1310568 & 1457494 & 6.301 & 5.3895 & TRN \\
\hline CHEMBL3188245 & 1457494 & 3.5229 & 4.2909 & TRN \\
\hline CHEMBL3182449 & 1457494 & 6.5229 & 6.7101 & TST \\
\hline CHEMBL 3182777 & 1457494 & 6.0132 & 5.3432 & TRN \\
\hline CHEMBL3181946 & 1457494 & 3.5229 & 4.2279 & TRN \\
\hline CHEMBL1541525 & 1457494 & 3.5229 & 4.1903 & TRN \\
\hline CHEMBL3317850 & 1457494 & 5.4949 & 3.758 & TRN \\
\hline CHEMBL3181939 & 1457494 & 6.0177 & 5.9374 & TRN \\
\hline CHEMBL1532914 & 1457494 & 3.5229 & 5.0083 & TRN \\
\hline CHEMBL3187764 & 1457494 & 6.0 & 6.5239 & TRN \\
\hline CHEMBL3186471 & 1457494 & 3.5229 & 4.3514 & TRN \\
\hline CHEMBL3317854 & 1457494 & 5.6144 & 5.1941 & TST \\
\hline CHEMBL3186695 & 1457494 & 5.8729 & 6.1135 & TRN \\
\hline CHEMBL3188857 & 1457494 & 5.8539 & 5.8834 & TST \\
\hline CHEMBL 3317853 & 1457494 & 3.5229 & 3.3259 & TRN \\
\hline CHEMBL 3317848 & 1457494 & 3.5229 & 3.9135 & TRN \\
\hline CHEMBL3184653 & 1457494 & 3.5229 & 4.0131 & TRN \\
\hline CHEMBL3188024 & 1457494 & 4.6021 & 4.9571 & TST \\
\hline CHEMBL3183938 & 1457494 & 5.3665 & 4.7886 & TRN \\
\hline CHEMBL3188749 & 1457494 & 6.3872 & 6.249 & TRN \\
\hline CHEMBL3317852 & 1457494 & 5.5686 & 5.9855 & TRN \\
\hline CHEMBL3182773 & 1457494 & 5.5686 & 5.6519 & TRN \\
\hline CHEMBL3317851 & 1457494 & 5.6383 & 5.3893 & TRN \\
\hline CHEMBL3182699 & 1457494 & 6.9586 & 6.5796 & TRN \\
\hline CHEMBL3184095 & 1457494 & 5.2612 & 4.9899 & TST \\
\hline CHEMBL3185736 & 1457494 & 6.8239 & 5.5148 & TRN \\
\hline CHEMBL3317849 & 1457494 & 3.5229 & 3.21199 & 99999999997 \\
\hline CHEMBL3317822 & 1457494 & 3.5229 & 3.7735 & TRN \\
\hline CHEMBL3188463 & 1457494 & 3.5229 & 4.106 & TRN \\
\hline CHEMBL3184966 & 1457494 & 5.6198 & 5.2795 & TRN \\
\hline CHEMBL3182725 & 1457494 & 6.1249 & 5.8649 & TRN \\
\hline CHEMBL1086899 & 1457494 & 6.3188 & 6.0425 & TRN \\
\hline CHEMBL3182809 & 1457494 & 5.1487 & 5.1708 & TRN \\
\hline CHEMBL3188671 & 1457494 & 3.5229 & 4.1854 & TRN \\
\hline CHEMBL3186489 & 1457494 & 4.6383 & 5.0193 & TRN \\
\hline CHEMBL3186207 & 1457494 & 5.1871 & 5.4535 & TRN \\
\hline CHEMBL1480257 & 1457494 & 5.6576 & 6.1258 & TRN \\
\hline CHEMBL3186030 & 1457494 & 5.6778 & 3.8265 & TRN \\
\hline CHEMBL3187482 & 1457494 & 6.3872 & 6.5538 & TRN \\
\hline CHEMBL3183497 & 1457494 & 7.1805 & 6.8365 & TRN \\
\hline CHEMBL3182091 & 1457494 & 6.4815 & 5.9128 & TST \\
\hline CHEMBL3186206 & 1457494 & 5.6021 & 5.0629 & TST \\
\hline CHEMBL3184075 & 1457494 & 4.699 & 4.4335 & TST \\
\hline CHEMBL3186000 & 1457494 & 6.1367 & 6.431 & TST \\
\hline CHEMBL1081188 & 1457494 & 6.4089 & 6.0424 & TST \\
\hline CHEMBL3187891 & 1457494 & 3.5229 & 4.4636 & TST \\
\hline CHEMBL3182551 & 1457494 & 6.2218 & 5.5702 & TST \\
\hline CHEMBL3187806 & 1457494 & 5.6576 & 5.3584 & TST \\
\hline
\end{tabular}


Supplemental Table S2.txt

\begin{tabular}{|c|c|c|c|c|}
\hline CHEMBL3183945 & 1457494 & 5.2518 & 5.1755 & TST \\
\hline CHEMBL 3665850 & 1527636 & 9.0086 & 8.8895 & TRN \\
\hline CHEMBL 3665754 & 1527636 & 8.8771 & 8.9516 & TRN \\
\hline CHEMBL 3665819 & 1527636 & 9.8894 & 8.5594 & TRN \\
\hline CHEMBL 3665767 & 1527636 & 8.6891 & 8.2388 & TRN \\
\hline CHEMBL 3665837 & 1527636 & 9.7838 & 9.0089 & TRN \\
\hline CHEMBL 3665855 & 1527636 & 9.3727 & 8.1917 & TRN \\
\hline CHEMBL 3665844 & 1527636 & 8.9454 & 9.074 & TRN \\
\hline CHEMBL 3665812 & 1527636 & 8.42 & 8.5119 & TRN \\
\hline CHEMBL 3665778 & 1527636 & 8.5408 & 8.3462 & TRN \\
\hline CHEMBL 3670733 & 1527636 & 6.8063 & 6.6827 & TRN \\
\hline CHEMBL 3665752 & 1527636 & 8.6704 & 8.4702 & TRN \\
\hline CHEMBL 3665756 & 1527636 & 8.493 & 8.3789 & TRN \\
\hline CHEMBL 3670729 & 1527636 & 6.6784 & 8.0198 & TST \\
\hline CHEMBL 3665839 & 1527636 & 9.61399 & 99999999 & 8.6299 \\
\hline CHEMBL 3665746 & 1527636 & 8.6979 & 7.8914 & TRN \\
\hline CHEMBL 3670750 & 1527636 & 8.9727 & 8.2013 & TRN \\
\hline CHEMBL 3665779 & 1527636 & 7.8431 & 7.3165 & TRN \\
\hline CHEMBL 3670743 & 1527636 & 6.7326 & 6.7309 & TRN \\
\hline CHEMBL 3665786 & 1527636 & 6.9512 & 7.1077 & TRN \\
\hline CHEMBL 3665770 & 1527636 & 7.4415 & 8.2237 & TRN \\
\hline CHEMBL 3670755 & 1527636 & 9.2595 & 9.1328 & TRN \\
\hline CHEMBL 3665842 & 1527636 & 9.33 & 9.9749 & TRN \\
\hline CHEMBL 3665766 & 1527636 & 8.6803 & 8.2273 & TRN \\
\hline CHEMBL 3665824 & 1527636 & 9.299 & 9.4182 & TRN \\
\hline CHEMBL 3665821 & 1527636 & 9.1005 & 9.548 & TRN \\
\hline CHEMBL 3670731 & 1527636 & 5.9311 & 7.3261 & TST \\
\hline CHEMBL 3665760 & 1527636 & 9.1306 & 8.4727 & TRN \\
\hline CHEMBL 3670751 & 1527636 & 7.9307 & 8.1356 & TRN \\
\hline CHEMBL 3670760 & 1527636 & 7.0461 & 7.8785 & TST \\
\hline CHEMBL 3665831 & 1527636 & 9.8173 & 9.3087 & TRN \\
\hline CHEMBL 3670730 & 1527636 & 7.3441 & 7.6424 & TST \\
\hline CHEMBL 3665847 & 1527636 & 9.4038 & 9.0387 & TST \\
\hline CHEMBL 3670722 & 1527636 & 8.8136 & 7.8611 & TST \\
\hline CHEMBL 3665793 & 1527636 & 6.6847 & 8.2082 & TRN \\
\hline CHEMBL 3665781 & 1527636 & 7.3883 & 7.1917 & TRN \\
\hline CHEMBL 3665825 & 1527636 & 9.2548 & 9.5572 & TRN \\
\hline CHEMBL 3665856 & 1527636 & 7.9485 & 8.418 & TRN \\
\hline CHEMBL 3665835 & 1527636 & 6.6605 & 7.8721 & TST \\
\hline CHEMBL 3670764 & 1527636 & 7.0654 & 7.622006 & 0000000001 \\
\hline CHEMBL 3665817 & 1527636 & 8.9382 & 8.3397 & TRN \\
\hline CHEMBL 3665789 & 1527636 & 8.7366 & 8.1286 & TRN \\
\hline CHEMBL 3670768 & 1527636 & 5.9948 & 7.7617 & TST \\
\hline CHEMBL 3665774 & 1527636 & 7.3509 & 7.5137 & TRN \\
\hline CHEMBL 3670726 & 1527636 & 8.4417 & 8.3325 & TST \\
\hline CHEMBL 3670744 & 1527636 & 9.5847 & 8.7299 & TRN \\
\hline CHEMBL 3665828 & 1527636 & 9.3243 & 9.1962 & TRN \\
\hline CHEMBL 3665758 & 1527636 & 8.6465 & 8.6116 & TRN \\
\hline
\end{tabular}


Supplemental Table S2.txt

\begin{tabular}{|c|c|c|c|c|c|c|c|}
\hline CHEMBL3665743 & 1527636 & 8.8116 & 8.8585 & TRN & & & \\
\hline CHEMBL3665773 & 1527636 & 8.2764 & 8.1975 & TRN & & & \\
\hline CHEMBL3665748 & 1527636 & 8.2738 & 8.4653 & TRN & & & \\
\hline CHEMBL3665796 & 1527636 & 7.5724 & 7.8009 & TRN & & & \\
\hline CHEMBL3665751 & 1527636 & 8.4208 & 8.3815 & TRN & & & \\
\hline CHEMBL3665765 & 1527636 & 8.7091 & 8.1889 & TRN & & & \\
\hline CHEMBL3665853 & 1527636 & 9.7657 & 8.7629 & TRN & & & \\
\hline CHEMBL3665785 & 1527636 & 7.04899 & 999999999 & 995 & 7.1723 & TRN & \\
\hline CHEMBL3665830 & 1527636 & 8.8262 & 9.0702 & TRN & & & \\
\hline CHEMBL3665784 & 1527636 & 5.365 & 7.1436 & TRN & & & \\
\hline CHEMBL3665808 & 1527636 & 8.9183 & 8.4743 & TRN & & & \\
\hline CHEMBL3670727 & 1527636 & 8.90200 & 000000000 & & 8.23299 & 9999999999 & TST \\
\hline CHEMBL 3665843 & 1527636 & 8.6379 & 9.0252 & TRN & & & \\
\hline CHEMBL 3670757 & 1527636 & 6.9248 & 8.3427 & TST & & & \\
\hline CHEMBL3665823 & 1527636 & 9.31 & 9.7579 & TRN & & & \\
\hline CHEMBL3665803 & 1527636 & 8.8533 & 8.3591 & TRN & & & \\
\hline CHEMBL3665805 & 1527636 & 8.0236 & 8.8841 & TRN & & & \\
\hline CHEMBL 3670724 & 1527636 & 7.5312 & 7.6114 & TST & & & \\
\hline CHEMBL3665809 & 1527636 & 8.075 & 8.3973 & TRN & & & \\
\hline CHEMBL3665755 & 1527636 & 8.2737 & 7.9615 & TRN & & & \\
\hline CHEMBL3665761 & 1527636 & 8.5656 & 8.4841 & TRN & & & \\
\hline CHEMBL3665798 & 1527636 & 8.2493 & 8.6291 & TRN & & & \\
\hline CHEMBL3665849 & 1527636 & 9.1527 & 8.9907 & TRN & & & \\
\hline CHEMBL3670759 & 1527636 & 9.1517 & 7.8613 & TST & & & \\
\hline CHEMBL3665846 & 1527636 & 8.823 & 9.3819 & TST & & & \\
\hline CHEMBL 3670752 & 1527636 & 8.0634 & 8.5409 & TST & & & \\
\hline CHEMBL3670766 & 1527636 & 5.9208 & 7.3415 & TST & & & \\
\hline CHEMBL3670765 & 1527636 & 8.7607 & 8.5679 & TST & & & \\
\hline CHEMBL 3665834 & 1527636 & 9.3907 & 9.0772 & TRN & & & \\
\hline CHEMBL3665797 & 1527636 & 7.2317 & 7.9592 & TRN & & & \\
\hline CHEMBL 3665780 & 1527636 & 7.6385 & 8.0028 & TRN & & & \\
\hline CHEMBL3665753 & 1527636 & 8.5683 & $7.91700 e$ & 000000000 & & TRN & \\
\hline CHEMBL3665745 & 1527636 & 8.6647 & 7.9599 & TRN & & & \\
\hline CHEMBL 3665749 & 1527636 & 8.3884 & 8.2442 & TRN & & & \\
\hline CHEMBL3665807 & 1527636 & 8.84799 & 99999999 & 99 & 8.6686 & TRN & \\
\hline CHEMBL3665838 & 1527636 & 9.6426 & 9.3087 & TRN & & & \\
\hline CHEMBL3665800 & 1527636 & 9.1145 & 8.7601 & TRN & & & \\
\hline CHEMBL3665818 & 1527636 & 9.4449 & 9.3807 & TRN & & & \\
\hline CHEMBL3665741 & 1527636 & 8.3386 & 8.3803 & TRN & & & \\
\hline CHEMBL3665815 & 1527636 & 8.9266 & 8.7851 & TRN & & & \\
\hline CHEMBL3665799 & 1527636 & 7.4853 & 8.1521 & TRN & & & \\
\hline CHEMBL3665772 & 1527636 & 8.7989 & 8.1703 & TRN & & & \\
\hline CHEMBL3665768 & 1527636 & 8.8891 & 8.8519 & TRN & & & \\
\hline CHEMBL3670747 & 1527636 & 7.2101 & 7.8328 & TST & & & \\
\hline CHEMBL3665854 & 1527636 & 9.6328 & 8.7647 & TRN & & & \\
\hline CHEMBL3665801 & 1527636 & 8.8345 & 8.925 & TRN & & & \\
\hline CHEMBL 3665790 & 1527636 & 7.9842 & 8.7527 & TRN & & & \\
\hline CHEMBL3665794 & 1527636 & 8.3067 & 8.8224 & TRN & & & \\
\hline
\end{tabular}

Page 13113 
Supplemental Table S2.txt

\begin{tabular}{|c|c|c|c|c|}
\hline HEM & & 6.3868 & & \\
\hline & & & 8.3208 & \\
\hline & & & & \\
\hline IEMBL & & & & \\
\hline HEMBL & 021636 & 151 & 3082 & \\
\hline HEMBL3665810 & 527636 & 9.0262 & 6153 & \\
\hline HEMBL & & .6653 & 779 & \\
\hline 769 & & & & \\
\hline HEMBL3 & 636 & 608 & 7715 & \\
\hline HEMBL36 & 536 & 291 & .2754 & \\
\hline AEMBL3665811 & 536 & 9.4912 & .9482 & \\
\hline IEMBL: & 36 & 159 & 433 & \\
\hline HEMBL; & & & & \\
\hline HEMBL & 36 & 97 & 4577 & \\
\hline AEMBL3 & 36 & 29 & 2963 & \\
\hline AEMBL3 & 0 & 7.8526 & 7.7873 & \\
\hline HEMBL & 0 & 98 & 008 & \\
\hline HEMBL; & & & 666 & \\
\hline HEMBL3 & & 8.5817 & .1488 & \\
\hline AEMBL3 & & 25 & & \\
\hline AEMIBL & 36 & 58 & 02 & I NIV \\
\hline HEMBL & & 34 & 06 & וזנה \\
\hline HEMBL & & 56 & 08 & \\
\hline 749 & & 681 & & \\
\hline AEMBL3 & & & & I RIV \\
\hline HEMBL & & 8 & 679 & RN \\
\hline HEMBL & & 34 & 48 & Niv \\
\hline HFMRI & & 11 & 222 & \\
\hline HEMBL3 & & & & 15 15 \\
\hline HEMBL36 & & & & IK \\
\hline HEMBL & & & 413 & RN \\
\hline HEMBL & & & 99 & ST \\
\hline HEMPI & & & 74 & IST \\
\hline HEMBL3 & & & 347 & ISI \\
\hline HEMBL 366579 & 36 & 71 & 8.1951 & TRN \\
\hline HEMBL & & 72 & 153 & TST \\
\hline HEMRI & & & 235 & RIV \\
\hline HEMBL; & & & 7.4966 & TST \\
\hline HEMBL3670740 & 36 & 6.8642 & .8976 & TST \\
\hline AEMBL & 36 & 827 & 3461 & TRN \\
\hline HEMBL3 & & 38 & 497 & \\
\hline CHEMBL3 & & & & RN \\
\hline HEMBL3 & & 9.3575 & 9.3608 & TRN \\
\hline HEMBL3665777 & 636 & 8.3298 & .0387 & TR \\
\hline 1 & & & & $\mathrm{~N}$ \\
\hline HEMBL3 & & & .8837 & \\
\hline CHEMBL3 & & .6507 & 3.1747 & \\
\hline HEMBL3665833 & 1527636 & 9.0073 & 9.7811 & \\
\hline
\end{tabular}

Page 13114 
Supplemental Table S2.txt

\begin{tabular}{|c|c|c|c|c|c|c|}
\hline CHEMBL 3665787 & 1527636 & 6.7192 & 7.8611 & TST & & \\
\hline CHEMBL3665851 & 1527636 & 7.1857 & 8.03 & TRN & & \\
\hline CHEMBL3665747 & 1527636 & 8.2047 & 8.3622 & TRN & & \\
\hline CHEMBL3665783 & 1527636 & 5.5306 & 7.1414 & TRN & & \\
\hline CHEMBL3665820 & 1527636 & 9.3591 & 8.878 & TRN & & \\
\hline CHEMBL3665841 & 1527636 & 9.4009 & 9.3297 & TRN & & \\
\hline CHEMBL3891107 & 1527636 & 6.5129 & 7.8474 & TST & & \\
\hline CHEMBL3665740 & 1527636 & 8.5511 & 7.7968 & TRN & & \\
\hline CHEMBL3665852 & 1527636 & \multicolumn{3}{|c|}{9.187000000000001} & 8.6763 & TRN \\
\hline CHEMBL3665804 & 1527636 & 8.6737 & 8.253 & TRN & & \\
\hline CHEMBL3670738 & 1527636 & 5.9208 & 7.4646 & TST & & \\
\hline CHEMBL3665814 & 1527636 & 8.5546 & 8.8425 & TRN & & \\
\hline CHEMBL3665776 & 1527636 & 7.9821 & 8.2229 & TRN & & \\
\hline CHEMBL3670767 & 1527636 & 7.8719 & 7.6328 & TST & & \\
\hline CHEMBL3665788 & 1527636 & 6.5518 & 6.9746 & TRN & & \\
\hline CHEMBL3665827 & 1527636 & 9.3884 & 9.3418 & TRN & & \\
\hline CHEMBL3665742 & 1527636 & 8.8145 & 8.8809 & TRN & & \\
\hline CHEMBL 3670758 & 1527636 & 8.8739 & 7.9864 & TST & & \\
\hline CHEMBL 3665840 & 1527636 & 9.1994 & 9.2428 & TRN & & \\
\hline CHEMBL3665836 & 1527636 & 9.5662 & 9.7309 & TRN & & \\
\hline CHEMBL3665739 & 1527636 & 9.0255 & 8.8787 & TRN & & \\
\hline CHEMBL3670735 & 1527636 & 6.8274 & 7.4309 & TST & & \\
\hline CHEMBL 3665757 & 1527636 & 8.3125 & 8.0093 & TRN & & \\
\hline CHEMBL 3665802 & 1527636 & 6.6409 & 8.2174 & TRN & & \\
\hline CHEMBL3670725 & 1527636 & 9.4984 & 8.3281 & TST & & \\
\hline CHEMBL3213562 & 737724 & 5.6038 & 5.5236 & TRN & & \\
\hline CHEMBL1375245 & 737724 & 4.6596 & 4.7691 & TST & & \\
\hline CHEMBL1462310 & 737724 & 5.0931 & 5.3694 & TRN & & \\
\hline CHEMBL1318817 & 737724 & \multicolumn{3}{|c|}{5.053999999999999} & 4.7946 & TRN \\
\hline CHEMBL 2004455 & 737724 & 5.3768 & 5.3758 & TRN & & \\
\hline CHEMBL1586442 & 737724 & 4.2774 & 4.8808 & TRN & & \\
\hline CHEMBL1503275 & 737724 & 4.8297 & 5.3555 & TRN & & \\
\hline CHEMBL1444730 & 737724 & 5.3116 & 4.5055 & TRN & & \\
\hline CHEMBL1503803 & 737724 & 5.5143 & 5.3443 & TRN & & \\
\hline CHEMBL1581450 & 737724 & 5.4711 & 5.3061 & TRN & & \\
\hline CHEMBL1350393 & 737724 & 5.0867 & 4.7512 & TST & & \\
\hline CHEMBL1446929 & 737724 & 5.5735 & 4.5779 & TST & & \\
\hline CHEMBL1527258 & 737724 & 5.2154 & 5.3049 & TRN & & \\
\hline CHEMBL1517167 & 737724 & 3.0 & 4.6776 & TST & & \\
\hline CHEMBL1412746 & 737724 & 5.8327 & 5.4242 & TRN & & \\
\hline CHEMBL1342570 & 737724 & 4.4449 & 4.6949 & TRN & & \\
\hline CHEMBL1479132 & 737724 & 5.2588 & 4.8822 & TRN & & \\
\hline CHEMBL1528584 & 737724 & 4.7852 & 4.7416 & TST & & \\
\hline CHEMBL1433041 & 737724 & 4.2541 & 4.7717 & TRN & & \\
\hline CHEMBL1337734 & 737724 & 4.8962 & 4.7995 & TRN & & \\
\hline CHEMBL1576073 & 737724 & 4.8601 & 5.2876 & TRN & & \\
\hline CHEMBL1441693 & 737724 & 5.4202 & 5.2117 & TRN & & \\
\hline CHEMBL3210492 & 737724 & 5.04 & 5.5141 & TRN & & \\
\hline
\end{tabular}


Supplemental Table S2.txt

\begin{tabular}{|c|c|c|c|c|}
\hline 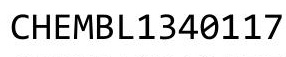 & 37724 & & & \\
\hline HEMBL3212555 & 37724 & 5114 & 5.4565 & \\
\hline HEMBL15 & 37724 & 547 & 74 & \\
\hline 22 & 7724 & & 22 & \\
\hline AEMBL156 & 7724 & & 572 & \\
\hline AEMBL1370221 & 37724 & 2668 & 4.59 & \\
\hline HEMBL1386461 & 37724 & 1487 & 5.2996 & \\
\hline HEMBL1561952 & 37724 & & 5.3109 & \\
\hline AEMBL15 & 37724 & & 999 & \\
\hline AEMBL153 & 37724 & & 3963 & \\
\hline HEMBL1448063 & 37724 & 086 & 0273 & \\
\hline HEMBL1345650 & 37724 & & 5.2611 & \\
\hline HEMBL1459627 & 24 & 89 & 0904 & \\
\hline HEMBL14 & 37724 & & 565 & \\
\hline AEMBL31 & 37724 & & & \\
\hline HEMBL1566805 & 37724 & 18 & 7487 & \\
\hline AEMBL1574141 & & & & \\
\hline HEMBL138 & 24 & 5 & 7966 & \\
\hline L13 & 724 & & 88 & \\
\hline AEMBL31 & 724 & & & \\
\hline HEMBL1367364 & 37724 & 96 & 2817 & \\
\hline AEMBL1302524 & & & & \\
\hline HEMBL319 & 24 & & 09 & \\
\hline L15 & 24 & & 22 & \\
\hline 25 & 724 & & 64 & \\
\hline HEMBL150 & 37724 & & 921 & \\
\hline AEMBL1601716 & & & & \\
\hline HEMBL15887 & 24 & & 45 & \\
\hline HEN & 24 & & & \\
\hline 14 & 37724 & 3. & 68 & \\
\hline AEMBL1359410 & & & & RN \\
\hline AEMBL3198938 & 24 & & & ST \\
\hline AEMBL3] & 24 & & & \\
\hline IrN & 24 & & & ST \\
\hline 0 & 24 & & & $\mathrm{RN}$ \\
\hline AEMBL1549278 & 37724 & & & RN \\
\hline AEMBL1335844 & 37724 & & 304 & $2 \mathrm{~N}$ \\
\hline 2 & & & & RIV \\
\hline 1 & 24 & & & RIN \\
\hline & 24 & & & $\mathrm{RN}$ \\
\hline AEMBL3194601 & 37724 & & 951 & $\mathrm{RN}$ \\
\hline AEMBL1323 & 37724 & & 384 & RN \\
\hline & 24 & & 821 & \\
\hline HEMBL45152 & 37724 & & & \\
\hline HEMBL 13707 & 37724 & & 905 & ST \\
\hline AEMBL1403357 & 37724 & 97 & 4.7219 & RN \\
\hline 121 & 24 & & & \\
\hline 19085 & 737724 & 5.2118 & & \\
\hline
\end{tabular}

Page 13116 


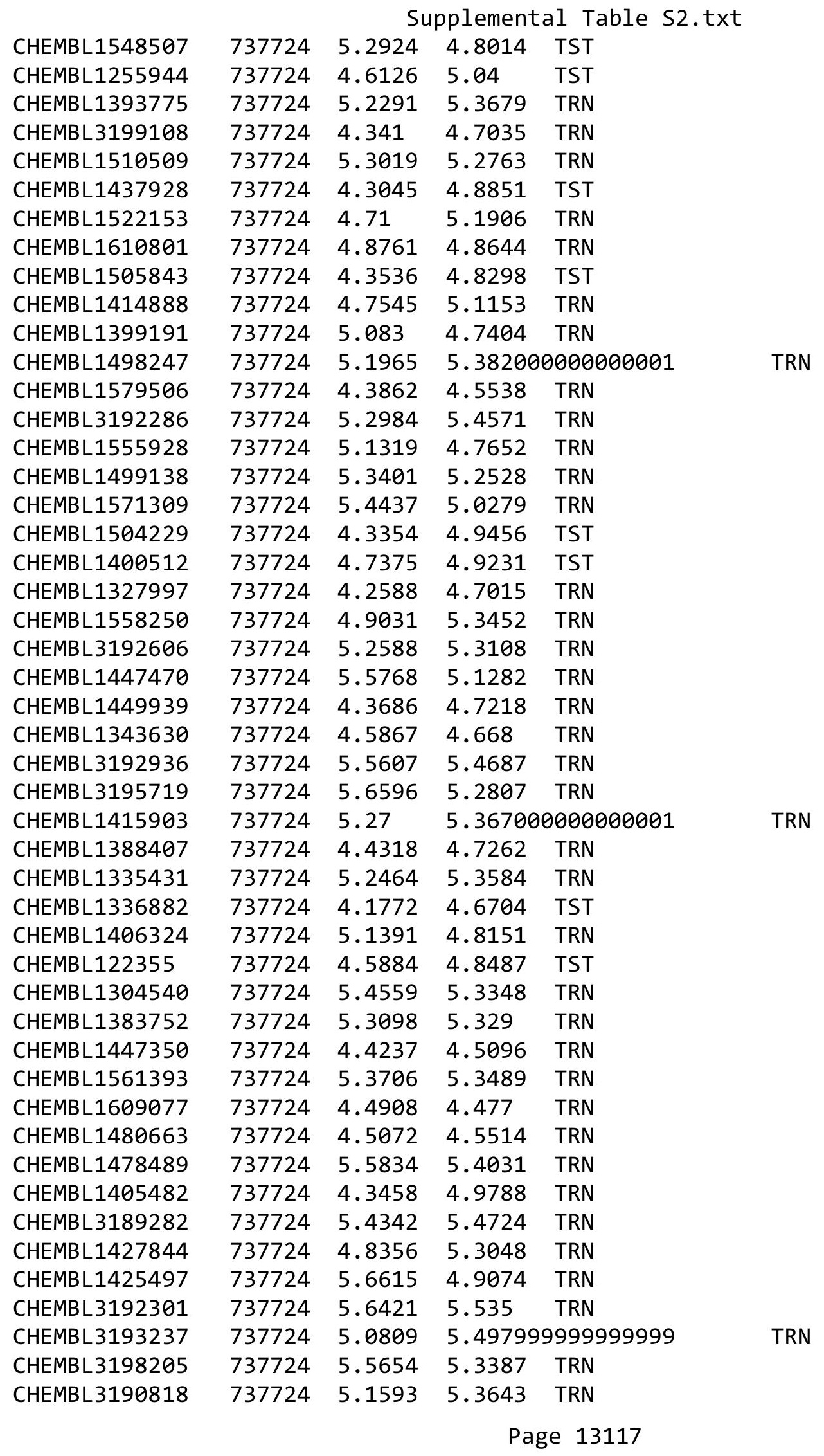


Supplemental Table S2.txt

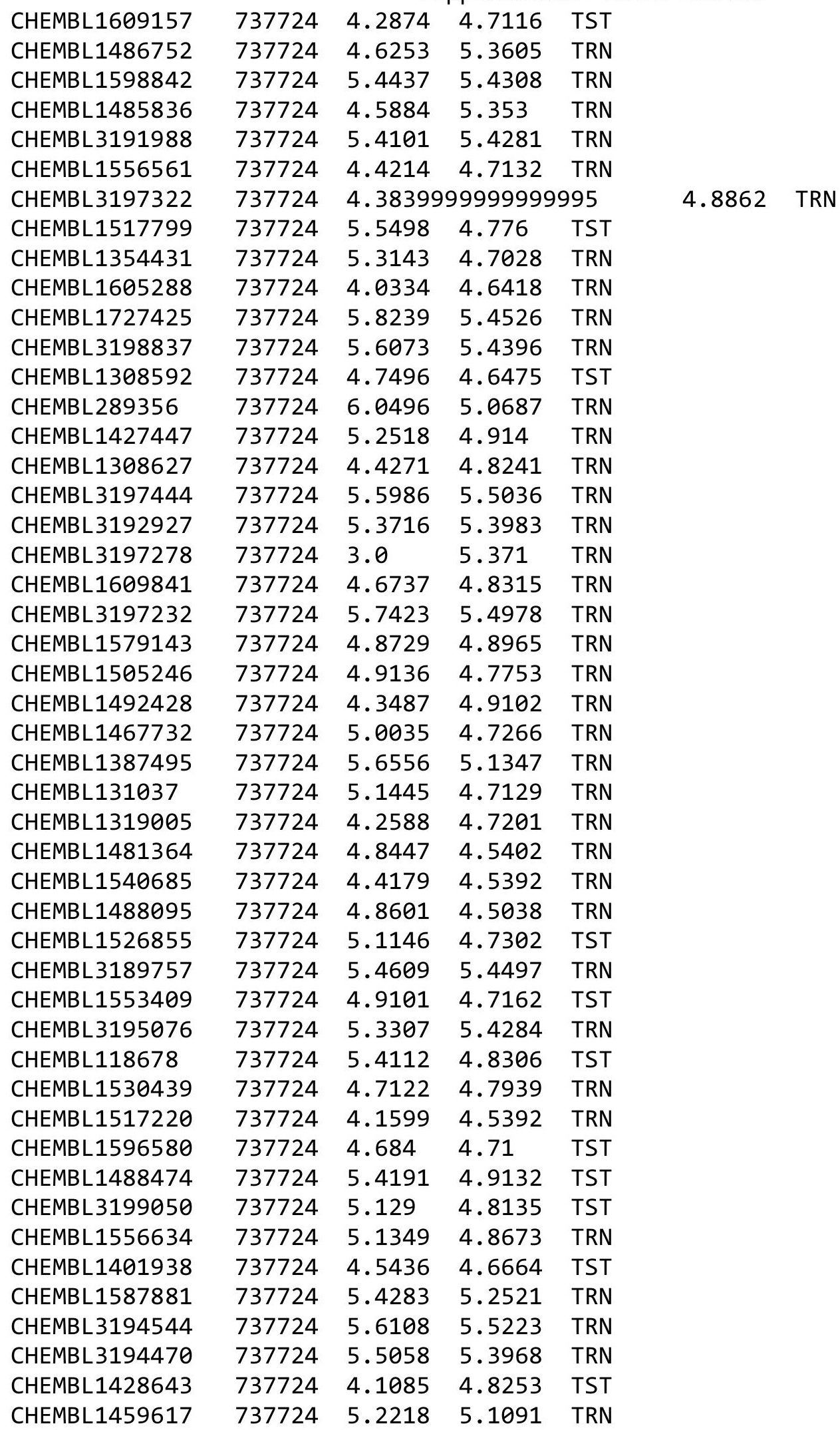

Page 13118 
Supplemental Table S2.txt

\begin{tabular}{|c|c|c|c|c|}
\hline CHEMBL1332718 & 737724 & 5.3893 & 5.3774 & TRN \\
\hline CHEMBL3192511 & 737724 & 5.4067 & 5.4687 & TRN \\
\hline CHEMBL3199787 & 737724 & 5.3197 & 5.3877 & TRN \\
\hline CHEMBL1310318 & 737724 & 5.0448 & 4.7382 & TRN \\
\hline CHEMBL1996315 & 737724 & 5.6055 & 5.5043 & TRN \\
\hline CHEMBL1571835 & 737724 & 5.1469 & 4.7688 & TST \\
\hline CHEMBL1496555 & 737724 & 4.8962 & 4.5612 & TST \\
\hline CHEMBL1390840 & 737724 & 5.1612 & 4.7637 & TST \\
\hline CHEMBL3192319 & 737724 & 5.6162 & 5.3033 & TRN \\
\hline CHEMBL3198789 & 737724 & 5.6055 & 5.4363 & TRN \\
\hline CHEMBL1579066 & 737724 & 4.7721 & 4.8083 & TST \\
\hline CHEMBL1507883 & 737724 & 5.2874 & 5.0432 & TRN \\
\hline CHEMBL3191661 & 737724 & 5.567 & 5.4632 & TRN \\
\hline CHEMBL3194609 & 737724 & 5.1308 & 4.8742 & TRN \\
\hline CHEMBL1396239 & 737724 & 5.5421 & 5.3855 & TRN \\
\hline CHEMBL1410244 & 737724 & 5.2958 & 4.6921 & TRN \\
\hline CHEMBL3198570 & 737724 & 5.6635 & 5.5414 & TRN \\
\hline CHEMBL1543030 & 737724 & 5.3063 & 5.3309 & TRN \\
\hline CHEMBL1549607 & 737724 & 5.2848 & 4.9821 & TRN \\
\hline CHEMBL1460199 & 737724 & 5.6038 & 5.2932 & TRN \\
\hline CHEMBL1461121 & 737724 & 5.3206 & 5.2586 & TRN \\
\hline CHEMBL585628 & 737724 & 3.0 & 4.737 & TST \\
\hline CHEMBL1304687 & 737724 & 4.1858 & 4.7888 & TST \\
\hline CHEMBL1524353 & 737724 & 5.0467 & 5.0959 & TRN \\
\hline CHEMBL1556308 & 737724 & 3.0 & 4.5664 & TRN \\
\hline CHEMBL1389969 & 737724 & 5.5391 & 5.3424 & TRN \\
\hline CHEMBL1368619 & 737724 & 5.5834 & 5.2952 & TRN \\
\hline CHEMBL3195511 & 737724 & 5.4425 & 5.4733 & TRN \\
\hline CHEMBL1424332 & 737724 & 5.6126 & 4.8775 & TRN \\
\hline CHEMBL1495785 & 737724 & 5.3197 & 5.42299 & 9999999999 \\
\hline CHEMBL3211177 & 737724 & 5.2472 & 5.4953 & TRN \\
\hline CHEMBL1311634 & 737724 & 4.8928 & 4.9842 & TRN \\
\hline CHEMBL3199871 & 737724 & 5.6326 & 5.4709 & TRN \\
\hline CHEMBL1338994 & 737724 & 4.3298 & 4.5094 & TRN \\
\hline CHEMBL1547804 & 737724 & 5.2226 & 4.8486 & TRN \\
\hline CHEMBL1352266 & 737724 & 5.1537 & 5.0916 & TRN \\
\hline CHEMBL1350178 & 737724 & 4.0915 & 4.7458 & TRN \\
\hline CHEMBL3192753 & 737724 & 5.5817 & 5.5199 & TRN \\
\hline CHEMBL1482944 & 737724 & 5.4841 & 5.4081 & TRN \\
\hline CHEMBL1350257 & 737724 & 4.3507 & 4.6912 & TRN \\
\hline CHEMBL3191118 & 737724 & 5.7496 & 5.4491 & TRN \\
\hline CHEMBL1519790 & 737724 & 4.6778 & 4.747 & TRN \\
\hline CHEMBL3194483 & 737724 & 5.699 & 5.5543 & TRN \\
\hline CHEMBL3192574 & 737724 & 5.2848 & 5.4583 & TRN \\
\hline CHEMBL3197116 & 737724 & 5.5003 & 5.4526 & TRN \\
\hline CHEMBL1417312 & 737724 & 5.0804 & 5.2394 & TRN \\
\hline CHEMBL1441534 & 737724 & 4.4584 & 5.1223 & TST \\
\hline CHEMBL1440161 & 737724 & 4.7696 & 4.8456 & TRN \\
\hline
\end{tabular}

Page 13119 
Supplemental Table S2.txt

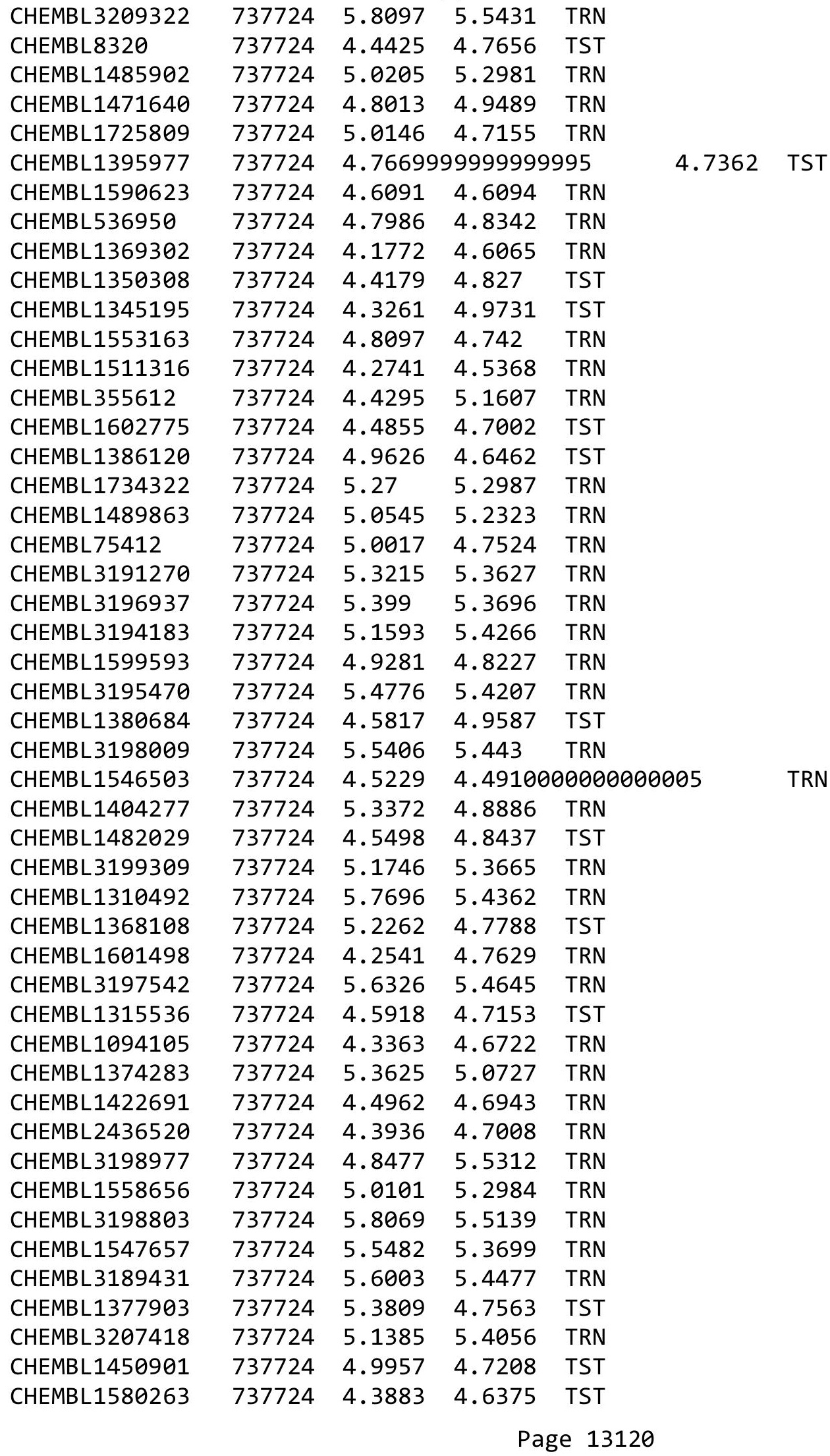


Supplemental Table S2.txt

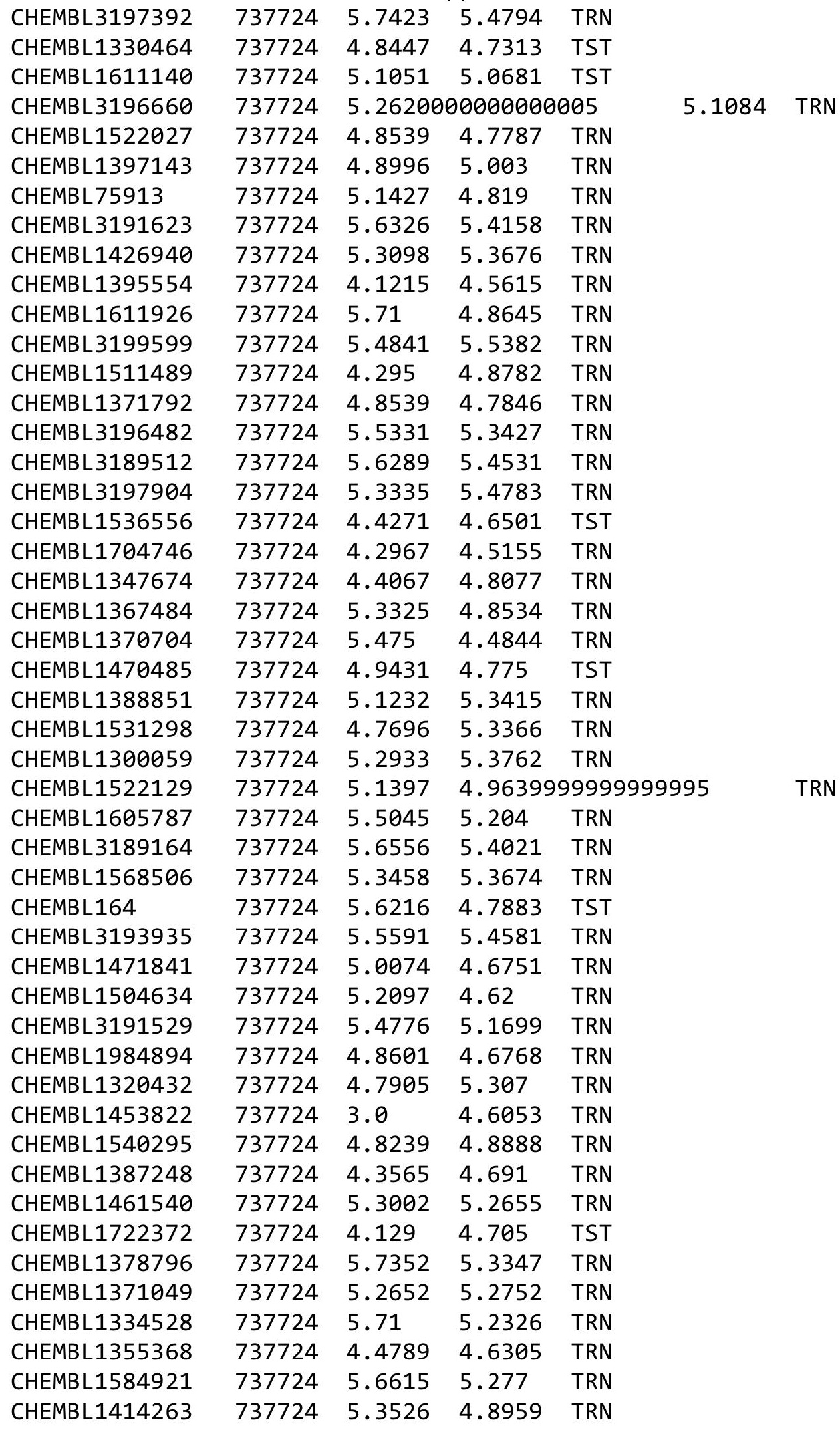

Page 13121 
Supplemental Table S2.txt

\begin{tabular}{|c|c|c|c|c|}
\hline CHEMBL1499937 & 737724 & 5.5317 & 5.4263 & TRN \\
\hline CHEMBL1446720 & 737724 & 5.4828 & 5.3236 & TRN \\
\hline CHEMBL3210230 & 737724 & 5.5735 & 5.3653 & TRN \\
\hline CHEMBL1471698 & 737724 & 5.1586 & 4.6375 & TRN \\
\hline CHEMBL1371679 & 737724 & 5.4112 & 5.2837 & TRN \\
\hline CHEMBL1511078 & 737724 & 6.0035 & 5.37799 & 9999999999 \\
\hline CHEMBL1353825 & 737724 & 5.015 & 4.8547 & TRN \\
\hline CHEMBL3214209 & 737724 & 5.1838 & 5.5167 & TRN \\
\hline CHEMBL1370381 & 737724 & 4.4306 & 4.5792 & TRN \\
\hline CHEMBL1339349 & 737724 & 4.7352 & 4.7203 & TRN \\
\hline CHEMBL3192182 & 737724 & 5.2069 & 5.4237 & TRN \\
\hline CHEMBL1595621 & 737724 & 5.6498 & 5.2567 & TRN \\
\hline CHEMBL568739 & 737724 & 5.1073 & 5.0865 & TRN \\
\hline CHEMBL1518799 & 737724 & 4.9586 & 4.7031 & TRN \\
\hline CHEMBL1598969 & 737724 & 4.1543 & 4.5294 & TRN \\
\hline CHEMBL3194365 & 737724 & 5.6021 & 5.5032 & TRN \\
\hline CHEMBL1477787 & 737724 & 4.2248 & 4.69 & TRN \\
\hline CHEMBL1510349 & 737724 & 5.2118 & 4.8376 & TST \\
\hline CHEMBL1540631 & 737724 & 4.5622 & 4.7616 & TST \\
\hline CHEMBL3192940 & 737724 & 5.5638 & 5.4264 & TRN \\
\hline CHEMBL1344136 & 737724 & 5.3635 & 5.3348 & TRN \\
\hline CHEMBL1417267 & 737724 & 4.9245 & 5.4094 & TRN \\
\hline CHEMBL1995878 & 737724 & 5.5513 & 5.4273 & TRN \\
\hline CHEMBL1406130 & 737724 & 5.0545 & 4.6968 & TRN \\
\hline CHEMBL1333250 & 737724 & 5.0391 & 4.6825 & TRN \\
\hline CHEMBL1518604 & 737724 & 4.8153 & 4.723 & TST \\
\hline CHEMBL1506548 & 737724 & 4.8069 & 4.5872 & TRN \\
\hline CHEMBL1426449 & 737724 & 5.2644 & 5.254 & TRN \\
\hline CHEMBL243652 & 737724 & 4.2534 & 4.6044 & TRN \\
\hline CHEMBL1301497 & 737724 & 5.0915 & 5.3568 & TRN \\
\hline CHEMBL1479190 & 737724 & 4.4789 & 4.8757 & TST \\
\hline CHEMBL1412731 & 737724 & 4.8996 & 4.7005 & TRN \\
\hline CHEMBL1320180 & 737724 & 4.2874 & 4.6023 & TRN \\
\hline CHEMBL3194699 & 737724 & 5.6778 & 5.3215 & TRN \\
\hline CHEMBL1385655 & 737724 & 5.1244 & 5.3484 & TRN \\
\hline CHEMBL1697970 & 737724 & 4.4056 & 4.6178 & TRN \\
\hline CHEMBL1314602 & 737724 & 4.9666 & 4.6704 & TRN \\
\hline CHEMBL1606561 & 737724 & 5.2565 & 5.4023 & TRN \\
\hline CHEMBL1527035 & 737724 & 5.3401 & 5.3836 & TRN \\
\hline CHEMBL3191431 & 737724 & 5.4168 & 5.443 & TRN \\
\hline CHEMBL1378582 & 737724 & 4.4921 & 4.6055 & TRN \\
\hline CHEMBL1387863 & 737724 & 5.0097 & 5.08 & TRN \\
\hline CHEMBL1338788 & 737724 & 4.2573 & 4.7837 & TST \\
\hline CHEMBL1498363 & 737724 & 5.8386 & 5.5918 & TRN \\
\hline CHEMBL3192950 & 737724 & 5.6126 & 5.5281 & TRN \\
\hline CHEMBL1530086 & 737724 & 5.3625 & 5.329 & TRN \\
\hline CHEMBL1438370 & 737724 & 5.0311 & 4.6471 & TRN \\
\hline CHEMBL1540610 & 737724 & 4.1694 & 4.6366 & TRN \\
\hline
\end{tabular}




\begin{tabular}{|c|c|c|c|c|c|c|}
\hline \multicolumn{7}{|c|}{ 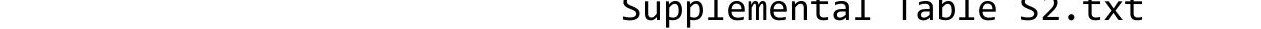 } \\
\hline CHEMBL1418689 & 737724 & 5.4295 & 5.2834 & TRN & & \\
\hline CHEMBL1570378 & 737724 & 5.0794 & 5.3365 & TRN & & \\
\hline CHEMBL1540656 & 737724 & 5.2676 & 5.3862 & TRN & & \\
\hline CHEMBL1504286 & 737724 & 5.1656 & 4.5322 & TRN & & \\
\hline CHEMBL1334983 & 737724 & 5.2314 & 5.3461 & TRN & & \\
\hline CHEMBL1522846 & 737724 & 5.0888 & 4.9557 & TST & & \\
\hline CHEMBL1339149 & 737724 & 5.0405 & 4.8389 & TRN & & \\
\hline CHEMBL1460460 & 737724 & 5.3862 & 5.2763 & TRN & & \\
\hline CHEMBL1509975 & 737724 & 4.224 & 4.7231 & TRN & & \\
\hline CHEMBL1385743 & 737724 & 4.5436 & 4.5786 & TRN & & \\
\hline CHEMBL 3194497 & 737724 & 5.3904 & 5.3891 & TRN & & \\
\hline CHEMBL1566909 & 737724 & 4.2782 & 4.7997 & TRN & & \\
\hline CHEMBL398233 & 737724 & 4.209 & 4.6073 & TRN & & \\
\hline CHEMBL1466798 & 737724 & 6.0287 & 5.2688 & TRN & & \\
\hline CHEMBL1509082 & 737724 & 5.3615 & 4.5786 & TRN & & \\
\hline CHEMBL1408163 & 737724 & 5.5654 & 5.1435 & TRN & & \\
\hline CHEMBL1465117 & 737724 & 4.8508 & 5.0134 & TRN & & \\
\hline CHEMBL1975289 & 737724 & 4.5114 & 4.7324 & TST & & \\
\hline CHEMBL1539778 & 737724 & 4.4634 & 4.7722 & TST & & \\
\hline CHEMBL3192810 & 737724 & 5.7144 & 5.4597 & TRN & & \\
\hline CHEMBL1481678 & 737724 & 5.0846 & 5.3228 & TRN & & \\
\hline CHEMBL1425837 & 737724 & 5.24799 & 99999999 & 99 & 4.5815 & TRN \\
\hline CHEMBL1516970 & 737724 & 5.3382 & 5.3665 & TRN & & \\
\hline CHEMBL1579020 & 737724 & 5.6345 & 4.8323 & TST & & \\
\hline CHEMBL1319001 & 737724 & 4.2848 & 4.6058 & TST & & \\
\hline CHEMBL1344163 & 737724 & 3.0 & 4.9779 & TRN & & \\
\hline CHEMBL1455989 & 737724 & 5.3307 & 5.3878 & TRN & & \\
\hline CHEMBL 3190345 & 737724 & 5.7471 & 5.5117 & TRN & & \\
\hline CHEMBL1575781 & 737724 & 4.7747 & 5.1293 & TRN & & \\
\hline CHEMBL1336959 & 737724 & 4.7399 & 4.7389 & TRN & & \\
\hline CHEMBL1560961 & 737724 & 4.1618 & 4.5406 & TRN & & \\
\hline CHEMBL1504939 & 737724 & 5.2916 & 4.5736 & TST & & \\
\hline CHEMBL290545 & 737724 & 5.9208 & 5.3032 & TRN & & \\
\hline CHEMBL3195376 & 737724 & 5.6383 & 5.4871 & TRN & & \\
\hline CHEMBL 3189233 & 737724 & 5.6778 & 5.4974 & TRN & & \\
\hline CHEMBL1598498 & 737724 & 4.4547 & 4.788 & TST & & \\
\hline CHEMBL1714415 & 737724 & 4.8125 & 4.7801 & TRN & & \\
\hline CHEMBL 3192661 & 737724 & 5.4622 & 5.4703 & TRN & & \\
\hline CHEMBL1602832 & 737724 & 4.158 & 4.5965 & TRN & & \\
\hline CHEMBL1559314 & 737724 & 4.8153 & 4.562 & TST & & \\
\hline CHEMBL3193554 & 737724 & 5.0334 & 5.4759 & TRN & & \\
\hline CHEMBL1448381 & 737724 & 5.0872 & 4.9561 & TRN & & \\
\hline CHEMBL3198376 & 737724 & 5.5376 & 5.5313 & TRN & & \\
\hline CHEMBL1394863 & 737724 & 4.8761 & 4.6469 & TRN & & \\
\hline CHEMBL 3189471 & 737724 & 5.2291 & 5.2127 & TRN & & \\
\hline CHEMBL1520143 & 737724 & 4.9066 & 4.7639 & TRN & & \\
\hline CHEMBL1499401 & 737724 & 5.0595 & 5.3625 & TRN & & \\
\hline CHEMBL1605172 & 737724 & 5.0975 & 4.7343 & TRN & & \\
\hline
\end{tabular}


Supplemental Table S2.txt

\begin{tabular}{|c|c|c|c|c|c|}
\hline CHEMBL1604932 & 737724 & 5.3595 & 5.4147 & TRN & \\
\hline CHEMBL1566720 & 737724 & 4.1325 & 4.5676 & TRN & \\
\hline CHEMBL1548024 & 737724 & 4.1891 & 4.7338 & TRN & \\
\hline CHEMBL1360902 & 737724 & 4.8268 & 4.8277 & TRN & \\
\hline CHEMBL1311546 & 737724 & 4.8761 & 4.8413 & TST & \\
\hline CHEMBL69086 & 737724 & 5.2782 & 5.0457 & TST & \\
\hline CHEMBL1304193 & 737724 & 5.2588 & 4.7236 & TRN & \\
\hline CHEMBL1471189 & 737724 & 5.0119 & 4.8045 & TST & \\
\hline CHEMBL1342423 & 737724 & 4.1811 & 4.6577 & TST & \\
\hline CHEMBL1471924 & 737724 & 5.4377 & 5.0892 & TST & \\
\hline CHEMBL1581721 & 737724 & 5.4202 & 5.3486 & TRN & \\
\hline CHEMBL1459508 & 737724 & 4.7077 & 4.5699 & TRN & \\
\hline CHEMBL3195600 & 737724 & 5.6946 & 5.5197 & TRN & \\
\hline CHEMBL3193080 & 737724 & 5.4306 & 5.4272 & TST & \\
\hline CHEMBL3210386 & 737724 & 5.5436 & 5.4808 & TST & \\
\hline CHEMBL1531249 & 737724 & 5.2069 & 5.3629 & TST & \\
\hline CHEMBL3213580 & 737724 & 5.5817 & 5.435 & TST & \\
\hline CHEMBL1443044 & 737724 & 5.2993 & 5.3854 & TST & \\
\hline CHEMBL1430606 & 737724 & 4.6498 & 5.1591 & TST & \\
\hline CHEMBL3189259 & 737724 & 5.3979 & 5.3073 & TST & \\
\hline CHEMBL1534979 & 737724 & 5.4202 & 5.3592 & TST & \\
\hline CHEMBL1496326 & 737724 & 5.2132 & 5.177000 & 00000000005 & TST \\
\hline CHEMBL1387791 & 737724 & 3.0 & 5.2562 & TST & \\
\hline CHEMBL1415221 & 737724 & 5.5528 & 5.3114 & TST & \\
\hline CHEMBL 3189478 & 737724 & 5.5607 & 5.5635 & TST & \\
\hline CHEMBL3198284 & 737724 & 5.4711 & 5.3764 & TST & \\
\hline CHEMBL116548 & 737724 & 5.5952 & 4.8099 & TST & \\
\hline CHEMBL1346526 & 737724 & 4.3045 & 4.6319 & TST & \\
\hline CHEMBL1430796 & 737724 & 4.262 & 4.6037 & TST & \\
\hline CHEMBL1439031 & 737724 & 5.1367 & 5.334 & TST & \\
\hline CHEMBL1302583 & 737724 & 5.1986 & 5.2368 & TST & \\
\hline CHEMBL3211429 & 737724 & 5.6517 & 5.3972 & TST & \\
\hline CHEMBL1613004 & 737724 & 4.8996 & 4.9967 & TST & \\
\hline CHEMBL1340417 & 737724 & 5.0259 & 5.1798 & TST & \\
\hline CHEMBL1728993 & 737724 & 4.9914 & 4.8027 & TST & \\
\hline CHEMBL1608601 & 737724 & 5.4622 & 5.1956 & TST & \\
\hline CHEMBL1465837 & 737724 & 5.0132 & 5.1486 & TST & \\
\hline CHEMBL1408293 & 737724 & 4.8539 & 4.8126 & TST & \\
\hline CHEMBL1429980 & 737724 & 4.2048 & 4.8261 & TST & \\
\hline CHEMBL3193324 & 737724 & 5.5918 & 5.5283 & TST & \\
\hline CHEMBL3190287 & 737724 & 5.6402 & 5.4778 & TST & \\
\hline CHEMBL3196558 & 737724 & 5.38399 & 99999999 & 5.4817 & TST \\
\hline CHEMBL1583212 & 737724 & 5.2343 & 5.3681 & TST & \\
\hline CHEMBL1363389 & 737724 & 5.5317 & 5.0764 & TST & \\
\hline CHEMBL1503011 & 737724 & 4.7144 & 4.8278 & TST & \\
\hline CHEMBL1587985 & 737724 & 5.8697 & 5.3883 & TST & \\
\hline CHEMBL1301673 & 737724 & 5.4672 & 4.8712 & TST & \\
\hline CHEMBL3198338 & 737724 & 5.3107 & 5.4808 & TST & \\
\hline
\end{tabular}




\begin{tabular}{|c|c|c|c|c|}
\hline \multicolumn{5}{|c|}{ Supplemental Table s2.txt } \\
\hline CHEMBL1533940 & 737724 & 3.0 & 4.84 & TST \\
\hline CHEMBL1406283 & 737724 & 5.3615 & 5.2881 & TST \\
\hline CHEMBL1527869 & 737724 & 4.3893 & 4.8581 & TST \\
\hline CHEMBL374671 & 366820 & 3.5017 & 3.4595 & TRN \\
\hline CHEMBL374420 & 366820 & 4.0809 & 3.763 & TRN \\
\hline CHEMBL409975 & 366820 & 3.9393 & 3.3487 & TRN \\
\hline CHEMBL436489 & 366820 & 4.0223 & 3.8728 & TRN \\
\hline CHEMBL211751 & 366820 & 3.301 & 3.2519 & TRN \\
\hline CHEMBL379730 & 366820 & 1.699 & 1.7735 & TRN \\
\hline CHEMBL219853 & 366820 & 2.4776 & 2.7589 & TRN \\
\hline CHEMBL262829 & 366820 & 2.4776 & 2.6913 & TRN \\
\hline CHEMBL265611 & 366820 & 1.699 & 1.6119 & TRN \\
\hline CHEMBL383932 & 366820 & 1.699 & 1.4951 & TRN \\
\hline CHEMBL211346 & 366820 & 2.0 & 1.9941 & TST \\
\hline CHEMBL267212 & 366820 & 5.4559 & 5.6185 & TRN \\
\hline CHEMBL434367 & 366820 & 4.0458 & 4.3369 & TRN \\
\hline CHEMBL373670 & 366820 & 5.3872 & 5.1817 & TRN \\
\hline CHEMBL380069 & 366820 & 1.699 & 1.705 & TRN \\
\hline CHEMBL415577 & 366820 & 3.5317 & 3.8045 & TRN \\
\hline CHEMBL426172 & 366820 & 2.4776 & 3.3487 & TRN \\
\hline CHEMBL406897 & 366820 & 4.4815 & 3.6503 & TRN \\
\hline CHEMBL413690 & 366820 & 1.699 & 1.5597 & TRN \\
\hline CHEMBL437254 & 366820 & 2.4776 & 3.3487 & TRN \\
\hline CHEMBL377022 & 366820 & 3.0 & 2.9168 & TRN \\
\hline CHEMBL414863 & 366820 & 3.5575 & 3.7362 & TRN \\
\hline CHEMBL219066 & 366820 & 2.4776 & 2.4089 & TRN \\
\hline CHEMBL384894 & 366820 & 4.0177 & 3.3487 & TRN \\
\hline CHEMBL427057 & 366820 & 3.7305 & 3.8798 & TRN \\
\hline CHEMBL414785 & 366820 & 2.4776 & 2.7497 & TRN \\
\hline CHEMBL437253 & 366820 & 3.6108 & 3.4911 & TRN \\
\hline CHEMBL409617 & 366820 & 1.699 & 1.7088 & TRN \\
\hline CHEMBL411159 & 366820 & 2.4776 & 2.5699 & TRN \\
\hline CHEMBL273566 & 366820 & 1.699 & 2.1585 & TST \\
\hline CHEMBL213959 & 366820 & 1.699 & 2.0816 & TST \\
\hline CHEMBL219359 & 366820 & 3.7144 & 3.4811 & TRN \\
\hline CHEMBL436517 & 366820 & 2.4776 & 2.3928 & TRN \\
\hline CHEMBL438244 & 366820 & 4.3372 & 4.412 & TRN \\
\hline CHEMBL 378468 & 366820 & 3.0 & 3.028 & TRN \\
\hline CHEMBL414784 & 366820 & 4.2076 & 4.1789 & TRN \\
\hline CHEMBL429024 & 366820 & 2.0 & 2.528 & TST \\
\hline CHEMBL445658 & 366820 & 1.699 & 1.8945 & TRN \\
\hline CHEMBL211491 & 366820 & 3.0 & 3.0241 & TRN \\
\hline CHEMBL412938 & 366820 & 4.0 & 3.985 & TRN \\
\hline CHEMBL424924 & 366820 & 3.9281 & 3.7774 & TRN \\
\hline CHEMBL211490 & 366820 & 3.0 & 3.41899 & 99999999996 \\
\hline CHEMBL 375326 & 366820 & 2.0 & 2.6171 & TST \\
\hline CHEMBL413479 & 366820 & 3.9469 & 3.7353 & TST \\
\hline CHEMBL438564 & 366820 & 2.4776 & 3.1415 & TST \\
\hline
\end{tabular}




\begin{tabular}{|c|c|c|c|c|}
\hline \multicolumn{5}{|c|}{ Supplemental Table S2.txt } \\
\hline CHEMBL 263689 & 366820 & 2.0 & 2.2538 & TST \\
\hline CHEMBL414084 & 366820 & 3.0 & 3.0137 & TST \\
\hline CHEMBL412724 & 366820 & 1.699 & 1.7707 & TST \\
\hline CHEMBL 377971 & 366820 & 4.699 & 4.2886 & TST \\
\hline CHEMBL409955 & 366820 & 2.4776 & 3.6503 & TST \\
\hline CHEMBL 3918062 & 1640951 & 8.8861 & 8.8643 & TRN \\
\hline CHEMBL 3897224 & 1640951 & 8.4089 & 8.4656 & TRN \\
\hline CHEMBL 3976970 & 1640951 & 7.2765 & 7.2509 & TRN \\
\hline CHEMBL 3976049 & 1640951 & 8.1675 & 8.1515 & TRN \\
\hline CHEMBL3967890 & 1640951 & 7.8508 & 7.8737 & TRN \\
\hline CHEMBL 3955323 & 1640951 & 7.3757 & 7.944 & TST \\
\hline CHEMBL 3944881 & 1640951 & 8.4089 & 8.1144 & TST \\
\hline CHEMBL3932448 & 1640951 & 7.7471 & 7.6598 & TRN \\
\hline CHEMBL 3959438 & 1640951 & 7.4078 & 7.5241 & TRN \\
\hline CHEMBL 3938823 & 1640951 & 8.8539 & 8.8356 & TRN \\
\hline CHEMBL 3899826 & 1640951 & 7.6038 & 7.5567 & TRN \\
\hline CHEMBL 3896327 & 1640951 & 7.7696 & 7.7141 & TRN \\
\hline CHEMBL3943773 & 1640951 & 8.5528 & 8.5239 & TRN \\
\hline CHEMBL 3920658 & 1640951 & 7.5114 & 7.5647 & TRN \\
\hline CHEMBL 3924336 & 1640951 & 7.7852 & 7.7657 & TRN \\
\hline CHEMBL3981692 & 1640951 & 8.0862 & 8.0044 & TST \\
\hline CHEMBL 3897839 & 1640951 & 8.5686 & 8.4716 & TRN \\
\hline CHEMBL3949665 & 1640951 & 8.4089 & 8.8003 & TST \\
\hline CHEMBL 3906882 & 1640951 & 8.5528 & 8.6561 & TRN \\
\hline CHEMBL 3892430 & 1640951 & 8.3565 & 8.2776 & TRN \\
\hline CHEMBL3969781 & 1640951 & 7.8962 & 7.7605 & TRN \\
\hline CHEMBL 3950723 & 1640951 & 7.5686 & 7.6394 & TRN \\
\hline CHEMBL3948076 & 1640951 & 8.4318 & 8.4812 & TRN \\
\hline CHEMBL 3924399 & 1640951 & 6.0 & 6.1053 & TRN \\
\hline CHEMBL3914307 & 1640951 & 8.6021 & 8.5115 & TRN \\
\hline CHEMBL3911335 & 1640951 & 6.0 & 6.8873 & TST \\
\hline CHEMBL 3889482 & 1640951 & 8.0044 & 8.0612 & TRN \\
\hline CHEMBL3945043 & 1640951 & 7.4067 & 7.4199 & TRN \\
\hline CHEMBL 3920657 & 1640951 & 7.5638 & 6.3218 & TST \\
\hline CHEMBL3939941 & 1640951 & 8.1612 & 8.021 & TRN \\
\hline CHEMBL 3929808 & 1640951 & 8.4815 & 8.7127 & TRN \\
\hline CHEMBL3983959 & 1640951 & 7.5686 & 8.6316 & TST \\
\hline CHEMBL3980564 & 1640951 & 8.2924 & 8.2368 & TRN \\
\hline CHEMBL 3895503 & 1640951 & 9.0458 & 9.1013 & TRN \\
\hline CHEMBL 3929322 & 1640951 & 8.8539 & 8.9094 & TRN \\
\hline CHEMBL 3905236 & 1640951 & 8.9586 & 8.9227 & TRN \\
\hline CHEMBL3934668 & 1640951 & 9.0 & 8.9267 & TRN \\
\hline CHEMBL 3925756 & 1640951 & 7.5784 & 7.5091 & TRN \\
\hline CHEMBL 3906839 & 1640951 & 6.0 & 6.1034 & TST \\
\hline CHEMBL3911960 & 1640951 & 7.6556 & 7.6469 & TRN \\
\hline CHEMBL 3927292 & 1640951 & 8.0605 & 8.0218 & TRN \\
\hline CHEMBL3924079 & 1640951 & 8.5086 & 8.5195 & TRN \\
\hline CHEMBL3951786 & 1640951 & 9.301 & 9.3688 & TST \\
\hline
\end{tabular}


Supplemental Table S2.txt

\begin{tabular}{|c|c|c|c|c|c|c|}
\hline CHEMBL3957859 & 1640951 & 7.9508 & 8.0343 & TST & & \\
\hline CHEMBL 3921263 & 1640951 & 8.0132 & 8.0707 & TRN & & \\
\hline CHEMBL 3938826 & 1640951 & 8.8239 & 8.843 & TRN & & \\
\hline CHEMBL 3977038 & 1640951 & 8.0458 & 8.5792 & TST & & \\
\hline CHEMBL 3896144 & 1640951 & 7.6003 & 8.2873 & TST & & \\
\hline CHEMBL3968346 & 1640951 & 8.301 & 8.4621 & TRN & & \\
\hline CHEMBL 3952635 & 1640951 & 8.7696 & 8.825 & TRN & & \\
\hline CHEMBL 3889953 & 1640951 & 8.7959 & 8.8232 & TRN & & \\
\hline CHEMBL 3917388 & 1640951 & 7.2125 & 7.1918 & TRN & & \\
\hline CHEMBL3909132 & 1640951 & 9.1549 & 9.1622 & TRN & & \\
\hline CHEMBL3916756 & 1640951 & 7.8386 & 7.9257 & TRN & & \\
\hline CHEMBL3919371 & 1640951 & 8.3872 & 8.3831 & TRN & & \\
\hline CHEMBL3937359 & 1640951 & $7.7570 e$ & 00000000 & 31 & 8.1663 & TST \\
\hline CHEMBL3985125 & 1640951 & 8.2518 & 8.3128 & TRN & & \\
\hline CHEMBL3933729 & 1640951 & 7.8996 & 7.7968 & TRN & & \\
\hline CHEMBL 3976420 & 1640951 & 7.0814 & 6.5849 & TST & & \\
\hline CHEMBL3974164 & 1640951 & 8.1675 & 8.0436 & TRN & & \\
\hline CHEMBL3911723 & 1640951 & 7.7235 & 8.22 & TST & & \\
\hline CHEMBL 3907380 & 1640951 & 8.4685 & 8.4844 & TRN & & \\
\hline CHEMBL3929725 & 1640951 & 8.6778 & 8.7217 & TRN & & \\
\hline CHEMBL3965694 & 1640951 & 8.6198 & 8.8697 & TST & & \\
\hline CHEMBL 3984301 & 1640951 & 8.6778 & 8.7423 & TRN & & \\
\hline CHEMBL3979384 & 1640951 & 9.0458 & 9.0043 & TRN & & \\
\hline CHEMBL3912904 & 1640951 & 8.0757 & 8.3108 & TST & & \\
\hline CHEMBL3901798 & 1640951 & 7.2636 & 7.2329 & TRN & & \\
\hline CHEMBL3938754 & 1640951 & 6.0 & 6.1585 & TST & & \\
\hline CHEMBL 3892887 & 1640951 & 9.0458 & 8.9062 & TRN & & \\
\hline CHEMBL3954561 & 1640951 & 8.4202 & 8.3663 & TRN & & \\
\hline CHEMBL3890365 & 1640951 & 7.2573 & 7.2097 & TRN & & \\
\hline CHEMBL3938513 & 1640951 & 8.7959 & 8.769 & TRN & & \\
\hline CHEMBL3905636 & 1640951 & 8.3565 & 8.4408 & TST & & \\
\hline CHEMBL 3947786 & 1640951 & 8.1675 & 8.3402 & TST & & \\
\hline CHEMBL3949626 & 1640951 & 8.4949 & 8.5633 & TST & & \\
\hline CHEMBL 3926373 & 1640951 & 9.0 & 8.8812 & TRN & & \\
\hline CHEMBL3895152 & 1640951 & 7.2782 & 7.7305 & TST & & \\
\hline CHEMBL 3889724 & 1640951 & 7.2636 & 7.2476 & TRN & & \\
\hline CHEMBL3948716 & 1640951 & 8.5229 & 8.5004 & TRN & & \\
\hline CHEMBL 3910837 & 1640951 & 7.0867 & 7.1458 & TRN & & \\
\hline CHEMBL3905179 & 1640951 & 7.0991 & 7.0817 & TRN & & \\
\hline CHEMBL 3983205 & 1640951 & 7.7905 & 7.1158 & TST & & \\
\hline CHEMBL3908158 & 1640951 & 7.2984 & 7.3173 & TRN & & \\
\hline CHEMBL3924925 & 1640951 & 7.8928 & 7.8818 & TRN & & \\
\hline CHEMBL3921890 & 1640951 & 8.0269 & 8.132 & TST & & \\
\hline CHEMBL3979989 & 1640951 & 6.0 & 5.9661 & TRN & & \\
\hline CHEMBL3934358 & 1640951 & 8.0555 & 9.8106 & TST & & \\
\hline CHEMBL3973687 & 1640951 & 8.0969 & 8.1219 & TRN & & \\
\hline CHEMBL3985178 & 1640951 & 9.0 & 9.043 & TRN & & \\
\hline CHEMBL3933274 & 1640951 & 7.7696 & 7.9893 & TST & & \\
\hline
\end{tabular}

Page 13127 
Supplemental Table S2.txt

\begin{tabular}{|c|c|c|c|c|c|}
\hline CHEMBL 3937124 & 1640951 & 8.8861 & 8.9216 & TRN & \\
\hline CHEMBL 3920417 & 1640951 & 8.3979 & 8.3859 & TRN & \\
\hline CHEMBL 3976573 & 1640951 & 8.301 & 8.3794 & TRN & \\
\hline CHEMBL 3923490 & 1640951 & 8.3768 & 8.2841 & TRN & \\
\hline CHEMBL3969060 & 1640951 & 8.6778 & 8.6967 & TRN & \\
\hline CHEMBL 3954008 & 1640951 & 8.2218 & 8.3251 & TRN & \\
\hline CHEMBL 3930278 & 1640951 & 7.5086 & 7.5413 & TRN & \\
\hline CHEMBL 3968059 & 1640951 & 8.2518 & 8.2438 & TRN & \\
\hline CHEMBL 3963485 & 1640951 & 6.0 & 6.0875 & TRN & \\
\hline CHEMBL3915403 & 1640951 & 7.9031 & 8.0361 & TRN & \\
\hline CHEMBL 3914178 & 1640951 & 7.6055 & 7.5578 & TRN & \\
\hline CHEMBL 3930377 & 1640951 & 8.4949 & 8.4704 & TRN & \\
\hline CHEMBL 3897866 & 1640951 & 8.0655 & 8.1495 & TRN & \\
\hline CHEMBL 3907995 & 1640951 & 8.8861 & 8.946 & TRN & \\
\hline CHEMBL 3962751 & 1640951 & 8.28399 & 799999999 & 99 & 8.2444 \\
\hline CHEMBL 3953385 & 1640951 & 8.4089 & 8.2352 & TRN & \\
\hline CHEMBL3969794 & 1640951 & 7.9508 & 8.7263 & TST & \\
\hline CHEMBL3951109 & 1640951 & 6.0 & 6.3242 & TST & \\
\hline CHEMBL 3958993 & 1640951 & 8.5528 & 8.5258 & TRN & \\
\hline CHEMBL433111 & 209473 & 4.4622 & 4.5658 & TRN & \\
\hline CHEMBL72991 & 209473 & 5.7447 & 5.8795 & TRN & \\
\hline CHEMBL310936 & 209473 & 7.699 & 7.0923 & TRN & \\
\hline CHEMBL 73314 & 209473 & 6.284 & 6.1028 & TST & \\
\hline CHEMBL 72458 & 209473 & 4.7747 & 4.992 & TRN & \\
\hline CHEMBL 73487 & 209473 & 6.4318 & 5.2635 & TST & \\
\hline CHEMBL 75376 & 209473 & 4.1319 & 4.2023 & TRN & \\
\hline CHEMBL 75556 & 209473 & 5.4437 & 5.3322 & TRN & \\
\hline CHEMBL307964 & 209473 & 5.0506 & 5.4408 & TRN & \\
\hline CHEMBL 312542 & 209473 & 6.7496 & 6.8228 & TRN & \\
\hline CHEMBL 73591 & 209473 & 5.8097 & 5.91 & TRN & \\
\hline CHEMBL 74485 & 209473 & 5.1249 & 4.8757 & TRN & \\
\hline CHEMBL 312313 & 209473 & 5.8827 & 5.6802 & TRN & \\
\hline CHEMBL 75894 & 209473 & 4.3565 & 4.3977 & TRN & \\
\hline CHEMBL 75891 & 209473 & 4.3429 & 4.8868 & TRN & \\
\hline CHEMBL 307237 & 209473 & 6.3098 & 6.2347 & TRN & \\
\hline CHEMBL 74311 & 209473 & 4.4486 & 4.1334 & TRN & \\
\hline CHEMBL446665 & 209473 & 5.0655 & 4.64 & TRN & \\
\hline CHEMBL 308790 & 209473 & 3.2581 & 3.75 & TRN & \\
\hline CHEMBL 76071 & 209473 & 4.3575 & 4.6495 & TST & \\
\hline CHEMBL 74558 & 209473 & 3.9706 & 4.2686 & TRN & \\
\hline CHEMBL306597 & 209473 & 7.6576 & 7.8351 & TRN & \\
\hline CHEMBL 307278 & 209473 & 5.8861 & 6.0748 & TRN & \\
\hline CHEMBL433327 & 209473 & 3.8371 & 4.0446 & TRN & \\
\hline CHEMBL 310263 & 209473 & 4.6021 & 4.3645 & TRN & \\
\hline CHEMBL 76272 & 209473 & 4.2604 & 4.5151 & TRN & \\
\hline CHEMBL 308862 & 209473 & 4.2299 & 4.4883 & TST & \\
\hline CHEMBL73228 & 209473 & 5.1079 & 4.6547 & TRN & \\
\hline CHEMBL 73713 & 209473 & 4.8182 & 4.231 & TRN & \\
\hline
\end{tabular}




\begin{tabular}{|c|c|c|c|c|c|}
\hline \multicolumn{6}{|c|}{ Supplemental Table S2.txt } \\
\hline CHEMBL305611 & 209473 & 5.4841 & 5.6827 & TRN & \\
\hline CHEMBL75731 & 209473 & 4.0778 & 3.9224 & TRN & \\
\hline CHEMBL74847 & 209473 & 6.9914 & 7.0328 & TRN & \\
\hline CHEMBL423859 & 209473 & 6.2218 & 5.9425 & TRN & \\
\hline CHEMBL311404 & 209473 & 4.3936 & 5.2213 & TST & \\
\hline CHEMBL75003 & 209473 & 4.8239 & 4.6342 & TRN & \\
\hline CHEMBL 74440 & 209473 & 6.301 & 6.6264 & TRN & \\
\hline CHEMBL75213 & 209473 & 6.9208 & 7.1141 & TRN & \\
\hline CHEMBL306775 & 209473 & 7.6021 & 7.1209 & TRN & \\
\hline CHEMBL73755 & 209473 & 5.1612 & 6.1598 & TRN & \\
\hline CHEMBL305926 & 209473 & 5.0757 & 5.4137 & TST & \\
\hline CHEMBL72371 & 209473 & 6.3372 & 6.2287 & TRN & \\
\hline CHEMBL73927 & 209473 & 4.8069 & 5.2687 & TRN & \\
\hline CHEMBL73440 & 209473 & 6.4437 & 6.5249 & TRN & \\
\hline CHEMBL75501 & 209473 & 5.5229 & 5.5412 & TST & \\
\hline CHEMBL306705 & 209473 & 7.6576 & 7.6531 & TRN & \\
\hline CHEMBL73594 & 209473 & 6.1487 & 5.7969 & TRN & \\
\hline CHEMBL443272 & 209473 & 4.585 & 4.7515 & TRN & \\
\hline CHEMBL73200 & 209473 & 6.2007 & 6.4592 & TRN & \\
\hline CHEMBL306046 & 209473 & 6.1427 & 5.902 & TST & \\
\hline CHEMBL75476 & 209473 & 5.6364 & 5.4415 & TRN & \\
\hline CHEMBL263192 & 209473 & 6.6383 & 6.03700 & 0000000001 & TRN \\
\hline CHEMBL76322 & 209473 & 6.4647 & 6.5349 & TST & \\
\hline CHEMBL 74702 & 209473 & 4.5421 & 5.4989 & TST & \\
\hline CHEMBL73018 & 209473 & 4.7696 & 5.434 & TST & \\
\hline CHEMBL 310040 & 209473 & 3.7149 & 3.3983 & TST & \\
\hline CHEMBL 75044 & 209473 & 6.4685 & 5.9665 & TRN & \\
\hline CHEMBL75759 & 209473 & 6.2676 & 7.2024 & TST & \\
\hline CHEMBL 76106 & 209473 & 5.5058 & 5.5992 & TRN & \\
\hline CHEMBL 74773 & 209473 & 5.0079 & 4.9898 & TST & \\
\hline CHEMBL 307015 & 209473 & 6.5376 & 6.5596 & TRN & \\
\hline CHEMBL 75194 & 209473 & 4.6198 & 4.8161 & TST & \\
\hline CHEMBL 76244 & 209473 & 5.3768 & 5.2925 & TRN & \\
\hline CHEMBL 74253 & 209473 & 5.9393 & 5.9421 & TST & \\
\hline CHEMBL73601 & 209473 & 5.1249 & 5.0719 & TRN & \\
\hline CHEMBL 306790 & 209473 & 6.3188 & 6.2864 & TRN & \\
\hline CHEMBL75592 & 209473 & 5.9666 & 6.1348 & TRN & \\
\hline CHEMBL 75473 & 209473 & 4.87 & 5.2546 & TST & \\
\hline CHEMBL1430425 & 737452 & 5.0 & 4.8937 & TRN & \\
\hline CHEMBL3191034 & 737452 & 4.0 & 4.5172 & TRN & \\
\hline CHEMBL3198659 & 737452 & 5.3487 & 4.7338 & TST & \\
\hline CHEMBL1363614 & 737452 & 4.0 & 4.7125 & TRN & \\
\hline CHEMBL1441545 & 737452 & 4.0 & 4.9583 & TRN & \\
\hline CHEMBL3191416 & 737452 & 4.3737 & 5.4504 & TRN & \\
\hline CHEMBL1501217 & 737452 & 4.0 & 4.697 & TRN & \\
\hline CHEMBL1597042 & 737452 & 5.0 & 4.9934 & TRN & \\
\hline CHEMBL1459795 & 737452 & 5.0 & 4.718 & TRN & \\
\hline CHEMBL2001895 & 737452 & 4.0 & 4.6431 & TST & \\
\hline
\end{tabular}




\begin{tabular}{|c|c|c|c|c|}
\hline \multicolumn{5}{|c|}{ Supplemental Table s2.txt } \\
\hline CHEMBL1325823 & 737452 & 5.0 & 4.7087 & TRN \\
\hline CHEMBL1607896 & 737452 & 5.0 & 5.1818 & TRN \\
\hline CHEMBL3190960 & 737452 & 5.0 & 5.0111 & TRN \\
\hline CHEMBL1582580 & 737452 & 4.0 & 4.6314 & TRN \\
\hline CHEMBL1985061 & 737452 & 6.2518 & 6.0994 & TRN \\
\hline CHEMBL1588660 & 737452 & 5.0 & 4.3021 & TRN \\
\hline CHEMBL1323139 & 737452 & 5.4134 & 5.2835 & TRN \\
\hline CHEMBL1574908 & 737452 & 4.0182 & 4.4629 & TRN \\
\hline CHEMBL1482998 & 737452 & 5.2097 & 4.9622 & TRN \\
\hline CHEMBL1422689 & 737452 & 4.308 & 4.8463 & TRN \\
\hline CHEMBL1337602 & 737452 & 5.0 & 4.382 & TST \\
\hline CHEMBL1359788 & 737452 & 5.0 & 4.4091 & TRN \\
\hline CHEMBL3190063 & 737452 & 4.0039 & 4.9502 & TRN \\
\hline CHEMBL1585404 & 737452 & 5.0 & 4.7723 & TRN \\
\hline CHEMBL1520595 & 737452 & 4.5575 & 4.8511 & TRN \\
\hline CHEMBL1392142 & 737452 & 5.7959 & 6.2934 & TRN \\
\hline CHEMBL1450266 & 737452 & 5.0 & 5.0371 & TRN \\
\hline CHEMBL1382884 & 737452 & 5.0487 & 5.3805 & TRN \\
\hline CHEMBL1374384 & 737452 & 4.0 & 4.6148 & TRN \\
\hline CHEMBL1438983 & 737452 & 5.007 & 4.6882 & TRN \\
\hline CHEMBL1483047 & 737452 & 5.0 & 4.6942 & TRN \\
\hline CHEMBL259784 & 737452 & 5.0752 & 5.0411 & TRN \\
\hline CHEMBL1994838 & 737452 & 5.5867 & 4.7829 & TRN \\
\hline CHEMBL1583461 & 737452 & 5.1057 & 4.5361 & TRN \\
\hline CHEMBL1417604 & 737452 & 4.1198 & 4.4931 & TRN \\
\hline CHEMBL1597245 & 737452 & 4.4461 & 5.1942 & TRN \\
\hline CHEMBL1377095 & 737452 & 6.0 & 4.5853 & TRN \\
\hline CHEMBL1533351 & 737452 & 4.0376 & 5.15600 & 3000000001 \\
\hline CHEMBL1524306 & 737452 & 7.2757 & 5.0381 & TRN \\
\hline CHEMBL1388831 & 737452 & 4.0 & 4.1993 & TRN \\
\hline CHEMBL1470112 & 737452 & 4.0 & 4.7666 & TST \\
\hline CHEMBL1470367 & 737452 & 4.0092 & 4.6125 & TRN \\
\hline CHEMBL1510833 & 737452 & 5.0 & 4.8846 & TRN \\
\hline CHEMBL1492648 & 737452 & 4.2457 & 4.6471 & TRN \\
\hline CHEMBL1304919 & 737452 & 5.0 & 4.3298 & TRN \\
\hline CHEMBL1984336 & 737452 & 5.0334 & 4.7679 & TRN \\
\hline CHEMBL1465040 & 737452 & 4.8297 & 5.1858 & TRN \\
\hline CHEMBL1586274 & 737452 & 4.1759 & 4.4132 & TRN \\
\hline CHEMBL1573267 & 737452 & 4.0246 & 4.479 & TRN \\
\hline CHEMBL1324256 & 737452 & 5.0 & 4.2234 & TRN \\
\hline CHEMBL3191488 & 737452 & 5.0 & 5.0124 & TRN \\
\hline CHEMBL3195389 & 737452 & 6.7959 & 6.7437 & TRN \\
\hline CHEMBL1406161 & 737452 & 5.0 & 4.2607 & TRN \\
\hline CHEMBL1445962 & 737452 & 4.0273 & 4.9771 & TRN \\
\hline CHEMBL1522184 & 737452 & 5.1959 & 4.8958 & TRN \\
\hline CHEMBL1490677 & 737452 & 5.0 & 5.0994 & TST \\
\hline CHEMBL1561080 & 737452 & 5.0 & 4.7608 & TRN \\
\hline CHEMBL3190201 & 737452 & 4.0 & 4.3 & TRN \\
\hline
\end{tabular}




\begin{tabular}{|c|c|c|c|c|c|c|}
\hline \multirow[b]{2}{*}{ CHEMBL1582448 } & & \multicolumn{5}{|c|}{ Supplemental Table S2.txt } \\
\hline & 737452 & 6.7959 & 6.4704 & TRN & & \\
\hline CHEMBL1341970 & 737452 & 4.0168 & 4.6755 & TRN & & \\
\hline CHEMBL1410479 & 737452 & 5.0 & 4.8988 & TRN & & \\
\hline CHEMBL1321531 & 737452 & 5.0 & 5.0724 & TRN & & \\
\hline CHEMBL1602581 & 737452 & 5.2147 & 4.6711 & TRN & & \\
\hline CHEMBL1319933 & 737452 & 5.38299 & 79999999 & 99 & 4.4763 & TRN \\
\hline CHEMBL1984130 & 737452 & 5.0159 & 4.5732 & TRN & & \\
\hline CHEMBL1602157 & 737452 & 4.0 & 4.7647 & TRN & & \\
\hline CHEMBL1496662 & 737452 & 5.0 & 4.8726 & TRN & & \\
\hline CHEMBL 3189258 & 737452 & 5.2916 & 4.9895 & TRN & & \\
\hline CHEMBL1392551 & 737452 & 4.7447 & 5.4742 & TST & & \\
\hline CHEMBL1583137 & 737452 & 5.0 & 4.7854 & TRN & & \\
\hline CHEMBL1587592 & 737452 & 4.0 & 4.8525 & TST & & \\
\hline CHEMBL1441792 & 737452 & 5.0 & 5.3614 & TRN & & \\
\hline CHEMBL1310804 & 737452 & 4.2306 & 4.5449 & TRN & & \\
\hline CHEMBL1493396 & 737452 & 5.1752 & 4.6735 & TST & & \\
\hline CHEMBL1561150 & 737452 & 4.2007 & 4.593 & TRN & & \\
\hline CHEMBL1455786 & 737452 & 5.0 & 5.1689 & TRN & & \\
\hline CHEMBL1576289 & 737452 & 5.0 & 4.8249 & TRN & & \\
\hline CHEMBL1329798 & 737452 & 6.7959 & 6.3826 & TRN & & \\
\hline CHEMBL1884996 & 737452 & 6.7959 & 6.4482 & TRN & & \\
\hline CHEMBL117966 & 737452 & 5.3161 & 4.8037 & TRN & & \\
\hline CHEMBL1501078 & 737452 & 4.0 & 4.73 & TRN & & \\
\hline CHEMBL1392570 & 737452 & 4.5086 & 4.8744 & TRN & & \\
\hline CHEMBL1346096 & 737452 & 5.2774 & 5.3811 & TST & & \\
\hline CHEMBL1589526 & 737452 & 5.2154 & 4.9183 & TRN & & \\
\hline CHEMBL1424264 & 737452 & 5.0 & 4.9575 & TRN & & \\
\hline CHEMBL1586531 & 737452 & 4.0031 & 4.2792 & TRN & & \\
\hline CHEMBL1422678 & 737452 & 5.0 & 4.9304 & TRN & & \\
\hline CHEMBL1369492 & 737452 & 5.0 & 4.7255 & TRN & & \\
\hline CHEMBL1326110 & 737452 & 5.0 & 4.8656 & TRN & & \\
\hline CHEMBL1571615 & 737452 & 5.0 & 4.7184 & TRN & & \\
\hline CHEMBL1323864 & 737452 & 4.007 & 4.7771 & TST & & \\
\hline CHEMBL1505206 & 737452 & 4.2418 & 4.3986 & TRN & & \\
\hline CHEMBL1469847 & 737452 & 5.0 & 5.0369 & TRN & & \\
\hline CHEMBL1299463 & 737452 & 4.0297 & 4.5587 & TRN & & \\
\hline CHEMBL19954 & 737452 & 4.0 & 5.1432 & TST & & \\
\hline CHEMBL1558210 & 737452 & 5.1314 & 5.0742 & TRN & & \\
\hline CHEMBL1567008 & 737452 & 4.007 & 4.1196 & TRN & & \\
\hline CHEMBL1526855 & 737452 & 5.2741 & 4.9999 & TRN & & \\
\hline CHEMBL1969593 & 737452 & 5.0 & 5.0455 & TRN & & \\
\hline CHEMBL1439773 & 737452 & 5.0 & 4.4938 & TRN & & \\
\hline CHEMBL433680 & 737452 & 6.7959 & 6.5083 & TST & & \\
\hline CHEMBL1361821 & 737452 & 4.0325 & 4.7661 & TRN & & \\
\hline CHEMBL1509108 & 737452 & 5.0 & 4.8824 & TRN & & \\
\hline CHEMBL1588356 & 737452 & 5.0 & 4.7581 & TRN & & \\
\hline CHEMBL1521702 & 737452 & 5.0926 & 5.1692 & TRN & & \\
\hline CHEMBL1362660 & 737452 & 5.7011 & 5.1067 & TRN & & \\
\hline
\end{tabular}

Page 13131 


\begin{tabular}{|c|c|c|c|c|c|}
\hline \multirow[b]{2}{*}{ CHEMBL1481836 } & \multicolumn{5}{|c|}{ Supplemental Table S2.txt } \\
\hline & 737452 & 5.2993 & 4.1945 & TRN & \\
\hline CHEMBL1477778 & 737452 & 4.2832 & 4.6829 & TRN & \\
\hline CHEMBL1562277 & 737452 & 4.0 & 4.8416 & TRN & \\
\hline CHEMBL1604527 & 737452 & 5.0 & 5.1309 & TRN & \\
\hline CHEMBL1498599 & 737452 & 4.025 & 4.842 & TRN & \\
\hline CHEMBL1496362 & 737452 & 5.0 & 4.7217 & TST & \\
\hline CHEMBL1517752 & 737452 & 4.032 & 4.5314 & TRN & \\
\hline CHEMBL3189960 & 737452 & 5.0 & 5.1344 & TRN & \\
\hline CHEMBL1256686 & 737452 & 5.8508 & 5.41799 & 9999999999 & TST \\
\hline CHEMBL394242 & 737452 & 4.0013 & 4.8246 & TRN & \\
\hline CHEMBL 1487938 & 737452 & 4.0 & 4.6713 & TRN & \\
\hline CHEMBL1345414 & 737452 & 5.0 & 4.4951 & TRN & \\
\hline CHEMBL1509120 & 737452 & 5.2668 & 4.4491 & TRN & \\
\hline CHEMBL1485112 & 737452 & 5.0 & 4.8507 & TRN & \\
\hline CHEMBL1337193 & 737452 & 5.2041 & 4.9597 & TRN & \\
\hline CHEMBL1990598 & 737452 & 6.2676 & 5.5969 & TRN & \\
\hline CHEMBL1393914 & 737452 & 5.7447 & 5.4665 & TRN & \\
\hline CHEMBL1555899 & 737452 & 5.0 & 4.5041 & TRN & \\
\hline CHEMBL1349727 & 737452 & $5.3820 e$ & 00000000 & 4.9175 & TRN \\
\hline CHEMBL1595864 & 737452 & 5.0 & 4.713 & TRN & \\
\hline CHEMBL 1387156 & 737452 & 4.0 & 4.3121 & TRN & \\
\hline CHEMBL1387474 & 737452 & 5.2668 & 5.0179 & TRN & \\
\hline CHEMBL3211781 & 737452 & 5.0278 & 4.8923 & TRN & \\
\hline CHEMBL1518326 & 737452 & 5.1561 & 4.8576 & TRN & \\
\hline CHEMBL1446234 & 737452 & 5.0 & 4.8033 & TRN & \\
\hline CHEMBL1731165 & 737452 & 4.0 & 4.3846 & TRN & \\
\hline CHEMBL1601712 & 737452 & 4.0 & 4.5195 & TRN & \\
\hline CHEMBL1431118 & 737452 & 4.0 & 4.5636 & TRN & \\
\hline CHEMBL1429129 & 737452 & 6.0 & 4.8148 & TST & \\
\hline CHEMBL3196367 & 737452 & 5.0 & 5.4787 & TRN & \\
\hline CHEMBL1562986 & 737452 & 4.0 & 4.8803 & TRN & \\
\hline CHEMBL1424243 & 737452 & 4.0 & 4.4611 & TRN & \\
\hline CHEMBL1427279 & 737452 & 5.3883 & 4.6114 & TRN & \\
\hline CHEMBL1526304 & 737452 & 5.0 & 5.1523 & TRN & \\
\hline CHEMBL1567389 & 737452 & 5.2907 & 5.4092 & TRN & \\
\hline CHEMBL1391630 & 737452 & 5.0 & 4.9289 & TRN & \\
\hline CHEMBL1309448 & 737452 & 5.0 & 5.0719 & TST & \\
\hline CHEMBL1597032 & 737452 & 5.0 & 4.67399 & 99999999995 & TRN \\
\hline CHEMBL3191327 & 737452 & 5.0 & 4.8025 & TRN & \\
\hline CHEMBL1339398 & 737452 & 5.0057 & 4.5499 & TST & \\
\hline CHEMBL1404541 & 737452 & 4.0605 & 4.3772 & TRN & \\
\hline CHEMBL1346640 & 737452 & 5.0 & 4.8383 & TRN & \\
\hline CHEMBL193872 & 737452 & 4.0 & 6.3611 & TRN & \\
\hline CHEMBL1301125 & 737452 & 5.3585 & 5.7309 & TST & \\
\hline CHEMBL1584933 & 737452 & 5.0 & 4.7131 & TRN & \\
\hline CHEMBL 3856090 & 737452 & 4.1662 & 4.76699 & 99999999995 & TRN \\
\hline CHEMBL1471141 & 737452 & 5.0 & 4.8897 & TRN & \\
\hline CHEMBL1494650 & 737452 & 7.3872 & 5.4097 & TRN & \\
\hline
\end{tabular}




\begin{tabular}{|c|c|c|c|c|c|}
\hline \multirow[b]{2}{*}{ CHEMBL1602759 } & \multicolumn{5}{|c|}{ Supplemental Table S2.txt } \\
\hline & 737452 & 5.4237 & 5.2659 & TRN & \\
\hline CHEMBL1564569 & 737452 & 5.2534 & 4.8354 & TRN & \\
\hline CHEMBL1541735 & 737452 & 5.0 & 4.3512 & TRN & \\
\hline CHEMBL1499127 & 737452 & 4.3002 & 4.4107 & TRN & \\
\hline CHEMBL1352586 & 737452 & 4.0343 & 4.5636 & TRN & \\
\hline CHEMBL1608078 & 737452 & 5.2899 & 5.1261 & TRN & \\
\hline CHEMBL1454183 & 737452 & 6.0 & 5.4848 & TST & \\
\hline CHEMBL1497950 & 737452 & 5.0 & 5.0438 & TRN & \\
\hline CHEMBL1413661 & 737452 & 5.1421 & 4.4153 & TST & \\
\hline CHEMBL1381567 & 737452 & 5.3344 & 4.9357 & TRN & \\
\hline CHEMBL1547342 & 737452 & 5.1733 & 4.8478 & TRN & \\
\hline CHEMBL1900850 & 737452 & 6.7959 & 6.6342 & TRN & \\
\hline CHEMBL1976507 & 737452 & 5.7375 & 5.45799 & 9999999999 & TRN \\
\hline CHEMBL1362109 & 737452 & 5.0 & 4.8952 & TRN & \\
\hline CHEMBL1580532 & 737452 & 4.0 & 4.6105 & TRN & \\
\hline CHEMBL3190181 & 737452 & 5.8827 & 5.8657 & TRN & \\
\hline CHEMBL3210051 & 737452 & 4.0 & 4.26699 & 99999999995 & TRN \\
\hline CHEMBL1562044 & 737452 & 5.3325 & 4.6395 & TRN & \\
\hline CHEMBL1379136 & 737452 & 5.0 & 4.2958 & TRN & \\
\hline CHEMBL1377682 & 737452 & 4.0 & 5.0002 & TRN & \\
\hline CHEMBL3211808 & 737452 & 5.0 & 4.9206 & TRN & \\
\hline CHEMBL1603410 & 737452 & 4.0137 & 5.2522 & TST & \\
\hline CHEMBL3189663 & 737452 & 4.0 & 4.678 & TRN & \\
\hline CHEMBL1458548 & 737452 & 6.0605 & 4.8604 & TRN & \\
\hline CHEMBL1585480 & 737452 & 4.0 & 4.6087 & TRN & \\
\hline CHEMBL1345961 & 737452 & 4.0 & 4.5182 & TRN & \\
\hline CHEMBL1500686 & 737452 & 4.0 & 4.5696 & TRN & \\
\hline CHEMBL1507337 & 737452 & 4.0 & 4.3653 & TRN & \\
\hline CHEMBL1517738 & 737452 & 4.0 & 5.171 & TST & \\
\hline CHEMBL1429929 & 737452 & 4.2041 & 4.7298 & TRN & \\
\hline CHEMBL1497295 & 737452 & 4.0209 & 4.9967 & TRN & \\
\hline CHEMBL1372914 & 737452 & 4.0 & 4.6054 & TRN & \\
\hline CHEMBL1565496 & 737452 & 5.0 & 4.6213 & TRN & \\
\hline CHEMBL1332979 & 737452 & 5.0 & 4.9459 & TRN & \\
\hline CHEMBL1440300 & 737452 & 5.6198 & 5.3911 & TRN & \\
\hline CHEMBL1558625 & 737452 & 5.0 & 4.8337 & TST & \\
\hline CHEMBL607299 & 737452 & 4.0 & 5.3255 & TST & \\
\hline CHEMBL1991215 & 737452 & 5.2749 & 4.7388 & TRN & \\
\hline CHEMBL1413963 & 737452 & 5.0 & 4.6761 & TRN & \\
\hline CHEMBL1306258 & 737452 & 6.0 & 5.1392 & TRN & \\
\hline CHEMBL2369275 & 737452 & 4.0 & 4.3806 & TRN & \\
\hline CHEMBL1460004 & 737452 & 5.0 & 5.2603 & TRN & \\
\hline CHEMBL1347390 & 737452 & 4.1878 & 4.8348 & TRN & \\
\hline CHEMBL1566847 & 737452 & 5.3737 & 4.7638 & TRN & \\
\hline CHEMBL1511363 & 737452 & 6.1308 & 4.9224 & TST & \\
\hline CHEMBL1348803 & 737452 & 5.0 & 4.9111 & TRN & \\
\hline CHEMBL1351269 & 737452 & 5.0 & 4.9784 & TRN & \\
\hline CHEMBL1444031 & 737452 & 4.0106 & 4.7524 & TRN & \\
\hline
\end{tabular}




$$
\text { Supplemental Table S2.txt }
$$

\begin{tabular}{|c|c|c|c|c|c|}
\hline CHEMBL 2006503 & 737452 & 4.9747 & 5.6726 & TRN & \\
\hline CHEMBL1365290 & 737452 & 4.0 & 4.8781 & TRN & \\
\hline CHEMBL1446480 & 737452 & 4.0 & 4.6578 & TRN & \\
\hline CHEMBL1613463 & 737452 & 4.0 & 4.3283 & TRN & \\
\hline CHEMBL3193204 & 737452 & 4.0 & 4.1691 & TRN & \\
\hline CHEMBL1594232 & 737452 & 5.0 & 4.8571 & TRN & \\
\hline CHEMBL193627 & 737452 & 7.6198 & 6.2011 & TRN & \\
\hline CHEMBL2005602 & 737452 & 4.091 & 4.7179 & TRN & \\
\hline CHEMBL1578101 & 737452 & 5.0 & 5.0355 & TST & \\
\hline CHEMBL1611013 & 737452 & 5.2154 & 5.0045 & TRN & \\
\hline CHEMBL1361883 & 737452 & 4.3372 & 4.5352 & TRN & \\
\hline CHEMBL1428228 & 737452 & 5.6478 & 4.9159 & TRN & \\
\hline CHEMBL1531906 & 737452 & 5.0 & 4.3417 & TRN & \\
\hline CHEMBL1420393 & 737452 & 5.2976 & 4.8044 & TRN & \\
\hline CHEMBL1506527 & 737452 & 5.3716 & 4.8221 & TRN & \\
\hline CHEMBL1437997 & 737452 & 5.0 & 4.9611 & TRN & \\
\hline CHEMBL3189563 & 737452 & 5.0 & 4.9143 & TRN & \\
\hline CHEMBL1589652 & 737452 & 5.0 & 4.7552 & TRN & \\
\hline CHEMBL1532377 & 737452 & 5.3706 & 5.1404 & TRN & \\
\hline CHEMBL1556017 & 737452 & 5.0 & 4.9669 & TRN & \\
\hline CHEMBL1607086 & 737452 & 6.4815 & 5.78799 & 9999999999 & TRN \\
\hline CHEMBL1337500 & 737452 & 5.3288 & 4.7974 & TST & \\
\hline CHEMBL1425486 & 737452 & 5.0 & 4.6223 & TRN & \\
\hline CHEMBL1547559 & 737452 & 6.0088 & 5.7548 & TRN & \\
\hline CHEMBL1573909 & 737452 & 5.0 & 5.1545 & TRN & \\
\hline CHEMBL1450616 & 737452 & 4.0 & 4.4945 & TRN & \\
\hline CHEMBL1519411 & 737452 & 4.0283 & 4.4734 & TRN & \\
\hline CHEMBL1450615 & 737452 & 5.0 & 5.2273 & TRN & \\
\hline CHEMBL3197230 & 737452 & 5.0 & 4.4155 & TRN & \\
\hline CHEMBL414890 & 737452 & 5.4157 & 5.1793 & TST & \\
\hline CHEMBL1448592 & 737452 & 4.6556 & 5.3341 & TST & \\
\hline CHEMBL1532375 & 737452 & 5.0 & 4.7058 & TRN & \\
\hline CHEMBL1420589 & 737452 & 5.2168 & 4.9845 & TRN & \\
\hline CHEMBL1491402 & 737452 & 4.0947 & 5.4284 & TRN & \\
\hline CHEMBL1481551 & 737452 & 4.0 & 4.7031 & TRN & \\
\hline CHEMBL1598843 & 737452 & 5.0 & 4.6283 & TRN & \\
\hline CHEMBL1469567 & 737452 & 4.0 & 4.7296 & TRN & \\
\hline CHEMBL1335165 & 737452 & 5.0 & 4.8436 & TRN & \\
\hline CHEMBL1545250 & 737452 & 4.0506 & 5.5053 & TRN & \\
\hline CHEMBL1989704 & 737452 & 5.0 & 4.8768 & TRN & \\
\hline CHEMBL1499792 & 737452 & 4.0106 & 5.3398 & TRN & \\
\hline CHEMBL1390139 & 737452 & 5.2882 & 4.4054 & TRN & \\
\hline CHEMBL3194916 & 737452 & 4.0 & \multicolumn{2}{|c|}{4.8469999999999995} & TRN \\
\hline CHEMBL1451348 & 737452 & 5.3242 & 4.6865 & TRN & \\
\hline CHEMBL1352375 & 737452 & 4.0931 & 4.6729 & TRN & \\
\hline CHEMBL3192732 & 737452 & 5.1319 & 4.9294 & TRN & \\
\hline CHEMBL2006634 & 737452 & 4.0 & 4.3862 & TRN & \\
\hline CHEMBL1377193 & 737452 & 4.0 & 4.7201 & TRN & \\
\hline
\end{tabular}




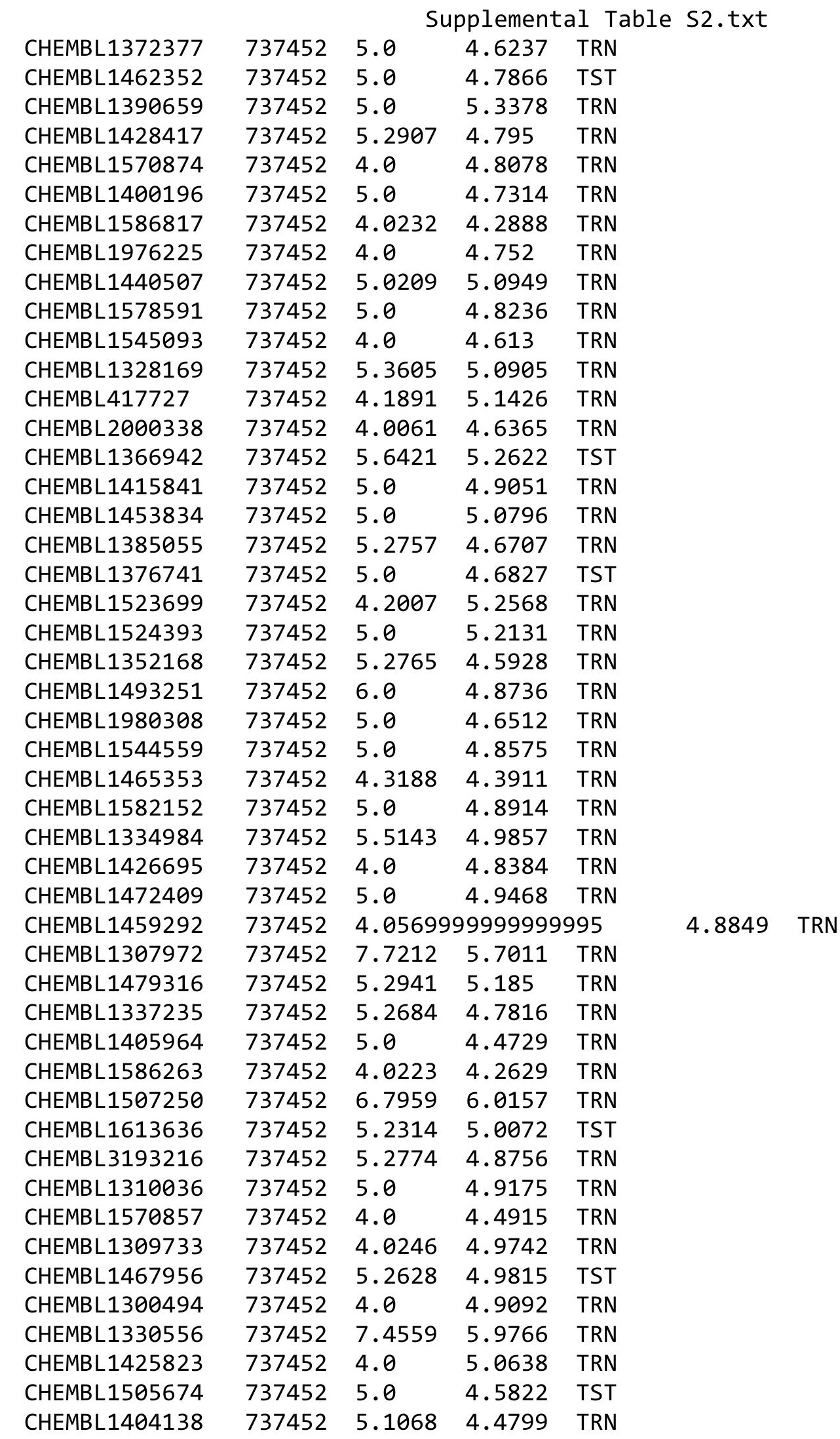

Page 13135 


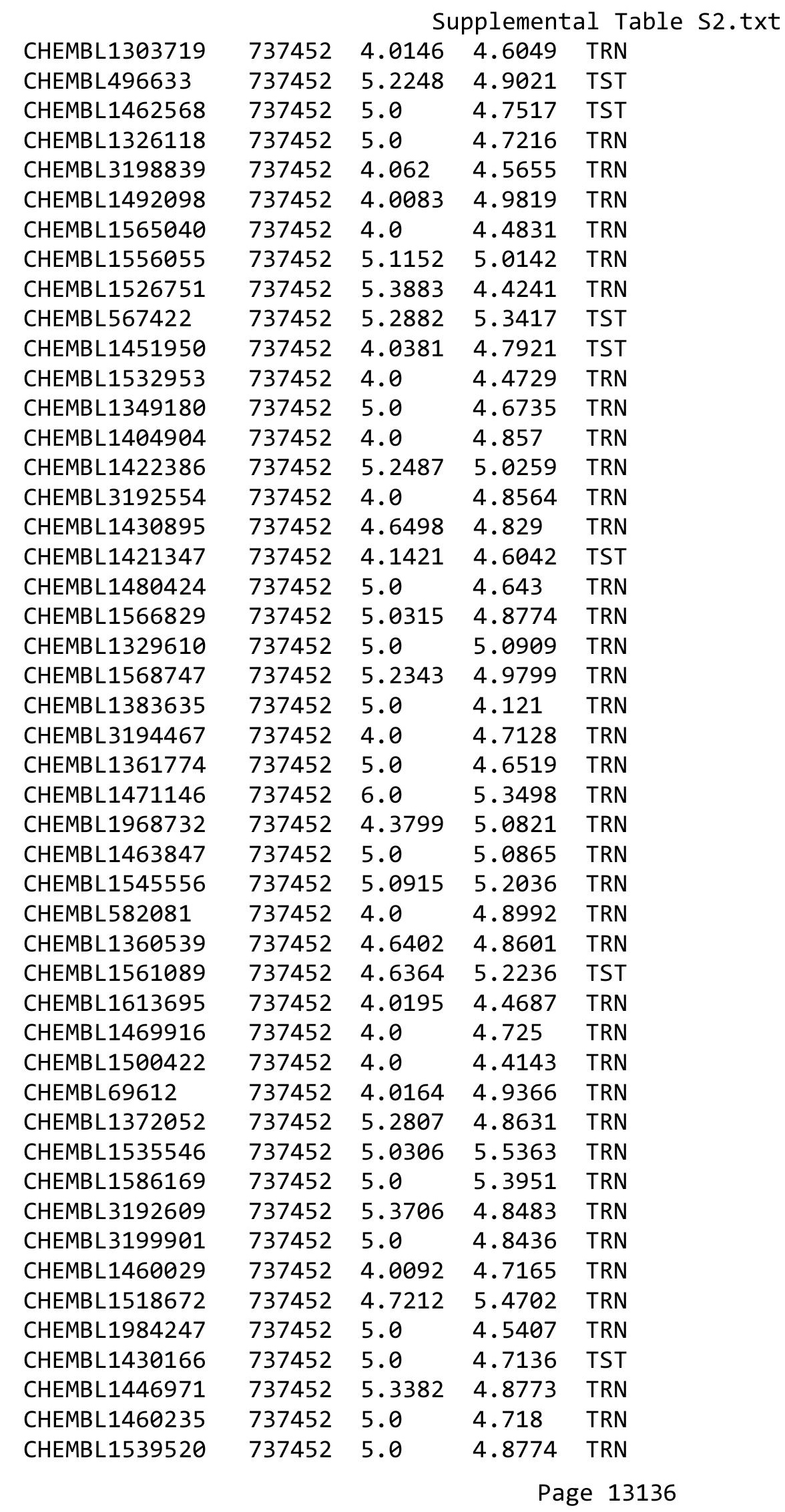




\begin{tabular}{|c|c|c|c|c|c|}
\hline \multicolumn{6}{|c|}{ Supplemental Table S2.txt } \\
\hline CHEMBL1467102 & 737452 & 5.0 & 4.7707 & TRN & \\
\hline CHEMBL1312928 & 737452 & 6.7959 & 6.3612 & TRN & \\
\hline CHEMBL1500489 & 737452 & 5.1537 & 4.6971 & TST & \\
\hline CHEMBL1424968 & 737452 & 4.2336 & 5.0175 & TRN & \\
\hline CHEMBL1384167 & 737452 & \multicolumn{3}{|c|}{5.757000000000001} & TRN \\
\hline CHEMBL3192274 & 737452 & 5.1798 & 4.6696 & TRN & \\
\hline CHEMBL1319488 & 737452 & 5.3344 & 4.8071 & TRN & \\
\hline CHEMBL1406703 & 737452 & 4.0 & 3.9332 & TRN & \\
\hline CHEMBL1311185 & 737452 & 5.5317 & 5.0877 & TRN & \\
\hline CHEMBL3197224 & 737452 & 4.0 & 4.8443 & TST & \\
\hline CHEMBL1500719 & 737452 & 5.0 & 4.7749 & TRN & \\
\hline CHEMBL1487337 & 737452 & 5.0 & \multicolumn{2}{|c|}{4.696000000000001} & TST \\
\hline CHEMBL1989225 & 737452 & 5.0 & 4.8334 & TRN & \\
\hline CHEMBL1581932 & 737452 & 5.0 & 4.8263 & TRN & \\
\hline CHEMBL1596234 & 737452 & 5.0 & 4.6872 & TRN & \\
\hline CHEMBL1427221 & 737452 & 4.0 & 4.6231 & TRN & \\
\hline CHEMBL1507523 & 737452 & 5.0 & 4.5791 & TRN & \\
\hline CHEMBL1381814 & 737452 & 6.0 & 5.3732 & TRN & \\
\hline CHEMBL1384702 & 737452 & 4.7122 & 4.8209 & TRN & \\
\hline CHEMBL1453996 & 737452 & 6.7959 & 5.9427 & TST & \\
\hline CHEMBL524222 & 737452 & 4.1163 & 4.0777 & TRN & \\
\hline CHEMBL1545584 & 737452 & 5.0 & 4.6649 & TRN & \\
\hline CHEMBL1421112 & 737452 & 4.0 & 4.5298 & TRN & \\
\hline CHEMBL1347144 & 737452 & 5.3449 & 5.0785 & TRN & \\
\hline CHEMBL1411912 & 737452 & 4.8125 & 4.7765 & TRN & \\
\hline CHEMBL1518766 & 737452 & 4.0 & 4.8173 & TRN & \\
\hline CHEMBL1539280 & 737452 & 4.0 & 4.7313 & TST & \\
\hline CHEMBL1564136 & 737452 & 5.8356 & 6.2088 & TST & \\
\hline CHEMBL451574 & 737452 & 5.0237 & \multicolumn{2}{|c|}{5.5120000000000005} & TST \\
\hline CHEMBL 3190364 & 737452 & 6.0 & 5.0595 & TRN & \\
\hline CHEMBL570400 & 737452 & 5.0 & 4.5382 & TRN & \\
\hline CHEMBL1387563 & 737452 & 4.0 & 4.7771 & TRN & \\
\hline CHEMBL1441304 & 737452 & 4.0 & 4.1239 & TRN & \\
\hline CHEMBL1387790 & 737452 & 7.7959 & 6.6322 & TRN & \\
\hline CHEMBL1411089 & 737452 & 4.0 & 5.2093 & TRN & \\
\hline CHEMBL1503962 & 737452 & 5.0 & 4.9873 & TRN & \\
\hline CHEMBL155563 & 737452 & 5.2716 & 5.3183 & TRN & \\
\hline CHEMBL1584002 & 737452 & 4.0 & 4.6847 & TRN & \\
\hline CHEMBL1613615 & 737452 & 5.0 & 4.9273 & TRN & \\
\hline CHEMBL 1415413 & 737452 & 5.0 & 4.9226 & TST & \\
\hline CHEMBL1530161 & 737452 & 5.0 & 4.6703 & TRN & \\
\hline CHEMBL1342665 & 737452 & 5.2083 & 4.4681 & TRN & \\
\hline CHEMBL1598287 & 737452 & 5.0 & 4.9214 & TRN & \\
\hline CHEMBL1520507 & 737452 & 4.0 & 4.9498 & TRN & \\
\hline CHEMBL1981103 & 737452 & 5.1979 & 5.0059 & TST & \\
\hline CHEMBL1518240 & 737452 & 5.0 & 4.2865 & TRN & \\
\hline CHEMBL1523938 & 737452 & 4.6421 & 5.1031 & TST & \\
\hline CHEMBL1425166 & 737452 & 5.2487 & 4.7407 & TRN & \\
\hline
\end{tabular}

Page 13137 


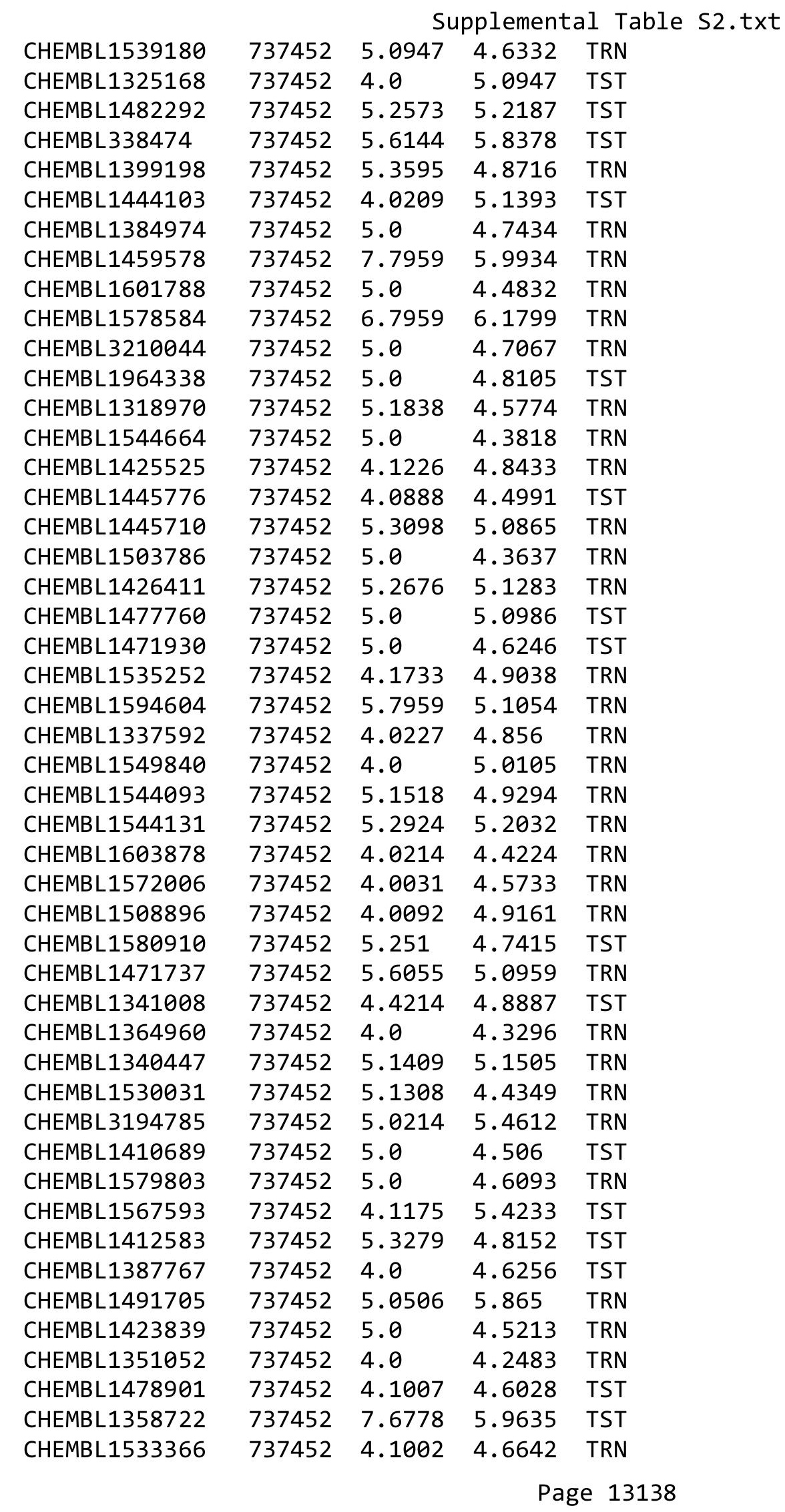




\begin{tabular}{|c|c|c|c|c|c|c|}
\hline & & \multicolumn{5}{|c|}{ Supplemental Table S2.txt } \\
\hline CHEMBL1458022 & 737452 & 5.6345 & 5.2227 & TRN & & \\
\hline CHEMBL1371873 & 737452 & 5.0 & 4.5747 & TRN & & \\
\hline CHEMBL1577081 & 737452 & 5.0 & 4.6459 & TRN & & \\
\hline CHEMBL1374970 & 737452 & 4.0448 & 4.6092 & TST & & \\
\hline CHEMBL1527794 & 737452 & 4.0306 & 4.5478 & TRN & & \\
\hline CHEMBL1535134 & 737452 & 5.3063 & 5.3746 & TRN & & \\
\hline CHEMBL1352854 & 737452 & 5.5045 & 5.6265 & TRN & & \\
\hline CHEMBL1364411 & 737452 & 5.0 & 4.4911 & TST & & \\
\hline CHEMBL3191594 & 737452 & 4.3605 & 5.1177 & TRN & & \\
\hline CHEMBL1732236 & 737452 & 4.02 & 5.0052 & TRN & & \\
\hline CHEMBL1399191 & 737452 & 4.0 & 4.8437 & TST & & \\
\hline CHEMBL1313521 & 737452 & 4.0872 & 4.5085 & TRN & & \\
\hline CHEMBL1505902 & 737452 & 4.0223 & 4.7648 & TRN & & \\
\hline CHEMBL1337226 & 737452 & 5.3595 & 5.24799 & 9999999999 & & TRN \\
\hline CHEMBL1485945 & 737452 & 4.025 & 4.8593 & TRN & & \\
\hline CHEMBL1335224 & 737452 & 5.3449 & 5.1531 & TRN & & \\
\hline CHEMBL1610756 & 737452 & 4.0 & 4.819 & TRN & & \\
\hline CHEMBL1400761 & 737452 & 6.0 & 4.7365 & TST & & \\
\hline CHEMBL1504590 & 737452 & 5.0 & 4.8288 & TST & & \\
\hline CHEMBL1303810 & 737452 & 5.3179 & 4.9517 & TRN & & \\
\hline CHEMBL1990510 & 737452 & 5.0 & 4.5636 & TRN & & \\
\hline CHEMBL1412369 & 737452 & \multicolumn{3}{|c|}{4.0569999999999995} & 4.7654 & TRN \\
\hline CHEMBL1349625 & 737452 & 6.4089 & 4.8977 & TST & & \\
\hline CHEMBL1594720 & 737452 & 5.0 & 4.9577 & TRN & & \\
\hline CHEMBL1464261 & 737452 & 4.0182 & 4.6905 & TRN & & \\
\hline CHEMBL 3213235 & 737452 & 4.0 & 4.6544 & TRN & & \\
\hline CHEMBL1518905 & 737452 & 6.7959 & 6.1969 & TRN & & \\
\hline CHEMBL1461400 & 737452 & 5.8729 & 5.5382 & TRN & & \\
\hline CHEMBL1363322 & 737452 & 5.0 & 4.7148 & TRN & & \\
\hline CHEMBL1319204 & 737452 & 5.0 & 4.4245 & TRN & & \\
\hline CHEMBL3196976 & 737452 & 5.5391 & 5.3971 & TRN & & \\
\hline CHEMBL1407622 & 737452 & 4.0074 & 4.8014 & TRN & & \\
\hline CHEMBL1341040 & 737452 & 5.0 & 4.739 & TRN & & \\
\hline CHEMBL1497939 & 737452 & 4.6383 & 5.5316 & TRN & & \\
\hline CHEMBL1508875 & 737452 & 4.0 & 4.1539 & TRN & & \\
\hline CHEMBL1527838 & 737452 & 5.0 & 4.6019 & TRN & & \\
\hline CHEMBL1510761 & 737452 & 5.0 & 4.0477 & TRN & & \\
\hline CHEMBL1607895 & 737452 & 5.1701 & 4.795 & TRN & & \\
\hline CHEMBL1459746 & 737452 & 5.2411 & 5.3685 & TRN & & \\
\hline CHEMBL1569585 & 737452 & 5.9872 & 5.0909 & TST & & \\
\hline CHEMBL1973525 & 737452 & \multicolumn{3}{|c|}{5.4510000000000005} & 5.3279 & TRN \\
\hline CHEMBL1561240 & 737452 & 5.0 & 4.5214 & TRN & & \\
\hline CHEMBL1452795 & 737452 & 5.5229 & 5.6464 & TRN & & \\
\hline CHEMBL3192138 & 737452 & 5.7959 & 6.0552 & TST & & \\
\hline CHEMBL1566903 & 737452 & 5.0 & 5.3582 & TST & & \\
\hline CHEMBL1581696 & 737452 & 5.5834 & 4.69 & TRN & & \\
\hline CHEMBL1467284 & 737452 & 5.1391 & 4.7534 & TRN & & \\
\hline CHEMBL1607568 & 737452 & 5.699 & 4.9944 & TRN & & \\
\hline
\end{tabular}




\begin{tabular}{|c|c|c|c|c|c|c|}
\hline & & \multicolumn{5}{|c|}{ Supplemental Table S2.txt } \\
\hline CHEMBL1456379 & 737452 & 4.0 & 4.6649 & TRN & & \\
\hline CHEMBL1319618 & 737452 & 5.2557 & 5.21700 & 00000000 & 205 & TRN \\
\hline CHEMBL1988798 & 737452 & 4.0 & 4.6472 & TRN & & \\
\hline CHEMBL1385193 & 737452 & 6.0 & 5.0249 & TRN & & \\
\hline CHEMBL1330736 & 737452 & 5.0 & 5.1058 & TRN & & \\
\hline CHEMBL1467896 & 737452 & 4.0074 & 4.7609 & TRN & & \\
\hline CHEMBL1308168 & 737452 & 4.0223 & 4.702 & TRN & & \\
\hline CHEMBL1467999 & 737452 & 5.2874 & 4.569 & TRN & & \\
\hline CHEMBL1347846 & 737452 & 5.0 & 4.7374 & TRN & & \\
\hline CHEMBL1458479 & 737452 & 5.3161 & 4.5316 & TRN & & \\
\hline CHEMBL1470373 & 737452 & 5.0 & 4.8535 & TRN & & \\
\hline CHEMBL528181 & 737452 & 6.0 & 5.0809 & TRN & & \\
\hline CHEMBL1305292 & 737452 & 4.0 & 4.7399 & TRN & & \\
\hline CHEMBL1497597 & 737452 & 5.0 & 4.7165 & TRN & & \\
\hline CHEMBL1541829 & 737452 & 4.0 & 4.3679 & TRN & & \\
\hline CHEMBL1392313 & 737452 & 5.0555 & 4.6359 & TST & & \\
\hline CHEMBL1379970 & 737452 & 4.5834 & 6.1922 & TRN & & \\
\hline CHEMBL601952 & 737452 & 4.0 & 4.8328 & TRN & & \\
\hline CHEMBL1555650 & 737452 & 5.0273 & 4.901 & TRN & & \\
\hline CHEMBL1470914 & 737452 & 4.0 & 4.6238 & TRN & & \\
\hline CHEMBL1555935 & 737452 & 5.7959 & 6.7436 & TRN & & \\
\hline CHEMBL1464968 & 737452 & 5.0 & 4.8085 & TRN & & \\
\hline CHEMBL582444 & 737452 & 5.3224 & 4.9749 & TST & & \\
\hline CHEMBL1336197 & 737452 & 4.0 & 5.3044 & TST & & \\
\hline CHEMBL3195749 & 737452 & 5.4413 & 5.4687 & TRN & & \\
\hline CHEMBL3194760 & 737452 & 4.0696 & 4.9634 & TRN & & \\
\hline CHEMBL1982010 & 737452 & 5.21399 & 99999999 & 995 & 5.4732 & TRN \\
\hline CHEMBL 3194091 & 737452 & 5.0 & 4.6557 & TRN & & \\
\hline CHEMBL1555913 & 737452 & 5.0 & 5.2714 & TST & & \\
\hline CHEMBL1500565 & 737452 & 4.0101 & 4.7673 & TRN & & \\
\hline CHEMBL1611733 & 737452 & 5.6778 & 5.4665 & TRN & & \\
\hline CHEMBL1506229 & 737452 & 5.0 & 4.8485 & TST & & \\
\hline CHEMBL1380000 & 737452 & 5.2457 & 4.918 & TRN & & \\
\hline CHEMBL1334593 & 737452 & 5.0 & 5.4406 & TRN & & \\
\hline CHEMBL3189304 & 737452 & 5.0 & 4.8078 & TRN & & \\
\hline CHEMBL1497323 & 737452 & 4.0942 & 4.684 & TST & & \\
\hline CHEMBL1569824 & 737452 & 5.3002 & 4.927 & TRN & & \\
\hline CHEMBL1319676 & 737452 & 5.3063 & 4.5452 & TRN & & \\
\hline CHEMBL1499951 & 737452 & 5.266 & 5.3132 & TRN & & \\
\hline CHEMBL1302406 & 737452 & 5.0 & 4.8321 & TRN & & \\
\hline CHEMBL1349225 & 737452 & 5.2588 & 5.1269 & TRN & & \\
\hline CHEMBL1335988 & 737452 & 5.2118 & 5.3536 & TST & & \\
\hline CHEMBL1388639 & 737452 & 4.0 & 4.5121 & TRN & & \\
\hline CHEMBL1402055 & 737452 & 5.4101 & 4.7191 & TST & & \\
\hline CHEMBL1311729 & 737452 & 4.2248 & 4.4494 & TRN & & \\
\hline CHEMBL1381257 & 737452 & 5.1469 & 4.7802 & TRN & & \\
\hline CHEMBL3198512 & 737452 & 4.0 & 4.8926 & TRN & & \\
\hline CHEMBL1521960 & 737452 & 6.7959 & 5.8324 & TRN & & \\
\hline
\end{tabular}




\begin{tabular}{|c|c|c|c|c|c|}
\hline \multirow[b]{2}{*}{ CHEMBL1543875 } & \multicolumn{5}{|c|}{ Supplemental Table S2.txt } \\
\hline & 737452 & 4.0915 & 4.2554 & TRN & \\
\hline CHEMBL1603615 & 737452 & 5.4034 & 5.1539 & TRN & \\
\hline CHEMBL1382323 & 737452 & 5.0 & 4.8925 & TRN & \\
\hline CHEMBL388978 & 737452 & 6.1805 & 6.2258 & TST & \\
\hline CHEMBL1457194 & 737452 & 5.0 & 4.7816 & TST & \\
\hline CHEMBL1500887 & 737452 & 5.0 & 5.0411 & TRN & \\
\hline CHEMBL1438038 & 737452 & 5.0 & 4.6187 & TRN & \\
\hline CHEMBL518292 & 737452 & 5.6289 & 5.8948 & TST & \\
\hline CHEMBL1399698 & 737452 & 5.0 & 4.771 & TRN & \\
\hline CHEMBL1698464 & 737452 & 5.6536 & 4.6602 & TRN & \\
\hline CHEMBL1595015 & 737452 & 5.0 & 5.5688 & TRN & \\
\hline CHEMBL1303281 & 737452 & 5.0 & 4.8554 & TRN & \\
\hline CHEMBL1576094 & 737452 & 4.0 & 4.492 & TRN & \\
\hline CHEMBL1555483 & 737452 & 4.0 & 4.375 & TRN & \\
\hline CHEMBL1335610 & 737452 & 5.0 & 4.5907 & TRN & \\
\hline CHEMBL3191430 & 737452 & 5.3497 & 4.5935 & TRN & \\
\hline CHEMBL1334404 & 737452 & 5.0 & 4.9404 & TST & \\
\hline CHEMBL1885024 & 737452 & 5.1959 & 4.38399 & 99999999995 & TRN \\
\hline CHEMBL1460352 & 737452 & 5.5969 & 5.2707 & TRN & \\
\hline CHEMBL3193201 & 737452 & 4.0 & 4.7394 & TRN & \\
\hline CHEMBL1544818 & 737452 & 6.7959 & 6.0329 & TRN & \\
\hline CHEMBL1443632 & 737452 & 6.0 & 4.8865 & TRN & \\
\hline CHEMBL1523651 & 737452 & 5.0 & 5.0803 & TRN & \\
\hline CHEMBL1517755 & 737452 & 4.0 & 4.789 & TRN & \\
\hline CHEMBL1388457 & 737452 & 5.0 & 5.0183 & TST & \\
\hline CHEMBL454580 & 737452 & 5.2807 & 4.6627 & TRN & \\
\hline CHEMBL1546628 & 737452 & 5.0 & 4.7598 & TRN & \\
\hline CHEMBL1438877 & 737452 & 4.2182 & 4.6849 & TST & \\
\hline CHEMBL1603547 & 737452 & 5.0 & 4.5877 & TRN & \\
\hline CHEMBL1881714 & 737452 & 5.2373 & 4.5006 & TRN & \\
\hline CHEMBL1537098 & 737452 & 7.7959 & 6.775 & TRN & \\
\hline CHEMBL1600073 & 737452 & 5.9208 & 5.1659 & TRN & \\
\hline CHEMBL3207920 & 737452 & 5.2168 & 5.0096 & TRN & \\
\hline CHEMBL1403242 & 737452 & 5.0 & 4.8459 & TRN & \\
\hline CHEMBL3191235 & 737452 & 5.2411 & 5.1288 & TRN & \\
\hline CHEMBL3192431 & 737452 & 5.0 & 4.4576 & TRN & \\
\hline CHEMBL1528880 & 737452 & 5.0 & 4.9905 & TST & \\
\hline CHEMBL1367089 & 737452 & 5.1284 & 4.5575 & TRN & \\
\hline CHEMBL1519375 & 737452 & 4.0 & 4.8324 & TRN & \\
\hline CHEMBL1561287 & 737452 & 4.0 & 4.7374 & TRN & \\
\hline CHEMBL1596965 & 737452 & 4.0 & 4.48600 & 0000000001 & TRN \\
\hline CHEMBL1420717 & 737452 & 5.0 & 4.7201 & TRN & \\
\hline CHEMBL1421518 & 737452 & 6.0 & 5.1801 & TRN & \\
\hline CHEMBL1420175 & 737452 & 5.2503 & 4.5664 & TRN & \\
\hline CHEMBL1581024 & 737452 & 5.5467 & 5.0032 & TST & \\
\hline CHEMBL1367885 & 737452 & 5.0 & 4.4675 & TRN & \\
\hline CHEMBL1537509 & 737452 & 5.2984 & 6.272 & TST & \\
\hline CHEMBL1374860 & 737452 & 5.0 & 5.2143 & TRN & \\
\hline
\end{tabular}




\begin{tabular}{|c|c|c|c|c|c|}
\hline \multirow[b]{2}{*}{ CHEMBL1415425 } & \multicolumn{5}{|c|}{ Supplemental Table S2.txt } \\
\hline & 737452 & 4.0048 & 4.6461 & TRN & \\
\hline CHEMBL523200 & 737452 & 5.0 & 4.7991 & TRN & \\
\hline CHEMBL3856095 & 737452 & 5.2907 & 4.9001 & TRN & \\
\hline CHEMBL1336745 & 737452 & 4.0 & 4.6522 & TRN & \\
\hline CHEMBL1974389 & 737452 & 5.7878 & 5.1047 & TRN & \\
\hline CHEMBL1560954 & 737452 & 4.2865 & 4.8127 & TRN & \\
\hline CHEMBL1532668 & 737452 & 5.2807 & 4.7406 & TRN & \\
\hline CHEMBL 3190220 & 737452 & 4.0 & 4.35800 & 00000000005 & TRN \\
\hline CHEMBL1598694 & 737452 & 4.0 & 4.6558 & TRN & \\
\hline CHEMBL1505552 & 737452 & 5.1035 & 5.2711 & TRN & \\
\hline CHEMBL1496754 & 737452 & 5.3862 & 4.6279 & TRN & \\
\hline CHEMBL1557782 & 737452 & 5.317 & 4.2771 & TRN & \\
\hline CHEMBL1545727 & 737452 & 4.0 & 5.0072 & TRN & \\
\hline CHEMBL1444859 & 737452 & 4.1752 & 4.832 & TRN & \\
\hline CHEMBL1321538 & 737452 & 5.4815 & 5.1347 & TRN & \\
\hline CHEMBL1339433 & 737452 & 5.2434 & 4.77 & TRN & \\
\hline CHEMBL1450156 & 737452 & 4.1904 & 4.5322 & TRN & \\
\hline CHEMBL1470148 & 737452 & 4.0448 & 4.7059 & TRN & \\
\hline CHEMBL3197151 & 737452 & 4.0 & 4.3341 & TRN & \\
\hline CHEMBL1605094 & 737452 & 5.0 & 4.2667 & TRN & \\
\hline CHEMBL1541441 & 737452 & 4.0 & 5.1937 & TST & \\
\hline CHEMBL1422030 & 737452 & 4.0 & 5.1654 & TRN & \\
\hline CHEMBL1448941 & 737452 & 5.0 & 4.5172 & TRN & \\
\hline CHEMBL1426059 & 737452 & 4.0123 & 4.86100 & 0000000001 & TRN \\
\hline CHEMBL1538215 & 737452 & 5.0477 & 5.1317 & TRN & \\
\hline CHEMBL1360493 & 737452 & 5.0 & 4.9667 & TST & \\
\hline CHEMBL1708334 & 737452 & 6.0 & 4.4436 & TST & \\
\hline CHEMBL1484741 & 737452 & 4.426 & 4.8807 & TRN & \\
\hline CHEMBL1888628 & 737452 & 5.0 & 4.7285 & TRN & \\
\hline CHEMBL1323101 & 737452 & 5.0 & 4.3231 & TRN & \\
\hline CHEMBL1402510 & 737452 & 7.3979 & 6.7028 & TRN & \\
\hline CHEMBL1439938 & 737452 & 5.857 & 5.313 & TRN & \\
\hline CHEMBL1498509 & 737452 & 5.4868 & 5.1718 & TRN & \\
\hline CHEMBL 2004918 & 737452 & 5.0 & 4.9953 & TRN & \\
\hline CHEMBL1448637 & 737452 & 5.0 & 5.6095 & TRN & \\
\hline CHEMBL1409272 & 737452 & 5.0 & 5.2739 & TRN & \\
\hline CHEMBL1525956 & 737452 & 5.0 & 4.6896 & TRN & \\
\hline CHEMBL1363662 & 737452 & 5.0 & 4.9515 & TST & \\
\hline CHEMBL1352270 & 737452 & 5.4547 & 4.6665 & TRN & \\
\hline CHEMBL1971875 & 737452 & 4.0259 & 4.3938 & TRN & \\
\hline CHEMBL1562493 & 737452 & 4.1249 & 5.0796 & TST & \\
\hline CHEMBL1411310 & 737452 & 5.0 & 4.6949 & TRN & \\
\hline CHEMBL1451278 & 737452 & 4.0 & 4.8375 & TRN & \\
\hline CHEMBL3189719 & 737452 & 4.1593 & 4.5826 & TRN & \\
\hline CHEMBL1505922 & 737452 & 5.0255 & 4.9438 & TRN & \\
\hline CHEMBL1524500 & 737452 & 5.0 & 5.1287 & TRN & \\
\hline CHEMBL1455813 & 737452 & 5.0 & 4.5335 & TRN & \\
\hline CHEMBL1586432 & 737452 & 4.0 & 4.5119 & TRN & \\
\hline
\end{tabular}


Supplemental Table S2.txt

\begin{tabular}{|c|c|c|c|c|c|}
\hline CHEMBL1453673 & 737452 & 5.3002 & 4.5484 & TRN & \\
\hline CHEMBL1485865 & 737452 & 5.1118 & 4.9234 & TRN & \\
\hline CHEMBL1493101 & 737452 & 5.0 & 5.0873 & TRN & \\
\hline CHEMBL1586425 & 737452 & 4.5186 & 4.699 & TRN & \\
\hline CHEMBL1580520 & 737452 & 5.0 & 4.9126 & TRN & \\
\hline CHEMBL1322082 & 737452 & 5.0 & 5.1486 & TRN & \\
\hline CHEMBL1541967 & 737452 & 5.1481 & 5.0559 & TRN & \\
\hline CHEMBL1353664 & 737452 & 4.0 & 4.6369 & TRN & \\
\hline CHEMBL494255 & 737452 & 5.2434 & 5.5351 & TST & \\
\hline CHEMBL1531073 & 737452 & 5.3546 & 5.2579 & TRN & \\
\hline CHEMBL1345063 & 737452 & 6.0 & 4.7144 & TRN & \\
\hline CHEMBL3193507 & 737452 & 4.0 & 4.6686 & TRN & \\
\hline CHEMBL1303463 & 737452 & 5.0 & 4.9875 & TRN & \\
\hline CHEMBL1446421 & 737452 & 5.0 & 4.6874 & TRN & \\
\hline CHEMBL1310617 & 737452 & 6.5229 & 6.4087 & TRN & \\
\hline CHEMBL1583552 & 737452 & 5.0 & 5.0616 & TRN & \\
\hline CHEMBL1374298 & 737452 & 5.2218 & 4.8739 & TRN & \\
\hline CHEMBL1328168 & 737452 & 5.0278 & 4.5683 & TRN & \\
\hline CHEMBL1490887 & 737452 & 4.0 & 4.8121 & TST & \\
\hline CHEMBL1600882 & 737452 & 5.0 & 4.8234 & TRN & \\
\hline CHEMBL1349747 & 737452 & 5.0 & 4.5109 & TST & \\
\hline CHEMBL1453722 & 737452 & 5.5719 & 5.892 & TRN & \\
\hline CHEMBL1558724 & 737452 & 4.0 & 4.6644 & TRN & \\
\hline CHEMBL1503834 & 737452 & 4.1707 & 4.6418 & TRN & \\
\hline CHEMBL1386876 & 737452 & 4.0 & 4.5255 & TRN & \\
\hline CHEMBL3197258 & 737452 & 5.0 & 4.42899 & 9999999999 & TRN \\
\hline CHEMBL270297 & 737452 & 5.6576 & 5.8143 & TST & \\
\hline CHEMBL1332308 & 737452 & 5.301 & 5.3463 & TRN & \\
\hline CHEMBL1365696 & 737452 & \multicolumn{3}{|c|}{5.3420000000000005} & TRN \\
\hline CHEMBL1457594 & 737452 & 5.0 & 5.0644 & TRN & \\
\hline CHEMBL1322557 & 737452 & 5.0 & 4.7266 & TRN & \\
\hline CHEMBL3192328 & 737452 & 5.0391 & 4.5053 & TRN & \\
\hline CHEMBL1419438 & 737452 & 5.0 & 4.6967 & TRN & \\
\hline CHEMBL1453212 & 737452 & 4.0 & 4.6844 & TRN & \\
\hline CHEMBL1489479 & 737452 & 4.0 & 4.4989 & TRN & \\
\hline CHEMBL1340420 & 737452 & 5.0 & 4.2958 & TRN & \\
\hline CHEMBL498373 & 737452 & 5.2581 & 5.0679 & TRN & \\
\hline CHEMBL1447341 & 737452 & 4.0 & 4.7058 & TRN & \\
\hline CHEMBL 259018 & 737452 & 5.3526 & 5.1264 & TRN & \\
\hline CHEMBL1464853 & 737452 & 4.0278 & 5.1971 & TST & \\
\hline CHEMBL1612558 & 737452 & 5.0 & 4.4181 & TRN & \\
\hline CHEMBL1369671 & 737452 & 5.0482 & 4.4897 & TRN & \\
\hline CHEMBL1550734 & 737452 & 4.1844 & 6.2164 & TRN & \\
\hline CHEMBL3185655 & 737452 & 6.7959 & 6.7136 & TRN & \\
\hline CHEMBL 300389 & 737452 & 6.7959 & 6.8375 & TRN & \\
\hline CHEMBL1341981 & 737452 & 5.0937 & 5.1917 & TRN & \\
\hline CHEMBL1324125 & 737452 & 7.7959 & 6.4723 & TRN & \\
\hline CHEMBL1501680 & 737452 & 4.0 & 4.2935 & TRN & \\
\hline
\end{tabular}




\begin{tabular}{|c|c|c|c|c|c|c|}
\hline \multicolumn{7}{|c|}{ Supplemental Table S2.txt } \\
\hline CHEMBL 3197580 & 737452 & 5.0 & 4.7301 & TRN & & \\
\hline CHEMBL1427397 & 737452 & 4.0 & 4.8356 & TRN & & \\
\hline CHEMBL1576787 & 737452 & 4.0 & 4.7779 & TRN & & \\
\hline CHEMBL1522800 & 737452 & 4.0 & 4.8811 & TRN & & \\
\hline CHEMBL1541177 & 737452 & 5.0 & 4.4785 & TRN & & \\
\hline CHEMBL1468721 & 737452 & 5.0 & 4.9121 & TRN & & \\
\hline CHEMBL1367572 & 737452 & 5.0 & 4.4459 & TRN & & \\
\hline CHEMBL1520777 & 737452 & 5.3645 & 5.3766 & TST & & \\
\hline CHEMBL1457060 & 737452 & 5.0044 & 4.5654 & TRN & & \\
\hline CHEMBL1448771 & 737452 & 5.0 & 4.811 & TST & & \\
\hline CHEMBL610198 & 737452 & 5.2815 & 5.2088 & TRN & & \\
\hline CHEMBL1447697 & 737452 & 5.2557 & 4.9378 & TRN & & \\
\hline CHEMBL3211865 & 737452 & 5.0 & 4.6026 & TRN & & \\
\hline CHEMBL1420682 & 737452 & 4.0 & 4.2468 & TRN & & \\
\hline CHEMBL1532453 & 737452 & 4.0 & 5.2196 & TST & & \\
\hline CHEMBL1563483 & 737452 & 5.5719 & 5.6272 & TST & & \\
\hline CHEMBL1587837 & 737452 & 4.0 & 4.2851 & TRN & & \\
\hline CHEMBL1409883 & 737452 & 5.8297 & 4.9814 & TRN & & \\
\hline CHEMBL1389966 & 737452 & 6.5376 & 5.4466 & TRN & & \\
\hline CHEMBL1363514 & 737452 & 5.0 & 5.3018 & TRN & & \\
\hline CHEMBL1542470 & 737452 & 4.0 & 4.6598 & TRN & & \\
\hline CHEMBL 2000517 & 737452 & 5.9172 & 5.9766 & TRN & & \\
\hline CHEMBL1494120 & 737452 & 5.4855 & 5.7168 & TRN & & \\
\hline CHEMBL1393615 & 737452 & 5.109 & 5.1201 & TRN & & \\
\hline CHEMBL3199665 & 737452 & 5.2204 & 4.5328 & TRN & & \\
\hline CHEMBL1545361 & 737452 & 4.0 & 4.4248 & TRN & & \\
\hline CHEMBL1541809 & 737452 & 5.0 & 4.8531 & TRN & & \\
\hline CHEMBL1575594 & 737452 & 5.3045 & 5.3533 & TST & & \\
\hline CHEMBL1385295 & 737452 & 5.0605 & 4.8612 & TST & & \\
\hline CHEMBL1385413 & 737452 & 5.0506 & 5.0071 & TRN & & \\
\hline CHEMBL 1472426 & 737452 & 4.0 & 4.2186 & TRN & & \\
\hline CHEMBL1418598 & 737452 & 4.0526 & 4.586 & TRN & & \\
\hline CHEMBL1371946 & 737452 & 5.6799 & 4.7757 & TST & & \\
\hline CHEMBL1516857 & 737452 & 5.0 & 4.6951 & TST & & \\
\hline CHEMBL1374511 & 737452 & 5.224 & 4.9212 & TRN & & \\
\hline CHEMBL1342907 & 737452 & 5.2104 & 4.7913 & TRN & & \\
\hline CHEMBL1335176 & 737452 & 5.32700 & 00000000 & 01 & 5.9169 & \\
\hline CHEMBL3193792 & 737452 & 4.0 & 4.1945 & TRN & & \\
\hline CHEMBL1313077 & 737452 & 4.0 & 4.4559 & TRN & & \\
\hline CHEMBL1379991 & 737452 & 5.0 & 4.3565 & TST & & \\
\hline CHEMBL1567571 & 737452 & 6.0044 & 4.7535 & TRN & & \\
\hline CHEMBL1559968 & 737452 & 5.0 & 5.2485 & TST & & \\
\hline CHEMBL1417937 & 737452 & 5.0 & 4.442 & TRN & & \\
\hline CHEMBL1448732 & 737452 & 4.2083 & 4.7714 & TRN & & \\
\hline CHEMBL1338958 & 737452 & 5.4248 & 4.9447 & TRN & & \\
\hline CHEMBL1344294 & 737452 & 4.0 & 4.5603 & TRN & & \\
\hline CHEMBL1557741 & 737452 & 5.0 & 4.6168 & TRN & & \\
\hline CHEMBL1596373 & 737452 & 4.0 & 4.6538 & TRN & & \\
\hline
\end{tabular}




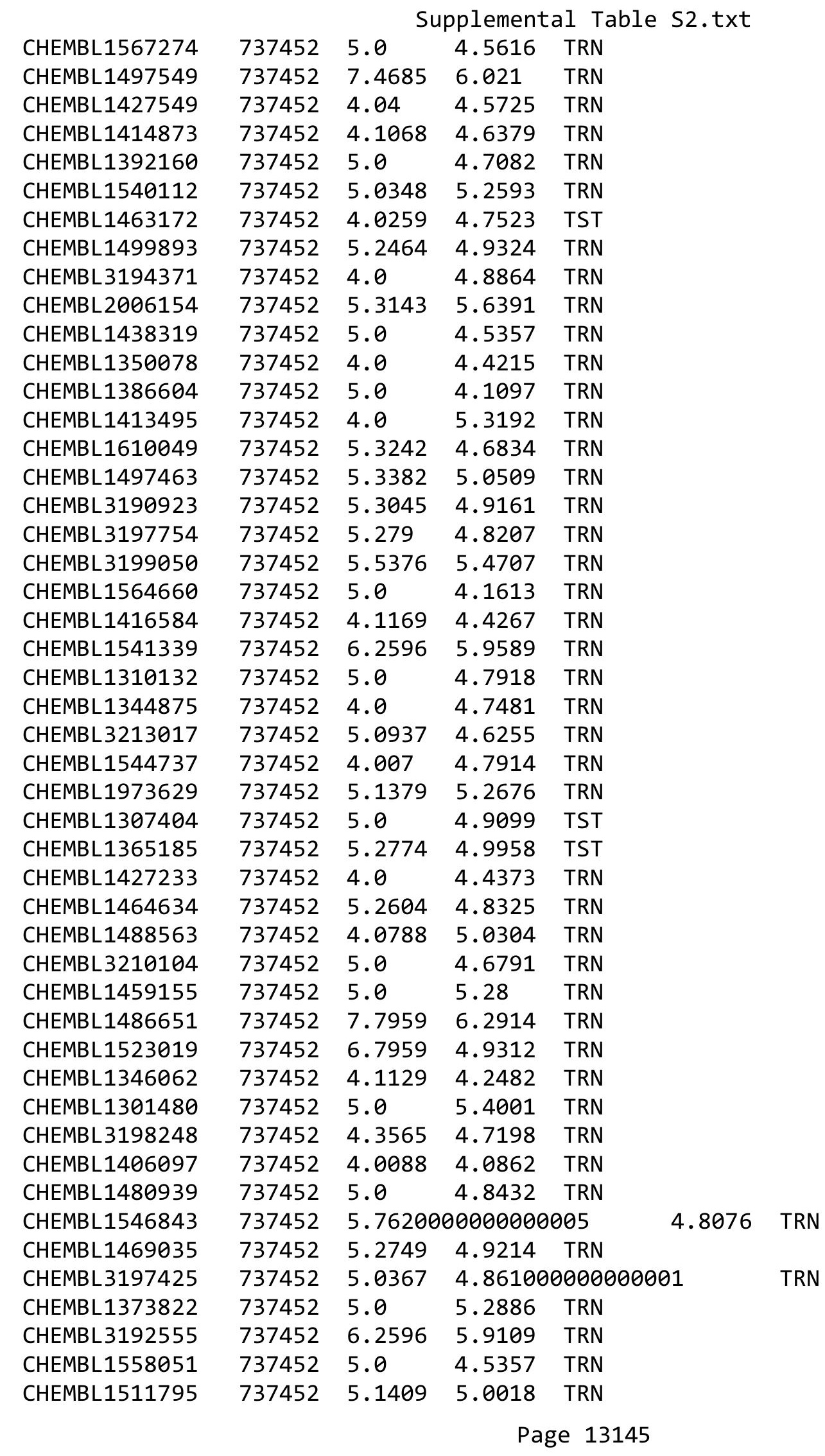




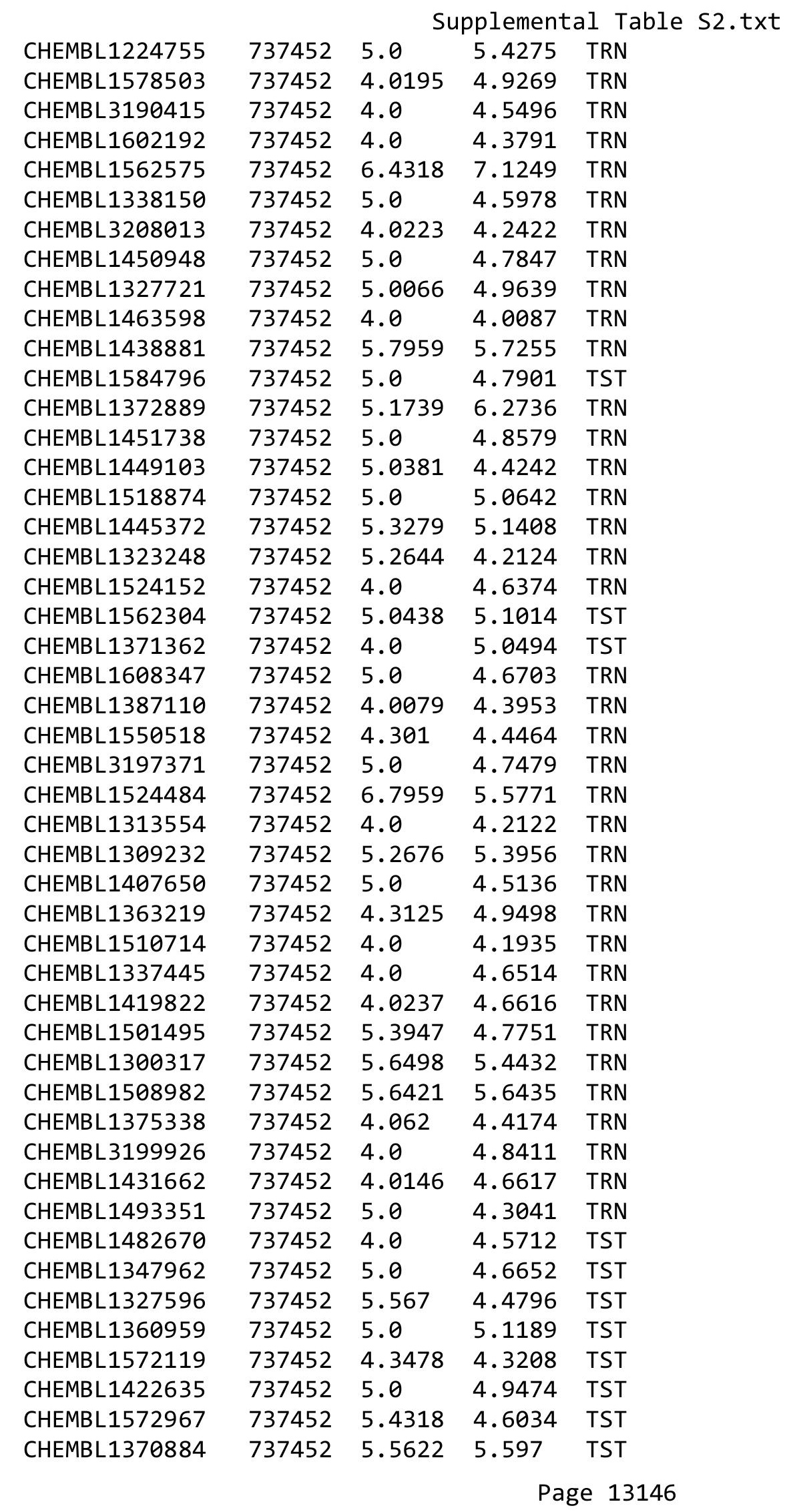




\begin{tabular}{|c|c|c|c|c|}
\hline \multicolumn{5}{|c|}{ Supplemental Table S2.txt } \\
\hline CHEMBL1576110 & 737452 & 5.0 & 4.9837 & TST \\
\hline CHEMBL1420411 & 737452 & 5.2048 & 4.1957 & TST \\
\hline CHEMBL1349113 & 737452 & 4.2358 & 4.8043 & TST \\
\hline CHEMBL1367316 & 737452 & 4.3325 & 5.1269 & TST \\
\hline CHEMBL1422414 & 737452 & 5.0 & 4.7214 & TST \\
\hline CHEMBL570399 & 737452 & 5.0 & 4.9232 & TST \\
\hline CHEMBL1414964 & 737452 & 5.0 & 4.9067 & TST \\
\hline CHEMBL1492922 & 737452 & 5.5317 & 5.2978 & TST \\
\hline CHEMBL1427542 & 737452 & 5.0 & 4.9244 & TST \\
\hline CHEMBL1503152 & 737452 & 5.0 & 4.298 & TST \\
\hline CHEMBL1532114 & 737452 & 4.0 & 4.9124 & TST \\
\hline CHEMBL1399102 & 737452 & 4.0883 & 4.3816 & TST \\
\hline CHEMBL1455039 & 737452 & 5.0 & 4.2972 & TST \\
\hline CHEMBL1375155 & 737452 & 5.5735 & 5.061 & TST \\
\hline CHEMBL1405957 & 737452 & 5.0 & 5.0769 & TST \\
\hline CHEMBL1482663 & 737452 & 6.0 & 5.2032 & TST \\
\hline CHEMBL1384253 & 737452 & 5.8508 & 5.6609 & TST \\
\hline CHEMBL1452159 & 737452 & 6.7959 & 6.4685 & TST \\
\hline CHEMBL1971234 & 737452 & 5.0 & 4.8827 & TST \\
\hline CHEMBL1972750 & 737452 & 5.0931 & 4.8859 & TST \\
\hline CHEMBL1524101 & 737452 & 4.0 & 4.7869 & TST \\
\hline CHEMBL1576870 & 737452 & 5.7959 & 6.224 & TST \\
\hline CHEMBL584269 & 737452 & 5.0 & 5.1371 & TST \\
\hline CHEMBL1340713 & 737452 & 4.0 & 4.9007 & TST \\
\hline CHEMBL1519585 & 737452 & 4.3696 & 4.6431 & TST \\
\hline CHEMBL3209649 & 737452 & 4.1221 & 4.3872 & TST \\
\hline CHEMBL1558847 & 737452 & 4.0218 & 5.0106 & TST \\
\hline CHEMBL3193769 & 737452 & 5.0 & 4.9667 & TST \\
\hline CHEMBL3196611 & 737452 & 5.0 & 4.6562 & TST \\
\hline CHEMBL1405952 & 737452 & 6.7959 & 6.5739 & TST \\
\hline CHEMBL1335844 & 737452 & 4.1798 & 4.6776 & TST \\
\hline CHEMBL3192030 & 737452 & 4.1512 & 4.9939 & TST \\
\hline CHEMBL1334291 & 737452 & 5.0 & 5.2806 & TST \\
\hline CHEMBL1402473 & 737452 & 5.0 & 4.7227 & TST \\
\hline CHEMBL1429906 & 737452 & 4.0 & 4.7707 & TST \\
\hline CHEMBL1994372 & 737452 & 4.0 & 4.8435 & TST \\
\hline CHEMBL1329054 & 737452 & 5.0 & 4.7656 & TST \\
\hline CHEMBL1422158 & 737452 & 4.06 & 4.2494 & TST \\
\hline CHEMBL1370379 & 737452 & 5.0 & 4.8351 & TST \\
\hline CHEMBL1303714 & 737452 & 5.0 & 4.8272 & TST \\
\hline CHEMBL1312016 & 737452 & 5.308 & 4.6538 & TST \\
\hline CHEMBL1456676 & 737452 & 5.0 & 4.5395 & TST \\
\hline CHEMBL1572266 & 737452 & 5.0 & 4.852 & TST \\
\hline CHEMBL1545384 & 737452 & 4.0223 & 5.2059 & TST \\
\hline CHEMBL1428071 & 737452 & 5.6676 & 5.0795 & TST \\
\hline CHEMBL578716 & 737452 & 4.0 & 5.6835 & TST \\
\hline CHEMBL1588525 & 737452 & 5.8962 & 5.439 & TST \\
\hline CHEMBL1345518 & 737452 & 4.0137 & 4.5032 & TST \\
\hline
\end{tabular}




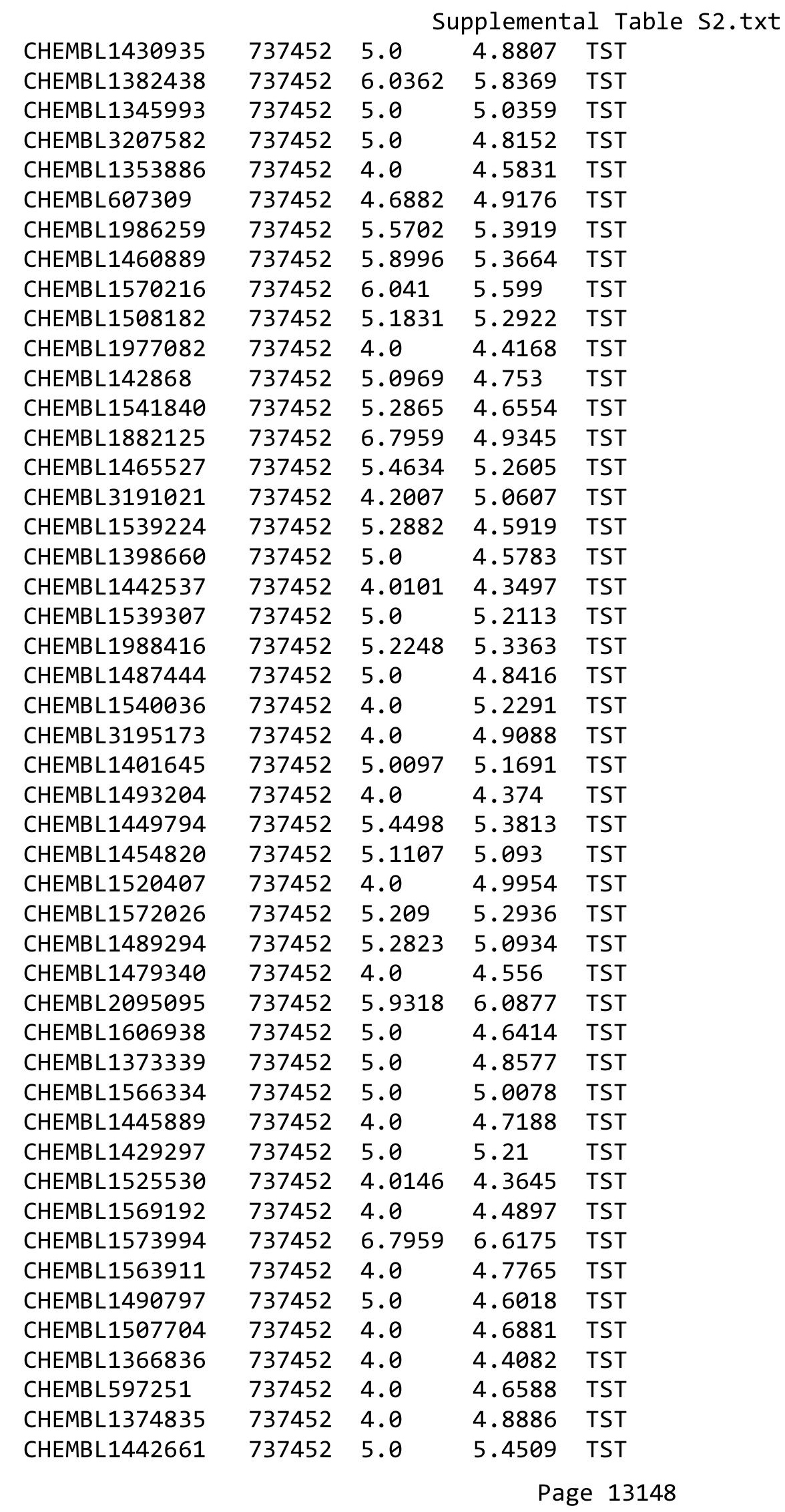




\begin{tabular}{|c|c|c|c|c|c|c|}
\hline \multirow[b]{2}{*}{ CHEMBL1587373 } & \multicolumn{6}{|c|}{ Supplemental Table S2.txt } \\
\hline & 737452 & 5.2668 & 4.8161 & TST & & \\
\hline CHEMBL1310221 & 737452 & 4.2069 & 4.8941 & TST & & \\
\hline CHEMBL261693 & 737452 & 4.172 & 4.6646 & TST & & \\
\hline CHEMBL1565993 & 737452 & 4.0391 & 4.6795 & TST & & \\
\hline CHEMBL3193107 & 737452 & 5.71899 & 99999999 & 99 & .5746 & TST \\
\hline CHEMBL2003943 & 737452 & 5.1524 & 4.8107 & TST & & \\
\hline CHEMBL 3193885 & 737452 & 4.0 & 4.2894 & TST & & \\
\hline CHEMBL3212285 & 737452 & 5.4572 & 4.7277 & TST & & \\
\hline CHEMBL 3672746 & 1528866 & 7.3098 & 7.1307 & TRN & & \\
\hline CHEMBL3672816 & 1528866 & 6.585 & 6.6138 & TRN & & \\
\hline CHEMBL 3672823 & 1528866 & 6.0 & 7.086 & TST & & \\
\hline CHEMBL 3672780 & 1528866 & 7.6253 & 7.5015 & TRN & & \\
\hline CHEMBL 3672744 & 1528866 & 8.0269 & 7.3117 & TRN & & \\
\hline CHEMBL 3672759 & 1528866 & 6.6105 & 6.819 & TRN & & \\
\hline CHEMBL 3672773 & 1528866 & 6.8147 & 7.5203 & TRN & & \\
\hline CHEMBL3672835 & 1528866 & 6.9586 & 6.9421 & TRN & & \\
\hline CHEMBL3672797 & 1528866 & 6.02 & 7.0584 & TRN & & \\
\hline CHEMBL 3672787 & 1528866 & 7.8069 & 7.45299 & 9999999999 & & TRN \\
\hline CHEMBL 3672777 & 1528866 & 6.2556 & 7.1586 & TST & & \\
\hline CHEMBL 3672805 & 1528866 & 6.4318 & 6.5354 & TRN & & \\
\hline CHEMBL 3672802 & 1528866 & 7.6459 & 6.8945 & TRN & & \\
\hline CHEMBL3672775 & 1528866 & 7.6737 & 7.4896 & TRN & & \\
\hline CHEMBL 3672786 & 1528866 & 7.3809 & 7.4872 & TRN & & \\
\hline CHEMBL 3672771 & 1528866 & 7.9626 & 7.5985 & TRN & & \\
\hline CHEMBL 3672750 & 1528866 & 7.0079 & 7.4059 & TRN & & \\
\hline CHEMBL 3672827 & 1528866 & 6.0263 & 7.08899 & 99999999995 & & TRN \\
\hline CHEMBL3093047 & 1528866 & 6.699 & 6.4983 & TRN & & \\
\hline CHEMBL 3672837 & 1528866 & 6.4134 & 6.8157 & TST & & \\
\hline CHEMBL 3672760 & 1528866 & 7.4248 & 7.3497 & TRN & & \\
\hline CHEMBL 3672764 & 1528866 & 7.7484 & 7.5016 & TRN & & \\
\hline CHEMBL 3672838 & 1528866 & 6.4572 & 6.9992 & TST & & \\
\hline CHEMBL 3672754 & 1528866 & 6.7129 & 7.0209 & TST & & \\
\hline CHEMBL 3672766 & 1528866 & 6.0101 & 7.5294 & TRN & & \\
\hline CHEMBL3672789 & 1528866 & 7.8268 & 7.3157 & TRN & & \\
\hline CHEMBL 3672803 & 1528866 & 6.0234 & 6.7826 & TRN & & \\
\hline CHEMBL 3672748 & 1528866 & 7.2118 & 7.3649 & TRN & & \\
\hline CHEMBL3672768 & 1528866 & 7.7122 & 7.6144 & TRN & & \\
\hline CHEMBL3672806 & 1528866 & 7.2596 & 6.5419 & TRN & & \\
\hline CHEMBL 3672813 & 1528866 & 6.0 & 7.1611 & TRN & & \\
\hline CHEMBL 3672794 & 1528866 & 7.1612 & 7.13200 & 0000000001 & & TRN \\
\hline CHEMBL 3672781 & 1528866 & 7.7959 & 7.5551 & TRN & & \\
\hline CHEMBL 3672810 & 1528866 & 6.6968 & 6.7031 & TRN & & \\
\hline CHEMBL 3672798 & 1528866 & 6.404 & 7.1152 & TRN & & \\
\hline CHEMBL3672749 & 1528866 & 8.8239 & 7.4082 & TRN & & \\
\hline CHEMBL 3938102 & 1528866 & 7.2487 & 6.9891 & TST & & \\
\hline CHEMBL 3672822 & 1528866 & 6.0 & 7.0978 & TST & & \\
\hline CHEMBL 3672833 & 1528866 & 6.7773 & 6.6758 & TST & & \\
\hline CHEMBL3672756 & 1528866 & 7.71899 & 99999999 & & .6371 & TRN \\
\hline
\end{tabular}


Supplemental Table S2.txt

\begin{tabular}{|c|c|c|c|c|c|c|}
\hline CHEMBL 3672745 & 1528866 & 7.5498 & 7.0578 & TRN & & \\
\hline CHEMBL3672818 & 1528866 & 6.6262 & 7.0704 & TRN & & \\
\hline CHEMBL3672767 & 1528866 & 7.1878 & 7.6354 & TRN & & \\
\hline CHEMBL 3672778 & 1528866 & 7.5258 & 7.3461 & TRN & & \\
\hline CHEMBL3672790 & 1528866 & 7.2907 & 7.3723 & TRN & & \\
\hline CHEMBL3672830 & 1528866 & 7.699 & 6.7464 & TST & & \\
\hline CHEMBL3672755 & 1528866 & 6.9654 & 7.061 & TRN & & \\
\hline CHEMBL3672831 & 1528866 & 6.7959 & 6.5747 & TRN & & \\
\hline CHEMBL 3672774 & 1528866 & 8.0757 & 7.6307 & TRN & & \\
\hline CHEMBL3672807 & 1528866 & 7.0044 & 6.6602 & TRN & & \\
\hline CHEMBL3672752 & 1528866 & 7.1186 & 7.0367 & TRN & & \\
\hline CHEMBL3672796 & 1528866 & 6.8254 & 7.1311 & TRN & & \\
\hline CHEMBL3672809 & 1528866 & 6.3651 & 6.83 & TST & & \\
\hline CHEMBL 3672765 & 1528866 & 7.5622 & 7.5226 & TRN & & \\
\hline CHEMBL3672791 & 1528866 & 7.5986 & 7.3214 & TRN & & \\
\hline CHEMBL3672801 & 1528866 & 7.2358 & 6.8048 & TRN & & \\
\hline CHEMBL3672795 & 1528866 & 7.4698 & 7.1471 & TRN & & \\
\hline CHEMBL3672836 & 1528866 & 6.8239 & 6.6284 & TRN & & \\
\hline CHEMBL 3672832 & 1528866 & 7.5686 & 6.7412 & TST & & \\
\hline CHEMBL3672769 & 1528866 & 7.7932 & 7.6658 & TRN & & \\
\hline CHEMBL3672788 & 1528866 & 7.21399 & 99999999 & 995 & 7.379 & TRN \\
\hline CHEMBL3672817 & 1528866 & 6.6407 & 6.8811 & TRN & & \\
\hline CHEMBL 3672747 & 1528866 & 8.0506 & 7.3242 & TRN & & \\
\hline CHEMBL 3672779 & 1528866 & 8.0269 & 7.4702 & TRN & & \\
\hline CHEMBL3672799 & 1528866 & 7.4001 & 7.108 & TRN & & \\
\hline CHEMBL3672753 & 1528866 & 6.8542 & 6.9937 & TRN & & \\
\hline CHEMBL3672804 & 1528866 & 6.9996 & 6.857 & TRN & & \\
\hline CHEMBL 3672763 & 1528866 & 7.9727 & 7.5402 & TRN & & \\
\hline CHEMBL 3672834 & 1528866 & 6.9666 & 6.7313 & TST & & \\
\hline CHEMBL3672825 & 1528866 & 6.5126 & 7.0607 & TRN & & \\
\hline CHEMBL3672757 & 1528866 & 7.8861 & 7.6229 & TRN & & \\
\hline CHEMBL 3672785 & 1528866 & 6.7894 & 7.4201 & TRN & & \\
\hline CHEMBL3672762 & 1528866 & 7.4868 & 7.355 & TRN & & \\
\hline CHEMBL 3672783 & 1528866 & 6.8111 & 7.5065 & TRN & & \\
\hline CHEMBL3672772 & 1528866 & 7.9208 & 7.6366 & TRN & & \\
\hline CHEMBL3672792 & 1528866 & 7.2321 & 7.2121 & TRN & & \\
\hline CHEMBL3672815 & 1528866 & 6.3679 & 6.7952 & TST & & \\
\hline CHEMBL 3672784 & 1528866 & 7.8928 & 7.6083 & TRN & & \\
\hline CHEMBL 3672782 & 1528866 & 6.6659 & 7.221 & TRN & & \\
\hline CHEMBL 3672770 & 1528866 & 7.3002 & 7.5846 & TRN & & \\
\hline CHEMBL3672758 & 1528866 & 8.1938 & 7.6108 & TST & & \\
\hline CHEMBL3972782 & 1528866 & 8.0269 & 6.7462 & TST & & \\
\hline CHEMBL3672808 & 1528866 & 7.1739 & 6.8106 & TST & & \\
\hline CHEMBL 3672800 & 1528866 & 7.5186 & 7.4635 & TST & & \\
\hline CHEMBL 3672761 & 1528866 & 7.2226 & 7.1671 & TST & & \\
\hline CHEMBL3639716 & 1528866 & 7.5017 & 7.5885 & TST & & \\
\hline CHEMBL3672793 & 1528866 & 7.3595 & 7.5551 & TST & & \\
\hline CHEMBL3672776 & 1528866 & 7.6676 & 7.5218 & TST & & \\
\hline
\end{tabular}


Supplemental Table S2.txt

\begin{tabular}{|c|c|c|c|c|}
\hline CHEMBL 3672751 & 1528866 & 7.9318 & 7.1791 & TST \\
\hline CHEMBL 3672828 & 1528866 & 6.0 & 7.0659 & TST \\
\hline CHEMBL3190829 & 688689 & 4.9578 & 5.1708 & TRN \\
\hline CHEMBL1515202 & 688689 & 4.9133 & 5.0732 & TST \\
\hline CHEMBL1486536 & 688689 & 3.301 & 4.2373 & TST \\
\hline CHEMBL1482585 & 688689 & 5.2197 & 5.3171 & TRN \\
\hline CHEMBL1605668 & 688689 & 5.0048 & 4.3437 & TRN \\
\hline CHEMBL1366367 & 688689 & 4.7823 & 4.8036 & TRN \\
\hline CHEMBL1699206 & 688689 & 4.7696 & 4.9161 & TRN \\
\hline CHEMBL1994007 & 688689 & 4.3956 & 4.0414 & TRN \\
\hline CHEMBL1471907 & 688689 & 4.9889 & 4.7491 & TRN \\
\hline CHEMBL1400492 & 688689 & 3.301 & 4.0511 & TRN \\
\hline CHEMBL1444094 & 688689 & 4.3465 & 4.3491 & TRN \\
\hline CHEMBL1430983 & 688689 & 3.301 & 4.0739 & TRN \\
\hline CHEMBL 3198341 & 688689 & 4.6264 & 4.7478 & TRN \\
\hline CHEMBL1329925 & 688689 & 5.6635 & 4.8729 & TRN \\
\hline CHEMBL1420379 & 688689 & 3.301 & 3.9445 & TRN \\
\hline CHEMBL1381868 & 688689 & 4.5677 & 4.3724 & TRN \\
\hline CHEMBL1523577 & 688689 & 4.3995 & 4.535 & TRN \\
\hline CHEMBL1596373 & 688689 & 4.3022 & 3.9303 & TRN \\
\hline CHEMBL1535636 & 688689 & 3.301 & 4.3504 & TRN \\
\hline CHEMBL1595563 & 688689 & 4.5219 & 3.6413 & TST \\
\hline CHEMBL1485064 & 688689 & 4.7084 & 5.0238 & TRN \\
\hline CHEMBL1390211 & 688689 & 4.7289 & 4.1951 & TRN \\
\hline CHEMBL1479888 & 688689 & 4.5556 & 4.4804 & TRN \\
\hline CHEMBL1492305 & 688689 & 5.3536 & 4.3064 & TRN \\
\hline CHEMBL1465297 & 688689 & 3.301 & 4.2942 & TRN \\
\hline CHEMBL1350958 & 688689 & 3.301 & 3.9705 & TRN \\
\hline CHEMBL1172192 & 688689 & 4.4162 & 3.7202 & TST \\
\hline CHEMBL1349290 & 688689 & 3.301 & 3.406 & TRN \\
\hline CHEMBL1497796 & 688689 & 4.3212 & 3.9795 & TRN \\
\hline CHEMBL1985327 & 688689 & 4.6012 & 4.689 & TRN \\
\hline CHEMBL1533561 & 688689 & 4.7585 & 4.5416 & TRN \\
\hline CHEMBL1571480 & 688689 & 4.372 & 4.5766 & TRN \\
\hline CHEMBL1339324 & 688689 & 4.3821 & 3.6434 & TST \\
\hline CHEMBL1303580 & 688689 & 5.2441 & 5.4883 & TRN \\
\hline CHEMBL1580170 & 688689 & 4.4377 & 5.1512 & TRN \\
\hline CHEMBL1585309 & 688689 & 3.301 & 4.211 & TRN \\
\hline CHEMBL1610008 & 688689 & 3.301 & 4.3867 & TRN \\
\hline CHEMBL1971033 & 688689 & 4.4987 & 4.1686 & TRN \\
\hline CHEMBL 3189418 & 688689 & 3.301 & 3.6119 & TRN \\
\hline CHEMBL1992702 & 688689 & 3.301 & 3.4081 & TRN \\
\hline CHEMBL1546890 & 688689 & 4.4059 & 5.2006 & TRN \\
\hline CHEMBL 3198976 & 688689 & 5.4425 & 5.0811 & TRN \\
\hline CHEMBL1578306 & 688689 & 4.341 & 4.201000 & 00000000005 \\
\hline CHEMBL1555218 & 688689 & 4.545 & 4.9047 & TRN \\
\hline CHEMBL1309484 & 688689 & 5.3716 & 4.3298 & TST \\
\hline CHEMBL1487870 & 688689 & 4.4105 & 3.7383 & TRN \\
\hline
\end{tabular}

Page 13151 


\begin{tabular}{|c|c|c|c|c|c|}
\hline \multirow[b]{2}{*}{ CHEMBL3199742 } & \multicolumn{5}{|c|}{ Supplemental Table S2.txt } \\
\hline & 688689 & 5.5186 & 5.0402 & TRN & \\
\hline CHEMBL1522531 & 688689 & 3.301 & 3.1733 & TRN & \\
\hline CHEMBL1409780 & 688689 & 3.301 & 3.6064 & TRN & \\
\hline CHEMBL1430309 & 688689 & 5.15 & 4.7673 & TRN & \\
\hline CHEMBL3194119 & 688689 & 4.453 & 4.2985 & TST & \\
\hline CHEMBL1602800 & 688689 & 5.699 & 5.2154 & TRN & \\
\hline CHEMBL1362734 & 688689 & 4.9237 & 4.1801 & TST & \\
\hline CHEMBL1527520 & 688689 & 4.5321 & 4.2005 & TST & \\
\hline CHEMBL1612433 & 688689 & 4.3601 & 3.4955 & TRN & \\
\hline CHEMBL1545384 & 688689 & 4.6844 & 4.1755 & TRN & \\
\hline CHEMBL1598628 & 688689 & 4.3862 & 4.1768 & TRN & \\
\hline CHEMBL1605235 & 688689 & 4.7883 & 4.5118 & TRN & \\
\hline CHEMBL1503209 & 688689 & 4.6643 & 3.8479 & TST & \\
\hline CHEMBL1553969 & 688689 & 4.4235 & 4.1129 & TRN & \\
\hline CHEMBL3195965 & 688689 & 5.1537 & 4.9007 & TRN & \\
\hline CHEMBL1367952 & 688689 & 4.9961 & 4.5599 & TRN & \\
\hline CHEMBL1351108 & 688689 & 4.3685 & 4.1889 & TRN & \\
\hline CHEMBL1392551 & 688689 & 5.0035 & 4.7407 & TRN & \\
\hline CHEMBL1162110 & 688689 & 3.301 & 3.9497 & TRN & \\
\hline CHEMBL3199737 & 688689 & 5.0057 & 4.1796 & TST & \\
\hline CHEMBL1528476 & 688689 & 4.4721 & 4.3985 & TRN & \\
\hline CHEMBL1543779 & 688689 & 5.3556 & 4.4408 & TRN & \\
\hline CHEMBL1431163 & 688689 & 4.312 & 4.6639 & TRN & \\
\hline CHEMBL3194804 & 688689 & 5.3516 & 5.1959 & TRN & \\
\hline CHEMBL1360615 & 688689 & 4.3246 & 4.2361 & TRN & \\
\hline CHEMBL3196762 & 688689 & 5.3224 & 5.2312 & TRN & \\
\hline CHEMBL1384843 & 688689 & 4.644 & 4.5222 & TRN & \\
\hline CHEMBL1521669 & 688689 & 3.301 & 3.6912 & TRN & \\
\hline CHEMBL1505688 & 688689 & 4.4274 & 4.1135 & TST & \\
\hline CHEMBL3194162 & 688689 & 4.3525 & 3.3781 & TST & \\
\hline CHEMBL3190873 & 688689 & 3.301 & 4.1764 & TST & \\
\hline CHEMBL1498887 & 688689 & 5.5186 & 4.0596 & TST & \\
\hline CHEMBL1979756 & 688689 & 4.3975 & 4.4878 & TST & \\
\hline CHEMBL1583537 & 688689 & 5.4672 & 4.396 & TST & \\
\hline CHEMBL1425600 & 688689 & 4.3514 & 4.3002 & TST & \\
\hline CHEMBL223453 & 688689 & 5.3215 & 5.104 & TST & \\
\hline CHEMBL1422601 & 688689 & 4.7256 & 3.6857 & TST & \\
\hline CHEMBL1417710 & 688689 & 5.0545 & 4.1242 & TST & \\
\hline CHEMBL1379894 & 688689 & 4.5237 & 4.3268 & TST & \\
\hline CHEMBL1775132 & 746117 & 7.699 & 7.7765 & TRN & \\
\hline CHEMBL1775163 & 746117 & 4.6003 & 4.8131 & TRN & \\
\hline CHEMBL1578785 & 746117 & 3.5003 & 3.6638 & TRN & \\
\hline CHEMBL1775144 & 746117 & 6.4089 & 6.6828 & TRN & \\
\hline CHEMBL1775133 & 746117 & 7.5229 & 7.57299 & 99999999995 & TRN \\
\hline CHEMBL1775124 & 746117 & 3.5003 & 4.6191 & TST & \\
\hline CHEMBL1532595 & 746117 & 5.2007 & 5.2811 & TRN & \\
\hline CHEMBL1775150 & 746117 & 6.7959 & 7.1793 & TRN & \\
\hline CHEMBL1775166 & 746117 & 5.3002 & 6.2837 & TST & \\
\hline
\end{tabular}

Page 13152 
Supplemental Table S2.txt

\begin{tabular}{|c|c|c|c|c|c|c|}
\hline CHEMBL1775127 & 746117 & 3.5003 & 3.988 & TRN & & \\
\hline CHEMBL1775155 & 746117 & 7.5229 & 7.101 & TRN & & \\
\hline CHEMBL1451935 & 746117 & 5.0 & 4.9083 & TRN & & \\
\hline CHEMBL1775140 & 746117 & 6.2518 & 6.5601 & TRN & & \\
\hline CHEMBL1775156 & 746117 & 3.5003 & 3.9581 & TRN & & \\
\hline CHEMBL1775117 & 746117 & 5.3107 & 5.1844 & TST & & \\
\hline CHEMBL1775049 & 746117 & 6.4318 & 6.1654 & TRN & & \\
\hline CHEMBL1775157 & 746117 & 4.7011 & 4.5616 & TRN & & \\
\hline CHEMBL1775159 & 746117 & 7.2007 & 7.0012 & TRN & & \\
\hline CHEMBL1775123 & 746117 & 4.7399 & 3.2458 & TST & & \\
\hline CHEMBL1775128 & 746117 & 3.5003 & 2.7835 & TRN & & \\
\hline CHEMBL1775121 & 746117 & 5.0 & 4.4529 & TRN & & \\
\hline CHEMBL1567269 & 746117 & 6.5086 & 6.1716 & TRN & & \\
\hline CHEMBL1775138 & 746117 & 6.4089 & 7.0508 & TRN & & \\
\hline CHEMBL1775129 & 746117 & 3.5003 & 3.72 & TRN & & \\
\hline CHEMBL1775113 & 746117 & 3.5003 & 4.1685 & TRN & & \\
\hline CHEMBL1775154 & 746117 & 4.9031 & 5.0855 & TRN & & \\
\hline CHEMBL1775160 & 746117 & 6.699 & 6.7266 & TRN & & \\
\hline CHEMBL1775142 & 746117 & 6.0 & 6.3665 & TRN & & \\
\hline CHEMBL1775136 & 746117 & 7.1024 & 7.1187 & TRN & & \\
\hline CHEMBL1775141 & 746117 & 5.9031 & 5.4703 & TRN & & \\
\hline CHEMBL1775122 & 746117 & 4.4949 & 4.4605 & TRN & & \\
\hline CHEMBL1542183 & 746117 & 3.5003 & 3.3703 & TRN & & \\
\hline CHEMBL1775168 & 746117 & 3.5003 & 3.5128 & TRN & & \\
\hline CHEMBL1775143 & 746117 & 6.8239 & 6.8776 & TRN & & \\
\hline CHEMBL1775131 & 746117 & 7.5229 & 6.6794 & TRN & & \\
\hline CHEMBL1775119 & 746117 & 5.0414 & 5.1685 & TRN & & \\
\hline CHEMBL1358782 & 746117 & 5.4001 & 5.5376 & TRN & & \\
\hline CHEMBL1775120 & 746117 & 5.0367 & 5.0859 & TRN & & \\
\hline CHEMBL1775145 & 746117 & 6.8239 & 6.6308 & TRN & & \\
\hline CHEMBL1775126 & 746117 & \multicolumn{3}{|c|}{4.821000000000001} & 4.8453 & TST \\
\hline CHEMBL1775158 & 746117 & 5.1002 & 5.3881 & TRN & & \\
\hline CHEMBL1775134 & 746117 & 5.6003 & 6.001 & TRN & & \\
\hline CHEMBL1775050 & 746117 & 5.8013 & 5.8417 & TRN & & \\
\hline CHEMBL1775162 & 746117 & 3.5003 & 3.4723 & TRN & & \\
\hline CHEMBL1775112 & 746117 & 5.7496 & 5.237 & TRN & & \\
\hline CHEMBL1775151 & 746117 & 7.0969 & 6.8976 & TRN & & \\
\hline CHEMBL1775152 & 746117 & 6.0 & 6.0891 & TRN & & \\
\hline CHEMBL1775125 & 746117 & 3.5003 & 3.3019 & TST & & \\
\hline CHEMBL1775137 & 746117 & 7.4949 & 6.919 & TRN & & \\
\hline CHEMBL1775118 & 746117 & 5.8239 & 5.8039 & TRN & & \\
\hline CHEMBL1775130 & 746117 & 3.5003 & 3.4156 & TRN & & \\
\hline CHEMBL1775116 & 746117 & 5.301 & 5.6849 & TRN & & \\
\hline CHEMBL1775146 & 746117 & 5.8013 & 6.4437 & TRN & & \\
\hline CHEMBL1775164 & 746117 & 5.2007 & 5.0754 & TRN & & \\
\hline CHEMBL1775114 & 746117 & 5.8013 & 5.3984 & TRN & & \\
\hline CHEMBL1775165 & 746117 & 3.5003 & 3.4588 & TRN & & \\
\hline CHEMBL1773093 & 746117 & 7.2007 & 6.9528 & TRN & & \\
\hline
\end{tabular}




\begin{tabular}{|c|c|c|c|c|c|}
\hline & & \multicolumn{4}{|c|}{ Supplemental Table S2.txt } \\
\hline CHEMBL1775115 & 746117 & 6.2007 & 5.9501 & TRN & \\
\hline CHEMBL1775149 & 746117 & 4.8601 & 5.3104 & TST & \\
\hline CHEMBL1346147 & 746117 & 6.301 & 5.4853 & TST & \\
\hline CHEMBL1775167 & 746117 & 3.5003 & 3.83600 & 00000000003 & TST \\
\hline CHEMBL1775051 & 746117 & 6.6021 & 5.8061 & TST & \\
\hline CHEMBL1775139 & 746117 & 7.699 & 6.7408 & TST & \\
\hline CHEMBL1775048 & 746117 & 5.6003 & 5.50799 & 9999999999 & TST \\
\hline CHEMBL1775147 & 746117 & 6.5086 & 6.6789 & TST & \\
\hline CHEMBL1558336 & 746117 & 5.58 & 6.646 & TST & \\
\hline CHEMBL1775153 & 746117 & 4.8861 & 5.1971 & TST & \\
\hline CHEMBL1775148 & 746117 & 7.0 & 7.2098 & TST & \\
\hline CHEMBL1775135 & 746117 & 6.7959 & 7.322 & TST & \\
\hline CHEMBL1775161 & 746117 & 3.5003 & 3.4622 & TST & \\
\hline CHEMBL46641 & 28331 & 6.9208 & 6.4449 & TRN & \\
\hline CHEMBL47030 & 28331 & 7.0655 & 7.7365 & TRN & \\
\hline CHEMBL42165 & 28331 & 7.0088 & 6.7244 & TRN & \\
\hline CHEMBL295184 & 28331 & 6.3188 & 5.8469 & TRN & \\
\hline CHEMBL42821 & 28331 & 7.0 & 6.3189 & TRN & \\
\hline CHEMBL417896 & 28331 & 7.301 & 6.5413 & TRN & \\
\hline CHEMBL46769 & 28331 & 5.0 & 5.7274 & TRN & \\
\hline CHEMBL43675 & 28331 & 6.7696 & 7.0635 & TRN & \\
\hline CHEMBL42477 & 28331 & 7.5086 & 7.8471 & TRN & \\
\hline CHEMBL47095 & 28331 & 6.7959 & 6.7344 & TRN & \\
\hline CHEMBL45200 & 28331 & 6.1367 & 6.5925 & TST & \\
\hline CHEMBL295846 & 28331 & 5.0 & 5.8502 & TRN & \\
\hline CHEMBL295878 & 28331 & 7.2007 & 6.638 & TRN & \\
\hline CHEMBL 297770 & 28331 & 6.3188 & 6.8299 & TRN & \\
\hline CHEMBL296714 & 28331 & 6.585 & 6.4725 & TRN & \\
\hline CHEMBL43422 & 28331 & 6.5086 & 6.5899 & TRN & \\
\hline CHEMBL45146 & 28331 & 5.0 & 4.9044 & TRN & \\
\hline CHEMBL295867 & 28331 & 7.3565 & 6.8036 & TRN & \\
\hline CHEMBL42128 & 28331 & 4.0 & 4.7511 & TRN & \\
\hline CHEMBL296852 & 28331 & 7.1675 & 6.7841 & TRN & \\
\hline CHEMBL42936 & 28331 & 5.4815 & 6.5305 & TRN & \\
\hline CHEMBL42873 & 28331 & 6.5086 & 6.1949 & TRN & \\
\hline CHEMBL290000 & 28331 & 6.7447 & 6.5121 & TST & \\
\hline CHEMBL42760 & 28331 & 7.2596 & 6.2733 & TRN & \\
\hline CHEMBL277986 & 28331 & 6.0458 & 7.1968 & TST & \\
\hline CHEMBL46756 & 28331 & 6.2291 & 6.4244 & TRN & \\
\hline CHEMBL288332 & 28331 & 6.699 & 6.4333 & TRN & \\
\hline CHEMBL42384 & 28331 & 5.0 & 5.5588 & TRN & \\
\hline CHEMBL46418 & 28331 & 7.0 & 6.4462 & TRN & \\
\hline CHEMBL296412 & 28331 & 7.0 & 7.2364 & TRN & \\
\hline CHEMBL295171 & 28331 & 7.0555 & 7.5308 & TRN & \\
\hline CHEMBL45033 & 28331 & 6.7696 & 6.6951 & TST & \\
\hline CHEMBL297351 & 28331 & 7.1549 & 7.0892 & TRN & \\
\hline CHEMBL294932 & 28331 & 6.4318 & 6.8968 & TST & \\
\hline CHEMBL46450 & 28331 & 7.9208 & 7.8547 & TRN & \\
\hline
\end{tabular}




\begin{tabular}{|c|c|c|c|c|c|}
\hline \multirow[b]{2}{*}{ CHEMBL 296094} & \multicolumn{5}{|c|}{ Supplemental Table S2.txt } \\
\hline & 28331 & 6.9586 & 6.8855 & TRN & \\
\hline CHEMBL43989 & 28331 & 7.1487 & 6.8942 & TRN & \\
\hline CHEMBL441429 & 28331 & 7.3468 & 7.54299 & 9999999999 & TRN \\
\hline CHEMBL297054 & 28331 & 6.6198 & 5.4473 & TST & \\
\hline CHEMBL43908 & 28331 & 6.5528 & 7.3847 & TST & \\
\hline CHEMBL290630 & 28331 & 6.6576 & 6.3861 & TRN & \\
\hline CHEMBL 297553 & 28331 & 7.7212 & 7.1416 & TRN & \\
\hline CHEMBL295466 & 28331 & 6.2291 & 6.4701 & TRN & \\
\hline CHEMBL44336 & 28331 & 7.1367 & 6.6738 & TST & \\
\hline CHEMBL42498 & 28331 & 5.0 & 4.5561 & TST & \\
\hline CHEMBL 297580 & 28331 & 7.0458 & 5.7797 & TST & \\
\hline CHEMBL46861 & 28331 & 6.3872 & 6.1273 & TST & \\
\hline CHEMBL44318 & 28331 & 7.1024 & 6.6531 & TRN & \\
\hline CHEMBL417177 & 28331 & 6.0177 & 6.3869 & TRN & \\
\hline CHEMBL297454 & 28331 & 7.0 & $7.19600 t$ & 0000000001 & TRN \\
\hline CHEMBL44863 & 28331 & 7.1675 & 6.854 & TRN & \\
\hline CHEMBL 297374 & 28331 & 5.0 & 6.301 & TST & \\
\hline CHEMBL46430 & 28331 & 7.2218 & 7.324 & TRN & \\
\hline CHEMBL44956 & 28331 & 6.9208 & 6.5191 & TRN & \\
\hline CHEMBL295616 & 28331 & 6.2218 & 6.3893 & TRN & \\
\hline CHEMBL43107 & 28331 & 6.7212 & 6.9383 & TRN & \\
\hline CHEMBL46503 & 28331 & 5.585 & 6.0221 & TRN & \\
\hline CHEMBL296463 & 28331 & 6.9208 & 6.9428 & TRN & \\
\hline CHEMBL44960 & 28331 & 5.0 & 4.8469 & TST & \\
\hline CHEMBL297185 & 28331 & 6.4089 & 6.4138 & TRN & \\
\hline CHEMBL45148 & 28331 & 5.7212 & 5.6097 & TRN & \\
\hline CHEMBL44702 & 28331 & 6.0458 & 5.4849 & TST & \\
\hline CHEMBL43603 & 28331 & 7.1427 & 7.1113 & TRN & \\
\hline CHEMBL44848 & 28331 & 7.3188 & 7.3043 & TRN & \\
\hline CHEMBL295033 & 28331 & 7.0757 & 7.2904 & TRN & \\
\hline CHEMBL45319 & 28331 & 6.5376 & 6.282 & TRN & \\
\hline CHEMBL47084 & 28331 & 6.5086 & 6.4053 & TST & \\
\hline CHEMBL44755 & 28331 & 6.8539 & 6.8878 & TRN & \\
\hline CHEMBL43537 & 28331 & 6.2518 & 6.5331 & TST & \\
\hline CHEMBL47235 & 28331 & 6.3565 & 6.2306 & TST & \\
\hline CHEMBL42296 & 28331 & 7.7212 & 7.6633 & TRN & \\
\hline CHEMBL47093 & 28331 & 6.6576 & 6.7495 & TST & \\
\hline CHEMBL298236 & 28331 & 6.6778 & 7.2443 & TRN & \\
\hline CHEMBL43592 & 28331 & 6.5376 & 6.3916 & TST & \\
\hline CHEMBL 3356027 & 1445189 & 5.7055 & 5.356 & TST & \\
\hline CHEMBL3356040 & 1445189 & 6.1945 & 5.8081 & TRN & \\
\hline CHEMBL3356060 & 1445189 & 6.8239 & 6.8842 & TRN & \\
\hline CHEMBL 3356054 & 1445189 & 6.7399 & 6.6561 & TRN & \\
\hline CHEMBL3356045 & 1445189 & 4.7235 & 4.6821 & TRN & \\
\hline CHEMBL 3356029 & 1445189 & 6.8894 & 6.8847 & TRN & \\
\hline CHEMBL3356038 & 1445189 & 6.1192 & 6.2856 & TRN & \\
\hline CHEMBL3356035 & 1445189 & 8.2218 & 8.2521 & TRN & \\
\hline CHEMBL 3356034 & 1445189 & 8.3979 & 8.2972 & TRN & \\
\hline
\end{tabular}

Page 13155 
Supplemental Table S2.txt

\begin{tabular}{|c|c|c|c|c|c|}
\hline CHEMBL3356053 & 1445189 & 7.3979 & 7.3786 & TRN & \\
\hline CHEMBL 3092468 & 1445189 & 7.3872 & 7.6297 & TRN & \\
\hline CHEMBL3356030 & 1445189 & 5.9547 & 6.0186 & TRN & \\
\hline CHEMBL3356033 & 1445189 & 7.2924 & 7.513 & TRN & \\
\hline CHEMBL3356057 & 1445189 & 5.2418 & 4.9637 & TRN & \\
\hline CHEMBL 3356042 & 1445189 & 5.8996 & 6.1183 & TRN & \\
\hline CHEMBL 3092462 & 1445189 & 7.301 & 7.6114 & TRN & \\
\hline CHEMBL3356021 & 1445189 & 7.2007 & 6.9136 & TRN & \\
\hline CHEMBL 3356043 & 1445189 & 5.3224 & 5.716 & TRN & \\
\hline CHEMBL3356051 & 1445189 & 6.5331 & 6.551 & TRN & \\
\hline CHEMBL 3356048 & 1445189 & 7.3872 & 7.2579 & TRN & \\
\hline CHEMBL3356018 & 1445189 & 6.1439 & 6.3045 & TST & \\
\hline CHEMBL3356032 & 1445189 & 6.7305 & 6.62799 & 9999999999 & TRN \\
\hline CHEMBL 3356020 & 1445189 & 5.1649 & 4.6872 & TST & \\
\hline CHEMBL3356016 & 1445189 & 5.0074 & 3.6492 & TST & \\
\hline CHEMBL 3356023 & 1445189 & 6.4023 & 6.1894 & TST & \\
\hline CHEMBL3356059 & 1445189 & 7.9586 & 7.5599 & TRN & \\
\hline CHEMBL3356036 & 1445189 & 6.7721 & 6.142 & TST & \\
\hline CHEMBL 3356041 & 1445189 & 6.041 & 5.8758 & TRN & \\
\hline CHEMBL3356055 & 1445189 & \multicolumn{3}{|c|}{5.3420000000000005} & TRN \\
\hline CHEMBL3356046 & 1445189 & 5.8268 & 5.7313 & TRN & \\
\hline CHEMBL3356031 & 1445189 & 5.5884 & 5.9336 & TST & \\
\hline CHEMBL3356028 & 1445189 & 7.7696 & 6.8833 & TST & \\
\hline CHEMBL 3356025 & 1445189 & 7.8539 & 7.5651 & TST & \\
\hline CHEMBL 3356022 & 1445189 & 5.0123 & 3.91300 & 30000000003 & TST \\
\hline CHEMBL3356049 & 1445189 & 7.4089 & 7.7313 & TRN & \\
\hline CHEMBL 3356026 & 1445189 & 6.7011 & 5.3869 & TST & \\
\hline CHEMBL3356052 & 1445189 & 7.2147 & 6.7582 & TRN & \\
\hline CHEMBL 3092463 & 1445189 & 7.8861 & 7.5835 & TRN & \\
\hline CHEMBL 3356037 & 1445189 & 8.1549 & 7.5745 & TST & \\
\hline CHEMBL 3356058 & 1445189 & 6.2182 & 6.2748 & TRN & \\
\hline CHEMBL3356050 & 1445189 & 8.3979 & 8.0658 & TRN & \\
\hline CHEMBL 3092460 & 1445189 & 6.3546 & 6.4868 & TRN & \\
\hline CHEMBL 3356056 & 1445189 & 5.4776 & 5.5555 & TRN & \\
\hline CHEMBL 3092465 & 1445189 & 6.2366 & 6.6554 & TRN & \\
\hline CHEMBL3356024 & 1445189 & 6.5834 & 5.7665 & TST & \\
\hline CHEMBL3356019 & 1445189 & 6.2857 & 5.6177 & TST & \\
\hline CHEMBL3356039 & 1445189 & 6.7375 & 6.8404 & TRN & \\
\hline CHEMBL 3356044 & 1445189 & 7.4685 & 7.6223 & TRN & \\
\hline CHEMBL3092464 & 1445189 & 7.0555 & 7.3958 & TRN & \\
\hline CHEMBL3356061 & 1445189 & 5.8729 & 5.8912 & TRN & \\
\hline CHEMBL 3092467 & 1445189 & 7.4685 & 7.5278 & TRN & \\
\hline CHEMBL 3092461 & 1445189 & 7.6021 & 7.2573 & TRN & \\
\hline CHEMBL 3356047 & 1445189 & 6.1367 & 6.1641 & TRN & \\
\hline CHEMBL3092466 & 1445189 & 7.5376 & 7.4611 & TRN & \\
\hline CHEMBL3426185 & 1476003 & 5.9136 & 5.8778 & TRN & \\
\hline CHEMBL3426031 & 1476003 & 7.284 & 7.2391 & TRN & \\
\hline CHEMBL 3426094 & 1476003 & 6.8794 & 6.8109 & TRN & \\
\hline
\end{tabular}


Supplemental Table S2.txt

\begin{tabular}{|c|c|c|c|c|c|}
\hline CHEMBL 3426186 & 1476003 & 6.9318 & 6.8529 & TRN & \\
\hline CHEMBL 3426075 & 1476003 & 6.0132 & 6.0067 & TRN & \\
\hline CHEMBL3426061 & 1476003 & 7.3768 & 7.0384 & TST & \\
\hline CHEMBL 3426182 & 1476003 & 3.52 & 3.5148 & TRN & \\
\hline CHEMBL 3426038 & 1476003 & 7.8861 & 8.0197 & TRN & \\
\hline CHEMBL 3426030 & 1476003 & 7.0506 & 7.1032 & TRN & \\
\hline CHEMBL 3426067 & 1476003 & 8.2757 & 8.3168 & TRN & \\
\hline CHEMBL3426057 & 1476003 & 7.5528 & 7.5646 & TRN & \\
\hline CHEMBL 3426029 & 1476003 & 7.2596 & 7.3733 & TRN & \\
\hline CHEMBL3426189 & 1476003 & 6.8477 & 6.8787 & TRN & \\
\hline CHEMBL 3426033 & 1476003 & 8.4089 & 8.3836 & TRN & \\
\hline CHEMBL 3426027 & 1476003 & 7.2366 & 7.1548 & TRN & \\
\hline CHEMBL548252 & 1476003 & 5.9172 & 6.2884 & TST & \\
\hline CHEMBL 3426058 & 1476003 & 7.585 & 7.6801 & TST & \\
\hline CHEMBL3426047 & 1476003 & 4.9431 & 4.7675 & TST & \\
\hline CHEMBL 3426060 & 1476003 & 7.2757 & 7.2016 & TRN & \\
\hline CHEMBL3426086 & 1476003 & 6.3372 & 6.4195 & TRN & \\
\hline CHEMBL 3426093 & 1476003 & 6.5513 & 6.4415 & TRN & \\
\hline CHEMBL 3426039 & 1476003 & 7.8239 & 7.9811 & TRN & \\
\hline CHEMBL3426064 & 1476003 & 8.4685 & 8.4803 & TRN & \\
\hline CHEMBL 3426184 & 1476003 & 6.8268 & 6.8466 & TRN & \\
\hline CHEMBL3426049 & 1476003 & 5.6383 & 5.0811 & TST & \\
\hline CHEMBL 3426077 & 1476003 & 5.9101 & 5.9443 & TRN & \\
\hline CHEMBL 3426081 & 1476003 & 6.1549 & 6.1178 & TRN & \\
\hline CHEMBL 3426035 & 1476003 & 8.0 & 8.027000 & 0000000001 & TRN \\
\hline CHEMBL3426192 & 1476003 & 6.0128 & 5.9371 & TRN & \\
\hline CHEMBL 3426091 & 1476003 & 5.1062 & 5.459 & TRN & \\
\hline CHEMBL 3426034 & 1476003 & 8.1367 & 8.009 & TRN & \\
\hline CHEMBL 3426037 & 1476003 & 8.4202 & 8.2501 & TRN & \\
\hline CHEMBL 3426028 & 1476003 & 7.2147 & 7.122999 & 9999999999 & TRN \\
\hline CHEMBL 3426068 & 1476003 & 6.5258 & 6.5431 & TRN & \\
\hline CHEMBL 3426052 & 1476003 & 5.327000 & 00000000 & 5.4076 & TRN \\
\hline CHEMBL 3426032 & 1476003 & 8.2218 & 8.2655 & TRN & \\
\hline CHEMBL 3426080 & 1476003 & 5.6676 & 5.6425 & TRN & \\
\hline CHEMBL 3426044 & 1476003 & 6.0182 & 5.9216 & TRN & \\
\hline CHEMBL 3426072 & 1476003 & 6.1549 & 6.1529 & TRN & \\
\hline CHEMBL 3426096 & 1476003 & 5.9747 & 5.2491 & TST & \\
\hline CHEMBL 3426051 & 1476003 & 3.52 & 4.6977 & TST & \\
\hline CHEMBL 3426088 & 1476003 & 4.9101 & 4.9098 & TRN & \\
\hline CHEMBL 3426092 & 1476003 & 5.7144 & 5.8872 & TST & \\
\hline CHEMBL 3426082 & 1476003 & 6.0132 & 6.0397 & TRN & \\
\hline CHEMBL 3426062 & 1476003 & 6.6108 & 7.3916 & TST & \\
\hline CHEMBL 3426055 & 1476003 & 6.58 & 6.5785 & TRN & \\
\hline CHEMBL 3426089 & 1476003 & 5.4045 & 5.3908 & TRN & \\
\hline CHEMBL 3426087 & 1476003 & 5.8356 & 7.136 & TST & \\
\hline CHEMBL 3426074 & 1476003 & 5.6326 & 5.6165 & TRN & \\
\hline CHEMBL 3426054 & 1476003 & 5.7986 & 5.7562 & TRN & \\
\hline CHEMBL 3426053 & 1476003 & 5.9355 & 5.8871 & TRN & \\
\hline
\end{tabular}


Supplemental Table S2.txt

\begin{tabular}{|c|c|c|c|c|}
\hline 5 & & & & \\
\hline & 476003 & 7.1079 & & \\
\hline A & 003 & 52 & & \\
\hline HEMBL & 5003 & 55 & 568 & \\
\hline AEMBL3426059 & 476003 & 938 & 266 & \\
\hline HEMBL 3 & 476003 & & 7244 & \\
\hline 6036 & 5003 & & 2016 & \\
\hline AEMBL & 003 & & 8349 & \\
\hline HEMBL3426076 & 476003 & 5.3298 & 3018 & \\
\hline HEMBL3426073 & 476003 & 5. & 5083 & \\
\hline HEMBL3 & 5003 & 4. & & \\
\hline 095 & 003 & & 356 & \\
\hline AEMBL: & 003 & & 752 & \\
\hline HEMBL3 & 476003 & 8.3188 & 2515 & \\
\hline AEMBL3 & 6003 & 6. & & \\
\hline HEMBL; & 803 & 5 . & 48 & \\
\hline AEMBL & 03 & & & \\
\hline AEMBL. & 003 & & & \\
\hline 6079 & 003 & 28 & & \\
\hline AEMBL3 & & & & \\
\hline AEMBL & 03 & & & RIV \\
\hline 63 & & & & ונס \\
\hline$A F M B$ & 303 & & & \\
\hline 5050 & 03 & & & 151 \\
\hline AEMBL: & & 7. & 963 & ISI \\
\hline AEMBL & 23 & & 23 & ST \\
\hline 69 & & & 37 & RN \\
\hline 04 & & 4. & 34 & RN \\
\hline AEMBL & & & & IRN \\
\hline AEMBL3 & 88 & 4. & 48 & RN \\
\hline AEMBL & 588 & 8 & 03 & $\mathrm{RN}$ \\
\hline 96 & & & & RN \\
\hline 3842 & & & & RN \\
\hline HEMBL3 & & & & 「RN \\
\hline AEMBL3 & 588 & & 213 & RN \\
\hline 811 & & & 26 & TRN \\
\hline 7 & & & & ГRN \\
\hline HEMBL & & & & TRN \\
\hline HEMBL & 588 & & & $\Gamma R$ \\
\hline EMBL & & & & RN \\
\hline HEMBL; & & & 1885 & TRN \\
\hline HEMBL & & 7. & 7.1166 & 「RN \\
\hline HEMBL3 & 588 & & 6618 & {$[R$} \\
\hline HEMBL & 588 & & 339 & TR \\
\hline 38 & & & & \\
\hline HEMBL3 & & & 3649 & \\
\hline CHEMBL3 & & 5.6364 & .6356 & \\
\hline CHEMBL3353809 & 144458 & 4.5229 & 4.5246 & \\
\hline
\end{tabular}

Page 13158 
Supplemental Table S2.txt

\begin{tabular}{|c|c|c|c|c|c|}
\hline CHEMBL3354402 & 1444588 & 4.5229 & 4.5237 & TRN & \\
\hline CHEMBL3354397 & 1444588 & 7.3768 & 7.3742 & TRN & \\
\hline CHEMBL3353826 & 1444588 & 5.7545 & 5.7548 & TRN & \\
\hline CHEMBL3354406 & 1444588 & 7.3372 & 7.336 & TRN & \\
\hline CHEMBL3354401 & 1444588 & 7.5686 & 7.5669 & TRN & \\
\hline CHEMBL3353810 & 1444588 & 4.5229 & 4.5214 & TRN & \\
\hline CHEMBL3353832 & 1444588 & 6.5686 & 6.5671 & TRN & \\
\hline CHEMBL587528 & 1444588 & 5.0 & 5.0016 & TRN & \\
\hline CHEMBL3353821 & 1444588 & 4.5229 & 4.5217 & TRN & \\
\hline CHEMBL3353831 & 1444588 & 6.8416 & 6.8461 & TRN & \\
\hline CHEMBL3353839 & 1444588 & 4.5229 & 4.523 & TRN & \\
\hline CHEMBL3353816 & 1444588 & 4.5229 & 4.5229 & TRN & \\
\hline CHEMBL 2179724 & 1444588 & 6.8239 & 4.8993 & TST & \\
\hline CHEMBL3353815 & 1444588 & 4.5229 & 5.852 & TST & \\
\hline CHEMBL3354399 & 1444588 & 7.1249 & 7.1215 & TRN & \\
\hline CHEMBL3353801 & 1444588 & 6.5287 & 5.3085 & TST & \\
\hline CHEMBL3353820 & 1444588 & 4.5229 & 4.5717 & TST & \\
\hline CHEMBL3354407 & 1444588 & 7.7212 & 7.7215 & TRN & \\
\hline CHEMBL3353829 & 1444588 & 6.1713 & 6.1678 & TRN & \\
\hline CHEMBL3353813 & 1444588 & 6.2097 & 6.5682 & TST & \\
\hline CHEMBL3353805 & 1444588 & 5.1904 & 5.3045 & TST & \\
\hline CHEMBL3353812 & 1444588 & 7.4815 & 7.0253 & TST & \\
\hline CHEMBL3353814 & 1444588 & 4.5229 & 5.7464 & TST & \\
\hline CHEMBL3354405 & 1444588 & 6.7959 & 6.7969 & TRN & \\
\hline CHEMBL3353822 & 1444588 & 7.4089 & 6.896 & TST & \\
\hline CHEMBL3353819 & 1444588 & 4.5229 & 5.9771 & TST & \\
\hline CHEMBL3353818 & 1444588 & 5.4498 & 7.1927 & TST & \\
\hline CHEMBL3354408 & 1444588 & 7.0362 & 7.0371 & TRN & \\
\hline CHEMBL3353803 & 1444588 & 4.5229 & 4.0893 & TST & \\
\hline CHEMBL3353825 & 1444588 & 4.5229 & 4.6086 & TST & \\
\hline CHEMBL3353833 & 1444588 & 6.6696 & 6.67299 & 9999999999 & TRN \\
\hline CHEMBL3353835 & 1444588 & 7.2757 & 7.2782 & TRN & \\
\hline CHEMBL3353804 & 1444588 & 4.5229 & 5.0556 & TST & \\
\hline CHEMBL 3353840 & 1444588 & 4.5229 & 4.5219 & TRN & \\
\hline CHEMBL3353806 & 1444588 & 4.5229 & 5.7792 & TST & \\
\hline CHEMBL3354398 & 1444588 & 6.9469 & 6.9474 & TRN & \\
\hline CHEMBL3353828 & 1444588 & 4.5229 & 4.5247 & TRN & \\
\hline CHEMBL430164 & 447824 & 7.7959 & 7.7247 & TRN & \\
\hline CHEMBL 233755 & 447824 & 8.585 & 8.127 & TRN & \\
\hline CHEMBL232530 & 447824 & 5.5834 & 6.2554 & TRN & \\
\hline CHEMBL399593 & 447824 & 8.8239 & 7.9107 & TST & \\
\hline CHEMBL232323 & 447824 & 7.5686 & 7.042006 & 2000000001 & TRN \\
\hline CHEMBL233543 & 447824 & 8.9586 & 7.5899 & TST & \\
\hline CHEMBL 233994 & 447824 & 9.0 & 7.5395 & TRN & \\
\hline CHEMBL393813 & 447824 & 6.0496 & 5.8618 & TRN & \\
\hline CHEMBL231748 & 447824 & 8.6778 & 8.6121 & TST & \\
\hline CHEMBL427952 & 447824 & 8.6198 & 7.8505 & TST & \\
\hline CHEMBL 232324 & 447824 & 5.9136 & 6.9724 & TRN & \\
\hline
\end{tabular}


Supplemental Table S2.txt

\begin{tabular}{|c|c|c|c|c|}
\hline CHEMBL392995 & 447824 & .1308 & 7.3785 & TRN \\
\hline CHEMBL232721 & 447824 & 6.6459 & 6.8808 & \\
\hline HEMBL398795 & 147824 & .6383 & .3613 & \\
\hline HEMBL 234812 & 147824 & .4949 & 502 & \\
\hline HEMBL428899 & 447824 & 8.0915 & 0063 & \\
\hline HEMBL398998 & 447824 & 8.5528 & 8.155 & \\
\hline HEMBL 231940 & 447824 & 8.8861 & 8.7507 & \\
\hline HEMBL427842 & 447824 & 8.585 & 7.9364 & \\
\hline HEMBL 232325 & 447824 & 8.1013 & 7.5296 & \\
\hline HEMBL232969 & 447824 & 7.0862 & 7.4241 & \\
\hline HEMBL 232108 & 447824 & 7.4685 & 7.5316 & RN \\
\hline HEMBL 233984 & 447824 & 6.0 & 7.5004 & \\
\hline HEMBL 232922 & 447824 & 6.2197 & 6.4435 & \\
\hline HEMBL440969 & 447824 & 8.0 & 7.4566 & \\
\hline HEMBL439054 & 447824 & 7.7696 & 8.1706 & RN \\
\hline HEMBL231750 & 447824 & 8.0 & 8.7109 & RN \\
\hline CHEMBL232529 & 447824 & 5.9259 & 6.6155 & RN \\
\hline HEMBL233964 & 447824 & 8.3979 & 8.0349 & \\
\hline HEMBL 231 & 447 & 8.3188 & 8.5651 & RN \\
\hline HEMBL232720 & 447824 & 6.8601 & 6.5049 & RN \\
\hline CHEMBL232921 & 447 & 6.8894 & 6.9629 & RN \\
\hline CHEMBL 391927 & 447824 & 5.0675 & 5.3624 & RN \\
\hline HEMBL400227 & 447824 & 9.3565 & 8.0342 & I \\
\hline HEMBL401 & 447 & 9.1487 & 7.9857 & RN \\
\hline CHEMBL393972 & 447824 & 7.4437 & 6697 & RN \\
\hline CHEMBL400816 & 447 & 8.3768 & 9516 & RN \\
\hline CHEMBL 393986 & 447824 & 6.4437 & 6.5115 & RN \\
\hline HEMBL393815 & 447824 & 8.8861 & 8.5651 & IRN \\
\hline CHEMBL 23 & 447 & 9.0223 & 4451 & ST \\
\hline CHEMBL 233173 & 44 & 8.3768 & 8.6217 & RN \\
\hline CHEMBL 232528 & 447 & 6.7696 & 5038 & TRN \\
\hline HEMBL231905 & 447824 & 6.5751 & 7.3715 & TRN \\
\hline HEMBL234171 & 447824 & 6.9706 & 7.5763 & TRN \\
\hline CHEMBL 23 & 44 & 87 & 936 & RN \\
\hline CHEMBL393521 & 447824 & 8.3279 & 7.8983 & TST \\
\hline CHEMBL231961 & 447824 & 8.4089 & 8.7109 & TRN \\
\hline CHEMBL 232109 & 447824 & 6.5406 & 7.5197 & TRN \\
\hline CHEMBL 393973 & 447824 & 6.9066 & 49 & $\mathrm{RN}$ \\
\hline CHEMBL233332 & 447 & 7.699 & 286 & RN \\
\hline CHEMBL232722 & 447824 & 6.3635 & 6.4702 & TRN \\
\hline CHEMBL410550 & 447824 & 4.9393 & 4.7285 & TRN \\
\hline CHEMBL 233541 & 447824 & 7.4318 & 6.8593 & RN \\
\hline CHEMBL232566 & 447824 & 8.8239 & 8.3049 & IST \\
\hline CHEMBL 233963 & 447824 & 8.301 & 8.0631 & TRN \\
\hline CHEMBL393814 & 447824 & 8.6021 & 8.4401 & TST \\
\hline CHEMBL400226 & 447824 & 8.3565 & 8.33 & ST \\
\hline CHEMBL231749 & 447824 & 7.8861 & 8.3476 & \\
\hline CHEMBL233131 & 447824 & 7.8539 & 7.5572 & \\
\hline
\end{tabular}

Page 13160 


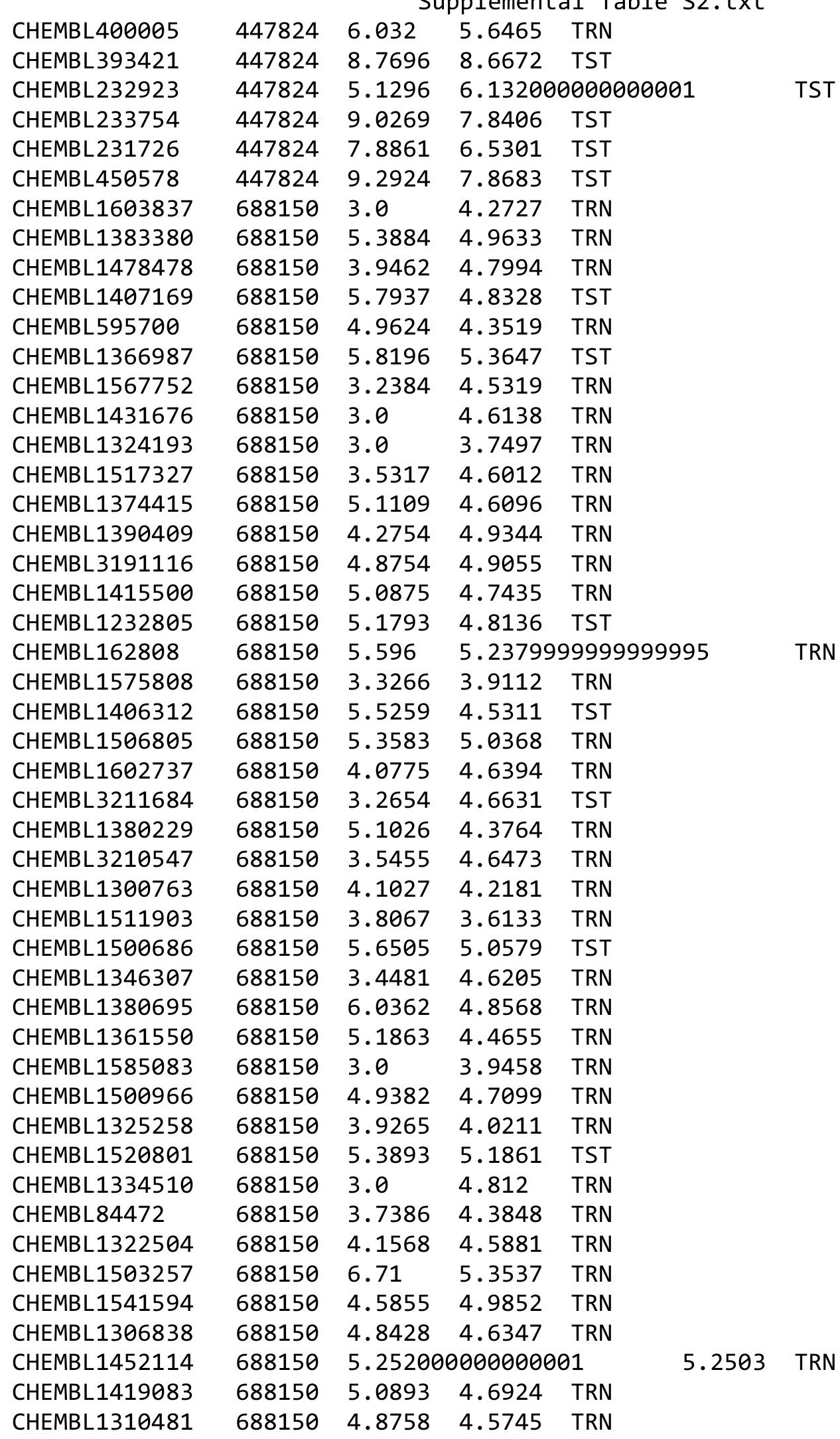

Page 13161 


\begin{tabular}{|c|c|c|c|c|c|}
\hline & & \multicolumn{4}{|c|}{ Supplemental Table S2.txt } \\
\hline CHEMBL1462334 & 688150 & 4.7569 & 4.5621 & TRN & \\
\hline CHEMBL1327783 & 688150 & 5.05 & 5.6087 & TRN & \\
\hline CHEMBL1365517 & 688150 & 5.1241 & 4.1264 & TRN & \\
\hline CHEMBL366435 & 688150 & 3.0 & 4.706 & TRN & \\
\hline CHEMBL1495589 & 688150 & 5.015 & 4.655 & TRN & \\
\hline CHEMBL1393095 & 688150 & 5.1789 & 5.0984 & TRN & \\
\hline CHEMBL1384233 & 688150 & 3.0754 & 4.3572 & TST & \\
\hline CHEMBL1423537 & 688150 & 5.1087 & 5.0178 & TRN & \\
\hline CHEMBL1338189 & 688150 & 4.2293 & 4.4377 & TRN & \\
\hline CHEMBL1389187 & 688150 & 5.2414 & 4.6195 & TRN & \\
\hline CHEMBL1968383 & 688150 & 3.0 & 4.4845 & TRN & \\
\hline CHEMBL1596003 & 688150 & 5.4108 & 4.9404 & TST & \\
\hline CHEMBL1328353 & 688150 & 3.5616 & 4.8646 & TRN & \\
\hline CHEMBL1381279 & 688150 & 4.9619 & 4.5208 & TRN & \\
\hline CHEMBL1532649 & 688150 & 4.6915 & 4.3978 & TRN & \\
\hline CHEMBL1325908 & 688150 & 4.9366 & 3.9376 & TRN & \\
\hline CHEMBL1574359 & 688150 & 4.7218 & 4.7103 & TRN & \\
\hline CHEMBL1438983 & 688150 & 5.1754 & 4.6827 & TST & \\
\hline CHEMBL 1350270 & 688150 & 5.0372 & 4.93199 & 99999999995 & TRN \\
\hline CHEMBL1430456 & 688150 & 5.2992 & 4.7758 & TRN & \\
\hline CHEMBL1508573 & 688150 & 4.56 & 5.2534 & TRN & \\
\hline CHEMBL1454171 & 688150 & 5.4051 & 4.6038 & TRN & \\
\hline CHEMBL1545832 & 688150 & 3.2921 & 4.6701 & TST & \\
\hline CHEMBL 1486262 & 688150 & 3.9149 & 4.6537 & TRN & \\
\hline CHEMBL1982782 & 688150 & 3.9336 & 4.5203 & TRN & \\
\hline CHEMBL3145030 & 688150 & 5.5522 & 5.0928 & TRN & \\
\hline CHEMBL1542886 & 688150 & 6.71 & 5.1435 & TRN & \\
\hline CHEMBL1546739 & 688150 & 6.71 & 4.8274 & TRN & \\
\hline CHEMBL1319482 & 688150 & 5.6347 & 4.8766 & TRN & \\
\hline CHEMBL1300902 & 688150 & 4.0241 & 5.0436 & TRN & \\
\hline CHEMBL1311826 & 688150 & 3.497 & 5.5034 & TRN & \\
\hline CHEMBL1508646 & 688150 & 5.1285 & 4.8953 & TRN & \\
\hline CHEMBL3196834 & 688150 & 5.3639 & 4.6111 & TRN & \\
\hline CHEMBL1502351 & 688150 & 5.5824 & 5.5751 & TRN & \\
\hline CHEMBL1596753 & 688150 & 5.71 & 4.4711 & TRN & \\
\hline CHEMBL1300609 & 688150 & 4.0643 & 4.9642 & TRN & \\
\hline CHEMBL1448023 & 688150 & 3.0 & 3.9733 & TRN & \\
\hline CHEMBL1520232 & 688150 & 4.8854 & 4.842 & TRN & \\
\hline CHEMBL1409525 & 688150 & 5.3169 & 4.9625 & TRN & \\
\hline CHEMBL1374260 & 688150 & 5.0671 & 4.8385 & TRN & \\
\hline CHEMBL1528201 & 688150 & 5.7476 & 4.5414 & TRN & \\
\hline CHEMBL1301746 & 688150 & 4.3222 & 4.5783 & TRN & \\
\hline CHEMBL1451016 & 688150 & 4.8958 & 4.5197 & TRN & \\
\hline CHEMBL1525672 & 688150 & 3.8765 & 4.1097 & TRN & \\
\hline CHEMBL1588463 & 688150 & 5.1946 & 4.6522 & TST & \\
\hline CHEMBL1371101 & 688150 & 5.7515 & 4.8232 & TRN & \\
\hline CHEMBL1450615 & 688150 & 5.4274 & 4.7249 & TST & \\
\hline CHEMBL1446981 & 688150 & 3.0 & 4.4234 & TRN & \\
\hline
\end{tabular}




\begin{tabular}{|c|c|c|c|c|c|c|}
\hline & & \multicolumn{5}{|c|}{ Supplemental Table S2.txt } \\
\hline CHEMBL86464 & 688150 & 5.7744 & 4.2533 & TRN & & \\
\hline CHEMBL1343073 & 688150 & 3.0 & 4.7565 & TST & & \\
\hline CHEMBL1349625 & 688150 & 3.7294 & 4.7866 & TRN & & \\
\hline CHEMBL1334152 & 688150 & 3.0 & 3.8852 & TRN & & \\
\hline CHEMBL 1367626 & 688150 & 5.8233 & 4.8272 & TRN & & \\
\hline CHEMBL1419536 & 688150 & 6.3507 & 5.4605 & TRN & & \\
\hline CHEMBL1349135 & 688150 & 5.7409 & 4.6692 & TRN & & \\
\hline CHEMBL1367691 & 688150 & 5.3776 & 4.5624 & TRN & & \\
\hline CHEMBL1609354 & 688150 & 4.7553 & 4.8983 & TRN & & \\
\hline CHEMBL1538410 & 688150 & \multicolumn{3}{|c|}{5.4879999999999995} & 5.2575 & TRN \\
\hline CHEMBL1459341 & 688150 & 4.9231 & 4.7328 & TST & & \\
\hline CHEMBL1369647 & 688150 & 3.2264 & 4.7007 & TRN & & \\
\hline CHEMBL1523251 & 688150 & 3.9623 & 4.2887 & TRN & & \\
\hline CHEMBL1523419 & 688150 & 3.9341 & 4.5337 & TRN & & \\
\hline CHEMBL1339696 & 688150 & 5.15 & 4.5171 & TRN & & \\
\hline CHEMBL1352698 & 688150 & 3.9064 & 5.3638 & TRN & & \\
\hline CHEMBL1501835 & 688150 & 4.5998 & 4.8219 & TRN & & \\
\hline CHEMBL1399035 & 688150 & 5.0706 & 5.1827 & TRN & & \\
\hline CHEMBL1600963 & 688150 & 5.088 & 5.0517 & TRN & & \\
\hline CHEMBL1488613 & 688150 & 5.0581 & 4.853 & TRN & & \\
\hline CHEMBL1366271 & 688150 & 5.3576 & 4.5369 & TRN & & \\
\hline CHEMBL1335052 & 688150 & 4.8931 & 4.8866 & TRN & & \\
\hline CHEMBL3183210 & 688150 & 7.71 & 5.301 & TRN & & \\
\hline CHEMBL1390717 & 688150 & 5.8111 & 5.1881 & TRN & & \\
\hline CHEMBL1609872 & 688150 & 4.6075 & 4.6893 & TRN & & \\
\hline CHEMBL493863 & 688150 & 5.2751 & 4.8767 & TST & & \\
\hline CHEMBL1339440 & 688150 & 3.5504 & 4.7499 & TRN & & \\
\hline CHEMBL1455633 & 688150 & 5.1289 & 5.073 & TST & & \\
\hline CHEMBL1611931 & 688150 & 3.0 & 4.8796 & TST & & \\
\hline CHEMBL1322521 & 688150 & 3.147 & 4.0037 & TRN & & \\
\hline CHEMBL1504973 & 688150 & 5.8636 & 5.1684 & TRN & & \\
\hline CHEMBL1370066 & 688150 & 4.3898 & 5.0738 & TRN & & \\
\hline CHEMBL1428166 & 688150 & 4.9427 & 5.4636 & TRN & & \\
\hline CHEMBL591137 & 688150 & 3.8794 & 5.8077 & TRN & & \\
\hline CHEMBL1550591 & 688150 & 3.7543 & 4.7637 & TST & & \\
\hline CHEMBL1348777 & 688150 & 6.1798 & 4.7083 & TRN & & \\
\hline CHEMBL 1465210 & 688150 & 3.9485 & 4.4609 & TRN & & \\
\hline CHEMBL3191380 & 688150 & 6.0035 & 4.7137 & TRN & & \\
\hline CHEMBL1363713 & 688150 & 4.9336 & 4.523 & TRN & & \\
\hline CHEMBL1338774 & 688150 & 3.1733 & 4.4661 & TRN & & \\
\hline CHEMBL1330558 & 688150 & 5.567 & 5.9395 & TRN & & \\
\hline CHEMBL1325883 & 688150 & 3.0 & 3.8504 & TRN & & \\
\hline CHEMBL1334928 & 688150 & 3.4087 & 4.5324 & TST & & \\
\hline CHEMBL1351020 & 688150 & 5.0441 & 4.521 & TRN & & \\
\hline CHEMBL1499306 & 688150 & 5.7471 & 4.8623 & TRN & & \\
\hline CHEMBL1369945 & 688150 & 5.8601 & 5.6545 & TRN & & \\
\hline CHEMBL1510371 & 688150 & 5.0373 & 4.6669 & TST & & \\
\hline CHEMBL1571540 & 688150 & 3.8966 & 4.7719 & TRN & & \\
\hline
\end{tabular}




\begin{tabular}{|c|c|c|c|c|c|c|}
\hline \multicolumn{7}{|c|}{ Supplemental Table S2.txt } \\
\hline CHEMBL1533594 & 688150 & 3.0 & 3.9548 & TRN & & \\
\hline CHEMBL1302695 & 688150 & 4.2866 & 5.1175 & TRN & & \\
\hline CHEMBL1382268 & 688150 & 5.0159 & 4.7614 & TST & & \\
\hline CHEMBL1303678 & 688150 & 3.7897 & 4.7452 & TST & & \\
\hline CHEMBL9843 & 688150 & 5.7724 & 4.6025 & TRN & & \\
\hline CHEMBL1462919 & 688150 & 3.8405 & 4.6376 & TRN & & \\
\hline CHEMBL1596151 & 688150 & 3.8659 & 4.2359 & TRN & & \\
\hline CHEMBL1549805 & 688150 & 5.7049 & 4.7394 & TST & & \\
\hline CHEMBL1431389 & 688150 & 3.4385 & 4.7989 & TRN & & \\
\hline CHEMBL1521044 & 688150 & 5.0618 & 5.0595 & TRN & & \\
\hline CHEMBL1484205 & 688150 & 3.1554 & 4.5362 & TRN & & \\
\hline CHEMBL1353760 & 688150 & 4.8169 & 4.9046 & TRN & & \\
\hline CHEMBL1485847 & 688150 & 5.574 & 4.4472 & TRN & & \\
\hline CHEMBL1579408 & 688150 & 4.2208 & 4.1383 & TRN & & \\
\hline CHEMBL1503966 & 688150 & 3.5501 & 4.5942 & TRN & & \\
\hline CHEMBL1483927 & 688150 & 3.0 & 4.6932 & TST & & \\
\hline CHEMBL1411001 & 688150 & 5.3544 & 3.9346 & TRN & & \\
\hline CHEMBL1530503 & 688150 & 3.8113 & 4.7541 & TST & & \\
\hline CHEMBL1610173 & 688150 & 3.338 & 4.6669 & TRN & & \\
\hline CHEMBL1485000 & 688150 & 4.9811 & 5.178 & TST & & \\
\hline CHEMBL1388234 & 688150 & 4.8531 & 4.7531 & TRN & & \\
\hline CHEMBL1495171 & 688150 & 3.969 & 3.9502 & TRN & & \\
\hline CHEMBL3197105 & 688150 & 5.5178 & 5.1283 & TRN & & \\
\hline CHEMBL1575405 & 688150 & 5.6312 & 4.5032 & TRN & & \\
\hline CHEMBL1342384 & 688150 & 4.8854 & 4.1783 & TRN & & \\
\hline CHEMBL1328168 & 688150 & 4.1353 & 4.8413 & TRN & & \\
\hline CHEMBL1500227 & 688150 & 5.3337 & 5.6837 & TRN & & \\
\hline CHEMBL1373145 & 688150 & 3.0 & 4.1969 & TRN & & \\
\hline CHEMBL1570958 & 688150 & 4.6937 & 5.5155 & TRN & & \\
\hline CHEMBL1314106 & 688150 & 5.8435 & 5.0003 & TRN & & \\
\hline CHEMBL1600679 & 688150 & 3.0 & 4.6736 & TST & & \\
\hline CHEMBL1555719 & 688150 & 4.00899 & 99999999 & 995 & 4.2821 & TRN \\
\hline CHEMBL1572356 & 688150 & 5.71 & 4.9024 & TRN & & \\
\hline CHEMBL1386615 & 688150 & 3.0 & 4.0615 & TRN & & \\
\hline CHEMBL1384700 & 688150 & 4.7343 & 4.8048 & TRN & & \\
\hline CHEMBL1333235 & 688150 & 4.409 & 4.5955 & TRN & & \\
\hline CHEMBL1304447 & 688150 & 4.2032 & $3.5780 e$ & 00006 & 003 & TRN \\
\hline CHEMBL1599994 & 688150 & 5.0984 & 5.6179 & TRN & & \\
\hline CHEMBL1400321 & 688150 & 3.7769 & 4.8767 & TST & & \\
\hline CHEMBL1392137 & 688150 & 4.0889 & 4.4508 & TST & & \\
\hline CHEMBL1311787 & 688150 & 4.1117 & 4.6474 & TRN & & \\
\hline CHEMBL1338960 & 688150 & 4.5103 & 5.255 & TST & & \\
\hline CHEMBL1537958 & 688150 & 3.8757 & 4.7819 & TST & & \\
\hline CHEMBL1410536 & 688150 & 5.25899 & 99999999 & 995 & 4.8934 & TRN \\
\hline CHEMBL1311143 & 688150 & 5.67200 & j000000e & & 4.6021 & TRN \\
\hline CHEMBL1388137 & 688150 & 5.5081 & 5.5942 & TRN & & \\
\hline CHEMBL146710 & 688150 & 6.4342 & 5.0314 & TRN & & \\
\hline CHEMBL172066 & 688150 & 3.0 & 4.7858 & TRN & & \\
\hline
\end{tabular}




\begin{tabular}{|c|c|c|c|c|}
\hline & & & pplement & al $\mathrm{T}$ \\
\hline CHEMBL1353797 & 688150 & 4.9323 & 4.681 & TST \\
\hline CHEMBL1516359 & 688150 & 5.5907 & 4.8181 & TRN \\
\hline CHEMBL1329861 & 688150 & 3.2926 & 3.9016 & TRN \\
\hline CHEMBL1601611 & 688150 & 3.1373 & 4.5719 & TRN \\
\hline CHEMBL1343936 & 688150 & 5.8713 & 4.4378 & TRN \\
\hline CHEMBL1531450 & 688150 & 4.0187 & 3.8759 & TRN \\
\hline CHEMBL1494613 & 688150 & 3.0 & 3.9274 & TRN \\
\hline CHEMBL1544997 & 688150 & 5.7948 & 5.5223 & TRN \\
\hline CHEMBL3145126 & 688150 & 6.71 & 4.707 & TRN \\
\hline CHEMBL1373577 & 688150 & 5.8262 & 4.9425 & TRN \\
\hline CHEMBL1543029 & 688150 & 5.4331 & 4.6896 & TRN \\
\hline CHEMBL1412475 & 688150 & 4.1122 & 4.7769 & TRN \\
\hline CHEMBL3197769 & 688150 & 3.5206 & 4.3933 & TRN \\
\hline CHEMBL1506966 & 688150 & 3.0 & 4.7881 & TRN \\
\hline CHEMBL1384984 & 688150 & 5.0464 & 5.099 & TRN \\
\hline CHEMBL1604690 & 688150 & 5.3543 & 4.9942 & TRN \\
\hline CHEMBL1335220 & 688150 & 4.9335 & 4.6548 & TRN \\
\hline CHEMBL1968316 & 688150 & 5.0557 & 5.402 & TRN \\
\hline CHEMBL1526899 & 688150 & 5.9634 & 4.7876 & TRN \\
\hline CHEMBL1452706 & 688150 & 4.8895 & 4.9227 & TRN \\
\hline CHEMBL1301355 & 688150 & 5.0647 & 4.4326 & TRN \\
\hline CHEMBL1300641 & 688150 & 6.71 & 4.9062 & TRN \\
\hline CHEMBL1344659 & 688150 & 3.5653 & 4.5777 & TRN \\
\hline CHEMBL1482294 & 688150 & 3.9415 & 4.8478 & TST \\
\hline CHEMBL1568747 & 688150 & 5.4584 & 4.8835 & TRN \\
\hline CHEMBL1518735 & 688150 & 4.9614 & 5.3616 & TRN \\
\hline CHEMBL559797 & 688150 & 5.3252 & 4.5398 & TRN \\
\hline CHEMBL1598864 & 688150 & 4.9226 & 3.8777 & TRN \\
\hline CHEMBL1502467 & 688150 & 4.3211 & 4.8294 & TST \\
\hline CHEMBL1353710 & 688150 & 5.1043 & 4.8381 & TRN \\
\hline CHEMBL1588222 & 688150 & 5.3802 & 4.7403 & TRN \\
\hline CHEMBL1423759 & 688150 & 3.042 & 4.0247 & TRN \\
\hline CHEMBL1364150 & 688150 & 3.7404 & 4.6554 & TRN \\
\hline CHEMBL1343453 & 688150 & 5.71 & 4.7303 & TST \\
\hline CHEMBL1343490 & 688150 & 5.596 & 5.1548 & TST \\
\hline CHEMBL1313724 & 688150 & 4.7849 & 4.3736 & TRN \\
\hline CHEMBL1333565 & 688150 & 6.0173 & 5.496 & TRN \\
\hline CHEMBL1302628 & 688150 & 4.936 & 4.2521 & TRN \\
\hline CHEMBL1461508 & 688150 & 4.5268 & 4.7538 & TST \\
\hline CHEMBL1511526 & 688150 & 4.7742 & 5.0039 & TST \\
\hline CHEMBL1569732 & 688150 & 4.9046 & 5.0754 & TRN \\
\hline CHEMBL1544409 & 688150 & 5.7029 & 5.4367 & TRN \\
\hline CHEMBL1321278 & 688150 & 5.3952 & 4.5617 & TRN \\
\hline CHEMBL 3196660 & 688150 & 5.4078 & 4.0336 & TRN \\
\hline CHEMBL1477450 & 688150 & 5.5675 & 4.6558 & TRN \\
\hline CHEMBL1558725 & 688150 & 5.3129 & 4.5492 & TRN \\
\hline CHEMBL1382558 & 688150 & 7.71 & 6.0058 & TRN \\
\hline CHEMBL 3208118 & 688150 & 5.2858 & 5.1103 & TST \\
\hline
\end{tabular}




\begin{tabular}{|c|c|c|c|c|c|c|}
\hline & & \multicolumn{5}{|c|}{ Supplemental Table s2.txt } \\
\hline CHEMBL1302146 & 688150 & 3.8219 & 4.9959 & TRN & & \\
\hline CHEMBL1300083 & 688150 & 5.5998 & 4.8085 & TRN & & \\
\hline CHEMBL1453644 & 688150 & 5.1327 & 4.9005 & TRN & & \\
\hline CHEMBL1450756 & 688150 & 3.2626 & 4.5293 & TRN & & \\
\hline CHEMBL1484167 & 688150 & 5.8861 & 5.0781 & TST & & \\
\hline CHEMBL1605552 & 688150 & 4.7314 & 4.5868 & TRN & & \\
\hline CHEMBL1588783 & 688150 & 3.4623 & 3.6712 & TRN & & \\
\hline CHEMBL1548354 & 688150 & 3.6946 & 3.5727 & TRN & & \\
\hline CHEMBL1565957 & 688150 & 3.4657 & 4.0165 & TRN & & \\
\hline CHEMBL1562926 & 688150 & 4.0 & 4.904 & TRN & & \\
\hline CHEMBL1548535 & 688150 & 5.067 & 5.1273 & TRN & & \\
\hline CHEMBL1564427 & 688150 & 3.6989 & 3.9831 & TRN & & \\
\hline CHEMBL1502435 & 688150 & 5.1844 & 4.8078 & TRN & & \\
\hline CHEMBL1421770 & 688150 & 6.6556 & 5.4373 & TRN & & \\
\hline CHEMBL1340629 & 688150 & 5.2309 & 4.93 & TST & & \\
\hline CHEMBL1602964 & 688150 & 5.7421 & 5.0848 & TRN & & \\
\hline CHEMBL1330405 & 688150 & 5.2493 & 4.6834 & TRN & & \\
\hline CHEMBL1348057 & 688150 & 5.4092 & 4.8394 & TRN & & \\
\hline CHEMBL1327635 & 688150 & 3.2101 & 4.6451 & TRN & & \\
\hline CHEMBL1484977 & 688150 & 4.9771 & 4.4897 & TRN & & \\
\hline CHEMBL1418280 & 688150 & 5.3882 & 4.8378 & TRN & & \\
\hline CHEMBL1454037 & 688150 & 3.7875 & 4.6309 & TRN & & \\
\hline CHEMBL1348810 & 688150 & 3.0 & 4.6948 & TST & & \\
\hline CHEMBL1535532 & 688150 & \multicolumn{3}{|c|}{5.053999999999999} & 5.2603 & TRN \\
\hline CHEMBL1432603 & 688150 & 4.2791 & 4.7183 & TRN & & \\
\hline CHEMBL1379408 & 688150 & 3.0 & 4.5696 & TRN & & \\
\hline CHEMBL1429713 & 688150 & 4.4857 & 4.9274 & TRN & & \\
\hline CHEMBL1382525 & 688150 & 4.9168 & 4.1472 & TRN & & \\
\hline CHEMBL1431776 & 688150 & 4.9609 & 4.9653 & TST & & \\
\hline CHEMBL1346226 & 688150 & 3.6897 & 4.7433 & TRN & & \\
\hline CHEMBL1527688 & 688150 & 4.0001 & 3.6873 & TRN & & \\
\hline CHEMBL1419598 & 688150 & 5.3292 & 5.0707 & TST & & \\
\hline CHEMBL1452517 & 688150 & 5.0466 & 5.3671 & TST & & \\
\hline CHEMBL1485640 & 688150 & 5.3615 & 4.4903 & TRN & & \\
\hline CHEMBL1453068 & 688150 & 3.0 & 4.5094 & TRN & & \\
\hline CHEMBL1583522 & 688150 & 3.9828 & 4.5443 & TRN & & \\
\hline CHEMBL530682 & 688150 & 5.2278 & 4.766 & TST & & \\
\hline CHEMBL1313101 & 688150 & 6.71 & 5.4989 & TRN & & \\
\hline CHEMBL1598311 & 688150 & 5.0365 & 4.3981 & TST & & \\
\hline CHEMBL1583338 & 688150 & 5.71 & 5.0544 & TRN & & \\
\hline CHEMBL1500650 & 688150 & 5.1965 & 4.657 & TRN & & \\
\hline CHEMBL1427161 & 688150 & 5.71 & 4.9205 & TRN & & \\
\hline CHEMBL1603937 & 688150 & 6.0931 & 4.825 & TRN & & \\
\hline CHEMBL1462288 & 688150 & 3.0 & 4.8811 & TRN & & \\
\hline CHEMBL1511026 & 688150 & 3.7541 & 4.6257 & TRN & & \\
\hline CHEMBL1482372 & 688150 & 3.97 & 4.6104 & TRN & & \\
\hline CHEMBL1455389 & 688150 & 3.2795 & 4.3388 & TRN & & \\
\hline CHEMBL1527275 & 688150 & 5.155 & 4.332 & TRN & & \\
\hline
\end{tabular}




\begin{tabular}{|c|c|c|c|c|c|c|}
\hline & & \multicolumn{5}{|c|}{ Supplemental Table S2.txt } \\
\hline CHEMBL1415946 & 688150 & 3.6366 & 3.8668 & TRN & & \\
\hline CHEMBL1524026 & 688150 & 3.0 & 4.6334 & TRN & & \\
\hline CHEMBL1523371 & 688150 & 3.6151 & 3.7519 & TRN & & \\
\hline CHEMBL1466893 & 688150 & 4.1043 & 4.4688 & TST & & \\
\hline CHEMBL1321297 & 688150 & 5.2317 & 4.7281 & TRN & & \\
\hline CHEMBL1498987 & 688150 & 5.7275 & 4.7005 & TRN & & \\
\hline CHEMBL1493585 & 688150 & 4.3967 & 4.8156 & TRN & & \\
\hline CHEMBL1532007 & 688150 & \multicolumn{3}{|c|}{3.2030000000000003} & 4.6087 & TRN \\
\hline CHEMBL1570464 & 688150 & 4.8421 & 4.7215 & TRN & & \\
\hline CHEMBL1454487 & 688150 & 3.0 & 4.298 & TRN & & \\
\hline CHEMBL1449278 & 688150 & 3.8546 & 4.2457 & TRN & & \\
\hline CHEMBL1321292 & 688150 & 5.5911 & 4.1437 & TRN & & \\
\hline CHEMBL1534019 & 688150 & 5.2939 & 4.7241 & TRN & & \\
\hline CHEMBL1606837 & 688150 & 5.0669 & 4.8371 & TST & & \\
\hline CHEMBL1478228 & 688150 & 3.0 & 4.3181 & TRN & & \\
\hline CHEMBL602909 & 688150 & 3.0 & 4.1341 & TRN & & \\
\hline CHEMBL1584777 & 688150 & 6.71 & 4.8025 & TRN & & \\
\hline CHEMBL1581964 & 688150 & 5.3109 & 4.7131 & TRN & & \\
\hline CHEMBL1537373 & 688150 & 3.6235 & 4.7084 & TST & & \\
\hline CHEMBL1432673 & 688150 & 3.0 & 4.7949 & TRN & & \\
\hline CHEMBL1550564 & 688150 & 6.71 & 4.6799 & TRN & & \\
\hline CHEMBL1485551 & 688150 & 4.6475 & 4.6181 & TST & & \\
\hline CHEMBL1586404 & 688150 & 5.0633 & 4.8576 & TRN & & \\
\hline CHEMBL1407260 & 688150 & 5.3852 & 4.7948 & TST & & \\
\hline CHEMBL1613463 & 688150 & 3.2283 & 4.6239 & TST & & \\
\hline CHEMBL1312536 & 688150 & 3.3895 & 4.2994 & TST & & \\
\hline CHEMBL1425696 & 688150 & 3.0 & 5.0514 & TRN & & \\
\hline CHEMBL1537488 & 688150 & 3.0507 & 4.8994 & TRN & & \\
\hline CHEMBL548615 & 688150 & 6.71 & 5.8459 & TRN & & \\
\hline CHEMBL1603455 & 688150 & 5.1633 & 4.7722 & TRN & & \\
\hline CHEMBL1335672 & 688150 & 5.7357 & 4.7719 & TRN & & \\
\hline CHEMBL1318883 & 688150 & 4.7485 & 4.7536 & TST & & \\
\hline CHEMBL1964415 & 688150 & 4.2091 & 4.7964 & TST & & \\
\hline CHEMBL1351599 & 688150 & 5.5174 & 5.2705 & TRN & & \\
\hline CHEMBL1572510 & 688150 & 5.5577 & 4.5415 & TRN & & \\
\hline CHEMBL1500719 & 688150 & 3.2484 & 3.9106 & TRN & & \\
\hline CHEMBL3199299 & 688150 & 3.5776 & 5.0676 & TRN & & \\
\hline CHEMBL3196221 & 688150 & 3.0 & 4.5105 & TRN & & \\
\hline CHEMBL3197404 & 688150 & 3.0 & 5.2033 & TRN & & \\
\hline CHEMBL1423935 & 688150 & 5.5658 & 5.829 & TRN & & \\
\hline CHEMBL3196505 & 688150 & 3.0 & 4.6064 & TRN & & \\
\hline CHEMBL1402662 & 688150 & 4.9628 & 4.2151 & TRN & & \\
\hline CHEMBL1369671 & 688150 & 5.0055 & 5.9393 & TRN & & \\
\hline CHEMBL1581013 & 688150 & 5.2548 & 4.7314 & TST & & \\
\hline CHEMBL1388700 & 688150 & 6.15799 & 99999999 & 995 & 5.0932 & $1 \mathrm{~K}$ \\
\hline CHEMBL1339488 & 688150 & 4.9529 & 4.7179 & TST & & \\
\hline CHEMBL1521499 & 688150 & 3.2746 & 4.0812 & TRN & & \\
\hline CHEMBL3191258 & 688150 & 6.71 & 5.0038 & TST & & \\
\hline
\end{tabular}




\begin{tabular}{|c|c|c|c|c|c|c|}
\hline & & \multicolumn{5}{|c|}{ Supplemental Table S2.txt } \\
\hline CHEMBL26320 & 688150 & 5.2822 & 4.5815 & TRN & & \\
\hline CHEMBL1462872 & 688150 & 5.6609 & 5.2697 & TRN & & \\
\hline CHEMBL1439773 & 688150 & 5.3547 & 4.3725 & TRN & & \\
\hline CHEMBL1332862 & 688150 & 3.2205 & 5.3065 & TRN & & \\
\hline CHEMBL1547797 & 688150 & 3.8949 & 4.6315 & TST & & \\
\hline CHEMBL1578636 & 688150 & 3.8955 & 4.3456 & TRN & & \\
\hline CHEMBL1563186 & 688150 & 4.9472 & 4.7685 & TRN & & \\
\hline CHEMBL1547267 & 688150 & 4.7491 & 4.4759 & TRN & & \\
\hline CHEMBL1321930 & 688150 & 5.5653 & 3.6048 & TRN & & \\
\hline CHEMBL1380679 & 688150 & 3.4521 & 3.9449 & TRN & & \\
\hline CHEMBL1494314 & 688150 & 6.4401 & 4.6239 & TRN & & \\
\hline CHEMBL1364137 & 688150 & 5.6451 & 4.9171 & TRN & & \\
\hline CHEMBL1431093 & 688150 & 4.9174 & 4.7719 & TRN & & \\
\hline CHEMBL3192392 & 688150 & 4.1249 & 4.5946 & TRN & & \\
\hline CHEMBL1445150 & 688150 & 5.9017 & 4.5247 & TRN & & \\
\hline CHEMBL1457337 & 688150 & 3.3873 & 4.6134 & TRN & & \\
\hline CHEMBL1399193 & 688150 & 5.5613 & 5.1493 & TRN & & \\
\hline CHEMBL1439909 & 688150 & 3.6896 & 4.5346 & TRN & & \\
\hline CHEMBL1589663 & 688150 & 4.8918 & 5.0745 & TRN & & \\
\hline CHEMBL1532716 & 688150 & 5.2493 & 5.1674 & TST & & \\
\hline CHEMBL1327114 & 688150 & 3.9219 & 4.8495 & TRN & & \\
\hline CHEMBL1454278 & 688150 & 5.4697 & 5.0226 & TRN & & \\
\hline CHEMBL187266 & 688150 & 5.4911 & 4.7245 & TST & & \\
\hline CHEMBL1543714 & 688150 & 5.074 & 4.8552 & TRN & & \\
\hline CHEMBL1456780 & 688150 & 7.71 & 6.1298 & TRN & & \\
\hline CHEMBL1406232 & 688150 & 3.0 & 4.6887 & TST & & \\
\hline CHEMBL1336382 & 688150 & 5.71 & 3.8837 & TRN & & \\
\hline CHEMBL1430667 & 688150 & 5.1677 & 4.7501 & TRN & & \\
\hline CHEMBL1305199 & 688150 & 4.9471 & 4.4538 & TRN & & \\
\hline CHEMBL1324909 & 688150 & 3.7058 & 4.8151 & TRN & & \\
\hline CHEMBL1503689 & 688150 & 5.6657 & 4.4382 & TRN & & \\
\hline CHEMBL1534285 & 688150 & 3.1596 & 4.0717 & TRN & & \\
\hline CHEMBL1448415 & 688150 & 5.3491 & 4.3452 & TRN & & \\
\hline CHEMBL1546494 & 688150 & 5.0949 & 4.5368 & TRN & & \\
\hline CHEMBL1344394 & 688150 & 3.0 & 4.4842 & TRN & & \\
\hline CHEMBL1503907 & 688150 & 4.7082 & 4.4463 & TRN & & \\
\hline CHEMBL487356 & 688150 & 5.5771 & 4.6286 & TRN & & \\
\hline CHEMBL1557157 & 688150 & 4.7957 & 4.6891 & TRN & & \\
\hline CHEMBL1393664 & 688150 & 5.3451 & 4.5626 & TST & & \\
\hline CHEMBL1389982 & 688150 & 4.7755 & 4.8798 & TST & & \\
\hline CHEMBL1523242 & 688150 & 5.2803 & 4.9212 & TRN & & \\
\hline CHEMBL1579592 & 688150 & 4.3797 & 5.0456 & TRN & & \\
\hline CHEMBL1559375 & 688150 & 3.0 & 4.6401 & TRN & & \\
\hline CHEMBL1523890 & 688150 & 4.0235 & 4.1501 & TRN & & \\
\hline CHEMBL1578341 & 688150 & 5.5209 & 4.9622 & TRN & & \\
\hline CHEMBL1386556 & 688150 & 5.26399 & 999999999 & 99 & 5.1644 & TRN \\
\hline CHEMBL1546103 & 688150 & 3.7956 & 5.0 & TRN & & \\
\hline CHEMBL1386788 & 688150 & 5.4208 & 4.9766 & TRN & & \\
\hline
\end{tabular}




\begin{tabular}{|c|c|c|c|c|c|c|}
\hline & & \multicolumn{5}{|c|}{ Supplemental Table S2.txt } \\
\hline CHEMBL1438956 & 688150 & 5.1115 & 4.5642 & TST & & \\
\hline CHEMBL1313417 & 688150 & 3.8809 & 4.4439 & TRN & & \\
\hline CHEMBL1320317 & 688150 & 3.7584 & 4.6842 & TRN & & \\
\hline CHEMBL1359762 & 688150 & 5.0712 & 4.47199 & 99999 & 995 & TRN \\
\hline CHEMBL1993708 & 688150 & 5.285 & 5.0063 & TST & & \\
\hline CHEMBL1572530 & 688150 & 5.1408 & 5.0006 & TRN & & \\
\hline CHEMBL1416410 & 688150 & 5.1194 & 4.454 & TRN & & \\
\hline CHEMBL1557451 & 688150 & 3.2355 & 4.6576 & TRN & & \\
\hline CHEMBL1429863 & 688150 & 5.5067 & 5.0512 & TRN & & \\
\hline CHEMBL543876 & 688150 & 5.3748 & 4.532 & TRN & & \\
\hline CHEMBL1339243 & 688150 & 3.0 & 4.428 & TRN & & \\
\hline CHEMBL1364769 & 688150 & 5.2045 & 4.9924 & TRN & & \\
\hline CHEMBL1460707 & 688150 & 3.6143 & 4.6151 & TRN & & \\
\hline CHEMBL1558865 & 688150 & 4.7081 & 4.8382 & TRN & & \\
\hline CHEMBL1339170 & 688150 & 4.3436 & 4.0593 & TRN & & \\
\hline CHEMBL1494284 & 688150 & 4.6194 & 5.2487 & TRN & & \\
\hline CHEMBL1460956 & 688150 & 3.0 & 5.142 & TRN & & \\
\hline CHEMBL1379541 & 688150 & 3.0 & 4.3191 & TRN & & \\
\hline CHEMBL1506202 & 688150 & 3.2414 & 4.0219 & TRN & & \\
\hline CHEMBL1414937 & 688150 & 3.41300 & 30000000 & 203 & 5.103 & TRN \\
\hline CHEMBL1981883 & 688150 & 5.1854 & 4.8431 & TST & & \\
\hline CHEMBL1606968 & 688150 & 5.3558 & 4.6908 & TRN & & \\
\hline CHEMBL1541013 & 688150 & 4.9618 & 4.7062 & TRN & & \\
\hline CHEMBL1566191 & 688150 & 5.0175 & 4.763 & TRN & & \\
\hline CHEMBL1598028 & 688150 & 3.1797 & 4.1406 & TRN & & \\
\hline CHEMBL1510054 & 688150 & 5.151 & 4.3266 & TRN & & \\
\hline CHEMBL1585666 & 688150 & 5.2784 & 4.5316 & TRN & & \\
\hline CHEMBL1391882 & 688150 & 3.8329 & 4.3128 & TRN & & \\
\hline CHEMBL1501102 & 688150 & 5.96899 & 79999999 & & 4.9326 & TST \\
\hline CHEMBL1525542 & 688150 & 4.2747 & 4.1955 & TRN & & \\
\hline CHEMBL1402628 & 688150 & 4.5476 & 4.4267 & TRN & & \\
\hline CHEMBL1600573 & 688150 & 5.0783 & 4.6624 & TST & & \\
\hline CHEMBL1467165 & 688150 & 3.5218 & 4.3737 & TRN & & \\
\hline CHEMBL1300170 & 688150 & 6.1931 & 4.7533 & TRN & & \\
\hline CHEMBL1372667 & 688150 & 5.0612 & 4.5112 & TST & & \\
\hline CHEMBL1508029 & 688150 & 3.0 & 3.627 & TRN & & \\
\hline CHEMBL1303785 & 688150 & 5.4264 & 4.8601 & TRN & & \\
\hline CHEMBL1324467 & 688150 & 3.24300 & 30000000 & 203 & 5.2267 & TST \\
\hline CHEMBL1308777 & 688150 & 3.9493 & 4.6206 & TRN & & \\
\hline CHEMBL1393761 & 688150 & 5.3398 & 4.4817 & TRN & & \\
\hline CHEMBL1584486 & 688150 & 3.95600 & 30000000 & 204 & 4.7855 & TRN \\
\hline CHEMBL1606700 & 688150 & 5.7366 & 4.7216 & TRN & & \\
\hline CHEMBL1559898 & 688150 & 4.9033 & 4.6292 & TST & & \\
\hline CHEMBL1602501 & 688150 & 5.71 & 3.7091 & TRN & & \\
\hline CHEMBL1305390 & 688150 & 3.5903 & 4.3347 & TRN & & \\
\hline CHEMBL1336405 & 688150 & 5.3149 & 4.8136 & TRN & & \\
\hline CHEMBL1426307 & 688150 & 4.4235 & 4.7549 & TST & & \\
\hline CHEMBL1523733 & 688150 & 5.0291 & 4.5244 & TRN & & \\
\hline
\end{tabular}


Supplemental Table S2.txt

\begin{tabular}{|c|c|c|c|c|}
\hline CHEMBL1313107 & 688150 & 5.3852 & 4.0121 & TRN \\
\hline CHEMBL1503325 & 688150 & 5.8768 & 5.2603 & TRN \\
\hline CHEMBL3195045 & 688150 & 6.1421 & 5.6511 & TRN \\
\hline CHEMBL1571837 & 688150 & 4.8034 & 5.2356 & TRN \\
\hline CHEMBL1578557 & 688150 & 3.447 & 4.4558 & TRN \\
\hline CHEMBL1390471 & 688150 & 4.9742 & 4.9562 & TRN \\
\hline CHEMBL1601129 & 688150 & 5.1225 & 5.7585 & TRN \\
\hline CHEMBL1477856 & 688150 & 5.7607 & 4.9647 & TRN \\
\hline CHEMBL1428501 & 688150 & 3.9991 & 4.7364 & TRN \\
\hline CHEMBL1308010 & 688150 & 5.3179 & 4.8264 & TRN \\
\hline CHEMBL1329269 & 688150 & 3.9723 & 4.9319 & TRN \\
\hline CHEMBL1535966 & 688150 & 3.0 & 4.0471 & TRN \\
\hline CHEMBL1571352 & 688150 & 5.4078 & 4.8963 & TRN \\
\hline CHEMBL1391752 & 688150 & 5.5357 & 4.6177 & TRN \\
\hline CHEMBL1385886 & 688150 & 5.0816 & 4.5523 & TRN \\
\hline CHEMBL1351883 & 688150 & 5.2358 & 4.9342 & TRN \\
\hline CHEMBL1550808 & 688150 & 4.2108 & 4.5179 & TRN \\
\hline CHEMBL1309065 & 688150 & 5.0557 & 4.5119 & TRN \\
\hline CHEMBL1470941 & 688150 & 5.0297 & 4.7391 & TST \\
\hline CHEMBL1407409 & 688150 & 5.0185 & 5.5829 & TRN \\
\hline CHEMBL1391788 & 688150 & 5.4927 & 4.4237 & TRN \\
\hline CHEMBL1399498 & 688150 & 3.3072 & 4.5512 & TRN \\
\hline CHEMBL1461400 & 688150 & 7.71 & 4.9094 & TRN \\
\hline CHEMBL1467919 & 688150 & 5.4338 & 4.9823 & TRN \\
\hline CHEMBL1443898 & 688150 & 4.2563 & 5.3051 & TST \\
\hline CHEMBL1529238 & 688150 & 5.9136 & 4.6942 & TST \\
\hline CHEMBL1386054 & 688150 & 4.7006 & 4.4634 & TRN \\
\hline CHEMBL1383312 & 688150 & 6.0273 & 5.1805 & TRN \\
\hline CHEMBL1425342 & 688150 & 5.51 & 5.1144 & TRN \\
\hline CHEMBL1309281 & 688150 & 3.6098 & 4.9519 & TRN \\
\hline CHEMBL1526649 & 688150 & 3.543 & 4.0501 & TRN \\
\hline CHEMBL1581381 & 688150 & 3.0 & 4.3891 & TRN \\
\hline CHEMBL1430981 & 688150 & 3.6563 & 4.6508 & TRN \\
\hline CHEMBL1572095 & 688150 & 5.1661 & 4.8275 & TRN \\
\hline CHEMBL1456134 & 688150 & 3.6253 & 4.9188 & TST \\
\hline CHEMBL1518309 & 688150 & 5.2326 & 4.7218 & TST \\
\hline CHEMBL3214119 & 688150 & 4.8049 & 5.2165 & TST \\
\hline CHEMBL1534588 & 688150 & 3.0 & 4.1602 & TRN \\
\hline CHEMBL1533981 & 688150 & 7.4078 & 4.8102 & TRN \\
\hline CHEMBL1408752 & 688150 & 3.7978 & 4.3691 & TRN \\
\hline CHEMBL1549574 & 688150 & 5.5072 & 4.3803 & TRN \\
\hline CHEMBL1409576 & 688150 & 5.379 & 4.9214 & TRN \\
\hline CHEMBL1522043 & 688150 & 5.71 & 5.2259 & TRN \\
\hline CHEMBL1333537 & 688150 & 5.5479 & 5.25299 & 9999999999 \\
\hline CHEMBL1344155 & 688150 & 3.9352 & 4.6116 & TRN \\
\hline CHEMBL1546374 & 688150 & 6.1192 & 5.8021 & TST \\
\hline CHEMBL306946 & 688150 & 6.71 & 4.8081 & TRN \\
\hline CHEMBL1570905 & 688150 & 3.0 & 4.2495 & TRN \\
\hline
\end{tabular}


Supplemental Table S2.txt

\begin{tabular}{|c|c|c|c|c|}
\hline HEM & 150 & .6378 & 4.7198 & \\
\hline HГMDI 191949 & & .7668 & 4.8365 & \\
\hline AEMBL1611074 & & & & \\
\hline AEMBL1424173 & & & & \\
\hline AEMBL1323774 & 150 & 41 & 3286 & \\
\hline HEMBL1344790 & 88150 & 3.7269 & 1548 & \\
\hline HEMBL132 & 38150 & & 207 & \\
\hline IFMBI 14 & & 2 & & \\
\hline AEMBL1173823 & 88150 & & 6329 & \\
\hline HEMBL1506527 & 38150 & 512 & 5866 & \\
\hline AEMBL600 & 38150 & & 23 & \\
\hline IEMBL14 & 150 & 13 & 673 & \\
\hline AEMBL15 & & & & \\
\hline HEMBL134 & 150 & 83 & 2028 & \\
\hline AEMBL134 & 50 & & 7671 & \\
\hline AEMBL14 & 50 & 36 & 44 & \\
\hline HEMBL53 & 50 & & 54 & \\
\hline HEMBL14 & & & & \\
\hline HEMBL31C & 150 & 2 & 5038 & \\
\hline HEMBL131 & & & & \\
\hline HEMBLI & & & 29 & NIN \\
\hline AEMBLI & & & 56 & +2 \\
\hline HEMBL15 & 50 & & 76 & \\
\hline HEMBL 14 & & & 125 & \\
\hline AEMBL15€ & & & & r \\
\hline HEMBL1C & & & 801 & RN \\
\hline HEMBL1: & & & & וכ \\
\hline HFMBI 31 & 50 & 3. & 639 & RN \\
\hline AEMBL1C & & & & 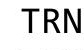 \\
\hline HEMBL156 & & & & r \\
\hline HEMBL14 & & . & 133 & RN \\
\hline HEMBL1 & & & 64 & RN \\
\hline HEMBL1 & 50 & & 03 & RN \\
\hline HEMBL130 & & & 313 & is \\
\hline HEMBL1392478 & & & 392 & TR \\
\hline HEMBL1C & & & & RN \\
\hline HFMRI 14 & & 14 & 385 & $\Gamma \mathrm{RN}$ \\
\hline HEMBL14 & & 3. & 346 & TRN \\
\hline HEMBL1390716 & 88150 & & 1966 & TRN \\
\hline AEMBL14 & & & & TRN \\
\hline HEMBL12 & & & 452 & ISI \\
\hline CHEMBL144 & & & 3972 & TRN \\
\hline HEMBL89671 & & & 2587 & $\Gamma \mathrm{RN}$ \\
\hline HEMBL150 & 3150 & 17 & 045 & $-S_{2}$ \\
\hline HEMBL19 & 88150 & & 5617 & $1 \mathrm{~S}$ \\
\hline CHEMBL 14 & & & 9005 & \\
\hline CHEMBL157 & & .9145 & .4553 & \\
\hline LHEMBL1481667 & 688150 & 3.0 & 5.0469 & ГST \\
\hline
\end{tabular}

Page 13171 


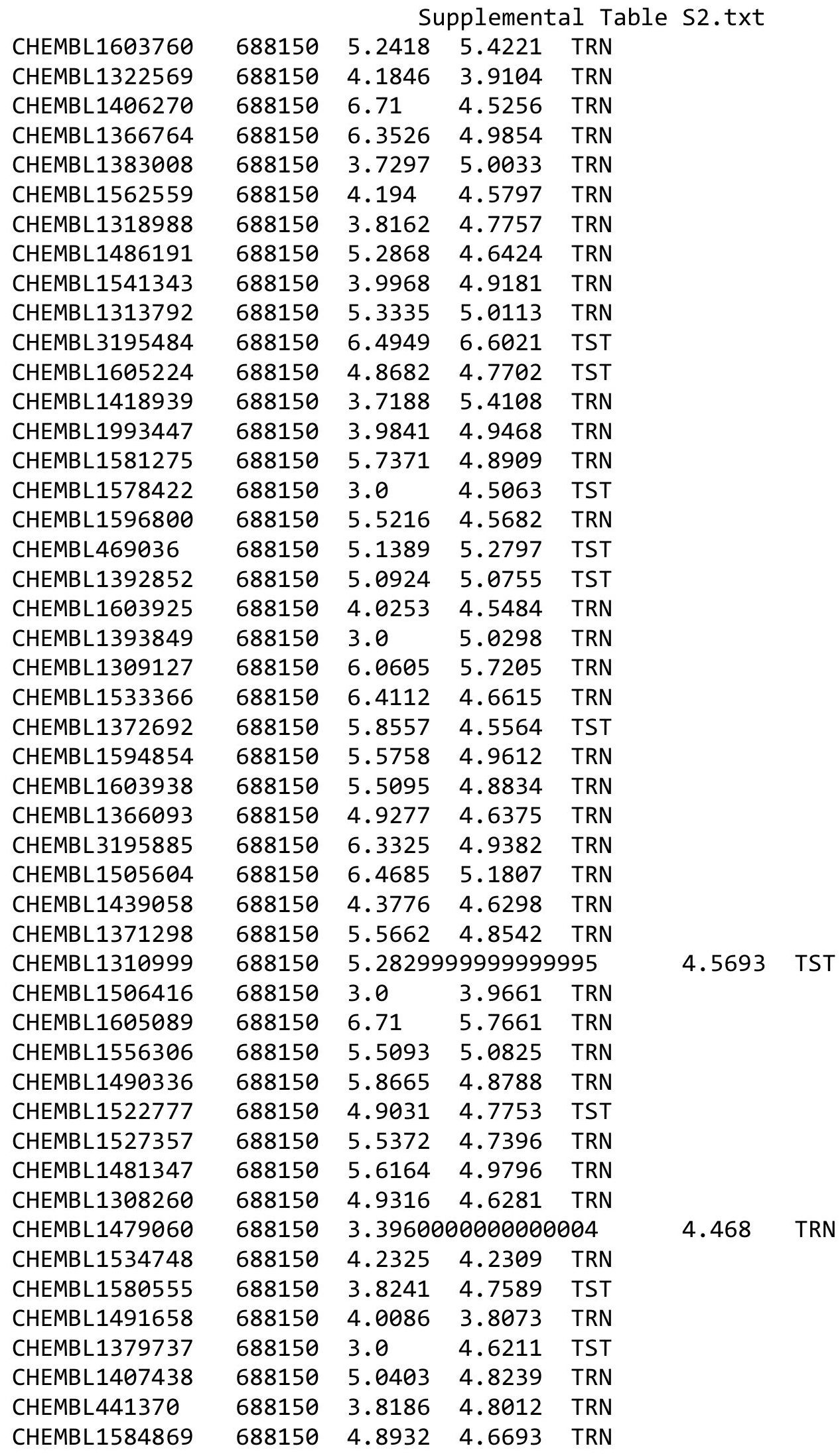

Page 13172 


\begin{tabular}{|c|c|c|c|c|}
\hline \multicolumn{5}{|c|}{ Supplemental Table s2.txt } \\
\hline CHEMBL1606586 & 688150 & 5.3616 & 4.8433 & TRN \\
\hline CHEMBL1544371 & 688150 & 5.5235 & 5.3241 & TRN \\
\hline CHEMBL392680 & 688150 & 5.0059 & 4.8513 & TRN \\
\hline CHEMBL1500054 & 688150 & 5.1104 & 4.0156 & TRN \\
\hline CHEMBL1564543 & 688150 & 5.0478 & 5.7611 & TRN \\
\hline CHEMBL1496579 & 688150 & 3.0 & 4.2136 & TRN \\
\hline CHEMBL1567628 & 688150 & 5.4492 & 5.0675 & TRN \\
\hline CHEMBL1603890 & 688150 & 4.9943 & 4.7848 & TST \\
\hline CHEMBL1483746 & 688150 & 5.6455 & 5.1315 & TRN \\
\hline CHEMBL1493120 & 688150 & 5.1288 & 5.311 & TRN \\
\hline CHEMBL1393625 & 688150 & 3.1083 & 5.1065 & TST \\
\hline CHEMBL1542804 & 688150 & 6.1555 & 5.1411 & TRN \\
\hline CHEMBL1504429 & 688150 & 5.1115 & 5.4008 & TRN \\
\hline CHEMBL1461486 & 688150 & 5.0884 & 4.7417 & TRN \\
\hline CHEMBL1992040 & 688150 & 4.1354 & 5.4507 & TRN \\
\hline CHEMBL1541336 & 688150 & 3.0 & 4.3292 & TRN \\
\hline CHEMBL1425667 & 688150 & 6.71 & 5.3157 & TST \\
\hline CHEMBL3190323 & 688150 & 3.0 & 4.7009 & TRN \\
\hline CHEMBL1346882 & 688150 & 3.0 & 4.2681 & TRN \\
\hline CHEMBL1466406 & 688150 & 5.5522 & 5.2455 & TRN \\
\hline CHEMBL1573754 & 688150 & 5.1375 & 4.8972 & TST \\
\hline CHEMBL1427457 & 688150 & 3.4918 & 4.8251 & TRN \\
\hline CHEMBL1511187 & 688150 & 3.0 & 4.6917 & TRN \\
\hline CHEMBL1368816 & 688150 & 3.912 & 4.4625 & TRN \\
\hline CHEMBL1526904 & 688150 & 3.6194 & 4.3699 & TRN \\
\hline CHEMBL1492849 & 688150 & 5.1517 & 5.0612 & TRN \\
\hline CHEMBL1556582 & 688150 & 4.1018 & 5.1551 & TRN \\
\hline CHEMBL1510023 & 688150 & 4.6899 & 4.6336 & TRN \\
\hline CHEMBL1502358 & 688150 & 4.7857 & 4.7042 & TST \\
\hline CHEMBL1575951 & 688150 & 5.563 & 4.5802 & TRN \\
\hline CHEMBL1390516 & 688150 & 5.6972 & 4.8423 & TRN \\
\hline CHEMBL1426910 & 688150 & 3.7638 & 4.5388 & TRN \\
\hline CHEMBL1483680 & 688150 & 3.4126 & 4.6686 & TRN \\
\hline CHEMBL1454039 & 688150 & 3.2653 & 4.5574 & TRN \\
\hline CHEMBL1589751 & 688150 & 6.1343 & 4.5282 & TRN \\
\hline CHEMBL1478852 & 688150 & 5.0832 & 5.0509 & TRN \\
\hline CHEMBL1602128 & 688150 & 5.8368 & 4.6891 & TRN \\
\hline CHEMBL1602607 & 688150 & 3.6561 & 4.4708 & TRN \\
\hline CHEMBL1461196 & 688150 & 6.71 & 5.4754 & TRN \\
\hline CHEMBL1409776 & 688150 & 4.0811 & 4.6084 & TRN \\
\hline CHEMBL1579471 & 688150 & 6.1255 & 4.4957 & TRN \\
\hline CHEMBL3192555 & 688150 & 5.4105 & 5.8514 & TST \\
\hline CHEMBL1563660 & 688150 & 5.0742 & 5.0717 & TST \\
\hline CHEMBL1489256 & 688150 & 3.5432 & 4.3709 & TRN \\
\hline CHEMBL1594821 & 688150 & 4.0619 & 4.8534 & TRN \\
\hline CHEMBL1330594 & 688150 & 3.8668 & 4.0004 & TRN \\
\hline CHEMBL1345093 & 688150 & 5.0584 & 4.2322 & TRN \\
\hline CHEMBL1996464 & 688150 & 5.8225 & 4.9211 & TST \\
\hline
\end{tabular}




\begin{tabular}{|c|c|c|c|c|c|c|}
\hline \multirow[b]{2}{*}{ CHEMBL1383971 } & & \multicolumn{5}{|c|}{ Supplemental Table S2.txt } \\
\hline & 688150 & 4.8164 & 4.9497 & TRN & & \\
\hline CHEMBL1467978 & 688150 & 3.0 & 4.6898 & TST & & \\
\hline CHEMBL1557616 & 688150 & 3.0 & 4.5539 & TRN & & \\
\hline CHEMBL3207782 & 688150 & 3.0 & 4.5972 & TRN & & \\
\hline CHEMBL1305304 & 688150 & 3.449 & 4.4883 & TRN & & \\
\hline CHEMBL1391048 & 688150 & 5.4991 & 5.1588 & TRN & & \\
\hline CHEMBL1386874 & 688150 & 4.9618 & 4.7422 & TRN & & \\
\hline CHEMBL1599254 & 688150 & \multicolumn{3}{|c|}{5.281000000000001} & 4.5047 & TRN \\
\hline CHEMBL1335669 & 688150 & 4.8238 & 4.8213 & TST & & \\
\hline CHEMBL1470450 & 688150 & 5.153 & 4.2621 & TST & & \\
\hline CHEMBL1521247 & 688150 & 4.9213 & 4.4127 & TRN & & \\
\hline CHEMBL1440883 & 688150 & 5.2326 & 4.8146 & TRN & & \\
\hline CHEMBL1388190 & 688150 & 3.9515 & 4.4395 & TRN & & \\
\hline CHEMBL1583010 & 688150 & 3.9989 & 4.3855 & TRN & & \\
\hline CHEMBL1432271 & 688150 & 3.6476 & 4.6592 & TRN & & \\
\hline CHEMBL1529042 & 688150 & 3.0 & 4.875 & TRN & & \\
\hline CHEMBL1544802 & 688150 & 5.1552 & 4.5946 & TST & & \\
\hline CHEMBL1390047 & 688150 & 3.0 & 3.9426 & TRN & & \\
\hline CHEMBL3196247 & 688150 & 3.9611 & 4.5276 & TRN & & \\
\hline CHEMBL1964836 & 688150 & 3.0 & 4.7122 & TRN & & \\
\hline CHEMBL1334793 & 688150 & 5.1231 & 4.9485 & TRN & & \\
\hline CHEMBL528506 & 688150 & 5.5588 & 4.6164 & TRN & & \\
\hline CHEMBL1521301 & 688150 & 3.0 & 4.6711 & TRN & & \\
\hline CHEMBL1392545 & 688150 & 5.2444 & 4.44600 & 0000000001 & & TRN \\
\hline CHEMBL1465276 & 688150 & 6.1543 & 4.6849 & TST & & \\
\hline CHEMBL81316 & 688150 & 4.0975 & 3.8815 & TRN & & \\
\hline CHEMBL1323764 & 688150 & 5.5519 & 4.6932 & TRN & & \\
\hline CHEMBL1428960 & 688150 & 3.6994 & 4.9785 & TRN & & \\
\hline CHEMBL1308319 & 688150 & 4.8254 & 5.0353 & TRN & & \\
\hline CHEMBL1385701 & 688150 & 5.0992 & 4.9389 & TRN & & \\
\hline CHEMBL528068 & 688150 & 4.9457 & 4.9193 & TRN & & \\
\hline CHEMBL1419184 & 688150 & 5.4175 & 3.6689 & TRN & & \\
\hline CHEMBL1602599 & 688150 & 5.5156 & 4.6835 & TRN & & \\
\hline CHEMBL1365262 & 688150 & 5.0276 & 4.7272 & TRN & & \\
\hline CHEMBL1425141 & 688150 & 3.1247 & 3.9937 & TRN & & \\
\hline CHEMBL1510733 & 688150 & 3.0 & 3.659 & TRN & & \\
\hline CHEMBL588038 & 688150 & 6.2434 & 4.7424 & TST & & \\
\hline CHEMBL1464261 & 688150 & 5.5869 & 5.0818 & TST & & \\
\hline CHEMBL1430266 & 688150 & 4.6249 & 4.4753 & TRN & & \\
\hline CHEMBL546170 & 688150 & 7.71 & 5.4559 & TRN & & \\
\hline CHEMBL1304620 & 688150 & 3.0 & 4.4029 & TRN & & \\
\hline CHEMBL1370099 & 688150 & 5.0529 & 5.2699 & TRN & & \\
\hline CHEMBL1608439 & 688150 & 3.1336 & 3.9796 & TRN & & \\
\hline CHEMBL1472570 & 688150 & 6.4078 & 4.9183 & TRN & & \\
\hline CHEMBL1546679 & 688150 & 4.6317 & 4.6245 & TRN & & \\
\hline CHEMBL1582997 & 688150 & 6.4078 & 5.4117 & TRN & & \\
\hline CHEMBL1427763 & 688150 & 5.3814 & 4.584 & TRN & & \\
\hline CHEMBL1535525 & 688150 & 5.4224 & 5.073 & TRN & & \\
\hline
\end{tabular}




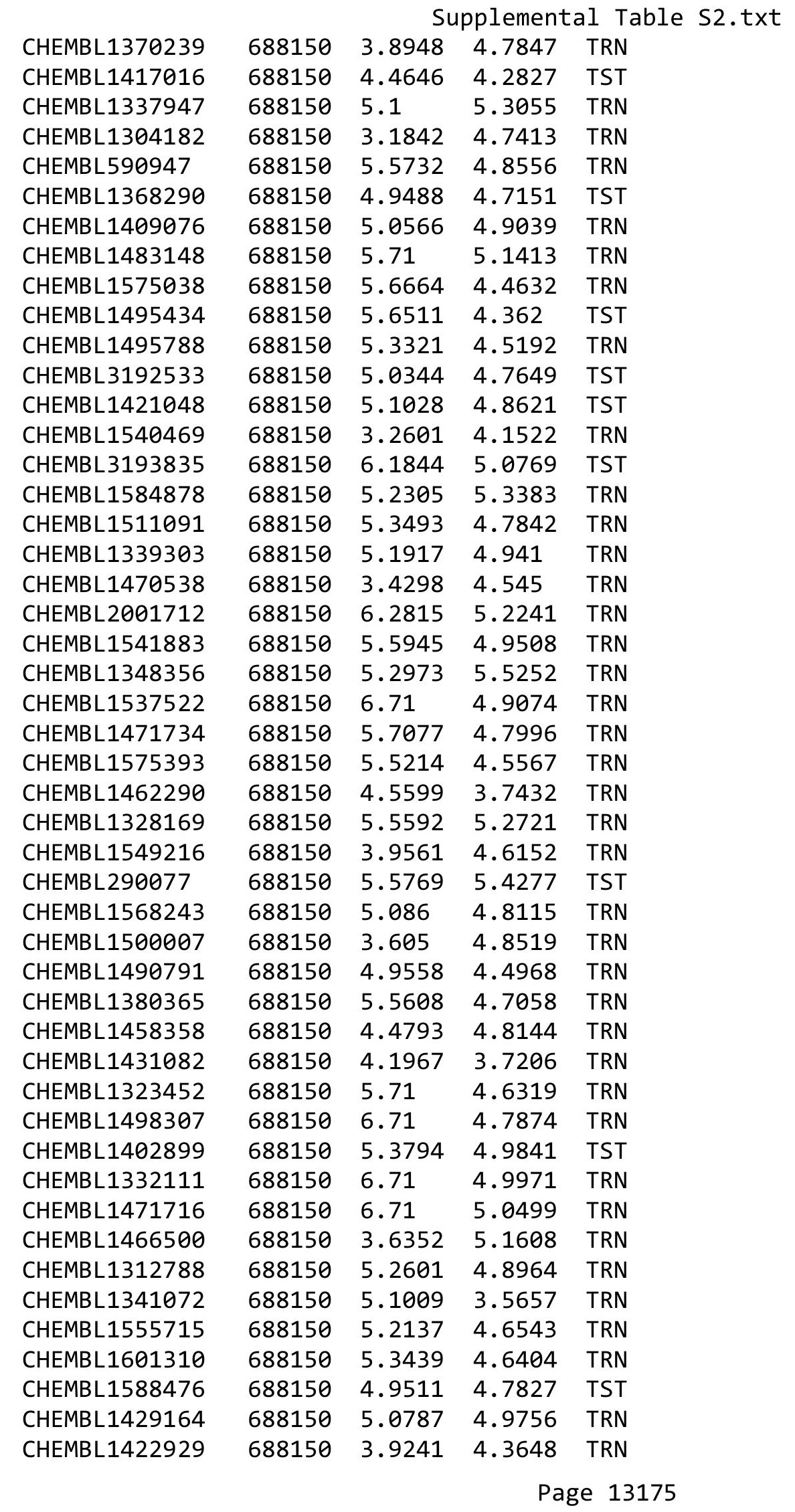




\begin{tabular}{|c|c|c|c|c|c|}
\hline & & \multicolumn{4}{|c|}{ Supplemental Table S2.txt } \\
\hline CHEMBL1522892 & 688150 & 4.9301 & 4.5553 & TRN & \\
\hline CHEMBL1235568 & 688150 & 4.933 & 5.2726 & TRN & \\
\hline CHEMBL1492922 & 688150 & 6.1561 & 4.6446 & TST & \\
\hline CHEMBL1571874 & 688150 & 5.0833 & 4.8085 & TST & \\
\hline CHEMBL1407295 & 688150 & 3.3501 & 4.9487 & TRN & \\
\hline CHEMBL1438681 & 688150 & 3.2893 & 4.867 & TRN & \\
\hline CHEMBL1606890 & 688150 & 4.1124 & 5.75899 & 99999999995 & TRN \\
\hline CHEMBL1362204 & 688150 & 5.565 & 5.0135 & TRN & \\
\hline CHEMBL1487641 & 688150 & 5.5629 & 4.99100 & 00000000005 & w \\
\hline CHEMBL1597345 & 688150 & 5.9776 & 4.4361 & TRN & \\
\hline CHEMBL1604556 & 688150 & 6.4078 & 5.6724 & TRN & \\
\hline CHEMBL1598442 & 688150 & 4.9838 & 5.1057 & TRN & \\
\hline CHEMBL1585843 & 688150 & 4.4024 & 5.329 & TRN & \\
\hline CHEMBL1596319 & 688150 & 6.1612 & 5.256 & TRN & \\
\hline CHEMBL1541102 & 688150 & 5.1811 & 4.7408 & TRN & \\
\hline CHEMBL1599800 & 688150 & 4.9289 & 4.7331 & TRN & \\
\hline CHEMBL1461082 & 688150 & 4.6536 & 4.9895 & TRN & \\
\hline CHEMBL1439184 & 688150 & 4.9778 & 4.5345 & TRN & \\
\hline CHEMBL1443136 & 688150 & 3.4386 & 4.2267 & TRN & \\
\hline CHEMBL1574822 & 688150 & 5.9255 & 4.3868 & TRN & \\
\hline CHEMBL1586274 & 688150 & 4.8817 & 4.7378 & TST & \\
\hline CHEMBL1545853 & 688150 & 5.2062 & 3.5601 & TRN & \\
\hline CHEMBL1498267 & 688150 & 5.1226 & 4.1432 & TRN & \\
\hline CHEMBL1378479 & 688150 & 4.9249 & 4.8003 & TST & \\
\hline CHEMBL1534886 & 688150 & 3.0 & 3.8071 & TRN & \\
\hline CHEMBL145762 & 688150 & 3.8955 & 4.763 & TRN & \\
\hline CHEMBL478501 & 688150 & 6.1972 & 5.5499 & TST & \\
\hline CHEMBL1359319 & 688150 & 5.5704 & 5.3307 & TRN & \\
\hline CHEMBL1509365 & 688150 & 3.5466 & 4.6969 & TRN & \\
\hline CHEMBL1556988 & 688150 & 5.5756 & 4.6381 & TRN & \\
\hline CHEMBL1540205 & 688150 & 5.71 & 3.8738 & TRN & \\
\hline CHEMBL1574280 & 688150 & 5.7667 & 4.5592 & TST & \\
\hline CHEMBL1429682 & 688150 & 6.1838 & 5.1199 & TRN & \\
\hline CHEMBL1502681 & 688150 & 5.8274 & 4.6822 & TRN & \\
\hline CHEMBL1530551 & 688150 & 5.2071 & 4.8025 & TRN & \\
\hline CHEMBL1517796 & 688150 & 6.5884 & 4.7036 & TST & \\
\hline CHEMBL1388751 & 688150 & 4.061 & 4.2264 & TRN & \\
\hline CHEMBL1445373 & 688150 & 3.0 & 4.5981 & TRN & \\
\hline CHEMBL1418230 & 688150 & 5.8176 & 5.7556 & TRN & \\
\hline CHEMBL1610051 & 688150 & 5.19799 & 99999999 & 5.1419 & I \\
\hline CHEMBL1525726 & 688150 & 5.2507 & 4.3702 & TST & \\
\hline CHEMBL1609270 & 688150 & 4.6552 & 3.9205 & TRN & \\
\hline CHEMBL1491079 & 688150 & 5.7889 & 4.8783 & TRN & \\
\hline CHEMBL1359321 & 688150 & 5.9755 & 4.812 & TRN & \\
\hline CHEMBL1343689 & 688150 & 5.8894 & 4.5616 & TRN & \\
\hline CHEMBL1547860 & 688150 & 4.335 & 5.0027 & TRN & \\
\hline CHEMBL1423946 & 688150 & 3.6544 & 4.6211 & TST & \\
\hline CHEMBL1584519 & 688150 & 3.88 & 3.6512 & TRN & \\
\hline
\end{tabular}




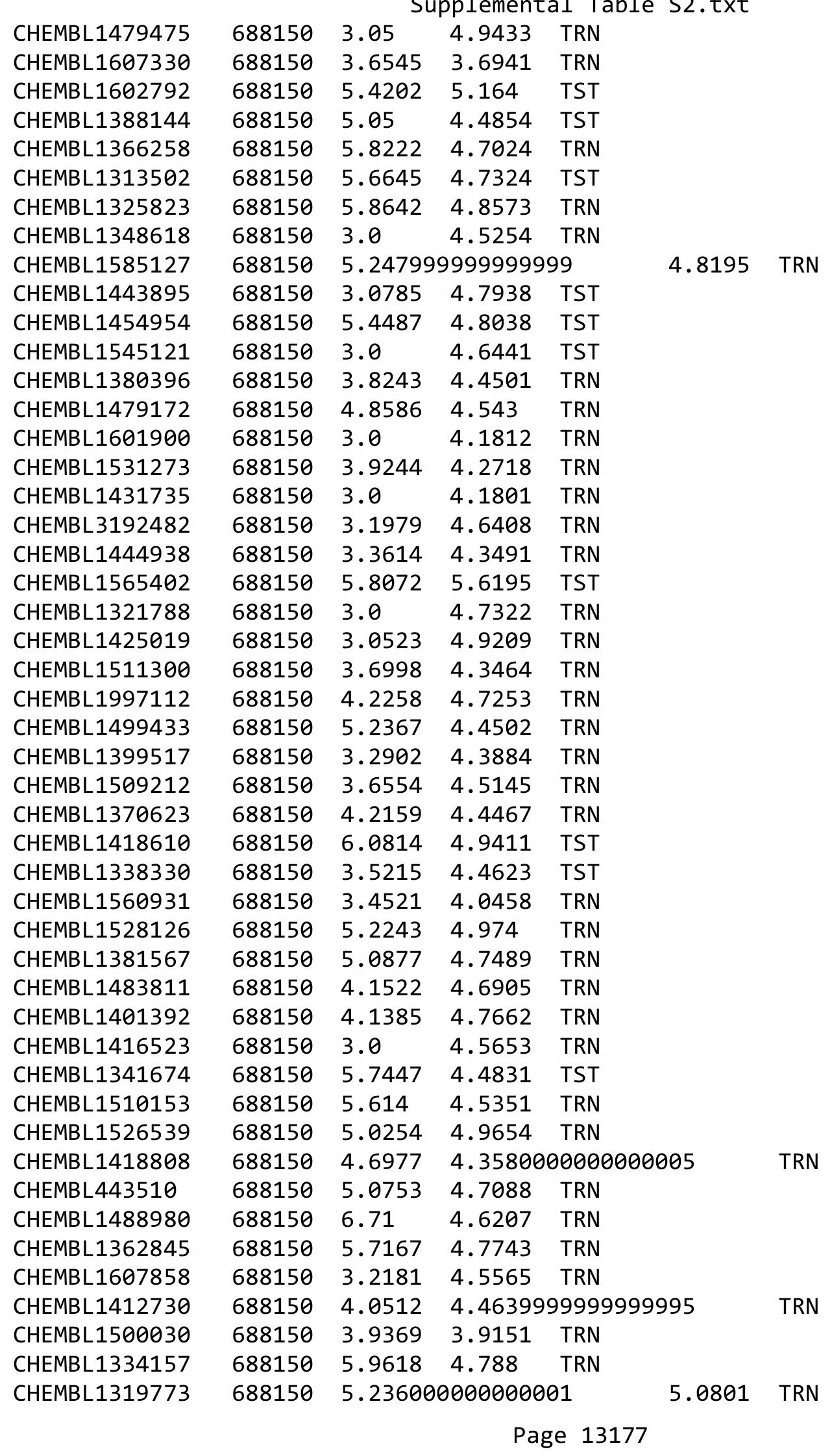




\begin{tabular}{|c|c|c|c|c|c|c|}
\hline & & \multicolumn{5}{|c|}{ Supplemental Table S2.txt } \\
\hline CHEMBL1580409 & 688150 & 4.1855 & 4.9419 & TRN & & \\
\hline CHEMBL1510489 & 688150 & 3.4536 & 4.0028 & TRN & & \\
\hline CHEMBL1385029 & 688150 & 4.3321 & 4.4005 & TRN & & \\
\hline CHEMBL1322679 & 688150 & 3.5577 & 4.4707 & TRN & & \\
\hline CHEMBL1508622 & 688150 & 5.2638 & 5.3635 & TRN & & \\
\hline CHEMBL1343221 & 688150 & 3.8471 & 4.148 & TRN & & \\
\hline CHEMBL1403917 & 688150 & 5.8564 & 5.768 & TRN & & \\
\hline CHEMBL1387794 & 688150 & 3.6298 & 4.7433 & TRN & & \\
\hline CHEMBL1432649 & 688150 & 3.0 & 4.6278 & TRN & & \\
\hline CHEMBL1368839 & 688150 & 4.5296 & 4.2969 & TRN & & \\
\hline CHEMBL1373590 & 688150 & 5.3756 & 5.1632 & TRN & & \\
\hline CHEMBL1428185 & 688150 & 4.7816 & 4.2481 & TRN & & \\
\hline CHEMBL1502002 & 688150 & 5.8365 & 5.0363 & TST & & \\
\hline CHEMBL1313688 & 688150 & 5.8703 & 5.1606 & TRN & & \\
\hline CHEMBL1548425 & 688150 & 5.5952 & 4.7199 & TRN & & \\
\hline CHEMBL1376516 & 688150 & \multicolumn{3}{|c|}{5.3420000000000005} & 4.648 & TRN \\
\hline CHEMBL1407334 & 688150 & 3.0129 & 4.2104 & TRN & & \\
\hline CHEMBL1509092 & 688150 & 5.7215 & 4.6321 & TRN & & \\
\hline CHEMBL1537065 & 688150 & 4.7807 & 4.5877 & TRN & & \\
\hline CHEMBL1442172 & 688150 & 3.5054 & 5.3382 & TRN & & \\
\hline CHEMBL489 & 688150 & 5.0576 & 4.4813 & TST & & \\
\hline CHEMBL1466352 & 688150 & 4.9914 & 4.3736 & TST & & \\
\hline CHEMBL1978279 & 688150 & 3.0 & 4.5037 & TRN & & \\
\hline CHEMBL1428563 & 688150 & 5.1184 & 5.1036 & TRN & & \\
\hline CHEMBL1310009 & 688150 & 5.2327 & 4.8561 & TST & & \\
\hline CHEMBL1306955 & 688150 & 3.9214 & 4.8953 & TST & & \\
\hline CHEMBL1560871 & 688150 & 4.7838 & 4.5832 & TRN & & \\
\hline CHEMBL1368549 & 688150 & 4.9386 & 4.4882 & TRN & & \\
\hline CHEMBL1484101 & 688150 & 5.7875 & 4.5128 & TRN & & \\
\hline CHEMBL1325958 & 688150 & 5.1151 & 4.7179 & TRN & & \\
\hline CHEMBL1365810 & 688150 & 5.2903 & 4.4721 & TRN & & \\
\hline CHEMBL1390784 & 688150 & 4.9243 & 4.5091 & TRN & & \\
\hline CHEMBL1509475 & 688150 & 6.71 & 5.269 & TRN & & \\
\hline CHEMBL1580179 & 688150 & 4.9969 & 4.7826 & TRN & & \\
\hline CHEMBL1505153 & 688150 & 4.5909 & 5.1829 & TRN & & \\
\hline CHEMBL1496329 & 688150 & 5.2059 & 5.6916 & TRN & & \\
\hline CHEMBL1491400 & 688150 & 3.0 & 4.6995 & TRN & & \\
\hline CHEMBL1527338 & 688150 & 3.0 & 4.1513 & TRN & & \\
\hline CHEMBL1504720 & 688150 & 4.8998 & 4.6652 & TRN & & \\
\hline CHEMBL1522033 & 688150 & 5.6946 & 5.4563 & TRN & & \\
\hline CHEMBL3192201 & 688150 & 3.0 & 4.5462 & TRN & & \\
\hline CHEMBL1572396 & 688150 & 4.7703 & 5.2734 & TRN & & \\
\hline CHEMBL1510985 & 688150 & 5.1743 & 3.9628 & TRN & & \\
\hline CHEMBL3211304 & 688150 & 5.6139 & 5.0842 & TST & & \\
\hline CHEMBL1596484 & 688150 & 4.2277 & 4.7445 & TST & & \\
\hline CHEMBL1399213 & 688150 & 4.4909 & 4.5753 & TRN & & \\
\hline CHEMBL1309346 & 688150 & 3.7105 & 4.221 & TRN & & \\
\hline CHEMBL1492961 & 688150 & 5.1017 & 4.4216 & TRN & & \\
\hline
\end{tabular}




\begin{tabular}{|c|c|c|c|c|c|}
\hline & & \multicolumn{4}{|c|}{ Supplemental Table S2.txt } \\
\hline CHEMBL1319243 & 688150 & 5.4853 & 4.547 & TRN & \\
\hline CHEMBL1500035 & 688150 & 5.7545 & 5.1976 & TRN & \\
\hline CHEMBL1321296 & 688150 & 3.0 & 4.4098 & TRN & \\
\hline CHEMBL586602 & 688150 & 5.3556 & 5.343 & TRN & \\
\hline CHEMBL1455971 & 688150 & 3.3786 & 4.4391 & TRN & \\
\hline CHEMBL1524866 & 688150 & 3.0 & 4.5897 & TST & \\
\hline CHEMBL1412519 & 688150 & 5.4309 & 5.0291 & TST & \\
\hline CHEMBL1375373 & 688150 & 3.8512 & 4.9698 & TRN & \\
\hline CHEMBL1481525 & 688150 & 3.0 & 4.9277 & TST & \\
\hline CHEMBL1543444 & 688150 & 3.5672 & 4.4366 & TRN & \\
\hline CHEMBL1352156 & 688150 & 5.1108 & 4.728 & TRN & \\
\hline CHEMBL1378913 & 688150 & 4.8026 & 4.7057 & TRN & \\
\hline CHEMBL1426775 & 688150 & 4.0727 & 4.0543 & TST & \\
\hline CHEMBL1402179 & 688150 & 3.9953 & 4.5506 & TRN & \\
\hline CHEMBL1329638 & 688150 & 4.8721 & 5.2796 & TST & \\
\hline CHEMBL1323859 & 688150 & 3.2626 & 4.4108 & TRN & \\
\hline CHEMBL363535 & 688150 & 6.4737 & 4.5835 & TST & \\
\hline CHEMBL1332327 & 688150 & 4.6053 & 4.8185 & TRN & \\
\hline CHEMBL530038 & 688150 & 4.498 & 5.9535 & TRN & \\
\hline CHEMBL1372921 & 688150 & 5.2128 & 5.0806 & TRN & \\
\hline CHEMBL1352234 & 688150 & 4.999 & \multicolumn{2}{|c|}{4.803999999999999} & TST \\
\hline CHEMBL445153 & 688150 & 5.2297 & 4.629 & TRN & \\
\hline CHEMBL1463624 & 688150 & 4.8098 & 3.9828 & TRN & \\
\hline CHEMBL3193644 & 688150 & 3.7047 & 4.6069 & TST & \\
\hline CHEMBL1456623 & 688150 & 5.0762 & 4.9727 & TST & \\
\hline CHEMBL1598316 & 688150 & 3.0 & 4.203 & TRN & \\
\hline CHEMBL1490656 & 688150 & 4.9461 & 5.0727 & TRN & \\
\hline CHEMBL1544073 & 688150 & 3.3424 & 4.2748 & TRN & \\
\hline CHEMBL1494620 & 688150 & 3.0 & 4.5119 & TRN & \\
\hline CHEMBL1613213 & 688150 & 4.8573 & 4.7357 & TRN & \\
\hline CHEMBL1481495 & 688150 & 5.1097 & \multicolumn{2}{|c|}{ 4.3839999999999995 } & TRN \\
\hline CHEMBL1460871 & 688150 & 5.2653 & 4.5057 & TRN & \\
\hline CHEMBL1429343 & 688150 & 4.6669 & 4.654 & TRN & \\
\hline CHEMBL1497418 & 688150 & 6.71 & 4.9208 & TRN & \\
\hline CHEMBL1313854 & 688150 & 3.0 & 4.8331 & TRN & \\
\hline CHEMBL1545553 & 688150 & 3.5857 & 4.9455 & TRN & \\
\hline CHEMBL1311015 & 688150 & 3.6451 & 3.6897 & TRN & \\
\hline CHEMBL1470370 & 688150 & 3.4947 & 3.8677 & TRN & \\
\hline CHEMBL1612019 & 688150 & 3.7389 & 4.8232 & TST & \\
\hline CHEMBL1492148 & 688150 & 5.1215 & 4.8188 & TST & \\
\hline CHEMBL1467194 & 688150 & 3.7193 & 4.335 & TRN & \\
\hline CHEMBL1312654 & 688150 & 7.71 & 6.0901 & TRN & \\
\hline CHEMBL1568905 & 688150 & 4.973 & 4.8043 & TST & \\
\hline CHEMBL1491623 & 688150 & 4.3314 & 4.2395 & TRN & \\
\hline CHEMBL1309290 & 688150 & 5.7721 & 5.7056 & TRN & \\
\hline CHEMBL1565286 & 688150 & 4.9663 & 4.647 & TRN & \\
\hline CHEMBL1347193 & 688150 & 5.1075 & \multicolumn{2}{|c|}{4.6610000000000005} & TRN \\
\hline CHEMBL1499408 & 688150 & 3.8983 & 3.2896 & TRN & \\
\hline
\end{tabular}




\begin{tabular}{|c|c|c|c|c|c|c|}
\hline & & \multicolumn{5}{|c|}{ Supplemental Table S2.txt } \\
\hline CHEMBL1464106 & 688150 & 3.8011 & 4.8983 & TRN & & \\
\hline CHEMBL1535050 & 688150 & 5.7144 & 4.4309 & TRN & & \\
\hline CHEMBL1508190 & 688150 & 3.0 & 4.6789 & TRN & & \\
\hline CHEMBL1391018 & 688150 & 3.7686 & 4.7863 & TRN & & \\
\hline CHEMBL1496105 & 688150 & 4.1555 & 4.5514 & TRN & & \\
\hline CHEMBL1407037 & 688150 & 3.7636 & 5.1021 & TRN & & \\
\hline CHEMBL1405104 & 688150 & 3.0 & 4.7273 & TRN & & \\
\hline CHEMBL1599654 & 688150 & 6.0 & 5.0438 & TRN & & \\
\hline CHEMBL1382993 & 688150 & 5.22 & 5.4718 & TRN & & \\
\hline CHEMBL1085765 & 688150 & 4.7872 & 4.71 & TRN & & \\
\hline CHEMBL1343853 & 688150 & 4.869 & 4.2903 & TRN & & \\
\hline CHEMBL1411125 & 688150 & 5.2444 & 4.7185 & TRN & & \\
\hline CHEMBL1388123 & 688150 & 3.0 & 4.1286 & TRN & & \\
\hline CHEMBL1412114 & 688150 & 4.9368 & 5.0982 & TST & & \\
\hline CHEMBL1407731 & 688150 & 3.0 & 3.9913 & TRN & & \\
\hline CHEMBL267099 & 688150 & \multicolumn{3}{|c|}{5.6129999999999995} & 4.9001 & TST \\
\hline CHEMBL1385868 & 688150 & 5.0783 & 4.7751 & TRN & & \\
\hline CHEMBL1309957 & 688150 & 5.768 & 4.7219 & TRN & & \\
\hline CHEMBL1543495 & 688150 & 4.4486 & 4.6013 & TRN & & \\
\hline CHEMBL1421724 & 688150 & 5.0609 & 4.7043 & TRN & & \\
\hline CHEMBL1600937 & 688150 & 5.4241 & 5.2644 & TRN & & \\
\hline CHEMBL1563671 & 688150 & 3.9188 & 5.0016 & TRN & & \\
\hline CHEMBL1506300 & 688150 & 5.1164 & 5.4972 & TRN & & \\
\hline CHEMBL1482215 & 688150 & 3.0 & 4.8609 & TRN & & \\
\hline CHEMBL3189770 & 688150 & 5.2596 & 4.9089 & TST & & \\
\hline CHEMBL1598279 & 688150 & 6.71 & 4.8912 & TRN & & \\
\hline CHEMBL1567870 & 688150 & 3.531 & 4.8372 & TRN & & \\
\hline CHEMBL1384880 & 688150 & 3.0 & 4.4439 & TRN & & \\
\hline CHEMBL1595660 & 688150 & 3.447 & 4.0999 & TRN & & \\
\hline CHEMBL1484818 & 688150 & 6.2652 & 4.7776 & TRN & & \\
\hline CHEMBL1470017 & 688150 & 3.0 & 3.7209 & TRN & & \\
\hline CHEMBL1491221 & 688150 & 4.0226 & 3.5404 & TRN & & \\
\hline CHEMBL586135 & 688150 & 6.4078 & 6.1147 & TRN & & \\
\hline CHEMBL3193905 & 688150 & 4.695 & 4.5708 & TRN & & \\
\hline CHEMBL1364323 & 688150 & 6.4078 & 4.4009 & TST & & \\
\hline CHEMBL1306270 & 688150 & 5.2372 & 4.5596 & TRN & & \\
\hline CHEMBL1311260 & 688150 & 4.766 & 4.8861 & TST & & \\
\hline CHEMBL1588732 & 688150 & 3.0 & 4.559 & TST & & \\
\hline CHEMBL417727 & 688150 & 6.3969 & 5.2331 & TRN & & \\
\hline CHEMBL1299448 & 688150 & 4.7704 & 4.3099 & TRN & & \\
\hline CHEMBL1589428 & 688150 & 5.607 & 4.9665 & TRN & & \\
\hline CHEMBL1462938 & 688150 & 6.2503 & 4.9258 & TST & & \\
\hline CHEMBL1535809 & 688150 & 3.6867 & 5.0678 & TST & & \\
\hline CHEMBL1463571 & 688150 & 6.1267 & 4.8133 & TRN & & \\
\hline CHEMBL1575531 & 688150 & 5.5277 & 5.2199 & TRN & & \\
\hline CHEMBL1445367 & 688150 & 4.8124 & 4.5384 & TRN & & \\
\hline CHEMBL1401649 & 688150 & 3.7027 & 3.9338 & TRN & & \\
\hline CHEMBL1483993 & 688150 & 3.7487 & 4.3192 & TRN & & \\
\hline
\end{tabular}

Page 13180 


\begin{tabular}{|c|c|c|c|c|c|c|}
\hline & & \multicolumn{5}{|c|}{ Supplemental Table S2.txt } \\
\hline CHEMBL1444516 & 688150 & 3.5254 & 3.8192 & TRN & & \\
\hline CHEMBL1337612 & 688150 & 5.2611 & 4.2804 & TRN & & \\
\hline CHEMBL592068 & 688150 & 5.845 & 5.608 & TRN & & \\
\hline CHEMBL1522373 & 688150 & 7.71 & 4.8373 & TRN & & \\
\hline CHEMBL1525863 & 688150 & 3.445 & 3.8196 & TRN & & \\
\hline CHEMBL1301536 & 688150 & 5.3475 & 5.4561 & TRN & & \\
\hline CHEMBL1375815 & 688150 & 6.4078 & 5.0133 & TRN & & \\
\hline CHEMBL1495849 & 688150 & 6.5017 & 5.3323 & TRN & & \\
\hline CHEMBL1363112 & 688150 & 3.5284 & 5.7325 & TRN & & \\
\hline CHEMBL3194785 & 688150 & 5.5936 & 5.1202 & TRN & & \\
\hline CHEMBL1543295 & 688150 & 5.5677 & 5.1331 & TRN & & \\
\hline CHEMBL1557014 & 688150 & 3.2568 & 4.195 & TRN & & \\
\hline CHEMBL1488001 & 688150 & 5.2412 & 4.4288 & TST & & \\
\hline CHEMBL1544793 & 688150 & 5.4153 & 5.6474 & TRN & & \\
\hline CHEMBL1611420 & 688150 & 3.0 & 4.5943 & TRN & & \\
\hline CHEMBL1567859 & 688150 & 5.0042 & 4.4638 & TRN & & \\
\hline CHEMBL1300736 & 688150 & 5.4645 & 4.6864 & TRN & & \\
\hline CHEMBL1525271 & 688150 & 3.8627 & 5.0275 & TRN & & \\
\hline CHEMBL1546713 & 688150 & 5.7093 & 4.8049 & TRN & & \\
\hline CHEMBL1429975 & 688150 & 5.553 & 5.0378 & TRN & & \\
\hline CHEMBL1535018 & 688150 & 4.3961 & 4.6545 & TRN & & \\
\hline CHEMBL1347799 & 688150 & 5.5314 & 4.8831 & TRN & & \\
\hline CHEMBL1530220 & 688150 & 5.26399 & 999999999 & 99 & 4.8811 & TST \\
\hline CHEMBL1353388 & 688150 & 6.4789 & 4.8708 & TRN & & \\
\hline CHEMBL1468087 & 688150 & 5.25299 & 999999999 & 99 & 5.2549 & TST \\
\hline CHEMBL1499250 & 688150 & 5.755 & 4.8495 & TRN & & \\
\hline CHEMBL1302845 & 688150 & 5.6271 & 4.7887 & TRN & & \\
\hline CHEMBL1423345 & 688150 & 5.7109 & 4.5706 & TRN & & \\
\hline CHEMBL1549700 & 688150 & 3.4137 & 4.0405 & TRN & & \\
\hline CHEMBL1609009 & 688150 & 4.7054 & 5.7509 & TST & & \\
\hline CHEMBL3195975 & 688150 & 5.0559 & 4.7052 & TST & & \\
\hline CHEMBL1995497 & 688150 & 5.8359 & 4.8431 & TRN & & \\
\hline CHEMBL1608530 & 688150 & 4.1806 & 4.9166 & TRN & & \\
\hline CHEMBL1375638 & 688150 & 4.9214 & 4.3641 & TRN & & \\
\hline CHEMBL1558928 & 688150 & 3.6354 & 4.744 & TRN & & \\
\hline CHEMBL1495409 & 688150 & 4.6284 & 4.9264 & TRN & & \\
\hline CHEMBL388978 & 688150 & 5.2447 & 5.5722 & TST & & \\
\hline CHEMBL3195629 & 688150 & 3.8119 & 4.3363 & TRN & & \\
\hline CHEMBL1387232 & 688150 & 5.71 & 5.0644 & TRN & & \\
\hline CHEMBL1568190 & 688150 & 5.2059 & 4.664 & TRN & & \\
\hline CHEMBL1415308 & 688150 & 4.8376 & 4.513 & TRN & & \\
\hline CHEMBL1526203 & 688150 & 3.0 & 4.5913 & TRN & & \\
\hline CHEMBL1313542 & 688150 & 5.273 & 4.7 & TST & & \\
\hline CHEMBL1333191 & 688150 & 5.5433 & 5.0181 & TRN & & \\
\hline CHEMBL1404731 & 688150 & 5.7245 & 4.7665 & TRN & & \\
\hline CHEMBL1572965 & 688150 & 3.7797 & 4.8197 & TRN & & \\
\hline CHEMBL1390963 & 688150 & 5.0369 & 5.3506 & TRN & & \\
\hline CHEMBL 299853 & 688150 & 4.9104 & 4.9125 & TRN & & \\
\hline
\end{tabular}




\begin{tabular}{|c|c|c|c|c|c|c|}
\hline & & \multicolumn{5}{|c|}{ Supplemental Table S2.txt } \\
\hline CHEMBL1324011 & 688150 & 3.1645 & 5.3402 & TRN & & \\
\hline CHEMBL1498633 & 688150 & 3.0 & 5.0283 & TST & & \\
\hline CHEMBL1459764 & 688150 & 4.9478 & 4.7461 & TRN & & \\
\hline CHEMBL1566045 & 688150 & 5.71 & 4.7112 & TRN & & \\
\hline CHEMBL1399198 & 688150 & \multicolumn{3}{|c|}{6.218999999999999} & 4.8112 & TRN \\
\hline CHEMBL1528219 & 688150 & 6.71 & 4.6246 & TRN & & \\
\hline CHEMBL1411960 & 688150 & 4.5891 & 3.9326 & TRN & & \\
\hline CHEMBL1440025 & 688150 & 5.8383 & 4.7923 & TRN & & \\
\hline CHEMBL1506397 & 688150 & 5.8052 & 4.8098 & TRN & & \\
\hline CHEMBL1428407 & 688150 & 5.1674 & 5.2295 & TRN & & \\
\hline CHEMBL1557648 & 688150 & 6.71 & 5.2688 & TRN & & \\
\hline CHEMBL1581581 & 688150 & 5.2425 & 4.7718 & TRN & & \\
\hline CHEMBL1382306 & 688150 & 5.3933 & 4.6553 & TRN & & \\
\hline CHEMBL1571893 & 688150 & 3.0 & 4.7192 & TRN & & \\
\hline CHEMBL1341563 & 688150 & 3.5004 & 4.63 & TRN & & \\
\hline CHEMBL1345558 & 688150 & 5.3218 & 3.7671 & TRN & & \\
\hline CHEMBL1458178 & 688150 & \multicolumn{3}{|c|}{5.957000000000001} & 5.2703 & TST \\
\hline CHEMBL504977 & 688150 & 7.71 & 5.0033 & TRN & & \\
\hline CHEMBL1612250 & 688150 & 5.0208 & 4.4843 & TRN & & \\
\hline CHEMBL1405281 & 688150 & 4.9776 & 4.9083 & TRN & & \\
\hline CHEMBL1596475 & 688150 & 3.8739 & 4.2908 & TRN & & \\
\hline CHEMBL1309573 & 688150 & 6.71 & 5.1461 & TRN & & \\
\hline CHEMBL1526174 & 688150 & 5.7865 & 4.7767 & TST & & \\
\hline CHEMBL1482610 & 688150 & 3.0 & 4.5823 & TRN & & \\
\hline CHEMBL1566193 & 688150 & 4.3492 & 5.5037 & TST & & \\
\hline CHEMBL1519422 & 688150 & 5.0111 & 4.7334 & TRN & & \\
\hline CHEMBL1542340 & 688150 & 3.0 & 4.3175 & TRN & & \\
\hline CHEMBL1426361 & 688150 & 5.3478 & 3.8858 & TRN & & \\
\hline CHEMBL1555793 & 688150 & 5.8271 & 5.1021 & TRN & & \\
\hline CHEMBL1575578 & 688150 & 4.9716 & 4.8277 & TRN & & \\
\hline CHEMBL1359317 & 688150 & 5.71 & 4.1554 & TRN & & \\
\hline CHEMBL1402051 & 688150 & 5.4435 & 5.5212 & TRN & & \\
\hline CHEMBL1492807 & 688150 & 5.1859 & 5.3561 & TRN & & \\
\hline CHEMBL1341270 & 688150 & 5.3078 & \multicolumn{3}{|c|}{5.242000000000001} & TST \\
\hline CHEMBL1612951 & 688150 & 3.0 & 3.9813 & TRN & & \\
\hline CHEMBL1351533 & 688150 & \multicolumn{3}{|c|}{3.9539999999999997} & 4.3796 & TST \\
\hline CHEMBL1569370 & 688150 & \multicolumn{3}{|c|}{5.8229999999999995} & 4.8421 & TRN \\
\hline CHEMBL1445427 & 688150 & 5.5998 & 4.7423 & TST & & \\
\hline CHEMBL1609533 & 688150 & 3.0 & 4.4574 & TRN & & \\
\hline CHEMBL1345452 & 688150 & 5.8945 & 4.6582 & TRN & & \\
\hline CHEMBL1478308 & 688150 & 3.5109 & 4.1422 & TRN & & \\
\hline CHEMBL1508896 & 688150 & 5.0784 & 4.9093 & TRN & & \\
\hline CHEMBL1390578 & 688150 & 6.2916 & 3.9941 & TRN & & \\
\hline CHEMBL1361721 & 688150 & 3.8308 & 4.4622 & TRN & & \\
\hline CHEMBL1558973 & 688150 & \multicolumn{3}{|c|}{5.1979999999999995} & 4.9834 & TRN \\
\hline CHEMBL1403629 & 688150 & 4.9211 & 4.8499 & TST & & \\
\hline CHEMBL1566610 & 688150 & 5.8333 & 4.8676 & TST & & \\
\hline CHEMBL1545105 & 688150 & 5.246 & 5.0367 & TRN & & \\
\hline
\end{tabular}




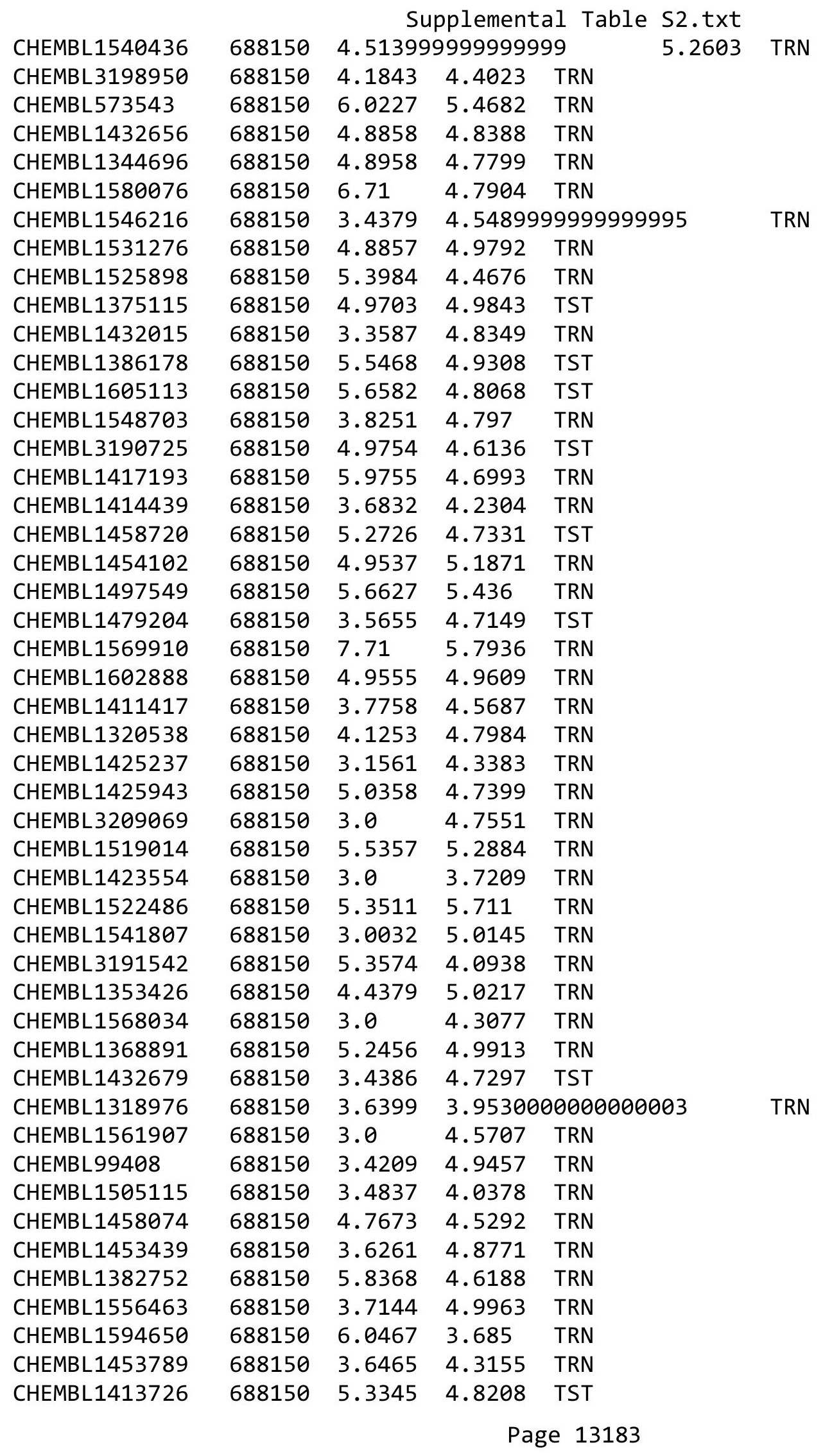




\begin{tabular}{|c|c|c|c|c|c|}
\hline \multicolumn{6}{|c|}{ Supplemental Table S2.txt } \\
\hline CHEMBL1338858 & 688150 & 3.0 & 3.9119 & TRN & \\
\hline CHEMBL1582746 & 688150 & 5.0482 & 5.065 & TRN & \\
\hline CHEMBL3193986 & 688150 & 5.8891 & 4.8355 & TST & \\
\hline CHEMBL1460004 & 688150 & 5.4765 & 4.7008 & TST & \\
\hline CHEMBL1427829 & 688150 & 6.3261 & 4.57600 & 00000000005 & TRN \\
\hline CHEMBL1469111 & 688150 & 5.71 & 5.118 & TRN & \\
\hline CHEMBL1373688 & 688150 & 3.4526 & 4.2166 & TRN & \\
\hline CHEMBL1335038 & 688150 & 4.1753 & 4.4845 & TST & \\
\hline CHEMBL1390565 & 688150 & 5.4403 & 4.5171 & TRN & \\
\hline CHEMBL1536155 & 688150 & 5.71 & 4.4314 & TRN & \\
\hline CHEMBL1508616 & 688150 & 5.3634 & 5.2754 & TRN & \\
\hline CHEMBL1387773 & 688150 & 5.1234 & 4.9322 & TRN & \\
\hline CHEMBL1456751 & 688150 & 3.9725 & 3.7854 & TRN & \\
\hline CHEMBL1531172 & 688150 & 4.4358 & 5.3596 & TRN & \\
\hline CHEMBL1360431 & 688150 & 4.2026 & 3.9746 & TRN & \\
\hline CHEMBL1599290 & 688150 & 3.6599 & 4.5692 & TRN & \\
\hline CHEMBL3189568 & 688150 & 3.4546 & 4.5527 & TST & \\
\hline CHEMBL1466712 & 688150 & 5.7172 & 5.0628 & TRN & \\
\hline CHEMBL1585539 & 688150 & 3.6233 & 4.4615 & TRN & \\
\hline CHEMBL1521482 & 688150 & 6.71 & 4.4404 & TRN & \\
\hline CHEMBL1613363 & 688150 & 3.1927 & 4.3857 & TRN & \\
\hline CHEMBL1609674 & 688150 & 4.8029 & 4.3802 & TRN & \\
\hline CHEMBL1346580 & 688150 & 3.0 & 4.519 & TRN & \\
\hline CHEMBL1575913 & 688150 & 4.0693 & 3.7284 & TRN & \\
\hline CHEMBL1477205 & 688150 & 4.7455 & 4.2131 & TRN & \\
\hline CHEMBL1465088 & 688150 & 5.8286 & 4.5866 & TRN & \\
\hline CHEMBL1361319 & 688150 & 5.9983 & 6.2444 & TRN & \\
\hline CHEMBL1332881 & 688150 & 5.4249 & 4.6719 & TRN & \\
\hline CHEMBL1498128 & 688150 & 3.7223 & 4.0124 & TRN & \\
\hline CHEMBL1463786 & 688150 & 5.9551 & 4.9586 & TRN & \\
\hline CHEMBL1376704 & 688150 & 5.528 & 4.7762 & TRN & \\
\hline CHEMBL1332245 & 688150 & 3.0 & 4.5567 & TRN & \\
\hline CHEMBL1463349 & 688150 & 6.20200 & 30000000 & 5.0142 & TRN \\
\hline CHEMBL1583035 & 688150 & 3.0 & 4.8704 & TRN & \\
\hline CHEMBL1588152 & 688150 & 3.0 & 3.965 & TRN & \\
\hline CHEMBL1307716 & 688150 & 4.2738 & 4.8469 & TST & \\
\hline CHEMBL1460452 & 688150 & 5.05 & 4.1544 & TRN & \\
\hline CHEMBL1499310 & 688150 & 5.3801 & 4.4636 & TRN & \\
\hline CHEMBL1360250 & 688150 & 4.1858 & 5.1856 & TST & \\
\hline CHEMBL1601781 & 688150 & 5.1717 & 5.5243 & TRN & \\
\hline CHEMBL1457011 & 688150 & 3.0 & 4.2219 & TRN & \\
\hline CHEMBL 2004900 & 688150 & 3.0 & 4.3322 & TRN & \\
\hline CHEMBL1549453 & 688150 & 4.6539 & 4.7533 & TST & \\
\hline CHEMBL581872 & 688150 & 6.0066 & 4.82600 & 00000000005 & TST \\
\hline CHEMBL1471888 & 688150 & 5.959 & 4.7979 & TRN & \\
\hline CHEMBL1526592 & 688150 & 3.0095 & 4.0703 & TRN & \\
\hline CHEMBL1522331 & 688150 & 5.5082 & 4.2443 & TRN & \\
\hline CHEMBL1608133 & 688150 & 5.2725 & 4.8373 & TRN & \\
\hline
\end{tabular}




\begin{tabular}{|c|c|c|c|c|c|}
\hline & & \multicolumn{4}{|c|}{ Supplemental Table S2.txt } \\
\hline CHEMBL1519133 & 688150 & 4.9318 & 4.6784 & TRN & \\
\hline CHEMBL1403554 & 688150 & 4.8242 & 4.9178 & TRN & \\
\hline CHEMBL1341120 & 688150 & 5.6354 & 4.8802 & TRN & \\
\hline CHEMBL1334593 & 688150 & 5.237 & 4.8158 & TRN & \\
\hline CHEMBL1444472 & 688150 & 3.5457 & 4.4685 & TRN & \\
\hline CHEMBL445311 & 688150 & 5.1363 & 4.7237 & TST & \\
\hline CHEMBL1611433 & 688150 & 5.7545 & 4.9929 & TRN & \\
\hline CHEMBL1399812 & 688150 & 5.71 & 4.8056 & TRN & \\
\hline CHEMBL1347469 & 688150 & 4.9278 & 4.7723 & TST & \\
\hline CHEMBL1391981 & 688150 & 3.8545 & 3.7999 & TRN & \\
\hline CHEMBL3193747 & 688150 & 5.5935 & 4.7648 & TRN & \\
\hline CHEMBL1518260 & 688150 & 3.6647 & 4.7883 & TST & \\
\hline CHEMBL1531073 & 688150 & 5.5378 & 5.4565 & TRN & \\
\hline CHEMBL1368871 & 688150 & 5.2889 & 4.5986 & TST & \\
\hline CHEMBL1594359 & 688150 & 5.551 & 4.7726 & TRN & \\
\hline CHEMBL1556350 & 688150 & 3.1485 & 4.9611 & TRN & \\
\hline CHEMBL1319873 & 688150 & 4.3998 & 4.7227 & TRN & \\
\hline CHEMBL1342471 & 688150 & 4.2193 & 4.6911 & TRN & \\
\hline CHEMBL 1344080 & 688150 & 6.2284 & 5.0139 & TRN & \\
\hline CHEMBL1532819 & 688150 & 5.5916 & 5.2772 & TRN & \\
\hline CHEMBL1333387 & 688150 & 5.8489 & 5.7133 & TRN & \\
\hline CHEMBL1538267 & 688150 & 3.4748 & 4.3027 & TRN & \\
\hline CHEMBL1599610 & 688150 & 5.5309 & 4.7488 & TRN & \\
\hline CHEMBL1587645 & 688150 & 6.71 & 5.0117 & TRN & \\
\hline CHEMBL1362499 & 688150 & 4.0538 & 4.3698 & TRN & \\
\hline CHEMBL1541834 & 688150 & 5.1166 & 5.6826 & TRN & \\
\hline CHEMBL1309755 & 688150 & 3.412 & 4.0781 & TRN & \\
\hline CHEMBL1429832 & 688150 & 4.3368 & 4.0951 & TRN & \\
\hline CHEMBL1492352 & 688150 & 3.3368 & 4.0084 & TRN & \\
\hline CHEMBL1496338 & 688150 & 5.4965 & 4.9575 & TRN & \\
\hline CHEMBL1506442 & 688150 & 5.7894 & 4.7337 & TRN & \\
\hline CHEMBL1480052 & 688150 & 3.0 & 4.77800 & 00000000005 & TST \\
\hline CHEMBL1526824 & 688150 & 5.8639 & 5.2642 & TRN & \\
\hline CHEMBL1594860 & 688150 & 3.0 & 4.7218 & TRN & \\
\hline CHEMBL1351876 & 688150 & 3.9089 & 4.5269 & TRN & \\
\hline CHEMBL1438878 & 688150 & 3.0 & 4.1865 & TRN & \\
\hline CHEMBL3193321 & 688150 & 3.5026 & 4.907 & TRN & \\
\hline CHEMBL1348638 & 688150 & 4.9165 & 4.6592 & TST & \\
\hline CHEMBL1544423 & 688150 & 5.5139 & 5.3212 & TRN & \\
\hline CHEMBL1582091 & 688150 & 4.9577 & 4.7045 & TST & \\
\hline CHEMBL1340540 & 688150 & 3.9444 & 3.9809 & TRN & \\
\hline CHEMBL1532412 & 688150 & 6.3116 & 4.8668 & TRN & \\
\hline CHEMBL1530993 & 688150 & 5.7027 & 4.5889 & TRN & \\
\hline CHEMBL1495170 & 688150 & 5.9825 & 4.5018 & TRN & \\
\hline CHEMBL1526910 & 688150 & 4.7984 & 4.9234 & TRN & \\
\hline CHEMBL1607863 & 688150 & 3.0 & 4.0847 & TRN & \\
\hline CHEMBL1342977 & 688150 & 3.5309 & 3.7082 & TRN & \\
\hline CHEMBL1393687 & 688150 & 5.567 & 5.2311 & TRN & \\
\hline
\end{tabular}




\begin{tabular}{|c|c|c|c|c|c|c|}
\hline & & \multicolumn{5}{|c|}{ Supplemental Table S2.txt } \\
\hline CHEMBL1438761 & 688150 & 4.9487 & 4.4772 & TRN & & \\
\hline CHEMBL1497282 & 688150 & 4.0548 & 4.9037 & TRN & & \\
\hline CHEMBL1381705 & 688150 & 3.0 & 3.9614 & TRN & & \\
\hline CHEMBL1414513 & 688150 & 3.9818 & 4.4389 & TRN & & \\
\hline CHEMBL1444473 & 688150 & 3.5733 & 5.391 & TRN & & \\
\hline CHEMBL1480415 & 688150 & 4.9977 & 4.7799 & TRN & & \\
\hline CHEMBL97407 & 688150 & 3.3632 & 4.8538 & TRN & & \\
\hline CHEMBL1975673 & 688150 & 3.3289 & 4.5798 & TRN & & \\
\hline CHEMBL3392057 & 688150 & 3.0 & 4.6265 & TST & & \\
\hline CHEMBL1366006 & 688150 & 5.7883 & 4.2915 & TRN & & \\
\hline CHEMBL1540846 & 688150 & 5.3721 & 4.6185 & TRN & & \\
\hline CHEMBL1332066 & 688150 & 5.511 & 4.6735 & TRN & & \\
\hline CHEMBL1489294 & 688150 & 5.3567 & 4.7471 & TRN & & \\
\hline CHEMBL1340049 & 688150 & 3.5484 & 4.7884 & TST & & \\
\hline CHEMBL1424738 & 688150 & 4.2043 & 4.7645 & TRN & & \\
\hline CHEMBL1562694 & 688150 & 4.7834 & 4.6465 & TRN & & \\
\hline CHEMBL1535309 & 688150 & 5.3308 & 4.5508 & TRN & & \\
\hline CHEMBL1605769 & 688150 & 5.3431 & 4.4798 & TRN & & \\
\hline CHEMBL1438354 & 688150 & 5.21299 & 99999999 & 99 & 4.9606 & TRN \\
\hline CHEMBL1545435 & 688150 & 5.7118 & 5.2408 & TRN & & \\
\hline CHEMBL1449875 & 688150 & 3.9747 & 4.7991 & TRN & & \\
\hline CHEMBL1371790 & 688150 & 5.1746 & 4.9169 & TST & & \\
\hline CHEMBL1575331 & 688150 & 5.8668 & 3.6578 & TRN & & \\
\hline CHEMBL1343966 & 688150 & 3.4827 & 5.3788 & TRN & & \\
\hline CHEMBL1300052 & 688150 & 3.3237 & 3.9082 & TRN & & \\
\hline CHEMBL1526479 & 688150 & 5.0644 & 5.0244 & TRN & & \\
\hline CHEMBL1424457 & 688150 & 3.58399 & 99999999 & 996 & 4.8237 & TRN \\
\hline CHEMBL1445490 & 688150 & 5.7905 & 4.783 & TRN & & \\
\hline CHEMBL1466769 & 688150 & 3.6751 & 4.7938 & TRN & & \\
\hline CHEMBL1589298 & 688150 & 6.0429 & 4.552 & TRN & & \\
\hline CHEMBL1377263 & 688150 & 5.6817 & 4.8165 & TRN & & \\
\hline CHEMBL1535546 & 688150 & 4.9194 & 5.0988 & TST & & \\
\hline CHEMBL1414151 & 688150 & 6.4078 & 4.8568 & TRN & & \\
\hline CHEMBL1453972 & 688150 & 5.6513 & 4.8832 & TRN & & \\
\hline CHEMBL3145137 & 688150 & 6.4123 & 4.3283 & TRN & & \\
\hline CHEMBL1607763 & 688150 & 5.5502 & 4.6961 & TRN & & \\
\hline CHEMBL1352443 & 688150 & 4.3302 & 4.1812 & TRN & & \\
\hline CHEMBL1583964 & 688150 & 5.0971 & 5.4188 & TST & & \\
\hline CHEMBL1349146 & 688150 & 5.4938 & 4.9153 & TST & & \\
\hline CHEMBL3197710 & 688150 & 3.0 & 4.8617 & TRN & & \\
\hline CHEMBL1404138 & 688150 & 5.245 & 4.6161 & TST & & \\
\hline CHEMBL1570475 & 688150 & 4.2186 & 3.8612 & TRN & & \\
\hline CHEMBL1332548 & 688150 & 4.6591 & 4.3159 & TRN & & \\
\hline CHEMBL1351668 & 688150 & 5.1987 & 4.842 & TRN & & \\
\hline CHEMBL1353023 & 688150 & 5.3435 & 4.6994 & TRN & & \\
\hline CHEMBL1567793 & 688150 & 5.0624 & 4.6003 & TRN & & \\
\hline CHEMBL3196266 & 688150 & 5.2365 & 4.5013 & TRN & & \\
\hline CHEMBL1424691 & 688150 & 5.0198 & 4.4316 & TRN & & \\
\hline
\end{tabular}




\begin{tabular}{|c|c|c|c|c|}
\hline & & & oplement & al Ta \\
\hline CHEMBL1303424 & 688150 & 3.911 & 4.6505 & TRN \\
\hline CHEMBL1531820 & 688150 & 5.0591 & 4.57 & TRN \\
\hline CHEMBL1601802 & 688150 & 3.8861 & 5.0253 & TST \\
\hline CHEMBL1558851 & 688150 & 5.239 & 4.8806 & TRN \\
\hline CHEMBL1484777 & 688150 & 6.2041 & 5.1758 & TRN \\
\hline CHEMBL1605815 & 688150 & 5.3569 & 4.5887 & TRN \\
\hline CHEMBL591370 & 688150 & 5.5406 & 5.565 & TRN \\
\hline CHEMBL1531354 & 688150 & 5.2716 & 4.8024 & TST \\
\hline CHEMBL1545864 & 688150 & 5.2278 & 4.6806 & TRN \\
\hline CHEMBL1508415 & 688150 & 3.8466 & 4.3976 & TRN \\
\hline CHEMBL1460328 & 688150 & 5.2045 & 4.9297 & TST \\
\hline CHEMBL1524515 & 688150 & 6.0585 & 5.1907 & TRN \\
\hline CHEMBL1522834 & 688150 & 5.0374 & 4.8711 & TRN \\
\hline CHEMBL1612828 & 688150 & 5.6474 & 4.2065 & TRN \\
\hline CHEMBL1494386 & 688150 & 3.5129 & 3.7043 & TRN \\
\hline CHEMBL1471154 & 688150 & 3.0937 & 3.9426 & TRN \\
\hline CHEMBL1525212 & 688150 & 5.2423 & 4.0766 & TRN \\
\hline CHEMBL1605229 & 688150 & 5.1953 & 4.2248 & TRN \\
\hline CHEMBL1531852 & 688150 & 5.8351 & 4.8622 & TRN \\
\hline CHEMBL1454261 & 688150 & 3.0 & 3.678 & TRN \\
\hline CHEMBL1325302 & 688150 & 4.0995 & 5.1536 & TRN \\
\hline CHEMBL1331801 & 688150 & 5.6101 & 4.5275 & TRN \\
\hline CHEMBL1312611 & 688150 & 5.224 & 4.3683 & TST \\
\hline CHEMBL1584939 & 688150 & 3.6084 & 4.0906 & TRN \\
\hline CHEMBL1377357 & 688150 & 3.0 & 3.7829 & TRN \\
\hline CHEMBL1407598 & 688150 & 5.0536 & 5.334 & TRN \\
\hline CHEMBL1385419 & 688150 & 4.2479 & 4.6795 & TRN \\
\hline CHEMBL1418531 & 688150 & 4.1555 & 4.8506 & TRN \\
\hline CHEMBL1379772 & 688150 & 3.8991 & 3.4216 & TRN \\
\hline CHEMBL1491717 & 688150 & 4.8531 & 5.5546 & TRN \\
\hline CHEMBL1400580 & 688150 & 5.9083 & 5.2934 & TRN \\
\hline CHEMBL1353551 & 688150 & 6.1152 & 5.0506 & TRN \\
\hline CHEMBL1529106 & 688150 & 5.268 & 4.8754 & TRN \\
\hline CHEMBL1483038 & 688150 & 5.9987 & 4.6929 & TRN \\
\hline CHEMBL1564731 & 688150 & 4.2794 & 5.2999 & TRN \\
\hline CHEMBL1430268 & 688150 & 4.7996 & 4.2687 & TRN \\
\hline CHEMBL1336991 & 688150 & 5.1424 & 4.6204 & TRN \\
\hline CHEMBL1608143 & 688150 & 4.9138 & 5.1466 & TST \\
\hline CHEMBL1429192 & 688150 & 3.9868 & 4.0086 & TRN \\
\hline CHEMBL1321025 & 688150 & 5.9519 & 5.1826 & TRN \\
\hline CHEMBL1580472 & 688150 & 6.71 & 6.0227 & TRN \\
\hline CHEMBL1441431 & 688150 & 4.4816 & 3.7448 & TRN \\
\hline CHEMBL1369287 & 688150 & 5.0643 & 5.2463 & TST \\
\hline CHEMBL1299711 & 688150 & 3.0 & 3.7004 & TRN \\
\hline CHEMBL1598547 & 688150 & 3.3354 & 4.5001 & TRN \\
\hline CHEMBL1491680 & 688150 & 3.0 & 4.6213 & TRN \\
\hline CHEMBL3214458 & 688150 & 3.0 & 4.6066 & TST \\
\hline CHEMBL1409883 & 688150 & 5.0583 & 5.5604 & TRN \\
\hline
\end{tabular}


Supplemental Table S2.txt

\begin{tabular}{|c|c|c|c|c|}
\hline CHEMBL1352586 & 688150 & 3.1671 & 5.4206 & TRN \\
\hline CHEMBL1418888 & 688150 & 3.8191 & 4.4992 & TRN \\
\hline CHEMBL1496648 & 688150 & 5.0979 & 4.6865 & TRN \\
\hline CHEMBL1587368 & 688150 & 4.9404 & 4.0314 & TRN \\
\hline CHEMBL1312100 & 688150 & 3.5303 & 4.181 & TRN \\
\hline CHEMBL1490339 & 688150 & 4.2111 & 5.305 & TRN \\
\hline CHEMBL1342270 & 688150 & 4.207 & 4.5661 & TRN \\
\hline CHEMBL1549267 & 688150 & 6.0273 & 5.0122 & TRN \\
\hline CHEMBL1602594 & 688150 & 6.4295 & 4.8082 & TRN \\
\hline CHEMBL1360203 & 688150 & 5.093 & 4.9281 & TRN \\
\hline CHEMBL1468929 & 688150 & 3.9976 & 5.2701 & TRN \\
\hline CHEMBL1407488 & 688150 & 4.9075 & 5.0682 & TRN \\
\hline CHEMBL1527091 & 688150 & 6.1656 & 4.4134 & TRN \\
\hline CHEMBL1350494 & 688150 & 3.9816 & 4.4139 & TRN \\
\hline CHEMBL1602616 & 688150 & 4.8506 & 4.2828 & TRN \\
\hline CHEMBL1428714 & 688150 & 4.1744 & 4.5948 & TST \\
\hline CHEMBL1381579 & 688150 & 3.9231 & 3.6576 & TRN \\
\hline CHEMBL1484618 & 688150 & 5.9172 & 4.8977 & TRN \\
\hline CHEMBL1520613 & 688150 & 5.8752 & 4.5955 & TRN \\
\hline CHEMBL1545628 & 688150 & 4.9965 & 5.0618 & TRN \\
\hline CHEMBL1541405 & 688150 & 4.6601 & 4.9026 & TRN \\
\hline CHEMBL567132 & 688150 & 3.0 & 4.5429 & TRN \\
\hline CHEMBL1303653 & 688150 & 5.2116 & 4.8123 & TRN \\
\hline CHEMBL578928 & 688150 & 4.9859 & 4.9317 & TRN \\
\hline CHEMBL1509483 & 688150 & 4.1615 & 4.8391 & TRN \\
\hline CHEMBL1410618 & 688150 & 5.71 & 6.0158 & TRN \\
\hline CHEMBL1577221 & 688150 & 5.6472 & 3.7826 & TRN \\
\hline CHEMBL1567386 & 688150 & 3.0 & 4.5138 & TST \\
\hline CHEMBL1328635 & 688150 & 4.8462 & 5.1049 & TRN \\
\hline CHEMBL1463172 & 688150 & 5.2952 & 5.2917 & TST \\
\hline CHEMBL1445659 & 688150 & 3.9234 & 5.2664 & TRN \\
\hline CHEMBL1458833 & 688150 & 5.71 & 5.0373 & TRN \\
\hline CHEMBL1499127 & 688150 & 5.0978 & 5.0706 & TRN \\
\hline CHEMBL1310449 & 688150 & 5.4459 & 5.0779 & TRN \\
\hline CHEMBL1491750 & 688150 & 4.0208 & 4.9525 & TST \\
\hline CHEMBL1523785 & 688150 & 5.1746 & 5.0444 & TRN \\
\hline CHEMBL1372813 & 688150 & 5.7867 & 5.00899 & 99999999995 \\
\hline CHEMBL1410436 & 688150 & 3.6891 & 5.5645 & TRN \\
\hline CHEMBL1377814 & 688150 & 3.0 & 3.7956 & TRN \\
\hline CHEMBL1440463 & 688150 & 5.5542 & 5.1316 & TRN \\
\hline CHEMBL1502723 & 688150 & 5.5646 & 3.9518 & TST \\
\hline CHEMBL1609937 & 688150 & 5.0417 & 5.0166 & TRN \\
\hline CHEMBL1455542 & 688150 & 5.0684 & 4.6731 & TRN \\
\hline CHEMBL1511522 & 688150 & 5.0508 & 4.4318 & TRN \\
\hline CHEMBL338474 & 688150 & 5.4153 & 5.0273 & TST \\
\hline CHEMBL1605093 & 688150 & 3.3026 & 4.7356 & TRN \\
\hline CHEMBL1600941 & 688150 & 6.2426 & 3.9121 & TRN \\
\hline CHEMBL935 & 688150 & 5.8222 & 4.5695 & TRN \\
\hline
\end{tabular}

Page 13188 
Supplemental Table S2.txt

\begin{tabular}{|c|c|c|c|c|c|}
\hline CHEMBL1346656 & 688150 & 4.6347 & 3.7215 & TRN & \\
\hline CHEMBL1377824 & 688150 & 5.1939 & 5.0688 & TRN & \\
\hline CHEMBL1344732 & 688150 & 4.7674 & 4.5807 & TRN & \\
\hline CHEMBL1377025 & 688150 & 5.1639 & 4.3494 & TRN & \\
\hline CHEMBL1377971 & 688150 & 3.2329 & 4.4177 & TRN & \\
\hline CHEMBL1495560 & 688150 & 3.4078 & 4.4891 & TRN & \\
\hline CHEMBL1555809 & 688150 & 4.8209 & 4.7084 & TST & \\
\hline CHEMBL1337120 & 688150 & 3.5446 & 3.8401 & TRN & \\
\hline CHEMBL1549758 & 688150 & 4.3425 & 4.1413 & TRN & \\
\hline CHEMBL1364990 & 688150 & 4.8519 & 4.9777 & TST & \\
\hline CHEMBL1360435 & 688150 & 3.3869 & 4.5081 & TST & \\
\hline CHEMBL1324556 & 688150 & 6.1824 & 5.2623 & TRN & \\
\hline CHEMBL602363 & 688150 & 6.3125 & 5.4721 & TRN & \\
\hline CHEMBL1385690 & 688150 & 4.7468 & 5.4032 & TRN & \\
\hline CHEMBL3190221 & 688150 & 3.0 & 4.9448 & TRN & \\
\hline CHEMBL1503152 & 688150 & 5.244 & 4.4651 & TRN & \\
\hline CHEMBL1340487 & 688150 & 5.3559 & 4.4219 & TRN & \\
\hline CHEMBL1495685 & 688150 & 3.7088 & 4.8438 & TST & \\
\hline CHEMBL1511730 & 688150 & 3.0 & 3.7445 & TRN & \\
\hline CHEMBL1418024 & 688150 & 3.7715 & 4.6414 & TRN & \\
\hline CHEMBL1347298 & 688150 & 3.8963 & 4.7912 & TRN & \\
\hline CHEMBL1572266 & 688150 & 5.9154 & 5.7864 & TRN & \\
\hline CHEMBL3199812 & 688150 & 5.2506 & 4.7297 & TRN & \\
\hline CHEMBL1428191 & 688150 & 3.3321 & 3.9013 & TRN & \\
\hline CHEMBL1393399 & 688150 & 4.7991 & 4.7511 & TST & \\
\hline CHEMBL1461050 & 688150 & 3.8277 & 4.5102 & TRN & \\
\hline CHEMBL1607059 & 688150 & 3.8234 & 4.2634 & TRN & \\
\hline CHEMBL1420808 & 688150 & 3.1391 & 4.8768 & TST & \\
\hline CHEMBL1257078 & 688150 & 4.8284 & 5.0037 & TST & \\
\hline CHEMBL1971185 & 688150 & 6.0414 & \multicolumn{2}{|c|}{4.9239999999999995} & TRN \\
\hline CHEMBL1415218 & 688150 & 5.71 & 4.4585 & TRN & \\
\hline CHEMBL140425 & 688150 & 4.787 & 6.07700 & 2000000001 & TRN \\
\hline CHEMBL1385148 & 688150 & 5.3695 & 4.7571 & TRN & \\
\hline CHEMBL1310629 & 688150 & 5.0251 & 5.0236 & TRN & \\
\hline CHEMBL1529075 & 688150 & 3.5474 & 4.3189 & TRN & \\
\hline CHEMBL1524381 & 688150 & 4.8773 & 4.6638 & TST & \\
\hline CHEMBL1438684 & 688150 & 5.5923 & 5.5995 & TRN & \\
\hline CHEMBL1362221 & 688150 & 3.2617 & 4.5936 & TRN & \\
\hline CHEMBL1598284 & 688150 & 3.0 & 4.8997 & TRN & \\
\hline CHEMBL490592 & 688150 & 6.4248 & 5.1708 & TRN & \\
\hline CHEMBL1322178 & 688150 & 3.9482 & 4.7689 & TRN & \\
\hline CHEMBL1348232 & 688150 & 5.8474 & 5.6158 & TRN & \\
\hline CHEMBL1492827 & 688150 & 3.0 & 4.0619 & TRN & \\
\hline CHEMBL1520975 & 688150 & 5.4019 & 5.5013 & TRN & \\
\hline CHEMBL1414913 & 688150 & 3.1839 & 4.3957 & TRN & \\
\hline CHEMBL1546781 & 688150 & 4.4097 & 4.5554 & TRN & \\
\hline CHEMBL1610972 & 688150 & 3.9272 & 4.6679 & TST & \\
\hline CHEMBL1576330 & 688150 & 6.71 & 4.7412 & TRN & \\
\hline
\end{tabular}

Page 13189 


\begin{tabular}{|c|c|c|c|c|c|}
\hline \multicolumn{6}{|c|}{ Supplemental Table S2.txt } \\
\hline CHEMBL476513 & 688150 & 5.2286 & 4.7742 & TRN & \\
\hline CHEMBL1457134 & 688150 & 4.0474 & 4.9753 & TRN & \\
\hline CHEMBL1392442 & 688150 & 4.8771 & 5.0135 & TRN & \\
\hline CHEMBL1505053 & 688150 & 4.2632 & 4.1171 & TRN & \\
\hline CHEMBL1550291 & 688150 & 4.6274 & 4.5103 & TRN & \\
\hline CHEMBL1416660 & 688150 & 5.5809 & 4.7663 & TST & \\
\hline CHEMBL1529223 & 688150 & 4.8813 & 4.729 & TRN & \\
\hline CHEMBL1429662 & 688150 & 6.4078 & 4.6322 & TRN & \\
\hline CHEMBL1333652 & 688150 & 3.0 & 4.5352 & TRN & \\
\hline CHEMBL1569144 & 688150 & 5.1484 & 4.7314 & TRN & \\
\hline CHEMBL1446156 & 688150 & 5.7978 & 4.7617 & TRN & \\
\hline CHEMBL1352127 & 688150 & 5.5646 & 5.119 & TRN & \\
\hline CHEMBL1489456 & 688150 & 4.9767 & 4.6796 & TRN & \\
\hline CHEMBL1422456 & 688150 & 3.5259 & 5.4096 & TST & \\
\hline CHEMBL1967586 & 688150 & 5.8085 & 4.9796 & TRN & \\
\hline CHEMBL1525533 & 688150 & 3.0 & 4.0556 & TRN & \\
\hline CHEMBL1580960 & 688150 & 4.9622 & 4.48600 & 0000000001 & TRN \\
\hline CHEMBL1304844 & 688150 & 7.71 & 4.9759 & TRN & \\
\hline CHEMBL1483161 & 688150 & 5.2173 & 4.61600 & 00000000005 & TST \\
\hline CHEMBL1549777 & 688150 & 5.1833 & 4.9087 & TRN & \\
\hline CHEMBL3144998 & 688150 & 4.4697 & 4.7782 & TRN & \\
\hline CHEMBL1432711 & 688150 & 6.2628 & 4.3992 & TRN & \\
\hline CHEMBL1528425 & 688150 & 5.8925 & 5.7842 & TRN & \\
\hline CHEMBL1463674 & 688150 & 3.3566 & 4.723 & TRN & \\
\hline CHEMBL1339257 & 688150 & 5.71 & 5.0444 & TRN & \\
\hline CHEMBL1427340 & 688150 & 3.2626 & 4.801 & TRN & \\
\hline CHEMBL1606504 & 688150 & 4.6354 & 4.6562 & TRN & \\
\hline CHEMBL1584784 & 688150 & 3.2668 & 4.6894 & TRN & \\
\hline CHEMBL1367268 & 688150 & 6.71 & 5.0104 & TST & \\
\hline CHEMBL1320386 & 688150 & 6.4056 & 5.0047 & TRN & \\
\hline CHEMBL1380511 & 688150 & 3.7082 & 4.7573 & TRN & \\
\hline CHEMBL1387605 & 688150 & 6.4078 & 5.4355 & TRN & \\
\hline CHEMBL1414460 & 688150 & 5.2142 & 4.8573 & TRN & \\
\hline CHEMBL1579507 & 688150 & 5.71 & 4.3716 & TRN & \\
\hline CHEMBL1547466 & 688150 & 3.4504 & 4.115 & TRN & \\
\hline CHEMBL1429861 & 688150 & 5.5914 & 4.8373 & TRN & \\
\hline CHEMBL1572824 & 688150 & 4.2008 & 4.4921 & TRN & \\
\hline CHEMBL1580616 & 688150 & 5.2645 & 4.8201 & TRN & \\
\hline CHEMBL1359820 & 688150 & 5.1552 & 4.4221 & TRN & \\
\hline CHEMBL1340027 & 688150 & 5.1482 & 4.9091 & TST & \\
\hline CHEMBL3209645 & 688150 & 4.9527 & 4.7265 & TRN & \\
\hline CHEMBL1538322 & 688150 & 5.1209 & 4.8928 & TRN & \\
\hline CHEMBL1448743 & 688150 & 3.2147 & 4.3402 & TRN & \\
\hline CHEMBL1598230 & 688150 & 5.2476 & 4.857 & TRN & \\
\hline CHEMBL1310758 & 688150 & 4.8375 & 4.7426 & TRN & \\
\hline CHEMBL1575617 & 688150 & 3.0 & 4.3391 & TRN & \\
\hline CHEMBL1523608 & 688150 & 4.3034 & 4.5791 & TRN & \\
\hline CHEMBL1460705 & 688150 & 6.466 & 5.2811 & TRN & \\
\hline
\end{tabular}


Supplemental Table S2.txt

\begin{tabular}{|c|c|c|c|c|}
\hline 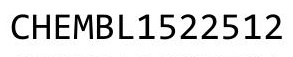 & & & & \\
\hline HEMBL1385784 & 88150 & 0514 & 5.7614 & \\
\hline HEMBL3145315 & 8150 & 294 & 23 & \\
\hline A & & & & \\
\hline AEMBL12 & & 772 & 8472 & \\
\hline AEMBL1480406 & 88150 & 2697 & 1027 & \\
\hline HEMBL1531933 & 88150 & .2186 & 4.508 & \\
\hline HEMBL1446949 & 50 & 2326 & 4.4829 & \\
\hline AEMBL13 & & 3.0 & 4.918 & \\
\hline IEMBL13 & & 2826 & 5.2421 & \\
\hline HEMBL1339811 & 88150 & 3.8901 & 4.6987 & \\
\hline HEMBL1533731 & 50 & .4724 & 4.1433 & \\
\hline HEMBL1407 & 50 & & 3.7222 & \\
\hline HEMBL15 & & 3232 & 4.2817 & \\
\hline AEMBL13 & & 734 & 4.4882 & \\
\hline HEMBL1367827 & 150 & 20 & 4.3794 & \\
\hline HEMBL1605292 & & 79 & & \\
\hline HEMBL137 & 50 & & 519 & \\
\hline L15 & & & & \\
\hline JEMBL14 & & 855 & 655 & \\
\hline AEMBL1461976 & & 5375 & 2245 & \\
\hline AEMBL1414813 & & & & \\
\hline HEMBL321 & & & 86 & \\
\hline L13 & & & 367 & \\
\hline 50 & & & 29 & RN \\
\hline L1428217 & & 969 & 209 & RN \\
\hline AEMBL1351516 & & & & $\mathrm{KN}$ \\
\hline HEMBL153 & & & 76 & Iv \\
\hline HEN & & & 09 & RN \\
\hline L16 & & 94 & 3771 & RN \\
\hline AEMBL1417974 & & & & RN \\
\hline HEMBL1579339 & & & 908 & RN \\
\hline AEMBL15 & & & 724 & RN \\
\hline 45 & & 8 & 353 & RN \\
\hline 37 & & 1 & 983 & RN \\
\hline AEMBL1502014 & & 51 & & ST \\
\hline AEMBL1536129 & & & 161 & RN \\
\hline 30 & & & & ST \\
\hline 10 & & 4 & 18 & RN \\
\hline HEMBL15 & & & 216 & RN \\
\hline AEMBL1341196 & 50 & & & RN \\
\hline AEMBL14 & & & 033 & RN \\
\hline 615 & & & 4.7549 & \\
\hline HEMBL 141 & & 953 & 5.2723 & ו \\
\hline HEMBL1392880 & & & 3.9614 & RN \\
\hline IEMBL 140 & & 4.9211 & 5621 & $\mathrm{~N}$ \\
\hline 1 & & & & \\
\hline 1 & & 6.28 & & \\
\hline
\end{tabular}

Page 13191 


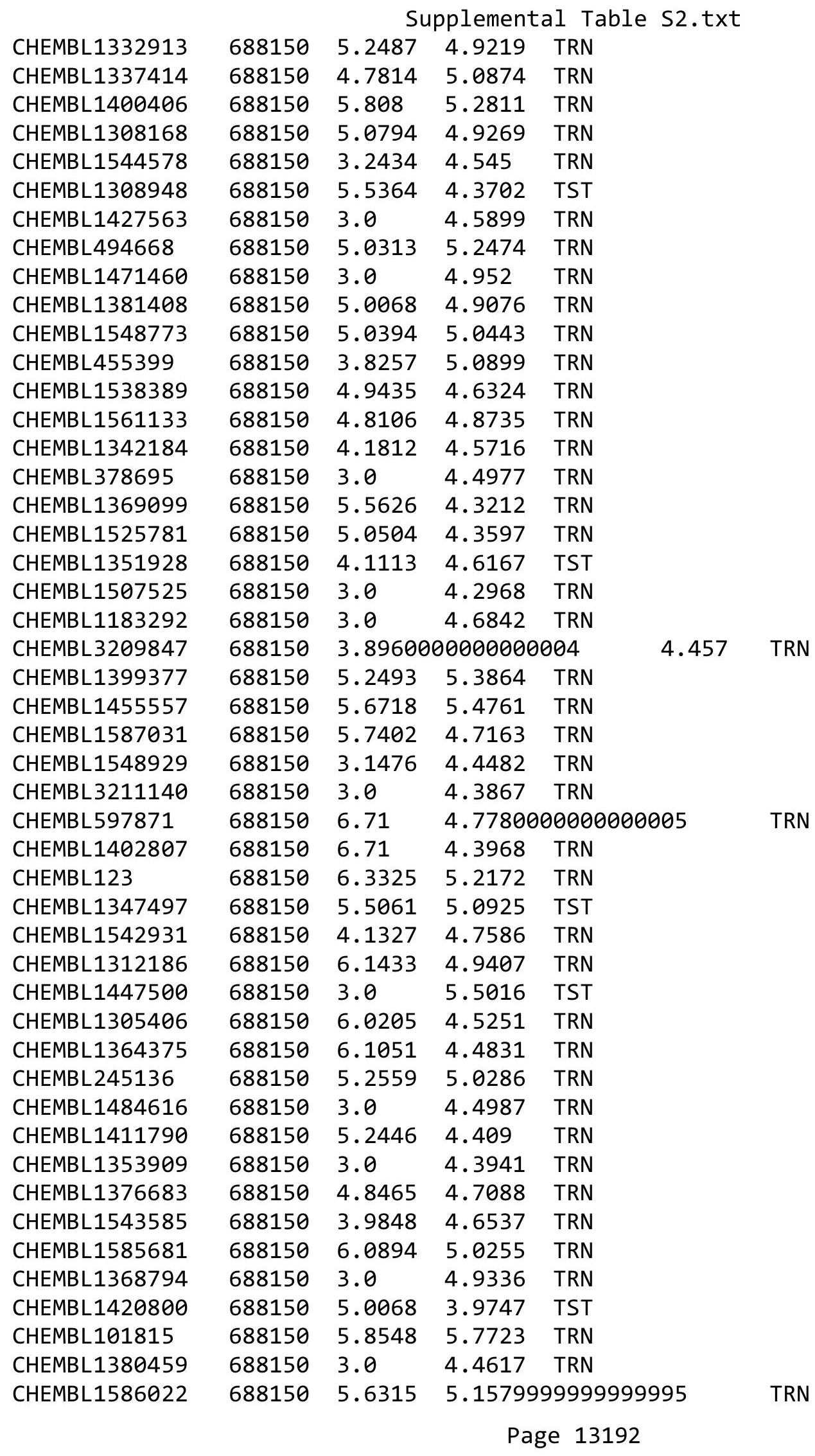




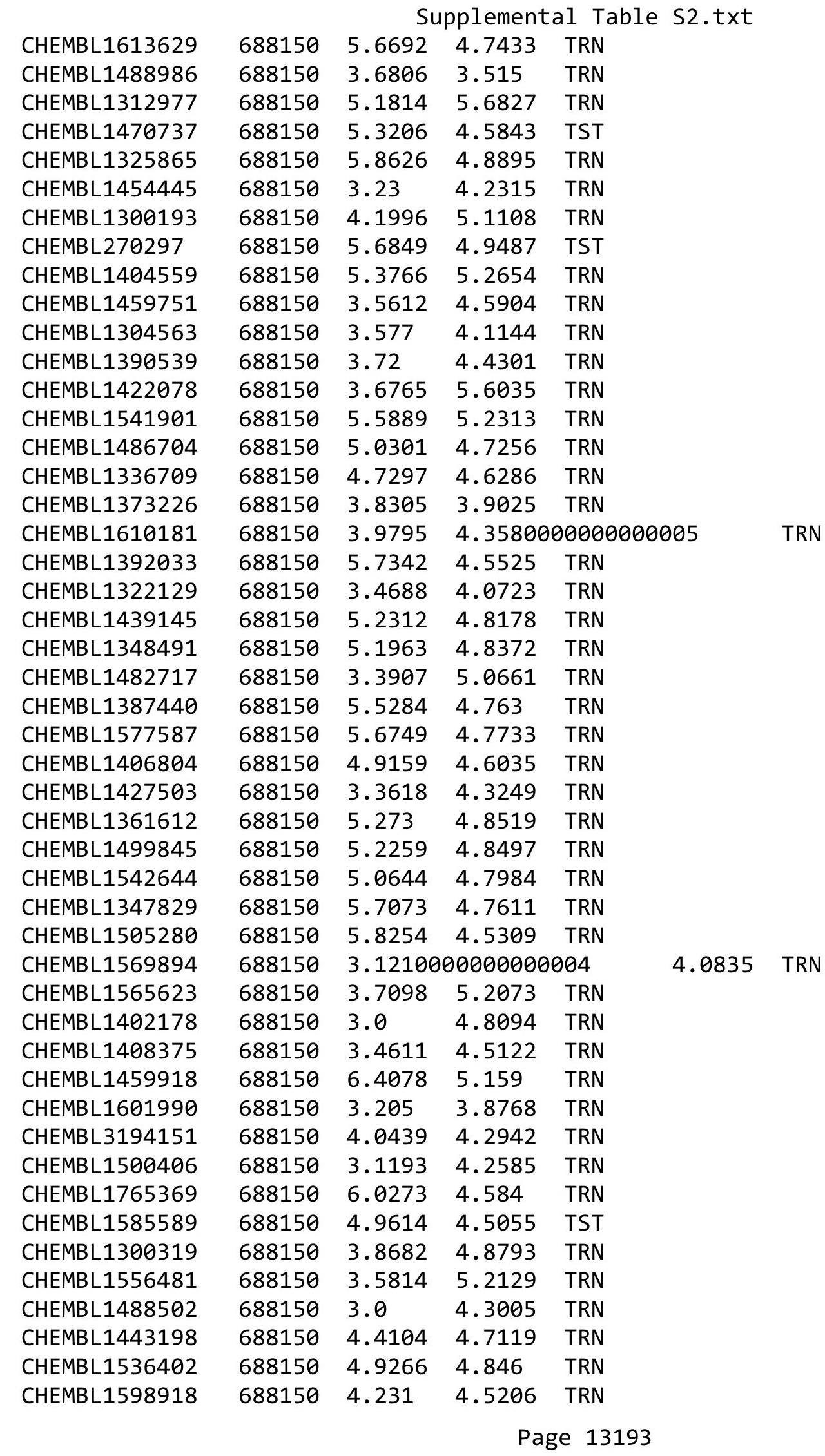




\begin{tabular}{|c|c|c|c|c|c|c|}
\hline & & \multicolumn{5}{|c|}{ Supplemental Table S2.txt } \\
\hline CHEMBL1610008 & 688150 & 4.7221 & 4.7905 & TRN & & \\
\hline CHEMBL3199627 & 688150 & 3.0 & 4.4205 & TRN & & \\
\hline CHEMBL57013 & 688150 & 3.0 & 4.9562 & TST & & \\
\hline CHEMBL1422034 & 688150 & 4.3244 & 4.1759 & TRN & & \\
\hline CHEMBL1423995 & 688150 & 3.0 & 4.76699 & 9999999 & 995 & TRN \\
\hline CHEMBL3212501 & 688150 & 3.0 & 4.3407 & TRN & & \\
\hline CHEMBL1545468 & 688150 & 5.2851 & 5.5129 & TRN & & \\
\hline CHEMBL1365756 & 688150 & 5.3581 & 4.987 & TRN & & \\
\hline CHEMBL1495124 & 688150 & 5.1993 & 4.4428 & TRN & & \\
\hline CHEMBL1404109 & 688150 & 6.71 & 5.1024 & TRN & & \\
\hline CHEMBL1328564 & 688150 & 3.8765 & 4.603 & TRN & & \\
\hline CHEMBL1428140 & 688150 & 5.4685 & 4.59399 & 99999995 & & TRN \\
\hline CHEMBL1441092 & 688150 & 4.9771 & 4.8623 & TST & & \\
\hline CHEMBL3192970 & 688150 & 4.6554 & 4.5799 & TRN & & \\
\hline CHEMBL1360965 & 688150 & 3.0 & 4.5362 & TST & & \\
\hline CHEMBL1540761 & 688150 & 4.9231 & 5.0414 & TRN & & \\
\hline CHEMBL1530113 & 688150 & 4.0559 & 4.3655 & TRN & & \\
\hline CHEMBL1546139 & 688150 & 5.1484 & 4.8108 & TRN & & \\
\hline CHEMBL1608180 & 688150 & 4.0907 & 4.4096 & TRN & & \\
\hline CHEMBL1326110 & 688150 & 5.4004 & 4.5473 & TRN & & \\
\hline CHEMBL3199221 & 688150 & 3.9551 & 4.5033 & TST & & \\
\hline CHEMBL1446377 & 688150 & 5.4084 & 4.7127 & TRN & & \\
\hline CHEMBL1390275 & 688150 & 6.71 & 4.7537 & TRN & & \\
\hline CHEMBL1303564 & 688150 & 5.2218 & 4.5973 & TRN & & \\
\hline CHEMBL1321538 & 688150 & 4.8711 & 5.1944 & TRN & & \\
\hline CHEMBL1519017 & 688150 & 6.5003 & 5.17 & TRN & & \\
\hline CHEMBL1348830 & 688150 & 3.9027 & 4.3697 & TRN & & \\
\hline CHEMBL1562794 & 688150 & 4.9406 & 4.8021 & TRN & & \\
\hline CHEMBL1572512 & 688150 & 3.0 & 4.5986 & TRN & & \\
\hline CHEMBL1491603 & 688150 & 3.4444 & 4.2913 & TRN & & \\
\hline CHEMBL1576719 & 688150 & 3.6553 & 4.2188 & TRN & & \\
\hline CHEMBL1439591 & 688150 & 3.0 & 4.6104 & TRN & & \\
\hline CHEMBL 1467140 & 688150 & 4.5174 & 4.8785 & TRN & & \\
\hline CHEMBL1445247 & 688150 & 4.9625 & 4.5476 & TRN & & \\
\hline CHEMBL1548565 & 688150 & 3.5543 & 4.5921 & TRN & & \\
\hline CHEMBL1578734 & 688150 & $6.2620 e$ & 00000000 & 005 & 5.256 & TRN \\
\hline CHEMBL1560965 & 688150 & 5.6849 & 4.8812 & TRN & & \\
\hline CHEMBL1330556 & 688150 & 5.0958 & 4.7108 & TST & & \\
\hline CHEMBL1335349 & 688150 & 3.6213 & 4.607 & TRN & & \\
\hline CHEMBL1339702 & 688150 & 3.5474 & 4.8208 & TRN & & \\
\hline CHEMBL598679 & 688150 & 5.1744 & 4.3665 & TRN & & \\
\hline CHEMBL1993431 & 688150 & 6.71 & 4.8814 & TRN & & \\
\hline CHEMBL 2006503 & 688150 & 5.7199 & 5.5875 & TST & & \\
\hline CHEMBL1430315 & 688150 & 5.025 & 4.8642 & TRN & & \\
\hline CHEMBL1347610 & 688150 & 3.6292 & 5.2882 & TRN & & \\
\hline CHEMBL1399142 & 688150 & 4.1178 & 4.2602 & TRN & & \\
\hline CHEMBL1353885 & 688150 & 6.1624 & 4.8199 & TRN & & \\
\hline CHEMBL1441761 & 688150 & 3.0 & 3.9351 & TRN & & \\
\hline
\end{tabular}




\begin{tabular}{|c|c|c|c|c|}
\hline \multicolumn{5}{|c|}{ Supplemental Table S2.txt } \\
\hline CHEMBL1535252 & 688150 & 5.2411 & 4.8789 & TRN \\
\hline CHEMBL1330874 & 688150 & 3.3713 & 4.9061 & TRN \\
\hline CHEMBL1308255 & 688150 & 6.0031 & 4.9688 & TRN \\
\hline CHEMBL1461960 & 688150 & 6.4921 & 4.4707 & TRN \\
\hline CHEMBL1328382 & 688150 & 3.5211 & 3.6135 & TRN \\
\hline CHEMBL1573650 & 688150 & 4.3979 & 4.6674 & TRN \\
\hline CHEMBL1380701 & 688150 & 5.4112 & 4.4426 & TRN \\
\hline CHEMBL1989453 & 688150 & 4.1665 & 3.9287 & TRN \\
\hline CHEMBL1374907 & 688150 & 6.699 & 4.9251 & TRN \\
\hline CHEMBL1522668 & 688150 & 3.3335 & 4.4133 & TRN \\
\hline CHEMBL1351519 & 688150 & 5.2362 & 4.8233 & TRN \\
\hline CHEMBL1549705 & 688150 & 5.5399 & 5.1234 & TRN \\
\hline CHEMBL1538651 & 688150 & 4.1208 & 4.6472 & TRN \\
\hline CHEMBL1379340 & 688150 & 3.2224 & 4.2675 & TRN \\
\hline CHEMBL1612924 & 688150 & 5.0303 & 4.4088 & TRN \\
\hline CHEMBL1471451 & 688150 & 5.232 & 4.6964 & TST \\
\hline CHEMBL486706 & 688150 & 5.8245 & 4.7014 & TST \\
\hline CHEMBL1489623 & 688150 & 6.0496 & 3.9978 & TRN \\
\hline CHEMBL1411023 & 688150 & 5.4167 & 4.7283 & TRN \\
\hline CHEMBL1341166 & 688150 & 3.6858 & 3.4891 & TRN \\
\hline CHEMBL1500409 & 688150 & 5.4802 & 4.6826 & TRN \\
\hline CHEMBL1445146 & 688150 & 4.3398 & 4.5138 & TRN \\
\hline CHEMBL1501506 & 688150 & 6.71 & 5.5264 & TST \\
\hline CHEMBL1461563 & 688150 & 5.1422 & 4.3703 & TRN \\
\hline CHEMBL1610909 & 688150 & 3.6852 & 3.5513 & TRN \\
\hline CHEMBL1340089 & 688150 & 7.4078 & 4.5694 & TRN \\
\hline CHEMBL1571348 & 688150 & 3.5241 & 4.905 & TRN \\
\hline CHEMBL1579223 & 688150 & 4.9126 & 4.0016 & TRN \\
\hline CHEMBL1588173 & 688150 & 3.0436 & 4.7639 & TRN \\
\hline CHEMBL1438451 & 688150 & 3.7533 & 4.7119 & TRN \\
\hline CHEMBL1578101 & 688150 & 4.9278 & 5.145 & TST \\
\hline CHEMBL1384995 & 688150 & 5.8407 & 5.1663 & TRN \\
\hline CHEMBL1493425 & 688150 & 5.4078 & 3.8939 & TRN \\
\hline CHEMBL1309668 & 688150 & 5.71 & 4.1456 & TRN \\
\hline CHEMBL1518625 & 688150 & 5.2047 & 5.2423 & TRN \\
\hline CHEMBL1311376 & 688150 & 5.7883 & 4.7636 & TRN \\
\hline CHEMBL1444824 & 688150 & 6.3851 & 5.1145 & TST \\
\hline CHEMBL1439149 & 688150 & 4.7409 & 4.8214 & TRN \\
\hline CHEMBL1427858 & 688150 & 6.71 & 4.9114 & TRN \\
\hline CHEMBL3196551 & 688150 & 3.7475 & 5.3387 & TRN \\
\hline CHEMBL1452913 & 688150 & 5.3124 & 4.6952 & TRN \\
\hline CHEMBL1594604 & 688150 & 5.2431 & 4.5562 & TRN \\
\hline CHEMBL1605749 & 688150 & 5.7757 & 4.7429 & TRN \\
\hline CHEMBL1456276 & 688150 & 5.5186 & 5.2348 & TRN \\
\hline CHEMBL1390384 & 688150 & 4.9635 & 4.5823 & TRN \\
\hline CHEMBL1544923 & 688150 & 4.8018 & 4.6533 & TRN \\
\hline CHEMBL1520030 & 688150 & 5.0467 & 5.237 & TST \\
\hline CHEMBL504598 & 688150 & 3.3102 & 4.5566 & TRN \\
\hline
\end{tabular}




\begin{tabular}{|c|c|c|c|c|c|}
\hline \multirow[b]{2}{*}{ CHEMBL1352191 } & \multicolumn{5}{|c|}{ Supplemental Table S2.txt } \\
\hline & 688150 & 5.71 & 4.194 & TRN & \\
\hline CHEMBL1532199 & 688150 & 5.71 & 4.6746 & TRN & \\
\hline CHEMBL1587237 & 688150 & 4.4454 & 3.92199 & 99999999997 & TRN \\
\hline CHEMBL1335007 & 688150 & 6.2306 & 4.9338 & TRN & \\
\hline CHEMBL 1468672 & 688150 & 6.1221 & 5.1509 & TRN & \\
\hline CHEMBL1543384 & 688150 & 5.1849 & 4.7013 & TRN & \\
\hline CHEMBL1388274 & 688150 & 4.6928 & 5.065 & TST & \\
\hline CHEMBL1300453 & 688150 & 5.1575 & 4.5082 & TRN & \\
\hline CHEMBL1511371 & 688150 & 3.9951 & 4.6609 & TRN & \\
\hline CHEMBL1489742 & 688150 & 4.1488 & 4.8069 & TRN & \\
\hline CHEMBL1373197 & 688150 & 5.0109 & 5.1996 & TRN & \\
\hline CHEMBL 210658 & 688150 & 3.0 & 4.724 & TRN & \\
\hline CHEMBL3211910 & 688150 & 4.9301 & 4.5369 & TST & \\
\hline CHEMBL1578962 & 688150 & 5.4763 & 5.5765 & TRN & \\
\hline CHEMBL1337610 & 688150 & 3.8273 & 4.0436 & TRN & \\
\hline CHEMBL1310994 & 688150 & 3.0 & 3.6597 & TRN & \\
\hline CHEMBL1423162 & 688150 & 4.6302 & 3.9726 & TRN & \\
\hline CHEMBL508941 & 688150 & 3.0 & 4.8424 & TRN & \\
\hline CHEMBL1440001 & 688150 & 3.9892 & 4.9666 & TRN & \\
\hline CHEMBL1510761 & 688150 & 5.2509 & 4.8389 & TRN & \\
\hline CHEMBL1502035 & 688150 & 3.5238 & 5.7418 & TRN & \\
\hline CHEMBL1368143 & 688150 & 6.4078 & 4.3421 & TRN & \\
\hline CHEMBL1458083 & 688150 & 4.9476 & 4.7544 & TST & \\
\hline CHEMBL1333226 & 688150 & 3.7447 & 4.2525 & TRN & \\
\hline CHEMBL523200 & 688150 & 5.4326 & 5.5874 & TRN & \\
\hline CHEMBL17201 & 688150 & 5.2319 & 4.6882 & TRN & \\
\hline CHEMBL1445163 & 688150 & 5.4256 & 4.5425 & TRN & \\
\hline CHEMBL1588046 & 688150 & 5.4853 & 5.4797 & TRN & \\
\hline CHEMBL1521687 & 688150 & 5.1423 & 4.5306 & TST & \\
\hline CHEMBL227423 & 688150 & 4.8402 & 4.8378 & TRN & \\
\hline CHEMBL604321 & 688150 & 5.5615 & 5.1691 & TST & \\
\hline CHEMBL1430700 & 688150 & 6.1979 & 4.6301 & TRN & \\
\hline CHEMBL1400960 & 688150 & 4.6577 & 5.0146 & TRN & \\
\hline CHEMBL342995 & 688150 & 4.7495 & 4.738 & TRN & \\
\hline CHEMBL1543615 & 688150 & 7.71 & 4.7385 & TRN & \\
\hline CHEMBL1405092 & 688150 & 5.145 & 4.9034 & TRN & \\
\hline CHEMBL1460377 & 688150 & 5.9031 & 4.7283 & TRN & \\
\hline CHEMBL1609375 & 688150 & 5.1319 & 4.5721 & TRN & \\
\hline CHEMBL1352004 & 688150 & 4.6441 & 4.4938 & TRN & \\
\hline CHEMBL1387731 & 688150 & 5.3847 & 5.3262 & TRN & \\
\hline CHEMBL1547352 & 688150 & 6.71 & 4.5627 & TRN & \\
\hline CHEMBL3209608 & 688150 & 3.4724 & 4.3762 & TRN & \\
\hline CHEMBL1600265 & 688150 & 3.2253 & 4.4966 & TRN & \\
\hline CHEMBL1467753 & 688150 & 5.0144 & 4.85 & TST & \\
\hline CHEMBL1547204 & 688150 & 6.2907 & 4.3019 & TRN & \\
\hline CHEMBL1612900 & 688150 & 4.3443 & 4.2796 & TRN & \\
\hline CHEMBL 1448713 & 688150 & 5.2084 & 5.3676 & TRN & \\
\hline CHEMBL1375998 & 688150 & 5.1884 & 4.0703 & TRN & \\
\hline
\end{tabular}




\begin{tabular}{|c|c|c|c|c|c|}
\hline \multicolumn{6}{|c|}{ Supplemental Table s2.txt } \\
\hline CHEMBL1588449 & 688150 & 4.1692 & 5.0405 & TRN & \\
\hline CHEMBL1345739 & 688150 & 5.2256 & 3.8057 & TRN & \\
\hline CHEMBL1338124 & 688150 & 3.0 & 4.7245 & TST & \\
\hline CHEMBL1348654 & 688150 & 5.2476 & 5.5763 & TRN & \\
\hline CHEMBL1520414 & 688150 & 4.7502 & 4.1444 & TRN & \\
\hline CHEMBL1456412 & 688150 & 3.7758 & 5.1924 & TST & \\
\hline CHEMBL1538127 & 688150 & 3.5554 & 4.559 & TST & \\
\hline CHEMBL1430364 & 688150 & 5.0677 & 5.2443 & TRN & \\
\hline CHEMBL1418459 & 688150 & 5.934 & 4.8049 & TRN & \\
\hline CHEMBL507899 & 688150 & 3.0 & 4.6608 & TRN & \\
\hline CHEMBL1488521 & 688150 & 3.4056 & 4.69 & TST & \\
\hline CHEMBL1535149 & 688150 & 3.7297 & 4.6429 & TRN & \\
\hline CHEMBL1509891 & 688150 & 3.0 & 4.2976 & TRN & \\
\hline CHEMBL1351115 & 688150 & 5.9108 & 4.9444 & TST & \\
\hline CHEMBL1458548 & 688150 & 4.5988 & 5.0498 & TRN & \\
\hline CHEMBL1393867 & 688150 & 3.8391 & 4.8293 & TRN & \\
\hline CHEMBL1331660 & 688150 & 4.8735 & 4.8893 & TRN & \\
\hline CHEMBL1508351 & 688150 & 5.345 & 5.3138 & TRN & \\
\hline CHEMBL1574799 & 688150 & 5.4204 & 5.1866 & TRN & \\
\hline CHEMBL1996376 & 688150 & 4.6321 & 5.4071 & TST & \\
\hline CHEMBL1527326 & 688150 & 3.4853 & 4.6286 & TRN & \\
\hline CHEMBL1300063 & 688150 & 4.9642 & 4.1673 & TRN & \\
\hline CHEMBL1603753 & 688150 & 4.7922 & 5.4484 & TRN & \\
\hline CHEMBL1328896 & 688150 & 3.5511 & 4.7139 & TST & \\
\hline CHEMBL1377084 & 688150 & 3.2382 & 4.7032 & TRN & \\
\hline CHEMBL1600936 & 688150 & 3.3041 & 4.4418 & TRN & \\
\hline CHEMBL3145205 & 688150 & 3.9783 & 4.6565 & TRN & \\
\hline CHEMBL1586425 & 688150 & 4.665 & 5.3485 & TRN & \\
\hline CHEMBL1457500 & 688150 & 3.0 & 4.8246 & TST & \\
\hline CHEMBL1562839 & 688150 & 3.1021 & 4.4774 & TRN & \\
\hline CHEMBL1431629 & 688150 & 3.0 & 4.7788 & TRN & \\
\hline CHEMBL1577631 & 688150 & 3.7025 & 4.5368 & TRN & \\
\hline CHEMBL1578267 & 688150 & 4.2743 & 4.7924 & TRN & \\
\hline CHEMBL1564301 & 688150 & 3.6021 & 3.8791 & TRN & \\
\hline CHEMBL2005664 & 688150 & 3.4867 & 4.9638 & TRN & \\
\hline CHEMBL1306184 & 688150 & 3.4909 & 4.8559 & TRN & \\
\hline CHEMBL1551022 & 688150 & 4.0126 & 5.0839 & TRN & \\
\hline CHEMBL1498509 & 688150 & 5.8333 & 5.0097 & TRN & \\
\hline CHEMBL1485945 & 688150 & 4.9633 & 4.9812 & TRN & \\
\hline CHEMBL1597241 & 688150 & 3.9373 & 4.7011 & TRN & \\
\hline CHEMBL476668 & 688150 & 3.6218 & 3.95300 & 00000000003 & TRN \\
\hline CHEMBL1429230 & 688150 & 3.4704 & 4.8168 & TRN & \\
\hline CHEMBL1451850 & 688150 & 5.0285 & 4.5025 & TRN & \\
\hline CHEMBL1430207 & 688150 & 3.0 & 4.6982 & TRN & \\
\hline CHEMBL1458662 & 688150 & 5.6308 & 4.8957 & TST & \\
\hline CHEMBL1341025 & 688150 & 3.0 & 5.0142 & TRN & \\
\hline CHEMBL1429559 & 688150 & 3.0 & 4.5 & TRN & \\
\hline CHEMBL1470284 & 688150 & 5.4136 & 4.25899 & 99999999995 & TRN \\
\hline & & & & 13197 & \\
\hline
\end{tabular}




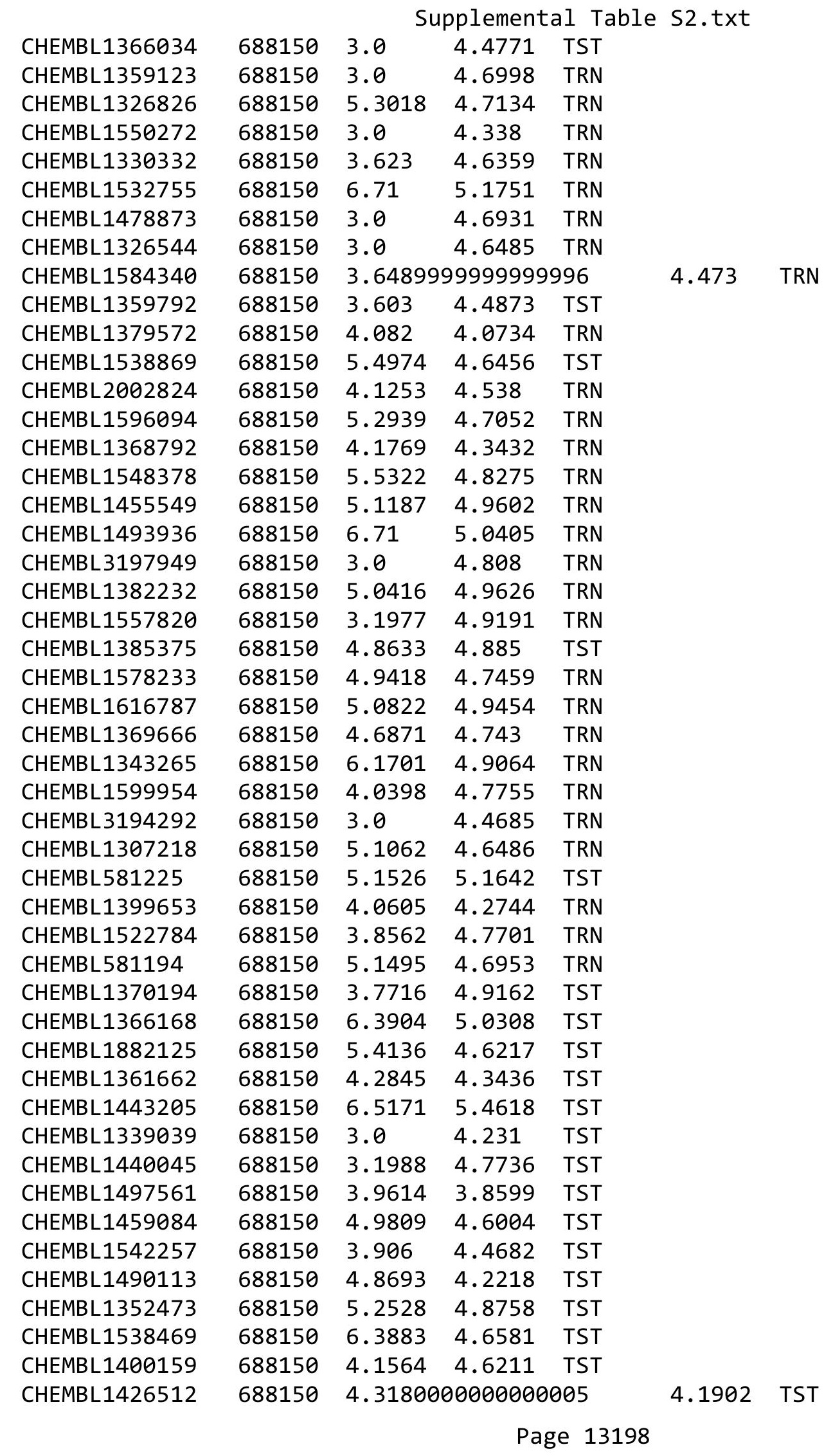




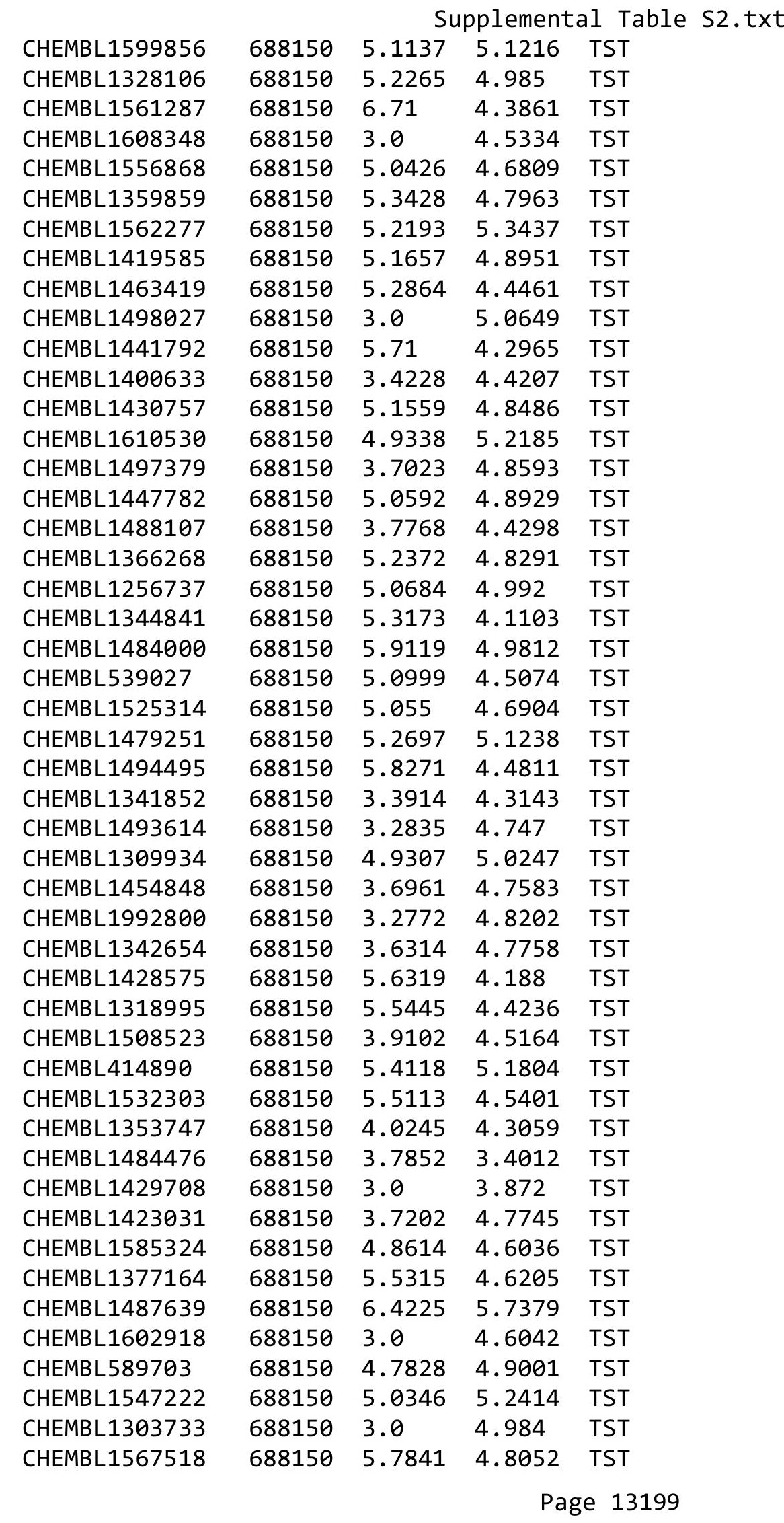


Supplemental Table S2.txt

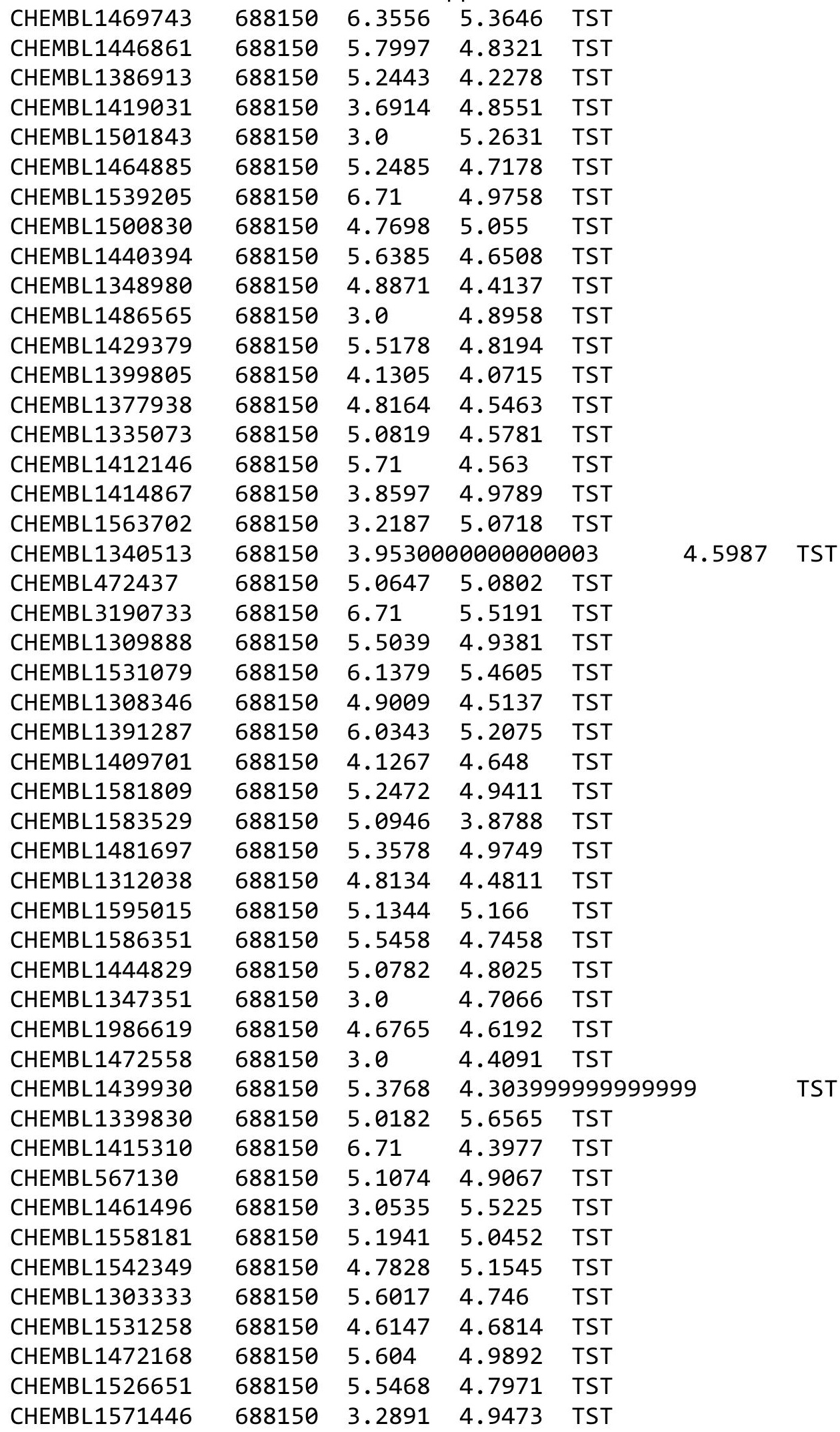

Page 13200 


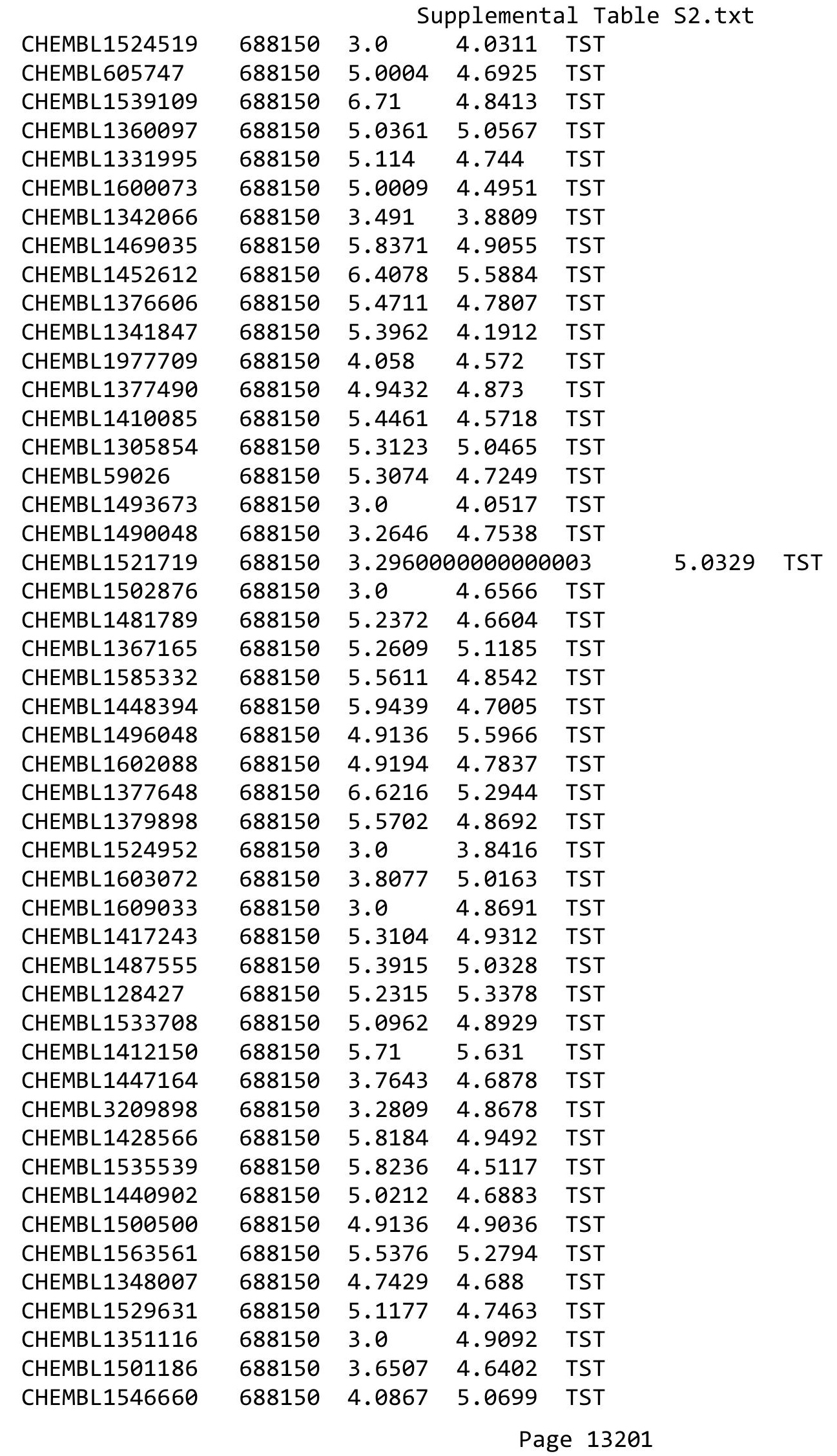




\begin{tabular}{|c|c|c|c|c|c|c|}
\hline \multirow[b]{2}{*}{ CHEMBL1611733 } & \multirow[b]{2}{*}{688150} & \multicolumn{5}{|c|}{ Supplemental Table S2.txt } \\
\hline & & 7.71 & 4.8412 & TST & & \\
\hline CHEMBL1542406 & 688150 & 3.891 & 4.9364 & TST & & \\
\hline CHEMBL1589287 & 688150 & 4.4637 & 4.4096 & TST & & \\
\hline CHEMBL1566656 & 688150 & 5.3915 & 3.7555 & TST & & \\
\hline CHEMBL1585467 & 688150 & 3.3327 & 4.0754 & TST & & \\
\hline CHEMBL1391533 & 688150 & 3.0 & 4.8285 & TST & & \\
\hline CHEMBL1451747 & 688150 & 5.3771 & 5.3198 & TST & & \\
\hline CHEMBL3144948 & 688150 & 4.1288 & 4.9058 & TST & & \\
\hline CHEMBL1529766 & 688150 & 4.9881 & 4.3199 & TST & & \\
\hline CHEMBL1347611 & 688150 & 5.7742 & 4.4012 & TST & & \\
\hline CHEMBL1391667 & 688150 & 3.347 & 4.1649 & TST & & \\
\hline CHEMBL1319984 & 688150 & 5.8383 & 5.7494 & TST & & \\
\hline CHEMBL1566393 & 688150 & 3.2525 & 4.7876 & TST & & \\
\hline CHEMBL1393899 & 688150 & 3.3673 & 5.0641 & TST & & \\
\hline CHEMBL1534197 & 688150 & 3.5966 & 4.5093 & TST & & \\
\hline CHEMBL1576587 & 688150 & 5.7773 & 4.5779 & TST & & \\
\hline CHEMBL1347985 & 688150 & 3.0 & 4.5701 & TST & & \\
\hline CHEMBL1360793 & 688150 & 3.0 & 5.4966 & TST & & \\
\hline CHEMBL1438389 & 688150 & 4.8333 & 5.2058 & TST & & \\
\hline CHEMBL1538736 & 688150 & 3.9687 & 3.4626 & TST & & \\
\hline CHEMBL1600144 & 688150 & 3.64899 & 99999999 & 996 & 3.4639 & TST \\
\hline CHEMBL1549935 & 688150 & 5.4438 & 5.1449 & TST & & \\
\hline CHEMBL1404113 & 688150 & 5.9278 & 5.2172 & TST & & \\
\hline CHEMBL1533651 & 688150 & 4.9429 & 4.7401 & TST & & \\
\hline CHEMBL1586809 & 688150 & 5.4684 & 4.3576 & TST & & \\
\hline CHEMBL1324490 & 688150 & 4.6291 & 5.2345 & TST & & \\
\hline CHEMBL1380192 & 688150 & 4.0373 & 4.5556 & TST & & \\
\hline CHEMBL1462433 & 688150 & 5.2401 & 5.3141 & TST & & \\
\hline CHEMBL1380762 & 688150 & 4.9845 & 4.7034 & TST & & \\
\hline CHEMBL1547092 & 688150 & 7.4078 & 5.4853 & TST & & \\
\hline CHEMBL1462097 & 688150 & 3.0 & 4.79 & TST & & \\
\hline CHEMBL1478065 & 688150 & 4.8796 & 4.6241 & TST & & \\
\hline CHEMBL1386651 & 688150 & 4.4152 & 5.0241 & TST & & \\
\hline CHEMBL1304496 & 688150 & 4.9135 & 4.3158 & TST & & \\
\hline CHEMBL1409670 & 688150 & 5.5265 & 4.8989 & TST & & \\
\hline CHEMBL1578717 & 688150 & 3.5161 & 4.5815 & TST & & \\
\hline CHEMBL1598340 & 688150 & 4.7133 & 4.8087 & TST & & \\
\hline CHEMBL1309321 & 688150 & 5.3322 & 4.9739 & TST & & \\
\hline CHEMBL1481301 & 688150 & 6.71 & 5.0564 & TST & & \\
\hline CHEMBL1332013 & 688150 & 5.3642 & 4.5425 & TST & & \\
\hline CHEMBL3207319 & 688150 & 3.0 & 4.6199 & TST & & \\
\hline CHEMBL1305526 & 688150 & 5.0356 & 4.6006 & TST & & \\
\hline CHEMBL1561309 & 688150 & 3.0 & 3.7094 & TST & & \\
\hline CHEMBL1304736 & 688150 & 3.4368 & 5.0246 & TST & & \\
\hline CHEMBL84010 & 688150 & 4.93199 & 99999999 & 995 & 4.8136 & TST \\
\hline CHEMBL1468981 & 688150 & 4.9917 & 4.953 & TST & & \\
\hline CHEMBL1459473 & 688150 & 3.5517 & 4.5307 & TST & & \\
\hline CHEMBL1537300 & 688150 & 5.1953 & 5.2284 & TST & & \\
\hline
\end{tabular}




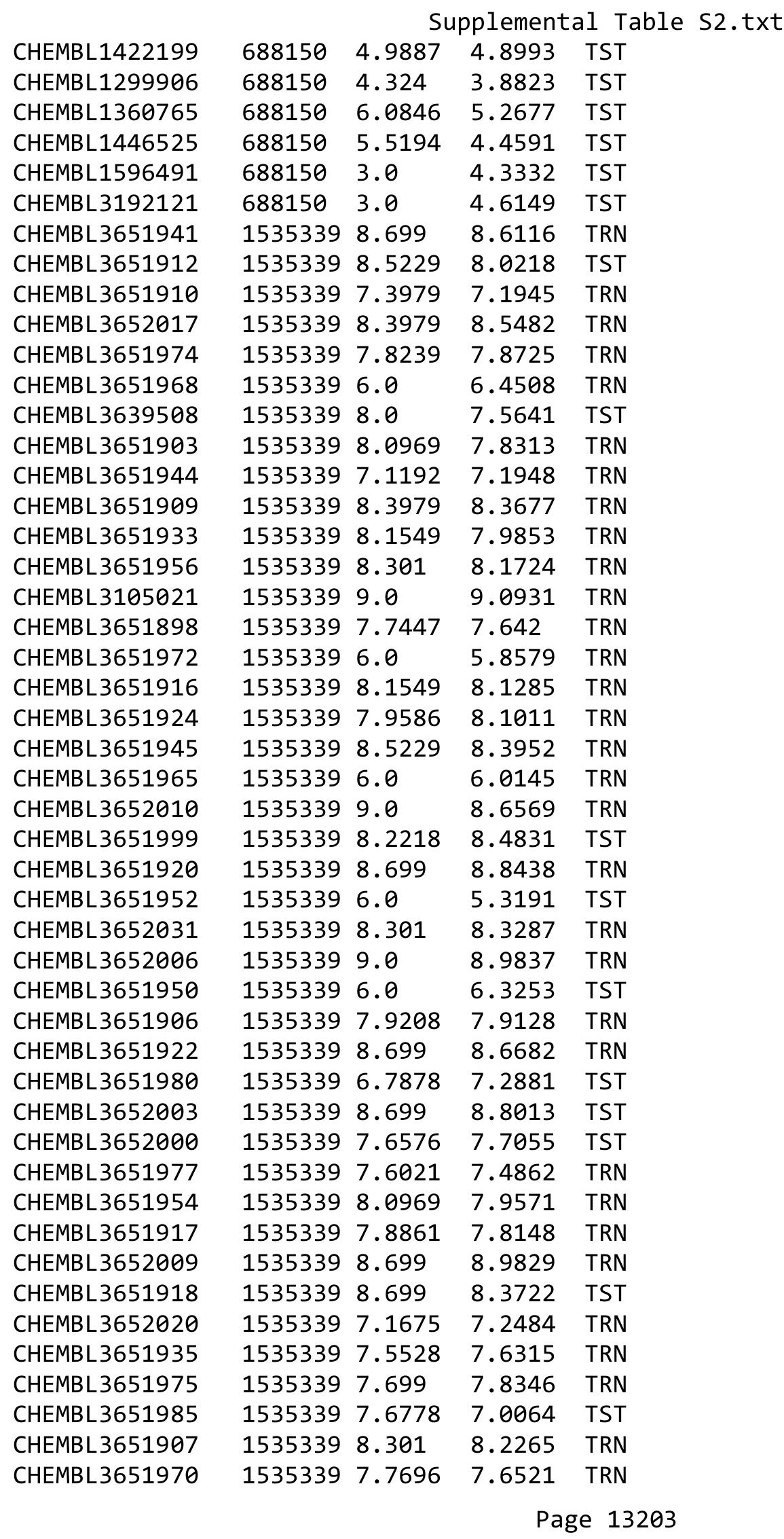


Supplemental Table S2.txt

\begin{tabular}{|c|c|c|c|c|c|}
\hline CHEMBL3652029 & 1535339 & 7.699 & 8.1038 & TST & \\
\hline CHEMBL3651959 & 1535339 & 8.5229 & 8.3349 & TRN & \\
\hline CHEMBL3652019 & 1535339 & 9.0 & 9.162 & TRN & \\
\hline CHEMBL3651942 & 1535339 & 8.699 & 8.4313 & TRN & \\
\hline CHEMBL3651994 & 1535339 & 9.0 & 8.5893 & TRN & \\
\hline CHEMBL3652013 & 1535339 & 8.3979 & 8.3658 & TST & \\
\hline CHEMBL3651978 & 1535339 & 7.0969 & 7.2439 & TRN & \\
\hline CHEMBL3651931 & 1535339 & 8.2218 & 8.0546 & TRN & \\
\hline CHEMBL3651947 & 1535339 & 6.0 & 6.817 & TRN & \\
\hline CHEMBL3652005 & 1535339 & 8.301 & 7.434 & TST & \\
\hline CHEMBL3651988 & 1535339 & 6.0 & 7.7365 & TST & \\
\hline CHEMBL3651919 & 1535339 & 8.301 & 8.1869 & TST & \\
\hline CHEMBL3651939 & 1535339 & 8.2218 & 8.0266 & TRN & \\
\hline CHEMBL3651995 & 1535339 & 8.1549 & 8.0953 & TRN & \\
\hline CHEMBL3651936 & 1535339 & 6.0 & 6.2451 & TRN & \\
\hline CHEMBL3652028 & 1535339 & 7.6198 & 7.8997 & TRN & \\
\hline CHEMBL3651932 & 1535339 & 8.5229 & 8.7149 & TRN & \\
\hline CHEMBL3651961 & 1535339 & 6.0 & 5.938 & TRN & \\
\hline CHEMBL3651960 & 1535339 & 7.1192 & 7.6661 & TST & \\
\hline CHEMBL3651913 & 1535339 & 6.0 & 5.5151 & TRN & \\
\hline CHEMBL3651973 & 1535339 & 7.8861 & 8.0296 & TRN & \\
\hline CHEMBL3651930 & 1535339 & 7.1739 & 7.4402 & TRN & \\
\hline CHEMBL3651979 & 1535339 & 7.3188 & 7.431 & TRN & \\
\hline CHEMBL3651957 & 1535339 & 8.2218 & 8.0921 & TRN & \\
\hline CHEMBL3652002 & 1535339 & 8.1549 & 8.1579 & TRN & \\
\hline CHEMBL3651953 & 1535339 & 8.3979 & 8.3772 & TRN & \\
\hline CHEMBL3651989 & 1535339 & 6.0 & 6.0667 & TRN & \\
\hline CHEMBL3651958 & 1535339 & 8.1549 & 8.0515 & TRN & \\
\hline CHEMBL3652030 & 1535339 & 6.0 & 6.202999 & 9999999999 & TRN \\
\hline CHEMBL3651902 & 1535339 & 7.9208 & 7.8464 & TRN & \\
\hline CHEMBL3652001 & 1535339 & 8.1549 & 8.2987 & TST & \\
\hline CHEMBL3651899 & 1535339 & 9.0 & 9.0073 & TST & \\
\hline CHEMBL3652015 & 1535339 & 9.0 & 8.1649 & TST & \\
\hline CHEMBL 3652023 & 1535339 & 8.5229 & 8.6384 & TRN & \\
\hline CHEMBL3651900 & 1535339 & 8.5229 & 8.5418 & TRN & \\
\hline CHEMBL3651963 & 1535339 & 8.1549 & 8.1655 & TST & \\
\hline CHEMBL3652008 & 1535339 & 8.5229 & 8.7781 & TST & \\
\hline CHEMBL3651926 & 1535339 & 6.0 & 5.5755 & TRN & \\
\hline CHEMBL3651901 & 1535339 & 7.699 & 8.0807 & TRN & \\
\hline CHEMBL3652018 & 1535339 & 8.699 & 8.7489 & TRN & \\
\hline CHEMBL3651904 & 1535339 & 8.3979 & 8.509 & TRN & \\
\hline CHEMBL3651955 & 1535339 & 8.5229 & 8.3398 & TRN & \\
\hline CHEMBL3651962 & 1535339 & 8.3979 & 7.7528 & TRN & \\
\hline CHEMBL3652021 & 1535339 & 6.8827 & 7.0181 & TRN & \\
\hline CHEMBL3651969 & 1535339 & 8.0969 & 8.2363 & TRN & \\
\hline CHEMBL3651928 & 1535339 & 8.3979 & 8.4944 & TRN & \\
\hline CHEMBL3651937 & 1535339 & 7.5686 & 7.5727 & TRN & \\
\hline CHEMBL3651908 & 1535339 & 8.0 & 8.0175 & TRN & \\
\hline
\end{tabular}


Supplemental Table S2.txt

\begin{tabular}{|c|c|c|c|c|}
\hline HEMB & & 969 & 7.7486 & זעיו \\
\hline & & 8.301 & 8.1712 & \\
\hline HFMRI & 339 & 076 & & \\
\hline AEMBL & & 979 & 3504 & \\
\hline AEMBL3651929 & 535339 & 8.0458 & 9899 & \\
\hline HEMBL3652012 & 39 & 7.5376 & 7992 & \\
\hline 998 & & 6.0 & .9628 & \\
\hline AEMBL36 & & & 6587 & \\
\hline HEMBL3651976 & 535339 & 7.3565 & .4899 & \\
\hline HEMBL3651938 & 39 & 8.699 & 5303 & \\
\hline HEMBL3651943 & כו & 979 & .6222 & \\
\hline 997 & & 969 & 9626 & \\
\hline HEMBL; & & 229 & & \\
\hline HEMBL3651921 & 39 & 8.699 & 8.4832 & \\
\hline HEMBL3651986 & & 7.9208 & & \\
\hline HEMBL3 & 39 & 7.2676 & 7 & KIV \\
\hline HEMBL & & & & \\
\hline HEMBL & & 969 & & \\
\hline HEMBI 3 & & 586 & & \\
\hline HEMBL365 & & & 55 & RIN \\
\hline HEMBL & 99 & 9 & 59 & ГRN \\
\hline AEM & & 9. & & MIV \\
\hline HEMBL & & 7. & & ST \\
\hline HEMBL & & 8 . & & RN \\
\hline AEMBL3 & 39 & 8.3979 & & RN \\
\hline HEMBL3 & 54 & 6 & 91 & RN \\
\hline HEMBL & 3 & 6. & & RN \\
\hline 26 & 3 & 6. & & RN \\
\hline AEMBL3 & & & & IRN \\
\hline HEMBL3935950 & 54 & 5.7258 & 24 & RN \\
\hline HEMBL; & & 279 & & RN \\
\hline HFM & & 51 & & RN \\
\hline+25 & & 4. & & 「RN \\
\hline HEMBL3218017 & & 6.301 & & 「RN \\
\hline HEMBL3218021 & 54 & 6 & 3652 & RN \\
\hline AFMRI 3 & 3 & 7. & 19 & TRN \\
\hline 3 & & 6 . & & RN \\
\hline HEMBL 321 & & 5. & 752 & TRN \\
\hline HEMBL3 & & 5 . & & $\Gamma R$ \\
\hline 25 & 3 & & & RN \\
\hline HFMRI 3 & & 6. & 16 & RN \\
\hline HEMBL3 & & 5.6696 & 1934 & RN \\
\hline HEMBL3919067 & & 4.8752 & 1033 & {$[R$} \\
\hline HEMBL3 & 164 & 5 . & & TR \\
\hline 16 & & & & \\
\hline HEMBL3 & & & & \\
\hline HEMBL3965078 & & 4.8374 & 4.4559 & RN \\
\hline CHEMBL3914256 & 1641063 & 5.7282 & 5.6391 & \\
\hline
\end{tabular}

Page 13205 
Supplemental Table S2.txt

\begin{tabular}{|c|c|c|c|c|}
\hline HEMBL39 & & 36 & 17 & \\
\hline HFMRI 3218927 & & 8239 & 7755 & \\
\hline HEMBL & & 6.0 & 017 & \\
\hline AEMBL3218010 & 063 & 226 & 3291 & \\
\hline HEMBL3966306 & 063 & 6.7212 & .6872 & \\
\hline HEMBL3 & 363 & 6.0 & .4969 & \\
\hline AEMBL & & 34 & & \\
\hline HEMBL3965107 & 363 & 261 & 4843 & \\
\hline HEMBL3913793 & 363 & 4.4616 & . 7179 & \\
\hline HEMBL3218009 & 363 & 7.301 & 6.8112 & \\
\hline HEMBL3218005 & 63 & 6.0 & 0943 & \\
\hline HEMBL & & 5 & 3933 & \\
\hline HEMBL3 & 63 & 7.2218 & 5386 & \\
\hline AEMBL3 & 63 & 5.0022 & 2294 & \\
\hline HEMBL3218289 & 63 & 6.0 & 8928 & \\
\hline AEMBL & 63 & & 003 & \\
\hline AEMBL & & 5 & 582 & iv \\
\hline HEMBL & & 4.8536 & 9695 & \\
\hline AEMBL 3218 & 63 & 6.0 & 716 & \\
\hline AEMBL3 & 53 & 84 & 763 & IRIV \\
\hline IEMBL & & 778 & 395 & I \\
\hline HEME & & 82 & 326 & ונ \\
\hline HEMBL & & 41 & 9903 & RN \\
\hline HEMBL: & & 318 & 917 & \\
\hline HEMBL 3218024 & 63 & 6.8539 & 578 & $R N$ \\
\hline IEMBL3 & & 817 & 952 & $R N_{-}$ \\
\hline EM & & & & ST \\
\hline 59 & & 85 & 287 & RN \\
\hline IEMBL: & & & & ISI \\
\hline AEMBL 3944452 & & 5.7399 & 432 & $\mathrm{RN}$ \\
\hline IEMBL: & & 874 & 73 & RN \\
\hline 5 & & & & RN \\
\hline & & & & RN \\
\hline AEMBL3 & & & 86 & 「RN \\
\hline AEMBL3218299 & & 188 & 545 & 「RN \\
\hline$A F M B$ & & 37 & 152 & RN \\
\hline & & & & ST \\
\hline HEMBL3 & & & & TRN \\
\hline AEMBL3962641 & & 937 & $\partial 69$ & TS \\
\hline EMBL3 & & 508 & 772 & TST \\
\hline HEMBL3218015 & & 6 . & 421 & TST \\
\hline HEMBL3 & & & & IST \\
\hline HEMBL3 & & & 5101 & TST \\
\hline AEMBL 3890 & & 4 . & 062 & TS \\
\hline EMBL3 & & & 995 & TST \\
\hline HEMBL 3900632 & & 1.0 & 4.5867 & \\
\hline CHEMBL3903548 & & 6.0 & 5.3157 & 1 \\
\hline CHEMBL561967 & 573011 & 5.5331 & 5.7873 & rRN \\
\hline
\end{tabular}

Page 13206 
Supplemental Table S2.txt

\begin{tabular}{|c|c|c|c|c|}
\hline CHEMBL560625 & 573011 & 5.7747 & 3.9224 & TRN \\
\hline CHEMBL550432 & 573011 & 5.8297 & 5.0793 & TRN \\
\hline CHEMBL564950 & 573011 & 5.5376 & 5.441 & TRN \\
\hline CHEMBL560044 & 573011 & 4.6576 & 4.0783 & TRN \\
\hline CHEMBL561642 & 573011 & 5.9172 & 5.6412 & TRN \\
\hline CHEMBL561905 & 573011 & 5.5421 & 5.5562 & TRN \\
\hline CHEMBL561441 & 573011 & 4.5638 & 4.5323 & TRN \\
\hline CHEMBL560103 & 573011 & 5.2204 & 5.4198 & TRN \\
\hline CHEMBL551155 & 573011 & 5.7352 & 5.6152 & TRN \\
\hline CHEMBL564683 & 573011 & 4.9666 & 5.215 & TST \\
\hline CHEMBL560441 & 573011 & 5.3675 & 5.4524 & TST \\
\hline CHEMBL564141 & 573011 & 5.4157 & 5.9036 & TRN \\
\hline CHEMBL557283 & 573011 & 5.4935 & 5.1167 & TRN \\
\hline CHEMBL557692 & 573011 & 5.0752 & 5.3452 & TRN \\
\hline CHEMBL471799 & 573011 & 5.5867 & 5.66799 & 7999999999 \\
\hline CHEMBL469444 & 573011 & 5.5686 & 5.4129 & TRN \\
\hline CHEMBL563314 & 573011 & 5.4023 & 4.9962 & TRN \\
\hline CHEMBL560626 & 573011 & 5.4225 & 4.1783 & TRN \\
\hline CHEMBL563349 & 573011 & 5.8182 & 5.7404 & TRN \\
\hline CHEMBL 232202 & 573011 & 3.9872 & 5.1631 & TST \\
\hline CHEMBL554068 & 573011 & 2.8356 & 4.0921 & TRN \\
\hline CHEMBL560560 & 573011 & 4.5513 & 3.7392 & TRN \\
\hline CHEMBL565008 & 573011 & 4.5686 & 4.845 & TRN \\
\hline CHEMBL560504 & 573011 & 5.5986 & 5.4057 & TRN \\
\hline CHEMBL562559 & 573011 & 5.1079 & 5.528 & TRN \\
\hline CHEMBL562225 & 573011 & 5.0788 & 5.2579 & TRN \\
\hline CHEMBL455372 & 573011 & 5.699 & 5.774 & TRN \\
\hline CHEMBL552346 & 573011 & 3.2774 & 4.3893 & TRN \\
\hline CHEMBL550774 & 573011 & 5.7878 & 5.3344 & TRN \\
\hline CHEMBL551902 & 573011 & 5.4134 & 5.1458 & TRN \\
\hline CHEMBL552510 & 573011 & 5.4283 & 5.5939 & TRN \\
\hline CHEMBL560442 & 573011 & 5.0825 & 4.925 & TRN \\
\hline CHEMBL555351 & 573011 & 5.6925 & 5.6 & TRN \\
\hline CHEMBL556752 & 573011 & 3.2774 & 4.4832 & TRN \\
\hline CHEMBL550223 & 573011 & 5.2104 & 5.446006 & 0000000001 \\
\hline CHEMBL44 & 573011 & 4.5346 & 5.3768 & TST \\
\hline CHEMBL561040 & 573011 & 5.0768 & 5.189 & TRN \\
\hline CHEMBL564881 & 573011 & 4.5482 & 4.9568 & TRN \\
\hline CHEMBL554273 & 573011 & 5.8327 & 5.4847 & TRN \\
\hline CHEMBL550775 & 573011 & 5.8416 & 5.6533 & TRN \\
\hline CHEMBL556260 & 573011 & 2.8697 & 3.7425 & TRN \\
\hline CHEMBL562301 & 573011 & 5.9101 & 5.6572 & TRN \\
\hline CHEMBL552302 & 573011 & 2.8697 & 3.9749 & TRN \\
\hline CHEMBL564362 & 573011 & 5.6596 & 5.3395 & TST \\
\hline CHEMBL559455 & 573011 & 5.3072 & 5.4864 & TST \\
\hline CHEMBL556062 & 573011 & 4.4023 & 4.9342 & TST \\
\hline CHEMBL557191 & 573011 & 4.4237 & 4.9329 & TST \\
\hline CHEMBL561966 & 573011 & 6.0088 & 5.6046 & TST \\
\hline
\end{tabular}




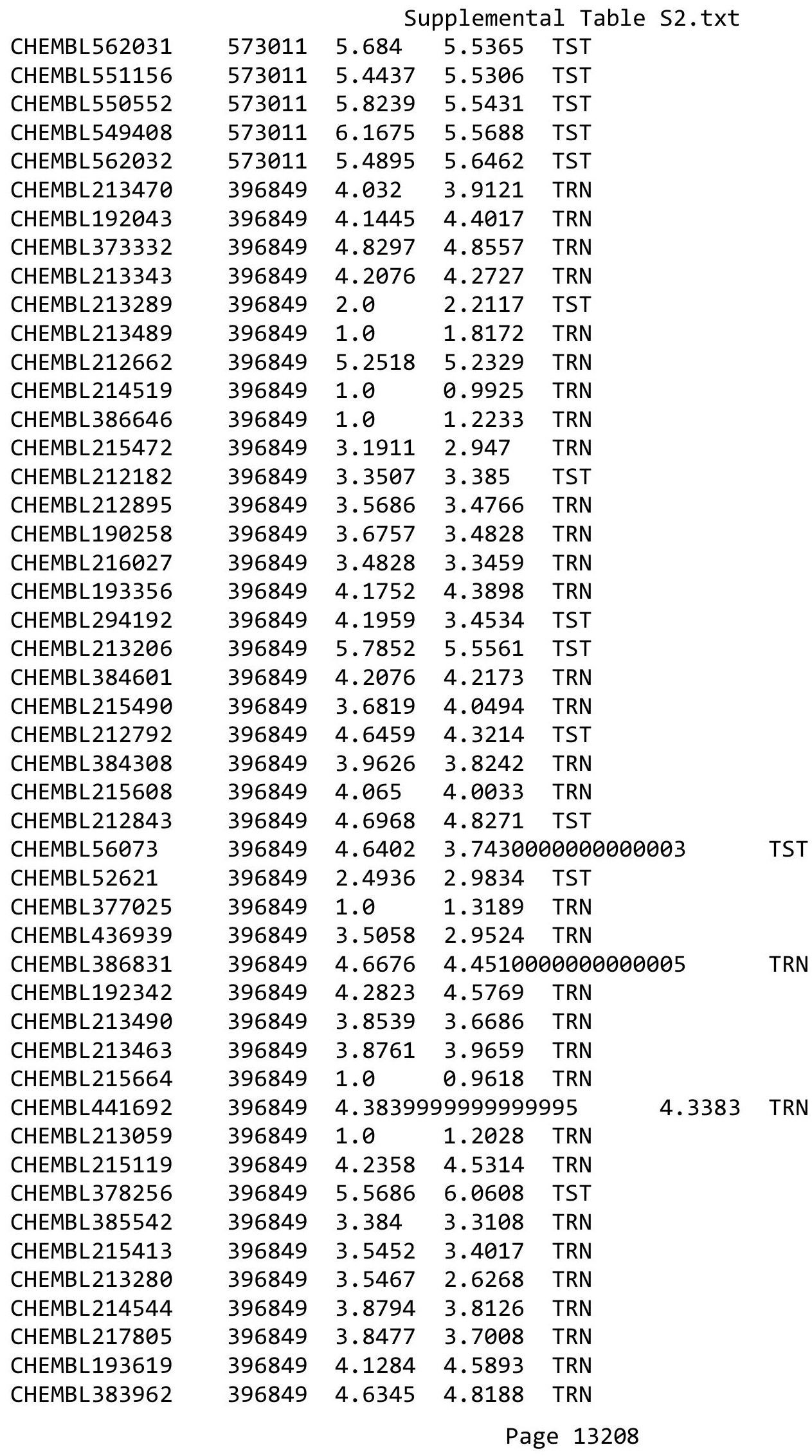




\begin{tabular}{|c|c|c|c|c|c|}
\hline \multicolumn{6}{|c|}{ splemental a } \\
\hline CHEMBL378940 & 396849 & 4.27 & 3.9934 & TRN & \\
\hline CHEMBL384162 & 396849 & 3.5544 & 3.4941 & TRN & \\
\hline CHEMBL212835 & 396849 & 6.2076 & 6.0968 & TST & \\
\hline CHEMBL214851 & 396849 & 5.2418 & 4.0488 & TST & \\
\hline CHEMBL363434 & 396849 & 4.7328 & 4.368 & TRN & \\
\hline CHEMBL378354 & 396849 & 4.2636 & 4.445 & TRN & \\
\hline CHEMBL383957 & 396849 & 4.4815 & 4.5675 & TRN & \\
\hline CHEMBL425896 & 396849 & 3.5272 & 3.0364 & TRN & \\
\hline CHEMBL212842 & 396849 & 5.3143 & 5.229 & TST & \\
\hline CHEMBL191634 & 396849 & 4.1555 & 4.1216 & TRN & \\
\hline CHEMBL378858 & 396849 & 1.0 & 1.2177 & TRN & \\
\hline CHEMBL56011 & 396849 & 3.3288 & 2.968 & TST & \\
\hline CHEMBL385291 & 396849 & 4.3288 & 3.9951 & TRN & \\
\hline CHEMBL294191 & 396849 & 4.8996 & 3.531 & TST & \\
\hline CHEMBL213327 & 396849 & 5.2255 & 5.1699 & TST & \\
\hline CHEMBL386386 & 396849 & 4.2291 & 4.192 & TRN & \\
\hline CHEMBL193722 & 396849 & 4.1818 & 4.6236 & TRN & \\
\hline CHEMBL192017 & 396849 & 3.9318 & 4.1767 & TRN & \\
\hline CHEMBL436772 & 396849 & 3.8508 & 3.0813 & TST & \\
\hline CHEMBL3923037 & 1642119 & 6.1385 & 6.1863 & TRN & \\
\hline CHEMBL3970228 & 1642119 & 6.6234 & 6.8066 & TST & \\
\hline CHEMBL3982470 & 1642119 & 6.5528 & 6.7626 & TRN & \\
\hline CHEMBL3925873 & 1642119 & 7.5528 & 7.4784 & TRN & \\
\hline CHEMBL3901328 & 1642119 & 7.6576 & 7.7304 & TRN & \\
\hline CHEMBL3926359 & 1642119 & 7.5528 & 7.29200 & 0000000001 & TRN \\
\hline CHEMBL3900012 & 1642119 & 8.3979 & 7.5793 & TST & \\
\hline CHEMBL3923722 & 1642119 & 7.1487 & 7.1073 & TRN & \\
\hline CHEMBL3960974 & 1642119 & 7.4089 & 7.218 & TRN & \\
\hline CHEMBL3968500 & 1642119 & 8.0458 & 7.9007 & TRN & \\
\hline CHEMBL3945488 & 1642119 & 6.9393 & 7.0584 & TRN & \\
\hline CHEMBL 3890542 & 1642119 & 7.041 & 7.14 & TRN & \\
\hline CHEMBL3959617 & 1642119 & 6.5157 & 6.4677 & TRN & \\
\hline CHEMBL3909062 & 1642119 & 6.6615 & 6.6887 & TRN & \\
\hline CHEMBL3930068 & 1642119 & 7.585 & 7.4539 & TRN & \\
\hline CHEMBL3930962 & 1642119 & 8.0 & 7.983 & TRN & \\
\hline CHEMBL3986689 & 1642119 & 8.2218 & 8.1683 & TRN & \\
\hline CHEMBL3944467 & 1642119 & 8.5229 & 8.425 & TRN & \\
\hline CHEMBL3946611 & 1642119 & 8.5229 & 8.5037 & TRN & \\
\hline CHEMBL3979924 & 1642119 & 5.9245 & 6.4946 & TST & \\
\hline CHEMBL3985158 & 1642119 & 8.301 & 7.83299 & 7999999999 & TST \\
\hline CHEMBL 3973440 & 1642119 & 7.3098 & 7.5454 & TRN & \\
\hline CHEMBL3983952 & 1642119 & 9.2218 & 8.8743 & TRN & \\
\hline CHEMBL3978623 & 1642119 & 8.0458 & 7.8483 & TRN & \\
\hline CHEMBL3976908 & 1642119 & 6.7696 & 6.8253 & TRN & \\
\hline CHEMBL3932896 & 1642119 & 6.6198 & 6.41100 & 00000000005 & TRN \\
\hline CHEMBL 3979585 & 1642119 & 6.4089 & 6.8059 & TRN & \\
\hline CHEMBL3922646 & 1642119 & 6.5751 & 6.5774 & TRN & \\
\hline CHEMBL 3902440 & 1642119 & 7.7696 & 7.6877 & TRN & \\
\hline
\end{tabular}

Page 13209 


$$
\text { Supplemental Table S2.txt }
$$

\begin{tabular}{|c|c|c|c|c|c|}
\hline CHEMBL3937139 & 1642119 & 8.3979 & 8.5137 & TRN & \\
\hline CHEMBL3893903 & 1642119 & 8.301 & 8.3058 & TRN & \\
\hline CHEMBL3894582 & 1642119 & 8.1549 & 8.0445 & TRN & \\
\hline CHEMBL3934595 & 1642119 & 8.3979 & 8.5051 & TRN & \\
\hline CHEMBL3954052 & 1642119 & 6.1701 & $6.12200 t$ & 0000000001 & TRN \\
\hline CHEMBL3917373 & 1642119 & 9.0 & 9.0499 & TRN & \\
\hline CHEMBL3923638 & 1642119 & 7.6383 & 7.7644 & TRN & \\
\hline CHEMBL3597964 & 1642119 & 9.1549 & 9.1348 & TRN & \\
\hline CHEMBL3966231 & 1642119 & 8.699 & 8.5638 & TRN & \\
\hline CHEMBL3929213 & 1642119 & 7.1367 & 7.0485 & TRN & \\
\hline CHEMBL3597963 & 1642119 & 8.699 & 8.4593 & TRN & \\
\hline CHEMBL3978378 & 1642119 & 8.0 & 8.1446 & TRN & \\
\hline CHEMBL3932276 & 1642119 & 8.5229 & 8.7385 & TRN & \\
\hline CHEMBL3915969 & 1642119 & 7.3872 & 7.2486 & TRN & \\
\hline CHEMBL3973919 & 1642119 & 7.0 & 7.4244 & TRN & \\
\hline CHEMBL3910736 & 1642119 & 8.0458 & 7.8802 & TST & \\
\hline CHEMBL3946899 & 1642119 & 6.4921 & 6.6307 & TST & \\
\hline CHEMBL3970835 & 1642119 & 9.0 & 9.2108 & TST & \\
\hline CHEMBL3972793 & 1642119 & 7.9586 & 7.2862 & TST & \\
\hline CHEMBL3957590 & 1642119 & 8.2218 & 8.2813 & TRN & \\
\hline CHEMBL3978561 & 1642119 & 9.0 & 8.8879 & TST & \\
\hline CHEMBL3959128 & 1642119 & 7.0362 & 7.0317 & TST & \\
\hline CHEMBL3949525 & 1642119 & 6.301 & 6.3952 & TRN & \\
\hline CHEMBL3964868 & 1642119 & 6.9136 & 6.6956 & TST & \\
\hline CHEMBL3918089 & 1642119 & 7.1612 & 7.2397 & TRN & \\
\hline CHEMBL3920218 & 1642119 & 8.0458 & 8.3101 & TRN & \\
\hline CHEMBL3917431 & 1642119 & 7.4202 & 7.5248 & TRN & \\
\hline CHEMBL3904643 & 1642119 & 6.7447 & 6.6456 & TRN & \\
\hline CHEMBL3896226 & 1642119 & 7.7959 & 7.5249 & TST & \\
\hline CHEMBL3925711 & 1642119 & 7.8239 & 7.8788 & TRN & \\
\hline CHEMBL3941877 & 1642119 & 6.2 & 6.4491 & TST & \\
\hline CHEMBL3986606 & 1642119 & 7.9586 & 7.7143 & TRN & \\
\hline CHEMBL3899648 & 1642119 & 6.5528 & 6.4743 & TRN & \\
\hline CHEMBL3915380 & 1642119 & 8.301 & 7.6244 & TST & \\
\hline CHEMBL3932611 & 1642119 & 7.4949 & 7.3254 & TST & \\
\hline CHEMBL3965024 & 1642119 & 8.0969 & 7.9828 & TRN & \\
\hline CHEMBL3894851 & 1642119 & 9.2218 & 9.0606 & TST & \\
\hline CHEMBL3903036 & 1642119 & 8.301 & 8.4768 & TRN & \\
\hline CHEMBL3964256 & 1642119 & 9.0 & 8.7681 & TST & \\
\hline CHEMBL3963773 & 1642119 & 6.9245 & 6.8693 & TRN & \\
\hline CHEMBL3968605 & 1642119 & 7.5686 & 7.5903 & TRN & \\
\hline CHEMBL3958706 & 1642119 & 7.1079 & 7.1823 & TRN & \\
\hline CHEMBL3965816 & 1642119 & 8.699 & 8.7991 & TRN & \\
\hline CHEMBL3912551 & 1642119 & 6.4473 & 6.5546 & TRN & \\
\hline CHEMBL3957489 & 1642119 & 7.7212 & 7.4304 & TRN & \\
\hline CHEMBL3916956 & 1642119 & 8.301 & 8.2518 & TRN & \\
\hline CHEMBL3956526 & 1642119 & 8.3979 & 8.3584 & TRN & \\
\hline CHEMBL3982171 & 1642119 & 7.1308 & 7.2808 & TRN & \\
\hline
\end{tabular}


Supplemental Table S2.txt

\begin{tabular}{|c|c|c|c|c|c|}
\hline CHEMBL 3941583 & 1642119 & 8.3979 & 8.675 & TRN & \\
\hline CHEMBL 3984374 & 1642119 & 6.5003 & 6.943 & TST & \\
\hline CHEMBL3974018 & 1642119 & 6.466 & 6.6218 & TRN & \\
\hline CHEMBL3939929 & 1642119 & 9.0 & 8.925 & TRN & \\
\hline CHEMBL 3956679 & 1642119 & 7.3979 & 7.3554 & TRN & \\
\hline CHEMBL3965500 & 1642119 & 7.4685 & 7.3908 & TRN & \\
\hline CHEMBL3916349 & 1642119 & 7.4089 & 6.9877 & TST & \\
\hline CHEMBL3964151 & 1642119 & 6.9393 & 7.0163 & TRN & \\
\hline CHEMBL 3899504 & 1642119 & 6.51 & 6.5077 & TRN & \\
\hline CHEMBL3905668 & 1642119 & 7.7696 & 7.6916 & TRN & \\
\hline CHEMBL3948694 & 1642119 & 8.5229 & 8.4146 & TRN & \\
\hline CHEMBL3904615 & 1642119 & 8.301 & 7.6431 & TST & \\
\hline CHEMBL 3947062 & 1642119 & 8.699 & 8.6244 & TRN & \\
\hline CHEMBL 3909762 & 1642119 & 8.0 & 7.0214 & TST & \\
\hline CHEMBL 3982981 & 1642119 & 6.6216 & 6.5776 & TRN & \\
\hline CHEMBL3952601 & 1642119 & 7.9586 & 7.9337 & TRN & \\
\hline CHEMBL3954049 & 1642119 & 8.0 & 8.0464 & TRN & \\
\hline CHEMBL3983377 & 1642119 & 8.5229 & 8.5785 & TRN & \\
\hline CHEMBL 3981923 & 1642119 & 8.0 & 7.7149 & TRN & \\
\hline CHEMBL3962927 & 1642119 & 6.4584 & 6.5897 & TST & \\
\hline CHEMBL 3895717 & 1642119 & 6.5421 & 6.6661 & TRN & \\
\hline CHEMBL 3932670 & 1642119 & 7.2291 & 7.0461 & TRN & \\
\hline CHEMBL3908104 & 1642119 & 8.0 & 8.0128 & TST & \\
\hline CHEMBL 3948019 & 1642119 & 7.7696 & 7.7935 & TRN & \\
\hline CHEMBL3959783 & 1642119 & 8.699 & 8.4097 & TST & \\
\hline CHEMBL3953989 & 1642119 & 7.8861 & 7.9877 & TRN & \\
\hline CHEMBL3929702 & 1642119 & 8.699 & 7.8215 & TST & \\
\hline CHEMBL3983998 & 1642119 & 8.2218 & 7.9675 & TST & \\
\hline CHEMBL 3971174 & 1642119 & 6.8761 & 6.7069 & TRN & \\
\hline CHEMBL3955074 & 1642119 & 6.1765 & 6.3474 & TST & \\
\hline CHEMBL 3970650 & 1642119 & 7.5686 & 7.4044 & TRN & \\
\hline CHEMBL3915192 & 1642119 & 6.3487 & 6.2721 & TRN & \\
\hline CHEMBL3919098 & 1642119 & 6.3468 & 6.3249 & TST & \\
\hline CHEMBL 3938546 & 1642119 & 7.3979 & 7.2821 & TRN & \\
\hline CHEMBL3892874 & 1642119 & 7.7696 & 6.9968 & TST & \\
\hline CHEMBL 3920867 & 1642119 & 7.699 & 6.9913 & TST & \\
\hline CHEMBL3946962 & 1642119 & 8.0 & 8.0407 & TRN & \\
\hline CHEMBL3958954 & 1642119 & 6.3809 & 6.6081 & TRN & \\
\hline CHEMBL 3916868 & 1642119 & 7.9208 & 7.9984 & TRN & \\
\hline CHEMBL 3975924 & 1642119 & 8.3979 & 8.31899 & 9999999999 & TRN \\
\hline CHEMBL 3911945 & 1642119 & 9.0 & 8.7458 & TRN & \\
\hline CHEMBL3911441 & 1642119 & 7.3279 & 7.3754 & TRN & \\
\hline CHEMBL3981349 & 1642119 & 7.8861 & 7.9418 & TRN & \\
\hline CHEMBL 3935511 & 1642119 & 7.6021 & 7.6136 & TRN & \\
\hline CHEMBL3901710 & 1642119 & 6.7696 & 6.8426 & TST & \\
\hline CHEMBL 3929858 & 1642119 & 6.9393 & 6.9184 & TRN & \\
\hline CHEMBL 3894407 & 1642119 & 8.0969 & 8.1902 & TRN & \\
\hline CHEMBL 3950689 & 1642119 & 6.7282 & 6.825 & TRN & \\
\hline
\end{tabular}


Supplemental Table S2.txt

\begin{tabular}{|c|c|c|c|c|c|}
\hline CHEMBL3945239 & 1642119 & 8.2218 & 8.2536 & TRN & \\
\hline CHEMBL3979471 & 1642119 & 8.699 & 8.9968 & TRN & \\
\hline CHEMBL3938169 & 1642119 & 8.3979 & 7.6939 & TST & \\
\hline CHEMBL3927468 & 1642119 & 6.2557 & 6.4725 & TST & \\
\hline CHEMBL3899022 & 1642119 & 7.2518 & 6.9389 & TST & \\
\hline CHEMBL3965076 & 1642119 & 6.4353 & 6.3829 & TRN & \\
\hline CHEMBL3982843 & 1642119 & 7.9586 & 8.0246 & TRN & \\
\hline CHEMBL3945314 & 1642119 & 7.6021 & 7.5489 & TRN & \\
\hline CHEMBL1583045 & 688282 & 4.9 & 5.2252 & TST & \\
\hline CHEMBL1551324 & 688282 & 6.0 & 5.2776 & TST & \\
\hline CHEMBL1473492 & 688282 & 5.0 & 5.1499 & TST & \\
\hline CHEMBL1408925 & 688282 & 6.0 & $5.29700 t$ & 2000000001 & TRN \\
\hline CHEMBL1359181 & 688282 & 5.6 & 5.062 & TRN & \\
\hline CHEMBL1494892 & 688282 & 6.0 & 5.1593 & TST & \\
\hline CHEMBL1314286 & 688282 & 4.9 & 5.1496 & TST & \\
\hline CHEMBL1446593 & 688282 & 5.0 & 5.1987 & TRN & \\
\hline CHEMBL1409120 & 688282 & 4.9 & 5.1873 & TRN & \\
\hline CHEMBL1518144 & 688282 & 4.7 & 5.0698 & TRN & \\
\hline CHEMBL1304408 & 688282 & 5.7 & 5.0492 & TRN & \\
\hline CHEMBL1512027 & 688282 & 5.7 & 5.007 & TRN & \\
\hline CHEMBL1374696 & 688282 & 5.0 & 5.1057 & TRN & \\
\hline CHEMBL3191258 & 688282 & 5.6 & 5.3179 & TST & \\
\hline CHEMBL1488280 & 688282 & 5.0 & 5.0042 & TRN & \\
\hline CHEMBL1473117 & 688282 & 5.5 & 5.2974 & TRN & \\
\hline CHEMBL1553577 & 688282 & 5.0 & 5.0823 & TRN & \\
\hline CHEMBL1516388 & 688282 & 6.6 & 5.2407 & TST & \\
\hline CHEMBL1608411 & 688282 & 4.9 & 4.987 & TRN & \\
\hline CHEMBL1501264 & 688282 & 5.0 & 5.0798 & TRN & \\
\hline CHEMBL1489195 & 688282 & 4.7 & 5.145 & TRN & \\
\hline CHEMBL1347052 & 688282 & 4.9 & 5.1634 & TRN & \\
\hline CHEMBL1312521 & 688282 & 4.6 & 5.16799 & 9999999999 & TRN \\
\hline CHEMBL1301505 & 688282 & 4.5 & 5.1573 & TRN & \\
\hline CHEMBL1587647 & 688282 & 4.6 & 5.1496 & TST & \\
\hline CHEMBL1394944 & 688282 & 5.0 & 5.0795 & TRN & \\
\hline CHEMBL1349943 & 688282 & 5.3 & 5.1391 & TRN & \\
\hline CHEMBL1489418 & 688282 & 4.9 & 5.0019 & TRN & \\
\hline CHEMBL1455018 & 688282 & 4.6 & 5.0702 & TRN & \\
\hline CHEMBL1471745 & 688282 & 5.3 & 5.1467 & TRN & \\
\hline CHEMBL1608205 & 688282 & 4.8 & 5.0899 & TRN & \\
\hline CHEMBL1508555 & 688282 & 5.0 & 4.9866 & TRN & \\
\hline CHEMBL1435276 & 688282 & 5.8 & 5.2734 & TRN & \\
\hline CHEMBL1479730 & 688282 & 4.5 & 5.16 & TRN & \\
\hline CHEMBL1415932 & 688282 & 4.7 & 5.0557 & TRN & \\
\hline CHEMBL1459370 & 688282 & 4.9 & 5.0517 & TRN & \\
\hline CHEMBL1441180 & 688282 & 4.5 & 5.1105 & TST & \\
\hline CHEMBL1432848 & 688282 & 4.9 & 5.0806 & TRN & \\
\hline CHEMBL1486698 & 688282 & 5.4 & 5.0825 & TRN & \\
\hline CHEMBL1576072 & 688282 & 5.3 & 5.1417 & TRN & \\
\hline
\end{tabular}




\begin{tabular}{|c|c|c|c|c|}
\hline \multicolumn{5}{|c|}{ lemental T } \\
\hline CHEMBL1515253 & 688282 & 5.0 & 5.0126 & TRN \\
\hline CHEMBL1396040 & 688282 & 5.2 & 5.1087 & TRN \\
\hline CHEMBL1494933 & 688282 & 5.5 & 5.0216 & TRN \\
\hline CHEMBL1359731 & 688282 & 6.8 & 5.1074 & TST \\
\hline CHEMBL1467004 & 688282 & 4.6 & 5.088 & TRN \\
\hline CHEMBL1548291 & 688282 & 5.5 & 5.2084 & TST \\
\hline CHEMBL1575051 & 688282 & 4.5 & 5.1612 & TRN \\
\hline CHEMBL1567304 & 688282 & 4.6 & 5.1146 & TST \\
\hline CHEMBL1313141 & 688282 & 4.7 & 5.1013 & TRN \\
\hline CHEMBL1376736 & 688282 & 5.0 & 5.2557 & TRN \\
\hline CHEMBL1445151 & 688282 & 4.5 & 5.1463 & TRN \\
\hline CHEMBL1415866 & 688282 & 4.6 & 5.0291 & TRN \\
\hline CHEMBL1589269 & 688282 & 5.2 & 5.0931 & TRN \\
\hline CHEMBL1406082 & 688282 & 5.0 & 5.1629 & TRN \\
\hline CHEMBL1611806 & 688282 & 5.3 & 5.1375 & TRN \\
\hline CHEMBL 258893 & 688282 & 4.6 & 5.0932 & TST \\
\hline CHEMBL1552071 & 688282 & 4.9 & 5.1547 & TRN \\
\hline CHEMBL1515852 & 688282 & 4.6 & 5.0955 & TRN \\
\hline CHEMBL1445142 & 688282 & 4.9 & 5.1671 & TRN \\
\hline CHEMBL1589925 & 688282 & 4.6 & 5.0252 & TRN \\
\hline CHEMBL1389498 & 688282 & 4.6 & 5.0862 & TRN \\
\hline CHEMBL1417225 & 688282 & 4.9 & 5.0453 & TRN \\
\hline CHEMBL1416391 & 688282 & 5.0 & 5.041 & TRN \\
\hline CHEMBL1560296 & 688282 & 5.1 & 5.1996 & TRN \\
\hline CHEMBL1405565 & 688282 & 6.8 & 5.2926 & TST \\
\hline CHEMBL1449204 & 688282 & 5.5 & 5.0656 & TRN \\
\hline CHEMBL546257 & 688282 & 6.0 & 4.9842 & TRN \\
\hline CHEMBL1485027 & 688282 & 5.0 & 5.1892 & TRN \\
\hline CHEMBL1491840 & 688282 & 5.5 & 5.0952 & TRN \\
\hline CHEMBL1382622 & 688282 & 5.5 & 4.9971 & TRN \\
\hline CHEMBL230156 & 688282 & 5.4 & 5.3065 & TST \\
\hline CHEMBL1567435 & 688282 & 6.5 & 5.1585 & TRN \\
\hline CHEMBL1386323 & 688282 & 5.4 & 5.0893 & TRN \\
\hline CHEMBL1302381 & 688282 & 5.2 & 5.1264 & TRN \\
\hline CHEMBL1531441 & 688282 & 4.6 & 5.2383 & TRN \\
\hline CHEMBL1598060 & 688282 & 4.5 & 5.1581 & TRN \\
\hline CHEMBL1563201 & 688282 & 5.0 & 4.9929 & TRN \\
\hline CHEMBL1505849 & 688282 & 4.7 & 5.2131 & TRN \\
\hline CHEMBL1407599 & 688282 & 4.6 & 5.2018 & TRN \\
\hline CHEMBL1583919 & 688282 & 4.5 & 5.0665 & TRN \\
\hline CHEMBL1564374 & 688282 & 5.5 & 4.9943 & TRN \\
\hline CHEMBL1512693 & 688282 & 5.0 & 5.186 & TRN \\
\hline CHEMBL1603518 & 688282 & 6.0 & 5.2034 & TRN \\
\hline CHEMBL1451329 & 688282 & 4.9 & 5.0979 & TRN \\
\hline CHEMBL1540513 & 688282 & 4.9 & 4.9839 & TRN \\
\hline CHEMBL1313839 & 688282 & 5.2 & 5.1607 & TRN \\
\hline CHEMBL1528643 & 688282 & 4.7 & 5.1 & TRN \\
\hline CHEMBL 22870 & 688282 & 4.9 & 5.1022 & TRN \\
\hline
\end{tabular}




\begin{tabular}{|c|c|c|c|c|}
\hline \multicolumn{5}{|c|}{ lemental T } \\
\hline CHEMBL1602568 & 688282 & 5.0 & 5.0212 & TRN \\
\hline CHEMBL1556594 & 688282 & 4.5 & 5.0239 & TRN \\
\hline CHEMBL1328935 & 688282 & 4.6 & 5.0917 & TRN \\
\hline CHEMBL1448978 & 688282 & 4.6 & 5.0481 & TRN \\
\hline CHEMBL1386749 & 688282 & 4.6 & 5.2198 & TRN \\
\hline CHEMBL3195638 & 688282 & 4.6 & 5.096 & TST \\
\hline CHEMBL1523028 & 688282 & 5.4 & 5.1004 & TRN \\
\hline CHEMBL1591556 & 688282 & 6.0 & 5.26 & TST \\
\hline CHEMBL1613347 & 688282 & 5.0 & 4.9991 & TRN \\
\hline CHEMBL1473191 & 688282 & 5.3 & 5.2686 & TST \\
\hline CHEMBL1559411 & 688282 & 4.6 & 5.0615 & TRN \\
\hline CHEMBL1426578 & 688282 & 5.0 & 5.1551 & TRN \\
\hline CHEMBL1558303 & 688282 & 4.5 & 5.269 & TRN \\
\hline CHEMBL1400667 & 688282 & 4.5 & 5.2391 & TST \\
\hline CHEMBL1431783 & 688282 & 5.0 & 5.0042 & TRN \\
\hline CHEMBL1551841 & 688282 & 4.6 & 4.9546 & TRN \\
\hline CHEMBL1500158 & 688282 & 5.0 & 5.0172 & TRN \\
\hline CHEMBL1582435 & 688282 & 5.0 & 5.1052 & TRN \\
\hline CHEMBL1416046 & 688282 & 4.9 & 5.0833 & TRN \\
\hline CHEMBL340807 & 688282 & 4.6 & 5.1027 & TST \\
\hline CHEMBL1474475 & 688282 & 5.6 & 5.1132 & TRN \\
\hline CHEMBL1335967 & 688282 & 4.9 & 5.1037 & TRN \\
\hline CHEMBL1371792 & 688282 & 6.8 & 5.23 & TRN \\
\hline CHEMBL1397088 & 688282 & 6.0 & 5.1212 & TRN \\
\hline CHEMBL1389445 & 688282 & 5.6 & 5.1137 & TRN \\
\hline CHEMBL1476871 & 688282 & 5.1 & 5.2009 & TRN \\
\hline CHEMBL1471980 & 688282 & 5.2 & 5.215 & TRN \\
\hline CHEMBL1389029 & 688282 & 6.2 & 5.2208 & TRN \\
\hline CHEMBL1434308 & 688282 & 4.9 & 5.0654 & TRN \\
\hline CHEMBL1551444 & 688282 & 5.3 & 5.1547 & TRN \\
\hline CHEMBL1590270 & 688282 & 5.0 & 5.1908 & TRN \\
\hline CHEMBL1350257 & 688282 & 4.9 & 5.1613 & TRN \\
\hline CHEMBL1578179 & 688282 & 5.3 & 5.0719 & TRN \\
\hline CHEMBL1544991 & 688282 & 5.3 & 5.2114 & TRN \\
\hline CHEMBL1575689 & 688282 & 5.0 & 5.1728 & TST \\
\hline CHEMBL1429687 & 688282 & 5.2 & 4.9863 & TRN \\
\hline CHEMBL1494182 & 688282 & 4.9 & 5.3206 & TST \\
\hline CHEMBL1333221 & 688282 & 5.3 & 5.1746 & TRN \\
\hline CHEMBL3210451 & 688282 & 4.9 & 5.0612 & TRN \\
\hline CHEMBL1398507 & 688282 & 6.5 & 5.1437 & TRN \\
\hline CHEMBL1504352 & 688282 & 4.8 & 5.1656 & TRN \\
\hline CHEMBL1302244 & 688282 & 5.3 & 5.1243 & TRN \\
\hline CHEMBL1448633 & 688282 & 4.9 & 5.2607 & TRN \\
\hline CHEMBL1563391 & 688282 & 5.0 & 5.1962 & TRN \\
\hline CHEMBL1316055 & 688282 & 5.5 & 5.07 & TRN \\
\hline CHEMBL1378744 & 688282 & 5.4 & 5.0218 & TRN \\
\hline CHEMBL1540968 & 688282 & 5.0 & 5.1037 & TRN \\
\hline CHEMBL1483373 & 688282 & 6.1 & 5.2157 & TRN \\
\hline
\end{tabular}




\begin{tabular}{|c|c|c|c|c|c|}
\hline & & & & & \\
\hline CHEMBL88147 & 688282 & 4.5 & 5.029 & TRN & \\
\hline CHEMBL1441843 & 688282 & 4.9 & 5.1959 & TRN & \\
\hline CHEMBL1578659 & 688282 & 5.3 & 5.0991 & TRN & \\
\hline CHEMBL1516054 & 688282 & 4.9 & 4.9758 & TRN & \\
\hline CHEMBL1329661 & 688282 & 5.3 & 4.9805 & TRN & \\
\hline CHEMBL1597177 & 688282 & 4.6 & 5.1889 & TST & \\
\hline CHEMBL1330907 & 688282 & 5.0 & 5.1626 & TRN & \\
\hline CHEMBL1477529 & 688282 & 5.0 & $5.1610 e$ & 00000000005 & TRN \\
\hline CHEMBL1589528 & 688282 & 5.1 & 5.1204 & TRN & \\
\hline CHEMBL1476851 & 688282 & 6.1 & 4.977 & TRN & \\
\hline CHEMBL1563501 & 688282 & 5.0 & 5.0738 & TRN & \\
\hline CHEMBL1591772 & 688282 & 4.6 & 5.0675 & TRN & \\
\hline CHEMBL1573532 & 688282 & 5.4 & 5.1264 & TRN & \\
\hline CHEMBL1375226 & 688282 & 5.0 & 5.1394 & TRN & \\
\hline CHEMBL1361905 & 688282 & 5.3 & 5.2623 & TRN & \\
\hline CHEMBL1574510 & 688282 & 4.5 & 5.1941 & TRN & \\
\hline CHEMBL1552540 & 688282 & 5.9 & 5.1426 & TRN & \\
\hline CHEMBL25230 & 688282 & 4.8 & 5.1874 & TST & \\
\hline CHEMBL 374632 & 688282 & 5.8 & 5.1804 & TRN & \\
\hline CHEMBL1558169 & 688282 & 5.3 & 5.1555 & TRN & \\
\hline CHEMBL1529948 & 688282 & 5.0 & 4.9469 & TRN & \\
\hline CHEMBL1470784 & 688282 & 4.6 & 5.1416 & TST & \\
\hline CHEMBL1353809 & 688282 & 5.3 & 5.1963 & TRN & \\
\hline CHEMBL1552098 & 688282 & 5.8 & 5.1472 & TRN & \\
\hline CHEMBL1481078 & 688282 & 5.2 & 5.0402 & TRN & \\
\hline CHEMBL1318105 & 688282 & 6.0 & 5.3137 & TST & \\
\hline CHEMBL1494622 & 688282 & 5.3 & 5.1587 & TRN & \\
\hline CHEMBL1389776 & 688282 & 4.5 & 5.1013 & TRN & \\
\hline CHEMBL1581549 & 688282 & 4.5 & 5.2674 & TST & \\
\hline CHEMBL51085 & 688282 & 6.0 & 5.3124 & TRN & \\
\hline CHEMBL1316897 & 688282 & 5.5 & 5.1814 & TRN & \\
\hline CHEMBL1529349 & 688282 & 5.3 & 5.041 & TRN & \\
\hline CHEMBL1323765 & 688282 & 4.5 & 5.1045 & TRN & \\
\hline CHEMBL1324295 & 688282 & 4.6 & 5.2192 & TST & \\
\hline CHEMBL1393067 & 688282 & 4.6 & 5.3104 & TRN & \\
\hline CHEMBL1604983 & 688282 & 5.6 & 5.2835 & TST & \\
\hline CHEMBL1528712 & 688282 & 4.6 & 5.1251 & TRN & \\
\hline CHEMBL1415465 & 688282 & 5.0 & 5.0687 & TRN & \\
\hline CHEMBL1605594 & 688282 & 4.6 & 5.1363 & TRN & \\
\hline CHEMBL1533903 & 688282 & 4.6 & 5.1436 & TRN & \\
\hline CHEMBL375126 & 688282 & 4.7 & 5.1706 & TST & \\
\hline CHEMBL1546895 & 688282 & 4.9 & 4.9985 & TRN & \\
\hline CHEMBL1569543 & 688282 & 5.6 & 5.02 & TRN & \\
\hline CHEMBL1405546 & 688282 & 5.0 & 5.1505 & TRN & \\
\hline CHEMBL1420106 & 688282 & 4.7 & 5.1179 & TRN & \\
\hline CHEMBL1308001 & 688282 & 5.3 & 5.1448 & TRN & \\
\hline CHEMBL1437979 & 688282 & 4.6 & 4.9519 & TRN & \\
\hline CHEMBL1574196 & 688282 & 4.9 & 5.1234 & TRN & \\
\hline & & & & 13215 & \\
\hline
\end{tabular}




\begin{tabular}{|c|c|c|c|c|}
\hline & & & & al lable \\
\hline CHEMBL1471631 & 688282 & 5.3 & 5.1125 & TRN \\
\hline CHEMBL1400900 & 688282 & 4.9 & 5.0876 & TRN \\
\hline CHEMBL1432698 & 688282 & 5.0 & 5.0931 & TST \\
\hline CHEMBL1322145 & 688282 & 5.6 & 5.0611 & TRN \\
\hline CHEMBL1370229 & 688282 & 5.6 & 5.1942 & TRN \\
\hline CHEMBL1431118 & 688282 & 4.8 & 5.188 & TRN \\
\hline CHEMBL1481683 & 688282 & 5.3 & 5.0368 & TRN \\
\hline CHEMBL1555208 & 688282 & 5.0 & 5.1966 & TRN \\
\hline CHEMBL 3208768 & 688282 & 5.1 & 5.1227 & TRN \\
\hline CHEMBL1576880 & 688282 & 5.1 & 5.2765 & TST \\
\hline CHEMBL1580503 & 688282 & 4.9 & 5.2974 & TST \\
\hline CHEMBL1529944 & 688282 & 5.8 & 5.1899 & TST \\
\hline CHEMBL1445061 & 688282 & 5.3 & 5.2605 & TRN \\
\hline CHEMBL1300039 & 688282 & 5.4 & 5.1847 & TRN \\
\hline CHEMBL1511537 & 688282 & 4.9 & 5.1982 & TRN \\
\hline CHEMBL406557 & 688282 & 5.7 & 5.1334 & TRN \\
\hline CHEMBL1572237 & 688282 & 5.0 & 5.1052 & TRN \\
\hline CHEMBL1362398 & 688282 & 5.4 & 5.2191 & TRN \\
\hline CHEMBL1382808 & 688282 & 5.0 & 5.1467 & TRN \\
\hline CHEMBL1564346 & 688282 & 4.9 & 5.2421 & TRN \\
\hline CHEMBL1383647 & 688282 & 5.3 & 5.2223 & TRN \\
\hline CHEMBL508779 & 688282 & 4.7 & 5.2327 & TST \\
\hline CHEMBL1605476 & 688282 & 4.5 & 5.0573 & TRN \\
\hline CHEMBL1412478 & 688282 & 4.9 & 5.1305 & TRN \\
\hline CHEMBL1457915 & 688282 & 4.6 & 5.1773 & TST \\
\hline CHEMBL1525993 & 688282 & 6.1 & 5.2524 & TRN \\
\hline CHEMBL1591515 & 688282 & 5.3 & $5.1670 e$ & 0000000001 \\
\hline CHEMBL1412225 & 688282 & 6.0 & 5.2146 & TRN \\
\hline CHEMBL1440650 & 688282 & 5.2 & 5.0922 & TRN \\
\hline CHEMBL1406449 & 688282 & 5.4 & 5.0894 & TRN \\
\hline CHEMBL1436507 & 688282 & 5.0 & 5.0988 & TRN \\
\hline CHEMBL1419836 & 688282 & 5.3 & 5.16 & TRN \\
\hline CHEMBL1401850 & 688282 & 4.5 & 5.0664 & TRN \\
\hline CHEMBL1309310 & 688282 & 4.9 & 5.1024 & TRN \\
\hline CHEMBL1303754 & 688282 & 4.9 & 5.0284 & TRN \\
\hline CHEMBL1425302 & 688282 & 5.1 & 5.0529 & TRN \\
\hline CHEMBL1590360 & 688282 & 4.9 & 5.079 & TRN \\
\hline CHEMBL1407141 & 688282 & 4.7 & 5.2187 & TRN \\
\hline CHEMBL1560323 & 688282 & 4.9 & 5.1044 & TRN \\
\hline CHEMBL1344850 & 688282 & 4.9 & 5.1978 & TRN \\
\hline CHEMBL1463086 & 688282 & 5.0 & 5.1562 & TRN \\
\hline CHEMBL1612774 & 688282 & 4.8 & 5.015 & TRN \\
\hline CHEMBL1378199 & 688282 & 5.3 & 5.1309 & TRN \\
\hline CHEMBL1588802 & 688282 & 5.3 & 5.0175 & TRN \\
\hline CHEMBL9113 & 688282 & 6.0 & 5.2458 & TRN \\
\hline CHEMBL1546387 & 688282 & 4.5 & 5.1485 & TRN \\
\hline CHEMBL 1473755 & 688282 & 5.0 & 5.1555 & TRN \\
\hline CHEMBL1591357 & 688282 & 5.4 & 5.2775 & TST \\
\hline
\end{tabular}




\begin{tabular}{|c|c|c|c|c|c|}
\hline & & & & & \\
\hline CHEMBL1407739 & 688282 & 4.9 & 5.0394 & TRN & \\
\hline CHEMBL1577889 & 688282 & 5.3 & 5.2316 & TRN & \\
\hline CHEMBL1352955 & 688282 & 5.5 & 5.0329 & TRN & \\
\hline CHEMBL1453277 & 688282 & 5.3 & 5.1865 & TRN & \\
\hline CHEMBL1516705 & 688282 & 4.9 & 5.1369 & TRN & \\
\hline CHEMBL1594761 & 688282 & 5.0 & 5.341 & TRN & \\
\hline CHEMBL1610721 & 688282 & 5.3 & 5.2405 & TRN & \\
\hline CHEMBL1474989 & 688282 & 5.0 & 5.0731 & TRN & \\
\hline CHEMBL1319432 & 688282 & 6.2 & 5.231 & TRN & \\
\hline CHEMBL1376290 & 688282 & 4.9 & 5.1576 & TRN & \\
\hline CHEMBL1536754 & 688282 & 4.6 & 5.0394 & TRN & \\
\hline CHEMBL1442802 & 688282 & 4.8 & 4.9852 & TRN & \\
\hline CHEMBL1402270 & 688282 & 4.6 & 5.2215 & TRN & \\
\hline CHEMBL1501864 & 688282 & 4.9 & $5.2020 e$ & 0000000001 & TRN \\
\hline CHEMBL3208836 & 688282 & 6.5 & 5.1709 & TRN & \\
\hline CHEMBL1556512 & 688282 & 4.9 & 5.1184 & TRN & \\
\hline CHEMBL1540421 & 688282 & 4.6 & 5.2432 & TST & \\
\hline CHEMBL1515526 & 688282 & 5.0 & 5.1784 & TRN & \\
\hline CHEMBL1409547 & 688282 & 4.8 & 5.0562 & TRN & \\
\hline CHEMBL1349014 & 688282 & 5.2 & 5.17399 & 99999999995 & TRN \\
\hline CHEMBL1485728 & 688282 & 5.3 & 5.1096 & TRN & \\
\hline CHEMBL1441375 & 688282 & 5.2 & 5.1241 & TRN & \\
\hline CHEMBL1490886 & 688282 & 5.6 & 5.1963 & TST & \\
\hline CHEMBL1439479 & 688282 & 5.3 & 5.1884 & TRN & \\
\hline CHEMBL1602693 & 688282 & 4.9 & 5.1847 & TST & \\
\hline CHEMBL1612410 & 688282 & 5.9 & 5.0201 & TRN & \\
\hline CHEMBL567175 & 688282 & 4.8 & 5.2088 & TST & \\
\hline CHEMBL1608078 & 688282 & 5.0 & 5.1498 & TRN & \\
\hline CHEMBL1539998 & 688282 & 5.6 & 5.0556 & TRN & \\
\hline CHEMBL1453299 & 688282 & 4.9 & 5.0878 & TRN & \\
\hline CHEMBL1470976 & 688282 & 4.7 & 5.218 & TRN & \\
\hline CHEMBL1411381 & 688282 & 5.3 & 5.1032 & TRN & \\
\hline CHEMBL1508221 & 688282 & 5.3 & 5.0922 & TRN & \\
\hline CHEMBL1474056 & 688282 & 4.9 & 5.038 & TRN & \\
\hline CHEMBL1403121 & 688282 & 4.6 & 4.9727 & TRN & \\
\hline CHEMBL1402381 & 688282 & 5.5 & 5.3362 & TRN & \\
\hline CHEMBL1314324 & 688282 & 5.3 & 5.2708 & TRN & \\
\hline CHEMBL1463132 & 688282 & 5.1 & 5.099 & TRN & \\
\hline CHEMBL1610978 & 688282 & 5.3 & 5.1005 & TRN & \\
\hline CHEMBL1331734 & 688282 & 4.6 & 5.1554 & TRN & \\
\hline CHEMBL90472 & 688282 & 4.9 & 5.197 & TST & \\
\hline CHEMBL1610082 & 688282 & 5.2 & 5.0653 & TRN & \\
\hline CHEMBL1505804 & 688282 & 4.7 & 5.1514 & TRN & \\
\hline CHEMBL1583096 & 688282 & 4.5 & 5.1021 & TRN & \\
\hline CHEMBL1572870 & 688282 & 5.3 & 5.1216 & TRN & \\
\hline CHEMBL1457908 & 688282 & 4.9 & 4.9436 & TRN & \\
\hline CHEMBL1481867 & 688282 & 5.0 & 5.1528 & TRN & \\
\hline CHEMBL1307783 & 688282 & 4.6 & 5.2895 & TRN & \\
\hline & & & & 13217 & \\
\hline
\end{tabular}




\begin{tabular}{|c|c|c|c|c|c|}
\hline & & & & & \\
\hline CHEMBL1568252 & 688282 & 5.0 & 5.0416 & TRN & \\
\hline CHEMBL1430058 & 688282 & 5.6 & 5.0334 & TRN & \\
\hline CHEMBL1372392 & 688282 & 4.6 & 5.044 & TST & \\
\hline CHEMBL1550366 & 688282 & 5.0 & 5.2446 & TRN & \\
\hline CHEMBL1492648 & 688282 & 4.5 & 5.16 & TRN & \\
\hline CHEMBL388676 & 688282 & 6.0 & 5.3073 & TST & \\
\hline CHEMBL1417970 & 688282 & 4.9 & 5.0331 & TRN & \\
\hline CHEMBL1554308 & 688282 & 5.2 & $4.9510 e$ & 00000000005 & TRN \\
\hline CHEMBL1513876 & 688282 & 6.1 & 5.2688 & TRN & \\
\hline CHEMBL1538493 & 688282 & 4.9 & 5.0022 & TRN & \\
\hline CHEMBL1508172 & 688282 & 5.3 & 5.1634 & TST & \\
\hline CHEMBL1480779 & 688282 & 5.9 & 5.3058 & TRN & \\
\hline CHEMBL1482950 & 688282 & 5.1 & 5.1014 & TRN & \\
\hline CHEMBL1449048 & 688282 & 4.9 & 5.2429 & TRN & \\
\hline CHEMBL1600292 & 688282 & 5.3 & 5.1941 & TRN & \\
\hline CHEMBL181633 & 688282 & 4.5 & 5.06 & TRN & \\
\hline CHEMBL1527530 & 688282 & 4.8 & 5.0063 & TRN & \\
\hline CHEMBL1491324 & 688282 & 5.0 & 5.0287 & TRN & \\
\hline CHEMBL1328000 & 688282 & 4.8 & 5.1453 & TRN & \\
\hline CHEMBL1591592 & 688282 & 5.8 & 5.1081 & TRN & \\
\hline CHEMBL1515310 & 688282 & 4.6 & 5.2064 & TST & \\
\hline CHEMBL1453784 & 688282 & 5.3 & 5.0684 & TRN & \\
\hline CHEMBL1336036 & 688282 & 4.6 & 5.1345 & TRN & \\
\hline CHEMBL1566701 & 688282 & 4.9 & 5.17899 & 9999999999 & TRN \\
\hline CHEMBL1446372 & 688282 & 4.9 & 5.2319 & TRN & \\
\hline CHEMBL1422256 & 688282 & 4.5 & 5.1293 & TRN & \\
\hline CHEMBL1510584 & 688282 & 4.9 & 5.1339 & TRN & \\
\hline CHEMBL1305990 & 688282 & 4.6 & 5.1445 & TRN & \\
\hline CHEMBL1300763 & 688282 & 5.3 & 5.1006 & TRN & \\
\hline CHEMBL1345124 & 688282 & 5.0 & 5.1219 & TRN & \\
\hline CHEMBL1608522 & 688282 & 5.1 & 5.1648 & TRN & \\
\hline CHEMBL1604035 & 688282 & 4.6 & 5.1104 & TRN & \\
\hline CHEMBL1434655 & 688282 & 4.6 & 5.1089 & TRN & \\
\hline CHEMBL574181 & 688282 & 4.9 & 5.1339 & TRN & \\
\hline CHEMBL356911 & 688282 & 4.9 & 5.3552 & TST & \\
\hline CHEMBL1315207 & 688282 & 4.9 & 5.0599 & TST & \\
\hline CHEMBL 221300 & 688282 & 5.7 & 5.0736 & TST & \\
\hline CHEMBL1453323 & 688282 & 5.5 & 5.279 & TST & \\
\hline CHEMBL1610513 & 688282 & 4.6 & 4.9276 & TRN & \\
\hline CHEMBL1484743 & 688282 & 5.6 & 5.1319 & TRN & \\
\hline CHEMBL1540689 & 688282 & 4.6 & 5.0934 & TRN & \\
\hline CHEMBL1409604 & 688282 & 5.0 & 5.0556 & TRN & \\
\hline CHEMBL1525557 & 688282 & 5.9 & 5.1811 & TRN & \\
\hline CHEMBL1440725 & 688282 & 6.9 & 5.2038 & TRN & \\
\hline CHEMBL1457363 & 688282 & 5.3 & 5.1377 & TRN & \\
\hline CHEMBL1549075 & 688282 & 4.9 & 5.0767 & TRN & \\
\hline CHEMBL1626274 & 688282 & 4.9 & 5.2205 & TST & \\
\hline CHEMBL1595345 & 688282 & 4.8 & 5.2303 & TST & \\
\hline & & & & 13218 & \\
\hline
\end{tabular}




\begin{tabular}{|c|c|c|c|c|c|}
\hline & & & & & \\
\hline CHEMBL1511385 & 688282 & 5.3 & 5.1115 & TRN & \\
\hline CHEMBL1400336 & 688282 & 4.6 & 5.1623 & TRN & \\
\hline CHEMBL1494874 & 688282 & 5.2 & 5.0432 & TRN & \\
\hline CHEMBL1479202 & 688282 & 5.8 & 5.0199 & TRN & \\
\hline CHEMBL123 & 688282 & 6.0 & 5.2925 & TRN & \\
\hline CHEMBL1429418 & 688282 & 5.3 & 5.1015 & TRN & \\
\hline CHEMBL1572590 & 688282 & 4.9 & 5.0517 & TRN & \\
\hline CHEMBL1404098 & 688282 & 5.0 & 5.0694 & TRN & \\
\hline CHEMBL429711 & 688282 & 4.9 & 5.1715 & TRN & \\
\hline CHEMBL1347516 & 688282 & 6.8 & 5.2713 & TST & \\
\hline CHEMBL1475902 & 688282 & 6.0 & 5.1659 & TRN & \\
\hline CHEMBL1525929 & 688282 & 4.9 & 5.1461 & TRN & \\
\hline CHEMBL1257234 & 688282 & 5.3 & 5.0768 & TRN & \\
\hline CHEMBL1510345 & 688282 & 5.3 & 5.048 & TRN & \\
\hline CHEMBL606675 & 688282 & 4.8 & 5.20100 & 00000000005 & TST \\
\hline CHEMBL1405771 & 688282 & 4.5 & 5.153 & TST & \\
\hline CHEMBL1317314 & 688282 & 4.9 & 5.0492 & TRN & \\
\hline CHEMBL1508452 & 688282 & 4.6 & 5.2439 & TRN & \\
\hline CHEMBL1606436 & 688282 & 5.0 & 5.0214 & TRN & \\
\hline CHEMBL1413521 & 688282 & 5.0 & 5.092 & TRN & \\
\hline CHEMBL1509092 & 688282 & 5.3 & 5.1374 & TRN & \\
\hline CHEMBL1489875 & 688282 & 5.0 & 5.1361 & TRN & \\
\hline CHEMBL1602372 & 688282 & 4.9 & 5.0513 & TRN & \\
\hline CHEMBL1490953 & 688282 & 4.5 & 5.13899 & 9999999999 & TRN \\
\hline CHEMBL1368261 & 688282 & 4.7 & 5.1097 & TST & \\
\hline CHEMBL429023 & 688282 & 6.0 & 5.1285 & TST & \\
\hline CHEMBL1508699 & 688282 & 5.1 & 5.0655 & TRN & \\
\hline CHEMBL1395862 & 688282 & 7.1002 & 5.2803 & TRN & \\
\hline CHEMBL1434286 & 688282 & 5.5 & 5.1512 & TRN & \\
\hline CHEMBL440084 & 688282 & 4.8 & 5.157 & TRN & \\
\hline CHEMBL1464420 & 688282 & 4.7 & 5.1725 & TRN & \\
\hline CHEMBL1475146 & 688282 & 4.9 & 5.0616 & TRN & \\
\hline CHEMBL1455977 & 688282 & 5.6 & 5.2798 & TRN & \\
\hline CHEMBL1509614 & 688282 & 5.3 & 5.2598 & TST & \\
\hline CHEMBL1532225 & 688282 & 5.0 & 5.0912 & TRN & \\
\hline CHEMBL29197 & 688282 & 5.2 & 4.9959 & TRN & \\
\hline CHEMBL1359157 & 688282 & 4.5 & 5.1666 & TRN & \\
\hline CHEMBL1526789 & 688282 & 4.8 & 5.1219 & TRN & \\
\hline CHEMBL1564253 & 688282 & 5.3 & 5.1924 & TRN & \\
\hline CHEMBL1550860 & 688282 & 4.6 & 5.0166 & TRN & \\
\hline CHEMBL1313647 & 688282 & 5.3 & 5.1912 & TRN & \\
\hline CHEMBL1377955 & 688282 & 4.6 & 5.07 & TRN & \\
\hline CHEMBL1255936 & 688282 & 4.6 & 5.2141 & TRN & \\
\hline CHEMBL1522253 & 688282 & 4.8 & 5.1118 & TRN & \\
\hline CHEMBL1336178 & 688282 & 4.5 & 5.2416 & TRN & \\
\hline CHEMBL1470412 & 688282 & 5.0 & 5.0714 & TRN & \\
\hline CHEMBL 3187257 & 688282 & 5.1 & 5.0826 & TRN & \\
\hline CHEMBL1590663 & 688282 & 4.5 & 5.2811 & TRN & \\
\hline & & & & 13219 & \\
\hline
\end{tabular}




\begin{tabular}{|c|c|c|c|c|c|}
\hline & & & & & \\
\hline CHEMBL1494650 & 688282 & 5.0 & 5.046 & TRN & \\
\hline CHEMBL1400580 & 688282 & 4.6 & 5.035 & TRN & \\
\hline CHEMBL1365455 & 688282 & 4.8 & 5.1974 & TRN & \\
\hline CHEMBL1414259 & 688282 & 6.1 & 5.13299 & 9999999999 & TRN \\
\hline CHEMBL1344838 & 688282 & 5.4 & 5.0533 & TRN & \\
\hline CHEMBL1606470 & 688282 & 4.6 & 5.0059 & TRN & \\
\hline CHEMBL1451120 & 688282 & 5.3 & 5.0011 & TRN & \\
\hline CHEMBL1546102 & 688282 & 5.0 & 5.0442 & TRN & \\
\hline CHEMBL1354375 & 688282 & 6.5 & 5.2588 & TST & \\
\hline CHEMBL1445786 & 688282 & 4.9 & 5.0604 & TRN & \\
\hline CHEMBL 2449003 & 688282 & 4.9 & 5.2254 & TRN & \\
\hline CHEMBL1419887 & 688282 & 4.6 & 5.1453 & TRN & \\
\hline CHEMBL1462213 & 688282 & 4.9 & 5.0681 & TRN & \\
\hline CHEMBL1494697 & 688282 & 6.1 & 5.1373 & TRN & \\
\hline CHEMBL1379838 & 688282 & 4.8 & 5.0526 & TRN & \\
\hline CHEMBL1420108 & 688282 & 4.9 & 5.1649 & TRN & \\
\hline CHEMBL1482582 & 688282 & 4.7 & 5.0493 & TRN & \\
\hline CHEMBL1570134 & 688282 & 4.9 & 5.2035 & TRN & \\
\hline CHEMBL1453502 & 688282 & 5.2 & 5.1327 & TRN & \\
\hline CHEMBL1434954 & 688282 & 6.0 & 5.1695 & TST & \\
\hline CHEMBL1557829 & 688282 & 5.3 & 5.1325 & TRN & \\
\hline CHEMBL1299340 & 688282 & 4.6 & 5.0582 & TRN & \\
\hline CHEMBL1476729 & 688282 & 4.9 & 5.2245 & TRN & \\
\hline CHEMBL1489060 & 688282 & 4.5 & 5.2827 & TRN & \\
\hline CHEMBL1346885 & 688282 & 5.0 & 5.0397 & TRN & \\
\hline CHEMBL1299357 & 688282 & 4.8 & 5.1541 & TRN & \\
\hline CHEMBL1392136 & 688282 & 5.0 & 5.1995 & TRN & \\
\hline CHEMBL1447498 & 688282 & 5.3 & 5.0015 & TRN & \\
\hline CHEMBL1414757 & 688282 & 5.3 & 5.1482 & TRN & \\
\hline CHEMBL1315690 & 688282 & 4.8 & 5.1379 & TRN & \\
\hline CHEMBL1608618 & 688282 & 4.9 & 5.1309 & TRN & \\
\hline CHEMBL1468870 & 688282 & 5.6 & 5.0321 & TRN & \\
\hline CHEMBL137803 & 688282 & 4.9 & 5.3012 & TST & \\
\hline CHEMBL1356085 & 688282 & 5.0 & 5.1417 & TRN & \\
\hline CHEMBL1568641 & 688282 & 5.0 & 5.0524 & TRN & \\
\hline CHEMBL1556063 & 688282 & 4.6 & 5.0207 & TRN & \\
\hline CHEMBL1310871 & 688282 & 6.7001 & 5.2419 & TRN & \\
\hline CHEMBL1585192 & 688282 & 4.9 & 5.2481 & TST & \\
\hline CHEMBL1416218 & 688282 & 5.0 & 5.2128 & TST & \\
\hline CHEMBL1318616 & 688282 & 4.9 & 5.1327 & TRN & \\
\hline CHEMBL1548533 & 688282 & 4.5 & 5.20299 & 9999999999 & TRN \\
\hline CHEMBL1597195 & 688282 & 4.8 & 5.0847 & TRN & \\
\hline CHEMBL1541466 & 688282 & 5.3 & 5.1362 & TRN & \\
\hline CHEMBL1547051 & 688282 & 5.6 & 5.1914 & TRN & \\
\hline CHEMBL195953 & 688282 & 5.8 & 5.2704 & TST & \\
\hline CHEMBL1492354 & 688282 & 5.3 & 5.1751 & TRN & \\
\hline CHEMBL 245121 & 688282 & 4.9 & 5.1397 & TRN & \\
\hline CHEMBL1425333 & 688282 & 6.3 & 5.0021 & TRN & \\
\hline
\end{tabular}




\begin{tabular}{|c|c|c|c|c|c|}
\hline \\
\hline CHEMBL1522024 & 688282 & 4.6 & 5.1537 & TRN & \\
\hline CHEMBL1523939 & 688282 & 5.0 & 5.022 & TRN & \\
\hline CHEMBL1404301 & 688282 & 4.6 & 5.1143 & TRN & \\
\hline CHEMBL1531476 & 688282 & 4.6 & 5.1674 & TRN & \\
\hline CHEMBL1304363 & 688282 & 5.2 & 5.11 & TRN & \\
\hline CHEMBL1587371 & 688282 & 4.6 & 5.1616 & TRN & \\
\hline CHEMBL1526223 & 688282 & 4.8 & 5.1443 & TRN & \\
\hline CHEMBL1528094 & 688282 & 4.9 & 5.0866 & TRN & \\
\hline CHEMBL1373323 & 688282 & 6.2 & 5.0031 & TRN & \\
\hline CHEMBL1390708 & 688282 & 4.9 & 5.1711 & TRN & \\
\hline CHEMBL1426396 & 688282 & 5.3 & 5.1212 & TRN & \\
\hline CHEMBL1543167 & 688282 & 5.0 & 5.0773 & TRN & \\
\hline CHEMBL595227 & 688282 & 7.6003 & 5.2594 & TST & \\
\hline CHEMBL1382503 & 688282 & 6.0 & 5.2465 & TRN & \\
\hline CHEMBL1595142 & 688282 & 5.0 & 5.1106 & TRN & \\
\hline CHEMBL1402641 & 688282 & 4.8 & 5.1443 & TRN & \\
\hline CHEMBL1344797 & 688282 & 4.8 & 5.1161 & TRN & \\
\hline CHEMBL1336044 & 688282 & 4.9 & 5.2354 & TST & \\
\hline CHEMBL1487215 & 688282 & 4.6 & 5.1586 & TRN & \\
\hline CHEMBL1316158 & 688282 & 5.0 & 5.2227 & TRN & \\
\hline CHEMBL1519225 & 688282 & 4.9 & 5.2926 & TRN & \\
\hline CHEMBL1568173 & 688282 & 4.8 & 5.0477 & TRN & \\
\hline CHEMBL1592452 & 688282 & 4.9 & 5.1011 & TRN & \\
\hline CHEMBL1526207 & 688282 & 5.3 & 5.1055 & TRN & \\
\hline CHEMBL1399358 & 688282 & 4.9 & 5.0988 & TRN & \\
\hline CHEMBL1580759 & 688282 & 4.8 & 5.1559 & TST & \\
\hline CHEMBL3197516 & 688282 & 6.7001 & 5.136 & TRN & \\
\hline CHEMBL1529807 & 688282 & 5.6 & $5.0760 e$ & 00000000005 & TRN \\
\hline CHEMBL1383050 & 688282 & 5.0 & 5.0908 & TRN & \\
\hline CHEMBL1327720 & 688282 & 5.0 & 5.0586 & TRN & \\
\hline CHEMBL1599847 & 688282 & 5.3 & 5.244 & TRN & \\
\hline CHEMBL1378485 & 688282 & 5.0 & 5.114 & TRN & \\
\hline CHEMBL1324563 & 688282 & 4.9 & 5.0759 & TRN & \\
\hline CHEMBL1408730 & 688282 & 4.9 & 5.2002 & TRN & \\
\hline CHEMBL1316408 & 688282 & 4.5 & 4.9333 & TRN & \\
\hline CHEMBL1473379 & 688282 & 5.4 & 4.9978 & TRN & \\
\hline CHEMBL1529388 & 688282 & 4.5 & 5.1465 & TRN & \\
\hline CHEMBL1312136 & 688282 & 4.6 & 5.1096 & TRN & \\
\hline CHEMBL1555118 & 688282 & 4.8 & 5.2231 & TRN & \\
\hline CHEMBL1400266 & 688282 & 4.9 & 5.1463 & TRN & \\
\hline CHEMBL1482816 & 688282 & 5.2 & 5.0595 & TRN & \\
\hline CHEMBL1554982 & 688282 & 4.7 & 5.0893 & TRN & \\
\hline CHEMBL1303866 & 688282 & 5.1 & 5.1432 & TRN & \\
\hline CHEMBL1563807 & 688282 & 4.9 & 5.1853 & TRN & \\
\hline CHEMBL1304593 & 688282 & 4.6 & 5.1583 & TRN & \\
\hline CHEMBL1420361 & 688282 & 5.4 & 5.1199 & TRN & \\
\hline CHEMBL1397782 & 688282 & 5.8 & 5.1321 & TST & \\
\hline CHEMBL1564690 & 688282 & 4.6 & 5.1407 & TST & \\
\hline
\end{tabular}




\begin{tabular}{|c|c|c|c|c|c|}
\hline \multicolumn{6}{|c|}{ Supplemental Table S2.txt } \\
\hline CHEMBL1365696 & 688282 & 4.5 & 5.0684 & TRN & \\
\hline CHEMBL1559410 & 688282 & 4.5 & 5.1441 & TRN & \\
\hline CHEMBL1571377 & 688282 & 4.6 & 5.2205 & TRN & \\
\hline CHEMBL1610476 & 688282 & 5.3 & 5.2004 & TRN & \\
\hline CHEMBL1350515 & 688282 & 4.5 & 5.005 & TRN & \\
\hline CHEMBL1593337 & 688282 & 4.9 & 5.1989 & TRN & \\
\hline CHEMBL1373974 & 688282 & 5.1 & 5.1587 & TRN & \\
\hline CHEMBL1416193 & 688282 & 5.3 & 5.1979 & TRN & \\
\hline CHEMBL3189194 & 688282 & 5.3 & 5.1334 & TRN & \\
\hline CHEMBL1319623 & 688282 & 4.8 & 5.0256 & TRN & \\
\hline CHEMBL1327167 & 688282 & 4.6 & 5.1106 & TRN & \\
\hline CHEMBL1387667 & 688282 & 4.6 & 5.0212 & TRN & \\
\hline CHEMBL1573328 & 688282 & 4.9 & 5.0826 & TRN & \\
\hline CHEMBL513116 & 688282 & 4.6 & 5.1336 & TRN & \\
\hline CHEMBL1401668 & 688282 & 4.9 & 5.0674 & TRN & \\
\hline CHEMBL1338358 & 688282 & 4.9 & 5.1518 & TRN & \\
\hline CHEMBL1397724 & 688282 & 5.0 & 5.104 & TRN & \\
\hline CHEMBL1341362 & 688282 & 4.7 & 5.2386 & TRN & \\
\hline CHEMBL1440883 & 688282 & 5.8 & 5.1316 & TRN & \\
\hline CHEMBL1542053 & 688282 & 4.6 & 5.1452 & TRN & \\
\hline CHEMBL1482554 & 688282 & 5.0 & 5.1494 & TRN & \\
\hline CHEMBL1370790 & 688282 & 5.2 & 5.1952 & TRN & \\
\hline CHEMBL1553930 & 688282 & 5.3 & 5.2629 & TRN & \\
\hline CHEMBL1569226 & 688282 & 5.3 & 5.2009 & TRN & \\
\hline CHEMBL1344681 & 688282 & 5.0 & 5.1419 & TRN & \\
\hline CHEMBL1394118 & 688282 & 6.0 & 5.0328 & TRN & \\
\hline CHEMBL1396989 & 688282 & 5.4 & 5.1049 & TRN & \\
\hline CHEMBL1589728 & 688282 & 4.6 & 5.1887 & TST & \\
\hline CHEMBL1337075 & 688282 & 5.0 & 4.94 & TRN & \\
\hline CHEMBL1394596 & 688282 & 4.6 & 5.2737 & TRN & \\
\hline CHEMBL1422542 & 688282 & 5.5 & 5.1363 & TRN & \\
\hline CHEMBL1603776 & 688282 & 4.9 & 5.1505 & TST & \\
\hline CHEMBL1569493 & 688282 & 5.1 & 5.3128 & TRN & \\
\hline CHEMBL573214 & 688282 & 8.1024 & 5.2333 & TST & \\
\hline CHEMBL1526559 & 688282 & 4.5 & 5.1181 & TRN & \\
\hline CHEMBL1551068 & 688282 & 4.6 & 5.1067 & TRN & \\
\hline CHEMBL1487164 & 688282 & 7.1002 & 5.2281 & TST & \\
\hline CHEMBL1307346 & 688282 & 6.0 & 5.0855 & TST & \\
\hline CHEMBL1490139 & 688282 & 4.9 & 5.1849 & TRN & \\
\hline CHEMBL1569400 & 688282 & 5.0 & 5.2343 & TRN & \\
\hline CHEMBL1427003 & 688282 & 5.3 & 5.2665 & TRN & \\
\hline CHEMBL567337 & 688282 & 5.0 & 5.1013 & TRN & \\
\hline CHEMBL1410698 & 688282 & 4.9 & 5.1395 & TRN & \\
\hline CHEMBL1302139 & 688282 & 4.7 & 5.0919 & TRN & \\
\hline CHEMBL1469134 & 688282 & 4.6 & 5.20299 & 9999999999 & TRN \\
\hline CHEMBL1520849 & 688282 & 4.5 & 5.1353 & TRN & \\
\hline CHEMBL268609 & 688282 & 5.6 & 5.1197 & TRN & \\
\hline CHEMBL1311916 & 688282 & 4.6 & 5.0438 & TRN & \\
\hline
\end{tabular}




\begin{tabular}{|c|c|c|c|c|c|}
\hline \multicolumn{6}{|c|}{ oplemental Iable s2.txt } \\
\hline CHEMBL1470840 & 688282 & 5.7 & 5.1472 & TRN & \\
\hline CHEMBL1300359 & 688282 & 4.6 & 4.9782 & TRN & \\
\hline CHEMBL1608678 & 688282 & 5.4 & 5.13700 & 00000000005 & TRN \\
\hline CHEMBL109095 & 688282 & 4.6 & 5.2286 & TRN & \\
\hline CHEMBL1592556 & 688282 & 5.7 & 5.0951 & TRN & \\
\hline CHEMBL1503027 & 688282 & 5.3 & 5.0629 & TRN & \\
\hline CHEMBL3184468 & 688282 & 5.1 & 5.2584 & TST & \\
\hline CHEMBL1317039 & 688282 & 4.5 & 5.142 & TRN & \\
\hline CHEMBL1475805 & 688282 & 5.1 & 5.1126 & TRN & \\
\hline CHEMBL1448979 & 688282 & 5.0 & 5.2394 & TST & \\
\hline CHEMBL1597827 & 688282 & 4.6 & 5.2157 & TRN & \\
\hline CHEMBL1482489 & 688282 & 4.5 & 5.0684 & TRN & \\
\hline CHEMBL1348395 & 688282 & 4.7 & 5.0117 & TRN & \\
\hline CHEMBL1431209 & 688282 & 4.6 & 5.171 & TRN & \\
\hline CHEMBL1404846 & 688282 & 5.0 & 5.0692 & TRN & \\
\hline CHEMBL1547699 & 688282 & 4.6 & 5.0378 & TRN & \\
\hline CHEMBL1415572 & 688282 & 7.6003 & 5.1722 & TRN & \\
\hline CHEMBL1586817 & 688282 & 5.4 & 5.0609 & TRN & \\
\hline CHEMBL1337529 & 688282 & 5.0 & 5.1887 & TRN & \\
\hline CHEMBL1527567 & 688282 & 4.5 & 5.1939 & TRN & \\
\hline CHEMBL1422320 & 688282 & 4.7 & 5.0633 & TRN & \\
\hline CHEMBL1514153 & 688282 & 5.5 & 5.0875 & TRN & \\
\hline CHEMBL1489769 & 688282 & 6.5 & 5.1577 & TST & \\
\hline CHEMBL1548168 & 688282 & 5.0 & 5.093 & TST & \\
\hline CHEMBL1593374 & 688282 & 4.8 & 5.0038 & TRN & \\
\hline CHEMBL1364458 & 688282 & 5.0 & 5.1659 & TRN & \\
\hline CHEMBL1484458 & 688282 & 4.8 & 5.0865 & TRN & \\
\hline CHEMBL1316056 & 688282 & 5.0 & 4.9846 & TRN & \\
\hline CHEMBL1567101 & 688282 & 6.2 & 5.2651 & TRN & \\
\hline CHEMBL454173 & 688282 & 4.8 & 5.2418 & TST & \\
\hline CHEMBL1313323 & 688282 & 4.8 & 5.0409 & TRN & \\
\hline CHEMBL 2373651 & 688282 & 4.6 & 5.3053 & TST & \\
\hline CHEMBL1340900 & 688282 & 5.7 & 5.1975 & TRN & \\
\hline CHEMBL1566158 & 688282 & 4.9 & 5.1255 & TRN & \\
\hline CHEMBL14377 & 688282 & 5.5 & 5.2373 & TRN & \\
\hline CHEMBL1371554 & 688282 & 5.6 & 5.1784 & TRN & \\
\hline CHEMBL1567656 & 688282 & 4.6 & 5.3101 & TST & \\
\hline CHEMBL1475589 & 688282 & 5.8 & 5.0842 & TRN & \\
\hline CHEMBL1579787 & 688282 & 6.7001 & 5.1705 & TRN & \\
\hline CHEMBL1461491 & 688282 & 6.0 & 5.2962 & TST & \\
\hline CHEMBL1341879 & 688282 & 5.0 & 5.1084 & TST & \\
\hline CHEMBL1603879 & 688282 & 4.9 & 5.1651 & TRN & \\
\hline CHEMBL1571186 & 688282 & 4.6 & 5.072 & TRN & \\
\hline CHEMBL1445223 & 688282 & 5.3 & 5.112 & TRN & \\
\hline CHEMBL1392276 & 688282 & 5.5 & 5.1598 & TRN & \\
\hline CHEMBL1187592 & 688282 & 4.9 & 5.1931 & TRN & \\
\hline CHEMBL1425987 & 688282 & 5.0 & 5.0618 & TRN & \\
\hline CHEMBL1467102 & 688282 & 4.9 & 5.0691 & TRN & \\
\hline & & & & 13223 & \\
\hline
\end{tabular}




\begin{tabular}{|c|c|c|c|c|c|}
\hline \multirow{2}{*}{ CHEMBL1596752 } & \multirow{2}{*}{688282} & \multirow[b]{2}{*}{5.0} & \\
\hline & & & 5.1243 & TRN & \\
\hline CHEMBL1418442 & 688282 & 4.6 & 5.0857 & TRN & \\
\hline CHEMBL1456716 & 688282 & 4.6 & 5.1512 & TRN & \\
\hline CHEMBL1593623 & 688282 & 5.4 & 5.2232 & TST & \\
\hline CHEMBL1322524 & 688282 & 4.5 & 5.171 & TST & \\
\hline CHEMBL3193293 & 688282 & 4.8 & 5.1393 & TST & \\
\hline CHEMBL1588416 & 688282 & 4.8 & 5.1332 & TRN & \\
\hline CHEMBL1448210 & 688282 & 4.6 & 5.1866 & TST & \\
\hline CHEMBL1499536 & 688282 & 4.5 & 5.1482 & TRN & \\
\hline CHEMBL1320854 & 688282 & 4.9 & 5.1901 & TRN & \\
\hline CHEMBL1424576 & 688282 & 5.4 & 5.114 & TRN & \\
\hline CHEMBL1363883 & 688282 & 5.3 & 5.2433 & TST & \\
\hline CHEMBL1299416 & 688282 & 4.9 & 5.0247 & TRN & \\
\hline CHEMBL1457125 & 688282 & 5.5 & 5.1423 & TRN & \\
\hline CHEMBL1489016 & 688282 & 5.0 & 5.1421 & TRN & \\
\hline CHEMBL1516362 & 688282 & 6.0 & 5.2371 & TRN & \\
\hline CHEMBL1612125 & 688282 & 4.6 & 5.1439 & TRN & \\
\hline CHEMBL1256735 & 688282 & 4.6 & 5.1267 & TRN & \\
\hline CHEMBL1529009 & 688282 & 4.6 & 5.0261 & TST & \\
\hline CHEMBL1536836 & 688282 & 5.5 & 5.1502 & TRN & \\
\hline CHEMBL1461480 & 688282 & 5.5 & 5.0695 & TRN & \\
\hline CHEMBL1582569 & 688282 & 5.3 & 5.1527 & TRN & \\
\hline CHEMBL1312114 & 688282 & 5.0 & 5.0297 & TRN & \\
\hline CHEMBL1581447 & 688282 & 5.3 & 5.2282 & TRN & \\
\hline CHEMBL1392085 & 688282 & 4.6 & 5.0729 & TST & \\
\hline CHEMBL428496 & 688282 & 4.9 & 5.2048 & TST & \\
\hline CHEMBL1312629 & 688282 & 5.0 & 5.0562 & TRN & \\
\hline CHEMBL1503401 & 688282 & 5.0 & 5.1483 & TRN & \\
\hline CHEMBL1395431 & 688282 & 5.0 & 5.1141 & TRN & \\
\hline CHEMBL1488194 & 688282 & 4.9 & 5.2396 & TST & \\
\hline CHEMBL1491965 & 688282 & 4.9 & 4.9912 & TRN & \\
\hline CHEMBL1363513 & 688282 & 4.9 & 5.0403 & TRN & \\
\hline CHEMBL 1605746 & 688282 & 5.0 & 5.1204 & TRN & \\
\hline CHEMBL1363298 & 688282 & 5.5 & 5.3066 & TRN & \\
\hline CHEMBL1417771 & 688282 & 4.5 & 5.0139 & 9999999999 & TRN \\
\hline CHEMBL1557372 & 688282 & 4.7 & 5.0904 & TRN & \\
\hline CHEMBL1511557 & 688282 & 4.9 & 5.0935 & TRN & \\
\hline CHEMBL152557 & 688282 & 4.9 & 5.1491 & TST & \\
\hline CHEMBL1491340 & 688282 & 4.7 & 5.308 & TST & \\
\hline CHEMBL1493772 & 688282 & 5.2 & 5.1148 & TRN & \\
\hline CHEMBL1539736 & 688282 & 5.0 & 5.0946 & TRN & \\
\hline CHEMBL1373492 & 688282 & 4.6 & 5.1665 & TRN & \\
\hline CHEMBL1504634 & 688282 & 5.2 & 5.1778 & TRN & \\
\hline CHEMBL1412273 & 688282 & 5.1 & 5.0767 & TRN & \\
\hline CHEMBL1531761 & 688282 & 5.5 & 5.0619 & TRN & \\
\hline CHEMBL1383872 & 688282 & 4.9 & 5.1055 & TRN & \\
\hline CHEMBL1389158 & 688282 & 4.6 & 5.2294 & TRN & \\
\hline CHEMBL1528135 & 688282 & 4.9 & 5.2375 & TRN & \\
\hline & & & & 13224 & \\
\hline
\end{tabular}




\begin{tabular}{|c|c|c|c|c|}
\hline \multicolumn{5}{|c|}{ spıemental } \\
\hline CHEMBL1302752 & 688282 & 5.6 & 5.048 & TRN \\
\hline CHEMBL1552051 & 688282 & 5.3 & 5.1731 & TRN \\
\hline CHEMBL1376163 & 688282 & 5.0 & 5.1107 & TRN \\
\hline CHEMBL1568081 & 688282 & 5.3 & 4.9983 & TRN \\
\hline CHEMBL1315965 & 688282 & 5.3 & 5.1496 & TRN \\
\hline CHEMBL1588686 & 688282 & 4.9 & 5.1648 & TRN \\
\hline CHEMBL1308126 & 688282 & 4.6 & 5.2924 & TRN \\
\hline CHEMBL1479625 & 688282 & 6.0 & 5.2491 & TST \\
\hline CHEMBL1440797 & 688282 & 5.4 & 5.2502 & TST \\
\hline CHEMBL1417381 & 688282 & 5.0 & 4.9916 & TRN \\
\hline CHEMBL1578194 & 688282 & 4.8 & 4.9962 & TST \\
\hline CHEMBL1513300 & 688282 & 6.0 & 4.956 & TRN \\
\hline CHEMBL194399 & 688282 & 4.7 & 5.2816 & TST \\
\hline CHEMBL1323897 & 688282 & 4.8 & 5.1738 & TRN \\
\hline CHEMBL 7917 & 688282 & 6.0 & 4.9513 & TRN \\
\hline CHEMBL103469 & 688282 & 4.9 & 5.2775 & TRN \\
\hline CHEMBL1340321 & 688282 & 5.0 & 5.026 & TRN \\
\hline CHEMBL38576 & 688282 & 5.2 & 5.1515 & TRN \\
\hline CHEMBL1531693 & 688282 & 4.6 & 4.9161 & TRN \\
\hline CHEMBL1447011 & 688282 & 4.8 & 5.1022 & TRN \\
\hline CHEMBL500996 & 688282 & 4.9 & 5.1053 & TRN \\
\hline CHEMBL1422695 & 688282 & 5.1 & 5.0218 & TRN \\
\hline CHEMBL1354693 & 688282 & 5.7 & 5.0777 & TRN \\
\hline CHEMBL1449737 & 688282 & 6.2 & 5.3399 & TST \\
\hline CHEMBL1320219 & 688282 & 5.1 & 5.0479 & TRN \\
\hline CHEMBL1423359 & 688282 & 5.2 & 5.1534 & TRN \\
\hline CHEMBL1438692 & 688282 & 4.8 & 5.1583 & TRN \\
\hline CHEMBL44641 & 688282 & 5.6 & 5.2831 & TST \\
\hline CHEMBL1472444 & 688282 & 5.0 & 5.041 & TRN \\
\hline CHEMBL1561349 & 688282 & 5.3 & 5.0642 & TRN \\
\hline CHEMBL1543402 & 688282 & 5.6 & 5.18 & TRN \\
\hline CHEMBL1373371 & 688282 & 5.3 & 5.1483 & TRN \\
\hline CHEMBL1474302 & 688282 & 5.2 & 5.2109 & TRN \\
\hline CHEMBL1527086 & 688282 & 5.5 & 5.1511 & TST \\
\hline CHEMBL1359803 & 688282 & 4.6 & 5.0854 & TRN \\
\hline CHEMBL1513825 & 688282 & 5.0 & 4.9518 & TRN \\
\hline CHEMBL1439255 & 688282 & 4.8 & 5.0545 & TRN \\
\hline CHEMBL3198373 & 688282 & 5.2 & 5.2249 & TRN \\
\hline CHEMBL1312686 & 688282 & 4.9 & 5.2073 & TRN \\
\hline CHEMBL 277127 & 688282 & 4.6 & 5.1975 & TRN \\
\hline CHEMBL1403733 & 688282 & 6.6 & 5.216 & TRN \\
\hline CHEMBL1520606 & 688282 & 5.3 & 5.2508 & TRN \\
\hline CHEMBL1424022 & 688282 & 4.5 & 4.9607 & TRN \\
\hline CHEMBL1609375 & 688282 & 4.9 & 5.0636 & TRN \\
\hline CHEMBL1514440 & 688282 & 4.9 & 5.1441 & TRN \\
\hline CHEMBL1341677 & 688282 & 4.6 & 5.1169 & TRN \\
\hline CHEMBL1488204 & 688282 & 4.8 & 5.1819 & TST \\
\hline CHEMBL3193107 & 688282 & 4.9 & 5.0656 & TRN \\
\hline
\end{tabular}




\begin{tabular}{|c|c|c|c|c|c|}
\hline \\
\hline CHEMBL1416274 & 688282 & 5.1 & 5.1938 & TRN & \\
\hline CHEMBL1536676 & 688282 & 5.3 & 5.0906 & TRN & \\
\hline CHEMBL1570149 & 688282 & 5.3 & 5.0805 & TRN & \\
\hline CHEMBL1327697 & 688282 & 4.6 & 5.151 & TRN & \\
\hline CHEMBL 71851 & 688282 & 6.0 & 5.1399 & TRN & \\
\hline CHEMBL1336290 & 688282 & 5.3 & 5.2734 & TRN & \\
\hline CHEMBL1480282 & 688282 & 4.6 & 5.0861 & TRN & \\
\hline CHEMBL1594149 & 688282 & 4.9 & \multicolumn{2}{|c|}{5.242000000000001} & TST \\
\hline CHEMBL1534864 & 688282 & 5.0 & 5.1237 & TRN & \\
\hline CHEMBL1352443 & 688282 & 4.5 & 5.0272 & TRN & \\
\hline CHEMBL1443124 & 688282 & 5.3 & 5.0758 & TRN & \\
\hline CHEMBL1571692 & 688282 & 4.5 & 5.1368 & TST & \\
\hline CHEMBL1540890 & 688282 & 4.9 & 5.1038 & TRN & \\
\hline CHEMBL1597481 & 688282 & 5.3 & 5.1533 & TRN & \\
\hline CHEMBL1357445 & 688282 & 5.8 & 5.1701 & TRN & \\
\hline CHEMBL1576895 & 688282 & 4.6 & 5.1594 & TRN & \\
\hline CHEMBL1473919 & 688282 & 5.0 & 5.0869 & TRN & \\
\hline CHEMBL1497557 & 688282 & 6.9 & 5.0817 & TRN & \\
\hline CHEMBL1467937 & 688282 & 5.0 & 5.19799 & 99999999995 & TRN \\
\hline CHEMBL1255649 & 688282 & 4.9 & 5.2274 & TST & \\
\hline CHEMBL1535257 & 688282 & 4.7 & 5.1454 & TRN & \\
\hline CHEMBL1519091 & 688282 & 5.0 & \multicolumn{2}{|c|}{5.127000000000001} & TRN \\
\hline CHEMBL1317335 & 688282 & 4.5 & 5.1018 & TRN & \\
\hline CHEMBL1460224 & 688282 & 5.3 & 5.13399 & 99999999995 & TST \\
\hline CHEMBL 34241 & 688282 & 6.0 & 5.2063 & TST & \\
\hline CHEMBL1488021 & 688282 & 8.1024 & 5.1604 & TST & \\
\hline CHEMBL1370317 & 688282 & 7.6003 & 5.2656 & TRN & \\
\hline CHEMBL1558886 & 688282 & 4.9 & 5.1142 & TRN & \\
\hline CHEMBL1422535 & 688282 & 4.9 & 5.2337 & TRN & \\
\hline CHEMBL1447807 & 688282 & 5.5 & 5.1659 & TST & \\
\hline CHEMBL1355909 & 688282 & 5.6 & 5.1716 & TRN & \\
\hline CHEMBL1417108 & 688282 & 5.3 & 5.1767 & TRN & \\
\hline CHEMBL 27403 & 688282 & 4.6 & 5.0897 & TRN & \\
\hline CHEMBL1505110 & 688282 & 4.6 & 5.2288 & TRN & \\
\hline CHEMBL1333180 & 688282 & 5.3 & 5.1926 & TRN & \\
\hline CHEMBL1331442 & 688282 & 5.0 & 5.1068 & TRN & \\
\hline CHEMBL1339467 & 688282 & 4.5 & 5.1406 & TRN & \\
\hline CHEMBL1487622 & 688282 & 6.1 & 5.2361 & TST & \\
\hline CHEMBL1436925 & 688282 & 4.8 & 5.1169 & TRN & \\
\hline CHEMBL1556102 & 688282 & 5.3 & 5.1491 & TRN & \\
\hline CHEMBL1398925 & 688282 & 4.7 & 5.1417 & TRN & \\
\hline CHEMBL1332275 & 688282 & 4.9 & 4.9508 & TRN & \\
\hline CHEMBL1594793 & 688282 & 4.9 & 5.0122 & TRN & \\
\hline CHEMBL1395297 & 688282 & 4.9 & 5.1744 & TRN & \\
\hline CHEMBL1315991 & 688282 & 5.0 & 5.2348 & TRN & \\
\hline CHEMBL1409812 & 688282 & 4.9 & 5.1835 & TRN & \\
\hline CHEMBL1588672 & 688282 & 4.9 & 5.1867 & TRN & \\
\hline CHEMBL1357199 & 688282 & 7.699 & 5.0338 & TRN & \\
\hline
\end{tabular}




\begin{tabular}{|c|c|c|c|c|}
\hline & & & & \\
\hline CHEMBL1414417 & 688282 & 5.5 & 5.0696 & TRN \\
\hline CHEMBL1378646 & 688282 & 5.3 & 5.0028 & TRN \\
\hline CHEMBL1553136 & 688282 & 5.0 & 4.9516 & TRN \\
\hline CHEMBL1311899 & 688282 & 5.3 & 5.2341 & TRN \\
\hline CHEMBL 3207510 & 688282 & 4.9 & 5.2433 & TRN \\
\hline CHEMBL1518422 & 688282 & 4.9 & 5.0901 & TRN \\
\hline CHEMBL1467754 & 688282 & 4.5 & 5.233 & TRN \\
\hline CHEMBL1359550 & 688282 & 4.9 & 5.1494 & TRN \\
\hline CHEMBL1256865 & 688282 & 4.5 & 5.1227 & TRN \\
\hline CHEMBL44 & 688282 & 6.0 & 5.2783 & TRN \\
\hline CHEMBL1424289 & 688282 & 4.7 & 5.1688 & TRN \\
\hline CHEMBL1498658 & 688282 & 4.6 & 5.1305 & TST \\
\hline CHEMBL408563 & 688282 & 5.0 & 5.1899 & TRN \\
\hline CHEMBL1379438 & 688282 & 5.0 & 5.072 & TRN \\
\hline CHEMBL1435028 & 688282 & 4.7 & 5.1102 & TRN \\
\hline CHEMBL1371387 & 688282 & 5.0 & 5.1169 & TRN \\
\hline CHEMBL1585469 & 688282 & 7.0 & 5.1905 & TST \\
\hline CHEMBL1532745 & 688282 & 5.0 & 5.1522 & TRN \\
\hline CHEMBL1594879 & 688282 & 7.8013 & 5.33 & TRN \\
\hline CHEMBL1469341 & 688282 & 5.6 & 5.2404 & TRN \\
\hline CHEMBL1401953 & 688282 & 5.1 & 5.1349 & TRN \\
\hline CHEMBL1363677 & 688282 & 4.6 & 5.083 & TRN \\
\hline CHEMBL1568622 & 688282 & 4.8 & 5.0804 & TRN \\
\hline CHEMBL1477659 & 688282 & 4.5 & 5.1947 & TRN \\
\hline CHEMBL1496203 & 688282 & 6.4 & 5.1102 & TRN \\
\hline CHEMBL1609393 & 688282 & 5.3 & 5.2743 & TRN \\
\hline CHEMBL1490887 & 688282 & 5.3 & 5.1605 & TRN \\
\hline CHEMBL1506339 & 688282 & 5.0 & 5.0645 & TRN \\
\hline CHEMBL1521747 & 688282 & 4.5 & 5.0611 & TRN \\
\hline CHEMBL1305537 & 688282 & 4.9 & 5.0798 & TRN \\
\hline CHEMBL1555453 & 688282 & 5.3 & 5.3214 & TST \\
\hline CHEMBL1565724 & 688282 & 4.5 & 5.2085 & TRN \\
\hline CHEMBL1368233 & 688282 & 4.8 & 5.0717 & TRN \\
\hline CHEMBL1546784 & 688282 & 5.0 & 5.0707 & TRN \\
\hline CHEMBL1532755 & 688282 & 4.5 & 5.145 & TRN \\
\hline CHEMBL579045 & 688282 & 5.4 & 5.1287 & TRN \\
\hline CHEMBL1467306 & 688282 & 5.3 & 5.1634 & TRN \\
\hline CHEMBL1477765 & 688282 & 5.3 & 5.1861 & TRN \\
\hline CHEMBL1357674 & 688282 & 4.6 & 5.2748 & TST \\
\hline CHEMBL1405378 & 688282 & 4.7 & 5.1531 & TRN \\
\hline CHEMBL1450711 & 688282 & 5.3 & 5.2137 & TRN \\
\hline CHEMBL1486808 & 688282 & 4.9 & 5.1811 & TRN \\
\hline CHEMBL1602127 & 688282 & 5.6 & 5.3266 & TST \\
\hline CHEMBL1490452 & 688282 & 4.8 & 5.1725 & TRN \\
\hline CHEMBL1486889 & 688282 & 7.8996 & 5.0501 & TRN \\
\hline CHEMBL1454544 & 688282 & 5.3 & 4.981 & TRN \\
\hline CHEMBL1471225 & 688282 & 4.5 & 5.1539 & TRN \\
\hline CHEMBL1435908 & 688282 & 5.3 & 5.1215 & TRN \\
\hline
\end{tabular}




\begin{tabular}{|c|c|c|c|c|}
\hline \multicolumn{5}{|c|}{ plement } \\
\hline CHEMBL1537855 & 688282 & 5.4 & 5.1635 & TST \\
\hline CHEMBL1516514 & 688282 & 6.0 & 5.0741 & TRN \\
\hline CHEMBL1502856 & 688282 & 4.8 & 5.1213 & TRN \\
\hline CHEMBL12344 & 688282 & 4.5 & 5.2848 & TST \\
\hline CHEMBL1520726 & 688282 & 5.3 & 5.239 & TST \\
\hline CHEMBL1555368 & 688282 & 4.8 & 5.2117 & TRN \\
\hline CHEMBL1527856 & 688282 & 5.1 & 5.0792 & TRN \\
\hline CHEMBL1602107 & 688282 & 4.6 & 5.17 & TRN \\
\hline CHEMBL1593158 & 688282 & 5.0 & 5.0663 & TRN \\
\hline CHEMBL1344773 & 688282 & 5.6 & 5.2763 & TRN \\
\hline CHEMBL1504619 & 688282 & 5.6 & 5.011 & TRN \\
\hline CHEMBL2373626 & 688282 & 5.9 & 5.1328 & TST \\
\hline CHEMBL1515899 & 688282 & 7.699 & 5.2318 & TRN \\
\hline CHEMBL1448625 & 688282 & 5.0 & 5.1389 & TRN \\
\hline CHEMBL1609763 & 688282 & 5.5 & 5.1592 & TRN \\
\hline CHEMBL1477216 & 688282 & 5.4 & 5.1099 & TRN \\
\hline CHEMBL3211066 & 688282 & 4.6 & 5.1255 & TRN \\
\hline CHEMBL1529769 & 688282 & 5.3 & 5.2215 & TRN \\
\hline CHEMBL1544616 & 688282 & 5.0 & 5.1288 & TRN \\
\hline CHEMBL1336328 & 688282 & 5.4 & 5.2033 & TRN \\
\hline CHEMBL1437488 & 688282 & 4.5 & 5.2069 & TST \\
\hline CHEMBL1316956 & 688282 & 4.9 & 5.0088 & TRN \\
\hline CHEMBL1512701 & 688282 & 5.0 & 4.9442 & TRN \\
\hline CHEMBL1513485 & 688282 & 5.1 & 4.9435 & TRN \\
\hline CHEMBL1412390 & 688282 & 4.7 & 5.0056 & TRN \\
\hline CHEMBL516616 & 688282 & 5.3 & 5.2357 & TST \\
\hline CHEMBL1599268 & 688282 & 4.5 & 5.1371 & TRN \\
\hline CHEMBL1601133 & 688282 & 5.0 & 5.1539 & TRN \\
\hline CHEMBL1358033 & 688282 & 5.0 & 5.0536 & TRN \\
\hline CHEMBL1480952 & 688282 & 4.8 & 5.0378 & TRN \\
\hline CHEMBL3192717 & 688282 & 4.5 & 5.1141 & TRN \\
\hline CHEMBL1512049 & 688282 & 5.0 & 5.1396 & TRN \\
\hline CHEMBL1448360 & 688282 & 5.0 & 5.1562 & TRN \\
\hline CHEMBL1315725 & 688282 & 5.5 & 5.1756 & TST \\
\hline CHEMBL1359613 & 688282 & 4.9 & 5.2831 & TRN \\
\hline CHEMBL1324314 & 688282 & 4.5 & 5.1584 & TRN \\
\hline CHEMBL1415784 & 688282 & 4.9 & 5.0622 & TRN \\
\hline CHEMBL476135 & 688282 & 5.3 & 5.0881 & TRN \\
\hline CHEMBL1333061 & 688282 & 5.0 & 5.1735 & TRN \\
\hline CHEMBL1336763 & 688282 & 5.3 & 5.2287 & TRN \\
\hline CHEMBL1511191 & 688282 & 5.0 & 5.1312 & TRN \\
\hline CHEMBL1547250 & 688282 & 4.9 & 5.0889 & TRN \\
\hline CHEMBL1570773 & 688282 & 5.4 & 5.215 & TRN \\
\hline CHEMBL1458475 & 688282 & 4.7 & 5.0101 & TRN \\
\hline CHEMBL1395098 & 688282 & 4.7 & 5.1341 & TRN \\
\hline CHEMBL1386652 & 688282 & 5.0 & 5.1905 & TRN \\
\hline CHEMBL1436644 & 688282 & 5.3 & 5.1352 & TRN \\
\hline CHEMBL126077 & 688282 & 6.0 & 5.2907 & TST \\
\hline
\end{tabular}




\begin{tabular}{|c|c|c|c|c|}
\hline \\
\hline CHEMBL1460562 & 688282 & 4.9 & 5.0247 & TRN \\
\hline CHEMBL1361600 & 688282 & 4.9 & 5.1172 & TRN \\
\hline CHEMBL1607885 & 688282 & 4.9 & 4.9695 & TRN \\
\hline CHEMBL1386928 & 688282 & 5.0 & 5.09 & TRN \\
\hline CHEMBL1255941 & 688282 & 5.5 & 5.2162 & TST \\
\hline CHEMBL1604106 & 688282 & 5.4 & 5.2708 & TST \\
\hline CHEMBL1576662 & 688282 & 4.9 & 5.1407 & TST \\
\hline CHEMBL512908 & 688282 & 5.5 & 5.2847 & TRN \\
\hline CHEMBL35482 & 688282 & 4.9 & 5.1032 & TRN \\
\hline CHEMBL1358694 & 688282 & 7.6003 & 5.3118 & TRN \\
\hline CHEMBL1356775 & 688282 & 6.0 & 5.0583 & TST \\
\hline CHEMBL1521902 & 688282 & 4.5 & 5.1328 & TRN \\
\hline CHEMBL1390006 & 688282 & 4.6 & 5.1456 & TRN \\
\hline CHEMBL1560839 & 688282 & 5.3 & 5.1816 & TRN \\
\hline CHEMBL3198038 & 688282 & 5.0 & 5.1944 & TST \\
\hline CHEMBL1386826 & 688282 & 5.1 & 5.1623 & TRN \\
\hline CHEMBL1595322 & 688282 & 4.9 & 5.1572 & TRN \\
\hline CHEMBL1356280 & 688282 & 4.6 & 5.1808 & TST \\
\hline CHEMBL76232 & 688282 & 6.0 & 5.3045 & TST \\
\hline CHEMBL1301214 & 688282 & 4.9 & 5.1111 & TRN \\
\hline CHEMBL1324202 & 688282 & 4.9 & 5.1459 & TRN \\
\hline CHEMBL1595576 & 688282 & 4.9 & 5.029 & TRN \\
\hline CHEMBL1538109 & 688282 & 5.0 & 5.0898 & TRN \\
\hline CHEMBL1615433 & 688282 & 4.9 & 5.2445 & TRN \\
\hline CHEMBL1514375 & 688282 & 4.6 & 5.0368 & TST \\
\hline CHEMBL316611 & 688282 & 6.4 & 5.0982 & TRN \\
\hline CHEMBL1422670 & 688282 & 4.6 & 5.2774 & TRN \\
\hline CHEMBL1428456 & 688282 & 5.0 & 5.1842 & TRN \\
\hline CHEMBL334255 & 688282 & 4.5 & 5.2531 & TST \\
\hline CHEMBL1339553 & 688282 & 4.9 & 5.1218 & TRN \\
\hline CHEMBL1331045 & 688282 & 4.5 & 5.2018 & TST \\
\hline CHEMBL1464202 & 688282 & 5.2 & 5.0747 & TRN \\
\hline CHEMBL1536637 & 688282 & 5.1 & 5.0019 & TRN \\
\hline CHEMBL531296 & 688282 & 5.0 & 5.03 & TRN \\
\hline CHEMBL1597839 & 688282 & 5.2 & 5.092 & TRN \\
\hline CHEMBL1408259 & 688282 & 6.3 & 5.1772 & TRN \\
\hline CHEMBL1440619 & 688282 & 5.0 & 5.0792 & TRN \\
\hline CHEMBL1591730 & 688282 & 7.6003 & 5.1713 & TRN \\
\hline CHEMBL1515764 & 688282 & 4.6 & 5.1135 & TRN \\
\hline CHEMBL1388457 & 688282 & 4.6 & 5.2952 & TRN \\
\hline CHEMBL1530963 & 688282 & 5.1 & 5.2138 & TRN \\
\hline CHEMBL1378972 & 688282 & 5.0 & 5.121 & TST \\
\hline CHEMBL1450476 & 688282 & 4.8 & 5.0967 & TRN \\
\hline CHEMBL1522678 & 688282 & 4.9 & 5.1961 & TRN \\
\hline CHEMBL1570135 & 688282 & 4.7 & 5.004 & TRN \\
\hline CHEMBL1408985 & 688282 & 8.301 & 5.1465 & TRN \\
\hline CHEMBL509150 & 688282 & 8.0 & 5.1793 & TRN \\
\hline CHEMBL1325766 & 688282 & 4.9 & 5.0601 & TRN \\
\hline
\end{tabular}




\begin{tabular}{|c|c|c|c|c|c|}
\hline & & & & & \\
\hline CHEMBL131091 & 688282 & 4.5 & 5.1567 & TST & \\
\hline CHEMBL1370884 & 688282 & 4.5 & 5.1652 & TRN & \\
\hline CHEMBL 374400 & 688282 & 6.0 & 5.2006 & TST & \\
\hline CHEMBL1341844 & 688282 & 4.8 & 5.2419 & TRN & \\
\hline CHEMBL1449973 & 688282 & 6.3 & 5.193 & TRN & \\
\hline CHEMBL1370770 & 688282 & 5.3 & 5.0838 & TRN & \\
\hline CHEMBL1609528 & 688282 & 4.6 & 5.131 & TRN & \\
\hline CHEMBL1349450 & 688282 & 5.3 & 5.1606 & TRN & \\
\hline CHEMBL523167 & 688282 & 4.6 & 5.0256 & TRN & \\
\hline CHEMBL1348090 & 688282 & 4.8 & 5.0974 & TRN & \\
\hline CHEMBL3199900 & 688282 & 5.0 & 5.0884 & TRN & \\
\hline CHEMBL1456755 & 688282 & 5.4 & 5.0986 & TRN & \\
\hline CHEMBL1483862 & 688282 & 4.9 & 5.2912 & TST & \\
\hline CHEMBL1388566 & 688282 & 4.8 & 5.0831 & TRN & \\
\hline CHEMBL1256364 & 688282 & 4.9 & $5.2120 e$ & 0000000001 & TRN \\
\hline CHEMBL1381553 & 688282 & 5.1 & 5.1619 & TRN & \\
\hline CHEMBL1359775 & 688282 & 4.6 & 5.1421 & TRN & \\
\hline CHEMBL1567944 & 688282 & 6.0 & 5.1412 & TRN & \\
\hline CHEMBL1373720 & 688282 & 4.5 & 5.1204 & TRN & \\
\hline CHEMBL1610232 & 688282 & 4.9 & 5.0216 & TRN & \\
\hline CHEMBL1428798 & 688282 & 4.5 & 5.0985 & TRN & \\
\hline CHEMBL1572637 & 688282 & 4.8 & 5.0213 & TRN & \\
\hline CHEMBL1213771 & 688282 & 5.0 & 5.0421 & TRN & \\
\hline CHEMBL1582006 & 688282 & 5.3 & 5.0607 & TRN & \\
\hline CHEMBL474415 & 688282 & 4.9 & 4.963 & TRN & \\
\hline CHEMBL1528726 & 688282 & 4.9 & 5.0157 & TRN & \\
\hline CHEMBL577887 & 688282 & 5.5 & 5.1701 & TRN & \\
\hline CHEMBL1570523 & 688282 & 4.5 & 5.2136 & TRN & \\
\hline CHEMBL1441574 & 688282 & 5.6 & 5.2127 & TRN & \\
\hline CHEMBL1591758 & 688282 & 5.5 & 5.1389 & TRN & \\
\hline CHEMBL1304930 & 688282 & 5.4 & 5.1214 & TRN & \\
\hline CHEMBL3209274 & 688282 & 5.9 & 5.1828 & TST & \\
\hline CHEMBL449690 & 688282 & 6.0 & 5.0963 & TRN & \\
\hline CHEMBL1491812 & 688282 & 5.0 & 5.0014 & TRN & \\
\hline CHEMBL1367565 & 688282 & 4.9 & 5.2318 & TRN & \\
\hline CHEMBL1488320 & 688282 & 6.3 & 5.1349 & TRN & \\
\hline CHEMBL1487863 & 688282 & 4.6 & 5.1497 & TRN & \\
\hline CHEMBL1450670 & 688282 & 5.3 & 5.1426 & TRN & \\
\hline CHEMBL1397427 & 688282 & 5.3 & 4.9553 & TRN & \\
\hline CHEMBL1423773 & 688282 & 4.5 & 5.0559 & TRN & \\
\hline CHEMBL1360448 & 688282 & 4.5 & 4.9971 & TRN & \\
\hline CHEMBL1583248 & 688282 & 5.0 & 5.1056 & TRN & \\
\hline CHEMBL1335409 & 688282 & 5.4 & 5.1252 & TST & \\
\hline CHEMBL1526411 & 688282 & 6.2 & 5.2459 & TRN & \\
\hline CHEMBL1230095 & 688282 & 4.9 & 5.2592 & TST & \\
\hline CHEMBL1335986 & 688282 & 5.0 & 5.1021 & TRN & \\
\hline CHEMBL1354563 & 688282 & 4.8 & 5.1079 & TRN & \\
\hline CHEMBL1406485 & 688282 & 4.7 & 5.0989 & TST & \\
\hline & & & & 13230 & \\
\hline
\end{tabular}




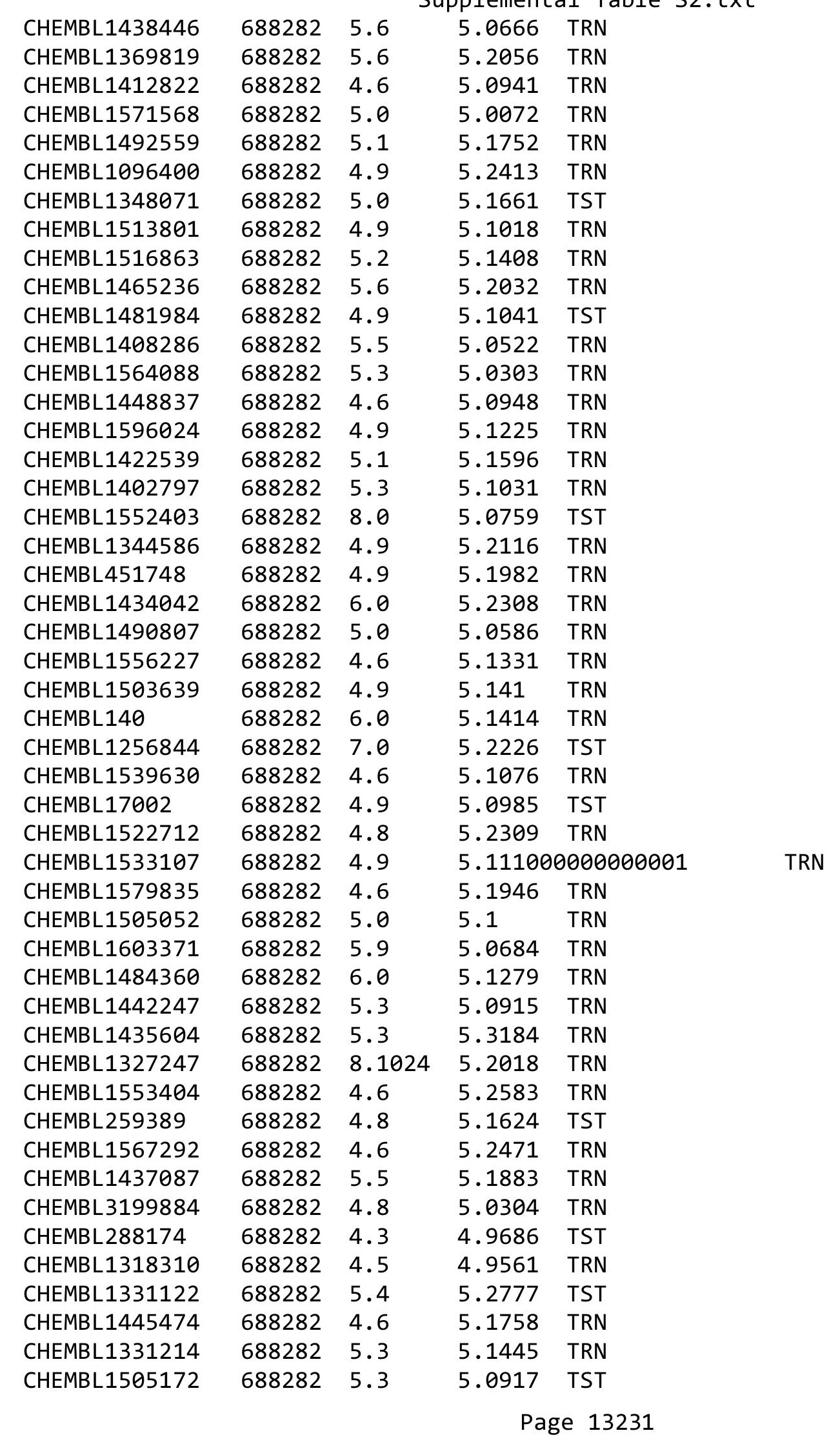




\begin{tabular}{|c|c|c|c|c|c|}
\hline \multirow{2}{*}{\multicolumn{2}{|c|}{ CHEMBL1327667 }} & \\
\hline & & 4.6 & 5.2925 & TRN & \\
\hline CHEMBL1570350 & 688282 & 4.8 & 5.0892 & TST & \\
\hline CHEMBL1571138 & 688282 & 5.3 & 5.1613 & TRN & \\
\hline CHEMBL1338857 & 688282 & 5.0 & 5.1639 & TRN & \\
\hline CHEMBL1375519 & 688282 & 4.6 & 5.0548 & TRN & \\
\hline CHEMBL1600780 & 688282 & 4.9 & 5.0418 & TRN & \\
\hline CHEMBL1493896 & 688282 & 4.6 & 5.1334 & TRN & \\
\hline CHEMBL1539286 & 688282 & 5.3 & 5.05699 & 99999999995 & TRN \\
\hline CHEMBL1565033 & 688282 & 5.1 & 5.065 & TRN & \\
\hline CHEMBL1412825 & 688282 & 5.4 & 5.1831 & TRN & \\
\hline CHEMBL1496487 & 688282 & 5.3 & 5.01399 & 9999999999 & TRN \\
\hline CHEMBL1340610 & 688282 & 4.6 & 5.0612 & TRN & \\
\hline CHEMBL2374259 & 688282 & 4.9 & 5.1431 & TST & \\
\hline CHEMBL1562510 & 688282 & 6.5 & 5.1091 & TST & \\
\hline CHEMBL 289277 & 688282 & 5.6 & 5.2364 & TST & \\
\hline CHEMBL243250 & 688282 & 4.5 & 5.085 & TRN & \\
\hline CHEMBL3198180 & 688282 & 5.0 & 5.0672 & TRN & \\
\hline CHEMBL1499882 & 688282 & 6.1 & 5.2068 & TRN & \\
\hline CHEMBL483835 & 688282 & 4.5 & 5.2128 & TRN & \\
\hline CHEMBL1537166 & 688282 & 4.5 & 4.9553 & TRN & \\
\hline CHEMBL1514280 & 688282 & 4.9 & 5.155 & TRN & \\
\hline CHEMBL1360151 & 688282 & 4.9 & 5.1407 & TRN & \\
\hline CHEMBL3195995 & 688282 & 5.0 & 5.0594 & TRN & \\
\hline CHEMBL1315335 & 688282 & 4.9 & 5.0847 & TRN & \\
\hline CHEMBL1591508 & 688282 & 4.9 & 5.1928 & TST & \\
\hline CHEMBL1358722 & 688282 & 6.0 & 5.2986 & TST & \\
\hline CHEMBL1503818 & 688282 & 4.7 & 5.1693 & TRN & \\
\hline CHEMBL1407078 & 688282 & 4.9 & 5.03600 & 00000000005 & TRN \\
\hline CHEMBL1369033 & 688282 & 6.5 & 5.2334 & TST & \\
\hline CHEMBL1561922 & 688282 & 6.3 & 5.3023 & TRN & \\
\hline CHEMBL1581258 & 688282 & 5.5 & 5.0219 & TRN & \\
\hline CHEMBL1591205 & 688282 & 6.3 & 5.3091 & TST & \\
\hline CHEMBL1488789 & 688282 & 5.3 & 5.0956 & TST & \\
\hline CHEMBL1353912 & 688282 & 8.4949 & 5.1563 & TRN & \\
\hline CHEMBL1427167 & 688282 & 4.6 & 5.1102 & TRN & \\
\hline CHEMBL1459444 & 688282 & 5.0 & 5.0321 & TRN & \\
\hline CHEMBL1436682 & 688282 & 5.4 & 5.0579 & TRN & \\
\hline CHEMBL1455924 & 688282 & 6.0 & 5.1588 & TRN & \\
\hline CHEMBL1476407 & 688282 & 5.9 & 5.3382 & TRN & \\
\hline CHEMBL1320188 & 688282 & 5.3 & 5.1522 & TRN & \\
\hline CHEMBL1358796 & 688282 & 4.5 & 5.0869 & TRN & \\
\hline CHEMBL1493765 & 688282 & 5.3 & 5.1216 & TRN & \\
\hline CHEMBL155625 & 688282 & 4.5 & 5.2391 & TRN & \\
\hline CHEMBL 371811 & 688282 & 4.8 & 5.2366 & TST & \\
\hline CHEMBL1383022 & 688282 & 5.6 & 5.1968 & TRN & \\
\hline CHEMBL1450376 & 688282 & 5.0 & 5.165 & TRN & \\
\hline CHEMBL1379985 & 688282 & 4.5 & 5.2745 & TRN & \\
\hline CHEMBL1465165 & 688282 & 4.6 & 5.0558 & TRN & \\
\hline & & & & 13232 & \\
\hline
\end{tabular}




\begin{tabular}{|c|c|c|c|c|c|}
\hline & & & & & \\
\hline CHEMBL1417180 & 688282 & 4.9 & 5.1069 & TRN & \\
\hline CHEMBL1496664 & 688282 & 5.3 & 5.143 & TRN & \\
\hline CHEMBL3351080 & 688282 & 6.1 & 5.2446 & TRN & \\
\hline CHEMBL1341400 & 688282 & 4.5 & 5.2491 & TRN & \\
\hline CHEMBL1579401 & 688282 & 5.6 & 5.0973 & TRN & \\
\hline CHEMBL1396997 & 688282 & 5.3 & 5.1182 & TRN & \\
\hline CHEMBL1373818 & 688282 & 4.5 & 5.1705 & TST & \\
\hline CHEMBL1580543 & 688282 & 4.9 & 4.9994 & TRN & \\
\hline CHEMBL 285819 & 688282 & 4.5 & 5.2417 & TRN & \\
\hline CHEMBL1325724 & 688282 & 5.2 & 5.1657 & TRN & \\
\hline CHEMBL 388054 & 688282 & 4.9 & 5.2086 & TRN & \\
\hline CHEMBL1533204 & 688282 & 5.4 & 5.3055 & TRN & \\
\hline CHEMBL1444488 & 688282 & 4.6 & 5.1258 & TRN & \\
\hline CHEMBL1533197 & 688282 & 5.1 & 5.1841 & TRN & \\
\hline CHEMBL1453210 & 688282 & 4.9 & 5.16799 & 9999999999 & TRN \\
\hline CHEMBL1417837 & 688282 & 5.0 & 4.9516 & TRN & \\
\hline CHEMBL1606170 & 688282 & 5.5 & 5.1821 & TST & \\
\hline CHEMBL601737 & 688282 & 6.1 & 5.2092 & TST & \\
\hline CHEMBL1532966 & 688282 & 5.3 & 5.1127 & TRN & \\
\hline CHEMBL1305185 & 688282 & 4.6 & 5.0714 & TRN & \\
\hline CHEMBL1314906 & 688282 & 5.5 & 5.14 & TRN & \\
\hline CHEMBL1415927 & 688282 & 4.8 & 5.0324 & TST & \\
\hline CHEMBL45281 & 688282 & 6.0 & 5.1125 & TST & \\
\hline CHEMBL1469552 & 688282 & 5.3 & 5.1038 & TRN & \\
\hline CHEMBL1445418 & 688282 & 4.6 & 5.1371 & TRN & \\
\hline CHEMBL1507273 & 688282 & 4.6 & 5.1745 & TRN & \\
\hline CHEMBL1314022 & 688282 & 4.9 & 5.1454 & TST & \\
\hline CHEMBL1595650 & 688282 & 6.2 & 5.1847 & TRN & \\
\hline CHEMBL1489960 & 688282 & 4.9 & 5.0537 & TRN & \\
\hline CHEMBL1386134 & 688282 & 4.5 & 5.1515 & TRN & \\
\hline CHEMBL1590919 & 688282 & 4.9 & 5.2921 & TRN & \\
\hline CHEMBL1523579 & 688282 & 5.7 & 5.1349 & TRN & \\
\hline CHEMBL1350167 & 688282 & 4.9 & 5.0805 & TRN & \\
\hline CHEMBL1517935 & 688282 & 5.0 & 5.1493 & TRN & \\
\hline CHEMBL1574997 & 688282 & 5.3 & 5.1672 & TRN & \\
\hline CHEMBL 285480 & 688282 & 4.9 & 5.2482 & TRN & \\
\hline CHEMBL1329718 & 688282 & 4.8 & 5.1907 & TRN & \\
\hline CHEMBL1414232 & 688282 & 6.0 & 5.1722 & TRN & \\
\hline CHEMBL1504651 & 688282 & 4.5 & 5.1272 & TRN & \\
\hline CHEMBL1562589 & 688282 & 5.3 & 5.1537 & TRN & \\
\hline CHEMBL1368964 & 688282 & 4.6 & 5.1713 & TRN & \\
\hline CHEMBL1237212 & 688282 & 4.5 & 5.3235 & TST & \\
\hline CHEMBL1504662 & 688282 & 5.3 & 5.1062 & TRN & \\
\hline CHEMBL1366697 & 688282 & 5.3 & 4.9538 & TRN & \\
\hline CHEMBL1428417 & 688282 & 4.9 & 5.0292 & TRN & \\
\hline CHEMBL1465194 & 688282 & 4.9 & 5.1953 & TRN & \\
\hline CHEMBL1479965 & 688282 & 5.3 & 5.1106 & TRN & \\
\hline CHEMBL1363615 & 688282 & 5.0 & 5.0497 & TRN & \\
\hline
\end{tabular}




\begin{tabular}{|c|c|c|c|c|c|}
\hline \multicolumn{6}{|c|}{ Supplemental Table s2.txt } \\
\hline CHEMBL1606369 & 688282 & 5.0 & 5.1596 & TRN & \\
\hline CHEMBL1500966 & 688282 & 4.8 & 5.0688 & TRN & \\
\hline CHEMBL1453790 & 688282 & 8.3979 & 5.1791 & TRN & \\
\hline CHEMBL1369564 & 688282 & 4.6 & 5.1319 & TRN & \\
\hline CHEMBL1257125 & 688282 & 4.8 & 5.2561 & TRN & \\
\hline CHEMBL39372 & 688282 & 4.9 & 5.2868 & TRN & \\
\hline CHEMBL15134 & 688282 & 6.4 & 5.1865 & TST & \\
\hline CHEMBL1326295 & 688282 & 5.0 & 5.1069 & TRN & \\
\hline CHEMBL1442094 & 688282 & 6.0 & 5.2272 & TST & \\
\hline CHEMBL1476214 & 688282 & 6.3 & 5.3234 & TST & \\
\hline CHEMBL1595910 & 688282 & 5.3 & 5.1681 & TRN & \\
\hline CHEMBL1504119 & 688282 & 4.9 & 5.0168 & TRN & \\
\hline CHEMBL1475990 & 688282 & 5.0 & 4.9885 & TRN & \\
\hline CHEMBL1568990 & 688282 & 4.7 & 5.2166 & TST & \\
\hline CHEMBL40274 & 688282 & 5.6 & 5.2615 & TST & \\
\hline CHEMBL1377714 & 688282 & 5.0 & 5.0608 & TRN & \\
\hline CHEMBL1464719 & 688282 & 5.0 & 5.2455 & TRN & \\
\hline CHEMBL1232952 & 688282 & 4.9 & 5.2809 & TST & \\
\hline CHEMBL259388 & 688282 & 5.0 & 5.1162 & TST & \\
\hline CHEMBL1584500 & 688282 & 5.3 & 5.0977 & TRN & \\
\hline CHEMBL492610 & 688282 & 6.1 & 5.0978 & TRN & \\
\hline CHEMBL1569501 & 688282 & 5.6 & 5.13899 & 9999999999 & TRN \\
\hline CHEMBL1412939 & 688282 & 5.5 & 5.1677 & TRN & \\
\hline CHEMBL1523194 & 688282 & 5.1 & 5.1899 & TRN & \\
\hline CHEMBL1412163 & 688282 & 4.5 & 5.0862 & TRN & \\
\hline CHEMBL1496902 & 688282 & 4.9 & 5.1187 & TRN & \\
\hline CHEMBL1434643 & 688282 & 5.3 & 5.3042 & TRN & \\
\hline CHEMBL286721 & 688282 & 4.6 & 5.0482 & TST & \\
\hline CHEMBL1395915 & 688282 & 4.5 & 5.1484 & TRN & \\
\hline CHEMBL281622 & 688282 & 4.8 & 5.1994 & TST & \\
\hline CHEMBL1467973 & 688282 & 5.3 & 5.2256 & TRN & \\
\hline CHEMBL1524845 & 688282 & 4.6 & 5.0291 & TRN & \\
\hline CHEMBL1604435 & 688282 & 4.9 & 5.2174 & TRN & \\
\hline CHEMBL1443465 & 688282 & 4.9 & 5.1423 & TRN & \\
\hline CHEMBL1609150 & 688282 & 5.2 & 5.1226 & TRN & \\
\hline CHEMBL1382476 & 688282 & 5.0 & 5.2454 & TRN & \\
\hline CHEMBL1436979 & 688282 & 4.9 & 5.1677 & TRN & \\
\hline CHEMBL1364404 & 688282 & 5.9 & 5.069 & TRN & \\
\hline CHEMBL1373779 & 688282 & 4.9 & 5.1665 & TRN & \\
\hline CHEMBL1475487 & 688282 & 6.3 & 5.1742 & TRN & \\
\hline CHEMBL1570219 & 688282 & 5.9 & 5.1193 & TRN & \\
\hline CHEMBL184074 & 688282 & 5.3 & 5.1384 & TST & \\
\hline CHEMBL1492366 & 688282 & 5.6 & 5.1016 & TRN & \\
\hline CHEMBL1437946 & 688282 & 4.6 & 5.1342 & TRN & \\
\hline CHEMBL1440302 & 688282 & 4.9 & 5.13299 & 9999999999 & TRN \\
\hline CHEMBL1461187 & 688282 & 5.3 & 5.1579 & TRN & \\
\hline CHEMBL1458941 & 688282 & 5.7 & 5.1061 & TST & \\
\hline CHEMBL490706 & 688282 & 4.8 & 4.9612 & TRN & \\
\hline
\end{tabular}




\begin{tabular}{|c|c|c|c|c|c|}
\hline \\
\hline CHEMBL1314647 & 688282 & 4.9 & 5.0961 & TRN & \\
\hline CHEMBL194400 & 688282 & 4.8 & 5.2757 & TST & \\
\hline CHEMBL1415873 & 688282 & 5.5 & 5.1287 & TRN & \\
\hline CHEMBL1409330 & 688282 & 5.1 & 5.2047 & TST & \\
\hline CHEMBL1551049 & 688282 & 5.4 & 4.9408 & TRN & \\
\hline CHEMBL1420829 & 688282 & 4.6 & 5.0861 & TRN & \\
\hline CHEMBL1521970 & 688282 & 5.0 & 5.1435 & TRN & \\
\hline CHEMBL1375001 & 688282 & 4.6 & 5.1881 & TRN & \\
\hline CHEMBL1257013 & 688282 & 5.2 & 5.2506 & TRN & \\
\hline CHEMBL3199579 & 688282 & 4.7 & 5.2265 & TRN & \\
\hline CHEMBL1532657 & 688282 & 5.5 & 5.1468 & TRN & \\
\hline CHEMBL1200765 & 688282 & 4.5 & 5.1968 & TST & \\
\hline CHEMBL3193151 & 688282 & 5.2 & 5.0949 & TRN & \\
\hline CHEMBL1493284 & 688282 & 5.0 & 5.1376 & TRN & \\
\hline CHEMBL1302584 & 688282 & 5.6 & 5.0219 & TRN & \\
\hline CHEMBL1307923 & 688282 & 4.5 & 5.2293 & TRN & \\
\hline CHEMBL1482880 & 688282 & 5.5 & 5.195 & TRN & \\
\hline CHEMBL1417379 & 688282 & 4.8 & 5.0201 & TRN & \\
\hline CHEMBL1494059 & 688282 & 5.5 & 5.1932 & TRN & \\
\hline CHEMBL1347376 & 688282 & 5.0 & 5.0054 & TRN & \\
\hline CHEMBL1360725 & 688282 & 4.7 & 5.1547 & TST & \\
\hline CHEMBL1317306 & 688282 & 4.5 & 5.1328 & TRN & \\
\hline CHEMBL1457417 & 688282 & 4.8 & 5.1906 & TRN & \\
\hline CHEMBL1600304 & 688282 & 4.6 & 5.1614 & TRN & \\
\hline CHEMBL54909 & 688282 & 4.5 & 5.1315 & TRN & \\
\hline CHEMBL1484047 & 688282 & 5.4 & 5.1664 & TRN & \\
\hline CHEMBL1452605 & 688282 & 5.3 & 5.2194 & TRN & \\
\hline CHEMBL1524060 & 688282 & 4.6 & 5.1270 & 0000000001 & TRN \\
\hline CHEMBL1319587 & 688282 & 4.6 & 5.0423 & TRN & \\
\hline CHEMBL167468 & 688282 & 4.9 & 5.2128 & TRN & \\
\hline CHEMBL1388273 & 688282 & 4.7 & 5.0664 & TRN & \\
\hline CHEMBL1342671 & 688282 & 5.3 & 5.2481 & TRN & \\
\hline CHEMBL1566877 & 688282 & 5.0 & 5.1393 & TRN & \\
\hline CHEMBL1600340 & 688282 & 4.9 & 5.164 & TRN & \\
\hline CHEMBL114957 & 688282 & 4.5 & 5.2654 & TRN & \\
\hline CHEMBL1352062 & 688282 & 5.1 & 5.1812 & TRN & \\
\hline CHEMBL1359258 & 688282 & 5.0 & 5.0962 & TRN & \\
\hline CHEMBL1344905 & 688282 & 5.4 & 5.2911 & TST & \\
\hline CHEMBL1374898 & 688282 & 6.2 & 5.1939 & TRN & \\
\hline CHEMBL1404907 & 688282 & 4.9 & 5.2946 & TRN & \\
\hline CHEMBL1348141 & 688282 & 4.9 & 5.0485 & TRN & \\
\hline CHEMBL1610977 & 688282 & 4.9 & 5.0766 & TRN & \\
\hline CHEMBL66966 & 688282 & 6.0 & 5.2264 & TRN & \\
\hline CHEMBL1481307 & 688282 & 5.3 & 5.1392 & TRN & \\
\hline CHEMBL1370245 & 688282 & 5.0 & 5.1277 & TRN & \\
\hline CHEMBL1397610 & 688282 & 4.9 & 5.2632 & TST & \\
\hline CHEMBL1451265 & 688282 & 5.3 & 5.2584 & TST & \\
\hline CHEMBL1458782 & 688282 & 5.0 & 4.9732 & TRN & \\
\hline & & & & 1323 & \\
\hline
\end{tabular}




\begin{tabular}{|c|c|c|c|c|}
\hline & & & & $a \perp 1 a$ \\
\hline CHEMBL1540651 & 688282 & 4.9 & 5.1251 & TRN \\
\hline CHEMBL1368802 & 688282 & 5.0 & 5.1296 & TRN \\
\hline CHEMBL1481465 & 688282 & 5.0 & 5.2697 & TRN \\
\hline CHEMBL1201091 & 688282 & 4.9 & 5.0935 & TRN \\
\hline CHEMBL1579175 & 688282 & 5.0 & 4.9749 & TRN \\
\hline CHEMBL1564313 & 688282 & 5.8 & 5.1702 & TRN \\
\hline CHEMBL1433014 & 688282 & 5.0 & 5.2787 & TST \\
\hline CHEMBL1601883 & 688282 & 5.6 & 5.1837 & TRN \\
\hline CHEMBL1448901 & 688282 & 4.6 & 5.0866 & TRN \\
\hline CHEMBL1409320 & 688282 & 5.3 & 5.0568 & TRN \\
\hline CHEMBL1578547 & 688282 & 4.5 & 5.1203 & TRN \\
\hline CHEMBL1564099 & 688282 & 5.3 & 5.1229 & TRN \\
\hline CHEMBL222519 & 688282 & 5.3 & 5.1782 & TST \\
\hline CHEMBL1332719 & 688282 & 6.0 & 5.21200 & 0000000001 \\
\hline CHEMBL571296 & 688282 & 4.6 & 5.1478 & TRN \\
\hline CHEMBL1384849 & 688282 & 4.6 & 5.1015 & TRN \\
\hline CHEMBL1532308 & 688282 & 4.6 & 5.0953 & TRN \\
\hline CHEMBL1523657 & 688282 & 5.5 & 5.0683 & TST \\
\hline CHEMBL1425696 & 688282 & 5.3 & 5.0986 & TRN \\
\hline CHEMBL1396754 & 688282 & 6.0 & 5.2134 & TRN \\
\hline CHEMBL1579004 & 688282 & 5.3 & 5.1748 & TRN \\
\hline CHEMBL1556428 & 688282 & 5.5 & 5.0887 & TRN \\
\hline CHEMBL1605685 & 688282 & 6.0 & 5.102 & TRN \\
\hline CHEMBL1533214 & 688282 & 5.0 & 5.1438 & TRN \\
\hline CHEMBL170408 & 688282 & 4.6 & 5.1847 & TRN \\
\hline CHEMBL1480843 & 688282 & 5.1 & 5.2083 & TRN \\
\hline CHEMBL1462507 & 688282 & 4.6 & 5.1115 & TRN \\
\hline CHEMBL1387089 & 688282 & 5.3 & 5.1634 & TST \\
\hline CHEMBL1508483 & 688282 & 5.3 & 5.0923 & TRN \\
\hline CHEMBL1372318 & 688282 & 5.5 & 5.1185 & TRN \\
\hline CHEMBL1359573 & 688282 & 4.9 & 5.0506 & TRN \\
\hline CHEMBL1571809 & 688282 & 5.4 & 4.9917 & TRN \\
\hline CHEMBL1600077 & 688282 & 4.8 & 5.1041 & TRN \\
\hline CHEMBL1551990 & 688282 & 6.0 & 5.1791 & TST \\
\hline CHEMBL375629 & 688282 & 4.6 & 5.2001 & TST \\
\hline CHEMBL1596955 & 688282 & 4.5 & 5.0653 & TRN \\
\hline CHEMBL1611804 & 688282 & 4.9 & 5.1781 & TRN \\
\hline CHEMBL1365172 & 688282 & 4.6 & 5.0856 & TRN \\
\hline CHEMBL1575213 & 688282 & 4.6 & 5.2019 & TRN \\
\hline CHEMBL1480497 & 688282 & 4.5 & 5.0782 & TRN \\
\hline CHEMBL1320757 & 688282 & 5.3 & 5.1125 & TRN \\
\hline CHEMBL1091971 & 688282 & 6.5 & 5.2729 & TST \\
\hline CHEMBL1440509 & 688282 & 4.9 & 5.0877 & TRN \\
\hline CHEMBL464467 & 688282 & 4.5 & 5.1281 & TST \\
\hline CHEMBL1435899 & 688282 & 4.9 & 5.175 & TRN \\
\hline CHEMBL1504057 & 688282 & 4.5 & 5.2976 & TRN \\
\hline CHEMBL1448668 & 688282 & 5.6 & 5.2978 & TRN \\
\hline CHEMBL1200471 & 688282 & 6.4 & 5.3213 & TST \\
\hline
\end{tabular}




\begin{tabular}{|c|c|c|c|c|}
\hline \\
\hline CHEMBL1578692 & 688282 & 5.4 & 5.0193 & TRN \\
\hline CHEMBL1336149 & 688282 & 6.1 & 5.159 & TRN \\
\hline CHEMBL1598986 & 688282 & 6.0 & 5.0744 & TRN \\
\hline CHEMBL1364263 & 688282 & 4.9 & 5.1637 & TRN \\
\hline CHEMBL1509597 & 688282 & 5.0 & 4.9907 & TRN \\
\hline CHEMBL1544161 & 688282 & 5.3 & 5.0745 & TRN \\
\hline CHEMBL1736254 & 688282 & 5.4 & 5.2052 & TST \\
\hline CHEMBL1188431 & 688282 & 4.5 & 5.1503 & TRN \\
\hline CHEMBL1495854 & 688282 & 5.4 & 4.9803 & TRN \\
\hline CHEMBL1404703 & 688282 & 5.3 & 5.0768 & TRN \\
\hline CHEMBL1383593 & 688282 & 4.9 & 5.1083 & TRN \\
\hline CHEMBL151 & 688282 & 6.0 & 5.2602 & TRN \\
\hline CHEMBL1514307 & 688282 & 5.0 & 5.0065 & TRN \\
\hline CHEMBL1552353 & 688282 & 4.9 & 5.0851 & TRN \\
\hline CHEMBL1318120 & 688282 & 5.3 & 5.0977 & TRN \\
\hline CHEMBL1321357 & 688282 & 5.0 & 5.1071 & TRN \\
\hline CHEMBL1518058 & 688282 & 4.6 & 5.1682 & TRN \\
\hline CHEMBL1357520 & 688282 & 5.9 & 5.0453 & TRN \\
\hline CHEMBL1432468 & 688282 & 6.5 & 5.1082 & TRN \\
\hline CHEMBL1485629 & 688282 & 4.9 & 5.1789 & TST \\
\hline CHEMBL572994 & 688282 & 5.7 & 5.2734 & TST \\
\hline CHEMBL1142 & 688282 & 4.5 & 5.2953 & TRN \\
\hline CHEMBL1534302 & 688282 & 5.5 & 5.1765 & TRN \\
\hline CHEMBL1452645 & 688282 & 4.9 & 5.1762 & TRN \\
\hline CHEMBL1526577 & 688282 & 6.0 & 5.1081 & TRN \\
\hline CHEMBL1584909 & 688282 & 7.0 & 5.2011 & TRN \\
\hline CHEMBL1552028 & 688282 & 4.9 & 5.0329 & TRN \\
\hline CHEMBL1439839 & 688282 & 4.9 & 5.0821 & TRN \\
\hline CHEMBL1423454 & 688282 & 5.7 & 5.2245 & TRN \\
\hline CHEMBL1591544 & 688282 & 4.9 & 5.1372 & TRN \\
\hline CHEMBL1466239 & 688282 & 4.5 & 5.1406 & TRN \\
\hline CHEMBL1448090 & 688282 & 5.3 & 5.0812 & TRN \\
\hline CHEMBL1519490 & 688282 & 6.0 & 5.2475 & TST \\
\hline CHEMBL1545426 & 688282 & 5.0 & 5.1429 & TRN \\
\hline CHEMBL1384351 & 688282 & 5.3 & 5.0944 & TRN \\
\hline CHEMBL1587018 & 688282 & 6.6 & 5.1088 & TRN \\
\hline CHEMBL1521329 & 688282 & 6.0 & 5.1993 & TRN \\
\hline CHEMBL1311173 & 688282 & 4.9 & 5.1382 & TRN \\
\hline CHEMBL1443366 & 688282 & 4.5 & 5.0977 & TRN \\
\hline CHEMBL1524851 & 688282 & 4.9 & 5.1845 & TRN \\
\hline CHEMBL1470766 & 688282 & 5.3 & 5.1086 & TRN \\
\hline CHEMBL1334327 & 688282 & 6.0 & 5.12799 & 9999999999 \\
\hline CHEMBL586 & 688282 & 5.4 & 5.2868 & TRN \\
\hline CHEMBL1564618 & 688282 & 5.0 & 5.1688 & TRN \\
\hline CHEMBL12998 & 688282 & 4.5 & 5.0251 & TST \\
\hline CHEMBL1328339 & 688282 & 5.0 & 5.239 & TRN \\
\hline CHEMBL 545050 & 688282 & 6.0 & 5.265 & TRN \\
\hline CHEMBL1337479 & 688282 & 6.2 & 5.2594 & TRN \\
\hline
\end{tabular}

TRN 


\begin{tabular}{|c|c|c|c|c|c|}
\hline \multirow[b]{2}{*}{ CHEMBL1605078 } & \\
\hline & 688282 & 5.2 & 5.05 & TRN & \\
\hline CHEMBL1479088 & 688282 & 4.5 & 5.1467 & TRN & \\
\hline CHEMBL1569619 & 688282 & 5.6 & 5.2363 & TRN & \\
\hline CHEMBL131244 & 688282 & 4.9 & 5.3728 & TST & \\
\hline CHEMBL287689 & 688282 & 5.4 & 5.24299 & 9999999999 & TST \\
\hline CHEMBL1529669 & 688282 & 4.5 & 5.0452 & TRN & \\
\hline CHEMBL1445729 & 688282 & 4.6 & 4.9789 & TRN & \\
\hline CHEMBL1993164 & 688282 & 5.7 & 5.0468 & TST & \\
\hline CHEMBL1407762 & 688282 & 5.0 & 5.0816 & TRN & \\
\hline CHEMBL1540011 & 688282 & 8.3979 & 5.1188 & TRN & \\
\hline CHEMBL1346626 & 688282 & 4.9 & 5.143 & TRN & \\
\hline CHEMBL1424313 & 688282 & 5.5 & 5.0826 & TRN & \\
\hline CHEMBL1513936 & 688282 & 5.0 & 5.0994 & TRN & \\
\hline CHEMBL1523375 & 688282 & 4.9 & 5.0625 & TRN & \\
\hline CHEMBL1497433 & 688282 & 5.7 & 5.0092 & TRN & \\
\hline CHEMBL1536007 & 688282 & 8.3979 & 5.1963 & TRN & \\
\hline CHEMBL1344112 & 688282 & 4.9 & 5.0121 & TRN & \\
\hline CHEMBL18115 & 688282 & 5.4 & 5.2057 & TRN & \\
\hline CHEMBL1495910 & 688282 & 5.5 & 5.0914 & TRN & \\
\hline CHEMBL1533155 & 688282 & 4.5 & 5.17399 & 99999999995 & TRN \\
\hline CHEMBL1329725 & 688282 & 5.3 & 5.0178 & TRN & \\
\hline CHEMBL 3195587 & 688282 & 4.6 & 5.1889 & TRN & \\
\hline CHEMBL1457192 & 688282 & 4.8 & 5.0375 & TRN & \\
\hline CHEMBL559612 & 688282 & 4.5 & 5.15 & TST & \\
\hline CHEMBL1471212 & 688282 & 5.0 & 5.0693 & TRN & \\
\hline CHEMBL1568019 & 688282 & 4.6 & 5.2056 & TRN & \\
\hline CHEMBL1385902 & 688282 & 4.5 & 5.1038 & TRN & \\
\hline CHEMBL1611300 & 688282 & 5.0 & 5.1531 & TRN & \\
\hline CHEMBL1331410 & 688282 & 4.8 & 5.1524 & TRN & \\
\hline CHEMBL1317232 & 688282 & 5.3 & 5.315 & TRN & \\
\hline CHEMBL1358065 & 688282 & 6.4 & 5.1149 & TRN & \\
\hline CHEMBL1401293 & 688282 & 5.3 & 5.1088 & TRN & \\
\hline CHEMBL1419804 & 688282 & 6.2 & 5.0201 & TRN & \\
\hline CHEMBL 244743 & 688282 & 4.9 & 5.2524 & TRN & \\
\hline CHEMBL1548294 & 688282 & 4.8 & 5.2059 & TST & \\
\hline CHEMBL1520793 & 688282 & 5.3 & 5.0918 & TRN & \\
\hline CHEMBL162598 & 688282 & 5.4 & 5.3365 & TST & \\
\hline CHEMBL1541721 & 688282 & 5.5 & 5.24799 & 9999999999 & TRN \\
\hline CHEMBL1590191 & 688282 & 5.4 & 5.2071 & TRN & \\
\hline CHEMBL1327534 & 688282 & 4.8 & 5.0835 & TRN & \\
\hline CHEMBL1302977 & 688282 & 5.3 & 5.0695 & TRN & \\
\hline CHEMBL1316779 & 688282 & 4.9 & 5.0349 & TRN & \\
\hline CHEMBL391997 & 688282 & 6.0 & 5.1572 & TST & \\
\hline CHEMBL1574106 & 688282 & 5.0 & 5.0978 & TRN & \\
\hline CHEMBL1331593 & 688282 & 4.6 & 5.1389 & TRN & \\
\hline CHEMBL1310133 & 688282 & 4.9 & 5.0751 & TRN & \\
\hline CHEMBL1481741 & 688282 & 5.5 & 5.295 & TRN & \\
\hline CHEMBL1324825 & 688282 & 4.6 & 5.2544 & TRN & \\
\hline & & & & 13238 & \\
\hline
\end{tabular}




\begin{tabular}{|c|c|c|c|c|c|}
\hline & & & & & \\
\hline CHEMBL1565677 & 688282 & 4.9 & 5.0901 & TRN & \\
\hline CHEMBL1576366 & 688282 & 4.6 & 5.1501 & TRN & \\
\hline CHEMBL1378666 & 688282 & 4.8 & 5.188 & TST & \\
\hline CHEMBL1532912 & 688282 & 6.4 & 5.0864 & TRN & \\
\hline CHEMBL1367021 & 688282 & 5.3 & 5.1425 & TRN & \\
\hline CHEMBL1414263 & 688282 & 4.6 & 5.2471 & TRN & \\
\hline CHEMBL1307769 & 688282 & 5.9 & 5.0355 & TRN & \\
\hline CHEMBL579111 & 688282 & 4.8 & 5.1912 & TRN & \\
\hline CHEMBL1545040 & 688282 & 5.2 & 5.0904 & TRN & \\
\hline CHEMBL1453552 & 688282 & 4.7 & 5.0398 & TRN & \\
\hline CHEMBL1330924 & 688282 & 5.9 & 5.1546 & TRN & \\
\hline CHEMBL1531569 & 688282 & 4.6 & 5.1933 & TRN & \\
\hline CHEMBL1433152 & 688282 & 5.0 & 5.0832 & TRN & \\
\hline CHEMBL1499554 & 688282 & 5.0 & 5.0806 & TRN & \\
\hline CHEMBL1592679 & 688282 & 4.9 & 5.1404 & TRN & \\
\hline CHEMBL1584470 & 688282 & 4.7 & 5.1275 & TRN & \\
\hline CHEMBL 270299 & 688282 & 6.0 & 5.2777 & TRN & \\
\hline CHEMBL1473420 & 688282 & 5.0 & 5.0813 & TRN & \\
\hline CHEMBL1524650 & 688282 & 4.9 & 5.2096 & TRN & \\
\hline CHEMBL1311609 & 688282 & 5.5 & 5.1962 & TRN & \\
\hline CHEMBL589101 & 688282 & 5.1 & 5.20100 & 00000000005 & TRN \\
\hline CHEMBL1449036 & 688282 & 6.7001 & 5.17899 & 9999999999 & TST \\
\hline CHEMBL1379766 & 688282 & 4.7 & 5.0483 & TRN & \\
\hline CHEMBL1433762 & 688282 & 4.5 & 5.0773 & TRN & \\
\hline CHEMBL311389 & 688282 & 4.9 & 5.2179 & TRN & \\
\hline CHEMBL1392736 & 688282 & 4.7 & 5.1936 & TRN & \\
\hline CHEMBL3351064 & 688282 & 5.4 & 5.2144 & TST & \\
\hline CHEMBL 1447674 & 688282 & 4.6 & 5.1316 & TRN & \\
\hline CHEMBL1543940 & 688282 & 5.0 & 5.0552 & TRN & \\
\hline CHEMBL1432983 & 688282 & 5.0 & 5.2164 & TRN & \\
\hline CHEMBL1351861 & 688282 & 5.9 & 5.1911 & TRN & \\
\hline CHEMBL318779 & 688282 & 4.8 & 5.2458 & TRN & \\
\hline CHEMBL1423690 & 688282 & 7.0 & 5.1946 & TRN & \\
\hline CHEMBL1379228 & 688282 & 5.0 & 5.0607 & TRN & \\
\hline CHEMBL1443682 & 688282 & 5.4 & 5.2969 & TST & \\
\hline CHEMBL1529110 & 688282 & 4.9 & 5.2476 & TRN & \\
\hline CHEMBL1607512 & 688282 & 6.1 & 5.1177 & TRN & \\
\hline CHEMBL1305681 & 688282 & 5.5 & 5.0671 & TRN & \\
\hline CHEMBL1503953 & 688282 & 4.5 & 5.0946 & TRN & \\
\hline CHEMBL1401837 & 688282 & 5.3 & 5.1672 & TRN & \\
\hline CHEMBL1580437 & 688282 & 4.6 & 5.0637 & TRN & \\
\hline CHEMBL1426535 & 688282 & 4.8 & 5.1524 & TRN & \\
\hline CHEMBL1397623 & 688282 & 6.4 & 5.1503 & TRN & \\
\hline CHEMBL1460497 & 688282 & 4.9 & 5.046 & TRN & \\
\hline CHEMBL1529538 & 688282 & 4.9 & 5.1289 & TST & \\
\hline CHEMBL1593707 & 688282 & 4.9 & 5.1915 & TRN & \\
\hline CHEMBL1430423 & 688282 & 5.7 & 5.1381 & TST & \\
\hline CHEMBL1452881 & 688282 & 4.9 & 5.2065 & TST & \\
\hline & & & & 13239 & \\
\hline
\end{tabular}




\begin{tabular}{|c|c|c|c|c|c|}
\hline & & & & & \\
\hline CHEMBL1527671 & 688282 & 5.1 & 5.1754 & TST & \\
\hline CHEMBL1608208 & 688282 & 4.9 & 5.0284 & TRN & \\
\hline CHEMBL1592220 & 688282 & 6.4 & 5.3035 & TRN & \\
\hline CHEMBL1613499 & 688282 & 5.0 & 5.1338 & TRN & \\
\hline CHEMBL467623 & 688282 & 4.6 & 5.178 & TRN & \\
\hline CHEMBL1610143 & 688282 & 4.9 & 5.1977 & TST & \\
\hline CHEMBL1387956 & 688282 & 5.3 & 5.0962 & TRN & \\
\hline CHEMBL463783 & 688282 & 6.0 & 4.9653 & TRN & \\
\hline CHEMBL1417726 & 688282 & 5.1 & 5.1278 & TRN & \\
\hline CHEMBL1516006 & 688282 & 5.0 & 5.0548 & TRN & \\
\hline CHEMBL1314388 & 688282 & 4.9 & 5.0939 & TRN & \\
\hline CHEMBL1497693 & 688282 & 4.6 & 5.0447 & TRN & \\
\hline CHEMBL1421772 & 688282 & 5.0 & 5.0781 & TST & \\
\hline CHEMBL56731 & 688282 & 4.6 & 5.2626 & TRN & \\
\hline CHEMBL1536604 & 688282 & 4.6 & 5.1097 & TRN & \\
\hline CHEMBL1486729 & 688282 & 4.9 & 5.2029 & TRN & \\
\hline CHEMBL3208922 & 688282 & 5.5 & 5.0767 & TRN & \\
\hline CHEMBL1443752 & 688282 & 5.3 & 5.1386 & TST & \\
\hline CHEMBL1507819 & 688282 & 5.1 & 5.0437 & TRN & \\
\hline CHEMBL1318041 & 688282 & 4.9 & 5.1149 & TRN & \\
\hline CHEMBL1256660 & 688282 & 4.6 & 5.1292 & TRN & \\
\hline CHEMBL1360852 & 688282 & 4.9 & 5.0765 & TRN & \\
\hline CHEMBL1446139 & 688282 & 5.8 & 5.274 & TRN & \\
\hline CHEMBL1320468 & 688282 & 5.3 & 5.1167 & TST & \\
\hline CHEMBL1329026 & 688282 & 6.4 & 5.1064 & TST & \\
\hline CHEMBL2002776 & 688282 & 5.0 & 5.0989 & TRN & \\
\hline CHEMBL1482155 & 688282 & 5.0 & 5.0 & TRN & \\
\hline CHEMBL1334016 & 688282 & 4.5 & 5.1722 & TRN & \\
\hline CHEMBL1464629 & 688282 & 4.5 & 5.17299 & 9999999999 & TRN \\
\hline CHEMBL1558130 & 688282 & 5.0 & 5.0789 & TRN & \\
\hline CHEMBL1398543 & 688282 & 4.9 & 5.0767 & TRN & \\
\hline CHEMBL1506967 & 688282 & 4.8 & 5.1758 & TRN & \\
\hline CHEMBL468759 & 688282 & 4.7 & 5.2752 & TRN & \\
\hline CHEMBL1325335 & 688282 & 4.9 & 5.1793 & TRN & \\
\hline CHEMBL1331836 & 688282 & 5.6 & 5.1742 & TST & \\
\hline CHEMBL1303766 & 688282 & 5.5 & 5.2291 & TRN & \\
\hline CHEMBL1537386 & 688282 & 5.0 & 5.2025 & TST & \\
\hline CHEMBL1367539 & 688282 & 6.4 & 5.1454 & TRN & \\
\hline CHEMBL1554826 & 688282 & 4.6 & 5.0993 & TRN & \\
\hline CHEMBL1429566 & 688282 & 4.9 & 5.0874 & TRN & \\
\hline CHEMBL1445578 & 688282 & 7.0 & 5.0523 & TRN & \\
\hline CHEMBL1567280 & 688282 & 6.8 & 5.2342 & TRN & \\
\hline CHEMBL1459733 & 688282 & 6.0 & 5.1954 & TRN & \\
\hline CHEMBL416657 & 688282 & 4.6 & 5.1471 & TST & \\
\hline CHEMBL1521409 & 688282 & 5.3 & 5.13 & TRN & \\
\hline CHEMBL1493037 & 688282 & 4.5 & 5.2438 & TRN & \\
\hline CHEMBL1606924 & 688282 & 5.0 & 5.225 & TRN & \\
\hline CHEMBL196590 & 688282 & 4.5 & 5.2178 & TRN & \\
\hline & & & & 13240 & \\
\hline
\end{tabular}




\begin{tabular}{|c|c|c|c|c|}
\hline \multicolumn{5}{|c|}{ Supplemental T } \\
\hline CHEMBL1422353 & 688282 & 5.7 & 5.1754 & TRN \\
\hline CHEMBL1568668 & 688282 & 4.6 & 5.1127 & TRN \\
\hline CHEMBL1442668 & 688282 & 5.2 & 5.0568 & TRN \\
\hline CHEMBL1329597 & 688282 & 6.0 & 5.175 & TRN \\
\hline CHEMBL1497248 & 688282 & 5.1 & 5.1543 & TRN \\
\hline CHEMBL1606419 & 688282 & 4.5 & 5.0372 & TRN \\
\hline CHEMBL1406937 & 688282 & 5.4 & 5.0685 & TRN \\
\hline CHEMBL1411146 & 688282 & 4.9 & 5.1162 & TRN \\
\hline CHEMBL1412044 & 688282 & 6.9 & 5.1858 & TST \\
\hline CHEMBL1434882 & 688282 & 4.8 & 5.1167 & TRN \\
\hline CHEMBL1613358 & 688282 & 6.4 & 5.2235 & TST \\
\hline CHEMBL1369097 & 688282 & 4.5 & 5.0186 & TRN \\
\hline CHEMBL1596769 & 688282 & 5.7 & 5.1649 & TST \\
\hline CHEMBL1491974 & 688282 & 6.5 & 5.2677 & TRN \\
\hline CHEMBL1304204 & 688282 & 4.9 & 5.1432 & TRN \\
\hline CHEMBL1604272 & 688282 & 4.8 & 5.1633 & TRN \\
\hline CHEMBL9352 & 688282 & 4.9 & 5.2677 & TRN \\
\hline CHEMBL1319312 & 688282 & 4.9 & 5.063 & TRN \\
\hline CHEMBL1488125 & 688282 & 4.6 & 5.1676 & TRN \\
\hline CHEMBL1593582 & 688282 & 4.9 & 5.0996 & TRN \\
\hline CHEMBL 2374026 & 688282 & 6.0 & 5.3143 & TST \\
\hline CHEMBL1523429 & 688282 & 5.0 & 5.1184 & TRN \\
\hline CHEMBL1384524 & 688282 & 5.3 & 5.1349 & TRN \\
\hline CHEMBL1610645 & 688282 & 4.9 & 5.1234 & TRN \\
\hline CHEMBL1554236 & 688282 & 5.2 & 5.0963 & TRN \\
\hline CHEMBL1569751 & 688282 & 5.0 & 5.0962 & TRN \\
\hline CHEMBL1447715 & 688282 & 5.3 & 5.143 & TRN \\
\hline CHEMBL1456751 & 688282 & 5.5 & 4.9543 & TRN \\
\hline CHEMBL1376627 & 688282 & 4.5 & 5.1102 & TRN \\
\hline CHEMBL1576518 & 688282 & 5.0 & 5.2419 & TRN \\
\hline CHEMBL1429929 & 688282 & 6.2 & 5.08 & TRN \\
\hline CHEMBL1421005 & 688282 & 4.9 & 5.1762 & TRN \\
\hline CHEMBL1424982 & 688282 & 4.6 & 5.0723 & TRN \\
\hline CHEMBL1415156 & 688282 & 5.0 & 5.1599 & TRN \\
\hline CHEMBL1571456 & 688282 & 4.6 & 5.1719 & TRN \\
\hline CHEMBL1474468 & 688282 & 5.0 & 5.1803 & TRN \\
\hline CHEMBL1182777 & 688282 & 4.5 & 5.2299 & TST \\
\hline CHEMBL502044 & 688282 & 4.5 & 5.2957 & TST \\
\hline CHEMBL1412368 & 688282 & 4.6 & 5.2695 & TRN \\
\hline CHEMBL1519472 & 688282 & 5.9 & 5.1261 & TRN \\
\hline CHEMBL157368 & 688282 & 5.6 & 5.2915 & TST \\
\hline CHEMBL1343750 & 688282 & 5.3 & 5.0603 & TRN \\
\hline CHEMBL1325701 & 688282 & 5.2 & 5.0953 & TRN \\
\hline CHEMBL1314625 & 688282 & 4.6 & 5.0525 & TRN \\
\hline CHEMBL1307887 & 688282 & 4.6 & 5.1793 & TRN \\
\hline CHEMBL1358252 & 688282 & 5.1 & 5.1236 & TRN \\
\hline CHEMBL1397169 & 688282 & 4.6 & 5.2205 & TST \\
\hline CHEMBL1484447 & 688282 & 4.9 & 5.16 & TST \\
\hline
\end{tabular}




\begin{tabular}{|c|c|c|c|c|}
\hline \multicolumn{5}{|c|}{ Supplemental Table S2.txt } \\
\hline CHEMBL1473753 & 688282 & 6.0 & 5.3024 & TRN \\
\hline CHEMBL3213599 & 688282 & 4.5 & 5.1112 & TRN \\
\hline CHEMBL1518947 & 688282 & 4.8 & 5.0697 & TRN \\
\hline CHEMBL1318739 & 688282 & 6.8 & 5.2804 & TST \\
\hline CHEMBL1354678 & 688282 & 5.6 & 5.1791 & TRN \\
\hline CHEMBL1407267 & 688282 & 5.1 & 5.0983 & TRN \\
\hline CHEMBL1423290 & 688282 & 5.3 & 5.1596 & TRN \\
\hline CHEMBL1592557 & 688282 & 4.9 & 4.9759 & TRN \\
\hline CHEMBL 34450 & 688282 & 4.5 & 5.0328 & TRN \\
\hline CHEMBL1516601 & 688282 & 4.9 & 4.9855 & TRN \\
\hline CHEMBL1510445 & 688282 & 5.1 & 5.0678 & TRN \\
\hline CHEMBL587714 & 688282 & 4.6 & 5.1541 & TRN \\
\hline CHEMBL1507573 & 688282 & 5.3 & 5.13200 & 0000000001 \\
\hline CHEMBL1558135 & 688282 & 4.9 & 5.0678 & TRN \\
\hline CHEMBL1367201 & 688282 & 4.9 & 5.2398 & TST \\
\hline CHEMBL1476108 & 688282 & 4.9 & 5.2504 & TRN \\
\hline CHEMBL1557820 & 688282 & 5.2 & 5.1335 & TST \\
\hline CHEMBL1330138 & 688282 & 5.1 & 5.0356 & TRN \\
\hline CHEMBL1554725 & 688282 & 4.7 & 5.0884 & TRN \\
\hline CHEMBL1316775 & 688282 & 5.0 & 5.1368 & TRN \\
\hline CHEMBL1598394 & 688282 & 4.6 & 5.1608 & TRN \\
\hline CHEMBL1556679 & 688282 & 5.6 & 5.2206 & TST \\
\hline CHEMBL1611220 & 688282 & 5.4 & 5.2035 & TST \\
\hline CHEMBL1546263 & 688282 & 5.1 & 5.1319 & TRN \\
\hline CHEMBL1527615 & 688282 & 4.9 & 5.1887 & TRN \\
\hline CHEMBL1983700 & 688282 & 5.3 & 5.1433 & TST \\
\hline CHEMBL1363818 & 688282 & 5.1 & 5.0309 & TRN \\
\hline CHEMBL1411201 & 688282 & 4.8 & 5.0962 & TRN \\
\hline CHEMBL1337448 & 688282 & 5.3 & 5.2174 & TST \\
\hline CHEMBL95431 & 688282 & 5.8 & 5.1616 & TRN \\
\hline CHEMBL1382629 & 688282 & 4.6 & 5.2203 & TRN \\
\hline CHEMBL 1378440 & 688282 & 4.8 & 5.0219 & TRN \\
\hline CHEMBL1526913 & 688282 & 4.9 & 5.1785 & TRN \\
\hline CHEMBL1373384 & 688282 & 4.6 & 5.059 & TRN \\
\hline CHEMBL510275 & 688282 & 6.0 & 5.146 & TST \\
\hline CHEMBL54277 & 688282 & 4.5 & 5.2114 & TRN \\
\hline CHEMBL1354424 & 688282 & 4.5 & 5.2327 & TST \\
\hline CHEMBL1363939 & 688282 & 5.8 & 5.0317 & TRN \\
\hline CHEMBL1406274 & 688282 & 6.0 & 5.1547 & TRN \\
\hline CHEMBL1568575 & 688282 & 8.3979 & 5.1449 & TRN \\
\hline CHEMBL1405600 & 688282 & 4.8 & 5.2091 & TRN \\
\hline CHEMBL558459 & 688282 & 4.9 & 5.2706 & TRN \\
\hline CHEMBL1477253 & 688282 & 4.6 & 5.0346 & TRN \\
\hline CHEMBL1516948 & 688282 & 5.3 & 5.142 & TRN \\
\hline CHEMBL1611681 & 688282 & 4.6 & 5.1373 & TRN \\
\hline CHEMBL1438751 & 688282 & 4.8 & 5.1183 & TST \\
\hline CHEMBL 283130 & 688282 & 4.9 & 5.2963 & TST \\
\hline CHEMBL92708 & 688282 & 4.9 & 5.1602 & TRN \\
\hline
\end{tabular}




\begin{tabular}{|c|c|c|c|c|c|}
\hline \multicolumn{6}{|c|}{ Supplemental Table S2.txt } \\
\hline CHEMBL1609700 & 688282 & 6.0 & 5.2806 & TRN & \\
\hline CHEMBL1533904 & 688282 & 8.3979 & 5.1175 & TRN & \\
\hline CHEMBL1309869 & 688282 & 4.8 & 5.1799 & TRN & \\
\hline CHEMBL1339735 & 688282 & 5.0 & 5.1018 & TRN & \\
\hline CHEMBL1422976 & 688282 & 4.9 & 5.0174 & TRN & \\
\hline CHEMBL1405122 & 688282 & 7.8013 & 5.2874 & TST & \\
\hline CHEMBL1492910 & 688282 & 4.7 & 5.1564 & TRN & \\
\hline CHEMBL1526168 & 688282 & 4.8 & 5.0819 & TRN & \\
\hline CHEMBL1602645 & 688282 & 4.9 & 5.1207 & TRN & \\
\hline CHEMBL1329478 & 688282 & 6.4 & 5.3092 & TST & \\
\hline CHEMBL1380257 & 688282 & 4.9 & 5.1255 & TRN & \\
\hline CHEMBL1397877 & 688282 & 5.0 & 5.0809 & TRN & \\
\hline CHEMBL1362939 & 688282 & 4.9 & 5.1798 & TRN & \\
\hline CHEMBL1542958 & 688282 & 5.3 & 5.12 & TRN & \\
\hline CHEMBL1981464 & 688282 & 4.5 & 5.1957 & TRN & \\
\hline CHEMBL455531 & 688282 & 4.6 & 5.1791 & TRN & \\
\hline CHEMBL1303731 & 688282 & 4.9 & 5.2156 & TRN & \\
\hline CHEMBL581194 & 688282 & 4.9 & 5.0757 & TRN & \\
\hline CHEMBL1546569 & 688282 & 5.3 & 5.2581 & TST & \\
\hline CHEMBL1511045 & 688282 & 5.3 & 4.98300 & 20000000005 & TRN \\
\hline CHEMBL3197660 & 688282 & 4.6 & 5.0403 & TST & \\
\hline CHEMBL1518338 & 688282 & 5.5 & 5.181 & TRN & \\
\hline CHEMBL1407012 & 688282 & 5.5 & 5.2532 & TRN & \\
\hline CHEMBL1516103 & 688282 & 4.5 & 5.0554 & TRN & \\
\hline CHEMBL1559756 & 688282 & 5.3 & 4.9697 & TRN & \\
\hline CHEMBL1408032 & 688282 & 4.6 & 5.008 & TRN & \\
\hline CHEMBL1600878 & 688282 & 5.0 & 5.2232 & TRN & \\
\hline CHEMBL1371239 & 688282 & 4.9 & 5.0617 & TRN & \\
\hline CHEMBL1465062 & 688282 & 5.3 & 5.2134 & TRN & \\
\hline CHEMBL1381064 & 688282 & 5.0 & 5.0862 & TRN & \\
\hline CHEMBL1355831 & 688282 & 5.0 & 5.3249 & TRN & \\
\hline CHEMBL1354142 & 688282 & 5.0 & 5.2491 & TRN & \\
\hline CHEMBL1403605 & 688282 & 4.5 & 5.1895 & TRN & \\
\hline CHEMBL1386920 & 688282 & 6.2 & 5.1553 & TST & \\
\hline CHEMBL1339679 & 688282 & 5.0 & 5.2413 & TRN & \\
\hline CHEMBL3191553 & 688282 & 5.4 & 5.1892 & TRN & \\
\hline CHEMBL1323139 & 688282 & 5.0 & 5.1415 & TRN & \\
\hline CHEMBL1594460 & 688282 & 4.6 & 5.0548 & TRN & \\
\hline CHEMBL1317373 & 688282 & 5.2 & 5.1547 & TRN & \\
\hline CHEMBL1581337 & 688282 & 5.6 & 5.1005 & TRN & \\
\hline CHEMBL1364723 & 688282 & 4.5 & 5.1712 & TRN & \\
\hline CHEMBL1340259 & 688282 & 4.7 & 5.1578 & TRN & \\
\hline CHEMBL1373061 & 688282 & 5.0 & 5.0819 & TRN & \\
\hline CHEMBL1403656 & 688282 & 4.9 & 5.11600 & 00000000005 & TRN \\
\hline CHEMBL1464387 & 688282 & 4.5 & 5.1992 & TRN & \\
\hline CHEMBL1590266 & 688282 & 4.9 & 4.9713 & TRN & \\
\hline CHEMBL3207894 & 688282 & 5.4 & 5.126 & TRN & \\
\hline CHEMBL1451306 & 688282 & 5.0 & 5.1663 & TRN & \\
\hline
\end{tabular}




\begin{tabular}{|c|c|c|c|c|}
\hline \multicolumn{5}{|c|}{ Supplemental Table S2.txt } \\
\hline CHEMBL489525 & 688282 & 4.9 & 5.1082 & TRN \\
\hline CHEMBL1303653 & 688282 & 4.9 & 5.1997 & TRN \\
\hline CHEMBL1544780 & 688282 & 5.0 & 5.0309 & TRN \\
\hline CHEMBL1390086 & 688282 & 4.9 & 5.1422 & TRN \\
\hline CHEMBL1410187 & 688282 & 4.7 & 5.0116 & TRN \\
\hline CHEMBL356688 & 688282 & 4.6 & 5.1277 & TRN \\
\hline CHEMBL1324042 & 688282 & 4.9 & 5.1152 & TST \\
\hline CHEMBL 323197 & 688282 & 4.9 & 5.1706 & TRN \\
\hline CHEMBL1528303 & 688282 & 5.0 & 5.1114 & TST \\
\hline CHEMBL1446829 & 688282 & 8.1024 & 5.1504 & TRN \\
\hline CHEMBL1380975 & 688282 & 4.9 & 5.0216 & TRN \\
\hline CHEMBL1439371 & 688282 & 5.0 & 5.1181 & TRN \\
\hline CHEMBL1412893 & 688282 & 4.6 & 5.1195 & TRN \\
\hline CHEMBL1565336 & 688282 & 6.0 & 5.2166 & TRN \\
\hline CHEMBL1354414 & 688282 & 5.4 & 5.2196 & TST \\
\hline CHEMBL1570352 & 688282 & 4.5 & 5.0592 & TRN \\
\hline CHEMBL1404954 & 688282 & 6.9 & 4.9993 & TRN \\
\hline CHEMBL1505133 & 688282 & 7.699 & 5.0232 & TRN \\
\hline CHEMBL1530314 & 688282 & 5.3 & 5.0843 & TRN \\
\hline CHEMBL1434411 & 688282 & 5.6 & 5.0404 & TRN \\
\hline CHEMBL1443376 & 688282 & 4.9 & 5.1628 & TRN \\
\hline CHEMBL1324079 & 688282 & 5.0 & 5.0315 & TRN \\
\hline CHEMBL1384025 & 688282 & 5.0 & 5.1234 & TRN \\
\hline CHEMBL1402218 & 688282 & 4.5 & 5.1072 & TRN \\
\hline CHEMBL1526699 & 688282 & 6.1 & 5.0869 & TRN \\
\hline CHEMBL1459428 & 688282 & 4.6 & 5.0791 & TRN \\
\hline CHEMBL1599856 & 688282 & 4.9 & 5.0722 & TRN \\
\hline CHEMBL1603128 & 688282 & 4.6 & 5.1788 & TRN \\
\hline CHEMBL1306058 & 688282 & 4.5 & 5.1088 & TRN \\
\hline CHEMBL1459318 & 688282 & 5.9 & 5.0093 & TRN \\
\hline CHEMBL1327368 & 688282 & 4.6 & 5.1087 & TRN \\
\hline CHEMBL1324546 & 688282 & 5.4 & 5.1758 & TRN \\
\hline CHEMBL1452057 & 688282 & 7.6003 & 5.2428 & TRN \\
\hline CHEMBL1573433 & 688282 & 6.6 & 5.2038 & TRN \\
\hline CHEMBL1449678 & 688282 & 4.9 & 5.0433 & TRN \\
\hline CHEMBL1490409 & 688282 & 4.8 & 5.0851 & TRN \\
\hline CHEMBL1410131 & 688282 & 5.4 & 5.1518 & TRN \\
\hline CHEMBL1602963 & 688282 & 5.1 & 4.9881 & TRN \\
\hline CHEMBL1523769 & 688282 & 4.6 & 5.0662 & TRN \\
\hline CHEMBL1610457 & 688282 & 5.4 & 5.0336 & TRN \\
\hline CHEMBL1515997 & 688282 & 4.6 & 5.2761 & TRN \\
\hline CHEMBL1327501 & 688282 & 5.0 & 5.088 & TRN \\
\hline CHEMBL1418282 & 688282 & 5.1 & 5.1497 & TRN \\
\hline CHEMBL1373796 & 688282 & 5.6 & 5.1789 & TRN \\
\hline CHEMBL294747 & 688282 & 4.9 & 5.0097 & TRN \\
\hline CHEMBL1318114 & 688282 & 4.9 & 4.9423 & TRN \\
\hline CHEMBL1543290 & 688282 & 5.3 & 5.1611 & TRN \\
\hline CHEMBL1372694 & 688282 & 4.9 & 5.0386 & TRN \\
\hline
\end{tabular}




\begin{tabular}{|c|c|c|c|c|}
\hline & & & & \\
\hline CHEMBL1567353 & 688282 & 6.0 & 5.2469 & TRN \\
\hline CHEMBL1593199 & 688282 & 5.8 & 5.146 & TRN \\
\hline CHEMBL1602519 & 688282 & 5.3 & 5.1425 & TRN \\
\hline CHEMBL1534488 & 688282 & 5.0 & 5.021 & TRN \\
\hline CHEMBL1598062 & 688282 & 5.6 & 5.26 & TRN \\
\hline CHEMBL56543 & 688282 & 4.9 & 5.263 & TRN \\
\hline CHEMBL1372039 & 688282 & 4.5 & 5.1079 & TRN \\
\hline CHEMBL93353 & 688282 & 5.0 & 5.1474 & TRN \\
\hline CHEMBL1403639 & 688282 & 5.4 & 4.997 & TRN \\
\hline CHEMBL3349050 & 688282 & 5.3 & 5.1373 & TRN \\
\hline CHEMBL1586872 & 688282 & 4.8 & 5.1806 & TRN \\
\hline CHEMBL1611372 & 688282 & 4.6 & 5.1174 & TRN \\
\hline CHEMBL1595774 & 688282 & 5.0 & 5.1102 & TRN \\
\hline CHEMBL1430644 & 688282 & 5.4 & 5.1557 & TRN \\
\hline CHEMBL1358341 & 688282 & 6.9 & 5.1764 & TRN \\
\hline CHEMBL1518405 & 688282 & 4.9 & 5.0461 & TRN \\
\hline CHEMBL1345964 & 688282 & 5.3 & 5.1508 & TRN \\
\hline CHEMBL1288014 & 688282 & 5.6 & 5.1547 & TRN \\
\hline CHEMBL1483133 & 688282 & 4.9 & 5.0292 & TRN \\
\hline CHEMBL1321552 & 688282 & 6.9 & 5.2115 & TST \\
\hline CHEMBL1498973 & 688282 & 4.6 & 5.1662 & TRN \\
\hline CHEMBL1524034 & 688282 & 4.6 & 5.2658 & TRN \\
\hline CHEMBL1441821 & 688282 & 4.5 & 5.225 & TRN \\
\hline CHEMBL1561932 & 688282 & 4.5 & 5.1699 & TRN \\
\hline CHEMBL 3199262 & 688282 & 5.0 & 5.2284 & TST \\
\hline CHEMBL445102 & 688282 & 4.8 & 5.1877 & TRN \\
\hline CHEMBL1539013 & 688282 & 5.3 & 5.0858 & TRN \\
\hline CHEMBL1497370 & 688282 & 4.6 & 5.0848 & TRN \\
\hline CHEMBL1599234 & 688282 & 5.5 & 5.1217 & TRN \\
\hline CHEMBL 1451690 & 688282 & 6.3 & 5.155 & TRN \\
\hline CHEMBL1472090 & 688282 & 5.0 & 5.0418 & TRN \\
\hline CHEMBL 21260 & 688282 & 6.0 & 5.1787 & TST \\
\hline CHEMBL1495861 & 688282 & 5.5 & 5.1375 & TST \\
\hline CHEMBL1555924 & 688282 & 4.5 & 5.1966 & TRN \\
\hline CHEMBL 3191024 & 688282 & 5.3 & 5.0849 & TST \\
\hline CHEMBL1534239 & 688282 & 5.1 & 5.1708 & TRN \\
\hline CHEMBL1401607 & 688282 & 4.8 & 5.0907 & TRN \\
\hline CHEMBL1459529 & 688282 & 5.0 & 5.1949 & TRN \\
\hline CHEMBL1603264 & 688282 & 5.6 & 5.1973 & TST \\
\hline CHEMBL432527 & 688282 & 5.5 & 5.1898 & TRN \\
\hline CHEMBL1565441 & 688282 & 4.6 & 5.169 & TRN \\
\hline CHEMBL 1400060 & 688282 & 5.3 & 5.2492 & TRN \\
\hline CHEMBL1474211 & 688282 & 4.9 & 5.0876 & TRN \\
\hline CHEMBL1449838 & 688282 & 5.4 & 5.1457 & TRN \\
\hline CHEMBL 1582505 & 688282 & 4.9 & 5.1709 & TRN \\
\hline CHEMBL1317066 & 688282 & 4.7 & 5.0571 & TRN \\
\hline CHEMBL1313554 & 688282 & 5.0 & 5.102 & TRN \\
\hline CHEMBL1452052 & 688282 & 6.0 & 5.0837 & TRN \\
\hline
\end{tabular}




\begin{tabular}{|c|c|c|c|c|c|}
\hline & & & & & \\
\hline CHEMBL1549184 & 688282 & 5.8 & 5.1678 & TRN & \\
\hline CHEMBL1541929 & 688282 & 4.5 & 5.2246 & TRN & \\
\hline CHEMBL68594 & 688282 & 6.0 & 5.2911 & TST & \\
\hline CHEMBL1348538 & 688282 & 4.7 & 5.1151 & TRN & \\
\hline CHEMBL18238 & 688282 & 5.4 & 5.1683 & TRN & \\
\hline CHEMBL1491541 & 688282 & 5.0 & 5.1973 & TRN & \\
\hline CHEMBL1526910 & 688282 & 4.9 & 5.21200 & 2000000001 & TRN \\
\hline CHEMBL1590738 & 688282 & 4.5 & 5.3288 & TRN & \\
\hline CHEMBL1486498 & 688282 & 6.0 & 5.1231 & TRN & \\
\hline CHEMBL1475191 & 688282 & 4.9 & 5.1996 & TRN & \\
\hline CHEMBL1444371 & 688282 & 5.8 & 5.267 & TRN & \\
\hline CHEMBL1530125 & 688282 & 4.5 & 5.1281 & TST & \\
\hline CHEMBL1605977 & 688282 & 4.9 & 5.025 & TRN & \\
\hline CHEMBL21241 & 688282 & 7.6003 & 5.195 & TST & \\
\hline CHEMBL1517862 & 688282 & 4.9 & 5.2801 & TRN & \\
\hline CHEMBL1380684 & 688282 & 6.0 & 5.2393 & TRN & \\
\hline CHEMBL1444000 & 688282 & 5.3 & 5.0633 & TRN & \\
\hline CHEMBL1444431 & 688282 & 5.0 & 5.11600 & 00000000005 & TRN \\
\hline CHEMBL1594227 & 688282 & 4.9 & 5.0696 & TRN & \\
\hline CHEMBL1449777 & 688282 & 6.9 & 5.2357 & TST & \\
\hline CHEMBL1561533 & 688282 & 5.5 & 4.9727 & TRN & \\
\hline CHEMBL1429838 & 688282 & 4.9 & 5.0613 & TRN & \\
\hline CHEMBL1419334 & 688282 & 4.6 & 5.1297 & TST & \\
\hline CHEMBL1322958 & 688282 & 5.6 & 5.1523 & TST & \\
\hline CHEMBL1369085 & 688282 & 4.8 & 5.0859 & TRN & \\
\hline CHEMBL1316516 & 688282 & 5.3 & 5.1022 & TRN & \\
\hline CHEMBL1580978 & 688282 & 5.2 & 4.9455 & TRN & \\
\hline CHEMBL1521069 & 688282 & 4.6 & 5.2288 & TRN & \\
\hline CHEMBL1587831 & 688282 & 5.0 & 5.1133 & TST & \\
\hline CHEMBL1564770 & 688282 & 4.6 & 5.2183 & TRN & \\
\hline CHEMBL1585260 & 688282 & 4.6 & 5.2014 & TRN & \\
\hline CHEMBL1462758 & 688282 & 6.1 & 5.1496 & TRN & \\
\hline CHEMBL1402280 & 688282 & 5.0 & 5.1322 & TRN & \\
\hline CHEMBL1354249 & 688282 & 5.3 & 5.1729 & TST & \\
\hline CHEMBL1539285 & 688282 & 6.4 & 5.1196 & TRN & \\
\hline CHEMBL1368002 & 688282 & 8.1024 & 5.2336 & TRN & \\
\hline CHEMBL1397704 & 688282 & 4.9 & 5.0496 & TRN & \\
\hline CHEMBL1377095 & 688282 & 5.1 & 5.1452 & TRN & \\
\hline CHEMBL73824 & 688282 & 4.5 & 5.1082 & TRN & \\
\hline CHEMBL1475509 & 688282 & 5.3 & 5.24 & TST & \\
\hline CHEMBL1323351 & 688282 & 4.5 & 5.2425 & TRN & \\
\hline CHEMBL1454686 & 688282 & 4.9 & 5.1017 & TRN & \\
\hline CHEMBL1476288 & 688282 & 4.9 & 5.0374 & TRN & \\
\hline CHEMBL1301206 & 688282 & 5.0 & 5.1092 & TRN & \\
\hline CHEMBL428814 & 688282 & 5.0 & 4.919 & TRN & \\
\hline CHEMBL1501184 & 688282 & 4.9 & 5.0719 & TRN & \\
\hline CHEMBL1607572 & 688282 & 4.6 & 5.0569 & TRN & \\
\hline CHEMBL1607905 & 688282 & 4.5 & 5.1737 & TST & \\
\hline & & & & 13246 & \\
\hline
\end{tabular}




\begin{tabular}{|c|c|c|c|c|}
\hline & & & pplement & al $\mathrm{Ta}$ \\
\hline CHEMBL1301906 & 688282 & 5.3 & 5.1734 & TRN \\
\hline CHEMBL1436664 & 688282 & 5.2 & 5.1941 & TRN \\
\hline CHEMBL1444489 & 688282 & 5.5 & 5.3115 & TRN \\
\hline CHEMBL1568805 & 688282 & 4.5 & 5.2144 & TRN \\
\hline CHEMBL3197322 & 688282 & 4.5 & 5.1367 & TRN \\
\hline CHEMBL1425974 & 688282 & 6.0 & 5.0531 & TST \\
\hline CHEMBL1348181 & 688282 & 5.0 & 5.1181 & TRN \\
\hline CHEMBL1525617 & 688282 & 4.8 & 4.9873 & TRN \\
\hline CHEMBL1429363 & 688282 & 4.9 & 5.0442 & TRN \\
\hline CHEMBL1369414 & 688282 & 4.9 & 5.1759 & TRN \\
\hline CHEMBL1352304 & 688282 & 5.0 & 4.9996 & TRN \\
\hline CHEMBL1354262 & 688282 & 5.6 & 5.1174 & TRN \\
\hline CHEMBL1423273 & 688282 & 5.3 & 5.1498 & TRN \\
\hline CHEMBL1489589 & 688282 & 4.9 & 5.1494 & TRN \\
\hline CHEMBL1572146 & 688282 & 5.0 & 5.1788 & TRN \\
\hline CHEMBL1565379 & 688282 & 5.0 & 5.0634 & TRN \\
\hline CHEMBL1361276 & 688282 & 4.7 & 5.1346 & TRN \\
\hline CHEMBL1550518 & 688282 & 5.3 & 5.0373 & TRN \\
\hline CHEMBL1550152 & 688282 & 5.3 & 5.1176 & TRN \\
\hline CHEMBL1356106 & 688282 & 4.9 & 5.2929 & TST \\
\hline CHEMBL1549860 & 688282 & 5.6 & 5.0382 & TRN \\
\hline CHEMBL1598064 & 688282 & 4.7 & 5.0853 & TRN \\
\hline CHEMBL1446277 & 688282 & 5.0 & 5.0906 & TRN \\
\hline CHEMBL1395805 & 688282 & 4.8 & 5.1002 & TRN \\
\hline CHEMBL1382976 & 688282 & 4.6 & 5.1989 & TRN \\
\hline CHEMBL1324439 & 688282 & 6.6 & 5.2969 & TST \\
\hline CHEMBL1469129 & 688282 & 4.9 & 5.1999 & TRN \\
\hline CHEMBL1370644 & 688282 & 6.0 & 5.2754 & TST \\
\hline CHEMBL1534074 & 688282 & 5.3 & 5.113 & TRN \\
\hline CHEMBL1321561 & 688282 & 5.2 & 5.1014 & TRN \\
\hline CHEMBL1559297 & 688282 & 4.6 & 5.1583 & TRN \\
\hline CHEMBL1574608 & 688282 & 5.3 & 5.2329 & TRN \\
\hline CHEMBL1390386 & 688282 & 5.6 & 5.1382 & TRN \\
\hline CHEMBL1495094 & 688282 & 5.2 & 5.0846 & TRN \\
\hline CHEMBL1358215 & 688282 & 4.9 & 5.1235 & TRN \\
\hline CHEMBL1421675 & 688282 & 4.9 & 5.0831 & TRN \\
\hline CHEMBL1581045 & 688282 & 5.0 & 4.9745 & TRN \\
\hline CHEMBL1353522 & 688282 & 4.9 & 5.1869 & TRN \\
\hline CHEMBL1352033 & 688282 & 5.3 & 5.0756 & TRN \\
\hline CHEMBL1523890 & 688282 & 4.6 & 4.9645 & TRN \\
\hline CHEMBL1556701 & 688282 & 5.3 & 5.1112 & TRN \\
\hline CHEMBL1424015 & 688282 & 4.9 & 5.0965 & TST \\
\hline CHEMBL1381308 & 688282 & 4.9 & 5.0631 & TRN \\
\hline CHEMBL1339659 & 688282 & 4.5 & 5.1183 & TRN \\
\hline CHEMBL491547 & 688282 & 5.0 & 4.9081 & TRN \\
\hline CHEMBL1388223 & 688282 & 5.0 & 5.0611 & TRN \\
\hline CHEMBL1905194 & 688282 & 4.6 & 5.1994 & TRN \\
\hline CHEMBL1475004 & 688282 & 4.9 & 5.2678 & TRN \\
\hline
\end{tabular}




\begin{tabular}{|c|c|c|c|c|c|}
\hline \\
\hline CHEMBL1555008 & 688282 & 4.9 & 5.093 & TRN & \\
\hline CHEMBL1373933 & 688282 & 4.8 & 5.0935 & TRN & \\
\hline CHEMBL1301758 & 688282 & 5.3 & 5.1357 & TRN & \\
\hline CHEMBL1319286 & 688282 & 5.0 & 5.1695 & TRN & \\
\hline CHEMBL1446696 & 688282 & 4.9 & 5.0234 & TRN & \\
\hline CHEMBL1520216 & 688282 & 5.0 & 5.1559 & TRN & \\
\hline CHEMBL1405369 & 688282 & 6.4 & 5.2437 & TST & \\
\hline CHEMBL1394135 & 688282 & 4.5 & 5.0673 & TRN & \\
\hline CHEMBL1561040 & 688282 & 5.3 & 5.1558 & TST & \\
\hline CHEMBL1345487 & 688282 & 5.1 & 5.1073 & TRN & \\
\hline CHEMBL1386050 & 688282 & 5.3 & 5.2294 & TRN & \\
\hline CHEMBL317364 & 688282 & 4.8 & 5.06800 & 00000000005 & TRN \\
\hline CHEMBL1587910 & 688282 & 5.3 & 5.142 & TRN & \\
\hline CHEMBL3196267 & 688282 & 5.0 & 5.2346 & TST & \\
\hline CHEMBL1306679 & 688282 & 5.3 & 5.0773 & TRN & \\
\hline CHEMBL1323355 & 688282 & 5.0 & 5.0911 & TRN & \\
\hline CHEMBL1333698 & 688282 & 4.9 & 5.1531 & TRN & \\
\hline CHEMBL1568018 & 688282 & 4.9 & 5.0823 & TRN & \\
\hline CHEMBL1319235 & 688282 & 5.0 & 5.0105 & TRN & \\
\hline CHEMBL1465340 & 688282 & 4.9 & 5.0737 & TRN & \\
\hline CHEMBL1527466 & 688282 & 5.4 & 5.2046 & TRN & \\
\hline CHEMBL1597656 & 688282 & 4.9 & 5.152 & TRN & \\
\hline CHEMBL1499489 & 688282 & 5.0 & 5.0429 & TRN & \\
\hline CHEMBL1507212 & 688282 & 4.9 & 5.0487 & TRN & \\
\hline CHEMBL1553838 & 688282 & 4.9 & 5.2863 & TST & \\
\hline CHEMBL1339993 & 688282 & 5.0 & 5.0897 & TRN & \\
\hline CHEMBL1318064 & 688282 & 5.0 & 5.1451 & TRN & \\
\hline CHEMBL3191002 & 688282 & 5.3 & 5.1443 & TRN & \\
\hline CHEMBL602213 & 688282 & 4.9 & 5.2036 & TRN & \\
\hline CHEMBL279841 & 688282 & 4.9 & 5.0959 & TRN & \\
\hline CHEMBL1568129 & 688282 & 4.5 & 5.3556 & TRN & \\
\hline CHEMBL1380300 & 688282 & 5.0 & 5.0895 & TRN & \\
\hline CHEMBL1355201 & 688282 & 5.0 & 4.9318 & TRN & \\
\hline CHEMBL1393001 & 688282 & 4.9 & 5.1453 & TRN & \\
\hline CHEMBL1347359 & 688282 & 4.6 & 5.0823 & TRN & \\
\hline CHEMBL1492073 & 688282 & 6.7001 & 5.3222 & TRN & \\
\hline CHEMBL1513643 & 688282 & 5.5 & 5.2304 & TST & \\
\hline CHEMBL1513280 & 688282 & 4.9 & 5.0171 & TRN & \\
\hline CHEMBL1256727 & 688282 & 5.4 & 5.1876 & TRN & \\
\hline CHEMBL45068 & 688282 & 5.1 & 5.2492 & TRN & \\
\hline CHEMBL1357449 & 688282 & 5.5 & 5.2505 & TRN & \\
\hline CHEMBL1367594 & 688282 & 5.0 & 5.0752 & TRN & \\
\hline CHEMBL1423096 & 688282 & 5.2 & 5.1412 & TST & \\
\hline CHEMBL1506773 & 688282 & 5.3 & 5.0486 & TRN & \\
\hline CHEMBL1509090 & 688282 & 4.6 & 4.9771 & TRN & \\
\hline CHEMBL1584720 & 688282 & 4.6 & 5.032 & TRN & \\
\hline CHEMBL1566305 & 688282 & 5.4 & 5.3354 & TST & \\
\hline CHEMBL1308453 & 688282 & 5.0 & 5.1933 & TRN & \\
\hline
\end{tabular}




\begin{tabular}{|c|c|c|c|c|}
\hline & & & pplemen & at \\
\hline CHEMBL1441942 & 688282 & 4.8 & 5.2477 & TRN \\
\hline CHEMBL1569001 & 688282 & 4.9 & 5.1632 & TRN \\
\hline CHEMBL1477559 & 688282 & 4.8 & 5.1563 & TRN \\
\hline CHEMBL1596484 & 688282 & 5.2 & 5.1335 & TRN \\
\hline CHEMBL1400575 & 688282 & 4.9 & 5.1431 & TRN \\
\hline CHEMBL1452139 & 688282 & 4.6 & 5.2241 & TRN \\
\hline CHEMBL60718 & 688282 & 4.8 & 5.1694 & TRN \\
\hline CHEMBL1489897 & 688282 & 5.3 & 5.1428 & TRN \\
\hline CHEMBL1441192 & 688282 & 5.0 & 5.0878 & TRN \\
\hline CHEMBL1488509 & 688282 & 5.3 & 5.0098 & TRN \\
\hline CHEMBL1397965 & 688282 & 5.0 & 5.0393 & TRN \\
\hline CHEMBL1570428 & 688282 & 7.1002 & 5.3192 & TST \\
\hline CHEMBL1496691 & 688282 & 4.9 & 5.181 & TRN \\
\hline CHEMBL1376987 & 688282 & 5.3 & 5.1681 & TRN \\
\hline CHEMBL1607623 & 688282 & 6.1 & 5.2568 & TRN \\
\hline CHEMBL1441838 & 688282 & 5.3 & 5.104 & TRN \\
\hline CHEMBL1422672 & 688282 & 4.6 & 5.0305 & TRN \\
\hline CHEMBL1552478 & 688282 & 4.9 & 5.2121 & TRN \\
\hline CHEMBL1399653 & 688282 & 5.7 & 5.0121 & TRN \\
\hline CHEMBL1368289 & 688282 & 5.3 & 5.1586 & TRN \\
\hline CHEMBL491771 & 688282 & 5.5 & 4.9997 & TRN \\
\hline CHEMBL1505394 & 688282 & 5.4 & 5.0566 & TRN \\
\hline CHEMBL1395252 & 688282 & 4.6 & 5.144 & TRN \\
\hline CHEMBL1462584 & 688282 & 4.5 & 5.2702 & TRN \\
\hline CHEMBL1473965 & 688282 & 4.8 & 5.0092 & TRN \\
\hline CHEMBL1565334 & 688282 & 5.3 & 5.1589 & TRN \\
\hline CHEMBL1371984 & 688282 & 4.9 & 5.1718 & TST \\
\hline CHEMBL1601592 & 688282 & 4.6 & 5.1013 & TRN \\
\hline CHEMBL1588224 & 688282 & 5.3 & 5.0395 & TRN \\
\hline CHEMBL1491676 & 688282 & 5.0 & 5.0923 & TRN \\
\hline CHEMBL1517390 & 688282 & 5.0 & 5.1788 & TRN \\
\hline CHEMBL1448568 & 688282 & 5.3 & 5.0729 & TST \\
\hline CHEMBL1318786 & 688282 & 6.4 & 5.21 & TRN \\
\hline CHEMBL114070 & 688282 & 4.5 & 5.2428 & TRN \\
\hline CHEMBL1309092 & 688282 & 4.9 & 5.2152 & TRN \\
\hline CHEMBL1471289 & 688282 & 4.9 & 5.1748 & TST \\
\hline CHEMBL1447496 & 688282 & 4.6 & 4.9287 & TRN \\
\hline CHEMBL188 & 688282 & 5.5 & 5.1896 & TRN \\
\hline CHEMBL1458404 & 688282 & 5.3 & 5.0905 & TRN \\
\hline CHEMBL1590982 & 688282 & 4.9 & 5.1733 & TRN \\
\hline CHEMBL1341099 & 688282 & 5.3 & 5.1397 & TST \\
\hline CHEMBL1552720 & 688282 & 4.7 & 5.0726 & TRN \\
\hline CHEMBL56331 & 688282 & 4.9 & 5.0533 & TRN \\
\hline CHEMBL 388342 & 688282 & 4.6 & 5.1299 & TRN \\
\hline CHEMBL1550630 & 688282 & 5.1 & 5.171 & TRN \\
\hline CHEMBL1572655 & 688282 & 4.9 & 5.2062 & TRN \\
\hline CHEMBL1507083 & 688282 & 4.5 & 5.107 & TRN \\
\hline CHEMBL1587932 & 688282 & 5.0 & 5.0421 & TRN \\
\hline
\end{tabular}




\begin{tabular}{|c|c|c|c|c|c|}
\hline \\
\hline CHEMBL1482751 & 688282 & 5.0 & 5.0182 & TRN & \\
\hline CHEMBL1593219 & 688282 & 5.0 & 5.0785 & TRN & \\
\hline CHEMBL1605510 & 688282 & 5.3 & 4.981 & TRN & \\
\hline CHEMBL1333052 & 688282 & 4.5 & 5.0767 & TRN & \\
\hline CHEMBL1321173 & 688282 & 5.3 & 5.0956 & TRN & \\
\hline CHEMBL1327752 & 688282 & 5.7 & 5.0504 & TRN & \\
\hline CHEMBL1352200 & 688282 & 4.8 & 4.9691 & TRN & \\
\hline CHEMBL1430166 & 688282 & 5.0 & 5.1749 & TRN & \\
\hline CHEMBL1602299 & 688282 & 5.0 & 5.1693 & TRN & \\
\hline CHEMBL495068 & 688282 & 4.5 & 4.9423 & TRN & \\
\hline CHEMBL107251 & 688282 & 4.5 & 5.1822 & TST & \\
\hline CHEMBL1406467 & 688282 & 5.5 & 5.141 & TST & \\
\hline CHEMBL1358272 & 688282 & 5.1 & 5.0241 & TRN & \\
\hline CHEMBL1347985 & 688282 & 5.2 & 5.0879 & TRN & \\
\hline CHEMBL31970 & 688282 & 5.3 & 5.1988 & TST & \\
\hline CHEMBL1325976 & 688282 & 4.9 & 5.1516 & TRN & \\
\hline CHEMBL1415277 & 688282 & 5.3 & 5.1037 & TST & \\
\hline CHEMBL1397913 & 688282 & 4.5 & 5.0925 & TRN & \\
\hline CHEMBL1562104 & 688282 & 5.3 & 5.209 & TST & \\
\hline CHEMBL1356923 & 688282 & 4.5 & 5.3067 & TRN & \\
\hline CHEMBL1487638 & 688282 & 4.7 & 5.1537 & TRN & \\
\hline CHEMBL1431620 & 688282 & 4.7 & 5.1759 & TRN & \\
\hline CHEMBL1417197 & 688282 & 4.7 & 5.1526 & TRN & \\
\hline CHEMBL1555098 & 688282 & 5.5 & 5.15799 & 99999999995 & TRN \\
\hline CHEMBL1355387 & 688282 & 6.3 & 4.9936 & TRN & \\
\hline CHEMBL1579670 & 688282 & 4.7 & 5.0301 & TRN & \\
\hline CHEMBL1555255 & 688282 & 6.2 & 5.1002 & TRN & \\
\hline CHEMBL1552814 & 688282 & 5.3 & 4.9962 & TRN & \\
\hline CHEMBL1402202 & 688282 & 6.2 & 5.096 & TRN & \\
\hline CHEMBL1378655 & 688282 & 4.9 & 5.1102 & TRN & \\
\hline CHEMBL1523450 & 688282 & 4.9 & 4.9833 & TRN & \\
\hline CHEMBL1571874 & 688282 & 4.8 & 5.1135 & TST & \\
\hline CHEMBL1432334 & 688282 & 5.0 & 5.0673 & TRN & \\
\hline CHEMBL1373568 & 688282 & 4.9 & 5.1491 & TRN & \\
\hline CHEMBL1390786 & 688282 & 4.6 & 5.1186 & TRN & \\
\hline CHEMBL1566428 & 688282 & 5.0 & 5.0043 & TRN & \\
\hline CHEMBL1434817 & 688282 & 5.0 & 5.1297 & TRN & \\
\hline CHEMBL1369793 & 688282 & 5.3 & 5.1882 & TRN & \\
\hline CHEMBL1525602 & 688282 & 4.9 & 5.1095 & TRN & \\
\hline CHEMBL1365271 & 688282 & 5.0 & 5.3009 & TRN & \\
\hline CHEMBL1549993 & 688282 & 4.7 & 5.1475 & TRN & \\
\hline CHEMBL525239 & 688282 & 4.9 & 5.1925 & TRN & \\
\hline CHEMBL1381518 & 688282 & 4.6 & 5.0873 & TRN & \\
\hline CHEMBL1501110 & 688282 & 5.0 & 5.0271 & TRN & \\
\hline CHEMBL1395355 & 688282 & 5.9 & 5.0409 & TRN & \\
\hline CHEMBL1453510 & 688282 & 5.0 & 5.2175 & TRN & \\
\hline CHEMBL1309795 & 688282 & 5.3 & 5.0198 & TRN & \\
\hline CHEMBL1611426 & 688282 & 5.0 & 5.0773 & TRN & \\
\hline
\end{tabular}




\begin{tabular}{|c|c|c|c|c|}
\hline & & & 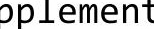 & \\
\hline CHEMBL1480173 & 688282 & 4.9 & 5.1474 & TRN \\
\hline CHEMBL1381642 & 688282 & 5.3 & 5.0814 & TRN \\
\hline CHEMBL1596537 & 688282 & 5.3 & 5.17 & TRN \\
\hline CHEMBL1578375 & 688282 & 4.5 & 5.1402 & TRN \\
\hline CHEMBL1527613 & 688282 & 5.0 & 5.1472 & TRN \\
\hline CHEMBL1576762 & 688282 & 4.9 & 5.1966 & TRN \\
\hline CHEMBL1393664 & 688282 & 6.0 & 5.1116 & TST \\
\hline CHEMBL1368396 & 688282 & 4.6 & 5.1621 & TRN \\
\hline CHEMBL573540 & 688282 & 4.5 & 5.2383 & TRN \\
\hline CHEMBL1564461 & 688282 & 4.8 & 5.1574 & TRN \\
\hline CHEMBL1560731 & 688282 & 5.1 & 5.0582 & TRN \\
\hline CHEMBL523318 & 688282 & 6.0 & 5.2414 & TRN \\
\hline CHEMBL1544223 & 688282 & 4.8 & 5.1296 & TRN \\
\hline CHEMBL1414619 & 688282 & 4.6 & 5.1068 & TST \\
\hline CHEMBL321691 & 688282 & 4.5 & 5.2653 & TST \\
\hline CHEMBL1591009 & 688282 & 4.6 & 5.2127 & TST \\
\hline CHEMBL1378691 & 688282 & 4.8 & 5.1843 & TRN \\
\hline CHEMBL1337163 & 688282 & 5.8 & 5.1518 & TRN \\
\hline CHEMBL1375541 & 688282 & 4.7 & 5.2052 & TRN \\
\hline CHEMBL1476362 & 688282 & 4.8 & 5.1985 & TST \\
\hline CHEMBL1354011 & 688282 & 6.0 & 5.1553 & TRN \\
\hline CHEMBL1300493 & 688282 & 6.7001 & 5.1568 & TRN \\
\hline CHEMBL1316463 & 688282 & 6.1 & 5.0986 & TRN \\
\hline CHEMBL1581798 & 688282 & 5.5 & 5.0614 & TRN \\
\hline CHEMBL1473149 & 688282 & 5.0 & 5.2109 & TRN \\
\hline CHEMBL283196 & 688282 & 4.6 & 5.1911 & TRN \\
\hline CHEMBL1586298 & 688282 & 4.5 & 5.0581 & TRN \\
\hline CHEMBL1346946 & 688282 & 4.6 & 5.2304 & TRN \\
\hline CHEMBL1256646 & 688282 & 4.9 & 5.2281 & TST \\
\hline CHEMBL1507559 & 688282 & 5.3 & 5.225 & TRN \\
\hline CHEMBL1522160 & 688282 & 4.5 & 5.0813 & TRN \\
\hline CHEMBL1310362 & 688282 & 5.3 & 5.1149 & TRN \\
\hline CHEMBL370152 & 688282 & 4.9 & 5.184 & TST \\
\hline CHEMBL1304521 & 688282 & 5.3 & 5.0495 & TRN \\
\hline CHEMBL1529702 & 688282 & 4.7 & 5.1375 & TST \\
\hline CHEMBL1989464 & 688282 & 4.5 & 5.1232 & TST \\
\hline CHEMBL1404708 & 688282 & 5.4 & 5.2135 & TRN \\
\hline CHEMBL1451526 & 688282 & 5.5 & 5.2905 & TRN \\
\hline CHEMBL1330107 & 688282 & 6.4 & 5.2398 & TRN \\
\hline CHEMBL1354122 & 688282 & 4.9 & 5.1176 & TRN \\
\hline CHEMBL1299736 & 688282 & 4.5 & 5.1037 & TRN \\
\hline CHEMBL1531863 & 688282 & 6.0 & 5.2268 & TRN \\
\hline CHEMBL 250447 & 688282 & 4.7 & 5.06 & TRN \\
\hline CHEMBL1436935 & 688282 & 5.4 & 5.2946 & TRN \\
\hline CHEMBL1430895 & 688282 & 4.5 & 5.1195 & TRN \\
\hline CHEMBL1448054 & 688282 & 5.9 & 5.2184 & TRN \\
\hline CHEMBL1358208 & 688282 & 5.6 & 5.0468 & TST \\
\hline CHEMBL1301184 & 688282 & 5.5 & 5.0602 & TRN \\
\hline
\end{tabular}




\begin{tabular}{|c|c|c|c|c|c|}
\hline \\
\hline CHEMBL1324163 & 688282 & 5.2 & 5.005 & TRN & \\
\hline CHEMBL1562086 & 688282 & 5.4 & 5.0506 & TRN & \\
\hline CHEMBL1333235 & 688282 & 5.6 & 5.1436 & TRN & \\
\hline CHEMBL1455450 & 688282 & 4.9 & 5.0327 & TRN & \\
\hline CHEMBL1390589 & 688282 & 4.9 & 5.1108 & TRN & \\
\hline CHEMBL608828 & 688282 & 4.9 & 5.3047 & TRN & \\
\hline CHEMBL1348128 & 688282 & 6.9 & 5.0596 & TRN & \\
\hline CHEMBL1390587 & 688282 & 4.5 & 5.0338 & TRN & \\
\hline CHEMBL1604134 & 688282 & 4.5 & 4.9834 & TRN & \\
\hline CHEMBL1563092 & 688282 & 4.6 & 5.0837 & TRN & \\
\hline CHEMBL1473875 & 688282 & 5.1 & 5.1996 & TRN & \\
\hline CHEMBL1440703 & 688282 & 6.0 & 5.154 & TRN & \\
\hline CHEMBL1378318 & 688282 & 5.0 & 5.0818 & TRN & \\
\hline CHEMBL326312 & 688282 & 7.4001 & 5.235 & TRN & \\
\hline CHEMBL1585079 & 688282 & 4.9 & 5.0461 & TRN & \\
\hline CHEMBL1381540 & 688282 & 4.9 & 5.1158 & TRN & \\
\hline CHEMBL1494747 & 688282 & 4.9 & 5.2329 & TRN & \\
\hline CHEMBL1517643 & 688282 & 5.0 & 5.1943 & TRN & \\
\hline CHEMBL1566571 & 688282 & 5.0 & 5.0884 & TRN & \\
\hline CHEMBL1581701 & 688282 & 5.3 & 5.09699 & 99999999995 & TRN \\
\hline CHEMBL1416762 & 688282 & 4.9 & 5.0734 & TRN & \\
\hline CHEMBL1571857 & 688282 & 5.3 & 5.0161 & TRN & \\
\hline CHEMBL1487441 & 688282 & 5.7 & 5.0715 & TRN & \\
\hline CHEMBL1542724 & 688282 & 5.3 & 5.187 & TST & \\
\hline CHEMBL1435248 & 688282 & 5.8 & 5.0042 & TRN & \\
\hline CHEMBL1487131 & 688282 & 5.0 & 5.0658 & TRN & \\
\hline CHEMBL1488632 & 688282 & 6.0 & 5.2031 & TRN & \\
\hline CHEMBL1497676 & 688282 & 5.0 & 5.1897 & TRN & \\
\hline CHEMBL1555899 & 688282 & 5.3 & 5.1258 & TRN & \\
\hline CHEMBL1435409 & 688282 & 5.3 & 5.0841 & TRN & \\
\hline CHEMBL1592754 & 688282 & 4.9 & 5.2329 & TRN & \\
\hline CHEMBL1314516 & 688282 & 6.5 & 5.0297 & TRN & \\
\hline CHEMBL145725 & 688282 & 4.9 & 5.1442 & TST & \\
\hline CHEMBL1358999 & 688282 & 5.3 & 5.2119 & TRN & \\
\hline CHEMBL1315527 & 688282 & 4.7 & 5.1603 & TRN & \\
\hline CHEMBL1427049 & 688282 & 5.3 & 5.1899 & TRN & \\
\hline CHEMBL1573134 & 688282 & 5.5 & 5.2012 & TST & \\
\hline CHEMBL364900 & 688282 & 5.4 & 5.2018 & TRN & \\
\hline CHEMBL1536524 & 688282 & 5.4 & 5.1261 & TRN & \\
\hline CHEMBL601534 & 688282 & 5.5 & 5.1127 & TRN & \\
\hline CHEMBL1403712 & 688282 & 4.6 & 5.244 & TRN & \\
\hline CHEMBL1590992 & 688282 & 5.4 & 5.3031 & TRN & \\
\hline CHEMBL1476693 & 688282 & 5.0 & 5.1449 & TRN & \\
\hline CHEMBL1560567 & 688282 & 5.6 & 5.25 & TRN & \\
\hline CHEMBL1321811 & 688282 & 5.0 & 5.1861 & TRN & \\
\hline CHEMBL1474169 & 688282 & 4.9 & 5.1363 & TRN & \\
\hline CHEMBL1363237 & 688282 & 4.9 & 5.0424 & TRN & \\
\hline CHEMBL1337146 & 688282 & 5.7 & 4.9405 & TRN & \\
\hline & & & $P a$ & 13252 & \\
\hline
\end{tabular}




\begin{tabular}{|c|c|c|c|c|c|}
\hline \\
\hline CHEMBL1513928 & 688282 & 5.3 & 5.1885 & TRN & \\
\hline CHEMBL1416913 & 688282 & 5.0 & 5.1167 & TRN & \\
\hline CHEMBL1535335 & 688282 & 4.9 & 5.2027 & TRN & \\
\hline CHEMBL1389412 & 688282 & 4.6 & 5.2582 & TST & \\
\hline CHEMBL1507940 & 688282 & 5.3 & 5.0542 & TRN & \\
\hline CHEMBL3199462 & 688282 & 5.2 & 5.1525 & TRN & \\
\hline CHEMBL1426818 & 688282 & 4.9 & 5.144 & TRN & \\
\hline CHEMBL1568049 & 688282 & 4.8 & 5.2249 & TRN & \\
\hline CHEMBL1301287 & 688282 & 5.4 & 5.2818 & TRN & \\
\hline CHEMBL315348 & 688282 & 4.8 & 5.1729 & TRN & \\
\hline CHEMBL1495406 & 688282 & 4.9 & 5.2017 & TRN & \\
\hline CHEMBL1417552 & 688282 & 6.0 & 5.1898 & TRN & \\
\hline CHEMBL1330442 & 688282 & 4.8 & 5.062 & TRN & \\
\hline CHEMBL1397821 & 688282 & 5.1 & 5.1371 & TRN & \\
\hline CHEMBL1604474 & 688282 & 5.0 & 5.1175 & TST & \\
\hline CHEMBL1415517 & 688282 & 5.9 & 5.0077 & TRN & \\
\hline CHEMBL1563367 & 688282 & 6.4 & 5.0654 & TRN & \\
\hline CHEMBL1410905 & 688282 & 4.9 & 5.1534 & TRN & \\
\hline CHEMBL1310308 & 688282 & 4.6 & 5.0736 & TRN & \\
\hline CHEMBL1383181 & 688282 & 5.6 & 5.2926 & TRN & \\
\hline CHEMBL3210159 & 688282 & 4.9 & 5.1813 & TRN & \\
\hline CHEMBL1346836 & 688282 & 4.6 & 4.9213 & TRN & \\
\hline CHEMBL9843 & 688282 & 6.0 & 5.0764 & TRN & \\
\hline CHEMBL1610492 & 688282 & 8.0 & 5.1428 & TRN & \\
\hline CHEMBL1385355 & 688282 & 5.0 & 5.1669 & TRN & \\
\hline CHEMBL1450920 & 688282 & 5.2 & 5.1299 & TRN & \\
\hline CHEMBL1410766 & 688282 & 5.0 & 5.1125 & TRN & \\
\hline CHEMBL60859 & 688282 & 4.9 & 5.1358 & TRN & \\
\hline CHEMBL1451386 & 688282 & 5.6 & 5.2562 & TST & \\
\hline CHEMBL1346385 & 688282 & 5.0 & 5.0455 & TRN & \\
\hline CHEMBL1365005 & 688282 & 5.0 & 5.1249 & TRN & \\
\hline CHEMBL1304205 & 688282 & 5.1 & 4.9695 & TRN & \\
\hline CHEMBL 280065 & 688282 & 5.0 & 5.1857 & TRN & \\
\hline CHEMBL1452142 & 688282 & 4.7 & 5.1044 & TRN & \\
\hline CHEMBL1323902 & 688282 & 7.2 & 5.1116 & TRN & \\
\hline CHEMBL1593232 & 688282 & 7.0 & 5.2827 & TST & \\
\hline CHEMBL1552957 & 688282 & 4.9 & 5.0124 & TRN & \\
\hline CHEMBL1423137 & 688282 & 5.3 & 5.15799 & 99999999995 & TRN \\
\hline CHEMBL1529543 & 688282 & 4.9 & 5.0724 & TRN & \\
\hline CHEMBL1355010 & 688282 & 5.1 & 5.0717 & TRN & \\
\hline CHEMBL1569816 & 688282 & 4.5 & 5.0612 & TRN & \\
\hline CHEMBL1522796 & 688282 & 5.5 & 5.2374 & TRN & \\
\hline CHEMBL1368493 & 688282 & 4.9 & 4.9841 & TRN & \\
\hline CHEMBL1556392 & 688282 & 4.9 & 5.1022 & TRN & \\
\hline CHEMBL1492819 & 688282 & 5.6 & 5.1881 & TST & \\
\hline CHEMBL1996902 & 688282 & 4.5 & 5.1659 & TRN & \\
\hline CHEMBL1357329 & 688282 & 6.0 & 5.1768 & TST & \\
\hline CHEMBL19980 & 688282 & 6.0 & 5.2969 & TST & \\
\hline & & & & 13253 & \\
\hline
\end{tabular}




\begin{tabular}{|c|c|c|c|c|}
\hline & & & pplement & 0 \\
\hline CHEMBL1452128 & 688282 & 5.0 & 5.151 & TRN \\
\hline CHEMBL1579130 & 688282 & 6.0 & 5.2669 & TST \\
\hline CHEMBL1515385 & 688282 & 5.6 & 5.2565 & TRN \\
\hline CHEMBL1398978 & 688282 & 5.3 & 5.1912 & TRN \\
\hline CHEMBL1553185 & 688282 & 5.0 & 4.9355 & TRN \\
\hline CHEMBL1456100 & 688282 & 6.5 & 5.1776 & TST \\
\hline CHEMBL1411878 & 688282 & 5.3 & 5.0572 & TRN \\
\hline CHEMBL1495359 & 688282 & 4.9 & 5.1416 & TRN \\
\hline CHEMBL1563624 & 688282 & 4.8 & 5.2141 & TST \\
\hline CHEMBL1450744 & 688282 & 4.9 & 5.0445 & TRN \\
\hline CHEMBL1379030 & 688282 & 5.0 & 5.1936 & TRN \\
\hline CHEMBL1519116 & 688282 & 5.0 & 5.0939 & TRN \\
\hline CHEMBL1467704 & 688282 & 5.5 & 5.1938 & TRN \\
\hline CHEMBL1600388 & 688282 & 4.5 & 5.2216 & TRN \\
\hline CHEMBL1460606 & 688282 & 4.9 & 5.0169 & TRN \\
\hline CHEMBL1542064 & 688282 & 4.6 & 5.1728 & TRN \\
\hline CHEMBL1513920 & 688282 & 4.9 & 4.9506 & TRN \\
\hline CHEMBL1552701 & 688282 & 4.9 & 5.3446 & TRN \\
\hline CHEMBL1479675 & 688282 & 5.1 & 5.1975 & TST \\
\hline CHEMBL1395974 & 688282 & 5.0 & 5.1033 & TRN \\
\hline CHEMBL1535806 & 688282 & 5.1 & 5.2274 & TST \\
\hline CHEMBL1351095 & 688282 & 4.8 & 5.1525 & TRN \\
\hline CHEMBL1601990 & 688282 & 5.2 & 5.0365 & TRN \\
\hline CHEMBL1581643 & 688282 & 5.0 & 5.0859 & TRN \\
\hline CHEMBL1515374 & 688282 & 5.7 & 5.0663 & TRN \\
\hline CHEMBL1395058 & 688282 & 4.5 & 5.1862 & TRN \\
\hline CHEMBL1594134 & 688282 & 4.7 & 4.9677 & TRN \\
\hline CHEMBL1490638 & 688282 & 5.2 & 5.1767 & TRN \\
\hline CHEMBL1368418 & 688282 & 5.4 & 4.968 & TRN \\
\hline CHEMBL1362307 & 688282 & 5.0 & 5.1692 & TRN \\
\hline CHEMBL1484660 & 688282 & 4.9 & 5.0636 & TRN \\
\hline CHEMBL1357089 & 688282 & 5.3 & 5.1777 & TRN \\
\hline CHEMBL1592803 & 688282 & 5.3 & 4.9397 & TRN \\
\hline CHEMBL1465868 & 688282 & 4.9 & 5.1561 & TRN \\
\hline CHEMBL 29878 & 688282 & 6.0 & 5.2015 & TRN \\
\hline CHEMBL1515004 & 688282 & 5.3 & 5.1424 & TRN \\
\hline CHEMBL1473480 & 688282 & 5.0 & 5.2816 & TRN \\
\hline CHEMBL1428964 & 688282 & 6.0 & 5.3165 & TRN \\
\hline CHEMBL3190739 & 688282 & 5.3 & 5.0957 & TRN \\
\hline CHEMBL1479781 & 688282 & 5.2 & 5.1922 & TRN \\
\hline CHEMBL1583513 & 688282 & 4.9 & 5.1191 & TRN \\
\hline CHEMBL1403769 & 688282 & 4.9 & 5.0581 & TRN \\
\hline CHEMBL 274844 & 688282 & 5.4 & 5.1976 & TST \\
\hline CHEMBL1321902 & 688282 & 4.8 & 5.1898 & TRN \\
\hline CHEMBL1534347 & 688282 & 4.9 & 5.15 & TRN \\
\hline CHEMBL1354433 & 688282 & 5.2 & 5.1371 & TRN \\
\hline CHEMBL1370938 & 688282 & 6.0 & 5.1281 & TST \\
\hline CHEMBL1466690 & 688282 & 5.3 & 5.1282 & TRN \\
\hline
\end{tabular}




\begin{tabular}{|c|c|c|c|c|c|}
\hline \multicolumn{6}{|c|}{ Supplemental Table S2.txt } \\
\hline CHEMBL253765 & 688282 & 5.5 & 5.2317 & TST & \\
\hline CHEMBL150 & 688282 & 5.3 & 5.2903 & TRN & \\
\hline CHEMBL1384204 & 688282 & 4.7 & 5.1746 & TRN & \\
\hline CHEMBL1596756 & 688282 & 4.9 & 4.9788 & TRN & \\
\hline CHEMBL1357648 & 688282 & 5.0 & 5.0598 & TRN & \\
\hline CHEMBL1485654 & 688282 & 6.0 & 5.24200 & 0000000001 & TRN \\
\hline CHEMBL1455566 & 688282 & 5.2 & 5.0855 & TRN & \\
\hline CHEMBL1536389 & 688282 & 5.3 & 5.26200 & 00000000005 & TRN \\
\hline CHEMBL6291 & 688282 & 4.9 & 5.2739 & TRN & \\
\hline CHEMBL1369406 & 688282 & 4.9 & 5.2705 & TST & \\
\hline CHEMBL1322646 & 688282 & 5.0 & 5.1241 & TRN & \\
\hline CHEMBL1319698 & 688282 & 6.0 & 5.1831 & TRN & \\
\hline CHEMBL1567163 & 688282 & 4.9 & 5.2596 & TST & \\
\hline CHEMBL1483237 & 688282 & 5.3 & 5.2939 & TST & \\
\hline CHEMBL 2002522 & 688282 & 5.0 & 5.2006 & TRN & \\
\hline CHEMBL1344571 & 688282 & 5.0 & 5.0588 & TRN & \\
\hline CHEMBL1314956 & 688282 & 5.6 & 5.1038 & TRN & \\
\hline CHEMBL491578 & 688282 & 4.5 & 5.0107 & TRN & \\
\hline CHEMBL1576563 & 688282 & 5.1 & 4.9757 & TRN & \\
\hline CHEMBL1407317 & 688282 & 6.1 & 5.1805 & TST & \\
\hline CHEMBL540294 & 688282 & 4.9 & 5.037 & TST & \\
\hline CHEMBL1314890 & 688282 & 5.2 & 5.2561 & TRN & \\
\hline CHEMBL1584629 & 688282 & 5.1 & 5.1239 & TRN & \\
\hline CHEMBL1311780 & 688282 & 5.3 & 5.1772 & TRN & \\
\hline CHEMBL1342567 & 688282 & 4.9 & 5.3469 & TST & \\
\hline CHEMBL1518723 & 688282 & 4.6 & 5.0488 & TRN & \\
\hline CHEMBL1343717 & 688282 & 4.5 & 5.1047 & TRN & \\
\hline CHEMBL1550751 & 688282 & 4.9 & 5.0947 & TRN & \\
\hline CHEMBL1465252 & 688282 & 4.5 & 4.9728 & TRN & \\
\hline CHEMBL1322959 & 688282 & 4.9 & 5.112 & TST & \\
\hline CHEMBL1444381 & 688282 & 4.9 & 5.046 & TRN & \\
\hline CHEMBL1317786 & 688282 & 4.7 & 5.1226 & TRN & \\
\hline CHEMBL1601019 & 688282 & 7.4001 & 5.2887 & TRN & \\
\hline CHEMBL1312369 & 688282 & 5.4 & 5.0975 & TRN & \\
\hline CHEMBL1593269 & 688282 & 4.6 & 4.99 & TRN & \\
\hline CHEMBL1467168 & 688282 & 4.9 & 4.9902 & TRN & \\
\hline CHEMBL1585211 & 688282 & 4.9 & 5.2172 & TRN & \\
\hline CHEMBL1382536 & 688282 & 5.1 & 5.0001 & TRN & \\
\hline CHEMBL579503 & 688282 & 4.6 & 5.0676 & TRN & \\
\hline CHEMBL1334461 & 688282 & 5.5 & 5.0513 & TRN & \\
\hline CHEMBL154580 & 688282 & 4.6 & 5.2242 & TRN & \\
\hline CHEMBL1526920 & 688282 & 5.3 & 5.1942 & TRN & \\
\hline CHEMBL1596886 & 688282 & 5.0 & 5.1551 & TRN & \\
\hline CHEMBL1401859 & 688282 & 4.8 & 5.013 & TRN & \\
\hline CHEMBL3661417 & 688282 & 4.8 & 5.245 & TRN & \\
\hline CHEMBL1370053 & 688282 & 5.0 & 5.1277 & TRN & \\
\hline CHEMBL1329817 & 688282 & 4.6 & 5.1996 & TRN & \\
\hline CHEMBL1569696 & 688282 & 4.5 & 5.1101 & TRN & \\
\hline
\end{tabular}




\begin{tabular}{|c|c|c|c|c|c|}
\hline \multicolumn{6}{|c|}{ Supplemental Table S2.txt } \\
\hline CHEMBL1413322 & 688282 & 5.4 & 5.1983 & TRN & \\
\hline CHEMBL1413571 & 688282 & 5.4 & 5.035 & TRN & \\
\hline CHEMBL1310381 & 688282 & 5.0 & 5.1339 & TRN & \\
\hline CHEMBL1502512 & 688282 & 5.9 & 5.0894 & TST & \\
\hline CHEMBL1563047 & 688282 & 5.0 & 5.0877 & TRN & \\
\hline CHEMBL1372465 & 688282 & 4.5 & 5.1257 & TRN & \\
\hline CHEMBL1611062 & 688282 & 5.3 & 5.1626 & TRN & \\
\hline CHEMBL1536946 & 688282 & 5.1 & 5.1701 & TRN & \\
\hline CHEMBL1553114 & 688282 & 5.5 & 4.9433 & TRN & \\
\hline CHEMBL1445850 & 688282 & 5.3 & 5.0965 & TRN & \\
\hline CHEMBL605003 & 688282 & 4.8 & 5.2506 & TRN & \\
\hline CHEMBL1433705 & 688282 & 5.0 & 5.1407 & TRN & \\
\hline CHEMBL 304291 & 688282 & 8.7959 & 5.1213 & TST & \\
\hline CHEMBL1426455 & 688282 & 5.4 & 5.0774 & TRN & \\
\hline CHEMBL223496 & 688282 & 5.2 & 5.1593 & TRN & \\
\hline CHEMBL286204 & 688282 & 4.9 & 5.3148 & TRN & \\
\hline CHEMBL1412344 & 688282 & 4.9 & 5.082 & TRN & \\
\hline CHEMBL67378 & 688282 & 5.0 & 5.0986 & TST & \\
\hline CHEMBL1373087 & 688282 & 4.6 & 5.1078 & TRN & \\
\hline CHEMBL1559164 & 688282 & 5.0 & 5.2036 & TRN & \\
\hline CHEMBL1517197 & 688282 & 5.0 & 5.0869 & TRN & \\
\hline CHEMBL1509422 & 688282 & 5.3 & 5.0466 & TRN & \\
\hline CHEMBL1356134 & 688282 & 5.2 & 5.1106 & TRN & \\
\hline CHEMBL73711 & 688282 & 4.9 & 5.0104 & TRN & \\
\hline CHEMBL1316796 & 688282 & 5.5 & 5.064 & TRN & \\
\hline CHEMBL1439000 & 688282 & 5.0 & 5.1203 & TST & \\
\hline CHEMBL1392653 & 688282 & 5.3 & 5.0028 & TRN & \\
\hline CHEMBL1368632 & 688282 & 4.9 & 5.2197 & TRN & \\
\hline CHEMBL1430204 & 688282 & 4.8 & 5.15600 & 0000000001 & TRN \\
\hline CHEMBL1312849 & 688282 & 4.9 & 5.2036 & TRN & \\
\hline CHEMBL1574303 & 688282 & 4.5 & 5.0777 & TRN & \\
\hline CHEMBL1368887 & 688282 & 4.5 & 5.153 & TRN & \\
\hline CHEMBL1589768 & 688282 & 5.3 & 5.0043 & TRN & \\
\hline CHEMBL1412386 & 688282 & 4.6 & 5.1168 & TRN & \\
\hline CHEMBL1536625 & 688282 & 4.9 & 5.1361 & TRN & \\
\hline CHEMBL1363246 & 688282 & 5.4 & 5.1654 & TRN & \\
\hline CHEMBL1607137 & 688282 & 5.5 & 5.1869 & TRN & \\
\hline CHEMBL1390073 & 688282 & 5.1 & 5.1085 & TRN & \\
\hline CHEMBL1351716 & 688282 & 5.1 & 5.1474 & TRN & \\
\hline CHEMBL1346587 & 688282 & 4.9 & 5.0219 & TRN & \\
\hline CHEMBL271624 & 688282 & 4.9 & 5.0668 & TRN & \\
\hline CHEMBL1500541 & 688282 & 7.6003 & 5.1588 & TRN & \\
\hline CHEMBL1370495 & 688282 & 4.9 & 5.0951 & TRN & \\
\hline CHEMBL1567236 & 688282 & 4.8 & 5.2049 & TRN & \\
\hline CHEMBL1538218 & 688282 & 4.5 & 5.0234 & TRN & \\
\hline CHEMBL1450035 & 688282 & 5.3 & 5.0467 & TRN & \\
\hline CHEMBL1486934 & 688282 & 5.5 & 5.0687 & TRN & \\
\hline CHEMBL1486789 & 688282 & 4.6 & 5.1928 & TRN & \\
\hline
\end{tabular}




\begin{tabular}{|c|c|c|c|c|c|}
\hline & & & & & \\
\hline CHEMBL1610147 & 688282 & 5.3 & 5.1514 & TRN & \\
\hline CHEMBL1521154 & 688282 & 4.9 & 5.1217 & TRN & \\
\hline CHEMBL1180 & 688282 & 5.0 & 5.191 & TST & \\
\hline CHEMBL1589324 & 688282 & 4.6 & 5.1382 & TRN & \\
\hline CHEMBL1574544 & 688282 & 5.6 & 5.2173 & TRN & \\
\hline CHEMBL1570413 & 688282 & 5.7 & 5.0188 & TRN & \\
\hline CHEMBL1271764 & 688282 & 5.1 & 5.1361 & TRN & \\
\hline CHEMBL3191913 & 688282 & 5.7 & 5.018 & TST & \\
\hline CHEMBL1509585 & 688282 & 5.0 & 5.2022 & TRN & \\
\hline CHEMBL1521274 & 688282 & 6.0 & 5.2351 & TST & \\
\hline CHEMBL1451058 & 688282 & 4.9 & 5.1319 & TRN & \\
\hline CHEMBL1515804 & 688282 & 5.1 & 5.0965 & TRN & \\
\hline CHEMBL1487687 & 688282 & 6.0 & 5.1995 & TRN & \\
\hline CHEMBL305195 & 688282 & 4.9 & 5.2461 & TRN & \\
\hline CHEMBL1454183 & 688282 & 5.4 & 5.2485 & TST & \\
\hline CHEMBL1305152 & 688282 & 5.0 & 5.0337 & TST & \\
\hline CHEMBL1393779 & 688282 & 4.9 & 5.1885 & TRN & \\
\hline CHEMBL273291 & 688282 & 4.5 & 5.1471 & TST & \\
\hline CHEMBL1552249 & 688282 & 8.4949 & 5.1882 & TST & \\
\hline CHEMBL1510496 & 688282 & 4.6 & 5.1505 & TRN & \\
\hline CHEMBL1386272 & 688282 & 5.0 & 5.0702 & TRN & \\
\hline CHEMBL1352392 & 688282 & 5.4 & 5.2605 & TRN & \\
\hline CHEMBL1450025 & 688282 & 4.5 & 5.2055 & TRN & \\
\hline CHEMBL1600620 & 688282 & 5.2 & 5.1561 & TRN & \\
\hline CHEMBL1365762 & 688282 & 5.3 & 5.0539 & TRN & \\
\hline CHEMBL1315559 & 688282 & 4.6 & 5.26399 & 9999999999 & TST \\
\hline CHEMBL1552332 & 688282 & 5.1 & 5.2003 & TRN & \\
\hline CHEMBL1462190 & 688282 & 4.7 & 4.9841 & TRN & \\
\hline CHEMBL1378036 & 688282 & 4.9 & 5.1206 & TRN & \\
\hline CHEMBL1392663 & 688282 & 5.0 & 5.1835 & TRN & \\
\hline CHEMBL1572415 & 688282 & 4.5 & 5.0985 & TRN & \\
\hline CHEMBL1320496 & 688282 & 5.4 & 5.1767 & TRN & \\
\hline CHEMBL1347618 & 688282 & 4.6 & 5.2961 & TRN & \\
\hline CHEMBL1339399 & 688282 & 4.5 & 5.1892 & TST & \\
\hline CHEMBL1540345 & 688282 & 5.3 & 5.0838 & TRN & \\
\hline CHEMBL1535589 & 688282 & 5.1 & 5.164 & TRN & \\
\hline CHEMBL1304412 & 688282 & 6.5 & 5.2644 & TRN & \\
\hline CHEMBL1393096 & 688282 & 4.8 & 4.9961 & TRN & \\
\hline CHEMBL1364366 & 688282 & 6.1 & 5.0673 & TRN & \\
\hline CHEMBL1440902 & 688282 & 4.5 & 5.2055 & TRN & \\
\hline CHEMBL1601040 & 688282 & 5.1 & 5.2245 & TST & \\
\hline CHEMBL1451172 & 688282 & 5.8 & 5.1251 & TRN & \\
\hline CHEMBL3198094 & 688282 & 6.0 & 5.2015 & TRN & \\
\hline CHEMBL1718952 & 688282 & 5.3 & 5.1096 & TRN & \\
\hline CHEMBL1528312 & 688282 & 5.4 & 5.28799 & 9999999999 & TRN \\
\hline CHEMBL1529671 & 688282 & 5.3 & 5.0894 & TRN & \\
\hline CHEMBL1461254 & 688282 & 4.5 & 5.0779 & TRN & \\
\hline CHEMBL1351838 & 688282 & 5.0 & 5.0334 & TRN & \\
\hline & & & & 13257 & \\
\hline
\end{tabular}




\begin{tabular}{|c|c|c|c|c|c|}
\hline & & & & & \\
\hline CHEMBL1472193 & 688282 & 5.4 & 5.0699 & TRN & \\
\hline CHEMBL1554194 & 688282 & 4.8 & 4.9636 & TRN & \\
\hline CHEMBL1329237 & 688282 & 5.4 & 5.1008 & TRN & \\
\hline CHEMBL1336479 & 688282 & 5.0 & 4.9988 & TRN & \\
\hline CHEMBL1346516 & 688282 & 4.9 & 5.1126 & TRN & \\
\hline CHEMBL1425326 & 688282 & 4.6 & 5.0737 & TRN & \\
\hline CHEMBL1339050 & 688282 & 4.7 & 5.176 & TRN & \\
\hline CHEMBL1256749 & 688282 & 4.5 & 5.1731 & TST & \\
\hline CHEMBL1490528 & 688282 & 4.9 & 5.1006 & TRN & \\
\hline CHEMBL1599037 & 688282 & 4.6 & 5.0896 & TRN & \\
\hline CHEMBL1458140 & 688282 & 5.0 & 5.2081 & TST & \\
\hline CHEMBL1087646 & 688282 & 4.6 & 5.1369 & TRN & \\
\hline CHEMBL1442864 & 688282 & 4.9 & 5.2104 & TRN & \\
\hline CHEMBL1435374 & 688282 & 4.9 & 5.1143 & TRN & \\
\hline CHEMBL1085948 & 688282 & 5.6 & 5.2229 & TST & \\
\hline CHEMBL1487205 & 688282 & 5.5 & 5.2238 & TST & \\
\hline CHEMBL1443828 & 688282 & 5.3 & 5.0769 & TRN & \\
\hline CHEMBL1413846 & 688282 & 5.0 & 5.0911 & TRN & \\
\hline CHEMBL1508313 & 688282 & 4.6 & 5.1781 & TRN & \\
\hline CHEMBL1582069 & 688282 & 5.3 & 5.2296 & TRN & \\
\hline CHEMBL1495665 & 688282 & 5.3 & 4.9813 & TRN & \\
\hline CHEMBL1394939 & 688282 & 4.9 & 5.0789 & TRN & \\
\hline CHEMBL1357186 & 688282 & 4.9 & 5.0212 & TRN & \\
\hline CHEMBL1332661 & 688282 & 4.9 & 5.1469 & TRN & \\
\hline CHEMBL1593068 & 688282 & 4.8 & 5.0625 & TRN & \\
\hline CHEMBL1466151 & 688282 & 5.0 & 5.1404 & TRN & \\
\hline CHEMBL1424909 & 688282 & 4.6 & 5.2386 & TRN & \\
\hline CHEMBL603028 & 688282 & 5.0 & 5.1643 & TRN & \\
\hline CHEMBL1594586 & 688282 & 4.6 & 5.0502 & TRN & \\
\hline CHEMBL1497696 & 688282 & 5.0 & 5.24700 & 0000000001 & TRN \\
\hline CHEMBL1596987 & 688282 & 5.3 & 5.2091 & TRN & \\
\hline CHEMBL1447721 & 688282 & 7.699 & 5.2244 & TST & \\
\hline CHEMBL 3208870 & 688282 & 4.6 & 5.0895 & TST & \\
\hline CHEMBL 22373 & 688282 & 4.5 & 5.0383 & TRN & \\
\hline CHEMBL1411108 & 688282 & 4.8 & 5.23799 & 99999999995 & TRN \\
\hline CHEMBL1310198 & 688282 & 4.5 & 5.1491 & TRN & \\
\hline CHEMBL1303635 & 688282 & 5.1 & 5.063 & TRN & \\
\hline CHEMBL1350845 & 688282 & 4.7 & 5.1831 & TRN & \\
\hline CHEMBL1370622 & 688282 & 4.6 & 4.9476 & TRN & \\
\hline CHEMBL1302694 & 688282 & 4.8 & 5.2259 & TST & \\
\hline CHEMBL1436715 & 688282 & 5.0 & 5.1288 & TRN & \\
\hline CHEMBL494081 & 688282 & 5.0 & 5.1893 & TRN & \\
\hline CHEMBL1585641 & 688282 & 5.6 & 5.1277 & TRN & \\
\hline CHEMBL1307067 & 688282 & 4.6 & 5.1658 & TRN & \\
\hline CHEMBL1334784 & 688282 & 4.8 & 5.2242 & TRN & \\
\hline CHEMBL1547798 & 688282 & 4.6 & 5.1895 & TRN & \\
\hline CHEMBL1441920 & 688282 & 6.0 & 5.1727 & TST & \\
\hline CHEMBL1606495 & 688282 & 4.6 & 5.2372 & TRN & \\
\hline & & & & 13258 & \\
\hline
\end{tabular}




\begin{tabular}{|c|c|c|c|c|c|}
\hline \\
\hline CHEMBL489738 & 688282 & 4.9 & 5.0869 & TRN & \\
\hline CHEMBL504722 & 688282 & 4.9 & 5.1671 & TRN & \\
\hline CHEMBL1358009 & 688282 & 6.3 & 5.249 & TRN & \\
\hline CHEMBL1408909 & 688282 & 5.0 & 5.0355 & TRN & \\
\hline CHEMBL1501332 & 688282 & 5.2 & 5.0999 & TRN & \\
\hline CHEMBL1601786 & 688282 & 4.6 & 5.1763 & TRN & \\
\hline CHEMBL1447042 & 688282 & 5.3 & 5.2134 & TRN & \\
\hline CHEMBL598952 & 688282 & 5.1 & 5.2082 & TRN & \\
\hline CHEMBL1567191 & 688282 & 6.3 & 5.0636 & TRN & \\
\hline CHEMBL131199 & 688282 & 5.1 & 5.228 & TRN & \\
\hline CHEMBL1613260 & 688282 & 4.9 & 5.2645 & TRN & \\
\hline CHEMBL1375563 & 688282 & 4.9 & 5.182 & TRN & \\
\hline CHEMBL1535418 & 688282 & 4.5 & 5.0882 & TRN & \\
\hline CHEMBL1400208 & 688282 & 4.9 & 5.2411 & TRN & \\
\hline CHEMBL1411164 & 688282 & 5.4 & 5.1683 & TRN & \\
\hline CHEMBL1326631 & 688282 & 5.3 & 5.1038 & TST & \\
\hline CHEMBL1332566 & 688282 & 5.0 & 5.1718 & TRN & \\
\hline CHEMBL1419676 & 688282 & 5.3 & $5.1110 e$ & 0000000001 & TRN \\
\hline CHEMBL1355262 & 688282 & 4.9 & 5.2522 & TRN & \\
\hline CHEMBL1411839 & 688282 & 4.8 & 5.1196 & TST & \\
\hline CHEMBL1499753 & 688282 & 6.5 & 5.2142 & TST & \\
\hline CHEMBL1411418 & 688282 & 4.9 & 5.152 & TRN & \\
\hline CHEMBL1514517 & 688282 & 6.2 & 5.2722 & TRN & \\
\hline CHEMBL1302992 & 688282 & 5.0 & 5.0671 & TRN & \\
\hline CHEMBL1605558 & 688282 & 4.5 & 5.1546 & TRN & \\
\hline CHEMBL1479610 & 688282 & 4.5 & 5.24799 & 9999999999 & TRN \\
\hline CHEMBL1303767 & 688282 & 4.9 & 5.0955 & TST & \\
\hline CHEMBL1609180 & 688282 & 5.3 & 5.1647 & TRN & \\
\hline CHEMBL1790030 & 688282 & 5.3 & 5.2721 & TRN & \\
\hline CHEMBL1534503 & 688282 & 5.8 & 5.0564 & TRN & \\
\hline CHEMBL1413213 & 688282 & 4.8 & 5.0024 & TRN & \\
\hline CHEMBL1356843 & 688282 & 5.3 & 5.1669 & TRN & \\
\hline CHEMBL1523900 & 688282 & 5.8 & 5.1033 & TRN & \\
\hline CHEMBL1316808 & 688282 & 5.0 & 5.1616 & TRN & \\
\hline CHEMBL578512 & 688282 & 5.9 & 5.20799 & 9999999999 & TST \\
\hline CHEMBL1422094 & 688282 & 4.8 & 5.1662 & TST & \\
\hline CHEMBL1504303 & 688282 & 4.5 & 5.1869 & TRN & \\
\hline CHEMBL1376239 & 688282 & 5.9 & 5.2593 & TRN & \\
\hline CHEMBL1448375 & 688282 & 4.9 & 5.2828 & TRN & \\
\hline CHEMBL1415972 & 688282 & 4.9 & 5.0999 & TRN & \\
\hline CHEMBL1403562 & 688282 & 4.9 & 5.0994 & TRN & \\
\hline CHEMBL1455807 & 688282 & 4.5 & 5.1201 & TRN & \\
\hline CHEMBL453376 & 688282 & 4.6 & 4.9426 & TRN & \\
\hline CHEMBL1324529 & 688282 & 4.9 & 5.0105 & TRN & \\
\hline CHEMBL1568299 & 688282 & 5.0 & 4.948 & TRN & \\
\hline CHEMBL58343 & 688282 & 5.6 & 5.2595 & TST & \\
\hline CHEMBL1313055 & 688282 & 5.0 & 5.0842 & TST & \\
\hline CHEMBL1334907 & 688282 & 5.0 & 5.0782 & TRN & \\
\hline
\end{tabular}




\begin{tabular}{|c|c|c|c|c|c|}
\hline \multicolumn{6}{|c|}{ Supplemental Table S2.txt } \\
\hline CHEMBL1477886 & 688282 & 5.9 & 5.1428 & TRN & \\
\hline CHEMBL1487725 & 688282 & 4.6 & 5.1773 & TRN & \\
\hline CHEMBL567323 & 688282 & 4.7 & 5.0111 & TRN & \\
\hline CHEMBL1384931 & 688282 & 4.7 & 5.1394 & TRN & \\
\hline CHEMBL1338673 & 688282 & 4.5 & 5.034 & TRN & \\
\hline CHEMBL1466068 & 688282 & 4.9 & 5.0919 & TRN & \\
\hline CHEMBL1424528 & 688282 & 4.9 & 5.2648 & TST & \\
\hline CHEMBL1453465 & 688282 & 5.3 & 5.0205 & TRN & \\
\hline CHEMBL1384172 & 688282 & 4.9 & 5.2017 & TRN & \\
\hline CHEMBL480626 & 688282 & 4.6 & 5.2369 & TRN & \\
\hline CHEMBL1562835 & 688282 & 5.3 & 5.2565 & TST & \\
\hline CHEMBL1526915 & 688282 & 5.3 & 5.1989 & TRN & \\
\hline CHEMBL1497531 & 688282 & 5.3 & 5.2097 & TRN & \\
\hline CHEMBL461903 & 688282 & 4.5 & 5.2614 & TST & \\
\hline CHEMBL1596917 & 688282 & 5.6 & 5.0893 & TRN & \\
\hline CHEMBL1438566 & 688282 & 6.3 & 5.2198 & TRN & \\
\hline CHEMBL1456649 & 688282 & 4.6 & 5.3245 & TRN & \\
\hline CHEMBL1359406 & 688282 & 4.9 & 5.12700 & 0000000001 & TRN \\
\hline CHEMBL1332962 & 688282 & 6.5 & 5.1513 & TRN & \\
\hline CHEMBL1452690 & 688282 & 4.9 & 5.1626 & TRN & \\
\hline CHEMBL1453739 & 688282 & 5.3 & 5.118 & TRN & \\
\hline CHEMBL1475620 & 688282 & 5.7 & 5.349 & TRN & \\
\hline CHEMBL1609324 & 688282 & 5.1 & 5.1783 & TRN & \\
\hline CHEMBL1398185 & 688282 & 5.3 & 5.1399 & TRN & \\
\hline CHEMBL1544592 & 688282 & 5.3 & 5.0551 & TRN & \\
\hline CHEMBL1421720 & 688282 & 4.6 & 5.1059 & TRN & \\
\hline CHEMBL592106 & 688282 & 4.9 & 5.0766 & TRN & \\
\hline CHEMBL1592819 & 688282 & 5.3 & 5.0817 & TRN & \\
\hline CHEMBL1501072 & 688282 & 4.9 & 5.1313 & TRN & \\
\hline CHEMBL1362394 & 688282 & 5.0 & 5.1699 & TRN & \\
\hline CHEMBL1436045 & 688282 & 8.3979 & 5.1776 & TRN & \\
\hline CHEMBL1426542 & 688282 & 6.2 & 5.1038 & TRN & \\
\hline CHEMBL1595205 & 688282 & 7.0 & 5.2029 & TRN & \\
\hline CHEMBL1444211 & 688282 & 4.6 & 5.2637 & TRN & \\
\hline CHEMBL1299666 & 688282 & 4.6 & 5.0595 & TRN & \\
\hline CHEMBL1575451 & 688282 & 4.9 & 4.9956 & TRN & \\
\hline CHEMBL1475750 & 688282 & 5.7 & 5.1834 & TRN & \\
\hline CHEMBL1577622 & 688282 & 5.4 & 5.0982 & TRN & \\
\hline CHEMBL1565054 & 688282 & 5.3 & 5.026 & TRN & \\
\hline CHEMBL1503105 & 688282 & 5.5 & 5.1253 & TRN & \\
\hline CHEMBL1505342 & 688282 & 4.5 & 4.9894 & TRN & \\
\hline CHEMBL1490911 & 688282 & 4.9 & 5.1082 & TRN & \\
\hline CHEMBL1603595 & 688282 & 5.3 & 5.2464 & TRN & \\
\hline CHEMBL1469564 & 688282 & 5.3 & 5.2546 & TRN & \\
\hline CHEMBL1579416 & 688282 & 5.1 & 5.0843 & TRN & \\
\hline CHEMBL60518 & 688282 & 4.8 & 5.1646 & TRN & \\
\hline CHEMBL1322295 & 688282 & 5.3 & 5.1172 & TRN & \\
\hline CHEMBL1332076 & 688282 & 4.5 & 5.1289 & TRN & \\
\hline
\end{tabular}




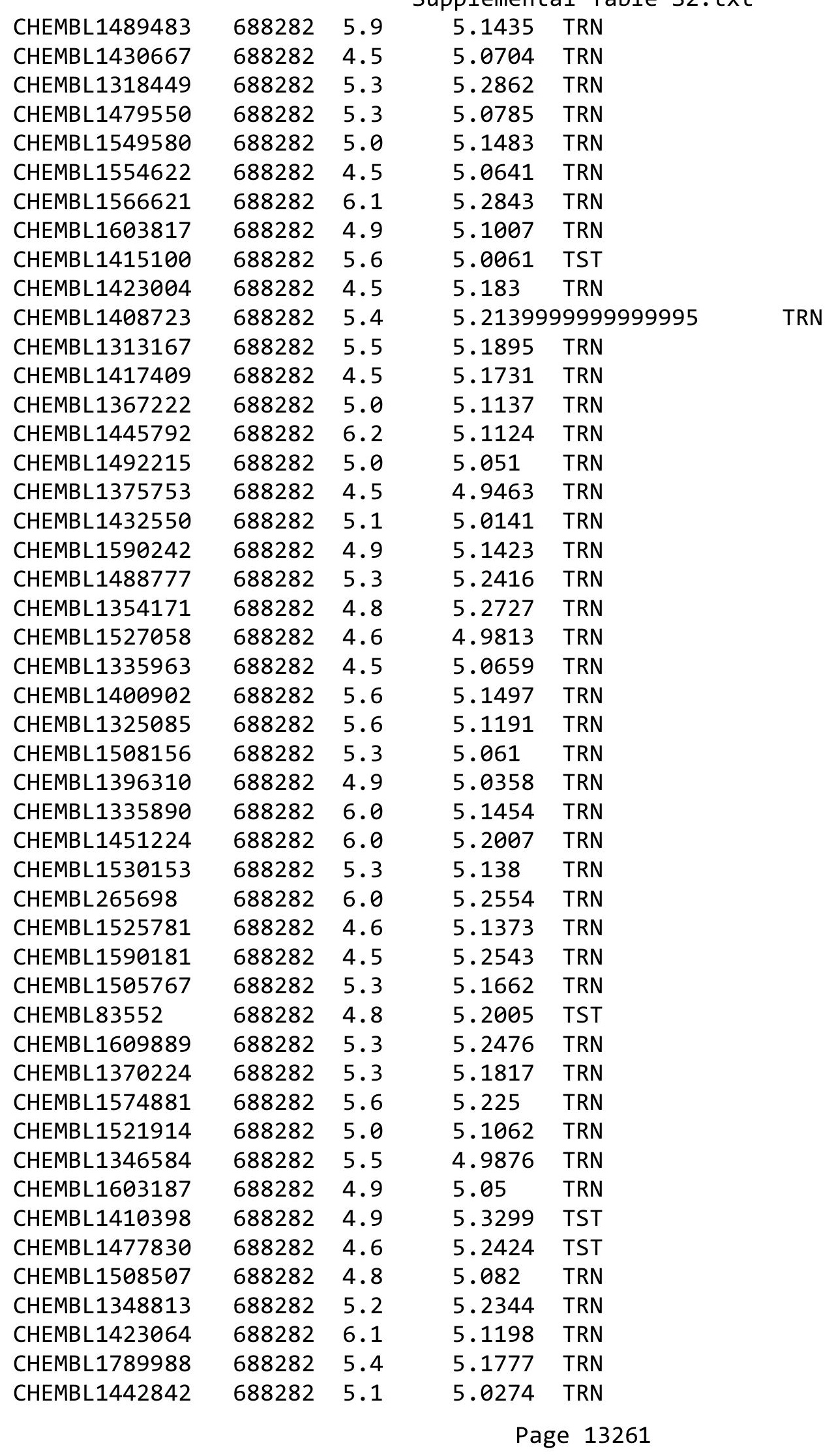




\begin{tabular}{|c|c|c|c|c|}
\hline \multicolumn{5}{|c|}{ Supplemental Table S2.txt } \\
\hline CHEMBL1459718 & 688282 & 6.0 & 5.1039 & TRN \\
\hline CHEMBL1402563 & 688282 & 4.6 & 5.0439 & TRN \\
\hline CHEMBL 277525 & 688282 & 5.9 & 5.2033 & TRN \\
\hline CHEMBL1496575 & 688282 & 5.3 & 5.2419 & TST \\
\hline CHEMBL 362223 & 688282 & 5.7 & 5.1527 & TST \\
\hline CHEMBL457504 & 688282 & 6.3 & 5.1985 & TST \\
\hline CHEMBL1503851 & 688282 & 5.0 & 5.157 & TRN \\
\hline CHEMBL1393339 & 688282 & 4.6 & 5.0237 & TRN \\
\hline CHEMBL1609076 & 688282 & 5.3 & 5.2326 & TRN \\
\hline CHEMBL1329110 & 688282 & 5.3 & 5.0835 & TRN \\
\hline CHEMBL1333559 & 688282 & 5.1 & 4.9685 & TRN \\
\hline CHEMBL1320525 & 688282 & 5.5 & 5.2107 & TRN \\
\hline CHEMBL1576338 & 688282 & 4.6 & 5.0762 & TRN \\
\hline CHEMBL1350980 & 688282 & 4.9 & 5.1352 & TRN \\
\hline CHEMBL1608471 & 688282 & 5.3 & 5.0564 & TRN \\
\hline CHEMBL1412483 & 688282 & 6.5 & 5.1522 & TRN \\
\hline CHEMBL1470303 & 688282 & 5.3 & 5.0299 & TRN \\
\hline CHEMBL1501651 & 688282 & 5.4 & 5.2979 & TST \\
\hline CHEMBL1572026 & 688282 & 4.9 & 4.9417 & TRN \\
\hline CHEMBL1565972 & 688282 & 5.1 & 5.0495 & TRN \\
\hline CHEMBL1317510 & 688282 & 6.0 & 5.2367 & TRN \\
\hline CHEMBL1575442 & 688282 & 5.8 & 5.1434 & TRN \\
\hline CHEMBL1366484 & 688282 & 4.7 & 5.272 & TRN \\
\hline CHEMBL1546312 & 688282 & 5.3 & 5.0822 & TRN \\
\hline CHEMBL1592584 & 688282 & 5.0 & 5.1319 & TRN \\
\hline CHEMBL1371305 & 688282 & 5.3 & 5.1117 & TRN \\
\hline CHEMBL1552542 & 688282 & 5.6 & 5.0445 & TRN \\
\hline CHEMBL1581518 & 688282 & 5.0 & 5.1942 & TST \\
\hline CHEMBL1496988 & 688282 & 5.6 & 5.1841 & TRN \\
\hline CHEMBL1417292 & 688282 & 4.6 & 5.0574 & TRN \\
\hline CHEMBL1598823 & 688282 & 4.9 & 5.1056 & TRN \\
\hline CHEMBL1400599 & 688282 & 5.5 & 5.1498 & TRN \\
\hline CHEMBL278980 & 688282 & 6.0 & 5.3069 & TST \\
\hline CHEMBL1395027 & 688282 & 7.4001 & 5.2893 & TRN \\
\hline CHEMBL1429415 & 688282 & 4.9 & 5.1189 & TRN \\
\hline CHEMBL1317135 & 688282 & 7.5003 & $5.2420 e$ & 0000000001 \\
\hline CHEMBL1600908 & 688282 & 6.0 & 5.1314 & TRN \\
\hline CHEMBL1324916 & 688282 & 5.1 & 5.1136 & TRN \\
\hline CHEMBL1355323 & 688282 & 6.8 & 5.2101 & TST \\
\hline CHEMBL1374810 & 688282 & 4.6 & 5.1684 & TRN \\
\hline CHEMBL1492411 & 688282 & 4.9 & 5.2561 & TRN \\
\hline CHEMBL1593375 & 688282 & 4.9 & 5.0218 & TRN \\
\hline CHEMBL1413097 & 688282 & 4.9 & 5.1584 & TST \\
\hline CHEMBL1328732 & 688282 & 4.9 & 5.0347 & TRN \\
\hline CHEMBL541847 & 688282 & 5.0 & 5.171 & TRN \\
\hline CHEMBL10284 & 688282 & 6.6 & 5.1542 & TRN \\
\hline CHEMBL1486023 & 688282 & 4.6 & 5.1543 & TRN \\
\hline CHEMBL1592804 & 688282 & 4.9 & 5.1393 & TRN \\
\hline
\end{tabular}




\begin{tabular}{|c|c|c|c|c|c|}
\hline \multirow{2}{*}{ CHEMBL1381668 } & \multirow{2}{*}{688282} & \multirow[b]{2}{*}{4.8} & \\
\hline & & & 5.0152 & TRN & \\
\hline CHEMBL1310073 & 688282 & 5.0 & 5.135 & TRN & \\
\hline CHEMBL1317302 & 688282 & 5.5 & 5.1134 & TRN & \\
\hline CHEMBL1612488 & 688282 & 5.0 & 5.0804 & TRN & \\
\hline CHEMBL1423842 & 688282 & 5.1 & 5.0766 & TRN & \\
\hline CHEMBL1505711 & 688282 & 4.7 & 5.0563 & TRN & \\
\hline CHEMBL311158 & 688282 & 4.9 & 5.0874 & TRN & \\
\hline CHEMBL1446608 & 688282 & 5.0 & 5.2059 & TST & \\
\hline CHEMBL1557436 & 688282 & 4.9 & 5.1756 & TRN & \\
\hline CHEMBL1507969 & 688282 & 5.6 & 4.9442 & TRN & \\
\hline CHEMBL1411055 & 688282 & 5.3 & 5.3099 & TST & \\
\hline CHEMBL1474701 & 688282 & 4.5 & 5.2597 & TST & \\
\hline CHEMBL1573554 & 688282 & 6.6 & 5.3379 & TST & \\
\hline CHEMBL1559341 & 688282 & 4.8 & \multicolumn{2}{|c|}{5.132000000000001} & TST \\
\hline CHEMBL1357724 & 688282 & 4.9 & 5.0284 & TRN & \\
\hline CHEMBL1326664 & 688282 & 5.0 & 5.0557 & TRN & \\
\hline CHEMBL1457262 & 688282 & 4.5 & 5.2103 & TRN & \\
\hline CHEMBL1532334 & 688282 & 5.0 & 5.1695 & TRN & \\
\hline CHEMBL1387217 & 688282 & 5.7 & 5.0629 & TRN & \\
\hline CHEMBL1375255 & 688282 & 5.0 & 5.1628 & TRN & \\
\hline CHEMBL1316557 & 688282 & 5.3 & 5.0453 & TRN & \\
\hline CHEMBL1576666 & 688282 & 4.9 & 5.1424 & TRN & \\
\hline CHEMBL1602967 & 688282 & 4.9 & 5.1692 & TRN & \\
\hline CHEMBL1455438 & 688282 & 5.0 & 5.0276 & TRN & \\
\hline CHEMBL1422252 & 688282 & 5.0 & 5.2464 & TST & \\
\hline CHEMBL1600084 & 688282 & 5.0 & 5.0351 & TRN & \\
\hline CHEMBL1370807 & 688282 & 4.5 & 5.114 & TRN & \\
\hline CHEMBL1388010 & 688282 & 4.6 & 5.1805 & TRN & \\
\hline CHEMBL1442326 & 688282 & 5.3 & 5.0987 & TRN & \\
\hline CHEMBL1511584 & 688282 & 5.3 & 5.1272 & TRN & \\
\hline CHEMBL106437 & 688282 & 4.6 & 5.1762 & TRN & \\
\hline CHEMBL1585726 & 688282 & 4.6 & \multicolumn{2}{|c|}{5.1770000000000005} & TST \\
\hline CHEMBL1588283 & 688282 & 5.3 & \multicolumn{2}{|c|}{5.122999999999999} & TRN \\
\hline CHEMBL1564783 & 688282 & 4.6 & 5.1146 & TRN & \\
\hline CHEMBL1567465 & 688282 & 4.9 & 5.0215 & TRN & \\
\hline CHEMBL1494600 & 688282 & 5.0 & 5.0895 & TRN & \\
\hline CHEMBL1372423 & 688282 & 5.3 & 5.1452 & TRN & \\
\hline CHEMBL1571847 & 688282 & 4.9 & 5.1394 & TRN & \\
\hline CHEMBL1395226 & 688282 & 5.4 & 5.1506 & TRN & \\
\hline CHEMBL1491485 & 688282 & 5.4 & 5.0616 & TRN & \\
\hline CHEMBL1504882 & 688282 & 5.6 & 5.1352 & TRN & \\
\hline CHEMBL1479737 & 688282 & 5.3 & 5.0439 & TRN & \\
\hline CHEMBL1400976 & 688282 & 6.5 & 5.24 & TRN & \\
\hline CHEMBL1328322 & 688282 & 6.0 & 5.1846 & TRN & \\
\hline CHEMBL1314211 & 688282 & 4.8 & 4.942 & TRN & \\
\hline CHEMBL1407488 & 688282 & 5.2 & 5.0179 & TRN & \\
\hline CHEMBL 34704 & 688282 & 6.0 & 5.2971 & TST & \\
\hline CHEMBL1324113 & 688282 & 4.9 & 5.1394 & TST & \\
\hline & & & & 13263 & \\
\hline
\end{tabular}




\begin{tabular}{|c|c|c|c|c|c|}
\hline & & & & & \\
\hline CHEMBL1482624 & 688282 & 4.8 & 5.0371 & TRN & \\
\hline CHEMBL1357735 & 688282 & 5.3 & 5.2646 & TST & \\
\hline CHEMBL1564828 & 688282 & 5.0 & 5.1681 & TRN & \\
\hline CHEMBL1551367 & 688282 & 6.0 & $5.2620 e$ & 00000000005 & TRN \\
\hline CHEMBL454761 & 688282 & 4.5 & 5.3259 & TST & \\
\hline CHEMBL584759 & 688282 & 6.0 & 5.1366 & TST & \\
\hline CHEMBL1446951 & 688282 & 4.9 & 5.0866 & TRN & \\
\hline CHEMBL1325833 & 688282 & 4.9 & 5.0494 & TRN & \\
\hline CHEMBL1576076 & 688282 & 4.6 & 5.1112 & TRN & \\
\hline CHEMBL1447735 & 688282 & 4.8 & 5.0898 & TRN & \\
\hline CHEMBL1453706 & 688282 & 4.6 & 5.2205 & TST & \\
\hline CHEMBL1608401 & 688282 & 4.9 & 5.1068 & TRN & \\
\hline CHEMBL1338854 & 688282 & 4.8 & 5.0685 & TRN & \\
\hline CHEMBL1894909 & 688282 & 6.0 & 5.2614 & TRN & \\
\hline CHEMBL1551051 & 688282 & 4.5 & 5.0572 & TRN & \\
\hline CHEMBL1553825 & 688282 & 4.6 & 5.0783 & TRN & \\
\hline CHEMBL1299599 & 688282 & 4.6 & 5.0694 & TRN & \\
\hline CHEMBL1344473 & 688282 & 4.6 & 4.9422 & TRN & \\
\hline CHEMBL1455030 & 688282 & 5.1 & 5.1526 & TRN & \\
\hline CHEMBL1516857 & 688282 & 5.5 & 5.1153 & TRN & \\
\hline CHEMBL1486717 & 688282 & 4.6 & 5.1609 & TRN & \\
\hline CHEMBL184450 & 688282 & 6.0 & 5.2063 & TRN & \\
\hline CHEMBL1523432 & 688282 & 4.6 & 5.148 & TRN & \\
\hline CHEMBL1582395 & 688282 & 4.9 & 5.1658 & TRN & \\
\hline CHEMBL1438705 & 688282 & 4.9 & 5.1855 & TRN & \\
\hline CHEMBL164 & 688282 & 6.0 & 5.3069 & TRN & \\
\hline CHEMBL1545617 & 688282 & 4.9 & 5.0587 & TRN & \\
\hline CHEMBL1437711 & 688282 & 4.5 & 5.2578 & TST & \\
\hline CHEMBL1315794 & 688282 & 5.0 & 5.1097 & TRN & \\
\hline CHEMBL1331809 & 688282 & 5.1 & 5.1019 & TST & \\
\hline CHEMBL1355408 & 688282 & 5.5 & 5.1549 & TRN & \\
\hline CHEMBL1474326 & 688282 & 5.3 & $5.2170 e$ & 00000000005 & TRN \\
\hline CHEMBL1526171 & 688282 & 5.3 & 5.0666 & TRN & \\
\hline CHEMBL1513030 & 688282 & 4.9 & 5.1449 & TRN & \\
\hline CHEMBL11684 & 688282 & 4.5 & 5.3193 & TST & \\
\hline CHEMBL1367995 & 688282 & 5.3 & 5.3098 & TRN & \\
\hline CHEMBL1526837 & 688282 & 6.1 & 5.2553 & TST & \\
\hline CHEMBL8747 & 688282 & 8.0 & 5.0288 & TST & \\
\hline CHEMBL 20562 & 688282 & 4.5 & 5.3276 & TST & \\
\hline CHEMBL1423050 & 688282 & 4.9 & 5.0231 & TRN & \\
\hline CHEMBL 243677 & 688282 & 4.5 & 5.2184 & TRN & \\
\hline CHEMBL1605113 & 688282 & 5.1 & 5.1218 & TST & \\
\hline CHEMBL1435787 & 688282 & 5.5 & 5.2933 & TRN & \\
\hline CHEMBL1510179 & 688282 & 5.3 & 5.1444 & TRN & \\
\hline CHEMBL1304486 & 688282 & 5.3 & 5.0542 & TRN & \\
\hline CHEMBL1458873 & 688282 & 4.8 & 5.1275 & TRN & \\
\hline CHEMBL1347808 & 688282 & 5.1 & 5.1362 & TRN & \\
\hline CHEMBL1539615 & 688282 & 5.4 & 5.1124 & TRN & \\
\hline & & & & 13264 & \\
\hline
\end{tabular}




\begin{tabular}{|c|c|c|c|c|}
\hline & & & 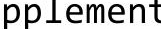 & al Ta \\
\hline CHEMBL1552890 & 688282 & 4.5 & 5.0712 & TRN \\
\hline CHEMBL1299531 & 688282 & 4.5 & 5.1252 & TRN \\
\hline CHEMBL 267160 & 688282 & 5.3 & 5.0272 & TRN \\
\hline CHEMBL1373305 & 688282 & 5.0 & 5.1884 & TRN \\
\hline CHEMBL1594421 & 688282 & 4.9 & 5.2505 & TRN \\
\hline CHEMBL 3192946 & 688282 & 5.1 & 5.0813 & TRN \\
\hline CHEMBL1523556 & 688282 & 4.9 & 5.1593 & TRN \\
\hline CHEMBL1419340 & 688282 & 5.3 & 5.0264 & TRN \\
\hline CHEMBL1369049 & 688282 & 5.4 & 5.0885 & TRN \\
\hline CHEMBL1343554 & 688282 & 4.5 & 5.2455 & TRN \\
\hline CHEMBL1588024 & 688282 & 4.9 & 5.085 & TRN \\
\hline CHEMBL1303203 & 688282 & 5.3 & 5.1043 & TRN \\
\hline CHEMBL1383428 & 688282 & 4.9 & 5.0891 & TRN \\
\hline CHEMBL1597480 & 688282 & 4.6 & 5.1325 & TRN \\
\hline CHEMBL1310490 & 688282 & 4.8 & 5.178 & TRN \\
\hline CHEMBL1563858 & 688282 & 5.3 & 5.0498 & TRN \\
\hline CHEMBL1536423 & 688282 & 4.6 & 5.3567 & TST \\
\hline CHEMBL1540280 & 688282 & 4.9 & 5.0739 & TRN \\
\hline CHEMBL1367899 & 688282 & 4.9 & 5.0738 & TRN \\
\hline CHEMBL1531038 & 688282 & 5.3 & 4.9801 & TRN \\
\hline CHEMBL14276 & 688282 & 5.1 & 5.0582 & TRN \\
\hline CHEMBL1584074 & 688282 & 4.6 & 5.2071 & TRN \\
\hline CHEMBL1566105 & 688282 & 5.3 & 5.2703 & TST \\
\hline CHEMBL1339709 & 688282 & 4.9 & 5.064 & TRN \\
\hline CHEMBL1362482 & 688282 & 4.6 & 5.1879 & TRN \\
\hline CHEMBL1590334 & 688282 & 5.3 & 5.2866 & TRN \\
\hline CHEMBL1613725 & 688282 & 4.9 & 5.0787 & TRN \\
\hline CHEMBL1372571 & 688282 & 5.0 & 5.1698 & TRN \\
\hline CHEMBL3207730 & 688282 & 5.0 & 5.104 & TRN \\
\hline CHEMBL1416448 & 688282 & 4.5 & 5.237 & TST \\
\hline CHEMBL1553399 & 688282 & 4.9 & 5.2068 & TST \\
\hline CHEMBL1607198 & 688282 & 5.5 & 4.9696 & TRN \\
\hline CHEMBL1370307 & 688282 & 5.3 & 5.182 & TRN \\
\hline CHEMBL123904 & 688282 & 4.9 & 5.2345 & TST \\
\hline CHEMBL1309249 & 688282 & 4.6 & 5.191 & TRN \\
\hline CHEMBL1579546 & 688282 & 5.5 & 5.3256 & TRN \\
\hline CHEMBL1537275 & 688282 & 5.4 & 5.2016 & TST \\
\hline CHEMBL1416940 & 688282 & 4.5 & 5.0925 & TRN \\
\hline CHEMBL1335880 & 688282 & 5.0 & 5.1024 & TRN \\
\hline CHEMBL 250711 & 688282 & 4.9 & 5.1353 & TRN \\
\hline CHEMBL1394764 & 688282 & 5.9 & 5.1271 & TST \\
\hline CHEMBL1453530 & 688282 & 5.8 & 5.1407 & TRN \\
\hline CHEMBL1401945 & 688282 & 5.0 & 5.0822 & TRN \\
\hline CHEMBL1435086 & 688282 & 5.9 & 5.1078 & TRN \\
\hline CHEMBL1357850 & 688282 & 4.9 & 5.1023 & TRN \\
\hline CHEMBL1429775 & 688282 & 4.7 & 5.1923 & TRN \\
\hline CHEMBL1317451 & 688282 & 5.7 & 5.0288 & TRN \\
\hline CHEMBL 1255578 & 688282 & 4.9 & 5.3262 & TST \\
\hline
\end{tabular}




\begin{tabular}{|c|c|c|c|c|}
\hline \multicolumn{5}{|c|}{ Supplemental Table S2.txt } \\
\hline CHEMBL1508646 & 688282 & 5.0 & 5.1789 & TRN \\
\hline CHEMBL1604394 & 688282 & 4.6 & 5.0632 & TRN \\
\hline CHEMBL1338425 & 688282 & 5.0 & 5.0975 & TRN \\
\hline CHEMBL1311882 & 688282 & 4.7 & 5.2145 & TST \\
\hline CHEMBL1321924 & 688282 & 5.0 & 5.2151 & TRN \\
\hline CHEMBL1448728 & 688282 & 4.9 & 5.0817 & TRN \\
\hline CHEMBL1523204 & 688282 & 4.9 & 5.2371 & TST \\
\hline CHEMBL 38288 & 688282 & 4.9 & 5.0681 & TRN \\
\hline CHEMBL1613329 & 688282 & 5.0 & 5.141 & TRN \\
\hline CHEMBL1536413 & 688282 & 5.0 & 5.2296 & TRN \\
\hline CHEMBL115121 & 688282 & 4.9 & 5.1113 & TST \\
\hline CHEMBL1527029 & 688282 & 4.9 & 5.142 & TRN \\
\hline CHEMBL73188 & 688282 & 5.1 & 5.2959 & TST \\
\hline CHEMBL1357222 & 688282 & 7.6003 & 5.3339 & TRN \\
\hline CHEMBL1459575 & 688282 & 5.3 & 5.1142 & TST \\
\hline CHEMBL1362416 & 688282 & 5.0 & 5.0832 & TRN \\
\hline CHEMBL1486876 & 688282 & 6.0 & 5.1032 & TST \\
\hline CHEMBL1338891 & 688282 & 4.8 & 5.0124 & TRN \\
\hline CHEMBL1536679 & 688282 & 4.9 & 5.1619 & TRN \\
\hline CHEMBL580183 & 688282 & 4.9 & 5.1263 & TRN \\
\hline CHEMBL1531767 & 688282 & 6.3 & 5.2311 & TST \\
\hline CHEMBL 282489 & 688282 & 4.8 & 5.2013 & TST \\
\hline CHEMBL93655 & 688282 & 4.6 & 5.1996 & TRN \\
\hline CHEMBL1363764 & 688282 & 4.9 & 5.1083 & TRN \\
\hline CHEMBL1459623 & 688282 & 5.0 & 5.1519 & TRN \\
\hline CHEMBL1450716 & 688282 & 5.3 & 5.0594 & TRN \\
\hline CHEMBL1603400 & 688282 & 4.5 & 5.0313 & TRN \\
\hline CHEMBL3196107 & 688282 & 4.5 & 5.1275 & TRN \\
\hline CHEMBL1428465 & 688282 & 4.5 & 5.0827 & TRN \\
\hline CHEMBL1528102 & 688282 & 4.6 & 5.0818 & TRN \\
\hline CHEMBL1479449 & 688282 & 4.5 & 5.1277 & TRN \\
\hline CHEMBL1540684 & 688282 & 4.9 & 5.0963 & TRN \\
\hline CHEMBL1308000 & 688282 & 4.6 & 5.0232 & TRN \\
\hline CHEMBL1255659 & 688282 & 4.5 & 5.255 & TRN \\
\hline CHEMBL1536048 & 688282 & 5.0 & 5.1207 & TRN \\
\hline CHEMBL1323268 & 688282 & 5.1 & 5.1587 & TRN \\
\hline CHEMBL 1437523 & 688282 & 6.3 & 5.1703 & TRN \\
\hline CHEMBL1364368 & 688282 & 4.9 & 5.1735 & TRN \\
\hline CHEMBL1397218 & 688282 & 7.1002 & 5.2894 & TST \\
\hline CHEMBL3214149 & 688282 & 5.0 & 5.2383 & TRN \\
\hline CHEMBL1369304 & 688282 & 5.6 & 5.0292 & TRN \\
\hline CHEMBL 276140 & 688282 & 4.9 & 5.1529 & TRN \\
\hline CHEMBL1330983 & 688282 & 5.2 & 5.1187 & TRN \\
\hline CHEMBL 202752 & 688282 & 5.6 & 5.2146 & TRN \\
\hline CHEMBL1527686 & 688282 & 5.3 & 5.1771 & TRN \\
\hline CHEMBL447507 & 688282 & 4.5 & 5.0218 & TRN \\
\hline CHEMBL1300161 & 688282 & 4.7 & 5.1091 & TRN \\
\hline CHEMBL1364572 & 688282 & 5.3 & 5.1812 & TRN \\
\hline
\end{tabular}




\begin{tabular}{|c|c|c|c|c|}
\hline \multicolumn{5}{|c|}{ Supplemental Table S2.txt } \\
\hline CHEMBL1368832 & 688282 & 4.5 & 5.085 & TRN \\
\hline CHEMBL1485429 & 688282 & 4.5 & 5.1642 & TRN \\
\hline CHEMBL393287 & 688282 & 5.2 & 5.1457 & TRN \\
\hline CHEMBL1482823 & 688282 & 5.3 & 5.1998 & TRN \\
\hline CHEMBL1397367 & 688282 & 8.6021 & 5.2437 & TRN \\
\hline CHEMBL1479767 & 688282 & 5.0 & 5.0986 & TRN \\
\hline CHEMBL1394302 & 688282 & 4.6 & 5.1059 & TST \\
\hline CHEMBL1513188 & 688282 & 4.7 & 5.09 & TRN \\
\hline CHEMBL1576244 & 688282 & 5.3 & 5.1837 & TRN \\
\hline CHEMBL1425624 & 688282 & 5.0 & 5.1241 & TRN \\
\hline CHEMBL1437142 & 688282 & 5.6 & 5.2483 & TRN \\
\hline CHEMBL1486638 & 688282 & 6.2 & 5.2165 & TRN \\
\hline CHEMBL165 & 688282 & 4.9 & 5.2676 & TRN \\
\hline CHEMBL1312153 & 688282 & 5.0 & 5.0628 & TRN \\
\hline CHEMBL1360959 & 688282 & 5.7 & 5.0984 & TRN \\
\hline CHEMBL1373169 & 688282 & 4.6 & 5.136 & TRN \\
\hline CHEMBL1404093 & 688282 & 5.1 & 5.1637 & TRN \\
\hline CHEMBL1367008 & 688282 & 4.9 & 5.1424 & TRN \\
\hline CHEMBL1499582 & 688282 & 4.7 & 5.0839 & TRN \\
\hline CHEMBL1386201 & 688282 & 5.3 & 5.0522 & TRN \\
\hline CHEMBL1327733 & 688282 & 4.9 & 5.0143 & TRN \\
\hline CHEMBL1425000 & 688282 & 5.5 & 5.0918 & TRN \\
\hline CHEMBL1475255 & 688282 & 5.0 & 5.1805 & TRN \\
\hline CHEMBL1307748 & 688282 & 5.0 & 5.1268 & TRN \\
\hline CHEMBL1449135 & 688282 & 5.3 & 5.1766 & TRN \\
\hline CHEMBL1323553 & 688282 & 4.7 & 5.1704 & TRN \\
\hline CHEMBL1597900 & 688282 & 8.301 & 5.1187 & TRN \\
\hline CHEMBL1257075 & 688282 & 4.5 & 5.2487 & TRN \\
\hline CHEMBL1404290 & 688282 & 5.0 & 5.1807 & TST \\
\hline CHEMBL44201 & 688282 & 4.5 & 5.2611 & TRN \\
\hline CHEMBL1407912 & 688282 & 4.5 & 5.1107 & TRN \\
\hline CHEMBL1421988 & 688282 & 5.1 & 5.228 & TRN \\
\hline CHEMBL1445979 & 688282 & 7.6003 & 5.2535 & TRN \\
\hline CHEMBL1547373 & 688282 & 4.6 & 5.1159 & TRN \\
\hline CHEMBL600060 & 688282 & 5.1 & 5.0505 & TST \\
\hline CHEMBL1584502 & 688282 & 5.0 & 5.2689 & TRN \\
\hline CHEMBL1433725 & 688282 & 5.1 & 5.1309 & TRN \\
\hline CHEMBL36060 & 688282 & 4.9 & 5.0751 & TRN \\
\hline CHEMBL1550164 & 688282 & 4.5 & 5.1453 & TRN \\
\hline CHEMBL1465221 & 688282 & 5.7 & 5.0588 & TRN \\
\hline CHEMBL1363920 & 688282 & 6.4 & 5.1884 & TRN \\
\hline CHEMBL1305412 & 688282 & 4.6 & 5.1598 & TRN \\
\hline CHEMBL1459579 & 688282 & 5.3 & 5.2743 & TST \\
\hline CHEMBL1484623 & 688282 & 5.4 & 5.0433 & TRN \\
\hline CHEMBL 278041 & 688282 & 6.1 & 5.2589 & TST \\
\hline CHEMBL1557424 & 688282 & 4.6 & 5.2336 & TRN \\
\hline CHEMBL1574014 & 688282 & 5.5 & 5.0068 & TRN \\
\hline CHEMBL1321515 & 688282 & 4.7 & 4.9944 & TRN \\
\hline
\end{tabular}




\begin{tabular}{|c|c|c|c|c|}
\hline & & & pplement & al $\mathrm{Ta}$ \\
\hline CHEMBL1594694 & 688282 & 4.7 & 5.077 & TRN \\
\hline CHEMBL446315 & 688282 & 4.9 & 5.1788 & TST \\
\hline CHEMBL1558796 & 688282 & 4.8 & 5.2143 & TRN \\
\hline CHEMBL1427890 & 688282 & 4.9 & 5.2395 & TRN \\
\hline CHEMBL1314042 & 688282 & 5.8 & 5.0459 & TRN \\
\hline CHEMBL1558083 & 688282 & 5.0 & 4.9811 & TRN \\
\hline CHEMBL1452932 & 688282 & 5.1 & 5.1916 & TRN \\
\hline CHEMBL1524393 & 688282 & 5.0 & 5.0216 & TRN \\
\hline CHEMBL1487712 & 688282 & 5.3 & 5.1351 & TRN \\
\hline CHEMBL1438852 & 688282 & 5.2 & 5.0817 & TRN \\
\hline CHEMBL1358384 & 688282 & 6.7001 & 5.3106 & TST \\
\hline CHEMBL1414319 & 688282 & 6.0 & 5.3126 & TST \\
\hline CHEMBL1320489 & 688282 & 5.0 & 5.1428 & TRN \\
\hline CHEMBL1376888 & 688282 & 5.0 & 5.1016 & TRN \\
\hline CHEMBL1581254 & 688282 & 4.9 & 5.1825 & TRN \\
\hline CHEMBL1457497 & 688282 & 4.9 & 5.1482 & TST \\
\hline CHEMBL1554960 & 688282 & 5.7 & 5.1258 & TRN \\
\hline CHEMBL1568369 & 688282 & 6.4 & 5.1758 & TST \\
\hline CHEMBL1596743 & 688282 & 5.0 & 5.2238 & TRN \\
\hline CHEMBL12014 & 688282 & 5.7 & 5.1779 & TRN \\
\hline CHEMBL1312261 & 688282 & 4.5 & 5.0278 & TRN \\
\hline CHEMBL1573961 & 688282 & 4.9 & 5.1447 & TRN \\
\hline CHEMBL1332868 & 688282 & 5.0 & 5.1314 & TRN \\
\hline CHEMBL1414910 & 688282 & 6.4 & 5.1317 & TRN \\
\hline CHEMBL1556840 & 688282 & 5.0 & 5.178 & TST \\
\hline CHEMBL1342198 & 688282 & 4.8 & 5.1986 & TST \\
\hline CHEMBL1601176 & 688282 & 5.1 & 5.0668 & TRN \\
\hline CHEMBL89445 & 688282 & 5.0 & 5.2228 & TRN \\
\hline CHEMBL1393104 & 688282 & 4.6 & 5.1011 & TRN \\
\hline CHEMBL1429619 & 688282 & 4.6 & 5.0157 & TRN \\
\hline CHEMBL1343403 & 688282 & 4.5 & 5.0019 & TRN \\
\hline CHEMBL1359872 & 688282 & 6.4 & 5.2298 & TRN \\
\hline CHEMBL1481361 & 688282 & 5.6 & 5.1761 & TRN \\
\hline CHEMBL1557841 & 688282 & 5.4 & 5.0426 & TRN \\
\hline CHEMBL1363347 & 688282 & 6.9 & 5.2291 & TRN \\
\hline CHEMBL159096 & 688282 & 4.9 & 5.0983 & TST \\
\hline CHEMBL1314182 & 688282 & 4.9 & 5.0087 & TRN \\
\hline CHEMBL1531826 & 688282 & 5.8 & 5.0959 & TRN \\
\hline CHEMBL1516224 & 688282 & 4.5 & 5.181 & TRN \\
\hline CHEMBL526034 & 688282 & 5.1 & 5.1976 & TRN \\
\hline CHEMBL82846 & 688282 & 4.8 & 5.1757 & TRN \\
\hline CHEMBL1415488 & 688282 & 6.2 & 5.1113 & TRN \\
\hline CHEMBL1398721 & 688282 & 4.8 & 5.0481 & TRN \\
\hline CHEMBL1442770 & 688282 & 4.6 & 5.0933 & TST \\
\hline CHEMBL1606460 & 688282 & 5.2 & 5.1206 & TRN \\
\hline CHEMBL1582760 & 688282 & 6.1 & 5.24 & TRN \\
\hline CHEMBL1602316 & 688282 & 5.3 & 5.0727 & TRN \\
\hline CHEMBL1529910 & 688282 & 5.2 & 5.2364 & TRN \\
\hline
\end{tabular}




\begin{tabular}{|c|c|c|c|c|}
\hline \multicolumn{5}{|c|}{ Supplemental Table s2.txt } \\
\hline CHEMBL1508410 & 688282 & 4.6 & 5.2073 & TRN \\
\hline CHEMBL1592982 & 688282 & 5.0 & 4.9417 & TRN \\
\hline CHEMBL1582419 & 688282 & 5.0 & 5.0897 & TRN \\
\hline CHEMBL1329831 & 688282 & 5.3 & 5.21299 & 9999999999 \\
\hline CHEMBL1602599 & 688282 & 4.5 & 5.1752 & TRN \\
\hline CHEMBL1411094 & 688282 & 5.0 & 5.2142 & TRN \\
\hline CHEMBL1472168 & 688282 & 4.6 & 5.1003 & TRN \\
\hline CHEMBL1560737 & 688282 & 6.2 & 5.1451 & TST \\
\hline CHEMBL1549209 & 688282 & 4.9 & 4.9847 & TRN \\
\hline CHEMBL1445260 & 688282 & 5.0 & 5.2004 & TST \\
\hline CHEMBL1438231 & 688282 & 6.0 & 5.0466 & TRN \\
\hline CHEMBL1580990 & 688282 & 5.4 & 5.0721 & TRN \\
\hline CHEMBL1322401 & 688282 & 4.6 & 5.0788 & TRN \\
\hline CHEMBL1395026 & 688282 & 4.9 & 5.1101 & TRN \\
\hline CHEMBL1533390 & 688282 & 4.9 & 5.0375 & TRN \\
\hline CHEMBL1412606 & 688282 & 5.0 & 5.148 & TRN \\
\hline CHEMBL1389032 & 688282 & 5.3 & 5.2841 & TST \\
\hline CHEMBL1603542 & 688282 & 5.4 & 5.2033 & TRN \\
\hline CHEMBL1440242 & 688282 & 5.3 & 5.2988 & TRN \\
\hline CHEMBL1489236 & 688282 & 4.9 & 5.192 & TRN \\
\hline CHEMBL1450386 & 688282 & 4.9 & 5.165 & TRN \\
\hline CHEMBL1604108 & 688282 & 5.4 & 5.1251 & TRN \\
\hline CHEMBL1476043 & 688282 & 5.6 & 5.0526 & TRN \\
\hline CHEMBL1589103 & 688282 & 5.1 & 5.0526 & TRN \\
\hline CHEMBL1447828 & 688282 & 5.0 & 5.048 & TRN \\
\hline CHEMBL1610544 & 688282 & 5.6 & 4.9848 & TRN \\
\hline CHEMBL1311755 & 688282 & 4.5 & 5.0964 & TRN \\
\hline CHEMBL1453749 & 688282 & 4.5 & 5.1779 & TRN \\
\hline CHEMBL1484774 & 688282 & 4.9 & 5.1966 & TRN \\
\hline CHEMBL222409 & 688282 & 5.2 & 5.2534 & TRN \\
\hline CHEMBL1384729 & 688282 & 4.9 & 5.0786 & TRN \\
\hline CHEMBL1342741 & 688282 & 4.5 & 5.1476 & TRN \\
\hline CHEMBL411085 & 688282 & 4.9 & 5.1149 & TRN \\
\hline CHEMBL1612778 & 688282 & 5.3 & 5.0993 & TRN \\
\hline CHEMBL1342109 & 688282 & 5.3 & 5.1888 & TRN \\
\hline CHEMBL1317055 & 688282 & 6.0 & 5.2176 & TST \\
\hline CHEMBL1472160 & 688282 & 4.9 & 5.2237 & TST \\
\hline CHEMBL554041 & 688282 & 5.0 & 5.1823 & TST \\
\hline CHEMBL1356196 & 688282 & 7.5003 & 5.301 & TRN \\
\hline CHEMBL1570537 & 688282 & 5.4 & 5.1187 & TRN \\
\hline CHEMBL1568475 & 688282 & 4.9 & 5.171 & TRN \\
\hline CHEMBL1388790 & 688282 & 5.5 & 5.1598 & TRN \\
\hline CHEMBL1300983 & 688282 & 5.0 & 5.1833 & TRN \\
\hline CHEMBL1403780 & 688282 & 5.4 & 5.2494 & TRN \\
\hline CHEMBL1490172 & 688282 & 6.9 & 5.1731 & TST \\
\hline CHEMBL1469912 & 688282 & 5.3 & 5.1553 & TRN \\
\hline CHEMBL1611496 & 688282 & 5.1 & 4.9734 & TRN \\
\hline CHEMBL1388103 & 688282 & 5.5 & 5.1832 & TRN \\
\hline
\end{tabular}

TRN 


\begin{tabular}{|c|c|c|c|c|c|}
\hline \multicolumn{6}{|c|}{ 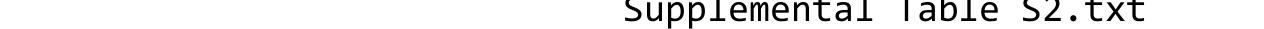 } \\
\hline CHEMBL1981833 & 688282 & 6.0 & 5.0419 & TRN & \\
\hline CHEMBL1304856 & 688282 & 4.5 & 5.1423 & TRN & \\
\hline CHEMBL1309024 & 688282 & 5.3 & 5.1092 & TRN & \\
\hline CHEMBL1517187 & 688282 & 4.6 & 5.1763 & TST & \\
\hline CHEMBL1507828 & 688282 & 5.3 & 5.1508 & TRN & \\
\hline CHEMBL1492877 & 688282 & 4.6 & 5.1368 & TRN & \\
\hline CHEMBL1522929 & 688282 & 4.6 & 5.3004 & TRN & \\
\hline CHEMBL1408982 & 688282 & 4.7 & 5.1604 & TRN & \\
\hline CHEMBL1603054 & 688282 & 5.8 & 5.1724 & TRN & \\
\hline CHEMBL1343238 & 688282 & 4.6 & 5.1387 & TRN & \\
\hline CHEMBL1496245 & 688282 & 4.5 & 5.0634 & TRN & \\
\hline CHEMBL1330418 & 688282 & 4.7 & 5.1039 & TRN & \\
\hline CHEMBL1518801 & 688282 & 4.9 & 5.0491 & TRN & \\
\hline CHEMBL1429850 & 688282 & 6.0 & 5.088 & TST & \\
\hline CHEMBL1530186 & 688282 & 5.3 & 5.0927 & TRN & \\
\hline CHEMBL1493616 & 688282 & 5.0 & 5.106 & TRN & \\
\hline CHEMBL1453992 & 688282 & 5.3 & 5.024 & TST & \\
\hline CHEMBL1585095 & 688282 & 4.5 & 5.0922 & TRN & \\
\hline CHEMBL13960 & 688282 & 5.3 & 5.3413 & TST & \\
\hline CHEMBL1596090 & 688282 & 4.5 & 5.2111 & TRN & \\
\hline CHEMBL3392050 & 688282 & 4.9 & 5.1644 & TST & \\
\hline CHEMBL1449641 & 688282 & 4.5 & 5.0607 & TRN & \\
\hline CHEMBL1339746 & 688282 & 5.0 & 5.1806 & TST & \\
\hline CHEMBL1444829 & 688282 & 4.6 & 4.9326 & TRN & \\
\hline CHEMBL1466192 & 688282 & 4.9 & 5.0785 & TRN & \\
\hline CHEMBL1443093 & 688282 & 4.8 & 5.0727 & TRN & \\
\hline CHEMBL1399001 & 688282 & 5.3 & 5.1513 & TRN & \\
\hline CHEMBL1345212 & 688282 & 4.9 & 5.1526 & TRN & \\
\hline CHEMBL1366061 & 688282 & 4.9 & 4.995 & TRN & \\
\hline CHEMBL 242080 & 688282 & 6.0 & 5.223 & TRN & \\
\hline CHEMBL138297 & 688282 & 4.5 & 5.2842 & TST & \\
\hline CHEMBL1583081 & 688282 & 4.8 & 5.2025 & TRN & \\
\hline CHEMBL1317823 & 688282 & 4.9 & 5.1791 & TRN & \\
\hline CHEMBL1357558 & 688282 & 6.0 & 5.1819 & TRN & \\
\hline CHEMBL1518794 & 688282 & 5.0 & 5.1541 & TRN & \\
\hline CHEMBL1496640 & 688282 & 5.1 & 5.0788 & TRN & \\
\hline CHEMBL1460491 & 688282 & 5.0 & 5.1582 & TRN & \\
\hline CHEMBL1543222 & 688282 & 5.0 & 5.0823 & TRN & \\
\hline CHEMBL 293749 & 688282 & 4.6 & 5.2847 & TRN & \\
\hline CHEMBL1338958 & 688282 & 4.5 & 5.0677 & TRN & \\
\hline CHEMBL1510716 & 688282 & 4.6 & 5.2195 & TRN & \\
\hline CHEMBL1478835 & 688282 & 8.0 & 5.1634 & TRN & \\
\hline CHEMBL1483013 & 688282 & 4.9 & 5.0101 & TRN & \\
\hline CHEMBL1427849 & 688282 & 5.3 & 5.0792 & TRN & \\
\hline CHEMBL1576234 & 688282 & 4.9 & 5.0598 & TRN & \\
\hline CHEMBL60662 & 688282 & 5.5 & 5.25899 & 99999999995 & TRN \\
\hline CHEMBL1340053 & 688282 & 5.3 & 5.1991 & TRN & \\
\hline CHEMBL1475657 & 688282 & 5.1 & 5.0686 & TRN & \\
\hline & & & & 13270 & \\
\hline
\end{tabular}

Supplemental Table S2.txt 


\begin{tabular}{|c|c|c|c|c|c|}
\hline CHEMBL1578363 & 688282 & 4.9 & \multicolumn{2}{|c|}{5.0280000000000005} & TRN \\
\hline CHEMBL1595889 & 688282 & 4.6 & 5.192 & TST & \\
\hline CHEMBL1328466 & 688282 & 5.8 & 5.2371 & TST & \\
\hline CHEMBL1585011 & 688282 & 5.9 & 5.1429 & TRN & \\
\hline CHEMBL1600915 & 688282 & 8.3979 & 5.1665 & TST & \\
\hline CHEMBL113142 & 688282 & 4.5 & 5.0995 & TRN & \\
\hline CHEMBL1331247 & 688282 & 4.8 & 5.1195 & TST & \\
\hline CHEMBL1442642 & 688282 & 5.5 & 5.1649 & TRN & \\
\hline CHEMBL1347677 & 688282 & 4.6 & 5.2421 & TRN & \\
\hline CHEMBL1551557 & 688282 & 4.5 & 5.0334 & TRN & \\
\hline CHEMBL1593926 & 688282 & 5.6 & 5.0744 & TRN & \\
\hline CHEMBL1436957 & 688282 & 4.9 & 5.2683 & TRN & \\
\hline CHEMBL1594680 & 688282 & 4.9 & 5.1327 & TRN & \\
\hline CHEMBL1337648 & 688282 & 6.0 & 5.1849 & TRN & \\
\hline CHEMBL1487947 & 688282 & 5.0 & 5.0863 & TRN & \\
\hline CHEMBL140254 & 688282 & 4.9 & 5.2917 & TST & \\
\hline CHEMBL1606698 & 688282 & 4.5 & 5.2223 & TST & \\
\hline CHEMBL1394045 & 688282 & 5.2 & 5.1859 & TRN & \\
\hline CHEMBL1568086 & 688282 & 8.0 & 4.9621 & TRN & \\
\hline CHEMBL1412410 & 688282 & 4.5 & 4.9169 & TRN & \\
\hline CHEMBL577455 & 688282 & 8.699 & 5.2547 & TST & \\
\hline CHEMBL1358525 & 688282 & 4.5 & 5.0708 & TRN & \\
\hline CHEMBL1508370 & 688282 & 5.0 & 5.1499 & TRN & \\
\hline CHEMBL2006154 & 688282 & 4.5 & 5.0551 & TRN & \\
\hline CHEMBL1326152 & 688282 & 5.3 & 5.141 & TRN & \\
\hline CHEMBL11458 & 688282 & 4.9 & 5.2345 & TRN & \\
\hline CHEMBL1368942 & 688282 & 4.9 & 5.191 & TRN & \\
\hline CHEMBL1359917 & 688282 & 5.0 & 5.148 & TRN & \\
\hline CHEMBL1554842 & 688282 & 5.5 & 5.2769 & TRN & \\
\hline CHEMBL1328353 & 688282 & 5.3 & 5.1771 & TRN & \\
\hline CHEMBL1401516 & 688282 & 4.6 & 5.2217 & TST & \\
\hline CHEMBL1316528 & 688282 & 5.4 & 5.3176 & TRN & \\
\hline CHEMBL1256686 & 688282 & 6.0 & 5.1668 & TST & \\
\hline CHEMBL1574897 & 688282 & 4.9 & 5.0604 & TRN & \\
\hline CHEMBL1339034 & 688282 & 5.5 & 5.2158 & TRN & \\
\hline CHEMBL1503318 & 688282 & 4.7 & 5.1619 & TRN & \\
\hline CHEMBL1363562 & 688282 & 5.5 & 5.1041 & TRN & \\
\hline CHEMBL1486659 & 688282 & 5.4 & 5.3055 & TRN & \\
\hline CHEMBL1566983 & 688282 & 4.6 & 5.1203 & TRN & \\
\hline CHEMBL1509778 & 688282 & 4.8 & 5.1368 & TRN & \\
\hline CHEMBL1432275 & 688282 & 5.6 & 5.0682 & TST & \\
\hline CHEMBL1553123 & 688282 & 4.5 & 5.1089 & TRN & \\
\hline CHEMBL1501556 & 688282 & 5.3 & 5.2031 & TRN & \\
\hline CHEMBL1311633 & 688282 & 4.5 & 5.0967 & TRN & \\
\hline CHEMBL1503665 & 688282 & 7.0 & 5.1804 & TRN & \\
\hline CHEMBL1520266 & 688282 & 4.8 & 5.077 & TRN & \\
\hline CHEMBL1576251 & 688282 & 6.7001 & 5.1094 & TRN & \\
\hline CHEMBL1359317 & 688282 & 5.3 & 5.0838 & TRN & \\
\hline
\end{tabular}




\begin{tabular}{|c|c|c|c|c|}
\hline \multicolumn{5}{|c|}{ Supplemental Table S2.txt } \\
\hline CHEMBL18879 & 688282 & 4.6 & 5.1835 & TST \\
\hline CHEMBL1568268 & 688282 & 4.9 & 5.17399 & 99999999995 \\
\hline CHEMBL1341351 & 688282 & 5.3 & 5.1076 & TRN \\
\hline CHEMBL1570160 & 688282 & 4.7 & 5.0176 & TRN \\
\hline CHEMBL1444096 & 688282 & 4.6 & 5.1466 & TRN \\
\hline CHEMBL1458634 & 688282 & 4.6 & 5.1507 & TRN \\
\hline CHEMBL1472228 & 688282 & 4.9 & 4.976 & TRN \\
\hline CHEMBL1317498 & 688282 & 5.0 & 5.0594 & TRN \\
\hline CHEMBL1532037 & 688282 & 5.2 & 5.0839 & TRN \\
\hline CHEMBL168 & 688282 & 6.6 & 5.3119 & TST \\
\hline CHEMBL1537239 & 688282 & 5.5 & 5.118 & TRN \\
\hline CHEMBL1432443 & 688282 & 4.5 & 5.0807 & TRN \\
\hline CHEMBL1540443 & 688282 & 5.3 & 5.0982 & TRN \\
\hline CHEMBL1591504 & 688282 & 5.5 & 5.3201 & TRN \\
\hline CHEMBL1530946 & 688282 & 4.6 & 5.0788 & TRN \\
\hline CHEMBL1570200 & 688282 & 5.1 & 4.9232 & TRN \\
\hline CHEMBL1322422 & 688282 & 5.7 & 5.1614 & TRN \\
\hline CHEMBL1429623 & 688282 & 5.3 & 5.2198 & TRN \\
\hline CHEMBL1534028 & 688282 & 8.3979 & 5.1761 & TRN \\
\hline CHEMBL42485 & 688282 & 4.6 & 5.1387 & TST \\
\hline CHEMBL1316491 & 688282 & 5.2 & 5.0455 & TRN \\
\hline CHEMBL36148 & 688282 & 5.9 & 5.0906 & TRN \\
\hline CHEMBL1342901 & 688282 & 4.5 & 5.0425 & TRN \\
\hline CHEMBL1354432 & 688282 & 6.4 & 5.3087 & TRN \\
\hline CHEMBL1580851 & 688282 & 4.6 & 5.2417 & TRN \\
\hline CHEMBL1592212 & 688282 & 5.6 & 5.1626 & TRN \\
\hline CHEMBL1522062 & 688282 & 4.8 & 5.1744 & TRN \\
\hline CHEMBL1442987 & 688282 & 6.2 & 5.2085 & TRN \\
\hline CHEMBL1333683 & 688282 & 4.6 & 5.2251 & TRN \\
\hline CHEMBL1469984 & 688282 & 5.0 & 5.1742 & TRN \\
\hline CHEMBL1572525 & 688282 & 5.3 & 5.0655 & TRN \\
\hline CHEMBL1306265 & 688282 & 7.8996 & 5.1448 & TST \\
\hline CHEMBL1592209 & 688282 & 4.6 & 5.1242 & TRN \\
\hline CHEMBL1336372 & 688282 & 4.6 & 5.2458 & TRN \\
\hline CHEMBL1356391 & 688282 & 5.3 & 5.0467 & TST \\
\hline CHEMBL1404408 & 688282 & 5.4 & 5.141 & TRN \\
\hline CHEMBL1454512 & 688282 & 5.3 & 5.2623 & TRN \\
\hline CHEMBL1488723 & 688282 & 4.9 & 5.1528 & TRN \\
\hline CHEMBL1464206 & 688282 & 5.0 & 5.0005 & TRN \\
\hline CHEMBL1585336 & 688282 & 6.3 & 5.0728 & TRN \\
\hline CHEMBL1605838 & 688282 & 5.6 & 5.0952 & TRN \\
\hline CHEMBL1504636 & 688282 & 4.6 & 5.1277 & TST \\
\hline CHEMBL1386593 & 688282 & 5.0 & 5.1911 & TST \\
\hline CHEMBL1528540 & 688282 & 7.8013 & 5.2504 & TST \\
\hline CHEMBL1551284 & 688282 & 5.3 & 4.9779 & TRN \\
\hline CHEMBL1364669 & 688282 & 5.2 & 5.0688 & TRN \\
\hline CHEMBL1312693 & 688282 & 5.3 & 5.015 & TRN \\
\hline CHEMBL1319485 & 688282 & 5.1 & 5.0948 & TRN \\
\hline
\end{tabular}

TRN 


\begin{tabular}{|c|c|c|c|c|c|}
\hline & & & & & \\
\hline CHEMBL1472732 & 688282 & 5.0 & 5.1497 & TRN & \\
\hline CHEMBL404613 & 688282 & 6.8 & 5.0909 & TRN & \\
\hline CHEMBL1309987 & 688282 & 4.9 & 5.2335 & TST & \\
\hline CHEMBL1488550 & 688282 & 5.3 & 5.2999 & TST & \\
\hline CHEMBL1566504 & 688282 & 4.6 & 5.2953 & TST & \\
\hline CHEMBL1487191 & 688282 & 4.7 & 5.0514 & TRN & \\
\hline CHEMBL1521867 & 688282 & 4.6 & 5.0689 & TRN & \\
\hline CHEMBL1471119 & 688282 & 5.6 & 5.1221 & TRN & \\
\hline CHEMBL1569535 & 688282 & 5.0 & 5.1501 & TRN & \\
\hline CHEMBL1424917 & 688282 & 5.0 & 5.1443 & TRN & \\
\hline CHEMBL1526794 & 688282 & 5.3 & 5.0897 & TRN & \\
\hline CHEMBL1386204 & 688282 & 4.6 & 5.01399 & 9999999999 & TRN \\
\hline CHEMBL3211149 & 688282 & 4.5 & 5.1564 & TST & \\
\hline CHEMBL 2134693 & 688282 & 5.7 & 5.1376 & TST & \\
\hline CHEMBL1368022 & 688282 & 5.3 & 5.1223 & TRN & \\
\hline CHEMBL1443163 & 688282 & 4.4 & 5.0667 & TRN & \\
\hline CHEMBL1374179 & 688282 & 5.1 & 5.1918 & TRN & \\
\hline CHEMBL1488179 & 688282 & 5.5 & 5.2634 & TRN & \\
\hline CHEMBL1365000 & 688282 & 4.9 & 5.0035 & TRN & \\
\hline CHEMBL1518195 & 688282 & 6.0 & 5.2718 & TRN & \\
\hline CHEMBL1450455 & 688282 & 4.9 & 5.0628 & TRN & \\
\hline CHEMBL1507104 & 688282 & 4.7 & 5.2148 & TRN & \\
\hline CHEMBL1479486 & 688282 & 6.1 & 5.0978 & TRN & \\
\hline CHEMBL1564979 & 688282 & 4.8 & 5.2799 & TST & \\
\hline CHEMBL1484189 & 688282 & 5.5 & 5.2358 & TST & \\
\hline CHEMBL1342999 & 688282 & 5.0 & 5.2256 & TRN & \\
\hline CHEMBL1316979 & 688282 & 4.9 & 5.0099 & TRN & \\
\hline CHEMBL1531244 & 688282 & 4.8 & 5.1195 & TRN & \\
\hline CHEMBL1502788 & 688282 & 5.1 & 5.13700 & j0000000005 & TRN \\
\hline CHEMBL1587062 & 688282 & 5.3 & 5.1456 & TRN & \\
\hline CHEMBL1513654 & 688282 & 4.8 & 5.2022 & TST & \\
\hline CHEMBL1324955 & 688282 & 4.8 & 5.152 & TRN & \\
\hline CHEMBL37081 & 688282 & 4.5 & 5.2074 & TRN & \\
\hline CHEMBL1600315 & 688282 & 5.0 & 5.1292 & TRN & \\
\hline CHEMBL1603373 & 688282 & 4.5 & 5.1212 & TRN & \\
\hline CHEMBL1525824 & 688282 & 5.0 & 5.0702 & TRN & \\
\hline CHEMBL1312282 & 688282 & 5.3 & 5.1452 & TRN & \\
\hline CHEMBL1326411 & 688282 & 5.5 & 5.0648 & TRN & \\
\hline CHEMBL1335042 & 688282 & 4.8 & 5.2113 & TRN & \\
\hline CHEMBL1301540 & 688282 & 5.4 & 5.1602 & TRN & \\
\hline CHEMBL1570196 & 688282 & 4.9 & 5.1433 & TST & \\
\hline CHEMBL1304669 & 688282 & 5.9 & 5.2057 & TRN & \\
\hline CHEMBL1492058 & 688282 & 5.2 & 5.1662 & TRN & \\
\hline CHEMBL1381437 & 688282 & 4.6 & 5.0892 & TRN & \\
\hline CHEMBL1504526 & 688282 & 4.9 & 5.0412 & TRN & \\
\hline CHEMBL1469352 & 688282 & 5.6 & 5.1166 & TRN & \\
\hline CHEMBL3213836 & 688282 & 5.3 & 5.1472 & TST & \\
\hline CHEMBL1443994 & 688282 & 4.9 & 5.1299 & TRN & \\
\hline & & & & 13273 & \\
\hline
\end{tabular}




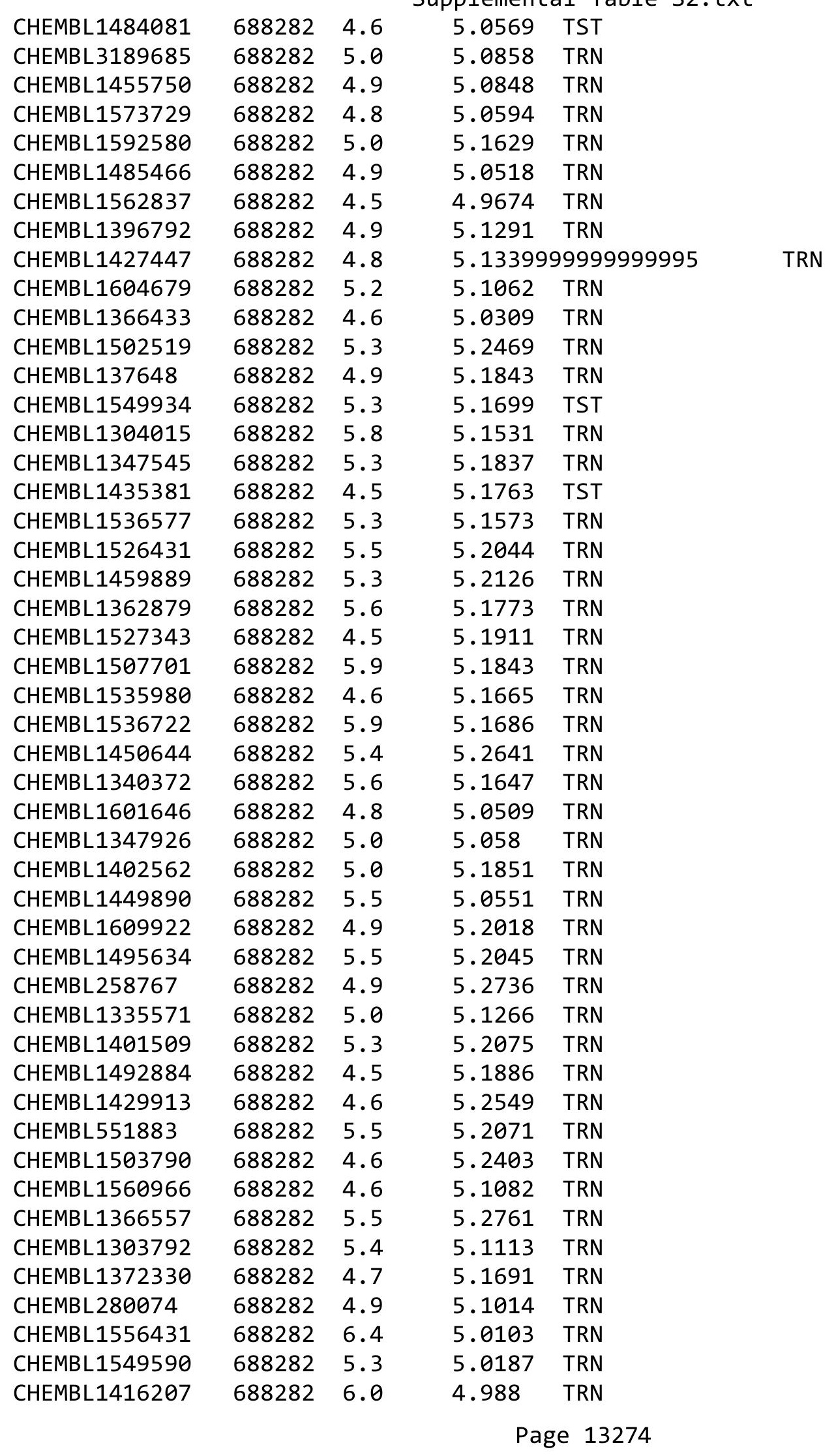




\begin{tabular}{|c|c|c|c|c|c|}
\hline & & & & & \\
\hline CHEMBL1447088 & 688282 & 5.1 & 5.0312 & TRN & \\
\hline CHEMBL1606250 & 688282 & 6.1 & 5.0964 & TRN & \\
\hline CHEMBL1439996 & 688282 & 5.3 & 5.0141 & TRN & \\
\hline CHEMBL1490253 & 688282 & 6.1 & 5.0857 & TRN & \\
\hline CHEMBL1325732 & 688282 & 5.3 & 5.2546 & TST & \\
\hline CHEMBL1419396 & 688282 & 4.6 & 5.17399 & 99999999995 & TRN \\
\hline CHEMBL1345384 & 688282 & 5.2 & 5.1682 & TRN & \\
\hline CHEMBL1372456 & 688282 & 4.9 & 5.2279 & TRN & \\
\hline CHEMBL1481416 & 688282 & 5.0 & $5.1270 e$ & $\partial 000000001$ & TRN \\
\hline CHEMBL1495981 & 688282 & 4.8 & 5.1384 & TRN & \\
\hline CHEMBL1568030 & 688282 & 4.7 & 5.2003 & TRN & \\
\hline CHEMBL1454820 & 688282 & 4.5 & 5.2041 & TRN & \\
\hline CHEMBL1478008 & 688282 & 5.0 & 5.2724 & TRN & \\
\hline CHEMBL1395002 & 688282 & 5.4 & 5.2174 & TST & \\
\hline CHEMBL1433119 & 688282 & 4.7 & 5.1118 & TST & \\
\hline CHEMBL1421689 & 688282 & 5.3 & 5.2661 & TRN & \\
\hline CHEMBL1520857 & 688282 & 4.9 & 5.0896 & TRN & \\
\hline CHEMBL1528688 & 688282 & 5.3 & 5.2534 & TST & \\
\hline CHEMBL1427567 & 688282 & 5.0 & 5.2062 & TRN & \\
\hline CHEMBL 78150 & 688282 & 5.9 & 5.2556 & TRN & \\
\hline CHEMBL1538477 & 688282 & 5.3 & 5.1993 & TRN & \\
\hline CHEMBL1571174 & 688282 & 4.8 & 5.1493 & TRN & \\
\hline CHEMBL1435009 & 688282 & 4.9 & 5.1867 & TRN & \\
\hline CHEMBL1363873 & 688282 & 5.0 & 5.1026 & TRN & \\
\hline CHEMBL1301040 & 688282 & 4.6 & 5.2376 & TRN & \\
\hline CHEMBL2373582 & 688282 & 6.9 & 5.2552 & TST & \\
\hline CHEMBL1362290 & 688282 & 5.3 & 5.1404 & TST & \\
\hline CHEMBL1527768 & 688282 & 5.0 & 5.105 & TRN & \\
\hline CHEMBL297569 & 688282 & 4.9 & 5.3242 & TST & \\
\hline CHEMBL1590378 & 688282 & 6.0 & 5.2531 & TST & \\
\hline CHEMBL1413280 & 688282 & 5.4 & 5.0933 & TST & \\
\hline CHEMBL1410075 & 688282 & 4.9 & 5.2045 & TRN & \\
\hline CHEMBL1521233 & 688282 & 5.7 & 5.2131 & TRN & \\
\hline CHEMBL1313615 & 688282 & 5.3 & 5.0599 & TRN & \\
\hline CHEMBL1362420 & 688282 & 5.5 & 5.0123 & TRN & \\
\hline CHEMBL1493644 & 688282 & 5.2 & 5.0557 & TRN & \\
\hline CHEMBL1547853 & 688282 & 4.9 & 5.0555 & TRN & \\
\hline CHEMBL1407054 & 688282 & 5.0 & 5.0668 & TRN & \\
\hline CHEMBL1303938 & 688282 & 4.9 & 5.1222 & TRN & \\
\hline CHEMBL1538165 & 688282 & 4.9 & 5.1222 & TRN & \\
\hline CHEMBL1491455 & 688282 & 6.5 & 5.2182 & TST & \\
\hline CHEMBL1505651 & 688282 & 5.5 & 5.1175 & TRN & \\
\hline CHEMBL1512850 & 688282 & 4.9 & 5.191 & TRN & \\
\hline CHEMBL1591487 & 688282 & 5.0 & 5.1505 & TRN & \\
\hline CHEMBL1308990 & 688282 & 5.6 & 5.1677 & TRN & \\
\hline CHEMBL1307173 & 688282 & 5.3 & 5.149 & TRN & \\
\hline CHEMBL 279556 & 688282 & 4.6 & 5.2475 & TST & \\
\hline CHEMBL1528573 & 688282 & 4.6 & 5.2015 & TRN & \\
\hline & & & & 13275 & \\
\hline
\end{tabular}




\begin{tabular}{|c|c|c|c|c|c|}
\hline \\
\hline CHEMBL1230270 & 688282 & 4.9 & 5.2921 & TST & \\
\hline CHEMBL1556067 & 688282 & 4.6 & 5.2428 & TRN & \\
\hline CHEMBL1390377 & 688282 & 4.6 & 5.0855 & TRN & \\
\hline CHEMBL1571700 & 688282 & 5.0 & 5.1811 & TRN & \\
\hline CHEMBL1554745 & 688282 & 4.8 & 4.9542 & TRN & \\
\hline CHEMBL1337502 & 688282 & 4.8 & 5.2263 & TRN & \\
\hline CHEMBL1565346 & 688282 & 5.0 & 5.0997 & TRN & \\
\hline CHEMBL1374544 & 688282 & 5.0 & 5.0828 & TRN & \\
\hline CHEMBL1472229 & 688282 & 4.6 & 5.1399 & TRN & \\
\hline CHEMBL1330459 & 688282 & 5.0 & 5.081 & TRN & \\
\hline CHEMBL1314185 & 688282 & 6.9 & 5.1434 & TRN & \\
\hline CHEMBL1351100 & 688282 & 4.8 & 5.157 & TRN & \\
\hline CHEMBL1613220 & 688282 & 5.0 & 5.2021 & TST & \\
\hline CHEMBL1518571 & 688282 & 6.8 & 5.28299 & 99999999995 & TST \\
\hline CHEMBL1569585 & 688282 & 4.9 & 5.1982 & TRN & \\
\hline CHEMBL1328143 & 688282 & 4.9 & 5.1462 & TRN & \\
\hline CHEMBL1359126 & 688282 & 5.4 & 4.9844 & TRN & \\
\hline CHEMBL1328369 & 688282 & 5.3 & 5.2044 & TRN & \\
\hline CHEMBL1392448 & 688282 & 5.9 & 5.027 & TRN & \\
\hline CHEMBL1256910 & 688282 & 5.0 & 5.0671 & TRN & \\
\hline CHEMBL1467479 & 688282 & 4.9 & 5.092 & TRN & \\
\hline CHEMBL1404682 & 688282 & 5.0 & 5.0825 & TRN & \\
\hline CHEMBL1497853 & 688282 & 5.0 & 5.0273 & TRN & \\
\hline CHEMBL1446025 & 688282 & 4.9 & 5.2004 & TRN & \\
\hline CHEMBL1328389 & 688282 & 6.0 & 5.2764 & TRN & \\
\hline CHEMBL1586234 & 688282 & 4.6 & 5.0894 & TRN & \\
\hline CHEMBL1318421 & 688282 & 5.5 & 5.2307 & TRN & \\
\hline CHEMBL1975975 & 688282 & 6.0 & 5.1167 & TRN & \\
\hline CHEMBL1447639 & 688282 & 5.3 & 5.0779 & TRN & \\
\hline CHEMBL48278 & 688282 & 4.5 & 5.2167 & TRN & \\
\hline CHEMBL1357941 & 688282 & 4.9 & 5.1917 & TRN & \\
\hline CHEMBL1510465 & 688282 & 5.1 & 5.1105 & TRN & \\
\hline CHEMBL1443317 & 688282 & 4.8 & 5.1998 & TST & \\
\hline CHEMBL1410947 & 688282 & 6.0 & 5.1802 & TRN & \\
\hline CHEMBL1525930 & 688282 & 4.9 & 5.13200 & 0000000001 & TRN \\
\hline CHEMBL1378470 & 688282 & 5.0 & 5.0983 & TRN & \\
\hline CHEMBL1533967 & 688282 & 5.3 & 5.1029 & TRN & \\
\hline CHEMBL1451808 & 688282 & 4.9 & 5.1354 & TST & \\
\hline CHEMBL1312768 & 688282 & 5.0 & 5.1562 & TRN & \\
\hline CHEMBL1372500 & 688282 & 4.6 & 5.1093 & TRN & \\
\hline CHEMBL1441690 & 688282 & 5.3 & 5.1367 & TRN & \\
\hline CHEMBL1467677 & 688282 & 5.4 & 5.2319 & TRN & \\
\hline CHEMBL1579020 & 688282 & 4.5 & 5.2188 & TST & \\
\hline CHEMBL448741 & 688282 & 4.9 & 5.1984 & TST & \\
\hline CHEMBL1317166 & 688282 & 4.6 & 5.2284 & TRN & \\
\hline CHEMBL1407035 & 688282 & 5.0 & 4.9839 & TRN & \\
\hline CHEMBL1377593 & 688282 & 4.9 & 5.0867 & TRN & \\
\hline CHEMBL1398425 & 688282 & 4.8 & 5.0713 & TRN & \\
\hline
\end{tabular}




\begin{tabular}{|c|c|c|c|c|c|}
\hline & & & & & \\
\hline CHEMBL1479222 & 688282 & 5.3 & 5.1178 & TRN & \\
\hline CHEMBL1409259 & 688282 & 5.3 & 5.164 & TRN & \\
\hline CHEMBL1365163 & 688282 & 5.5 & 5.1343 & TRN & \\
\hline CHEMBL1436037 & 688282 & 5.0 & 5.0143 & TRN & \\
\hline CHEMBL1574201 & 688282 & 4.6 & 5.1137 & TRN & \\
\hline CHEMBL1529735 & 688282 & 5.0 & 5.1198 & TRN & \\
\hline CHEMBL1591533 & 688282 & 4.9 & 5.1855 & TRN & \\
\hline CHEMBL1559728 & 688282 & 5.3 & 5.3102 & TRN & \\
\hline CHEMBL1373998 & 688282 & 6.5 & 5.0907 & TRN & \\
\hline CHEMBL1472651 & 688282 & 5.5 & 5.1556 & TRN & \\
\hline CHEMBL1334255 & 688282 & 5.6 & 5.1669 & TRN & \\
\hline CHEMBL1477512 & 688282 & 4.6 & 5.1078 & TRN & \\
\hline CHEMBL1413071 & 688282 & 5.3 & 5.1982 & TRN & \\
\hline CHEMBL1453969 & 688282 & 5.6 & 5.1731 & TRN & \\
\hline CHEMBL1377868 & 688282 & 4.6 & 5.1686 & TRN & \\
\hline CHEMBL1516080 & 688282 & 5.3 & 5.1265 & TST & \\
\hline CHEMBL1510344 & 688282 & 6.5 & 5.2111 & TRN & \\
\hline CHEMBL1398638 & 688282 & 5.1 & 5.13299 & 9999999999 & TRN \\
\hline CHEMBL1442495 & 688282 & 5.3 & 5.0969 & TRN & \\
\hline CHEMBL1600981 & 688282 & 5.1 & 5.1305 & TRN & \\
\hline CHEMBL 267458 & 688282 & 4.9 & 5.1414 & TRN & \\
\hline CHEMBL1355720 & 688282 & 4.8 & 5.006 & TRN & \\
\hline CHEMBL1482962 & 688282 & 5.3 & 5.1725 & TRN & \\
\hline CHEMBL1556323 & 688282 & 5.0 & 5.0353 & TRN & \\
\hline CHEMBL1357746 & 688282 & 5.0 & 5.2316 & TRN & \\
\hline CHEMBL1438748 & 688282 & 4.7 & 5.1281 & TRN & \\
\hline CHEMBL1434663 & 688282 & 5.0 & 5.0999 & TRN & \\
\hline CHEMBL1405461 & 688282 & 4.7 & 4.9578 & TRN & \\
\hline CHEMBL1380507 & 688282 & 5.1 & 5.11 & TRN & \\
\hline CHEMBL1346299 & 688282 & 5.3 & 5.1026 & TRN & \\
\hline CHEMBL1564508 & 688282 & 5.3 & 5.2584 & TST & \\
\hline CHEMBL1352912 & 688282 & 4.6 & 5.1073 & TRN & \\
\hline CHEMBL1368365 & 688282 & 5.0 & 5.1348 & TRN & \\
\hline CHEMBL1519704 & 688282 & 6.3 & 5.1898 & TST & \\
\hline CHEMBL1358092 & 688282 & 4.6 & 5.0708 & TRN & \\
\hline CHEMBL1311424 & 688282 & 4.8 & 4.9771 & TRN & \\
\hline CHEMBL1574110 & 688282 & 4.9 & 5.1044 & TRN & \\
\hline CHEMBL1435450 & 688282 & 4.6 & 5.0465 & TRN & \\
\hline CHEMBL1526446 & 688282 & 5.3 & 5.1642 & TRN & \\
\hline CHEMBL1360944 & 688282 & 6.7001 & 5.0829 & TST & \\
\hline CHEMBL 3207378 & 688282 & 5.0 & 5.2101 & TST & \\
\hline CHEMBL1304586 & 688282 & 4.5 & 5.0667 & TRN & \\
\hline CHEMBL1578422 & 688282 & 4.7 & 5.0681 & TRN & \\
\hline CHEMBL1585164 & 688282 & 5.0 & 5.0644 & TRN & \\
\hline CHEMBL1304169 & 688282 & 5.3 & 5.1882 & TST & \\
\hline CHEMBL1594363 & 688282 & 5.3 & 5.1795 & TRN & \\
\hline CHEMBL1491759 & 688282 & 5.4 & 5.2568 & TST & \\
\hline CHEMBL1554664 & 688282 & 4.7 & 5.05399 & 9999999999 & TRN \\
\hline & & & & 13277 & \\
\hline
\end{tabular}




\begin{tabular}{|c|c|c|c|c|}
\hline & & & Premcim & \\
\hline CHEMBL1320662 & 688282 & 4.5 & 5.2413 & TRN \\
\hline CHEMBL1358122 & 688282 & 4.6 & 5.0937 & TRN \\
\hline CHEMBL1477140 & 688282 & 5.5 & 5.0691 & TRN \\
\hline CHEMBL1545212 & 688282 & 5.3 & 5.1754 & TRN \\
\hline CHEMBL3392068 & 688282 & 4.9 & 5.2837 & TST \\
\hline CHEMBL1408486 & 688282 & 4.9 & 5.2283 & TRN \\
\hline CHEMBL1477247 & 688282 & 5.0 & 5.1124 & TRN \\
\hline CHEMBL1339737 & 688282 & 4.9 & 5.2002 & TST \\
\hline CHEMBL1542403 & 688282 & 5.3 & 5.1417 & TRN \\
\hline CHEMBL1364003 & 688282 & 4.9 & 5.1731 & TRN \\
\hline CHEMBL1461189 & 688282 & 5.8 & 5.0499 & TRN \\
\hline CHEMBL1338051 & 688282 & 4.7 & 5.0702 & TRN \\
\hline CHEMBL1554433 & 688282 & 5.1 & 4.9715 & TRN \\
\hline CHEMBL1436865 & 688282 & 5.0 & 5.0885 & TRN \\
\hline CHEMBL32503 & 688282 & 6.0 & 5.0518 & TRN \\
\hline CHEMBL323668 & 688282 & 4.9 & 5.1985 & TST \\
\hline CHEMBL1455056 & 688282 & 4.9 & 5.1699 & TST \\
\hline CHEMBL1312638 & 688282 & 4.9 & 5.1188 & TRN \\
\hline CHEMBL1411897 & 688282 & 4.9 & 5.2232 & TST \\
\hline CHEMBL1393543 & 688282 & 5.2 & 5.0278 & TRN \\
\hline CHEMBL1493023 & 688282 & 4.6 & 5.0694 & TRN \\
\hline CHEMBL1720282 & 688282 & 6.3 & 5.1768 & TRN \\
\hline CHEMBL1389999 & 688282 & 4.9 & 5.1136 & TRN \\
\hline CHEMBL1565212 & 688282 & 5.8 & 5.0703 & TRN \\
\hline CHEMBL1161936 & 688282 & 5.3 & 5.2834 & TST \\
\hline CHEMBL1366699 & 688282 & 4.7 & 5.0334 & TRN \\
\hline CHEMBL602807 & 688282 & 4.9 & 5.1063 & TRN \\
\hline CHEMBL1411484 & 688282 & 5.1 & 5.1787 & TRN \\
\hline CHEMBL1613319 & 688282 & 4.6 & 5.0646 & TRN \\
\hline CHEMBL1353698 & 688282 & 5.2 & 5.0631 & TRN \\
\hline CHEMBL1380295 & 688282 & 5.3 & 5.1863 & TRN \\
\hline CHEMBL543557 & 688282 & 4.9 & 5.2934 & TRN \\
\hline CHEMBL1356029 & 688282 & 4.5 & 5.1918 & TRN \\
\hline CHEMBL1482317 & 688282 & 4.9 & 5.0043 & TRN \\
\hline CHEMBL1566378 & 688282 & 5.0 & 5.2269 & TRN \\
\hline CHEMBL1590132 & 688282 & 7.699 & 5.1561 & TRN \\
\hline CHEMBL1441608 & 688282 & 4.9 & 5.3374 & TRN \\
\hline CHEMBL1595221 & 688282 & 5.0 & 5.159 & TRN \\
\hline CHEMBL1534132 & 688282 & 4.6 & 5.1237 & TRN \\
\hline CHEMBL1410926 & 688282 & 4.9 & 5.1 & TRN \\
\hline CHEMBL1399096 & 688282 & 4.5 & 5.2314 & TRN \\
\hline CHEMBL1488599 & 688282 & 4.9 & 5.2419 & TRN \\
\hline CHEMBL1338613 & 688282 & 5.3 & 5.1651 & TST \\
\hline CHEMBL1492318 & 688282 & 4.9 & 5.0649 & TRN \\
\hline CHEMBL1355307 & 688282 & 4.5 & 5.0513 & TRN \\
\hline CHEMBL1344611 & 688282 & 5.0 & 5.1118 & TRN \\
\hline CHEMBL1452607 & 688282 & 5.3 & 5.075 & TRN \\
\hline CHEMBL1570673 & 688282 & 4.6 & 4.9887 & TRN \\
\hline
\end{tabular}




\begin{tabular}{|c|c|c|c|c|}
\hline \\
\hline CHEMBL1582982 & 688282 & 5.0 & 5.1446 & TRN \\
\hline CHEMBL1603658 & 688282 & 5.7 & 5.232 & TRN \\
\hline CHEMBL1412821 & 688282 & 4.9 & 5.1511 & TST \\
\hline CHEMBL3193883 & 688282 & 5.0 & 5.2377 & TST \\
\hline CHEMBL1335540 & 688282 & 4.7 & 5.1662 & TRN \\
\hline CHEMBL1558655 & 688282 & 4.6 & 5.211 & TRN \\
\hline CHEMBL1315417 & 688282 & 4.9 & 5.1936 & TST \\
\hline CHEMBL1371455 & 688282 & 5.3 & 5.2343 & TRN \\
\hline CHEMBL1462785 & 688282 & 5.7 & 5.0733 & TRN \\
\hline CHEMBL1300503 & 688282 & 5.5 & 5.1771 & TRN \\
\hline CHEMBL1431729 & 688282 & 5.3 & 5.0375 & TRN \\
\hline CHEMBL1378731 & 688282 & 5.4 & 5.1403 & TRN \\
\hline CHEMBL1385353 & 688282 & 4.9 & 5.1442 & TRN \\
\hline CHEMBL1416091 & 688282 & 4.8 & 5.0636 & TRN \\
\hline CHEMBL1502697 & 688282 & 5.5 & 5.1999 & TST \\
\hline CHEMBL1567409 & 688282 & 4.8 & 5.1294 & TRN \\
\hline CHEMBL1562491 & 688282 & 4.6 & 5.1515 & TRN \\
\hline CHEMBL1392466 & 688282 & 5.6 & 5.1937 & TRN \\
\hline CHEMBL1362247 & 688282 & 4.5 & 5.0316 & TRN \\
\hline CHEMBL1574982 & 688282 & 5.4 & 5.2341 & TRN \\
\hline CHEMBL140220 & 688282 & 6.2 & 5.1378 & TRN \\
\hline CHEMBL1412121 & 688282 & 4.9 & 5.102 & TRN \\
\hline CHEMBL475376 & 688282 & 4.9 & 5.0036 & TRN \\
\hline CHEMBL1368142 & 688282 & 6.0 & 5.2776 & TRN \\
\hline CHEMBL1513041 & 688282 & 5.3 & 5.1321 & TRN \\
\hline CHEMBL1331114 & 688282 & 4.6 & 5.0526 & TRN \\
\hline CHEMBL1469620 & 688282 & 5.7 & 5.1313 & TRN \\
\hline CHEMBL1575586 & 688282 & 4.9 & 5.0246 & TRN \\
\hline CHEMBL1303226 & 688282 & 4.9 & 5.1953 & TRN \\
\hline CHEMBL1516148 & 688282 & 4.7 & 5.2742 & TRN \\
\hline CHEMBL1479715 & 688282 & 4.5 & 5.1958 & TRN \\
\hline CHEMBL1315257 & 688282 & 4.7 & 5.1882 & TRN \\
\hline CHEMBL565654 & 688282 & 4.9 & 4.9393 & TRN \\
\hline CHEMBL1368984 & 688282 & 6.5 & 5.2949 & TRN \\
\hline CHEMBL1316492 & 688282 & 4.9 & 5.0802 & TRN \\
\hline CHEMBL1461305 & 688282 & 4.6 & 5.2458 & TST \\
\hline CHEMBL1527565 & 688282 & 5.3 & 5.2296 & TRN \\
\hline CHEMBL1324889 & 688282 & 4.6 & 5.2408 & TRN \\
\hline CHEMBL1253351 & 688282 & 4.5 & 5.1452 & TST \\
\hline CHEMBL1558374 & 688282 & 4.9 & 5.25899 & 99999999995 \\
\hline CHEMBL1449082 & 688282 & 5.6 & 5.1917 & TRN \\
\hline CHEMBL1317588 & 688282 & 4.9 & 5.1497 & TRN \\
\hline CHEMBL1397532 & 688282 & 4.9 & 5.0273 & TRN \\
\hline CHEMBL1527194 & 688282 & 4.6 & 5.107 & TRN \\
\hline CHEMBL3207615 & 688282 & 4.9 & 5.0764 & TRN \\
\hline CHEMBL1554763 & 688282 & 5.1 & 5.1139 & TRN \\
\hline CHEMBL1368572 & 688282 & 5.6 & 5.2061 & TST \\
\hline CHEMBL1591209 & 688282 & 4.9 & 5.1098 & TRN \\
\hline
\end{tabular}




\begin{tabular}{|c|c|c|c|c|c|}
\hline \multirow[b]{2}{*}{ CHEMBL1604118 } & \multirow[b]{2}{*}{688282} & \\
\hline & & 4.9 & 5.215 & TRN & \\
\hline CHEMBL1489100 & 688282 & 4.7 & 5.0773 & TRN & \multirow{2}{*}{ TRN } \\
\hline CHEMBL1436042 & 688282 & 5.3 & \multicolumn{2}{|c|}{5.156000000000001} & \\
\hline CHEMBL1459207 & 688282 & 5.3 & 5.1107 & TRN & \\
\hline CHEMBL1480648 & 688282 & 5.0 & 5.0337 & TRN & \\
\hline CHEMBL1577717 & 688282 & 5.7 & 5.0615 & TRN & \\
\hline CHEMBL1532193 & 688282 & 5.0 & 5.2243 & TRN & \\
\hline CHEMBL1369003 & 688282 & 6.0 & 5.1626 & TRN & \\
\hline CHEMBL1441259 & 688282 & 5.9 & 5.1281 & TRN & \\
\hline CHEMBL567130 & 688282 & 5.5 & 5.1802 & TRN & \\
\hline CHEMBL1315145 & 688282 & 5.0 & 5.1605 & TRN & \\
\hline CHEMBL1436075 & 688282 & 5.1 & 4.9677 & TRN & \\
\hline CHEMBL1380395 & 688282 & 4.9 & 5.0582 & TRN & \\
\hline CHEMBL1400703 & 688282 & 4.6 & 5.1655 & TRN & \\
\hline CHEMBL1564477 & 688282 & 5.7 & 5.1251 & TRN & \\
\hline CHEMBL1501033 & 688282 & 5.0 & 5.2751 & TST & \\
\hline CHEMBL1352633 & 688282 & 4.5 & 5.1644 & TRN & \\
\hline CHEMBL1449948 & 688282 & 4.9 & 5.1537 & TRN & \\
\hline CHEMBL1543477 & 688282 & 4.6 & 5.0519 & TRN & \\
\hline CHEMBL1311847 & 688282 & 5.1 & 5.1468 & TRN & \\
\hline CHEMBL1566928 & 688282 & 5.6 & 5.1465 & TRN & \\
\hline CHEMBL1591965 & 688282 & 4.6 & 5.2247 & TRN & \\
\hline CHEMBL1544661 & 688282 & 4.6 & 5.0823 & TRN & \\
\hline CHEMBL72410 & 688282 & 4.9 & 5.0797 & TRN & \\
\hline CHEMBL1537732 & 688282 & 5.1 & 5.0469 & TRN & \\
\hline CHEMBL1441453 & 688282 & 4.9 & 5.1567 & TRN & \\
\hline CHEMBL1448042 & 688282 & 4.6 & 5.2091 & TRN & \\
\hline CHEMBL1564518 & 688282 & 5.0 & 5.2198 & TRN & \\
\hline CHEMBL1379900 & 688282 & 4.9 & 4.9999 & TRN & \\
\hline CHEMBL1330407 & 688282 & 6.0 & 5.114 & TRN & \\
\hline CHEMBL1428336 & 688282 & 5.3 & 5.0545 & TRN & \\
\hline CHEMBL1489365 & 688282 & 4.5 & 5.1121 & TST & \\
\hline CHEMBL1609218 & 688282 & 4.6 & 5.0709 & TRN & \\
\hline CHEMBL1408013 & 688282 & 6.0 & 5.1077 & TRN & \\
\hline CHEMBL1336709 & 688282 & 5.0 & 5.1413 & TRN & \\
\hline CHEMBL1533166 & 688282 & 6.5 & 5.2442 & TRN & \\
\hline CHEMBL71929 & 688282 & 6.3 & 5.2796 & TST & \\
\hline CHEMBL1487944 & 688282 & 4.5 & 5.2493 & TRN & \\
\hline CHEMBL1473793 & 688282 & 5.6 & 5.1177 & TRN & \\
\hline CHEMBL1550202 & 688282 & 5.0 & 5.3021 & TST & \\
\hline CHEMBL1208858 & 688282 & 4.5 & 5.1147 & TST & \\
\hline CHEMBL1513392 & 688282 & 5.4 & 5.1968 & TRN & \\
\hline CHEMBL90882 & 688282 & 4.5 & 5.1135 & TRN & \\
\hline CHEMBL1611646 & 688282 & 4.9 & 5.1226 & TRN & \\
\hline CHEMBL1316562 & 688282 & 5.6 & 5.1715 & TRN & \\
\hline CHEMBL1544137 & 688282 & 5.3 & 5.0138 & TRN & \\
\hline CHEMBL1519375 & 688282 & 4.8 & 5.21700 & 00000000005 & TRN \\
\hline CHEMBL1993627 & 688282 & 5.1 & 5.2176 & TST & \\
\hline & & & & 13280 & \\
\hline
\end{tabular}




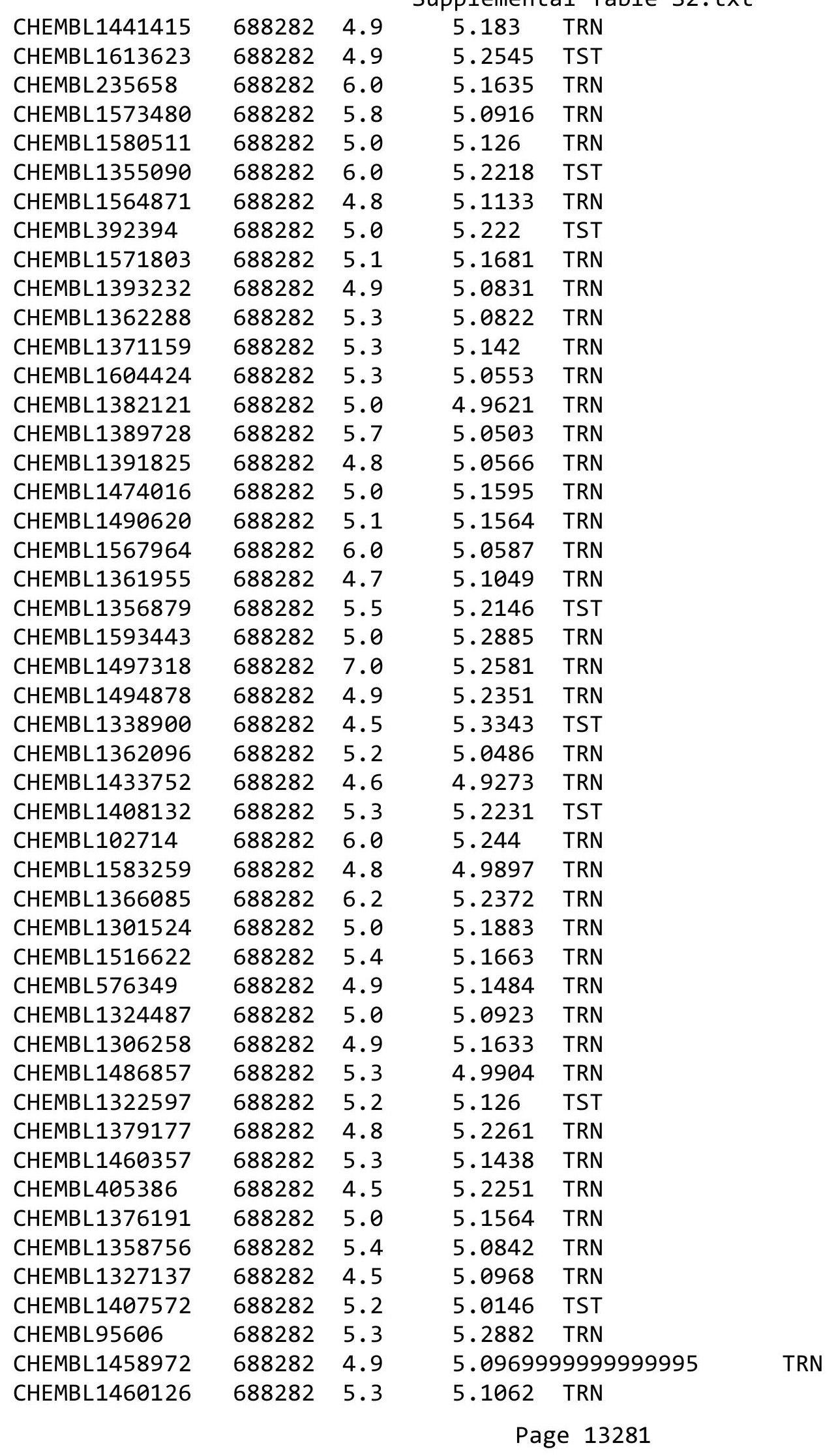




\begin{tabular}{|c|c|c|c|c|}
\hline \multirow[b]{2}{*}{ CHEMBL1406899 } & \multicolumn{4}{|c|}{ Supplemental Table S2.txt } \\
\hline & 688282 & 4.5 & 5.2203 & TRN \\
\hline CHEMBL1548952 & 688282 & 4.8 & 5.0047 & TRN \\
\hline CHEMBL1573425 & 688282 & 5.3 & 5.2991 & TRN \\
\hline CHEMBL343732 & 688282 & 4.7 & 5.1854 & TRN \\
\hline CHEMBL1568767 & 688282 & 5.3 & 5.0838 & TRN \\
\hline CHEMBL1569782 & 688282 & 4.9 & 5.1667 & TRN \\
\hline CHEMBL464176 & 688282 & 4.9 & 5.2468 & TST \\
\hline CHEMBL1448387 & 688282 & 4.8 & 5.2293 & TST \\
\hline CHEMBL1501892 & 688282 & 5.3 & 5.2146 & TRN \\
\hline CHEMBL37708 & 688282 & 5.0 & 5.1889 & TST \\
\hline CHEMBL1608914 & 688282 & 4.6 & 5.0999 & TRN \\
\hline CHEMBL1409097 & 688282 & 5.4 & 5.2553 & TST \\
\hline CHEMBL1406865 & 688282 & 4.5 & 5.2271 & TRN \\
\hline CHEMBL1573549 & 688282 & 4.5 & 5.1163 & TST \\
\hline CHEMBL1612289 & 688282 & 5.3 & 5.1698 & TRN \\
\hline CHEMBL1310694 & 688282 & 5.0 & 5.0633 & TRN \\
\hline CHEMBL1542752 & 688282 & 4.9 & 5.1695 & TRN \\
\hline CHEMBL1598493 & 688282 & 5.5 & 5.1825 & TRN \\
\hline CHEMBL1526721 & 688282 & 4.6 & 5.2678 & TST \\
\hline CHEMBL1567282 & 688282 & 4.9 & 5.0972 & TRN \\
\hline CHEMBL1512478 & 688282 & 5.5 & 5.1921 & TST \\
\hline CHEMBL1445525 & 688282 & 5.3 & 5.0899 & TRN \\
\hline CHEMBL1521887 & 688282 & 5.3 & 5.2215 & TRN \\
\hline CHEMBL1506451 & 688282 & 4.5 & 5.0657 & TRN \\
\hline CHEMBL1427829 & 688282 & 5.2 & 5.1062 & TRN \\
\hline CHEMBL1433687 & 688282 & 5.3 & 5.1523 & TRN \\
\hline CHEMBL175858 & 688282 & 8.1024 & 5.1357 & TST \\
\hline CHEMBL1404693 & 688282 & 5.1 & 5.1714 & TST \\
\hline CHEMBL1460147 & 688282 & 4.9 & 5.0675 & TRN \\
\hline CHEMBL1358553 & 688282 & 6.5 & 5.1934 & TRN \\
\hline CHEMBL1496363 & 688282 & 5.4 & 5.2173 & TST \\
\hline CHEMBL1439594 & 688282 & 4.6 & 5.2308 & TRN \\
\hline CHEMBL3210268 & 688282 & 5.3 & 5.1935 & TST \\
\hline CHEMBL1360804 & 688282 & 4.6 & 5.1036 & TRN \\
\hline CHEMBL1561796 & 688282 & 4.9 & 5.1139 & TRN \\
\hline CHEMBL1308349 & 688282 & 4.6 & 5.1071 & TRN \\
\hline CHEMBL1421070 & 688282 & 4.7 & 5.1507 & TRN \\
\hline CHEMBL1345705 & 688282 & 5.2 & 5.0218 & TRN \\
\hline CHEMBL1561768 & 688282 & 4.5 & 5.1118 & TRN \\
\hline CHEMBL1427637 & 688282 & 4.8 & 5.0789 & TST \\
\hline CHEMBL1407440 & 688282 & 5.0 & 5.1015 & TRN \\
\hline CHEMBL1564992 & 688282 & 5.1 & 5.1323 & TRN \\
\hline CHEMBL1492346 & 688282 & 4.8 & 5.3713 & TRN \\
\hline CHEMBL1419472 & 688282 & 5.0 & 5.1126 & TRN \\
\hline CHEMBL1315716 & 688282 & 5.0 & 5.1433 & TRN \\
\hline CHEMBL1428826 & 688282 & 4.9 & 5.0343 & TRN \\
\hline CHEMBL1436272 & 688282 & 5.0 & 5.138 & TRN \\
\hline CHEMBL198759 & 688282 & 4.8 & 5.1944 & TRN \\
\hline
\end{tabular}




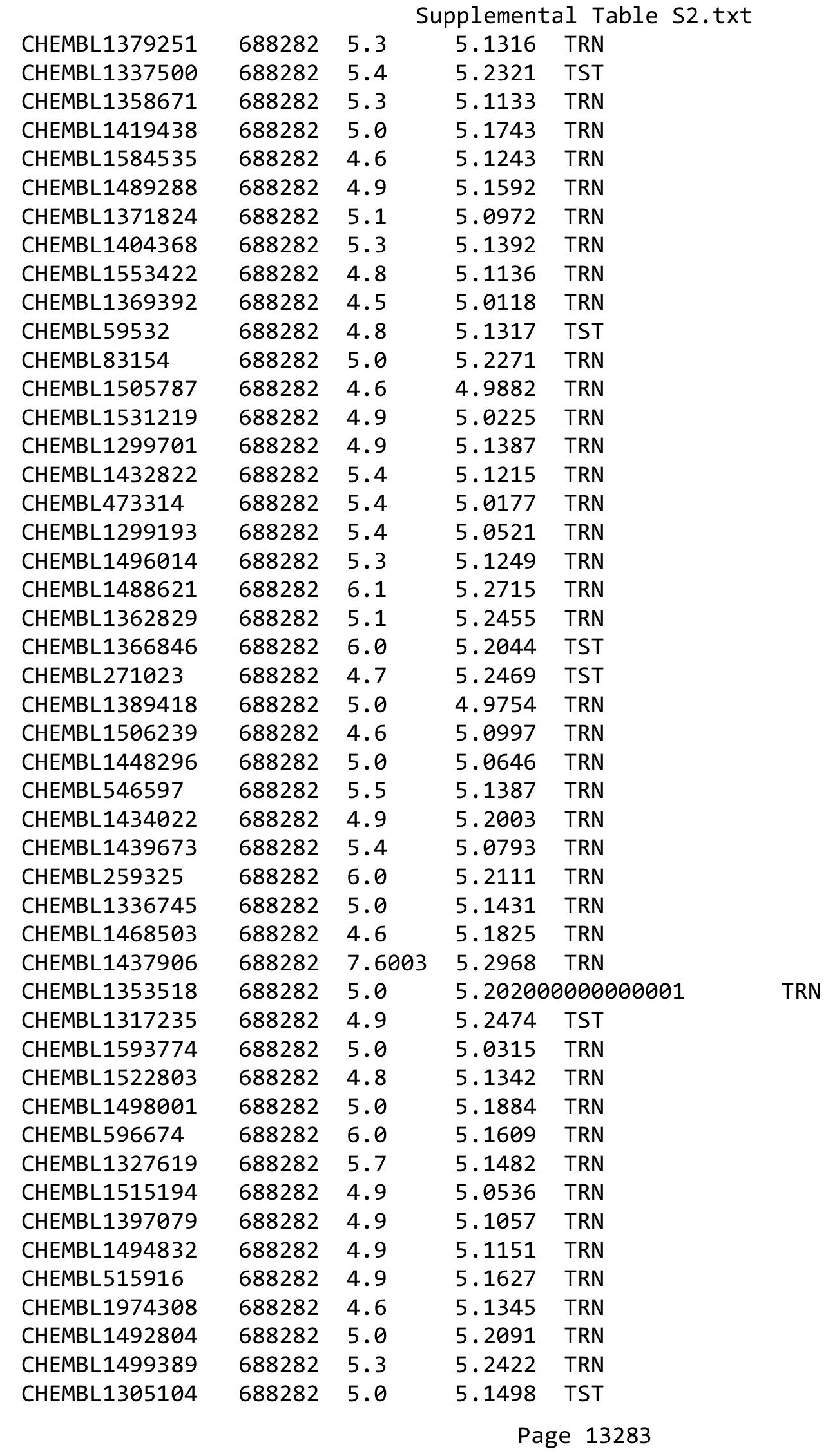




\begin{tabular}{|c|c|c|c|c|c|}
\hline & & & & & \\
\hline CHEMBL275311 & 688282 & 4.5 & 5.2672 & TST & \\
\hline CHEMBL1341395 & 688282 & 4.9 & 5.0115 & TRN & \\
\hline CHEMBL1477191 & 688282 & 5.3 & 5.0726 & TRN & \\
\hline CHEMBL1359168 & 688282 & 4.6 & 5.1693 & TRN & \\
\hline CHEMBL1424501 & 688282 & 5.3 & 5.2204 & TRN & \\
\hline CHEMBL1583650 & 688282 & 5.0 & 5.0914 & TRN & \\
\hline CHEMBL1367492 & 688282 & 5.3 & 5.0719 & TRN & \\
\hline CHEMBL1365104 & 688282 & 5.0 & 5.1611 & TST & \\
\hline CHEMBL1458566 & 688282 & 5.1 & 5.1918 & TRN & \\
\hline CHEMBL1419849 & 688282 & 5.1 & 5.0707 & TRN & \\
\hline CHEMBL1473429 & 688282 & 4.9 & 5.2392 & TST & \\
\hline CHEMBL1432507 & 688282 & 4.5 & 5.1099 & TRN & \\
\hline CHEMBL1593754 & 688282 & 4.9 & 5.17899 & 9999999999 & TST \\
\hline CHEMBL1540332 & 688282 & 5.1 & 5.1233 & TRN & \\
\hline CHEMBL355014 & 688282 & 4.8 & 5.2504 & TRN & \\
\hline CHEMBL3209071 & 688282 & 5.4 & 5.1421 & TRN & \\
\hline CHEMBL443949 & 688282 & 4.6 & 5.2483 & TRN & \\
\hline CHEMBL1309179 & 688282 & 4.6 & 5.2965 & TST & \\
\hline CHEMBL1567601 & 688282 & 5.3 & 5.1043 & TRN & \\
\hline CHEMBL1524704 & 688282 & 5.0 & 5.0697 & TRN & \\
\hline CHEMBL1443205 & 688282 & 5.0 & 5.1898 & TRN & \\
\hline CHEMBL1351651 & 688282 & 5.6 & 5.0136 & TRN & \\
\hline CHEMBL1568922 & 688282 & 6.0 & 5.2048 & TRN & \\
\hline CHEMBL1534172 & 688282 & 4.9 & 5.0849 & TRN & \\
\hline CHEMBL577938 & 688282 & 4.9 & 5.2278 & TRN & \\
\hline CHEMBL1477620 & 688282 & 4.8 & 5.1281 & TRN & \\
\hline CHEMBL1449481 & 688282 & 4.9 & 5.1493 & TRN & \\
\hline CHEMBL1336114 & 688282 & 4.7 & $4.9910 e$ & 00000000005 & TRN \\
\hline CHEMBL1549529 & 688282 & 4.9 & 4.999 & TRN & \\
\hline CHEMBL1382508 & 688282 & 5.0 & 5.1027 & TRN & \\
\hline CHEMBL1568917 & 688282 & 6.0 & 5.0943 & TRN & \\
\hline CHEMBL1583671 & 688282 & 5.0 & 5.0996 & TRN & \\
\hline CHEMBL1581560 & 688282 & 5.3 & 5.2483 & TRN & \\
\hline CHEMBL1559783 & 688282 & 4.9 & 5.0862 & TRN & \\
\hline CHEMBL1367788 & 688282 & 4.9 & 5.1922 & TRN & \\
\hline CHEMBL1420094 & 688282 & 4.8 & 5.0759 & TST & \\
\hline CHEMBL1571716 & 688282 & 5.3 & 5.1696 & TRN & \\
\hline CHEMBL1542366 & 688282 & 4.6 & 5.1744 & TST & \\
\hline CHEMBL1413056 & 688282 & 4.7 & 5.1442 & TRN & \\
\hline CHEMBL1395137 & 688282 & 5.7 & 5.1963 & TRN & \\
\hline CHEMBL1300249 & 688282 & 5.9 & 5.0551 & TRN & \\
\hline CHEMBL1527092 & 688282 & 4.6 & 5.2085 & TRN & \\
\hline CHEMBL1438928 & 688282 & 5.0 & 5.141 & TRN & \\
\hline CHEMBL1362279 & 688282 & 5.0 & 5.1627 & TRN & \\
\hline CHEMBL1373244 & 688282 & 4.6 & 5.125 & TRN & \\
\hline CHEMBL1380598 & 688282 & 4.6 & 5.2285 & TRN & \\
\hline CHEMBL1568748 & 688282 & 5.2 & 5.1068 & TRN & \\
\hline CHEMBL476833 & 688282 & 4.5 & 5.08899 & 99999999995 & TST \\
\hline & & & & 13284 & \\
\hline
\end{tabular}




\begin{tabular}{|c|c|c|c|c|c|}
\hline \multirow[b]{2}{*}{ CHEMBL1540621 } & \\
\hline & 688282 & 5.2 & 5.0544 & TRN & \\
\hline CHEMBL1321276 & 688282 & 4.6 & 5.20100 & 00000000005 & TRN \\
\hline CHEMBL120806 & 688282 & 5.5 & 5.2467 & TST & \\
\hline CHEMBL1355089 & 688282 & 5.0 & 5.0697 & TRN & \\
\hline CHEMBL1558175 & 688282 & 5.0 & 4.9854 & TRN & \\
\hline CHEMBL1526533 & 688282 & 7.6003 & 5.1867 & TRN & \\
\hline CHEMBL1454468 & 688282 & 5.2 & 5.2445 & TRN & \\
\hline CHEMBL315268 & 688282 & 4.9 & 5.2031 & TST & \\
\hline CHEMBL1476712 & 688282 & 4.8 & 5.0126 & TRN & \\
\hline CHEMBL1531079 & 688282 & 4.5 & 5.0906 & TRN & \\
\hline CHEMBL1385926 & 688282 & 4.9 & 5.1927 & TRN & \\
\hline CHEMBL52 & 688282 & 4.8 & 5.2424 & TRN & \\
\hline CHEMBL1566451 & 688282 & 4.9 & 5.2212 & TRN & \\
\hline CHEMBL1492666 & 688282 & 4.6 & 5.1804 & TRN & \\
\hline CHEMBL1350974 & 688282 & 5.3 & 5.19 & TRN & \\
\hline CHEMBL1333056 & 688282 & 4.9 & 5.2892 & TST & \\
\hline CHEMBL1492217 & 688282 & 5.0 & 5.0444 & TRN & \\
\hline CHEMBL164660 & 688282 & 4.9 & 5.2174 & TRN & \\
\hline CHEMBL1321421 & 688282 & 5.5 & 5.11 & TST & \\
\hline CHEMBL504525 & 688282 & 5.3 & 5.109 & TRN & \\
\hline CHEMBL1304579 & 688282 & 5.3 & 5.1418 & TRN & \\
\hline CHEMBL1471717 & 688282 & 4.6 & 5.1151 & TRN & \\
\hline CHEMBL1407091 & 688282 & 5.1 & 5.1306 & TRN & \\
\hline CHEMBL1313955 & 688282 & 5.0 & 5.0531 & TRN & \\
\hline CHEMBL1576578 & 688282 & 5.1 & 5.2353 & TRN & \\
\hline CHEMBL122270 & 688282 & 6.0 & 5.2472 & TRN & \\
\hline CHEMBL1300796 & 688282 & 5.3 & 5.1203 & TRN & \\
\hline CHEMBL 200309 & 688282 & 6.1 & 5.221 & TRN & \\
\hline CHEMBL1354561 & 688282 & 6.4 & 5.1838 & TRN & \\
\hline CHEMBL1491360 & 688282 & 5.0 & 5.0922 & TST & \\
\hline CHEMBL1506987 & 688282 & 5.0 & 5.2719 & TST & \\
\hline CHEMBL1256697 & 688282 & 4.6 & 5.1819 & TRN & \\
\hline CHEMBL1383874 & 688282 & 4.9 & 5.1809 & TST & \\
\hline CHEMBL1491026 & 688282 & 5.0 & 4.9986 & TRN & \\
\hline CHEMBL1574534 & 688282 & 5.4 & 5.1892 & TRN & \\
\hline CHEMBL1441622 & 688282 & 5.0 & 5.0933 & TRN & \\
\hline CHEMBL1356234 & 688282 & 7.6003 & 5.2566 & TRN & \\
\hline CHEMBL1354341 & 688282 & 4.9 & 5.0699 & TRN & \\
\hline CHEMBL1570716 & 688282 & 6.0 & 5.1857 & TRN & \\
\hline CHEMBL 242341 & 688282 & 4.9 & 5.1001 & TRN & \\
\hline CHEMBL1538587 & 688282 & 5.3 & 5.2841 & TST & \\
\hline CHEMBL1411691 & 688282 & 4.9 & 4.9635 & TRN & \\
\hline CHEMBL1496243 & 688282 & 5.4 & 5.0999 & TRN & \\
\hline CHEMBL1592966 & 688282 & 5.1 & 5.1715 & TRN & \\
\hline CHEMBL1444141 & 688282 & 7.0 & 5.3298 & TRN & \\
\hline CHEMBL1467622 & 688282 & 5.3 & 5.145 & TRN & \\
\hline CHEMBL1354901 & 688282 & 4.8 & 5.0931 & TRN & \\
\hline CHEMBL1560093 & 688282 & 4.9 & 5.1301 & TST & \\
\hline & & & & 13285 & \\
\hline
\end{tabular}




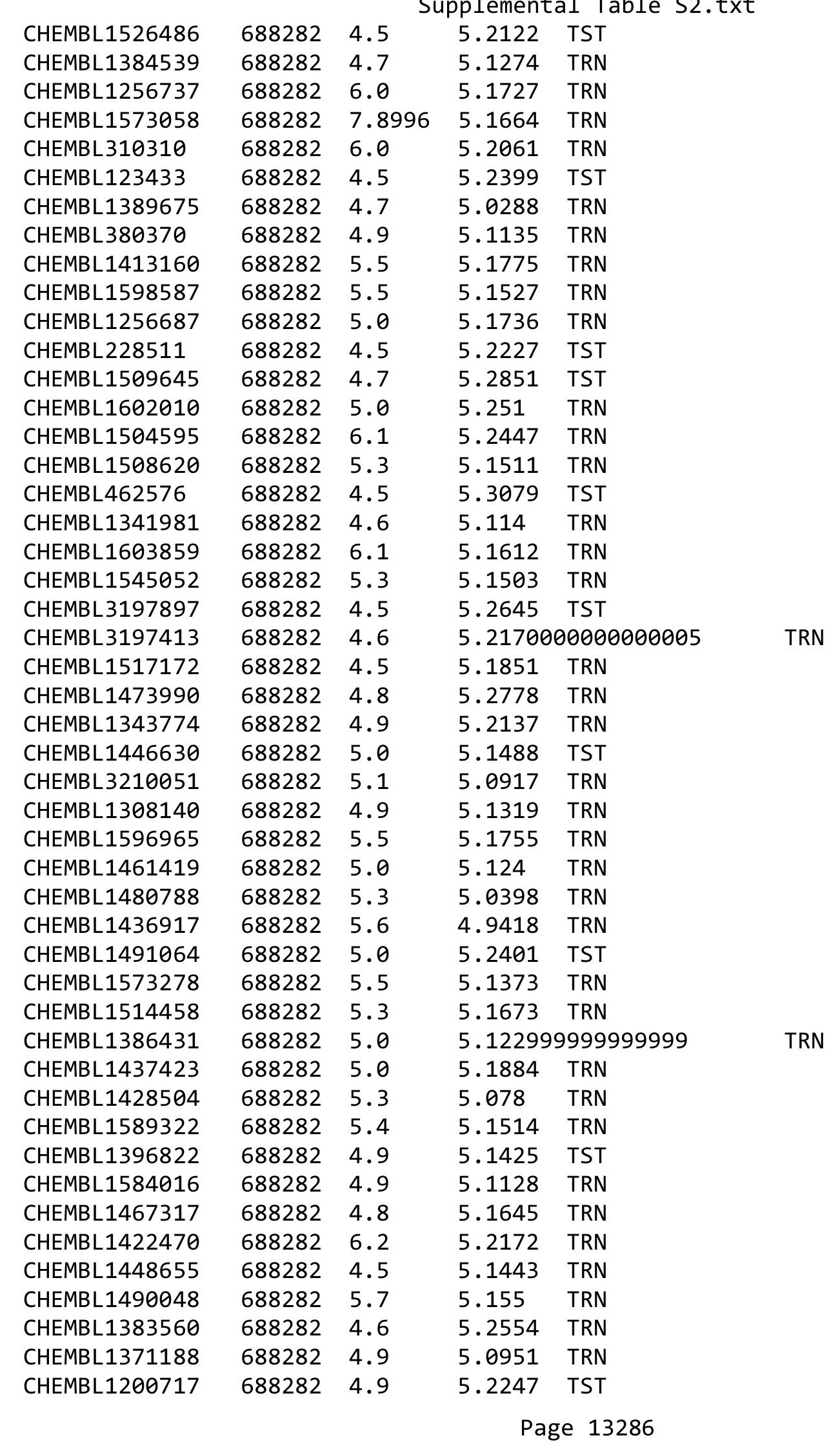




\begin{tabular}{|c|c|c|c|c|}
\hline & & & & l Tabl \\
\hline CHEMBL1453911 & 688282 & 4.9 & 5.0497 & TRN \\
\hline CHEMBL1449884 & 688282 & 5.0 & 5.1488 & TRN \\
\hline CHEMBL1478263 & 688282 & 4.9 & 5.0567 & TRN \\
\hline CHEMBL1450445 & 688282 & 5.3 & 5.12299 & 9999999999 \\
\hline CHEMBL 325238 & 688282 & 5.7 & 5.266 & TRN \\
\hline CHEMBL1431763 & 688282 & 5.0 & 5.0268 & TRN \\
\hline CHEMBL1317921 & 688282 & 6.0 & 5.2286 & TST \\
\hline CHEMBL1377276 & 688282 & 4.5 & 5.0488 & TRN \\
\hline CHEMBL1314371 & 688282 & 4.6 & 5.0209 & TRN \\
\hline CHEMBL 282731 & 688282 & 4.8 & 5.2717 & TRN \\
\hline CHEMBL1299946 & 688282 & 5.8 & 5.038 & TRN \\
\hline CHEMBL1594436 & 688282 & 5.0 & 5.1307 & TRN \\
\hline CHEMBL1613407 & 688282 & 4.6 & 5.0564 & TRN \\
\hline CHEMBL1470115 & 688282 & 4.6 & 5.2113 & TST \\
\hline CHEMBL105712 & 688282 & 4.9 & 5.266 & TRN \\
\hline CHEMBL 263376 & 688282 & 4.5 & 5.2217 & TRN \\
\hline CHEMBL1435902 & 688282 & 5.5 & 5.2168 & TST \\
\hline CHEMBL1452952 & 688282 & 5.0 & 5.0583 & TRN \\
\hline CHEMBL1551548 & 688282 & 4.9 & 5.169 & TRN \\
\hline CHEMBL1609672 & 688282 & 4.9 & 5.0574 & TRN \\
\hline CHEMBL1397860 & 688282 & 5.0 & 5.0889 & TRN \\
\hline CHEMBL1454337 & 688282 & 5.3 & 5.0831 & TRN \\
\hline CHEMBL1374550 & 688282 & 4.6 & 5.096 & TRN \\
\hline CHEMBL1380628 & 688282 & 5.5 & 5.2573 & TRN \\
\hline CHEMBL1344249 & 688282 & 5.0 & 5.0862 & TRN \\
\hline CHEMBL58353 & 688282 & 4.9 & 5.1461 & TST \\
\hline CHEMBL1608779 & 688282 & 6.0 & 5.1651 & TST \\
\hline CHEMBL1730100 & 688282 & 4.6 & 5.2575 & TST \\
\hline CHEMBL1583101 & 688282 & 4.6 & 5.1775 & TRN \\
\hline CHEMBL1388995 & 688282 & 5.2 & 5.0592 & TRN \\
\hline CHEMBL1480329 & 688282 & 5.4 & 5.1292 & TRN \\
\hline CHEMBL1599249 & 688282 & 4.8 & 5.1706 & TRN \\
\hline CHEMBL1456266 & 688282 & 5.0 & 5.0888 & TRN \\
\hline CHEMBL1452611 & 688282 & 5.3 & 5.1545 & TRN \\
\hline CHEMBL1256746 & 688282 & 4.5 & 5.1993 & TRN \\
\hline CHEMBL1256750 & 688282 & 4.9 & 5.0904 & TRN \\
\hline CHEMBL1363506 & 688282 & 4.9 & 5.1096 & TRN \\
\hline CHEMBL1412745 & 688282 & 5.2 & 5.1603 & TRN \\
\hline CHEMBL1332208 & 688282 & 5.0 & 5.055 & TRN \\
\hline CHEMBL1502125 & 688282 & 5.3 & 5.1678 & TRN \\
\hline CHEMBL1479203 & 688282 & 6.7001 & 5.2333 & TRN \\
\hline CHEMBL1594432 & 688282 & 5.0 & 5.1881 & TST \\
\hline CHEMBL1607673 & 688282 & 4.9 & 5.0632 & TRN \\
\hline CHEMBL1416214 & 688282 & 4.6 & 5.1242 & TRN \\
\hline CHEMBL1314387 & 688282 & 5.2 & 5.1178 & TRN \\
\hline CHEMBL1334840 & 688282 & 4.6 & 5.1587 & TRN \\
\hline CHEMBL1500584 & 688282 & 4.6 & 5.0771 & TRN \\
\hline CHEMBL1430319 & 688282 & 5.0 & 5.0887 & TRN \\
\hline
\end{tabular}

TRN 


\begin{tabular}{|c|c|c|c|c|c|}
\hline & & & & & \\
\hline CHEMBL1441471 & 688282 & 5.3 & 5.1262 & TRN & \\
\hline CHEMBL1570581 & 688282 & 5.3 & 5.0131 & TRN & \\
\hline CHEMBL1358007 & 688282 & 5.3 & 5.2141 & TST & \\
\hline CHEMBL1572855 & 688282 & 5.0 & 5.21700 & 00000000005 & TRN \\
\hline CHEMBL1542340 & 688282 & 5.0 & 4.9783 & TRN & \\
\hline CHEMBL1588811 & 688282 & 4.9 & 5.1932 & TRN & \\
\hline CHEMBL1362986 & 688282 & 5.0 & 5.1369 & TST & \\
\hline CHEMBL195789 & 688282 & 5.4 & 5.1624 & TRN & \\
\hline CHEMBL1533673 & 688282 & 5.0 & 5.2412 & TRN & \\
\hline CHEMBL1451087 & 688282 & 4.5 & 5.1173 & TRN & \\
\hline CHEMBL1608077 & 688282 & 5.0 & 5.151 & TRN & \\
\hline CHEMBL1564845 & 688282 & 5.3 & 5.0005 & TRN & \\
\hline CHEMBL1406410 & 688282 & 5.0 & 5.0967 & TRN & \\
\hline CHEMBL118109 & 688282 & 6.0 & 5.0223 & TRN & \\
\hline CHEMBL1388467 & 688282 & 4.9 & 5.2869 & TST & \\
\hline CHEMBL1516211 & 688282 & 4.9 & 5.0568 & TRN & \\
\hline CHEMBL1414084 & 688282 & 5.4 & 5.0905 & TRN & \\
\hline CHEMBL1417789 & 688282 & 5.0 & 5.043 & TRN & \\
\hline CHEMBL1441874 & 688282 & 4.9 & 5.153 & TRN & \\
\hline CHEMBL1421580 & 688282 & 4.8 & 5.154 & TRN & \\
\hline CHEMBL 88272 & 688282 & 4.5 & 5.0908 & TST & \\
\hline CHEMBL3195020 & 688282 & 4.6 & 5.1276 & TRN & \\
\hline CHEMBL1559279 & 688282 & 5.0 & 5.1545 & TRN & \\
\hline CHEMBL1380574 & 688282 & 4.8 & 5.0354 & TRN & \\
\hline CHEMBL1548323 & 688282 & 5.1 & 5.0347 & TRN & \\
\hline CHEMBL1391746 & 688282 & 5.6 & 5.1612 & TRN & \\
\hline CHEMBL1443299 & 688282 & 5.3 & 5.0321 & TRN & \\
\hline CHEMBL1374617 & 688282 & 5.0 & 5.0845 & TRN & \\
\hline CHEMBL1555382 & 688282 & 6.1 & 5.1596 & TST & \\
\hline CHEMBL1331148 & 688282 & 4.5 & 5.1336 & TRN & \\
\hline CHEMBL1430627 & 688282 & 5.3 & 5.1726 & TRN & \\
\hline CHEMBL3198071 & 688282 & 4.9 & 5.0572 & TRN & \\
\hline CHEMBL1347479 & 688282 & 4.9 & 5.25200 & 0000000001 & TRN \\
\hline CHEMBL1489424 & 688282 & 5.4 & 5.2466 & TRN & \\
\hline CHEMBL1497812 & 688282 & 5.2 & 5.0957 & TRN & \\
\hline CHEMBL1412260 & 688282 & 4.7 & 5.0953 & TRN & \\
\hline CHEMBL1551295 & 688282 & 5.6 & 5.1845 & TRN & \\
\hline CHEMBL1489353 & 688282 & 4.9 & 5.2244 & TST & \\
\hline CHEMBL1526319 & 688282 & 4.8 & 5.1762 & TRN & \\
\hline CHEMBL1335889 & 688282 & 5.6 & 5.1991 & TRN & \\
\hline CHEMBL1342602 & 688282 & 5.0 & 5.0944 & TRN & \\
\hline CHEMBL1566552 & 688282 & 6.3 & 5.2797 & TRN & \\
\hline CHEMBL1602901 & 688282 & 4.6 & 5.2195 & TRN & \\
\hline CHEMBL1394223 & 688282 & 5.3 & 5.2607 & TRN & \\
\hline CHEMBL1487219 & 688282 & 6.5 & 5.215 & TRN & \\
\hline CHEMBL186526 & 688282 & 4.9 & 5.1115 & TRN & \\
\hline CHEMBL 7463 & 688282 & 6.4 & 5.2464 & TRN & \\
\hline CHEMBL3208627 & 688282 & 5.1 & 5.0905 & TST & \\
\hline & & & & 13288 & \\
\hline
\end{tabular}




\begin{tabular}{|c|c|c|c|c|}
\hline \multicolumn{5}{|c|}{ Supplemental Table S2.txt } \\
\hline CHEMBL1371927 & 688282 & 5.3 & 5.2535 & TRN \\
\hline CHEMBL1527083 & 688282 & 4.9 & 5.3169 & TST \\
\hline CHEMBL242384 & 688282 & 4.9 & 5.1032 & TRN \\
\hline CHEMBL12252 & 688282 & 4.5 & 5.245 & TRN \\
\hline CHEMBL1538824 & 688282 & 8.4949 & 5.0081 & TRN \\
\hline CHEMBL1424952 & 688282 & 4.5 & 5.1059 & TRN \\
\hline CHEMBL1507694 & 688282 & 4.6 & 5.0869 & TRN \\
\hline CHEMBL1317924 & 688282 & 4.9 & 5.0187 & TRN \\
\hline CHEMBL1613717 & 688282 & 5.1 & 5.0944 & TRN \\
\hline CHEMBL1529398 & 688282 & 5.3 & 5.1147 & TRN \\
\hline CHEMBL1409241 & 688282 & 5.4 & 5.1902 & TRN \\
\hline CHEMBL1313479 & 688282 & 4.9 & 5.2133 & TRN \\
\hline CHEMBL1542164 & 688282 & 4.9 & 5.1709 & TRN \\
\hline CHEMBL1574966 & 688282 & 7.6003 & 5.1166 & TRN \\
\hline CHEMBL1368593 & 688282 & 6.4 & 5.1681 & TRN \\
\hline CHEMBL1417135 & 688282 & 5.2 & 5.1926 & TRN \\
\hline CHEMBL1483313 & 688282 & 5.3 & 5.1665 & TRN \\
\hline CHEMBL1412847 & 688282 & 4.5 & 5.0198 & TRN \\
\hline CHEMBL1531056 & 688282 & 4.9 & 5.1793 & TRN \\
\hline CHEMBL1535546 & 688282 & 4.9 & 5.1798 & TRN \\
\hline CHEMBL1368728 & 688282 & 5.0 & 5.0441 & TRN \\
\hline CHEMBL1487869 & 688282 & 5.5 & 5.083 & TRN \\
\hline CHEMBL408501 & 688282 & 4.8 & 5.0627 & TST \\
\hline CHEMBL1404937 & 688282 & 5.7 & 5.0749 & TRN \\
\hline CHEMBL1450205 & 688282 & 4.9 & 5.2013 & TRN \\
\hline CHEMBL1518192 & 688282 & 4.6 & 5.2667 & TST \\
\hline CHEMBL1311641 & 688282 & 4.9 & 5.1005 & TRN \\
\hline CHEMBL1507262 & 688282 & 4.8 & 5.1511 & TRN \\
\hline CHEMBL1733652 & 688282 & 5.9 & 5.0414 & TST \\
\hline CHEMBL1242017 & 688282 & 5.1 & 5.1836 & TST \\
\hline CHEMBL1605033 & 688282 & 4.8 & 5.1531 & TRN \\
\hline CHEMBL1354492 & 688282 & 4.8 & 5.1753 & TST \\
\hline CHEMBL1501170 & 688282 & 4.6 & 5.2427 & TRN \\
\hline CHEMBL1594305 & 688282 & 5.6 & 5.2033 & TRN \\
\hline CHEMBL1369861 & 688282 & 4.6 & 5.0285 & TRN \\
\hline CHEMBL1570093 & 688282 & 4.8 & 5.1298 & TRN \\
\hline CHEMBL1303139 & 688282 & 4.6 & 5.2468 & TRN \\
\hline CHEMBL1600765 & 688282 & 4.6 & 5.1931 & TRN \\
\hline CHEMBL1409985 & 688282 & 4.9 & 5.2101 & TRN \\
\hline CHEMBL1503576 & 688282 & 4.6 & 5.2835 & TST \\
\hline CHEMBL1396142 & 688282 & 5.4 & 5.184 & TRN \\
\hline CHEMBL1200766 & 688282 & 5.5 & 5.2111 & TRN \\
\hline CHEMBL1529881 & 688282 & 5.0 & 5.1757 & TRN \\
\hline CHEMBL1447406 & 688282 & 4.9 & 5.175 & TST \\
\hline CHEMBL1356107 & 688282 & 5.0 & 5.1677 & TRN \\
\hline CHEMBL1559487 & 688282 & 5.0 & 5.1492 & TRN \\
\hline CHEMBL363207 & 688282 & 6.0 & 5.1881 & TST \\
\hline CHEMBL1575699 & 688282 & 4.5 & 5.1515 & TST \\
\hline
\end{tabular}




\begin{tabular}{|c|c|c|c|c|c|}
\hline \multirow[b]{2}{*}{ CHEMBL1546987 } & \multirow[b]{2}{*}{688282} & \\
\hline & & 4.8 & 5.1067 & TRN & \\
\hline CHEMBL1304004 & 688282 & 4.7 & 5.1352 & TRN & \\
\hline CHEMBL1364570 & 688282 & 6.3 & 5.2029 & TST & \\
\hline CHEMBL1561828 & 688282 & 4.9 & 5.0073 & TRN & \\
\hline CHEMBL320159 & 688282 & 5.4 & 5.2726 & TST & \\
\hline CHEMBL1507817 & 688282 & 4.8 & 5.1367 & TRN & \\
\hline CHEMBL1568714 & 688282 & 4.8 & 5.1063 & TRN & \\
\hline CHEMBL1503483 & 688282 & 5.1 & 4.9526 & TRN & \\
\hline CHEMBL1475366 & 688282 & 5.1 & 4.9218 & TRN & \\
\hline CHEMBL1313319 & 688282 & 4.6 & 5.131 & TRN & \\
\hline CHEMBL1389959 & 688282 & 4.7 & 5.0218 & TRN & \\
\hline CHEMBL1559098 & 688282 & 4.9 & 5.0962 & TRN & \\
\hline CHEMBL1536859 & 688282 & 5.3 & 5.0688 & TRN & \\
\hline CHEMBL1371349 & 688282 & 5.0 & 5.0009 & TRN & \\
\hline CHEMBL1465254 & 688282 & 4.5 & 5.0159 & TRN & \\
\hline CHEMBL1590645 & 688282 & 5.0 & 4.9859 & TRN & \\
\hline CHEMBL1403351 & 688282 & 4.8 & 5.115 & TRN & \\
\hline CHEMBL1319715 & 688282 & 4.9 & 5.1238 & TRN & \\
\hline CHEMBL1437164 & 688282 & 5.0 & 5.0367 & TRN & \\
\hline CHEMBL1382592 & 688282 & 5.3 & 5.2041 & TRN & \\
\hline CHEMBL1323790 & 688282 & 5.5 & 5.0964 & TRN & \\
\hline CHEMBL1379217 & 688282 & 4.6 & 5.2166 & TRN & \\
\hline CHEMBL1440954 & 688282 & 4.6 & 5.1091 & TRN & \\
\hline CHEMBL1513458 & 688282 & 5.3 & 5.1951 & TRN & \\
\hline CHEMBL1607205 & 688282 & 5.0 & 5.099 & TRN & \\
\hline CHEMBL1424144 & 688282 & 5.4 & 5.1315 & TRN & \\
\hline CHEMBL1365219 & 688282 & 4.6 & 5.2684 & TRN & \\
\hline CHEMBL1585266 & 688282 & 4.6 & 5.16 & TST & \\
\hline CHEMBL1494177 & 688282 & 5.5 & 5.2038 & TRN & \\
\hline CHEMBL1355186 & 688282 & 4.9 & 5.1077 & TRN & \\
\hline CHEMBL1574779 & 688282 & 5.0 & 5.033 & TRN & \\
\hline CHEMBL1610557 & 688282 & 5.6 & 5.0994 & TRN & \\
\hline CHEMBL1521545 & 688282 & 4.8 & 5.1549 & TRN & \\
\hline CHEMBL1382394 & 688282 & 4.9 & 5.1346 & TST & \\
\hline CHEMBL1468159 & 688282 & 5.0 & $4.9860 e$ & 0000000001 & TRN \\
\hline CHEMBL1307154 & 688282 & 5.3 & 5.1578 & TRN & \\
\hline CHEMBL1529847 & 688282 & 4.9 & 5.0913 & TRN & \\
\hline CHEMBL1553740 & 688282 & 5.4 & 5.1939 & TRN & \\
\hline CHEMBL1563566 & 688282 & 5.0 & 5.1856 & TRN & \\
\hline CHEMBL1426403 & 688282 & 5.3 & 5.2173 & TRN & \\
\hline CHEMBL1449998 & 688282 & 5.3 & 5.1542 & TRN & \\
\hline CHEMBL70902 & 688282 & 5.5 & 5.2969 & TST & \\
\hline CHEMBL1414047 & 688282 & 4.8 & 5.2404 & TRN & \\
\hline CHEMBL1565169 & 688282 & 5.3 & 5.2607 & TRN & \\
\hline CHEMBL40157 & 688282 & 6.9 & 5.2365 & TST & \\
\hline CHEMBL1402299 & 688282 & 5.3 & 5.1626 & TRN & \\
\hline CHEMBL261889 & 688282 & 5.0 & 5.1568 & TRN & \\
\hline CHEMBL591458 & 688282 & 4.9 & 5.2183 & TRN & \\
\hline & & & & 13290 & \\
\hline
\end{tabular}




\begin{tabular}{|c|c|c|c|c|}
\hline \multicolumn{5}{|c|}{ Supplemental Table S2.txt } \\
\hline CHEMBL489934 & 688282 & 6.0 & 5.0597 & TRN \\
\hline CHEMBL1441849 & 688282 & 5.3 & 5.1435 & TRN \\
\hline CHEMBL423081 & 688282 & 4.8 & 5.2782 & TRN \\
\hline CHEMBL1382567 & 688282 & 5.0 & 5.0592 & TRN \\
\hline CHEMBL1502892 & 688282 & 4.8 & 5.186 & TRN \\
\hline CHEMBL62 & 688282 & 4.9 & 5.2277 & TST \\
\hline CHEMBL1560268 & 688282 & 5.3 & 5.2046 & TRN \\
\hline CHEMBL1609089 & 688282 & 5.0 & 5.1894 & TRN \\
\hline CHEMBL1314473 & 688282 & 4.9 & 5.0513 & TRN \\
\hline CHEMBL1569529 & 688282 & 5.0 & 5.062 & TRN \\
\hline CHEMBL1424702 & 688282 & 5.0 & 5.135 & TRN \\
\hline CHEMBL1454322 & 688282 & 4.7 & 4.9918 & TRN \\
\hline CHEMBL1559056 & 688282 & 5.3 & 5.2384 & TRN \\
\hline CHEMBL1518173 & 688282 & 6.0 & 5.1946 & TST \\
\hline CHEMBL1440311 & 688282 & 5.0 & 5.0078 & TRN \\
\hline CHEMBL56 & 688282 & 4.9 & 5.2129 & TST \\
\hline CHEMBL1371117 & 688282 & 7.6003 & 5.0877 & TRN \\
\hline CHEMBL1375883 & 688282 & 4.6 & 5.2828 & TRN \\
\hline CHEMBL1392315 & 688282 & 6.9 & 5.2587 & TRN \\
\hline CHEMBL1526694 & 688282 & 5.3 & 5.1359 & TRN \\
\hline CHEMBL455491 & 688282 & 4.5 & 5.2841 & TST \\
\hline CHEMBL1594325 & 688282 & 4.9 & 5.1224 & TRN \\
\hline CHEMBL1301731 & 688282 & 4.9 & 5.1779 & TRN \\
\hline CHEMBL1437690 & 688282 & 4.9 & 5.0061 & TRN \\
\hline CHEMBL1612222 & 688282 & 4.7 & 5.1243 & TRN \\
\hline CHEMBL1459126 & 688282 & 4.6 & 5.1128 & TRN \\
\hline CHEMBL1608949 & 688282 & 5.0 & 5.0033 & TRN \\
\hline CHEMBL1380858 & 688282 & 4.6 & 5.1035 & TRN \\
\hline CHEMBL1337543 & 688282 & 5.5 & 5.193 & TRN \\
\hline CHEMBL1452199 & 688282 & 5.1 & 5.1278 & TRN \\
\hline CHEMBL1407760 & 688282 & 6.0 & 5.1875 & TRN \\
\hline CHEMBL192627 & 688282 & 5.3 & 5.2708 & TST \\
\hline CHEMBL1329527 & 688282 & 5.3 & 5.0582 & TRN \\
\hline CHEMBL1371693 & 688282 & 5.3 & 5.0594 & TRN \\
\hline CHEMBL1504328 & 688282 & 5.0 & 5.1162 & TRN \\
\hline CHEMBL23731 & 688282 & 4.9 & 5.1761 & TRN \\
\hline CHEMBL1545160 & 688282 & 4.8 & 5.1278 & TRN \\
\hline CHEMBL1452646 & 688282 & 4.5 & 5.1187 & TRN \\
\hline CHEMBL1461686 & 688282 & 5.4 & 5.0573 & TRN \\
\hline CHEMBL1256835 & 688282 & 4.5 & 5.2074 & TRN \\
\hline CHEMBL1437119 & 688282 & 4.9 & 5.1673 & TRN \\
\hline CHEMBL1523660 & 688282 & 4.9 & 5.21 & TRN \\
\hline CHEMBL1410737 & 688282 & 4.6 & 5.0187 & TRN \\
\hline CHEMBL1404314 & 688282 & 4.8 & 5.0801 & TRN \\
\hline CHEMBL1593430 & 688282 & 4.6 & 5.2255 & TRN \\
\hline CHEMBL3196610 & 688282 & 4.9 & 5.1218 & TST \\
\hline CHEMBL1589879 & 688282 & 6.2 & 5.102 & TRN \\
\hline CHEMBL362919 & 688282 & 6.0 & 5.1196 & TRN \\
\hline
\end{tabular}




\begin{tabular}{|c|c|c|c|c|}
\hline \multicolumn{5}{|c|}{ Supplemental Table S2.txt } \\
\hline CHEMBL1527826 & 688282 & 4.5 & 4.9991 & TRN \\
\hline CHEMBL1494408 & 688282 & 5.0 & 5.0971 & TRN \\
\hline CHEMBL595250 & 688282 & 6.7001 & 5.0856 & TRN \\
\hline CHEMBL1354281 & 688282 & 4.8 & 5.1312 & TRN \\
\hline CHEMBL1401031 & 688282 & 5.0 & 4.9696 & TRN \\
\hline CHEMBL1472761 & 688282 & 5.3 & 5.1499 & TRN \\
\hline CHEMBL1536058 & 688282 & 5.3 & 5.2979 & TST \\
\hline CHEMBL1301227 & 688282 & 5.0 & 5.0083 & TRN \\
\hline CHEMBL330320 & 688282 & 6.0 & 5.181 & TST \\
\hline CHEMBL1399528 & 688282 & 4.5 & 4.9747 & TRN \\
\hline CHEMBL1471216 & 688282 & 5.3 & 5.2175 & TRN \\
\hline CHEMBL1725279 & 688282 & 4.8 & 5.2707 & TST \\
\hline CHEMBL 22075 & 688282 & 5.0 & 5.1977 & TRN \\
\hline CHEMBL1605845 & 688282 & 5.5 & 5.2035 & TRN \\
\hline CHEMBL1461525 & 688282 & 5.3 & 5.1681 & TRN \\
\hline CHEMBL1477833 & 688282 & 5.3 & 5.2319 & TRN \\
\hline CHEMBL1487393 & 688282 & 4.6 & 5.1795 & TRN \\
\hline CHEMBL510515 & 688282 & 5.0 & 5.1899 & TRN \\
\hline CHEMBL1973866 & 688282 & 6.0 & 5.078 & TST \\
\hline CHEMBL1540335 & 688282 & 5.0 & 5.0525 & TRN \\
\hline CHEMBL1578783 & 688282 & 5.0 & 5.0073 & TRN \\
\hline CHEMBL1414688 & 688282 & 6.4 & 5.1991 & TST \\
\hline CHEMBL1384454 & 688282 & 5.0 & 5.1854 & TRN \\
\hline CHEMBL3392074 & 688282 & 4.9 & 5.2287 & TST \\
\hline CHEMBL1517892 & 688282 & 5.0 & 5.1477 & TRN \\
\hline CHEMBL447001 & 688282 & 4.5 & 5.2943 & TRN \\
\hline CHEMBL1524757 & 688282 & 5.0 & 5.0922 & TRN \\
\hline CHEMBL1378707 & 688282 & 4.8 & 5.1552 & TRN \\
\hline CHEMBL1362298 & 688282 & 4.6 & 5.1611 & TRN \\
\hline CHEMBL1592560 & 688282 & 5.1 & 5.0665 & TRN \\
\hline CHEMBL1386803 & 688282 & 5.0 & 5.0737 & TRN \\
\hline CHEMBL1507348 & 688282 & 5.1 & 5.1941 & TRN \\
\hline CHEMBL1712181 & 688282 & 5.1 & 5.1739 & TST \\
\hline CHEMBL1415521 & 688282 & 4.6 & 5.1582 & TRN \\
\hline CHEMBL1368062 & 688282 & 5.9 & 5.0989 & TRN \\
\hline CHEMBL1357781 & 688282 & 5.3 & 5.1303 & TRN \\
\hline CHEMBL1317537 & 688282 & 4.5 & 5.0781 & TRN \\
\hline CHEMBL1552984 & 688282 & 4.9 & 5.2289 & TST \\
\hline CHEMBL1380189 & 688282 & 4.6 & 5.2124 & TRN \\
\hline CHEMBL3191796 & 688282 & 4.9 & 5.2082 & TST \\
\hline CHEMBL1503314 & 688282 & 4.6 & 5.0767 & TRN \\
\hline CHEMBL1309821 & 688282 & 4.9 & 5.1142 & TRN \\
\hline CHEMBL1544164 & 688282 & 4.5 & 5.0856 & TRN \\
\hline CHEMBL1411246 & 688282 & 4.5 & 5.2811 & TST \\
\hline CHEMBL1465470 & 688282 & 4.6 & 5.1612 & TRN \\
\hline CHEMBL1317009 & 688282 & 4.9 & 5.0214 & TRN \\
\hline CHEMBL1257012 & 688282 & 5.0 & 5.164 & TST \\
\hline CHEMBL1421966 & 688282 & 4.5 & 5.2413 & TRN \\
\hline
\end{tabular}




\begin{tabular}{|c|c|c|c|c|}
\hline & & & & $a \perp 1 a$ \\
\hline CHEMBL1374610 & 688282 & 4.9 & 5.2389 & TRN \\
\hline CHEMBL1397454 & 688282 & 4.9 & 5.1963 & TRN \\
\hline CHEMBL1386337 & 688282 & 5.3 & 5.0836 & TRN \\
\hline CHEMBL1443695 & 688282 & 4.6 & 5.1461 & TRN \\
\hline CHEMBL1470271 & 688282 & 4.6 & 5.1512 & TST \\
\hline CHEMBL1315457 & 688282 & 5.0 & 5.1856 & TST \\
\hline CHEMBL82870 & 688282 & 5.4 & 5.2248 & TRN \\
\hline CHEMBL1535431 & 688282 & 4.9 & 5.0966 & TRN \\
\hline CHEMBL1557016 & 688282 & 5.3 & 5.0778 & TRN \\
\hline CHEMBL1567097 & 688282 & 4.7 & 5.1906 & TRN \\
\hline CHEMBL1352525 & 688282 & 5.3 & 5.1358 & TRN \\
\hline CHEMBL1316265 & 688282 & 4.8 & 5.1589 & TRN \\
\hline CHEMBL1374451 & 688282 & 6.9 & 5.1849 & TRN \\
\hline CHEMBL3197622 & 688282 & 5.2 & 5.2417 & TST \\
\hline CHEMBL1528477 & 688282 & 4.6 & 5.1473 & TRN \\
\hline CHEMBL1528054 & 688282 & 5.3 & 5.1024 & TRN \\
\hline CHEMBL1351263 & 688282 & 5.0 & 5.2066 & TST \\
\hline CHEMBL1540025 & 688282 & 6.0 & 4.9998 & TRN \\
\hline CHEMBL1533817 & 688282 & 4.8 & 5.1738 & TST \\
\hline CHEMBL39317 & 688282 & 4.9 & 5.0288 & TRN \\
\hline CHEMBL1532709 & 688282 & 4.6 & 5.2832 & TST \\
\hline CHEMBL1554098 & 688282 & 5.9 & 5.0744 & TST \\
\hline CHEMBL399249 & 688282 & 4.9 & 5.2773 & TRN \\
\hline CHEMBL1395415 & 688282 & 4.9 & 5.039 & TRN \\
\hline CHEMBL534084 & 688282 & 4.5 & 5.1283 & TRN \\
\hline CHEMBL1403793 & 688282 & 4.9 & 5.0679 & TRN \\
\hline CHEMBL253998 & 688282 & 4.5 & 5.2095 & TRN \\
\hline CHEMBL1583826 & 688282 & 5.3 & 5.0685 & TRN \\
\hline CHEMBL1173522 & 688282 & 4.7 & 5.1399 & TRN \\
\hline CHEMBL1317124 & 688282 & 5.0 & 5.2384 & TST \\
\hline CHEMBL1553689 & 688282 & 4.6 & 5.2908 & TRN \\
\hline CHEMBL1412350 & 688282 & 5.3 & 5.1504 & TRN \\
\hline CHEMBL 230056 & 688282 & 4.5 & 5.1568 & TST \\
\hline CHEMBL1574569 & 688282 & 5.0 & 5.1461 & TRN \\
\hline CHEMBL1369824 & 688282 & 4.9 & 5.0132 & TRN \\
\hline CHEMBL1605285 & 688282 & 4.6 & 5.1316 & TRN \\
\hline CHEMBL1598144 & 688282 & 5.6 & 5.0331 & TRN \\
\hline CHEMBL1318909 & 688282 & 4.6 & 5.044 & TRN \\
\hline CHEMBL1584901 & 688282 & 4.9 & 5.1464 & TST \\
\hline CHEMBL1256971 & 688282 & 6.0 & 5.2516 & TST \\
\hline CHEMBL1539031 & 688282 & 5.3 & 5.1809 & TRN \\
\hline CHEMBL261123 & 688282 & 5.5 & 5.1224 & TRN \\
\hline CHEMBL1422039 & 688282 & 5.0 & 5.2765 & TRN \\
\hline CHEMBL1452208 & 688282 & 5.0 & 5.141 & TRN \\
\hline CHEMBL1307897 & 688282 & 5.3 & 5.0845 & TRN \\
\hline CHEMBL1551009 & 688282 & 5.0 & 4.9429 & TRN \\
\hline CHEMBL1585127 & 688282 & 4.9 & 5.2108 & TRN \\
\hline CHEMBL3186408 & 688282 & 6.0 & 5.3289 & TST \\
\hline
\end{tabular}




\begin{tabular}{|c|c|c|c|c|c|}
\hline CHEMBL1373961 & 688282 & 5.0 & \multicolumn{2}{|c|}{5.122000000000001} & \multirow[t]{2}{*}{ TRN } \\
\hline CHEMBL1510829 & 688282 & 5.3 & 5.0709 & TRN & \\
\hline CHEMBL1361777 & 688282 & 4.8 & 5.1936 & TRN & \\
\hline CHEMBL1325152 & 688282 & 5.2 & 5.1763 & TRN & \\
\hline CHEMBL 39878 & 688282 & 4.6 & 5.1773 & TRN & \\
\hline CHEMBL1557576 & 688282 & 4.6 & 5.1898 & TRN & \\
\hline CHEMBL1550081 & 688282 & 5.3 & 5.2112 & TRN & \\
\hline CHEMBL1496341 & 688282 & 5.2 & 5.1256 & TRN & \\
\hline CHEMBL1462631 & 688282 & 5.6 & 5.1436 & TRN & \\
\hline CHEMBL475375 & 688282 & 4.7 & 4.9557 & TRN & \\
\hline CHEMBL1316514 & 688282 & 5.3 & 5.2868 & TRN & \\
\hline CHEMBL1369522 & 688282 & 5.0 & \multicolumn{2}{|c|}{5.1739999999999995} & TRN \\
\hline CHEMBL1574693 & 688282 & 6.0 & 5.2407 & TST & \\
\hline CHEMBL1570672 & 688282 & 6.2 & \multicolumn{2}{|c|}{5.0760000000000005} & TRN \\
\hline CHEMBL1473934 & 688282 & 6.8 & 5.1054 & TRN & \\
\hline CHEMBL1377988 & 688282 & 4.8 & 4.9853 & TRN & \\
\hline CHEMBL3192808 & 688282 & 5.0 & 5.0625 & TRN & \\
\hline CHEMBL1476430 & 688282 & 5.0 & 5.0383 & TRN & \\
\hline CHEMBL1447188 & 688282 & 5.6 & 4.9892 & TRN & \\
\hline CHEMBL1570319 & 688282 & 4.6 & 5.0529 & TRN & \\
\hline CHEMBL1325403 & 688282 & 5.3 & 5.0883 & TRN & \\
\hline CHEMBL1313522 & 688282 & 4.9 & 5.0146 & TRN & \\
\hline CHEMBL1373007 & 688282 & 5.0 & 5.2086 & TST & \\
\hline CHEMBL1516982 & 688282 & 5.0 & 5.0752 & TRN & \\
\hline CHEMBL1550024 & 688282 & 5.3 & 5.1843 & TRN & \\
\hline CHEMBL1410561 & 688282 & 4.9 & 5.3363 & TRN & \\
\hline CHEMBL 3145170 & 688282 & 5.0 & 5.2664 & TST & \\
\hline CHEMBL1449058 & 688282 & 5.3 & 5.2733 & TST & \\
\hline CHEMBL1530832 & 688282 & 4.6 & 5.1641 & TRN & \\
\hline CHEMBL1314891 & 688282 & 5.3 & 5.0505 & TRN & \\
\hline CHEMBL1475695 & 688282 & 4.8 & 5.0394 & TRN & \\
\hline CHEMBL1581308 & 688282 & 5.4 & 5.1188 & TRN & \\
\hline CHEMBL1419612 & 688282 & 4.5 & 5.1932 & TRN & \\
\hline CHEMBL1608662 & 688282 & 4.8 & 5.0996 & TRN & \\
\hline CHEMBL1544890 & 688282 & 4.5 & 5.1528 & TRN & \\
\hline CHEMBL319244 & 688282 & 4.8 & 5.2503 & TRN & \\
\hline CHEMBL1516608 & 688282 & 5.5 & 5.2326 & TRN & \\
\hline CHEMBL1316461 & 688282 & 5.7 & 5.2568 & TRN & \\
\hline CHEMBL1604690 & 688282 & 5.3 & 4.9837 & TRN & \\
\hline CHEMBL1466031 & 688282 & 4.6 & 5.0377 & TRN & \\
\hline CHEMBL1589856 & 688282 & 4.9 & 5.1707 & TRN & \\
\hline CHEMBL1438273 & 688282 & 4.5 & 5.1271 & TRN & \\
\hline CHEMBL1327772 & 688282 & 6.2 & 5.1324 & TRN & \\
\hline CHEMBL1415701 & 688282 & 5.0 & 5.1271 & TRN & \\
\hline CHEMBL1306181 & 688282 & 4.9 & 5.0211 & TRN & \\
\hline CHEMBL1327256 & 688282 & 6.0 & 5.0876 & TRN & \\
\hline CHEMBL1530665 & 688282 & 5.3 & 5.069 & TRN & \\
\hline CHEMBL99344 & 688282 & 4.9 & 5.2196 & TRN & \\
\hline & & & & 13294 & \\
\hline
\end{tabular}




\begin{tabular}{|c|c|c|c|c|c|}
\hline \\
\hline CHEMBL1477778 & 688282 & 4.5 & 5.0742 & TRN & \\
\hline CHEMBL1411328 & 688282 & 4.9 & 5.0601 & TRN & \\
\hline CHEMBL1377706 & 688282 & 4.9 & 4.9851 & TRN & \\
\hline CHEMBL1573064 & 688282 & 5.3 & 5.1593 & TRN & \\
\hline CHEMBL1371501 & 688282 & 4.9 & 5.124 & TRN & \\
\hline CHEMBL1531590 & 688282 & 5.3 & 5.1767 & TRN & \\
\hline CHEMBL1329499 & 688282 & 4.9 & 4.9869 & TRN & \\
\hline CHEMBL1335465 & 688282 & 5.0 & 5.1421 & TRN & \\
\hline CHEMBL196537 & 688282 & 4.5 & 5.2688 & TST & \\
\hline CHEMBL1453943 & 688282 & 5.3 & 5.2096 & TRN & \\
\hline CHEMBL1335945 & 688282 & 5.0 & 5.2552 & TST & \\
\hline CHEMBL1364808 & 688282 & 4.9 & 5.23600 & 0000000001 & TRN \\
\hline CHEMBL1415598 & 688282 & 4.9 & 5.024 & TRN & \\
\hline CHEMBL1593128 & 688282 & 5.5 & 5.0201 & TRN & \\
\hline CHEMBL1507882 & 688282 & 6.1 & 5.1838 & TRN & \\
\hline CHEMBL1354355 & 688282 & 4.8 & 5.0263 & TRN & \\
\hline CHEMBL262083 & 688282 & 4.5 & 5.2342 & TRN & \\
\hline CHEMBL1345333 & 688282 & 5.0 & 5.1946 & TST & \\
\hline CHEMBL1561537 & 688282 & 5.0 & 5.0571 & TRN & \\
\hline CHEMBL 242383 & 688282 & 4.5 & 5.2539 & TRN & \\
\hline CHEMBL567529 & 688282 & 5.7 & 5.144 & TRN & \\
\hline CHEMBL3190358 & 688282 & 4.5 & 5.1164 & TRN & \\
\hline CHEMBL1310739 & 688282 & 4.5 & 5.1885 & TRN & \\
\hline CHEMBL1542284 & 688282 & 5.3 & 5.1808 & TRN & \\
\hline CHEMBL1376013 & 688282 & 5.0 & 5.1741 & TRN & \\
\hline CHEMBL1573989 & 688282 & 4.9 & 5.1665 & TRN & \\
\hline CHEMBL1541256 & 688282 & 5.6 & 5.1523 & TRN & \\
\hline CHEMBL1362854 & 688282 & 4.6 & 5.0799 & TRN & \\
\hline CHEMBL1495875 & 688282 & 6.2 & 5.3668 & TRN & \\
\hline CHEMBL1305293 & 688282 & 5.0 & 5.1 & TRN & \\
\hline CHEMBL1571785 & 688282 & 4.6 & 5.1614 & TRN & \\
\hline CHEMBL1315382 & 688282 & 5.0 & 5.0565 & TRN & \\
\hline CHEMBL1421468 & 688282 & 5.6 & 5.1691 & TRN & \\
\hline CHEMBL1398260 & 688282 & 4.6 & 5.2728 & TST & \\
\hline CHEMBL1414070 & 688282 & 8.0 & 5.2147 & TRN & \\
\hline CHEMBL1339083 & 688282 & 4.5 & 5.0451 & TRN & \\
\hline CHEMBL1373041 & 688282 & 4.6 & 5.1145 & TRN & \\
\hline CHEMBL1491575 & 688282 & 4.9 & 5.102 & TRN & \\
\hline CHEMBL1473849 & 688282 & 5.3 & 5.2608 & TST & \\
\hline CHEMBL1607188 & 688282 & 7.2 & 5.0472 & TRN & \\
\hline CHEMBL1577908 & 688282 & 4.7 & 5.0548 & TRN & \\
\hline CHEMBL1594349 & 688282 & 4.9 & 5.1313 & TRN & \\
\hline CHEMBL275516 & 688282 & 5.0 & 5.3678 & TST & \\
\hline CHEMBL1312298 & 688282 & 5.0 & 5.0118 & TRN & \\
\hline CHEMBL1539227 & 688282 & 4.5 & 5.0467 & TRN & \\
\hline CHEMBL1552409 & 688282 & 6.3 & 5.1809 & TST & \\
\hline CHEMBL1543657 & 688282 & 4.6 & 4.9335 & TRN & \\
\hline CHEMBL1605179 & 688282 & 5.1 & 5.2664 & TRN & \\
\hline
\end{tabular}




\begin{tabular}{|c|c|c|c|c|}
\hline & & & pplement & $\mathrm{a} \perp \mathrm{Ta}$ \\
\hline CHEMBL1395402 & 688282 & 5.0 & 5.0826 & TRN \\
\hline CHEMBL1599196 & 688282 & 5.3 & 5.0891 & TRN \\
\hline CHEMBL1437883 & 688282 & 4.9 & 5.1188 & TRN \\
\hline CHEMBL1432238 & 688282 & 4.9 & 5.0231 & TRN \\
\hline CHEMBL1376310 & 688282 & 5.5 & 5.1494 & TRN \\
\hline CHEMBL1320632 & 688282 & 5.3 & 5.1317 & TRN \\
\hline CHEMBL1419737 & 688282 & 5.3 & 5.106 & TRN \\
\hline CHEMBL1532436 & 688282 & 5.0 & 5.1032 & TRN \\
\hline CHEMBL1494196 & 688282 & 4.5 & 5.0127 & TRN \\
\hline CHEMBL1300967 & 688282 & 5.4 & 5.0315 & TRN \\
\hline CHEMBL1356003 & 688282 & 6.0 & 5.3402 & TRN \\
\hline CHEMBL1588737 & 688282 & 4.6 & 5.1596 & TRN \\
\hline CHEMBL 3192913 & 688282 & 4.6 & 5.0911 & TRN \\
\hline CHEMBL1531037 & 688282 & 4.8 & 5.0658 & TRN \\
\hline CHEMBL1414125 & 688282 & 5.6 & 5.0503 & TRN \\
\hline CHEMBL1360037 & 688282 & 5.1 & 5.229 & TRN \\
\hline CHEMBL1585300 & 688282 & 4.7 & 5.0369 & TRN \\
\hline CHEMBL1319074 & 688282 & 4.9 & 5.1136 & TST \\
\hline CHEMBL1482460 & 688282 & 4.9 & 5.1622 & TRN \\
\hline CHEMBL1394626 & 688282 & 5.3 & 5.3038 & TRN \\
\hline CHEMBL1516163 & 688282 & 5.0 & 4.9987 & TRN \\
\hline CHEMBL1419320 & 688282 & 5.5 & 5.0029 & TST \\
\hline CHEMBL398673 & 688282 & 5.6 & 5.1092 & TST \\
\hline CHEMBL1390986 & 688282 & 4.9 & 5.0477 & TRN \\
\hline CHEMBL1481743 & 688282 & 4.6 & 5.2427 & TRN \\
\hline CHEMBL1420487 & 688282 & 4.6 & 5.1718 & TRN \\
\hline CHEMBL3192583 & 688282 & 4.7 & 5.1434 & TST \\
\hline CHEMBL1411054 & 688282 & 4.5 & 5.0798 & TRN \\
\hline CHEMBL1508182 & 688282 & 5.1 & 5.1709 & TRN \\
\hline CHEMBL1322743 & 688282 & 5.6 & 5.1376 & TRN \\
\hline CHEMBL1383919 & 688282 & 5.2 & 5.1807 & TRN \\
\hline CHEMBL1470546 & 688282 & 4.6 & 5.1864 & TST \\
\hline CHEMBL1606636 & 688282 & 5.6 & 5.0517 & TRN \\
\hline CHEMBL266158 & 688282 & 5.9 & 5.3524 & TST \\
\hline CHEMBL1549992 & 688282 & 4.9 & 5.0612 & TRN \\
\hline CHEMBL1461319 & 688282 & 4.9 & 5.0842 & TRN \\
\hline CHEMBL1489033 & 688282 & 4.8 & 5.0976 & TRN \\
\hline CHEMBL1566336 & 688282 & 4.9 & 5.1012 & TRN \\
\hline CHEMBL581886 & 688282 & 7.2 & 5.1498 & TRN \\
\hline CHEMBL1601452 & 688282 & 4.6 & 5.1624 & TRN \\
\hline CHEMBL1603770 & 688282 & 5.3 & 5.1212 & TRN \\
\hline CHEMBL1421178 & 688282 & 4.5 & 5.1394 & TRN \\
\hline CHEMBL1305658 & 688282 & 4.9 & 5.0731 & TRN \\
\hline CHEMBL1452914 & 688282 & 5.2 & 5.135 & TRN \\
\hline CHEMBL1431659 & 688282 & 5.1 & 5.0722 & TRN \\
\hline CHEMBL1475338 & 688282 & 4.9 & 5.0233 & TRN \\
\hline CHEMBL1329957 & 688282 & 4.9 & 5.221 & TST \\
\hline CHEMBL1417815 & 688282 & 5.0 & 5.0813 & TRN \\
\hline
\end{tabular}




\begin{tabular}{|c|c|c|c|c|c|}
\hline & & & & & \\
\hline CHEMBL1568482 & 688282 & 5.0 & 5.0571 & TRN & \\
\hline CHEMBL365739 & 688282 & 4.8 & 5.2992 & TST & \\
\hline CHEMBL1603808 & 688282 & 5.5 & 5.0751 & TRN & \\
\hline CHEMBL1445235 & 688282 & 5.0 & 5.0233 & TRN & \\
\hline CHEMBL1423392 & 688282 & 4.6 & 5.166 & TRN & \\
\hline CHEMBL 88402 & 688282 & 4.9 & 5.0777 & TRN & \\
\hline CHEMBL1327319 & 688282 & 4.9 & 5.0722 & TRN & \\
\hline CHEMBL1571025 & 688282 & 4.5 & 5.1629 & TRN & \\
\hline CHEMBL1566094 & 688282 & 4.9 & 5.2131 & TRN & \\
\hline CHEMBL1505632 & 688282 & 4.6 & 5.2515 & TRN & \\
\hline CHEMBL1403934 & 688282 & 4.9 & 5.0654 & TRN & \\
\hline CHEMBL1518305 & 688282 & 4.9 & 4.9675 & TRN & \\
\hline CHEMBL1602729 & 688282 & 5.3 & 5.0685 & TRN & \\
\hline CHEMBL1515348 & 688282 & 4.6 & 5.0358 & TRN & \\
\hline CHEMBL1551200 & 688282 & 8.0 & 5.0579 & TRN & \\
\hline CHEMBL8260 & 688282 & 6.0 & 5.2657 & TRN & \\
\hline CHEMBL1522523 & 688282 & 5.1 & $5.0710 e$ & 0000000001 & TRN \\
\hline CHEMBL1528855 & 688282 & 4.9 & 5.1064 & TST & \\
\hline CHEMBL1560368 & 688282 & 4.8 & 5.0717 & TST & \\
\hline CHEMBL1371458 & 688282 & 5.6 & 5.1861 & TRN & \\
\hline CHEMBL1549328 & 688282 & 4.6 & 5.1451 & TRN & \\
\hline CHEMBL1512833 & 688282 & 6.3 & 5.1832 & TRN & \\
\hline CHEMBL1597469 & 688282 & 4.9 & 5.2552 & TRN & \\
\hline CHEMBL1474114 & 688282 & 6.8 & 5.107 & TRN & \\
\hline CHEMBL1327398 & 688282 & 4.6 & 5.1681 & TRN & \\
\hline CHEMBL1357857 & 688282 & 6.3 & 5.0264 & TRN & \\
\hline CHEMBL1386456 & 688282 & 5.5 & 5.1781 & TRN & \\
\hline CHEMBL1360881 & 688282 & 4.9 & 5.0649 & TRN & \\
\hline CHEMBL1499545 & 688282 & 4.9 & 5.2461 & TST & \\
\hline CHEMBL1173475 & 688282 & 5.3 & 5.2963 & TRN & \\
\hline CHEMBL1549823 & 688282 & 5.5 & 5.1706 & TRN & \\
\hline CHEMBL1417503 & 688282 & 4.5 & 5.1143 & TRN & \\
\hline CHEMBL1345813 & 688282 & 6.4 & 5.2096 & TRN & \\
\hline CHEMBL1255966 & 688282 & 4.9 & 5.1906 & TST & \\
\hline CHEMBL1437747 & 688282 & 4.9 & 5.0996 & TRN & \\
\hline CHEMBL1366453 & 688282 & 4.8 & 5.1088 & TST & \\
\hline CHEMBL1539876 & 688282 & 5.0 & 5.1451 & TRN & \\
\hline CHEMBL1300662 & 688282 & 5.4 & 5.21899 & 9999999999 & TRN \\
\hline CHEMBL1562477 & 688282 & 4.9 & 5.1134 & TRN & \\
\hline CHEMBL1533630 & 688282 & 5.4 & 5.2404 & TRN & \\
\hline CHEMBL1378817 & 688282 & 5.0 & 5.3092 & TST & \\
\hline CHEMBL1541505 & 688282 & 4.5 & 5.1492 & TST & \\
\hline CHEMBL1361847 & 688282 & 4.8 & 5.0003 & TRN & \\
\hline CHEMBL1554717 & 688282 & 4.8 & 5.0172 & TRN & \\
\hline CHEMBL1456771 & 688282 & 4.5 & 4.9462 & TRN & \\
\hline CHEMBL1554791 & 688282 & 4.9 & 5.0896 & TRN & \\
\hline CHEMBL1539496 & 688282 & 4.6 & 5.2431 & TRN & \\
\hline CHEMBL1505904 & 688282 & 5.5 & 5.1657 & TST & \\
\hline & & & & 13297 & \\
\hline
\end{tabular}




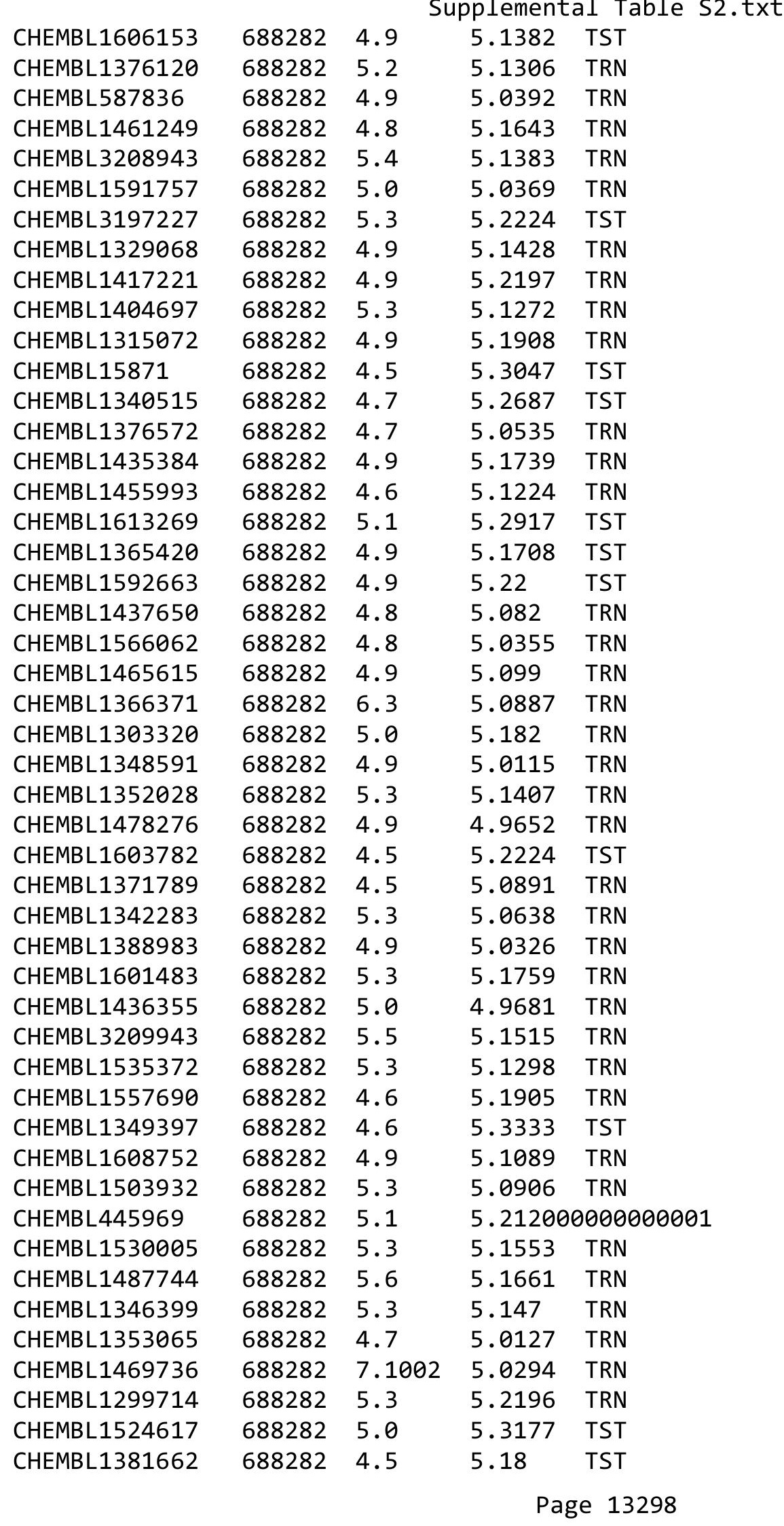




\begin{tabular}{|c|c|c|c|c|c|}
\hline & & & & & \\
\hline CHEMBL1498654 & 688282 & 5.4 & 5.2664 & TRN & \\
\hline CHEMBL1316453 & 688282 & 5.0 & 5.1254 & TRN & \\
\hline CHEMBL1476670 & 688282 & 5.8 & 4.9498 & TRN & \\
\hline CHEMBL498770 & 688282 & 4.6 & 5.2287 & TST & \\
\hline CHEMBL1457317 & 688282 & 5.3 & 5.0377 & TRN & \\
\hline CHEMBL1540038 & 688282 & 4.7 & 5.048 & TRN & \\
\hline CHEMBL1610350 & 688282 & 5.4 & 5.1281 & TRN & \\
\hline CHEMBL1552482 & 688282 & 5.4 & 5.2318 & TST & \\
\hline CHEMBL1482809 & 688282 & 4.6 & 5.084 & TRN & \\
\hline CHEMBL1387227 & 688282 & 5.1 & 5.0856 & TRN & \\
\hline CHEMBL1516882 & 688282 & 4.6 & 4.9633 & TRN & \\
\hline CHEMBL 3192370 & 688282 & 4.5 & 5.1076 & TST & \\
\hline CHEMBL1595365 & 688282 & 5.3 & 5.159 & TRN & \\
\hline CHEMBL1377507 & 688282 & 4.9 & 5.245 & TST & \\
\hline CHEMBL1611075 & 688282 & 5.3 & 5.2092 & TRN & \\
\hline CHEMBL26320 & 688282 & 4.6 & 5.2291 & TRN & \\
\hline CHEMBL1518981 & 688282 & 4.9 & 5.1251 & TRN & \\
\hline CHEMBL1319908 & 688282 & 6.1 & 5.1456 & TRN & \\
\hline CHEMBL1418087 & 688282 & 4.7 & 5.12200 & 0000000001 & TRN \\
\hline CHEMBL1586056 & 688282 & 4.9 & 5.0393 & TRN & \\
\hline CHEMBL1426219 & 688282 & 5.0 & 5.2053 & TRN & \\
\hline CHEMBL1560269 & 688282 & 5.0 & 5.1516 & TRN & \\
\hline CHEMBL1519940 & 688282 & 5.0 & 5.11100 & 0000000001 & TRN \\
\hline CHEMBL1316647 & 688282 & 5.0 & 5.0343 & TRN & \\
\hline CHEMBL66998 & 688282 & 6.1 & 5.1008 & TRN & \\
\hline CHEMBL1578446 & 688282 & 5.0 & 5.1541 & TRN & \\
\hline CHEMBL1491104 & 688282 & 5.0 & 5.1288 & TRN & \\
\hline CHEMBL1612606 & 688282 & 5.1 & 5.1797 & TRN & \\
\hline CHEMBL1485835 & 688282 & 5.0 & 5.2037 & TRN & \\
\hline CHEMBL1385434 & 688282 & 5.3 & 5.1386 & TRN & \\
\hline CHEMBL1584661 & 688282 & 4.9 & 5.0346 & TRN & \\
\hline CHEMBL1518249 & 688282 & 4.5 & 5.2319 & TST & \\
\hline CHEMBL1386096 & 688282 & 5.0 & 5.279 & TST & \\
\hline CHEMBL1334282 & 688282 & 6.7001 & 5.1764 & TRN & \\
\hline CHEMBL1603418 & 688282 & 5.0 & 5.061 & TRN & \\
\hline CHEMBL1357076 & 688282 & 4.9 & 5.0752 & TRN & \\
\hline CHEMBL38832 & 688282 & 5.4 & 5.0724 & TST & \\
\hline CHEMBL1379362 & 688282 & 4.9 & 5.0902 & TRN & \\
\hline CHEMBL1396791 & 688282 & 6.1 & 5.1876 & TST & \\
\hline CHEMBL445206 & 688282 & 4.5 & 5.1482 & TRN & \\
\hline CHEMBL1488628 & 688282 & 4.9 & 5.1475 & TST & \\
\hline CHEMBL1313646 & 688282 & 4.8 & 5.2065 & TST & \\
\hline CHEMBL1431735 & 688282 & 4.6 & 5.0909 & TRN & \\
\hline CHEMBL1369340 & 688282 & 5.3 & 5.0456 & TRN & \\
\hline CHEMBL1524533 & 688282 & 5.8 & 5.1729 & TRN & \\
\hline CHEMBL1331980 & 688282 & 5.5 & 5.265 & TST & \\
\hline CHEMBL1868202 & 688282 & 4.9 & 5.1918 & TRN & \\
\hline CHEMBL1363056 & 688282 & 5.0 & 5.1179 & TRN & \\
\hline & & & & 13299 & \\
\hline
\end{tabular}




\begin{tabular}{|c|c|c|c|c|}
\hline & & & ient & al Ta \\
\hline CHEMBL1463982 & 688282 & 5.0 & 5.0367 & TRN \\
\hline CHEMBL1340480 & 688282 & 4.9 & 5.1831 & TRN \\
\hline CHEMBL1302340 & 688282 & 5.1 & 5.1729 & TRN \\
\hline CHEMBL1468529 & 688282 & 5.1 & 5.0984 & TRN \\
\hline CHEMBL1421207 & 688282 & 5.1 & 5.0694 & TRN \\
\hline CHEMBL1304227 & 688282 & 5.5 & 5.1443 & TRN \\
\hline CHEMBL1386806 & 688282 & 5.0 & 5.0296 & TRN \\
\hline CHEMBL1414783 & 688282 & 4.6 & 4.9851 & TRN \\
\hline CHEMBL1468653 & 688282 & 5.3 & 5.1158 & TRN \\
\hline CHEMBL1592549 & 688282 & 4.9 & 5.0465 & TRN \\
\hline CHEMBL1458953 & 688282 & 4.5 & 5.086 & TRN \\
\hline CHEMBL1319185 & 688282 & 5.0 & 5.1553 & TRN \\
\hline CHEMBL272005 & 688282 & 5.9 & 5.1241 & TRN \\
\hline CHEMBL1429397 & 688282 & 4.6 & 5.1302 & TRN \\
\hline CHEMBL1463380 & 688282 & 5.6 & 5.0884 & TRN \\
\hline CHEMBL1393129 & 688282 & 5.1 & 5.2128 & TST \\
\hline CHEMBL1487526 & 688282 & 4.9 & 5.0609 & TRN \\
\hline CHEMBL15766 & 688282 & 4.6 & 5.1324 & TST \\
\hline CHEMBL1503631 & 688282 & 6.2 & 5.0562 & TRN \\
\hline CHEMBL1324032 & 688282 & 5.8 & 5.1335 & TST \\
\hline CHEMBL1318544 & 688282 & 6.5 & 5.1282 & TRN \\
\hline CHEMBL1609226 & 688282 & 5.3 & 5.169 & TST \\
\hline CHEMBL1364030 & 688282 & 4.8 & 5.1547 & TST \\
\hline CHEMBL1336047 & 688282 & 4.9 & 5.1651 & TRN \\
\hline CHEMBL1305615 & 688282 & 5.3 & 5.1861 & TRN \\
\hline CHEMBL1368340 & 688282 & 4.6 & 5.1991 & TST \\
\hline CHEMBL1373547 & 688282 & 4.5 & 5.1484 & TRN \\
\hline CHEMBL1256775 & 688282 & 5.1 & 5.1712 & TRN \\
\hline CHEMBL1443125 & 688282 & 5.6 & 5.317 & TRN \\
\hline CHEMBL1319971 & 688282 & 4.9 & 5.1777 & TRN \\
\hline CHEMBL1546788 & 688282 & 5.3 & 5.1365 & TST \\
\hline CHEMBL1594058 & 688282 & 4.7 & 5.2364 & TRN \\
\hline CHEMBL288096 & 688282 & 5.1 & 5.2042 & TRN \\
\hline CHEMBL1542351 & 688282 & 4.6 & 5.102 & TRN \\
\hline CHEMBL1698217 & 688282 & 4.8 & 5.0655 & TRN \\
\hline CHEMBL1363832 & 688282 & 4.6 & 5.1551 & TST \\
\hline CHEMBL1327243 & 688282 & 4.9 & 5.2736 & TST \\
\hline CHEMBL1305911 & 688282 & 5.0 & 5.1563 & TRN \\
\hline CHEMBL1516632 & 688282 & 4.9 & 5.0702 & TRN \\
\hline CHEMBL1421115 & 688282 & 4.6 & 5.1729 & TRN \\
\hline CHEMBL1200450 & 688282 & 4.9 & 5.1945 & TST \\
\hline CHEMBL1468353 & 688282 & 4.9 & 5.1189 & TRN \\
\hline CHEMBL1579699 & 688282 & 5.3 & 5.0504 & TRN \\
\hline CHEMBL1317178 & 688282 & 4.9 & 5.1121 & TRN \\
\hline CHEMBL42013 & 688282 & 4.9 & 5.2673 & TST \\
\hline CHEMBL1332282 & 688282 & 5.3 & 4.9933 & TRN \\
\hline CHEMBL1437263 & 688282 & 5.0 & 4.9978 & TRN \\
\hline CHEMBL1577441 & 688282 & 4.9 & 5.2405 & TRN \\
\hline
\end{tabular}




\begin{tabular}{|c|c|c|c|c|}
\hline \multicolumn{5}{|c|}{ lemental T } \\
\hline CHEMBL1585567 & 688282 & 4.6 & 5.1374 & TRN \\
\hline CHEMBL1553218 & 688282 & 4.9 & 4.9728 & TRN \\
\hline CHEMBL1510323 & 688282 & 4.6 & 5.1756 & TRN \\
\hline CHEMBL1613591 & 688282 & 5.0 & 5.1641 & TRN \\
\hline CHEMBL1445622 & 688282 & 4.6 & 5.2351 & TRN \\
\hline CHEMBL1312087 & 688282 & 4.9 & 5.0991 & TRN \\
\hline CHEMBL1569160 & 688282 & 5.0 & 5.2336 & TRN \\
\hline CHEMBL533954 & 688282 & 5.4 & 5.0855 & TRN \\
\hline CHEMBL1314247 & 688282 & 4.9 & 5.1561 & TRN \\
\hline CHEMBL1367656 & 688282 & 5.5 & 5.1813 & TST \\
\hline CHEMBL1569484 & 688282 & 5.0 & 5.1302 & TRN \\
\hline CHEMBL1530439 & 688282 & 6.8 & 5.2559 & TRN \\
\hline CHEMBL1481914 & 688282 & 4.9 & 5.0876 & TRN \\
\hline CHEMBL1538538 & 688282 & 4.6 & 5.1754 & TRN \\
\hline CHEMBL1473021 & 688282 & 6.8 & 5.1412 & TRN \\
\hline CHEMBL1371787 & 688282 & 5.3 & 5.2087 & TRN \\
\hline CHEMBL1327681 & 688282 & 4.9 & 5.1647 & TRN \\
\hline CHEMBL1355970 & 688282 & 5.0 & 5.1113 & TRN \\
\hline CHEMBL1348083 & 688282 & 5.3 & 5.1166 & TRN \\
\hline CHEMBL1342162 & 688282 & 4.9 & 4.9434 & TRN \\
\hline CHEMBL1414774 & 688282 & 5.3 & 5.1259 & TST \\
\hline CHEMBL1402656 & 688282 & 5.1 & 5.1585 & TST \\
\hline CHEMBL1534577 & 688282 & 5.0 & 5.0109 & TRN \\
\hline CHEMBL1584479 & 688282 & 4.5 & 5.1479 & TRN \\
\hline CHEMBL1573112 & 688282 & 4.9 & 5.2171 & TRN \\
\hline CHEMBL1396203 & 688282 & 4.5 & 5.0418 & TRN \\
\hline CHEMBL1315184 & 688282 & 5.0 & 4.9533 & TRN \\
\hline CHEMBL1324137 & 688282 & 4.8 & 5.0136 & TRN \\
\hline CHEMBL1331913 & 688282 & 6.9 & 5.2521 & TRN \\
\hline CHEMBL1469865 & 688282 & 5.6 & 5.1648 & TRN \\
\hline CHEMBL1411292 & 688282 & 6.0 & 5.0343 & TRN \\
\hline CHEMBL1472753 & 688282 & 5.3 & 5.0186 & TRN \\
\hline CHEMBL1577767 & 688282 & 4.8 & 5.1123 & TRN \\
\hline CHEMBL1412477 & 688282 & 5.5 & 5.2255 & TRN \\
\hline CHEMBL1528479 & 688282 & 5.1 & 5.2208 & TRN \\
\hline CHEMBL1403748 & 688282 & 5.0 & 5.1092 & TRN \\
\hline CHEMBL1553700 & 688282 & 6.0 & 5.0685 & TRN \\
\hline CHEMBL1385176 & 688282 & 5.0 & 5.1239 & TRN \\
\hline CHEMBL337173 & 688282 & 4.8 & 5.1404 & TRN \\
\hline CHEMBL1486289 & 688282 & 5.3 & 5.2368 & TRN \\
\hline CHEMBL1352943 & 688282 & 4.6 & 5.2427 & TRN \\
\hline CHEMBL1523844 & 688282 & 4.9 & 5.0694 & TRN \\
\hline CHEMBL1396374 & 688282 & 4.9 & 5.0572 & TRN \\
\hline CHEMBL1590886 & 688282 & 4.9 & 5.1253 & TRN \\
\hline CHEMBL1429057 & 688282 & 6.0 & 5.1417 & TRN \\
\hline CHEMBL1345836 & 688282 & 5.3 & 5.2174 & TRN \\
\hline CHEMBL471225 & 688282 & 7.6003 & 5.1543 & TST \\
\hline CHEMBL1356721 & 688282 & 5.0 & 4.9343 & TRN \\
\hline
\end{tabular}




\begin{tabular}{|c|c|c|c|c|c|}
\hline \multirow[b]{2}{*}{ CHEMBL1447259 } & \\
\hline & 688282 & 4.9 & 5.0806 & TRN & \\
\hline CHEMBL1612381 & 688282 & 5.0 & 5.0921 & TRN & \\
\hline CHEMBL1609583 & 688282 & 4.9 & 5.2936 & TRN & \\
\hline CHEMBL1400296 & 688282 & 5.3 & 5.2826 & TST & \\
\hline CHEMBL1349978 & 688282 & 4.9 & 5.0606 & TRN & \\
\hline CHEMBL1479591 & 688282 & 4.9 & 5.1821 & TRN & \\
\hline CHEMBL1475642 & 688282 & 5.0 & 4.9861 & TRN & \\
\hline CHEMBL1450162 & 688282 & 7.6003 & 5.2718 & TRN & \\
\hline CHEMBL1537900 & 688282 & 5.0 & 5.0787 & TRN & \\
\hline CHEMBL1477870 & 688282 & 5.0 & 5.0259 & TRN & \\
\hline CHEMBL1319789 & 688282 & 4.6 & 5.1367 & TRN & \\
\hline CHEMBL1429245 & 688282 & 4.7 & 5.2252 & TRN & \\
\hline CHEMBL1332579 & 688282 & 7.0 & 5.3492 & TST & \\
\hline CHEMBL1532407 & 688282 & 5.0 & 5.2033 & TRN & \\
\hline CHEMBL1323204 & 688282 & 6.5 & 5.1505 & TRN & \\
\hline CHEMBL 20730 & 688282 & 4.9 & 5.3242 & TRN & \\
\hline CHEMBL1564004 & 688282 & 5.6 & 5.1559 & TRN & \\
\hline CHEMBL1581335 & 688282 & 5.0 & 5.1235 & TRN & \\
\hline CHEMBL1303734 & 688282 & 4.6 & 5.0355 & TRN & \\
\hline CHEMBL1413165 & 688282 & 6.3 & 5.1588 & TRN & \\
\hline CHEMBL1607420 & 688282 & 5.3 & 5.1691 & TRN & \\
\hline CHEMBL1997059 & 688282 & 5.0 & 5.1222 & TST & \\
\hline CHEMBL1582826 & 688282 & 5.0 & 5.1205 & TRN & \\
\hline CHEMBL1365672 & 688282 & 4.7 & 5.0322 & TRN & \\
\hline CHEMBL1361552 & 688282 & 5.0 & 5.16200 & 3000000001 & TRN \\
\hline CHEMBL1401753 & 688282 & 4.8 & 5.1459 & TRN & \\
\hline CHEMBL1436386 & 688282 & 6.1 & 5.1434 & TRN & \\
\hline CHEMBL1419108 & 688282 & 5.3 & 5.1671 & TST & \\
\hline CHEMBL1606371 & 688282 & 5.4 & 5.0585 & TRN & \\
\hline CHEMBL1588183 & 688282 & 4.9 & 4.9572 & TRN & \\
\hline CHEMBL1468593 & 688282 & 5.0 & 5.1004 & TRN & \\
\hline CHEMBL1609659 & 688282 & 4.9 & 5.1177 & TRN & \\
\hline CHEMBL1598091 & 688282 & 5.1 & 5.0891 & TRN & \\
\hline CHEMBL1446603 & 688282 & 5.3 & 5.1755 & TST & \\
\hline CHEMBL1318222 & 688282 & 5.6 & 5.1368 & TRN & \\
\hline CHEMBL1373388 & 688282 & 5.0 & 5.12299 & 9999999999 & TRN \\
\hline CHEMBL1565816 & 688282 & 5.3 & 5.2285 & TRN & \\
\hline CHEMBL1536497 & 688282 & 5.3 & 5.1009 & TRN & \\
\hline CHEMBL1508682 & 688282 & 4.9 & 5.0541 & TRN & \\
\hline CHEMBL1576851 & 688282 & 4.9 & 5.0223 & TRN & \\
\hline CHEMBL1607475 & 688282 & 4.9 & 5.0708 & TRN & \\
\hline CHEMBL1302713 & 688282 & 5.3 & 5.1866 & TRN & \\
\hline CHEMBL1518293 & 688282 & 5.0 & 5.1551 & TRN & \\
\hline CHEMBL1311319 & 688282 & 6.3 & 5.1431 & TST & \\
\hline CHEMBL1328576 & 688282 & 6.0 & 5.1924 & TST & \\
\hline CHEMBL1338601 & 688282 & 5.0 & 5.0575 & TRN & \\
\hline CHEMBL1429951 & 688282 & 4.9 & 5.1595 & TST & \\
\hline CHEMBL1407952 & 688282 & 5.9 & 5.1141 & TRN & \\
\hline & & & & 13302 & \\
\hline
\end{tabular}




\begin{tabular}{|c|c|c|c|c|}
\hline & & & pplemen & at \\
\hline CHEMBL1538088 & 688282 & 4.5 & 4.9701 & TRN \\
\hline CHEMBL1480712 & 688282 & 4.9 & 5.0876 & TRN \\
\hline CHEMBL1393762 & 688282 & 4.9 & 5.1072 & TRN \\
\hline CHEMBL1453019 & 688282 & 4.9 & 5.1176 & TRN \\
\hline CHEMBL1451878 & 688282 & 4.5 & 5.144 & TST \\
\hline CHEMBL1317244 & 688282 & 5.9 & 5.26 & TRN \\
\hline CHEMBL475198 & 688282 & 4.5 & 5.04 & TRN \\
\hline CHEMBL1398636 & 688282 & 5.3 & 5.215 & TST \\
\hline CHEMBL1582223 & 688282 & 5.3 & 5.113 & TRN \\
\hline CHEMBL1404781 & 688282 & 5.4 & 5.1466 & TRN \\
\hline CHEMBL1431235 & 688282 & 4.7 & 4.9639 & TRN \\
\hline CHEMBL1412724 & 688282 & 4.6 & 5.1431 & TRN \\
\hline CHEMBL1605768 & 688282 & 5.0 & 5.1089 & TRN \\
\hline CHEMBL1363895 & 688282 & 4.5 & 5.1212 & TRN \\
\hline CHEMBL1494087 & 688282 & 4.9 & 5.1212 & TRN \\
\hline CHEMBL1326434 & 688282 & 5.5 & 5.2251 & TRN \\
\hline CHEMBL1579264 & 688282 & 5.3 & 5.1385 & TRN \\
\hline CHEMBL1410374 & 688282 & 4.8 & 5.0811 & TRN \\
\hline CHEMBL1354272 & 688282 & 4.6 & 5.2125 & TRN \\
\hline CHEMBL145 & 688282 & 4.9 & 5.3026 & TRN \\
\hline CHEMBL1364090 & 688282 & 5.3 & 5.2105 & TRN \\
\hline CHEMBL1540099 & 688282 & 7.0 & 5.189 & TRN \\
\hline CHEMBL1429381 & 688282 & 5.3 & 5.0604 & TRN \\
\hline CHEMBL1370789 & 688282 & 4.6 & 5.2792 & TRN \\
\hline CHEMBL1534168 & 688282 & 5.4 & 4.9691 & TRN \\
\hline CHEMBL1465439 & 688282 & 4.5 & 5.1562 & TRN \\
\hline CHEMBL1331754 & 688282 & 7.1002 & 5.1232 & TST \\
\hline CHEMBL1429901 & 688282 & 4.6 & 5.1154 & TRN \\
\hline CHEMBL1542833 & 688282 & 5.7 & 5.0243 & TRN \\
\hline CHEMBL1323550 & 688282 & 4.5 & 4.9558 & TRN \\
\hline CHEMBL1603491 & 688282 & 5.0 & 5.1125 & TRN \\
\hline CHEMBL1466790 & 688282 & 5.3 & 5.1296 & TST \\
\hline CHEMBL1303634 & 688282 & 5.0 & 5.0762 & TRN \\
\hline CHEMBL317757 & 688282 & 5.0 & 5.2137 & TRN \\
\hline CHEMBL1593545 & 688282 & 5.0 & 5.1111 & TRN \\
\hline CHEMBL1499886 & 688282 & 4.8 & 5.1761 & TRN \\
\hline CHEMBL1402807 & 688282 & 4.7 & 4.9985 & TRN \\
\hline CHEMBL1437138 & 688282 & 4.8 & 5.195 & TRN \\
\hline CHEMBL3198121 & 688282 & 5.2 & 5.1476 & TRN \\
\hline CHEMBL1363762 & 688282 & 4.9 & 5.0753 & TRN \\
\hline CHEMBL1384728 & 688282 & 4.8 & 5.0858 & TRN \\
\hline CHEMBL1375431 & 688282 & 5.6 & 5.1384 & TRN \\
\hline CHEMBL1374546 & 688282 & 4.6 & 5.1887 & TRN \\
\hline CHEMBL1434833 & 688282 & 4.9 & 5.1112 & TRN \\
\hline CHEMBL1409369 & 688282 & 5.0 & 5.0452 & TRN \\
\hline CHEMBL1323237 & 688282 & 4.9 & 5.1387 & TRN \\
\hline CHEMBL1409408 & 688282 & 4.9 & 5.1353 & TRN \\
\hline CHEMBL1326619 & 688282 & 6.0 & 5.2813 & TST \\
\hline
\end{tabular}




\begin{tabular}{|c|c|c|c|c|c|}
\hline \multicolumn{6}{|c|}{ Supplemental Table S2.txt } \\
\hline CHEMBL1436716 & 688282 & 5.7 & 5.2631 & TRN & \\
\hline CHEMBL1343702 & 688282 & 4.5 & 5.1847 & TRN & \\
\hline CHEMBL1611004 & 688282 & 4.9 & 5.0688 & TRN & \\
\hline CHEMBL1527443 & 688282 & 4.9 & 5.1111 & TRN & \\
\hline CHEMBL1473925 & 688282 & 5.3 & 5.2108 & TRN & \\
\hline CHEMBL1483801 & 688282 & 5.3 & 5.1119 & TST & \\
\hline CHEMBL1349215 & 688282 & 4.9 & 5.1877 & TRN & \\
\hline CHEMBL1451833 & 688282 & 4.9 & 5.358 & TST & \\
\hline CHEMBL1591459 & 688282 & 4.5 & 5.0409 & TRN & \\
\hline CHEMBL1307495 & 688282 & 5.0 & 5.086 & TRN & \\
\hline CHEMBL1454587 & 688282 & 4.9 & 5.1321 & TRN & \\
\hline CHEMBL1343258 & 688282 & 6.2 & 5.0828 & TRN & \\
\hline CHEMBL1549469 & 688282 & 4.8 & 5.0625 & TRN & \\
\hline CHEMBL1559267 & 688282 & 4.9 & 5.1201 & TRN & \\
\hline CHEMBL1328553 & 688282 & 4.9 & 5.0808 & TST & \\
\hline CHEMBL1467886 & 688282 & 5.7 & 5.2228 & TRN & \\
\hline CHEMBL1369497 & 688282 & 4.9 & 5.0842 & TRN & \\
\hline CHEMBL 306764 & 688282 & 5.6 & 5.1834 & TRN & \\
\hline CHEMBL1391214 & 688282 & 5.0 & 5.0892 & TRN & \\
\hline CHEMBL1334465 & 688282 & 4.8 & 5.1275 & TST & \\
\hline CHEMBL1493496 & 688282 & 5.0 & 5.1363 & TRN & \\
\hline CHEMBL1345809 & 688282 & 5.3 & 5.2899 & TST & \\
\hline CHEMBL 1487880 & 688282 & 5.3 & 5.1345 & TRN & \\
\hline CHEMBL1435889 & 688282 & 4.9 & 5.0593 & TRN & \\
\hline CHEMBL1325061 & 688282 & 5.0 & 5.0521 & TRN & \\
\hline CHEMBL1383746 & 688282 & 5.0 & 5.1979 & TRN & \\
\hline CHEMBL1367226 & 688282 & 4.6 & 5.0574 & TRN & \\
\hline CHEMBL1584692 & 688282 & 4.5 & 5.2796 & TST & \\
\hline CHEMBL1390307 & 688282 & 4.9 & $5.1770 e$ & 00000000005 & TRN \\
\hline CHEMBL566064 & 688282 & 5.3 & 5.0883 & TRN & \\
\hline CHEMBL1488104 & 688282 & 5.0 & 5.0405 & TRN & \\
\hline CHEMBL1595111 & 688282 & 7.2 & 5.2008 & TRN & \\
\hline CHEMBL1396583 & 688282 & 6.9 & 5.2893 & TRN & \\
\hline CHEMBL1457765 & 688282 & 4.9 & 5.1653 & TRN & \\
\hline CHEMBL1578674 & 688282 & 5.5 & 5.0657 & TST & \\
\hline CHEMBL1445335 & 688282 & 5.0 & 5.1102 & TRN & \\
\hline CHEMBL1512317 & 688282 & 5.3 & 5.1823 & TRN & \\
\hline CHEMBL1340774 & 688282 & 5.8 & 4.9917 & TRN & \\
\hline CHEMBL1585014 & 688282 & 5.1 & 4.9712 & TRN & \\
\hline CHEMBL1569896 & 688282 & 4.6 & 5.1216 & TRN & \\
\hline CHEMBL1563507 & 688282 & 4.5 & 5.055 & TRN & \\
\hline CHEMBL1323569 & 688282 & 5.4 & 5.1415 & TRN & \\
\hline CHEMBL1407524 & 688282 & 5.8 & 5.146 & TRN & \\
\hline CHEMBL 2374027 & 688282 & 4.9 & 5.2021 & TST & \\
\hline CHEMBL1402893 & 688282 & 5.0 & 5.1124 & TRN & \\
\hline CHEMBL1506225 & 688282 & 6.1 & 5.2508 & TRN & \\
\hline CHEMBL1544093 & 688282 & 4.8 & 5.1191 & TRN & \\
\hline CHEMBL1593547 & 688282 & 7.699 & 5.0997 & TRN & \\
\hline
\end{tabular}




\begin{tabular}{|c|c|c|c|c|c|}
\hline \multicolumn{6}{|c|}{ Supplemental Table S2.txt } \\
\hline CHEMBL1469282 & 688282 & 5.4 & 5.1588 & TRN & \\
\hline CHEMBL1387428 & 688282 & 4.8 & 5.2251 & TST & \\
\hline CHEMBL136906 & 688282 & 6.3 & 5.1893 & TST & \\
\hline CHEMBL1485269 & 688282 & 5.3 & 5.2695 & TRN & \\
\hline CHEMBL1491675 & 688282 & 5.3 & 5.2454 & TST & \\
\hline CHEMBL1414269 & 688282 & 4.8 & 5.1717 & TRN & \\
\hline CHEMBL1517264 & 688282 & 5.2 & 5.0655 & TRN & \\
\hline CHEMBL1375046 & 688282 & 4.9 & 4.9859 & TRN & \\
\hline CHEMBL1301295 & 688282 & 5.3 & 5.042 & TRN & \\
\hline CHEMBL1541834 & 688282 & 5.1 & 5.1473 & TRN & \\
\hline CHEMBL1476227 & 688282 & 7.6003 & 5.2987 & TRN & \\
\hline CHEMBL1379111 & 688282 & 5.3 & 5.1644 & TRN & \\
\hline CHEMBL1331573 & 688282 & 5.4 & 5.0967 & TST & \\
\hline CHEMBL1583586 & 688282 & 4.6 & 5.1408 & TRN & \\
\hline CHEMBL1318083 & 688282 & 5.0 & 5.0814 & TRN & \\
\hline CHEMBL1336174 & 688282 & 5.3 & 5.1339 & TST & \\
\hline CHEMBL1529518 & 688282 & 5.3 & 5.1144 & TRN & \\
\hline CHEMBL1444568 & 688282 & 5.5 & 5.0605 & TRN & \\
\hline CHEMBL1343147 & 688282 & 5.6 & 5.244 & TST & \\
\hline CHEMBL402063 & 688282 & 4.5 & 5.3002 & TST & \\
\hline CHEMBL1340418 & 688282 & 4.9 & 5.0468 & TRN & \\
\hline CHEMBL1611118 & 688282 & 4.9 & 5.0769 & TRN & \\
\hline CHEMBL1419096 & 688282 & 6.4 & 5.0842 & TRN & \\
\hline CHEMBL1583580 & 688282 & 7.8996 & 5.1597 & TRN & \\
\hline CHEMBL1586964 & 688282 & 4.5 & 4.9782 & TRN & \\
\hline CHEMBL299155 & 688282 & 4.9 & 5.2901 & TST & \\
\hline CHEMBL375107 & 688282 & 4.8 & 5.2604 & TST & \\
\hline CHEMBL1394469 & 688282 & 4.9 & 5.1768 & TRN & \\
\hline CHEMBL1305970 & 688282 & 4.6 & 5.0741 & TRN & \\
\hline CHEMBL1534381 & 688282 & 5.0 & 5.1795 & TST & \\
\hline CHEMBL1331486 & 688282 & 4.7 & 5.1882 & TRN & \\
\hline CHEMBL1445714 & 688282 & 5.4 & 5.0426 & TRN & \\
\hline CHEMBL1424486 & 688282 & 5.1 & 5.16799 & 9999999999 & TRN \\
\hline CHEMBL1525659 & 688282 & 5.6 & 5.1067 & TRN & \\
\hline CHEMBL1370379 & 688282 & 4.9 & 5.2097 & TRN & \\
\hline CHEMBL1526979 & 688282 & 5.8 & 5.086 & TRN & \\
\hline CHEMBL1460498 & 688282 & 4.6 & 5.2739 & TRN & \\
\hline CHEMBL1319229 & 688282 & 5.4 & 5.0934 & TRN & \\
\hline CHEMBL1477887 & 688282 & 4.9 & 5.2148 & TRN & \\
\hline CHEMBL1486368 & 688282 & 4.8 & 5.1778 & TRN & \\
\hline CHEMBL1565171 & 688282 & 4.9 & 5.1893 & TRN & \\
\hline CHEMBL1431830 & 688282 & 5.3 & 5.2301 & TRN & \\
\hline CHEMBL1522897 & 688282 & 5.5 & 5.1018 & TRN & \\
\hline CHEMBL1374573 & 688282 & 4.7 & 5.1202 & TRN & \\
\hline CHEMBL1399181 & 688282 & 5.0 & 5.0349 & TRN & \\
\hline CHEMBL3193888 & 688282 & 5.5 & 5.2221 & TRN & \\
\hline CHEMBL1430823 & 688282 & 4.5 & 4.9198 & TRN & \\
\hline CHEMBL1518118 & 688282 & 6.2 & 5.2493 & TRN & \\
\hline
\end{tabular}




\begin{tabular}{|c|c|c|c|c|}
\hline \multicolumn{5}{|c|}{ Supplemental Table S2.txt } \\
\hline CHEMBL1312163 & 688282 & 4.9 & 5.1224 & TRN \\
\hline CHEMBL1316447 & 688282 & 4.9 & 5.1131 & TRN \\
\hline CHEMBL1532597 & 688282 & 4.9 & 5.1733 & TRN \\
\hline CHEMBL1585944 & 688282 & 4.9 & 5.2326 & TST \\
\hline CHEMBL1544932 & 688282 & 4.6 & 5.2332 & TRN \\
\hline CHEMBL1328324 & 688282 & 4.6 & 5.2227 & TST \\
\hline CHEMBL1372302 & 688282 & 4.5 & 5.2059 & TST \\
\hline CHEMBL1488918 & 688282 & 5.3 & 5.1288 & TRN \\
\hline CHEMBL1329850 & 688282 & 4.6 & 5.2191 & TRN \\
\hline CHEMBL1364051 & 688282 & 4.6 & 5.0482 & TRN \\
\hline CHEMBL 1400050 & 688282 & 4.6 & 5.1319 & TRN \\
\hline CHEMBL1607464 & 688282 & 4.9 & 5.1586 & TST \\
\hline CHEMBL1575830 & 688282 & 4.9 & 5.1795 & TRN \\
\hline CHEMBL1513578 & 688282 & 5.0 & 5.1258 & TRN \\
\hline CHEMBL1519798 & 688282 & 5.4 & 5.0837 & TRN \\
\hline CHEMBL1453083 & 688282 & 5.1 & 5.1633 & TRN \\
\hline CHEMBL221137 & 688282 & 6.0 & 5.2059 & TRN \\
\hline CHEMBL1603655 & 688282 & 5.3 & 5.1338 & TRN \\
\hline CHEMBL1462722 & 688282 & 4.5 & 5.1607 & TRN \\
\hline CHEMBL 32142 & 688282 & 5.4 & 5.33799 & 9999999999 \\
\hline CHEMBL1521813 & 688282 & 8.3979 & 5.1599 & TRN \\
\hline CHEMBL182310 & 688282 & 4.5 & 5.3279 & TST \\
\hline CHEMBL428768 & 688282 & 5.6 & 5.1006 & TRN \\
\hline CHEMBL1603975 & 688282 & 4.9 & 5.0913 & TRN \\
\hline CHEMBL1412168 & 688282 & 5.4 & 5.0501 & TRN \\
\hline CHEMBL1319604 & 688282 & 5.0 & 5.0749 & TRN \\
\hline CHEMBL516075 & 688282 & 4.9 & 4.967 & TRN \\
\hline CHEMBL1300301 & 688282 & 5.0 & 5.0533 & TRN \\
\hline CHEMBL1407590 & 688282 & 5.4 & 5.2922 & TRN \\
\hline CHEMBL 1577952 & 688282 & 5.0 & 5.0518 & TRN \\
\hline CHEMBL1399561 & 688282 & 6.2 & 5.0481 & TRN \\
\hline CHEMBL1371175 & 688282 & 4.7 & 5.0385 & TRN \\
\hline CHEMBL1488028 & 688282 & 5.0 & 5.1472 & TRN \\
\hline CHEMBL1575725 & 688282 & 5.1 & 5.0651 & TRN \\
\hline CHEMBL 1456745 & 688282 & 5.0 & 5.265 & TRN \\
\hline CHEMBL1447004 & 688282 & 5.1 & 5.1814 & TRN \\
\hline CHEMBL1606278 & 688282 & 4.6 & 5.0542 & TRN \\
\hline CHEMBL1411578 & 688282 & 5.0 & 5.1107 & TST \\
\hline CHEMBL 75913 & 688282 & 4.6 & 5.1039 & TST \\
\hline CHEMBL1569358 & 688282 & 4.8 & 5.2298 & TRN \\
\hline CHEMBL1587578 & 688282 & 4.8 & 5.2098 & TRN \\
\hline CHEMBL1468996 & 688282 & 5.0 & 5.0924 & TRN \\
\hline CHEMBL1429106 & 688282 & 5.3 & 5.1588 & TST \\
\hline CHEMBL1544460 & 688282 & 5.1 & 5.1977 & TRN \\
\hline CHEMBL1311050 & 688282 & 5.0 & 5.2422 & TRN \\
\hline CHEMBL1487454 & 688282 & 4.5 & 5.0728 & TRN \\
\hline CHEMBL1400290 & 688282 & 5.4 & 5.093 & TRN \\
\hline CHEMBL1566704 & 688282 & 5.0 & 5.1445 & TRN \\
\hline
\end{tabular}




\begin{tabular}{|c|c|c|c|c|c|}
\hline & & & & & \\
\hline CHEMBL1367620 & 688282 & 4.9 & 5.1879 & TST & \\
\hline CHEMBL1476139 & 688282 & 5.0 & 5.1972 & TRN & \\
\hline CHEMBL1349721 & 688282 & 5.0 & 5.1892 & TRN & \\
\hline CHEMBL1593589 & 688282 & 5.1 & 5.28 & TRN & \\
\hline CHEMBL1299672 & 688282 & 5.2 & 5.0705 & TRN & \\
\hline CHEMBL1364622 & 688282 & 5.3 & 5.2692 & TRN & \\
\hline CHEMBL1470593 & 688282 & 4.9 & 5.135 & TRN & \\
\hline CHEMBL1433742 & 688282 & 5.3 & $5.2810 e$ & 0000000001 & TRN \\
\hline CHEMBL1470718 & 688282 & 5.5 & 5.1518 & TRN & \\
\hline CHEMBL1553797 & 688282 & 5.3 & 5.2503 & TRN & \\
\hline CHEMBL1513174 & 688282 & 4.9 & 5.1647 & TRN & \\
\hline CHEMBL1356292 & 688282 & 5.6 & 5.1787 & TST & \\
\hline CHEMBL1464928 & 688282 & 5.0 & 5.141 & TRN & \\
\hline CHEMBL1462011 & 688282 & 5.0 & 5.1184 & TRN & \\
\hline CHEMBL576997 & 688282 & 4.9 & 5.0673 & TST & \\
\hline CHEMBL393417 & 688282 & 4.7 & 5.1063 & TST & \\
\hline CHEMBL1593661 & 688282 & 5.5 & 5.0277 & TRN & \\
\hline CHEMBL1550293 & 688282 & 6.0 & 5.0808 & TRN & \\
\hline CHEMBL1476021 & 688282 & 5.7 & $5.0360 e$ & 20000000005 & TRN \\
\hline CHEMBL1441224 & 688282 & 5.6 & 5.1024 & TRN & \\
\hline CHEMBL1325377 & 688282 & 6.0 & 5.1048 & TRN & \\
\hline CHEMBL1366480 & 688282 & 6.0 & 5.3266 & TRN & \\
\hline CHEMBL1606330 & 688282 & 4.6 & 5.2293 & TRN & \\
\hline CHEMBL1558538 & 688282 & 5.0 & 5.1321 & TRN & \\
\hline CHEMBL1549969 & 688282 & 5.0 & 5.0104 & TRN & \\
\hline CHEMBL1415132 & 688282 & 5.5 & 5.1706 & TRN & \\
\hline CHEMBL1475686 & 688282 & 5.8 & 4.9856 & TRN & \\
\hline CHEMBL3194719 & 688282 & 5.5 & 5.1555 & TST & \\
\hline CHEMBL1599850 & 688282 & 4.6 & 5.1674 & TRN & \\
\hline CHEMBL1546431 & 688282 & 5.0 & 5.1042 & TRN & \\
\hline CHEMBL1472705 & 688282 & 5.1 & 5.1169 & TRN & \\
\hline CHEMBL1455957 & 688282 & 5.0 & 5.2119 & TST & \\
\hline CHEMBL 2373602 & 688282 & 4.6 & 5.2103 & TST & \\
\hline CHEMBL1409718 & 688282 & 4.5 & 5.1575 & TRN & \\
\hline CHEMBL167667 & 688282 & 4.5 & 5.2682 & TST & \\
\hline CHEMBL1462977 & 688282 & 4.7 & 5.0216 & TRN & \\
\hline CHEMBL1386171 & 688282 & 5.0 & 5.0259 & TRN & \\
\hline CHEMBL1396384 & 688282 & 4.9 & 5.1205 & TRN & \\
\hline CHEMBL1477383 & 688282 & 5.3 & 5.1436 & TST & \\
\hline CHEMBL1586800 & 688282 & 5.0 & 5.0262 & TRN & \\
\hline CHEMBL1437090 & 688282 & 4.5 & 5.235 & TST & \\
\hline CHEMBL1609274 & 688282 & 5.3 & 5.1801 & TRN & \\
\hline CHEMBL1304981 & 688282 & 5.5 & 5.2878 & TST & \\
\hline CHEMBL1526068 & 688282 & 4.6 & 5.1151 & TRN & \\
\hline CHEMBL299613 & 688282 & 4.9 & 5.1906 & TRN & \\
\hline CHEMBL608699 & 688282 & 6.5 & 5.2238 & TRN & \\
\hline CHEMBL1464905 & 688282 & 5.3 & 5.1734 & TRN & \\
\hline CHEMBL1460192 & 688282 & 5.8 & 5.1892 & TST & \\
\hline & & & & 13307 & \\
\hline
\end{tabular}




\begin{tabular}{|c|c|c|c|c|}
\hline \multicolumn{5}{|c|}{ Supplemental Table S2.txt } \\
\hline CHEMBL1541030 & 688282 & 4.8 & 5.023 & TRN \\
\hline CHEMBL1379697 & 688282 & 5.3 & 5.0595 & TRN \\
\hline CHEMBL1549188 & 688282 & 5.3 & 5.1043 & TRN \\
\hline CHEMBL1420867 & 688282 & 4.9 & 4.9525 & TRN \\
\hline CHEMBL1319389 & 688282 & 4.6 & 5.1145 & TRN \\
\hline CHEMBL1477224 & 688282 & 6.1 & 5.2144 & TRN \\
\hline CHEMBL1368860 & 688282 & 6.0 & 5.2183 & TRN \\
\hline CHEMBL1597158 & 688282 & 5.4 & 5.0983 & TRN \\
\hline CHEMBL1350141 & 688282 & 4.9 & 5.0655 & TRN \\
\hline CHEMBL1522459 & 688282 & 5.9 & 5.2646 & TRN \\
\hline CHEMBL1408351 & 688282 & 4.7 & 5.1335 & TRN \\
\hline CHEMBL1323561 & 688282 & 5.3 & 5.1412 & TRN \\
\hline CHEMBL1479951 & 688282 & 4.9 & 5.1472 & TRN \\
\hline CHEMBL1398910 & 688282 & 4.5 & 5.0438 & TRN \\
\hline CHEMBL1369215 & 688282 & 6.3 & 5.3084 & TST \\
\hline CHEMBL1593998 & 688282 & 4.6 & 5.2097 & TRN \\
\hline CHEMBL1602759 & 688282 & 5.4 & 5.2493 & TRN \\
\hline CHEMBL 3207743 & 688282 & 4.7 & 5.2699 & TST \\
\hline CHEMBL1243269 & 688282 & 4.9 & 5.1953 & TST \\
\hline CHEMBL1357167 & 688282 & 4.9 & 4.9767 & TRN \\
\hline CHEMBL1270169 & 688282 & 5.4 & 5.2869 & TRN \\
\hline CHEMBL1389389 & 688282 & 5.4 & 5.1797 & TRN \\
\hline CHEMBL1593153 & 688282 & 4.9 & 4.9735 & TRN \\
\hline CHEMBL1347687 & 688282 & 5.0 & 5.131 & TRN \\
\hline CHEMBL1317767 & 688282 & 6.2 & 5.2999 & TRN \\
\hline CHEMBL 244707 & 688282 & 5.4 & 5.2527 & TRN \\
\hline CHEMBL1394348 & 688282 & 4.9 & 5.1782 & TRN \\
\hline CHEMBL1528147 & 688282 & 5.3 & 5.1716 & TRN \\
\hline CHEMBL1548756 & 688282 & 4.7 & 5.1373 & TRN \\
\hline CHEMBL1472411 & 688282 & 4.7 & 5.1326 & TST \\
\hline CHEMBL1327707 & 688282 & 4.9 & 5.1289 & TRN \\
\hline CHEMBL3208767 & 688282 & 4.7 & 5.0959 & TST \\
\hline CHEMBL1411209 & 688282 & 5.4 & 5.1392 & TRN \\
\hline CHEMBL1410321 & 688282 & 4.9 & 5.0993 & TRN \\
\hline CHEMBL1487321 & 688282 & 5.9 & 4.9917 & TRN \\
\hline CHEMBL1361543 & 688282 & 6.2 & 5.3022 & TRN \\
\hline CHEMBL1313013 & 688282 & 4.7 & 5.0882 & TRN \\
\hline CHEMBL1556277 & 688282 & 4.9 & 5.164 & TRN \\
\hline CHEMBL1476640 & 688282 & 5.3 & 5.2015 & TRN \\
\hline CHEMBL1539584 & 688282 & 4.5 & 5.113 & TRN \\
\hline CHEMBL1585929 & 688282 & 5.3 & 5.0886 & TRN \\
\hline CHEMBL1446363 & 688282 & 5.0 & 5.0115 & TRN \\
\hline CHEMBL1382837 & 688282 & 4.6 & 5.209 & TRN \\
\hline CHEMBL1327766 & 688282 & 5.5 & 4.9834 & TRN \\
\hline CHEMBL1309118 & 688282 & 4.6 & 5.0958 & TRN \\
\hline CHEMBL1310517 & 688282 & 5.0 & 5.0846 & TRN \\
\hline CHEMBL1361000 & 688282 & 5.3 & 5.2784 & TRN \\
\hline CHEMBL1374108 & 688282 & 7.4001 & 5.2447 & TRN \\
\hline
\end{tabular}




\begin{tabular}{|c|c|c|c|c|}
\hline \multicolumn{5}{|c|}{ Supplemental Table S2.txt } \\
\hline CHEMBL1567437 & 688282 & 4.6 & 5.1018 & TRN \\
\hline CHEMBL1450521 & 688282 & 7.4001 & 4.9894 & TRN \\
\hline CHEMBL1311328 & 688282 & 4.5 & 5.0342 & TRN \\
\hline CHEMBL1463630 & 688282 & 5.8 & 5.1428 & TRN \\
\hline CHEMBL1537739 & 688282 & 5.6 & 5.0297 & TRN \\
\hline CHEMBL1322929 & 688282 & 4.7 & 5.1757 & TRN \\
\hline CHEMBL1315618 & 688282 & 6.5 & 5.2086 & TST \\
\hline CHEMBL1595870 & 688282 & 4.5 & 5.0923 & TRN \\
\hline CHEMBL1403488 & 688282 & 5.6 & 5.1579 & TRN \\
\hline CHEMBL1602710 & 688282 & 5.3 & 5.2436 & TRN \\
\hline CHEMBL1562116 & 688282 & 4.6 & 5.1149 & TRN \\
\hline CHEMBL1206126 & 688282 & 4.5 & 5.1187 & TST \\
\hline CHEMBL1392191 & 688282 & 4.5 & 5.2042 & TRN \\
\hline CHEMBL1401735 & 688282 & 4.6 & 5.1454 & TRN \\
\hline CHEMBL1436054 & 688282 & 4.9 & 5.1528 & TRN \\
\hline CHEMBL441282 & 688282 & 4.8 & 5.1753 & TRN \\
\hline CHEMBL597035 & 688282 & 4.5 & 5.0783 & TRN \\
\hline CHEMBL1553990 & 688282 & 5.3 & 5.077 & TRN \\
\hline CHEMBL1533629 & 688282 & 5.5 & 5.2385 & TRN \\
\hline CHEMBL1396742 & 688282 & 5.7 & 5.1718 & TRN \\
\hline CHEMBL1484980 & 688282 & 5.5 & 5.0475 & TRN \\
\hline CHEMBL1448138 & 688282 & 5.0 & 5.1962 & TRN \\
\hline CHEMBL1575123 & 688282 & 5.6 & 5.1042 & TRN \\
\hline CHEMBL1190214 & 688282 & 5.5 & 5.2099 & TST \\
\hline CHEMBL1483640 & 688282 & 5.6 & 5.0774 & TRN \\
\hline CHEMBL1333531 & 688282 & 4.6 & 5.2571 & TRN \\
\hline CHEMBL1388653 & 688282 & 4.6 & 5.0758 & TRN \\
\hline CHEMBL1452066 & 688282 & 5.3 & 5.1784 & TRN \\
\hline CHEMBL1377119 & 688282 & 5.0 & 5.2036 & TRN \\
\hline CHEMBL1407196 & 688282 & 4.9 & 5.1431 & TRN \\
\hline CHEMBL1516925 & 688282 & 5.1 & 5.0777 & TRN \\
\hline CHEMBL1447439 & 688282 & 5.0 & 5.0526 & TRN \\
\hline CHEMBL1490209 & 688282 & 4.9 & 5.1069 & TST \\
\hline CHEMBL1361422 & 688282 & 4.8 & 5.2235 & TRN \\
\hline CHEMBL1421059 & 688282 & 4.9 & 5.0611 & TRN \\
\hline CHEMBL1613454 & 688282 & 4.6 & 5.2163 & TRN \\
\hline CHEMBL1344297 & 688282 & 5.0 & 5.2656 & TRN \\
\hline CHEMBL1590909 & 688282 & 4.9 & 4.9613 & TRN \\
\hline CHEMBL1443425 & 688282 & 5.0 & 5.1313 & TRN \\
\hline CHEMBL328710 & 688282 & 6.0 & 5.3189 & TRN \\
\hline CHEMBL1568854 & 688282 & 4.5 & 4.9689 & TRN \\
\hline CHEMBL137743 & 688282 & 4.5 & 5.2201 & TRN \\
\hline CHEMBL1546420 & 688282 & 4.6 & 5.0997 & TRN \\
\hline CHEMBL1356764 & 688282 & 5.9 & 5.3318 & TRN \\
\hline CHEMBL1515324 & 688282 & 5.0 & 5.3011 & TRN \\
\hline CHEMBL1358654 & 688282 & 5.4 & 5.1223 & TRN \\
\hline CHEMBL1439280 & 688282 & 5.7 & 5.29200 & 0000000001 \\
\hline CHEMBL1383147 & 688282 & 5.0 & 5.084 & TRN \\
\hline
\end{tabular}

TRN 


\begin{tabular}{|c|c|c|c|c|c|}
\hline \\
\hline CHEMBL1457187 & 688282 & 5.0 & 5.1454 & TRN & \\
\hline CHEMBL1544061 & 688282 & 5.3 & 5.1979 & TRN & \\
\hline CHEMBL1562591 & 688282 & 4.8 & 5.1504 & TST & \\
\hline CHEMBL1371504 & 688282 & 7.6003 & 5.1612 & TRN & \\
\hline CHEMBL352396 & 688282 & 4.5 & 5.1716 & TST & \\
\hline CHEMBL1613338 & 688282 & 5.0 & 5.0785 & TRN & \\
\hline CHEMBL254348 & 688282 & 4.5 & 5.2363 & TRN & \\
\hline CHEMBL1329108 & 688282 & 7.6003 & 5.1302 & TRN & \\
\hline CHEMBL1438688 & 688282 & 5.0 & 4.9262 & TRN & \\
\hline CHEMBL1079460 & 688282 & 5.0 & 5.1544 & TST & \\
\hline CHEMBL1426337 & 688282 & 4.5 & 5.1536 & TRN & \\
\hline CHEMBL1411473 & 688282 & 5.1 & 5.1508 & TRN & \\
\hline CHEMBL1516331 & 688282 & 5.0 & 5.1246 & TRN & \\
\hline CHEMBL1327670 & 688282 & 5.2 & 5.1384 & TRN & \\
\hline CHEMBL1487017 & 688282 & 4.7 & 5.1849 & TRN & \\
\hline CHEMBL1556831 & 688282 & 4.5 & 5.126 & TST & \\
\hline CHEMBL1572253 & 688282 & 4.6 & 5.154 & TRN & \\
\hline CHEMBL1568406 & 688282 & 4.6 & 5.0164 & TRN & \\
\hline CHEMBL1332244 & 688282 & 4.9 & 5.1586 & TRN & \\
\hline CHEMBL1511500 & 688282 & 4.6 & 5.0813 & TRN & \\
\hline CHEMBL1534995 & 688282 & 5.3 & 5.1904 & TRN & \\
\hline CHEMBL1369930 & 688282 & 6.3 & 5.2521 & TRN & \\
\hline CHEMBL1991908 & 688282 & 5.0 & 5.0434 & TRN & \\
\hline CHEMBL1428914 & 688282 & 5.4 & 5.2316 & TRN & \\
\hline CHEMBL1427394 & 688282 & 5.3 & 5.063 & TRN & \\
\hline CHEMBL1575869 & 688282 & 5.0 & 5.0843 & TRN & \\
\hline CHEMBL1419263 & 688282 & 5.0 & 5.0885 & TRN & \\
\hline CHEMBL1515635 & 688282 & 5.0 & 5.1657 & TRN & \\
\hline CHEMBL1376158 & 688282 & 5.3 & 5.1654 & TRN & \\
\hline CHEMBL1361264 & 688282 & 5.3 & 5.1435 & TRN & \\
\hline CHEMBL1337691 & 688282 & 5.4 & 5.17399 & 99999999995 & TRN \\
\hline CHEMBL1460674 & 688282 & 5.0 & 5.2095 & TRN & \\
\hline CHEMBL1562453 & 688282 & 5.5 & 5.0283 & TRN & \\
\hline CHEMBL1587655 & 688282 & 5.5 & 5.1153 & TRN & \\
\hline CHEMBL1605965 & 688282 & 5.0 & 5.21 & TRN & \\
\hline CHEMBL1572834 & 688282 & 5.2 & 5.1658 & TRN & \\
\hline CHEMBL1319827 & 688282 & 5.3 & 5.1261 & TRN & \\
\hline CHEMBL1450097 & 688282 & 5.2 & 4.9622 & TRN & \\
\hline CHEMBL1586300 & 688282 & 5.0 & 5.159 & TRN & \\
\hline CHEMBL1451209 & 688282 & 5.4 & 5.00899 & 99999999995 & TRN \\
\hline CHEMBL1328771 & 688282 & 4.8 & 5.1409 & TRN & \\
\hline CHEMBL1535520 & 688282 & 5.0 & 5.066 & TRN & \\
\hline CHEMBL1588229 & 688282 & 5.0 & 5.164 & TRN & \\
\hline CHEMBL3392041 & 688282 & 5.7 & 5.2557 & TST & \\
\hline CHEMBL1437176 & 688282 & 4.9 & 5.0969 & TRN & \\
\hline CHEMBL1404884 & 688282 & 5.6 & 5.0955 & TRN & \\
\hline CHEMBL1504284 & 688282 & 4.7 & 5.1815 & TRN & \\
\hline CHEMBL1464159 & 688282 & 5.3 & 5.0671 & TRN & \\
\hline & & & & 3310 & \\
\hline
\end{tabular}




\begin{tabular}{|c|c|c|c|c|c|}
\hline \multirow[b]{2}{*}{ CHEMBL1534844 } & \multirow[b]{2}{*}{688282} & \multirow[b]{2}{*}{5.0} & \\
\hline & & & 5.1844 & TST & \\
\hline CHEMBL1433939 & 688282 & 6.6 & 5.2731 & TST & \\
\hline CHEMBL1311219 & 688282 & 5.4 & 4.9839 & TRN & \\
\hline CHEMBL1335123 & 688282 & 4.7 & 5.2159 & TST & \\
\hline CHEMBL1594610 & 688282 & 4.8 & 5.2043 & TST & \\
\hline CHEMBL1503663 & 688282 & 4.7 & 5.1308 & TRN & \\
\hline CHEMBL1374337 & 688282 & 5.6 & 5.1839 & TRN & \\
\hline CHEMBL1369874 & 688282 & 5.6 & 5.1994 & TST & \\
\hline CHEMBL539947 & 688282 & 5.1 & 5.2307 & TRN & \\
\hline CHEMBL1333212 & 688282 & 4.8 & 5.0232 & TRN & \\
\hline CHEMBL1597166 & 688282 & 4.6 & 5.1331 & TRN & \\
\hline CHEMBL1454284 & 688282 & 4.9 & 5.2883 & TST & \\
\hline CHEMBL1445473 & 688282 & 5.4 & 5.0073 & TRN & \\
\hline CHEMBL486817 & 688282 & 4.9 & 5.2107 & TST & \\
\hline CHEMBL1596927 & 688282 & 4.5 & 5.091 & TRN & \\
\hline CHEMBL1330758 & 688282 & 5.0 & 5.1439 & TRN & \\
\hline CHEMBL1563204 & 688282 & 4.5 & 5.1733 & TRN & \\
\hline CHEMBL1595336 & 688282 & 4.6 & 5.1896 & TRN & \\
\hline CHEMBL1256914 & 688282 & 4.5 & 5.1633 & TST & \\
\hline CHEMBL1597970 & 688282 & 5.0 & 5.0689 & TRN & \\
\hline CHEMBL1391716 & 688282 & 4.8 & 5.1294 & TRN & \\
\hline CHEMBL1578553 & 688282 & 4.8 & 5.0138 & TRN & \\
\hline CHEMBL1507997 & 688282 & 5.0 & 4.9953 & TRN & \\
\hline CHEMBL1489036 & 688282 & 4.9 & 5.1638 & TRN & \\
\hline CHEMBL1467626 & 688282 & 5.3 & 5.1217 & TRN & \\
\hline CHEMBL531269 & 688282 & 6.0 & 5.1306 & TRN & \\
\hline CHEMBL1582203 & 688282 & 4.9 & 5.1148 & TRN & \\
\hline CHEMBL1408469 & 688282 & 4.6 & 5.1164 & TRN & \\
\hline CHEMBL1444859 & 688282 & 5.0 & 5.1061 & TRN & \\
\hline CHEMBL169 & 688282 & 5.1 & 5.29799 & 9999999999 & TST \\
\hline CHEMBL1437064 & 688282 & 5.0 & 5.1616 & TST & \\
\hline CHEMBL1484147 & 688282 & 4.6 & 5.2722 & TST & \\
\hline CHEMBL1360475 & 688282 & 5.3 & 5.0961 & TRN & \\
\hline CHEMBL1394187 & 688282 & 4.8 & 5.197 & TRN & \\
\hline CHEMBL1595524 & 688282 & 4.6 & 5.157 & TRN & \\
\hline CHEMBL1529365 & 688282 & 5.0 & 5.1218 & TRN & \\
\hline CHEMBL1336031 & 688282 & 5.0 & 5.138 & TRN & \\
\hline CHEMBL1564823 & 688282 & 5.8 & 5.074 & TRN & \\
\hline CHEMBL1484738 & 688282 & 4.9 & 5.21899 & 9999999999 & TST \\
\hline CHEMBL1337629 & 688282 & 5.3 & 5.1667 & TRN & \\
\hline CHEMBL1316944 & 688282 & 5.2 & 5.1046 & TRN & \\
\hline CHEMBL1590230 & 688282 & 4.9 & 5.11600 & 00000000005 & TRN \\
\hline CHEMBL1404132 & 688282 & 4.6 & 5.1344 & TRN & \\
\hline CHEMBL1365553 & 688282 & 4.9 & 5.0977 & TST & \\
\hline CHEMBL1395112 & 688282 & 6.2 & 5.3341 & TRN & \\
\hline CHEMBL1365011 & 688282 & 6.4 & 5.0588 & TRN & \\
\hline CHEMBL1435259 & 688282 & 6.1 & 5.0003 & TRN & \\
\hline CHEMBL1611235 & 688282 & 4.8 & 5.1613 & TRN & \\
\hline & & & & 13311 & \\
\hline
\end{tabular}




\begin{tabular}{|c|c|c|c|c|}
\hline & & & & \\
\hline CHEMBL1392201 & 688282 & 5.3 & 5.0981 & TST \\
\hline CHEMBL1424125 & 688282 & 4.9 & 5.1959 & TST \\
\hline CHEMBL1459888 & 688282 & 4.6 & 5.1408 & TST \\
\hline CHEMBL2373595 & 688282 & 5.0 & 5.078 & TRN \\
\hline CHEMBL1326352 & 688282 & 4.5 & 5.1685 & TRN \\
\hline CHEMBL1488689 & 688282 & 4.9 & 5.0629 & TRN \\
\hline CHEMBL1522495 & 688282 & 5.3 & 5.05 & TRN \\
\hline CHEMBL1256656 & 688282 & 6.0 & 4.9383 & TRN \\
\hline CHEMBL1578014 & 688282 & 5.6 & 5.1046 & TRN \\
\hline CHEMBL1370805 & 688282 & 5.3 & 5.2618 & TRN \\
\hline CHEMBL1373259 & 688282 & 4.9 & 5.1333 & TRN \\
\hline CHEMBL1369528 & 688282 & 5.0 & 4.992 & TRN \\
\hline CHEMBL491940 & 688282 & 5.4 & 4.9245 & TRN \\
\hline CHEMBL88961 & 688282 & 4.5 & 5.1654 & TRN \\
\hline CHEMBL1365094 & 688282 & 5.3 & 5.1127 & TRN \\
\hline CHEMBL1352121 & 688282 & 5.4 & 5.1331 & TRN \\
\hline CHEMBL1388009 & 688282 & 4.9 & 5.0742 & TRN \\
\hline CHEMBL1458076 & 688282 & 4.9 & 4.9809 & TRN \\
\hline CHEMBL1606431 & 688282 & 5.0 & 5.1861 & TRN \\
\hline CHEMBL1597434 & 688282 & 5.0 & 5.0865 & TRN \\
\hline CHEMBL1568168 & 688282 & 4.6 & 5.0844 & TRN \\
\hline CHEMBL1484261 & 688282 & 4.5 & 5.0087 & TRN \\
\hline CHEMBL509531 & 688282 & 5.6 & 5.269 & TST \\
\hline CHEMBL1586621 & 688282 & 4.9 & 5.1652 & TRN \\
\hline CHEMBL1559127 & 688282 & 4.8 & 5.0874 & TRN \\
\hline CHEMBL1570846 & 688282 & 5.1 & 5.0551 & TRN \\
\hline CHEMBL1591381 & 688282 & 5.4 & 5.282 & TRN \\
\hline CHEMBL1410385 & 688282 & 5.3 & 5.1141 & TRN \\
\hline CHEMBL1350196 & 688282 & 5.0 & 5.2026 & TRN \\
\hline CHEMBL1509969 & 688282 & 5.3 & 5.0341 & TRN \\
\hline CHEMBL169233 & 688282 & 4.5 & 5.227 & TST \\
\hline CHEMBL1489716 & 688282 & 4.9 & 4.9813 & TRN \\
\hline CHEMBL1569981 & 688282 & 4.7 & 4.9603 & TRN \\
\hline CHEMBL1598058 & 688282 & 4.9 & 5.0998 & TRN \\
\hline CHEMBL1475562 & 688282 & 4.6 & 5.2069 & TRN \\
\hline CHEMBL1494151 & 688282 & 6.3 & 5.3036 & TST \\
\hline CHEMBL1611005 & 688282 & 4.5 & 5.1233 & TRN \\
\hline CHEMBL1410865 & 688282 & 5.0 & 5.1835 & TRN \\
\hline CHEMBL1590048 & 688282 & 4.9 & 5.2131 & TRN \\
\hline CHEMBL1602407 & 688282 & 4.9 & 5.1685 & TRN \\
\hline CHEMBL1448764 & 688282 & 5.7 & 5.0493 & TRN \\
\hline CHEMBL1473205 & 688282 & 6.0 & 5.2199 & TST \\
\hline CHEMBL1514071 & 688282 & 5.0 & 5.1511 & TRN \\
\hline CHEMBL1370530 & 688282 & 4.9 & 5.1664 & TRN \\
\hline CHEMBL1369897 & 688282 & 5.3 & 5.1517 & TRN \\
\hline CHEMBL1537805 & 688282 & 4.5 & 5.0972 & TRN \\
\hline CHEMBL1492104 & 688282 & 5.4 & 5.294 & TST \\
\hline CHEMBL1441523 & 688282 & 5.3 & 5.0272 & TRN \\
\hline
\end{tabular}




\begin{tabular}{|c|c|c|c|c|}
\hline \multicolumn{5}{|c|}{ lemental T } \\
\hline CHEMBL1346595 & 688282 & 5.0 & 5.0799 & TRN \\
\hline CHEMBL1347816 & 688282 & 5.7 & 5.1339 & TRN \\
\hline CHEMBL1476129 & 688282 & 4.9 & 5.0573 & TRN \\
\hline CHEMBL1331926 & 688282 & 6.2 & 5.1317 & TRN \\
\hline CHEMBL1412731 & 688282 & 5.5 & 5.1339 & TRN \\
\hline CHEMBL1583305 & 688282 & 5.6 & 5.2529 & TRN \\
\hline CHEMBL1331263 & 688282 & 4.9 & 5.1417 & TRN \\
\hline CHEMBL1558425 & 688282 & 5.0 & 5.1319 & TRN \\
\hline CHEMBL1496092 & 688282 & 4.5 & 5.1784 & TRN \\
\hline CHEMBL1541009 & 688282 & 5.0 & 5.1006 & TRN \\
\hline CHEMBL1412116 & 688282 & 4.9 & 4.9908 & TRN \\
\hline CHEMBL1458840 & 688282 & 4.9 & 5.1558 & TRN \\
\hline CHEMBL1396595 & 688282 & 5.1 & 5.1335 & TRN \\
\hline CHEMBL1483764 & 688282 & 4.9 & 5.0175 & TRN \\
\hline CHEMBL1347695 & 688282 & 5.7 & 5.1531 & TRN \\
\hline CHEMBL1535124 & 688282 & 4.9 & 5.1073 & TRN \\
\hline CHEMBL1372023 & 688282 & 5.1 & 5.0646 & TRN \\
\hline CHEMBL1577977 & 688282 & 4.5 & 5.0931 & TRN \\
\hline CHEMBL1397833 & 688282 & 4.9 & 5.1026 & TST \\
\hline CHEMBL1460155 & 688282 & 5.0 & 5.1591 & TRN \\
\hline CHEMBL1538713 & 688282 & 4.9 & 5.0369 & TRN \\
\hline CHEMBL1341002 & 688282 & 5.3 & 5.1719 & TRN \\
\hline CHEMBL1570863 & 688282 & 4.9 & 4.9866 & TRN \\
\hline CHEMBL1394774 & 688282 & 5.7 & 5.2905 & TRN \\
\hline CHEMBL1491241 & 688282 & 4.5 & 5.0585 & TRN \\
\hline CHEMBL1439580 & 688282 & 4.6 & 5.1673 & TST \\
\hline CHEMBL1550580 & 688282 & 5.0 & 4.9791 & TRN \\
\hline CHEMBL1498246 & 688282 & 4.8 & 5.0297 & TRN \\
\hline CHEMBL1357909 & 688282 & 4.9 & 4.9879 & TRN \\
\hline CHEMBL1557265 & 688282 & 4.6 & 5.2082 & TRN \\
\hline CHEMBL1458209 & 688282 & 4.6 & 5.1207 & TRN \\
\hline CHEMBL229760 & 688282 & 5.8 & 5.2004 & TST \\
\hline CHEMBL1356652 & 688282 & 4.9 & 5.1187 & TRN \\
\hline CHEMBL1519327 & 688282 & 5.4 & 5.3242 & TST \\
\hline CHEMBL1377478 & 688282 & 4.9 & 5.1882 & TRN \\
\hline CHEMBL1502851 & 688282 & 5.0 & 5.1854 & TRN \\
\hline CHEMBL 303579 & 688282 & 4.8 & 5.2278 & TRN \\
\hline CHEMBL 1473715 & 688282 & 5.0 & 5.3199 & TRN \\
\hline CHEMBL1364473 & 688282 & 4.6 & 5.2768 & TRN \\
\hline CHEMBL1531319 & 688282 & 5.3 & 5.1156 & TRN \\
\hline CHEMBL1578945 & 688282 & 4.9 & 5.0816 & TRN \\
\hline CHEMBL1371774 & 688282 & 4.7 & 5.0264 & TRN \\
\hline CHEMBL1331615 & 688282 & 4.7 & 5.1581 & TRN \\
\hline CHEMBL1474151 & 688282 & 4.9 & 5.1969 & TRN \\
\hline CHEMBL1441572 & 688282 & 5.3 & 5.2174 & TRN \\
\hline CHEMBL1330396 & 688282 & 5.4 & 5.3049 & TRN \\
\hline CHEMBL1449430 & 688282 & 4.7 & 5.1498 & TRN \\
\hline CHEMBL 282003 & 688282 & 5.3 & 5.1803 & TRN \\
\hline
\end{tabular}




\begin{tabular}{|c|c|c|c|c|}
\hline & & & pplement & al $\mathrm{Ta}$ \\
\hline CHEMBL1402888 & 688282 & 5.0 & 5.0874 & TRN \\
\hline CHEMBL1970272 & 688282 & 5.9 & 5.0995 & TRN \\
\hline CHEMBL1451733 & 688282 & 6.0 & 5.2753 & TST \\
\hline CHEMBL1556217 & 688282 & 5.1 & 5.1098 & TRN \\
\hline CHEMBL1592227 & 688282 & 4.9 & 5.0162 & TRN \\
\hline CHEMBL1336116 & 688282 & 4.5 & 5.2059 & TRN \\
\hline CHEMBL323356 & 688282 & 4.6 & 5.1407 & TST \\
\hline CHEMBL1329225 & 688282 & 4.9 & 5.0945 & TRN \\
\hline CHEMBL1578304 & 688282 & 6.4 & 5.1533 & TRN \\
\hline CHEMBL1331649 & 688282 & 5.3 & 5.1018 & TRN \\
\hline CHEMBL1978075 & 688282 & 5.3 & 5.2198 & TRN \\
\hline CHEMBL1516772 & 688282 & 4.5 & 5.1398 & TRN \\
\hline CHEMBL1462334 & 688282 & 4.8 & 5.0644 & TRN \\
\hline CHEMBL1592186 & 688282 & 5.0 & 5.1046 & TRN \\
\hline CHEMBL1438341 & 688282 & 4.8 & 5.191 & TST \\
\hline CHEMBL1494386 & 688282 & 5.3 & 5.0033 & TRN \\
\hline CHEMBL1461931 & 688282 & 5.3 & 5.2458 & TRN \\
\hline CHEMBL1360981 & 688282 & 5.2 & 5.0559 & TRN \\
\hline CHEMBL1398683 & 688282 & 4.9 & 5.1822 & TST \\
\hline CHEMBL1373523 & 688282 & 5.4 & 5.2277 & TRN \\
\hline CHEMBL1455462 & 688282 & 5.0 & 5.1496 & TRN \\
\hline CHEMBL580421 & 688282 & 5.0 & 5.2685 & TRN \\
\hline CHEMBL1451924 & 688282 & 4.5 & 5.1641 & TRN \\
\hline CHEMBL1546068 & 688282 & 5.3 & 5.2397 & TRN \\
\hline CHEMBL1396539 & 688282 & 6.2 & 5.322 & TRN \\
\hline CHEMBL1452504 & 688282 & 4.9 & 5.266 & TST \\
\hline CHEMBL115511 & 688282 & 4.5 & 5.2422 & TRN \\
\hline CHEMBL1489182 & 688282 & 4.7 & 5.1358 & TRN \\
\hline CHEMBL1474498 & 688282 & 4.5 & 5.2872 & TST \\
\hline CHEMBL1542869 & 688282 & 5.3 & 5.0317 & TRN \\
\hline CHEMBL1600640 & 688282 & 4.6 & 5.184 & TRN \\
\hline CHEMBL1464070 & 688282 & 4.6 & 5.0011 & TRN \\
\hline CHEMBL1467517 & 688282 & 5.5 & 5.2791 & TRN \\
\hline CHEMBL1595866 & 688282 & 5.0 & 5.1056 & TRN \\
\hline CHEMBL1447657 & 688282 & 4.6 & 5.0671 & TRN \\
\hline CHEMBL1384133 & 688282 & 4.9 & 5.1734 & TRN \\
\hline CHEMBL1355835 & 688282 & 4.6 & 5.1533 & TRN \\
\hline CHEMBL1484516 & 688282 & 5.0 & 5.1899 & TRN \\
\hline CHEMBL1519384 & 688282 & 5.3 & 5.0274 & TRN \\
\hline CHEMBL348107 & 688282 & 5.6 & 5.3269 & TST \\
\hline CHEMBL1320709 & 688282 & 5.0 & 5.166 & TRN \\
\hline CHEMBL1371999 & 688282 & 5.3 & 5.0204 & TRN \\
\hline CHEMBL1445150 & 688282 & 5.3 & 5.1515 & TRN \\
\hline CHEMBL1512222 & 688282 & 5.4 & 5.129 & TRN \\
\hline CHEMBL1455517 & 688282 & 5.0 & 5.1797 & TRN \\
\hline CHEMBL72365 & 688282 & 5.1 & 5.2444 & TRN \\
\hline CHEMBL1311726 & 688282 & 4.9 & 5.2008 & TRN \\
\hline CHEMBL1502328 & 688282 & 4.7 & 5.1174 & TRN \\
\hline
\end{tabular}




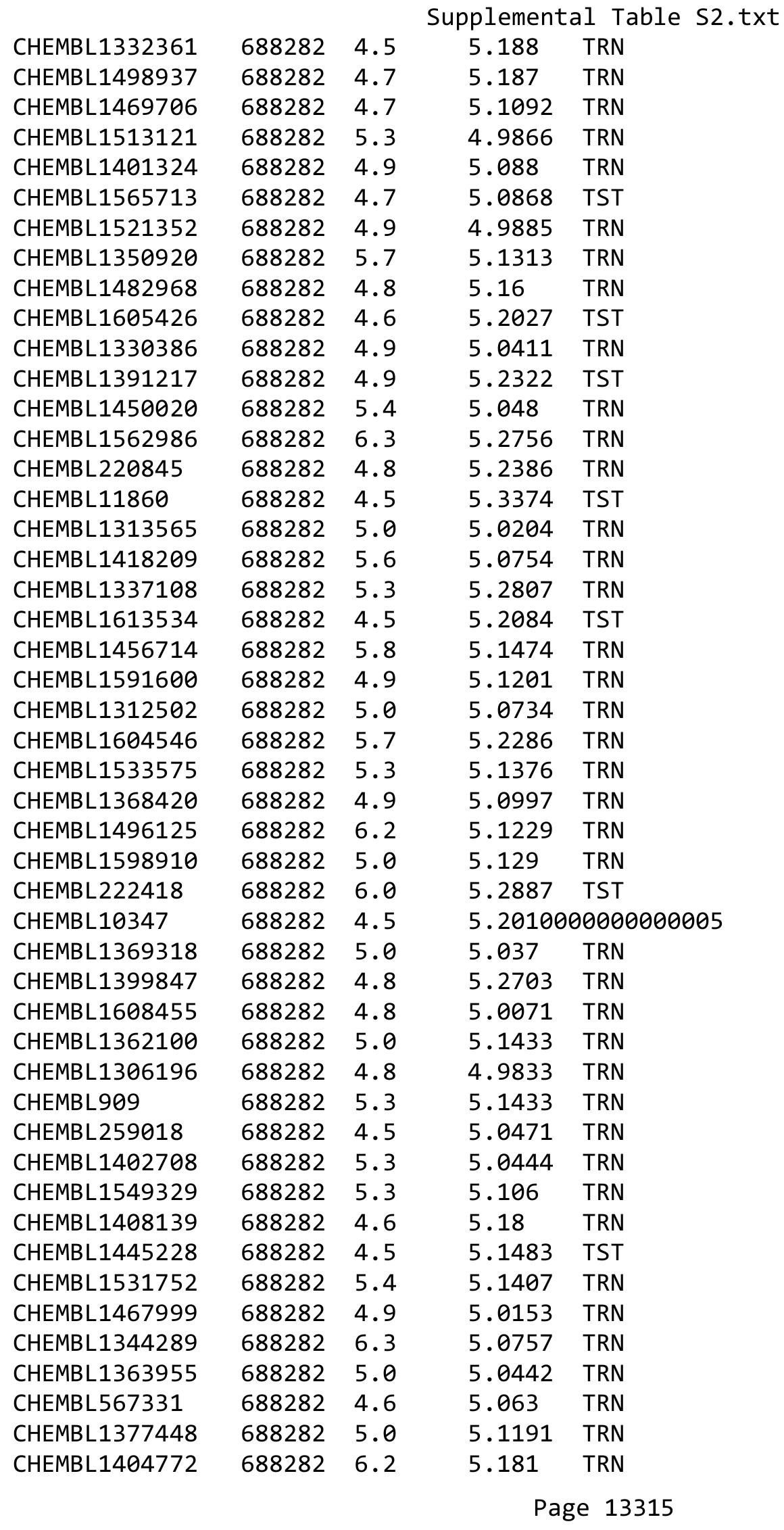




\begin{tabular}{|c|c|c|c|c|c|}
\hline \\
\hline CHEMBL1307816 & 688282 & 6.4 & 5.2323 & TST & \\
\hline CHEMBL1349521 & 688282 & 4.6 & 5.0521 & TRN & \\
\hline CHEMBL585481 & 688282 & 5.4 & 5.1148 & TRN & \\
\hline CHEMBL1568307 & 688282 & 6.0 & 5.2278 & TST & \\
\hline CHEMBL1299529 & 688282 & 4.8 & 5.0209 & TRN & \\
\hline CHEMBL1595437 & 688282 & 5.3 & 5.1893 & TRN & \\
\hline CHEMBL1517051 & 688282 & 5.2 & 5.1703 & TRN & \\
\hline CHEMBL1385673 & 688282 & 4.5 & 4.9778 & TRN & \\
\hline CHEMBL1379412 & 688282 & 5.3 & 5.1668 & TRN & \\
\hline CHEMBL1544407 & 688282 & 5.3 & 5.052 & TRN & \\
\hline CHEMBL1493396 & 688282 & 4.8 & 5.205 & TST & \\
\hline CHEMBL1553179 & 688282 & 5.0 & 5.0931 & TRN & \\
\hline CHEMBL1469840 & 688282 & 5.0 & 5.2298 & TRN & \\
\hline CHEMBL1470391 & 688282 & 5.4 & 5.1572 & TRN & \\
\hline CHEMBL1415642 & 688282 & 5.0 & 5.1454 & TRN & \\
\hline CHEMBL1552551 & 688282 & 4.9 & 5.1583 & TRN & \\
\hline CHEMBL1370850 & 688282 & 4.6 & 5.3377 & TST & \\
\hline CHEMBL1506223 & 688282 & 4.6 & 5.1926 & TST & \\
\hline CHEMBL1355200 & 688282 & 5.5 & 5.3196 & TRN & \\
\hline CHEMBL1456577 & 688282 & 5.2 & 5.0487 & TRN & \\
\hline CHEMBL1550267 & 688282 & 5.3 & 5.0774 & TRN & \\
\hline CHEMBL63426 & 688282 & 4.6 & 5.1478 & TST & \\
\hline CHEMBL1978364 & 688282 & 4.5 & 5.0005 & TST & \\
\hline CHEMBL1472271 & 688282 & 5.0 & 5.0114 & TRN & \\
\hline CHEMBL1093246 & 688282 & 5.0 & 5.25299 & 9999999999 & TRN \\
\hline CHEMBL 273103 & 688282 & 5.5 & 5.2208 & TRN & \\
\hline CHEMBL1476897 & 688282 & 5.9 & 5.1969 & TRN & \\
\hline CHEMBL1432760 & 688282 & 4.9 & 5.0554 & TRN & \\
\hline CHEMBL1468934 & 688282 & 5.5 & 5.1553 & TRN & \\
\hline CHEMBL1608831 & 688282 & 5.3 & 5.2542 & TRN & \\
\hline CHEMBL1543469 & 688282 & 4.6 & 5.1727 & TST & \\
\hline CHEMBL1483698 & 688282 & 4.8 & 5.2197 & TRN & \\
\hline CHEMBL1592493 & 688282 & 4.9 & 5.1993 & TRN & \\
\hline CHEMBL1457700 & 688282 & 4.5 & 5.0209 & TRN & \\
\hline CHEMBL1348507 & 688282 & 5.6 & 4.977 & TRN & \\
\hline CHEMBL1399886 & 688282 & 4.6 & 5.061 & TRN & \\
\hline CHEMBL1385628 & 688282 & 4.8 & 5.0813 & TRN & \\
\hline CHEMBL1325270 & 688282 & 5.3 & 5.1859 & TRN & \\
\hline CHEMBL1530911 & 688282 & 5.6 & 5.0726 & TST & \\
\hline CHEMBL1593827 & 688282 & 4.5 & 4.9636 & TRN & \\
\hline CHEMBL3214457 & 688282 & 5.0 & 5.2896 & TRN & \\
\hline CHEMBL1424508 & 688282 & 4.5 & 5.1864 & TRN & \\
\hline CHEMBL1442784 & 688282 & 5.3 & 5.1172 & TST & \\
\hline CHEMBL1470726 & 688282 & 5.2 & 5.1971 & TRN & \\
\hline CHEMBL1355634 & 688282 & 4.9 & 5.0287 & TRN & \\
\hline CHEMBL1351018 & 688282 & 4.8 & 5.1426 & TRN & \\
\hline CHEMBL1345738 & 688282 & 4.8 & 5.1616 & TRN & \\
\hline CHEMBL1383415 & 688282 & 6.2 & 5.1375 & TRN & \\
\hline & & & & 13316 & \\
\hline
\end{tabular}




\begin{tabular}{|c|c|c|c|c|}
\hline \\
\hline CHEMBL29097 & 688282 & 4.5 & 5.1596 & TST \\
\hline CHEMBL1507895 & 688282 & 5.3 & 5.17299 & 9999999999 \\
\hline CHEMBL1470808 & 688282 & 5.0 & 5.0888 & TRN \\
\hline CHEMBL1472649 & 688282 & 4.5 & 5.273 & TRN \\
\hline CHEMBL1310926 & 688282 & 6.9 & 5.1933 & TST \\
\hline CHEMBL1386938 & 688282 & 4.6 & 5.0947 & TRN \\
\hline CHEMBL1561363 & 688282 & 4.9 & 5.0485 & TRN \\
\hline CHEMBL1422602 & 688282 & 5.2 & 5.1223 & TRN \\
\hline CHEMBL1373475 & 688282 & 5.3 & 5.2563 & TST \\
\hline CHEMBL1565060 & 688282 & 5.0 & 5.1855 & TRN \\
\hline CHEMBL1553808 & 688282 & 5.0 & 4.928 & TRN \\
\hline CHEMBL1514804 & 688282 & 5.0 & 5.2799 & TRN \\
\hline CHEMBL1419488 & 688282 & 4.9 & 5.0619 & TRN \\
\hline CHEMBL1453322 & 688282 & 4.9 & 5.3074 & TST \\
\hline CHEMBL 362051 & 688282 & 4.8 & 5.1083 & TRN \\
\hline CHEMBL1419431 & 688282 & 5.3 & 5.1453 & TRN \\
\hline CHEMBL1591380 & 688282 & 5.4 & 5.1377 & TRN \\
\hline CHEMBL1471841 & 688282 & 5.5 & 5.2099 & TRN \\
\hline CHEMBL1308162 & 688282 & 4.6 & 5.1122 & TRN \\
\hline CHEMBL1482184 & 688282 & 6.0 & 5.2344 & TST \\
\hline CHEMBL1560588 & 688282 & 4.6 & 5.2258 & TRN \\
\hline CHEMBL1607113 & 688282 & 5.2 & 5.1026 & TRN \\
\hline CHEMBL1382159 & 688282 & 8.3979 & 5.178 & TRN \\
\hline CHEMBL1315129 & 688282 & 5.0 & 5.1202 & TRN \\
\hline CHEMBL1441981 & 688282 & 4.8 & 5.1103 & TRN \\
\hline CHEMBL1564030 & 688282 & 4.9 & 5.1884 & TST \\
\hline CHEMBL1408907 & 688282 & 4.9 & 5.1208 & TRN \\
\hline CHEMBL1526543 & 688282 & 4.5 & 5.2444 & TST \\
\hline CHEMBL1428100 & 688282 & 5.5 & 5.1666 & TST \\
\hline CHEMBL1566195 & 688282 & 4.8 & 5.1506 & TRN \\
\hline CHEMBL1609048 & 688282 & 5.1 & 5.0634 & TRN \\
\hline CHEMBL 2003973 & 688282 & 4.5 & 5.2385 & TST \\
\hline CHEMBL1411270 & 688282 & 4.6 & 5.2289 & TRN \\
\hline CHEMBL1513511 & 688282 & 5.8 & 5.1509 & TRN \\
\hline CHEMBL1356501 & 688282 & 5.0 & 5.0791 & TRN \\
\hline CHEMBL1609896 & 688282 & 4.9 & 5.1404 & TRN \\
\hline CHEMBL1478430 & 688282 & 5.6 & 5.1045 & TRN \\
\hline CHEMBL1419662 & 688282 & 4.6 & 5.0724 & TST \\
\hline CHEMBL1487465 & 688282 & 5.3 & 5.2442 & TRN \\
\hline CHEMBL 260451 & 688282 & 4.6 & 5.1989 & TRN \\
\hline CHEMBL1403616 & 688282 & 5.7 & 4.9993 & TRN \\
\hline CHEMBL1557564 & 688282 & 4.7 & 5.1825 & TRN \\
\hline CHEMBL1505715 & 688282 & 5.3 & 5.2226 & TRN \\
\hline CHEMBL1397151 & 688282 & 6.0 & 5.1625 & TRN \\
\hline CHEMBL1480715 & 688282 & 6.7001 & 5.2268 & TRN \\
\hline CHEMBL1370467 & 688282 & 4.7 & 5.2069 & TRN \\
\hline CHEMBL1604366 & 688282 & 5.6 & 5.2381 & TRN \\
\hline CHEMBL496894 & 688282 & 4.5 & 5.2446 & TST \\
\hline
\end{tabular}

TRN 


\begin{tabular}{|c|c|c|c|c|}
\hline \multicolumn{5}{|c|}{ lemental T } \\
\hline CHEMBL1173823 & 688282 & 4.5 & 5.1657 & TRN \\
\hline CHEMBL1526783 & 688282 & 5.3 & 5.1331 & TRN \\
\hline CHEMBL1606292 & 688282 & 4.9 & 5.1067 & TRN \\
\hline CHEMBL1347369 & 688282 & 5.1 & 5.0478 & TRN \\
\hline CHEMBL1576457 & 688282 & 4.6 & 5.1122 & TRN \\
\hline CHEMBL1538363 & 688282 & 4.5 & 5.2979 & TRN \\
\hline CHEMBL1531320 & 688282 & 5.0 & 5.1647 & TRN \\
\hline CHEMBL1361750 & 688282 & 4.6 & 5.0446 & TRN \\
\hline CHEMBL1337068 & 688282 & 5.7 & 5.221 & TRN \\
\hline CHEMBL1350028 & 688282 & 5.6 & 5.1957 & TRN \\
\hline CHEMBL580819 & 688282 & 4.8 & 5.0853 & TRN \\
\hline CHEMBL1440067 & 688282 & 4.8 & 5.0867 & TRN \\
\hline CHEMBL1315530 & 688282 & 5.0 & 5.2002 & TRN \\
\hline CHEMBL1412681 & 688282 & 5.3 & 5.142 & TRN \\
\hline CHEMBL1320469 & 688282 & 6.2 & 5.1753 & TRN \\
\hline CHEMBL 1589555 & 688282 & 4.9 & 5.2487 & TST \\
\hline CHEMBL1519258 & 688282 & 4.9 & 5.0932 & TRN \\
\hline CHEMBL1440908 & 688282 & 5.0 & 5.13 & TRN \\
\hline CHEMBL18132 & 688282 & 4.8 & 5.0547 & TST \\
\hline CHEMBL1387498 & 688282 & 5.3 & 5.2303 & TRN \\
\hline CHEMBL 1566386 & 688282 & 5.3 & 5.2141 & TRN \\
\hline CHEMBL164290 & 688282 & 4.6 & 5.2815 & TST \\
\hline CHEMBL1368192 & 688282 & 5.6 & 4.9879 & TRN \\
\hline CHEMBL1488591 & 688282 & 5.5 & 5.1117 & TRN \\
\hline CHEMBL1374271 & 688282 & 8.301 & 5.1683 & TRN \\
\hline CHEMBL1536041 & 688282 & 4.9 & 5.1408 & TRN \\
\hline CHEMBL1548265 & 688282 & 4.5 & 5.1263 & TRN \\
\hline CHEMBL452887 & 688282 & 6.0 & 5.2751 & TRN \\
\hline CHEMBL1445495 & 688282 & 5.3 & 5.1344 & TRN \\
\hline CHEMBL542700 & 688282 & 4.6 & 5.3007 & TST \\
\hline CHEMBL1350275 & 688282 & 4.9 & 5.1066 & TRN \\
\hline CHEMBL1489891 & 688282 & 4.9 & 5.2221 & TRN \\
\hline CHEMBL1581440 & 688282 & 6.0 & 5.2295 & TRN \\
\hline CHEMBL528080 & 688282 & 5.0 & 5.1299 & TRN \\
\hline CHEMBL1583764 & 688282 & 5.7 & 5.2059 & TRN \\
\hline CHEMBL1595377 & 688282 & 5.0 & 5.0916 & TRN \\
\hline CHEMBL1470619 & 688282 & 5.4 & 5.1772 & TRN \\
\hline CHEMBL1531699 & 688282 & 4.5 & 5.2923 & TRN \\
\hline CHEMBL197014 & 688282 & 5.0 & 5.1661 & TRN \\
\hline CHEMBL1535312 & 688282 & 4.9 & 5.1347 & TRN \\
\hline CHEMBL1605525 & 688282 & 5.7 & 5.0895 & TRN \\
\hline CHEMBL1517358 & 688282 & 4.6 & 5.0715 & TRN \\
\hline CHEMBL1405744 & 688282 & 5.0 & 5.0853 & TRN \\
\hline CHEMBL1703229 & 688282 & 5.7 & 5.2204 & TRN \\
\hline CHEMBL1391091 & 688282 & 5.4 & 5.1244 & TRN \\
\hline CHEMBL1501066 & 688282 & 5.3 & 5.1343 & TRN \\
\hline CHEMBL1612246 & 688282 & 4.8 & 5.2708 & TRN \\
\hline CHEMBL1383968 & 688282 & 5.0 & 5.2743 & TST \\
\hline
\end{tabular}




\begin{tabular}{|c|c|c|c|c|}
\hline \multicolumn{5}{|c|}{ plemental } \\
\hline CHEMBL1335319 & 688282 & 4.5 & 4.9972 & TRN \\
\hline CHEMBL1518599 & 688282 & 5.1 & 5.2275 & TRN \\
\hline CHEMBL1473754 & 688282 & 4.9 & 5.3069 & TRN \\
\hline CHEMBL1480918 & 688282 & 4.6 & 5.1191 & TRN \\
\hline CHEMBL1454920 & 688282 & 4.9 & 5.096 & TRN \\
\hline CHEMBL1408847 & 688282 & 4.9 & 5.1878 & TRN \\
\hline CHEMBL1362994 & 688282 & 5.0 & 5.0415 & TRN \\
\hline CHEMBL1475788 & 688282 & 5.3 & 5.1534 & TRN \\
\hline CHEMBL1478852 & 688282 & 4.9 & 5.1152 & TST \\
\hline CHEMBL1517644 & 688282 & 6.4 & 5.3039 & TRN \\
\hline CHEMBL1565345 & 688282 & 5.0 & 5.1878 & TRN \\
\hline CHEMBL1489081 & 688282 & 4.5 & 5.1152 & TRN \\
\hline CHEMBL1605279 & 688282 & 4.8 & 5.1824 & TST \\
\hline CHEMBL1391259 & 688282 & 4.7 & 5.0799 & TRN \\
\hline CHEMBL1515975 & 688282 & 6.2 & 5.2844 & TRN \\
\hline CHEMBL1451533 & 688282 & 4.6 & 5.1767 & TRN \\
\hline CHEMBL1608975 & 688282 & 6.5 & 5.1437 & TRN \\
\hline CHEMBL1433085 & 688282 & 5.3 & 5.1197 & TRN \\
\hline CHEMBL1561383 & 688282 & 5.0 & 5.0967 & TRN \\
\hline CHEMBL1464673 & 688282 & 5.3 & 5.0378 & TRN \\
\hline CHEMBL1379705 & 688282 & 5.1 & 5.2734 & TRN \\
\hline CHEMBL508494 & 688282 & 4.9 & 5.1101 & TRN \\
\hline CHEMBL1377521 & 688282 & 4.5 & 5.2484 & TRN \\
\hline CHEMBL1574497 & 688282 & 5.0 & 5.1563 & TRN \\
\hline CHEMBL1445973 & 688282 & 4.7 & 4.9565 & TRN \\
\hline CHEMBL1587226 & 688282 & 4.6 & 4.9602 & TRN \\
\hline CHEMBL1604036 & 688282 & 6.1 & 5.1521 & TST \\
\hline CHEMBL342375 & 688282 & 4.9 & 5.303 & TRN \\
\hline CHEMBL1410147 & 688282 & 6.9 & 5.1503 & TST \\
\hline CHEMBL1255934 & 688282 & 4.9 & 5.2649 & TST \\
\hline CHEMBL1401037 & 688282 & 5.2 & 5.1418 & TRN \\
\hline CHEMBL1437226 & 688282 & 4.6 & 5.0817 & TRN \\
\hline CHEMBL1613288 & 688282 & 5.1 & 5.1188 & TRN \\
\hline CHEMBL1567818 & 688282 & 5.3 & 5.2275 & TRN \\
\hline CHEMBL1448896 & 688282 & 5.3 & 5.1452 & TRN \\
\hline CHEMBL 2374058 & 688282 & 8.0 & 5.1451 & TST \\
\hline CHEMBL1526325 & 688282 & 4.9 & 5.0697 & TRN \\
\hline CHEMBL1561274 & 688282 & 4.6 & 5.2245 & TRN \\
\hline CHEMBL1405209 & 688282 & 5.0 & 5.0194 & TRN \\
\hline CHEMBL428784 & 688282 & 6.0 & 5.1604 & TRN \\
\hline CHEMBL1307026 & 688282 & 4.6 & 5.0324 & TRN \\
\hline CHEMBL1562420 & 688282 & 4.9 & 5.2654 & TRN \\
\hline CHEMBL77030 & 688282 & 4.6 & 5.2815 & TRN \\
\hline CHEMBL1521269 & 688282 & 5.5 & 5.0031 & TRN \\
\hline CHEMBL1456625 & 688282 & 5.0 & 5.0825 & TRN \\
\hline CHEMBL1607024 & 688282 & 5.0 & 5.047 & TRN \\
\hline CHEMBL1311753 & 688282 & 4.9 & 5.1757 & TST \\
\hline CHEMBL1336339 & 688282 & 5.6 & 5.1424 & TRN \\
\hline
\end{tabular}




\begin{tabular}{|c|c|c|c|c|c|}
\hline & & & & & \\
\hline CHEMBL1597277 & 688282 & 6.3 & 5.1424 & TRN & \\
\hline CHEMBL1487823 & 688282 & 5.2 & 5.1193 & TRN & \\
\hline CHEMBL1578183 & 688282 & 5.0 & 5.2954 & TRN & \\
\hline CHEMBL1375469 & 688282 & 5.8 & 5.1565 & TRN & \\
\hline CHEMBL3216654 & 688282 & 4.9 & 5.0124 & TRN & \\
\hline CHEMBL1526410 & 688282 & 4.9 & 5.2261 & TRN & \\
\hline CHEMBL1459923 & 688282 & 7.0 & 5.1074 & TRN & \\
\hline CHEMBL1327738 & 688282 & 5.9 & 5.0507 & TST & \\
\hline CHEMBL1549270 & 688282 & 5.5 & 5.0322 & TRN & \\
\hline CHEMBL1448422 & 688282 & 5.0 & 5.2014 & TRN & \\
\hline CHEMBL1306407 & 688282 & 5.3 & 5.102 & TRN & \\
\hline CHEMBL1349359 & 688282 & 5.0 & 4.94600 & 0000000001 & TRN \\
\hline CHEMBL1328193 & 688282 & 5.3 & 5.1895 & TST & \\
\hline CHEMBL1322272 & 688282 & 5.6 & 5.1239 & TRN & \\
\hline CHEMBL1496590 & 688282 & 5.3 & 4.9681 & TRN & \\
\hline CHEMBL1424106 & 688282 & 8.3979 & 5.0839 & TRN & \\
\hline CHEMBL567531 & 688282 & 4.6 & 5.0552 & TRN & \\
\hline CHEMBL1549293 & 688282 & 4.7 & 5.1332 & TRN & \\
\hline CHEMBL1611974 & 688282 & 6.0 & 5.3464 & TST & \\
\hline CHEMBL1486930 & 688282 & 4.9 & 5.1984 & TRN & \\
\hline CHEMBL1320722 & 688282 & 5.0 & 5.2149 & TRN & \\
\hline CHEMBL1555037 & 688282 & 4.9 & 5.0784 & TRN & \\
\hline CHEMBL1310190 & 688282 & 6.8 & 5.1161 & TRN & \\
\hline CHEMBL1593440 & 688282 & 5.6 & 5.1979 & TRN & \\
\hline CHEMBL1384489 & 688282 & 4.9 & 5.0531 & TRN & \\
\hline CHEMBL1333225 & 688282 & 4.9 & 5.1334 & TRN & \\
\hline CHEMBL1328565 & 688282 & 5.5 & 4.9994 & TRN & \\
\hline CHEMBL1544046 & 688282 & 4.6 & 5.0563 & TRN & \\
\hline CHEMBL1565371 & 688282 & 5.3 & 5.0688 & TRN & \\
\hline CHEMBL1424345 & 688282 & 4.5 & 5.1229 & TRN & \\
\hline CHEMBL1518624 & 688282 & 4.6 & 5.1266 & TRN & \\
\hline CHEMBL1419356 & 688282 & 6.8 & 5.2028 & TRN & \\
\hline CHEMBL1403280 & 688282 & 6.1 & 5.1828 & TRN & \\
\hline CHEMBL1515724 & 688282 & 5.9 & 5.2859 & TRN & \\
\hline CHEMBL1474854 & 688282 & 5.0 & 5.1884 & TRN & \\
\hline CHEMBL1351487 & 688282 & 4.9 & 5.1949 & TRN & \\
\hline CHEMBL1541840 & 688282 & 6.3 & 4.975 & TRN & \\
\hline CHEMBL430893 & 688282 & 4.9 & 5.1918 & TRN & \\
\hline CHEMBL1520286 & 688282 & 5.0 & 5.1394 & TRN & \\
\hline CHEMBL503763 & 688282 & 5.4 & 5.2007 & TRN & \\
\hline CHEMBL1326803 & 688282 & 6.4 & 5.2255 & TRN & \\
\hline CHEMBL1301057 & 688282 & 5.1 & 5.0577 & TRN & \\
\hline CHEMBL1373923 & 688282 & 5.2 & 5.0778 & TRN & \\
\hline CHEMBL516952 & 688282 & 4.9 & 5.17700 & 00000000005 & TRN \\
\hline CHEMBL1332059 & 688282 & 4.9 & 5.2808 & TST & \\
\hline CHEMBL1578082 & 688282 & 4.5 & 5.1854 & TST & \\
\hline CHEMBL1573333 & 688282 & 5.0 & 4.987 & TRN & \\
\hline CHEMBL1603464 & 688282 & 4.6 & 5.1962 & TST & \\
\hline & & & & 13320 & \\
\hline
\end{tabular}




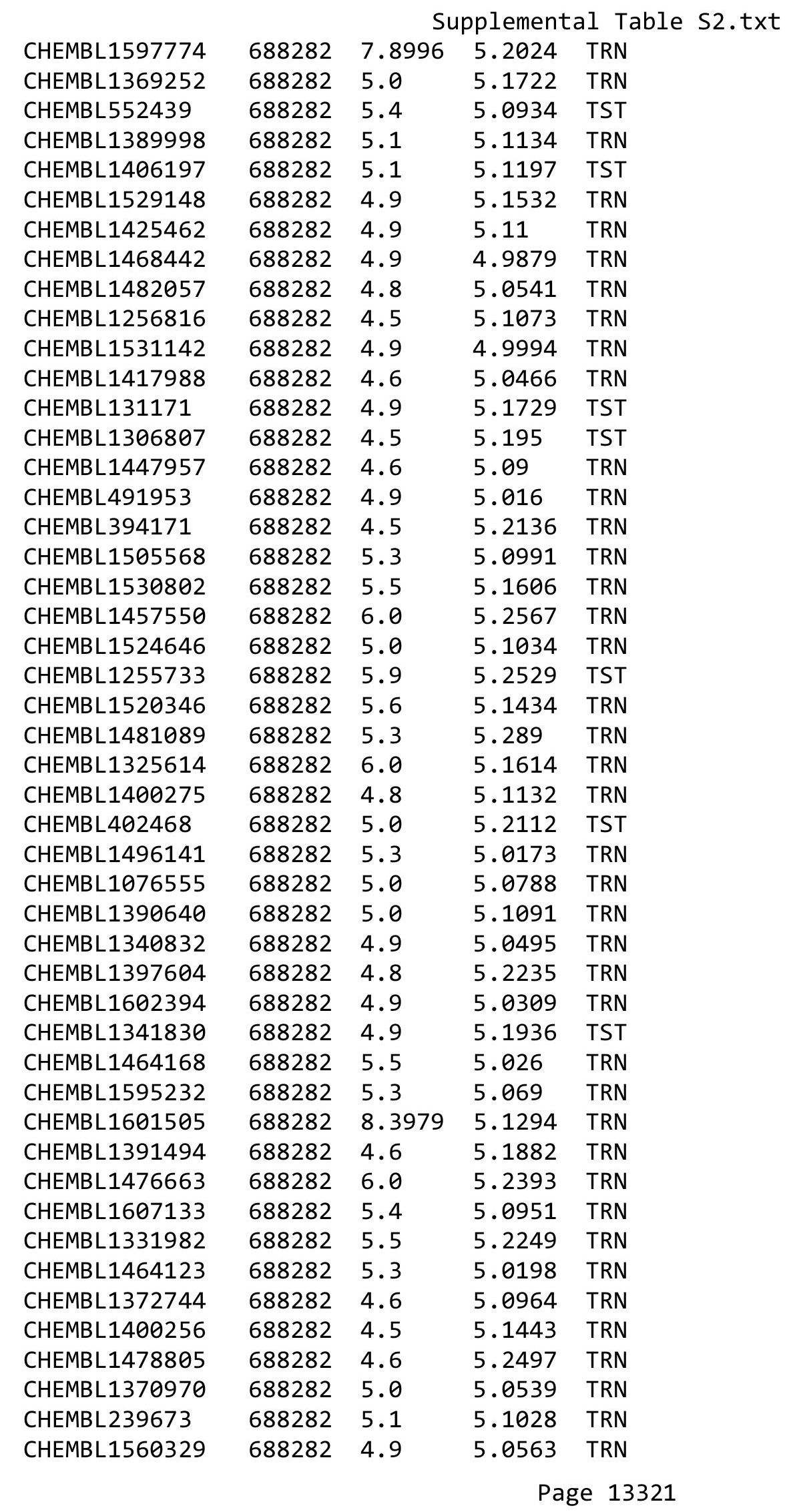




\begin{tabular}{|c|c|c|c|c|}
\hline & & & & at \\
\hline CHEMBL52030 & 688282 & 4.9 & 5.0644 & TST \\
\hline CHEMBL1394095 & 688282 & 5.3 & 5.0516 & TRN \\
\hline CHEMBL1378755 & 688282 & 5.0 & 5.1579 & TRN \\
\hline CHEMBL1484210 & 688282 & 4.6 & 5.003 & TRN \\
\hline CHEMBL1435638 & 688282 & 4.5 & 4.9615 & TRN \\
\hline CHEMBL1611746 & 688282 & 4.9 & 5.1425 & TRN \\
\hline CHEMBL1482847 & 688282 & 4.9 & 5.1033 & TRN \\
\hline CHEMBL1425853 & 688282 & 4.9 & 5.1482 & TST \\
\hline CHEMBL1408176 & 688282 & 5.0 & 5.0335 & TRN \\
\hline CHEMBL1409828 & 688282 & 5.0 & 5.1036 & TRN \\
\hline CHEMBL1372895 & 688282 & 5.1 & 5.184 & TRN \\
\hline CHEMBL1513845 & 688282 & 4.9 & 5.2847 & TRN \\
\hline CHEMBL1464614 & 688282 & 4.9 & 5.0725 & TRN \\
\hline CHEMBL1549175 & 688282 & 5.0 & 5.1169 & TRN \\
\hline CHEMBL1396109 & 688282 & 5.0 & 5.0592 & TRN \\
\hline CHEMBL393136 & 688282 & 5.5 & 5.1631 & TST \\
\hline CHEMBL1363931 & 688282 & 4.6 & 4.9853 & TRN \\
\hline CHEMBL1588307 & 688282 & 4.9 & 5.1903 & TST \\
\hline CHEMBL1430524 & 688282 & 5.0 & 5.0052 & TRN \\
\hline CHEMBL1517999 & 688282 & 5.1 & 5.0815 & TRN \\
\hline CHEMBL1356628 & 688282 & 5.0 & 5.1906 & TST \\
\hline CHEMBL1525989 & 688282 & 5.3 & 5.2317 & TST \\
\hline CHEMBL1543076 & 688282 & 5.3 & 5.1975 & TRN \\
\hline CHEMBL1304398 & 688282 & 5.0 & 5.1333 & TRN \\
\hline CHEMBL1390210 & 688282 & 5.0 & 5.0286 & TRN \\
\hline CHEMBL1454855 & 688282 & 5.9 & 5.1125 & TRN \\
\hline CHEMBL1501884 & 688282 & 5.6 & 5.0541 & TRN \\
\hline CHEMBL1574614 & 688282 & 5.3 & 5.2661 & TST \\
\hline CHEMBL1554677 & 688282 & 5.1 & 5.0686 & TRN \\
\hline CHEMBL1404747 & 688282 & 5.0 & 5.1589 & TRN \\
\hline CHEMBL1489133 & 688282 & 5.0 & 5.2068 & TRN \\
\hline CHEMBL1514016 & 688282 & 6.5 & 5.1554 & TRN \\
\hline CHEMBL1482759 & 688282 & 4.9 & 5.0832 & TRN \\
\hline CHEMBL1355712 & 688282 & 5.3 & 4.9953 & TRN \\
\hline CHEMBL1473430 & 688282 & 5.3 & 5.1185 & TRN \\
\hline CHEMBL198159 & 688282 & 4.9 & 5.3006 & TRN \\
\hline CHEMBL1484422 & 688282 & 5.0 & 4.9488 & TRN \\
\hline CHEMBL1332463 & 688282 & 4.5 & 5.0704 & TRN \\
\hline CHEMBL1324769 & 688282 & 4.9 & 5.121 & TRN \\
\hline CHEMBL1528565 & 688282 & 4.5 & 5.1197 & TST \\
\hline CHEMBL1561888 & 688282 & 5.5 & 5.0193 & TRN \\
\hline CHEMBL1475207 & 688282 & 4.8 & 5.1803 & TRN \\
\hline CHEMBL1340140 & 688282 & 5.3 & 5.1532 & TRN \\
\hline CHEMBL1410635 & 688282 & 4.9 & 5.1384 & TRN \\
\hline CHEMBL1359214 & 688282 & 4.8 & 5.1414 & TRN \\
\hline CHEMBL1603924 & 688282 & 4.6 & 5.2943 & TST \\
\hline CHEMBL1567762 & 688282 & 4.9 & 5.0911 & TRN \\
\hline CHEMBL1308892 & 688282 & 5.0 & 5.0396 & TRN \\
\hline
\end{tabular}




\begin{tabular}{|c|c|c|c|c|}
\hline \multicolumn{5}{|c|}{ Supplemental Table s2.txt } \\
\hline CHEMBL1480125 & 688282 & 8.301 & 5.2446 & TRN \\
\hline CHEMBL1331931 & 688282 & 5.1 & 5.0218 & TRN \\
\hline CHEMBL1577505 & 688282 & 5.1 & 5.0655 & TRN \\
\hline CHEMBL 24450 & 688282 & 4.9 & 5.1967 & TRN \\
\hline CHEMBL1596241 & 688282 & 6.4 & 4.9588 & TRN \\
\hline CHEMBL1301760 & 688282 & 5.2 & 5.1302 & TRN \\
\hline CHEMBL 3144830 & 688282 & 4.8 & 5.1431 & TRN \\
\hline CHEMBL1441287 & 688282 & 4.7 & 5.3301 & TRN \\
\hline CHEMBL1483112 & 688282 & 5.0 & 5.1922 & TRN \\
\hline CHEMBL1604063 & 688282 & 5.3 & 5.2038 & TST \\
\hline CHEMBL1514910 & 688282 & 4.5 & 5.2127 & TST \\
\hline CHEMBL1490438 & 688282 & 6.0 & 5.1983 & TRN \\
\hline CHEMBL1518182 & 688282 & 5.8 & 5.171 & TRN \\
\hline CHEMBL1550339 & 688282 & 5.0 & 5.1758 & TRN \\
\hline CHEMBL1581108 & 688282 & 5.0 & 5.1506 & TRN \\
\hline CHEMBL1527923 & 688282 & 5.0 & 4.9537 & TRN \\
\hline CHEMBL1446444 & 688282 & 5.1 & 5.0823 & TRN \\
\hline CHEMBL3198170 & 688282 & 4.9 & 5.0748 & TST \\
\hline CHEMBL1389552 & 688282 & 4.6 & 5.2225 & TST \\
\hline CHEMBL1611371 & 688282 & 5.1 & 5.1637 & TRN \\
\hline CHEMBL1877767 & 688282 & 5.4 & 5.1619 & TST \\
\hline CHEMBL583849 & 688282 & 7.5003 & 5.0656 & TST \\
\hline CHEMBL1397192 & 688282 & 4.9 & 5.1349 & TRN \\
\hline CHEMBL1313927 & 688282 & 4.5 & 5.1076 & TRN \\
\hline CHEMBL1461654 & 688282 & 5.9 & 5.0452 & TRN \\
\hline CHEMBL1457123 & 688282 & 5.5 & 5.1217 & TRN \\
\hline CHEMBL1497878 & 688282 & 4.8 & 5.15 & TST \\
\hline CHEMBL1567402 & 688282 & 5.2 & 5.1442 & TRN \\
\hline CHEMBL1437323 & 688282 & 6.1 & 5.2362 & TRN \\
\hline CHEMBL1603692 & 688282 & 5.0 & 5.1184 & TRN \\
\hline CHEMBL1327425 & 688282 & 4.5 & 5.1764 & TRN \\
\hline CHEMBL1369688 & 688282 & 4.5 & 5.0294 & TRN \\
\hline CHEMBL1534811 & 688282 & 6.3 & 5.2329 & TST \\
\hline CHEMBL1522603 & 688282 & 5.0 & 5.0917 & TRN \\
\hline CHEMBL1407442 & 688282 & 4.7 & 5.205 & TST \\
\hline CHEMBL1490736 & 688282 & 4.6 & 5.1529 & TRN \\
\hline CHEMBL1400280 & 688282 & 5.0 & 5.2274 & TRN \\
\hline CHEMBL1527693 & 688282 & 4.9 & 5.1527 & TRN \\
\hline CHEMBL1489392 & 688282 & 4.9 & 5.3279 & TST \\
\hline CHEMBL1376954 & 688282 & 5.5 & 5.0895 & TRN \\
\hline CHEMBL1470367 & 688282 & 4.9 & 5.2439 & TRN \\
\hline CHEMBL189724 & 688282 & 6.0 & 5.1457 & TST \\
\hline CHEMBL1448506 & 688282 & 4.6 & 5.1484 & TRN \\
\hline CHEMBL1384007 & 688282 & 5.0 & 4.9593 & TRN \\
\hline CHEMBL1337235 & 688282 & 5.1 & 5.0916 & TRN \\
\hline CHEMBL1526043 & 688282 & 5.0 & 5.205 & TRN \\
\hline CHEMBL1334959 & 688282 & 5.0 & 4.9898 & TRN \\
\hline CHEMBL1349820 & 688282 & 6.3 & 5.0095 & TRN \\
\hline
\end{tabular}




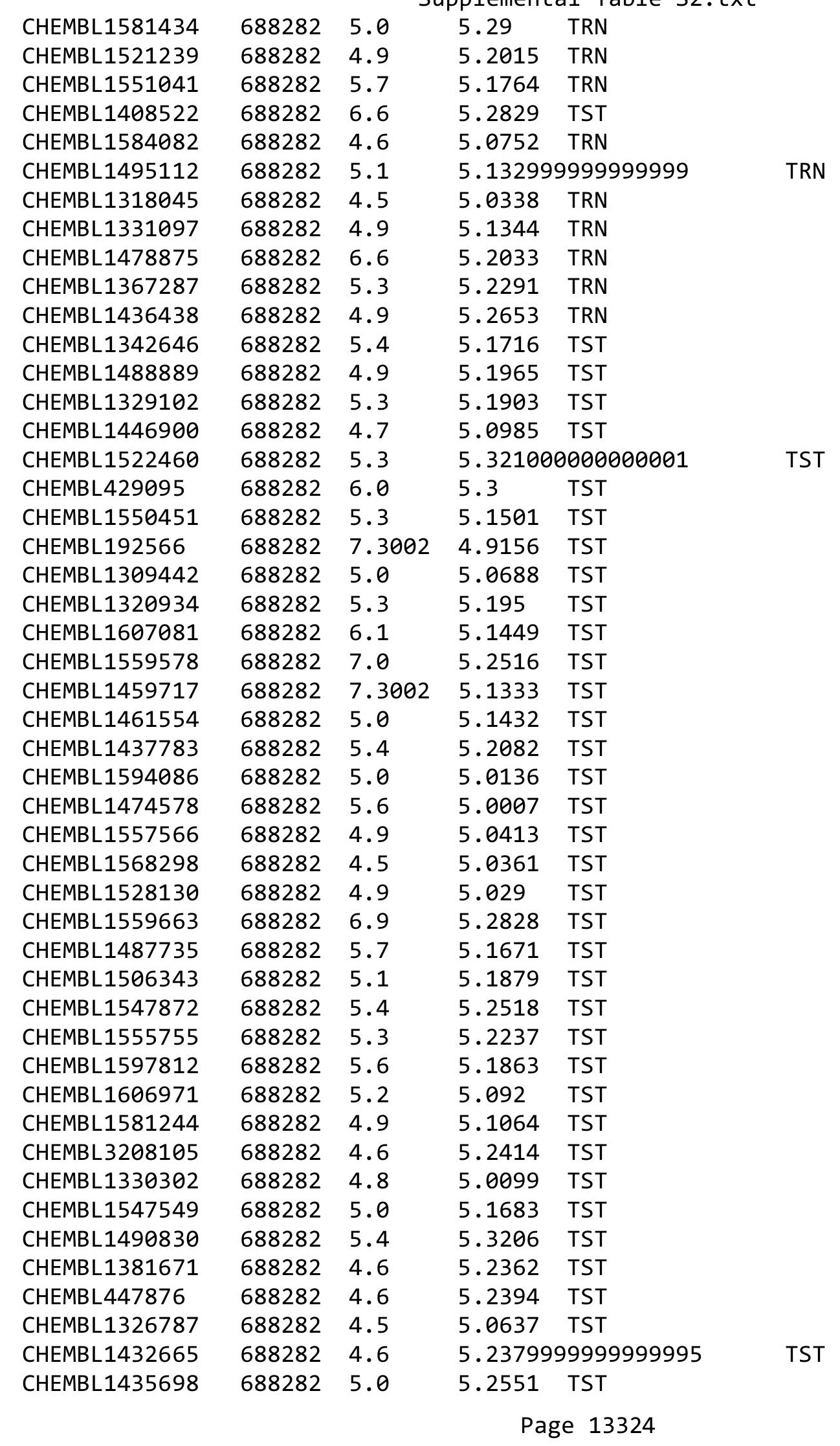




\begin{tabular}{|c|c|c|c|c|c|}
\hline \\
\hline CHEMBL1565100 & 688282 & 5.3 & 5.0954 & TST & \\
\hline CHEMBL1610806 & 688282 & 5.3 & 5.0458 & TST & \\
\hline CHEMBL1325296 & 688282 & 4.6 & 5.2111 & TST & \\
\hline CHEMBL224214 & 688282 & 5.6 & 5.1597 & TST & \\
\hline CHEMBL1373402 & 688282 & 4.9 & 5.046 & TST & \\
\hline CHEMBL1418483 & 688282 & 5.1 & 5.1829 & TST & \\
\hline CHEMBL1255657 & 688282 & 4.9 & 5.1962 & TST & \\
\hline CHEMBL1608321 & 688282 & 5.0 & 5.1322 & TST & \\
\hline CHEMBL1455767 & 688282 & 5.1 & 5.1242 & TST & \\
\hline CHEMBL1312571 & 688282 & 4.6 & 5.1947 & TST & \\
\hline CHEMBL1433783 & 688282 & 5.3 & 5.17399 & 99999999995 & TST \\
\hline CHEMBL539027 & 688282 & 6.0 & 5.2106 & TST & \\
\hline CHEMBL1536547 & 688282 & 5.2 & 5.1208 & TST & \\
\hline CHEMBL3190658 & 688282 & 4.8 & 5.0618 & TST & \\
\hline CHEMBL14690 & 688282 & 4.8 & 5.1551 & TST & \\
\hline CHEMBL1411739 & 688282 & 4.6 & 5.1192 & TST & \\
\hline CHEMBL1411360 & 688282 & 5.3 & 5.0999 & TST & \\
\hline CHEMBL1443979 & 688282 & 5.0 & 5.0148 & TST & \\
\hline CHEMBL1597278 & 688282 & 5.0 & 5.0789 & TST & \\
\hline CHEMBL1466937 & 688282 & 4.6 & 5.2429 & TST & \\
\hline CHEMBL163970 & 688282 & 6.7001 & 5.2261 & TST & \\
\hline CHEMBL1409138 & 688282 & 5.1 & 5.1678 & TST & \\
\hline CHEMBL1338186 & 688282 & 4.8 & 5.1734 & TST & \\
\hline CHEMBL1386609 & 688282 & 4.8 & 5.0018 & TST & \\
\hline CHEMBL1430826 & 688282 & 5.1 & 4.998 & TST & \\
\hline CHEMBL1338330 & 688282 & 4.9 & 5.19600 & 2000000001 & TST \\
\hline CHEMBL1314453 & 688282 & 6.3 & 5.0597 & TST & \\
\hline CHEMBL1595914 & 688282 & 4.9 & 5.254 & TST & \\
\hline CHEMBL1512385 & 688282 & 5.0 & 5.1353 & TST & \\
\hline CHEMBL1345810 & 688282 & 5.1 & 5.0603 & TST & \\
\hline CHEMBL3197626 & 688282 & 5.0 & 5.1912 & TST & \\
\hline CHEMBL1432151 & 688282 & 5.1 & 5.1878 & TST & \\
\hline CHEMBL1343187 & 688282 & 5.8 & 5.2566 & TST & \\
\hline CHEMBL1315109 & 688282 & 4.9 & 5.1635 & TST & \\
\hline CHEMBL1475941 & 688282 & 4.9 & 5.072 & TST & \\
\hline CHEMBL77287 & 688282 & 4.9 & 5.2235 & TST & \\
\hline CHEMBL1326451 & 688282 & 4.5 & 5.0423 & TST & \\
\hline CHEMBL1545280 & 688282 & 4.9 & 5.1002 & TST & \\
\hline CHEMBL1536391 & 688282 & 4.7 & 5.0992 & TST & \\
\hline CHEMBL1532033 & 688282 & 4.9 & 5.1385 & TST & \\
\hline CHEMBL1547846 & 688282 & 4.7 & 5.1506 & TST & \\
\hline CHEMBL1373679 & 688282 & 6.4 & 5.0868 & TST & \\
\hline CHEMBL1408334 & 688282 & 5.2 & 5.1289 & TST & \\
\hline CHEMBL1562442 & 688282 & 5.3 & 5.1956 & TST & \\
\hline CHEMBL332898 & 688282 & 5.4 & 5.1186 & TST & \\
\hline CHEMBL1419206 & 688282 & 5.0 & 5.119 & TST & \\
\hline CHEMBL1469044 & 688282 & 4.9 & 5.1316 & TST & \\
\hline CHEMBL1446815 & 688282 & 4.9 & 5.0729 & TST & \\
\hline
\end{tabular}




\begin{tabular}{|c|c|c|c|c|}
\hline & & & 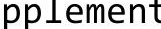 & al Ta \\
\hline CHEMBL1490600 & 688282 & 4.5 & 5.2225 & TST \\
\hline CHEMBL1519435 & 688282 & 4.5 & 4.9644 & TST \\
\hline CHEMBL1335707 & 688282 & 4.7 & 5.0968 & TST \\
\hline CHEMBL1336032 & 688282 & 4.9 & 5.0775 & TST \\
\hline CHEMBL1489758 & 688282 & 4.9 & 5.2205 & TST \\
\hline CHEMBL1546351 & 688282 & 5.0 & 5.1194 & TST \\
\hline CHEMBL1583236 & 688282 & 5.3 & 5.0554 & TST \\
\hline CHEMBL1407511 & 688282 & 4.5 & 5.176 & TST \\
\hline CHEMBL1611099 & 688282 & 4.6 & 5.1283 & TST \\
\hline CHEMBL1521879 & 688282 & 4.5 & 5.0076 & TST \\
\hline CHEMBL389162 & 688282 & 4.6 & 5.2455 & TST \\
\hline CHEMBL1394833 & 688282 & 5.3 & 5.3144 & TST \\
\hline CHEMBL1530147 & 688282 & 4.9 & 5.1416 & TST \\
\hline CHEMBL1426762 & 688282 & 4.8 & 5.1755 & TST \\
\hline CHEMBL1299274 & 688282 & 5.6 & 5.1487 & TST \\
\hline CHEMBL1353216 & 688282 & 4.6 & 5.0244 & TST \\
\hline CHEMBL1307638 & 688282 & 4.8 & 5.1614 & TST \\
\hline CHEMBL1449514 & 688282 & 5.6 & 5.1844 & TST \\
\hline CHEMBL1454728 & 688282 & 5.2 & 5.0552 & TST \\
\hline CHEMBL16687 & 688282 & 4.9 & 5.0639 & TST \\
\hline CHEMBL1301372 & 688282 & 4.7 & 5.2719 & TST \\
\hline CHEMBL1367420 & 688282 & 6.4 & 5.0619 & TST \\
\hline CHEMBL1537813 & 688282 & 5.3 & 5.2714 & TST \\
\hline CHEMBL1417782 & 688282 & 4.6 & 5.1142 & TST \\
\hline CHEMBL1422096 & 688282 & 5.3 & 5.1363 & TST \\
\hline CHEMBL1486533 & 688282 & 5.0 & 5.0668 & TST \\
\hline CHEMBL520107 & 688282 & 4.8 & 5.1084 & TST \\
\hline CHEMBL221721 & 688282 & 5.5 & 5.0115 & TST \\
\hline CHEMBL1317884 & 688282 & 5.3 & 4.9796 & TST \\
\hline CHEMBL1433668 & 688282 & 4.5 & 4.942 & TST \\
\hline CHEMBL1372215 & 688282 & 4.6 & 5.113 & TST \\
\hline CHEMBL1381938 & 688282 & 4.5 & 5.1599 & TST \\
\hline CHEMBL1299324 & 688282 & 4.9 & 5.0852 & TST \\
\hline CHEMBL1487918 & 688282 & 4.9 & 5.2342 & TST \\
\hline CHEMBL1361294 & 688282 & 5.0 & 5.1343 & TST \\
\hline CHEMBL1378629 & 688282 & 4.8 & 4.9838 & TST \\
\hline CHEMBL592712 & 688282 & 5.2 & 5.2183 & TST \\
\hline CHEMBL1451302 & 688282 & 6.9 & 5.2718 & TST \\
\hline CHEMBL1607456 & 688282 & 4.9 & 5.0624 & TST \\
\hline CHEMBL1555853 & 688282 & 4.5 & 5.0827 & TST \\
\hline CHEMBL1375546 & 688282 & 4.9 & 5.0575 & TST \\
\hline CHEMBL1451956 & 688282 & 4.6 & 5.0982 & TST \\
\hline CHEMBL1337997 & 688282 & 5.0 & 5.0961 & TST \\
\hline CHEMBL1510870 & 688282 & 4.9 & 5.3507 & TST \\
\hline CHEMBL1595687 & 688282 & 4.9 & 5.1549 & TST \\
\hline CHEMBL1553354 & 688282 & 5.3 & 5.3086 & TST \\
\hline CHEMBL1431312 & 688282 & 4.7 & 5.0426 & TST \\
\hline CHEMBL1339447 & 688282 & 6.4 & 5.1413 & TST \\
\hline
\end{tabular}




\begin{tabular}{|c|c|c|c|c|}
\hline \\
\hline CHEMBL1306319 & 688282 & 5.0 & 5.0742 & TST \\
\hline CHEMBL1473331 & 688282 & 5.1 & 5.1737 & TST \\
\hline CHEMBL1330763 & 688282 & 5.4 & 5.0853 & TST \\
\hline CHEMBL1480897 & 688282 & 6.2 & 5.1572 & TST \\
\hline CHEMBL1309141 & 688282 & 5.3 & 5.1059 & TST \\
\hline CHEMBL1401242 & 688282 & 5.0 & 5.0857 & TST \\
\hline CHEMBL1394938 & 688282 & 5.3 & 5.2753 & TST \\
\hline CHEMBL1424200 & 688282 & 5.1 & 5.1089 & TST \\
\hline CHEMBL 265703 & 688282 & 5.9 & 5.0355 & TST \\
\hline CHEMBL1487254 & 688282 & 5.3 & 5.1719 & TST \\
\hline CHEMBL1418542 & 688282 & 6.4 & 5.2664 & TST \\
\hline CHEMBL1397826 & 688282 & 6.3 & 5.2927 & TST \\
\hline CHEMBL1481029 & 688282 & 5.5 & 5.1623 & TST \\
\hline CHEMBL1392793 & 688282 & 5.0 & 5.0626 & TST \\
\hline CHEMBL1452405 & 688282 & 4.8 & 5.2044 & TST \\
\hline CHEMBL1462886 & 688282 & 5.3 & 4.9842 & TST \\
\hline CHEMBL313737 & 688282 & 4.9 & 5.225 & TST \\
\hline CHEMBL1378195 & 688282 & 4.6 & 5.0869 & TST \\
\hline CHEMBL1517087 & 688282 & 5.3 & 5.0364 & TST \\
\hline CHEMBL1377929 & 688282 & 5.4 & 5.1608 & TST \\
\hline CHEMBL1376785 & 688282 & 4.6 & 5.1004 & TST \\
\hline CHEMBL1609406 & 688282 & 5.6 & 5.1432 & TST \\
\hline CHEMBL1545634 & 688282 & 4.9 & 5.2693 & TST \\
\hline CHEMBL1431520 & 688282 & 4.9 & 5.1072 & TST \\
\hline CHEMBL1313639 & 688282 & 4.8 & 5.0028 & TST \\
\hline CHEMBL1417896 & 688282 & 4.9 & 5.1918 & TST \\
\hline CHEMBL1330718 & 688282 & 5.3 & 5.1345 & TST \\
\hline CHEMBL1576303 & 688282 & 4.9 & 5.0787 & TST \\
\hline CHEMBL1382686 & 688282 & 4.6 & 5.1105 & TST \\
\hline CHEMBL1601692 & 688282 & 4.6 & 5.2093 & TST \\
\hline CHEMBL1569370 & 688282 & 5.1 & 5.1456 & TST \\
\hline CHEMBL1429324 & 688282 & 5.6 & 5.1714 & TST \\
\hline CHEMBL1333047 & 688282 & 5.2 & 5.3133 & TST \\
\hline CHEMBL1390673 & 688282 & 5.3 & 4.9701 & TST \\
\hline CHEMBL1439882 & 688282 & 5.0 & 5.0386 & TST \\
\hline CHEMBL1546161 & 688282 & 4.8 & 5.0874 & TST \\
\hline CHEMBL1530927 & 688282 & 5.3 & 5.2151 & TST \\
\hline CHEMBL1383388 & 688282 & 4.6 & 5.2731 & TST \\
\hline CHEMBL1452910 & 688282 & 6.1 & 5.1501 & TST \\
\hline CHEMBL1322563 & 688282 & 4.6 & 5.0372 & TST \\
\hline CHEMBL465843 & 688282 & 6.8 & 5.1582 & TST \\
\hline CHEMBL1399249 & 688282 & 4.9 & 5.1382 & TST \\
\hline CHEMBL1479506 & 688282 & 4.6 & 5.0074 & TST \\
\hline CHEMBL1520900 & 688282 & 5.1 & 5.1721 & TST \\
\hline CHEMBL1319723 & 688282 & 5.3 & 5.17700 & 00000000005 \\
\hline CHEMBL1594312 & 688282 & 4.7 & 5.1591 & TST \\
\hline CHEMBL1595951 & 688282 & 4.6 & 5.1911 & TST \\
\hline CHEMBL1316828 & 688282 & 4.5 & 5.2306 & TST \\
\hline & & & & 13327 \\
\hline
\end{tabular}




CHEMBL1323605
CHEMBL1515717
CHEMBL1410164
CHEMBL1478986
CHEMBL1335413
CHEMBL1476303
CHEMBL1333708
CHEMBL1422720
CHEMBL1584441
CHEMBL1328536
CHEMBL305978
CHEMBL1538316
CHEMBL1524741
CHEMBL1599179
CHEMBL1566762
CHEMBL1392532
CHEMBL1567886
CHEMBL1442142
CHEMBL1516542
CHEMBL1598764
CHEMBL3193983
CHEMBL1612501
CHEMBL1491012
CHEMBL1548353
CHEMBL1434149
CHEMBL1605725
CHEMBL1440704
CHEMBL1547624
CHEMBL1607818
CHEMBL1348040
CHEMBL1387442
CHEMBL1572390
CHEMBL1256396
CHEMBL1478761
CHEMBL1489836
CHEMBL111545
CHEMBL1541399
CHEMBL1469470
CHEMBL1591107
CHEMBL1395089
CHEMBL1402796
CHEMBL1411130
CHEMBL1424968
CHEMBL1336008
CHEMB1341119

Supplemental Table S2.txt

\begin{tabular}{|c|c|c|c|}
\hline 688282 & 4.9 & 5.1306 & TST \\
\hline 688282 & 4.9 & 4.9698 & TST \\
\hline 688282 & 6.0 & 5.3104 & TST \\
\hline 688282 & 5.0 & 5.1179 & TST \\
\hline 688282 & 4.6 & 5.1023 & TST \\
\hline 688282 & 4.9 & 5.3237 & TST \\
\hline 688282 & 5.4 & 5.1805 & TST \\
\hline 688282 & 5.5 & 5.0919 & TST \\
\hline 688282 & 5.0 & 5.1437 & TST \\
\hline 688282 & 5.5 & 5.2114 & TST \\
\hline 688282 & 4.6 & 5.1743 & TST \\
\hline 688282 & 5.4 & 5.1781 & TST \\
\hline 688282 & 5.0 & 5.1942 & TST \\
\hline 688282 & 5.5 & 5.0989 & TST \\
\hline 688282 & 5.3 & 5.0261 & TST \\
\hline 688282 & 5.0 & 5.2219 & TST \\
\hline 688282 & 5.3 & 5.1847 & TST \\
\hline 688282 & 5.5 & 5.1001 & TST \\
\hline 688282 & 6.3 & 5.1226 & TST \\
\hline 688282 & 4.6 & 4.9654 & TST \\
\hline 688282 & 4.5 & 5.1395 & TST \\
\hline 688282 & 5.3 & 5.1284 & TST \\
\hline 688282 & 5.0 & 5.1111 & TST \\
\hline 688282 & 4.9 & 5.1939 & TST \\
\hline 688282 & 4.8 & 5.2687 & TST \\
\hline 688282 & 5.0 & 5.2169 & TST \\
\hline 688282 & 5.8 & 5.2127 & TST \\
\hline 688282 & 4.8 & 5.1218 & TST \\
\hline 688282 & 5.2 & 5.1135 & TST \\
\hline 688282 & 4.6 & 4.9811 & TST \\
\hline 688282 & 5.0 & 5.0186 & TST \\
\hline 688282 & 6.0 & 5.1276 & TST \\
\hline 688282 & 4.9 & 5.1896 & TST \\
\hline 688282 & 5.0 & 5.1017 & TST \\
\hline 688282 & 4.6 & 5.3309 & TST \\
\hline 688282 & 4.6 & 5.1519 & TST \\
\hline 688282 & 4.8 & 5.141 & TST \\
\hline 688282 & 4.9 & 5.1093 & TST \\
\hline 688282 & 4.6 & 5.0061 & TST \\
\hline 688282 & 6.0 & 5.104 & TST \\
\hline 688282 & 4.9 & 5.17700 & 00000000005 \\
\hline 688282 & 5.2 & 5.0338 & TST \\
\hline 688282 & 5.3 & 5.2292 & TST \\
\hline 688282 & 5.4 & 5.083 & TST \\
\hline 688282 & 4.9 & 5.059 & TST \\
\hline 688282 & 6.1 & 5.2135 & TST \\
\hline 688282 & 4.9 & 5.2669 & TST \\
\hline 688282 & 5.0 & 5.1252 & TST \\
\hline
\end{tabular}




\begin{tabular}{|c|c|c|c|c|c|}
\hline \\
\hline CHEMBL3198214 & 688282 & 5.0 & 5.2457 & TST & \\
\hline CHEMBL1359341 & 688282 & 5.0 & 5.0534 & TST & \\
\hline CHEMBL1554577 & 688282 & 5.0 & 4.9973 & TST & \\
\hline CHEMBL1578156 & 688282 & 4.6 & 5.1106 & TST & \\
\hline CHEMBL1365983 & 688282 & 5.0 & 5.2309 & TST & \\
\hline CHEMBL3192965 & 688282 & 5.5 & 5.0859 & TST & \\
\hline CHEMBL1424036 & 688282 & 5.0 & 5.0512 & TST & \\
\hline CHEMBL1312010 & 688282 & 5.6 & 5.1317 & TST & \\
\hline CHEMBL1501431 & 688282 & 4.9 & 4.9521 & TST & \\
\hline CHEMBL1337912 & 688282 & 5.5 & 5.1427 & TST & \\
\hline CHEMBL1355431 & 688282 & 4.7 & 5.2021 & TST & \\
\hline CHEMBL1506457 & 688282 & 5.0 & 5.2078 & TST & \\
\hline CHEMBL1501745 & 688282 & 5.5 & 5.1883 & TST & \\
\hline CHEMBL1334615 & 688282 & 4.5 & 5.1203 & TST & \\
\hline CHEMBL1586096 & 688282 & 4.5 & 5.1036 & TST & \\
\hline CHEMBL1483442 & 688282 & 4.9 & 5.1062 & TST & \\
\hline CHEMBL1575759 & 688282 & 5.0 & 5.15799 & 99999999995 & TST \\
\hline CHEMBL1478 & 688282 & 5.3 & 5.3077 & TST & \\
\hline CHEMBL1517885 & 688282 & 6.2 & 5.2817 & TST & \\
\hline CHEMBL491748 & 688282 & 5.1 & 5.0217 & TST & \\
\hline CHEMBL1386623 & 688282 & 4.9 & 5.1222 & TST & \\
\hline CHEMBL1426502 & 688282 & 4.6 & 5.2902 & TST & \\
\hline CHEMBL1459294 & 688282 & 5.0 & 5.2035 & TST & \\
\hline CHEMBL553503 & 688282 & 4.9 & 5.2398 & TST & \\
\hline CHEMBL1256751 & 688282 & 5.2 & 5.2344 & TST & \\
\hline CHEMBL1427650 & 688282 & 4.9 & 4.9999 & TST & \\
\hline CHEMBL1485984 & 688282 & 4.9 & 5.261 & TST & \\
\hline CHEMBL1561370 & 688282 & 4.9 & 5.1958 & TST & \\
\hline CHEMBL1159900 & 688282 & 4.9 & 5.2939 & TST & \\
\hline CHEMBL1349063 & 688282 & 5.6 & 5.2887 & TST & \\
\hline CHEMBL1414873 & 688282 & 5.0 & 4.9986 & TST & \\
\hline CHEMBL1372635 & 688282 & 5.0 & 5.0962 & TST & \\
\hline CHEMBL1513223 & 688282 & 5.0 & 5.0983 & TST & \\
\hline CHEMBL1374712 & 688282 & 4.9 & 5.0737 & TST & \\
\hline CHEMBL1598368 & 688282 & 5.9 & 5.2347 & TST & \\
\hline CHEMBL1476146 & 688282 & 5.7 & 5.165 & TST & \\
\hline CHEMBL1378704 & 688282 & 6.1 & 5.246 & TST & \\
\hline CHEMBL1555480 & 688282 & 6.2 & 5.2357 & TST & \\
\hline CHEMBL1367608 & 688282 & 5.1 & 4.9541 & TST & \\
\hline CHEMBL1353501 & 688282 & 5.3 & 5.1982 & TST & \\
\hline CHEMBL1508543 & 688282 & 7.3002 & 5.1028 & TST & \\
\hline CHEMBL1320893 & 688282 & 5.0 & 5.0487 & TST & \\
\hline CHEMBL1481510 & 688282 & 4.6 & 5.2218 & TST & \\
\hline CHEMBL1499616 & 688282 & 4.6 & 5.1296 & TST & \\
\hline CHEMBL1366157 & 688282 & 4.8 & 5.0744 & TST & \\
\hline CHEMBL1402418 & 688282 & 5.0 & 5.0922 & TST & \\
\hline CHEMBL1560015 & 688282 & 4.5 & 5.0708 & TST & \\
\hline CHEMBL538595 & 688282 & 4.5 & 5.1964 & TST & \\
\hline
\end{tabular}




\begin{tabular}{|c|c|c|c|c|}
\hline \multicolumn{5}{|r|}{11 Table S } \\
\hline CHEMBL1524331 & 688282 & 5.6 & 5.1329 & TST \\
\hline CHEMBL1342370 & 688282 & 7.2 & 5.0265 & TST \\
\hline CHEMBL1507718 & 688282 & 4.6 & 5.1591 & TST \\
\hline CHEMBL1450573 & 688282 & 7.6003 & 5.1368 & TST \\
\hline CHEMBL1526851 & 688282 & 4.9 & 5.145 & TST \\
\hline CHEMBL1460698 & 688282 & 5.6 & 5.1422 & TST \\
\hline CHEMBL1399268 & 688282 & 4.6 & 5.0474 & TST \\
\hline CHEMBL1402865 & 688282 & 5.6 & 5.0848 & TST \\
\hline CHEMBL1336035 & 688282 & 5.0 & 5.1204 & TST \\
\hline CHEMBL1309478 & 688282 & 5.0 & 5.0804 & TST \\
\hline CHEMBL1416666 & 688282 & 5.7 & 5.0564 & TST \\
\hline CHEMBL1503397 & 688282 & 4.9 & 5.1221 & TST \\
\hline CHEMBL1510394 & 688282 & 4.9 & 5.0266 & TST \\
\hline CHEMBL1327059 & 688282 & 4.9 & 5.1589 & TST \\
\hline CHEMBL1436761 & 688282 & 5.0 & 5.2548 & TST \\
\hline CHEMBL1300405 & 688282 & 5.1 & 5.1001 & TST \\
\hline CHEMBL1429693 & 688282 & 4.9 & 5.0685 & TST \\
\hline CHEMBL1376685 & 688282 & 6.8 & 5.1693 & TST \\
\hline CHEMBL1463057 & 688282 & 4.7 & 5.0527 & TST \\
\hline CHEMBL1551503 & 688282 & 4.5 & 5.1208 & TST \\
\hline CHEMBL1514819 & 688282 & 5.0 & 5.0469 & TST \\
\hline CHEMBL1515867 & 688282 & 4.5 & 5.0721 & TST \\
\hline CHEMBL1529542 & 688282 & 4.6 & 5.0606 & TST \\
\hline CHEMBL1456906 & 688282 & 4.6 & 5.1657 & TST \\
\hline CHEMBL1314799 & 688282 & 4.5 & 4.95100 & 20000000005 \\
\hline CHEMBL376103 & 688282 & 6.6 & 5.2807 & TST \\
\hline CHEMBL1400630 & 688282 & 5.3 & 5.1174 & TST \\
\hline CHEMBL1559997 & 688282 & 4.5 & 5.1588 & TST \\
\hline CHEMBL20963 & 688282 & 4.8 & 4.9653 & TST \\
\hline CHEMBL10 & 688282 & 6.0 & 5.256 & TST \\
\hline CHEMBL1408861 & 688282 & 5.4 & 5.0258 & TST \\
\hline CHEMBL153062 & 688282 & 4.6 & 5.2037 & TST \\
\hline CHEMBL1336136 & 688282 & 4.9 & 5.1996 & TST \\
\hline CHEMBL535307 & 688282 & 6.5 & 5.1078 & TST \\
\hline CHEMBL1470631 & 688282 & 5.4 & 5.2237 & TST \\
\hline CHEMBL1468601 & 688282 & 4.6 & 5.12 & TST \\
\hline CHEMBL275938 & 688282 & 4.9 & 5.2554 & TST \\
\hline CHEMBL1542101 & 688282 & 4.8 & 5.1914 & TST \\
\hline CHEMBL1610129 & 688282 & 4.5 & 5.0711 & TST \\
\hline CHEMBL1428617 & 688282 & 4.7 & 5.0798 & TST \\
\hline CHEMBL1299532 & 688282 & 4.8 & 5.2387 & TST \\
\hline CHEMBL1559204 & 688282 & 4.5 & 5.1049 & TST \\
\hline CHEMBL1540017 & 688282 & 4.6 & 5.1099 & TST \\
\hline CHEMBL1401211 & 688282 & 4.5 & 5.1303 & TST \\
\hline CHEMBL 1457174 & 688282 & 4.9 & 5.2506 & TST \\
\hline CHEMBL1364184 & 688282 & 5.0 & 5.2379 & TST \\
\hline CHEMBL1302503 & 688282 & 4.9 & 5.1397 & TST \\
\hline CHEMBL1316285 & 688282 & 5.0 & 5.1712 & TST \\
\hline
\end{tabular}




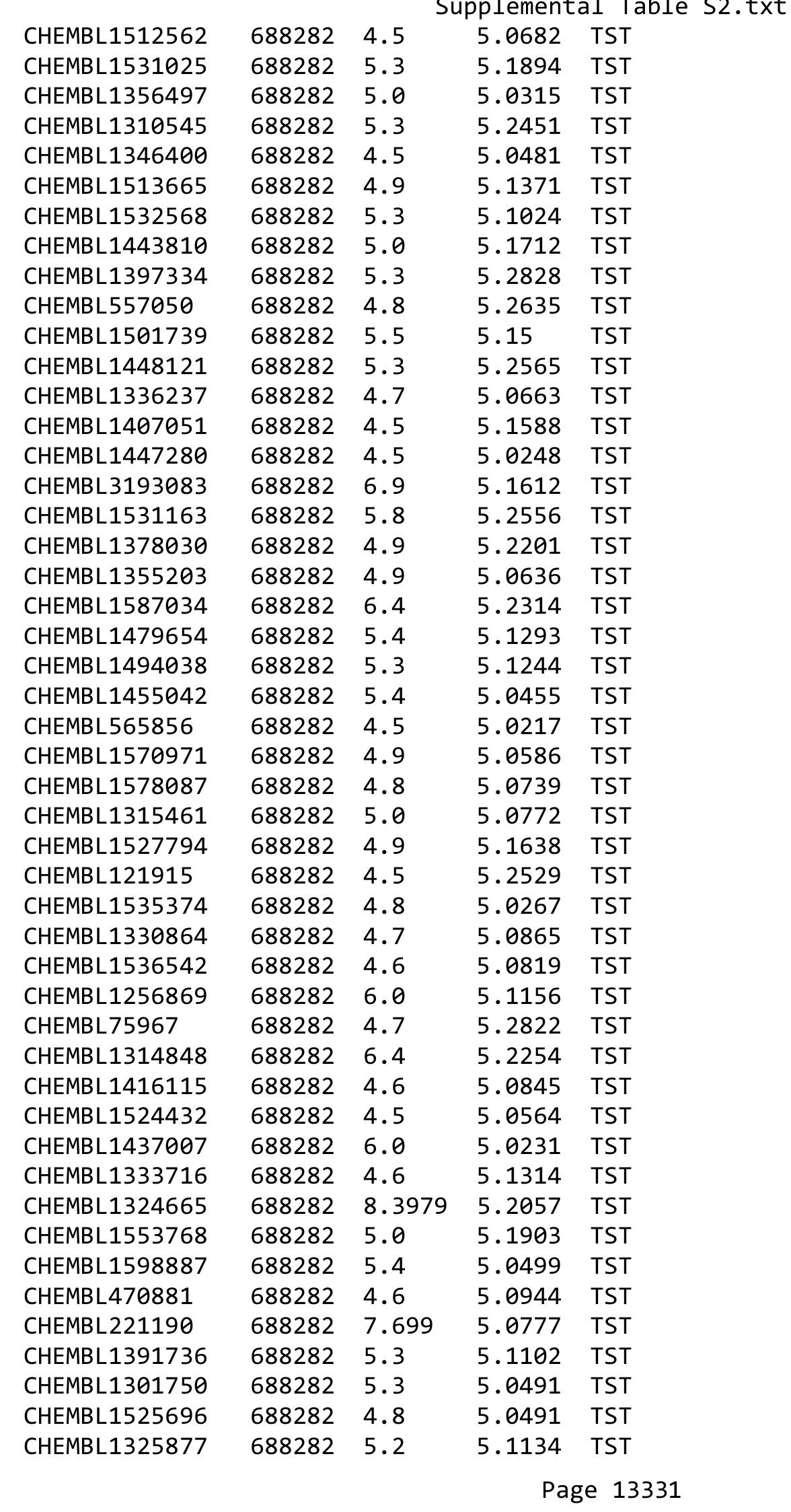




\begin{tabular}{|c|c|c|c|c|}
\hline & & & & e S2 \\
\hline CHEMBL1539517 & 688282 & 5.0 & 5.1383 & TST \\
\hline CHEMBL547833 & 688282 & 4.9 & 5.1838 & TST \\
\hline CHEMBL1519044 & 688282 & 5.3 & 5.0726 & TST \\
\hline CHEMBL1479741 & 688282 & 4.6 & 5.042 & TST \\
\hline CHEMBL1610375 & 688282 & 6.2 & 5.1918 & TST \\
\hline CHEMBL1551195 & 688282 & 5.3 & 5.2159 & TST \\
\hline CHEMBL471397 & 688282 & 5.3 & 5.1377 & TST \\
\hline CHEMBL1606699 & 688282 & 5.9 & 5.1133 & TST \\
\hline CHEMBL1539432 & 688282 & 4.9 & 5.1299 & TST \\
\hline CHEMBL1323385 & 688282 & 4.8 & 4.9695 & TST \\
\hline CHEMBL1487601 & 688282 & 4.9 & 5.1921 & TST \\
\hline CHEMBL1565705 & 688282 & 4.8 & 5.2196 & TST \\
\hline CHEMBL1325093 & 688282 & 5.3 & 5.0851 & TST \\
\hline CHEMBL1611574 & 688282 & 4.6 & 5.0679 & TST \\
\hline CHEMBL1333976 & 688282 & 4.6 & 5.1572 & TST \\
\hline CHEMBL1451520 & 688282 & 5.5 & 5.1646 & TST \\
\hline CHEMBL1590831 & 688282 & 4.9 & 5.1806 & TST \\
\hline CHEMBL1525426 & 688282 & 5.0 & 5.1784 & TST \\
\hline CHEMBL1542927 & 688282 & 4.6 & 5.1613 & TST \\
\hline CHEMBL1570792 & 688282 & 4.9 & 4.9832 & TST \\
\hline CHEMBL1597692 & 688282 & 4.9 & 5.157 & TST \\
\hline CHEMBL1332728 & 688282 & 5.3 & 5.17399 & 99999999995 \\
\hline CHEMBL1611550 & 688282 & 5.9 & 5.1304 & TST \\
\hline CHEMBL1388031 & 688282 & 5.3 & 4.9978 & TST \\
\hline CHEMBL23957 & 688282 & 4.9 & 5.2733 & TST \\
\hline CHEMBL530664 & 688282 & 5.0 & 5.043 & TST \\
\hline CHEMBL1503349 & 688282 & 5.8 & 5.2631 & TST \\
\hline CHEMBL1487677 & 688282 & 4.8 & 5.1472 & TST \\
\hline CHEMBL1328827 & 688282 & 6.0 & 5.0907 & TST \\
\hline CHEMBL3350578 & 688282 & 5.4 & 5.0814 & TST \\
\hline CHEMBL1474561 & 688282 & 4.8 & 5.1247 & TST \\
\hline CHEMBL 2079752 & 688282 & 5.4 & 5.2094 & TST \\
\hline CHEMBL1592470 & 688282 & 4.9 & 5.1699 & TST \\
\hline CHEMBL3197866 & 688282 & 4.6 & 5.1104 & TST \\
\hline CHEMBL1517350 & 688282 & 4.9 & 5.2442 & TST \\
\hline CHEMBL335231 & 688282 & 5.5 & 5.3316 & TST \\
\hline CHEMBL1439775 & 688282 & 4.9 & 5.0537 & TST \\
\hline CHEMBL1509442 & 688282 & 4.5 & 5.3239 & TST \\
\hline CHEMBL1444833 & 688282 & 4.5 & 5.0621 & TST \\
\hline CHEMBL1549739 & 688282 & 6.4 & 5.0464 & TST \\
\hline CHEMBL1424253 & 688282 & 5.0 & 5.0498 & TST \\
\hline CHEMBL1397914 & 688282 & 4.9 & 5.2663 & TST \\
\hline CHEMBL1431695 & 688282 & 4.9 & 5.0995 & TST \\
\hline CHEMBL1546620 & 688282 & 5.5 & 5.0662 & TST \\
\hline CHEMBL1451723 & 688282 & 4.6 & 5.1389 & TST \\
\hline CHEMBL1395620 & 688282 & 5.0 & 5.0954 & TST \\
\hline CHEMBL1310889 & 688282 & 5.3 & 5.0616 & TST \\
\hline CHEMBL1406829 & 688282 & 5.0 & 5.1633 & TST \\
\hline
\end{tabular}




\begin{tabular}{|c|c|c|c|c|}
\hline & & & 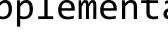 & \\
\hline CHEMBL1460378 & 688282 & 4.7 & 5.0664 & TST \\
\hline CHEMBL1507657 & 688282 & 4.8 & 5.1748 & TST \\
\hline CHEMBL1398704 & 688282 & 4.6 & 5.1297 & TST \\
\hline CHEMBL153036 & 688282 & 4.5 & 5.1734 & TST \\
\hline CHEMBL1593601 & 688282 & 5.0 & 5.1894 & TST \\
\hline CHEMBL1357151 & 688282 & 4.5 & 5.3215 & TST \\
\hline CHEMBL1323549 & 688282 & 4.6 & 5.1348 & TST \\
\hline CHEMBL1368134 & 688282 & 4.9 & 5.1891 & TST \\
\hline CHEMBL1575147 & 688282 & 4.6 & 5.0952 & TST \\
\hline CHEMBL 76897 & 688282 & 4.9 & 5.2781 & TST \\
\hline CHEMBL1316760 & 688282 & 5.0 & 5.1409 & TST \\
\hline CHEMBL1395567 & 688282 & 6.3 & 5.0805 & TST \\
\hline CHEMBL1598717 & 688282 & 5.0 & 5.0763 & TST \\
\hline CHEMBL1409148 & 688282 & 5.0 & 5.1136 & TST \\
\hline CHEMBL1596675 & 688282 & 4.5 & 5.2779 & TST \\
\hline CHEMBL1520991 & 688282 & 5.0 & 5.1568 & TST \\
\hline CHEMBL1543896 & 688282 & 5.3 & 5.2052 & TST \\
\hline CHEMBL1527558 & 688282 & 5.3 & 4.9986 & TST \\
\hline CHEMBL 1605550 & 688282 & 5.0 & 5.1658 & TST \\
\hline CHEMBL1317300 & 688282 & 4.9 & 5.0717 & TST \\
\hline CHEMBL1529490 & 688282 & 5.5 & 5.1799 & TST \\
\hline CHEMBL1573958 & 688282 & 5.0 & 5.1064 & TST \\
\hline CHEMBL3194523 & 688282 & 5.0 & 5.0371 & TST \\
\hline CHEMBL1535689 & 688282 & 5.1 & 5.2922 & TST \\
\hline CHEMBL1487837 & 688282 & 5.9 & 5.2505 & TST \\
\hline CHEMBL1521108 & 688282 & 5.0 & 5.1111 & TST \\
\hline CHEMBL1453240 & 688282 & 4.9 & 5.0723 & TST \\
\hline CHEMBL1587985 & 688282 & 5.3 & 5.1287 & TST \\
\hline CHEMBL1453649 & 688282 & 5.0 & 5.1462 & TST \\
\hline CHEMBL3192719 & 688282 & 5.0 & 5.25899 & 99999999995 \\
\hline CHEMBL1307971 & 688282 & 4.6 & 5.2132 & TST \\
\hline CHEMBL1437258 & 688282 & 4.7 & 5.1506 & TST \\
\hline CHEMBL1338311 & 688282 & 5.4 & 5.2607 & TST \\
\hline CHEMBL1301940 & 688282 & 5.3 & 5.2429 & TST \\
\hline CHEMBL530963 & 688282 & 5.0 & 5.1243 & TST \\
\hline CHEMBL1521453 & 688282 & 4.9 & 5.2478 & TST \\
\hline CHEMBL511207 & 688282 & 4.5 & 5.2379 & TST \\
\hline CHEMBL1548645 & 688282 & 8.1024 & 5.1635 & TST \\
\hline CHEMBL490744 & 688282 & 5.5 & 5.0621 & TST \\
\hline CHEMBL1512123 & 688282 & 5.3 & 5.1232 & TST \\
\hline CHEMBL1517860 & 688282 & 5.0 & 5.1501 & TST \\
\hline CHEMBL23327 & 688282 & 4.9 & 4.9996 & TST \\
\hline CHEMBL1355292 & 688282 & 4.5 & 5.2717 & TST \\
\hline CHEMBL 167423 & 688282 & 4.6 & 5.2323 & TST \\
\hline CHEMBL1306321 & 688282 & 6.1 & 5.0191 & TST \\
\hline CHEMBL1493168 & 688282 & 4.8 & 5.2793 & TST \\
\hline CHEMBL1445500 & 688282 & 4.5 & 5.1406 & TST \\
\hline CHEMBL1409043 & 688282 & 4.9 & 5.115 & TST \\
\hline
\end{tabular}




\begin{tabular}{|c|c|c|c|c|}
\hline & & & & $a \perp 1$ \\
\hline CHEMBL1568022 & 688282 & 5.8 & 5.0264 & TST \\
\hline CHEMBL1255837 & 688282 & 4.6 & 5.1661 & TST \\
\hline CHEMBL1424522 & 688282 & 5.5 & 5.0628 & TST \\
\hline CHEMBL1498584 & 688282 & 4.9 & 5.1689 & TST \\
\hline CHEMBL1515417 & 688282 & 4.7 & 5.1991 & TST \\
\hline CHEMBL1435188 & 688282 & 4.5 & 5.204 & TST \\
\hline CHEMBL1549825 & 688282 & 4.5 & 5.1848 & TST \\
\hline CHEMBL1508674 & 688282 & 5.1 & 5.0712 & TST \\
\hline CHEMBL1575682 & 688282 & 5.3 & 5.2398 & TST \\
\hline CHEMBL1488436 & 688282 & 5.7 & 5.1769 & TST \\
\hline CHEMBL1607991 & 688282 & 4.8 & 5.1049 & TST \\
\hline CHEMBL1606774 & 688282 & 5.6 & 5.1773 & TST \\
\hline CHEMBL1410021 & 688282 & 5.0 & 5.2082 & TST \\
\hline CHEMBL1450004 & 688282 & 4.9 & 5.2276 & TST \\
\hline CHEMBL1383591 & 688282 & 5.0 & 5.1924 & TST \\
\hline CHEMBL1470485 & 688282 & 4.5 & 5.24100 & 00000000005 \\
\hline CHEMBL1493810 & 688282 & 5.1 & 5.2553 & TST \\
\hline CHEMBL1370387 & 688282 & 4.5 & 5.0561 & TST \\
\hline CHEMBL1318278 & 688282 & 5.5 & 5.2979 & TST \\
\hline CHEMBL606166 & 688282 & 4.6 & 5.178 & TST \\
\hline CHEMBL1370320 & 688282 & 5.6 & 5.1937 & TST \\
\hline CHEMBL1459796 & 688282 & 4.9 & 5.2521 & TST \\
\hline CHEMBL186872 & 688282 & 4.9 & 5.3405 & TST \\
\hline CHEMBL1524001 & 688282 & 4.9 & 5.1642 & TST \\
\hline CHEMBL1531919 & 688282 & 5.0 & 5.1053 & TST \\
\hline CHEMBL1328545 & 688282 & 6.4 & 5.2353 & TST \\
\hline CHEMBL1376371 & 688282 & 4.9 & 5.2518 & TST \\
\hline CHEMBL1441425 & 688282 & 4.9 & 5.0656 & TST \\
\hline CHEMBL1466582 & 688282 & 5.0 & 5.1803 & TST \\
\hline CHEMBL3191413 & 688282 & 5.0 & 5.1498 & TST \\
\hline CHEMBL1489461 & 688282 & 5.0 & 5.1237 & TST \\
\hline CHEMBL1517581 & 688282 & 4.9 & 5.1864 & TST \\
\hline CHEMBL160929 & 688282 & 5.6 & 5.3223 & TST \\
\hline CHEMBL1481813 & 688282 & 5.2 & 5.1327 & TST \\
\hline CHEMBL1412519 & 688282 & 5.5 & 5.1119 & TST \\
\hline CHEMBL1520921 & 688282 & 4.6 & 5.2108 & TST \\
\hline CHEMBL1483302 & 688282 & 5.4 & 5.0701 & TST \\
\hline CHEMBL1306064 & 688282 & 5.3 & 5.1317 & TST \\
\hline CHEMBL1454949 & 688282 & 6.0 & 5.1952 & TST \\
\hline CHEMBL1437846 & 688282 & 5.4 & 5.0851 & TST \\
\hline CHEMBL1410969 & 688282 & 5.0 & 5.0877 & TST \\
\hline CHEMBL1519692 & 688282 & 5.0 & 5.0443 & TST \\
\hline CHEMBL1492461 & 688282 & 5.4 & 5.1304 & TST \\
\hline CHEMBL1320607 & 688282 & 5.0 & 5.1511 & TST \\
\hline CHEMBL1416389 & 688282 & 6.5 & 5.2303 & TST \\
\hline CHEMBL1374224 & 688282 & 5.5 & 5.102 & TST \\
\hline CHEMBL405760 & 688282 & 4.9 & 5.0455 & TST \\
\hline CHEMBL1397406 & 688282 & 4.9 & 5.2664 & TST \\
\hline
\end{tabular}




\begin{tabular}{|c|c|c|c|c|}
\hline & & & & $a \perp 1 a$ \\
\hline CHEMBL1526230 & 688282 & 5.4 & 5.164 & TST \\
\hline CHEMBL1548568 & 688282 & 5.2 & 5.1244 & TST \\
\hline CHEMBL1602699 & 688282 & 5.0 & 5.2843 & TST \\
\hline CHEMBL1358989 & 688282 & 6.3 & 5.1554 & TST \\
\hline CHEMBL1336782 & 688282 & 5.6 & 5.1364 & TST \\
\hline CHEMBL1366732 & 688282 & 4.6 & 5.0326 & TST \\
\hline CHEMBL1334342 & 688282 & 4.6 & 5.1222 & TST \\
\hline CHEMBL1610609 & 688282 & 5.0 & 5.0771 & TST \\
\hline CHEMBL1334940 & 688282 & 5.0 & 5.0803 & TST \\
\hline CHEMBL2373654 & 688282 & 5.9 & 5.3125 & TST \\
\hline CHEMBL1516411 & 688282 & 4.8 & 5.1885 & TST \\
\hline CHEMBL1552181 & 688282 & 5.8 & 5.1189 & TST \\
\hline CHEMBL1516313 & 688282 & 6.9 & 5.1556 & TST \\
\hline CHEMBL1327881 & 688282 & 6.3 & 5.2888 & TST \\
\hline CHEMBL2374077 & 688282 & 4.9 & 5.2438 & TST \\
\hline CHEMBL1406879 & 688282 & 4.8 & 5.0584 & TST \\
\hline CHEMBL13791 & 688282 & 6.8 & 5.2133 & TST \\
\hline CHEMBL1303715 & 688282 & 6.4 & 5.0932 & TST \\
\hline CHEMBL1587164 & 688282 & 4.9 & 5.1429 & TST \\
\hline CHEMBL1432712 & 688282 & 5.0 & 5.2402 & TST \\
\hline CHEMBL1512208 & 688282 & 5.0 & 5.1404 & TST \\
\hline CHEMBL1341563 & 688282 & 4.5 & 5.1505 & TST \\
\hline CHEMBL1489370 & 688282 & 4.9 & 5.0629 & TST \\
\hline CHEMBL1551254 & 688282 & 5.4 & 5.2571 & TST \\
\hline CHEMBL65 & 688282 & 6.0 & 4.9443 & TST \\
\hline CHEMBL1513247 & 688282 & 4.6 & 5.2221 & TST \\
\hline CHEMBL1439266 & 688282 & 4.7 & 4.9834 & TST \\
\hline CHEMBL1451493 & 688282 & 4.9 & 5.2489 & TST \\
\hline CHEMBL1512756 & 688282 & 4.9 & 4.9815 & TST \\
\hline CHEMBL1484120 & 688282 & 4.8 & 5.0228 & TST \\
\hline CHEMBL48449 & 688282 & 6.0 & 5.3182 & TST \\
\hline CHEMBL1501292 & 688282 & 4.9 & 5.1135 & TST \\
\hline CHEMBL1535215 & 688282 & 4.6 & 5.1402 & TST \\
\hline CHEMBL101263 & 688282 & 4.5 & 5.3078 & TST \\
\hline CHEMBL1380384 & 688282 & 5.4 & 5.0936 & TST \\
\hline CHEMBL3194456 & 688282 & 4.6 & 5.086 & TST \\
\hline CHEMBL1516530 & 688282 & 5.3 & 4.9775 & TST \\
\hline CHEMBL1377154 & 688282 & 4.9 & 5.0932 & TST \\
\hline CHEMBL1455653 & 688282 & 5.0 & 5.1441 & TST \\
\hline CHEMBL1593056 & 688282 & 5.0 & 5.1037 & TST \\
\hline CHEMBL1605350 & 688282 & 4.5 & 5.1343 & TST \\
\hline CHEMBL1612620 & 688282 & 4.9 & 5.0723 & TST \\
\hline CHEMBL1514836 & 688282 & 5.2 & 5.2699 & TST \\
\hline CHEMBL1417249 & 688282 & 4.8 & 5.0703 & TST \\
\hline CHEMBL1418567 & 688282 & 4.9 & 5.1342 & TST \\
\hline CHEMBL1415442 & 688282 & 5.0 & 5.1412 & TST \\
\hline CHEMBL1424622 & 688282 & 4.6 & 5.0855 & TST \\
\hline CHEMBL1440612 & 688282 & 5.3 & 5.2563 & TST \\
\hline
\end{tabular}




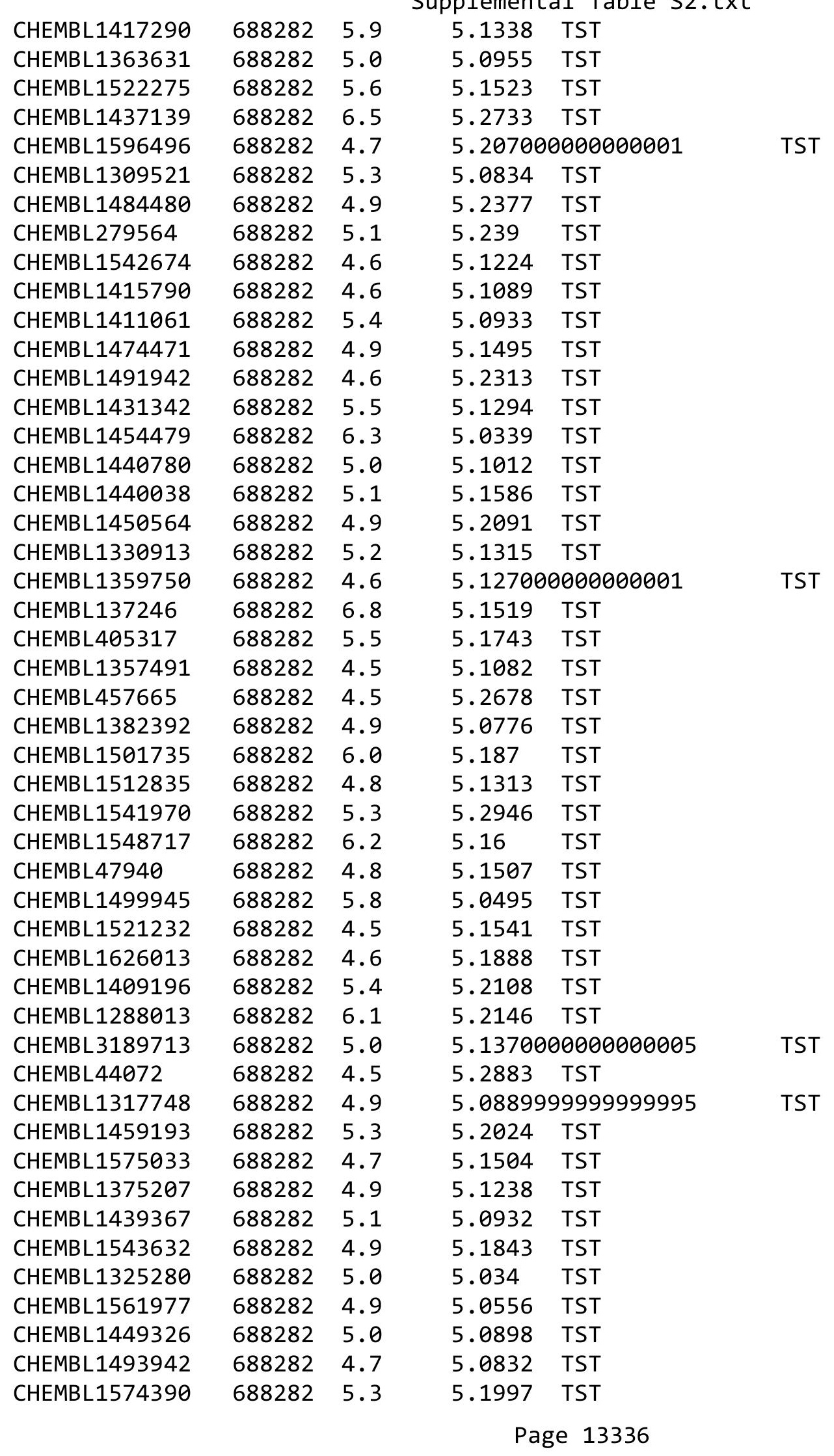




\begin{tabular}{|c|c|c|c|c|c|}
\hline \multirow[b]{2}{*}{ CHEMBL1551962 } & \multicolumn{5}{|c|}{ plemental } \\
\hline & 688282 & 5.0 & 5.1126 & TST & \\
\hline CHEMBL1473438 & 688282 & 6.2 & 5.2551 & TST & \\
\hline CHEMBL1603803 & 688282 & 4.5 & 5.16100 & 00000000005 & TST \\
\hline CHEMBL1608732 & 688282 & 4.9 & 5.2249 & TST & \\
\hline CHEMBL1492643 & 688282 & 4.9 & 5.2007 & TST & \\
\hline CHEMBL1560836 & 688282 & 5.6 & 5.3121 & TST & \\
\hline CHEMBL1300022 & 688282 & 5.3 & 4.9636 & TST & \\
\hline CHEMBL1545039 & 688282 & 4.9 & 5.2064 & TST & \\
\hline CHEMBL1330444 & 688282 & 4.6 & 5.17399 & 99999999995 & TST \\
\hline CHEMBL1546638 & 688282 & 5.3 & 5.1919 & TST & \\
\hline CHEMBL1426729 & 688282 & 5.2 & 5.0867 & TST & \\
\hline CHEMBL1516400 & 688282 & 5.3 & 5.1664 & TST & \\
\hline CHEMBL1377135 & 688282 & 5.1 & 5.1628 & TST & \\
\hline CHEMBL1336793 & 688282 & 4.6 & 5.1078 & TST & \\
\hline CHEMBL50378 & 688282 & 4.9 & 5.1339 & TST & \\
\hline CHEMBL1383175 & 688282 & 5.3 & 5.2226 & TST & \\
\hline CHEMBL1544647 & 688282 & 5.2 & 5.0227 & TST & \\
\hline CHEMBL1445984 & 688282 & 5.7 & 5.2761 & TST & \\
\hline CHEMBL1356115 & 688282 & 4.9 & 5.2179 & TST & \\
\hline CHEMBL1502338 & 688282 & 5.5 & 5.0705 & TST & \\
\hline CHEMBL1540153 & 688282 & 5.0 & 5.1916 & TST & \\
\hline CHEMBL1466475 & 688282 & 5.2 & 5.1122 & TST & \\
\hline CHEMBL1598939 & 688282 & 6.0 & 5.2232 & TST & \\
\hline CHEMBL1488305 & 688282 & 4.6 & 5.1907 & TST & \\
\hline CHEMBL1390021 & 688282 & 5.3 & 4.9923 & TST & \\
\hline CHEMBL64569 & 688282 & 6.6 & 5.1675 & TST & \\
\hline CHEMBL1426284 & 688282 & 5.0 & 5.1607 & TST & \\
\hline CHEMBL1515287 & 688282 & 4.6 & 5.2293 & TST & \\
\hline CHEMBL349253 & 86312 & 7.2218 & 7.2537 & TRN & \\
\hline CHEMBL163544 & 86312 & 7.6778 & 7.5792 & TRN & \\
\hline CHEMBL161303 & 86312 & 7.2518 & 7.3272 & TRN & \\
\hline CHEMBL161720 & 86312 & 7.7959 & 7.5787 & TRN & \\
\hline CHEMBL348989 & 86312 & 6.8539 & 6.7697 & TRN & \\
\hline CHEMBL161612 & 86312 & 7.4559 & 7.4024 & TRN & \\
\hline CHEMBL161640 & 86312 & 6.0862 & 7.0953 & TST & \\
\hline CHEMBL348939 & 86312 & 7.699 & 7.6588 & TRN & \\
\hline CHEMBL353563 & 86312 & 6.3098 & 7.0766 & TST & \\
\hline CHEMBL159910 & 86312 & 6.8477 & 7.4959 & TRN & \\
\hline CHEMBL158767 & 86312 & 7.3188 & 7.7239 & TRN & \\
\hline CHEMBL159765 & 86312 & 7.5686 & 7.46700 & 00000000005 & TRN \\
\hline CHEMBL 350950 & 86312 & 6.8447 & 7.2315 & TST & \\
\hline CHEMBL159909 & 86312 & 7.284 & 7.6984 & TRN & \\
\hline CHEMBL163222 & 86312 & 7.5686 & 7.6296 & TRN & \\
\hline CHEMBL355374 & 86312 & 7.8539 & 7.9948 & TRN & \\
\hline CHEMBL163164 & 86312 & 7.7696 & 7.2369 & TRN & \\
\hline CHEMBL161414 & 86312 & 7.2218 & 7.0917 & TRN & \\
\hline CHEMBL158108 & 86312 & 7.0605 & 7.2401 & TRN & \\
\hline CHEMBL2110174 & 86312 & 7.4685 & 7.4881 & TRN & \\
\hline & & & & 13337 & \\
\hline
\end{tabular}




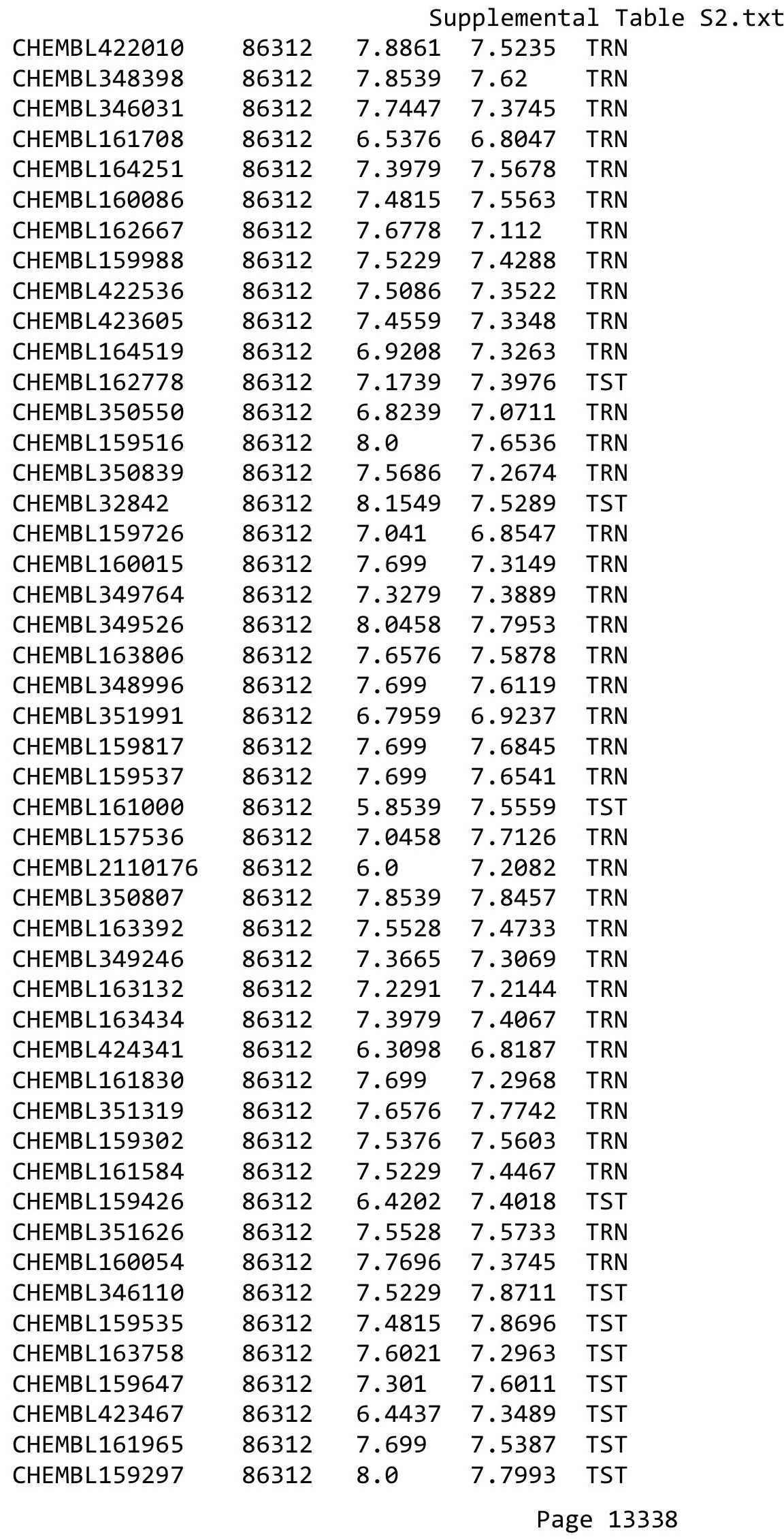




\begin{tabular}{|c|c|c|c|c|c|c|}
\hline & & \multicolumn{5}{|c|}{ Supplemental Table S2.txt } \\
\hline CHEMBL163931 & 86312 & 7.5086 & 7.3621 & TST & & \\
\hline CHEMBL159664 & 86312 & 6.7423 & 7.3909 & TST & & \\
\hline CHEMBL161818 & 86312 & 5.9208 & 6.8514 & TST & & \\
\hline CHEMBL 350842 & 86312 & 6.7959 & 7.1594 & TST & & \\
\hline CHEMBL161132 & 86312 & 7.699 & 7.4622 & TST & & \\
\hline CHEMBL192566 & 955035 & 7.9674 & 8.2207 & TST & & \\
\hline CHEMBL 300389 & 955035 & 6.8995 & 6.8998 & TRN & & \\
\hline CHEMBL202721 & 955035 & 5.16299 & 79999999 & 99 & 5.1625 & TRN \\
\hline CHEMBL65 & 955035 & 7.4033 & 7.4032 & TRN & & \\
\hline CHEMBL483847 & 955035 & 6.2981 & 6.2974 & TRN & & \\
\hline CHEMBL1516890 & 955035 & 4.0465 & 4.0455 & TRN & & \\
\hline CHEMBL1404918 & 955035 & 2.7923 & 2.7946 & TRN & & \\
\hline CHEMBL3392440 & 955035 & 3.4128 & 3.4127 & TRN & & \\
\hline CHEMBL 2005886 & 955035 & 5.3756 & 5.3755 & TRN & & \\
\hline CHEMBL188678 & 955035 & 3.8419 & 3.8435 & TRN & & \\
\hline CHEMBL 210618 & 955035 & 3.1309 & 3.1322 & TRN & & \\
\hline CHEMBL9470 & 955035 & 6.3456 & 5.9682 & TST & & \\
\hline CHEMBL 222102 & 955035 & 3.3848 & 3.3837 & TRN & & \\
\hline CHEMBL 240954 & 955035 & 3.5762 & 4.1588 & TST & & \\
\hline CHEMBL1256459 & 955035 & 6.7298 & 6.7292 & TRN & & \\
\hline CHEMBL 213100 & 955035 & 10.7889 & 10.7894 & TRN & & \\
\hline CHEMBL1643959 & 955035 & 3.2388 & 3.2379 & TRN & & \\
\hline CHEMBL92309 & 955035 & 3.3149 & 2.7749 & TST & & \\
\hline CHEMBL 209148 & 955035 & 4.1116 & 4.113 & TRN & & \\
\hline CHEMBL 373751 & 955035 & 3.0826 & 3.0829 & TRN & & \\
\hline CHEMBL392695 & 955035 & 5.7449 & 5.7453 & TRN & & \\
\hline CHEMBL1590308 & 955035 & 3.182 & 3.4708 & TST & & \\
\hline CHEMBL1909414 & 955035 & 4.6156 & 4.6153 & TRN & & \\
\hline CHEMBL 3186408 & 955035 & 4.3874 & 3.6593 & TST & & \\
\hline CHEMBL2144069 & 955035 & 6.4248 & 6.425 & TRN & & \\
\hline CHEMBL189584 & 955035 & 4.7983 & 4.7988 & TRN & & \\
\hline CHEMBL 221137 & 955035 & 4.5939 & 4.623 & TST & & \\
\hline CHEMBL558642 & 955035 & 5.2788 & 5.2787 & TRN & & \\
\hline CHEMBL3349342 & 955035 & 6.1047 & 6.1049 & TRN & & \\
\hline CHEMBL180127 & 955035 & 4.7943 & 4.7945 & TRN & & \\
\hline CHEMBL1242367 & 955035 & 5.2321 & 5.2334 & TRN & & \\
\hline CHEMBL3199475 & 955035 & 4.8823 & 4.8828 & TRN & & \\
\hline CHEMBL1970879 & 955035 & 6.7721 & 6.7719 & TRN & & \\
\hline CHEMBL515416 & 955035 & 4.0835 & 4.0838 & TRN & & \\
\hline CHEMBL1190711 & 955035 & 5.2774 & 5.2775 & TRN & & \\
\hline CHEMBL393929 & 955035 & 4.082 & 4.0822 & TRN & & \\
\hline CHEMBL573107 & 955035 & 5.2706 & 5.271 & TRN & & \\
\hline CHEMBL412142 & 955035 & 5.0462 & 5.0454 & TRN & & \\
\hline CHEMBL135561 & 955035 & 3.7361 & 3.7344 & TRN & & \\
\hline CHEMBL449158 & 955035 & 6.3601 & 6.3055 & TST & & \\
\hline CHEMBL1788116 & 955035 & 5.0954 & 5.0942 & TRN & & \\
\hline CHEMBL483849 & 955035 & 3.3495 & 3.3481 & TRN & & \\
\hline CHEMBL585951 & 955035 & 6.165 & 6.1666 & TRN & & \\
\hline
\end{tabular}




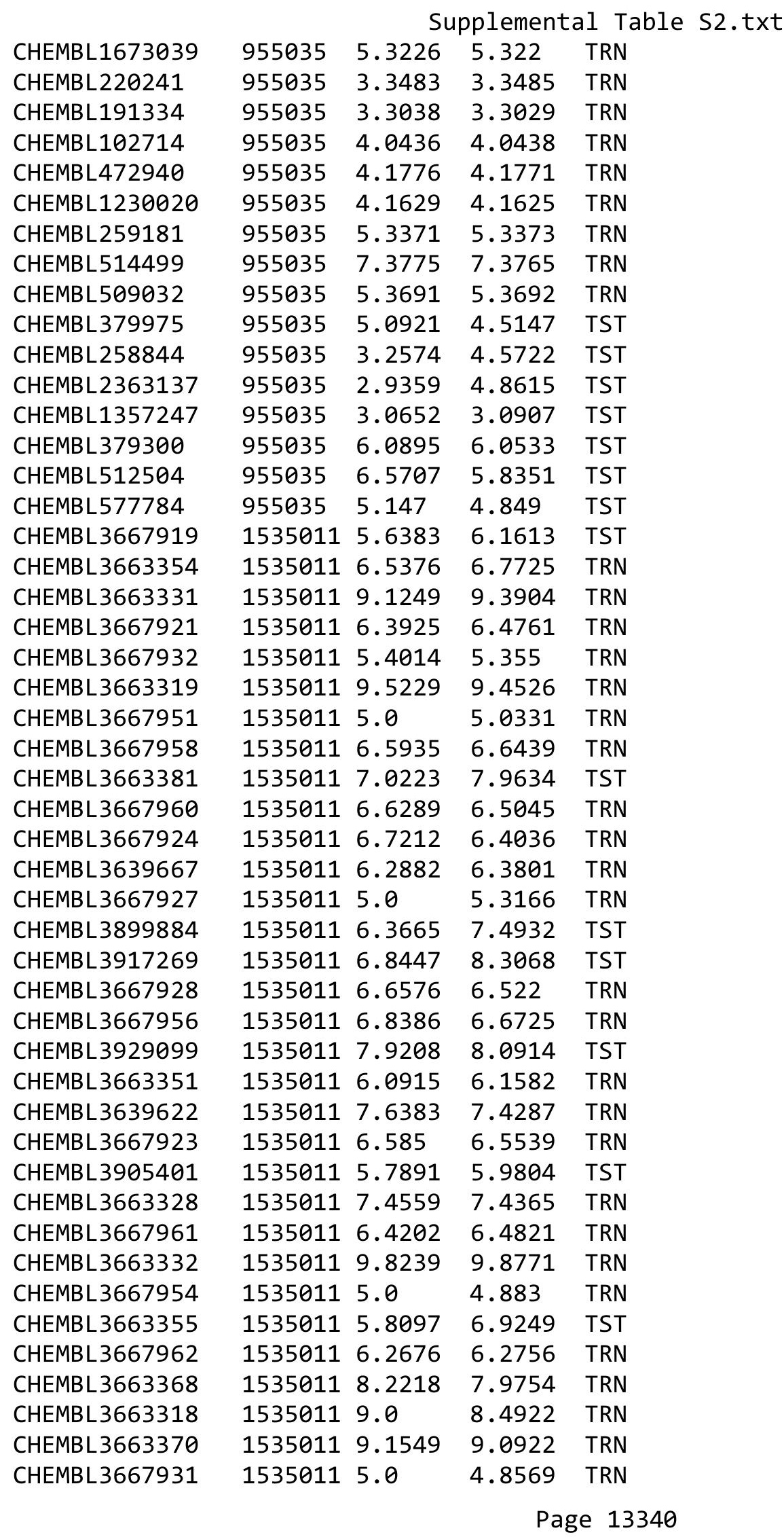


Supplemental Table S2.txt

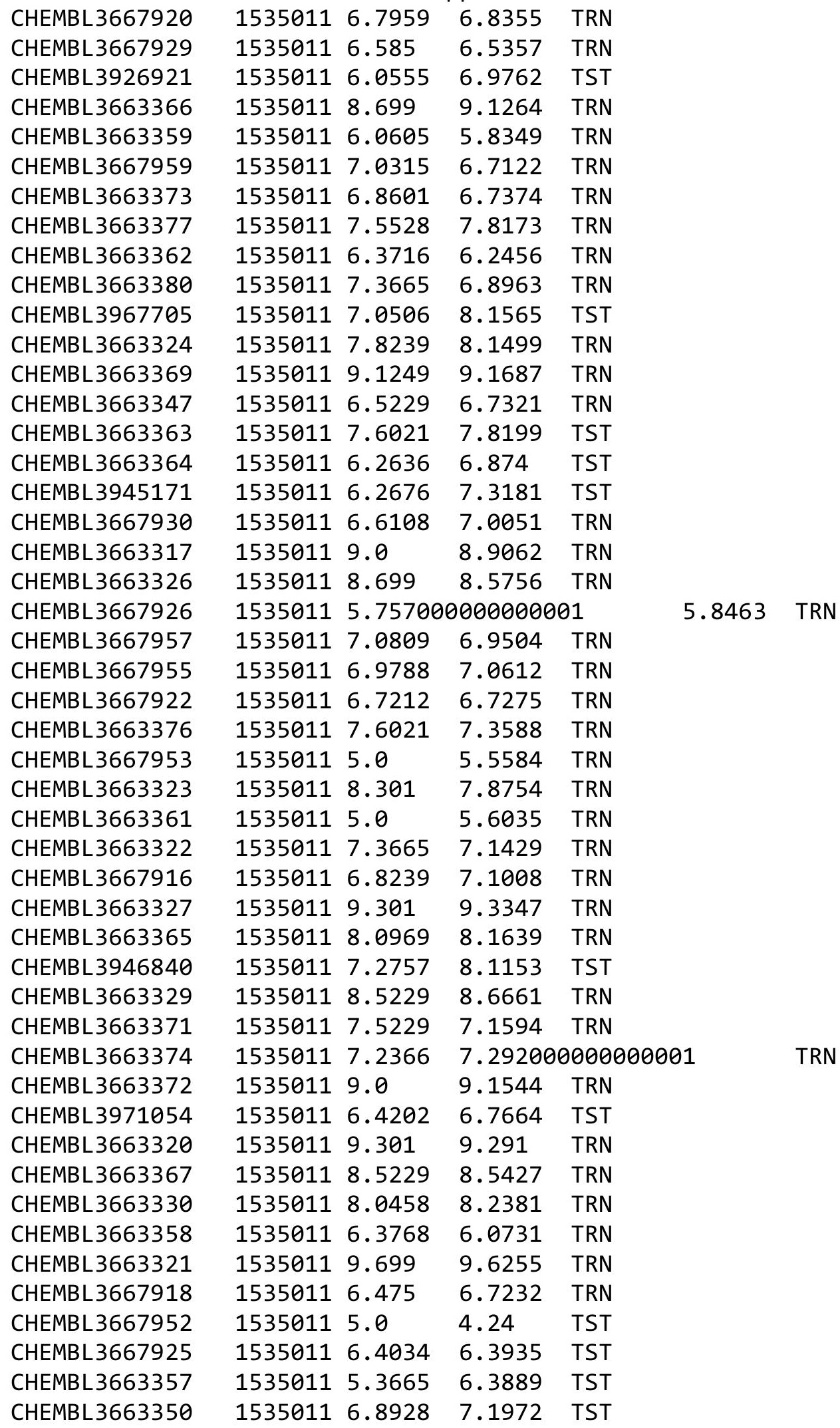

Page 13341 
Supplemental Table S2.txt

\begin{tabular}{|c|c|c|c|c|c|}
\hline CHEMBL3663325 & 1535011 & 9.0969 & 8.7521 & TST & \\
\hline CHEMBL3667915 & 1535011 & 7.4815 & 7.329 & TST & \\
\hline CHEMBL3667917 & 1535011 & 6.7696 & 6.8146 & TST & \\
\hline CHEMBL359093 & 102353 & 4.5229 & 5.1005 & TRN & \\
\hline CHEMBL359155 & 102353 & 3.5229 & 3.9465 & TRN & \\
\hline CHEMBL151411 & 102353 & 5.7696 & 6.4644 & TRN & \\
\hline CHEMBL436263 & 102353 & 4.9208 & 5.6552 & TRN & \\
\hline CHEMBL356876 & 102353 & 4.8861 & 4.518 & TRN & \\
\hline CHEMBL147509 & 102353 & 3.1427 & 3.4756 & TRN & \\
\hline CHEMBL150930 & 102353 & 2.5229 & 2.7504 & TRN & \\
\hline CHEMBL357276 & 102353 & 3.8239 & 2.8449 & TST & \\
\hline CHEMBL261989 & 102353 & 2.6055 & 2.9135 & TRN & \\
\hline CHEMBL147505 & 102353 & 4.3665 & 4.9351 & TRN & \\
\hline CHEMBL147508 & 102353 & 2.5229 & 2.62100 & 00000000004 & TRN \\
\hline CHEMBL358207 & 102353 & 4.8239 & 5.0012 & TRN & \\
\hline CHEMBL 357793 & 102353 & 4.699 & 6.001 & TST & \\
\hline CHEMBL146954 & 102353 & 4.0223 & 6.4916 & TST & \\
\hline CHEMBL149581 & 102353 & 2.5229 & 4.1284 & TRN & \\
\hline CHEMBL151735 & 102353 & 4.301 & 3.4113 & TRN & \\
\hline CHEMBL151620 & 102353 & 6.0 & 5.4622 & TRN & \\
\hline CHEMBL151896 & 102353 & 6.7447 & 6.4141 & TRN & \\
\hline CHEMBL151529 & 102353 & 4.2218 & 4.6134 & TRN & \\
\hline CHEMBL151077 & 102353 & 5.0088 & 4.4622 & TRN & \\
\hline CHEMBL151541 & 102353 & 3.1249 & 2.99899 & 99999999997 & וצנו \\
\hline CHEMBL148867 & 102353 & 3.4437 & 4.8825 & TST & \\
\hline CHEMBL151664 & 102353 & 5.0 & 4.6339 & TRN & \\
\hline CHEMBL151869 & 102353 & 2.5229 & 3.2758 & TRN & \\
\hline CHEMBL436260 & 102353 & 2.6421 & 5.1887 & TST & \\
\hline CHEMBL147512 & 102353 & 5.699 & 5.1949 & TRN & \\
\hline CHEMBL356611 & 102353 & 6.6576 & 6.084 & TRN & \\
\hline CHEMBL347521 & 102353 & \multicolumn{3}{|c|}{3.0410000000000004} & ST \\
\hline CHEMBL357456 & 102353 & 2.6234 & 2.952 & TRN & \\
\hline CHEMBL149530 & 102353 & 4.5686 & 4.561 & TRN & \\
\hline CHEMBL148697 & 102353 & 2.5229 & 2.7989 & TRN & \\
\hline CHEMBL344547 & 102353 & 2.5229 & 4.3907 & TST & \\
\hline CHEMBL146957 & 102353 & 4.6576 & 5.1371 & TRN & \\
\hline CHEMBL150518 & 102353 & 3.8239 & 3.8689 & TRN & \\
\hline CHEMBL149275 & 102353 & 6.3979 & 6.5262 & TRN & \\
\hline CHEMBL356832 & 102353 & 2.5229 & 2.7808 & TRN & \\
\hline CHEMBL 356410 & 102353 & 3.6073 & 3.2311 & TRN & \\
\hline CHEMBL151723 & 102353 & 2.5229 & 3.6982 & TRN & \\
\hline CHEMBL423398 & 102353 & 3.9208 & 4.5049 & TRN & \\
\hline CHEMBL347304 & 102353 & 2.5229 & 2.8054 & TRN & \\
\hline CHEMBL357679 & 102353 & 4.0 & 4.8937 & TRN & \\
\hline CHEMBL146909 & 102353 & 4.1249 & 3.113 & TRN & \\
\hline CHEMBL405364 & 102353 & 4.8239 & 2.8399 & TRN & \\
\hline CHEMBL 345750 & 102353 & 3.9208 & 4.2591 & TRN & \\
\hline CHEMBL356875 & 102353 & 5.301 & 4.9546 & TRN & \\
\hline
\end{tabular}




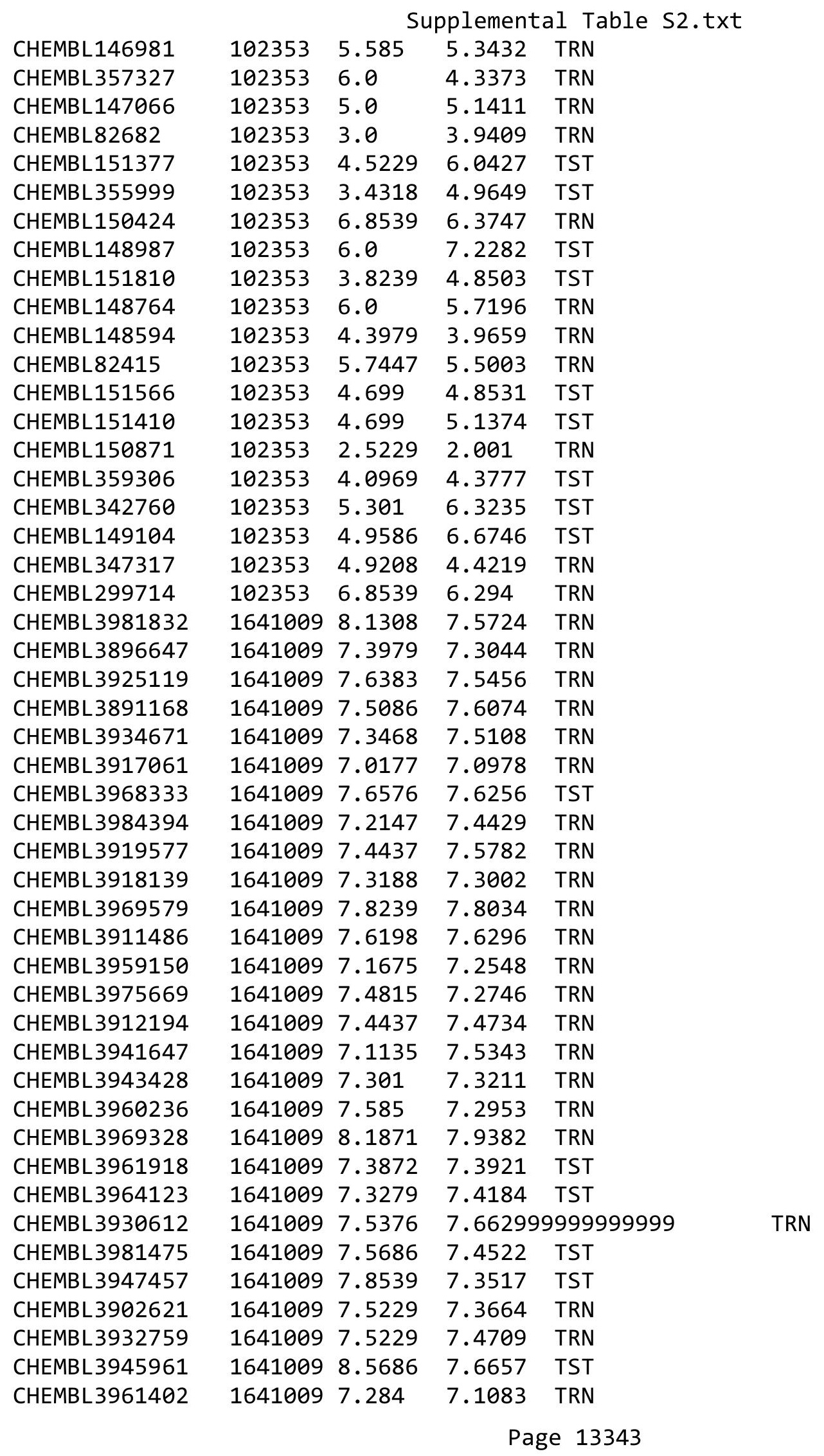


Supplemental Table S2.txt

\begin{tabular}{|c|c|c|c|c|c|}
\hline CHEMBL3948964 & 1641009 & 7.3872 & \multicolumn{2}{|c|}{ 7.343999999999999 } & TRN \\
\hline CHEMBL3938258 & 1641009 & 7.4437 & 7.3409 & TRN & \\
\hline CHEMBL3925781 & 1641009 & 7.6383 & 7.6107 & TRN & \\
\hline CHEMBL3964477 & 1641009 & 7.8239 & 7.5065 & TRN & \\
\hline CHEMBL 3898849 & 1641009 & 7.5086 & 7.7347 & TRN & \\
\hline CHEMBL3983792 & 1641009 & 7.2291 & 7.1388 & TST & \\
\hline CHEMBL3957417 & 1641009 & 7.5686 & \multicolumn{2}{|c|}{7.656000000000001} & TRN \\
\hline CHEMBL3935833 & 1641009 & 6.2857 & 6.6277 & TRN & \\
\hline CHEMBL3960986 & 1641009 & 8.7447 & 7.6549 & TST & \\
\hline CHEMBL 3933374 & 1641009 & 7.4202 & 7.4296 & TRN & \\
\hline CHEMBL3924827 & 1641009 & 8.0757 & 7.8066 & TRN & \\
\hline CHEMBL3905586 & 1641009 & 7.4089 & 7.3927 & TST & \\
\hline CHEMBL3947046 & 1641009 & 7.0862 & 7.0513 & TRN & \\
\hline CHEMBL3915636 & 1641009 & 7.8239 & 7.8531 & TRN & \\
\hline CHEMBL 3921465 & 1641009 & 7.9208 & 8.1045 & TRN & \\
\hline CHEMBL3924675 & 1641009 & 7.5229 & 7.3929 & TRN & \\
\hline CHEMBL3951625 & 1641009 & 7.4318 & 7.0581 & TRN & \\
\hline CHEMBL3976279 & 1641009 & 7.9208 & 8.0176 & TRN & \\
\hline CHEMBL3893452 & 1641009 & 8.0809 & 7.9237 & TRN & \\
\hline CHEMBL3913661 & 1641009 & 7.8539 & 7.7195 & TRN & \\
\hline CHEMBL3946357 & 1641009 & 6.9957 & 7.1983 & TRN & \\
\hline CHEMBL3918653 & 1641009 & 6.857 & 6.8361 & TRN & \\
\hline CHEMBL3906085 & 1641009 & 6.5884 & 6.8583 & TRN & \\
\hline CHEMBL3920366 & 1641009 & 7.8239 & 7.8276 & TRN & \\
\hline CHEMBL 3943600 & 1641009 & 8.0506 & 7.905 & TRN & \\
\hline CHEMBL3897689 & 1641009 & 7.3872 & 7.5325 & TRN & \\
\hline CHEMBL3909305 & 1641009 & 6.4685 & 6.5242 & TRN & \\
\hline CHEMBL3907639 & 1641009 & 6.8794 & \multicolumn{2}{|c|}{6.712999999999999} & I I TIV \\
\hline CHEMBL3944771 & 1641009 & 7.8539 & 7.6075 & TST & \\
\hline CHEMBL 3954531 & 1641009 & 7.7696 & 7.8599 & TRN & \\
\hline CHEMBL3891735 & 1641009 & 7.9208 & 8.0935 & TRN & \\
\hline CHEMBL3976327 & 1641009 & 7.1487 & 7.1183 & TRN & \\
\hline CHEMBL3940202 & 1641009 & 7.3979 & 7.8275 & TRN & \\
\hline CHEMBL3956412 & 1641009 & 6.9318 & 7.1041 & TRN & \\
\hline CHEMBL3928438 & 1641009 & 7.7696 & 7.5736 & TST & \\
\hline CHEMBL3903173 & 1641009 & 7.585 & 7.3229 & TRN & \\
\hline CHEMBL3953801 & 1641009 & 8.8539 & 7.8073 & TST & \\
\hline CHEMBL3977026 & 1641009 & 6.5591 & 7.0979 & TRN & \\
\hline CHEMBL3978007 & 1641009 & 7.4815 & 7.5441 & TRN & \\
\hline CHEMBL3920584 & 1641009 & 6.7852 & 6.6905 & TRN & \\
\hline CHEMBL3909204 & 1641009 & 7.8861 & 7.4521 & TST & \\
\hline CHEMBL3959822 & 1641009 & 7.3279 & 7.5455 & TRN & \\
\hline CHEMBL3917987 & 1641009 & 8.4559 & 8.1226 & TRN & \\
\hline CHEMBL3933034 & 1641009 & 6.6289 & 6.3422 & TRN & \\
\hline CHEMBL3893551 & 1641009 & 8.6021 & \multicolumn{2}{|c|}{7.662999999999999} & TST \\
\hline CHEMBL3953688 & 1641009 & 7.5086 & \multicolumn{2}{|c|}{7.497000000000001} & TRN \\
\hline CHEMBL3944772 & 1641009 & 8.5086 & 7.8491 & TST & \\
\hline CHEMBL3937494 & 1641009 & 7.699 & 7.7009 & TRN & \\
\hline
\end{tabular}


Supplemental Table S2.txt

\begin{tabular}{|c|c|c|c|c|}
\hline CHEMBL3945490 & 1641009 & 7.7212 & 7.6968 & TRN \\
\hline CHEMBL3928149 & 1641009 & 7.4559 & 7.5836 & TST \\
\hline CHEMBL3962210 & 1641009 & 7.7447 & 7.6208 & TST \\
\hline CHEMBL3948760 & 1641009 & 7.9586 & 7.6536 & TRN \\
\hline CHEMBL3933601 & 1641009 & 7.5376 & 7.7622 & TST \\
\hline CHEMBL3944974 & 1641009 & 7.2218 & 7.4289 & TRN \\
\hline CHEMBL3948385 & 1641009 & 6.0985 & 6.96 & TST \\
\hline CHEMBL3982983 & 1641009 & 8.0757 & 7.6459 & TST \\
\hline CHEMBL3951690 & 1641009 & 7.1739 & 7.4157 & TRN \\
\hline CHEMBL3942563 & 1641009 & 7.4949 & 7.6162 & TST \\
\hline CHEMBL3891143 & 1641009 & 8.5086 & 7.5465 & TST \\
\hline CHEMBL3896911 & 1528320 & 7.8539 & 7.7678 & TRN \\
\hline CHEMBL3933866 & 1528320 & 9.3979 & 9.8648 & TRN \\
\hline CHEMBL3912718 & 1528320 & 8.1249 & 7.9061 & TRN \\
\hline CHEMBL3892948 & 1528320 & 8.2441 & 8.3117 & TST \\
\hline CHEMBL3973333 & 1528320 & 10.0 & 9.3937 & TRN \\
\hline CHEMBL3936116 & 1528320 & 7.5638 & 7.7838 & TRN \\
\hline CHEMBL3979854 & 1528320 & 9.301 & 9.7035 & TRN \\
\hline CHEMBL3899062 & 1528320 & 2.6664 & 7.1547 & TST \\
\hline CHEMBL3983613 & 1528320 & 7.8386 & 7.8962 & TRN \\
\hline CHEMBL3948273 & 1528320 & 8.4318 & 8.726 & TRN \\
\hline CHEMBL3985908 & 1528320 & 6.0 & 8.4027 & TRN \\
\hline CHEMBL3945047 & 1528320 & 7.9281 & 6.94799 & 99999999995 \\
\hline CHEMBL3911526 & 1528320 & 6.9255 & 8.888 & TST \\
\hline CHEMBL3954044 & 1528320 & 8.5229 & 9.2261 & TRN \\
\hline CHEMBL3696018 & 1528320 & 7.4134 & 6.9243 & TRN \\
\hline CHEMBL3695973 & 1528320 & 7.1733 & 8.0746 & TRN \\
\hline CHEMBL3695963 & 1528320 & 7.8665 & 6.7427 & TST \\
\hline CHEMBL3920460 & 1528320 & 7.2403 & 7.4057 & TST \\
\hline CHEMBL3946587 & 1528320 & 7.644 & 7.5327 & TST \\
\hline CHEMBL3969754 & 1528320 & 10.0 & 9.8506 & TRN \\
\hline CHEMBL3956936 & 1528320 & 8.1427 & 7.8583 & TRN \\
\hline CHEMBL3696032 & 1528320 & 7.7959 & 8.6113 & TRN \\
\hline CHEMBL3695974 & 1528320 & 5.4772 & 6.8419 & TRN \\
\hline CHEMBL3902422 & 1528320 & 6.0 & 7.426 & TRN \\
\hline CHEMBL3907472 & 1528320 & 6.0 & 7.1387 & TRN \\
\hline CHEMBL3964846 & 1528320 & 7.3344 & 7.8546 & TRN \\
\hline CHEMBL3696010 & 1528320 & 9.1549 & 8.9013 & TRN \\
\hline CHEMBL3897176 & 1528320 & 10.0 & 9.9333 & TRN \\
\hline CHEMBL3961907 & 1528320 & 10.0 & 9.4034 & TRN \\
\hline CHEMBL3696008 & 1528320 & 8.3872 & 9.0497 & TST \\
\hline CHEMBL3980565 & 1528320 & 8.3872 & 7.4738 & TRN \\
\hline CHEMBL3892528 & 1528320 & 7.8153 & 7.5883 & TRN \\
\hline CHEMBL3970511 & 1528320 & 7.6517 & 7.2909 & TRN \\
\hline CHEMBL3696030 & 1528320 & 7.3979 & 7.5561 & TRN \\
\hline CHEMBL3973780 & 1528320 & 9.1549 & 8.747 & TRN \\
\hline CHEMBL3696009 & 1528320 & 9.3979 & 8.4921 & TST \\
\hline CHEMBL3982615 & 1528320 & 5.7212 & 5.9464 & TRN \\
\hline
\end{tabular}




\begin{tabular}{|c|c|c|c|c|c|}
\hline \multicolumn{6}{|c|}{ Supplemental Table s2.txt } \\
\hline CHEMBL 3696015 & 1528320 & 8.0 & 7.9992 & TRN & \\
\hline CHEMBL3967228 & 1528320 & 9.0 & 9.4713 & TRN & \\
\hline CHEMBL 3891847 & 1528320 & 9.0458 & 8.1437 & TRN & \\
\hline CHEMBL 3925960 & 1528320 & 8.6778 & 8.4987 & TRN & \\
\hline CHEMBL 3696001 & 1528320 & 7.1068 & 9.2032 & TST & \\
\hline CHEMBL3967463 & 1528320 & 8.7696 & 8.2222 & TRN & \\
\hline CHEMBL3914741 & 1528320 & 7.7595 & 8.1735 & TST & \\
\hline CHEMBL 3979661 & 1528320 & 9.0 & 7.9359 & TRN & \\
\hline CHEMBL 3696029 & 1528320 & 8.0915 & 7.8166 & TRN & \\
\hline CHEMBL3967644 & 1528320 & 6.0944 & 7.797006 & 0000000001 & TST \\
\hline CHEMBL3951478 & 1528320 & 7.8761 & 8.0409 & TST & \\
\hline CHEMBL3939398 & 1528320 & 7.7932 & 8.1993 & TRN & \\
\hline CHEMBL3962356 & 1528320 & 7.8729 & 6.8629 & TRN & \\
\hline CHEMBL3947341 & 1528320 & 6.0 & 6.8927 & TRN & \\
\hline CHEMBL3964778 & 1528320 & 9.301 & 8.4307 & TRN & \\
\hline CHEMBL3894929 & 1528320 & 9.1549 & 8.7068 & TRN & \\
\hline CHEMBL3912925 & 1528320 & 8.301 & 8.3097 & TRN & \\
\hline CHEMBL 3948174 & 1528320 & 7.9318 & 8.536 & TST & \\
\hline CHEMBL3695976 & 1528320 & 7.76200 & 0000000 & 9.0422 & TST \\
\hline CHEMBL3911422 & 1528320 & 10.0 & 10.1091 & TRN & \\
\hline CHEMBL3905750 & 1528320 & 7.9066 & 8.1495 & TRN & \\
\hline CHEMBL3975618 & 1528320 & 7.4597 & 7.1719 & TRN & \\
\hline CHEMBL3696057 & 1528320 & 3.0 & 9.6493 & TST & \\
\hline CHEMBL 3960581 & 1528320 & 8.2218 & 8.052 & TST & \\
\hline CHEMBL3908379 & 1528320 & 6.6824 & 5.8663 & TRN & \\
\hline CHEMBL3696024 & 1528320 & 6.0 & 9.1765 & TST & \\
\hline CHEMBL3969542 & 1528320 & 8.4318 & 8.7743 & TRN & \\
\hline CHEMBL3923869 & 1528320 & 5.8167 & 7.7404 & TST & \\
\hline CHEMBL 3985710 & 1528320 & 8.6383 & 8.6172 & TRN & \\
\hline CHEMBL3974472 & 1528320 & 5.1003 & 5.2001 & TRN & \\
\hline CHEMBL3897631 & 1528320 & 8.3665 & 8.5285 & TRN & \\
\hline CHEMBL3939975 & 1528320 & 8.7212 & 8.3319 & TRN & \\
\hline CHEMBL3952697 & 1528320 & 9.1549 & 8.9191 & TRN & \\
\hline CHEMBL3969490 & 1528320 & 11.0 & 10.1625 & TRN & \\
\hline CHEMBL3695969 & 1528320 & 8.301 & 8.5252 & TST & \\
\hline CHEMBL3977921 & 1528320 & 7.8827 & 8.118 & TRN & \\
\hline CHEMBL3932371 & 1528320 & 7.9066 & 8.3832 & TRN & \\
\hline CHEMBL3696006 & 1528320 & 8.2007 & 8.904 & TST & \\
\hline CHEMBL 3895957 & 1528320 & 9.1549 & 9.4376 & TRN & \\
\hline CHEMBL3935929 & 1528320 & 9.3979 & 10.055 & TRN & \\
\hline CHEMBL3695968 & 1528320 & 7.7645 & 7.6582 & TST & \\
\hline CHEMBL3942731 & 1528320 & 8.3665 & 8.4646 & TRN & \\
\hline CHEMBL3940881 & 1528320 & 9.0969 & 9.1742 & TRN & \\
\hline CHEMBL3936638 & 1528320 & 10.0 & 9.1979 & TRN & \\
\hline CHEMBL3695975 & 1528320 & 6.978 & 8.92799 & 9999999999 & TST \\
\hline CHEMBL3924957 & 1528320 & 8.2007 & 7.7051 & TRN & \\
\hline CHEMBL 3937310 & 1528320 & 9.699 & 9.4593 & TRN & \\
\hline CHEMBL3920601 & 1528320 & 9.5229 & 8.6469 & TRN & \\
\hline
\end{tabular}


Supplemental Table S2.txt

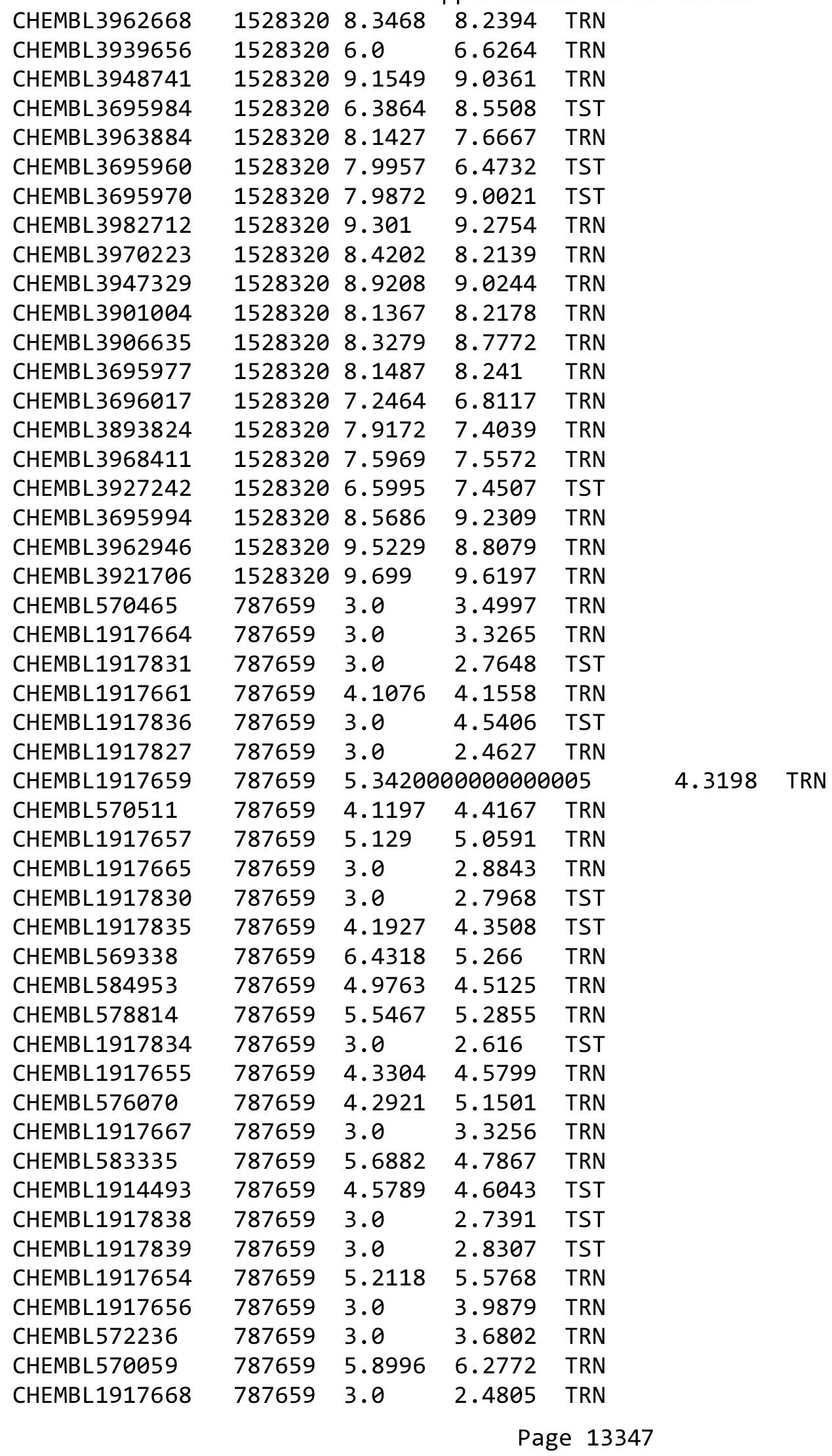




\begin{tabular}{|c|c|c|c|c|}
\hline & & \multicolumn{3}{|c|}{ Supplemental Table S2.txt } \\
\hline CHEMBL1917660 & 787659 & 4.8945 & 4.416 & TRN \\
\hline CHEMBL571359 & 787659 & 4.6696 & 3.9588 & TRN \\
\hline CHEMBL1917829 & 787659 & 3.0 & 3.0025 & TST \\
\hline CHEMBL569557 & 787659 & 5.8996 & 4.9221 & TRN \\
\hline CHEMBL572026 & 787659 & 3.0 & 3.5961 & TRN \\
\hline CHEMBL1917832 & 787659 & 3.0 & 4.9343 & TST \\
\hline CHEMBL1917833 & 787659 & 4.3931 & 4.5746 & TST \\
\hline CHEMBL570466 & 787659 & 4.4911 & 4.919 & TRN \\
\hline CHEMBL569558 & 787659 & 3.0 & 3.9588 & TRN \\
\hline CHEMBL571146 & 787659 & 4.841 & 5.0834 & TRN \\
\hline CHEMBL1917828 & 787659 & 4.9512 & 4.8697 & TRN \\
\hline CHEMBL569115 & 787659 & 6.7212 & 6.3884 & TRN \\
\hline CHEMBL570510 & 787659 & 5.0 & 4.5234 & TRN \\
\hline CHEMBL1917658 & 787659 & 3.0 & 2.9745 & TRN \\
\hline CHEMBL1917837 & 787659 & 3.0 & 3.9811 & TST \\
\hline CHEMBL1917662 & 787659 & 3.0 & 2.7028 & TRN \\
\hline CHEMBL1917671 & 787659 & 3.0 & 3.7797 & TRN \\
\hline CHEMBL1917669 & 787659 & 3.0 & 2.7356 & TRN \\
\hline CHEMBL572024 & 787659 & 5.7375 & 5.9196 & TRN \\
\hline CHEMBL1917663 & 787659 & 4.8794 & 5.1589 & TRN \\
\hline CHEMBL1917666 & 787659 & 4.683 & 4.9033 & TRN \\
\hline CHEMBL1917670 & 787659 & 3.0 & 3.9727 & TST \\
\hline CHEMBL1952113 & 803130 & 8.2218 & 8.0338 & TRN \\
\hline CHEMBL1952108 & 803130 & 6.7905 & 6.5767 & TST \\
\hline CHEMBL1952326 & 803130 & 7.6021 & 6.938 & TRN \\
\hline CHEMBL1952116 & 803130 & 6.6459 & 6.7983 & TRN \\
\hline CHEMBL1952145 & 803130 & 7.8539 & 7.70200 & 0000000001 \\
\hline CHEMBL1952102 & 803130 & 5.4078 & 5.0848 & TST \\
\hline CHEMBL1952119 & 803130 & 6.0737 & 5.9536 & TRN \\
\hline CHEMBL1952107 & 803130 & 7.1612 & 6.8785 & TRN \\
\hline CHEMBL1952122 & 803130 & 7.0605 & 6.8798 & TRN \\
\hline CHEMBL1952143 & 803130 & 8.8239 & 9.1532 & TRN \\
\hline CHEMBL1952131 & 803130 & 5.6162 & 5.9698 & TRN \\
\hline CHEMBL1952126 & 803130 & 8.3979 & 8.3995 & TRN \\
\hline CHEMBL1952120 & 803130 & 6.3605 & 6.5985 & TRN \\
\hline CHEMBL1952332 & 803130 & 7.1024 & 7.3616 & TRN \\
\hline CHEMBL1952105 & 803130 & 6.5003 & 6.6031 & TRN \\
\hline CHEMBL1952121 & 803130 & 7.4202 & 7.2009 & TRN \\
\hline CHEMBL1952124 & 803130 & 8.0 & 7.7161 & TRN \\
\hline CHEMBL1952141 & 803130 & 8.1549 & 6.9692 & TST \\
\hline CHEMBL1952117 & 803130 & 6.5751 & 6.8877 & TRN \\
\hline CHEMBL1952125 & 803130 & 7.9586 & 7.8888 & TRN \\
\hline CHEMBL1952110 & 803130 & 5.4868 & 3.5214 & TST \\
\hline CHEMBL1952147 & 803130 & 7.1871 & 7.2138 & TST \\
\hline CHEMBL1952142 & 803130 & 9.0 & 8.9204 & TRN \\
\hline CHEMBL1952104 & 803130 & 5.585 & 5.0069 & TST \\
\hline CHEMBL1952331 & 803130 & 7.7447 & 7.1394 & TST \\
\hline CHEMBL1952138 & 803130 & 6.8761 & 7.2054 & TRN \\
\hline
\end{tabular}




\begin{tabular}{|c|c|c|c|c|c|}
\hline & & \multicolumn{4}{|c|}{ Supplemental Table S2.txt } \\
\hline CHEMBL1952109 & 803130 & 6.4949 & 6.8396 & TRN & \\
\hline CHEMBL1952135 & 803130 & 7.8539 & 7.5956 & TRN & \\
\hline CHEMBL1952128 & 803130 & 6.8996 & 6.9266 & TRN & \\
\hline CHEMBL1952111 & 803130 & 4.0 & 3.8155 & TRN & \\
\hline CHEMBL1949698 & 803130 & 6.3979 & 6.5657 & TRN & \\
\hline CHEMBL1952101 & 803130 & 6.5498 & 6.4862 & TRN & \\
\hline CHEMBL1952118 & 803130 & 6.6234 & 6.7026 & TRN & \\
\hline CHEMBL1952129 & 803130 & 6.9666 & 6.74700 & 0000000001 & TRN \\
\hline CHEMBL1952324 & 803130 & 6.4306 & 6.6726 & TST & \\
\hline CHEMBL1952137 & 803130 & 7.8539 & 7.6408 & TRN & \\
\hline CHEMBL1952328 & 803130 & 6.8861 & 7.2043 & TST & \\
\hline CHEMBL1952103 & 803130 & 6.0696 & 6.1631 & TRN & \\
\hline CHEMBL1952112 & 803130 & 6.8097 & 6.7387 & TRN & \\
\hline CHEMBL1952136 & 803130 & 8.0458 & 8.184 & TRN & \\
\hline CHEMBL1952114 & 803130 & 7.4559 & 7.0175 & TRN & \\
\hline CHEMBL1952127 & 803130 & 7.1675 & 7.1295 & TRN & \\
\hline CHEMBL1952325 & 803130 & 7.2441 & 6.6291 & TST & \\
\hline CHEMBL1952327 & 803130 & 6.6635 & 6.715 & TST & \\
\hline CHEMBL1952115 & 803130 & 7.1135 & 7.1051 & TRN & \\
\hline CHEMBL1952106 & 803130 & 6.3635 & 6.5621 & TRN & \\
\hline CHEMBL1952330 & 803130 & 6.8962 & 8.0196 & TST & \\
\hline CHEMBL1952146 & 803130 & 7.0177 & 6.6503 & TST & \\
\hline CHEMBL1952123 & 803130 & 6.4737 & 6.6302 & TRN & \\
\hline CHEMBL1952144 & 803130 & 8.2218 & 8.4653 & TRN & \\
\hline CHEMBL1952139 & 803130 & 6.4989 & 6.688 & TRN & \\
\hline CHEMBL1952140 & 803130 & 6.3925 & 6.4697 & TRN & \\
\hline CHEMBL1952134 & 803130 & 8.301 & 8.0082 & TRN & \\
\hline CHEMBL1952130 & 803130 & 6.7825 & 6.8648 & TRN & \\
\hline CHEMBL294136 & 88176 & 4.0 & 3.9871 & TRN & \\
\hline CHEMBL299689 & 88176 & 4.0 & 4.0098 & TRN & \\
\hline CHEMBL58400 & 88176 & 4.0 & 3.9919 & TRN & \\
\hline CHEMBL58868 & 88176 & 4.0 & 3.9729 & TRN & \\
\hline CHEMBL58442 & 88176 & 4.0 & 4.80399 & 9999999999 & TST \\
\hline CHEMBL59060 & 88176 & 5.3279 & 5.2129 & TRN & \\
\hline CHEMBL 304238 & 88176 & 4.0 & 3.9435 & TRN & \\
\hline CHEMBL59187 & 88176 & 5.9586 & 5.99100 & 00000000005 & In \\
\hline CHEMBL58864 & 88176 & 4.0 & 4.0855 & TRN & \\
\hline CHEMBL57599 & 88176 & 4.0 & 3.9318 & TRN & \\
\hline CHEMBL60125 & 88176 & 5.5686 & 5.5945 & TRN & \\
\hline CHEMBL58537 & 88176 & 4.0 & 3.9601 & TRN & \\
\hline CHEMBL294165 & 88176 & 5.4318 & 4.3277 & TST & \\
\hline CHEMBL 300380 & 88176 & 4.0 & 3.9913 & TRN & \\
\hline CHEMBL61183 & 88176 & 4.0 & 3.5976 & TST & \\
\hline CHEMBL59561 & 88176 & 5.5528 & 5.585 & TRN & \\
\hline CHEMBL 300374 & 88176 & 4.0 & 3.991 & TRN & \\
\hline CHEMBL431327 & 88176 & 4.0 & 3.9935 & TRN & \\
\hline CHEMBL432510 & 88176 & 4.0 & 4.0594 & TRN & \\
\hline CHEMBL293281 & 88176 & 4.0 & 3.9359 & TRN & \\
\hline
\end{tabular}




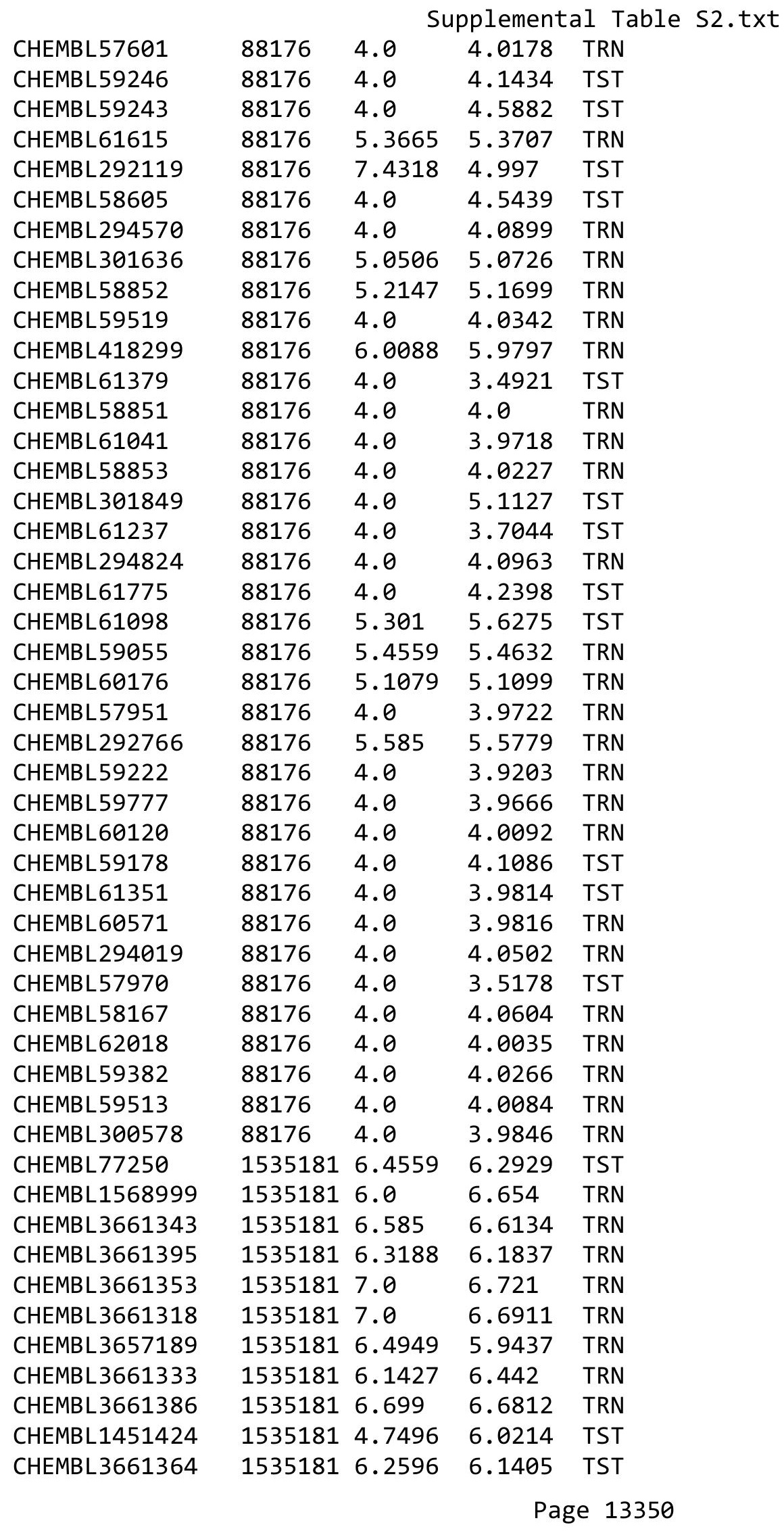


Supplemental Table S2.txt

\begin{tabular}{|c|c|c|c|c|}
\hline HEMBI & 535181 & 6.6576 & & TST \\
\hline & & 5.6925 & & \\
\hline HFMRI & 181 & 91 & & \\
\hline HEMBL2031927 & 35181 & 7.0 & & \\
\hline HEMBL3661377 & 535181 & 6.2366 & 8248 & \\
\hline HEMBL3661402 & 535181 & 5376 & 8132 & \\
\hline HEMBL 203 & 181 & & 7202 & \\
\hline HEMBL363 & 35181 & & & \\
\hline HEMBL 2098452 & 535181 & 7.0 & 6.6006 & \\
\hline HEMBL1469609 & 535181 & 5.8447 & 7103 & \\
\hline HEMBL11524 & 535 & 5 . & 6077 & \\
\hline AEMBL3 & 81 & 528 & 2782 & \\
\hline HEMBL3 & & & 3327 & \\
\hline HEMBL3661362 & 535181 & 6.7959 & 7184 & \\
\hline HEMBL3263303 & 535181 & 7.0 & 6562 & \\
\hline HEMBL3 & 31 & & 308 & \\
\hline HEMBL & 31 & & & Miv \\
\hline HEMBL3 & 81 & 7. & 5972 & \\
\hline HEMBL67158 & 535181 & 7. & 721 & \\
\hline HEMBL 366 & 31 & & 7696 & RIN \\
\hline HEMBL3 & 31 & 7 & 229 & RI \\
\hline AEME & 1 & & 06 & RN \\
\hline HEMBL & 81 & 6 & 114 & RN \\
\hline HEMBL 366 & 81 & & 3386 & TRN \\
\hline AEMBL366 & 31 & 6. & 93 & IRN \\
\hline HEMBL3 & $\perp$ & 5. & 933 & 「RN \\
\hline HEME & 31 & & & $\mathrm{RN}$ \\
\hline HEME & 81 & 7. & 923 & ST \\
\hline HEMBL3 & & 7 & & $\Gamma \mathrm{RN}$ \\
\hline HEMBL366 & 535181 & 7. & 7117 & TRN \\
\hline HEMBL & 53 & & 327 & TRN \\
\hline HFM & 31 & & 335 & ST \\
\hline נ & & & 479 & TRN \\
\hline HEMBL 366 & 535 & 7.0 & & $\mathrm{RN}$ \\
\hline HEMBL3661401 & 535181 & 4. & 5842 & TST \\
\hline HFMRI 3 & 53 & 1 & 487 & TRN \\
\hline (זM & 31 & 6 & 08 & ГRN \\
\hline HEMBL36 & & & 7039 & TST \\
\hline HEMBL3 & 535 & 6 . & 19 & TRN \\
\hline HEMBL & 31 & 208 & 326 & 「RN \\
\hline HEMBL3 & 525. & 6 & 3888 & TRN \\
\hline HEMBL3 & 31 & 3.5 & 074 & ST \\
\hline HEMBL3 & 535181 & 7. & & ГRN \\
\hline HEMBL 36 & 535 & 7. & 978 & TR \\
\hline 西 & & & & \\
\hline HEMBL 36 & 1535181 & 7.1549 & & \\
\hline CHEMBL11 & 1535181 & 4.9547 & 5.965 & \\
\hline CHEMBL1733373 & 1535181 & 6.5229 & 5.3666 & ב \\
\hline
\end{tabular}

Page 13351 
Supplemental Table S2.txt

\begin{tabular}{|c|c|c|c|c|}
\hline CHEMBL192293 & 1535181 & 6.7212 & 6.5633 & TRN \\
\hline CHEMBL3661379 & 1535181 & 7.0 & 6.7122 & TST \\
\hline CHEMBL3657193 & 1535181 & 6.7447 & 6.2658 & TRN \\
\hline CHEMBL 3661322 & 1535181 & 5.5406 & 6.0693 & TRN \\
\hline CHEMBL3661399 & 1535181 & 5.9508 & 5.8234 & TRN \\
\hline CHEMBL3661418 & 1535181 & 6.0706 & 5.8104 & TST \\
\hline CHEMBL10835 & 1535181 & 6.585 & 5.9023 & TST \\
\hline CHEMBL3661390 & 1535181 & 6.4437 & 6.1325 & TRN \\
\hline CHEMBL3661413 & 1535181 & 4.4089 & 4.7849 & TST \\
\hline CHEMBL3661417 & 1535181 & 6.699 & 6.1159 & TST \\
\hline CHEMBL3661368 & 1535181 & 7.0 & 6.7229 & TRN \\
\hline CHEMBL1458 & 1535181 & 6.7959 & 6.7229 & TRN \\
\hline CHEMBL1413197 & 1535181 & 6.2596 & 6.1688 & TRN \\
\hline CHEMBL3661348 & 1535181 & 5.6576 & 6.4986 & TRN \\
\hline CHEMBL1713120 & 1535181 & 6.3188 & 5.9493 & TRN \\
\hline CHEMBL1231909 & 1535181 & 6.5376 & 6.862 & TRN \\
\hline CHEMBL3661321 & 1535181 & 6.4815 & 5.5565 & TRN \\
\hline CHEMBL3661406 & 1535181 & 6.1427 & 5.4731 & TST \\
\hline CHEMBL3661416 & 1535181 & 6.5229 & 5.4995 & TST \\
\hline CHEMBL 3661344 & 1535181 & 4.8239 & 6.0146 & TRN \\
\hline CHEMBL 3661329 & 1535181 & 6.9586 & 6.2607 & TRN \\
\hline CHEMBL3661349 & 1535181 & 6.8539 & 6.7064 & TRN \\
\hline CHEMBL 3661347 & 1535181 & 5.301 & 6.0189 & TRN \\
\hline CHEMBL3661320 & 1535181 & 7.0 & 6.4025 & TRN \\
\hline CHEMBL3661366 & 1535181 & 5.0809 & 5.9654 & TRN \\
\hline CHEMBL 3661372 & 1535181 & 6.7447 & 6.6822 & TRN \\
\hline CHEMBL11405 & 1535181 & 6.3979 & 6.3799 & TRN \\
\hline CHEMBL 3657187 & 1535181 & 5.5376 & 6.1139 & TST \\
\hline CHEMBL3661335 & 1535181 & 6.6198 & 6.442 & TRN \\
\hline CHEMBL3661360 & 1535181 & 7.0 & 6.7536 & TRN \\
\hline CHEMBL3661410 & 1535181 & 6.7212 & 6.2644 & TST \\
\hline CHEMBL 3661411 & 1535181 & 6.8239 & 6.2053 & TST \\
\hline CHEMBL 3657186 & 1535181 & 6.3188 & 6.4022 & TRN \\
\hline CHEMBL1557995 & 1535181 & 5.6021 & 6.0157 & TRN \\
\hline CHEMBL1533919 & 1535181 & 7.0 & 6.7146 & TRN \\
\hline CHEMBL3661400 & 1535181 & 7.0 & 6.7365 & TRN \\
\hline CHEMBL191968 & 1535181 & 6.6383 & 6.01 & TRN \\
\hline CHEMBL3661389 & 1535181 & 5.8239 & 6.6842 & TRN \\
\hline CHEMBL3661405 & 1535181 & 4.7447 & 4.2814 & TST \\
\hline CHEMBL162598 & 1535181 & 6.3279 & 6.1308 & TST \\
\hline CHEMBL 3661409 & 1535181 & 5.8665 & 5.4493 & TST \\
\hline CHEMBL 3661341 & 1535181 & 6.5229 & 6.3106 & TRN \\
\hline CHEMBL 3661388 & 1535181 & 5.8239 & 6.7047 & TRN \\
\hline CHEMBL3661337 & 1535181 & 6.9208 & 6.721 & TRN \\
\hline CHEMBL 3661317 & 1535181 & 7.0 & 6.0601 & TRN \\
\hline CHEMBL 3661387 & 1535181 & 6.9586 & \multicolumn{2}{|c|}{6.372000000000001} \\
\hline CHEMBL 3661403 & 1535181 & 6.5086 & 4.8887 & TST \\
\hline CHEMBL3661378 & 1535181 & 6.8239 & 6.5009 & TRN \\
\hline
\end{tabular}

Page 13352 
Supplemental Table S2.txt

\begin{tabular}{|c|c|c|c|c|c|}
\hline CHEMBL3661404 & 1535181 & 4.4685 & 4.1811 & TST & \\
\hline CHEMBL3657191 & 1535181 & 6.4685 & 5.9023 & TST & \\
\hline CHEMBL3661407 & 1535181 & 4.4559 & 4.6135 & TST & \\
\hline CHEMBL193888 & 1535181 & 6.7959 & 6.7362 & TRN & \\
\hline CHEMBL1546415 & 1535181 & 5.6576 & 6.3636 & TRN & \\
\hline CHEMBL1609005 & 1535181 & 7.0 & 6.7755 & TRN & \\
\hline CHEMBL 2029374 & 1535181 & 6.6383 & 6.6658 & TRN & \\
\hline CHEMBL 2031923 & 1535181 & 7.0 & 6.6747 & TST & \\
\hline CHEMBL3661376 & 1535181 & 6.2757 & 6.6443 & TRN & \\
\hline CHEMBL3661327 & 1535181 & 6.1675 & 6.6797 & TRN & \\
\hline CHEMBL1379831 & 1535181 & 5.7212 & 6.7292 & TRN & \\
\hline CHEMBL3661352 & 1535181 & 5.6021 & 6.7621 & TRN & \\
\hline CHEMBL3661356 & 1535181 & 7.0 & 6.7541 & TRN & \\
\hline CHEMBL 2031931 & 1535181 & 7.0 & 6.6497 & TRN & \\
\hline CHEMBL3661392 & 1535181 & 5.1192 & 5.9349 & TRN & \\
\hline CHEMBL365939 & 1535181 & 5.857 & 6.0696 & TRN & \\
\hline CHEMBL3661338 & 1535181 & 6.2366 & 5.7103 & TRN & \\
\hline CHEMBL3661393 & 1535181 & 5.6576 & 6.16299 & 9999999999 & TRN \\
\hline CHEMBL 2031928 & 1535181 & 7.0 & 6.6905 & TRN & \\
\hline CHEMBL1360431 & 1535181 & 7.1549 & 6.4904 & TRN & \\
\hline CHEMBL3661397 & 1535181 & 5.4237 & 6.0669 & TRN & \\
\hline CHEMBL3661359 & 1535181 & 5.7721 & 6.7229 & TRN & \\
\hline CHEMBL3661339 & 1535181 & 6.7447 & 6.3106 & TRN & \\
\hline CHEMBL3661358 & 1535181 & 6.6198 & 6.721 & TRN & \\
\hline CHEMBL1573741 & 1535181 & 6.3665 & 5.9612 & TRN & \\
\hline CHEMBL1330191 & 1535181 & 7.0458 & 6.7229 & TRN & \\
\hline CHEMBL 3661340 & 1535181 & 6.2147 & 5.7103 & TRN & \\
\hline CHEMBL3661328 & 1535181 & 6.0 & 5.9998 & TRN & \\
\hline CHEMBL3661367 & 1535181 & 7.0 & 6.7765 & TST & \\
\hline CHEMBL3661371 & 1535181 & 6.7447 & 6.5967 & TST & \\
\hline CHEMBL3661396 & 1535181 & 7.0 & 6.3785 & TST & \\
\hline CHEMBL3661346 & 1535181 & 4.6383 & 5.9386 & TST & \\
\hline CHEMBL3657188 & 1535181 & 6.8861 & 6.598 & TST & \\
\hline CHEMBL 75476 & 208754 & 5.0088 & 4.6794 & TST & \\
\hline CHEMBL 75556 & 208754 & 5.2218 & 4.5166 & TRN & \\
\hline CHEMBL305611 & 208754 & 5.3665 & 5.1218 & TRN & \\
\hline CHEMBL 75501 & 208754 & 4.58 & 4.9206 & TRN & \\
\hline CHEMBL 72371 & 208754 & 5.7959 & 5.53 & TRN & \\
\hline CHEMBL306172 & 208754 & 4.3665 & 3.9506 & TRN & \\
\hline CHEMBL310263 & 208754 & 3.6819 & 3.725 & TRN & \\
\hline CHEMBL309184 & 208754 & 5.1739 & 4.7322 & TRN & \\
\hline CHEMBL 73591 & 208754 & 5.5376 & 4.9831 & TRN & \\
\hline CHEMBL 76322 & 208754 & 5.7959 & 5.6546 & TRN & \\
\hline CHEMBL307015 & 208754 & 5.1612 & 5.8109 & TRN & \\
\hline CHEMBL306790 & 208754 & 5.7352 & 5.8733 & TRN & \\
\hline CHEMBL310936 & 208754 & 6.7696 & 6.4551 & TRN & \\
\hline CHEMBL446665 & 208754 & 3.9918 & 4.2935 & TRN & \\
\hline CHEMBL 74847 & 208754 & 5.301 & 6.0422 & TRN & \\
\hline
\end{tabular}




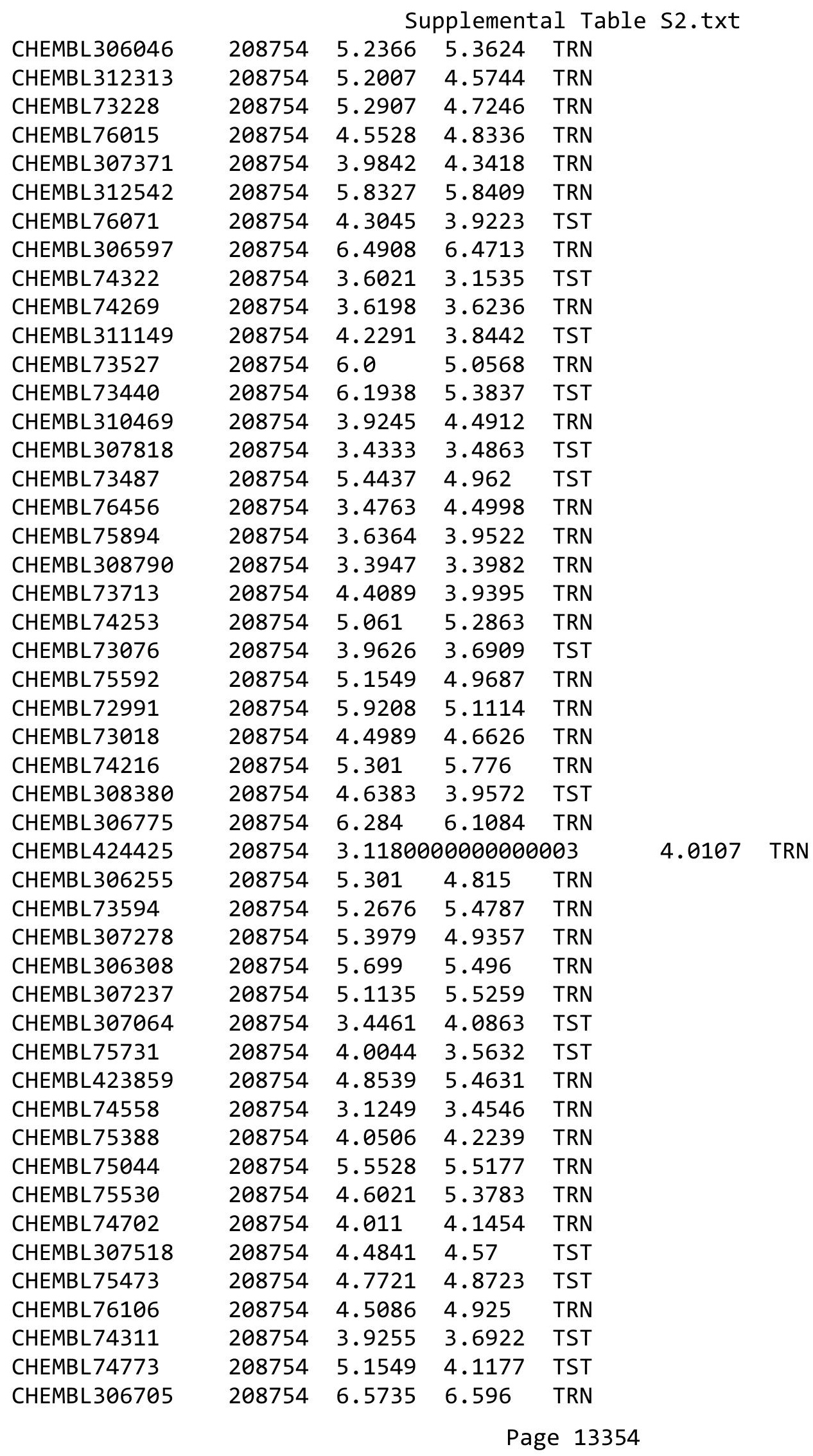




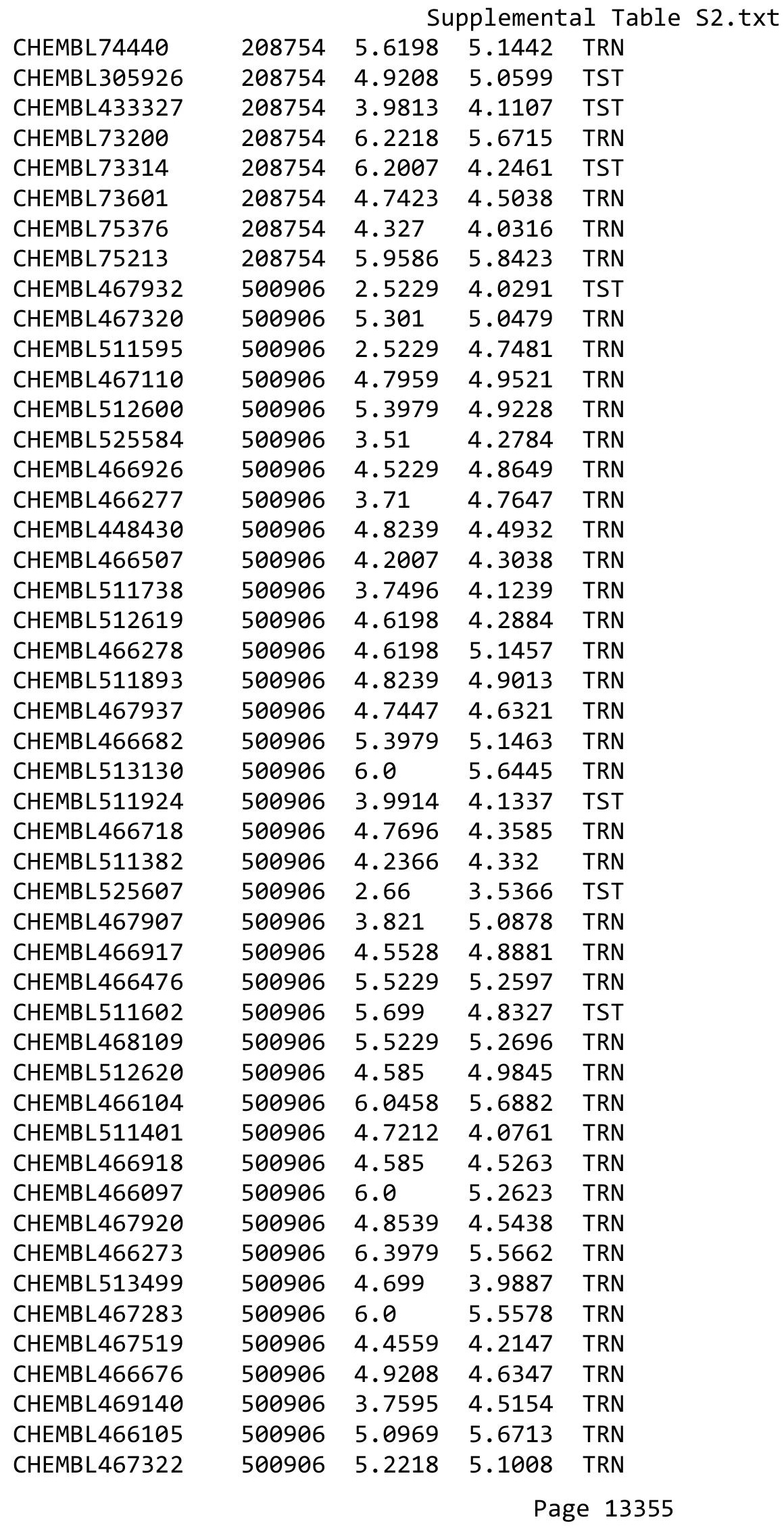




\begin{tabular}{|c|c|c|c|c|}
\hline & & & pplement & al $\mathrm{T}$ \\
\hline CHEMBL466871 & 500906 & 4.0177 & 4.3753 & TST \\
\hline CHEMBL467520 & 500906 & 4.5229 & 4.3513 & TRN \\
\hline CHEMBL467707 & 500906 & 4.4559 & 4.5249 & TST \\
\hline CHEMBL511217 & 500906 & 5.301 & 4.508 & TRN \\
\hline CHEMBL466692 & 500906 & 5.3979 & 5.2973 & TRN \\
\hline CHEMBL513134 & 500906 & 4.585 & 4.4801 & TRN \\
\hline CHEMBL512434 & 500906 & 4.0706 & 4.8017 & TRN \\
\hline CHEMBL466715 & 500906 & 4.3546 & 3.8017 & TRN \\
\hline CHEMBL467908 & 500906 & 5.3979 & 5.1227 & TRN \\
\hline CHEMBL467111 & 500906 & 6.0 & 5.0123 & TRN \\
\hline CHEMBL466927 & 500906 & 4.4685 & 4.5277 & TRN \\
\hline CHEMBL448556 & 500906 & 5.585 & 3.9006 & TST \\
\hline CHEMBL511760 & 500906 & 3.8794 & 4.8 & TRN \\
\hline CHEMBL467708 & 500906 & 4.585 & 4.9719 & TST \\
\hline CHEMBL467936 & 500906 & 5.301 & 4.523 & TST \\
\hline CHEMBL510336 & 500906 & 4.8539 & 4.0996 & TST \\
\hline CHEMBL467496 & 500906 & 3.71 & 4.463 & TST \\
\hline CHEMBL467291 & 500906 & 4.4202 & 4.3927 & TST \\
\hline CHEMBL511409 & 500906 & 5.699 & 5.1138 & TST \\
\hline CHEMBL467129 & 500906 & 4.699 & 4.8696 & TST \\
\hline CHEMBL511926 & 500906 & 5.301 & 4.8764 & TST \\
\hline CHEMBL512079 & 500906 & 4.757 & 4.0678 & TST \\
\hline CHEMBL1460107 & 737302 & 4.6556 & 4.3674 & TRN \\
\hline CHEMBL1460896 & 737302 & 3.301 & 3.6142 & TRN \\
\hline CHEMBL1453822 & 737302 & 4.3696 & 3.325 & TRN \\
\hline CHEMBL 2000167 & 737302 & 4.3089 & 4.0016 & TRN \\
\hline CHEMBL3194601 & 737302 & 5.6383 & 3.4911 & TRN \\
\hline CHEMBL1386349 & 737302 & 5.9626 & 4.2144 & TRN \\
\hline CHEMBL1406990 & 737302 & 4.9508 & 3.4895 & TST \\
\hline CHEMBL1388892 & 737302 & 3.301 & 3.7094 & TRN \\
\hline CHEMBL1374398 & 737302 & 4.5317 & 4.2291 & TRN \\
\hline CHEMBL1441874 & 737302 & 3.301 & 4.0261 & TRN \\
\hline CHEMBL1538966 & 737302 & 5.5607 & 3.8239 & TRN \\
\hline CHEMBL1555566 & 737302 & 5.4271 & 4.4244 & TRN \\
\hline CHEMBL1447467 & 737302 & 6.2832 & 4.1809 & TST \\
\hline CHEMBL1584061 & 737302 & 3.301 & 5.3576 & TST \\
\hline CHEMBL 2002223 & 737302 & 3.301 & 3.7945 & TST \\
\hline CHEMBL1580684 & 737302 & 3.301 & 3.3297 & TRN \\
\hline CHEMBL1533279 & 737302 & 3.301 & 4.0554 & TRN \\
\hline CHEMBL1494713 & 737302 & 5.2907 & 4.4759 & TST \\
\hline CHEMBL1583534 & 737302 & 5.3969 & 5.6428 & TRN \\
\hline CHEMBL1527793 & 737302 & 3.301 & 3.6794 & TRN \\
\hline CHEMBL1419255 & 737302 & 3.301 & 3.2289 & TRN \\
\hline CHEMBL1362015 & 737302 & 3.301 & 3.7136 & TRN \\
\hline CHEMBL1511284 & 737302 & 3.301 & 4.0036 & TRN \\
\hline CHEMBL1704267 & 737302 & 5.1911 & 4.0905 & TRN \\
\hline CHEMBL1543232 & 737302 & 4.5361 & 3.6179 & TRN \\
\hline CHEMBL1999908 & 737302 & 3.301 & 3.9442 & TRN \\
\hline
\end{tabular}




\begin{tabular}{|c|c|c|c|c|c|}
\hline & & \multicolumn{4}{|c|}{ Supplemental Table S2.txt } \\
\hline CHEMBL1381419 & 737302 & 3.301 & 3.8398 & TRN & \\
\hline CHEMBL3194609 & 737302 & 4.9626 & 3.4132 & TRN & \\
\hline CHEMBL1529201 & 737302 & 6.585 & 5.3396 & TRN & \\
\hline CHEMBL1372046 & 737302 & 3.301 & 3.81699 & 99999999997 & TRN \\
\hline CHEMBL1425837 & 737302 & 3.301 & 3.6158 & TRN & \\
\hline CHEMBL1534730 & 737302 & 3.301 & 3.7357 & TST & \\
\hline CHEMBL1537405 & 737302 & 4.3757 & 4.2622 & TRN & \\
\hline CHEMBL1465224 & 737302 & 3.301 & 3.8877 & TST & \\
\hline CHEMBL1992702 & 737302 & 3.301 & 3.8168 & TRN & \\
\hline CHEMBL1555556 & 737302 & 3.301 & 3.963 & TRN & \\
\hline CHEMBL1382305 & 737302 & 3.301 & 3.2467 & TRN & \\
\hline CHEMBL1506195 & 737302 & 4.3054 & 3.4724 & TRN & \\
\hline CHEMBL1346724 & 737302 & 3.301 & 3.7978 & TRN & \\
\hline CHEMBL1611910 & 737302 & 4.382 & 3.7909 & TRN & \\
\hline CHEMBL1464280 & 737302 & 3.301 & 3.5475 & TRN & \\
\hline CHEMBL1389260 & 737302 & 3.301 & 3.4353 & TRN & \\
\hline CHEMBL1507308 & 737302 & 5.5498 & 4.2119 & TRN & \\
\hline CHEMBL3191831 & 737302 & 3.301 & 3.6987 & TRN & \\
\hline CHEMBL1541779 & 737302 & 3.301 & 3.447 & TST & \\
\hline CHEMBL578742 & 737302 & 3.301 & 4.0398 & TRN & \\
\hline CHEMBL1466605 & 737302 & 3.301 & 3.5654 & TRN & \\
\hline CHEMBL1600114 & 737302 & 5.6055 & 3.7634 & TST & \\
\hline CHEMBL1387961 & 737302 & 3.301 & 3.7769 & TRN & \\
\hline CHEMBL1521635 & 737302 & 3.301 & 3.8756 & TRN & \\
\hline CHEMBL1706577 & 737302 & 5.0857 & 3.7302 & TRN & \\
\hline CHEMBL1511181 & 737302 & 3.301 & 3.62399 & 99999999997 & TRN \\
\hline CHEMBL1525242 & 737302 & 3.301 & 3.73100 & 00000000003 & TRN \\
\hline CHEMBL1379677 & 737302 & 3.301 & 3.9202 & TST & \\
\hline CHEMBL1487750 & 737302 & 3.301 & 3.7534 & TRN & \\
\hline CHEMBL1448381 & 737302 & 3.301 & 3.6797 & TRN & \\
\hline CHEMBL1376711 & 737302 & 5.3516 & 3.8655 & TRN & \\
\hline CHEMBL1402286 & 737302 & 5.4248 & 4.1705 & TRN & \\
\hline CHEMBL1585333 & 737302 & 5.3215 & 4.5912 & TRN & \\
\hline CHEMBL1572375 & 737302 & 3.301 & 3.5679 & TRN & \\
\hline CHEMBL1359410 & 737302 & 3.301 & 3.4994 & TRN & \\
\hline CHEMBL1358059 & 737302 & 5.129 & 4.5765 & TST & \\
\hline CHEMBL1446932 & 737302 & 3.301 & 4.2329 & TRN & \\
\hline CHEMBL1488925 & 737302 & 4.5346 & 3.6041 & TRN & \\
\hline CHEMBL1367163 & 737302 & 3.301 & 3.6125 & TRN & \\
\hline CHEMBL1978449 & 737302 & 3.301 & 3.8124 & TRN & \\
\hline CHEMBL1501645 & 737302 & 5.2541 & 3.9638 & TRN & \\
\hline CHEMBL1517673 & 737302 & 3.301 & 3.7227 & TRN & \\
\hline CHEMBL1601009 & 737302 & 3.301 & 3.7918 & TRN & \\
\hline CHEMBL1438182 & 737302 & 4.8665 & 4.7299 & TRN & \\
\hline CHEMBL1549607 & 737302 & 3.301 & 3.6093 & TRN & \\
\hline CHEMBL1443268 & 737302 & 3.301 & 3.9159 & TRN & \\
\hline CHEMBL1536896 & 737302 & 4.4413 & 4.112 & TRN & \\
\hline CHEMBL1433088 & 737302 & 3.301 & 3.7152 & TRN & \\
\hline
\end{tabular}




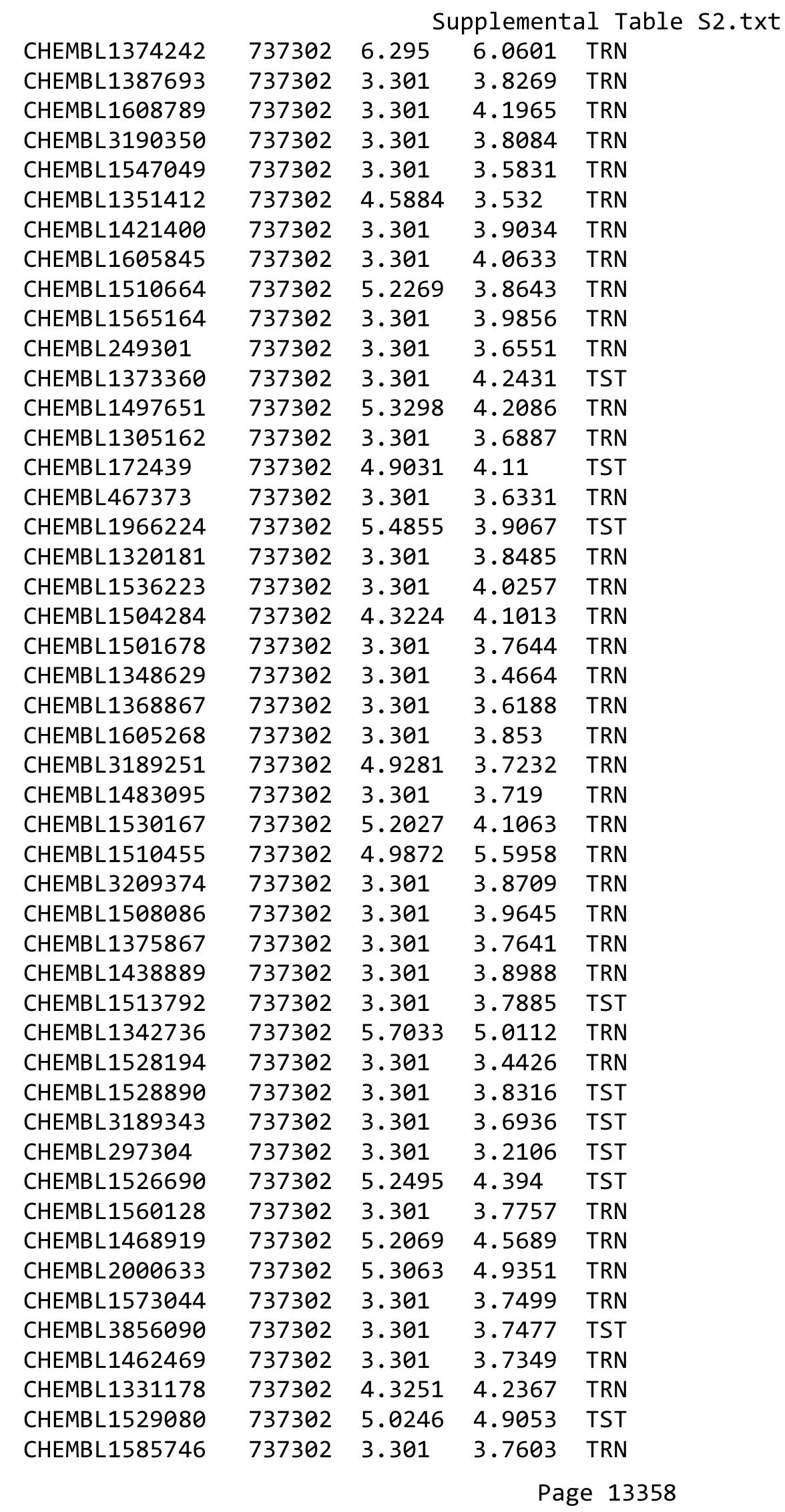




\begin{tabular}{|c|c|c|c|c|c|}
\hline \multirow[b]{2}{*}{ CHEMBL1571835 } & \multicolumn{5}{|c|}{ Supplemental Table S2.txt } \\
\hline & 737302 & 5.5129 & 4.6953 & TRN & \\
\hline CHEMBL1300876 & 737302 & 3.301 & 3.6495 & TRN & \\
\hline CHEMBL1443090 & 737302 & 3.301 & 3.8756 & TRN & \\
\hline CHEMBL1499996 & 737302 & 4.3372 & 3.6998 & TRN & \\
\hline CHEMBL3196265 & 737302 & 4.6968 & 4.5397 & TST & \\
\hline CHEMBL1507888 & 737302 & 3.301 & 3.5397 & TST & \\
\hline CHEMBL1597055 & 737302 & 3.301 & 3.9821 & TRN & \\
\hline CHEMBL1584440 & 737302 & 3.301 & 3.5651 & TRN & \\
\hline CHEMBL1515088 & 737302 & 3.301 & 3.8588 & TRN & \\
\hline CHEMBL1321103 & 737302 & 4.7033 & 3.36 & TRN & \\
\hline CHEMBL1731995 & 737302 & 5.2358 & 4.4992 & TRN & \\
\hline CHEMBL1364395 & 737302 & 3.301 & 3.7509 & TRN & \\
\hline CHEMBL1576392 & 737302 & 3.301 & 3.6901 & TRN & \\
\hline CHEMBL1457149 & 737302 & 4.4353 & 3.6875 & TRN & \\
\hline CHEMBL1406727 & 737302 & 3.301 & 3.9286 & TST & \\
\hline CHEMBL1360585 & 737302 & 3.301 & 3.3067 & TRN & \\
\hline CHEMBL1471841 & 737302 & 3.301 & 3.5777 & TRN & \\
\hline CHEMBL1431531 & 737302 & 3.301 & 4.1798 & TRN & \\
\hline CHEMBL1427539 & 737302 & 4.3958 & 3.7294 & TRN & \\
\hline CHEMBL1326648 & 737302 & 3.301 & 3.8398 & TRN & \\
\hline CHEMBL1338442 & 737302 & 6.06 & 4.66100 & 00000000005 & TRN \\
\hline CHEMBL1481947 & 737302 & 3.301 & 3.7272 & TST & \\
\hline CHEMBL1364723 & 737302 & 3.301 & 3.73100 & 00000000003 & TST \\
\hline CHEMBL1452774 & 737302 & 3.301 & 3.6996 & TRN & \\
\hline CHEMBL1302524 & 737302 & 6.6478 & 6.0562 & TRN & \\
\hline CHEMBL513150 & 737302 & 3.301 & 3.7374 & TRN & \\
\hline CHEMBL1406195 & 737302 & 3.301 & 3.8858 & TRN & \\
\hline CHEMBL1362221 & 737302 & 3.301 & 3.9257 & TRN & \\
\hline CHEMBL1099177 & 737302 & 3.301 & 3.9629 & TRN & \\
\hline CHEMBL1301315 & 737302 & 3.301 & 3.9056 & TRN & \\
\hline CHEMBL1531512 & 737302 & 3.301 & 3.7801 & TRN & \\
\hline CHEMBL1319009 & 737302 & 3.301 & 4.08 & TRN & \\
\hline CHEMBL1440977 & 737302 & 3.301 & 3.5979 & TST & \\
\hline CHEMBL484640 & 737302 & 3.301 & 3.6409 & TST & \\
\hline CHEMBL1302139 & 737302 & 4.3116 & 3.3975 & TRN & \\
\hline CHEMBL1530652 & 737302 & 3.301 & 3.4306 & TRN & \\
\hline CHEMBL1581797 & 737302 & 3.301 & 3.8828 & TRN & \\
\hline CHEMBL1440962 & 737302 & 3.301 & 3.57 & TST & \\
\hline CHEMBL1438038 & 737302 & 5.4034 & 4.38399 & 99999999995 & TRN \\
\hline CHEMBL1728993 & 737302 & 5.5452 & 3.324 & TRN & \\
\hline CHEMBL466930 & 737302 & 3.301 & 3.5336 & TRN & \\
\hline CHEMBL1984894 & 737302 & 5.1469 & 3.6212 & TRN & \\
\hline CHEMBL1600748 & 737302 & 3.301 & 3.6922 & TRN & \\
\hline CHEMBL1427249 & 737302 & 3.301 & 3.8894 & TRN & \\
\hline CHEMBL1405161 & 737302 & 3.301 & 3.6048 & TRN & \\
\hline CHEMBL1301673 & 737302 & 4.4647 & 4.6498 & TRN & \\
\hline CHEMBL1310730 & 737302 & 3.301 & 3.5731 & TRN & \\
\hline CHEMBL1414465 & 737302 & 3.301 & 3.6877 & TRN & \\
\hline
\end{tabular}




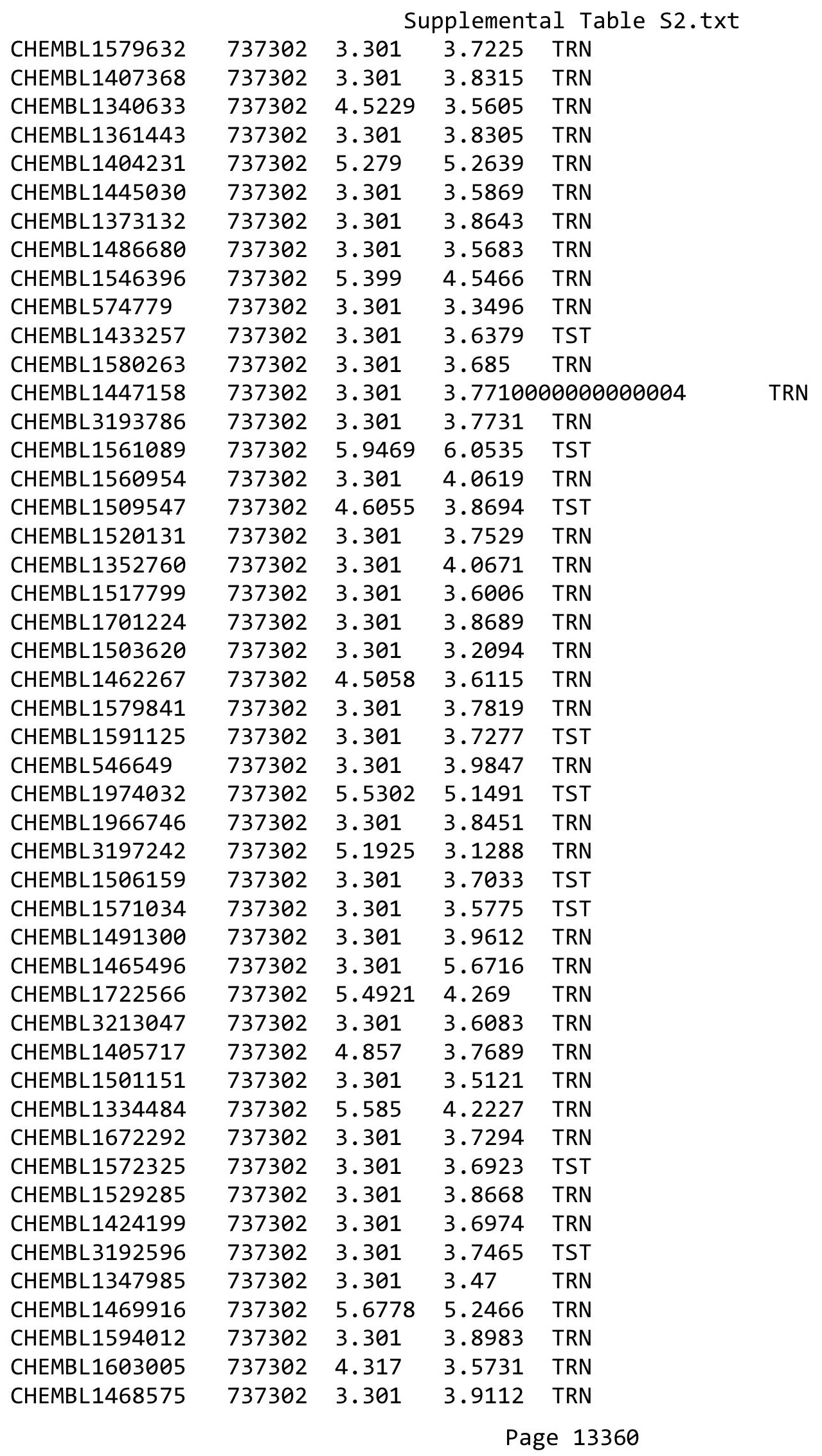




\begin{tabular}{|c|c|c|c|c|c|}
\hline & & \multicolumn{4}{|c|}{ Supplemental Table S2.txt } \\
\hline CHEMBL3198439 & 737302 & 3.301 & 3.7036 & TRN & \\
\hline CHEMBL1530437 & 737302 & 5.308 & 5.1545 & TRN & \\
\hline CHEMBL1417064 & 737302 & 3.301 & 3.8089 & TRN & \\
\hline CHEMBL1432336 & 737302 & 5.5045 & 5.5251 & TRN & \\
\hline CHEMBL1302528 & 737302 & 3.301 & 3.5833 & TRN & \\
\hline CHEMBL1350622 & 737302 & 3.301 & 3.7531 & TRN & \\
\hline CHEMBL1330161 & 737302 & 4.6517 & 4.1447 & TRN & \\
\hline CHEMBL1346055 & 737302 & 4.3179 & 3.4695 & TRN & \\
\hline CHEMBL 1558585 & 737302 & 3.301 & 3.9197 & TRN & \\
\hline CHEMBL1610393 & 737302 & 3.301 & 3.7345 & TRN & \\
\hline CHEMBL1526855 & 737302 & 6.1278 & 6.0907 & TRN & \\
\hline CHEMBL1424041 & 737302 & 3.301 & 3.8843 & TRN & \\
\hline CHEMBL1369433 & 737302 & 4.4634 & 4.0551 & TRN & \\
\hline CHEMBL1510394 & 737302 & 3.301 & 3.5236 & TRN & \\
\hline CHEMBL1512159 & 737302 & 4.5391 & 3.9039 & TRN & \\
\hline CHEMBL1571238 & 737302 & 3.301 & 3.7399 & TRN & \\
\hline CHEMBL1427185 & 737302 & 5.8153 & 5.7877 & TST & \\
\hline CHEMBL1367314 & 737302 & 5.8153 & 5.4777 & TRN & \\
\hline CHEMBL1399979 & 737302 & 5.6676 & 4.7977 & TRN & \\
\hline CHEMBL305469 & 737302 & 4.4609 & 3.5697 & TRN & \\
\hline CHEMBL1494895 & 737302 & 3.301 & 3.91899 & 99999999996 & TRN \\
\hline CHEMBL1427775 & 737302 & 4.5391 & 3.3779 & TRN & \\
\hline CHEMBL1535216 & 737302 & 3.301 & 3.5183 & TRN & \\
\hline CHEMBL1388509 & 737302 & 3.301 & 5.0356 & TST & \\
\hline CHEMBL1600270 & 737302 & 3.301 & 3.9408 & TRN & \\
\hline CHEMBL1504286 & 737302 & 3.301 & 3.4864 & TRN & \\
\hline CHEMBL1481546 & 737302 & 3.301 & 3.6648 & TRN & \\
\hline CHEMBL1326167 & 737302 & 4.8447 & 5.1343 & TRN & \\
\hline CHEMBL 1471788 & 737302 & 3.301 & 3.6995 & TST & \\
\hline CHEMBL1978327 & 737302 & 4.6091 & 3.7502 & TRN & \\
\hline CHEMBL1342429 & 737302 & 5.0141 & 3.8668 & TRN & \\
\hline CHEMBL1398964 & 737302 & 4.9318 & 4.1979 & TRN & \\
\hline CHEMBL 211481 & 737302 & 3.301 & 3.7274 & TRN & \\
\hline CHEMBL3212539 & 737302 & 3.301 & 3.886 & TRN & \\
\hline CHEMBL1541862 & 737302 & 3.301 & 3.8042 & TRN & \\
\hline CHEMBL1582771 & 737302 & 5.7799 & 4.5554 & TRN & \\
\hline CHEMBL1481413 & 737302 & 5.5058 & 4.7096 & TRN & \\
\hline CHEMBL1550366 & 737302 & 3.301 & 3.8544 & TRN & \\
\hline CHEMBL1497568 & 737302 & 3.301 & 4.1345 & TRN & \\
\hline CHEMBL1349417 & 737302 & 5.0315 & 3.9504 & TST & \\
\hline CHEMBL1443570 & 737302 & 3.301 & 3.7467 & TRN & \\
\hline CHEMBL1313195 & 737302 & 4.8041 & 3.8508 & TST & \\
\hline CHEMBL1579066 & 737302 & 4.4168 & 3.7929 & TST & \\
\hline CHEMBL1321933 & 737302 & 3.301 & 3.5986 & TRN & \\
\hline CHEMBL1381817 & 737302 & 3.301 & 3.6852 & TRN & \\
\hline CHEMBL1310699 & 737302 & 5.6421 & 4.9595 & TRN & \\
\hline CHEMBL1340587 & 737302 & 5.8928 & 4.0897 & TRN & \\
\hline CHEMBL1562523 & 737302 & 4.51 & 3.6486 & TRN & \\
\hline
\end{tabular}


Supplemental Table S2.txt

\begin{tabular}{|c|c|c|c|c|c|}
\hline CHEMBL1424694 & 737302 & 4.9172 & 3.6342 & TRN & \\
\hline CHEMBL274921 & 737302 & 3.301 & 3.6394 & TRN & \\
\hline CHEMBL1569090 & 737302 & 3.301 & 3.8982 & TRN & \\
\hline CHEMBL1412731 & 737302 & 3.301 & 3.6866 & TRN & \\
\hline CHEMBL1502860 & 737302 & 4.7328 & \multicolumn{2}{|c|}{4.906000000000001} & TRN \\
\hline CHEMBL1533561 & 737302 & 3.301 & 3.8686 & TRN & \\
\hline CHEMBL1534359 & 737302 & 3.301 & 3.8163 & TRN & \\
\hline CHEMBL1427447 & 737302 & 3.301 & 3.7977 & TRN & \\
\hline CHEMBL1467719 & 737302 & 4.8861 & 3.6284 & TRN & \\
\hline CHEMBL 2006639 & 737302 & 3.301 & \multicolumn{2}{|c|}{3.8789999999999996} & TRN \\
\hline CHEMBL1610008 & 737302 & 3.301 & 3.5518 & TRN & \\
\hline CHEMBL1486729 & 737302 & 5.7144 & 5.4466 & TST & \\
\hline CHEMBL1323590 & 737302 & 3.301 & 4.0815 & TRN & \\
\hline CHEMBL1346321 & 737302 & 4.3468 & 3.6465 & TST & \\
\hline CHEMBL1489711 & 737302 & 3.301 & 3.8391 & TRN & \\
\hline CHEMBL1528814 & 737302 & 5.3507 & 4.7354 & TRN & \\
\hline CHEMBL1429145 & 737302 & 3.301 & 3.9332 & TRN & \\
\hline CHEMBL1548107 & 737302 & 3.301 & 3.8576 & TRN & \\
\hline CHEMBL1520245 & 737302 & 4.6459 & 3.5409 & TRN & \\
\hline CHEMBL1398763 & 737302 & 3.301 & 3.8643 & TST & \\
\hline CHEMBL1547938 & 737302 & 3.301 & 4.2683 & TRN & \\
\hline CHEMBL1471715 & 737302 & 3.301 & \multicolumn{2}{|c|}{3.8989999999999996} & TRN \\
\hline CHEMBL3213007 & 737302 & 3.301 & 3.5837 & TRN & \\
\hline CHEMBL1380889 & 737302 & 3.301 & 3.7976 & TRN & \\
\hline CHEMBL3196114 & 737302 & 3.301 & 3.6973 & TRN & \\
\hline CHEMBL1442893 & 737302 & 5.1765 & 5.7076 & TRN & \\
\hline CHEMBL1569711 & 737302 & 5.567 & 3.4992 & TRN & \\
\hline CHEMBL1509832 & 737302 & 5.1681 & 5.3678 & TRN & \\
\hline CHEMBL1383746 & 737302 & 5.857 & 5.1768 & TRN & \\
\hline CHEMBL1449746 & 737302 & 3.301 & 3.8019 & TRN & \\
\hline CHEMBL1509082 & 737302 & 3.301 & 3.5977 & TRN & \\
\hline CHEMBL1387248 & 737302 & 5.7055 & 5.7835 & TST & \\
\hline CHEMBL1563317 & 737302 & 4.7352 & 3.7565 & TRN & \\
\hline CHEMBL1530272 & 737302 & 5.0159 & 3.8129 & TRN & \\
\hline CHEMBL1610801 & 737302 & 3.301 & 3.6663 & TST & \\
\hline CHEMBL1516563 & 737302 & 3.301 & 3.3806 & TRN & \\
\hline CHEMBL 74497 & 737302 & 5.0931 & 3.3444 & TRN & \\
\hline CHEMBL1988133 & 737302 & 4.8539 & 3.1012 & TRN & \\
\hline CHEMBL1343751 & 737302 & 3.301 & 3.8579 & TRN & \\
\hline CHEMBL1459808 & 737302 & 3.301 & 3.4772 & TRN & \\
\hline CHEMBL3715797 & 737302 & 3.301 & 3.9693 & TRN & \\
\hline CHEMBL1454848 & 737302 & 3.301 & 3.7374 & TRN & \\
\hline CHEMBL1381676 & 737302 & 3.301 & 3.8072 & TRN & \\
\hline CHEMBL1391622 & 737302 & 3.301 & 3.8644 & TRN & \\
\hline CHEMBL1523209 & 737302 & 3.301 & 4.0136 & TRN & \\
\hline CHEMBL1342469 & 737302 & 5.266 & 3.7517 & TRN & \\
\hline CHEMBL1391075 & 737302 & 3.301 & 3.9227 & TST & \\
\hline CHEMBL1609392 & 737302 & 3.301 & 3.6682 & TRN & \\
\hline
\end{tabular}




\begin{tabular}{|c|c|c|c|c|}
\hline \multicolumn{5}{|c|}{ Supplemental Table S2.txt } \\
\hline CHEMBL1519298 & 737302 & 5.6091 & 5.7568 & TRN \\
\hline CHEMBL1390710 & 737302 & 4.3737 & 4.5584 & TRN \\
\hline CHEMBL1309456 & 737302 & 3.301 & 3.7028 & TRN \\
\hline CHEMBL1527520 & 737302 & 5.3028 & 4.6153 & TRN \\
\hline CHEMBL1419339 & 737302 & 3.301 & 3.7881 & TRN \\
\hline CHEMBL 3190104 & 737302 & 4.7496 & 3.6057 & TRN \\
\hline CHEMBL1501987 & 737302 & 3.301 & 3.8321 & TRN \\
\hline CHEMBL1336733 & 737302 & 3.301 & 3.4617 & TRN \\
\hline CHEMBL1302483 & 737302 & 3.301 & 4.1453 & TST \\
\hline CHEMBL3145364 & 737302 & 3.301 & 3.6148 & TST \\
\hline CHEMBL1586267 & 737302 & 3.301 & 3.523 & TST \\
\hline CHEMBL1522413 & 737302 & 3.301 & 6.0184 & TST \\
\hline CHEMBL1983083 & 737302 & 3.301 & 3.5398 & TST \\
\hline CHEMBL131037 & 737302 & 6.4802 & 7.0937 & TST \\
\hline CHEMBL1508121 & 737302 & 4.3391 & 4.1408 & TST \\
\hline CHEMBL1598722 & 737302 & 3.301 & 3.7254 & TST \\
\hline CHEMBL1599593 & 737302 & 3.301 & 4.1572 & TST \\
\hline CHEMBL1451059 & 737302 & 5.6882 & 4.7186 & TST \\
\hline CHEMBL3213108 & 737302 & 3.301 & 4.1495 & TST \\
\hline CHEMBL1393902 & 737302 & 3.301 & 4.499 & TST \\
\hline CHEMBL3192879 & 737302 & 3.301 & 3.8784 & TST \\
\hline CHEMBL1518503 & 737302 & 3.301 & 4.2901 & TST \\
\hline CHEMBL1968355 & 737302 & 3.301 & 3.661 & TST \\
\hline CHEMBL1349296 & 737302 & 3.301 & 4.0312 & TST \\
\hline CHEMBL1548870 & 737302 & 5.6596 & 4.6203 & TST \\
\hline CHEMBL1566536 & 737302 & 3.301 & 3.5835 & TST \\
\hline CHEMBL1492565 & 737302 & 3.301 & 3.6261 & TST \\
\hline CHEMBL399293 & 737302 & 4.6925 & 4.6052 & TST \\
\hline CHEMBL1519229 & 737302 & 5.4989 & 4.0403 & TST \\
\hline CHEMBL1612116 & 737302 & 3.301 & 3.9898 & TST \\
\hline CHEMBL1576530 & 737302 & 3.301 & 4.6441 & TST \\
\hline CHEMBL3198930 & 737302 & 4.7033 & 3.7071 & TST \\
\hline CHEMBL1543134 & 737302 & 5.3036 & 4.4519 & TST \\
\hline CHEMBL1584651 & 737302 & 3.301 & 3.7643 & TST \\
\hline CHEMBL1422097 & 737302 & 5.3872 & 3.8954 & TST \\
\hline CHEMBL1500997 & 737302 & 3.301 & 3.7219 & TST \\
\hline CHEMBL1387563 & 737302 & 3.301 & 4.426 & TST \\
\hline CHEMBL1708334 & 737302 & 5.3809 & 3.5228 & TST \\
\hline CHEMBL1505757 & 737302 & 3.301 & 3.7539 & TST \\
\hline CHEMBL1584379 & 737302 & 3.301 & 3.9189 & TST \\
\hline CHEMBL1497791 & 737302 & 3.301 & 5.2412 & TST \\
\hline CHEMBL1504634 & 737302 & 3.301 & 3.4908 & TST \\
\hline CHEMBL1688693 & 737302 & 3.301 & 3.9525 & TST \\
\hline CHEMBL1318757 & 737302 & 3.301 & 3.7265 & TST \\
\hline CHEMBL602213 & 737302 & 4.8539 & 3.7852 & TST \\
\hline CHEMBL75913 & 737302 & 5.2823 & 3.2659 & TST \\
\hline CHEMBL1608043 & 737302 & 4.3307 & 3.5649 & TST \\
\hline CHEMBL1441794 & 737302 & 3.301 & 4.0102 & TST \\
\hline
\end{tabular}


Supplemental Table S2.txt

\begin{tabular}{|c|c|c|c|c|c|}
\hline CHEMBL1305930 & 737302 & 4.5421 & 3.7965 & TST & \\
\hline CHEMBL 3656427 & 1527619 & 7.8539 & \multicolumn{2}{|c|}{7.8389999999999995} & TST \\
\hline CHEMBL3656435 & 1527619 & 8.3979 & 8.5526 & TRN & \\
\hline CHEMBL 3656395 & 1527619 & 8.1549 & 8.22 & TRN & \\
\hline CHEMBL3656417 & 1527619 & 8.301 & 7.7871 & TRN & \\
\hline CHEMBL3656442 & 1527619 & 8.301 & 8.1383 & TRN & \\
\hline CHEMBL3656451 & 1527619 & 7.9208 & \multicolumn{2}{|c|}{6.2989999999999995} & TST \\
\hline CHEMBL 3408253 & 1527619 & 8.301 & 8.0575 & TRN & \\
\hline CHEMBL3656392 & 1527619 & 8.3979 & 8.2649 & TRN & \\
\hline CHEMBL3656387 & 1527619 & 9.0 & 8.2626 & TRN & \\
\hline CHEMBL3408266 & 1527619 & 8.5229 & 8.2838 & TRN & \\
\hline CHEMBL3656396 & 1527619 & 8.2218 & 8.1872 & TRN & \\
\hline CHEMBL 3408265 & 1527619 & 8.301 & 8.1116 & TRN & \\
\hline CHEMBL3656425 & 1527619 & 7.6778 & 8.0287 & TST & \\
\hline CHEMBL3656408 & 1527619 & 8.301 & 7.6344 & TRN & \\
\hline CHEMBL3408255 & 1527619 & 8.301 & 8.0483 & TRN & \\
\hline CHEMBL3656391 & 1527619 & 8.2218 & 8.247 & TST & \\
\hline CHEMBL 3656390 & 1527619 & 8.1549 & 8.0421 & TRN & \\
\hline CHEMBL3656426 & 1527619 & 7.3665 & 7.7181 & TST & \\
\hline CHEMBL3656401 & 1527619 & 7.9586 & 7.8986 & TST & \\
\hline CHEMBL3408261 & 1527619 & 8.3979 & 8.2422 & TRN & \\
\hline CHEMBL3656455 & 1527619 & 8.1549 & 8.245 & TRN & \\
\hline CHEMBL 3656412 & 1527619 & 8.2218 & 7.8971 & TRN & \\
\hline CHEMBL3408263 & 1527619 & 8.3979 & 8.1686 & TRN & \\
\hline CHEMBL 3408245 & 1527619 & 8.3979 & 7.9099 & TRN & \\
\hline CHEMBL3656433 & 1527619 & 8.3979 & 8.0608 & TRN & \\
\hline CHEMBL3656420 & 1527619 & 8.3979 & 7.9611 & TRN & \\
\hline CHEMBL 3656447 & 1527619 & 6.0 & 6.0624 & TRN & \\
\hline CHEMBL3656438 & 1527619 & 7.6383 & 8.533 & TRN & \\
\hline CHEMBL 3656386 & 1527619 & 8.699 & 8.3063 & TRN & \\
\hline CHEMBL 3656452 & 1527619 & 7.9586 & 6.5267 & TST & \\
\hline CHEMBL3656414 & 1527619 & 8.3979 & 8.2188 & TRN & \\
\hline CHEMBL 3656445 & 1527619 & 8.1549 & 8.1042 & TST & \\
\hline CHEMBL3656394 & 1527619 & 8.2218 & 8.2151 & TST & \\
\hline CHEMBL 3407508 & 1527619 & 6.0 & 7.79799 & 9999999999 & TRN \\
\hline CHEMBL 3656423 & 1527619 & 7.9208 & 8.309 & TST & \\
\hline CHEMBL3656397 & 1527619 & 7.9586 & 7.8496 & TST & \\
\hline CHEMBL3639553 & 1527619 & 8.3979 & 8.1381 & TRN & \\
\hline CHEMBL3656441 & 1527619 & 8.5229 & 8.3875 & TRN & \\
\hline CHEMBL 3656388 & 1527619 & 8.699 & 8.325 & TRN & \\
\hline CHEMBL3656415 & 1527619 & 8.0458 & 8.0619 & TRN & \\
\hline CHEMBL3656453 & 1527619 & 8.0458 & 6.5635 & TST & \\
\hline CHEMBL 3656443 & 1527619 & 8.3979 & 8.2371 & TRN & \\
\hline CHEMBL3408259 & 1527619 & 8.3979 & 8.429 & TRN & \\
\hline CHEMBL 3656446 & 1527619 & 8.1549 & 8.2 & TST & \\
\hline CHEMBL3408254 & 1527619 & 8.3979 & 8.1254 & TRN & \\
\hline CHEMBL3656406 & 1527619 & 8.0 & 7.3731 & TRN & \\
\hline CHEMBL3408269 & 1527619 & 8.3979 & 8.5526 & TRN & \\
\hline
\end{tabular}

Page 13364 


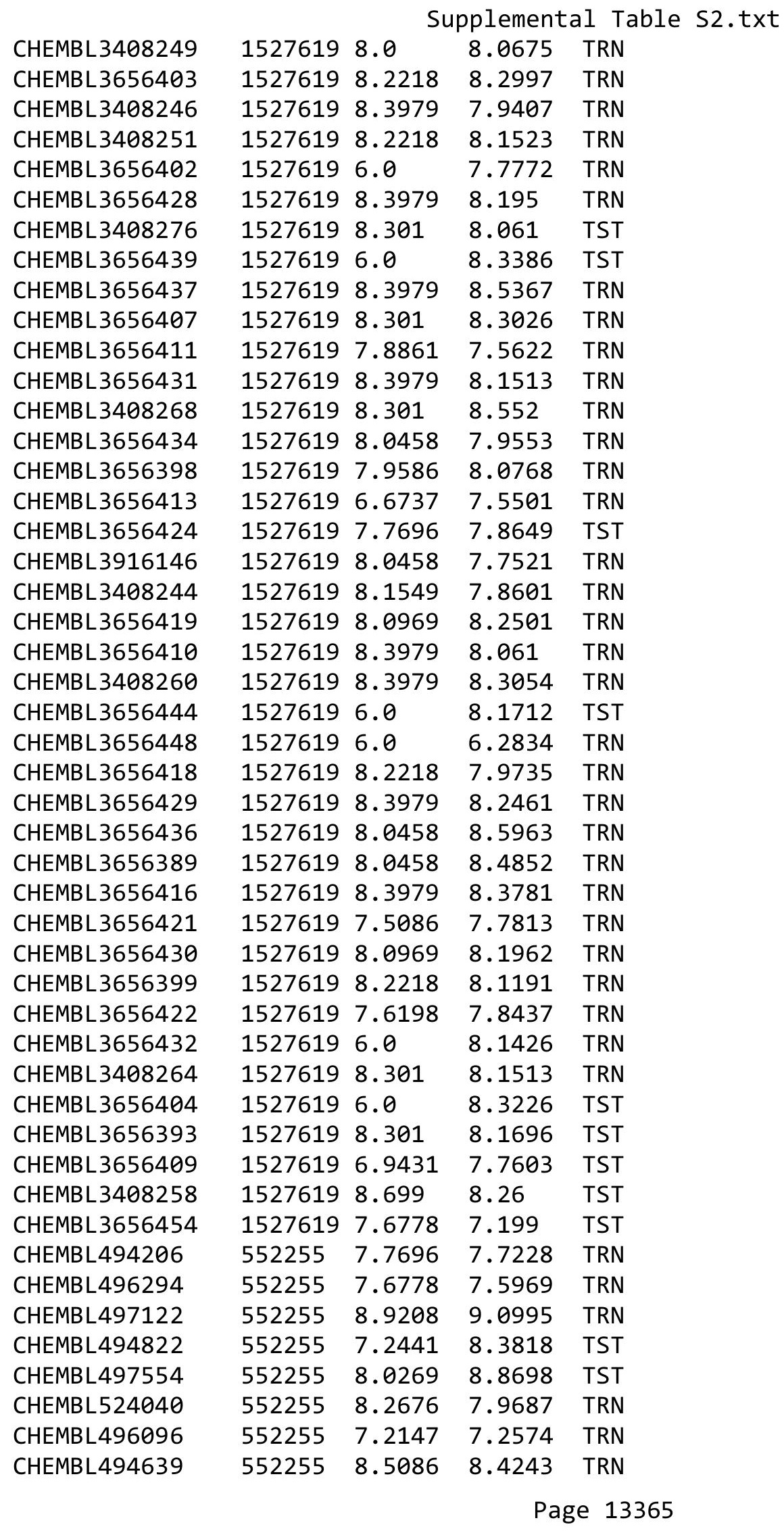


Supplemental Table S2.txt

\begin{tabular}{|c|c|c|c|c|c|}
\hline CHEMBL525003 & 552255 & 8.1079 & 8.0087 & TRN & \\
\hline CHEMBL493801 & 552255 & 8.4318 & 8.4129 & TRN & \\
\hline CHEMBL494809 & 552255 & 8.3872 & 8.3271 & TRN & \\
\hline CHEMBL495691 & 552255 & 7.7447 & 7.8376 & TRN & \\
\hline CHEMBL497121 & 552255 & 8.8539 & 8.985 & TRN & \\
\hline CHEMBL494638 & 552255 & 8.8539 & 8.4799 & TRN & \\
\hline CHEMBL521536 & 552255 & 9.0088 & 8.875 & TRN & \\
\hline CHEMBL524623 & 552255 & 8.4089 & 8.3736 & TST & \\
\hline CHEMBL497960 & 552255 & 8.6576 & 8.6484 & TRN & \\
\hline CHEMBL508147 & 552255 & 6.9957 & 7.4245 & TRN & \\
\hline CHEMBL498153 & 552255 & 8.1427 & 8.3823 & TST & \\
\hline CHEMBL497748 & 552255 & 8.4559 & 8.1955 & TRN & \\
\hline CHEMBL498352 & 552255 & 7.6778 & 7.8282 & TRN & \\
\hline CHEMBL497951 & 552255 & 7.4685 & 7.3246 & TRN & \\
\hline CHEMBL496495 & 552255 & 8.3279 & 8.492 & TRN & \\
\hline CHEMBL523177 & 552255 & 7.284 & 7.5478 & TRN & \\
\hline CHEMBL522701 & 552255 & 8.8861 & 8.8998 & TRN & \\
\hline CHEMBL495690 & 552255 & 8.041 & 7.5272 & TRN & \\
\hline CHEMBL525360 & 552255 & 8.0177 & 8.4681 & TST & \\
\hline CHEMBL498351 & 552255 & 8.0862 & 7.9574 & TRN & \\
\hline CHEMBL525924 & 552255 & 7.2518 & 7.51399 & 999999999 & TRN \\
\hline CHEMBL522066 & 552255 & 8.699 & 8.779 & TRN & \\
\hline CHEMBL494819 & 552255 & 7.3665 & 7.7762 & TRN & \\
\hline CHEMBL522533 & 552255 & 8.1612 & 8.5266 & TRN & \\
\hline CHEMBL523414 & 552255 & 8.5528 & 8.265 & TRN & \\
\hline CHEMBL495889 & 552255 & 9.0088 & 8.9445 & TRN & \\
\hline CHEMBL496307 & 552255 & 8.9208 & 8.9673 & TRN & \\
\hline CHEMBL496095 & 552255 & 7.8861 & 8.0385 & TRN & \\
\hline CHEMBL494637 & 552255 & 7.3372 & 7.9378 & TRN & \\
\hline CHEMBL521688 & 552255 & 7.7212 & 7.3794 & TRN & \\
\hline CHEMBL497555 & 552255 & 9.0088 & 9.037 & TRN & \\
\hline CHEMBL525361 & 552255 & 8.3979 & 7.8711 & TRN & \\
\hline CHEMBL428429 & 552255 & 6.9626 & 7.5943 & TST & \\
\hline CHEMBL498353 & 552255 & 7.585 & 8.055 & TRN & \\
\hline CHEMBL 256777 & 552255 & 7.0088 & 7.9394 & TST & \\
\hline CHEMBL497558 & 552255 & 8.7447 & 8.5077 & TRN & \\
\hline CHEMBL496097 & 552255 & 7.3768 & 7.4881 & TRN & \\
\hline CHEMBL 257149 & 552255 & 7.8697 & 7.8249 & TST & \\
\hline CHEMBL524824 & 552255 & 8.3979 & 8.1162 & TRN & \\
\hline CHEMBL522572 & 552255 & 8.2218 & 8.6037 & TST & \\
\hline CHEMBL496295 & 552255 & 6.7878 & 7.1247 & TST & \\
\hline CHEMBL525606 & 552255 & 7.4437 & 8.1363 & TST & \\
\hline CHEMBL494180 & 552255 & 7.7212 & 7.6977 & TST & \\
\hline CHEMBL496714 & 552255 & 9.0177 & 8.5235 & TST & \\
\hline CHEMBL 6973 & 458931 & 8.06 & 6.6751 & TST & \\
\hline CHEMBL 251440 & 458931 & 8.47 & 6.4755 & TST & \\
\hline CHEMBL 7390 & 458931 & 9.0 & 6.5614 & TST & \\
\hline CHEMBL 7108 & 458931 & 9.0 & 6.6068 & TST & \\
\hline
\end{tabular}




\begin{tabular}{|c|c|c|c|c|c|}
\hline \multicolumn{6}{|c|}{ Supplemental Table s2.txt } \\
\hline CHEMBL269019 & 458931 & 9.15 & 7.2604 & TST & \\
\hline CHEMBL 268377 & 458931 & 8.28 & 6.7142 & TST & \\
\hline CHEMBL264495 & 458931 & 7.7 & 8.5117 & TRN & \\
\hline CHEMBL60196 & 458931 & 7.52 & 8.5117 & TRN & \\
\hline CHEMBL59722 & 458931 & 9.0 & 8.5117 & TRN & \\
\hline CHEMBL60546 & 458931 & 8.7 & 8.5117 & TRN & \\
\hline CHEMBL62056 & 458931 & 9.0 & 8.5117 & TRN & \\
\hline CHEMBL294066 & 458931 & 9.22 & 8.5117 & TRN & \\
\hline CHEMBL62245 & 458931 & 9.0 & 8.5117 & TRN & \\
\hline CHEMBL58945 & 458931 & 8.0 & 8.5117 & TRN & \\
\hline CHEMBL61538 & 458931 & 7.3 & 6.08299 & 9999999999 & TRN \\
\hline CHEMBL 294133 & 458931 & 6.1 & 6.08299 & 9999999999 & TRN \\
\hline CHEMBL61517 & 458931 & 6.7 & 6.08299 & 9999999999 & TRN \\
\hline CHEMBL 294337 & 458931 & 6.3 & 6.08299 & 9999999999 & TRN \\
\hline CHEMBL60674 & 458931 & 6.0 & 6.08299 & 9999999999 & TRN \\
\hline CHEMBL416510 & 458931 & 6.22 & 6.08299 & 9999999999 & TRN \\
\hline CHEMBL58235 & 458931 & 6.7 & 6.08299 & 9999999999 & TRN \\
\hline CHEMBL59185 & 458931 & 5.0 & 6.08299 & 9999999999 & TRN \\
\hline CHEMBL62186 & 458931 & 4.4 & 6.08299 & 9999999999 & TRN \\
\hline CHEMBL 293382 & 458931 & 7.82 & 7.8631 & TRN & \\
\hline CHEMBL 305222 & 458931 & 8.4 & 8.3764 & TRN & \\
\hline CHEMBL329298 & 458931 & 7.02 & 6.6169 & TST & \\
\hline CHEMBL98017 & 458931 & 6.4 & 6.4335 & TRN & \\
\hline CHEMBL318716 & 458931 & 6.3 & 6.2765 & TRN & \\
\hline CHEMBL99189 & 458931 & 6.52 & 6.4812 & TRN & \\
\hline CHEMBL329313 & 458931 & 7.0 & 6.7735 & TST & \\
\hline CHEMBL 99981 & 458931 & 6.4 & 6.4652 & TRN & \\
\hline CHEMBL318455 & 458931 & 5.15 & 5.1654 & TRN & \\
\hline CHEMBL95614 & 458931 & 5.7 & 5.8124 & TRN & \\
\hline CHEMBL318023 & 458931 & 5.52 & 5.4619 & TRN & \\
\hline CHEMBL329287 & 458931 & 5.52 & 5.5036 & TRN & \\
\hline CHEMBL97936 & 458931 & 7.3 & 5.824 & TST & \\
\hline CHEMBL 100100 & 458931 & 7.7 & 6.1312 & TST & \\
\hline CHEMBL328162 & 458931 & 7.22 & 6.3487 & TST & \\
\hline CHEMBL99148 & 458931 & 6.22 & 6.2807 & TRN & \\
\hline CHEMBL 98044 & 458931 & 6.05 & 5.949 & TRN & \\
\hline CHEMBL100273 & 458931 & 5.7 & 5.8392 & TST & \\
\hline CHEMBL316954 & 458931 & 7.1 & 5.3299 & TST & \\
\hline CHEMBL318190 & 458931 & 6.22 & 5.5902 & TST & \\
\hline CHEMBL97382 & 458931 & 5.7 & 5.6611 & TRN & \\
\hline CHEMBL98917 & 458931 & 5.0 & 4.9949 & TRN & \\
\hline CHEMBL3827185 & 458931 & 6.11 & 6.1161 & TRN & \\
\hline CHEMBL3827433 & 458931 & 5.61 & 5.5561 & TRN & \\
\hline CHEMBL3828457 & 458931 & 6.55 & 6.6772 & TRN & \\
\hline CHEMBL3828077 & 458931 & 7.08 & 7.0125 & TRN & \\
\hline CHEMBL 3827238 & 458931 & 7.42 & 7.4093 & TRN & \\
\hline CHEMBL3827117 & 458931 & 7.27 & 7.2231 & TRN & \\
\hline CHEMBL3828712 & 458931 & 8.19 & 8.2374 & TRN & \\
\hline & & & & 13367 & \\
\hline
\end{tabular}




\begin{tabular}{|c|c|c|c|c|c|}
\hline \multirow[b]{2}{*}{ CHEMBL 3827120} & \multirow[b]{2}{*}{458931} & \multicolumn{4}{|c|}{ Supplemental Table s2.txt } \\
\hline & & 7.52 & \multirow{2}{*}{$\begin{array}{l}7.5264 \\
7.9366\end{array}$} & \multicolumn{2}{|c|}{ TRN } \\
\hline CHEMBL 3828398 & 458931 & 7.96 & & \multicolumn{2}{|l|}{ TRN } \\
\hline CHEMBL 3828753 & 458931 & 7.59 & 7.5572 & \multicolumn{2}{|l|}{ TRN } \\
\hline CHEMBL3828059 & 458931 & 6.38 & 6.5103 & \multicolumn{2}{|l|}{ TRN } \\
\hline CHEMBL3827768 & 458931 & 8.47 & 8.2835 & \multicolumn{2}{|l|}{ TRN } \\
\hline CHEMBL 3827627 & 458931 & 8.24 & 8.3257 & \multicolumn{2}{|l|}{ TRN } \\
\hline CHEMBL 3828521 & 458931 & 8.89 & 8.9382 & \multicolumn{2}{|l|}{ TRN } \\
\hline CHEMBL 3827566 & 458931 & 8.8 & 8.7998 & \multicolumn{2}{|l|}{ TRN } \\
\hline CHEMBL 3827831 & 458931 & 9.7 & 9.673 & \multicolumn{2}{|l|}{ TRN } \\
\hline CHEMBL3827521 & 458931 & 9.0 & 8.9796 & \multicolumn{2}{|l|}{ TRN } \\
\hline CHEMBL 3828455 & 458931 & 9.47 & 9.494 & \multicolumn{2}{|l|}{ TRN } \\
\hline CHEMBL329302 & 458931 & 5.66 & 5.6137 & \multicolumn{2}{|l|}{ TRN } \\
\hline CHEMBL252309 & 458931 & 5.4 & 5.3969 & \multicolumn{2}{|l|}{ TRN } \\
\hline CHEMBL99318 & 458931 & 6.0 & 6.0655 & \multicolumn{2}{|l|}{ TRN } \\
\hline CHEMBL329232 & 458931 & 5.47 & 5.39 & \multicolumn{2}{|l|}{ TRN } \\
\hline CHEMBL99283 & 458931 & 7.02 & 7.0435 & \multicolumn{2}{|l|}{ TRN } \\
\hline CHEMBL98304 & 458931 & 6.64 & 6.6316 & TRN & \\
\hline CHEMBL99547 & 458931 & 7.96 & 7.9603 & TRN & \\
\hline CHEMBL95718 & 458931 & 6.96 & 6.9971 & TRN & \\
\hline CHEMBL99120 & 458931 & 7.89 & 7.2504 & TST & \\
\hline CHEMBL318005 & 458931 & 8.0 & 7.0495 & TST & \\
\hline CHEMBL98770 & 458931 & 9.1 & 8.228 & TST & \\
\hline CHEMBL318860 & 458931 & 9.59 & 8.5947 & TST & \\
\hline CHEMBL333896 & 458931 & 7.06 & 6.6195 & TST & \\
\hline CHEMBL146202 & 579922 & 6.99 & 7.6667 & TST & \\
\hline CHEMBL149606 & 579922 & 7.15 & 7.6667 & TST & \\
\hline CHEMBL95152 & 579922 & 5.82 & 6.0161 & TRN & \\
\hline CHEMBL95916 & 579922 & 6.3 & 6.6658 & TRN & \\
\hline CHEMBL95959 & 579922 & 7.19 & 6.6658 & TRN & \\
\hline CHEMBL99810 & 579922 & 6.87 & 6.6658 & TRN & \\
\hline CHEMBL95990 & 579922 & 6.35 & 7.1006 & TRN & \\
\hline CHEMBL320909 & 579922 & 7.46 & 7.5084 & TRN & \\
\hline CHEMBL98911 & 579922 & 6.82 & 6.9245 & TRN & \\
\hline CHEMBL95885 & 579922 & 7.02 & 7.0313 & TRN & \\
\hline CHEMBL95835 & 579922 & 7.82 & 7.1006 & TRN & \\
\hline CHEMBL95241 & 579922 & 7.35 & 7.2989 & 99999999995 & TRN \\
\hline CHEMBL319070 & 579922 & 7.35 & 7.4910 & 00000000005 & TRN \\
\hline CHEMBL95313 & 579922 & 8.3 & 8.3627 & TRN & \\
\hline CHEMBL96984 & 579922 & 8.07 & 8.0707 & TRN & \\
\hline CHEMBL95552 & 579922 & 8.4 & 8.4495 & TRN & \\
\hline CHEMBL95535 & 579922 & 8.1 & 8.1108 & TRN & \\
\hline CHEMBL99456 & 579922 & 8.7 & 8.5833 & TRN & \\
\hline CHEMBL99877 & 579922 & 8.02 & 7.8957 & TRN & \\
\hline CHEMBL99216 & 579922 & 8.35 & 8.3447 & TRN & \\
\hline CHEMBL95510 & 579922 & 6.22 & 6.2041 & TRN & \\
\hline CHEMBL451182 & 579922 & 8.22 & 8.2412 & TRN & \\
\hline CHEMBL95747 & 579922 & 7.6 & 7.5779 & 9999999999 & TRN \\
\hline CHEMBL319738 & 579922 & 7.46 & 7.5126 & TRN & \\
\hline & & & & 13368 & \\
\hline
\end{tabular}




\begin{tabular}{|c|c|c|c|c|c|}
\hline \multicolumn{6}{|c|}{ Supplemental Table S2.txt } \\
\hline CHEMBL98345 & 579922 & 6.05 & 6.0078 & TRN & \\
\hline CHEMBL319248 & 579922 & 6.0 & 6.1072 & TRN & \\
\hline CHEMBL98346 & 579922 & 7.0 & 6.9251 & TRN & \\
\hline CHEMBL97860 & 579922 & 6.0 & 6.0064 & TRN & \\
\hline CHEMBL317814 & 579922 & 6.7 & 6.7622 & TRN & \\
\hline CHEMBL100035 & 579922 & 5.7 & 5.6705 & TRN & \\
\hline CHEMBL97108 & 579922 & 4.77 & 4.75899 & 99999999995 & TRN \\
\hline CHEMBL97387 & 579922 & 6.22 & 6.1379 & TRN & \\
\hline CHEMBL318642 & 579922 & 7.12 & 7.1294 & TRN & \\
\hline CHEMBL95850 & 579922 & 7.0 & 7.0431 & TRN & \\
\hline CHEMBL95849 & 579922 & 6.52 & 6.5153 & TRN & \\
\hline CHEMBL97384 & 579922 & 6.22 & 6.1908 & TRN & \\
\hline CHEMBL95195 & 579922 & 7.0 & 7.0189 & TRN & \\
\hline CHEMBL 317570 & 579922 & 6.52 & 6.5029 & TRN & \\
\hline CHEMBL96966 & 579922 & 7.0 & 6.9924 & TRN & \\
\hline CHEMBL 97272 & 579922 & 7.0 & 6.1014 & TST & \\
\hline CHEMBL316457 & 579922 & 6.22 & 5.5295 & TST & \\
\hline CHEMBL95553 & 579922 & 7.22 & 6.6084 & TST & \\
\hline CHEMBL98669 & 579922 & 7.05 & 6.7647 & TST & \\
\hline CHEMBL539664 & 579922 & 4.28 & 5.1711 & TST & \\
\hline CHEMBL552058 & 579922 & 4.92 & 5.2532 & TST & \\
\hline CHEMBL541000 & 579922 & 5.01 & 5.2263 & TST & \\
\hline CHEMBL539180 & 579922 & 4.95 & 4.9828 & TST & \\
\hline CHEMBL561118 & 579922 & 5.62 & 5.6386 & TRN & \\
\hline CHEMBL552465 & 579922 & 6.08 & 6.5402 & TST & \\
\hline CHEMBL557560 & 579922 & 5.7 & 5.6027 & TST & \\
\hline CHEMBL541426 & 579922 & 6.0 & 5.6137 & TST & \\
\hline CHEMBL1825038 & 765426 & 4.8986 & 5.0427 & TRN & \\
\hline CHEMBL1824762 & 765426 & 4.505 & 4.8307 & TRN & \\
\hline CHEMBL1825018 & 765426 & 4.9252 & 5.0207 & TST & \\
\hline CHEMBL1824761 & 765426 & 4.8881 & 4.7701 & TRN & \\
\hline CHEMBL272339 & 765426 & 4.9747 & 5.0983 & TRN & \\
\hline CHEMBL1824748 & 765426 & 4.9598 & 4.9839 & TRN & \\
\hline CHEMBL1825034 & 765426 & 5.2503 & 5.3917 & TRN & \\
\hline CHEMBL1824753 & 765426 & 4.9151 & 5.1178 & TRN & \\
\hline CHEMBL1824757 & 765426 & 4.8289 & 4.755 & TRN & \\
\hline CHEMBL1824754 & 765426 & 4.8745 & 4.9878 & TRN & \\
\hline CHEMBL1825027 & 765426 & 5.5129 & 5.2679 & TRN & \\
\hline CHEMBL 29482 & 765426 & 8.3979 & 5.05699 & 99999999995 & TST \\
\hline CHEMBL1825023 & 765426 & 4.9205 & 4.7804 & TST & \\
\hline CHEMBL1825026 & 765426 & 5.279 & 5.2679 & TRN & \\
\hline CHEMBL1824765 & 765426 & 4.9352 & 4.9346 & TRN & \\
\hline CHEMBL1825037 & 765426 & 4.9367 & 5.2551 & TRN & \\
\hline CHEMBL1824742 & 765426 & 5.3279 & 5.0329 & TRN & \\
\hline CHEMBL1825047 & 765426 & 5.644 & 5.13200 & 0000000001 & TRN \\
\hline CHEMBL1825029 & 765426 & 4.9706 & 5.2376 & TRN & \\
\hline CHEMBL349822 & 765426 & 8.1549 & 5.2554 & TST & \\
\hline CHEMBL1824767 & 765426 & 4.8179 & 4.8836 & TRN & \\
\hline
\end{tabular}




\begin{tabular}{|c|c|c|c|c|c|c|}
\hline & & \multicolumn{5}{|c|}{ Supplemental Table S2.txt } \\
\hline CHEMBL1824766 & 765426 & 4.5724 & 4.8726 & TRN & & \\
\hline CHEMBL1824758 & 765426 & 4.7131 & 4.755 & TRN & & \\
\hline CHEMBL1825028 & 765426 & 5.1035 & 5.2679 & TRN & & \\
\hline CHEMBL1825021 & 765426 & 5.3862 & 5.0103 & TST & & \\
\hline CHEMBL1824763 & 765426 & 4.8739 & 4.927 & TRN & & \\
\hline CHEMBL1824752 & 765426 & 4.9606 & 5.1027 & TRN & & \\
\hline CHEMBL1824769 & 765426 & 7.0 & 5.2935 & TST & & \\
\hline CHEMBL1825025 & 765426 & 5.3595 & 5.3055 & TRN & & \\
\hline CHEMBL1825045 & 765426 & 5.8665 & 5.2629 & TRN & & \\
\hline CHEMBL1824756 & 765426 & 4.9602 & 4.7764 & TRN & & \\
\hline CHEMBL1825046 & 765426 & 5.556 & 5.1862 & TRN & & \\
\hline CHEMBL1824747 & 765426 & 4.9859 & 4.9423 & TRN & & \\
\hline CHEMBL1824759 & 765426 & 4.8684 & 4.755 & TRN & & \\
\hline CHEMBL1824743 & 765426 & 5.295 & 5.0039 & TRN & & \\
\hline CHEMBL1825024 & 765426 & 5.9586 & 4.82100 & 000000000 & & TST \\
\hline CHEMBL1825031 & 765426 & 5.2154 & 5.2603 & TRN & & \\
\hline CHEMBL1825049 & 765426 & 4.9706 & 5.0993 & TRN & & \\
\hline CHEMBL1824749 & 765426 & 4.7929 & 5.1548 & TRN & & \\
\hline CHEMBL336638 & 765426 & 7.699 & 4.7908 & TST & & \\
\hline CHEMBL14192 & 765426 & 6.8239 & 4.9834 & TST & & \\
\hline CHEMBL1825036 & 765426 & 5.6308 & 5.3703 & TRN & & \\
\hline CHEMBL1825040 & 765426 & 5.0209 & 5.0118 & TRN & & \\
\hline CHEMBL1825043 & 765426 & 5.0101 & 5.0306 & TRN & & \\
\hline CHEMBL1825030 & 765426 & 5.4711 & 5.2114 & TRN & & \\
\hline CHEMBL1825032 & 765426 & 5.4078 & 5.3915 & TRN & & \\
\hline CHEMBL1824750 & 765426 & 5.3335 & 5.0947 & TRN & & \\
\hline CHEMBL1825048 & 765426 & 4.761 & 5.1291 & TRN & & \\
\hline CHEMBL1824760 & 765426 & 4.8626 & 4.7411 & TRN & & \\
\hline CHEMBL1824768 & 765426 & 4.8102 & 4.8391 & TRN & & \\
\hline CHEMBL1824745 & 765426 & 4.7953 & 5.0039 & TRN & & \\
\hline CHEMBL1824746 & 765426 & 4.71399 & 99999999 & 995 & 4.9885 & TRN \\
\hline CHEMBL1824744 & 765426 & 4.9747 & 5.0039 & TRN & & \\
\hline CHEMBL1824755 & 765426 & 5.3391 & 4.7989 & TST & & \\
\hline CHEMBL1825042 & 765426 & 5.098 & 4.9827 & TRN & & \\
\hline CHEMBL1825039 & 765426 & 5.1267 & 5.0118 & TRN & & \\
\hline CHEMBL1825020 & 765426 & 6.8239 & 5.2869 & TST & & \\
\hline CHEMBL1824751 & 765426 & 5.1118 & 5.1357 & TRN & & \\
\hline CHEMBL1825022 & 765426 & 4.09699 & و9999999 & 995 & 5.0738 & TST \\
\hline CHEMBL1825017 & 765426 & 4.9136 & 5.2598 & TST & & \\
\hline CHEMBL1825019 & 765426 & 4.7875 & 4.9797 & TST & & \\
\hline CHEMBL1825041 & 765426 & 5.1938 & 5.0118 & TRN & & \\
\hline CHEMBL224789 & 765426 & 8.0969 & 5.0669 & TST & & \\
\hline CHEMBL1825035 & 765426 & 5.3799 & 5.3654 & TRN & & \\
\hline CHEMBL1825033 & 765426 & 5.0381 & 5.3679 & TRN & & \\
\hline CHEMBL1825044 & 765426 & 5.2976 & 5.1555 & TST & & \\
\hline CHEMBL1824764 & 765426 & 4.7849 & 4.9868 & TST & & \\
\hline CHEMBL1673039 & 954743 & 4.787 & 4.6025 & TRN & & \\
\hline CHEMBL412142 & 954743 & 4.7781 & 3.998 & TRN & & \\
\hline
\end{tabular}




\begin{tabular}{|c|c|c|c|c|c|c|}
\hline \multirow[b]{2}{*}{ CHEMBL258844 } & \multirow[b]{2}{*}{954743} & \multicolumn{5}{|c|}{ Supplemental Table S2.txt } \\
\hline & & \multicolumn{5}{|c|}{$5.3067 \quad 4.5423$ TRN } \\
\hline CHEMBL188678 & 954743 & 4.1634 & 4.7214 & TRN & & \\
\hline CHEMBL 379300 & 954743 & \multicolumn{3}{|c|}{6.8420000000000005} & 6.7088 & TRN \\
\hline CHEMBL509032 & 954743 & 4.6046 & 4.9121 & TRN & & \\
\hline CHEMBL2144069 & 954743 & 4.8173 & 4.1259 & TRN & & \\
\hline CHEMBL1788116 & 954743 & 3.6977 & 4.378 & TRN & & \\
\hline CHEMBL102714 & 954743 & 3.7735 & 3.7626 & TRN & & \\
\hline CHEMBL2363137 & 954743 & 5.1034 & 4.9249 & TRN & & \\
\hline CHEMBL1190711 & 954743 & \multicolumn{3}{|c|}{5.702999999999999} & 5.5843 & TRN \\
\hline CHEMBL1357247 & 954743 & 3.7318 & 3.1512 & TRN & & \\
\hline CHEMBL483849 & 954743 & 1.9454 & 2.6056 & TRN & & \\
\hline CHEMBL240954 & 954743 & 4.8973 & 4.2413 & TST & & \\
\hline CHEMBL472940 & 954743 & 5.2235 & 4.4738 & TRN & & \\
\hline CHEMBL1230020 & 954743 & 3.9672 & 4.1561 & TRN & & \\
\hline CHEMBL222102 & 954743 & 3.8431 & 3.9665 & TRN & & \\
\hline CHEMBL1643959 & 954743 & 4.0173 & 3.3962 & TRN & & \\
\hline CHEMBL221137 & 954743 & 5.5205 & 4.9836 & TST & & \\
\hline CHEMBL3349342 & 954743 & 3.3712 & 3.9098 & TRN & & \\
\hline CHEMBL3186408 & 954743 & 3.5918 & 3.7805 & TST & & \\
\hline CHEMBL300389 & 954743 & 7.3284 & 7.1574 & TRN & & \\
\hline CHEMBL393929 & 954743 & 3.5443 & 4.0256 & TRN & & \\
\hline CHEMBL1242367 & 954743 & 4.2537 & 4.2262 & TRN & & \\
\hline CHEMBL483847 & 954743 & 3.8613 & 4.0722 & TRN & & \\
\hline CHEMBL515416 & 954743 & 5.5332 & 4.461 & TRN & & \\
\hline CHEMBL 2005886 & 954743 & 4.1847 & 4.6014 & TRN & & \\
\hline CHEMBL577784 & 954743 & 3.9073 & 5.0859 & TRN & & \\
\hline CHEMBL 373751 & 954743 & 3.0753 & 3.5522 & TRN & & \\
\hline CHEMBL1590308 & 954743 & 2.9253 & 3.3958 & TST & & \\
\hline CHEMBL379975 & 954743 & 4.4999 & 5.5829 & TRN & & \\
\hline CHEMBL210618 & 954743 & 3.1832 & 3.5428 & TRN & & \\
\hline CHEMBL585951 & 954743 & 6.4391 & 6.6427 & TRN & & \\
\hline CHEMBL180127 & 954743 & 4.7296 & 4.50899 & 9999999999 & כy & TRN \\
\hline CHEMBL92309 & 954743 & 4.4228 & 2.9958 & TST & & \\
\hline CHEMBL259181 & 954743 & 5.2395 & 4.9389 & TRN & & \\
\hline CHEMBL512504 & 954743 & 6.8364 & 6.7817 & TRN & & \\
\hline CHEMBL213100 & 954743 & 3.3302 & 3.6084 & TRN & & \\
\hline CHEMBL191334 & 954743 & 3.2738 & 4.0018 & TRN & & \\
\hline CHEMBL1516890 & 954743 & 3.6541 & 4.0393 & TRN & & \\
\hline CHEMBL514499 & 954743 & 7.8286 & 7.4741 & TRN & & \\
\hline CHEMBL3392440 & 954743 & 4.3739 & 3.835 & TRN & & \\
\hline CHEMBL392695 & 954743 & 5.6756 & 5.4548 & TRN & & \\
\hline CHEMBL 209148 & 954743 & 4.3006 & 4.0894 & TRN & & \\
\hline CHEMBL1970879 & 954743 & 4.6673 & 3.8547 & TRN & & \\
\hline CHEMBL189584 & 954743 & 5.4553 & 4.9708 & TRN & & \\
\hline CHEMBL1256459 & 954743 & 7.4722 & 7.5158 & TRN & & \\
\hline CHEMBL220241 & 954743 & 5.0628 & 4.5182 & TRN & & \\
\hline CHEMBL573107 & 954743 & 4.1841 & 5.1085 & TRN & & \\
\hline CHEMBL 9470 & 954743 & 6.2464 & 6.171 & TST & & \\
\hline
\end{tabular}




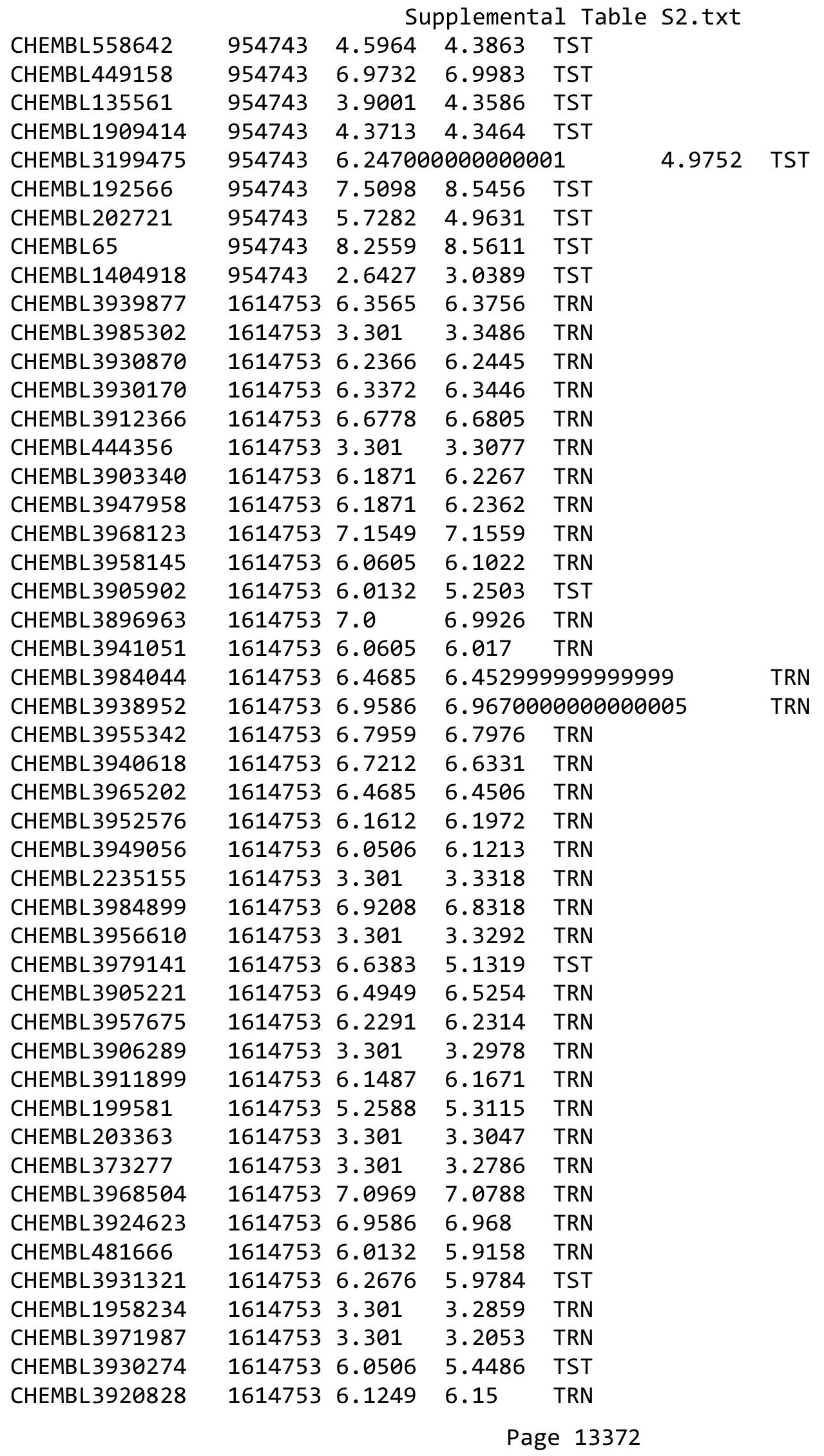


Supplemental Table S2.txt

\begin{tabular}{|c|c|c|c|c|c|}
\hline CHEMBL3954125 & 1614753 & 6.6383 & 6.6511 & TRN & \\
\hline CHEMBL3965219 & 1614753 & 6.7696 & 6.7202 & TRN & \\
\hline CHEMBL3937547 & 1614753 & 3.301 & 3.2879 & TRN & \\
\hline CHEMBL3976628 & 1614753 & 5.9914 & 5.7518 & TST & \\
\hline CHEMBL3985367 & 1614753 & 6.1135 & 6.3794 & TST & \\
\hline CHEMBL3957107 & 1614753 & 6.1079 & 5.4373 & TST & \\
\hline CHEMBL3938619 & 1614753 & 5.9706 & 5.966 & TRN & \\
\hline CHEMBL3940356 & 1614753 & 6.3665 & 6.4631 & TST & \\
\hline CHEMBL3921935 & 1614753 & 6.3279 & 6.3468 & TRN & \\
\hline CHEMBL3963346 & 1614753 & 6.1938 & 6.1673 & TRN & \\
\hline CHEMBL 3985073 & 1614753 & 6.699 & 6.5534 & TST & \\
\hline CHEMBL3957764 & 1614753 & 6.2147 & 5.0731 & TST & \\
\hline CHEMBL 3914895 & 1614753 & 6.5686 & 5.9109 & TST & \\
\hline CHEMBL3967501 & 1614753 & 6.3979 & 6.4928 & TST & \\
\hline CHEMBL 3984704 & 1614753 & 5.9172 & 4.7821 & TST & \\
\hline CHEMBL 3938022 & 1614753 & 6.3872 & 6.4415 & TST & \\
\hline CHEMBL3956254 & 1614753 & 6.7447 & 6.7816 & TRN & \\
\hline CHEMBL 3964097 & 1614753 & 6.1805 & 6.1876 & TRN & \\
\hline CHEMBL 3968719 & 1614753 & 6.1135 & 4.7396 & TST & \\
\hline CHEMBL 3921225 & 1614753 & 6.4949 & 6.4856 & TRN & \\
\hline CHEMBL1409445 & 809418 & 5.9281 & 5.5717 & TRN & \\
\hline CHEMBL1711359 & 809418 & 7.585 & 5.9613 & TST & \\
\hline CHEMBL1373276 & 809418 & 4.4376 & 5.0647 & TRN & \\
\hline CHEMBL1711360 & 809418 & 6.0872 & 5.5493 & TRN & \\
\hline CHEMBL1349225 & 809418 & 4.5835 & 5.0817 & TRN & \\
\hline CHEMBL1726113 & 809418 & 4.6801 & 4.7482 & TRN & \\
\hline CHEMBL1727333 & 809418 & 5.8013 & 5.34399 & 9999999999 & TRN \\
\hline CHEMBL1997017 & 809418 & 5.4067 & 5.0354 & TST & \\
\hline CHEMBL1491288 & 809418 & 4.8377 & 5.0935 & TRN & \\
\hline CHEMBL1300959 & 809418 & 5.4584 & 5.25899 & & TRN \\
\hline CHEMBL1972072 & 809418 & 5.3778 & 5.1872 & TRN & \\
\hline CHEMBL1504766 & 809418 & 3.1549 & 5.2658 & TRN & \\
\hline CHEMBL1346409 & 809418 & 5.4634 & 4.9152 & TRN & \\
\hline CHEMBL1335146 & 809418 & 4.738 & 5.2781 & TRN & \\
\hline CHEMBL1565005 & 809418 & 5.7077 & 5.3715 & TRN & \\
\hline CHEMBL1323536 & 809418 & 4.8867 & 5.0756 & TRN & \\
\hline CHEMBL1609419 & 809418 & 5.2034 & 5.3293 & TRN & \\
\hline CHEMBL1455137 & 809418 & 5.3098 & 5.2437 & TRN & \\
\hline CHEMBL1360862 & 809418 & 4.9322 & 5.0629 & TRN & \\
\hline CHEMBL1575588 & 809418 & 6.3098 & 5.33299 & 9999999999 & TRN \\
\hline CHEMBL1453723 & 809418 & 4.4537 & 5.0299 & TRN & \\
\hline CHEMBL1597777 & 809418 & 5.9469 & 5.4025 & TRN & \\
\hline CHEMBL1496993 & 809418 & 5.1062 & 5.3705 & TRN & \\
\hline CHEMBL1733762 & 809418 & 4.9855 & 4.9857 & TRN & \\
\hline CHEMBL1483562 & 809418 & 5.0205 & 5.1564 & TRN & \\
\hline CHEMBL1326083 & 809418 & $5.2020 e$ & 00000000 & 5.3408 & TRN \\
\hline CHEMBL1613582 & 809418 & 4.8462 & 5.0123 & TRN & \\
\hline CHEMBL1449499 & 809418 & 4.9516 & 4.7471 & TRN & \\
\hline
\end{tabular}

Page 13373 
Supplemental Table S2.txt

\begin{tabular}{|c|c|c|c|c|c|}
\hline CHEMBL1405331 & 809418 & 5.7352 & 5.3553 & TST & \\
\hline CHEMBL1594119 & 809418 & 5.5575 & 5.5243 & TRN & \\
\hline CHEMBL1706381 & 809418 & 5.8539 & 5.7219 & TRN & \\
\hline CHEMBL1388951 & 809418 & 5.2041 & 5.0254 & TRN & \\
\hline CHEMBL1492096 & 809418 & 5.5834 & 5.4505 & TRN & \\
\hline CHEMBL1378716 & 809418 & 4.6921 & 5.1688 & TST & \\
\hline CHEMBL1444328 & 809418 & 4.9285 & 5.3187 & TST & \\
\hline CHEMBL1409423 & 809418 & 5.3737 & 5.1272 & TRN & \\
\hline CHEMBL433680 & 809418 & 7.585 & 6.069 & TST & \\
\hline CHEMBL1358722 & 809418 & 5.6615 & 5.5573 & TST & \\
\hline CHEMBL1502830 & 809418 & 4.6737 & 4.9147 & TRN & \\
\hline CHEMBL591876 & 809418 & 5.7959 & 5.8924 & TRN & \\
\hline CHEMBL1425438 & 809418 & 4.9614 & 5.3897 & TRN & \\
\hline CHEMBL1495310 & 809418 & 5.5045 & 5.1133 & TRN & \\
\hline CHEMBL1598721 & 809418 & 5.2306 & 5.1733 & TRN & \\
\hline CHEMBL590665 & 809418 & 6.065 & 5.7828 & TRN & \\
\hline CHEMBL1450483 & 809418 & 5.5086 & 5.1853 & TRN & \\
\hline CHEMBL1724993 & 809418 & 5.1662 & 4.8064 & TRN & \\
\hline CHEMBL1462791 & 809418 & 4.539 & 4.6535 & TRN & \\
\hline CHEMBL1415184 & 809418 & 7.585 & 6.2638 & TRN & \\
\hline CHEMBL1497797 & 809418 & 5.0246 & 5.2217 & TST & \\
\hline CHEMBL1486214 & 809418 & 4.8768 & 5.5902 & TRN & \\
\hline CHEMBL1727038 & 809418 & 3.1549 & 4.5539 & TST & \\
\hline CHEMBL1502020 & 809418 & 5.9101 & 5.3803 & TRN & \\
\hline CHEMBL1352586 & 809418 & 5.0477 & 5.1159 & TRN & \\
\hline CHEMBL1568022 & 809418 & 5.1898 & 5.2614 & TRN & \\
\hline CHEMBL1732062 & 809418 & 5.4962 & 5.1873 & TRN & \\
\hline CHEMBL1396345 & 809418 & 5.3768 & 5.1272 & TRN & \\
\hline CHEMBL1311094 & 809418 & 4.6929 & 5.1138 & TST & \\
\hline CHEMBL1502771 & 809418 & 5.1818 & 5.056 & TRN & \\
\hline CHEMBL1307319 & 809418 & 5.699 & 5.3258 & TST & \\
\hline CHEMBL1342821 & 809418 & 5.1007 & 5.1914 & TRN & \\
\hline CHEMBL1711797 & 809418 & 5.4413 & \multicolumn{2}{|c|}{5.2989999999999995} & TST \\
\hline CHEMBL1863767 & 809418 & 5.2034 & 5.0656 & TRN & \\
\hline CHEMBL1515132 & 809418 & 5.3778 & 5.3322 & TST & \\
\hline CHEMBL1391921 & 809418 & 5.1707 & 5.315 & TRN & \\
\hline CHEMBL1300836 & 809418 & 5.6073 & 5.066 & TRN & \\
\hline CHEMBL1352995 & 809418 & 5.0004 & 5.0732 & TRN & \\
\hline CHEMBL225963 & 809418 & 7.585 & 5.2082 & TST & \\
\hline CHEMBL1537642 & 809418 & 5.5969 & \multicolumn{2}{|c|}{5.0680000000000005} & TRN \\
\hline CHEMBL1544743 & 809418 & 6.0964 & 5.4771 & TRN & \\
\hline CHEMBL1447350 & 809418 & 5.0092 & 5.1998 & TRN & \\
\hline CHEMBL1421029 & 809418 & 5.2233 & 5.2821 & TRN & \\
\hline CHEMBL1703510 & 809418 & 5.2798 & 5.2507 & TRN & \\
\hline CHEMBL1397359 & 809418 & 4.6817 & 5.1479 & TRN & \\
\hline CHEMBL1365328 & 809418 & 4.9578 & 4.9601 & TRN & \\
\hline CHEMBL203695 & 809418 & 5.399 & 5.2188 & TRN & \\
\hline CHEMBL1400084 & 809418 & 4.6381 & 4.2178 & TRN & \\
\hline
\end{tabular}


Supplemental Table S2.txt

\begin{tabular}{|c|c|c|c|c|c|}
\hline CHEMBL1574879 & 809418 & 7.585 & 6.2081 & TRN & \\
\hline CHEMBL1403523 & 809418 & 4.7071 & 4.9111 & TRN & \\
\hline CHEMBL1384068 & 809418 & 5.1851 & 4.9802 & TRN & \\
\hline CHEMBL1412298 & 809418 & 5.2291 & 5.1042 & TRN & \\
\hline CHEMBL1532068 & 809418 & 5.8761 & 5.775 & TRN & \\
\hline CHEMBL1513705 & 809418 & 6.1385 & 5.5273 & TRN & \\
\hline CHEMBL1397089 & 809418 & 5.8928 & 5.372999 & 9999999999 & TST \\
\hline CHEMBL578675 & 809418 & 5.5003 & 5.2701 & TRN & \\
\hline CHEMBL1329925 & 809418 & 4.7392 & 4.9791 & TRN & \\
\hline CHEMBL1425521 & 809418 & 5.5884 & 5.4044 & TST & \\
\hline CHEMBL1729345 & 809418 & 5.224 & 5.2469 & TRN & \\
\hline CHEMBL1417566 & 809418 & 4.6202 & 5.2357 & TRN & \\
\hline CHEMBL1605758 & 809418 & 4.8665 & 4.9995 & TRN & \\
\hline CHEMBL1361227 & 809418 & 5.0273 & 5.0403 & TRN & \\
\hline CHEMBL1511254 & 809418 & 6.2798 & 5.447999 & 99999999995 & TRN \\
\hline CHEMBL1424697 & 809418 & 5.2111 & 5.31 & TRN & \\
\hline CHEMBL1488056 & 809418 & 5.0841 & 4.8261 & TRN & \\
\hline CHEMBL1474608 & 809418 & 5.1979 & 5.1301 & TST & \\
\hline CHEMBL1377352 & 809418 & 5.7447 & 5.2177 & TRN & \\
\hline CHEMBL 1407690 & 809418 & 4.8294 & 5.2413 & TRN & \\
\hline CHEMBL1610049 & 809418 & 6.2495 & 5.2719 & TRN & \\
\hline CHEMBL1335155 & 809418 & 5.1278 & 5.0027 & TRN & \\
\hline CHEMBL1374797 & 809418 & 5.4023 & 5.199 & TRN & \\
\hline CHEMBL1458016 & 809418 & 4.6386 & 5.352 & TRN & \\
\hline CHEMBL1300908 & 809418 & 4.8019 & 4.8736 & TRN & \\
\hline CHEMBL1408634 & 809418 & 4.7967 & 5.2025 & TRN & \\
\hline CHEMBL1543839 & 809418 & 5.4486 & 5.1282 & TRN & \\
\hline CHEMBL1339909 & 809418 & 5.1891 & 5.2346 & TRN & \\
\hline CHEMBL1480424 & 809418 & 4.5824 & 4.9758 & TRN & \\
\hline CHEMBL606532 & 809418 & 5.9431 & 5.6155 & TRN & \\
\hline CHEMBL1487952 & 809418 & 5.1135 & 5.4753 & TRN & \\
\hline CHEMBL1393568 & 809418 & 4.8857 & 5.2218 & TRN & \\
\hline CHEMBL1562926 & 809418 & 6.2418 & 5.4799 & TRN & \\
\hline CHEMBL1481061 & 809418 & 4.7366 & 5.1934 & TST & \\
\hline CHEMBL1572169 & 809418 & 5.3507 & 5.0312 & TRN & \\
\hline CHEMBL1458840 & 809418 & 5.1524 & 5.2384 & TRN & \\
\hline CHEMBL 1460352 & 809418 & 5.5171 & 5.2841 & TRN & \\
\hline CHEMBL585266 & 809418 & 5.4498 & 5.7582 & TRN & \\
\hline CHEMBL1436518 & 809418 & 5.6021 & 5.1674 & TST & \\
\hline CHEMBL 1535665 & 809418 & 5.3206 & 5.4339 & TRN & \\
\hline CHEMBL1360480 & 809418 & 4.8668 & 5.5574 & TRN & \\
\hline CHEMBL1492912 & 809418 & 4.5819 & 5.1552 & TRN & \\
\hline CHEMBL1464261 & 809418 & 5.0311 & 5.0051 & TRN & \\
\hline CHEMBL1329129 & 809418 & 5.6126 & 5.365 & TRN & \\
\hline CHEMBL1433979 & 809418 & 4.7932 & 4.9044 & TRN & \\
\hline CHEMBL1508699 & 809418 & 6.1113 & 5.0478 & TRN & \\
\hline CHEMBL1716834 & 809418 & \multicolumn{3}{|c|}{4.5360000000000005} & SI \\
\hline CHEMBL1601129 & 809418 & 4.8333 & 5.0757 & TRN & \\
\hline
\end{tabular}




\begin{tabular}{|c|c|c|c|c|c|}
\hline & & \multicolumn{4}{|c|}{ Supplemental Table S2.txt } \\
\hline CHEMBL1583715 & 809418 & 5.0696 & 5.1568 & TRN & \\
\hline CHEMBL1535361 & 809418 & 5.1612 & 5.3719 & TRN & \\
\hline CHEMBL1526851 & 809418 & 5.2933 & 4.9978 & TRN & \\
\hline CHEMBL1343711 & 809418 & 4.9314 & 5.4851 & TRN & \\
\hline CHEMBL1496814 & 809418 & 5.1124 & 5.1796 & TRN & \\
\hline CHEMBL1342907 & 809418 & 5.3215 & 5.16799 & 9999999999 & Tाк \\
\hline CHEMBL1438590 & 809418 & 5.3536 & 4.9904 & TRN & \\
\hline CHEMBL1865502 & 809418 & 5.4101 & 5.1776 & TST & \\
\hline CHEMBL1535959 & 809418 & \multicolumn{3}{|c|}{5.821000000000001} & TRN \\
\hline CHEMBL1730684 & 809418 & 5.1858 & 4.8764 & TST & \\
\hline CHEMBL1966132 & 809418 & 5.3298 & 5.3515 & TRN & \\
\hline CHEMBL1605956 & 809418 & 4.919 & 5.1493 & TRN & \\
\hline CHEMBL1482389 & 809418 & 5.2549 & 5.0221 & TRN & \\
\hline CHEMBL1734534 & 809418 & 5.5391 & 5.1518 & TRN & \\
\hline CHEMBL1300295 & 809418 & 4.8807 & 5.0389 & TRN & \\
\hline CHEMBL1719155 & 809418 & 5.007 & 5.0952 & TST & \\
\hline CHEMBL1608578 & 809418 & 4.7523 & 4.9763 & TRN & \\
\hline CHEMBL1583471 & 809418 & 5.6737 & 5.5384 & TRN & \\
\hline CHEMBL1455060 & 809418 & 4.9179 & 5.1085 & TRN & \\
\hline CHEMBL1563714 & 809418 & 5.1101 & 5.109 & TST & \\
\hline CHEMBL1565371 & 809418 & 6.041 & 5.1488 & TRN & \\
\hline CHEMBL1714315 & 809418 & 5.1759 & 5.0613 & TRN & \\
\hline CHEMBL1403320 & 809418 & 4.9658 & 5.3542 & TRN & \\
\hline CHEMBL1449794 & 809418 & 5.0799 & 5.2482 & TRN & \\
\hline CHEMBL1612227 & 809418 & 5.2941 & 5.1434 & TST & \\
\hline CHEMBL1570080 & 809418 & 5.9393 & 5.1699 & TRN & \\
\hline CHEMBL1516127 & 809418 & 5.5391 & 5.4149 & TRN & \\
\hline CHEMBL1463930 & 809418 & 4.5751 & 5.0902 & TST & \\
\hline CHEMBL1353013 & 809418 & 5.1965 & 5.6071 & TRN & \\
\hline CHEMBL1588217 & 809418 & 5.308 & 5.2626 & TRN & \\
\hline CHEMBL1310852 & 809418 & 4.833 & 5.0236 & TRN & \\
\hline CHEMBL1421441 & 809418 & 4.9378 & 5.03 & TRN & \\
\hline CHEMBL1410008 & 809418 & 6.091 & 5.3191 & TRN & \\
\hline CHEMBL1526148 & 809418 & 4.9465 & 5.0914 & TRN & \\
\hline CHEMBL1338922 & 809418 & 4.5217 & 4.748 & TRN & \\
\hline CHEMBL604361 & 809418 & 4.7181 & 4.7801 & TRN & \\
\hline CHEMBL319244 & 809418 & 5.9547 & 5.3608 & TRN & \\
\hline CHEMBL482050 & 809418 & 4.8658 & 5.0255 & TST & \\
\hline CHEMBL1349485 & 809418 & 5.4535 & 5.2824 & TRN & \\
\hline CHEMBL116919 & 809418 & 5.2676 & 5.5095 & TRN & \\
\hline CHEMBL1490222 & 809418 & 5.4828 & 5.57299 & 99999999995 & WT \\
\hline CHEMBL1384414 & 809418 & 4.6992 & 4.9823 & TRN & \\
\hline CHEMBL 2003351 & 809418 & 4.6482 & 4.7894 & TRN & \\
\hline CHEMBL1361883 & 809418 & 5.1124 & 5.2404 & TRN & \\
\hline CHEMBL1327783 & 809418 & 5.1337 & 5.3008 & TRN & \\
\hline CHEMBL1515801 & 809418 & 5.1361 & 5.0677 & TST & \\
\hline CHEMBL1341031 & 809418 & 5.0372 & 5.5842 & TRN & \\
\hline CHEMBL306380 & 809418 & 5.7055 & 4.9855 & TST & \\
\hline
\end{tabular}




\begin{tabular}{|c|c|c|c|c|c|}
\hline & & \multicolumn{4}{|c|}{ Supplemental Table s2.txt } \\
\hline CHEMBL1310479 & 809418 & 5.4949 & 5.314 & TST & \\
\hline CHEMBL1375155 & 809418 & 5.1113 & 5.2934 & TST & \\
\hline CHEMBL1418818 & 809418 & 5.3947 & 5.1135 & TRN & \\
\hline CHEMBL 2007188 & 809418 & 4.5923 & 5.0194 & TRN & \\
\hline CHEMBL1555876 & 809418 & 5.7905 & 5.3792 & TRN & \\
\hline CHEMBL1587031 & 809418 & 5.2161 & 5.0922 & TST & \\
\hline CHEMBL1501567 & 809418 & 4.919 & 5.0063 & TST & \\
\hline CHEMBL1301232 & 809418 & 4.9154 & 5.0886 & TRN & \\
\hline CHEMBL1473985 & 809418 & 4.8088 & 5.1032 & TST & \\
\hline CHEMBL1570078 & 809418 & 4.5379 & 4.6805 & TST & \\
\hline CHEMBL1708171 & 809418 & 4.9423 & 4.8257 & TRN & \\
\hline CHEMBL1424968 & 809418 & 5.0477 & 5.1669 & TRN & \\
\hline CHEMBL1351099 & 809418 & 5.1421 & 4.9998 & TST & \\
\hline CHEMBL1500469 & 809418 & 5.8697 & 5.4531 & TRN & \\
\hline CHEMBL1366942 & 809418 & 5.3645 & 6.2309 & TRN & \\
\hline CHEMBL1488036 & 809418 & 5.7959 & 5.1002 & TRN & \\
\hline CHEMBL1477103 & 809418 & 5.0799 & 4.8905 & TRN & \\
\hline CHEMBL1358447 & 809418 & 4.9961 & 5.1409 & TRN & \\
\hline CHEMBL1502434 & 809418 & 5.8477 & 5.4129 & TRN & \\
\hline CHEMBL1573534 & 809418 & 4.5887 & 4.944 & TST & \\
\hline CHEMBL1372112 & 809418 & 4.9731 & 4.7766 & TRN & \\
\hline CHEMBL1317160 & 809418 & 5.3161 & 5.0573 & TRN & \\
\hline CHEMBL1412039 & 809418 & 5.2604 & 5.0802 & TRN & \\
\hline CHEMBL1332925 & 809418 & 5.3288 & 4.9266 & TRN & \\
\hline CHEMBL1581838 & 809418 & 5.1791 & 4.1028 & TRN & \\
\hline CHEMBL1334550 & 809418 & 4.8536 & 5.2366 & TRN & \\
\hline CHEMBL1474553 & 809418 & 5.3936 & 5.0976 & TRN & \\
\hline CHEMBL1430094 & 809418 & 4.3584 & 5.3836 & TRN & \\
\hline CHEMBL1299281 & 809418 & 6.1007 & 5.1395 & TRN & \\
\hline CHEMBL1478826 & 809418 & 5.8477 & 5.3178 & TRN & \\
\hline CHEMBL1490503 & 809418 & 7.585 & 6.2212 & TRN & \\
\hline CHEMBL1385770 & 809418 & 4.7349 & 4.7362 & TRN & \\
\hline CHEMBL1300618 & 809418 & 5.0376 & 4.9063 & TRN & \\
\hline CHEMBL1499012 & 809418 & 5.058 & 5.0378 & TRN & \\
\hline CHEMBL1433325 & 809418 & 4.4056 & 4.9852 & TST & \\
\hline CHEMBL1412002 & 809418 & 3.1549 & 5.8513 & TRN & \\
\hline CHEMBL1398686 & 809418 & 5.4547 & 5.18 & TRN & \\
\hline CHEMBL1440303 & 809418 & 5.1878 & 5.2787 & TRN & \\
\hline CHEMBL1299470 & 809418 & 4.6927 & 5.20200 & 0000000001 & TRN \\
\hline CHEMBL1369965 & 809418 & 5.3915 & 5.1428 & TRN & \\
\hline CHEMBL1514042 & 809418 & 3.1549 & 4.9772 & TRN & \\
\hline CHEMBL1327276 & 809418 & 4.9772 & 5.3063 & TRN & \\
\hline CHEMBL543876 & 809418 & 5.091 & 4.9303 & TRN & \\
\hline CHEMBL1565115 & 809418 & 5.5058 & 5.6745 & TRN & \\
\hline CHEMBL1710184 & 809418 & 5.0778 & 5.0453 & TRN & \\
\hline CHEMBL1989082 & 809418 & 5.2573 & 5.0923 & TST & \\
\hline CHEMBL1581141 & 809418 & 4.8677 & 5.1505 & TRN & \\
\hline CHEMBL1505780 & 809418 & 5.8633 & 5.3283 & TRN & \\
\hline
\end{tabular}




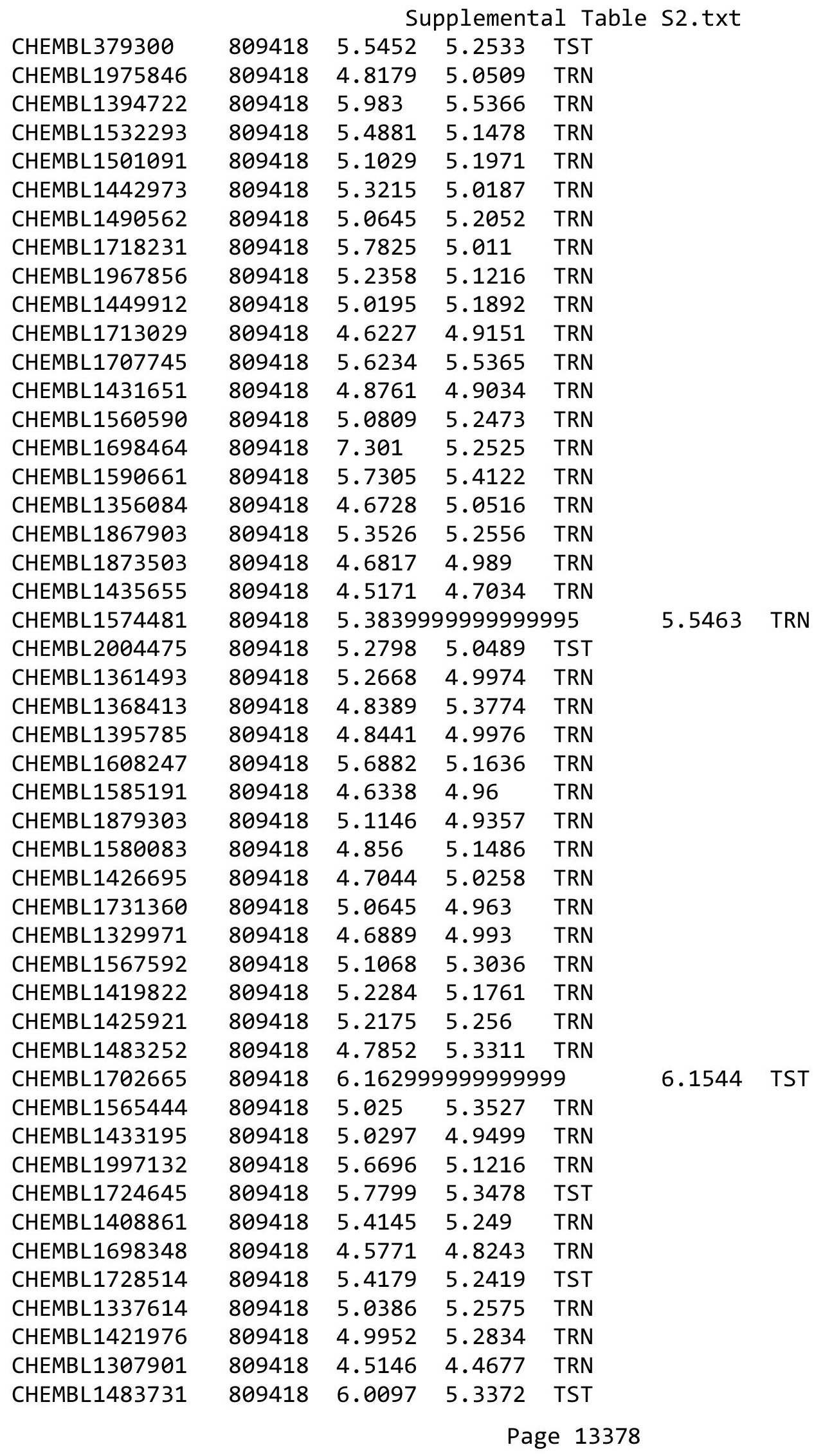




\begin{tabular}{|c|c|c|c|c|c|c|}
\hline \multirow{3}{*}{$\begin{array}{l}\text { CHEMBL } 338474 \\
\text { CHEMBL1464024 }\end{array}$} & \multirow{3}{*}{$\begin{array}{l}809418 \\
809418\end{array}$} & \multirow{2}{*}{\multicolumn{4}{|c|}{ 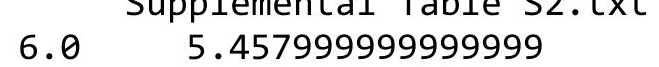 }} & \multirow{2}{*}{ TST } \\
\hline & & & & & & \\
\hline & & 5.4034 & 6.0459 & TRN & & \\
\hline CHEMBL1410758 & 809418 & 6.0343 & 5.7134 & TRN & & \\
\hline CHEMBL1370278 & 809418 & 6.0675 & 5.7782 & TRN & & \\
\hline CHEMBL1526446 & 809418 & 4.4647 & 5.09 & TRN & & \\
\hline CHEMBL1483380 & 809418 & 5.4225 & 5.0842 & TRN & & \\
\hline CHEMBL1427185 & 809418 & 4.9248 & 5.3255 & TST & & \\
\hline CHEMBL1607435 & 809418 & 4.506 & 4.9069 & TRN & & \\
\hline CHEMBL1607568 & 809418 & 5.3737 & 5.1416 & TST & & \\
\hline CHEMBL1300527 & 809418 & 4.7902 & 5.037 & TRN & & \\
\hline CHEMBL1394747 & 809418 & 4.673 & 4.9457 & TST & & \\
\hline CHEMBL1511215 & 809418 & 5.8041 & 5.2536 & TRN & & \\
\hline CHEMBL1606837 & 809418 & 5.1824 & 5.0126 & TST & & \\
\hline CHEMBL1490987 & 809418 & 4.9045 & \multicolumn{3}{|c|}{5.321000000000001} & TRN \\
\hline CHEMBL1504634 & 809418 & 5.1249 & 4.7986 & TRN & & \\
\hline CHEMBL1541657 & 809418 & 4.9805 & 5.0224 & TST & & \\
\hline CHEMBL1439933 & 809418 & 5.2218 & 5.0179 & TRN & & \\
\hline CHEMBL1486109 & 809418 & 4.5701 & 5.4418 & TRN & & \\
\hline CHEMBL1475774 & 809418 & 4.7575 & 5.0322 & TRN & & \\
\hline CHEMBL1721502 & 809418 & 4.8847 & 5.1595 & TRN & & \\
\hline CHEMBL589238 & 809418 & 6.0429 & 5.3609 & TRN & & \\
\hline CHEMBL1724428 & 809418 & 7.585 & 6.1557 & TST & & \\
\hline CHEMBL1602160 & 809418 & 5.1249 & 5.1637 & TST & & \\
\hline CHEMBL1348803 & 809418 & 5.2426 & 5.1649 & TRN & & \\
\hline CHEMBL1510332 & 809418 & 6.1457 & 5.4125 & TRN & & \\
\hline CHEMBL3392476 & 809418 & 5.3478 & 5.2705 & TRN & & \\
\hline CHEMBL1343814 & 809418 & 5.1518 & 5.091 & TRN & & \\
\hline CHEMBL1494120 & 809418 & 5.4584 & 5.7066 & TRN & & \\
\hline CHEMBL1590136 & 809418 & 4.5116 & 4.602 & TST & & \\
\hline CHEMBL1492648 & 809418 & 5.1506 & \multicolumn{3}{|c|}{5.257999999999999} & TRN \\
\hline CHEMBL1573697 & 809418 & 4.7865 & 5.3657 & TRN & & \\
\hline CHEMBL1476739 & 809418 & 6.5058 & 5.184 & TRN & & \\
\hline CHEMBL1544175 & 809418 & 5.1952 & 5.1169 & TRN & & \\
\hline CHEMBL1305254 & 809418 & 5.0443 & 5.1636 & TST & & \\
\hline CHEMBL1305077 & 809418 & 4.9038 & 5.2862 & TRN & & \\
\hline CHEMBL1573351 & 809418 & 4.5226 & 5.2135 & TRN & & \\
\hline CHEMBL1529190 & 809418 & 5.7799 & 5.5845 & TRN & & \\
\hline CHEMBL493153 & 809418 & 6.0259 & 5.5254 & TRN & & \\
\hline CHEMBL1612044 & 809418 & 4.5646 & 5.4411 & TRN & & \\
\hline CHEMBL1352313 & 809418 & 5.2069 & 5.2005 & TST & & \\
\hline CHEMBL1596347 & 809418 & 5.2255 & 5.277 & TST & & \\
\hline CHEMBL1324857 & 809418 & 5.5157 & 5.0992 & TRN & & \\
\hline CHEMBL1416089 & 809418 & \multicolumn{3}{|c|}{5.718999999999999} & .6446 & TRN \\
\hline CHEMBL1699284 & 809418 & 5.2774 & 5.2695 & TRN & & \\
\hline CHEMBL593211 & 809418 & 5.4237 & 5.3855 & TRN & & \\
\hline CHEMBL1367466 & 809418 & 4.869 & 5.2875 & TRN & & \\
\hline CHEMBL1557454 & 809418 & 5.0241 & 5.2089 & TRN & & \\
\hline CHEMBL1605536 & 809418 & 4.9622 & 5.59 & TRN & & \\
\hline
\end{tabular}


Supplemental Table S2.txt

\begin{tabular}{|c|c|c|c|c|c|}
\hline CHEMBL1409554 & 809418 & 5.2027 & 5.5351 & TRN & \\
\hline CHEMBL1397463 & 809418 & 5.3261 & 5.3315 & TRN & \\
\hline CHEMBL1509727 & 809418 & 4.6562 & 5.2302 & TRN & \\
\hline CHEMBL1390112 & 809418 & 5.7496 & \multicolumn{2}{|c|}{5.507999999999999} & TRN \\
\hline CHEMBL1565460 & 809418 & 6.1481 & 5.3449 & TRN & \\
\hline CHEMBL1544664 & 809418 & 4.678 & 4.8608 & TST & \\
\hline CHEMBL1457902 & 809418 & 6.3439 & 5.3907 & TRN & \\
\hline CHEMBL1443802 & 809418 & 4.6807 & 4.988 & TRN & \\
\hline CHEMBL1302109 & 809418 & 4.6315 & 5.441 & TRN & \\
\hline CHEMBL1367089 & 809418 & 4.4374 & 4.958 & TST & \\
\hline CHEMBL1730189 & 809418 & 5.1427 & 4.9245 & TRN & \\
\hline CHEMBL1550670 & 809418 & 5.7212 & 5.1909 & TRN & \\
\hline CHEMBL1484231 & 809418 & 4.9473 & 5.1828 & TST & \\
\hline CHEMBL1566487 & 809418 & 5.301 & 5.2855 & TRN & \\
\hline CHEMBL1352748 & 809418 & 4.4349 & 5.0909 & TRN & \\
\hline CHEMBL317115 & 809418 & 5.4045 & \multicolumn{2}{|c|}{5.252000000000001} & TRN \\
\hline CHEMBL1393625 & 809418 & 4.9543 & 5.1405 & TRN & \\
\hline CHEMBL1900870 & 809418 & 5.8297 & 5.4531 & TST & \\
\hline CHEMBL1598985 & 809418 & 4.9562 & 5.1428 & TRN & \\
\hline CHEMBL1398721 & 809418 & 4.6308 & 5.1648 & TRN & \\
\hline CHEMBL1355963 & 809418 & 4.6934 & 5.0946 & TST & \\
\hline CHEMBL1998498 & 809418 & 3.1549 & 4.9419 & TRN & \\
\hline CHEMBL1320969 & 809418 & 5.3706 & 5.1715 & TST & \\
\hline CHEMBL1455567 & 809418 & 5.2343 & 5.3468 & TST & \\
\hline CHEMBL1353317 & 809418 & 4.9446 & 5.3419 & TRN & \\
\hline CHEMBL1422217 & 809418 & 5.4089 & 5.1571 & TRN & \\
\hline CHEMBL1973442 & 809418 & 5.7878 & 4.8653 & TRN & \\
\hline CHEMBL1711023 & 809418 & 4.5535 & 4.6687 & TRN & \\
\hline CHEMBL1382368 & 809418 & 4.5432 & 4.9185 & TRN & \\
\hline CHEMBL1527986 & 809418 & 6.0794 & 5.3778 & TRN & \\
\hline CHEMBL592600 & 809418 & 6.4559 & 6.0419 & TRN & \\
\hline CHEMBL1563198 & 809418 & 5.2034 & 4.8747 & TRN & \\
\hline CHEMBL1608757 & 809418 & 4.9311 & 4.9263 & TST & \\
\hline CHEMBL1428095 & 809418 & 5.1986 & 5.4892 & TRN & \\
\hline CHEMBL1510131 & 809418 & 5.0039 & 5.0237 & TST & \\
\hline CHEMBL1585527 & 809418 & 5.1952 & 5.2513 & TRN & \\
\hline CHEMBL1550690 & 809418 & 5.0862 & 5.0359 & TRN & \\
\hline CHEMBL1424420 & 809418 & 3.1549 & 5.067 & TRN & \\
\hline CHEMBL472437 & 809418 & 5.3143 & 5.3214 & TST & \\
\hline CHEMBL1579552 & 809418 & 4.9935 & 4.8595 & TRN & \\
\hline CHEMBL1464730 & 809418 & 4.6413 & \multicolumn{2}{|c|}{5.2170000000000005} & TRN \\
\hline CHEMBL1973156 & 809418 & 4.9303 & 4.8777 & TST & \\
\hline CHEMBL1336527 & 809418 & 4.7518 & 4.9665 & TRN & \\
\hline CHEMBL1497597 & 809418 & 5.2874 & 5.1509 & TRN & \\
\hline CHEMBL1594828 & 809418 & 4.9694 & 4.8381 & TRN & \\
\hline CHEMBL1343705 & 809418 & 4.8788 & 5.176 & TRN & \\
\hline CHEMBL1888851 & 809418 & 4.6265 & 5.0401 & TRN & \\
\hline CHEMBL1455102 & 809418 & 4.8236 & 4.8342 & TRN & \\
\hline
\end{tabular}


Supplemental Table S2.txt

\begin{tabular}{|c|c|c|c|c|}
\hline 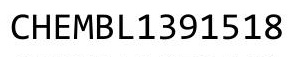 & & & & \\
\hline HEMBL1879461 & 99418 & 3851 & & \\
\hline HEMBL1555866 & & & & \\
\hline IEMBL1\& & & & & \\
\hline EMBL18 & & 11 & 3884 & \\
\hline HEMBL1512575 & 09418 & 2182 & 1679 & \\
\hline HEMBL1420175 & 09418 & .8765 & 0746 & \\
\hline HEMBL1375563 & 18 & 819 & .733 & \\
\hline AEMBL14 & 18 & & 9051 & \\
\hline IEMBL15؟ & 18 & 83 & .7849 & \\
\hline HEMBL1462900 & 09 & 9547 & 1821 & \\
\hline AEMBL1312083 & $0 s$ & 3013 & 1965 & \\
\hline HEMBL1477197 & 18 & 044 & 1635 & \\
\hline HEMBL17 & & 348 & 0384 & \\
\hline HEMBL12 & 8 & 15 & & \\
\hline HEMBL133 & 8 & 259 & 5741 & \\
\hline HEMBL1375884 & 305 & 44 & 5.4071 & \\
\hline HEMBL1387479 & 8 & 199 & 831 & \\
\hline HEMBL14 & & & & \\
\hline HEMBL15 & 8 & 28 & & ST \\
\hline HEMBL14 & 8 & & & RN \\
\hline HEMBL1425364 & 0 & 11 & 121 & NIV \\
\hline HEMBL 15 & 8 & & 3846 & \\
\hline HEMBL 14 & & & & RN \\
\hline JEMBL14 & & & 947 & RN \\
\hline JEMBL13 & & & & 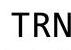 \\
\hline HEMBL 581152 & 8 & 76 & 24 & $\mathrm{RN}$ \\
\hline HEMBL1889015 & 8 & 364 & 598 & RN \\
\hline HEM & & 26 & & RN \\
\hline HEMBL14 & & & 938 & ST \\
\hline HEMBL 144 & & & & RN \\
\hline HEMBL1438737 & $0 s$ & 354 & 1522 & ST \\
\hline HEMBL15 & 8 & 76 & 505 & ST \\
\hline 5 & & & & RN \\
\hline HEMBL157 & & & 513 & RN \\
\hline HEMBL1413931 & & & 373 & RN \\
\hline HEMBL1985082 & 8 & 39 & 329 & RN \\
\hline HEMBL1725584 & 8 & 62 & 971 & I \\
\hline 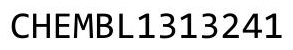 & & & & RN \\
\hline HEMBL1431608 & & & & RN \\
\hline HEMBL1522655 & 8 & & 513 & RN \\
\hline HEMBL1389268 & 8 & & & RN \\
\hline HEMBL1483682 & & & 819 & \\
\hline CHEMBL1550278 & & & & RN \\
\hline HEMBL15 & & 862 & 9988 & RN \\
\hline HEMBL1408604 & 8 & 123 & 506 & $N$ \\
\hline-13 & & & & \\
\hline & & & & \\
\hline
\end{tabular}

Page 13381 


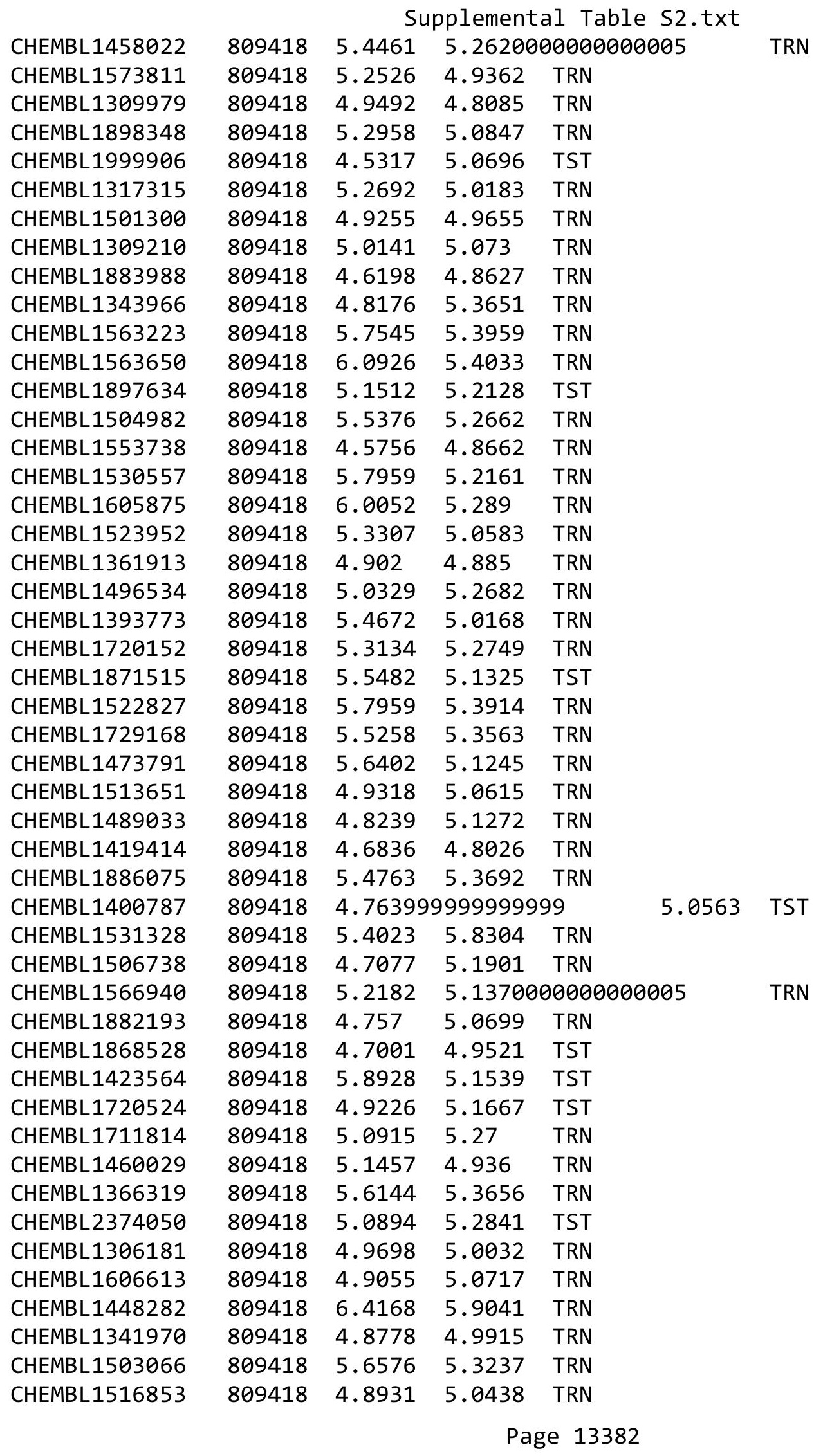


Supplemental Table S2.txt

\begin{tabular}{|c|c|c|c|c|}
\hline 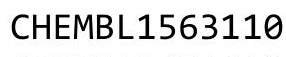 & & & & \\
\hline HEMBL1434912 & 309418 & 1791 & 3763 & \\
\hline HEMBL1455813 & 8 & 1169 & .76 & \\
\hline 09 & & & & \\
\hline AEMBL14 & 8 & 85 & & \\
\hline AEMBL1870103 & 3094 & .1637 & 8432 & \\
\hline HEMBL1468351 & 309418 & .8735 & .0306 & \\
\hline HEMBL14 & 09 & & & \\
\hline AEMBL1 14 & 8 & 31 & 24 & \\
\hline AEMBL13 & & & & \\
\hline HEMBL1545677 & 305 & .2306 & .7034 & \\
\hline HEMBL1876725 & 305 & .813 & .1454 & \\
\hline HEMBL1550676 & 305 & 18 & 1144 & \\
\hline AEMBL15 & 8 & & & \\
\hline AEMBL14 & 8 & & & \\
\hline HEMBL1547169 & $30 s$ & 589 & & \\
\hline HEMBL1581280 & 18 & 73 & & \\
\hline HEMBL 14 & 305 & 3 & 53 & \\
\hline L17 & 8 & & & \\
\hline AEMBL1C & & & & \\
\hline HEMBL1432816 & 8 & 62 & 81 & \\
\hline AEMBL1326053 & $\theta$ & & & \\
\hline HEMBL15 & 305 & & & IV \\
\hline HEM & & & & \\
\hline 75 & & & & \\
\hline 479 & 8 & & & IV \\
\hline AEMBL19 & $\theta$ & & & 1 \\
\hline HEMBL13 & 8 & & & RN \\
\hline HEN & & & & RN \\
\hline HFMRI 1 & 8 & 46 & 66 & RN \\
\hline AEMBL15 & & & & IRN \\
\hline HEMBL1498382 & $\theta$ & & 75 & RN \\
\hline AEMBL1: & 8 & & & RN \\
\hline 0 & 8 & & & RN \\
\hline 92 & & & & RN \\
\hline AEMBL1473229 & $0 s$ & & & IRN \\
\hline AEMBL1411665 & 8 & & & RN \\
\hline 5 & & & & ST \\
\hline גד 1. & & & & RN \\
\hline HEMBL13 & & & & $\mathrm{RN}$ \\
\hline AEMBL1351173 & 8 & 4 . & & $\mathrm{RN}$ \\
\hline AEMBL1C & 8 & & & TRN \\
\hline & & & & \\
\hline HEMBL1S & & & 5.3621 & RN \\
\hline HEMBL1594890 & & & 4.9497 & ST \\
\hline AEMBL 2007282 & $30 s$ & 4.7897 & 4.9397 & RN \\
\hline 15 15 & 8 & & & \\
\hline 190021 & 09418 & & & \\
\hline
\end{tabular}

Page 13383 


\begin{tabular}{|c|c|c|c|c|c|}
\hline & & \multicolumn{4}{|c|}{ Supplemental Table S2.txt } \\
\hline CHEMBL1473402 & 809418 & 5.8633 & 5.4011 & TRN & \\
\hline CHEMBL1328473 & 809418 & 5.1694 & 5.0697 & TRN & \\
\hline CHEMBL1983653 & 809418 & 4.5287 & 4.1341 & TRN & \\
\hline CHEMBL1577745 & 809418 & 5.1325 & 5.0663 & TRN & \\
\hline CHEMBL585827 & 809418 & 5.8827 & 5.6846 & TRN & \\
\hline CHEMBL1544364 & 809418 & 4.5935 & 4.8414 & TRN & \\
\hline CHEMBL1565349 & 809418 & 5.6308 & 5.3117 & TRN & \\
\hline CHEMBL1993889 & 809418 & 5.5157 & 5.1935 & TRN & \\
\hline CHEMBL144514 & 809418 & 7.585 & 5.996 & TRN & \\
\hline CHEMBL1872338 & 809418 & \multicolumn{3}{|c|}{5.2139999999999995} & TRN \\
\hline CHEMBL1369099 & 809418 & 4.6451 & 5.0321 & TRN & \\
\hline CHEMBL1500615 & 809418 & 5.0255 & 5.0761 & TST & \\
\hline CHEMBL1728642 & 809418 & 6.0 & 5.0998 & TRN & \\
\hline CHEMBL1431075 & 809418 & 5.3625 & 5.1038 & TRN & \\
\hline CHEMBL1497024 & 809418 & 4.9237 & 5.1251 & TST & \\
\hline CHEMBL1874456 & 809418 & 4.9658 & 4.9932 & TRN & \\
\hline CHEMBL1323821 & 809418 & 5.3251 & \multicolumn{2}{|c|}{4.9510000000000005} & TRN \\
\hline CHEMBL1559226 & 809418 & 4.9566 & 5.3295 & TST & \\
\hline CHEMBL1384253 & 809418 & 6.0 & \multicolumn{2}{|c|}{5.492000000000001} & TRN \\
\hline CHEMBL1510371 & 809418 & 5.6737 & 5.1668 & TST & \\
\hline CHEMBL1574080 & 809418 & 6.1871 & 5.3599 & TRN & \\
\hline CHEMBL591370 & 809418 & 5.4881 & 5.3176 & TRN & \\
\hline CHEMBL1465706 & 809418 & 6.3915 & 5.5866 & TRN & \\
\hline CHEMBL1436618 & 809418 & 6.3233 & 5.087 & TRN & \\
\hline CHEMBL1499935 & 809418 & 5.27 & 5.0454 & TRN & \\
\hline CHEMBL1572468 & 809418 & 5.9788 & 5.3202 & TRN & \\
\hline CHEMBL1722169 & 809418 & 5.3565 & \multicolumn{2}{|c|}{5.132999999999999} & TST \\
\hline CHEMBL1340112 & 809418 & 5.2013 & 5.2335 & TRN & \\
\hline CHEMBL1388922 & 809418 & 5.5607 & 5.4496 & TRN & \\
\hline CHEMBL1709857 & 809418 & 4.6782 & 4.6082 & TRN & \\
\hline CHEMBL1387462 & 809418 & 5.3516 & 5.1062 & TRN & \\
\hline CHEMBL1726266 & 809418 & 5.8447 & 5.2017 & TRN & \\
\hline CHEMBL1403416 & 809418 & 5.51 & 4.9562 & TRN & \\
\hline CHEMBL1534781 & 809418 & 6.0362 & 5.3847 & TRN & \\
\hline CHEMBL1375365 & 809418 & 4.994 & 4.9692 & TRN & \\
\hline CHEMBL1328541 & 809418 & 4.9727 & 4.9034 & TRN & \\
\hline CHEMBL1881663 & 809418 & 4.8668 & 4.9774 & TRN & \\
\hline CHEMBL1422720 & 809418 & 5.4622 & 4.9945 & TRN & \\
\hline CHEMBL1387563 & 809418 & 4.8236 & 5.0438 & TRN & \\
\hline CHEMBL1529797 & 809418 & 4.5581 & 5.1737 & TRN & \\
\hline CHEMBL1543473 & 809418 & 5.6364 & 5.2638 & TRN & \\
\hline CHEMBL1380787 & 809418 & 5.109 & 5.056 & TRN & \\
\hline CHEMBL1900730 & 809418 & 5.4023 & 5.0796 & TRN & \\
\hline CHEMBL1865123 & 809418 & 4.838 & 5.0686 & TST & \\
\hline CHEMBL1547860 & 809418 & 4.7921 & 4.9833 & TRN & \\
\hline CHEMBL1335610 & 809418 & 4.8837 & 4.9459 & TRN & \\
\hline CHEMBL1354459 & 809418 & 4.9755 & 4.8945 & TST & \\
\hline CHEMBL1325594 & 809418 & 4.5602 & 5.0094 & TRN & \\
\hline
\end{tabular}




\begin{tabular}{|c|c|c|c|c|c|}
\hline & & \multicolumn{4}{|c|}{ Supplemental Table S2.txt } \\
\hline CHEMBL1424801 & 809418 & 5.6364 & 4.9327 & TRN & \\
\hline CHEMBL1445297 & 809418 & 5.1818 & 5.0992 & TRN & \\
\hline CHEMBL1533366 & 809418 & 5.3799 & 5.1085 & TRN & \\
\hline CHEMBL1710816 & 809418 & 4.9024 & 5.186 & TRN & \\
\hline CHEMBL592068 & 809418 & 5.52 & 5.3607 & TRN & \\
\hline CHEMBL1324616 & 809418 & 5.4179 & 5.1977 & TRN & \\
\hline CHEMBL1901606 & 809418 & 6.0 & 5.2102 & TRN & \\
\hline CHEMBL1523841 & 809418 & 4.5239 & 5.3627 & TST & \\
\hline CHEMBL 1463640 & 809418 & 4.8002 & 4.7745 & TRN & \\
\hline CHEMBL1730353 & 809418 & 5.7645 & 5.13200 & 0000000001 & TST \\
\hline CHEMBL1352607 & 809418 & 5.8477 & 5.1574 & TRN & \\
\hline CHEMBL1547539 & 809418 & 3.1549 & 5.1263 & TRN & \\
\hline CHEMBL1416171 & 809418 & 4.7421 & 5.4585 & TRN & \\
\hline CHEMBL1391353 & 809418 & 5.2248 & 5.1055 & TRN & \\
\hline CHEMBL1443454 & 809418 & 5.1979 & 5.0002 & TRN & \\
\hline CHEMBL1328510 & 809418 & 5.4634 & 5.496 & TRN & \\
\hline CHEMBL1302158 & 809418 & 4.9606 & 4.9916 & TRN & \\
\hline CHEMBL1707874 & 809418 & 3.1549 & 4.9829 & TRN & \\
\hline CHEMBL 1326110 & 809418 & 5.1791 & 5.1244 & TRN & \\
\hline CHEMBL1901877 & 809418 & 5.0329 & 4.9778 & TRN & \\
\hline CHEMBL1386344 & 809418 & 4.569 & 5.1561 & TST & \\
\hline CHEMBL1889837 & 809418 & 5.1439 & 5.1353 & TRN & \\
\hline CHEMBL1539505 & 809418 & 4.7375 & 4.8698 & TRN & \\
\hline CHEMBL1524710 & 809418 & 5.4168 & 5.1107 & TRN & \\
\hline CHEMBL1461392 & 809418 & 5.2807 & 5.015 & TRN & \\
\hline CHEMBL1575440 & 809418 & 4.7721 & 4.9567 & TRN & \\
\hline CHEMBL1383742 & 809418 & 5.6946 & 5.31 & TRN & \\
\hline CHEMBL1404578 & 809418 & 5.4214 & 5.3147 & TRN & \\
\hline CHEMBL1402371 & 809418 & 5.2823 & 5.3034 & TRN & \\
\hline CHEMBL1721568 & 809418 & 5.5186 & 5.0788 & TRN & \\
\hline CHEMBL1598843 & 809418 & 4.5501 & 4.9399 & TRN & \\
\hline CHEMBL1518163 & 809418 & 4.4421 & 4.988 & TRN & \\
\hline CHEMBL1731138 & 809418 & 4.8022 & 5.0257 & TRN & \\
\hline CHEMBL1608413 & 809418 & 5.7545 & 4.8191 & TRN & \\
\hline CHEMBL1550076 & 809418 & 5.1113 & 5.1602 & TRN & \\
\hline CHEMBL1414571 & 809418 & 5.5607 & 5.1916 & TST & \\
\hline CHEMBL1608707 & 809418 & 5.2916 & 5.38200 & 0000000001 & I RI \\
\hline CHEMBL1386067 & 809418 & 5.2984 & 4.8486 & TST & \\
\hline CHEMBL1364793 & 809418 & 5.0128 & 5.2216 & TRN & \\
\hline CHEMBL1448198 & 809418 & 4.5081 & 5.2779 & TRN & \\
\hline CHEMBL1599782 & 809418 & 5.1884 & 5.0398 & TRN & \\
\hline CHEMBL580340 & 809418 & 5.4921 & 5.2614 & TRN & \\
\hline CHEMBL1390386 & 809418 & 5.2596 & 5.1893 & TRN & \\
\hline CHEMBL579919 & 809418 & 5.27 & 5.1555 & TRN & \\
\hline CHEMBL1553954 & 809418 & 4.8633 & 5.1306 & TRN & \\
\hline CHEMBL1428507 & 809418 & 4.9535 & 5.0356 & TRN & \\
\hline CHEMBL1497589 & 809418 & 5.3883 & 5.1918 & TRN & \\
\hline CHEMBL599924 & 809418 & 5.2373 & 5.2616 & TRN & \\
\hline
\end{tabular}


Supplemental Table S2.txt

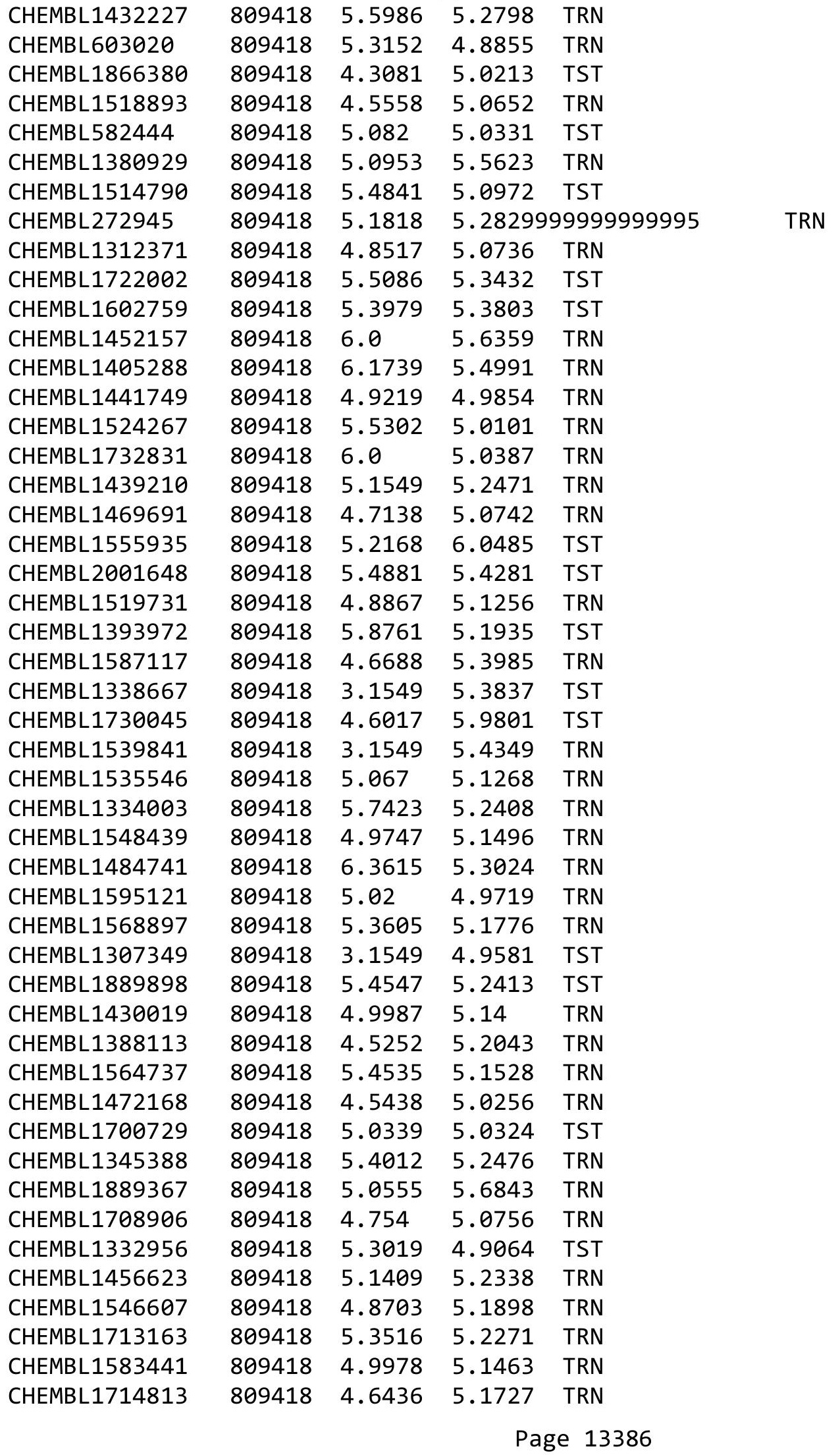


Supplemental Table S2.txt

\begin{tabular}{|c|c|c|c|c|c|}
\hline CHEMBL1476183 & 809418 & 5.0947 & 5.2094 & TST & \\
\hline CHEMBL1456780 & 809418 & 5.0878 & 5.4007 & TRN & \\
\hline CHEMBL1339536 & 809418 & 5.2503 & 5.0026 & TRN & \\
\hline CHEMBL1889303 & 809418 & 5.3002 & 5.1133 & TST & \\
\hline CHEMBL1346972 & 809418 & 5.1669 & 5.0188 & TRN & \\
\hline CHEMBL1561146 & 809418 & 5.4522 & 4.945 & TRN & \\
\hline CHEMBL601614 & 809418 & 6.0511 & 5.8847 & TST & \\
\hline CHEMBL1717507 & 809418 & 5.9547 & 5.1215 & TRN & \\
\hline CHEMBL1538267 & 809418 & 4.6629 & 5.1695 & TRN & \\
\hline CHEMBL1582580 & 809418 & 5.2487 & 5.4018 & TRN & \\
\hline CHEMBL1358184 & 809418 & 4.3366 & 5.0621 & TRN & \\
\hline CHEMBL1548492 & 809418 & 6.1278 & 5.8942 & TRN & \\
\hline CHEMBL1344491 & 809418 & 4.9991 & 5.1228 & TRN & \\
\hline CHEMBL1404398 & 809418 & 5.7773 & 5.3078 & TRN & \\
\hline CHEMBL1888102 & 809418 & 4.2796 & 5.1155 & TRN & \\
\hline CHEMBL1984654 & 809418 & 6.2076 & 5.572 & TST & \\
\hline CHEMBL1477341 & 809418 & 4.7203 & 4.6874 & TST & \\
\hline CHEMBL1493864 & 809418 & 5.6635 & 5.3661 & TRN & \\
\hline CHEMBL1978882 & 809418 & 5.7305 & 5.3066 & TST & \\
\hline CHEMBL1482025 & 809418 & 4.8438 & 5.1082 & TRN & \\
\hline CHEMBL1352525 & 809418 & 5.4584 & 5.1084 & TRN & \\
\hline CHEMBL1538692 & 809418 & 4.6183 & 5.5829 & TRN & \\
\hline CHEMBL1536041 & 809418 & 4.9266 & 4.9007 & TRN & \\
\hline CHEMBL579837 & 809418 & 5.2495 & 4.9632 & TRN & \\
\hline CHEMBL1712981 & 809418 & 4.48 & 4.8178 & TST & \\
\hline CHEMBL1300831 & 809418 & 5.5072 & 5.1643 & TST & \\
\hline CHEMBL1736684 & 809418 & 4.9481 & 4.9679 & TRN & \\
\hline CHEMBL1981589 & 809418 & 5.8539 & 5.433 & TRN & \\
\hline CHEMBL1450195 & 809418 & 4.53 & 5.1868 & TRN & \\
\hline CHEMBL556140 & 809418 & 6.0467 & 5.2439 & TRN & \\
\hline CHEMBL1572920 & 809418 & 4.9516 & 5.3343 & TRN & \\
\hline CHEMBL19980 & 809418 & 6.0 & 5.3799 & TST & \\
\hline CHEMBL1512747 & 809418 & 4.5146 & 4.923 & TRN & \\
\hline CHEMBL1341696 & 809418 & 5.2321 & 5.0898 & TRN & \\
\hline CHEMBL1431684 & 809418 & 5.4921 & 4.8988 & TRN & \\
\hline CHEMBL1877386 & 809418 & 5.3883 & 5.1883 & TRN & \\
\hline CHEMBL1484306 & 809418 & 5.3893 & 5.0753 & TRN & \\
\hline CHEMBL1520753 & 809418 & 5.4023 & 5.1963 & TRN & \\
\hline CHEMBL1546843 & 809418 & 4.8474 & 5.3022 & TRN & \\
\hline CHEMBL1528275 & 809418 & 4.5325 & 4.865 & TRN & \\
\hline CHEMBL1594473 & 809418 & 4.5542 & 4.8194 & TRN & \\
\hline CHEMBL1702031 & 809418 & 5.1911 & 5.1042 & TRN & \\
\hline CHEMBL1516966 & 809418 & 5.2097 & 5.3049 & TRN & \\
\hline CHEMBL1412196 & 809418 & 4.5555 & 4.3158 & TST & \\
\hline CHEMBL1553023 & 809418 & 7.585 & 6.1245 & TST & \\
\hline CHEMBL1310132 & 809418 & 5.6904 & 5.9909 & TRN & \\
\hline CHEMBL1475769 & 809418 & 5.3224 & 5.3358 & TRN & \\
\hline CHEMBL1323139 & 809418 & 5.21399 & 99999999 & 995 & 5.2068 \\
\hline
\end{tabular}




\begin{tabular}{|c|c|c|c|c|c|}
\hline \multicolumn{6}{|c|}{ Supplemental Table S2.txt } \\
\hline CHEMBL1511363 & 809418 & 5.7447 & 5.2147 & TST & \\
\hline CHEMBL1379149 & 809418 & 5.1904 & 5.2009 & TRN & \\
\hline CHEMBL1722145 & 809418 & 4.8111 & 4.9076 & TRN & \\
\hline CHEMBL1540682 & 809418 & 5.5229 & 5.9765 & TST & \\
\hline CHEMBL1305380 & 809418 & 5.2857 & 4.9914 & TRN & \\
\hline CHEMBL1374701 & 809418 & 4.5299 & 5.0393 & TRN & \\
\hline CHEMBL1313978 & 809418 & 4.9646 & 5.0627 & TRN & \\
\hline CHEMBL1368013 & 809418 & 5.0357 & 5.0539 & TRN & \\
\hline CHEMBL1314757 & 809418 & 4.7802 & 5.1868 & TRN & \\
\hline CHEMBL1891071 & 809418 & 4.8837 & 5.2771 & TRN & \\
\hline CHEMBL1606291 & 809418 & 5.6655 & 5.7215 & TRN & \\
\hline CHEMBL1530686 & 809418 & 5.7235 & 5.6686 & TRN & \\
\hline CHEMBL1700479 & 809418 & 5.6925 & 5.1139 & TST & \\
\hline CHEMBL1735624 & 809418 & 5.4647 & 5.222 & TRN & \\
\hline CHEMBL578716 & 809418 & 5.7011 & 5.2782 & TST & \\
\hline CHEMBL1481192 & 809418 & 4.5776 & 5.0001 & TST & \\
\hline CHEMBL1594821 & 809418 & 5.4342 & 5.2701 & TRN & \\
\hline CHEMBL1629966 & 809418 & 4.9788 & 5.2659 & TRN & \\
\hline CHEMBL1559053 & 809418 & 5.0752 & 5.2497 & TRN & \\
\hline CHEMBL1460871 & 809418 & 5.7905 & 5.1107 & TRN & \\
\hline CHEMBL1716472 & 809418 & 5.2069 & 5.1806 & TRN & \\
\hline CHEMBL1879344 & 809418 & 4.782 & 4.9631 & TRN & \\
\hline CHEMBL1337235 & 809418 & 4.8908 & 5.3892 & TRN & \\
\hline CHEMBL1873644 & 809418 & 6.4989 & 5.8005 & TST & \\
\hline CHEMBL1429108 & 809418 & 4.6778 & 5.1247 & TRN & \\
\hline CHEMBL1525735 & 809418 & 5.6055 & 5.1939 & TRN & \\
\hline CHEMBL1723391 & 809418 & 5.0348 & 5.1524 & TRN & \\
\hline CHEMBL1370024 & 809418 & 4.6112 & 5.2623 & TRN & \\
\hline CHEMBL1309059 & 809418 & 6.3197 & 5.6057 & TRN & \\
\hline CHEMBL1736634 & 809418 & 5.1778 & 5.0956 & TRN & \\
\hline CHEMBL1332450 & 809418 & 5.7352 & 5.4687 & TRN & \\
\hline CHEMBL1301125 & 809418 & 5.7773 & 5.4155 & TST & \\
\hline CHEMBL1373370 & 809418 & 5.5768 & 5.233 & TRN & \\
\hline CHEMBL1502550 & 809418 & 5.2534 & 5.0511 & TST & \\
\hline CHEMBL1426340 & 809418 & 5.7282 & 5.6536 & TRN & \\
\hline CHEMBL1343490 & 809418 & 5.1451 & 5.25700 & 0000000001 & TST \\
\hline CHEMBL1467940 & 809418 & 6.064 & 5.3256 & TRN & \\
\hline CHEMBL1574573 & 809418 & 5.1361 & 5.0348 & TRN & \\
\hline CHEMBL1468672 & 809418 & 5.1487 & 5.2237 & TRN & \\
\hline CHEMBL1369945 & 809418 & 4.2124 & 5.3899 & TRN & \\
\hline CHEMBL1422962 & 809418 & 5.1798 & 5.5471 & TRN & \\
\hline CHEMBL1332404 & 809418 & 5.5258 & 5.5772 & TRN & \\
\hline CHEMBL1510973 & 809418 & 5.5229 & 5.4351 & TRN & \\
\hline CHEMBL1896491 & 809418 & 4.5028 & 5.0443 & TRN & \\
\hline CHEMBL1353983 & 809418 & 5.9469 & 5.6432 & TRN & \\
\hline CHEMBL1453555 & 809418 & 5.1918 & 5.1323 & TRN & \\
\hline CHEMBL1993539 & 809418 & 5.2815 & 5.0506 & TST & \\
\hline CHEMBL1882159 & 809418 & 5.0092 & 5.0203 & TRN & \\
\hline
\end{tabular}




\begin{tabular}{|c|c|c|c|c|c|c|}
\hline \multirow[b]{2}{*}{ CHEMBL1710051 } & \multirow[b]{2}{*}{809418} & \multicolumn{5}{|c|}{ Supplemental Table S2.txt } \\
\hline & & 5.1391 & 5.1651 & TRN & & \\
\hline CHEMBL1734467 & 809418 & 4.9488 & 5.1682 & TRN & & \\
\hline CHEMBL1419529 & 809418 & 4.6866 & 4.8953 & TRN & & \\
\hline CHEMBL578294 & 809418 & 6.24799 & 99999999 & 99 & 5.2117 & TRN \\
\hline CHEMBL 2068165 & 809418 & 4.5727 & 4.4095 & TST & & \\
\hline CHEMBL1714720 & 809418 & 5.2941 & 5.129 & TRN & & \\
\hline CHEMBL1369804 & 809418 & 4.6349 & 4.3973 & TRN & & \\
\hline CHEMBL1586531 & 809418 & 4.8419 & 4.9822 & TRN & & \\
\hline CHEMBL1482468 & 809418 & 5.6308 & 5.3687 & TRN & & \\
\hline CHEMBL1721226 & 809418 & 5.2941 & 5.9552 & TST & & \\
\hline CHEMBL1525157 & 809418 & 5.3224 & 5.0204 & TRN & & \\
\hline CHEMBL1458376 & 809418 & 5.2676 & 5.1985 & TRN & & \\
\hline CHEMBL1588579 & 809418 & 4.4346 & 5.0067 & TRN & & \\
\hline CHEMBL1578700 & 809418 & 5.4584 & 5.044 & TRN & & \\
\hline CHEMBL453974 & 809418 & 4.9108 & 5.1647 & TST & & \\
\hline CHEMBL1705201 & 809418 & 5.5229 & 5.2314 & TRN & & \\
\hline CHEMBL1501755 & 809418 & 4.6271 & 4.9415 & TRN & & \\
\hline CHEMBL1329658 & 809418 & 5.4101 & 5.2305 & TRN & & \\
\hline CHEMBL1415720 & 809418 & 4.7823 & 4.9889 & TRN & & \\
\hline CHEMBL1464832 & 809418 & 5.0031 & 5.0536 & TRN & & \\
\hline CHEMBL1422386 & 809418 & 5.4828 & 5.2544 & TRN & & \\
\hline CHEMBL 2003567 & 809418 & 5.6615 & 5.3722 & TRN & & \\
\hline CHEMBL1699532 & 809418 & 4.6198 & 4.987 & TRN & & \\
\hline CHEMBL1449204 & 809418 & 5.1593 & 5.1531 & TRN & & \\
\hline CHEMBL1531172 & 809418 & 5.82100 & 00000000 & & 5.1453 & TRN \\
\hline CHEMBL1332013 & 809418 & 5.466 & 5.0639 & TRN & & \\
\hline CHEMBL1532668 & 809418 & 5.8633 & 5.2208 & TRN & & \\
\hline CHEMBL1560061 & 809418 & 5.857 & 6.0957 & TRN & & \\
\hline CHEMBL1730238 & 809418 & 5.3233 & 5.4153 & TST & & \\
\hline CHEMBL1717596 & 809418 & 5.5317 & 5.0411 & TRN & & \\
\hline CHEMBL1466292 & 809418 & 5.4711 & 5.0849 & TRN & & \\
\hline CHEMBL1607013 & 809418 & 4.9535 & 5.0467 & TRN & & \\
\hline CHEMBL1369725 & 809418 & 5.3429 & 5.0627 & TRN & & \\
\hline CHEMBL510650 & 809418 & 7.585 & 5.8091 & TST & & \\
\hline CHEMBL509617 & 809418 & 5.2111 & 5.6501 & TST & & \\
\hline CHEMBL1345932 & 809418 & 5.2472 & 5.1852 & TRN & & \\
\hline CHEMBL1529783 & 809418 & 5.0106 & 5.2921 & TRN & & \\
\hline CHEMBL1366948 & 809418 & 5.0227 & 5.2563 & TST & & \\
\hline CHEMBL1700777 & 809418 & 4.8908 & 5.0652 & TRN & & \\
\hline CHEMBL1458782 & 809418 & 4.5224 & 5.1409 & TRN & & \\
\hline CHEMBL1901445 & 809418 & 5.3556 & 4.9488 & TRN & & \\
\hline CHEMBL1725309 & 809418 & 5.0424 & 5.0377 & TRN & & \\
\hline CHEMBL1432251 & 809418 & 5.1649 & 5.9738 & TRN & & \\
\hline CHEMBL1716027 & 809418 & 4.5882 & 4.9502 & TRN & & \\
\hline CHEMBL1315948 & 809418 & 4.7113 & 5.0942 & TRN & & \\
\hline CHEMBL1609580 & 809418 & 4.6513 & 5.1929 & TRN & & \\
\hline CHEMBL1560954 & 809418 & 4.8996 & 5.0548 & TRN & & \\
\hline CHEMBL3392223 & 809418 & 4.5294 & 5.2052 & TST & & \\
\hline
\end{tabular}


Supplemental Table S2.txt

\begin{tabular}{|c|c|c|c|c|c|}
\hline CHEMBL1477528 & 809418 & 4.9378 & 5.185 & TRN & \\
\hline CHEMBL1608392 & 809418 & 4.7572 & 5.0751 & TRN & \\
\hline CHEMBL1469379 & 809418 & 5.5654 & 5.3753 & TRN & \\
\hline CHEMBL1592249 & 809418 & 4.5141 & 4.9023 & TRN & \\
\hline CHEMBL1722300 & 809418 & 5.6946 & 5.4623 & TRN & \\
\hline CHEMBL1476734 & 809418 & 3.1549 & 5.6017 & TRN & \\
\hline CHEMBL1715333 & 809418 & 4.5387 & 4.5738 & TRN & \\
\hline CHEMBL1721451 & 809418 & 5.7496 & 5.5052 & TST & \\
\hline CHEMBL1518827 & 809418 & 4.6379 & 5.084 & TRN & \\
\hline CHEMBL1700569 & 809418 & 7.585 & 6.1965 & TST & \\
\hline CHEMBL1452234 & 809418 & 4.5168 & 4.1642 & TRN & \\
\hline CHEMBL1353194 & 809418 & 4.5807 & 5.0745 & TRN & \\
\hline CHEMBL1386738 & 809418 & 5.058 & 5.0371 & TRN & \\
\hline CHEMBL1727030 & 809418 & 5.3161 & 4.9957 & TRN & \\
\hline CHEMBL1520276 & 809418 & 5.2373 & 5.1189 & TRN & \\
\hline CHEMBL1867221 & 809418 & 5.1296 & 5.0134 & TRN & \\
\hline CHEMBL1348931 & 809418 & 4.5336 & 5.2348 & TRN & \\
\hline CHEMBL1507490 & 809418 & 5.8962 & 5.2366 & TRN & \\
\hline CHEMBL1539522 & 809418 & 5.0931 & 5.4888 & TRN & \\
\hline CHEMBL1383521 & 809418 & 7.301 & 5.2058 & TRN & \\
\hline CHEMBL1543258 & 809418 & 6.0752 & 5.3256 & TST & \\
\hline CHEMBL607140 & 809418 & 5.4425 & 5.825 & TRN & \\
\hline CHEMBL1453108 & 809418 & 5.1029 & 5.3739 & TRN & \\
\hline CHEMBL1473160 & 809418 & 4.9285 & 5.059 & TRN & \\
\hline CHEMBL1726140 & 809418 & 4.7719 & 4.7832 & TST & \\
\hline CHEMBL1465815 & 809418 & 5.6716 & 5.1639 & TRN & \\
\hline CHEMBL1513566 & 809418 & 4.6338 & 5.2046 & TST & \\
\hline CHEMBL1609391 & 809418 & 5.7423 & 4.9375 & TRN & \\
\hline CHEMBL1598383 & 809418 & 4.8438 & 5.1825 & TRN & \\
\hline CHEMBL1371706 & 809418 & 5.6882 & 5.593 & TRN & \\
\hline CHEMBL1447442 & 809418 & 5.382000 & \multirow{2}{*}{\multicolumn{3}{|c|}{$\begin{array}{ccc}00000000001 & 5.2789 & \text { TRN } \\
5.156000000000001 & \text { TRN }\end{array}$}} \\
\hline CHEMBL1334026 & 809418 & 5.5045 & & & \\
\hline CHEMBL1607286 & 809418 & 4.9314 & 4.94 & TRN & \\
\hline CHEMBL1387704 & 809418 & 5.0315 & 5.1972 & TRN & \\
\hline CHEMBL1332756 & 809418 & 3.1549 & 5.9171 & TRN & \\
\hline CHEMBL1373316 & 809418 & 4.8775 & 5.31 & TST & \\
\hline CHEMBL1452421 & 809418 & 5.4976 & 5.7448 & TRN & \\
\hline CHEMBL1560784 & 809418 & 4.9458 & 4.9944 & TRN & \\
\hline CHEMBL1439019 & 809418 & 4.4936 & 4.8165 & TRN & \\
\hline CHEMBL1301851 & 809418 & 4.5933 & 5.0738 & TRN & \\
\hline CHEMBL1988268 & 809418 & 5.2154 & 5.0263 & TRN & \\
\hline CHEMBL1446971 & 809418 & 5.3344 & 5.8278 & TRN & \\
\hline CHEMBL1431189 & 809418 & 5.2464 & 5.1252 & TRN & \\
\hline CHEMBL1318151 & 809418 & 5.0013 & 5.0346 & TST & \\
\hline CHEMBL1428415 & 809418 & 5.341 & 5.5396 & TRN & \\
\hline CHEMBL1450616 & 809418 & 5.0516 & 4.9107 & TRN & \\
\hline CHEMBL1503190 & 809418 & 5.1904 & 5.0991 & TST & \\
\hline CHEMBL1516044 & 809418 & 4.5632 & 4.898 & TRN & \\
\hline
\end{tabular}




\begin{tabular}{|c|c|c|c|c|c|}
\hline \multirow{3}{*}{$\begin{array}{l}\text { CHEMBL1699062 } \\
\text { CHFMBI } 1340089\end{array}$} & & \multicolumn{4}{|c|}{ Supplemental Table S2.txt } \\
\hline & & 4.6155 & \multicolumn{2}{|c|}{4.656000000000001} & TST \\
\hline & 809418 & 4.8697 & 5.2102 & TRN & \\
\hline CHEMBL1555483 & 809418 & 5.4413 & 5.025 & TRN & \\
\hline CHEMBL395263 & 809418 & 4.6362 & 5.0477 & TST & \\
\hline CHEMBL1399408 & 809418 & 4.908 & 5.1295 & TRN & \\
\hline CHEMBL1966062 & 809418 & 7.585 & 5.8071 & TST & \\
\hline CHEMBL1531357 & 809418 & 4.8567 & 5.0484 & TRN & \\
\hline CHEMBL1438624 & 809418 & 5.0182 & \multicolumn{2}{|c|}{5.071000000000001} & TRN \\
\hline CHEMBL1331851 & 809418 & 5.6402 & 5.2226 & TRN & \\
\hline CHEMBL1723968 & 809418 & 4.6407 & 5.0477 & TST & \\
\hline CHEMBL1501632 & 809418 & 5.9747 & 5.3808 & TRN & \\
\hline CHEMBL1543907 & 809418 & 5.2277 & 5.0799 & TRN & \\
\hline CHEMBL1558462 & 809418 & 5.1385 & 5.4687 & TRN & \\
\hline CHEMBL1377682 & 809418 & 4.856 & 4.9329 & TRN & \\
\hline CHEMBL1469929 & 809418 & 4.6388 & 5.2043 & TRN & \\
\hline CHEMBL1348057 & 809418 & 4.9289 & 5.0706 & TRN & \\
\hline CHEMBL1341553 & 809418 & 5.0937 & 5.4972 & TRN & \\
\hline CHEMBL1974927 & 809418 & 4.4908 & 4.9985 & TRN & \\
\hline CHEMBL1717328 & 809418 & 4.8128 & 4.9651 & TRN & \\
\hline CHEMBL528791 & 809418 & 4.9292 & 5.131 & TRN & \\
\hline CHEMBL1330184 & 809418 & 4.8921 & 5.2332 & TRN & \\
\hline CHEMBL1611695 & 809418 & 5.2055 & 5.0573 & TRN & \\
\hline CHEMBL1897013 & 809418 & 4.7113 & 4.9851 & TRN & \\
\hline CHEMBL1549500 & 809418 & 5.3686 & 5.5261 & TRN & \\
\hline CHEMBL1715327 & 809418 & 4.8268 & 4.8053 & TRN & \\
\hline CHEMBL1341870 & 809418 & 5.1993 & 5.3185 & TRN & \\
\hline CHEMBL1467697 & 809418 & 5.5031 & 5.2154 & TRN & \\
\hline CHEMBL1551507 & 809418 & 4.626 & 4.9551 & TST & \\
\hline CHEMBL1470450 & 809418 & 5.055 & 5.1286 & TRN & \\
\hline CHEMBL1546018 & 809418 & 4.5709 & 4.301 & TRN & \\
\hline CHEMBL1722228 & 809418 & 4.945 & 5.029 & TST & \\
\hline CHEMBL1458548 & 809418 & 5.5406 & 5.1807 & TRN & \\
\hline CHEMBL1904071 & 809418 & 4.5714 & 5.0347 & TST & \\
\hline CHEMBL1556277 & 809418 & 5.3288 & 5.2993 & TRN & \\
\hline CHEMBL1308497 & 809418 & 5.3325 & 5.1912 & TRN & \\
\hline CHEMBL1734661 & 809418 & 4.6216 & 4.9524 & TRN & \\
\hline CHEMBL1876267 & 809418 & 4.2152 & 5.2352 & TRN & \\
\hline CHEMBL1541379 & 809418 & 4.8395 & 5.2003 & TRN & \\
\hline CHEMBL1437997 & 809418 & 5.2248 & 5.0775 & TST & \\
\hline CHEMBL1981103 & 809418 & 5.1605 & 5.0779 & TST & \\
\hline CHEMBL1882125 & 809418 & 5.2055 & 5.2118 & TRN & \\
\hline CHEMBL1570765 & 809418 & 6.1198 & 5.3547 & TRN & \\
\hline CHEMBL1436844 & 809418 & 3.1549 & 4.225 & TRN & \\
\hline CHEMBL1336541 & 809418 & 5.6271 & 5.3803 & TRN & \\
\hline CHEMBL1584502 & 809418 & 5.0685 & 5.1697 & TRN & \\
\hline CHEMBL1721017 & 809418 & 5.1898 & 4.9483 & TRN & \\
\hline CHEMBL591363 & 809418 & 6.0101 & 6.1264 & TRN & \\
\hline CHEMBL1351584 & 809418 & 4.5943 & 5.0664 & TRN & \\
\hline
\end{tabular}


Supplemental Table S2.txt

\begin{tabular}{|c|c|c|c|c|c|}
\hline CHEMBL1463659 & 809418 & 5.5287 & 5.6761 & TRN & \\
\hline CHEMBL1464631 & 809418 & 4.7258 & 4.9192 & TST & \\
\hline CHEMBL601135 & 809418 & 5.2027 & 5.0746 & TRN & \\
\hline CHEMBL548615 & 809418 & 6.129 & 5.6417 & TRN & \\
\hline CHEMBL1369262 & 809418 & 5.9788 & 5.2834 & TST & \\
\hline CHEMBL1610300 & 809418 & 4.8713 & 5.6393 & TRN & \\
\hline CHEMBL1732556 & 809418 & 5.4123 & 5.3693 & TRN & \\
\hline CHEMBL1429297 & 809418 & 4.9796 & 5.0395 & TST & \\
\hline CHEMBL1531073 & 809418 & $5.3820 e$ & 00000000 & 5.8495 & TST \\
\hline CHEMBL577660 & 809418 & 5.2941 & 5.0963 & TRN & \\
\hline CHEMBL 2002162 & 809418 & 4.9543 & 5.2056 & TST & \\
\hline CHEMBL1570879 & 809418 & 4.5126 & 5.012 & TRN & \\
\hline CHEMBL1979212 & 809418 & 5.9208 & 5.2756 & TRN & \\
\hline CHEMBL1381892 & 809418 & 4.6421 & 4.965 & TRN & \\
\hline CHEMBL 2002411 & 809418 & 5.2757 & 5.0479 & TRN & \\
\hline CHEMBL1375338 & 809418 & 5.1314 & 5.1586 & TRN & \\
\hline CHEMBL1385690 & 809418 & 4.9119 & 5.0803 & TRN & \\
\hline CHEMBL1975935 & 809418 & 4.9755 & 4.9206 & TRN & \\
\hline CHEMBL1522275 & 809418 & 4.655 & 4.9461 & TRN & \\
\hline CHEMBL1287980 & 809418 & 5.2518 & 5.2537 & TST & \\
\hline CHEMBL1382633 & 809418 & 4.8821 & 4.9577 & TST & \\
\hline CHEMBL1556615 & 809418 & 5.3936 & 5.0449 & TRN & \\
\hline CHEMBL1728670 & 809418 & 5.3429 & 4.9284 & TST & \\
\hline CHEMBL1413424 & 809418 & 5.6925 & 5.3712 & TRN & \\
\hline CHEMBL1347469 & 809418 & 7.585 & 5.4669 & TRN & \\
\hline CHEMBL1366622 & 809418 & 6.4067 & 5.5244 & TRN & \\
\hline CHEMBL1524431 & 809418 & 5.4584 & 5.2132 & TRN & \\
\hline CHEMBL1904727 & 809418 & 5.5901 & 5.4272 & TRN & \\
\hline CHEMBL607553 & 809418 & 4.9048 & 5.1149 & TRN & \\
\hline CHEMBL1994626 & 809418 & 5.2426 & 5.2685 & TRN & \\
\hline CHEMBL1736280 & 809418 & 3.1549 & 4.9884 & TRN & \\
\hline CHEMBL1469557 & 809418 & 5.251 & 5.0195 & TRN & \\
\hline CHEMBL1430715 & 809418 & 4.5493 & 4.3464 & TRN & \\
\hline CHEMBL1503659 & 809418 & 5.5086 & 5.1251 & TST & \\
\hline CHEMBL590927 & 809418 & 5.9666 & 5.8035 & TRN & \\
\hline CHEMBL1452671 & 809418 & 4.9718 & 5.0747 & TRN & \\
\hline CHEMBL1567488 & 809418 & 4.7768 & 5.0947 & TRN & \\
\hline CHEMBL367376 & 809418 & 6.3655 & 5.9402 & TST & \\
\hline CHEMBL1532525 & 809418 & 5.6778 & 5.2962 & TRN & \\
\hline CHEMBL1884965 & 809418 & 6.0696 & 5.064 & TRN & \\
\hline CHEMBL1863734 & 809418 & 5.1203 & 4.9906 & TRN & \\
\hline CHEMBL1336277 & 809418 & 4.5174 & 5.2801 & TRN & \\
\hline CHEMBL1879480 & 809418 & 5.2464 & 5.0635 & TRN & \\
\hline CHEMBL1372452 & 809418 & 5.1409 & 4.9788 & TRN & \\
\hline CHEMBL1470373 & 809418 & 4.6527 & 4.9531 & TST & \\
\hline CHEMBL1482188 & 809418 & 4.9918 & 5.2281 & TST & \\
\hline CHEMBL1700880 & 809418 & 5.7852 & 5.3084 & TRN & \\
\hline \multirow[t]{2}{*}{ CHEMBL1436389 } & 809418 & 4.9024 & $5.0680 e$ & 0000 & וכ \\
\hline & & \multicolumn{3}{|c|}{ Page 13392} & \\
\hline
\end{tabular}


Supplemental Table S2.txt

\begin{tabular}{|c|c|c|c|c|}
\hline 983 & & 7.585 & 5.9305 & 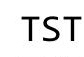 \\
\hline HEMBL1370126 & & .6216 & 5.1296 & \\
\hline 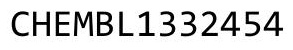 & & & & \\
\hline AEMBL1 & & & & \\
\hline AEMBL1324564 & 18 & & & \\
\hline HEMBL1440300 & 09418 & 2388 & 6116 & \\
\hline HEMBL13 & 8 & & & \\
\hline 211 & & & & \\
\hline AEMBL1512670 & $30 s$ & & 3428 & \\
\hline HEMBL1313502 & 09 & & 2659 & \\
\hline AEMBL1501645 & $0 s$ & & 441 & \\
\hline IEMBL142 & 8 & & 231 & \\
\hline IEMBL13 & & & & \\
\hline JEMBL588038 & 8 & & 5854 & \\
\hline HEMBL140 & 8 & & 396 & \\
\hline AEMBL1448732 & $30 s$ & & 9981 & \\
\hline AEMBL14 & 8 & & 288 & \\
\hline HEMBL15 & & & 108 & \\
\hline HEMBL 15 & 8 & & 3402 & \\
\hline AEMBL18 & 8 & & & \\
\hline AEMBLII & 0 & & 82 & Niv \\
\hline AEMBL15 & & & 198 & . \\
\hline AEMBL13 & & & 05 & \\
\hline AEMBL13 & & & 2665 & \\
\hline JEMBL15 & & & & I RIV \\
\hline HEMBL14 & & & 773 & RIN \\
\hline HEMBL2C & & & 221 & Niv \\
\hline HEMBL17 & & & & \\
\hline HEMBL13 & & & 1061 & 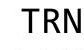 \\
\hline HEMBL1541828 & & & & s \\
\hline HEMBL15 & & & 494 & RN \\
\hline HEMBL1 & & & 998 & RN \\
\hline 61 & 8 & & 545 & ST \\
\hline HEMBL1720661 & 8 & & & in \\
\hline HEMBL1878609 & $30 s$ & & 4668 & ГRN \\
\hline HEMBL135 & & & 105 & RN \\
\hline HFMRI 1 & & & 42 & RN \\
\hline HEMBL14 & & & 3967 & RN \\
\hline HEMBL1423660 & 305 & & 1434 & TRN \\
\hline AEMBL18 & 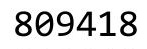 & & 354 & TRN \\
\hline HEMBL14ع & $a c$ & & 2654 & \\
\hline CHEMBL1901984 & & & 5.2219 & IST \\
\hline HEMBL1337570 & & & 5.1593 & $\Gamma \mathrm{RN}$ \\
\hline AEMBL1491847 & $0 s$ & 78 & 1471 & ГST \\
\hline MBL14 & & & 5171 & \\
\hline HEMBL1983107 & & & 9884 & \\
\hline CHEMBL156661e & & & .8999 & \\
\hline CHEMBL1491279 & 809418 & 5.4962 & 5.0583 & $r$ \\
\hline
\end{tabular}

Page 13393 
Supplemental Table S2.txt

\begin{tabular}{|c|c|c|c|c|}
\hline 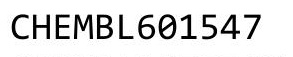 & & & & \\
\hline HEMBL1575768 & 39418 & 6.1656 & 2791 & \\
\hline HEMBL1451491 & & 3862 & 9634 & \\
\hline AEMBL14 & & & & \\
\hline IEMBL1555566 & 8 & 172 & 8177 & \\
\hline HEMBL1311185 & 09418 & 9872 & 3549 & \\
\hline HEMBL1452116 & 09418 & .6253 & .1482 & \\
\hline HEMBL1507537 & 18 & 931 & 1635 & \\
\hline AEMBL1 & 18 & & 74 & \\
\hline IEMBL13 & 18 & 062 & & \\
\hline HEMBL1376794 & 09 & .251 & 1311 & \\
\hline HEMBL 260148 & 18 & 4.869 & 2391 & \\
\hline HEMBL190 & 18 & 5726 & 283 & \\
\hline HEMBL13 & & 233 & & \\
\hline HEMBL13 & 8 & 106 & & \\
\hline HEMBL1420393 & 18 & 33 & 06 & \\
\hline HEMBL486706 & 09 & 1622 & 3768 & \\
\hline HEMBL13 & 8 & 855 & 55 & \\
\hline HEMBL15 & & & & \\
\hline HEMBL16 & 8 & 76 & & PN \\
\hline HEMBL596 & 8 & & & \\
\hline HEMBL1897229 & 8 & 78 & 38 & RN \\
\hline HEMBL197 & 8 & 214 & 92 & \\
\hline HEMBL15 & & & & \\
\hline HEME & & & & RN \\
\hline HEMBL152 & 8 & & & RN \\
\hline HEMBL1711326 & 8 & 433 & 15 & RN \\
\hline HEMBL130 & 8 & 37 & 45 & RN \\
\hline HEM & & & & RN \\
\hline HEME & & 51 & & RN \\
\hline HEMBL14916 & & & & RN \\
\hline HEMBL1834675 & 09 & & 171 & ST \\
\hline HEMBL53 & 8 & 37 & 12 & RN \\
\hline 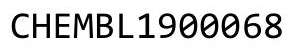 & & & & RN \\
\hline HEMBL15ऽ & & & & RN \\
\hline HEMBL14234 & & & & ST \\
\hline HEMBL160 & -8 & 49 & 467 & RN \\
\hline HEMBL13e & 8 & 8 & 73 & RN \\
\hline 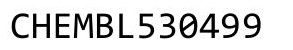 & & & & RN \\
\hline HEMBL151 & & & & RN \\
\hline HEMBL154 & & & & RN \\
\hline HEMBL14 & 8 & $\partial 91$ & & $\mathrm{RN}$ \\
\hline HEMBL152 & & & & \\
\hline CHEMBL1470633 & & & & RN \\
\hline HEMBL1312502 & & 4.7557 & & RN \\
\hline HEMBL17136 & 309 & 5.9872 & 49 & RN \\
\hline HEN & & & & \\
\hline & & & & \\
\hline
\end{tabular}

Page 13394 


\begin{tabular}{|c|c|c|c|c|c|}
\hline & & \multicolumn{4}{|c|}{ Supplemental Table S2.txt } \\
\hline CHEMBL1449349 & 809418 & 4.9038 & 5.0821 & TRN & \\
\hline CHEMBL1701330 & 809418 & 5.1618 & 5.0957 & TRN & \\
\hline CHEMBL1895200 & 809418 & 6.0 & 5.1333 & TST & \\
\hline CHEMBL1518077 & 809418 & 5.1851 & 5.45799 & 9999999999 & TRN \\
\hline CHEMBL1529991 & 809418 & 5.3737 & 5.1583 & TRN & \\
\hline CHEMBL1894067 & 809418 & 4.6409 & 4.8855 & TRN & \\
\hline CHEMBL1510261 & 809418 & 5.0711 & 5.3807 & TRN & \\
\hline CHEMBL1429289 & 809418 & 5.4271 & 5.2304 & TST & \\
\hline CHEMBL1704518 & 809418 & 5.2464 & 5.244 & TST & \\
\hline CHEMBL1561936 & 809418 & 5.1046 & 4.9942 & TRN & \\
\hline CHEMBL1461774 & 809418 & 5.1688 & 5.0183 & TST & \\
\hline CHEMBL1315463 & 809418 & 5.3585 & 4.988 & TRN & \\
\hline CHEMBL1457279 & 809418 & 3.1549 & 4.26699 & 99999999995 & TRN \\
\hline CHEMBL1395980 & 809418 & 4.5538 & 4.8368 & TRN & \\
\hline CHEMBL1302286 & 809418 & 5.0195 & 4.9157 & TRN & \\
\hline CHEMBL1362612 & 809418 & 5.0825 & 5.3333 & TRN & \\
\hline CHEMBL1572233 & 809418 & 5.567 & 5.4429 & TRN & \\
\hline CHEMBL1394624 & 809418 & 5.2874 & 5.5362 & TRN & \\
\hline CHEMBL1372292 & 809418 & 4.9801 & 5.8176 & TRN & \\
\hline CHEMBL1312738 & 809418 & 4.5265 & 5.9682 & TST & \\
\hline CHEMBL1869116 & 809418 & 4.9796 & 4.9682 & TRN & \\
\hline CHEMBL1301480 & 809418 & 5.4802 & 5.0458 & TRN & \\
\hline CHEMBL1539471 & 809418 & 5.1146 & 5.2229 & TST & \\
\hline CHEMBL 1585742 & 809418 & 4.6635 & 5.0445 & TRN & \\
\hline CHEMBL1305642 & 809418 & 4.9805 & 5.1092 & TRN & \\
\hline CHEMBL1571123 & 809418 & 5.2211 & 5.215 & TRN & \\
\hline CHEMBL1324082 & 809418 & 5.1481 & 5.2171 & TST & \\
\hline CHEMBL600778 & 809418 & 6.109 & 6.0429 & TRN & \\
\hline CHEMBL 1487720 & 809418 & 7.585 & 5.4638 & TRN & \\
\hline CHEMBL1482542 & 809418 & 5.8041 & 5.4382 & TRN & \\
\hline CHEMBL1340698 & 809418 & 5.1314 & 5.2396 & TRN & \\
\hline CHEMBL124006 & 809418 & 3.1549 & 5.2894 & TRN & \\
\hline CHEMBL1302130 & 809418 & 6.2175 & 5.6217 & TRN & \\
\hline CHEMBL1491238 & 809418 & 4.5057 & 5.008 & TRN & \\
\hline CHEMBL1580472 & 809418 & 5.0716 & 5.1448 & TRN & \\
\hline CHEMBL533602 & 809418 & 6.2676 & 5.6629 & TST & \\
\hline CHEMBL1435226 & 809418 & 6.067 & 5.3415 & TRN & \\
\hline CHEMBL1540099 & 809418 & 5.4023 & 5.2266 & TST & \\
\hline CHEMBL1526462 & 809418 & 5.0731 & 5.3494 & TRN & \\
\hline CHEMBL1409750 & 809418 & 4.5872 & 4.9759 & TRN & \\
\hline CHEMBL1504077 & 809418 & 5.1798 & 5.2094 & TRN & \\
\hline CHEMBL1529115 & 809418 & 5.3478 & 5.4356 & TRN & \\
\hline CHEMBL1966192 & 809418 & 5.1506 & 5.0726 & TST & \\
\hline CHEMBL1702199 & 809418 & 5.6861 & 5.1946 & TRN & \\
\hline CHEMBL1316828 & 809418 & 5.109 & 5.0347 & TST & \\
\hline CHEMBL1497019 & 809418 & 4.8784 & 5.0746 & TRN & \\
\hline CHEMBL1526371 & 809418 & 4.8102 & 5.1298 & TST & \\
\hline CHEMBL1342007 & 809418 & 4.5986 & 5.0507 & TRN & \\
\hline
\end{tabular}




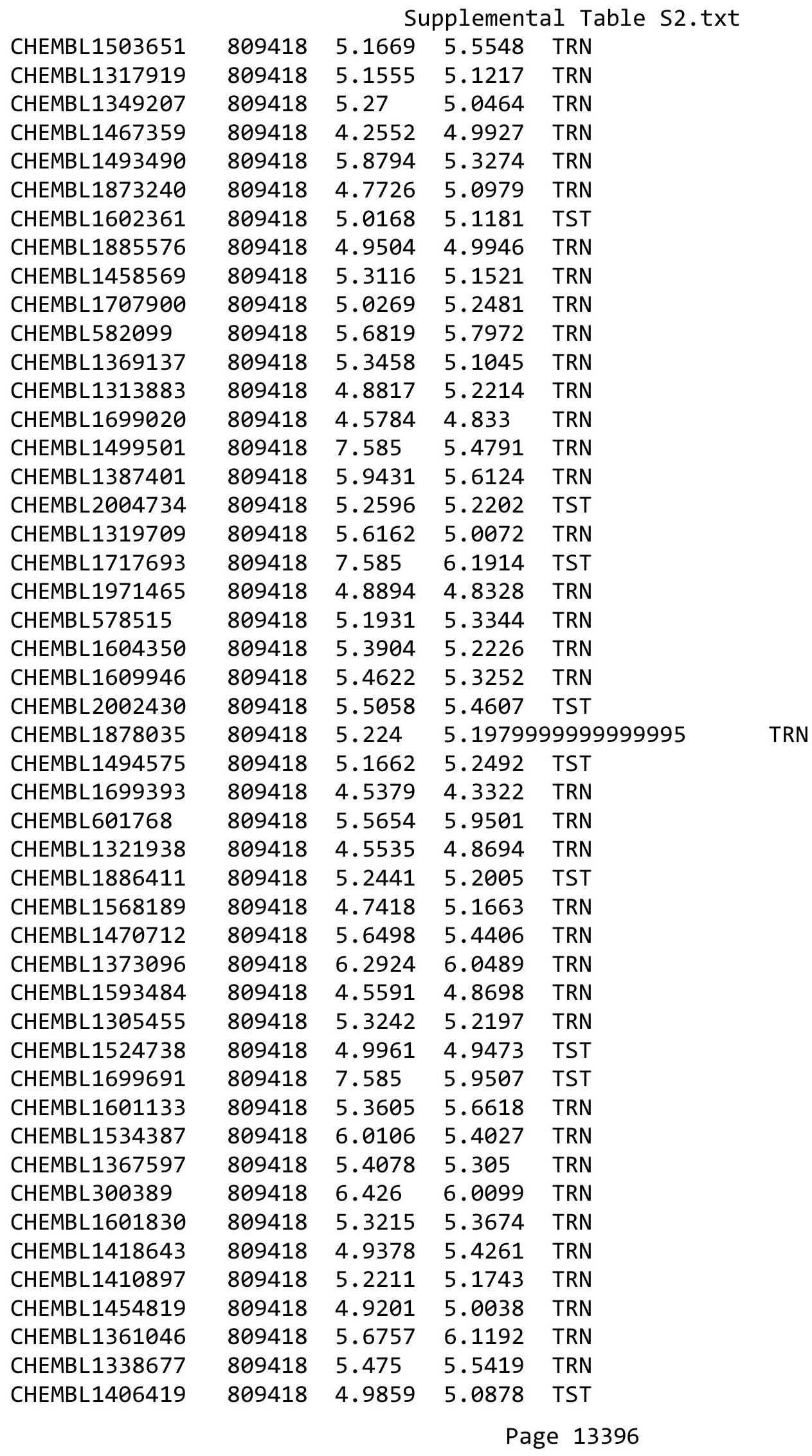


Supplemental Table S2.txt

\begin{tabular}{|c|c|c|c|c|}
\hline CHEMBL1315704 & 809418 & 4.6611 & 4.8895 & TST \\
\hline CHEMBL1341270 & 809418 & 5.6925 & 5.43 & TST \\
\hline CHEMBL578929 & 809418 & 5.9666 & 5.9252 & TST \\
\hline CHEMBL1890126 & 809418 & 4.4989 & 4.9513 & TST \\
\hline CHEMBL1578341 & 809418 & 4.8894 & 5.0064 & TRN \\
\hline CHEMBL1584329 & 809418 & 5.9355 & 5.0941 & TRN \\
\hline CHEMBL1547516 & 809418 & 5.7122 & 5.0183 & TST \\
\hline CHEMBL1330307 & 809418 & 5.5406 & 5.4545 & TRN \\
\hline CHEMBL1326253 & 809418 & 4.5429 & 5.1691 & TST \\
\hline CHEMBL1587722 & 809418 & 5.3665 & 5.142 & TRN \\
\hline CHEMBL1454614 & 809418 & 5.082 & 5.0945 & TRN \\
\hline CHEMBL1383333 & 809418 & 5.6778 & 5.4381 & TRN \\
\hline CHEMBL1424665 & 809418 & 5.6421 & 5.4431 & TRN \\
\hline CHEMBL1388140 & 809418 & 4.5931 & 4.9357 & TRN \\
\hline CHEMBL1521492 & 809418 & 5.055 & 5.2635 & TRN \\
\hline CHEMBL1414585 & 809418 & 5.8125 & 5.0619 & TRN \\
\hline CHEMBL1716540 & 809418 & 6.0757 & 5.3397 & TST \\
\hline CHEMBL1581759 & 809418 & 5.24799 & 999999999 & 5.2212 \\
\hline CHEMBL1566706 & 809418 & 4.6728 & 4.9724 & TRN \\
\hline CHEMBL1307050 & 809418 & 5.0915 & 5.5031 & TRN \\
\hline CHEMBL47940 & 809418 & 4.4994 & 5.2355 & TST \\
\hline CHEMBL1701308 & 809418 & 5.5186 & 5.1005 & TRN \\
\hline CHEMBL1300302 & 809418 & 5.3675 & 5.1828 & TRN \\
\hline CHEMBL1534503 & 809418 & 5.0535 & 5.1 & TRN \\
\hline CHEMBL1705098 & 809418 & 7.0 & 5.3193 & TRN \\
\hline CHEMBL1479496 & 809418 & 5.2284 & 5.2328 & TRN \\
\hline CHEMBL1327721 & 809418 & 5.0964 & 5.327000 & 0000000001 \\
\hline CHEMBL1529741 & 809418 & 5.5031 & 5.4115 & TRN \\
\hline CHEMBL1459155 & 809418 & 5.4609 & 5.2979 & TRN \\
\hline CHEMBL1322995 & 809418 & 5.209 & 5.1388 & TRN \\
\hline CHEMBL1464525 & 809418 & 5.1057 & 5.1351 & TST \\
\hline CHEMBL1487136 & 809418 & 7.585 & 6.4205 & TRN \\
\hline CHEMBL1564958 & 809418 & 5.8962 & 5.5313 & TRN \\
\hline CHEMBL1304647 & 809418 & 5.1524 & 5.0872 & TRN \\
\hline CHEMBL1366727 & 809418 & 4.471 & 5.7212 & TRN \\
\hline CHEMBL309474 & 809418 & 5.3809 & 5.117 & TST \\
\hline CHEMBL1724177 & 809418 & 5.1278 & 5.1838 & TST \\
\hline CHEMBL1465040 & 809418 & 5.5607 & 5.3309 & TRN \\
\hline CHEMBL1567159 & 809418 & 5.0872 & 5.3264 & TRN \\
\hline CHEMBL1349747 & 809418 & 4.6834 & 4.7928 & TST \\
\hline CHEMBL1729203 & 809418 & 4.8834 & 5.1953 & TST \\
\hline CHEMBL1570958 & 809418 & 5.3809 & 5.3015 & TRN \\
\hline CHEMBL1456022 & 809418 & 4.9759 & 5.1197 & TRN \\
\hline CHEMBL1893385 & 809418 & 4.5021 & 4.9052 & TRN \\
\hline CHEMBL1597454 & 809418 & 4.9062 & 5.2704 & TRN \\
\hline CHEMBL1901126 & 809418 & 5.3487 & 5.0613 & TST \\
\hline CHEMBL1335844 & 809418 & 4.9062 & 5.1157 & TRN \\
\hline CHEMBL1896316 & 809418 & 5.284 & 5.0572 & TRN \\
\hline
\end{tabular}


Supplemental Table S2.txt

\begin{tabular}{|c|c|c|c|c|}
\hline & & 097 & & \\
\hline CHEMBL 2000067 & 99418 & 717 & 46 & \\
\hline 177 & 9418 & 834 & & \\
\hline 594 & & 566 & & \\
\hline 469 & 9418 & 317 & 509 & \\
\hline IEMBL1519450 & 09418 & & 718 & \\
\hline AEMBL1606097 & 09418 & 5.8125 & 326 & \\
\hline AEMBL1606066 & $\partial 9418$ & & & \\
\hline IEMBL1308996 & 99418 & 577 & 382 & \\
\hline 36768 & $\partial 9418$ & 258 & & \\
\hline AEMBL1541693 & 09418 & 386 & 117 & \\
\hline AEMBL1338958 & 09418 & 19 & & \\
\hline AEMBL1444764 & 309418 & 47 & & \\
\hline 307 & 29418 & 45 & & \\
\hline 07 & 09418 & 318 & & \\
\hline IEMBL1524438 & 09418 & & 16 & \\
\hline 989 & 8 & & & \\
\hline 7 & 8 & & & \\
\hline 8 & 8 & & & \\
\hline 594 & 09418 & 83 & & \\
\hline 80495 & 8 & & & \\
\hline 93900 & 8 & & & \\
\hline 22 & 8 & & & \\
\hline 2 & 18 & 02 & & \\
\hline+38 & 18 & & & \\
\hline 500686 & 8 & & & \\
\hline 84723 & 8 & & & \\
\hline 3 & 8 & & & \\
\hline 4 & 8 & & & \\
\hline 990 & 18 & & & \\
\hline & 8 & & & \\
\hline 28992 & 09418 & & & \\
\hline & 8 & & & \\
\hline 7 & 8 & & 58 & \\
\hline AEMBL1442788 & 809418 & & & \\
\hline AEMBL3392492 & 09418 & & & \\
\hline-1713335 & 8 & & 02 & \\
\hline & & & & \\
\hline 2 & 8 & & & \\
\hline & 809418 & & & \\
\hline 700347 & 09418 & 197 & & \\
\hline & 809 & & 52 & \\
\hline & 09418 & & & \\
\hline 709973 & 809418 & & & \\
\hline 000 & 809418 & 711 & 293 & K \\
\hline IEMBL1406540 & 809418 & 713 & 384 & \\
\hline & 809 & & & \\
\hline & 809418 & & 4.887 & \\
\hline
\end{tabular}

Page 13398 


\begin{tabular}{|c|c|c|c|c|c|c|}
\hline & & \multicolumn{5}{|c|}{ Supplemental Table S2.txt } \\
\hline CHEMBL1504035 & 809418 & 4.5859 & 5.048 & TRN & & \\
\hline CHEMBL1541840 & 809418 & 4.7959 & 4.9961 & TRN & & \\
\hline CHEMBL1420384 & 809418 & 5.426 & 4.9755 & TRN & & \\
\hline CHEMBL1430068 & 809418 & 4.8303 & 4.9263 & TRN & & \\
\hline CHEMBL1401989 & 809418 & 5.6882 & 5.0622 & TRN & & \\
\hline CHEMBL1590423 & 809418 & \multicolumn{3}{|c|}{5.0680000000000005} & 4.8778 & TRN \\
\hline CHEMBL600862 & 809418 & 6.1972 & 5.8527 & TRN & & \\
\hline CHEMBL1526784 & 809418 & 4.5496 & 5.0286 & TRN & & \\
\hline CHEMBL1329798 & 809418 & 4.4557 & 5.3202 & TRN & & \\
\hline CHEMBL1346801 & 809418 & 5.1308 & 5.2019 & TRN & & \\
\hline CHEMBL1554436 & 809418 & 5.0419 & 5.1261 & TST & & \\
\hline CHEMBL1303799 & 809418 & 5.0301 & 5.0486 & TRN & & \\
\hline CHEMBL1580463 & 809418 & 5.9208 & 5.1511 & TRN & & \\
\hline CHEMBL1386580 & 809418 & 4.622 & 4.7189 & TST & & \\
\hline CHEMBL1603001 & 809418 & 6.0991 & 6.3259 & TST & & \\
\hline CHEMBL1539929 & 809418 & 4.5408 & 5.105 & TST & & \\
\hline CHEMBL1550749 & 809418 & 5.0057 & 4.7976 & TST & & \\
\hline CHEMBL1308223 & 809418 & 5.4413 & 5.348 & TST & & \\
\hline CHEMBL1492922 & 809418 & 4.7791 & 5.0979 & TST & & \\
\hline CHEMBL1715463 & 809418 & 4.9731 & 5.2135 & TST & & \\
\hline CHEMBL1570307 & 809418 & 4.4083 & 4.7992 & TST & & \\
\hline CHEMBL1563896 & 809418 & 5.2411 & 5.1358 & TST & & \\
\hline CHEMBL1491222 & 809418 & 6.2725 & 5.4464 & TST & & \\
\hline CHEMBL1334638 & 809418 & 4.8523 & 5.1825 & TST & & \\
\hline CHEMBL405317 & 809418 & \multicolumn{3}{|c|}{4.486000000000001} & 5.3527 & TST \\
\hline CHEMBL1522108 & 809418 & 5.9914 & 5.4068 & TST & & \\
\hline CHEMBL1337862 & 809418 & 4.5621 & 5.1626 & TST & & \\
\hline CHEMBL1498599 & 809418 & 4.8955 & 5.1444 & TST & & \\
\hline CHEMBL1544093 & 809418 & 4.6874 & 5.0938 & TST & & \\
\hline CHEMBL1331100 & 809418 & 5.2644 & 5.0517 & TST & & \\
\hline CHEMBL1702773 & 809418 & 4.8658 & 4.8788 & TST & & \\
\hline CHEMBL1551810 & 809418 & 4.5807 & 4.7243 & TST & & \\
\hline CHEMBL1514530 & 809418 & 6.0414 & 5.9147 & TST & & \\
\hline CHEMBL1459140 & 809418 & 6.0 & 5.4838 & TST & & \\
\hline CHEMBL2355890 & 809418 & 4.5588 & 4.8992 & TST & & \\
\hline CHEMBL1727997 & 809418 & 4.8716 & 5.1203 & TST & & \\
\hline CHEMBL1409883 & 809418 & 5.1561 & 5.3152 & TST & & \\
\hline CHEMBL588804 & 809418 & 6.1694 & 5.7561 & TST & & \\
\hline CHEMBL1492214 & 809418 & 4.9024 & 4.6498 & TST & & \\
\hline CHEMBL 2007530 & 809418 & 4.9151 & 4.4257 & TST & & \\
\hline CHEMBL1505604 & 809418 & 5.6556 & 5.2436 & TST & & \\
\hline CHEMBL1421779 & 809418 & 6.0123 & 5.2652 & TST & & \\
\hline CHEMBL1549279 & 809418 & 5.0283 & 5.0227 & TST & & \\
\hline CHEMBL1530707 & 809418 & 5.466 & 4.9347 & TST & & \\
\hline CHEMBL1432721 & 809418 & 5.6655 & 5.3622 & TST & & \\
\hline CHEMBL1531374 & 809418 & 4.7003 & 4.2665 & TST & & \\
\hline CHEMBL1538234 & 809418 & 4.9431 & 5.0199 & TST & & \\
\hline CHEMBL1727091 & 809418 & 5.4157 & 5.4007 & TST & & \\
\hline
\end{tabular}


Supplemental Table S2.txt

\begin{tabular}{|c|c|c|c|c|c|c|}
\hline CHEMBL1524692 & 809418 & 5.2596 & 4.9494 & TST & & \\
\hline CHEMBL1303653 & 809418 & 5.1605 & 4.731 & TST & & \\
\hline CHEMBL1425718 & 809418 & 5.4191 & 4.9469 & TST & & \\
\hline CHEMBL1312239 & 809418 & 5.1013 & 4.794 & TST & & \\
\hline CHEMBL1358740 & 809418 & 5.3468 & 5.0111 & TST & & \\
\hline CHEMBL1555271 & 809418 & 5.8962 & 5.8052 & TST & & \\
\hline CHEMBL595700 & 809418 & 5.5952 & 5.3629 & TST & & \\
\hline CHEMBL1886345 & 809418 & 5.1494 & 5.1885 & TST & & \\
\hline CHEMBL1489769 & 809418 & 5.0846 & 5.1157 & TST & & \\
\hline CHEMBL1558461 & 809418 & 4.5929 & 4.7885 & TST & & \\
\hline CHEMBL1564519 & 809418 & 5.2588 & 5.1765 & TST & & \\
\hline CHEMBL1500252 & 809418 & 5.4841 & 5.1282 & TST & & \\
\hline CHEMBL1533399 & 809418 & 5.556 & 5.2958 & TST & & \\
\hline CHEMBL1571157 & 809418 & 5.585 & 5.2324 & TST & & \\
\hline CHEMBL1437030 & 809418 & 4.6238 & 5.4706 & TST & & \\
\hline CHEMBL1443900 & 809418 & 5.58 & 5.6172 & TST & & \\
\hline CHEMBL1329235 & 809418 & 5.1457 & 5.8061 & TST & & \\
\hline CHEMBL1493936 & 809418 & 5.2097 & 5.2589 & TST & & \\
\hline CHEMBL1340458 & 809418 & 4.5166 & 5.0549 & TST & & \\
\hline CHEMBL1369425 & 809418 & 4.5038 & 4.9842 & TST & & \\
\hline CHEMBL1307972 & 809418 & 6.3915 & 5.4204 & TST & & \\
\hline CHEMBL1531219 & 809418 & 4.5586 & 4.8909 & TST & & \\
\hline CHEMBL1705708 & 809418 & 5.2882 & 5.3298 & TST & & \\
\hline CHEMBL1553183 & 809418 & 4.8428 & 5.4347 & TST & & \\
\hline CHEMBL1301325 & 809418 & 5.6383 & 5.3974 & TST & & \\
\hline CHEMBL1707309 & 809418 & 5.3242 & 5.1559 & TST & & \\
\hline CHEMBL1613695 & 809418 & 4.6057 & 5.2432 & TST & & \\
\hline CHEMBL1322350 & 809418 & \multirow{2}{*}{\multicolumn{3}{|c|}{$\begin{array}{l}5.0569999999999995 \\
4.9910000000000005\end{array}$}} & 5.1335 & TST \\
\hline CHEMBL1314042 & 809418 & & & & 5.067 & TST \\
\hline CHEMBL580955 & 809418 & 6.0278 & 5.9984 & TST & & \\
\hline CHEMBL1478547 & 809418 & 4.6019 & 4.9686 & TST & & \\
\hline CHEMBL1486664 & 809418 & 4.8422 & 4.95 & TST & & \\
\hline CHEMBL1399478 & 809418 & 4.9292 & 5.4751 & TST & & \\
\hline CHEMBL1866074 & 809418 & 5.5058 & 5.1787 & TST & & \\
\hline CHEMBL1445650 & 809418 & 4.8601 & 5.315 & TST & & \\
\hline CHEMBL1705928 & 809418 & 5.2549 & 5.1391 & TST & & \\
\hline CHEMBL1470932 & 809418 & 5.399 & 5.121 & TST & & \\
\hline CHEMBL1580910 & 809418 & 5.2692 & 5.1232 & TST & & \\
\hline CHEMBL1700186 & 809418 & 4.8153 & 4.8837 & TST & & \\
\hline CHEMBL1720610 & 809418 & 4.8871 & 4.9733 & TST & & \\
\hline CHEMBL1734142 & 809418 & 5.4498 & 5.3736 & TST & & \\
\hline CHEMBL1360774 & 809418 & 4.6817 & 5.0087 & TST & & \\
\hline CHEMBL1428765 & 809418 & 4.9488 & 5.1552 & TST & & \\
\hline CHEMBL1361220 & 809418 & 5.0453 & 5.0965 & TST & & \\
\hline CHEMBL1503312 & 809418 & 5.1068 & 5.2374 & TST & & \\
\hline CHEMBL1510652 & 809418 & 4.5764 & 5.1197 & TST & & \\
\hline CHEMBL1405968 & 809418 & 5.6904 & 5.1356 & TST & & \\
\hline CHEMBL580727 & 809418 & 5.4473 & 5.5461 & TST & & \\
\hline
\end{tabular}


Supplemental Table S2.txt

\begin{tabular}{|c|c|c|c|c|c|}
\hline CHEMBL1611182 & 809418 & 5.2472 & 5.4883 & TST & \\
\hline CHEMBL1331836 & 809418 & 4.8147 & 4.8991 & TST & \\
\hline CHEMBL1337266 & 809418 & 4.9987 & 5.0042 & TST & \\
\hline CHEMBL1517486 & 809418 & 5.4425 & 5.13899 & 9999999999 & TST \\
\hline CHEMBL1447872 & 809418 & 4.8784 & 4.934 & TST & \\
\hline CHEMBL1583665 & 809418 & 4.8582 & 5.1526 & TST & \\
\hline CHEMBL1402332 & 809418 & 5.1543 & 5.3896 & TST & \\
\hline CHEMBL1966666 & 809418 & 5.2518 & 5.2336 & TST & \\
\hline CHEMBL1483768 & 809418 & 4.902 & 5.25 & TST & \\
\hline CHEMBL1324027 & 809418 & 5.064 & 5.3641 & TST & \\
\hline CHEMBL1463077 & 809418 & 5.3179 & 5.2068 & TST & \\
\hline CHEMBL1344025 & 809418 & 4.5286 & 5.4006 & TST & \\
\hline CHEMBL1881962 & 809418 & 4.4455 & 5.0771 & TST & \\
\hline CHEMBL1596126 & 809418 & 4.9516 & 5.1758 & TST & \\
\hline CHEMBL1417970 & 809418 & 5.1568 & 5.2107 & TST & \\
\hline CHEMBL1460653 & 809418 & 5.2652 & 4.9316 & TST & \\
\hline CHEMBL1256655 & 809418 & 5.1494 & 5.2613 & TST & \\
\hline CHEMBL414890 & 809418 & 5.3497 & 5.1809 & TST & \\
\hline CHEMBL2070345 & 835704 & 6.7959 & 6.6893 & TRN & \\
\hline CHEMBL 2070464 & 835704 & 6.301 & 6.5887 & TRN & \\
\hline CHEMBL2070465 & 835704 & 6.5229 & 6.6104 & TRN & \\
\hline CHEMBL2070353 & 835704 & 3.5229 & 6.2188 & TST & \\
\hline CHEMBL 2070357 & 835704 & 5.9586 & 5.8616 & TRN & \\
\hline CHEMBL2070352 & 835704 & 5.3872 & 6.7255 & TST & \\
\hline CHEMBL 2070372 & 835704 & 6.1549 & 5.9423 & TRN & \\
\hline CHEMBL 2070458 & 835704 & 4.0 & 5.596 & TRN & \\
\hline CHEMBL 2070449 & 835704 & 5.4559 & 5.4269 & TRN & \\
\hline CHEMBL 2070371 & 835704 & 6.1549 & 6.1333 & TRN & \\
\hline CHEMBL2070355 & 835704 & 5.9586 & 6.0879 & TRN & \\
\hline CHEMBL 2070365 & 835704 & 6.5229 & 6.0001 & TRN & \\
\hline CHEMBL2070459 & 835704 & 5.7447 & 6.0096 & TRN & \\
\hline CHEMBL383657 & 835704 & 4.0 & 6.8547 & TST & \\
\hline CHEMBL 2070460 & 835704 & 6.301 & 6.0816 & TRN & \\
\hline CHEMBL 2070453 & 835704 & 6.2218 & \multicolumn{2}{|c|}{6.252000000000001} & TRN \\
\hline CHEMBL 2070354 & 835704 & 5.8539 & 6.7147 & TST & \\
\hline CHEMBL2070363 & 835704 & 5.4949 & 5.4563 & TRN & \\
\hline CHEMBL 2070462 & 835704 & 6.301 & 6.1802 & TRN & \\
\hline CHEMBL2070359 & 835704 & 5.9586 & 5.8959 & TRN & \\
\hline CHEMBL2070348 & 835704 & 5.4437 & 6.7364 & TST & \\
\hline CHEMBL 2069318 & 835704 & 4.0 & 6.3748 & TST & \\
\hline CHEMBL2070360 & 835704 & 5.4202 & 5.5263 & TRN & \\
\hline CHEMBL 2070451 & 835704 & 6.2218 & 6.1467 & TRN & \\
\hline CHEMBL203454 & 835704 & 4.0 & 6.5706 & TST & \\
\hline CHEMBL2069319 & 835704 & 5.5528 & 5.2853 & TRN & \\
\hline CHEMBL 203824 & 835704 & 5.6576 & 6.9082 & TST & \\
\hline CHEMBL2070366 & 835704 & 5.8539 & 6.0156 & TRN & \\
\hline CHEMBL2070346 & 835704 & 4.0 & 6.5186 & TST & \\
\hline CHEMBL2070461 & 835704 & 6.0 & 6.2167 & TRN & \\
\hline
\end{tabular}


Supplemental Table S2.txt

\begin{tabular}{|c|c|c|c|c|c|}
\hline CHEMBL2070368 & 835704 & 6.301 & 6.053 & TRN & \\
\hline CHEMBL2070456 & 835704 & 6.2218 & 6.1988 & TRN & \\
\hline CHEMBL2070466 & 835704 & 6.8239 & 6.6292 & TRN & \\
\hline CHEMBL2070369 & 835704 & 5.6021 & 5.7904 & TRN & \\
\hline CHEMBL2070362 & 835704 & 5.2924 & 5.4853 & TRN & \\
\hline CHEMBL 2070454 & 835704 & 6.3979 & 6.4606 & TRN & \\
\hline CHEMBL 2070450 & 835704 & 6.0969 & 5.8492 & TRN & \\
\hline CHEMBL2070347 & 835704 & 5.8239 & 6.5546 & TST & \\
\hline CHEMBL2070358 & 835704 & 6.2218 & 5.8844 & TRN & \\
\hline CHEMBL2070349 & 835704 & 5.1249 & 6.4233 & TST & \\
\hline CHEMBL2070351 & 835704 & 4.0 & 6.4399 & TST & \\
\hline CHEMBL2070356 & 835704 & 6.2218 & 5.965 & TRN & \\
\hline CHEMBL2070463 & 835704 & 5.9208 & 6.1869 & TRN & \\
\hline CHEMBL 2070370 & 835704 & 6.0 & 6.3145 & TRN & \\
\hline CHEMBL 2070350 & 835704 & 4.0 & 6.2942 & TST & \\
\hline CHEMBL2070367 & 835704 & 6.2218 & 6.2864 & TRN & \\
\hline CHEMBL2070361 & 835704 & 6.3979 & 5.7895 & TRN & \\
\hline CHEMBL 2070448 & 835704 & 6.2218 & 5.9428 & TRN & \\
\hline CHEMBL2070457 & 835704 & 5.3665 & 5.9784 & TRN & \\
\hline CHEMBL 2070364 & 835704 & 5.7696 & 5.5287 & TRN & \\
\hline CHEMBL 2070455 & 835704 & 6.2218 & 5.9056 & TRN & \\
\hline CHEMBL2070452 & 835704 & 6.2218 & 6.1671 & TRN & \\
\hline CHEMBL3954430 & 1642519 & 7.3372 & 6.415 & TST & \\
\hline CHEMBL3945595 & 1642519 & 6.0 & 6.2338 & TRN & \\
\hline CHEMBL3947112 & 1642519 & 6.0 & 7.2295 & TRN & \\
\hline CHEMBL3911011 & 1642519 & 6.317 & 6.3749 & TRN & \\
\hline CHEMBL3965141 & 1642519 & 6.4461 & 6.1474 & TRN & \\
\hline CHEMBL 3982846 & 1642519 & 7.3665 & 7.4793 & TRN & \\
\hline CHEMBL3961545 & 1642519 & 6.02 & 6.1111 & TRN & \\
\hline CHEMBL3901451 & 1642519 & 6.0 & 6.2742 & TRN & \\
\hline CHEMBL 3894941 & 1642519 & 6.9066 & 6.6622 & TST & \\
\hline CHEMBL3973686 & 1642519 & 8.0969 & 7.6241 & TRN & \\
\hline CHEMBL3950256 & 1642519 & 7.7212 & 6.6793 & TST & \\
\hline CHEMBL3942158 & 1642519 & 7.8239 & 7.2471 & TST & \\
\hline CHEMBL3945558 & 1642519 & 6.0 & 6.8703 & TRN & \\
\hline CHEMBL3924270 & 1642519 & 5.852 & 6.6079 & TST & \\
\hline CHEMBL3936698 & 1642519 & 6.0 & 7.7912 & TRN & \\
\hline CHEMBL3954573 & 1642519 & 6.3288 & 6.257999 & & TRN \\
\hline CHEMBL3964877 & 1642519 & 6.0 & 6.3255 & TRN & \\
\hline CHEMBL 3891888 & 1642519 & 6.9508 & 6.8391 & TST & \\
\hline CHEMBL 3977162 & 1642519 & 7.5686 & 7.1268 & TST & \\
\hline CHEMBL3971186 & 1642519 & 7.1938 & 6.5577 & TST & \\
\hline CHEMBL3965059 & 1642519 & 6.7258 & 6.9272 & TRN & \\
\hline CHEMBL3935517 & 1642519 & 7.6198 & 6.4285 & TRN & \\
\hline CHEMBL 3897784 & 1642519 & 7.8539 & 7.6508 & TRN & \\
\hline CHEMBL 3956423 & 1642519 & 6.0 & 7.2459 & TRN & \\
\hline CHEMBL 3945440 & 1642519 & 7.9208 & 7.1547 & TRN & \\
\hline CHEMBL3987196 & 1642519 & 7.3872 & 7.3913 & TRN & \\
\hline
\end{tabular}

Page 13402 


\begin{tabular}{|c|c|c|c|c|c|}
\hline \multicolumn{6}{|c|}{ Supplemental Table s2.txt } \\
\hline CHEMBL 3890536 & 1642519 & 6.0 & 6.1024 & TRN & \\
\hline CHEMBL3911766 & 1642519 & 8.5229 & 8.0913 & TRN & \\
\hline CHEMBL3912099 & 1642519 & 7.3979 & 6.9703 & TRN & \\
\hline CHEMBL3913952 & 1642519 & 6.0186 & 6.4127 & TRN & \\
\hline CHEMBL3961209 & 1642519 & 8.3979 & 7.6502 & TRN & \\
\hline CHEMBL 3980583 & 1642519 & 7.4089 & 7.1695 & TST & \\
\hline CHEMBL 3980868 & 1642519 & 7.5686 & 7.4806 & TRN & \\
\hline CHEMBL 3920629 & 1642519 & 6.0 & 6.0581 & TRN & \\
\hline CHEMBL 3899401 & 1642519 & 7.1308 & 6.9043 & TRN & \\
\hline CHEMBL 3967248 & 1642519 & 6.7905 & 7.3005 & TRN & \\
\hline CHEMBL3946157 & 1642519 & 6.6615 & 6.9878 & TRN & \\
\hline CHEMBL 3908814 & 1642519 & 6.4763 & 6.1072 & TRN & \\
\hline CHEMBL 3961925 & 1642519 & 6.3028 & 6.2526 & TRN & \\
\hline CHEMBL 3949809 & 1642519 & 7.2366 & 7.0712 & TRN & \\
\hline CHEMBL 3959873 & 1642519 & 6.0 & 6.7577 & TST & \\
\hline CHEMBL 3962782 & 1642519 & 7.1487 & 7.0288 & TRN & \\
\hline CHEMBL3910499 & 1642519 & 7.8539 & 7.2756 & TST & \\
\hline CHEMBL 3950729 & 1642519 & 7.2924 & 7.2184 & TST & \\
\hline CHEMBL3953066 & 1642519 & 6.0 & 6.3483 & TRN & \\
\hline CHEMBL 3909717 & 1642519 & 6.0 & 6.1114 & TRN & \\
\hline CHEMBL 3976781 & 1642519 & 5.3194 & 6.4098 & TST & \\
\hline CHEMBL 3942430 & 1642519 & 6.0 & 6.3655 & TRN & \\
\hline CHEMBL 3962775 & 1642519 & 6.0 & 6.473 & TRN & \\
\hline CHEMBL 3893132 & 1642519 & 7.9586 & 6.8799 & TRN & \\
\hline CHEMBL 3951907 & 1642519 & 6.5901 & 6.2889 & TST & \\
\hline CHEMBL 3916748 & 1642519 & 5.9066 & 6.6403 & TST & \\
\hline CHEMBL3933003 & 1642519 & 7.284 & 6.5252 & TRN & \\
\hline CHEMBL 3979958 & 1642519 & 7.1079 & 6.7168 & TST & \\
\hline CHEMBL 3918025 & 1642519 & 6.0 & 6.5653 & TRN & \\
\hline CHEMBL 3971591 & 1642519 & 7.4559 & 6.9121 & TRN & \\
\hline CHEMBL 3892558 & 1642519 & 6.0 & 6.37299 & 9999999999 & TRN \\
\hline CHEMBL3901505 & 1642519 & 5.871 & 6.1211 & TRN & \\
\hline CHEMBL 3895990 & 1642519 & 8.2218 & 8.1393 & TRN & \\
\hline CHEMBL3965223 & 1642519 & 6.8013 & 7.4998 & TRN & \\
\hline CHEMBL 3894346 & 1642519 & 5.8477 & 6.6523 & TST & \\
\hline CHEMBL 3959514 & 1642519 & 7.3872 & 7.2654 & TRN & \\
\hline CHEMBL3977819 & 1642519 & 6.0 & 6.0768 & TRN & \\
\hline CHEMBL 3967431 & 1642519 & 6.8013 & 6.348 & TRN & \\
\hline CHEMBL 3938937 & 1642519 & 6.0 & 7.3582 & TRN & \\
\hline CHEMBL 3940830 & 1642519 & 8.1549 & 7.5056 & TRN & \\
\hline CHEMBL3904938 & 1642519 & 7.699 & 7.0863 & TRN & \\
\hline CHEMBL3965456 & 1642519 & 5.7338 & 6.6023 & TST & \\
\hline CHEMBL3921645 & 1642519 & 6.6055 & 6.8913 & TRN & \\
\hline CHEMBL 3919422 & 1642519 & 8.5229 & 8.0582 & TRN & \\
\hline CHEMBL 3915125 & 1642519 & 6.0 & 6.6548 & TST & \\
\hline CHEMBL3971626 & 1642519 & 6.7595 & 6.1223 & TRN & \\
\hline CHEMBL3953016 & 1642519 & 7.3979 & 7.443 & TRN & \\
\hline CHEMBL3901836 & 1642519 & 7.7696 & 7.1935 & TRN & \\
\hline
\end{tabular}

Page 13403 
Supplemental Table S2.txt

\begin{tabular}{|c|c|c|c|c|}
\hline - & 2519 & & - & \\
\hline HEMBL3943910 & 642519 & 6.3686 & 6.416 & \\
\hline & 519 & & & \\
\hline 136 & 519 & 129 & 9672 & \\
\hline AEMBL3936667 & 542519 & 157 & & \\
\hline AEMBL3907444 & 642519 & 8.301 & 5988 & \\
\hline HEMBL 3892228 & 519 & 2518 & 6894 & \\
\hline IEMBL 391 & 19 & 979 & & \\
\hline EMBL3894016 & 19 & 1033 & & \\
\hline AEMBL3947905 & 519 & 3979 & 4776 & \\
\hline AEMBL2316537 & 29 & 2.699 & 1021 & \\
\hline AEMBL 231 & 29 & 547 & 7292 & \\
\hline AEMBL 23 & & & & \\
\hline HEMBL 231 & 29 & & & \\
\hline AEMBL2316539 & 29 & 212 & 9499 & \\
\hline HEMBL1539990 & 29 & 857 & 4213 & \\
\hline HEMBL231 & 29 & 99 & 378 & \\
\hline HEMBL133 & & & & \\
\hline HEMBL 231 & & & & \\
\hline AEMBL131 & 29 & 99 & 237 & RIV \\
\hline AEMBL 231 & & 99 & 14 & RN \\
\hline HEMBL 231 & & 076 & 813 & - \\
\hline HEMBL 231 & & 828 & 227 & RN \\
\hline AFMRI 14 & & & & RN \\
\hline IEMBL 23 & 9 & & 02 & ST \\
\hline$L 23$ & & 559 & 426 & RN \\
\hline L14 & & & 332 & RN \\
\hline 49 & & & & RN \\
\hline AEMBL231 & & & & RN \\
\hline JEMBL 231 & 9 & 586 & 42 & RN \\
\hline AEMBL 231 & & & 443 & RN \\
\hline AFMBI 231 & & & & ST \\
\hline 51 & & & & RN \\
\hline HEMBL2316558 & & & 951 & SI \\
\hline AEMBL 231 & 9 & 8 & 632 & RN \\
\hline AEMBL231 & & 08 & 52 & \\
\hline HEMRI $2=$ & & & & RN \\
\hline L231 & & & & RN \\
\hline HEMBL2316565 & & 4.5143 & & RN \\
\hline IEMBL173 & & 827 & 574 & RN \\
\hline HEMBL 231 & & 239 & 244 & ST \\
\hline HEMBL172 & & & & RN \\
\hline HEMBL2316544 & & 5.3979 & & RN \\
\hline HEMBL1474103 & 29 & 2.699 & 8666 & RN \\
\hline 3L1 & & & 899 & \\
\hline HEMBL 231 & & 4.3947 & & \\
\hline CHEMBL 2316574 & 29 & 2.699 & 2.5077 & \\
\hline CHEMBL2316543 & 933429 & 5.301 & 5.001 & RN \\
\hline
\end{tabular}




\begin{tabular}{|c|c|c|c|c|}
\hline \multicolumn{5}{|c|}{ Supplemental Table S2.txt } \\
\hline CHEMBL1535354 & 933429 & 2.699 & 3.6579 & TST \\
\hline CHEMBL 2316560 & 933429 & 4.8962 & 5.135 & TRN \\
\hline CHEMBL2316548 & 933429 & 2.699 & 3.5188 & TRN \\
\hline CHEMBL 2316571 & 933429 & 2.699 & 3.3832 & TRN \\
\hline CHEMBL 2316538 & 933429 & 5.1308 & 4.0707 & TRN \\
\hline CHEMBL 2316570 & 933429 & 4.2596 & 3.5602 & TRN \\
\hline CHEMBL 2316550 & 933429 & 2.699 & 2.8801 & TRN \\
\hline CHEMBL2316575 & 933429 & 2.699 & 3.9742 & TST \\
\hline CHEMBL 2316572 & 933429 & 2.699 & 3.8947 & TST \\
\hline CHEMBL 2316562 & 933429 & 4.8508 & 3.6851 & TST \\
\hline CHEMBL 2316552 & 933429 & 2.699 & 3.2375 & TST \\
\hline CHEMBL 2316557 & 933429 & 2.699 & 4.0236 & TST \\
\hline CHEMBL2316540 & 933429 & 5.7447 & 4.8706 & TST \\
\hline CHEMBL1504501 & 933429 & 2.699 & 3.4034 & TST \\
\hline CHEMBL1563710 & 933429 & 5.3768 & 4.2266 & TST \\
\hline CHEMBL3908626 & 1641000 & 8.699 & 8.3318 & TRN \\
\hline CHEMBL3966854 & 1641000 & 8.699 & 8.0701 & TST \\
\hline CHEMBL3906481 & 1641000 & 10.0 & 10.1896 & TST \\
\hline CHEMBL3948640 & 1641000 & 10.0 & 9.9742 & TST \\
\hline CHEMBL3940654 & 1641000 & 10.0 & 9.9208 & TST \\
\hline CHEMBL3899654 & 1641000 & 8.699 & 8.2079 & TRN \\
\hline CHEMBL3955742 & 1641000 & 9.0 & 8.519 & TRN \\
\hline CHEMBL3889819 & 1641000 & 6.9208 & 7.3024 & TRN \\
\hline CHEMBL3911901 & 1641000 & 10.0 & 9.7833 & TRN \\
\hline CHEMBL3927674 & 1641000 & 7.7447 & 7.4553 & TRN \\
\hline CHEMBL3984443 & 1641000 & 10.0 & 9.9159 & TST \\
\hline CHEMBL3978977 & 1641000 & 7.9586 & 7.6804 & TRN \\
\hline CHEMBL3935393 & 1641000 & 8.699 & 8.6174 & TRN \\
\hline CHEMBL3949172 & 1641000 & 9.0 & 9.1714 & TRN \\
\hline CHEMBL3966675 & 1641000 & 10.0 & 9.1343 & TST \\
\hline CHEMBL3974089 & 1641000 & 5.9586 & 7.8625 & TRN \\
\hline CHEMBL3984690 & 1641000 & 7.1135 & 7.5845 & TRN \\
\hline CHEMBL3983346 & 1641000 & 10.0 & 10.1308 & TRN \\
\hline CHEMBL3912006 & 1641000 & 8.301 & 8.7858 & TRN \\
\hline CHEMBL3928116 & 1641000 & 10.0 & 9.0925 & TST \\
\hline CHEMBL3900093 & 1641000 & 6.7447 & 7.756 & TRN \\
\hline CHEMBL 3905248 & 1641000 & 8.3979 & 8.3855 & TRN \\
\hline CHEMBL3900693 & 1641000 & 8.1549 & 8.4409 & TRN \\
\hline CHEMBL3950416 & 1641000 & 8.8239 & 9.1272 & TRN \\
\hline CHEMBL3964023 & 1641000 & 8.2218 & 7.6674 & TRN \\
\hline CHEMBL3952424 & 1641000 & 7.2441 & 8.8226 & TST \\
\hline CHEMBL3965838 & 1641000 & 9.0 & 8.6491 & TRN \\
\hline CHEMBL3913589 & 1641000 & 8.3979 & 8.4073 & TRN \\
\hline CHEMBL3942108 & 1641000 & 10.0 & 10.2348 & TRN \\
\hline CHEMBL3943494 & 1641000 & 10.0 & 9.5613 & TST \\
\hline CHEMBL3891022 & 1641000 & 10.0 & 9.2497 & TRN \\
\hline CHEMBL3962852 & 1641000 & 10.0 & 10.0811 & TRN \\
\hline CHEMBL3931291 & 1641000 & 10.0 & 9.5948 & TST \\
\hline
\end{tabular}




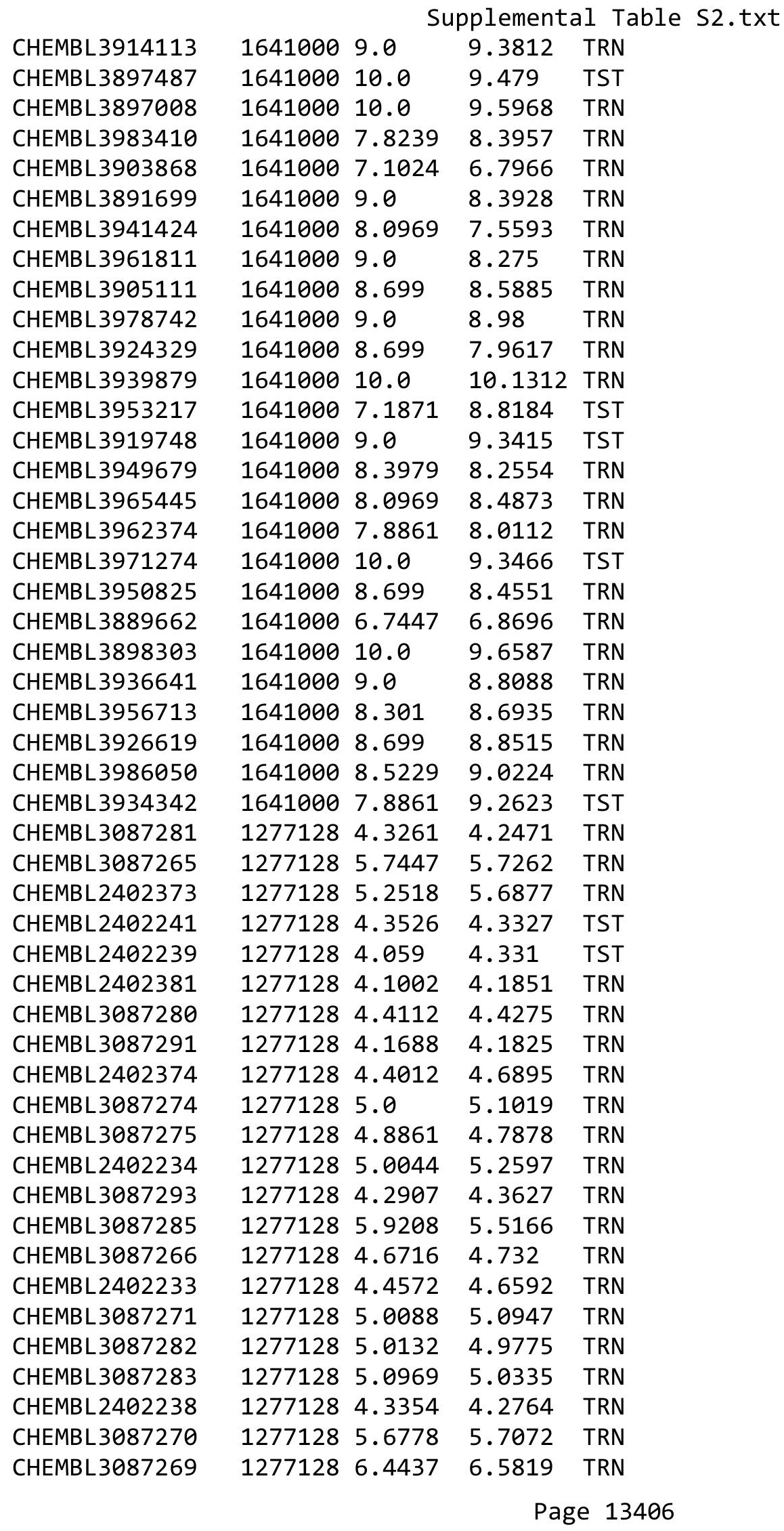


Supplemental Table S2.txt

\begin{tabular}{|c|c|c|c|c|}
\hline & 128 & & & \\
\hline 2371 & 277128 & 6.6198 & 6.0586 & \\
\hline 2367 & 77128 & & & \\
\hline 37 & 277128 & 467 & & \\
\hline 87286 & 277128 & 3861 & 726 & \\
\hline IEMBL 3087267 & 277128 & 208 & 501 & \\
\hline 380 & 277128 & 562 & 247 & \\
\hline 76 & 28 & 522 & & \\
\hline IEMBL 2 & 277128 & 007 & 383 & \\
\hline IEMBL 3087294 & 277128 & 886 & 046 & \\
\hline IEMBL 2402240 & 277128 & 591 & 544 & \\
\hline 7292 & 128 & 557 & $\partial 78$ & \\
\hline 84 & 28 & & & \\
\hline 7295 & 128 & 459 & & \\
\hline 3L3087268 & 1277128 & 147 & 301 & \\
\hline 231 & 28 & & 282 & \\
\hline 377 & 128 & 78 & 399 & \\
\hline 32 & 128 & & 03 & \\
\hline 2369 & 127 & 576 & 131 & \\
\hline 242 & 28 & 319 & 18 & \\
\hline 279 & 28 & 14 & & \\
\hline 35 & 28 & 44 & 86 & \\
\hline 88 & 128 & 47 & & \\
\hline 2368 & 128 & 788 & 17 & \\
\hline 375 & & 97 & & \\
\hline 90 & 127 & & 55 & \\
\hline 96 & 28 & & 68 & \\
\hline 72 & 28 & 96 & & \\
\hline & 28 & & & \\
\hline & & & & \\
\hline & 127 & & 57 & \\
\hline & 28 & & 55 & \\
\hline & 28 & & & \\
\hline & 127 & & & \\
\hline & 28 & & & \\
\hline & 127 & 76 & 84 & \\
\hline & 127 & 61 & 61 & \\
\hline & 127 & & & \\
\hline & 163 & 68 & 889 & \\
\hline & 946 & 49 & 65 & \\
\hline & 163 & 41 & 46 & \\
\hline & & & & \\
\hline & 946 & 6 & 241 & 3 \\
\hline 8825 & 1639946 & 6.1694 & 762 & $R$ \\
\hline & 163 & 58 & 996 & \\
\hline & 163 & 94 & 254 & \\
\hline & 163 & & 4.9261 & \\
\hline HEMBL3931123 & 1639946 & 4.6564 & 5.6695 & \\
\hline
\end{tabular}

Page 13407 
Supplemental Table S2.txt

\begin{tabular}{|c|c|c|c|c|}
\hline . & 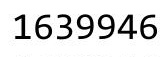 & 936 & & \\
\hline HEMBL3926054 & 639946 & 5.9863 & 6.1434 & \\
\hline HEMBL3979290 & 639946 & 5.7528 & 5.8457 & \\
\hline AEMBL3933103 & & 3.6826 & 0585 & \\
\hline IEMBL583050 & 639946 & 6.5243 & 5531 & \\
\hline HEMBL3926473 & 639946 & 5.5322 & .3094 & \\
\hline HEMBL3970316 & 639946 & 6.3439 & 5.4957 & \\
\hline HEMBL3929144 & 639946 & 5.7817 & .9855 & \\
\hline AEMBL3921998 & L639946 & 6.3737 & .2506 & \\
\hline HEMBL568569 & L639946 & 6.3307 & 3911 & \\
\hline HEMBL570168 & 639946 & 5.6728 & 5.7759 & \\
\hline HEMBL3977301 & 639946 & 5.4145 & 4.6927 & \\
\hline HEMBL3972044 & 639946 & 6.3872 & .5343 & \\
\hline HEMBL3920896 & 639946 & 6.0429 & .0965 & \\
\hline HEMBL 576864 & 163 & 5.4381 & .4273 & \\
\hline HEMBL3901294 & L639946 & 6.0273 & 5.9961 & \\
\hline HEMBL3979861 & 639946 & 6.2373 & 6.2494 & \\
\hline HEMBL3979918 & 639 & 5.8837 & .7728 & \\
\hline HEMBL 39 & 6 & 94 & .8184 & \\
\hline HEMBL3933873 & 163 & 5 . & 5.9427 & \\
\hline HEMBL3934717 & 1639 & 7. & 6.6377 & \\
\hline HEMBL566677 & 639 & 6. & 6.6186 & \\
\hline HEMBL3981410 & 1639 & 6.4737 & 6.53 & \\
\hline HEMBL39 & 16 & & 6.2866 & \\
\hline HEMBL56 & 163 & 6. & 6.2877 & \\
\hline HEMBL3941185 & 163 & 6 . & 3294 & \\
\hline HEMBL566888 & 1639 & 6.4841 & 6.5876 & \\
\hline HEMBL3896500 & 163 & 914 & 5.5605 & \\
\hline HEMBL3 & 6 & 6. & 49 & \\
\hline HEMBL 39 & 163 & 5 . & 5.8819 & \\
\hline HEMBL568823 & 63 & 3. & 4.3537 & \\
\hline HEMBL3972976 & 1639946 & 5.7091 & 5.6315 & \\
\hline HEMBL3941578 & 1639 & 4. & 4.5299 & \\
\hline HEMBL3 & 6 & 6. & 153 & \\
\hline HEMBL3889966 & 163 & & 5.7382 & \\
\hline HEMBL 3891176 & 1639946 & 6 . & 6.4255 & \\
\hline HEMBL3963724 & 1639946 & 6.7423 & 6.6942 & \\
\hline HEMBL3927395 & 1639 & 5 . & 5 . & \\
\hline HEMBL 39 & & 4. & 169 & \\
\hline CHEMBL3959525 & 1639 & 6.7144 & 6.7139 & \\
\hline CHEMBL3983378 & 1639946 & 6.3089 & 6.1535 & \\
\hline CHEMBL566461 & 1639 & 6.1068 & 6.2457 & \\
\hline CHEMBL3897769 & 1639946 & 6.5935 & 6.6313 & \\
\hline CHEMBL3911927 & 1639 & & 5.9362 & \\
\hline CHEMBL577072 & 1639 & 5.3737 & 5.6202 & \\
\hline CHEMBL3928449 & 1639946 & 6.0168 & 6.0032 & \\
\hline CHEMBL 39 & 1639 & 6.0501 & 6.0967 & \\
\hline SHEMBL 201859 & 1639946 & & & \\
\hline
\end{tabular}

Page 13408 
Supplemental Table S2.txt

\begin{tabular}{|c|c|c|c|c|c|c|}
\hline CHEMBL 3911257 & 1639946 & 5.3777 & 5.5143 & TRN & & \\
\hline CHEMBL583471 & 1639946 & 5.83 & 5.9011 & TRN & & \\
\hline CHEMBL3897759 & 1639946 & 6.9747 & 6.78299 & 9999999999 & 95 & TRN \\
\hline CHEMBL3931398 & 1639946 & 6.5143 & 6.4418 & TRN & & \\
\hline CHEMBL 3968876 & 1639946 & 5.65600 & 0000000 & $\partial 1$ & 5.8211 & TST \\
\hline CHEMBL3919633 & 1639946 & 3.6488 & 4.4741 & TRN & & \\
\hline CHEMBL 3942828 & 1639946 & 5.8286 & 5.6223 & TRN & & \\
\hline CHEMBL 3938256 & 1639946 & 5.7359 & 6.0788 & TST & & \\
\hline CHEMBL569002 & 1639946 & 6.1972 & 5.9427 & TRN & & \\
\hline CHEMBL 3947971 & 1639946 & 6.0996 & 6.0947 & TST & & \\
\hline CHEMBL3929301 & 1639946 & 5.9694 & 5.6931 & TRN & & \\
\hline CHEMBL 3942535 & 1639946 & 6.5017 & 6.3353 & TRN & & \\
\hline CHEMBL565622 & 1639946 & 3.6978 & 4.6191 & TRN & & \\
\hline CHEMBL566887 & 1639946 & 5.9439 & 6.0241 & TRN & & \\
\hline CHEMBL569231 & 1639946 & 6.475 & 6.3184 & TRN & & \\
\hline CHEMBL3955599 & 1639946 & 6.0937 & 6.2141 & TRN & & \\
\hline CHEMBL3907900 & 1639946 & 6.1555 & 6.1939 & TRN & & \\
\hline CHEMBL569533 & 1639946 & 6.2668 & 6.0433 & TST & & \\
\hline CHEMBL 3893297 & 1639946 & 6.3716 & 6.1267 & TST & & \\
\hline CHEMBL 3903820 & 1639946 & 6.341 & 6.3406 & TRN & & \\
\hline CHEMBL 3938552 & 1639946 & 5.8847 & 5.82299 & 9999999999 & 95 & TRN \\
\hline CHEMBL3949019 & 1639946 & 6.0625 & 6.1989 & TRN & & \\
\hline CHEMBL3972069 & 1639946 & 6.2757 & 6.1585 & TRN & & \\
\hline CHEMBL570194 & 1639946 & 6.0 & 6.148 & TRN & & \\
\hline CHEMBL 3911971 & 1639946 & 4.2206 & 4.698 & TST & & \\
\hline CHEMBL583242 & 1639946 & 6.38399 & 99999999 & 995 & 6.3311 & TRN \\
\hline CHEMBL3964185 & 1639946 & 3.6665 & 4.3686 & TST & & \\
\hline CHEMBL3897819 & 1639946 & 6.4214 & 6.3393 & TRN & & \\
\hline CHEMBL 3893819 & 1639946 & 6.1244 & 5.9928 & TRN & & \\
\hline CHEMBL 3962869 & 1639946 & 5.277 & 4.6582 & TRN & & \\
\hline CHEMBL567285 & 1639946 & 6.6676 & 6.4736 & TRN & & \\
\hline CHEMBL 3896455 & 1639946 & 6.0039 & 5.8954 & TST & & \\
\hline CHEMBL3911521 & 1639946 & 5.4957 & 5.8578 & TST & & \\
\hline CHEMBL 3971423 & 1639946 & 6.0 & 6.1805 & TST & & \\
\hline CHEMBL 3891070 & 1639946 & 5.8887 & 5.8837 & TRN & & \\
\hline CHEMBL 3954942 & 1639946 & 5.4577 & 4.6407 & TRN & & \\
\hline CHEMBL 3919477 & 1639946 & 5.9097 & 6.0201 & TRN & & \\
\hline CHEMBL3896117 & 1639946 & 6.5114 & 6.3643 & TRN & & \\
\hline CHEMBL 3979833 & 1639946 & 6.0343 & 6.1683 & TRN & & \\
\hline CHEMBL 3896092 & 1639946 & 5.6966 & 5.3094 & TRN & & \\
\hline CHEMBL568800 & 1639946 & 6.5361 & 6.4255 & TRN & & \\
\hline CHEMBL568853 & 1639946 & 6.2007 & 6.1011 & TRN & & \\
\hline CHEMBL3923367 & 1639946 & 5.9412 & 5.943 & TST & & \\
\hline CHEMBL 3962724 & 1639946 & 6.2604 & 6.2459 & TRN & & \\
\hline CHEMBL 3965888 & 1639946 & 5.5724 & 5.79 & TRN & & \\
\hline CHEMBL 3948345 & 1639946 & 5.265 & 5.2281 & TRN & & \\
\hline CHEMBL570418 & 1639946 & 5.5574 & 5.7262 & TRN & & \\
\hline CHEMBL3895093 & 1639946 & 6.1512 & 6.1668 & TRN & & \\
\hline
\end{tabular}


Supplemental Table S2.txt

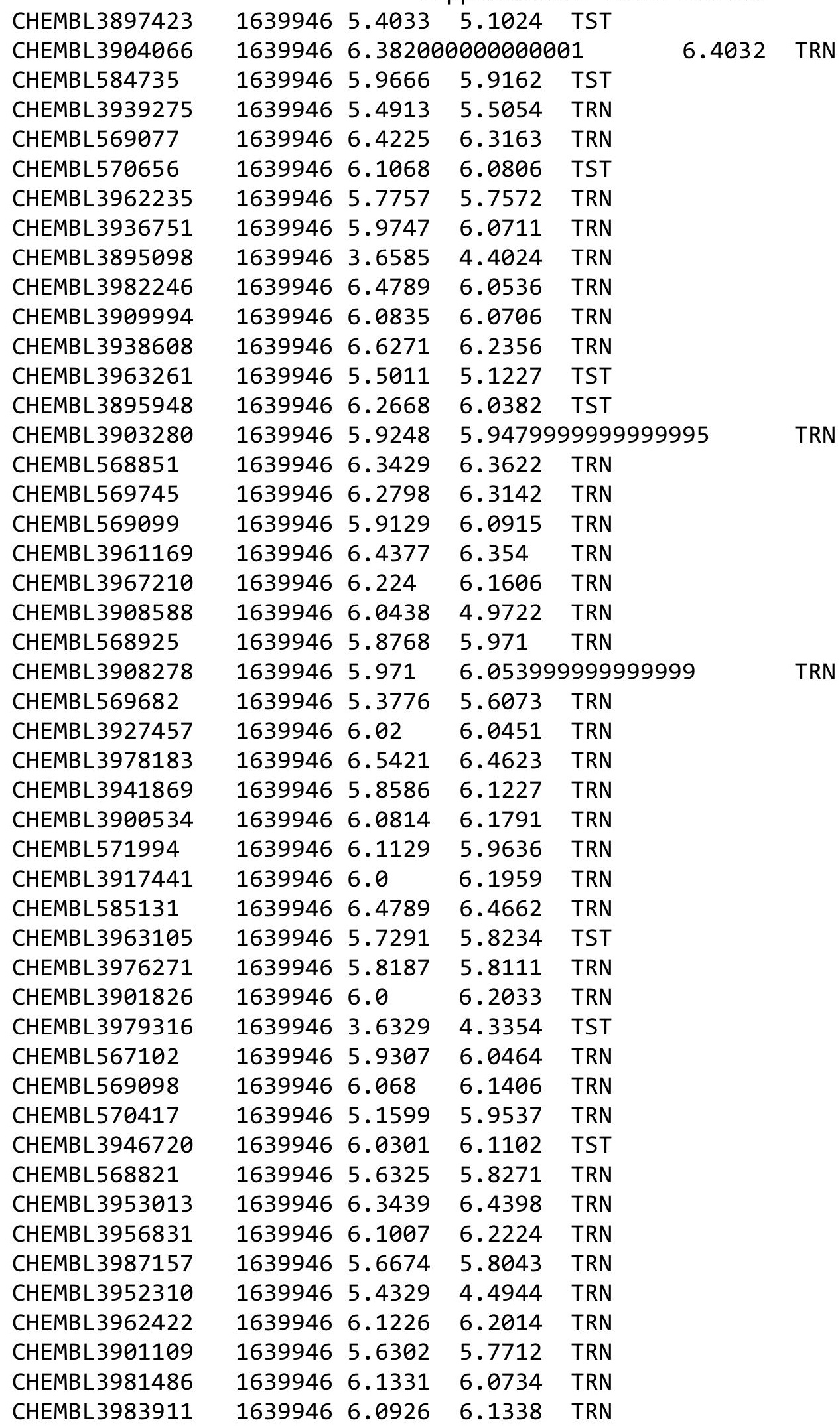

Page 13410 
Supplemental Table S2.txt

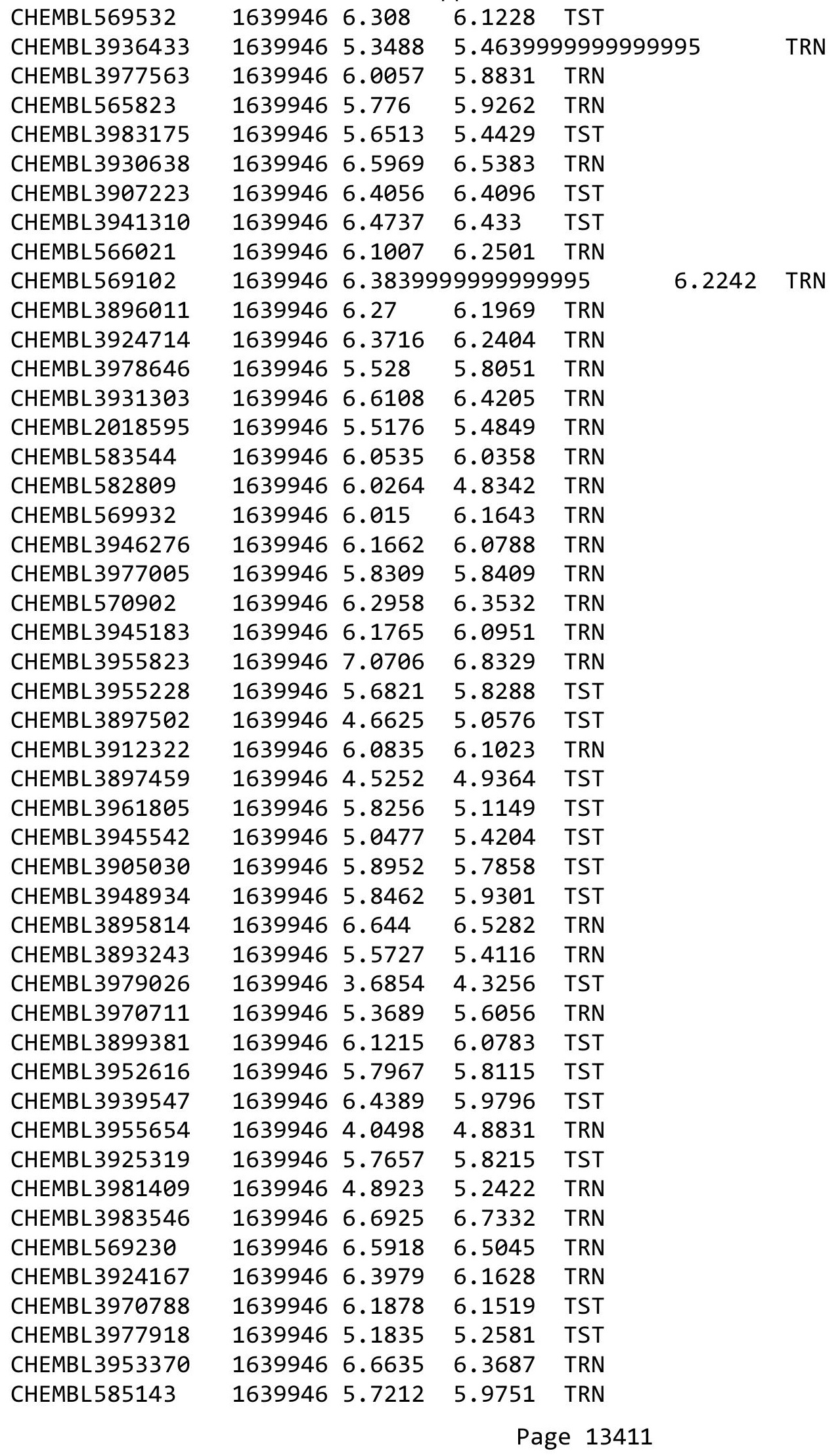


Supplemental Table S2.txt

\begin{tabular}{|c|c|c|c|c|}
\hline CHEMBL3948625 & 1639946 & 5.529 & 5.0439 & TST \\
\hline CHEMBL 3939761 & 1639946 & 4.8913 & 4.2527 & TRN \\
\hline CHEMBL570167 & 1639946 & 5.8807 & 5.9613 & TRN \\
\hline CHEMBL569004 & 1639946 & 6.5229 & 6.3812 & TST \\
\hline CHEMBL 3927222 & 1639946 & 6.4179 & 6.5517 & TST \\
\hline CHEMBL3983901 & 1639946 & 6.0899 & 6.2294 & TRN \\
\hline CHEMBL 3893387 & 1639946 & 5.4866 & 5.1956 & TST \\
\hline CHEMBL565549 & 1639946 & 6.0691 & 6.1677 & TRN \\
\hline CHEMBL3979392 & 1639946 & 5.7131 & \multicolumn{2}{|c|}{5.8229999999999995} \\
\hline CHEMBL569962 & 1639946 & 6.3862 & 6.3801 & TST \\
\hline CHEMBL3910026 & 1639946 & 5.8321 & 5.6677 & TST \\
\hline CHEMBL 3924750 & 1639946 & 6.0721 & 5.8958 & TRN \\
\hline CHEMBL3940932 & 1639946 & 4.084 & \multicolumn{2}{|c|}{4.4110000000000005} \\
\hline CHEMBL 3960762 & 1639946 & 6.1391 & 6.1175 & TRN \\
\hline CHEMBL585294 & 1639946 & 5.7135 & 5.9806 & TRN \\
\hline CHEMBL566462 & 1639946 & 6.5935 & 6.4682 & TRN \\
\hline CHEMBL3925812 & 1639946 & 5.5299 & 5.7093 & TST \\
\hline CHEMBL568799 & 1639946 & 6.9469 & 6.5219 & TRN \\
\hline CHEMBL577512 & 1639946 & 6.5686 & 6.5272 & TRN \\
\hline CHEMBL3925813 & 1639946 & 5.3648 & 5.6161 & TRN \\
\hline CHEMBL3979666 & 1639946 & 4.447 & 4.387 & TRN \\
\hline CHEMBL 3900218 & 1639946 & 5.8147 & 5.6895 & TRN \\
\hline CHEMBL 3986685 & 1639946 & 5.8339 & 5.9299 & TRN \\
\hline CHEMBL3970869 & 1639946 & 6.5346 & 6.4763 & TST \\
\hline CHEMBL3957422 & 1639946 & 5.945 & 5.8781 & TST \\
\hline CHEMBL569754 & 1639946 & 6.104 & 6.1264 & TST \\
\hline CHEMBL 3906144 & 1639946 & 6.3958 & 6.3073 & TRN \\
\hline CHEMBL 3922726 & 1639946 & 5.8983 & 5.79 & TRN \\
\hline CHEMBL3986596 & 1639946 & 6.4855 & 6.2302 & TRN \\
\hline CHEMBL3916233 & 1639946 & 5.8576 & 5.9226 & TST \\
\hline CHEMBL3935359 & 1639946 & 5.5743 & 5.7378 & TST \\
\hline CHEMBL 3904530 & 1639946 & 5.0168 & 6.1638 & TRN \\
\hline CHEMBL 3943536 & 1639946 & 5.7399 & 4.7289 & TRN \\
\hline CHEMBL 3936798 & 1639946 & 6.1778 & 6.0576 & TRN \\
\hline CHEMBL3966823 & 1639946 & 4.6008 & 4.7207 & TST \\
\hline CHEMBL3937480 & 1639946 & 5.3846 & 5.6074 & TRN \\
\hline CHEMBL3939175 & 1639946 & 6.7122 & 6.6957 & TRN \\
\hline CHEMBL 2018598 & 1639946 & 6.2306 & 6.0475 & TRN \\
\hline CHEMBL 3941067 & 1639946 & 5.5331 & 5.5075 & TST \\
\hline CHEMBL 3968980 & 1639946 & 6.15 & 6.058 & TRN \\
\hline CHEMBL 3897766 & 1639946 & 6.308 & 6.2211 & TRN \\
\hline CHEMBL3985655 & 1639946 & 6.2314 & 6.0085 & TST \\
\hline CHEMBL3981008 & 1639946 & 5.4339 & 5.9255 & TST \\
\hline CHEMBL 3940417 & 1639946 & 6.9281 & 6.6288 & TRN \\
\hline CHEMBL566676 & 1639946 & 6.0921 & 6.2169 & TRN \\
\hline CHEMBL 3923694 & 1639946 & 5.8489 & 5.994 & TRN \\
\hline CHEMBL565824 & 1639946 & 6.6716 & 6.4712 & TRN \\
\hline CHEMBL 3892602 & 1639946 & 6.3675 & 6.2536 & TRN \\
\hline
\end{tabular}

Page 13412 
Supplemental Table S2.txt

\begin{tabular}{|c|c|c|c|c|c|}
\hline CHEMBL3948185 & 1639946 & 5.9241 & 5.9162 & TRN & \\
\hline CHEMBL3958263 & 1639946 & 6.6925 & 6.7213 & TRN & \\
\hline CHEMBL3894633 & 1639946 & 6.1871 & 6.1464 & TST & \\
\hline CHEMBL568852 & 1639946 & 6.4921 & 6.3076 & TST & \\
\hline CHEMBL571284 & 1639946 & 5.8401 & 5.8598 & TRN & \\
\hline CHEMBL3980303 & 1639946 & 5.3652 & 5.2807 & TST & \\
\hline CHEMBL3960193 & 1641737 & 8.699 & 8.7384 & TRN & \\
\hline CHEMBL3931863 & 1641737 & 8.3979 & 8.63 & TRN & \\
\hline CHEMBL3965690 & 1641737 & 6.3261 & 7.716 & TRN & \\
\hline CHEMBL3941591 & 1641737 & 8.5229 & 8.1784 & TST & \\
\hline CHEMBL3927152 & 1641737 & 7.8539 & 7.8118 & TRN & \\
\hline CHEMBL3959731 & 1641737 & 8.699 & 8.6047 & TST & \\
\hline CHEMBL3928685 & 1641737 & 8.3979 & 7.8612 & TRN & \\
\hline CHEMBL3969576 & 1641737 & 8.301 & 7.8213 & TRN & \\
\hline CHEMBL3914429 & 1641737 & 8.2218 & 8.1693 & TRN & \\
\hline CHEMBL3939833 & 1641737 & 8.5229 & 8.532 & TRN & \\
\hline CHEMBL3959711 & 1641737 & 8.0 & 7.8387 & TRN & \\
\hline CHEMBL3938200 & 1641737 & 8.5229 & 8.7845 & TRN & \\
\hline CHEMBL3915212 & 1641737 & 8.5229 & 8.6243 & TRN & \\
\hline CHEMBL3960490 & 1641737 & 8.699 & 8.2996 & TRN & \\
\hline CHEMBL3971087 & 1641737 & 7.6383 & 8.7205 & TST & \\
\hline CHEMBL3940014 & 1641737 & 8.699 & 8.7611 & TRN & \\
\hline CHEMBL3965977 & 1641737 & 6.8416 & 7.7647 & TRN & \\
\hline CHEMBL3891051 & 1641737 & 9.0 & 8.6723 & TRN & \\
\hline CHEMBL3940854 & 1641737 & 7.5528 & 8.31200 & 0000000001 & TRN \\
\hline CHEMBL3900025 & 1641737 & 8.5229 & 8.3152 & TRN & \\
\hline CHEMBL3947731 & 1641737 & 8.3979 & 7.8507 & TRN & \\
\hline CHEMBL3913367 & 1641737 & 8.5229 & 8.5853 & TST & \\
\hline CHEMBL3935724 & 1641737 & 8.699 & 8.4252 & TRN & \\
\hline CHEMBL3917986 & 1641737 & 7.7696 & 8.4665 & TRN & \\
\hline CHEMBL3950107 & 1641737 & 8.0458 & 8.5177 & TRN & \\
\hline CHEMBL3969515 & 1641737 & 8.699 & 8.5332 & TRN & \\
\hline CHEMBL3960118 & 1641737 & 8.2218 & 8.3154 & TRN & \\
\hline CHEMBL3950999 & 1641737 & 8.3979 & 7.8206 & TRN & \\
\hline CHEMBL3966393 & 1641737 & 8.5229 & 8.5507 & TRN & \\
\hline CHEMBL3952050 & 1641737 & 8.699 & 8.3769 & TRN & \\
\hline CHEMBL3936321 & 1641737 & 8.699 & 8.5932 & TRN & \\
\hline CHEMBL3962522 & 1641737 & 8.2218 & 8.2399 & TRN & \\
\hline CHEMBL3963197 & 1641737 & 8.301 & 8.2971 & TRN & \\
\hline CHEMBL3979350 & 1641737 & 8.3979 & 8.2172 & TRN & \\
\hline CHEMBL3976277 & 1641737 & 8.2218 & 8.3017 & TRN & \\
\hline CHEMBL3897699 & 1641737 & 7.3468 & 8.7735 & TST & \\
\hline CHEMBL3941483 & 1641737 & 8.301 & 8.3713 & TRN & \\
\hline CHEMBL3905563 & 1641737 & 8.301 & 8.5127 & TRN & \\
\hline CHEMBL3960692 & 1641737 & 7.699 & 8.2426 & TRN & \\
\hline CHEMBL3971255 & 1641737 & 8.699 & 8.6101 & TRN & \\
\hline CHEMBL3946697 & 1641737 & 8.1549 & 8.2682 & TRN & \\
\hline CHEMBL3893520 & 1641737 & 8.699 & 8.2501 & TRN & \\
\hline
\end{tabular}


Supplemental Table S2.txt

\begin{tabular}{|c|c|c|c|c|}
\hline S & 641737 & & 8.2588 & \\
\hline & 641737 & 8.5229 & & \\
\hline HEMRI & 737 & & & \\
\hline HEMBL & 37 & 79 & & \\
\hline AEMBL3977950 & 641737 & & 7753 & \\
\hline HEMBL3956584 & 737 & 8. & 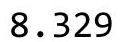 & \\
\hline HEMBL39 & 737 & 9.0 & & \\
\hline HEMBL396 & & 8.52 & & \\
\hline HEMBL3919944 & 737 & 6.9666 & 49 & \\
\hline HEMBL3966077 & 737 & 8.5229 & & \\
\hline HEMBL 389 & 37 & 9.0 & & \\
\hline AEMBL3S & 37 & 979 & & \\
\hline AEMBL3 & & & & \\
\hline HEMBL 398 & 737 & 8.5229 & & \\
\hline HEMBL395 & 737 & & & TST \\
\hline HEMBL3S & 6 & 8. & 94 & RIV \\
\hline HEMBL3 & & 9. & & RN \\
\hline HEMBL3 & & & 35 & $\mathrm{RN}$ \\
\hline HEMBL3 & 37 & 8. & & 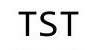 \\
\hline HEMBL390 & & 9 . & & 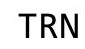 \\
\hline HEMBL & 6 & & & SI \\
\hline HEM & & & & ST \\
\hline HEMBL & 37 & & & RN \\
\hline HEMBL3 & & & & ГST \\
\hline HEMBL389 & & & & ISI \\
\hline HEMBL3 & & & & 「RN \\
\hline HEME & 37 & & & ST \\
\hline 9 & & & & IST \\
\hline AEMBL3 & & & & $\mid$ \\
\hline HEMBL390 & & & 19 & TRN \\
\hline AEMBL: & & & 77 & 「RN \\
\hline HFM & & & & ST \\
\hline - & & & & TST \\
\hline HEMBL 397 & & & & 「RN \\
\hline HEMBL3979951 & 37 & 6. & 16 & RN \\
\hline 3 & & & & TRN \\
\hline 5 & & & & ГRN \\
\hline HEMBL 398 & & & & TST \\
\hline HEMBL 393 & & 7.522 & & TRN \\
\hline AEMBL3 & & 9 & & ГRN \\
\hline HEMRI 3 & & & & 「RN \\
\hline HEMBL3 & & 7. & & 「RN \\
\hline HEMBL3893854 & & 8.1549 & 5785 & TST \\
\hline HEMBL 394 & 37 & 8 . & & TST \\
\hline 0 & & & & \\
\hline HEMBL391 & & 8.522 & & \\
\hline CHEMBL 394 & 737 & 8.699 & 531 & \\
\hline CHEMBL3982743 & 1641737 & 8.1549 & 8.6193 & TST \\
\hline
\end{tabular}

Page 13414 
Supplemental Table S2.txt

\begin{tabular}{|c|c|c|c|c|}
\hline CHEMBL3945345 & 1641737 & 8.301 & 8.637 & TST \\
\hline CHEMBL3964886 & 1641737 & 8.699 & 8.081 & TRN \\
\hline CHEMBL3967658 & 1641737 & 8.301 & 7.7329 & TRN \\
\hline CHEMBL3961626 & 1641737 & 9.0 & 8.6565 & TST \\
\hline CHEMBL3967693 & 1641737 & 8.5229 & 8.6242 & TRN \\
\hline CHEMBL3936850 & 1641737 & 8.3979 & 8.6675 & TST \\
\hline CHEMBL3962312 & 1641737 & 8.5229 & 8.6655 & TRN \\
\hline CHEMBL3897070 & 1641737 & 8.699 & 8.5043 & TRN \\
\hline CHEMBL3908898 & 1641737 & 8.301 & 8.6839 & TST \\
\hline CHEMBL3968964 & 1641737 & 9.0 & 8.7737 & TRN \\
\hline CHEMBL3915292 & 1641737 & 8.5229 & 8.0125 & TRN \\
\hline CHEMBL3934743 & 1641737 & 8.3979 & 8.6331 & TRN \\
\hline CHEMBL3914139 & 1641737 & 7.1871 & 8.4968 & TRN \\
\hline CHEMBL1493736 & 752462 & 3.0341 & 3.1155 & TRN \\
\hline CHEMBL1458515 & 752462 & 3.034 & 3.5259 & TRN \\
\hline CHEMBL1531172 & 752462 & 3.0341 & 2.8765 & TRN \\
\hline CHEMBL1460676 & 752462 & 3.0339 & 3.1803 & TRN \\
\hline CHEMBL1348719 & 752462 & 3.034 & 2.9961 & TRN \\
\hline CHEMBL1613445 & 752462 & 3.034 & 3.2355 & TRN \\
\hline CHEMBL1353993 & 752462 & 5.3875 & 3.5719 & TRN \\
\hline CHEMBL300117 & 752462 & 4.0633 & 3.3414 & TRN \\
\hline CHEMBL1307063 & 752462 & 4.7492 & 4.6888 & TRN \\
\hline CHEMBL1730502 & 752462 & 3.0341 & 2.6257 & TST \\
\hline CHEMBL1722570 & 752462 & 3.034 & 4.2147 & TRN \\
\hline CHEMBL1430335 & 752462 & 3.034 & 3.682 & TRN \\
\hline CHEMBL1412340 & 752462 & 3.0346 & 3.6394 & TST \\
\hline CHEMBL1356740 & 752462 & 4.4867 & 3.802 & TRN \\
\hline CHEMBL1709988 & 752462 & 4.5695 & 4.5098 & TRN \\
\hline CHEMBL1334918 & 752462 & 4.1967 & 3.3481 & TRN \\
\hline CHEMBL1473706 & 752462 & 3.034 & 3.2209 & TRN \\
\hline CHEMBL 3191251 & 752462 & 3.034 & 3.113 & TST \\
\hline CHEMBL1732043 & 752462 & 3.034 & 3.6358 & TRN \\
\hline CHEMBL1700880 & 752462 & 3.0345 & 3.1971 & TRN \\
\hline CHEMBL1307021 & 752462 & 5.519 & 3.7672 & TST \\
\hline CHEMBL1583291 & 752462 & 4.2903 & 3.4999 & TRN \\
\hline CHEMBL1363204 & 752462 & 3.034 & 3.0406 & TRN \\
\hline CHEMBL 2005743 & 752462 & 4.5307 & 3.46100 & 00000000003 \\
\hline CHEMBL1734772 & 752462 & 3.0344 & 3.5576 & TST \\
\hline CHEMBL1458967 & 752462 & 3.034 & 2.7739 & TRN \\
\hline CHEMBL1437810 & 752462 & 3.034 & 3.4367 & TRN \\
\hline CHEMBL1463894 & 752462 & 4.4279 & 3.9359 & TRN \\
\hline CHEMBL1599024 & 752462 & 3.034 & 3.0982 & TRN \\
\hline CHEMBL1468190 & 752462 & 3.0341 & 2.8272 & TRN \\
\hline CHEMBL1708311 & 752462 & 3.034 & 3.1473 & TRN \\
\hline CHEMBL1699902 & 752462 & 3.0341 & 3.5621 & TRN \\
\hline CHEMBL1256750 & 752462 & 4.765 & 3.3748 & TRN \\
\hline CHEMBL1898602 & 752462 & 3.0345 & 3.2634 & TRN \\
\hline CHEMBL1710136 & 752462 & 3.0342 & 2.8327 & TST \\
\hline
\end{tabular}

Page 13415 


\begin{tabular}{|c|c|c|c|c|c|}
\hline & & \multicolumn{4}{|c|}{ Supplemental Table S2.txt } \\
\hline CHEMBL1379878 & 752462 & 3.034 & 3.0393 & TRN & \\
\hline CHEMBL1902708 & 752462 & 3.0343 & 3.3317 & TRN & \\
\hline CHEMBL3189940 & 752462 & 3.0341 & 3.8632 & TRN & \\
\hline CHEMBL1563176 & 752462 & 3.034 & 3.5101 & TRN & \\
\hline CHEMBL1419563 & 752462 & 3.034 & 2.9109 & TRN & \\
\hline CHEMBL1509052 & 752462 & 4.9345 & 3.8773 & TRN & \\
\hline CHEMBL1550403 & 752462 & 3.0338 & 2.9551 & TRN & \\
\hline CHEMBL1512925 & 752462 & 3.034 & 2.9854 & TRN & \\
\hline CHEMBL3208729 & 752462 & 3.0341 & 3.1135 & TRN & \\
\hline CHEMBL1440235 & 752462 & 3.9883 & 3.8748 & TRN & \\
\hline CHEMBL1332208 & 752462 & 7.7617 & 5.231 & TRN & \\
\hline CHEMBL1607240 & 752462 & 3.0339 & 3.6428 & TRN & \\
\hline CHEMBL1416425 & 752462 & 4.9403 & 4.7904 & TRN & \\
\hline CHEMBL 1700227 & 752462 & 4.4424 & 4.0562 & TRN & \\
\hline CHEMBL1423927 & 752462 & 3.0339 & 3.03899 & 99999999997 & TRN \\
\hline CHEMBL1548948 & 752462 & 3.0341 & 4.2282 & TRN & \\
\hline CHEMBL570399 & 752462 & 3.034 & 3.8441 & TST & \\
\hline CHEMBL1600506 & 752462 & 3.034 & 2.8937 & TST & \\
\hline CHEMBL1604493 & 752462 & 6.2588 & 4.1509 & TRN & \\
\hline CHEMBL1345157 & 752462 & 3.034 & 3.1069 & TRN & \\
\hline CHEMBL1569933 & 752462 & 3.034 & 3.3277 & TRN & \\
\hline CHEMBL1445858 & 752462 & 4.1259 & 3.4406 & TST & \\
\hline CHEMBL1609119 & 752462 & 3.0339 & 3.661 & TRN & \\
\hline CHEMBL1440652 & 752462 & 3.034 & 3.1459 & TRN & \\
\hline CHEMBL1698841 & 752462 & 4.6892 & 4.8599 & TRN & \\
\hline CHEMBL1898779 & 752462 & 3.9884 & 3.6366 & TST & \\
\hline CHEMBL1364960 & 752462 & 3.0341 & 3.2512 & TRN & \\
\hline CHEMBL1582232 & 752462 & 3.0341 & 3.4174 & TRN & \\
\hline CHEMBL1198307 & 752462 & 3.034 & 3.3404 & TRN & \\
\hline CHEMBL1361813 & 752462 & 3.034 & 3.5558 & TRN & \\
\hline CHEMBL1506767 & 752462 & 3.0341 & 3.4158 & TRN & \\
\hline CHEMBL1600293 & 752462 & 3.034 & 2.7465 & TRN & \\
\hline CHEMBL1387977 & 752462 & 3.034 & 2.9879 & TST & \\
\hline CHEMBL1720300 & 752462 & 3.0339 & 3.0231 & TRN & \\
\hline CHEMBL1722730 & 752462 & 3.0344 & 3.5275 & TRN & \\
\hline CHEMBL517986 & 752462 & 4.1933 & 3.2038 & TST & \\
\hline CHEMBL1423609 & 752462 & 3.034 & 3.1221 & TRN & \\
\hline CHEMBL1893806 & 752462 & 4.9316 & 3.5736 & TRN & \\
\hline CHEMBL1713682 & 752462 & 3.0339 & 3.9635 & TRN & \\
\hline CHEMBL1165197 & 752462 & 3.034 & 2.6355 & TRN & \\
\hline CHEMBL1731939 & 752462 & 4.9234 & 3.1704 & TST & \\
\hline CHEMBL1513567 & 752462 & 4.2458 & 3.5348 & TRN & \\
\hline CHEMBL1427690 & 752462 & 3.034 & 3.3852 & TRN & \\
\hline CHEMBL1545927 & 752462 & 3.0339 & 2.6547 & TRN & \\
\hline CHEMBL1332532 & 752462 & 5.4935 & 3.5624 & TRN & \\
\hline CHEMBL1610756 & 752462 & 3.034 & 3.4632 & TST & \\
\hline CHEMBL1719184 & 752462 & 3.034 & 4.5838 & TRN & \\
\hline CHEMBL1398707 & 752462 & 3.034 & 3.7953 & TRN & \\
\hline
\end{tabular}




\begin{tabular}{|c|c|c|c|c|c|}
\hline & & \multicolumn{4}{|c|}{ Supplemental Table S2.txt } \\
\hline CHEMBL1728200 & 752462 & 3.034 & 3.4733 & TST & \\
\hline CHEMBL1429212 & 752462 & 3.0341 & 3.5195 & TRN & \\
\hline CHEMBL1380599 & 752462 & 4.301 & 4.177 & TRN & \\
\hline CHEMBL1704769 & 752462 & 3.0339 & 3.0359 & TRN & \\
\hline CHEMBL1548987 & 752462 & 3.034 & 3.0772 & TST & \\
\hline CHEMBL1385823 & 752462 & 3.034 & 3.2294 & TRN & \\
\hline CHEMBL1387006 & 752462 & 3.0339 & 3.2042 & TRN & \\
\hline CHEMBL1721095 & 752462 & 3.0343 & 3.1734 & TST & \\
\hline CHEMBL1500489 & 752462 & 3.0337 & 3.1699 & TST & \\
\hline CHEMBL1722360 & 752462 & 3.034 & 3.0299 & TRN & \\
\hline CHEMBL1533638 & 752462 & 3.034 & 3.1774 & TRN & \\
\hline CHEMBL1488501 & 752462 & 3.0341 & 3.1353 & TRN & \\
\hline CHEMBL1700847 & 752462 & 4.5703 & 4.6012 & TRN & \\
\hline CHEMBL1378959 & 752462 & 3.0341 & 3.2338 & TRN & \\
\hline CHEMBL1581674 & 752462 & 3.0339 & 3.5504 & TRN & \\
\hline CHEMBL1567143 & 752462 & 4.1519 & 4.2323 & TRN & \\
\hline CHEMBL 2001739 & 752462 & 3.0341 & 3.8974 & TST & \\
\hline CHEMBL1607286 & 752462 & 3.0339 & 2.3913 & TRN & \\
\hline CHEMBL1872339 & 752462 & 3.0337 & 3.6641 & TRN & \\
\hline CHEMBL1705302 & 752462 & 3.0339 & 3.59800 & 00000000003 & TRN \\
\hline CHEMBL1365563 & 752462 & 3.034 & 3.2273 & TRN & \\
\hline CHEMBL 1727246 & 752462 & 5.0091 & 4.2019 & TRN & \\
\hline CHEMBL1713166 & 752462 & 3.034 & 3.8983 & TRN & \\
\hline CHEMBL1306479 & 752462 & 4.1695 & 3.3462 & TRN & \\
\hline CHEMBL1720903 & 752462 & 3.0342 & 3.9863 & TRN & \\
\hline CHEMBL1531675 & 752462 & 3.034 & 3.4634 & TRN & \\
\hline CHEMBL1586285 & 752462 & 3.0341 & 3.3982 & TST & \\
\hline CHEMBL1352185 & 752462 & 3.0341 & 3.1197 & TRN & \\
\hline CHEMBL1208858 & 752462 & 3.0339 & 3.9593 & TST & \\
\hline CHEMBL1447060 & 752462 & 3.034 & 3.0549 & TRN & \\
\hline CHEMBL1708714 & 752462 & 3.0344 & 3.0455 & TST & \\
\hline CHEMBL1327306 & 752462 & 3.0341 & 3.4992 & TRN & \\
\hline CHEMBL1708052 & 752462 & 3.034 & 3.4562 & TRN & \\
\hline CHEMBL1303361 & 752462 & 3.034 & 3.1321 & TRN & \\
\hline CHEMBL1724267 & 752462 & 4.1 & 4.3727 & TRN & \\
\hline CHEMBL1388222 & 752462 & 5.9698 & 4.6173 & TRN & \\
\hline CHEMBL1564646 & 752462 & 3.034 & 3.5999 & TRN & \\
\hline CHEMBL1612697 & 752462 & 5.3466 & 3.9986 & TRN & \\
\hline CHEMBL1587837 & 752462 & 3.0339 & 3.2154 & TRN & \\
\hline CHEMBL1403842 & 752462 & 3.0341 & 3.6471 & TRN & \\
\hline CHEMBL1892729 & 752462 & 4.8099 & 3.5722 & TRN & \\
\hline CHEMBL1407554 & 752462 & 3.5111 & 3.4085 & TRN & \\
\hline CHEMBL1581275 & 752462 & 3.034 & 3.0891 & TRN & \\
\hline CHEMBL1463367 & 752462 & 3.034 & 2.9878 & TRN & \\
\hline CHEMBL1587574 & 752462 & 3.0339 & 3.8991 & TRN & \\
\hline CHEMBL1486861 & 752462 & 3.034 & 3.5718 & TRN & \\
\hline CHEMBL1732484 & 752462 & 5.1332 & 4.9832 & TRN & \\
\hline CHEMBL1882125 & 752462 & 4.9524 & 4.6172 & TRN & \\
\hline
\end{tabular}




\begin{tabular}{|c|c|c|c|c|c|}
\hline \multirow[b]{2}{*}{ CHEMBL1482107 } & \multicolumn{5}{|c|}{ Supplemental Table S2.txt } \\
\hline & 752462 & 3.0341 & 3.293 & TRN & \\
\hline CHEMBL1584594 & 752462 & 4.4475 & 3.9548 & TRN & \\
\hline CHEMBL1587149 & 752462 & 5.4022 & 4.1097 & TRN & \\
\hline CHEMBL1572068 & 752462 & 3.034 & 3.39300 & 00000000002 & TRN \\
\hline CHEMBL1425453 & 752462 & 3.034 & 3.3103 & TST & \\
\hline CHEMBL1728422 & 752462 & 3.0338 & 2.8279 & TRN & \\
\hline CHEMBL1439686 & 752462 & 4.1548 & 3.6774 & TRN & \\
\hline CHEMBL1735778 & 752462 & 3.034 & 3.2539 & TRN & \\
\hline CHEMBL1448229 & 752462 & 4.4592 & 3.8262 & TRN & \\
\hline CHEMBL1603928 & 752462 & 3.034 & 3.3575 & TRN & \\
\hline CHEMBL1447552 & 752462 & 4.0675 & 4.2496 & TRN & \\
\hline CHEMBL1986259 & 752462 & 3.0339 & 3.5539 & TST & \\
\hline CHEMBL1437975 & 752462 & 3.0337 & 3.5463 & TRN & \\
\hline CHEMBL1355165 & 752462 & 3.0341 & 3.4617 & TRN & \\
\hline CHEMBL1524932 & 752462 & 3.034 & 3.1091 & TRN & \\
\hline CHEMBL1458051 & 752462 & 3.0342 & 2.9347 & TRN & \\
\hline CHEMBL1727052 & 752462 & 3.0344 & 3.4565 & TRN & \\
\hline CHEMBL1579434 & 752462 & 3.034 & 2.897 & TRN & \\
\hline CHEMBL1308389 & 752462 & 4.1272 & 4.3372 & TRN & \\
\hline CHEMBL1304909 & 752462 & 3.0342 & 3.4426 & TRN & \\
\hline CHEMBL1699738 & 752462 & 3.0341 & 3.3513 & TRN & \\
\hline CHEMBL2003819 & 752462 & 3.034 & 3.0596 & TRN & \\
\hline CHEMBL1561591 & 752462 & 3.034 & 3.2574 & TRN & \\
\hline CHEMBL1256770 & 752462 & 3.034 & 3.2713 & TRN & \\
\hline CHEMBL1544567 & 752462 & 3.034 & 4.329 & TRN & \\
\hline CHEMBL1315401 & 752462 & 3.034 & 3.7067 & TRN & \\
\hline CHEMBL1494093 & 752462 & 3.034 & 3.3283 & TRN & \\
\hline CHEMBL1720091 & 752462 & 3.034 & 2.965 & TRN & \\
\hline CHEMBL1968356 & 752462 & 3.034 & 3.4399 & TRN & \\
\hline CHEMBL1426979 & 752462 & 4.5771 & 3.948 & TRN & \\
\hline CHEMBL1722228 & 752462 & 3.0345 & 3.2098 & TRN & \\
\hline CHEMBL1169627 & 752462 & 4.3548 & 3.7538 & TST & \\
\hline CHEMBL1365254 & 752462 & 3.0341 & 3.897 & TRN & \\
\hline CHEMBL1898753 & 752462 & 3.0337 & 2.6594 & TRN & \\
\hline CHEMBL1458770 & 752462 & 3.034 & 2.9285 & TRN & \\
\hline CHEMBL1548542 & 752462 & 3.034 & 3.1354 & TRN & \\
\hline CHEMBL1596869 & 752462 & 3.0341 & 3.2379 & TRN & \\
\hline CHEMBL1714015 & 752462 & 3.034 & 3.167 & TRN & \\
\hline CHEMBL1422217 & 752462 & 3.034 & 2.8345 & TRN & \\
\hline CHEMBL1540756 & 752462 & 3.0336 & 2.886 & TRN & \\
\hline CHEMBL1515502 & 752462 & 4.8523 & 4.4804 & TRN & \\
\hline CHEMBL3213958 & 752462 & 3.034 & 3.1431 & TRN & \\
\hline CHEMBL1566963 & 752462 & 3.0341 & 3.1855 & TRN & \\
\hline CHEMBL1344909 & 752462 & 3.034 & 3.9468 & TRN & \\
\hline CHEMBL1566118 & 752462 & 4.4917 & 3.9504 & TRN & \\
\hline CHEMBL1706148 & 752462 & 3.0343 & 4.2979 & TRN & \\
\hline CHEMBL1450071 & 752462 & 4.3648 & 3.5926 & TRN & \\
\hline CHEMBL1522542 & 752462 & 4.1596 & 3.2084 & TRN & \\
\hline
\end{tabular}




\begin{tabular}{|c|c|c|c|c|c|c|}
\hline & & \multicolumn{5}{|c|}{ Supplemental Table S2.txt } \\
\hline CHEMBL1728158 & 752462 & 3.034 & 3.3772 & TRN & & \\
\hline CHEMBL1985575 & 752462 & 3.0342 & 2.4968 & TRN & & \\
\hline CHEMBL1437660 & 752462 & 4.1028 & 3.3623 & TRN & & \\
\hline CHEMBL1392786 & 752462 & 3.034 & 3.6089 & TRN & & \\
\hline CHEMBL1736138 & 752462 & 3.0341 & 3.2334 & TRN & & \\
\hline CHEMBL1603547 & 752462 & 3.034 & 2.8748 & TRN & & \\
\hline CHEMBL1464640 & 752462 & 3.0341 & 3.1225 & TRN & & \\
\hline CHEMBL1487650 & 752462 & 4.1292 & 3.0458 & TRN & & \\
\hline CHEMBL1378322 & 752462 & 3.034 & 2.7574 & TRN & & \\
\hline CHEMBL1457803 & 752462 & 5.0318 & 3.5371 & TST & & \\
\hline CHEMBL1595735 & 752462 & 4.508999 & 99999999 & 995 & 4.0322 & TRN \\
\hline CHEMBL1606743 & 752462 & 3.034 & 3.0597 & TRN & & \\
\hline CHEMBL1707116 & 752462 & 4.0409 & 3.6889 & TRN & & \\
\hline CHEMBL1454070 & 752462 & 3.034 & 2.7736 & TRN & & \\
\hline CHEMBL1734003 & 752462 & 5.8277 & 3.5026 & TST & & \\
\hline CHEMBL1597912 & 752462 & 3.0341 & 3.4981 & TST & & \\
\hline CHEMBL1315948 & 752462 & 4.849 & 3.7816 & TST & & \\
\hline CHEMBL1548019 & 752462 & 3.034 & 3.3431 & TST & & \\
\hline CHEMBL1382321 & 752462 & 3.034 & 3.5611 & TST & & \\
\hline CHEMBL1558215 & 752462 & 3.034 & 3.2666 & TST & & \\
\hline CHEMBL1727653 & 752462 & 3.034 & 3.43300 & 000000000 & 03 & TST \\
\hline CHEMBL1587604 & 752462 & 3.0342 & 3.17100 & 000000000 & 03 & TST \\
\hline CHEMBL1325945 & 752462 & 3.0339 & 2.5266 & TST & & \\
\hline CHEMBL1722114 & 752462 & 3.034 & 3.5212 & TST & & \\
\hline CHEMBL1703982 & 752462 & 3.034 & 3.1626 & TST & & \\
\hline CHEMBL1563669 & 752462 & 3.5113 & 3.696 & TST & & \\
\hline CHEMBL1340264 & 752462 & 3.034 & 3.3129 & TST & & \\
\hline CHEMBL1717557 & 752462 & 4.5918 & 4.3785 & TST & & \\
\hline CHEMBL1550356 & 752462 & 4.535 & 3.7078 & TST & & \\
\hline CHEMBL1393837 & 752462 & 3.0341 & 3.3416 & TST & & \\
\hline CHEMBL1399743 & 752462 & 4.0634 & 3.6167 & TST & & \\
\hline CHEMBL1345947 & 752462 & 3.0337 & 3.6928 & TST & & \\
\hline CHEMBL1370471 & 752462 & 3.034 & 3.2249 & TST & & \\
\hline CHEMBL1419241 & 752462 & 3.034 & 3.0218 & TST & & \\
\hline CHEMBL 3213181 & 752462 & 3.034 & 3.1383 & TST & & \\
\hline CHEMBL1490069 & 752462 & 3.034 & 3.6441 & TST & & \\
\hline CHEMBL1588202 & 752462 & 4.3012 & 3.4674 & TST & & \\
\hline CHEMBL67378 & 752462 & 7.96899 & 99999999 & 99 & 4.2428 & TST \\
\hline CHEMBL1331866 & 752462 & 3.034 & 3.3835 & TST & & \\
\hline CHEMBL1390846 & 752462 & 4.405 & 3.9178 & TST & & \\
\hline CHEMBL1472987 & 752462 & 3.0341 & 3.551 & TST & & \\
\hline CHEMBL1507251 & 752462 & 4.8223 & 3.2704 & TST & & \\
\hline CHEMBL1444121 & 752462 & 3.0339 & 4.061 & TST & & \\
\hline CHEMBL3701085 & 1528884 & 7.4949 & 7.8057 & TRN & & \\
\hline CHEMBL3701073 & 1528884 & 7.1079 & 7.2769 & TST & & \\
\hline CHEMBL3701146 & 1528884 & 8.0458 & 8.388 & TRN & & \\
\hline CHEMBL3701147 & 1528884 & 8.2218 & 8.384 & TRN & & \\
\hline CHEMBL3701134 & 1528884 & 8.699 & 8.4184 & TRN & & \\
\hline
\end{tabular}


Supplemental Table S2.txt

\begin{tabular}{|c|c|c|c|c|c|}
\hline CHEMBL3701181 & 1528884 & 8.5229 & 7.942 & TRN & \\
\hline CHEMBL3701140 & 1528884 & 6.9469 & 6.5588 & TST & \\
\hline CHEMBL3701121 & 1528884 & 7.699 & 7.4166 & TRN & \\
\hline CHEMBL3701177 & 1528884 & 7.4815 & 7.7245 & TRN & \\
\hline CHEMBL3701167 & 1528884 & 8.0 & 7.8582 & TRN & \\
\hline CHEMBL3701136 & 1528884 & 8.301 & 7.1647 & TST & \\
\hline CHEMBL3701072 & 1528884 & 8.0458 & 7.6579 & TST & \\
\hline CHEMBL3701127 & 1528884 & 8.699 & 8.5577 & TRN & \\
\hline CHEMBL3701122 & 1528884 & 6.9788 & 7.2286 & TRN & \\
\hline CHEMBL3701069 & 1528884 & 8.0 & 7.3519 & TST & \\
\hline CHEMBL3701166 & 1528884 & 7.7212 & 7.6874 & TRN & \\
\hline CHEMBL3701095 & 1528884 & 7.3768 & 7.8372 & TRN & \\
\hline CHEMBL3701176 & 1528884 & 7.6198 & 7.4442 & TST & \\
\hline CHEMBL3701160 & 1528884 & 7.6778 & 7.5089 & TRN & \\
\hline CHEMBL3701108 & 1528884 & 8.0458 & 7.5707 & TRN & \\
\hline CHEMBL3701133 & 1528884 & 8.699 & 8.6666 & TRN & \\
\hline CHEMBL3701163 & 1528884 & 8.3979 & 8.0675 & TRN & \\
\hline CHEMBL3701131 & 1528884 & 8.699 & 8.47 & TRN & \\
\hline CHEMBL3701065 & 1528884 & 8.0969 & 8.1431 & TRN & \\
\hline CHEMBL3701169 & 1528884 & 7.8861 & 7.7792 & TRN & \\
\hline CHEMBL3701137 & 1528884 & 7.1135 & 6.9977 & TRN & \\
\hline CHEMBL3701149 & 1528884 & 7.3768 & 8.0137 & TRN & \\
\hline CHEMBL 3701171 & 1528884 & 7.1024 & 7.4614 & TRN & \\
\hline CHEMBL3701126 & 1528884 & 8.1549 & 7.9199 & TRN & \\
\hline CHEMBL3701141 & 1528884 & 8.3979 & 8.419 & TRN & \\
\hline CHEMBL3701175 & 1528884 & 7.8239 & 6.6102 & TST & \\
\hline CHEMBL3701135 & 1528884 & 7.0706 & 7.1928 & TRN & \\
\hline CHEMBL3701132 & 1528884 & 8.699 & 8.3708 & TRN & \\
\hline CHEMBL3701164 & 1528884 & 8.301 & 7.9473 & TRN & \\
\hline CHEMBL3701116 & 1528884 & 7.1612 & 7.411006 & 20000000005 & TRN \\
\hline CHEMBL3701057 & 1528884 & 6.6271 & 7.6331 & TST & \\
\hline CHEMBL3701159 & 1528884 & 7.4318 & 7.5815 & TST & \\
\hline CHEMBL3701104 & 1528884 & 8.301 & 8.5315 & TRN & \\
\hline CHEMBL3701076 & 1528884 & 8.5229 & 8.5456 & TRN & \\
\hline CHEMBL3701061 & 1528884 & 8.3979 & 8.5954 & TRN & \\
\hline CHEMBL3701080 & 1528884 & 7.9586 & 7.8515 & TRN & \\
\hline CHEMBL3701071 & 1528884 & 7.0315 & 7.5846 & TST & \\
\hline CHEMBL3701086 & 1528884 & 8.3979 & 8.5563 & TRN & \\
\hline CHEMBL3701151 & 1528884 & 8.301 & 7.7305 & TRN & \\
\hline CHEMBL3701070 & 1528884 & 8.301 & 7.9775 & TRN & \\
\hline CHEMBL3701058 & 1528884 & 8.301 & 8.58 & TRN & \\
\hline CHEMBL3701066 & 1528884 & 8.5229 & 7.9349 & TRN & \\
\hline CHEMBL3701077 & 1528884 & 8.3979 & 8.43 & TRN & \\
\hline CHEMBL3701068 & 1528884 & 8.1549 & 8.1407 & TRN & \\
\hline CHEMBL3701074 & 1528884 & 7.3279 & 7.3911 & TST & \\
\hline CHEMBL3701180 & 1528884 & 7.9586 & 7.8978 & TRN & \\
\hline CHEMBL3639999 & 1528884 & 8.699 & 8.3495 & TRN & \\
\hline CHEMBL3701102 & 1528884 & 7.699 & 7.6344 & TRN & \\
\hline
\end{tabular}


Supplemental Table S2.txt

\begin{tabular}{|c|c|c|c|c|c|}
\hline CHEMBL 3701097 & 1528884 & 8.301 & 8.0025 & TRN & \\
\hline CHEMBL 3701084 & 1528884 & 8.0458 & 7.82 & TRN & \\
\hline CHEMBL3701153 & 1528884 & 7.1612 & \multicolumn{2}{|c|}{7.6979999999999995} & TRN \\
\hline CHEMBL3701099 & 1528884 & 8.3979 & 8.4944 & TRN & \\
\hline CHEMBL 3701115 & 1528884 & 7.4815 & 7.4393 & TRN & \\
\hline CHEMBL3701103 & 1528884 & 7.585 & 8.2997 & TRN & \\
\hline CHEMBL3701059 & 1528884 & 8.3979 & 8.4647 & TRN & \\
\hline CHEMBL3701168 & 1528884 & 7.8539 & 7.6337 & TRN & \\
\hline CHEMBL 3701098 & 1528884 & 7.0132 & 7.3035 & TST & \\
\hline CHEMBL3701089 & 1528884 & 8.301 & 8.1303 & TRN & \\
\hline CHEMBL 3701125 & 1528884 & 8.699 & 8.2461 & TRN & \\
\hline CHEMBL3701118 & 1528884 & 7.7696 & 7.7448 & TRN & \\
\hline CHEMBL 3701162 & 1528884 & 8.5229 & 7.8484 & TRN & \\
\hline CHEMBL3701130 & 1528884 & 8.699 & 8.4657 & TRN & \\
\hline CHEMBL 3701067 & 1528884 & 8.1549 & 8.2609 & TRN & \\
\hline CHEMBL 3701054 & 1528884 & 8.699 & 8.6604 & TRN & \\
\hline CHEMBL3701157 & 1528884 & 7.7696 & 7.7608 & TRN & \\
\hline CHEMBL 3701152 & 1528884 & 7.4202 & 7.6676 & TRN & \\
\hline CHEMBL3701100 & 1528884 & 7.7212 & 7.7996 & TRN & \\
\hline CHEMBL 3701138 & 1528884 & 8.301 & 7.0676 & TST & \\
\hline CHEMBL 3701170 & 1528884 & 7.8861 & 8.0137 & TRN & \\
\hline CHEMBL3701179 & 1528884 & 7.2518 & 7.8212 & TST & \\
\hline CHEMBL 3701172 & 1528884 & 7.3872 & 7.742999 & 9999999999 & TRN \\
\hline CHEMBL3701087 & 1528884 & 9.0 & 8.7497 & TRN & \\
\hline CHEMBL3701156 & 1528884 & 7.3565 & 7.787006 & 0000000001 & TRN \\
\hline CHEMBL 3701053 & 1528884 & 9.1805 & 8.6877 & TRN & \\
\hline CHEMBL3701092 & 1528884 & 6.3036 & 7.112999 & 99999999995 & TRN \\
\hline CHEMBL 3701113 & 1528884 & 7.7212 & 7.3684 & TRN & \\
\hline CHEMBL3701119 & 1528884 & 7.0555 & 7.2243 & TRN & \\
\hline CHEMBL 3701124 & 1528884 & 8.699 & 8.5502 & TRN & \\
\hline CHEMBL 3701081 & 1528884 & 8.2218 & 7.8314 & TRN & \\
\hline CHEMBL3701109 & 1528884 & 7.0223 & 7.5864 & TST & \\
\hline CHEMBL3701161 & 1528884 & 7.9586 & 7.787999 & 7999999999 & TRN \\
\hline CHEMBL3701078 & 1528884 & 8.699 & 8.5265 & TRN & \\
\hline CHEMBL 3701056 & 1528884 & 8.1549 & 8.6224 & TRN & \\
\hline CHEMBL3701114 & 1528884 & 7.6383 & 7.5122 & TRN & \\
\hline CHEMBL 3701158 & 1528884 & 7.5686 & 7.3955 & TST & \\
\hline CHEMBL3701110 & 1528884 & 7.4318 & 7.5092 & TRN & \\
\hline CHEMBL3701150 & 1528884 & 7.5528 & 7.4608 & TRN & \\
\hline CHEMBL 3701075 & 1528884 & 7.585 & 7.1463 & TST & \\
\hline CHEMBL 3701117 & 1528884 & 7.2218 & 7.4255 & TRN & \\
\hline CHEMBL 3701154 & 1528884 & 7.6778 & 7.906006 & 0000000001 & TRN \\
\hline CHEMBL3701111 & 1528884 & 8.5229 & 7.5854 & TST & \\
\hline CHEMBL3701120 & 1528884 & 7.5528 & 7.672006 & 0000000001 & TRN \\
\hline CHEMBL 3701155 & 1528884 & 8.3979 & 8.8422 & TRN & \\
\hline CHEMBL 3701112 & 1528884 & 8.5229 & 7.5858 & TST & \\
\hline CHEMBL 3701093 & 1528884 & 8.3979 & 7.9024 & TRN & \\
\hline CHEMBL3701106 & 1528884 & 8.0 & 7.1984 & TST & \\
\hline
\end{tabular}


Supplemental Table S2.txt

\begin{tabular}{|c|c|c|c|c|c|}
\hline CHEMBL 3701096 & 1528884 & 8.2218 & 8.0156 & TST & \\
\hline CHEMBL 3701173 & 1528884 & 7.0177 & 7.7361 & TRN & \\
\hline CHEMBL3701094 & 1528884 & 7.9208 & 7.7303 & TST & \\
\hline CHEMBL 3701142 & 1528884 & 8.5229 & 8.4804 & TRN & \\
\hline CHEMBL 3701129 & 1528884 & 8.5229 & 8.4157 & TRN & \\
\hline CHEMBL 3701091 & 1528884 & 6.684 & 7.5235 & TST & \\
\hline CHEMBL 3701128 & 1528884 & 8.0 & 8.4891 & TRN & \\
\hline CHEMBL 3701063 & 1528884 & 9.0 & 8.21 & TST & \\
\hline CHEMBL 3701148 & 1528884 & 8.0458 & 8.2436 & TRN & \\
\hline CHEMBL3701082 & 1528884 & 8.699 & 8.4452 & TRN & \\
\hline CHEMBL 3701062 & 1528884 & 8.5229 & 8.7495 & TRN & \\
\hline CHEMBL 3701101 & 1528884 & 8.2218 & 7.7494 & TST & \\
\hline CHEMBL 3701055 & 1528884 & 8.1549 & 7.3346 & TST & \\
\hline CHEMBL 3701144 & 1528884 & 8.0 & 8.2119 & TRN & \\
\hline CHEMBL3701123 & 1528884 & 7.6778 & 7.5789 & TRN & \\
\hline CHEMBL3701165 & 1528884 & 8.301 & 7.825 & TRN & \\
\hline CHEMBL 3701107 & 1528884 & 7.5528 & 7.3327 & TST & \\
\hline CHEMBL 3701064 & 1528884 & 7.7696 & 7.6844 & TST & \\
\hline CHEMBL 3701090 & 1528884 & 8.5229 & 8.158999 & 9999999999 & TST \\
\hline CHEMBL3701139 & 1528884 & 8.3979 & 7.3214 & TST & \\
\hline CHEMBL3701178 & 1528884 & 7.5686 & 7.6191 & TRN & \\
\hline CHEMBL 3701143 & 1528884 & 8.0458 & 8.405 & TRN & \\
\hline CHEMBL3701174 & 1528884 & 7.3565 & 6.8843 & TST & \\
\hline CHEMBL 3701145 & 1528884 & 8.0458 & 8.357000 & 0000000001 & TRN \\
\hline CHEMBL 3701060 & 1528884 & 8.699 & 8.7062 & TRN & \\
\hline CHEMBL 3701105 & 1528884 & 7.4559 & 7.3433 & TST & \\
\hline CHEMBL606000 & 611971 & 5.9987 & 6.065 & TRN & \\
\hline CHEMBL599631 & 611971 & 5.3833 & 5.3882 & TRN & \\
\hline CHEMBL599210 & 611971 & 6.3188 & 6.2453 & TRN & \\
\hline CHEMBL605153 & 611971 & 6.2541 & 6.1231 & TRN & \\
\hline CHEMBL599224 & 611971 & 6.699 & 6.2667 & TRN & \\
\hline CHEMBL597353 & 611971 & 5.5935 & 5.4038 & TST & \\
\hline CHEMBL607852 & 611971 & 5.2903 & 5.3081 & TRN & \\
\hline CHEMBL592256 & 611971 & 7.7212 & 7.9154 & TRN & \\
\hline CHEMBL598186 & 611971 & 4.0 & 3.9013 & TRN & \\
\hline CHEMBL597362 & 611971 & 5.2863 & 5.099 & TRN & \\
\hline CHEMBL607187 & 611971 & 6.0757 & 6.1659 & TRN & \\
\hline CHEMBL591467 & 611971 & 6.3872 & 6.5089 & TRN & \\
\hline CHEMBL599629 & 611971 & 6.0301 & 5.9746 & TRN & \\
\hline CHEMBL598382 & 611971 & 4.0 & 4.4807 & TRN & \\
\hline CHEMBL597977 & 611971 & 5.6647 & 5.5808 & TRN & \\
\hline CHEMBL598986 & 611971 & 6.0443 & 6.1352 & TRN & \\
\hline CHEMBL605774 & 611971 & \multicolumn{3}{|c|}{5.212000000000001} & TST \\
\hline CHEMBL599427 & 611971 & 4.0 & 4.4057 & TRN & \\
\hline CHEMBL608444 & 611971 & 5.119 & 6.0644 & TST & \\
\hline CHEMBL604092 & 611971 & 6.2958 & 6.296 & TRN & \\
\hline CHEMBL603079 & 611971 & 7.1549 & 7.3243 & TRN & \\
\hline CHEMBL597352 & 611971 & 5.8579 & 5.7514 & TST & \\
\hline
\end{tabular}


Supplemental Table S2.txt

\begin{tabular}{|c|c|c|c|c|}
\hline CHEMBL598987 & 611971 & 5.6273 & 5.9251 & TST \\
\hline CHEMBL605781 & 611971 & 5.4016 & 5.5955 & TRN \\
\hline CHEMBL597379 & 611971 & 5.3859 & 5.6164 & TRN \\
\hline CHEMBL599401 & 611971 & 5.6091 & 5.5956 & TRN \\
\hline CHEMBL599428 & 611971 & 7.4949 & 7.4971 & TRN \\
\hline CHEMBL600876 & 611971 & 6.4815 & 6.4958 & TRN \\
\hline CHEMBL606428 & 611971 & 4.0 & 3.84 & TRN \\
\hline CHEMBL606409 & 611971 & 6.0851 & 6.006 & TRN \\
\hline CHEMBL603108 & 611971 & 7.3372 & 7.3949 & TRN \\
\hline CHEMBL597753 & 611971 & 7.6198 & 7.7078 & TRN \\
\hline CHEMBL598185 & 611971 & 5.8861 & 5.8631 & TRN \\
\hline CHEMBL603080 & 611971 & 5.699 & 5.8174 & TRN \\
\hline CHEMBL603313 & 611971 & 5.6576 & 4.7436 & TST \\
\hline CHEMBL599630 & 611971 & 5.7033 & 5.3547 & TST \\
\hline CHEMBL598401 & 611971 & 7.699 & 7.5054 & TRN \\
\hline CHEMBL602904 & 611971 & 6.4318 & 6.4846 & TRN \\
\hline CHEMBL605208 & 611971 & 5.0622 & 5.039 & TST \\
\hline CHEMBL591230 & 611971 & 5.9052 & 5.7494 & TST \\
\hline CHEMBL592272 & 611971 & 6.9318 & 6.7694 & TRN \\
\hline CHEMBL599824 & 611971 & 5.2571 & 5.3736 & TRN \\
\hline CHEMBL597754 & 611971 & 6.4112 & 6.3462 & TRN \\
\hline CHEMBL597361 & 611971 & 4.0 & 4.0796 & TST \\
\hline CHEMBL599607 & 611971 & 6.6108 & 6.426 & TRN \\
\hline CHEMBL610218 & 611971 & 6.2464 & 5.642 & TST \\
\hline CHEMBL605350 & 611971 & 6.0362 & 6.0264 & TST \\
\hline CHEMBL591463 & 611971 & 5.0655 & 4.6657 & TRN \\
\hline CHEMBL598988 & 611971 & 5.8 & 5.9564 & TST \\
\hline CHEMBL600394 & 611971 & 5.7981 & 5.6253 & TRN \\
\hline CHEMBL298771 & 312866 & 3.8983 & 3.9278 & TRN \\
\hline CHEMBL298547 & 312866 & 4.8601 & 5.5783 & TRN \\
\hline CHEMBL293522 & 312866 & 3.8318 & 3.8455 & TRN \\
\hline CHEMBL55856 & 312866 & 3.8697 & 3.8781 & TRN \\
\hline CHEMBL291727 & 312866 & 4.6801 & 4.7077 & TRN \\
\hline CHEMBL197944 & 312866 & 3.6621 & 3.6525 & TRN \\
\hline CHEMBL412889 & 312866 & 4.3643 & 4.3286 & TST \\
\hline CHEMBL55264 & 312866 & 4.5967 & 5.5783 & TRN \\
\hline CHEMBL333503 & 312866 & 3.8052 & 3.8093 & TRN \\
\hline CHEMBL124796 & 312866 & 4.2908 & 4.262 & TRN \\
\hline CHEMBL55140 & 312866 & 4.3518 & 4.397 & TRN \\
\hline CHEMBL125188 & 312866 & 4.3197 & 4.2975 & TRN \\
\hline CHEMBL110971 & 312866 & 5.6234 & 5.5783 & TRN \\
\hline CHEMBL375226 & 312866 & 3.6451 & 3.6473 & TRN \\
\hline CHEMBL338917 & 312866 & 3.8807 & 3.9982 & TST \\
\hline CHEMBL56556 & 312866 & 4.0446 & 4.0576 & TRN \\
\hline CHEMBL55608 & 312866 & 4.1184 & 4.1025 & TRN \\
\hline CHEMBL127588 & 312866 & 4.4387 & 4.4197 & TRN \\
\hline CHEMBL191613 & 312866 & 3.8139 & 3.7247 & TST \\
\hline \multirow[t]{2}{*}{ CHEMBL55557 } & 312866 & 4.2289 & 4.22199 & 99999999995 \\
\hline & & \multicolumn{3}{|c|}{ Page 13423} \\
\hline
\end{tabular}




\begin{tabular}{|c|c|c|c|c|c|}
\hline & & & & & \\
\hline CHEMBL434024 & 312866 & 5.091 & 5.1254 & TRN & \\
\hline CHEMBL293116 & 312866 & 4.5098 & 4.4878 & TRN & \\
\hline CHEMBL1161778 & 312866 & 5.1739 & 5.1782 & TRN & \\
\hline CHEMBL55359 & 312866 & 4.1395 & 4.1453 & TRN & \\
\hline CHEMBL54004 & 312866 & 6.2596 & 5.5783 & TRN & \\
\hline CHEMBL58830 & 312866 & 4.1648 & 4.4174 & TST & \\
\hline CHEMBL374042 & 312866 & 4.1152 & 4.1008 & TRN & \\
\hline CHEMBL192793 & 312866 & 4.2506 & 4.2808 & TRN & \\
\hline CHEMBL55886 & 312866 & 5.4559 & 5.4064 & TRN & \\
\hline CHEMBL55779 & 312866 & 4.3762 & 4.3749 & TST & \\
\hline CHEMBL56011 & 312866 & 4.4365 & 4.444 & TRN & \\
\hline CHEMBL55353 & 312866 & 3.8794 & 3.8849 & TRN & \\
\hline CHEMBL364728 & 312866 & 3.7948 & 3.7799 & TRN & \\
\hline CHEMBL298852 & 312866 & 6.5528 & 5.5783 & TRN & \\
\hline CHEMBL299717 & 312866 & 4.1596 & 4.2298 & TRN & \\
\hline CHEMBL52620 & 312866 & 3.6295 & 3.6247 & TRN & \\
\hline CHEMBL301065 & 312866 & 4.3773 & 4.3764 & TRN & \\
\hline CHEMBL291736 & 312866 & 4.3504 & 4.3205 & TRN & \\
\hline CHEMBL54472 & 312866 & 4.0469 & 4.287 & TST & \\
\hline CHEMBL199858 & 312866 & 5.3468 & 4.6346 & TST & \\
\hline CHEMBL1161777 & 312866 & 4.7595 & 4.7513 & TRN & \\
\hline CHEMBL292224 & 312866 & 4.6368 & 4.4618 & TST & \\
\hline CHEMBL299563 & 312866 & 3.7937 & 4.511 & TST & \\
\hline CHEMBL417932 & 312866 & 4.0951 & 5.0836 & TST & \\
\hline CHEMBL52137 & 312866 & 4.2906 & 4.287 & TST & \\
\hline CHEMBL218745 & 312866 & 3.7844 & 3.7441 & TRN & \\
\hline CHEMBL54926 & 312866 & 3.9176 & 4.5443 & TST & \\
\hline CHEMBL192881 & 312866 & 4.1627 & 4.4614 & TST & \\
\hline CHEMBL417549 & 312866 & 5.0511 & 5.0512 & TRN & \\
\hline CHEMBL299491 & 312866 & 3.8248 & 3.8112 & TRN & \\
\hline CHEMBL3940342 & 1637363 & 5.9996 & 6.2047 & TRN & \\
\hline CHEMBL3941649 & 1637363 & 5.9996 & 6.0089 & TRN & \\
\hline CHEMBL3907157 & 1637363 & 5.9996 & 6.409 & TST & \\
\hline CHEMBL3959523 & 1637363 & 5.9996 & 6.0564 & TRN & \\
\hline CHEMBL3941290 & 1637363 & 5.9996 & 6.6813 & TRN & \\
\hline CHEMBL3928770 & 1637363 & 6.9957 & 6.50899 & 99999999995 & TRN \\
\hline CHEMBL3985573 & 1637363 & 5.9996 & 6.0033 & TRN & \\
\hline CHEMBL3960415 & 1637363 & 6.9957 & 7.0564 & TST & \\
\hline CHEMBL3940292 & 1637363 & 6.9957 & 7.4194 & TRN & \\
\hline CHEMBL3985240 & 1637363 & 6.9957 & 7.4224 & TRN & \\
\hline CHEMBL3986666 & 1637363 & 8.0 & 7.2803 & TRN & \\
\hline CHEMBL3947909 & 1637363 & 5.9996 & 6.38899 & 9999999999 & TRN \\
\hline CHEMBL3979171 & 1637363 & 8.0 & 7.3955 & TST & \\
\hline CHEMBL3890807 & 1637363 & 5.9996 & 5.5881 & TRN & \\
\hline CHEMBL3907356 & 1637363 & 6.9957 & 7.3008 & TRN & \\
\hline CHEMBL3943231 & 1637363 & 5.9996 & 5.8506 & TRN & \\
\hline CHEMBL3985317 & 1637363 & 5.0 & 5.9348 & TRN & \\
\hline CHEMBL3947169 & 1637363 & 5.9996 & 6.1696 & TRN & \\
\hline
\end{tabular}

Page 13424 
Supplemental Table S2.txt

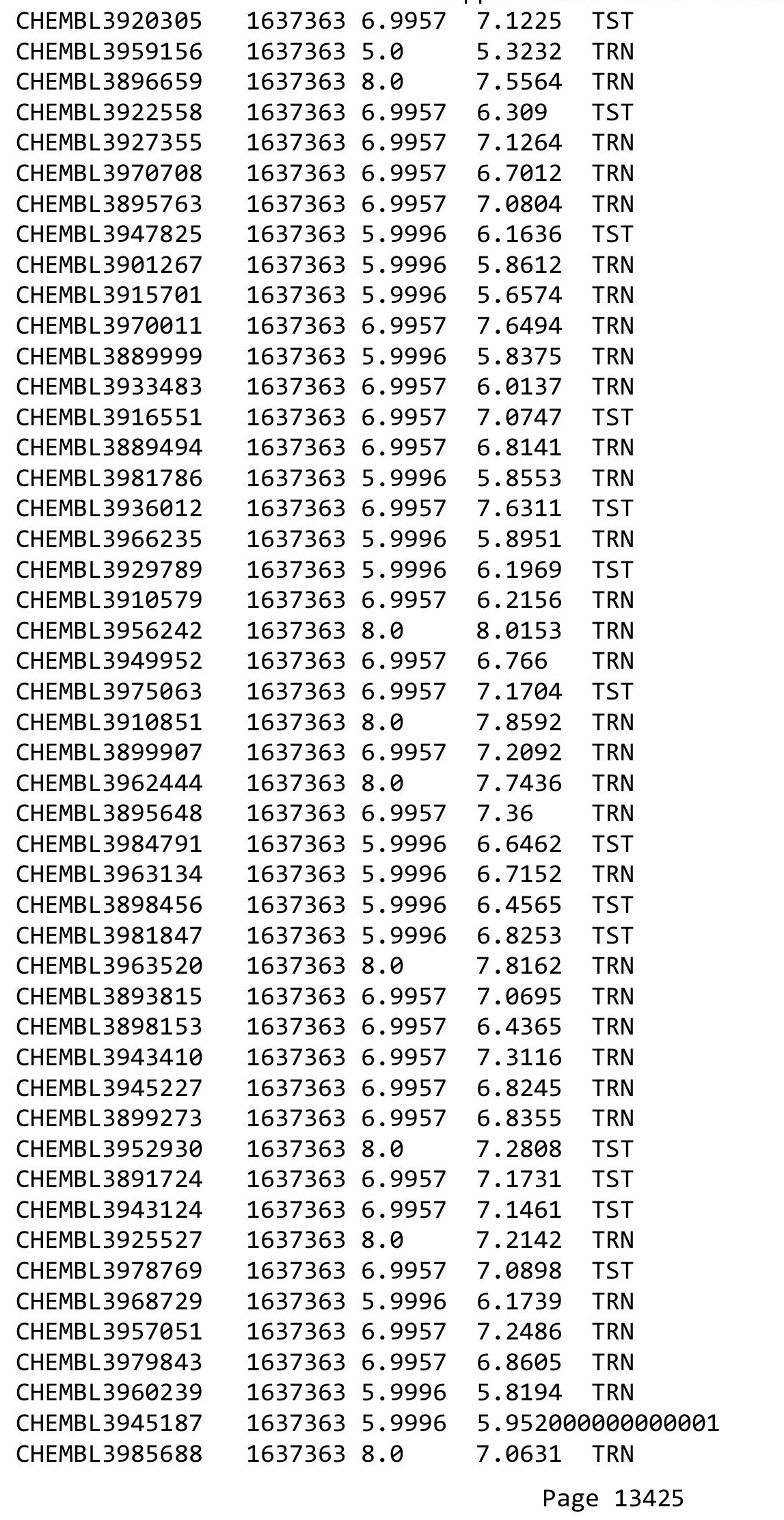


Supplemental Table S2.txt

\begin{tabular}{|c|c|c|c|c|}
\hline The & 537363 & & & \\
\hline & & 6.9957 & 6821 & \\
\hline & & & & \\
\hline AEMBL & 53 & & & \\
\hline AEMBL3909606 & 37363 & 996 & 6657 & \\
\hline HEMBL3890922 & 537363 & 6.9957 & 2374 & \\
\hline HEMBL3926114 & 363 & 0 & 584 & \\
\hline IEMBL 3929075 & & 7 & 5307 & \\
\hline AEMBL3910325 & 363 & 9957 & 2471 & \\
\hline HEMBL3959743 & 363 & 996 & 8581 & \\
\hline HEMBL3922882 & 53 & 5.9996 & 1543 & \\
\hline IEMBL 3909355 & 53 & 957 & 198 & \\
\hline AEMBL3S & & & & \\
\hline HEMBL3896778 & 63 & 957 & 2189 & \\
\hline AEMBL3977275 & 53 & 96 & 356 & \\
\hline AEMBL3893397 & בת & 957 & 225 & \\
\hline HEMBL39 & & 57 & 87 & \\
\hline HEMBL39 & & 57 & & \\
\hline HEMBL3896421 & & 957 & 909 & \\
\hline AEMBL391 & & 57 & & \\
\hline HEIMBLSS & 63 & 57 & 271 & RIN \\
\hline AEMBL3S & & 7 & & RIN \\
\hline HEMBL3S & & & & \\
\hline AEMBL3897143 & & & 229 & \\
\hline AEMBL3918772 & & & & I NIV \\
\hline HEMBL3S & 63 & 7 & 84 & IS \\
\hline HEMBL3S & & & & וד וכ \\
\hline HFMBI $3 c$ & & & 725 & \\
\hline HEMBL3982639 & & & 744 & TRN \\
\hline HEMBL3924960 & & & 84 & I RN \\
\hline HEMBL3926304 & & & 533 & RN \\
\hline HEMBL; & & & & RN \\
\hline HEMBL & & & & 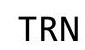 \\
\hline AEMBL3917718 & & & 494 & IRN \\
\hline HEMBL3957350 & 6373 & 996 & 202 & TST \\
\hline HEMBL3890459 & & & 144 & TRN \\
\hline HFMRI 3 & & & 495 & $\Gamma \mathrm{RN}$ \\
\hline HEMBL3 & & & 566 & IRN \\
\hline HEMBL3975590 & 637363 & 57 & 1926 & TRN \\
\hline AEMBL3943205 & $62=$ & & 3298 & TR \\
\hline HEMBL 39 & $6:-7$ & & 858 & TST \\
\hline HEMBL3919197 & & & 401 & ГST \\
\hline HEMBL3944343 & 363 & 996 & 1925 & RN \\
\hline HEMBL3928965 & 637363 & & 5277 & TR \\
\hline MBL39 & & & 3663 & $\mathrm{~N}$ \\
\hline HEMBL 389 & & & 3999 & \\
\hline CHEMBL 3944433 & & & & \\
\hline HEMBL3983821 & 1637363 & 6.9957 & 6.4325 & ГRN \\
\hline
\end{tabular}

Page 13426 
Supplemental Table S2.txt

\begin{tabular}{|c|c|c|c|c|c|}
\hline CHEMBL3905430 & 1637363 & 5.9996 & 5.9945 & TRN & \\
\hline CHEMBL3904961 & 1637363 & 5.9996 & 5.3952 & TRN & \\
\hline CHEMBL3909719 & 1637363 & 5.9996 & 6.1186 & TRN & \\
\hline CHEMBL3912990 & 1637363 & 5.9996 & 6.1294 & TRN & \\
\hline CHEMBL3901154 & 1637363 & 5.9996 & 6.4089 & TST & \\
\hline CHEMBL3968900 & 1637363 & 8.0 & 7.6109 & TRN & \\
\hline CHEMBL3959460 & 1637363 & 6.9957 & 6.4228 & TRN & \\
\hline CHEMBL3925073 & 1637363 & 6.9957 & 6.9834 & TRN & \\
\hline CHEMBL3938549 & 1637363 & 5.9996 & 5.6367 & TRN & \\
\hline CHEMBL3910540 & 1637363 & 6.9957 & 6.7323 & TRN & \\
\hline CHEMBL3928473 & 1637363 & 5.9996 & 6.5801 & TRN & \\
\hline CHEMBL3960602 & 1637363 & 8.0 & 7.6442 & TRN & \\
\hline CHEMBL3933662 & 1637363 & 6.9957 & 7.374 & TRN & \\
\hline CHEMBL 3893221 & 1637363 & 6.9957 & 7.0143 & TRN & \\
\hline CHEMBL3921352 & 1637363 & 6.9957 & 7.0299 & TRN & \\
\hline CHEMBL3912237 & 1637363 & 5.9996 & 6.1136 & TRN & \\
\hline CHEMBL3973363 & 1637363 & 6.9957 & 6.6069 & TRN & \\
\hline CHEMBL 3902680 & 1637363 & 6.9957 & 7.337999 & 9999999999 & TRN \\
\hline CHEMBL3958390 & 1637363 & 5.9996 & 6.0461 & TRN & \\
\hline CHEMBL3942441 & 1637363 & 5.9996 & 5.8238 & TRN & \\
\hline CHEMBL3891414 & 1637363 & 6.9957 & 6.4683 & TRN & \\
\hline CHEMBL3901231 & 1637363 & 8.0 & 7.6932 & TRN & \\
\hline CHEMBL3983062 & 1637363 & 5.0 & 5.3479 & TRN & \\
\hline CHEMBL3985432 & 1637363 & 5.9996 & 6.1683 & TST & \\
\hline CHEMBL3896539 & 1637363 & 6.9957 & 6.8783 & TRN & \\
\hline CHEMBL3936288 & 1637363 & 6.9957 & 7.284 & TST & \\
\hline CHEMBL3920442 & 1637363 & 3.699 & 5.4796 & TRN & \\
\hline CHEMBL3928547 & 1637363 & 6.9957 & 7.6079 & TRN & \\
\hline CHEMBL3984431 & 1637363 & 5.9996 & 6.6631 & TRN & \\
\hline CHEMBL3906553 & 1637363 & 6.9957 & 7.5813 & TRN & \\
\hline CHEMBL3913886 & 1637363 & 5.0 & 5.5084 & TRN & \\
\hline CHEMBL3980202 & 1637363 & 6.9957 & 6.0762 & TRN & \\
\hline CHEMBL3916066 & 1637363 & 5.9996 & 6.1824 & TST & \\
\hline CHEMBL3952979 & 1637363 & 6.9957 & 7.4664 & TRN & \\
\hline CHEMBL3917581 & 1637363 & 6.9957 & 7.229 & TRN & \\
\hline CHEMBL3966974 & 1637363 & 8.0 & 7.4509 & TRN & \\
\hline CHEMBL3923632 & 1637363 & 6.9957 & 7.3045 & TRN & \\
\hline CHEMBL3954820 & 1637363 & 6.9957 & 6.5678 & TST & \\
\hline CHEMBL3958159 & 1637363 & 6.9957 & \multicolumn{2}{|c|}{6.882999999999999} & TRN \\
\hline CHEMBL3902279 & 1637363 & 3.699 & 5.6225 & TRN & \\
\hline CHEMBL3946950 & 1637363 & 5.9996 & 5.6545 & TRN & \\
\hline CHEMBL3987017 & 1637363 & 6.9957 & 7.1526 & TRN & \\
\hline CHEMBL3985527 & 1637363 & 5.9996 & 6.5234 & TRN & \\
\hline CHEMBL3911947 & 1637363 & 6.9957 & 7.4683 & TRN & \\
\hline CHEMBL3944543 & 1637363 & 5.9996 & 6.4167 & TRN & \\
\hline CHEMBL3963906 & 1637363 & 5.9996 & 5.6617 & TRN & \\
\hline CHEMBL 3971771 & 1637363 & 3.699 & 5.9956 & TRN & \\
\hline CHEMBL 3962174 & 1637363 & 6.9957 & 6.6698 & TRN & \\
\hline
\end{tabular}

Page 13427 
Supplemental Table S2.txt

\begin{tabular}{|c|c|c|c|c|}
\hline CHEMBL3924231 & 1637363 & 6.9957 & 7.4554 & TRN \\
\hline CHEMBL3890629 & 1637363 & 6.9957 & 7.5381 & TRN \\
\hline CHEMBL3922931 & 1637363 & 6.9957 & 6.62 & TRN \\
\hline CHEMBL3916638 & 1637363 & 6.9957 & 6.5415 & TST \\
\hline CHEMBL3986002 & 1637363 & 6.9957 & 7.2179 & TRN \\
\hline CHEMBL3975798 & 1637363 & 6.9957 & 6.8413 & TRN \\
\hline CHEMBL3916202 & 1637363 & 5.9996 & 6.3707 & TRN \\
\hline CHEMBL3986339 & 1637363 & 5.9996 & 6.6365 & TST \\
\hline CHEMBL3898653 & 1637363 & 6.9957 & 7.5857 & TRN \\
\hline CHEMBL3890529 & 1637363 & 5.9996 & 5.8814 & TRN \\
\hline CHEMBL3922397 & 1637363 & 6.9957 & 6.7135 & TRN \\
\hline CHEMBL3962230 & 1637363 & 5.0 & 5.865 & TRN \\
\hline CHEMBL3973841 & 1637363 & 6.9957 & 6.9187 & TRN \\
\hline CHEMBL 3893934 & 1637363 & 8.0 & 7.528 & TRN \\
\hline CHEMBL3906658 & 1637363 & 6.9957 & 7.1095 & TST \\
\hline CHEMBL3936822 & 1637363 & 6.9957 & 6.6323 & TST \\
\hline CHEMBL3905390 & 1637363 & 6.9957 & 7.49200 & 0000000001 \\
\hline CHEMBL3906591 & 1637363 & 6.9957 & 7.1157 & TRN \\
\hline CHEMBL3898039 & 1637363 & 6.9957 & 6.9068 & TRN \\
\hline CHEMBL 3987146 & 1637363 & 6.9957 & 6.8512 & TRN \\
\hline CHEMBL3974877 & 1637363 & 6.9957 & 6.5543 & TRN \\
\hline CHEMBL3898507 & 1637363 & 5.9996 & 6.2033 & TRN \\
\hline CHEMBL3906316 & 1637363 & 5.0 & 5.557 & TRN \\
\hline CHEMBL3891681 & 1637363 & 6.9957 & 6.8958 & TRN \\
\hline CHEMBL3983508 & 1637363 & 6.9957 & 6.9998 & TRN \\
\hline CHEMBL3976295 & 1637363 & 6.9957 & 7.13899 & 9999999999 \\
\hline CHEMBL3923543 & 1637363 & 8.0 & 7.374 & TRN \\
\hline CHEMBL3965210 & 1637363 & 6.9957 & 7.1792 & TRN \\
\hline CHEMBL3896996 & 1637363 & 6.0 & 6.4486 & TRN \\
\hline CHEMBL 3898318 & 1637363 & 8.0 & 7.817 & TRN \\
\hline CHEMBL3956160 & 1637363 & 6.9957 & 6.7494 & TRN \\
\hline CHEMBL3913586 & 1637363 & 6.0 & 6.8207 & TRN \\
\hline CHEMBL3918386 & 1637363 & 6.9957 & 6.6372 & TRN \\
\hline CHEMBL3905635 & 1637363 & 6.9957 & 6.7478 & TRN \\
\hline CHEMBL3899914 & 1637363 & 6.0 & 6.7032 & TST \\
\hline CHEMBL3925818 & 1637363 & 6.9957 & 7.2726 & TRN \\
\hline CHEMBL3963298 & 1637363 & 8.0 & 7.5692 & TRN \\
\hline CHEMBL3919157 & 1637363 & 6.9957 & 6.7613 & TRN \\
\hline CHEMBL3986772 & 1637363 & 5.9996 & 6.5902 & TST \\
\hline CHEMBL3973095 & 1637363 & 5.9996 & 6.774 & TRN \\
\hline CHEMBL3941426 & 1637363 & 6.9957 & 6.4869 & TST \\
\hline CHEMBL3984769 & 1637363 & 6.9957 & 7.5691 & TRN \\
\hline CHEMBL3955096 & 1637363 & 6.9957 & 6.6847 & TRN \\
\hline CHEMBL3955049 & 1637363 & 6.9957 & 7.04200 & 0000000001 \\
\hline CHEMBL3897206 & 1637363 & 6.0 & 6.2882 & TST \\
\hline CHEMBL3977569 & 1637363 & 6.9957 & 7.36 & TRN \\
\hline CHEMBL3960918 & 1637363 & 5.9996 & 5.8381 & TRN \\
\hline CHEMBL3917463 & 1637363 & 8.0 & 7.8477 & TRN \\
\hline
\end{tabular}


Supplemental Table S2.txt

\begin{tabular}{|c|c|c|c|c|}
\hline ra & & & & \\
\hline ר ניחזיו & & 5.9996 & 6.0051 & \\
\hline & & 996 & & \\
\hline HEMBL & 53 & 957 & & (N) \\
\hline AEMBL3950225 & 537363 & 8.0 & & \\
\hline HEMBL3946437 & 537363 & 5.9996 & 993 & \\
\hline HEMBL3S & & 957 & & \\
\hline IFMRI 396 & & & & \\
\hline AEMBL3907657 & 363 & 5.9996 & & \\
\hline HEMBL3980343 & 637363 & 957 & & \\
\hline HEMBL3893985 & 63 & 8.0 & & \\
\hline IEMBL39 & 53 & 957 & & \\
\hline AEMBL39 & & & & \\
\hline HEMBL3892082 & 63 & 957 & & \\
\hline AEMBL39 & 53 & 957 & & \\
\hline AEMBL397 & כנק & 957 & 03 & \\
\hline HEMBL39 & & 957 & & \\
\hline HEMBL39 & & 996 & & \\
\hline HEMBL3890473 & 363 & 3.699 & & \\
\hline AEMBL3S & & 996 & & \\
\hline HEIMBLSS & ס3 & 96 & & \\
\hline AEMBL3S & & 957 & & 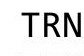 \\
\hline HEMBL3S & & 957 & & \\
\hline 740 & & 957 & & \\
\hline HEMBL389 & & 996 & & \\
\hline HEMBL38 & 6 & & 7. & $\cdots$ \\
\hline HEMBL3 & & 57 & & $\mathrm{RN}$ \\
\hline HFMBI $3 c$ & & 96 & & \\
\hline HEMBL3 & & 996 & & 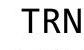 \\
\hline HEMBL3890752 & & 57 & 6.79 & 151 \\
\hline HEMBL3S & & 57 & & RN \\
\hline HEMBL; & & 96 & & Niv \\
\hline AFMRI & & 57 & 79 & RN \\
\hline HEMBL3966491 & & 957 & & IRN \\
\hline HEMBL3964615 & $-1+2+3$ & 996 & & TRN \\
\hline HEMBL3S & & & & TRN \\
\hline HFMRI $=$ & & 57 & & RN \\
\hline HEMBL3 & & 957 & & RN \\
\hline HEMBL3891133 & 637363 & & 198 & TRN \\
\hline HEMBL392 & 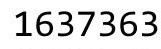 & & & $\Gamma \mathrm{RN}$ \\
\hline HEMBL3 3 & 35 & 6 & 75 & \\
\hline HEMBL39 & & 957 & & IST \\
\hline HEMBL3963844 & 363 & 5.9996 & 9975 & RN \\
\hline HEMBL3957514 & 637363 & 5.9996 & 5805 & TRN \\
\hline HEMBL39 & 627 & 957 & 7.4 & RN \\
\hline CHEMBL 39 & & & 5.8801 & \\
\hline LHEMBL 3980173 & & & .965 & \\
\hline CHEMBL3935766 & 1637363 & 5.9996 & 5.765 & ГRN \\
\hline
\end{tabular}

Page 13429 
Supplemental Table S2.txt

\begin{tabular}{|c|c|c|c|c|}
\hline 然 & 537363 & 7 & 6.6072 & \\
\hline HEMBL3904147 & 637363 & 8.0 & 7.6479 & \\
\hline 565 & & 9996 & 461 & \\
\hline EMBL3908186 & 53 & 9996 & 5442 & \\
\hline JEMBL3899100 & 537363 & 6.9957 & 9074 & \\
\hline AEMBL3952615 & 637363 & . 9996 & 6281 & \\
\hline HEMBL 391 & 637363 & . 9957 & .5129 & \\
\hline HEMBL398 & 53 & & 6 & \\
\hline AEMBL 391 & 363 & 6.9957 & .9276 & \\
\hline HEMBL3896220 & 637363 & 5.9996 & .6202 & \\
\hline HEMBL392e & 363 & 5.9996 & 4527 & \\
\hline HEMBL 395 & 63 & 5.9996 & .6226 & \\
\hline AEMBL $39 e$ & & 957 & & \\
\hline HEMBL 389 & 63 & 5.9996 & 6.2626 & \\
\hline HEMBL 394 & 63 & 6.9957 & 3651 & \\
\hline AEMBL3937654 & 3מ & 8.0 & 7.7091 & \\
\hline HEMBL390 & 3 & 9 & 35 & \\
\hline HEMBL 394 & & & & \\
\hline HEMBL389 & 53 & 6.9957 & 6.2911 & \\
\hline AEMBL39 & 53 & & & TT \\
\hline EMBL 395 & 33 & 6. & 7.2082 & I \\
\hline HEMBL391 & 3 & 996 & 3254 & \\
\hline HEMBL 39 & & 57 & 37 & \\
\hline HFMRI 30 & & 6 & 6.4094 & \\
\hline HEMBL 389 & 3 & 96 & & II \\
\hline HEMBL 397 & 63 & 1996 & 6 & ST \\
\hline HEMBL $39 \angle$ & 3 & 57 & 39 & \\
\hline HEMBL39 & & 57 & 05 & \\
\hline HEMBL 391 & & 6 & & RN \\
\hline HEMBL 396 & 3 & 57 & 069 & |SI \\
\hline AEMBL 390 & 63 & 57 & 36 & ST \\
\hline HEMBL 392 & & 6 & 71 & RN \\
\hline 7 & & & .08 & ST \\
\hline HEMBL393: & & 6.9957 & 048 & TST \\
\hline HEMBL 393 & 3 & & 7.1101 & TST \\
\hline HEMBL396 & 63 & 6 & .2297 & ST \\
\hline HFMRI 30 & & & 902 & ST \\
\hline HEMBL401 & & 7.1871 & 7.1761 & TRN \\
\hline HEMBL 246 & 59 & 7.7696 & 8.0689 & TRN \\
\hline JEMBL400 & 59 & 6.7212 & 5.3267 & 「RN \\
\hline HEMBL 247 & 9 & 202 & .3624 & TRN \\
\hline HEMBL 248 & & 5.8239 & 5.9279 & RN \\
\hline HEMBL 248 & 69 & 7.0 & 7.0977 & TRN \\
\hline HEMBL 247 & 58669 & 6.2924 & .1805 & TRN \\
\hline EMBL406 & & 49 & .0601 & RIV \\
\hline CHEMBL 398 & & 7.9208 & .0344 & \\
\hline CHEMBL397 & 458669 & 6.6576 & 6.8241 & RN \\
\hline CHEMBL400249 & 458669 & 7.0458 & 7.1548 & ГRN \\
\hline
\end{tabular}

Page 13430 


\begin{tabular}{|c|c|c|c|c|c|}
\hline \\
\hline CHEMBL248028 & 458669 & 6.1612 & 6.2261 & TRN & \\
\hline CHEMBL400162 & 458669 & 6.4089 & 6.6651 & TST & \\
\hline CHEMBL247009 & 458669 & 7.5686 & 7.5265 & TRN & \\
\hline CHEMBL249269 & 458669 & 7.284 & 7.1849 & TRN & \\
\hline CHEMBL247045 & 458669 & 5.9208 & 5.7968 & TRN & \\
\hline CHEMBL400058 & 458669 & 7.6198 & 7.6132 & TRN & \\
\hline CHEMBL398542 & 458669 & 6.8539 & 6.978 & TRN & \\
\hline CHEMBL391570 & 458669 & 6.4815 & 6.6098 & TRN & \\
\hline CHEMBL249267 & 458669 & 7.3565 & 7.4065 & TRN & \\
\hline CHEMBL248205 & 458669 & 8.2596 & 8.0689 & TRN & \\
\hline CHEMBL398929 & 458669 & 9.301 & 9.2566 & TRN & \\
\hline CHEMBL402266 & 458669 & 6.9586 & 6.9042 & TRN & \\
\hline CHEMBL250701 & 458669 & 6.2518 & 6.5245 & TST & \\
\hline CHEMBL397312 & 458669 & 7.1249 & 7.1423 & TRN & \\
\hline CHEMBL247010 & 458669 & 8.7447 & 8.7035 & TRN & \\
\hline CHEMBL391780 & 458669 & 6.5086 & 6.3204 & TST & \\
\hline CHEMBL246606 & 458669 & 6.8861 & 6.8766 & TST & \\
\hline CHEMBL399112 & 458669 & 7.9586 & 7.9916 & TRN & \\
\hline CHEMBL247230 & 458669 & 6.4685 & 6.4307 & TRN & \\
\hline CHEMBL273565 & 458669 & 6.699 & 6.768 & TRN & \\
\hline CHEMBL398285 & 458669 & 6.7447 & 6.6827 & TRN & \\
\hline CHEMBL248669 & 458669 & 5.5229 & 5.5732 & TRN & \\
\hline CHEMBL399570 & 458669 & 5.5686 & 5.2136 & TRN & \\
\hline CHEMBL251699 & 458669 & 5.6576 & 5.5498 & TST & \\
\hline CHEMBL249473 & 458669 & 7.7959 & 8.2169 & TRN & \\
\hline CHEMBL400789 & 458669 & 5.7447 & 5.9164 & TRN & \\
\hline CHEMBL397607 & 458669 & 7.4559 & 7.4665 & TRN & \\
\hline CHEMBL391183 & 458669 & 6.5229 & 6.4985 & TRN & \\
\hline CHEMBL399766 & 458669 & 8.0809 & 8.0062 & TRN & \\
\hline CHEMBL395355 & 458669 & 7.585 & 7.3702 & TRN & \\
\hline CHEMBL247411 & 458669 & 5.9208 & 7.44799 & 99999999995 & TST \\
\hline CHEMBL400263 & 458669 & 7.5376 & 7.4082 & TRN & \\
\hline CHEMBL251495 & 458669 & 7.0 & 6.8822 & TRN & \\
\hline CHEMBL251288 & 458669 & 6.7212 & 6.7403 & TRN & \\
\hline CHEMBL399667 & 458669 & 7.6576 & 7.7452 & TRN & \\
\hline CHEMBL 251494 & 458669 & 6.6778 & 6.6541 & TRN & \\
\hline CHEMBL248048 & 458669 & 6.9586 & 6.8118 & TRN & \\
\hline CHEMBL248670 & 458669 & 5.3372 & 5.2706 & TRN & \\
\hline CHEMBL394744 & 458669 & 7.9586 & 6.8142 & TST & \\
\hline CHEMBL246807 & 458669 & 5.8861 & 5.9919 & TRN & \\
\hline CHEMBL401487 & 458669 & 8.4437 & 7.9031 & TRN & \\
\hline CHEMBL249271 & 458669 & 8.6778 & 8.7349 & TRN & \\
\hline CHEMBL398408 & 458669 & 5.5086 & 5.7368 & TRN & \\
\hline CHEMBL398667 & 458669 & 6.9586 & 6.9709 & TRN & \\
\hline CHEMBL247088 & 458669 & 6.8539 & 6.8975 & TRN & \\
\hline CHEMBL 248861 & 458669 & 5.4685 & 5.5153 & TRN & \\
\hline CHEMBL399564 & 458669 & 5.5528 & 6.0803 & TRN & \\
\hline CHEMBL249065 & 458669 & 7.5229 & 7.4503 & TRN & \\
\hline
\end{tabular}




\begin{tabular}{|c|c|c|c|c|c|}
\hline \multicolumn{6}{|c|}{ Supplemental Table s2.txt } \\
\hline CHEMBL248862 & 458669 & 7.6021 & 7.6173 & TRN & \\
\hline CHEMBL 249268 & 458669 & 6.8861 & 6.8218 & TRN & \\
\hline CHEMBL250495 & 458669 & 6.6576 & 6.5669 & TST & \\
\hline CHEMBL246605 & 458669 & 7.4318 & 7.2133 & TST & \\
\hline CHEMBL247636 & 458669 & 7.1192 & 6.7407 & TST & \\
\hline CHEMBL 246631 & 458669 & 7.5376 & 8.0447 & TST & \\
\hline CHEMBL 251287 & 458669 & 6.7212 & 6.2477 & TST & \\
\hline CHEMBL249270 & 458669 & 7.4949 & 7.3994 & TST & \\
\hline CHEMBL398266 & 458669 & 6.1739 & 6.5623 & TST & \\
\hline CHEMBL438348 & 458669 & 6.6778 & 6.4069 & TST & \\
\hline CHEMBL397608 & 458669 & 7.5686 & 6.8868 & TST & \\
\hline CHEMBL248224 & 458669 & 5.8861 & 5.5929 & TST & \\
\hline CHEMBL251698 & 458669 & 6.3665 & 6.3949 & TST & \\
\hline CHEMBL249064 & 458669 & 7.2076 & 7.6508 & TST & \\
\hline CHEMBL 3687826 & 1528218 & 5.1746 & 4.6146 & TRN & \\
\hline CHEMBL3687851 & 1528218 & 6.6885 & 6.3577 & TRN & \\
\hline CHEMBL3678033 & 1528218 & 5.0947 & 2.9134 & TST & \\
\hline CHEMBL 3687858 & 1528218 & 4.0 & 4.4185 & TRN & \\
\hline CHEMBL3682913 & 1528218 & 5.9355 & 5.9042 & TRN & \\
\hline CHEMBL3682918 & 1528218 & 7.0453 & 6.5317 & TRN & \\
\hline CHEMBL3687765 & 1528218 & 5.0778 & 5.1005 & TRN & \\
\hline CHEMBL 3682885 & 1528218 & 5.5768 & 5.0929 & TRN & \\
\hline CHEMBL3682853 & 1528218 & 5.1561 & 5.1048 & TRN & \\
\hline CHEMBL 3683022 & 1528218 & 6.6517 & 7.0494 & TRN & \\
\hline CHEMBL3687796 & 1528218 & 7.2434 & 7.3755 & TRN & \\
\hline CHEMBL3682929 & 1528218 & 4.0 & 4.8541 & TRN & \\
\hline CHEMBL3683012 & 1528218 & 6.0083 & 6.2228 & TRN & \\
\hline CHEMBL3683059 & 1528218 & 4.0 & 4.2692 & TRN & \\
\hline CHEMBL 3687946 & 1528218 & 4.9872 & 4.8835 & TRN & \\
\hline CHEMBL3687953 & 1528218 & 6.9274 & 6.5045 & TRN & \\
\hline CHEMBL 3683044 & 1528218 & 5.7865 & 6.7849 & TRN & \\
\hline CHEMBL3683009 & 1528218 & 5.4572 & 5.055 & TRN & \\
\hline CHEMBL3682954 & 1528218 & 6.9431 & 6.2656 & TRN & \\
\hline CHEMBL3687909 & 1528218 & 5.8356 & 5.7867 & TRN & \\
\hline CHEMBL3682989 & 1528218 & 5.8976 & 6.2755 & TRN & \\
\hline CHEMBL 3687853 & 1528218 & 4.0 & 5.5236 & TST & \\
\hline CHEMBL3682844 & 1528218 & 6.8996 & 6.6774 & TRN & \\
\hline CHEMBL3682995 & 1528218 & 7.1244 & 6.1702 & TRN & \\
\hline CHEMBL 3687930 & 1528218 & 3.5229 & 4.6918 & TST & \\
\hline CHEMBL3687915 & 1528218 & 5.6421 & 5.739 & TRN & \\
\hline CHEMBL 3687801 & 1528218 & 5.4214 & 5.4142 & TRN & \\
\hline CHEMBL3682948 & 1528218 & 5.0685 & 4.7122 & TRN & \\
\hline CHEMBL3687884 & 1528218 & 5.2733 & 6.0345 & TST & \\
\hline CHEMBL 3682950 & 1528218 & 4.0 & 4.2038 & TRN & \\
\hline CHEMBL3683026 & 1528218 & 5.0343 & 4.7601 & TRN & \\
\hline CHEMBL 3687780 & 1528218 & 6.9352 & 6.7318 & TRN & \\
\hline CHEMBL3682905 & 1528218 & 6.5157 & 6.53600 & 20000000005 & TRN \\
\hline CHEMBL 3687867 & 1528218 & 5.2782 & 5.6586 & TST & \\
\hline
\end{tabular}


Supplemental Table S2.txt

\begin{tabular}{|c|c|c|c|c|c|c|}
\hline CHEMBL 3687823 & 1528218 & 6.7167 & 6.4969 & TRN & & \\
\hline CHEMBL 3682942 & 1528218 & 5.9935 & 5.6315 & TRN & & \\
\hline CHEMBL 3683027 & 1528218 & 5.8447 & 5.843 & TRN & & \\
\hline CHEMBL 3678036 & 1528218 & 5.1062 & 5.5564 & TST & & \\
\hline CHEMBL 3678047 & 1528218 & 5.3143 & 5.8867 & TRN & & \\
\hline CHEMBL 3678013 & 1528218 & 6.0737 & 5.6903 & TST & & \\
\hline CHEMBL 3682858 & 1528218 & 7.1656 & 7.3726 & TRN & & \\
\hline CHEMBL 3687948 & 1528218 & 5.0947 & 4.9063 & TRN & & \\
\hline CHEMBL 3678061 & 1528218 & 5.8097 & 4.5918 & TST & & \\
\hline CHEMBL 3683006 & 1528218 & 5.0061 & 4.9366 & TRN & & \\
\hline CHEMBL 3682983 & 1528218 & 4.0 & 4.875 & TST & & \\
\hline CHEMBL 3678043 & 1528218 & 5.4318 & 5.5674 & TST & & \\
\hline CHEMBL 3687795 & 1528218 & 6.8225 & 6.8011 & TRN & & \\
\hline CHEMBL 3678053 & 1528218 & 7.301 & 6.4649 & TRN & & \\
\hline CHEMBL 3687775 & 1528218 & 4.0 & 4.8336 & TRN & & \\
\hline CHEMBL 3682987 & 1528218 & 7.0899 & 6.5962 & TRN & & \\
\hline CHEMBL 3687827 & 1528218 & 6.7991 & 5.5317 & TRN & & \\
\hline CHEMBL 3687842 & 1528218 & 6.3344 & 6.4258 & TST & & \\
\hline CHEMBL 3678028 & 1528218 & 5.289 & 4.8909 & TST & & \\
\hline CHEMBL 3678001 & 1528218 & 4.9957 & 5.0789 & TST & & \\
\hline CHEMBL 3678017 & 1528218 & 5.644 & 5.8584 & TRN & & \\
\hline CHEMBL 3687929 & 1528218 & 3.5229 & 4.1032 & TST & & \\
\hline CHEMBL 3682859 & 1528218 & 6.5391 & 6.3118 & TRN & & \\
\hline CHEMBL3687896 & 1528218 & 6.7959 & 5.9642 & TRN & & \\
\hline CHEMBL 3639867 & 1528218 & 6.3915 & 5.4953 & TRN & & \\
\hline CHEMBL 3687923 & 1528218 & 6.5017 & 5.9928 & TRN & & \\
\hline CHEMBL3682931 & 1528218 & 5.2782 & 5.3899 & TRN & & \\
\hline CHEMBL 3678040 & 1528218 & 6.0223 & 4.7544 & TST & & \\
\hline CHEMBL 3687901 & 1528218 & 5.1337 & 6.2812 & TRN & & \\
\hline CHEMBL 3687825 & 1528218 & 5.0227 & 4.6839 & TRN & & \\
\hline CHEMBL 3687891 & 1528218 & 6.71 & 5.8992 & TRN & & \\
\hline CHEMBL 3678010 & 1528218 & 5.3215 & 5.9804 & TRN & & \\
\hline CHEMBL 3683007 & 1528218 & 4.0 & 4.2083 & TRN & & \\
\hline CHEMBL3677991 & 1528218 & 6.26200 & 000000000 & 305 & 6.103 & TRN \\
\hline CHEMBL 3682986 & 1528218 & 7.3152 & 6.3884 & TRN & & \\
\hline CHEMBL 3682884 & 1528218 & 6.808 & 6.817 & TRN & & \\
\hline CHEMBL 3687922 & 1528218 & 5.7799 & 5.8011 & TRN & & \\
\hline CHEMBL 3687832 & 1528218 & 6.7011 & 6.6927 & TRN & & \\
\hline CHEMBL3687916 & 1528218 & 5.4056 & 5.4773 & TRN & & \\
\hline CHEMBL 3683047 & 1528218 & 4.98300 & 000000000 & 305 & 4.7227 & TRN \\
\hline CHEMBL 3677995 & 1528218 & 4.0 & 4.6964 & TST & & \\
\hline CHEMBL 3687882 & 1528218 & 5.3585 & 5.9537 & TRN & & \\
\hline CHEMBL 3687773 & 1528218 & 4.98300 & 000000000 & 305 & 4.2666 & TRN \\
\hline CHEMBL 3687804 & 1528218 & 6.9234 & 6.7133 & TRN & & \\
\hline CHEMBL 3682861 & 1528218 & 6.6345 & 6.1205 & TRN & & \\
\hline CHEMBL 3687777 & 1528218 & 5.0535 & 5.2215 & TRN & & \\
\hline CHEMBL 3683017 & 1528218 & 6.2321 & 5.9121 & TRN & & \\
\hline CHEMBL 3683011 & 1528218 & 5.083 & 4.9374 & TRN & & \\
\hline
\end{tabular}


Supplemental Table S2.txt

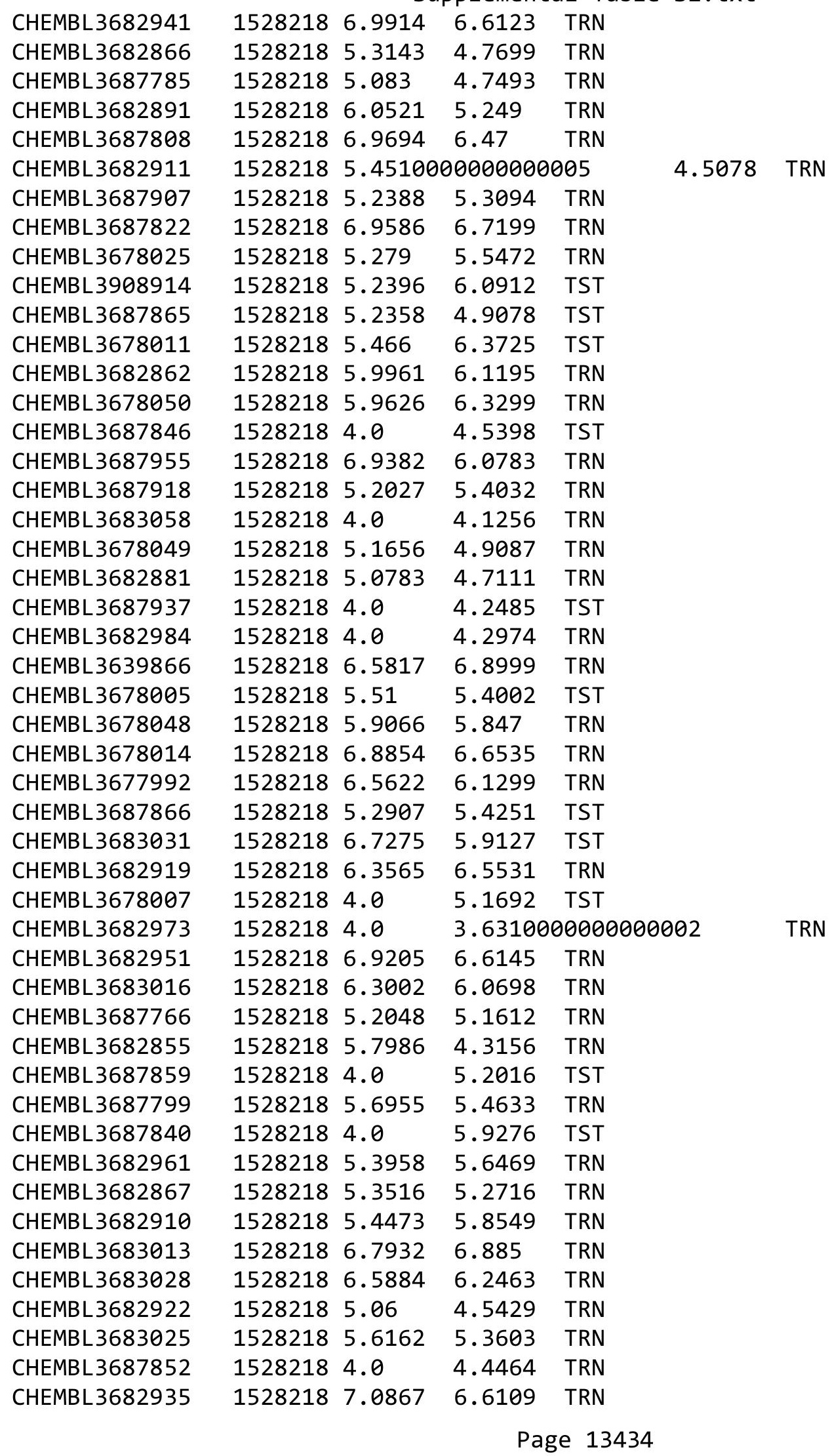


Supplemental Table S2.txt

\begin{tabular}{|c|c|c|c|c|c|}
\hline CHEMBL 3687816 & 1528218 & 5.3737 & 5.1665 & TRN & \\
\hline CHEMBL 3682926 & 1528218 & 5.3915 & 5.5366 & TRN & \\
\hline CHEMBL 3687893 & 1528218 & 6.38299 & 99999999 & 99 & 6.4791 \\
\hline CHEMBL 3682872 & 1528218 & 5.5622 & 5.8327 & TRN & \\
\hline CHEMBL3678026 & 1528218 & 4.9547 & 5.8949 & TST & \\
\hline CHEMBL 3687794 & 1528218 & 4.0 & 4.9934 & TST & \\
\hline CHEMBL 3682852 & 1528218 & 6.0888 & 5.6411 & TRN & \\
\hline CHEMBL 3678032 & 1528218 & 5.4881 & 5.5652 & TST & \\
\hline CHEMBL 3687863 & 1528218 & 4.9914 & 4.5892 & TST & \\
\hline CHEMBL3683040 & 1528218 & 5.1255 & 5.1236 & TRN & \\
\hline CHEMBL 3678015 & 1528218 & 5.9666 & 5.9384 & TST & \\
\hline CHEMBL 3683061 & 1528218 & 4.0 & 4.1656 & TRN & \\
\hline CHEMBL 3682994 & 1528218 & 5.4271 & 5.8165 & TRN & \\
\hline CHEMBL 3682923 & 1528218 & 4.0 & 4.8825 & TST & \\
\hline CHEMBL3683030 & 1528218 & 6.4145 & 6.8191 & TRN & \\
\hline CHEMBL 3687860 & 1528218 & 6.2495 & 6.0608 & TST & \\
\hline CHEMBL 3687888 & 1528218 & 4.9318 & 4.2205 & TST & \\
\hline CHEMBL 3682974 & 1528218 & 5.5346 & 5.7383 & TRN & \\
\hline CHEMBL 3687805 & 1528218 & 6.9698 & 6.6948 & TRN & \\
\hline CHEMBL 3687936 & 1528218 & 4.0 & 4.7984 & TRN & \\
\hline CHEMBL 3678008 & 1528218 & 6.2487 & 6.4005 & TRN & \\
\hline CHEMBL 3682880 & 1528218 & 4.0 & 4.5188 & TRN & \\
\hline CHEMBL 3682876 & 1528218 & 6.7986 & 6.5631 & TRN & \\
\hline CHEMBL 3682886 & 1528218 & 5.1296 & 5.6375 & TRN & \\
\hline CHEMBL 3682975 & 1528218 & 4.0 & 4.3652 & TRN & \\
\hline CHEMBL 3687774 & 1528218 & 4.0 & 4.5784 & TRN & \\
\hline CHEMBL 3687821 & 1528218 & 6.4324 & 6.5998 & TRN & \\
\hline CHEMBL 3687854 & 1528218 & 4.0 & 4.6438 & TST & \\
\hline CHEMBL 3687813 & 1528218 & 5.1675 & 5.1806 & TRN & \\
\hline CHEMBL 3687772 & 1528218 & 4.0 & 3.697 & TRN & \\
\hline CHEMBL 3682921 & 1528218 & 4.0 & 4.3963 & TRN & \\
\hline CHEMBL 3687920 & 1528218 & 5.6345 & 5.7198 & TRN & \\
\hline CHEMBL 3687868 & 1528218 & 5.1163 & 5.5701 & TRN & \\
\hline CHEMBL 3683056 & 1528218 & 4.0 & 3.2167 & TRN & \\
\hline CHEMBL 3682846 & 1528218 & 6.3261 & 6.2456 & TRN & \\
\hline CHEMBL 3687898 & 1528218 & 6.2676 & 5.9642 & TRN & \\
\hline CHEMBL 3678022 & 1528218 & 5.1118 & 4.6883 & TST & \\
\hline CHEMBL 3687834 & 1528218 & 7.2954 & 6.4202 & TRN & \\
\hline CHEMBL 3683050 & 1528218 & 4.0 & 3.7616 & TRN & \\
\hline CHEMBL 3687800 & 1528218 & 5.7959 & 5.6182 & TRN & \\
\hline CHEMBL 3682930 & 1528218 & 5.8986 & 5.8776 & TRN & \\
\hline CHEMBL 3678057 & 1528218 & 5.5003 & 5.796 & TRN & \\
\hline CHEMBL3677993 & 1528218 & 6.4522 & 5.8931 & TST & \\
\hline CHEMBL 3682976 & 1528218 & 4.0 & 5.2986 & TRN & \\
\hline CHEMBL 3682857 & 1528218 & 5.4789 & 5.7897 & TRN & \\
\hline CHEMBL 3687833 & 1528218 & 5.9776 & 5.9509 & TRN & \\
\hline CHEMBL 3678062 & 1528218 & 5.9245 & 5.925 & TRN & \\
\hline CHEMBL 3687845 & 1528218 & 4.0 & 4.7189 & TST & \\
\hline
\end{tabular}


Supplemental Table S2.txt

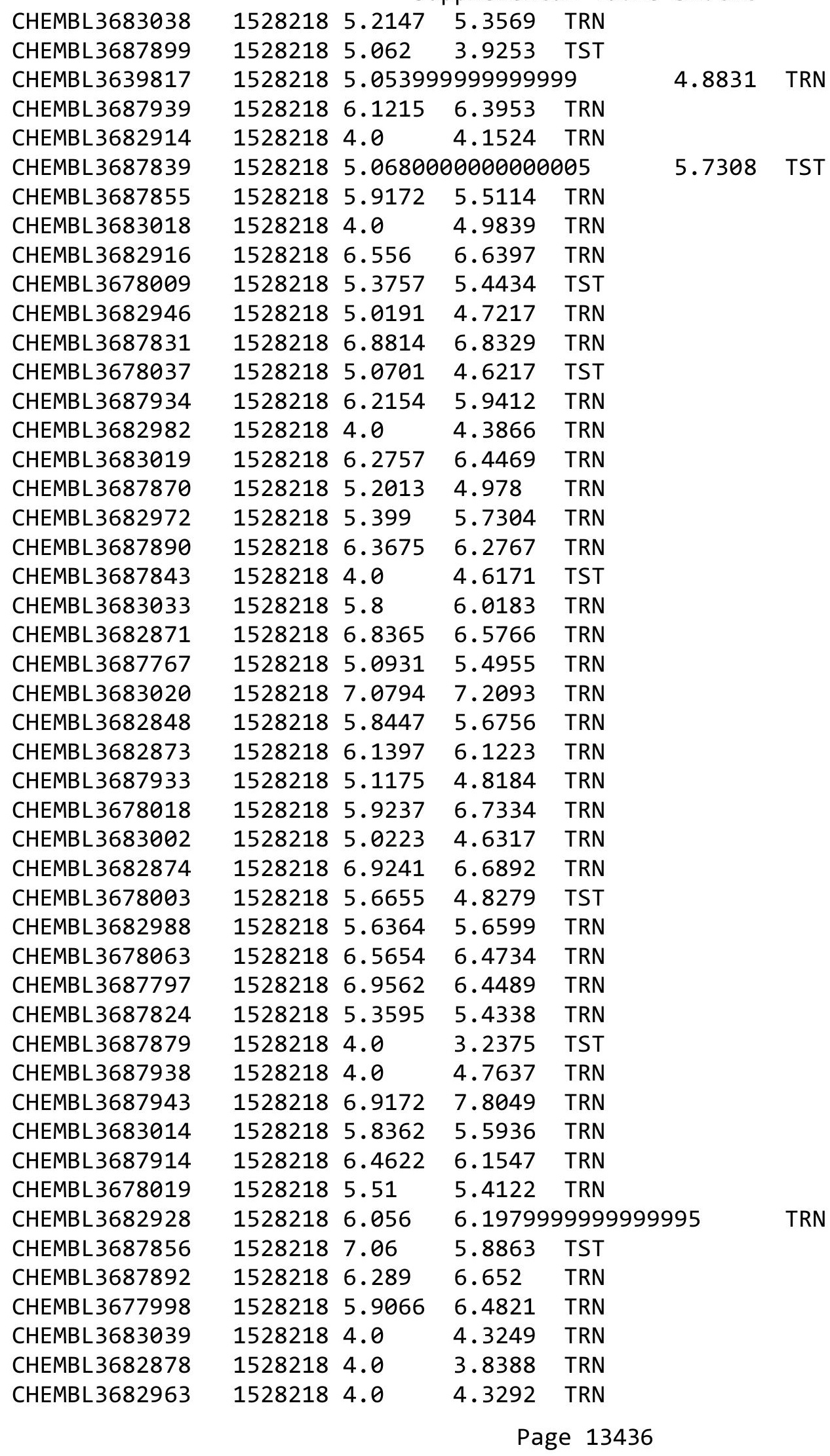


Supplemental Table S2.txt

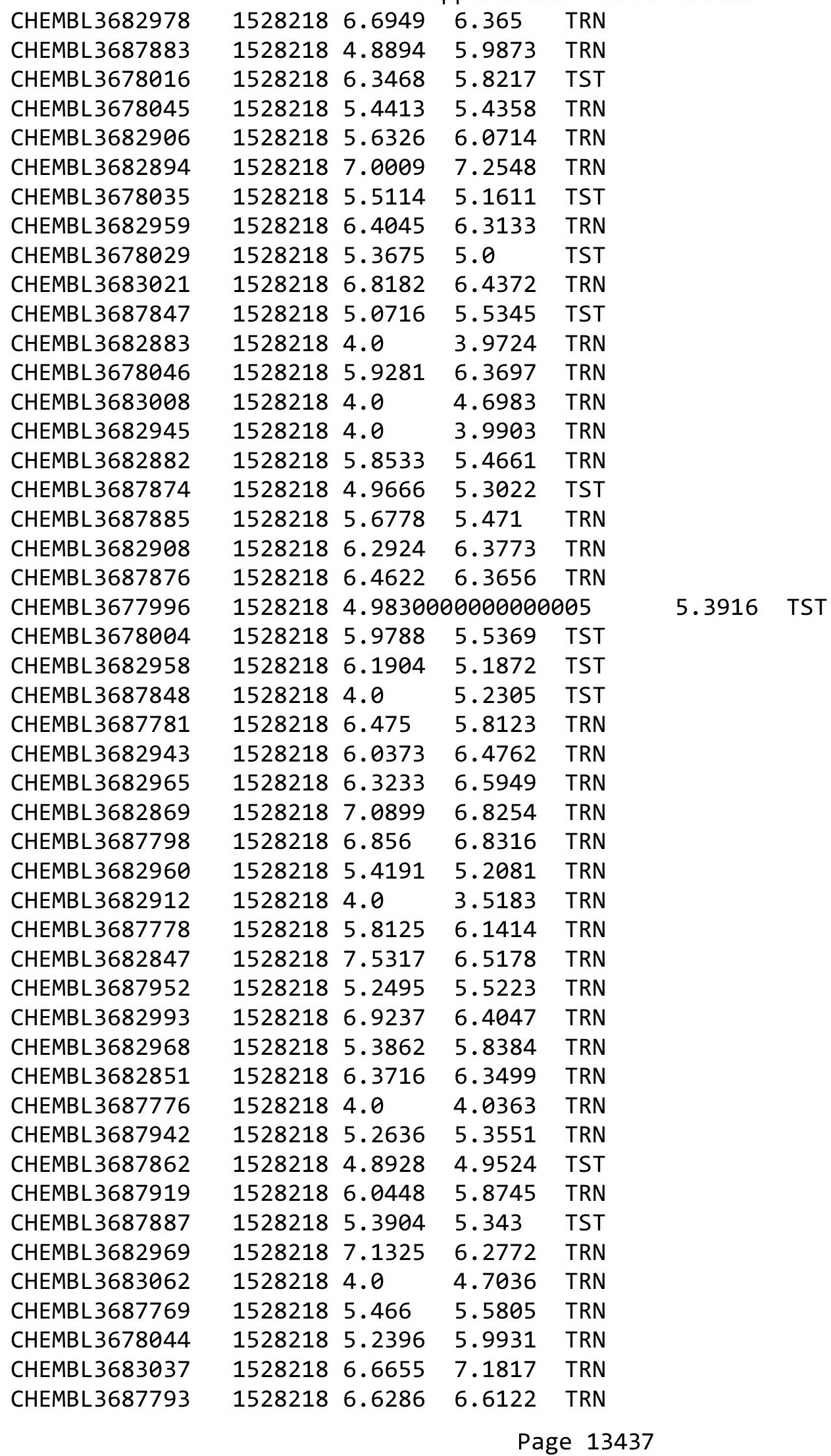


Supplemental Table S2.txt

\begin{tabular}{|c|c|c|c|c|}
\hline HEMBL 368787 & 18 & 4.0 & & \\
\hline HEMBL3687764 & 528218 & 5.9259 & 5.3005 & \\
\hline 836 & 28218 & & & \\
\hline AEMBL: & 28218 & & 702 & \\
\hline AEMBL3687762 & 528218 & 438 & 5908 & \\
\hline AEMBL3682991 & 528218 & 5.0726 & 8464 & \\
\hline HEMBL3687838 & 528218 & 7.1688 & .5982 & \\
\hline IEMBL3 & 528218 & & 17 & \\
\hline IEMBL368 & 528218 & & 1018 & \\
\hline HEMBL3687791 & 528218 & 5.6216 & 5.2972 & \\
\hline HEMBL 3687818 & 528218 & 6. & .9575 & \\
\hline HEMBL 368 & 528218 & 5.767 & .892 & \\
\hline HEMBL & 8218 & & & \\
\hline HEMBL & 528218 & & .7551 & \\
\hline AEMBL367 & 528218 & 5 . & .9103 & \\
\hline HEMBL 368 & 528218 & $6.7 x-7$ & 4891 & \\
\hline AEMBL36 & 528218 & & 4.8875 & \\
\hline HEMBL & 8218 & & & \\
\hline HEMBL & 528218 & 4 & .3503 & \\
\hline HEMBL36 & 528218 & 4 & 5.1754 & \\
\hline HEMBL 368 & 528218 & 5 . & 5.4022 & KIV \\
\hline HEMBL3 & 28218 & 5 & 192 & SI \\
\hline HEMBL; & 528218 & & 51 & RN \\
\hline 39 & 3218 & 4 & 308 & RN \\
\hline AEMBL36 & 218 & 4 & 7272 & RN \\
\hline HEMBL36ई & 18 & 5 . & 5.6501 & ГRN \\
\hline HEMBL36 & 528218 & 5 & 1.9857 & 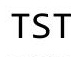 \\
\hline HEMBL3 & 218 & & .3806 & ST \\
\hline HEM & 18 & & 935 & RN \\
\hline AEMBL36 & 18 & 5 . & 15 & RN \\
\hline HEMBL 368 & 218 & & 4861 & ГRN \\
\hline HEMBL 36 & 3218 & & 3.7223 & I \\
\hline HEMBL3 & 18 & & 59 & RN \\
\hline 3 & & & 847 & RN \\
\hline AEMBL 363 & 528218 & 4 & a & RN \\
\hline EMBL 368 & 8218 & 0 & 721 & \\
\hline HEMBL 368 & 218 & 7. & 434 & RIV \\
\hline & & & & RN \\
\hline HEMBL 368 & 528218 & 6 . & 514 & RN \\
\hline HEMBL 368 & 528218 & 4 & 4.6796 & RN \\
\hline AEMBL368 & 28218 & 4 & 716 & \\
\hline HEMBL368 & & & 5.7915 & \\
\hline HEMBL 36 & & & & RN \\
\hline HEMBL368 & 528218 & 4.0 & 4.0784 & RN \\
\hline JEMBL368 & 528218 & & t. & $K$ \\
\hline HEMBL36 & 528218 & & & \\
\hline CHEMBL3 & 1528218 & 5.87 & & \\
\hline 3682902 & 152821 & .0 & 59 & \\
\hline
\end{tabular}

Page 13438 


\begin{tabular}{|c|c|c|c|c|c|c|}
\hline \multicolumn{7}{|c|}{ Supplemental Table S2.txt } \\
\hline CHEMBL 3687841 & 1528218 & 4.0 & 5.1407 & TST & & \\
\hline CHEMBL3639768 & 1528218 & 5.7423 & 5.7288 & TRN & & \\
\hline CHEMBL3687837 & 1528218 & 5.5436 & 5.5509 & TRN & & \\
\hline CHEMBL3682896 & 1528218 & 6.8447 & 5.0759 & TST & & \\
\hline CHEMBL3687869 & 1528218 & 4.9914 & 5.0737 & TST & & \\
\hline CHEMBL3682962 & 1528218 & 5.38399 & 99999999 & 995 & 5.1282 & TRN \\
\hline CHEMBL3678012 & 1528218 & 5.295 & 5.8905 & TST & & \\
\hline CHEMBL3687880 & 1528218 & 4.0 & 3.9643 & TST & & \\
\hline CHEMBL3682953 & 1528218 & 5.5058 & 5.4238 & TRN & & \\
\hline CHEMBL 3683045 & 1528218 & 5.6216 & 5.4642 & TRN & & \\
\hline CHEMBL3682909 & 1528218 & 4.0 & 4.7947 & TRN & & \\
\hline CHEMBL3687812 & 1528218 & 7.0031 & 7.0737 & TRN & & \\
\hline CHEMBL3678056 & 1528218 & 5.6655 & 5.0402 & TRN & & \\
\hline CHEMBL3682915 & 1528218 & 4.0 & 5.3853 & TRN & & \\
\hline CHEMBL3687947 & 1528218 & 4.0 & 3.8138 & TST & & \\
\hline CHEMBL3682944 & 1528218 & 7.3788 & 6.8512 & TRN & & \\
\hline CHEMBL3682854 & 1528218 & 5.4935 & 6.1943 & TRN & & \\
\hline CHEMBL3687908 & 1528218 & 5.8386 & 6.2599 & TRN & & \\
\hline CHEMBL 3678024 & 1528218 & 5.5482 & 6.7329 & TST & & \\
\hline CHEMBL3687941 & 1528218 & 4.0 & 3.5505 & TST & & \\
\hline CHEMBL3683029 & 1528218 & 5.0339 & 5.4945 & TST & & \\
\hline CHEMBL 3682947 & 1528218 & 4.0 & 4.5643 & TRN & & \\
\hline CHEMBL3683042 & 1528218 & 5.2733 & 4.9497 & TRN & & \\
\hline CHEMBL 3687768 & 1528218 & 4.0 & 4.2702 & TST & & \\
\hline CHEMBL 3687954 & 1528218 & 5.05699 & 99999999 & 995 & 5.1357 & TRN \\
\hline CHEMBL 3687878 & 1528218 & 4.9547 & 4.0795 & TST & & \\
\hline CHEMBL3683054 & 1528218 & 5.4248 & 5.0105 & TST & & \\
\hline CHEMBL3687906 & 1528218 & 5.8477 & 4.8372 & TRN & & \\
\hline CHEMBL3687861 & 1528218 & 4.0 & 5.7735 & TST & & \\
\hline CHEMBL 3687957 & 1528218 & 4.0 & 4.3798 & TST & & \\
\hline CHEMBL 3683001 & 1528218 & 5.5045 & 5.2461 & TRN & & \\
\hline CHEMBL3682865 & 1528218 & 5.4486 & 5.4467 & TRN & & \\
\hline CHEMBL3687889 & 1528218 & 5.6615 & 6.3875 & TRN & & \\
\hline CHEMBL 3683051 & 1528218 & 6.1537 & 4.7581 & TST & & \\
\hline CHEMBL3687782 & 1528218 & 6.8327 & 6.7933 & TRN & & \\
\hline CHEMBL3677994 & 1528218 & 5.4001 & 5.8771 & TST & & \\
\hline CHEMBL3683060 & 1528218 & 4.0 & 3.5451 & TST & & \\
\hline CHEMBL3683015 & 1528218 & 6.5735 & 6.6136 & TRN & & \\
\hline CHEMBL 3687815 & 1528218 & 6.7525 & 7.1103 & TRN & & \\
\hline CHEMBL3687951 & 1528218 & 6.4597 & 6.9805 & TRN & & \\
\hline CHEMBL3683034 & 1528218 & 6.3401 & 6.3056 & TRN & & \\
\hline CHEMBL3682967 & 1528218 & 5.7375 & 6.1157 & TRN & & \\
\hline CHEMBL3678038 & 1528218 & 5.567 & 6.0567 & TST & & \\
\hline CHEMBL 3678041 & 1528218 & 5.9957 & 5.4117 & TST & & \\
\hline CHEMBL 3687759 & 1528218 & 5.0 & 4.5599 & TST & & \\
\hline CHEMBL 3687903 & 1528218 & 5.3107 & 5.8876 & TRN & & \\
\hline CHEMBL 3687792 & 1528218 & 5.7077 & 5.7303 & TRN & & \\
\hline CHEMBL3687873 & 1528218 & 5.7959 & 5.8395 & TRN & & \\
\hline
\end{tabular}


Supplemental Table S2.txt

\begin{tabular}{|c|c|c|c|c|c|c|}
\hline CHEMBL3687905 & 1528218 & 6.4921 & 6.3639 & TRN & & \\
\hline CHEMBL 3683023 & 1528218 & 4.0 & 4.5872 & TRN & & \\
\hline CHEMBL 3687786 & 1528218 & 4.0 & 4.6419 & TRN & & \\
\hline CHEMBL 3687790 & 1528218 & 7.3089 & 6.9219 & TRN & & \\
\hline CHEMBL3682992 & 1528218 & 5.1355 & 5.3777 & TRN & & \\
\hline CHEMBL 3678052 & 1528218 & 6.7937 & 6.2371 & TRN & & \\
\hline CHEMBL 3678059 & 1528218 & 5.9914 & 5.7592 & TRN & & \\
\hline CHEMBL 3682925 & 1528218 & 4.0 & 4.1699 & TRN & & \\
\hline CHEMBL 3678027 & 1528218 & 4.9408 & 3.7685 & TST & & \\
\hline CHEMBL3682957 & 1528218 & 6.767 & 7.0361 & TRN & & \\
\hline CHEMBL 3687787 & 1528218 & 5.3768 & 4.9349 & TRN & & \\
\hline CHEMBL 3678000 & 1528218 & 5.1355 & 5.3283 & TRN & & \\
\hline CHEMBL3677999 & 1528218 & 4.0 & 5.3182 & TST & & \\
\hline CHEMBL 3682864 & 1528218 & 5.8897 & 5.9968 & TRN & & \\
\hline CHEMBL3682977 & 1528218 & 6.5817 & 6.3375 & TRN & & \\
\hline CHEMBL 3682964 & 1528218 & 5.3458 & 5.4 & TRN & & \\
\hline CHEMBL 3687877 & 1528218 & 5.9666 & 5.7307 & TRN & & \\
\hline CHEMBL 3682924 & 1528218 & 5.0487 & 4.3542 & TRN & & \\
\hline CHEMBL3682890 & 1528218 & 6.8248 & 6.4611 & TRN & & \\
\hline CHEMBL3678030 & 1528218 & 5.3036 & 5.2853 & TST & & \\
\hline CHEMBL 3678055 & 1528218 & 5.1273 & 4.9253 & TRN & & \\
\hline CHEMBL3683005 & 1528218 & 5.82100 & 000000000 & 01 & 6.0922 & TRN \\
\hline CHEMBL 3682887 & 1528218 & 7.1574 & 6.2165 & TRN & & \\
\hline CHEMBL 3682937 & 1528218 & 6.7471 & 6.4085 & TRN & & \\
\hline CHEMBL 3687850 & 1528218 & 4.0 & 5.2579 & TST & & \\
\hline CHEMBL 3687900 & 1528218 & 6.4698 & 5.6987 & TRN & & \\
\hline CHEMBL 3682932 & 1528218 & 5.3002 & 4.9443 & TRN & & \\
\hline CHEMBL 3687758 & 1528218 & 5.4089 & 5.5867 & TST & & \\
\hline CHEMBL 3682868 & 1528218 & 4.0 & 4.3652 & TRN & & \\
\hline CHEMBL 3687761 & 1528218 & 5.2418 & 4.9896 & TST & & \\
\hline CHEMBL 3682980 & 1528218 & 5.4498 & 4.9113 & TRN & & \\
\hline CHEMBL 3687828 & 1528218 & 5.3054 & 4.9335 & TST & & \\
\hline CHEMBL 3678039 & 1528218 & 6.08299 & 999999999 & 99 & 4.9079 & TST \\
\hline CHEMBL 3682990 & 1528218 & 5.4461 & 5.1725 & TRN & & \\
\hline CHEMBL 3682981 & 1528218 & 4.0 & 4.5081 & TRN & & \\
\hline CHEMBL3682939 & 1528218 & 5.8996 & 5.9064 & TRN & & \\
\hline CHEMBL 3682956 & 1528218 & 6.6308 & 6.7909 & TRN & & \\
\hline CHEMBL 3678020 & 1528218 & 5.0026 & 4.4814 & TST & & \\
\hline CHEMBL 3687911 & 1528218 & 5.4145 & 5.092 & TST & & \\
\hline CHEMBL 3687927 & 1528218 & 7.2774 & 6.7744 & TRN & & \\
\hline CHEMBL3682952 & 1528218 & 5.4145 & 5.0934 & TRN & & \\
\hline CHEMBL 3687849 & 1528218 & 4.0 & 4.7216 & TST & & \\
\hline CHEMBL3682893 & 1528218 & 7.0448 & 6.7084 & TRN & & \\
\hline CHEMBL 3682998 & 1528218 & 6.0414 & 6.0635 & TRN & & \\
\hline CHEMBL3683036 & 1528218 & 5.6055 & 5.9721 & TRN & & \\
\hline CHEMBL3682877 & 1528218 & 6.6421 & 6.8249 & TRN & & \\
\hline CHEMBL 3683043 & 1528218 & 6.3036 & 6.3166 & TRN & & \\
\hline CHEMBL 3683046 & 1528218 & 5.9393 & 6.0115 & TRN & & \\
\hline
\end{tabular}


Supplemental Table S2.txt

\begin{tabular}{|c|c|c|c|c|c|}
\hline CHEMBL 3682889 & 1528218 & 6.3757 & 5.1456 & TRN & \\
\hline CHEMBL 3678051 & 1528218 & 5.8041 & 6.2093 & TRN & \\
\hline CHEMBL3683000 & 1528218 & 5.6478 & 5.0008 & TRN & \\
\hline CHEMBL3678006 & 1528218 & 5.5143 & 5.6983 & TST & \\
\hline CHEMBL 3682997 & 1528218 & 5.2807 & 5.3646 & TRN & \\
\hline CHEMBL3687917 & 1528218 & 6.0555 & 5.7594 & TRN & \\
\hline CHEMBL3682970 & 1528218 & 4.0 & 4.0722 & TRN & \\
\hline CHEMBL 3687771 & 1528218 & 5.9654 & 5.3702 & TST & \\
\hline CHEMBL 3687763 & 1528218 & 5.2692 & 4.8982 & TST & \\
\hline CHEMBL 3687770 & 1528218 & 5.3134 & 5.3144 & TST & \\
\hline CHEMBL3678002 & 1528218 & 5.3615 & 5.6758 & TST & \\
\hline CHEMBL 3682888 & 1528218 & 5.1238 & 4.7494 & TST & \\
\hline CHEMBL 3687910 & 1528218 & 5.5482 & 5.8632 & TRN & \\
\hline CHEMBL3682879 & 1528218 & 4.0 & 4.5196 & TRN & \\
\hline CHEMBL 3687871 & 1528218 & 5.2941 & 4.7155 & TST & \\
\hline CHEMBL3682845 & 1528218 & 4.8416 & 5.3519 & TST & \\
\hline CHEMBL3687932 & 1528218 & 4.0 & 5.2714 & TRN & \\
\hline CHEMBL 3682966 & 1528218 & 6.4101 & 6.4826 & TRN & \\
\hline CHEMBL 3682850 & 1528218 & 6.0164 & 5.5497 & TRN & \\
\hline CHEMBL 3682901 & 1528218 & 5.4868 & 5.45 & TRN & \\
\hline CHEMBL 3683052 & 1528218 & 4.9747 & 4.6098 & TST & \\
\hline CHEMBL3683048 & 1528218 & 5.0255 & 4.1416 & TST & \\
\hline CHEMBL 3682900 & 1528218 & 5.4698 & 5.6394 & TRN & \\
\hline CHEMBL3687844 & 1528218 & 4.0 & 5.6988 & TST & \\
\hline CHEMBL 3683004 & 1528218 & 5.556 & 5.6058 & TRN & \\
\hline CHEMBL 3678021 & 1528218 & 5.7773 & 6.2834 & TRN & \\
\hline CHEMBL 3682843 & 1528218 & 5.6091 & 5.6541 & TRN & \\
\hline CHEMBL 3682927 & 1528218 & 6.7404 & 6.0963 & TRN & \\
\hline CHEMBL 3682856 & 1528218 & 5.6271 & 5.5403 & TRN & \\
\hline CHEMBL 3687925 & 1528218 & \multicolumn{2}{|c|}{4.9830000000000005} & 4.4648 & TST \\
\hline CHEMBL3687779 & 1528218 & 5.1481 & 4.7147 & TRN & \\
\hline CHEMBL 3677990 & 1528218 & 6.9097 & 6.7319 & TRN & \\
\hline CHEMBL 3683055 & 1528218 & 5.1824 & 4.7179 & TST & \\
\hline CHEMBL3683057 & 1528218 & 4.0 & 3.7366 & TST & \\
\hline CHEMBL 3687835 & 1528218 & 4.9431 & 5.4366 & TRN & \\
\hline CHEMBL3683024 & 1528218 & 5.3478 & 5.1995 & TRN & \\
\hline CHEMBL 3683049 & 1528218 & 5.1475 & 4.2565 & TST & \\
\hline CHEMBL 3682938 & 1528218 & 5.7647 & 5.8779 & TRN & \\
\hline CHEMBL 3687864 & 1528218 & 5.3045 & \multicolumn{2}{|c|}{5.7010000000000005} & TRN \\
\hline CHEMBL3682999 & 1528218 & 5.7423 & 5.6978 & TRN & \\
\hline CHEMBL 3687820 & 1528218 & 4.0 & 4.447 & TRN & \\
\hline CHEMBL 3687819 & 1528218 & 6.2366 & 6.0729 & TRN & \\
\hline CHEMBL3687829 & 1528218 & 4.0 & 4.3954 & TRN & \\
\hline CHEMBL3687912 & 1528218 & 7.2055 & 6.5921 & TRN & \\
\hline CHEMBL 3687803 & 1528218 & 5.6021 & 5.41 & TRN & \\
\hline CHEMBL 3678023 & 1528218 & 5.4342 & 5.8921 & TST & \\
\hline CHEMBL 3687931 & 1528218 & 5.015 & 4.4772 & TRN & \\
\hline CHEMBL 3678060 & 1528218 & 5.9281 & 6.1176 & TRN & \\
\hline
\end{tabular}

Page 13441 


\begin{tabular}{|c|c|c|c|c|c|}
\hline \multicolumn{6}{|c|}{ e SL.tXt } \\
\hline CHEMBL3687857 & 1528218 & 4.0 & 4.2099 & TST & \\
\hline CHEMBL3687830 & 1528218 & 4.0 & 4.606 & TRN & \\
\hline CHEMBL3682971 & 1528218 & 4.0 & 4.9325 & TRN & \\
\hline CHEMBL3682849 & 1528218 & 7.025 & 6.5152 & TRN & \\
\hline CHEMBL3687806 & 1528218 & 6.38200 & 00000000 & 6.4513 & TRN \\
\hline CHEMBL3683010 & 1528218 & 4.0 & 4.3678 & TST & \\
\hline CHEMBL3683041 & 1528218 & 4.0 & 5.6269 & TST & \\
\hline CHEMBL3687913 & 1528218 & 7.0953 & 6.6516 & TRN & \\
\hline CHEMBL3678031 & 1528218 & 5.8539 & 5.2856 & TST & \\
\hline CHEMBL3682904 & 1528218 & 6.9535 & 6.7816 & TRN & \\
\hline CHEMBL3682949 & 1528218 & 5.6655 & 5.2965 & TRN & \\
\hline CHEMBL 3687944 & 1528218 & 5.7959 & 5.5198 & TRN & \\
\hline CHEMBL3687817 & 1528218 & 7.0177 & 7.3688 & TRN & \\
\hline CHEMBL3682897 & 1528218 & 6.6216 & 6.4971 & TRN & \\
\hline CHEMBL 3678042 & 1528218 & 5.2782 & 4.3611 & TST & \\
\hline CHEMBL3683053 & 1528218 & 4.0 & 3.79399 & 99999999996 & TST \\
\hline CHEMBL3682899 & 1528218 & 5.8881 & 5.4292 & TRN & \\
\hline CHEMBL3683032 & 1528218 & 6.8801 & 7.4366 & TRN & \\
\hline CHEMBL3682933 & 1528218 & 5.2857 & 5.176 & TRN & \\
\hline CHEMBL3687894 & 1528218 & 4.8069 & 5.8906 & TRN & \\
\hline CHEMBL3682863 & 1528218 & 4.0 & 5.0261 & TRN & \\
\hline CHEMBL 3682870 & 1528218 & 5.3401 & 5.5067 & TRN & \\
\hline CHEMBL3687928 & 1528218 & 5.0491 & 4.3697 & TST & \\
\hline CHEMBL 3687875 & 1528218 & 4.9547 & 4.8666 & TST & \\
\hline CHEMBL3687809 & 1528218 & 5.0804 & 5.0083 & TRN & \\
\hline CHEMBL3687902 & 1528218 & 6.9706 & 6.6611 & TRN & \\
\hline CHEMBL 3687924 & 1528218 & 5.4461 & 5.44600 & 3000000001 & TST \\
\hline CHEMBL 3687904 & 1528218 & 6.4698 & 6.4382 & TRN & \\
\hline CHEMBL3678058 & 1528218 & 5.3565 & 6.37200 & 0000000001 & TRN \\
\hline CHEMBL3682936 & 1528218 & 5.2958 & 5.484 & TRN & \\
\hline CHEMBL3687940 & 1528218 & 4.0 & 4.8381 & TRN & \\
\hline CHEMBL 3678054 & 1528218 & 7.1349 & 6.5117 & TRN & \\
\hline CHEMBL3687897 & 1528218 & 3.5229 & 6.0577 & TST & \\
\hline CHEMBL1726231 & 736975 & 5.1774 & 4.263 & TRN & \\
\hline CHEMBL1499258 & 736975 & 5.8342 & 5.4831 & TRN & \\
\hline CHEMBL1341226 & 736975 & 3.1454 & 3.3123 & TST & \\
\hline CHEMBL 27871 & 736975 & 4.4642 & 3.2621 & TRN & \\
\hline CHEMBL1468228 & 736975 & 3.1458 & 3.1759 & TRN & \\
\hline CHEMBL162609 & 736975 & 3.1457 & 3.198 & TRN & \\
\hline CHEMBL1480330 & 736975 & 3.1461 & 3.3761 & TRN & \\
\hline CHEMBL1502674 & 736975 & 4.7463 & 4.7605 & TRN & \\
\hline CHEMBL1509367 & 736975 & 3.1459 & 3.292 & TRN & \\
\hline CHEMBL1399818 & 736975 & 3.1457 & 3.0146 & TRN & \\
\hline CHEMBL3189964 & 736975 & 4.9343 & 4.8886 & TRN & \\
\hline CHEMBL1462008 & 736975 & 5.654 & 5.95299 & 9999999999 & TRN \\
\hline CHEMBL1427679 & 736975 & 3.1458 & 3.3205 & TRN & \\
\hline CHEMBL1506534 & 736975 & 3.1458 & 3.2298 & TRN & \\
\hline CHEMBL1544706 & 736975 & 3.1459 & 3.1375 & TST & \\
\hline
\end{tabular}




\begin{tabular}{|c|c|c|c|c|c|c|}
\hline & & \multicolumn{5}{|c|}{ Supplemental Table S2.txt } \\
\hline CHEMBL1445509 & 736975 & 3.1462 & 3.2086 & TRN & & \\
\hline CHEMBL1454559 & 736975 & 3.1457 & 3.8092 & TRN & & \\
\hline CHEMBL1596709 & 736975 & 3.1457 & 3.2244 & TRN & & \\
\hline CHEMBL1491376 & 736975 & 3.1457 & 3.0177 & TRN & & \\
\hline CHEMBL1432363 & 736975 & 3.1457 & 2.9944 & TRN & & \\
\hline CHEMBL1575502 & 736975 & 4.9843 & 3.9927 & TRN & & \\
\hline CHEMBL1492639 & 736975 & 4.6291 & 4.2359 & TRN & & \\
\hline CHEMBL1576236 & 736975 & 5.2208 & 5.3941 & TRN & & \\
\hline CHEMBL1501398 & 736975 & 3.1458 & 3.3235 & TRN & & \\
\hline CHEMBL1399757 & 736975 & 3.1459 & 3.3967 & TRN & & \\
\hline CHEMBL1549782 & 736975 & 3.1458 & 3.1498 & TRN & & \\
\hline CHEMBL1576630 & 736975 & 3.1459 & 3.0905 & TRN & & \\
\hline CHEMBL1344981 & 736975 & 3.1457 & 3.2532 & TRN & & \\
\hline CHEMBL1346219 & 736975 & 4.7461 & 4.8989 & TRN & & \\
\hline CHEMBL1605348 & 736975 & 3.1458 & 3.2677 & TRN & & \\
\hline CHEMBL1720979 & 736975 & 3.1458 & 3.2551 & TRN & & \\
\hline CHEMBL1404423 & 736975 & 4.9091 & 4.8103 & TRN & & \\
\hline CHEMBL1597335 & 736975 & 3.1458 & 3.0406 & TRN & & \\
\hline CHEMBL1564363 & 736975 & 5.2881 & 4.438 & TRN & & \\
\hline CHEMBL1391348 & 736975 & 3.1457 & 3.0888 & TRN & & \\
\hline CHEMBL1340183 & 736975 & 3.1458 & 3.59 & TRN & & \\
\hline CHEMBL1405077 & 736975 & 3.1458 & 3.2865 & TRN & & \\
\hline CHEMBL1599509 & 736975 & 3.1455 & 3.1261 & TRN & & \\
\hline CHEMBL1714965 & 736975 & 3.1457 & 3.068 & TRN & & \\
\hline CHEMBL3195681 & 736975 & 6.7836 & 7.4883 & TRN & & \\
\hline CHEMBL1501273 & 736975 & 5.8636 & 5.7517 & TRN & & \\
\hline CHEMBL1497570 & 736975 & 3.1458 & 3.1267 & TRN & & \\
\hline CHEMBL1583108 & 736975 & 5.1546 & 5.3301 & TRN & & \\
\hline CHEMBL1703753 & 736975 & 3.1459 & 3.4591 & TST & & \\
\hline CHEMBL1334200 & 736975 & 3.1457 & 3.1564 & TRN & & \\
\hline CHEMBL1408986 & 736975 & 4.9181 & 4.8959 & TRN & & \\
\hline CHEMBL1316113 & 736975 & $3.1460 e$ & 00000000 & 304 & 3.194 & TRN \\
\hline CHEMBL1432495 & 736975 & 3.1458 & 3.6222 & TRN & & \\
\hline CHEMBL1506234 & 736975 & 5.2256 & 5.7087 & TRN & & \\
\hline CHEMBL1326200 & 736975 & 3.1462 & 3.1221 & TRN & & \\
\hline CHEMBL1711883 & 736975 & 3.1459 & 3.0538 & TRN & & \\
\hline CHEMBL1596655 & 736975 & 5.4781 & 5.1435 & TST & & \\
\hline CHEMBL1349147 & 736975 & 4.8402 & 5.0331 & TRN & & \\
\hline CHEMBL1542169 & 736975 & 5.8133 & 6.3146 & TRN & & \\
\hline CHEMBL1429158 & 736975 & 4.7471 & 4.2953 & TRN & & \\
\hline CHEMBL1600756 & 736975 & 3.1457 & 3.4353 & TRN & & \\
\hline CHEMBL1718663 & 736975 & 3.1457 & 3.2854 & TST & & \\
\hline CHEMBL1713654 & 736975 & 5.9176 & 5.6625 & TST & & \\
\hline CHEMBL1537100 & 736975 & 3.1457 & 3.1757 & TRN & & \\
\hline CHEMBL1323495 & 736975 & 3.1458 & 3.2862 & TRN & & \\
\hline CHEMBL1595259 & 736975 & 3.1457 & 3.2622 & TRN & & \\
\hline CHEMBL1607288 & 736975 & 3.1462 & 3.0911 & TRN & & \\
\hline CHEMBL1445941 & 736975 & 3.1457 & 3.125 & TRN & & \\
\hline
\end{tabular}




\begin{tabular}{|c|c|c|c|c|c|c|}
\hline & & \multicolumn{5}{|c|}{ Supplemental Table S2.txt } \\
\hline CHEMBL3192753 & 736975 & 3.1455 & 3.3629 & TRN & & \\
\hline CHEMBL1455121 & 736975 & 4.7319 & 4.3008 & TRN & & \\
\hline CHEMBL1562006 & 736975 & 4.6121 & 4.2235 & TRN & & \\
\hline CHEMBL1723906 & 736975 & 3.1465 & 3.3431 & TST & & \\
\hline CHEMBL 1451210 & 736975 & 3.1457 & 3.3239 & TRN & & \\
\hline CHEMBL1573529 & 736975 & 6.2875 & 6.5164 & TRN & & \\
\hline CHEMBL1499439 & 736975 & 3.1462 & 3.0245 & TRN & & \\
\hline CHEMBL1342181 & 736975 & 5.3807 & 5.4691 & TRN & & \\
\hline CHEMBL1971695 & 736975 & 5.7298 & 5.2619 & TST & & \\
\hline CHEMBL1550816 & 736975 & 6.1188 & 5.8343 & TRN & & \\
\hline CHEMBL1306801 & 736975 & \multicolumn{3}{|c|}{3.1460000000000004} & 3.5624 & TRN \\
\hline CHEMBL1172020 & 736975 & 3.1454 & 3.5784 & TRN & & \\
\hline CHEMBL1432075 & 736975 & 4.5771 & 5.0507 & TRN & & \\
\hline CHEMBL1549392 & 736975 & 5.0456 & 4.9082 & TST & & \\
\hline CHEMBL1313885 & 736975 & 3.1458 & 3.2478 & TST & & \\
\hline CHEMBL1398812 & 736975 & \multicolumn{3}{|c|}{6.3839999999999995} & 5.9098 & TRN \\
\hline CHEMBL1732292 & 736975 & 3.1462 & 3.6013 & TST & & \\
\hline CHEMBL1338266 & 736975 & 3.1461 & 3.2712 & TRN & & \\
\hline CHEMBL1735946 & 736975 & 3.1458 & 3.3994 & TST & & \\
\hline CHEMBL1380339 & 736975 & 5.0749 & 5.0092 & TRN & & \\
\hline CHEMBL1719142 & 736975 & 3.1452 & 3.1361 & TRN & & \\
\hline CHEMBL1346165 & 736975 & 5.2678 & 5.4863 & TRN & & \\
\hline CHEMBL1574521 & 736975 & 5.8102 & 5.0437 & TRN & & \\
\hline CHEMBL1711538 & 736975 & 3.1455 & 3.1511 & TRN & & \\
\hline CHEMBL1710960 & 736975 & 4.8895 & 4.7748 & TRN & & \\
\hline CHEMBL1477915 & 736975 & 6.4012 & 6.1886 & TRN & & \\
\hline CHEMBL 2004884 & 736975 & 5.556 & 5.5872 & TRN & & \\
\hline CHEMBL1332386 & 736975 & 3.1458 & 3.3169 & TRN & & \\
\hline CHEMBL1471056 & 736975 & 3.1459 & 3.3473 & TRN & & \\
\hline CHEMBL1382511 & 736975 & 3.1461 & 3.1466 & TRN & & \\
\hline CHEMBL1506407 & 736975 & 3.1462 & 3.1805 & TRN & & \\
\hline CHEMBL3213293 & 736975 & 3.1459 & 3.1859 & TRN & & \\
\hline CHEMBL1311198 & 736975 & 5.5349 & 4.77 & TRN & & \\
\hline CHEMBL1466606 & 736975 & 5.5891 & 6.4918 & TRN & & \\
\hline CHEMBL1581326 & 736975 & 6.7823 & 6.3996 & TRN & & \\
\hline CHEMBL1557186 & 736975 & 5.5677 & 4.5717 & TRN & & \\
\hline CHEMBL1362442 & 736975 & 3.1458 & 2.9312 & TRN & & \\
\hline CHEMBL1465189 & 736975 & 3.1458 & 3.2152 & TRN & & \\
\hline CHEMBL1349035 & 736975 & 3.1457 & 3.2591 & TRN & & \\
\hline CHEMBL1304227 & 736975 & 3.1457 & 3.1665 & TRN & & \\
\hline CHEMBL1412285 & 736975 & 4.8277 & 4.5679 & TRN & & \\
\hline CHEMBL1524590 & 736975 & 3.6229 & 4.5058 & TRN & & \\
\hline CHEMBL1722129 & 736975 & 4.5752 & 4.4427 & TRN & & \\
\hline CHEMBL1309545 & 736975 & 3.1455 & 3.1342 & TRN & & \\
\hline CHEMBL1583356 & 736975 & 3.1457 & 3.4111 & TRN & & \\
\hline CHEMBL1611373 & 736975 & 3.1458 & 2.9664 & TRN & & \\
\hline CHEMBL1575396 & 736975 & 3.1459 & 3.3875 & TST & & \\
\hline CHEMBL1366427 & 736975 & 4.8632 & 4.9524 & TRN & & \\
\hline
\end{tabular}




\begin{tabular}{|c|c|c|c|c|c|c|}
\hline & & & & & & \\
\hline CHEMBL1565855 & 736975 & 4.1001 & 5.1085 & TRN & & \\
\hline CHEMBL1712933 & 736975 & 3.1456 & 3.6143 & TRN & & \\
\hline CHEMBL3197404 & 736975 & 6.2477 & 6.7544 & TRN & & \\
\hline CHEMBL1367178 & 736975 & 5.118 & 5.0895 & TRN & & \\
\hline CHEMBL1494231 & 736975 & 3.1457 & 3.2017 & TRN & & \\
\hline CHEMBL1504676 & 736975 & 5.3109 & 5.6003 & TRN & & \\
\hline CHEMBL1540557 & 736975 & 5.6225 & 5.8901 & TRN & & \\
\hline CHEMBL1310204 & 736975 & 5.9442 & 5.8819 & TRN & & \\
\hline CHEMBL1525885 & 736975 & 3.1457 & 2.9476 & TRN & & \\
\hline CHEMBL1492819 & 736975 & 5.2559 & 5.3142 & TRN & & \\
\hline CHEMBL1308386 & 736975 & 4.5772 & 5.4669 & TRN & & \\
\hline CHEMBL1313968 & 736975 & 5.9535 & 5.8901 & TRN & & \\
\hline CHEMBL3209826 & 736975 & 3.1457 & 3.3061 & TST & & \\
\hline CHEMBL1612586 & 736975 & 3.1457 & 3.1871 & TRN & & \\
\hline CHEMBL1466913 & 736975 & 5.6942 & 5.6105 & TRN & & \\
\hline CHEMBL1353321 & 736975 & 5.2801 & 5.5052 & TRN & & \\
\hline CHEMBL1586067 & 736975 & 5.7375 & 5.7727 & TRN & & \\
\hline CHEMBL1484719 & 736975 & 3.1459 & 3.127 & TRN & & \\
\hline CHEMBL1407632 & 736975 & 5.8022 & 5.8595 & TRN & & \\
\hline CHEMBL1305157 & 736975 & 3.1457 & 3.0547 & TRN & & \\
\hline CHEMBL1390304 & 736975 & 3.1458 & 3.2497 & TRN & & \\
\hline CHEMBL1511157 & 736975 & 4.9551 & 4.2845 & TRN & & \\
\hline CHEMBL1564313 & 736975 & 6.9638 & 6.6647 & TRN & & \\
\hline CHEMBL1353385 & 736975 & 3.1459 & 3.2708 & TRN & & \\
\hline CHEMBL1530583 & 736975 & 3.1458 & 3.0686 & TRN & & \\
\hline CHEMBL 2002008 & 736975 & 5.4077 & 4.6963 & TRN & & \\
\hline CHEMBL1569366 & 736975 & 3.1457 & 3.3379 & TRN & & \\
\hline CHEMBL1516552 & 736975 & 3.1458 & 3.4828 & TRN & & \\
\hline CHEMBL1991936 & 736975 & 4.6893 & 3.6605 & TRN & & \\
\hline CHEMBL1701437 & 736975 & 5.7031 & 5.4629 & TST & & \\
\hline CHEMBL1329017 & 736975 & 3.1459 & 3.4039 & TRN & & \\
\hline CHEMBL1580769 & 736975 & 5.34399 & 79999999 & 99 & 5.2709 & TRN \\
\hline CHEMBL1302896 & 736975 & 3.1459 & 3.0415 & TRN & & \\
\hline CHEMBL1582976 & 736975 & 3.1458 & 3.1812 & TRN & & \\
\hline CHEMBL1728420 & 736975 & 3.1455 & 3.1267 & TRN & & \\
\hline CHEMBL1430285 & 736975 & 3.1458 & 3.3261 & TRN & & \\
\hline CHEMBL 3195005 & 736975 & 4.9802 & 4.6153 & TRN & & \\
\hline CHEMBL1538548 & 736975 & 3.14600 & 00000000 & 204 & 3.4972 & TRN \\
\hline CHEMBL1559585 & 736975 & 3.1457 & 3.3524 & TRN & & \\
\hline CHEMBL3195851 & 736975 & 6.7197 & 6.5237 & TRN & & \\
\hline CHEMBL1735920 & 736975 & 3.14600 & 30000000 & 804 & 3.0316 & TRN \\
\hline CHEMBL1342856 & 736975 & 3.1457 & 3.353 & TRN & & \\
\hline CHEMBL1435559 & 736975 & 3.1455 & 3.1905 & TRN & & \\
\hline CHEMBL1705075 & 736975 & 3.1461 & 3.5457 & TRN & & \\
\hline CHEMBL1587067 & 736975 & 3.1458 & 3.27399 & 9999 & 996 & TRN \\
\hline CHEMBL1429070 & 736975 & 5.942 & 5.5753 & TST & & \\
\hline CHEMBL1329597 & 736975 & 4.6715 & 4.638 & TRN & & \\
\hline CHEMBL1991136 & 736975 & 5.3471 & 4.9899 & TRN & & \\
\hline
\end{tabular}




\begin{tabular}{|c|c|c|c|c|c|c|}
\hline & & \multicolumn{5}{|c|}{ Supplemental Table S2.txt } \\
\hline CHEMBL3193288 & 736975 & 3.1459 & 3.5463 & TST & & \\
\hline CHEMBL1363713 & 736975 & 3.1457 & 3.548 & TRN & & \\
\hline CHEMBL1331195 & 736975 & 6.9638 & 6.6547 & TRN & & \\
\hline CHEMBL1412068 & 736975 & 3.1458 & 3.0051 & TRN & & \\
\hline CHEMBL1388372 & 736975 & 6.2109 & 4.8654 & TRN & & \\
\hline CHEMBL1318929 & 736975 & 3.1459 & 3.2641 & TRN & & \\
\hline CHEMBL3208896 & 736975 & 3.1457 & 3.1183 & TRN & & \\
\hline CHEMBL1613705 & 736975 & 3.1457 & 3.2755 & TRN & & \\
\hline CHEMBL1429021 & 736975 & \multicolumn{3}{|c|}{3.1460000000000004} & .3786 & TRN \\
\hline CHEMBL1732393 & 736975 & 3.1461 & 3.23 & TST & & \\
\hline CHEMBL1316798 & 736975 & 5.3043 & 5.1482 & TRN & & \\
\hline CHEMBL1432585 & 736975 & 3.1459 & 3.7803 & TRN & & \\
\hline CHEMBL1535241 & 736975 & 3.1457 & 3.6076 & TRN & & \\
\hline CHEMBL1450816 & 736975 & 3.1465 & 3.1433 & TRN & & \\
\hline CHEMBL1313434 & 736975 & 6.0607 & 6.2256 & TRN & & \\
\hline CHEMBL1611715 & 736975 & 3.145 & 3.1373 & TRN & & \\
\hline CHEMBL1725983 & 736975 & 5.5894 & 5.2929 & TRN & & \\
\hline CHEMBL3211686 & 736975 & 3.1459 & 3.1265 & TRN & & \\
\hline CHEMBL1468444 & 736975 & 6.5546 & 5.9514 & TRN & & \\
\hline CHEMBL1604510 & 736975 & 6.1296 & 5.9876 & TRN & & \\
\hline CHEMBL1702047 & 736975 & 3.1462 & 3.5947 & TST & & \\
\hline CHEMBL1408792 & 736975 & 5.1111 & 5.2565 & TRN & & \\
\hline CHEMBL1409105 & 736975 & 3.1455 & 3.17 & TRN & & \\
\hline CHEMBL1499887 & 736975 & 3.1459 & 3.2328 & TRN & & \\
\hline CHEMBL1419680 & 736975 & 5.2511 & 5.0526 & TRN & & \\
\hline CHEMBL1719517 & 736975 & 3.1459 & 3.3257 & TRN & & \\
\hline CHEMBL1548190 & 736975 & 4.9779 & 5.0007 & TRN & & \\
\hline CHEMBL1379673 & 736975 & 6.5423 & 6.4735 & TRN & & \\
\hline CHEMBL1993522 & 736975 & 3.1459 & 3.1245 & TRN & & \\
\hline CHEMBL1975147 & 736975 & 5.9582 & 5.9162 & TRN & & \\
\hline CHEMBL1977499 & 736975 & 5.8422 & 4.1911 & TRN & & \\
\hline CHEMBL1483385 & 736975 & 3.1453 & 3.4628 & TST & & \\
\hline CHEMBL1377757 & 736975 & 3.1458 & 3.3107 & TRN & & \\
\hline CHEMBL1375635 & 736975 & 3.1458 & 3.1496 & TRN & & \\
\hline CHEMBL1577997 & 736975 & 3.1457 & 3.0473 & TRN & & \\
\hline CHEMBL475244 & 736975 & 3.1454 & 3.0804 & TRN & & \\
\hline CHEMBL1558400 & 736975 & 4.1001 & 5.0091 & TST & & \\
\hline CHEMBL1733019 & 736975 & 3.1457 & 3.0213 & TRN & & \\
\hline CHEMBL1465113 & 736975 & 3.1458 & 3.1463 & TRN & & \\
\hline CHEMBL1328572 & 736975 & 3.1462 & 3.0405 & TRN & & \\
\hline CHEMBL1369691 & 736975 & 6.3006 & 6.54700 & 0000000001 & & TRN \\
\hline CHEMBL1346568 & 736975 & 3.1459 & 3.2478 & TRN & & \\
\hline CHEMBL1612010 & 736975 & 3.1459 & 3.33699 & 99999999997 & & TST \\
\hline CHEMBL1572028 & 736975 & 4.1 & 5.0273 & TRN & & \\
\hline CHEMBL1733692 & 736975 & 5.2018 & 4.987 & TRN & & \\
\hline CHEMBL1497655 & 736975 & 3.1457 & 3.2247 & TST & & \\
\hline CHEMBL1408111 & 736975 & 4.3975 & 4.484 & TST & & \\
\hline CHEMBL1305039 & 736975 & 3.1462 & 3.0396 & TST & & \\
\hline
\end{tabular}




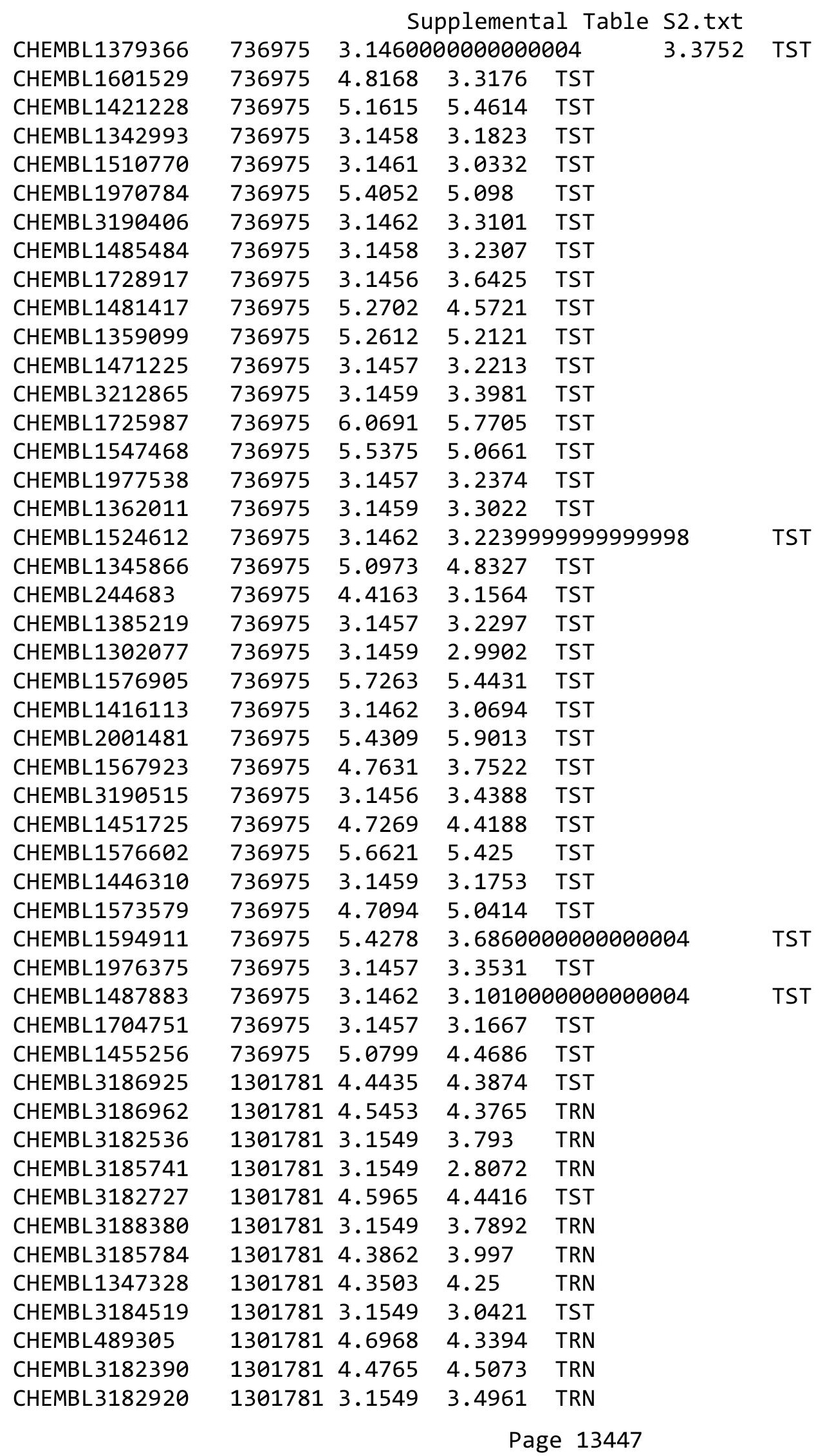


Supplemental Table S2.txt

\begin{tabular}{|c|c|c|c|c|c|}
\hline CHEMBL 3187616 & 1301781 & 3.1549 & 3.4157 & TST & \\
\hline CHEMBL3184404 & 1301781 & 3.1549 & 3.216 & TRN & \\
\hline CHEMBL3184099 & 1301781 & 3.1549 & 3.0404 & TRN & \\
\hline CHEMBL3186611 & 1301781 & 3.1549 & 3.5658 & TST & \\
\hline CHEMBL1165723 & 1301781 & 3.1549 & 3.6709 & TST & \\
\hline CHEMBL3183310 & 1301781 & 3.1549 & 3.1233 & TRN & \\
\hline CHEMBL514665 & 1301781 & 4.4191 & 4.3753 & TRN & \\
\hline CHEMBL 3182880 & 1301781 & 4.9165 & 4.8476 & TST & \\
\hline CHEMBL 3185707 & 1301781 & 3.1549 & 3.3042 & TRN & \\
\hline CHEMBL1576149 & 1301781 & 3.1549 & 2.9103 & TRN & \\
\hline CHEMBL502336 & 1301781 & 4.8072 & 4.8148 & TRN & \\
\hline CHEMBL1464975 & 1301781 & 3.1549 & 3.4136 & TRN & \\
\hline CHEMBL489304 & 1301781 & 4.5306 & 4.2745 & TRN & \\
\hline CHEMBL 3187525 & 1301781 & 3.1549 & 3.4517 & TRN & \\
\hline CHEMBL475546 & 1301781 & 4.4523 & 4.4558 & TRN & \\
\hline CHEMBL 2032078 & 1301781 & 3.1549 & 3.3268 & TRN & \\
\hline CHEMBL3185600 & 1301781 & 4.2095 & 4.0893 & TRN & \\
\hline CHEMBL3183900 & 1301781 & 3.1549 & 2.9458 & TRN & \\
\hline CHEMBL473541 & 1301781 & 4.3234 & 4.4184 & TRN & \\
\hline CHEMBL 3189091 & 1301781 & 4.567 & 4.5845 & TST & \\
\hline CHEMBL3182980 & 1301781 & 3.1549 & 3.3481 & TRN & \\
\hline CHEMBL3182801 & 1301781 & 3.1549 & 3.0918 & TRN & \\
\hline CHEMBL3184406 & 1301781 & 4.5732 & 4.7748 & TRN & \\
\hline CHEMBL 3187721 & 1301781 & 3.1549 & 3.0913 & TST & \\
\hline CHEMBL502910 & 1301781 & 4.3381 & 4.2734 & TRN & \\
\hline CHEMBL3185543 & 1301781 & 4.1873 & 3.8832 & TRN & \\
\hline CHEMBL3184515 & 1301781 & 3.1549 & 3.1218 & TRN & \\
\hline CHEMBL3183450 & 1301781 & 3.1549 & 3.3823 & TST & \\
\hline CHEMBL3183210 & 1301781 & 3.1549 & 3.6734 & TST & \\
\hline CHEMBL1556256 & 1301781 & 3.1549 & 3.2042 & TRN & \\
\hline CHEMBL84010 & 1301781 & 3.1549 & \multicolumn{2}{|c|}{ 2.9019999999999997 } & TRN \\
\hline CHEMBL3183317 & 1301781 & 4.6708 & 4.623 & TRN & \\
\hline CHEMBL1733869 & 1301781 & 3.1549 & 3.3394 & TRN & \\
\hline CHEMBL3185954 & 1301781 & 3.1549 & 3.8367 & TRN & \\
\hline CHEMBL3183984 & 1301781 & 5.2733 & 4.8849 & TST & \\
\hline CHEMBL3184415 & 1301781 & 4.3916 & 4.3013 & TRN & \\
\hline CHEMBL 3187287 & 1301781 & 3.1549 & \multicolumn{2}{|c|}{3.1489999999999996} & TRN \\
\hline CHEMBL3183416 & 1301781 & 4.4631 & 4.7635 & TRN & \\
\hline CHEMBL491280 & 1301781 & 3.1549 & 3.6608 & TRN & \\
\hline CHEMBL3185112 & 1301781 & 4.3868 & 4.3533 & TRN & \\
\hline CHEMBL3188115 & 1301781 & 3.1549 & 2.9317 & TRN & \\
\hline CHEMBL1403744 & 1301781 & 4.2978 & 3.9611 & TST & \\
\hline CHEMBL 3186625 & 1301781 & 4.6137 & 4.4511 & TRN & \\
\hline CHEMBL474124 & 1301781 & 4.8729 & 4.6052 & TRN & \\
\hline CHEMBL1436964 & 1301781 & 3.1549 & 3.8409 & TST & \\
\hline CHEMBL473542 & 1301781 & 4.6786 & 4.4277 & TRN & \\
\hline CHEMBL3188635 & 1301781 & 4.4667 & 4.2898 & TRN & \\
\hline CHEMBL3184857 & 1301781 & 4.4632 & 4.4064 & TRN & \\
\hline
\end{tabular}


Supplemental Table S2.txt

\begin{tabular}{|c|c|c|c|c|c|}
\hline CHEMBL3188325 & 1301781 & 4.5327 & 4.6116 & TRN & \\
\hline CHEMBL3186861 & 1301781 & 4.6293 & 4.4805 & TRN & \\
\hline CHEMBL3186408 & 1301781 & 3.1549 & 3.7795 & TST & \\
\hline CHEMBL490301 & 1301781 & 3.1549 & 3.3074 & TRN & \\
\hline CHEMBL 3183778 & 1301781 & 4.5704 & 4.7583 & TRN & \\
\hline CHEMBL 3182750 & 1301781 & 3.1549 & 3.5242 & TRN & \\
\hline CHEMBL472736 & 1301781 & 4.9066 & 4.9639 & TRN & \\
\hline CHEMBL3182979 & 1301781 & 3.1549 & 3.1641 & TRN & \\
\hline CHEMBL3188596 & 1301781 & 3.1549 & 4.4822 & TST & \\
\hline CHEMBL3185499 & 1301781 & 4.4612 & 4.1345 & TRN & \\
\hline CHEMBL 3182344 & 1301781 & 3.1549 & 3.4612 & TST & \\
\hline CHEMBL3187471 & 1301781 & 5.0496 & 5.0903 & TST & \\
\hline CHEMBL 3188038 & 1301781 & 4.4925 & 4.5072 & TRN & \\
\hline CHEMBL 3186322 & 1301781 & 3.1549 & 3.3603 & TRN & \\
\hline CHEMBL3187661 & 1301781 & 3.1549 & 3.658 & TRN & \\
\hline CHEMBL1543340 & 1301781 & 3.1549 & 3.4044 & TST & \\
\hline CHEMBL472735 & 1301781 & 4.8404 & 4.992 & TRN & \\
\hline CHEMBL3183431 & 1301781 & 3.1549 & 3.0203 & TRN & \\
\hline CHEMBL 3185080 & 1301781 & 3.1549 & 3.11 & TRN & \\
\hline CHEMBL1340868 & 1301781 & 3.1549 & 3.1602 & TRN & \\
\hline CHEMBL3185446 & 1301781 & 4.5369 & 4.5848 & TRN & \\
\hline CHEMBL3184626 & 1301781 & 3.1549 & 2.8925 & TRN & \\
\hline CHEMBL578905 & 1301781 & 4.4269 & 3.7113 & TRN & \\
\hline CHEMBL473338 & 1301781 & 4.229 & 4.2995 & TRN & \\
\hline CHEMBL3184792 & 1301781 & 3.1549 & 3.9216 & TRN & \\
\hline CHEMBL1403890 & 1301781 & 4.2561 & 3.8556 & TST & \\
\hline CHEMBL3187699 & 1301781 & 3.1549 & 2.9204 & TRN & \\
\hline CHEMBL3188682 & 1301781 & 4.1868 & 3.8005 & TST & \\
\hline CHEMBL578502 & 1301781 & 4.4938 & 4.3991 & TST & \\
\hline CHEMBL3185555 & 1301781 & 4.2646 & 3.9569 & TRN & \\
\hline CHEMBL3186235 & 1301781 & 3.1549 & 3.3234 & TRN & \\
\hline CHEMBL3183946 & 1301781 & 3.1549 & 3.089 & TRN & \\
\hline CHEMBL3181884 & 1301781 & 4.9052 & 4.7967 & TST & \\
\hline CHEMBL 3186570 & 1301781 & 3.1549 & 3.2325 & TRN & \\
\hline CHEMBL3184898 & 1301781 & 3.1549 & 3.1997 & TRN & \\
\hline CHEMBL489693 & 1301781 & 3.1549 & 3.48100 & 00000000003 & TRN \\
\hline CHEMBL3182975 & 1301781 & 3.1549 & 3.1195 & TRN & \\
\hline CHEMBL415711 & 1301781 & 3.1549 & 3.3879 & TST & \\
\hline CHEMBL3185577 & 1301781 & 3.1549 & 3.00600 & 00000000002 & TRN \\
\hline CHEMBL 3187580 & 1301781 & 3.1549 & 3.5089 & TRN & \\
\hline CHEMBL 3188820 & 1301781 & 4.3388 & 4.0857 & TRN & \\
\hline CHEMBL3182643 & 1301781 & 3.1549 & 3.0842 & TST & \\
\hline CHEMBL3182398 & 1301781 & 4.3318 & 4.0291 & TRN & \\
\hline CHEMBL490493 & 1301781 & 4.6178 & 4.4285 & TRN & \\
\hline CHEMBL3182935 & 1301781 & 4.7696 & 4.8644 & TRN & \\
\hline CHEMBL 3183820 & 1301781 & 3.1549 & 2.8997 & TRN & \\
\hline CHEMBL2032070 & 1301781 & 3.1549 & 3.1067 & TST & \\
\hline CHEMBL 3188122 & 1301781 & 4.3902 & 4.2453 & TRN & \\
\hline
\end{tabular}

Page 13449 
Supplemental Table S2.txt

\begin{tabular}{|c|c|c|c|c|c|}
\hline CHEMBL490302 & 1301781 & 4.7577 & 4.6215 & TRN & \\
\hline CHEMBL3184216 & 1301781 & 4.817 & 4.4494 & TRN & \\
\hline CHEMBL3189117 & 1301781 & 3.1549 & 2.8598 & TST & \\
\hline CHEMBL3185869 & 1301781 & 4.6607 & 4.5848 & TST & \\
\hline CHEMBL3971134 & 1642360 & 6.0 & 6.809 & TRN & \\
\hline CHEMBL3945859 & 1642360 & 7.9208 & 7.4478 & TRN & \\
\hline CHEMBL3902081 & 1642360 & 7.3768 & 7.1069 & TRN & \\
\hline CHEMBL3973284 & 1642360 & 6.7696 & 6.8845 & TST & \\
\hline CHEMBL3891412 & 1642360 & 6.0 & 6.1528 & TRN & \\
\hline CHEMBL3981282 & 1642360 & 6.6757 & 6.631 & TRN & \\
\hline CHEMBL3905391 & 1642360 & 7.4202 & 6.3151 & TRN & \\
\hline CHEMBL3899936 & 1642360 & 6.0405 & 6.4483 & TST & \\
\hline CHEMBL3971674 & 1642360 & 6.5229 & 6.69 & TRN & \\
\hline CHEMBL3947537 & 1642360 & 7.9586 & 7.2649 & TRN & \\
\hline CHEMBL3890804 & 1642360 & 6.9172 & 6.9092 & TRN & \\
\hline CHEMBL3913801 & 1642360 & 7.1739 & 6.9186 & TRN & \\
\hline CHEMBL3985940 & 1642360 & 6.5376 & 6.7182 & TRN & \\
\hline CHEMBL3913635 & 1642360 & 6.0 & 6.4613 & TST & \\
\hline CHEMBL3962357 & 1642360 & 6.2328 & 6.433 & TRN & \\
\hline CHEMBL3897491 & 1642360 & 5.9076 & 6.1768 & TST & \\
\hline CHEMBL3933108 & 1642360 & 6.4214 & 6.8239 & TRN & \\
\hline CHEMBL3978800 & 1642360 & 7.2041 & 6.737 & TRN & \\
\hline CHEMBL3966163 & 1642360 & 6.0 & 6.1419 & TST & \\
\hline CHEMBL3939204 & 1642360 & 6.0 & 6.6111 & TRN & \\
\hline CHEMBL3964333 & 1642360 & 7.4089 & 7.1624 & TRN & \\
\hline CHEMBL3942030 & 1642360 & 7.2757 & 7.0964 & TST & \\
\hline CHEMBL3896034 & 1642360 & 7.6478 & 7.2981 & TRN & \\
\hline CHEMBL3961440 & 1642360 & 7.0223 & 7.2547 & TRN & \\
\hline CHEMBL3928350 & 1642360 & 6.1524 & 6.3206 & TRN & \\
\hline CHEMBL3914286 & 1642360 & 5.5804 & 6.5879 & TST & \\
\hline CHEMBL3975109 & 1642360 & 6.3107 & 6.428 & TRN & \\
\hline CHEMBL3963189 & 1642360 & 6.0496 & 5.6686 & TRN & \\
\hline CHEMBL3939420 & 1642360 & 7.6778 & 7.3782 & TST & \\
\hline CHEMBL3934735 & 1642360 & 6.6478 & 6.9696 & TST & \\
\hline CHEMBL3909044 & 1642360 & 6.0 & 6.342006 & 00000000005 & TRN \\
\hline CHEMBL3904836 & 1642360 & 6.4622 & 6.7788 & TST & \\
\hline CHEMBL3986728 & 1642360 & 8.0969 & 8.0661 & TRN & \\
\hline CHEMBL3950245 & 1642360 & 6.0 & 6.1997 & TRN & \\
\hline CHEMBL 3921957 & 1642360 & 5.6968 & 5.8322 & TRN & \\
\hline CHEMBL3959016 & 1642360 & 6.5452 & 6.8754 & TRN & \\
\hline CHEMBL3973431 & 1642360 & 6.0 & 6.3091 & TRN & \\
\hline CHEMBL3927758 & 1642360 & 7.7212 & 7.3437 & TST & \\
\hline CHEMBL3955826 & 1642360 & 7.3372 & 6.8922 & TRN & \\
\hline CHEMBL3936871 & 1642360 & 6.2541 & 6.6318 & TST & \\
\hline CHEMBL3973362 & 1642360 & 7.2291 & 7.0867 & TRN & \\
\hline CHEMBL3905290 & 1642360 & 6.0 & 6.9121 & TRN & \\
\hline CHEMBL3968871 & 1642360 & 6.6055 & 6.8942 & TRN & \\
\hline CHEMBL3965350 & 1642360 & 6.2487 & 6.484 & TRN & \\
\hline
\end{tabular}


Supplemental Table S2.txt

\begin{tabular}{|c|c|c|c|c|}
\hline HEMB I & 542360 & & & \\
\hline HEMPI 2012301 & 642360 & 6.3615 & 6.3672 & \\
\hline 3 & 360 & 6. & & \\
\hline HEMBL 389 & 360 & 383 & & S \\
\hline AEMBL3976299 & 360 & 786 & 221 & \\
\hline HEMBL3973110 & 642360 & 6.4191 & .621 & \\
\hline 56 & 360 & 6.0 & 921 & \\
\hline AEMBL398 & & & & Du \\
\hline HEMBL3978669 & 360 & 7.03 & 8913 & \\
\hline HEMBL3941489 & 360 & 665 & 1389 & \\
\hline HEMBL3932904 & 60 & 6.0 & .9405 & \\
\hline IEMBL39 & 60 & 225 & 37 & \\
\hline AEMBL39 & & & & RN \\
\hline HEMBL3890043 & 60 & 6.0 & 6.1723 & \\
\hline AEMBL393. & 60 & 6.0 & 12 & \\
\hline AEMBL392 & 62 & 6 & 7.2469 & \\
\hline HEMBL391 & ש & & 067 & . \\
\hline HEMBL 390 & & & & \\
\hline HEMBL389 & & 5.8851 & 6.5619 & \\
\hline HEMBL 390 & & 6.0 & & \\
\hline AEMBL39 & 0 & 861 & 58 & ו \\
\hline AEMBL39 & & 50 & 25 & 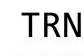 \\
\hline HEMBL39 & & 27 & & \\
\hline HFMRI 397 & & 6.7122 & 6.4903 & \\
\hline HEMBL 396 & & & & N \\
\hline HEMBL3S & $\theta$ & 706 & 7224 & RN \\
\hline HEMBL; & & 402 & 083 & RN \\
\hline$H F M B I=$ & 50 & 6 . & 782 & \\
\hline HEMBL395 & & 6 & & I KIV \\
\hline HEMBL 392 & & 6.7708 & & IRIV \\
\hline HEMBL 39 & 50 & 6 & 572 & RN \\
\hline HEMBL & & 6 & 77 & RN \\
\hline HEMBL & & 7 & 101 & ST \\
\hline HEMBL397 & & & & $2 \mathrm{~N}$ \\
\hline HEMBL3949375 & 60 & 815 & 6.9722 & TRN \\
\hline HEMBL39e & & 928 & 713 & RN \\
\hline HFMRI 3 & 0 & 6 . & 92 & RN \\
\hline HEMBL3 & & 5 . & 424 & IRN \\
\hline HEMBL3920067 & 60 & 6.9208 & 7.0684 & TST \\
\hline HEMBL396 & & 586 & 7.7431 & TST \\
\hline HEMBL396 & 50 & 655 & 7.1869 & \\
\hline CHEMBL391 & & & & RN \\
\hline HEMBL397 & & 7.2757 & 7.2469 & TST \\
\hline HEMBL388 & 360 & 6.9245 & .0729 & TRN \\
\hline $1=2+3+2$ & & 11 & & RN \\
\hline HEMBL 39 & & & 6.6854 & \\
\hline CHEMBL 391 & & .83 & 7.0254 & \\
\hline LHEMBL 3904714 & $164236 e$ & 6.8928 & 7.1291 & ГST \\
\hline
\end{tabular}

Page 13451 
Supplemental Table S2.txt

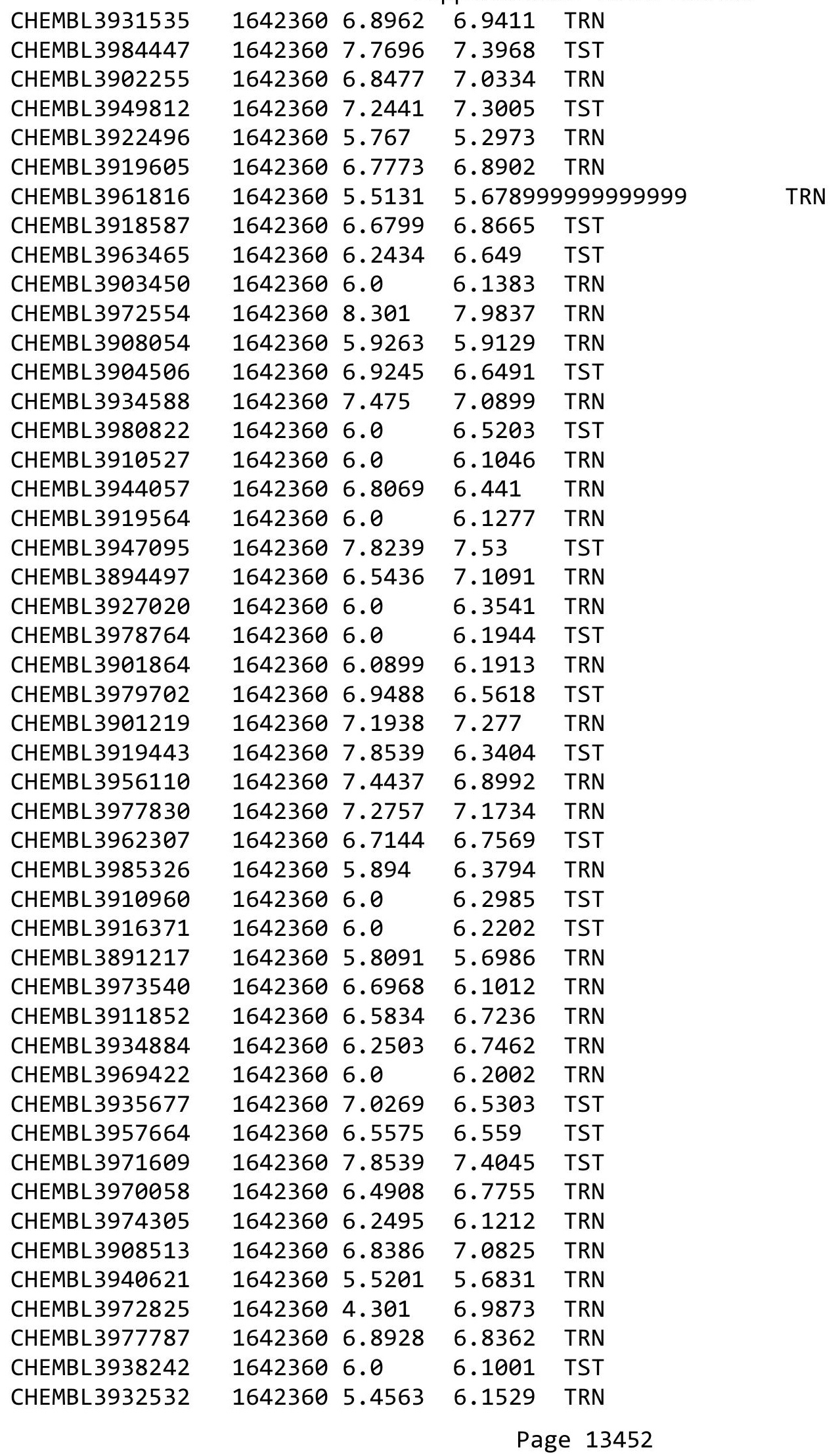




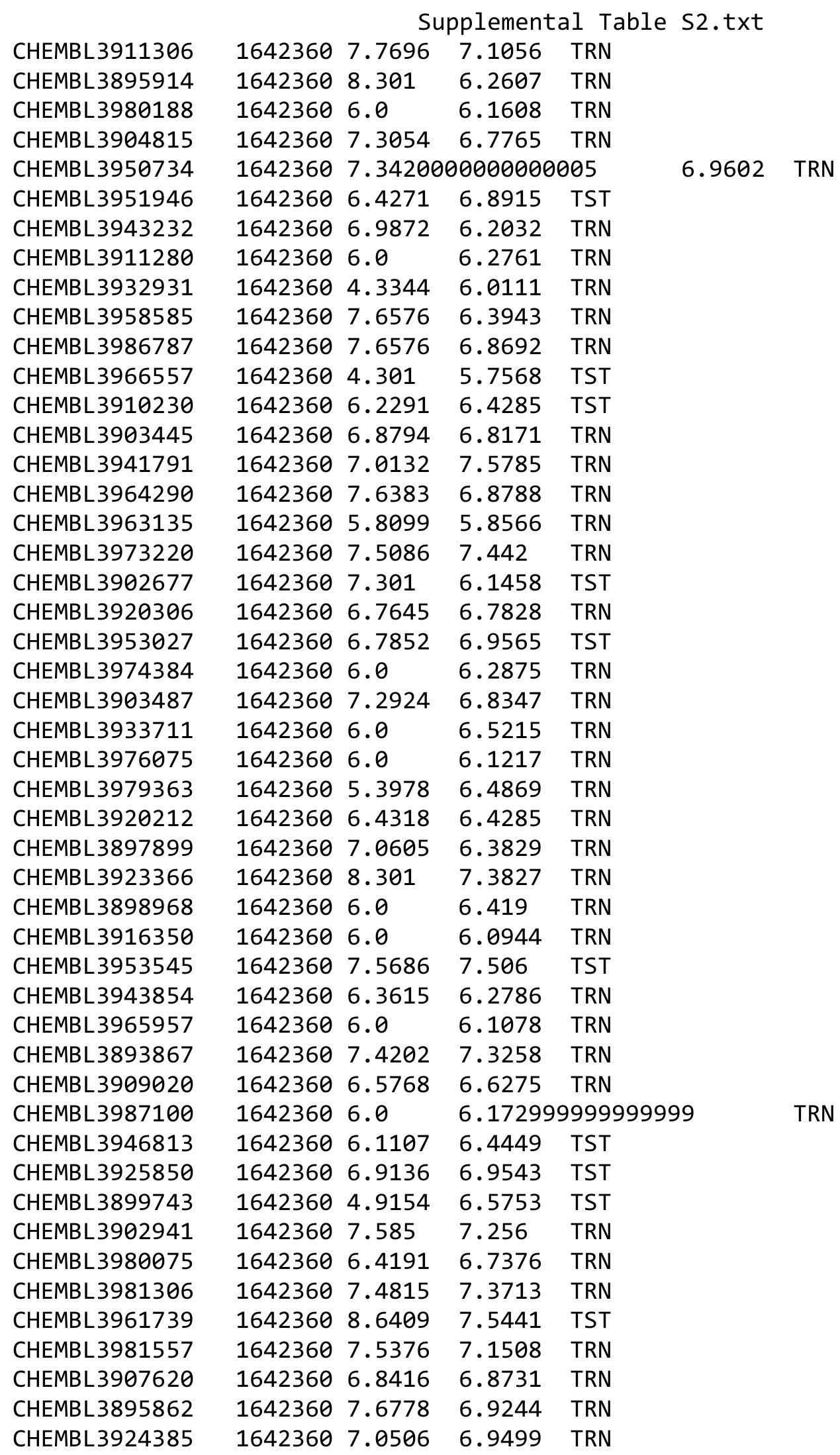

Page 13453 
Supplemental Table S2.txt

\begin{tabular}{|c|c|c|c|c|}
\hline CHEMBL3965474 & 1642360 & 6.61799 & (99999999 & \\
\hline CHEMBL3978877 & 1642360 & 6.0 & \multicolumn{2}{|c|}{6.3020000000000005} \\
\hline CHEMBL3972454 & 1642360 & 6.0 & 6.471 & TRN \\
\hline CHEMBL3955967 & 1642360 & 6.0 & 6.0906 & TRN \\
\hline CHEMBL3955271 & 1642360 & 5.8938 & 6.5577 & TRN \\
\hline CHEMBL3917973 & 1642360 & 7.699 & 7.1055 & TRN \\
\hline CHEMBL3968221 & 1642360 & 7.5376 & 7.1699 & TRN \\
\hline CHEMBL3964688 & 1642360 & 5.4337 & 5.1543 & TRN \\
\hline CHEMBL3960325 & 1642360 & 5.6103 & 5.5071 & TRN \\
\hline CHEMBL3981136 & 1642360 & 6.1938 & 6.2097 & TST \\
\hline CHEMBL3980514 & 1642360 & 6.0 & 6.1907 & TRN \\
\hline CHEMBL3955964 & 1642360 & 6.1079 & \multicolumn{2}{|c|}{6.667999999999999} \\
\hline CHEMBL3898756 & 1642360 & 7.0088 & 6.6505 & TRN \\
\hline CHEMBL3984716 & 1642360 & 8.301 & 6.6369 & TRN \\
\hline CHEMBL 3980106 & 1642360 & 7.7959 & 7.3663 & TRN \\
\hline CHEMBL3927323 & 1642360 & 6.7878 & 6.9726 & TRN \\
\hline CHEMBL3917057 & 1642360 & 6.2941 & 6.7068 & TRN \\
\hline CHEMBL3894775 & 1642360 & 7.8861 & 6.0986 & TRN \\
\hline CHEMBL3979270 & 1642360 & 6.3575 & 6.5056 & TRN \\
\hline CHEMBL3956829 & 1642360 & 6.9706 & 7.1065 & TST \\
\hline CHEMBL3895121 & 1642360 & 6.6904 & 6.2142 & TRN \\
\hline CHEMBL3898271 & 1642360 & 6.0 & 6.1766 & TRN \\
\hline CHEMBL3979315 & 1642360 & 6.5072 & 6.4815 & TST \\
\hline CHEMBL3904882 & 1642360 & 7.5935 & 7.3909 & TST \\
\hline CHEMBL 3895367 & 1642360 & 7.2291 & 6.8044 & TRN \\
\hline CHEMBL3950128 & 1642360 & 8.301 & 7.0086 & TST \\
\hline CHEMBL3946446 & 1642360 & 6.0 & 6.1972 & TRN \\
\hline CHEMBL3909399 & 1642360 & 7.1367 & 6.9063 & TST \\
\hline CHEMBL3929409 & 1642360 & 6.7423 & 7.2455 & TRN \\
\hline CHEMBL3904609 & 1642360 & 7.2596 & 6.9485 & TRN \\
\hline CHEMBL3914536 & 1642360 & 6.0255 & 6.6019 & TRN \\
\hline CHEMBL3934745 & 1642360 & 7.6576 & 7.3889 & TST \\
\hline CHEMBL3956033 & 1642360 & 6.9586 & 6.6553 & TRN \\
\hline CHEMBL3895987 & 1642360 & 6.7496 & 7.1715 & TRN \\
\hline CHEMBL3905837 & 1642360 & 6.3516 & 6.4339 & TRN \\
\hline CHEMBL3897081 & 1642360 & 6.9586 & 6.7739 & TRN \\
\hline CHEMBL 3946830 & 1642360 & 7.5686 & 6.822 & TST \\
\hline CHEMBL3986908 & 1642360 & 5.9465 & 6.3309 & TRN \\
\hline CHEMBL3985642 & 1642360 & 6.0 & 6.1118 & TRN \\
\hline CHEMBL3951969 & 1642360 & 6.0 & 6.1989 & TRN \\
\hline CHEMBL3944541 & 1642360 & 6.3909 & 6.5847 & TRN \\
\hline CHEMBL146609 & 48837 & 5.301 & 6.8572 & TRN \\
\hline CHEMBL422844 & 48837 & 7.8539 & 6.2406 & TST \\
\hline CHEMBL149393 & 48837 & 8.1487 & 7.3406 & TRN \\
\hline CHEMBL146160 & 48837 & 4.301 & 6.1319 & TRN \\
\hline CHEMBL149756 & 48837 & 8.301 & 7.8066 & TRN \\
\hline CHEMBL146207 & 48837 & 8.6383 & 7.7071 & TRN \\
\hline CHEMBL356132 & 48837 & 4.301 & 4.5169 & TRN \\
\hline
\end{tabular}




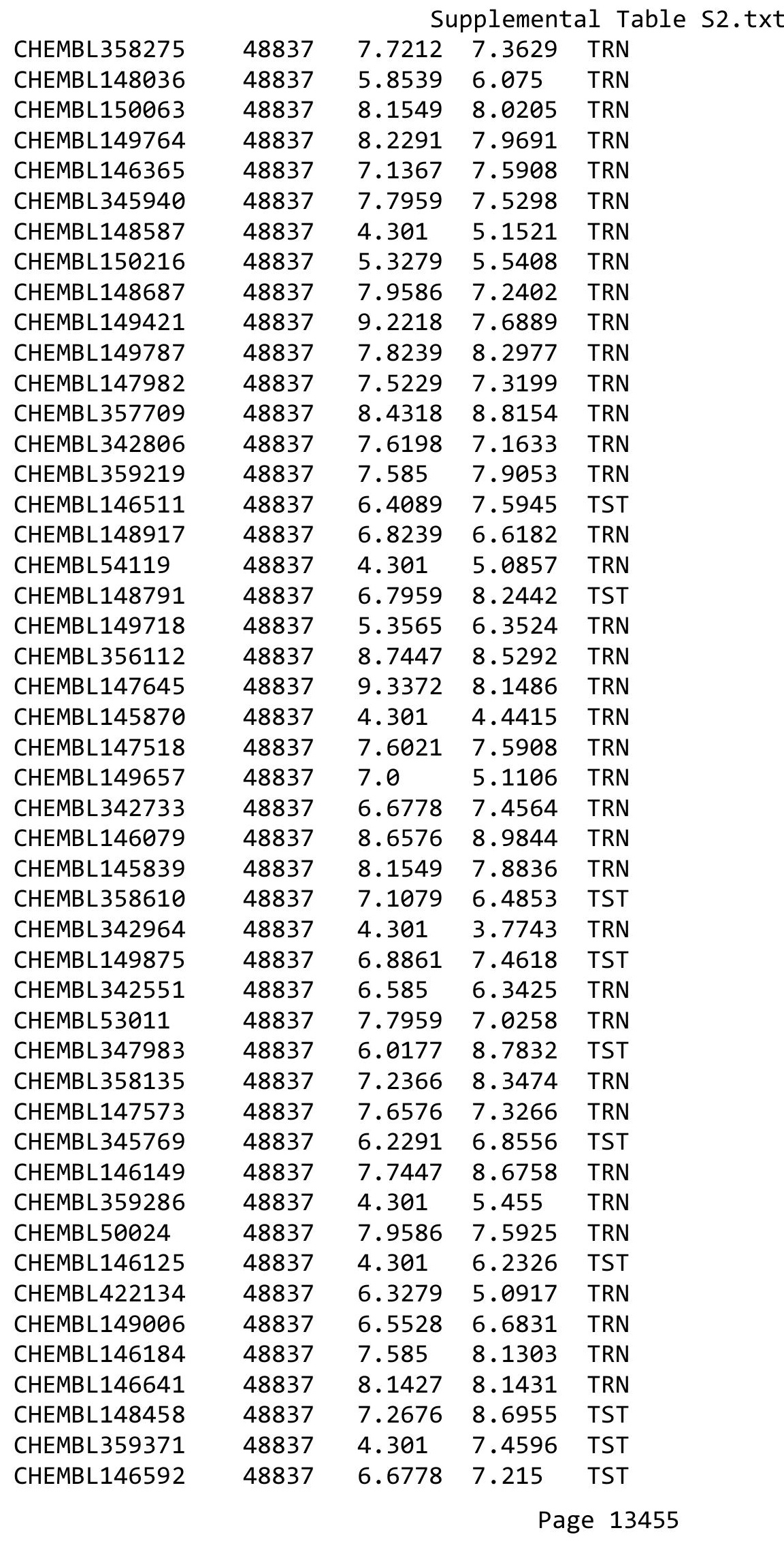




\begin{tabular}{|c|c|c|c|c|c|}
\hline \multicolumn{6}{|c|}{ Supplemental Table S2.txt } \\
\hline CHEMBL342988 & 48837 & 4.301 & 6.9611 & TST & \\
\hline CHEMBL347122 & 48837 & 4.301 & 7.6798 & TST & \\
\hline CHEMBL54237 & 48837 & 9.4949 & 7.5942 & TST & \\
\hline CHEMBL357971 & 48837 & 7.6576 & 8.741 & TST & \\
\hline CHEMBL3765428 & 1556115 & 5.1805 & 4.9219 & TRN & \\
\hline CHEMBL3765378 & 1556115 & 3.3979 & 5.0181 & TST & \\
\hline CHEMBL3763436 & 1556115 & 3.3979 & 2.9274 & TRN & \\
\hline CHEMBL3764633 & 1556115 & 5.6778 & 4.2688 & TRN & \\
\hline CHEMBL3765095 & 1556115 & 5.7212 & 5.5846 & TRN & \\
\hline CHEMBL3763771 & 1556115 & 3.3979 & 3.5708 & TRN & \\
\hline CHEMBL3763767 & 1556115 & 5.2757 & 4.5647 & TRN & \\
\hline CHEMBL3765484 & 1556115 & 4.9957 & 4.3869 & TRN & \\
\hline CHEMBL 2143829 & 1556115 & 6.3979 & 4.5205 & TRN & \\
\hline CHEMBL3764110 & 1556115 & 3.3979 & 4.9758 & TST & \\
\hline CHEMBL3763556 & 1556115 & 4.8761 & 4.4606 & TST & \\
\hline CHEMBL3763259 & 1556115 & 5.7696 & 4.9115 & TRN & \\
\hline CHEMBL3764171 & 1556115 & 4.5072 & 4.4214 & TRN & \\
\hline CHEMBL 3764148 & 1556115 & 4.8996 & 4.5458 & TRN & \\
\hline CHEMBL3765799 & 1556115 & 4.6861 & 4.1606 & TRN & \\
\hline CHEMBL3764232 & 1556115 & 3.3979 & 4.44300 & 00000000005 & TRN \\
\hline CHEMBL3765727 & 1556115 & 3.3979 & 4.4031 & TRN & \\
\hline CHEMBL3763565 & 1556115 & 6.0458 & 5.6543 & TRN & \\
\hline CHEMBL1739206 & 1556115 & 3.3979 & 4.5057 & TST & \\
\hline CHEMBL 3764242 & 1556115 & 3.3979 & 3.16600 & 00000000004 & TRN \\
\hline CHEMBL3763603 & 1556115 & 5.699 & 4.2048 & TRN & \\
\hline CHEMBL 3765248 & 1556115 & 4.6289 & 5.4911 & TRN & \\
\hline CHEMBL3763358 & 1556115 & 5.9208 & 5.0206 & TRN & \\
\hline CHEMBL3765373 & 1556115 & 6.0969 & 5.5289 & TRN & \\
\hline CHEMBL3764689 & 1556115 & 3.3979 & 3.7969 & TRN & \\
\hline CHEMBL3763939 & 1556115 & 6.0969 & 5.5465 & TRN & \\
\hline CHEMBL3765535 & 1556115 & 3.3979 & 4.345 & TRN & \\
\hline CHEMBL3764983 & 1556115 & 5.7696 & 5.3989 & TRN & \\
\hline CHEMBL3764259 & 1556115 & 4.9031 & 4.3699 & TST & \\
\hline CHEMBL 3765418 & 1556115 & 3.3979 & 3.489 & TRN & \\
\hline CHEMBL3764231 & 1556115 & 6.0969 & 5.6794 & TRN & \\
\hline CHEMBL222102 & 1556115 & 6.5229 & 3.137 & TST & \\
\hline CHEMBL3763896 & 1556115 & 3.3979 & 4.1516 & TRN & \\
\hline CHEMBL3765767 & 1556115 & 3.3979 & 4.3506 & TST & \\
\hline CHEMBL3764051 & 1556115 & 5.6576 & 4.9484 & TRN & \\
\hline CHEMBL3763710 & 1556115 & 3.3979 & 3.2245 & TRN & \\
\hline CHEMBL3764371 & 1556115 & 5.6198 & 4.4323 & TST & \\
\hline CHEMBL3763930 & 1556115 & 3.3979 & 4.4378 & TRN & \\
\hline CHEMBL3765543 & 1556115 & 3.3979 & 4.9484 & TRN & \\
\hline CHEMBL 3763843 & 1556115 & 4.5436 & 5.6423 & TRN & \\
\hline CHEMBL3763904 & 1556115 & 3.3979 & 3.6049 & TRN & \\
\hline CHEMBL3763268 & 1556115 & 3.3979 & 4.1744 & TRN & \\
\hline CHEMBL3764560 & 1556115 & 3.3979 & 4.6861 & TRN & \\
\hline CHEMBL3763450 & 1556115 & 3.3979 & 3.9539 & TRN & \\
\hline
\end{tabular}


Supplemental Table S2.txt

\begin{tabular}{|c|c|c|c|c|}
\hline HEMBL 37 & 556115 & 3.3979 & 2.6552 & TR \\
\hline HEMBL3764626 & 556115 & 5.5376 & 5.4474 & \\
\hline HFMBI 376489 & & 3979 & 5172 & \\
\hline HEMBL3765342 & & & 8024 & 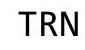 \\
\hline HEMBL3764372 & 556115 & 7959 & 249 & \\
\hline HEMBL3763908 & 556115 & 3.3979 & 0942 & \\
\hline HEMBL 37 & 15 & 3.3979 & 5528 & \\
\hline HEMBL37 & & & & RN \\
\hline HEMBL3763579 & 556115 & 3.3979 & 3.9954 & PN \\
\hline HEMBL 37 & 556115 & 4.8239 & .3283 & \\
\hline HEMBL 3764300 & 556 & 5.6 & .7324 & \\
\hline HEMBL3 & 15 & 3.3979 & 5522 & \\
\hline HEMBL3 & & & & \\
\hline HEMBL37 & 556 & 3979 & .739 & \\
\hline HEMBL37 & 15 & & 1334 & \\
\hline HEMBL37 & 556 & 79 & . 9744 & \\
\hline HEMBL3 & כ & & 5861 & . \\
\hline HEMBL3 & & & & \\
\hline HEMBL37 & 15 & 21 & 4.1419 & N \\
\hline HEMBL3 & 5 & & 53 & ב \\
\hline HEMBL3 & 15 & & 11 & 1 \\
\hline HEMBL: & כ & 79 & 39 & ST \\
\hline HEMBL & 15 & & 67 & CT \\
\hline HEMBL3 & & & 4.8757 & $\pi$ \\
\hline HEMBL3 & & & 17 & ISI \\
\hline HEMBL3 & 5 & & 43 & SI \\
\hline HEMBL; & & 59 & & ST \\
\hline HEMBL3 & 15 & 5 . & 942 & TST \\
\hline HEMBL3 & 15 & 6 & & TS \\
\hline HEMBL1€ & 15 & & & IR \\
\hline HEMBL 7 & 3 & & 58 & $\mathrm{RN}$ \\
\hline HEMBL1 & 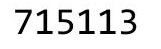 & & 66 & RN \\
\hline HEMBL1 & 3 & 7 & 05 & RN \\
\hline HEMBL73 & 151 & & 7.2088 & TRN \\
\hline HEMBL11 & 15113 & & 7.1886 & TRN \\
\hline HEMBL1 & 3 & 7.64 & 7.2577 & ГRN \\
\hline CHEMBL1 & 3 & 7 & 11 & $\Gamma \mathrm{RN}$ \\
\hline CHEMBL1 & 3 & 7 & 7.3851 & TRN \\
\hline HEMBL1651129 & 15113 & & .4675 & TRN \\
\hline HEMBL16 & 151 & & 5896 & TR \\
\hline HEMBL16 & 13 & & 3.0837 & TRN \\
\hline CHEMBL16 & 15113 & 8 & 3.208 & TRN \\
\hline CHEMBL16 & 15113 & & .888 & TRN \\
\hline HEMBL165 & 15113 & 8.31 & .0117 & $T R$ \\
\hline CHEMBL16 & 15113 & & 7.7368 & TR \\
\hline CHEMBL1 & 15 & & 3.0201 & \\
\hline CHEMBL1651137 & 715113 & 6.9 & 8.0514 & \\
\hline CHEMBL1651138 & 715113 & 6.46 & 7.8784 & $\mid$ \\
\hline
\end{tabular}

Page 13457 


\begin{tabular}{|c|c|c|c|c|c|}
\hline \multirow[b]{2}{*}{ CHEMBL1651139 } & \multicolumn{5}{|c|}{ Supplemental Table S2.txt } \\
\hline & 715113 & 8.96 & 7.7167 & TST & \\
\hline CHEMBL1651140 & 715113 & 8.06 & 7.9702 & TST & \\
\hline CHEMBL1651141 & 715113 & 7.05 & 8.1116 & TST & \\
\hline CHEMBL1651243 & 715113 & 8.54 & 8.1931 & TST & \\
\hline CHEMBL1651244 & 715113 & 7.8 & 7.5481 & TRN & \\
\hline CHEMBL1651245 & 715113 & 7.28 & 7.5757 & TRN & \\
\hline CHEMBL92460 & 715113 & 7.26 & 7.3979 & TRN & \\
\hline CHEMBL433379 & 715113 & 8.11 & 8.3041 & TRN & \\
\hline CHEMBL91291 & 715113 & 8.24 & 8.3683 & TRN & \\
\hline CHEMBL94186 & 715113 & 8.14 & 8.3398 & TRN & \\
\hline CHEMBL418955 & 715113 & 8.08 & 8.3626 & TRN & \\
\hline CHEMBL93619 & 715113 & 8.15 & 8.1144 & TRN & \\
\hline CHEMBL92736 & 715113 & 8.55 & 8.6339 & TRN & \\
\hline CHEMBL329231 & 715113 & 9.24 & 9.2253 & TRN & \\
\hline CHEMBL1179697 & 715113 & 9.32 & 9.2601 & TRN & \\
\hline CHEMBL95020 & 715113 & 8.44 & 8.5335 & TRN & \\
\hline CHEMBL93123 & 715113 & 8.03 & 8.5227 & TRN & \\
\hline CHEMBL1651246 & 715113 & 7.85 & 8.4436 & TRN & \\
\hline CHEMBL1651247 & 715113 & 9.1 & 8.2016 & TRN & \\
\hline CHEMBL420625 & 715113 & 7.7 & 8.0319 & TRN & \\
\hline CHEMBL330004 & 715113 & 7.3 & 7.875 & TRN & \\
\hline CHEMBL 328102 & 715113 & 7.0 & 7.1347 & TST & \\
\hline CHEMBL92142 & 715113 & 6.66 & 6.9628 & TST & \\
\hline CHEMBL126939 & 715113 & 6.68 & 6.5329 & TST & \\
\hline CHEMBL94059 & 715113 & 5.59 & 6.2283 & TRN & \\
\hline CHEMBL92629 & 715113 & 6.49 & 6.1328 & TRN & \\
\hline CHEMBL328715 & 715113 & 6.09 & 6.2165 & TRN & \\
\hline CHEMBL1084790 & 715113 & 7.92 & 7.71200 & 2000000001 & TRN \\
\hline CHEMBL1084275 & 715113 & 8.17 & 7.7029 & TRN & \\
\hline CHEMBL1083661 & 715113 & 7.19 & 7.2621 & TRN & \\
\hline CHEMBL1651248 & 715113 & 8.34 & 8.0035 & TST & \\
\hline CHEMBL1651249 & 715113 & 9.31 & 7.8733 & TST & \\
\hline CHEMBL1651250 & 715113 & 7.37 & 8.0475 & TST & \\
\hline CHEMBL328468 & 715113 & 9.02 & 9.081 & TRN & \\
\hline CHEMBL92463 & 715113 & 7.59 & 8.0792 & TRN & \\
\hline CHEMBL92663 & 715113 & 8.06 & 8.3294 & TRN & \\
\hline CHEMBL92958 & 715113 & 6.92 & 7.2359 & TST & \\
\hline CHEMBL329531 & 715113 & 6.47 & 7.1787 & TST & \\
\hline CHEMBL 93241 & 715113 & 6.05 & 6.854 & TRN & \\
\hline CHEMBL596727 & 609464 & 5.8861 & 5.74700 & 2000000001 & TRN \\
\hline CHEMBL596915 & 609464 & 6.2676 & 6.5227 & TRN & \\
\hline CHEMBL599784 & 609464 & 6.2518 & 5.9514 & TRN & \\
\hline CHEMBL600475 & 609464 & 6.4089 & 6.3788 & TRN & \\
\hline CHEMBL596712 & 609464 & 6.4559 & 6.6001 & TRN & \\
\hline CHEMBL600261 & 609464 & 6.0862 & 5.7651 & TRN & \\
\hline CHEMBL598964 & 609464 & 3.0 & 3.0342 & TRN & \\
\hline CHEMBL592458 & 609464 & 6.5686 & 6.3256 & TRN & \\
\hline CHEMBL607423 & 609464 & 6.2924 & 6.3568 & TRN & \\
\hline
\end{tabular}




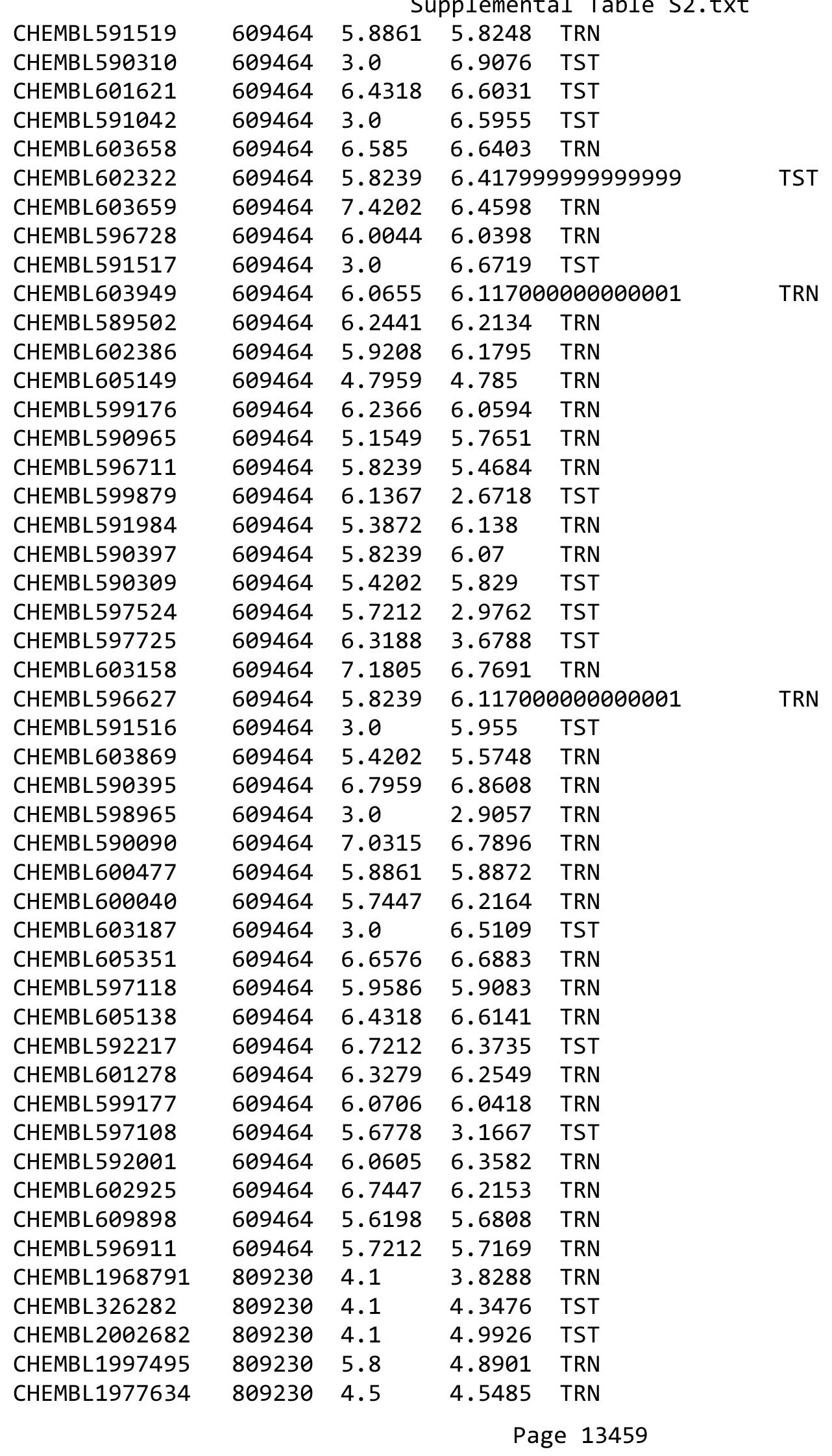




\begin{tabular}{|c|c|c|c|c|}
\hline & & & Supplement & \\
\hline CHEMBL1992732 & 809230 & 4.1 & 4.0042 & TST \\
\hline CHEMBL1971186 & 809230 & 4.1 & 4.0403 & TRN \\
\hline CHEMBL 2003482 & 809230 & 4.1 & 4.2175 & TRN \\
\hline CHEMBL1976872 & 809230 & 3.1 & 3.5967 & TRN \\
\hline CHEMBL1969156 & 809230 & 3.1 & 4.0928 & TRN \\
\hline CHEMBL1973211 & 809230 & 4.1 & 3.7576 & TRN \\
\hline CHEMBL1984700 & 809230 & 4.1 & 4.4326 & TRN \\
\hline CHEMBL2007151 & 809230 & 4.1 & 3.5958 & TRN \\
\hline CHEMBL1972125 & 809230 & 4.1 & 4.1429 & TRN \\
\hline CHEMBL1461728 & 809230 & 4.1 & 4.2056 & TRN \\
\hline CHEMBL1999120 & 809230 & 4.9 & 4.2985 & TST \\
\hline CHEMBL1976134 & 809230 & 5.4 & 4.6608 & TRN \\
\hline CHEMBL1965131 & 809230 & 4.1 & 4.1339 & TRN \\
\hline CHEMBL1995448 & 809230 & 4.1 & 4.4962 & TRN \\
\hline CHEMBL1972158 & 809230 & 4.1 & 3.9802 & TRN \\
\hline CHEMBL1981215 & 809230 & 4.5 & 4.0994 & TRN \\
\hline CHEMBL1974457 & 809230 & 4.1 & 4.099 & TRN \\
\hline CHEMBL 2006580 & 809230 & 4.1 & 3.8205 & TRN \\
\hline CHEMBL2006581 & 809230 & 4.1 & 4.0171 & TRN \\
\hline CHEMBL 2006481 & 809230 & 4.1 & 3.6785 & TRN \\
\hline CHEMBL1979855 & 809230 & 4.1 & 4.9876 & TRN \\
\hline CHEMBL1970340 & 809230 & 4.1 & 4.3422 & TRN \\
\hline CHEMBL1967992 & 809230 & 4.5 & 4.5386 & TRN \\
\hline CHEMBL2005186 & 809230 & 4.1 & 4.3775 & TRN \\
\hline CHEMBL1995927 & 809230 & 4.1 & 4.3662 & TRN \\
\hline CHEMBL1981671 & 809230 & 6.4 & 5.1471 & TRN \\
\hline CHEMBL1975534 & 809230 & 4.1 & 4.0799 & TRN \\
\hline CHEMBL1993424 & 809230 & 4.1 & 4.3584 & TRN \\
\hline CHEMBL1966703 & 809230 & 4.1 & 3.8452 & TST \\
\hline CHEMBL1969561 & 809230 & 4.1 & 3.9011 & TRN \\
\hline CHEMBL1994555 & 809230 & 4.5 & 4.9739 & TRN \\
\hline CHEMBL1983640 & 809230 & 4.5 & 4.3488 & TRN \\
\hline CHEMBL1997023 & 809230 & 4.1 & 3.7335 & TST \\
\hline CHEMBL1964687 & 809230 & 4.2 & 4.4253 & TRN \\
\hline CHEMBL1971943 & 809230 & 6.1 & 5.8268 & TRN \\
\hline CHEMBL1999918 & 809230 & 5.1 & 5.6674 & TRN \\
\hline CHEMBL1974254 & 809230 & 4.1 & 4.4477 & TRN \\
\hline CHEMBL1988537 & 809230 & 4.1 & 4.481 & TST \\
\hline CHEMBL1969049 & 809230 & 4.1 & 4.7851 & TRN \\
\hline CHEMBL 2005828 & 809230 & 4.1 & 3.9643 & TRN \\
\hline CHEMBL 2002240 & 809230 & 4.1 & 3.8531 & TRN \\
\hline CHEMBL1991143 & 809230 & 4.1 & 4.188 & TST \\
\hline CHEMBL1998611 & 809230 & 4.1 & 4.272 & TRN \\
\hline CHEMBL485556 & 809230 & 4.1 & 4.035 & TRN \\
\hline CHEMBL1975900 & 809230 & 6.4 & 5.3451 & TRN \\
\hline CHEMBL255822 & 809230 & 4.1 & 4.1445 & TRN \\
\hline CHEMBL1972221 & 809230 & 4.1 & 3.9336 & TRN \\
\hline CHEMBL 2006778 & 809230 & 4.1 & 4.4943 & TRN \\
\hline
\end{tabular}




\begin{tabular}{|c|c|c|c|c|}
\hline \multicolumn{5}{|c|}{ Supplemental Table S2.txt } \\
\hline CHEMBL378627 & 809230 & 4.1 & 4.3129 & TRN \\
\hline CHEMBL1996979 & 809230 & 4.1 & 4.3639 & TRN \\
\hline CHEMBL1997025 & 809230 & 4.1 & 4.453 & TRN \\
\hline CHEMBL1968406 & 809230 & 4.1 & 4.3439 & TRN \\
\hline CHEMBL1982476 & 809230 & 4.1 & 4.1989 & TRN \\
\hline CHEMBL1984274 & 809230 & 5.2 & 5.3438 & TRN \\
\hline CHEMBL1998545 & 809230 & 4.1 & 4.0415 & TRN \\
\hline CHEMBL1986869 & 809230 & 4.1 & 4.4381 & TRN \\
\hline CHEMBL 2004033 & 809230 & 6.2 & 4.7194 & TST \\
\hline CHEMBL1975923 & 809230 & 7.1 & 5.4457 & TST \\
\hline CHEMBL 2005449 & 809230 & 4.5 & 4.8289 & TRN \\
\hline CHEMBL1987998 & 809230 & 4.5 & 4.4412 & TRN \\
\hline CHEMBL 2006010 & 809230 & 4.1 & 4.121 & TRN \\
\hline CHEMBL1682558 & 809230 & 4.1 & 3.8456 & TRN \\
\hline CHEMBL1971534 & 809230 & 4.9 & 4.6188 & TRN \\
\hline CHEMBL1990496 & 809230 & 4.2 & 3.9116 & TRN \\
\hline CHEMBL242865 & 809230 & 4.5 & 4.9391 & TRN \\
\hline CHEMBL1997623 & 809230 & 4.1 & 3.6979 & TRN \\
\hline CHEMBL 2002479 & 809230 & 5.4 & 5.2669 & TRN \\
\hline CHEMBL1472492 & 809230 & 4.1 & 4.2216 & TST \\
\hline CHEMBL1993166 & 809230 & 5.2 & 5.6732 & TRN \\
\hline CHEMBL1967094 & 809230 & 4.1 & 4.5866 & TRN \\
\hline CHEMBL1966035 & 809230 & 4.1 & 4.45 & TRN \\
\hline CHEMBL 2003341 & 809230 & 4.1 & 4.3571 & TRN \\
\hline CHEMBL1992644 & 809230 & 3.7 & 3.9276 & TRN \\
\hline CHEMBL1992645 & 809230 & 4.1 & 4.1945 & TST \\
\hline CHEMBL1982992 & 809230 & 4.1 & 3.8201 & TRN \\
\hline CHEMBL1998110 & 809230 & 4.5 & 4.3546 & TRN \\
\hline CHEMBL1999590 & 809230 & 4.1 & 3.6993 & TST \\
\hline CHEMBL1981079 & 809230 & 4.1 & 4.2549 & TRN \\
\hline CHEMBL1978166 & 809230 & 5.5 & 5.1548 & TRN \\
\hline CHEMBL1999632 & 809230 & 5.8 & 3.662 & TST \\
\hline CHEMBL1982993 & 809230 & 6.0 & 5.1209 & TRN \\
\hline CHEMBL1972276 & 809230 & 4.1 & 4.5265 & TRN \\
\hline CHEMBL1980489 & 809230 & 6.3 & 5.4465 & TRN \\
\hline CHEMBL 2000832 & 809230 & 7.2 & 7.3421 & TRN \\
\hline CHEMBL1967116 & 809230 & 4.1 & 4.0624 & TRN \\
\hline CHEMBL1972454 & 809230 & 5.7 & 4.6379 & TRN \\
\hline CHEMBL1977814 & 809230 & 4.2 & 3.8968 & TST \\
\hline CHEMBL513846 & 809230 & 4.1 & 3.9442 & TRN \\
\hline CHEMBL1970709 & 809230 & 4.1 & 4.2497 & TRN \\
\hline CHEMBL1974617 & 809230 & 4.4 & 4.5469 & TRN \\
\hline CHEMBL1965660 & 809230 & 4.1 & 4.3574 & TRN \\
\hline CHEMBL1998112 & 809230 & 4.1 & 4.1422 & TRN \\
\hline CHEMBL1969126 & 809230 & 4.1 & 4.1175 & TRN \\
\hline CHEMBL1980896 & 809230 & 4.1 & 4.0477 & TRN \\
\hline CHEMBL1975208 & 809230 & 4.1 & 4.3784 & TRN \\
\hline CHEMBL1178727 & 809230 & 4.3 & 3.7763 & TRN \\
\hline
\end{tabular}




\begin{tabular}{|c|c|c|c|c|}
\hline & & & pplement & al $\mathrm{Ta}$ \\
\hline CHEMBL1970104 & 809230 & 5.9 & 5.3758 & TRN \\
\hline CHEMBL1991429 & 809230 & 4.1 & 3.9522 & TRN \\
\hline CHEMBL1967612 & 809230 & 4.1 & 4.0768 & TST \\
\hline CHEMBL1964777 & 809230 & 4.1 & 4.3215 & TRN \\
\hline CHEMBL1971149 & 809230 & 4.1 & 4.1407 & TRN \\
\hline CHEMBL1999714 & 809230 & 4.1 & 4.5845 & TRN \\
\hline CHEMBL1987533 & 809230 & 4.1 & 4.4182 & TRN \\
\hline CHEMBL1994040 & 809230 & 4.1 & 4.5798 & TRN \\
\hline CHEMBL388978 & 809230 & 8.6 & 8.4527 & TST \\
\hline CHEMBL579246 & 809230 & 4.1 & 5.1243 & TRN \\
\hline CHEMBL1971150 & 809230 & 5.6 & 4.6946 & TST \\
\hline CHEMBL1982506 & 809230 & 4.1 & 5.1495 & TST \\
\hline CHEMBL2004716 & 809230 & 4.1 & 4.3284 & TRN \\
\hline CHEMBL1968127 & 809230 & 4.1 & 3.9334 & TRN \\
\hline CHEMBL1975233 & 809230 & 7.9 & 7.2383 & TRN \\
\hline CHEMBL1985406 & 809230 & 4.1 & 3.8594 & TRN \\
\hline CHEMBL207400 & 809230 & 4.1 & 3.7242 & TST \\
\hline CHEMBL 2000894 & 809230 & 4.1 & 4.1711 & TST \\
\hline CHEMBL1421720 & 809230 & 6.5 & 5.9332 & TRN \\
\hline CHEMBL1968130 & 809230 & 5.8 & 5.0102 & TRN \\
\hline CHEMBL 2002553 & 809230 & 4.1 & 4.0246 & TRN \\
\hline CHEMBL1982135 & 809230 & 4.1 & 4.2259 & TRN \\
\hline CHEMBL1976090 & 809230 & 4.1 & 4.5792 & TRN \\
\hline CHEMBL1993243 & 809230 & 4.1 & 4.5144 & TRN \\
\hline CHEMBL2004771 & 809230 & 4.1 & 4.1024 & TRN \\
\hline CHEMBL1992922 & 809230 & 5.2 & 4.6033 & TRN \\
\hline CHEMBL399021 & 809230 & 4.1 & 3.8164 & TRN \\
\hline CHEMBL1997597 & 809230 & 4.1 & 4.1622 & TRN \\
\hline CHEMBL1969537 & 809230 & 4.1 & 4.9612 & TST \\
\hline CHEMBL576113 & 809230 & 6.4 & 4.4617 & TST \\
\hline CHEMBL1976093 & 809230 & 4.1 & 4.1578 & TRN \\
\hline CHEMBL 210032 & 809230 & 4.1 & 3.8284 & TRN \\
\hline CHEMBL1996543 & 809230 & 4.1 & 3.6305 & TRN \\
\hline CHEMBL1975256 & 809230 & 4.1 & 3.9863 & TST \\
\hline CHEMBL508928 & 809230 & 4.1 & 3.9256 & TRN \\
\hline CHEMBL1991356 & 809230 & 4.1 & 3.9362 & TST \\
\hline CHEMBL1983309 & 809230 & 4.1 & 3.9467 & TRN \\
\hline CHEMBL 2004892 & 809230 & 4.1 & 4.3606 & TRN \\
\hline CHEMBL1999126 & 809230 & 4.1 & 4.1357 & TST \\
\hline CHEMBL1997503 & 809230 & 4.1 & 4.7082 & TST \\
\hline CHEMBL116070 & 809230 & 4.1 & 4.3269 & TRN \\
\hline CHEMBL1990821 & 809230 & 4.1 & 5.078 & TST \\
\hline CHEMBL1970314 & 809230 & 4.1 & 4.1921 & TRN \\
\hline CHEMBL 2004871 & 809230 & 4.1 & 4.118 & TRN \\
\hline CHEMBL2004872 & 809230 & 4.1 & 4.154 & TRN \\
\hline CHEMBL1727312 & 809230 & 4.0 & 4.0372 & TRN \\
\hline CHEMBL1990223 & 809230 & 4.5 & 4.6128 & TRN \\
\hline CHEMBL1969879 & 809230 & 4.1 & 4.0877 & TRN \\
\hline
\end{tabular}




\begin{tabular}{|c|c|c|c|c|c|}
\hline \\
\hline CHEMBL1964382 & 809230 & 5.8 & 5.3643 & TST & \\
\hline CHEMBL101311 & 809230 & 4.5 & 4.6988 & TRN & \\
\hline CHEMBL1981720 & 809230 & 5.2 & 4.6433 & TRN & \\
\hline CHEMBL419932 & 809230 & 4.1 & 4.3945 & TRN & \\
\hline CHEMBL 262433 & 809230 & 4.1 & 3.8328 & TRN & \\
\hline CHEMBL 306380 & 809230 & 4.1 & 4.5918 & TRN & \\
\hline CHEMBL1986588 & 809230 & 3.1 & 3.5887 & TRN & \\
\hline CHEMBL1966722 & 809230 & 4.1 & 4.1561 & TRN & \\
\hline CHEMBL1988581 & 809230 & 7.5 & 6.5393 & TST & \\
\hline CHEMBL 2005699 & 809230 & 4.5 & 4.4887 & TRN & \\
\hline CHEMBL1975500 & 809230 & 7.2 & 6.5583 & TRN & \\
\hline CHEMBL1976328 & 809230 & 4.1 & 3.6451 & TRN & \\
\hline CHEMBL394619 & 809230 & 4.1 & 4.186 & TRN & \\
\hline CHEMBL1964399 & 809230 & 7.0 & 6.439 & TRN & \\
\hline CHEMBL1996831 & 809230 & 4.1 & 4.3696 & TST & \\
\hline CHEMBL411903 & 809230 & 4.1 & 4.0043 & TRN & \\
\hline CHEMBL1978167 & 809230 & 4.5 & 5.0421 & TST & \\
\hline CHEMBL1965988 & 809230 & 4.1 & 4.2526 & TRN & \\
\hline CHEMBL418203 & 809230 & 4.2 & 4.63399 & 99999999995 & TST \\
\hline CHEMBL1989646 & 809230 & 4.1 & 3.8121 & TRN & \\
\hline CHEMBL1682357 & 809230 & 4.1 & 4.2988 & TRN & \\
\hline CHEMBL225519 & 809230 & 4.2 & 4.4204 & TRN & \\
\hline CHEMBL209534 & 809230 & 4.1 & 4.2148 & TRN & \\
\hline CHEMBL1978200 & 809230 & 4.1 & 3.6574 & TRN & \\
\hline CHEMBL 2006631 & 809230 & 4.1 & 4.5946 & TRN & \\
\hline CHEMBL1970522 & 809230 & 4.1 & 4.2676 & TRN & \\
\hline CHEMBL402846 & 809230 & 4.1 & 3.9642 & TRN & \\
\hline CHEMBL1990415 & 809230 & 4.1 & 4.2975 & TRN & \\
\hline CHEMBL1966087 & 809230 & 4.1 & 4.2993 & TRN & \\
\hline CHEMBL1964692 & 809230 & 4.1 & 4.0724 & TRN & \\
\hline CHEMBL1996931 & 809230 & 4.1 & 4.4393 & TRN & \\
\hline CHEMBL1964413 & 809230 & 4.1 & 4.0786 & TRN & \\
\hline CHEMBL1973483 & 809230 & 4.1 & 3.9776 & TRN & \\
\hline CHEMBL1984432 & 809230 & 4.1 & 3.9746 & TRN & \\
\hline CHEMBL1970735 & 809230 & 4.1 & 4.4217 & TRN & \\
\hline CHEMBL219722 & 809230 & 4.1 & 3.7254 & TRN & \\
\hline CHEMBL1975903 & 809230 & 4.5 & 4.9194 & TRN & \\
\hline CHEMBL1997340 & 809230 & 4.1 & 3.6775 & TRN & \\
\hline CHEMBL2004365 & 809230 & 4.1 & 4.4149 & TST & \\
\hline CHEMBL1522508 & 809230 & 4.1 & 4.0067 & TRN & \\
\hline CHEMBL1989474 & 809230 & 4.1 & 3.8899 & TRN & \\
\hline CHEMBL1090360 & 809230 & 4.1 & 3.8761 & TRN & \\
\hline CHEMBL210887 & 809230 & 4.1 & 3.9015 & TRN & \\
\hline CHEMBL1988805 & 809230 & 4.5 & 5.4788 & TST & \\
\hline CHEMBL458997 & 809230 & 6.0 & 5.6953 & TRN & \\
\hline CHEMBL1971021 & 809230 & 4.1 & 4.3092 & TRN & \\
\hline CHEMBL 227271 & 809230 & 4.1 & 4.729 & TRN & \\
\hline CHEMBL583144 & 809230 & 4.1 & 3.8236 & TRN & \\
\hline & & & & 3463 & \\
\hline
\end{tabular}




\begin{tabular}{|c|c|c|c|c|}
\hline \multicolumn{5}{|c|}{ lemental T } \\
\hline CHEMBL1974310 & 809230 & 4.1 & 4.9615 & TRN \\
\hline CHEMBL1969942 & 809230 & 4.5 & 4.8172 & TRN \\
\hline CHEMBL1978567 & 809230 & 4.5 & 4.3546 & TRN \\
\hline CHEMBL1982660 & 809230 & 4.1 & 3.5373 & TRN \\
\hline CHEMBL1994693 & 809230 & 4.1 & 4.0655 & TRN \\
\hline CHEMBL1965838 & 809230 & 4.5 & 3.9255 & TST \\
\hline CHEMBL1982957 & 809230 & 5.5 & 5.7521 & TRN \\
\hline CHEMBL1725279 & 809230 & 5.9 & 4.9368 & TST \\
\hline CHEMBL86755 & 809230 & 5.9 & 5.5316 & TRN \\
\hline CHEMBL 2002346 & 809230 & 6.8 & 5.5654 & TRN \\
\hline CHEMBL1975138 & 809230 & 4.1 & 4.3758 & TRN \\
\hline CHEMBL424872 & 809230 & 4.1 & 4.2345 & TRN \\
\hline CHEMBL 2006836 & 809230 & 4.1 & 4.707 & TST \\
\hline CHEMBL1971947 & 809230 & 4.1 & 4.3436 & TRN \\
\hline CHEMBL412142 & 809230 & 4.1 & 4.9949 & TST \\
\hline CHEMBL1980704 & 809230 & 4.1 & 4.7507 & TST \\
\hline CHEMBL 2003271 & 809230 & 4.1 & 3.8215 & TRN \\
\hline CHEMBL1972365 & 809230 & 3.1 & 3.7302 & TRN \\
\hline CHEMBL1966808 & 809230 & 4.1 & 4.0018 & TRN \\
\hline CHEMBL 2004447 & 809230 & 4.1 & 3.8838 & TRN \\
\hline CHEMBL1983111 & 809230 & 7.8 & 5.8809 & TST \\
\hline CHEMBL1973860 & 809230 & 4.1 & 4.0902 & TRN \\
\hline CHEMBL1977713 & 809230 & 4.1 & 4.8814 & TRN \\
\hline CHEMBL 260135 & 809230 & 4.1 & 4.2607 & TRN \\
\hline CHEMBL220241 & 809230 & 4.1 & 4.9684 & TRN \\
\hline CHEMBL 2004544 & 809230 & 4.1 & 4.6784 & TST \\
\hline CHEMBL1988141 & 809230 & 6.4 & 6.6675 & TST \\
\hline CHEMBL1982610 & 809230 & 4.1 & 3.9792 & TRN \\
\hline CHEMBL1977134 & 809230 & 4.5 & 4.6186 & TRN \\
\hline CHEMBL1969787 & 809230 & 5.3 & 4.5648 & TST \\
\hline CHEMBL1999496 & 809230 & 4.1 & 4.5004 & TRN \\
\hline CHEMBL 2006933 & 809230 & 4.1 & 5.1621 & TST \\
\hline CHEMBL1985206 & 809230 & 4.5 & 5.2551 & TRN \\
\hline CHEMBL1988300 & 809230 & 4.1 & 4.1367 & TRN \\
\hline CHEMBL1991078 & 809230 & 5.4 & 6.0753 & TRN \\
\hline CHEMBL1987359 & 809230 & 4.1 & 4.2342 & TST \\
\hline CHEMBL1977749 & 809230 & 4.5 & 5.1959 & TST \\
\hline CHEMBL 2000685 & 809230 & 6.8 & 6.9584 & TRN \\
\hline CHEMBL2001613 & 809230 & 5.6 & 4.8839 & TRN \\
\hline CHEMBL1993904 & 809230 & 4.5 & 5.2529 & TRN \\
\hline CHEMBL1980376 & 809230 & 4.4 & 4.2413 & TRN \\
\hline CHEMBL1985311 & 809230 & 4.1 & 3.9471 & TRN \\
\hline CHEMBL1989265 & 809230 & 4.1 & 4.4494 & TST \\
\hline CHEMBL1982413 & 809230 & 7.3 & 4.9406 & TST \\
\hline CHEMBL 2004647 & 809230 & 4.1 & 4.7021 & TRN \\
\hline CHEMBL1965910 & 809230 & 4.1 & 3.7987 & TRN \\
\hline CHEMBL1682553 & 809230 & 4.1 & 3.6198 & TRN \\
\hline CHEMBL1971430 & 809230 & 4.1 & 4.1921 & TRN \\
\hline
\end{tabular}




\begin{tabular}{|c|c|c|c|c|}
\hline \multicolumn{5}{|c|}{ Supplemental Table S2.txt } \\
\hline CHEMBL1997764 & 809230 & 4.1 & 4.1626 & TRN \\
\hline CHEMBL1983963 & 809230 & 4.1 & 4.348 & TRN \\
\hline CHEMBL2000271 & 809230 & 5.2 & 4.5204 & TRN \\
\hline CHEMBL562488 & 809230 & 3.1 & 4.136 & TRN \\
\hline CHEMBL1987535 & 809230 & 5.7 & 6.2512 & TRN \\
\hline CHEMBL354676 & 809230 & 3.3 & 3.5126 & TRN \\
\hline CHEMBL1985092 & 809230 & 4.1 & 4.477 & TRN \\
\hline CHEMBL2004692 & 809230 & 4.1 & 3.6942 & TST \\
\hline CHEMBL1981410 & 809230 & 4.1 & 4.3353 & TRN \\
\hline CHEMBL2002586 & 809230 & 4.5 & 3.9794 & TRN \\
\hline CHEMBL1996234 & 809230 & 4.1 & 4.3668 & TRN \\
\hline CHEMBL1991434 & 809230 & 4.1 & 4.6352 & TRN \\
\hline CHEMBL1967544 & 809230 & 4.1 & 4.4305 & TRN \\
\hline CHEMBL1973138 & 809230 & 4.5 & 4.3636 & TRN \\
\hline CHEMBL 223367 & 809230 & 8.4 & 6.7258 & TST \\
\hline CHEMBL1992673 & 809230 & 4.6 & 4.523 & TRN \\
\hline CHEMBL407391 & 809230 & 4.9 & 4.2682 & TST \\
\hline CHEMBL340384 & 809230 & 4.1 & 4.8495 & TST \\
\hline CHEMBL1996587 & 809230 & 4.1 & 3.9967 & TRN \\
\hline CHEMBL1993335 & 809230 & 4.5 & 5.7707 & TST \\
\hline CHEMBL1988692 & 809230 & 4.5 & 4.4236 & TRN \\
\hline CHEMBL1964804 & 809230 & 4.1 & 4.3273 & TRN \\
\hline CHEMBL443962 & 809230 & 4.1 & 4.1857 & TST \\
\hline CHEMBL 2000354 & 809230 & 4.1 & 4.1777 & TRN \\
\hline CHEMBL1965507 & 809230 & 4.1 & 4.1828 & TRN \\
\hline CHEMBL1981107 & 809230 & 3.7 & 3.8315 & TST \\
\hline CHEMBL274064 & 809230 & 4.1 & 4.0024 & TRN \\
\hline CHEMBL1998680 & 809230 & 4.5 & 3.9329 & TRN \\
\hline CHEMBL1967564 & 809230 & 4.1 & 3.8102 & TRN \\
\hline CHEMBL592030 & 809230 & 5.9 & 5.2853 & TST \\
\hline CHEMBL 2000071 & 809230 & 4.1 & 4.0257 & TRN \\
\hline CHEMBL1979176 & 809230 & 4.1 & 3.9639 & TRN \\
\hline CHEMBL1970317 & 809230 & 4.1 & 4.1598 & TRN \\
\hline CHEMBL 2000408 & 809230 & 4.1 & 3.8739 & TRN \\
\hline CHEMBL 248757 & 809230 & 8.4 & 5.6698 & TST \\
\hline CHEMBL1978014 & 809230 & 4.1 & 3.7513 & TRN \\
\hline CHEMBL1997007 & 809230 & 5.6 & 5.4925 & TRN \\
\hline CHEMBL1994538 & 809230 & 4.1 & 4.2725 & TRN \\
\hline CHEMBL1983195 & 809230 & 4.1 & 3.7777 & TST \\
\hline CHEMBL1975490 & 809230 & 5.4 & 5.36700 & 0000000001 \\
\hline CHEMBL1964444 & 809230 & 4.1 & 4.1976 & TRN \\
\hline CHEMBL1989957 & 809230 & 4.1 & 3.9347 & TRN \\
\hline CHEMBL 2002690 & 809230 & 4.5 & 4.4571 & TRN \\
\hline CHEMBL 2006567 & 809230 & 4.1 & 4.0137 & TRN \\
\hline CHEMBL1986139 & 809230 & 4.1 & 3.6369 & TRN \\
\hline CHEMBL1975503 & 809230 & 4.9 & 4.5619 & TRN \\
\hline CHEMBL383527 & 809230 & 4.1 & 4.3258 & TRN \\
\hline CHEMBL1980540 & 809230 & 4.1 & 3.7392 & TRN \\
\hline
\end{tabular}




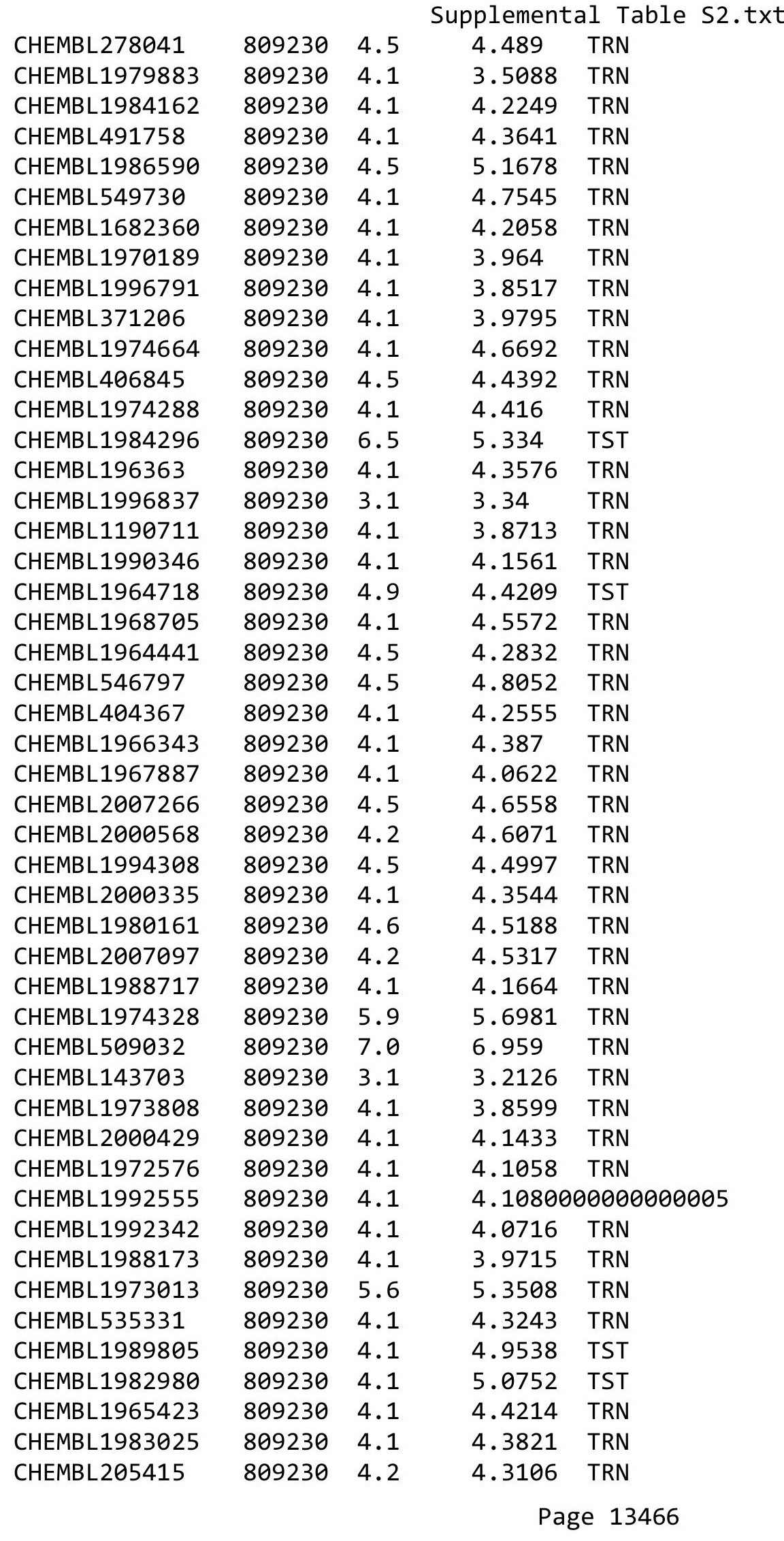




\begin{tabular}{|c|c|c|c|c|}
\hline \multicolumn{5}{|c|}{ Supplemental T } \\
\hline CHEMBL1977135 & 809230 & 4.1 & 3.8151 & TRN \\
\hline CHEMBL 2001920 & 809230 & 4.1 & 4.1444 & TRN \\
\hline CHEMBL 2002322 & 809230 & 4.1 & 4.2117 & TRN \\
\hline CHEMBL1977138 & 809230 & 5.8 & 6.0005 & TST \\
\hline CHEMBL 2002323 & 809230 & 4.1 & 3.9795 & TRN \\
\hline CHEMBL1241473 & 809230 & 6.5 & 6.0168 & TRN \\
\hline CHEMBL1978448 & 809230 & 4.2 & 4.2539 & TST \\
\hline CHEMBL 2004513 & 809230 & 4.1 & 4.6139 & TRN \\
\hline CHEMBL1972258 & 809230 & 4.1 & 4.5117 & TRN \\
\hline CHEMBL1980329 & 809230 & 7.7 & 6.9869 & TRN \\
\hline CHEMBL2004515 & 809230 & 5.8 & 5.4407 & TRN \\
\hline CHEMBL 2001257 & 809230 & 4.1 & 3.8678 & TRN \\
\hline CHEMBL1992042 & 809230 & 6.2 & 6.0765 & TRN \\
\hline CHEMBL 2005548 & 809230 & 4.1 & 3.9959 & TRN \\
\hline CHEMBL 2001704 & 809230 & 4.4 & 4.1181 & TRN \\
\hline CHEMBL1987793 & 809230 & 4.1 & 4.7388 & TST \\
\hline CHEMBL1992536 & 809230 & 4.1 & 4.3142 & TRN \\
\hline CHEMBL 21156 & 809230 & 5.5 & 6.1404 & TST \\
\hline CHEMBL1380050 & 809230 & 4.6 & 4.1778 & TRN \\
\hline CHEMBL1992740 & 809230 & 4.1 & 4.3327 & TRN \\
\hline CHEMBL1994724 & 809230 & 7.1 & 5.1957 & TRN \\
\hline CHEMBL1989267 & 809230 & 5.5 & 5.0454 & TRN \\
\hline CHEMBL 2002373 & 809230 & 4.1 & 3.7336 & TRN \\
\hline CHEMBL439340 & 809230 & 4.1 & 4.1215 & TRN \\
\hline CHEMBL539660 & 809230 & 5.8 & 4.8367 & TST \\
\hline CHEMBL1974574 & 809230 & 6.4 & 5.0179 & TST \\
\hline CHEMBL 2006188 & 809230 & 4.1 & 4.3493 & TRN \\
\hline CHEMBL1967531 & 809230 & 4.1 & 3.9809 & TRN \\
\hline CHEMBL1970913 & 809230 & 4.1 & 4.0169 & TRN \\
\hline CHEMBL1973893 & 809230 & 4.1 & 3.8293 & TRN \\
\hline CHEMBL1995736 & 809230 & 4.1 & 4.6194 & TRN \\
\hline CHEMBL1997534 & 809230 & 4.1 & 4.167 & TRN \\
\hline CHEMBL1993877 & 809230 & 4.5 & 4.5633 & TRN \\
\hline CHEMBL1996500 & 809230 & 4.4 & 4.1533 & TRN \\
\hline CHEMBL1985095 & 809230 & 4.1 & 5.4347 & TST \\
\hline CHEMBL1998551 & 809230 & 4.1 & 4.0348 & TRN \\
\hline CHEMBL1977374 & 809230 & 4.1 & 4.3008 & TRN \\
\hline CHEMBL1973363 & 809230 & 5.5 & 5.2761 & TRN \\
\hline CHEMBL 2005352 & 809230 & 5.6 & 4.8588 & TRN \\
\hline CHEMBL1991180 & 809230 & 4.1 & 5.4536 & TST \\
\hline CHEMBL1989708 & 809230 & 4.1 & 4.5901 & TRN \\
\hline CHEMBL1682540 & 809230 & 4.1 & 3.8431 & TRN \\
\hline CHEMBL1978656 & 809230 & 4.1 & 4.0633 & TRN \\
\hline CHEMBL1976420 & 809230 & 5.4 & 4.6038 & TRN \\
\hline CHEMBL1998253 & 809230 & 6.5 & 4.525 & TST \\
\hline CHEMBL413779 & 809230 & 8.3 & 6.6915 & TST \\
\hline CHEMBL1994864 & 809230 & 6.1 & 5.3402 & TRN \\
\hline CHEMBL2002446 & 809230 & 5.2 & 5.1895 & TRN \\
\hline
\end{tabular}




\begin{tabular}{|c|c|c|c|c|}
\hline \multicolumn{5}{|c|}{ Supplemental Table S2.txt } \\
\hline CHEMBL497151 & 809230 & 4.1 & 4.4739 & TRN \\
\hline CHEMBL 2000029 & 809230 & 4.5 & 4.7495 & TRN \\
\hline CHEMBL1973961 & 809230 & 4.5 & 4.564 & TRN \\
\hline CHEMBL 246970 & 809230 & 4.1 & 3.9386 & TRN \\
\hline CHEMBL340921 & 809230 & 4.1 & 4.0457 & TST \\
\hline CHEMBL373598 & 809230 & 8.3 & 6.6201 & TST \\
\hline CHEMBL 2001149 & 809230 & 6.1 & 5.6893 & TRN \\
\hline CHEMBL1999718 & 809230 & 4.1 & 4.8637 & TRN \\
\hline CHEMBL 2005478 & 809230 & 4.5 & 5.5437 & TST \\
\hline CHEMBL1276446 & 809230 & 6.8 & 5.4037 & TST \\
\hline CHEMBL1996646 & 809230 & 4.5 & 5.1339 & TRN \\
\hline CHEMBL1977346 & 809230 & 4.1 & 4.4607 & TRN \\
\hline CHEMBL 2003657 & 809230 & 4.1 & 4.2738 & TRN \\
\hline CHEMBL1971649 & 809230 & 4.1 & 3.8832 & TRN \\
\hline CHEMBL1992723 & 809230 & 4.2 & 4.1615 & TRN \\
\hline CHEMBL1996702 & 809230 & 6.8 & 6.8368 & TRN \\
\hline CHEMBL 2007124 & 809230 & 4.5 & 4.4923 & TRN \\
\hline CHEMBL1998435 & 809230 & 4.1 & 4.1779 & TRN \\
\hline CHEMBL 2006439 & 809230 & 5.4 & 5.4178 & TRN \\
\hline CHEMBL 2006156 & 809230 & 4.1 & 3.5649 & TST \\
\hline CHEMBL1985681 & 809230 & 4.5 & 6.1155 & TST \\
\hline CHEMBL1969190 & 809230 & 4.1 & 3.7652 & TRN \\
\hline CHEMBL1949851 & 809230 & 4.8 & 4.6986 & TRN \\
\hline CHEMBL1973937 & 809230 & 4.1 & 3.9505 & TRN \\
\hline CHEMBL1991674 & 809230 & 6.0 & 6.5075 & TRN \\
\hline CHEMBL1982711 & 809230 & 5.8 & 5.915 & TRN \\
\hline CHEMBL262623 & 809230 & 4.6 & 4.4 & TRN \\
\hline CHEMBL1987982 & 809230 & 4.1 & 4.4274 & TST \\
\hline CHEMBL1984842 & 809230 & 4.2 & 4.4683 & TRN \\
\hline CHEMBL1969102 & 809230 & 4.1 & 4.4511 & TRN \\
\hline CHEMBL 2004118 & 809230 & 5.7 & 5.6244 & TRN \\
\hline CHEMBL1682346 & 809230 & 4.1 & 4.4352 & TRN \\
\hline CHEMBL1996795 & 809230 & 6.3 & 4.4873 & TST \\
\hline CHEMBL 2007044 & 809230 & 8.5 & 8.0936 & TRN \\
\hline CHEMBL1994241 & 809230 & 6.1 & 5.7145 & TRN \\
\hline CHEMBL223460 & 809230 & 7.9 & 6.0423 & TST \\
\hline CHEMBL1998829 & 809230 & 4.1 & 4.3349 & TRN \\
\hline CHEMBL50894 & 809230 & 4.8 & 5.1083 & TRN \\
\hline CHEMBL1988838 & 809230 & 5.2 & 5.2223 & TRN \\
\hline CHEMBL1981725 & 809230 & 5.1 & 4.9695 & TRN \\
\hline CHEMBL375284 & 809230 & 4.1 & 4.2085 & TRN \\
\hline CHEMBL 2006299 & 809230 & 4.5 & 4.372 & TRN \\
\hline CHEMBL1965169 & 809230 & 4.5 & 5.3046 & TST \\
\hline CHEMBL1991818 & 809230 & 5.7 & 5.7184 & TST \\
\hline CHEMBL1081312 & 809230 & 4.5 & 4.2023 & TRN \\
\hline CHEMBL1965170 & 809230 & 4.5 & 4.6722 & TRN \\
\hline CHEMBL1982866 & 809230 & 4.1 & 3.7173 & TRN \\
\hline CHEMBL2005792 & 809230 & 4.2 & 4.465 & TRN \\
\hline
\end{tabular}




\begin{tabular}{|c|c|c|c|c|}
\hline \multicolumn{5}{|c|}{ Supplemental Table S2.txt } \\
\hline CHEMBL1968926 & 809230 & 4.1 & 4.4687 & TRN \\
\hline CHEMBL1984206 & 809230 & 4.1 & 4.3813 & TRN \\
\hline CHEMBL462120 & 809230 & 4.1 & 3.9466 & TRN \\
\hline CHEMBL1991577 & 809230 & 4.1 & 4.1301 & TRN \\
\hline CHEMBL1986503 & 809230 & 6.4 & 4.2637 & TST \\
\hline CHEMBL1965570 & 809230 & 4.1 & 3.8892 & TRN \\
\hline CHEMBL 2007592 & 809230 & 4.1 & 4.1953 & TRN \\
\hline CHEMBL1972355 & 809230 & 7.4 & 6.8465 & TRN \\
\hline CHEMBL1997892 & 809230 & 4.5 & 4.8555 & TRN \\
\hline CHEMBL2001641 & 809230 & 4.2 & 4.388 & TRN \\
\hline CHEMBL1997193 & 809230 & 4.5 & 5.6375 & TST \\
\hline CHEMBL210963 & 809230 & 4.1 & 4.3724 & TRN \\
\hline CHEMBL1964902 & 809230 & 4.5 & 4.0765 & TRN \\
\hline CHEMBL1082440 & 809230 & 4.1 & 4.4956 & TST \\
\hline CHEMBL1614705 & 809230 & 4.1 & 4.3769 & TRN \\
\hline CHEMBL1972362 & 809230 & 4.1 & 4.1079 & TRN \\
\hline CHEMBL1984633 & 809230 & 4.1 & 4.4773 & TRN \\
\hline CHEMBL1965845 & 809230 & 7.4 & 6.5878 & TRN \\
\hline CHEMBL2007372 & 809230 & 4.1 & 3.9978 & TRN \\
\hline CHEMBL1983715 & 809230 & 6.4 & 6.3377 & TRN \\
\hline CHEMBL1982167 & 809230 & 4.1 & 4.3028 & TRN \\
\hline CHEMBL1971017 & 809230 & 5.3 & 5.2548 & TRN \\
\hline CHEMBL 2006715 & 809230 & 4.1 & 4.1709 & TRN \\
\hline CHEMBL1986597 & 809230 & 4.1 & 4.1736 & TRN \\
\hline CHEMBL1990482 & 809230 & 4.1 & 4.3842 & TRN \\
\hline CHEMBL1990904 & 809230 & 4.1 & 4.4674 & TRN \\
\hline CHEMBL 2000104 & 809230 & 4.1 & 3.987 & TRN \\
\hline CHEMBL 2005475 & 809230 & 4.1 & 4.0534 & TRN \\
\hline CHEMBL1997349 & 809230 & 4.1 & 4.9187 & TST \\
\hline CHEMBL183844 & 809230 & 4.1 & 4.0398 & TRN \\
\hline CHEMBL220057 & 809230 & 4.1 & 4.1031 & TRN \\
\hline CHEMBL1682545 & 809230 & 4.1 & 3.7138 & TRN \\
\hline CHEMBL 383541 & 809230 & 4.1 & 3.9076 & TRN \\
\hline CHEMBL2001224 & 809230 & 8.0 & 7.1237 & TRN \\
\hline CHEMBL1966799 & 809230 & 4.2 & 4.3797 & TRN \\
\hline CHEMBL10 & 809230 & 4.3 & 4.2017 & TRN \\
\hline CHEMBL1976732 & 809230 & 4.1 & 3.9833 & TRN \\
\hline CHEMBL1969506 & 809230 & 4.1 & 4.1022 & TRN \\
\hline CHEMBL1980763 & 809230 & 5.8 & 5.4057 & TRN \\
\hline CHEMBL1964937 & 809230 & 5.8 & 6.1872 & TRN \\
\hline CHEMBL1980163 & 809230 & 4.1 & 4.2269 & TRN \\
\hline CHEMBL590109 & 809230 & 5.6 & 5.2066 & TST \\
\hline CHEMBL1970879 & 809230 & 4.1 & 4.4027 & TRN \\
\hline CHEMBL1989856 & 809230 & 4.1 & 4.4215 & TST \\
\hline CHEMBL2005899 & 809230 & 4.1 & 4.4111 & TRN \\
\hline CHEMBL1682552 & 809230 & 4.1 & 3.5327 & TRN \\
\hline CHEMBL259850 & 809230 & 4.1 & 3.9166 & TRN \\
\hline CHEMBL1972568 & 809230 & 4.1 & 3.9926 & TRN \\
\hline
\end{tabular}




\begin{tabular}{|c|c|c|c|c|c|}
\hline & & & & & \\
\hline CHEMBL 2007479 & 809230 & 4.5 & 4.2159 & TRN & \\
\hline CHEMBL1996155 & 809230 & 4.1 & 4.3258 & TRN & \\
\hline CHEMBL229799 & 809230 & 5.2 & 4.7905 & TRN & \\
\hline CHEMBL105739 & 809230 & 4.1 & 4.5187 & TRN & \\
\hline CHEMBL1682359 & 809230 & 4.1 & 4.0981 & TRN & \\
\hline CHEMBL1972220 & 809230 & 4.5 & 4.7164 & TRN & \\
\hline CHEMBL 379300 & 809230 & 4.1 & 4.1582 & TRN & \\
\hline CHEMBL203673 & 809230 & 4.1 & 3.8134 & TRN & \\
\hline CHEMBL1969523 & 809230 & 6.9 & 6.3749 & TRN & \\
\hline CHEMBL1988995 & 809230 & 4.1 & 4.2214 & TRN & \\
\hline CHEMBL207995 & 809230 & 7.5 & 7.1235 & TRN & \\
\hline CHEMBL2001923 & 809230 & 7.7 & 6.8506 & TRN & \\
\hline CHEMBL1986781 & 809230 & 4.1 & 4.2659 & TRN & \\
\hline CHEMBL526133 & 809230 & 4.1 & 4.2778 & TRN & \\
\hline CHEMBL 2003514 & 809230 & 4.5 & 4.8792 & TRN & \\
\hline CHEMBL1989043 & 809230 & 4.5 & 4.3515 & TRN & \\
\hline CHEMBL1967538 & 809230 & 3.1 & 3.38100 & 00000000002 & TRN \\
\hline CHEMBL1979057 & 809230 & 4.1 & 3.8936 & TRN & \\
\hline CHEMBL1981045 & 809230 & 7.7 & 7.1204 & TRN & \\
\hline CHEMBL387971 & 809230 & 4.1 & 4.2588 & TRN & \\
\hline CHEMBL1975418 & 809230 & 4.1 & 4.6033 & TRN & \\
\hline CHEMBL1992796 & 809230 & 4.1 & 4.0067 & TRN & \\
\hline CHEMBL1164180 & 809230 & 5.5 & 5.2571 & TST & \\
\hline CHEMBL223257 & 809230 & 7.6 & 6.7274 & TST & \\
\hline CHEMBL1999428 & 809230 & 4.1 & 4.2059 & TRN & \\
\hline CHEMBL1967560 & 809230 & 4.1 & 4.2118 & TRN & \\
\hline CHEMBL1997611 & 809230 & 6.0 & 5.1408 & TST & \\
\hline CHEMBL1516890 & 809230 & 4.1 & 4.8683 & TRN & \\
\hline CHEMBL211378 & 809230 & 4.1 & 4.0853 & TRN & \\
\hline CHEMBL1982465 & 809230 & 4.1 & 3.7837 & TRN & \\
\hline CHEMBL2001751 & 809230 & 6.4 & 6.239 & TRN & \\
\hline CHEMBL 2003420 & 809230 & 4.1 & 4.25899 & 99999999995 & TRN \\
\hline CHEMBL1984586 & 809230 & 4.1 & 4.0803 & TRN & \\
\hline CHEMBL1999774 & 809230 & 4.1 & 4.1056 & TRN & \\
\hline CHEMBL1972659 & 809230 & 4.1 & 5.2877 & TST & \\
\hline CHEMBL2002723 & 809230 & 6.1 & 4.8927 & TST & \\
\hline CHEMBL1973395 & 809230 & 5.4 & 5.1498 & TRN & \\
\hline CHEMBL272453 & 809230 & 4.1 & 3.988 & TRN & \\
\hline CHEMBL1987143 & 809230 & 3.1 & 3.7006 & TRN & \\
\hline CHEMBL1970217 & 809230 & 5.3 & 5.0154 & TRN & \\
\hline CHEMBL1971801 & 809230 & 4.1 & 4.0332 & TRN & \\
\hline CHEMBL1968850 & 809230 & 4.1 & 4.4709 & TRN & \\
\hline CHEMBL2005528 & 809230 & 4.1 & 4.7804 & TST & \\
\hline CHEMBL1984686 & 809230 & 4.5 & 4.8671 & TRN & \\
\hline CHEMBL185569 & 809230 & 4.1 & 3.8889 & TRN & \\
\hline CHEMBL1969843 & 809230 & 4.1 & 3.8954 & TRN & \\
\hline CHEMBL 2007002 & 809230 & 4.1 & 4.1924 & TRN & \\
\hline CHEMBL1990288 & 809230 & 4.1 & 4.005 & TRN & \\
\hline & & & & 13470 & \\
\hline
\end{tabular}




\begin{tabular}{|c|c|c|c|c|c|}
\hline \\
\hline CHEMBL1987007 & 809230 & 4.1 & 4.1764 & TRN & \\
\hline CHEMBL1973793 & 809230 & 4.5 & 3.7629 & TST & \\
\hline CHEMBL1969588 & 809230 & 5.1 & 5.4791 & TRN & \\
\hline CHEMBL1984711 & 809230 & 4.1 & 4.2002 & TRN & \\
\hline CHEMBL1990212 & 809230 & 4.1 & 4.1371 & TRN & \\
\hline CHEMBL484390 & 809230 & 4.1 & 4.2403 & TRN & \\
\hline CHEMBL1979252 & 809230 & 5.3 & 5.2465 & TRN & \\
\hline CHEMBL1986143 & 809230 & 4.5 & 4.4871 & TRN & \\
\hline CHEMBL1972934 & 809230 & 5.1 & 4.6528 & TRN & \\
\hline CHEMBL 2007559 & 809230 & 4.5 & 4.2127 & TRN & \\
\hline CHEMBL1992581 & 809230 & 4.5 & 4.4546 & TRN & \\
\hline CHEMBL1682341 & 809230 & 4.1 & 4.4861 & TRN & \\
\hline CHEMBL 2004290 & 809230 & 4.2 & 4.1233 & TRN & \\
\hline CHEMBL1986499 & 809230 & 4.1 & 3.8725 & TRN & \\
\hline CHEMBL1972937 & 809230 & 4.1 & 4.1484 & TRN & \\
\hline CHEMBL1972250 & 809230 & 7.4 & 7.5833 & TRN & \\
\hline CHEMBL 2000393 & 809230 & 4.1 & 5.2927 & TST & \\
\hline CHEMBL 2004072 & 809230 & 4.1 & 3.6396 & TRN & \\
\hline CHEMBL 2004311 & 809230 & 4.1 & 4.0462 & TRN & \\
\hline CHEMBL1992634 & 809230 & 4.1 & 4.602 & TRN & \\
\hline CHEMBL1242373 & 809230 & 4.1 & 4.4348 & TRN & \\
\hline CHEMBL 2000433 & 809230 & 4.1 & 4.4821 & TST & \\
\hline CHEMBL56543 & 809230 & 4.1 & 4.3825 & TRN & \\
\hline CHEMBL316264 & 809230 & 4.1 & 4.0149 & TRN & \\
\hline CHEMBL1988075 & 809230 & 4.1 & $4.1080 e$ & 00000000005 & TRN \\
\hline CHEMBL1996576 & 809230 & 4.5 & 5.1313 & TST & \\
\hline CHEMBL1991678 & 809230 & 4.4 & 3.9847 & TRN & \\
\hline CHEMBL2001239 & 809230 & 7.0 & 5.2091 & TST & \\
\hline CHEMBL1988594 & 809230 & 4.1 & 3.8717 & TRN & \\
\hline CHEMBL 2001288 & 809230 & 4.1 & 4.2633 & TRN & \\
\hline CHEMBL260092 & 809230 & 4.1 & 4.2035 & TRN & \\
\hline CHEMBL1999811 & 809230 & 4.1 & 4.4214 & TRN & \\
\hline CHEMBL1965495 & 809230 & 5.4 & 5.018 & TRN & \\
\hline CHEMBL1985074 & 809230 & 4.1 & 4.6359 & TST & \\
\hline CHEMBL 2000481 & 809230 & 4.1 & 4.3266 & TRN & \\
\hline CHEMBL1982874 & 809230 & 4.1 & 4.2696 & TRN & \\
\hline CHEMBL1991725 & 809230 & 4.1 & 4.1153 & TRN & \\
\hline CHEMBL1992242 & 809230 & 4.1 & 3.9325 & TRN & \\
\hline CHEMBL 2007296 & 809230 & 4.1 & 4.3335 & TRN & \\
\hline CHEMBL 208637 & 809230 & 4.1 & 4.252 & TRN & \\
\hline CHEMBL396523 & 809230 & 5.9 & 5.567 & TRN & \\
\hline CHEMBL 2004159 & 809230 & 4.5 & 4.7741 & TRN & \\
\hline CHEMBL 2007138 & 809230 & 4.9 & 4.1368 & TRN & \\
\hline CHEMBL1978371 & 809230 & 7.0 & 6.4552 & TST & \\
\hline CHEMBL1970203 & 809230 & 4.1 & 3.9023 & TRN & \\
\hline CHEMBL1986530 & 809230 & 4.1 & 4.7085 & TST & \\
\hline CHEMBL1965351 & 809230 & 4.1 & 5.5416 & TST & \\
\hline CHEMBL1999321 & 809230 & 4.1 & 5.0462 & TRN & \\
\hline
\end{tabular}




\begin{tabular}{|c|c|c|c|c|c|}
\hline \\
\hline CHEMBL1968590 & 809230 & 4.1 & 4.2015 & TRN & \\
\hline CHEMBL385478 & 809230 & 4.1 & 5.1584 & TRN & \\
\hline CHEMBL1999749 & 809230 & 4.1 & 3.6806 & TRN & \\
\hline CHEMBL2005375 & 809230 & 4.1 & 3.9738 & TRN & \\
\hline CHEMBL1984191 & 809230 & 4.1 & 4.0181 & TRN & \\
\hline CHEMBL1983006 & 809230 & 7.1 & 6.9039 & TRN & \\
\hline CHEMBL1972183 & 809230 & 4.1 & 3.6343 & TRN & \\
\hline CHEMBL1971029 & 809230 & 6.1 & 6.1103 & TRN & \\
\hline CHEMBL1971679 & 809230 & 4.4 & 4.5373 & TST & \\
\hline CHEMBL1995391 & 809230 & 3.7 & 4.1193 & TRN & \\
\hline CHEMBL 394790 & 809230 & 4.1 & 3.8127 & TRN & \\
\hline CHEMBL226471 & 809230 & 4.1 & 3.9834 & TRN & \\
\hline CHEMBL1974702 & 809230 & 4.1 & 4.3188 & TRN & \\
\hline CHEMBL1996111 & 809230 & 4.1 & 3.74899 & 99999999997 & TRN \\
\hline CHEMBL1965589 & 809230 & 4.1 & 4.2554 & TRN & \\
\hline CHEMBL1998193 & 809230 & 4.1 & 4.0695 & TRN & \\
\hline CHEMBL474432 & 809230 & 5.4 & 5.5693 & TST & \\
\hline CHEMBL1973016 & 809230 & 4.5 & 4.2111 & TRN & \\
\hline CHEMBL1965387 & 809230 & 4.5 & 4.7372 & TRN & \\
\hline CHEMBL2001539 & 809230 & 4.1 & 4.4032 & TST & \\
\hline CHEMBL1988153 & 809230 & 4.1 & 3.8249 & TRN & \\
\hline CHEMBL550418 & 809230 & 6.4 & 6.54200 & 0000000001 & TRN \\
\hline CHEMBL1972584 & 809230 & 4.1 & 3.645 & TRN & \\
\hline CHEMBL1971289 & 809230 & 6.4 & 5.75200 & 0000000001 & TRN \\
\hline CHEMBL1999556 & 809230 & 5.1 & 5.0452 & TRN & \\
\hline CHEMBL1988437 & 809230 & 4.2 & 4.3733 & TRN & \\
\hline CHEMBL1968245 & 809230 & 4.1 & 4.3195 & TRN & \\
\hline CHEMBL1979577 & 809230 & 4.1 & 4.3729 & TRN & \\
\hline CHEMBL1998121 & 809230 & 6.0 & 5.6485 & TRN & \\
\hline CHEMBL1992607 & 809230 & 4.6 & 4.8579 & TRN & \\
\hline CHEMBL1991800 & 809230 & 4.1 & 4.3355 & TRN & \\
\hline CHEMBL52387 & 809230 & 4.1 & 4.01 & TST & \\
\hline CHEMBL1985566 & 809230 & 7.6 & 7.3221 & TRN & \\
\hline CHEMBL2003689 & 809230 & 4.5 & 4.6869 & TRN & \\
\hline CHEMBL379835 & 809230 & 4.1 & 3.5271 & TST & \\
\hline CHEMBL1979357 & 809230 & 4.1 & 4.4701 & TRN & \\
\hline CHEMBL1980802 & 809230 & 8.2 & 5.6731 & TST & \\
\hline CHEMBL1996817 & 809230 & 5.3 & 4.7317 & TRN & \\
\hline CHEMBL1979554 & 809230 & 4.1 & 4.496 & TRN & \\
\hline CHEMBL3197315 & 809230 & 4.1 & 3.7389 & TST & \\
\hline CHEMBL2004355 & 809230 & 4.1 & 3.9709 & TRN & \\
\hline CHEMBL468280 & 809230 & 4.1 & 4.9231 & TST & \\
\hline CHEMBL1990884 & 809230 & 4.1 & 3.844 & TRN & \\
\hline CHEMBL3109278 & 809230 & 4.9 & 4.6568 & TRN & \\
\hline CHEMBL256835 & 809230 & 4.1 & 3.7528 & TRN & \\
\hline CHEMBL1970006 & 809230 & 4.1 & 4.0268 & TST & \\
\hline CHEMBL1980142 & 809230 & 4.1 & 3.6547 & TRN & \\
\hline CHEMBL41783 & 809230 & 4.1 & 3.778 & TRN & \\
\hline & & & & 3472 & \\
\hline
\end{tabular}




\begin{tabular}{|c|c|c|c|c|}
\hline \multicolumn{5}{|c|}{ Supplemental Table S2.txt } \\
\hline CHEMBL 2004438 & 809230 & 4.2 & 4.2538 & TRN \\
\hline CHEMBL 2006276 & 809230 & 6.9 & 6.3226 & TRN \\
\hline CHEMBL191003 & 809230 & 4.5 & 4.9613 & TRN \\
\hline CHEMBL271381 & 809230 & 4.1 & 3.762 & TRN \\
\hline CHEMBL 2006785 & 809230 & 4.1 & 4.7431 & TRN \\
\hline CHEMBL1982466 & 809230 & 4.1 & 4.1114 & TRN \\
\hline CHEMBL1973359 & 809230 & 7.3 & 5.584 & TST \\
\hline CHEMBL1995740 & 809230 & 6.9 & 6.6022 & TRN \\
\hline CHEMBL1996390 & 809230 & 4.1 & 4.0585 & TRN \\
\hline CHEMBL1986943 & 809230 & 6.4 & 6.6372 & TRN \\
\hline CHEMBL1979690 & 809230 & 6.2 & 6.7803 & TRN \\
\hline CHEMBL 234085 & 809230 & 4.4 & 4.5444 & TRN \\
\hline CHEMBL1995832 & 809230 & 4.1 & 4.4378 & TRN \\
\hline CHEMBL1998414 & 809230 & 4.1 & 4.0935 & TRN \\
\hline CHEMBL1969042 & 809230 & 4.1 & 4.6855 & TRN \\
\hline CHEMBL 2000345 & 809230 & 6.5 & 6.1109 & TRN \\
\hline CHEMBL1999931 & 809230 & 5.5 & 5.8146 & TRN \\
\hline CHEMBL1976376 & 809230 & 4.5 & 4.4964 & TRN \\
\hline CHEMBL1991640 & 809230 & 4.1 & 4.7717 & TST \\
\hline CHEMBL1983575 & 809230 & 6.5 & 5.7097 & TRN \\
\hline CHEMBL1375418 & 809230 & 4.1 & 4.3017 & TRN \\
\hline CHEMBL 2007064 & 809230 & 5.6 & 5.2966 & TRN \\
\hline CHEMBL1981047 & 809230 & 4.3 & 4.3407 & TRN \\
\hline CHEMBL 229968 & 809230 & 5.1 & 5.0011 & TRN \\
\hline CHEMBL1976196 & 809230 & 6.0 & 5.6307 & TST \\
\hline CHEMBL1976240 & 809230 & 5.1 & 4.9295 & TRN \\
\hline CHEMBL1997197 & 809230 & 4.5 & 4.481 & TRN \\
\hline CHEMBL1983630 & 809230 & 5.4 & 5.061 & TRN \\
\hline CHEMBL1979093 & 809230 & 4.1 & 3.6094 & TRN \\
\hline CHEMBL1968151 & 809230 & 4.1 & 4.1558 & TRN \\
\hline CHEMBL1381197 & 809230 & 4.1 & 3.91 & TRN \\
\hline CHEMBL1987009 & 809230 & 5.3 & 4.3857 & TRN \\
\hline CHEMBL379218 & 809230 & 4.1 & 4.2208 & TRN \\
\hline CHEMBL 2003817 & 809230 & 4.1 & 4.6108 & TRN \\
\hline CHEMBL336961 & 809230 & 4.1 & 4.4651 & TRN \\
\hline CHEMBL1994830 & 809230 & 4.1 & 4.1927 & TRN \\
\hline CHEMBL1987054 & 809230 & 4.1 & 4.1349 & TRN \\
\hline CHEMBL1970083 & 809230 & 4.1 & 4.3642 & TRN \\
\hline CHEMBL 226403 & 809230 & 4.1 & 4.4253 & TRN \\
\hline CHEMBL 2005631 & 809230 & 4.1 & 4.1175 & TRN \\
\hline CHEMBL1994938 & 809230 & 4.1 & 4.0153 & TRN \\
\hline CHEMBL1825138 & 809230 & 4.1 & 5.0939 & TST \\
\hline CHEMBL1977223 & 809230 & 4.1 & 4.1271 & TRN \\
\hline CHEMBL1995765 & 809230 & 5.6 & 4.5257 & TST \\
\hline CHEMBL1966279 & 809230 & 4.1 & 4.1679 & TRN \\
\hline CHEMBL1236126 & 809230 & 4.1 & 4.1861 & TRN \\
\hline CHEMBL1984760 & 809230 & 4.5 & 5.3081 & TRN \\
\hline CHEMBL1997846 & 809230 & 6.0 & 5.6876 & TRN \\
\hline
\end{tabular}




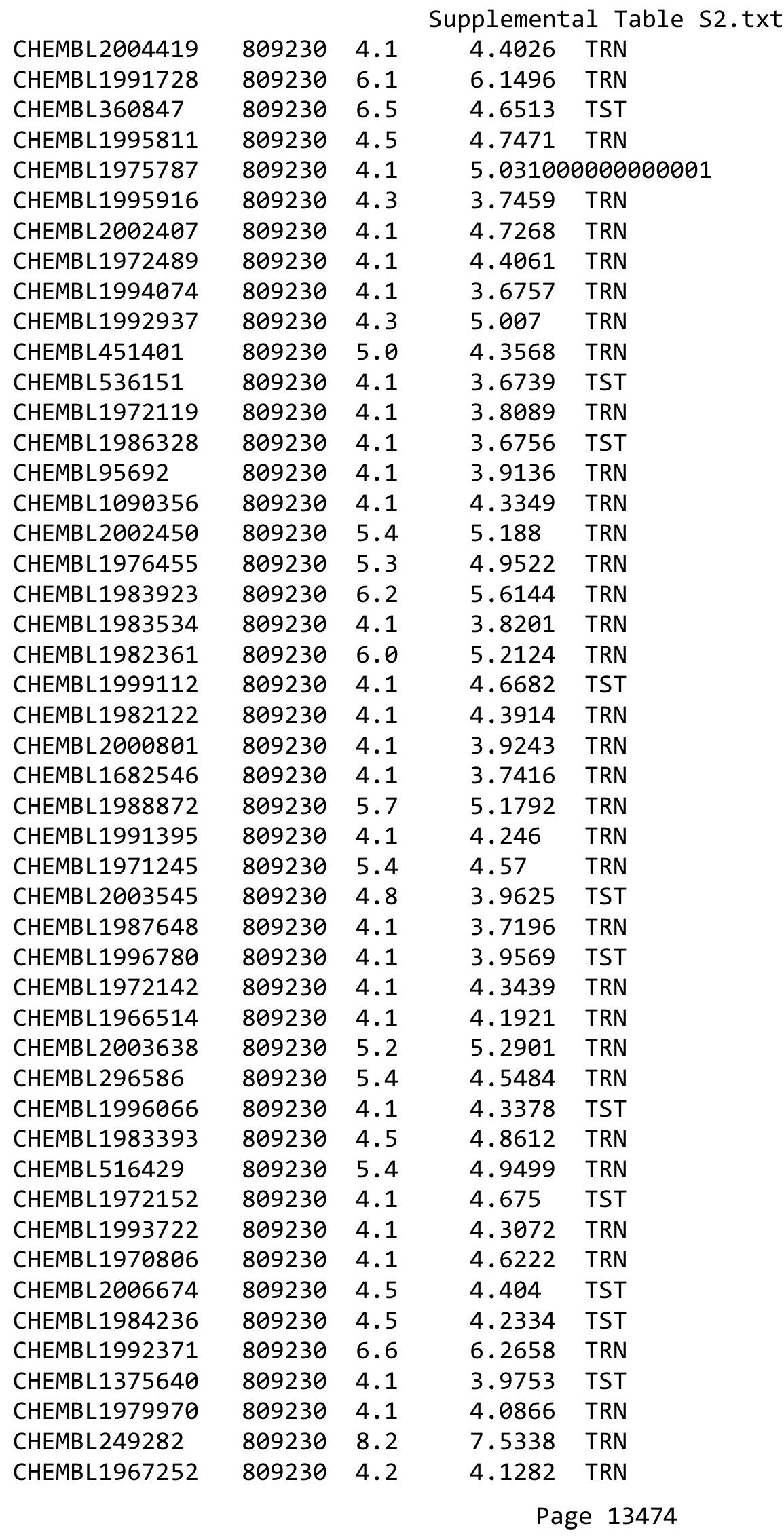

TRN 


\begin{tabular}{|c|c|c|c|c|}
\hline & & & CIIL & al Ta \\
\hline CHEMBL1993374 & 809230 & 4.5 & 4.9981 & TRN \\
\hline CHEMBL1969264 & 809230 & 5.3 & 4.9459 & TRN \\
\hline CHEMBL1973711 & 809230 & 4.1 & 4.5903 & TRN \\
\hline CHEMBL 2006237 & 809230 & 4.1 & 4.2782 & TRN \\
\hline CHEMBL1965604 & 809230 & 6.1 & 4.5003 & TST \\
\hline CHEMBL1967719 & 809230 & 5.7 & 4.9384 & TRN \\
\hline CHEMBL1967720 & 809230 & 4.1 & 4.4858 & TRN \\
\hline CHEMBL1572266 & 809230 & 4.1 & 4.4389 & TST \\
\hline CHEMBL1991138 & 809230 & 4.1 & 3.6218 & TRN \\
\hline CHEMBL1969755 & 809230 & 4.1 & 3.6419 & TRN \\
\hline CHEMBL1979516 & 809230 & 4.1 & 4.0047 & TRN \\
\hline CHEMBL1972820 & 809230 & 4.1 & 4.3734 & TST \\
\hline CHEMBL1605605 & 809230 & 4.5 & 4.363 & TRN \\
\hline CHEMBL1996208 & 809230 & 4.1 & 5.5641 & TST \\
\hline CHEMBL1989029 & 809230 & 4.1 & 3.6977 & TRN \\
\hline CHEMBL 392642 & 809230 & 4.1 & 3.8015 & TRN \\
\hline CHEMBL1970352 & 809230 & 7.3 & 4.8292 & TST \\
\hline CHEMBL1965631 & 809230 & 4.1 & 3.7673 & TRN \\
\hline CHEMBL1980144 & 809230 & 4.1 & 4.1021 & TRN \\
\hline CHEMBL1991188 & 809230 & 4.1 & 4.6133 & TRN \\
\hline CHEMBL1980167 & 809230 & 6.3 & 4.2568 & TST \\
\hline CHEMBL1972849 & 809230 & 4.1 & 4.2262 & TRN \\
\hline CHEMBL 377408 & 809230 & 4.1 & 4.1411 & TRN \\
\hline CHEMBL215152 & 809230 & 4.2 & 4.5251 & TRN \\
\hline CHEMBL231209 & 809230 & 4.1 & 3.9905 & TRN \\
\hline CHEMBL1975357 & 809230 & 4.1 & 3.9048 & TST \\
\hline CHEMBL 2006765 & 809230 & 6.8 & 5.824 & TRN \\
\hline CHEMBL1976220 & 809230 & 4.1 & 3.7978 & TRN \\
\hline CHEMBL259922 & 809230 & 4.1 & 4.045 & TST \\
\hline CHEMBL1997617 & 809230 & 4.1 & 4.3458 & TRN \\
\hline CHEMBL1969301 & 809230 & 4.1 & 4.1972 & TRN \\
\hline CHEMBL1982383 & 809230 & 4.1 & 3.9095 & TRN \\
\hline CHEMBL17370 & 809230 & 4.1 & 3.8391 & TRN \\
\hline CHEMBL1980246 & 809230 & 4.5 & 4.6553 & TST \\
\hline CHEMBL1987910 & 809230 & 4.1 & 3.804 & TRN \\
\hline CHEMBL1983932 & 809230 & 4.1 & 4.1405 & TRN \\
\hline CHEMBL1983980 & 809230 & 6.0 & 6.3598 & TRN \\
\hline CHEMBL1999484 & 809230 & 6.9 & 6.9423 & TRN \\
\hline CHEMBL1973399 & 809230 & 3.2 & 3.7851 & TST \\
\hline CHEMBL1966069 & 809230 & 4.1 & 4.3356 & TRN \\
\hline CHEMBL1986899 & 809230 & 4.5 & 4.8756 & TRN \\
\hline CHEMBL1991285 & 809230 & 7.0 & 7.1825 & TRN \\
\hline CHEMBL1997822 & 809230 & 4.1 & 3.9284 & TRN \\
\hline CHEMBL 243088 & 809230 & 5.5 & 5.25 & TRN \\
\hline CHEMBL1984038 & 809230 & 4.2 & 5.2466 & TRN \\
\hline CHEMBL1993661 & 809230 & 7.3 & 7.1398 & TRN \\
\hline CHEMBL1974416 & 809230 & 4.1 & 4.0747 & TRN \\
\hline CHEMBL 2004615 & 809230 & 4.1 & 3.2393 & TST \\
\hline
\end{tabular}




\begin{tabular}{|c|c|c|c|c|}
\hline & & & ipplement & al $\mathrm{T}$ \\
\hline CHEMBL1984039 & 809230 & 4.1 & 4.749 & TST \\
\hline CHEMBL1997872 & 809230 & 4.1 & 4.3177 & TRN \\
\hline CHEMBL1964290 & 809230 & 4.1 & 3.9986 & TRN \\
\hline CHEMBL 2003768 & 809230 & 4.1 & 5.1012 & TRN \\
\hline CHEMBL213505 & 809230 & 4.1 & 4.1178 & TRN \\
\hline CHEMBL202721 & 809230 & 4.5 & 4.4613 & TRN \\
\hline CHEMBL1982880 & 809230 & 4.1 & 4.0893 & TRN \\
\hline CHEMBL1987034 & 809230 & 6.4 & 6.1342 & TRN \\
\hline CHEMBL1993941 & 809230 & 4.1 & 4.2546 & TRN \\
\hline CHEMBL 377383 & 809230 & 4.1 & 4.1038 & TRN \\
\hline CHEMBL578061 & 809230 & 4.7 & 4.3147 & TRN \\
\hline CHEMBL 2005886 & 809230 & 5.6 & 5.3672 & TRN \\
\hline CHEMBL481491 & 809230 & 4.1 & 4.6423 & TST \\
\hline CHEMBL1682345 & 809230 & 4.1 & 4.085 & TRN \\
\hline CHEMBL1973142 & 809230 & 4.1 & 3.7097 & TRN \\
\hline CHEMBL388311 & 809230 & 6.6 & 7.1412 & TRN \\
\hline CHEMBL1973145 & 809230 & 4.1 & 4.3547 & TRN \\
\hline CHEMBL1982924 & 809230 & 4.1 & 4.6462 & TRN \\
\hline CHEMBL 2005936 & 809230 & 4.1 & 3.7235 & TRN \\
\hline CHEMBL1807515 & 809230 & 5.7 & 6.2619 & TRN \\
\hline CHEMBL1971141 & 809230 & 4.1 & 4.2654 & TRN \\
\hline CHEMBL1995813 & 809230 & 5.9 & 6.2695 & TRN \\
\hline CHEMBL1979718 & 809230 & 4.1 & 4.2647 & TRN \\
\hline CHEMBL 206236 & 809230 & 4.1 & 3.9625 & TRN \\
\hline CHEMBL1989834 & 809230 & 3.7 & 3.7554 & TRN \\
\hline CHEMBL523823 & 809230 & 4.1 & 5.4627 & TST \\
\hline CHEMBL1562756 & 809230 & 4.1 & 3.9834 & TST \\
\hline CHEMBL1987430 & 809230 & 4.5 & 4.4155 & TRN \\
\hline CHEMBL 244378 & 809230 & 6.3 & 6.1152 & TRN \\
\hline CHEMBL 2001957 & 809230 & 4.1 & 4.2213 & TRN \\
\hline CHEMBL1969372 & 809230 & 4.1 & 4.21 & TRN \\
\hline CHEMBL1990583 & 809230 & 4.1 & 4.1776 & TRN \\
\hline CHEMBL289959 & 809230 & 3.3 & 3.8027 & TRN \\
\hline CHEMBL 2006263 & 809230 & 4.1 & 4.3421 & TST \\
\hline CHEMBL1993584 & 809230 & 4.1 & 4.1069 & TRN \\
\hline CHEMBL1986263 & 809230 & 4.1 & 4.8551 & TRN \\
\hline CHEMBL 2000114 & 809230 & 4.1 & 3.8139 & TRN \\
\hline CHEMBL 210618 & 809230 & 4.1 & 4.3487 & TRN \\
\hline CHEMBL1986265 & 809230 & 4.5 & 4.7765 & TRN \\
\hline CHEMBL1975647 & 809230 & 4.1 & 4.5834 & TRN \\
\hline CHEMBL1968380 & 809230 & 4.1 & 4.2143 & TRN \\
\hline CHEMBL1964644 & 809230 & 4.1 & 3.7426 & TRN \\
\hline CHEMBL1991734 & 809230 & 9.0 & 5.8899 & TST \\
\hline CHEMBL1981782 & 809230 & 4.1 & 4.5235 & TRN \\
\hline CHEMBL1977681 & 809230 & 4.1 & 3.6851 & TRN \\
\hline CHEMBL1970142 & 809230 & 4.1 & 4.5095 & TRN \\
\hline CHEMBL1990912 & 809230 & 4.1 & 4.064 & TRN \\
\hline CHEMBL1991782 & 809230 & 3.2 & 3.0421 & TRN \\
\hline
\end{tabular}




\begin{tabular}{|c|c|c|c|c|c|}
\hline \multirow{3}{*}{$\begin{array}{l}\text { CHEMBL } 2002105 \\
\text { CHEMBL1983348 }\end{array}$} & \multirow{3}{*}{$\begin{array}{l}809230 \\
809230\end{array}$} & \multicolumn{4}{|c|}{ Supplemental Table S2.txt } \\
\hline & & 6.0 & \multicolumn{2}{|c|}{5.236000000000001} & \multirow[t]{2}{*}{ TRN } \\
\hline & & 5.7 & 6.2112 & TRN & \\
\hline CHEMBL1988163 & 809230 & 5.6 & 5.1508 & TRN & \\
\hline CHEMBL1995592 & 809230 & 4.1 & 4.6259 & TST & \\
\hline CHEMBL 2006493 & 809230 & 4.1 & 4.8665 & TST & \\
\hline CHEMBL1986177 & 809230 & 4.5 & 4.0524 & TRN & \\
\hline CHEMBL1982541 & 809230 & 4.1 & 4.4441 & TRN & \\
\hline CHEMBL1996923 & 809230 & 4.1 & 4.6517 & TST & \\
\hline CHEMBL1983449 & 809230 & 4.1 & 5.0079 & TRN & \\
\hline CHEMBL1992323 & 809230 & 4.1 & 4.1009 & TRN & \\
\hline CHEMBL1969735 & 809230 & 4.1 & 4.0696 & TRN & \\
\hline CHEMBL 2003524 & 809230 & 5.1 & 5.2306 & TST & \\
\hline CHEMBL 2002649 & 809230 & 5.6 & 5.5103 & TRN & \\
\hline CHEMBL1989423 & 809230 & 3.2 & 3.5033 & TRN & \\
\hline CHEMBL1985367 & 809230 & 4.5 & 4.3613 & TRN & \\
\hline CHEMBL1977874 & 809230 & 4.1 & 4.1578 & TST & \\
\hline CHEMBL437747 & 809230 & 5.8 & 4.423 & TST & \\
\hline CHEMBL1995172 & 809230 & 4.2 & 4.8756 & TST & \\
\hline CHEMBL 2001584 & 809230 & 4.5 & 4.4878 & TST & \\
\hline CHEMBL1971227 & 809230 & 5.9 & 5.1777 & TST & \\
\hline CHEMBL104264 & 809230 & 5.4 & 5.0425 & TST & \\
\hline CHEMBL1994321 & 809230 & 4.1 & 4.1916 & TST & \\
\hline CHEMBL1978562 & 809230 & 4.5 & 6.3006 & TST & \\
\hline CHEMBL1997129 & 809230 & 6.3 & 5.0028 & TST & \\
\hline CHEMBL1984788 & 809230 & 4.1 & 4.2485 & TST & \\
\hline CHEMBL451964 & 809230 & 4.1 & 4.1576 & TST & \\
\hline CHEMBL1974875 & 809230 & 5.6 & 4.5087 & TST & \\
\hline CHEMBL1964307 & 809230 & 4.1 & 4.3923 & TST & \\
\hline CHEMBL1989471 & 809230 & 4.5 & 4.8662 & TST & \\
\hline CHEMBL 2000508 & 809230 & 4.1 & 3.9706 & TST & \\
\hline CHEMBL1971694 & 809230 & 4.1 & 4.2597 & TST & \\
\hline CHEMBL 2001547 & 809230 & 4.1 & 4.3553 & TST & \\
\hline CHEMBL 210928 & 809230 & 4.1 & 4.3458 & TST & \\
\hline CHEMBL1978195 & 809230 & 4.5 & 5.0969 & TST & \\
\hline CHEMBL1994361 & 809230 & 4.1 & 3.8766 & TST & \\
\hline CHEMBL1986603 & 809230 & 4.1 & 3.9788 & TST & \\
\hline CHEMBL1972840 & 809230 & 4.1 & 4.596 & TST & \\
\hline CHEMBL1977148 & 809230 & 4.1 & 3.944 & TST & \\
\hline CHEMBL1968025 & 809230 & 5.5 & 4.5635 & TST & \\
\hline CHEMBL 2003286 & 809230 & 4.1 & 4.4141 & TST & \\
\hline CHEMBL1992306 & 809230 & 4.1 & 3.6793 & TST & \\
\hline CHEMBL 2002165 & 809230 & 4.1 & 4.6456 & TST & \\
\hline CHEMBL2001668 & 809230 & 4.1 & 4.0542 & TST & \\
\hline CHEMBL1979318 & 809230 & 4.1 & 3.8327 & TST & \\
\hline CHEMBL 206382 & 809230 & 4.1 & 4.3589 & TST & \\
\hline CHEMBL1998585 & 809230 & 4.1 & 3.9499 & TST & \\
\hline CHEMBL127898 & 809230 & 4.1 & 5.17899 & 9999999999 & TST \\
\hline CHEMBL519697 & 809230 & 4.1 & 3.9585 & TST & \\
\hline
\end{tabular}




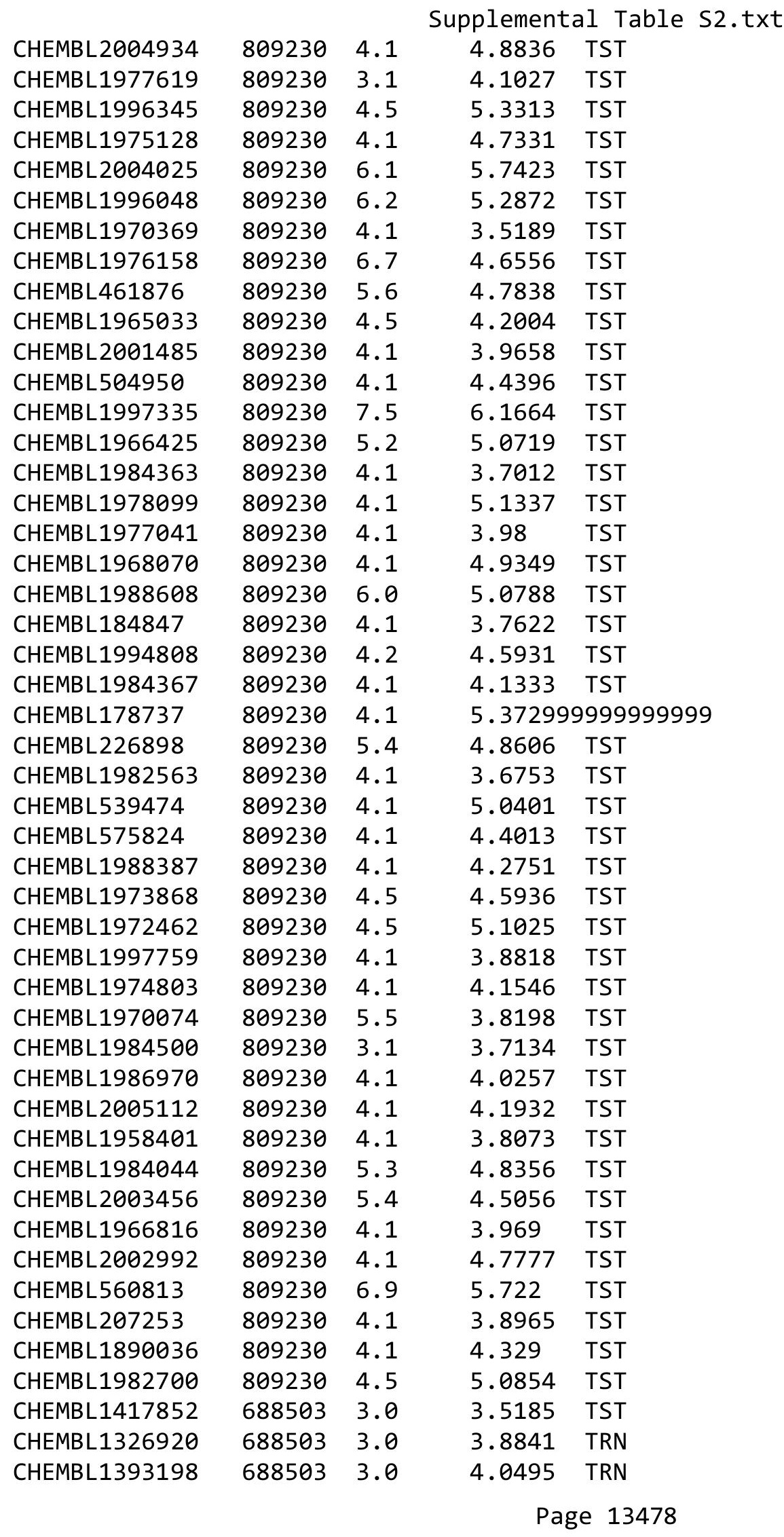




\begin{tabular}{|c|c|c|c|c|c|}
\hline & & \multicolumn{4}{|c|}{ Supplemental Table s2.txt } \\
\hline CHEMBL1575586 & 688503 & 5.1637 & 3.748 & TRN & \\
\hline CHEMBL1403497 & 688503 & 5.8827 & 3.8727 & TRN & \\
\hline CHEMBL1458213 & 688503 & 3.0 & 3.6778 & TST & \\
\hline CHEMBL1540038 & 688503 & 3.0 & 3.7223 & TRN & \\
\hline CHEMBL1399711 & 688503 & 5.6615 & 4.4675 & TRN & \\
\hline CHEMBL1517093 & 688503 & 3.0 & 3.2423 & TRN & \\
\hline CHEMBL1445674 & 688503 & 3.0 & 3.4556 & TRN & \\
\hline CHEMBL1500485 & 688503 & 3.0 & 3.585 & TRN & \\
\hline CHEMBL1589502 & 688503 & 3.0 & 3.4378 & TRN & \\
\hline CHEMBL1337991 & 688503 & 3.0 & 3.7925 & TST & \\
\hline CHEMBL1588072 & 688503 & 3.0 & 3.3144 & TRN & \\
\hline CHEMBL1449105 & 688503 & 4.6655 & 3.7891 & TRN & \\
\hline CHEMBL1507002 & 688503 & 3.0 & 3.6979 & TRN & \\
\hline CHEMBL1433062 & 688503 & 5.0835 & 4.6805 & TRN & \\
\hline CHEMBL1374064 & 688503 & 3.0 & 3.5352 & TST & \\
\hline CHEMBL1353989 & 688503 & 5.3737 & 4.0505 & TRN & \\
\hline CHEMBL1568497 & 688503 & 5.6737 & 3.9419 & TRN & \\
\hline CHEMBL1536618 & 688503 & 3.0 & 3.3793 & TRN & \\
\hline CHEMBL1426947 & 688503 & 5.9318 & 5.5081 & TRN & \\
\hline CHEMBL1577661 & 688503 & 5.9172 & 4.733006 & 00000000005 & TST \\
\hline CHEMBL1334684 & 688503 & 6.0757 & 6.7871 & TRN & \\
\hline CHEMBL1374536 & 688503 & 5.2782 & 4.8264 & TRN & \\
\hline CHEMBL1582693 & 688503 & 3.0 & 3.4088 & TST & \\
\hline CHEMBL1429064 & 688503 & 4.9747 & 4.9562 & TRN & \\
\hline CHEMBL1310396 & 688503 & 3.0 & 3.3046 & TRN & \\
\hline CHEMBL1366738 & 688503 & 3.0 & 4.1799 & TRN & \\
\hline CHEMBL1525343 & 688503 & 3.0 & 3.5261 & TRN & \\
\hline CHEMBL1519773 & 688503 & 5.3316 & 3.8027 & TRN & \\
\hline CHEMBL1577023 & 688503 & 3.0 & 3.6706 & TRN & \\
\hline CHEMBL1350887 & 688503 & 5.8239 & 3.8752 & TRN & \\
\hline CHEMBL1346112 & 688503 & 3.0 & 3.1483 & TRN & \\
\hline CHEMBL1301715 & 688503 & 3.0 & 3.5624 & TRN & \\
\hline CHEMBL1367636 & 688503 & 3.0 & 3.7717 & TRN & \\
\hline CHEMBL1364583 & 688503 & 5.5952 & 4.3754 & TRN & \\
\hline CHEMBL1376959 & 688503 & 3.0 & 3.1211 & TRN & \\
\hline CHEMBL1505300 & 688503 & 5.5622 & 3.7711 & TRN & \\
\hline CHEMBL1566536 & 688503 & 3.0 & 3.7962 & TRN & \\
\hline CHEMBL1531452 & 688503 & 3.0 & 3.6061 & TRN & \\
\hline CHEMBL1526171 & 688503 & 5.9508 & 6.2703 & TRN & \\
\hline CHEMBL1391256 & 688503 & 5.2255 & 5.3141 & TRN & \\
\hline CHEMBL1463801 & 688503 & 3.0 & 3.7068 & TST & \\
\hline CHEMBL1546630 & 688503 & 3.0 & 3.3236 & TRN & \\
\hline CHEMBL1376870 & 688503 & 6.3872 & 6.2681 & TRN & \\
\hline CHEMBL1481712 & 688503 & 5.4237 & 3.7469 & TRN & \\
\hline CHEMBL1505545 & 688503 & 3.0 & 3.715 & TRN & \\
\hline CHEMBL1412790 & 688503 & 3.0 & 3.0539 & TRN & \\
\hline CHEMBL1360599 & 688503 & 3.0 & 4.029 & TRN & \\
\hline CHEMBL1542064 & 688503 & 3.0 & 3.8395 & TST & \\
\hline
\end{tabular}




\begin{tabular}{|c|c|c|c|c|c|c|}
\hline \multicolumn{7}{|c|}{ Supplemental Table S2.txt } \\
\hline CHEMBL1312040 & 688503 & 3.0 & 3.0647 & TRN & & \\
\hline CHEMBL1599031 & 688503 & 3.0 & 3.1675 & TRN & & \\
\hline CHEMBL1465481 & 688503 & 3.0 & 3.9022 & TRN & & \\
\hline CHEMBL1442903 & 688503 & 3.0 & 3.7787 & TRN & & \\
\hline CHEMBL1451000 & 688503 & 3.0 & 3.2674 & TRN & & \\
\hline CHEMBL1384184 & 688503 & 3.0 & 3.8805 & TRN & & \\
\hline CHEMBL1506716 & 688503 & 5.9393 & 3.3335 & TST & & \\
\hline CHEMBL1979696 & 688503 & 3.0 & 3.6177 & TRN & & \\
\hline CHEMBL1569543 & 688503 & 3.0 & 3.4939 & TRN & & \\
\hline CHEMBL1371869 & 688503 & 5.7471 & 4.2034 & TRN & & \\
\hline CHEMBL1465369 & 688503 & 3.0 & 3.5905 & TST & & \\
\hline CHEMBL1364005 & 688503 & 3.0 & 4.1146 & TRN & & \\
\hline CHEMBL1498495 & 688503 & 3.0 & 3.8751 & TRN & & \\
\hline CHEMBL1468228 & 688503 & 3.0 & 3.7937 & TRN & & \\
\hline CHEMBL1300636 & 688503 & 3.0 & 3.3363 & TST & & \\
\hline CHEMBL1322474 & 688503 & 3.0 & 3.5914 & TRN & & \\
\hline CHEMBL1489360 & 688503 & 3.0 & 3.0376 & TRN & & \\
\hline CHEMBL1492028 & 688503 & 3.0 & 2.9008 & TST & & \\
\hline CHEMBL1400857 & 688503 & 3.0 & 3.6296 & TST & & \\
\hline CHEMBL1447034 & 688503 & 5.6737 & 6.8181 & TRN & & \\
\hline CHEMBL1465739 & 688503 & 5.7721 & 5.2393 & TRN & & \\
\hline CHEMBL1384454 & 688503 & 3.0 & 4.1335 & TRN & & \\
\hline CHEMBL1458903 & 688503 & 3.0 & 2.6192 & TRN & & \\
\hline CHEMBL1594309 & 688503 & 3.0 & 3.5723 & TRN & & \\
\hline CHEMBL1995948 & 688503 & 5.8539 & 4.8287 & TRN & & \\
\hline CHEMBL1511858 & 688503 & 3.0 & 4.0687 & TRN & & \\
\hline CHEMBL1326067 & 688503 & 3.0 & 3.6458 & TRN & & \\
\hline CHEMBL1337575 & 688503 & 5.6326 & 4.9078 & TRN & & \\
\hline CHEMBL1415369 & 688503 & 3.0 & 3.4556 & TRN & & \\
\hline CHEMBL1565703 & 688503 & 3.0 & 3.6026 & TRN & & \\
\hline CHEMBL1350082 & 688503 & 3.0 & 3.1733 & TRN & & \\
\hline CHEMBL1380139 & 688503 & 3.0 & 3.3611 & TRN & & \\
\hline CHEMBL1520835 & 688503 & 3.0 & 3.8644 & TRN & & \\
\hline CHEMBL571296 & 688503 & 5.6144 & 4.3209 & TRN & & \\
\hline CHEMBL1511442 & 688503 & 3.0 & 3.1604 & TRN & & \\
\hline CHEMBL1334633 & 688503 & 6.5528 & 6.6428 & TRN & & \\
\hline CHEMBL1305391 & 688503 & 5.8894 & 4.9485 & TRN & & \\
\hline CHEMBL1324051 & 688503 & 6.3872 & 5.2369 & TRN & & \\
\hline CHEMBL1353227 & 688503 & 6.3098 & 4.6842 & TRN & & \\
\hline CHEMBL1587620 & 688503 & 5.3344 & 4.6296 & TRN & & \\
\hline CHEMBL1456053 & 688503 & 3.0 & 4.3879 & TRN & & \\
\hline CHEMBL1491063 & 688503 & 3.0 & 3.7945 & TRN & & \\
\hline CHEMBL1301670 & 688503 & 3.0 & 3.2293 & TRN & & \\
\hline CHEMBL1528758 & 688503 & 3.0 & 3.5903 & TRN & & \\
\hline CHEMBL418068 & 688503 & 4.7073 & 4.3437 & TRN & & \\
\hline CHEMBL1500890 & 688503 & 5.38200 & 00000000 & 01 & 3.4753 & TRN \\
\hline CHEMBL1084643 & 688503 & 4.8633 & 4.4099 & TST & & \\
\hline CHEMBL1449836 & 688503 & 5.5622 & 5.5022 & TRN & & \\
\hline
\end{tabular}




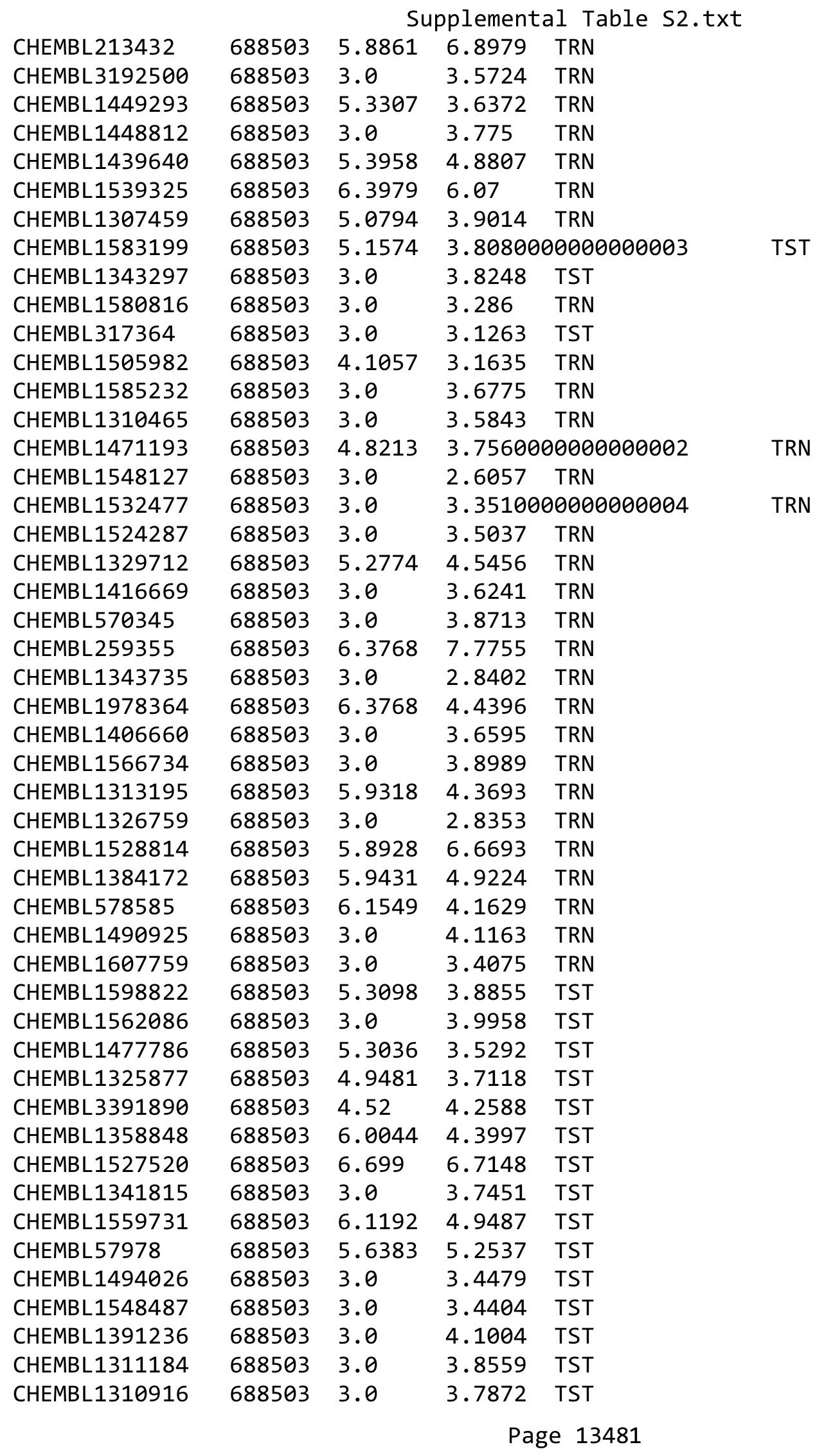




\begin{tabular}{|c|c|c|c|c|c|}
\hline \multicolumn{6}{|c|}{ Supplemental Table S2.txt } \\
\hline CHEMBL1386499 & 688503 & 3.0 & 3.7078 & TST & \\
\hline CHEMBL1520260 & 688503 & 3.0 & 4.0315 & TST & \\
\hline CHEMBL1407181 & 688503 & 3.0 & 3.6886 & TST & \\
\hline CHEMBL1362277 & 688503 & 3.0 & 3.3561 & TST & \\
\hline CHEMBL1451357 & 688503 & 3.0 & 3.80899 & 99999999997 & TST \\
\hline CHEMBL1350387 & 688503 & 3.0 & 3.5058 & TST & \\
\hline CHEMBL1487253 & 688503 & 4.1653 & 3.5908 & TST & \\
\hline CHEMBL3134216 & 1300254 & 3.8931 & 4.6601 & TST & \\
\hline CHEMBL 3134205 & 1300254 & 4.1428 & 4.0786 & TRN & \\
\hline CHEMBL 3134208 & 1300254 & 4.0399 & 4.3119 & TRN & \\
\hline CHEMBL3134191 & 1300254 & 4.848 & 5.0151 & TRN & \\
\hline CHEMBL3134169 & 1300254 & 3.6234 & 3.6322 & TRN & \\
\hline CHEMBL3134184 & 1300254 & 3.0144 & 2.8315 & TRN & \\
\hline CHEMBL 3134182 & 1300254 & 3.2257 & 3.5909 & TRN & \\
\hline CHEMBL3134209 & 1300254 & 3.9965 & 4.3825 & TRN & \\
\hline CHEMBL3134212 & 1300254 & 3.9543 & 3.8316 & TRN & \\
\hline CHEMBL3134168 & 1300254 & 3.6336 & 4.0903 & TRN & \\
\hline CHEMBL 3134202 & 1300254 & 4.2175 & 4.0504 & TRN & \\
\hline CHEMBL 3134215 & 1300254 & 3.9208 & 3.8471 & TRN & \\
\hline CHEMBL3134193 & 1300254 & 4.7701 & 4.0572 & TRN & \\
\hline CHEMBL3134217 & 1300254 & 3.8867 & 4.4099 & TST & \\
\hline CHEMBL 3134171 & 1300254 & 3.5877 & 3.7402 & TRN & \\
\hline CHEMBL 3134188 & 1300254 & 4.9727 & 4.2854 & TRN & \\
\hline CHEMBL 3134187 & 1300254 & 5.0851 & 4.9341 & TRN & \\
\hline CHEMBL3134186 & 1300254 & 5.1831 & 4.7435 & TRN & \\
\hline CHEMBL3134179 & 1300254 & 3.4111 & 3.4445 & TRN & \\
\hline CHEMBL 3134190 & 1300254 & 4.8492 & 4.9308 & TRN & \\
\hline CHEMBL 3134218 & 1300254 & 3.7314 & 3.968 & TRN & \\
\hline CHEMBL3134196 & 1300254 & 4.4464 & 4.6541 & TRN & \\
\hline CHEMBL3134180 & 1300254 & 3.36 & 3.5989 & TRN & \\
\hline CHEMBL3134194 & 1300254 & 4.5 & 3.9681 & TST & \\
\hline CHEMBL 3134206 & 1300254 & 4.1009 & 4.2953 & TRN & \\
\hline CHEMBL 3134211 & 1300254 & 3.9772 & 3.9424 & TRN & \\
\hline CHEMBL3134201 & 1300254 & 4.2645 & 3.6513 & TRN & \\
\hline CHEMBL 3134203 & 1300254 & 4.1655 & 4.2779 & TRN & \\
\hline CHEMBL191334 & 1300254 & 6.3242 & 4.1738 & TST & \\
\hline CHEMBL3134198 & 1300254 & 4.3203 & 5.0334 & TST & \\
\hline CHEMBL3134210 & 1300254 & 3.9897 & 3.6118 & TRN & \\
\hline CHEMBL 3134214 & 1300254 & 3.9292 & 3.8463 & TRN & \\
\hline CHEMBL3134200 & 1300254 & 4.2671 & 4.2772 & TRN & \\
\hline CHEMBL3134192 & 1300254 & 4.776 & 4.9363 & TRN & \\
\hline CHEMBL3134199 & 1300254 & 4.285 & 4.7945 & TST & \\
\hline CHEMBL3134183 & 1300254 & 3.1386 & 3.2669 & TRN & \\
\hline CHEMBL 3134174 & 1300254 & 3.4833 & 3.6347 & TRN & \\
\hline CHEMBL3134207 & 1300254 & 4.0623 & 3.9526 & TRN & \\
\hline CHEMBL3134189 & 1300254 & 4.8545 & 4.2104 & TRN & \\
\hline CHEMBL 3134213 & 1300254 & 3.937 & 4.2532 & TRN & \\
\hline CHEMBL3134181 & 1300254 & 3.3476 & 3.2951 & TRN & \\
\hline
\end{tabular}


Supplemental Table S2.txt

\begin{tabular}{|c|c|c|c|c|}
\hline CHEMBL3134185 & 1300254 & 2.9923 & 3.5022 & TRN \\
\hline CHEMBL3134195 & 1300254 & 4.4683 & 4.2341 & TST \\
\hline CHEMBL3134170 & 1300254 & 3.6041 & 4.0284 & TRN \\
\hline CHEMBL3134178 & 1300254 & 3.4526 & 3.5369 & TRN \\
\hline CHEMBL3134197 & 1300254 & 4.4104 & 4.2291 & TRN \\
\hline CHEMBL3134204 & 1300254 & 4.1627 & 4.3031 & TST \\
\hline CHEMBL3134177 & 1300254 & 3.4582 & 3.092 & TST \\
\hline CHEMBL3132875 & 1300254 & 4.3125 & 4.3854 & TST \\
\hline CHEMBL3134172 & 1300254 & 3.5412 & 2.985 & TST \\
\hline CHEMBL3134175 & 1300254 & 3.4695 & 3.4084 & TST \\
\hline CHEMBL3134176 & 1300254 & 3.4604 & 3.873 & TST \\
\hline CHEMBL3134173 & 1300254 & 3.5309 & 3.7513 & TST \\
\hline CHEMBL 2418179 & 978479 & 5.1487 & 5.126 & TRN \\
\hline CHEMBL 2418177 & 978479 & 4.2588 & 4.265 & TRN \\
\hline CHEMBL2418139 & 978479 & 5.3768 & 5.2891 & TRN \\
\hline CHEMBL 2418167 & 978479 & 3.6021 & 3.489 & TRN \\
\hline CHEMBL 2418176 & 978479 & 5.5686 & 5.4566 & TRN \\
\hline CHEMBL 2418186 & 978479 & 3.6021 & 3.7037 & TRN \\
\hline CHEMBL 2418148 & 978479 & 5.0969 & 4.3917 & TST \\
\hline CHEMBL 2418157 & 978479 & 3.6021 & 3.7393 & TST \\
\hline CHEMBL 2418149 & 978479 & 5.6778 & 4.6298 & TST \\
\hline CHEMBL 2418174 & 978479 & 5.8239 & 5.5263 & TRN \\
\hline CHEMBL 2418171 & 978479 & 3.6021 & 3.5791 & TRN \\
\hline CHEMBL 2418168 & 978479 & 3.6021 & 3.7151 & TRN \\
\hline CHEMBL 2418153 & 978479 & 3.6021 & 3.6319 & TRN \\
\hline CHEMBL 2418155 & 978479 & 5.2291 & 4.7611 & TST \\
\hline CHEMBL 2418160 & 978479 & 3.6021 & 3.5805 & TRN \\
\hline CHEMBL 2418146 & 978479 & 3.6021 & 3.3677 & TST \\
\hline CHEMBL 2418173 & 978479 & 5.5376 & 5.6674 & TRN \\
\hline CHEMBL 2418156 & 978479 & 3.6021 & 3.835 & TST \\
\hline CHEMBL 2418181 & 978479 & 5.8539 & 5.5342 & TST \\
\hline CHEMBL 2418141 & 978479 & 3.6021 & 3.6292 & TRN \\
\hline CHEMBL 2418178 & 978479 & 5.2757 & 5.2804 & TRN \\
\hline CHEMBL 2418189 & 978479 & 3.6021 & 3.5851 & TRN \\
\hline CHEMBL 2418152 & 978479 & 3.6021 & 3.7827 & TST \\
\hline CHEMBL 2418169 & 978479 & 3.6021 & 3.7073 & TRN \\
\hline CHEMBL 2418158 & 978479 & 3.6021 & 3.574 & TRN \\
\hline CHEMBL 2418187 & 978479 & 3.6021 & 3.5665 & TRN \\
\hline CHEMBL 2418151 & 978479 & 3.6021 & 3.8964 & TST \\
\hline CHEMBL 2418166 & 978479 & 3.6021 & 3.5796 & TRN \\
\hline CHEMBL 2418145 & 978479 & 3.6021 & 3.4688 & TRN \\
\hline CHEMBL 2418188 & 978479 & 3.6021 & 3.5754 & TRN \\
\hline CHEMBL 2418143 & 978479 & 3.6021 & 3.50699 & 99999999997 \\
\hline CHEMBL 2418191 & 978479 & 3.6021 & 3.6781 & TRN \\
\hline CHEMBL 2418159 & 978479 & 3.6021 & 3.5618 & TRN \\
\hline CHEMBL 2418170 & 978479 & 3.6021 & 3.5741 & TRN \\
\hline CHEMBL 2418150 & 978479 & 3.6021 & 3.8255 & TST \\
\hline CHEMBL 2418172 & 978479 & 5.4202 & 5.483 & TRN \\
\hline
\end{tabular}


Supplemental Table S2.txt

\begin{tabular}{|c|c|c|c|c|}
\hline CHEMBL 2418147 & 978479 & 3.6021 & 3.6641 & TST \\
\hline CHEMBL 2418163 & 978479 & 3.6021 & 3.6324 & TRN \\
\hline CHEMBL 2418175 & 978479 & 4.6716 & 4.8385 & TRN \\
\hline CHEMBL 2418184 & 978479 & 3.6021 & 3.5243 & TRN \\
\hline CHEMBL 2418165 & 978479 & 3.6021 & 3.6119 & TRN \\
\hline CHEMBL 2418180 & 978479 & 4.6556 & 4.7623 & TRN \\
\hline CHEMBL 2418164 & 978479 & 3.6021 & 3.6118 & TRN \\
\hline CHEMBL 2418162 & 978479 & 3.6021 & 3.6564 & TRN \\
\hline CHEMBL 2418142 & 978479 & 3.6021 & 3.5478 & TRN \\
\hline CHEMBL 2418192 & 978479 & 3.6021 & 3.5224 & TRN \\
\hline CHEMBL 2418190 & 978479 & 3.6021 & 3.5985 & TRN \\
\hline CHEMBL 2418183 & 978479 & 3.6021 & 3.5952 & TRN \\
\hline CHEMBL 2418161 & 978479 & 3.6021 & 3.9567 & TST \\
\hline CHEMBL 2418182 & 978479 & 5.1938 & 5.2589 & TRN \\
\hline CHEMBL 2418144 & 978479 & 3.6021 & 3.4089 & TST \\
\hline CHEMBL 2418140 & 978479 & 3.301 & 3.2327 & TST \\
\hline CHEMBL 2418194 & 978479 & 3.6021 & 3.5251 & TRN \\
\hline CHEMBL236232 & 978479 & 3.301 & 3.3135 & TRN \\
\hline CHEMBL 2418154 & 978479 & 3.6021 & 3.6232 & TRN \\
\hline CHEMBL 2418193 & 978479 & 3.6021 & 3.6177 & TRN \\
\hline CHEMBL 2418185 & 978479 & 3.6021 & 3.7614 & TRN \\
\hline CHEMBL 2392392 & 965916 & 4.6345 & 4.5652 & TRN \\
\hline CHEMBL1440157 & 965916 & 5.6576 & 5.6896 & TST \\
\hline CHEMBL1885748 & 965916 & 6.8861 & 5.9775 & TRN \\
\hline CHEMBL 2392234 & 965916 & 4.585 & 4.82100 & 0000000001 \\
\hline CHEMBL 2392241 & 965916 & 4.6345 & 4.9456 & TRN \\
\hline CHEMBL 2392365 & 965916 & 7.3979 & 7.4615 & TRN \\
\hline CHEMBL 2392239 & 965916 & 4.3851 & 4.5887 & TRN \\
\hline CHEMBL1884711 & 965916 & 6.8239 & 5.5152 & TST \\
\hline CHEMBL 2392222 & 965916 & 4.8861 & 4.7753 & TRN \\
\hline CHEMBL1894742 & 965916 & 7.3979 & 7.1965 & TST \\
\hline CHEMBL 2392379 & 965916 & 4.3851 & 4.3946 & TRN \\
\hline CHEMBL 2392359 & 965916 & 6.5376 & 6.3148 & TRN \\
\hline CHEMBL1899640 & 965916 & 6.4318 & 6.7398 & TRN \\
\hline CHEMBL 2392238 & 965916 & 4.4841 & 4.6805 & TRN \\
\hline CHEMBL 2392230 & 965916 & 5.3344 & 5.3793 & TRN \\
\hline CHEMBL1436125 & 965916 & 4.6345 & 4.9688 & TRN \\
\hline CHEMBL 2392229 & 965916 & 5.6345 & 5.3648 & TRN \\
\hline CHEMBL 2392369 & 965916 & 4.5346 & 4.9681 & TRN \\
\hline CHEMBL 2392363 & 965916 & 7.301 & 6.9833 & TRN \\
\hline CHEMBL 2392367 & 965916 & 5.2351 & 6.5883 & TST \\
\hline CHEMBL1877990 & 965916 & 7.699 & 7.5625 & TRN \\
\hline CHEMBL 2392368 & 965916 & 6.8861 & 6.8496 & TRN \\
\hline CHEMBL 2392383 & 965916 & 4.3851 & 4.7269 & TRN \\
\hline CHEMBL 2392370 & 965916 & 4.585 & 4.8226 & TRN \\
\hline CHEMBL1898197 & 965916 & 7.3979 & \multicolumn{2}{|c|}{7.077000000000001} \\
\hline CHEMBL1898211 & 965916 & 6.5376 & 4.9614 & TST \\
\hline CHEMBL1872011 & 965916 & 6.5376 & 5.4014 & TST \\
\hline
\end{tabular}




\begin{tabular}{|c|c|c|c|c|c|c|}
\hline \multirow{3}{*}{$\begin{array}{l}\text { CHEMBL1357018 } \\
\text { CHEMBL2392223 }\end{array}$} & \multirow{3}{*}{$\begin{array}{l}965916 \\
965916\end{array}$} & \multicolumn{5}{|c|}{ Supplemental Table S2.txt } \\
\hline & & 7.2007 & \multicolumn{3}{|c|}{5.162999999999999} & TRN \\
\hline & & 4.98300 & 00000000 & 205 & 4.8108 & TRN \\
\hline CHEMBL1882945 & 965916 & 5.2351 & 5.5369 & TRN & & \\
\hline CHEMBL1899256 & 965916 & 7.0969 & 7.0987 & TRN & & \\
\hline CHEMBL 2392382 & 965916 & 4.585 & 4.8043 & TRN & & \\
\hline CHEMBL 2392389 & 965916 & 4.8861 & 4.7111 & TRN & & \\
\hline CHEMBL 2392246 & 965916 & 4.5346 & 4.8644 & TRN & & \\
\hline CHEMBL 2392361 & 965916 & 5.2351 & 6.0774 & TRN & & \\
\hline CHEMBL1355387 & 965916 & 4.8013 & 4.7376 & TRN & & \\
\hline CHEMBL 2392244 & 965916 & 5.0362 & 4.9448 & TRN & & \\
\hline CHEMBL1904905 & 965916 & 6.9208 & 7.0491 & TRN & & \\
\hline CHEMBL 2392364 & 965916 & 7.301 & 7.397 & TRN & & \\
\hline CHEMBL 2392391 & 965916 & 5.0362 & 4.9622 & TRN & & \\
\hline CHEMBL 2392378 & 965916 & 4.6345 & 4.8165 & TRN & & \\
\hline CHEMBL 1885536 & 965916 & 6.9208 & 6.9778 & TRN & & \\
\hline CHEMBL 2392227 & 965916 & 5.0862 & 4.8868 & TRN & & \\
\hline CHEMBL2392358 & 965916 & 4.5346 & 5.3762 & TST & & \\
\hline CHEMBL1868723 & 965916 & 7.1549 & 6.9648 & TRN & & \\
\hline CHEMBL 2392377 & 965916 & 4.6345 & 4.6311 & TRN & & \\
\hline CHEMBL 2392240 & 965916 & 5.0362 & 4.8801 & TRN & & \\
\hline CHEMBL 2392362 & 965916 & 5.4342 & 6.0854 & TRN & & \\
\hline CHEMBL 2392376 & 965916 & 4.8356 & 4.7612 & TRN & & \\
\hline CHEMBL 2392385 & 965916 & 4.8861 & 4.4543 & TRN & & \\
\hline CHEMBL 2392247 & 965916 & 4.4342 & 4.7777 & TRN & & \\
\hline CHEMBL2392360 & 965916 & 6.6778 & 6.3225 & TST & & \\
\hline CHEMBL 2392249 & 965916 & 4.585 & 5.6213 & TST & & \\
\hline CHEMBL 2392228 & 965916 & 6.2366 & 5.754 & TRN & & \\
\hline CHEMBL 2392388 & 965916 & 4.7852 & 4.8438 & TST & & \\
\hline CHEMBL 2392242 & 965916 & 4.585 & 4.9626 & TRN & & \\
\hline CHEMBL 2392237 & 965916 & 5.0862 & 4.9962 & TRN & & \\
\hline CHEMBL 2392372 & 965916 & 4.8356 & 4.5115 & TST & & \\
\hline CHEMBL 2392233 & 965916 & 4.5346 & 4.6527 & TRN & & \\
\hline CHEMBL 2392355 & 965916 & 4.7852 & 5.0607 & TST & & \\
\hline CHEMBL 2392375 & 965916 & 4.8861 & 4.8292 & TST & & \\
\hline CHEMBL 2392225 & 965916 & 5.284 & 4.7892 & TRN & & \\
\hline CHEMBL 2392235 & 965916 & 5.0862 & 4.916 & TRN & & \\
\hline CHEMBL 2392245 & 965916 & 5.0362 & 5.0689 & TRN & & \\
\hline CHEMBL1433724 & 965916 & 4.5003 & 5.2112 & TST & & \\
\hline CHEMBL1318509 & 965916 & 4.8508 & 5.1935 & TST & & \\
\hline CHEMBL1357429 & 965916 & 5.1844 & 5.7006 & TRN & & \\
\hline CHEMBL1356808 & 965916 & 6.1024 & 5.6275 & TST & & \\
\hline CHEMBL1892019 & 965916 & 7.5229 & 6.7622 & TST & & \\
\hline CHEMBL1355701 & 965916 & 4.6498 & 5.1064 & TST & & \\
\hline CHEMBL 2392236 & 965916 & 4.7352 & 4.8671 & TRN & & \\
\hline CHEMBL1902528 & 965916 & 7.5229 & 7.2797 & TST & & \\
\hline CHEMBL1331525 & 965916 & 5.0348 & 5.8982 & TRN & & \\
\hline CHEMBL 2392224 & 965916 & 5.284 & 5.0289 & TRN & & \\
\hline CHEMBL 2392226 & 965916 & 4.8861 & 4.918 & TRN & & \\
\hline
\end{tabular}


Supplemental Table S2.txt

\begin{tabular}{|c|c|c|c|c|c|}
\hline CHEMBL 2392231 & 965916 & 5.7852 & 5.6917 & TRN & \\
\hline CHEMBL 2392232 & 965916 & 4.5346 & 4.6203 & TRN & \\
\hline CHEMBL 2392243 & 965916 & 5.3872 & 5.0044 & TRN & \\
\hline CHEMBL 2392366 & 965916 & 4.5847 & 6.1785 & TST & \\
\hline CHEMBL1449883 & 737298 & 2.926 & 2.6946 & TRN & \\
\hline CHEMBL1986418 & 737298 & 2.926 & 2.8652 & TRN & \\
\hline CHEMBL1439833 & 737298 & 2.9261 & 2.8132 & TRN & \\
\hline CHEMBL1461482 & 737298 & 4.1055 & 4.5189 & TRN & \\
\hline CHEMBL1400298 & 737298 & 2.9264 & 3.3011 & TRN & \\
\hline CHEMBL601768 & 737298 & 2.9258 & 2.8368 & TRN & \\
\hline CHEMBL1728955 & 737298 & 4.1668 & 4.1008 & TRN & \\
\hline CHEMBL1508788 & 737298 & 2.9261 & 2.8719 & TRN & \\
\hline CHEMBL 81782 & 737298 & 4.1067 & 4.0152 & TST & \\
\hline CHEMBL547285 & 737298 & 2.9257 & 2.8269 & TRN & \\
\hline CHEMBL1405150 & 737298 & 2.926 & 2.9267 & TRN & \\
\hline CHEMBL1532068 & 737298 & 2.926 & 2.7996 & TRN & \\
\hline CHEMBL1484328 & 737298 & 4.8145 & 4.5255 & TRN & \\
\hline CHEMBL580955 & 737298 & 2.9261 & 2.7733 & TRN & \\
\hline CHEMBL1393829 & 737298 & 2.926 & 2.9548 & TRN & \\
\hline CHEMBL1543157 & 737298 & 2.9262 & 3.0967 & TRN & \\
\hline CHEMBL1430038 & 737298 & 4.5094 & 4.8476 & TRN & \\
\hline CHEMBL1381627 & 737298 & 2.9261 & 3.2257 & TRN & \\
\hline CHEMBL1574982 & 737298 & 2.926 & 2.9807 & TRN & \\
\hline CHEMBL1426340 & 737298 & 2.926 & 3.3426 & TRN & \\
\hline CHEMBL1476029 & 737298 & 4.8182 & 3.9718 & TRN & \\
\hline CHEMBL 3208475 & 737298 & 2.9258 & 2.8561 & TRN & \\
\hline CHEMBL1574121 & 737298 & 3.403 & 3.9115 & TRN & \\
\hline CHEMBL1342907 & 737298 & 2.9261 & 2.8006 & TRN & \\
\hline CHEMBL1304383 & 737298 & 2.926 & 2.8487 & TRN & \\
\hline CHEMBL1396843 & 737298 & 4.6623 & 4.7052 & TRN & \\
\hline CHEMBL1998606 & 737298 & 2.9261 & 3.3681 & TRN & \\
\hline CHEMBL1427059 & 737298 & 2.9257 & 2.8955 & TRN & \\
\hline CHEMBL1382917 & 737298 & 4.3252 & 4.2296 & TST & \\
\hline CHEMBL3192868 & 737298 & 2.9264 & 3.4362 & TRN & \\
\hline CHEMBL1414746 & 737298 & 3.9351 & 3.6096 & TRN & \\
\hline CHEMBL3191064 & 737298 & 4.4542 & 2.99899 & 99999999997 & TST \\
\hline CHEMBL1428883 & 737298 & 4.7544 & 4.8085 & TRN & \\
\hline CHEMBL3198128 & 737298 & 4.2874 & 3.2257 & TST & \\
\hline CHEMBL1979954 & 737298 & 2.9261 & 3.3095 & TRN & \\
\hline CHEMBL1729758 & 737298 & 4.7892 & 4.2154 & TST & \\
\hline CHEMBL3190268 & 737298 & 2.9259 & 2.6401 & TRN & \\
\hline CHEMBL3195943 & 737298 & 5.0287 & 4.9036 & TRN & \\
\hline CHEMBL1530412 & 737298 & 2.926 & 2.9524 & TRN & \\
\hline CHEMBL3214118 & 737298 & 2.9261 & 3.463 & TRN & \\
\hline CHEMBL1887153 & 737298 & 2.926 & \multicolumn{2}{|c|}{2.6689999999999996} & TRN \\
\hline CHEMBL1988851 & 737298 & 4.4244 & 3.694 & TRN & \\
\hline CHEMBL1545729 & 737298 & 2.9259 & 3.0148 & TRN & \\
\hline CHEMBL533226 & 737298 & $4.0360 e$ & 0000000 & 3.5611 & TST \\
\hline
\end{tabular}




\begin{tabular}{|c|c|c|c|c|}
\hline & & & pplement & al $\mathrm{T}$ \\
\hline CHEMBL67311 & 737298 & 4.1091 & 3.6358 & TST \\
\hline CHEMBL 273103 & 737298 & 2.926 & 3.0334 & TST \\
\hline CHEMBL3199025 & 737298 & 4.5329 & 4.2092 & TRN \\
\hline CHEMBL1548492 & 737298 & 2.926 & 2.8134 & TRN \\
\hline CHEMBL1332139 & 737298 & 2.926 & 3.0425 & TST \\
\hline CHEMBL3211859 & 737298 & 2.9261 & 2.7868 & TRN \\
\hline CHEMBL1582507 & 737298 & 2.926 & 3.1472 & TRN \\
\hline CHEMBL548540 & 737298 & 2.9261 & 2.9464 & TRN \\
\hline CHEMBL1709779 & 737298 & 2.9261 & 3.2167 & TRN \\
\hline CHEMBL3193510 & 737298 & 2.9261 & 2.9307 & TRN \\
\hline CHEMBL592600 & 737298 & 2.9263 & 2.8811 & TRN \\
\hline CHEMBL1977995 & 737298 & 2.9258 & 3.8308 & TRN \\
\hline CHEMBL1311879 & 737298 & 2.926 & 3.16 & TRN \\
\hline CHEMBL588804 & 737298 & 2.926 & 2.8436 & TRN \\
\hline CHEMBL1299566 & 737298 & 4.3073 & 4.0779 & TRN \\
\hline CHEMBL2359911 & 737298 & 2.926 & 2.9555 & TRN \\
\hline CHEMBL1967099 & 737298 & 4.9672 & 4.7999 & TRN \\
\hline CHEMBL1546374 & 737298 & 4.7663 & 4.5341 & TRN \\
\hline CHEMBL1480659 & 737298 & 4.9214 & 4.1256 & TRN \\
\hline CHEMBL1396209 & 737298 & 4.7346 & 4.1657 & TST \\
\hline CHEMBL1522486 & 737298 & 4.5281 & 4.0376 & TRN \\
\hline CHEMBL1378931 & 737298 & 4.0879 & 4.6173 & TRN \\
\hline CHEMBL1457613 & 737298 & 2.9261 & 2.9453 & TRN \\
\hline CHEMBL3194449 & 737298 & 2.9261 & 3.7498 & TRN \\
\hline CHEMBL1365585 & 737298 & 2.926 & 3.1361 & TRN \\
\hline CHEMBL1388595 & 737298 & 4.7745 & 4.0303 & TRN \\
\hline CHEMBL530499 & 737298 & 2.9262 & 2.912 & TRN \\
\hline CHEMBL1998863 & 737298 & 2.926 & 2.7453 & TRN \\
\hline CHEMBL1585527 & 737298 & 3.9382 & 3.5963 & TRN \\
\hline CHEMBL1979957 & 737298 & 2.9259 & 3.1895 & TST \\
\hline CHEMBL602718 & 737298 & 2.926 & 2.8368 & TRN \\
\hline CHEMBL1499658 & 737298 & 2.9261 & 2.9723 & TRN \\
\hline CHEMBL1514530 & 737298 & 2.926 & 2.8657 & TRN \\
\hline CHEMBL1448965 & 737298 & 2.9259 & 3.0262 & TRN \\
\hline CHEMBL1385451 & 737298 & 2.926 & 3.0524 & TRN \\
\hline CHEMBL305469 & 737298 & 4.671 & 4.5617 & TRN \\
\hline CHEMBL1410758 & 737298 & 2.926 & 2.8474 & TRN \\
\hline CHEMBL1502020 & 737298 & 2.926 & 3.3023 & TRN \\
\hline CHEMBL1407684 & 737298 & 4.4366 & 4.7149 & TRN \\
\hline CHEMBL1392820 & 737298 & 2.926 & 3.0044 & TRN \\
\hline CHEMBL1378495 & 737298 & 2.9261 & 2.7841 & TRN \\
\hline CHEMBL3191835 & 737298 & 2.9257 & 2.6437 & TRN \\
\hline CHEMBL1431189 & 737298 & 4.4079 & 3.6356 & TRN \\
\hline CHEMBL1557815 & 737298 & 2.9261 & 3.1952 & TRN \\
\hline CHEMBL570105 & 737298 & 5.5957 & 5.143 & TRN \\
\hline CHEMBL1426155 & 737298 & 2.926 & 2.8216 & TRN \\
\hline CHEMBL1605805 & 737298 & 3.4027 & 3.6304 & TRN \\
\hline CHEMBL517615 & 737298 & 2.9261 & 3.2415 & TST \\
\hline
\end{tabular}




\begin{tabular}{|c|c|c|c|c|c|}
\hline & & & & & \\
\hline CHEMBL1511879 & 737298 & 2.9257 & 3.016 & TRN & \\
\hline CHEMBL1396797 & 737298 & 2.9259 & 3.0034 & TRN & \\
\hline CHEMBL1607070 & 737298 & 2.9257 & 3.4279 & TRN & \\
\hline CHEMBL3192656 & 737298 & 2.926 & 2.6823 & TRN & \\
\hline CHEMBL1977678 & 737298 & 2.9261 & 2.8593 & TRN & \\
\hline CHEMBL1370278 & 737298 & 2.926 & 2.9248 & TRN & \\
\hline CHEMBL1559564 & 737298 & 3.4032 & 4.0533 & TST & \\
\hline CHEMBL3193098 & 737298 & 2.9261 & 2.8939 & TRN & \\
\hline CHEMBL1372085 & 737298 & 2.9259 & 3.3756 & TST & \\
\hline CHEMBL1983939 & 737298 & 2.926 & 2.924 & TRN & \\
\hline CHEMBL1391911 & 737298 & 2.9262 & 3.1717 & TST & \\
\hline CHEMBL1503359 & 737298 & 2.926 & 2.95399 & 99999999997 & TST \\
\hline CHEMBL1527754 & 737298 & 2.926 & 3.3504 & TRN & \\
\hline CHEMBL1983530 & 737298 & 2.926 & 3.0829 & TRN & \\
\hline CHEMBL1413203 & 737298 & 2.9261 & 2.9884 & TST & \\
\hline CHEMBL3194778 & 737298 & 4.437 & 3.8146 & TRN & \\
\hline CHEMBL1350252 & 737298 & 2.926 & 3.1227 & TRN & \\
\hline CHEMBL1489745 & 737298 & 2.9262 & 4.0994 & TRN & \\
\hline CHEMBL 2004847 & 737298 & 4.5226 & 4.6183 & TRN & \\
\hline CHEMBL3190230 & 737298 & 2.9259 & 3.3605 & TST & \\
\hline CHEMBL1483355 & 737298 & 4.6764 & 4.8131 & TRN & \\
\hline CHEMBL1527155 & 737298 & 3.9538 & 4.058 & TRN & \\
\hline CHEMBL1353878 & 737298 & 2.9261 & 2.7195 & TRN & \\
\hline CHEMBL1351542 & 737298 & 2.926 & 3.7755 & TRN & \\
\hline CHEMBL1448282 & 737298 & 2.9261 & 2.8442 & TRN & \\
\hline CHEMBL1312320 & 737298 & 2.926 & 2.9869 & TRN & \\
\hline CHEMBL1532238 & 737298 & 4.1975 & 3.6549 & TST & \\
\hline CHEMBL1968085 & 737298 & 2.9259 & 2.8861 & TRN & \\
\hline CHEMBL1577983 & 737298 & 3.4032 & 3.1808 & TRN & \\
\hline CHEMBL1531670 & 737298 & 2.9261 & 2.6669 & TRN & \\
\hline CHEMBL1600086 & 737298 & 2.926 & 3.0151 & TRN & \\
\hline CHEMBL590927 & 737298 & 2.9258 & 2.6929 & TRN & \\
\hline CHEMBL1456876 & 737298 & 2.9257 & 3.0638 & TRN & \\
\hline CHEMBL1412002 & 737298 & 2.926 & 2.8569 & TRN & \\
\hline CHEMBL1419414 & 737298 & 2.9257 & 4.1862 & TRN & \\
\hline CHEMBL1502000 & 737298 & 2.9261 & 2.969 & TRN & \\
\hline CHEMBL3195237 & 737298 & 2.926 & 2.90199 & 99999999997 & TRN \\
\hline CHEMBL1598785 & 737298 & 2.9261 & 2.8158 & TRN & \\
\hline CHEMBL1519450 & 737298 & 2.9261 & 2.6973 & TRN & \\
\hline CHEMBL3193844 & 737298 & 2.926 & 2.9413 & TRN & \\
\hline CHEMBL1588513 & 737298 & 2.9261 & 3.1247 & TRN & \\
\hline CHEMBL607140 & 737298 & 2.9261 & 2.7825 & TRN & \\
\hline CHEMBL1454721 & 737298 & 4.32100 & 300000000 & 4.5661 & TRN \\
\hline CHEMBL1380414 & 737298 & 4.6769 & 4.7527 & TRN & \\
\hline CHEMBL1367050 & 737298 & 2.9259 & 3.4405 & TRN & \\
\hline CHEMBL1999960 & 737298 & 4.3295 & 4.2757 & TST & \\
\hline CHEMBL591412 & 737298 & 2.926 & 2.8495 & TRN & \\
\hline CHEMBL1541622 & 737298 & 2.9259 & 3.4715 & TRN & \\
\hline
\end{tabular}




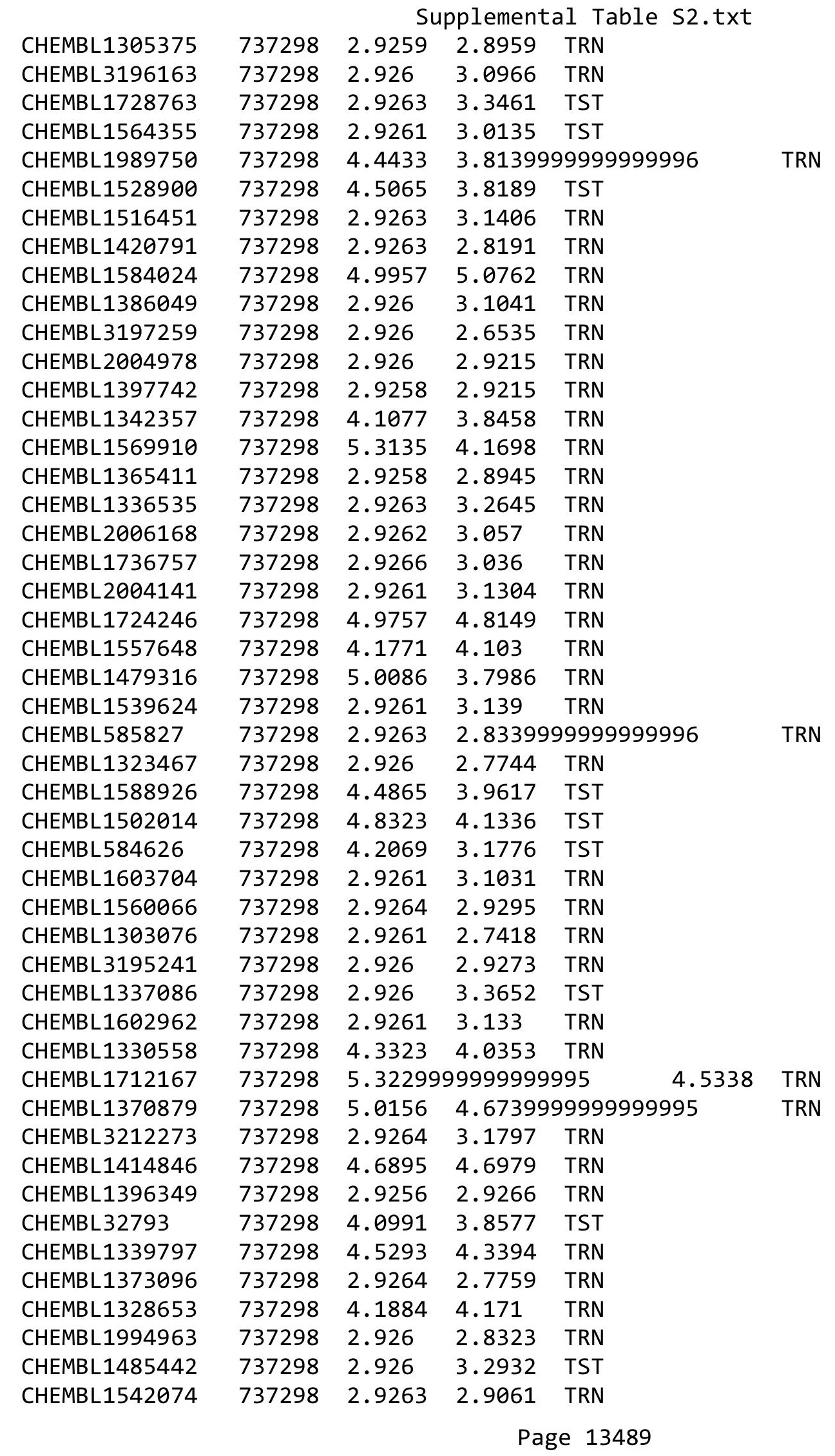




\begin{tabular}{|c|c|c|c|c|c|}
\hline \multicolumn{6}{|c|}{ Supplemental Table S2.txt } \\
\hline CHEMBL1369525 & 737298 & 3.88 & 4.1136 & TRN & \\
\hline CHEMBL505734 & 737298 & 2.926 & 3.2415 & TST & \\
\hline CHEMBL600862 & 737298 & 2.9261 & 2.8109 & TRN & \\
\hline CHEMBL1372509 & 737298 & 2.926 & 3.0542 & TRN & \\
\hline CHEMBL1605292 & 737298 & 4.3239 & 4.4743 & TRN & \\
\hline CHEMBL 3190283 & 737298 & 4.3452 & 4.2482 & TRN & \\
\hline CHEMBL1567847 & 737298 & 2.9257 & 4.0155 & TST & \\
\hline CHEMBL1321620 & 737298 & 4.0311 & 3.6566 & TST & \\
\hline CHEMBL1407952 & 737298 & 2.926 & 2.8678 & TST & \\
\hline CHEMBL1535139 & 737298 & 2.9255 & 2.9493 & TST & \\
\hline CHEMBL1547780 & 737298 & 2.9261 & 3.3441 & TST & \\
\hline CHEMBL1342852 & 737298 & 2.926 & 2.7547 & TST & \\
\hline CHEMBL1549308 & 737298 & 2.926 & 2.9133 & TST & \\
\hline CHEMBL1369571 & 737298 & 2.926 & 3.2237 & TST & \\
\hline CHEMBL1443977 & 737298 & 2.9261 & 2.5939 & TST & \\
\hline CHEMBL1436964 & 737298 & 4.1517 & 3.8287 & TST & \\
\hline CHEMBL1583914 & 737298 & 2.9257 & 3.0355 & TST & \\
\hline CHEMBL1447058 & 737298 & 5.0859 & 5.0607 & TST & \\
\hline CHEMBL1588557 & 737298 & 2.9263 & 3.0766 & TST & \\
\hline CHEMBL1552296 & 737298 & 2.9259 & 2.9079 & TST & \\
\hline CHEMBL591876 & 737298 & 2.9261 & 2.8423 & TST & \\
\hline CHEMBL1499233 & 737298 & 2.926 & 2.9099 & TST & \\
\hline CHEMBL1404029 & 737298 & 2.926 & 2.8745 & TST & \\
\hline CHEMBL1499914 & 737298 & 2.926 & 3.5722 & TST & \\
\hline CHEMBL1481632 & 737298 & 3.4032 & 3.5872 & TST & \\
\hline CHEMBL 3199020 & 737298 & 2.9263 & 2.90100 & 00000000002 & TST \\
\hline CHEMBL1423626 & 737298 & 4.9272 & 4.2193 & TST & \\
\hline CHEMBL3194594 & 737298 & 4.5178 & 3.8787 & TST & \\
\hline CHEMBL 1347598 & 737298 & 2.926 & 3.2016 & TST & \\
\hline CHEMBL1484231 & 737298 & 2.926 & 3.1324 & TST & \\
\hline CHEMBL1427508 & 737298 & 2.926 & 3.089 & TST & \\
\hline CHEMBL 3907402 & 1637138 & 7.0 & 6.9376 & TRN & \\
\hline CHEMBL 3926189 & 1637138 & 6.301 & 6.3478 & TRN & \\
\hline CHEMBL3971807 & 1637138 & 7.0 & 7.0513 & TRN & \\
\hline CHEMBL3942988 & 1637138 & 6.301 & 6.5346 & TRN & \\
\hline CHEMBL3899101 & 1637138 & 7.0 & 7.0411 & TRN & \\
\hline CHEMBL3904333 & 1637138 & 7.0 & 7.0371 & TRN & \\
\hline CHEMBL 3895266 & 1637138 & 7.0 & 6.9394 & TRN & \\
\hline CHEMBL 3890467 & 1637138 & 6.0 & 5.9103 & TRN & \\
\hline CHEMBL3942381 & 1637138 & 7.0 & 7.5166 & TRN & \\
\hline CHEMBL 3912374 & 1637138 & 7.0 & 7.2302 & TRN & \\
\hline CHEMBL3981784 & 1637138 & 7.0 & 6.9094 & TRN & \\
\hline CHEMBL3949992 & 1637138 & 8.0 & 7.6563 & TST & \\
\hline CHEMBL3968167 & 1637138 & 7.0 & 6.9481 & TRN & \\
\hline CHEMBL3907089 & 1637138 & 6.301 & 6.5953 & TRN & \\
\hline CHEMBL 3954978 & 1637138 & 8.0 & 7.8746 & TST & \\
\hline CHEMBL3904980 & 1637138 & 7.0 & 6.9295 & TRN & \\
\hline CHEMBL3981425 & 1637138 & 8.0 & 7.6299 & TRN & \\
\hline
\end{tabular}




\begin{tabular}{|c|c|c|c|c|}
\hline & & & pplement & al $\mathrm{Ta}$ \\
\hline CHEMBL3971789 & 1637138 & 7.0 & 6.9981 & TRN \\
\hline CHEMBL3914107 & 1637138 & 6.0 & 5.9798 & TRN \\
\hline CHEMBL3968460 & 1637138 & 7.0 & 7.001 & TRN \\
\hline CHEMBL3903656 & 1637138 & 7.0 & 7.0357 & TRN \\
\hline CHEMBL3896039 & 1637138 & 8.0 & 7.3767 & TST \\
\hline CHEMBL3945059 & 1637138 & 7.0 & 6.9214 & TRN \\
\hline CHEMBL 3919462 & 1637138 & 7.0 & 6.8754 & TRN \\
\hline CHEMBL 3920821 & 1637138 & 7.0 & 6.9552 & TRN \\
\hline CHEMBL3935744 & 1637138 & 7.0 & 6.8284 & TRN \\
\hline CHEMBL3892676 & 1637138 & 7.0 & 7.4878 & TST \\
\hline CHEMBL3949599 & 1637138 & 6.301 & 6.2542 & TRN \\
\hline CHEMBL3934437 & 1637138 & 6.301 & 6.6033 & TRN \\
\hline CHEMBL 3961672 & 1637138 & 6.301 & 6.2988 & TRN \\
\hline CHEMBL3939013 & 1637138 & 7.0 & 6.9415 & TRN \\
\hline CHEMBL3977421 & 1637138 & 6.301 & 6.4122 & TRN \\
\hline CHEMBL3899027 & 1637138 & 7.0 & 6.9116 & TRN \\
\hline CHEMBL3928075 & 1637138 & 8.0 & 7.9051 & TRN \\
\hline CHEMBL3956643 & 1637138 & 7.0 & 6.8211 & TRN \\
\hline CHEMBL 3899285 & 1637138 & 8.0 & 7.6318 & TRN \\
\hline CHEMBL 3890797 & 1637138 & 6.301 & 6.1982 & TRN \\
\hline CHEMBL3918722 & 1637138 & 7.0 & 7.5278 & TRN \\
\hline CHEMBL3921859 & 1637138 & 7.0 & 6.6654 & TRN \\
\hline CHEMBL 3916725 & 1637138 & 7.0 & 6.9382 & TRN \\
\hline CHEMBL 3985076 & 1637138 & 7.0 & 7.0185 & TRN \\
\hline CHEMBL3966021 & 1637138 & 6.301 & 6.216 & TST \\
\hline CHEMBL3944290 & 1637138 & 6.301 & 6.3065 & TRN \\
\hline CHEMBL3956565 & 1637138 & 7.0 & 6.1014 & TST \\
\hline CHEMBL 3979042 & 1637138 & 7.0 & 6.9661 & TST \\
\hline CHEMBL 3964025 & 1637138 & 7.0 & 7.0729 & TRN \\
\hline CHEMBL3911079 & 1637138 & 6.301 & 6.6684 & TST \\
\hline CHEMBL3980636 & 1637138 & 6.0 & 6.0151 & TRN \\
\hline CHEMBL3986998 & 1637138 & 7.0 & 7.0509 & TRN \\
\hline CHEMBL3955478 & 1637138 & 8.0 & 7.9715 & TRN \\
\hline CHEMBL 3958968 & 1637138 & 8.0 & 7.7554 & TST \\
\hline CHEMBL 3981313 & 1637138 & 6.301 & 6.5733 & TST \\
\hline CHEMBL3940360 & 1637138 & 6.301 & 6.5254 & TRN \\
\hline CHEMBL3951586 & 1637138 & 7.0 & 6.5327 & TST \\
\hline CHEMBL3979361 & 1637138 & 7.0 & 7.0652 & TRN \\
\hline CHEMBL 3917210 & 1637138 & 8.0 & 7.0379 & TST \\
\hline CHEMBL3909499 & 1637138 & 7.0 & 7.0206 & TRN \\
\hline CHEMBL3896422 & 1637138 & 7.0 & 6.7378 & TST \\
\hline CHEMBL3935100 & 1637138 & 8.0 & 8.1412 & TRN \\
\hline CHEMBL3956999 & 1637138 & 6.301 & 6.3266 & TRN \\
\hline CHEMBL 3985717 & 1637138 & 8.0 & 7.0851 & TST \\
\hline CHEMBL3931676 & 1637138 & 6.301 & 6.4431 & TRN \\
\hline CHEMBL3967303 & 1637138 & 6.301 & 6.0659 & TRN \\
\hline CHEMBL3954395 & 1637138 & 7.0 & 6.9145 & TRN \\
\hline CHEMBL3945707 & 1637138 & 7.0 & 6.8064 & TST \\
\hline
\end{tabular}


Supplemental Table S2.txt

\begin{tabular}{|c|c|c|c|c|c|}
\hline CHEMBL 3923610 & 1637138 & 8.0 & \multicolumn{2}{|c|}{ 7.787999999999999 } & \multirow[t]{2}{*}{ TRN } \\
\hline CHEMBL 3948349 & 1637138 & 7.0 & 6.8879 & TST & \\
\hline CHEMBL3919966 & 1637138 & 8.0 & \multicolumn{2}{|c|}{7.8260000000000005} & TRN \\
\hline CHEMBL 3904681 & 1637138 & 6.301 & 6.4625 & TRN & \\
\hline CHEMBL3968095 & 1637138 & 6.0 & 6.4959 & TRN & \\
\hline CHEMBL 3928507 & 1637138 & 7.0 & 6.965 & TRN & \\
\hline CHEMBL 3952336 & 1637138 & 7.0 & 7.3832 & TST & \\
\hline CHEMBL 3896589 & 1637138 & 7.0 & 7.0887 & TRN & \\
\hline CHEMBL 3913674 & 1637138 & 7.0 & \multicolumn{2}{|c|}{7.507000000000001} & TST \\
\hline CHEMBL3928847 & 1637138 & 6.301 & 6.6306 & TST & \\
\hline CHEMBL 3933168 & 1637138 & 7.0 & 6.9053 & TRN & \\
\hline CHEMBL 3948750 & 1637138 & 7.0 & 6.4826 & TRN & \\
\hline CHEMBL 3907740 & 1637138 & 7.0 & 7.4402 & TST & \\
\hline CHEMBL 3968497 & 1637138 & 6.301 & 6.2692 & TRN & \\
\hline CHEMBL3941565 & 1637138 & 8.0 & 7.8744 & TST & \\
\hline CHEMBL 3957835 & 1637138 & 7.0 & 6.9769 & TRN & \\
\hline CHEMBL3932389 & 1637138 & 7.0 & 6.935 & TRN & \\
\hline CHEMBL 3941703 & 1637138 & 7.0 & 6.9287 & TRN & \\
\hline CHEMBL 3979607 & 1637138 & 6.301 & 6.0391 & TST & \\
\hline CHEMBL3897700 & 1637138 & 7.0 & 7.0587 & TRN & \\
\hline CHEMBL3969082 & 1637138 & 7.0 & \multirow{2}{*}{\multicolumn{2}{|c|}{$\begin{array}{l}6.843999999999999 \\
7.252000000000001\end{array}$}} & TRN \\
\hline CHEMBL3917962 & 1637138 & 7.0 & & & TRN \\
\hline CHEMBL 3893235 & 1637138 & 6.301 & 6.4481 & TST & \\
\hline CHEMBL 3904645 & 1637138 & 7.0 & \multicolumn{2}{|c|}{7.047999999999999} & TRN \\
\hline CHEMBL 3919128 & 1637138 & 7.0 & 6.9888 & TRN & \\
\hline CHEMBL1964290 & 809250 & 6.5 & 6.6254 & TRN & \\
\hline CHEMBL 2003768 & 809250 & 6.0 & 3.8942 & TRN & \\
\hline CHEMBL213505 & 809250 & 5.3 & 5.0975 & TRN & \\
\hline CHEMBL1987034 & 809250 & 7.6 & 7.4839 & TRN & \\
\hline CHEMBL1993941 & 809250 & 4.1 & 4.3674 & TRN & \\
\hline CHEMBL 377383 & 809250 & 4.1 & 4.115 & TRN & \\
\hline CHEMBL 2005886 & 809250 & 5.6 & 5.4119 & TRN & \\
\hline CHEMBL481491 & 809250 & 4.1 & 4.258 & TST & \\
\hline CHEMBL1973142 & 809250 & 5.2 & 5.1445 & TRN & \\
\hline CHEMBL1973145 & 809250 & 5.4 & 4.1232 & TRN & \\
\hline CHEMBL1982924 & 809250 & 5.3 & 5.2456 & TRN & \\
\hline CHEMBL 2005936 & 809250 & 5.3 & 4.8261 & TRN & \\
\hline CHEMBL1807515 & 809250 & 6.9 & 7.4863 & TRN & \\
\hline CHEMBL1971141 & 809250 & 4.1 & 4.1361 & TRN & \\
\hline CHEMBL1995813 & 809250 & 7.4 & 7.4411 & TRN & \\
\hline CHEMBL206236 & 809250 & 4.1 & 4.0508 & TRN & \\
\hline CHEMBL 244378 & 809250 & 7.1 & 7.1579 & TRN & \\
\hline CHEMBL 2001957 & 809250 & 4.1 & 4.4786 & TRN & \\
\hline CHEMBL1969372 & 809250 & 4.1 & 4.3188 & TRN & \\
\hline CHEMBL1986943 & 809250 & 7.1 & 7.3582 & TRN & \\
\hline CHEMBL 2006263 & 809250 & 4.1 & 4.5199 & TRN & \\
\hline CHEMBL2001646 & 809250 & 5.3 & 4.8518 & TST & \\
\hline CHEMBL1993584 & 809250 & 4.1 & 4.5621 & TRN & \\
\hline
\end{tabular}




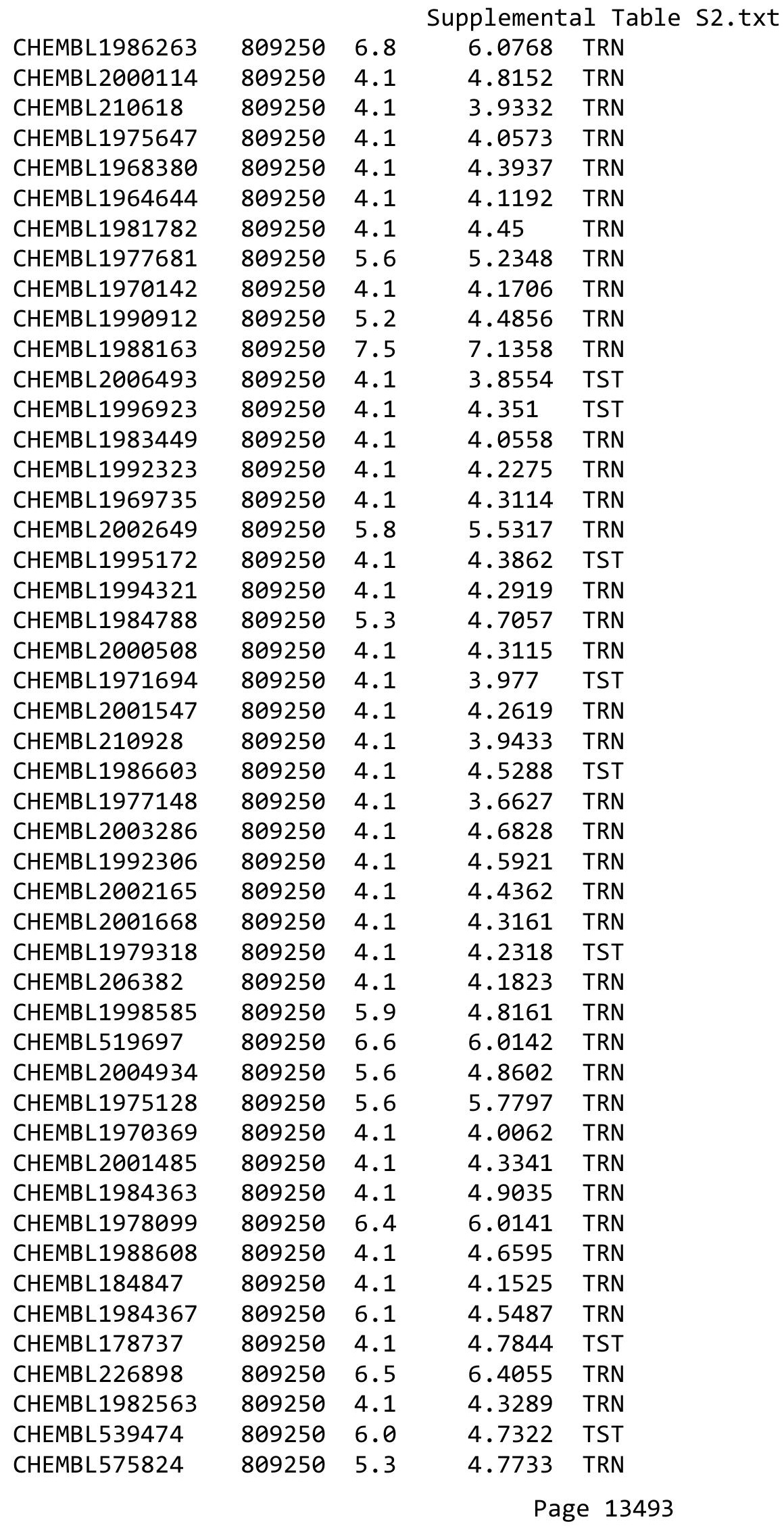




\begin{tabular}{|c|c|c|c|c|c|}
\hline & & & & & \\
\hline CHEMBL1988387 & 809250 & 5.3 & 4.5226 & TRN & \\
\hline CHEMBL1989708 & 809250 & 4.1 & 4.3259 & TRN & \\
\hline CHEMBL1990288 & 809250 & 4.1 & 4.3052 & TRN & \\
\hline CHEMBL1974803 & 809250 & 5.8 & 5.0444 & TRN & \\
\hline CHEMBL1970074 & 809250 & 4.1 & 4.7228 & TRN & \\
\hline CHEMBL1986970 & 809250 & 5.6 & 4.3937 & TRN & \\
\hline CHEMBL 2005112 & 809250 & 5.3 & 4.314 & TST & \\
\hline CHEMBL1958401 & 809250 & 6.3 & 5.7717 & TRN & \\
\hline CHEMBL1984044 & 809250 & 4.1 & 4.6264 & TRN & \\
\hline CHEMBL 2003456 & 809250 & 4.1 & 4.6731 & TRN & \\
\hline CHEMBL1966816 & 809250 & 4.1 & 4.2842 & TRN & \\
\hline CHEMBL1972584 & 809250 & 4.1 & 4.3521 & TRN & \\
\hline CHEMBL2002992 & 809250 & 5.1 & 4.9887 & TRN & \\
\hline CHEMBL560813 & 809250 & 5.4 & 4.5492 & TRN & \\
\hline CHEMBL207253 & 809250 & 4.1 & 4.421 & TST & \\
\hline CHEMBL1990635 & 809250 & 5.1 & 4.934 & TST & \\
\hline CHEMBL1968791 & 809250 & 4.1 & 4.1758 & TRN & \\
\hline CHEMBL 2002682 & 809250 & 5.4 & 4.5807 & TST & \\
\hline CHEMBL1971186 & 809250 & 4.1 & 4.3297 & TRN & \\
\hline CHEMBL 2003482 & 809250 & 4.1 & 4.1737 & TRN & \\
\hline CHEMBL1973211 & 809250 & 5.6 & 4.4091 & TRN & \\
\hline CHEMBL1984700 & 809250 & 4.1 & 4.4896 & TRN & \\
\hline CHEMBL1972125 & 809250 & 4.1 & 3.7878 & TRN & \\
\hline CHEMBL1461728 & 809250 & 4.1 & 4.2409 & TRN & \\
\hline CHEMBL1976134 & 809250 & 5.2 & 5.1486 & TRN & \\
\hline CHEMBL1965131 & 809250 & 5.3 & 5.269 & TRN & \\
\hline CHEMBL1972158 & 809250 & 6.1 & 5.0226 & TRN & \\
\hline CHEMBL 2006580 & 809250 & 5.1 & 4.9312 & TRN & \\
\hline CHEMBL 2006481 & 809250 & 4.1 & 4.0844 & TRN & \\
\hline CHEMBL1970340 & 809250 & 4.1 & 4.157 & TRN & \\
\hline CHEMBL 2005186 & 809250 & 4.1 & 4.1254 & TRN & \\
\hline CHEMBL1995927 & 809250 & 4.1 & 4.3824 & TST & \\
\hline CHEMBL1975534 & 809250 & 5.5 & 5.056 & TRN & \\
\hline CHEMBL1993424 & 809250 & 6.3 & 6.5261 & TRN & \\
\hline CHEMBL1966703 & 809250 & 4.1 & 4.1315 & TST & \\
\hline CHEMBL1969561 & 809250 & 5.8 & 4.39 & TRN & \\
\hline CHEMBL1997023 & 809250 & 4.1 & 4.1561 & TST & \\
\hline CHEMBL1964687 & 809250 & 6.2 & 4.5122 & TRN & \\
\hline CHEMBL1971943 & 809250 & 6.5 & 5.5998 & TST & \\
\hline CHEMBL1974254 & 809250 & 4.1 & 4.2933 & TRN & \\
\hline CHEMBL1988537 & 809250 & 4.1 & 4.4404 & TST & \\
\hline CHEMBL1969049 & 809250 & 4.1 & 4.8802 & TRN & \\
\hline CHEMBL 2005828 & 809250 & 5.7 & $5.8670 e$ & 0000000001 & TRN \\
\hline CHEMBL 2002240 & 809250 & 4.1 & 4.0694 & TRN & \\
\hline CHEMBL1991143 & 809250 & 4.1 & 4.0573 & TST & \\
\hline CHEMBL1998611 & 809250 & 4.1 & 4.3469 & TRN & \\
\hline CHEMBL1975900 & 809250 & 4.1 & 4.9209 & TRN & \\
\hline CHEMBL 255822 & 809250 & 5.5 & 4.9277 & TRN & \\
\hline & & & & 13494 & \\
\hline
\end{tabular}




\begin{tabular}{|c|c|c|c|c|c|}
\hline \multirow{3}{*}{$\begin{array}{l}\text { CHEMBL1972221 } \\
\text { CHEMBL } 2006778\end{array}$} & \multirow{3}{*}{$\begin{array}{l}809250 \\
809250\end{array}$} & \multicolumn{4}{|c|}{ Supplemental Table S2.txt } \\
\hline & & 4.1 & 4.2639 & 9999999999 & TRN \\
\hline & & 4.1 & 4.3491 & TRN & \\
\hline CHEMBL378627 & 809250 & 4.1 & 3.9414 & TRN & \\
\hline CHEMBL1996979 & 809250 & 5.7 & 5.517 & TRN & \\
\hline CHEMBL1997025 & 809250 & 5.6 & 4.5252 & TRN & \\
\hline CHEMBL1968406 & 809250 & 5.3 & 4.9603 & TRN & \\
\hline CHEMBL1984274 & 809250 & 5.5 & 4.4526 & TST & \\
\hline CHEMBL1998545 & 809250 & 5.4 & 4.3327 & TRN & \\
\hline CHEMBL1986869 & 809250 & 4.1 & 4.0324 & TRN & \\
\hline CHEMBL 2006010 & 809250 & 4.1 & 3.8619 & TRN & \\
\hline CHEMBL1682558 & 809250 & 4.1 & 4.0201 & TRN & \\
\hline CHEMBL1990496 & 809250 & 4.1 & 4.0963 & TRN & \\
\hline CHEMBL1967094 & 809250 & 4.1 & 5.0409 & TRN & \\
\hline CHEMBL1966035 & 809250 & 5.2 & 4.0618 & TRN & \\
\hline CHEMBL 2003341 & 809250 & 4.1 & 4.5073 & TRN & \\
\hline CHEMBL1982992 & 809250 & 5.6 & 5.3187 & TRN & \\
\hline CHEMBL1999590 & 809250 & 4.1 & 4.3266 & TST & \\
\hline CHEMBL1981079 & 809250 & 6.8 & 7.1819 & TRN & \\
\hline CHEMBL1972276 & 809250 & 4.1 & 4.1772 & TRN & \\
\hline CHEMBL1980489 & 809250 & 4.1 & 4.9315 & TRN & \\
\hline CHEMBL1967116 & 809250 & 4.1 & 4.2112 & TRN & \\
\hline CHEMBL 2000832 & 809250 & 5.6 & 5.6189 & TRN & \\
\hline CHEMBL1970709 & 809250 & 4.1 & 4.1146 & TRN & \\
\hline CHEMBL1965660 & 809250 & 7.0 & 7.3368 & TRN & \\
\hline CHEMBL1998112 & 809250 & 4.1 & 4.6756 & TRN & \\
\hline CHEMBL1969126 & 809250 & 4.1 & 3.8538 & TRN & \\
\hline CHEMBL1980896 & 809250 & 6.1 & 4.7412 & TRN & \\
\hline CHEMBL1975208 & 809250 & 4.1 & 4.1736 & TST & \\
\hline CHEMBL1970104 & 809250 & 6.5 & 6.3431 & TRN & \\
\hline CHEMBL1991429 & 809250 & 4.1 & 4.2541 & TRN & \\
\hline CHEMBL1964777 & 809250 & 5.6 & 5.5218 & TST & \\
\hline CHEMBL1971149 & 809250 & 4.1 & 4.3151 & TRN & \\
\hline CHEMBL1999714 & 809250 & 4.1 & 4.3763 & TRN & \\
\hline CHEMBL1987533 & 809250 & 4.1 & 4.2565 & TRN & \\
\hline CHEMBL1994040 & 809250 & 4.1 & 4.3048 & TRN & \\
\hline CHEMBL579246 & 809250 & 4.1 & 5.0061 & TRN & \\
\hline CHEMBL398951 & 809250 & 4.1 & 4.7203 & TRN & \\
\hline CHEMBL1982506 & 809250 & 4.1 & 3.6116 & TST & \\
\hline CHEMBL 2004716 & 809250 & 5.4 & 4.7879 & TRN & \\
\hline CHEMBL1968127 & 809250 & 4.1 & 4.1536 & TRN & \\
\hline CHEMBL1975233 & 809250 & 6.2 & 4.4464 & TRN & \\
\hline CHEMBL1985406 & 809250 & 4.1 & 4.5325 & TRN & \\
\hline CHEMBL207400 & 809250 & 4.1 & 4.2206 & TST & \\
\hline CHEMBL 2000894 & 809250 & 5.9 & 4.263 & TST & \\
\hline CHEMBL1982135 & 809250 & 4.1 & 4.9276 & TRN & \\
\hline CHEMBL1976090 & 809250 & 5.9 & 5.1684 & TRN & \\
\hline CHEMBL1993243 & 809250 & 4.1 & 4.1242 & TRN & \\
\hline CHEMBL1992922 & 809250 & 5.4 & 5.5261 & TRN & \\
\hline
\end{tabular}




\begin{tabular}{|c|c|c|c|c|}
\hline & & & ple & \\
\hline CHEMBL1997597 & 809250 & 4.1 & 4.2015 & TRN \\
\hline CHEMBL1969537 & 809250 & 5.9 & 4.6806 & TST \\
\hline CHEMBL1976093 & 809250 & 4.1 & 4.1809 & TRN \\
\hline CHEMBL210032 & 809250 & 4.1 & 4.1912 & TRN \\
\hline CHEMBL1975256 & 809250 & 4.1 & 3.6845 & TST \\
\hline CHEMBL508928 & 809250 & 4.1 & 4.7679 & TRN \\
\hline CHEMBL1991356 & 809250 & 4.1 & 4.2048 & TRN \\
\hline CHEMBL1983309 & 809250 & 5.1 & 4.4535 & TRN \\
\hline CHEMBL 2004892 & 809250 & 4.1 & 4.3283 & TRN \\
\hline CHEMBL1999126 & 809250 & 5.3 & 4.2909 & TST \\
\hline CHEMBL1997503 & 809250 & 4.1 & 4.3811 & TST \\
\hline CHEMBL116070 & 809250 & 4.1 & 5.2065 & TST \\
\hline CHEMBL1990821 & 809250 & 4.1 & 4.6727 & TST \\
\hline CHEMBL1970314 & 809250 & 4.1 & 4.8942 & TRN \\
\hline CHEMBL 2004871 & 809250 & 4.1 & 4.0324 & TRN \\
\hline CHEMBL 2004872 & 809250 & 4.1 & 4.6379 & TRN \\
\hline CHEMBL1727312 & 809250 & 4.1 & 4.0547 & TRN \\
\hline CHEMBL1969879 & 809250 & 4.1 & 4.2195 & TRN \\
\hline CHEMBL1981720 & 809250 & 5.3 & 4.5317 & TRN \\
\hline CHEMBL419932 & 809250 & 4.1 & 4.4209 & TRN \\
\hline CHEMBL262433 & 809250 & 5.1 & 4.6205 & TRN \\
\hline CHEMBL 306380 & 809250 & 4.1 & 4.4618 & TRN \\
\hline CHEMBL1966722 & 809250 & 4.1 & 4.2531 & TRN \\
\hline CHEMBL1975500 & 809250 & 5.8 & 5.6376 & TRN \\
\hline CHEMBL394619 & 809250 & 4.1 & 4.9988 & TRN \\
\hline CHEMBL1996831 & 809250 & 4.1 & 4.7317 & TST \\
\hline CHEMBL411903 & 809250 & 6.9 & 5.2107 & TRN \\
\hline CHEMBL1965988 & 809250 & 4.1 & 4.5985 & TRN \\
\hline CHEMBL418203 & 809250 & 5.6 & 5.0402 & TST \\
\hline CHEMBL1989646 & 809250 & 4.1 & 5.3195 & TRN \\
\hline CHEMBL225519 & 809250 & 7.1 & 5.9916 & TRN \\
\hline CHEMBL1978200 & 809250 & 4.1 & 4.4247 & TRN \\
\hline CHEMBL 2006631 & 809250 & 4.1 & 4.6982 & TRN \\
\hline CHEMBL1970522 & 809250 & 5.7 & 4.9644 & TRN \\
\hline CHEMBL402846 & 809250 & 5.5 & 5.4411 & TRN \\
\hline CHEMBL1990415 & 809250 & 4.1 & 4.7861 & TRN \\
\hline CHEMBL1966087 & 809250 & 4.1 & 4.3138 & TRN \\
\hline CHEMBL1964692 & 809250 & 6.0 & 5.9567 & TRN \\
\hline CHEMBL1996931 & 809250 & 5.1 & 4.3448 & TRN \\
\hline CHEMBL1964413 & 809250 & 4.1 & 4.2122 & TRN \\
\hline CHEMBL1973483 & 809250 & 4.1 & 4.0543 & TRN \\
\hline CHEMBL1970735 & 809250 & 4.1 & 3.9746 & TRN \\
\hline CHEMBL1997340 & 809250 & 4.1 & 4.2067 & TRN \\
\hline CHEMBL 2004365 & 809250 & 4.1 & 4.5702 & TST \\
\hline CHEMBL1522508 & 809250 & 5.2 & 4.2873 & TRN \\
\hline CHEMBL1989474 & 809250 & 4.1 & 4.0739 & TRN \\
\hline CHEMBL1090360 & 809250 & 4.1 & 4.2469 & TRN \\
\hline CHEMBL210887 & 809250 & 7.7 & 5.9752 & TRN \\
\hline
\end{tabular}




\begin{tabular}{|c|c|c|c|c|c|}
\hline \multirow[b]{2}{*}{ CHEMBL458997 } & \multirow[b]{2}{*}{809250} & \multirow[b]{2}{*}{6.3} & \\
\hline & & & 6.8676 & TRN & \\
\hline CHEMBL227271 & 809250 & 5.8 & 6.1137 & TRN & \\
\hline CHEMBL1971021 & 809250 & 5.3 & 4.1382 & TRN & \\
\hline CHEMBL583144 & 809250 & 4.1 & 4.1314 & TRN & \\
\hline CHEMBL1974310 & 809250 & 6.1 & 5.4028 & TST & \\
\hline CHEMBL1982660 & 809250 & 4.2 & 5.0588 & TRN & \\
\hline CHEMBL1994693 & 809250 & 4.1 & 4.8922 & TRN & \\
\hline CHEMBL1982957 & 809250 & 4.1 & 4.8757 & TRN & \\
\hline CHEMBL1975138 & 809250 & 5.6 & \multicolumn{2}{|c|}{ 4.428999999999999 } & TRN \\
\hline CHEMBL424872 & 809250 & 4.1 & 4.0834 & TRN & \\
\hline CHEMBL2006836 & 809250 & 4.1 & 4.3276 & TST & \\
\hline CHEMBL412142 & 809250 & 4.1 & 4.1175 & TST & \\
\hline CHEMBL1980704 & 809250 & 4.1 & 4.1865 & TST & \\
\hline CHEMBL2003271 & 809250 & 5.6 & 5.4723 & TRN & \\
\hline CHEMBL1966808 & 809250 & 4.1 & 3.9088 & TST & \\
\hline CHEMBL 2004447 & 809250 & 4.1 & 3.9808 & TST & \\
\hline CHEMBL1983111 & 809250 & 7.2 & 6.6384 & TST & \\
\hline CHEMBL1973860 & 809250 & 4.1 & 4.2155 & TRN & \\
\hline CHEMBL1977713 & 809250 & 4.1 & 4.5015 & TRN & \\
\hline CHEMBL260135 & 809250 & 4.1 & 4.3561 & TRN & \\
\hline CHEMBL220241 & 809250 & 4.1 & 4.5662 & TST & \\
\hline CHEMBL2004544 & 809250 & 4.1 & 4.7395 & TST & \\
\hline CHEMBL1982610 & 809250 & 4.1 & 4.4595 & TRN & \\
\hline CHEMBL1999496 & 809250 & 4.1 & 4.1099 & TRN & \\
\hline CHEMBL1988300 & 809250 & 4.1 & 4.9349 & TRN & \\
\hline CHEMBL1989265 & 809250 & 5.1 & 3.7963 & TST & \\
\hline CHEMBL2004647 & 809250 & 4.1 & 4.3046 & TST & \\
\hline CHEMBL1969502 & 809250 & 6.0 & 5.4945 & TRN & \\
\hline CHEMBL1682553 & 809250 & 4.1 & 4.1225 & TRN & \\
\hline CHEMBL1971430 & 809250 & 4.1 & 4.0997 & TRN & \\
\hline CHEMBL1997764 & 809250 & 5.2 & \multicolumn{2}{|c|}{5.167000000000001} & TRN \\
\hline CHEMBL1983963 & 809250 & 5.1 & 5.1026 & TRN & \\
\hline CHEMBL1985092 & 809250 & 5.1 & 5.0748 & TST & \\
\hline CHEMBL 2004692 & 809250 & 4.1 & 3.6768 & TST & \\
\hline CHEMBL1981410 & 809250 & 5.4 & 4.5237 & TRN & \\
\hline CHEMBL1996234 & 809250 & 4.1 & 4.2278 & TRN & \\
\hline CHEMBL1991434 & 809250 & 4.1 & 4.053 & TRN & \\
\hline CHEMBL1967544 & 809250 & 4.1 & 4.4805 & TRN & \\
\hline CHEMBL223367 & 809250 & 5.4 & 4.0725 & TST & \\
\hline CHEMBL340384 & 809250 & 6.8 & 5.3875 & TST & \\
\hline CHEMBL1996587 & 809250 & 4.1 & 3.7831 & TRN & \\
\hline CHEMBL1964804 & 809250 & 5.4 & 4.7759 & TRN & \\
\hline CHEMBL443962 & 809250 & 5.6 & 4.883 & TST & \\
\hline CHEMBL 2000354 & 809250 & 6.1 & 5.3756 & TRN & \\
\hline CHEMBL1965507 & 809250 & 4.1 & 4.4794 & TRN & \\
\hline CHEMBL274064 & 809250 & 5.2 & 4.5013 & TRN & \\
\hline CHEMBL1967564 & 809250 & 4.1 & 4.1867 & TRN & \\
\hline CHEMBL592030 & 809250 & 5.9 & 5.9895 & TST & \\
\hline & & & & 13497 & \\
\hline
\end{tabular}




\begin{tabular}{|c|c|c|c|c|}
\hline & & & ipplement & al $\mathrm{T}$ \\
\hline CHEMBL 2000071 & 809250 & 5.1 & 5.4597 & TRN \\
\hline CHEMBL1979176 & 809250 & 5.4 & 4.4927 & TRN \\
\hline CHEMBL 2000408 & 809250 & 4.1 & 4.447 & TRN \\
\hline CHEMBL248757 & 809250 & 5.5 & 4.1875 & TST \\
\hline CHEMBL1978014 & 809250 & 4.1 & 4.6928 & TRN \\
\hline CHEMBL1994538 & 809250 & 4.1 & 3.8335 & TRN \\
\hline CHEMBL1983195 & 809250 & 4.1 & 4.5268 & TST \\
\hline CHEMBL1964444 & 809250 & 4.1 & 4.4014 & TRN \\
\hline CHEMBL1989957 & 809250 & 4.1 & 4.2636 & TRN \\
\hline CHEMBL1986139 & 809250 & 5.1 & 4.9428 & TRN \\
\hline CHEMBL1980540 & 809250 & 4.1 & 4.0712 & TRN \\
\hline CHEMBL1979883 & 809250 & 4.1 & 4.5216 & TRN \\
\hline CHEMBL1984162 & 809250 & 4.1 & 4.2739 & TRN \\
\hline CHEMBL491758 & 809250 & 6.4 & 5.3811 & TRN \\
\hline CHEMBL549730 & 809250 & 4.1 & 4.0089 & TRN \\
\hline CHEMBL1970189 & 809250 & 4.1 & 4.4239 & TST \\
\hline CHEMBL1996791 & 809250 & 5.8 & 5.3548 & TRN \\
\hline CHEMBL371206 & 809250 & 6.1 & 5.5217 & TRN \\
\hline CHEMBL1974664 & 809250 & 4.1 & 4.6398 & TRN \\
\hline CHEMBL1974288 & 809250 & 5.3 & 4.8035 & TRN \\
\hline CHEMBL196363 & 809250 & 5.1 & 4.5526 & TRN \\
\hline CHEMBL1190711 & 809250 & 5.1 & 4.7525 & TRN \\
\hline CHEMBL404367 & 809250 & 5.4 & 5.6938 & TRN \\
\hline CHEMBL1966343 & 809250 & 5.3 & 4.8886 & TRN \\
\hline CHEMBL1967887 & 809250 & 4.1 & 4.8978 & TRN \\
\hline CHEMBL 2000568 & 809250 & 5.2 & 4.7963 & TRN \\
\hline CHEMBL 2000335 & 809250 & 5.3 & 4.882 & TRN \\
\hline CHEMBL1977604 & 809250 & 4.1 & 3.8875 & TST \\
\hline CHEMBL1988717 & 809250 & 4.1 & 4.498 & TRN \\
\hline CHEMBL1974328 & 809250 & 7.2 & 6.482 & TRN \\
\hline CHEMBL509032 & 809250 & 7.1 & 7.1692 & TRN \\
\hline CHEMBL573339 & 809250 & 4.1 & 4.5768 & TRN \\
\hline CHEMBL1973808 & 809250 & 4.1 & 3.9404 & TRN \\
\hline CHEMBL 2000429 & 809250 & 4.1 & 4.6374 & TRN \\
\hline CHEMBL1972576 & 809250 & 4.1 & 4.8165 & TRN \\
\hline CHEMBL1992555 & 809250 & 4.1 & 4.3017 & TRN \\
\hline CHEMBL1992342 & 809250 & 4.1 & 4.2208 & TRN \\
\hline CHEMBL1988173 & 809250 & 5.8 & 5.1345 & TRN \\
\hline CHEMBL535331 & 809250 & 4.1 & 4.9636 & TRN \\
\hline CHEMBL1989805 & 809250 & 4.1 & 4.1815 & TST \\
\hline CHEMBL1965423 & 809250 & 4.1 & 4.0482 & TRN \\
\hline CHEMBL1982980 & 809250 & 5.6 & 4.8136 & TST \\
\hline CHEMBL1983025 & 809250 & 4.1 & 4.4986 & TRN \\
\hline CHEMBL205415 & 809250 & 4.1 & 4.9023 & TRN \\
\hline CHEMBL1977135 & 809250 & 4.1 & 4.5171 & TRN \\
\hline CHEMBL 2001920 & 809250 & 4.1 & 4.2884 & TRN \\
\hline CHEMBL1978448 & 809250 & 6.8 & 5.1096 & TST \\
\hline CHEMBL 2004513 & 809250 & 4.1 & 4.5862 & TRN \\
\hline
\end{tabular}




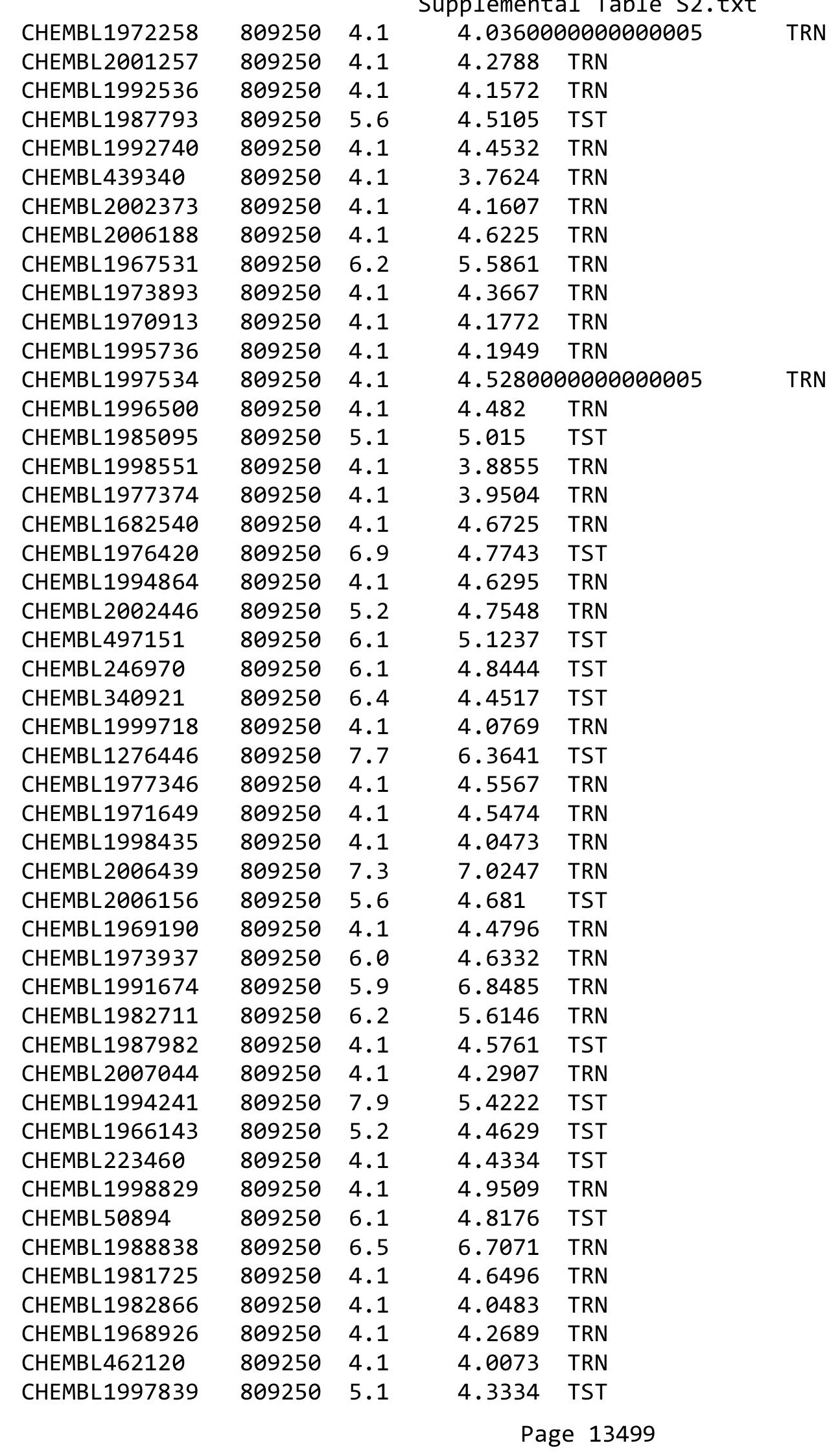




\begin{tabular}{|c|c|c|c|c|c|}
\hline \multirow[b]{2}{*}{ CHEMBL1965570 } & \multirow{2}{*}{809250} & \\
\hline & & 4.1 & 4.7848 & TRN & \\
\hline CHEMBL2007592 & 809250 & 4.1 & \multicolumn{2}{|c|}{ 3.9739999999999998 } & TST \\
\hline CHEMBL210963 & 809250 & 4.1 & 3.8402 & TRN & \\
\hline CHEMBL1082440 & 809250 & 5.1 & 4.6136 & TST & \\
\hline CHEMBL1614705 & 809250 & 4.1 & 4.346 & TRN & \\
\hline CHEMBL1984633 & 809250 & 4.1 & 4.6694 & TRN & \\
\hline CHEMBL 2007372 & 809250 & 4.1 & 4.1954 & TRN & \\
\hline CHEMBL1965845 & 809250 & 6.1 & \multicolumn{2}{|c|}{6.167999999999999} & TRN \\
\hline CHEMBL 2006715 & 809250 & 4.1 & 4.0101 & TRN & \\
\hline CHEMBL1990482 & 809250 & 4.1 & 3.9389 & TRN & \\
\hline CHEMBL1990904 & 809250 & 4.1 & 4.3439 & TRN & \\
\hline CHEMBL 2005475 & 809250 & 4.1 & \multicolumn{2}{|c|}{4.656000000000001} & TRN \\
\hline CHEMBL183844 & 809250 & 4.1 & 4.2392 & TRN & \\
\hline CHEMBL1997349 & 809250 & 4.1 & 4.7764 & TST & \\
\hline CHEMBL220057 & 809250 & 5.2 & 5.2683 & TRN & \\
\hline CHEMBL1682545 & 809250 & 4.1 & 4.0973 & TRN & \\
\hline CHEMBL383541 & 809250 & 4.1 & 4.9487 & TRN & \\
\hline CHEMBL2001224 & 809250 & 4.1 & 4.6134 & TRN & \\
\hline CHEMBL10 & 809250 & 4.1 & 4.4199 & TRN & \\
\hline CHEMBL1976732 & 809250 & 4.1 & 3.8764 & TRN & \\
\hline CHEMBL1964937 & 809250 & 5.2 & 5.771 & TRN & \\
\hline CHEMBL1969506 & 809250 & 4.1 & 4.4416 & TRN & \\
\hline CHEMBL1980163 & 809250 & 4.1 & 4.5048 & TRN & \\
\hline CHEMBL 2005899 & 809250 & 4.1 & 4.1061 & TRN & \\
\hline CHEMBL1682552 & 809250 & 4.1 & 4.4922 & TRN & \\
\hline CHEMBL1972568 & 809250 & 4.1 & 4.2102 & TRN & \\
\hline CHEMBL229799 & 809250 & 5.9 & 6.6336 & TRN & \\
\hline CHEMBL105739 & 809250 & 5.7 & 5.3956 & TRN & \\
\hline CHEMBL 379300 & 809250 & 6.6 & 6.1446 & TRN & \\
\hline CHEMBL1969523 & 809250 & 6.0 & 5.1746 & TRN & \\
\hline CHEMBL1988995 & 809250 & 4.1 & 3.8499 & TRN & \\
\hline CHEMBL1986781 & 809250 & 4.1 & 4.2943 & TRN & \\
\hline CHEMBL526133 & 809250 & 5.3 & 4.6344 & TRN & \\
\hline CHEMBL387971 & 809250 & 4.1 & 4.3637 & TRN & \\
\hline CHEMBL1979057 & 809250 & 5.2 & 5.0044 & TRN & \\
\hline CHEMBL1999428 & 809250 & 4.1 & 4.6555 & TRN & \\
\hline CHEMBL1967560 & 809250 & 4.1 & 4.3387 & TRN & \\
\hline CHEMBL 211378 & 809250 & 4.1 & 4.6209 & TRN & \\
\hline CHEMBL1516890 & 809250 & 5.8 & 5.4575 & TRN & \\
\hline CHEMBL1982465 & 809250 & 4.1 & 4.3305 & TRN & \\
\hline CHEMBL2001751 & 809250 & 6.3 & 6.6513 & TRN & \\
\hline CHEMBL1984586 & 809250 & 5.7 & 5.8225 & TRN & \\
\hline CHEMBL1972659 & 809250 & 4.1 & 4.3029 & TST & \\
\hline CHEMBL 272453 & 809250 & 4.1 & 4.3411 & TRN & \\
\hline CHEMBL1970217 & 809250 & 6.2 & 5.0364 & TRN & \\
\hline CHEMBL 2005528 & 809250 & 4.1 & 4.2574 & TST & \\
\hline CHEMBL185569 & 809250 & 4.1 & 4.2218 & TRN & \\
\hline CHEMBL1969843 & 809250 & 4.1 & 4.5247 & TRN & \\
\hline
\end{tabular}




\begin{tabular}{|c|c|c|c|c|c|}
\hline \\
\hline CHEMBL2007002 & 809250 & 4.1 & 5.1888 & TRN & \\
\hline CHEMBL1987007 & 809250 & 5.4 & 4.3207 & TRN & \\
\hline CHEMBL1969588 & 809250 & 7.3 & 6.9641 & TRN & \\
\hline CHEMBL1984711 & 809250 & 5.9 & 4.993 & TRN & \\
\hline CHEMBL484390 & 809250 & 7.3 & 6.3866 & TRN & \\
\hline CHEMBL1979252 & 809250 & 4.1 & 4.5649 & TRN & \\
\hline CHEMBL1986499 & 809250 & 5.4 & 4.7815 & TRN & \\
\hline CHEMBL2004290 & 809250 & 4.1 & 4.0272 & TRN & \\
\hline CHEMBL1972937 & 809250 & 4.1 & 4.7181 & TRN & \\
\hline CHEMBL 2000393 & 809250 & 5.4 & 5.2447 & TST & \\
\hline CHEMBL 2004311 & 809250 & 4.1 & 4.4006 & TRN & \\
\hline CHEMBL1992634 & 809250 & 6.5 & 5.9268 & TRN & \\
\hline CHEMBL1242373 & 809250 & 4.1 & 4.9396 & TRN & \\
\hline CHEMBL56543 & 809250 & 5.5 & 4.4058 & TRN & \\
\hline CHEMBL1988075 & 809250 & 4.1 & 4.5438 & TRN & \\
\hline CHEMBL316264 & 809250 & 4.1 & 4.159 & TRN & \\
\hline CHEMBL1991678 & 809250 & 4.1 & 4.4218 & TRN & \\
\hline CHEMBL2001239 & 809250 & 5.6 & 5.0991 & TST & \\
\hline CHEMBL1988594 & 809250 & 5.4 & 5.4392 & TRN & \\
\hline CHEMBL 2001288 & 809250 & 5.1 & 5.2453 & TRN & \\
\hline CHEMBL1999811 & 809250 & 6.3 & 5.1884 & TST & \\
\hline CHEMBL1985074 & 809250 & 5.1 & 4.5823 & TST & \\
\hline CHEMBL1982874 & 809250 & 4.1 & 4.1316 & TRN & \\
\hline CHEMBL 2000481 & 809250 & 4.1 & 4.3044 & TRN & \\
\hline CHEMBL1991725 & 809250 & 4.1 & 4.8271 & TRN & \\
\hline CHEMBL1992242 & 809250 & 4.1 & 3.9735 & TRN & \\
\hline CHEMBL2007296 & 809250 & 5.6 & 4.8724 & TRN & \\
\hline CHEMBL396523 & 809250 & 7.1 & 7.2023 & TRN & \\
\hline CHEMBL 208637 & 809250 & 4.1 & 3.8146 & TRN & \\
\hline CHEMBL1970203 & 809250 & 4.1 & 4.6222 & TRN & \\
\hline CHEMBL1986530 & 809250 & 4.1 & 5.2792 & TST & \\
\hline CHEMBL1968590 & 809250 & 4.1 & 4.13899 & 9999999999 & TRN \\
\hline CHEMBL 2005375 & 809250 & 4.1 & 4.172 & TRN & \\
\hline CHEMBL1984191 & 809250 & 4.1 & 4.5513 & TRN & \\
\hline CHEMBL1972183 & 809250 & 4.1 & 4.2233 & TST & \\
\hline CHEMBL1971029 & 809250 & 7.5 & 6.8487 & TRN & \\
\hline CHEMBL394790 & 809250 & 5.5 & 4.885 & TRN & \\
\hline CHEMBL226471 & 809250 & 5.9 & 5.23 & TRN & \\
\hline CHEMBL1996111 & 809250 & 5.7 & 4.5367 & TRN & \\
\hline CHEMBL1974702 & 809250 & 4.1 & 4.4277 & TRN & \\
\hline CHEMBL1965589 & 809250 & 4.1 & 4.3387 & TRN & \\
\hline CHEMBL474432 & 809250 & 4.1 & 4.9972 & TST & \\
\hline CHEMBL1988153 & 809250 & 4.1 & 5.0525 & TST & \\
\hline CHEMBL1988437 & 809250 & 5.2 & 4.8825 & TST & \\
\hline CHEMBL1998121 & 809250 & 4.1 & 5.0836 & TRN & \\
\hline CHEMBL1979577 & 809250 & 5.1 & 4.5973 & TRN & \\
\hline CHEMBL1991800 & 809250 & 4.1 & 4.5707 & TRN & \\
\hline CHEMBL52387 & 809250 & 4.1 & 4.9517 & TST & \\
\hline
\end{tabular}




\begin{tabular}{|c|c|c|c|c|c|}
\hline \multicolumn{6}{|c|}{ Supplemental Table S2.txt } \\
\hline CHEMBL379835 & 809250 & 4.1 & 4.1382 & TST & \\
\hline CHEMBL1979357 & 809250 & 4.1 & 4.3568 & TRN & \\
\hline CHEMBL1996817 & 809250 & 6.3 & 6.1295 & TRN & \\
\hline CHEMBL 3197315 & 809250 & 4.1 & 3.6805 & TST & \\
\hline CHEMBL468280 & 809250 & 4.1 & 3.7573 & TST & \\
\hline CHEMBL1990884 & 809250 & 4.1 & 4.4325 & TRN & \\
\hline CHEMBL 3109278 & 809250 & 6.9 & 5.5713 & TRN & \\
\hline CHEMBL256835 & 809250 & 4.1 & 4.3394 & TRN & \\
\hline CHEMBL1980142 & 809250 & 4.1 & 3.8526 & TRN & \\
\hline CHEMBL41783 & 809250 & 4.1 & 4.6862 & TRN & \\
\hline CHEMBL 2006276 & 809250 & 4.1 & 4.9475 & TRN & \\
\hline CHEMBL271381 & 809250 & 4.1 & 4.6349 & TRN & \\
\hline CHEMBL 2006785 & 809250 & 5.3 & 4.7248 & TRN & \\
\hline CHEMBL1982466 & 809250 & 4.1 & 4.2649 & TRN & \\
\hline CHEMBL1995740 & 809250 & 4.1 & 4.348 & TRN & \\
\hline CHEMBL 234085 & 809250 & 4.1 & 4.1495 & TRN & \\
\hline CHEMBL1995832 & 809250 & 4.1 & 4.5647 & TRN & \\
\hline CHEMBL1998414 & 809250 & 5.3 & 4.5398 & TRN & \\
\hline CHEMBL1969042 & 809250 & 4.1 & 4.8951 & TST & \\
\hline CHEMBL 2000345 & 809250 & 7.9 & 5.7511 & TST & \\
\hline CHEMBL1999931 & 809250 & 7.5 & 6.9561 & TRN & \\
\hline CHEMBL1375418 & 809250 & 4.1 & 3.815 & TRN & \\
\hline CHEMBL 2007064 & 809250 & 4.1 & 5.0149 & TRN & \\
\hline CHEMBL1981047 & 809250 & 4.1 & 5.0627 & TST & \\
\hline CHEMBL 229968 & 809250 & 6.3 & 6.5917 & TRN & \\
\hline CHEMBL1976240 & 809250 & 5.7 & 5.23799 & 99999999995 & TRN \\
\hline CHEMBL1979093 & 809250 & 4.1 & 4.442 & TRN & \\
\hline CHEMBL1968151 & 809250 & 4.1 & 3.9891 & TST & \\
\hline CHEMBL1987009 & 809250 & 4.1 & 5.0697 & TRN & \\
\hline CHEMBL 379218 & 809250 & 6.0 & 6.2071 & TRN & \\
\hline CHEMBL 2003817 & 809250 & 4.1 & 4.1609 & TRN & \\
\hline CHEMBL1994830 & 809250 & 4.1 & 5.2579 & TST & \\
\hline CHEMBL226403 & 809250 & 5.3 & 5.1606 & TRN & \\
\hline CHEMBL 2005631 & 809250 & 4.1 & 4.5583 & TRN & \\
\hline CHEMBL1994938 & 809250 & 4.1 & 4.4187 & TRN & \\
\hline CHEMBL1977223 & 809250 & 5.3 & 5.5159 & TRN & \\
\hline CHEMBL1825138 & 809250 & 6.7 & 4.8583 & TST & \\
\hline CHEMBL1236126 & 809250 & 6.4 & 5.5634 & TRN & \\
\hline CHEMBL1966279 & 809250 & 4.1 & 3.983 & TRN & \\
\hline CHEMBL1997846 & 809250 & 5.6 & 6.6812 & TRN & \\
\hline CHEMBL2004419 & 809250 & 4.1 & 3.9129 & TRN & \\
\hline CHEMBL1972489 & 809250 & 4.1 & 4.2851 & TRN & \\
\hline CHEMBL1994074 & 809250 & 4.1 & 4.941 & TRN & \\
\hline CHEMBL1992937 & 809250 & 6.9 & 6.3957 & TRN & \\
\hline CHEMBL1972119 & 809250 & 4.1 & 4.0227 & TRN & \\
\hline CHEMBL1090356 & 809250 & 4.1 & 4.042 & TRN & \\
\hline CHEMBL95692 & 809250 & 4.1 & 4.3318 & TRN & \\
\hline CHEMBL1986328 & 809250 & 4.1 & 4.489 & TST & \\
\hline
\end{tabular}




\begin{tabular}{|c|c|c|c|c|c|}
\hline \\
\hline CHEMBL1976455 & 809250 & 5.3 & 4.7595 & TRN & \\
\hline CHEMBL1983923 & 809250 & 5.3 & 5.4343 & TST & \\
\hline CHEMBL1982361 & 809250 & 4.1 & 4.1714 & TRN & \\
\hline CHEMBL1983534 & 809250 & 6.0 & 4.8172 & TRN & \\
\hline CHEMBL1982122 & 809250 & 6.2 & 5.0705 & TRN & \\
\hline CHEMBL2000801 & 809250 & 4.1 & 4.1597 & TRN & \\
\hline CHEMBL1999112 & 809250 & 5.5 & 4.3686 & TST & \\
\hline CHEMBL1682546 & 809250 & 4.1 & 4.1001 & TRN & \\
\hline CHEMBL1991395 & 809250 & 4.1 & 4.3946 & TRN & \\
\hline CHEMBL1971245 & 809250 & 4.1 & 5.1161 & TRN & \\
\hline CHEMBL1972142 & 809250 & 5.2 & 4.9027 & TRN & \\
\hline CHEMBL1966514 & 809250 & 4.1 & 4.7863 & TRN & \\
\hline CHEMBL2003638 & 809250 & 6.6 & 7.1612 & TRN & \\
\hline CHEMBL1996066 & 809250 & 4.1 & 5.9281 & TST & \\
\hline CHEMBL1972152 & 809250 & 4.1 & 4.6281 & TST & \\
\hline CHEMBL1993722 & 809250 & 5.5 & 5.1792 & TRN & \\
\hline CHEMBL1970806 & 809250 & 4.1 & 3.6682 & TST & \\
\hline CHEMBL1979970 & 809250 & 4.1 & 4.61 & TRN & \\
\hline CHEMBL1375640 & 809250 & 5.8 & 5.4879 & TST & \\
\hline CHEMBL 249282 & 809250 & 4.1 & 4.6101 & TST & \\
\hline CHEMBL 2006237 & 809250 & 4.1 & 3.9372 & TST & \\
\hline CHEMBL1967720 & 809250 & 4.1 & 4.8639 & TST & \\
\hline CHEMBL1991138 & 809250 & 4.1 & 3.8139 & TST & \\
\hline CHEMBL1969755 & 809250 & 4.1 & 4.2007 & TST & \\
\hline CHEMBL1979516 & 809250 & 4.1 & 3.9279 & TST & \\
\hline CHEMBL1605605 & 809250 & 4.1 & 4.2862 & TST & \\
\hline CHEMBL1972820 & 809250 & 4.1 & 4.3808 & TST & \\
\hline CHEMBL1989029 & 809250 & 4.1 & 5.4702 & TST & \\
\hline CHEMBL392642 & 809250 & 6.0 & 4.987 & TST & \\
\hline CHEMBL514499 & 809250 & 4.1 & 4.5007 & TST & \\
\hline CHEMBL1965631 & 809250 & 4.1 & 5.38399 & 99999999995 & TST \\
\hline CHEMBL1980144 & 809250 & 4.1 & 5.0817 & TST & \\
\hline CHEMBL1991188 & 809250 & 5.6 & 4.7531 & TST & \\
\hline CHEMBL1972849 & 809250 & 4.1 & 3.7911 & TST & \\
\hline CHEMBL 377408 & 809250 & 4.1 & $4.0280 e$ & 00000000005 & TST \\
\hline CHEMBL231209 & 809250 & 5.7 & 4.7392 & TST & \\
\hline CHEMBL1975357 & 809250 & 4.1 & 4.2272 & TST & \\
\hline CHEMBL1976220 & 809250 & 5.7 & 4.8779 & TST & \\
\hline CHEMBL 259922 & 809250 & 4.1 & 4.3509 & TST & \\
\hline CHEMBL1997617 & 809250 & 4.2 & 4.5845 & TST & \\
\hline CHEMBL1982383 & 809250 & 4.1 & 4.5799 & TST & \\
\hline CHEMBL1969301 & 809250 & 7.8 & 6.4858 & TST & \\
\hline CHEMBL17370 & 809250 & 4.1 & 4.0628 & TST & \\
\hline CHEMBL1987910 & 809250 & 5.5 & 4.9749 & TST & \\
\hline CHEMBL1983932 & 809250 & 4.1 & 5.2654 & TST & \\
\hline CHEMBL1997822 & 809250 & 5.2 & 4.6036 & TST & \\
\hline CHEMBL1991285 & 809250 & 5.4 & 4.511 & TST & \\
\hline CHEMBL1984038 & 809250 & 5.2 & 4.5237 & TST & \\
\hline
\end{tabular}




\begin{tabular}{|c|c|c|c|c|c|}
\hline \multicolumn{6}{|c|}{ Supplemental Table S2.txt } \\
\hline CHEMBL243088 & 809250 & 6.6 & 6.6831 & TST & \\
\hline CHEMBL1974416 & 809250 & 4.1 & 4.7829 & TST & \\
\hline CHEMBL2004615 & 809250 & 5.7 & 4.4868 & TST & \\
\hline CHEMBL1984039 & 809250 & 4.1 & 4.5369 & TST & \\
\hline CHEMBL1997872 & 809250 & 4.1 & 4.7279 & TST & \\
\hline CHEMBL70613 & 103290 & 7.7959 & 7.334 & TRN & \\
\hline CHEMBL69503 & 103290 & 8.699 & 8.9652 & TRN & \\
\hline CHEMBL303226 & 103290 & 7.5229 & 8.422 & TRN & \\
\hline CHEMBL 303212 & 103290 & 6.4214 & 6.5005 & TRN & \\
\hline CHEMBL73008 & 103290 & 9.2218 & 9.269 & TRN & \\
\hline CHEMBL71683 & 103290 & 8.6198 & 8.2143 & TRN & \\
\hline CHEMBL311132 & 103290 & 6.5452 & 5.856 & TRN & \\
\hline CHEMBL72059 & 103290 & 8.1549 & 7.6609 & TRN & \\
\hline CHEMBL 307865 & 103290 & 8.3372 & 7.8866 & TRN & \\
\hline CHEMBL305805 & 103290 & 8.1367 & 7.8975 & TRN & \\
\hline CHEMBL 307474 & 103290 & 7.2924 & 7.3324 & TRN & \\
\hline CHEMBL72289 & 103290 & 8.5229 & 8.1629 & TRN & \\
\hline CHEMBL73939 & 103290 & 8.5376 & 9.1788 & TST & \\
\hline CHEMBL73250 & 103290 & 8.5686 & 8.1254 & TRN & \\
\hline CHEMBL70683 & 103290 & 7.0269 & 7.1404 & TRN & \\
\hline CHEMBL73673 & 103290 & 8.6021 & 8.1083 & TST & \\
\hline CHEMBL 70745 & 103290 & 7.041 & 6.8583 & TRN & \\
\hline CHEMBL70374 & 103290 & 8.6198 & 8.616 & TRN & \\
\hline CHEMBL 304055 & 103290 & 9.0969 & 9.0726 & TRN & \\
\hline CHEMBL421492 & 103290 & 6.7799 & 6.7851 & TRN & \\
\hline CHEMBL 74174 & 103290 & 9.0 & 9.4686 & TRN & \\
\hline CHEMBL268935 & 103290 & 7.5086 & 7.3769 & TRN & \\
\hline CHEMBL71750 & 103290 & 6.8861 & 7.3288 & TRN & \\
\hline CHEMBL 302791 & 103290 & 8.8239 & 8.725 & TRN & \\
\hline CHEMBL71659 & 103290 & 8.4559 & 8.7121 & TRN & \\
\hline CHEMBL71298 & 103290 & 7.8539 & 7.4332 & TST & \\
\hline CHEMBL 72529 & 103290 & 9.301 & 9.6211 & TRN & \\
\hline CHEMBL 312080 & 103290 & 7.9208 & 7.5757 & TRN & \\
\hline CHEMBL70559 & 103290 & 7.0655 & 7.33700 & 3000000001 & TRN \\
\hline CHEMBL 70967 & 103290 & 8.5086 & 8.0229 & TRN & \\
\hline CHEMBL71728 & 103290 & 9.5229 & 9.661 & TRN & \\
\hline CHEMBL304569 & 103290 & 6.7122 & 7.4809 & TST & \\
\hline CHEMBL72011 & 103290 & 5.9666 & 6.5888 & TRN & \\
\hline CHEMBL305838 & 103290 & 9.0 & 9.1837 & TST & \\
\hline CHEMBL307297 & 103290 & 8.2007 & 8.0831 & TRN & \\
\hline CHEMBL73044 & 103290 & 8.6778 & 8.9269 & TST & \\
\hline CHEMBL 74409 & 103290 & 8.5086 & 7.6827 & TRN & \\
\hline CHEMBL71579 & 103290 & 7.9208 & 7.4955 & TRN & \\
\hline CHEMBL302551 & 103290 & 8.3979 & 8.5349 & TST & \\
\hline CHEMBL419252 & 103290 & 8.2076 & 8.3073 & TRN & \\
\hline CHEMBL72343 & 103290 & 7.8539 & 7.671 & TRN & \\
\hline CHEMBL 70468 & 103290 & 8.699 & 8.5759 & TST & \\
\hline CHEMBL 74003 & 103290 & 6.7959 & 7.2347 & TRN & \\
\hline
\end{tabular}




\begin{tabular}{|c|c|c|c|c|c|}
\hline \multirow[b]{2}{*}{ CHEMBL71042 } & & \multicolumn{4}{|c|}{ Supplemental Table S2.txt } \\
\hline & 103290 & 5.279 & 5.79899 & 99999999995 & TRN \\
\hline CHEMBL70956 & 103290 & 6.0711 & 7.6903 & TRN & \\
\hline CHEMBL310247 & 103290 & 8.2596 & 7.9883 & TRN & \\
\hline CHEMBL71521 & 103290 & 9.0 & 9.1528 & TST & \\
\hline CHEMBL308091 & 103290 & 5.8097 & 6.2591 & TRN & \\
\hline CHEMBL 302542 & 103290 & 8.8861 & 9.1623 & TST & \\
\hline CHEMBL 306385 & 103290 & 9.2218 & 9.3502 & TST & \\
\hline CHEMBL431572 & 103290 & 8.699 & 9.5029 & TST & \\
\hline CHEMBL72459 & 103290 & 8.2676 & 8.4213 & TST & \\
\hline CHEMBL74410 & 103290 & 8.9208 & 8.2739 & TRN & \\
\hline CHEMBL 306023 & 103290 & 8.301 & 8.1784 & TRN & \\
\hline CHEMBL 70528 & 103290 & 6.2147 & 7.0166 & TRN & \\
\hline CHEMBL70990 & 103290 & 7.7447 & 7.2731 & TRN & \\
\hline CHEMBL421114 & 103290 & 8.5086 & 8.1689 & TST & \\
\hline CHEMBL71684 & 103290 & 8.8539 & 8.8352 & TRN & \\
\hline CHEMBL302538 & 103290 & 5.1062 & 5.8022 & TST & \\
\hline CHEMBL1190711 & 955024 & 5.6001 & 5.5602 & TRN & \\
\hline CHEMBL 240954 & 955024 & 3.7592 & 4.2573 & TST & \\
\hline CHEMBL135561 & 955024 & 4.4697 & 4.4029 & TRN & \\
\hline CHEMBL9470 & 955024 & 5.747999 & 99999999 & 5.8461 & TST \\
\hline CHEMBL102714 & 955024 & 3.6827 & 3.64899 & 99999999996 & TRN \\
\hline CHEMBL1788116 & 955024 & 5.499 & 5.4834 & TRN & \\
\hline CHEMBL 210618 & 955024 & 3.5354 & 3.4973 & TRN & \\
\hline CHEMBL188678 & 955024 & 3.9455 & 4.131 & TRN & \\
\hline CHEMBL1643959 & 955024 & 4.6587 & 4.7393 & TRN & \\
\hline CHEMBL 2005886 & 955024 & 4.8634 & 4.8526 & TRN & \\
\hline CHEMBL258844 & 955024 & 4.9 & 4.7611 & TRN & \\
\hline CHEMBL585951 & 955024 & 6.3865 & 6.416 & TRN & \\
\hline CHEMBL2363137 & 955024 & 5.5033 & 5.4126 & TRN & \\
\hline CHEMBL1357247 & 955024 & 2.7869 & 2.7989 & TRN & \\
\hline CHEMBL 222102 & 955024 & 4.2375 & 3.9848 & TRN & \\
\hline CHEMBL209148 & 955024 & 4.127 & 4.19300 & 00000000005 & TRN \\
\hline CHEMBL221137 & 955024 & 5.55 & 5.2607 & TST & \\
\hline CHEMBL202721 & 955024 & 3.6352 & 3.7417 & TRN & \\
\hline CHEMBL189584 & 955024 & 4.7453 & 4.8437 & TRN & \\
\hline CHEMBL1256459 & 955024 & 7.5719 & 7.5605 & TRN & \\
\hline CHEMBL558642 & 955024 & 4.6723 & 4.6683 & TRN & \\
\hline CHEMBL1590308 & 955024 & 3.339 & 4.3899 & TST & \\
\hline CHEMBL449158 & 955024 & 6.4746 & 6.8929 & TST & \\
\hline CHEMBL1970879 & 955024 & 6.0673 & 6.1251 & TRN & \\
\hline CHEMBL 220241 & 955024 & 4.346 & 4.3587 & TRN & \\
\hline CHEMBL 213100 & 955024 & 5.5441 & 5.5427 & TRN & \\
\hline CHEMBL 379300 & 955024 & 6.8618 & 6.8197 & TRN & \\
\hline CHEMBL573107 & 955024 & 4.7092 & 4.8181 & TRN & \\
\hline CHEMBL 373751 & 955024 & 3.2854 & 3.3968 & TRN & \\
\hline CHEMBL1909414 & 955024 & 4.5612 & 4.5727 & TRN & \\
\hline CHEMBL412142 & 955024 & 5.1375 & 5.0977 & TRN & \\
\hline CHEMBL1404918 & 955024 & 2.6712 & 2.5215 & TRN & \\
\hline
\end{tabular}




\begin{tabular}{|c|c|c|c|c|}
\hline \multicolumn{5}{|c|}{ Supplemental Table S2.txt } \\
\hline CHEMBL472940 & 955024 & 3.8736 & 3.9142 & TRN \\
\hline CHEMBL392695 & 955024 & 6.1492 & 6.1464 & TRN \\
\hline CHEMBL2144069 & 955024 & 3.5539 & 3.4259 & TRN \\
\hline CHEMBL483847 & 955024 & 3.7063 & 3.7255 & TRN \\
\hline CHEMBL65 & 955024 & 7.7997 & 7.8529 & TRN \\
\hline CHEMBL509032 & 955024 & 5.3062 & 5.3351 & TRN \\
\hline CHEMBL1242367 & 955024 & 4.3505 & 4.4898 & TRN \\
\hline CHEMBL3392440 & 955024 & 3.5892 & 3.6603 & TRN \\
\hline CHEMBL379975 & 955024 & 4.6703 & 4.6684 & TRN \\
\hline CHEMBL512504 & 955024 & 6.9994 & 6.9813 & TRN \\
\hline CHEMBL514499 & 955024 & 7.4394 & 7.3268 & TRN \\
\hline CHEMBL180127 & 955024 & 4.9505 & 5.0521 & TRN \\
\hline CHEMBL3349342 & 955024 & 3.6644 & 3.6281 & TRN \\
\hline CHEMBL3199475 & 955024 & 5.9164 & 5.9261 & TRN \\
\hline CHEMBL92309 & 955024 & 3.7584 & 3.2849 & TST \\
\hline CHEMBL259181 & 955024 & 4.5125 & 4.4432 & TRN \\
\hline CHEMBL393929 & 955024 & 3.3832 & 3.4269 & TRN \\
\hline CHEMBL577784 & 955024 & 4.7857 & 4.7024 & TRN \\
\hline CHEMBL192566 & 955024 & 10.6107 & 8.1556 & TST \\
\hline CHEMBL515416 & 955024 & 5.0703 & 4.8876 & TST \\
\hline CHEMBL3186408 & 955024 & 3.1211 & 4.0645 & TST \\
\hline CHEMBL1516890 & 955024 & 3.8223 & 3.9584 & TST \\
\hline CHEMBL483849 & 955024 & 2.8893 & 2.8956 & TST \\
\hline CHEMBL191334 & 955024 & 3.3202 & 4.2683 & TST \\
\hline CHEMBL300389 & 955024 & 7.3908 & 7.1289 & TST \\
\hline CHEMBL1230020 & 955024 & 3.7048 & 4.0389 & TST \\
\hline CHEMBL1673039 & 955024 & 5.1417 & 5.0261 & TST \\
\hline CHEMBL3957853 & 1641177 & 10.1864 & 7.9813 & TRN \\
\hline CHEMBL3948279 & 1641177 & 9.0888 & 9.7574 & TST \\
\hline CHEMBL3892683 & 1641177 & 10.5421 & 10.5775 & TRN \\
\hline CHEMBL3957062 & 1641177 & 9.8665 & 8.3084 & TRN \\
\hline CHEMBL3928079 & 1641177 & 10.6882 & 9.551 & TRN \\
\hline CHEMBL3959256 & 1641177 & 6.0 & 7.8846 & TRN \\
\hline CHEMBL3951487 & 1641177 & 6.5467 & 8.9739 & TST \\
\hline CHEMBL3893928 & 1641177 & 6.0 & 6.3198 & TRN \\
\hline CHEMBL3939350 & 1641177 & 10.4647 & 10.1665 & TRN \\
\hline CHEMBL3919675 & 1641177 & 9.4271 & 8.4025 & TRN \\
\hline CHEMBL3932226 & 1641177 & 6.0 & 8.0826 & TRN \\
\hline CHEMBL3944591 & 1641177 & 9.2328 & 9.7994 & TST \\
\hline CHEMBL3970028 & 1641177 & 7.2154 & 9.0885 & TST \\
\hline CHEMBL3914692 & 1641177 & 11.058 & 10.9139 & TRN \\
\hline CHEMBL3984760 & 1641177 & 10.3125 & 10.3608 & TRN \\
\hline CHEMBL3920520 & 1641177 & 6.4191 & 9.6451 & TST \\
\hline CHEMBL3929389 & 1641177 & 6.0 & 8.2111 & TRN \\
\hline CHEMBL3922317 & 1641177 & 10.3615 & 8.5672 & TRN \\
\hline CHEMBL 3940587 & 1641177 & 9.9747 & 10.3561 & TRN \\
\hline CHEMBL3964961 & 1641177 & 6.0 & 7.4629 & TRN \\
\hline CHEMBL3896859 & 1641177 & 10.8153 & 10.42406 & 20000 \\
\hline
\end{tabular}

Page 13506 
Supplemental Table S2.txt

CHEMBL 3944688

CHEMBL 3928081

CHEMBL3956113

CHEMBL 3961700

CHEMBL 3978198

CHEMBL 3922523

CHEMBL 3908660

CHEMBL3906431

CHEMBL 3905189

CHEMBL3895902

CHEMBL3913708

CHEMBL3927870

CHEMBL 3928720

CHEMBL3900375

CHEMBL 3977150

CHEMBL 3939187

CHEMBL3976489

CHEMBL 3915179

CHEMBL 3928948

CHEMBL 3899467

CHEMBL3928857

CHEMBL3911368

CHEMBL 3890798

CHEMBL 3899226

CHEMBL3940921

CHEMBL 3914176

CHEMBL3953306

CHEMBL3981161

CHEMBL3948464

CHEMBL3978744

CHEMBL3943800

CHEMBL3978282

CHEMBL 3913706

CHEMBL 3908768

CHEMBL3970349

CHEMBL 3898826

CHEMBL 3898018

CHEMBL3898623

CHEMBL3968887

CHEMBL3902220

CHEMBL3972515

CHEMBL 3899894

CHEMBL 3959022

CHEMBL 3892015

CHEMBL3959370

CHEMBL 3934390

CHEMBL3951155

CHEMBL 3934781

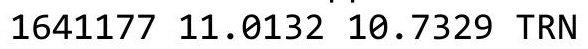

$\begin{array}{lll}1641177 & 10.6778 & 10.0323 \text { TRN }\end{array}$

$\begin{array}{llll}1641177 & 10.8013 & 10.2063 \text { TRN }\end{array}$

$\begin{array}{llll}1641177 & 7.1694 & 9.2238 & \text { TST }\end{array}$

$\begin{array}{llll}1641177 & 10.6799 & 8.6438 & \text { TRN }\end{array}$

$\begin{array}{lll}1641177 & 10.129 & 10.6914\end{array}$

$\begin{array}{lll}1641177 & 10.0283 & 10.0495 \\ \text { TRN }\end{array}$

$\begin{array}{lll}1641177 & 8.8827 & 10.5149\end{array}$

$\begin{array}{llll}1641177 & 6.6799 & 9.6544 & \text { TST }\end{array}$

$\begin{array}{llll}1641177 & 10.0846 & 8.7541 & \text { TRN }\end{array}$

$\begin{array}{llll}1641177 & 11.1772 & 8.6255 & \text { TRN }\end{array}$

$\begin{array}{llll}1641177 & 6.0 & 8.4354 & \text { TRN }\end{array}$

$\begin{array}{llll}1641177 & 6.0 & 8.0981 & \text { TRN }\end{array}$

$164117711.0 \quad 10.3378$ TRN

$\begin{array}{llll}16411778.0 & 9.4858 & \text { TST }\end{array}$

$16411776.0 \quad 6.5787$ TRN

$\begin{array}{lll}1641177 & 10.6536 & 10.4064 \text { TRN }\end{array}$

$\begin{array}{llll}1641177 & 7.2628 & 9.5257 & \text { TST }\end{array}$

$\begin{array}{llll}1641177 & 9.2924 & 9.4689 & \text { TST }\end{array}$

$\begin{array}{lllll}1641177 & 9.4647 & 8.9461 & \text { TRN }\end{array}$

$\begin{array}{llll}1641177 & 6.0 & 8.1624 & \text { TRN }\end{array}$

$\begin{array}{lll}1641177 & 10.6162 & 10.1482 \text { TRN }\end{array}$

$\begin{array}{lll}1641177 & 9.9393 & 10.3998 \\ \text { TRN }\end{array}$

$\begin{array}{lll}1641177 & 6.4802 & 10.0162\end{array}$

$\begin{array}{llll}1641177 & 10.4389 & 10.6659 & \text { TRN }\end{array}$

$\begin{array}{llll}16411776.0 & 8.5088 & \text { TRN }\end{array}$

$\begin{array}{llll}1641177 & 6.9469 & 9.0834 & \text { TST }\end{array}$

$\begin{array}{llll}1641177 & 10.5702 & 8.2682 & \text { TRN }\end{array}$

$\begin{array}{llll}1641177 & 6.0 & 7.2197 & \text { TRN }\end{array}$

$\begin{array}{llll}1641177 & 6.0 & 7.4478 & \text { TRN }\end{array}$

$\begin{array}{lll}1641177 & 10.681910 .9418 \text { TRN }\end{array}$

$\begin{array}{lll}1641177 & 10.6799 & 11.2503 \\ \text { TRN }\end{array}$

$\begin{array}{llll}1641177 & 7.6925 & 8.8841 & \text { TRN }\end{array}$

$\begin{array}{lllll}1641177 & 9.4401 & 8.2331 & \text { TRN }\end{array}$

$\begin{array}{llll}1641177 & 8.3605 & 9.2848 & \text { TST }\end{array}$

$\begin{array}{llll}1641177 & 10.1543 & 7.4819 & \text { TRN }\end{array}$

$\begin{array}{llll}1641177 & 8.5171 & 9.0511 & \text { TRN }\end{array}$

$\begin{array}{llll}1641177 & 10.4389 & 11.0722 & \text { TRN }\end{array}$

$\begin{array}{llll}1641177 & 10.8962 & 10.3541 \text { TRN }\end{array}$

$\begin{array}{llll}16411776.0 & 6.6728 & \text { TRN }\end{array}$

$\begin{array}{lll}1641177 & 10.5114 & 11.252\end{array}$

$\begin{array}{lll}1641177 & 8.1931 & 10.4649\end{array}$

$\begin{array}{llll}1641177 & 9.8665 & 10.6759 & \text { TST }\end{array}$

$\begin{array}{llll}1641177 & 9.7878 & 9.3016 & \text { TST }\end{array}$

$\begin{array}{lll}1641177 & 10.5884 & 10.5156\end{array}$

$\begin{array}{llll}1641177 & 8.426 & 8.6833 & \text { TST }\end{array}$

$\begin{array}{llll}1641177 & 10.3344 & 8.2808 & \text { TRN }\end{array}$

$\begin{array}{lll}1641177 & 6.0 & 7.4352\end{array}$ 
Supplemental Table S2.txt

\begin{tabular}{|c|c|c|c|c|c|c|}
\hline CHEMBL3944713 & 1641177 & 10.6819 & 10.1073 & TRN & & \\
\hline CHEMBL3892268 & 1641177 & 6.0 & 6.9314 & TRN & & \\
\hline CHEMBL3907844 & 1641177 & 9.4698 & 7.1708 & TRN & & \\
\hline CHEMBL3961443 & 1641177 & 10.5086 & 10.4381 & TRN & & \\
\hline CHEMBL3900490 & 1641177 & 6.0 & 7.5927 & TRN & & \\
\hline CHEMBL3986595 & 1641177 & 10.1549 & 9.0461 & TRN & & \\
\hline CHEMBL3902374 & 1641177 & 10.7033 & 8.5535 & TRN & & \\
\hline CHEMBL3965238 & 1641177 & 10.0894 & 10.0504 & TRN & & \\
\hline CHEMBL3928360 & 1641177 & 6.0 & 7.2335 & TRN & & \\
\hline CHEMBL3969829 & 1641177 & 10.1618 & 9.4346 & TRN & & \\
\hline CHEMBL3895304 & 1641177 & 10.9172 & 11.0137 & TRN & & \\
\hline CHEMBL3937754 & 1641177 & 9.5513 & 8.0658 & TRN & & \\
\hline CHEMBL3951646 & 1641177 & 10.3449 & 7.7842 & TRN & & \\
\hline CHEMBL3978049 & 1641177 & 9.6635 & 7.3992 & TRN & & \\
\hline CHEMBL3919035 & 1641177 & 6.0 & 7.7805 & TRN & & \\
\hline CHEMBL3969789 & 1641177 & 11.30099 & 999999999 & 998 & 7.6766 & TRN \\
\hline CHEMBL3983348 & 1641177 & 10.69906 & 000000000 & 302 & 10.4667 & TRN \\
\hline CHEMBL3969946 & 1641177 & 10.6108 & 10.1436 & TRN & & \\
\hline CHEMBL3955771 & 1641177 & 11.0 & 10.4061 & TRN & & \\
\hline CHEMBL3921490 & 1641177 & 7.8013 & 7.8842 & TST & & \\
\hline CHEMBL3923033 & 1641177 & 10.9245 & 10.6315 & TRN & & \\
\hline CHEMBL3914528 & 1641177 & 10.1506 & 11.035 & TRN & & \\
\hline CHEMBL3984429 & 1641177 & 9.2269 & 10.1416 & TRN & & \\
\hline CHEMBL3942139 & 1641177 & 10.7011 & 10.0102 & TRN & & \\
\hline CHEMBL 3953627 & 1641177 & 10.1838 & 10.1828 & TRN & & \\
\hline CHEMBL3923773 & 1641177 & 6.8697 & 9.1001 & TST & & \\
\hline CHEMBL3983287 & 1641177 & 6.0 & 7.8538 & TRN & & \\
\hline CHEMBL3891056 & 1641177 & 10.8539 & 10.4837 & TRN & & \\
\hline CHEMBL 3976291 & 1641177 & 6.2967 & 8.8792 & TST & & \\
\hline CHEMBL 3978143 & 1641177 & 7.0711 & 10.1831 & TST & & \\
\hline CHEMBL3948885 & 1641177 & 10.4023 & 9.0482 & TRN & & \\
\hline CHEMBL3910028 & 1641177 & 10.6968 & 10.8193 & TRN & & \\
\hline CHEMBL3987168 & 1641177 & 10.1192 & 8.2274 & TRN & & \\
\hline CHEMBL3901057 & 1641177 & 10.9706 & 9.4445 & TRN & & \\
\hline CHEMBL 3933382 & 1641177 & 6.0 & 7.5923 & TRN & & \\
\hline CHEMBL3931406 & 1641177 & 10.1198 & 9.9353 & TRN & & \\
\hline CHEMBL3974272 & 1641177 & 9.6234 & 8.2034 & TRN & & \\
\hline CHEMBL3923999 & 1641177 & 6.0 & 7.0176 & TRN & & \\
\hline CHEMBL 3916150 & 1641177 & 11.0773 & 8.1472 & TRN & & \\
\hline CHEMBL 3931362 & 1641177 & 7.3788 & 9.0383 & TST & & \\
\hline CHEMBL3922449 & 1641177 & 10.0301 & 10.4762 & TRN & & \\
\hline CHEMBL3893174 & 1641177 & 10.7055 & 9.8426 & TRN & & \\
\hline CHEMBL3977369 & 1641177 & 10.7747 & 10.1382 & TRN & & \\
\hline CHEMBL 3890881 & 1641177 & 6.0 & 8.4476 & TRN & & \\
\hline CHEMBL 3945881 & 1641177 & 6.0 & 7.6427 & TST & & \\
\hline CHEMBL3907182 & 1641177 & 10.5229 & 11.0014 & TRN & & \\
\hline CHEMBL3891085 & 1641177 & 6.0 & 8.3104 & TRN & & \\
\hline CHEMBL3920041 & 1641177 & 9.0458 & 10.8574 & TST & & \\
\hline
\end{tabular}

Page 13508 
Supplemental Table S2.txt

CHEMBL 3946951

CHEMBL 3895057

CHEMBL3902331

CHEMBL3933813

CHEMBL 3901227

CHEMBL3927504

CHEMBL3960210

CHEMBL 3900356

CHEMBL 3895586

CHEMBL3891146

CHEMBL3936735

CHEMBL3936215

CHEMBL3924577

CHEMBL3913591

CHEMBL 3929178

CHEMBL 3933774

CHEMBL3920590

CHEMBL 3898254

CHEMBL3920289

CHEMBL 3982225

CHEMBL3983225

CHEMBL3960925

CHEMBL3912603

CHEMBL 3967296

CHEMBL 3902398

CHEMBL 3916673

CHEMBL 3890880

CHEMBL3945827

CHEMBL 3899872

CHEMBL3970505

CHEMBL3901403

CHEMBL 3956128

CHEMBL3895946

CHEMBL3964975

CHEMBL3943715

CHEMBL3906991

CHEMBL3925911

CHEMBL 3980160

CHEMBL 3891114

CHEMBL 3938286

CHEMBL 3955860

CHEMBL 3937397

CHEMBL3964071

CHEMBL 3964245

CHEMBL3959455

CHEMBL3919189

CHEMBL 3889745

CHEMBL 3929111 $\begin{array}{lll}1641177 & 10.8447 & 10.8543 \text { TRN }\end{array}$

$\begin{array}{llll}1641177 & 11.1733 & 10.7209 & \text { TRN }\end{array}$

$\begin{array}{lll}1641177 & 10.4622 & 10.3715 \text { TRN }\end{array}$

$\begin{array}{llll}1641177 & 11.0825 & 10.7598 & \text { TRN }\end{array}$

$\begin{array}{lll}1641177 & 6.0 & 7.4742\end{array}$

$\begin{array}{lll}1641177 & 9.6556 & 11.1075\end{array}$

$\begin{array}{llll}1641177 & 7.6946 & 8.7724 & \text { TST }\end{array}$

$\begin{array}{lll}1641177 & 10.317 & 10.7637\end{array}$

164117710.03257 .6664 TRN

$\begin{array}{llll}1641177 & 10.4225 & 10.9338 & \text { TRN }\end{array}$

$\begin{array}{llll}1641177 & 7.1518 & 8.8726 & \text { TST }\end{array}$

$\begin{array}{llll}1641177 & 8.0565 & 9.4204 & \text { TRN }\end{array}$

$\begin{array}{llll}1641177 & 9.9788 & 8.1807 & \text { TRN }\end{array}$

$\begin{array}{llll}1641177 & 9.4389 & 9.9659 & \text { TST }\end{array}$

$\begin{array}{llll}1641177 & 7.4815 & 8.6403 & \text { TRN }\end{array}$

$\begin{array}{lll}1641177 & 10.58 \quad 10.9855 \text { TRN }\end{array}$

$\begin{array}{llll}1641177 & 8.6946 & 8.5694 & \text { TST }\end{array}$

$\begin{array}{llll}1641177 & 10.3143 & 7.943 & \text { TRN }\end{array}$

$\begin{array}{llll}1641177 & 10.2097 & 8.6848 & \text { TRN }\end{array}$

$\begin{array}{llll}1641177 & 6.0 & 8.3355 & \text { TRN }\end{array}$

$16411776.0 \quad 8.2595$ TRN

$\begin{array}{llll}1641177 & 10.0348 & 9.6674 & \text { TRN }\end{array}$

$\begin{array}{llll}1641177 & 6.0 & 7.6955 & \text { TRN }\end{array}$

$\begin{array}{lll}1641177 & 10.6055 & 10.7783 \\ \text { TRN }\end{array}$

$\begin{array}{llll}1641177 & 10.9586 & 7.6746 & \text { TRN }\end{array}$

$\begin{array}{lllll}1641177 & 9.4449 & 8.4556 & \text { TRN }\end{array}$

$\begin{array}{lll}1641177 & 6.0 & 10.3336\end{array}$

$\begin{array}{llll}1641177 & 6.0 & 7.9788 & \text { TRN }\end{array}$

$16411776.0 \quad 8.6411$ TRN

$\begin{array}{llll}1641177 & 9.025 & 9.9264 & \text { TRN }\end{array}$

$\begin{array}{lll}1641177 & 10.3307 & 11.3836\end{array}$

$\begin{array}{llll}1641177 & 6.0 & 7.3884 & \text { TRN }\end{array}$

164117710.365510 .1583 TRN

$\begin{array}{llll}1641177 & 9.3675 & 10.446 & \text { TRN }\end{array}$

$\begin{array}{llll}1641177 & 6.0 & 7.9208 & \text { TST }\end{array}$

164117710.025511 .0876 TRN

$\begin{array}{lll}1641177 & 10.262 & 10.5146 \text { TRN }\end{array}$

$\begin{array}{lll}1641177 & 9.4776 \quad 10.4872 \text { TRN }\end{array}$

$\begin{array}{llll}1641177 & 6.0 & 8.0822 & \text { TRN }\end{array}$

$\begin{array}{llll}1641177 & 10.6819 & 10.4907 & \text { TRN }\end{array}$

$\begin{array}{lll}1641177 & 8.1319 & 10.6913\end{array}$

164117710.190410 .0138 TRN

$\begin{array}{llll}1641177 & 10.5058 & 10.823 & \text { TRN }\end{array}$

$\begin{array}{llll}1641177 & 8.0141 & 7.9511 & \text { TST }\end{array}$

$\begin{array}{lll}1641177 & 10.2083 & 10.7964 \text { TRN }\end{array}$

$\begin{array}{lll}1641177 & 10.5498 & 10.2845\end{array}$

$\begin{array}{lllll}1641177 & 10.4437 & 8.5332 & \text { TRN }\end{array}$

$\begin{array}{lll}1641177 & 10.2118 & 8.972000000000001\end{array}$

TST

Page 13509 


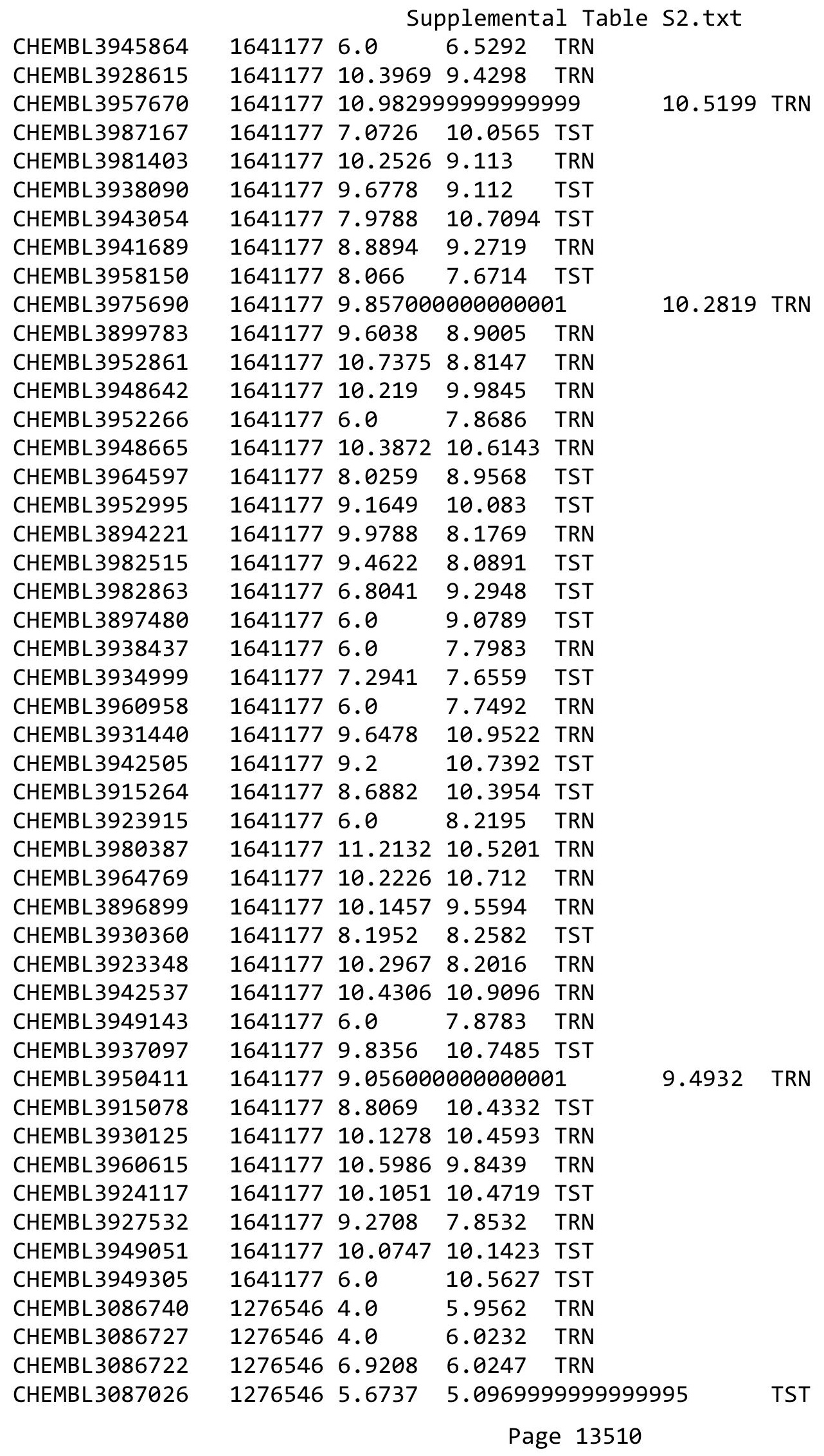


Supplemental Table S2.txt

\begin{tabular}{|c|c|c|c|c|c|}
\hline CHEMBL 3086550 & 1276546 & 6.7447 & 6.0165 & TRN & \\
\hline CHEMBL 3086742 & 1276546 & 6.1805 & 6.0304 & TRN & \\
\hline CHEMBL 3086721 & 1276546 & 6.8239 & 6.0861 & TRN & \\
\hline CHEMBL 3087038 & 1276546 & 6.5528 & 5.1296 & TRN & \\
\hline CHEMBL 3087033 & 1276546 & 6.2441 & 5.8111 & TRN & \\
\hline CHEMBL 3087349 & 1276546 & 5.6126 & 4.867 & TRN & \\
\hline CHEMBL 3087355 & 1276546 & 5.5607 & 4.9153 & TRN & \\
\hline CHEMBL 3087032 & 1276546 & 5.1549 & 5.5859 & TRN & \\
\hline CHEMBL 3086553 & 1276546 & 6.6021 & 6.0386 & TRN & \\
\hline CHEMBL 3087030 & 1276546 & 6.0862 & 5.5311 & TRN & \\
\hline CHEMBL 3087020 & 1276546 & 5.8697 & 5.2809 & TRN & \\
\hline CHEMBL 3087018 & 1276546 & 6.585 & 6.0193 & TRN & \\
\hline CHEMBL 3087344 & 1276546 & 5.8386 & 5.2434 & TST & \\
\hline CHEMBL3087029 & 1276546 & 5.6716 & 5.4553 & TRN & \\
\hline CHEMBL3086549 & 1276546 & 6.0458 & 5.2155 & TST & \\
\hline CHEMBL 3086738 & 1276546 & 5.2218 & 5.9284 & TRN & \\
\hline CHEMBL 3087021 & 1276546 & 4.0 & 5.1192 & TRN & \\
\hline CHEMBL 3087028 & 1276546 & 4.0 & 5.4775 & TRN & \\
\hline CHEMBL 3086552 & 1276546 & 6.8861 & 5.3504 & TST & \\
\hline CHEMBL 3087023 & 1276546 & 4.0 & 5.107 & TRN & \\
\hline CHEMBL 3086554 & 1276546 & 6.6576 & 6.0553 & TRN & \\
\hline CHEMBL 3087042 & 1276546 & 6.6778 & 5.16200 & 0000000001 & TRN \\
\hline CHEMBL 3087346 & 1276546 & 6.301 & 5.6292 & TRN & \\
\hline CHEMBL 3085787 & 1276546 & 6.8239 & 6.12799 & 9999999999 & TRN \\
\hline CHEMBL 3087034 & 1276546 & 6.2676 & 5.9521 & TRN & \\
\hline CHEMBL 3087037 & 1276546 & 6.1427 & 5.1187 & TRN & \\
\hline CHEMBL3087039 & 1276546 & 6.2757 & 5.2966 & TRN & \\
\hline CHEMBL 3087348 & 1276546 & 4.0 & 4.8965 & TRN & \\
\hline CHEMBL 3087345 & 1276546 & 5.8153 & 5.4744 & TST & \\
\hline CHEMBL 3087040 & 1276546 & 5.7375 & 5.2234 & TRN & \\
\hline CHEMBL 3087024 & 1276546 & 5.9547 & 5.2847 & TRN & \\
\hline CHEMBL3086739 & 1276546 & 5.3188 & 6.0536 & TRN & \\
\hline CHEMBL 3087353 & 1276546 & 5.0269 & 4.9966 & TRN & \\
\hline CHEMBL 3087347 & 1276546 & 5.8125 & 4.873 & TRN & \\
\hline CHEMBL 3087027 & 1276546 & 6.4949 & 5.6091 & TST & \\
\hline CHEMBL3087354 & 1276546 & 5.9747 & 5.1537 & TST & \\
\hline CHEMBL3086733 & 1276546 & 5.9788 & 5.8641 & TRN & \\
\hline CHEMBL 3087036 & 1276546 & 4.0 & 4.8762 & TRN & \\
\hline CHEMBL 3086555 & 1276546 & 6.2441 & 6.065 & TRN & \\
\hline CHEMBL 3086730 & 1276546 & 6.7696 & 6.0577 & TRN & \\
\hline CHEMBL3087339 & 1276546 & 4.0 & 5.26 & TRN & \\
\hline CHEMBL 3086732 & 1276546 & 5.556 & 5.6052 & TRN & \\
\hline CHEMBL 3087025 & 1276546 & 4.0 & 5.2471 & TRN & \\
\hline CHEMBL 3087019 & 1276546 & 4.0 & 5.9014 & TRN & \\
\hline CHEMBL 3087352 & 1276546 & 5.6778 & 4.9288 & TRN & \\
\hline CHEMBL3087351 & 1276546 & 4.0 & 4.8505 & TRN & \\
\hline CHEMBL 3086743 & 1276546 & 6.8539 & 6.0004 & TRN & \\
\hline CHEMBL3087031 & 1276546 & 4.0 & 5.2209 & TRN & \\
\hline
\end{tabular}


Supplemental Table S2.txt

\begin{tabular}{|c|c|c|c|c|}
\hline CHEMBL3086737 & 1276546 & 4.0 & 5.8672 & TRN \\
\hline CHEMBL3086734 & 1276546 & 6.2676 & 5.8628 & TRN \\
\hline CHEMBL3086728 & 1276546 & 5.8894 & 6.059 & TRN \\
\hline CHEMBL3086551 & 1276546 & 6.1871 & 6.1127 & TRN \\
\hline CHEMBL 3086741 & 1276546 & 6.7959 & 6.0389 & TRN \\
\hline CHEMBL 3087022 & 1276546 & 4.0 & 5.2586 & TRN \\
\hline CHEMBL3087341 & 1276546 & 6.3372 & 5.23600 & 0000000001 \\
\hline CHEMBL1224151 & 1276546 & 6.7959 & 5.496 & TST \\
\hline CHEMBL3087035 & 1276546 & 4.0 & 4.9723 & TST \\
\hline CHEMBL 3087340 & 1276546 & 4.0 & 5.2309 & TST \\
\hline CHEMBL3086729 & 1276546 & 5.9208 & 5.9789 & TST \\
\hline CHEMBL3087041 & 1276546 & 5.8996 & 5.1019 & TST \\
\hline CHEMBL3087350 & 1276546 & 4.0 & 4.9764 & TST \\
\hline CHEMBL3086731 & 1276546 & 6.0315 & 6.0156 & TST \\
\hline CHEMBL3086726 & 1276546 & 7.699 & 6.0905 & TST \\
\hline CHEMBL 3085790 & 1276546 & 6.3768 & 5.1421 & TST \\
\hline CHEMBL3086735 & 1276546 & 6.3098 & 5.8809 & TST \\
\hline CHEMBL3087043 & 1276546 & 5.3915 & 5.1783 & TST \\
\hline CHEMBL130338 & 43853 & 7.0655 & 7.3535 & TRN \\
\hline CHEMBL3706740 & 43853 & 6.585 & 6.7374 & TRN \\
\hline CHEMBL132587 & 43853 & 7.1308 & 6.6783 & TRN \\
\hline CHEMBL335706 & 43853 & 6.8861 & 6.9015 & TST \\
\hline CHEMBL130629 & 43853 & 6.7447 & 6.5488 & TRN \\
\hline CHEMBL420872 & 43853 & 7.4089 & 6.9551 & TRN \\
\hline CHEMBL337462 & 43853 & 6.3188 & 6.5136 & TST \\
\hline CHEMBL130756 & 43853 & 6.7959 & 7.23 & TRN \\
\hline CHEMBL133749 & 43853 & 6.8239 & 6.9534 & TRN \\
\hline CHEMBL132886 & 43853 & 6.9586 & 6.6344 & TRN \\
\hline CHEMBL134092 & 43853 & 6.5528 & 6.5215 & TRN \\
\hline CHEMBL338957 & 43853 & 5.0044 & 6.7322 & TST \\
\hline CHEMBL132566 & 43853 & 6.7959 & 6.8936 & TST \\
\hline CHEMBL273817 & 43853 & 6.5528 & 6.9543 & TST \\
\hline CHEMBL421910 & 43853 & 6.9586 & 6.8028 & TRN \\
\hline CHEMBL131639 & 43853 & 6.9208 & 6.7932 & TRN \\
\hline CHEMBL116863 & 43853 & 6.6021 & 7.0588 & TRN \\
\hline CHEMBL134283 & 43853 & 7.6383 & 7.0497 & TRN \\
\hline CHEMBL130359 & 43853 & 6.6576 & 6.836 & TRN \\
\hline CHEMBL133521 & 43853 & 6.9208 & 6.7881 & TRN \\
\hline CHEMBL132987 & 43853 & 6.7696 & 6.8735 & TRN \\
\hline CHEMBL131257 & 43853 & 6.2366 & 6.846 & TST \\
\hline CHEMBL439798 & 43853 & 6.9208 & 7.0431 & TRN \\
\hline CHEMBL424074 & 43853 & 7.4815 & 7.1898 & TRN \\
\hline CHEMBL132526 & 43853 & 6.699 & 6.2762 & TRN \\
\hline CHEMBL117336 & 43853 & 7.6576 & \multicolumn{2}{|c|}{7.281000000000001} \\
\hline CHEMBL413308 & 43853 & 6.3468 & 6.4573 & TRN \\
\hline CHEMBL133243 & 43853 & 4.9586 & 6.4154 & TRN \\
\hline CHEMBL131779 & 43853 & 5.9208 & 6.4552 & TRN \\
\hline CHEMBL130506 & 43853 & 7.8239 & 6.6393 & TRN \\
\hline
\end{tabular}


Supplemental Table S2.txt

\begin{tabular}{|c|c|c|c|c|}
\hline AEMBL4 & 53 & 372 & 7.1353 & TRN \\
\hline CHEMBL130345 & 43853 & 6.7959 & 6.9899 & TRN \\
\hline IEMBL129492 & 3853 & 1437 & 4979 & \\
\hline HEMBL 337608 & 3853 & .3372 & .0298 & 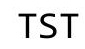 \\
\hline HEMBL3706738 & 3853 & .7212 & 6.8476 & \\
\hline HEMBL133970 & 3853 & .2218 & 7.1083 & \\
\hline AEMBL131866 & 13853 & .0809 & 7.0311 & DN \\
\hline HEMBL129933 & 43853 & 5.5686 & 6.9174 & \\
\hline HEMBL116477 & 43853 & 7.301 & 6.9788 & \\
\hline HEMBL1 & 43853 & 7.1805 & 1569 & \\
\hline HEMBL3: & 43853 & 7.6576 & 7.3606 & 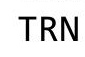 \\
\hline HEMBL3 & 43853 & .4685 & 6.5603 & \\
\hline HEMBL132732 & 43853 & 5.5086 & 6.4077 & $\mathrm{RN}$ \\
\hline HEMBL117888 & 43853 & 7.3565 & 7.0885 & \\
\hline HEMBL1 & 43853 & 7.3872 & 7.1449 & \\
\hline HEMBL1 & 3853 & 75 & 9975 & RN \\
\hline HEMBL; & 3853 & 778 & 3376 & \\
\hline HEMBL1 & 43853 & 6.699 & 6.7747 & \\
\hline HEMBL4 & 43853 & 5.8239 & 7.0936 & \\
\hline HEMBL1 & 438 & 6.5 & 7.1345 & Niv \\
\hline HEMBL1 & 3853 & 79 & 189 & RN \\
\hline HEMBL & 43853 & 7. & 469 & \\
\hline HEMBL 4 & 43853 & 6.5376 & 6.4838 & $2 \mathrm{~N}$ \\
\hline AEMBL3 & 3 & 59 & 992 & \\
\hline CHEMBL3 & 43853 & 7.0 & 7.0043 & RN \\
\hline HEMBL] & 43853 & 7.2218 & 7.3482 & RN \\
\hline HEMBL & 43853 & 59 & 7.0725 & 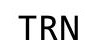 \\
\hline AEMBL1 & 43853 & 09 & 6.5444 & \\
\hline HEMBL1 & 43853 & 6.9208 & 7903 & $1 \mathrm{~h}$ \\
\hline CHEMBL 3 & 43853 & 6.699 & 6.8043 & RN \\
\hline HEMBL & 43853 & 91 & 5241 & \\
\hline HEMBL & 43853 & 79 & 7.0991 & 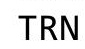 \\
\hline HEMBL3 & 43853 & 7.6198 & 7.2131 & RN \\
\hline CHEMBL119622 & 43853 & 7.3665 & 7.2311 & Th \\
\hline CHEMBL 3 & 43853 & 6.6198 & 6.7148 & I R R \\
\hline HEMBL & 43853 & 7.1 & 6.9579 & \\
\hline HEMBL: & 43853 & 6. & 6.6421 & RN \\
\hline CHEMBL4 & 43853 & 7.0458 & 6.4593 & TRN \\
\hline CHEMBL1 & 43853 & 6.5376 & 7107 & TR \\
\hline CHEMBL: & & 7. & & I KIV \\
\hline CHEMBLI & 43853 & 6.5229 & 6.6479 & \\
\hline CHEMBL1 & 43853 & 6.6021 & 6.9035 & TST \\
\hline CHEMBL134173 & 43853 & 7.3372 & 7.5195 & $\mathrm{TRI}$ \\
\hline CHEMBL3 & 43853 & 6.699 & 6.7831 & TR \\
\hline CHEMBLI & 43853 & 6.3872 & & IT \\
\hline CHEMBL130146 & 43853 & 7.0 & 6.7372 & \\
\hline CHEMBL336649 & 43853 & 7.0 & 6.9344 & RI \\
\hline CHEMBL133106 & 43853 & 7.2924 & 7.0424 & TS \\
\hline
\end{tabular}

Page 13513 


\begin{tabular}{|c|c|c|c|c|c|}
\hline \multicolumn{6}{|c|}{ Supplemental Table S2.txt } \\
\hline CHEMBL132773 & 43853 & 7.1192 & 7.1157 & TST & \\
\hline CHEMBL134179 & 43853 & 7.301 & 6.5669 & TST & \\
\hline CHEMBL339869 & 43853 & 6.1367 & 6.27 & TST & \\
\hline CHEMBL133806 & 43853 & 6.1739 & 6.6736 & TST & \\
\hline CHEMBL134508 & 43853 & 6.5686 & 6.989 & TST & \\
\hline CHEMBL132586 & 43853 & 6.9208 & 6.7896 & TST & \\
\hline CHEMBL118025 & 43853 & 6.4559 & 7.2082 & TST & \\
\hline CHEMBL335291 & 43853 & 6.4815 & 7.0786 & TST & \\
\hline CHEMBL130107 & 43853 & 6.7959 & 7.1326 & TST & \\
\hline CHEMBL130580 & 43853 & 6.9586 & 6.6748 & TST & \\
\hline CHEMBL1276708 & 685575 & 7.49 & 7.4487 & TRN & \\
\hline CHEMBL1276709 & 685575 & 7.15 & 7.1119 & TRN & \\
\hline CHEMBL1276738 & 685575 & 8.1 & 8.0602 & TRN & \\
\hline CHEMBL1276739 & 685575 & 7.96 & 8.0021 & TRN & \\
\hline CHEMBL 23464 & 685575 & 9.17 & 9.1399 & TRN & \\
\hline CHEMBL1276763 & 685575 & 8.3 & 8.2248 & TRN & \\
\hline CHEMBL1276764 & 685575 & 6.96 & 6.9985 & TRN & \\
\hline CHEMBL1276765 & 685575 & 6.91 & 7.069 & TRN & \\
\hline CHEMBL1276325 & 685575 & 9.54 & 9.3961 & TRN & \\
\hline CHEMBL1276326 & 685575 & 8.96 & 7.9264 & TST & \\
\hline CHEMBL1276327 & 685575 & 8.89 & 9.2115 & TRN & \\
\hline CHEMBL1276350 & 685575 & 8.57 & 8.5899 & TRN & \\
\hline CHEMBL1276351 & 685575 & 7.17 & 7.7684 & TST & \\
\hline CHEMBL1276238 & 685575 & 6.59 & 8.3688 & TST & \\
\hline CHEMBL1276352 & 685575 & 7.7 & 7.7044 & TRN & \\
\hline CHEMBL1276374 & 685575 & 8.25 & 8.2139 & TRN & \\
\hline CHEMBL1276268 & 685575 & 7.34 & 8.3247 & TST & \\
\hline CHEMBL1276375 & 685575 & 8.38 & 8.2953 & TRN & \\
\hline CHEMBL1276399 & 685575 & 7.19 & 7.3529 & TRN & \\
\hline CHEMBL1276400 & 685575 & 8.06 & 7.9015 & TRN & \\
\hline CHEMBL1276401 & 685575 & 6.44 & 6.2631 & TRN & \\
\hline CHEMBL1276426 & 685575 & 7.41 & 7.3855 & TST & \\
\hline CHEMBL1276427 & 685575 & 7.24 & 7.4809 & TRN & \\
\hline CHEMBL1276428 & 685575 & 7.92 & 7.8413 & TRN & \\
\hline CHEMBL1276459 & 685575 & 8.08 & 7.2897 & TST & \\
\hline CHEMBL1276460 & 685575 & 7.77 & 7.6784 & TRN & \\
\hline CHEMBL1276461 & 685575 & 7.59 & 7.67299 & 9999999999 & TRN \\
\hline CHEMBL1276494 & 685575 & 8.85 & 8.8066 & TRN & \\
\hline CHEMBL1276495 & 685575 & 6.73 & 6.6717 & TRN & \\
\hline CHEMBL1276496 & 685575 & 8.52 & 7.3939 & TST & \\
\hline CHEMBL1276527 & 685575 & 7.59 & 7.7372 & TRN & \\
\hline CHEMBL 1276528 & 685575 & 8.11 & 8.1722 & TRN & \\
\hline CHEMBL1276529 & 685575 & 8.54 & 7.3272 & TST & \\
\hline CHEMBL1276559 & 685575 & 8.82 & 8.9476 & TRN & \\
\hline CHEMBL1276560 & 685575 & 9.04 & 9.0108 & TRN & \\
\hline CHEMBL1276561 & 685575 & 8.64 & 8.5529 & TRN & \\
\hline CHEMBL1276585 & 685575 & 9.3 & 6.8792 & TST & \\
\hline CHEMBL1276586 & 685575 & 6.69 & 7.2932 & TST & \\
\hline
\end{tabular}




\begin{tabular}{|c|c|c|c|c|}
\hline \multicolumn{5}{|c|}{ Supplemental Table S2.txt } \\
\hline CHEMBL1276587 & 685575 & 7.17 & 7.1811 & TRN \\
\hline CHEMBL283099 & 685575 & 8.0 & 8.1642 & TRN \\
\hline CHEMBL1276615 & 685575 & 8.49 & 8.4299 & TRN \\
\hline CHEMBL1276616 & 685575 & 8.26 & 8.0123 & TRN \\
\hline CHEMBL1276645 & 685575 & 8.28 & 8.3269 & TRN \\
\hline CHEMBL1276646 & 685575 & 7.77 & 7.7262 & TRN \\
\hline CHEMBL1276647 & 685575 & 8.75 & 8.7555 & TRN \\
\hline CHEMBL 282925 & 685575 & 8.89 & 8.8442 & TRN \\
\hline CHEMBL 282024 & 685575 & 7.28 & 7.92299 & 9999999999 \\
\hline CHEMBL1276677 & 685575 & 7.4 & 8.3898 & TST \\
\hline CHEMBL1276269 & 685575 & 6.5 & 6.9532 & TST \\
\hline CHEMBL1276710 & 685575 & 7.25 & 7.3353 & TRN \\
\hline CHEMBL1276711 & 685575 & 7.96 & 7.9187 & TRN \\
\hline CHEMBL1276712 & 685575 & 8.77 & 8.708 & TRN \\
\hline CHEMBL1276740 & 685575 & 8.15 & 8.1434 & TRN \\
\hline CHEMBL1276741 & 685575 & 7.96 & 7.9277 & TRN \\
\hline CHEMBL1276742 & 685575 & 7.72 & 7.3201 & TST \\
\hline CHEMBL1276766 & 685575 & 6.85 & 6.8801 & TRN \\
\hline CHEMBL1276767 & 685575 & 5.52 & 5.7197 & TST \\
\hline CHEMBL2003768 & 809260 & 4.2 & 4.6845 & TRN \\
\hline CHEMBL213505 & 809260 & 7.1 & 6.9352 & TRN \\
\hline CHEMBL1982880 & 809260 & 4.2 & 4.4803 & TRN \\
\hline CHEMBL1987034 & 809260 & 8.1 & 8.3522 & TRN \\
\hline CHEMBL 377383 & 809260 & 4.2 & 4.203 & TRN \\
\hline CHEMBL 2005886 & 809260 & 7.0 & 7.1164 & TST \\
\hline CHEMBL481491 & 809260 & 4.2 & 4.9353 & TST \\
\hline CHEMBL1682345 & 809260 & 4.2 & 4.5645 & TRN \\
\hline CHEMBL1973142 & 809260 & 5.8 & 5.4367 & TST \\
\hline CHEMBL1973145 & 809260 & 6.8 & 6.6913 & TRN \\
\hline CHEMBL1982924 & 809260 & 5.6 & 5.456 & TRN \\
\hline CHEMBL 2005936 & 809260 & 4.2 & 4.5461 & TRN \\
\hline CHEMBL1971141 & 809260 & 4.2 & 5.2325 & TRN \\
\hline CHEMBL1979718 & 809260 & 4.2 & 4.7576 & TRN \\
\hline CHEMBL 206236 & 809260 & 4.2 & 4.1118 & TRN \\
\hline CHEMBL523823 & 809260 & 4.2 & 4.7379 & TST \\
\hline CHEMBL1973178 & 809260 & 7.9 & 7.7188 & TRN \\
\hline CHEMBL1562756 & 809260 & 4.2 & 4.8158 & TST \\
\hline CHEMBL1988778 & 809260 & 8.4 & 8.8145 & TRN \\
\hline CHEMBL 2001957 & 809260 & 4.2 & 4.3954 & TRN \\
\hline CHEMBL1969372 & 809260 & 6.0 & 4.6526 & TRN \\
\hline CHEMBL1990583 & 809260 & 4.2 & 5.4239 & TRN \\
\hline CHEMBL1986943 & 809260 & 6.7 & 7.6201 & TRN \\
\hline CHEMBL 2006263 & 809260 & 4.2 & 4.4119 & TST \\
\hline CHEMBL1993584 & 809260 & 4.2 & 4.5112 & TRN \\
\hline CHEMBL1986263 & 809260 & 6.9 & 6.8094 & TRN \\
\hline CHEMBL 2000114 & 809260 & 5.2 & 5.2745 & TRN \\
\hline CHEMBL210618 & 809260 & 4.2 & 3.9308 & TRN \\
\hline CHEMBL1975647 & 809260 & 5.9 & 5.6407 & TRN \\
\hline
\end{tabular}




\begin{tabular}{|c|c|c|c|c|c|}
\hline \\
\hline CHEMBL1968380 & 809260 & 4.2 & 4.1945 & TRN & \\
\hline CHEMBL1964644 & 809260 & 4.2 & 4.3758 & TRN & \\
\hline CHEMBL1981782 & 809260 & 4.2 & 4.4798 & TRN & \\
\hline CHEMBL1977681 & 809260 & 6.1 & $6.2420 e$ & 0000000001 & TRN \\
\hline CHEMBL1970142 & 809260 & 8.5 & 7.8381 & TRN & \\
\hline CHEMBL1990912 & 809260 & 5.2 & 4.6271 & TRN & \\
\hline CHEMBL1988163 & 809260 & 8.3 & 8.0268 & TRN & \\
\hline CHEMBL1995592 & 809260 & 7.0 & 5.6876 & TST & \\
\hline CHEMBL 2006493 & 809260 & 4.2 & 4.17399 & 99999999995 & TST \\
\hline CHEMBL1996923 & 809260 & 4.2 & 4.671 & TST & \\
\hline CHEMBL1983449 & 809260 & 4.2 & 4.6857 & TRN & \\
\hline CHEMBL1992323 & 809260 & 4.2 & 4.6335 & TST & \\
\hline CHEMBL1969735 & 809260 & 4.2 & 4.2927 & TRN & \\
\hline CHEMBL 2003524 & 809260 & 6.1 & 4.9508 & TST & \\
\hline CHEMBL2002649 & 809260 & 6.4 & 6.4586 & TRN & \\
\hline CHEMBL437747 & 809260 & 5.8 & 5.0856 & TRN & \\
\hline CHEMBL1995172 & 809260 & 5.3 & 4.6482 & TST & \\
\hline CHEMBL507936 & 809260 & 6.0 & 6.0556 & TRN & \\
\hline CHEMBL104264 & 809260 & 4.2 & 5.3 & TST & \\
\hline CHEMBL1994321 & 809260 & 8.3 & 8.0442 & TRN & \\
\hline CHEMBL1997129 & 809260 & 6.3 & 6.2385 & TST & \\
\hline CHEMBL1984788 & 809260 & 5.2 & 4.9494 & TRN & \\
\hline CHEMBL451964 & 809260 & 4.2 & 4.0575 & TRN & \\
\hline CHEMBL1964307 & 809260 & 6.6 & 7.0301 & TRN & \\
\hline CHEMBL 2000508 & 809260 & 4.2 & 4.276 & TRN & \\
\hline CHEMBL1971694 & 809260 & 4.2 & 4.3777 & TST & \\
\hline CHEMBL 2001547 & 809260 & 4.2 & 4.1839 & TRN & \\
\hline CHEMBL210928 & 809260 & 4.2 & 4.0305 & TRN & \\
\hline CHEMBL1994361 & 809260 & 4.2 & 4.3773 & TRN & \\
\hline CHEMBL1972840 & 809260 & 5.9 & 5.855 & TRN & \\
\hline CHEMBL 2003286 & 809260 & 4.2 & 4.1722 & TRN & \\
\hline CHEMBL2001668 & 809260 & 4.2 & 4.4981 & TST & \\
\hline CHEMBL1979318 & 809260 & 4.2 & 4.8425 & TRN & \\
\hline CHEMBL 206382 & 809260 & 4.2 & 4.2779 & TRN & \\
\hline CHEMBL127898 & 809260 & 4.2 & 4.6957 & TST & \\
\hline CHEMBL519697 & 809260 & 4.2 & 5.0008 & TST & \\
\hline CHEMBL 2004934 & 809260 & 5.2 & 4.8648 & TRN & \\
\hline CHEMBL 2000652 & 809260 & 8.5 & 8.9358 & TRN & \\
\hline CHEMBL1975128 & 809260 & 5.5 & 5.2398 & TRN & \\
\hline CHEMBL1996048 & 809260 & 5.7 & 5.0687 & TST & \\
\hline CHEMBL1970369 & 809260 & 4.2 & 3.8345 & TRN & \\
\hline CHEMBL461876 & 809260 & 4.2 & 4.7713 & TST & \\
\hline CHEMBL 2001485 & 809260 & 7.4 & 7.1863 & TRN & \\
\hline CHEMBL504950 & 809260 & 5.4 & 5.0118 & TRN & \\
\hline CHEMBL1966425 & 809260 & 5.4 & 4.8777 & TRN & \\
\hline CHEMBL1984363 & 809260 & 6.9 & 7.0281 & TRN & \\
\hline CHEMBL1978099 & 809260 & 7.3 & 7.3489 & TRN & \\
\hline CHEMBL1977041 & 809260 & 8.1 & 6.8675 & TRN & \\
\hline
\end{tabular}




\begin{tabular}{|c|c|c|c|c|c|}
\hline & & & & & \\
\hline CHEMBL1968070 & 809260 & 5.5 & 5.1689 & TRN & \\
\hline CHEMBL1988608 & 809260 & 4.2 & 4.6412 & TRN & \\
\hline CHEMBL184847 & 809260 & 4.2 & 4.7749 & TRN & \\
\hline CHEMBL1984367 & 809260 & 6.0 & 5.5654 & TRN & \\
\hline CHEMBL178737 & 809260 & 4.2 & 4.8024 & TST & \\
\hline CHEMBL226898 & 809260 & 5.5 & 5.5971 & TRN & \\
\hline CHEMBL1982563 & 809260 & 4.2 & 4.2186 & TRN & \\
\hline CHEMBL575824 & 809260 & 4.2 & 4.8315 & TRN & \\
\hline CHEMBL1988387 & 809260 & 8.2 & 8.1029 & TRN & \\
\hline CHEMBL1997759 & 809260 & 4.2 & 4.4683 & TRN & \\
\hline CHEMBL1974803 & 809260 & 4.2 & 4.9301 & TST & \\
\hline CHEMBL1970074 & 809260 & 6.7 & 7.1355 & TRN & \\
\hline CHEMBL1986970 & 809260 & 4.2 & 4.3196 & TRN & \\
\hline CHEMBL 2005112 & 809260 & 4.2 & 4.6243 & TST & \\
\hline CHEMBL1984044 & 809260 & 4.2 & 4.6632 & TRN & \\
\hline CHEMBL 2003456 & 809260 & 5.9 & 5.324 & TRN & \\
\hline CHEMBL1966816 & 809260 & 6.4 & 5.67700 & 20000000005 & TRN \\
\hline CHEMBL1972584 & 809260 & 4.4 & 5.0802 & TRN & \\
\hline CHEMBL2002992 & 809260 & 4.2 & 4.7251 & TRN & \\
\hline CHEMBL560813 & 809260 & 4.2 & 4.7542 & TRN & \\
\hline CHEMBL207253 & 809260 & 4.2 & 4.5721 & TST & \\
\hline CHEMBL1968791 & 809260 & 6.2 & 6.1851 & TRN & \\
\hline CHEMBL326282 & 809260 & 4.2 & 4.8019 & TST & \\
\hline CHEMBL2002682 & 809260 & 4.2 & 5.3584 & TST & \\
\hline CHEMBL1992732 & 809260 & 4.2 & 3.8746 & TST & \\
\hline CHEMBL1971186 & 809260 & 4.2 & 4.05399 & 9999999999 & TRN \\
\hline CHEMBL 2003482 & 809260 & 4.2 & 4.4595 & TRN & \\
\hline CHEMBL1973211 & 809260 & 8.4 & 8.1795 & TRN & \\
\hline CHEMBL1984700 & 809260 & 4.2 & 4.3548 & TRN & \\
\hline CHEMBL 2007151 & 809260 & 5.5 & 6.2077 & TRN & \\
\hline CHEMBL1972125 & 809260 & 4.2 & 4.169 & TRN & \\
\hline CHEMBL1461728 & 809260 & 4.2 & 4.1052 & TRN & \\
\hline CHEMBL1976134 & 809260 & 5.9 & 5.9562 & TRN & \\
\hline CHEMBL1965131 & 809260 & 5.4 & 5.154 & TST & \\
\hline CHEMBL1995448 & 809260 & 4.2 & 5.3208 & TRN & \\
\hline CHEMBL1972158 & 809260 & 4.3 & 4.7746 & TRN & \\
\hline CHEMBL1974457 & 809260 & 5.2 & 5.0968 & TRN & \\
\hline CHEMBL 2006580 & 809260 & 5.3 & 4.6445 & TRN & \\
\hline CHEMBL 2006581 & 809260 & 4.2 & 4.4559 & TRN & \\
\hline CHEMBL 2006481 & 809260 & 4.2 & 4.0537 & TRN & \\
\hline CHEMBL1979855 & 809260 & 4.2 & 4.6338 & TRN & \\
\hline CHEMBL1970340 & 809260 & 4.2 & 4.467 & TRN & \\
\hline CHEMBL 2005186 & 809260 & 4.2 & 4.3987 & TRN & \\
\hline CHEMBL1995927 & 809260 & 4.2 & 4.6577 & TST & \\
\hline CHEMBL1975534 & 809260 & 4.2 & 4.5091 & TRN & \\
\hline CHEMBL1993424 & 809260 & 7.6 & 7.6389 & TRN & \\
\hline CHEMBL1966703 & 809260 & 4.2 & 4.5348 & TST & \\
\hline CHEMBL1969561 & 809260 & 4.2 & 4.4028 & TRN & \\
\hline
\end{tabular}




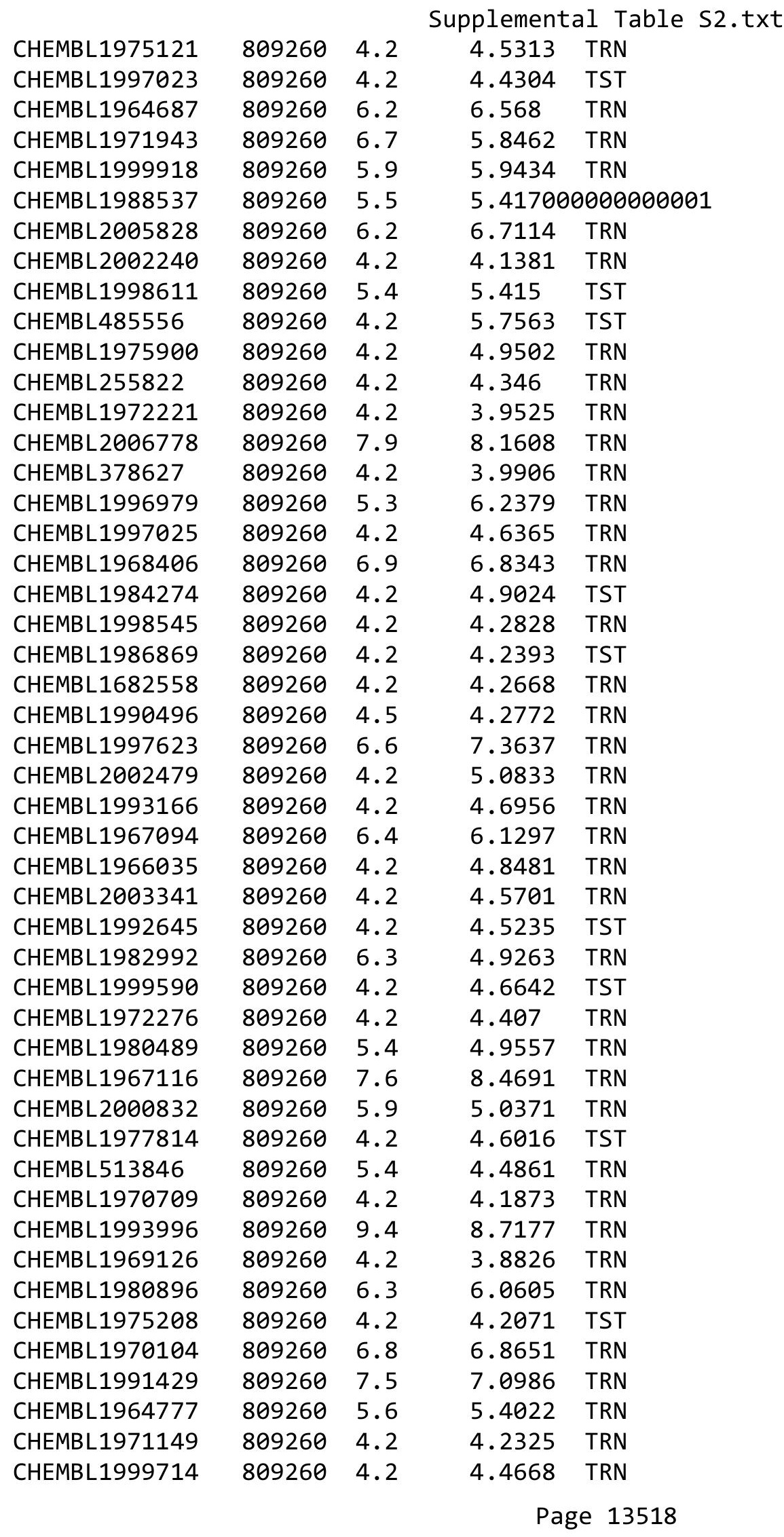




\begin{tabular}{|c|c|c|c|c|}
\hline \multicolumn{5}{|c|}{ lemental T } \\
\hline CHEMBL1987533 & 809260 & 4.2 & 4.4119 & TRN \\
\hline CHEMBL1994040 & 809260 & 4.2 & 4.1297 & TRN \\
\hline CHEMBL388978 & 809260 & 8.2 & 7.7778 & TST \\
\hline CHEMBL579246 & 809260 & 5.5 & 4.9451 & TRN \\
\hline CHEMBL398951 & 809260 & 6.1 & 5.1874 & TST \\
\hline CHEMBL1982506 & 809260 & 6.0 & 5.1391 & TST \\
\hline CHEMBL 2004716 & 809260 & 8.4 & 8.1347 & TRN \\
\hline CHEMBL1968127 & 809260 & 4.2 & 4.0196 & TRN \\
\hline CHEMBL1975233 & 809260 & 5.8 & 4.86 & TRN \\
\hline CHEMBL1985406 & 809260 & 5.2 & 4.4304 & TRN \\
\hline CHEMBL 207400 & 809260 & 4.2 & 4.4441 & TST \\
\hline CHEMBL 2000894 & 809260 & 4.2 & 4.4414 & TST \\
\hline CHEMBL1982135 & 809260 & 5.3 & 5.3874 & TRN \\
\hline CHEMBL1976090 & 809260 & 5.9 & 5.3503 & TRN \\
\hline CHEMBL1993243 & 809260 & 6.8 & 7.0049 & TRN \\
\hline CHEMBL1992922 & 809260 & 5.5 & 5.5639 & TRN \\
\hline CHEMBL 2004771 & 809260 & 5.9 & 5.6605 & TRN \\
\hline CHEMBL399021 & 809260 & 5.2 & 5.6189 & TRN \\
\hline CHEMBL1997597 & 809260 & 4.2 & 4.0068 & TRN \\
\hline CHEMBL1969537 & 809260 & 6.0 & 5.2424 & TST \\
\hline CHEMBL1976093 & 809260 & 4.2 & 4.2648 & TRN \\
\hline CHEMBL210032 & 809260 & 4.2 & 4.1556 & TRN \\
\hline CHEMBL1996543 & 809260 & 4.2 & 4.5342 & TRN \\
\hline CHEMBL1975256 & 809260 & 4.2 & 3.6391 & TST \\
\hline CHEMBL1991356 & 809260 & 4.2 & 4.5996 & TST \\
\hline CHEMBL1983309 & 809260 & 4.2 & 4.5709 & TRN \\
\hline CHEMBL 2004892 & 809260 & 4.2 & 4.232 & TRN \\
\hline CHEMBL1999126 & 809260 & 4.2 & 4.6406 & TST \\
\hline CHEMBL116070 & 809260 & 5.4 & 4.9497 & TRN \\
\hline CHEMBL1990821 & 809260 & 4.2 & 4.8596 & TST \\
\hline CHEMBL1970314 & 809260 & 4.2 & 4.5277 & TRN \\
\hline CHEMBL 2004871 & 809260 & 4.2 & 4.1453 & TRN \\
\hline CHEMBL1727312 & 809260 & 4.2 & 4.1692 & TRN \\
\hline CHEMBL1969879 & 809260 & 4.2 & 4.107 & TRN \\
\hline CHEMBL1981720 & 809260 & 5.7 & 5.3896 & TRN \\
\hline CHEMBL419932 & 809260 & 4.2 & 4.405 & TRN \\
\hline CHEMBL262433 & 809260 & 7.3 & 7.2393 & TRN \\
\hline CHEMBL373798 & 809260 & 9.1 & 8.7368 & TRN \\
\hline CHEMBL 306380 & 809260 & 6.2 & 5.8035 & TRN \\
\hline CHEMBL1966722 & 809260 & 4.2 & 4.5248 & TST \\
\hline CHEMBL1976328 & 809260 & 5.5 & 6.0012 & TRN \\
\hline CHEMBL1975500 & 809260 & 5.2 & 4.8774 & TRN \\
\hline CHEMBL1964399 & 809260 & 7.3 & 6.5372 & TRN \\
\hline CHEMBL1996831 & 809260 & 4.2 & 4.4751 & TST \\
\hline CHEMBL411903 & 809260 & 8.2 & 7.4739 & TRN \\
\hline CHEMBL1965988 & 809260 & 8.3 & 8.0075 & TRN \\
\hline CHEMBL418203 & 809260 & 4.2 & 4.657 & TST \\
\hline CHEMBL1682357 & 809260 & 5.2 & 4.747 & TRN \\
\hline
\end{tabular}




\begin{tabular}{|c|c|c|c|c|}
\hline & & & & al Tabl \\
\hline CHEMBL225519 & 809260 & 4.2 & 5.0001 & TST \\
\hline CHEMBL209534 & 809260 & 4.2 & 4.7056 & TRN \\
\hline CHEMBL1978200 & 809260 & 4.2 & 4.3564 & TRN \\
\hline CHEMBL1970522 & 809260 & 4.2 & 4.8005 & TRN \\
\hline CHEMBL402846 & 809260 & 9.1 & 8.6347 & TRN \\
\hline CHEMBL1990415 & 809260 & 4.2 & 4.5269 & TRN \\
\hline CHEMBL1966087 & 809260 & 4.2 & 4.3386 & TRN \\
\hline CHEMBL1964692 & 809260 & 8.0 & 8.7451 & TRN \\
\hline CHEMBL1996931 & 809260 & 4.2 & 4.5039 & TRN \\
\hline CHEMBL1964413 & 809260 & 4.2 & 4.1645 & TRN \\
\hline CHEMBL1984432 & 809260 & 4.2 & 4.3627 & TRN \\
\hline CHEMBL1970735 & 809260 & 4.2 & 4.0668 & TRN \\
\hline CHEMBL 219722 & 809260 & 6.3 & 7.6107 & TRN \\
\hline CHEMBL1997340 & 809260 & 4.2 & 3.8708 & TRN \\
\hline CHEMBL 2004365 & 809260 & 4.2 & 4.0112 & TST \\
\hline CHEMBL1522508 & 809260 & 4.2 & 4.1513 & TRN \\
\hline CHEMBL1989474 & 809260 & 4.2 & 4.1626 & TRN \\
\hline CHEMBL1090360 & 809260 & 7.3 & 7.2834 & TRN \\
\hline CHEMBL227271 & 809260 & 5.4 & 5.4253 & TRN \\
\hline CHEMBL1971021 & 809260 & 5.4 & 5.4692 & TRN \\
\hline CHEMBL583144 & 809260 & 4.2 & 4.7302 & TST \\
\hline CHEMBL1974310 & 809260 & 4.2 & 5.5985 & TRN \\
\hline CHEMBL1994693 & 809260 & 5.9 & 5.9171 & TRN \\
\hline CHEMBL1982957 & 809260 & 6.6 & 6.7253 & TRN \\
\hline CHEMBL1725279 & 809260 & 7.8 & 6.8312 & TST \\
\hline CHEMBL1975138 & 809260 & 4.2 & 4.3275 & TST \\
\hline CHEMBL424872 & 809260 & 4.2 & 4.3013 & TRN \\
\hline CHEMBL 2006836 & 809260 & 4.2 & 4.5614 & TST \\
\hline CHEMBL1971947 & 809260 & 7.5 & 8.042 & TRN \\
\hline CHEMBL412142 & 809260 & 4.2 & 4.80399 & 9999999999 \\
\hline CHEMBL1980704 & 809260 & 4.2 & 4.3513 & TST \\
\hline CHEMBL 2003271 & 809260 & 4.2 & 5.3336 & TST \\
\hline CHEMBL1966808 & 809260 & 4.2 & 4.1528 & TST \\
\hline CHEMBL1996255 & 809260 & 9.0 & 8.5257 & TRN \\
\hline CHEMBL 2004447 & 809260 & 4.2 & 4.3113 & TRN \\
\hline CHEMBL1973860 & 809260 & 4.2 & 4.0664 & TRN \\
\hline CHEMBL260135 & 809260 & 5.3 & 4.6806 & TRN \\
\hline CHEMBL220241 & 809260 & 5.5 & 4.6973 & TST \\
\hline CHEMBL 2004544 & 809260 & 4.2 & 4.749 & TST \\
\hline CHEMBL1982610 & 809260 & 4.2 & 4.5437 & TST \\
\hline CHEMBL1986996 & 809260 & 5.8 & 5.2774 & TST \\
\hline CHEMBL1999496 & 809260 & 4.2 & 4.6073 & TRN \\
\hline CHEMBL2006933 & 809260 & 5.6 & 5.4138 & TST \\
\hline CHEMBL1988300 & 809260 & 6.6 & 6.1743 & TRN \\
\hline CHEMBL1991078 & 809260 & 6.7 & 6.5405 & TRN \\
\hline CHEMBL1987359 & 809260 & 5.2 & 4.5682 & TST \\
\hline CHEMBL 2000685 & 809260 & 4.2 & 4.7466 & TRN \\
\hline CHEMBL1985311 & 809260 & 6.8 & 7.5907 & TRN \\
\hline
\end{tabular}




\begin{tabular}{|c|c|c|c|c|}
\hline \multicolumn{5}{|c|}{ lemental T } \\
\hline CHEMBL1989265 & 809260 & 4.2 & 4.2308 & TST \\
\hline CHEMBL1969502 & 809260 & 7.3 & 6.6662 & TRN \\
\hline CHEMBL1965910 & 809260 & 6.2 & 5.5889 & TRN \\
\hline CHEMBL 1682553 & 809260 & 4.2 & 4.5928 & TRN \\
\hline CHEMBL1971430 & 809260 & 4.3 & 4.4132 & TRN \\
\hline CHEMBL1997764 & 809260 & 5.4 & 5.2097 & TRN \\
\hline CHEMBL1983963 & 809260 & 7.5 & 7.6826 & TRN \\
\hline CHEMBL 2000271 & 809260 & 4.2 & 5.5393 & TRN \\
\hline CHEMBL1985092 & 809260 & 4.2 & 5.1555 & TRN \\
\hline CHEMBL 2004692 & 809260 & 4.2 & 3.6276 & TST \\
\hline CHEMBL1981410 & 809260 & 5.8 & 5.7956 & TRN \\
\hline CHEMBL1996234 & 809260 & 7.0 & 4.7699 & TRN \\
\hline CHEMBL1991434 & 809260 & 4.2 & 4.0934 & TST \\
\hline CHEMBL1967544 & 809260 & 4.2 & 4.5741 & TRN \\
\hline CHEMBL 223367 & 809260 & 4.2 & 5.2616 & TST \\
\hline CHEMBL340384 & 809260 & 6.0 & 5.666 & TST \\
\hline CHEMBL1964804 & 809260 & 4.2 & 4.7391 & TRN \\
\hline CHEMBL443962 & 809260 & 6.1 & 5.0966 & TST \\
\hline CHEMBL 2000354 & 809260 & 4.2 & 4.6221 & TRN \\
\hline CHEMBL1965507 & 809260 & 4.3 & 4.324 & TRN \\
\hline CHEMBL 274064 & 809260 & 5.2 & 4.4543 & TRN \\
\hline CHEMBL1967564 & 809260 & 4.2 & 4.2285 & TRN \\
\hline CHEMBL592030 & 809260 & 6.0 & 5.012 & TST \\
\hline CHEMBL 2000071 & 809260 & 5.6 & 5.5706 & TRN \\
\hline CHEMBL1985491 & 809260 & 8.5 & 8.1617 & TRN \\
\hline CHEMBL 2000408 & 809260 & 4.2 & 4.2612 & TRN \\
\hline CHEMBL 248757 & 809260 & 5.2 & 5.5817 & TST \\
\hline CHEMBL1978014 & 809260 & 4.2 & 4.0835 & TRN \\
\hline CHEMBL1994538 & 809260 & 5.3 & 4.846 & TRN \\
\hline CHEMBL1983195 & 809260 & 4.2 & 4.0289 & TST \\
\hline CHEMBL1975490 & 809260 & 5.2 & 5.042 & TRN \\
\hline CHEMBL1964444 & 809260 & 6.0 & 5.2194 & TRN \\
\hline CHEMBL 2006567 & 809260 & 5.8 & 3.9967 & TRN \\
\hline CHEMBL1986139 & 809260 & 4.2 & 4.4246 & TRN \\
\hline CHEMBL383527 & 809260 & 4.2 & 4.4519 & TRN \\
\hline CHEMBL1980540 & 809260 & 4.2 & 4.9769 & TRN \\
\hline CHEMBL1979883 & 809260 & 8.4 & 7.8125 & TRN \\
\hline CHEMBL1984162 & 809260 & 7.9 & 7.6814 & TRN \\
\hline CHEMBL491758 & 809260 & 6.6 & 7.0455 & TRN \\
\hline CHEMBL549730 & 809260 & 4.3 & 4.6527 & TRN \\
\hline CHEMBL1682360 & 809260 & 4.2 & 4.4159 & TRN \\
\hline CHEMBL1970189 & 809260 & 4.2 & 4.5261 & TRN \\
\hline CHEMBL1996791 & 809260 & 5.7 & 4.8106 & TRN \\
\hline CHEMBL371206 & 809260 & 7.3 & 6.9791 & TRN \\
\hline CHEMBL1974664 & 809260 & 5.9 & 5.8158 & TST \\
\hline CHEMBL1974288 & 809260 & 4.2 & 4.5594 & TRN \\
\hline CHEMBL196363 & 809260 & 8.6 & 7.5251 & TRN \\
\hline CHEMBL1990346 & 809260 & 4.2 & 5.0403 & TRN \\
\hline
\end{tabular}




\begin{tabular}{|c|c|c|c|c|c|}
\hline \multirow[b]{2}{*}{ CHEMBL1968705 } & \multirow{2}{*}{809260} & \\
\hline & & 4.2 & 4.5554 & TRN & \\
\hline CHEMBL404367 & 809260 & 8.4 & 8.373 & TRN & \\
\hline CHEMBL1966343 & 809260 & 4.2 & 4.6649 & TRN & \\
\hline CHEMBL1967887 & 809260 & 4.2 & 4.5913 & TRN & \\
\hline CHEMBL 2000568 & 809260 & 5.4 & 5.2753 & TRN & \\
\hline CHEMBL 2000335 & 809260 & 7.7 & \multicolumn{2}{|c|}{7.638999999999999} & TRN \\
\hline CHEMBL1977604 & 809260 & 4.2 & 4.0876 & TST & \\
\hline CHEMBL1988717 & 809260 & 8.5 & 7.8479 & TRN & \\
\hline CHEMBL509032 & 809260 & 8.1 & 7.7887 & TRN & \\
\hline CHEMBL1973808 & 809260 & 4.2 & 4.0813 & TRN & \\
\hline CHEMBL 2000429 & 809260 & 4.2 & 4.2711 & TRN & \\
\hline CHEMBL1972576 & 809260 & 4.2 & 4.0194 & TRN & \\
\hline CHEMBL1992555 & 809260 & 4.2 & 4.6818 & TST & \\
\hline CHEMBL1990254 & 809260 & 4.2 & 4.6652 & TRN & \\
\hline CHEMBL1992342 & 809260 & 4.2 & 4.1851 & TRN & \\
\hline CHEMBL1988173 & 809260 & 5.2 & 5.0638 & TST & \\
\hline CHEMBL1164265 & 809260 & 6.0 & 5.4307 & TST & \\
\hline CHEMBL535331 & 809260 & 4.2 & 5.0796 & TRN & \\
\hline CHEMBL1989805 & 809260 & 4.2 & 4.393 & TST & \\
\hline CHEMBL1965423 & 809260 & 5.4 & 4.0306 & TRN & \\
\hline CHEMBL1982980 & 809260 & 4.2 & 4.9998 & TST & \\
\hline CHEMBL1983025 & 809260 & 7.9 & 7.4673 & TRN & \\
\hline CHEMBL 205415 & 809260 & 5.8 & 4.7203 & TRN & \\
\hline CHEMBL1977135 & 809260 & 4.2 & 4.4092 & TRN & \\
\hline CHEMBL 2001920 & 809260 & 4.2 & 4.8864 & TRN & \\
\hline CHEMBL 2002322 & 809260 & 4.2 & 4.9244 & TRN & \\
\hline CHEMBL1980904 & 809260 & 8.5 & 9.0198 & TRN & \\
\hline CHEMBL1241473 & 809260 & 7.7 & 8.1025 & TRN & \\
\hline CHEMBL2002323 & 809260 & 4.2 & 4.1951 & TST & \\
\hline CHEMBL 2004513 & 809260 & 4.2 & 4.8885 & TRN & \\
\hline CHEMBL1972258 & 809260 & 4.2 & 4.2807 & TRN & \\
\hline CHEMBL 2001257 & 809260 & 7.0 & 7.2586 & TRN & \\
\hline CHEMBL 2005548 & 809260 & 4.2 & 4.5423 & TRN & \\
\hline CHEMBL 271441 & 809260 & 9.5 & 9.0463 & TRN & \\
\hline CHEMBL1992536 & 809260 & 4.2 & 4.1446 & TRN & \\
\hline CHEMBL1987793 & 809260 & 4.2 & 4.8619 & TST & \\
\hline CHEMBL1992740 & 809260 & 4.2 & 4.5652 & TRN & \\
\hline CHEMBL2002373 & 809260 & 4.2 & 4.2768 & TRN & \\
\hline CHEMBL439340 & 809260 & 4.2 & 4.2262 & TRN & \\
\hline CHEMBL2006188 & 809260 & 4.2 & 4.4879 & TRN & \\
\hline CHEMBL1967531 & 809260 & 6.7 & 6.50899 & 99999999995 & TRN \\
\hline CHEMBL1970913 & 809260 & 4.2 & 4.1247 & TRN & \\
\hline CHEMBL1973893 & 809260 & 4.2 & 3.9695 & TRN & \\
\hline CHEMBL1995736 & 809260 & 4.2 & 4.123 & TRN & \\
\hline CHEMBL1997534 & 809260 & 4.2 & 4.6038 & TRN & \\
\hline CHEMBL1996500 & 809260 & 4.2 & 4.2252 & TRN & \\
\hline CHEMBL1985095 & 809260 & 5.6 & 5.2035 & TST & \\
\hline CHEMBL1998551 & 809260 & 4.2 & 3.8772 & TRN & \\
\hline & & & & 13522 & \\
\hline
\end{tabular}




\begin{tabular}{|c|c|c|c|c|c|}
\hline & & & & & \\
\hline CHEMBL1977374 & 809260 & 4.2 & 4.0104 & TRN & \\
\hline CHEMBL273187 & 809260 & 9.9 & 9.5716 & TRN & \\
\hline CHEMBL1991180 & 809260 & 5.2 & 4.6172 & TST & \\
\hline CHEMBL1682540 & 809260 & 4.2 & 4.4826 & TRN & \\
\hline CHEMBL1978656 & 809260 & 4.2 & 4.5261 & TRN & \\
\hline CHEMBL1986979 & 809260 & 9.5 & 9.1711 & TRN & \\
\hline CHEMBL1994864 & 809260 & 4.2 & 4.5881 & TRN & \\
\hline CHEMBL413779 & 809260 & 4.2 & 5.3066 & TST & \\
\hline CHEMBL 2002446 & 809260 & 8.1 & 7.3017 & TST & \\
\hline CHEMBL497151 & 809260 & 4.2 & 5.1475 & TRN & \\
\hline CHEMBL1973961 & 809260 & 4.2 & 4.4742 & TRN & \\
\hline CHEMBL246970 & 809260 & 4.2 & 5.0395 & TRN & \\
\hline CHEMBL340921 & 809260 & 4.2 & 4.5148 & TST & \\
\hline CHEMBL373598 & 809260 & 4.2 & 5.3531 & TST & \\
\hline CHEMBL1276446 & 809260 & 8.5 & 7.8934 & TST & \\
\hline CHEMBL1977346 & 809260 & 5.3 & 5.5376 & TRN & \\
\hline CHEMBL1971649 & 809260 & 5.8 & 5.8133 & TRN & \\
\hline CHEMBL 2003657 & 809260 & 5.3 & 4.4422 & TRN & \\
\hline CHEMBL 2006439 & 809260 & 6.6 & 6.6503 & TRN & \\
\hline CHEMBL 2006156 & 809260 & 4.2 & 4.2982 & TST & \\
\hline CHEMBL1969190 & 809260 & 6.1 & 6.3488 & TRN & \\
\hline CHEMBL1973937 & 809260 & 6.7 & 7.6127 & TRN & \\
\hline CHEMBL1991674 & 809260 & 7.2 & 6.756 & TRN & \\
\hline CHEMBL1982711 & 809260 & 6.2 & 5.9319 & TRN & \\
\hline CHEMBL1987982 & 809260 & 4.2 & 4.3681 & TST & \\
\hline CHEMBL1984842 & 809260 & 4.2 & 4.2712 & TRN & \\
\hline CHEMBL1969102 & 809260 & 8.6 & 8.3929 & TRN & \\
\hline CHEMBL1682346 & 809260 & 5.2 & 4.9878 & TRN & \\
\hline CHEMBL 2007044 & 809260 & 4.2 & 4.6536 & TST & \\
\hline CHEMBL2001998 & 809260 & 4.2 & 5.5149 & TST & \\
\hline CHEMBL1994241 & 809260 & 6.1 & 5.8692 & TRN & \\
\hline CHEMBL223460 & 809260 & 4.2 & 5.3822 & TST & \\
\hline CHEMBL1998829 & 809260 & 5.2 & 5.0606 & TRN & \\
\hline CHEMBL50894 & 809260 & 6.8 & 5.6544 & TRN & \\
\hline CHEMBL1988838 & 809260 & 7.4 & 7.6361 & TRN & \\
\hline CHEMBL 375284 & 809260 & 6.4 & 6.6446 & TRN & \\
\hline CHEMBL1982866 & 809260 & 4.2 & 4.3549 & TRN & \\
\hline CHEMBL 2005792 & 809260 & 4.2 & 4.2003 & TRN & \\
\hline CHEMBL1968926 & 809260 & 4.2 & 4.6038 & TRN & \\
\hline CHEMBL462120 & 809260 & 4.2 & 4.8677 & TST & \\
\hline CHEMBL1984206 & 809260 & 4.2 & 4.4409 & TRN & \\
\hline CHEMBL1991577 & 809260 & 4.2 & 4.4552 & TRN & \\
\hline CHEMBL1965570 & 809260 & 7.3 & 7.2645 & TRN & \\
\hline CHEMBL 2007592 & 809260 & 4.2 & 3.9704 & TST & \\
\hline CHEMBL210963 & 809260 & 4.2 & 3.8909 & TRN & \\
\hline CHEMBL1082440 & 809260 & 5.7 & 5.2902 & TST & \\
\hline CHEMBL1614705 & 809260 & 4.2 & 4.5589 & TST & \\
\hline CHEMBL1972362 & 809260 & 5.5 & 5.26399 & 9999999999 & TRN \\
\hline & & & & 13523 & \\
\hline
\end{tabular}




\begin{tabular}{|c|c|c|c|c|}
\hline & & & pplement & al $\mathrm{Ta}$ \\
\hline CHEMBL2007372 & 809260 & 4.2 & 4.03 & TRN \\
\hline CHEMBL1965845 & 809260 & 7.2 & 6.3723 & TRN \\
\hline CHEMBL1982167 & 809260 & 4.2 & 4.5152 & TRN \\
\hline CHEMBL 2006715 & 809260 & 7.1 & 6.815 & TRN \\
\hline CHEMBL1986597 & 809260 & 5.2 & 4.5848 & TRN \\
\hline CHEMBL1971017 & 809260 & 6.0 & 5.8021 & TRN \\
\hline CHEMBL1990482 & 809260 & 4.2 & 4.3504 & TRN \\
\hline CHEMBL1990904 & 809260 & 5.2 & 4.5106 & TRN \\
\hline CHEMBL 2005475 & 809260 & 6.3 & 5.9525 & TRN \\
\hline CHEMBL 2000104 & 809260 & 6.3 & 5.0455 & TRN \\
\hline CHEMBL1997349 & 809260 & 4.2 & 4.8166 & TST \\
\hline CHEMBL183844 & 809260 & 7.3 & 6.3586 & TRN \\
\hline CHEMBL220057 & 809260 & 7.4 & 8.2724 & TRN \\
\hline CHEMBL1682545 & 809260 & 5.5 & 4.4895 & TRN \\
\hline CHEMBL383541 & 809260 & 4.2 & 4.6604 & TRN \\
\hline CHEMBL 2001224 & 809260 & 4.2 & 4.7027 & TRN \\
\hline CHEMBL10 & 809260 & 5.2 & 4.381 & TRN \\
\hline CHEMBL1976732 & 809260 & 4.2 & 3.9597 & TRN \\
\hline CHEMBL1969506 & 809260 & 4.2 & 4.4961 & TRN \\
\hline CHEMBL1964937 & 809260 & 5.5 & 5.8438 & TRN \\
\hline CHEMBL1980163 & 809260 & 4.2 & 4.1356 & TRN \\
\hline CHEMBL590109 & 809260 & 5.4 & 5.1732 & TST \\
\hline CHEMBL1970879 & 809260 & 4.2 & 4.7475 & TRN \\
\hline CHEMBL1989856 & 809260 & 6.1 & 4.8593 & TST \\
\hline CHEMBL2005899 & 809260 & 5.6 & 4.9017 & TRN \\
\hline CHEMBL1682552 & 809260 & 4.2 & 4.457 & TRN \\
\hline CHEMBL 259850 & 809260 & 4.2 & 4.2481 & TRN \\
\hline CHEMBL1972568 & 809260 & 4.2 & 4.2226 & TRN \\
\hline CHEMBL1996155 & 809260 & 4.2 & 4.5371 & TRN \\
\hline CHEMBL229799 & 809260 & 5.6 & 6.0575 & TRN \\
\hline CHEMBL1682359 & 809260 & 4.2 & 4.2271 & TRN \\
\hline CHEMBL105739 & 809260 & 6.5 & 7.2069 & TRN \\
\hline CHEMBL 379300 & 809260 & 5.8 & 5.8605 & TRN \\
\hline CHEMBL 203673 & 809260 & 4.2 & 4.2155 & TRN \\
\hline CHEMBL1969523 & 809260 & 7.3 & 6.9443 & TRN \\
\hline CHEMBL207995 & 809260 & 6.0 & 4.9872 & TRN \\
\hline CHEMBL1988995 & 809260 & 4.2 & 3.9185 & TRN \\
\hline CHEMBL 2001923 & 809260 & 4.2 & 4.5403 & TRN \\
\hline CHEMBL1986781 & 809260 & 4.2 & 4.0616 & TRN \\
\hline CHEMBL526133 & 809260 & 5.2 & 4.6906 & TRN \\
\hline CHEMBL1966836 & 809260 & 8.8 & 8.5517 & TRN \\
\hline CHEMBL1979057 & 809260 & 5.2 & 5.0374 & TRN \\
\hline CHEMBL1981045 & 809260 & 4.2 & 4.1364 & TRN \\
\hline CHEMBL 387971 & 809260 & 6.9 & 6.5091 & TST \\
\hline CHEMBL1975418 & 809260 & 4.2 & 4.9739 & TRN \\
\hline CHEMBL1992796 & 809260 & 4.2 & 4.7187 & TST \\
\hline CHEMBL1999428 & 809260 & 6.3 & 5.282 & TRN \\
\hline CHEMBL 223257 & 809260 & 4.2 & 5.2364 & TST \\
\hline
\end{tabular}




\begin{tabular}{|c|c|c|c|c|}
\hline & & & ipplement & al $\mathrm{T}$ \\
\hline CHEMBL1967560 & 809260 & 4.2 & 4.2625 & TRN \\
\hline CHEMBL1516890 & 809260 & 6.4 & 6.237 & TRN \\
\hline CHEMBL1982465 & 809260 & 8.3 & 8.0199 & TRN \\
\hline CHEMBL 2001751 & 809260 & 7.6 & 6.9927 & TRN \\
\hline CHEMBL 2003420 & 809260 & 5.4 & 5.1383 & TRN \\
\hline CHEMBL1984586 & 809260 & 5.7 & 5.9833 & TRN \\
\hline CHEMBL1999774 & 809260 & 5.5 & 4.3252 & TST \\
\hline CHEMBL272938 & 809260 & 9.5 & 9.1547 & TRN \\
\hline CHEMBL1972659 & 809260 & 4.2 & 4.3081 & TST \\
\hline CHEMBL1973395 & 809260 & 5.8 & 5.4501 & TRN \\
\hline CHEMBL272453 & 809260 & 6.9 & 7.2602 & TRN \\
\hline CHEMBL1970217 & 809260 & 4.2 & 4.8296 & TRN \\
\hline CHEMBL1971801 & 809260 & 4.2 & 4.8047 & TRN \\
\hline CHEMBL1968850 & 809260 & 5.4 & 5.1589 & TRN \\
\hline CHEMBL 2005528 & 809260 & 4.2 & 4.5289 & TST \\
\hline CHEMBL185569 & 809260 & 6.5 & 6.3387 & TRN \\
\hline CHEMBL1969843 & 809260 & 4.2 & 4.1254 & TRN \\
\hline CHEMBL 2007002 & 809260 & 4.2 & 4.0335 & TRN \\
\hline CHEMBL1987007 & 809260 & 6.0 & 5.575 & TRN \\
\hline CHEMBL1984711 & 809260 & 4.2 & 6.4448 & TRN \\
\hline CHEMBL1990212 & 809260 & 4.2 & 4.4425 & TRN \\
\hline CHEMBL484390 & 809260 & 4.2 & 5.0305 & TST \\
\hline CHEMBL1979252 & 809260 & 4.2 & 4.8243 & TRN \\
\hline CHEMBL1682341 & 809260 & 4.2 & 4.6013 & TRN \\
\hline CHEMBL 2004290 & 809260 & 8.2 & 7.3155 & TRN \\
\hline CHEMBL1972937 & 809260 & 4.2 & 4.3088 & TRN \\
\hline CHEMBL1972250 & 809260 & 4.2 & 5.0317 & TST \\
\hline CHEMBL 2000393 & 809260 & 6.4 & 5.6798 & TST \\
\hline CHEMBL403402 & 809260 & 9.0 & 9.2912 & TRN \\
\hline CHEMBL 2004072 & 809260 & 4.2 & 4.9434 & TRN \\
\hline CHEMBL 2004311 & 809260 & 5.9 & 6.1191 & TRN \\
\hline CHEMBL1992634 & 809260 & 5.7 & 6.317 & TRN \\
\hline CHEMBL1242373 & 809260 & 6.8 & 6.6254 & TRN \\
\hline CHEMBL56543 & 809260 & 4.2 & 4.871 & TST \\
\hline CHEMBL1988075 & 809260 & 7.1 & 7.3674 & TRN \\
\hline CHEMBL316264 & 809260 & 4.2 & 4.3066 & TRN \\
\hline CHEMBL1991678 & 809260 & 4.2 & 4.1941 & TRN \\
\hline CHEMBL2001239 & 809260 & 4.2 & 5.1357 & TST \\
\hline CHEMBL1988594 & 809260 & 5.2 & 4.0061 & TRN \\
\hline CHEMBL 2001288 & 809260 & 4.2 & 4.6129 & TRN \\
\hline CHEMBL 260092 & 809260 & 8.2 & 7.4887 & TRN \\
\hline CHEMBL1999811 & 809260 & 6.4 & 5.2526 & TST \\
\hline CHEMBL1965495 & 809260 & 6.5 & 5.9489 & TRN \\
\hline CHEMBL1985074 & 809260 & 4.2 & 4.8776 & TST \\
\hline CHEMBL1982874 & 809260 & 4.2 & 4.2107 & TRN \\
\hline CHEMBL 2000481 & 809260 & 4.2 & 4.5182 & TRN \\
\hline CHEMBL1991725 & 809260 & 5.2 & 5.1632 & TRN \\
\hline CHEMBL1992242 & 809260 & 4.2 & 5.5914 & TRN \\
\hline
\end{tabular}




\begin{tabular}{|c|c|c|c|c|c|}
\hline CHEMBL 2007296 & 809260 & 4.2 & 4.6039 & TRN & \\
\hline CHEMBL208637 & 809260 & 4.2 & \multicolumn{2}{|c|}{3.9339999999999997} & TRN \\
\hline CHEMBL1970203 & 809260 & 4.2 & 4.3533 & TRN & \\
\hline CHEMBL1999321 & 809260 & 7.2 & 5.2624 & TRN & \\
\hline CHEMBL1968590 & 809260 & 7.0 & 7.3497 & TRN & \\
\hline CHEMBL1999749 & 809260 & 4.2 & 4.2081 & TRN & \\
\hline CHEMBL 2005375 & 809260 & 4.2 & 4.1357 & TRN & \\
\hline CHEMBL1984191 & 809260 & 4.2 & 4.666 & TRN & \\
\hline CHEMBL1983006 & 809260 & 5.6 & 4.9512 & TRN & \\
\hline CHEMBL1972183 & 809260 & 4.2 & 4.4114 & TRN & \\
\hline CHEMBL1971029 & 809260 & 7.0 & 7.8912 & TRN & \\
\hline CHEMBL394790 & 809260 & 7.2 & 7.5358 & TRN & \\
\hline CHEMBL226471 & 809260 & 4.2 & 5.0374 & TST & \\
\hline CHEMBL1974702 & 809260 & 4.2 & 4.7918 & TST & \\
\hline CHEMBL1996111 & 809260 & 4.2 & 4.4276 & TRN & \\
\hline CHEMBL1965589 & 809260 & 4.3 & \multicolumn{2}{|c|}{4.3469999999999995} & TRN \\
\hline CHEMBL1998193 & 809260 & 7.5 & 4.8506 & TRN & \\
\hline CHEMBL474432 & 809260 & 7.0 & 6.1543 & TST & \\
\hline CHEMBL1988153 & 809260 & 4.2 & 4.7914 & TRN & \\
\hline CHEMBL1999556 & 809260 & 5.9 & 5.7791 & TRN & \\
\hline CHEMBL1988437 & 809260 & 7.7 & 7.3412 & TST & \\
\hline CHEMBL1968245 & 809260 & 4.2 & 4.8385 & TRN & \\
\hline CHEMBL1998121 & 809260 & 5.9 & 5.6208 & TRN & \\
\hline CHEMBL1979577 & 809260 & 8.5 & 8.0611 & TRN & \\
\hline CHEMBL1991800 & 809260 & 4.2 & 4.0826 & TRN & \\
\hline CHEMBL52387 & 809260 & 4.2 & 4.496 & TST & \\
\hline CHEMBL 379835 & 809260 & 4.2 & 4.4975 & TST & \\
\hline CHEMBL1980802 & 809260 & 4.2 & 5.0865 & TST & \\
\hline CHEMBL1979357 & 809260 & 4.2 & 4.5052 & TRN & \\
\hline CHEMBL1979554 & 809260 & 4.2 & 4.6715 & TRN & \\
\hline CHEMBL1996817 & 809260 & 6.4 & 6.3452 & TRN & \\
\hline CHEMBL3197315 & 809260 & 4.2 & 3.7001 & TST & \\
\hline CHEMBL409349 & 809260 & 8.7 & 7.7762 & TRN & \\
\hline CHEMBL2004355 & 809260 & 4.2 & 4.4474 & TRN & \\
\hline CHEMBL468280 & 809260 & 4.2 & 4.4706 & TST & \\
\hline CHEMBL1990884 & 809260 & 6.1 & 6.2716 & TRN & \\
\hline CHEMBL3109278 & 809260 & 7.6 & \multicolumn{2}{|c|}{7.0920000000000005} & TRN \\
\hline CHEMBL 256835 & 809260 & 4.2 & 3.9998 & TRN & \\
\hline CHEMBL41783 & 809260 & 4.2 & 4.3528 & TRN & \\
\hline CHEMBL 2004438 & 809260 & 6.6 & 6.2605 & TRN & \\
\hline CHEMBL 2006276 & 809260 & 4.2 & 4.2978 & TRN & \\
\hline CHEMBL 271381 & 809260 & 6.5 & 6.7432 & TRN & \\
\hline CHEMBL 2006785 & 809260 & 4.2 & 4.5291 & TST & \\
\hline CHEMBL1982466 & 809260 & 8.4 & 8.0328 & TRN & \\
\hline CHEMBL1995740 & 809260 & 4.2 & 4.3171 & TRN & \\
\hline CHEMBL1994638 & 809260 & 9.1 & 8.9252 & TRN & \\
\hline CHEMBL1985888 & 809260 & 8.8 & 8.9963 & TRN & \\
\hline CHEMBL1996390 & 809260 & 4.2 & 4.9258 & TRN & \\
\hline
\end{tabular}




\begin{tabular}{|c|c|c|c|c|c|}
\hline \multicolumn{6}{|c|}{ Supplemental Table S2.txt } \\
\hline CHEMBL234085 & 809260 & 4.2 & 4.3806 & TRN & \\
\hline CHEMBL1995832 & 809260 & 4.2 & 4.3411 & TRN & \\
\hline CHEMBL1998414 & 809260 & 5.3 & 5.4283 & TRN & \\
\hline CHEMBL1969042 & 809260 & 5.5 & 5.3472 & TRN & \\
\hline CHEMBL 2000345 & 809260 & 6.4 & 6.0565 & TRN & \\
\hline CHEMBL1999931 & 809260 & 7.2 & 6.73799 & 99999999995 & TRN \\
\hline CHEMBL1991640 & 809260 & 4.2 & 4.5792 & TST & \\
\hline CHEMBL1375418 & 809260 & 4.2 & 4.1071 & TRN & \\
\hline CHEMBL 302449 & 809260 & 6.9 & 7.0186 & TST & \\
\hline CHEMBL 2007064 & 809260 & 6.1 & 6.6883 & TRN & \\
\hline CHEMBL1981047 & 809260 & 6.8 & 6.4214 & TRN & \\
\hline CHEMBL229968 & 809260 & 5.8 & 5.6786 & TRN & \\
\hline CHEMBL1976240 & 809260 & 4.2 & 4.7059 & TRN & \\
\hline CHEMBL1979093 & 809260 & 6.5 & 7.0096 & TRN & \\
\hline CHEMBL1381197 & 809260 & 5.2 & 4.6222 & TRN & \\
\hline CHEMBL1987009 & 809260 & 6.5 & 6.2568 & TRN & \\
\hline CHEMBL379218 & 809260 & 5.4 & 5.3344 & TRN & \\
\hline CHEMBL 2003817 & 809260 & 6.2 & 5.3407 & TRN & \\
\hline CHEMBL336961 & 809260 & 5.4 & 5.1149 & TRN & \\
\hline CHEMBL1994830 & 809260 & 5.7 & 4.7993 & TRN & \\
\hline CHEMBL1987054 & 809260 & 7.5 & 7.5874 & TRN & \\
\hline CHEMBL1970083 & 809260 & 7.2 & 8.0189 & TRN & \\
\hline CHEMBL226403 & 809260 & 4.2 & 4.6025 & TST & \\
\hline CHEMBL1994938 & 809260 & 7.1 & 7.5548 & TRN & \\
\hline CHEMBL1977223 & 809260 & 4.2 & 4.7853 & TRN & \\
\hline CHEMBL1236126 & 809260 & 4.2 & 4.5059 & TST & \\
\hline CHEMBL1966279 & 809260 & 4.2 & 4.3469 & TRN & \\
\hline CHEMBL1997846 & 809260 & 6.0 & 6.0543 & TRN & \\
\hline CHEMBL2004419 & 809260 & 4.2 & 3.8642 & TRN & \\
\hline CHEMBL1991728 & 809260 & 4.2 & 4.8963 & TRN & \\
\hline CHEMBL1975787 & 809260 & 6.1 & 5.8157 & TRN & \\
\hline CHEMBL 2002407 & 809260 & 6.0 & 4.8803 & TRN & \\
\hline CHEMBL1972489 & 809260 & 4.2 & 4.1645 & TRN & \\
\hline CHEMBL1994074 & 809260 & 5.3 & 5.2629 & TRN & \\
\hline CHEMBL1992937 & 809260 & 6.0 & 6.0373 & TST & \\
\hline CHEMBL1985566 & 809260 & 4.2 & 4.2141 & TRN & \\
\hline CHEMBL1972119 & 809260 & 4.2 & 4.7364 & TRN & \\
\hline CHEMBL1986328 & 809260 & 4.2 & 3.9985 & TST & \\
\hline CHEMBL95692 & 809260 & 4.2 & 3.9853 & TRN & \\
\hline CHEMBL1090356 & 809260 & 7.4 & 6.9914 & TRN & \\
\hline CHEMBL1976455 & 809260 & 4.3 & 5.268 & TRN & \\
\hline CHEMBL1982361 & 809260 & 5.2 & 4.9063 & TRN & \\
\hline CHEMBL1983534 & 809260 & 4.2 & 4.7097 & TRN & \\
\hline CHEMBL1999112 & 809260 & 4.2 & 4.5038 & TST & \\
\hline CHEMBL1982122 & 809260 & 5.3 & 4.6521 & TRN & \\
\hline CHEMBL 2000801 & 809260 & 5.3 & 5.8806 & TRN & \\
\hline CHEMBL1682546 & 809260 & 4.3 & 4.292 & TRN & \\
\hline CHEMBL1991395 & 809260 & 4.2 & 4.3235 & TRN & \\
\hline
\end{tabular}




\begin{tabular}{|c|c|c|c|c|}
\hline \multicolumn{5}{|c|}{ Supplemental Table s2.txt } \\
\hline CHEMBL1987648 & 809260 & 4.2 & 4.178 & TRN \\
\hline CHEMBL1972142 & 809260 & 5.7 & 5.659 & TRN \\
\hline CHEMBL1966514 & 809260 & 7.1 & 7.3232 & TRN \\
\hline CHEMBL296586 & 809260 & 6.4 & 5.7912 & TRN \\
\hline CHEMBL516429 & 809260 & 7.0 & 6.4459 & TRN \\
\hline CHEMBL1993722 & 809260 & 5.4 & 6.2761 & TRN \\
\hline CHEMBL1970806 & 809260 & 4.2 & 4.2899 & TST \\
\hline CHEMBL 202635 & 809260 & 5.5 & 5.1361 & TRN \\
\hline CHEMBL1375640 & 809260 & 4.2 & 4.7286 & TST \\
\hline CHEMBL1979970 & 809260 & 5.5 & 4.4438 & TRN \\
\hline CHEMBL249282 & 809260 & 4.2 & 4.9212 & TST \\
\hline CHEMBL1969264 & 809260 & 5.8 & 4.9785 & TRN \\
\hline CHEMBL1973711 & 809260 & 4.2 & 4.9516 & TST \\
\hline CHEMBL 2006237 & 809260 & 5.4 & 4.7343 & TRN \\
\hline CHEMBL1967720 & 809260 & 8.3 & 7.8515 & TRN \\
\hline CHEMBL1572266 & 809260 & 7.5 & 4.2496 & TST \\
\hline CHEMBL1991138 & 809260 & 5.7 & 4.8223 & TRN \\
\hline CHEMBL1969755 & 809260 & 4.2 & 4.1023 & TRN \\
\hline CHEMBL1605605 & 809260 & 4.2 & 4.2216 & TRN \\
\hline CHEMBL1972820 & 809260 & 4.2 & 4.2412 & TST \\
\hline CHEMBL1996208 & 809260 & 4.2 & 5.3165 & TST \\
\hline CHEMBL1989029 & 809260 & 5.6 & 5.843 & TRN \\
\hline CHEMBL392642 & 809260 & 4.2 & 4.8212 & TRN \\
\hline CHEMBL514499 & 809260 & 7.0 & 6.1294 & TST \\
\hline CHEMBL1965631 & 809260 & 4.2 & 4.6294 & TRN \\
\hline CHEMBL1980144 & 809260 & 4.2 & 3.8112 & TRN \\
\hline CHEMBL1991188 & 809260 & 4.2 & 4.6939 & TRN \\
\hline CHEMBL1972849 & 809260 & 4.2 & 3.7017 & TRN \\
\hline CHEMBL 377408 & 809260 & 4.2 & 4.6042 & TST \\
\hline CHEMBL215152 & 809260 & 5.9 & 5.3346 & TST \\
\hline CHEMBL231209 & 809260 & 6.4 & 6.7366 & TST \\
\hline CHEMBL1976220 & 809260 & 7.4 & 7.6123 & TST \\
\hline CHEMBL259922 & 809260 & 4.2 & 5.0358 & TST \\
\hline CHEMBL1997617 & 809260 & 7.5 & 6.8333 & TST \\
\hline CHEMBL1982383 & 809260 & 4.2 & 4.6835 & TST \\
\hline CHEMBL1969301 & 809260 & 4.2 & 5.1921 & TST \\
\hline CHEMBL17370 & 809260 & 4.2 & 4.3307 & TST \\
\hline CHEMBL1987910 & 809260 & 6.1 & 6.1239 & TST \\
\hline CHEMBL374044 & 809260 & 9.4 & 9.0731 & TST \\
\hline CHEMBL404366 & 809260 & 9.7 & 9.0554 & TST \\
\hline CHEMBL1966069 & 809260 & 4.2 & 4.6299 & TST \\
\hline CHEMBL1997822 & 809260 & 7.8 & 6.9662 & TST \\
\hline CHEMBL1991285 & 809260 & 6.4 & 5.4549 & TST \\
\hline CHEMBL1984038 & 809260 & 4.2 & 4.4611 & TST \\
\hline CHEMBL1974416 & 809260 & 5.4 & 5.4623 & TST \\
\hline CHEMBL 2004615 & 809260 & 4.2 & 5.0109 & TST \\
\hline CHEMBL1984039 & 809260 & 4.2 & 4.7984 & TST \\
\hline CHEMBL1997872 & 809260 & 5.4 & 5.6724 & TST \\
\hline
\end{tabular}




\begin{tabular}{|c|c|c|c|c|c|c|}
\hline \multicolumn{7}{|c|}{ Supplemental Table S2.txt } \\
\hline CHEMBL191334 & 954696 & 3.9952 & 3.9952 & TRN & & \\
\hline CHEMBL392695 & 954696 & 6.346 & 6.346 & TRN & & \\
\hline CHEMBL1186585 & 954696 & 4.1346 & 4.1346 & TRN & & \\
\hline CHEMBL 258844 & 954696 & 4.2778 & 4.2778 & TRN & & \\
\hline CHEMBL1190711 & 954696 & 3.8889 & 3.8889 & TRN & & \\
\hline CHEMBL1909414 & 954696 & 3.3411 & 3.3411 & TRN & & \\
\hline CHEMBL3392440 & 954696 & 4.5839 & 3.9995 & TST & & \\
\hline CHEMBL300389 & 954696 & 7.4655 & 7.4655 & TRN & & \\
\hline CHEMBL512504 & 954696 & 4.40600 & 00000000 & $\partial 1$ & 4.406000000000001 & TRN \\
\hline CHEMBL221137 & 954696 & 4.3273 & 4.4612 & TST & & \\
\hline CHEMBL102714 & 954696 & 3.3519 & 3.3519 & TRN & & \\
\hline CHEMBL577784 & 954696 & 5.7818 & 5.7818 & TRN & & \\
\hline CHEMBL189584 & 954696 & 4.0002 & 4.0002 & TRN & & \\
\hline CHEMBL209148 & 954696 & 4.9869 & 4.9869 & TRN & & \\
\hline CHEMBL92309 & 954696 & 3.3772 & 2.8491 & TST & & \\
\hline CHEMBL 213100 & 954696 & 4.4191 & 4.4191 & TRN & & \\
\hline CHEMBL3349342 & 954696 & 4.2067 & 4.2067 & TRN & & \\
\hline CHEMBL483847 & 954696 & 4.1989 & 4.1989 & TRN & & \\
\hline CHEMBL515416 & 954696 & 3.9785 & 3.9785 & TRN & & \\
\hline CHEMBL259181 & 954696 & 2.8935 & 2.8935 & TRN & & \\
\hline CHEMBL217354 & 954696 & 6.8216 & 6.8216 & TRN & & \\
\hline CHEMBL 379300 & 954696 & 6.8855 & 6.8855 & TRN & & \\
\hline CHEMBL 2363137 & 954696 & 4.1993 & 4.1993 & TRN & & \\
\hline CHEMBL573107 & 954696 & 4.55699 & 99999999 & 995 & 4.5569999999999995 & TRN \\
\hline CHEMBL472940 & 954696 & 3.2228 & 3.2228 & TRN & & \\
\hline CHEMBL449158 & 954696 & 7.6254 & 6.7635 & TST & & \\
\hline CHEMBL1357247 & 954696 & 3.388 & 3.388 & TRN & & \\
\hline CHEMBL 210618 & 954696 & 4.1704 & 4.1705 & TRN & & \\
\hline CHEMBL1256459 & 954696 & 7.6249 & 7.6249 & TRN & & \\
\hline CHEMBL188678 & 954696 & 4.9233 & 4.9233 & TRN & & \\
\hline CHEMBL399530 & 954696 & 4.23600 & 00000000 & $\partial 1$ & 4.236000000000001 & TRN \\
\hline CHEMBL135561 & 954696 & 4.0152 & 4.0151 & TRN & & \\
\hline CHEMBL1404918 & 954696 & 3.0562 & 3.0562 & TRN & & \\
\hline CHEMBL1242367 & 954696 & 4.8644 & 4.8644 & TRN & & \\
\hline CHEMBL192566 & 954696 & 8.0389 & 7.0695 & TST & & \\
\hline CHEMBL255342 & 954696 & 3.3705 & 3.3705 & TRN & & \\
\hline CHEMBL514499 & 954696 & 7.9702 & 7.9702 & TRN & & \\
\hline CHEMBL 2137530 & 954696 & 4.8162 & 4.8162 & TRN & & \\
\hline CHEMBL412142 & 954696 & 3.9926 & 3.9926 & TRN & & \\
\hline CHEMBL1788116 & 954696 & 6.5226 & 6.5226 & TRN & & \\
\hline CHEMBL 2134202 & 954696 & 3.3799 & 3.3799 & TRN & & \\
\hline CHEMBL1230020 & 954696 & 4.2512 & 4.2512 & TRN & & \\
\hline CHEMBL202721 & 954696 & 6.27 & 6.27 & TRN & & \\
\hline CHEMBL 393929 & 954696 & 3.5358 & 3.5357 & TRN & & \\
\hline CHEMBL222102 & 954696 & 4.4374 & 4.4374 & TRN & & \\
\hline CHEMBL1970879 & 954696 & 5.8012 & 5.8012 & TRN & & \\
\hline CHEMBL1643959 & 954696 & 4.9536 & 4.9536 & TRN & & \\
\hline CHEMBL3199475 & 954696 & 3.847 & 3.847 & TRN & & \\
\hline
\end{tabular}




\begin{tabular}{|c|c|c|c|c|c|}
\hline & & & pplement & al Ta & $S$ \\
\hline CHEMBL509032 & 954696 & 6.7933 & 6.7933 & TRN & \\
\hline CHEMBL65 & 954696 & 7.78700 & 00000000 & & 7 \\
\hline CHEMBL9470 & 954696 & 5.3964 & 5.1709 & TST & \\
\hline CHEMBL 240954 & 954696 & 4.2125 & 4.21399 & 99999 & 995 \\
\hline CHEMBL558642 & 954696 & 4.6278 & 3.8332 & TST & \\
\hline CHEMBL 2005886 & 954696 & 6.8182 & 5.7055 & TST & \\
\hline CHEMBL585951 & 954696 & 5.6225 & 5.8691 & TST & \\
\hline CHEMBL151176 & 954696 & 4.4624 & 4.6061 & TST & \\
\hline CHEMBL1516890 & 954696 & 4.0161 & 4.2935 & TST & \\
\hline CHEMBL483849 & 954696 & 3.23100 & 00000000 & 003 & 2. \\
\hline CHEMBL379975 & 954696 & 5.6676 & 5.5349 & TST & \\
\hline CHEMBL575652 & 587662 & 3.0 & 3.679 & TRN & \\
\hline CHEMBL574095 & 587662 & 4.9208 & 3.9347 & TRN & \\
\hline CHEMBL573624 & 587662 & 3.0 & 3.0973 & TRN & \\
\hline CHEMBL575651 & 587662 & 4.9208 & 4.262 & TRN & \\
\hline CHEMBL573132 & 587662 & 4.5229 & 3.9882 & TRN & \\
\hline CHEMBL574101 & 587662 & 3.0 & 3.2015 & TRN & \\
\hline CHEMBL573626 & 587662 & 3.0 & 3.3176 & TRN & \\
\hline CHEMBL583739 & 587662 & 3.0 & 2.9689 & TRN & \\
\hline CHEMBL573628 & 587662 & 3.0 & 2.9432 & TRN & \\
\hline CHEMBL573864 & 587662 & 3.0458 & 2.7803 & TRN & \\
\hline CHEMBL573369 & 587662 & 3.3468 & 3.0774 & TRN & \\
\hline CHEMBL575656 & 587662 & 3.0 & 3.1387 & TST & \\
\hline CHEMBL575657 & 587662 & 3.1249 & 3.5004 & TRN & \\
\hline CHEMBL572449 & 587662 & 3.0 & 3.0411 & TRN & \\
\hline CHEMBL573850 & 587662 & 3.0969 & 2.9924 & TRN & \\
\hline CHEMBL573540 & 587662 & 3.0458 & 3.0646 & TRN & \\
\hline CHEMBL585009 & 587662 & 3.2596 & 3.3081 & TRN & \\
\hline CHEMBL564201 & 587662 & 3.699 & 3.2449 & TST & \\
\hline CHEMBL575432 & 587662 & 3.0 & 2.9503 & TRN & \\
\hline CHEMBL573352 & 587662 & 3.0 & 3.2975 & TST & \\
\hline CHEMBL573852 & 587662 & 3.0969 & 3.3611 & TST & \\
\hline CHEMBL573541 & 587662 & 3.0 & 3.2034 & TRN & \\
\hline CHEMBL583379 & 587662 & 3.3979 & 3.7822 & TRN & \\
\hline CHEMBL575862 & 587662 & 3.4815 & 3.1995 & TRN & \\
\hline CHEMBL418899 & 587662 & 3.0 & 3.3155 & TST & \\
\hline CHEMBL575209 & 587662 & 4.1549 & 4.4508 & TRN & \\
\hline CHEMBL575861 & 587662 & 3.2218 & 3.10399 & 99999 & 996 \\
\hline CHEMBL575426 & 587662 & 3.0 & 3.0987 & TRN & \\
\hline CHEMBL573625 & 587662 & 3.301 & 3.2469 & TRN & \\
\hline CHEMBL574549 & 587662 & 3.301 & 3.3815 & TST & \\
\hline CHEMBL574322 & 587662 & 3.0969 & 3.1099 & TST & \\
\hline CHEMBL573609 & 587662 & 3.1871 & 4.1162 & TRN & \\
\hline CHEMBL583512 & 587662 & 4.8539 & 4.1877 & TRN & \\
\hline CHEMBL584804 & 587662 & 3.0 & 2.8907 & TRN & \\
\hline CHEMBL573606 & 587662 & 3.5229 & 4.4697 & TRN & \\
\hline CHEMBL574096 & 587662 & 3.2366 & 3.18300 & 00000 & 003 \\
\hline CHEMBL583763 & 587662 & 3.2366 & 3.0481 & TRN & \\
\hline
\end{tabular}




\begin{tabular}{|c|c|c|c|c|c|c|}
\hline & & \multicolumn{5}{|c|}{ Supplemental Table S2.txt } \\
\hline CHEMBL575208 & 587662 & 3.0969 & 3.612 & TST & & \\
\hline CHEMBL575433 & 587662 & 3.2218 & 3.7631 & TRN & & \\
\hline CHEMBL575210 & 587662 & 3.0809 & 2.9858 & TRN & & \\
\hline CHEMBL573627 & 587662 & 3.0 & 3.3632 & TRN & & \\
\hline CHEMBL575655 & 587662 & 3.1871 & 3.0342 & TRN & & \\
\hline CHEMBL573607 & 587662 & 3.5229 & 3.9203 & TRN & & \\
\hline CHEMBL573539 & 587662 & 3.0706 & 3.0428 & TRN & & \\
\hline CHEMBL583948 & 587662 & 3.0 & 3.6218 & TRN & & \\
\hline CHEMBL573618 & 587662 & 4.2596 & 3.7209 & TRN & & \\
\hline CHEMBL573372 & 587662 & 3.0 & 3.1572 & TRN & & \\
\hline CHEMBL573608 & 587662 & 3.8239 & 3.5629 & TST & & \\
\hline CHEMBL573370 & 587662 & 4.1938 & 3.6651 & TST & & \\
\hline CHEMBL584359 & 587662 & 3.301 & 3.6684 & TRN & & \\
\hline CHEMBL573842 & 587662 & 5.2218 & 4.0184 & TRN & & \\
\hline CHEMBL573371 & 587662 & 3.0458 & 3.1126 & TRN & & \\
\hline CHEMBL573611 & 587662 & 3.8239 & 3.4647 & TRN & & \\
\hline CHEMBL573542 & 587662 & 3.0458 & 2.937 & TRN & & \\
\hline CHEMBL573619 & 587662 & 3.0 & 3.1995 & TRN & & \\
\hline CHEMBL575650 & 587662 & 4.9208 & 4.3647 & TRN & & \\
\hline CHEMBL573752 & 587662 & 3.0 & 3.5047 & TST & & \\
\hline CHEMBL577182 & 587662 & 3.0969 & 3.7885 & TST & & \\
\hline CHEMBL572677 & 587662 & 3.2218 & 3.0236 & TST & & \\
\hline CHEMBL572646 & 587662 & 3.0458 & 3.1617 & TST & & \\
\hline CHEMBL574100 & 587662 & 3.0 & 2.8881 & TST & & \\
\hline CHEMBL259181 & 954399 & 2.9675 & 2.9093 & TRN & & \\
\hline CHEMBL220241 & 954399 & 3.2758 & 3.3173 & TRN & & \\
\hline CHEMBL515416 & 954399 & 3.8781 & 3.8446 & TRN & & \\
\hline CHEMBL483849 & 954399 & 1.2441 & 2.4138 & TST & & \\
\hline CHEMBL258844 & 954399 & 3.7563 & 3.6979 & TRN & & \\
\hline CHEMBL1673039 & 954399 & 4.22199 & 99999999 & 995 & 4.3022 & TRN \\
\hline CHEMBL188678 & 954399 & 4.1005 & 4.1247 & TRN & & \\
\hline CHEMBL 2137530 & 954399 & 4.9469 & 4.9123 & TRN & & \\
\hline CHEMBL1788116 & 954399 & 4.1403 & 4.1438 & TRN & & \\
\hline CHEMBL1186585 & 954399 & 3.5053 & 3.5118 & TRN & & \\
\hline CHEMBL379975 & 954399 & 4.6065 & 4.6445 & TRN & & \\
\hline CHEMBL1590308 & 954399 & 2.8896 & 3.4039 & TST & & \\
\hline CHEMBL558642 & 954399 & 2.7918 & 2.8158 & TRN & & \\
\hline CHEMBL1256459 & 954399 & 4.695 & 4.6925 & TRN & & \\
\hline CHEMBL373751 & 954399 & 3.3328 & 3.4324 & TRN & & \\
\hline CHEMBL192566 & 954399 & 4.3328 & 4.3893 & TST & & \\
\hline CHEMBL483847 & 954399 & 3.9995 & 4.0175 & TRN & & \\
\hline CHEMBL 2363137 & 954399 & 3.4425 & 3.4315 & TRN & & \\
\hline CHEMBL585951 & 954399 & 4.643 & 4.5759 & TRN & & \\
\hline CHEMBL 2134202 & 954399 & 3.3538 & 3.3892 & TRN & & \\
\hline CHEMBL189584 & 954399 & 3.8859 & 3.9486 & TRN & & \\
\hline CHEMBL210618 & 954399 & 3.9963 & 3.88 & TRN & & \\
\hline CHEMBL3186408 & 954399 & 3.1864 & 2.7426 & TST & & \\
\hline CHEMBL102714 & 954399 & 3.4409 & 3.3826 & TRN & & \\
\hline
\end{tabular}




\begin{tabular}{|c|c|c|c|c|c|}
\hline \multirow[b]{2}{*}{ CHEMBL 300389} & \multicolumn{5}{|c|}{ Supplemental Table S2.txt } \\
\hline & 954399 & 6.138 & 6.13399 & 99999999995 & TRN \\
\hline CHEMBL221137 & 954399 & 2.7213 & 3.4353 & TST & \\
\hline CHEMBL240954 & 954399 & 3.582 & 3.7084 & TST & \\
\hline CHEMBL393929 & 954399 & 3.3364 & 3.4663 & TRN & \\
\hline CHEMBL92309 & 954399 & 1.84 & 2.6714 & TST & \\
\hline CHEMBL3199475 & 954399 & 3.9652 & 3.9414 & TRN & \\
\hline CHEMBL209148 & 954399 & 3.705 & 3.7141 & TRN & \\
\hline CHEMBL472940 & 954399 & 3.6212 & 3.5502 & TRN & \\
\hline CHEMBL379300 & 954399 & 5.0829 & 5.0896 & TRN & \\
\hline CHEMBL2144069 & 954399 & 3.9339 & 3.9213 & TRN & \\
\hline CHEMBL 255342 & 954399 & 3.4283 & 3.3458 & TRN & \\
\hline CHEMBL392695 & 954399 & 3.3783 & 3.393006 & 00000000002 & TRN \\
\hline CHEMBL1643959 & 954399 & 3.6068 & 3.653 & TRN & \\
\hline CHEMBL3349342 & 954399 & 4.4268 & 4.3747 & TRN & \\
\hline CHEMBL512504 & 954399 & 3.6107 & 3.6555 & TRN & \\
\hline CHEMBL514499 & 954399 & 4.6146 & 4.6187 & TRN & \\
\hline CHEMBL1230020 & 954399 & 3.6838 & 3.6589 & TRN & \\
\hline CHEMBL1190711 & 954399 & 3.7105 & 3.6939 & TRN & \\
\hline CHEMBL180127 & 954399 & 3.9136 & 3.9365 & TRN & \\
\hline CHEMBL1970879 & 954399 & 3.5905 & 3.5312 & TRN & \\
\hline CHEMBL573107 & 954399 & 4.3156 & 4.2886 & TRN & \\
\hline CHEMBL509032 & 954399 & 3.6597 & 3.6114 & TRN & \\
\hline CHEMBL1357247 & 954399 & 2.8286 & 2.8241 & TRN & \\
\hline CHEMBL 213100 & 954399 & 4.1693 & 4.2364 & TRN & \\
\hline CHEMBL217354 & 954399 & 5.6663 & 5.6911 & TRN & \\
\hline CHEMBL449158 & 954399 & 5.7866 & 5.3217 & TST & \\
\hline CHEMBL2005886 & 954399 & 3.3547 & 3.3691 & TRN & \\
\hline CHEMBL135561 & 954399 & 3.7275 & 3.7674 & TRN & \\
\hline CHEMBL577784 & 954399 & 4.5685 & 4.5415 & TRN & \\
\hline CHEMBL202721 & 954399 & 3.7334 & 3.7313 & TRN & \\
\hline CHEMBL1404918 & 954399 & 3.2094 & 3.2249 & TRN & \\
\hline CHEMBL1242367 & 954399 & 3.5662 & 3.5881 & TRN & \\
\hline CHEMBL222102 & 954399 & 4.9513 & 3.4743 & TST & \\
\hline CHEMBL191334 & 954399 & 3.486 & 3.9685 & TST & \\
\hline CHEMBL9470 & 954399 & 4.6491 & 4.6464 & TST & \\
\hline CHEMBL1516890 & 954399 & 4.2114 & 4.3331 & TST & \\
\hline CHEMBL3392440 & 954399 & 3.3718 & 3.6465 & TST & \\
\hline CHEMBL399530 & 954399 & 3.6138 & 4.2352 & TST & \\
\hline CHEMBL65 & 954399 & 6.5966 & 6.2804 & TST & \\
\hline CHEMBL1909414 & 954399 & 3.4712 & 3.4978 & TST & \\
\hline CHEMBL412142 & 954399 & 3.4437 & 4.2307 & TST & \\
\hline CHEMBL3682159 & 1528101 & 6.0491 & 6.1466 & TST & \\
\hline CHEMBL3686953 & 1528101 & 8.3979 & 8.4909 & TRN & \\
\hline CHEMBL 3687100 & 1528101 & 9.0044 & 8.2488 & TRN & \\
\hline CHEMBL3682205 & 1528101 & 6.7878 & 6.7499 & TRN & \\
\hline CHEMBL 3686921 & 1528101 & 11.4248 & 10.2327 & TRN & \\
\hline CHEMBL3687078 & 1528101 & 7.109 & 7.1779 & TRN & \\
\hline CHEMBL3691513 & 1528101 & 7.5376 & 8.3288 & TST & \\
\hline
\end{tabular}




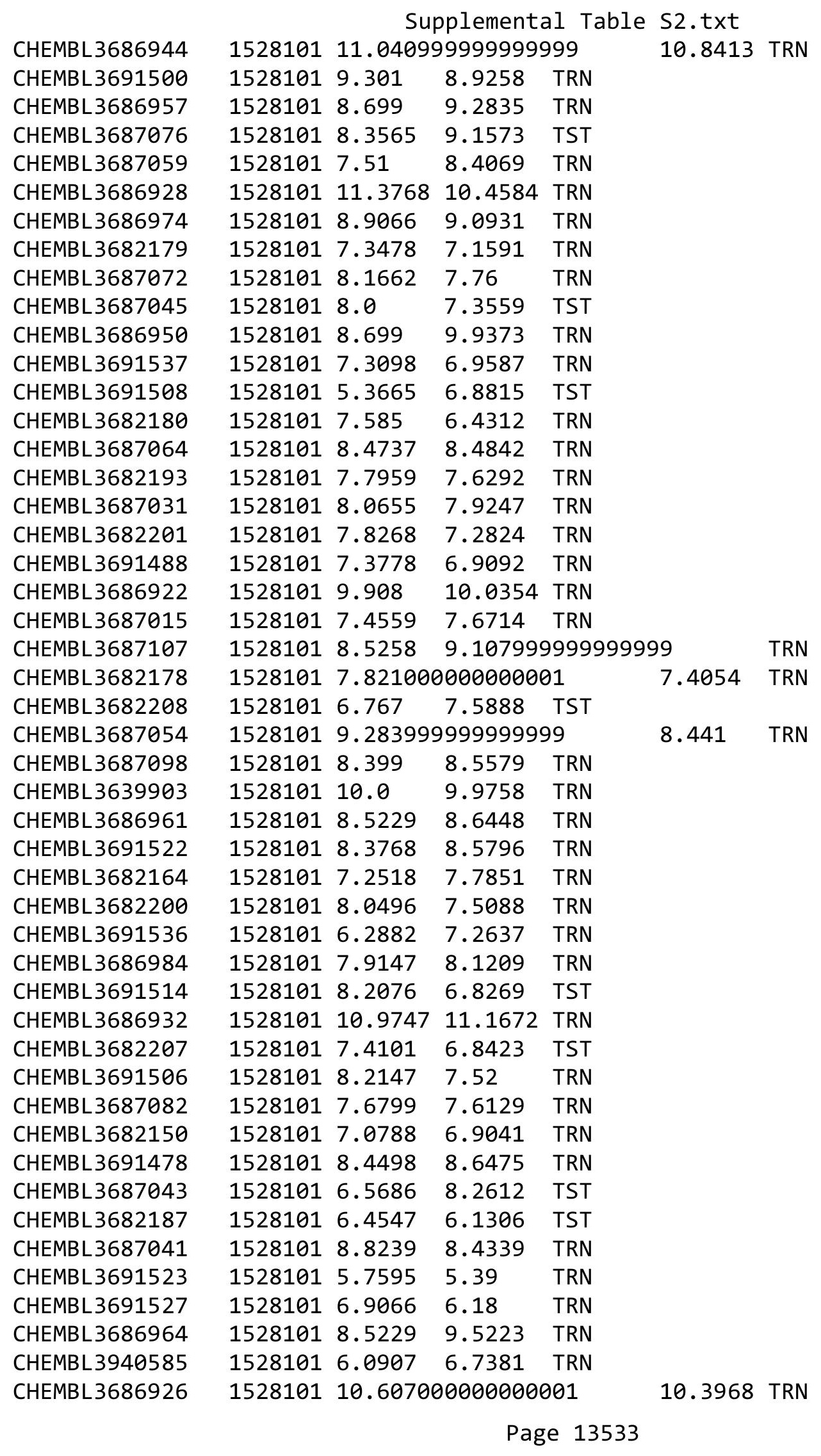


Supplemental Table S2.txt

\begin{tabular}{|c|c|c|c|c|c|c|}
\hline CHEMBL 3682197 & 1528101 & 7.4191 & 7.9147 & TRN & & \\
\hline CHEMBL 3687109 & 1528101 & 8.4056 & 8.2598 & TRN & & \\
\hline CHEMBL3691492 & 1528101 & 6.3098 & 5.9449 & TRN & & \\
\hline CHEMBL 3687063 & 1528101 & 9.1972 & 8.6123 & TRN & & \\
\hline CHEMBL3691489 & 1528101 & 8.9355 & 8.9498 & TRN & & \\
\hline CHEMBL 3687007 & 1528101 & 8.2218 & 8.0648 & TRN & & \\
\hline CHEMBL 3686898 & 1528101 & 7.7959 & 8.4485 & TRN & & \\
\hline CHEMBL 3687071 & 1528101 & 8.3768 & 8.8531 & TST & & \\
\hline CHEMBL 3687062 & 1528101 & 8.8665 & 8.2395 & TRN & & \\
\hline CHEMBL3691530 & 1528101 & 7.3585 & 6.5197 & TRN & & \\
\hline CHEMBL 3682166 & 1528101 & 6.3726 & 6.7958 & TRN & & \\
\hline CHEMBL3691535 & 1528101 & 7.4921 & 6.8759 & TRN & & \\
\hline CHEMBL 3639857 & 1528101 & 10.7670 & 000000000 & 001 & 10.8582 & TRN \\
\hline CHEMBL 2180770 & 1528101 & 7.6596 & 7.3579 & TRN & & \\
\hline CHEMBL3687068 & 1528101 & 8.5258 & 8.4241 & TST & & \\
\hline CHEMBL 3687036 & 1528101 & 7.1805 & 8.2593 & TST & & \\
\hline CHEMBL3691532 & 1528101 & 7.16299 & 999999999 & & 6.7251 & TRN \\
\hline CHEMBL 3686949 & 1528101 & 8.699 & 8.9369 & TRN & & \\
\hline CHEMBL3682181 & 1528101 & 6.6021 & 6.7699 & TRN & & \\
\hline CHEMBL 3687084 & 1528101 & 8.5243 & 8.6661 & TRN & & \\
\hline CHEMBL3691529 & 1528101 & 7.1599 & 7.2775 & TRN & & \\
\hline CHEMBL 3687081 & 1528101 & 7.9208 & 7.8391 & TRN & & \\
\hline CHEMBL3686925 & 1528101 & 10.7891 & 10.3428 & TRN & & \\
\hline CHEMBL 3687039 & 1528101 & 8.2218 & 7.5959 & TRN & & \\
\hline CHEMBL 3682169 & 1528101 & 7.8861 & 8.5885 & TRN & & \\
\hline CHEMBL3686937 & 1528101 & 11.0044 & 9.9287 & TRN & & \\
\hline CHEMBL 3687037 & 1528101 & 7.699 & 8.8006 & TST & & \\
\hline CHEMBL 3686920 & 1528101 & 11.556 & 10.8943 & TRN & & \\
\hline CHEMBL 3686978 & 1528101 & 8.4724 & 8.5071 & TRN & & \\
\hline CHEMBL 3682188 & 1528101 & 6.2403 & 6.8149 & TST & & \\
\hline CHEMBL 3686900 & 1528101 & 7.9245 & 8.1399 & TRN & & \\
\hline CHEMBL 3686998 & 1528101 & 9.0 & 8.3795 & TST & & \\
\hline CHEMBL 3687042 & 1528101 & 7.041 & 8.2412 & TST & & \\
\hline CHEMBL3682199 & 1528101 & 7.7328 & 7.9971 & TRN & & \\
\hline CHEMBL3918378 & 1528101 & 7.8111 & 8.3464 & TST & & \\
\hline CHEMBL3686991 & 1528101 & 8.0 & 8.2044 & TRN & & \\
\hline CHEMBL3686904 & 1528101 & 7.9706 & 8.1034 & TRN & & \\
\hline CHEMBL 3686981 & 1528101 & 8.2848 & 8.4625 & TRN & & \\
\hline CHEMBL 3687067 & 1528101 & 8.2255 & 8.055 & TST & & \\
\hline CHEMBL 3682153 & 1528101 & \multicolumn{3}{|c|}{6.082000000000001} & 5.6447 & TST \\
\hline CHEMBL3686933 & 1528101 & 11.4559 & 11.0455 & TRN & & \\
\hline CHEMBL3955809 & 1528101 & 7.6778 & 8.2471 & TST & & \\
\hline CHEMBL3682183 & 1528101 & 7.4318 & 6.9691 & TRN & & \\
\hline CHEMBL 3682170 & 1528101 & 7.6968 & 8.3772 & TRN & & \\
\hline CHEMBL3682212 & 1528101 & 7.6861 & 7.5788 & TRN & & \\
\hline CHEMBL3682204 & 1528101 & 7.3298 & 7.8344 & TRN & & \\
\hline CHEMBL3691516 & 1528101 & 7.2976 & 8.267999 & 9999999999 & & ודנו \\
\hline CHEMBL3691531 & 1528101 & 7.4283 & 7.8963 & TRN & & \\
\hline
\end{tabular}


Supplemental Table S2.txt

\begin{tabular}{|c|c|c|c|c|}
\hline 6 & & 7.4815 & 7.7887 & . \\
\hline & & & & \\
\hline HFMRI : & 101 & & & \\
\hline IEMBL & L01 & & & \\
\hline HEMBL 369148 & 528101 & 9318 & 0009 & \\
\hline HEMBL368 & 101 & 8.2218 & 8013 & \\
\hline 53 & & & 1898 & \\
\hline AEMBL & & & 504 & \\
\hline HEMBL3682218 & 528101 & 6.0 & 6.9994 & \\
\hline HEMBL 369 & 528101 & 8.6003 & 8.7873 & \\
\hline HEMBL36 & 101 & & 0568 & \\
\hline IEM & 101 & & 4076 & \\
\hline AEMBL: & & 9. & 8.1766 & \\
\hline HEMBL3687001 & 528101 & 8.52 & 0881 & \\
\hline HEMBL369 & 101 & & & \\
\hline AEMBL3 & 91 & 8 . & 7393 & \\
\hline HEMBL & 01 & & 811 & \\
\hline HEMBL; & 01 & 6 & 663 & \\
\hline HEMBL3 & 01 & & 10.7411 & \\
\hline HEMBL 368 & 01 & & & KIN \\
\hline HEMBL; & 1 & & 52 & RI \\
\hline HEM & & & & Niv \\
\hline AEMBL & 01 & 72 & 096 & TRN \\
\hline HEMBL & & & & $\mathrm{RN}$ \\
\hline AEMBL3 & 01 & & 73 & RIN \\
\hline HEMBL3 & 01 & & 79 & RN \\
\hline HEM & & & & ST \\
\hline HEME & & & & RN \\
\hline AEMBL & & & 054 & TR \\
\hline HEMBL389 & 01 & 8 & 72 & RN \\
\hline HEMB & & & 52 & TRN \\
\hline 0 & & & 312 & TRN \\
\hline 4 & & & & RN \\
\hline HEMBL3 & & 11 & & ST \\
\hline HEMBL 368 & 01 & & 362 & RN \\
\hline AEMRI & $\partial 1$ & & 12 & ST \\
\hline 1 & & & & RN \\
\hline HEMBL3 & & & & RN \\
\hline HEMBL3 & 01 & & 896 & $\mathrm{RN}$ \\
\hline 21 & & & 94 & ST \\
\hline HFMRI 3 & & & 975 & RN \\
\hline & 01 & & 568 & RN \\
\hline HEMBL3 & & & 291 & RN \\
\hline HEMBL3 & 01 & & & TS \\
\hline 10 & & & & TST \\
\hline HEMBL3 & & 0.6423 & & RN \\
\hline HEMBL3 & 01 & .5245 & & ST \\
\hline CHEMBL3686919 & 1528101 & 11.5817 & 9.7826 & $T R$ \\
\hline
\end{tabular}

Page 13535 
Supplemental Table S2.txt

\begin{tabular}{|c|c|c|c|c|c|c|}
\hline CHEMBL 3691484 & 1528101 & 8.6271 & 8.8706 & TRN & & \\
\hline CHEMBL 3686927 & 1528101 & 11.6383 & 11.6105 & TRN & & \\
\hline CHEMBL 3682184 & 1528101 & 7.8297 & 6.8939 & TRN & & \\
\hline CHEMBL 3686977 & 1528101 & 7.9678 & 8.4344 & TRN & & \\
\hline CHEMBL3687088 & 1528101 & 6.0635 & 7.9218 & TRN & & \\
\hline CHEMBL 3682158 & 1528101 & 7.475 & 7.048999 & 999999999 & 95 & TRN \\
\hline CHEMBL3686939 & 1528101 & 11.2596 & 10.4459 & TRN & & \\
\hline CHEMBL 3686914 & 1528101 & 11.8697 & 11.3363 & TRN & & \\
\hline CHEMBL 3687066 & 1528101 & 8.2798 & 9.881 & TST & & \\
\hline CHEMBL3686892 & 1528101 & 7.066 & 7.34 & TRN & & \\
\hline CHEMBL 3686916 & 1528101 & 11.10400 & 00000000 & 01 & 11.763 & TRN \\
\hline CHEMBL 3687004 & 1528101 & 6.6478 & 6.7678 & TRN & & \\
\hline CHEMBL 3686982 & 1528101 & 8.0022 & 7.9293 & TRN & & \\
\hline CHEMBL3686899 & 1528101 & 7.7799 & 8.1276 & TRN & & \\
\hline CHEMBL 3686992 & 1528101 & 8.301 & 8.6094 & TRN & & \\
\hline CHEMBL 3686967 & 1528101 & 8.699 & 8.7998 & TRN & & \\
\hline CHEMBL 3687029 & 1528101 & 8.1871 & 8.7184 & TRN & & \\
\hline CHEMBL 3686963 & 1528101 & 7.5686 & 8.5986 & TRN & & \\
\hline CHEMBL 3687048 & 1528101 & 4.0 & 4.9874 & TRN & & \\
\hline CHEMBL 3687025 & 1528101 & 8.4023 & 7.2595 & TRN & & \\
\hline CHEMBL 3687055 & 1528101 & 8.2457 & 7.582000 & 3000000001 & & IV \\
\hline CHEMBL 3686955 & 1528101 & 8.5229 & 8.6002 & TRN & & \\
\hline CHEMBL 3682206 & 1528101 & 7.4401 & 6.7951 & TST & & \\
\hline CHEMBL 3691480 & 1528101 & 7.5376 & 7.4239 & TRN & & \\
\hline CHEMBL 3686994 & 1528101 & 8.699 & 8.1203 & TRN & & \\
\hline CHEMBL 3686952 & 1528101 & 8.3979 & 9.9984 & TRN & & \\
\hline CHEMBL 3686910 & 1528101 & 11.5544 & 11.6812 & TRN & & \\
\hline CHEMBL 3686940 & 1528101 & 11.1739 & 11.1925 & TRN & & \\
\hline CHEMBL 3687027 & 1528101 & 7.8945 & 8.0031 & TRN & & \\
\hline CHEMBL 3682157 & 1528101 & 5.327000 & 00000000 & 1 & 4.5108 & .0 \\
\hline CHEMBL 3687010 & 1528101 & 7.8027 & 7.1375 & TRN & & \\
\hline CHEMBL 3686903 & 1528101 & 6.0 & 7.1454 & TRN & & \\
\hline CHEMBL 3687097 & 1528101 & 7.4921 & 8.1694 & TST & & \\
\hline CHEMBL3686958 & 1528101 & 8.699 & 9.1958 & TRN & & \\
\hline CHEMBL 3687105 & 1528101 & 6.8761 & 8.0826 & TRN & & \\
\hline CHEMBL 3687017 & 1528101 & 8.301 & 8.6437 & TRN & & \\
\hline CHEMBL3687096 & 1528101 & 6.7423 & 9.4842 & TST & & \\
\hline CHEMBL 3686951 & 1528101 & 8.0 & 8.896 & TRN & & \\
\hline CHEMBL 3682165 & 1528101 & 7.5243 & 7.2418 & TRN & & \\
\hline CHEMBL 3687016 & 1528101 & 7.794 & 6.9839 & TRN & & \\
\hline CHEMBL 3682177 & 1528101 & 7.6073 & 7.0508 & TRN & & \\
\hline CHEMBL 3682147 & 1528101 & 7.567 & 8.2149 & TRN & & \\
\hline CHEMBL 3682211 & 1528101 & 8.5058 & 8.6025 & TRN & & \\
\hline CHEMBL3682171 & 1528101 & 7.4056 & 8.5278 & TRN & & \\
\hline CHEMBL 3687089 & 1528101 & 8.2823 & 7.9816 & TRN & & \\
\hline CHEMBL 3682196 & 1528101 & 8.1427 & 8.2673 & TRN & & \\
\hline CHEMBL 3691538 & 1528101 & 7.2495 & 7.8278 & TRN & & \\
\hline CHEMBL3686969 & 1528101 & 8.1549 & 8.8621 & TRN & & \\
\hline
\end{tabular}

Page 13536 
Supplemental Table S2.txt

\begin{tabular}{|c|c|c|c|c|c|}
\hline CHEMBL 3687046 & 1528101 & 7.8861 & \multicolumn{2}{|c|}{7.1129999999999995} & TST \\
\hline CHEMBL 3687058 & 1528101 & 8.2111 & 8.2666 & TRN & \\
\hline CHEMBL 3687000 & 1528101 & 9.0 & 8.3041 & TRN & \\
\hline CHEMBL 3686972 & 1528101 & 7.8716 & 8.3536 & TRN & \\
\hline CHEMBL3682156 & 1528101 & 5.6925 & 5.4953 & TST & \\
\hline CHEMBL 3687095 & 1528101 & 8.6144 & 8.6546 & TRN & \\
\hline CHEMBL3691525 & 1528101 & 5.6904 & 6.0453 & TRN & \\
\hline CHEMBL 3686934 & 1528101 & 10.9586 & 10.7998 & TRN & \\
\hline CHEMBL 3687079 & 1528101 & 7.2518 & 7.5021 & TST & \\
\hline CHEMBL3686906 & 1528101 & 7.5591 & 6.6294 & TST & \\
\hline CHEMBL3682195 & 1528101 & 7.3179 & 7.5503 & TST & \\
\hline CHEMBL 3682172 & 1528101 & 6.71 & 7.8818 & TRN & \\
\hline CHEMBL 3687077 & 1528101 & 7.5406 & 7.4862 & TRN & \\
\hline CHEMBL 3691504 & 1528101 & 6.9547 & 7.3676 & TRN & \\
\hline CHEMBL3691496 & 1528101 & 7.6326 & 7.6874 & TRN & \\
\hline CHEMBL3682190 & 1528101 & 7.6635 & 8.1283 & TST & \\
\hline CHEMBL3686891 & 1528101 & 5.3686 & 5.9698 & TST & \\
\hline CHEMBL 3686894 & 1528101 & 7.1772 & 7.8339 & TST & \\
\hline CHEMBL 3682213 & 1528101 & 6.0 & 7.1504 & TST & \\
\hline CHEMBL3686907 & 1528101 & 6.8794 & \multicolumn{2}{|c|}{6.242999999999999} & TST \\
\hline CHEMBL 3686962 & 1528101 & 7.4685 & 8.3174 & TRN & \\
\hline CHEMBL 3691528 & 1528101 & 6.8827 & 6.6194 & TRN & \\
\hline CHEMBL3686989 & 1528101 & 7.6739 & 7.9499 & TRN & \\
\hline CHEMBL 3686990 & 1528101 & 9.0 & 8.8912 & TRN & \\
\hline CHEMBL3686976 & 1528101 & 8.1772 & 8.4166 & TRN & \\
\hline CHEMBL 3687011 & 1528101 & 6.1838 & 7.0645 & TRN & \\
\hline CHEMBL3691510 & 1528101 & 8.0 & 6.8653 & TST & \\
\hline CHEMBL3639858 & 1528101 & 7.8327 & 7.6952 & TRN & \\
\hline CHEMBL3686901 & 1528101 & 6.7167 & 7.1187 & TST & \\
\hline CHEMBL3686987 & 1528101 & 8.1325 & 8.2207 & TRN & \\
\hline CHEMBL 3682168 & 1528101 & 6.1938 & 7.6848 & TRN & \\
\hline CHEMBL3686913 & 1528101 & 10.8477 & 11.2557 & TRN & \\
\hline CHEMBL 3687030 & 1528101 & 9.8861 & 9.1812 & TRN & \\
\hline CHEMBL 3686947 & 1528101 & 11.1549 & 11.2633 & TRN & \\
\hline CHEMBL3682173 & 1528101 & 7.8861 & 7.4309 & TRN & \\
\hline CHEMBL3686897 & 1528101 & 7.0615 & 7.5303 & TST & \\
\hline CHEMBL3686909 & 1528101 & 11.6308 & 10.1917 & TRN & \\
\hline CHEMBL3691497 & 1528101 & 7.9318 & 7.9392 & TRN & \\
\hline CHEMBL3691533 & 1528101 & 7.0097 & 6.312 & TRN & \\
\hline CHEMBL3687026 & 1528101 & 7.659 & 7.3042 & TRN & \\
\hline CHEMBL3691493 & 1528101 & 6.3316 & 5.6056 & TRN & \\
\hline CHEMBL3686924 & 1528101 & 10.5807 & 10.0883 & TST & \\
\hline CHEMBL3682151 & 1528101 & 7.6635 & 7.3083 & TRN & \\
\hline CHEMBL 3687074 & 1528101 & 7.7597 & 7.4359 & TST & \\
\hline CHEMBL3687019 & 1528101 & 6.7235 & 8.0974 & TST & \\
\hline CHEMBL 3686980 & 1528101 & 7.7652 & 8.7655 & TRN & \\
\hline CHEMBL 3682175 & 1528101 & 7.4737 & 7.2803 & TRN & \\
\hline CHEMBL3687091 & 1528101 & 8.5918 & 8.0255 & TRN & \\
\hline
\end{tabular}


Supplemental Table S2.txt

CHEMBL3686931

CHEMBL 3686918

CHEMBL3682210

CHEMBL3691499

CHEMBL3691487

CHEMBL 3682194

CHEMBL 3687033

CHEMBL3682155

CHEMBL 3682145

CHEMBL 3682191

CHEMBL 3687083

CHEMBL 3687106

CHEMBL3686946

CHEMBL3682162

CHEMBL3691534

CHEMBL 3691485

CHEMBL 3687038

CHEMBL3682215

CHEMBL3691519

CHEMBL3682154

CHEMBL 3686908

CHEMBL3682214

CHEMBL3686966

CHEMBL3682174

CHEMBL3691509

CHEMBL 3682182

CHEMBL 3682185

CHEMBL 3682148

CHEMBL3682202

CHEMBL3682209

CHEMBL 3682146

CHEMBL3687092

CHEMBL3691526

CHEMBL3682144

CHEMBL3687047

CHEMBL3686942

CHEMBL3686943

CHEMBL 3691476

CHEMBL3682163

CHEMBL 3691490

CHEMBL3687094

CHEMBL 3687056

CHEMBL3686893

CHEMBL 3687034

CHEMBL 3687013

CHEMBL 3686929

CHEMBL 3686996

CHEMBL3691524 $\begin{array}{lll}1528101 & 11.2076 & 10.1818 \text { TRN }\end{array}$

152810111.104000000000001

$\begin{array}{llll}1528101 & 7.2321 & 7.4376 & \text { TST }\end{array}$

$\begin{array}{llll}1528101 & 8.1675 & 8.6292 & \text { TRN }\end{array}$

$\begin{array}{llll}1528101 & 8.4318 & 9.6287 & \text { TRN }\end{array}$

$\begin{array}{llll}1528101 & 7.5654 & 8.1302 & \text { TST }\end{array}$

$\begin{array}{llll}1528101 & 7.6778 & 8.1781 & \text { TRN }\end{array}$

$\begin{array}{llll}1528101 & 4.9245 & 6.2232 & \text { TST }\end{array}$

$\begin{array}{llll}1528101 & 7.0362 & 7.1336 & \text { TRN }\end{array}$

$\begin{array}{llll}1528101 & 7.6882 & 7.9642 & \text { TST }\end{array}$

$\begin{array}{llll}1528101 & 7.4962 & 7.7472 & \text { TST }\end{array}$

$\begin{array}{llll}1528101 & 7.9547 & 8.4568 & \text { TRN }\end{array}$

$\begin{array}{llll}1528101 & 12.0 & 7.7641 & \text { TST }\end{array}$

$\begin{array}{llll}1528101 & 7.4535 & 6.8533 & \text { TRN }\end{array}$

$\begin{array}{llll}1528101 & 7.0605 & 6.6779 & \text { TRN }\end{array}$

$\begin{array}{llll}1528101 & 9.2218 & 7.6156 & \text { TST }\end{array}$

$\begin{array}{llll}1528101 & 8.2518 & 7.5277 & \text { TST }\end{array}$

$\begin{array}{llll}1528101 & 7.0545 & 7.9015 & \text { TST }\end{array}$

$\begin{array}{llll}1528101 & 9.0969 & 8.4229 & \text { TRN }\end{array}$

$\begin{array}{llll}1528101 & 5.4353 & 5.6806 & \text { TST }\end{array}$

$\begin{array}{llll}1528101 & 6.3098 & 7.0341 & \text { TST }\end{array}$

$\begin{array}{llll}1528101 & 7.466 & 8.1034 & \text { TST }\end{array}$

$\begin{array}{llll}1528101 & 9.1549 & 7.4991 & \text { TST }\end{array}$

$\begin{array}{llll}1528101 & 6.6655 & 7.0536 & \text { TRN }\end{array}$

$\begin{array}{llll}1528101 & 7.7959 & 7.8644 & \text { TST }\end{array}$

$\begin{array}{llll}1528101 & 6.2314 & 7.0534 & \text { TRN }\end{array}$

$\begin{array}{llll}1528101 & 6.6459 & 6.7358 & \text { TRN }\end{array}$

$\begin{array}{llll}1528101 & 7.9393 & 8.163 & \text { TST }\end{array}$

$\begin{array}{llll}1528101 & 8.1701 & 7.4147 & \text { TST }\end{array}$

$\begin{array}{llll}1528101 & 6.1308 & 7.2033 & \text { TST }\end{array}$

$\begin{array}{llll}1528101 & 6.3507 & 7.3673 & \text { TST }\end{array}$

$\begin{array}{llll}1528101 & 7.4908 & 8.1019 & \text { TST }\end{array}$

$\begin{array}{llll}1528101 & 6.1367 & 6.3373 & \text { TRN }\end{array}$

$\begin{array}{llll}1528101 & 6.0742 & 6.8391 & \text { TRN }\end{array}$

$\begin{array}{llll}1528101 & 8.3979 & 7.8981 & \text { TST }\end{array}$

$\begin{array}{lll}1528101 & 11.193810 .8258 \text { TRN }\end{array}$

$\begin{array}{llll}1528101 & 10.0521 & 9.7572 & \text { TRN }\end{array}$

$\begin{array}{llll}1528101 & 9.0953 & 8.6132 & \text { TRN }\end{array}$

$\begin{array}{llll}1528101 & 7.4473 & 6.9924 & \text { TRN }\end{array}$

$\begin{array}{llll}1528101 & 7.8416 & 8.6886 & \text { TRN }\end{array}$

$\begin{array}{llll}1528101 & 6.2343 & 5.6818 & \text { TRN }\end{array}$

$\begin{array}{llll}1528101 & 8.699 & 8.6145 & \text { TRN }\end{array}$

$\begin{array}{llll}1528101 & 7.4342 & 8.0979 & \text { TST }\end{array}$

$\begin{array}{llll}1528101 & 7.5686 & 7.5918 & \text { TRN }\end{array}$

$\begin{array}{llll}1528101 & 8.5229 & 8.2598 & \text { TRN }\end{array}$

$\begin{array}{lll}1528101 & 11.6383 & 10.6328 \\ \text { TRN }\end{array}$

$\begin{array}{llll}1528101 & 8.5229 & 8.099 & \text { TRN }\end{array}$

$\begin{array}{llll}1528101 & 6.1079 & 6.1092 & \text { TRN }\end{array}$
9.8819 TRN 
Supplemental Table S2.txt

\begin{tabular}{|c|c|c|c|c|}
\hline CHEMBL3919984 & 1528101 & 6.0 & 7.2653 & TRN \\
\hline CHEMBL3691495 & 1528101 & 8.6421 & 7.337999 & 9999999999 \\
\hline CHEMBL 3686970 & 1528101 & 7.7447 & 7.5507 & TRN \\
\hline CHEMBL 3686890 & 1528101 & 7.2027 & 7.3915 & TST \\
\hline CHEMBL 3682198 & 1528101 & 8.2765 & 8.4417 & TST \\
\hline CHEMBL3686911 & 1528101 & 11.1884 & 10.3397 & TRN \\
\hline CHEMBL 3687104 & 1528101 & 8.3546 & 8.5676 & TRN \\
\hline CHEMBL 3687060 & 1528101 & 7.7496 & 8.0137 & TRN \\
\hline CHEMBL3691483 & 1528101 & 7.466 & 7.0254 & TRN \\
\hline CHEMBL3691498 & 1528101 & 10.0 & 9.2042 & TRN \\
\hline CHEMBL3682192 & 1528101 & 7.1965 & 7.2864 & TST \\
\hline CHEMBL 3687101 & 1528101 & 8.6536 & 8.7015 & TRN \\
\hline CHEMBL3687099 & 1528101 & 8.8069 & 8.7368 & TST \\
\hline CHEMBL3682186 & 1528101 & 6.8665 & 6.2301 & TST \\
\hline CHEMBL 3686983 & 1528101 & 8.2154 & 9.0139 & TRN \\
\hline CHEMBL3675659 & 1528101 & 9.1549 & 8.7409 & TRN \\
\hline CHEMBL3686985 & 1528101 & 7.7577 & 8.4813 & TRN \\
\hline CHEMBL3682149 & 1528101 & 6.0362 & 6.6591 & TST \\
\hline CHEMBL3686938 & 1528101 & 11.0757 & 10.9488 & TRN \\
\hline CHEMBL3687061 & 1528101 & 8.1319 & 7.8529 & TRN \\
\hline CHEMBL3686889 & 1528101 & 8.0269 & 7.8259 & TST \\
\hline CHEMBL 3687014 & 1528101 & 6.6326 & 5.7418 & TRN \\
\hline CHEMBL3686956 & 1528101 & 9.699 & 9.2509 & TRN \\
\hline CHEMBL3686941 & 1528101 & 11.1427 & 10.4623 & TRN \\
\hline CHEMBL3691491 & 1528101 & 6.6635 & 6.3862 & TRN \\
\hline CHEMBL3691502 & 1528101 & 6.0013 & 6.8363 & TRN \\
\hline CHEMBL3675660 & 1528101 & 8.8861 & 8.3949 & TRN \\
\hline CHEMBL3691501 & 1528101 & 4.0 & 7.5721 & TST \\
\hline CHEMBL3687049 & 1528101 & 7.4202 & 8.0352 & TRN \\
\hline CHEMBL 3687044 & 1528101 & 8.6576 & 7.4605 & TST \\
\hline CHEMBL3687075 & 1528101 & 7.9151 & 10.7371 & TST \\
\hline CHEMBL 3687087 & 1528101 & 8.2154 & 8.6469 & TRN \\
\hline CHEMBL3687018 & 1528101 & 7.0706 & 7.5012 & TRN \\
\hline CHEMBL3687035 & 1528101 & 8.0132 & 7.834 & TRN \\
\hline CHEMBL 3687108 & 1528101 & 8.3595 & 8.5652 & TRN \\
\hline CHEMBL3686905 & 1528101 & 7.6326 & 7.9912 & TST \\
\hline CHEMBL 3687093 & 1528101 & 5.6635 & 7.2074 & TST \\
\hline CHEMBL3686965 & 1528101 & 8.699 & 8.1081 & TRN \\
\hline CHEMBL3686979 & 1528101 & 7.7688 & 7.6839 & TRN \\
\hline CHEMBL3682203 & 1528101 & 7.3665 & 7.6358 & TST \\
\hline CHEMBL3686973 & 1528101 & 8.4112 & 8.7917 & TRN \\
\hline CHEMBL 3687051 & 1528101 & 7.9586 & 7.8083 & TRN \\
\hline CHEMBL3686971 & 1528101 & 8.699 & 8.3395 & TRN \\
\hline CHEMBL3691482 & 1528101 & 7.1965 & 7.527 & TRN \\
\hline CHEMBL 3687050 & 1528101 & 8.699 & 8.0994 & TST \\
\hline CHEMBL3686954 & 1528101 & 8.5229 & 8.5224 & TRN \\
\hline CHEMBL 3639810 & 1528101 & 6.27 & 6.1311 & TRN \\
\hline CHEMBL3691520 & 1528101 & 9.2218 & 8.73 & TRN \\
\hline
\end{tabular}

TRN 
Supplemental Table S2.txt

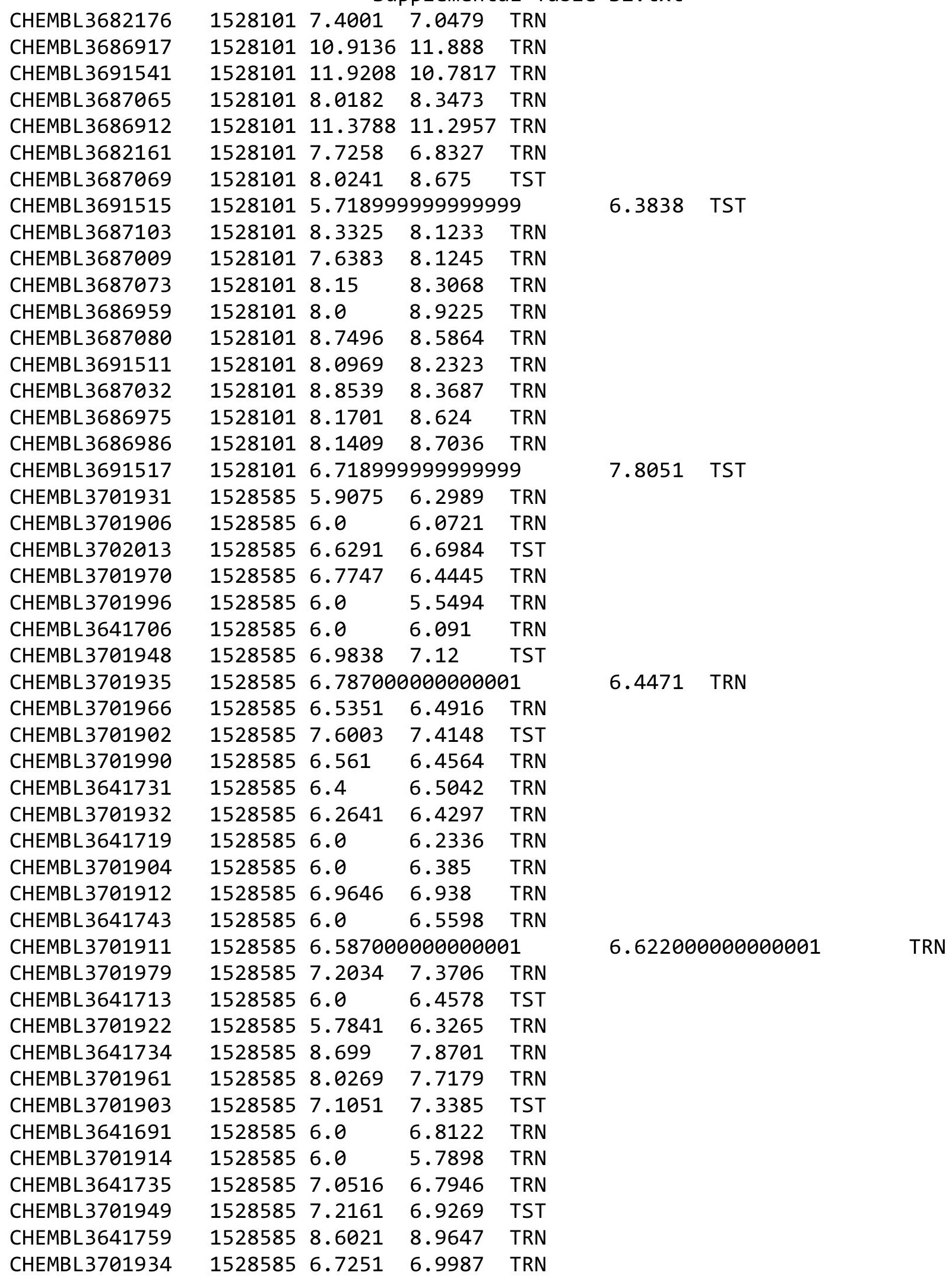




\begin{tabular}{|c|c|c|c|c|c|c|}
\hline \multicolumn{7}{|c|}{ Supplemental Table S2.txt } \\
\hline CHEMBL3701905 & 1528585 & 6.0 & 5.9708 & TRN & & \\
\hline CHEMBL3701994 & 1528585 & 6.0 & 5.8991 & TRN & & \\
\hline CHEMBL3702019 & 1528585 & 6.0 & 5.7039 & TRN & & \\
\hline CHEMBL3701965 & 1528585 & 6.5902 & 5.3578 & TST & & \\
\hline CHEMBL3701936 & 1528585 & 5.9304 & 5.8782 & TRN & & \\
\hline CHEMBL3701943 & 1528585 & 7.9281 & 7.9363 & TRN & & \\
\hline CHEMBL 3641700 & 1528585 & 6.0 & 5.8912 & TRN & & \\
\hline CHEMBL3641692 & 1528585 & 6.0 & 5.865 & TRN & & \\
\hline CHEMBL3701958 & 1528585 & 6.6834 & 6.9691 & TRN & & \\
\hline CHEMBL3641748 & 1528585 & 6.7883 & 6.9039 & TRN & & \\
\hline CHEMBL3701954 & 1528585 & 5.7024 & 4.9766 & TRN & & \\
\hline CHEMBL3641695 & 1528585 & 6.0 & 5.6209 & TRN & & \\
\hline CHEMBL3701913 & 1528585 & 6.2976 & 6.4148 & TRN & & \\
\hline CHEMBL3641751 & 1528585 & 7.2034 & 7.0799 & TRN & & \\
\hline CHEMBL3641723 & 1528585 & 7.2041 & 6.956 & TRN & & \\
\hline CHEMBL3701986 & 1528585 & 6.0 & 5.9005 & TRN & & \\
\hline CHEMBL3641717 & 1528585 & 6.4692 & 6.7136 & TRN & & \\
\hline CHEMBL 3701940 & 1528585 & 5.9662 & 5.3589 & TRN & & \\
\hline CHEMBL3701907 & 1528585 & 7.4881 & 7.1961 & TRN & & \\
\hline CHEMBL3701957 & 1528585 & 6.2333 & 6.3734 & TRN & & \\
\hline CHEMBL3702012 & 1528585 & 6.0018 & 6.7281 & TST & & \\
\hline CHEMBL3641702 & 1528585 & 6.0 & 5.9281 & TRN & & \\
\hline CHEMBL3701933 & 1528585 & 7.7423 & 7.5449 & TRN & & \\
\hline CHEMBL 3641698 & 1528585 & 6.0 & 6.586 & TRN & & \\
\hline CHEMBL3701928 & 1528585 & 6.0 & 5.9949 & TRN & & \\
\hline CHEMBL3701989 & 1528585 & 6.0 & 6.3693 & TRN & & \\
\hline CHEMBL3641715 & 1528585 & 6.0 & 6.2411 & TST & & \\
\hline CHEMBL3701977 & 1528585 & 5.4959 & 5.7289 & TRN & & \\
\hline CHEMBL3701998 & 1528585 & 6.0 & 5.9058 & TRN & & \\
\hline CHEMBL 3640008 & 1528585 & 7.9957 & 7.9512 & TRN & & \\
\hline CHEMBL3701980 & 1528585 & 6.6931 & 6.4327 & TRN & & \\
\hline CHEMBL3641728 & 1528585 & 7.5258 & 7.4132 & TRN & & \\
\hline CHEMBL 3702000 & 1528585 & 6.0 & 5.9398 & TRN & & \\
\hline CHEMBL 3641755 & 1528585 & 6.7902 & 6.8991 & TRN & & \\
\hline CHEMBL3701987 & 1528585 & 6.7528 & 6.4837 & TRN & & \\
\hline CHEMBL3641749 & 1528585 & 7.2518 & 6.8891 & TRN & & \\
\hline CHEMBL3701974 & 1528585 & 6.6421 & 6.6322 & TRN & & \\
\hline CHEMBL3701969 & 1528585 & 5.3908 & 5.8266 & TRN & & \\
\hline CHEMBL 3641724 & 1528585 & $7.2020 e$ & 0000000 & $\partial 1$ & 7.7197 & TRN \\
\hline CHEMBL3701939 & 1528585 & 6.7254 & 7.0505 & TRN & & \\
\hline CHEMBL3701971 & 1528585 & 6.6576 & 6.9966 & TRN & & \\
\hline CHEMBL3701915 & 1528585 & 6.3484 & 6.2297 & TRN & & \\
\hline CHEMBL3641736 & 1528585 & 5.9579 & 6.2656 & TRN & & \\
\hline CHEMBL3701910 & 1528585 & 7.6326 & 7.392 & TRN & & \\
\hline CHEMBL 3641757 & 1528585 & 7.9914 & 8.1795 & TRN & & \\
\hline CHEMBL3701921 & 1528585 & 6.3298 & 6.1818 & TRN & & \\
\hline CHEMBL3701930 & 1528585 & 6.6533 & 6.6083 & TRN & & \\
\hline CHEMBL3701901 & 1528585 & 5.4541 & 5.9949 & TST & & \\
\hline
\end{tabular}


Supplemental Table S2.txt

\begin{tabular}{|c|c|c|c|c|c|}
\hline CHEMBL 3701925 & 1528585 & 8.0809 & 7.4774 & TST & \\
\hline CHEMBL 3641761 & 1528585 & 8.9586 & 8.5251 & TRN & \\
\hline CHEMBL3701962 & 1528585 & 5.8269 & 6.0342 & TRN & \\
\hline CHEMBL 3701982 & 1528585 & 7.2441 & 7.5229 & TRN & \\
\hline CHEMBL3701929 & 1528585 & 7.3799 & 7.0525 & TRN & \\
\hline CHEMBL 3701951 & 1528585 & 8.0757 & 8.1837 & TRN & \\
\hline CHEMBL 3701917 & 1528585 & 6.504 & 6.3033 & TRN & \\
\hline CHEMBL 3701926 & 1528585 & 6.0924 & 6.0023 & TRN & \\
\hline CHEMBL 3701920 & 1528585 & 6.0 & 5.933 & TRN & \\
\hline CHEMBL3701988 & 1528585 & 6.6338 & 6.6367 & TRN & \\
\hline CHEMBL 3701956 & 1528585 & 7.0625 & 7.0408 & TRN & \\
\hline CHEMBL 3701942 & 1528585 & 6.1882 & 6.5915 & TRN & \\
\hline CHEMBL 3641740 & 1528585 & 7.3747 & 7.6955 & TRN & \\
\hline CHEMBL 3641697 & 1528585 & 6.5473 & 6.1259 & TST & \\
\hline CHEMBL3701955 & 1528585 & 6.6757 & 6.5364 & TRN & \\
\hline CHEMBL 3641733 & 1528585 & 6.7602 & 6.7715 & TRN & \\
\hline CHEMBL3641699 & 1528585 & 6.8526 & 6.8764 & TST & \\
\hline CHEMBL 3641752 & 1528585 & 8.1871 & 7.5786 & TRN & \\
\hline CHEMBL 3701927 & 1528585 & 6.251 & 5.9561 & TST & \\
\hline CHEMBL3701964 & 1528585 & 6.2013 & 6.9616 & TST & \\
\hline CHEMBL3701916 & 1528585 & 6.0 & 5.5941 & TRN & \\
\hline CHEMBL 3641710 & 1528585 & 6.0 & 5.8526 & TRN & \\
\hline CHEMBL 3701946 & 1528585 & 8.1739 & 7.9893 & TRN & \\
\hline CHEMBL 3641742 & 1528585 & 6.0 & 6.4043 & TRN & \\
\hline CHEMBL 3641725 & 1528585 & 8.1805 & 7.9753 & TRN & \\
\hline CHEMBL3701975 & 1528585 & 7.3468 & 7.4586 & TRN & \\
\hline CHEMBL 3701997 & 1528585 & 7.7328 & 7.2768 & TRN & \\
\hline CHEMBL 3641741 & 1528585 & 8.4949 & 7.7252 & TRN & \\
\hline CHEMBL 3701950 & 1528585 & 6.5524 & 7.006 & TST & \\
\hline CHEMBL 3641704 & 1528585 & 6.0 & 5.8355 & TRN & \\
\hline CHEMBL 3701963 & 1528585 & 6.9957 & 7.334 & TRN & \\
\hline CHEMBL 3641712 & 1528585 & 5.5608 & 6.7717 & TST & \\
\hline CHEMBL 3641753 & 1528585 & 8.7696 & 8.7528 & TRN & \\
\hline CHEMBL 3701918 & 1528585 & 6.0 & 5.9168 & TRN & \\
\hline CHEMBL 3641729 & 1528585 & 7.2865 & 7.3795 & TRN & \\
\hline CHEMBL 3701978 & 1528585 & 7.1451 & 7.1501 & TRN & \\
\hline CHEMBL 3701959 & 1528585 & 6.1202 & 6.4968 & TST & \\
\hline CHEMBL 3701960 & 1528585 & 6.29899 & 999999999 & 995 & 6.4824 \\
\hline CHEMBL 3641746 & 1528585 & 6.0 & 6.7368 & TRN & \\
\hline CHEMBL 3641718 & 1528585 & 6.0 & 5.8807 & TRN & \\
\hline CHEMBL 3701924 & 1528585 & 7.1518 & 7.4834 & TRN & \\
\hline CHEMBL 3641722 & 1528585 & 6.0 & 6.8271 & TRN & \\
\hline CHEMBL 3641758 & 1528585 & 8.4559 & 8.1919 & TRN & \\
\hline CHEMBL 3641760 & 1528585 & 7.5751 & 7.5303 & TRN & \\
\hline CHEMBL 3701985 & 1528585 & 6.0 & 5.5613 & TRN & \\
\hline CHEMBL 3701947 & 1528585 & 6.6315 & 6.4624 & TST & \\
\hline CHEMBL 3641727 & 1528585 & 7.5243 & 7.3409 & TRN & \\
\hline CHEMBL 3641694 & 1528585 & 5.2798 & 6.3367 & TST & \\
\hline
\end{tabular}


Supplemental Table S2.txt

\begin{tabular}{|c|c|c|c|c|c|}
\hline CHEMBL3701952 & 1528585 & 8.3468 & 8.0511 & TRN & \\
\hline CHEMBL3701945 & 1528585 & 7.1918 & 7.6795 & TRN & \\
\hline CHEMBL3701938 & 1528585 & 6.5996 & 6.5478 & TRN & \\
\hline CHEMBL3701973 & 1528585 & 7.5302 & 7.5084 & TRN & \\
\hline CHEMBL3701999 & 1528585 & 6.0 & 5.9072 & TRN & \\
\hline CHEMBL3641726 & 1528585 & 4.0 & 5.0908 & TRN & \\
\hline CHEMBL3641730 & 1528585 & 7.4815 & 7.1155 & TRN & \\
\hline CHEMBL3641738 & 1528585 & 8.4815 & 8.3467 & TRN & \\
\hline CHEMBL3702018 & 1528585 & 7.4389 & 7.5407 & TRN & \\
\hline CHEMBL3701923 & 1528585 & 6.8268 & 6.8293 & TRN & \\
\hline CHEMBL3701953 & 1528585 & 7.8601 & 7.7689 & TRN & \\
\hline CHEMBL3641732 & 1528585 & 6.3502 & 6.8056 & TST & \\
\hline CHEMBL3701941 & 1528585 & 7.2857 & 6.995 & TST & \\
\hline CHEMBL3701919 & 1528585 & 6.1168 & 6.7374 & TST & \\
\hline CHEMBL3702011 & 1528585 & 7.057 & 7.172999 & 9999999999 & TST \\
\hline CHEMBL3701976 & 1528585 & 6.8847 & 6.7219 & TST & \\
\hline CHEMBL3702010 & 1528585 & 6.7064 & 6.7294 & TST & \\
\hline CHEMBL3641756 & 1528585 & 7.0164 & 6.9309 & TST & \\
\hline CHEMBL 3641754 & 1528585 & 8.6778 & 7.655 & TST & \\
\hline CHEMBL 3641750 & 1528585 & 7.2306 & 6.8937 & TST & \\
\hline CHEMBL3701944 & 1528585 & 6.8993 & 6.8996 & TST & \\
\hline CHEMBL3701981 & 1528585 & 7.6536 & 7.5737 & TST & \\
\hline CHEMBL3701972 & 1528585 & 7.4559 & 7.0727 & TST & \\
\hline CHEMBL3701900 & 1528585 & 5.8208 & 6.6209 & TST & \\
\hline CHEMBL3641739 & 1528585 & 7.2182 & 6.1529 & TST & \\
\hline CHEMBL3701909 & 1528585 & 7.4724 & 7.1989 & TST & \\
\hline CHEMBL3702020 & 1528585 & 6.0 & 6.0211 & TST & \\
\hline CHEMBL3701908 & 1528585 & 7.0491 & 6.7795 & TST & \\
\hline CHEMBL3701983 & 1528585 & 7.7122 & 7.5859 & TST & \\
\hline CHEMBL 3641703 & 1528585 & \multicolumn{3}{|c|}{6.827999999999999} & TST \\
\hline CHEMBL142738 & 417162 & 6.72 & 6.4477 & TST & \\
\hline CHEMBL145781 & 417162 & 7.26 & 7.2652 & TRN & \\
\hline CHEMBL339565 & 417162 & 5.75 & 5.6769 & TRN & \\
\hline CHEMBL124935 & 417162 & 6.3 & 6.3054 & TRN & \\
\hline CHEMBL123895 & 417162 & 4.1 & 4.0731 & TRN & \\
\hline CHEMBL339429 & 417162 & 5.66 & 5.6784 & TRN & \\
\hline CHEMBL339027 & 417162 & 5.43 & 5.4335 & TRN & \\
\hline CHEMBL127983 & 417162 & 7.05 & \multicolumn{2}{|c|}{7.1160000000000005} & TRN \\
\hline CHEMBL127774 & 417162 & 6.55 & 6.5403 & TRN & \\
\hline CHEMBL338094 & 417162 & 5.88 & 5.9278 & TRN & \\
\hline CHEMBL127622 & 417162 & 6.18 & 6.1133 & TRN & \\
\hline CHEMBL127517 & 417162 & 6.04 & 6.1005 & TRN & \\
\hline CHEMBL339626 & 417162 & 6.05 & 6.1326 & TRN & \\
\hline CHEMBL127518 & 417162 & 4.8 & 4.8829 & TRN & \\
\hline CHEMBL125921 & 417162 & 6.04 & 5.9249 & TRN & \\
\hline CHEMBL340701 & 417162 & 6.04 & 5.9556 & TRN & \\
\hline CHEMBL127751 & 417162 & 5.38 & 5.4432 & TRN & \\
\hline \multirow[t]{2}{*}{ CHEMBL125044 } & 417162 & 5.49 & 5.94799 & (9999999995 & ונ \\
\hline & & \multicolumn{3}{|c|}{ Page 13543} & \\
\hline
\end{tabular}




\begin{tabular}{|c|c|c|c|c|c|}
\hline & & & & & \\
\hline CHEMBL125094 & 417162 & 5.8 & 5.9766 & TST & \\
\hline CHEMBL127757 & 417162 & 5.0 & 4.8686 & TST & \\
\hline CHEMBL339561 & 417162 & 4.51 & 5.2008 & TST & \\
\hline CHEMBL420523 & 417162 & 4.49 & 4.0339 & TST & \\
\hline CHEMBL127982 & 417162 & 5.66 & 5.6942 & TST & \\
\hline CHEMBL125843 & 417162 & 5.82 & 5.1734 & TST & \\
\hline CHEMBL126505 & 417162 & 4.65 & 5.1936 & TST & \\
\hline CHEMBL338035 & 417162 & 4.51 & 4.8505 & TST & \\
\hline CHEMBL128029 & 417162 & 5.02 & 4.9393 & TST & \\
\hline CHEMBL421088 & 417162 & 4.68 & 5.391 & TST & \\
\hline CHEMBL126504 & 417162 & 4.68 & 4.6763 & TST & \\
\hline CHEMBL341071 & 417162 & 4.13 & 4.6704 & TST & \\
\hline CHEMBL357614 & 417162 & 8.23 & 8.2541 & TRN & \\
\hline CHEMBL142582 & 417162 & 8.07 & 8.2337 & TRN & \\
\hline CHEMBL145792 & 417162 & 8.43 & 8.3202 & TRN & \\
\hline CHEMBL 274030 & 417162 & 8.59 & 8.5679 & TRN & \\
\hline CHEMBL 276076 & 417162 & 8.52 & 8.503 & TRN & \\
\hline CHEMBL18966 & 417162 & 8.21 & 8.1219 & TRN & \\
\hline CHEMBL356977 & 417162 & 8.59 & 8.6407 & TRN & \\
\hline CHEMBL356714 & 417162 & 7.97 & 8.0465 & TRN & \\
\hline CHEMBL143555 & 417162 & 8.24 & 8.2101 & TRN & \\
\hline CHEMBL109018 & 417162 & 8.48 & 8.4973 & TRN & \\
\hline CHEMBL108697 & 417162 & 8.55 & 8.4164 & TRN & \\
\hline CHEMBL439811 & 417162 & 6.6 & 6.5607 & TRN & \\
\hline CHEMBL145003 & 417162 & 7.94 & 7.8732 & TRN & \\
\hline CHEMBL111310 & 417162 & 8.44 & 8.5872 & TRN & \\
\hline CHEMBL109085 & 417162 & 8.36 & 8.3292 & TRN & \\
\hline CHEMBL342327 & 417162 & 7.64 & 7.5903 & TRN & \\
\hline CHEMBL214255 & 417162 & 4.26 & 4.2542 & TRN & \\
\hline CHEMBL342724 & 417162 & 5.51 & 5.7073 & TRN & \\
\hline CHEMBL142916 & 417162 & 7.55 & 7.2441 & TRN & \\
\hline CHEMBL145452 & 417162 & 4.77 & 4.7724 & TRN & \\
\hline CHEMBL18978 & 417162 & 5.28 & 5.2952 & TRN & \\
\hline CHEMBL145292 & 417162 & 7.3 & 7.2979 & TRN & \\
\hline CHEMBL146222 & 417162 & 7.87 & 8.0342 & TRN & \\
\hline CHEMBL142799 & 417162 & 8.46 & 8.2877 & TRN & \\
\hline CHEMBL348922 & 417162 & 6.79 & 6.9114 & TST & \\
\hline CHEMBL111309 & 417162 & 8.36 & 8.5381 & TRN & \\
\hline CHEMBL145374 & 417162 & 5.4 & 5.3699 & TRN & \\
\hline CHEMBL145503 & 417162 & 7.88 & 7.9195 & TRN & \\
\hline CHEMBL108660 & 417162 & 7.74 & 7.79899 & 99999999995 & TRN \\
\hline CHEMBL143316 & 417162 & 5.67 & 5.34399 & 9999999999 & TST \\
\hline CHEMBL434695 & 417162 & 7.07 & 6.9784 & TRN & \\
\hline CHEMBL1083911 & 635221 & 6.6 & 3.1755 & TST & \\
\hline CHEMBL1082362 & 635221 & 5.3 & 4.8713 & TRN & \\
\hline CHEMBL1082363 & 635221 & 4.0 & 5.1705 & TRN & \\
\hline CHEMBL1082679 & 635221 & 7.3 & 5.7518 & TRN & \\
\hline CHEMBL1082680 & 635221 & 7.8 & $7.1720 e$ & $\partial 000000001$ & TRN \\
\hline & & & & 13544 & \\
\hline
\end{tabular}




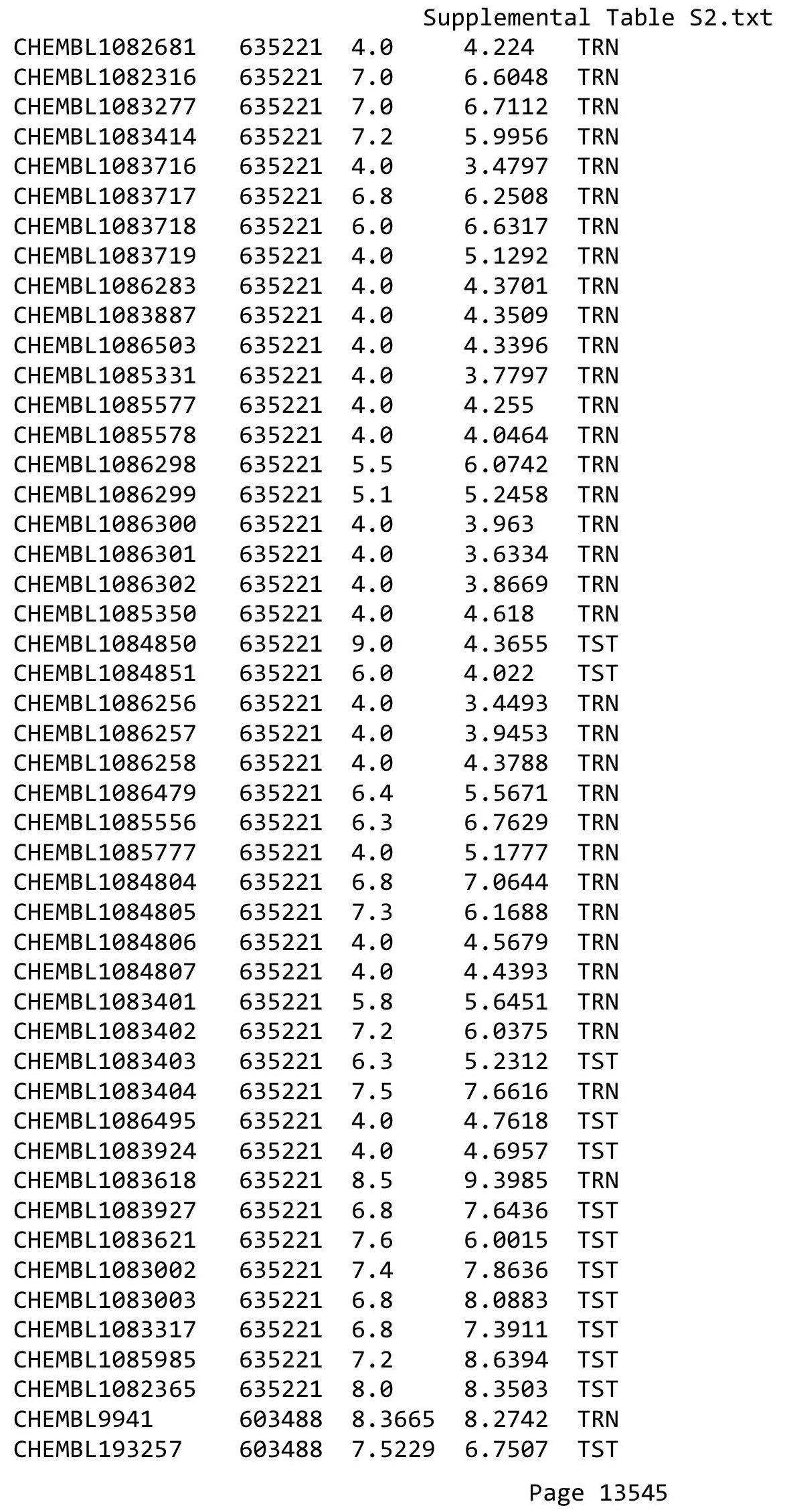




\begin{tabular}{|c|c|c|c|c|c|}
\hline & & & oplement & al Table S & \\
\hline CHEMBL594397 & 603488 & 8.585 & 9.164 & TRN & \\
\hline CHEMBL593207 & 603488 & 4.6198 & 4.8325 & TRN & \\
\hline CHEMBL61592 & 603488 & 5.7959 & 6.03700 & 0000000001 & TRN \\
\hline CHEMBL260867 & 603488 & 5.3565 & 5.4705 & TRN & \\
\hline CHEMBL227779 & 603488 & 6.5229 & 6.2796 & TRN & \\
\hline CHEMBL273256 & 603488 & 7.0969 & 6.7151 & TRN & \\
\hline CHEMBL61998 & 603488 & 5.8239 & 5.9768 & TRN & \\
\hline CHEMBL609571 & 603488 & 9.9208 & 9.3255 & TRN & \\
\hline CHEMBL240660 & 603488 & 4.699 & 4.298 & TRN & \\
\hline CHEMBL595816 & 603488 & 5.6576 & 5.2209 & TRN & \\
\hline CHEMBL593437 & 603488 & 3.5229 & 3.3533 & TRN & \\
\hline CHEMBL609286 & 603488 & 5.1938 & 5.3221 & TRN & \\
\hline CHEMBL607821 & 603488 & 5.8239 & 6.3532 & TRN & \\
\hline CHEMBL595341 & 603488 & 8.6576 & 8.7494 & TRN & \\
\hline CHEMBL594618 & 603488 & 3.6021 & 4.4716 & TRN & \\
\hline CHEMBL276600 & 603488 & 6.5229 & 6.3783 & TRN & \\
\hline CHEMBL593243 & 603488 & 6.2218 & 7.2365 & TST & \\
\hline CHEMBL604793 & 603488 & 5.3098 & 4.6373 & TST & \\
\hline CHEMBL595808 & 603488 & 6.699 & 6.0808 & TRN & \\
\hline CHEMBL364034 & 603488 & 8.8239 & 9.5923 & TRN & \\
\hline CHEMBL593439 & 603488 & 6.5229 & 5.8428 & TRN & \\
\hline CHEMBL593208 & 603488 & 4.9208 & 3.2639 & TST & \\
\hline CHEMBL594640 & 603488 & 5.7696 & 5.8825 & TRN & \\
\hline CHEMBL609014 & 603488 & 7.9586 & 7.8063 & TRN & \\
\hline CHEMBL594170 & 603488 & 5.3979 & 6.3793 & TST & \\
\hline CHEMBL427543 & 603488 & 8.0 & 7.9526 & TRN & \\
\hline CHEMBL576131 & 603488 & 6.0 & 7.2247 & TST & \\
\hline CHEMBL594390 & 603488 & 3.5229 & 3.8301 & TST & \\
\hline CHEMBL126617 & 603488 & 5.9208 & 5.9096 & TRN & \\
\hline CHEMBL596022 & 603488 & 5.0969 & 5.5397 & TRN & \\
\hline CHEMBL195899 & 603488 & 6.4559 & 6.3256 & TRN & \\
\hline CHEMBL406861 & 603488 & 5.0132 & 4.6104 & TRN & \\
\hline CHEMBL594612 & 603488 & 5.4685 & 4.2428 & TST & \\
\hline CHEMBL593228 & 603488 & 6.301 & 8.3876 & TST & \\
\hline CHEMBL 36619 & 603488 & 5.0 & 5.4296 & TRN & \\
\hline CHEMBL595568 & 603488 & 6.5229 & 6.103 & TRN & \\
\hline CHEMBL596041 & 603488 & 5.9586 & 5.8997 & TRN & \\
\hline CHEMBL595803 & 603488 & 7.699 & 7.7589 & TRN & \\
\hline CHEMBL371839 & 603488 & 8.4318 & 8.122 & TRN & \\
\hline CHEMBL194094 & 603488 & 5.4559 & 5.5894 & TRN & \\
\hline CHEMBL195840 & 603488 & 8.0 & 7.7198 & TRN & \\
\hline CHEMBL595342 & 603488 & 3.5229 & 2.6333 & TST & \\
\hline CHEMBL608673 & 603488 & 5.2518 & 5.6909 & TRN & \\
\hline CHEMBL138314 & 603488 & 4.8239 & 5.1171 & TRN & \\
\hline CHEMBL191407 & 603488 & 5.2076 & 5.6683 & TRN & \\
\hline CHEMBL596472 & 603488 & 5.0 & 5.3141 & TST & \\
\hline CHEMBL595343 & 603488 & 5.3979 & 5.0777 & TST & \\
\hline CHEMBL596239 & 603488 & 6.5229 & 6.1478 & TRN & \\
\hline
\end{tabular}




\begin{tabular}{|c|c|c|c|c|c|}
\hline \multicolumn{6}{|c|}{ Supplemental Table S2.txt } \\
\hline CHEMBL191957 & 603488 & 7.0458 & 9.0025 & TST & \\
\hline CHEMBL7976 & 603488 & 5.4202 & 5.7556 & TST & \\
\hline CHEMBL593011 & 603488 & 6.6576 & 6.1698 & TRN & \\
\hline CHEMBL610057 & 603488 & 6.301 & 5.193 & TST & \\
\hline CHEMBL417873 & 603488 & 5.3098 & 5.5963 & TRN & \\
\hline CHEMBL593250 & 603488 & 8.0969 & 8.13 & TRN & \\
\hline CHEMBL59026 & 603488 & 5.7959 & 5.2716 & TRN & \\
\hline CHEMBL596241 & 603488 & 5.3979 & 5.3314 & TST & \\
\hline CHEMBL595815 & 603488 & 6.5229 & 6.6328 & TST & \\
\hline CHEMBL 276828 & 603488 & 7.3979 & 7.2816 & TRN & \\
\hline CHEMBL195819 & 603488 & 7.301 & 6.4571 & TRN & \\
\hline CHEMBL607818 & 603488 & 6.301 & 7.26399 & 9999999999 & TRN \\
\hline CHEMBL595780 & 603488 & 5.7212 & 5.8386 & TST & \\
\hline CHEMBL594391 & 603488 & 6.0 & 6.9509 & TST & \\
\hline CHEMBL252659 & 603488 & 4.9586 & 4.7918 & TRN & \\
\hline CHEMBL596021 & 603488 & 5.1427 & 5.8649 & TST & \\
\hline CHEMBL596240 & 603488 & 5.4202 & 5.8052 & TRN & \\
\hline CHEMBL187437 & 603488 & 5.3468 & 5.4946 & TRN & \\
\hline CHEMBL465998 & 603488 & 5.3979 & 5.6614 & TRN & \\
\hline CHEMBL593440 & 603488 & 5.6383 & 5.6998 & TST & \\
\hline CHEMBL596033 & 603488 & 5.4318 & 4.7386 & TST & \\
\hline CHEMBL268559 & 603488 & 5.0044 & 5.0085 & TRN & \\
\hline CHEMBL192221 & 603488 & 5.3188 & 5.8808 & TRN & \\
\hline CHEMBL593249 & 603488 & 6.6383 & 6.216 & TRN & \\
\hline CHEMBL9652 & 603488 & 7.9208 & 8.0577 & TRN & \\
\hline CHEMBL608109 & 603488 & 5.2924 & 5.2661 & TRN & \\
\hline CHEMBL609287 & 603488 & 4.8239 & 2.6333 & TST & \\
\hline CHEMBL512571 & 603488 & 5.1487 & 5.0464 & TRN & \\
\hline CHEMBL9859 & 603488 & 9.6778 & 9.5847 & TRN & \\
\hline CHEMBL596040 & 603488 & 5.9586 & 5.8835 & TRN & \\
\hline CHEMBL194925 & 603488 & 6.4437 & 6.4443 & TRN & \\
\hline CHEMBL193038 & 603488 & 6.5229 & 6.8905 & TRN & \\
\hline CHEMBL136422 & 603488 & 6.5229 & 6.3436 & TRN & \\
\hline CHEMBL17442 & 603488 & 5.8239 & 5.4949 & TRN & \\
\hline CHEMBL188132 & 603488 & 5.8239 & 5.8932 & TRN & \\
\hline CHEMBL194386 & 603488 & 5.0506 & 5.6908 & TRN & \\
\hline CHEMBL426644 & 603488 & 8.699 & 8.1514 & TRN & \\
\hline CHEMBL190474 & 603488 & 6.5229 & 6.4315 & TRN & \\
\hline CHEMBL595779 & 603488 & 5.5376 & 5.3357 & TRN & \\
\hline CHEMBL 364517 & 603488 & 7.2218 & 6.7864 & TRN & \\
\hline CHEMBL262597 & 603488 & 4.7959 & 5.0749 & TRN & \\
\hline CHEMBL593224 & 603488 & 5.6021 & 6.2316 & TRN & \\
\hline CHEMBL593438 & 603488 & 4.9208 & 5.3707 & TST & \\
\hline CHEMBL596471 & 603488 & 5.0044 & 4.7713 & TRN & \\
\hline CHEMBL2086505 & 841033 & 3.0969 & 3.0929 & TRN & \\
\hline CHEMBL2089386 & 841033 & 3.0969 & 3.157 & TRN & \\
\hline CHEMBL 2086887 & 841033 & 3.0969 & 2.9359 & TST & \\
\hline CHEMBL 2086532 & 841033 & 3.0969 & 3.0838 & TRN & \\
\hline
\end{tabular}

Page 13547 
Supplemental Table S2.txt

\begin{tabular}{|c|c|c|c|c|}
\hline CHEMBL 2086514 & 841033 & 3.0969 & 3.1157 & TRN \\
\hline CHEMBL2086889 & 841033 & 7.9586 & 3.52 & TST \\
\hline CHEMBL 2086526 & 841033 & 3.0969 & 3.071 & TRN \\
\hline CHEMBL 2086511 & 841033 & 3.0969 & 3.1227 & TRN \\
\hline CHEMBL 2089397 & 841033 & 3.0969 & 3.0988 & TRN \\
\hline CHEMBL 2086523 & 841033 & 3.0969 & 3.0718 & TRN \\
\hline CHEMBL 2086525 & 841033 & 3.0969 & 3.0935 & TRN \\
\hline CHEMBL 2086529 & 841033 & 3.0969 & 3.1219 & TRN \\
\hline CHEMBL 2086539 & 841033 & 3.0969 & 3.09 & TRN \\
\hline CHEMBL 2086518 & 841033 & 3.9586 & 3.9963 & TRN \\
\hline CHEMBL 2086891 & 841033 & 4.1612 & 4.1734 & TRN \\
\hline CHEMBL 2086537 & 841033 & 3.0969 & 3.0893 & TRN \\
\hline CHEMBL 2086524 & 841033 & 3.0969 & 3.0652 & TRN \\
\hline CHEMBL 2086522 & 841033 & 3.9586 & 3.8709 & TRN \\
\hline CHEMBL 2089396 & 841033 & 3.0969 & 3.0865 & TRN \\
\hline CHEMBL 2089387 & 841033 & 3.0969 & 3.1081 & TRN \\
\hline CHEMBL2086509 & 841033 & 3.0969 & 3.0751 & TRN \\
\hline CHEMBL 2086540 & 841033 & 3.0969 & 3.1681 & TRN \\
\hline CHEMBL 2086504 & 841033 & 3.0969 & 3.0861 & TRN \\
\hline CHEMBL 2086480 & 841033 & 3.3768 & 3.4111 & TRN \\
\hline CHEMBL 2086516 & 841033 & 3.0969 & 3.1098 & TRN \\
\hline CHEMBL2086533 & 841033 & 3.0969 & 3.1228 & TRN \\
\hline CHEMBL 2089394 & 841033 & 3.0969 & 3.3139 & TST \\
\hline CHEMBL 2089399 & 841033 & 3.0969 & 3.1085 & TRN \\
\hline CHEMBL 2086528 & 841033 & 3.0969 & 3.0879 & TRN \\
\hline CHEMBL 2086503 & 841033 & 3.0969 & 3.098999 & 99999999998 \\
\hline CHEMBL 2089391 & 841033 & 3.0969 & 3.0919 & TRN \\
\hline CHEMBL 2086534 & 841033 & 3.0969 & 3.1016 & TRN \\
\hline CHEMBL 2086508 & 841033 & 3.0969 & 3.0871 & TRN \\
\hline CHEMBL 2086506 & 841033 & 3.5376 & 3.554 & TRN \\
\hline CHEMBL 2086538 & 841033 & 3.0969 & 3.0642 & TRN \\
\hline CHEMBL 2086888 & 841033 & 3.0969 & 3.3712 & TST \\
\hline CHEMBL 2086517 & 841033 & 3.0969 & 3.0666 & TRN \\
\hline CHEMBL 2086535 & 841033 & 3.0969 & 3.0736 & TRN \\
\hline CHEMBL 2086531 & 841033 & 4.2518 & 4.2628 & TRN \\
\hline CHEMBL2086515 & 841033 & 3.0969 & 3.0775 & TRN \\
\hline CHEMBL1605548 & 841033 & 4.2757 & 3.3883 & TST \\
\hline CHEMBL 2086544 & 841033 & 3.0969 & 3.1036 & TRN \\
\hline CHEMBL2367730 & 841033 & 3.8539 & 3.858 & TRN \\
\hline CHEMBL 2089388 & 841033 & 3.0969 & 3.1324 & TRN \\
\hline CHEMBL 2086519 & 841033 & 3.0969 & 3.0843 & TRN \\
\hline CHEMBL 2089385 & 841033 & 3.0969 & 2.5758 & TST \\
\hline CHEMBL 2086479 & 841033 & 4.1487 & 4.1165 & TRN \\
\hline CHEMBL 2086527 & 841033 & 3.0969 & 3.1006 & TRN \\
\hline CHEMBL 2089393 & 841033 & 3.0969 & 3.0902 & TRN \\
\hline CHEMBL 2086536 & 841033 & 3.0969 & 3.0986 & TRN \\
\hline CHEMBL 2086502 & 841033 & 3.0969 & 3.0923 & TRN \\
\hline CHEMBL 2086473 & 841033 & 3.0969 & 3.2054 & TST \\
\hline
\end{tabular}




\begin{tabular}{|c|c|c|c|c|c|c|}
\hline \multirow{3}{*}{$\begin{array}{l}\text { CHEMBL } 2086541 \\
\text { CHFMBI } 2089400\end{array}$} & & \multicolumn{5}{|c|}{ Supplemental Table S2.txt } \\
\hline & 841033 & 3.0969 & \multicolumn{3}{|c|}{2.9160000000000004} & TST \\
\hline & 841033 & 3.0969 & 2.9285 & TST & & \\
\hline CHEMBL 2086530 & 841033 & 4.1427 & 3.1467 & TST & & \\
\hline CHEMBL2086890 & 841033 & 3.0969 & 3.3216 & TST & & \\
\hline CHEMBL 2089398 & 841033 & 3.0969 & 3.1449 & TST & & \\
\hline CHEMBL 2086512 & 841033 & 3.5686 & 3.1594 & TST & & \\
\hline CHEMBL 2086501 & 841033 & 3.0969 & 3.3048 & TST & & \\
\hline CHEMBL 2086510 & 841033 & 3.0969 & 2.886 & TST & & \\
\hline CHEMBL 2005886 & 954988 & 6.7652 & 6.766 & TRN & & \\
\hline CHEMBL373751 & 954988 & \multicolumn{3}{|c|}{3.5780000000000003} & 3.5736 & TRN \\
\hline CHEMBL259181 & 954988 & 3.7898 & 3.7935 & TRN & & \\
\hline CHEMBL221137 & 954988 & 4.1251 & 4.2763 & TST & & \\
\hline CHEMBL 2363137 & 954988 & 4.6902 & 4.6895 & TRN & & \\
\hline CHEMBL210618 & 954988 & 3.0867 & 3.0859 & TRN & & \\
\hline CHEMBL514499 & 954988 & 6.8581 & 6.8594 & TRN & & \\
\hline CHEMBL192566 & 954988 & 6.1736 & 7.3361 & TST & & \\
\hline CHEMBL483849 & 954988 & 0.8153 & 1.7044 & TST & & \\
\hline CHEMBL577784 & 954988 & 3.2689 & 3.2688 & TRN & & \\
\hline CHEMBL92309 & 954988 & 2.6815 & 2.2207 & TST & & \\
\hline CHEMBL3199475 & 954988 & 4.145 & 4.1508 & TRN & & \\
\hline CHEMBL3392440 & 954988 & 3.4848 & 3.4847 & TRN & & \\
\hline CHEMBL379300 & 954988 & 6.0527 & 6.0478 & TRN & & \\
\hline CHEMBL1190711 & 954988 & 4.2856 & 4.2892 & TRN & & \\
\hline CHEMBL 2134202 & 954988 & \multicolumn{3}{|c|}{3.8810000000000002} & 3.8747 & TRN \\
\hline CHEMBL220241 & 954988 & 3.7092 & 3.7085 & TRN & & \\
\hline CHEMBL9470 & 954988 & 5.4923 & 5.87799 & 9999999999 & & TST \\
\hline CHEMBL1970879 & 954988 & 2.5988 & 2.5999 & TRN & & \\
\hline CHEMBL 240954 & 954988 & 3.2658 & 3.2209 & TST & & \\
\hline CHEMBL1673039 & 954988 & 5.0987 & 5.0992 & TRN & & \\
\hline CHEMBL 202721 & 954988 & 4.7211 & 4.7182 & TRN & & \\
\hline CHEMBL449158 & 954988 & 5.7842 & 6.7689 & TST & & \\
\hline CHEMBL472940 & 954988 & 3.9103 & 3.9077 & TRN & & \\
\hline CHEMBL515416 & 954988 & 4.3229 & 4.3248 & TRN & & \\
\hline CHEMBL189584 & 954988 & 3.7087 & 3.7096 & TRN & & \\
\hline CHEMBL1230020 & 954988 & 2.8936 & 2.89 & TRN & & \\
\hline CHEMBL217354 & 954988 & 6.7961 & 6.7893 & TRN & & \\
\hline CHEMBL188678 & 954988 & 4.677 & 4.6765 & TRN & & \\
\hline CHEMBL255342 & 954988 & 3.5703 & 3.5714 & TRN & & \\
\hline CHEMBL573107 & 954988 & 4.7484 & 4.7506 & TRN & & \\
\hline CHEMBL1909414 & 954988 & 3.3511 & 3.3532 & TRN & & \\
\hline CHEMBL483847 & 954988 & 3.6258 & 3.6261 & TRN & & \\
\hline CHEMBL3186408 & 954988 & 3.1019 & 3.9036 & TST & & \\
\hline CHEMBL1516890 & 954988 & 4.1826 & 4.1793 & TRN & & \\
\hline CHEMBL1788116 & 954988 & 4.8288 & 4.8248 & TRN & & \\
\hline CHEMBL 258844 & 954988 & 4.163 & 4.165 & TRN & & \\
\hline CHEMBL2144069 & 954988 & 6.166 & 6.1683 & TRN & & \\
\hline CHEMBL135561 & 954988 & 4.0705 & 4.0704 & TRN & & \\
\hline CHEMBL209148 & 954988 & 5.1373 & 5.1421 & TRN & & \\
\hline
\end{tabular}




\begin{tabular}{|c|c|c|c|c|c|}
\hline & & & & & \\
\hline CHEMBL300389 & 954988 & 6.8282 & 6.8261 & TRN & \\
\hline CHEMBL393929 & 954988 & 3.5334 & 3.5324 & TRN & \\
\hline CHEMBL1357247 & 954988 & 3.0549 & 3.0563 & TRN & \\
\hline CHEMBL509032 & 954988 & 6.7584 & 6.7594 & TRN & \\
\hline CHEMBL1404918 & 954988 & 2.9073 & 2.9084 & TRN & \\
\hline CHEMBL3349342 & 954988 & 6.2829 & 6.2856 & TRN & \\
\hline CHEMBL585951 & 954988 & 5.7518 & 5.7509 & TRN & \\
\hline CHEMBL 2137530 & 954988 & 4.8466 & 4.8516 & TRN & \\
\hline CHEMBL558642 & 954988 & 2.7374 & 2.7363 & TRN & \\
\hline CHEMBL399530 & 954988 & 3.1998 & 3.2004 & TRN & \\
\hline CHEMBL191334 & 954988 & 4.9211 & 4.9211 & TRN & \\
\hline CHEMBL1242367 & 954988 & 3.5225 & 3.5215 & TRN & \\
\hline CHEMBL1256459 & 954988 & 5.2583 & 5.2598 & TRN & \\
\hline CHEMBL65 & 954988 & 6.9049 & 6.90600 & 2000000001 & TRN \\
\hline CHEMBL1590308 & 954988 & 2.5573 & 3.1379 & TST & \\
\hline CHEMBL412142 & 954988 & 3.4724 & 3.4707 & TRN & \\
\hline CHEMBL512504 & 954988 & 4.1173 & 4.1177 & TRN & \\
\hline CHEMBL222102 & 954988 & 2.944 & 3.8946 & TST & \\
\hline CHEMBL180127 & 954988 & 4.4794 & 4.1389 & TST & \\
\hline CHEMBL 213100 & 954988 & 3.8036 & 3.5831 & TST & \\
\hline CHEMBL102714 & 954988 & 3.6632 & 3.9758 & TST & \\
\hline CHEMBL379975 & 954988 & 4.1682 & 4.808 & TST & \\
\hline CHEMBL1643959 & 954988 & 3.09 & 2.8865 & TST & \\
\hline CHEMBL1186585 & 954988 & 3.8249 & 4.4902 & TST & \\
\hline CHEMBL392695 & 954988 & 5.4332 & 5.4134 & TST & \\
\hline CHEMBL1522216 & 688214 & 2.9208 & 2.9206 & TRN & \\
\hline CHEMBL1370730 & 688214 & 2.9208 & 2.9174 & TRN & \\
\hline CHEMBL1599549 & 688214 & 2.9208 & 2.9259 & TRN & \\
\hline CHEMBL1411944 & 688214 & 2.9208 & 2.9224 & TRN & \\
\hline CHEMBL1598567 & 688214 & 2.9208 & 2.9185 & TRN & \\
\hline CHEMBL1331522 & 688214 & 2.9208 & 2.9243 & TRN & \\
\hline CHEMBL1322375 & 688214 & 5.1824 & 5.1814 & TRN & \\
\hline CHEMBL602135 & 688214 & 2.9208 & 2.9204 & TRN & \\
\hline CHEMBL1341948 & 688214 & 2.9208 & 2.9218 & TRN & \\
\hline CHEMBL1409692 & 688214 & 2.9208 & 2.9198 & TRN & \\
\hline CHEMBL1463953 & 688214 & 4.9354 & 2.9591 & TST & \\
\hline CHEMBL256042 & 688214 & 2.9208 & 2.9194 & TRN & \\
\hline CHEMBL1569910 & 688214 & 5.2331 & 5.2308 & TRN & \\
\hline CHEMBL1448472 & 688214 & 4.9421 & 4.9391 & TRN & \\
\hline CHEMBL1348536 & 688214 & 2.9208 & 2.9204 & TRN & \\
\hline CHEMBL1389934 & 688214 & 2.9208 & 2.9244 & TRN & \\
\hline CHEMBL1384706 & 688214 & 2.9208 & 2.9196 & TRN & \\
\hline CHEMBL1306087 & 688214 & 2.9208 & 2.9222 & TRN & \\
\hline CHEMBL1471827 & 688214 & 4.9783 & 4.9754 & TRN & \\
\hline CHEMBL1532096 & 688214 & 2.9208 & 2.9202 & TRN & \\
\hline CHEMBL3209415 & 688214 & 2.9208 & 2.9188 & TRN & \\
\hline CHEMBL1452422 & 688214 & 2.9208 & 2.9233 & TRN & \\
\hline CHEMBL1462940 & 688214 & 2.9208 & 2.9202 & TRN & \\
\hline
\end{tabular}

Page 13550 
Supplemental Table S2.txt

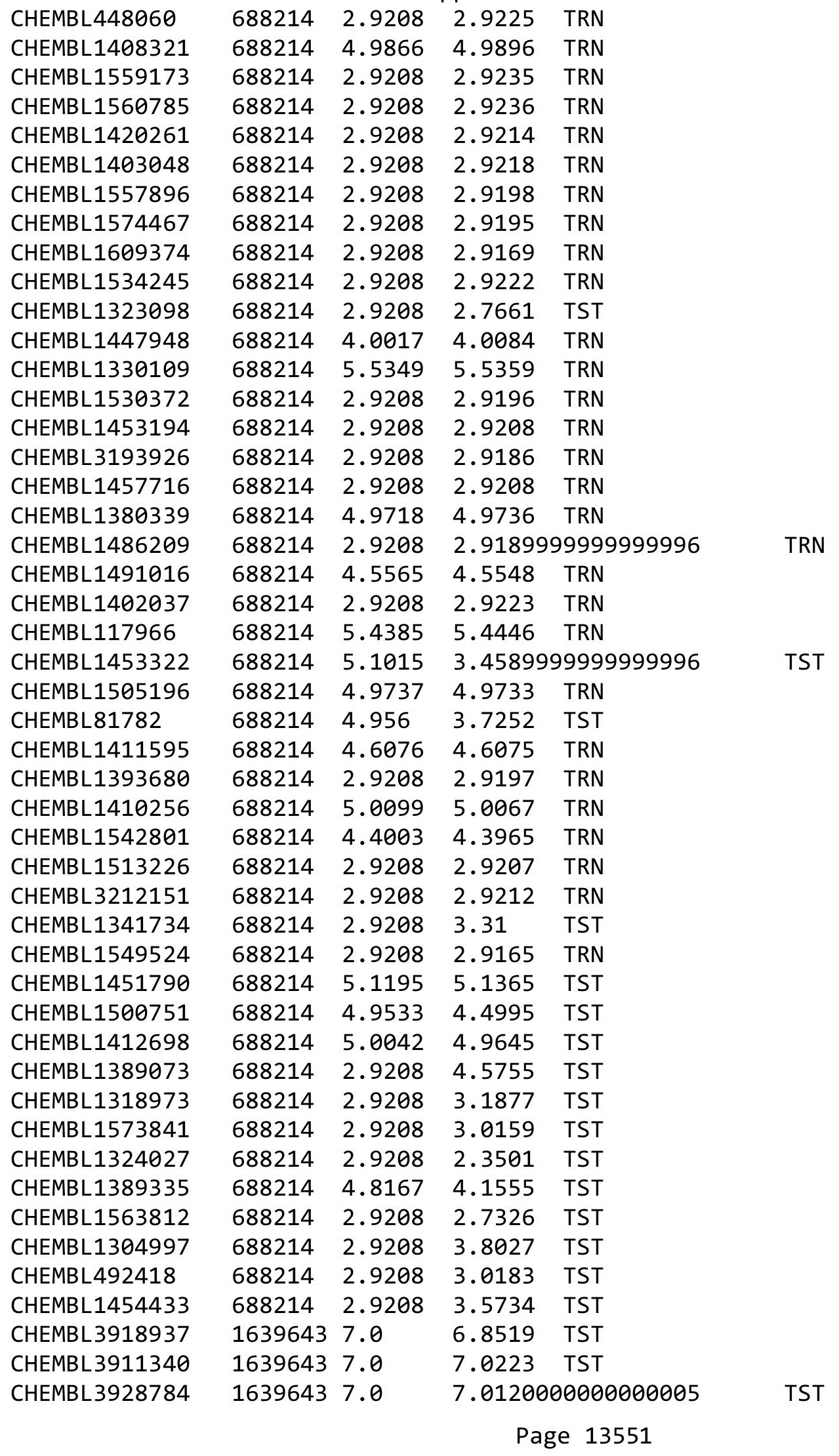




\begin{tabular}{|c|c|c|c|c|}
\hline & & & & $a \perp 1 a$ \\
\hline CHEMBL3926128 & 1639643 & 7.0 & 6.9031 & TRN \\
\hline CHEMBL3940401 & 1639643 & 6.0 & 6.8983 & TRN \\
\hline CHEMBL3930609 & 1639643 & 8.0 & 7.9117 & TST \\
\hline CHEMBL3919333 & 1639643 & 8.0 & 8.0143 & TST \\
\hline CHEMBL3897153 & 1639643 & 6.0 & 8.035 & TST \\
\hline CHEMBL 3982471 & 1639643 & 8.0 & 7.2248 & TST \\
\hline CHEMBL3985011 & 1639643 & 6.0 & 7.5355 & TST \\
\hline CHEMBL3978486 & 1639643 & 8.0 & 7.8691 & TST \\
\hline CHEMBL3980871 & 1639643 & 8.0 & 7.6133 & TST \\
\hline CHEMBL3932468 & 1639643 & 8.0 & 7.2876 & TST \\
\hline CHEMBL 3942220 & 1639643 & 8.0 & 7.8922 & TST \\
\hline CHEMBL3957976 & 1639643 & 8.0 & 7.7294 & TST \\
\hline CHEMBL3960623 & 1639643 & 8.0 & 7.474 & TST \\
\hline CHEMBL3956956 & 1639643 & 8.0 & 7.9251 & TST \\
\hline CHEMBL3970155 & 1639643 & 8.0 & 7.8238 & TRN \\
\hline CHEMBL 3974421 & 1639643 & 8.0 & 7.721 & TST \\
\hline CHEMBL448668 & 1639643 & 8.0 & 7.7264 & TST \\
\hline CHEMBL3923275 & 1639643 & 6.0 & 7.8137 & TST \\
\hline CHEMBL506862 & 1639643 & 8.0 & 7.6154 & TRN \\
\hline CHEMBL3976855 & 1639643 & 7.0 & 6.7415 & TRN \\
\hline CHEMBL3916077 & 1639643 & 8.0 & 8.0152 & TST \\
\hline CHEMBL3901819 & 1639643 & 7.0 & 7.114 & TST \\
\hline CHEMBL3904524 & 1639643 & 7.0 & 7.0298 & TST \\
\hline CHEMBL3947568 & 1639643 & 8.0 & 7.7764 & TST \\
\hline CHEMBL3909929 & 1639643 & 7.0 & 7.0335 & TST \\
\hline CHEMBL 3957183 & 1639643 & 8.0 & 7.7731 & TST \\
\hline CHEMBL3954571 & 1639643 & 6.0 & 7.5428 & TRN \\
\hline CHEMBL3961627 & 1639643 & 7.0 & 6.7322 & TRN \\
\hline CHEMBL 3896404 & 1639643 & 8.0 & 7.6686 & TRN \\
\hline CHEMBL 3902678 & 1639643 & 8.0 & 7.6738 & TRN \\
\hline CHEMBL 3951967 & 1639643 & 8.0 & 7.6098 & TRN \\
\hline CHEMBL3981747 & 1639643 & 8.0 & 7.6108 & TRN \\
\hline CHEMBL 3973006 & 1639643 & 8.0 & 7.6287 & TST \\
\hline CHEMBL 3941287 & 1639643 & 8.0 & 7.8836 & TST \\
\hline CHEMBL502652 & 1639643 & 8.0 & 7.9532 & TRN \\
\hline CHEMBL 3983417 & 1639643 & 8.0 & 7.8142 & TRN \\
\hline CHEMBL3891515 & 1639643 & 8.0 & 7.7214 & TRN \\
\hline CHEMBL 3893349 & 1639643 & 8.0 & 7.7296 & TRN \\
\hline CHEMBL3896056 & 1639643 & 8.0 & 7.7594 & TRN \\
\hline CHEMBL3903251 & 1639643 & 8.0 & 8.0227 & TRN \\
\hline CHEMBL3905921 & 1639643 & 6.0 & 6.9787 & TRN \\
\hline CHEMBL3907756 & 1639643 & 6.0 & 7.0864 & TRN \\
\hline CHEMBL 3917543 & 1639643 & 8.0 & 7.817 & TRN \\
\hline CHEMBL454796 & 1639643 & 8.0 & 7.914 & TRN \\
\hline CHEMBL3920487 & 1639643 & 8.0 & 7.9126 & TRN \\
\hline CHEMBL 3957642 & 1639643 & 8.0 & 7.7876 & TRN \\
\hline CHEMBL3902608 & 1639643 & 8.0 & 7.6154 & TRN \\
\hline CHEMBL3937659 & 1639643 & 8.0 & 7.8539 & TRN \\
\hline
\end{tabular}




\begin{tabular}{|c|c|c|c|c|c|}
\hline CHEMBL 3934864 & 1639643 & 8.0 & 7.8997 & TRN & \\
\hline CHEMBL 3927706 & 1639643 & 8.0 & 7.6904 & TRN & \\
\hline CHEMBL3975048 & 1639643 & 8.0 & 7.858 & TST & \\
\hline CHEMBL 3889680 & 1639643 & 7.0 & 6.9821 & TST & \\
\hline CHEMBL3984698 & 1639643 & 7.0 & 6.9904 & TST & \\
\hline CHEMBL3936093 & 1639643 & 8.0 & 7.9681 & TRN & \\
\hline CHEMBL507714 & 1639643 & 8.0 & 7.655 & TRN & \\
\hline CHEMBL3898863 & 1639643 & 8.0 & 7.971 & TRN & \\
\hline CHEMBL3917108 & 1639643 & 8.0 & 8.3539 & TRN & \\
\hline CHEMBL3950296 & 1639643 & 6.0 & 7.0708 & TRN & \\
\hline CHEMBL3953006 & 1639643 & 8.0 & 8.1525 & TRN & \\
\hline CHEMBL 3912542 & 1639643 & 7.0 & 7.0683 & TRN & \\
\hline CHEMBL3915209 & 1639643 & 8.0 & 7.8595 & TRN & \\
\hline CHEMBL3971235 & 1639643 & 7.0 & 7.0983 & TRN & \\
\hline CHEMBL3973792 & 1639643 & 7.0 & 7.1004 & TRN & \\
\hline CHEMBL3911054 & 1639643 & 8.0 & 8.3459 & TRN & \\
\hline CHEMBL 3908294 & 1639643 & 8.0 & 8.064 & TRN & \\
\hline CHEMBL3920934 & 1639643 & 7.0 & \multicolumn{2}{|c|}{6.7860000000000005} & TRN \\
\hline CHEMBL447639 & 1639643 & 8.0 & 7.8251 & TRN & \\
\hline CHEMBL 3967622 & 1639643 & 8.0 & 7.7994 & TRN & \\
\hline CHEMBL3955829 & 1639643 & 6.0 & 7.1069 & TRN & \\
\hline CHEMBL 3906473 & 1639643 & 6.0 & 7.6892 & TRN & \\
\hline CHEMBL 3903740 & 1639643 & 8.0 & 7.7202 & TRN & \\
\hline CHEMBL 3946744 & 1639643 & 8.0 & 7.8126 & TRN & \\
\hline CHEMBL502198 & 1639643 & 8.0 & 7.6788 & TRN & \\
\hline CHEMBL449110 & 1639643 & 8.0 & 7.9306 & TRN & \\
\hline CHEMBL 3950577 & 1639643 & 8.0 & 7.7915 & TRN & \\
\hline CHEMBL 3936820 & 1639643 & 7.0 & 6.9443 & TRN & \\
\hline CHEMBL453438 & 1639643 & 8.0 & 7.6454 & TST & \\
\hline CHEMBL3982306 & 1639643 & 8.0 & 7.8141 & TRN & \\
\hline CHEMBL 3984843 & 1639643 & 7.0 & 6.9384 & TRN & \\
\hline CHEMBL 3922419 & 1639643 & 8.0 & 7.7948 & TRN & \\
\hline CHEMBL3925159 & 1639643 & 8.0 & 7.8778 & TST & \\
\hline CHEMBL3933134 & 1639643 & 8.0 & 7.9904 & TRN & \\
\hline CHEMBL 3930437 & 1639643 & 7.0 & 7.1809 & TRN & \\
\hline CHEMBL3895132 & 1639643 & 8.0 & 7.905 & TRN & \\
\hline CHEMBL 3937160 & 1639643 & 8.0 & 7.9039 & TRN & \\
\hline CHEMBL3918769 & 1639643 & 8.0 & 7.8348 & TRN & \\
\hline CHEMBL3915988 & 1639643 & 8.0 & 7.8234 & TRN & \\
\hline CHEMBL 3968247 & 1639643 & 8.0 & 7.8423 & TRN & \\
\hline CHEMBL3946116 & 1639643 & 7.0 & 6.9332 & TRN & \\
\hline CHEMBL 3961740 & 1639643 & 8.0 & 7.8354 & TRN & \\
\hline CHEMBL3952208 & 1639643 & 7.0 & 6.9625 & TRN & \\
\hline CHEMBL3896094 & 1639643 & 8.0 & 8.1083 & TRN & \\
\hline CHEMBL3898780 & 1639643 & 8.0 & 8.1225 & TRN & \\
\hline CHEMBL 3947685 & 1639643 & 8.0 & 7.9041 & TRN & \\
\hline CHEMBL 3950325 & 1639643 & 7.0 & 7.0338 & TRN & \\
\hline CHEMBL3902796 & 1639643 & 7.0 & 7.0399 & TRN & \\
\hline
\end{tabular}




\begin{tabular}{|c|c|c|c|c|c|}
\hline CHEMBL 3930321 & 1639643 & 8.0 & 7.6137 & TRN & \\
\hline CHEMBL3971629 & 1639643 & 7.0 & 6.7669 & TRN & \\
\hline CHEMBL3901509 & 1639643 & 8.0 & 7.836 & TRN & \\
\hline CHEMBL3944142 & 1639643 & 7.0 & 6.9697 & TRN & \\
\hline CHEMBL3934382 & 1639643 & 8.0 & 7.86299 & 99999999995 & TRN \\
\hline CHEMBL3982596 & 1639643 & 7.0 & 6.9991 & TRN & \\
\hline CHEMBL3980159 & 1639643 & 8.0 & 7.8158 & TRN & \\
\hline CHEMBL3930497 & 1639643 & 8.0 & 8.1626 & TRN & \\
\hline CHEMBL3927744 & 1639643 & 8.0 & 7.9682 & TRN & \\
\hline CHEMBL3899043 & 1639643 & 8.0 & 8.2135 & TRN & \\
\hline CHEMBL3896361 & 1639643 & 8.0 & 7.9665 & TRN & \\
\hline CHEMBL3951670 & 1639643 & 8.0 & 8.2067 & TRN & \\
\hline CHEMBL3942170 & 1639643 & 8.0 & 7.8977 & TRN & \\
\hline CHEMBL3921580 & 1639643 & 8.0 & 7.79799 & 9999999999 & TRN \\
\hline CHEMBL3918852 & 1639643 & 8.0 & 7.9546 & TRN & \\
\hline CHEMBL3981549 & 1639643 & 8.0 & 7.8845 & TRN & \\
\hline CHEMBL3979137 & 1639643 & 8.0 & 8.0199 & TRN & \\
\hline CHEMBL3907119 & 1639643 & 8.0 & 7.9916 & TRN & \\
\hline CHEMBL3904361 & 1639643 & 7.0 & 6.8211 & TRN & \\
\hline CHEMBL3968197 & 1639643 & 8.0 & 7.8932 & TRN & \\
\hline CHEMBL3956400 & 1639643 & 7.0 & 7.0116 & TRN & \\
\hline CHEMBL3985754 & 1639643 & 8.0 & 7.7326 & TRN & \\
\hline CHEMBL3983122 & 1639643 & 7.0 & 6.8144 & TRN & \\
\hline CHEMBL3895710 & 1639643 & 7.0 & 6.8938 & TST & \\
\hline CHEMBL3898403 & 1639643 & 8.0 & 7.7809 & TST & \\
\hline CHEMBL3938043 & 1639643 & 8.0 & 7.6477 & TST & \\
\hline CHEMBL3936478 & 1639643 & 7.0 & 7.2034 & TST & \\
\hline CHEMBL3973285 & 1639643 & 7.0 & 7.0294 & TST & \\
\hline CHEMBL3982002 & 1639643 & 8.0 & 7.9322 & TST & \\
\hline CHEMBL3919366 & 1639643 & 7.0 & 7.0258 & TST & \\
\hline CHEMBL3922091 & 1639643 & 7.0 & 7.0578 & TST & \\
\hline CHEMBL3959181 & 1639643 & 7.0 & 6.8742 & TRN & \\
\hline CHEMBL3961913 & 1639643 & 8.0 & 7.7551 & TRN & \\
\hline CHEMBL3930141 & 1639643 & 7.0 & 7.039 & TRN & \\
\hline CHEMBL3927429 & 1639643 & 8.0 & 7.9211 & TRN & \\
\hline CHEMBL3973106 & 1639643 & 8.0 & 7.7672 & TST & \\
\hline CHEMBL3940382 & 1639643 & 7.0 & 6.8771 & TST & \\
\hline CHEMBL3915736 & 1639643 & 8.0 & 7.9432 & TST & \\
\hline CHEMBL 3890844 & 1639643 & 7.0 & 7.0425 & TST & \\
\hline CHEMBL3953464 & 1639643 & 7.0 & 6.8113 & TRN & \\
\hline CHEMBL3950784 & 1639643 & 7.0 & 6.8159 & TRN & \\
\hline CHEMBL 3894261 & 1639643 & 8.0 & 7.6475 & TRN & \\
\hline CHEMBL3963200 & 1639643 & 8.0 & 6.8154 & TRN & \\
\hline CHEMBL3931447 & 1639643 & 7.0 & 7.6354 & TRN & \\
\hline CHEMBL3934152 & 1639643 & 8.0 & 7.9833 & TRN & \\
\hline CHEMBL 3970170 & 1639643 & 7.0 & 7.1187 & TRN & \\
\hline CHEMBL3896138 & 1639643 & 7.0 & 7.1131 & TRN & \\
\hline CHEMBL3945814 & 1639643 & 7.0 & 6.7234 & TRN & \\
\hline
\end{tabular}




\begin{tabular}{|c|c|c|c|c|}
\hline & & & & al lable s \\
\hline CHEMBL3948450 & 1639643 & 7.0 & 6.734 & TRN \\
\hline CHEMBL3907857 & 1639643 & 8.0 & 7.5873 & TRN \\
\hline CHEMBL3910640 & 1639643 & 7.0 & 6.9991 & TRN \\
\hline CHEMBL 3968940 & 1639643 & 8.0 & 7.856 & TRN \\
\hline CHEMBL3971673 & 1639643 & 7.0 & 7.0122 & TRN \\
\hline CHEMBL3937303 & 1639643 & 6.0 & 7.0794 & TST \\
\hline CHEMBL3896493 & 1639643 & 7.0 & 7.0786 & TST \\
\hline CHEMBL3914814 & 1639643 & 8.0 & 7.9564 & TST \\
\hline CHEMBL3948809 & 1639643 & 7.0 & 6.9997 & TRN \\
\hline CHEMBL3913651 & 1639643 & 7.0 & 6.9996 & TRN \\
\hline CHEMBL3910989 & 1639643 & 8.0 & 7.8777 & TRN \\
\hline CHEMBL3903866 & 1639643 & 7.0 & 7.1759 & TST \\
\hline CHEMBL3972006 & 1639643 & 7.0 & 7.17299 & 9999999999 \\
\hline CHEMBL3891415 & 1639643 & 8.0 & 8.0486 & TST \\
\hline CHEMBL3986506 & 1639643 & 8.0 & 8.0362 & TST \\
\hline CHEMBL3913225 & 1639643 & 7.0 & 7.1888 & TRN \\
\hline CHEMBL3923001 & 1639643 & 7.0 & 7.1345 & TRN \\
\hline CHEMBL3983732 & 1639643 & 8.0 & 7.4612 & TRN \\
\hline CHEMBL3937417 & 1639643 & 6.0 & 6.5972 & TRN \\
\hline CHEMBL3974124 & 1639643 & 8.0 & 7.6822 & TRN \\
\hline CHEMBL 3976571 & 1639643 & 6.0 & 6.7846 & TRN \\
\hline CHEMBL3964932 & 1639643 & 8.0 & 7.5159 & TRN \\
\hline CHEMBL3915202 & 1639643 & 6.0 & 6.6172 & TRN \\
\hline CHEMBL3969290 & 1639643 & 7.0 & 6.6598 & TRN \\
\hline CHEMBL3957456 & 1639643 & 7.0 & 6.7888 & TRN \\
\hline CHEMBL 3908198 & 1639643 & 7.0 & 7.1101 & TRN \\
\hline CHEMBL3905410 & 1639643 & 8.0 & 8.0056 & TRN \\
\hline CHEMBL3953680 & 1639643 & 7.0 & 7.1283 & TRN \\
\hline CHEMBL3951002 & 1639643 & 7.0 & 7.1292 & TRN \\
\hline CHEMBL3893256 & 1639643 & 8.0 & 7.9315 & TRN \\
\hline CHEMBL3919927 & 1639643 & 7.0 & 7.0886 & TRN \\
\hline CHEMBL3976565 & 1639643 & 7.0 & 7.0975 & TRN \\
\hline CHEMBL3967372 & 1639643 & 7.0 & 7.0918 & TRN \\
\hline CHEMBL3910511 & 1639643 & 7.0 & 7.0793 & TRN \\
\hline CHEMBL3913169 & 1639643 & 8.0 & 8.3106 & TRN \\
\hline CHEMBL 3940222 & 1639643 & 8.0 & 8.3301 & TRN \\
\hline CHEMBL3944498 & 1639643 & 8.0 & 7.9595 & TRN \\
\hline CHEMBL3896003 & 1639643 & 8.0 & 8.0022 & TRN \\
\hline CHEMBL 3898691 & 1639643 & 8.0 & 7.9996 & TRN \\
\hline CHEMBL3899525 & 1639643 & 8.0 & 8.2831 & TRN \\
\hline CHEMBL 3957736 & 1639643 & 8.0 & 8.0853 & TRN \\
\hline CHEMBL3918216 & 1639643 & 8.0 & 7.7098 & TRN \\
\hline CHEMBL3920947 & 1639643 & 8.0 & 7.7432 & TRN \\
\hline CHEMBL 3952960 & 1639643 & 7.0 & 7.1515 & TRN \\
\hline CHEMBL3950255 & 1639643 & 7.0 & 6.8126 & TRN \\
\hline CHEMBL 3915154 & 1639643 & 7.0 & 6.8583 & TRN \\
\hline CHEMBL 3912500 & 1639643 & 7.0 & 6.9245 & TRN \\
\hline CHEMBL 3938801 & 1639643 & 7.0 & 6.9154 & TRN \\
\hline
\end{tabular}




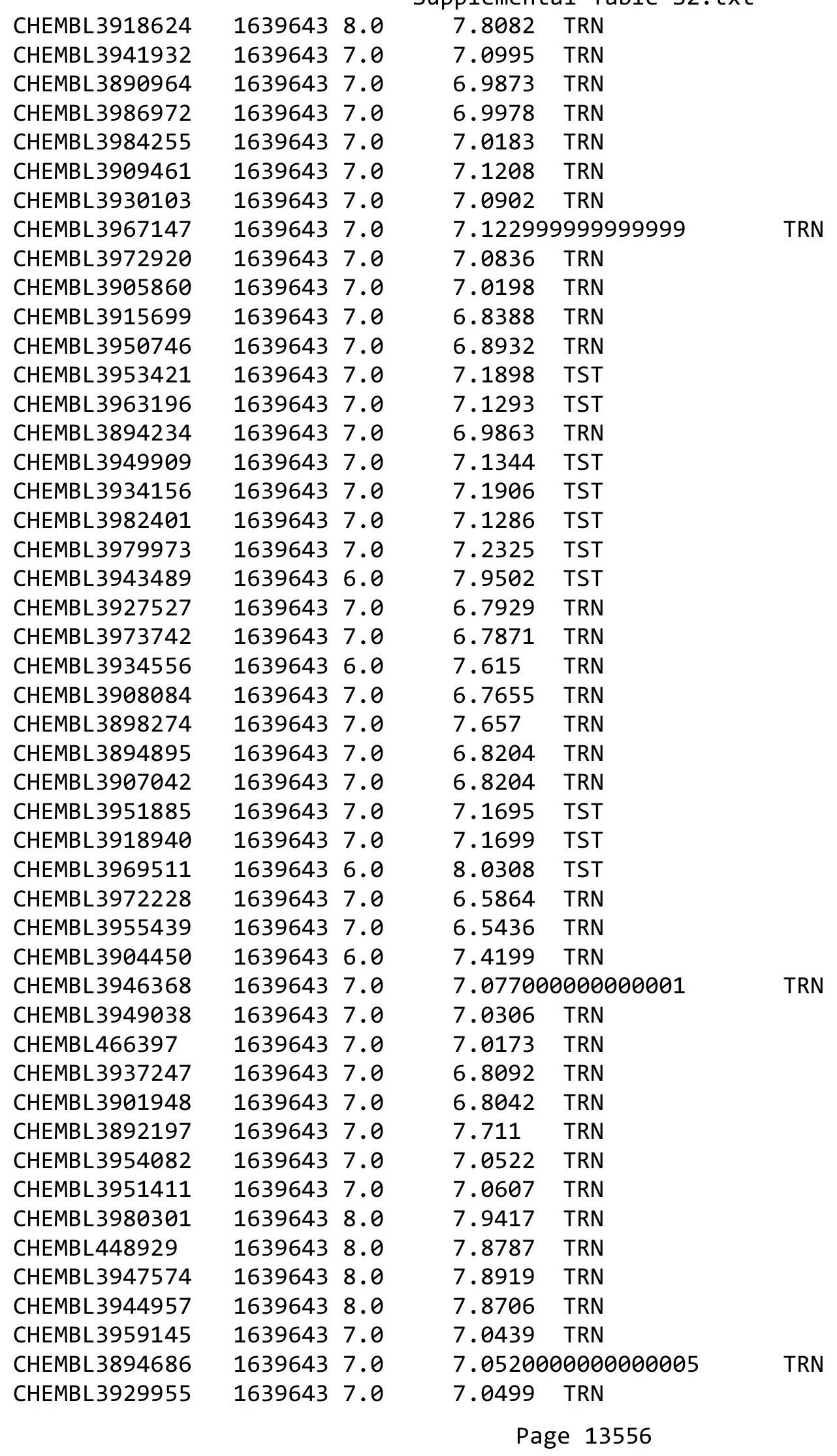


Supplemental Table S2.txt

\begin{tabular}{|c|c|c|c|c|c|}
\hline CHEMBL3932707 & 1639643 & 7.0 & 6.8714 & TST & \\
\hline CHEMBL3903782 & 1640611 & 6.7212 & 6.8568 & TST & \\
\hline CHEMBL3969455 & 1640611 & 5.8861 & 4.0847 & TST & \\
\hline CHEMBL3941157 & 1640611 & 7.9586 & 7.5256 & TRN & \\
\hline CHEMBL3913305 & 1640611 & 8.301 & 6.936 & TRN & \\
\hline CHEMBL3358113 & 1640611 & 7.6198 & 7.7111 & TRN & \\
\hline CHEMBL3976624 & 1640611 & 6.0 & 6.1257 & TRN & \\
\hline CHEMBL3892644 & 1640611 & 7.8239 & 7.5476 & TRN & \\
\hline CHEMBL3918165 & 1640611 & 7.7447 & 7.4289 & TRN & \\
\hline CHEMBL3940875 & 1640611 & 3.0 & 2.2728 & TST & \\
\hline CHEMBL3936245 & 1640611 & 6.9586 & 6.7922 & TRN & \\
\hline CHEMBL3896512 & 1640611 & 7.4815 & 7.114 & TRN & \\
\hline CHEMBL3901983 & 1640611 & 5.4202 & 6.2225 & TRN & \\
\hline CHEMBL3959734 & 1640611 & 5.0 & 5.7937 & TRN & \\
\hline CHEMBL3925632 & 1640611 & 6.9586 & 7.3955 & TRN & \\
\hline CHEMBL3909978 & 1640611 & 7.7959 & 7.2837 & TRN & \\
\hline CHEMBL3890782 & 1640611 & 7.7212 & 7.2921 & TRN & \\
\hline CHEMBL 3952070 & 1640611 & 6.8239 & 7.2393 & TRN & \\
\hline CHEMBL3934451 & 1640611 & 5.0 & \multicolumn{2}{|c|}{5.247000000000001} & TST \\
\hline CHEMBL 3971847 & 1640611 & 6.3098 & 6.9563 & TRN & \\
\hline CHEMBL3942428 & 1640611 & 8.5229 & 8.3365 & TRN & \\
\hline CHEMBL3948239 & 1640611 & 6.7747 & 7.0902 & TRN & \\
\hline CHEMBL3983207 & 1640611 & 4.0 & 4.9535 & TRN & \\
\hline CHEMBL3938432 & 1640611 & 7.0177 & \multicolumn{2}{|c|}{6.542999999999999} & TRN \\
\hline CHEMBL3974917 & 1640611 & 4.1549 & 3.3735 & TST & \\
\hline CHEMBL3358120 & 1640611 & 8.2218 & 7.7224 & TRN & \\
\hline CHEMBL3933171 & 1640611 & 8.0458 & 7.4118 & TRN & \\
\hline CHEMBL3942893 & 1640611 & 6.8239 & 6.4167 & TST & \\
\hline CHEMBL3913848 & 1640611 & 3.0 & 2.7783 & TST & \\
\hline CHEMBL3983158 & 1640611 & 7.7212 & 7.9347 & TST & \\
\hline CHEMBL3893295 & 1640611 & 8.0969 & 7.8519 & TRN & \\
\hline CHEMBL3986941 & 1640611 & 5.6198 & 6.9869 & TRN & \\
\hline CHEMBL3987131 & 1640611 & 5.2007 & 5.0695 & TST & \\
\hline CHEMBL 3950779 & 1640611 & 5.4318 & 5.9306 & TRN & \\
\hline CHEMBL3927779 & 1640611 & 6.8508 & 7.2708 & TRN & \\
\hline CHEMBL3961560 & 1640611 & 7.2218 & \multicolumn{2}{|c|}{6.832999999999999} & TRN \\
\hline CHEMBL3961422 & 1640611 & 6.6778 & 7.1176 & TRN & \\
\hline CHEMBL3951353 & 1640611 & 5.0 & 4.3784 & TRN & \\
\hline CHEMBL3949096 & 1640611 & 7.9586 & 7.4562 & TRN & \\
\hline CHEMBL3358116 & 1640611 & 6.4908 & 7.3397 & TRN & \\
\hline CHEMBL3978785 & 1640611 & 6.6778 & 6.9145 & TST & \\
\hline CHEMBL3962837 & 1640611 & 7.5376 & 7.1963 & TRN & \\
\hline CHEMBL3358119 & 1640611 & 8.3979 & 7.7869 & TRN & \\
\hline CHEMBL 3917083 & 1640611 & 6.7595 & 6.0783 & TRN & \\
\hline CHEMBL3958400 & 1640611 & 7.7447 & 7.5745 & TST & \\
\hline CHEMBL3904089 & 1640611 & 7.4685 & 7.9848 & TRN & \\
\hline CHEMBL3967171 & 1640611 & 8.1549 & 7.1322 & TRN & \\
\hline CHEMBL 3935267 & 1640611 & 7.2366 & 7.3007 & TRN & \\
\hline
\end{tabular}

Page 13557 
Supplemental Table S2.txt

\begin{tabular}{|c|c|c|c|c|c|c|}
\hline CHEMBL3931388 & 1640611 & 7.6021 & \multicolumn{2}{|c|}{7.412999999999999} & & \multirow[t]{2}{*}{ TRN } \\
\hline CHEMBL3914967 & 1640611 & 5.0 & 5.4831 & TRN & & \\
\hline CHEMBL3935642 & 1640611 & 6.6198 & 6.8485 & TRN & & \\
\hline CHEMBL3913358 & 1640611 & 6.0915 & 7.4188 & TRN & & \\
\hline CHEMBL3890420 & 1640611 & \multicolumn{3}{|c|}{6.757000000000001} & 7.1016 & TRN \\
\hline CHEMBL3900805 & 1640611 & 7.3279 & 6.17 & TST & & \\
\hline CHEMBL 3980267 & 1640611 & 5.585 & 5.4132 & TRN & & \\
\hline CHEMBL3931957 & 1640611 & 6.6326 & 6.6821 & TRN & & \\
\hline CHEMBL 3949901 & 1640611 & 7.3372 & 7.8137 & TRN & & \\
\hline CHEMBL3970518 & 1640611 & 5.0 & 5.3006 & TRN & & \\
\hline CHEMBL 3948608 & 1640611 & 6.5376 & 7.8167 & TRN & & \\
\hline CHEMBL3920645 & 1640611 & 7.6778 & 7.1723 & TRN & & \\
\hline CHEMBL3942939 & 1640611 & 7.9586 & 7.4069 & TRN & & \\
\hline CHEMBL3942889 & 1640611 & 6.284 & 6.9132 & TRN & & \\
\hline CHEMBL3908101 & 1640611 & 6.5031 & 6.5331 & TRN & & \\
\hline CHEMBL 3896484 & 1640611 & 6.3979 & 6.5884 & TST & & \\
\hline CHEMBL3938568 & 1640611 & 5.4737 & 3.5192 & TST & & \\
\hline CHEMBL3358109 & 1640611 & 6.3279 & 7.1711 & TRN & & \\
\hline CHEMBL3971269 & 1640611 & 6.9208 & 7.1095 & TRN & & \\
\hline CHEMBL3912803 & 1640611 & 7.2676 & 7.2879 & TRN & & \\
\hline CHEMBL3946215 & 1640611 & 6.1135 & 6.8749 & TRN & & \\
\hline CHEMBL3358118 & 1640611 & 6.8386 & 7.5263 & TRN & & \\
\hline CHEMBL3961717 & 1640611 & 5.3979 & 5.63299 & 9999999999 & & TRN \\
\hline CHEMBL3909390 & 1640611 & 3.0 & 3.4485 & TST & & \\
\hline CHEMBL3911002 & 1640611 & 7.3872 & 7.12299 & 9999999999 & & TRN \\
\hline CHEMBL3946900 & 1640611 & 8.0458 & 7.7029 & TRN & & \\
\hline CHEMBL3940798 & 1640611 & 6.0088 & 6.8032 & TRN & & \\
\hline CHEMBL3927126 & 1640611 & 3.0 & 4.2471 & TST & & \\
\hline CHEMBL3900458 & 1640611 & 7.699 & 7.0381 & TRN & & \\
\hline CHEMBL3921265 & 1640611 & 5.6778 & 5.6845 & TRN & & \\
\hline CHEMBL3969027 & 1640611 & 6.699 & 6.0768 & TRN & & \\
\hline CHEMBL3947962 & 1640611 & 7.0269 & 6.9492 & TRN & & \\
\hline CHEMBL3985307 & 1640611 & 7.4437 & 6.5341 & TRN & & \\
\hline CHEMBL3955939 & 1640611 & 5.0 & 4.5663 & TRN & & \\
\hline CHEMBL3924294 & 1640611 & 6.7447 & 7.1724 & TRN & & \\
\hline CHEMBL3925688 & 1640611 & 6.9957 & 7.4286 & TRN & & \\
\hline CHEMBL3908305 & 1640611 & 5.0 & 7.0237 & TRN & & \\
\hline CHEMBL3932409 & 1640611 & 5.0223 & 5.8596 & TST & & \\
\hline CHEMBL3961881 & 1640611 & 7.4949 & 7.2786 & TRN & & \\
\hline CHEMBL3898264 & 1640611 & 7.0 & 6.8504 & TST & & \\
\hline CHEMBL3922363 & 1640611 & 5.0 & 5.4503 & TRN & & \\
\hline CHEMBL3935978 & 1640611 & 5.5376 & 5.6845 & TRN & & \\
\hline CHEMBL3968535 & 1640611 & 8.0 & 6.8394 & TST & & \\
\hline CHEMBL3969457 & 1640611 & 5.0 & 4.6028 & TRN & & \\
\hline CHEMBL3958873 & 1640611 & 7.7696 & 7.5123 & TRN & & \\
\hline CHEMBL3938106 & 1640611 & 5.6383 & 5.4435 & TRN & & \\
\hline CHEMBL3927295 & 1640611 & 4.0 & 5.3323 & TRN & & \\
\hline CHEMBL3971180 & 1640611 & 6.1308 & 6.0519 & TRN & & \\
\hline
\end{tabular}


Supplemental Table S2.txt

\begin{tabular}{|c|c|c|c|c|}
\hline CHEMBL 3897905 & 1640611 & 8.0 & 7.9491 & TRN \\
\hline CHEMBL3979069 & 1640611 & 6.8297 & 7.3802 & TRN \\
\hline CHEMBL3358111 & 1640611 & 7.7447 & 7.631 & TRN \\
\hline CHEMBL 3918312 & 1640611 & 4.0605 & 4.2704 & TST \\
\hline CHEMBL 3968196 & 1640611 & 5.8633 & 6.1031 & TRN \\
\hline CHEMBL 3945163 & 1640611 & 6.2007 & 6.4571 & TST \\
\hline CHEMBL 3899760 & 1640611 & 5.0 & 4.5342 & TRN \\
\hline CHEMBL3917062 & 1640611 & 6.7852 & 6.8469 & TRN \\
\hline CHEMBL3977065 & 1640611 & 5.6383 & 5.9161 & TRN \\
\hline CHEMBL 3902686 & 1640611 & 3.9706 & 4.1762 & TST \\
\hline CHEMBL 3959914 & 1640611 & 6.5086 & 6.7062 & TRN \\
\hline CHEMBL 3936759 & 1640611 & 7.1192 & 6.5341 & TRN \\
\hline CHEMBL 3975176 & 1640611 & 7.1938 & 6.3142 & TRN \\
\hline CHEMBL 3891297 & 1640611 & 8.5229 & 8.2021 & TST \\
\hline CHEMBL 3961187 & 1640611 & 7.0915 & 7.4402 & TRN \\
\hline CHEMBL 3939608 & 1640611 & 6.6308 & 6.7607 & TRN \\
\hline CHEMBL3926712 & 1640611 & 7.1135 & 6.7378 & TRN \\
\hline CHEMBL 3979203 & 1640611 & 7.2518 & 7.3422 & TRN \\
\hline CHEMBL3923289 & 1640611 & 8.2218 & 7.8806 & TST \\
\hline CHEMBL 3954455 & 1640611 & 7.4815 & 7.6339 & TRN \\
\hline CHEMBL 3925299 & 1640611 & 8.0969 & 7.6377 & TRN \\
\hline CHEMBL3941930 & 1640611 & 8.5229 & 8.2019 & TST \\
\hline CHEMBL 3933235 & 1640611 & 8.0458 & 7.039 & TRN \\
\hline CHEMBL3924504 & 1640611 & 7.5229 & 7.7084 & TST \\
\hline CHEMBL 3933420 & 1640611 & 6.4815 & 6.645 & TST \\
\hline CHEMBL 3918876 & 1640611 & 6.1308 & 6.1638 & TRN \\
\hline CHEMBL3358121 & 1640611 & 8.301 & 7.7869 & TRN \\
\hline CHEMBL 3952154 & 1640611 & 5.0315 & 5.4601 & TST \\
\hline CHEMBL3908890 & 1640611 & 7.2218 & 7.6262 & TRN \\
\hline CHEMBL 3964038 & 1640611 & 7.4089 & 7.0159 & TRN \\
\hline CHEMBL 3942746 & 1640611 & 6.8416 & 6.6333 & TST \\
\hline CHEMBL 3912318 & 1640611 & 7.2924 & 7.5864 & TRN \\
\hline CHEMBL 3357703 & 1640611 & 7.699 & 7.8427 & TST \\
\hline CHEMBL 3984237 & 1640611 & 6.0706 & 6.8957 & TRN \\
\hline CHEMBL3920615 & 1640611 & 8.3979 & 7.6961 & TRN \\
\hline CHEMBL3956613 & 1640611 & 7.8861 & 7.3991 & TRN \\
\hline CHEMBL 3358115 & 1640611 & 6.4622 & 7.6788 & TRN \\
\hline CHEMBL 3357702 & 1640611 & 8.301 & 7.876 & TST \\
\hline CHEMBL 3928322 & 1640611 & 7.3279 & 7.3027 & TRN \\
\hline CHEMBL 3977548 & 1640611 & 8.0969 & 6.6015 & TRN \\
\hline CHEMBL 3976191 & 1640611 & 7.6778 & 6.5341 & TRN \\
\hline CHEMBL 3908370 & 1640611 & 4.0 & 5.20299 & 9999999999 \\
\hline CHEMBL 3943982 & 1640611 & 5.0 & 5.74200 & 0000000001 \\
\hline CHEMBL3357701 & 1640611 & 5.3979 & 5.5482 & TRN \\
\hline CHEMBL 3911487 & 1640611 & 5.6778 & 6.4625 & TRN \\
\hline CHEMBL 3939644 & 1640611 & 7.3279 & 7.0689 & TRN \\
\hline CHEMBL 3898675 & 1640611 & 5.0 & 5.8855 & TRN \\
\hline CHEMBL 3922714 & 1640611 & 7.7212 & 6.7234 & TRN \\
\hline
\end{tabular}


Supplemental Table S2.txt

\begin{tabular}{|c|c|c|c|c|c|}
\hline CHEMBL3956897 & 1640611 & 8.0969 & 7.3685 & TRN & \\
\hline CHEMBL3913151 & 1640611 & 7.6778 & 7.0954 & TRN & \\
\hline CHEMBL3933932 & 1640611 & 7.1192 & 6.9106 & TRN & \\
\hline CHEMBL3955412 & 1640611 & 6.2612 & 6.1885 & TST & \\
\hline CHEMBL 3905924 & 1640611 & 6.4815 & 6.6477 & TRN & \\
\hline CHEMBL3901961 & 1640611 & 6.2076 & 6.1892 & TST & \\
\hline CHEMBL3964159 & 1640611 & 7.7959 & 7.603 & TRN & \\
\hline CHEMBL 3893679 & 1640611 & 8.2218 & 6.8273 & TRN & \\
\hline CHEMBL 3898035 & 1640611 & 6.9208 & 7.1197 & TRN & \\
\hline CHEMBL3357705 & 1640611 & 7.7696 & 6.8438 & TRN & \\
\hline CHEMBL3968653 & 1640611 & 6.1871 & 7.0616 & TST & \\
\hline CHEMBL3893567 & 1640611 & 7.0555 & 7.3589 & TRN & \\
\hline CHEMBL 3980411 & 1640611 & 8.5229 & 7.9927 & TST & \\
\hline CHEMBL 3973018 & 1640611 & 7.284 & 6.9536 & TRN & \\
\hline CHEMBL3960699 & 1640611 & 8.0 & 7.7154 & TRN & \\
\hline CHEMBL3985114 & 1640611 & 8.0969 & 7.4367 & TST & \\
\hline CHEMBL3358112 & 1640611 & 6.4012 & 6.5265 & TRN & \\
\hline CHEMBL 3924293 & 1640611 & 6.76200 & 00000000 & 205 & 7.0262 \\
\hline CHEMBL3926050 & 1640611 & 6.1192 & 6.5341 & TRN & \\
\hline CHEMBL3950436 & 1640611 & 6.8539 & 6.6905 & TST & \\
\hline CHEMBL3961747 & 1640611 & 8.0458 & 7.8821 & TST & \\
\hline CHEMBL3981548 & 1640611 & 6.0273 & 6.3826 & TRN & \\
\hline CHEMBL 3904140 & 1640611 & 8.3979 & 7.5006 & TRN & \\
\hline CHEMBL3893953 & 1640611 & 8.0 & 7.437 & TRN & \\
\hline CHEMBL3358114 & 1640611 & 7.6778 & 7.6999 & TRN & \\
\hline CHEMBL3923265 & 1640611 & 5.7696 & 7.1865 & TRN & \\
\hline CHEMBL3904856 & 1640611 & 4.752 & 4.3973 & TST & \\
\hline CHEMBL3949204 & 1640611 & 4.699 & 3.8885 & TST & \\
\hline CHEMBL3959452 & 1640611 & 6.1141 & 5.9515 & TRN & \\
\hline CHEMBL3965395 & 1640611 & 7.7212 & 7.3342 & TST & \\
\hline CHEMBL3934422 & 1640611 & 5.3665 & 5.6145 & TST & \\
\hline CHEMBL 3894086 & 1640611 & 8.1549 & 7.5512 & TRN & \\
\hline CHEMBL 3948370 & 1640611 & 5.2147 & 5.7093 & TRN & \\
\hline CHEMBL 3945023 & 1640611 & 7.8861 & 7.0487 & TST & \\
\hline CHEMBL 3932878 & 1640611 & 7.1487 & 7.3801 & TRN & \\
\hline CHEMBL3974010 & 1640611 & 7.5376 & 7.232 & TRN & \\
\hline CHEMBL3358108 & 1640611 & 6.4535 & 7.4341 & TRN & \\
\hline CHEMBL3901668 & 1640611 & 6.8729 & 7.1606 & TRN & \\
\hline CHEMBL3916124 & 1640611 & 8.1549 & 8.1097 & TST & \\
\hline CHEMBL 3908790 & 1640611 & 4.15 & 3.6683 & TST & \\
\hline CHEMBL3982330 & 1640611 & 5.0 & 3.4871 & TST & \\
\hline CHEMBL3959497 & 1640611 & 6.5654 & 6.2354 & TRN & \\
\hline CHEMBL3935150 & 1640611 & 6.6576 & 6.7545 & TST & \\
\hline CHEMBL3946709 & 1640611 & 7.1249 & 6.5181 & TRN & \\
\hline CHEMBL 3955480 & 1640611 & 7.6576 & 7.211 & TRN & \\
\hline CHEMBL3944899 & 1640611 & 7.699 & 7.1628 & TRN & \\
\hline CHEMBL3937674 & 1640611 & 5.9586 & 7.0251 & TRN & \\
\hline CHEMBL 3960850 & 1640611 & 6.7447 & 5.8339 & TRN & \\
\hline
\end{tabular}

Page 13560 
Supplemental Table S2.txt

\begin{tabular}{|c|c|c|c|c|c|}
\hline CHEMBL3930636 & 1640611 & 8.699 & 7.0026 & TRN & \\
\hline CHEMBL3898749 & 1640611 & 5.0 & 4.4326 & TRN & \\
\hline CHEMBL3913730 & 1640611 & 7.8539 & 7.4745 & TRN & \\
\hline CHEMBL3932225 & 1640611 & 7.2147 & 7.0553 & TRN & \\
\hline CHEMBL3929504 & 1640611 & 7.2441 & 7.1583 & TRN & \\
\hline CHEMBL3944999 & 1640611 & 7.2924 & 7.463999 & 9999999995 & TRN \\
\hline CHEMBL3932991 & 1640611 & 6.8153 & 6.9953 & TRN & \\
\hline CHEMBL 3974330 & 1640611 & 5.0 & 4.7054 & TRN & \\
\hline CHEMBL3896984 & 1640611 & 7.3768 & 7.3867 & TRN & \\
\hline CHEMBL3962497 & 1640611 & 3.0 & 2.3743 & TST & \\
\hline CHEMBL3358117 & 1640611 & 8.0458 & 7.7052 & TRN & \\
\hline CHEMBL3933135 & 1640611 & 5.6383 & 4.7937 & TST & \\
\hline CHEMBL3908598 & 1640611 & 5.3487 & 5.9566 & TRN & \\
\hline CHEMBL3963287 & 1640611 & 7.0969 & 7.0381 & TST & \\
\hline CHEMBL3975663 & 1640611 & 6.6198 & 6.6877 & TST & \\
\hline CHEMBL3904991 & 1640611 & 6.2518 & 6.8843 & TRN & \\
\hline CHEMBL3357706 & 1640611 & 6.7258 & 7.3857 & TRN & \\
\hline CHEMBL3929549 & 1640611 & 6.6021 & 6.4408 & TRN & \\
\hline CHEMBL3954901 & 1640611 & 7.6778 & 7.8317 & TST & \\
\hline CHEMBL3937436 & 1640611 & 5.0 & 6.6896 & TRN & \\
\hline CHEMBL3955353 & 1640611 & 6.8861 & 6.7277 & TRN & \\
\hline CHEMBL3903865 & 1640611 & 5.8239 & 6.5934 & TST & \\
\hline CHEMBL3949562 & 1640611 & 6.8962 & 7.1016 & TRN & \\
\hline CHEMBL3969385 & 1640611 & 7.3979 & 6.5782 & TST & \\
\hline CHEMBL 3953146 & 1640611 & 6.7747 & 7.1711 & TRN & \\
\hline CHEMBL 3959131 & 1640611 & 7.4318 & 6.829 & TST & \\
\hline CHEMBL3911634 & 1640611 & 8.301 & 7.2982 & TRN & \\
\hline CHEMBL3962021 & 1640611 & 7.7696 & 7.1651 & TRN & \\
\hline CHEMBL3889829 & 1640611 & 5.0 & 4.3176 & TRN & \\
\hline CHEMBL3899218 & 1640611 & 6.4318 & 5.6845 & TRN & \\
\hline CHEMBL3937813 & 1640611 & 7.9208 & 7.7455 & TST & \\
\hline CHEMBL 3899382 & 1640611 & 6.5214 & 7.6088 & TRN & \\
\hline CHEMBL3903663 & 1642074 & 7.8477 & 8.2881 & TRN & \\
\hline CHEMBL 3915285 & 1642074 & 8.28399 & 99999999 & 7.725 & IJ \\
\hline CHEMBL3983324 & 1642074 & 8.4202 & 7.8598 & TRN & \\
\hline CHEMBL3915073 & 1642074 & 7.7986 & 7.6128 & TST & \\
\hline CHEMBL3981805 & 1642074 & 8.8239 & 8.058 & TRN & \\
\hline CHEMBL3968103 & 1642074 & 7.4685 & 7.2346 & TST & \\
\hline CHEMBL 3897474 & 1642074 & 7.3054 & 7.1865 & TRN & \\
\hline CHEMBL3986516 & 1642074 & 8.2757 & 8.3817 & TRN & \\
\hline CHEMBL 3968570 & 1642074 & 8.9208 & 8.4065 & TRN & \\
\hline CHEMBL3922211 & 1642074 & 7.466 & 7.8058 & TRN & \\
\hline CHEMBL3985018 & 1642074 & 7.9066 & 8.1536 & TRN & \\
\hline CHEMBL3975293 & 1642074 & 8.2007 & 8.4886 & TRN & \\
\hline CHEMBL3902525 & 1642074 & 6.0 & 6.1868 & TRN & \\
\hline CHEMBL 3940808 & 1642074 & 8.5376 & 9.0407 & TRN & \\
\hline CHEMBL 3890648 & 1642074 & 8.1249 & 8.1247 & TRN & \\
\hline CHEMBL 3970144 & 1642074 & 8.5528 & 7.9039 & TRN & \\
\hline
\end{tabular}

Page 13561 
Supplemental Table S2.txt

\begin{tabular}{|c|c|c|c|c|c|}
\hline CHEMBL3943939 & 1642074 & 7.8928 & \multicolumn{2}{|c|}{7.542999999999999} & TRN \\
\hline CHEMBL3906821 & 1642074 & 8.9586 & 8.6599 & TST & \\
\hline CHEMBL3986310 & 1642074 & 7.6861 & 7.2387 & TRN & \\
\hline CHEMBL3921045 & 1642074 & 7.2933 & 7.3632 & TRN & \\
\hline CHEMBL 3889660 & 1642074 & 6.0 & \multicolumn{2}{|c|}{6.281000000000001} & TRN \\
\hline CHEMBL3957082 & 1642074 & 7.4145 & 7.3967 & TRN & \\
\hline CHEMBL3933170 & 1642074 & 8.699 & 7.89 & TRN & \\
\hline CHEMBL3981339 & 1642074 & 8.0506 & 8.3817 & TRN & \\
\hline CHEMBL3934975 & 1642074 & 8.5686 & 7.8368 & TST & \\
\hline CHEMBL3963838 & 1642074 & 8.5229 & 8.8878 & TRN & \\
\hline CHEMBL3892866 & 1642074 & 8.699 & 8.2001 & TRN & \\
\hline CHEMBL3916316 & 1642074 & 8.0506 & 8.379 & TRN & \\
\hline CHEMBL3928978 & 1642074 & 6.6536 & 7.8324 & TRN & \\
\hline CHEMBL 3981435 & 1642074 & 7.8508 & 7.1607 & TRN & \\
\hline CHEMBL 3908049 & 1642074 & 8.585 & 8.49 & TRN & \\
\hline CHEMBL3935691 & 1642074 & 6.0 & 6.1464 & TRN & \\
\hline CHEMBL3937054 & 1642074 & 9.5229 & 9.2817 & TRN & \\
\hline CHEMBL3928492 & 1642074 & 9.0969 & 8.7429 & TRN & \\
\hline CHEMBL3973448 & 1642074 & 6.8761 & 6.3015 & TST & \\
\hline CHEMBL 3897895 & 1642074 & 8.1739 & 7.8526 & TST & \\
\hline CHEMBL3905357 & 1642074 & 7.8268 & 7.2752 & TRN & \\
\hline CHEMBL3921271 & 1642074 & 6.644 & 7.3898 & TRN & \\
\hline CHEMBL3936246 & 1642074 & 8.0809 & 8.1633 & TRN & \\
\hline CHEMBL3916900 & 1642074 & 9.0458 & 8.6565 & TRN & \\
\hline CHEMBL3967572 & 1642074 & 9.0969 & 8.7798 & TRN & \\
\hline CHEMBL3974903 & 1642074 & 8.1549 & 7.4846 & TRN & \\
\hline CHEMBL3972504 & 1642074 & 8.3872 & 7.9976 & TRN & \\
\hline CHEMBL3964505 & 1642074 & 8.3279 & 8.1348 & TRN & \\
\hline CHEMBL3810085 & 1642074 & 8.8239 & 8.9379 & TST & \\
\hline CHEMBL 3981885 & 1642074 & 7.9172 & 8.0111 & TRN & \\
\hline CHEMBL3900533 & 1642074 & 8.3468 & 8.2124 & TST & \\
\hline CHEMBL3971351 & 1642074 & 9.5229 & 9.18799 & 9999999999 & TRN \\
\hline CHEMBL3913508 & 1642074 & 7.3757 & 7.1162 & TRN & \\
\hline CHEMBL3939032 & 1642074 & 9.0 & 8.4728 & TRN & \\
\hline CHEMBL3945081 & 1642074 & 8.1612 & 8.0377 & TRN & \\
\hline CHEMBL3966443 & 1642074 & 8.3872 & 8.2285 & TRN & \\
\hline CHEMBL3966407 & 1642074 & 8.1308 & 7.5706 & TRN & \\
\hline CHEMBL 3889720 & 1642074 & 7.6326 & 7.4612 & TRN & \\
\hline CHEMBL3952715 & 1642074 & 6.9586 & 7.6445 & TRN & \\
\hline CHEMBL3958651 & 1642074 & 8.4437 & 7.8382 & TRN & \\
\hline CHEMBL3959725 & 1642074 & 8.9586 & 9.0917 & TRN & \\
\hline CHEMBL3966805 & 1642074 & 8.2291 & 8.0429 & TRN & \\
\hline CHEMBL3904282 & 1642074 & 8.699 & 8.9756 & TRN & \\
\hline CHEMBL3925905 & 1642074 & 8.2366 & 8.5666 & TRN & \\
\hline CHEMBL3973961 & 1642074 & 8.3979 & 7.6572 & TST & \\
\hline CHEMBL3906819 & 1642074 & 7.5498 & 7.67200 & 3000000001 & $1 k$ \\
\hline CHEMBL3961180 & 1642074 & 7.4584 & 7.7814 & TRN & \\
\hline CHEMBL3925557 & 1642074 & 8.3565 & 7.6749 & TST & \\
\hline
\end{tabular}


Supplemental Table S2.txt

\begin{tabular}{|c|c|c|c|c|}
\hline CHEMBL3966499 & 1642074 & 8.0915 & 7.3621 & TRN \\
\hline CHEMBL3953144 & 1642074 & 8.2147 & 8.1996 & TRN \\
\hline CHEMBL3969001 & 1642074 & 7.6234 & 8.2941 & TRN \\
\hline CHEMBL3902209 & 1642074 & 6.0 & 6.5381 & TRN \\
\hline CHEMBL3940639 & 1642074 & 6.0 & 6.3266 & TRN \\
\hline CHEMBL3944428 & 1642074 & 8.3372 & 8.3225 & TRN \\
\hline CHEMBL3895191 & 1642074 & 7.0362 & 7.3319 & TST \\
\hline CHEMBL3927926 & 1642074 & 6.4318 & 6.75299 & 9999999999 \\
\hline CHEMBL3893275 & 1642074 & 6.5482 & 7.6634 & TRN \\
\hline CHEMBL3913060 & 1642074 & 6.0 & 6.4932 & TST \\
\hline CHEMBL3949372 & 1642074 & 8.7447 & 8.1035 & TST \\
\hline CHEMBL3899005 & 1642074 & 8.7212 & 8.7449 & TRN \\
\hline CHEMBL3937446 & 1642074 & 7.8665 & 7.4956 & TRN \\
\hline CHEMBL3959074 & 1642074 & 7.7471 & 7.6647 & TRN \\
\hline CHEMBL3956063 & 1642074 & 7.2154 & 6.4917 & TRN \\
\hline CHEMBL 3898719 & 1642074 & 7.767 & 8.2666 & TRN \\
\hline CHEMBL3960320 & 1642074 & 8.301 & 8.7702 & TRN \\
\hline CHEMBL3958307 & 1642074 & 6.0 & 6.1637 & TRN \\
\hline CHEMBL3894335 & 1642074 & 6.2161 & 6.8509 & TST \\
\hline CHEMBL3937510 & 1642074 & 8.0915 & 7.9179 & TRN \\
\hline CHEMBL 3986342 & 1642074 & 8.9586 & 8.5832 & TST \\
\hline CHEMBL3906206 & 1642074 & 8.8239 & 8.3727 & TST \\
\hline CHEMBL3913032 & 1642074 & 8.0315 & 8.2055 & TRN \\
\hline CHEMBL3976162 & 1642074 & 8.4318 & 8.8533 & TRN \\
\hline CHEMBL 3904349 & 1642074 & 8.5528 & 8.5945 & TRN \\
\hline CHEMBL 3893318 & 1642074 & 7.3788 & 6.9425 & TST \\
\hline CHEMBL3942833 & 1642074 & 8.7959 & 8.3323 & TST \\
\hline CHEMBL 3898587 & 1642074 & 6.0 & 6.5864 & TRN \\
\hline CHEMBL3931277 & 1642074 & 6.1733 & 6.6267 & TST \\
\hline CHEMBL3977073 & 1642074 & 8.5528 & 8.1938 & TST \\
\hline CHEMBL3966072 & 1642074 & 6.0 & 6.3087 & TRN \\
\hline CHEMBL3980526 & 1642074 & 8.1675 & 8.3026 & TRN \\
\hline CHEMBL3922499 & 1642074 & 6.4685 & 8.138 & TST \\
\hline CHEMBL3942347 & 1642074 & 6.8153 & 6.4302 & TRN \\
\hline CHEMBL 3975214 & 1642074 & 7.5436 & 7.4428 & TST \\
\hline CHEMBL3973354 & 1642074 & 6.0 & 6.6484 & TRN \\
\hline CHEMBL3964527 & 1642074 & 9.0458 & 8.5686 & TST \\
\hline CHEMBL3970213 & 1642074 & 7.9747 & 7.4986 & TRN \\
\hline CHEMBL3980066 & 1642074 & 8.7212 & 8.2808 & TRN \\
\hline CHEMBL3927624 & 1642074 & 7.3507 & 7.9983 & TST \\
\hline CHEMBL 3938933 & 1642074 & 6.5017 & 6.6324 & TRN \\
\hline CHEMBL3978196 & 1642074 & 8.5229 & 9.2914 & TST \\
\hline CHEMBL3929257 & 1642074 & 7.2358 & 7.4269 & TRN \\
\hline CHEMBL3927283 & 1642074 & 7.4045 & 6.9632 & TST \\
\hline CHEMBL3950494 & 1642074 & 8.4437 & 8.1988 & TRN \\
\hline CHEMBL3929510 & 1642074 & 7.8097 & 7.6185 & TRN \\
\hline CHEMBL3904025 & 1642074 & 8.2218 & 7.1581 & TRN \\
\hline CHEMBL3891519 & 1642074 & 8.1427 & 7.8883 & TST \\
\hline
\end{tabular}


Supplemental Table S2.txt

\begin{tabular}{|c|c|c|c|c|c|}
\hline CHEMBL3949181 & 1642074 & 8.1192 & 8.586 & TRN & \\
\hline CHEMBL3957810 & 1642074 & 7.0297 & 7.3912 & TRN & \\
\hline CHEMBL3918521 & 1642074 & 7.5969 & 7.6377 & TRN & \\
\hline CHEMBL3925980 & 1642074 & 6.6144 & 7.614 & TST & \\
\hline CHEMBL3937248 & 1642074 & 7.7545 & 7.9268 & TRN & \\
\hline CHEMBL3898550 & 1642074 & 7.2612 & 7.0923 & TRN & \\
\hline CHEMBL3975341 & 1642074 & 6.5702 & 7.7121 & TRN & \\
\hline CHEMBL3897814 & 1642074 & 8.1427 & 8.6168 & TRN & \\
\hline CHEMBL3808459 & 1642074 & 8.0315 & 8.5138 & TST & \\
\hline CHEMBL3976993 & 1642074 & 8.3098 & 8.0948 & TRN & \\
\hline CHEMBL3947727 & 1642074 & 8.6778 & 8.31899 & 9999999999 & TRN \\
\hline CHEMBL3920246 & 1642074 & 6.0 & 6.3878 & TST & \\
\hline CHEMBL3899619 & 1642074 & 7.4413 & 8.1199 & TRN & \\
\hline CHEMBL3903003 & 1642074 & 8.9586 & 8.4569 & TRN & \\
\hline CHEMBL3942200 & 1642074 & 6.0 & 6.5958 & TST & \\
\hline CHEMBL3983065 & 1642074 & 8.6576 & 8.6578 & TRN & \\
\hline CHEMBL3577536 & 1496997 & 5.3439 & 5.349 & TRN & \\
\hline CHEMBL3577526 & 1496997 & 5.4724 & 5.38899 & 9999999999 & TST \\
\hline CHEMBL3577506 & 1496997 & 5.7447 & 5.5799 & TRN & \\
\hline CHEMBL3577508 & 1496997 & 5.8447 & 5.8463 & TRN & \\
\hline CHEMBL3577514 & 1496997 & 6.0044 & 5.9531 & TRN & \\
\hline CHEMBL3577504 & 1496997 & 5.7545 & 5.8388 & TRN & \\
\hline CHEMBL3577513 & 1496997 & 5.9706 & 6.0814 & TST & \\
\hline CHEMBL3577519 & 1496997 & 5.301 & 5.2865 & TRN & \\
\hline CHEMBL3577511 & 1496997 & 6.9208 & 6.8645 & TRN & \\
\hline CHEMBL3577520 & 1496997 & 5.6716 & 5.7325 & TRN & \\
\hline CHEMBL3577551 & 1496997 & 5.7986 & 5.6128 & TRN & \\
\hline CHEMBL3577507 & 1496997 & 5.0809 & 5.077 & TST & \\
\hline CHEMBL3577538 & 1496997 & 5.5834 & 5.6836 & TRN & \\
\hline CHEMBL3577522 & 1496997 & 6.2076 & 6.1267 & TRN & \\
\hline CHEMBL3577509 & 1496997 & 6.0969 & 6.1484 & TST & \\
\hline CHEMBL3577515 & 1496997 & 6.4685 & 6.2099 & TST & \\
\hline CHEMBL3577533 & 1496997 & 6.4815 & 6.5021 & TRN & \\
\hline CHEMBL3577539 & 1496997 & 6.0969 & 6.2751 & TRN & \\
\hline CHEMBL3577552 & 1496997 & 5.8962 & 6.0883 & TRN & \\
\hline CHEMBL3577527 & 1496997 & 5.4921 & 5.4842 & TRN & \\
\hline CHEMBL3577531 & 1496997 & 5.2676 & 5.4625 & TST & \\
\hline CHEMBL3577503 & 1496997 & 5.6904 & 6.0844 & TST & \\
\hline CHEMBL3577537 & 1496997 & 5.6289 & 5.4364 & TST & \\
\hline CHEMBL3577518 & 1496997 & 5.0931 & 5.1833 & TRN & \\
\hline CHEMBL3577517 & 1496997 & 6.6778 & 6.612 & TRN & \\
\hline CHEMBL3577523 & 1496997 & 5.295 & 5.4135 & TRN & \\
\hline CHEMBL3577542 & 1496997 & 5.6716 & 5.7195 & TRN & \\
\hline CHEMBL3577535 & 1496997 & 5.1267 & 5.095 & TRN & \\
\hline CHEMBL3577540 & 1496997 & 5.3947 & 5.295 & TRN & \\
\hline CHEMBL3577546 & 1496997 & 5.1349 & 5.1122 & TRN & \\
\hline CHEMBL3577505 & 1496997 & 6.7696 & 6.9285 & TRN & \\
\hline CHEMBL55415 & 1496997 & 2.301 & 5.1836 & TST & \\
\hline
\end{tabular}


Supplemental Table S2.txt

\begin{tabular}{|c|c|c|c|c|}
\hline CHEMBL 3577543 & 1496997 & 5.6925 & 5.3167 & TST \\
\hline CHEMBL 3577528 & 1496997 & 5.9281 & 5.8848 & TRN \\
\hline CHEMBL3577549 & 1496997 & 5.1118 & 5.1743 & TRN \\
\hline CHEMBL 3577502 & 1496997 & 5.5817 & 5.7741 & TST \\
\hline CHEMBL 3577541 & 1496997 & 6.6021 & 6.64 & TRN \\
\hline CHEMBL 3577521 & 1496997 & 5.4647 & 5.4311 & TRN \\
\hline CHEMBL 3577548 & 1496997 & 5.8013 & 5.6262 & TRN \\
\hline CHEMBL 3577524 & 1496997 & 5.9245 & 5.9767 & TRN \\
\hline CHEMBL3577532 & 1496997 & 6.4202 & 6.282999 & 9999999995 \\
\hline CHEMBL 3577534 & 1496997 & 5.5058 & 5.7152 & TRN \\
\hline CHEMBL 3577547 & 1496997 & 5.0915 & 5.162999 & (999999999 \\
\hline CHEMBL 3577545 & 1496997 & 6.6576 & 6.4536 & TRN \\
\hline CHEMBL 3577516 & 1496997 & 6.3468 & 6.2745 & TRN \\
\hline CHEMBL 3577512 & 1496997 & 5.5918 & 5.6218 & TRN \\
\hline CHEMBL 3577510 & 1496997 & 6.2441 & 6.1869 & TRN \\
\hline CHEMBL 3577525 & 1496997 & 5.0362 & 4.5364 & TST \\
\hline CHEMBL 3577529 & 1496997 & 5.0862 & 5.0785 & TRN \\
\hline CHEMBL 3577550 & 1496997 & 5.6198 & 5.5379 & TRN \\
\hline CHEMBL 3577530 & 1496997 & 5.2865 & 5.3011 & TST \\
\hline CHEMBL 3577544 & 1496997 & 6.0177 & 6.0899 & TRN \\
\hline CHEMBL 373751 & 954705 & 3.2423 & 3.2945 & TRN \\
\hline CHEMBL449158 & 954705 & 5.9155 & 6.5715 & TST \\
\hline CHEMBL392695 & 954705 & 5.6162 & 5.6327 & TRN \\
\hline CHEMBL585951 & 954705 & 5.7257 & 5.6784 & TRN \\
\hline CHEMBL102714 & 954705 & 3.3493 & 3.4609 & TRN \\
\hline CHEMBL220241 & 954705 & 3.8189 & 3.7981 & TRN \\
\hline CHEMBL300389 & 954705 & 7.6273 & 7.8037 & TRN \\
\hline CHEMBL 3349342 & 954705 & 5.1274 & 5.1621 & TRN \\
\hline CHEMBL202721 & 954705 & 4.2298 & 4.2086 & TRN \\
\hline CHEMBL3199475 & 954705 & 4.5985 & 4.6072 & TRN \\
\hline CHEMBL577784 & 954705 & 4.4331 & 4.5144 & TRN \\
\hline CHEMBL1190711 & 954705 & 3.4537 & 3.5061 & TRN \\
\hline CHEMBL 2144069 & 954705 & 3.4468 & 3.4941 & TRN \\
\hline CHEMBL221137 & 954705 & 4.9596 & 4.7471 & TST \\
\hline CHEMBL191334 & 954705 & 3.4249 & 3.3919 & TRN \\
\hline CHEMBL 2363137 & 954705 & 5.0771 & 4.9759 & TRN \\
\hline CHEMBL483849 & 954705 & 3.0892 & 2.0169 & TST \\
\hline CHEMBL512504 & 954705 & 4.0257 & 4.1539 & TRN \\
\hline CHEMBL210618 & 954705 & 3.3051 & 3.2362 & TRN \\
\hline CHEMBL135561 & 954705 & 4.3676 & 4.4511 & TRN \\
\hline CHEMBL558642 & 954705 & 3.5266 & 3.3704 & TRN \\
\hline CHEMBL209148 & 954705 & 4.6828 & 4.7203 & TRN \\
\hline CHEMBL 3392440 & 954705 & 4.1287 & 4.05 & TRN \\
\hline CHEMBL399530 & 954705 & 3.8418 & 3.9447 & TRN \\
\hline CHEMBL1516890 & 954705 & 3.8144 & 3.8433 & TRN \\
\hline CHEMBL514499 & 954705 & 7.4731 & 7.3004 & TRN \\
\hline CHEMBL217354 & 954705 & 5.9479 & 5.9242 & TRN \\
\hline CHEMBL379300 & 954705 & 6.9193 & 6.8707 & TRN \\
\hline
\end{tabular}

Page 13565 


\begin{tabular}{|c|c|c|c|c|c|}
\hline \multicolumn{6}{|c|}{ Supplemental Table S2.txt } \\
\hline CHEMBL1230020 & 954705 & 3.5029 & 3.5363 & TRN & \\
\hline CHEMBL1970879 & 954705 & 5.4396 & 5.4716 & TRN & \\
\hline CHEMBL192566 & 954705 & 9.2931 & 7.6822 & TST & \\
\hline CHEMBL412142 & 954705 & 3.5971 & 3.6273 & TRN & \\
\hline CHEMBL2134202 & 954705 & 3.3812 & 3.4785 & TRN & \\
\hline CHEMBL189584 & 954705 & 3.8611 & 3.8689 & TRN & \\
\hline CHEMBL1673039 & 954705 & 4.3556 & 4.3098 & TRN & \\
\hline CHEMBL3186408 & 954705 & 3.4279 & 3.4357 & TST & \\
\hline CHEMBL1256459 & 954705 & 8.4211 & 8.4573 & TRN & \\
\hline CHEMBL240954 & 954705 & 3.3699 & 3.5916 & TST & \\
\hline CHEMBL1357247 & 954705 & 3.2064 & 3.2004 & TRN & \\
\hline CHEMBL259181 & 954705 & 2.9137 & 3.0445 & TRN & \\
\hline CHEMBL1909414 & 954705 & 3.3228 & 3.1767 & TRN & \\
\hline CHEMBL1404918 & 954705 & 3.0836 & 3.0424 & TRN & \\
\hline CHEMBL472940 & 954705 & 3.7626 & 3.8074 & TRN & \\
\hline CHEMBL 255342 & 954705 & 3.4405 & 3.3869 & TRN & \\
\hline CHEMBL 2137530 & 954705 & 4.4046 & 4.4746 & TRN & \\
\hline CHEMBL 222102 & 954705 & 3.8958 & 3.97600 & 00000000004 & TRN \\
\hline CHEMBL483847 & 954705 & 5.0739 & 4.9018 & TRN & \\
\hline CHEMBL509032 & 954705 & 5.3293 & 5.205 & TRN & \\
\hline CHEMBL1186585 & 954705 & 3.4518 & 3.3855 & TRN & \\
\hline CHEMBL 213100 & 954705 & 4.6323 & 4.5057 & TRN & \\
\hline CHEMBL 2005886 & 954705 & 5.6371 & 5.7492 & TRN & \\
\hline CHEMBL393929 & 954705 & 4.257 & 4.2502 & TRN & \\
\hline CHEMBL1788116 & 954705 & 4.2975 & 4.169 & TRN & \\
\hline CHEMBL 258844 & 954705 & 3.9166 & 3.9694 & TRN & \\
\hline CHEMBL1242367 & 954705 & 5.0408 & 4.0723 & TST & \\
\hline CHEMBL1590308 & 954705 & 3.1232 & 3.3437 & TST & \\
\hline CHEMBL573107 & 954705 & 5.1455 & 4.3544 & TST & \\
\hline CHEMBL379975 & 954705 & 4.5623 & 4.6168 & TST & \\
\hline CHEMBL188678 & 954705 & 4.2269 & 4.1354 & TST & \\
\hline CHEMBL1643959 & 954705 & 4.763 & 3.4091 & TST & \\
\hline CHEMBL515416 & 954705 & 4.9545 & 4.7733 & TST & \\
\hline CHEMBL 9470 & 954705 & 5.8452 & 5.5775 & TST & \\
\hline CHEMBL92309 & 954705 & 2.7476 & 3.017 & TST & \\
\hline CHEMBL180127 & 954705 & 3.8707 & 4.1611 & TST & \\
\hline CHEMBL65 & 954705 & 6.9587 & 6.4443 & TST & \\
\hline CHEMBL496465 & 1348900 & 5.3325 & 5.4561 & TRN & \\
\hline CHEMBL3260193 & 1348900 & 3.4772 & 3.3167 & TRN & \\
\hline CHEMBL 318170 & 1348900 & 4.4949 & 4.1351 & TST & \\
\hline CHEMBL147067 & 1348900 & 3.9788 & 3.3992 & TST & \\
\hline CHEMBL32147 & 1348900 & 4.0757 & 3.3331 & TST & \\
\hline CHEMBL3260179 & 1348900 & 3.3019 & 3.37100 & 00000000004 & TRN \\
\hline CHEMBL3260556 & 1348900 & 7.0 & 5.1022 & TST & \\
\hline CHEMBL3260555 & 1348900 & 4.2441 & 4.2575 & TRN & \\
\hline CHEMBL3260191 & 1348900 & 3.3458 & 3.4053 & TRN & \\
\hline CHEMBL3260187 & 1348900 & 3.3449 & 3.3337 & TRN & \\
\hline CHEMBL456156 & 1348900 & 3.8474 & 4.0139 & TRN & \\
\hline
\end{tabular}


Supplemental Table S2.txt

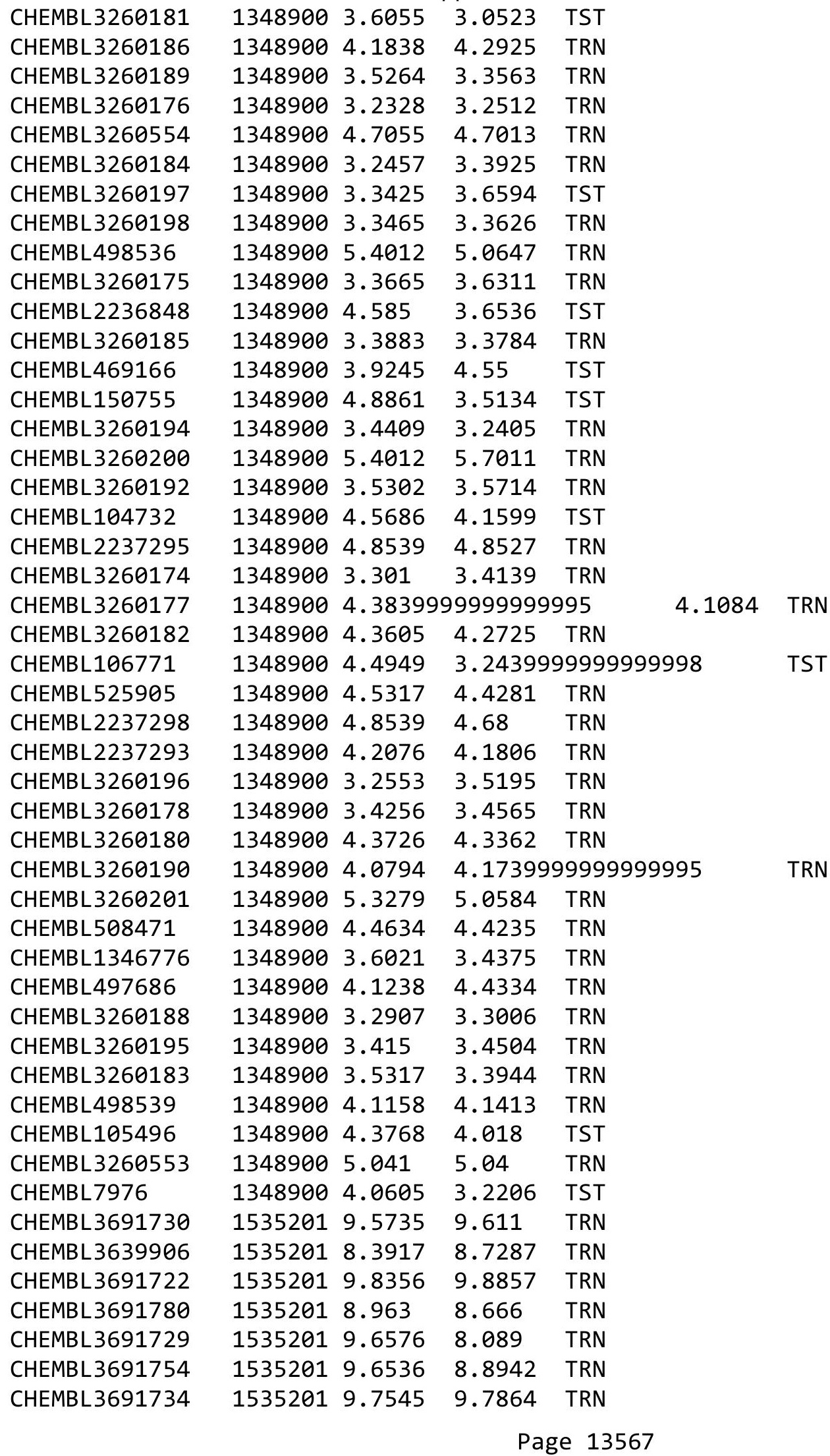


Supplemental Table S2.txt

\begin{tabular}{|c|c|c|c|c|}
\hline S & & & & \\
\hline & & 9.3768 & & \\
\hline 70 & 201 & & & \\
\hline AEMBL & 201 & & 7907 & \\
\hline HEMBL & 35201 & 6.0 & 4871 & \\
\hline HEMBL3691755 & 535201 & 9.1124 & 894 & \\
\hline 10 & 201 & & 765 & \\
\hline 715 & 201 & & 947 & \\
\hline AEMBL3691720 & 535201 & & 2442 & \\
\hline AEMBL3691783 & 35201 & 9.2573 & 3511 & \\
\hline HEMBL3691733 & 5201 & 8.9889 & 4587 & \\
\hline IEMBL: & 201 & 248 & 126 & \\
\hline EMBL & & & 271 & \\
\hline HEMBL3 & 201 & 676 & 7486 & \\
\hline AEMBL 369 & 201 & 872 & 29 & \\
\hline IEMBL 369 & 201 & 7077 & .0386 & \\
\hline AEMBL & 201 & 872 & & \\
\hline HEMBL; & 201 & 861 & 589 & \\
\hline AEMBL3 & 201 & 9.3716 & 382 & \\
\hline IEMBL3 & 01 & 37 & & \\
\hline AEMIBL & 01 & 6 & & RIV \\
\hline AEMBL & & & 62 & RN \\
\hline AEMBL & 01 & & 76 & \\
\hline 708 & & 735 & 507 & \\
\hline AEMBL3691737 & 01 & 32 & & TST \\
\hline AEMBL & & 234 & 13 & SI \\
\hline AEMBL & 01 & 6. & 12 & RN \\
\hline HFMBL & 01 & 19 & 236 & \\
\hline HEMBL3 & & 893 & 199 & TRN \\
\hline AEMBL 3691 & & 9. & & is \\
\hline HEMBL3 & & 9. & 43 & RN \\
\hline HEMBL & & & 36 & ST \\
\hline HEMBL & $\partial 1$ & 8. & 04 & 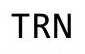 \\
\hline HEMBL3691776 & 35201 & 6 & & IRN \\
\hline HEMBL3691702 & 535201 & 9.71 & 206 & TST \\
\hline HEMBL & $\partial 1$ & 8. & 104 & RN \\
\hline 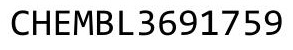 & & & & RN \\
\hline HEMBL & & 041 & 06 & RN \\
\hline HEMBL3687250 & 535201 & 8.959 & 463 & TST \\
\hline EMBL. & 5201 & 852 & 572 & RN \\
\hline HEMBL3 & 5201 & 9.8097 & 506 & DA \\
\hline HEMBL3 & & & 296 & RN \\
\hline HEMBL3 & 535201 & 9. & 3897 & ST \\
\hline AEMBL3691768 & 535201 & 9.4306 & 135 & $R$ \\
\hline$M P$ & & & 05 & ST \\
\hline HEMBL3 & L & 3928 & 918 & \\
\hline HEMBL3 & 535201 & 9.4584 & 9985 & \\
\hline HEMBL369175 & 1535201 & 8.8395 & 8.9585 & RN \\
\hline
\end{tabular}

Page 13568 
Supplemental Table S2.txt

\begin{tabular}{|c|c|c|c|c|}
\hline CHEMBL3691705 & 535201 & 9.4237 & 9.3217 & TS \\
\hline CHEMBL 3691706 & 535201 & 9.4056 & 9.44 & \\
\hline HEMBL 3687312 & 535201 & 9.3019 & 9.5079 & \\
\hline HEMBL3691789 & 535201 & 9.7055 & 9.2104 & RN \\
\hline HEMBL3691771 & 535201 & 9.4353 & 9.2459 & RN \\
\hline HEMBL3691772 & 535201 & 6.0 & 7.7218 & \\
\hline HEMBL3691741 & 535201 & 9.2757 & 8.4122 & RN \\
\hline HEMBL3691718 & 535201 & 8.7011 & 9.6492 & \\
\hline HEMBL3691703 & 535201 & 9.1543 & 9.5271 & ST \\
\hline HEMBL3687226 & 535201 & 8.1866 & 9.6455 & ST \\
\hline HEMBL3691794 & 535201 & 8.6716 & 8.9648 & \\
\hline HEMBL3691739 & 535201 & 9.9957 & 9.4861 & ST \\
\hline HEMBL3691787 & 535201 & 9.6716 & 9.0155 & RN \\
\hline HEMBL3691762 & 535201 & 9.4473 & 9.4917 & RN \\
\hline HEMBL3691791 & 535201 & 9.7825 & 9.1193 & N \\
\hline HEMBL3691769 & .535201 & 9.1798 & 9.1141 & RN \\
\hline HEMBL3691795 & 535201 & 9.2774 & 9. & RN \\
\hline HEMBL3691726 & 535201 & 9.2588 & 9.6332 & \\
\hline HEMBL314798 & 63615 & 3.0 & 3.0673 & TST \\
\hline HEMBL431 & 3615 & 3. & 3 . & RN \\
\hline HEMBL873 & 3615 & 3 . & 3 . & RN \\
\hline HEMBL 312 & 3615 & 3.0 & 3 . & $\mathrm{RN}$ \\
\hline HEMBL 89723 & 63615 & 5.02 & 976 & RN \\
\hline HEMBL88405 & 63615 & 3 . & 3.3428 & N \\
\hline LHEMBL 328710 & 3615 & 3.0 & 2.9783 & TRN \\
\hline HEMBL314 & 53615 & 4.3565 & 3.313 & RN \\
\hline HEMBL314 & 63615 & 3.0 & 3. & ST \\
\hline LHEMBL87402 & 63615 & 3 . & 3.2812 & TST \\
\hline LHEMBL 89040 & 53615 & 3. & 2.9642 & TRN \\
\hline CHEMBL87783 & 3615 & 3. & 3.0009 & TRN \\
\hline CHEMBL 313 & 3615 & 3 & 3.23 & TRN \\
\hline HEMBL8 & 15 & 3. & 2.9528 & TRN \\
\hline CHEMBL87810 & 3615 & 3. & 3.2629 & TRN \\
\hline CHEMBL313259 & 53615 & 3.0 & 3.1057 & TRN \\
\hline LHEMBL 89363 & 63615 & 3 . & 3.0773 & TRN \\
\hline CHEMBL87746 & 3615 & 4.72 & 3.9745 & TRN \\
\hline CHEMBL 8 & 15 & 4.71 & 4.4573 & TRN \\
\hline CHEMBL86944 & 63615 & 3.0 & 4.467 & TRN \\
\hline CHEMBL89505 & 63615 & 5.1024 & 4.1173 & TRN \\
\hline CHEMBL 315701 & 3615 & 3.0 & 3.0664 & TRN \\
\hline CHEMBL328452 & 63615 & 3 . & 3.2496 & TRN \\
\hline CHEMBL 87325 & 63615 & 3.0 & 3.1798 & TRN \\
\hline CHEMBL 85021 & 63615 & 4.8153 & 4.6143 & TRN \\
\hline CHEMBL315546 & 63615 & 3.0 & 3.0684 & TRN \\
\hline CHEMBL86837 & 63615 & 3. & 3.0841 & I RIV \\
\hline CHEMBL420411 & 63615 & 3.0 & 3.0732 & I NIV \\
\hline CHEMBL 89646 & 63615 & 3.0 & 3.4655 & IS \\
\hline CHEMBL86945 & 63615 & 3.0 & 3.9808 & TRN \\
\hline
\end{tabular}

Page 13569 


\begin{tabular}{|c|c|c|c|c|c|}
\hline \multicolumn{6}{|c|}{ Supplemental Table s2.txt } \\
\hline CHEMBL86755 & 63615 & 3.0 & 2.8705 & TRN & \\
\hline CHEMBL89483 & 63615 & 3.0 & 3.1805 & TRN & \\
\hline CHEMBL316268 & 63615 & 3.0 & 3.11 & TRN & \\
\hline CHEMBL 313433 & 63615 & 3.0 & 3.08699 & 99999999997 & TST \\
\hline CHEMBL316009 & 63615 & 3.0 & 3.2786 & TST & \\
\hline CHEMBL86432 & 63615 & 3.0 & 3.2273 & TST & \\
\hline CHEMBL89721 & 63615 & 3.0 & 3.2442 & TST & \\
\hline CHEMBL86943 & 63615 & 3.0 & 3.1926 & TST & \\
\hline CHEMBL316008 & 63615 & 3.0 & 3.3279 & TST & \\
\hline CHEMBL89697 & 63615 & 3.0 & 3.0783 & TST & \\
\hline CHEMBL86631 & 63615 & 3.0 & 3.2019 & TST & \\
\hline CHEMBL48760 & 63615 & 4.7328 & 4.1211 & TRN & \\
\hline CHEMBL86480 & 63615 & 3.0 & 2.998 & TRN & \\
\hline CHEMBL85403 & 63615 & 3.0 & 2.8773 & TRN & \\
\hline CHEMBL89809 & 63615 & 3.0 & 2.8762 & TRN & \\
\hline CHEMBL421548 & 63615 & 4.0 & 3.7927 & TRN & \\
\hline CHEMBL90277 & 63615 & 3.0 & 3.0884 & TRN & \\
\hline CHEMBL330321 & 63615 & 3.0 & 3.0358 & TRN & \\
\hline CHEMBL329367 & 63615 & 3.0 & 3.0989 & TRN & \\
\hline CHEMBL316020 & 63615 & 3.0 & 2.9807 & TST & \\
\hline CHEMBL87080 & 63615 & 4.0 & 3.4375 & TRN & \\
\hline CHEMBL86921 & 63615 & 3.0 & 3.199 & TST & \\
\hline CHEMBL314217 & 63615 & 3.0 & 2.9899 & TRN & \\
\hline CHEMBL 3601120 & 1509387 & 5.4547 & 5.3809 & TRN & \\
\hline CHEMBL3601728 & 1509387 & 5.4932 & 5.5949 & TRN & \\
\hline CHEMBL3601230 & 1509387 & 5.8801 & 5.6551 & TRN & \\
\hline CHEMBL3601724 & 1509387 & 4.6085 & 4.5044 & TST & \\
\hline CHEMBL3601231 & 1509387 & 5.6284 & 5.3861 & TRN & \\
\hline CHEMBL 3601718 & 1509387 & 5.4999 & 5.5744 & TRN & \\
\hline CHEMBL3601226 & 1509387 & 5.8794 & 6.295 & TRN & \\
\hline CHEMBL3601723 & 1509387 & 5.3509 & 5.8272 & TST & \\
\hline CHEMBL3601236 & 1509387 & 5.3311 & 5.3883 & TRN & \\
\hline CHEMBL3601118 & 1509387 & 4.5017 & 4.2009 & TRN & \\
\hline CHEMBL3601243 & 1509387 & 5.187 & 5.41200 & 0000000001 & TRN \\
\hline CHEMBL3601727 & 1509387 & 5.2256 & 5.3107 & TST & \\
\hline CHEMBL3601237 & 1509387 & 5.3277 & 5.4644 & TRN & \\
\hline CHEMBL3601127 & 1509387 & 5.7964 & 5.76 & TRN & \\
\hline CHEMBL3601711 & 1509387 & 5.8801 & 5.8421 & TRN & \\
\hline CHEMBL3601716 & 1509387 & 5.7361 & 5.5723 & TRN & \\
\hline CHEMBL3601710 & 1509387 & 5.2846 & 5.2733 & TRN & \\
\hline CHEMBL3601706 & 1509387 & 6.1226 & 6.0654 & TRN & \\
\hline CHEMBL3601712 & 1509387 & 5.95 & 5.5875 & TRN & \\
\hline CHEMBL3601709 & 1509387 & 5.3752 & 5.6369 & TRN & \\
\hline CHEMBL3601123 & 1509387 & 4.8213 & 4.80699 & 99999999995 & TRN \\
\hline CHEMBL3601239 & 1509387 & 4.762 & 5.0052 & TST & \\
\hline CHEMBL3601235 & 1509387 & 3.301 & 3.5572 & TRN & \\
\hline CHEMBL3601725 & 1509387 & 5.4779 & 5.7374 & TST & \\
\hline CHEMBL3601106 & 1509387 & 6.0026 & 5.8582 & TRN & \\
\hline
\end{tabular}


Supplemental Table S2.txt

\begin{tabular}{|c|c|c|c|c|}
\hline CHEMBL 3601117 & 1509387 & 5.8024 & 5.2264 & TRN \\
\hline CHEMBL3601705 & 1509387 & 6.109 & 6.3405 & TRN \\
\hline CHEMBL3601708 & 1509387 & 5.4499 & 5.4971 & TRN \\
\hline CHEMBL 3601110 & 1509387 & 4.763 & 5.0772 & TRN \\
\hline CHEMBL3601704 & 1509387 & 5.2634 & 5.8326 & TRN \\
\hline CHEMBL3601722 & 1509387 & 4.8115 & 5.00899 & 99999999995 \\
\hline CHEMBL 3601233 & 1509387 & 5.1796 & 4.744 & TRN \\
\hline CHEMBL 3601714 & 1509387 & 5.2311 & 5.2642 & TRN \\
\hline CHEMBL 3601715 & 1509387 & 5.6979 & 5.7942 & TRN \\
\hline CHEMBL3601107 & 1509387 & 6.1198 & 5.6603 & TRN \\
\hline CHEMBL3601223 & 1509387 & 5.6447 & 5.7885 & TRN \\
\hline CHEMBL3601713 & 1509387 & 5.4042 & 5.6896 & TST \\
\hline CHEMBL3601122 & 1509387 & 5.0521 & 5.468 & TRN \\
\hline CHEMBL3601232 & 1509387 & 5.8119 & 5.1346 & TRN \\
\hline CHEMBL3600393 & 1509387 & 5.959 & 5.6012 & TRN \\
\hline CHEMBL3601115 & 1509387 & 3.301 & 4.3447 & TRN \\
\hline CHEMBL3601242 & 1509387 & 5.845 & 5.795 & TRN \\
\hline CHEMBL3601109 & 1509387 & 3.301 & 3.3856 & TRN \\
\hline CHEMBL3601119 & 1509387 & 5.4912 & 5.4489 & TRN \\
\hline CHEMBL3601228 & 1509387 & 6.0585 & 6.4605 & TRN \\
\hline CHEMBL3601125 & 1509387 & 4.8969 & 5.4043 & TRN \\
\hline CHEMBL 3601114 & 1509387 & 5.6523 & 5.3484 & TRN \\
\hline CHEMBL 3601121 & 1509387 & 5.3883 & 5.3587 & TRN \\
\hline CHEMBL3601112 & 1509387 & 5.3012 & 4.9623 & TRN \\
\hline CHEMBL 3601116 & 1509387 & 5.64 & 5.2249 & TRN \\
\hline CHEMBL3601229 & 1509387 & 6.0035 & 6.0572 & TRN \\
\hline CHEMBL 3601234 & 1509387 & 3.301 & 3.4852 & TRN \\
\hline CHEMBL 3601244 & 1509387 & 5.6035 & 5.4193 & TST \\
\hline CHEMBL3601113 & 1509387 & 5.7242 & 5.4245 & TRN \\
\hline CHEMBL 3601224 & 1509387 & 5.4253 & 5.5147 & TST \\
\hline CHEMBL 3601111 & 1509387 & 5.5167 & 5.1764 & TST \\
\hline CHEMBL 3601861 & 1509387 & 5.3054 & 5.4129 & TST \\
\hline CHEMBL 3601108 & 1509387 & 5.2533 & 5.4505 & TST \\
\hline CHEMBL3601238 & 1509387 & 5.3798 & 5.1927 & TST \\
\hline CHEMBL 3601227 & 1509387 & 6.2226 & 6.29200 & 0000000001 \\
\hline CHEMBL3601726 & 1509387 & 5.4556 & 5.2824 & TST \\
\hline CHEMBL3601707 & 1509387 & 5.1639 & 4.84 & TST \\
\hline CHEMBL1215290 & 650216 & 4.5086 & 4.7244 & TRN \\
\hline CHEMBL1215797 & 650216 & 2.5229 & 3.4896 & TRN \\
\hline CHEMBL1214647 & 650216 & 4.6383 & 4.0322 & TRN \\
\hline CHEMBL1214797 & 650216 & 2.5229 & 1.9457 & TRN \\
\hline CHEMBL1215364 & 650216 & 4.0177 & 3.62100 & 00000000004 \\
\hline CHEMBL1215006 & 650216 & 3.9586 & 3.3674 & TRN \\
\hline CHEMBL1214941 & 650216 & 4.1938 & 3.8874 & TRN \\
\hline CHEMBL1215648 & 650216 & 3.6126 & 3.3117 & TRN \\
\hline CHEMBL1215649 & 650216 & 2.5229 & 3.2215 & TRN \\
\hline CHEMBL1214867 & 650216 & 2.5229 & 2.1929 & TRN \\
\hline CHEMBL1214869 & 650216 & 2.5229 & 2.3222 & TRN \\
\hline
\end{tabular}

Page 13571 
Supplemental Table S2.txt

\begin{tabular}{|c|c|c|c|c|c|}
\hline CHEMBL1215080 & 650216 & 2.5229 & 3.5554 & TRN & \\
\hline CHEMBL1214715 & 650216 & 5.2218 & 4.3368 & TRN & \\
\hline CHEMBL1215154 & 650216 & 2.5229 & 3.6421 & TRN & \\
\hline CHEMBL1214648 & 650216 & 4.6778 & 3.9515 & TRN & \\
\hline CHEMBL1214865 & 650216 & 3.7011 & 3.6987 & TST & \\
\hline CHEMBL1214935 & 650216 & 3.6021 & 3.4174 & TRN & \\
\hline CHEMBL1215366 & 650216 & 5.3979 & 4.582 & TRN & \\
\hline CHEMBL1214798 & 650216 & 2.5229 & 1.9319 & TRN & \\
\hline CHEMBL1214646 & 650216 & 2.5229 & 2.4651 & TST & \\
\hline CHEMBL1214719 & 650216 & 4.0862 & 3.987 & TRN & \\
\hline CHEMBL1214861 & 650216 & 2.5229 & 2.4699 & TRN & \\
\hline CHEMBL1215156 & 650216 & 4.3872 & 4.0923 & TRN & \\
\hline CHEMBL1215293 & 650216 & 2.5229 & 3.7606 & TRN & \\
\hline CHEMBL1214864 & 650216 & 2.5229 & 2.3896 & TST & \\
\hline CHEMBL1215717 & 650216 & 2.5229 & 2.3016 & TRN & \\
\hline CHEMBL1214717 & 650216 & 2.5229 & 3.86800 & 00000000003 & TRN \\
\hline CHEMBL400566 & 650216 & 4.4437 & 3.9228 & TRN & \\
\hline CHEMBL1214795 & 650216 & 4.1308 & 3.2147 & TST & \\
\hline CHEMBL1214720 & 650216 & 2.5229 & 2.7522 & TRN & \\
\hline CHEMBL 1215579 & 650216 & 2.5229 & 2.8212 & TRN & \\
\hline CHEMBL1215651 & 650216 & 3.6819 & 3.4505 & TRN & \\
\hline CHEMBL1215440 & 650216 & 3.699 & 4.0801 & TRN & \\
\hline CHEMBL1215716 & 650216 & 2.5229 & 2.9297 & TRN & \\
\hline CHEMBL1215719 & 650216 & 2.5229 & 3.4069 & TRN & \\
\hline CHEMBL1214645 & 650216 & 3.5391 & 3.2718 & TRN & \\
\hline CHEMBL1214716 & 650216 & 5.301 & 4.1963 & TRN & \\
\hline CHEMBL1215079 & 650216 & 4.6198 & 3.9442 & TRN & \\
\hline CHEMBL1215580 & 650216 & 4.3872 & 3.6412 & TRN & \\
\hline CHEMBL1214937 & 650216 & 4.4202 & 3.8024 & TRN & \\
\hline CHEMBL1215581 & 650216 & 2.5229 & 2.8574 & TRN & \\
\hline CHEMBL1215798 & 650216 & 2.5229 & 2.4972 & TST & \\
\hline CHEMBL1215439 & 650216 & 2.5229 & 3.4625 & TRN & \\
\hline CHEMBL1214863 & 650216 & 3.6517 & 2.8532 & TST & \\
\hline CHEMBL1214939 & 650216 & 2.5229 & 3.5077 & TST & \\
\hline CHEMBL1214791 & 650216 & 2.5229 & \multicolumn{2}{|c|}{2.0909999999999997} & TRN \\
\hline CHEMBL1214649 & 650216 & 2.5229 & 3.0268 & TST & \\
\hline CHEMBL1215157 & 650216 & 4.0605 & 3.9265 & TRN & \\
\hline CHEMBL1215367 & 650216 & 2.5229 & 3.0422 & TRN & \\
\hline CHEMBL1215441 & 650216 & 4.301 & 4.3436 & TRN & \\
\hline CHEMBL1214793 & 650216 & 3.7496 & 2.4551 & TRN & \\
\hline CHEMBL1215365 & 650216 & 5.301 & 4.6348 & TRN & \\
\hline CHEMBL1215224 & 650216 & 2.5229 & 3.818 & TRN & \\
\hline CHEMBL1214713 & 650216 & 4.4949 & 3.8458 & TRN & \\
\hline CHEMBL1215512 & 650216 & 2.5229 & 2.8286 & TRN & \\
\hline CHEMBL1214938 & 650216 & 2.5229 & 2.101 & TRN & \\
\hline CHEMBL1212961 & 650216 & 2.5229 & 2.3034 & TRN & \\
\hline CHEMBL 1215292 & 650216 & 2.5229 & 3.4964 & TRN & \\
\hline CHEMBL1215226 & 650216 & 5.1549 & 4.3054 & TRN & \\
\hline
\end{tabular}


Supplemental Table S2.txt

\begin{tabular}{|c|c|c|c|c|c|}
\hline CHEMBL1215800 & 650216 & 2.5229 & 3.4467 & TRN & \\
\hline CHEMBL1215796 & 650216 & 2.5229 & 3.533 & TRN & \\
\hline CHEMBL1215802 & 650216 & 2.5229 & 3.3632 & TRN & \\
\hline CHEMBL1215005 & 650216 & 2.5229 & 3.4086 & TRN & \\
\hline CHEMBL1215082 & 650216 & 4.2076 & 3.597 & TRN & \\
\hline CHEMBL1215799 & 650216 & 4.4949 & 4.1269 & TRN & \\
\hline CHEMBL1215513 & 650216 & 3.8601 & 3.3329 & TRN & \\
\hline CHEMBL1214714 & 650216 & 2.5229 & 2.84 & TST & \\
\hline CHEMBL1214940 & 650216 & 4.2147 & 4.0235 & TRN & \\
\hline CHEMBL1214934 & 650216 & 4.6021 & 3.5182 & TRN & \\
\hline CHEMBL1215155 & 650216 & 5.1549 & 4.4792 & TRN & \\
\hline CHEMBL1214866 & 650216 & 2.5229 & 2.1776 & TRN & \\
\hline CHEMBL1214796 & 650216 & 2.5229 & 2.5944 & TRN & \\
\hline CHEMBL1215801 & 650216 & 4.6778 & 4.5178 & TRN & \\
\hline CHEMBL1214792 & 650216 & 2.5229 & 2.2343 & TST & \\
\hline CHEMBL1215225 & 650216 & 2.5229 & 3.1545 & TRN & \\
\hline CHEMBL1215510 & 650216 & 3.8827 & 4.2903 & TRN & \\
\hline CHEMBL1214718 & 650216 & 3.9872 & 3.7711 & TRN & \\
\hline CHEMBL1215007 & 650216 & 4.8539 & 3.9861 & TST & \\
\hline CHEMBL1215803 & 650216 & 2.5229 & 3.2447 & TRN & \\
\hline CHEMBL1214794 & 650216 & 2.5229 & 3.1448 & TST & \\
\hline CHEMBL1215081 & 650216 & 2.5229 & 4.0564 & TRN & \\
\hline CHEMBL1215578 & 650216 & 3.6576 & 3.5944 & TRN & \\
\hline CHEMBL1215511 & 650216 & 2.5229 & 2.0683 & TST & \\
\hline CHEMBL1214862 & 650216 & 2.5229 & 2.4383 & TST & \\
\hline CHEMBL1215291 & 650216 & 4.5686 & 4.3955 & TST & \\
\hline CHEMBL1214868 & 650216 & 4.0809 & 3.0775 & TST & \\
\hline CHEMBL1215004 & 650216 & 4.6576 & 4.1463 & TST & \\
\hline CHEMBL1214936 & 650216 & 4.5686 & 4.0253 & TST & \\
\hline CHEMBL1215718 & 650216 & 2.5229 & 2.5198 & TST & \\
\hline CHEMBL1214790 & 650216 & 2.5229 & 2.4902 & TST & \\
\hline CHEMBL1215650 & 650216 & 2.5229 & 2.7187 & TST & \\
\hline CHEMBL1215003 & 650216 & 3.6326 & 3.5092 & TST & \\
\hline CHEMBL1215442 & 650216 & 3.5528 & 4.1722 & TST & \\
\hline CHEMBL1215227 & 650216 & 5.0969 & 4.5199 & TST & \\
\hline CHEMBL 3678301 & 1640389 & 9.0 & 9.0358 & TRN & \\
\hline CHEMBL 3678302 & 1640389 & 7.7696 & 8.1402 & TST & \\
\hline CHEMBL 3673443 & 1640389 & 6.75700 & 00000000 & 1 & 6.7676 \\
\hline CHEMBL 3673457 & 1640389 & 6.9469 & 6.9687 & TRN & \\
\hline CHEMBL 3678287 & 1640389 & 9.699 & 9.6914 & TRN & \\
\hline CHEMBL 3673477 & 1640389 & 9.699 & 9.6433 & TRN & \\
\hline CHEMBL 3673472 & 1640389 & 5.8297 & 5.8728 & TST & \\
\hline CHEMBL3673459 & 1640389 & 7.6021 & 7.6424 & TRN & \\
\hline CHEMBL 3673461 & 1640389 & 8.0969 & 8.1029 & TRN & \\
\hline CHEMBL 3673451 & 1640389 & 5.0467 & 5.0405 & TRN & \\
\hline CHEMBL 3673440 & 1640389 & 8.1549 & 8.1804 & TRN & \\
\hline CHEMBL 3673450 & 1640389 & 5.9469 & 5.8805 & TRN & \\
\hline CHEMBL 3673445 & 1640389 & 4.9547 & 4.9702 & TRN & \\
\hline
\end{tabular}

Page 13573 
Supplemental Table S2.txt

\begin{tabular}{|c|c|c|c|c|}
\hline CHEMBL 3673437 & 1640389 & 7.0655 & 7.039 & TRN \\
\hline CHEMBL 3673439 & 1640389 & 8.5229 & 8.4834 & TRN \\
\hline CHEMBL3678304 & 1640389 & 6.3478 & 6.3506 & TST \\
\hline CHEMBL 3639723 & 1640389 & 6.2291 & 6.2858 & TRN \\
\hline CHEMBL3678289 & 1640389 & 8.1549 & 8.1954 & TRN \\
\hline CHEMBL3673436 & 1640389 & 9.0 & 8.8221 & TRN \\
\hline CHEMBL 3678291 & 1640389 & 7.4089 & 7.5741 & TST \\
\hline CHEMBL 3673482 & 1640389 & 8.0458 & 8.1282 & TRN \\
\hline CHEMBL3673466 & 1640389 & 7.2924 & 7.2326 & TRN \\
\hline CHEMBL3673456 & 1640389 & 7.0458 & 6.9981 & TRN \\
\hline CHEMBL3678292 & 1640389 & 8.5229 & 8.3308 & TST \\
\hline CHEMBL 3678300 & 1640389 & 9.3979 & 9.3875 & TRN \\
\hline CHEMBL3673452 & 1640389 & 9.5229 & 9.7106 & TRN \\
\hline CHEMBL 3673474 & 1640389 & 5.9355 & 6.23 & TST \\
\hline CHEMBL3673438 & 1640389 & 8.0969 & 8.1625 & TRN \\
\hline CHEMBL3673469 & 1640389 & 6.0696 & 6.0588 & TRN \\
\hline CHEMBL3673475 & 1640389 & 7.4949 & 7.5311 & TRN \\
\hline CHEMBL3673455 & 1640389 & 7.2676 & 7.2432 & TRN \\
\hline CHEMBL3678294 & 1640389 & 5.9066 & 5.7557 & TRN \\
\hline CHEMBL3673442 & 1640389 & 8.2218 & 8.2444 & TRN \\
\hline CHEMBL3673453 & 1640389 & 9.301 & 9.2418 & TRN \\
\hline CHEMBL3673458 & 1640389 & 6.3279 & 6.2829 & TRN \\
\hline CHEMBL3673444 & 1640389 & 6.3625 & 6.3963 & TRN \\
\hline CHEMBL3678306 & 1640389 & 6.6676 & 6.5231 & TST \\
\hline CHEMBL3673465 & 1640389 & 6.5143 & 6.547999 & 99999999999 \\
\hline CHEMBL3678285 & 1640389 & 9.699 & 9.6882 & TRN \\
\hline CHEMBL3678293 & 1640389 & 7.0706 & 6.9536 & TST \\
\hline CHEMBL3678283 & 1640389 & 9.699 & 9.7108 & TRN \\
\hline CHEMBL3673485 & 1640389 & 7.8539 & 7.8499 & TRN \\
\hline CHEMBL3678290 & 1640389 & 7.2366 & 7.3052 & TRN \\
\hline CHEMBL3678284 & 1640389 & 9.699 & 9.6164 & TRN \\
\hline CHEMBL3678296 & 1640389 & 6.1599 & 6.1276 & TRN \\
\hline CHEMBL3673480 & 1640389 & 9.301 & 9.2814 & TRN \\
\hline CHEMBL3673489 & 1640389 & 9.5229 & 9.5147 & TRN \\
\hline CHEMBL3673467 & 1640389 & 7.0555 & 7.12 & TST \\
\hline CHEMBL3673460 & 1640389 & 6.6345 & 6.7308 & TRN \\
\hline CHEMBL3673488 & 1640389 & 8.3979 & 8.3794 & TRN \\
\hline CHEMBL3678299 & 1640389 & 8.1549 & 8.1829 & TRN \\
\hline CHEMBL3673448 & 1640389 & 6.8697 & 6.8569 & TRN \\
\hline CHEMBL3673479 & 1640389 & 9.699 & 9.6727 & TRN \\
\hline CHEMBL3678305 & 1640389 & 6.7959 & 6.3737 & TST \\
\hline CHEMBL3673476 & 1640389 & 9.2218 & 9.0334 & TRN \\
\hline CHEMBL3673484 & 1640389 & 7.2924 & 7.372000 & 0000000001 \\
\hline CHEMBL3678288 & 1640389 & 7.1871 & 7.2042 & TRN \\
\hline CHEMBL3673486 & 1640389 & 8.699 & 8.6841 & TRN \\
\hline CHEMBL3678286 & 1640389 & 9.699 & 9.7035 & TRN \\
\hline CHEMBL 3673487 & 1640389 & 8.301 & 8.2849 & TRN \\
\hline CHEMBL3673481 & 1640389 & 8.2218 & 8.225 & TRN \\
\hline
\end{tabular}


Supplemental Table S2.txt

\begin{tabular}{|c|c|c|c|c|}
\hline CHEMBL3673464 & 1640389 & 7.585 & 7.5931 & TRN \\
\hline CHEMBL3673449 & 1640389 & 5.9872 & 5.9329 & \\
\hline HEMBL3678303 & 640389 & 7.4559 & 2734 & \\
\hline HEMBL3678295 & 640389 & 6.9914 & 1517 & \\
\hline HEMBL 3673473 & 1640389 & 6.4437 & 6.9465 & \\
\hline HEMBL3673471 & 1640389 & 6.6968 & .7662 & \\
\hline HEMBL3673441 & 640389 & 6.0778 & 6.266 & \\
\hline HEMBL3673462 & 640389 & 9.0 & 9.0057 & \\
\hline HEMBL3673446 & 1640389 & 6.1007 & 5.3341 & \\
\hline HEMBL3673483 & 1640389 & 8.5229 & 8.5261 & RN \\
\hline HEMBL3673470 & 1640389 & 5.2204 & 4.8747 & ST \\
\hline HEMBL3673463 & 640389 & 9.0458 & 9.3153 & \\
\hline HEMBL3673447 & 640389 & 6.1858 & 6.3166 & \\
\hline HEMBL3673478 & 640389 & 9.699 & 9.7744 & RN \\
\hline HEMBL3673468 & 1640389 & 7.4949 & 7.5962 & ST \\
\hline HEMBL127389 & 48451 & 6.4685 & 6.3935 & RN \\
\hline HEMBL133006 & 48451 & 7.0 & 6.8791 & RN \\
\hline HEMBL422079 & 48451 & 5.7959 & 5.829 & \\
\hline HEMBL13 & 48451 & 5.3665 & 29 & \\
\hline HEMBL130120 & 48451 & 6.2218 & 6.2243 & RN \\
\hline HEMBL130067 & 48451 & 6.3279 & 49 & RN \\
\hline HEMBL336273 & 48451 & 3.0 & 4.0639 & I \\
\hline HEMBL130287 & 48451 & 5.8539 & 5.8242 & RN \\
\hline HEMBL13 & 484 & 6.3979 & 916 & RN \\
\hline HEMBL129894 & 48451 & 3.0 & 5998 & ST \\
\hline HEMBL130178 & 48451 & 6.699 & 87 & RN \\
\hline HEMBL336144 & 48451 & 6.3665 & 6.3173 & RN \\
\hline HEMBL131400 & 48451 & .301 & 2873 & RN \\
\hline HEMBL42. & 48451 & 01 & 332 & RN \\
\hline HEMBL336074 & 48451 & 5.2007 & 5.2158 & RN \\
\hline HEMBL133110 & 48451 & 3.0 & 66 & ST \\
\hline HEMBL127553 & 48451 & 6.1427 & 6.1497 & TRN \\
\hline HEMBL132845 & 48451 & 3.5229 & 5.8556 & ST \\
\hline CHEMBL 33 & 48 & 6 & 01 & RN \\
\hline LHEMBL337278 & 48451 & 5.7447 & 5.7912 & RN \\
\hline CHEMBL133273 & 48451 & 5.2218 & 599 & TRN \\
\hline HEMBL130815 & 48451 & 4.6299 & 4.6396 & TRN \\
\hline HEMBL132855 & 48451 & 686 & 5.3525 & $\mathrm{RN}$ \\
\hline CHEMBL13 & & & 466 & RN \\
\hline CHEMBL130443 & 48451 & 6.2218 & 6.2408 & TRN \\
\hline CHEMBL336977 & 48451 & 7.301 & 7.4117 & TRN \\
\hline CHEMBL131831 & 48451 & 6.0555 & 5.9728 & RN \\
\hline CHEMBL339732 & 48451 & 5.5229 & 5.5163 & RN \\
\hline CHEMBL130808 & 48451 & 3.5229 & 4.6811 & ST \\
\hline CHEMBL132042 & 48451 & 4.9508 & 4.8815 & RN \\
\hline CHEMBL339692 & 48451 & 6.3468 & 6.3758 & RN \\
\hline CHEMBL133683 & 48451 & 4.8996 & 5.1066 & \\
\hline HEMBL12992 & 4845 & 7.2218 & 7.1879 & \\
\hline
\end{tabular}

Page 13575 
Supplemental Table S2.txt

\begin{tabular}{|c|c|c|c|c|}
\hline LHEMBL339164 & 48451 & 5.4622 & 5.4637 & TRN \\
\hline CHEMBL 335484 & 48451 & 5.0516 & 4.9123 & TRN \\
\hline HEMBL130166 & 8451 & .0757 & 6.053 & \\
\hline CHEMBL130447 & 48451 & .1938 & 5.5752 & \\
\hline HEMBL436370 & 48451 & 6.1549 & 6.2002 & \\
\hline HEMBL133383 & 48451 & 6.0088 & 6.0062 & \\
\hline HEMBL133456 & 48451 & .5229 & 4.4518 & \\
\hline HEMBL131326 & 48451 & .4685 & 5.5134 & ST \\
\hline HEMBL335406 & 48451 & 6.2218 & 6.2278 & RN \\
\hline HEMBL132151 & 48451 & 7.1549 & 7.1791 & RN \\
\hline HEMBL127554 & 48451 & 5.7932 & 5.7809 & RIN \\
\hline HEMBL133009 & 48451 & 6.699 & 6.6709 & NIV \\
\hline HEMBL337214 & 48451 & .7545 & 4.7255 & RN \\
\hline HEMBL131056 & 48451 & 5.284 & 5.2426 & RN \\
\hline HEMBL133404 & 48451 & 5.7447 & 5.734 & $\mathrm{RN}$ \\
\hline HEMBL336704 & 48451 & 3.5229 & 3.6605 & RN \\
\hline HEMBL131436 & 48451 & .8539 & 6.9277 & RN \\
\hline CHEMBL 335187 & 48451 & .7033 & 5.7629 & RN \\
\hline HEMBL131554 & 48451 & 5.3768 & 5.436 & RN \\
\hline CHEMBL130812 & 48451 & 5.5229 & 5.4627 & $\mathrm{RN}$ \\
\hline HEMBL338869 & 48451 & 4.5229 & 4.5922 & TRN \\
\hline HEMBL130897 & 48451 & 1079 & 6.0667 & RN \\
\hline CHEMBL132051 & 48451 & 458 & 6.066 & RN \\
\hline CHEMBL424264 & 48451 & 6.2218 & 6.3483 & RN \\
\hline CHEMBL335491 & 48451 & 5.5986 & 5.6154 & TRN \\
\hline HEMBL131521 & 48451 & 5.2007 & 6.0789 & TST \\
\hline CHEMBL335076 & 48451 & .3665 & 6.2466 & TRN \\
\hline CHEMBL131472 & 48451 & .8861 & 5.3776 & ST \\
\hline CHEMBL336768 & 48451 & 5.6778 & 5.5785 & RN \\
\hline CHEMBL 75084 & 48451 & .2007 & 5.9582 & TRN \\
\hline CHEMBL133125 & 48451 & .6383 & 5.6459 & TRN \\
\hline CHEMBL130371 & 48451 & .0506 & 6.0271 & TRN \\
\hline CHEMBL130702 & 48451 & .041 & 5.6664 & ST \\
\hline CHEMBL338952 & 48451 & 5.3872 & 5.306 & TRN \\
\hline CHEMBL341487 & 48451 & 7.699 & 7.8023 & TRN \\
\hline HEMBL128685 & 48451 & .4949 & 5.6027 & TRN \\
\hline CHEMBL338615 & 48451 & .0969 & 5.1253 & TRN \\
\hline CHEMBL133007 & 48451 & 7.3979 & 7.4146 & TRN \\
\hline CHEMBL131878 & 48451 & 6.3979 & 6.3225 & TRN \\
\hline CHEMBL 77076 & 48451 & 7.7959 & 7.5986 & TRN \\
\hline CHEMBL338322 & 48451 & .5686 & 5.6259 & TRN \\
\hline CHEMBL131947 & 48451 & 5.5376 & 5.3626 & TRN \\
\hline CHEMBL340945 & 48451 & 3.5229 & 3.5395 & TRN \\
\hline CHEMBL412136 & 48451 & 5.0915 & 5.1873 & TRN \\
\hline CHEMBL130537 & 48451 & 3.5229 & 3.5389 & IRN \\
\hline CHEMBL131490 & 48451 & .1549 & 6.235 & Tा⿰ \\
\hline CHEMBL444600 & 48451 & 7.699 & 7.8195 & RN \\
\hline THEMBL131884 & 48451 & 5.4202 & 5.3288 & 「RN \\
\hline
\end{tabular}

Page 13576 


\begin{tabular}{|c|c|c|c|c|c|c|}
\hline & & \multicolumn{5}{|c|}{ Supplemental Table S2.txt } \\
\hline CHEMBL335755 & 48451 & 4.7773 & 5.1036 & TST & & \\
\hline CHEMBL133623 & 48451 & 6.1135 & 6.0849 & TRN & & \\
\hline CHEMBL131473 & 48451 & 6.4437 & 7.2858 & TST & & \\
\hline CHEMBL128284 & 48451 & 5.9208 & 5.7737 & TST & & \\
\hline CHEMBL335186 & 48451 & 6.1612 & 6.3724 & TST & & \\
\hline CHEMBL133174 & 48451 & 7.0458 & 7.2364 & TST & & \\
\hline CHEMBL130603 & 48451 & 6.3979 & 6.3688 & TST & & \\
\hline CHEMBL130228 & 48451 & 4.6799 & 4.8852 & TST & & \\
\hline CHEMBL133069 & 48451 & 3.0 & 4.4991 & TST & & \\
\hline CHEMBL130100 & 48451 & 5.38299 & 99999999 & 99 & 5.006 & TST \\
\hline CHEMBL130202 & 48451 & 3.0 & 3.9063 & TST & & \\
\hline CHEMBL131190 & 48451 & 5.8539 & 6.029 & TST & & \\
\hline CHEMBL131250 & 48451 & 5.0088 & 5.5289 & TST & & \\
\hline CHEMBL337678 & 48451 & 6.0 & 6.0637 & TST & & \\
\hline CHEMBL3983200 & 1638263 & 7.9788 & 8.0125 & TRN & & \\
\hline CHEMBL3977559 & 1638263 & 7.9788 & 7.9462 & TRN & & \\
\hline CHEMBL3961761 & 1638263 & 7.9788 & 8.0394 & TRN & & \\
\hline CHEMBL3937089 & 1638263 & 7.9788 & 8.0137 & TRN & & \\
\hline CHEMBL3952569 & 1638263 & 7.9788 & 8.0139 & TRN & & \\
\hline CHEMBL3926491 & 1638263 & 7.9788 & 7.6891 & TST & & \\
\hline CHEMBL3955699 & 1638263 & 7.9788 & 8.0248 & TRN & & \\
\hline CHEMBL3893059 & 1638263 & 7.9788 & 7.9393 & TRN & & \\
\hline CHEMBL3920236 & 1638263 & 7.9788 & 8.0399 & TRN & & \\
\hline CHEMBL3921158 & 1638263 & 7.9788 & 7.9732 & TRN & & \\
\hline CHEMBL3980758 & 1638263 & 7.9788 & 8.0206 & TRN & & \\
\hline CHEMBL3922686 & 1638263 & 7.9788 & 7.9622 & TRN & & \\
\hline CHEMBL3900038 & 1638263 & 6.0 & 5.9256 & TRN & & \\
\hline CHEMBL3900091 & 1638263 & 7.9788 & 8.0592 & TST & & \\
\hline CHEMBL 3959044 & 1638263 & 7.9788 & 7.9404 & TRN & & \\
\hline CHEMBL3926078 & 1638263 & 7.9788 & 7.9834 & TRN & & \\
\hline CHEMBL 3914174 & 1638263 & 7.9788 & 8.0206 & TRN & & \\
\hline CHEMBL3970829 & 1638263 & 7.9788 & 8.0914 & TRN & & \\
\hline CHEMBL 3917222 & 1638263 & 7.9788 & 8.0114 & TRN & & \\
\hline CHEMBL 3918258 & 1638263 & 7.9788 & 8.0569 & TRN & & \\
\hline CHEMBL3957516 & 1638263 & 7.9788 & 7.9868 & TRN & & \\
\hline CHEMBL3896069 & 1638263 & 7.9788 & 7.9405 & TRN & & \\
\hline CHEMBL3969137 & 1638263 & 7.9788 & 8.0746 & TRN & & \\
\hline CHEMBL3919269 & 1638263 & 7.9788 & 7.8535 & TRN & & \\
\hline CHEMBL3981509 & 1638263 & 7.9788 & 7.9988 & TRN & & \\
\hline CHEMBL3985726 & 1638263 & 7.9788 & 7.9925 & TRN & & \\
\hline CHEMBL3931899 & 1638263 & 7.9788 & 8.03399 & 9999999999 & & 10 \\
\hline CHEMBL3914495 & 1638263 & 7.9788 & 7.9651 & TRN & & \\
\hline CHEMBL3924965 & 1638263 & 7.9788 & 7.9827 & TRN & & \\
\hline CHEMBL3912947 & 1638263 & 7.9788 & 7.8197 & TRN & & \\
\hline CHEMBL3966307 & 1638263 & 6.0 & 6.3216 & TRN & & \\
\hline CHEMBL3952439 & 1638263 & 7.9788 & 7.9468 & TRN & & \\
\hline CHEMBL3934336 & 1638263 & 7.9788 & 7.9471 & TRN & & \\
\hline CHEMBL3921534 & 1638263 & 7.9788 & 8.2545 & TST & & \\
\hline
\end{tabular}


Supplemental Table S2.txt

\begin{tabular}{|c|c|c|c|c|}
\hline CHEMBL3939932 & 1638263 & 7.9788 & 7.9775 & TRN \\
\hline CHEMBL3977415 & 1638263 & 7.9788 & 7.9006 & TRN \\
\hline CHEMBL3902808 & 1638263 & 7.9788 & 7.8618 & TRN \\
\hline CHEMBL3943161 & 1638263 & 7.9788 & 7.6308 & TST \\
\hline CHEMBL3917017 & 1638263 & 7.9788 & 7.981 & TRN \\
\hline CHEMBL3893346 & 1638263 & 6.0 & 6.0705 & TRN \\
\hline CHEMBL3917503 & 1638263 & 7.9788 & 8.7259 & TST \\
\hline CHEMBL3907754 & 1638263 & 7.9788 & 8.0906 & TRN \\
\hline CHEMBL3952293 & 1638263 & 7.1549 & 7.2835 & TRN \\
\hline CHEMBL3977761 & 1638263 & 7.9788 & 7.906006 & 0000000001 \\
\hline CHEMBL3938716 & 1638263 & 7.9788 & 7.8918 & TRN \\
\hline CHEMBL3935961 & 1638263 & 7.9788 & 7.9593 & TRN \\
\hline CHEMBL3943011 & 1638263 & 7.9788 & 7.8949 & TRN \\
\hline CHEMBL3983767 & 1638263 & 7.9788 & 8.0193 & TRN \\
\hline CHEMBL3981383 & 1638263 & 6.0 & 5.8274 & TRN \\
\hline CHEMBL3941036 & 1638263 & 7.9788 & 7.8358 & TRN \\
\hline CHEMBL3964788 & 1638263 & 7.9788 & 8.0382 & TRN \\
\hline CHEMBL3926604 & 1638263 & 7.9788 & 7.9535 & TRN \\
\hline CHEMBL3953739 & 1638263 & 7.9788 & 7.9897 & TRN \\
\hline CHEMBL 3896580 & 1638263 & 7.9788 & 7.8921 & TRN \\
\hline CHEMBL3961361 & 1638263 & 7.9788 & 8.2316 & TRN \\
\hline CHEMBL3981484 & 1638263 & 7.9788 & 8.0005 & TRN \\
\hline CHEMBL3984207 & 1638263 & 7.9788 & 7.9413 & TST \\
\hline CHEMBL3928658 & 1638263 & 7.9788 & 7.9115 & TRN \\
\hline CHEMBL 3975263 & 1638263 & 6.0 & 6.1774 & TRN \\
\hline CHEMBL3923745 & 1638263 & 6.0 & 6.0039 & TRN \\
\hline CHEMBL3890828 & 1638263 & 7.9788 & 7.8763 & TRN \\
\hline CHEMBL3982288 & 1638263 & 7.9788 & 7.9852 & TRN \\
\hline CHEMBL3968156 & 1638263 & 7.8996 & 7.9795 & TRN \\
\hline CHEMBL3968835 & 1638263 & 7.9788 & 8.0141 & TRN \\
\hline CHEMBL3942683 & 1638263 & 6.0 & 5.9418 & TRN \\
\hline CHEMBL3917276 & 1638263 & 7.9788 & 7.9989 & TRN \\
\hline CHEMBL3932106 & 1638263 & 7.9788 & 7.9682 & TRN \\
\hline CHEMBL3934619 & 1638263 & 7.9788 & 8.007 & TST \\
\hline CHEMBL3961754 & 1638263 & 7.9788 & 7.5695 & TRN \\
\hline CHEMBL3925563 & 1638263 & 7.9788 & 7.9919 & TRN \\
\hline CHEMBL3893909 & 1638263 & 7.9788 & 8.446 & TST \\
\hline CHEMBL3961809 & 1638263 & 7.9788 & 8.1419 & TST \\
\hline CHEMBL3914231 & 1638263 & 7.9788 & 7.9122 & TRN \\
\hline CHEMBL 3914443 & 1638263 & 7.9788 & 8.026 & TRN \\
\hline CHEMBL3933131 & 1638263 & 7.9788 & 7.8309 & TST \\
\hline CHEMBL3960203 & 1638263 & 7.9788 & 8.0056 & TRN \\
\hline CHEMBL3902855 & 1638263 & 7.9788 & 8.044 & TST \\
\hline CHEMBL3915367 & 1638263 & 7.9788 & 8.0486 & TST \\
\hline CHEMBL3979096 & 1638263 & 7.9788 & 8.2353 & TST \\
\hline CHEMBL3890685 & 1638263 & 7.9788 & 8.1056 & TST \\
\hline CHEMBL 3938313 & 1638263 & 7.9788 & 8.0648 & TST \\
\hline CHEMBL3943791 & 1638263 & 7.9788 & 7.8956 & TST \\
\hline
\end{tabular}


Supplemental Table S2.txt

\begin{tabular}{|c|c|c|c|c|}
\hline CHEMBL3945849 & 1638263 & 7.9788 & 7.9423 & TST \\
\hline CHEMBL3976286 & 1638263 & 7.9788 & 7.9874 & TST \\
\hline CHEMBL3984010 & 1638263 & 7.9788 & 7.9488 & TST \\
\hline CHEMBL 3957760 & 1638263 & 7.9788 & 8.089 & TST \\
\hline CHEMBL3966331 & 1638263 & 7.9788 & 8.0351 & TST \\
\hline CHEMBL3975307 & 1638263 & 7.9788 & 7.8312 & TST \\
\hline CHEMBL1582535 & 752414 & 8.301 & 4.9813 & TRN \\
\hline CHEMBL1720801 & 752414 & 3.6021 & 3.543 & TRN \\
\hline CHEMBL1871127 & 752414 & 3.6021 & 3.4888 & TRN \\
\hline CHEMBL1500226 & 752414 & 3.6021 & 3.412 & TST \\
\hline CHEMBL1601082 & 752414 & 3.6021 & 3.8732 & TRN \\
\hline CHEMBL1384636 & 752414 & 3.6021 & 3.6194 & TRN \\
\hline CHEMBL1443660 & 752414 & 3.6021 & 3.7944 & TRN \\
\hline CHEMBL1437139 & 752414 & 8.301 & 3.7258 & TST \\
\hline CHEMBL1899264 & 752414 & 3.6021 & 3.6455 & TST \\
\hline CHEMBL1546223 & 752414 & 3.6021 & 3.4336 & TRN \\
\hline CHEMBL1901889 & 752414 & 3.6021 & 3.6206 & TRN \\
\hline CHEMBL1506436 & 752414 & 3.9031 & 3.8331 & TRN \\
\hline CHEMBL1324082 & 752414 & 4.2041 & 3.7671 & TRN \\
\hline CHEMBL1377193 & 752414 & 3.9031 & 3.742 & TRN \\
\hline CHEMBL3190770 & 752414 & 3.6021 & 3.6926 & TRN \\
\hline CHEMBL448741 & 752414 & 3.6021 & 3.7478 & TST \\
\hline CHEMBL1600146 & 752414 & 3.6021 & 3.4853 & TRN \\
\hline CHEMBL1312665 & 752414 & 3.6021 & 3.4717 & TRN \\
\hline CHEMBL1414729 & 752414 & 3.9031 & 3.5454 & TRN \\
\hline CHEMBL1571443 & 752414 & 3.6021 & 3.43399 & 99999999997 \\
\hline CHEMBL1554589 & 752414 & 3.6021 & 3.6559 & TRN \\
\hline CHEMBL1970422 & 752414 & 8.301 & 3.8181 & TST \\
\hline CHEMBL1718227 & 752414 & 3.6021 & 3.7936 & TST \\
\hline CHEMBL1992918 & 752414 & 3.6021 & 3.7129 & TST \\
\hline CHEMBL1719818 & 752414 & 3.6021 & 3.73 & TRN \\
\hline CHEMBL 3197070 & 752414 & 3.6021 & 3.5604 & TRN \\
\hline CHEMBL1698608 & 752414 & 3.6021 & 3.4548 & TRN \\
\hline CHEMBL1730953 & 752414 & 3.6021 & 3.7784 & TST \\
\hline CHEMBL1973156 & 752414 & 3.6021 & 3.4414 & TRN \\
\hline CHEMBL1376177 & 752414 & 3.6021 & 3.7827 & TRN \\
\hline CHEMBL1699869 & 752414 & 3.6021 & 3.842 & TRN \\
\hline CHEMBL1440877 & 752414 & 3.6021 & 3.8174 & TRN \\
\hline CHEMBL1865025 & 752414 & 3.6021 & 3.6533 & TRN \\
\hline CHEMBL1531150 & 752414 & 3.6021 & 3.6157 & TRN \\
\hline CHEMBL1393126 & 752414 & 8.301 & 3.8338 & TST \\
\hline CHEMBL1422078 & 752414 & 3.6021 & 3.5769 & TRN \\
\hline CHEMBL1333422 & 752414 & 3.6021 & 3.9043 & TRN \\
\hline CHEMBL1580558 & 752414 & 3.6021 & 3.5634 & TST \\
\hline CHEMBL1526479 & 752414 & 3.6021 & 3.6016 & TRN \\
\hline CHEMBL1428326 & 752414 & 3.6021 & 3.6392 & TRN \\
\hline CHEMBL1370719 & 752414 & 3.6021 & 3.5682 & TRN \\
\hline CHEMBL1734136 & 752414 & 3.6021 & 3.7356 & TRN \\
\hline
\end{tabular}

Page 13579 
Supplemental Table S2.txt

\begin{tabular}{|c|c|c|c|c|c|}
\hline CHEMBL1332450 & 752414 & 3.9031 & 3.4548 & TRN & \\
\hline CHEMBL3190594 & 752414 & 3.6021 & 3.6807 & TRN & \\
\hline CHEMBL1361509 & 752414 & 3.6021 & 3.7641 & TRN & \\
\hline CHEMBL1500987 & 752414 & 3.6021 & 3.6603 & TRN & \\
\hline CHEMBL1400858 & 752414 & 3.6021 & 3.7015 & TST & \\
\hline CHEMBL584759 & 752414 & 3.6021 & 3.9151 & TST & \\
\hline CHEMBL17201 & 752414 & 3.6021 & 3.3836 & TRN & \\
\hline CHEMBL1709186 & 752414 & 3.6021 & 3.5311 & TRN & \\
\hline CHEMBL1326403 & 752414 & 3.6021 & 3.615 & TRN & \\
\hline CHEMBL1611546 & 752414 & 3.6021 & 3.7424 & TRN & \\
\hline CHEMBL1589213 & 752414 & 3.6021 & 3.6846 & TRN & \\
\hline CHEMBL1461477 & 752414 & 3.6021 & 3.726006 & 00000000004 & TRN \\
\hline CHEMBL1487689 & 752414 & 3.6021 & 3.7137 & TRN & \\
\hline CHEMBL1527747 & 752414 & 3.6021 & 3.6482 & TRN & \\
\hline CHEMBL1883170 & 752414 & 3.6021 & 3.5671 & TRN & \\
\hline CHEMBL1434502 & 752414 & 3.6021 & 3.7623 & TRN & \\
\hline CHEMBL1505604 & 752414 & 3.6021 & 3.6872 & TRN & \\
\hline CHEMBL1462608 & 752414 & 3.6021 & 3.7329 & TRN & \\
\hline CHEMBL1589526 & 752414 & 3.6021 & 3.5017 & TRN & \\
\hline CHEMBL1723719 & 752414 & 3.6021 & 3.65 & TRN & \\
\hline CHEMBL1984876 & 752414 & 3.6021 & 3.6361 & TRN & \\
\hline CHEMBL1302824 & 752414 & 3.6021 & 3.8187 & TRN & \\
\hline CHEMBL1447104 & 752414 & 3.6021 & 3.7719 & TRN & \\
\hline CHEMBL1479670 & 752414 & 3.6021 & 3.5235 & TRN & \\
\hline CHEMBL1998263 & 752414 & 3.9031 & 3.5863 & TRN & \\
\hline CHEMBL1496226 & 752414 & 3.6021 & 3.4055 & TRN & \\
\hline CHEMBL3214167 & 752414 & 3.6021 & 3.6091 & TRN & \\
\hline CHEMBL1436988 & 752414 & 3.6021 & 3.7605 & TRN & \\
\hline CHEMBL1551177 & 752414 & 3.6021 & 3.5799 & TRN & \\
\hline CHEMBL1460034 & 752414 & 3.6021 & 3.6546 & TRN & \\
\hline CHEMBL1411125 & 752414 & 3.6021 & 3.5632 & TRN & \\
\hline CHEMBL1605540 & 752414 & 4.2041 & 3.7794 & TRN & \\
\hline CHEMBL1453996 & 752414 & 3.6021 & 3.5988 & TRN & \\
\hline CHEMBL1540333 & 752414 & 3.6021 & 3.7291 & TRN & \\
\hline CHEMBL1560341 & 752414 & 3.6021 & 3.5308 & TRN & \\
\hline CHEMBL1391949 & 752414 & 3.6021 & 3.8105 & TRN & \\
\hline CHEMBL3193406 & 752414 & 3.6021 & 3.852 & TRN & \\
\hline CHEMBL1436557 & 752414 & 3.6021 & 3.748999 & 99999999997 & TRN \\
\hline CHEMBL1398260 & 752414 & 8.301 & 3.748999 & & TST \\
\hline CHEMBL1688556 & 752414 & 3.6021 & 3.5511 & TRN & \\
\hline CHEMBL1424783 & 752414 & 3.6021 & 3.549 & TRN & \\
\hline CHEMBL1522995 & 752414 & 3.6021 & 3.4301 & TRN & \\
\hline CHEMBL1536488 & 752414 & 3.9031 & 4.3328 & TRN & \\
\hline CHEMBL1528206 & 752414 & 3.6021 & 3.7351 & TRN & \\
\hline CHEMBL460601 & 752414 & 3.6021 & 3.7785 & TRN & \\
\hline CHEMBL1305077 & 752414 & 3.6021 & 3.6854 & TRN & \\
\hline CHEMBL1299739 & 752414 & 3.6021 & 3.5332 & TRN & \\
\hline CHEMBL1587715 & 752414 & 3.6021 & 3.5415 & TRN & \\
\hline
\end{tabular}


Supplemental Table S2.txt

\begin{tabular}{|c|c|c|c|c|c|}
\hline CHEMBL1301368 & 752414 & 3.6021 & 3.5994 & TRN & \\
\hline CHEMBL1430038 & 752414 & 3.6021 & 3.6264 & TRN & \\
\hline CHEMBL1317135 & 752414 & 3.6021 & 3.7678 & TST & \\
\hline CHEMBL1452116 & 752414 & 3.6021 & 3.5664 & TRN & \\
\hline CHEMBL1700479 & 752414 & 3.6021 & 4.053 & TST & \\
\hline CHEMBL1599610 & 752414 & 3.6021 & 3.4745 & TRN & \\
\hline CHEMBL3192616 & 752414 & 3.9031 & 3.659 & TRN & \\
\hline CHEMBL1326228 & 752414 & 3.6021 & 3.5569 & TST & \\
\hline CHEMBL1567973 & 752414 & 3.6021 & 3.4405 & TRN & \\
\hline CHEMBL1610676 & 752414 & 3.6021 & 3.5562 & TRN & \\
\hline CHEMBL1718952 & 752414 & 3.6021 & 3.7271 & TRN & \\
\hline CHEMBL1506663 & 752414 & 3.6021 & 3.4672 & TRN & \\
\hline CHEMBL1347154 & 752414 & 3.6021 & 3.6693 & TRN & \\
\hline CHEMBL1408268 & 752414 & 3.6021 & 3.6102 & TST & \\
\hline CHEMBL1428562 & 752414 & 3.6021 & 3.6978 & TST & \\
\hline CHEMBL1330242 & 752414 & 3.6021 & 3.7717 & TST & \\
\hline CHEMBL1558021 & 752414 & 3.6021 & 3.3141 & TRN & \\
\hline CHEMBL1346773 & 752414 & 3.6021 & 3.8449 & TRN & \\
\hline CHEMBL1509364 & 752414 & 3.6021 & 3.4642 & TRN & \\
\hline CHEMBL1535901 & 752414 & 3.6021 & 3.5467 & TRN & \\
\hline CHEMBL1527447 & 752414 & 3.6021 & 3.9968 & TRN & \\
\hline CHEMBL1470614 & 752414 & 3.6021 & 3.316999 & 99999999997 & TRN \\
\hline CHEMBL1610831 & 752414 & 3.6021 & 3.6315 & TRN & \\
\hline CHEMBL1558144 & 752414 & 3.6021 & 3.7076 & TRN & \\
\hline CHEMBL1411508 & 752414 & 3.6021 & 3.6765 & TRN & \\
\hline CHEMBL3191081 & 752414 & 3.6021 & 3.931 & TRN & \\
\hline CHEMBL1341919 & 752414 & 3.6021 & 3.6123 & TST & \\
\hline CHEMBL1560774 & 752414 & 3.6021 & 3.5302 & TRN & \\
\hline CHEMBL1700106 & 752414 & 3.6021 & 3.6745 & TRN & \\
\hline CHEMBL1390038 & 752414 & 3.6021 & 3.608 & TRN & \\
\hline CHEMBL186248 & 752414 & 3.6021 & 3.4954 & TRN & \\
\hline CHEMBL1596325 & 752414 & 3.6021 & 3.842 & TRN & \\
\hline CHEMBL1458733 & 752414 & 3.6021 & 3.7666 & TRN & \\
\hline CHEMBL1420428 & 752414 & 3.6021 & 3.742 & TST & \\
\hline CHEMBL1532491 & 752414 & 3.6021 & 3.6563 & TST & \\
\hline CHEMBL1524804 & 752414 & 3.9031 & 3.6982 & TRN & \\
\hline CHEMBL1581582 & 752414 & 3.6021 & 3.8214 & TRN & \\
\hline CHEMBL3392037 & 752414 & 3.9031 & 3.8176 & TST & \\
\hline CHEMBL3391721 & 752414 & 8.301 & 4.1722 & TST & \\
\hline CHEMBL1213045 & 752414 & 3.6021 & 3.4174 & TRN & \\
\hline CHEMBL3197771 & 752414 & 3.6021 & 3.7364 & TRN & \\
\hline CHEMBL1255733 & 752414 & 8.301 & 3.8719 & TST & \\
\hline CHEMBL1483146 & 752414 & 3.6021 & 4.2437 & TRN & \\
\hline CHEMBL1519422 & 752414 & 3.6021 & 3.3983 & TRN & \\
\hline CHEMBL1604983 & 752414 & 3.9031 & 3.6856 & TST & \\
\hline CHEMBL 300389 & 752414 & 3.6021 & 3.5871 & TRN & \\
\hline CHEMBL1404909 & 752414 & 3.6021 & 3.7852 & TST & \\
\hline CHEMBL1471418 & 752414 & 3.6021 & 3.5632 & TRN & \\
\hline
\end{tabular}

Page 13581 
Supplemental Table S2.txt

\begin{tabular}{|c|c|c|c|c|}
\hline 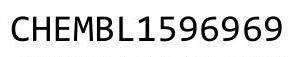 & & & & \\
\hline & 52414 & .6021 & & \\
\hline 1 & 14 & & & \\
\hline AEMBL133213 & 2414 & 5021 & & S \\
\hline AEMBL1388469 & 52414 & 5021 & 5974 & \\
\hline HEMBL1333901 & 52414 & 6021 & 0425 & \\
\hline 766 & 52414 & & & \\
\hline FMBI 186 & 52414 & & & me \\
\hline AEMBL1451888 & 52414 & 5021 & & \\
\hline HEMBL577635 & 52414 & 21 & & \\
\hline HEMBL1568905 & 52414 & 1 & & \\
\hline AEMBL140 & 52414 & 1 & 21 & \\
\hline AEMBL1383 & & & & RN \\
\hline HEMBL1518020 & 52414 & 21 & & \\
\hline AEMBL1606752 & 52414 & 1 & & \\
\hline AEMBL1376914 & 52414 & 1 & 92 & \\
\hline IEMBL152 & 414 & 1 & & . \\
\hline HEMBL159 & 414 & & & \\
\hline HEMBL1544114 & 52414 & & & \\
\hline AEMBL170 & 14 & & & \\
\hline FEMBLI98/938 & 14 & & & KIV \\
\hline IEMBL15 & 14 & & & 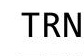 \\
\hline JEMBL14 & 14 & & & \\
\hline HEMBL1399005 & 52414 & & & \\
\hline AEMBL1536721 & & & & 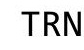 \\
\hline AEMBL136 & 14 & & & $\cdots$ \\
\hline AEMBL1 & 14 & & & RN \\
\hline HFMRI 143 & 14 & & & \\
\hline HEMBL1713939 & & & & I KIV \\
\hline HEMBL1605668 & 14 & & & r \\
\hline HEMBL1723055 & 14 & & & SI \\
\hline HEMBL1 & 14 & & & RN \\
\hline 705 & 14 & & & $\mathrm{RN}$ \\
\hline HEMBL1313351 & 14 & & & IRN \\
\hline HEMBL1577001 & 14 & & & TRN \\
\hline AEMBL1537827 & 14 & & 07 & RN \\
\hline HFMRI 1 & 4 & 1 & & $\Gamma \mathrm{RN}$ \\
\hline HEMBL1336727 & & & & $\Gamma \mathrm{RN}$ \\
\hline HEMBL1333987 & 14 & & & TRN \\
\hline AEMBL1335881 & 14 & & & TST \\
\hline HEMBL1348807 & 14 & & & \\
\hline HEMBL1334134 & & & & TRN \\
\hline HEMBL1906281 & 52414 & & & RN \\
\hline AEMBL1512182 & 14 & 1 & 71 & TRN \\
\hline MPI 3 & 14 & & & \\
\hline HEMBL14 & & & & \\
\hline CHEMBL1326215 & & 3.60 & & \\
\hline CHEMBL1331355 & 752414 & 3.6021 & 3.9901 & ГRN \\
\hline
\end{tabular}

Page 13582 
Supplemental Table S2.txt

\begin{tabular}{|c|c|c|c|c|c|c|}
\hline CHEMBL1588513 & 752414 & 3.6021 & 3.6956 & TRN & & \\
\hline CHEMBL1410860 & 752414 & 3.6021 & 3.6914 & TRN & & \\
\hline CHEMBL1590402 & 752414 & 3.6021 & 3.7 & TRN & & \\
\hline CHEMBL269821 & 752414 & 3.6021 & 3.4305 & TST & & \\
\hline CHEMBL1601367 & 752414 & 3.6021 & 3.7523 & TST & & \\
\hline CHEMBL1406487 & 752414 & 3.6021 & 3.4899 & TST & & \\
\hline CHEMBL1706162 & 752414 & 3.6021 & 3.5447 & TST & & \\
\hline CHEMBL1525358 & 752414 & 3.6021 & 3.7004 & TST & & \\
\hline CHEMBL1544629 & 752414 & 3.6021 & 3.5346 & TST & & \\
\hline CHEMBL1496329 & 752414 & 3.6021 & 3.5271 & TST & & \\
\hline CHEMBL1363614 & 752414 & 3.6021 & 3.7067 & TST & & \\
\hline CHEMBL1556764 & 752414 & 3.6021 & 3.5147 & TST & & \\
\hline CHEMBL1486214 & 752414 & 3.6021 & 3.5749 & TST & & \\
\hline CHEMBL 3196324 & 752414 & 3.6021 & 3.5991 & TST & & \\
\hline CHEMBL1543524 & 752414 & 3.6021 & 3.7054 & TST & & \\
\hline CHEMBL1479120 & 752414 & 3.6021 & 3.98 & TST & & \\
\hline CHEMBL1449349 & 752414 & 3.6021 & 3.6984 & TST & & \\
\hline CHEMBL1984764 & 752414 & 3.6021 & 3.7368 & TST & & \\
\hline CHEMBL427692 & 752414 & 3.6021 & 3.5682 & TST & & \\
\hline CHEMBL1546334 & 752414 & 3.6021 & 3.7563 & TST & & \\
\hline CHEMBL580955 & 752414 & 3.6021 & 3.6703 & TST & & \\
\hline CHEMBL1720547 & 752414 & 3.6021 & 3.7379 & TST & & \\
\hline CHEMBL1371138 & 688616 & 4.1911 & 3.8605 & TRN & & \\
\hline CHEMBL1332346 & 688616 & 4.9541 & 4.6123 & TRN & & \\
\hline CHEMBL1382150 & 688616 & 4.52800 & 0000000 & 05 & 4.6361 & iniv \\
\hline CHEMBL1579913 & 688616 & 3.3585 & 3.6999 & TRN & & \\
\hline CHEMBL1359426 & 688616 & 4.9206 & 4.7408 & TRN & & \\
\hline CHEMBL1499675 & 688616 & 4.9245 & 4.0957 & TST & & \\
\hline CHEMBL1537947 & 688616 & 4.875 & 4.6676 & TRN & & \\
\hline CHEMBL1447678 & 688616 & 4.6392 & 4.0105 & TRN & & \\
\hline CHEMBL1314041 & 688616 & 4.7534 & 4.3164 & TRN & & \\
\hline CHEMBL1421312 & 688616 & 3.3585 & 3.5258 & TRN & & \\
\hline CHEMBL1493564 & 688616 & 4.6538 & 4.16 & TRN & & \\
\hline CHEMBL186174 & 688616 & 3.8356 & 4.4032 & TST & & \\
\hline CHEMBL1584538 & 688616 & 4.6267 & 4.5844 & TRN & & \\
\hline CHEMBL1484343 & 688616 & 5.3228 & 3.6345 & TRN & & \\
\hline CHEMBL1359489 & 688616 & 4.7971 & 4.3749 & TRN & & \\
\hline CHEMBL1589201 & 688616 & 4.9487 & 4.162 & TRN & & \\
\hline CHEMBL1977747 & 688616 & 4.8857 & 4.3581 & TST & & \\
\hline CHEMBL1460465 & 688616 & 3.3585 & 4.0333 & TRN & & \\
\hline CHEMBL1501491 & 688616 & 3.3585 & 3.9793 & TST & & \\
\hline CHEMBL1582511 & 688616 & 4.7993 & 3.4059 & TRN & & \\
\hline CHEMBL1498512 & 688616 & 3.3585 & 4.1576 & TST & & \\
\hline CHEMBL1536967 & 688616 & 4.4441 & 4.4622 & TRN & & \\
\hline CHEMBL1543278 & 688616 & \multicolumn{3}{|c|}{4.486000000000001} & 4.4108 & TRN \\
\hline CHEMBL1344766 & 688616 & 4.6203 & 4.1879 & TST & & \\
\hline CHEMBL1517453 & 688616 & 3.3585 & 3.4264 & TRN & & \\
\hline CHEMBL3211795 & 688616 & 3.3585 & 3.5842 & TRN & & \\
\hline
\end{tabular}

Page 13583 


\begin{tabular}{|c|c|c|c|c|c|}
\hline \multirow[b]{2}{*}{ CHEMBL1480448 } & & \multicolumn{4}{|c|}{ Supplemental Table S2.txt } \\
\hline & 688616 & 4.7246 & 4.49100 & 00000000005 & TRN \\
\hline CHEMBL1306232 & 688616 & 3.3585 & 4.128 & TRN & \\
\hline CHEMBL1350024 & 688616 & 4.7914 & 4.8012 & TRN & \\
\hline CHEMBL1436519 & 688616 & 4.9748 & 4.8634 & TRN & \\
\hline CHEMBL1337101 & 688616 & 3.3585 & 4.0042 & TRN & \\
\hline CHEMBL1413393 & 688616 & 3.8356 & 3.8272 & TRN & \\
\hline CHEMBL1540447 & 688616 & 4.5541 & 3.8471 & TRN & \\
\hline CHEMBL1503352 & 688616 & 3.3585 & 3.7009 & TRN & \\
\hline CHEMBL1572885 & 688616 & 3.3585 & 3.8414 & TRN & \\
\hline CHEMBL1335094 & 688616 & 4.5812 & 3.8588 & TST & \\
\hline CHEMBL1585808 & 688616 & 4.499 & 3.9646 & TRN & \\
\hline CHEMBL1300997 & 688616 & 3.3585 & 3.7782 & TRN & \\
\hline CHEMBL1531690 & 688616 & 3.3585 & 3.4075 & TRN & \\
\hline CHEMBL1582334 & 688616 & 5.1807 & 4.4672 & TST & \\
\hline CHEMBL1459221 & 688616 & 3.3585 & 3.4258 & TRN & \\
\hline CHEMBL1539046 & 688616 & 4.7663 & 4.3239 & TRN & \\
\hline CHEMBL1458112 & 688616 & 5.0964 & 4.8895 & TRN & \\
\hline CHEMBL1595945 & 688616 & 3.3585 & 3.9802 & TRN & \\
\hline CHEMBL1538063 & 688616 & 4.7384 & 4.5239 & TRN & \\
\hline CHEMBL1344848 & 688616 & 3.3585 & 4.0316 & TRN & \\
\hline CHEMBL3193144 & 688616 & 3.3585 & 3.6215 & TST & \\
\hline CHEMBL1509579 & 688616 & 3.3585 & 4.0981 & TRN & \\
\hline CHEMBL1587146 & 688616 & 3.3585 & 3.6914 & TRN & \\
\hline CHEMBL1386141 & 688616 & 4.6271 & 3.5852 & TRN & \\
\hline CHEMBL1609697 & 688616 & 3.3585 & 3.3334 & TRN & \\
\hline CHEMBL1565197 & 688616 & 3.3585 & 3.4802 & TRN & \\
\hline CHEMBL3209782 & 688616 & 3.3585 & 4.4211 & TRN & \\
\hline CHEMBL1500235 & 688616 & 3.3585 & 3.5525 & TRN & \\
\hline CHEMBL1416734 & 688616 & 4.54 & 4.4275 & TRN & \\
\hline CHEMBL1589399 & 688616 & 4.4773 & 4.2547 & TRN & \\
\hline CHEMBL1461182 & 688616 & 4.7023 & 4.6015 & TST & \\
\hline CHEMBL1335692 & 688616 & 4.4814 & 4.5439 & TRN & \\
\hline CHEMBL1562905 & 688616 & 3.3585 & 3.6542 & TRN & \\
\hline CHEMBL1454002 & 688616 & 3.3585 & 3.5886 & TRN & \\
\hline CHEMBL1588709 & 688616 & 3.3585 & 3.5794 & TRN & \\
\hline CHEMBL1402796 & 688616 & 3.3585 & 3.4124 & TRN & \\
\hline CHEMBL1371990 & 688616 & 3.3585 & 3.4191 & TRN & \\
\hline CHEMBL1339046 & 688616 & 3.8356 & 4.5892 & TRN & \\
\hline CHEMBL1388448 & 688616 & 4.5677 & 4.1757 & TRN & \\
\hline CHEMBL1467280 & 688616 & 4.8234 & 4.2539 & TST & \\
\hline CHEMBL1586617 & 688616 & 4.7807 & 4.7018 & TRN & \\
\hline CHEMBL1418691 & 688616 & 4.7731 & 4.6872 & TRN & \\
\hline CHEMBL1358771 & 688616 & 3.3585 & 3.7131 & TRN & \\
\hline CHEMBL 1343746 & 688616 & 4.7811 & 3.9501 & TRN & \\
\hline CHEMBL1342885 & 688616 & 4.9006 & 4.3276 & TRN & \\
\hline CHEMBL1452812 & 688616 & 4.6229 & 4.1906 & TRN & \\
\hline CHEMBL 1335256 & 688616 & 3.8356 & 4.1615 & TRN & \\
\hline CHEMBL1578660 & 688616 & 4.8043 & 4.3341 & TRN & \\
\hline
\end{tabular}




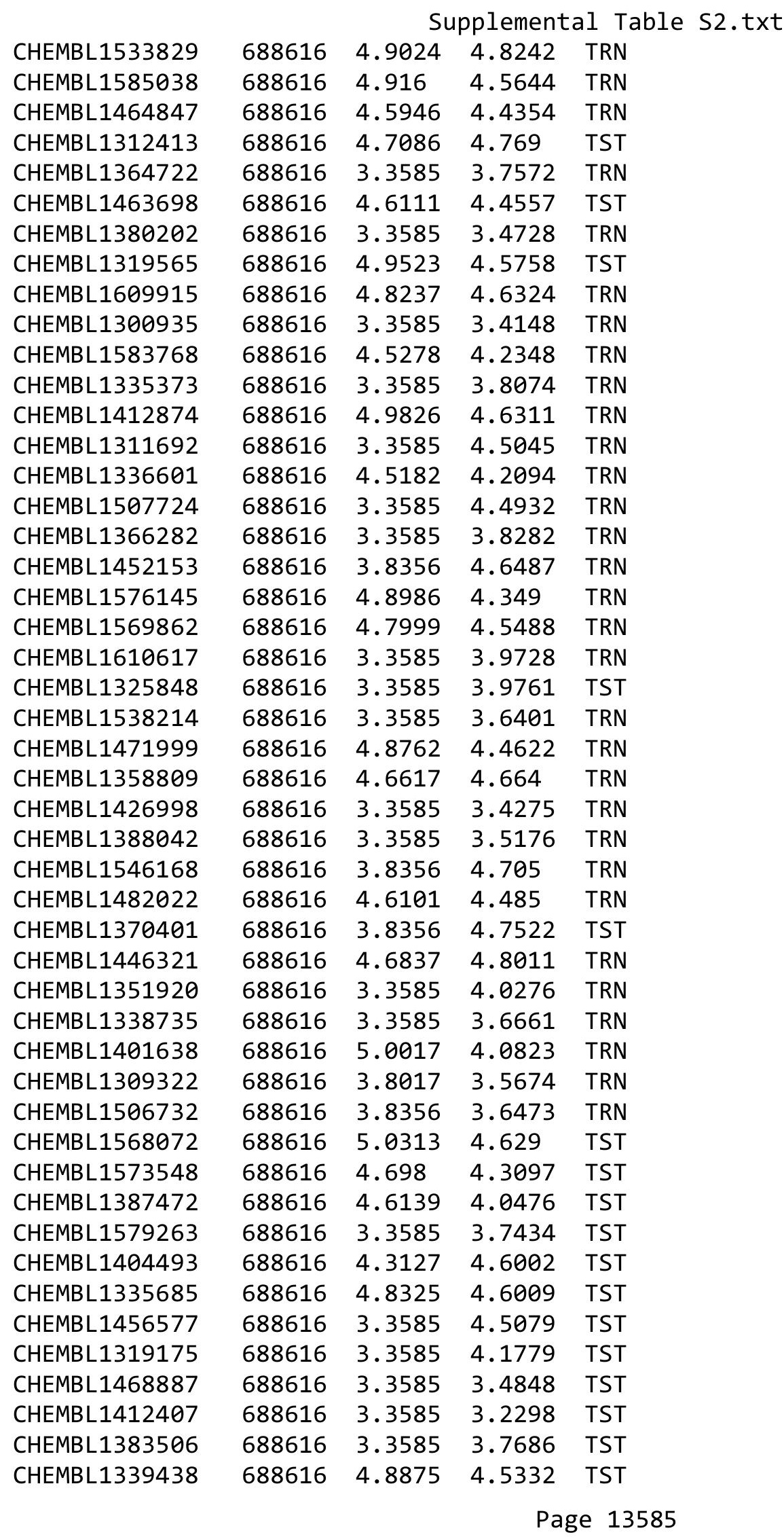


Supplemental Table S2.txt

\begin{tabular}{|c|c|c|c|c|c|}
\hline CHEMBL1353612 & 688616 & 4.6673 & 4.5356 & TST & \\
\hline CHEMBL1518183 & 688616 & 4.6422 & 4.6941 & TST & \\
\hline CHEMBL1549996 & 688616 & 5.074 & 4.8773 & TST & \\
\hline CHEMBL1595687 & 688616 & 4.7956 & 4.2851 & TST & \\
\hline CHEMBL367916 & 44689 & 8.9586 & 8.9741 & TRN & \\
\hline CHEMBL174214 & 44689 & 9.3979 & 9.2079 & TRN & \\
\hline CHEMBL433793 & 44689 & 9.3979 & 9.2875 & TRN & \\
\hline CHEMBL173308 & 44689 & 6.0 & 7.2045 & TST & \\
\hline CHEMBL173630 & 44689 & 8.4559 & 8.734 & TRN & \\
\hline CHEMBL176604 & 44689 & 9.0458 & 9.3608 & TRN & \\
\hline CHEMBL 2112952 & 44689 & 8.4089 & 8.5874 & TRN & \\
\hline CHEMBL173091 & 44689 & 9.301 & 9.1922 & TRN & \\
\hline CHEMBL368332 & 44689 & 9.0458 & 9.2898 & TRN & \\
\hline CHEMBL173479 & 44689 & 9.301 & 9.2637 & TRN & \\
\hline CHEMBL171468 & 44689 & 9.0458 & 7.1804 & TRN & \\
\hline CHEMBL172806 & 44689 & 8.9208 & 9.3499 & TST & \\
\hline CHEMBL172004 & 44689 & 8.5086 & 8.8752 & TRN & \\
\hline CHEMBL174904 & 44689 & 9.0458 & 9.3517 & TST & \\
\hline CHEMBL 367700 & 44689 & 9.2218 & 7.1571 & TRN & \\
\hline CHEMBL172019 & 44689 & 8.699 & 8.5787 & TRN & \\
\hline CHEMBL177648 & 44689 & 6.0 & 6.9572 & TRN & \\
\hline CHEMBL367489 & 44689 & 8.9586 & 9.27700 & 0000000001 & TRN \\
\hline CHEMBL366873 & 44689 & 9.3979 & 9.3134 & TRN & \\
\hline CHEMBL177127 & 44689 & 6.0 & 7.1343 & TRN & \\
\hline CHEMBL369278 & 44689 & 9.0969 & 8.5709 & TRN & \\
\hline CHEMBL174927 & 44689 & 9.699 & 9.2896 & TST & \\
\hline CHEMBL368329 & 44689 & 9.5229 & 9.1842 & TRN & \\
\hline CHEMBL367987 & 44689 & 9.5229 & 8.76100 & 0000000001 & TRN \\
\hline CHEMBL171958 & 44689 & 9.699 & 9.2386 & TST & \\
\hline CHEMBL427493 & 44689 & 9.5229 & 9.0667 & TRN & \\
\hline CHEMBL177157 & 44689 & 8.6383 & 9.1292 & TST & \\
\hline CHEMBL355809 & 44689 & 9.0969 & 9.0812 & TRN & \\
\hline CHEMBL172854 & 44689 & 9.0969 & 9.352 & TRN & \\
\hline CHEMBL263787 & 44689 & 6.0 & 7.1125 & TRN & \\
\hline CHEMBL 262663 & 44689 & 9.2218 & 8.7459 & TRN & \\
\hline CHEMBL 367461 & 44689 & 8.7959 & 9.2155 & TRN & \\
\hline CHEMBL173400 & 44689 & 6.0 & 7.0928 & TRN & \\
\hline CHEMBL170829 & 44689 & 8.9586 & 8.8754 & TRN & \\
\hline CHEMBL368459 & 44689 & 8.7696 & 9.27 & TST & \\
\hline CHEMBL 263529 & 44689 & 9.2218 & 9.2551 & TRN & \\
\hline CHEMBL366600 & 44689 & 9.0458 & 9.2729 & TST & \\
\hline CHEMBL176850 & 44689 & 8.8861 & 8.873 & TRN & \\
\hline CHEMBL176391 & 44689 & 8.9586 & 8.8731 & TRN & \\
\hline CHEMBL368823 & 44689 & 8.8239 & 9.4089 & TRN & \\
\hline CHEMBL435347 & 44689 & 8.9208 & 7.317 & TRN & \\
\hline CHEMBL 366770 & 44689 & 6.0 & 7.0141 & TST & \\
\hline CHEMBL176859 & 44689 & 8.6383 & 9.0387 & TRN & \\
\hline CHEMBL177033 & 44689 & 9.1549 & 9.1878 & TRN & \\
\hline
\end{tabular}




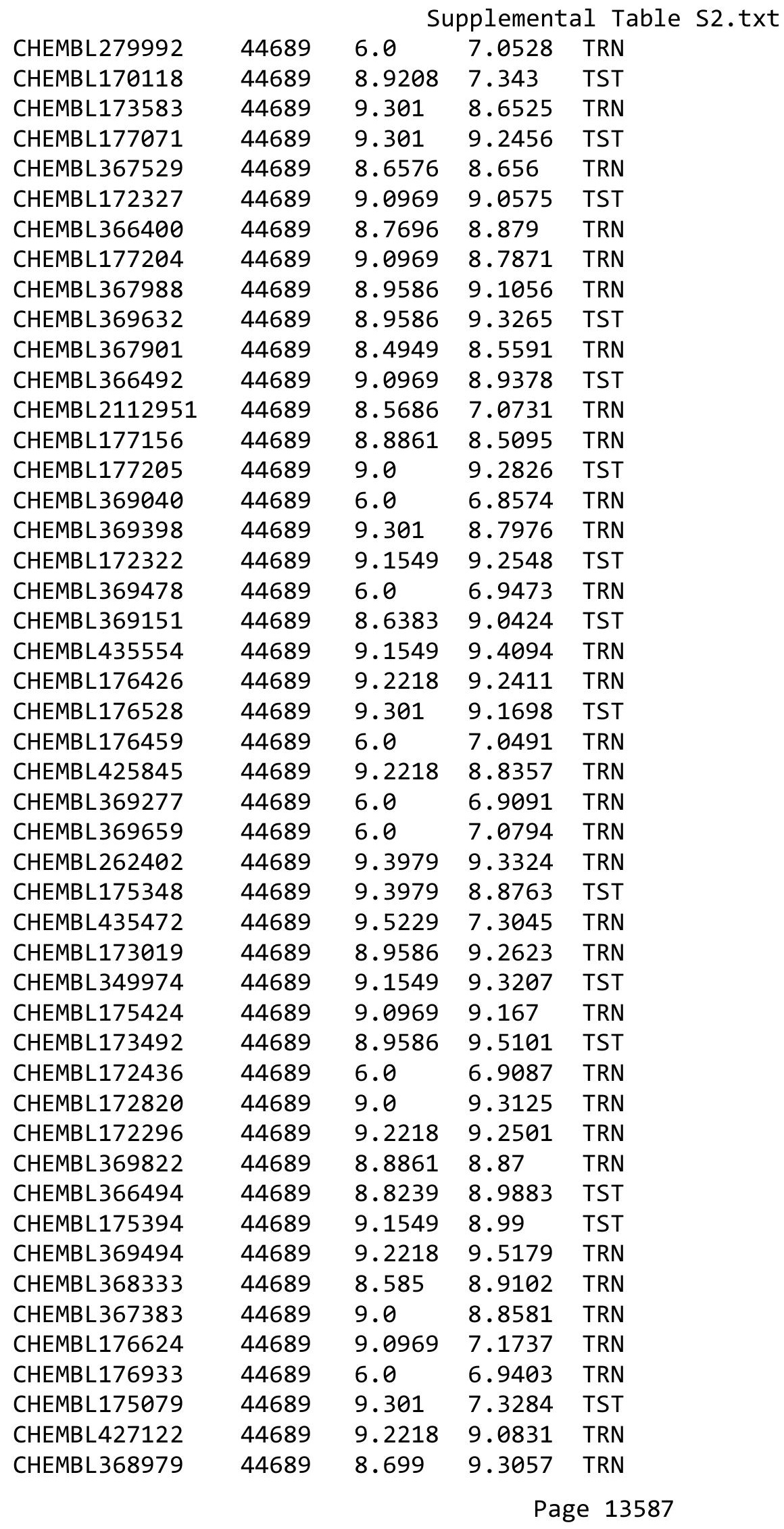




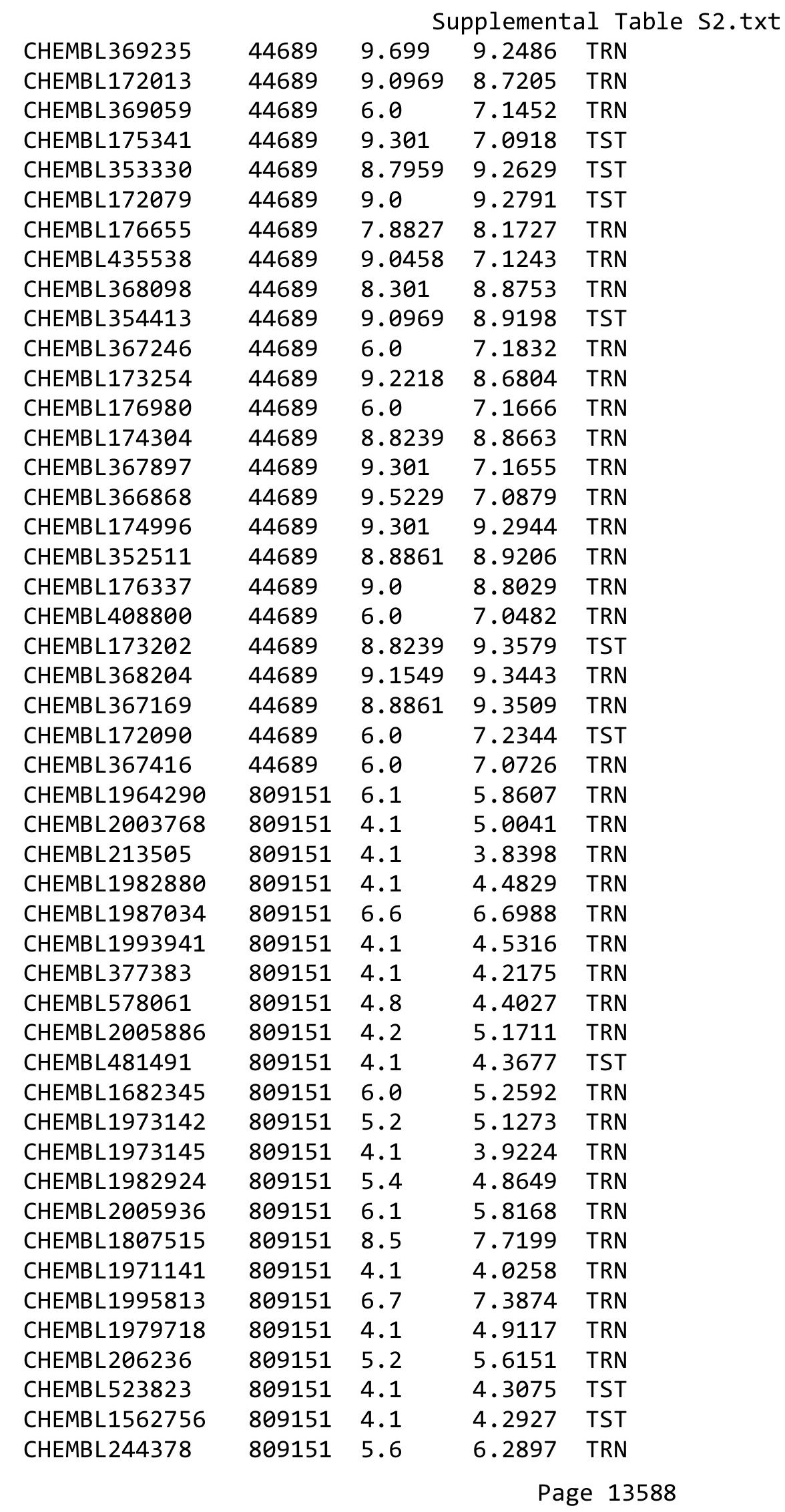




\begin{tabular}{|c|c|c|c|c|}
\hline & & & ipplemen & \\
\hline CHEMBL2001957 & 809151 & 4.1 & 4.1435 & TRN \\
\hline CHEMBL1969372 & 809151 & 4.1 & 4.1429 & TRN \\
\hline CHEMBL1990583 & 809151 & 5.5 & 4.6696 & TRN \\
\hline CHEMBL1986943 & 809151 & 7.2 & 7.6842 & TRN \\
\hline CHEMBL2006263 & 809151 & 4.1 & 4.8194 & TST \\
\hline CHEMBL1993584 & 809151 & 5.8 & 5.3675 & TRN \\
\hline CHEMBL1986263 & 809151 & 4.3 & 5.4678 & TRN \\
\hline CHEMBL 2000114 & 809151 & 4.1 & 4.5016 & TRN \\
\hline CHEMBL 210618 & 809151 & 4.1 & 4.0866 & TRN \\
\hline CHEMBL1975647 & 809151 & 4.1 & 4.3725 & TRN \\
\hline CHEMBL1968380 & 809151 & 4.2 & 4.5165 & TRN \\
\hline CHEMBL1964644 & 809151 & 4.1 & 3.9864 & TRN \\
\hline CHEMBL1981782 & 809151 & 5.5 & 5.2332 & TRN \\
\hline CHEMBL1977681 & 809151 & 4.1 & 4.619 & TRN \\
\hline CHEMBL1970142 & 809151 & 4.1 & 4.1284 & TRN \\
\hline CHEMBL1990912 & 809151 & 4.1 & 4.2632 & TRN \\
\hline CHEMBL1988163 & 809151 & 5.9 & 5.8417 & TRN \\
\hline CHEMBL1995592 & 809151 & 6.0 & 5.251 & TST \\
\hline CHEMBL 2006493 & 809151 & 4.1 & 4.1443 & TST \\
\hline CHEMBL1982541 & 809151 & 4.1 & 4.4781 & TRN \\
\hline CHEMBL1996923 & 809151 & 4.1 & 3.9612 & TST \\
\hline CHEMBL1983449 & 809151 & 4.1 & 5.4364 & TRN \\
\hline CHEMBL1992323 & 809151 & 4.1 & 4.1534 & TRN \\
\hline CHEMBL1969735 & 809151 & 4.1 & 4.1831 & TRN \\
\hline CHEMBL2003524 & 809151 & 4.1 & 4.3981 & TST \\
\hline CHEMBL2002649 & 809151 & 4.1 & 5.1366 & TRN \\
\hline CHEMBL437747 & 809151 & 6.0 & 5.4488 & TRN \\
\hline CHEMBL1995172 & 809151 & 4.1 & 3.7581 & TST \\
\hline CHEMBL507936 & 809151 & 4.1 & 3.7997 & TRN \\
\hline CHEMBL104264 & 809151 & 6.3 & 5.3407 & TST \\
\hline CHEMBL1994321 & 809151 & 4.1 & 4.5557 & TRN \\
\hline CHEMBL1997129 & 809151 & 5.7 & 5.2888 & TRN \\
\hline CHEMBL1984788 & 809151 & 4.1 & 4.189 & TRN \\
\hline CHEMBL451964 & 809151 & 4.1 & 4.1154 & TRN \\
\hline CHEMBL1964307 & 809151 & 5.3 & 4.9638 & TRN \\
\hline CHEMBL 2000508 & 809151 & 5.1 & 4.1778 & TRN \\
\hline CHEMBL1971694 & 809151 & 4.1 & 3.8844 & TST \\
\hline CHEMBL2001547 & 809151 & 4.1 & 4.0314 & TRN \\
\hline CHEMBL 210928 & 809151 & 4.1 & 3.9865 & TRN \\
\hline CHEMBL1994361 & 809151 & 5.7 & 5.3511 & TRN \\
\hline CHEMBL1986603 & 809151 & 4.1 & 3.7551 & TST \\
\hline CHEMBL1972840 & 809151 & 6.4 & 6.9278 & TRN \\
\hline CHEMBL1977148 & 809151 & 4.1 & 4.1409 & TRN \\
\hline CHEMBL 2003286 & 809151 & 4.1 & 3.5531 & TRN \\
\hline CHEMBL1992306 & 809151 & 4.1 & 3.977 & TRN \\
\hline CHEMBL 2002165 & 809151 & 4.1 & 4.7041 & TRN \\
\hline CHEMBL2001668 & 809151 & 4.1 & 3.7538 & TST \\
\hline CHEMBL1979318 & 809151 & 4.1 & 3.9803 & TRN \\
\hline
\end{tabular}




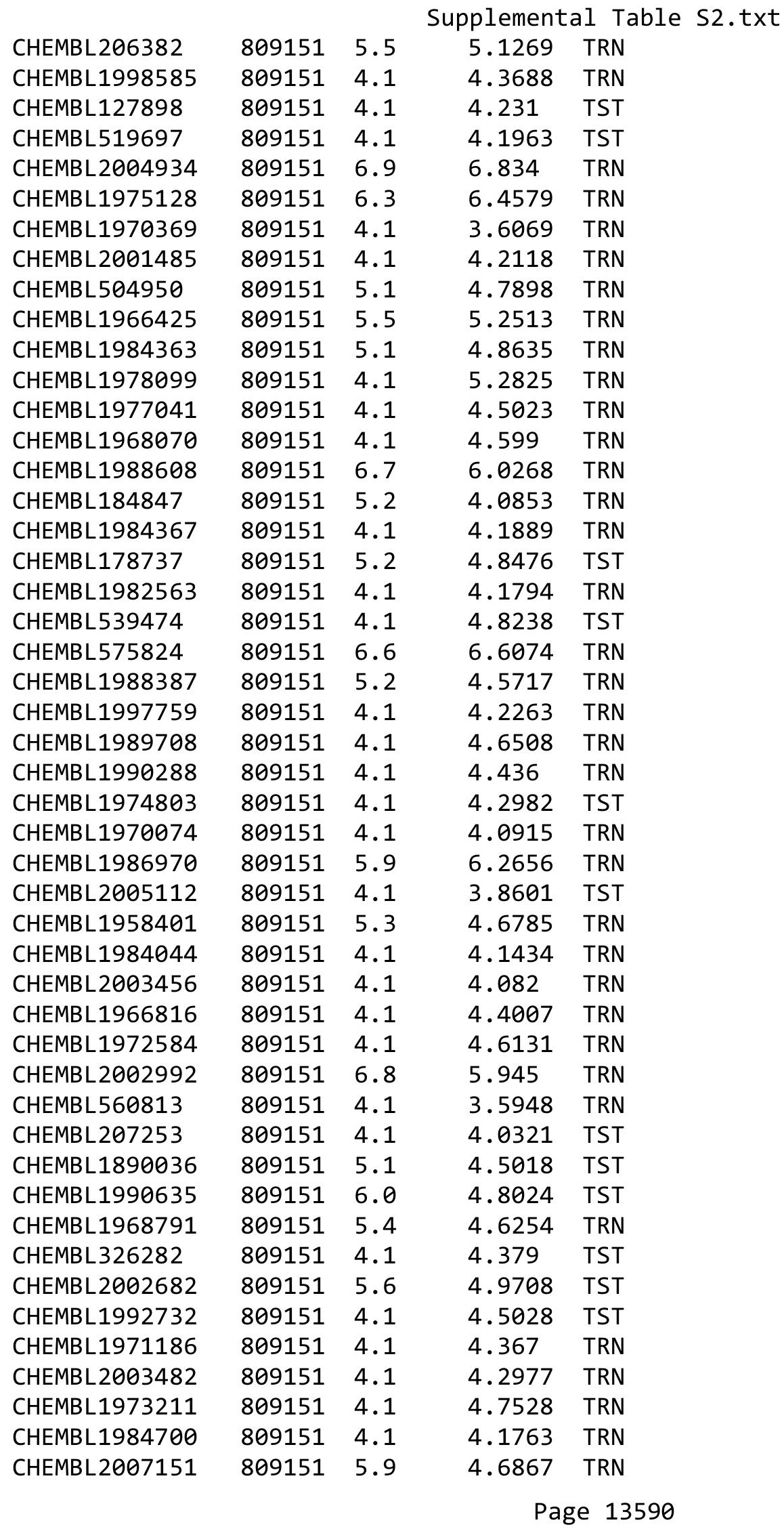




\begin{tabular}{|c|c|c|c|c|c|}
\hline \multicolumn{6}{|c|}{ Supplemental Table S2.txt } \\
\hline CHEMBL1972125 & 809151 & 5.8 & 5.1286 & TRN & \\
\hline CHEMBL1461728 & 809151 & 4.1 & 3.8544 & TRN & \\
\hline CHEMBL1976134 & 809151 & 4.1 & 4.8273 & TRN & \\
\hline CHEMBL1965131 & 809151 & 5.3 & 5.2719 & TRN & \\
\hline CHEMBL1995448 & 809151 & 5.7 & 4.9245 & TRN & \\
\hline CHEMBL1972158 & 809151 & 6.6 & 6.2592 & TRN & \\
\hline CHEMBL1974457 & 809151 & 4.1 & 4.2118 & TRN & \\
\hline CHEMBL 2006580 & 809151 & 5.2 & 3.9511 & TRN & \\
\hline CHEMBL 2006581 & 809151 & 4.1 & 4.3532 & TRN & \\
\hline CHEMBL 2006481 & 809151 & 4.1 & 3.4449 & TRN & \\
\hline CHEMBL1979855 & 809151 & 4.1 & 4.1901 & TRN & \\
\hline CHEMBL1970340 & 809151 & 4.1 & 4.3827 & TRN & \\
\hline CHEMBL 2005186 & 809151 & 4.1 & 4.4416 & TRN & \\
\hline CHEMBL1995927 & 809151 & 4.1 & 4.0006 & TST & \\
\hline CHEMBL1975534 & 809151 & 4.1 & 4.4844 & TRN & \\
\hline CHEMBL1993424 & 809151 & 5.4 & 5.599 & TRN & \\
\hline CHEMBL1966703 & 809151 & 4.1 & 4.4494 & TST & \\
\hline CHEMBL1969561 & 809151 & 5.7 & 6.5534 & TRN & \\
\hline CHEMBL1997023 & 809151 & 5.3 & 4.3965 & TST & \\
\hline CHEMBL1964687 & 809151 & 4.1 & 4.312 & TRN & \\
\hline CHEMBL1971943 & 809151 & 6.2 & 6.0632 & TRN & \\
\hline CHEMBL1999918 & 809151 & 5.9 & 5.71700 & 00000000005 & TRN \\
\hline CHEMBL1974254 & 809151 & 4.1 & 4.3225 & TRN & \\
\hline CHEMBL1988537 & 809151 & 4.1 & 5.2807 & TST & \\
\hline CHEMBL1969049 & 809151 & 6.9 & 6.731 & TRN & \\
\hline CHEMBL 2005828 & 809151 & 4.1 & 4.1688 & TRN & \\
\hline CHEMBL 2002240 & 809151 & 4.1 & 3.6279 & TRN & \\
\hline CHEMBL1991143 & 809151 & 4.1 & 3.8032 & TST & \\
\hline CHEMBL1998611 & 809151 & 4.1 & 5.2901 & TRN & \\
\hline CHEMBL485556 & 809151 & 4.1 & 4.2968 & TST & \\
\hline CHEMBL1975900 & 809151 & 5.1 & 5.865 & TRN & \\
\hline CHEMBL255822 & 809151 & 4.1 & 3.8187 & TRN & \\
\hline CHEMBL1972221 & 809151 & 4.1 & 4.2441 & TRN & \\
\hline CHEMBL 2006778 & 809151 & 4.1 & 4.27800 & 20000000005 & TRN \\
\hline CHEMBL378627 & 809151 & 4.1 & 4.2481 & TRN & \\
\hline CHEMBL1996979 & 809151 & 4.1 & 5.1824 & TRN & \\
\hline CHEMBL1997025 & 809151 & 5.1 & 4.2065 & TRN & \\
\hline CHEMBL1968406 & 809151 & 4.1 & 4.4352 & TRN & \\
\hline CHEMBL1982476 & 809151 & 5.1 & 4.5506 & TRN & \\
\hline CHEMBL1984274 & 809151 & 4.1 & 4.4248 & TST & \\
\hline CHEMBL1998545 & 809151 & 4.1 & 5.2229 & TRN & \\
\hline CHEMBL1986869 & 809151 & 4.1 & 4.466 & TRN & \\
\hline CHEMBL 2006010 & 809151 & 5.1 & 4.2597 & TRN & \\
\hline CHEMBL1682558 & 809151 & 4.1 & 4.0733 & TRN & \\
\hline CHEMBL1990496 & 809151 & 5.3 & 5.2627 & TRN & \\
\hline CHEMBL1997623 & 809151 & 4.1 & 4.0497 & TRN & \\
\hline CHEMBL1977294 & 809151 & 5.6 & 4.872 & TST & \\
\hline CHEMBL2002479 & 809151 & 5.1 & 5.3354 & TRN & \\
\hline
\end{tabular}




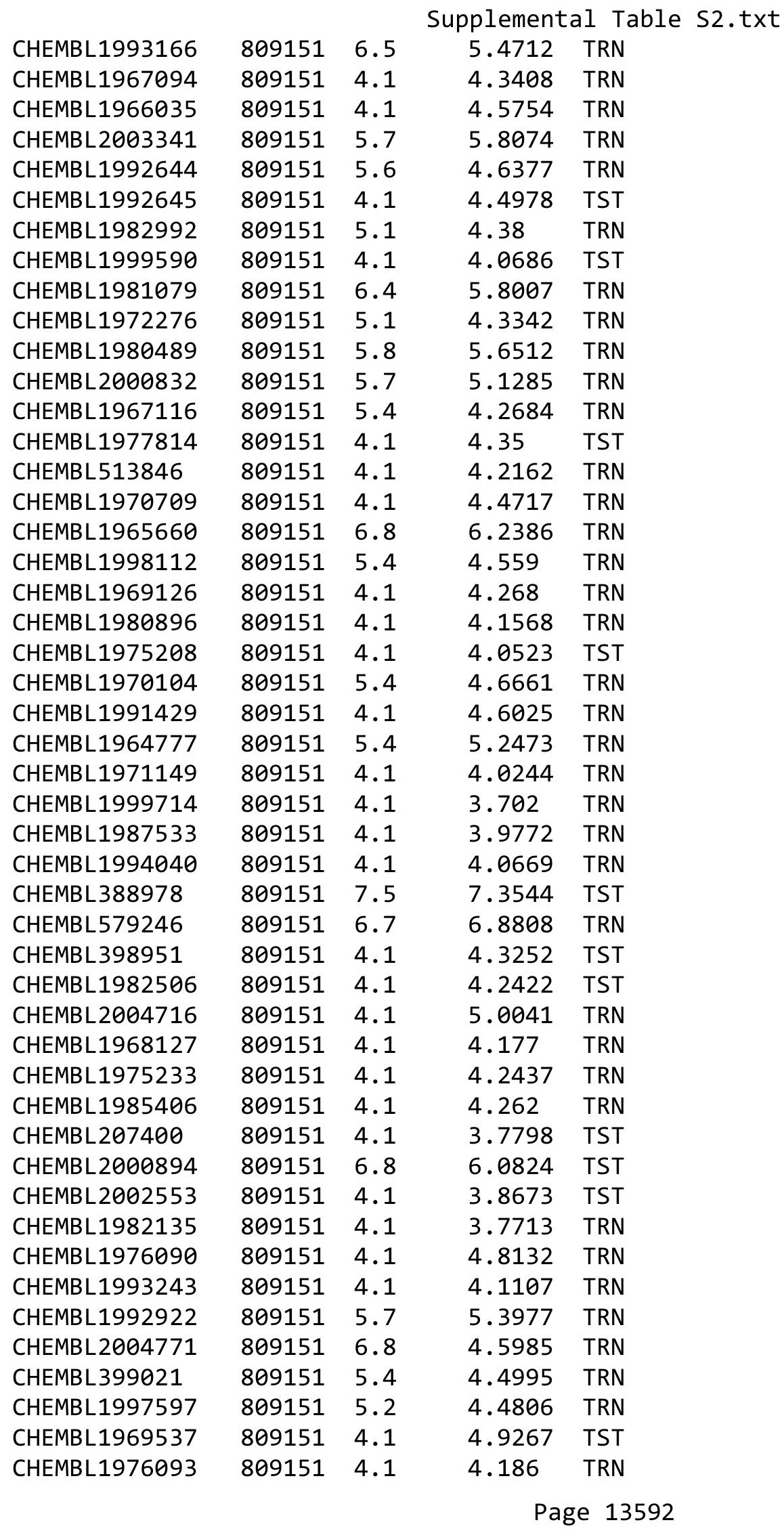




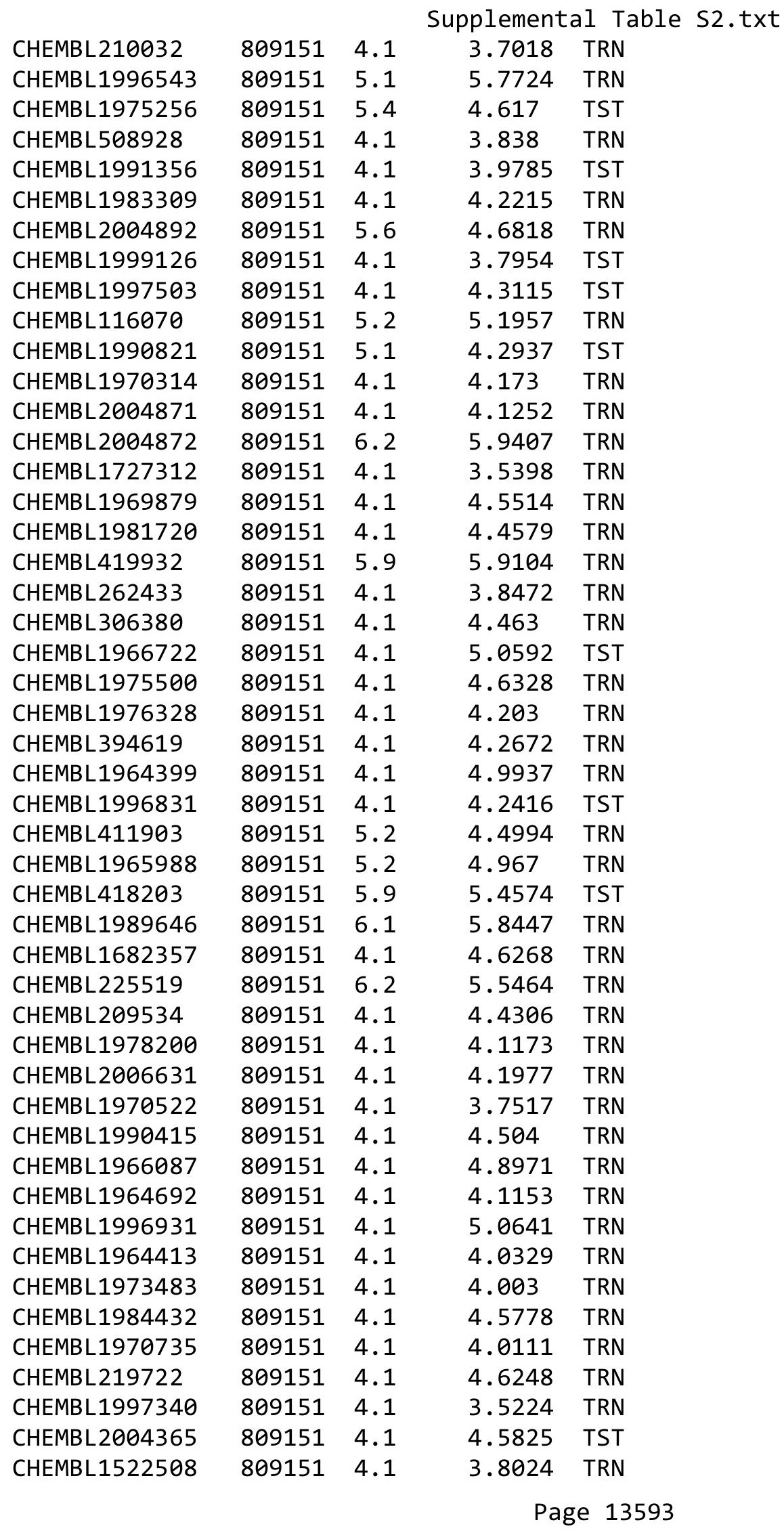




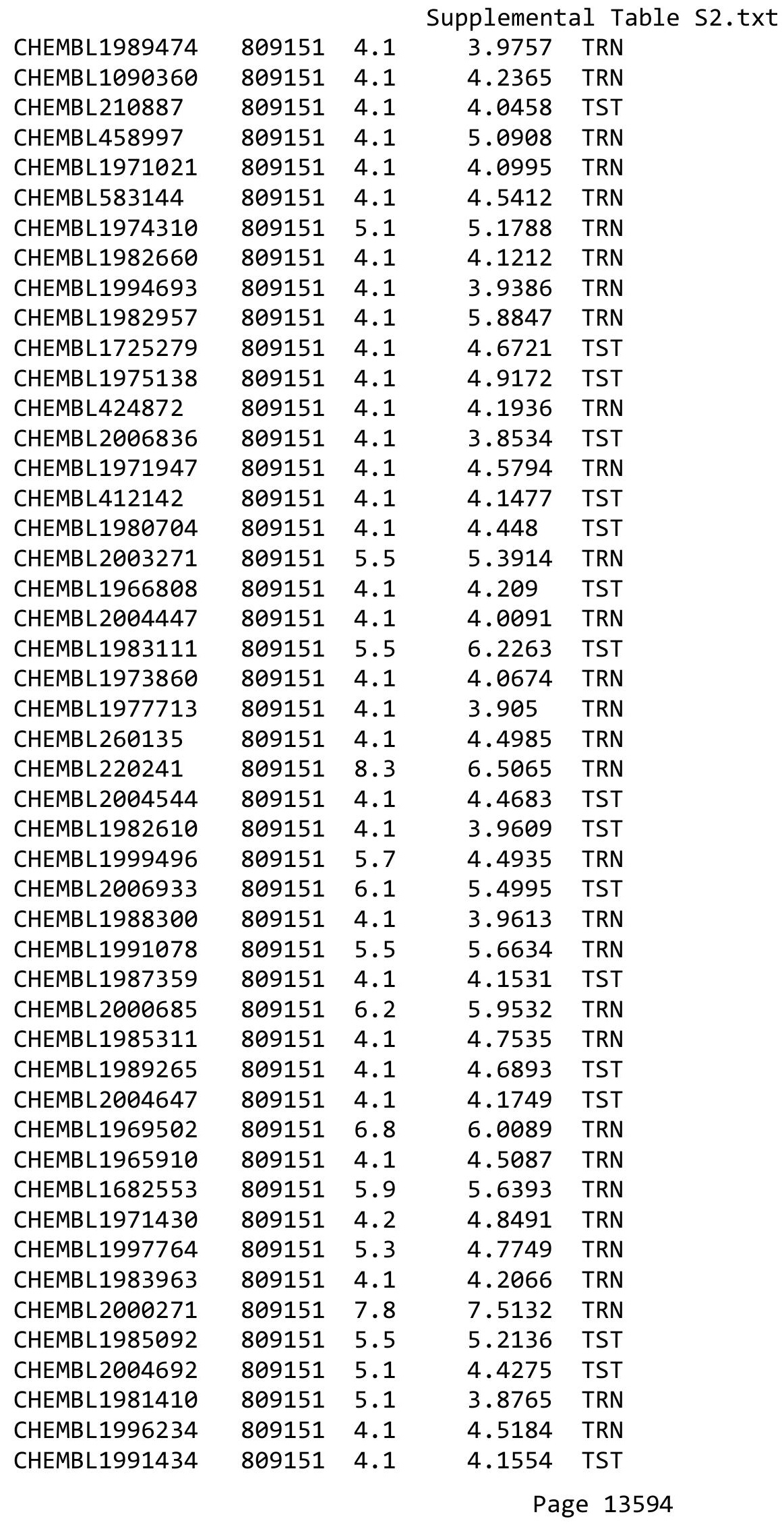




\begin{tabular}{|c|c|c|c|c|c|}
\hline \multirow{3}{*}{$\begin{array}{l}\text { CHEMBL1967544 } \\
\text { CHEMBL223367 }\end{array}$} & \multirow{3}{*}{$\begin{array}{l}809151 \\
809151\end{array}$} & \multicolumn{4}{|c|}{ Supplemental Table S2.txt } \\
\hline & & 6.5 & 6.2029 & 9999999999 & TRN \\
\hline & & 4.1 & 4.9295 & TST & \\
\hline CHEMBL407391 & 809151 & 4.9 & 4.4796 & TST & \\
\hline CHEMBL340384 & 809151 & 7.8 & 6.6286 & TST & \\
\hline CHEMBL1996587 & 809151 & 4.1 & 4.0534 & TRN & \\
\hline CHEMBL1964804 & 809151 & 6.1 & 5.4436 & TRN & \\
\hline CHEMBL443962 & 809151 & 4.1 & 4.0533 & TST & \\
\hline CHEMBL 2000354 & 809151 & 4.1 & 3.8978 & TRN & \\
\hline CHEMBL1965507 & 809151 & 4.1 & 4.5611 & TRN & \\
\hline CHEMBL1981107 & 809151 & 3.7 & 3.7164 & TST & \\
\hline CHEMBL274064 & 809151 & 4.1 & 4.5527 & TRN & \\
\hline CHEMBL1967564 & 809151 & 4.1 & 3.9484 & TRN & \\
\hline CHEMBL592030 & 809151 & 6.5 & 6.5661 & TST & \\
\hline CHEMBL 2000071 & 809151 & 5.6 & 4.9825 & TRN & \\
\hline CHEMBL1979176 & 809151 & 4.1 & 3.5396 & TRN & \\
\hline CHEMBL1970317 & 809151 & 5.5 & 4.1952 & TRN & \\
\hline CHEMBL 2000408 & 809151 & 4.1 & 4.1902 & TRN & \\
\hline CHEMBL248757 & 809151 & 4.1 & 4.3885 & TST & \\
\hline CHEMBL1978014 & 809151 & 4.1 & 4.3405 & TRN & \\
\hline CHEMBL1994538 & 809151 & 4.1 & 4.0678 & TRN & \\
\hline CHEMBL1983195 & 809151 & 4.1 & 4.2269 & TST & \\
\hline CHEMBL1975490 & 809151 & 5.5 & 5.3671 & TRN & \\
\hline CHEMBL1964444 & 809151 & 4.1 & 4.2577 & TRN & \\
\hline CHEMBL1989957 & 809151 & 4.1 & 3.7107 & TRN & \\
\hline CHEMBL 2006567 & 809151 & 4.1 & 3.8074 & TRN & \\
\hline CHEMBL1986139 & 809151 & 4.1 & 3.7602 & TRN & \\
\hline CHEMBL383527 & 809151 & 5.7 & 5.4245 & TRN & \\
\hline CHEMBL1980540 & 809151 & 4.1 & 3.9361 & TRN & \\
\hline CHEMBL1979883 & 809151 & 4.1 & 4.6942 & TRN & \\
\hline CHEMBL1984162 & 809151 & 4.1 & 5.3302 & TRN & \\
\hline CHEMBL491758 & 809151 & 4.1 & 4.6959 & TRN & \\
\hline CHEMBL549730 & 809151 & 4.1 & 4.2768 & TRN & \\
\hline CHEMBL1682360 & 809151 & 4.1 & 4.2003 & TRN & \\
\hline CHEMBL1970189 & 809151 & 4.1 & 3.985 & TRN & \\
\hline CHEMBL1996791 & 809151 & 4.1 & 4.3495 & TRN & \\
\hline CHEMBL371206 & 809151 & 4.1 & 4.1419 & TRN & \\
\hline CHEMBL 1974664 & 809151 & 4.1 & 4.4242 & TST & \\
\hline CHEMBL1974288 & 809151 & 6.3 & 6.4859 & TRN & \\
\hline CHEMBL196363 & 809151 & 4.1 & 4.1042 & TRN & \\
\hline CHEMBL1190711 & 809151 & 4.1 & 5.0396 & TRN & \\
\hline CHEMBL1990346 & 809151 & 4.1 & 4.575 & TRN & \\
\hline CHEMBL1968705 & 809151 & 5.5 & 5.0671 & TRN & \\
\hline CHEMBL404367 & 809151 & 4.1 & 4.1258 & TRN & \\
\hline CHEMBL1966343 & 809151 & 5.6 & 5.044 & TRN & \\
\hline CHEMBL1967887 & 809151 & 7.5 & 6.5396 & TRN & \\
\hline CHEMBL 2000568 & 809151 & 4.1 & 4.2325 & TRN & \\
\hline CHEMBL 2000335 & 809151 & 5.1 & 4.4253 & TRN & \\
\hline CHEMBL1977604 & 809151 & 4.1 & 4.4633 & TST & \\
\hline
\end{tabular}




\begin{tabular}{|c|c|c|c|c|c|}
\hline \multicolumn{6}{|c|}{ Supplemental Table S2.txt } \\
\hline CHEMBL1988717 & 809151 & 4.1 & 3.9949 & TRN & \\
\hline CHEMBL1974328 & 809151 & 6.9 & 6.1599 & TRN & \\
\hline CHEMBL509032 & 809151 & 6.5 & 6.6627 & TRN & \\
\hline CHEMBL573339 & 809151 & 4.1 & 4.3957 & TRN & \\
\hline CHEMBL1973808 & 809151 & 4.1 & 3.8061 & TRN & \\
\hline CHEMBL 2000429 & 809151 & 4.1 & 4.2663 & TRN & \\
\hline CHEMBL1972576 & 809151 & 4.1 & 4.3691 & TRN & \\
\hline CHEMBL1992555 & 809151 & 4.1 & 4.3827 & TST & \\
\hline CHEMBL1990254 & 809151 & 7.8 & 6.7435 & TRN & \\
\hline CHEMBL1992342 & 809151 & 6.0 & \multicolumn{2}{|c|}{4.7860000000000005} & TRN \\
\hline CHEMBL1988173 & 809151 & 4.1 & 5.3454 & TST & \\
\hline CHEMBL535331 & 809151 & 4.1 & 3.9718 & TRN & \\
\hline CHEMBL1989805 & 809151 & 4.1 & 4.3974 & TST & \\
\hline CHEMBL1965423 & 809151 & 4.1 & 4.5942 & TRN & \\
\hline CHEMBL1982980 & 809151 & 5.5 & 4.4025 & TST & \\
\hline CHEMBL1983025 & 809151 & 5.5 & 4.7599 & TRN & \\
\hline CHEMBL205415 & 809151 & 6.3 & 5.983 & TRN & \\
\hline CHEMBL1977135 & 809151 & 5.9 & 5.4113 & TRN & \\
\hline CHEMBL2001920 & 809151 & 4.1 & 4.2495 & TRN & \\
\hline CHEMBL 2002322 & 809151 & 4.1 & 4.5997 & TRN & \\
\hline CHEMBL 2002323 & 809151 & 4.1 & 4.1139 & TRN & \\
\hline CHEMBL1241473 & 809151 & 6.5 & 6.6245 & TRN & \\
\hline CHEMBL1978448 & 809151 & 4.1 & 4.791 & TST & \\
\hline CHEMBL2004513 & 809151 & 4.1 & 4.0446 & TRN & \\
\hline CHEMBL1972258 & 809151 & 4.1 & 4.9417 & TRN & \\
\hline CHEMBL 2001257 & 809151 & 4.1 & 4.4734 & TRN & \\
\hline CHEMBL 2005548 & 809151 & 4.1 & 4.8872 & TRN & \\
\hline CHEMBL1992536 & 809151 & 4.1 & 4.5541 & TRN & \\
\hline CHEMBL1987793 & 809151 & 4.1 & 4.4275 & TST & \\
\hline CHEMBL1992740 & 809151 & 4.1 & 4.1633 & TRN & \\
\hline CHEMBL 2002373 & 809151 & 4.1 & 4.2553 & TRN & \\
\hline CHEMBL439340 & 809151 & 4.2 & 5.0297 & TRN & \\
\hline CHEMBL 2006188 & 809151 & 7.0 & 6.5935 & TRN & \\
\hline CHEMBL1967531 & 809151 & 4.1 & 4.0616 & TRN & \\
\hline CHEMBL1970913 & 809151 & 4.1 & 4.0872 & TRN & \\
\hline CHEMBL1973893 & 809151 & 4.1 & 4.0907 & TRN & \\
\hline CHEMBL1995736 & 809151 & 4.1 & 4.3079 & TRN & \\
\hline CHEMBL1997534 & 809151 & 8.1 & 6.7464 & TRN & \\
\hline CHEMBL1996500 & 809151 & 4.1 & 4.1556 & TRN & \\
\hline CHEMBL1985095 & 809151 & 5.3 & 5.8177 & TST & \\
\hline CHEMBL1998551 & 809151 & 4.1 & 4.1507 & TRN & \\
\hline CHEMBL1977374 & 809151 & 4.1 & 4.2404 & TRN & \\
\hline CHEMBL1991180 & 809151 & 6.8 & 5.7875 & TST & \\
\hline CHEMBL1682540 & 809151 & 4.1 & 4.8003 & TRN & \\
\hline CHEMBL1978656 & 809151 & 4.1 & 4.0516 & TRN & \\
\hline CHEMBL1976420 & 809151 & 4.1 & 4.478 & TST & \\
\hline CHEMBL1994864 & 809151 & 5.7 & $5.3820 e$ & 0000000001 & TRN \\
\hline CHEMBL413779 & 809151 & 4.1 & 4.8867 & TST & \\
\hline
\end{tabular}




\begin{tabular}{|c|c|c|c|c|c|}
\hline \\
\hline CHEMBL 2002446 & 809151 & 5.2 & 4.7074 & TST & \\
\hline CHEMBL497151 & 809151 & 5.7 & 4.947 & TRN & \\
\hline CHEMBL246970 & 809151 & 7.3 & 5.901 & TRN & \\
\hline CHEMBL340921 & 809151 & 6.6 & 6.0026 & TST & \\
\hline CHEMBL373598 & 809151 & 4.1 & 4.7621 & TST & \\
\hline CHEMBL1999718 & 809151 & 4.1 & 3.5784 & TRN & \\
\hline CHEMBL1276446 & 809151 & 5.9 & 5.7299 & TST & \\
\hline CHEMBL1977346 & 809151 & 4.1 & 4.0924 & TRN & \\
\hline CHEMBL1971649 & 809151 & 4.1 & 3.8522 & TRN & \\
\hline CHEMBL2003657 & 809151 & 4.1 & 4.4361 & TRN & \\
\hline CHEMBL1998435 & 809151 & 4.1 & 3.9784 & TRN & \\
\hline CHEMBL2006439 & 809151 & 4.1 & 6.6509 & TRN & \\
\hline CHEMBL2006156 & 809151 & 4.1 & 4.1652 & TST & \\
\hline CHEMBL1969190 & 809151 & 4.1 & 4.0673 & TRN & \\
\hline CHEMBL1973937 & 809151 & 4.1 & 4.4652 & TRN & \\
\hline CHEMBL1991674 & 809151 & 6.9 & 7.1473 & TRN & \\
\hline CHEMBL1982711 & 809151 & 6.1 & 6.2041 & TRN & \\
\hline CHEMBL1987982 & 809151 & 5.8 & 4.2856 & TST & \\
\hline CHEMBL1984842 & 809151 & 4.1 & 4.2267 & TRN & \\
\hline CHEMBL1969102 & 809151 & 4.1 & 4.5422 & TRN & \\
\hline CHEMBL1682346 & 809151 & 6.3 & 5.3843 & TRN & \\
\hline CHEMBL 2007044 & 809151 & 4.1 & 4.3318 & TST & \\
\hline CHEMBL 2001998 & 809151 & 4.1 & 4.0914 & TST & \\
\hline CHEMBL1994241 & 809151 & 4.1 & 4.5318 & TRN & \\
\hline CHEMBL 223460 & 809151 & 4.1 & 4.4359 & TST & \\
\hline CHEMBL1998829 & 809151 & 4.1 & 4.532 & TRN & \\
\hline CHEMBL50894 & 809151 & 5.5 & 5.21700 & 30000000005 & TRN \\
\hline CHEMBL1988838 & 809151 & 5.1 & 5.9087 & TRN & \\
\hline CHEMBL1981725 & 809151 & 4.1 & 5.0083 & TRN & \\
\hline CHEMBL 375284 & 809151 & 4.1 & 4.1314 & TRN & \\
\hline CHEMBL1982866 & 809151 & 4.1 & 4.1532 & TRN & \\
\hline CHEMBL 2005792 & 809151 & 4.1 & 4.131 & TRN & \\
\hline CHEMBL1968926 & 809151 & 4.1 & 4.3888 & TRN & \\
\hline CHEMBL1984206 & 809151 & 4.1 & 4.3937 & TRN & \\
\hline CHEMBL462120 & 809151 & 4.1 & 4.2017 & TST & \\
\hline CHEMBL1991577 & 809151 & 4.1 & 4.4925 & TRN & \\
\hline CHEMBL1965570 & 809151 & 4.1 & 3.9503 & TRN & \\
\hline CHEMBL2007592 & 809151 & 4.1 & 3.9345 & TST & \\
\hline CHEMBL 210963 & 809151 & 4.1 & 3.9253 & TRN & \\
\hline CHEMBL1082440 & 809151 & 6.5 & 5.2667 & TST & \\
\hline CHEMBL1614705 & 809151 & 4.1 & 4.4749 & TRN & \\
\hline CHEMBL1972362 & 809151 & 5.2 & 4.9424 & TRN & \\
\hline CHEMBL1984633 & 809151 & 6.2 & 6.0337 & TRN & \\
\hline CHEMBL1994214 & 809151 & 5.1 & 4.6396 & TST & \\
\hline CHEMBL 2007372 & 809151 & 4.1 & 3.9411 & TRN & \\
\hline CHEMBL1965845 & 809151 & 8.0 & 7.2108 & TRN & \\
\hline CHEMBL1982167 & 809151 & 4.1 & 4.0504 & TRN & \\
\hline CHEMBL 2006715 & 809151 & 4.1 & 4.7393 & TRN & \\
\hline
\end{tabular}




\begin{tabular}{|c|c|c|c|c|}
\hline \multicolumn{5}{|c|}{ Supplemental Table S2.txt } \\
\hline CHEMBL1986597 & 809151 & 4.1 & 4.316 & TRN \\
\hline CHEMBL1971017 & 809151 & 5.9 & 5.4599 & TRN \\
\hline CHEMBL1990482 & 809151 & 4.1 & 4.8299 & TRN \\
\hline CHEMBL1990904 & 809151 & 4.1 & 4.3036 & TRN \\
\hline CHEMBL 2005475 & 809151 & 4.1 & 4.1787 & TRN \\
\hline CHEMBL 2000104 & 809151 & 4.1 & 4.9497 & TRN \\
\hline CHEMBL402846 & 809151 & 4.1 & 4.0518 & TRN \\
\hline CHEMBL1997349 & 809151 & 5.1 & 4.3081 & TST \\
\hline CHEMBL183844 & 809151 & 4.1 & 3.9855 & TRN \\
\hline CHEMBL220057 & 809151 & 4.1 & 4.7278 & TRN \\
\hline CHEMBL1682545 & 809151 & 4.1 & 4.1709 & TRN \\
\hline CHEMBL 383541 & 809151 & 6.2 & 6.3676 & TRN \\
\hline CHEMBL 2001224 & 809151 & 4.1 & 4.224 & TRN \\
\hline CHEMBL10 & 809151 & 4.1 & 4.1813 & TRN \\
\hline CHEMBL1976732 & 809151 & 4.1 & 4.1368 & TRN \\
\hline CHEMBL1969506 & 809151 & 4.1 & 4.4586 & TRN \\
\hline CHEMBL1964937 & 809151 & 5.8 & 6.5092 & TRN \\
\hline CHEMBL1980163 & 809151 & 4.1 & 3.8736 & TRN \\
\hline CHEMBL590109 & 809151 & 6.1 & 6.3518 & TST \\
\hline CHEMBL1970879 & 809151 & 4.1 & 4.7371 & TRN \\
\hline CHEMBL1989856 & 809151 & 4.1 & 3.9803 & TST \\
\hline CHEMBL 2005899 & 809151 & 4.1 & 4.3185 & TRN \\
\hline CHEMBL1682552 & 809151 & 5.8 & 5.2783 & TRN \\
\hline CHEMBL259850 & 809151 & 4.1 & 3.9787 & TRN \\
\hline CHEMBL1972568 & 809151 & 4.1 & 4.473 & TRN \\
\hline CHEMBL1996155 & 809151 & 5.1 & 4.8639 & TRN \\
\hline CHEMBL1682359 & 809151 & 4.1 & 4.1464 & TRN \\
\hline CHEMBL105739 & 809151 & 4.1 & 4.5322 & TRN \\
\hline CHEMBL 203673 & 809151 & 5.5 & 5.687 & TRN \\
\hline CHEMBL1969523 & 809151 & 4.1 & 5.1387 & TRN \\
\hline CHEMBL207995 & 809151 & 4.1 & 4.4006 & TRN \\
\hline CHEMBL1988995 & 809151 & 4.1 & 4.1969 & TRN \\
\hline CHEMBL 2001923 & 809151 & 4.1 & 4.4793 & TRN \\
\hline CHEMBL1986781 & 809151 & 4.1 & 4.3025 & TRN \\
\hline CHEMBL526133 & 809151 & 4.1 & 4.7007 & TRN \\
\hline CHEMBL1979057 & 809151 & 4.1 & 4.2782 & TRN \\
\hline CHEMBL1981045 & 809151 & 4.1 & 4.2341 & TRN \\
\hline CHEMBL387971 & 809151 & 4.1 & 3.9367 & TST \\
\hline CHEMBL1975418 & 809151 & 6.5 & 6.0807 & TRN \\
\hline CHEMBL1992796 & 809151 & 5.1 & 4.7012 & TST \\
\hline CHEMBL1999428 & 809151 & 6.4 & 6.3141 & TRN \\
\hline CHEMBL 223257 & 809151 & 4.1 & 4.7448 & TST \\
\hline CHEMBL1967560 & 809151 & 4.1 & 4.2737 & TRN \\
\hline CHEMBL1516890 & 809151 & 4.1 & 4.6988 & TRN \\
\hline CHEMBL211378 & 809151 & 4.1 & 3.7194 & TRN \\
\hline CHEMBL1982465 & 809151 & 5.4 & 4.3305 & TRN \\
\hline CHEMBL 2001751 & 809151 & 7.7 & 7.8577 & TRN \\
\hline CHEMBL 2003420 & 809151 & 4.1 & 4.0845 & TRN \\
\hline
\end{tabular}




\begin{tabular}{|c|c|c|c|c|c|}
\hline \multicolumn{6}{|c|}{ Supplemental Table s2.txt } \\
\hline CHEMBL1984586 & 809151 & 4.1 & 4.0224 & TRN & \\
\hline CHEMBL1999774 & 809151 & 5.1 & 4.5121 & TST & \\
\hline CHEMBL1972659 & 809151 & 4.1 & 4.9413 & TST & \\
\hline CHEMBL1973395 & 809151 & 6.2 & 5.3785 & TRN & \\
\hline CHEMBL272453 & 809151 & 4.1 & 4.3404 & TRN & \\
\hline CHEMBL1970217 & 809151 & 7.4 & 6.8398 & TRN & \\
\hline CHEMBL1971801 & 809151 & 4.1 & 3.8834 & TRN & \\
\hline CHEMBL1968850 & 809151 & 4.1 & 4.2833 & TRN & \\
\hline CHEMBL 2005528 & 809151 & 4.1 & 4.3545 & TST & \\
\hline CHEMBL185569 & 809151 & 4.1 & 3.9257 & TRN & \\
\hline CHEMBL1969843 & 809151 & 4.1 & 4.2232 & TRN & \\
\hline CHEMBL 2006113 & 809151 & 5.1 & 4.6118 & TST & \\
\hline CHEMBL 2007002 & 809151 & 4.1 & 3.9167 & TRN & \\
\hline CHEMBL1987007 & 809151 & 4.1 & 4.5628 & TRN & \\
\hline CHEMBL1969588 & 809151 & 8.1 & 7.2307 & TRN & \\
\hline CHEMBL1984711 & 809151 & 4.1 & 4.3451 & TRN & \\
\hline CHEMBL1990212 & 809151 & 4.1 & 4.3866 & TRN & \\
\hline CHEMBL484390 & 809151 & 4.1 & 4.393 & TST & \\
\hline CHEMBL1983255 & 809151 & 5.3 & 4.7054 & TST & \\
\hline CHEMBL1979252 & 809151 & 4.1 & 5.5308 & TRN & \\
\hline CHEMBL1682341 & 809151 & 5.4 & 4.9643 & TRN & \\
\hline CHEMBL 2004290 & 809151 & 4.1 & 4.2648 & TRN & \\
\hline CHEMBL1986499 & 809151 & 6.1 & 5.9897 & TRN & \\
\hline CHEMBL1972937 & 809151 & 4.1 & 3.9424 & TRN & \\
\hline CHEMBL1972250 & 809151 & 4.1 & 4.1499 & TST & \\
\hline CHEMBL 2000393 & 809151 & 5.9 & 5.2034 & TST & \\
\hline CHEMBL 2004072 & 809151 & 4.1 & 4.0592 & TRN & \\
\hline CHEMBL 2004311 & 809151 & 4.1 & 3.9174 & TRN & \\
\hline CHEMBL1992634 & 809151 & 4.1 & 4.7308 & TRN & \\
\hline CHEMBL1242373 & 809151 & 5.1 & 4.1656 & TRN & \\
\hline CHEMBL 2000433 & 809151 & 4.1 & 3.9233 & TST & \\
\hline CHEMBL56543 & 809151 & 4.1 & 4.1432 & TRN & \\
\hline CHEMBL316264 & 809151 & 4.1 & 4.0317 & TRN & \\
\hline CHEMBL1988075 & 809151 & 4.1 & 4.1347 & TRN & \\
\hline CHEMBL1991678 & 809151 & 4.1 & 4.2054 & TRN & \\
\hline CHEMBL 2001239 & 809151 & 5.1 & 5.6083 & TST & \\
\hline CHEMBL1976396 & 809151 & 5.6 & 4.94300 & 00000000005 & TST \\
\hline CHEMBL1988594 & 809151 & 4.1 & 4.4008 & TRN & \\
\hline CHEMBL 2001288 & 809151 & 4.1 & 3.9777 & TRN & \\
\hline CHEMBL260092 & 809151 & 5.5 & 4.1973 & TRN & \\
\hline CHEMBL1999811 & 809151 & 6.1 & 4.6397 & TST & \\
\hline CHEMBL1965495 & 809151 & 4.1 & 4.6158 & TRN & \\
\hline CHEMBL1985074 & 809151 & 4.1 & 4.184 & TST & \\
\hline CHEMBL1982874 & 809151 & 4.1 & 4.3808 & TRN & \\
\hline CHEMBL 2000481 & 809151 & 5.3 & 4.9316 & TRN & \\
\hline CHEMBL1991725 & 809151 & 5.6 & 5.4634 & TRN & \\
\hline CHEMBL1992242 & 809151 & 4.1 & 3.8045 & TRN & \\
\hline CHEMBL 2007296 & 809151 & 6.0 & 6.1979 & TRN & \\
\hline
\end{tabular}




\begin{tabular}{|c|c|c|c|c|}
\hline \multicolumn{5}{|c|}{ Supplemental Table S2.txt } \\
\hline CHEMBL208637 & 809151 & 4.1 & 3.9494 & TRN \\
\hline CHEMBL396523 & 809151 & 5.9 & 6.1161 & TRN \\
\hline CHEMBL 2007138 & 809151 & 3.7 & 3.8198 & TRN \\
\hline CHEMBL1970203 & 809151 & 4.1 & 4.08 & TRN \\
\hline CHEMBL1986530 & 809151 & 4.1 & 4.0215 & TST \\
\hline CHEMBL1965351 & 809151 & 4.1 & 4.539 & TST \\
\hline CHEMBL1999321 & 809151 & 4.1 & 4.4115 & TRN \\
\hline CHEMBL1968590 & 809151 & 4.1 & 4.1948 & TRN \\
\hline CHEMBL1999749 & 809151 & 5.6 & 4.3073 & TRN \\
\hline CHEMBL 2005375 & 809151 & 4.1 & 4.4717 & TRN \\
\hline CHEMBL1984191 & 809151 & 4.1 & 4.3817 & TRN \\
\hline CHEMBL1983006 & 809151 & 4.1 & 4.0667 & TRN \\
\hline CHEMBL1972183 & 809151 & 4.1 & 4.4124 & TRN \\
\hline CHEMBL1971029 & 809151 & 6.6 & 6.1814 & TRN \\
\hline CHEMBL1995391 & 809151 & 3.7 & 4.0081 & TRN \\
\hline CHEMBL394790 & 809151 & 5.1 & 4.2774 & TRN \\
\hline CHEMBL226471 & 809151 & 4.1 & 4.2222 & TRN \\
\hline CHEMBL1974702 & 809151 & 4.1 & 4.3519 & TRN \\
\hline CHEMBL1996111 & 809151 & 5.8 & 6.2543 & TRN \\
\hline CHEMBL1965589 & 809151 & 4.1 & 4.1804 & TRN \\
\hline CHEMBL1998193 & 809151 & 4.1 & 4.1716 & TRN \\
\hline CHEMBL474432 & 809151 & 4.1 & 4.6667 & TST \\
\hline CHEMBL1988153 & 809151 & 4.1 & 4.2498 & TRN \\
\hline CHEMBL1999556 & 809151 & 5.8 & 5.3337 & TRN \\
\hline CHEMBL1988437 & 809151 & 4.1 & 4.744 & TST \\
\hline CHEMBL1968245 & 809151 & 5.7 & 5.8926 & TRN \\
\hline CHEMBL1998121 & 809151 & 6.5 & 6.4439 & TRN \\
\hline CHEMBL1979577 & 809151 & 5.6 & 4.7344 & TRN \\
\hline CHEMBL1991800 & 809151 & 4.1 & 3.9012 & TRN \\
\hline CHEMBL1985566 & 809151 & 4.1 & 4.1612 & TRN \\
\hline CHEMBL52387 & 809151 & 4.1 & 4.4375 & TST \\
\hline CHEMBL379835 & 809151 & 4.1 & 3.7323 & TST \\
\hline CHEMBL1979357 & 809151 & 5.5 & 5.4641 & TRN \\
\hline CHEMBL1980802 & 809151 & 4.1 & 4.2365 & TST \\
\hline CHEMBL1979554 & 809151 & 7.0 & 5.5487 & TRN \\
\hline CHEMBL1996817 & 809151 & 6.1 & 5.8365 & TRN \\
\hline CHEMBL3197315 & 809151 & 4.1 & 4.5339 & TST \\
\hline CHEMBL 2004355 & 809151 & 4.1 & 4.2147 & TRN \\
\hline CHEMBL468280 & 809151 & 4.1 & 4.2742 & TST \\
\hline CHEMBL1990884 & 809151 & 4.1 & 4.3793 & TRN \\
\hline CHEMBL3109278 & 809151 & 5.3 & 4.95 & TRN \\
\hline CHEMBL256835 & 809151 & 4.1 & 4.2107 & TRN \\
\hline CHEMBL1970006 & 809151 & 4.1 & 4.4932 & TST \\
\hline CHEMBL1980142 & 809151 & 4.1 & 4.1106 & TRN \\
\hline CHEMBL41783 & 809151 & 5.3 & 4.2066 & TRN \\
\hline CHEMBL 2004438 & 809151 & 4.1 & 3.8837 & TRN \\
\hline CHEMBL 2006276 & 809151 & 4.1 & 4.8314 & TRN \\
\hline CHEMBL271381 & 809151 & 4.1 & 4.1407 & TRN \\
\hline
\end{tabular}




\begin{tabular}{|c|c|c|c|c|c|}
\hline \multicolumn{6}{|c|}{ Supplemental Table S2.txt } \\
\hline CHEMBL 2006785 & 809151 & 4.1 & 4.0301 & TRN & \\
\hline CHEMBL1982466 & 809151 & 4.1 & 3.9934 & TRN & \\
\hline CHEMBL1995740 & 809151 & 4.1 & 4.7111 & TRN & \\
\hline CHEMBL1996390 & 809151 & 4.1 & 4.4386 & TRN & \\
\hline CHEMBL234085 & 809151 & 5.2 & 4.8724 & TRN & \\
\hline CHEMBL1995832 & 809151 & 4.1 & 4.2576 & TRN & \\
\hline CHEMBL1998414 & 809151 & 4.1 & 4.1419 & TRN & \\
\hline CHEMBL1969042 & 809151 & 4.1 & 4.8767 & TST & \\
\hline CHEMBL 2000345 & 809151 & 4.1 & 4.4548 & TRN & \\
\hline CHEMBL1999931 & 809151 & 6.6 & 6.0567 & TRN & \\
\hline CHEMBL1991640 & 809151 & 5.7 & 4.7652 & TST & \\
\hline CHEMBL1375418 & 809151 & 4.1 & 4.2678 & TRN & \\
\hline CHEMBL 302449 & 809151 & 6.7 & 6.1533 & TST & \\
\hline CHEMBL 2007064 & 809151 & 4.1 & 4.5912 & TRN & \\
\hline CHEMBL1981047 & 809151 & 5.2 & 4.9163 & TST & \\
\hline CHEMBL1976240 & 809151 & 7.6 & 7.3216 & TRN & \\
\hline CHEMBL1979093 & 809151 & 4.1 & 4.2668 & TRN & \\
\hline CHEMBL1968151 & 809151 & 4.1 & 4.2228 & TST & \\
\hline CHEMBL1381197 & 809151 & 4.1 & 4.2262 & TRN & \\
\hline CHEMBL1987009 & 809151 & 4.1 & 4.7163 & TRN & \\
\hline CHEMBL379218 & 809151 & 8.1 & 8.1089 & TRN & \\
\hline CHEMBL 2003817 & 809151 & 4.1 & 3.9307 & TRN & \\
\hline CHEMBL336961 & 809151 & 4.1 & 4.3058 & TRN & \\
\hline CHEMBL1994830 & 809151 & 4.1 & 4.4302 & TRN & \\
\hline CHEMBL1987054 & 809151 & 5.4 & 5.2292 & TRN & \\
\hline CHEMBL1970083 & 809151 & 4.1 & 4.5625 & TRN & \\
\hline CHEMBL 226403 & 809151 & 4.1 & 4.2351 & TRN & \\
\hline CHEMBL 2005631 & 809151 & 4.1 & 3.9883 & TRN & \\
\hline CHEMBL1994938 & 809151 & 4.1 & 4.5477 & TRN & \\
\hline CHEMBL1825138 & 809151 & 4.1 & 4.888 & TST & \\
\hline CHEMBL1977223 & 809151 & 5.5 & 4.9189 & TRN & \\
\hline CHEMBL1236126 & 809151 & 4.1 & 4.1202 & TST & \\
\hline CHEMBL1966279 & 809151 & 4.1 & 4.6624 & TRN & \\
\hline CHEMBL1997846 & 809151 & 6.5 & 6.4698 & TRN & \\
\hline CHEMBL 2004419 & 809151 & 4.1 & 4.6459 & TRN & \\
\hline CHEMBL1991728 & 809151 & 6.5 & 5.5363 & TRN & \\
\hline CHEMBL1975787 & 809151 & 6.3 & 5.2615 & TRN & \\
\hline CHEMBL 2002407 & 809151 & 4.1 & 4.23300 & 00000000005 & TRN \\
\hline CHEMBL1972489 & 809151 & 4.1 & 3.7046 & TRN & \\
\hline CHEMBL1994074 & 809151 & 4.1 & 3.7824 & TRN & \\
\hline CHEMBL1992937 & 809151 & 4.1 & 4.2145 & TST & \\
\hline CHEMBL536151 & 809151 & 4.1 & 3.9352 & TST & \\
\hline CHEMBL1972119 & 809151 & 4.1 & 3.9175 & TRN & \\
\hline CHEMBL1986328 & 809151 & 4.1 & 4.1173 & TST & \\
\hline CHEMBL95692 & 809151 & 4.1 & 4.2994 & TRN & \\
\hline CHEMBL1090356 & 809151 & 4.1 & 4.3164 & TRN & \\
\hline CHEMBL1976455 & 809151 & 4.2 & 4.2567 & TRN & \\
\hline CHEMBL1983923 & 809151 & 4.1 & 4.1255 & TST & \\
\hline
\end{tabular}




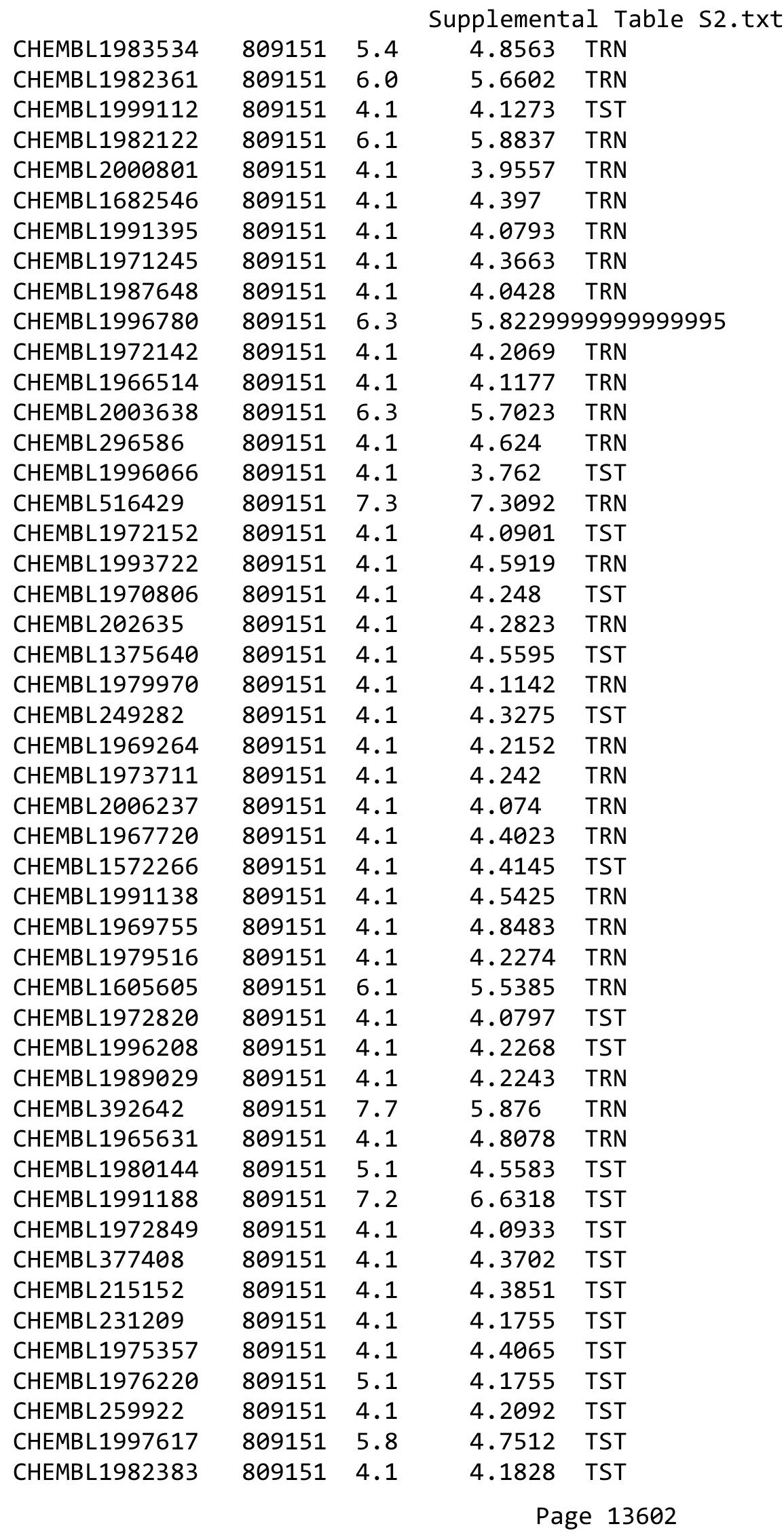




\begin{tabular}{|c|c|c|c|c|c|}
\hline \multicolumn{6}{|c|}{ Supplemental Table S2.txt } \\
\hline CHEMBL1969301 & 809151 & 4.1 & 4.4066 & TST & \\
\hline CHEMBL17370 & 809151 & 4.1 & 4.3222 & TST & \\
\hline CHEMBL1987910 & 809151 & 4.1 & 4.2019 & TST & \\
\hline CHEMBL1983932 & 809151 & 4.1 & 3.9249 & TST & \\
\hline CHEMBL1966069 & 809151 & 5.8 & 5.0614 & TST & \\
\hline CHEMBL1997822 & 809151 & 4.1 & 4.0549 & TST & \\
\hline CHEMBL1991285 & 809151 & 4.1 & 4.2076 & TST & \\
\hline CHEMBL243088 & 809151 & 5.1 & 5.6578 & TST & \\
\hline CHEMBL1984038 & 809151 & 4.1 & 4.2817 & TST & \\
\hline CHEMBL1993661 & 809151 & 7.1 & 6.865 & TST & \\
\hline CHEMBL1974416 & 809151 & 4.1 & 4.8187 & TST & \\
\hline CHEMBL 2004615 & 809151 & 4.1 & 4.2943 & TST & \\
\hline CHEMBL1984039 & 809151 & 5.4 & 4.2054 & TST & \\
\hline CHEMBL1997872 & 809151 & 4.1 & 4.1585 & TST & \\
\hline CHEMBL1474289 & 688310 & 5.0 & 4.9624 & TRN & \\
\hline CHEMBL1549184 & 688310 & 4.6 & 5.8172 & TST & \\
\hline CHEMBL1357280 & 688310 & 5.1 & 4.82 & TRN & \\
\hline CHEMBL1397496 & 688310 & 5.95 & 6.1777 & TRN & \\
\hline CHEMBL1341162 & 688310 & 4.85 & 4.6509 & TRN & \\
\hline CHEMBL 223453 & 688310 & 5.15 & 5.3863 & TST & \\
\hline CHEMBL1523562 & 688310 & 4.85 & 6.0084 & TRN & \\
\hline CHEMBL1458713 & 688310 & 6.95 & 5.2301 & TST & \\
\hline CHEMBL1453110 & 688310 & 4.85 & 5.12299 & 9999999999 & TST \\
\hline CHEMBL1580372 & 688310 & 4.55 & 5.6486 & TST & \\
\hline CHEMBL1353569 & 688310 & 4.4 & 5.4976 & TST & \\
\hline CHEMBL1495609 & 688310 & 6.15 & 5.9245 & TRN & \\
\hline CHEMBL1557181 & 688310 & 4.6 & 4.6597 & TRN & \\
\hline CHEMBL1321452 & 688310 & 5.55 & 5.1332 & TST & \\
\hline CHEMBL568172 & 688310 & 6.4 & 6.3641 & TRN & \\
\hline CHEMBL 224214 & 688310 & 4.8 & 5.6225 & TRN & \\
\hline CHEMBL3196087 & 688310 & 5.4 & 4.9519 & TST & \\
\hline CHEMBL1436606 & 688310 & 4.9 & 4.86 & TRN & \\
\hline CHEMBL1524925 & 688310 & 5.95 & 4.9971 & TST & \\
\hline CHEMBL1334990 & 688310 & 4.95 & 4.7979 & TRN & \\
\hline CHEMBL567142 & 688310 & 7.6498 & $6.7620 e$ & 00000000005 & TRN \\
\hline CHEMBL1552043 & 688310 & 5.7 & $5.9860 e$ & 0000000001 & TRN \\
\hline CHEMBL1525892 & 688310 & 4.85 & 5.54299 & 9999999999 & TRN \\
\hline CHEMBL1522920 & 688310 & 6.7001 & 6.0963 & TRN & \\
\hline CHEMBL1454447 & 688310 & 5.8 & 5.0048 & TRN & \\
\hline CHEMBL1443494 & 688310 & 6.25 & 6.0788 & TRN & \\
\hline CHEMBL1333720 & 688310 & 5.2 & 6.3429 & TST & \\
\hline CHEMBL566069 & 688310 & 6.15 & 6.1167 & TRN & \\
\hline CHEMBL1512456 & 688310 & 5.95 & 6.0038 & TRN & \\
\hline CHEMBL1591862 & 688310 & 4.8 & 5.0192 & TRN & \\
\hline CHEMBL1555175 & 688310 & 4.8 & 5.584 & TST & \\
\hline CHEMBL1377504 & 688310 & 5.7 & 5.755 & TRN & \\
\hline CHEMBL1601339 & 688310 & 5.15 & 5.2303 & TRN & \\
\hline CHEMBL1367407 & 688310 & 5.55 & 5.3598 & TRN & \\
\hline
\end{tabular}





\begin{tabular}{|c|c|c|c|c|c|}
\hline \multicolumn{6}{|c|}{ Supplemental Table S2.txt } \\
\hline CHEMBL1312804 & 688310 & 5.45 & 4.9445 & TST & \\
\hline CHEMBL1593399 & 688310 & 5.15 & 5.5297 & TST & \\
\hline CHEMBL1326558 & 688310 & 5.95 & 5.6153 & TST & \\
\hline CHEMBL60718 & 688310 & 6.0 & 5.303 & TRN & \\
\hline CHEMBL 1450796 & 688310 & 5.85 & 5.309 & TRN & \\
\hline CHEMBL1439265 & 688310 & 5.5 & 4.9223 & TRN & \\
\hline CHEMBL1513843 & 688310 & 6.5 & 5.6847 & TRN & \\
\hline CHEMBL1409603 & 688310 & 4.9 & 5.9316 & TST & \\
\hline CHEMBL1585137 & 688310 & 4.85 & 4.9306 & TRN & \\
\hline CHEMBL567135 & 688310 & 6.05 & 5.96299 & 9999999999 & TRN \\
\hline CHEMBL1476664 & 688310 & 6.0 & 6.1998 & TRN & \\
\hline CHEMBL1512106 & 688310 & 5.55 & 5.53 & TRN & \\
\hline CHEMBL1459149 & 688310 & 4.75 & 6.0402 & TST & \\
\hline CHEMBL1612601 & 688310 & 4.9 & 4.7775 & TRN & \\
\hline CHEMBL1612802 & 688310 & 4.45 & 5.3833 & TST & \\
\hline CHEMBL1317861 & 688310 & 6.1 & 6.1692 & TRN & \\
\hline CHEMBL1355124 & 688310 & 6.0 & 5.4842 & TRN & \\
\hline CHEMBL585873 & 688310 & 6.5 & 6.653 & TRN & \\
\hline CHEMBL1438218 & 688310 & 6.2 & 5.9852 & TRN & \\
\hline CHEMBL1570986 & 688310 & 4.9 & 4.6862 & TRN & \\
\hline CHEMBL1373890 & 688310 & 5.5 & 4.9753 & TST & \\
\hline CHEMBL1492311 & 688310 & 5.05 & 5.2129 & TST & \\
\hline CHEMBL1495719 & 688310 & 5.45 & 6.0572 & TRN & \\
\hline CHEMBL1977007 & 688310 & 4.95 & 5.2268 & TST & \\
\hline CHEMBL1173694 & 688310 & 6.45 & 5.8652 & TRN & \\
\hline CHEMBL1350660 & 688310 & 6.2 & 5.7237 & TRN & \\
\hline CHEMBL1612858 & 688310 & 4.6 & 5.275 & TRN & \\
\hline CHEMBL1461524 & 688310 & 4.2 & 4.9382 & TRN & \\
\hline CHEMBL 567137 & 688310 & 6.05 & 6.0363 & TRN & \\
\hline CHEMBL1604906 & 688310 & 4.6 & 5.6705 & TST & \\
\hline CHEMBL1317068 & 688310 & 6.05 & 5.9518 & TRN & \\
\hline CHEMBL1369136 & 688310 & 4.4 & 4.6846 & TRN & \\
\hline CHEMBL1398482 & 688310 & 4.5 & 5.9343 & TST & \\
\hline CHEMBL1553144 & 688310 & 4.85 & 5.7332 & TRN & \\
\hline CHEMBL1172971 & 688310 & 4.85 & 4.9707 & TRN & \\
\hline CHEMBL1355261 & 688310 & 5.6 & 5.6013 & TRN & \\
\hline CHEMBL 1357707 & 688310 & 4.6 & 4.9835 & TRN & \\
\hline CHEMBL1433908 & 688310 & 5.4 & 5.7624 & TST & \\
\hline CHEMBL1592112 & 688310 & 5.45 & 5.835 & TRN & \\
\hline CHEMBL1494881 & 688310 & 6.0 & 5.5833 & TRN & \\
\hline CHEMBL3392454 & 688310 & 4.2 & 6.0674 & TRN & \\
\hline CHEMBL1483589 & 688310 & 5.8 & 6.2373 & TRN & \\
\hline CHEMBL1464803 & 688310 & 4.8 & 5.1483 & TRN & \\
\hline CHEMBL1437024 & 688310 & 5.85 & 5.2898 & TRN & \\
\hline CHEMBL1593310 & 688310 & 4.8 & 4.5225 & TRN & \\
\hline CHEMBL566067 & 688310 & 6.05 & 5.9755 & TRN & \\
\hline CHEMBL 1415550 & 688310 & 4.75 & 5.9654 & TRN & \\
\hline CHEMBL1358229 & 688310 & 4.55 & 6.1153 & TRN & \\
\hline
\end{tabular}




\begin{tabular}{|c|c|c|c|c|c|}
\hline \\
\hline CHEMBL1394616 & 688310 & 5.3 & 5.2303 & TRN & \\
\hline CHEMBL1551555 & 688310 & 5.9 & 5.4456 & TRN & \\
\hline CHEMBL1509422 & 688310 & 4.4 & 5.015 & TST & \\
\hline CHEMBL1527124 & 688310 & 5.95 & 5.9845 & TRN & \\
\hline CHEMBL1358773 & 688310 & 4.9 & 5.0114 & TRN & \\
\hline CHEMBL1320868 & 688310 & 4.8 & 4.723 & TRN & \\
\hline CHEMBL1414011 & 688310 & 6.0 & 5.449 & TRN & \\
\hline CHEMBL1521571 & 688310 & 4.55 & 5.6305 & TST & \\
\hline CHEMBL3191547 & 688310 & 4.65 & 5.3912 & TST & \\
\hline CHEMBL1440407 & 688310 & 5.4 & 5.2486 & TST & \\
\hline CHEMBL1431490 & 688310 & 4.9 & 5.5331 & TST & \\
\hline CHEMBL1569025 & 688310 & 5.6 & 5.4093 & TRN & \\
\hline CHEMBL1395922 & 688310 & 5.3 & 5.7367 & TRN & \\
\hline CHEMBL1316790 & 688310 & 5.05 & 5.7701 & TRN & \\
\hline CHEMBL1496776 & 688310 & 6.0 & 5.3633 & TRN & \\
\hline CHEMBL1476406 & 688310 & 5.4 & 5.396 & TRN & \\
\hline CHEMBL1517028 & 688310 & 4.5 & 5.268 & TST & \\
\hline CHEMBL1395189 & 688310 & 6.15 & 6.1688 & TRN & \\
\hline CHEMBL1334062 & 688310 & 6.05 & 5.6708 & TRN & \\
\hline CHEMBL1559057 & 688310 & 5.55 & 5.1516 & TRN & \\
\hline CHEMBL1256974 & 688310 & 6.5501 & 5.1629 & TRN & \\
\hline CHEMBL1484890 & 688310 & 5.05 & 4.9003 & TRN & \\
\hline CHEMBL1408350 & 688310 & 5.65 & 5.1425 & TRN & \\
\hline CHEMBL1355700 & 688310 & 5.05 & 4.9211 & TRN & \\
\hline CHEMBL1513512 & 688310 & 4.95 & 4.9625 & TRN & \\
\hline CHEMBL1523915 & 688310 & 4.5 & 4.5742 & TRN & \\
\hline CHEMBL1092115 & 688310 & 5.4 & 4.6381 & TST & \\
\hline CHEMBL1523699 & 688310 & 4.45 & 5.0132 & TST & \\
\hline CHEMBL1324051 & 688310 & 4.95 & 5.2977 & TST & \\
\hline CHEMBL1333514 & 688310 & 5.45 & 4.8687 & TRN & \\
\hline CHEMBL1303200 & 688310 & 4.4 & 5.3166 & TST & \\
\hline CHEMBL1410000 & 688310 & 5.65 & 6.0037 & TRN & \\
\hline CHEMBL1565554 & 688310 & 4.7 & 6.3338 & TRN & \\
\hline CHEMBL1334432 & 688310 & 4.8 & 6.1627 & TST & \\
\hline CHEMBL1594004 & 688310 & 5.65 & 5.6894 & TRN & \\
\hline CHEMBL1568318 & 688310 & 5.15 & 5.4878 & TST & \\
\hline CHEMBL18879 & 688310 & 4.6 & 5.3663 & TST & \\
\hline CHEMBL1402055 & 688310 & 4.85 & 5.0237 & TST & \\
\hline CHEMBL1442974 & 688310 & 5.05 & 4.6354 & TRN & \\
\hline CHEMBL1608151 & 688310 & 5.0 & 5.0802 & TRN & \\
\hline CHEMBL1474911 & 688310 & 6.2 & 5.5832 & TST & \\
\hline CHEMBL1483184 & 688310 & 4.85 & 4.8859 & TRN & \\
\hline CHEMBL1385088 & 688310 & 4.6 & 5.3393 & TST & \\
\hline CHEMBL1453827 & 688310 & 5.65 & 5.53100 & 0000000001 & TRN \\
\hline CHEMBL1448946 & 688310 & 6.0 & 6.0015 & TRN & \\
\hline CHEMBL1512276 & 688310 & 4.6 & 4.9816 & TRN & \\
\hline CHEMBL1487298 & 688310 & 5.1 & 5.9826 & TST & \\
\hline CHEMBL1541949 & 688310 & 5.15 & 4.8456 & TRN & \\
\hline
\end{tabular}




\begin{tabular}{|c|c|c|c|c|c|}
\hline \multicolumn{6}{|c|}{ Supplemental Table S2.txt } \\
\hline CHEMBL1561260 & 688310 & 5.85 & 5.9483 & TRN & \\
\hline CHEMBL1433846 & 688310 & 5.8 & 6.0497 & TRN & \\
\hline CHEMBL1555151 & 688310 & 7.1002 & 6.4418 & TRN & \\
\hline CHEMBL1586610 & 688310 & 4.85 & 5.3801 & TST & \\
\hline CHEMBL1446719 & 688310 & 4.85 & 4.6802 & TRN & \\
\hline CHEMBL1478615 & 688310 & 4.5 & 4.9392 & TRN & \\
\hline CHEMBL1411358 & 688310 & 5.55 & 5.6953 & TRN & \\
\hline CHEMBL1434650 & 688310 & 4.55 & 4.9376 & TRN & \\
\hline CHEMBL1488604 & 688310 & 5.35 & 6.1605 & TST & \\
\hline CHEMBL370152 & 688310 & 5.05 & 5.3988 & TST & \\
\hline CHEMBL1412405 & 688310 & 5.15 & 5.0265 & TRN & \\
\hline CHEMBL1336524 & 688310 & 5.1 & 5.2202 & TRN & \\
\hline CHEMBL1500229 & 688310 & 4.85 & 5.6926 & TRN & \\
\hline CHEMBL1397593 & 688310 & 4.6 & 4.6741 & TRN & \\
\hline CHEMBL1316434 & 688310 & 6.8 & 6.353 & TRN & \\
\hline CHEMBL1437307 & 688310 & 4.9 & 5.2489 & TRN & \\
\hline CHEMBL1610339 & 688310 & 5.95 & 6.0424 & TRN & \\
\hline CHEMBL1516776 & 688310 & 5.55 & 6.0035 & TRN & \\
\hline CHEMBL1324306 & 688310 & 6.0 & 6.0055 & TRN & \\
\hline CHEMBL1328481 & 688310 & 5.15 & 5.7121 & TRN & \\
\hline CHEMBL1358646 & 688310 & 4.5 & 4.6904 & TRN & \\
\hline CHEMBL1454505 & 688310 & 5.8 & 6.3519 & TRN & \\
\hline CHEMBL 1434640 & 688310 & 5.1 & 5.0659 & TRN & \\
\hline CHEMBL567354 & 688310 & 5.9 & 5.9317 & TRN & \\
\hline CHEMBL1590043 & 688310 & 5.05 & 4.8583 & TRN & \\
\hline CHEMBL1566266 & 688310 & 4.85 & 5.6814 & TST & \\
\hline CHEMBL1316847 & 688310 & 6.05 & 5.3157 & TRN & \\
\hline CHEMBL1538976 & 688310 & 4.45 & 5.6639 & TST & \\
\hline CHEMBL576847 & 688310 & 6.1 & 5.9798 & TRN & \\
\hline CHEMBL577764 & 688310 & 6.0 & 5.4707 & TRN & \\
\hline CHEMBL1555958 & 688310 & 6.0 & 5.2273 & TRN & \\
\hline CHEMBL1302195 & 688310 & 4.9 & 5.25299 & & TRN \\
\hline CHEMBL567769 & 688310 & 5.8 & 5.8882 & TRN & \\
\hline CHEMBL567786 & 688310 & 7.2503 & 6.5195 & TRN & \\
\hline CHEMBL1451188 & 688310 & 5.15 & 4.9716 & TRN & \\
\hline CHEMBL1327669 & 688310 & 5.6 & 5.1375 & TRN & \\
\hline CHEMBL578161 & 688310 & 5.85 & 6.1376 & TRN & \\
\hline CHEMBL566903 & 688310 & 6.3 & 6.2213 & TRN & \\
\hline CHEMBL1975975 & 688310 & 4.6 & 4.9267 & TST & \\
\hline CHEMBL1974901 & 688310 & 6.0 & 5.1846 & TST & \\
\hline CHEMBL1572238 & 688310 & 5.4 & 5.3351 & TRN & \\
\hline CHEMBL1516091 & 688310 & 4.9 & 4.9422 & TRN & \\
\hline CHEMBL567147 & 688310 & 6.9 & 6.6186 & TRN & \\
\hline CHEMBL566924 & 688310 & 7.0 & 6.1867 & TRN & \\
\hline CHEMBL579273 & 688310 & 4.45 & 5.5599 & TRN & \\
\hline CHEMBL1356904 & 688310 & 5.9 & 6.1734 & TRN & \\
\hline CHEMBL1599275 & 688310 & 5.65 & 6.0274 & TRN & \\
\hline CHEMBL1317780 & 688310 & 5.3 & 5.7834 & TRN & \\
\hline
\end{tabular}




\begin{tabular}{|c|c|c|c|c|c|}
\hline \multicolumn{6}{|c|}{ Supplemental Table S2.txt } \\
\hline CHEMBL1597946 & 688310 & 4.85 & 4.9709 & TRN & \\
\hline CHEMBL1367896 & 688310 & 4.5 & 4.6001 & TRN & \\
\hline CHEMBL1531241 & 688310 & 6.05 & 5.9936 & TRN & \\
\hline CHEMBL1559134 & 688310 & 5.85 & 6.0564 & TRN & \\
\hline CHEMBL1348345 & 688310 & 5.1 & 5.8123 & TST & \\
\hline CHEMBL1357689 & 688310 & 4.8 & 4.8905 & TRN & \\
\hline CHEMBL1368620 & 688310 & 5.55 & 5.2233 & TRN & \\
\hline CHEMBL1446626 & 688310 & 5.1 & 5.4382 & TST & \\
\hline CHEMBL1395607 & 688310 & 4.9 & 4.9627 & TRN & \\
\hline CHEMBL3196233 & 688310 & 6.1 & 5.0905 & TRN & \\
\hline CHEMBL1554060 & 688310 & 4.5 & 5.3074 & TRN & \\
\hline CHEMBL1325517 & 688310 & 5.45 & 5.0176 & TRN & \\
\hline CHEMBL567784 & 688310 & 7.1002 & 6.5676 & TRN & \\
\hline CHEMBL1334452 & 688310 & 4.85 & 5.7752 & TST & \\
\hline CHEMBL1401211 & 688310 & 4.8 & 5.79799 & 9999999999 & TST \\
\hline CHEMBL1326976 & 688310 & 7.15 & 5.9706 & TRN & \\
\hline CHEMBL579104 & 688310 & 4.9 & 5.8901 & TST & \\
\hline CHEMBL1387871 & 688310 & 4.85 & 5.6016 & TRN & \\
\hline CHEMBL1408468 & 688310 & 4.45 & 5.3314 & TST & \\
\hline CHEMBL1419509 & 688310 & 4.8 & 4.919 & TRN & \\
\hline CHEMBL1564322 & 688310 & 4.6 & 4.9231 & TRN & \\
\hline CHEMBL1373133 & 688310 & 4.95 & 5.0689 & TRN & \\
\hline CHEMBL1333234 & 688310 & 4.9 & 5.3083 & TRN & \\
\hline CHEMBL1514928 & 688310 & 5.75 & 6.0658 & TRN & \\
\hline CHEMBL1605676 & 688310 & 4.85 & 5.4963 & TRN & \\
\hline CHEMBL596674 & 688310 & 4.5 & 5.1417 & TRN & \\
\hline CHEMBL1454058 & 688310 & 4.9 & 4.83899 & 99999999995 & TRN \\
\hline CHEMBL1545632 & 688310 & 4.6 & 5.7911 & TST & \\
\hline CHEMBL1173672 & 688310 & 5.3 & 4.9573 & TRN & \\
\hline CHEMBL1354623 & 688310 & 4.35 & 6.1242 & TRN & \\
\hline CHEMBL1395288 & 688310 & 4.8 & 5.2715 & TST & \\
\hline CHEMBL566904 & 688310 & 7.2 & 6.3983 & TRN & \\
\hline CHEMBL1435794 & 688310 & 5.05 & 4.8017 & TRN & \\
\hline CHEMBL1327765 & 688310 & 4.4 & 6.072 & TST & \\
\hline CHEMBL1321641 & 688310 & 6.0 & 5.6344 & TRN & \\
\hline CHEMBL154580 & 688310 & 4.6 & 5.0303 & TRN & \\
\hline CHEMBL597857 & 688310 & 4.9 & 6.2361 & TST & \\
\hline CHEMBL1371567 & 688310 & 4.85 & 5.2888 & TST & \\
\hline CHEMBL1322086 & 688310 & 4.9 & 5.2295 & TRN & \\
\hline CHEMBL1484556 & 688310 & 5.65 & 6.1518 & TRN & \\
\hline CHEMBL1488456 & 688310 & 5.35 & 5.0754 & TRN & \\
\hline CHEMBL1325904 & 688310 & 4.45 & 5.8193 & TRN & \\
\hline CHEMBL1333194 & 688310 & 5.9 & 5.2452 & TRN & \\
\hline CHEMBL578512 & 688310 & 5.65 & 5.398 & TRN & \\
\hline CHEMBL1531857 & 688310 & 6.0 & 6.0916 & TRN & \\
\hline CHEMBL1572409 & 688310 & 4.9 & 4.7638 & TRN & \\
\hline CHEMBL1371902 & 688310 & 5.3 & 5.6437 & TRN & \\
\hline CHEMBL1349574 & 688310 & 5.55 & 5.7238 & TRN & \\
\hline
\end{tabular}




\begin{tabular}{|c|c|c|c|c|c|}
\hline \multicolumn{6}{|c|}{ Supplemental Table S2.txt } \\
\hline CHEMBL567161 & 688310 & 6.15 & 5.8389 & TRN & \\
\hline CHEMBL1449180 & 688310 & 6.05 & 5.4773 & TRN & \\
\hline CHEMBL1595749 & 688310 & 4.75 & 5.0431 & TRN & \\
\hline CHEMBL567134 & 688310 & 6.6499 & 6.527 & TRN & \\
\hline CHEMBL1475762 & 688310 & 5.85 & 5.9795 & TRN & \\
\hline CHEMBL1433496 & 688310 & 4.9 & 5.1154 & TRN & \\
\hline CHEMBL1433431 & 688310 & 4.4 & 5.4339 & TRN & \\
\hline CHEMBL1365564 & 688310 & 5.1 & 4.7284 & TRN & \\
\hline CHEMBL1394078 & 688310 & 5.15 & 5.2902 & TRN & \\
\hline CHEMBL1307622 & 688310 & 5.4 & 5.6108 & TRN & \\
\hline CHEMBL1355151 & 688310 & 5.25 & 5.0574 & TRN & \\
\hline CHEMBL1328753 & 688310 & 5.3 & 5.1493 & TRN & \\
\hline CHEMBL1365696 & 688310 & 4.85 & 4.8995 & TST & \\
\hline CHEMBL1570004 & 688310 & 4.75 & 5.2648 & TST & \\
\hline CHEMBL578159 & 688310 & 8.0 & 6.6762 & TRN & \\
\hline CHEMBL1336551 & 688310 & 5.0 & 4.9761 & TRN & \\
\hline CHEMBL1584359 & 688310 & 4.7 & 5.0941 & TST & \\
\hline CHEMBL1611662 & 688310 & 6.1 & 4.973 & TST & \\
\hline CHEMBL1990036 & 688310 & 5.7 & 5.4057 & TST & \\
\hline CHEMBL567341 & 688310 & 8.0 & 6.5755 & TRN & \\
\hline CHEMBL1443714 & 688310 & 4.85 & 4.9064 & TRN & \\
\hline CHEMBL1411806 & 688310 & 4.45 & 4.9011 & TRN & \\
\hline CHEMBL1519380 & 688310 & 8.1487 & 6.1174 & TRN & \\
\hline CHEMBL1370548 & 688310 & 5.35 & 6.4298 & TST & \\
\hline CHEMBL1481398 & 688310 & 4.25 & 5.7781 & TST & \\
\hline CHEMBL567783 & 688310 & 7.2 & 6.1694 & TRN & \\
\hline CHEMBL3194398 & 688310 & 5.95 & 5.3531 & TST & \\
\hline CHEMBL1319462 & 688310 & 6.0 & 6.1124 & TRN & \\
\hline CHEMBL1552712 & 688310 & 5.95 & 6.0193 & TRN & \\
\hline CHEMBL1354509 & 688310 & 4.9 & 5.0721 & TRN & \\
\hline CHEMBL1435685 & 688310 & 6.25 & 6.146 & TRN & \\
\hline CHEMBL1609513 & 688310 & 5.05 & 4.8035 & TST & \\
\hline CHEMBL1517083 & 688310 & 5.05 & 5.3914 & TRN & \\
\hline CHEMBL1328042 & 688310 & 5.05 & 4.7545 & TRN & \\
\hline CHEMBL1310699 & 688310 & 5.05 & 5.8692 & TST & \\
\hline CHEMBL1493834 & 688310 & 6.35 & 6.04299 & 9999999999 & TRN \\
\hline CHEMBL1314700 & 688310 & 5.6 & 5.4779 & TRN & \\
\hline CHEMBL1595217 & 688310 & 4.85 & 5.28100 & 0000000001 & TRN \\
\hline CHEMBL3193305 & 688310 & 5.7 & 5.3602 & TST & \\
\hline CHEMBL1316091 & 688310 & 7.0 & 6.0069 & TRN & \\
\hline CHEMBL1401550 & 688310 & 4.75 & 5.1189 & TST & \\
\hline CHEMBL1408367 & 688310 & 5.45 & 5.6538 & TRN & \\
\hline CHEMBL567785 & 688310 & 7.1002 & 6.3276 & TRN & \\
\hline CHEMBL1495524 & 688310 & 4.45 & 5.2147 & TRN & \\
\hline CHEMBL1417979 & 688310 & 4.55 & 5.2108 & TST & \\
\hline CHEMBL1567904 & 688310 & 6.05 & 6.3213 & TRN & \\
\hline CHEMBL1407458 & 688310 & 4.8 & 5.2218 & TST & \\
\hline CHEMBL1394178 & 688310 & 4.6 & 5.8417 & TRN & \\
\hline
\end{tabular}




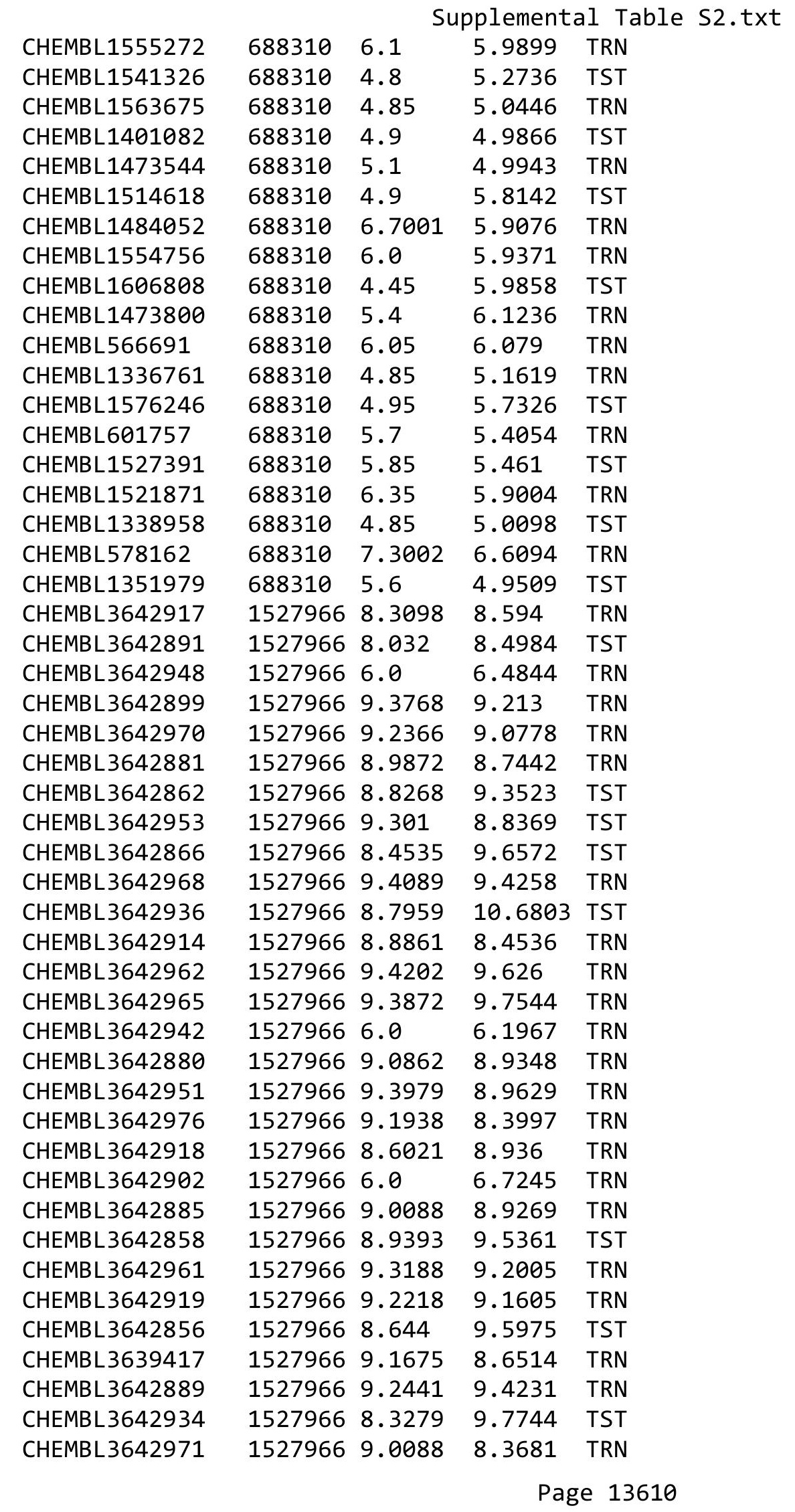


Supplemental Table S2.txt

\begin{tabular}{|c|c|c|c|c|c|c|}
\hline CHEMBL3642956 & 1527966 & 8.699 & 8.9945 & TRN & & \\
\hline CHEMBL 3642922 & 1527966 & 9.4089 & 8.7656 & TRN & & \\
\hline CHEMBL3642980 & 1527966 & 8.4949 & 8.5812 & TRN & & \\
\hline CHEMBL 3642960 & 1527966 & 9.6778 & 9.6619 & TRN & & \\
\hline CHEMBL 3642888 & 1527966 & 9.1938 & 9.1346 & TRN & & \\
\hline CHEMBL3642969 & 1527966 & 8.3188 & 8.2489 & TRN & & \\
\hline CHEMBL 3642949 & 1527966 & 8.5528 & 8.4246 & TRN & & \\
\hline CHEMBL3642859 & 1527966 & 8.5719 & 9.0097 & TRN & & \\
\hline CHEMBL3642940 & 1527966 & 8.2464 & 9.6189 & TST & & \\
\hline CHEMBL3642957 & 1527966 & 9.5686 & 9.7214 & TRN & & \\
\hline CHEMBL 3642938 & 1527966 & 9.0555 & 9.3129 & TRN & & \\
\hline CHEMBL 3642895 & 1527966 & 9.0757 & 9.838 & TST & & \\
\hline CHEMBL 3642958 & 1527966 & 9.4318 & 10.0326 & TRN & & \\
\hline CHEMBL3642861 & 1527966 & 6.0 & 6.5434 & TRN & & \\
\hline CHEMBL 3642897 & 1527966 & 8.6556 & 8.3605 & TRN & & \\
\hline CHEMBL 3642867 & 1527966 & 6.0 & 6.2569 & TRN & & \\
\hline CHEMBL 3642963 & 1527966 & 8.6021 & 9.07 & TRN & & \\
\hline CHEMBL 3642893 & 1527966 & 8.8416 & 8.3059 & TRN & & \\
\hline CHEMBL 3642882 & 1527966 & 9.301 & 9.1576 & TRN & & \\
\hline CHEMBL3642937 & 1527966 & 9.1675 & 8.5936 & TRN & & \\
\hline CHEMBL 3642947 & 1527966 & 9.4815 & 8.8819 & TRN & & \\
\hline CHEMBL 3642950 & 1527966 & 8.6576 & 9.0814 & TST & & \\
\hline CHEMBL3642863 & 1527966 & 8.4989 & 8.4213 & TRN & & \\
\hline CHEMBL 3642923 & 1527966 & 9.1549 & 9.4329 & TRN & & \\
\hline CHEMBL 3642890 & 1527966 & 9.1739 & 9.1556 & TRN & & \\
\hline CHEMBL 3642898 & 1527966 & 9.5376 & 9.12 & TRN & & \\
\hline CHEMBL 3642915 & 1527966 & 8.1192 & 8.6679 & TRN & & \\
\hline CHEMBL 3642964 & 1527966 & 9.0555 & 9.9 & TRN & & \\
\hline CHEMBL3642887 & 1527966 & 9.2366 & 9.0466 & TRN & & \\
\hline CHEMBL3642896 & 1527966 & 8.8508 & 9.0732 & TST & & \\
\hline CHEMBL3642913 & 1527966 & 8.7212 & 8.4815 & TRN & & \\
\hline CHEMBL 3642916 & 1527966 & 8.3565 & 8.8056 & TRN & & \\
\hline CHEMBL3642935 & 1527966 & 8.5686 & 9.9892 & TST & & \\
\hline CHEMBL3642925 & 1527966 & 9.5086 & 8.5853 & TRN & & \\
\hline CHEMBL3642886 & 1527966 & 9.6021 & 9.4187 & TRN & & \\
\hline CHEMBL 3642932 & 1527966 & 9.28399 & 999999999 & 99 & 9.7319 & TRIV \\
\hline CHEMBL 3642903 & 1527966 & 9.2518 & 9.7643 & TRN & & \\
\hline CHEMBL 3642860 & 1527966 & 8.8633 & 8.7053 & TRN & & \\
\hline CHEMBL 3642978 & 1527966 & 9.2596 & 9.1866 & TST & & \\
\hline CHEMBL3642906 & 1527966 & 9.3098 & 9.3958 & TRN & & \\
\hline CHEMBL3642959 & 1527966 & 9.3768 & 9.7852 & TRN & & \\
\hline CHEMBL 3642977 & 1527966 & 9.2441 & 9.4278 & TRN & & \\
\hline CHEMBL3642981 & 1527966 & 9.1367 & 8.9338 & TRN & & \\
\hline CHEMBL 3642928 & 1527966 & 9.2757 & 9.4344 & TRN & & \\
\hline CHEMBL 3642871 & 1527966 & 8.719 & 8.4719 & TRN & & \\
\hline CHEMBL3642864 & 1527966 & 8.172 & 8.5639 & TST & & \\
\hline CHEMBL3642857 & 1527966 & 8.7055 & 9.7137 & TST & & \\
\hline CHEMBL 3642973 & 1527966 & 8.5229 & 9.7537 & TST & & \\
\hline
\end{tabular}

Page 13611 
Supplemental Table S2.txt

\begin{tabular}{|c|c|c|c|c|c|}
\hline CHEMBL3642955 & 1527966 & 9.0223 & 8.8111 & TRN & \\
\hline CHEMBL3639418 & 1527966 & 9.8861 & 9.2049 & TRN & \\
\hline CHEMBL3642972 & 1527966 & 8.0223 & 9.4278 & TST & \\
\hline CHEMBL3642869 & 1527966 & 8.6144 & 8.8724 & TRN & \\
\hline CHEMBL3642876 & 1527966 & 6.0 & 5.8948 & TRN & \\
\hline CHEMBL3642884 & 1527966 & 9.1871 & 9.1648 & TRN & \\
\hline CHEMBL3642966 & 1527966 & 9.0506 & 9.5425 & TRN & \\
\hline CHEMBL3642931 & 1527966 & 9.4949 & 9.6518 & TRN & \\
\hline CHEMBL3642901 & 1527966 & 9.3768 & 9.3186 & TRN & \\
\hline CHEMBL3642865 & 1527966 & 8.4802 & 9.2778 & TST & \\
\hline CHEMBL3642892 & 1527966 & 8.2426 & 8.514 & TST & \\
\hline CHEMBL3642921 & 1527966 & 8.9586 & 8.9559 & TRN & \\
\hline CHEMBL3642954 & 1527966 & 9.1249 & 9.1535 & TST & \\
\hline CHEMBL3642927 & 1527966 & 8.6778 & 8.4617 & TRN & \\
\hline CHEMBL 3642870 & 1527966 & 6.0 & 6.3267 & TRN & \\
\hline CHEMBL3642967 & 1527966 & 9.1427 & 9.2666 & TRN & \\
\hline CHEMBL3642924 & 1527966 & 9.4559 & 10.0869 & TRN & \\
\hline CHEMBL 3642926 & 1527966 & 9.3768 & 8.5863 & TRN & \\
\hline CHEMBL3642894 & 1527966 & 8.6676 & 8.4064 & TST & \\
\hline CHEMBL3642930 & 1527966 & 9.0 & 8.6583 & TRN & \\
\hline CHEMBL3642883 & 1527966 & 9.2076 & 8.875 & TRN & \\
\hline CHEMBL 3642872 & 1527966 & 6.0 & 6.5973 & TRN & \\
\hline CHEMBL3642933 & 1527966 & 8.6576 & 10.2462 & TST & \\
\hline CHEMBL3642946 & 1527966 & 9.28399 & 999999999 & 99 & 9.2074 \\
\hline CHEMBL3642929 & 1527966 & 8.6021 & 8.8798 & TRN & \\
\hline CHEMBL3642868 & 1527966 & 8.7258 & 8.851 & TRN & \\
\hline CHEMBL3642979 & 1527966 & 9.8539 & 9.1223 & TRN & \\
\hline CHEMBL3642975 & 1527966 & 8.0862 & 8.6683 & TST & \\
\hline CHEMBL3642920 & 1527966 & 8.8861 & 9.1772 & TRN & \\
\hline CHEMBL 3642974 & 1527966 & 8.0088 & 9.0635 & TST & \\
\hline CHEMBL3642982 & 1527966 & 8.4318 & 9.5579 & TST & \\
\hline CHEMBL 3642900 & 1527966 & 6.0 & 6.4235 & TST & \\
\hline CHEMBL3642939 & 1527966 & 8.585 & 8.5508 & TST & \\
\hline CHEMBL195956 & 321446 & 3.5229 & 3.7046 & TRN & \\
\hline CHEMBL195034 & 321446 & 5.1249 & 4.374 & TRN & \\
\hline CHEMBL192793 & 321446 & 4.3307 & 4.8126 & TRN & \\
\hline CHEMBL198439 & 321446 & 4.5421 & 4.7409 & TRN & \\
\hline CHEMBL370330 & 321446 & 4.7212 & 4.5553 & TRN & \\
\hline CHEMBL300755 & 321446 & 4.7878 & 4.9604 & TRN & \\
\hline CHEMBL53982 & 321446 & 3.4881 & 3.9006 & TST & \\
\hline CHEMBL425748 & 321446 & 3.2676 & 4.115 & TRN & \\
\hline CHEMBL196254 & 321446 & 5.2076 & 4.8806 & TRN & \\
\hline CHEMBL199206 & 321446 & 5.0969 & 4.4376 & TST & \\
\hline CHEMBL381465 & 321446 & 4.5272 & 4.3516 & TRN & \\
\hline CHEMBL198013 & 321446 & 4.5482 & 4.4327 & TRN & \\
\hline CHEMBL199653 & 321446 & 3.0748 & 3.9598 & TRN & \\
\hline CHEMBL371885 & 321446 & 4.0825 & 4.2034 & TRN & \\
\hline CHEMBL197173 & 321446 & 4.2733 & 4.0064 & TRN & \\
\hline
\end{tabular}




\begin{tabular}{|c|c|c|c|c|c|}
\hline \multirow{2}{*}{ CHEMBL198409 } & \multicolumn{5}{|c|}{ Supplemental Table S2. } \\
\hline & 321446 & 5.0132 & 4.967 & TRN & \\
\hline CHEMBL371263 & 321446 & 3.6743 & 3.40100 & 00000000002 & TRN \\
\hline CHEMBL434978 & 321446 & 4.4012 & 4.5297 & TRN & \\
\hline CHEMBL197836 & 321446 & 4.9101 & 4.7833 & TRN & \\
\hline CHEMBL450938 & 321446 & 5.1871 & 5.1868 & TRN & \\
\hline CHEMBL54925 & 321446 & 5.6198 & 5.1936 & TRN & \\
\hline CHEMBL371673 & 321446 & 4.3188 & 4.4518 & TST & \\
\hline CHEMBL293479 & 321446 & 3.4498 & 3.8666 & TRN & \\
\hline CHEMBL125188 & 321446 & 4.7773 & 4.5343 & TRN & \\
\hline CHEMBL383778 & 321446 & 4.1549 & 4.0502 & TRN & \\
\hline CHEMBL197944 & 321446 & 4.2596 & 4.7845 & TRN & \\
\hline CHEMBL55608 & 321446 & 4.3635 & 4.6113 & TST & \\
\hline CHEMBL196554 & 321446 & 4.7282 & 4.36100 & 0000000001 & TRN \\
\hline CHEMBL197132 & 321446 & 4.1079 & 4.335 & TRN & \\
\hline CHEMBL426281 & 321446 & 3.9654 & 4.2297 & TRN & \\
\hline CHEMBL110971 & 321446 & 4.3215 & 4.0351 & TST & \\
\hline CHEMBL425925 & 321446 & 3.6676 & 4.4049 & TRN & \\
\hline CHEMBL102478 & 321446 & 5.2596 & 4.5388 & TRN & \\
\hline CHEMBL299717 & 321446 & 4.3215 & 4.7403 & TST & \\
\hline CHEMBL198380 & 321446 & 4.8327 & 3.7977 & TRN & \\
\hline CHEMBL382291 & 321446 & 3.3768 & 3.6972 & TRN & \\
\hline CHEMBL294192 & 321446 & 3.4165 & 4.0177 & TRN & \\
\hline CHEMBL198014 & 321446 & 3.3665 & 4.141 & TRN & \\
\hline CHEMBL55837 & 321446 & 3.4685 & 4.0351 & TST & \\
\hline CHEMBL198126 & 321446 & 4.9469 & 4.4758 & TRN & \\
\hline CHEMBL194801 & 321446 & 4.6021 & 3.8775 & TRN & \\
\hline CHEMBL55889 & 321446 & 5.0132 & 4.9831 & TST & \\
\hline CHEMBL54004 & 321446 & 3.4477 & 4.0351 & TST & \\
\hline CHEMBL417549 & 321446 & 4.2464 & 4.2598 & TST & \\
\hline CHEMBL196631 & 321446 & 4.762 & 4.6457 & TRN & \\
\hline CHEMBL127588 & 321446 & 4.5969 & 4.4787 & TRN & \\
\hline CHEMBL417932 & 321446 & 4.2596 & 4.4856 & TRN & \\
\hline CHEMBL55371 & 321446 & 5.3665 & 4.6778 & TRN & \\
\hline CHEMBL194213 & 321446 & 3.4357 & 3.7491 & TRN & \\
\hline CHEMBL194800 & 321446 & 4.6144 & 4.5966 & TRN & \\
\hline CHEMBL199012 & 321446 & 4.5969 & 4.8529 & TRN & \\
\hline CHEMBL198826 & 321446 & 5.0 & 4.4955 & TST & \\
\hline CHEMBL196049 & 321446 & 3.8861 & 4.3867 & TRN & \\
\hline CHEMBL431139 & 321446 & 4.4202 & 4.6573 & TRN & \\
\hline CHEMBL196726 & 321446 & 4.4522 & 3.8234 & TRN & \\
\hline CHEMBL198066 & 321446 & 3.3615 & 3.6494 & TRN & \\
\hline CHEMBL371912 & 321446 & 3.8752 & 4.9285 & TRN & \\
\hline CHEMBL196676 & 321446 & 4.5086 & 4.2982 & TRN & \\
\hline CHEMBL333503 & 321446 & 4.8761 & 5.1483 & TRN & \\
\hline CHEMBL52761 & 321446 & 4.6676 & 4.4764 & TST & \\
\hline CHEMBL196749 & 321446 & 3.8592 & 4.1679 & TRN & \\
\hline CHEMBL194302 & 321446 & 3.7174 & 3.8229 & TRN & \\
\hline CHEMBL414849 & 321446 & 5.6778 & 4.5269 & TRN & \\
\hline
\end{tabular}




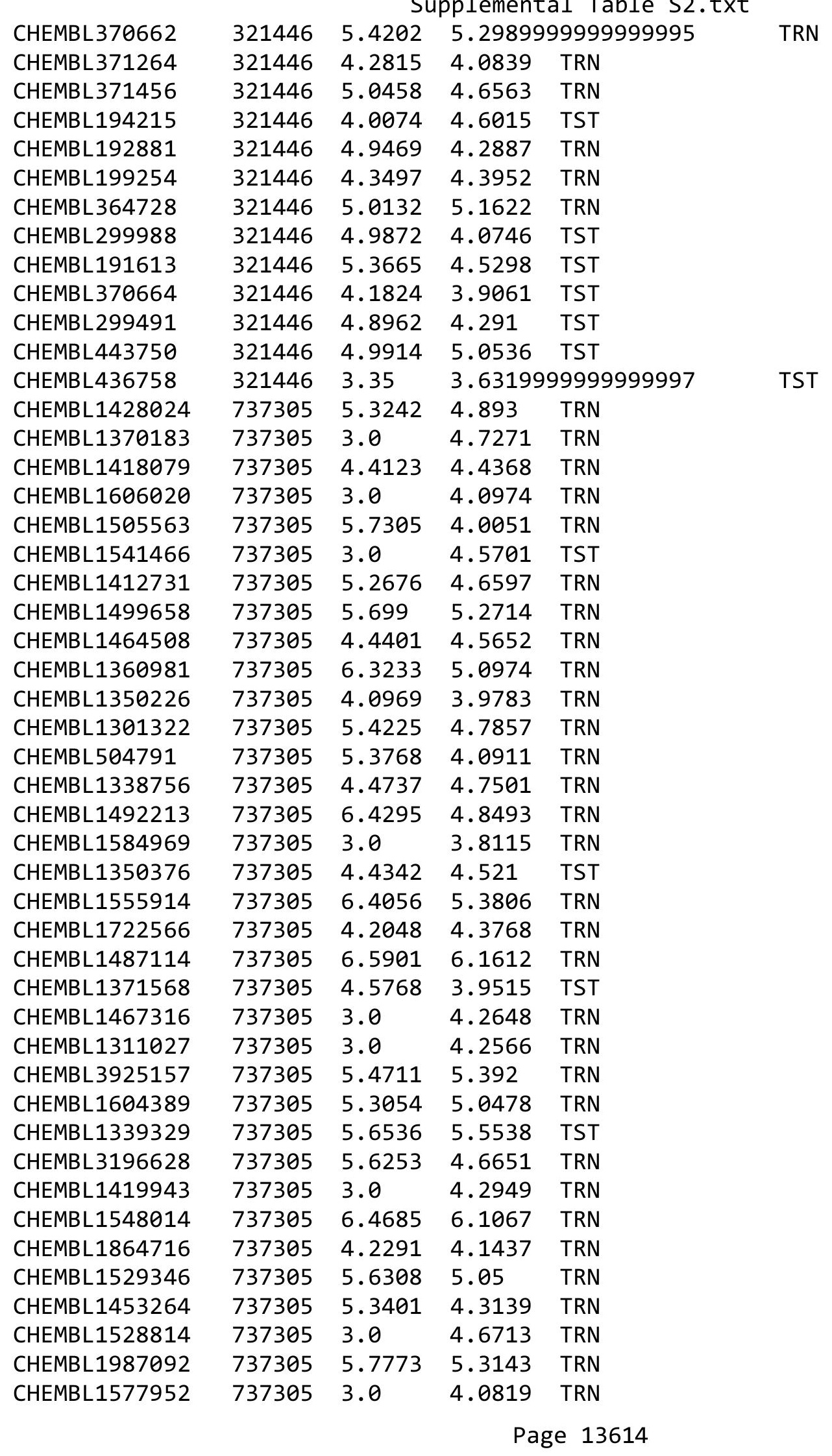




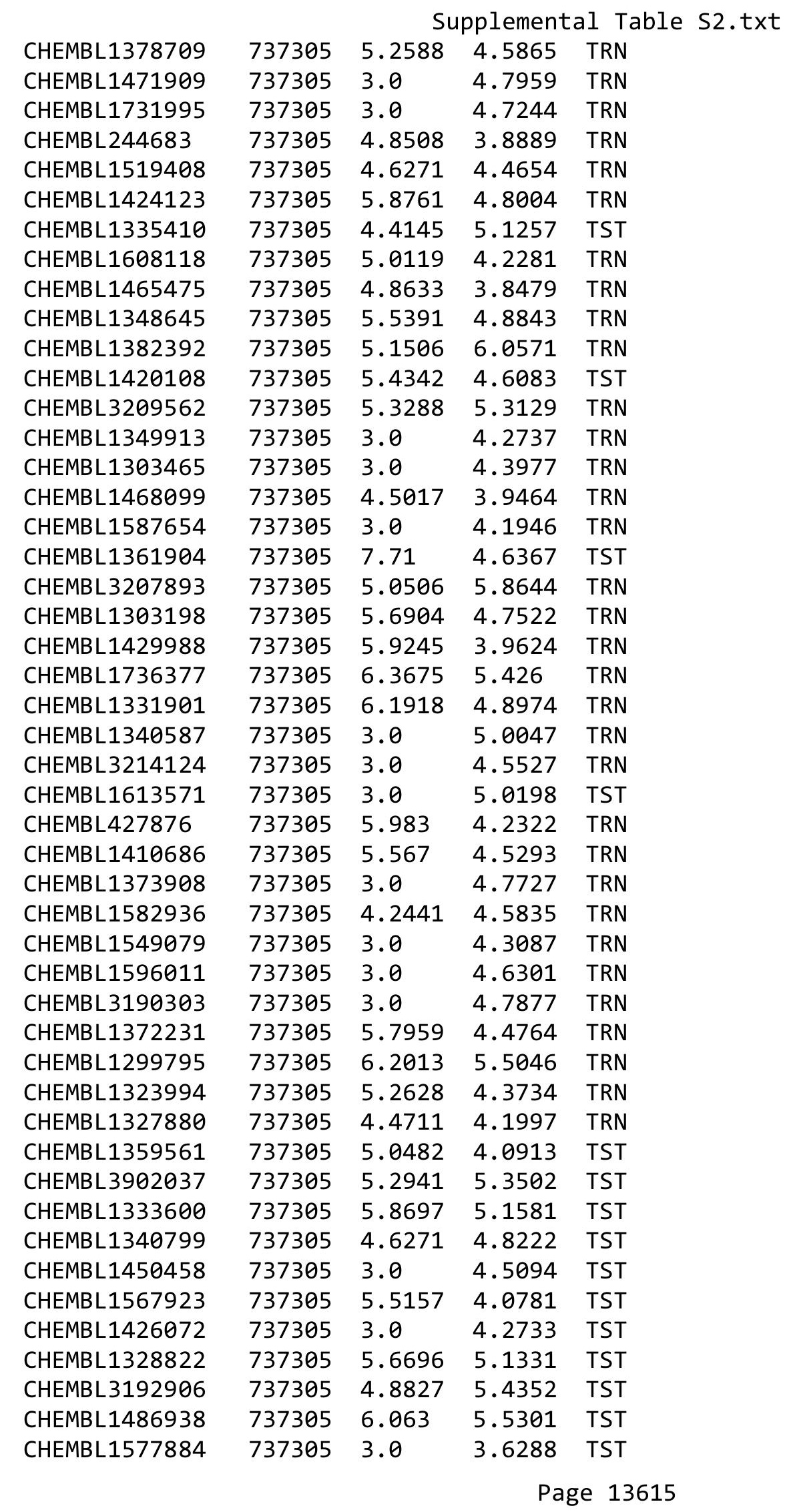




\begin{tabular}{|c|c|c|c|c|c|c|}
\hline \multirow[b]{2}{*}{ CHEMBL1490677 } & & \multicolumn{5}{|c|}{ Supplemental Table s2.txt } \\
\hline & 737305 & 4.9957 & \multicolumn{3}{|c|}{4.343999999999999} & TST \\
\hline CHEMBL1609317 & 737305 & 4.6402 & 4.725 & TST & & \\
\hline CHEMBL1544951 & 737305 & 4.3161 & 4.1506 & TST & & \\
\hline CHEMBL1480992 & 737168 & \multicolumn{3}{|c|}{5.2620000000000005} & 5.1893 & TRN \\
\hline CHEMBL1318162 & 737168 & 4.921 & 5.2051 & TRN & & \\
\hline CHEMBL1303289 & 737168 & 5.4861 & 4.9455 & TRN & & \\
\hline CHEMBL1307845 & 737168 & 4.3485 & 3.9565 & TRN & & \\
\hline CHEMBL1451147 & 737168 & 5.1798 & 5.1276 & TRN & & \\
\hline CHEMBL1416798 & 737168 & 5.3561 & 5.2718 & TRN & & \\
\hline CHEMBL3210843 & 737168 & 5.2538 & 4.8731 & TST & & \\
\hline CHEMBL1595086 & 737168 & 3.0 & 4.151 & TRN & & \\
\hline CHEMBL1469858 & 737168 & 5.3434 & 4.8541 & TRN & & \\
\hline CHEMBL1560104 & 737168 & 5.0168 & 5.28 & TRN & & \\
\hline CHEMBL1570406 & 737168 & 4.9259 & 4.98600 & 0000000001 & & TRN \\
\hline CHEMBL 2001904 & 737168 & 5.1672 & 4.3144 & TST & & \\
\hline CHEMBL589711 & 737168 & 5.6536 & 4.9741 & TRN & & \\
\hline CHEMBL1364684 & 737168 & 5.3645 & 4.8836 & TRN & & \\
\hline CHEMBL1423915 & 737168 & 5.7328 & 5.2773 & TRN & & \\
\hline CHEMBL1582188 & 737168 & 3.0 & 3.8234 & TRN & & \\
\hline CHEMBL1439545 & 737168 & 4.6174 & 4.0136 & TRN & & \\
\hline CHEMBL3191942 & 737168 & 4.1624 & 3.847 & TRN & & \\
\hline CHEMBL1575292 & 737168 & 3.0 & 3.5231 & TRN & & \\
\hline CHEMBL3192559 & 737168 & 3.0 & 4.6748 & TST & & \\
\hline CHEMBL1789987 & 737168 & 5.4336 & 5.3796 & TRN & & \\
\hline CHEMBL1382280 & 737168 & 4.5086 & 3.957 & TRN & & \\
\hline CHEMBL1587391 & 737168 & 4.1132 & 4.0448 & TRN & & \\
\hline CHEMBL1591536 & 737168 & 4.894 & 5.2863 & TRN & & \\
\hline CHEMBL1423236 & 737168 & 5.2656 & 5.1215 & TRN & & \\
\hline CHEMBL1383779 & 737168 & 5.6055 & 5.22 & TRN & & \\
\hline CHEMBL1359526 & 737168 & 5.3645 & 5.2761 & TRN & & \\
\hline CHEMBL1400038 & 737168 & 4.8474 & 4.9203 & TRN & & \\
\hline CHEMBL1573412 & 737168 & 5.2741 & 3.8208 & TRN & & \\
\hline CHEMBL1497097 & 737168 & 5.4566 & 5.5804 & TRN & & \\
\hline CHEMBL3195960 & 737168 & 5.357 & 5.3397 & TRN & & \\
\hline CHEMBL1364118 & 737168 & 4.1895 & 4.0385 & TRN & & \\
\hline CHEMBL1483521 & 737168 & 5.2179 & 4.8136 & TRN & & \\
\hline CHEMBL1479067 & 737168 & 3.0 & 4.5608 & TRN & & \\
\hline CHEMBL1423536 & 737168 & 5.1287 & 5.3831 & TRN & & \\
\hline CHEMBL3190268 & 737168 & 3.0 & 2.7523 & TRN & & \\
\hline CHEMBL1369880 & 737168 & 5.1848 & 5.2834 & TRN & & \\
\hline CHEMBL1441794 & 737168 & 3.0 & 3.7369 & TRN & & \\
\hline CHEMBL1334858 & 737168 & 4.9991 & 5.0587 & TRN & & \\
\hline CHEMBL1379062 & 737168 & 5.1972 & 4.5883 & TRN & & \\
\hline CHEMBL1970493 & 737168 & 4.9886 & 4.2608 & TST & & \\
\hline CHEMBL1563641 & 737168 & 5.5513 & 5.1995 & TRN & & \\
\hline CHEMBL3199328 & 737168 & 3.0 & 2.9406 & TRN & & \\
\hline CHEMBL1578367 & 737168 & 4.3346 & 3.9975 & TRN & & \\
\hline CHEMBL1991440 & 737168 & 3.0 & 3.5133 & TRN & & \\
\hline
\end{tabular}




\begin{tabular}{|c|c|c|c|c|c|}
\hline \multicolumn{6}{|c|}{ Supplemental Table S2.txt } \\
\hline CHEMBL1487716 & 737168 & 3.0 & 3.3874 & TRN & \\
\hline CHEMBL1985932 & 737168 & 4.1918 & 3.7871 & TRN & \\
\hline CHEMBL3210536 & 737168 & 3.0 & 2.98199 & 99999999998 & TRN \\
\hline CHEMBL1535072 & 737168 & 5.2251 & 5.2166 & TRN & \\
\hline CHEMBL1547939 & 737168 & 5.1861 & 5.1761 & TRN & \\
\hline CHEMBL3213476 & 737168 & 5.2347 & 4.5832 & TST & \\
\hline CHEMBL1333544 & 737168 & 5.1503 & 5.0465 & TRN & \\
\hline CHEMBL1589193 & 737168 & 4.2008 & 4.7975 & TRN & \\
\hline CHEMBL1497457 & 737168 & 5.1469 & 4.6836 & TRN & \\
\hline CHEMBL1312519 & 737168 & 5.2277 & 4.7216 & TRN & \\
\hline CHEMBL3212986 & 737168 & 5.0355 & 4.4713 & TRN & \\
\hline CHEMBL1596870 & 737168 & 4.2453 & 4.6393 & TRN & \\
\hline CHEMBL1506901 & 737168 & 3.0 & 3.5352 & TRN & \\
\hline CHEMBL1445700 & 737168 & 5.5591 & 5.227 & TRN & \\
\hline CHEMBL1965155 & 737168 & 4.3416 & 4.1438 & TRN & \\
\hline CHEMBL1603147 & 737168 & 4.5478 & 4.6318 & TRN & \\
\hline CHEMBL1993780 & 737168 & 4.3372 & 3.6273 & TRN & \\
\hline CHEMBL1612391 & 737168 & 3.0 & 3.4035 & TRN & \\
\hline CHEMBL1586498 & 737168 & 4.2054 & 4.3078 & TRN & \\
\hline CHEMBL1422684 & 737168 & 5.2073 & 5.0626 & TRN & \\
\hline CHEMBL1452833 & 737168 & 5.1349 & 5.6264 & TST & \\
\hline CHEMBL1610821 & 737168 & 5.2269 & 5.584 & TRN & \\
\hline CHEMBL1317842 & 737168 & 5.035 & 5.0124 & TRN & \\
\hline CHEMBL1485592 & 737168 & 4.7904 & 5.2537 & TRN & \\
\hline CHEMBL1542453 & 737168 & 5.0453 & 4.6612 & TRN & \\
\hline CHEMBL1577127 & 737168 & 5.5646 & 5.5422 & TRN & \\
\hline CHEMBL1318253 & 737168 & 5.2737 & 5.1983 & TRN & \\
\hline CHEMBL1339518 & 737168 & 5.1586 & 5.2417 & TST & \\
\hline CHEMBL1414701 & 737168 & 5.1198 & 5.4014 & TRN & \\
\hline CHEMBL1463019 & 737168 & 5.0417 & 5.0521 & TRN & \\
\hline CHEMBL1422657 & 737168 & 4.4759 & 4.657 & TRN & \\
\hline CHEMBL1449357 & 737168 & 5.1099 & 4.5792 & TRN & \\
\hline CHEMBL1602624 & 737168 & 4.0435 & 4.0492 & TRN & \\
\hline CHEMBL1430103 & 737168 & 5.1769 & 5.346 & TRN & \\
\hline CHEMBL1482955 & 737168 & 3.0 & 4.4863 & TRN & \\
\hline CHEMBL1561115 & 737168 & 3.0 & 3.6057 & TRN & \\
\hline CHEMBL1321632 & 737168 & 4.8731 & 5.1474 & TRN & \\
\hline CHEMBL1599517 & 737168 & 5.1593 & 5.3938 & TRN & \\
\hline CHEMBL1319613 & 737168 & 4.169 & 4.4017 & TRN & \\
\hline CHEMBL1378601 & 737168 & 5.2182 & 5.3655 & TST & \\
\hline CHEMBL1448744 & 737168 & 4.5728 & 3.8402 & TRN & \\
\hline CHEMBL3196705 & 737168 & 5.289 & 4.6912 & TRN & \\
\hline CHEMBL1489703 & 737168 & 4.9765 & 5.3265 & TRN & \\
\hline CHEMBL1464460 & 737168 & 5.3979 & 4.7905 & TRN & \\
\hline CHEMBL1343383 & 737168 & 5.2441 & 5.3647 & TRN & \\
\hline CHEMBL1349518 & 737168 & 4.6666 & 4.9944 & TRN & \\
\hline CHEMBL1572009 & 737168 & 4.9144 & 5.4101 & TRN & \\
\hline CHEMBL1355123 & 737168 & 5.2495 & 5.2835 & TRN & \\
\hline
\end{tabular}




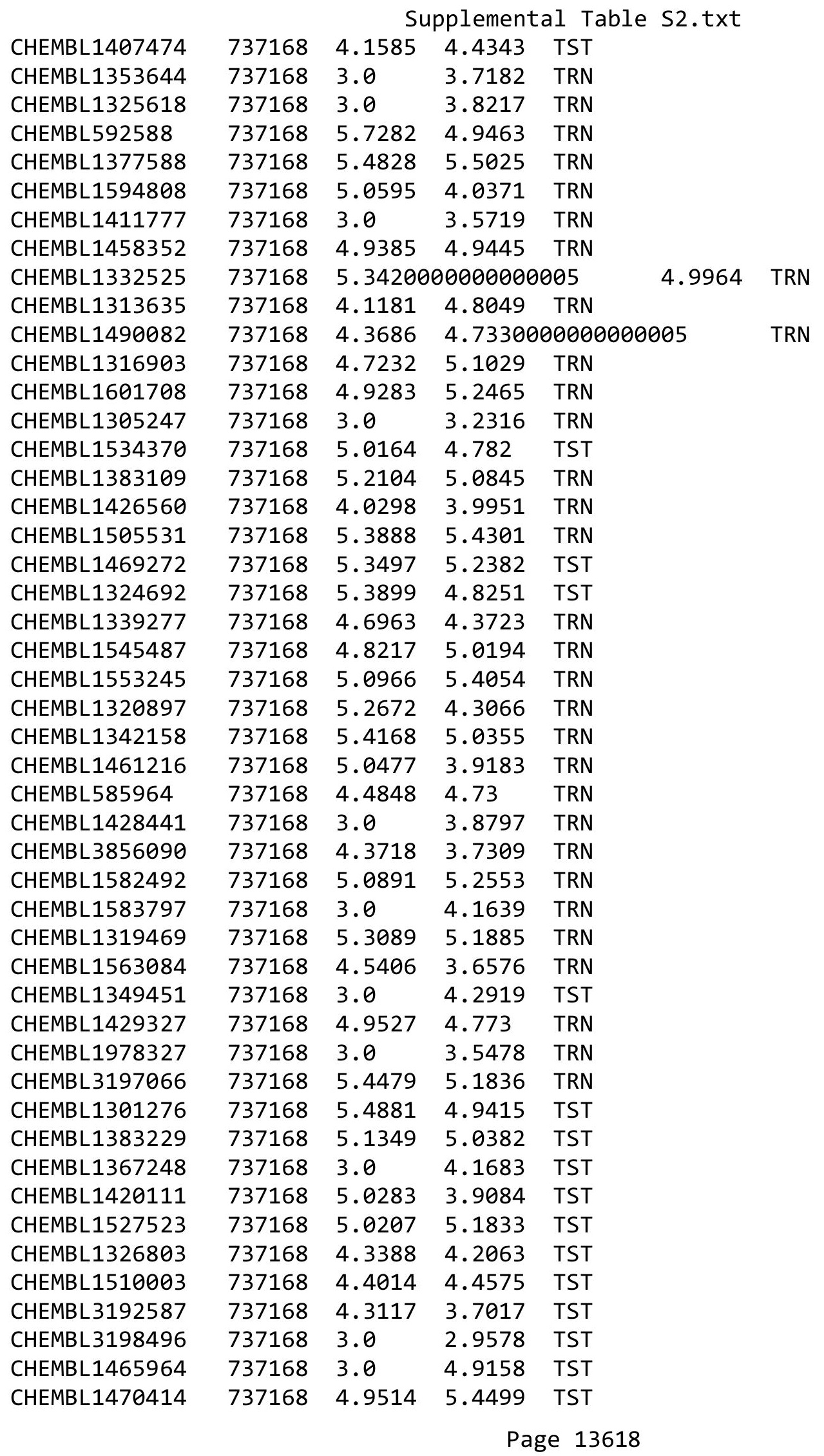




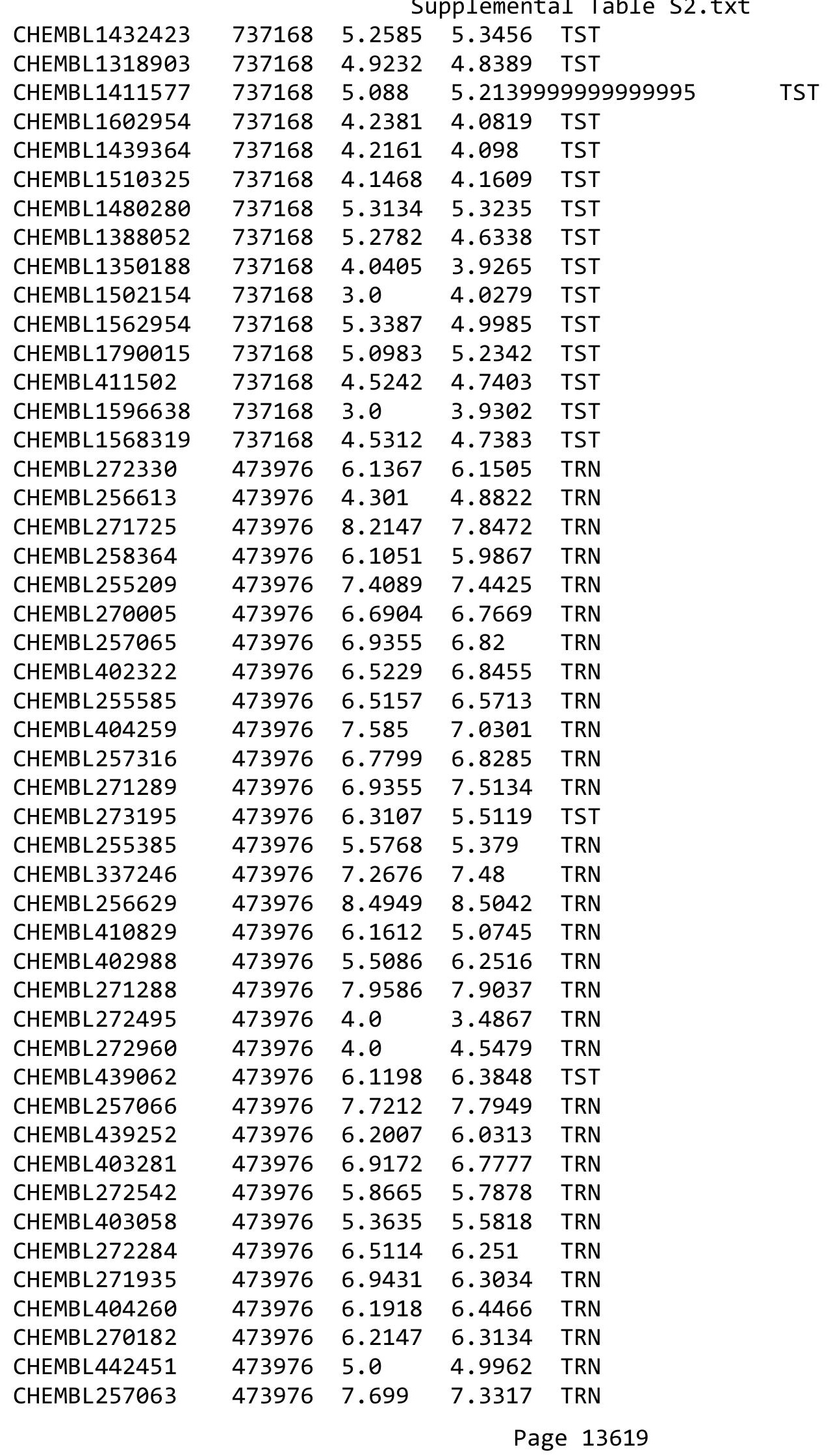




\begin{tabular}{|c|c|c|c|c|c|}
\hline \multicolumn{6}{|c|}{ Supplemental Table S2 } \\
\hline CHEMBL271494 & 473976 & 4.0 & 4.4978 & TST & \\
\hline CHEMBL257062 & 473976 & 8.3872 & 7.5742 & TST & \\
\hline CHEMBL255408 & 473976 & 6.7447 & 5.9734 & TRN & \\
\hline CHEMBL256612 & 473976 & 4.301 & 4.0526 & TRN & \\
\hline CHEMBL272331 & 473976 & 6.8153 & 6.4143 & TRN & \\
\hline CHEMBL270435 & 473976 & 8.2757 & 7.3546 & TST & \\
\hline CHEMBL409679 & 473976 & 4.0 & 5.3417 & TST & \\
\hline CHEMBL405633 & 473976 & 7.2291 & 6.8645 & TRN & \\
\hline CHEMBL272283 & 473976 & 7.0555 & 6.8225 & TST & \\
\hline CHEMBL429912 & 473976 & 5.4989 & 5.6756 & TRN & \\
\hline CHEMBL272543 & 473976 & 6.0177 & 6.3715 & TRN & \\
\hline CHEMBL404533 & 473976 & 4.0 & 4.6672 & TRN & \\
\hline CHEMBL404837 & 473976 & 6.6819 & 6.0466 & TST & \\
\hline CHEMBL271726 & 473976 & 5.6198 & 5.0285 & TRN & \\
\hline CHEMBL 257866 & 473976 & 4.301 & 5.6682 & TRN & \\
\hline CHEMBL257511 & 473976 & 5.8097 & 6.2093 & TRN & \\
\hline CHEMBL258366 & 473976 & 4.0 & 4.0949 & TRN & \\
\hline CHEMBL270205 & 473976 & 7.0177 & 7.9218 & TST & \\
\hline CHEMBL408908 & 473976 & 7.8539 & 7.3802 & TST & \\
\hline CHEMBL 257510 & 473976 & 6.0799 & 5.3688 & TST & \\
\hline CHEMBL257702 & 473976 & 6.0177 & 6.3393 & TRN & \\
\hline CHEMBL405632 & 473976 & 5.6234 & 5.584 & TRN & \\
\hline CHEMBL404577 & 473976 & 4.0 & 5.0125 & TST & \\
\hline CHEMBL272496 & 473976 & 4.0 & 4.9374 & TST & \\
\hline CHEMBL 257064 & 473976 & 7.3768 & 7.5219 & TST & \\
\hline CHEMBL404269 & 473976 & 7.2757 & 7.5468 & TST & \\
\hline CHEMBL271290 & 473976 & 7.699 & 7.88399 & 99999999995 & TST \\
\hline CHEMBL402723 & 473976 & 6.6459 & 6.481 & TRN & \\
\hline CHEMBL 3678106 & 1528468 & 8.5229 & 5.7021 & TST & \\
\hline CHEMBL 3678153 & 1528468 & 7.2147 & 7.099 & TRN & \\
\hline CHEMBL 3678112 & 1528468 & 7.1612 & 7.3547 & TRN & \\
\hline CHEMBL 3678151 & 1528468 & 6.983 & 7.6965 & TRN & \\
\hline CHEMBL3678159 & 1528468 & 7.7959 & 7.2262 & TRN & \\
\hline CHEMBL 3678097 & 1528468 & 6.8327 & 6.015 & TRN & \\
\hline CHEMBL 3678147 & 1528468 & 7.0132 & 6.9777 & TRN & \\
\hline CHEMBL3639769 & 1528468 & 6.9706 & 6.7786 & TRN & \\
\hline CHEMBL 3678128 & 1528468 & 6.0 & 7.8566 & TRN & \\
\hline CHEMBL 3678107 & 1528468 & 7.3565 & 6.8818 & TRN & \\
\hline CHEMBL 3678156 & 1528468 & 7.2147 & 7.1897 & TRN & \\
\hline CHEMBL 3678124 & 1528468 & 6.9957 & 6.8996 & TRN & \\
\hline CHEMBL 3678095 & 1528468 & 5.0 & 5.7401 & TRN & \\
\hline CHEMBL 3678139 & 1528468 & 7.1192 & 7.1334 & TRN & \\
\hline CHEMBL 3678126 & 1528468 & 9.2218 & 8.5359 & TRN & \\
\hline CHEMBL 3678080 & 1528468 & 6.4989 & 6.4907 & TRN & \\
\hline CHEMBL 3678102 & 1528468 & 5.0 & 6.1339 & TST & \\
\hline CHEMBL 3678145 & 1528468 & 6.9208 & 7.1759 & TRN & \\
\hline CHEMBL 3678136 & 1528468 & 8.301 & 8.6897 & TRN & \\
\hline CHEMBL 3678133 & 1528468 & 9.5229 & 9.2669 & TRN & \\
\hline
\end{tabular}


Supplemental Table S2.txt

\begin{tabular}{|c|c|c|c|c|c|}
\hline CHEMBL 3678119 & 1528468 & 6.9706 & 7.0107 & TRN & \\
\hline CHEMBL 3678108 & 1528468 & 6.8996 & 7.0682 & TRN & \\
\hline CHEMBL 3678155 & 1528468 & 7.3979 & 7.2576 & TRN & \\
\hline CHEMBL 3678089 & 1528468 & 8.3979 & 5.9776 & TST & \\
\hline CHEMBL 3678150 & 1528468 & 7.0862 & 7.1959 & TRN & \\
\hline CHEMBL 3678111 & 1528468 & 7.2518 & 7.2646 & TRN & \\
\hline CHEMBL 3678149 & 1528468 & 7.2291 & 7.0816 & TRN & \\
\hline CHEMBL 3678138 & 1528468 & 6.4976 & 6.3028 & TRN & \\
\hline CHEMBL 3678086 & 1528468 & 9.0 & 6.1837 & TST & \\
\hline CHEMBL3678110 & 1528468 & 6.4318 & 6.4437 & TRN & \\
\hline CHEMBL 3678143 & 1528468 & 6.4547 & 6.2904 & TRN & \\
\hline CHEMBL 3678141 & 1528468 & 7.1739 & 7.2971 & TRN & \\
\hline CHEMBL 3678092 & 1528468 & 7.3098 & 6.2551 & TST & \\
\hline CHEMBL 3678096 & 1528468 & 5.1739 & 5.7463 & TST & \\
\hline CHEMBL 3678118 & 1528468 & 7.2291 & 7.3046 & TRN & \\
\hline CHEMBL 3678103 & 1528468 & 6.2495 & 6.0746 & TST & \\
\hline CHEMBL 3678160 & 1528468 & 7.699 & 7.6198 & TRN & \\
\hline CHEMBL 3678135 & 1528468 & 8.7959 & 8.8552 & TRN & \\
\hline CHEMBL 3678121 & 1528468 & 7.1308 & 7.2896 & TRN & \\
\hline CHEMBL 3678154 & 1528468 & 7.0862 & 6.8067 & TRN & \\
\hline CHEMBL3678130 & 1528468 & 8.301 & 8.3295 & TRN & \\
\hline CHEMBL 3678113 & 1528468 & 6.8827 & 6.8063 & TRN & \\
\hline CHEMBL 3678132 & 1528468 & 9.2218 & 9.0585 & TRN & \\
\hline CHEMBL 3678152 & 1528468 & 6.6716 & 6.7388 & TRN & \\
\hline CHEMBL 3678098 & 1528468 & 10.0 & 6.6745 & TST & \\
\hline CHEMBL3678157 & 1528468 & 7.1549 & 7.5891 & TRN & \\
\hline CHEMBL 3678100 & 1528468 & 5.0 & 6.0135 & TST & \\
\hline CHEMBL 3678140 & 1528468 & 7.6021 & 6.4424 & TRN & \\
\hline CHEMBL 3678129 & 1528468 & 8.7959 & 8.3329 & TRN & \\
\hline CHEMBL 3678162 & 1528468 & 7.4089 & 7.1044 & TRN & \\
\hline CHEMBL 3678122 & 1528468 & 6.0 & 7.1138 & TRN & \\
\hline CHEMBL 3678087 & 1528468 & 8.301 & 5.8912 & TST & \\
\hline CHEMBL 3678090 & 1528468 & 8.1549 & 6.2062 & TST & \\
\hline CHEMBL 3678148 & 1528468 & 6.5935 & 6.58799 & & TRN \\
\hline CHEMBL 3678091 & 1528468 & 5.0 & 5.7444 & TST & \\
\hline CHEMBL 3678083 & 1528468 & 6.0 & 6.0586 & TST & \\
\hline CHEMBL 3678104 & 1528468 & 7.0088 & 6.0011 & TST & \\
\hline CHEMBL 3678146 & 1528468 & 6.0 & 6.6961 & TRN & \\
\hline CHEMBL 3678125 & 1528468 & 9.2218 & 8.5011 & TRN & \\
\hline CHEMBL 3678127 & 1528468 & 9.1549 & 8.7871 & TRN & \\
\hline CHEMBL3678134 & 1528468 & 6.0 & 8.3577 & TRN & \\
\hline CHEMBL3678137 & 1528468 & 7.5086 & 7.1258 & TRN & \\
\hline CHEMBL 3678099 & 1528468 & 7.5376 & 6.3907 & TST & \\
\hline CHEMBL 3678163 & 1528468 & 7.1135 & 7.6153 & TRN & \\
\hline CHEMBL 3678158 & 1528468 & 8.0 & 7.3893 & TRN & \\
\hline CHEMBL 3678142 & 1528468 & 6.8447 & 6.6692 & TRN & \\
\hline CHEMBL 3678101 & 1528468 & 6.0 & 6.1542 & TST & \\
\hline CHEMBL 3678161 & 1528468 & 7.8861 & 7.1145 & TRN & \\
\hline
\end{tabular}

Page 13621 
Supplemental Table S2.txt

\begin{tabular}{|c|c|c|c|c|}
\hline HEMBL3678109 & 1528468 & 6.9066 & 7.0374 & TRN \\
\hline HEMBL 3678081 & 1528468 & 5.0 & 6.0934 & TST \\
\hline AEMBL 36 & 528468 & 10.2218 & 9.0472 & rRN \\
\hline HEMBL 3678082 & 528468 & 6.5229 & 6.3463 & ST \\
\hline HEMBL3678120 & 528468 & 6.4935 & .5805 & N \\
\hline HEMBL3678105 & 528468 & 8.1549 & 6.5812 & TST \\
\hline HEMBL3678144 & 528468 & 5.3979 & 5.7176 & RN \\
\hline HEMBL 24257 & 10574 & 5.0 & 4.7753 & ST \\
\hline HEMBL 26117 & 10574 & 5.3979 & 5.2564 & RN \\
\hline HEMBL281893 & 10574 & 6.301 & 6.4059 & rRN \\
\hline HEMBL 25928 & 10574 & 6.8239 & 7.0657 & $\mathrm{RN}$ \\
\hline HEMBL 24284 & 10574 & 6.0 & 3.7325 & ST \\
\hline HEMBL 26161 & 10574 & 5.5229 & 5.6202 & RN \\
\hline HEMBL 281220 & 210574 & 4.301 & 4.0125 & $\mathrm{RN}$ \\
\hline HEMBL 24749 & 10574 & 5.699 & 4.8358 & TST \\
\hline JEMBL 24559 & 10574 & 5.6021 & 5.8337 & TRN \\
\hline HEMBL 280736 & 10574 & 6.4685 & 998 & $\mathrm{RN}$ \\
\hline HEMBL 24100 & 210574 & 5.301 & & $\mathrm{RN}$ \\
\hline HEMBL 26458 & 210574 & 7.0 & & TST \\
\hline HEMBL 25997 & 10574 & 5.301 & & TRN \\
\hline HEMBL 285126 & 10574 & 3.0 & 3.2087 & TRN \\
\hline HEMBL 284432 & 10574 & 4.3979 & 902 & RN \\
\hline HEMBL 26174 & 10574 & 6.8239 & 579 & $\mathrm{RN}$ \\
\hline HEMBL 24439 & 210574 & 3.0 & & TRN \\
\hline HEMBL 25831 & 10574 & 5.301 & & TRN \\
\hline HEMBL 24156 & 10574 & 5.301 & 3. & TST \\
\hline HEMBL280994 & 10574 & 6.301 & 5 . & TRN \\
\hline HEMBL 283012 & 10574 & 3.8239 & 26 & TRN \\
\hline HEMBL24160 & 210574 & 6.699 & & TRN \\
\hline HEMBL 280738 & 10574 & 6.3979 & & TRN \\
\hline CHEMBL 285102 & 10574 & 4.5229 & 3. & TST \\
\hline HEMBL26051 & 10574 & 6.0 & 5 . & TRN \\
\hline HEMBL 26063 & 10574 & 4.3979 & 25 & TRN \\
\hline HEMBL 24166 & 10574 & 6.301 & 6 . & TRN \\
\hline HEMBL 24318 & 10574 & 6.5229 & 5 . & TRN \\
\hline CHEMBL24617 & 10574 & 5.301 & & rRN \\
\hline HEMBL 24103 & 10574 & 3.0 & 3 . & TRN \\
\hline CHEMBL418752 & 10574 & 5.301 & 979 & TRN \\
\hline CHEMBL24492 & 10574 & 4.0 & $\partial 91$ & TRN \\
\hline CHEMBL26450 & 10574 & 5.6021 & & TST \\
\hline CHEMBL422043 & 210574 & 5.3468 & 4. & TRN \\
\hline CHEMBL26228 & 10574 & 6.8239 & 5.2878 & TRN \\
\hline CHEMBL283688 & 10574 & 6.5229 & 5.8079 & TRN \\
\hline CHEMBL 24372 & 10574 & 5.5229 & 5.9599 & TRN \\
\hline CHEMBL 24437 & 10574 & 5.0969 & 5.3692 & TRN \\
\hline CHEMBL23332 & 210574 & 5.3979 & 4.3071 & TST \\
\hline CHEMBL430540 & 210574 & 7.0 & 6.9319 & TRN \\
\hline CHEMBL25241 & 210574 & 5.3979 & 3.4839 & STT \\
\hline
\end{tabular}

Page 13622 


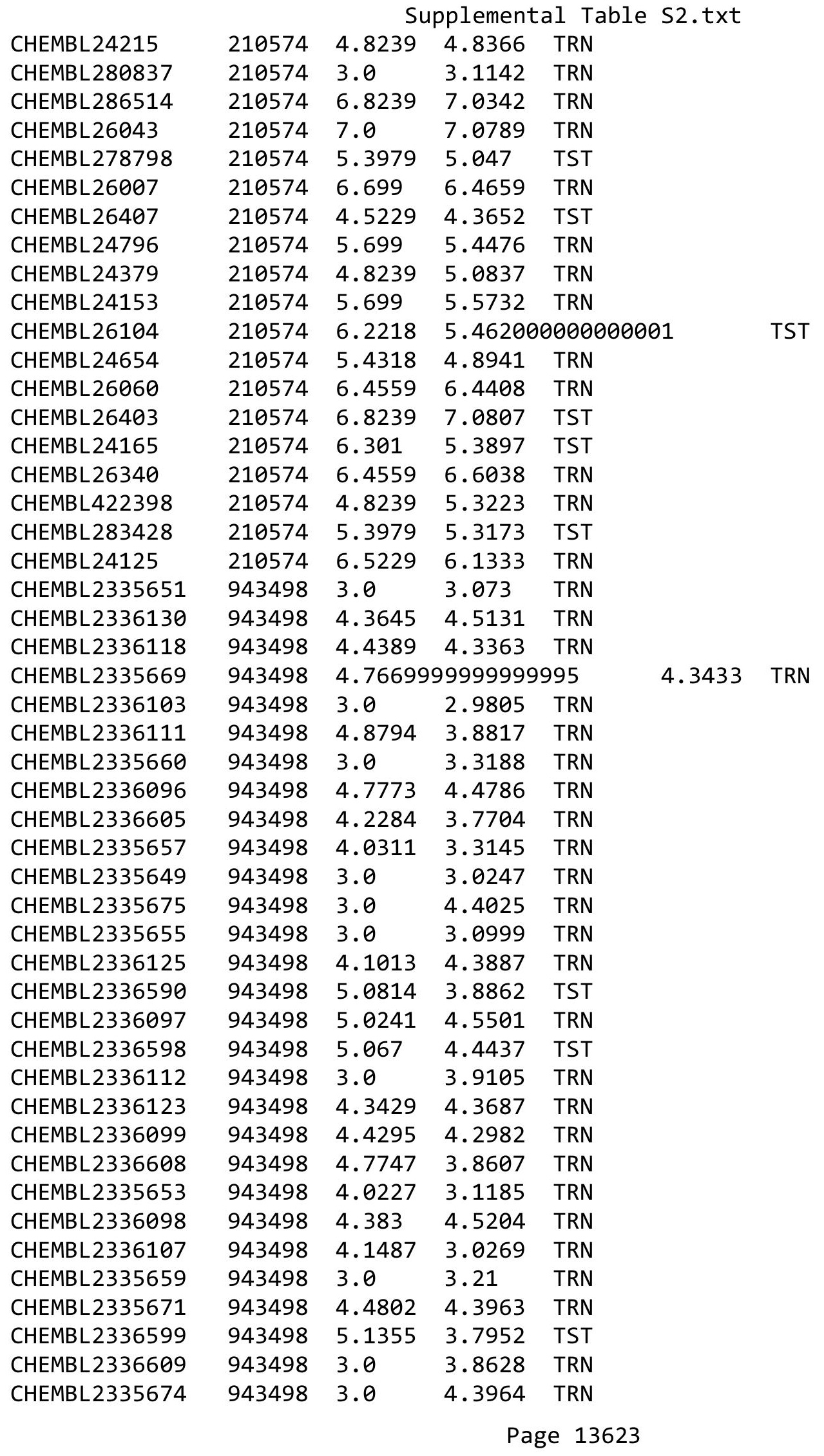




\begin{tabular}{|c|c|c|c|c|c|c|}
\hline & & \multicolumn{5}{|c|}{ Supplemental Table S2.txt } \\
\hline CHEMBL2336591 & 943498 & 4.7282 & 4.3508 & TST & & \\
\hline CHEMBL2335662 & 943498 & 3.0 & 3.3657 & TRN & & \\
\hline CHEMBL2336600 & 943498 & 5.0434 & 3.0737 & TST & & \\
\hline CHEMBL2336128 & 943498 & 4.2027 & 4.4178 & TRN & & \\
\hline CHEMBL2335679 & 943498 & 3.0 & 4.4021 & TRN & & \\
\hline CHEMBL2336092 & 943498 & 4.3645 & 4.5706 & TRN & & \\
\hline CHEMBL2336587 & 943498 & \multicolumn{3}{|c|}{4.9830000000000005} & 4.4709 & TRN \\
\hline CHEMBL 2336100 & 943498 & 3.0 & 4.45 & TST & & \\
\hline CHEMBL2336109 & 943498 & 3.0 & 3.8238 & TRN & & \\
\hline CHEMBL2335667 & 943498 & 4.5622 & 4.4549 & TRN & & \\
\hline CHEMBL2336124 & 943498 & 4.585 & 4.3865 & TRN & & \\
\hline CHEMBL2336116 & 943498 & 4.2321 & 4.2906 & TRN & & \\
\hline CHEMBL 2336108 & 943498 & 3.0 & 3.89300 & 0000000000 & 02 & TRN \\
\hline CHEMBL 2335672 & 943498 & 4.4547 & 4.4036 & TRN & & \\
\hline CHEMBL2336119 & 943498 & 4.5086 & 4.3511 & TRN & & \\
\hline CHEMBL 2335654 & 943498 & 3.0 & 3.1084 & TRN & & \\
\hline CHEMBL2336126 & 943498 & 4.4306 & 4.3856 & TRN & & \\
\hline CHEMBL 2336594 & 943498 & 4.5229 & 3.1928 & TST & & \\
\hline CHEMBL 2335664 & 943498 & 3.0 & 3.2537 & TRN & & \\
\hline CHEMBL2335676 & 943498 & 4.6737 & 4.3844 & TRN & & \\
\hline CHEMBL2336105 & 943498 & 3.0 & 3.0381 & TRN & & \\
\hline CHEMBL2336120 & 943498 & 4.1898 & 4.3222 & TRN & & \\
\hline CHEMBL 2335681 & 943498 & 4.4698 & 4.4365 & TRN & & \\
\hline CHEMBL2335658 & 943498 & 3.0 & 3.3651 & TRN & & \\
\hline CHEMBL2336115 & 943498 & 4.9706 & 3.9474 & TRN & & \\
\hline CHEMBL2336095 & 943498 & 4.8794 & 4.57600 & 0000000000 & & TRN \\
\hline CHEMBL2336593 & 943498 & 4.6216 & 3.0095 & TST & & \\
\hline CHEMBL 2335677 & 943498 & 4.6003 & 4.4062 & TRN & & \\
\hline CHEMBL2336101 & 943498 & 3.0 & 4.496 & TST & & \\
\hline CHEMBL 2336114 & 943498 & 4.6234 & 3.92100 & 0000000000 & 03 & TST \\
\hline CHEMBL2336131 & 943498 & 4.7645 & 4.4304 & TRN & & \\
\hline CHEMBL2336604 & 943498 & 4.15300 & 30000000 & 205 & 3.7718 & TST \\
\hline CHEMBL2336113 & 943498 & 4.3936 & 3.9191 & TST & & \\
\hline CHEMBL2336606 & 943498 & 4.9136 & 3.8279 & TST & & \\
\hline CHEMBL 2335648 & 943498 & 3.0 & 3.0237 & TRN & & \\
\hline CHEMBL2336117 & 943498 & 4.6003 & 4.2881 & TRN & & \\
\hline CHEMBL2336129 & 943498 & 4.9318 & 4.4437 & TRN & & \\
\hline CHEMBL2335656 & 943498 & 3.0 & 3.1462 & TRN & & \\
\hline CHEMBL 2335668 & 943498 & 4.1979 & 4.2419 & TRN & & \\
\hline CHEMBL 2336603 & 943498 & 4.2865 & 3.0014 & TST & & \\
\hline CHEMBL 2336093 & 943498 & 4.6556 & 4.4878 & TRN & & \\
\hline CHEMBL 2335680 & 943498 & 4.762 & 4.4285 & TRN & & \\
\hline CHEMBL2335665 & 943498 & 5.1831 & 4.4339 & TRN & & \\
\hline CHEMBL 2336602 & 943498 & 3.0 & 4.395 & TST & & \\
\hline CHEMBL2336106 & 943498 & 3.0 & 3.0582 & TRN & & \\
\hline CHEMBL2336122 & 943498 & 4.0804 & 4.3456 & TRN & & \\
\hline CHEMBL 2335670 & 943498 & 4.556 & 4.3395 & TRN & & \\
\hline CHEMBL2335663 & 943498 & 3.0 & 3.1319 & TRN & & \\
\hline
\end{tabular}




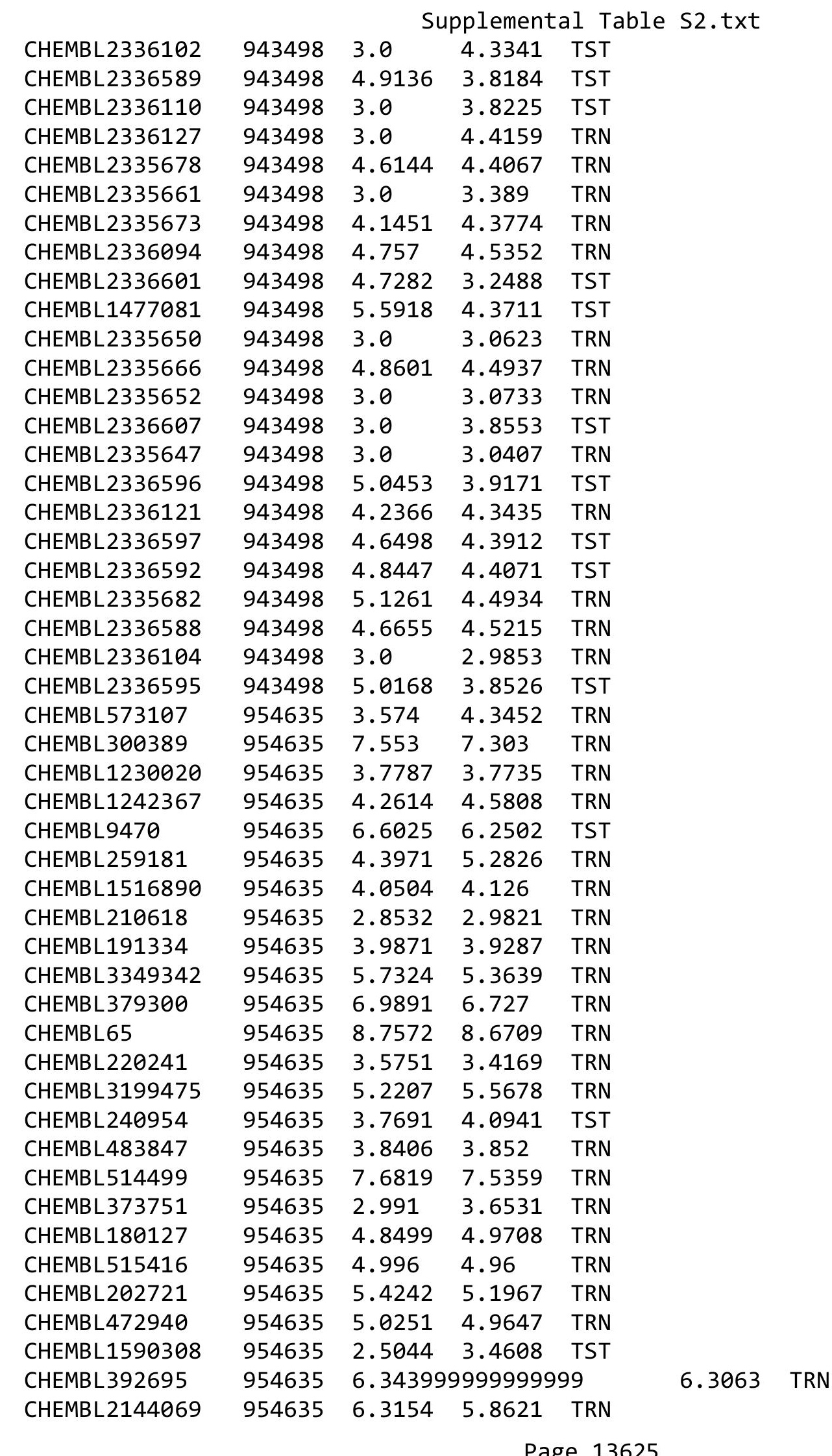

Page 13625 
Supplemental Table S2.txt

\begin{tabular}{|c|c|c|c|c|}
\hline CHEMBL3186408 & 954635 & 3.6171 & 4.1572 & TST \\
\hline CHEMBL 221137 & 954635 & 4.3054 & 5.1754 & TST \\
\hline CHEMBL512504 & 954635 & 3.7144 & 4.0823 & TRN \\
\hline CHEMBL558642 & 954635 & 4.8257 & 5.0274 & TRN \\
\hline CHEMBL393929 & 954635 & 5.687 & 4.7069 & TRN \\
\hline CHEMBL577784 & 954635 & 5.0791 & 5.1507 & TRN \\
\hline CHEMBL585951 & 954635 & 6.0121 & 6.2573 & TRN \\
\hline CHEMBL449158 & 954635 & 6.539 & 6.4263 & TST \\
\hline CHEMBL1357247 & 954635 & 4.2308 & 3.5804 & TRN \\
\hline CHEMBL1909414 & 954635 & 3.4387 & 3.6226 & TRN \\
\hline CHEMBL209148 & 954635 & 5.7911 & 5.8027 & TRN \\
\hline CHEMBL1643959 & 954635 & 3.4694 & 3.4456 & TRN \\
\hline CHEMBL192566 & 954635 & 10.2859 & 8.4269 & TST \\
\hline CHEMBL379975 & 954635 & 5.2272 & 5.2011 & TRN \\
\hline CHEMBL509032 & 954635 & 7.2545 & 6.9992 & TRN \\
\hline CHEMBL 2005886 & 954635 & 7.2384 & 7.2574 & TRN \\
\hline CHEMBL1404918 & 954635 & 2.7955 & 3.2205 & TRN \\
\hline CHEMBL1190711 & 954635 & 5.7428 & 5.8402 & TRN \\
\hline CHEMBL1256459 & 954635 & 7.8798 & 8.3102 & TRN \\
\hline CHEMBL412142 & 954635 & 3.3425 & 3.2004 & TRN \\
\hline CHEMBL3392440 & 954635 & 3.4507 & 3.5356 & TRN \\
\hline CHEMBL 258844 & 954635 & 5.7309 & 5.2542 & TRN \\
\hline CHEMBL102714 & 954635 & 3.0745 & 3.3545 & TRN \\
\hline CHEMBL483849 & 954635 & 3.5269 & 2.996006 & 20000000004 \\
\hline CHEMBL 213100 & 954635 & 3.986 & 3.0844 & TRN \\
\hline CHEMBL135561 & 954635 & 4.1733 & 4.5691 & TRN \\
\hline CHEMBL189584 & 954635 & 5.1719 & 3.9773 & TST \\
\hline CHEMBL 222102 & 954635 & 3.2742 & 3.98100 & 00000000003 \\
\hline CHEMBL1788116 & 954635 & 4.2155 & 4.6406 & TST \\
\hline CHEMBL 92309 & 954635 & 4.3464 & 3.4191 & TST \\
\hline CHEMBL1673039 & 954635 & 5.4138 & 5.4507 & TST \\
\hline CHEMBL1970879 & 954635 & 3.2327 & 5.0086 & TST \\
\hline CHEMBL 2363137 & 954635 & 3.8225 & 4.9104 & TST \\
\hline CHEMBL188678 & 954635 & 3.7991 & 4.7175 & TST \\
\hline CHEMBL1163726 & 637408 & 6.2007 & 6.13200 & $\partial 000000001$ \\
\hline CHEMBL1164340 & 637408 & 6.4685 & 6.4386 & TRN \\
\hline CHEMBL1163969 & 637408 & 6.0 & 6.0439 & TRN \\
\hline CHEMBL1164179 & 637408 & 5.7696 & 5.735 & TRN \\
\hline CHEMBL512986 & 637408 & 7.585 & 7.5509 & TRN \\
\hline CHEMBL 1164090 & 637408 & 7.7696 & 7.6103 & TRN \\
\hline CHEMBL1165681 & 637408 & 7.3872 & 7.4489 & TRN \\
\hline CHEMBL1163583 & 637408 & 6.0 & 5.7399 & TST \\
\hline CHEMBL1164061 & 637408 & 6.2757 & 6.3575 & TRN \\
\hline CHEMBL1163837 & 637408 & 6.1612 & 5.9531 & TRN \\
\hline CHEMBL1164441 & 637408 & 6.0 & 6.1764 & TRN \\
\hline CHEMBL1164152 & 637408 & 7.6198 & 7.5512 & TRN \\
\hline CHEMBL1165522 & 637408 & 6.699 & 6.767 & TRN \\
\hline CHEMBL1163682 & 637408 & 6.6021 & 6.443 & TRN \\
\hline
\end{tabular}




\begin{tabular}{|c|c|c|c|c|c|}
\hline & & \multicolumn{4}{|c|}{ Supplemental Table S2.txt } \\
\hline CHEMBL1163134 & 637408 & 6.4949 & 6.5137 & TRN & \\
\hline CHEMBL1163752 & 637408 & 6.8539 & 6.7807 & TRN & \\
\hline CHEMBL1164062 & 637408 & 6.699 & 6.5855 & TRN & \\
\hline CHEMBL1163883 & 637408 & 5.7212 & 5.7269 & TRN & \\
\hline CHEMBL1164077 & 637408 & 6.7959 & 6.8861 & TRN & \\
\hline CHEMBL1163988 & 637408 & 4.7959 & 4.8489 & TRN & \\
\hline CHEMBL1163182 & 637408 & 5.699 & 5.6248 & TRN & \\
\hline CHEMBL1165839 & 637408 & 5.5086 & 5.5241 & TRN & \\
\hline CHEMBL1163580 & 637408 & 6.0 & 6.1264 & TRN & \\
\hline CHEMBL1163679 & 637408 & 5.8861 & 5.535 & TST & \\
\hline CHEMBL1163502 & 637408 & 4.1938 & 4.2203 & TRN & \\
\hline CHEMBL1163586 & 637408 & 7.7959 & 7.8707 & TST & \\
\hline CHEMBL1164057 & 637408 & 5.9586 & 5.9115 & TRN & \\
\hline CHEMBL1164918 & 637408 & 6.4949 & 6.2315 & TST & \\
\hline CHEMBL1163589 & 637408 & 7.2366 & 6.699 & TST & \\
\hline CHEMBL1163724 & 637408 & 5.9586 & 5.9453 & TRN & \\
\hline CHEMBL1164654 & 637408 & 7.3372 & 7.4947 & TST & \\
\hline CHEMBL1164159 & 637408 & 6.4202 & 6.6128 & TST & \\
\hline CHEMBL1164751 & 637408 & 6.1135 & 6.0849 & TRN & \\
\hline CHEMBL 3138451 & 637408 & 6.9586 & 7.11600 & 00000000005 & TRN \\
\hline CHEMBL1163158 & 637408 & 6.0 & 5.7957 & TST & \\
\hline CHEMBL1164443 & 637408 & 6.9586 & 6.8963 & TST & \\
\hline CHEMBL1165633 & 637408 & 6.7959 & 6.7947 & TRN & \\
\hline CHEMBL1163971 & 637408 & 7.3768 & 7.2588 & TRN & \\
\hline CHEMBL1164004 & 637408 & 5.9586 & 5.8778 & TRN & \\
\hline CHEMBL1164755 & 637408 & 6.6576 & 6.5298 & TST & \\
\hline CHEMBL1163631 & 637408 & 7.585 & 6.4596 & TST & \\
\hline CHEMBL1164005 & 637408 & 6.0706 & 6.1137 & TST & \\
\hline CHEMBL1163962 & 637408 & 6.041 & 6.0476 & TRN & \\
\hline CHEMBL1164551 & 637408 & 4.3468 & 4.2775 & TRN & \\
\hline CHEMBL1163587 & 637408 & 7.7447 & 7.8626 & TST & \\
\hline CHEMBL1164003 & 637408 & 6.7212 & 6.7079 & TRN & \\
\hline CHEMBL1164091 & 637408 & 5.7696 & 5.9008 & TRN & \\
\hline CHEMBL1165523 & 637408 & 6.4815 & 6.6613 & TRN & \\
\hline CHEMBL1163833 & 637408 & 5.9208 & 5.9906 & TRN & \\
\hline CHEMBL1164754 & 637408 & 7.6778 & 7.0883 & TST & \\
\hline CHEMBL1163884 & 637408 & 5.3979 & 5.3985 & TRN & \\
\hline CHEMBL1163706 & 637408 & 6.2441 & 6.3808 & TRN & \\
\hline CHEMBL1163205 & 637408 & 4.3665 & 4.3141 & TRN & \\
\hline CHEMBL1163725 & 637408 & 6.3872 & 6.3844 & TRN & \\
\hline CHEMBL1964290 & 809166 & 4.6 & 4.977 & TRN & \\
\hline CHEMBL 2001398 & 809166 & 4.2 & 4.7399 & TRN & \\
\hline CHEMBL 213505 & 809166 & 6.6 & 6.5905 & TRN & \\
\hline CHEMBL 202721 & 809166 & 7.2 & 6.1839 & TRN & \\
\hline CHEMBL1987034 & 809166 & 6.9 & 7.1632 & TRN & \\
\hline CHEMBL 377383 & 809166 & 4.6 & 4.5384 & TRN & \\
\hline CHEMBL 2005886 & 809166 & 7.0 & 6.9835 & TRN & \\
\hline CHEMBL481491 & 809166 & 4.6 & 4.6141 & TST & \\
\hline
\end{tabular}




\begin{tabular}{|c|c|c|c|c|c|}
\hline & & & & & \\
\hline CHEMBL1682345 & 809166 & 4.6 & 4.4898 & TRN & \\
\hline CHEMBL1973142 & 809166 & 4.6 & 4.4267 & TRN & \\
\hline CHEMBL388311 & 809166 & 6.6 & 6.7919 & TRN & \\
\hline CHEMBL1973145 & 809166 & 4.6 & 5.0189 & TRN & \\
\hline CHEMBL1982924 & 809166 & 5.8 & 5.1036 & TRN & \\
\hline CHEMBL 2005936 & 809166 & 4.6 & 4.4405 & TRN & \\
\hline CHEMBL1807515 & 809166 & 6.6 & 5.6809 & TRN & \\
\hline CHEMBL1964948 & 809166 & 4.2 & 4.2574 & TRN & \\
\hline CHEMBL1971141 & 809166 & 4.6 & 4.6575 & TRN & \\
\hline CHEMBL1995813 & 809166 & 4.6 & 5.55 & TRN & \\
\hline CHEMBL1979718 & 809166 & 4.6 & 4.6404 & TRN & \\
\hline CHEMBL 206236 & 809166 & 4.6 & 4.8636 & TRN & \\
\hline CHEMBL523823 & 809166 & 4.6 & 4.43199 & 99999999995 & TST \\
\hline CHEMBL1973178 & 809166 & 7.5 & 7.6338 & TRN & \\
\hline CHEMBL1987430 & 809166 & 4.2 & 3.9183 & TRN & \\
\hline CHEMBL244378 & 809166 & 6.3 & 6.2836 & TRN & \\
\hline CHEMBL1988778 & 809166 & 6.3 & 6.3337 & TRN & \\
\hline CHEMBL 2001957 & 809166 & 4.6 & 4.6904 & TRN & \\
\hline CHEMBL1969372 & 809166 & 4.6 & 4.8114 & TRN & \\
\hline CHEMBL1993413 & 809166 & 4.2 & 4.4478 & TRN & \\
\hline CHEMBL1990583 & 809166 & 6.8 & 6.7042 & TRN & \\
\hline CHEMBL1986943 & 809166 & 5.9 & 5.7608 & TRN & \\
\hline CHEMBL 2006263 & 809166 & 4.6 & 4.6644 & TST & \\
\hline CHEMBL1993584 & 809166 & 4.6 & 4.7682 & TRN & \\
\hline CHEMBL1986263 & 809166 & 4.6 & 4.9432 & TRN & \\
\hline CHEMBL 2000114 & 809166 & 4.6 & 4.6854 & TRN & \\
\hline CHEMBL 210618 & 809166 & 4.6 & 4.5432 & TRN & \\
\hline CHEMBL1986265 & 809166 & 4.2 & 3.8967 & TRN & \\
\hline CHEMBL1975647 & 809166 & 4.6 & 4.7211 & TRN & \\
\hline CHEMBL1968380 & 809166 & 4.6 & 4.9105 & TRN & \\
\hline CHEMBL1964644 & 809166 & 4.6 & 4.4631 & TRN & \\
\hline CHEMBL1991734 & 809166 & 5.3 & 5.5447 & TST & \\
\hline CHEMBL1981782 & 809166 & 4.6 & 4.4607 & TRN & \\
\hline CHEMBL1977681 & 809166 & 4.6 & 4.7089 & TRN & \\
\hline CHEMBL1970142 & 809166 & 9.0 & 8.648 & TRN & \\
\hline CHEMBL1990912 & 809166 & 4.6 & 4.7043 & TRN & \\
\hline CHEMBL 1983348 & 809166 & 5.4 & 5.1094 & TRN & \\
\hline CHEMBL1988163 & 809166 & 6.7 & 6.4778 & TRN & \\
\hline CHEMBL1995592 & 809166 & 6.1 & 4.9822 & TST & \\
\hline CHEMBL1974480 & 809166 & 5.4 & 5.1622 & TRN & \\
\hline CHEMBL1980671 & 809166 & 5.4 & $4.9510 €$ & 00000000005 & TRN \\
\hline CHEMBL 2006493 & 809166 & 4.6 & 4.624 & TST & \\
\hline CHEMBL1986177 & 809166 & 4.2 & 4.3233 & TRN & \\
\hline CHEMBL1983449 & 809166 & 4.6 & 4.5061 & TRN & \\
\hline CHEMBL1992323 & 809166 & 4.6 & 4.893 & TRN & \\
\hline CHEMBL1969735 & 809166 & 4.6 & 4.8143 & TRN & \\
\hline CHEMBL 2003524 & 809166 & 5.6 & 4.3578 & TST & \\
\hline CHEMBL 2002649 & 809166 & 5.8 & 5.6288 & TRN & \\
\hline & & & & 13628 & \\
\hline
\end{tabular}




\begin{tabular}{|c|c|c|c|c|}
\hline \multicolumn{5}{|c|}{$=11$} \\
\hline CHEMBL1985367 & 809166 & 5.9 & 4.7543 & TST \\
\hline CHEMBL1996510 & 809166 & 4.2 & 4.4037 & TST \\
\hline CHEMBL437747 & 809166 & 4.6 & 4.798 & TRN \\
\hline CHEMBL1995172 & 809166 & 4.4 & 4.0893 & TST \\
\hline CHEMBL 2001584 & 809166 & 4.2 & 4.4652 & TRN \\
\hline CHEMBL507936 & 809166 & 5.9 & 5.3796 & TRN \\
\hline CHEMBL104264 & 809166 & 4.6 & 4.6243 & TST \\
\hline CHEMBL1967998 & 809166 & 7.5 & 7.3544 & TRN \\
\hline CHEMBL1994321 & 809166 & 6.9 & 6.5667 & TRN \\
\hline CHEMBL1978562 & 809166 & 5.3 & 5.4476 & TST \\
\hline CHEMBL1997129 & 809166 & 6.6 & 5.2672 & TRN \\
\hline CHEMBL1984788 & 809166 & 4.6 & 5.2487 & TRN \\
\hline CHEMBL451964 & 809166 & 4.6 & 4.7161 & TRN \\
\hline CHEMBL1964307 & 809166 & 4.6 & 4.921 & TRN \\
\hline CHEMBL1989471 & 809166 & 6.1 & 5.3447 & TST \\
\hline CHEMBL2000508 & 809166 & 4.6 & 4.6125 & TRN \\
\hline CHEMBL1971694 & 809166 & 4.6 & 4.6747 & TST \\
\hline CHEMBL2001547 & 809166 & 4.6 & 4.5672 & TRN \\
\hline CHEMBL 2005824 & 809166 & 5.4 & 5.5229 & TRN \\
\hline CHEMBL 210928 & 809166 & 4.6 & 4.4849 & TRN \\
\hline CHEMBL1978195 & 809166 & 4.2 & 4.0898 & TRN \\
\hline CHEMBL1994361 & 809166 & 4.6 & 4.6272 & TRN \\
\hline CHEMBL1986603 & 809166 & 4.6 & 4.7922 & TST \\
\hline CHEMBL1972840 & 809166 & 4.6 & 4.4165 & TRN \\
\hline CHEMBL1966842 & 809166 & 6.6 & 6.1339 & TRN \\
\hline CHEMBL 2003286 & 809166 & 4.6 & 4.6999 & TRN \\
\hline CHEMBL1992306 & 809166 & 6.6 & 6.2323 & TRN \\
\hline CHEMBL 2002165 & 809166 & 8.5 & 8.6234 & TRN \\
\hline CHEMBL1979318 & 809166 & 4.6 & 4.5787 & TRN \\
\hline CHEMBL 206382 & 809166 & 4.6 & 4.9371 & TRN \\
\hline CHEMBL1998585 & 809166 & 6.9 & 7.1957 & TRN \\
\hline CHEMBL127898 & 809166 & 4.6 & 5.0747 & TST \\
\hline CHEMBL519697 & 809166 & 4.6 & 5.0673 & TRN \\
\hline CHEMBL 2004934 & 809166 & 4.6 & 4.4228 & TRN \\
\hline CHEMBL 2000652 & 809166 & 7.0 & 6.4356 & TRN \\
\hline CHEMBL1996345 & 809166 & 4.2 & 4.6836 & TST \\
\hline CHEMBL1975128 & 809166 & 4.6 & 4.5441 & TRN \\
\hline CHEMBL 2004025 & 809166 & 4.2 & 4.9478 & TRN \\
\hline CHEMBL1996048 & 809166 & 4.2 & 5.1193 & TST \\
\hline CHEMBL1976158 & 809166 & 4.5 & 4.4136 & TST \\
\hline CHEMBL461876 & 809166 & 4.2 & 4.2681 & TRN \\
\hline CHEMBL1965033 & 809166 & 4.2 & 4.5412 & TRN \\
\hline CHEMBL 2001485 & 809166 & 8.4 & 8.3115 & TRN \\
\hline CHEMBL1971519 & 809166 & 5.0 & 4.9857 & TRN \\
\hline CHEMBL504950 & 809166 & 4.6 & 4.8231 & TRN \\
\hline CHEMBL1997335 & 809166 & 4.2 & 4.7011 & TRN \\
\hline CHEMBL1966425 & 809166 & 5.9 & 5.4899 & TRN \\
\hline CHEMBL1984363 & 809166 & 4.6 & 5.268 & TRN \\
\hline
\end{tabular}




\begin{tabular}{|c|c|c|c|c|c|}
\hline & & & & & \\
\hline CHEMBL1978099 & 809166 & 5.7 & 6.3761 & TRN & \\
\hline CHEMBL1977041 & 809166 & 6.5 & 7.0194 & TRN & \\
\hline CHEMBL1968070 & 809166 & 4.6 & 4.4657 & TRN & \\
\hline CHEMBL1988608 & 809166 & 4.6 & 4.3819 & TRN & \\
\hline CHEMBL184847 & 809166 & 6.0 & 5.4134 & TRN & \\
\hline CHEMBL1971132 & 809166 & 4.2 & 3.9583 & TRN & \\
\hline CHEMBL1984367 & 809166 & 4.6 & 4.51699 & 99999999995 & TRN \\
\hline CHEMBL178737 & 809166 & 6.0 & 5.0332 & TST & \\
\hline CHEMBL 226898 & 809166 & 4.6 & 4.7156 & TRN & \\
\hline CHEMBL1982563 & 809166 & 4.6 & 4.7908 & TRN & \\
\hline CHEMBL1991377 & 809166 & 4.2 & 4.0461 & TRN & \\
\hline CHEMBL539474 & 809166 & 4.6 & 5.6521 & TST & \\
\hline CHEMBL575824 & 809166 & 4.6 & 4.8431 & TRN & \\
\hline CHEMBL1988387 & 809166 & 9.0 & 9.3723 & TRN & \\
\hline CHEMBL1973868 & 809166 & 4.2 & 4.3366 & TRN & \\
\hline CHEMBL1972462 & 809166 & 4.2 & 4.3482 & TRN & \\
\hline CHEMBL1997759 & 809166 & 4.6 & 5.0404 & TRN & \\
\hline CHEMBL1970074 & 809166 & 4.6 & 5.0595 & TRN & \\
\hline CHEMBL1986970 & 809166 & 4.6 & 4.6601 & TRN & \\
\hline CHEMBL1958401 & 809166 & 4.6 & 4.6505 & TRN & \\
\hline CHEMBL1984044 & 809166 & 5.6 & 5.1168 & TRN & \\
\hline CHEMBL 2003456 & 809166 & 4.6 & 4.8245 & TRN & \\
\hline CHEMBL1966816 & 809166 & 4.6 & 4.7697 & TRN & \\
\hline CHEMBL 2002992 & 809166 & 4.4 & 4.2943 & TRN & \\
\hline CHEMBL560813 & 809166 & 4.6 & 4.9395 & TRN & \\
\hline CHEMBL1982700 & 809166 & 4.2 & 4.1278 & TST & \\
\hline CHEMBL1968791 & 809166 & 6.3 & 6.3464 & TRN & \\
\hline CHEMBL326282 & 809166 & 4.6 & 4.7959 & TST & \\
\hline CHEMBL1977634 & 809166 & 4.2 & 4.0814 & TRN & \\
\hline CHEMBL1992732 & 809166 & 4.6 & 4.8883 & TST & \\
\hline CHEMBL1971186 & 809166 & 4.6 & 5.1031 & TRN & \\
\hline CHEMBL 2003482 & 809166 & 4.6 & 4.5894 & TRN & \\
\hline CHEMBL1969156 & 809166 & 4.5 & 4.7365 & TRN & \\
\hline CHEMBL1973211 & 809166 & 7.0 & 6.5546 & TRN & \\
\hline CHEMBL1984700 & 809166 & 4.6 & 4.8137 & TRN & \\
\hline CHEMBL 2007151 & 809166 & 6.4 & 6.4651 & TRN & \\
\hline CHEMBL1998953 & 809166 & 4.3 & 4.8571 & TRN & \\
\hline CHEMBL1971606 & 809166 & 4.2 & 4.3583 & TRN & \\
\hline CHEMBL1972125 & 809166 & 4.6 & 4.5082 & TRN & \\
\hline CHEMBL1461728 & 809166 & 4.6 & 4.7381 & TRN & \\
\hline CHEMBL1976134 & 809166 & 4.6 & 5.5464 & TRN & \\
\hline CHEMBL1965131 & 809166 & 4.6 & 4.6481 & TRN & \\
\hline CHEMBL1972158 & 809166 & 4.6 & 4.5759 & TRN & \\
\hline CHEMBL1981215 & 809166 & 4.2 & 4.1306 & TRN & \\
\hline CHEMBL1974457 & 809166 & 4.6 & 4.5258 & TRN & \\
\hline CHEMBL1999414 & 809166 & 7.5 & 7.5213 & TRN & \\
\hline CHEMBL1967336 & 809166 & 4.2 & 4.2102 & TRN & \\
\hline CHEMBL 2001228 & 809166 & 7.4 & 6.4691 & TRN & \\
\hline & & & & 13630 & \\
\hline
\end{tabular}




\begin{tabular}{|c|c|c|c|c|}
\hline & & & & al lable \\
\hline CHEMBL2006581 & 809166 & 4.6 & 4.5917 & TRN \\
\hline CHEMBL1979855 & 809166 & 4.6 & 4.1574 & TRN \\
\hline CHEMBL1970340 & 809166 & 3.6 & 4.314 & TRN \\
\hline CHEMBL1967992 & 809166 & 4.2 & 4.0805 & TRN \\
\hline CHEMBL2005186 & 809166 & 4.6 & 4.8253 & TRN \\
\hline CHEMBL1981671 & 809166 & 4.2 & 4.5443 & TRN \\
\hline CHEMBL 2006450 & 809166 & 4.2 & 4.1577 & TRN \\
\hline CHEMBL1975534 & 809166 & 4.6 & 5.1809 & TRN \\
\hline CHEMBL1993424 & 809166 & 7.0 & 6.3406 & TRN \\
\hline CHEMBL1966703 & 809166 & 4.6 & 4.7191 & TST \\
\hline CHEMBL 2001987 & 809166 & 4.2 & 4.3491 & TRN \\
\hline CHEMBL1969561 & 809166 & 4.6 & 4.7514 & TRN \\
\hline CHEMBL1994555 & 809166 & 4.2 & 5.2958 & TST \\
\hline CHEMBL1983640 & 809166 & 7.1 & 6.5473 & TRN \\
\hline CHEMBL1997023 & 809166 & 4.6 & 4.44 & TST \\
\hline CHEMBL1964687 & 809166 & 4.8 & 6.0785 & TRN \\
\hline CHEMBL1971943 & 809166 & 4.3 & 4.762 & TRN \\
\hline CHEMBL1999918 & 809166 & 5.9 & 4.4717 & TRN \\
\hline CHEMBL1974254 & 809166 & 8.8 & 9.3845 & TRN \\
\hline CHEMBL1997924 & 809166 & 6.6 & 6.2253 & TRN \\
\hline CHEMBL1988537 & 809166 & 4.6 & 4.4183 & TST \\
\hline CHEMBL1969049 & 809166 & 4.6 & 4.3614 & TRN \\
\hline CHEMBL 2005828 & 809166 & 7.0 & 6.7369 & TRN \\
\hline CHEMBL1978267 & 809166 & 5.9 & 5.6105 & TRN \\
\hline CHEMBL1971485 & 809166 & 5.9 & 5.5355 & TRN \\
\hline CHEMBL1998611 & 809166 & 4.6 & 4.5766 & TRN \\
\hline CHEMBL485556 & 809166 & 5.9 & 5.062 & TRN \\
\hline CHEMBL1975900 & 809166 & 4.6 & 4.5159 & TRN \\
\hline CHEMBL1992334 & 809166 & 4.2 & 4.244 & TRN \\
\hline CHEMBL 255822 & 809166 & 4.6 & 4.6536 & TRN \\
\hline CHEMBL1972221 & 809166 & 4.6 & 4.6642 & TRN \\
\hline CHEMBL 2006778 & 809166 & 7.1 & 7.4909 & TRN \\
\hline CHEMBL 378627 & 809166 & 4.6 & 4.476 & TRN \\
\hline CHEMBL1996979 & 809166 & 7.9 & 7.2173 & TRN \\
\hline CHEMBL1997025 & 809166 & 4.6 & 5.2377 & TRN \\
\hline CHEMBL1968406 & 809166 & 6.9 & 6.5313 & TRN \\
\hline CHEMBL1982476 & 809166 & 7.9 & 8.7365 & TRN \\
\hline CHEMBL1998545 & 809166 & 4.6 & 4.546 & TRN \\
\hline CHEMBL1986869 & 809166 & 4.6 & 4.4819 & TRN \\
\hline CHEMBL1975923 & 809166 & 4.5 & 5.1052 & TST \\
\hline CHEMBL 2005449 & 809166 & 5.6 & 5.69600 & 0000000001 \\
\hline CHEMBL1987998 & 809166 & 4.2 & 4.0407 & TRN \\
\hline CHEMBL 2006010 & 809166 & 4.6 & 4.4123 & TRN \\
\hline CHEMBL1682558 & 809166 & 4.6 & 4.8435 & TRN \\
\hline CHEMBL1990496 & 809166 & 4.4 & 4.6189 & TRN \\
\hline CHEMBL2002799 & 809166 & 4.2 & 4.4269 & TST \\
\hline CHEMBL 242865 & 809166 & 4.2 & 5.5116 & TRN \\
\hline CHEMBL1997623 & 809166 & 7.2 & 6.4905 & TRN \\
\hline
\end{tabular}




\begin{tabular}{|c|c|c|c|c|c|}
\hline \\
\hline CHEMBL2002479 & 809166 & 6.4 & 5.5308 & TRN & \\
\hline CHEMBL1993166 & 809166 & 4.6 & 4.94600 & 0000000001 & TRN \\
\hline CHEMBL1967094 & 809166 & 4.6 & 4.6713 & TRN & \\
\hline CHEMBL1966035 & 809166 & 4.6 & 4.675 & TRN & \\
\hline CHEMBL2003341 & 809166 & 4.6 & 4.6082 & TRN & \\
\hline CHEMBL1992645 & 809166 & 4.6 & 4.8775 & TST & \\
\hline CHEMBL1982992 & 809166 & 4.6 & 4.4325 & TRN & \\
\hline CHEMBL1998110 & 809166 & 4.2 & 3.7682 & TRN & \\
\hline CHEMBL1999590 & 809166 & 6.0 & 5.7748 & TST & \\
\hline CHEMBL1981079 & 809166 & 4.6 & 4.9942 & TRN & \\
\hline CHEMBL1978166 & 809166 & 6.5 & 6.7227 & TRN & \\
\hline CHEMBL1972276 & 809166 & 4.6 & 5.0207 & TRN & \\
\hline CHEMBL1980489 & 809166 & 4.6 & 4.5882 & TRN & \\
\hline CHEMBL 2000832 & 809166 & 4.6 & 5.0527 & TRN & \\
\hline CHEMBL1967116 & 809166 & 9.0 & 8.759 & TRN & \\
\hline CHEMBL1990590 & 809166 & 4.2 & 3.7547 & TRN & \\
\hline CHEMBL1977814 & 809166 & 4.4 & 4.6447 & TST & \\
\hline CHEMBL86755 & 809166 & 5.4 & 5.3523 & TRN & \\
\hline CHEMBL1970709 & 809166 & 4.6 & 4.4785 & TRN & \\
\hline CHEMBL1974617 & 809166 & 4.0 & 4.257 & TRN & \\
\hline CHEMBL1965660 & 809166 & 5.6 & 5.143 & TRN & \\
\hline CHEMBL1992125 & 809166 & 5.3 & 5.8445 & TRN & \\
\hline CHEMBL1998112 & 809166 & 7.1 & 5.9239 & TRN & \\
\hline CHEMBL1993996 & 809166 & 6.0 & 6.5154 & TRN & \\
\hline CHEMBL1969126 & 809166 & 4.6 & 4.6889 & TRN & \\
\hline CHEMBL1980896 & 809166 & 5.9 & 6.1428 & TRN & \\
\hline CHEMBL1975208 & 809166 & 4.6 & 4.8243 & TST & \\
\hline CHEMBL1970104 & 809166 & 6.2 & 5.9384 & TRN & \\
\hline CHEMBL1991429 & 809166 & 8.0 & 7.5074 & TRN & \\
\hline CHEMBL1964777 & 809166 & 4.6 & 4.6217 & TRN & \\
\hline CHEMBL1971149 & 809166 & 4.6 & 4.421 & TRN & \\
\hline CHEMBL1999714 & 809166 & 4.6 & 4.329 & TRN & \\
\hline CHEMBL1987533 & 809166 & 4.6 & 4.3885 & TRN & \\
\hline CHEMBL1994040 & 809166 & 4.6 & 4.82600 & 00000000005 & TRN \\
\hline CHEMBL 388978 & 809166 & 7.6 & 8.1936 & TST & \\
\hline CHEMBL579246 & 809166 & 4.6 & 4.6629 & TRN & \\
\hline CHEMBL 398951 & 809166 & 4.3 & 4.6932 & TST & \\
\hline CHEMBL1982506 & 809166 & 5.9 & 4.4141 & TST & \\
\hline CHEMBL 2004716 & 809166 & 8.0 & 7.7974 & TRN & \\
\hline CHEMBL1968127 & 809166 & 4.6 & 4.9446 & TRN & \\
\hline CHEMBL1975233 & 809166 & 4.6 & 4.6259 & TRN & \\
\hline CHEMBL1985406 & 809166 & 4.6 & 4.4631 & TRN & \\
\hline CHEMBL 207400 & 809166 & 4.6 & 4.3861 & TST & \\
\hline CHEMBL 2000894 & 809166 & 4.6 & 4.9581 & TST & \\
\hline CHEMBL 1421720 & 809166 & 4.2 & 4.5561 & TRN & \\
\hline CHEMBL1982135 & 809166 & 6.0 & 6.1912 & TRN & \\
\hline CHEMBL1976090 & 809166 & 4.6 & 4.8064 & TRN & \\
\hline CHEMBL1993243 & 809166 & 6.8 & 7.6006 & TRN & \\
\hline
\end{tabular}




\begin{tabular}{|c|c|c|c|c|c|}
\hline & & & & & \\
\hline CHEMBL2004771 & 809166 & 4.6 & 5.062 & TRN & \\
\hline CHEMBL1992922 & 809166 & 6.0 & 5.4602 & TRN & \\
\hline CHEMBL399021 & 809166 & 6.7 & 6.4274 & TRN & \\
\hline CHEMBL1997597 & 809166 & 4.6 & 4.794 & TRN & \\
\hline CHEMBL1969537 & 809166 & 4.6 & 5.6694 & TST & \\
\hline CHEMBL576113 & 809166 & 4.2 & 4.4623 & TRN & \\
\hline CHEMBL1976093 & 809166 & 4.6 & 4.8435 & TRN & \\
\hline CHEMBL1996543 & 809166 & 4.6 & 4.6502 & TRN & \\
\hline CHEMBL1975256 & 809166 & 4.6 & 4.6627 & TST & \\
\hline CHEMBL1991356 & 809166 & 4.6 & 4.9458 & TST & \\
\hline CHEMBL 2004892 & 809166 & 4.6 & $4.4860 e$ & 0000000001 & TRN \\
\hline CHEMBL1997503 & 809166 & 4.6 & 4.9918 & TST & \\
\hline CHEMBL116070 & 809166 & 4.6 & 4.6511 & TRN & \\
\hline CHEMBL1990821 & 809166 & 4.6 & 4.9382 & TST & \\
\hline CHEMBL1970314 & 809166 & 4.6 & 4.5405 & TRN & \\
\hline CHEMBL 2004871 & 809166 & 4.6 & 4.7917 & TRN & \\
\hline CHEMBL2004872 & 809166 & 4.6 & 4.5604 & TRN & \\
\hline CHEMBL1990223 & 809166 & 4.2 & 3.8963 & TRN & \\
\hline CHEMBL1969879 & 809166 & 4.6 & 4.8089 & TRN & \\
\hline CHEMBL2006149 & 809166 & 4.2 & 3.8989 & TRN & \\
\hline CHEMBL1964382 & 809166 & 4.2 & 4.2215 & TST & \\
\hline CHEMBL101311 & 809166 & 6.7 & 5.8576 & TRN & \\
\hline CHEMBL1981720 & 809166 & 4.6 & 4.58 & TRN & \\
\hline CHEMBL419932 & 809166 & 4.6 & 4.9811 & TRN & \\
\hline CHEMBL262433 & 809166 & 6.8 & 6.5437 & TRN & \\
\hline CHEMBL373798 & 809166 & 6.7 & 6.6096 & TRN & \\
\hline CHEMBL 306380 & 809166 & 7.2 & 7.6296 & TRN & \\
\hline CHEMBL1966722 & 809166 & 4.6 & 4.3525 & TST & \\
\hline CHEMBL1988581 & 809166 & 6.5 & 6.572 & TST & \\
\hline CHEMBL2005699 & 809166 & 4.2 & 3.9571 & TRN & \\
\hline CHEMBL1975500 & 809166 & 5.7 & 5.2781 & TRN & \\
\hline CHEMBL1976328 & 809166 & 4.6 & 5.3445 & TRN & \\
\hline CHEMBL394619 & 809166 & 6.2 & 5.697 & TRN & \\
\hline CHEMBL 2006564 & 809166 & 7.0 & 6.8996 & TRN & \\
\hline CHEMBL1964399 & 809166 & 4.6 & 4.8448 & TRN & \\
\hline CHEMBL1996831 & 809166 & 4.6 & 4.5949 & TST & \\
\hline CHEMBL411903 & 809166 & 6.7 & 6.4066 & TRN & \\
\hline CHEMBL1978167 & 809166 & 4.2 & 5.0692 & TST & \\
\hline CHEMBL1965988 & 809166 & 6.8 & 6.6958 & TRN & \\
\hline CHEMBL418203 & 809166 & 4.4 & 4.5133 & TST & \\
\hline CHEMBL1989646 & 809166 & 4.6 & 4.3881 & TRN & \\
\hline CHEMBL1682357 & 809166 & 4.6 & 4.5706 & TRN & \\
\hline CHEMBL225519 & 809166 & 4.4 & 4.4862 & TRN & \\
\hline CHEMBL209534 & 809166 & 4.6 & 4.7456 & TRN & \\
\hline CHEMBL1978200 & 809166 & 4.6 & 4.5236 & TRN & \\
\hline CHEMBL1970522 & 809166 & 4.6 & 4.8327 & TRN & \\
\hline CHEMBL402846 & 809166 & 6.3 & 6.0307 & TRN & \\
\hline CHEMBL1990415 & 809166 & 4.6 & 4.8171 & TRN & \\
\hline & & & & 13633 & \\
\hline
\end{tabular}




\begin{tabular}{|c|c|c|c|c|}
\hline \multicolumn{5}{|c|}{ plemental T } \\
\hline CHEMBL1966087 & 809166 & 4.6 & 4.7521 & TRN \\
\hline CHEMBL1996931 & 809166 & 4.6 & 4.6278 & TRN \\
\hline CHEMBL1964692 & 809166 & 7.2 & 7.1616 & TRN \\
\hline CHEMBL1971223 & 809166 & 4.2 & 4.138 & TRN \\
\hline CHEMBL1964413 & 809166 & 4.6 & 4.3735 & TRN \\
\hline CHEMBL1973483 & 809166 & 4.6 & 4.4014 & TRN \\
\hline CHEMBL1998470 & 809166 & 4.2 & 4.1126 & TRN \\
\hline CHEMBL1995428 & 809166 & 4.2 & 5.4009 & TRN \\
\hline CHEMBL1984432 & 809166 & 4.6 & 4.5058 & TRN \\
\hline CHEMBL 219722 & 809166 & 5.8 & 6.2008 & TRN \\
\hline CHEMBL1975903 & 809166 & 5.4 & 4.7687 & TRN \\
\hline CHEMBL1997340 & 809166 & 4.6 & 4.6909 & TRN \\
\hline CHEMBL1522508 & 809166 & 3.6 & 4.0606 & TRN \\
\hline CHEMBL1989474 & 809166 & 4.6 & 4.8918 & TRN \\
\hline CHEMBL1090360 & 809166 & 7.7 & 7.2713 & TRN \\
\hline CHEMBL 210887 & 809166 & 4.6 & 4.35 & TRN \\
\hline CHEMBL1988805 & 809166 & 4.2 & 4.2172 & TST \\
\hline CHEMBL458997 & 809166 & 5.9 & 5.2872 & TRN \\
\hline CHEMBL1971021 & 809166 & 4.6 & 4.7388 & TRN \\
\hline CHEMBL 227271 & 809166 & 4.6 & 4.706 & TRN \\
\hline CHEMBL583144 & 809166 & 4.6 & 4.8857 & TRN \\
\hline CHEMBL1974310 & 809166 & 4.6 & 4.6157 & TRN \\
\hline CHEMBL1969942 & 809166 & 5.4 & 4.5294 & TRN \\
\hline CHEMBL1978567 & 809166 & 4.2 & 3.7682 & TRN \\
\hline CHEMBL1982660 & 809166 & 4.7 & 4.5665 & TRN \\
\hline CHEMBL1994693 & 809166 & 7.0 & 6.6331 & TRN \\
\hline CHEMBL1982957 & 809166 & 6.1 & 5.4974 & TRN \\
\hline CHEMBL1725279 & 809166 & 5.7 & 4.8978 & TST \\
\hline CHEMBL1975138 & 809166 & 4.6 & 4.362 & TST \\
\hline CHEMBL424872 & 809166 & 4.4 & 4.4206 & TRN \\
\hline CHEMBL1971947 & 809166 & 7.3 & 6.8233 & TRN \\
\hline CHEMBL412142 & 809166 & 4.6 & 4.7297 & TST \\
\hline CHEMBL1980704 & 809166 & 4.6 & 4.6178 & TST \\
\hline CHEMBL 2003271 & 809166 & 4.6 & 4.7135 & TRN \\
\hline CHEMBL1966808 & 809166 & 4.6 & 4.8283 & TST \\
\hline CHEMBL1996255 & 809166 & 6.2 & 6.2863 & TRN \\
\hline CHEMBL 2004447 & 809166 & 4.6 & 4.6342 & TRN \\
\hline CHEMBL1983111 & 809166 & 6.7 & 6.6623 & TRN \\
\hline CHEMBL1973860 & 809166 & 4.6 & 4.6352 & TRN \\
\hline CHEMBL 260135 & 809166 & 4.6 & 4.522 & TRN \\
\hline CHEMBL220241 & 809166 & 5.6 & 5.1059 & TRN \\
\hline CHEMBL 2004544 & 809166 & 4.6 & 4.5334 & TST \\
\hline CHEMBL1988141 & 809166 & 5.8 & 5.756 & TST \\
\hline CHEMBL1982610 & 809166 & 4.6 & 5.1036 & TST \\
\hline CHEMBL1977134 & 809166 & 7.5 & 7.2371 & TRN \\
\hline CHEMBL1999496 & 809166 & 4.6 & 4.3738 & TRN \\
\hline CHEMBL 2006933 & 809166 & 4.6 & 4.5747 & TST \\
\hline CHEMBL1985206 & 809166 & 4.2 & 4.3498 & TST \\
\hline
\end{tabular}




\begin{tabular}{|c|c|c|c|c|}
\hline & & & upplement & al Table S \\
\hline CHEMBL1988300 & 809166 & 6.8 & 7.1129 & TRN \\
\hline CHEMBL1991078 & 809166 & 5.6 & 5.3496 & TRN \\
\hline CHEMBL1987359 & 809166 & 4.6 & 4.4522 & TST \\
\hline CHEMBL1977749 & 809166 & 4.2 & 4.3835 & TST \\
\hline CHEMBL1975212 & 809166 & 5.5 & 5.2967 & TRN \\
\hline CHEMBL2000685 & 809166 & 4.6 & 4.5656 & TRN \\
\hline CHEMBL1997275 & 809166 & 4.2 & 4.8441 & TRN \\
\hline CHEMBL1993904 & 809166 & 5.4 & 5.0913 & TRN \\
\hline CHEMBL1980376 & 809166 & 4.0 & 4.2577 & TRN \\
\hline CHEMBL1967513 & 809166 & 4.2 & 4.1394 & TRN \\
\hline CHEMBL 2000724 & 809166 & 4.2 & 3.5263 & TRN \\
\hline CHEMBL1985311 & 809166 & 5.9 & 5.6563 & TRN \\
\hline CHEMBL1989265 & 809166 & 4.6 & 4.9831 & TST \\
\hline CHEMBL1982413 & 809166 & 4.2 & 5.0446 & TST \\
\hline CHEMBL1969502 & 809166 & 6.4 & 6.2503 & TRN \\
\hline CHEMBL1965910 & 809166 & 6.2 & $6.3770 e$ & 0000000001 \\
\hline CHEMBL1682553 & 809166 & 4.6 & 4.8323 & TRN \\
\hline CHEMBL1971430 & 809166 & 4.6 & 4.5776 & TRN \\
\hline CHEMBL1983963 & 809166 & 6.6 & 6.9077 & TRN \\
\hline CHEMBL1997764 & 809166 & 4.6 & 5.0803 & TRN \\
\hline CHEMBL 2000271 & 809166 & 4.6 & 5.1083 & TRN \\
\hline CHEMBL1981792 & 809166 & 4.2 & 4.2803 & TRN \\
\hline CHEMBL1987535 & 809166 & 4.2 & 4.2575 & TRN \\
\hline CHEMBL1985092 & 809166 & 4.6 & 4.4482 & TRN \\
\hline CHEMBL2004692 & 809166 & 4.6 & 4.5481 & TST \\
\hline CHEMBL1981410 & 809166 & 4.6 & 5.0675 & TRN \\
\hline CHEMBL 2002586 & 809166 & 5.5 & 4.8783 & TRN \\
\hline CHEMBL1996234 & 809166 & 6.1 & 5.4518 & TRN \\
\hline CHEMBL383264 & 809166 & 4.2 & 4.4534 & TRN \\
\hline CHEMBL 2007421 & 809166 & 6.4 & 5.9309 & TRN \\
\hline CHEMBL1991434 & 809166 & 4.6 & 4.8424 & TST \\
\hline CHEMBL1967544 & 809166 & 4.6 & 4.6934 & TRN \\
\hline CHEMBL1973138 & 809166 & 4.2 & 4.296 & TRN \\
\hline CHEMBL223367 & 809166 & 4.6 & 4.7243 & TST \\
\hline CHEMBL1992673 & 809166 & 4.3 & 4.7612 & TRN \\
\hline CHEMBL 340384 & 809166 & 4.6 & 4.5326 & TST \\
\hline CHEMBL1969151 & 809166 & 5.3 & 4.8773 & TRN \\
\hline CHEMBL1996587 & 809166 & 4.6 & 4.6249 & TRN \\
\hline CHEMBL1993335 & 809166 & 5.8 & 5.8805 & TST \\
\hline CHEMBL1988692 & 809166 & 6.1 & 5.8648 & TRN \\
\hline CHEMBL 2007574 & 809166 & 4.2 & 4.5195 & TRN \\
\hline CHEMBL1964804 & 809166 & 4.6 & 4.81 & TRN \\
\hline CHEMBL443962 & 809166 & 4.6 & 5.0271 & TST \\
\hline CHEMBL 2000354 & 809166 & 4.6 & 4.8735 & TRN \\
\hline CHEMBL1965507 & 809166 & 4.6 & 5.2626 & TRN \\
\hline CHEMBL 274064 & 809166 & 6.9 & 5.4148 & TRN \\
\hline CHEMBL1998680 & 809166 & 4.2 & 3.8779 & TRN \\
\hline CHEMBL1967564 & 809166 & 4.6 & 4.3186 & TRN \\
\hline
\end{tabular}




\begin{tabular}{|c|c|c|c|c|}
\hline & & & & $a+1 a$ \\
\hline CHEMBL592030 & 809166 & 4.4 & 3.9429 & TST \\
\hline CHEMBL2000071 & 809166 & 6.0 & 4.9753 & TRN \\
\hline CHEMBL1979176 & 809166 & 4.6 & 4.6787 & TRN \\
\hline CHEMBL1970317 & 809166 & 8.8 & 8.7342 & TRN \\
\hline CHEMBL1985491 & 809166 & 5.8 & 5.4012 & TRN \\
\hline CHEMBL 2000408 & 809166 & 4.6 & 4.6038 & TRN \\
\hline CHEMBL 248757 & 809166 & 4.6 & 4.66 & TST \\
\hline CHEMBL1978014 & 809166 & 4.6 & 4.6677 & TRN \\
\hline CHEMBL 2002736 & 809166 & 4.2 & 4.4171 & TRN \\
\hline CHEMBL1997007 & 809166 & 4.2 & 4.5545 & TRN \\
\hline CHEMBL1994538 & 809166 & 4.6 & 4.5083 & TRN \\
\hline CHEMBL1975490 & 809166 & 6.1 & 5.449 & TRN \\
\hline CHEMBL1964444 & 809166 & 4.6 & 4.3434 & TRN \\
\hline CHEMBL 2002690 & 809166 & 4.2 & 4.2338 & TRN \\
\hline CHEMBL2006567 & 809166 & 4.6 & 4.3918 & TRN \\
\hline CHEMBL1986139 & 809166 & 4.6 & 4.4198 & TRN \\
\hline CHEMBL383527 & 809166 & 4.6 & 4.5245 & TRN \\
\hline CHEMBL1980540 & 809166 & 4.6 & 4.5858 & TRN \\
\hline CHEMBL 278041 & 809166 & 4.3 & 4.2243 & TRN \\
\hline CHEMBL1979883 & 809166 & 6.8 & 6.8181 & TRN \\
\hline CHEMBL1984162 & 809166 & 8.0 & 8.0747 & TRN \\
\hline CHEMBL1997051 & 809166 & 6.7 & 6.4325 & TRN \\
\hline CHEMBL491758 & 809166 & 5.9 & 6.1806 & TRN \\
\hline CHEMBL1986590 & 809166 & 5.2 & 5.1562 & TRN \\
\hline CHEMBL549730 & 809166 & 4.6 & 4.4714 & TRN \\
\hline CHEMBL1682360 & 809166 & 4.6 & 4.6267 & TRN \\
\hline CHEMBL1970189 & 809166 & 4.6 & 4.329 & TRN \\
\hline CHEMBL1870106 & 809166 & 4.2 & 4.3426 & TRN \\
\hline CHEMBL1996791 & 809166 & 5.6 & 5.8688 & TRN \\
\hline CHEMBL371206 & 809166 & 6.8 & 6.6079 & TRN \\
\hline CHEMBL1974664 & 809166 & 6.9 & 6.7727 & TST \\
\hline CHEMBL406845 & 809166 & 7.1 & 7.2755 & TRN \\
\hline CHEMBL1974288 & 809166 & 4.6 & 4.5381 & TRN \\
\hline CHEMBL1984296 & 809166 & 4.2 & 4.5935 & TST \\
\hline CHEMBL196363 & 809166 & 6.8 & 6.789 & TRN \\
\hline CHEMBL1190711 & 809166 & 4.6 & 5.1925 & TRN \\
\hline CHEMBL1990346 & 809166 & 5.8 & $5.0710 e$ & 0000000001 \\
\hline CHEMBL1968705 & 809166 & 4.4 & 4.6192 & TRN \\
\hline CHEMBL1964441 & 809166 & 6.8 & 6.1591 & TRN \\
\hline CHEMBL1991410 & 809166 & 4.2 & 4.7176 & TRN \\
\hline CHEMBL546797 & 809166 & 5.3 & 4.9462 & TRN \\
\hline CHEMBL404367 & 809166 & 4.8 & 5.7311 & TRN \\
\hline CHEMBL1966343 & 809166 & 4.6 & 4.798 & TRN \\
\hline CHEMBL1978271 & 809166 & 4.2 & 4.2232 & TRN \\
\hline CHEMBL1967887 & 809166 & 4.6 & 4.7952 & TRN \\
\hline CHEMBL 2007266 & 809166 & 4.2 & 4.9028 & TRN \\
\hline CHEMBL1985469 & 809166 & 4.2 & 4.5488 & TST \\
\hline CHEMBL 2000568 & 809166 & 4.4 & 4.3888 & TRN \\
\hline
\end{tabular}




\begin{tabular}{|c|c|c|c|c|c|}
\hline & & & & & \\
\hline CHEMBL1994308 & 809166 & 4.2 & 3.9137 & TST & \\
\hline CHEMBL 2000335 & 809166 & 7.3 & 6.9656 & TRN & \\
\hline CHEMBL1988717 & 809166 & 8.8 & 8.5912 & TRN & \\
\hline CHEMBL1974328 & 809166 & 5.7 & 5.4267 & TRN & \\
\hline CHEMBL509032 & 809166 & 6.9 & 6.8863 & TRN & \\
\hline CHEMBL1973808 & 809166 & 4.6 & 4.6661 & TRN & \\
\hline CHEMBL 2000429 & 809166 & 4.6 & 4.6986 & TRN & \\
\hline CHEMBL1972576 & 809166 & 6.1 & 5.9145 & TRN & \\
\hline CHEMBL1992555 & 809166 & 4.6 & 4.8256 & TRN & \\
\hline CHEMBL1992342 & 809166 & 4.6 & 4.7679 & TRN & \\
\hline CHEMBL1988173 & 809166 & 4.6 & 4.2768 & TST & \\
\hline CHEMBL1973013 & 809166 & 5.8 & 5.1737 & TRN & \\
\hline CHEMBL1164265 & 809166 & 5.6 & 5.1698 & TST & \\
\hline CHEMBL1989805 & 809166 & 4.6 & 5.7606 & TST & \\
\hline CHEMBL1965423 & 809166 & 4.6 & 4.8147 & TRN & \\
\hline CHEMBL1983025 & 809166 & 6.2 & 5.9753 & TRN & \\
\hline CHEMBL1975927 & 809166 & 6.1 & 6.0932 & TRN & \\
\hline CHEMBL205415 & 809166 & 4.4 & 4.2797 & TRN & \\
\hline CHEMBL1977135 & 809166 & 4.6 & 4.5244 & TRN & \\
\hline CHEMBL 2001920 & 809166 & 4.6 & 4.6362 & TST & \\
\hline CHEMBL 2002322 & 809166 & 4.6 & 4.5469 & TRN & \\
\hline CHEMBL1997119 & 809166 & 4.1 & 4.3141 & TRN & \\
\hline CHEMBL1980904 & 809166 & 6.7 & 6.8939 & TRN & \\
\hline CHEMBL1977138 & 809166 & 6.2 & 5.7886 & TST & \\
\hline CHEMBL 2002323 & 809166 & 4.6 & 4.9539 & TST & \\
\hline CHEMBL1241473 & 809166 & 7.4 & 7.2084 & TRN & \\
\hline CHEMBL1978448 & 809166 & 4.4 & 4.8908 & TST & \\
\hline CHEMBL1972258 & 809166 & 4.6 & 4.9623 & TRN & \\
\hline CHEMBL1969483 & 809166 & 4.2 & 5.4395 & TRN & \\
\hline CHEMBL1980329 & 809166 & 6.0 & 5.4097 & TRN & \\
\hline CHEMBL 2004515 & 809166 & 4.2 & 4.499 & TRN & \\
\hline CHEMBL 2001257 & 809166 & 6.0 & 6.0199 & TRN & \\
\hline CHEMBL1992042 & 809166 & 4.2 & 4.7645 & TST & \\
\hline CHEMBL 2005548 & 809166 & 4.6 & 4.7433 & TRN & \\
\hline CHEMBL 271441 & 809166 & 7.1 & 6.8168 & TRN & \\
\hline CHEMBL1992536 & 809166 & 4.6 & 4.5193 & TRN & \\
\hline CHEMBL 21156 & 809166 & 4.2 & 4.5477 & TST & \\
\hline CHEMBL1992740 & 809166 & 4.6 & 4.7712 & TRN & \\
\hline CHEMBL1994724 & 809166 & 4.2 & 4.284 & TRN & \\
\hline CHEMBL1989267 & 809166 & 8.1 & 8.1674 & TRN & \\
\hline CHEMBL 2002373 & 809166 & 4.6 & 4.7293 & TRN & \\
\hline CHEMBL439340 & 809166 & 4.7 & 4.4749 & TRN & \\
\hline CHEMBL1974574 & 809166 & 4.2 & 4.254 & TST & \\
\hline CHEMBL 2006188 & 809166 & 4.6 & 4.615 & TRN & \\
\hline CHEMBL1970290 & 809166 & 5.2 & 5.3966 & TRN & \\
\hline CHEMBL1967531 & 809166 & 6.9 & 6.9419 & TRN & \\
\hline CHEMBL1970913 & 809166 & 4.6 & $4.5680 e$ & 00000000005 & TRN \\
\hline CHEMBL1973893 & 809166 & 4.6 & 4.8175 & TRN & \\
\hline & & & & 13637 & \\
\hline
\end{tabular}




\begin{tabular}{|c|c|c|c|c|}
\hline & & & & al lable s \\
\hline CHEMBL1997534 & 809166 & 4.6 & 4.8024 & TRN \\
\hline CHEMBL1993877 & 809166 & 5.6 & 5.7118 & TRN \\
\hline CHEMBL1985095 & 809166 & 4.6 & 4.5261 & TST \\
\hline CHEMBL1996500 & 809166 & 4.3 & 4.293 & TRN \\
\hline CHEMBL273187 & 809166 & 7.4 & 7.2215 & TRN \\
\hline CHEMBL1991180 & 809166 & 4.6 & 4.7531 & TST \\
\hline CHEMBL1989708 & 809166 & 8.4 & 8.1809 & TRN \\
\hline CHEMBL1682540 & 809166 & 4.6 & 4.6706 & TRN \\
\hline CHEMBL1976420 & 809166 & 5.9 & 5.6013 & TST \\
\hline CHEMBL1986979 & 809166 & 6.6 & 6.1308 & TRN \\
\hline CHEMBL1998253 & 809166 & 4.2 & 4.1582 & TST \\
\hline CHEMBL413779 & 809166 & 4.6 & 4.9007 & TST \\
\hline CHEMBL1994864 & 809166 & 4.6 & 4.4863 & TRN \\
\hline CHEMBL1981744 & 809166 & 4.2 & 4.2469 & TRN \\
\hline CHEMBL2002446 & 809166 & 6.7 & 5.6279 & TST \\
\hline CHEMBL497151 & 809166 & 4.6 & 4.8623 & TRN \\
\hline CHEMBL 2000029 & 809166 & 4.2 & 4.1382 & TRN \\
\hline CHEMBL1973961 & 809166 & 4.2 & 4.2858 & TRN \\
\hline CHEMBL 246970 & 809166 & 4.6 & 4.7851 & TRN \\
\hline CHEMBL340921 & 809166 & 4.6 & 4.5219 & TST \\
\hline CHEMBL1994977 & 809166 & 4.2 & 3.9842 & TRN \\
\hline CHEMBL373598 & 809166 & 4.6 & 4.827 & TST \\
\hline CHEMBL 2001149 & 809166 & 4.2 & 4.2581 & TRN \\
\hline CHEMBL1999718 & 809166 & 4.6 & 4.4902 & TRN \\
\hline CHEMBL2000078 & 809166 & 6.1 & 5.8591 & TRN \\
\hline CHEMBL1276446 & 809166 & 6.9 & 6.4432 & TST \\
\hline CHEMBL 2005478 & 809166 & 5.6 & 5.6735 & TST \\
\hline CHEMBL1996646 & 809166 & 6.0 & 5.8732 & TRN \\
\hline CHEMBL1979773 & 809166 & 4.2 & 4.427 & TRN \\
\hline CHEMBL1977346 & 809166 & 4.6 & 4.5068 & TRN \\
\hline CHEMBL 2003657 & 809166 & 4.6 & 5.2074 & TRN \\
\hline CHEMBL1971649 & 809166 & 6.2 & 5.5883 & TRN \\
\hline CHEMBL 2005482 & 809166 & 7.1 & 6.2541 & TRN \\
\hline CHEMBL1996702 & 809166 & 6.4 & 5.185 & TRN \\
\hline CHEMBL1997909 & 809166 & 4.2 & 5.347 & TRN \\
\hline CHEMBL 2007124 & 809166 & 4.2 & 4.7006 & TRN \\
\hline CHEMBL 2006439 & 809166 & 4.4 & 4.9025 & TRN \\
\hline CHEMBL1985681 & 809166 & 4.2 & 5.0705 & TST \\
\hline CHEMBL1969190 & 809166 & 6.9 & 7.2144 & TRN \\
\hline CHEMBL 2002660 & 809166 & 4.2 & 4.3722 & TRN \\
\hline CHEMBL1973937 & 809166 & 4.7 & 5.4658 & TRN \\
\hline CHEMBL1991674 & 809166 & 4.5 & $5.0310 e$ & 0000000001 \\
\hline CHEMBL1982711 & 809166 & 4.4 & 4.3267 & TRN \\
\hline CHEMBL262623 & 809166 & 4.6 & 4.8833 & TRN \\
\hline CHEMBL1984842 & 809166 & 4.4 & 4.5565 & TRN \\
\hline CHEMBL1969102 & 809166 & 7.5 & 8.379 & TRN \\
\hline CHEMBL 2004118 & 809166 & 4.2 & 4.3578 & TRN \\
\hline CHEMBL1682346 & 809166 & 4.6 & 4.6291 & TRN \\
\hline
\end{tabular}

TRN 


\begin{tabular}{|c|c|c|c|c|}
\hline & & & ipplement & al $\mathrm{T}$ \\
\hline CHEMBL1996795 & 809166 & 4.2 & 4.6964 & TST \\
\hline CHEMBL 2007044 & 809166 & 4.6 & 4.9693 & TST \\
\hline CHEMBL 2001998 & 809166 & 5.9 & 5.0235 & TST \\
\hline CHEMBL1994241 & 809166 & 4.6 & 4.9392 & TRN \\
\hline CHEMBL223460 & 809166 & 4.6 & 4.8389 & TST \\
\hline CHEMBL1998829 & 809166 & 5.8 & 5.6282 & TRN \\
\hline CHEMBL50894 & 809166 & 4.5 & 4.9178 & TRN \\
\hline CHEMBL1995211 & 809166 & 4.2 & 4.3105 & TRN \\
\hline CHEMBL1988838 & 809166 & 6.3 & 6.9599 & TRN \\
\hline CHEMBL1981725 & 809166 & 8.7 & 8.1643 & TRN \\
\hline CHEMBL1982753 & 809166 & 4.3 & 4.8435 & TRN \\
\hline CHEMBL375284 & 809166 & 4.6 & 4.742 & TRN \\
\hline CHEMBL 2006299 & 809166 & 4.2 & 4.0477 & TRN \\
\hline CHEMBL1972346 & 809166 & 4.3 & 4.8202 & TST \\
\hline CHEMBL1965169 & 809166 & 4.2 & 4.4309 & TST \\
\hline CHEMBL1991818 & 809166 & 4.2 & 4.563 & TST \\
\hline CHEMBL1081312 & 809166 & 6.8 & 7.0453 & TRN \\
\hline CHEMBL1965170 & 809166 & 8.8 & 8.8547 & TRN \\
\hline CHEMBL1982866 & 809166 & 4.6 & 4.9607 & TRN \\
\hline CHEMBL 2005792 & 809166 & 4.4 & 4.5175 & TRN \\
\hline CHEMBL1968926 & 809166 & 4.6 & 4.6164 & TRN \\
\hline CHEMBL1984206 & 809166 & 4.6 & 4.7105 & TRN \\
\hline CHEMBL462120 & 809166 & 5.6 & 4.7897 & TRN \\
\hline CHEMBL1991577 & 809166 & 4.6 & 4.8083 & TRN \\
\hline CHEMBL1986503 & 809166 & 4.2 & 4.1078 & TST \\
\hline CHEMBL 2007592 & 809166 & 4.6 & 4.8223 & TST \\
\hline CHEMBL1965570 & 809166 & 7.8 & 8.1503 & TRN \\
\hline CHEMBL1972355 & 809166 & 4.2 & 5.6214 & TST \\
\hline CHEMBL1997892 & 809166 & 4.2 & 4.4823 & TRN \\
\hline CHEMBL1997193 & 809166 & 4.2 & 4.6983 & TST \\
\hline CHEMBL210963 & 809166 & 4.6 & 4.4456 & TRN \\
\hline CHEMBL1964902 & 809166 & 4.2 & 3.9727 & TRN \\
\hline CHEMBL1082440 & 809166 & 5.7 & 4.3575 & TST \\
\hline CHEMBL1614705 & 809166 & 4.6 & 4.8939 & TRN \\
\hline CHEMBL1972362 & 809166 & 4.6 & 4.2795 & TRN \\
\hline CHEMBL1984633 & 809166 & 4.6 & 4.5783 & TRN \\
\hline CHEMBL1965845 & 809166 & 4.6 & 4.8353 & TRN \\
\hline CHEMBL 2007372 & 809166 & 4.6 & 4.5773 & TRN \\
\hline CHEMBL1983715 & 809166 & 6.6 & 6.7304 & TRN \\
\hline CHEMBL1971017 & 809166 & 4.6 & 4.4805 & TRN \\
\hline CHEMBL 2006715 & 809166 & 8.6 & 8.1088 & TRN \\
\hline CHEMBL1986597 & 809166 & 4.6 & 4.9003 & TRN \\
\hline CHEMBL1990482 & 809166 & 4.6 & 4.4987 & TRN \\
\hline CHEMBL1990904 & 809166 & 4.6 & 4.9108 & TRN \\
\hline CHEMBL 2000104 & 809166 & 4.6 & 4.4311 & TRN \\
\hline CHEMBL 2005475 & 809166 & 4.6 & 4.6183 & TRN \\
\hline CHEMBL183844 & 809166 & 4.6 & 4.7557 & TRN \\
\hline CHEMBL220057 & 809166 & 5.9 & 5.3988 & TRN \\
\hline
\end{tabular}




\begin{tabular}{|c|c|c|c|c|}
\hline & & & pplement & al $\mathrm{Ta}$ \\
\hline CHEMBL1682545 & 809166 & 4.6 & 4.3058 & TRN \\
\hline CHEMBL 383541 & 809166 & 4.6 & 4.9389 & TRN \\
\hline CHEMBL 2001224 & 809166 & 4.6 & 4.6235 & TRN \\
\hline CHEMBL10 & 809166 & 5.3 & 4.3096 & TRN \\
\hline CHEMBL1976732 & 809166 & 4.6 & 4.5683 & TRN \\
\hline CHEMBL1969506 & 809166 & 4.6 & 4.8035 & TRN \\
\hline CHEMBL1980763 & 809166 & 4.2 & 4.5315 & TRN \\
\hline CHEMBL1964937 & 809166 & 4.6 & 4.8 & TRN \\
\hline CHEMBL1980163 & 809166 & 4.6 & 4.5426 & TRN \\
\hline CHEMBL590109 & 809166 & 5.9 & 4.4758 & TST \\
\hline CHEMBL1989856 & 809166 & 4.6 & 5.3867 & TST \\
\hline CHEMBL 2005899 & 809166 & 4.6 & 4.5781 & TRN \\
\hline CHEMBL1682552 & 809166 & 4.6 & 4.7398 & TRN \\
\hline CHEMBL 259850 & 809166 & 4.6 & 4.6065 & TRN \\
\hline CHEMBL2007479 & 809166 & 4.2 & 4.1059 & TRN \\
\hline CHEMBL1996155 & 809166 & 4.6 & 4.83 & TRN \\
\hline CHEMBL1986851 & 809166 & 8.1 & 8.1055 & TRN \\
\hline CHEMBL229799 & 809166 & 4.6 & 5.0183 & TRN \\
\hline CHEMBL105739 & 809166 & 6.0 & 6.124 & TRN \\
\hline CHEMBL1682359 & 809166 & 4.6 & 4.4139 & TRN \\
\hline CHEMBL1972220 & 809166 & 8.9 & 9.3414 & TRN \\
\hline CHEMBL 379300 & 809166 & 4.6 & 4.7708 & TRN \\
\hline CHEMBL 203673 & 809166 & 4.6 & 4.8469 & TRN \\
\hline CHEMBL 2003785 & 809166 & 4.1 & 4.4869 & TST \\
\hline CHEMBL1973720 & 809166 & 5.5 & 5.4428 & TRN \\
\hline CHEMBL1969523 & 809166 & 4.6 & 4.5363 & TRN \\
\hline CHEMBL207995 & 809166 & 4.6 & 4.7322 & TRN \\
\hline CHEMBL2001923 & 809166 & 4.4 & 4.8639 & TRN \\
\hline CHEMBL1986781 & 809166 & 4.6 & 5.0204 & TRN \\
\hline CHEMBL1983070 & 809166 & 4.2 & 4.258 & TRN \\
\hline CHEMBL526133 & 809166 & 4.6 & 4.4788 & TRN \\
\hline CHEMBL 2003514 & 809166 & 4.2 & 4.0204 & TRN \\
\hline CHEMBL1966836 & 809166 & 6.8 & 6.6999 & TRN \\
\hline CHEMBL1989043 & 809166 & 4.2 & 4.5227 & TRN \\
\hline CHEMBL1979057 & 809166 & 4.6 & 4.7459 & TRN \\
\hline CHEMBL1981045 & 809166 & 4.6 & 5.0817 & TRN \\
\hline CHEMBL 387971 & 809166 & 6.7 & 5.6644 & TST \\
\hline CHEMBL1975418 & 809166 & 4.6 & 4.8726 & TRN \\
\hline CHEMBL1992796 & 809166 & 4.6 & 4.816 & TRN \\
\hline CHEMBL1164180 & 809166 & 5.7 & 5.032 & TST \\
\hline CHEMBL 223257 & 809166 & 4.6 & 4.8512 & TST \\
\hline CHEMBL1999428 & 809166 & 4.6 & 4.5535 & TRN \\
\hline CHEMBL1967560 & 809166 & 4.6 & 4.9916 & TRN \\
\hline CHEMBL1997611 & 809166 & 4.2 & 4.5839 & TST \\
\hline CHEMBL1516890 & 809166 & 6.4 & 5.8493 & TRN \\
\hline CHEMBL 211378 & 809166 & 6.2 & 6.0961 & TRN \\
\hline CHEMBL1982465 & 809166 & 7.2 & 6.5204 & TRN \\
\hline CHEMBL2001751 & 809166 & 6.4 & 6.5333 & TRN \\
\hline
\end{tabular}




\begin{tabular}{|c|c|c|c|c|c|}
\hline \\
\hline CHEMBL 2003420 & 809166 & 4.6 & 4.3588 & TRN & \\
\hline CHEMBL1984586 & 809166 & 6.1 & 6.3772 & TRN & \\
\hline CHEMBL1999774 & 809166 & 4.6 & 4.5629 & TST & \\
\hline CHEMBL272938 & 809166 & 6.5 & 6.4512 & TRN & \\
\hline CHEMBL1972659 & 809166 & 4.6 & 4.5109 & TST & \\
\hline CHEMBL 2002723 & 809166 & 5.2 & 5.3467 & TST & \\
\hline CHEMBL1973395 & 809166 & 6.1 & 5.4013 & TRN & \\
\hline CHEMBL 272453 & 809166 & 6.1 & 6.4682 & TRN & \\
\hline CHEMBL1970217 & 809166 & 4.6 & 4.5521 & TRN & \\
\hline CHEMBL1971801 & 809166 & 5.6 & 5.2633 & TRN & \\
\hline CHEMBL1968850 & 809166 & 4.6 & 4.6013 & TRN & \\
\hline CHEMBL 2005528 & 809166 & 4.6 & 4.7833 & TST & \\
\hline CHEMBL1984686 & 809166 & 4.2 & 4.3706 & TRN & \\
\hline CHEMBL185569 & 809166 & 5.8 & 5.4329 & TRN & \\
\hline CHEMBL1969843 & 809166 & 4.6 & 4.6474 & TRN & \\
\hline CHEMBL 2007002 & 809166 & 4.6 & 4.6364 & TRN & \\
\hline CHEMBL1987007 & 809166 & 4.6 & 4.6353 & TRN & \\
\hline CHEMBL1973793 & 809166 & 4.2 & 4.0911 & TST & \\
\hline CHEMBL1969588 & 809166 & 7.2 & 6.5779 & TRN & \\
\hline CHEMBL1984711 & 809166 & 8.1 & 7.2058 & TRN & \\
\hline CHEMBL1992073 & 809166 & 5.4 & 4.9758 & TRN & \\
\hline CHEMBL484390 & 809166 & 4.6 & 4.8987 & TRN & \\
\hline CHEMBL1979252 & 809166 & 4.6 & $4.6530 e$ & 20000000005 & TRN \\
\hline CHEMBL1986143 & 809166 & 4.2 & 4.1699 & TRN & \\
\hline CHEMBL1972934 & 809166 & 4.0 & 4.0976 & TRN & \\
\hline CHEMBL2007559 & 809166 & 4.2 & 4.2483 & TRN & \\
\hline CHEMBL1992581 & 809166 & 5.5 & 5.3821 & TRN & \\
\hline CHEMBL1682341 & 809166 & 4.6 & 4.6733 & TRN & \\
\hline CHEMBL2004290 & 809166 & 8.4 & 8.5387 & TRN & \\
\hline CHEMBL1986499 & 809166 & 4.6 & 4.6818 & TRN & \\
\hline CHEMBL1972937 & 809166 & 4.6 & 4.6237 & TRN & \\
\hline CHEMBL1972250 & 809166 & 4.6 & 5.0012 & TST & \\
\hline CHEMBL 2000393 & 809166 & 6.4 & 6.1035 & TST & \\
\hline CHEMBL403402 & 809166 & 6.8 & 7.1908 & TRN & \\
\hline CHEMBL 2004311 & 809166 & 6.2 & 5.414 & TRN & \\
\hline CHEMBL1992634 & 809166 & 4.6 & 5.0045 & TRN & \\
\hline CHEMBL1242373 & 809166 & 6.5 & 6.2502 & TRN & \\
\hline CHEMBL1984847 & 809166 & 4.2 & 4.5532 & TRN & \\
\hline CHEMBL316264 & 809166 & 4.6 & 4.6509 & TRN & \\
\hline CHEMBL1988075 & 809166 & 7.1 & 7.4931 & TRN & \\
\hline CHEMBL1996576 & 809166 & 4.2 & 4.3505 & TST & \\
\hline CHEMBL1988076 & 809166 & 6.0 & 5.5245 & TRN & \\
\hline CHEMBL1991678 & 809166 & 4.3 & 4.1466 & TRN & \\
\hline CHEMBL2001239 & 809166 & 5.8 & 5.1833 & TST & \\
\hline CHEMBL1988594 & 809166 & 6.3 & 5.7162 & TRN & \\
\hline CHEMBL2001288 & 809166 & 4.6 & 5.5019 & TRN & \\
\hline CHEMBL 260092 & 809166 & 6.7 & 6.3267 & TRN & \\
\hline CHEMBL1999811 & 809166 & 4.6 & 4.9795 & TRN & \\
\hline
\end{tabular}




\begin{tabular}{|c|c|c|c|c|c|}
\hline & & & & & \\
\hline CHEMBL1965495 & 809166 & 4.6 & 4.4641 & TRN & \\
\hline CHEMBL235157 & 809166 & 4.2 & 4.1071 & TST & \\
\hline CHEMBL1985074 & 809166 & 4.6 & 4.6875 & TST & \\
\hline CHEMBL 2000481 & 809166 & 4.6 & 4.9188 & TRN & \\
\hline CHEMBL1982874 & 809166 & 5.7 & 5.157 & TRN & \\
\hline CHEMBL1991725 & 809166 & 5.9 & $5.1080 e$ & 00000000005 & TRN \\
\hline CHEMBL1992242 & 809166 & 4.6 & 4.6499 & TRN & \\
\hline CHEMBL2007296 & 809166 & 4.6 & 4.4238 & TRN & \\
\hline CHEMBL 208637 & 809166 & 4.6 & 4.6179 & TRN & \\
\hline CHEMBL2004159 & 809166 & 4.2 & 3.93300 & 00000000003 & TRN \\
\hline CHEMBL396523 & 809166 & 6.4 & 6.3675 & TRN & \\
\hline CHEMBL1978371 & 809166 & 4.2 & 4.984 & TST & \\
\hline CHEMBL1970203 & 809166 & 6.0 & 5.7381 & TRN & \\
\hline CHEMBL1986530 & 809166 & 4.6 & 5.0565 & TST & \\
\hline CHEMBL440084 & 809166 & 4.2 & 4.3921 & TRN & \\
\hline CHEMBL1999321 & 809166 & 4.6 & 4.5832 & TRN & \\
\hline CHEMBL1968590 & 809166 & 7.1 & 7.2518 & TRN & \\
\hline CHEMBL1999749 & 809166 & 6.5 & 6.9111 & TRN & \\
\hline CHEMBL 2005375 & 809166 & 4.6 & 4.8238 & TRN & \\
\hline CHEMBL1984191 & 809166 & 4.6 & 4.8224 & TRN & \\
\hline CHEMBL1983006 & 809166 & 4.6 & 4.6282 & TRN & \\
\hline CHEMBL1966501 & 809166 & 4.2 & 4.0295 & TRN & \\
\hline CHEMBL1971029 & 809166 & 7.0 & 7.2464 & TRN & \\
\hline CHEMBL394790 & 809166 & 6.3 & 5.9311 & TRN & \\
\hline CHEMBL226471 & 809166 & 4.6 & 4.9202 & TRN & \\
\hline CHEMBL1974702 & 809166 & 4.6 & $4.5280 e$ & 00000000005 & TRN \\
\hline CHEMBL1996111 & 809166 & 4.6 & 4.6971 & TRN & \\
\hline CHEMBL1966175 & 809166 & 5.6 & 4.876 & TRN & \\
\hline CHEMBL1965589 & 809166 & 4.6 & 4.6573 & TRN & \\
\hline CHEMBL2007375 & 809166 & 4.2 & 3.9275 & TRN & \\
\hline CHEMBL1998193 & 809166 & 4.6 & 4.3719 & TRN & \\
\hline CHEMBL379975 & 809166 & 5.5 & 5.0876 & TRN & \\
\hline CHEMBL474432 & 809166 & 6.7 & 5.1459 & TST & \\
\hline CHEMBL1973016 & 809166 & 4.2 & 3.9305 & TRN & \\
\hline CHEMBL1965387 & 809166 & 4.2 & 4.7894 & TRN & \\
\hline CHEMBL1988153 & 809166 & 4.6 & 4.7173 & TRN & \\
\hline CHEMBL550418 & 809166 & 4.2 & 4.4303 & TRN & \\
\hline CHEMBL1971289 & 809166 & 4.2 & 4.18 & TRN & \\
\hline CHEMBL1999556 & 809166 & 4.6 & 4.46899 & 9999999999 & TRN \\
\hline CHEMBL1988437 & 809166 & 5.8 & 4.999 & TST & \\
\hline CHEMBL1968245 & 809166 & 4.6 & 5.2211 & TRN & \\
\hline CHEMBL1979577 & 809166 & 6.5 & 6.4415 & TRN & \\
\hline CHEMBL1998121 & 809166 & 4.6 & 4.8151 & TRN & \\
\hline CHEMBL1233887 & 809166 & 5.7 & $4.5710 e$ & 0000000001 & TST \\
\hline CHEMBL1991800 & 809166 & 4.6 & 4.8264 & TRN & \\
\hline CHEMBL52387 & 809166 & 4.6 & 5.0713 & TST & \\
\hline CHEMBL2003689 & 809166 & 4.2 & 4.0766 & TRN & \\
\hline CHEMBL379835 & 809166 & 4.6 & 4.4609 & TST & \\
\hline & & & & 13642 & \\
\hline
\end{tabular}




\begin{tabular}{|c|c|c|c|c|}
\hline & & & ipplement & al Table S \\
\hline CHEMBL1979357 & 809166 & 4.6 & 4.824 & TRN \\
\hline CHEMBL1980802 & 809166 & 4.6 & 4.8614 & TST \\
\hline CHEMBL1996649 & 809166 & 7.4 & 7.9427 & TRN \\
\hline CHEMBL1996817 & 809166 & 6.4 & 5.6339 & TRN \\
\hline CHEMBL1979554 & 809166 & 4.6 & 4.6264 & TRN \\
\hline CHEMBL1986756 & 809166 & 4.2 & 3.9059 & TRN \\
\hline CHEMBL409349 & 809166 & 6.9 & 6.5119 & TRN \\
\hline CHEMBL 2004355 & 809166 & 4.6 & 4.5242 & TRN \\
\hline CHEMBL468280 & 809166 & 4.6 & 4.4866 & TST \\
\hline CHEMBL1990884 & 809166 & 6.0 & 5.8708 & TRN \\
\hline CHEMBL 3109278 & 809166 & 7.5 & 6.6068 & TRN \\
\hline CHEMBL 256835 & 809166 & 5.9 & 5.0619 & TRN \\
\hline CHEMBL1974998 & 809166 & 4.2 & 4.2274 & TRN \\
\hline CHEMBL1980142 & 809166 & 4.6 & 4.502 & TRN \\
\hline CHEMBL41783 & 809166 & 4.6 & 4.6702 & TRN \\
\hline CHEMBL 2004438 & 809166 & 5.8 & 5.5711 & TRN \\
\hline CHEMBL 2006276 & 809166 & 4.6 & 4.8142 & TRN \\
\hline CHEMBL191003 & 809166 & 5.6 & 5.221 & TRN \\
\hline CHEMBL 271381 & 809166 & 6.5 & 6.8185 & TRN \\
\hline CHEMBL 2006785 & 809166 & 4.6 & 4.4543 & TRN \\
\hline CHEMBL1973359 & 809166 & 4.2 & 5.6605 & TST \\
\hline CHEMBL1994638 & 809166 & 6.3 & 5.9882 & TRN \\
\hline CHEMBL1995740 & 809166 & 4.6 & 4.7501 & TRN \\
\hline CHEMBL1985888 & 809166 & 6.5 & 7.07799 & 9999999999 \\
\hline CHEMBL1996390 & 809166 & 4.6 & 4.442 & TRN \\
\hline CHEMBL1979690 & 809166 & 7.5 & 7.3846 & TRN \\
\hline CHEMBL 234085 & 809166 & 4.2 & 4.6081 & TRN \\
\hline CHEMBL1995832 & 809166 & 4.6 & 4.6036 & TRN \\
\hline CHEMBL1969042 & 809166 & 4.6 & 4.6651 & TRN \\
\hline CHEMBL 2000345 & 809166 & 4.6 & 4.756 & TRN \\
\hline CHEMBL1999931 & 809166 & 4.6 & 5.3375 & TRN \\
\hline CHEMBL1976376 & 809166 & 8.6 & 7.3278 & TRN \\
\hline CHEMBL1991640 & 809166 & 4.6 & 4.9797 & TST \\
\hline CHEMBL1983575 & 809166 & 5.6 & 5.1396 & TRN \\
\hline CHEMBL1968868 & 809166 & 4.2 & 4.2371 & TRN \\
\hline CHEMBL1375418 & 809166 & 4.6 & 5.1516 & TRN \\
\hline CHEMBL 302449 & 809166 & 5.7 & 6.2486 & TST \\
\hline CHEMBL 2007064 & 809166 & 5.8 & 5.7545 & TRN \\
\hline CHEMBL1981047 & 809166 & 7.2 & 6.9737 & TRN \\
\hline CHEMBL 229968 & 809166 & 4.6 & 5.0003 & TRN \\
\hline CHEMBL1976196 & 809166 & 4.2 & 4.2436 & TST \\
\hline CHEMBL 2002432 & 809166 & 7.1 & 5.3716 & TRN \\
\hline CHEMBL1976240 & 809166 & 4.6 & 4.6418 & TRN \\
\hline CHEMBL1997197 & 809166 & 4.2 & 4.1999 & TRN \\
\hline CHEMBL1968151 & 809166 & 4.6 & 4.5792 & TST \\
\hline CHEMBL1979093 & 809166 & 6.7 & 7.0172 & TRN \\
\hline CHEMBL1381197 & 809166 & 6.5 & 5.5417 & TRN \\
\hline CHEMBL1987009 & 809166 & 4.6 & 4.4772 & TRN \\
\hline
\end{tabular}

TRN 


\begin{tabular}{|c|c|c|c|c|}
\hline \multicolumn{5}{|c|}{ Supplemental Table S2.txt } \\
\hline CHEMBL379218 & 809166 & 4.6 & 4.8308 & TRN \\
\hline CHEMBL 2003817 & 809166 & 4.6 & 4.5796 & TRN \\
\hline CHEMBL336961 & 809166 & 6.2 & 5.4037 & TRN \\
\hline CHEMBL1994830 & 809166 & 4.6 & 4.912 & TRN \\
\hline CHEMBL1987054 & 809166 & 6.8 & 7.7615 & TRN \\
\hline CHEMBL1970083 & 809166 & 7.6 & 8.0833 & TRN \\
\hline CHEMBL226403 & 809166 & 4.6 & 4.8369 & TRN \\
\hline CHEMBL 2005631 & 809166 & 8.2 & 7.8183 & TRN \\
\hline CHEMBL1994938 & 809166 & 7.8 & 8.4892 & TRN \\
\hline CHEMBL1977223 & 809166 & 4.6 & 4.3737 & TRN \\
\hline CHEMBL1966279 & 809166 & 4.6 & 4.9752 & TRN \\
\hline CHEMBL1236126 & 809166 & 4.6 & 4.3792 & TRN \\
\hline CHEMBL1997846 & 809166 & 4.4 & 4.7343 & TRN \\
\hline CHEMBL1984760 & 809166 & 4.2 & 4.5834 & TRN \\
\hline CHEMBL 2004419 & 809166 & 5.9 & 4.8404 & TRN \\
\hline CHEMBL1991728 & 809166 & 4.6 & 4.8547 & TRN \\
\hline CHEMBL360847 & 809166 & 4.2 & 4.5838 & TST \\
\hline CHEMBL 2007073 & 809166 & 4.2 & 3.9929 & TRN \\
\hline CHEMBL1995811 & 809166 & 4.2 & 4.1138 & TRN \\
\hline CHEMBL1975787 & 809166 & 4.6 & 4.3263 & TRN \\
\hline CHEMBL 2002407 & 809166 & 5.8 & 5.4285 & TRN \\
\hline CHEMBL1972489 & 809166 & 4.6 & 4.7329 & TRN \\
\hline CHEMBL1994074 & 809166 & 4.6 & 4.5207 & TRN \\
\hline CHEMBL1992937 & 809166 & 4.3 & 4.1332 & TST \\
\hline CHEMBL1985566 & 809166 & 4.6 & 5.0401 & TRN \\
\hline CHEMBL1972119 & 809166 & 4.6 & 4.6725 & TRN \\
\hline CHEMBL1986328 & 809166 & 4.6 & 4.9069 & TST \\
\hline CHEMBL95692 & 809166 & 4.6 & 5.0895 & TRN \\
\hline CHEMBL1090356 & 809166 & 7.4 & 7.3698 & TRN \\
\hline CHEMBL1976455 & 809166 & 4.6 & 4.7749 & TRN \\
\hline CHEMBL261849 & 809166 & 4.2 & 4.1695 & TST \\
\hline CHEMBL1983923 & 809166 & 7.5 & 6.6851 & TRN \\
\hline CHEMBL1983534 & 809166 & 4.6 & 4.749 & TRN \\
\hline CHEMBL1982361 & 809166 & 4.6 & 4.6152 & TRN \\
\hline CHEMBL1999112 & 809166 & 6.6 & 5.9972 & TST \\
\hline CHEMBL1982122 & 809166 & 4.6 & 4.5165 & TRN \\
\hline CHEMBL 2000801 & 809166 & 4.6 & 4.9662 & TRN \\
\hline CHEMBL1682546 & 809166 & 4.6 & 4.3739 & TST \\
\hline CHEMBL1988872 & 809166 & 4.2 & 4.223 & TST \\
\hline CHEMBL1991395 & 809166 & 4.6 & 4.7738 & TST \\
\hline CHEMBL1971245 & 809166 & 5.8 & 5.2639 & TST \\
\hline CHEMBL1987648 & 809166 & 4.6 & 4.4761 & TST \\
\hline CHEMBL1996780 & 809166 & 4.6 & 4.6249 & TST \\
\hline CHEMBL1993634 & 809166 & 4.2 & 4.7704 & TST \\
\hline CHEMBL1972142 & 809166 & 4.6 & 4.7021 & TST \\
\hline CHEMBL1966514 & 809166 & 7.7 & 8.1182 & TST \\
\hline CHEMBL 2003638 & 809166 & 4.6 & 5.0105 & TST \\
\hline CHEMBL296586 & 809166 & 5.8 & 5.4803 & TST \\
\hline
\end{tabular}




\begin{tabular}{|c|c|c|c|c|}
\hline & & & upplement & $d+1$ \\
\hline CHEMBL1996066 & 809166 & 6.6 & 5.3368 & TST \\
\hline CHEMBL1983393 & 809166 & 4.2 & 4.3709 & TST \\
\hline CHEMBL516429 & 809166 & 4.6 & 4.2898 & TST \\
\hline CHEMBL1970806 & 809166 & 4.6 & 4.9379 & TST \\
\hline CHEMBL1993722 & 809166 & 4.6 & 5.5913 & TST \\
\hline CHEMBL 2006674 & 809166 & 4.2 & 4.2385 & TST \\
\hline CHEMBL1984236 & 809166 & 4.2 & 4.2312 & TST \\
\hline CHEMBL1992371 & 809166 & 4.2 & 4.1435 & TST \\
\hline CHEMBL1375640 & 809166 & 4.6 & 4.5438 & TST \\
\hline CHEMBL1979970 & 809166 & 4.6 & 4.4093 & TST \\
\hline CHEMBL2002599 & 809166 & 4.2 & 4.5755 & TST \\
\hline CHEMBL 249282 & 809166 & 4.6 & 4.9577 & TST \\
\hline CHEMBL1967252 & 809166 & 4.2 & 4.2101 & TST \\
\hline CHEMBL1992473 & 809166 & 6.3 & 5.973 & TST \\
\hline CHEMBL 2004637 & 809166 & 4.2 & 5.3672 & TST \\
\hline CHEMBL1993374 & 809166 & 4.2 & 4.1951 & TST \\
\hline CHEMBL1969264 & 809166 & 4.6 & 4.7291 & TST \\
\hline CHEMBL1994318 & 809166 & 4.2 & 4.565 & TST \\
\hline CHEMBL1973711 & 809166 & 4.6 & 4.8279 & TST \\
\hline CHEMBL 2006237 & 809166 & 4.6 & 4.8803 & TST \\
\hline CHEMBL1999506 & 809166 & 4.2 & 4.0025 & TST \\
\hline CHEMBL1967720 & 809166 & 8.6 & 8.1494 & TST \\
\hline CHEMBL1572266 & 809166 & 4.6 & 4.3832 & TST \\
\hline CHEMBL1991138 & 809166 & 4.8 & 5.3149 & TST \\
\hline CHEMBL1979516 & 809166 & 8.1 & 8.3037 & TST \\
\hline CHEMBL1969755 & 809166 & 4.6 & 4.5773 & TST \\
\hline CHEMBL1972820 & 809166 & 4.6 & 4.7325 & TST \\
\hline CHEMBL1605605 & 809166 & 4.2 & 4.2903 & TST \\
\hline CHEMBL1996208 & 809166 & 4.4 & 5.2712 & TST \\
\hline CHEMBL1989029 & 809166 & 6.3 & 5.2861 & TST \\
\hline CHEMBL392642 & 809166 & 4.6 & 4.8369 & TST \\
\hline CHEMBL514499 & 809166 & 5.7 & 4.8491 & TST \\
\hline CHEMBL1970352 & 809166 & 4.2 & 4.8518 & TST \\
\hline CHEMBL1965631 & 809166 & 4.6 & 4.5079 & TST \\
\hline CHEMBL1980144 & 809166 & 6.2 & 5.5104 & TST \\
\hline CHEMBL1991188 & 809166 & 4.6 & 4.6897 & TST \\
\hline CHEMBL1980167 & 809166 & 4.2 & 4.6069 & TST \\
\hline CHEMBL1972849 & 809166 & 4.6 & 4.6039 & TST \\
\hline CHEMBL 377408 & 809166 & 4.3 & 4.6046 & TST \\
\hline CHEMBL215152 & 809166 & 6.9 & 5.2583 & TST \\
\hline CHEMBL231209 & 809166 & 6.2 & 6.1772 & TST \\
\hline CHEMBL1976220 & 809166 & 6.4 & 5.96 & TST \\
\hline CHEMBL 2006765 & 809166 & 5.6 & 5.7627 & TST \\
\hline CHEMBL 259922 & 809166 & 6.6 & 5.529 & TST \\
\hline CHEMBL1969301 & 809166 & 4.6 & 4.8644 & TST \\
\hline CHEMBL1982383 & 809166 & 5.8 & 4.9813 & TST \\
\hline CHEMBL17370 & 809166 & 5.9 & 4.7445 & TST \\
\hline CHEMBL1980246 & 809166 & 4.2 & 4.5088 & TST \\
\hline
\end{tabular}




\begin{tabular}{|c|c|c|c|c|c|}
\hline \\
\hline CHEMBL1987910 & 809166 & 5.7 & 5.5893 & TST & \\
\hline CHEMBL 374044 & 809166 & 6.4 & 6.5153 & TST & \\
\hline CHEMBL1983932 & 809166 & 4.6 & 4.8871 & TST & \\
\hline CHEMBL1983980 & 809166 & 4.2 & 5.65799 & 99999999995 & TST \\
\hline CHEMBL1999484 & 809166 & 4.5 & 6.6686 & TST & \\
\hline CHEMBL404366 & 809166 & 7.3 & 6.1812 & TST & \\
\hline CHEMBL1966069 & 809166 & 4.6 & 4.6409 & TST & \\
\hline CHEMBL1986899 & 809166 & 5.8 & 4.6385 & TST & \\
\hline CHEMBL1991285 & 809166 & 4.6 & 4.8354 & TST & \\
\hline CHEMBL1997822 & 809166 & 4.6 & 6.4514 & TST & \\
\hline CHEMBL 243088 & 809166 & 6.2 & 6.0421 & TST & \\
\hline CHEMBL1984038 & 809166 & 4.4 & 4.5577 & TST & \\
\hline CHEMBL1968606 & 809166 & 4.2 & 4.2365 & TST & \\
\hline CHEMBL1974416 & 809166 & 6.3 & 6.4316 & TST & \\
\hline CHEMBL1993661 & 809166 & 7.1 & 7.187 & TST & \\
\hline CHEMBL1997872 & 809166 & 4.6 & 4.8552 & TST & \\
\hline CHEMBL1864262 & 752532 & 3.0044 & 2.9819 & TRN & \\
\hline CHEMBL1599544 & 752532 & 3.0044 & 3.5117 & TST & \\
\hline CHEMBL1408676 & 752532 & 3.0044 & 2.9098 & TRN & \\
\hline CHEMBL1865265 & 752532 & 3.0044 & 3.0975 & TST & \\
\hline CHEMBL1413278 & 752532 & 3.0044 & 3.7864 & TRN & \\
\hline CHEMBL1517170 & 752532 & 3.0044 & 3.0242 & TRN & \\
\hline CHEMBL1880043 & 752532 & 3.0044 & 3.383 & TRN & \\
\hline CHEMBL1877788 & 752532 & 3.0044 & 3.0151 & TST & \\
\hline CHEMBL1345096 & 752532 & 4.9208 & 4.7986 & TST & \\
\hline CHEMBL 2448581 & 752532 & 3.0044 & 3.0199 & TRN & \\
\hline CHEMBL1905211 & 752532 & 3.0044 & 3.2905 & TRN & \\
\hline CHEMBL1891588 & 752532 & 6.1805 & 6.4385 & TRN & \\
\hline CHEMBL1469489 & 752532 & 4.2069 & 4.1126 & TST & \\
\hline CHEMBL 1880875 & 752532 & 4.7282 & 5.1116 & TST & \\
\hline CHEMBL1892270 & 752532 & 5.2418 & 4.9931 & TRN & \\
\hline CHEMBL1906326 & 752532 & 3.0044 & 3.4685 & TST & \\
\hline CHEMBL1875168 & 752532 & 3.0044 & 3.3898 & TRN & \\
\hline CHEMBL1408953 & 752532 & 4.3936 & 3.1797 & TST & \\
\hline CHEMBL1871384 & 752532 & 3.0044 & 3.0373 & TRN & \\
\hline CHEMBL1897477 & 752532 & 3.0044 & 3.1103 & TRN & \\
\hline CHEMBL1705186 & 752532 & 4.6021 & 5.084 & TRN & \\
\hline CHEMBL1890253 & 752532 & 3.0044 & 3.2194 & TRN & \\
\hline CHEMBL1412015 & 752532 & 5.6882 & 5.6101 & TST & \\
\hline CHEMBL1866357 & 752532 & 3.0044 & 3.398 & TRN & \\
\hline CHEMBL1432044 & 752532 & 5.2958 & 3.443 & TST & \\
\hline CHEMBL1864637 & 752532 & 3.0044 & 3.3633 & TST & \\
\hline CHEMBL1322894 & 752532 & 5.2907 & 4.99 & TRN & \\
\hline CHEMBL1886317 & 752532 & 4.7696 & 3.1607 & TRN & \\
\hline CHEMBL1880833 & 752532 & 3.0044 & 3.5459 & TRN & \\
\hline CHEMBL1897044 & 752532 & 4.1118 & 4.0678 & TST & \\
\hline CHEMBL1871228 & 752532 & 6.1024 & 6.1454 & TRN & \\
\hline CHEMBL1904443 & 752532 & 3.0044 & 2.9942 & TRN & \\
\hline
\end{tabular}




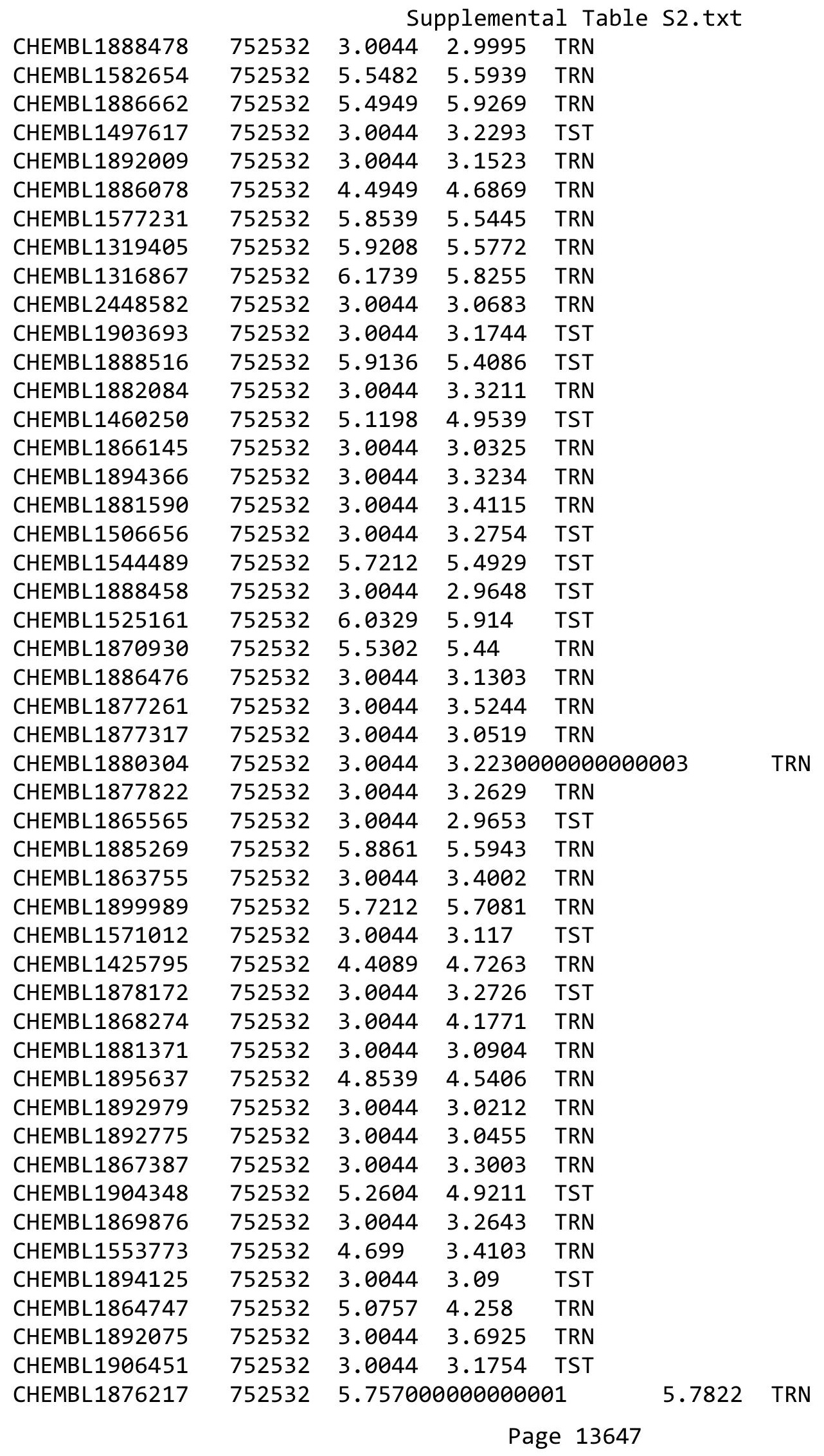




\begin{tabular}{|c|c|c|c|c|c|c|}
\hline & & \multicolumn{5}{|c|}{ Supplemental Table S2.txt } \\
\hline CHEMBL1873177 & 752532 & 3.0044 & 3.4849 & TST & & \\
\hline CHEMBL1886235 & 752532 & 3.0044 & 2.8896 & TRN & & \\
\hline CHEMBL1892156 & 752532 & 3.0044 & 3.0402 & TRN & & \\
\hline CHEMBL1897885 & 752532 & 4.3098 & 4.2491 & TRN & & \\
\hline CHEMBL1495113 & 752532 & 3.0044 & 3.1971 & TRN & & \\
\hline CHEMBL1302779 & 752532 & 5.8539 & 5.7249 & TRN & & \\
\hline CHEMBL1897015 & 752532 & 3.0044 & 3.4365 & TRN & & \\
\hline CHEMBL233119 & 752532 & 3.0044 & 3.1214 & TRN & & \\
\hline CHEMBL1902151 & 752532 & 3.0044 & 2.9995 & TRN & & \\
\hline CHEMBL1884064 & 752532 & 3.0044 & 3.0372 & TRN & & \\
\hline CHEMBL1898951 & 752532 & 3.0044 & 3.0522 & TRN & & \\
\hline CHEMBL1896895 & 752532 & 3.0044 & 3.1307 & TRN & & \\
\hline CHEMBL1872457 & 752532 & 4.9788 & 3.0141 & TRN & & \\
\hline CHEMBL1896157 & 752532 & 3.0044 & 3.3537 & TRN & & \\
\hline CHEMBL1514860 & 752532 & 3.0044 & 3.2041 & TRN & & \\
\hline CHEMBL1883048 & 752532 & 3.0044 & 3.0128 & TRN & & \\
\hline CHEMBL1905640 & 752532 & 3.0044 & 3.0191 & TST & & \\
\hline CHEMBL1609828 & 752532 & 5.466 & 5.2263 & TST & & \\
\hline CHEMBL1876316 & 752532 & 4.0737 & 3.8849 & TRN & & \\
\hline CHEMBL1867713 & 752532 & 3.0044 & 3.3872 & TRN & & \\
\hline CHEMBL1872249 & 752532 & 4.82100 & 0000000 & 3. & .0183 & TRN \\
\hline CHEMBL1865088 & 752532 & 3.0044 & 2.9384 & TRN & & \\
\hline CHEMBL1884437 & 752532 & 4.3747 & 4.3908 & TRN & & \\
\hline CHEMBL1898076 & 752532 & 3.0044 & 2.9169 & TRN & & \\
\hline CHEMBL1894672 & 752532 & 3.0044 & 3.2718 & TRN & & \\
\hline CHEMBL1876157 & 752532 & 3.0044 & 2.8922 & TRN & & \\
\hline CHEMBL1477200 & 752532 & 4.4473 & 3.1895 & TRN & & \\
\hline CHEMBL1864348 & 752532 & 4.7423 & 2.9632 & TRN & & \\
\hline CHEMBL1887007 & 752532 & 3.0044 & 2.9424 & TRN & & \\
\hline CHEMBL1870590 & 752532 & 3.0044 & 3.0986 & TST & & \\
\hline CHEMBL1870914 & 752532 & 6.2676 & 6.2538 & TRN & & \\
\hline CHEMBL1871327 & 752532 & 3.0044 & 3.2697 & TRN & & \\
\hline CHEMBL1903194 & 752532 & 3.0044 & 2.9142 & TRN & & \\
\hline CHEMBL1898917 & 752532 & 3.0044 & 3.1179 & TRN & & \\
\hline CHEMBL1875316 & 752532 & 3.0044 & 2.8997 & TST & & \\
\hline CHEMBL1901952 & 752532 & 3.0044 & 3.4006 & TRN & & \\
\hline CHEMBL1885025 & 752532 & 3.0044 & 3.4744 & TRN & & \\
\hline CHEMBL1893628 & 752532 & 3.0044 & 3.1156 & TRN & & \\
\hline CHEMBL1510959 & 752532 & 4.0862 & 3.2814 & TST & & \\
\hline CHEMBL1379448 & 752532 & 5.8447 & 5.5338 & TRN & & \\
\hline CHEMBL1477061 & 752532 & 5.6383 & 5.49299 & 9999999999 & & TRN \\
\hline CHEMBL1873019 & 752532 & 3.0044 & 3.2569 & TRN & & \\
\hline CHEMBL1895018 & 752532 & 3.0044 & 2.888 & TRN & & \\
\hline CHEMBL1899086 & 752532 & 3.0044 & 3.0931 & TRN & & \\
\hline CHEMBL1870597 & 752532 & 3.0044 & 2.9789 & TRN & & \\
\hline CHEMBL1878043 & 752532 & 4.699 & 4.70100 & 00000000005 & & TRN \\
\hline CHEMBL1877777 & 752532 & 5.8861 & 5.9724 & TRN & & \\
\hline CHEMBL1893046 & 752532 & 3.0044 & 3.1512 & TRN & & \\
\hline
\end{tabular}


Supplemental Table S2.txt

\begin{tabular}{|c|c|c|c|c|c|c|}
\hline CHEMBL1869506 & 752532 & 5.3279 & 5.0319 & TST & & \\
\hline CHEMBL1322834 & 752532 & 5.0625 & 4.8919 & TRN & & \\
\hline CHEMBL1879394 & 752532 & 6.1296 & 6.3809 & TRN & & \\
\hline CHEMBL1892340 & 752532 & 3.0044 & 3.0055 & TRN & & \\
\hline CHEMBL 2028088 & 752532 & 3.0044 & 3.1639 & TRN & & \\
\hline CHEMBL1586985 & 752532 & 6.0434 & 5.7431 & TRN & & \\
\hline CHEMBL1869393 & 752532 & 6.0132 & 6.4239 & TRN & & \\
\hline CHEMBL1903946 & 752532 & 3.0044 & 2.9971 & TRN & & \\
\hline CHEMBL1876647 & 752532 & 3.0044 & 3.0699 & TRN & & \\
\hline CHEMBL1871956 & 752532 & \multicolumn{3}{|c|}{5.382000000000001} & 3.3542 & TST \\
\hline CHEMBL1897928 & 752532 & 3.0044 & 3.3938 & TST & & \\
\hline CHEMBL1887414 & 752532 & 4.2933 & 3.1083 & TST & & \\
\hline CHEMBL1878061 & 752532 & 5.8539 & 6.1398 & TRN & & \\
\hline CHEMBL1883288 & 752532 & 3.0044 & 3.2824 & TST & & \\
\hline CHEMBL1883257 & 752532 & 3.0044 & 3.4207 & TRN & & \\
\hline CHEMBL1863714 & 752532 & 3.0044 & 3.2109 & TRN & & \\
\hline CHEMBL1888321 & 752532 & 3.0044 & 3.013 & TRN & & \\
\hline CHEMBL1468256 & 752532 & 3.0044 & 3.2529 & TRN & & \\
\hline CHEMBL1905817 & 752532 & 5.2154 & 4.84 & TRN & & \\
\hline CHEMBL1885809 & 752532 & 3.0044 & 2.9484 & TRN & & \\
\hline CHEMBL546865 & 752532 & 3.0044 & 3.2686 & TST & & \\
\hline CHEMBL1534143 & 752532 & 5.699 & 5.7192 & TRN & & \\
\hline CHEMBL1897633 & 752532 & 3.0044 & 3.497 & TRN & & \\
\hline CHEMBL1872062 & 752532 & 5.1549 & 4.7483 & TST & & \\
\hline CHEMBL1613411 & 752532 & 3.0044 & 3.088 & TRN & & \\
\hline CHEMBL1866613 & 752532 & 5.6778 & 5.945 & TRN & & \\
\hline CHEMBL1873238 & 752532 & 4.3595 & 3.9079 & TST & & \\
\hline CHEMBL1879541 & 752532 & 3.0044 & 3.2839 & TRN & & \\
\hline CHEMBL1906504 & 752532 & 3.0044 & 3.0782 & TRN & & \\
\hline CHEMBL1866663 & 752532 & 3.0044 & 3.0192 & TRN & & \\
\hline CHEMBL1773702 & 752532 & 5.7423 & 5.3786 & TRN & & \\
\hline CHEMBL1879256 & 752532 & 3.0044 & 3.1335 & TRN & & \\
\hline CHEMBL1877931 & 752532 & 3.0044 & 2.9736 & TRN & & \\
\hline CHEMBL1547213 & 752532 & 3.0044 & 3.0738 & TRN & & \\
\hline CHEMBL1874319 & 752532 & 5.1701 & 4.9902 & TRN & & \\
\hline CHEMBL1867839 & 752532 & 3.0044 & 3.1115 & TRN & & \\
\hline CHEMBL1900215 & 752532 & 3.0044 & 3.1337 & TRN & & \\
\hline CHEMBL1620972 & 752532 & 3.0044 & 3.245 & TRN & & \\
\hline CHEMBL1449672 & 752532 & 3.0044 & 3.1809 & TRN & & \\
\hline CHEMBL1898778 & 752532 & 3.0044 & 2.978 & TRN & & \\
\hline CHEMBL1873053 & 752532 & 3.0044 & 3.0961 & TRN & & \\
\hline CHEMBL1598762 & 752532 & 4.8447 & 4.3566 & TST & & \\
\hline CHEMBL1898479 & 752532 & 4.6904 & 3.0012 & TRN & & \\
\hline CHEMBL 1877442 & 752532 & 3.0044 & 3.1695 & TRN & & \\
\hline CHEMBL1898718 & 752532 & 3.0044 & 2.9557 & TST & & \\
\hline CHEMBL1884495 & 752532 & 6.0809 & 6.2053 & TRN & & \\
\hline CHEMBL1893076 & 752532 & 3.0044 & 2.957 & TRN & & \\
\hline CHEMBL1416561 & 752532 & 3.0044 & 2.8635 & TRN & & \\
\hline
\end{tabular}

Page 13649 


\begin{tabular}{|c|c|c|c|c|}
\hline \multicolumn{5}{|c|}{ Supplemental Table S2.txt } \\
\hline CHEMBL1880791 & 752532 & 3.0044 & 3.1019 & TRN \\
\hline CHEMBL1333222 & 752532 & 3.0044 & 3.5013 & TRN \\
\hline CHEMBL68442 & 752532 & 3.0044 & 2.9772 & TRN \\
\hline CHEMBL1899771 & 752532 & 4.9586 & 4.3084 & TRN \\
\hline CHEMBL1564500 & 752532 & 3.0044 & 3.0408 & TRN \\
\hline CHEMBL1874506 & 752532 & 5.5528 & 5.2571 & TRN \\
\hline CHEMBL1370991 & 752532 & 5.0942 & 4.6837 & TRN \\
\hline CHEMBL1883904 & 752532 & 3.0044 & 3.1156 & TST \\
\hline CHEMBL1895014 & 752532 & 3.0044 & 3.0789 & TRN \\
\hline CHEMBL1886298 & 752532 & 3.0044 & 3.0355 & TRN \\
\hline CHEMBL1899595 & 752532 & 5.4559 & 5.2628 & TRN \\
\hline CHEMBL1898553 & 752532 & 4.4895 & 3.0385 & TST \\
\hline CHEMBL1901170 & 752532 & 5.6968 & 5.5458 & TRN \\
\hline CHEMBL1883428 & 752532 & 3.0044 & 2.9312 & TRN \\
\hline CHEMBL1865625 & 752532 & 3.0044 & 3.3199 & TRN \\
\hline CHEMBL1872841 & 752532 & 4.3468 & 4.2541 & TRN \\
\hline CHEMBL1905576 & 752532 & 3.0044 & 3.0217 & TRN \\
\hline CHEMBL1565912 & 752532 & 5.7747 & 5.4997 & TST \\
\hline CHEMBL1613216 & 752532 & 5.9318 & 5.5612 & TST \\
\hline CHEMBL1904648 & 752532 & 5.6778 & 4.4506 & TRN \\
\hline CHEMBL1532745 & 752532 & 3.0044 & 2.8635 & TRN \\
\hline CHEMBL1888363 & 752532 & 3.0044 & 3.5058 & TRN \\
\hline CHEMBL1902079 & 752532 & 4.4976 & 3.0482 & TRN \\
\hline CHEMBL1884507 & 752532 & 4.8861 & 4.936 & TRN \\
\hline CHEMBL1889650 & 752532 & 5.8097 & 5.2782 & TRN \\
\hline CHEMBL1901962 & 752532 & 3.0044 & 3.0083 & TRN \\
\hline CHEMBL1414729 & 752532 & 3.0044 & 3.4103 & TST \\
\hline CHEMBL1875486 & 752532 & 3.0044 & 3.2212 & TRN \\
\hline CHEMBL1879721 & 752532 & 3.0044 & 3.6044 & TRN \\
\hline CHEMBL576846 & 752532 & 3.0044 & 3.1268 & TRN \\
\hline CHEMBL1885498 & 752532 & 3.0044 & 2.9232 & TRN \\
\hline CHEMBL1902852 & 752532 & 3.0044 & 3.3595 & TRN \\
\hline CHEMBL1867373 & 752532 & 3.0044 & 3.1933 & TRN \\
\hline CHEMBL1471498 & 752532 & 4.1752 & 3.3545 & TST \\
\hline CHEMBL1306211 & 752532 & 4.7282 & 4.8944 & TST \\
\hline CHEMBL1900453 & 752532 & 5.0315 & 4.6002 & TST \\
\hline CHEMBL1483649 & 752532 & 5.7212 & 5.3965 & TRN \\
\hline CHEMBL1486906 & 752532 & 3.0044 & 3.0376 & TRN \\
\hline CHEMBL1890591 & 752532 & 5.8125 & 5.5046 & TST \\
\hline CHEMBL1870966 & 752532 & 5.1675 & 4.85 & TRN \\
\hline CHEMBL1890161 & 752532 & 4.0501 & 2.9862 & TRN \\
\hline CHEMBL1554455 & 752532 & 3.0044 & 3.5035 & TRN \\
\hline CHEMBL1876946 & 752532 & 3.0044 & 2.9022 & TRN \\
\hline CHEMBL1866897 & 752532 & 3.0044 & 3.2573 & TRN \\
\hline CHEMBL1880120 & 752532 & 4.3325 & 4.2524 & TRN \\
\hline CHEMBL 3144856 & 752532 & 5.0264 & 4.5354 & TST \\
\hline CHEMBL1887272 & 752532 & 3.0044 & 3.3808 & TRN \\
\hline CHEMBL1868306 & 752532 & 4.1898 & 2.9347 & TST \\
\hline
\end{tabular}




\begin{tabular}{|c|c|c|c|c|c|}
\hline \multicolumn{6}{|c|}{ Supplemental Table S2.txt } \\
\hline CHEMBL1869875 & 752532 & 6.061 & 5.3804 & TRN & \\
\hline CHEMBL1877896 & 752532 & 3.0044 & 3.0646 & TST & \\
\hline CHEMBL1891751 & 752532 & 5.3468 & 5.0524 & TRN & \\
\hline CHEMBL1892581 & 752532 & 3.0044 & 3.3957 & TST & \\
\hline CHEMBL1405521 & 752532 & 3.0044 & 3.0491 & TST & \\
\hline CHEMBL1886693 & 752532 & 4.5884 & 4.5263 & TRN & \\
\hline CHEMBL1883060 & 752532 & 3.0044 & 3.0415 & TRN & \\
\hline CHEMBL1575970 & 752532 & 5.4034 & 4.947 & TRN & \\
\hline CHEMBL1901827 & 752532 & 5.4559 & 5.652 & TRN & \\
\hline CHEMBL1902007 & 752532 & 4.8539 & 4.5733 & TRN & \\
\hline CHEMBL1869120 & 752532 & 3.0044 & 3.0181 & TRN & \\
\hline CHEMBL1866482 & 752532 & 3.0044 & 3.0595 & TRN & \\
\hline CHEMBL1470146 & 752532 & 5.2396 & 5.263 & TST & \\
\hline CHEMBL1906573 & 752532 & 3.0044 & 3.1888 & TRN & \\
\hline CHEMBL1435486 & 752532 & 3.0044 & 3.3233 & TRN & \\
\hline CHEMBL1876373 & 752532 & 3.0044 & 3.2446 & TRN & \\
\hline CHEMBL1884442 & 752532 & 6.1079 & 6.6779 & TRN & \\
\hline CHEMBL1904202 & 752532 & 3.0044 & 2.9283 & TST & \\
\hline CHEMBL1882443 & 752532 & 5.3565 & 5.6379 & TRN & \\
\hline CHEMBL1902173 & 752532 & 5.1232 & 4.7131 & TRN & \\
\hline CHEMBL1864818 & 752532 & 3.0044 & 2.9544 & TRN & \\
\hline CHEMBL1873343 & 752532 & 3.0044 & 3.4241 & TRN & \\
\hline CHEMBL1542557 & 752532 & 3.0044 & 3.1901 & TST & \\
\hline CHEMBL1874988 & 752532 & 3.0044 & 3.3604 & TRN & \\
\hline CHEMBL1892809 & 752532 & 3.0044 & 3.3873 & TST & \\
\hline CHEMBL1868902 & 752532 & 5.5528 & 5.8105 & TRN & \\
\hline CHEMBL3195749 & 752532 & 5.6676 & 5.4436 & TST & \\
\hline CHEMBL1309254 & 752532 & 3.0044 & 3.1589 & TST & \\
\hline CHEMBL1885482 & 752532 & 4.4559 & 4.6323 & TRN & \\
\hline CHEMBL1881903 & 752532 & 3.0044 & 3.14300 & 00000000002 & TRN \\
\hline CHEMBL1896263 & 752532 & 5.7447 & 5.8316 & TRN & \\
\hline CHEMBL1864057 & 752532 & 3.0044 & 3.4512 & TRN & \\
\hline CHEMBL1893952 & 752532 & 3.0044 & 3.0598 & TRN & \\
\hline CHEMBL1891206 & 752532 & 6.1249 & 6.6667 & TRN & \\
\hline CHEMBL1898423 & 752532 & 4.4949 & 4.2276 & TRN & \\
\hline CHEMBL1905093 & 752532 & 4.757 & 4.613 & TST & \\
\hline CHEMBL1888528 & 752532 & 4.9469 & 4.4926 & TST & \\
\hline CHEMBL1494979 & 752532 & 5.2749 & 4.7624 & TST & \\
\hline CHEMBL1365469 & 752532 & 4.6778 & 4.4332 & TRN & \\
\hline CHEMBL1893535 & 752532 & 4.7721 & 4.1581 & TST & \\
\hline CHEMBL1881878 & 752532 & 3.0044 & 3.1187 & TRN & \\
\hline CHEMBL1890186 & 752532 & 4.1864 & 4.2363 & TST & \\
\hline CHEMBL3898000 & 1638439 & 4.301 & 6.3898 & TST & \\
\hline CHEMBL 3979368 & 1638439 & 7.5686 & 7.0817 & TRN & \\
\hline CHEMBL3936119 & 1638439 & 7.1192 & 6.7381 & TRN & \\
\hline CHEMBL3965139 & 1638439 & 7.3665 & 6.3113 & TRN & \\
\hline CHEMBL3971577 & 1638439 & 6.9706 & 6.3689 & TRN & \\
\hline CHEMBL3895146 & 1638439 & 7.4815 & 7.0274 & TST & \\
\hline
\end{tabular}




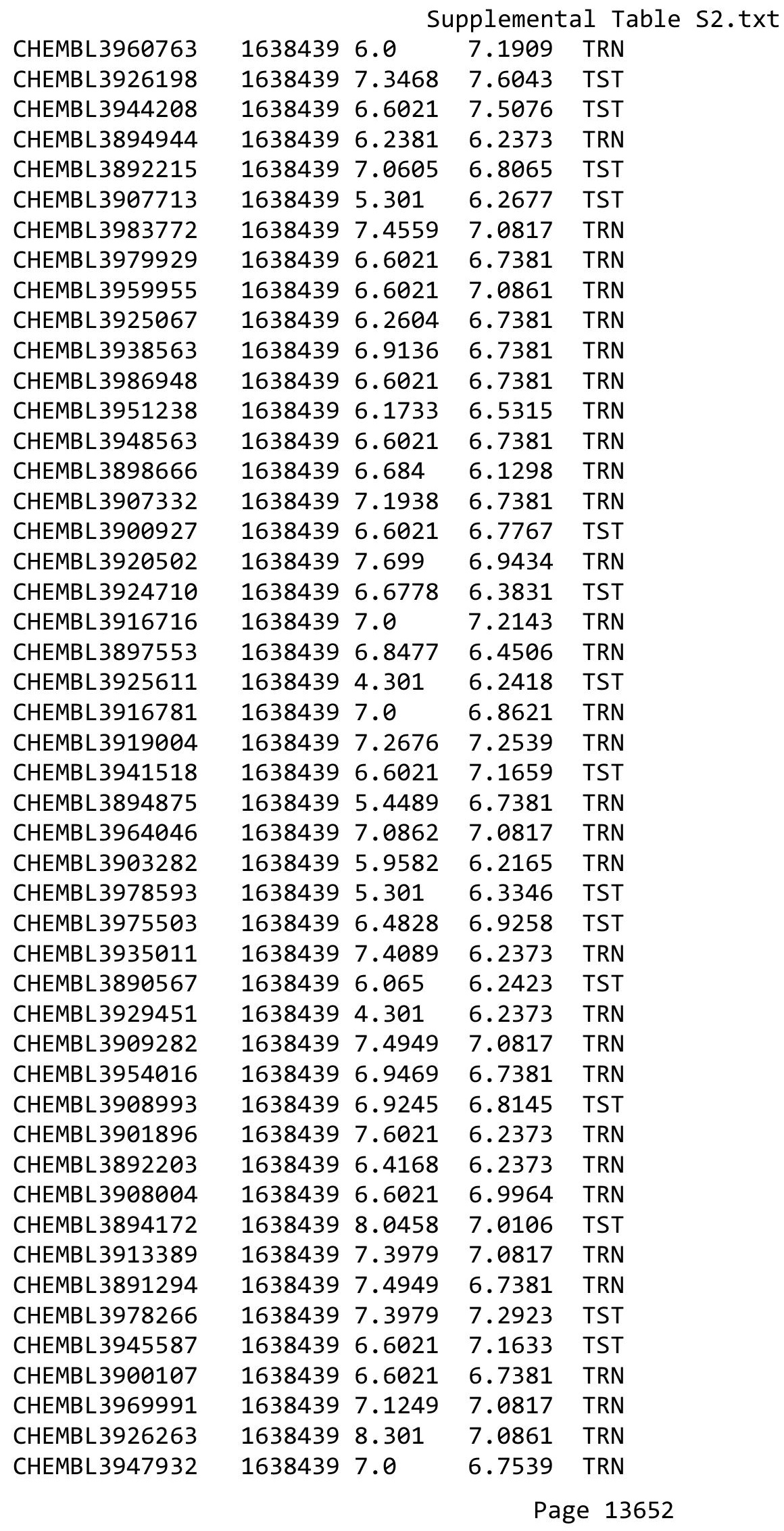


Supplemental Table S2.txt

\begin{tabular}{|c|c|c|c|c|c|}
\hline CHEMBL 3896674 & 1638439 & 6.5031 & 6.1377 & TST & \\
\hline CHEMBL 3970847 & 1638439 & 7.2757 & 7.1385 & TRN & \\
\hline CHEMBL3973530 & 1638439 & 6.6021 & 6.8183 & TST & \\
\hline CHEMBL 3960342 & 1638439 & 8.301 & 7.2788 & TRN & \\
\hline CHEMBL3923963 & 1638439 & 6.6038 & 6.7667 & TST & \\
\hline CHEMBL3969649 & 1638439 & 4.301 & 5.6727 & TRN & \\
\hline CHEMBL3950581 & 1638439 & 7.4089 & 6.7381 & TRN & \\
\hline CHEMBL 3951421 & 1638439 & 6.1851 & 6.2373 & TRN & \\
\hline CHEMBL 3976435 & 1638439 & 4.301 & 6.1585 & TST & \\
\hline CHEMBL3912278 & 1638439 & 6.9393 & 6.4392 & TRN & \\
\hline CHEMBL 3907724 & 1638439 & 6.9101 & 6.3113 & TRN & \\
\hline CHEMBL3938250 & 1638439 & 8.301 & 6.7381 & TRN & \\
\hline CHEMBL 3986750 & 1638439 & 6.8125 & 6.2373 & TRN & \\
\hline CHEMBL3929419 & 1638439 & 7.9208 & 7.1588 & TST & \\
\hline CHEMBL 3979281 & 1638439 & 7.1871 & 7.302006 & 00000000005 & TST \\
\hline CHEMBL3913226 & 1638439 & 6.6021 & 7.0861 & TRN & \\
\hline CHEMBL3934143 & 1638439 & 7.3768 & 6.8539 & TRN & \\
\hline CHEMBL 3930078 & 1638439 & 6.6021 & 6.7381 & TRN & \\
\hline CHEMBL 3924757 & 1638439 & 6.6021 & 6.7381 & TRN & \\
\hline CHEMBL3945045 & 1638439 & 6.6021 & 6.7381 & TRN & \\
\hline CHEMBL 3919840 & 1638439 & 7.3188 & 6.255 & TST & \\
\hline CHEMBL 3899092 & 1638439 & 7.5686 & 6.1111 & TRN & \\
\hline CHEMBL3901462 & 1638439 & 6.6021 & 6.7381 & TRN & \\
\hline CHEMBL 3910505 & 1638439 & 4.301 & 6.7381 & TRN & \\
\hline CHEMBL3965347 & 1638439 & 7.0223 & 6.7899 & TRN & \\
\hline CHEMBL 3935855 & 1638439 & 6.6021 & 6.8507 & TST & \\
\hline CHEMBL 3958172 & 1638439 & 6.6021 & 6.7381 & TRN & \\
\hline CHEMBL3982744 & 1638439 & 6.6345 & 7.1527 & TRN & \\
\hline CHEMBL 3962820 & 1638439 & 7.1612 & 6.2373 & TRN & \\
\hline CHEMBL3969906 & 1638439 & 6.6021 & 6.7381 & TRN & \\
\hline CHEMBL 3890707 & 1638439 & 6.6021 & 6.8786 & TRN & \\
\hline CHEMBL3942921 & 1638439 & 6.6021 & 6.9381 & TRN & \\
\hline CHEMBL3914919 & 1638439 & 6.9208 & 6.1111 & TRN & \\
\hline CHEMBL3973609 & 1638439 & 7.0 & 7.0861 & TRN & \\
\hline CHEMBL3927207 & 1638439 & 7.5686 & 7.0371 & TST & \\
\hline CHEMBL3917203 & 1638439 & 6.2993 & 6.2373 & TRN & \\
\hline CHEMBL3960037 & 1638439 & 7.0 & 6.8183 & TST & \\
\hline CHEMBL3975597 & 1638439 & 7.3565 & 7.1367 & TRN & \\
\hline CHEMBL 3900852 & 1638439 & 5.0 & 5.6727 & TRN & \\
\hline CHEMBL3954995 & 1638439 & 7.0 & 7.0366 & TRN & \\
\hline CHEMBL 3960575 & 1638439 & 7.6383 & 7.0861 & TRN & \\
\hline CHEMBL3917162 & 1638439 & 7.2924 & 6.4851 & TRN & \\
\hline CHEMBL3933128 & 1638439 & 4.301 & 6.4011 & TST & \\
\hline CHEMBL3908317 & 1638439 & 7.3979 & 6.4851 & TRN & \\
\hline CHEMBL3917929 & 1638439 & 6.6021 & 7.1047 & TST & \\
\hline CHEMBL 3945527 & 1638439 & 6.7878 & 6.3632 & TST & \\
\hline CHEMBL3964606 & 1638439 & 6.6021 & 6.9247 & TRN & \\
\hline CHEMBL3983163 & 1638439 & 7.0 & 7.0861 & TRN & \\
\hline
\end{tabular}


Supplemental Table S2.txt

\begin{tabular}{|c|c|c|c|c|c|}
\hline CHEMBL 3950682 & 1638439 & 7.5376 & 6.6884 & TST & \\
\hline CHEMBL 3912798 & 1638439 & 7.3979 & 7.0518 & TST & \\
\hline CHEMBL3922562 & 1638439 & 7.3665 & 6.7004 & TST & \\
\hline CHEMBL 3942138 & 1638439 & 5.301 & 6.7381 & TRN & \\
\hline CHEMBL3892766 & 1638439 & 6.6021 & 6.7381 & TRN & \\
\hline CHEMBL 3953920 & 1638439 & 6.0255 & 6.2373 & TRN & \\
\hline CHEMBL3908506 & 1638439 & 6.9281 & 6.5298 & TST & \\
\hline CHEMBL3958887 & 1638439 & 7.0088 & 6.7381 & TRN & \\
\hline CHEMBL3915051 & 1638439 & 7.2291 & 7.1832 & TST & \\
\hline CHEMBL3961787 & 1638439 & 6.6021 & 7.0817 & TRN & \\
\hline CHEMBL3942874 & 1638439 & 6.6021 & 7.0861 & TRN & \\
\hline CHEMBL 3917857 & 1638439 & 6.6021 & 6.9381 & TRN & \\
\hline CHEMBL3921391 & 1638439 & 6.6021 & 7.0817 & TRN & \\
\hline CHEMBL3893237 & 1638439 & 7.0 & 7.0861 & TRN & \\
\hline CHEMBL3959168 & 1638439 & 7.0 & 7.2677 & TRN & \\
\hline CHEMBL3984029 & 1638439 & 6.6021 & 6.5547 & TRN & \\
\hline CHEMBL3918860 & 1638439 & 5.8033 & 6.0847 & TRN & \\
\hline CHEMBL 3890750 & 1638439 & 7.0 & 6.7381 & TRN & \\
\hline CHEMBL 3950270 & 1638439 & 6.6021 & 6.8183 & TST & \\
\hline CHEMBL3941983 & 1638439 & 8.301 & 6.7381 & TRN & \\
\hline CHEMBL3921679 & 1638439 & 5.8881 & 6.2283 & TRN & \\
\hline CHEMBL3935596 & 1638439 & 7.6198 & 6.4562 & TST & \\
\hline CHEMBL 3942986 & 1638439 & 7.3098 & \multicolumn{2}{|c|}{ 7.428999999999999 } & TRN \\
\hline CHEMBL3902569 & 1638439 & 5.6861 & 6.2373 & TRN & \\
\hline CHEMBL3918793 & 1638439 & 4.301 & 6.9959 & TST & \\
\hline CHEMBL3905574 & 1638439 & 6.1273 & 6.2373 & TRN & \\
\hline CHEMBL3915524 & 1638439 & 7.4685 & 7.1007 & TRN & \\
\hline CHEMBL 3982403 & 1638439 & 6.9788 & 6.7381 & TRN & \\
\hline CHEMBL3935538 & 1638439 & 6.6021 & 6.7899 & TRN & \\
\hline CHEMBL3917102 & 1638439 & 7.2007 & 7.0817 & TRN & \\
\hline CHEMBL3897655 & 1638439 & 6.7959 & 6.7381 & TRN & \\
\hline CHEMBL3985851 & 1638439 & 6.1152 & \multicolumn{2}{|c|}{6.093999999999999} & TRN \\
\hline CHEMBL3943075 & 1638439 & 6.9706 & 6.222 & TRN & \\
\hline CHEMBL3890202 & 1638439 & 7.6383 & 7.0861 & TRN & \\
\hline CHEMBL3899887 & 1638439 & 5.5078 & 6.3218 & TST & \\
\hline CHEMBL3964254 & 1638439 & 7.0362 & 6.9381 & TRN & \\
\hline CHEMBL3922848 & 1638439 & 7.5376 & 6.7539 & TRN & \\
\hline CHEMBL3933332 & 1638439 & 6.7258 & 6.1772 & TRN & \\
\hline CHEMBL3955215 & 1638439 & 5.301 & 7.108 & TST & \\
\hline CHEMBL3956163 & 1638439 & 5.301 & 7.0742 & TST & \\
\hline CHEMBL3902328 & 1638439 & 6.5045 & 6.5738 & TST & \\
\hline CHEMBL3941386 & 1638439 & 8.301 & 6.9262 & TRN & \\
\hline CHEMBL3916916 & 1638439 & 7.6383 & 7.1909 & TRN & \\
\hline CHEMBL3952295 & 1638439 & 6.6253 & 6.2145 & TST & \\
\hline CHEMBL 3898747 & 1638439 & 6.6021 & 7.0938 & TRN & \\
\hline CHEMBL3933384 & 1638439 & 7.2596 & 6.8786 & TRN & \\
\hline CHEMBL3927668 & 1638439 & 6.6021 & \multicolumn{2}{|c|}{6.361000000000001} & TRN \\
\hline CHEMBL3900729 & 1638439 & 6.0 & 6.147 & TRN & \\
\hline
\end{tabular}


Supplemental Table S2.txt

\begin{tabular}{|c|c|c|c|c|c|}
\hline CHEMBL3911650 & 1638439 & 5.6796 & 6.4267 & TST & \\
\hline CHEMBL3926965 & 1638439 & 6.6021 & 6.6088 & TRN & \\
\hline CHEMBL3974454 & 1638439 & 7.4949 & 6.4851 & TRN & \\
\hline CHEMBL3955930 & 1638439 & 4.301 & 6.251 & TST & \\
\hline CHEMBL3985949 & 1638439 & 7.3098 & 7.0861 & TRN & \\
\hline CHEMBL3974806 & 1638439 & 6.6021 & 6.8852 & TRN & \\
\hline CHEMBL3936035 & 1638439 & 6.0 & 6.6494 & TRN & \\
\hline CHEMBL3925965 & 1638439 & 6.279 & 6.734 & TST & \\
\hline CHEMBL3967934 & 1638439 & 5.301 & 6.5228 & TST & \\
\hline CHEMBL3984087 & 1638439 & 7.7447 & 6.9593 & TST & \\
\hline CHEMBL3907534 & 1638439 & 5.856 & 6.2373 & TRN & \\
\hline CHEMBL3949739 & 1638439 & 7.5086 & 7.1909 & TRN & \\
\hline CHEMBL3926366 & 1638439 & 6.0 & 7.1909 & TRN & \\
\hline CHEMBL3956604 & 1638439 & 6.9355 & 6.7899 & TRN & \\
\hline CHEMBL3926670 & 1638439 & 7.0 & 6.6494 & TRN & \\
\hline CHEMBL3898698 & 1638439 & 6.6021 & 6.1949 & TRN & \\
\hline CHEMBL3900443 & 1638439 & 7.8539 & 7.4462 & TST & \\
\hline CHEMBL 3965457 & 1638439 & 7.5528 & 6.8542 & TRN & \\
\hline CHEMBL3929501 & 1638439 & 4.301 & 6.2917 & TRN & \\
\hline CHEMBL3962085 & 1638439 & 6.7352 & 6.2917 & TRN & \\
\hline CHEMBL3923993 & 1638439 & 6.0531 & 6.2373 & TRN & \\
\hline CHEMBL3975191 & 1638439 & 7.0 & 6.9381 & TRN & \\
\hline CHEMBL3936849 & 1638439 & 6.6021 & 7.2551 & TRN & \\
\hline CHEMBL 3955487 & 1638439 & 6.6021 & 6.8369 & TRN & \\
\hline CHEMBL3961034 & 1638439 & 5.301 & 6.2373 & TRN & \\
\hline CHEMBL3932877 & 1638439 & 5.57299 & 9999999 & 6.2373 & TRN \\
\hline CHEMBL 3890020 & 1638439 & 6.6021 & 6.7539 & TRN & \\
\hline CHEMBL3968265 & 1638439 & 7.3565 & 6.1111 & TRN & \\
\hline CHEMBL3970093 & 1638439 & 4.301 & 6.843999 & 9999999999 & TST \\
\hline CHEMBL3968762 & 1638439 & 6.8633 & 6.8852 & TRN & \\
\hline CHEMBL3978746 & 1638439 & 6.6021 & 6.9381 & TRN & \\
\hline CHEMBL 3891627 & 1638439 & 7.3768 & 6.9381 & TRN & \\
\hline CHEMBL3929568 & 1638439 & 7.0132 & 6.3616 & TST & \\
\hline CHEMBL 3898002 & 1638439 & 6.6925 & 6.2373 & TRN & \\
\hline CHEMBL3959739 & 1638439 & 6.0 & 6.8153 & TST & \\
\hline CHEMBL3940709 & 1638439 & 5.5564 & 5.6727 & TRN & \\
\hline CHEMBL3912779 & 1638439 & 6.6021 & 7.0504 & TST & \\
\hline CHEMBL3966539 & 1638439 & 6.6021 & 7.2296 & TRN & \\
\hline CHEMBL 3978894 & 1638439 & 4.301 & 6.2373 & TRN & \\
\hline CHEMBL3891587 & 1638439 & 7.0362 & 6.9381 & TRN & \\
\hline CHEMBL 3895434 & 1638439 & 7.3279 & 6.7475 & TRN & \\
\hline CHEMBL3937934 & 1638439 & 7.1938 & 7.1416 & TRN & \\
\hline CHEMBL3951975 & 1638439 & 6.6021 & 6.6924 & TRN & \\
\hline CHEMBL3903028 & 1638439 & 7.0 & 6.5711 & TRN & \\
\hline CHEMBL3915234 & 1638439 & 6.6021 & 6.5472 & TRN & \\
\hline CHEMBL3908703 & 1638439 & 8.301 & 7.2677 & TRN & \\
\hline CHEMBL 3947442 & 1638439 & 6.5346 & \multicolumn{2}{|c|}{6.207000000000001} & TRN \\
\hline CHEMBL 3895374 & 1638439 & 7.1367 & 6.7616 & TRN & \\
\hline
\end{tabular}




\begin{tabular}{|c|c|c|c|c|}
\hline \multicolumn{5}{|c|}{ Supplemental Table S2.txt } \\
\hline CHEMBL3927717 & 1638439 & 6.0 & 7.3449 & TRN \\
\hline CHEMBL 3956250 & 1638439 & 6.6021 & 6.7381 & TRN \\
\hline CHEMBL3918498 & 1638439 & 5.301 & 6.7319 & TST \\
\hline CHEMBL3915796 & 1638439 & 4.301 & 6.2418 & TST \\
\hline CHEMBL3968938 & 1638439 & 6.6021 & 6.6924 & TRN \\
\hline CHEMBL3971760 & 1638439 & 6.9318 & 6.7381 & TRN \\
\hline CHEMBL 3938840 & 1638439 & 6.6021 & 6.7381 & TRN \\
\hline CHEMBL3907253 & 1638439 & 7.0 & 7.0861 & TRN \\
\hline CHEMBL 3894850 & 1638439 & 5.301 & 6.7381 & TRN \\
\hline CHEMBL 3945480 & 1638439 & 8.301 & 7.0817 & TRN \\
\hline CHEMBL3956236 & 1638439 & 6.6021 & 6.6924 & TRN \\
\hline CHEMBL 3900392 & 1638439 & 7.0 & 6.7539 & TRN \\
\hline CHEMBL3928613 & 1638439 & 6.4449 & 6.2373 & TRN \\
\hline CHEMBL3892115 & 1638439 & 6.9393 & 6.7381 & TRN \\
\hline CHEMBL3911262 & 1638439 & 5.301 & 6.7381 & TRN \\
\hline CHEMBL3951145 & 1638439 & 6.6021 & 6.7381 & TRN \\
\hline CHEMBL3944455 & 1638439 & 6.1624 & 6.2373 & TRN \\
\hline CHEMBL3902358 & 1638439 & 4.301 & 6.7146 & TST \\
\hline CHEMBL3970832 & 1638439 & 7.0 & 6.6723 & TST \\
\hline CHEMBL3924118 & 1638439 & 6.6021 & 6.8183 & TST \\
\hline CHEMBL3940379 & 1638439 & 6.1331 & 6.2373 & TRN \\
\hline CHEMBL3971805 & 1638439 & 6.6021 & 6.7381 & TRN \\
\hline CHEMBL3919000 & 1638439 & 7.5528 & 7.0861 & TRN \\
\hline CHEMBL3974275 & 1638439 & 8.301 & 6.619 & TST \\
\hline CHEMBL3937252 & 1638439 & 4.301 & 6.1824 & TRN \\
\hline CHEMBL3930678 & 1638439 & 7.1612 & 6.7381 & TRN \\
\hline CHEMBL3941201 & 1638439 & 7.699 & 6.9741 & TST \\
\hline CHEMBL3910636 & 1638439 & 6.6021 & 6.8183 & TST \\
\hline CHEMBL3959414 & 1638439 & 6.7545 & 6.7539 & TRN \\
\hline CHEMBL3974620 & 1638439 & 6.5346 & 6.7899 & TRN \\
\hline CHEMBL3940008 & 1638439 & 7.1487 & 6.7381 & TRN \\
\hline CHEMBL 3972648 & 1638439 & 6.6021 & 7.0817 & TRN \\
\hline CHEMBL3920447 & 1638439 & 5.8608 & 6.2373 & TRN \\
\hline CHEMBL3944076 & 1638439 & 6.6021 & 6.7381 & TRN \\
\hline CHEMBL3933991 & 1638439 & 4.301 & 6.7381 & TRN \\
\hline CHEMBL3942879 & 1638439 & 6.8356 & 6.2373 & TRN \\
\hline CHEMBL 3979223 & 1638439 & 7.0 & 6.7381 & TRN \\
\hline CHEMBL3914461 & 1638439 & 6.6021 & 6.6836 & TRN \\
\hline CHEMBL3896439 & 1638439 & 6.6021 & 6.7381 & TRN \\
\hline CHEMBL3928936 & 1638439 & 6.3354 & 7.2849 & TST \\
\hline CHEMBL3987118 & 1638439 & 6.8125 & 6.6684 & TST \\
\hline CHEMBL3896172 & 1638439 & 8.301 & 7.0817 & TRN \\
\hline CHEMBL3913180 & 1638439 & 6.6021 & 6.7381 & TRN \\
\hline CHEMBL3901626 & 1638439 & 6.6021 & 6.7381 & TRN \\
\hline CHEMBL3910698 & 1638439 & 8.301 & 7.0861 & TRN \\
\hline CHEMBL3962979 & 1638439 & 7.3565 & 6.905 & TST \\
\hline CHEMBL 3945254 & 1638439 & 8.301 & 7.2143 & TRN \\
\hline CHEMBL3971205 & 1638439 & 7.0969 & 6.7026 & TST \\
\hline
\end{tabular}


Supplemental Table S2.txt

\begin{tabular}{|c|c|c|c|c|}
\hline CHEMBL3962936 & 1638439 & 7.6021 & 6.8763 & TST \\
\hline CHEMBL3966086 & 1638439 & 7.5086 & 7.2143 & TRN \\
\hline CHEMBL3921292 & 1638439 & 5.301 & 7.074 & TST \\
\hline CHEMBL3896444 & 1638439 & 7.1871 & 6.3113 & TRN \\
\hline CHEMBL3896901 & 1638439 & 7.5528 & 6.8979 & TRN \\
\hline CHEMBL3900531 & 1638439 & 6.6021 & 6.7381 & TRN \\
\hline CHEMBL3918969 & 1638439 & 6.6073 & 7.4361 & TRN \\
\hline CHEMBL3961574 & 1638439 & 7.2007 & 7.0518 & TST \\
\hline CHEMBL3985881 & 1638439 & 4.301 & 6.2963 & TST \\
\hline CHEMBL3924693 & 1638439 & 7.5376 & 6.2373 & TRN \\
\hline CHEMBL3916823 & 1638439 & 6.9136 & 6.5129 & TST \\
\hline CHEMBL3904753 & 1638439 & 6.8097 & 6.2373 & TRN \\
\hline CHEMBL3974125 & 1638439 & 6.6021 & 7.2143 & TRN \\
\hline CHEMBL3911868 & 1638439 & 7.4559 & 7.2677 & TRN \\
\hline CHEMBL3934216 & 1638439 & 6.6021 & 6.7381 & TRN \\
\hline CHEMBL3956722 & 1638439 & 5.301 & 6.9381 & TRN \\
\hline CHEMBL3899868 & 1638439 & 7.301 & 6.5574 & TST \\
\hline CHEMBL3947230 & 1638439 & 7.0 & 6.7381 & TRN \\
\hline CHEMBL3910796 & 1638439 & 7.585 & 6.7381 & TRN \\
\hline CHEMBL3980096 & 1638439 & 7.6198 & 7.1884 & TST \\
\hline CHEMBL3985929 & 1638439 & 6.9957 & 6.3811 & TST \\
\hline CHEMBL3945626 & 1638439 & 6.6021 & 6.8786 & TRN \\
\hline CHEMBL3966877 & 1638439 & 6.8356 & 7.0817 & TRN \\
\hline CHEMBL3954087 & 1638439 & 6.38399 & 99999999 & 6.4314 \\
\hline CHEMBL3981890 & 1638439 & 5.7533 & 6.2373 & TRN \\
\hline CHEMBL3919731 & 1638439 & 6.567 & 7.0938 & TRN \\
\hline CHEMBL3914491 & 1638439 & 8.301 & 7.4093 & TST \\
\hline CHEMBL3976722 & 1638439 & 7.4318 & 6.9828 & TST \\
\hline CHEMBL3983215 & 1638439 & 5.301 & 6.7539 & TRN \\
\hline CHEMBL3986727 & 1638439 & 4.301 & 6.7381 & TRN \\
\hline CHEMBL3969334 & 1638439 & 7.6383 & 6.7539 & TRN \\
\hline CHEMBL3896345 & 1638439 & 7.3872 & 6.1119 & TRN \\
\hline CHEMBL3919778 & 1638439 & 6.6021 & 7.0763 & TRN \\
\hline CHEMBL3987036 & 1638439 & 6.6021 & 6.8979 & TRN \\
\hline CHEMBL3945156 & 1638439 & 7.3372 & 7.0817 & TRN \\
\hline CHEMBL3951010 & 1638439 & 6.6021 & 7.0861 & TRN \\
\hline CHEMBL3984729 & 1638439 & 6.6021 & 6.7381 & TRN \\
\hline CHEMBL3961378 & 1638439 & 7.3468 & 7.3329 & TST \\
\hline CHEMBL3894071 & 1638439 & 6.0395 & 7.00299 & 9999999999 \\
\hline CHEMBL3967876 & 1638439 & 7.6576 & 7.3357 & TRN \\
\hline CHEMBL3960153 & 1638439 & 6.9706 & 6.7381 & TRN \\
\hline CHEMBL3928988 & 1638439 & 6.6021 & 6.7381 & TRN \\
\hline CHEMBL3978030 & 1638439 & 6.8962 & 6.9381 & TRN \\
\hline CHEMBL3927364 & 1638439 & 6.6021 & 6.7381 & TRN \\
\hline CHEMBL3960484 & 1638439 & 6.6021 & 7.1313 & TST \\
\hline CHEMBL3925247 & 1638439 & 6.6021 & 6.9381 & TRN \\
\hline CHEMBL3938365 & 1638439 & 7.0 & 6.4834 & TRN \\
\hline CHEMBL3936558 & 1638439 & 7.0 & 6.8183 & TST \\
\hline
\end{tabular}


Supplemental Table S2.txt

\begin{tabular}{|c|c|c|c|c|c|}
\hline CHEMBL 3944655 & 1638439 & 7.4202 & 6.8946 & TRN & \\
\hline CHEMBL3920510 & 1638439 & 6.6021 & 6.8852 & TRN & \\
\hline CHEMBL3935188 & 1638439 & 6.2154 & 6.7381 & TRN & \\
\hline CHEMBL 3898183 & 1638439 & 6.6021 & 7.0861 & TRN & \\
\hline CHEMBL3919923 & 1638439 & 7.0 & 6.9964 & TRN & \\
\hline CHEMBL 3971964 & 1638439 & 7.0809 & 7.0817 & TRN & \\
\hline CHEMBL3958375 & 1638439 & 5.301 & 6.2373 & TRN & \\
\hline CHEMBL3936061 & 1638439 & 4.301 & 6.2391 & TST & \\
\hline CHEMBL3945603 & 1638439 & 7.5528 & 6.6924 & TRN & \\
\hline CHEMBL3940362 & 1638439 & 5.2123 & 5.8091 & TRN & \\
\hline CHEMBL 3908454 & 1638439 & 7.3979 & 6.6185 & TRN & \\
\hline CHEMBL3899107 & 1638439 & 6.76200 & 00000000 & 6.9381 & TRN \\
\hline CHEMBL 3937163 & 1638439 & 6.9706 & 6.1916 & TRN & \\
\hline CHEMBL3976572 & 1638439 & 6.6021 & 7.2551 & TRN & \\
\hline CHEMBL 3986714 & 1638439 & 6.6021 & 6.9381 & TRN & \\
\hline CHEMBL3904998 & 1638439 & 6.5952 & 6.2373 & TRN & \\
\hline CHEMBL3928357 & 1638439 & 7.0 & 6.9964 & TRN & \\
\hline CHEMBL3910375 & 1638439 & 7.0 & 6.7381 & TRN & \\
\hline CHEMBL 3938403 & 1638439 & 6.2403 & \multicolumn{2}{|c|}{6.207000000000001} & TRN \\
\hline CHEMBL3901689 & 1638439 & 7.4202 & 6.7539 & TRN & \\
\hline CHEMBL 3924868 & 1638439 & 7.2757 & 6.7381 & TRN & \\
\hline CHEMBL3903148 & 1638439 & 7.7696 & 7.2891 & TST & \\
\hline CHEMBL3964595 & 1638439 & 6.1681 & 6.7869 & TST & \\
\hline CHEMBL3975304 & 1638439 & 7.699 & 7.0861 & TRN & \\
\hline CHEMBL 3899025 & 1638439 & 7.4437 & 6.3113 & TRN & \\
\hline CHEMBL3985955 & 1638439 & 7.1308 & 6.8786 & TRN & \\
\hline CHEMBL 3904427 & 1638439 & 6.6021 & 6.7381 & TRN & \\
\hline CHEMBL 3950054 & 1638439 & 7.2518 & 6.7539 & TRN & \\
\hline CHEMBL3968118 & 1638439 & 7.0 & 6.7297 & TST & \\
\hline CHEMBL3896013 & 1638439 & 6.6021 & 6.9381 & TRN & \\
\hline CHEMBL 3944824 & 1638439 & 5.301 & 6.9247 & TRN & \\
\hline CHEMBL 3920588 & 1638439 & 6.6021 & 6.9381 & TRN & \\
\hline CHEMBL3902164 & 1638439 & 7.3279 & 6.7381 & TRN & \\
\hline CHEMBL3916183 & 1638439 & 4.0809 & 6.7097 & TRN & \\
\hline CHEMBL3984098 & 1638439 & 6.0 & 6.6494 & TRN & \\
\hline CHEMBL3927966 & 1638439 & 6.1439 & 6.2373 & TRN & \\
\hline CHEMBL 3985888 & 1638439 & 6.6108 & \multicolumn{2}{|c|}{6.207000000000001} & TRN \\
\hline CHEMBL3906603 & 1638439 & 6.4737 & 5.6727 & TRN & \\
\hline CHEMBL3985512 & 1638439 & 8.301 & 7.2677 & TRN & \\
\hline CHEMBL3889705 & 1638439 & 6.6021 & 6.7381 & TRN & \\
\hline CHEMBL 3945593 & 1638439 & 7.0088 & 6.2696 & TRN & \\
\hline CHEMBL3968634 & 1638439 & 7.0 & 6.6494 & TRN & \\
\hline CHEMBL3919368 & 1638439 & 7.0 & 7.2677 & TRN & \\
\hline CHEMBL3913163 & 1638439 & 4.301 & 6.7381 & TRN & \\
\hline CHEMBL3960826 & 1638439 & 7.4089 & 6.4851 & TRN & \\
\hline CHEMBL3980958 & 1638439 & 5.301 & 6.2694 & TST & \\
\hline CHEMBL3967331 & 1638439 & 6.6021 & 6.7381 & TRN & \\
\hline CHEMBL3957266 & 1638439 & 6.6021 & 7.0861 & TRN & \\
\hline
\end{tabular}

Page 13658 
Supplemental Table S2.txt

\begin{tabular}{|c|c|c|c|c|}
\hline 046 & & & 8 & \\
\hline HEMPI 3025710 & & & & \\
\hline IEMBL 3973210 & & & & \\
\hline 36395 & 538439 & & & \\
\hline HEMBL3972498 & 638439 & & 911 & \\
\hline 97824 & 538439 & & 722 & \\
\hline 3754 & & & 861 & \\
\hline IEMBL 3891921 & 638439 & & 381 & \\
\hline AEMBL3982914 & 638439 & & 9938 & \\
\hline HEMBL3979253 & 638439 & & 625 & \\
\hline 1733 & 638439 & & 362 & \\
\hline 4803 & 638439 & & 852 & \\
\hline HEMBL & 638439 & & 111 & \\
\hline 99572 & 638439 & & 539 & \\
\hline 6287 & 638 & & 373 & \\
\hline 3439 & 39 & & 214 & \\
\hline 2454 & 9 & & 308 & \\
\hline 9955 & 39 & & 852 & \\
\hline 2003 & 39 & & 846 & \\
\hline 8085 & 638 & & 916 & \\
\hline 208 & 9 & & 373 & \\
\hline 8999 & 9 & & 397 & \\
\hline 1042 & 39 & & 129 & \\
\hline 158 & 39 & & & \\
\hline IEMBL & 638 & & 924 & \\
\hline 466 & 9 & & 381 & \\
\hline 947 & 9 & & & No \\
\hline & & & & \\
\hline 511 & 9 & & & \\
\hline 8572 & 1638 & & 76 & ST \\
\hline 660 & 9 & & 77 & \\
\hline 12 & 9 & & & IIT \\
\hline & & & & \\
\hline & 9 & & & \\
\hline 2607 & 63 & & 53 & ST \\
\hline 128 & 9 & & 42 & \\
\hline & & & & 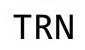 \\
\hline & & & & $\mathrm{RN}$ \\
\hline 59738 & 39 & & & \\
\hline 245 & 39 & & & \\
\hline 1590 & 9 & & 07 & \\
\hline & 39 & & 381 & $\mathbf{n}$ \\
\hline 12675 & 638439 & & & RI \\
\hline 5606 & 638 & & 763 & $\mathrm{R}$ \\
\hline 75 & 163 & & & \\
\hline CHEMBL3902779 & 1638439 & & 7.0861 & \\
\hline CHEMBL3889859 & 638439 & 6.9788 & 6.9782 & \\
\hline CHEMBL3931963 & 1638439 & 6.0 & 5.6727 & \\
\hline
\end{tabular}

Page 13659 
Supplemental Table S2.txt

\begin{tabular}{|c|c|c|c|c|}
\hline 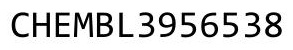 & & & & \\
\hline HEMBL & 538439 & 6.6021 & & \\
\hline AEMBL 3942297 & 538439 & 6.8894 & 5124 & \\
\hline HEMBL3963306 & 638439 & 6.7645 & 6924 & \\
\hline & & 7.0269 & 381 & \\
\hline AEMBL: & 38439 & 6.6021 & 381 & \\
\hline HEMBL3976179 & 638439 & 7.5086 & 9624 & \\
\hline HEMBL3954006 & 638439 & 5.301 & 3592 & \\
\hline HEMBL3953398 & 638 & 6.6021 & 7381 & \\
\hline HEMBL396 & 638439 & 7.0 & $\partial 861$ & \\
\hline AEMBL3935584 & 39 & 5.4 & 7381 & \\
\hline HEMBL3954240 & 638439 & 6.6021 & 147 & \\
\hline HEMBL3920951 & 638439 & 5.8044 & 4077 & \\
\hline HEMBL3921908 & 638 & 6.6021 & & \\
\hline L3966975 & 39 & 7.0 & 2677 & \\
\hline AEMBL3930209 & 39 & & 817 & \\
\hline AEMBL3976455 & 638439 & 7. & 7.0817 & \\
\hline HEMBL 3982200 & 39 & 7. & 5924 & \\
\hline HEMBL3898327 & 63 & 7. & 924 & \\
\hline L3943465 & 39 & & 655 & \\
\hline L3943199 & 39 & 021 & 247 & \\
\hline HEMBL3983695 & 638439 & 7.0 & 7616 & \\
\hline HEMBL 391 & 39 & 6. & 3786 & \\
\hline HEMBL39e & 63 & 6 & 381 & \\
\hline 269 & 9 & cos 0 & 373 & \\
\hline 494 & 39 & 7. & 817 & \\
\hline L 3924409 & & 6.6021 & 7539 & RN \\
\hline AEMBL 3952262 & & & & \\
\hline HEMBL393 & 638 & 5 . & 3658 & ST \\
\hline 740 & 9 & 21 & 381 & RN \\
\hline 781 & 39 & 6. & 507 & ST \\
\hline AEMBL3908913 & & 7. & & ST \\
\hline AEMBL3901522 & $\cos _{0}$ & & 362 & RN \\
\hline HEMBL 394 & 638 & 3. & 111 & $\mathrm{RN}$ \\
\hline 354 & 9 & $\partial 21$ & 381 & RN \\
\hline 37 & 39 & 6. & 381 & RN \\
\hline HEMBL3972707 & 638439 & 6.6021 & 9381 & RN \\
\hline AEMBL3936598 & 50 & 7.50 & 373 & $\mathrm{RN}$ \\
\hline HEMBL39 & 63 & 6 . & 381 & RN \\
\hline 343 & -7 & 5 . & 373 & RIN \\
\hline & & 7. & 494 & RN \\
\hline HEMBL3979709 & 638439 & 7.40 & 1111 & RN \\
\hline HEMBL 391 & 638 & 6. & 824 & RN \\
\hline HEMBL 38 & & & 247 & \\
\hline HEMBL 395 & & & & \\
\hline HEMBL3948308 & 39 & 4.301 & 5.7485 & ST \\
\hline _3926137 & 638439 & 7.0 & 6.9092 & RN \\
\hline CHEMBL3954650 & 1638439 & 6.1805 & 6.8961 & \\
\hline
\end{tabular}

Page 13660 
Supplemental Table S2.txt

\begin{tabular}{|c|c|c|c|c|c|}
\hline CHEMBL 3916252 & 1638439 & 7.0506 & 6.8786 & TRN & \\
\hline CHEMBL 3902697 & 1638439 & 7.5086 & 6.8598 & TST & \\
\hline CHEMBL 3967004 & 1638439 & 7.3872 & 6.9765 & TRN & \\
\hline CHEMBL 3974158 & 1638439 & 7.699 & 6.7033 & TST & \\
\hline CHEMBL3925622 & 1638439 & 7.4202 & 6.7381 & TRN & \\
\hline CHEMBL3946207 & 1638439 & 6.6021 & 6.8183 & TST & \\
\hline CHEMBL 3947528 & 1638439 & 7.0706 & 7.1367 & TRN & \\
\hline CHEMBL 3943262 & 1638439 & 6.6021 & 7.145 & TST & \\
\hline CHEMBL3890169 & 1638439 & 6.6021 & 6.2373 & TRN & \\
\hline CHEMBL3905959 & 1638439 & 5.9389 & 6.251 & TST & \\
\hline CHEMBL3939160 & 1638439 & 7.5376 & 7.2354 & TRN & \\
\hline CHEMBL 3907845 & 1638439 & 7.4437 & 6.9381 & TRN & \\
\hline CHEMBL 3940024 & 1638439 & 4.301 & 6.1 & TRN & \\
\hline CHEMBL 3955542 & 1638439 & 6.6021 & 7.1097 & TST & \\
\hline CHEMBL 3952104 & 1638439 & 7.2441 & 7.6043 & TST & \\
\hline CHEMBL3900436 & 1638439 & 6.9101 & 7.0655 & TST & \\
\hline CHEMBL3962856 & 1638439 & 7.0362 & 7.1656 & TST & \\
\hline CHEMBL3986290 & 1638439 & 5.9416 & 6.9258 & TST & \\
\hline CHEMBL3919192 & 1638439 & 6.6021 & 6.6559 & TST & \\
\hline CHEMBL 3936172 & 1638439 & 6.2147 & 6.9481 & TST & \\
\hline CHEMBL 3937793 & 1638439 & 7.5686 & 6.8539 & TRN & \\
\hline CHEMBL3904519 & 1638439 & 7.3279 & 6.8786 & TRN & \\
\hline CHEMBL3929337 & 1638439 & 6.0 & 6.7381 & TRN & \\
\hline CHEMBL 3972349 & 1638439 & 4.301 & 6.207006 & 0000000001 & TRN \\
\hline CHEMBL3895336 & 1638439 & 4.301 & 6.3914 & TST & \\
\hline CHEMBL 3903381 & 1638439 & 7.301 & 7.0817 & TRN & \\
\hline CHEMBL 3983961 & 1638439 & 6.6021 & 7.0861 & TRN & \\
\hline CHEMBL3894237 & 1638439 & 6.6021 & 6.7381 & TRN & \\
\hline CHEMBL3981219 & 1638439 & 5.5892 & 6.1386 & TST & \\
\hline CHEMBL3930464 & 1638439 & 7.4685 & 7.106 & TRN & \\
\hline CHEMBL 3953025 & 1638439 & 6.6021 & 6.7381 & TRN & \\
\hline CHEMBL3935801 & 1638439 & 6.6021 & 6.7381 & TRN & \\
\hline CHEMBL3964045 & 1638439 & 7.4815 & 7.0747 & TST & \\
\hline CHEMBL3890819 & 1638439 & 7.7212 & 6.9741 & TST & \\
\hline CHEMBL3931103 & 1638439 & 6.6289 & 6.7381 & TRN & \\
\hline CHEMBL 3927791 & 1638439 & 7.0655 & 6.2373 & TRN & \\
\hline CHEMBL3923344 & 1638439 & 7.5376 & 6.6235 & TRN & \\
\hline CHEMBL3969329 & 1638439 & 6.6021 & 7.0861 & TRN & \\
\hline CHEMBL3909190 & 1638439 & 7.4202 & 6.4506 & TRN & \\
\hline CHEMBL3984334 & 1638439 & 6.6021 & 7.0861 & TRN & \\
\hline CHEMBL 3942467 & 1638439 & 6.6021 & 6.1949 & TRN & \\
\hline CHEMBL3939603 & 1638439 & 6.6021 & 7.0938 & TRN & \\
\hline CHEMBL3938544 & 1638439 & 7.0 & 7.0861 & TRN & \\
\hline CHEMBL 3966760 & 1638439 & 7.3768 & 6.8539 & TRN & \\
\hline CHEMBL3981655 & 1638439 & 6.8894 & 6.2373 & TRN & \\
\hline CHEMBL3909709 & 1638439 & 6.6459 & 6.9381 & TRN & \\
\hline CHEMBL 3959762 & 1638439 & 4.301 & 6.2373 & TRN & \\
\hline CHEMBL3956512 & 1638439 & 7.0 & 7.1757 & TRN & \\
\hline
\end{tabular}


Supplemental Table S2.txt

\begin{tabular}{|c|c|c|c|c|}
\hline CHEMBL3914557 & 1638439 & 7.3979 & 7.2981 & TRN \\
\hline CHEMBL3940466 & 1638439 & 4.7778 & 6.2373 & TRN \\
\hline CHEMBL3914228 & 1638439 & 7.0 & 7.0861 & TRN \\
\hline CHEMBL3955356 & 1638439 & 5.7496 & 6.2854 & TRN \\
\hline CHEMBL3966351 & 1638439 & 5.301 & 6.6232 & TST \\
\hline CHEMBL3907037 & 1638439 & 7.0 & 6.7381 & TRN \\
\hline CHEMBL3900650 & 1638439 & 7.2441 & 6.8852 & TRN \\
\hline CHEMBL3968329 & 1638439 & 7.3188 & 6.2854 & TRN \\
\hline CHEMBL3916096 & 1638439 & 5.8703 & 6.0892 & TRN \\
\hline CHEMBL3936991 & 1638439 & 6.6021 & 6.7053 & TST \\
\hline CHEMBL3935783 & 1638439 & 7.0 & 6.7381 & TRN \\
\hline CHEMBL3937994 & 1638439 & 7.0 & 6.2258 & TST \\
\hline CHEMBL3939096 & 1638439 & 7.4202 & 6.2603 & TST \\
\hline CHEMBL3900301 & 1638439 & 7.0 & 7.0817 & TRN \\
\hline CHEMBL3980629 & 1638439 & 8.301 & 6.7053 & TST \\
\hline CHEMBL3941162 & 1638439 & 6.6021 & 6.8364 & TRN \\
\hline CHEMBL3962615 & 1638439 & 6.6021 & 6.8076 & TST \\
\hline CHEMBL3923656 & 1638439 & 6.7258 & 6.2373 & TRN \\
\hline CHEMBL3976800 & 1638439 & 6.8239 & 7.2981 & TRN \\
\hline CHEMBL3981638 & 1638439 & 6.0 & 6.5711 & TRN \\
\hline CHEMBL3969036 & 1638439 & 6.6021 & 7.106 & TRN \\
\hline CHEMBL3958468 & 1638439 & 7.5686 & 6.6185 & TRN \\
\hline CHEMBL3920656 & 1638439 & 6.6021 & 7.1097 & TST \\
\hline CHEMBL3902601 & 1638439 & 6.6021 & 6.9381 & TRN \\
\hline CHEMBL3928927 & 1638439 & 7.699 & 7.0861 & TRN \\
\hline CHEMBL3976606 & 1638439 & 7.4685 & 6.78799 & 9999999999 \\
\hline CHEMBL3917038 & 1638439 & 6.6021 & 6.8852 & TRN \\
\hline CHEMBL3937666 & 1638439 & 5.4356 & 6.8546 & TST \\
\hline CHEMBL3892381 & 1638439 & 6.6021 & 6.7969 & TRN \\
\hline CHEMBL 3975755 & 1638439 & 7.3468 & 7.1429 & TST \\
\hline CHEMBL3966852 & 1638439 & 7.6383 & 6.8539 & TRN \\
\hline CHEMBL3913399 & 1638439 & 7.7959 & 7.3158 & TST \\
\hline CHEMBL3891410 & 1638439 & 4.7775 & 6.2373 & TRN \\
\hline CHEMBL 3937894 & 1638439 & 3.301 & 5.8297 & TRN \\
\hline CHEMBL3974226 & 1638439 & 6.6021 & 6.2373 & TRN \\
\hline CHEMBL3931437 & 1638439 & 7.5229 & 6.2373 & TRN \\
\hline CHEMBL3925868 & 1638439 & 7.6198 & 7.2677 & TRN \\
\hline CHEMBL3966578 & 1638439 & 6.6021 & 6.7381 & TRN \\
\hline CHEMBL3937920 & 1638439 & 7.0 & 7.0861 & TRN \\
\hline CHEMBL3911238 & 1638439 & 7.0 & 7.2143 & TRN \\
\hline CHEMBL 3890331 & 1638439 & 6.6021 & 6.6924 & TRN \\
\hline CHEMBL3945955 & 1638439 & 6.3726 & 7.0861 & TRN \\
\hline CHEMBL3911199 & 1638439 & 8.301 & 6.6494 & TRN \\
\hline CHEMBL3945973 & 1638439 & 5.301 & 6.7381 & TRN \\
\hline CHEMBL3926293 & 1638439 & 6.0 & 7.2551 & TRN \\
\hline CHEMBL3954905 & 1638439 & 6.2104 & 6.3824 & TST \\
\hline CHEMBL3980725 & 1638439 & 7.0 & 7.0861 & TRN \\
\hline CHEMBL 3904040 & 1638439 & 7.585 & 6.7426 & TST \\
\hline
\end{tabular}




\begin{tabular}{|c|c|c|c|c|}
\hline & & & oplement & Table \\
\hline CHEMBL3951338 & 1638439 & 7.0 & 6.7381 & TRN \\
\hline CHEMBL 3965061 & 1638439 & 6.6021 & 6.7381 & TRN \\
\hline CHEMBL3930306 & 1638439 & 7.5376 & 6.7381 & TRN \\
\hline CHEMBL3898687 & 1638439 & 4.301 & 6.7381 & TRN \\
\hline CHEMBL3899635 & 1638439 & 6.0 & 6.82 & TST \\
\hline CHEMBL3951336 & 1638439 & 4.0809 & 6.7012 & TST \\
\hline CHEMBL3921812 & 1638439 & 5.9337 & 6.2373 & TRN \\
\hline CHEMBL3974919 & 1638439 & 6.6021 & 6.2373 & TRN \\
\hline CHEMBL 3927702 & 1638439 & 4.301 & 5.9893 & TRN \\
\hline CHEMBL3961987 & 1638439 & 7.0 & 6.9247 & TRN \\
\hline CHEMBL 3981460 & 1638439 & 6.6021 & 7.2308 & TST \\
\hline CHEMBL 3902367 & 1638439 & 7.0 & 6.7381 & TRN \\
\hline CHEMBL3976185 & 1638439 & 6.6021 & 6.1949 & TRN \\
\hline CHEMBL3983060 & 1638439 & 7.3372 & 6.6494 & TRN \\
\hline CHEMBL3899378 & 1638439 & 6.4559 & 6.2373 & TRN \\
\hline CHEMBL 3908293 & 1638439 & 6.9031 & 6.9381 & TRN \\
\hline CHEMBL3898869 & 1638439 & 7.3872 & 6.7381 & TRN \\
\hline CHEMBL3965439 & 1638439 & 6.6596 & 6.7381 & TRN \\
\hline CHEMBL3967269 & 1638439 & 6.6021 & 6.5547 & TRN \\
\hline CHEMBL3890418 & 1638439 & 4.301 & 6.251 & TST \\
\hline CHEMBL3919315 & 1638439 & 7.3188 & 6.7381 & TRN \\
\hline CHEMBL3947562 & 1638439 & 7.1308 & 6.3548 & TST \\
\hline CHEMBL 3944000 & 1638439 & 4.301 & 6.4314 & TST \\
\hline CHEMBL3900165 & 1638439 & 7.699 & 6.8968 & TST \\
\hline CHEMBL3974196 & 1638439 & 6.6021 & 6.6494 & TRN \\
\hline CHEMBL3895340 & 1638439 & 6.9031 & 6.2917 & TRN \\
\hline CHEMBL3900537 & 1638439 & 6.8761 & 6.5042 & TRN \\
\hline CHEMBL 3957750 & 1638439 & 6.6021 & 6.9305 & TRN \\
\hline CHEMBL3931208 & 1638439 & 6.6021 & 7.0861 & TRN \\
\hline CHEMBL3985737 & 1638439 & 4.7781 & 6.1949 & TRN \\
\hline CHEMBL3975674 & 1638439 & 6.2269 & 7.0987 & TST \\
\hline CHEMBL3895857 & 1638439 & 6.9957 & 7.3035 & TRN \\
\hline CHEMBL 3983264 & 1638439 & 7.2924 & 6.1752 & TST \\
\hline CHEMBL3946585 & 1638439 & 6.6021 & 6.7381 & TRN \\
\hline CHEMBL3971667 & 1638439 & 6.6021 & 6.7381 & TRN \\
\hline CHEMBL3906847 & 1638439 & 5.301 & 6.0664 & TST \\
\hline CHEMBL3959269 & 1638439 & 7.0 & 6.5546 & TRN \\
\hline CHEMBL 3943623 & 1638439 & 7.4559 & 6.9381 & TRN \\
\hline CHEMBL3950940 & 1638439 & 4.301 & 6.7381 & TRN \\
\hline CHEMBL3928718 & 1638439 & 5.9241 & 6.222 & TRN \\
\hline CHEMBL3916013 & 1638439 & 4.301 & 7.2471 & TST \\
\hline CHEMBL3910744 & 1638439 & 6.6021 & 6.5846 & TRN \\
\hline CHEMBL3923472 & 1638439 & 7.1871 & 7.3921 & TST \\
\hline CHEMBL3947907 & 1638439 & 8.301 & 7.0861 & TRN \\
\hline CHEMBL3899841 & 1638439 & 6.8928 & 6.7539 & TRN \\
\hline CHEMBL 3947324 & 1638439 & 6.6021 & 6.7402 & TRN \\
\hline CHEMBL3957052 & 1638439 & 6.0 & 6.4314 & TST \\
\hline CHEMBL3905832 & 1638439 & 6.6021 & 6.7381 & TRN \\
\hline
\end{tabular}


Supplemental Table S2.txt

\begin{tabular}{|c|c|c|c|c|}
\hline - & & & & \\
\hline & & 5.7737 & 6.2418 & \\
\hline & & & & \\
\hline AEMBL & & 6021 & & \\
\hline AEMBL3980738 & 638439 & 6021 & 469 & \\
\hline HEMBL3977502 & 638439 & 6.9508 & .7381 & \\
\hline 254 & 39 & 21 & 3786 & \\
\hline IFMRI = & & & & \\
\hline AEMBL3917724 & 638 & & & \\
\hline HEMBL3906782 & 638439 & 7.4815 & 516 & \\
\hline HEMBL3903092 & 638 & 7.0 & & \\
\hline IEMBL39 & 39 & 21 & & \\
\hline AEMBL3S & & & & \\
\hline HEMBL 39 & 638439 & 809 & 5.1119 & \\
\hline AEMBL39 & 638 & 7. & & \\
\hline AEMBL39 & 39 & 6. & 61 & \\
\hline HEMBL3S & 9 & 6 & & \\
\hline HEMBL3S & & & & \\
\hline HEMBL39 & 39 & 6. & & \\
\hline AEMBL3S & 39 & 6 . & & \\
\hline HEMBLS & 638 & 6 & & 1SI \\
\hline HEMBL3 & 9 & 7. & & 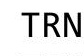 \\
\hline HEMBL & & 7. & & \\
\hline 514 & & 7.3768 & & \\
\hline AEMBL39 & & & & r. \\
\hline HEMBL3S & 39 & & & RIN \\
\hline HEMBL & & & & RN \\
\hline$H F M B I=$ & 39 & & & \\
\hline HEMBL3 & & & & 0 \\
\hline HEMBL 3899 & & 7.0 & & 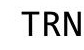 \\
\hline HEMBL3 & 39 & & & RN \\
\hline HEMBL; & & & & RN \\
\hline HEMBL & & 6 & 71 & RN \\
\hline HEMBL 393 & & 7. & & IRN \\
\hline HEMBL 3941453 & 6384 & & 305 & TRN \\
\hline HEMBL3S & 39 & & 81 & RN \\
\hline HFMRI & & 1 & & RN \\
\hline HEMBL & & & & ST \\
\hline HEMBL3905484 & 638439 & 6. & 81 & $\Gamma \mathrm{RN}$ \\
\hline HEMBL391 & 620 & & & $\Gamma \mathrm{RN}$ \\
\hline HEMBL39 & 638 & & & \\
\hline CHEMBL 39 & & & & RIV \\
\hline HEMBL3937166 & 638 & 7. & 6.2373 & $\Gamma \mathrm{RN}$ \\
\hline HEMBL3957205 & 638439 & 6. & 7666 & IST \\
\hline MRI 3 & 6381 & & & RN \\
\hline HEMBL3S & 820 & $0.00<1$ & & \\
\hline CHEMBL3917259 & 1638 & & & \\
\hline CHEMBL3910631 & 1638439 & 7.6383 & 6.9446 & ST \\
\hline
\end{tabular}

Page 13664 


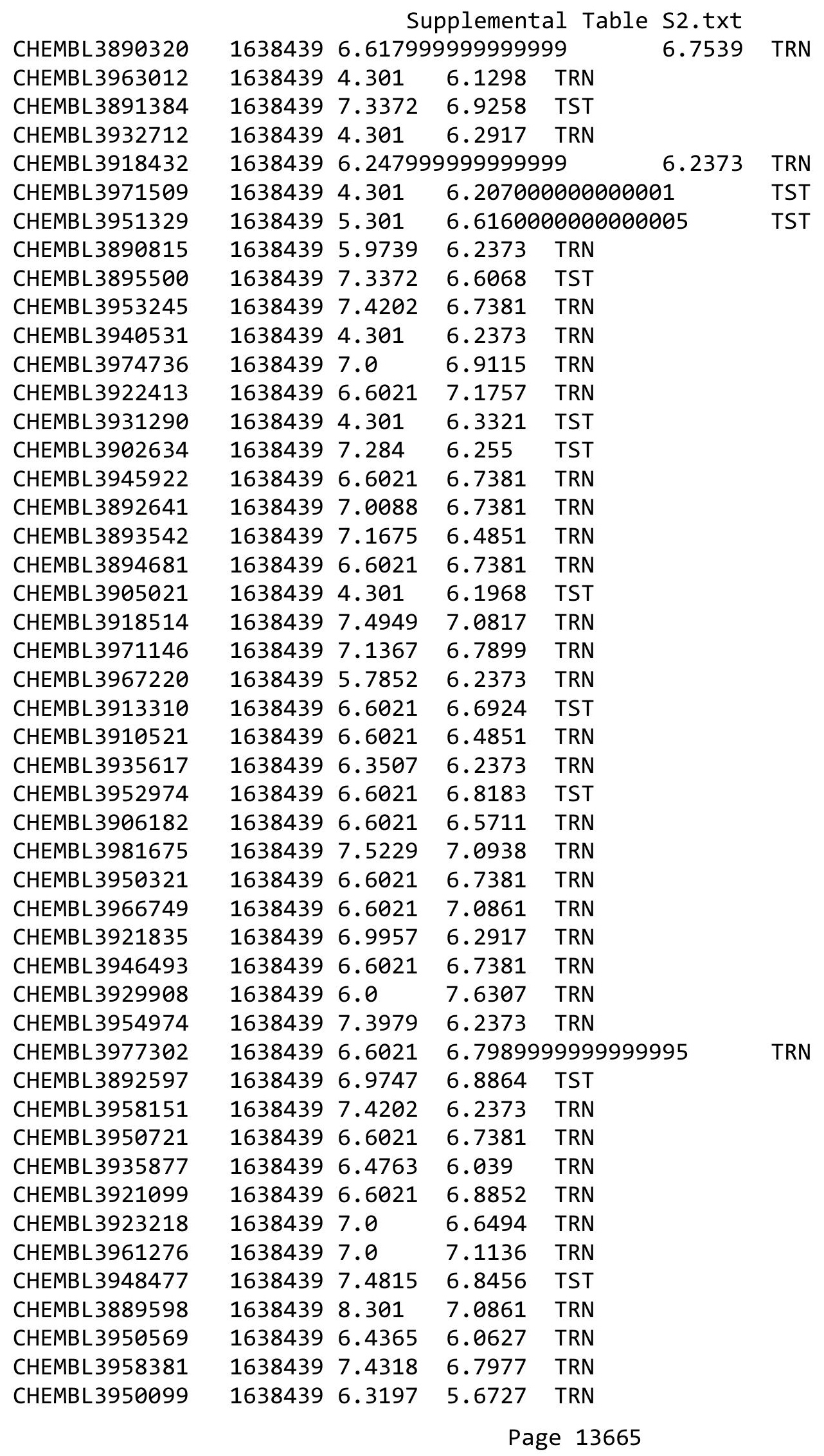


Supplemental Table S2.txt

\begin{tabular}{|c|c|c|c|c|}
\hline CHEMBL3926064 & 1638439 & 5.8465 & 6.0892 & TRN \\
\hline CHEMBL3921704 & 1638439 & 7.0 & 7.2677 & TRN \\
\hline CHEMBL3940275 & 1638439 & 4.3799 & 6.3571 & TST \\
\hline CHEMBL3972699 & 1638439 & 7.0 & 7.3035 & TRN \\
\hline CHEMBL3946145 & 1638439 & 6.8097 & 6.6342 & TRN \\
\hline CHEMBL3907414 & 1638439 & 6.6021 & 6.7381 & TRN \\
\hline CHEMBL3920817 & 1638439 & 6.6021 & \multicolumn{2}{|c|}{6.2070000000} \\
\hline CHEMBL3923091 & 1638439 & 8.301 & 7.2143 & TRN \\
\hline CHEMBL 3914290 & 1638439 & 5.6908 & 6.4942 & TST \\
\hline CHEMBL3893683 & 1638439 & 6.6021 & 6.9027 & TRN \\
\hline CHEMBL3923036 & 1638439 & 8.301 & 6.8852 & TRN \\
\hline CHEMBL3907276 & 1638439 & 7.301 & 6.7539 & TRN \\
\hline CHEMBL3903418 & 1638439 & 6.6021 & 6.9916 & TRN \\
\hline CHEMBL3952366 & 1638439 & 7.4089 & 7.2288 & TRN \\
\hline CHEMBL 3953354 & 1638439 & 7.3979 & 7.0406 & TST \\
\hline CHEMBL3986671 & 1638439 & 8.301 & 6.7381 & TRN \\
\hline CHEMBL3946712 & 1638439 & 6.6021 & 6.9247 & TRN \\
\hline CHEMBL3940948 & 1638439 & 7.3098 & 6.7381 & TRN \\
\hline CHEMBL3911436 & 1638439 & 7.7212 & 7.0861 & TRN \\
\hline CHEMBL3924267 & 1638439 & 6.6021 & 6.7381 & TRN \\
\hline CHEMBL3976677 & 1638439 & 6.6021 & 6.5052 & TRN \\
\hline CHEMBL3910700 & 1638439 & 6.6021 & 6.7381 & TRN \\
\hline CHEMBL3914021 & 1638439 & 7.0 & 6.8771 & TRN \\
\hline CHEMBL3928680 & 1638439 & 6.6021 & 6.2373 & TRN \\
\hline CHEMBL3955549 & 1638439 & 7.0706 & 6.7381 & TRN \\
\hline CHEMBL3927409 & 1638439 & 6.6655 & 6.7899 & TRN \\
\hline CHEMBL3934602 & 1638439 & 6.6021 & 6.5805 & TRN \\
\hline CHEMBL3972026 & 1638439 & 6.6021 & 6.7485 & TST \\
\hline CHEMBL 3930887 & 1638439 & 6.0 & 6.7539 & TRN \\
\hline CHEMBL 3909671 & 1638439 & 6.8327 & 6.147 & TRN \\
\hline CHEMBL 3893751 & 1638439 & 7.7447 & 7.2293 & TST \\
\hline CHEMBL3961012 & 1638439 & 6.0 & 6.7381 & TRN \\
\hline CHEMBL3948427 & 1638439 & 6.0501 & 6.2571 & TST \\
\hline CHEMBL3958899 & 1638439 & 6.6021 & 6.1949 & TRN \\
\hline CHEMBL3964725 & 1638439 & 4.7783 & 6.4314 & TST \\
\hline CHEMBL3910331 & 1638439 & 5.8204 & 6.3969 & TST \\
\hline CHEMBL3949923 & 1638439 & 4.301 & 6.8252 & TST \\
\hline CHEMBL3899607 & 1638439 & 6.2426 & 6.7899 & TRN \\
\hline CHEMBL3975108 & 1638439 & 6.6021 & 6.7381 & TRN \\
\hline CHEMBL 3975202 & 1638439 & 6.6021 & 6.9381 & TRN \\
\hline CHEMBL 3897272 & 1638439 & 7.5686 & 7.4806 & TST \\
\hline CHEMBL3890619 & 1638439 & 7.0 & 6.7381 & TRN \\
\hline CHEMBL3909925 & 1638439 & 6.6021 & 6.7381 & TRN \\
\hline CHEMBL3976854 & 1638439 & 7.0362 & 6.9258 & TST \\
\hline CHEMBL3984141 & 1638439 & 6.6021 & 6.7381 & TRN \\
\hline CHEMBL3972265 & 1638439 & 7.0 & 7.0589 & TST \\
\hline CHEMBL 3979278 & 1638439 & 8.301 & 7.0366 & TRN \\
\hline CHEMBL3935294 & 1638439 & 6.6021 & 6.7381 & TRN \\
\hline
\end{tabular}

Page 13666 
Supplemental Table S2.txt

\begin{tabular}{|c|c|c|c|c|c|}
\hline CHEMBL3981290 & 1638439 & 7.5229 & 6.3534 & TRN & \\
\hline CHEMBL3956049 & 1638439 & 6.6021 & 6.7381 & TRN & \\
\hline CHEMBL3902658 & 1638439 & 5.4802 & 6.2373 & TRN & \\
\hline CHEMBL3963690 & 1638439 & 6.6364 & 6.2373 & TRN & \\
\hline CHEMBL3907531 & 1638439 & 6.9066 & 6.5429 & TST & \\
\hline CHEMBL3968010 & 1638439 & 6.6882 & 6.7381 & TRN & \\
\hline CHEMBL3908160 & 1638439 & 7.0506 & 6.2373 & TRN & \\
\hline CHEMBL3983034 & 1638439 & 7.0 & 6.7381 & TRN & \\
\hline CHEMBL3959676 & 1638439 & 5.301 & 6.496 & TST & \\
\hline CHEMBL3977575 & 1638439 & 6.6021 & 7.098 & TST & \\
\hline CHEMBL3963160 & 1638439 & 7.6383 & 7.0861 & TRN & \\
\hline CHEMBL3912686 & 1638439 & 7.0 & 7.4019 & TST & \\
\hline CHEMBL3905447 & 1638439 & 6.6021 & 6.7381 & TRN & \\
\hline CHEMBL3930719 & 1638439 & 6.5214 & 6.6494 & TRN & \\
\hline CHEMBL3915951 & 1638439 & 6.6021 & 7.2551 & TRN & \\
\hline CHEMBL3916511 & 1638439 & 6.0 & 6.9964 & TRN & \\
\hline CHEMBL3971380 & 1638439 & 7.0 & 6.6924 & TST & \\
\hline CHEMBL3896235 & 1638439 & 7.2291 & 6.2373 & TRN & \\
\hline CHEMBL 3924371 & 1638439 & 5.9378 & 6.7148 & TRN & \\
\hline CHEMBL3915365 & 1638439 & 6.767 & 7.2677 & TRN & \\
\hline CHEMBL3910583 & 1638439 & 4.301 & 6.147 & TRN & \\
\hline CHEMBL3954831 & 1638439 & 6.1215 & 6.1 & TRN & \\
\hline CHEMBL3899802 & 1638439 & 6.6478 & 6.2373 & TRN & \\
\hline CHEMBL3931688 & 1638439 & 6.0214 & 6.9517 & TST & \\
\hline CHEMBL3949081 & 1638439 & 7.6021 & 6.7381 & TRN & \\
\hline CHEMBL3968153 & 1638439 & 4.301 & 6.2373 & TRN & \\
\hline CHEMBL3985946 & 1638439 & 6.3969 & 6.0598 & TRN & \\
\hline CHEMBL3933047 & 1638439 & 6.6021 & 6.6697 & TRN & \\
\hline CHEMBL3920162 & 1638439 & 7.3872 & 7.0817 & TRN & \\
\hline CHEMBL3965493 & 1638439 & 5.301 & 6.617000 & $\partial 000000001$ & TST \\
\hline CHEMBL3973898 & 1638439 & 6.9666 & 6.2373 & TRN & \\
\hline CHEMBL3965915 & 1638439 & 5.654 & 6.3162 & TST & \\
\hline CHEMBL3924300 & 1638439 & 6.6021 & 6.7381 & TRN & \\
\hline CHEMBL3975153 & 1638439 & 6.8794 & 6.7381 & TRN & \\
\hline CHEMBL3975098 & 1638439 & 5.9237 & 6.4619 & TST & \\
\hline CHEMBL3980062 & 1638439 & 7.2518 & 6.2373 & TRN & \\
\hline CHEMBL3892291 & 1638439 & 8.301 & 7.362999 & 99999999995 & TST \\
\hline CHEMBL3979413 & 1638439 & 6.6021 & 7.2509 & TST & \\
\hline CHEMBL 3979191 & 1638439 & 6.5735 & 6.3775 & TST & \\
\hline CHEMBL3970734 & 1638439 & 6.718999 & 999999999 & 6.7381 & TRN \\
\hline CHEMBL3940473 & 1638439 & 7.1192 & 6.9897 & TRN & \\
\hline CHEMBL3951838 & 1638439 & 7.0 & 6.7381 & TRN & \\
\hline CHEMBL3968513 & 1638439 & 6.6021 & 6.2373 & TRN & \\
\hline CHEMBL3972224 & 1638439 & 7.301 & 6.7539 & TRN & \\
\hline CHEMBL3954910 & 1638439 & 7.0 & 6.7381 & TRN & \\
\hline CHEMBL3910006 & 1638439 & 7.7447 & 6.3113 & TRN & \\
\hline CHEMBL55572 & 69839 & 5.1739 & 5.2451 & TRN & \\
\hline CHEMBL56254 & 69839 & 5.7696 & 6.0657 & TRN & \\
\hline
\end{tabular}




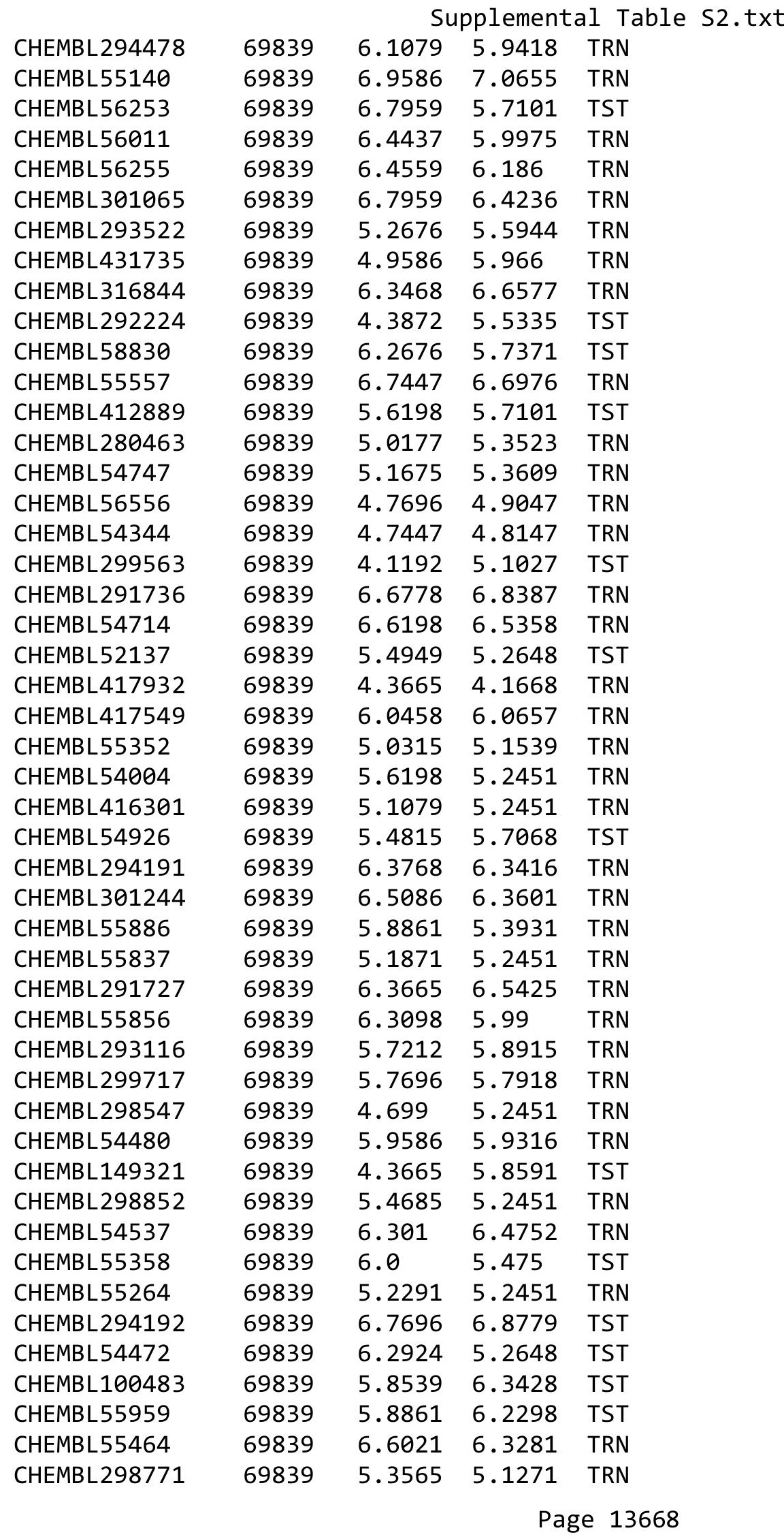




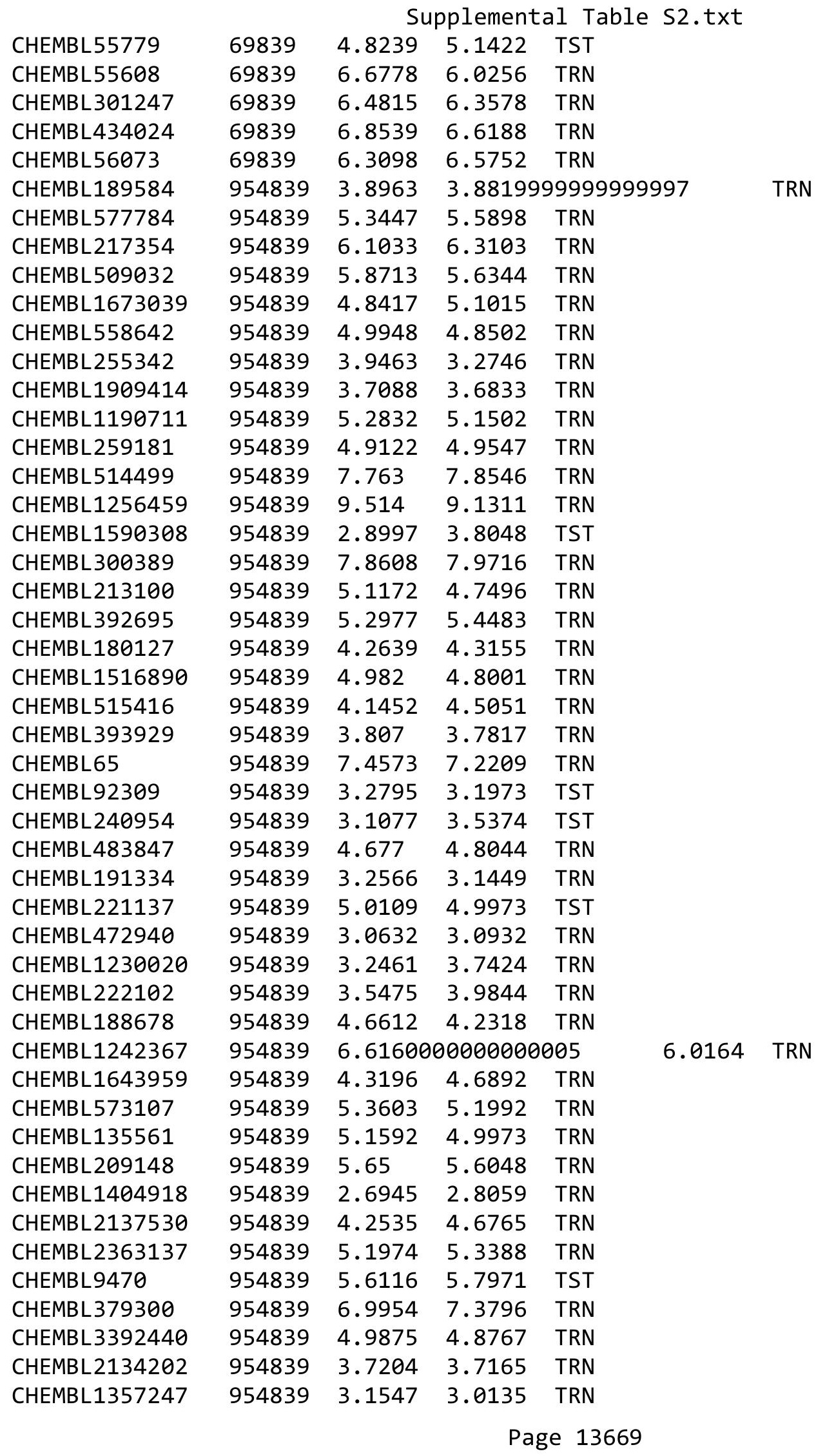


Supplemental Table S2.txt

\begin{tabular}{|c|c|c|c|c|}
\hline CHEMBL1970879 & 954839 & 6.4571 & 6.2367 & TRN \\
\hline CHEMBL585951 & 954839 & 5.9763 & 6.0599 & TRN \\
\hline CHEMBL 258844 & 954839 & 5.3397 & 5.4523 & TRN \\
\hline CHEMBL 210618 & 954839 & 3.1714 & 2.9578 & TRN \\
\hline CHEMBL1186585 & 954839 & 3.457 & 3.5033 & TRN \\
\hline CHEMBL 2144069 & 954839 & 3.9239 & 4.2438 & TRN \\
\hline CHEMBL 220241 & 954839 & 4.0942 & 3.7847 & TRN \\
\hline CHEMBL512504 & 954839 & 3.8419 & 3.6681 & TRN \\
\hline CHEMBL192566 & 954839 & 9.5242 & 8.7406 & TST \\
\hline CHEMBL 3349342 & 954839 & 5.3724 & 5.6152 & TRN \\
\hline CHEMBL102714 & 954839 & 3.8493 & 4.1067 & TRN \\
\hline CHEMBL1788116 & 954839 & 4.8014 & 4.9854 & TST \\
\hline CHEMBL 373751 & 954839 & 3.6447 & 3.9204 & TST \\
\hline CHEMBL399530 & 954839 & 4.4988 & 4.5302 & TST \\
\hline CHEMBL 3199475 & 954839 & 5.6056 & 4.3857 & TST \\
\hline CHEMBL 2005886 & 954839 & 7.0171 & 6.4138 & TST \\
\hline CHEMBL449158 & 954839 & 6.3495 & 6.9134 & TST \\
\hline CHEMBL483849 & 954839 & 3.2665 & 2.4999 & TST \\
\hline CHEMBL 202721 & 954839 & 3.9706 & 4.3495 & TST \\
\hline CHEMBL 379975 & 954839 & 5.0234 & 4.6202 & TST \\
\hline CHEMBL 3186408 & 954839 & 3.6175 & 3.6645 & TST \\
\hline CHEMBL412142 & 954839 & 3.7208 & 4.3137 & TST \\
\hline CHEMBL 3673583 & 1528777 & 5.8097 & 5.75899 & 99999999995 \\
\hline CHEMBL 3964600 & 1528777 & 6.0 & 5.8605 & TRN \\
\hline CHEMBL 3673584 & 1528777 & 5.699 & 6.2895 & TST \\
\hline CHEMBL 3673663 & 1528777 & 7.2441 & 6.7608 & TRN \\
\hline CHEMBL 3673667 & 1528777 & 7.7696 & 7.8022 & TRN \\
\hline CHEMBL 3673664 & 1528777 & 6.9208 & 6.5601 & TRN \\
\hline CHEMBL3673612 & 1528777 & 8.1739 & 7.63399 & \\
\hline CHEMBL 3639724 & 1528777 & 7.4815 & 7.6413 & TRN \\
\hline CHEMBL 3673651 & 1528777 & 6.9626 & 6.8274 & TRN \\
\hline CHEMBL 3673659 & 1528777 & 7.8861 & 7.7031 & TRN \\
\hline CHEMBL 3673642 & 1528777 & 7.7212 & 7.5202 & TRN \\
\hline CHEMBL 3673626 & 1528777 & 6.0 & 6.2698 & TRN \\
\hline CHEMBL 3673656 & 1528777 & 6.4437 & 6.8783 & TRN \\
\hline CHEMBL 3673573 & 1528777 & 7.1612 & 6.7853 & TST \\
\hline CHEMBL 3673653 & 1528777 & 7.3665 & 7.3141 & TRN \\
\hline CHEMBL 3673621 & 1528777 & 5.6383 & 6.0433 & TRN \\
\hline CHEMBL 3673604 & 1528777 & 8.3188 & 7.9371 & TRN \\
\hline CHEMBL 3673623 & 1528777 & 6.0 & 6.6425 & TRN \\
\hline CHEMBL 3673571 & 1528777 & 6.0177 & 5.9617 & TRN \\
\hline CHEMBL 3673599 & 1528777 & 7.8861 & 8.0531 & TRN \\
\hline CHEMBL 3673631 & 1528777 & 9.5686 & 9.6396 & TRN \\
\hline CHEMBL 3673657 & 1528777 & 8.4815 & 8.589 & TRN \\
\hline CHEMBL 3639725 & 1528777 & 8.7959 & 8.1423 & TST \\
\hline CHEMBL 3673577 & 1528777 & 5.3979 & 5.9593 & TRN \\
\hline CHEMBL 3673601 & 1528777 & 8.4202 & 8.5501 & TRN \\
\hline CHEMBL 3673608 & 1528777 & 7.301 & 7.3374 & TRN \\
\hline
\end{tabular}


Supplemental Table S2.txt

\begin{tabular}{|c|c|c|c|c|c|}
\hline CHEMBL3673585 & 1528777 & 5.7696 & 5.7916 & TRN & \\
\hline CHEMBL3673569 & 1528777 & 7.3565 & 6.8405 & TRN & \\
\hline CHEMBL3673666 & 1528777 & 6.4815 & 6.4313 & TST & \\
\hline CHEMBL3956346 & 1528777 & 8.585 & 6.5707 & TST & \\
\hline CHEMBL3673567 & 1528777 & 8.2596 & 8.0634 & TRN & \\
\hline CHEMBL3673587 & 1528777 & 7.2518 & 7.2608 & TRN & \\
\hline CHEMBL3673566 & 1528777 & 7.4559 & 7.2361 & TRN & \\
\hline CHEMBL3673645 & 1528777 & 8.28399 & 999999999 & 8.0113 & TRI \\
\hline CHEMBL3673654 & 1528777 & 6.4034 & 6.2476 & TRN & \\
\hline CHEMBL3673592 & 1528777 & 8.6778 & 8.6236 & TRN & \\
\hline CHEMBL3673586 & 1528777 & 8.0362 & 7.44 & TRN & \\
\hline CHEMBL3673581 & 1528777 & 8.3279 & 7.7809 & TRN & \\
\hline CHEMBL3673591 & 1528777 & 7.0458 & 7.6209 & TST & \\
\hline CHEMBL3673595 & 1528777 & 8.6383 & 8.7078 & TRN & \\
\hline CHEMBL3673574 & 1528777 & 6.0605 & 5.8399 & TRN & \\
\hline CHEMBL3673575 & 1528777 & 5.9208 & 6.382000 & 0000000001 & TRN \\
\hline CHEMBL3673609 & 1528777 & 9.4089 & 9.0591 & TRN & \\
\hline CHEMBL3673606 & 1528777 & 8.9586 & 9.0031 & TRN & \\
\hline CHEMBL3673579 & 1528777 & 7.0362 & 7.6065 & TRN & \\
\hline CHEMBL3673634 & 1528777 & 6.0 & 5.6961 & TRN & \\
\hline CHEMBL3673605 & 1528777 & 7.1427 & 7.2837 & TRN & \\
\hline CHEMBL3673580 & 1528777 & 7.6383 & 7.862 & TRN & \\
\hline CHEMBL3673603 & 1528777 & 9.1079 & 9.0657 & TRN & \\
\hline CHEMBL3673615 & 1528777 & 5.6021 & 5.7253 & TRN & \\
\hline CHEMBL3673570 & 1528777 & 5.7696 & 5.6897 & TRN & \\
\hline CHEMBL3673598 & 1528777 & 8.7959 & 8.9644 & TRN & \\
\hline CHEMBL 3673644 & 1528777 & 8.3665 & 7.7227 & TST & \\
\hline CHEMBL3673590 & 1528777 & 7.4318 & 7.4816 & TRN & \\
\hline CHEMBL3673568 & 1528777 & 5.4949 & 7.1174 & TST & \\
\hline CHEMBL3673588 & 1528777 & 7.699 & 7.7054 & TRN & \\
\hline CHEMBL3673652 & 1528777 & 6.9031 & 6.1626 & TST & \\
\hline CHEMBL3673576 & 1528777 & 6.4949 & 6.1858 & TRN & \\
\hline CHEMBL3673610 & 1528777 & 8.4202 & 8.1647 & TRN & \\
\hline CHEMBL3673655 & 1528777 & 6.2993 & 6.6989 & TST & \\
\hline CHEMBL3938416 & 1528777 & 6.0 & 6.8959 & TRN & \\
\hline CHEMBL3894458 & 1528777 & 8.2924 & 6.8514 & TST & \\
\hline CHEMBL3673649 & 1528777 & 6.9586 & 6.1014 & TST & \\
\hline CHEMBL3673593 & 1528777 & 7.6021 & 7.765 & TRN & \\
\hline CHEMBL3673602 & 1528777 & 7.041 & 6.9431 & TRN & \\
\hline CHEMBL3673632 & 1528777 & 7.8239 & 8.0632 & TRN & \\
\hline CHEMBL3673611 & 1528777 & 7.9208 & 7.484 & TRN & \\
\hline CHEMBL 3673643 & 1528777 & 7.7212 & 7.0322 & TST & \\
\hline CHEMBL3673600 & 1528777 & 7.6021 & 7.638999 & & 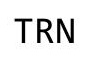 \\
\hline CHEMBL3673572 & 1528777 & 6.5302 & 6.4339 & TST & \\
\hline CHEMBL3673650 & 1528777 & 6.75700 & 000000000 & 6.7874 & ובנו \\
\hline CHEMBL3673578 & 1528777 & 7.3468 & 7.4615 & TRN & \\
\hline CHEMBL 3673638 & 1528777 & 6.0 & 5.47 & TRN & \\
\hline CHEMBL 3673658 & 1528777 & 8.4437 & 6.9884 & TST & \\
\hline
\end{tabular}


Supplemental Table S2.txt

\begin{tabular}{|c|c|c|c|c|}
\hline - & . & & & \\
\hline HEMBL3673565 & 528777 & 5.2518 & 5.3113 & \\
\hline & 28777 & & & \\
\hline 518 & 28777 & 39 & 261 & \\
\hline IEMBL3673596 & 528777 & 699 & 7261 & \\
\hline AEMBL3673619 & 528777 & 6.71 & 3814 & \\
\hline HEMBL & 528777 & 6.8861 & 7994 & \\
\hline 546 & 28777 & & & \\
\hline AEMBL & 528777 & & 2946 & \\
\hline AEMBL3673633 & 528777 & 7.5686 & .7435 & \\
\hline HEMBL3673597 & 528777 & 7.2076 & 3643 & \\
\hline AEMBL & 528777 & 8.2147 & 571 & \\
\hline 613 & & 96 & & ST \\
\hline AEMBL & 528777 & 788 & 9831 & \\
\hline AEMBL3 & 528777 & .007 & & \\
\hline AEMBL3673589 & 528777 & 8.6383 & 5422 & \\
\hline HEMBL; & 3777 & 377 & 951 & \\
\hline 617 & & 861 & & \\
\hline HEMBL & 77 & 5108 & 778 & \\
\hline AEMBL1 & 2 & 24 & & \\
\hline AEMIBL $\perp$ & 2 & 18 & 892 & I KIV \\
\hline HEMBL & 2 & 24 & 821 & RIN \\
\hline 271 & & & & \\
\hline 282 & & & 2037 & \\
\hline AEMBL5 & 2 & 3. & & RIV \\
\hline HBLS & 2 & 24 & 544 & RN \\
\hline AEMBL1 & $2<$ & 24 & 228 & KIV \\
\hline HEM & 2 & & 95 & \\
\hline 367 & & & & RIN \\
\hline AEMBL1 & 2 & 3 & 57 & RN \\
\hline IEMBL1 & 2 & $\partial 24$ & 31 & RN \\
\hline 6 & 2 & 97 & 09 & RN \\
\hline 8 & & & 387 & 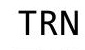 \\
\hline HEMBL1S & & & & RN \\
\hline HEMBL1339830 & 52 & 66 & 174 & RN \\
\hline AEMBL] & 52 & 24 & 132 & RN \\
\hline 946 & 2 & & & RN \\
\hline & & 24 & 046 & RN \\
\hline HEMBL1393944 & 52352 & 6.0655 & 3.0695 & ГST \\
\hline AEMBL1 & 52. & 24 & 126 & RN \\
\hline HEMBL1 & - & 7.5229 & 323 & ST \\
\hline & & & 9991 & ST \\
\hline HEMBL1 & 52352 & 3.1024 & 117 & RN \\
\hline AEMBL1379163 & 52352 & 4.2097 & .081 & $\mathrm{R}$ \\
\hline EMBL5 & - & 3 & 137 & RN \\
\hline HEMBL1878645 & 52352 & & 3.1758 & \\
\hline HEMBL187249 & 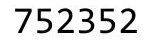 & 4.2211 & 2.9537 & \\
\hline CHEMBL 585827 & 752352 & 3.1024 & 3.037 & RN \\
\hline
\end{tabular}

Page 13672 
Supplemental Table S2.txt

\begin{tabular}{|c|c|c|c|c|c|}
\hline CHEMBL1503124 & 752352 & 7.7959 & 2.4772 & TST & \\
\hline CHEMBL1443069 & 752352 & 3.1024 & 3.1114 & TRN & \\
\hline CHEMBL592600 & 752352 & 3.1024 & 3.213 & TRN & \\
\hline CHEMBL1496048 & 752352 & 3.1024 & 3.1751 & TRN & \\
\hline CHEMBL1865457 & 752352 & 3.1024 & 3.6673 & TST & \\
\hline CHEMBL1899890 & 752352 & 3.1024 & 3.0641 & TRN & \\
\hline CHEMBL1887169 & 752352 & 4.2299 & 4.1805 & TRN & \\
\hline CHEMBL1522618 & 752352 & 3.1024 & 2.9352 & TRN & \\
\hline CHEMBL1902496 & 752352 & 3.1024 & 3.2364 & TRN & \\
\hline CHEMBL1514530 & 752352 & 3.1024 & 3.153 & TRN & \\
\hline CHEMBL1875095 & 752352 & 3.1024 & 3.113 & TRN & \\
\hline CHEMBL1578584 & 752352 & 6.5376 & 2.4447 & TST & \\
\hline CHEMBL602720 & 752352 & 3.1024 & 3.0937 & TRN & \\
\hline CHEMBL1902224 & 752352 & 3.1024 & 3.1304 & TRN & \\
\hline CHEMBL1572920 & 752352 & 4.2055 & 4.2884 & TRN & \\
\hline CHEMBL1525213 & 752352 & 4.5376 & 2.7034 & TST & \\
\hline CHEMBL1863881 & 752352 & 3.1024 & 3.0967 & TRN & \\
\hline CHEMBL1899180 & 752352 & 3.1024 & 3.0995 & TRN & \\
\hline CHEMBL1880835 & 752352 & 3.1024 & 3.1602 & TRN & \\
\hline CHEMBL580530 & 752352 & 3.1024 & 3.0113 & TRN & \\
\hline CHEMBL1879735 & 752352 & 3.1024 & 3.3154 & TST & \\
\hline CHEMBL1316506 & 752352 & 4.359 & 4.2212 & TRN & \\
\hline CHEMBL1885380 & 752352 & 3.1024 & 3.1815 & TRN & \\
\hline CHEMBL1576870 & 752352 & 6.2596 & 2.411 & TST & \\
\hline CHEMBL1452490 & 752352 & 3.1024 & 3.0097 & TRN & \\
\hline CHEMBL1902698 & 752352 & 5.6021 & 2.5136 & TST & \\
\hline CHEMBL1864401 & 752352 & 3.1024 & 2.9594 & TST & \\
\hline CHEMBL1877680 & 752352 & 4.8356 & 2.6185 & TST & \\
\hline CHEMBL251603 & 752352 & 3.1024 & 2.9886 & TRN & \\
\hline CHEMBL590927 & 752352 & 3.1024 & 3.1311 & TRN & \\
\hline CHEMBL1604735 & 752352 & 4.341 & 4.4408 & TRN & \\
\hline CHEMBL1419414 & 752352 & 3.1024 & 3.0656 & TRN & \\
\hline CHEMBL590665 & 752352 & 3.1024 & 3.0715 & TRN & \\
\hline CHEMBL1902332 & 752352 & 3.1024 & 3.1914 & TRN & \\
\hline CHEMBL1519450 & 752352 & 3.1024 & 3.0439 & TRN & \\
\hline CHEMBL1373096 & 752352 & 3.1024 & 3.0363 & TRN & \\
\hline CHEMBL1313101 & 752352 & 3.1024 & 3.24399 & 99999999998 & TRN \\
\hline CHEMBL1438842 & 752352 & 6.6778 & 2.8979 & TST & \\
\hline CHEMBL1885580 & 752352 & 3.1024 & 3.5026 & TST & \\
\hline CHEMBL1906106 & 752352 & 3.1024 & 3.1166 & TRN & \\
\hline CHEMBL1503612 & 752352 & 5.3401 & 2.7186 & TST & \\
\hline CHEMBL1589983 & 752352 & 3.1024 & 3.25 & TST & \\
\hline CHEMBL1894788 & 752352 & 3.1024 & 3.56100 & 00000000004 & TST \\
\hline CHEMBL1903426 & 752352 & 3.1024 & 2.9901 & TRN & \\
\hline CHEMBL547285 & 752352 & 3.1024 & 3.09800 & 00000000003 & TRN \\
\hline CHEMBL1864059 & 752352 & 3.1024 & 3.5635 & TST & \\
\hline CHEMBL1890797 & 752352 & 3.1024 & 4.0125 & TST & \\
\hline CHEMBL1890613 & 752352 & 3.1024 & 3.1711 & TRN & \\
\hline
\end{tabular}


Supplemental Table S2.txt

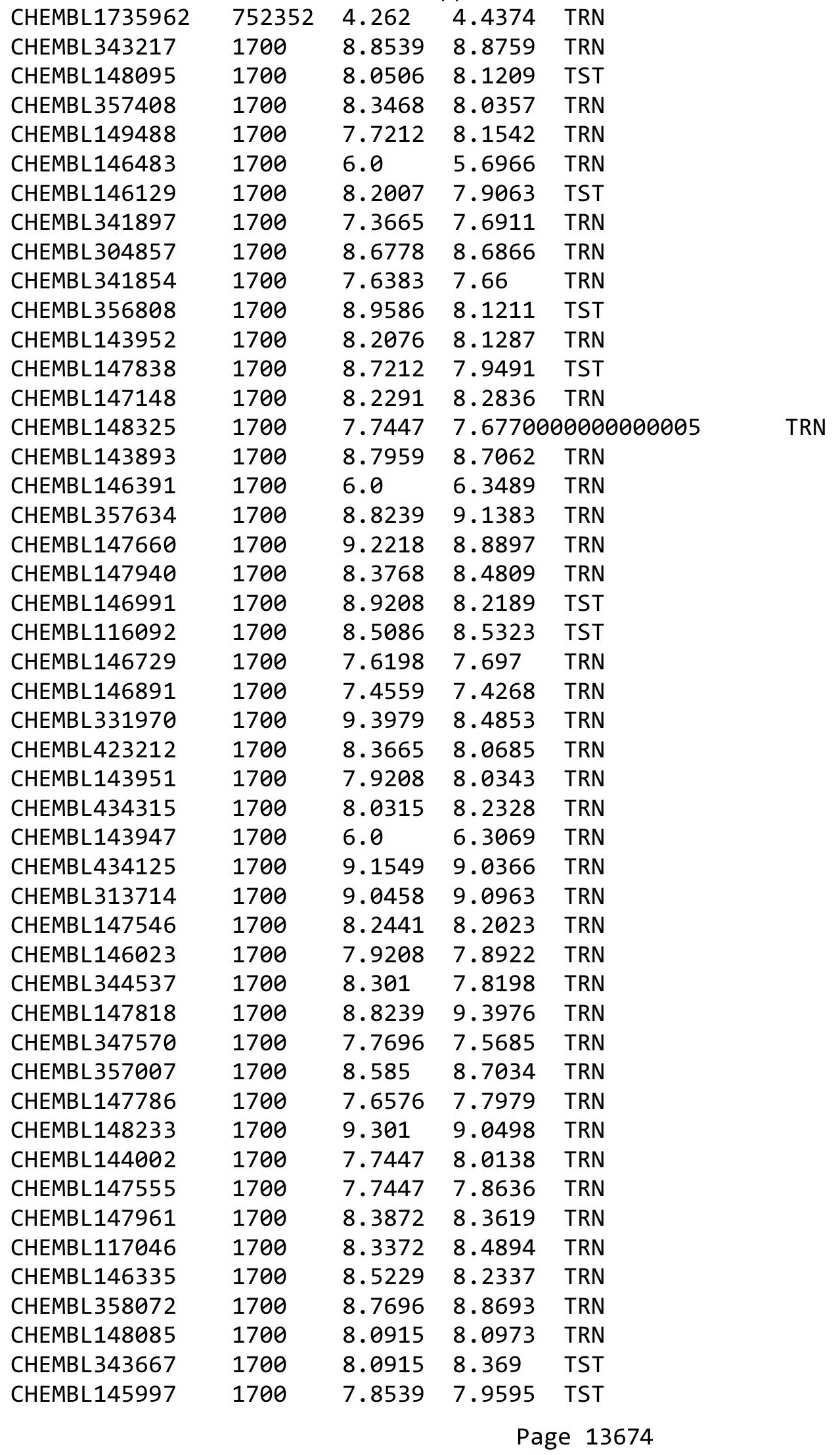




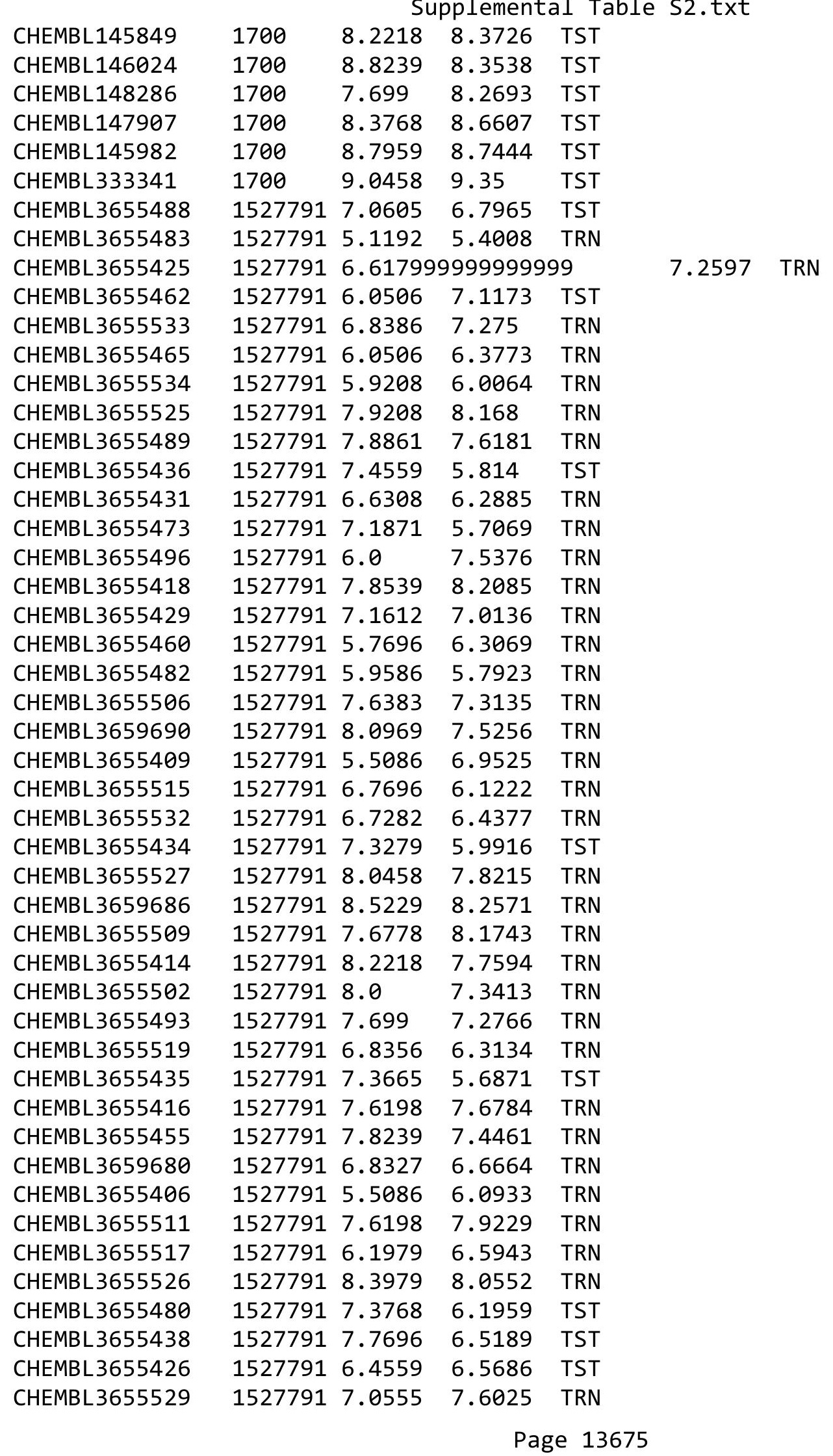


Supplemental Table S2.txt

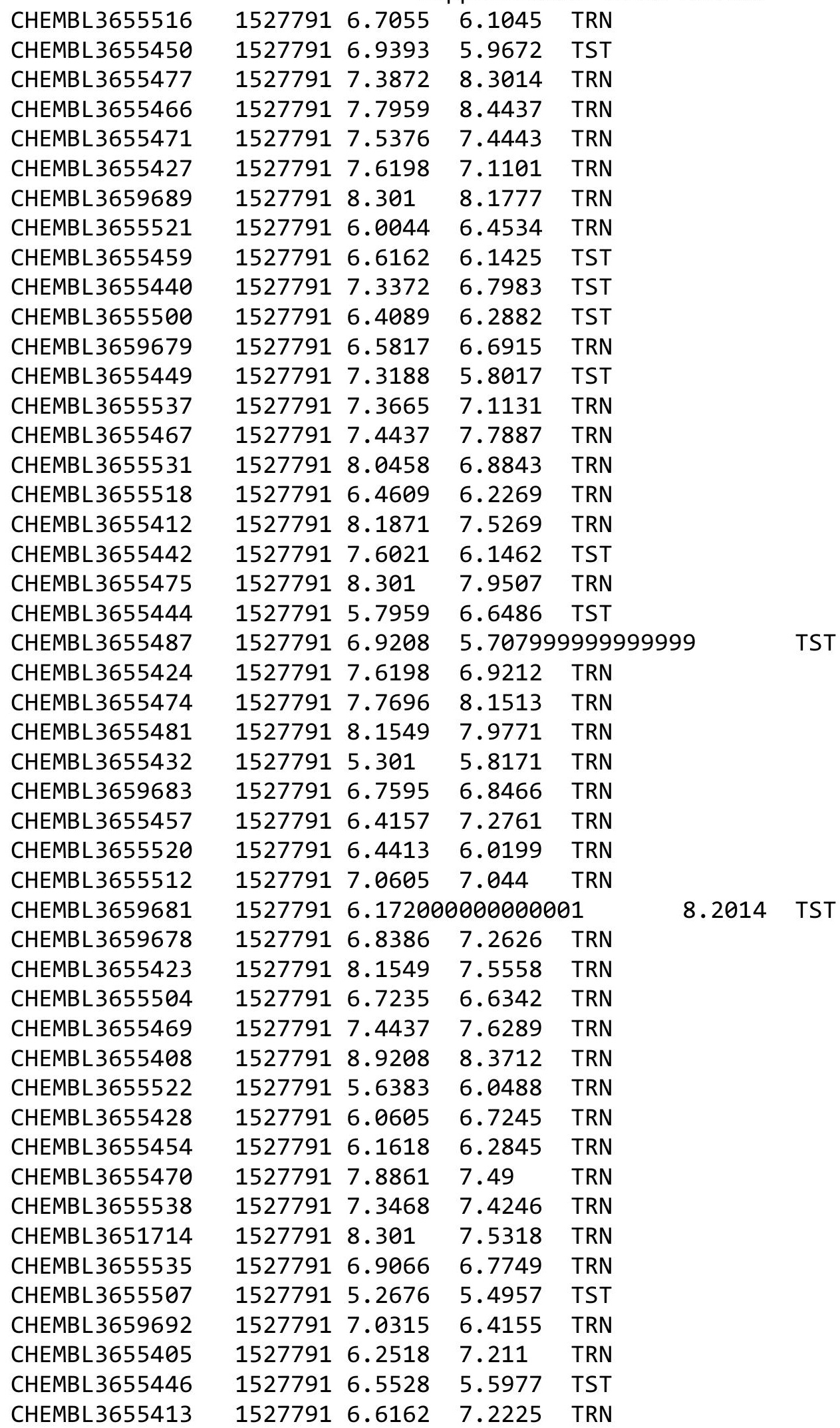

Page 13676 
Supplemental Table S2.txt

\begin{tabular}{|c|c|c|c|c|c|}
\hline CHEMBL 3659684 & 1527791 & 7.2366 & 7.4609 & TRN & \\
\hline CHEMBL3655503 & 1527791 & 6.4056 & 6.5116 & TRN & \\
\hline CHEMBL 3655508 & 1527791 & 7.4202 & 7.4634 & TRN & \\
\hline CHEMBL 3651713 & 1527791 & 7.7212 & 7.6791 & TRN & \\
\hline CHEMBL3655452 & 1527791 & 5.4089 & 5.9749 & TST & \\
\hline CHEMBL3655501 & 1527791 & 6.8861 & 5.5297 & TST & \\
\hline CHEMBL3655495 & 1527791 & 7.1739 & 7.3896 & TRN & \\
\hline CHEMBL 3655464 & 1527791 & 7.3565 & 7.4056 & TRN & \\
\hline CHEMBL 3655513 & 1527791 & 7.9208 & 7.7044 & TRN & \\
\hline CHEMBL3655530 & 1527791 & 7.0655 & 7.0037 & TRN & \\
\hline CHEMBL3655498 & 1527791 & 6.2366 & 6.0201 & TST & \\
\hline CHEMBL 3655415 & 1527791 & 7.0915 & 7.5629 & TRN & \\
\hline CHEMBL3659687 & 1527791 & 6.5406 & 7.3609 & TRN & \\
\hline CHEMBL 3655447 & 1527791 & 7.3979 & 5.8702 & TST & \\
\hline CHEMBL3655514 & 1527791 & 4.0 & 5.4267 & TRN & \\
\hline CHEMBL3655458 & 1527791 & 6.58 & 6.4723 & TRN & \\
\hline CHEMBL3655410 & 1527791 & 6.585 & 7.2623 & TRN & \\
\hline CHEMBL3655461 & 1527791 & \multicolumn{2}{|c|}{6.752000000000001} & 7.11 & TRN \\
\hline CHEMBL3655510 & 1527791 & 8.0 & 7.7377 & TRN & \\
\hline CHEMBL3655523 & 1527791 & 5.6021 & 6.1703 & TRN & \\
\hline CHEMBL3651715 & 1527791 & 8.2218 & 7.7533 & TRN & \\
\hline CHEMBL3655479 & 1527791 & 7.2596 & 7.4729 & TRN & \\
\hline CHEMBL 3655419 & 1527791 & 7.699 & 7.5859 & TRN & \\
\hline CHEMBL3659688 & 1527791 & 6.4895 & 6.7338 & TRN & \\
\hline CHEMBL 3655451 & 1527791 & 6.1993 & 5.9852 & TRN & \\
\hline CHEMBL3639543 & 1527791 & 7.2291 & 6.1355 & TST & \\
\hline CHEMBL3655472 & 1527791 & 8.301 & 8.4595 & TRN & \\
\hline CHEMBL 3655417 & 1527791 & 8.3979 & 8.513 & TRN & \\
\hline CHEMBL3655528 & 1527791 & 7.6778 & 7.2338 & TRN & \\
\hline CHEMBL3655536 & 1527791 & 7.3768 & 6.9873 & TRN & \\
\hline CHEMBL 3655486 & 1527791 & 4.0809 & 6.2133 & TST & \\
\hline CHEMBL3655456 & 1527791 & 7.6778 & 7.2729 & TRN & \\
\hline CHEMBL 3655485 & 1527791 & 6.8182 & 7.2054 & TRN & \\
\hline CHEMBL 3655448 & 1527791 & 7.7447 & 6.0341 & TST & \\
\hline CHEMBL 3655491 & 1527791 & 7.1549 & 7.0047 & TRN & \\
\hline CHEMBL3655421 & 1527791 & 7.4089 & 7.6698 & TRN & \\
\hline CHEMBL3655468 & 1527791 & 7.3188 & 7.11799 & 9999999999 & TRN \\
\hline CHEMBL 3655407 & 1527791 & 8.5229 & 7.695 & TRN & \\
\hline CHEMBL 3655484 & 1527791 & 6.301 & 6.0312 & TST & \\
\hline CHEMBL 3655453 & 1527791 & 6.3143 & 6.5225 & TRN & \\
\hline CHEMBL3655494 & 1527791 & 7.2924 & 7.2139 & TRN & \\
\hline CHEMBL3659685 & 1527791 & 7.7212 & 7.5838 & TRN & \\
\hline CHEMBL3655499 & 1527791 & 6.4248 & 6.4291 & TST & \\
\hline CHEMBL3655463 & 1527791 & 6.2993 & 5.7697 & TST & \\
\hline CHEMBL 3655422 & 1527791 & 8.2218 & 7.8473 & TRN & \\
\hline CHEMBL3655476 & 1527791 & 7.8239 & 7.2946 & TRN & \\
\hline CHEMBL3659691 & 1527791 & 7.8239 & 7.4226 & TRN & \\
\hline CHEMBL3655420 & 1527791 & 7.8539 & 7.7798 & TRN & \\
\hline
\end{tabular}

Page 13677 
Supplemental Table S2.txt

\begin{tabular}{|c|c|c|c|c|}
\hline CHEMBL 3655411 & 1527791 & 8.5229 & 8.3826 & TRN \\
\hline CHEMBL 3655433 & 1527791 & 7.4437 & 6.1763 & TST \\
\hline CHEMBL3655490 & 1527791 & 7.4202 & 7.0939 & TRN \\
\hline CHEMBL3655497 & 1527791 & 7.2924 & 6.8024 & TRN \\
\hline CHEMBL 3655524 & 1527791 & 5.585 & 6.4265 & TST \\
\hline CHEMBL 3659682 & 1527791 & 5.6198 & 8.195 & TST \\
\hline CHEMBL 3659693 & 1527791 & 6.8633 & 7.0 & TST \\
\hline CHEMBL3655478 & 1527791 & 7.6576 & 6.1343 & TST \\
\hline CHEMBL 3655443 & 1527791 & 8.1549 & 6.4019 & TST \\
\hline CHEMBL 3655505 & 1527791 & 7.2757 & 7.5576 & TST \\
\hline CHEMBL 3655492 & 1527791 & 6.0 & 6.6431 & TST \\
\hline CHEMBL 3655430 & 1527791 & 5.699 & 6.5517 & TST \\
\hline CHEMBL1408099 & 845106 & 3.1938 & 3.8042 & TRN \\
\hline CHEMBL1332371 & 845106 & 4.4145 & 3.6991 & TRN \\
\hline CHEMBL1523365 & 845106 & 5.3116 & 4.4753 & TRN \\
\hline CHEMBL1424434 & 845106 & 4.3737 & 3.7464 & TRN \\
\hline CHEMBL1359529 & 845106 & 4.3556 & 4.1448 & TRN \\
\hline CHEMBL1509778 & 845106 & 3.1938 & 3.4127 & TRN \\
\hline CHEMBL1409219 & 845106 & 3.1938 & 3.1748 & TST \\
\hline CHEMBL1995078 & 845106 & 3.1938 & 3.6182 & TST \\
\hline CHEMBL1608480 & 845106 & 3.1938 & 3.1696 & TRN \\
\hline CHEMBL286593 & 845106 & 4.2594 & 3.8987 & TRN \\
\hline CHEMBL191015 & 845106 & 3.1938 & 3.3279 & TRN \\
\hline CHEMBL1575708 & 845106 & 4.3101 & 4.042 & TRN \\
\hline CHEMBL1431189 & 845106 & 3.1938 & 3.7868 & TRN \\
\hline CHEMBL1727324 & 845106 & 3.1938 & 3.5302 & TRN \\
\hline CHEMBL1363917 & 845106 & 4.475 & 3.7928 & TRN \\
\hline CHEMBL1510806 & 845106 & 3.1938 & 3.768999 & 99999999997 \\
\hline CHEMBL1488141 & 845106 & 5.3716 & 4.2164 & TRN \\
\hline CHEMBL1866688 & 845106 & 4.3019 & 3.6708 & TRN \\
\hline CHEMBL1446106 & 845106 & 4.3417 & 4.0516 & TRN \\
\hline CHEMBL1440055 & 845106 & 4.3344 & 3.6502 & TRN \\
\hline CHEMBL1348618 & 845106 & 4.4237 & 4.1841 & TRN \\
\hline CHEMBL1390388 & 845106 & 3.1938 & 3.5854 & TRN \\
\hline CHEMBL1608686 & 845106 & 3.1938 & 2.8431 & TRN \\
\hline CHEMBL1598347 & 845106 & 3.1938 & 3.6107 & TRN \\
\hline CHEMBL1711260 & 845106 & 3.1938 & 3.8615 & TRN \\
\hline CHEMBL1535899 & 845106 & 3.1938 & 3.6793 & TST \\
\hline CHEMBL1347021 & 845106 & 3.1938 & 3.6627 & TRN \\
\hline CHEMBL1462691 & 845106 & 4.7986 & 4.0233 & TST \\
\hline CHEMBL1461506 & 845106 & 3.1938 & 2.9527 & TRN \\
\hline CHEMBL1440061 & 845106 & 4.3514 & 3.6551 & TST \\
\hline CHEMBL1442084 & 845106 & 3.1938 & 3.6159 & TST \\
\hline CHEMBL1565955 & 845106 & 4.3194 & 3.8909 & TRN \\
\hline CHEMBL 1446942 & 845106 & 4.3429 & 4.3 & TRN \\
\hline CHEMBL1323785 & 845106 & 4.3325 & 3.8553 & TRN \\
\hline CHEMBL1882962 & 845106 & 3.1938 & 3.7751 & TRN \\
\hline CHEMBL1493429 & 845106 & 5.2284 & 3.7994 & TRN \\
\hline
\end{tabular}

Page 13678 


\begin{tabular}{|c|c|c|c|c|}
\hline \multicolumn{5}{|c|}{ Supplemental Table S2.txt } \\
\hline CHEMBL1596719 & 845106 & 3.1938 & 3.3127 & TRN \\
\hline CHEMBL 1467579 & 845106 & 3.1938 & 3.4613 & TST \\
\hline CHEMBL1389668 & 845106 & 3.1938 & 3.4894 & TRN \\
\hline CHEMBL1899739 & 845106 & 4.5948 & 3.9077 & TRN \\
\hline CHEMBL1577311 & 845106 & 3.1938 & 3.0617 & TRN \\
\hline CHEMBL1705423 & 845106 & 3.1938 & 3.6408 & TRN \\
\hline CHEMBL1311206 & 845106 & 3.1938 & 3.5951 & TST \\
\hline CHEMBL1365356 & 845106 & 4.5143 & 4.1788 & TRN \\
\hline CHEMBL1706710 & 845106 & 4.6392 & 4.012 & TRN \\
\hline CHEMBL1539388 & 845106 & 3.1938 & 2.9855 & TRN \\
\hline CHEMBL1462011 & 845106 & 4.3608 & 3.2238 & TRN \\
\hline CHEMBL1307910 & 845106 & 3.1938 & 3.1597 & TRN \\
\hline CHEMBL1543194 & 845106 & 3.1938 & 3.7222 & TRN \\
\hline CHEMBL1519452 & 845106 & 3.1938 & 3.7299 & TRN \\
\hline CHEMBL1420133 & 845106 & 3.1938 & 3.9813 & TRN \\
\hline CHEMBL1582199 & 845106 & 3.1938 & 3.5798 & TST \\
\hline CHEMBL1325071 & 845106 & 3.1938 & 4.0067 & TRN \\
\hline CHEMBL1598424 & 845106 & 4.4631 & 4.1428 & TST \\
\hline CHEMBL1582368 & 845106 & 5.1818 & 4.3069 & TRN \\
\hline CHEMBL1376214 & 845106 & 3.1938 & 3.5594 & TRN \\
\hline CHEMBL1564386 & 845106 & 3.1938 & 3.7928 & TRN \\
\hline CHEMBL1549529 & 845106 & 3.1938 & 2.7194 & TRN \\
\hline CHEMBL1523565 & 845106 & 3.1938 & 3.1774 & TRN \\
\hline CHEMBL1595178 & 845106 & 5.5719 & 4.2982 & TRN \\
\hline CHEMBL1575487 & 845106 & 4.3695 & 3.6253 & TRN \\
\hline CHEMBL1407390 & 845106 & 3.1938 & 3.6117 & TRN \\
\hline CHEMBL1469808 & 845106 & 4.2776 & 3.9128 & TRN \\
\hline CHEMBL1378710 & 845106 & 3.1938 & 3.5671 & TRN \\
\hline CHEMBL1880991 & 845106 & 3.1938 & 3.8942 & TRN \\
\hline CHEMBL1417740 & 845106 & 5.5901 & 4.4626 & TRN \\
\hline CHEMBL1698134 & 845106 & 3.1938 & 3.1746 & TRN \\
\hline CHEMBL1456197 & 845106 & 3.1938 & 3.5093 & TRN \\
\hline CHEMBL1526993 & 845106 & 3.1938 & 4.2651 & TRN \\
\hline CHEMBL1477304 & 845106 & 4.5837 & 4.2272 & TRN \\
\hline CHEMBL1358924 & 845106 & 3.1938 & 3.4956 & TRN \\
\hline CHEMBL1373822 & 845106 & 4.6362 & 3.8183 & TRN \\
\hline CHEMBL1403349 & 845106 & 3.1938 & 3.8999 & TRN \\
\hline CHEMBL1364058 & 845106 & 3.1938 & 3.903 & TRN \\
\hline CHEMBL1560655 & 845106 & 3.1938 & 3.7811 & TRN \\
\hline CHEMBL1604614 & 845106 & 3.1938 & 4.0717 & TRN \\
\hline CHEMBL1868380 & 845106 & 3.1938 & 3.8782 & TST \\
\hline CHEMBL1428659 & 845106 & 3.1938 & 4.0762 & TRN \\
\hline CHEMBL1983033 & 845106 & 5.4413 & 3.5717 & TST \\
\hline CHEMBL1511924 & 845106 & 3.1938 & 3.1858 & TRN \\
\hline CHEMBL1550800 & 845106 & 4.8665 & 3.5113 & TRN \\
\hline CHEMBL1412393 & 845106 & 3.1938 & 2.9977 & TRN \\
\hline CHEMBL1467262 & 845106 & 4.2961 & 4.3863 & TRN \\
\hline CHEMBL1487784 & 845106 & 4.3616 & 3.6978 & TRN \\
\hline
\end{tabular}




\begin{tabular}{|c|c|c|c|c|c|}
\hline \multicolumn{6}{|c|}{ Supplemental Table S2.txt } \\
\hline CHEMBL1505809 & 845106 & 3.1938 & 3.0834 & TRN & \\
\hline CHEMBL1311572 & 845106 & 3.1938 & 3.6305 & TRN & \\
\hline CHEMBL1490017 & 845106 & 3.1938 & 3.6227 & TRN & \\
\hline CHEMBL53738 & 845106 & 3.1938 & 3.7444 & TRN & \\
\hline CHEMBL1885880 & 845106 & 3.1938 & 3.3341 & TRN & \\
\hline CHEMBL1594218 & 845106 & 3.1938 & 3.4092 & TRN & \\
\hline CHEMBL1600421 & 845106 & 3.1938 & 3.7572 & TRN & \\
\hline CHEMBL1713227 & 845106 & 3.1938 & 3.6172 & TRN & \\
\hline CHEMBL1532349 & 845106 & 4.3152 & 3.9873 & TRN & \\
\hline CHEMBL1489565 & 845106 & 3.1938 & 4.2876 & TRN & \\
\hline CHEMBL1530862 & 845106 & 3.1938 & 3.9274 & TRN & \\
\hline CHEMBL502315 & 845106 & 3.1938 & 3.8533 & TRN & \\
\hline CHEMBL1526471 & 845106 & 4.6467 & 3.4948 & TRN & \\
\hline CHEMBL1454747 & 845106 & 3.1938 & 3.633 & TRN & \\
\hline CHEMBL1608954 & 845106 & 3.1938 & 3.5481 & TRN & \\
\hline CHEMBL1524205 & 845106 & 4.346 & 4.1714 & TRN & \\
\hline CHEMBL1381097 & 845106 & 4.3215 & 3.5172 & TRN & \\
\hline CHEMBL1592023 & 845106 & 3.1938 & 3.8489 & TST & \\
\hline CHEMBL1509727 & 845106 & 3.1938 & 3.6211 & TRN & \\
\hline CHEMBL1308898 & 845106 & 3.1938 & 3.3728 & TRN & \\
\hline CHEMBL1522206 & 845106 & 3.1938 & 3.6834 & TST & \\
\hline CHEMBL1347600 & 845106 & 3.1938 & 3.7486 & TRN & \\
\hline CHEMBL1421547 & 845106 & 3.1938 & 3.79399 & 99999999996 & TST \\
\hline CHEMBL1887321 & 845106 & 4.364 & 4.0041 & TST & \\
\hline CHEMBL1491651 & 845106 & 3.1938 & 3.8566 & TST & \\
\hline CHEMBL1416100 & 845106 & 3.1938 & 3.7617 & TST & \\
\hline CHEMBL1418667 & 845106 & 3.1938 & 3.6947 & TST & \\
\hline CHEMBL1408919 & 845106 & 3.1938 & 3.8384 & TST & \\
\hline CHEMBL1346114 & 845106 & 4.3013 & 3.6196 & TST & \\
\hline CHEMBL1344582 & 845106 & 4.6692 & 3.5152 & TST & \\
\hline CHEMBL1347974 & 845106 & 3.1938 & 3.9597 & TST & \\
\hline CHEMBL1719443 & 845106 & 4.3524 & 4.2462 & TST & \\
\hline CHEMBL1466102 & 845106 & 3.1938 & 3.9527 & TST & \\
\hline CHEMBL1335915 & 845106 & 3.1938 & 3.3176 & TST & \\
\hline CHEMBL1544408 & 845106 & 3.1938 & 4.1467 & TST & \\
\hline CHEMBL1603696 & 845106 & 3.1938 & 4.0141 & TST & \\
\hline CHEMBL1503172 & 845106 & 3.1938 & 3.5365 & TST & \\
\hline CHEMBL1610263 & 845106 & 3.1938 & 3.4439 & TST & \\
\hline CHEMBL17201 & 845106 & 3.1938 & 3.2429 & TST & \\
\hline CHEMBL3717086 & 1536918 & 11.0 & 10.8698 & TRN & \\
\hline CHEMBL3715656 & 1536918 & 11.0 & 12.1351 & TRN & \\
\hline CHEMBL 3718331 & 1536918 & 11.0 & 10.5829 & TRN & \\
\hline CHEMBL3715009 & 1536918 & 6.9957 & 7.9711 & TRN & \\
\hline CHEMBL 3718174 & 1536918 & 11.0 & 11.5297 & TRN & \\
\hline CHEMBL3716184 & 1536918 & 11.0 & 9.3618 & TRN & \\
\hline CHEMBL3718720 & 1536918 & 6.0 & 8.3264 & TRN & \\
\hline CHEMBL 3719364 & 1536918 & 11.0 & 10.6239 & TRN & \\
\hline CHEMBL 3717390 & 1536918 & 11.0 & 10.4373 & TRN & \\
\hline
\end{tabular}




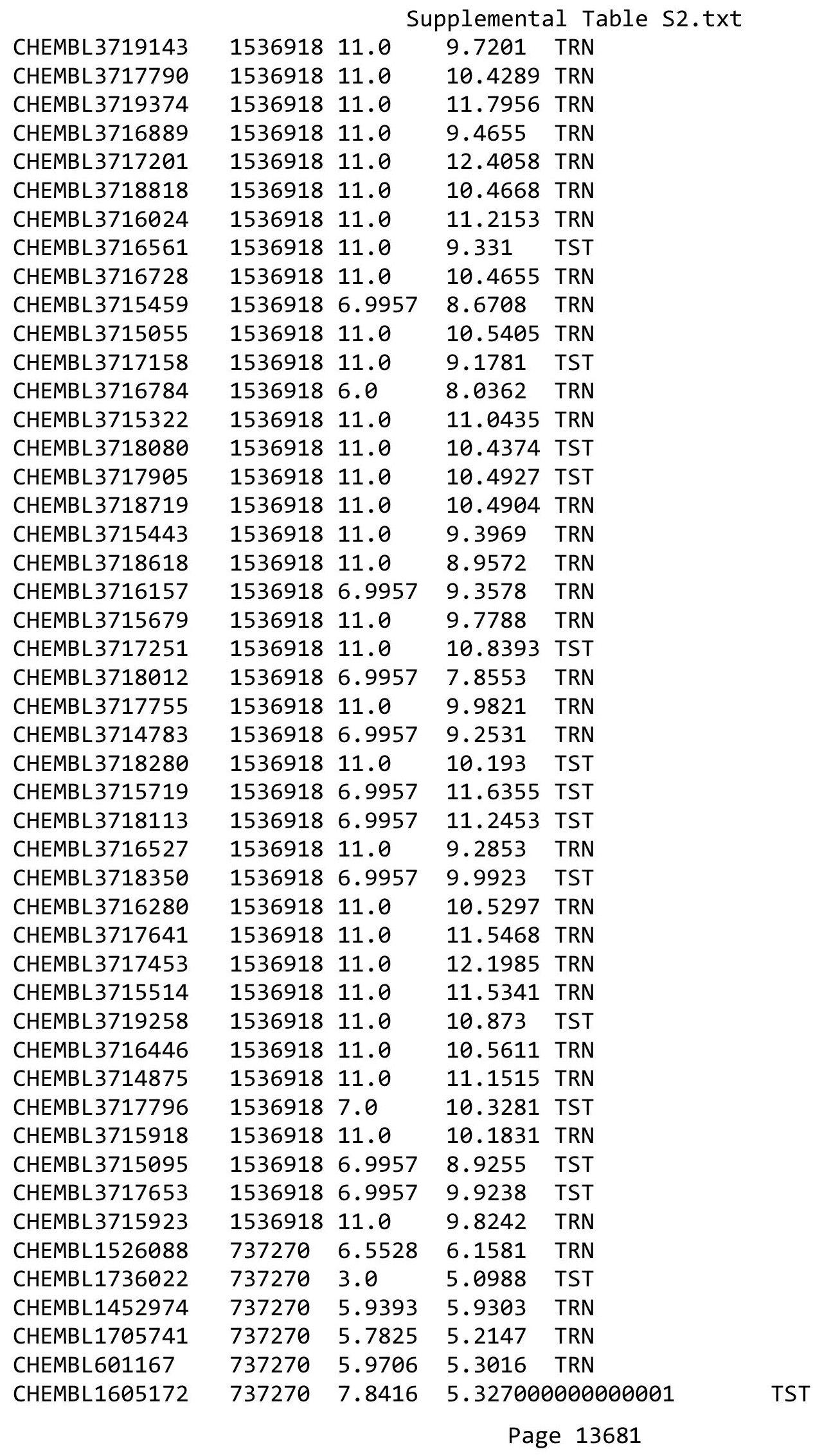




\begin{tabular}{|c|c|c|c|c|c|c|}
\hline & & \multicolumn{5}{|c|}{ Supplemental Table S2.txt } \\
\hline CHEMBL1735040 & 737270 & 4.4989 & 4.3908 & TRN & & \\
\hline CHEMBL1701471 & 737270 & 5.5143 & 4.8795 & TRN & & \\
\hline CHEMBL1708418 & 737270 & 4.3261 & 4.3815 & TRN & & \\
\hline CHEMBL1705521 & 737270 & 3.301 & 5.7617 & TRN & & \\
\hline CHEMBL1608654 & 737270 & 6.0942 & 5.9837 & TRN & & \\
\hline CHEMBL1446668 & 737270 & 5.399 & 5.515 & TRN & & \\
\hline CHEMBL305978 & 737270 & 4.9066 & 5.6436 & TRN & & \\
\hline CHEMBL1305450 & 737270 & 5.5544 & 5.4459 & TRN & & \\
\hline CHEMBL1722185 & 737270 & 5.5884 & 5.2994 & TRN & & \\
\hline CHEMBL1408579 & 737270 & 7.4622 & 5.1955 & TST & & \\
\hline CHEMBL1728362 & 737270 & 5.8996 & 5.5244 & TRN & & \\
\hline CHEMBL1385949 & 737270 & 7.71 & 5.3479 & TST & & \\
\hline CHEMBL1374242 & 737270 & 6.0 & 5.7116 & TRN & & \\
\hline CHEMBL1707169 & 737270 & 6.1593 & 5.7075 & TRN & & \\
\hline CHEMBL1447397 & 737270 & 6.7077 & 5.1133 & TST & & \\
\hline CHEMBL1526669 & 737270 & 5.38399 & 99999999 & 995 & 5.97 & TRN \\
\hline CHEMBL1304193 & 737270 & 7.2321 & 5.1796 & TST & & \\
\hline CHEMBL1729688 & 737270 & 5.1284 & 5.3693 & TRN & & \\
\hline CHEMBL1708762 & 737270 & 5.3883 & 5.5386 & TST & & \\
\hline CHEMBL1707279 & 737270 & 5.9586 & 5.7081 & TRN & & \\
\hline CHEMBL1709111 & 737270 & 5.9957 & 5.8049 & TRN & & \\
\hline CHEMBL1343331 & 737270 & 5.3439 & 5.7876 & TRN & & \\
\hline CHEMBL1407368 & 737270 & 6.5918 & 6.2932 & TRN & & \\
\hline CHEMBL 1445488 & 737270 & 6.9788 & 6.3268 & TST & & \\
\hline CHEMBL1672291 & 737270 & 6.4078 & 6.3713 & TRN & & \\
\hline CHEMBL1462768 & 737270 & 3.0 & 5.3114 & TST & & \\
\hline CHEMBL1727475 & 737270 & 6.1158 & 5.2317 & TRN & & \\
\hline CHEMBL1721618 & 737270 & 5.4401 & 5.784 & TRN & & \\
\hline CHEMBL1736524 & 737270 & 3.0 & 5.2789 & TST & & \\
\hline CHEMBL1718472 & 737270 & 4.9788 & 5.5758 & TRN & & \\
\hline CHEMBL1719568 & 737270 & 4.1278 & 4.6969 & TRN & & \\
\hline CHEMBL1672292 & 737270 & 6.284 & 6.4122 & TRN & & \\
\hline CHEMBL1721258 & 737270 & 4.7471 & 5.7927 & TRN & & \\
\hline CHEMBL1441524 & 737270 & 5.7932 & 4.9518 & TRN & & \\
\hline CHEMBL1724547 & 737270 & 5.7825 & 6.1673 & TRN & & \\
\hline CHEMBL1304974 & 737270 & 5.75700 & 00000000 & 01 & 6.0007 & 151 \\
\hline CHEMBL1732186 & 737270 & 4.262 & 4.4182 & TST & & \\
\hline CHEMBL1425948 & 737270 & 4.8416 & 5.6501 & TRN & & \\
\hline CHEMBL1603381 & 737270 & 6.8962 & 6.2771 & TRN & & \\
\hline CHEMBL1530046 & 737270 & 4.0074 & 5.3607 & TRN & & \\
\hline CHEMBL1501132 & 737270 & 6.7033 & 5.8082 & TRN & & \\
\hline CHEMBL1721385 & 737270 & 4.82100 & 30000000 & 01 & 4.6602 & IS \\
\hline CHEMBL1733670 & 737270 & 5.3635 & 4.814 & TRN & & \\
\hline CHEMBL1708834 & 737270 & 5.6289 & 4.3798 & TRN & & \\
\hline CHEMBL3193786 & 737270 & 6.27 & 6.2033 & TRN & & \\
\hline CHEMBL1393151 & 737270 & 6.644 & 5.8033 & TST & & \\
\hline CHEMBL1735214 & 737270 & 6.2403 & 5.7885 & TRN & & \\
\hline CHEMBL1715760 & 737270 & 3.0 & 4.2333 & TRN & & \\
\hline
\end{tabular}




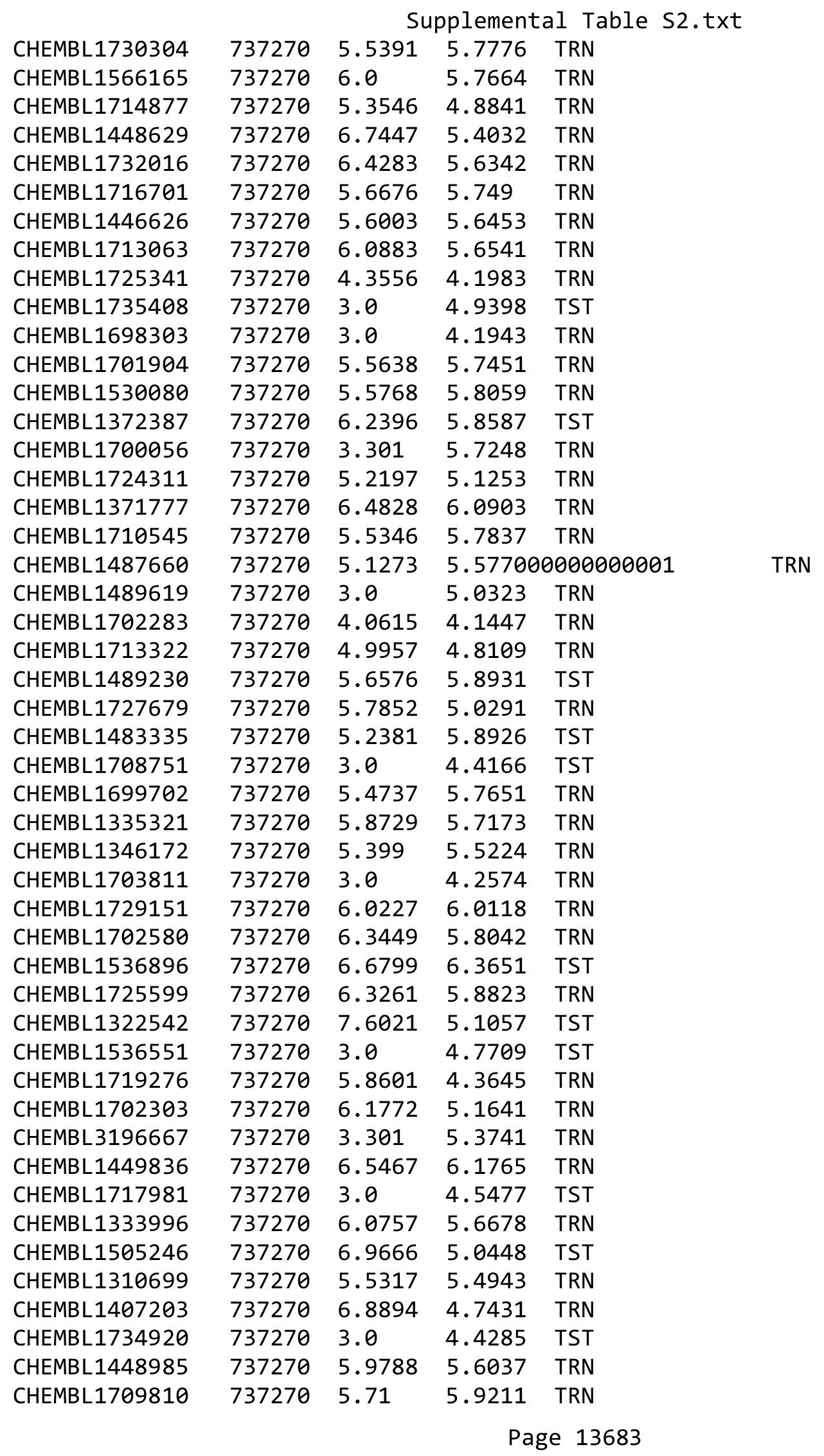




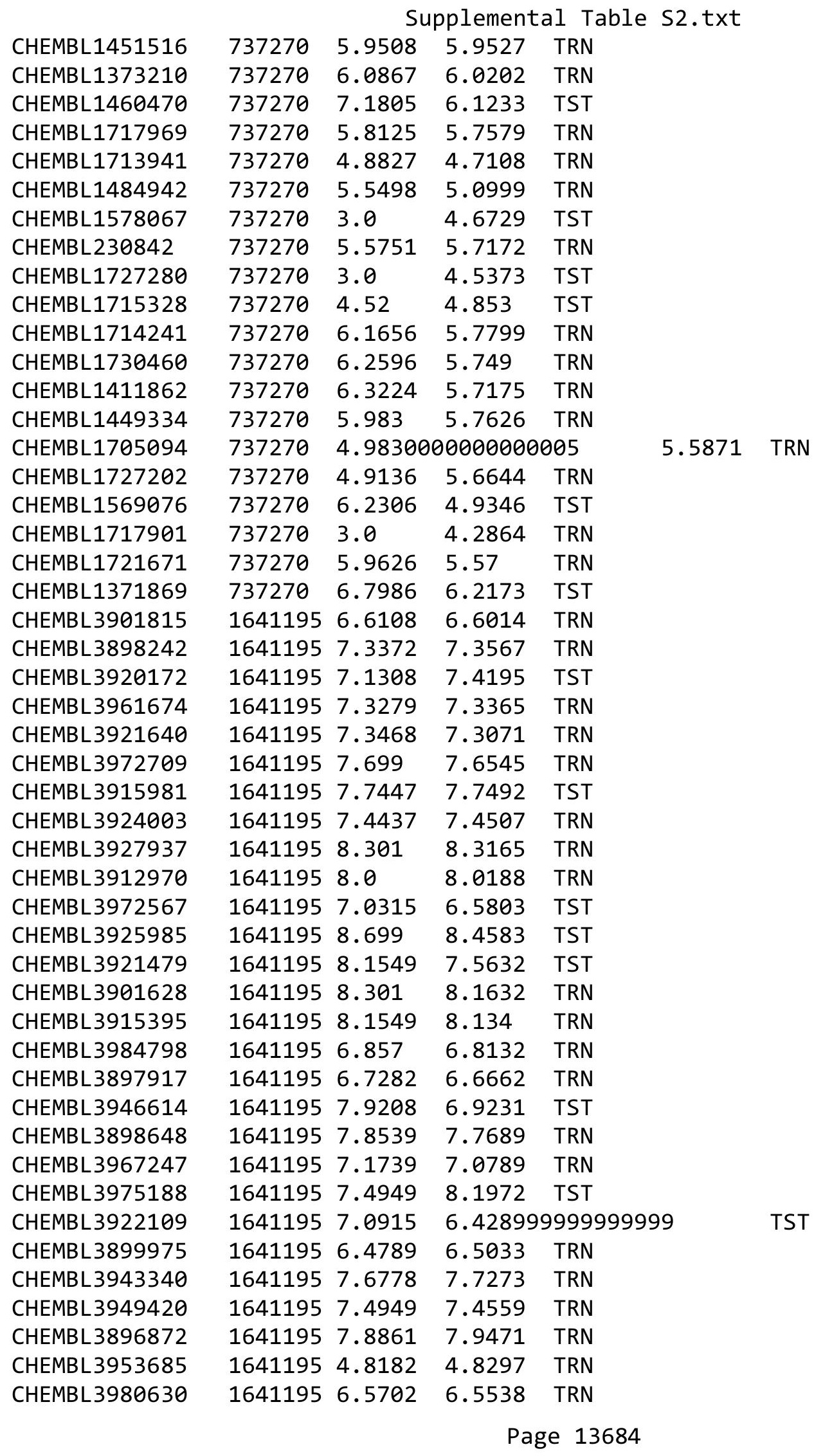


Supplemental Table S2.txt

\begin{tabular}{|c|c|c|c|c|c|}
\hline CHEMBL3935024 & 1641195 & 6.8928 & 6.9596 & TRN & \\
\hline CHEMBL3912657 & 1641195 & 8.0969 & 8.3359 & TRN & \\
\hline CHEMBL3891402 & 1641195 & 7.7447 & 7.7993 & TRN & \\
\hline CHEMBL3964270 & 1641195 & 6.4248 & 6.4784 & TRN & \\
\hline CHEMBL3899391 & 1641195 & 7.1805 & 7.1824 & TRN & \\
\hline CHEMBL3936603 & 1641195 & 7.5686 & 7.6844 & TRN & \\
\hline CHEMBL3973916 & 1641195 & 7.2007 & 7.1029 & TRN & \\
\hline CHEMBL3936935 & 1641195 & 7.5086 & 7.4719 & TRN & \\
\hline CHEMBL3940079 & 1641195 & 7.7212 & 7.6826 & TRN & \\
\hline CHEMBL3907109 & 1641195 & 6.8386 & 6.7904 & TRN & \\
\hline CHEMBL3986904 & 1641195 & 7.3565 & 7.566 & TRN & \\
\hline CHEMBL3943934 & 1641195 & 7.4202 & 7.3607 & TRN & \\
\hline CHEMBL3979828 & 1641195 & 7.0655 & 7.01 & TRN & \\
\hline CHEMBL 3905700 & 1641195 & 6.475 & 6.5207 & TRN & \\
\hline CHEMBL 3932522 & 1641195 & 7.1024 & 6.8699 & TST & \\
\hline CHEMBL 3958953 & 1641195 & 7.8239 & 7.7356 & TRN & \\
\hline CHEMBL3965728 & 1641195 & 7.6576 & 7.5793 & TST & \\
\hline CHEMBL3958914 & 1641195 & 6.5114 & 6.4952 & TRN & \\
\hline CHEMBL3966684 & 1641195 & 7.5376 & 7.9137 & TST & \\
\hline CHEMBL3695569 & 1641195 & 7.9208 & 7.75299 & 9999999999 & TST \\
\hline CHEMBL3971588 & 1641195 & 7.5229 & 7.65600 & 000000001 & TRN \\
\hline CHEMBL3893816 & 1641195 & 8.0969 & 8.1044 & TRN & \\
\hline CHEMBL3958297 & 1641195 & 7.5229 & 7.5038 & TRN & \\
\hline CHEMBL3956405 & 1641195 & 6.58 & 6.7431 & TRN & \\
\hline CHEMBL 3960541 & 1641195 & 7.1612 & 7.1503 & TRN & \\
\hline CHEMBL3957923 & 1641195 & 7.7212 & 7.6455 & TRN & \\
\hline CHEMBL3975927 & 1641195 & 7.2147 & 6.6291 & TST & \\
\hline CHEMBL3978244 & 1641195 & 6.2815 & 6.2846 & TRN & \\
\hline CHEMBL3944099 & 1641195 & 8.1549 & 7.8852 & TRN & \\
\hline CHEMBL3900304 & 1641195 & 7.3979 & 7.4164 & TST & \\
\hline CHEMBL3909641 & 1641195 & 6.8268 & 6.87700 & 0000000001 & TRN \\
\hline CHEMBL3928618 & 1641195 & 6.9957 & 6.9671 & TRN & \\
\hline CHEMBL3921959 & 1641195 & 6.433 & 6.4667 & TRN & \\
\hline CHEMBL3964537 & 1641195 & \multicolumn{3}{|c|}{6.752000000000001} & \\
\hline CHEMBL3918561 & 1641195 & 6.3799 & 6.3325 & TRN & \\
\hline CHEMBL3935885 & 1641195 & 7.2518 & 7.1015 & TRN & \\
\hline CHEMBL3955192 & 1641195 & 5.8668 & 5.8239 & TRN & \\
\hline CHEMBL3936257 & 1641195 & 8.301 & 7.7628 & TST & \\
\hline CHEMBL3894106 & 1641195 & 7.0969 & 7.1238 & TRN & \\
\hline CHEMBL3919491 & 1641195 & 7.4815 & 7.4036 & TRN & \\
\hline CHEMBL3919242 & 1641195 & 7.0506 & 7.0205 & TRN & \\
\hline CHEMBL3922538 & 1641195 & 7.9208 & 8.6096 & TST & \\
\hline CHEMBL3890213 & 1641195 & 7.8539 & 7.8386 & TRN & \\
\hline CHEMBL3935126 & 1641195 & 9.8239 & 9.6228 & TRN & \\
\hline CHEMBL3983442 & 1641195 & 6.3575 & 6.347 & TRN & \\
\hline CHEMBL3938312 & 1641195 & 7.0269 & 6.9713 & TRN & \\
\hline CHEMBL3931027 & 1641195 & 7.1135 & 7.1623 & TRN & \\
\hline CHEMBL 3892167 & 1641195 & 10.0 & 7.7766 & TST & \\
\hline
\end{tabular}


Supplemental Table S2.txt

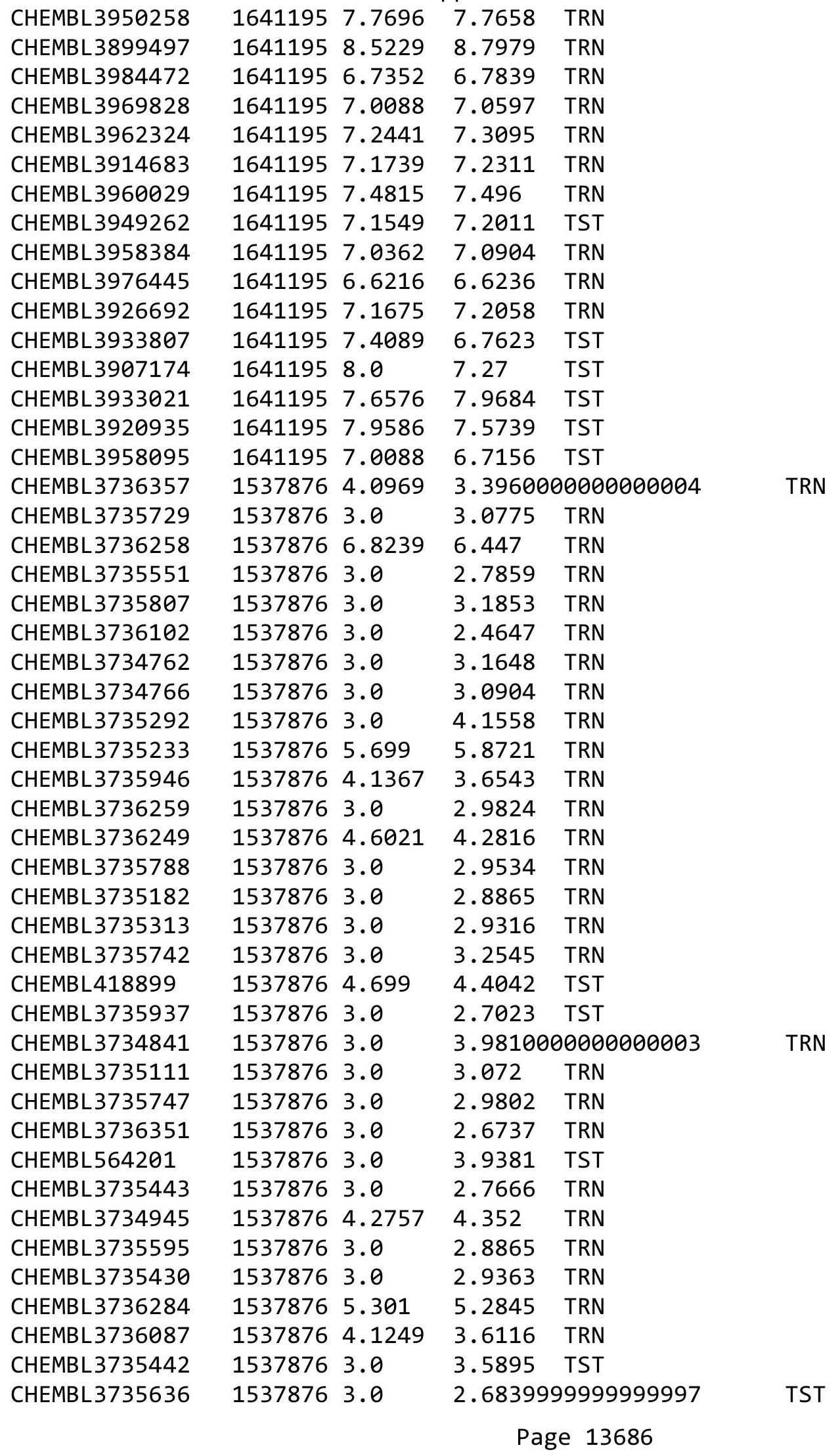


Supplemental Table S2.txt

\begin{tabular}{|c|c|c|c|c|}
\hline CHEMBL3736492 & 1537876 & 3.0 & 2.7614 & TST \\
\hline CHEMBL 3734848 & 1537876 & 3.0 & 3.1709 & TRN \\
\hline CHEMBL3734996 & 1537876 & 3.0 & 3.2765 & TST \\
\hline CHEMBL3736219 & 1537876 & 3.0 & 2.7636 & TRN \\
\hline CHEMBL3735084 & 1537876 & 3.0 & 2.7535 & TST \\
\hline CHEMBL 3736362 & 1537876 & 3.0 & 3.6141 & TRN \\
\hline CHEMBL 3735262 & 1537876 & 3.0 & \multicolumn{2}{|c|}{2.6910000000000003} \\
\hline CHEMBL 3734874 & 1537876 & 3.0 & 3.1029 & TRN \\
\hline CHEMBL 3735922 & 1537876 & 6.1549 & 6.0415 & TRN \\
\hline CHEMBL3734808 & 1537876 & 5.3979 & 5.388 & TRN \\
\hline CHEMBL 3736497 & 1537876 & 3.0 & 3.4271 & TST \\
\hline CHEMBL 3735615 & 1537876 & 3.0 & 3.0894 & TST \\
\hline CHEMBL3735299 & 1537876 & 3.0 & 3.4151 & TRN \\
\hline CHEMBL 3735377 & 1537876 & 4.3979 & 4.2627 & TRN \\
\hline CHEMBL3735786 & 1537876 & 4.6021 & 3.3256 & TST \\
\hline CHEMBL 3735328 & 1537876 & 3.0 & 2.9485 & TST \\
\hline CHEMBL3734886 & 1537876 & 4.6198 & 4.687 & TRN \\
\hline CHEMBL3735991 & 1537876 & 5.7696 & 4.8922 & TRN \\
\hline CHEMBL 3735768 & 1537876 & 3.0 & 3.3193 & TRN \\
\hline CHEMBL 98778 & 1537876 & 4.5229 & 4.0346 & TST \\
\hline CHEMBL 3735685 & 1537876 & 3.0 & 3.2282 & TRN \\
\hline CHEMBL3735011 & 1537876 & 3.0 & 2.7408 & TRN \\
\hline CHEMBL1515627 & 1537876 & 3.0 & 3.1097 & TRN \\
\hline CHEMBL 3736487 & 1537876 & 3.0 & 3.536 & TRN \\
\hline CHEMBL3735248 & 1537876 & 4.4202 & 3.5367 & TST \\
\hline CHEMBL75982 & 205220 & 5.4559 & 5.6926 & TRN \\
\hline CHEMBL307181 & 205220 & 7.0132 & 6.8672 & TRN \\
\hline CHEMBL311045 & 205220 & 8.4949 & 8.3327 & TRN \\
\hline CHEMBL 24291 & 205220 & 5.6576 & 5.8796 & TRN \\
\hline CHEMBL430617 & 205220 & 8.3979 & \multicolumn{2}{|c|}{7.997999999999999} \\
\hline CHEMBL310710 & 205220 & 5.0655 & 5.4409 & TRN \\
\hline CHEMBL3706584 & 205220 & 7.1308 & 6.9314 & TRN \\
\hline CHEMBL412425 & 205220 & 7.699 & 7.3873 & TRN \\
\hline CHEMBL77765 & 205220 & 7.3979 & 6.7609 & TRN \\
\hline CHEMBL309261 & 205220 & 5.8861 & 5.7187 & TRN \\
\hline CHEMBL77328 & 205220 & 7.699 & 6.836 & TRN \\
\hline CHEMBL 312531 & 205220 & 7.8539 & 7.2991 & TRN \\
\hline CHEMBL311783 & 205220 & 5.0 & 5.2138 & TST \\
\hline CHEMBL308532 & 205220 & 5.8861 & 5.8482 & TST \\
\hline CHEMBL 78275 & 205220 & 7.9208 & 7.5933 & TRN \\
\hline CHEMBL308258 & 205220 & 8.0862 & 7.6661 & TRN \\
\hline CHEMBL76192 & 205220 & 6.0862 & 6.776 & TRN \\
\hline CHEMBL3706586 & 205220 & 5.6198 & 5.6799 & TRN \\
\hline CHEMBL 78161 & 205220 & 6.0 & 5.7719 & TRN \\
\hline CHEMBL306722 & 205220 & 7.699 & 7.5903 & TRN \\
\hline CHEMBL76693 & 205220 & 4.8539 & 6.1873 & TST \\
\hline CHEMBL24088 & 205220 & 7.5229 & 7.9457 & TRN \\
\hline CHEMBL77024 & 205220 & 7.9586 & 8.1478 & TRN \\
\hline
\end{tabular}




\begin{tabular}{|c|c|c|c|c|c|}
\hline & & & & & \\
\hline CHEMBL 77144 & 205220 & 7.0862 & 6.7001 & TST & \\
\hline CHEMBL307626 & 205220 & 5.6383 & 6.4931 & TRN & \\
\hline CHEMBL311818 & 205220 & 5.0 & 5.29299 & 9999999999 & TRN \\
\hline CHEMBL306554 & 205220 & 8.1938 & 8.3639 & TRN & \\
\hline CHEMBL 3706585 & 205220 & 6.5528 & 5.94 & TRN & \\
\hline CHEMBL76536 & 205220 & 5.4685 & 6.0766 & TST & \\
\hline CHEMBL 308107 & 205220 & 6.5528 & 7.1729 & TRN & \\
\hline CHEMBL76260 & 205220 & 8.0655 & 8.2568 & TRN & \\
\hline CHEMBL80520 & 205220 & 5.3872 & 5.9128 & TRN & \\
\hline CHEMBL3706581 & 205220 & 7.3188 & 7.0568 & TRN & \\
\hline CHEMBL 307745 & 205220 & 9.0 & 8.633 & TRN & \\
\hline CHEMBL80160 & 205220 & 8.5086 & 8.3709 & TST & \\
\hline CHEMBL73816 & 205220 & 6.2441 & 6.4161 & TRN & \\
\hline CHEMBL 305932 & 205220 & 5.0809 & 5.2093 & TST & \\
\hline CHEMBL76671 & 205220 & 5.0 & 5.3017 & TST & \\
\hline CHEMBL311874 & 205220 & 4.3098 & 6.41100 & 00000000005 & TST \\
\hline CHEMBL80669 & 205220 & 5.0 & 6.5013 & TST & \\
\hline CHEMBL 76803 & 205220 & 6.1612 & 6.4226 & TRN & \\
\hline CHEMBL1159458 & 205220 & 9.3979 & 8.5979 & TST & \\
\hline CHEMBL3706583 & 205220 & 5.2366 & 5.5082 & TRN & \\
\hline CHEMBL77124 & 205220 & 6.5528 & 6.8525 & TRN & \\
\hline CHEMBL 307398 & 205220 & 8.2076 & 8.21600 & 0000000001 & TRN \\
\hline CHEMBL420020 & 205220 & 8.0458 & 8.18 & TRN & \\
\hline CHEMBL 309585 & 205220 & 6.4685 & 7.0624 & TST & \\
\hline CHEMBL442747 & 205220 & 4.3979 & 4.6517 & TST & \\
\hline CHEMBL77290 & 205220 & 8.4437 & 8.6703 & TRN & \\
\hline CHEMBL 312143 & 205220 & 7.0605 & 7.3281 & TRN & \\
\hline CHEMBL310711 & 205220 & 8.0706 & 8.6498 & TRN & \\
\hline CHEMBL 306781 & 205220 & 7.4089 & 7.7374 & TRN & \\
\hline CHEMBL75320 & 205220 & 7.2218 & 7.0595 & TRN & \\
\hline CHEMBL2298601 & 205220 & 8.301 & 6.1943 & TST & \\
\hline CHEMBL297524 & 205220 & 6.8239 & 6.9231 & TRN & \\
\hline CHEMBL 76892 & 205220 & 6.7447 & 6.6011 & TST & \\
\hline CHEMBL 305855 & 205220 & 8.3468 & 8.8437 & TRN & \\
\hline CHEMBL 76637 & 205220 & 7.8239 & 8.1005 & TRN & \\
\hline CHEMBL306507 & 205220 & 5.8539 & 6.0422 & TRN & \\
\hline CHEMBL78064 & 205220 & 7.4202 & 6.898 & TRN & \\
\hline CHEMBL306289 & 205220 & 8.9586 & 8.8977 & TRN & \\
\hline CHEMBL311577 & 205220 & 7.9208 & 7.8304 & TRN & \\
\hline CHEMBL 76648 & 205220 & 6.1249 & 6.22 & TRN & \\
\hline CHEMBL 3085538 & 205220 & 8.1612 & 7.5584 & TRN & \\
\hline CHEMBL77129 & 205220 & 7.0706 & 6.4227 & TRN & \\
\hline CHEMBL421696 & 205220 & 5.2291 & 5.5176 & TST & \\
\hline CHEMBL 80163 & 205220 & 4.6198 & 5.6513 & TST & \\
\hline CHEMBL77378 & 205220 & 5.1079 & 5.3717 & TST & \\
\hline CHEMBL432729 & 205220 & 7.2924 & 6.5902 & TRN & \\
\hline CHEMBL3960587 & 1641729 & 8.1938 & 8.1923 & TST & \\
\hline CHEMBL3945557 & 1641729 & 8.3279 & 8.3152 & TRN & \\
\hline
\end{tabular}


Supplemental Table S2.txt

\begin{tabular}{|c|c|c|c|c|c|}
\hline CHEMBL3915979 & 1641729 & 7.585 & 7.5965 & TRN & \\
\hline CHEMBL3897018 & 1641729 & 8.2007 & 8.1796 & TRN & \\
\hline CHEMBL3942006 & 1641729 & 9.0 & 8.9859 & TRN & \\
\hline CHEMBL3971706 & 1641729 & 8.3872 & 8.3689 & TRN & \\
\hline CHEMBL3952737 & 1641729 & 7.9626 & 8.6275 & TST & \\
\hline CHEMBL3985965 & 1641729 & 8.5229 & 8.5324 & TRN & \\
\hline CHEMBL3969105 & 1641729 & 8.2441 & 8.243 & TRN & \\
\hline CHEMBL3932907 & 1641729 & 8.6383 & 8.616 & TRN & \\
\hline CHEMBL3964337 & 1641729 & 8.1249 & 8.1177 & TRN & \\
\hline CHEMBL 3901289 & 1641729 & 8.1549 & 8.1593 & TRN & \\
\hline CHEMBL3905802 & 1641729 & 6.0 & 8.4027 & TST & \\
\hline CHEMBL3937747 & 1641729 & 8.7959 & 8.2948 & TST & \\
\hline CHEMBL3985342 & 1641729 & 8.6021 & 8.5995 & TRN & \\
\hline CHEMBL3965348 & 1641729 & 8.3279 & 7.9663 & TST & \\
\hline CHEMBL 3933019 & 1641729 & 8.8239 & 8.3747 & TST & \\
\hline CHEMBL3903446 & 1641729 & 7.3904 & 7.4007 & TRN & \\
\hline CHEMBL3906932 & 1641729 & 8.5086 & \multicolumn{2}{|c|}{8.517999999999999} & TRN \\
\hline CHEMBL3930467 & 1641729 & 8.5686 & 8.5826 & TRN & \\
\hline CHEMBL3924976 & 1641729 & 7.9914 & 8.0118 & TRN & \\
\hline CHEMBL 3890562 & 1641729 & 8.4089 & 8.4065 & TRN & \\
\hline CHEMBL3906737 & 1641729 & 7.8069 & 7.7871 & TRN & \\
\hline CHEMBL3966338 & 1641729 & 8.9208 & 8.9323 & TRN & \\
\hline CHEMBL3971586 & 1641729 & 8.2366 & 8.3028 & TST & \\
\hline CHEMBL3944897 & 1641729 & 8.0132 & 7.9694 & TST & \\
\hline CHEMBL 3985900 & 1641729 & 8.3002 & 8.5595 & TST & \\
\hline CHEMBL3955189 & 1641729 & 6.4614 & 8.2094 & TST & \\
\hline CHEMBL3946656 & 1641729 & 8.0969 & 8.1014 & TRN & \\
\hline CHEMBL3965103 & 1641729 & 8.4815 & 8.4826 & TRN & \\
\hline CHEMBL3971211 & 1641729 & 8.4815 & 8.4557 & TRN & \\
\hline CHEMBL3969151 & 1641729 & 8.3468 & 8.3341 & TRN & \\
\hline CHEMBL3897109 & 1641729 & 8.8861 & 8.8858 & TRN & \\
\hline CHEMBL3918614 & 1641729 & 8.6576 & 8.6551 & TRN & \\
\hline CHEMBL3968240 & 1641729 & 8.7959 & 8.7871 & TRN & \\
\hline CHEMBL3892331 & 1641729 & 8.4559 & 8.4809 & TRN & \\
\hline CHEMBL3916203 & 1641729 & 8.5528 & 8.5654 & TRN & \\
\hline CHEMBL3948170 & 1641729 & 8.8539 & 8.2255 & TST & \\
\hline CHEMBL 3980810 & 1641729 & 8.5686 & 8.6386 & TST & \\
\hline CHEMBL3906979 & 1641729 & 8.0915 & 8.9667 & TST & \\
\hline CHEMBL3952681 & 1641729 & 8.3665 & 8.3665 & TRN & \\
\hline CHEMBL3931589 & 1641729 & 8.9208 & 8.9129 & TRN & \\
\hline CHEMBL3954641 & 1641729 & 9.0458 & 9.0529 & TRN & \\
\hline CHEMBL3945945 & 1641729 & 6.0 & 8.1971 & TST & \\
\hline CHEMBL3940064 & 1641729 & 7.983 & 7.9921 & TRN & \\
\hline CHEMBL3977807 & 1641729 & 8.4685 & 8.4771 & TRN & \\
\hline CHEMBL3980605 & 1641729 & 8.3565 & 8.3456 & TRN & \\
\hline CHEMBL3956004 & 1641729 & 8.3665 & 8.3725 & TRN & \\
\hline CHEMBL3980639 & 1641729 & 8.4685 & 8.9173 & TST & \\
\hline CHEMBL 3930471 & 1641729 & 8.6778 & 8.6933 & TRN & \\
\hline
\end{tabular}

Page 13689 
Supplemental Table S2.txt

\begin{tabular}{|c|c|c|c|c|}
\hline CHEMBL3907652 & 1641729 & 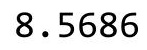 & 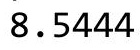 & TRN \\
\hline 83677 & 41729 & 8.5229 & 8.1975 & \\
\hline HEMBL3909563 & 641729 & 8.4815 & 4901 & \\
\hline HEMBL3961310 & 641729 & 8.5686 & .547 & \\
\hline HEMBL3898141 & 541729 & 1427 & 1677 & \\
\hline AEMBL3900057 & 641729 & .0595 & 112 & \\
\hline HEMBL3892564 & 641729 & 8.2924 & .2951 & \\
\hline HEMBL3940503 & 641729 & 8.1487 & .1423 & \\
\hline HEMBL3927578 & 641729 & 6383 & .662 & \\
\hline HEMBL3971708 & 641729 & 2147 & .2264 & \\
\hline AEMBL 3896040 & 1641729 & 6198 & 8.6277 & \\
\hline HEMBL3897916 & 1641729 & 8.5229 & 8.544 & \\
\hline HEMBL3903527 & 729 & 7.4134 & 7.4092 & \\
\hline HEMBL3897962 & 29 & 8.699 & 6839 & \\
\hline HEMBL3925032 & 729 & 696 & 6628 & \\
\hline AEMBL3955299 & 729 & 871 & 1738 & \\
\hline HEMBL3979690 & 729 & 8.2757 & 8.2811 & \\
\hline HEMBL3901770 & 729 & 7.4776 & 7.4644 & \\
\hline HEMBL3960140 & 16 & 8 & 3266 & \\
\hline HEMBL3908486 & 29 & 76 & 546 & \\
\hline HEMBL3969485 & 29 & 6. & 8.2434 & \\
\hline HEMBL3910807 & 729 & 8.5229 & 8.5162 & RN \\
\hline HEMBL 3972846 & 29 & 8.7696 & 8.7599 & $\{N$ \\
\hline HEMBL3968895 & 164 & 8. & 339 & \\
\hline HEMBL 380299 & 39 & 58 & 726 & \\
\hline HEMBL 380018 & 59 & 862 & 6.254 & \\
\hline HEMBL 215531 & 397 & 5.6778 & 5.5537 & ST \\
\hline AEMBL 378671 & 9 & 5.5528 & 3472 & RN \\
\hline HEMBL378425 & 397 & 6. & 6.1462 & RN \\
\hline L214799 & 39 & $\partial 8$ & 386 & RN \\
\hline L212779 & 59 & 7. & 7.4078 & RN \\
\hline HEMBL 215609 & 37 & & 6.2909 & ST \\
\hline AEMBL 384852 & - & 5 . & 5.7347 & RN \\
\hline HEMBL 385003 & 97 & 7.1739 & 7.529 & RN \\
\hline HEMBL 383849 & 397 & 5 . & 7461 & ST \\
\hline HEMBL 214551 & 397 & 7. & 6.6219 & RN \\
\hline HEMBL438275 & 397 & 6.4089 & 7.3918 & TRN \\
\hline AEMBL 213469 & - & 7. & 6.585 & RN \\
\hline HEMBL 213153 & 397 & & 5.4017 & RN \\
\hline HEMBL 386707 & 3 & 362 & 6.2822 & RN \\
\hline HEMBL 378448 & 397 & 6.699 & 6.1292 & RN \\
\hline HEMBL 212882 & 397 & 6.0 & 7.4795 & TRN \\
\hline HEMBL 379591 & 397 & 5 . & 5.6801 & ST \\
\hline CHEMBL 215617 & & 6. & 6.5297 & \\
\hline LHEMBL 215502 & & & 5.6239 & \\
\hline CHEMBL 215106 & 397 & 7.1487 & 6.3379 & RN \\
\hline HEMBL 212841 & 397859 & 4.0 & 5.3134 & RN \\
\hline CHEMBL215905 & 397859 & 7.2218 & 6.5797 & \\
\hline
\end{tabular}

Page 13690 


\begin{tabular}{|c|c|c|c|c|c|}
\hline & & \multicolumn{4}{|c|}{ Supplemental Table S2.txt } \\
\hline CHEMBL386162 & 397859 & 6.7959 & 7.2629 & TRN & \\
\hline CHEMBL379202 & 397859 & 4.0 & 5.7394 & TST & \\
\hline CHEMBL213214 & 397859 & 5.3979 & 5.7454 & TRN & \\
\hline CHEMBL215481 & 397859 & 6.0 & 6.5852 & TRN & \\
\hline CHEMBL212664 & 397859 & 5.8239 & 6.301 & TRN & \\
\hline CHEMBL 212606 & 397859 & 4.0 & 5.7588 & TST & \\
\hline CHEMBL215906 & 397859 & 7.1739 & 7.3659 & TRN & \\
\hline CHEMBL 215332 & 397859 & 5.585 & 5.6699 & TRN & \\
\hline CHEMBL215354 & 397859 & 5.3872 & 5.7119 & TST & \\
\hline CHEMBL214559 & 397859 & 5.6021 & 5.6277 & TRN & \\
\hline CHEMBL214886 & 397859 & 8.0915 & 7.6026 & TRN & \\
\hline CHEMBL 386771 & 397859 & 7.699 & 7.6057 & TRN & \\
\hline CHEMBL 214560 & 397859 & 5.4437 & 5.6128 & TST & \\
\hline CHEMBL 214582 & 397859 & 5.6021 & 5.6467 & TRN & \\
\hline CHEMBL215238 & 397859 & 5.3372 & 5.3949 & TRN & \\
\hline CHEMBL 378327 & 397859 & 8.2291 & 7.6743 & TRN & \\
\hline CHEMBL 215290 & 397859 & 5.5086 & 5.2876 & TRN & \\
\hline CHEMBL 214155 & 397859 & 5.4202 & 5.405 & TRN & \\
\hline CHEMBL 213152 & 397859 & 5.5376 & 5.8999 & TST & \\
\hline CHEMBL378913 & 397859 & 6.6383 & 6.2066 & TRN & \\
\hline CHEMBL 212024 & 397859 & 5.3565 & 5.596 & TST & \\
\hline CHEMBL215066 & 397859 & 8.041 & 7.441 & TRN & \\
\hline CHEMBL 213122 & 397859 & 7.6021 & 7.6583 & TRN & \\
\hline CHEMBL385274 & 397859 & 7.7959 & 7.4637 & TRN & \\
\hline CHEMBL215519 & 397859 & 6.0362 & 6.2584 & TRN & \\
\hline CHEMBL379200 & 397859 & 5.699 & 5.32799 & 9999999999 & TST \\
\hline CHEMBL 212180 & 397859 & 8.0555 & 7.7041 & TRN & \\
\hline CHEMBL 213213 & 397859 & 5.3468 & 5.7186 & TST & \\
\hline CHEMBL1964290 & 809248 & 4.8 & 5.6042 & TRN & \\
\hline CHEMBL213505 & 809248 & 4.8 & 4.6485 & TRN & \\
\hline CHEMBL 202721 & 809248 & 4.5 & 4.9677 & TRN & \\
\hline CHEMBL1987034 & 809248 & 5.9 & 6.528 & TRN & \\
\hline CHEMBL1993941 & 809248 & 4.8 & 4.5971 & TRN & \\
\hline CHEMBL1980435 & 809248 & 7.0 & 6.5321 & TRN & \\
\hline CHEMBL377383 & 809248 & 4.8 & 4.8292 & TRN & \\
\hline CHEMBL 2005886 & 809248 & 4.8 & 6.2592 & TRN & \\
\hline CHEMBL481491 & 809248 & 4.8 & 5.1126 & TST & \\
\hline CHEMBL1973142 & 809248 & 4.8 & 5.4661 & TRN & \\
\hline CHEMBL388311 & 809248 & 7.4 & 8.3946 & TRN & \\
\hline CHEMBL1973145 & 809248 & 4.8 & 4.6629 & TRN & \\
\hline CHEMBL1982924 & 809248 & 4.8 & 4.8942 & TRN & \\
\hline CHEMBL 2005936 & 809248 & 7.3 & 7.1989 & TRN & \\
\hline CHEMBL1807515 & 809248 & 8.2 & 7.1888 & TRN & \\
\hline CHEMBL1964948 & 809248 & 4.5 & 4.6252 & TRN & \\
\hline CHEMBL1971141 & 809248 & 4.8 & 4.6535 & TRN & \\
\hline CHEMBL1995813 & 809248 & 7.5 & 7.1876 & TRN & \\
\hline CHEMBL206236 & 809248 & 7.7 & 6.9735 & TRN & \\
\hline CHEMBL1989834 & 809248 & 3.7 & 4.3461 & TRN & \\
\hline
\end{tabular}




\begin{tabular}{|c|c|c|c|c|}
\hline & & & Supplement & \\
\hline CHEMBL1987430 & 809248 & 4.5 & 4.3619 & TRN \\
\hline CHEMBL 244378 & 809248 & 4.8 & 5.6183 & TRN \\
\hline CHEMBL 2001957 & 809248 & 4.8 & 4.558 & TRN \\
\hline CHEMBL1969372 & 809248 & 4.8 & 4.2837 & TRN \\
\hline CHEMBL1993413 & 809248 & 4.5 & 5.55 & TRN \\
\hline CHEMBL1986943 & 809248 & 7.2 & 7.6003 & TRN \\
\hline CHEMBL 2006263 & 809248 & 6.4 & 5.2171 & TST \\
\hline CHEMBL1986263 & 809248 & 4.8 & 4.9257 & TRN \\
\hline CHEMBL 2000114 & 809248 & 4.8 & 4.8275 & TRN \\
\hline CHEMBL210618 & 809248 & 4.8 & 4.6598 & TRN \\
\hline CHEMBL1986265 & 809248 & 4.5 & 4.8559 & TRN \\
\hline CHEMBL1971172 & 809248 & 7.3 & 6.7942 & TRN \\
\hline CHEMBL1975647 & 809248 & 4.8 & 5.1531 & TRN \\
\hline CHEMBL1968380 & 809248 & 4.8 & 5.0186 & TRN \\
\hline CHEMBL1964644 & 809248 & 4.8 & 4.7295 & TRN \\
\hline CHEMBL1991734 & 809248 & 6.4 & 5.6904 & TST \\
\hline CHEMBL1981782 & 809248 & 8.8 & 7.2641 & TRN \\
\hline CHEMBL1990912 & 809248 & 4.8 & 5.1895 & TRN \\
\hline CHEMBL1991782 & 809248 & 3.2 & 4.3543 & TRN \\
\hline CHEMBL1983348 & 809248 & 5.6 & 5.596 & TRN \\
\hline CHEMBL1988163 & 809248 & 4.8 & 5.0755 & TRN \\
\hline CHEMBL1974480 & 809248 & 5.6 & 5.4753 & TST \\
\hline CHEMBL 2000934 & 809248 & 4.5 & 4.3973 & TRN \\
\hline CHEMBL1980671 & 809248 & 4.6 & 4.1661 & TRN \\
\hline CHEMBL 2006493 & 809248 & 4.8 & 4.5715 & TST \\
\hline CHEMBL1986177 & 809248 & 4.5 & 4.9965 & TRN \\
\hline CHEMBL1992323 & 809248 & 4.8 & 4.3814 & TRN \\
\hline CHEMBL1969735 & 809248 & 4.8 & 4.5797 & TRN \\
\hline CHEMBL1983589 & 809248 & 7.6 & 6.8052 & TRN \\
\hline CHEMBL1985367 & 809248 & 4.5 & 4.7596 & TST \\
\hline CHEMBL1996510 & 809248 & 4.7 & 6.0125 & TRN \\
\hline CHEMBL 2005718 & 809248 & 7.6 & 7.1926 & TRN \\
\hline CHEMBL1995172 & 809248 & 4.5 & 4.3327 & TST \\
\hline CHEMBL2001584 & 809248 & 4.5 & 4.7881 & TST \\
\hline CHEMBL1967998 & 809248 & 6.0 & 6.5673 & TRN \\
\hline CHEMBL1994321 & 809248 & 4.8 & 5.3294 & TRN \\
\hline CHEMBL1978562 & 809248 & 4.5 & 5.4386 & TRN \\
\hline CHEMBL1997129 & 809248 & 5.8 & 5.6416 & TRN \\
\hline CHEMBL1974875 & 809248 & 4.6 & 4.6115 & TST \\
\hline CHEMBL1989471 & 809248 & 4.5 & 5.5118 & TST \\
\hline CHEMBL 2002099 & 809248 & 4.5 & 5.1592 & TRN \\
\hline CHEMBL 2000508 & 809248 & 4.8 & 4.4256 & TRN \\
\hline CHEMBL 2001547 & 809248 & 4.8 & 4.5066 & TRN \\
\hline CHEMBL210928 & 809248 & 4.8 & 4.6751 & TRN \\
\hline CHEMBL1978195 & 809248 & 4.5 & 5.0835 & TRN \\
\hline CHEMBL1986603 & 809248 & 4.8 & 4.7505 & TST \\
\hline CHEMBL1977148 & 809248 & 4.8 & 4.7661 & TRN \\
\hline CHEMBL 2003286 & 809248 & 4.8 & 5.1237 & TRN \\
\hline
\end{tabular}




\begin{tabular}{|c|c|c|c|c|c|}
\hline \multicolumn{6}{|c|}{ Supplemental Table S2.txt } \\
\hline CHEMBL1992306 & 809248 & 4.8 & 4.5148 & TRN & \\
\hline CHEMBL 2002165 & 809248 & 4.8 & 4.8274 & TRN & \\
\hline CHEMBL206382 & 809248 & 6.5 & 6.0484 & TRN & \\
\hline CHEMBL1998585 & 809248 & 4.8 & 5.2334 & TRN & \\
\hline CHEMBL519697 & 809248 & 4.8 & 4.7675 & TST & \\
\hline CHEMBL2004934 & 809248 & 6.9 & 6.4979 & TRN & \\
\hline CHEMBL1987261 & 809248 & 8.0 & 6.6864 & TRN & \\
\hline CHEMBL1973516 & 809248 & 4.5 & 6.1421 & TRN & \\
\hline CHEMBL1996345 & 809248 & 4.5 & 4.7459 & TST & \\
\hline CHEMBL1975128 & 809248 & 8.3 & 8.3501 & TRN & \\
\hline CHEMBL2004025 & 809248 & 4.5 & 5.6217 & TRN & \\
\hline CHEMBL1996048 & 809248 & 6.5 & 5.6679 & TST & \\
\hline CHEMBL461876 & 809248 & 4.5 & 5.0251 & TRN & \\
\hline CHEMBL1965033 & 809248 & 4.5 & 4.9453 & TRN & \\
\hline CHEMBL1971519 & 809248 & 6.3 & 5.1047 & TRN & \\
\hline CHEMBL1997335 & 809248 & 6.4 & 5.2207 & TRN & \\
\hline CHEMBL1966425 & 809248 & 5.9 & 5.0379 & TRN & \\
\hline CHEMBL1984363 & 809248 & 6.5 & 5.9148 & TRN & \\
\hline CHEMBL1988608 & 809248 & 7.2 & 7.1942 & TRN & \\
\hline CHEMBL184847 & 809248 & 4.8 & 4.4961 & TRN & \\
\hline CHEMBL1994808 & 809248 & 4.1 & 4.4881 & TRN & \\
\hline CHEMBL1984367 & 809248 & 4.8 & 5.3138 & TRN & \\
\hline CHEMBL1985723 & 809248 & 7.7 & 7.2747 & TRN & \\
\hline CHEMBL1982563 & 809248 & 4.8 & 4.5218 & TRN & \\
\hline CHEMBL539474 & 809248 & 6.6 & 5.5066 & TST & \\
\hline CHEMBL575824 & 809248 & 6.2 & 6.3387 & TRN & \\
\hline CHEMBL1973868 & 809248 & 4.5 & $5.1270 e$ & 0000000001 & TRN \\
\hline CHEMBL1972462 & 809248 & 4.5 & 4.7068 & TRN & \\
\hline CHEMBL1977128 & 809248 & 6.5 & 6.4172 & TRN & \\
\hline CHEMBL1990288 & 809248 & 4.8 & 4.8005 & TRN & \\
\hline CHEMBL1970074 & 809248 & 5.9 & 4.5798 & TRN & \\
\hline CHEMBL1965702 & 809248 & 7.4 & 7.6165 & TRN & \\
\hline CHEMBL1984500 & 809248 & 3.2 & 4.2542 & TRN & \\
\hline CHEMBL1986970 & 809248 & 7.3 & 7.5439 & TRN & \\
\hline CHEMBL1958401 & 809248 & 4.8 & 4.7194 & TRN & \\
\hline CHEMBL2003456 & 809248 & 4.8 & 4.5218 & TRN & \\
\hline CHEMBL1966816 & 809248 & 4.8 & 4.0716 & TRN & \\
\hline CHEMBL1972584 & 809248 & 4.8 & 5.5034 & TRN & \\
\hline CHEMBL2002992 & 809248 & 6.3 & 5.8866 & TRN & \\
\hline CHEMBL560813 & 809248 & 4.8 & 4.8542 & TRN & \\
\hline CHEMBL1982700 & 809248 & 4.5 & 5.0996 & TST & \\
\hline CHEMBL1968791 & 809248 & 4.8 & 4.8892 & TRN & \\
\hline CHEMBL 2002682 & 809248 & 6.1 & 5.0941 & TST & \\
\hline CHEMBL1977634 & 809248 & 4.5 & 4.697 & TRN & \\
\hline CHEMBL1971186 & 809248 & 4.8 & $4.8660 e$ & 00000000005 & TRN \\
\hline CHEMBL 2004887 & 809248 & 4.1 & 4.7275 & TRN & \\
\hline CHEMBL 2006456 & 809248 & 7.6 & 7.5239 & TRN & \\
\hline CHEMBL1973211 & 809248 & 4.8 & 5.3742 & TRN & \\
\hline
\end{tabular}




\begin{tabular}{|c|c|c|c|c|c|}
\hline \\
\hline CHEMBL1984700 & 809248 & 4.8 & 4.5671 & TRN & \\
\hline CHEMBL1998953 & 809248 & 4.5 & 4.7195 & TRN & \\
\hline CHEMBL1971606 & 809248 & 6.3 & 5.8794 & TRN & \\
\hline CHEMBL1972125 & 809248 & 4.8 & 5.1252 & TRN & \\
\hline CHEMBL1976134 & 809248 & 4.8 & 5.6197 & TRN & \\
\hline CHEMBL1965131 & 809248 & 4.8 & 5.6042 & TRN & \\
\hline CHEMBL1972158 & 809248 & 7.3 & 7.3569 & TRN & \\
\hline CHEMBL1981215 & 809248 & 4.5 & 4.5658 & TRN & \\
\hline CHEMBL 2006580 & 809248 & 5.9 & 4.603 & TRN & \\
\hline CHEMBL1999414 & 809248 & 5.5 & 5.4819 & TRN & \\
\hline CHEMBL1967336 & 809248 & 4.5 & 4.872 & TRN & \\
\hline CHEMBL1979855 & 809248 & 4.8 & 4.6943 & TRN & \\
\hline CHEMBL1970340 & 809248 & 5.3 & 5.0487 & TRN & \\
\hline CHEMBL1967992 & 809248 & 4.5 & 5.5225 & TRN & \\
\hline CHEMBL 2006450 & 809248 & 4.5 & 5.6508 & TRN & \\
\hline CHEMBL1975534 & 809248 & 4.8 & 4.8599 & TRN & \\
\hline CHEMBL1993424 & 809248 & 4.8 & $4.9430 e$ & 00000000005 & TRN \\
\hline CHEMBL1966703 & 809248 & 4.8 & 4.6178 & TST & \\
\hline CHEMBL 2001987 & 809248 & 4.5 & 4.378 & TRN & \\
\hline CHEMBL1969561 & 809248 & 7.9 & 7.8369 & TRN & \\
\hline CHEMBL1994555 & 809248 & 4.5 & 4.6343 & TRN & \\
\hline CHEMBL1975121 & 809248 & 7.4 & 7.1568 & TRN & \\
\hline CHEMBL1983640 & 809248 & 4.5 & 5.0862 & TRN & \\
\hline CHEMBL1997023 & 809248 & 4.8 & 4.8705 & TST & \\
\hline CHEMBL1964687 & 809248 & 6.1 & 4.8963 & TRN & \\
\hline CHEMBL1971943 & 809248 & 6.1 & 6.0098 & TRN & \\
\hline CHEMBL1974254 & 809248 & 6.0 & 5.0099 & TRN & \\
\hline CHEMBL1988537 & 809248 & 6.9 & 5.6435 & TST & \\
\hline CHEMBL1969049 & 809248 & 7.2 & 6.5701 & TRN & \\
\hline CHEMBL 2005828 & 809248 & 5.8 & 4.6212 & TRN & \\
\hline CHEMBL1980178 & 809248 & 7.0 & 7.2313 & TRN & \\
\hline CHEMBL1998611 & 809248 & 5.8 & 5.8794 & TRN & \\
\hline CHEMBL1975900 & 809248 & 8.4 & 7.8246 & TRN & \\
\hline CHEMBL 255822 & 809248 & 4.8 & $5.2010 e$ & 00000000005 & TRN \\
\hline CHEMBL1972221 & 809248 & 4.8 & 5.3005 & TRN & \\
\hline CHEMBL 2006778 & 809248 & 4.8 & $4.5710 e$ & $\partial 000000001$ & TRN \\
\hline CHEMBL 378627 & 809248 & 4.8 & 4.687 & TRN & \\
\hline CHEMBL1968406 & 809248 & 4.8 & 5.043 & TRN & \\
\hline CHEMBL1975921 & 809248 & 4.9 & 4.5441 & TRN & \\
\hline CHEMBL1998545 & 809248 & 6.7 & 6.4496 & TRN & \\
\hline CHEMBL1975923 & 809248 & 6.1 & 4.7618 & TST & \\
\hline CHEMBL 2005449 & 809248 & 4.5 & 5.8959 & TRN & \\
\hline CHEMBL1987998 & 809248 & 5.9 & 4.7422 & TRN & \\
\hline CHEMBL1682558 & 809248 & 4.8 & 4.8597 & TRN & \\
\hline CHEMBL1971534 & 809248 & 4.8 & 5.165 & TRN & \\
\hline CHEMBL1990496 & 809248 & 4.6 & 5.0599 & TRN & \\
\hline CHEMBL 242865 & 809248 & 4.5 & 5.0565 & TRN & \\
\hline CHEMBL 2002479 & 809248 & 6.2 & 5.9631 & TRN & \\
\hline
\end{tabular}




\begin{tabular}{|c|c|c|c|c|}
\hline & & & & $a+1 a$ \\
\hline CHEMBL1967094 & 809248 & 7.0 & 5.6084 & TRN \\
\hline CHEMBL1966035 & 809248 & 6.6 & 5.8436 & TRN \\
\hline CHEMBL2003341 & 809248 & 6.9 & 7.055 & TRN \\
\hline CHEMBL1982992 & 809248 & 4.8 & 4.6761 & TRN \\
\hline CHEMBL1998110 & 809248 & 4.5 & 5.645 & TRN \\
\hline CHEMBL1999590 & 809248 & 4.8 & 4.6408 & TST \\
\hline CHEMBL1981079 & 809248 & 4.8 & 5.6216 & TRN \\
\hline CHEMBL1978166 & 809248 & 6.4 & 6.2289 & TRN \\
\hline CHEMBL 2000832 & 809248 & 6.5 & 5.6002 & TRN \\
\hline CHEMBL1967116 & 809248 & 4.8 & 4.7931 & TRN \\
\hline CHEMBL1990590 & 809248 & 8.2 & 4.9745 & TRN \\
\hline CHEMBL1977814 & 809248 & 4.5 & 4.6296 & TST \\
\hline CHEMBL 86755 & 809248 & 4.5 & 5.1508 & TRN \\
\hline CHEMBL1970709 & 809248 & 8.9 & 6.0772 & TRN \\
\hline CHEMBL1974617 & 809248 & 4.8 & 5.3755 & TRN \\
\hline CHEMBL1965660 & 809248 & 6.0 & 5.9262 & TRN \\
\hline CHEMBL1992125 & 809248 & 6.0 & 5.5057 & TRN \\
\hline CHEMBL1998112 & 809248 & 4.8 & 4.4382 & TRN \\
\hline CHEMBL1972290 & 809248 & 8.5 & 7.38299 & 9999999999 \\
\hline CHEMBL1969126 & 809248 & 4.8 & 4.6835 & TRN \\
\hline CHEMBL1980896 & 809248 & 4.8 & 4.588 & TRN \\
\hline CHEMBL1970104 & 809248 & 4.8 & 5.3631 & TRN \\
\hline CHEMBL1991429 & 809248 & 6.1 & 5.6344 & TRN \\
\hline CHEMBL1967612 & 809248 & 4.2 & 4.6464 & TST \\
\hline CHEMBL1964777 & 809248 & 6.0 & 5.0252 & TRN \\
\hline CHEMBL1971149 & 809248 & 5.8 & 4.6056 & TRN \\
\hline CHEMBL1999714 & 809248 & 4.8 & 4.3115 & TRN \\
\hline CHEMBL1987533 & 809248 & 6.3 & 5.0966 & TRN \\
\hline CHEMBL1994040 & 809248 & 4.8 & 4.7188 & TRN \\
\hline CHEMBL388978 & 809248 & 9.5 & 8.1865 & TST \\
\hline CHEMBL1984548 & 809248 & 7.4 & 6.657 & TRN \\
\hline CHEMBL579246 & 809248 & 6.8 & 7.3051 & TRN \\
\hline CHEMBL398951 & 809248 & 4.6 & 4.7163 & TRN \\
\hline CHEMBL1982506 & 809248 & 4.8 & 4.5454 & TST \\
\hline CHEMBL1968127 & 809248 & 4.8 & 4.6109 & TRN \\
\hline CHEMBL1975233 & 809248 & 4.8 & 4.6186 & TRN \\
\hline CHEMBL1985406 & 809248 & 4.8 & 4.8325 & TRN \\
\hline CHEMBL 2007603 & 809248 & 4.5 & 4.2878 & TRN \\
\hline CHEMBL 207400 & 809248 & 4.8 & 4.5335 & TST \\
\hline CHEMBL 2000894 & 809248 & 6.5 & 5.8869 & TST \\
\hline CHEMBL1421720 & 809248 & 5.9 & 5.3521 & TRN \\
\hline CHEMBL1968130 & 809248 & 4.9 & 4.6208 & TST \\
\hline CHEMBL1982135 & 809248 & 6.1 & 4.6912 & TRN \\
\hline CHEMBL1976090 & 809248 & 4.8 & 4.9557 & TRN \\
\hline CHEMBL1993243 & 809248 & 4.8 & 4.6813 & TRN \\
\hline CHEMBL 2004771 & 809248 & 4.8 & 4.2878 & TRN \\
\hline CHEMBL1992922 & 809248 & 4.8 & 5.0464 & TRN \\
\hline CHEMBL1997597 & 809248 & 4.8 & 5.1201 & TRN \\
\hline
\end{tabular}




\begin{tabular}{|c|c|c|c|c|}
\hline & & & & \\
\hline CHEMBL1969537 & 809248 & 4.8 & 5.5402 & TST \\
\hline CHEMBL1976093 & 809248 & 4.8 & 4.4441 & TRN \\
\hline CHEMBL1975256 & 809248 & 4.8 & 5.2356 & TST \\
\hline CHEMBL508928 & 809248 & 4.8 & 4.9865 & TRN \\
\hline CHEMBL2004892 & 809248 & 4.8 & 4.8516 & TRN \\
\hline CHEMBL1949855 & 809248 & 5.4 & 4.8603 & TRN \\
\hline CHEMBL1972339 & 809248 & 8.6 & 7.2966 & TRN \\
\hline CHEMBL116070 & 809248 & 4.8 & 4.8992 & TRN \\
\hline CHEMBL 2004871 & 809248 & 4.8 & 4.732 & TRN \\
\hline CHEMBL2004872 & 809248 & 6.0 & 6.3487 & TRN \\
\hline CHEMBL1727312 & 809248 & 3.3 & 3.9309 & TRN \\
\hline CHEMBL1990223 & 809248 & 4.5 & 4.863 & TRN \\
\hline CHEMBL1969879 & 809248 & 4.8 & 4.6451 & TRN \\
\hline CHEMBL1964382 & 809248 & 4.5 & 5.1225 & TST \\
\hline CHEMBL101311 & 809248 & 4.5 & 5.4554 & TRN \\
\hline CHEMBL1981720 & 809248 & 4.8 & 4.851 & TRN \\
\hline CHEMBL419932 & 809248 & 7.5 & 6.8274 & TRN \\
\hline CHEMBL 262433 & 809248 & 4.8 & 4.9493 & TRN \\
\hline CHEMBL 306380 & 809248 & 4.8 & 4.8101 & TRN \\
\hline CHEMBL1966722 & 809248 & 5.9 & 5.2729 & TRN \\
\hline CHEMBL1983595 & 809248 & 6.5 & 6.2956 & TRN \\
\hline CHEMBL1988581 & 809248 & 6.7 & 5.9874 & TST \\
\hline CHEMBL2005699 & 809248 & 4.5 & 4.6957 & TRN \\
\hline CHEMBL1975500 & 809248 & 4.8 & 5.5579 & TRN \\
\hline CHEMBL394619 & 809248 & 4.8 & 4.7321 & TRN \\
\hline CHEMBL 2006564 & 809248 & 4.5 & 5.4735 & TRN \\
\hline CHEMBL411903 & 809248 & 4.8 & 5.5978 & TRN \\
\hline CHEMBL1980253 & 809248 & 6.8 & 7.2532 & TRN \\
\hline CHEMBL1978167 & 809248 & 4.5 & 5.0851 & TRN \\
\hline CHEMBL1965988 & 809248 & 5.9 & 5.3412 & TRN \\
\hline CHEMBL418203 & 809248 & 4.5 & 5.3229 & TST \\
\hline CHEMBL1989646 & 809248 & 6.8 & 7.2352 & TRN \\
\hline CHEMBL225519 & 809248 & 6.2 & 6.5261 & TRN \\
\hline CHEMBL1978200 & 809248 & 4.8 & 4.5129 & TRN \\
\hline CHEMBL1970522 & 809248 & 4.8 & 4.9824 & TRN \\
\hline CHEMBL1966087 & 809248 & 6.4 & 5.7399 & TRN \\
\hline CHEMBL1964692 & 809248 & 4.8 & 4.7614 & TRN \\
\hline CHEMBL1996931 & 809248 & 6.8 & 6.4418 & TRN \\
\hline CHEMBL1964413 & 809248 & 4.8 & 5.7555 & TRN \\
\hline CHEMBL1973483 & 809248 & 4.8 & 4.4799 & TRN \\
\hline CHEMBL1998470 & 809248 & 6.1 & 6.2532 & TRN \\
\hline CHEMBL1996980 & 809248 & 7.5 & 7.5818 & TRN \\
\hline CHEMBL1975903 & 809248 & 4.5 & 4.8135 & TRN \\
\hline CHEMBL1997340 & 809248 & 4.8 & 4.9781 & TRN \\
\hline CHEMBL1994669 & 809248 & 7.7 & 6.4666 & TRN \\
\hline CHEMBL 2004365 & 809248 & 5.9 & 5.2811 & TST \\
\hline CHEMBL1522508 & 809248 & 4.8 & 4.3889 & TRN \\
\hline CHEMBL1090360 & 809248 & 4.8 & 4.8528 & TRN \\
\hline
\end{tabular}




\begin{tabular}{|c|c|c|c|c|c|}
\hline & & & & & \\
\hline CHEMBL210887 & 809248 & 4.8 & 4.9718 & TST & \\
\hline CHEMBL1988805 & 809248 & 4.5 & 5.0423 & TST & \\
\hline CHEMBL458997 & 809248 & 4.6 & 5.7723 & TRN & \\
\hline CHEMBL227271 & 809248 & 8.3 & 8.6168 & TRN & \\
\hline CHEMBL583144 & 809248 & 6.2 & 5.5661 & TRN & \\
\hline CHEMBL1974310 & 809248 & 4.8 & 5.0231 & TRN & \\
\hline CHEMBL1969942 & 809248 & 7.4 & 4.7781 & TRN & \\
\hline CHEMBL1978567 & 809248 & 4.5 & 5.645 & TRN & \\
\hline CHEMBL1982660 & 809248 & 4.8 & 4.4797 & TRN & \\
\hline CHEMBL1994693 & 809248 & 6.1 & 4.9566 & TRN & \\
\hline CHEMBL1965838 & 809248 & 4.1 & 4.8533 & TST & \\
\hline CHEMBL1982957 & 809248 & 6.3 & 5.6733 & TRN & \\
\hline CHEMBL1725279 & 809248 & 4.8 & 5.1514 & TST & \\
\hline CHEMBL1975138 & 809248 & 4.8 & 5.2417 & TRN & \\
\hline CHEMBL424872 & 809248 & 4.6 & 4.8633 & TRN & \\
\hline CHEMBL412142 & 809248 & 4.8 & 4.9136 & TST & \\
\hline CHEMBL1980704 & 809248 & 4.8 & 5.1091 & TST & \\
\hline CHEMBL 2003271 & 809248 & 4.8 & 5.6074 & TRN & \\
\hline CHEMBL1966808 & 809248 & 4.8 & 4.8453 & TST & \\
\hline CHEMBL 2004447 & 809248 & 4.8 & 4.7011 & TST & \\
\hline CHEMBL1992231 & 809248 & 4.5 & 4.6991 & TRN & \\
\hline CHEMBL1983111 & 809248 & 6.0 & 6.4522 & TRN & \\
\hline CHEMBL1973860 & 809248 & 4.8 & 5.334 & TRN & \\
\hline CHEMBL260135 & 809248 & 4.8 & $4.9030 e$ & 00000000005 & TRN \\
\hline CHEMBL220241 & 809248 & 7.3 & 6.3523 & TRN & \\
\hline CHEMBL1988141 & 809248 & 6.2 & 6.1996 & TST & \\
\hline CHEMBL1982610 & 809248 & 4.8 & 4.6807 & TST & \\
\hline CHEMBL1977134 & 809248 & 4.5 & 4.8232 & TRN & \\
\hline CHEMBL1985206 & 809248 & 4.5 & 5.0334 & TRN & \\
\hline CHEMBL1988300 & 809248 & 4.8 & 4.9036 & TRN & \\
\hline CHEMBL1991078 & 809248 & 7.3 & 6.5962 & TRN & \\
\hline CHEMBL1987359 & 809248 & 4.8 & 4.6941 & TST & \\
\hline CHEMBL1977749 & 809248 & 4.5 & 4.8963 & TST & \\
\hline CHEMBL1975212 & 809248 & 4.2 & 4.6429 & TRN & \\
\hline CHEMBL2001613 & 809248 & 4.7 & 4.8529 & TRN & \\
\hline CHEMBL1997275 & 809248 & 4.5 & 5.0919 & TRN & \\
\hline CHEMBL1993904 & 809248 & 4.5 & 4.9863 & TRN & \\
\hline CHEMBL1994438 & 809248 & 8.4 & 7.9755 & TRN & \\
\hline CHEMBL1967513 & 809248 & 4.5 & 4.3418 & TRN & \\
\hline CHEMBL2000724 & 809248 & 4.5 & 4.8892 & TRN & \\
\hline CHEMBL1982413 & 809248 & 4.5 & 5.3683 & TRN & \\
\hline CHEMBL1969502 & 809248 & 8.8 & 6.1306 & TRN & \\
\hline CHEMBL1682553 & 809248 & 6.5 & 6.6269 & TRN & \\
\hline CHEMBL1983963 & 809248 & 4.8 & 4.7304 & TRN & \\
\hline CHEMBL1997764 & 809248 & 4.8 & 4.853 & TRN & \\
\hline CHEMBL1985042 & 809248 & 4.2 & 4.5737 & TST & \\
\hline CHEMBL1981792 & 809248 & 4.5 & 4.3609 & TRN & \\
\hline CHEMBL1987535 & 809248 & 6.8 & 6.5019 & TRN & \\
\hline & & & & 13697 & \\
\hline
\end{tabular}




\begin{tabular}{|c|c|c|c|c|c|}
\hline \\
\hline CHEMBL1985092 & 809248 & 6.4 & 6.1825 & TRN & \\
\hline CHEMBL1981410 & 809248 & 4.8 & 4.7418 & TRN & \\
\hline CHEMBL2002586 & 809248 & 4.5 & 5.0873 & TRN & \\
\hline CHEMBL1996234 & 809248 & 4.8 & 4.8949 & TRN & \\
\hline CHEMBL 383264 & 809248 & 8.2 & 6.8248 & TRN & \\
\hline CHEMBL 2007421 & 809248 & 4.5 & 5.402 & TRN & \\
\hline CHEMBL1967544 & 809248 & 7.6 & 7.0755 & TRN & \\
\hline CHEMBL1973138 & 809248 & 4.5 & 4.8501 & TST & \\
\hline CHEMBL223367 & 809248 & 5.8 & 5.3239 & TST & \\
\hline CHEMBL340384 & 809248 & 6.8 & 6.2779 & TST & \\
\hline CHEMBL1969151 & 809248 & 7.6 & 7.7233 & TRN & \\
\hline CHEMBL1996587 & 809248 & 4.8 & 4.5429 & TRN & \\
\hline CHEMBL1993335 & 809248 & 4.5 & 5.2821 & TRN & \\
\hline CHEMBL1988692 & 809248 & 4.5 & 5.0965 & TRN & \\
\hline CHEMBL 2007574 & 809248 & 7.0 & 7.1245 & TRN & \\
\hline CHEMBL1964804 & 809248 & 6.1 & 5.8803 & TRN & \\
\hline CHEMBL443962 & 809248 & 4.8 & 4.383 & TST & \\
\hline CHEMBL2000354 & 809248 & 4.8 & 4.9663 & TRN & \\
\hline CHEMBL1965507 & 809248 & 4.8 & 5.3778 & TRN & \\
\hline CHEMBL274064 & 809248 & 4.8 & 5.0015 & TRN & \\
\hline CHEMBL1998680 & 809248 & 4.5 & 4.7777 & TRN & \\
\hline CHEMBL1967564 & 809248 & 4.8 & 4.657 & TRN & \\
\hline CHEMBL592030 & 809248 & 8.5 & 7.4008 & TST & \\
\hline CHEMBL 2000071 & 809248 & 4.8 & 4.9096 & TRN & \\
\hline CHEMBL1979176 & 809248 & 4.8 & 4.4736 & TRN & \\
\hline CHEMBL1970317 & 809248 & 4.5 & 4.6091 & TRN & \\
\hline CHEMBL 2002613 & 809248 & 6.2 & 6.1134 & TRN & \\
\hline CHEMBL2000408 & 809248 & 4.8 & 4.5551 & TRN & \\
\hline CHEMBL248757 & 809248 & 4.8 & 5.2757 & TST & \\
\hline CHEMBL1997007 & 809248 & 4.5 & 5.0982 & TRN & \\
\hline CHEMBL1994538 & 809248 & 4.8 & 4.8018 & TRN & \\
\hline CHEMBL1975490 & 809248 & 4.8 & 5.0877 & TRN & \\
\hline CHEMBL1964444 & 809248 & 4.6 & 4.2594 & TRN & \\
\hline CHEMBL2002690 & 809248 & 4.5 & 4.7431 & TRN & \\
\hline CHEMBL1986139 & 809248 & 4.8 & 4.46899 & 9999999999 & TRN \\
\hline CHEMBL1980540 & 809248 & 4.8 & 4.4701 & TRN & \\
\hline CHEMBL278041 & 809248 & 4.5 & 4.762 & TRN & \\
\hline CHEMBL1979883 & 809248 & 4.8 & 5.55200 & 00000000005 & TRN \\
\hline CHEMBL1984162 & 809248 & 4.8 & 6.44 & TRN & \\
\hline CHEMBL1998432 & 809248 & 8.3 & 7.6735 & TRN & \\
\hline CHEMBL491758 & 809248 & 4.8 & 4.7917 & TRN & \\
\hline CHEMBL1986590 & 809248 & 4.5 & 4.9322 & TRN & \\
\hline CHEMBL549730 & 809248 & 6.4 & 5.6187 & TRN & \\
\hline CHEMBL1970189 & 809248 & 4.8 & 4.48600 & 0000000001 & TST \\
\hline CHEMBL1870106 & 809248 & 7.7 & 6.0944 & TRN & \\
\hline CHEMBL1996791 & 809248 & 4.8 & 4.6932 & TRN & \\
\hline CHEMBL371206 & 809248 & 4.8 & 4.8538 & TRN & \\
\hline CHEMBL1974664 & 809248 & 4.8 & 4.7173 & TRN & \\
\hline & & & & 1369 & \\
\hline
\end{tabular}




\begin{tabular}{|c|c|c|c|c|}
\hline & & & & e S2 \\
\hline CHEMBL406845 & 809248 & 4.5 & 5.1346 & TRN \\
\hline CHEMBL1998478 & 809248 & 5.6 & 4.9118 & TRN \\
\hline CHEMBL482538 & 809248 & 4.4 & 5.0974 & TRN \\
\hline CHEMBL1974288 & 809248 & 8.9 & 7.3854 & TRN \\
\hline CHEMBL1984296 & 809248 & 6.0 & 5.3067 & TST \\
\hline CHEMBL196363 & 809248 & 4.8 & 5.0334 & TRN \\
\hline CHEMBL1190711 & 809248 & 4.8 & 4.075 & TRN \\
\hline CHEMBL1964718 & 809248 & 4.1 & 4.3442 & TST \\
\hline CHEMBL1968705 & 809248 & 4.8 & 5.7299 & TRN \\
\hline CHEMBL1991410 & 809248 & 4.7 & 5.6387 & TRN \\
\hline CHEMBL1964441 & 809248 & 4.5 & 5.3585 & TRN \\
\hline CHEMBL546797 & 809248 & 4.5 & 5.0166 & TST \\
\hline CHEMBL404367 & 809248 & 4.8 & 4.9145 & TRN \\
\hline CHEMBL1966343 & 809248 & 6.5 & 6.0893 & TRN \\
\hline CHEMBL1978271 & 809248 & 4.5 & 4.6741 & TRN \\
\hline CHEMBL1967887 & 809248 & 7.3 & 6.4756 & TRN \\
\hline CHEMBL2007266 & 809248 & 4.5 & 5.3719 & TRN \\
\hline CHEMBL 2000568 & 809248 & 4.6 & 4.5276 & TRN \\
\hline CHEMBL1994308 & 809248 & 4.5 & $5.3420 e$ & 00000000005 \\
\hline CHEMBL2000335 & 809248 & 6.5 & 5.1991 & TRN \\
\hline CHEMBL1988717 & 809248 & 4.8 & 4.811 & TRN \\
\hline CHEMBL1974328 & 809248 & 4.9 & 5.5592 & TRN \\
\hline CHEMBL509032 & 809248 & 5.0 & 6.0639 & TRN \\
\hline CHEMBL243298 & 809248 & 4.5 & 4.9171 & TRN \\
\hline CHEMBL1973808 & 809248 & 4.8 & 5.3787 & TRN \\
\hline CHEMBL 2000429 & 809248 & 4.8 & 4.5829 & TRN \\
\hline CHEMBL1972576 & 809248 & 4.8 & 5.3088 & TRN \\
\hline CHEMBL1992342 & 809248 & 4.8 & 5.6795 & TRN \\
\hline CHEMBL1988173 & 809248 & 6.4 & 5.5489 & TRN \\
\hline CHEMBL1973013 & 809248 & 4.5 & 5.5516 & TRN \\
\hline CHEMBL1989805 & 809248 & 6.5 & 5.0538 & TST \\
\hline CHEMBL1966204 & 809248 & 7.9 & 6.7532 & TRN \\
\hline CHEMBL1965423 & 809248 & 4.8 & 4.7273 & TRN \\
\hline CHEMBL1983025 & 809248 & 4.8 & 5.0344 & TRN \\
\hline CHEMBL1975927 & 809248 & 4.5 & 5.2251 & TRN \\
\hline CHEMBL205415 & 809248 & 6.5 & 7.0703 & TRN \\
\hline CHEMBL1977135 & 809248 & 8.1 & 6.5938 & TRN \\
\hline CHEMBL 2001920 & 809248 & 4.8 & 5.3588 & TRN \\
\hline CHEMBL1997119 & 809248 & 4.0 & 4.5244 & TRN \\
\hline CHEMBL1977138 & 809248 & 4.5 & 6.1116 & TST \\
\hline CHEMBL1241473 & 809248 & 4.8 & 5.7711 & TRN \\
\hline CHEMBL1978448 & 809248 & 4.8 & 5.3787 & TST \\
\hline CHEMBL1972258 & 809248 & 6.1 & 6.0323 & TRN \\
\hline CHEMBL1980329 & 809248 & 5.7 & 5.9432 & TRN \\
\hline CHEMBL 2001257 & 809248 & 4.8 & 5.4215 & TRN \\
\hline CHEMBL1992042 & 809248 & 4.5 & 5.8053 & TST \\
\hline CHEMBL 21156 & 809248 & 4.5 & 5.4172 & TST \\
\hline CHEMBL1992740 & 809248 & 4.8 & 4.628 & TRN \\
\hline
\end{tabular}




\begin{tabular}{|c|c|c|c|c|c|}
\hline & & & & & \\
\hline CHEMBL1994724 & 809248 & 5.7 & 6.1437 & TRN & \\
\hline CHEMBL1989267 & 809248 & 6.4 & 5.2979 & TRN & \\
\hline CHEMBL439340 & 809248 & 4.8 & 5.2462 & TRN & \\
\hline CHEMBL 2006188 & 809248 & 6.9 & 7.0893 & TRN & \\
\hline CHEMBL1970290 & 809248 & 6.4 & 5.2767 & TRN & \\
\hline CHEMBL1967531 & 809248 & 4.8 & 4.9251 & TRN & \\
\hline CHEMBL1970913 & 809248 & 4.8 & 4.5947 & TRN & \\
\hline CHEMBL1973893 & 809248 & 4.8 & 5.1002 & TRN & \\
\hline CHEMBL1997534 & 809248 & 4.8 & 5.7932 & TRN & \\
\hline CHEMBL1993877 & 809248 & 5.5 & 5.04899 & 99999999995 & TRN \\
\hline CHEMBL1996500 & 809248 & 4.6 & 4.4294 & TRN & \\
\hline CHEMBL1985095 & 809248 & 7.4 & 6.4434 & TST & \\
\hline CHEMBL1973363 & 809248 & 5.8 & 5.3005 & TRN & \\
\hline CHEMBL1682540 & 809248 & 4.8 & 5.2891 & TRN & \\
\hline CHEMBL1976420 & 809248 & 4.6 & 4.2707 & TRN & \\
\hline CHEMBL1981744 & 809248 & 4.5 & 4.3822 & TRN & \\
\hline CHEMBL 2002446 & 809248 & 6.1 & 5.3372 & TRN & \\
\hline CHEMBL497151 & 809248 & 6.8 & 5.69 & TRN & \\
\hline CHEMBL 2000029 & 809248 & 6.9 & 7.3729 & TRN & \\
\hline CHEMBL1973961 & 809248 & 4.5 & 5.3719 & TRN & \\
\hline CHEMBL340921 & 809248 & 5.9 & 5.8549 & TST & \\
\hline CHEMBL1994977 & 809248 & 4.5 & 4.7833 & TRN & \\
\hline CHEMBL 2001149 & 809248 & 6.0 & 5.1238 & TRN & \\
\hline CHEMBL1999718 & 809248 & 4.8 & 4.6943 & TRN & \\
\hline CHEMBL1987073 & 809248 & 8.2 & 6.2703 & TRN & \\
\hline CHEMBL 2005478 & 809248 & 4.5 & 5.4037 & TRN & \\
\hline CHEMBL1996646 & 809248 & 5.7 & 5.4237 & TRN & \\
\hline CHEMBL1995712 & 809248 & 8.0 & 7.37299 & 9999999999 & TRN \\
\hline CHEMBL1979773 & 809248 & 4.5 & 4.6205 & TRN & \\
\hline CHEMBL1977346 & 809248 & 4.8 & 4.341 & TRN & \\
\hline CHEMBL1971649 & 809248 & 4.8 & 4.6215 & TRN & \\
\hline CHEMBL1996702 & 809248 & 5.9 & 5.9093 & TRN & \\
\hline CHEMBL 2007124 & 809248 & 4.5 & 4.8914 & TRN & \\
\hline CHEMBL 2006439 & 809248 & 4.9 & 7.1278 & TRN & \\
\hline CHEMBL1985681 & 809248 & 4.5 & 5.3772 & TST & \\
\hline CHEMBL1969190 & 809248 & 4.8 & 4.7499 & TRN & \\
\hline CHEMBL1973937 & 809248 & 6.1 & 5.3988 & TRN & \\
\hline CHEMBL1991674 & 809248 & 6.4 & 6.393 & TRN & \\
\hline CHEMBL1982711 & 809248 & 6.7 & 6.6187 & TRN & \\
\hline CHEMBL 262623 & 809248 & 4.1 & 4.7004 & TRN & \\
\hline CHEMBL1984842 & 809248 & 4.5 & 4.5737 & TRN & \\
\hline CHEMBL 2004118 & 809248 & 4.5 & 5.0952 & TRN & \\
\hline CHEMBL 2007044 & 809248 & 4.8 & 4.8987 & TRN & \\
\hline CHEMBL1994241 & 809248 & 4.8 & 5.3564 & TST & \\
\hline CHEMBL 223460 & 809248 & 4.8 & 5.2178 & TST & \\
\hline CHEMBL50894 & 809248 & 4.7 & 4.6478 & TST & \\
\hline CHEMBL1995211 & 809248 & 4.5 & 4.84399 & 9999999999 & TRN \\
\hline CHEMBL1981725 & 809248 & 4.8 & 5.435 & TRN & \\
\hline & & & & 13700 & \\
\hline
\end{tabular}




\begin{tabular}{|c|c|c|c|c|c|}
\hline \\
\hline CHEMBL1982753 & 809248 & 4.5 & 5.5397 & TRN & \\
\hline CHEMBL2006299 & 809248 & 6.3 & 6.0796 & TRN & \\
\hline CHEMBL1972346 & 809248 & 6.2 & 5.66200 & 0000000001 & TST \\
\hline CHEMBL1980562 & 809248 & 6.7 & 7.5573 & TRN & \\
\hline CHEMBL1965169 & 809248 & 4.5 & 5.02 & TRN & \\
\hline CHEMBL1991818 & 809248 & 5.7 & 5.0603 & TST & \\
\hline CHEMBL1081312 & 809248 & 4.5 & 5.3212 & TRN & \\
\hline CHEMBL1965170 & 809248 & 4.5 & 4.8098 & TRN & \\
\hline CHEMBL1982866 & 809248 & 4.8 & 4.7802 & TRN & \\
\hline CHEMBL2005792 & 809248 & 4.5 & 4.4938 & TRN & \\
\hline CHEMBL1968926 & 809248 & 6.6 & 5.1653 & TRN & \\
\hline CHEMBL1991867 & 809248 & 4.3 & 4.8607 & TST & \\
\hline CHEMBL1979933 & 809248 & 5.6 & 4.6505 & TRN & \\
\hline CHEMBL1965570 & 809248 & 4.8 & 4.7842 & TRN & \\
\hline CHEMBL 2007592 & 809248 & 4.8 & 4.7652 & TST & \\
\hline CHEMBL1972355 & 809248 & 4.5 & 5.7173 & TST & \\
\hline CHEMBL1997892 & 809248 & 4.5 & 4.9208 & TRN & \\
\hline CHEMBL2001641 & 809248 & 4.7 & 5.2394 & TRN & \\
\hline CHEMBL1976936 & 809248 & 7.7 & 6.5912 & TRN & \\
\hline CHEMBL1997193 & 809248 & 4.5 & 5.4297 & TST & \\
\hline CHEMBL210963 & 809248 & 4.8 & 4.6557 & TRN & \\
\hline CHEMBL1964902 & 809248 & 4.5 & 4.7553 & TRN & \\
\hline CHEMBL1082440 & 809248 & 7.8 & 5.3551 & TST & \\
\hline CHEMBL1614705 & 809248 & 4.8 & 5.0628 & TRN & \\
\hline CHEMBL1984633 & 809248 & 4.8 & 6.0278 & TRN & \\
\hline CHEMBL1972988 & 809248 & 5.6 & 6.4967 & TRN & \\
\hline CHEMBL1965845 & 809248 & 7.4 & 6.9069 & TRN & \\
\hline CHEMBL1983715 & 809248 & 6.2 & 5.8368 & TRN & \\
\hline CHEMBL 2006715 & 809248 & 4.8 & 5.9799 & TRN & \\
\hline CHEMBL1986597 & 809248 & 4.8 & 4.9328 & TRN & \\
\hline CHEMBL1990482 & 809248 & 6.7 & 5.7999 & TRN & \\
\hline CHEMBL1990904 & 809248 & 4.8 & 4.6843 & TRN & \\
\hline CHEMBL1987448 & 809248 & 7.5 & 6.9338 & TRN & \\
\hline CHEMBL402846 & 809248 & 4.8 & 5.0164 & TRN & \\
\hline CHEMBL1997349 & 809248 & 6.4 & 5.2808 & TST & \\
\hline CHEMBL183844 & 809248 & 4.8 & 4.6895 & TRN & \\
\hline CHEMBL 220057 & 809248 & 4.8 & 5.7346 & TRN & \\
\hline CHEMBL1682545 & 809248 & 4.8 & 4.8871 & TRN & \\
\hline CHEMBL383541 & 809248 & 7.6 & 7.13700 & 00000000005 & TRN \\
\hline CHEMBL 2001224 & 809248 & 4.8 & 4.6767 & TRN & \\
\hline CHEMBL10 & 809248 & 4.5 & 4.6193 & TRN & \\
\hline CHEMBL1976732 & 809248 & 4.8 & 4.8699 & TRN & \\
\hline CHEMBL2005216 & 809248 & 7.1 & 6.6355 & TRN & \\
\hline CHEMBL1969506 & 809248 & 7.0 & 4.8886 & TRN & \\
\hline CHEMBL1980763 & 809248 & 4.5 & 5.1395 & TRN & \\
\hline CHEMBL1980163 & 809248 & 4.8 & 4.4663 & TRN & \\
\hline CHEMBL1977931 & 809248 & 4.4 & 4.6237 & TRN & \\
\hline CHEMBL2005899 & 809248 & 6.4 & 5.6932 & TRN & \\
\hline
\end{tabular}




\begin{tabular}{|c|c|c|c|c|c|}
\hline & & & & & \\
\hline CHEMBL1682552 & 809248 & 4.8 & 6.3106 & TRN & \\
\hline CHEMBL 2007479 & 809248 & 4.5 & 4.9545 & TRN & \\
\hline CHEMBL229799 & 809248 & 9.0 & 8.9758 & TRN & \\
\hline CHEMBL105739 & 809248 & 4.8 & 4.541 & TRN & \\
\hline CHEMBL1972220 & 809248 & 4.5 & 4.9037 & TRN & \\
\hline CHEMBL 379300 & 809248 & 7.2 & 8.3496 & TRN & \\
\hline CHEMBL1973720 & 809248 & 8.5 & 7.8949 & TRN & \\
\hline CHEMBL1969523 & 809248 & 6.6 & 5.91299 & 9999999999 & TRN \\
\hline CHEMBL 2001923 & 809248 & 6.0 & 5.0927 & TST & \\
\hline CHEMBL1986781 & 809248 & 4.8 & 4.8074 & TRN & \\
\hline CHEMBL1983070 & 809248 & 6.5 & 4.8984 & TRN & \\
\hline CHEMBL526133 & 809248 & 4.8 & 5.2411 & TRN & \\
\hline CHEMBL 2003514 & 809248 & 5.9 & 6.5026 & TRN & \\
\hline CHEMBL1989043 & 809248 & 4.5 & 5.0489 & TRN & \\
\hline CHEMBL1979057 & 809248 & 4.8 & 4.9595 & TRN & \\
\hline CHEMBL 387971 & 809248 & 4.8 & 4.8878 & TRN & \\
\hline CHEMBL1164180 & 809248 & 4.6 & 5.2243 & TST & \\
\hline CHEMBL1999428 & 809248 & 8.6 & 7.0588 & TRN & \\
\hline CHEMBL1967560 & 809248 & 4.8 & 4.8831 & TRN & \\
\hline CHEMBL1997611 & 809248 & 5.8 & 5.4538 & TST & \\
\hline CHEMBL1516890 & 809248 & 4.8 & 4.9285 & TRN & \\
\hline CHEMBL 211378 & 809248 & 4.8 & 4.51399 & 9999999999 & TRN \\
\hline CHEMBL1982465 & 809248 & 4.8 & 5.1141 & TRN & \\
\hline CHEMBL2001751 & 809248 & 8.1 & 9.1201 & TRN & \\
\hline CHEMBL 2003420 & 809248 & 4.8 & 4.7984 & TRN & \\
\hline CHEMBL1984586 & 809248 & 4.8 & 4.6922 & TRN & \\
\hline CHEMBL1972659 & 809248 & 7.0 & 5.5131 & TST & \\
\hline CHEMBL 2002723 & 809248 & 5.5 & 5.4962 & TST & \\
\hline CHEMBL272453 & 809248 & 4.8 & 5.2382 & TRN & \\
\hline CHEMBL1970217 & 809248 & 7.4 & 6.4146 & TRN & \\
\hline CHEMBL 2005528 & 809248 & 4.8 & 5.3328 & TST & \\
\hline CHEMBL1984686 & 809248 & 4.5 & 4.8825 & TRN & \\
\hline CHEMBL185569 & 809248 & 4.8 & 4.4863 & TRN & \\
\hline CHEMBL1969843 & 809248 & 4.8 & 5.6369 & TRN & \\
\hline CHEMBL 2007002 & 809248 & 4.8 & 4.8886 & TRN & \\
\hline CHEMBL1987007 & 809248 & 6.2 & 5.3408 & TRN & \\
\hline CHEMBL1973793 & 809248 & 4.5 & 4.8999 & TST & \\
\hline CHEMBL1969588 & 809248 & 7.1 & 7.6154 & TRN & \\
\hline CHEMBL1984711 & 809248 & 4.8 & 5.1049 & TRN & \\
\hline CHEMBL1992073 & 809248 & 4.9 & 5.6998 & TRN & \\
\hline CHEMBL484390 & 809248 & 4.8 & 4.657 & TST & \\
\hline CHEMBL1986143 & 809248 & 6.5 & 6.8983 & TRN & \\
\hline CHEMBL2007559 & 809248 & 4.5 & 5.0639 & TRN & \\
\hline CHEMBL1992581 & 809248 & 4.5 & 4.9916 & TRN & \\
\hline CHEMBL 2004290 & 809248 & 4.6 & 4.4984 & TRN & \\
\hline CHEMBL1986499 & 809248 & 7.3 & 7.3023 & TRN & \\
\hline CHEMBL1972937 & 809248 & 4.8 & 4.9621 & TRN & \\
\hline CHEMBL2000393 & 809248 & 4.8 & 5.4378 & TST & \\
\hline & & & & 13702 & \\
\hline
\end{tabular}




\begin{tabular}{|c|c|c|c|c|c|}
\hline \\
\hline CHEMBL1992634 & 809248 & 4.8 & 4.9957 & TRN & \\
\hline CHEMBL1242373 & 809248 & 4.8 & 4.8501 & TRN & \\
\hline CHEMBL1984847 & 809248 & 5.7 & 5.1122 & TST & \\
\hline CHEMBL316264 & 809248 & 4.8 & 4.5149 & TRN & \\
\hline CHEMBL1988075 & 809248 & 4.8 & 4.6634 & TRN & \\
\hline CHEMBL1996576 & 809248 & 4.5 & 5.0595 & TST & \\
\hline CHEMBL1991678 & 809248 & 4.5 & 4.4236 & TRN & \\
\hline CHEMBL2001239 & 809248 & 4.8 & 5.9607 & TRN & \\
\hline CHEMBL1988594 & 809248 & 4.8 & 5.5004 & TRN & \\
\hline CHEMBL2001288 & 809248 & 4.8 & 4.8249 & TRN & \\
\hline CHEMBL1992363 & 809248 & 7.9 & 6.7162 & TRN & \\
\hline CHEMBL1999811 & 809248 & 4.8 & 5.256 & TRN & \\
\hline CHEMBL235157 & 809248 & 4.5 & 4.9359 & TST & \\
\hline CHEMBL 2000481 & 809248 & 4.8 & 4.7412 & TRN & \\
\hline CHEMBL1982874 & 809248 & 4.8 & 4.8804 & TRN & \\
\hline CHEMBL1991725 & 809248 & 7.0 & 6.013 & TRN & \\
\hline CHEMBL1992242 & 809248 & 4.8 & 4.6008 & TRN & \\
\hline CHEMBL1982271 & 809248 & 7.5 & 7.4903 & TRN & \\
\hline CHEMBL2007296 & 809248 & 6.8 & 6.506 & TRN & \\
\hline CHEMBL396523 & 809248 & 4.8 & 5.3248 & TRN & \\
\hline CHEMBL2004159 & 809248 & 5.7 & 5.6406 & TRN & \\
\hline CHEMBL1978371 & 809248 & 4.5 & 5.0577 & TST & \\
\hline CHEMBL1970203 & 809248 & 4.8 & 4.9852 & TRN & \\
\hline CHEMBL1986530 & 809248 & 4.8 & 4.6525 & TST & \\
\hline CHEMBL440084 & 809248 & 4.5 & 4.9126 & TRN & \\
\hline CHEMBL1999321 & 809248 & 4.8 & $5.2020 e$ & 2000000001 & TRN \\
\hline CHEMBL1968590 & 809248 & 4.8 & 4.6806 & TRN & \\
\hline CHEMBL 2005375 & 809248 & 4.8 & 4.7991 & TRN & \\
\hline CHEMBL1971029 & 809248 & 4.8 & 5.5724 & TRN & \\
\hline CHEMBL394790 & 809248 & 4.8 & 4.5495 & TRN & \\
\hline CHEMBL2001451 & 809248 & 5.6 & 4.9341 & TRN & \\
\hline CHEMBL226471 & 809248 & 4.8 & 5.7297 & TRN & \\
\hline CHEMBL1974702 & 809248 & 4.8 & 5.282 & TRN & \\
\hline CHEMBL1996111 & 809248 & 8.0 & 7.2354 & TRN & \\
\hline CHEMBL1966175 & 809248 & 6.5 & 5.0577 & TRN & \\
\hline CHEMBL1965589 & 809248 & 4.8 & 4.6131 & TRN & \\
\hline CHEMBL2007375 & 809248 & 4.5 & 4.2919 & TRN & \\
\hline CHEMBL1998193 & 809248 & 4.8 & 4.7836 & TRN & \\
\hline CHEMBL379975 & 809248 & 5.8 & 5.9477 & TST & \\
\hline CHEMBL474432 & 809248 & 4.8 & 5.7413 & TST & \\
\hline CHEMBL1965387 & 809248 & 4.5 & 5.3514 & TRN & \\
\hline CHEMBL2001539 & 809248 & 7.3 & 4.7956 & TST & \\
\hline CHEMBL1988153 & 809248 & 6.9 & 4.9165 & TRN & \\
\hline CHEMBL550418 & 809248 & 5.7 & 5.3719 & TRN & \\
\hline CHEMBL1986666 & 809248 & 6.0 & 5.3073 & TRN & \\
\hline CHEMBL1971289 & 809248 & 4.5 & 5.4372 & TRN & \\
\hline CHEMBL1988437 & 809248 & 4.6 & 5.0341 & TST & \\
\hline CHEMBL1979577 & 809248 & 4.8 & 5.2018 & TRN & \\
\hline & & & & 3703 & \\
\hline
\end{tabular}




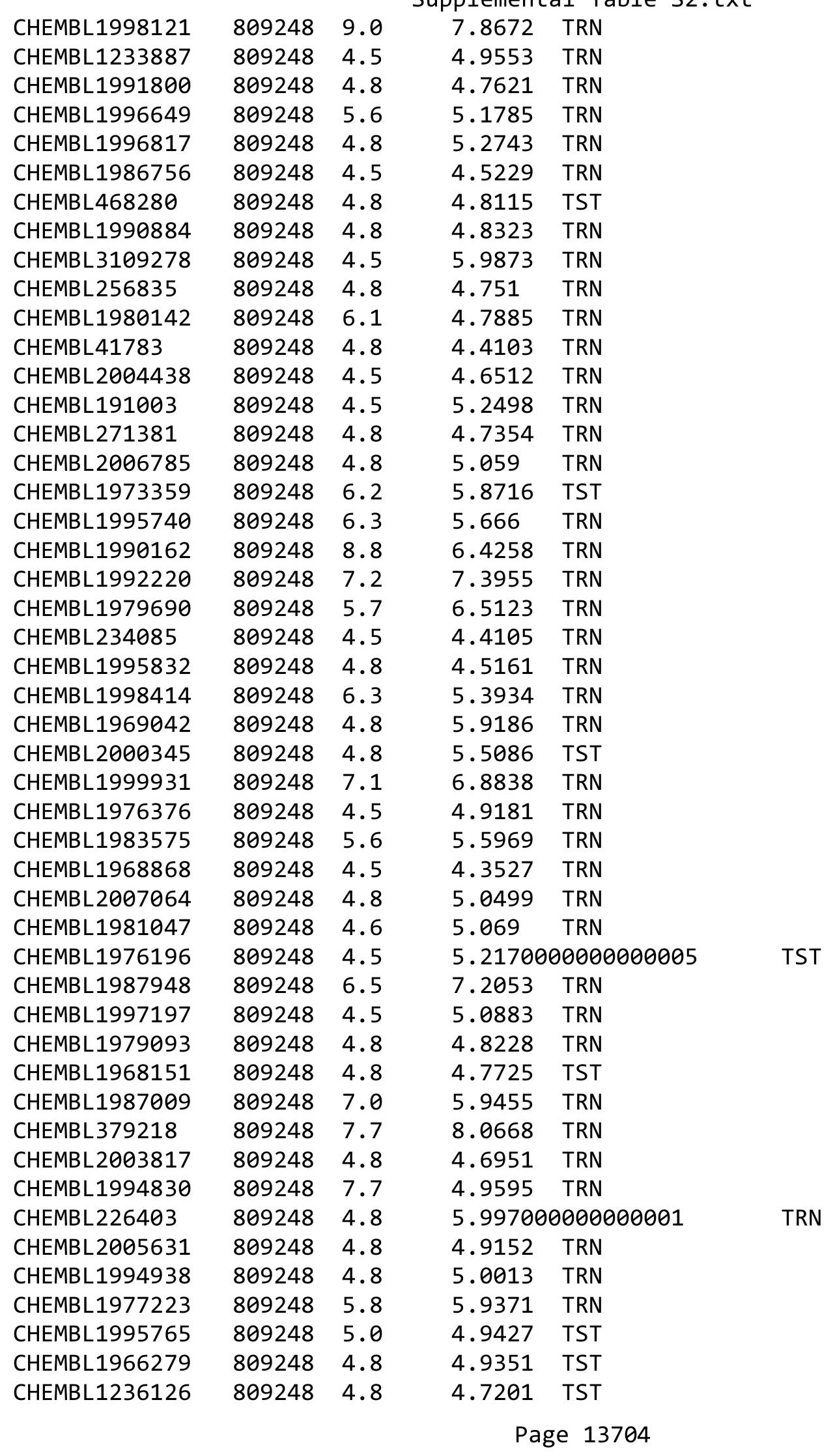




\begin{tabular}{|c|c|c|c|c|}
\hline & & & pplement & al $\mathrm{T}$ \\
\hline CHEMBL1997846 & 809248 & 6.3 & 6.2561 & TST \\
\hline CHEMBL1984760 & 809248 & 4.5 & 5.0829 & TST \\
\hline CHEMBL2004419 & 809248 & 4.8 & 4.7436 & TST \\
\hline CHEMBL360847 & 809248 & 4.5 & 4.9703 & TST \\
\hline CHEMBL1995811 & 809248 & 6.5 & 6.3724 & TST \\
\hline CHEMBL1994074 & 809248 & 4.8 & 4.8003 & TST \\
\hline CHEMBL1992937 & 809248 & 4.6 & 4.9917 & TST \\
\hline CHEMBL451401 & 809248 & 4.1 & 4.2632 & TST \\
\hline CHEMBL1968930 & 809248 & 8.7 & 7.3914 & TST \\
\hline CHEMBL1972119 & 809248 & 4.8 & 4.5814 & TST \\
\hline CHEMBL95692 & 809248 & 4.8 & 4.9567 & TST \\
\hline CHEMBL1090356 & 809248 & 4.8 & 4.8722 & TST \\
\hline CHEMBL1976455 & 809248 & 4.8 & 4.4908 & TST \\
\hline CHEMBL261849 & 809248 & 4.5 & 4.8279 & TST \\
\hline CHEMBL1983923 & 809248 & 4.6 & 5.6394 & TST \\
\hline CHEMBL1983534 & 809248 & 6.4 & 5.5435 & TST \\
\hline CHEMBL1999112 & 809248 & 4.8 & 4.7712 & TST \\
\hline CHEMBL1982122 & 809248 & 6.5 & 6.0321 & TST \\
\hline CHEMBL1682546 & 809248 & 7.3 & 5.3167 & TST \\
\hline CHEMBL1991395 & 809248 & 4.8 & 4.4111 & TST \\
\hline CHEMBL1971245 & 809248 & 4.8 & 4.7779 & TST \\
\hline CHEMBL1966514 & 809248 & 4.8 & 4.6074 & TST \\
\hline CHEMBL 2003638 & 809248 & 6.7 & 6.8825 & TST \\
\hline CHEMBL1996066 & 809248 & 4.8 & 4.8448 & TST \\
\hline CHEMBL1983393 & 809248 & 5.8 & 4.8954 & TST \\
\hline CHEMBL1993722 & 809248 & 6.6 & 5.8585 & TST \\
\hline CHEMBL 2006674 & 809248 & 4.5 & 5.4098 & TST \\
\hline CHEMBL1984236 & 809248 & 4.5 & 4.9907 & TST \\
\hline CHEMBL1992371 & 809248 & 4.5 & 5.2716 & TST \\
\hline CHEMBL1375640 & 809248 & 4.8 & 5.3078 & TST \\
\hline CHEMBL1979970 & 809248 & 4.8 & 4.5227 & TST \\
\hline CHEMBL 2002599 & 809248 & 4.5 & 4.8591 & TST \\
\hline CHEMBL 249282 & 809248 & 4.8 & 4.8555 & TST \\
\hline CHEMBL1967252 & 809248 & 5.2 & 5.4928 & TST \\
\hline CHEMBL 2004637 & 809248 & 4.5 & 5.0944 & TST \\
\hline CHEMBL1993374 & 809248 & 4.5 & 5.1661 & TST \\
\hline CHEMBL1994318 & 809248 & 6.1 & 4.9458 & TST \\
\hline CHEMBL 2006237 & 809248 & 4.8 & 4.6726 & TST \\
\hline CHEMBL1999506 & 809248 & 4.5 & 4.8281 & TST \\
\hline CHEMBL1967720 & 809248 & 4.8 & 4.6579 & TST \\
\hline CHEMBL2005509 & 809248 & 7.4 & 7.4381 & TST \\
\hline CHEMBL1572266 & 809248 & 4.8 & 4.9604 & TST \\
\hline CHEMBL1991138 & 809248 & 4.8 & 4.7702 & TST \\
\hline CHEMBL1969755 & 809248 & 6.4 & 6.2156 & TST \\
\hline CHEMBL1979516 & 809248 & 4.8 & 4.792 & TST \\
\hline CHEMBL1605605 & 809248 & 6.2 & 4.8609 & TST \\
\hline CHEMBL1989029 & 809248 & 4.8 & 4.9801 & TST \\
\hline CHEMBL392642 & 809248 & 4.8 & 4.4568 & TST \\
\hline
\end{tabular}




\begin{tabular}{|c|c|c|c|c|c|}
\hline \\
\hline CHEMBL514499 & 809248 & 6.0 & 5.9846 & TST & \\
\hline CHEMBL1970352 & 809248 & 4.5 & 5.2119 & TST & \\
\hline CHEMBL1965631 & 809248 & 4.8 & 5.8688 & TST & \\
\hline CHEMBL1980144 & 809248 & 4.8 & 5.4202 & TST & \\
\hline CHEMBL1991188 & 809248 & 6.1 & 6.5726 & TST & \\
\hline CHEMBL1980167 & 809248 & 4.5 & 5.3763 & TST & \\
\hline CHEMBL1972849 & 809248 & 4.8 & 4.5957 & TST & \\
\hline CHEMBL 377408 & 809248 & 4.5 & 5.0255 & TST & \\
\hline CHEMBL1986855 & 809248 & 7.7 & 6.3544 & TST & \\
\hline CHEMBL215152 & 809248 & 4.5 & 4.9484 & TST & \\
\hline CHEMBL231209 & 809248 & 4.8 & 4.7603 & TST & \\
\hline CHEMBL 2006765 & 809248 & 5.5 & 5.5105 & TST & \\
\hline CHEMBL1976220 & 809248 & 4.8 & 4.5609 & TST & \\
\hline CHEMBL259922 & 809248 & 4.8 & 4.7681 & TST & \\
\hline CHEMBL1997617 & 809248 & 4.8 & 4.6764 & TST & \\
\hline CHEMBL1982383 & 809248 & 4.8 & 4.5472 & TST & \\
\hline CHEMBL1969301 & 809248 & 4.8 & 4.5393 & TST & \\
\hline CHEMBL17370 & 809248 & 4.8 & 4.7111 & TST & \\
\hline CHEMBL1983932 & 809248 & 4.8 & 4.7634 & TST & \\
\hline CHEMBL1980246 & 809248 & 4.5 & 5.0569 & TST & \\
\hline CHEMBL1983980 & 809248 & 5.6 & 5.6986 & TST & \\
\hline CHEMBL1999484 & 809248 & 6.0 & 5.942 & TST & \\
\hline CHEMBL1986899 & 809248 & 4.5 & 4.5611 & TST & \\
\hline CHEMBL1991285 & 809248 & 4.8 & 4.5896 & TST & \\
\hline CHEMBL1997822 & 809248 & 6.0 & 4.5427 & TST & \\
\hline CHEMBL 243088 & 809248 & 4.8 & 5.2056 & TST & \\
\hline CHEMBL1984038 & 809248 & 4.6 & 4.621 & TST & \\
\hline CHEMBL1993661 & 809248 & 7.0 & 6.1842 & TST & \\
\hline CHEMBL1974416 & 809248 & 4.8 & 5.2843 & TST & \\
\hline CHEMBL 2440845 & 992729 & 4.4572 & 4.52800 & 00000000005 & TST \\
\hline CHEMBL 2440867 & 992729 & 4.2604 & 4.0303 & TRN & \\
\hline CHEMBL2440839 & 992729 & 5.2396 & 3.641 & TST & \\
\hline CHEMBL2440799 & 992729 & 5.0123 & 5.0834 & TRN & \\
\hline CHEMBL 2440843 & 992729 & 2.0 & 2.9611 & TST & \\
\hline CHEMBL477465 & 992729 & 3.6716 & 3.7899 & TRN & \\
\hline CHEMBL 2440811 & 992729 & 5.3595 & 4.9505 & TRN & \\
\hline CHEMBL 2440862 & 992729 & 4.82100 & 00000000 & 4.695 & TRN \\
\hline CHEMBL 2440813 & 992729 & 4.8125 & 4.9657 & TRN & \\
\hline CHEMBL 2440859 & 992729 & 4.5528 & 4.1247 & TRN & \\
\hline CHEMBL2440849 & 992729 & 5.4498 & 5.4722 & TRN & \\
\hline CHEMBL 2440814 & 992729 & 4.6968 & 4.6118 & TRN & \\
\hline CHEMBL 2440786 & 992729 & 4.9318 & 4.2119 & TST & \\
\hline CHEMBL 2440824 & 992729 & 4.1818 & 3.6468 & TST & \\
\hline CHEMBL 2440873 & 992729 & 4.6402 & 4.2279 & TRN & \\
\hline CHEMBL 2440832 & 992729 & 2.0 & 3.7285 & TST & \\
\hline CHEMBL 2440802 & 992729 & 5.0114 & 5.0826 & TRN & \\
\hline CHEMBL2440846 & 992729 & 4.2027 & 3.9127 & TST & \\
\hline CHEMBL 2440815 & 992729 & 4.9066 & 4.769 & TRN & \\
\hline
\end{tabular}




\begin{tabular}{|c|c|c|c|c|c|c|}
\hline & & \multicolumn{5}{|c|}{ Supplemental Table S2.txt } \\
\hline CHEMBL 2440801 & 992729 & 4.7986 & 4.8854 & TRN & & \\
\hline CHEMBL 2440830 & 992729 & 2.0 & 2.3633 & TRN & & \\
\hline CHEMBL 2440827 & 992729 & 4.1215 & 4.592 & TST & & \\
\hline CHEMBL 2440875 & 992729 & 3.4389 & 3.0183 & TRN & & \\
\hline CHEMBL 2440852 & 992729 & 4.1561 & 3.5242 & TRN & & \\
\hline CHEMBL 2440831 & 992729 & 3.3344 & 3.6031 & TST & & \\
\hline CHEMBL 2440869 & 992729 & 4.5834 & 4.6407 & TRN & & \\
\hline CHEMBL 2440806 & 992729 & 4.7033 & 4.1597 & TRN & & \\
\hline CHEMBL 2440783 & 992729 & 4.7932 & 4.665 & TRN & & \\
\hline CHEMBL2440794 & 992729 & 4.6126 & 5.0744 & TRN & & \\
\hline CHEMBL 2440857 & 992729 & 4.4647 & 3.3527 & TST & & \\
\hline CHEMBL2440792 & 992729 & 4.699 & 4.8562 & TRN & & \\
\hline CHEMBL 2440803 & 992729 & 5.2034 & 5.6454 & TRN & & \\
\hline CHEMBL 2440820 & 992729 & 4.5214 & 4.3731 & TRN & & \\
\hline CHEMBL 2440817 & 992729 & 4.063 & 3.1903 & TRN & & \\
\hline CHEMBL 2440868 & 992729 & 4.4535 & 4.0663 & TRN & & \\
\hline CHEMBL2440822 & 992729 & 4.7399 & 4.8684 & TRN & & \\
\hline CHEMBL 2440876 & 992729 & 2.0 & 2.9228 & TRN & & \\
\hline CHEMBL 2440825 & 992729 & $4.8210 e$ & 00000000 & $\partial 1$ & 4.802 & TRN \\
\hline CHEMBL 2440874 & 992729 & 4.062 & 4.0434 & TRN & & \\
\hline CHEMBL 2440781 & 992729 & 4.0123 & 4.0411 & TRN & & \\
\hline CHEMBL2440864 & 992729 & 4.9355 & 4.9001 & TRN & & \\
\hline CHEMBL 2440785 & 992729 & 4.4535 & 4.1231 & TRN & & \\
\hline CHEMBL 2440793 & 992729 & 5.0218 & 5.1665 & TRN & & \\
\hline CHEMBL 2440858 & 992729 & 4.9508 & 4.9873 & TRN & & \\
\hline CHEMBL 2440866 & 992729 & 5.0696 & 5.053 & TRN & & \\
\hline CHEMBL 2440837 & 992729 & 2.0 & 3.9143 & TST & & \\
\hline CHEMBL 2440860 & 992729 & 4.7747 & 4.6817 & TRN & & \\
\hline CHEMBL 2440850 & 992729 & 5.4401 & 5.4889 & TRN & & \\
\hline CHEMBL 2440836 & 992729 & 2.0 & 2.1732 & TRN & & \\
\hline CHEMBL 2440787 & 992729 & 4.7747 & 5.1633 & TRN & & \\
\hline CHEMBL2440125 & 992729 & 4.9914 & 5.2407 & TRN & & \\
\hline CHEMBL2440816 & 992729 & 2.0 & 2.3359 & TRN & & \\
\hline CHEMBL 2440819 & 992729 & 4.7696 & 5.074 & TRN & & \\
\hline CHEMBL 2440826 & 992729 & 5.0101 & 4.9285 & TRN & & \\
\hline CHEMBL 2440795 & 992729 & 4.5735 & 4.6407 & TRN & & \\
\hline CHEMBL2440829 & 992729 & 4.5528 & 4.4877 & TST & & \\
\hline CHEMBL 2440788 & 992729 & 4.8356 & 4.046 & TRN & & \\
\hline CHEMBL 2440796 & 992729 & 5.1113 & 5.1671 & TRN & & \\
\hline CHEMBL 2440842 & 992729 & 5.065 & 3.4874 & TST & & \\
\hline CHEMBL 2440823 & 992729 & 5.2441 & 4.1112 & TST & & \\
\hline CHEMBL 2440807 & 992729 & 4.8356 & 4.4861 & TRN & & \\
\hline CHEMBL 2440872 & 992729 & 4.2765 & 3.4612 & TRN & & \\
\hline CHEMBL 2440847 & 992729 & 4.7033 & 4.9447 & TST & & \\
\hline CHEMBL 2440835 & 992729 & 3.2636 & 2.7495 & TRN & & \\
\hline CHEMBL 2440871 & 992729 & 2.0 & 3.3455 & TRN & & \\
\hline CHEMBL 2440838 & 992729 & 2.0 & 3.0223 & TST & & \\
\hline CHEMBL 2440790 & 992729 & 4.8697 & 5.0202 & TRN & & \\
\hline
\end{tabular}




\begin{tabular}{|c|c|c|c|c|}
\hline \multicolumn{5}{|c|}{ Supplemental Table S2.txt } \\
\hline CHEMBL 2440856 & 992729 & 2.0 & 3.5752 & TST \\
\hline CHEMBL 2440798 & 992729 & 3.3605 & 3.6634 & TRN \\
\hline CHEMBL2440828 & 992729 & 4.5272 & 4.2455 & TST \\
\hline CHEMBL 2440865 & 992729 & 5.129 & 5.1277 & TRN \\
\hline CHEMBL 2440812 & 992729 & 4.9914 & 4.9999 & TRN \\
\hline CHEMBL 2440844 & 992729 & 2.0 & 3.696 & TST \\
\hline CHEMBL 2440841 & 992729 & 4.7055 & 3.5786 & TST \\
\hline CHEMBL 2440797 & 992729 & 5.2076 & 4.7375 & TRN \\
\hline CHEMBL 2440784 & 992729 & 4.7375 & 4.7694 & TRN \\
\hline CHEMBL 2440800 & 992729 & 5.3316 & 5.0127 & TRN \\
\hline CHEMBL 2440780 & 992729 & 4.064 & 4.2434 & TRN \\
\hline CHEMBL 2440809 & 992729 & 3.451 & 2.8331 & TRN \\
\hline CHEMBL 2440861 & 992729 & 5.118 & 5.2774 & TRN \\
\hline CHEMBL2440789 & 992729 & 4.9431 & 4.9322 & TRN \\
\hline CHEMBL 2440805 & 992729 & 4.7496 & 4.5806 & TRN \\
\hline CHEMBL 2440834 & 992729 & 2.0 & 2.6156 & TRN \\
\hline CHEMBL 2440840 & 992729 & 4.8013 & 3.9234 & TST \\
\hline CHEMBL 2440808 & 992729 & 2.0 & 3.1612 & TRN \\
\hline CHEMBL 2440848 & 992729 & 4.0246 & 4.0294 & TRN \\
\hline CHEMBL 2440810 & 992729 & 5.2596 & 5.2146 & TRN \\
\hline CHEMBL 2440818 & 992729 & 4.7595 & 5.0486 & TRN \\
\hline CHEMBL2440804 & 992729 & 4.7799 & 4.994 & TRN \\
\hline CHEMBL 2440863 & 992729 & 4.7852 & 4.7253 & TRN \\
\hline CHEMBL 2440851 & 992729 & 2.0 & 4.1216 & TST \\
\hline CHEMBL2440853 & 992729 & 2.0 & 2.8815 & TRN \\
\hline CHEMBL 2440821 & 992729 & 4.9586 & 5.2711 & TRN \\
\hline CHEMBL2440791 & 992729 & 4.062 & 4.2771 & TST \\
\hline CHEMBL 2440870 & 992729 & 2.0 & 4.3623 & TST \\
\hline CHEMBL2440833 & 992729 & 3.9957 & 3.167 & TRN \\
\hline CHEMBL 2440782 & 992729 & 3.9469 & 3.1109 & TST \\
\hline CHEMBL 3702654 & 1528447 & 4.0 & 3.9874 & TRN \\
\hline CHEMBL3702648 & 1528447 & 4.0 & 4.0495 & TRN \\
\hline CHEMBL3702601 & 1528447 & 5.5258 & 5.5878 & TRN \\
\hline CHEMBL3702617 & 1528447 & 6.5129 & 7.3945 & TST \\
\hline CHEMBL3702670 & 1528447 & 4.0 & 3.7965 & TRN \\
\hline CHEMBL3702639 & 1528447 & 4.0 & 3.9831 & TRN \\
\hline CHEMBL3702614 & 1528447 & 4.0 & 3.9634 & TRN \\
\hline CHEMBL3644547 & 1528447 & 5.6576 & 2.8182 & TST \\
\hline CHEMBL3644548 & 1528447 & 4.0 & 3.358 & TST \\
\hline CHEMBL3702666 & 1528447 & 6.983 & 7.0593 & TRN \\
\hline CHEMBL 3702660 & 1528447 & 5.0 & 5.059 & TRN \\
\hline CHEMBL3702603 & 1528447 & 6.9431 & 7.0803 & TRN \\
\hline CHEMBL3644549 & 1528447 & 5.0 & 2.4775 & TST \\
\hline CHEMBL3702627 & 1528447 & 4.0 & 3.8912 & TRN \\
\hline CHEMBL3702642 & 1528447 & 5.1965 & 5.2315 & TRN \\
\hline CHEMBL 3644546 & 1528447 & 4.0 & 4.523 & TST \\
\hline CHEMBL3702628 & 1528447 & 4.0 & 4.0694 & TRN \\
\hline CHEMBL 3644560 & 1528447 & 7.5686 & 7.5796 & TRN \\
\hline
\end{tabular}


Supplemental Table S2.txt

\begin{tabular}{|c|c|c|c|c|}
\hline נד & 28447 & & & \\
\hline & 528447 & 5.6716 & 6.7712 & \\
\hline & 47 & 72 & & \\
\hline IEMBL 3702623 & 28447 & & & \\
\hline IEMBL 3702606 & 528447 & 6.106 & & \\
\hline AEMBL 3702644 & 528447 & 4.0 & 282 & \\
\hline 535 & 28447 & 4.0 & & \\
\hline 571 & 528447 & & & \\
\hline AEMBL3 & .528447 & 6.5114 & & \\
\hline AEMBL3702612 & .528447 & 7.1739 & 7.2141 & \\
\hline 2622 & 528447 & 4.0 & & \\
\hline 508 & 528447 & 6.8386 & & \\
\hline 519 & 528447 & & & \\
\hline 662 & 1528447 & 7.5686 & 7.5824 & \\
\hline AEMBL & .528447 & 4.0 & & \\
\hline 550 & 152 & 4. & 7 & \\
\hline 56 & 17 & 9 & & \\
\hline 10 & 17 & & & \\
\hline 649 & 1528447 & 4.0 & & \\
\hline 07 & 7 & 6. & & \\
\hline 29 & 7 & 4. & & \\
\hline & 7 & 4.0 & & \\
\hline 40 & 17 & 4.0 & & \\
\hline 557 & & & & \\
\hline 557 & & & & \\
\hline 69 & 7 & 6.7 & & \\
\hline 21 & 7 & 5 & & \\
\hline 44 & 17 & 6.2 & & \\
\hline 555 & & $8 . e$ & & \\
\hline 2646 & 7 & 4. & & \\
\hline 668 & 7 & & & \\
\hline & 7 & 6. & & \\
\hline 45 & 7 & 6. & 6. & \\
\hline 630 & 15284 & 4.0 & & \\
\hline 645 & 528447 & 4.0 & & \\
\hline & & 7.2 & & \\
\hline $\mathrm{Cl}$ & 7 & 7. & & \\
\hline & & & & \\
\hline 611 & 528447 & 5.9281 & & TS \\
\hline 504 & $52 \varepsilon$ & 7.387 & & \\
\hline 24 & & 4. & & \\
\hline & 7 & 7.7696 & & \\
\hline 655 & 1528447 & 4.0 & & \\
\hline 658 & 1528447 & 5.0 & 81 & TR \\
\hline 58 & 1520 & 730 & & \\
\hline 561 & $152 \varepsilon$ & 8.09 & & \\
\hline 2626 & 1528447 & 4.0 & 3.9333 & \\
\hline CHEMBL3644552 & 1528447 & 7.4089 & 6.9361 & \\
\hline
\end{tabular}

Page 13709 
Supplemental Table S2.txt

\begin{tabular}{|c|c|c|c|c|c|c|}
\hline CHEMBL3702616 & 1528447 & 5.3925 & 7.2996 & TST & & \\
\hline CHEMBL3702632 & 1528447 & 4.0 & 3.8386 & TRN & & \\
\hline CHEMBL3702631 & 1528447 & 4.0 & 4.0668 & TRN & & \\
\hline CHEMBL3702602 & 1528447 & 7.6778 & 7.4139 & TRN & & \\
\hline CHEMBL3702637 & 1528447 & 4.0 & 4.1324 & TRN & & \\
\hline CHEMBL3702625 & 1528447 & 4.0 & 4.1329 & TRN & & \\
\hline CHEMBL3702667 & 1528447 & 6.1952 & 6.1585 & TRN & & \\
\hline CHEMBL3702653 & 1528447 & 4.0 & 3.9457 & TST & & \\
\hline CHEMBL3702663 & 1528447 & 7.8539 & 8.0296 & TRN & & \\
\hline CHEMBL3702659 & 1528447 & 7.5086 & 7.4182 & TRN & & \\
\hline CHEMBL 3702641 & 1528447 & 4.0 & 4.059 & TRN & & \\
\hline CHEMBL3644556 & 1528447 & 6.4353 & 7.28299 & 999999999 & 95 & TST \\
\hline CHEMBL3702605 & 1528447 & 7.7212 & 7.7398 & TRN & & \\
\hline CHEMBL3702613 & 1528447 & 4.0 & 4.0346 & TRN & & \\
\hline CHEMBL3702651 & 1528447 & 4.0 & 4.0237 & TRN & & \\
\hline CHEMBL3702652 & 1528447 & 4.0 & 3.9867 & TRN & & \\
\hline CHEMBL3702633 & 1528447 & 4.0 & 3.9128 & TRN & & \\
\hline CHEMBL 3644551 & 1528447 & 6.3429 & 4.1801 & TST & & \\
\hline CHEMBL3702609 & 1528447 & 7.6576 & 7.6445 & TRN & & \\
\hline CHEMBL3702638 & 1528447 & 4.0 & 3.8712 & TRN & & \\
\hline CHEMBL3702634 & 1528447 & 4.0 & 4.0987 & TRN & & \\
\hline CHEMBL3702647 & 1528447 & 4.0 & 3.9982 & TRN & & \\
\hline CHEMBL3649411 & 1536390 & 8.0655 & 8.1974 & TRN & & \\
\hline CHEMBL3649366 & 1536390 & 4.6021 & 6.4301 & TST & & \\
\hline CHEMBL3649409 & 1536390 & 8.0269 & 8.0815 & TRN & & \\
\hline CHEMBL 3649420 & 1536390 & 8.2147 & 8.1298 & TRN & & \\
\hline CHEMBL3649391 & 1536390 & 7.6308 & 7.6591 & TRN & & \\
\hline CHEMBL3649395 & 1536390 & 7.5528 & 7.5828 & TRN & & \\
\hline CHEMBL 3649408 & 1536390 & 6.5487 & 6.5295 & TRN & & \\
\hline CHEMBL3649413 & 1536390 & 8.7696 & 8.3068 & TRN & & \\
\hline CHEMBL3649387 & 1536390 & 5.50799 & 99999999 & 99 & 6.579 & TST \\
\hline CHEMBL3649362 & 1536390 & 5.7179 & 6.2456 & TST & & \\
\hline CHEMBL 3649378 & 1536390 & 7.9957 & 8.1652 & TRN & & \\
\hline CHEMBL 3649400 & 1536390 & 7.9431 & 8.0583 & TRN & & \\
\hline CHEMBL3649374 & 1536390 & 7.9469 & 8.01100 & 200000000 & & TRN \\
\hline CHEMBL3649414 & 1536390 & 8.585 & 8.4428 & TRN & & \\
\hline CHEMBL3649410 & 1536390 & 8.699 & 8.5395 & TRN & & \\
\hline CHEMBL3649399 & 1536390 & 7.9747 & 7.944 & TRN & & \\
\hline CHEMBL 3649370 & 1536390 & 8.3279 & 8.1966 & TRN & & \\
\hline CHEMBL3649363 & 1536390 & 5.5863 & 6.3563 & TST & & \\
\hline CHEMBL 3649380 & 1536390 & 7.4895 & 7.5402 & TRN & & \\
\hline CHEMBL3649403 & 1536390 & 7.9318 & 7.9438 & TRN & & \\
\hline CHEMBL3649422 & 1536390 & 8.2218 & 8.1538 & TRN & & \\
\hline CHEMBL3649372 & 1536390 & 7.1993 & 7.235 & TRN & & \\
\hline CHEMBL3649365 & 1536390 & 6.25899 & 99999999 & 995 & 6.6632 & TST \\
\hline CHEMBL3649398 & 1536390 & 7.82100 & 000000006 & $\partial 1$ & 7.7682 & TRN \\
\hline CHEMBL3649421 & 1536390 & 8.2076 & 8.1522 & TRN & & \\
\hline CHEMBL3649379 & 1536390 & 8.0757 & 8.141 & TRN & & \\
\hline
\end{tabular}


Supplemental Table S2.txt

\begin{tabular}{|c|c|c|c|c|}
\hline CHEMBL3649385 & 1536390 & 7.9666 & 7.9878 & TRN \\
\hline CHEMBL3649415 & 1536390 & 8.585 & 8.3124 & TRN \\
\hline CHEMBL3649369 & 1536390 & 8.3665 & 8.2263 & TRN \\
\hline CHEMBL3649406 & 1536390 & 7.1255 & 7.2 & TRN \\
\hline CHEMBL3649393 & 1536390 & 8.1135 & 8.408999 & 999999999 \\
\hline CHEMBL3649396 & 1536390 & 8.0088 & 8.2557 & TRN \\
\hline CHEMBL3649373 & 1536390 & 7.6737 & 7.6697 & TST \\
\hline CHEMBL3649381 & 1536390 & 7.7328 & 7.55 & TRN \\
\hline CHEMBL3649371 & 1536390 & 7.2565 & 7.3573 & TRN \\
\hline CHEMBL3649367 & 1536390 & 6.6942 & 7.0579 & TST \\
\hline CHEMBL 3649375 & 1536390 & 7.983 & 8.0308 & TRN \\
\hline CHEMBL3639482 & 1536390 & 7.8861 & 7.8668 & TRN \\
\hline CHEMBL 3649404 & 1536390 & 7.8665 & 8.0498 & TRN \\
\hline CHEMBL3649389 & 1536390 & 8.28399 & 99999999 & 8.0602 \\
\hline CHEMBL 3649386 & 1536390 & 8.0088 & 8.0043 & TRN \\
\hline CHEMBL3649419 & 1536390 & 8.1938 & 7.9505 & TRN \\
\hline CHEMBL3649376 & 1536390 & 8.0862 & 8.2333 & TRN \\
\hline CHEMBL 3649394 & 1536390 & 7.8665 & 8.2414 & TRN \\
\hline CHEMBL 3649407 & 1536390 & 7.1733 & 7.1475 & TRN \\
\hline CHEMBL 3649383 & 1536390 & 7.5751 & 7.4912 & TRN \\
\hline CHEMBL 3649417 & 1536390 & 7.6038 & 7.7422 & TRN \\
\hline CHEMBL 3649412 & 1536390 & 8.0269 & 7.8341 & TRN \\
\hline CHEMBL3649416 & 1536390 & 7.6861 & 7.8256 & TRN \\
\hline CHEMBL3649377 & 1536390 & 8.2291 & 8.2649 & TRN \\
\hline CHEMBL 3649390 & 1536390 & 7.7352 & 8.0317 & TRN \\
\hline CHEMBL 3649401 & 1536390 & 7.5243 & 7.5035 & TRN \\
\hline CHEMBL 3649388 & 1536390 & 5.1678 & 6.7794 & TST \\
\hline CHEMBL 3649402 & 1536390 & 7.9318 & 7.6887 & TRN \\
\hline CHEMBL3649405 & 1536390 & 7.8665 & 7.9557 & TST \\
\hline CHEMBL3649397 & 1536390 & 7.7825 & 7.7984 & TST \\
\hline CHEMBL 3649392 & 1536390 & 7.9508 & 8.4036 & TST \\
\hline CHEMBL 3649384 & 1536390 & 7.3757 & 7.7344 & TST \\
\hline CHEMBL 3649418 & 1536390 & 9.0458 & 8.0835 & TST \\
\hline CHEMBL3649368 & 1536390 & 5.5171 & 6.7736 & TST \\
\hline CHEMBL 3649382 & 1536390 & 7.5421 & 7.55 & TST \\
\hline CHEMBL 3649364 & 1536390 & 5.8095 & 6.8782 & TST \\
\hline CHEMBL1259033 & 665765 & 7.5686 & 7.2883 & TRN \\
\hline CHEMBL1259032 & 665765 & 7.5686 & 7.2026 & TRN \\
\hline CHEMBL1259053 & 665765 & 6.041 & 6.2664 & TRN \\
\hline CHEMBL1259035 & 665765 & 6.7447 & 7.0804 & TST \\
\hline CHEMBL1259074 & 665765 & 5.4559 & 5.9394 & TRN \\
\hline CHEMBL1259198 & 665765 & 7.7447 & 8.0927 & TRN \\
\hline CHEMBL1259055 & 665765 & 6.4202 & 5.914 & TRN \\
\hline CHEMBL1258997 & 665765 & 5.8861 & 7.0779 & TST \\
\hline CHEMBL1259154 & 665765 & 6.9208 & 7.3054 & TRN \\
\hline CHEMBL1259167 & 665765 & 6.4685 & 6.814 & TRN \\
\hline CHEMBL1259242 & 665765 & 6.7212 & 7.2486 & TRN \\
\hline CHEMBL1258996 & 665765 & 5.8861 & 7.2503 & TST \\
\hline
\end{tabular}

Page 13711 


\begin{tabular}{|c|c|c|c|c|c|}
\hline \multicolumn{6}{|c|}{ Supplemental Table S2.txt } \\
\hline CHEMBL1259180 & 665765 & 7.1612 & 6.666 & TRN & \\
\hline CHEMBL1259152 & 665765 & 7.4559 & 7.4516 & TRN & \\
\hline CHEMBL1259087 & 665765 & 7.4949 & 7.5204 & TRN & \\
\hline CHEMBL1259163 & 665765 & 6.5229 & 6.6122 & TRN & \\
\hline CHEMBL1259036 & 665765 & 7.2924 & 7.1335 & TRN & \\
\hline CHEMBL1259197 & 665765 & 6.4949 & 7.6845 & TST & \\
\hline CHEMBL1259166 & 665765 & 8.3188 & 7.7981 & TRN & \\
\hline CHEMBL1259225 & 665765 & 6.3468 & 6.8409 & TRN & \\
\hline CHEMBL1259224 & 665765 & 7.0362 & 7.5031 & TST & \\
\hline CHEMBL1259182 & 665765 & 8.0506 & 7.9961 & TRN & \\
\hline CHEMBL1259014 & 665765 & 6.3279 & 6.724 & TST & \\
\hline CHEMBL1259226 & 665765 & 6.4437 & 6.9009 & TRN & \\
\hline CHEMBL1259155 & 665765 & 7.9586 & 7.9004 & TRN & \\
\hline CHEMBL1259241 & 665765 & 8.5686 & 7.73799 & 99999999995 & TRN \\
\hline CHEMBL1259072 & 665765 & 7.7212 & 7.7162 & TRN & \\
\hline CHEMBL1259051 & 665765 & 6.7399 & 7.2174 & TRN & \\
\hline CHEMBL1259121 & 665765 & 7.8539 & 7.36299 & 99999999995 & TRN \\
\hline CHEMBL1259052 & 665765 & 6.1805 & 6.3118 & TRN & \\
\hline CHEMBL1259211 & 665765 & 6.3768 & 6.9326 & TRN & \\
\hline CHEMBL1259210 & 665765 & 7.7212 & 7.4014 & TST & \\
\hline CHEMBL1259223 & 665765 & 7.9586 & 7.3206 & TST & \\
\hline CHEMBL1259168 & 665765 & 6.9586 & 7.6169 & TRN & \\
\hline CHEMBL1259109 & 665765 & 7.3372 & 7.21399 & 99999999995 & TRN \\
\hline CHEMBL1259108 & 665765 & 7.4318 & 7.38299 & 9999999999 & TRN \\
\hline CHEMBL1259200 & 665765 & 7.7696 & 7.7757 & TRN & \\
\hline CHEMBL1259240 & 665765 & 7.5376 & 7.3505 & TST & \\
\hline CHEMBL1259016 & 665765 & 7.1938 & 7.3967 & TRN & \\
\hline CHEMBL1259106 & 665765 & 7.585 & 7.6168 & TRN & \\
\hline CHEMBL1259124 & 665765 & 7.1308 & 7.7127 & TST & \\
\hline CHEMBL1259089 & 665765 & 7.699 & 7.4493 & TRN & \\
\hline CHEMBL1258998 & 665765 & 6.6576 & 7.6492 & TRN & \\
\hline CHEMBL1258999 & 665765 & 8.3768 & 7.6836 & TRN & \\
\hline CHEMBL1259239 & 665765 & 6.9208 & 7.5962 & TST & \\
\hline CHEMBL1259153 & 665765 & 7.7447 & 7.5443 & TRN & \\
\hline CHEMBL1259140 & 665765 & 7.1024 & 6.9859 & TRN & \\
\hline CHEMBL1259199 & 665765 & 6.301 & 6.8764 & TRN & \\
\hline CHEMBL1259017 & 665765 & 7.0315 & 7.3872 & TST & \\
\hline CHEMBL1259164 & 665765 & 6.4815 & 6.9136 & TRN & \\
\hline CHEMBL1259034 & 665765 & 7.2076 & 7.4146 & TRN & \\
\hline CHEMBL1259071 & 665765 & 8.2076 & 7.7693 & TRN & \\
\hline CHEMBL1259196 & 665765 & 6.7959 & 7.2568 & TST & \\
\hline CHEMBL1259088 & 665765 & 7.7959 & 7.6461 & TRN & \\
\hline CHEMBL1259181 & 665765 & 7.8239 & 7.0684 & TRN & \\
\hline CHEMBL1259090 & 665765 & 7.4949 & 7.7297 & TST & \\
\hline CHEMBL1259165 & 665765 & 7.2518 & 7.8051 & TRN & \\
\hline CHEMBL1259073 & 665765 & 6.041 & 5.8954 & TRN & \\
\hline CHEMBL1259212 & 665765 & 6.3279 & 6.8327 & TRN & \\
\hline CHEMBL1259138 & 665765 & 7.6778 & 7.6401 & TRN & \\
\hline
\end{tabular}




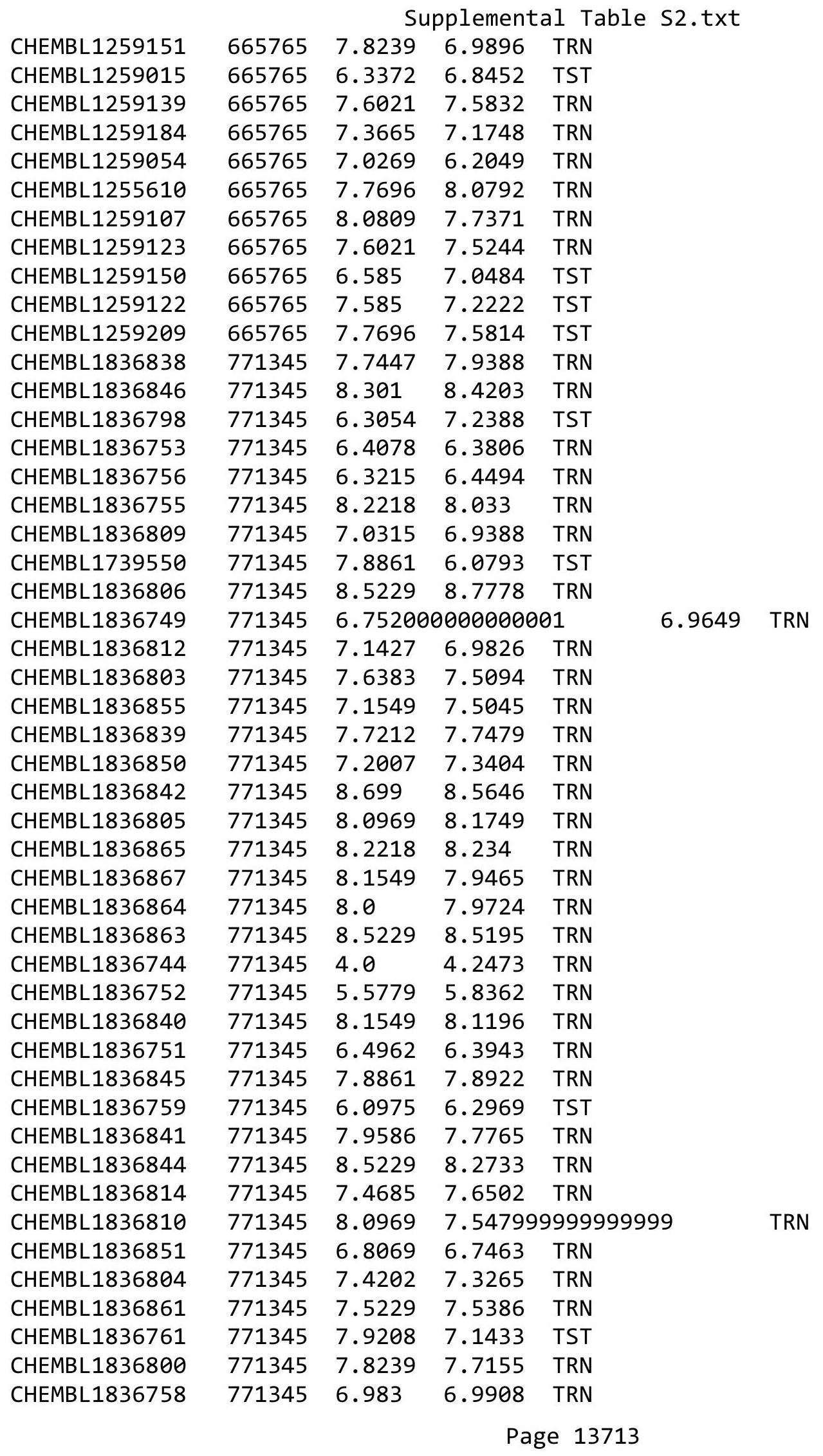




\begin{tabular}{|c|c|c|c|c|c|}
\hline \multicolumn{6}{|c|}{ Supplemental Table S2.txt } \\
\hline CHEMBL1836796 & 771345 & 7.9586 & 8.1225 & TRN & \\
\hline CHEMBL1836754 & 771345 & 8.0 & 7.9681 & TRN & \\
\hline CHEMBL1836757 & 771345 & 7.0132 & 6.9005 & TRN & \\
\hline CHEMBL1836797 & 771345 & 7.1249 & 7.0532 & TRN & \\
\hline CHEMBL1836847 & 771345 & 8.0 & 8.1031 & TRN & \\
\hline CHEMBL1836743 & 771345 & 5.817 & 5.6175 & TRN & \\
\hline CHEMBL1836815 & 771345 & 8.0 & 8.1996 & TRN & \\
\hline CHEMBL1836848 & 771345 & 6.9066 & 7.5219 & TRN & \\
\hline CHEMBL1836852 & 771345 & 6.8069 & 6.7256 & TRN & \\
\hline CHEMBL1836808 & 771345 & 7.1675 & 7.0652 & TRN & \\
\hline CHEMBL1836854 & 771345 & 8.5229 & 8.1835 & TRN & \\
\hline CHEMBL1836811 & 771345 & 6.4214 & 6.436 & TRN & \\
\hline CHEMBL1836745 & 771345 & 4.0 & 4.1543 & TRN & \\
\hline CHEMBL1836853 & 771345 & 8.0 & 8.0468 & TRN & \\
\hline CHEMBL1836747 & 771345 & 6.5918 & 6.6474 & TRN & \\
\hline CHEMBL1836746 & 771345 & 4.0 & 3.7053 & TRN & \\
\hline CHEMBL1836866 & 771345 & 6.301 & 6.9442 & TST & \\
\hline CHEMBL1836807 & 771345 & 7.7959 & 7.6819 & TST & \\
\hline CHEMBL1836760 & 771345 & 8.0 & 6.0592 & TST & \\
\hline CHEMBL1836750 & 771345 & 6.4498 & 6.631 & TST & \\
\hline CHEMBL1836802 & 771345 & 8.1549 & 7.3852 & TST & \\
\hline CHEMBL1836799 & 771345 & 8.0 & 6.5141 & TST & \\
\hline CHEMBL1836748 & 771345 & 7.2924 & 7.0222 & TST & \\
\hline CHEMBL1836801 & 771345 & 7.4949 & 8.3644 & TST & \\
\hline CHEMBL1836837 & 771345 & 7.7959 & 8.15200 & 0000000001 & TST \\
\hline CHEMBL1836862 & 771345 & 8.0458 & 8.2128 & TST & \\
\hline CHEMBL1836843 & 771345 & 8.0 & 8.2883 & TST & \\
\hline CHEMBL1836813 & 771345 & 7.2218 & 7.2312 & TST & \\
\hline CHEMBL1836849 & 771345 & 7.1938 & 7.2468 & TST & \\
\hline CHEMBL3664713 & 1527877 & 8.5272 & 8.5988 & TRN & \\
\hline CHEMBL3664703 & 1527877 & 8.3686 & 8.4351 & TRN & \\
\hline CHEMBL3664702 & 1527877 & 7.0205 & 8.2185 & TST & \\
\hline CHEMBL3664637 & 1527877 & 7.4551 & 7.4193 & TRN & \\
\hline CHEMBL1829759 & 1527877 & 9.1427 & 9.2316 & TRN & \\
\hline CHEMBL3664716 & 1527877 & 9.0177 & 8.8524 & TRN & \\
\hline CHEMBL3664673 & 1527877 & 8.6968 & 8.6528 & TRN & \\
\hline CHEMBL3664643 & 1527877 & 8.9547 & 9.1371 & TRN & \\
\hline CHEMBL3664678 & 1527877 & 8.7011 & 8.7084 & TRN & \\
\hline CHEMBL3664667 & 1527877 & 8.8539 & 8.8453 & TRN & \\
\hline CHEMBL3664711 & 1527877 & 8.4461 & 8.5327 & TRN & \\
\hline CHEMBL 3664725 & 1527877 & 8.4962 & 8.5337 & TRN & \\
\hline CHEMBL3664647 & 1527877 & 8.4572 & 8.53 & TRN & \\
\hline CHEMBL3664694 & 1527877 & 8.7986 & 8.8581 & TRN & \\
\hline CHEMBL3664693 & 1527877 & 6.0 & 8.38600 & 0000000001 & TST \\
\hline CHEMBL3664721 & 1527877 & 6.0 & 8.4655 & TST & \\
\hline CHEMBL3664672 & 1527877 & 8.8327 & 8.8633 & TRN & \\
\hline CHEMBL3664695 & 1527877 & 8.7447 & 8.7523 & TRN & \\
\hline CHEMBL3664712 & 1527877 & 8.6517 & 8.5052 & TRN & \\
\hline
\end{tabular}

Page 13714 
Supplemental Table S2.txt

\begin{tabular}{|c|c|c|c|c|c|}
\hline CHEMBL3664722 & 1527877 & 7.3675 & 8.5466 & TST & \\
\hline CHEMBL3664635 & 1527877 & 8.821 & 8.9152 & TRN & \\
\hline CHEMBL3664657 & 1527877 & 8.9872 & 8.8456 & TRN & \\
\hline CHEMBL3645520 & 1527877 & 9.1135 & 9.3622 & TST & \\
\hline CHEMBL3664719 & 1527877 & 9.1871 & 9.1068 & TRN & \\
\hline CHEMBL1829763 & 1527877 & 9.1249 & 9.0226 & TRN & \\
\hline CHEMBL3664668 & 1527877 & 8.6055 & 8.6268 & TRN & \\
\hline CHEMBL 3664677 & 1527877 & 8.3936 & 8.3729 & TRN & \\
\hline CHEMBL3664679 & 1527877 & 8.8539 & 8.9015 & TRN & \\
\hline CHEMBL3664666 & 1527877 & 9.1249 & 9.0559 & TRN & \\
\hline CHEMBL1829782 & 1527877 & 8.7471 & 9.0481 & TST & \\
\hline CHEMBL3664706 & 1527877 & 8.7011 & 8.7133 & TRN & \\
\hline CHEMBL3664699 & 1527877 & 9.0458 & 8.8762 & TRN & \\
\hline CHEMBL3664718 & 1527877 & 8.8153 & 8.8382 & TRN & \\
\hline CHEMBL 3664648 & 1527877 & 8.0453 & 8.3074 & TRN & \\
\hline CHEMBL3664676 & 1527877 & 8.9957 & 8.9555 & TRN & \\
\hline CHEMBL3664720 & 1527877 & 8.9172 & 9.019 & TRN & \\
\hline CHEMBL 3664645 & 1527877 & 8.4318 & 8.3946 & TRN & \\
\hline CHEMBL3664707 & 1527877 & 8.6308 & 8.5682 & TRN & \\
\hline CHEMBL1829761 & 1527877 & 9.2596 & 9.3733 & TRN & \\
\hline CHEMBL3664670 & 1527877 & 8.7852 & 8.7775 & TRN & \\
\hline CHEMBL 3664671 & 1527877 & 9.0969 & 9.0368 & TRN & \\
\hline CHEMBL3664717 & 1527877 & 8.7905 & 8.8739 & TRN & \\
\hline CHEMBL 3664690 & 1527877 & 6.0 & 8.3953 & TST & \\
\hline CHEMBL 3645527 & 1527877 & 8.8861 & 8.9183 & TRN & \\
\hline CHEMBL3664651 & 1527877 & 8.7305 & 8.7726 & TRN & \\
\hline CHEMBL 3664710 & 1527877 & 8.8416 & 8.7206 & TRN & \\
\hline CHEMBL3645526 & 1527877 & 9.1192 & 9.0453 & TRN & \\
\hline CHEMBL 3664654 & 1527877 & 8.9666 & 8.9872 & TRN & \\
\hline CHEMBL3645523 & 1527877 & 8.8297 & 9.0821 & TRN & \\
\hline CHEMBL 3664714 & 1527877 & 8.6925 & 8.6474 & TRN & \\
\hline CHEMBL 3645521 & 1527877 & 8.7447 & 9.0342 & TST & \\
\hline CHEMBL3664669 & 1527877 & 8.4145 & 8.346 & TRN & \\
\hline CHEMBL3664646 & 1527877 & 8.8268 & 8.8621 & TRN & \\
\hline CHEMBL3664650 & 1527877 & 8.8827 & 8.7774 & TRN & \\
\hline CHEMBL3664642 & 1527877 & 8.2692 & 8.2724 & TRN & \\
\hline CHEMBL3664689 & 1527877 & 8.9208 & 8.8874 & TRN & \\
\hline CHEMBL3664658 & 1527877 & 8.2628 & 8.2088 & TRN & \\
\hline CHEMBL 3664724 & 1527877 & 8.5528 & 8.5679 & TRN & \\
\hline CHEMBL3664698 & 1527877 & 8.1415 & 8.30299 & 9999999999 & TRN \\
\hline CHEMBL3664665 & 1527877 & 9.0605 & 9.1569 & TRN & \\
\hline CHEMBL 3664641 & 1527877 & 8.2262 & 8.1234 & TRN & \\
\hline CHEMBL3664656 & 1527877 & 8.3726 & 8.7347 & TST & \\
\hline CHEMBL 3664644 & 1527877 & 9.2366 & 8.9077 & TST & \\
\hline CHEMBL1829777 & 1527877 & 9.0044 & 8.9569 & TRN & \\
\hline CHEMBL3664652 & 1527877 & 8.0325 & 7.9735 & TRN & \\
\hline CHEMBL3664655 & 1527877 & 8.8013 & 8.965 & TRN & \\
\hline CHEMBL 3645522 & 1527877 & 8.8416 & 9.1013 & TST & \\
\hline
\end{tabular}


Supplemental Table S2.txt

\begin{tabular}{|c|c|c|c|c|c|c|}
\hline CHEMBL 3664663 & 1527877 & 8.9872 & 9.0713 & TRN & & \\
\hline CHEMBL3664653 & 1527877 & 8.6517 & 8.7494 & TRN & & \\
\hline CHEMBL3664715 & 1527877 & 8.7773 & 8.7469 & TRN & & \\
\hline CHEMBL3664636 & 1527877 & 9.5086 & 9.0977 & TRN & & \\
\hline CHEMBL 3645528 & 1527877 & 9.1024 & 9.1833 & TRN & & \\
\hline CHEMBL3664649 & 1527877 & 8.2857 & 8.433 & TRN & & \\
\hline CHEMBL3664660 & 1527877 & 8.8697 & 8.7934 & TRN & & \\
\hline CHEMBL 3664638 & 1527877 & 7.7368 & 7.7658 & TRN & & \\
\hline CHEMBL 3664709 & 1527877 & $8.8570 e$ & 0000000 & 01 & 8.8185 & TRI \\
\hline CHEMBL 3645524 & 1527877 & 9.2596 & 9.1907 & TRN & & \\
\hline CHEMBL 3664723 & 1527877 & 8.8539 & 8.8504 & TRN & & \\
\hline CHEMBL1829768 & 1527877 & 9.2924 & 9.0819 & TRN & & \\
\hline CHEMBL 3664674 & 1527877 & 9.0177 & 9.02700 & 000000000 & & RN \\
\hline CHEMBL3664692 & 1527877 & 6.0 & 8.566 & TST & & \\
\hline CHEMBL 3664639 & 1527877 & 8.3675 & 7.9391 & TST & & \\
\hline CHEMBL 3664640 & 1527877 & 8.5361 & 8.2997 & TST & & \\
\hline CHEMBL3664675 & 1527877 & 9.1427 & 8.6796 & TST & & \\
\hline CHEMBL3664696 & 1527877 & 8.9031 & 8.8813 & TST & & \\
\hline CHEMBL 3664697 & 1527877 & 8.6271 & 8.0545 & TST & & \\
\hline CHEMBL 3639635 & 1527877 & 9.2147 & 8.9666 & TST & & \\
\hline CHEMBL 3664662 & 1527877 & 8.7799 & 9.088 & TST & & \\
\hline CHEMBL3664664 & 1527877 & 8.8996 & 9.0702 & TST & & \\
\hline CHEMBL3664688 & 1527877 & 7.9172 & 8.3226 & TST & & \\
\hline CHEMBL 3645525 & 1527877 & 8.9666 & 9.4157 & TST & & \\
\hline CHEMBL 3664661 & 1527877 & 8.6198 & 8.9994 & TST & & \\
\hline CHEMBL303227 & 49558 & 8.8861 & 7.9718 & TRN & & \\
\hline CHEMBL 73745 & 49558 & 6.5686 & 5.9993 & TRN & & \\
\hline CHEMBL306271 & 49558 & 3.0 & 4.6775 & TST & & \\
\hline CHEMBL 70405 & 49558 & 5.5229 & 4.0284 & TRN & & \\
\hline CHEMBL307659 & 49558 & \multicolumn{3}{|c|}{6.821000000000001} & 6.7147 & Км \\
\hline CHEMBL308756 & 49558 & 5.4437 & 4.9409 & TRN & & \\
\hline CHEMBL306958 & 49558 & 6.0458 & 5.303 & TRN & & \\
\hline CHEMBL1907849 & 49558 & 6.0 & 7.1357 & TRN & & \\
\hline CHEMBL 74181 & 49558 & 5.3188 & 5.3992 & TRN & & \\
\hline CHEMBL 72894 & 49558 & 4.8861 & 6.1937 & TRN & & \\
\hline CHEMBL 70550 & 49558 & 6.8239 & 6.6049 & TRN & & \\
\hline CHEMBL 72667 & 49558 & 6.9208 & 6.9182 & TRN & & \\
\hline CHEMBL1907846 & 49558 & 6.0 & 7.773 & TRN & & \\
\hline CHEMBL 2092869 & 49558 & 6.0 & 6.8058 & TRN & & \\
\hline CHEMBL302359 & 49558 & 6.6198 & 6.2764 & TRN & & \\
\hline CHEMBL 72616 & 49558 & 6.301 & 6.7813 & TRN & & \\
\hline CHEMBL 74125 & 49558 & 7.0915 & 7.1406 & TRN & & \\
\hline CHEMBL1907847 & 49558 & 7.3665 & 7.0679 & TRN & & \\
\hline CHEMBL 72710 & 49558 & 6.1367 & 6.87 & TRN & & \\
\hline CHEMBL308769 & 49558 & 5.5686 & 3.5766 & TST & & \\
\hline CHEMBL306396 & 49558 & 3.0 & 4.079 & TST & & \\
\hline CHEMBL306369 & 49558 & 6.0458 & 5.0741 & TST & & \\
\hline CHEMBL 70456 & 49558 & 8.8539 & 8.6199 & TRN & & \\
\hline
\end{tabular}

Page 13716 


\begin{tabular}{|c|c|c|c|c|c|}
\hline & & \multicolumn{4}{|c|}{ Supplemental Table S2.txt } \\
\hline CHEMBL70499 & 49558 & 5.8239 & 5.3323 & TRN & \\
\hline CHEMBL74066 & 49558 & 7.1487 & 7.2213 & TRN & \\
\hline CHEMBL73621 & 49558 & 7.4949 & 7.4485 & TRN & \\
\hline CHEMBL 308414 & 49558 & 7.1487 & 7.5991 & TRN & \\
\hline CHEMBL73522 & 49558 & 6.0 & 8.3716 & TRN & \\
\hline CHEMBL73535 & 49558 & 6.0 & 4.0829 & TST & \\
\hline CHEMBL 74170 & 49558 & 4.5686 & 4.0752 & TRN & \\
\hline CHEMBL1907854 & 49558 & 6.0 & 6.3095 & TRN & \\
\hline CHEMBL70856 & 49558 & 8.0458 & 7.7489 & TRN & \\
\hline CHEMBL419997 & 49558 & 4.0 & 5.0143 & TRN & \\
\hline CHEMBL 308404 & 49558 & 5.5086 & 3.8011 & TST & \\
\hline CHEMBL 70593 & 49558 & 7.7447 & \multicolumn{3}{|c|}{8.283999999999999} \\
\hline CHEMBL 307370 & 49558 & 5.9586 & \multicolumn{3}{|c|}{5.6370000000000005} \\
\hline CHEMBL70259 & 49558 & 6.0 & 5.1624 & TST & \\
\hline CHEMBL13095 & 49558 & 4.3768 & 4.5917 & TST & \\
\hline CHEMBL1907848 & 49558 & 9.0969 & 7.7657 & TRN & \\
\hline CHEMBL422951 & 49558 & 7.699 & 7.901 & TRN & \\
\hline CHEMBL 72727 & 49558 & 5.7696 & 5.7697 & TRN & \\
\hline CHEMBL1907851 & 49558 & 8.4559 & 7.9558 & TRN & \\
\hline CHEMBL431185 & 49558 & 4.2366 & 3.7672 & TST & \\
\hline CHEMBL71079 & 49558 & 8.8539 & 7.9846 & TRN & \\
\hline CHEMBL 308111 & 49558 & 8.301 & 6.794 & TRN & \\
\hline CHEMBL73510 & 49558 & 7.6778 & 7.3238 & TRN & \\
\hline CHEMBL302825 & 49558 & 7.1805 & 7.4547 & TST & \\
\hline CHEMBL72670 & 49558 & 4.0 & 4.9457 & TRN & \\
\hline CHEMBL422411 & 49558 & 6.0 & 5.3018 & TRN & \\
\hline CHEMBL 306394 & 49558 & 6.3188 & 6.8074 & TRN & \\
\hline CHEMBL 72300 & 49558 & 8.2218 & 7.5884 & TRN & \\
\hline CHEMBL1907852 & 49558 & 6.0 & 7.5523 & TST & \\
\hline CHEMBL 302282 & 49558 & 5.8539 & 5.8768 & TRN & \\
\hline CHEMBL72841 & 49558 & 5.1249 & 5.4425 & TRN & \\
\hline CHEMBL306806 & 49558 & 8.6778 & 8.0404 & TRN & \\
\hline CHEMBL 70896 & 49558 & 6.5229 & 6.3403 & TRN & \\
\hline CHEMBL303386 & 49558 & 6.1549 & 4.8017 & TST & \\
\hline CHEMBL73096 & 49558 & 4.6091 & 4.8758 & TST & \\
\hline CHEMBL 73272 & 49558 & 6.9586 & 6.4608 & TRN & \\
\hline CHEMBL73561 & 49558 & 7.8239 & 7.1338 & TRN & \\
\hline CHEMBL1907850 & 49558 & 9.0969 & 7.4522 & TST & \\
\hline CHEMBL310250 & 49558 & 5.7447 & 6.2689 & TRN & \\
\hline CHEMBL1907841 & 49558 & 6.0 & 7.184 & TST & \\
\hline CHEMBL1907667 & 49558 & 5.4685 & 6.2448 & TST & \\
\hline CHEMBL 309017 & 49558 & 5.7959 & 6.2572 & TRN & \\
\hline CHEMBL1907840 & 49558 & 6.0 & 6.5588 & TST & \\
\hline CHEMBL 73885 & 49558 & 8.3279 & 7.6703 & TRN & \\
\hline CHEMBL308297 & 49558 & 4.0 & 4.1189 & TRN & \\
\hline CHEMBL 307878 & 49558 & 6.699 & 6.6868 & TRN & \\
\hline CHEMBL1907660 & 49558 & 5.7959 & 5.8321 & TST & \\
\hline \multirow[t]{2}{*}{ CHEMBL306760 } & 49558 & 8.3279 & 7.74700 & 000000001 & KIN \\
\hline & & \multicolumn{3}{|c|}{ Page 13717} & \\
\hline
\end{tabular}




\begin{tabular}{|c|c|c|c|c|c|}
\hline \multicolumn{6}{|c|}{ Supplemental Table S2.txt } \\
\hline CHEMBL72057 & 49558 & 4.3979 & 5.2722 & TRN & \\
\hline CHEMBL 70549 & 49558 & 7.6576 & 5.4387 & TST & \\
\hline CHEMBL73110 & 49558 & 4.699 & 5.5975 & TRN & \\
\hline CHEMBL73563 & 49558 & 6.0 & 6.21399 & 99999999995 & TST \\
\hline CHEMBL 72073 & 49558 & 8.0809 & 7.2361 & TST & \\
\hline CHEMBL309575 & 49558 & 6.6576 & 6.3537 & TRN & \\
\hline CHEMBL304768 & 49558 & 7.5528 & 6.8447 & TST & \\
\hline CHEMBL72599 & 49558 & 7.0177 & 7.8289 & TRN & \\
\hline CHEMBL72550 & 49558 & 7.0605 & 6.8407 & TRN & \\
\hline CHEMBL303724 & 49558 & 6.9586 & 6.8077 & TRN & \\
\hline CHEMBL 74580 & 49558 & 7.3872 & 7.5583 & TRN & \\
\hline CHEMBL 74515 & 49558 & 7.5376 & 7.1568 & TRN & \\
\hline CHEMBL73892 & 49558 & 5.2596 & 6.2959 & TRN & \\
\hline CHEMBL307661 & 49558 & 8.8239 & 9.0229 & TRN & \\
\hline CHEMBL72491 & 49558 & 4.0 & 5.5511 & TRN & \\
\hline CHEMBL443009 & 49558 & 7.9586 & 6.534 & TRN & \\
\hline CHEMBL39263 & 49558 & 9.0969 & 8.0605 & TRN & \\
\hline CHEMBL40668 & 49558 & 6.9586 & 8.0442 & TST & \\
\hline CHEMBL597714 & 607926 & 5.8539 & 6.0241 & TST & \\
\hline CHEMBL598114 & 607926 & 5.7696 & 5.5769 & TRN & \\
\hline CHEMBL596662 & 607926 & 4.8861 & 5.1824 & TRN & \\
\hline CHEMBL599129 & 607926 & 5.1079 & 5.4509 & TRN & \\
\hline CHEMBL598522 & 607926 & 7.0915 & 6.5899 & TRN & \\
\hline CHEMBL601264 & 607926 & 5.9208 & 5.7306 & TRN & \\
\hline CHEMBL598240 & 607926 & 5.9586 & 5.6305 & TRN & \\
\hline CHEMBL598294 & 607926 & 5.7212 & 5.2107 & TST & \\
\hline CHEMBL611674 & 607926 & 5.1308 & 4.5145 & TST & \\
\hline CHEMBL598238 & 607926 & 5.5686 & 5.4014 & TRN & \\
\hline CHEMBL597916 & 607926 & 7.0 & 6.6058 & TRN & \\
\hline CHEMBL598084 & 607926 & 5.8239 & 5.33200 & 0000000001 & TST \\
\hline CHEMBL611389 & 607926 & 5.3665 & 5.4406 & TRN & \\
\hline CHEMBL598653 & 607926 & 5.2924 & 4.6994 & TRN & \\
\hline CHEMBL596661 & 607926 & 5.9586 & 5.3696 & TRN & \\
\hline CHEMBL611978 & 607926 & 6.2147 & 6.3949 & TRN & \\
\hline CHEMBL598706 & 607926 & 4.585 & 4.8996 & TRN & \\
\hline CHEMBL599130 & 607926 & 5.4815 & 5.3781 & TRN & \\
\hline CHEMBL602665 & 607926 & 6.1135 & 6.0901 & TST & \\
\hline CHEMBL600383 & 607926 & 4.9208 & 4.8147 & TRN & \\
\hline CHEMBL599350 & 607926 & 6.1675 & 5.6753 & TRN & \\
\hline CHEMBL600588 & 607926 & 4.9208 & 5.1649 & TRN & \\
\hline CHEMBL598705 & 607926 & 5.4437 & 5.4964 & TRN & \\
\hline CHEMBL598501 & 607926 & 5.0044 & 5.2566 & TRN & \\
\hline CHEMBL590246 & 607926 & 6.1871 & 6.4143 & TRN & \\
\hline CHEMBL599534 & 607926 & 6.3565 & 5.8067 & TRN & \\
\hline CHEMBL600082 & 607926 & 6.0809 & 6.1371 & TRN & \\
\hline CHEMBL598529 & 607926 & 6.6778 & 6.0727 & TST & \\
\hline CHEMBL599331 & 607926 & 5.6383 & 5.6287 & TRN & \\
\hline CHEMBL591454 & 607926 & 5.1024 & 5.1432 & TRN & \\
\hline
\end{tabular}




\begin{tabular}{|c|c|c|c|c|c|}
\hline & & & & & \\
\hline CHEMBL603964 & 607926 & 5.7696 & 5.8018 & TRN & \\
\hline CHEMBL611673 & 607926 & 4.9208 & 5.2642 & TRN & \\
\hline CHEMBL607866 & 607926 & 5.7696 & 5.9094 & TRN & \\
\hline CHEMBL601842 & 607926 & 4.9586 & 5.3471 & TRN & \\
\hline CHEMBL597099 & 607926 & 5.6021 & 5.6074 & TRN & \\
\hline CHEMBL596947 & 607926 & 5.6383 & 6.011 & TRN & \\
\hline CHEMBL601627 & 607926 & 5.7212 & 5.9794 & TRN & \\
\hline CHEMBL598295 & 607926 & 5.585 & 5.5346 & TRN & \\
\hline CHEMBL609894 & 607926 & 5.8861 & 5.954 & TRN & \\
\hline CHEMBL598451 & 607926 & 3.5229 & 4.4057 & TRN & \\
\hline CHEMBL611668 & 607926 & 5.0809 & 5.0486 & TRN & \\
\hline CHEMBL604958 & 607926 & 5.5686 & 5.5112 & TST & \\
\hline CHEMBL600659 & 607926 & 5.9208 & 5.5575 & TRN & \\
\hline CHEMBL591683 & 607926 & 5.4559 & 5.4576 & TRN & \\
\hline CHEMBL598521 & 607926 & 6.7212 & 6.61700 & 0000000001 & TRN \\
\hline CHEMBL590247 & 607926 & 4.6576 & 4.4552 & TST & \\
\hline CHEMBL596674 & 607926 & 5.3979 & 5.3166 & TRN & \\
\hline CHEMBL599751 & 607926 & 5.6778 & 5.6126 & TRN & \\
\hline CHEMBL610215 & 607926 & 6.9208 & 6.1782 & TRN & \\
\hline CHEMBL600382 & 607926 & 4.9586 & 4.8747 & TRN & \\
\hline CHEMBL597918 & 607926 & 5.8239 & 6.1413 & TRN & \\
\hline CHEMBL599770 & 607926 & 5.0 & 5.3983 & TRN & \\
\hline CHEMBL582724 & 607926 & 5.0 & 4.8775 & TRN & \\
\hline CHEMBL611080 & 607926 & 6.0706 & 6.1341 & TST & \\
\hline CHEMBL597511 & 607926 & 5.8539 & 6.0536 & TRN & \\
\hline CHEMBL598319 & 607926 & 6.3768 & 5.7171 & TST & \\
\hline CHEMBL599729 & 607926 & 6.3279 & 6.0743 & TRN & \\
\hline CHEMBL589994 & 607926 & 6.4437 & 6.0454 & TRN & \\
\hline CHEMBL598034 & 607926 & 4.7696 & 4.9917 & TRN & \\
\hline CHEMBL598927 & 607926 & 5.0706 & 5.3215 & TST & \\
\hline CHEMBL592774 & 607926 & 5.1612 & 5.7212 & TRN & \\
\hline CHEMBL598051 & 607926 & 6.0757 & 6.1021 & TRN & \\
\hline CHEMBL611979 & 607926 & 6.6383 & 6.6283 & TRN & \\
\hline CHEMBL599147 & 607926 & 5.1308 & 5.5226 & TRN & \\
\hline CHEMBL596663 & 607926 & 5.7447 & 5.8396 & TRN & \\
\hline CHEMBL590731 & 607926 & 5.9208 & 5.6079 & TRN & \\
\hline CHEMBL590250 & 607926 & 5.2147 & 5.3893 & TRN & \\
\hline CHEMBL597711 & 607926 & 5.0 & 5.3211 & TRN & \\
\hline CHEMBL592151 & 607926 & 5.1871 & 5.2245 & TRN & \\
\hline CHEMBL608729 & 607926 & 4.7447 & 5.6379 & TST & \\
\hline CHEMBL602864 & 607926 & 4.8861 & 4.6977 & TRN & \\
\hline CHEMBL582295 & 607926 & 6.2596 & 6.2426 & TRN & \\
\hline CHEMBL598655 & 607926 & 5.2676 & 4.9041 & TRN & \\
\hline CHEMBL598910 & 607926 & 6.1739 & 6.00200 & 0000000001 & TRN \\
\hline CHEMBL599349 & 607926 & 4.9586 & 5.0832 & TRN & \\
\hline CHEMBL599535 & 607926 & 5.8539 & 5.8372 & TRN & \\
\hline CHEMBL599107 & 607926 & 6.2757 & 6.2327 & TRN & \\
\hline CHEMBL608737 & 607926 & 6.2441 & 6.16200 & 0000000001 & TRN \\
\hline & & & & 13719 & \\
\hline
\end{tabular}




\begin{tabular}{|c|c|c|c|c|c|}
\hline & & & & & \\
\hline CHEMBL590973 & 607926 & 5.0 & 4.8366 & TRN & \\
\hline CHEMBL598239 & 607926 & 6.0 & 5.57799 & 9999999999 & TRN \\
\hline CHEMBL597886 & 607926 & 5.7696 & 6.0771 & TST & \\
\hline CHEMBL596898 & 607926 & 4.9586 & 5.528 & TRN & \\
\hline CHEMBL609613 & 607926 & 5.0 & 5.3206 & TRN & \\
\hline CHEMBL598718 & 607926 & 5.8539 & 5.7859 & TST & \\
\hline CHEMBL596871 & 607926 & 4.7959 & 4.6262 & TRN & \\
\hline CHEMBL609631 & 607926 & 5.8539 & 5.284 & TST & \\
\hline CHEMBL600788 & 607926 & 5.0 & 4.7535 & TRN & \\
\hline CHEMBL599541 & 607926 & 5.3188 & 5.6204 & TRN & \\
\hline CHEMBL598701 & 607926 & 5.7696 & 5.6439 & TRN & \\
\hline CHEMBL590493 & 607926 & 6.0362 & 6.08799 & & TST \\
\hline CHEMBL598050 & 607926 & 5.3468 & 6.0692 & TRN & \\
\hline CHEMBL598941 & 607926 & 5.1612 & 5.1627 & TST & \\
\hline CHEMBL597917 & 607926 & 6.3768 & 6.4089 & TRN & \\
\hline CHEMBL601477 & 607926 & 5.0 & 4.8698 & TRN & \\
\hline CHEMBL599124 & 607926 & 5.7447 & 5.5178 & TST & \\
\hline CHEMBL590249 & 607926 & 6.0969 & 5.6564 & TST & \\
\hline CHEMBL591215 & 607926 & 5.5686 & 5.4905 & TRN & \\
\hline CHEMBL611669 & 607926 & 5.1675 & 5.154 & TRN & \\
\hline CHEMBL597079 & 607926 & 6.4949 & 6.4602 & TRN & \\
\hline CHEMBL609038 & 607926 & 5.3665 & 5.2056 & TST & \\
\hline CHEMBL597103 & 607926 & 6.4949 & 6.0436 & TST & \\
\hline CHEMBL602863 & 607926 & 5.6021 & 5.8513 & TST & \\
\hline CHEMBL598947 & 607926 & 5.284 & 5.078 & TRN & \\
\hline CHEMBL587295 & 607926 & 4.6778 & 4.6977 & TRN & \\
\hline CHEMBL602862 & 607926 & 6.0088 & 6.3158 & TST & \\
\hline CHEMBL609903 & 607926 & 6.1549 & 6.0216 & TRN & \\
\hline CHEMBL600789 & 607926 & 4.9208 & 4.8676 & TRN & \\
\hline CHEMBL599730 & 607926 & 6.0809 & 6.1239 & TRN & \\
\hline CHEMBL582069 & 607926 & 4.8539 & 4.3977 & TRN & \\
\hline CHEMBL601841 & 607926 & 5.0655 & 5.3895 & TRN & \\
\hline CHEMBL598113 & 607926 & 5.6383 & 5.5754 & TST & \\
\hline CHEMBL599752 & 607926 & 5.0 & 5.2132 & TRN & \\
\hline CHEMBL597712 & 607926 & 5.3979 & 4.7475 & TRN & \\
\hline CHEMBL599123 & 607926 & 5.3279 & 4.8488 & TST & \\
\hline CHEMBL598656 & 607926 & 5.3098 & 5.6463 & TRN & \\
\hline CHEMBL608730 & 607926 & 6.0 & 6.0233 & TRN & \\
\hline CHEMBL607572 & 607926 & 5.7696 & 5.841 & TRN & \\
\hline CHEMBL597709 & 607926 & 4.7212 & 5.1405 & TRN & \\
\hline CHEMBL598717 & 607926 & 5.0269 & 5.3931 & TST & \\
\hline CHEMBL599332 & 607926 & 5.3979 & 5.5166 & TRN & \\
\hline CHEMBL599122 & 607926 & 5.0 & 5.2378 & TST & \\
\hline CHEMBL589274 & 607926 & 5.4949 & 5.8349 & TST & \\
\hline CHEMBL598708 & 607926 & 4.7447 & 4.6319 & TRN & \\
\hline CHEMBL610784 & 607926 & 5.2518 & 5.6151 & TRN & \\
\hline CHEMBL597080 & 607926 & 4.8239 & 5.4818 & TST & \\
\hline CHEMBL598452 & 607926 & 4.9208 & 4.8246 & TRN & \\
\hline
\end{tabular}




\begin{tabular}{|c|c|c|c|c|c|}
\hline \multicolumn{6}{|c|}{ Supplemental Table S2.txt } \\
\hline CHEMBL598905 & 607926 & 5.8239 & 5.7197 & TRN & \\
\hline CHEMBL592643 & 607926 & 5.2676 & 6.13 & TST & \\
\hline CHEMBL607868 & 607926 & 5.1871 & 5.5801 & TST & \\
\hline CHEMBL591684 & 607926 & 5.6021 & 5.5476 & TRN & \\
\hline CHEMBL599555 & 607926 & 6.2291 & 5.8813 & TRN & \\
\hline CHEMBL598700 & 607926 & 5.5686 & 5.6303 & TRN & \\
\hline CHEMBL597512 & 607926 & 5.6576 & 5.5489 & TRN & \\
\hline CHEMBL609314 & 607926 & 5.1135 & 5.6383 & TST & \\
\hline CHEMBL598928 & 607926 & 4.7959 & 5.3255 & TST & \\
\hline CHEMBL607563 & 607926 & 5.8539 & 6.066 & TRN & \\
\hline CHEMBL598320 & 607926 & 5.1805 & 5.5461 & TST & \\
\hline CHEMBL599743 & 607926 & 5.5528 & 5.8283 & TST & \\
\hline CHEMBL611675 & 607926 & 5.585 & 5.6016 & TST & \\
\hline CHEMBL597178 & 607926 & 5.8539 & 5.8898 & TRN & \\
\hline CHEMBL598325 & 607926 & 5.699 & 5.4951 & TRN & \\
\hline CHEMBL293774 & 47516 & 5.699 & 5.5555 & TRN & \\
\hline CHEMBL122711 & 47516 & 6.8962 & 6.7435 & TRN & \\
\hline CHEMBL332755 & 47516 & 7.0555 & 6.8241 & TRN & \\
\hline CHEMBL331669 & 47516 & 8.1549 & 8.1125 & TRN & \\
\hline CHEMBL450327 & 47516 & 5.699 & 5.6877 & TRN & \\
\hline CHEMBL440714 & 47516 & 5.699 & 5.6013 & TRN & \\
\hline CHEMBL311336 & 47516 & 5.699 & 5.9356 & TRN & \\
\hline CHEMBL333248 & 47516 & 7.5376 & 7.4661 & TST & \\
\hline CHEMBL122651 & 47516 & 5.699 & 5.675 & TRN & \\
\hline CHEMBL55110 & 47516 & 5.699 & 5.729 & TRN & \\
\hline CHEMBL330950 & 47516 & 4.9208 & 4.7327 & TST & \\
\hline CHEMBL332439 & 47516 & 5.7447 & 5.297999 & 9999999999 & TST \\
\hline CHEMBL333532 & 47516 & 4.6021 & 4.5923 & TRN & \\
\hline CHEMBL 83508 & 47516 & 7.5229 & 7.5864 & TRN & \\
\hline CHEMBL332362 & 47516 & 4.4815 & 4.5279 & TRN & \\
\hline CHEMBL121501 & 47516 & 4.8239 & 3.8727 & TST & \\
\hline CHEMBL123167 & 47516 & 8.1549 & 8.7642 & TST & \\
\hline CHEMBL306726 & 47516 & 5.699 & 5.7353 & TRN & \\
\hline CHEMBL340461 & 47516 & 7.0 & 6.8255 & TRN & \\
\hline CHEMBL123041 & 47516 & 6.9172 & 6.9467 & TRN & \\
\hline CHEMBL123443 & 47516 & 7.4437 & 7.5519 & TST & \\
\hline CHEMBL122109 & 47516 & 5.7959 & 5.3351 & TST & \\
\hline CHEMBL123233 & 47516 & 4.3979 & 4.4199 & TRN & \\
\hline CHEMBL121729 & 47516 & 4.2441 & 4.1729 & TRN & \\
\hline CHEMBL123775 & 47516 & 5.699 & 5.8896 & TRN & \\
\hline CHEMBL121559 & 47516 & 4.2924 & 4.3306 & TRN & \\
\hline CHEMBL120934 & 47516 & 4.8239 & 4.8369 & TRN & \\
\hline CHEMBL82868 & 47516 & 5.699 & 5.7476 & TRN & \\
\hline CHEMBL122925 & 47516 & 4.5229 & 5.8987 & TST & \\
\hline CHEMBL304281 & 47516 & 5.699 & 5.6052 & TRN & \\
\hline CHEMBL333896 & 47516 & 7.4949 & 7.5494 & TRN & \\
\hline CHEMBL 98328 & 47516 & 6.0 & 5.0748 & TST & \\
\hline CHEMBL122868 & 47516 & 4.1675 & 4.0087 & TRN & \\
\hline
\end{tabular}

Page 13721 


\begin{tabular}{|c|c|c|c|c|c|}
\hline & & & & & \\
\hline CHEMBL332145 & 47516 & 4.8239 & 4.8916 & TRN & \\
\hline CHEMBL123404 & 47516 & 4.4202 & 4.48300 & 00000000005 & TRN \\
\hline CHEMBL332406 & 47516 & 8.0969 & 8.096 & TRN & \\
\hline CHEMBL 331342 & 47516 & 5.699 & 5.7992 & TRN & \\
\hline CHEMBL432223 & 47516 & 5.699 & 5.8161 & TRN & \\
\hline CHEMBL123105 & 47516 & 4.2076 & 4.2468 & TRN & \\
\hline CHEMBL301469 & 47516 & 4.5686 & 4.5799 & TRN & \\
\hline CHEMBL332120 & 47516 & 5.699 & 5.8742 & TRN & \\
\hline CHEMBL331114 & 47516 & 4.7696 & 4.7328 & TRN & \\
\hline CHEMBL121592 & 47516 & 4.7696 & 4.7414 & TRN & \\
\hline CHEMBL330857 & 47516 & 6.8539 & 6.7567 & TRN & \\
\hline CHEMBL122831 & 47516 & 5.699 & 5.7561 & TRN & \\
\hline CHEMBL262676 & 47516 & 7.0458 & 7.4714 & TRN & \\
\hline CHEMBL441084 & 47516 & 6.9788 & 6.7844 & TRN & \\
\hline CHEMBL 293503 & 47516 & 6.8239 & 6.6143 & TRN & \\
\hline CHEMBL332858 & 47516 & 7.7447 & 8.0434 & TST & \\
\hline CHEMBL121916 & 47516 & 7.4815 & 7.4733 & TRN & \\
\hline CHEMBL316169 & 47516 & 6.71 & 6.4528 & TRN & \\
\hline CHEMBL124237 & 47516 & 4.6383 & 5.3533 & TST & \\
\hline CHEMBL120049 & 47516 & 8.0 & 7.9624 & TRN & \\
\hline CHEMBL123064 & 47516 & 4.1427 & 4.897 & TST & \\
\hline CHEMBL331311 & 47516 & 6.7447 & 6.8441 & TRN & \\
\hline CHEMBL123382 & 47516 & 7.301 & 7.3213 & TRN & \\
\hline CHEMBL122950 & 47516 & 4.3872 & 4.3765 & TRN & \\
\hline CHEMBL122719 & 47516 & 5.699 & 5.8594 & TRN & \\
\hline CHEMBL333122 & 47516 & 4.7212 & 5.5561 & TST & \\
\hline CHEMBL55310 & 47516 & 4.7447 & 4.7037 & TRN & \\
\hline CHEMBL123463 & 47516 & 7.0757 & 7.0628 & TRN & \\
\hline CHEMBL122836 & 47516 & 5.699 & 5.706 & TST & \\
\hline CHEMBL331308 & 47516 & 4.699 & 5.13399 & 99999999995 & TST \\
\hline CHEMBL332429 & 47516 & 7.6778 & 7.6583 & TST & \\
\hline CHEMBL1829417 & 770426 & 5.6364 & 5.4072 & TRN & \\
\hline CHEMBL1829428 & 770426 & 6.4908 & 6.3196 & TRN & \\
\hline CHEMBL1829413 & 770426 & 6.301 & 6.1773 & TRN & \\
\hline CHEMBL1829247 & 770426 & 6.8539 & 6.8969 & TRN & \\
\hline CHEMBL1829248 & 770426 & 7.699 & 7.9893 & TRN & \\
\hline CHEMBL1829401 & 770426 & 7.5229 & 6.8673 & TRN & \\
\hline CHEMBL1829262 & 770426 & 5.5346 & 5.6849 & TRN & \\
\hline CHEMBL1829268 & 770426 & 5.3747 & 5.0216 & TRN & \\
\hline CHEMBL1829260 & 770426 & 5.9706 & 5.015 & TST & \\
\hline CHEMBL1829253 & 770426 & 5.4559 & 4.9199 & TRN & \\
\hline CHEMBL1829433 & 770426 & 6.0 & 7.4943 & TST & \\
\hline CHEMBL1829431 & 770426 & 7.7959 & 7.3821 & TST & \\
\hline CHEMBL1829249 & 770426 & 6.6778 & 6.9793 & TRN & \\
\hline CHEMBL1829415 & 770426 & 6.3872 & 6.1911 & TRN & \\
\hline CHEMBL1829425 & 770426 & 6.8508 & 8.0372 & TST & \\
\hline CHEMBL1829422 & 770426 & 7.8861 & 7.5684 & TRN & \\
\hline CHEMBL1829409 & 770426 & 6.6778 & 6.5169 & TRN & \\
\hline
\end{tabular}


Supplemental Table S2.txt

\begin{tabular}{|c|c|c|c|c|c|}
\hline CHEMBL1829408 & 770426 & 6.0269 & 6.7564 & TRN & \\
\hline CHEMBL1829261 & 770426 & 5.8416 & 5.3965 & TST & \\
\hline CHEMBL1829418 & 770426 & 7.3979 & 6.9925 & TRN & \\
\hline CHEMBL1829423 & 770426 & 7.6778 & 7.5928 & TRN & \\
\hline CHEMBL1829267 & 770426 & 5.1739 & 5.2194 & TRN & \\
\hline CHEMBL1829414 & 770426 & 5.857 & \multicolumn{2}{|c|}{5.9110000000000005} & TRN \\
\hline CHEMBL1829402 & 770426 & 6.6778 & 6.4011 & TRN & \\
\hline CHEMBL1829265 & 770426 & 5.2581 & 5.5154 & TRN & \\
\hline CHEMBL1829432 & 770426 & 8.301 & 7.4907 & TRN & \\
\hline CHEMBL1829421 & 770426 & 6.8239 & 6.9376 & TRN & \\
\hline CHEMBL1829410 & 770426 & 6.8539 & 7.506 & TRN & \\
\hline CHEMBL1829404 & 770426 & 5.6091 & 6.4892 & TRN & \\
\hline CHEMBL1829426 & 770426 & 7.0706 & 8.1244 & TST & \\
\hline CHEMBL1829405 & 770426 & 5.9747 & 6.1527 & TRN & \\
\hline CHEMBL1829429 & 770426 & 5.2628 & 6.5478 & TRN & \\
\hline CHEMBL1829246 & 770426 & 8.0 & 6.6593 & TRN & \\
\hline CHEMBL1829398 & 770426 & 6.2147 & 6.3414 & TRN & \\
\hline CHEMBL1829419 & 770426 & 5.4935 & 5.9187 & TRN & \\
\hline CHEMBL1829245 & 770426 & 5.0458 & 6.2012 & TST & \\
\hline CHEMBL1829250 & 770426 & 6.8861 & 6.4434 & TRN & \\
\hline CHEMBL1829259 & 770426 & 6.5086 & \multicolumn{2}{|c|}{5.872999999999999} & TST \\
\hline CHEMBL1829269 & 770426 & 5.0458 & 4.8388 & TRN & \\
\hline CHEMBL1829399 & 770426 & 7.301 & 7.0544 & TRN & \\
\hline CHEMBL1829263 & 770426 & 5.2226 & 5.6086 & TRN & \\
\hline CHEMBL1829403 & 770426 & 6.5086 & 7.0273 & TRN & \\
\hline CHEMBL1829258 & 770426 & 6.4089 & 6.6399 & TRN & \\
\hline CHEMBL1829406 & 770426 & 7.699 & 7.4464 & TRN & \\
\hline CHEMBL1829411 & 770426 & 5.5686 & 5.9151 & TRN & \\
\hline CHEMBL1829256 & 770426 & 6.2007 & 6.1648 & TRN & \\
\hline CHEMBL1829266 & 770426 & 5.3429 & 5.4976 & TRN & \\
\hline CHEMBL1829407 & 770426 & 7.0458 & 6.7434 & TRN & \\
\hline CHEMBL1829255 & 770426 & 5.2749 & 5.1857 & TRN & \\
\hline CHEMBL1829264 & 770426 & 5.0 & 5.4763 & TRN & \\
\hline CHEMBL1829254 & 770426 & 5.4202 & 5.0371 & TRN & \\
\hline CHEMBL1829427 & 770426 & 6.7932 & 8.0401 & TST & \\
\hline CHEMBL1828638 & 770426 & 7.0458 & 7.0051 & TRN & \\
\hline CHEMBL1829270 & 770426 & 6.699 & 6.3883 & TRN & \\
\hline CHEMBL1829257 & 770426 & 5.0414 & 5.3682 & TRN & \\
\hline CHEMBL1829416 & 770426 & 6.0088 & 6.1448 & TST & \\
\hline CHEMBL1829420 & 770426 & 7.5229 & 6.9668 & TST & \\
\hline CHEMBL1829400 & 770426 & 6.8239 & 6.9346 & TST & \\
\hline CHEMBL1829251 & 770426 & 6.7959 & 6.4021 & TST & \\
\hline CHEMBL1829412 & 770426 & 5.2248 & 5.9904 & TST & \\
\hline CHEMBL1829442 & 770426 & 5.0458 & 5.2809 & TST & \\
\hline CHEMBL1829252 & 770426 & 6.1192 & 5.3284 & TST & \\
\hline CHEMBL3639985 & 1528385 & 6.6556 & 6.0353 & TST & \\
\hline CHEMBL3699668 & 1528385 & 5.3284 & 6.1289 & TST & \\
\hline CHEMBL 3703113 & 1528385 & 6.2596 & 6.3854 & TRN & \\
\hline
\end{tabular}


Supplemental Table S2.txt

\begin{tabular}{|c|c|c|c|c|}
\hline CHEMBL 3699725 & 1528385 & 6.7447 & 6.5988 & TRN \\
\hline CHEMBL3703147 & 1528385 & 7.2076 & 7.0151 & TRN \\
\hline CHEMBL3703129 & 1528385 & 6.2668 & 6.2831 & TRN \\
\hline CHEMBL3699672 & 1528385 & 6.1643 & 6.2664 & TRN \\
\hline CHEMBL3703169 & 1528385 & 7.0915 & 6.9925 & TRN \\
\hline CHEMBL 3699757 & 1528385 & 7.7447 & 7.5325 & TST \\
\hline CHEMBL3703124 & 1528385 & 6.6596 & 6.6639 & TRN \\
\hline CHEMBL 3699764 & 1528385 & 6.4306 & 6.5641 & TRN \\
\hline CHEMBL 3699682 & 1528385 & 6.6383 & 6.0195 & TST \\
\hline CHEMBL3703170 & 1528385 & 5.8225 & 6.0753 & TST \\
\hline CHEMBL 3703122 & 1528385 & 6.4935 & 6.6716 & TRN \\
\hline CHEMBL3703120 & 1528385 & 6.75700 & 00000000 & 6.7864 \\
\hline CHEMBL3699719 & 1528385 & 7.2076 & 7.1217 & TRN \\
\hline CHEMBL 3640020 & 1528385 & 6.1624 & 6.0662 & TRN \\
\hline CHEMBL 3699697 & 1528385 & 7.1739 & 7.2509 & TRN \\
\hline CHEMBL3699705 & 1528385 & 6.7471 & 5.9173 & TST \\
\hline CHEMBL3699673 & 1528385 & 6.5421 & 6.525 & TST \\
\hline CHEMBL 3699738 & 1528385 & 6.4248 & 6.5307 & TRN \\
\hline CHEMBL3699769 & 1528385 & 6.0491 & 6.5425 & TRN \\
\hline CHEMBL 3699677 & 1528385 & 6.2306 & 6.1111 & TRN \\
\hline CHEMBL 3699720 & 1528385 & 6.8477 & 7.0796 & TRN \\
\hline CHEMBL3699680 & 1528385 & 6.8477 & 6.4459 & TST \\
\hline CHEMBL3703102 & 1528385 & 6.6904 & 7.0106 & TRN \\
\hline CHEMBL 3699728 & 1528385 & 7.7212 & 7.7059 & TRN \\
\hline CHEMBL 3699753 & 1528385 & 7.7696 & 7.7814 & TRN \\
\hline CHEMBL3703118 & 1528385 & 6.2211 & 6.1681 & TRN \\
\hline CHEMBL3699671 & 1528385 & 6.6326 & 6.57100 & 0000000001 \\
\hline CHEMBL3699700 & 1528385 & 6.7258 & 6.8713 & TRN \\
\hline CHEMBL 3703171 & 1528385 & 6.8508 & 6.9972 & TRN \\
\hline CHEMBL3699707 & 1528385 & 5.9119 & 5.5193 & TST \\
\hline CHEMBL3703121 & 1528385 & 6.71 & 6.329 & TST \\
\hline CHEMBL3699749 & 1528385 & 7.2366 & 7.2519 & TRN \\
\hline CHEMBL3699679 & 1528385 & 6.6421 & 6.5413 & TST \\
\hline CHEMBL 3703163 & 1528385 & 6.5884 & 6.4023 & TRN \\
\hline CHEMBL3703135 & 1528385 & 7.2596 & 7.3689 & TRN \\
\hline CHEMBL3699718 & 1528385 & 4.7118 & 4.6363 & TRN \\
\hline CHEMBL 3699693 & 1528385 & 5.7518 & 5.7829 & TRN \\
\hline CHEMBL3703104 & 1528385 & 6.7423 & 6.4708 & TRN \\
\hline CHEMBL 3699734 & 1528385 & 6.466 & 6.4475 & TRN \\
\hline CHEMBL3699723 & 1528385 & 6.8539 & 6.7724 & TRN \\
\hline CHEMBL 3699708 & 1528385 & 5.8811 & 6.1296 & TST \\
\hline CHEMBL 3703107 & 1528385 & 6.8153 & 6.9949 & TRN \\
\hline CHEMBL3699670 & 1528385 & 6.9626 & 6.9442 & TRN \\
\hline CHEMBL 3699694 & 1528385 & 6.7747 & 6.9023 & TRN \\
\hline CHEMBL 3703114 & 1528385 & 6.3883 & 6.4042 & TRN \\
\hline CHEMBL 3703167 & 1528385 & 5.8952 & 5.8541 & TRN \\
\hline CHEMBL 3703137 & 1528385 & 7.6383 & 7.5354 & TRN \\
\hline CHEMBL 3703134 & 1528385 & 7.0315 & 7.1911 & TRN \\
\hline
\end{tabular}

Page 13724 
Supplemental Table S2.txt

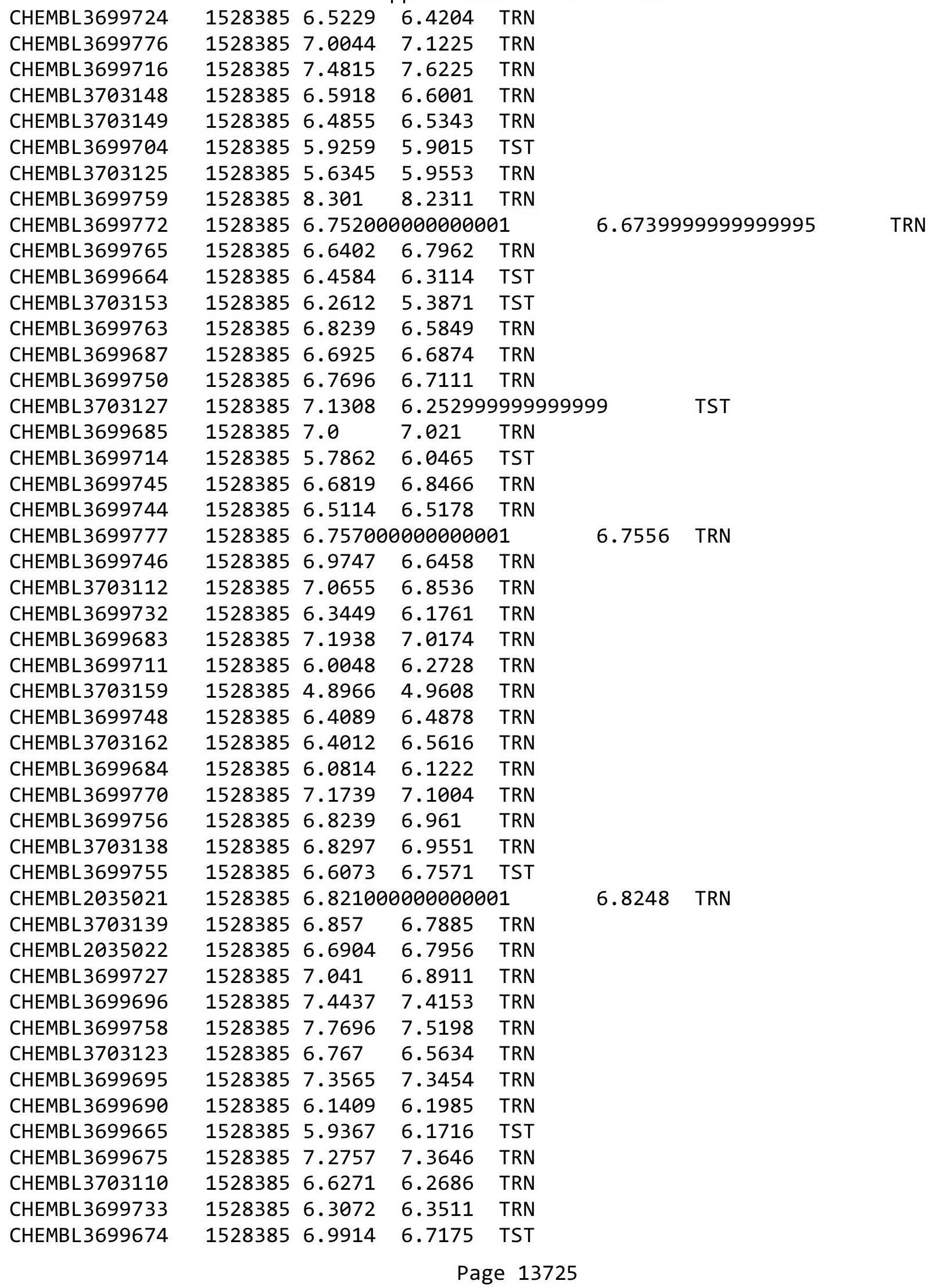


Supplemental Table S2.txt

\begin{tabular}{|c|c|c|c|c|c|c|}
\hline CHEMBL3699715 & 1528385 & 6.585 & 6.4623 & TRN & & \\
\hline CHEMBL3699666 & 1528385 & 5.9961 & 6.1555 & TST & & \\
\hline CHEMBL3703131 & 1528385 & 7.4437 & 7.5741 & TRN & & \\
\hline CHEMBL3699747 & 1528385 & 7.1938 & 6.9374 & TST & & \\
\hline CHEMBL 3703140 & 1528385 & 6.7033 & 7.1428 & TST & & \\
\hline CHEMBL3699689 & 1528385 & 6.8416 & 6.7819 & TRN & & \\
\hline CHEMBL3703145 & 1528385 & 5.6686 & 5.70299 & 9999999999 & & TRN \\
\hline CHEMBL3699742 & 1528385 & 6.9469 & 7.1517 & TRN & & \\
\hline CHEMBL3699743 & 1528385 & 7.1938 & 6.8076 & TRN & & \\
\hline CHEMBL3699701 & 1528385 & 7.3279 & 7.2157 & TRN & & \\
\hline CHEMBL3703105 & 1528385 & 6.8894 & 6.70200 & 0000000001 & & TRN \\
\hline CHEMBL3699774 & 1528385 & 7.8539 & 7.6561 & TRN & & \\
\hline CHEMBL3703103 & 1528385 & 5.7097 & 6.0446 & TRN & & \\
\hline CHEMBL3703166 & 1528385 & 7.0177 & 6.8198 & TRN & & \\
\hline CHEMBL 3699686 & 1528385 & 6.8386 & 6.3938 & TST & & \\
\hline CHEMBL 3699710 & 1528385 & 6.4214 & 6.4296 & TRN & & \\
\hline CHEMBL3699778 & 1528385 & 6.6635 & 6.5849 & TRN & & \\
\hline CHEMBL 3699722 & 1528385 & 6.9957 & 6.6612 & TRN & & \\
\hline CHEMBL3703130 & 1528385 & 6.2757 & 6.2803 & TRN & & \\
\hline CHEMBL3703151 & 1528385 & 6.71899 & 79999999 & 99 & 6.6739 & Tw \\
\hline CHEMBL3703111 & 1528385 & 7.585 & 6.3992 & TST & & \\
\hline CHEMBL3699731 & 1528385 & 5.9446 & 5.9984 & TRN & & \\
\hline CHEMBL3703116 & 1528385 & 6.7595 & 6.5436 & TRN & & \\
\hline CHEMBL3703133 & 1528385 & 6.4597 & 6.6499 & TRN & & \\
\hline CHEMBL3703115 & 1528385 & 6.4622 & 6.5936 & TRN & & \\
\hline CHEMBL3703156 & 1528385 & 7.2366 & 7.1773 & TRN & & \\
\hline CHEMBL3699667 & 1528385 & 6.7545 & 6.3544 & TST & & \\
\hline CHEMBL3699721 & 1528385 & 7.3665 & 7.1173 & TRN & & \\
\hline CHEMBL3703164 & 1528385 & 6.1838 & 6.4605 & TRN & & \\
\hline CHEMBL3703155 & 1528385 & 6.2291 & 6.3485 & TRN & & \\
\hline CHEMBL3703108 & 1528385 & 7.1487 & 7.0818 & TRN & & \\
\hline CHEMBL3703165 & 1528385 & 6.7471 & 6.9902 & TRN & & \\
\hline CHEMBL3699678 & 1528385 & 5.6444 & 5.9448 & TST & & \\
\hline CHEMBL3699762 & 1528385 & 6.4815 & 6.8194 & TRN & & \\
\hline CHEMBL3703132 & 1528385 & 6.7077 & 6.6714 & TRN & & \\
\hline CHEMBL3699752 & 1528385 & 7.6021 & 7.5775 & TRN & & \\
\hline CHEMBL3699751 & 1528385 & 7.284 & 7.2493 & TST & & \\
\hline CHEMBL3699726 & 1528385 & 7.0044 & 7.0077 & TRN & & \\
\hline CHEMBL3699740 & 1528385 & 5.7802 & 5.30399 & 9999999999 & & |S| \\
\hline CHEMBL3699741 & 1528385 & 5.9722 & 6.0474 & TST & & \\
\hline CHEMBL3699761 & 1528385 & 6.7282 & 6.6104 & TRN & & \\
\hline CHEMBL 3703168 & 1528385 & \multicolumn{3}{|c|}{5.821000000000001} & 5.8209 & TRN \\
\hline CHEMBL3699706 & 1528385 & 6.7212 & 6.2123 & TST & & \\
\hline CHEMBL3699766 & 1528385 & 7.0915 & 6.9334 & TRN & & \\
\hline CHEMBL3699702 & 1528385 & 5.2485 & 5.3371 & TRN & & \\
\hline CHEMBL3699773 & 1528385 & 6.6968 & 6.9763 & TST & & \\
\hline CHEMBL3699771 & 1528385 & 7.1612 & 7.0316 & TRN & & \\
\hline CHEMBL3699768 & 1528385 & 7.9586 & 7.9528 & TST & & \\
\hline
\end{tabular}

Page 13726 
Supplemental Table S2.txt

\begin{tabular}{|c|c|c|c|c|c|}
\hline CHEMBL3703128 & 1528385 & 6.2733 & 6.0412 & TRN & \\
\hline CHEMBL3703144 & 1528385 & 6.3401 & 6.1577 & TRN & \\
\hline CHEMBL3703146 & 1528385 & 6.0685 & 6.1182 & TRN & \\
\hline CHEMBL 3699669 & 1528385 & 6.4112 & 6.3957 & TRN & \\
\hline CHEMBL3703161 & 1528385 & 6.8013 & 6.7369 & TRN & \\
\hline CHEMBL 3703136 & 1528385 & 7.6198 & 7.6056 & TST & \\
\hline CHEMBL3699691 & 1528385 & \multicolumn{3}{|c|}{6.7620000000000005} & TRN \\
\hline CHEMBL 3703117 & 1528385 & 5.4639 & 5.2663 & TRN & \\
\hline CHEMBL3699739 & 1528385 & 6.1343 & 6.1927 & TST & \\
\hline CHEMBL3703143 & 1528385 & 6.2565 & 6.4891 & TRN & \\
\hline CHEMBL 3703152 & 1528385 & 6.4157 & 6.0292 & TST & \\
\hline CHEMBL3699692 & 1528385 & 6.767 & 5.4835 & TST & \\
\hline CHEMBL3703150 & 1528385 & 5.5246 & 5.3958 & TRN & \\
\hline CHEMBL 3703157 & 1528385 & 7.9208 & 7.5613 & TST & \\
\hline CHEMBL3699754 & 1528385 & 8.1549 & 7.7279 & TST & \\
\hline CHEMBL3703106 & 1528385 & 6.6904 & 6.7339 & TRN & \\
\hline CHEMBL3699760 & 1528385 & 5.8639 & 6.0932 & TRN & \\
\hline CHEMBL3699681 & 1528385 & 6.2644 & 6.0619 & TST & \\
\hline CHEMBL 3703154 & 1528385 & 6.5186 & 6.4107 & TRN & \\
\hline CHEMBL3699699 & 1528385 & 5.7807 & 5.936 & TRN & \\
\hline CHEMBL 3703142 & 1528385 & 6.289 & 6.1312 & TRN & \\
\hline CHEMBL3699737 & 1528385 & 5.7203 & 5.9452 & TRN & \\
\hline CHEMBL3703109 & 1528385 & 6.6737 & 6.6368 & TST & \\
\hline CHEMBL 3699676 & 1528385 & 7.6198 & 7.5256 & TST & \\
\hline CHEMBL 3703141 & 1528385 & 6.2534 & 6.2801 & TST & \\
\hline CHEMBL3699703 & 1528385 & 6.2976 & 6.3778 & TRN & \\
\hline CHEMBL3699712 & 1528385 & 6.6459 & 6.7777 & TRN & \\
\hline CHEMBL 3699730 & 1528385 & 6.3737 & 6.327999 & э999999999 & TRN \\
\hline CHEMBL 3699775 & 1528385 & 6.9747 & 7.1139 & TRN & \\
\hline CHEMBL3699735 & 1528385 & 6.5901 & 6.8059 & TRN & \\
\hline CHEMBL 3699688 & 1528385 & 7.0177 & 7.0848 & TRN & \\
\hline CHEMBL3703126 & 1528385 & 6.1605 & 6.0392 & TST & \\
\hline CHEMBL3699736 & 1528385 & 7.5086 & 7.4623 & TST & \\
\hline CHEMBL 3699729 & 1528385 & 5.7675 & 5.7577 & TRN & \\
\hline CHEMBL3703119 & 1528385 & 6.8794 & 6.4827 & TRN & \\
\hline CHEMBL3699713 & 1528385 & 7.2147 & 7.1856 & TRN & \\
\hline CHEMBL3703158 & 1528385 & 5.7804 & 5.9397 & TST & \\
\hline CHEMBL3699709 & 1528385 & 5.8586 & 6.6027 & TST & \\
\hline CHEMBL 3699698 & 1528385 & 6.8861 & 6.7994 & TRN & \\
\hline CHEMBL599801 & 609454 & 7.8539 & 7.8848 & TRN & \\
\hline CHEMBL604291 & 609454 & 9.0 & 7.7923 & TST & \\
\hline CHEMBL591515 & 609454 & 9.1549 & 9.3204 & TRN & \\
\hline CHEMBL590058 & 609454 & 6.699 & 7.1612 & TRN & \\
\hline CHEMBL597339 & 609454 & 8.7447 & 7.8923 & TST & \\
\hline CHEMBL602535 & 609454 & 8.2007 & 8.2536 & TRN & \\
\hline CHEMBL597116 & 609454 & 8.6198 & 8.4854 & TRN & \\
\hline CHEMBL590579 & 609454 & 8.0458 & 8.4227 & TST & \\
\hline CHEMBL597117 & 609454 & 8.6021 & 8.4011 & TRN & \\
\hline
\end{tabular}




\begin{tabular}{|c|c|c|c|c|}
\hline & & & pplement & al $\mathrm{T}$ \\
\hline CHEMBL604040 & 609454 & 8.5528 & 8.6262 & TRN \\
\hline CHEMBL598751 & 609454 & 8.6198 & 8.529 & TRN \\
\hline CHEMBL603873 & 609454 & 8.699 & 8.379 & TRN \\
\hline CHEMBL590880 & 609454 & 8.6383 & 8.2734 & TRN \\
\hline CHEMBL610164 & 609454 & 8.7959 & 7.8954 & TST \\
\hline CHEMBL590400 & 609454 & 7.8539 & 8.0711 & TRN \\
\hline CHEMBL599596 & 609454 & 7.2291 & 7.1126 & TRN \\
\hline CHEMBL603448 & 609454 & 7.9208 & 8.4992 & TRN \\
\hline CHEMBL599595 & 609454 & 8.3979 & 7.96 & TST \\
\hline CHEMBL592543 & 609454 & 8.6778 & 8.3472 & TRN \\
\hline CHEMBL600840 & 609454 & 7.7447 & 7.8403 & TRN \\
\hline CHEMBL599793 & 609454 & 8.7959 & 7.9879 & TST \\
\hline CHEMBL590805 & 609454 & 8.7447 & 8.5569 & TRN \\
\hline CHEMBL590881 & 609454 & 7.3872 & 7.8065 & TRN \\
\hline CHEMBL592542 & 609454 & 7.8861 & 7.933 & TRN \\
\hline CHEMBL591750 & 609454 & 7.8239 & 8.4724 & TRN \\
\hline CHEMBL604547 & 609454 & 8.1487 & 8.2248 & TRN \\
\hline CHEMBL605284 & 609454 & 8.4949 & 8.2576 & TRN \\
\hline CHEMBL598543 & 609454 & 9.0 & 8.7332 & TRN \\
\hline CHEMBL590561 & 609454 & 7.6576 & 7.8279 & TRN \\
\hline CHEMBL601260 & 609454 & 8.2076 & 8.4189 & TRN \\
\hline CHEMBL596720 & 609454 & 8.301 & 7.6189 & TRN \\
\hline CHEMBL602752 & 609454 & 7.8539 & 9.2279 & TST \\
\hline CHEMBL598544 & 609454 & 8.4318 & 8.1589 & TRN \\
\hline CHEMBL589575 & 609454 & 8.1427 & 8.2793 & TRN \\
\hline CHEMBL590791 & 609454 & 8.6778 & 8.8082 & TRN \\
\hline CHEMBL589257 & 609454 & 8.5086 & 8.4363 & TRN \\
\hline CHEMBL597925 & 609454 & 8.0458 & 8.4427 & TRN \\
\hline CHEMBL603457 & 609454 & 8.5086 & 8.4314 & TRN \\
\hline CHEMBL592459 & 609454 & 7.6198 & 7.9821 & TRN \\
\hline CHEMBL589574 & 609454 & 7.8861 & 7.6156 & TRN \\
\hline CHEMBL589834 & 609454 & 9.0 & 8.3757 & TRN \\
\hline CHEMBL589833 & 609454 & 8.2676 & 8.1797 & TRN \\
\hline CHEMBL606029 & 609454 & 8.6021 & 8.478 & TRN \\
\hline CHEMBL596713 & 609454 & 8.8539 & 8.2982 & TST \\
\hline CHEMBL590088 & 609454 & 8.0862 & 8.3805 & TRN \\
\hline CHEMBL603407 & 609454 & 8.6383 & 8.5306 & TRN \\
\hline CHEMBL597324 & 609454 & 8.2924 & 8.5891 & TST \\
\hline CHEMBL596721 & 609454 & 7.7212 & 7.9842 & TST \\
\hline CHEMBL603135 & 609454 & 9.0 & 8.234 & TST \\
\hline CHEMBL590327 & 609454 & 8.585 & 8.1188 & TST \\
\hline CHEMBL596933 & 609454 & 8.585 & 8.0356 & TST \\
\hline CHEMBL153763 & 312997 & 6.6073 & 6.82 & TRN \\
\hline CHEMBL179458 & 312997 & 6.1135 & 6.4316 & TST \\
\hline CHEMBL367754 & 312997 & 5.9241 & 6.3154 & TRN \\
\hline CHEMBL175840 & 312997 & 6.301 & 6.6334 & TRN \\
\hline CHEMBL175492 & 312997 & 6.6517 & 6.8051 & TRN \\
\hline CHEMBL179577 & 312997 & 7.3468 & 6.8034 & TRN \\
\hline
\end{tabular}




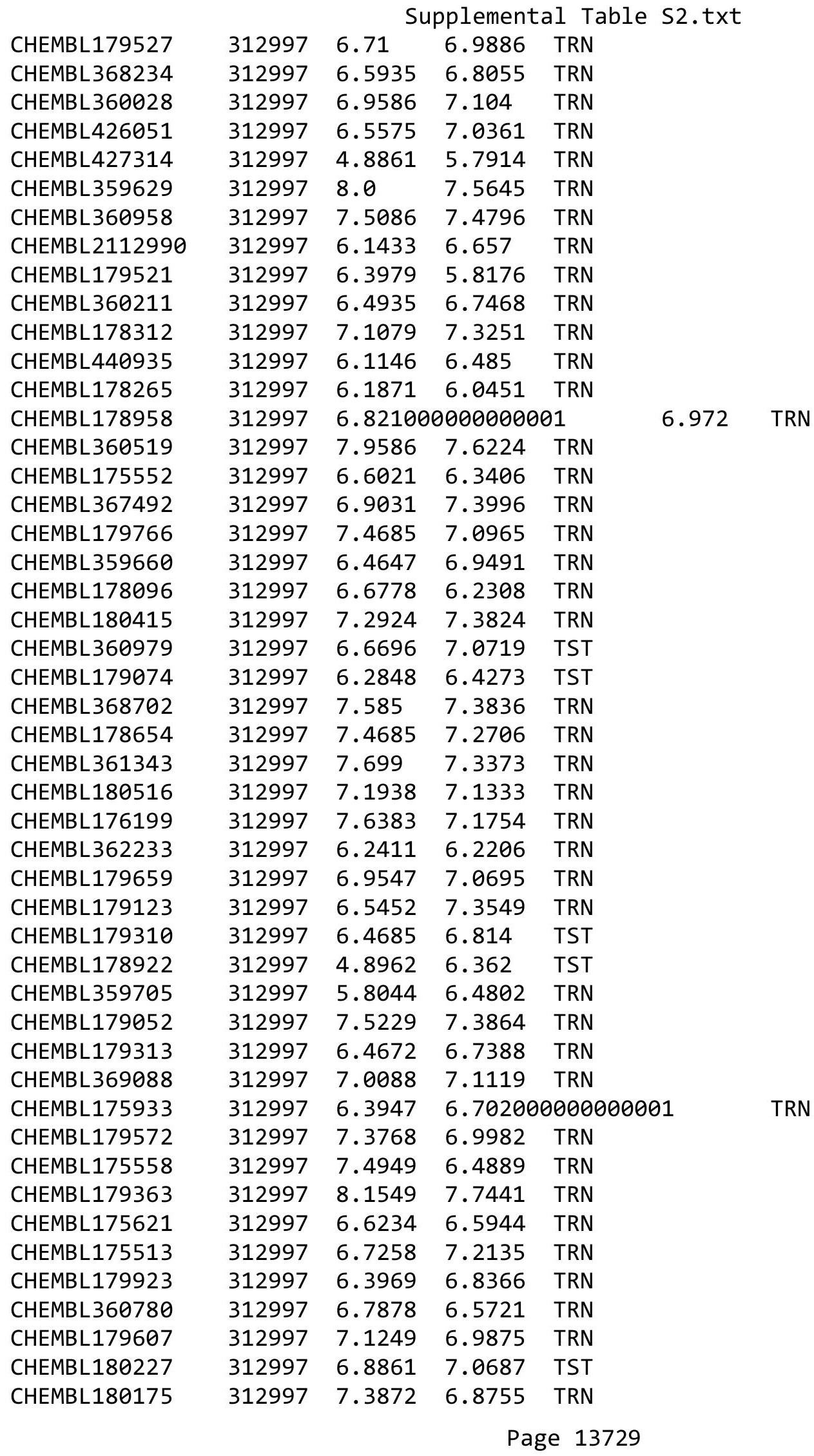




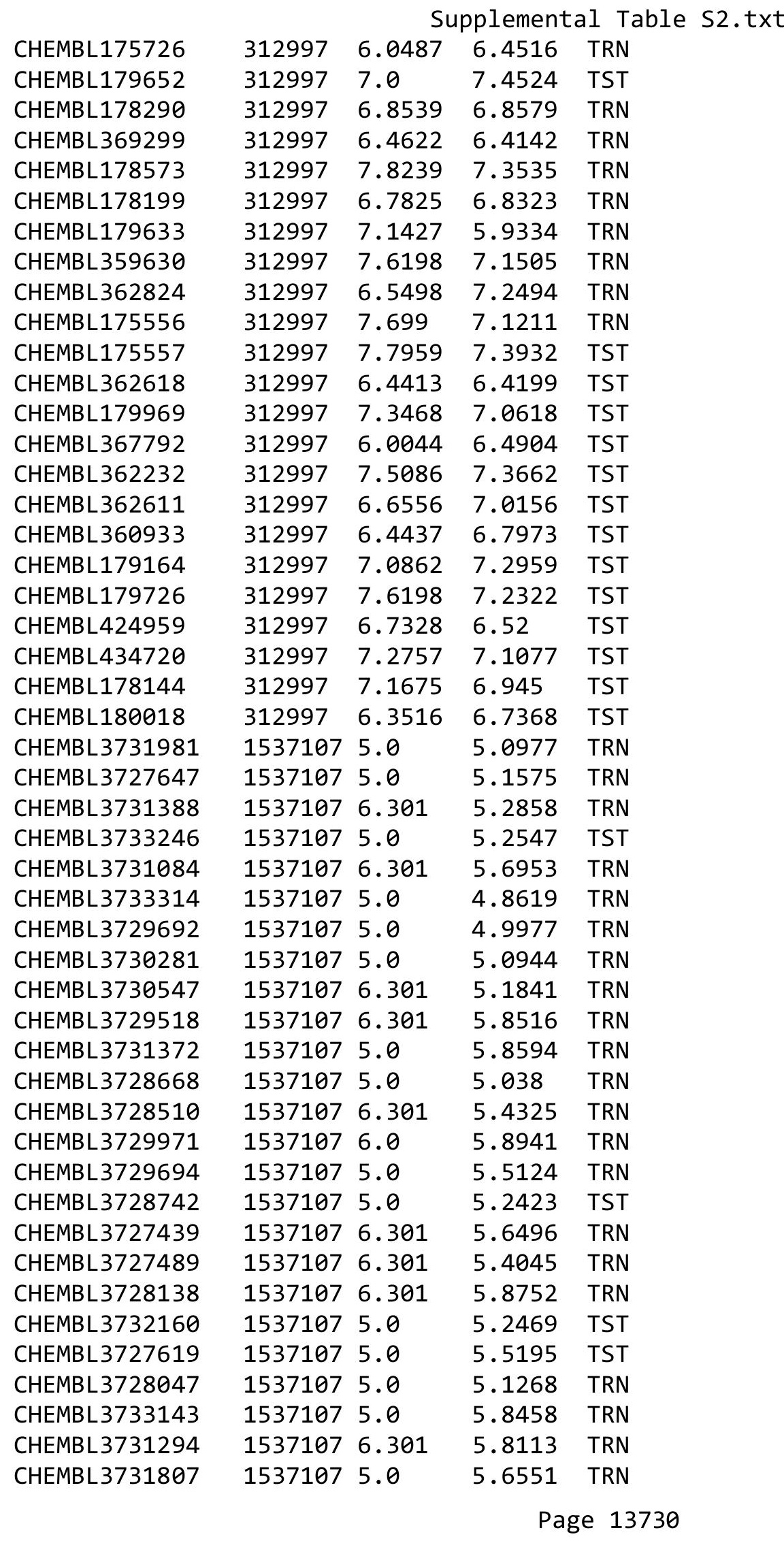


Supplemental Table S2.txt

\begin{tabular}{|c|c|c|c|c|c|}
\hline CHEMBL 3730887 & 1537107 & 6.301 & 5.3845 & TRN & \\
\hline CHEMBL 3731574 & 1537107 & 6.301 & 5.1661 & TST & \\
\hline CHEMBL 3727978 & 1537107 & 6.301 & 5.5494 & TRN & \\
\hline CHEMBL 3729287 & 1537107 & 5.0 & 5.473 & TRN & \\
\hline CHEMBL 3729394 & 1537107 & 5.0 & 5.4422 & TRN & \\
\hline CHEMBL 3728664 & 1537107 & 5.0 & 5.0897 & TST & \\
\hline CHEMBL 3732926 & 1537107 & 6.301 & \multicolumn{2}{|c|}{5.757999999999999} & TRN \\
\hline CHEMBL 3729363 & 1537107 & 6.301 & 5.8256 & TRN & \\
\hline CHEMBL 3727683 & 1537107 & 5.0 & 5.3554 & TRN & \\
\hline CHEMBL3730835 & 1537107 & 5.0 & 5.6995 & TRN & \\
\hline CHEMBL 3727892 & 1537107 & 6.301 & 5.8423 & TRN & \\
\hline CHEMBL 3733224 & 1537107 & 5.0 & 5.3216 & TRN & \\
\hline CHEMBL 3732590 & 1537107 & 5.0 & 5.6075 & TST & \\
\hline CHEMBL 3733252 & 1537107 & 5.0 & 5.1727 & TRN & \\
\hline CHEMBL3729066 & 1537107 & 5.0 & 5.2289 & TRN & \\
\hline CHEMBL 3732506 & 1537107 & 6.301 & 5.34 & TRN & \\
\hline CHEMBL 3728834 & 1537107 & 5.0 & 5.2684 & TRN & \\
\hline CHEMBL 3728163 & 1537107 & 6.301 & 5.6976 & TST & \\
\hline CHEMBL 3731938 & 1537107 & 5.0 & 5.5876 & TRN & \\
\hline CHEMBL 3728242 & 1537107 & 5.0 & 5.0701 & TRN & \\
\hline CHEMBL 3730460 & 1537107 & 5.0 & 5.6657 & TRN & \\
\hline CHEMBL 3730880 & 1537107 & 5.0 & 5.7507 & TRN & \\
\hline CHEMBL 3733103 & 1537107 & 5.0 & 5.4564 & TRN & \\
\hline CHEMBL 3730164 & 1537107 & 5.0 & 5.0255 & TST & \\
\hline CHEMBL 3731722 & 1537107 & 5.0 & 5.657 & TST & \\
\hline CHEMBL 3730750 & 1537107 & 6.301 & 5.4757 & TST & \\
\hline CHEMBL 3730728 & 1537107 & 5.0 & 5.6406 & TST & \\
\hline CHEMBL3732772 & 1537107 & 5.0 & 5.6868 & TRN & \\
\hline CHEMBL 3730776 & 1537107 & 5.0 & 5.1798 & TRN & \\
\hline CHEMBL 3730826 & 1537107 & 5.0 & 5.207999 & 9999999999 & TST \\
\hline CHEMBL 3728161 & 1537107 & 6.301 & 5.7197 & TRN & \\
\hline CHEMBL 3727985 & 1537107 & 6.301 & 5.7673 & TRN & \\
\hline CHEMBL3727575 & 1537107 & 6.301 & 5.6044 & TRN & \\
\hline CHEMBL 3730954 & 1537107 & 6.301 & 5.3693 & TRN & \\
\hline CHEMBL 3730926 & 1537107 & 5.0 & 5.1808 & TRN & \\
\hline CHEMBL 3730726 & 1537107 & 5.0 & 5.3761 & TRN & \\
\hline CHEMBL 3727504 & 1537107 & 6.301 & 5.4224 & TRN & \\
\hline CHEMBL3729202 & 1537107 & 5.0 & 5.244 & TRN & \\
\hline CHEMBL 3732913 & 1537107 & 5.0 & 5.2435 & TST & \\
\hline CHEMBL 3727750 & 1537107 & 5.0 & 5.635 & TRN & \\
\hline CHEMBL3731976 & 1537107 & 5.0 & 5.6421 & TRN & \\
\hline CHEMBL 3731076 & 1537107 & 5.0 & 5.3081 & TRN & \\
\hline CHEMBL3729294 & 1537107 & 6.301 & 5.6611 & TRN & \\
\hline CHEMBL 3732016 & 1537107 & 6.301 & 5.7097 & TRN & \\
\hline CHEMBL 3733060 & 1537107 & 6.301 & 5.2527 & TRN & \\
\hline CHEMBL 3731658 & 1537107 & 6.301 & 5.8474 & TRN & \\
\hline CHEMBL 3732874 & 1537107 & 5.0 & 5.3948 & TRN & \\
\hline CHEMBL3729648 & 1537107 & 6.301 & 5.7756 & TRN & \\
\hline
\end{tabular}




\begin{tabular}{|c|c|c|c|c|}
\hline \multicolumn{5}{|c|}{ Supplemental Table S2.txt } \\
\hline CHEMBL 3728038 & 1537107 & 5.0 & 5.2156 & TRN \\
\hline CHEMBL 3727988 & 1537107 & 5.0 & 5.6719 & TRN \\
\hline CHEMBL 3732850 & 1537107 & 6.301 & 5.0533 & TRN \\
\hline CHEMBL 3728524 & 1537107 & 6.301 & 5.4591 & TST \\
\hline CHEMBL 3729020 & 1537107 & 5.0 & 5.1837 & TST \\
\hline CHEMBL 3730238 & 1537107 & 6.0 & 5.8274 & TRN \\
\hline CHEMBL3733029 & 1537107 & 6.301 & 5.6342 & TST \\
\hline CHEMBL3730314 & 1537107 & 5.0 & 5.6484 & TST \\
\hline CHEMBL3729636 & 1537107 & 6.301 & 5.3433 & TRN \\
\hline CHEMBL3731989 & 1537107 & 5.0 & 5.7744 & TRN \\
\hline CHEMBL3732914 & 1537107 & 6.301 & 5.7565 & TRN \\
\hline CHEMBL 3731678 & 1537107 & 6.301 & 5.7481 & TRN \\
\hline CHEMBL 3729431 & 1537107 & 5.0 & 5.5232 & TRN \\
\hline CHEMBL3731919 & 1537107 & 5.0 & 5.5144 & TRN \\
\hline CHEMBL3729008 & 1537107 & 6.301 & 5.5614 & TRN \\
\hline CHEMBL3730309 & 1537107 & 5.0 & 5.2952 & TRN \\
\hline CHEMBL3727918 & 1537107 & 5.0 & 5.2443 & TRN \\
\hline CHEMBL 3729240 & 1537107 & 5.0 & 5.3525 & TRN \\
\hline CHEMBL3729603 & 1537107 & 5.0 & 5.2616 & TRN \\
\hline CHEMBL3733304 & 1537107 & 5.0 & 5.6653 & TRN \\
\hline CHEMBL3727851 & 1537107 & 5.0 & 5.8543 & TRN \\
\hline CHEMBL3732406 & 1537107 & 6.301 & 5.5328 & TST \\
\hline CHEMBL 3728631 & 1537107 & 6.301 & 5.814 & TRN \\
\hline CHEMBL3731331 & 1537107 & 6.301 & 5.7429 & TST \\
\hline CHEMBL3732249 & 1537107 & 5.0 & 5.6593 & TRN \\
\hline CHEMBL3727817 & 1537107 & 5.0 & 5.5231 & TRN \\
\hline CHEMBL3729912 & 1537107 & 6.301 & 5.7768 & TRN \\
\hline CHEMBL 3728677 & 1537107 & 5.0 & 5.1188 & TRN \\
\hline CHEMBL 3732745 & 1537107 & 5.0 & 5.8467 & TRN \\
\hline CHEMBL3727992 & 1537107 & 5.0 & 5.2463 & TRN \\
\hline CHEMBL 3728375 & 1537107 & 5.0 & 5.6369 & TRN \\
\hline CHEMBL 3727931 & 1537107 & 6.301 & 5.2744 & TRN \\
\hline CHEMBL 3727474 & 1537107 & 6.301 & 5.8352 & TRN \\
\hline CHEMBL3728955 & 1537107 & 5.0 & 5.1497 & TST \\
\hline CHEMBL3729619 & 1537107 & 6.301 & 5.7454 & TRN \\
\hline CHEMBL3729187 & 1537107 & 5.0 & 5.784 & TRN \\
\hline CHEMBL 3731278 & 1537107 & 5.0 & 5.5815 & TRN \\
\hline CHEMBL3730336 & 1537107 & 5.0 & 5.4708 & TRN \\
\hline CHEMBL 3732497 & 1537107 & 5.0 & 5.343 & TRN \\
\hline CHEMBL3730635 & 1537107 & 5.0 & 4.9578 & TRN \\
\hline CHEMBL3728991 & 1537107 & 5.0 & 5.2425 & TRN \\
\hline CHEMBL3728381 & 1537107 & 5.0 & 5.2327 & TRN \\
\hline CHEMBL3731584 & 1537107 & 5.0 & 5.1989 & TST \\
\hline CHEMBL 3728438 & 1537107 & 5.0 & 4.9753 & TRN \\
\hline CHEMBL3731618 & 1537107 & 5.0 & 5.1509 & TST \\
\hline CHEMBL3730949 & 1537107 & 6.301 & 5.312 & TRN \\
\hline CHEMBL3729628 & 1537107 & 5.0 & 5.6692 & TRN \\
\hline CHEMBL3733233 & 1537107 & 5.0 & 5.2766 & TRN \\
\hline
\end{tabular}


Supplemental Table S2.txt

\begin{tabular}{|c|c|c|c|c|c|}
\hline CHEMBL3730857 & 1537107 & 6.301 & 5.8551 & TRN & \\
\hline CHEMBL3732181 & 1537107 & 5.0 & 5.4773 & TST & \\
\hline CHEMBL3729803 & 1537107 & 6.301 & 5.2727 & TRN & \\
\hline CHEMBL3728692 & 1537107 & 5.0 & 5.5288 & TRN & \\
\hline CHEMBL3732751 & 1537107 & 5.0 & 5.3957 & TRN & \\
\hline CHEMBL3728549 & 1537107 & 5.0 & 5.5317 & TRN & \\
\hline CHEMBL3731911 & 1537107 & 6.301 & 5.8147 & TRN & \\
\hline CHEMBL3730527 & 1537107 & 5.0 & 4.9623 & TRN & \\
\hline CHEMBL3731413 & 1537107 & 6.0 & 5.5628 & TRN & \\
\hline CHEMBL3730193 & 1537107 & 5.0 & 5.1569 & TRN & \\
\hline CHEMBL3731791 & 1537107 & 5.0 & 5.455 & TST & \\
\hline CHEMBL3733312 & 1537107 & 6.0 & 5.8004 & TRN & \\
\hline CHEMBL3729026 & 1537107 & 5.0 & 5.7308 & TRN & \\
\hline CHEMBL3731069 & 1537107 & 6.301 & 5.6996 & TRN & \\
\hline CHEMBL3731225 & 1537107 & 5.0 & 5.2427 & TRN & \\
\hline CHEMBL3733214 & 1537107 & 5.0 & 5.1731 & TRN & \\
\hline CHEMBL3731429 & 1537107 & 5.0 & 5.1169 & TRN & \\
\hline CHEMBL3731575 & 1537107 & 5.0 & 5.4748 & TRN & \\
\hline CHEMBL3732336 & 1537107 & 5.0 & \multicolumn{2}{|c|}{5.162000000000001} & TRN \\
\hline CHEMBL3731501 & 1537107 & 6.301 & 5.3327 & TRN & \\
\hline CHEMBL3728278 & 1537107 & 5.0 & 5.0154 & TRN & \\
\hline CHEMBL 3730178 & 1537107 & 5.0 & 5.3677 & TRN & \\
\hline CHEMBL3730875 & 1537107 & 5.0 & 5.5156 & TRN & \\
\hline CHEMBL3730743 & 1537107 & 5.0 & 5.4168 & TST & \\
\hline CHEMBL3730975 & 1537107 & 5.0 & 5.678 & TST & \\
\hline CHEMBL3731206 & 1537107 & 5.0 & 5.1023 & TRN & \\
\hline CHEMBL3731158 & 1537107 & 5.0 & 5.227 & TST & \\
\hline CHEMBL3727823 & 1537107 & 5.0 & 5.2964 & TRN & \\
\hline CHEMBL3730144 & 1537107 & 5.0 & \multicolumn{2}{|c|}{5.617999999999999} & TRN \\
\hline CHEMBL3728305 & 1537107 & 5.0 & 5.2076 & TST & \\
\hline CHEMBL3731523 & 1537107 & 5.0 & 5.5326 & TST & \\
\hline CHEMBL3731313 & 1537107 & 5.0 & 5.6395 & TRN & \\
\hline CHEMBL3731524 & 1537107 & 5.0 & 5.2463 & TST & \\
\hline CHEMBL3729334 & 1537107 & 6.301 & 5.8342 & TRN & \\
\hline CHEMBL3731642 & 1537107 & 5.0 & 5.0963 & TST & \\
\hline CHEMBL3731061 & 1537107 & 6.301 & 5.5861 & TRN & \\
\hline CHEMBL 3729423 & 1537107 & 5.0 & 5.6834 & TST & \\
\hline CHEMBL3729280 & 1537107 & 5.0 & 5.4665 & TST & \\
\hline CHEMBL 3728565 & 1537107 & 5.0 & 5.6871 & TRN & \\
\hline CHEMBL3728896 & 1537107 & 5.0 & 5.6551 & TST & \\
\hline CHEMBL3729269 & 1537107 & 5.0 & \multicolumn{2}{|c|}{5.2010000000000005} & TRN \\
\hline CHEMBL3732610 & 1537107 & 6.301 & 5.6992 & TRN & \\
\hline CHEMBL3729410 & 1537107 & 5.0 & 5.5963 & TST & \\
\hline CHEMBL3730347 & 1537107 & 5.0 & 5.6119 & TRN & \\
\hline CHEMBL3730565 & 1537107 & 5.0 & 5.3544 & TRN & \\
\hline CHEMBL3728433 & 1537107 & 5.0 & 5.6425 & TRN & \\
\hline CHEMBL3730687 & 1537107 & 5.0 & 5.5629 & TRN & \\
\hline CHEMBL3731773 & 1537107 & 5.0 & 5.2078 & TST & \\
\hline
\end{tabular}


Supplemental Table S2.txt

\begin{tabular}{|c|c|c|c|c|c|}
\hline CHEMBL3730973 & 1537107 & 6.301 & 5.8521 & TRN & \\
\hline CHEMBL 3731046 & 1537107 & 6.0 & 5.6133 & TRN & \\
\hline CHEMBL3731662 & 1537107 & 6.301 & \multicolumn{2}{|c|}{5.917000000000001} & TRN \\
\hline CHEMBL3729226 & 1537107 & 5.0 & 5.2396 & TRN & \\
\hline CHEMBL3731712 & 1537107 & 5.0 & 5.3263 & TST & \\
\hline CHEMBL3730085 & 1537107 & 6.0 & 5.6363 & TRN & \\
\hline CHEMBL 3729561 & 1537107 & 6.301 & 5.9233 & TRN & \\
\hline CHEMBL3731706 & 1537107 & 6.301 & 5.7623 & TRN & \\
\hline CHEMBL3733290 & 1537107 & 5.0 & 5.6253 & TRN & \\
\hline CHEMBL3730102 & 1537107 & 6.301 & 5.7537 & TRN & \\
\hline CHEMBL 3731533 & 1537107 & 5.0 & 5.3361 & TST & \\
\hline CHEMBL3729147 & 1537107 & 5.0 & 5.795 & TRN & \\
\hline CHEMBL3728369 & 1537107 & 5.0 & 5.4039 & TST & \\
\hline CHEMBL3729388 & 1537107 & 5.0 & 5.2683 & TST & \\
\hline CHEMBL3731886 & 1537107 & 6.301 & 5.3318 & TRN & \\
\hline CHEMBL3731585 & 1537107 & 6.301 & 5.6823 & TRN & \\
\hline CHEMBL 3732484 & 1537107 & 5.0 & 5.8141 & TRN & \\
\hline CHEMBL 3729623 & 1537107 & 6.0 & 5.7264 & TRN & \\
\hline CHEMBL3730510 & 1537107 & 5.0 & 5.7773 & TRN & \\
\hline CHEMBL3732348 & 1537107 & 5.0 & 4.8822 & TST & \\
\hline CHEMBL3728632 & 1537107 & 6.301 & 5.7557 & TRN & \\
\hline CHEMBL3731679 & 1537107 & 5.0 & 5.7787 & TRN & \\
\hline CHEMBL3731463 & 1537107 & 6.301 & 5.199 & TST & \\
\hline CHEMBL3728785 & 1537107 & 6.301 & 5.2798 & TST & \\
\hline CHEMBL3731945 & 1537107 & 6.301 & 5.1895 & TST & \\
\hline CHEMBL3729674 & 1537107 & 5.0 & 5.38899 & 9999999999 & TRN \\
\hline CHEMBL3727994 & 1537107 & 5.0 & 5.1666 & TST & \\
\hline CHEMBL3728598 & 1537107 & 5.0 & 5.5484 & TRN & \\
\hline CHEMBL3732438 & 1537107 & 5.0 & 5.5947 & TST & \\
\hline CHEMBL3731321 & 1537107 & 5.0 & 5.6791 & TRN & \\
\hline CHEMBL3730788 & 1537107 & 5.0 & 5.6707 & TRN & \\
\hline CHEMBL3732230 & 1537107 & 6.301 & 5.0017 & TST & \\
\hline CHEMBL3729272 & 1537107 & 5.0 & 5.79799 & 9999999999 & TRN \\
\hline CHEMBL3732257 & 1537107 & 6.301 & 5.8898 & TRN & \\
\hline CHEMBL3732035 & 1537107 & 6.301 & 5.4909 & TST & \\
\hline CHEMBL3727510 & 1537107 & 5.0 & 5.4205 & TST & \\
\hline CHEMBL3731480 & 1537107 & 5.0 & 5.7783 & TRN & \\
\hline CHEMBL3732896 & 1537107 & 6.301 & 5.641 & TRN & \\
\hline CHEMBL3729134 & 1537107 & 5.0 & 5.7522 & TRN & \\
\hline CHEMBL3733078 & 1537107 & 5.0 & 5.6986 & TRN & \\
\hline CHEMBL 3727539 & 1537107 & 5.0 & 5.4167 & TRN & \\
\hline CHEMBL3727967 & 1537107 & 5.0 & 5.1884 & TRN & \\
\hline CHEMBL3729759 & 1537107 & 5.0 & 5.6928 & TRN & \\
\hline CHEMBL3728189 & 1537107 & 6.301 & 5.7719 & TRN & \\
\hline CHEMBL3732461 & 1537107 & 5.0 & 5.1949 & TRN & \\
\hline CHEMBL 3727808 & 1537107 & 5.0 & 5.434 & TRN & \\
\hline CHEMBL3729815 & 1537107 & 6.301 & 5.3505 & TST & \\
\hline CHEMBL3729625 & 1537107 & 5.0 & 5.4782 & TRN & \\
\hline
\end{tabular}




\begin{tabular}{|c|c|c|c|c|c|}
\hline \multicolumn{6}{|c|}{ Supplemental Table S2.txt } \\
\hline CHEMBL3733265 & 1537107 & 6.301 & 5.2462 & TST & \\
\hline CHEMBL3728844 & 1537107 & 6.301 & 5.7601 & TRN & \\
\hline CHEMBL3733133 & 1537107 & 6.0 & 5.3818 & TST & \\
\hline CHEMBL3731779 & 1537107 & 5.0 & 5.7823 & TRN & \\
\hline CHEMBL 3728738 & 1537107 & 6.301 & 5.6246 & TRN & \\
\hline CHEMBL3729708 & 1537107 & 5.0 & 5.5502 & TRN & \\
\hline CHEMBL3728797 & 1537107 & 5.0 & 5.0694 & TST & \\
\hline CHEMBL3730053 & 1537107 & 5.0 & 5.2599 & TST & \\
\hline CHEMBL3728329 & 1537107 & 5.0 & 5.24 & TRN & \\
\hline CHEMBL 3729825 & 1537107 & 5.0 & 5.3128 & TST & \\
\hline CHEMBL 3731652 & 1537107 & 6.301 & 5.8523 & TRN & \\
\hline CHEMBL 3729583 & 1537107 & 5.0 & 5.1504 & TST & \\
\hline CHEMBL3727580 & 1537107 & 5.0 & 5.2168 & TRN & \\
\hline CHEMBL 3731475 & 1537107 & 5.0 & 5.3198 & TRN & \\
\hline CHEMBL3727948 & 1537107 & 6.301 & 5.6621 & TRN & \\
\hline CHEMBL3729592 & 1537107 & 5.0 & 5.7185 & TRN & \\
\hline CHEMBL3731947 & 1537107 & 5.0 & 5.4908 & TRN & \\
\hline CHEMBL3732274 & 1537107 & 6.301 & 5.2825 & TST & \\
\hline CHEMBL3729417 & 1537107 & 5.0 & 5.2502 & TST & \\
\hline CHEMBL3728028 & 1537107 & 6.301 & 5.2865 & TST & \\
\hline CHEMBL3733031 & 1537107 & 6.301 & 5.88899 & 9999999999 & TRN \\
\hline CHEMBL3733099 & 1537107 & 5.0 & 5.1674 & TRN & \\
\hline CHEMBL3731409 & 1537107 & 6.0 & 5.8185 & TRN & \\
\hline CHEMBL3728829 & 1537107 & 5.0 & 5.6162 & TST & \\
\hline CHEMBL3731555 & 1537107 & 6.301 & 5.814 & TRN & \\
\hline CHEMBL 3730870 & 1537107 & 6.301 & 5.8679 & TRN & \\
\hline CHEMBL3731868 & 1537107 & 6.301 & 5.8049 & TRN & \\
\hline CHEMBL3729678 & 1537107 & 6.301 & 5.8502 & TRN & \\
\hline CHEMBL3731527 & 1537107 & 6.301 & 5.7576 & TRN & \\
\hline CHEMBL 3728277 & 1537107 & 5.0 & 5.1345 & TST & \\
\hline CHEMBL3730004 & 1537107 & 6.301 & 5.7171 & TRN & \\
\hline CHEMBL 3733124 & 1537107 & 5.0 & 5.6878 & TST & \\
\hline CHEMBL3730098 & 1537107 & 6.301 & 5.6311 & TRN & \\
\hline CHEMBL3730945 & 1537107 & 5.0 & 5.3706 & TRN & \\
\hline CHEMBL 3727563 & 1537107 & 6.301 & 5.16299 & 9999999999 & TST \\
\hline CHEMBL3731123 & 1537107 & 6.301 & 5.7935 & TRN & \\
\hline CHEMBL 3730072 & 1537107 & 6.301 & 5.484 & TRN & \\
\hline CHEMBL3729426 & 1537107 & 5.0 & 5.8306 & TRN & \\
\hline CHEMBL3728655 & 1537107 & 5.0 & 5.2606 & TRN & \\
\hline CHEMBL 3733257 & 1537107 & 5.0 & 5.847 & TRN & \\
\hline CHEMBL3733001 & 1537107 & 6.301 & 5.7215 & TRN & \\
\hline CHEMBL 3727760 & 1537107 & 5.0 & 5.1154 & TRN & \\
\hline CHEMBL3727863 & 1537107 & 6.301 & 5.1803 & TST & \\
\hline CHEMBL3732812 & 1537107 & 5.0 & 5.4825 & TRN & \\
\hline CHEMBL3732581 & 1537107 & 6.301 & 5.8334 & TRN & \\
\hline CHEMBL3729096 & 1537107 & 5.0 & 5.7513 & TRN & \\
\hline CHEMBL 3728020 & 1537107 & 6.301 & 5.2004 & TRN & \\
\hline CHEMBL3730221 & 1537107 & 6.301 & 5.7914 & TRN & \\
\hline
\end{tabular}




\begin{tabular}{|c|c|c|c|c|c|}
\hline \multicolumn{6}{|c|}{ Supplemental Table S2.txt } \\
\hline CHEMBL3731013 & 1537107 & 5.0 & 5.1039 & TST & \\
\hline CHEMBL3727871 & 1537107 & 6.301 & 5.8358 & TRN & \\
\hline CHEMBL3728636 & 1537107 & 5.0 & 5.0168 & TST & \\
\hline CHEMBL3729627 & 1537107 & 6.301 & 5.6447 & TRN & \\
\hline CHEMBL3733066 & 1537107 & 6.0 & 5.8788 & TRN & \\
\hline CHEMBL3730841 & 1537107 & 6.301 & 5.1819 & TRN & \\
\hline CHEMBL3732847 & 1537107 & 6.301 & 5.8859 & TRN & \\
\hline CHEMBL3731265 & 1537107 & 6.301 & 5.6576 & TRN & \\
\hline CHEMBL3731351 & 1537107 & 5.0 & 5.0806 & TST & \\
\hline CHEMBL3733050 & 1537107 & 5.0 & 5.1327 & TST & \\
\hline CHEMBL3732632 & 1537107 & 5.0 & 5.1932 & TST & \\
\hline CHEMBL3727673 & 1537107 & 5.0 & 5.5391 & TRN & \\
\hline CHEMBL 3823374 & 1587602 & 8.0 & 8.1977 & TRN & \\
\hline CHEMBL 3822590 & 1587602 & 8.5229 & 8.5475 & TRN & \\
\hline CHEMBL3823763 & 1587602 & 6.0 & 5.9923 & TRN & \\
\hline CHEMBL3822915 & 1587602 & 8.699 & 8.2649 & TST & \\
\hline CHEMBL3823508 & 1587602 & 9.699 & 9.8842 & TRN & \\
\hline CHEMBL 3824320 & 1587602 & 8.699 & 8.6974 & TRN & \\
\hline CHEMBL3822820 & 1587602 & 9.3979 & 9.4142 & TRN & \\
\hline CHEMBL3822639 & 1587602 & 7.9208 & 7.8579 & TRN & \\
\hline CHEMBL3823137 & 1587602 & 8.5229 & 8.55 & TRN & \\
\hline CHEMBL 3823386 & 1587602 & 9.0969 & 9.1019 & TRN & \\
\hline CHEMBL 3823339 & 1587602 & 7.8861 & 7.8723 & TRN & \\
\hline CHEMBL 3823487 & 1587602 & 9.699 & 9.4589 & TRN & \\
\hline CHEMBL3824167 & 1587602 & 9.0 & 8.6562 & TRN & \\
\hline CHEMBL3823996 & 1587602 & 8.3979 & 8.8797 & TST & \\
\hline CHEMBL 3823085 & 1587602 & 9.0 & 9.0076 & TRN & \\
\hline CHEMBL 3823462 & 1587602 & 8.3979 & 8.0915 & TST & \\
\hline CHEMBL 3823005 & 1587602 & 7.7696 & 7.8382 & TST & \\
\hline CHEMBL 3823348 & 1587602 & 7.3872 & 7.38399 & 99999999995 & TRN \\
\hline CHEMBL 3823713 & 1587602 & 9.699 & 9.6989 & TRN & \\
\hline CHEMBL 3824128 & 1587602 & 8.0969 & 8.0317 & TRN & \\
\hline CHEMBL 3822855 & 1587602 & 9.699 & 9.736 & TRN & \\
\hline CHEMBL3823595 & 1587602 & 9.301 & 9.3063 & TRN & \\
\hline CHEMBL3824211 & 1587602 & 8.699 & 8.7219 & TRN & \\
\hline CHEMBL 3822708 & 1587602 & 7.6021 & 7.606 & TRN & \\
\hline CHEMBL3822738 & 1587602 & 8.1549 & 8.1636 & TRN & \\
\hline CHEMBL 3822922 & 1587602 & 8.699 & 8.6933 & TRN & \\
\hline CHEMBL3822868 & 1587602 & 8.2218 & 8.173 & TRN & \\
\hline CHEMBL3823477 & 1587602 & 9.699 & 9.6712 & TRN & \\
\hline CHEMBL3822665 & 1587602 & 9.3979 & 9.4552 & TRN & \\
\hline CHEMBL3824025 & 1587602 & 9.301 & 9.3209 & TRN & \\
\hline CHEMBL3823298 & 1587602 & 5.0 & 5.0717 & TRN & \\
\hline CHEMBL3824302 & 1587602 & 8.699 & 8.6974 & TRN & \\
\hline CHEMBL3824117 & 1587602 & 8.699 & 8.6627 & TRN & \\
\hline CHEMBL 3823304 & 1587602 & 8.5229 & 8.5296 & TRN & \\
\hline CHEMBL3822731 & 1587602 & 8.1549 & 8.117 & TRN & \\
\hline CHEMBL 3823064 & 1587602 & 9.0 & 9.0445 & TRN & \\
\hline
\end{tabular}


Supplemental Table S2.txt

\begin{tabular}{|c|c|c|c|c|}
\hline CHEMBL3822649 & 1587602 & 7.5528 & 7.5154 & TRN \\
\hline CHEMBL3822783 & 1587602 & 7.6198 & 7.6081 & TRN \\
\hline CHEMBL3823406 & 1587602 & 8.5229 & 8.5959 & TRN \\
\hline CHEMBL 3823413 & 1587602 & 10.0 & 9.9979 & TRN \\
\hline CHEMBL3823433 & 1587602 & 8.5229 & 8.6562 & TRN \\
\hline CHEMBL 3824254 & 1587602 & 8.0 & 8.0413 & TST \\
\hline CHEMBL3824360 & 1587602 & 8.5229 & 8.7934 & TST \\
\hline CHEMBL 3824348 & 1587602 & 8.301 & 8.351 & TST \\
\hline CHEMBL 3823673 & 1587602 & 10.2218 & 9.8842 & TST \\
\hline CHEMBL3823011 & 1587602 & 8.5229 & 8.9176 & TST \\
\hline CHEMBL 3824145 & 1587602 & 8.699 & 8.4287 & TST \\
\hline CHEMBL3823778 & 1587602 & 9.3979 & 8.423 & TST \\
\hline CHEMBL3823963 & 1587602 & 8.1871 & 10.429 & TST \\
\hline CHEMBL 3822854 & 1587602 & 9.0 & 8.6809 & TST \\
\hline CHEMBL1698745 & 736997 & 5.0872 & 4.4546 & TRN \\
\hline CHEMBL1703772 & 736997 & 4.7595 & 4.0367 & TST \\
\hline CHEMBL1715078 & 736997 & 3.4948 & 3.1451 & TRN \\
\hline CHEMBL1534425 & 736997 & 5.2403 & 4.6063 & TRN \\
\hline CHEMBL1703615 & 736997 & 3.4948 & 3.7018 & TRN \\
\hline CHEMBL1416169 & 736997 & 3.4948 & 4.0719 & TRN \\
\hline CHEMBL1713770 & 736997 & 3.4948 & 3.4457 & TRN \\
\hline CHEMBL1721058 & 736997 & 3.4948 & 4.3614 & TRN \\
\hline CHEMBL1728454 & 736997 & 3.4948 & 3.9126 & TST \\
\hline CHEMBL1705660 & 736997 & 4.5272 & 4.1042 & TRN \\
\hline CHEMBL1368569 & 736997 & 3.4948 & 3.2466 & TRN \\
\hline CHEMBL1705807 & 736997 & 3.4948 & 4.2792 & TRN \\
\hline CHEMBL1465869 & 736997 & 3.4948 & 3.0986 & TRN \\
\hline CHEMBL1420151 & 736997 & 3.4948 & 3.3565 & TRN \\
\hline CHEMBL1715275 & 736997 & 4.6676 & 4.8458 & TRN \\
\hline CHEMBL1729479 & 736997 & 5.02 & 3.5953 & TST \\
\hline CHEMBL1586567 & 736997 & 4.5482 & 5.0855 & TRN \\
\hline CHEMBL1430124 & 736997 & 4.8633 & 4.4441 & TRN \\
\hline CHEMBL1729109 & 736997 & 3.4948 & 4.0334 & TRN \\
\hline CHEMBL1484306 & 736997 & 6.2782 & 5.3434 & TRN \\
\hline CHEMBL1698983 & 736997 & 5.1618 & 4.2669 & TRN \\
\hline CHEMBL1382214 & 736997 & 5.1135 & 4.6325 & TRN \\
\hline CHEMBL1722450 & 736997 & 5.2125 & 4.8101 & TRN \\
\hline CHEMBL1730381 & 736997 & 5.3872 & 4.652 & TRN \\
\hline CHEMBL1734939 & 736997 & 4.7167 & 3.1009 & TST \\
\hline CHEMBL1704084 & 736997 & 5.5686 & 4.2143 & TST \\
\hline CHEMBL1701998 & 736997 & 4.6696 & 4.5201 & TRN \\
\hline CHEMBL1710129 & 736997 & 4.644 & 4.5234 & TRN \\
\hline CHEMBL1698243 & 736997 & 4.8069 & 3.0404 & TST \\
\hline CHEMBL1707517 & 736997 & 3.4948 & 3.8419 & TRN \\
\hline CHEMBL1481494 & 736997 & 4.7399 & 4.8094 & TRN \\
\hline CHEMBL1719423 & 736997 & 5.1192 & 3.7152 & TST \\
\hline CHEMBL1402210 & 736997 & 5.3344 & 5.8496 & TRN \\
\hline CHEMBL1310336 & 736997 & 6.58 & 6.6318 & TRN \\
\hline
\end{tabular}




\begin{tabular}{|c|c|c|c|c|c|c|}
\hline & & \multicolumn{5}{|c|}{ Supplemental Table S2.txt } \\
\hline CHEMBL1720072 & 736997 & 5.2328 & 5.1584 & TRN & & \\
\hline CHEMBL1726562 & 736997 & 3.4948 & 2.3492 & TST & & \\
\hline CHEMBL1542448 & 736997 & 5.4034 & 5.5692 & TRN & & \\
\hline CHEMBL1721827 & 736997 & 4.9747 & 4.6476 & TRN & & \\
\hline CHEMBL1386647 & 736997 & 5.38399 & 99999999 & 995 & 5.277 & TRN \\
\hline CHEMBL1586706 & 736997 & 3.4948 & 4.3497 & TRN & & \\
\hline CHEMBL1733320 & 736997 & 4.5376 & 4.3235 & TRN & & \\
\hline CHEMBL1725618 & 736997 & 5.2676 & 4.7992 & TST & & \\
\hline CHEMBL1713756 & 736997 & 3.4948 & 3.79699 & 999999999 & 997 & TRN \\
\hline CHEMBL1725686 & 736997 & 3.4948 & 4.2578 & TRN & & \\
\hline CHEMBL1411573 & 736997 & 5.0947 & 5.0745 & TRN & & \\
\hline CHEMBL1719526 & 736997 & 3.4948 & 3.0895 & TST & & \\
\hline CHEMBL1706882 & 736997 & 3.4948 & 3.9757 & TRN & & \\
\hline CHEMBL1709480 & 736997 & 3.4948 & 3.5245 & TST & & \\
\hline CHEMBL1708243 & 736997 & 4.7352 & 3.6494 & TST & & \\
\hline CHEMBL1449870 & 736997 & 3.4948 & 4.2262 & TRN & & \\
\hline CHEMBL1736438 & 736997 & \multicolumn{3}{|c|}{5.752000000000001} & 5.5826 & TRN \\
\hline CHEMBL1703896 & 736997 & 4.8827 & 4.6278 & TRN & & \\
\hline CHEMBL1305795 & 736997 & 3.4948 & 3.6289 & TRN & & \\
\hline CHEMBL1726224 & 736997 & 4.7167 & 5.0442 & TRN & & \\
\hline CHEMBL1717402 & 736997 & 5.2277 & 4.5708 & TRN & & \\
\hline CHEMBL1703285 & 736997 & 4.8861 & 5.0005 & TRN & & \\
\hline CHEMBL1336209 & 736997 & 3.4948 & 3.0361 & TRN & & \\
\hline CHEMBL1718537 & 736997 & 5.0343 & 4.9576 & TRN & & \\
\hline CHEMBL1443900 & 736997 & 5.5302 & 4.345 & TST & & \\
\hline CHEMBL1700716 & 736997 & 3.4948 & 3.9299 & TRN & & \\
\hline CHEMBL1727434 & 736997 & 4.5376 & 4.2213 & TRN & & \\
\hline CHEMBL1702412 & 736997 & 3.4948 & 4.1982 & TRN & & \\
\hline CHEMBL1727053 & 736997 & 4.9318 & 4.5394 & TST & & \\
\hline CHEMBL1730076 & 736997 & 5.4486 & 4.3964 & TST & & \\
\hline CHEMBL1736309 & 736997 & 3.4948 & 4.0917 & TST & & \\
\hline CHEMBL1718220 & 736997 & 5.2782 & 5.2974 & TST & & \\
\hline CHEMBL102714 & 955091 & 3.7465 & 3.7446 & TRN & & \\
\hline CHEMBL577784 & 955091 & 5.002 & 4.9993 & TRN & & \\
\hline CHEMBL1516890 & 955091 & 4.5533 & 4.5524 & TRN & & \\
\hline CHEMBL449158 & 955091 & 5.9388 & 5.9152 & TST & & \\
\hline CHEMBL92309 & 955091 & 1.3329 & 2.9389 & TST & & \\
\hline CHEMBL 220241 & 955091 & 4.6406 & 4.6403 & TRN & & \\
\hline CHEMBL191334 & 955091 & 3.1252 & 3.1234 & TRN & & \\
\hline CHEMBL483849 & 955091 & 1.1664 & 2.7547 & TST & & \\
\hline CHEMBL 2134202 & 955091 & 3.7654 & 3.7686 & TRN & & \\
\hline CHEMBL1970879 & 955091 & 4.8749 & 4.877 & TRN & & \\
\hline CHEMBL558642 & 955091 & 3.013 & 3.0162 & TRN & & \\
\hline CHEMBL 213100 & 955091 & 3.8996 & 3.9002 & TRN & & \\
\hline CHEMBL259181 & 955091 & 3.5939 & 3.5942 & TRN & & \\
\hline CHEMBL573107 & 955091 & 5.6071 & 5.608 & TRN & & \\
\hline CHEMBL3392440 & 955091 & 4.9665 & 4.9666 & TRN & & \\
\hline CHEMBL209148 & 955091 & 3.457 & 3.4584 & TRN & & \\
\hline
\end{tabular}




\begin{tabular}{|c|c|c|c|c|c|c|}
\hline \multirow[b]{2}{*}{ CHEMBL515416 } & \multirow[b]{2}{*}{955091} & \multicolumn{5}{|c|}{ Supplemental Table S2.txt } \\
\hline & & 4.2245 & 4.2256 & TRN & & \\
\hline CHEMBL1909414 & 955091 & \multicolumn{3}{|c|}{3.4010000000000002} & 3.3999 & TRN \\
\hline CHEMBL1404918 & 955091 & 2.537 & 2.5356 & TRN & & \\
\hline CHEMBL585951 & 955091 & 5.218 & 5.2172 & TRN & & \\
\hline CHEMBL 2137530 & 955091 & \multicolumn{3}{|c|}{4.5569999999999995} & 4.5599 & TRN \\
\hline CHEMBL514499 & 955091 & 5.9769 & 5.9749 & TRN & & \\
\hline CHEMBL1357247 & 955091 & 3.4324 & 3.4321 & TRN & & \\
\hline CHEMBL9470 & 955091 & 3.0124 & 4.3817 & TST & & \\
\hline CHEMBL221137 & 955091 & 3.4725 & 3.9934 & TST & & \\
\hline CHEMBL412142 & 955091 & 3.3107 & 3.31 & TRN & & \\
\hline CHEMBL189584 & 955091 & 4.0876 & 4.0872 & TRN & & \\
\hline CHEMBL1242367 & 955091 & 3.7894 & 3.7899 & TRN & & \\
\hline CHEMBL1590308 & 955091 & 3.7447 & 3.5338 & TST & & \\
\hline CHEMBL393929 & 955091 & 4.155 & 4.1565 & TRN & & \\
\hline CHEMBL472940 & 955091 & 3.1904 & 3.1931 & TRN & & \\
\hline CHEMBL65 & 955091 & 6.9582 & 6.9599 & TRN & & \\
\hline CHEMBL2363137 & 955091 & 3.5351 & 3.5362 & TRN & & \\
\hline CHEMBL222102 & 955091 & 4.2581 & 4.256 & TRN & & \\
\hline CHEMBL 210618 & 955091 & 2.9473 & 2.9431 & TRN & & \\
\hline CHEMBL1190711 & 955091 & 4.2247 & 4.2249 & TRN & & \\
\hline CHEMBL1788116 & 955091 & 4.1183 & 4.1171 & TRN & & \\
\hline CHEMBL3186408 & 955091 & 3.4073 & 3.8674 & TST & & \\
\hline CHEMBL 258844 & 955091 & 4.0063 & 4.0047 & TRN & & \\
\hline CHEMBL 2144069 & 955091 & 4.0252 & 4.026 & TRN & & \\
\hline CHEMBL3199475 & 955091 & 4.5203 & 4.5208 & TRN & & \\
\hline CHEMBL399530 & 955091 & 3.7901 & 3.7899 & TRN & & \\
\hline CHEMBL188678 & 955091 & 4.4675 & 4.4714 & TRN & & \\
\hline CHEMBL509032 & 955091 & 5.5497 & 5.5484 & TRN & & \\
\hline CHEMBL379975 & 955091 & 4.02800 & 30000000 & 005 & 4.029 & TRN \\
\hline CHEMBL1186585 & 955091 & 5.1214 & 5.1208 & TRN & & \\
\hline CHEMBL 240954 & 955091 & 3.6602 & 3.6214 & TST & & \\
\hline CHEMBL1673039 & 955091 & 4.2431 & 4.2438 & TRN & & \\
\hline CHEMBL192566 & 955091 & 6.7547 & 6.1416 & TST & & \\
\hline CHEMBL483847 & 955091 & 3.7013 & 3.7015 & TRN & & \\
\hline CHEMBL512504 & 955091 & 3.9271 & 3.9264 & TRN & & \\
\hline CHEMBL 373751 & 955091 & 3.7943 & 3.7944 & TRN & & \\
\hline CHEMBL1643959 & 955091 & 3.06600 & 30000000 & 003 & 3.0656 & TRN \\
\hline CHEMBL1256459 & 955091 & 4.9112 & 4.9086 & TRN & & \\
\hline CHEMBL 2005886 & 955091 & 3.0694 & 3.0695 & TRN & & \\
\hline CHEMBL392695 & 955091 & 4.9985 & 4.9973 & TRN & & \\
\hline CHEMBL180127 & 955091 & 3.8483 & 3.8479 & TRN & & \\
\hline CHEMBL 379300 & 955091 & 4.1199 & 4.5118 & TST & & \\
\hline CHEMBL3349342 & 955091 & 5.0344 & 4.3234 & TST & & \\
\hline CHEMBL135561 & 955091 & 4.6658 & 4.2274 & TST & & \\
\hline CHEMBL1230020 & 955091 & 3.4019 & 3.6118 & TST & & \\
\hline CHEMBL300389 & 955091 & 6.5606 & 5.0261 & TST & & \\
\hline CHEMBL 217354 & 955091 & 6.2133 & 5.6502 & TST & & \\
\hline CHEMBL 202721 & 955091 & 4.3247 & 5.2762 & TST & & \\
\hline
\end{tabular}




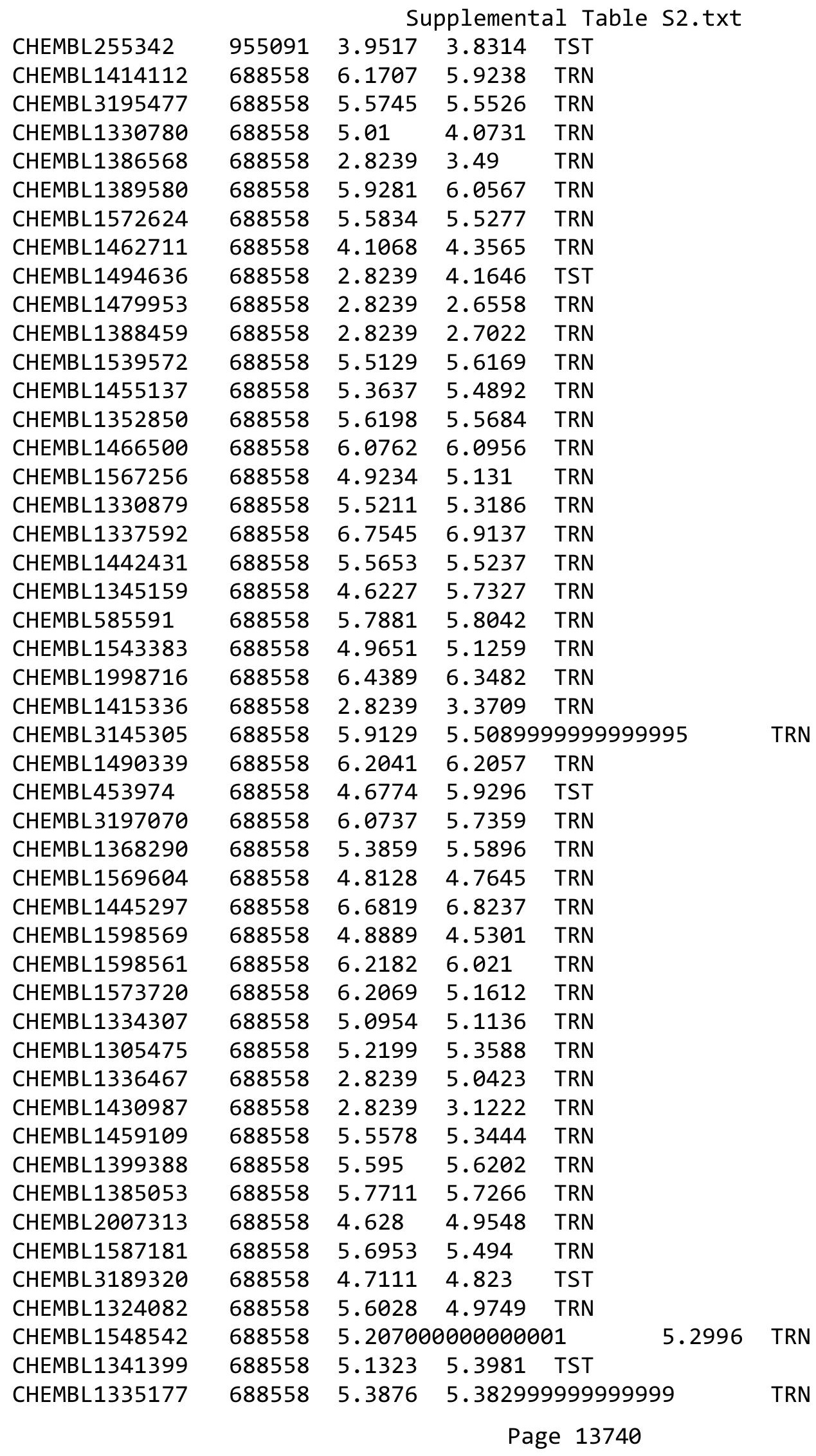


Supplemental Table S2.txt

\begin{tabular}{|c|c|c|c|c|c|c|}
\hline CHEMBL1967952 & 688558 & 5.6767 & 5.5123 & TRN & & \\
\hline CHEMBL1383090 & 688558 & 6.3546 & 6.2453 & TRN & & \\
\hline CHEMBL1308404 & 688558 & 5.7174 & 5.6544 & TRN & & \\
\hline CHEMBL1432727 & 688558 & 4.578 & 2.7986 & TRN & & \\
\hline CHEMBL1609270 & 688558 & 5.0116 & 4.8262 & TRN & & \\
\hline CHEMBL1516407 & 688558 & 2.8239 & 3.2811 & TRN & & \\
\hline CHEMBL1581648 & 688558 & 4.5937 & 4.853 & TRN & & \\
\hline CHEMBL1549192 & 688558 & 4.9246 & 5.3252 & TRN & & \\
\hline CHEMBL1549611 & 688558 & 5.4326 & 5.4693 & TST & & \\
\hline CHEMBL1430227 & 688558 & 4.8818 & 4.3426 & TRN & & \\
\hline CHEMBL1326803 & 688558 & 5.5468 & 6.1001 & TRN & & \\
\hline CHEMBL1407944 & 688558 & 6.2197 & 6.1773 & TRN & & \\
\hline CHEMBL1537340 & 688558 & 2.8239 & 3.0666 & TRN & & \\
\hline CHEMBL 3210428 & 688558 & 5.37299 & 79999999 & 99 & 5.1809 & TRN \\
\hline CHEMBL1445386 & 688558 & 4.9853 & 5.5667 & TST & & \\
\hline CHEMBL1450116 & 688558 & 5.0901 & 5.0251 & TRN & & \\
\hline CHEMBL1256876 & 688558 & 4.9868 & 5.0551 & TST & & \\
\hline CHEMBL1340089 & 688558 & 5.3051 & 5.276 & TRN & & \\
\hline CHEMBL1424269 & 688558 & 2.8239 & 4.9663 & TRN & & \\
\hline CHEMBL1457201 & 688558 & 5.5308 & 5.51 & TRN & & \\
\hline CHEMBL1996752 & 688558 & 4.5776 & 4.6605 & TRN & & \\
\hline CHEMBL1516533 & 688558 & 6.1445 & 6.063 & TRN & & \\
\hline CHEMBL1566835 & 688558 & 5.0509 & 5.1989 & TRN & & \\
\hline CHEMBL518292 & 688558 & 5.2916 & 5.8704 & TST & & \\
\hline CHEMBL1584364 & 688558 & 2.8239 & 2.9667 & TRN & & \\
\hline CHEMBL1411142 & 688558 & 5.0148 & 5.1375 & TST & & \\
\hline CHEMBL1451142 & 688558 & 2.8239 & 3.0972 & TRN & & \\
\hline CHEMBL1369126 & 688558 & 2.8239 & 2.6583 & TRN & & \\
\hline CHEMBL57013 & 688558 & 5.2287 & 5.2901 & TST & & \\
\hline CHEMBL1457480 & 688558 & 5.052 & 4.758 & TRN & & \\
\hline CHEMBL570345 & 688558 & 6.0953 & 5.5129 & TST & & \\
\hline CHEMBL1460869 & 688558 & 5.3512 & 5.1153 & TRN & & \\
\hline CHEMBL1324197 & 688558 & 6.4634 & 6.4153 & TRN & & \\
\hline CHEMBL 2135351 & 688558 & 5.96899 & 79999999 & 99 & 6.1426 & TST \\
\hline CHEMBL 261114 & 688558 & 6.1124 & 5.7869 & TRN & & \\
\hline CHEMBL3209269 & 688558 & 5.0974 & 4.6307 & TRN & & \\
\hline CHEMBL1966241 & 688558 & 5.8339 & 5.8197 & TRN & & \\
\hline CHEMBL1484547 & 688558 & 5.9634 & 5.8874 & TRN & & \\
\hline CHEMBL 2004475 & 688558 & 5.4144 & 5.3826 & TST & & \\
\hline CHEMBL1533067 & 688558 & 5.3156 & 5.3896 & TST & & \\
\hline CHEMBL1991242 & 688558 & 5.794 & 5.6847 & TRN & & \\
\hline CHEMBL1608301 & 688558 & 4.6323 & 4.5824 & TRN & & \\
\hline CHEMBL1386941 & 688558 & 2.8239 & 3.9295 & TRN & & \\
\hline CHEMBL1368683 & 688558 & 5.5672 & 5.6358 & TRN & & \\
\hline CHEMBL1995769 & 688558 & 5.7224 & 5.6561 & TRN & & \\
\hline CHEMBL604321 & 688558 & 5.1892 & 5.5743 & TST & & \\
\hline CHEMBL1542833 & 688558 & 5.4706 & 5.3799 & TRN & & \\
\hline CHEMBL1330058 & 688558 & 5.3415 & 5.7114 & TRN & & \\
\hline
\end{tabular}




\begin{tabular}{|c|c|c|c|c|c|}
\hline \multicolumn{6}{|c|}{ Supplemental Table S2.txt } \\
\hline CHEMBL1612556 & 688558 & 2.8239 & 3.4399 & TRN & \\
\hline CHEMBL512048 & 688558 & 5.131 & 4.5915 & TRN & \\
\hline CHEMBL1453212 & 688558 & 5.2604 & 5.5631 & TRN & \\
\hline CHEMBL1373252 & 688558 & 4.6762 & 5.0254 & TRN & \\
\hline CHEMBL1546843 & 688558 & 5.5924 & 5.6521 & TRN & \\
\hline CHEMBL1569975 & 688558 & 6.1612 & 5.8863 & TRN & \\
\hline CHEMBL1595632 & 688558 & 5.2272 & 5.4974 & TRN & \\
\hline CHEMBL3198970 & 688558 & 6.4855 & 6.2212 & TRN & \\
\hline CHEMBL1349455 & 688558 & 5.1156 & 4.8858 & TRN & \\
\hline CHEMBL1528030 & 688558 & 2.8239 & 3.2608 & TRN & \\
\hline CHEMBL3196518 & 688558 & 6.5086 & 6.3649 & TRN & \\
\hline CHEMBL1519014 & 688558 & 4.4307 & 4.6964 & TRN & \\
\hline CHEMBL1400319 & 688558 & 2.8239 & 3.5213 & TRN & \\
\hline CHEMBL1530741 & 688558 & $4.4460 e$ & 0000000 & 4.1709 & TRN \\
\hline CHEMBL1569698 & 688558 & 5.8407 & 5.6473 & TRN & \\
\hline CHEMBL1580848 & 688558 & 5.7375 & 5.46200 & 0000000001 & TRN \\
\hline CHEMBL405317 & 688558 & 5.4391 & 6.0457 & TRN & \\
\hline CHEMBL1541834 & 688558 & 5.0655 & 5.3132 & TRN & \\
\hline CHEMBL1567841 & 688558 & 5.1605 & 5.4036 & TRN & \\
\hline CHEMBL1520067 & 688558 & 4.4725 & 3.9555 & TRN & \\
\hline CHEMBL1505813 & 688558 & 5.8976 & 5.1394 & TRN & \\
\hline CHEMBL1529669 & 688558 & 2.8239 & 4.5816 & TRN & \\
\hline CHEMBL1511179 & 688558 & 5.8801 & 5.3562 & TRN & \\
\hline CHEMBL1520030 & 688558 & 2.8239 & 4.689 & TST & \\
\hline CHEMBL 328834 & 688558 & 6.0585 & 6.0636 & TST & \\
\hline CHEMBL1322738 & 688558 & 5.8041 & 5.4046 & TRN & \\
\hline CHEMBL1491358 & 688558 & 2.8239 & 3.0671 & TRN & \\
\hline CHEMBL1550640 & 688558 & 2.8239 & 4.1711 & TRN & \\
\hline CHEMBL3196139 & 688558 & 5.5696 & 5.6446 & TRN & \\
\hline CHEMBL1535695 & 688558 & 5.0666 & 4.7474 & TST & \\
\hline CHEMBL1500188 & 688558 & 5.4167 & 5.2412 & TRN & \\
\hline CHEMBL1520346 & 688558 & 7.9208 & 6.1132 & TRN & \\
\hline CHEMBL1610036 & 688558 & 2.8239 & 3.8025 & TRN & \\
\hline CHEMBL 31840 & 688558 & 5.8752 & 5.6939 & TRN & \\
\hline CHEMBL1564670 & 688558 & 2.8239 & 3.213 & TRN & \\
\hline CHEMBL1502738 & 688558 & 5.5962 & 5.5003 & TRN & \\
\hline CHEMBL1346284 & 688558 & 6.4609 & 6.3259 & TRN & \\
\hline CHEMBL1527242 & 688558 & 6.2472 & 5.5352 & TRN & \\
\hline CHEMBL1502522 & 688558 & 4.8484 & 5.3488 & TRN & \\
\hline CHEMBL1349727 & 688558 & 5.2253 & 4.0238 & TRN & \\
\hline CHEMBL257286 & 688558 & 4.5516 & 4.6009 & TRN & \\
\hline CHEMBL1556239 & 688558 & 6.1669 & 5.9904 & TST & \\
\hline CHEMBL1373969 & 688558 & 6.4572 & 6.2087 & TRN & \\
\hline CHEMBL1466523 & 688558 & 5.7713 & 5.6455 & TRN & \\
\hline CHEMBL15968 & 688558 & 5.9846 & 5.8575 & TRN & \\
\hline CHEMBL1524921 & 688558 & 6.7423 & 5.7019 & TRN & \\
\hline CHEMBL1566108 & 688558 & 5.6718 & 5.6424 & TRN & \\
\hline CHEMBL1455485 & 688558 & 5.5445 & 5.2941 & TRN & \\
\hline
\end{tabular}




\begin{tabular}{|c|c|c|c|c|c|c|}
\hline & & \multicolumn{5}{|c|}{ Supplemental Table S2.txt } \\
\hline CHEMBL1451921 & 688558 & 6.4609 & 6.1123 & TRN & & \\
\hline CHEMBL1459746 & 688558 & 5.7503 & 5.9342 & TRN & & \\
\hline CHEMBL309016 & 688558 & 4.9749 & 4.8767 & TRN & & \\
\hline CHEMBL1242180 & 688558 & 5.7572 & 5.9282 & TRN & & \\
\hline CHEMBL1582519 & 688558 & 2.8239 & 2.7085 & TRN & & \\
\hline CHEMBL 3199020 & 688558 & 5.4799 & 5.3913 & TRN & & \\
\hline CHEMBL1575428 & 688558 & 5.5669 & 4.9823 & TRN & & \\
\hline CHEMBL590184 & 688558 & 4.6987 & 4.7663 & TRN & & \\
\hline CHEMBL1392473 & 688558 & 5.5068 & 5.2368 & TRN & & \\
\hline CHEMBL1378385 & 688558 & 6.5406 & 6.0934 & TRN & & \\
\hline CHEMBL1462373 & 688558 & 5.414 & 5.2697 & TRN & & \\
\hline CHEMBL1977480 & 688558 & 5.3265 & 4.9114 & TRN & & \\
\hline CHEMBL117966 & 688558 & 5.6445 & 4.8058 & TRN & & \\
\hline CHEMBL1516637 & 688558 & 4.9985 & 5.2453 & TRN & & \\
\hline CHEMBL1492289 & 688558 & 5.5429 & 5.5228 & TRN & & \\
\hline CHEMBL1375740 & 688558 & 5.61299 & 99999999 & 995 & 5.5468 & TRN \\
\hline CHEMBL1597716 & 688558 & 4.527 & 3.4989 & TRN & & \\
\hline CHEMBL1390868 & 688558 & 4.8263 & 4.9793 & TRN & & \\
\hline CHEMBL1458951 & 688558 & 2.8239 & 3.0316 & TRN & & \\
\hline CHEMBL1342147 & 688558 & 4.9945 & 4.8804 & TRN & & \\
\hline CHEMBL1988511 & 688558 & 4.8965 & 4.9516 & TRN & & \\
\hline CHEMBL1327703 & 688558 & 5.4001 & 5.6416 & TRN & & \\
\hline CHEMBL1522007 & 688558 & 6.1811 & 4.8908 & TRN & & \\
\hline CHEMBL1312720 & 688558 & 4.605 & 3.9754 & TRN & & \\
\hline CHEMBL131037 & 688558 & 5.4043 & 5.7505 & TRN & & \\
\hline CHEMBL1546005 & 688558 & 4.6483 & 4.4733 & TRN & & \\
\hline CHEMBL1544402 & 688558 & 5.5147 & 4.6274 & TRN & & \\
\hline CHEMBL1595952 & 688558 & 6.1118 & 6.3481 & TRN & & \\
\hline CHEMBL1483324 & 688558 & 4.5129 & 4.717 & TRN & & \\
\hline CHEMBL1609900 & 688558 & 2.8239 & 2.4613 & TRN & & \\
\hline CHEMBL580955 & 688558 & 5.6381 & 6.3389 & TRN & & \\
\hline CHEMBL1449669 & 688558 & 5.3041 & 5.1735 & TRN & & \\
\hline CHEMBL1507407 & 688558 & 5.75200 & 30000000 & 01 & 5.6673 & $\mathrm{TR}$ \\
\hline CHEMBL1592917 & 688558 & 5.3012 & 5.5084 & TST & & \\
\hline CHEMBL1303910 & 688558 & 5.9083 & 5.6923 & TRN & & \\
\hline CHEMBL1599438 & 688558 & 6.1618 & 6.0543 & TRN & & \\
\hline CHEMBL1576791 & 688558 & 4.9159 & 4.8846 & TRN & & \\
\hline CHEMBL1406462 & 688558 & 2.8239 & 2.8216 & TRN & & \\
\hline CHEMBL3145285 & 688558 & 5.5468 & 5.5725 & TRN & & \\
\hline CHEMBL1309463 & 688558 & 5.2916 & 4.8752 & TRN & & \\
\hline CHEMBL1416693 & 688558 & 2.8239 & 2.7415 & TRN & & \\
\hline CHEMBL1569585 & 688558 & 6.4776 & 5.767 & TST & & \\
\hline CHEMBL1611922 & 688558 & 5.4777 & 5.6495 & TRN & & \\
\hline CHEMBL1503006 & 688558 & 4.0335 & 4.246 & TRN & & \\
\hline CHEMBL1518085 & 688558 & 5.4976 & 4.8773 & TRN & & \\
\hline CHEMBL1447885 & 688558 & 4.6227 & 4.6664 & TRN & & \\
\hline CHEMBL1491717 & 688558 & 5.5776 & 5.88899 & 99999 & & \\
\hline CHEMBL1544726 & 688558 & 4.7964 & 4.7979 & TRN & & \\
\hline
\end{tabular}

Page 13743 


\begin{tabular}{|c|c|c|c|c|c|}
\hline \multicolumn{6}{|c|}{ splemental lable S2. } \\
\hline CHEMBL1431376 & 688558 & 5.0355 & 5.1145 & TRN & \\
\hline CHEMBL1529883 & 688558 & 5.7978 & 5.8564 & TRN & \\
\hline CHEMBL1377164 & 688558 & 4.5123 & 3.3464 & TST & \\
\hline CHEMBL1545099 & 688558 & 6.5072 & 5.95700 & 0000000001 & TRN \\
\hline CHEMBL1440862 & 688558 & 2.8239 & 2.5654 & TRN & \\
\hline CHEMBL1371028 & 688558 & 4.5002 & 4.3501 & TRN & \\
\hline CHEMBL1408307 & 688558 & 4.6424 & 4.5612 & TRN & \\
\hline CHEMBL1421333 & 688558 & 2.8239 & 3.4179 & TRN & \\
\hline CHEMBL1302639 & 688558 & 5.7263 & 4.8839 & TRN & \\
\hline CHEMBL1498509 & 688558 & 5.9914 & 6.0998 & TRN & \\
\hline CHEMBL512749 & 688558 & 5.0185 & 5.2014 & TRN & \\
\hline CHEMBL1380801 & 688558 & 5.2891 & 5.5631 & TRN & \\
\hline CHEMBL1560237 & 688558 & 6.1904 & 6.4633 & TST & \\
\hline CHEMBL 2094484 & 688558 & 5.2418 & 5.8216 & TRN & \\
\hline CHEMBL1343823 & 688558 & 5.551 & 5.4808 & TRN & \\
\hline CHEMBL1339398 & 688558 & 4.9291 & 4.8976 & TST & \\
\hline CHEMBL1545480 & 688558 & 4.7442 & 4.581 & TRN & \\
\hline CHEMBL1424468 & 688558 & 6.4763 & 6.6535 & TRN & \\
\hline CHEMBL1305304 & 688558 & 4.2214 & 4.2687 & TRN & \\
\hline CHEMBL1977018 & 688558 & 6.1101 & 5.0475 & TRN & \\
\hline CHEMBL1361740 & 688558 & 5.6796 & 5.2296 & TST & \\
\hline CHEMBL1342448 & 688558 & 5.8935 & 5.4722 & TRN & \\
\hline CHEMBL1564522 & 688558 & 5.2837 & 5.6289 & TRN & \\
\hline CHEMBL1311809 & 688558 & 5.6627 & 5.6222 & TST & \\
\hline CHEMBL417727 & 688558 & 5.5885 & 5.7493 & TRN & \\
\hline CHEMBL1310861 & 688558 & 5.5906 & 5.1635 & TST & \\
\hline CHEMBL587801 & 688558 & 5.4295 & 5.3273 & TRN & \\
\hline CHEMBL3199286 & 688558 & 5.131 & 5.2786 & TRN & \\
\hline CHEMBL1413355 & 688558 & 5.5592 & 5.1593 & TRN & \\
\hline CHEMBL3194563 & 688558 & 5.1841 & 5.3829 & TRN & \\
\hline CHEMBL1372356 & 688558 & 4.6005 & 4.6307 & TRN & \\
\hline CHEMBL1430094 & 688558 & 5.2367 & 5.2531 & TRN & \\
\hline CHEMBL1445372 & 688558 & 5.5735 & 5.6117 & TST & \\
\hline CHEMBL1448503 & 688558 & 5.3935 & 5.5 & TRN & \\
\hline CHEMBL1506351 & 688558 & 2.8239 & 3.6739 & TRN & \\
\hline CHEMBL1444020 & 688558 & 6.0757 & 6.7202 & TRN & \\
\hline CHEMBL1386228 & 688558 & 6.1618 & 6.1331 & TRN & \\
\hline CHEMBL1989858 & 688558 & 5.4978 & 5.296 & TST & \\
\hline CHEMBL1323872 & 688558 & 5.5127 & 5.6271 & TRN & \\
\hline CHEMBL1326464 & 688558 & 5.0248 & 4.9601 & TST & \\
\hline CHEMBL1380239 & 688558 & 4.8715 & 5.02800 & 30000000005 & TRN \\
\hline CHEMBL1419227 & 688558 & 2.8239 & 3.1477 & TRN & \\
\hline CHEMBL1360530 & 688558 & 2.8239 & 2.9302 & TRN & \\
\hline CHEMBL1994221 & 688558 & 4.5579 & 4.8154 & TRN & \\
\hline CHEMBL1492222 & 688558 & 5.6149 & 5.4937 & TRN & \\
\hline CHEMBL1992918 & 688558 & 5.4397 & 5.6328 & TST & \\
\hline CHEMBL1485562 & 688558 & 5.1801 & 4.3939 & TRN & \\
\hline CHEMBL1534959 & 688558 & 5.2414 & 5.3454 & TST & \\
\hline
\end{tabular}


Supplemental Table S2.txt

\begin{tabular}{|c|c|c|c|c|c|}
\hline CHEMBL1328069 & 688558 & 5.5592 & 5.3865 & TRN & \\
\hline CHEMBL1520080 & 688558 & 4.8256 & 4.479 & TRN & \\
\hline CHEMBL1567899 & 688558 & 5.9003 & 5.7099 & TRN & \\
\hline CHEMBL1444013 & 688558 & 2.8239 & 3.0066 & TRN & \\
\hline CHEMBL1419082 & 688558 & 5.6325 & 5.7027 & TRN & \\
\hline CHEMBL1480475 & 688558 & 5.2249 & 5.4742 & TST & \\
\hline CHEMBL1592124 & 688558 & 6.1858 & 6.187 & TRN & \\
\hline CHEMBL3195943 & 688558 & 2.8239 & 4.4036 & TRN & \\
\hline CHEMBL 82134 & 688558 & 5.4928 & 5.4874 & TRN & \\
\hline CHEMBL1519279 & 688558 & 5.1072 & 5.1696 & TRN & \\
\hline CHEMBL546170 & 688558 & 4.9089 & 5.2763 & TRN & \\
\hline CHEMBL1476215 & 688558 & 6.3344 & 5.5919 & TRN & \\
\hline CHEMBL1460522 & 688558 & 4.6236 & 3.42199 & 99999999997 & TST \\
\hline CHEMBL1343525 & 688558 & 2.8239 & 3.35 & TRN & \\
\hline CHEMBL1990919 & 688558 & 6.1965 & 6.1113 & TRN & \\
\hline CHEMBL1568243 & 688558 & 4.9923 & 4.6151 & TRN & \\
\hline CHEMBL1514238 & 688558 & 2.8239 & 5.2242 & TRN & \\
\hline CHEMBL1508051 & 688558 & 5.1576 & 5.0043 & TST & \\
\hline CHEMBL1457561 & 688558 & 5.1259 & 5.6268 & TRN & \\
\hline CHEMBL 2004304 & 688558 & 5.2986 & 5.3546 & TRN & \\
\hline CHEMBL1589042 & 688558 & 4.8927 & 4.88899 & 9999999999 & TRN \\
\hline CHEMBL1602792 & 688558 & 4.9883 & 5.4247 & TST & \\
\hline CHEMBL1332139 & 688558 & 6.1918 & 6.2065 & TRN & \\
\hline CHEMBL1993058 & 688558 & 4.9062 & 4.5608 & TRN & \\
\hline CHEMBL1584985 & 688558 & 6.2321 & 5.9101 & TRN & \\
\hline CHEMBL1411266 & 688558 & 2.8239 & 3.1225 & TRN & \\
\hline CHEMBL1404792 & 688558 & 6.4318 & 5.4871 & TRN & \\
\hline CHEMBL1313766 & 688558 & 4.5564 & 3.6527 & TRN & \\
\hline CHEMBL1311094 & 688558 & 4.9583 & 5.6219 & TRN & \\
\hline CHEMBL1443205 & 688558 & 5.0183 & 4.8745 & TRN & \\
\hline CHEMBL1323140 & 688558 & 5.6558 & 5.7573 & TRN & \\
\hline CHEMBL1514474 & 688558 & 2.8239 & 3.5161 & TRN & \\
\hline CHEMBL1301700 & 688558 & 6.2041 & 6.2031 & TRN & \\
\hline CHEMBL486504 & 688558 & 6.7144 & 6.8192 & TST & \\
\hline CHEMBL452328 & 688558 & 4.6295 & 4.3799 & TRN & \\
\hline CHEMBL1563623 & 688558 & 5.1522 & 4.8048 & TRN & \\
\hline CHEMBL1346521 & 688558 & 2.8239 & 4.4753 & TRN & \\
\hline CHEMBL1441122 & 688558 & 4.8607 & 5.1726 & TST & \\
\hline CHEMBL1544486 & 688558 & 5.8719 & 5.7532 & TRN & \\
\hline CHEMBL1558993 & 688558 & 2.8239 & 4.6736 & TRN & \\
\hline CHEMBL1424118 & 688558 & 7.9208 & 6.3669 & TRN & \\
\hline CHEMBL1349067 & 688558 & 4.7436 & 4.5483 & TRN & \\
\hline CHEMBL1482663 & 688558 & 5.8784 & 5.7135 & TST & \\
\hline CHEMBL1610540 & 688558 & 5.4959 & 5.4178 & TRN & \\
\hline CHEMBL1308497 & 688558 & 4.7527 & 4.9552 & TRN & \\
\hline CHEMBL1549450 & 688558 & 5.0734 & 5.079 & TRN & \\
\hline CHEMBL1586531 & 688558 & 5.3779 & 5.2661 & TST & \\
\hline CHEMBL1568793 & 688558 & 2.8239 & 3.4409 & TRN & \\
\hline
\end{tabular}

Page 13745 


\begin{tabular}{|c|c|c|c|c|c|}
\hline \multicolumn{6}{|c|}{ Supplemental Table S2.txt } \\
\hline CHEMBL1397089 & 688558 & 5.1867 & 5.4968 & TRN & \\
\hline CHEMBL1461858 & 688558 & 2.8239 & 2.9963 & TRN & \\
\hline CHEMBL1611614 & 688558 & 5.9219 & 5.9511 & TRN & \\
\hline CHEMBL1542809 & 688558 & 4.9276 & 4.9262 & TRN & \\
\hline CHEMBL1578061 & 688558 & 6.4437 & 5.7095 & TRN & \\
\hline CHEMBL1481538 & 688558 & 6.1765 & 5.9719 & TRN & \\
\hline CHEMBL1487218 & 688558 & 4.8652 & 4.6966 & TRN & \\
\hline CHEMBL1607187 & 688558 & 4.6216 & 4.2369 & TRN & \\
\hline CHEMBL 330320 & 688558 & 6.4584 & 6.76 & TST & \\
\hline CHEMBL1345208 & 688558 & 5.2331 & 4.3193 & TST & \\
\hline CHEMBL1544797 & 688558 & 5.6908 & 5.7135 & TRN & \\
\hline CHEMBL1321754 & 688558 & 4.4213 & 4.704 & TRN & \\
\hline CHEMBL1303034 & 688558 & 6.1746 & 6.0135 & TST & \\
\hline CHEMBL1511219 & 688558 & 5.9927 & 5.9783 & TRN & \\
\hline CHEMBL1419369 & 688558 & 5.6747 & 5.4622 & TRN & \\
\hline CHEMBL3196853 & 688558 & 2.8239 & 4.5092 & TRN & \\
\hline CHEMBL 89445 & 688558 & 4.9506 & 5.1682 & TRN & \\
\hline CHEMBL1459468 & 688558 & 6.0958 & 5.9462 & TRN & \\
\hline CHEMBL1500581 & 688558 & 5.8831 & 5.7758 & TST & \\
\hline CHEMBL1349116 & 688558 & 6.6517 & 6.2573 & TRN & \\
\hline CHEMBL1548492 & 688558 & 5.6014 & 6.2621 & TRN & \\
\hline CHEMBL 3193510 & 688558 & 5.3887 & 5.46299 & 9999999999 & TRN \\
\hline CHEMBL1343458 & 688558 & 4.6912 & 4.9292 & TST & \\
\hline CHEMBL1335248 & 688558 & 2.8239 & 3.9034 & TRN & \\
\hline CHEMBL1900055 & 688558 & 5.0722 & 5.2157 & TRN & \\
\hline CHEMBL1429164 & 688558 & 5.2034 & 4.6422 & TRN & \\
\hline CHEMBL1548695 & 688558 & 5.5088 & 4.593 & TRN & \\
\hline CHEMBL1315921 & 688558 & 4.9334 & 4.7576 & TRN & \\
\hline CHEMBL1319676 & 688558 & 5.5277 & 5.3285 & TRN & \\
\hline CHEMBL1416406 & 688558 & 2.8239 & 4.5902 & TRN & \\
\hline CHEMBL1491324 & 688558 & 5.0805 & 5.6125 & TRN & \\
\hline CHEMBL1521217 & 688558 & 6.4145 & 5.8508 & TRN & \\
\hline CHEMBL1572746 & 688558 & 6.2464 & 6.3553 & TRN & \\
\hline CHEMBL1300069 & 688558 & 5.4843 & 5.2602 & TST & \\
\hline CHEMBL1369513 & 688558 & 2.8239 & 3.2494 & TRN & \\
\hline CHEMBL1525381 & 688558 & 5.0065 & 5.0916 & TRN & \\
\hline CHEMBL1582024 & 688558 & 2.8239 & 4.2051 & TRN & \\
\hline CHEMBL1417428 & 688558 & 4.671 & 5.4177 & TST & \\
\hline CHEMBL1566559 & 688558 & 2.8239 & 3.0733 & TRN & \\
\hline CHEMBL1445962 & 688558 & 6.6021 & 6.0316 & TRN & \\
\hline CHEMBL1464686 & 688558 & 4.7301 & 4.8546 & TRN & \\
\hline CHEMBL1500296 & 688558 & 4.0902 & 3.2101 & TRN & \\
\hline CHEMBL1366838 & 688558 & 6.2062 & 6.0416 & TRN & \\
\hline CHEMBL1608333 & 688558 & 5.5334 & 5.5467 & TRN & \\
\hline CHEMBL1547706 & 688558 & 5.7104 & 5.8721 & TRN & \\
\hline CHEMBL1303916 & 688558 & 5.1171 & 4.5626 & TRN & \\
\hline CHEMBL 1454029 & 688558 & 5.67 & 5.9066 & TRN & \\
\hline CHEMBL1307506 & 688558 & 4.8955 & 4.5259 & TRN & \\
\hline
\end{tabular}




\begin{tabular}{|c|c|c|c|c|c|c|}
\hline & & \multicolumn{5}{|c|}{ Supplemental Table S2.txt } \\
\hline CHEMBL1539359 & 688558 & 4.9754 & 4.9424 & TRN & & \\
\hline CHEMBL1589167 & 688558 & 2.8239 & 3.2478 & TRN & & \\
\hline CHEMBL1418818 & 688558 & 4.8415 & 5.138 & TRN & & \\
\hline CHEMBL592600 & 688558 & 6.0186 & 5.7897 & TRN & & \\
\hline CHEMBL1535161 & 688558 & 2.8239 & 2.9151 & TRN & & \\
\hline CHEMBL461579 & 688558 & 5.6045 & 5.8031 & TST & & \\
\hline CHEMBL1551000 & 688558 & 4.8633 & 5.3019 & TRN & & \\
\hline CHEMBL1374578 & 688558 & 2.8239 & 2.9535 & TRN & & \\
\hline CHEMBL1417726 & 688558 & 2.8239 & 3.6506 & TRN & & \\
\hline CHEMBL1613188 & 688558 & 4.8873 & 5.2594 & TRN & & \\
\hline CHEMBL1350673 & 688558 & 5.5136 & 5.6697 & TRN & & \\
\hline CHEMBL1455689 & 688558 & 4.9307 & 4.6869 & TRN & & \\
\hline CHEMBL1547295 & 688558 & 4.8021 & 4.2057 & TRN & & \\
\hline CHEMBL1555271 & 688558 & 5.9523 & 6.2647 & TRN & & \\
\hline CHEMBL600121 & 688558 & 4.9227 & 4.5333 & TRN & & \\
\hline CHEMBL 3192555 & 688558 & 5.6007 & 6.2524 & TRN & & \\
\hline CHEMBL1334804 & 688558 & 5.0411 & 5.1661 & TST & & \\
\hline CHEMBL1393820 & 688558 & 4.645 & 3.5991 & TRN & & \\
\hline CHEMBL3199428 & 688558 & 6.0 & 5.4525 & TRN & & \\
\hline CHEMBL1393193 & 688558 & 4.9825 & 4.5405 & TRN & & \\
\hline CHEMBL1985165 & 688558 & 5.3766 & 5.2139 & TRN & & \\
\hline CHEMBL578915 & 688558 & 4.7268 & 4.5726 & TRN & & \\
\hline CHEMBL1317682 & 688558 & 2.8239 & 3.5414 & TRN & & \\
\hline CHEMBL1567159 & 688558 & 5.7089 & 5.5336 & TRN & & \\
\hline CHEMBL1995692 & 688558 & 6.2161 & 6.2493 & TRN & & \\
\hline CHEMBL1413680 & 688558 & 5.6558 & 5.3615 & TST & & \\
\hline CHEMBL1998521 & 688558 & 6.1481 & 5.9347 & TRN & & \\
\hline CHEMBL1416671 & 688558 & 4.8114 & 4.4257 & TRN & & \\
\hline CHEMBL1460638 & 688558 & 2.8239 & 3.7328 & TST & & \\
\hline CHEMBL1384771 & 688558 & 4.8663 & 4.7858 & TST & & \\
\hline CHEMBL1321538 & 688558 & 6.1506 & 6.3049 & TRN & & \\
\hline CHEMBL578944 & 688558 & 5.4027 & 5.3417 & TST & & \\
\hline CHEMBL1525300 & 688558 & 4.6804 & 4.7282 & TRN & & \\
\hline CHEMBL1485006 & 688558 & 4.9322 & 4.8756 & TRN & & \\
\hline CHEMBL1360793 & 688558 & 5.2773 & 5.4052 & TRN & & \\
\hline CHEMBL1563712 & 688558 & 4.9506 & 3.3201 & TRN & & \\
\hline CHEMBL1569918 & 688558 & 4.9444 & 4.546 & TRN & & \\
\hline CHEMBL1364681 & 688558 & 5.8136 & 4.8532 & TRN & & \\
\hline CHEMBL1586255 & 688558 & 6.1811 & 4.9971 & TRN & & \\
\hline CHEMBL1453099 & 688558 & 5.0851 & 4.7059 & TST & & \\
\hline CHEMBL528791 & 688558 & 5.58200 & g0000000 & 01 & 5.4864 & TST \\
\hline CHEMBL1423935 & 688558 & 5.1671 & 5.4017 & TRN & & \\
\hline CHEMBL1450195 & 688558 & 5.6558 & 5.2113 & TRN & & \\
\hline CHEMBL1364172 & 688558 & 4.1688 & 4.7041 & TRN & & \\
\hline CHEMBL1337416 & 688558 & 5.5563 & 5.2529 & TST & & \\
\hline CHEMBL601933 & 688558 & 5.0104 & 4.9496 & TRN & & \\
\hline CHEMBL1566610 & 688558 & 6.45100 & 00000000 & 005 & 6.2455 & נכו \\
\hline CHEMBL260342 & 688558 & 5.6149 & 5.595 & TRN & & \\
\hline
\end{tabular}


Supplemental Table S2.txt

\begin{tabular}{|c|c|c|c|c|c|}
\hline CHEMBL1587116 & 688558 & 7.9208 & 5.3491 & TRN & \\
\hline CHEMBL1412002 & 688558 & 5.9792 & 6.1554 & TRN & \\
\hline CHEMBL1469676 & 688558 & 6.1549 & 5.8401 & TRN & \\
\hline CHEMBL1492564 & 688558 & 5.7196 & 5.7262 & TST & \\
\hline CHEMBL3212654 & 688558 & 4.9737 & 5.0975 & TRN & \\
\hline CHEMBL 3198720 & 688558 & 5.1354 & \multicolumn{2}{|c|}{5.627000000000001} & TRN \\
\hline CHEMBL1539678 & 688558 & 4.9959 & 5.3164 & TST & \\
\hline CHEMBL1569783 & 688558 & 5.9714 & 5.6654 & TRN & \\
\hline CHEMBL1430060 & 688558 & 5.9646 & 5.2489 & TRN & \\
\hline CHEMBL1326896 & 688558 & 2.8239 & 4.4924 & TRN & \\
\hline CHEMBL600862 & 688558 & 6.1445 & 5.9241 & TRN & \\
\hline CHEMBL1365332 & 688558 & 4.7479 & 5.1018 & TRN & \\
\hline CHEMBL1467533 & 688558 & 6.7352 & 6.4921 & TRN & \\
\hline CHEMBL568092 & 688558 & 5.5658 & 4.9496 & TRN & \\
\hline CHEMBL1511371 & 688558 & 5.6533 & 5.5627 & TST & \\
\hline CHEMBL3194449 & 688558 & 4.7966 & 5.5877 & TRN & \\
\hline CHEMBL1560590 & 688558 & 4.7834 & 4.9612 & TRN & \\
\hline CHEMBL1967436 & 688558 & 5.524 & 5.3332 & TST & \\
\hline CHEMBL1498959 & 688558 & 4.8817 & 5.2957 & TRN & \\
\hline CHEMBL1589457 & 688558 & 4.8509 & 4.1042 & TRN & \\
\hline CHEMBL1393126 & 688558 & 5.9944 & 6.1117 & TST & \\
\hline CHEMBL1371056 & 688558 & 6.059 & 6.0784 & TRN & \\
\hline CHEMBL1426410 & 688558 & 4.9436 & 5.2131 & TRN & \\
\hline CHEMBL1396209 & 688558 & 5.9714 & 5.8217 & TRN & \\
\hline CHEMBL1429789 & 688558 & 5.0166 & 5.0026 & TRN & \\
\hline CHEMBL1597628 & 688558 & 5.8539 & 4.6347 & TRN & \\
\hline CHEMBL 290077 & 688558 & 6.9066 & 6.296 & TST & \\
\hline CHEMBL473721 & 688558 & 5.1616 & 4.9238 & TRN & \\
\hline CHEMBL1533621 & 688558 & 5.8035 & \multicolumn{2}{|c|}{5.627000000000001} & TRN \\
\hline CHEMBL1612044 & 688558 & \multicolumn{3}{|c|}{5.287999999999999} & TRN \\
\hline CHEMBL1486214 & 688558 & 4.8976 & 5.3364 & TRN & \\
\hline CHEMBL1514534 & 688558 & 2.8239 & 5.5184 & TRN & \\
\hline CHEMBL1344300 & 688558 & 2.8239 & 4.323 & TST & \\
\hline CHEMBL1387605 & 688558 & 4.7548 & 4.7687 & TRN & \\
\hline CHEMBL1606328 & 688558 & \multicolumn{3}{|c|}{4.6419999999999995} & TST \\
\hline CHEMBL1365523 & 688558 & 4.3272 & 3.2517 & TST & \\
\hline CHEMBL1531500 & 688558 & 5.4139 & 5.2144 & TRN & \\
\hline CHEMBL1576754 & 688558 & 5.3673 & 5.553999 & 9999999999 & In \\
\hline CHEMBL1971142 & 688558 & 4.8815 & 5.4696 & TRN & \\
\hline CHEMBL1526174 & 688558 & 5.2231 & 5.2733 & TRN & \\
\hline CHEMBL3190965 & 688558 & 5.5328 & 5.7341 & TRN & \\
\hline CHEMBL1353184 & 688558 & 2.8239 & 3.5506 & TRN & \\
\hline CHEMBL1603293 & 688558 & 2.8239 & 3.3182 & TRN & \\
\hline CHEMBL1486332 & 688558 & 5.8874 & 6.1274 & TRN & \\
\hline CHEMBL1481192 & 688558 & 5.3953 & 5.5883 & TST & \\
\hline CHEMBL1563136 & 688558 & 2.8239 & 3.3646 & TRN & \\
\hline CHEMBL1456851 & 688558 & 6.7595 & 5.682 & TRN & \\
\hline CHEMBL1346796 & 688558 & 4.7635 & 3.5633 & TRN & \\
\hline
\end{tabular}

Page 13748 


\begin{tabular}{|c|c|c|c|c|c|c|}
\hline & & \multicolumn{5}{|c|}{ Supplemental Table s2.txt } \\
\hline CHEMBL1448625 & 688558 & 4.7345 & 4.6801 & TRN & & \\
\hline CHEMBL1425008 & 688558 & 2.8239 & 2.8389 & TRN & & \\
\hline CHEMBL1342728 & 688558 & 5.0125 & 5.0269 & TRN & & \\
\hline CHEMBL1347192 & 688558 & 4.77 & 5.1111 & TST & & \\
\hline CHEMBL1544114 & 688558 & 5.1136 & 5.414 & TRN & & \\
\hline CHEMBL3196369 & 688558 & 2.8239 & 3.7983 & TRN & & \\
\hline CHEMBL1391582 & 688558 & 5.3428 & 5.3871 & TST & & \\
\hline CHEMBL1331514 & 688558 & 4.9923 & 5.0049 & TRN & & \\
\hline CHEMBL1386418 & 688558 & 5.1967 & 4.6401 & TRN & & \\
\hline CHEMBL1521127 & 688558 & 2.8239 & 3.4484 & TRN & & \\
\hline CHEMBL1309860 & 688558 & 4.7817 & 4.7766 & TRN & & \\
\hline CHEMBL1600963 & 688558 & 2.8239 & 3.5811 & TRN & & \\
\hline CHEMBL1523841 & 688558 & 5.8642 & 5.9892 & TST & & \\
\hline CHEMBL1477197 & 688558 & 5.5667 & 5.601 & TRN & & \\
\hline CHEMBL607553 & 688558 & 5.9914 & 5.73 & TRN & & \\
\hline CHEMBL1544508 & 688558 & 5.3238 & 5.5079 & TRN & & \\
\hline CHEMBL1466997 & 688558 & 4.9791 & 5.0467 & TRN & & \\
\hline CHEMBL1572278 & 688558 & 5.9551 & 5.7224 & TRN & & \\
\hline CHEMBL1394314 & 688558 & 5.067 & 5.1175 & TRN & & \\
\hline CHEMBL1987454 & 688558 & 6.1785 & 6.2342 & TRN & & \\
\hline CHEMBL1334919 & 688558 & 5.24799 & 99999999 & 99 & 5.6964 & TRN \\
\hline CHEMBL1990093 & 688558 & 6.0675 & 5.8015 & TRN & & \\
\hline CHEMBL3209306 & 688558 & 5.7726 & 5.6451 & TRN & & \\
\hline CHEMBL1501720 & 688558 & 2.8239 & 4.6387 & TST & & \\
\hline CHEMBL1383793 & 688558 & 5.4583 & 5.1755 & TRN & & \\
\hline CHEMBL1969992 & 688558 & 4.6097 & 5.6609 & TRN & & \\
\hline CHEMBL1310508 & 688558 & 5.6582 & 5.7351 & TRN & & \\
\hline CHEMBL1491893 & 688558 & 7.9208 & 6.3073 & TRN & & \\
\hline CHEMBL353764 & 688558 & 3.9519 & 4.8837 & TRN & & \\
\hline CHEMBL1602160 & 688558 & 4.9309 & 4.5421 & TRN & & \\
\hline CHEMBL1460991 & 688558 & 2.8239 & 3.2372 & TRN & & \\
\hline CHEMBL1440293 & 688558 & 5.7457 & 5.4961 & TST & & \\
\hline CHEMBL1501238 & 688558 & 5.0799 & 4.9546 & TST & & \\
\hline CHEMBL1497939 & 688558 & 5.1527 & 5.8072 & TRN & & \\
\hline CHEMBL1373586 & 688558 & 4.6416 & 4.8776 & TRN & & \\
\hline CHEMBL1401327 & 688558 & 4.5067 & 4.1199 & TRN & & \\
\hline CHEMBL1466445 & 688558 & 6.2161 & 5.462006 & 0000000001 & & TRN \\
\hline CHEMBL1372924 & 688558 & 5.3706 & 5.4383 & TST & & \\
\hline CHEMBL1987461 & 688558 & 5.3777 & 5.48 & TRN & & \\
\hline CHEMBL1444065 & 688558 & 5.2961 & 5.1657 & TRN & & \\
\hline CHEMBL1610510 & 688558 & 5.4938 & 5.5266 & TRN & & \\
\hline CHEMBL1438717 & 688558 & 5.2295 & 5.1096 & TRN & & \\
\hline CHEMBL1455421 & 688558 & 5.0766 & 5.1611 & TRN & & \\
\hline CHEMBL1319113 & 688558 & 5.104 & 4.5353 & TST & & \\
\hline CHEMBL1985575 & 688558 & 5.3535 & 5.4803 & TRN & & \\
\hline CHEMBL1392026 & 688558 & 5.29899 & 99999999 & 995 & 5.1054 & TRN \\
\hline CHEMBL1393671 & 688558 & 4.8524 & 5.1722 & TRN & & \\
\hline CHEMBL1380406 & 688558 & 5.0707 & 5.0295 & TRN & & \\
\hline
\end{tabular}




\begin{tabular}{|c|c|c|c|c|}
\hline \multicolumn{5}{|c|}{ Supplemental Tab. } \\
\hline CHEMBL1978479 & 688558 & 4.8154 & 4.2924 & TRN \\
\hline CHEMBL1566211 & 688558 & 5.5659 & 5.4333 & TRN \\
\hline CHEMBL1408268 & 688558 & 6.1904 & 6.0536 & TRN \\
\hline CHEMBL493863 & 688558 & 5.4312 & 5.4654 & TST \\
\hline CHEMBL1993287 & 688558 & 5.6098 & 5.522 & TRN \\
\hline CHEMBL3191151 & 688558 & 5.7303 & 5.7714 & TRN \\
\hline CHEMBL1587981 & 688558 & 4.6434 & 3.3308 & TRN \\
\hline CHEMBL3197908 & 688558 & 5.9059 & 5.7183 & TRN \\
\hline CHEMBL1462675 & 688558 & 5.4368 & 4.9254 & TRN \\
\hline CHEMBL1331451 & 688558 & 2.8239 & 3.4846 & TRN \\
\hline CHEMBL1439227 & 688558 & 5.8199 & 5.7884 & TRN \\
\hline CHEMBL1970286 & 688558 & 6.5114 & 5.836 & TRN \\
\hline CHEMBL1588661 & 688558 & 6.1273 & 6.1373 & TRN \\
\hline CHEMBL1360484 & 688558 & 5.5758 & 5.6618 & TRN \\
\hline CHEMBL1996068 & 688558 & 5.211 & 4.9247 & TRN \\
\hline CHEMBL1541554 & 688558 & 5.6321 & 5.6189 & TRN \\
\hline CHEMBL1341680 & 688558 & 2.8239 & 4.9294 & TRN \\
\hline CHEMBL1462630 & 688558 & 6.4522 & 6.1315 & TST \\
\hline CHEMBL1448895 & 688558 & 2.8239 & 3.5185 & TST \\
\hline CHEMBL598883 & 688558 & 2.8239 & 4.7518 & TRN \\
\hline CHEMBL1443513 & 688558 & 2.8239 & 3.2444 & TRN \\
\hline CHEMBL1469642 & 688558 & 5.113 & 5.1374 & TST \\
\hline CHEMBL1314208 & 688558 & 5.0959 & 5.0906 & TST \\
\hline CHEMBL1386058 & 688558 & 2.8239 & 2.5425 & TRN \\
\hline CHEMBL3192894 & 688558 & 6.1249 & 5.2262 & TRN \\
\hline CHEMBL603129 & 688558 & 5.1442 & 5.2827 & TRN \\
\hline CHEMBL1995045 & 688558 & 5.7217 & 5.8552 & TST \\
\hline CHEMBL1427709 & 688558 & 4.6975 & 4.6422 & TRN \\
\hline CHEMBL1541771 & 688558 & 2.8239 & 3.3672 & TRN \\
\hline CHEMBL1317322 & 688558 & 5.2409 & 4.9137 & TRN \\
\hline CHEMBL1986514 & 688558 & 4.7535 & 4.6744 & TRN \\
\hline CHEMBL1539486 & 688558 & 6.3969 & 5.6558 & TRN \\
\hline CHEMBL1550486 & 688558 & 4.6517 & 4.6824 & TRN \\
\hline CHEMBL1372082 & 688558 & 6.0701 & 6.2269 & TRN \\
\hline CHEMBL1544445 & 688558 & 6.1759 & 6.2813 & TRN \\
\hline CHEMBL1403148 & 688558 & 5.9961 & 6.2264 & TRN \\
\hline CHEMBL1497078 & 688558 & 5.3337 & 5.0226 & TRN \\
\hline CHEMBL1506210 & 688558 & 5.1645 & 5.1142 & TRN \\
\hline CHEMBL1406552 & 688558 & 4.7411 & 4.4819 & TST \\
\hline CHEMBL3199216 & 688558 & 4.9201 & 5.704 & TRN \\
\hline CHEMBL3196976 & 688558 & 5.5564 & 5.5713 & TRN \\
\hline CHEMBL583584 & 688558 & 2.8239 & 5.4139 & TRN \\
\hline CHEMBL1460639 & 688558 & 5.5933 & 5.7069 & TST \\
\hline CHEMBL1480701 & 688558 & 2.8239 & 3.5629 & TRN \\
\hline CHEMBL1332450 & 688558 & 5.2843 & 5.085 & TRN \\
\hline CHEMBL1967744 & 688558 & 5.0241 & 5.1717 & TRN \\
\hline CHEMBL1376974 & 688558 & 2.8239 & 5.7057 & TST \\
\hline CHEMBL1500190 & 688558 & 5.6334 & 5.7093 & TST \\
\hline
\end{tabular}




\begin{tabular}{|c|c|c|c|c|c|}
\hline \multirow[b]{2}{*}{ CHEMBL1358473 } & \multicolumn{5}{|c|}{ Supplemental Table S2.txt } \\
\hline & 688558 & 4.5481 & 3.7957 & TRN & \\
\hline CHEMBL1483312 & 688558 & 6.4634 & 5.4571 & TRN & \\
\hline CHEMBL1313990 & 688558 & 6.0985 & 5.2921 & TST & \\
\hline CHEMBL1505209 & 688558 & 6.5406 & 6.3116 & TST & \\
\hline CHEMBL1468200 & 688558 & 4.9667 & 4.511 & TST & \\
\hline CHEMBL1596681 & 688558 & 5.9412 & 5.5125 & TRN & \\
\hline CHEMBL1408486 & 688558 & 6.1524 & 5.9018 & TRN & \\
\hline CHEMBL1428662 & 688558 & 5.5412 & 4.4164 & TRN & \\
\hline CHEMBL1451736 & 688558 & 6.1512 & 6.0261 & TRN & \\
\hline CHEMBL1395962 & 688558 & 4.7698 & 5.2038 & TRN & \\
\hline CHEMBL1543599 & 688558 & 4.6772 & 4.3771 & TRN & \\
\hline CHEMBL1301125 & 688558 & 5.5672 & 5.9141 & TST & \\
\hline CHEMBL1353341 & 688558 & 5.4181 & 5.3967 & TRN & \\
\hline CHEMBL1350780 & 688558 & 5.1744 & 5.4341 & TRN & \\
\hline CHEMBL1409606 & 688558 & 5.5242 & 5.4104 & TRN & \\
\hline CHEMBL1470728 & 688558 & 5.4087 & 5.6207 & TST & \\
\hline CHEMBL1583767 & 688558 & 4.9468 & 4.9526 & TRN & \\
\hline CHEMBL1493225 & 688558 & 5.0195 & 4.8504 & TRN & \\
\hline CHEMBL1361821 & 688558 & 5.4587 & 5.5296 & TRN & \\
\hline CHEMBL1363614 & 688558 & 5.2428 & 5.0442 & TRN & \\
\hline CHEMBL1471808 & 688558 & 2.8239 & 3.6191 & TRN & \\
\hline CHEMBL 225903 & 688558 & 5.0303 & 4.8894 & TRN & \\
\hline CHEMBL1979662 & 688558 & 4.3507 & 3.5205 & TRN & \\
\hline CHEMBL1309091 & 688558 & 5.4693 & 5.0887 & TRN & \\
\hline CHEMBL1547278 & 688558 & 4.8592 & 4.1145 & TRN & \\
\hline CHEMBL3191962 & 688558 & 5.5206 & 5.4467 & TRN & \\
\hline CHEMBL1402096 & 688558 & 5.3003 & 5.4412 & TRN & \\
\hline CHEMBL1328466 & 688558 & 5.8658 & 6.2918 & TRN & \\
\hline CHEMBL1993380 & 688558 & 5.6844 & 5.5843 & TRN & \\
\hline CHEMBL1583677 & 688558 & 5.6031 & 5.4891 & TRN & \\
\hline CHEMBL3199512 & 688558 & 4.9654 & 5.7027 & TRN & \\
\hline CHEMBL1372889 & 688558 & 5.1744 & 5.4673 & TRN & \\
\hline CHEMBL1330793 & 688558 & 6.2132 & 6.0955 & TST & \\
\hline CHEMBL1587877 & 688558 & 4.8537 & 5.1187 & TRN & \\
\hline CHEMBL1520297 & 688558 & 4.601 & 2.9127 & TRN & \\
\hline CHEMBL1399938 & 688558 & 6.4486 & 5.9237 & TRN & \\
\hline CHEMBL1301647 & 688558 & 4.4107 & 4.5418 & TRN & \\
\hline CHEMBL1613639 & 688558 & 5.5745 & 5.435 & TRN & \\
\hline CHEMBL1363706 & 688558 & 4.9384 & 4.8948 & TRN & \\
\hline CHEMBL1358722 & 688558 & 6.1379 & 6.3448 & TST & \\
\hline CHEMBL1544633 & 688558 & 6.0438 & 5.4174 & TRN & \\
\hline CHEMBL1447362 & 688558 & 4.4025 & 3.0815 & TRN & \\
\hline CHEMBL1341518 & 688558 & 4.8074 & 5.246 & TST & \\
\hline CHEMBL1321326 & 688558 & 5.66799 & 79999999 & 99 & 5.4552 \\
\hline CHEMBL1609605 & 688558 & 2.8239 & 3.3848 & TRN & \\
\hline CHEMBL1318088 & 688558 & 5.8047 & 5.7649 & TRN & \\
\hline CHEMBL1349146 & 688558 & 6.2211 & 5.5292 & TRN & \\
\hline CHEMBL1481030 & 688558 & 6.1858 & 6.2175 & TRN & \\
\hline
\end{tabular}


Supplemental Table S2.txt

\begin{tabular}{|c|c|c|c|c|c|}
\hline CHEMBL1351755 & 688558 & 6.8182 & 6.8369 & TRN & \\
\hline CHEMBL1395404 & 688558 & 5.4303 & 5.4798 & TRN & \\
\hline CHEMBL1523997 & 688558 & 2.8239 & 5.2246 & TRN & \\
\hline CHEMBL37570 & 688558 & 6.2573 & 5.5175 & TRN & \\
\hline CHEMBL1548898 & 688558 & 5.1498 & 5.2406 & TRN & \\
\hline CHEMBL1436988 & 688558 & 5.9245 & 5.6259 & TRN & \\
\hline CHEMBL1361005 & 688558 & 2.8239 & 2.8634 & TRN & \\
\hline CHEMBL1482760 & 688558 & 5.3403 & 5.1332 & TRN & \\
\hline CHEMBL1462074 & 688558 & 6.1057 & 6.2209 & TST & \\
\hline CHEMBL1360194 & 688558 & 2.8239 & 2.7853 & TRN & \\
\hline CHEMBL1583955 & 688558 & 5.4951 & 5.6925 & TRN & \\
\hline CHEMBL1506397 & 688558 & 4.2361 & 4.1494 & TST & \\
\hline CHEMBL1322645 & 688558 & 5.279 & 5.0167 & TST & \\
\hline CHEMBL1533738 & 688558 & 4.9978 & 4.5747 & TST & \\
\hline CHEMBL1388358 & 688558 & 6.767 & 6.6155 & TRN & \\
\hline CHEMBL1471587 & 688558 & 4.8034 & 4.6154 & TRN & \\
\hline CHEMBL1353737 & 688558 & 5.4923 & 3.1845 & TRN & \\
\hline CHEMBL1305972 & 688558 & 4.8395 & 5.2029 & TST & \\
\hline CHEMBL1422429 & 688558 & 6.4449 & 5.8039 & TRN & \\
\hline CHEMBL1382191 & 688558 & 5.1095 & 4.9739 & TRN & \\
\hline CHEMBL1396519 & 688558 & 4.9314 & 5.3562 & TRN & \\
\hline CHEMBL1404493 & 688558 & 6.4724 & 5.9286 & TRN & \\
\hline CHEMBL1324061 & 688558 & 5.1271 & 6.0335 & TRN & \\
\hline CHEMBL3192181 & 688558 & 5.9126 & 5.9286 & TRN & \\
\hline CHEMBL1352313 & 688558 & 5.6726 & 5.6588 & TRN & \\
\hline CHEMBL1505003 & 688558 & 5.027 & 4.9926 & TRN & \\
\hline CHEMBL3198544 & 688558 & 6.4609 & 6.2829 & TRN & \\
\hline CHEMBL1392527 & 688558 & 6.466 & 6.1198 & TRN & \\
\hline CHEMBL1447125 & 688558 & 5.6588 & 5.9006 & TRN & \\
\hline CHEMBL3193945 & 688558 & 4.7111 & 4.5073 & TRN & \\
\hline CHEMBL1523206 & 688558 & 5.5166 & 5.5786 & TST & \\
\hline CHEMBL1473676 & 688558 & 6.7235 & 7.3003 & TST & \\
\hline CHEMBL1458479 & 688558 & 6.767 & 5.8912 & TRN & \\
\hline CHEMBL1535055 & 688558 & 4.401 & 3.2227 & TRN & \\
\hline CHEMBL1580075 & 688558 & 4.5933 & 3.3694 & TRN & \\
\hline CHEMBL1876078 & 688558 & 4.7649 & 4.7361 & TRN & \\
\hline CHEMBL1455654 & 688558 & 2.8239 & 4.0833 & TRN & \\
\hline CHEMBL1382517 & 688558 & 5.5045 & 5.2953 & TST & \\
\hline CHEMBL1342038 & 688558 & 5.1885 & 5.5973 & TRN & \\
\hline CHEMBL3199665 & 688558 & 6.1669 & 6.1541 & TRN & \\
\hline CHEMBL1389728 & 688558 & 5.0262 & 4.8103 & TST & \\
\hline CHEMBL1339289 & 688558 & 5.5867 & 5.9508 & TST & \\
\hline CHEMBL1586263 & 688558 & 5.269 & 5.0281 & TRN & \\
\hline CHEMBL1335846 & 688558 & 6.1618 & 5.8742 & TRN & \\
\hline CHEMBL1316978 & 688558 & 6.4473 & 6.2485 & TRN & \\
\hline CHEMBL3210936 & 688558 & 5.3541 & 4.4726 & TST & \\
\hline CHEMBL1405940 & 688558 & $4.9860 e$ & 00000006 & 31 & 5.1923 \\
\hline CHEMBL1579277 & 688558 & 5.2385 & 4.8334 & TRN & \\
\hline
\end{tabular}




\begin{tabular}{|c|c|c|c|c|c|}
\hline & & \multicolumn{4}{|c|}{ Supplemental Table S2.txt } \\
\hline CHEMBL1329255 & 688558 & 2.8239 & 4.2147 & TRN & \\
\hline CHEMBL1596798 & 688558 & 5.5735 & 5.9236 & TRN & \\
\hline CHEMBL1500284 & 688558 & 5.1088 & 5.3655 & TST & \\
\hline CHEMBL1488760 & 688558 & 6.6968 & 5.9244 & TST & \\
\hline CHEMBL1602759 & 688558 & 5.8289 & 5.5471 & TRN & \\
\hline CHEMBL1605299 & 688558 & 2.8239 & 4.2305 & TRN & \\
\hline CHEMBL1476358 & 688558 & 2.8239 & 5.5034 & TRN & \\
\hline CHEMBL1478237 & 688558 & 2.8239 & 5.0698 & TRN & \\
\hline CHEMBL1606557 & 688558 & 2.8239 & 3.1587 & TRN & \\
\hline CHEMBL 2000499 & 688558 & 4.5284 & 5.0927 & TRN & \\
\hline CHEMBL1459394 & 688558 & 5.506 & 4.9119 & TRN & \\
\hline CHEMBL1457139 & 688558 & 5.09 & 5.4495 & TRN & \\
\hline CHEMBL1318350 & 688558 & 5.9318 & 6.0603 & TRN & \\
\hline CHEMBL1526851 & 688558 & 5.539 & 5.2599 & TST & \\
\hline CHEMBL1611182 & 688558 & 5.5854 & 5.529 & TRN & \\
\hline CHEMBL1332756 & 688558 & 5.769 & $5.6720 e$ & 0000000001 & TRN \\
\hline CHEMBL1483593 & 688558 & 6.7471 & 6.2556 & TST & \\
\hline CHEMBL1986214 & 688558 & 5.0592 & 5.3687 & TRN & \\
\hline CHEMBL1410102 & 688558 & 5.0764 & 5.3363 & TRN & \\
\hline CHEMBL1488712 & 688558 & 4.8641 & 4.9619 & TRN & \\
\hline CHEMBL1481347 & 688558 & 5.4869 & 5.5125 & TRN & \\
\hline CHEMBL1548433 & 688558 & 4.4186 & 4.4529 & TRN & \\
\hline CHEMBL1997171 & 688558 & 6.1918 & 6.2716 & TRN & \\
\hline CHEMBL1327496 & 688558 & 5.9083 & 5.6558 & TST & \\
\hline CHEMBL3194752 & 688558 & 4.6866 & 4.6886 & TRN & \\
\hline CHEMBL1575588 & 688558 & 5.2121 & 5.4105 & TRN & \\
\hline CHEMBL51931 & 688558 & 5.7069 & 5.6438 & TRN & \\
\hline CHEMBL1967031 & 688558 & 4.9486 & 4.6983 & TRN & \\
\hline CHEMBL1447563 & 688558 & 5.6231 & 5.614 & TRN & \\
\hline CHEMBL1427790 & 688558 & 5.1333 & 4.9528 & TRN & \\
\hline CHEMBL1999480 & 688558 & 5.7675 & 5.7598 & TST & \\
\hline CHEMBL3210375 & 688558 & 2.8239 & 3.2548 & TRN & \\
\hline CHEMBL1445776 & 688558 & 5.0559 & 4.8479 & TRN & \\
\hline CHEMBL1970422 & 688558 & 6.4935 & 6.1919 & TST & \\
\hline CHEMBL1546134 & 688558 & 5.3421 & 5.3652 & TRN & \\
\hline CHEMBL1373992 & 688558 & 5.2418 & 4.8805 & TST & \\
\hline CHEMBL 1427287 & 688558 & 4.5465 & 4.92899 & 9999999999 & TRN \\
\hline CHEMBL1333830 & 688558 & 5.605 & 4.7364 & TRN & \\
\hline CHEMBL1486176 & 688558 & 5.0466 & 4.9831 & TRN & \\
\hline CHEMBL1347563 & 688558 & 4.5452 & 4.7583 & TRN & \\
\hline CHEMBL1487345 & 688558 & 5.404 & 4.898 & TRN & \\
\hline CHEMBL1411388 & 688558 & 5.1066 & 5.2462 & TRN & \\
\hline CHEMBL1389248 & 688558 & 6.5157 & 6.0955 & TRN & \\
\hline CHEMBL1549738 & 688558 & 5.0931 & 5.2196 & TST & \\
\hline CHEMBL1509637 & 688558 & 2.8239 & 3.2214 & TRN & \\
\hline CHEMBL1532887 & 688558 & 4.5346 & 4.3304 & TRN & \\
\hline CHEMBL1573883 & 688558 & 5.0846 & 5.0395 & TRN & \\
\hline CHEMBL1469534 & 688558 & 3.1249 & 3.085 & TRN & \\
\hline
\end{tabular}


Supplemental Table S2.txt

\begin{tabular}{|c|c|c|c|c|c|}
\hline CHEMBL1993934 & 688558 & 6.2403 & 5.6616 & TRN & \\
\hline CHEMBL1982032 & 688558 & 5.2232 & 5.4265 & TRN & \\
\hline CHEMBL1517325 & 688558 & 5.5479 & 5.5793 & TRN & \\
\hline CHEMBL1307663 & 688558 & 5.3509 & 5.3478 & TRN & \\
\hline CHEMBL1583976 & 688558 & 5.7464 & 5.8452 & TRN & \\
\hline CHEMBL1978117 & 688558 & 6.1805 & 6.1886 & TRN & \\
\hline CHEMBL1570706 & 688558 & 5.5615 & 5.7367 & TRN & \\
\hline CHEMBL1502098 & 688558 & 4.852 & 4.7001 & TRN & \\
\hline CHEMBL1501191 & 688558 & 4.8272 & 4.6971 & TRN & \\
\hline CHEMBL1501375 & 688558 & 4.99 & 5.1222 & TRN & \\
\hline CHEMBL1378118 & 688558 & 5.6209 & 5.4735 & TST & \\
\hline CHEMBL1335650 & 688558 & 2.8239 & 4.4117 & TST & \\
\hline CHEMBL1392509 & 688558 & 4.6356 & 4.4413 & TRN & \\
\hline CHEMBL1417496 & 688558 & 5.0783 & 4.7466 & TRN & \\
\hline CHEMBL3182775 & 688558 & 5.9927 & 5.6917 & TST & \\
\hline CHEMBL1530673 & 688558 & 5.1218 & 4.9243 & TST & \\
\hline CHEMBL1340058 & 688558 & 6.2248 & 5.9642 & TRN & \\
\hline CHEMBL1333449 & 688558 & 6.1568 & 5.825 & TRN & \\
\hline CHEMBL1588452 & 688558 & 4.631 & 4.897 & TRN & \\
\hline CHEMBL1864040 & 688558 & 5.0435 & 5.1794 & TRN & \\
\hline CHEMBL1455468 & 688558 & 5.5033 & 6.1005 & TRN & \\
\hline CHEMBL1363437 & 688558 & 6.8239 & 7.2618 & TRN & \\
\hline CHEMBL1329725 & 688558 & 4.6337 & 4.3428 & TRN & \\
\hline CHEMBL1583292 & 688558 & 5.7414 & 5.2333 & TST & \\
\hline CHEMBL1568294 & 688558 & 4.8687 & 4.8278 & TRN & \\
\hline CHEMBL1541779 & 688558 & 4.914 & 5.2922 & TRN & \\
\hline CHEMBL1553717 & 688558 & 5.7825 & 5.6026 & TRN & \\
\hline CHEMBL1448054 & 688558 & 5.9931 & 6.2641 & TRN & \\
\hline CHEMBL585071 & 688558 & 5.9594 & 5.6891 & TRN & \\
\hline CHEMBL492468 & 688558 & 5.3433 & 5.4757 & TST & \\
\hline CHEMBL1522486 & 688558 & 5.2983 & 5.1234 & TRN & \\
\hline CHEMBL1430460 & 688558 & 2.8239 & 3.7559 & TRN & \\
\hline CHEMBL1540682 & 688558 & 5.7142 & 5.6311 & TST & \\
\hline CHEMBL1458812 & 688558 & 5.2994 & 5.0433 & TRN & \\
\hline CHEMBL3214583 & 688558 & 4.8911 & 4.5513 & TRN & \\
\hline CHEMBL1426871 & 688558 & 4.9962 & 4.8345 & TRN & \\
\hline CHEMBL80799 & 688558 & 5.4126 & 5.29700 & 0000000001 & TRN \\
\hline CHEMBL1423192 & 688558 & 4.7898 & 4.6201 & TRN & \\
\hline CHEMBL3189712 & 688558 & 5.2596 & 5.6464 & TRN & \\
\hline CHEMBL1380099 & 688558 & 4.9952 & 4.7858 & TST & \\
\hline CHEMBL1577840 & 688558 & 5.2755 & 5.5192 & TST & \\
\hline CHEMBL1492548 & 688558 & 2.8239 & 4.1577 & TRN & \\
\hline CHEMBL3199311 & 688558 & 6.2204 & 6.126 & TRN & \\
\hline CHEMBL1599070 & 688558 & 4.7513 & 4.4385 & TRN & \\
\hline CHEMBL1522827 & 688558 & 5.3117 & 5.494 & TRN & \\
\hline CHEMBL1524929 & 688558 & 5.0756 & 5.3456 & TRN & \\
\hline CHEMBL1350192 & 688558 & 7.9208 & 6.8036 & TRN & \\
\hline CHEMBL1503190 & 688558 & 5.2284 & 5.1177 & TRN & \\
\hline
\end{tabular}

Page 13754 


\begin{tabular}{|c|c|c|c|c|c|}
\hline \multirow[b]{2}{*}{ CHEMBL1428163 } & \multicolumn{5}{|c|}{ Supplemental Table S2.txt } \\
\hline & 688558 & 5.8286 & 5.6051 & TRN & \\
\hline CHEMBL1374715 & 688558 & 6.2343 & 5.7378 & TST & \\
\hline CHEMBL1407996 & 688558 & 5.5561 & 4.4639 & TRN & \\
\hline CHEMBL1524608 & 688558 & 2.8239 & 3.2072 & TRN & \\
\hline CHEMBL1361866 & 688558 & 4.9046 & 5.1186 & TST & \\
\hline CHEMBL1341756 & 688558 & 6.0405 & 5.8828 & TRN & \\
\hline CHEMBL1530911 & 688558 & 5.5859 & 5.6824 & TRN & \\
\hline CHEMBL1983871 & 688558 & 4.8642 & 4.6894 & TRN & \\
\hline CHEMBL1310355 & 688558 & 4.9463 & 4.7055 & TRN & \\
\hline CHEMBL224869 & 688558 & 2.8239 & 4.60800 & 00000000005 & TRN \\
\hline CHEMBL1312676 & 688558 & 4.2191 & 4.2403 & TRN & \\
\hline CHEMBL1484332 & 688558 & 5.2131 & 5.4027 & TRN & \\
\hline CHEMBL1611744 & 688558 & 5.539 & 5.4633 & TRN & \\
\hline CHEMBL602722 & 688558 & 5.9003 & 5.7679 & TRN & \\
\hline CHEMBL1555066 & 688558 & 5.3387 & 5.4976 & TRN & \\
\hline CHEMBL1514691 & 688558 & 5.2678 & 4.7607 & TRN & \\
\hline CHEMBL1600146 & 688558 & 4.8684 & 4.8915 & TST & \\
\hline CHEMBL1485865 & 688558 & 5.409 & 5.2675 & TRN & \\
\hline CHEMBL1498488 & 688558 & 6.7399 & 6.3603 & TRN & \\
\hline CHEMBL267099 & 688558 & 5.6815 & 5.8475 & TST & \\
\hline CHEMBL1518905 & 688558 & 6.4034 & 5.8599 & TRN & \\
\hline CHEMBL1524034 & 688558 & 5.0926 & 5.3471 & TRN & \\
\hline CHEMBL1556634 & 688558 & 5.2108 & 4.6595 & TST & \\
\hline CHEMBL1997978 & 688558 & 3.9068 & 4.65 & TRN & \\
\hline CHEMBL1520801 & 688558 & 5.0115 & 4.4731 & TRN & \\
\hline CHEMBL1987894 & 688558 & 5.8202 & 6.1984 & TRN & \\
\hline CHEMBL1611686 & 688558 & 5.3627 & 5.5894 & TRN & \\
\hline CHEMBL1464984 & 688558 & 5.013 & 5.1458 & TRN & \\
\hline CHEMBL1321427 & 688558 & 6.6696 & 6.3794 & TRN & \\
\hline CHEMBL1323313 & 688558 & 5.5433 & 5.6268 & TRN & \\
\hline CHEMBL3199403 & 688558 & 4.9074 & 5.2703 & TRN & \\
\hline CHEMBL1424127 & 688558 & 5.9104 & 6.1149 & TRN & \\
\hline CHEMBL1385516 & 688558 & 4.8176 & 4.9809 & TRN & \\
\hline CHEMBL1605372 & 688558 & 5.0374 & 4.9169 & TST & \\
\hline CHEMBL1569667 & 688558 & 5.7228 & 5.9176 & TRN & \\
\hline CHEMBL1586439 & 688558 & 4.6121 & 3.5482 & TRN & \\
\hline CHEMBL 2354875 & 688558 & 4.913 & 5.1927 & TRN & \\
\hline CHEMBL1367034 & 688558 & 5.0046 & 6.074 & TST & \\
\hline CHEMBL1329221 & 688558 & 4.1063 & 5.2444 & TRN & \\
\hline CHEMBL1588716 & 688558 & 4.8217 & 3.3312 & TRN & \\
\hline CHEMBL1581233 & 688558 & 5.0161 & 4.4215 & TRN & \\
\hline CHEMBL1477354 & 688558 & 4.1329 & 4.2516 & TRN & \\
\hline CHEMBL1495325 & 688558 & 5.2913 & 4.9694 & TST & \\
\hline CHEMBL1416089 & 688558 & 6.1057 & 5.7421 & TRN & \\
\hline CHEMBL3190220 & 688558 & 5.291 & 5.1978 & TRN & \\
\hline CHEMBL1380592 & 688558 & 5.3488 & 4.7128 & TRN & \\
\hline CHEMBL1577495 & 688558 & 5.1894 & 4.9611 & TRN & \\
\hline CHEMBL1966751 & 688558 & 4.9689 & 4.9767 & TRN & \\
\hline
\end{tabular}

Page 13755 


\begin{tabular}{|c|c|c|c|c|c|c|}
\hline & & \multicolumn{5}{|c|}{ Supplemental Table S2.txt } \\
\hline CHEMBL 3145088 & 688558 & 5.1002 & 5.351 & TRN & & \\
\hline CHEMBL1545422 & 688558 & 4.5692 & 3.5343 & TRN & & \\
\hline CHEMBL1329069 & 688558 & 5.306 & 5.496 & TRN & & \\
\hline CHEMBL1484195 & 688558 & 5.5173 & 5.0905 & TRN & & \\
\hline CHEMBL1513325 & 688558 & \multicolumn{3}{|c|}{6.3839999999999995} & .4774 & TRN \\
\hline CHEMBL1481328 & 688558 & 4.2055 & 5.1578 & TRN & & \\
\hline CHEMBL1388951 & 688558 & 4.765 & 4.625 & TRN & & \\
\hline CHEMBL1467284 & 688558 & 5.2938 & 5.6496 & TRN & & \\
\hline CHEMBL1611472 & 688558 & 2.8239 & 3.0509 & TRN & & \\
\hline CHEMBL1373253 & 688558 & 6.2716 & 5.3355 & TRN & & \\
\hline CHEMBL1608077 & 688558 & 4.9557 & 5.2344 & TRN & & \\
\hline CHEMBL1417929 & 688558 & 4.9585 & 4.928 & TST & & \\
\hline CHEMBL1357063 & 688558 & 4.9782 & 4.9754 & TRN & & \\
\hline CHEMBL586135 & 688558 & 6.2604 & 5.3077 & TRN & & \\
\hline CHEMBL1257013 & 688558 & 4.8178 & 4.9905 & TST & & \\
\hline CHEMBL1342029 & 688558 & 6.5544 & 6.3202 & TRN & & \\
\hline CHEMBL1493731 & 688558 & 5.9223 & 6.0013 & TRN & & \\
\hline CHEMBL1448905 & 688558 & 5.23 & 5.1131 & TRN & & \\
\hline CHEMBL602126 & 688558 & 5.8088 & 5.46899 & 9999999999 & & TRN \\
\hline CHEMBL1469827 & 688558 & 4.6422 & 4.5353 & TRN & & \\
\hline CHEMBL1510344 & 688558 & 6.4318 & 6.2584 & TRN & & \\
\hline CHEMBL585622 & 688558 & 5.3102 & 5.3051 & TRN & & \\
\hline CHEMBL6742 & 688558 & 2.8239 & 4.6994 & TRN & & \\
\hline CHEMBL600778 & 688558 & 6.0773 & 6.348 & TRN & & \\
\hline CHEMBL1579636 & 688558 & 5.6726 & 6.3068 & TRN & & \\
\hline CHEMBL1491847 & 688558 & 5.5782 & 5.5931 & TST & & \\
\hline CHEMBL1337919 & 688558 & 2.8239 & 4.309 & TRN & & \\
\hline CHEMBL1537106 & 688558 & 5.3292 & 5.32299 & 99999999995 & & TST \\
\hline CHEMBL1997659 & 688558 & 4.6729 & 4.7778 & TRN & & \\
\hline CHEMBL1442452 & 688558 & 2.8239 & 3.4501 & TRN & & \\
\hline CHEMBL1407169 & 688558 & 5.0356 & 5.3373 & TRN & & \\
\hline CHEMBL1446353 & 688558 & 5.0365 & 5.1088 & TRN & & \\
\hline CHEMBL1446306 & 688558 & 6.2076 & 5.8281 & TRN & & \\
\hline CHEMBL1396099 & 688558 & 4.3044 & 5.5017 & TST & & \\
\hline CHEMBL1305612 & 688558 & 5.0341 & 5.0238 & TRN & & \\
\hline CHEMBL1330417 & 688558 & 4.9114 & 4.6451 & TRN & & \\
\hline CHEMBL1387436 & 688558 & 4.8498 & 4.5495 & TRN & & \\
\hline CHEMBL3189245 & 688558 & 4.8308 & 5.3186 & TRN & & \\
\hline CHEMBL1389427 & 688558 & 4.9974 & 4.9048 & TRN & & \\
\hline CHEMBL1419266 & 688558 & 4.7209 & 4.0337 & TRN & & \\
\hline CHEMBL1572558 & 688558 & 5.7025 & 5.8036 & TST & & \\
\hline CHEMBL1475774 & 688558 & 5.4862 & 5.4451 & TRN & & \\
\hline CHEMBL1524734 & 688558 & 2.8239 & 4.8941 & TRN & & \\
\hline CHEMBL1441181 & 688558 & 5.3297 & 4.7924 & TRN & & \\
\hline CHEMBL1600403 & 688558 & 2.8239 & 3.8496 & TRN & & \\
\hline CHEMBL1547092 & 688558 & 5.3189 & 5.171 & TRN & & \\
\hline CHEMBL1321240 & 688558 & 5.9154 & 5.4822 & TRN & & \\
\hline CHEMBL1320414 & 688558 & 4.9411 & 4.7665 & TRN & & \\
\hline
\end{tabular}




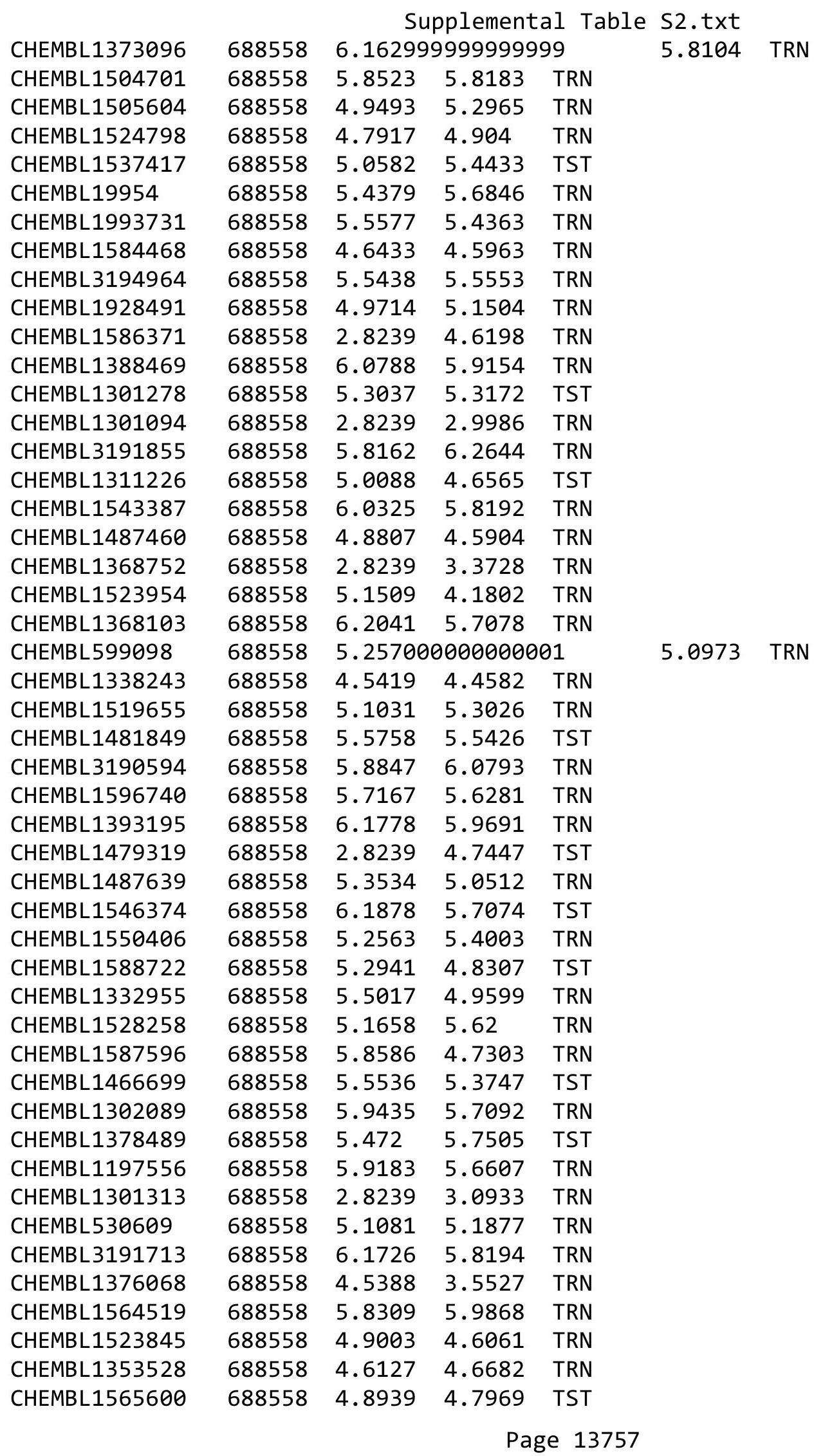




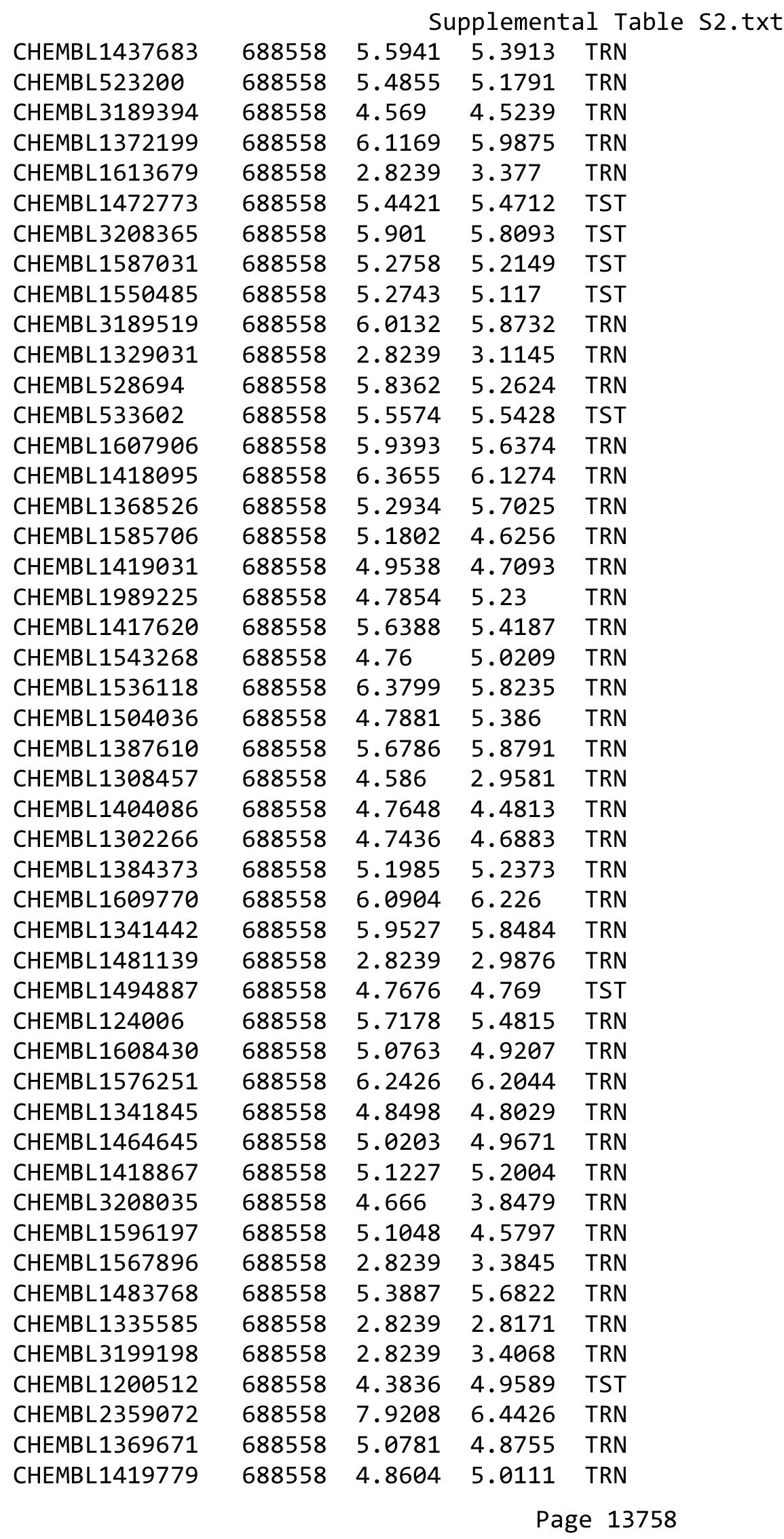




\begin{tabular}{|c|c|c|c|c|c|c|}
\hline \multirow[b]{2}{*}{ CHEMBL1372163 } & & \multicolumn{5}{|c|}{ Supplemental Table S2.txt } \\
\hline & 688558 & 6.1701 & 5.76 & TRN & & \\
\hline CHEMBL1472126 & 688558 & 5.914 & 6.1135 & TRN & & \\
\hline CHEMBL379179 & 688558 & $5.0710 e$ & 0000000 & $\partial 1$ & 5.1855 & TRN \\
\hline CHEMBL1605614 & 688558 & 4.0055 & 4.0363 & TRN & & \\
\hline CHEMBL1541441 & 688558 & 5.5423 & 5.7707 & TST & & \\
\hline CHEMBL578487 & 688558 & 5.4436 & 4.7599 & TRN & & \\
\hline CHEMBL1567957 & 688558 & 2.8239 & 4.7957 & TRN & & \\
\hline CHEMBL1431587 & 688558 & 4.8852 & 5.3837 & TRN & & \\
\hline CHEMBL1468340 & 688558 & 5.4585 & 5.6594 & TRN & & \\
\hline CHEMBL1464824 & 688558 & 4.5113 & 3.2669 & TRN & & \\
\hline CHEMBL1363578 & 688558 & 2.8239 & 3.5027 & TST & & \\
\hline CHEMBL576208 & 688558 & 4.7534 & 4.9083 & TRN & & \\
\hline CHEMBL3199573 & 688558 & 2.8239 & 4.4677 & TRN & & \\
\hline CHEMBL1982575 & 688558 & 4.8126 & 4.7666 & TRN & & \\
\hline CHEMBL1369594 & 688558 & 5.3697 & 5.4368 & TRN & & \\
\hline CHEMBL3195455 & 688558 & 5.4977 & 5.5093 & TRN & & \\
\hline CHEMBL1586733 & 688558 & 6.2668 & 5.9199 & TRN & & \\
\hline CHEMBL1368681 & 688558 & 2.8239 & 3.5429 & TRN & & \\
\hline CHEMBL1987938 & 688558 & 5.0447 & 5.6468 & TRN & & \\
\hline CHEMBL533226 & 688558 & 5.4934 & 5.5045 & TRN & & \\
\hline CHEMBL 2094567 & 688558 & 6.4202 & 5.996 & TRN & & \\
\hline CHEMBL1544837 & 688558 & 2.8239 & 2.7465 & TRN & & \\
\hline CHEMBL1975754 & 688558 & 5.7238 & 4.9064 & TRN & & \\
\hline CHEMBL3199050 & 688558 & 5.5913 & 5.4949 & TRN & & \\
\hline CHEMBL1994078 & 688558 & 5.0744 & 5.1223 & TRN & & \\
\hline CHEMBL1414345 & 688558 & 4.9468 & 3.3517 & TRN & & \\
\hline CHEMBL1503930 & 688558 & 5.0403 & 4.6183 & TRN & & \\
\hline CHEMBL1408708 & 688558 & 5.819 & 5.6284 & TRN & & \\
\hline CHEMBL1581425 & 688558 & 5.0745 & 5.2779 & TRN & & \\
\hline CHEMBL1359872 & 688558 & 6.4237 & 6.5602 & TRN & & \\
\hline CHEMBL1558285 & 688558 & 4.773 & 4.9547 & TRN & & \\
\hline CHEMBL1328050 & 688558 & 5.0249 & 5.1707 & TRN & & \\
\hline CHEMBL1547901 & 688558 & 5.5458 & 4.6485 & TST & & \\
\hline CHEMBL1454183 & 688558 & 5.6501 & 4.9582 & TST & & \\
\hline CHEMBL3198332 & 688558 & 5.251 & 5.6895 & TRN & & \\
\hline CHEMBL1497549 & 688558 & 5.871 & 5.7549 & TRN & & \\
\hline CHEMBL1312644 & 688558 & 2.8239 & 2.5544 & TRN & & \\
\hline CHEMBL1403980 & 688558 & 5.5685 & 5.9416 & TRN & & \\
\hline CHEMBL 86464 & 688558 & 5.5809 & 5.5857 & TRN & & \\
\hline CHEMBL1385375 & 688558 & 2.8239 & 3.7035 & TRN & & \\
\hline CHEMBL 2006168 & 688558 & 5.2467 & 5.2669 & TRN & & \\
\hline CHEMBL1540795 & 688558 & 5.7899 & 5.3867 & TRN & & \\
\hline CHEMBL1489824 & 688558 & 5.5995 & 5.4324 & TST & & \\
\hline CHEMBL1414754 & 688558 & 2.8239 & 4.7086 & TRN & & \\
\hline CHEMBL1988660 & 688558 & 5.505 & 5.6957 & TRN & & \\
\hline CHEMBL1487099 & 688558 & 5.7891 & 6.1486 & TST & & \\
\hline CHEMBL1376861 & 688558 & 5.3557 & 5.1789 & TRN & & \\
\hline CHEMBL391123 & 688558 & 4.8621 & 4.7367 & TST & & \\
\hline
\end{tabular}




\begin{tabular}{|c|c|c|c|c|c|}
\hline & & \multicolumn{4}{|c|}{ Supplemental Table S2.txt } \\
\hline CHEMBL1580774 & 688558 & 4.8837 & 5.0169 & TRN & \\
\hline CHEMBL1577016 & 688558 & 5.4333 & 5.4788 & TST & \\
\hline CHEMBL1489856 & 688558 & 4.5265 & 3.9879 & TRN & \\
\hline CHEMBL1347277 & 688558 & 5.3976 & 5.0769 & TRN & \\
\hline CHEMBL1374957 & 688558 & 5.2618 & 5.0759 & TST & \\
\hline CHEMBL1401175 & 688558 & 5.8318 & 5.7122 & TST & \\
\hline CHEMBL1373967 & 688558 & 6.433 & 5.5542 & TRN & \\
\hline CHEMBL1606521 & 688558 & 5.553 & 5.57799 & 9999999999 & TRN \\
\hline CHEMBL 29711 & 688558 & 4.413 & 3.5382 & TST & \\
\hline CHEMBL1403322 & 688558 & 5.7069 & 5.5467 & TRN & \\
\hline CHEMBL1353271 & 688558 & 5.0657 & 5.2331 & TRN & \\
\hline CHEMBL1421500 & 688558 & 4.7391 & 3.4221 & TRN & \\
\hline CHEMBL1345835 & 688558 & 5.2592 & 5.2738 & TRN & \\
\hline CHEMBL1387238 & 688558 & 4.5013 & 4.6105 & TRN & \\
\hline CHEMBL1606861 & 688558 & 4.7184 & 5.3091 & TRN & \\
\hline CHEMBL1359327 & 688558 & 2.8239 & 3.2727 & TRN & \\
\hline CHEMBL1487444 & 688558 & 5.3714 & 5.2897 & TRN & \\
\hline CHEMBL1393944 & 688558 & 4.6968 & 4.1558 & TRN & \\
\hline CHEMBL1572157 & 688558 & 2.8239 & 4.5931 & TRN & \\
\hline CHEMBL1312489 & 688558 & 2.8239 & 3.3571 & TRN & \\
\hline CHEMBL1576132 & 688558 & 5.5825 & 6.004 & TRN & \\
\hline CHEMBL1543337 & 688558 & 5.1904 & 5.6496 & TRN & \\
\hline CHEMBL1521348 & 688558 & 6.3028 & 5.6086 & TRN & \\
\hline CHEMBL1582760 & 688558 & 6.4342 & 6.1905 & TRN & \\
\hline CHEMBL1319307 & 688558 & 4.9597 & 4.9629 & TRN & \\
\hline CHEMBL1588704 & 688558 & 3.9411 & 4.0649 & TRN & \\
\hline CHEMBL1524484 & 688558 & 5.6619 & 5.6723 & TRN & \\
\hline CHEMBL1611041 & 688558 & 5.2235 & 5.2904 & TST & \\
\hline CHEMBL1311879 & 688558 & 5.5522 & 5.7524 & TRN & \\
\hline CHEMBL1527380 & 688558 & 6.3458 & 6.0743 & TRN & \\
\hline CHEMBL1488923 & 688558 & 5.9739 & 5.8693 & TRN & \\
\hline CHEMBL601135 & 688558 & 4.7607 & 4.5128 & TRN & \\
\hline CHEMBL193872 & 688558 & 5.3409 & 5.4678 & TRN & \\
\hline CHEMBL1439210 & 688558 & 5.3913 & 5.5337 & TRN & \\
\hline CHEMBL1981103 & 688558 & 5.3063 & 5.5519 & TST & \\
\hline CHEMBL1971727 & 688558 & 5.5923 & 5.6286 & TRN & \\
\hline CHEMBL1540024 & 688558 & 5.3523 & 5.2357 & TRN & \\
\hline CHEMBL225951 & 688558 & 4.9677 & 5.0939 & TRN & \\
\hline CHEMBL1429086 & 688558 & 4.5579 & 3.1761 & TRN & \\
\hline CHEMBL1520803 & 688558 & 4.9396 & 5.1009 & TRN & \\
\hline CHEMBL1361550 & 688558 & 5.3526 & 5.1043 & TRN & \\
\hline CHEMBL1575441 & 688558 & 5.4069 & 5.4344 & TST & \\
\hline CHEMBL1344556 & 688558 & 2.8239 & 3.3282 & TRN & \\
\hline CHEMBL1563218 & 688558 & 4.8922 & 4.824 & TRN & \\
\hline CHEMBL1576851 & 688558 & 5.0717 & 5.4677 & TRN & \\
\hline CHEMBL1446695 & 688558 & 5.1301 & 4.3199 & TRN & \\
\hline CHEMBL601757 & 688558 & 5.3412 & 5.6192 & TST & \\
\hline CHEMBL1527310 & 688558 & 5.4683 & 4.9835 & TST & \\
\hline
\end{tabular}




\begin{tabular}{|c|c|c|c|c|c|c|}
\hline \multirow[b]{2}{*}{ CHEMBL1324319 } & \multicolumn{6}{|c|}{ Supplemental Table S2.txt } \\
\hline & 688558 & 5.5586 & 5.0161 & TRN & & \\
\hline CHEMBL1330279 & 688558 & 6.2725 & 6.1708 & TRN & & \\
\hline CHEMBL1466305 & 688558 & 5.053 & 5.3342 & TRN & & \\
\hline CHEMBL1887153 & 688558 & 5.0021 & 5.6792 & TRN & & \\
\hline CHEMBL1379740 & 688558 & 5.4803 & 5.547999 & 99999 & 99 & TRN \\
\hline CHEMBL1452795 & 688558 & 5.63299 & 999999999 & 99 & 6.0596 & TST \\
\hline CHEMBL1366104 & 688558 & 2.8239 & 3.5411 & TRN & & \\
\hline CHEMBL 3212271 & 688558 & 4.6039 & 4.6105 & TST & & \\
\hline CHEMBL1394035 & 688558 & 2.8239 & 3.1794 & TST & & \\
\hline CHEMBL1420007 & 688558 & 4.9287 & 4.6331 & TST & & \\
\hline CHEMBL1528867 & 688558 & 4.7543 & 4.6011 & TST & & \\
\hline CHEMBL1337130 & 688558 & 2.8239 & 4.4768 & TST & & \\
\hline CHEMBL1404448 & 688558 & 6.5884 & 5.682 & TST & & \\
\hline CHEMBL1789993 & 688558 & 5.6428 & 5.0398 & TST & & \\
\hline CHEMBL1437888 & 688558 & 5.295 & 5.4367 & TST & & \\
\hline CHEMBL1462938 & 688558 & 4.7999 & 5.1802 & TST & & \\
\hline CHEMBL1572446 & 688558 & 2.8239 & 3.5345 & TST & & \\
\hline CHEMBL1462919 & 688558 & 5.0515 & 4.7245 & TST & & \\
\hline CHEMBL1501508 & 688558 & 5.2874 & 5.245 & TST & & \\
\hline CHEMBL1335176 & 688558 & 5.9318 & 6.1648 & TST & & \\
\hline CHEMBL1461027 & 688558 & 4.563 & 2.8119 & TST & & \\
\hline CHEMBL1610733 & 688558 & 5.0243 & 4.9079 & TST & & \\
\hline CHEMBL1529978 & 688558 & 5.4873 & 5.6871 & TST & & \\
\hline CHEMBL199868 & 688558 & 5.5691 & 5.5848 & TST & & \\
\hline CHEMBL1255733 & 688558 & 6.3925 & 5.9864 & TST & & \\
\hline CHEMBL1370884 & 688558 & 5.9108 & 5.8411 & TST & & \\
\hline CHEMBL1490060 & 688558 & 4.904 & 5.1587 & TST & & \\
\hline CHEMBL1452391 & 688558 & 5.7331 & 6.1717 & TST & & \\
\hline CHEMBL1376166 & 688558 & 6.51 & 5.8336 & TST & & \\
\hline CHEMBL1539745 & 688558 & 2.8239 & 2.9988 & TST & & \\
\hline CHEMBL1430068 & 688558 & 5.9408 & 6.6597 & TST & & \\
\hline CHEMBL1549860 & 688558 & 5.0411 & 5.1561 & TST & & \\
\hline CHEMBL1399212 & 688558 & 4.885 & 4.6354 & TST & & \\
\hline CHEMBL1404547 & 688558 & 5.171 & 5.2573 & TST & & \\
\hline CHEMBL1323828 & 688558 & 4.6808 & 3.8049 & TST & & \\
\hline CHEMBL1348389 & 688558 & 6.025 & 5.9459 & TST & & \\
\hline CHEMBL1613644 & 688558 & 4.3711 & 4.5407 & TST & & \\
\hline CHEMBL1328504 & 688558 & 5.0232 & 4.7334 & TST & & \\
\hline CHEMBL1535665 & 688558 & 5.5645 & 5.4656 & TST & & \\
\hline CHEMBL1362687 & 688558 & 6.1972 & 6.2173 & TST & & \\
\hline CHEMBL1393156 & 688558 & 4.6974 & 3.1885 & TST & & \\
\hline CHEMBL1974506 & 688558 & 5.06 & 5.6298 & TST & & \\
\hline CHEMBL1596609 & 688558 & 4.5423 & 3.8599 & TST & & \\
\hline CHEMBL1977570 & 688558 & 4.9233 & 5.0034 & TST & & \\
\hline CHEMBL1388137 & 688558 & 6.1844 & 6.4147 & TST & & \\
\hline CHEMBL1421396 & 688558 & 4.9027 & 4.8578 & TST & & \\
\hline CHEMBL1558695 & 688558 & 5.5964 & 5.6548 & TST & & \\
\hline CHEMBL1393689 & 688558 & 5.0606 & 4.7211 & TST & & \\
\hline
\end{tabular}




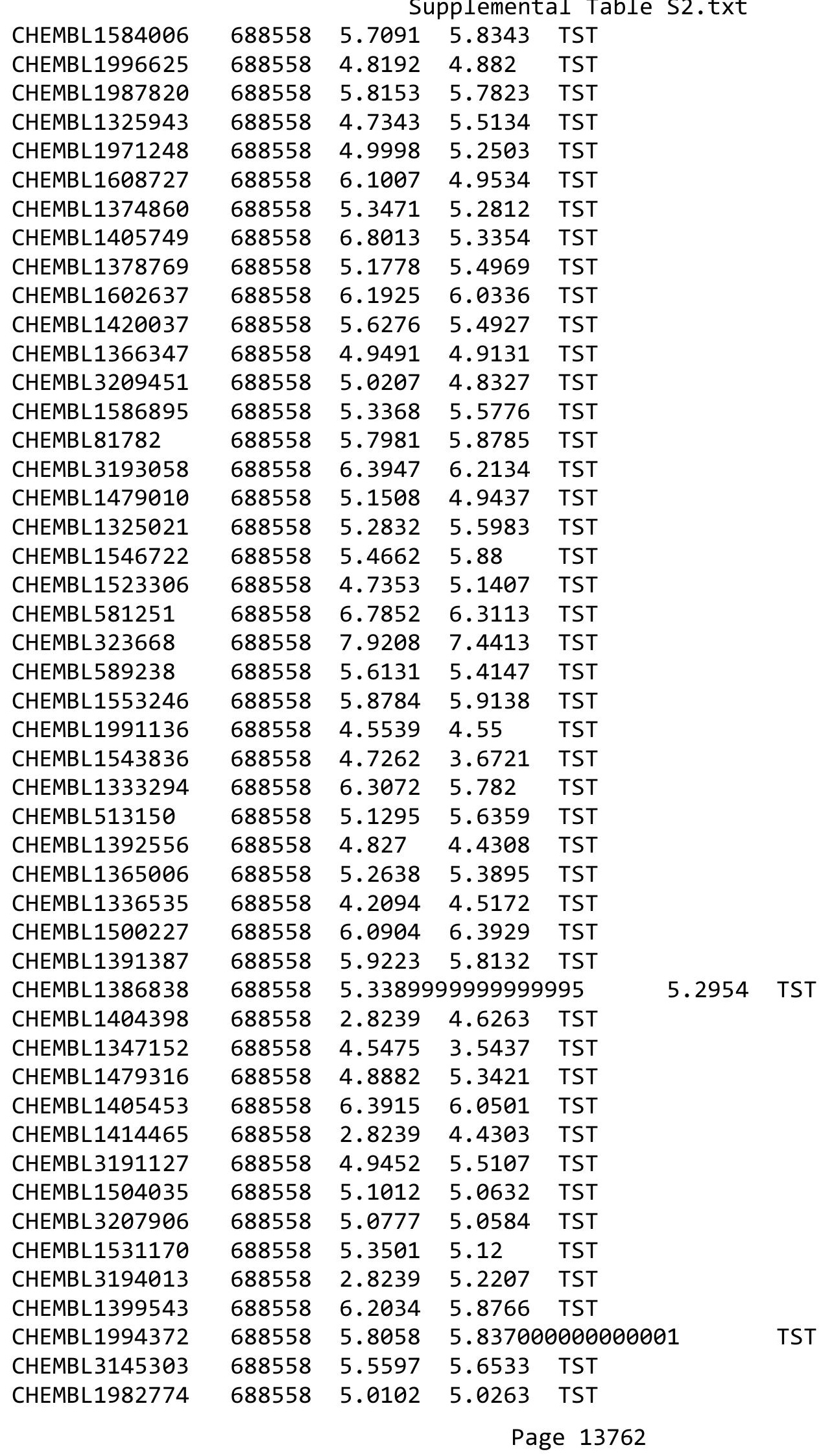


Supplemental Table S2.txt

\begin{tabular}{|c|c|c|c|c|}
\hline CHEMBL1584727 & 688558 & 2.8239 & 3.1425 & TST \\
\hline CHEMBL1469579 & 688558 & 4.6256 & 4.396 & TST \\
\hline CHEMBL1442056 & 688558 & 5.4067 & 5.4769 & TST \\
\hline CHEMBL1583715 & 688558 & 5.3237 & \multicolumn{2}{|c|}{5.537000000000001} \\
\hline CHEMBL 2002262 & 688558 & 5.106 & 5.2261 & TST \\
\hline CHEMBL1519965 & 688558 & 5.4389 & 5.6096 & TST \\
\hline CHEMBL1609431 & 688558 & 5.341 & 5.6309 & TST \\
\hline CHEMBL1491711 & 688558 & 5.7147 & 4.6331 & TST \\
\hline CHEMBL1611670 & 688558 & 5.0087 & 5.1193 & TST \\
\hline CHEMBL1392025 & 688558 & 2.8239 & 4.1741 & TST \\
\hline CHEMBL1385784 & 688558 & 6.7033 & 6.4716 & TST \\
\hline CHEMBL1514187 & 688558 & 4.676 & 3.8442 & TST \\
\hline CHEMBL1344025 & 688558 & 2.8239 & 3.6357 & TST \\
\hline CHEMBL1426340 & 688558 & 5.0074 & 5.5609 & TST \\
\hline CHEMBL1349063 & 688558 & 5.9897 & 5.8997 & TST \\
\hline CHEMBL1360618 & 688558 & 5.185 & 5.4419 & TST \\
\hline CHEMBL1608535 & 688558 & 5.2933 & 4.5869 & TST \\
\hline CHEMBL1402510 & 688558 & 4.7251 & 5.2124 & TST \\
\hline CHEMBL585502 & 688558 & 6.1355 & 5.8775 & TST \\
\hline CHEMBL1347156 & 688558 & 4.7619 & 4.1 & TST \\
\hline CHEMBL1565526 & 688558 & 5.4973 & 5.6675 & TST \\
\hline CHEMBL1369945 & 688558 & 5.1327 & 5.4038 & TST \\
\hline CHEMBL1422078 & 688558 & 4.9844 & 5.4433 & TST \\
\hline CHEMBL1390304 & 736967 & 3.1458 & 3.1739 & TRN \\
\hline CHEMBL1172020 & 736967 & 3.1454 & 3.1198 & TRN \\
\hline CHEMBL3208896 & 736967 & 3.1457 & 3.0781 & TRN \\
\hline CHEMBL1718663 & 736967 & 3.1457 & 2.9269 & TST \\
\hline CHEMBL1583108 & 736967 & 4.7973 & 4.6677 & TRN \\
\hline CHEMBL1380339 & 736967 & 4.6325 & 4.5715 & TRN \\
\hline CHEMBL1524590 & 736967 & 4.2066 & 3.5672 & TRN \\
\hline CHEMBL1340183 & 736967 & 3.1458 & 3.4019 & TRN \\
\hline CHEMBL1455256 & 736967 & 4.1 & 4.6861 & TST \\
\hline CHEMBL1492639 & 736967 & 4.2311 & 4.1347 & TRN \\
\hline CHEMBL1313885 & 736967 & 3.1458 & 3.1135 & TST \\
\hline CHEMBL1722129 & 736967 & 4.2025 & 4.297 & TRN \\
\hline CHEMBL1485484 & 736967 & 3.1458 & 3.3183 & TRN \\
\hline CHEMBL1454559 & 736967 & 3.1457 & 3.3682 & TRN \\
\hline CHEMBL1480330 & 736967 & 3.1461 & 3.2377 & TRN \\
\hline CHEMBL1412285 & 736967 & 4.4061 & 4.1869 & TRN \\
\hline CHEMBL1432495 & 736967 & 3.1458 & 3.0893 & TRN \\
\hline CHEMBL1429158 & 736967 & 3.6233 & 4.3897 & TRN \\
\hline CHEMBL1419680 & 736967 & 5.0934 & 4.9222 & TRN \\
\hline CHEMBL1567923 & 736967 & 3.6228 & 4.383 & TRN \\
\hline CHEMBL1611373 & 736967 & 3.1458 & 3.1096 & TRN \\
\hline CHEMBL3213293 & 736967 & 3.1459 & 3.1543 & TRN \\
\hline CHEMBL1362011 & 736967 & 3.1459 & 3.1182 & TST \\
\hline CHEMBL1558400 & 736967 & 4.629 & 4.0636 & TST \\
\hline CHEMBL1465113 & 736967 & 3.1458 & 3.1101 & TRN \\
\hline
\end{tabular}




\begin{tabular}{|c|c|c|c|c|c|c|}
\hline & & \multicolumn{5}{|c|}{ Supplemental Table S2.txt } \\
\hline CHEMBL1316798 & 736967 & 4.8031 & 4.6867 & TRN & & \\
\hline CHEMBL1497570 & 736967 & 3.1458 & 3.1401 & TRN & & \\
\hline CHEMBL1600756 & 736967 & 3.1457 & 2.8705 & TRN & & \\
\hline CHEMBL1451210 & 736967 & 3.1457 & 3.2491 & TRN & & \\
\hline CHEMBL1385219 & 736967 & 3.1457 & 3.1217 & TRN & & \\
\hline CHEMBL1605348 & 736967 & 3.1458 & 3.1865 & TRN & & \\
\hline CHEMBL3189964 & 736967 & 4.6992 & 4.4616 & TRN & & \\
\hline CHEMBL1516552 & 736967 & 3.1458 & 3.2179 & TRN & & \\
\hline CHEMBL1702047 & 736967 & 3.1462 & 3.2918 & TST & & \\
\hline CHEMBL1407632 & 736967 & 5.4401 & 5.1166 & TRN & & \\
\hline CHEMBL1557186 & 736967 & 3.6229 & 4.9731 & TRN & & \\
\hline CHEMBL1572028 & 736967 & 4.5249 & 3.932 & TRN & & \\
\hline CHEMBL1506234 & 736967 & 4.8534 & 4.5647 & TRN & & \\
\hline CHEMBL1313434 & 736967 & 5.6426 & 5.4776 & TRN & & \\
\hline CHEMBL1305039 & 736967 & 3.1462 & 3.0451 & TRN & & \\
\hline CHEMBL1349035 & 736967 & 3.1457 & 3.1406 & TRN & & \\
\hline CHEMBL1530583 & 736967 & 3.1458 & 3.0679 & TRN & & \\
\hline CHEMBL1316113 & 736967 & $3.1460 e$ & 00000000 & 204 & 3.0988 & TRN \\
\hline CHEMBL3197404 & 736967 & 5.7635 & 5.7053 & TRN & & \\
\hline CHEMBL1416113 & 736967 & 3.1462 & 3.2116 & TRN & & \\
\hline CHEMBL1499258 & 736967 & 5.0452 & 4.9984 & TRN & & \\
\hline CHEMBL1975147 & 736967 & 5.3043 & 5.3108 & TRN & & \\
\hline CHEMBL1346219 & 736967 & 4.4705 & 4.3177 & TRN & & \\
\hline CHEMBL3211686 & 736967 & 3.1459 & 3.0157 & TRN & & \\
\hline CHEMBL1379673 & 736967 & 6.0052 & 5.4351 & TRN & & \\
\hline CHEMBL1574521 & 736967 & 4.5409 & 5.1708 & TRN & & \\
\hline CHEMBL1705075 & 736967 & 3.1461 & 3.0859 & TRN & & \\
\hline CHEMBL1318929 & 736967 & 3.1459 & 3.1266 & TRN & & \\
\hline CHEMBL1562006 & 736967 & 4.2038 & 4.1233 & TRN & & \\
\hline CHEMBL1586067 & 736967 & 5.2566 & 5.5171 & TRN & & \\
\hline CHEMBL1993522 & 736967 & 3.1459 & 3.0643 & TRN & & \\
\hline CHEMBL1582976 & 736967 & 3.1458 & 2.9347 & TRN & & \\
\hline CHEMBL1601529 & 736967 & 3.1457 & 4.4657 & TST & & \\
\hline CHEMBL1599509 & 736967 & 3.1455 & 3.1499 & TRN & & \\
\hline CHEMBL1564363 & 736967 & 4.1 & 4.5406 & TRN & & \\
\hline CHEMBL1310204 & 736967 & 5.3612 & 5.182 & TRN & & \\
\hline CHEMBL1466913 & 736967 & 5.2461 & 5.141 & TRN & & \\
\hline CHEMBL1391348 & 736967 & 3.1457 & 2.966 & TRN & & \\
\hline CHEMBL1575502 & 736967 & 3.1461 & 4.6569 & TRN & & \\
\hline CHEMBL1465189 & 736967 & 3.1458 & 3.1008 & TRN & & \\
\hline CHEMBL1342856 & 736967 & 3.1457 & 3.2447 & TRN & & \\
\hline CHEMBL1576602 & 736967 & 5.2572 & 5.1103 & TST & & \\
\hline CHEMBL1313968 & 736967 & 5.5977 & 5.2657 & TRN & & \\
\hline CHEMBL1970784 & 736967 & 5.138 & 4.672 & TRN & & \\
\hline CHEMBL1612010 & 736967 & 3.1459 & 3.0058 & TST & & \\
\hline CHEMBL 3193288 & 736967 & 3.1459 & 3.0951 & TST & & \\
\hline CHEMBL1991936 & 736967 & 3.1458 & 4.2873 & TRN & & \\
\hline CHEMBL1445509 & 736967 & 3.1462 & 3.2069 & TRN & & \\
\hline
\end{tabular}




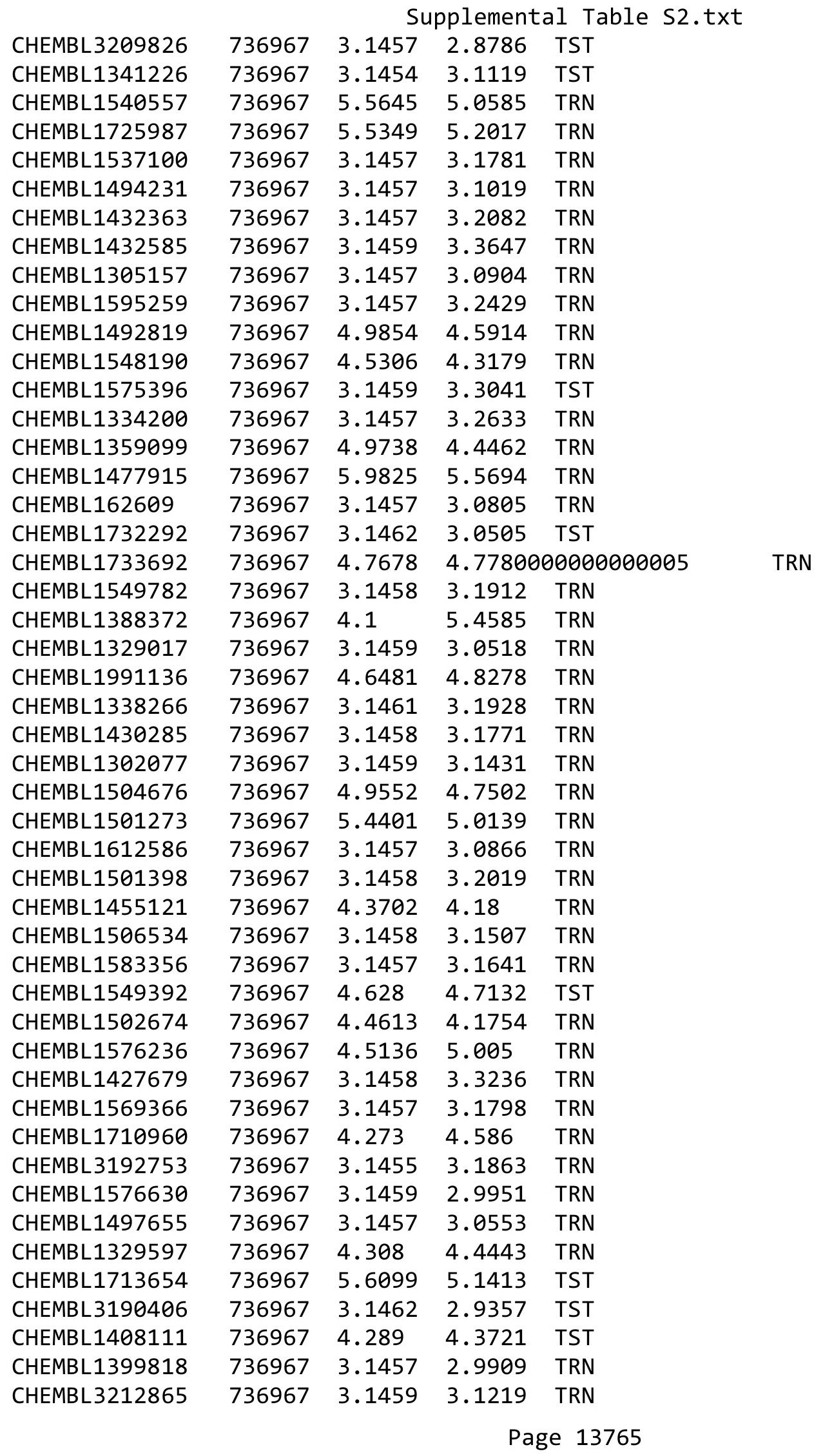




\begin{tabular}{|c|c|c|c|c|c|c|}
\hline & & \multicolumn{5}{|c|}{ Supplemental Table S2.txt } \\
\hline CHEMBL1353385 & 736967 & 3.1459 & 3.1757 & TRN & & \\
\hline CHEMBL1704751 & 736967 & 3.1457 & 3.1087 & TRN & & \\
\hline CHEMBL244683 & 736967 & 3.1455 & 4.2045 & TRN & & \\
\hline CHEMBL1723906 & 736967 & 3.1465 & 3.0828 & TST & & \\
\hline CHEMBL1712933 & 736967 & 3.1456 & 3.23100 & 0000 & 003 & TRN \\
\hline CHEMBL1725983 & 736967 & 5.034 & 4.9091 & TRN & & \\
\hline CHEMBL3190515 & 736967 & 3.1456 & 3.1923 & TRN & & \\
\hline CHEMBL1382511 & 736967 & 3.1461 & 3.0623 & TRN & & \\
\hline CHEMBL1483385 & 736967 & 3.1453 & 3.0626 & TST & & \\
\hline CHEMBL1429070 & 736967 & 5.5327 & 5.2208 & TST & & \\
\hline CHEMBL1408792 & 736967 & 4.8163 & 4.7462 & TRN & & \\
\hline CHEMBL1714965 & 736967 & 3.1457 & 3.2528 & TRN & & \\
\hline CHEMBL1363713 & 736967 & 3.1457 & 3.0893 & TRN & & \\
\hline CHEMBL 27871 & 736967 & 3.1457 & 4.0799 & TRN & & \\
\hline CHEMBL1346568 & 736967 & 3.1459 & 3.2634 & TRN & & \\
\hline CHEMBL1573579 & 736967 & 4.466 & 4.4716 & TRN & & \\
\hline CHEMBL 2004884 & 736967 & 4.8414 & 5.2556 & TRN & & \\
\hline CHEMBL1432075 & 736967 & 5.0174 & 4.368 & TRN & & \\
\hline CHEMBL1732393 & 736967 & 3.1461 & 3.2132 & TST & & \\
\hline CHEMBL1499439 & 736967 & 3.1462 & 3.0601 & TRN & & \\
\hline CHEMBL1525885 & 736967 & 3.1457 & 3.1439 & TRN & & \\
\hline CHEMBL1304227 & 736967 & 3.1457 & 3.3108 & TRN & & \\
\hline CHEMBL1311198 & 736967 & 4.9426 & 4.7921 & TRN & & \\
\hline CHEMBL1445941 & 736967 & 3.1457 & 3.2885 & TRN & & \\
\hline CHEMBL1377757 & 736967 & 3.1458 & 3.0738 & TRN & & \\
\hline CHEMBL1344981 & 736967 & 3.1457 & 3.1802 & TRN & & \\
\hline CHEMBL1375635 & 736967 & 3.1458 & 3.1173 & TRN & & \\
\hline CHEMBL1701437 & 736967 & 5.0386 & 5.1129 & TST & & \\
\hline CHEMBL1559585 & 736967 & 3.1457 & 3.2788 & TRN & & \\
\hline CHEMBL1719517 & 736967 & 3.1459 & 3.1915 & TRN & & \\
\hline CHEMBL1349147 & 736967 & 4.4523 & 4.6001 & TRN & & \\
\hline CHEMBL1510770 & 736967 & 3.1461 & 3.1692 & TRN & & \\
\hline CHEMBL1573529 & 736967 & 5.9846 & 5.6134 & TRN & & \\
\hline CHEMBL1544706 & 736967 & 3.1459 & 2.965 & TST & & \\
\hline CHEMBL2002008 & 736967 & 4.7471 & 4.6346 & TRN & & \\
\hline CHEMBL1450816 & 736967 & 3.1465 & 3.2727 & TRN & & \\
\hline CHEMBL1328572 & 736967 & 3.1462 & 3.0885 & TRN & & \\
\hline CHEMBL1613705 & 736967 & 3.1457 & 3.3784 & TRN & & \\
\hline CHEMBL1487883 & 736967 & 3.1462 & 3.0757 & TRN & & \\
\hline CHEMBL1306801 & 736967 & 3.14600 & 00000000 & 204 & 2.9047 & TRN \\
\hline CHEMBL1499887 & 736967 & 3.1459 & 3.1646 & TRN & & \\
\hline CHEMBL3195851 & 736967 & 6.1911 & 5.7929 & TRN & & \\
\hline CHEMBL1577997 & 736967 & 3.1457 & 3.1503 & TRN & & \\
\hline CHEMBL1720979 & 736967 & 3.1458 & 3.1876 & TRN & & \\
\hline CHEMBL1398812 & 736967 & 5.9337 & 5.7898 & TRN & & \\
\hline CHEMBL1369691 & 736967 & 5.862 & 5.648 & TRN & & \\
\hline CHEMBL1538548 & 736967 & 3.14600 & 00000000 & 204 & 3.0657 & TRN \\
\hline CHEMBL1976375 & 736967 & 3.1457 & 3.2191 & TRN & & \\
\hline
\end{tabular}




\begin{tabular}{|c|c|c|c|c|c|c|}
\hline & & \multicolumn{5}{|c|}{ Supplemental Table S2.txt } \\
\hline CHEMBL1576905 & 736967 & 5.3332 & 4.7963 & TST & & \\
\hline CHEMBL1506407 & 736967 & 3.1462 & 3.2535 & TRN & & \\
\hline CHEMBL1309545 & 736967 & 3.1455 & 3.2328 & TRN & & \\
\hline CHEMBL1412068 & 736967 & 3.1458 & 3.013 & TRN & & \\
\hline CHEMBL1524612 & 736967 & 3.1462 & 3.2469 & TRN & & \\
\hline CHEMBL1564313 & 736967 & 6.9638 & 5.9294 & TRN & & \\
\hline CHEMBL1404423 & 736967 & 4.59 & 4.3162 & TRN & & \\
\hline CHEMBL1345866 & 736967 & 4.9712 & 4.6193 & TRN & & \\
\hline CHEMBL1468444 & 736967 & \multicolumn{3}{|c|}{6.138999999999999} & 5.3801 & TRN \\
\hline CHEMBL1977499 & 736967 & 3.1457 & 5.5618 & TRN & & \\
\hline CHEMBL1587067 & 736967 & 3.1458 & 3.1465 & TRN & & \\
\hline CHEMBL1509367 & 736967 & 3.1459 & 3.1093 & TRN & & \\
\hline CHEMBL1462008 & 736967 & 5.3014 & 4.9449 & TRN & & \\
\hline CHEMBL1451725 & 736967 & 4.1818 & 4.2777 & TST & & \\
\hline CHEMBL1971695 & 736967 & 5.3048 & 4.6944 & TST & & \\
\hline CHEMBL1308386 & 736967 & 4.9208 & 4.2976 & TRN & & \\
\hline CHEMBL1511157 & 736967 & 4.3068 & 4.2776 & TRN & & \\
\hline CHEMBL1565855 & 736967 & 4.6545 & 3.9241 & TRN & & \\
\hline CHEMBL1379366 & 736967 & \multicolumn{3}{|c|}{3.1460000000000004} & 3.2616 & TRN \\
\hline CHEMBL1409105 & 736967 & 3.1455 & 3.2272 & TRN & & \\
\hline CHEMBL1733019 & 736967 & 3.1457 & 3.1081 & TRN & & \\
\hline CHEMBL475244 & 736967 & 3.1454 & 3.0581 & TRN & & \\
\hline CHEMBL3195005 & 736967 & 4.5709 & 4.3055 & TRN & & \\
\hline CHEMBL1547468 & 736967 & \multicolumn{3}{|c|}{4.8580000000000005} & 4.9103 & TRN \\
\hline CHEMBL 2001481 & 736967 & 5.1651 & 4.8327 & TRN & & \\
\hline CHEMBL1604510 & 736967 & 5.8435 & 5.41200 & 0000000001 & & TRN \\
\hline CHEMBL1607288 & 736967 & 3.1462 & 3.0875 & TRN & & \\
\hline CHEMBL1326200 & 736967 & 3.1462 & 2.9321 & TRN & & \\
\hline CHEMBL1435559 & 736967 & 3.1455 & 3.1436 & TRN & & \\
\hline CHEMBL1596709 & 736967 & 3.1457 & 2.9229 & TRN & & \\
\hline CHEMBL1726231 & 736967 & 3.623 & 4.7166 & TRN & & \\
\hline CHEMBL1594911 & 736967 & 3.1458 & 4.5315 & TRN & & \\
\hline CHEMBL1405077 & 736967 & 3.1458 & 3.0762 & TRN & & \\
\hline CHEMBL1596655 & 736967 & 5.2334 & 4.7381 & TST & & \\
\hline CHEMBL1466606 & 736967 & 5.7675 & 5.0022 & TRN & & \\
\hline CHEMBL1353321 & 736967 & 5.0224 & 4.7735 & TRN & & \\
\hline CHEMBL 1535241 & 736967 & 3.1457 & 3.1756 & TRN & & \\
\hline CHEMBL1728917 & 736967 & 3.1456 & 3.0048 & TST & & \\
\hline CHEMBL1491376 & 736967 & 3.1457 & 3.1923 & TRN & & \\
\hline CHEMBL1597335 & 736967 & 3.1458 & 3.0326 & TRN & & \\
\hline CHEMBL1421228 & 736967 & 4.7825 & 4.8819 & TRN & & \\
\hline CHEMBL3195681 & 736967 & 6.4748 & 6.1864 & TRN & & \\
\hline CHEMBL1481417 & 736967 & 4.7462 & 4.8003 & TST & & \\
\hline CHEMBL1611715 & 736967 & 3.145 & 3.0954 & TST & & \\
\hline CHEMBL1399757 & 736967 & 3.1459 & 2.9683 & TST & & \\
\hline CHEMBL1408986 & 736967 & 4.6285 & 4.8955 & TST & & \\
\hline CHEMBL1711538 & 736967 & 3.1455 & 3.1112 & TST & & \\
\hline CHEMBL1977538 & 736967 & 3.1457 & 3.1365 & TST & & \\
\hline
\end{tabular}




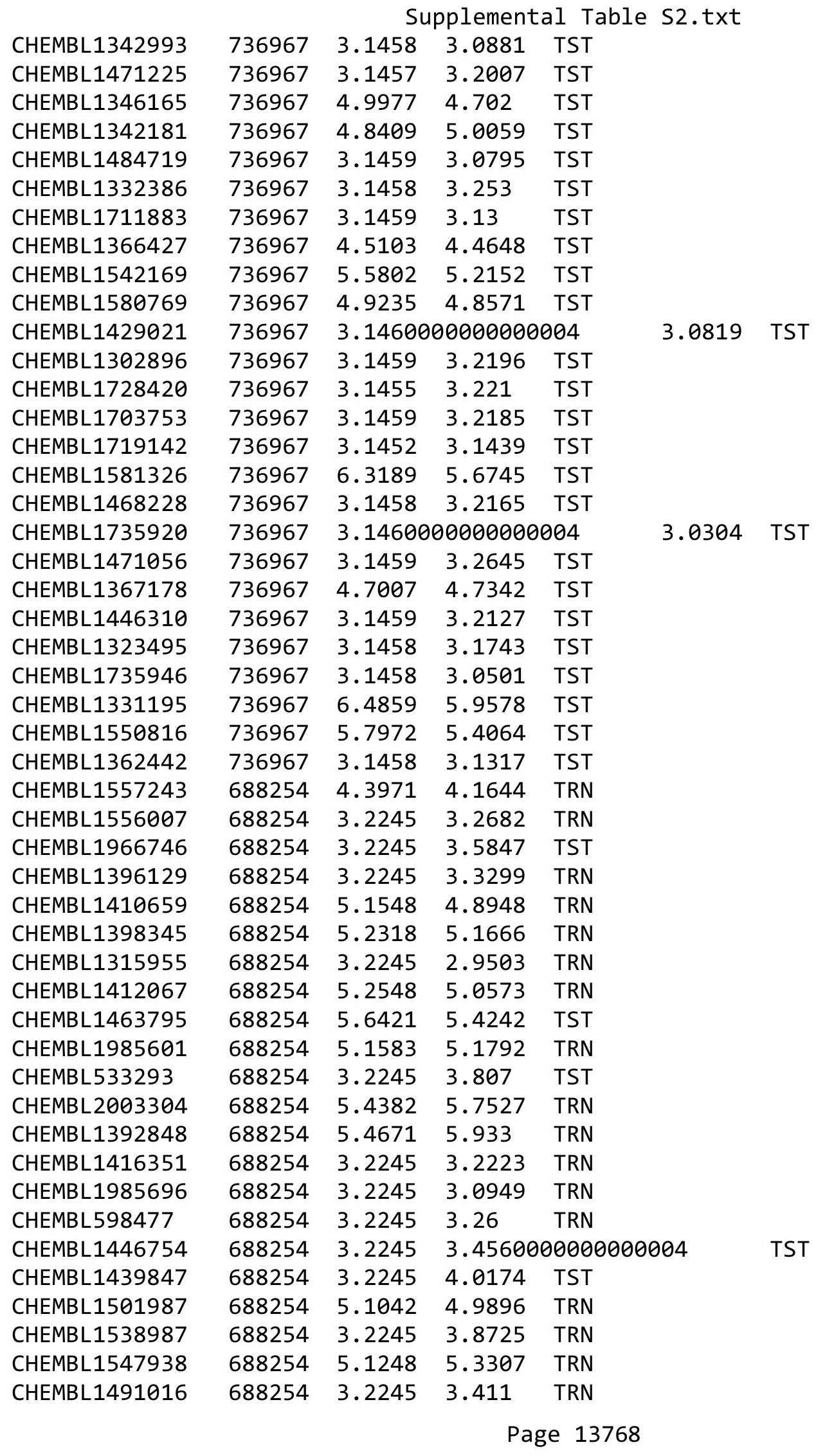




\begin{tabular}{|c|c|c|c|c|c|c|}
\hline & & \multicolumn{5}{|c|}{ Supplemental Table S2.txt } \\
\hline CHEMBL1430184 & 688254 & 3.2245 & 3.6882 & TRN & & \\
\hline CHEMBL1571034 & 688254 & 5.6724 & 5.5572 & TRN & & \\
\hline CHEMBL1607380 & 688254 & 4.9521 & 4.2847 & TRN & & \\
\hline CHEMBL1453652 & 688254 & 5.1714 & 4.4113 & TRN & & \\
\hline CHEMBL1724937 & 688254 & \multicolumn{3}{|c|}{6.207999999999999} & 6.3808 & TRN \\
\hline CHEMBL1398812 & 688254 & 4.6494 & 3.7599 & TRN & & \\
\hline CHEMBL1605743 & 688254 & 6.721 & 6.38899 & 9999999999 & & TRN \\
\hline CHEMBL1523652 & 688254 & 4.6257 & 4.5975 & TST & & \\
\hline CHEMBL1498210 & 688254 & \multicolumn{3}{|c|}{5.5120000000000005} & 5.3955 & TST \\
\hline CHEMBL1606773 & 688254 & 3.2245 & 3.3191 & TRN & & \\
\hline CHEMBL1303641 & 688254 & 6.0506 & 6.3258 & TRN & & \\
\hline CHEMBL1510317 & 688254 & 5.1222 & 5.2865 & TRN & & \\
\hline CHEMBL1518886 & 688254 & 5.9817 & 5.3829 & TST & & \\
\hline CHEMBL1583872 & 688254 & 5.9119 & 5.3829 & TST & & \\
\hline CHEMBL1513792 & 688254 & 3.2245 & 3.7046 & TST & & \\
\hline CHEMBL581251 & 688254 & 3.2245 & 3.8783 & TST & & \\
\hline CHEMBL1557268 & 688254 & 3.2245 & 4.0368 & TRN & & \\
\hline CHEMBL1379677 & 688254 & 5.5201 & 5.6218 & TRN & & \\
\hline CHEMBL1604962 & 688254 & 5.8271 & 5.2022 & TST & & \\
\hline CHEMBL1331195 & 688254 & 6.4293 & 6.5206 & TRN & & \\
\hline CHEMBL1372920 & 688254 & 5.0996 & 5.0609 & TRN & & \\
\hline CHEMBL1415476 & 688254 & 5.0133 & 4.6613 & TRN & & \\
\hline CHEMBL1527994 & 688254 & 5.5098 & 4.9006 & TRN & & \\
\hline CHEMBL1713905 & 688254 & 5.6594 & 5.7659 & TRN & & \\
\hline CHEMBL1500251 & 688254 & 4.7743 & 4.9313 & TRN & & \\
\hline CHEMBL 3207378 & 688254 & 3.2245 & 3.7697 & TST & & \\
\hline CHEMBL1419637 & 688254 & 3.2245 & 4.107 & TRN & & \\
\hline CHEMBL1390971 & 688254 & 5.2798 & 5.2851 & TRN & & \\
\hline CHEMBL1413533 & 688254 & 3.2245 & 3.1091 & TRN & & \\
\hline CHEMBL1409608 & 688254 & 4.9627 & 4.4089 & TRN & & \\
\hline CHEMBL1420142 & 688254 & 5.2157 & 4.931 & TRN & & \\
\hline CHEMBL1490312 & 688254 & 3.2245 & 4.1126 & TRN & & \\
\hline CHEMBL1604510 & 688254 & 3.2245 & 3.7537 & TRN & & \\
\hline CHEMBL1524257 & 688254 & 4.9959 & 4.8182 & TRN & & \\
\hline CHEMBL1373849 & 688254 & 5.501 & 3.9661 & TRN & & \\
\hline CHEMBL1310325 & 688254 & 3.2245 & 3.3264 & TRN & & \\
\hline CHEMBL1322893 & 688254 & 3.2245 & 3.3634 & TRN & & \\
\hline CHEMBL1502002 & 688254 & 4.9783 & 4.3009 & TRN & & \\
\hline CHEMBL1413510 & 688254 & 5.3561 & 5.1027 & TRN & & \\
\hline CHEMBL1333292 & 688254 & 3.2245 & 3.488 & TRN & & \\
\hline CHEMBL1472131 & 688254 & 5.4098 & 5.03 & TRN & & \\
\hline CHEMBL3198439 & 688254 & 3.2245 & 3.4748 & TRN & & \\
\hline CHEMBL1399400 & 688254 & 3.2245 & 4.092 & TRN & & \\
\hline CHEMBL1431610 & 688254 & 5.254 & 4.3653 & TRN & & \\
\hline CHEMBL1304024 & 688254 & 4.5543 & 4.7725 & TRN & & \\
\hline CHEMBL1332522 & 688254 & 5.8339 & 4.8819 & TST & & \\
\hline CHEMBL1582196 & 688254 & 3.2245 & 4.2663 & TRN & & \\
\hline CHEMBL1502551 & 688254 & 4.5506 & 3.6294 & TRN & & \\
\hline
\end{tabular}




\begin{tabular}{|c|c|c|c|c|c|c|}
\hline \multicolumn{7}{|c|}{ Supplemental Table S2.txt } \\
\hline CHEMBL1510658 & 688254 & 3.2245 & 3.891 & TRN & & \\
\hline CHEMBL1583960 & 688254 & 4.5727 & 4.356 & TRN & & \\
\hline CHEMBL1432003 & 688254 & 3.2245 & 3.2117 & TRN & & \\
\hline CHEMBL1611002 & 688254 & 3.2245 & 4.0417 & TRN & & \\
\hline CHEMBL374632 & 688254 & 6.1493 & 5.5458 & TRN & & \\
\hline CHEMBL1458472 & 688254 & 3.2245 & 4.2233 & TRN & & \\
\hline CHEMBL1565458 & 688254 & 3.2245 & 4.035 & TRN & & \\
\hline CHEMBL1387366 & 688254 & 5.6576 & 5.5795 & TRN & & \\
\hline CHEMBL1372738 & 688254 & 3.2245 & 2.9761 & TRN & & \\
\hline CHEMBL1991136 & 688254 & 4.63899 & 99999999 & & 5.071000000000001 & TRN \\
\hline CHEMBL1977499 & 688254 & 3.2245 & 3.1428 & TRN & & \\
\hline CHEMBL1320566 & 688254 & 4.3076 & 3.9491 & TRN & & \\
\hline CHEMBL1542877 & 688254 & 3.2245 & 4.456 & TST & & \\
\hline CHEMBL1576762 & 688254 & 4.5556 & 3.6039 & TRN & & \\
\hline CHEMBL1495079 & 688254 & 3.2245 & 3.5903 & TST & & \\
\hline CHEMBL1362746 & 688254 & 5.8739 & $5.32100 t$ & 0000000001 & TST & \\
\hline CHEMBL1597682 & 688254 & 3.2245 & 3.2312 & TST & & \\
\hline CHEMBL3190111 & 688254 & 3.2245 & 3.3403 & TST & & \\
\hline CHEMBL1492044 & 688254 & 3.2245 & 5.0722 & TST & & \\
\hline CHEMBL1522563 & 688254 & 5.118 & 5.2748 & TST & & \\
\hline CHEMBL1990694 & 688254 & 5.3685 & 5.6442 & TST & & \\
\hline CHEMBL1306565 & 688254 & 3.2245 & 4.1321 & TST & & \\
\hline CHEMBL1966700 & 688254 & 3.2245 & 3.2248 & TST & & \\
\hline CHEMBL3727377 & 1537411 & 7.2218 & 6.3649 & TRN & & \\
\hline CHEMBL3728485 & 1537411 & 7.2218 & 7.0668 & TRN & & \\
\hline CHEMBL3729995 & 1537411 & 7.2218 & 7.1124 & TRN & & \\
\hline CHEMBL3730293 & 1537411 & 7.2218 & 7.0927 & TRN & & \\
\hline CHEMBL3730254 & 1537411 & 7.2218 & 6.1482 & TST & & \\
\hline CHEMBL3732620 & 1537411 & 7.2218 & 7.301 & TST & & \\
\hline CHEMBL3733237 & 1537411 & 6.2218 & 6.8034 & TRN & & \\
\hline CHEMBL3733040 & 1537411 & 7.2218 & 7.2526 & TRN & & \\
\hline CHEMBL3727989 & 1537411 & 7.2218 & 7.1733 & TRN & & \\
\hline CHEMBL 3728875 & 1537411 & 7.2218 & 7.4275 & TRN & & \\
\hline CHEMBL3729109 & 1537411 & 7.2218 & 7.6376 & TST & & \\
\hline CHEMBL3728855 & 1537411 & 7.2218 & 6.8132 & TRN & & \\
\hline CHEMBL3729261 & 1537411 & 7.2218 & 7.2249 & TRN & & \\
\hline CHEMBL3732982 & 1537411 & 7.2218 & 6.4911 & TRN & & \\
\hline CHEMBL3731485 & 1537411 & 6.2218 & 6.504 & TRN & & \\
\hline CHEMBL3729841 & 1537411 & 7.2218 & 7.5251 & TRN & & \\
\hline CHEMBL3731030 & 1537411 & 6.2218 & 6.9655 & TRN & & \\
\hline CHEMBL3727381 & 1537411 & 7.2218 & 7.0549 & TRN & & \\
\hline CHEMBL 3730810 & 1537411 & 4.9208 & 6.2069 & TRN & & \\
\hline CHEMBL3732761 & 1537411 & 6.2218 & 6.8652 & TRN & & \\
\hline CHEMBL3732999 & 1537411 & 7.2218 & 7.1287 & TRN & & \\
\hline CHEMBL3729739 & 1537411 & 6.2218 & 6.6443 & TRN & & \\
\hline CHEMBL 3727600 & 1537411 & 6.2218 & 6.4553 & TRN & & \\
\hline CHEMBL3730656 & 1537411 & 7.2218 & 7.0648 & TRN & & \\
\hline CHEMBL3732450 & 1537411 & 6.2218 & 6.8384 & TRN & & \\
\hline
\end{tabular}


Supplemental Table S2.txt

\begin{tabular}{|c|c|c|c|c|c|}
\hline CHEMBL3731310 & 1537411 & 6.2218 & 6.6581 & TRN & \\
\hline CHEMBL3731651 & 1537411 & 7.2218 & 7.32 & TST & \\
\hline CHEMBL3731765 & 1537411 & 7.2218 & 6.8789 & TRN & \\
\hline CHEMBL3733355 & 1537411 & 7.2218 & 7.1978 & TRN & \\
\hline CHEMBL 3732630 & 1537411 & 7.2218 & 7.1894 & TRN & \\
\hline CHEMBL3729059 & 1537411 & 7.2218 & 7.1027 & TRN & \\
\hline CHEMBL 3732547 & 1537411 & 7.2218 & 6.9334 & TRN & \\
\hline CHEMBL3730339 & 1537411 & 7.2218 & 6.9307 & TRN & \\
\hline CHEMBL3733059 & 1537411 & 6.2218 & 6.5568 & TRN & \\
\hline CHEMBL3728969 & 1537411 & 6.2218 & 6.6444 & TRN & \\
\hline CHEMBL 3727734 & 1537411 & 7.2218 & 6.5163 & TRN & \\
\hline CHEMBL 3728323 & 1537411 & 7.2218 & 7.7892 & TST & \\
\hline CHEMBL3731738 & 1537411 & 7.2218 & 7.4303 & TST & \\
\hline CHEMBL3732677 & 1537411 & 7.2218 & 6.5804 & TST & \\
\hline CHEMBL 3728450 & 1537411 & 7.2218 & 7.2874 & TRN & \\
\hline CHEMBL 3731876 & 1537411 & 7.2218 & 7.3006 & TRN & \\
\hline CHEMBL3732779 & 1537411 & 7.2218 & 7.1718 & TST & \\
\hline CHEMBL3731964 & 1537411 & 6.2218 & 6.3314 & TRN & \\
\hline CHEMBL3729158 & 1537411 & 7.2218 & 7.2701 & TRN & \\
\hline CHEMBL 3727649 & 1537411 & 6.2218 & 7.0896 & TST & \\
\hline CHEMBL 3732104 & 1537411 & 7.2218 & 6.5357 & TRN & \\
\hline CHEMBL3730679 & 1537411 & 7.2218 & 6.5691 & TRN & \\
\hline CHEMBL3729551 & 1537411 & 7.2218 & 7.0454 & TRN & \\
\hline CHEMBL3732708 & 1537411 & 7.2218 & 7.8838 & TST & \\
\hline CHEMBL 3728704 & 1537411 & 7.2218 & 7.5141 & TRN & \\
\hline CHEMBL3729771 & 1537411 & 7.2218 & 7.1672 & TRN & \\
\hline CHEMBL3727934 & 1537411 & 7.2218 & 6.9593 & TST & \\
\hline CHEMBL 3727480 & 1537411 & 7.2218 & 7.5863 & TST & \\
\hline CHEMBL3727938 & 1537411 & 7.2218 & 7.5573 & TRN & \\
\hline CHEMBL 3729900 & 1537411 & 7.2218 & 7.5148 & TST & \\
\hline CHEMBL 3730009 & 1537411 & 7.2218 & 6.7242 & TRN & \\
\hline CHEMBL 3730952 & 1537411 & 7.2218 & 6.718999 & 9999999999 & TRN \\
\hline CHEMBL3729101 & 1537411 & 7.2218 & 7.7497 & TST & \\
\hline CHEMBL3727447 & 1537411 & 6.2218 & 6.5131 & TRN & \\
\hline CHEMBL 3732114 & 1537411 & 7.2218 & 7.2108 & TST & \\
\hline CHEMBL 3730740 & 1537411 & 7.2218 & 7.6093 & TST & \\
\hline CHEMBL 3733254 & 1537411 & 7.2218 & 7.1084 & TRN & \\
\hline CHEMBL 3731488 & 1537411 & 7.2218 & 7.4778 & TRN & \\
\hline CHEMBL3730598 & 1537411 & 7.2218 & 6.9605 & TRN & \\
\hline CHEMBL3730579 & 1537411 & 7.2218 & 7.78 & TST & \\
\hline CHEMBL 3731250 & 1537411 & 7.2218 & 6.7517 & TRN & \\
\hline CHEMBL 3728931 & 1537411 & 4.9208 & 5.3327 & TRN & \\
\hline CHEMBL 3732522 & 1537411 & 7.2218 & 6.8623 & TRN & \\
\hline CHEMBL1590308 & 954542 & 2.8837 & 3.3548 & TST & \\
\hline CHEMBL1190711 & 954542 & 4.9575 & 5.1322 & TRN & \\
\hline CHEMBL1909414 & 954542 & 3.298 & 3.4073 & TRN & \\
\hline CHEMBL 2144069 & 954542 & 3.9583 & 3.9984 & TRN & \\
\hline CHEMBL399530 & 954542 & 5.0446 & 4.9061 & TRN & \\
\hline
\end{tabular}

Page 13771 


\begin{tabular}{|c|c|c|c|c|c|c|}
\hline \multicolumn{7}{|c|}{ Supplemental T } \\
\hline CHEMBL 9470 & 954542 & 6.3511 & 4.8027 & TST & & \\
\hline CHEMBL449158 & 954542 & 6.1556 & 6.1217 & TST & & \\
\hline CHEMBL 300389 & 954542 & 6.8102 & 6.7648 & TRN & & \\
\hline CHEMBL259181 & 954542 & 3.687 & 3.7607 & TRN & & \\
\hline CHEMBL135561 & 954542 & 3.93600 & 00000006 & 004 & 4.1674 & TRN \\
\hline CHEMBL 213100 & 954542 & 3.3672 & 3.5418 & TRN & & \\
\hline CHEMBL393929 & 954542 & 4.5609 & 4.4224 & TRN & & \\
\hline CHEMBL 2005886 & 954542 & 3.3735 & 3.3782 & TRN & & \\
\hline CHEMBL 255342 & 954542 & 3.5183 & 3.5052 & TRN & & \\
\hline CHEMBL558642 & 954542 & 3.0359 & 3.1154 & TRN & & \\
\hline CHEMBL412142 & 954542 & 3.5293 & 3.5143 & TRN & & \\
\hline CHEMBL189584 & 954542 & 3.6565 & 3.7438 & TRN & & \\
\hline CHEMBL1643959 & 954542 & 2.8156 & 2.8908 & TRN & & \\
\hline CHEMBL 217354 & 954542 & 6.3454 & 6.2907 & TRN & & \\
\hline CHEMBL1788116 & 954542 & 4.3406 & 4.3208 & TRN & & \\
\hline CHEMBL1673039 & 954542 & 3.4415 & 3.3526 & TRN & & \\
\hline CHEMBL180127 & 954542 & 4.4049 & 4.4571 & TRN & & \\
\hline CHEMBL1186585 & 954542 & 4.5391 & 4.5428 & TRN & & \\
\hline CHEMBL3392440 & 954542 & 3.3412 & 3.141 & TRN & & \\
\hline CHEMBL577784 & 954542 & 3.4248 & 3.6567 & TRN & & \\
\hline CHEMBL3349342 & 954542 & 3.3018 & 3.1145 & TRN & & \\
\hline CHEMBL92309 & 954542 & 3.0859 & 2.4053 & TST & & \\
\hline CHEMBL1516890 & 954542 & 3.9899 & 3.912 & TRN & & \\
\hline CHEMBL573107 & 954542 & 4.3647 & 4.2303 & TRN & & \\
\hline CHEMBL472940 & 954542 & 2.8055 & 2.7796 & TRN & & \\
\hline CHEMBL202721 & 954542 & 4.7172 & 4.6569 & TRN & & \\
\hline CHEMBL222102 & 954542 & 3.0823 & 3.1439 & TRN & & \\
\hline CHEMBL512504 & 954542 & 6.4168 & 6.5212 & TRN & & \\
\hline CHEMBL392695 & 954542 & 5.1508 & 5.2428 & TRN & & \\
\hline CHEMBL 2363137 & 954542 & 4.6409 & 4.7443 & TRN & & \\
\hline CHEMBL221137 & 954542 & 4.185 & 4.3781 & TST & & \\
\hline CHEMBL1230020 & 954542 & 3.1469 & 2.9711 & TRN & & \\
\hline CHEMBL220241 & 954542 & 3.5961 & 3.5296 & TRN & & \\
\hline CHEMBL191334 & 954542 & 4.9011 & 4.9201 & TRN & & \\
\hline CHEMBL1404918 & 954542 & 2.498 & 2.4237 & TRN & & \\
\hline CHEMBL1242367 & 954542 & 3.8691 & 3.6999 & TRN & & \\
\hline CHEMBL379975 & 954542 & 4.0999 & 4.1699 & TRN & & \\
\hline CHEMBL483849 & 954542 & 1.7713 & 2.1235 & TST & & \\
\hline CHEMBL1357247 & 954542 & 2.9542 & 2.8586 & TRN & & \\
\hline CHEMBL585951 & 954542 & 6.0835 & 6.0221 & TRN & & \\
\hline CHEMBL373751 & 954542 & 3.2106 & 3.3966 & TRN & & \\
\hline CHEMBL102714 & 954542 & 3.1197 & 3.0929 & TRN & & \\
\hline CHEMBL515416 & 954542 & 3.83600 & 0000000 & 203 & 3.8814 & \\
\hline CHEMBL192566 & 954542 & 7.2282 & 6.9565 & TST & & \\
\hline CHEMBL240954 & 954542 & 4.5764 & 3.528 & TST & & \\
\hline CHEMBL3199475 & 954542 & 3.8679 & 3.8987 & TRN & & \\
\hline CHEMBL514499 & 954542 & 7.2417 & 7.0019 & TRN & & \\
\hline CHEMBL1256459 & 954542 & 5.2255 & 5.2663 & TRN & & \\
\hline
\end{tabular}




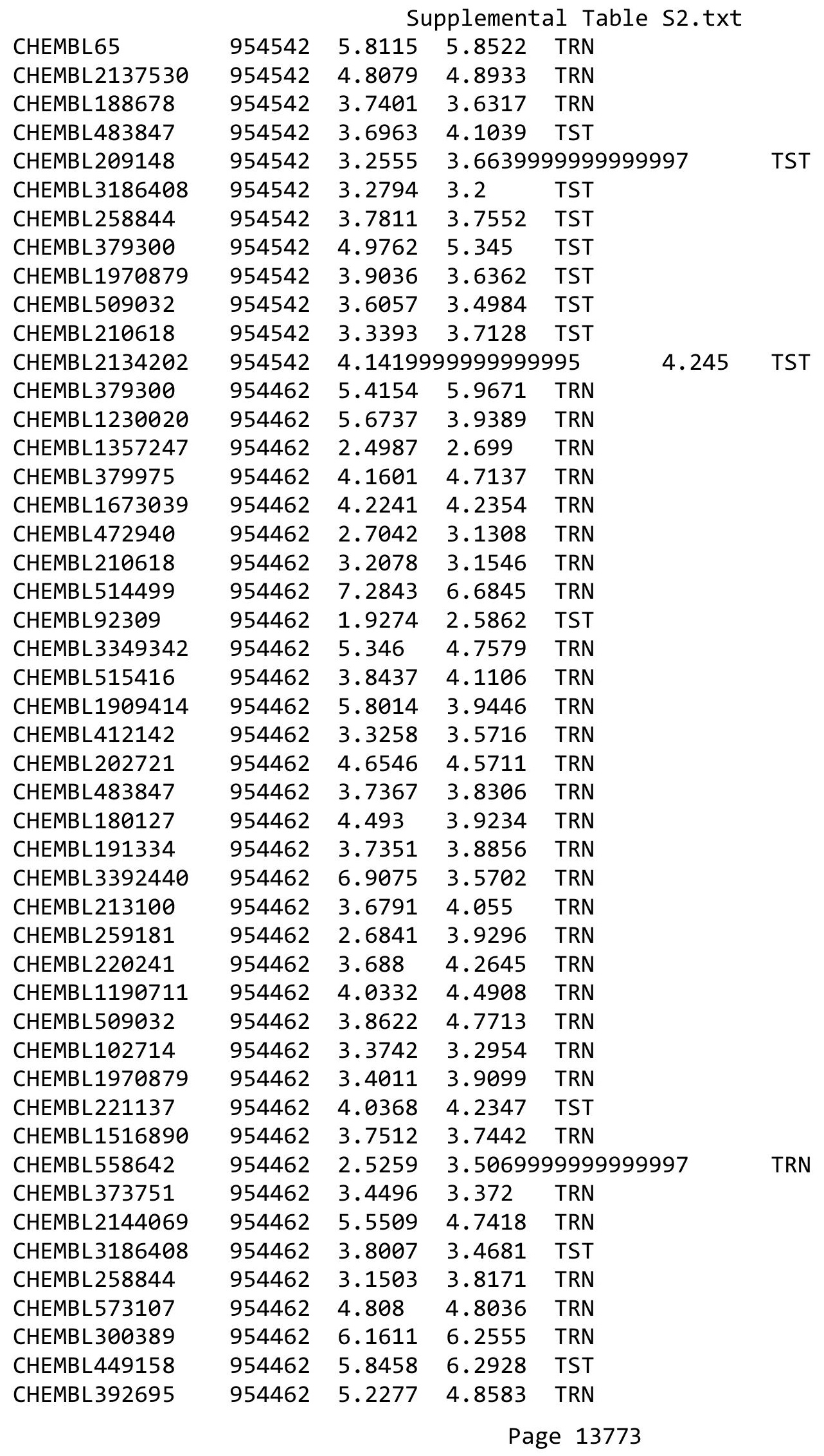


Supplemental Table S2.txt

\begin{tabular}{|c|c|c|c|c|c|}
\hline CHEMBL189584 & 954462 & 4.4974 & 4.3169 & TRN & \\
\hline CHEMBL1788116 & 954462 & 3.5066 & 3.7864 & TRN & \\
\hline CHEMBL393929 & 954462 & 3.5213 & 3.62399 & 99999999997 & TRN \\
\hline CHEMBL 3199475 & 954462 & 3.5207 & 3.9549 & TRN & \\
\hline CHEMBL 2363137 & 954462 & 4.2716 & 4.3411 & TRN & \\
\hline CHEMBL9470 & 954462 & 5.0206 & 5.1435 & TST & \\
\hline CHEMBL1256459 & 954462 & 6.8666 & 6.6015 & TRN & \\
\hline CHEMBL 209148 & 954462 & 3.1747 & 4.0141 & TRN & \\
\hline CHEMBL 2005886 & 954462 & 3.4351 & 4.6149 & TRN & \\
\hline CHEMBL240954 & 954462 & 4.216 & 3.4913 & TST & \\
\hline CHEMBL585951 & 954462 & 4.9699 & 5.5779 & TRN & \\
\hline CHEMBL512504 & 954462 & 6.0251 & 4.8103 & TRN & \\
\hline CHEMBL1643959 & 954462 & 3.4014 & 3.2252 & TST & \\
\hline CHEMBL1242367 & 954462 & 3.3255 & 3.7624 & TST & \\
\hline CHEMBL135561 & 954462 & 3.8408 & 3.9829 & TST & \\
\hline CHEMBL192566 & 954462 & 7.039 & 7.32799 & 9999999999 & TST \\
\hline CHEMBL65 & 954462 & 7.3695 & 7.3656 & TST & \\
\hline CHEMBL1404918 & 954462 & 2.9773 & 2.6099 & TST & \\
\hline CHEMBL483849 & 954462 & 1.5491 & 2.1518 & TST & \\
\hline CHEMBL1590308 & 954462 & 2.5207 & 3.16 & TST & \\
\hline CHEMBL248492 & 453490 & 4.0 & 3.929 & TRN & \\
\hline CHEMBL248292 & 453490 & 5.20200 & 00000000 & 5.2913 & TRN \\
\hline CHEMBL 245408 & 453490 & 4.0 & 3.9662 & TRN & \\
\hline CHEMBL398597 & 453490 & 5.8697 & 5.8988 & TRN & \\
\hline CHEMBL400621 & 453490 & 4.0 & 3.9796 & TRN & \\
\hline CHEMBL437191 & 453490 & 4.0 & 4.0088 & TRN & \\
\hline CHEMBL398077 & 453490 & 4.0 & 4.0191 & TRN & \\
\hline CHEMBL 245445 & 453490 & 6.4647 & \multicolumn{2}{|c|}{6.4270000000000005} & TRN \\
\hline CHEMBL392968 & 453490 & 5.4547 & 5.5408 & TRN & \\
\hline CHEMBL392107 & 453490 & 5.8697 & 5.6309 & TST & \\
\hline CHEMBL240893 & 453490 & 5.5498 & 5.5383 & TRN & \\
\hline CHEMBL248471 & 453490 & 4.0 & 4.0112 & TRN & \\
\hline CHEMBL241113 & 453490 & 6.0 & 6.0046 & TRN & \\
\hline CHEMBL397839 & 453490 & 5.9626 & 5.9545 & TRN & \\
\hline CHEMBL398399 & 453490 & 5.3487 & 5.3547 & TRN & \\
\hline CHEMBL241683 & 453490 & 6.0088 & 6.0734 & TRN & \\
\hline CHEMBL245407 & 453490 & 6.2857 & 4.4636 & TST & \\
\hline CHEMBL240672 & 453490 & 5.9788 & 5.8272 & TRN & \\
\hline CHEMBL392082 & 453490 & 7.041 & 7.0056 & TRN & \\
\hline CHEMBL394136 & 453490 & 5.4685 & 5.5166 & TRN & \\
\hline CHEMBL247072 & 453490 & 5.9788 & 5.9845 & TRN & \\
\hline CHEMBL391746 & 453490 & 5.644 & 5.7531 & TRN & \\
\hline CHEMBL399192 & 453490 & 5.4841 & 5.4542 & TRN & \\
\hline CHEMBL240613 & 453490 & 6.6576 & 6.6398 & TRN & \\
\hline CHEMBL240034 & 453490 & 6.9393 & 6.8633 & TRN & \\
\hline CHEMBL392339 & 453490 & 5.4802 & 5.7645 & TST & \\
\hline CHEMBL248093 & 453490 & 6.2924 & 6.2632 & TRN & \\
\hline CHEMBL248092 & 453490 & 6.6498 & 6.7557 & TRN & \\
\hline
\end{tabular}

Page 13774 


\begin{tabular}{|c|c|c|c|c|c|}
\hline & & & oplement & al lable S2 & \\
\hline CHEMBL248493 & 453490 & 4.0 & 4.5212 & TST & \\
\hline CHEMBL396623 & 453490 & 4.0 & 3.97399 & 99999999998 & TRN \\
\hline CHEMBL393313 & 453490 & 6.6253 & 6.7484 & TRN & \\
\hline CHEMBL 241292 & 453490 & 5.8861 & 5.8663 & TRN & \\
\hline CHEMBL 239380 & 453490 & 5.7773 & 5.7321 & TRN & \\
\hline CHEMBL 248472 & 453490 & 5.7055 & 5.7626 & TRN & \\
\hline CHEMBL397638 & 453490 & 4.0 & 4.0542 & TRN & \\
\hline CHEMBL392106 & 453490 & 6.2175 & 6.1176 & TRN & \\
\hline CHEMBL 392282 & 453490 & 5.4214 & 5.5408 & TRN & \\
\hline CHEMBL241474 & 453490 & 5.857 & 5.7639 & TRN & \\
\hline CHEMBL 239376 & 453490 & 4.0 & 3.9533 & TRN & \\
\hline CHEMBL393314 & 453490 & 6.8297 & 6.9361 & TRN & \\
\hline CHEMBL429097 & 453490 & 6.9788 & 6.8726 & TRN & \\
\hline CHEMBL248086 & 453490 & 5.9547 & 5.8071 & TRN & \\
\hline CHEMBL394998 & 453490 & 5.9101 & 5.9902 & TRN & \\
\hline CHEMBL 241528 & 453490 & 6.6055 & 6.5633 & TRN & \\
\hline CHEMBL 241291 & 453490 & 5.7399 & 5.72 & TRN & \\
\hline CHEMBL394154 & 453490 & 6.0 & 6.16100 & 00000000005 & TRN \\
\hline CHEMBL 239360 & 453490 & 6.5768 & 6.0421 & TST & \\
\hline CHEMBL394155 & 453490 & 6.9872 & 7.0026 & TRN & \\
\hline CHEMBL 393945 & 453490 & 4.0 & 6.2323 & TST & \\
\hline CHEMBL392788 & 453490 & 7.2218 & 7.1168 & TRN & \\
\hline CHEMBL 239377 & 453490 & 6.0467 & 6.0005 & TRN & \\
\hline CHEMBL 240435 & 453490 & 5.2381 & 5.2958 & TRN & \\
\hline CHEMBL 240035 & 453490 & 7.0915 & 7.0761 & TRN & \\
\hline CHEMBL 240885 & 453490 & 4.0 & 5.891 & TST & \\
\hline CHEMBL 240670 & 453490 & 4.0 & 4.9396 & TST & \\
\hline CHEMBL398082 & 453490 & 5.6737 & 5.6474 & TRN & \\
\hline CHEMBL 241526 & 453490 & 6.4828 & 6.6169 & TST & \\
\hline CHEMBL398596 & 453490 & 6.6676 & 6.1587 & TST & \\
\hline CHEMBL 392768 & 453490 & 4.0 & 5.2264 & TST & \\
\hline CHEMBL 245612 & 453490 & 5.4559 & 5.9993 & TST & \\
\hline CHEMBL 240884 & 453490 & 5.7747 & 5.9312 & TST & \\
\hline CHEMBL401429 & 453490 & 6.7799 & 7.1636 & TST & \\
\hline CHEMBL 247892 & 453490 & 4.0 & 5.5148 & TST & \\
\hline CHEMBL 240671 & 453490 & 4.0 & 5.4491 & TST & \\
\hline CHEMBL2094769 & 842697 & 5.1938 & 3.9766 & TST & \\
\hline CHEMBL 2095053 & 842697 & 3.3802 & 3.8605 & TRN & \\
\hline CHEMBL2094582 & 842697 & 5.1537 & 4.1242 & TRN & \\
\hline CHEMBL1390650 & 842697 & 3.6813 & 3.88199 & 99999999997 & TRN \\
\hline CHEMBL2094508 & 842697 & 4.3799 & 4.0501 & TRN & \\
\hline CHEMBL 2094688 & 842697 & 3.6813 & 3.8222 & TRN & \\
\hline CHEMBL2095066 & 842697 & 3.3802 & 3.5063 & TRN & \\
\hline CHEMBL 2094823 & 842697 & 3.3802 & 3.7631 & TRN & \\
\hline CHEMBL 2094563 & 842697 & 3.9821 & 3.8909 & TRN & \\
\hline CHEMBL 2094717 & 842697 & 4.3799 & 3.549 & TRN & \\
\hline CHEMBL1190605 & 842697 & 4.3799 & 3.767 & TRN & \\
\hline CHEMBL2094779 & 842697 & 3.3802 & 4.3712 & TRN & \\
\hline
\end{tabular}


Supplemental Table S2.txt

\begin{tabular}{|c|c|c|c|c|c|}
\hline CHEMBL2094937 & 842697 & 3.6813 & 3.7722 & TRN & \\
\hline CHEMBL 2094614 & 842697 & 4.3799 & 3.6499 & TRN & \\
\hline CHEMBL 2094511 & 842697 & 4.3799 & 4.0722 & TRN & \\
\hline CHEMBL 2095023 & 842697 & 3.3802 & 3.74 & TRN & \\
\hline CHEMBL 2094847 & 842697 & 3.3802 & 3.6846 & TRN & \\
\hline CHEMBL1728864 & 842697 & 3.6813 & 3.9475 & TRN & \\
\hline CHEMBL 2094745 & 842697 & 3.6813 & 4.0918 & TRN & \\
\hline CHEMBL 2094521 & 842697 & 6.00700 & 00000006 & 4.6439 & ThN \\
\hline CHEMBL1420457 & 842697 & 3.6813 & 3.532 & TRN & \\
\hline CHEMBL 2094620 & 842697 & 5.3768 & 5.1773 & TRN & \\
\hline CHEMBL602579 & 842697 & 3.3802 & 3.7242 & TST & \\
\hline CHEMBL 2094284 & 842697 & 3.6813 & 3.5723 & TRN & \\
\hline CHEMBL 2095117 & 842697 & 3.3802 & 3.9661 & TRN & \\
\hline CHEMBL600142 & 842697 & 5.3116 & 3.981999 & э99999999998 & \\
\hline CHEMBL600718 & 842697 & 5.9747 & 3.9347 & TST & \\
\hline CHEMBL 2095025 & 842697 & 3.3802 & 3.7585 & TRN & \\
\hline CHEMBL 2094858 & 842697 & 3.3802 & 3.6663 & TRN & \\
\hline CHEMBL 2094942 & 842697 & 4.3799 & 3.7726 & TRN & \\
\hline CHEMBL1442783 & 842697 & 3.3802 & 3.4776 & TRN & \\
\hline CHEMBL 2094360 & 842697 & 4.3799 & 4.0453 & TST & \\
\hline CHEMBL1431017 & 842697 & 3.6813 & 3.7695 & TRN & \\
\hline CHEMBL1407401 & 842697 & 3.6813 & 3.5411 & TRN & \\
\hline CHEMBL 2094560 & 842697 & 3.6813 & 4.1732 & TRN & \\
\hline CHEMBL 2094458 & 842697 & 3.3802 & 3.4999 & TRN & \\
\hline CHEMBL 2094821 & 842697 & 4.3799 & 4.173 & TRN & \\
\hline CHEMBL1490332 & 842697 & 5.8356 & 4.1119 & TRN & \\
\hline CHEMBL 2094875 & 842697 & 3.6813 & 4.2265 & TRN & \\
\hline CHEMBL 2094669 & 842697 & 3.6813 & 3.6054 & TST & \\
\hline CHEMBL600977 & 842697 & \multicolumn{3}{|c|}{4.9830000000000005} & \\
\hline CHEMBL 2094802 & 842697 & 4.3799 & 3.8932 & TRN & \\
\hline CHEMBL 2095012 & 842697 & 3.3802 & 3.9084 & TRN & \\
\hline CHEMBL 2094706 & 842697 & 3.3802 & 3.8589 & TRN & \\
\hline CHEMBL 2095044 & 842697 & 3.6813 & 3.5501 & TRN & \\
\hline CHEMBL 2094516 & 842697 & 3.6813 & 3.7012 & TST & \\
\hline CHEMBL 2094270 & 842697 & \multicolumn{2}{|c|}{4.9830000000000005} & 4.0483 & \\
\hline CHEMBL2094639 & 842697 & 5.2381 & 4.31 & TRN & \\
\hline CHEMBL1417180 & 842697 & 5.0491 & 3.6451 & TRN & \\
\hline CHEMBL2094434 & 842697 & 4.3799 & 3.7668 & TRN & \\
\hline CHEMBL 2095114 & 842697 & 5.4283 & 4.1491 & TRN & \\
\hline CHEMBL 2094441 & 842697 & 6.2291 & 4.8492 & TRN & \\
\hline CHEMBL 2094925 & 842697 & 3.3802 & 3.5579 & TRN & \\
\hline CHEMBL 2095083 & 842697 & 3.6813 & 4.1822 & TRN & \\
\hline CHEMBL2094484 & 842697 & 4.3799 & 4.3782 & TRN & \\
\hline CHEMBL1526167 & 842697 & 4.3799 & 3.9265 & TRN & \\
\hline CHEMBL 2094765 & 842697 & 3.3802 & 3.2493 & TRN & \\
\hline CHEMBL2094610 & 842697 & 3.6813 & 3.8153 & TRN & \\
\hline CHEMBL 2094946 & 842697 & 3.3802 & 3.5932 & TRN & \\
\hline CHEMBL 2094566 & 842697 & 3.3802 & 3.2175 & TRN & \\
\hline
\end{tabular}




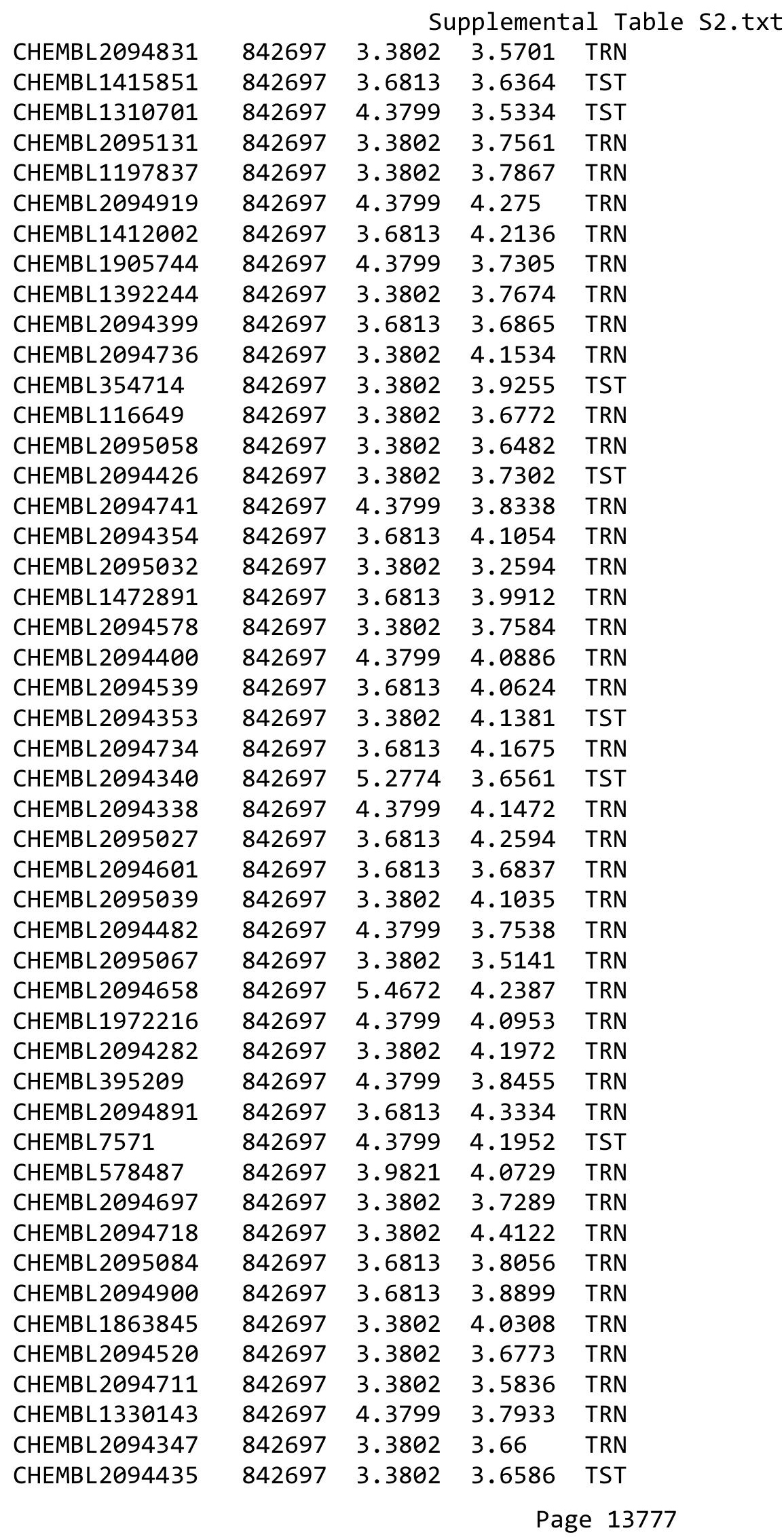




\begin{tabular}{|c|c|c|c|c|c|}
\hline \multicolumn{6}{|c|}{ Supplemental Table S2.txt } \\
\hline CHEMBL1163998 & 842697 & 3.3802 & 4.0196 & TRN & \\
\hline CHEMBL 2095076 & 842697 & 3.3802 & 3.6713 & TRN & \\
\hline CHEMBL 2094510 & 842697 & 4.3799 & 4.0543 & TST & \\
\hline CHEMBL 2094749 & 842697 & 3.6813 & 3.5474 & TRN & \\
\hline CHEMBL 2094815 & 842697 & 4.3799 & 3.8178 & TRN & \\
\hline CHEMBL1368428 & 842697 & 3.6813 & 4.29 & TRN & \\
\hline CHEMBL 2094934 & 842697 & 3.3802 & 3.40100 & 00000000002 & TRN \\
\hline CHEMBL 2094577 & 842697 & 3.6813 & 3.74600 & 20000000004 & TRN \\
\hline CHEMBL1333049 & 842697 & 3.6813 & 3.5434 & TRN & \\
\hline CHEMBL 2094649 & 842697 & 3.6813 & 3.4756 & TRN & \\
\hline CHEMBL 2094766 & 842697 & 4.3799 & 4.132 & TRN & \\
\hline CHEMBL1460809 & 842697 & 3.3802 & 3.6091 & TST & \\
\hline CHEMBL1492017 & 842697 & 3.6813 & 3.8852 & TRN & \\
\hline CHEMBL 2094503 & 842697 & 3.6813 & 3.5521 & TRN & \\
\hline CHEMBL 2094763 & 842697 & 3.6813 & 3.9771 & TRN & \\
\hline CHEMBL590199 & 842697 & 4.3799 & 3.5743 & TRN & \\
\hline CHEMBL 2094541 & 842697 & 5.3439 & 3.5549 & TRN & \\
\hline CHEMBL 2094328 & 842697 & 3.3802 & 3.6756 & TRN & \\
\hline CHEMBL 2094701 & 842697 & 3.3802 & 3.6868 & TRN & \\
\hline CHEMBL 2094905 & 842697 & 3.3802 & 3.2161 & TRN & \\
\hline CHEMBL1346468 & 842697 & 3.6813 & 4.3203 & TRN & \\
\hline CHEMBL1975211 & 842697 & $4.9830 e$ & 00000000 & 4.4664 & TRN \\
\hline CHEMBL 2094546 & 842697 & 3.3802 & 3.5422 & TRN & \\
\hline CHEMBL 2094839 & 842697 & 5.289 & 4.1696 & TRN & \\
\hline CHEMBL1526692 & 842697 & 3.3802 & 3.7293 & TRN & \\
\hline CHEMBL 2094693 & 842697 & 3.6813 & 3.6318 & TST & \\
\hline CHEMBL 2094567 & 842697 & 3.3802 & 4.1111 & TRN & \\
\hline CHEMBL 2094945 & 842697 & 3.3802 & 3.6429 & TST & \\
\hline CHEMBL 2094721 & 842697 & 5.3072 & 4.2031 & TRN & \\
\hline CHEMBL 2094515 & 842697 & 3.3802 & 3.4707 & TST & \\
\hline CHEMBL602633 & 842697 & 3.3802 & 3.7518 & TRN & \\
\hline CHEMBL 2094366 & 842697 & 3.3802 & 3.7877 & TST & \\
\hline CHEMBL 2095133 & 842697 & 3.6813 & 4.0618 & TRN & \\
\hline CHEMBL 2094634 & 842697 & 3.6813 & 3.5144 & TRN & \\
\hline CHEMBL 2094667 & 842697 & 3.6813 & 3.6667 & TRN & \\
\hline CHEMBL 2094465 & 842697 & 3.3802 & 3.5209 & TRN & \\
\hline CHEMBL 2094716 & 842697 & 3.3802 & 3.7473 & TST & \\
\hline CHEMBL577374 & 842697 & 5.4737 & 4.2115 & TRN & \\
\hline CHEMBL 2094867 & 842697 & 3.6813 & 3.9307 & TRN & \\
\hline CHEMBL 2094460 & 842697 & 3.6813 & 4.0408 & TST & \\
\hline CHEMBL 2094644 & 842697 & 4.3799 & 4.0009 & TRN & \\
\hline CHEMBL 2094420 & 842697 & 3.6813 & 4.0843 & TRN & \\
\hline CHEMBL1454397 & 842697 & 3.3802 & 3.6524 & TRN & \\
\hline CHEMBL 2094461 & 842697 & 3.3802 & 3.6314 & TRN & \\
\hline CHEMBL1428836 & 842697 & 3.6813 & 3.6182 & TRN & \\
\hline CHEMBL1553566 & 842697 & 3.3802 & 4.3312 & TRN & \\
\hline CHEMBL 2094320 & 842697 & 5.4425 & 3.9829 & TST & \\
\hline CHEMBL 2095010 & 842697 & 3.9821 & 4.3243 & TRN & \\
\hline
\end{tabular}


Supplemental Table S2.txt

\begin{tabular}{|c|c|c|c|c|}
\hline CHEMBL 2095115 & 842697 & 3.3802 & 3.7127 & TRN \\
\hline CHEMBL 2094723 & 842697 & 3.3802 & 3.4372 & TRN \\
\hline CHEMBL 2094335 & 842697 & 3.6813 & 3.8999 & TRN \\
\hline CHEMBL97706 & 842697 & 3.6813 & 4.0206 & TRN \\
\hline CHEMBL522887 & 842697 & 5.2269 & 3.9489 & TRN \\
\hline CHEMBL1429899 & 842697 & 4.3799 & 3.7251 & TRN \\
\hline CHEMBL 2095035 & 842697 & 3.3802 & 3.5963 & TRN \\
\hline CHEMBL 2094874 & 842697 & 3.6813 & 4.298 & TRN \\
\hline CHEMBL 2095130 & 842697 & 3.3802 & 3.6108 & TRN \\
\hline CHEMBL 2094982 & 842697 & 3.6813 & 3.5882 & TRN \\
\hline CHEMBL1565444 & 842697 & 3.6813 & 4.1403 & TRN \\
\hline CHEMBL 2094681 & 842697 & 3.3802 & 3.6552 & TRN \\
\hline CHEMBL 2094611 & 842697 & 3.6813 & 3.7764 & TRN \\
\hline CHEMBL1449731 & 842697 & 3.3802 & 3.8189 & TRN \\
\hline CHEMBL146976 & 842697 & 3.6813 & 4.1421 & TRN \\
\hline CHEMBL 2094830 & 842697 & 3.3802 & 4.0826 & TRN \\
\hline CHEMBL564874 & 842697 & 4.3799 & 4.2473 & TRN \\
\hline CHEMBL 2094872 & 842697 & 3.6813 & 3.6708 & TRN \\
\hline CHEMBL598287 & 842697 & 3.6813 & 4.1928 & TRN \\
\hline CHEMBL 2094640 & 842697 & 3.6813 & 3.5288 & TRN \\
\hline CHEMBL 2094761 & 842697 & 3.6813 & 3.6782 & TRN \\
\hline CHEMBL 2094327 & 842697 & 3.3802 & 3.8711 & TST \\
\hline CHEMBL 2094997 & 842697 & 4.3799 & 3.6857 & TRN \\
\hline CHEMBL 2094742 & 842697 & 3.3802 & 3.6071 & TRN \\
\hline CHEMBL 2094662 & 842697 & 3.3802 & 3.8466 & TRN \\
\hline CHEMBL 2094403 & 842697 & 3.3802 & 3.8752 & TRN \\
\hline CHEMBL 2094657 & 842697 & 3.6813 & 3.8213 & TRN \\
\hline CHEMBL1731432 & 842697 & 3.3802 & 3.7696 & TRN \\
\hline CHEMBL1427413 & 842697 & 3.6813 & 3.6634 & TRN \\
\hline CHEMBL 2094517 & 842697 & 3.3802 & 3.5172 & TRN \\
\hline CHEMBL 381688 & 842697 & 4.3799 & 4.2955 & TRN \\
\hline CHEMBL 2095108 & 842697 & 3.3802 & 3.5231 & TRN \\
\hline CHEMBL 2094930 & 842697 & 3.6813 & 3.9366 & TRN \\
\hline CHEMBL 2094864 & 842697 & 3.6813 & 4.011 & TRN \\
\hline CHEMBL 2094392 & 842697 & 3.3802 & 4.1655 & TRN \\
\hline CHEMBL 2094630 & 842697 & 3.3802 & 3.5329 & TRN \\
\hline CHEMBL598663 & 842697 & 3.3802 & 3.9606 & TRN \\
\hline CHEMBL 2094377 & 842697 & 4.98300 & 00000006 & 4.3041 \\
\hline CHEMBL 2094989 & 842697 & 3.6813 & 4.0425 & TRN \\
\hline CHEMBL530067 & 842697 & 3.3802 & 3.9582 & TRN \\
\hline CHEMBL 2094606 & 842697 & 4.3799 & 4.026 & TRN \\
\hline CHEMBL 2094314 & 842697 & 4.3799 & 3.8314 & TRN \\
\hline CHEMBL1462710 & 842697 & 3.9821 & 4.071006 & 0000000001 \\
\hline CHEMBL1453126 & 842697 & 6.0458 & 4.3183 & TRN \\
\hline CHEMBL 2094732 & 842697 & 4.3799 & 4.2506 & TRN \\
\hline CHEMBL 2094933 & 842697 & 3.3802 & 3.8532 & TST \\
\hline CHEMBL2094291 & 842697 & 3.3802 & 3.2875 & TRN \\
\hline CHEMBL1989750 & 842697 & 3.6813 & 4.1403 & TRN \\
\hline
\end{tabular}

Page 13779 


\begin{tabular}{|c|c|c|c|c|c|c|}
\hline & & \multicolumn{5}{|c|}{ Supplemental Table S2.txt } \\
\hline CHEMBL2094524 & 842697 & 3.6813 & 4.1168 & TRN & & \\
\hline CHEMBL 2094423 & 842697 & 3.3802 & 4.0399 & TRN & & \\
\hline CHEMBL579905 & 842697 & 5.3054 & 4.2481 & TRN & & \\
\hline CHEMBL2094653 & 842697 & 3.6813 & 4.3392 & TRN & & \\
\hline CHEMBL 2095006 & 842697 & \multicolumn{3}{|c|}{4.9830000000000005} & 4.2069 & TRN \\
\hline CHEMBL601957 & 842697 & 3.3802 & 3.7791 & TRN & & \\
\hline CHEMBL 2094411 & 842697 & 3.3802 & 3.6412 & TST & & \\
\hline CHEMBL2094628 & 842697 & 3.6813 & 4.1335 & TRN & & \\
\hline CHEMBL 2094330 & 842697 & 3.3802 & 3.8745 & TRN & & \\
\hline CHEMBL2094707 & 842697 & 3.3802 & 3.8235 & TRN & & \\
\hline CHEMBL2094358 & 842697 & 3.9821 & 3.6648 & TRN & & \\
\hline CHEMBL3193662 & 842697 & 3.3802 & 3.912 & TRN & & \\
\hline CHEMBL2094951 & 842697 & \multicolumn{3}{|c|}{4.9830000000000005} & 4.1095 & TRN \\
\hline CHEMBL 2094457 & 842697 & 3.6813 & 4.1226 & TRN & & \\
\hline CHEMBL 2094445 & 842697 & 3.6813 & 3.6829 & TST & & \\
\hline CHEMBL501131 & 842697 & 5.2396 & 3.9198 & TRN & & \\
\hline CHEMBL 2095093 & 842697 & 4.3799 & 3.4198 & TRN & & \\
\hline CHEMBL2094918 & 842697 & 3.9821 & 4.4187 & TRN & & \\
\hline CHEMBL 2094877 & 842697 & 3.3802 & 3.8737 & TST & & \\
\hline CHEMBL 2094586 & 842697 & 3.9821 & 4.23300 & 00006 & 005 & TRN \\
\hline CHEMBL 2094587 & 842697 & 3.6813 & 3.7874 & TRN & & \\
\hline CHEMBL 2095085 & 842697 & 3.6813 & 4.2282 & TRN & & \\
\hline CHEMBL1466745 & 842697 & 3.3802 & 3.8257 & TRN & & \\
\hline CHEMBL 2095013 & 842697 & 3.3802 & 3.5342 & TRN & & \\
\hline CHEMBL 2094466 & 842697 & 3.6813 & 3.7849 & TST & & \\
\hline CHEMBL577446 & 842697 & 3.6813 & 4.1671 & TRN & & \\
\hline CHEMBL 2094848 & 842697 & 3.6813 & 3.5703 & TRN & & \\
\hline CHEMBL 2095040 & 842697 & 3.3802 & 3.7479 & TRN & & \\
\hline CHEMBL2094911 & 842697 & 3.6813 & 3.7242 & TST & & \\
\hline CHEMBL 2094888 & 842697 & 3.3802 & 3.5128 & TRN & & \\
\hline CHEMBL 2095090 & 842697 & 3.3802 & 3.3209 & TRN & & \\
\hline CHEMBL 2094295 & 842697 & 3.9821 & 4.1823 & TRN & & \\
\hline CHEMBL601137 & 842697 & 3.6813 & 4.1048 & TRN & & \\
\hline CHEMBL 2094938 & 842697 & 4.3799 & 3.9828 & TRN & & \\
\hline CHEMBL 2094811 & 842697 & 4.3799 & 3.5634 & TRN & & \\
\hline CHEMBL2094349 & 842697 & 3.6813 & 3.7466 & TRN & & \\
\hline CHEMBL 2095136 & 842697 & 3.6813 & 3.5655 & TRN & & \\
\hline CHEMBL 2094851 & 842697 & 3.6813 & 3.7463 & TRN & & \\
\hline CHEMBL2095015 & 842697 & 4.3799 & 4.073 & TRN & & \\
\hline CHEMBL1311879 & 842697 & 3.6813 & 4.3047 & TRN & & \\
\hline CHEMBL1522909 & 842697 & 3.6813 & 3.4496 & TRN & & \\
\hline CHEMBL2094612 & 842697 & 3.6813 & 4.041 & TRN & & \\
\hline CHEMBL2002849 & 842697 & 4.3799 & 4.2512 & TRN & & \\
\hline CHEMBL 2094687 & 842697 & 3.6813 & 3.9762 & TRN & & \\
\hline CHEMBL2094790 & 842697 & 4.3799 & 3.6659 & TRN & & \\
\hline CHEMBL582264 & 842697 & 3.3802 & 3.7139 & TRN & & \\
\hline CHEMBL2094359 & 842697 & 3.3802 & 3.9104 & TRN & & \\
\hline CHEMBL2094910 & 842697 & 4.3799 & 4.1743 & TRN & & \\
\hline
\end{tabular}




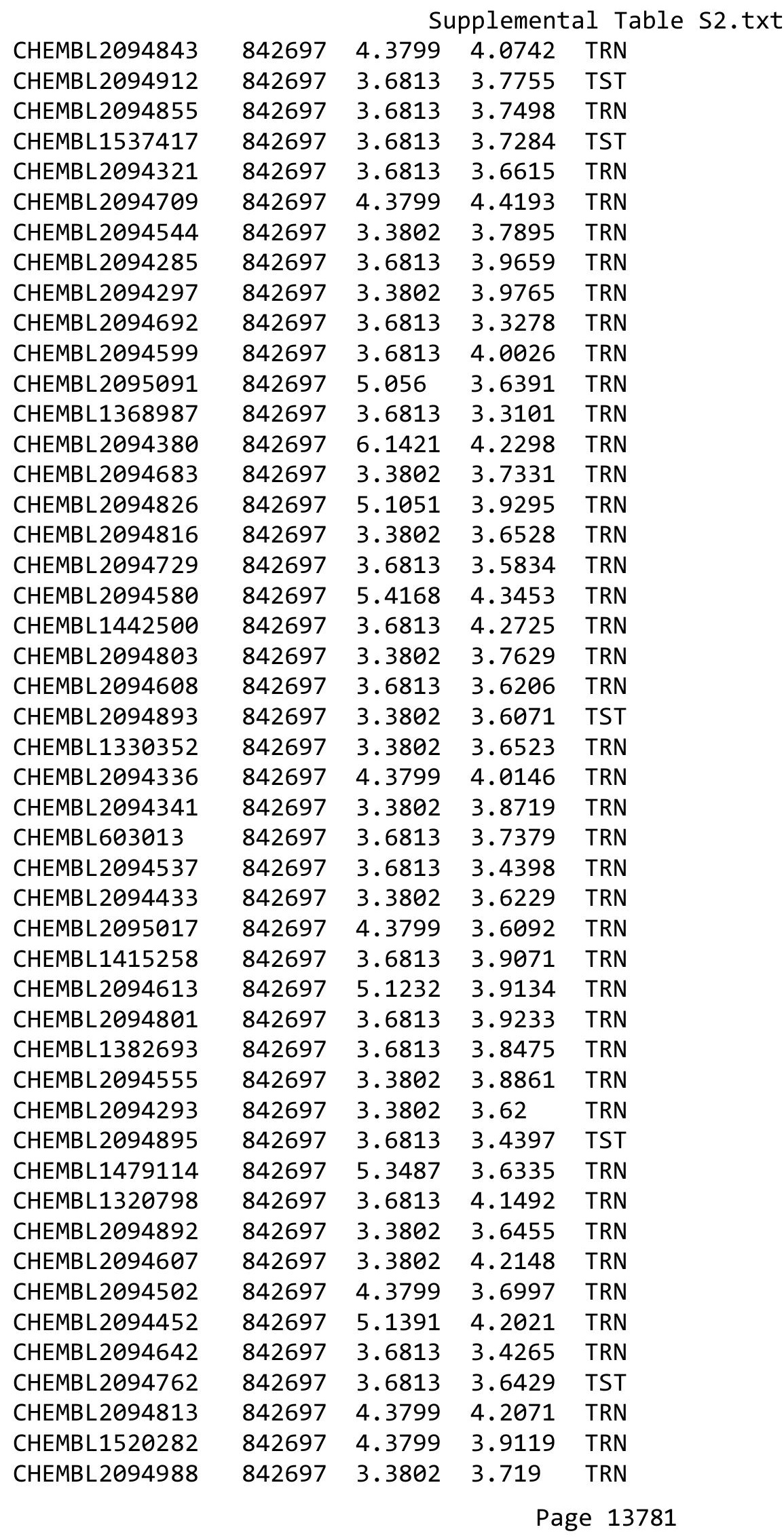


Supplemental Table S2.txt

\begin{tabular}{|c|c|c|c|c|}
\hline CHEMBL1740237 & 842697 & 3.3802 & 3.6822 & TRN \\
\hline CHEMBL 2094318 & 842697 & 3.3802 & 3.7749 & TRN \\
\hline CHEMBL 2094914 & 842697 & 3.6813 & 4.1486 & TRN \\
\hline CHEMBL578928 & 842697 & 3.3802 & 3.6165 & TRN \\
\hline CHEMBL577668 & 842697 & 4.3799 & 4.2947 & TRN \\
\hline CHEMBL1351628 & 842697 & 3.3802 & 3.7494 & TRN \\
\hline CHEMBL 2094882 & 842697 & 3.3802 & 4.0067 & TST \\
\hline CHEMBL564921 & 842697 & 3.6813 & 3.957 & TRN \\
\hline CHEMBL 2095003 & 842697 & 3.3802 & 3.6384 & TRN \\
\hline CHEMBL2094421 & 842697 & 3.3802 & 3.2127 & TRN \\
\hline CHEMBL 2094814 & 842697 & 3.3802 & \multicolumn{2}{|c|}{3.5260000000000002} \\
\hline CHEMBL1380650 & 842697 & 3.3802 & 3.63 & TST \\
\hline CHEMBL 2094915 & 842697 & 3.6813 & 3.7894 & TRN \\
\hline CHEMBL 2094375 & 842697 & 3.3802 & 3.8426 & TRN \\
\hline CHEMBL 2094715 & 842697 & 3.3802 & 3.9684 & TRN \\
\hline CHEMBL586013 & 842697 & 3.6813 & 4.1696 & TRN \\
\hline CHEMBL 2094430 & 842697 & 3.3802 & 4.1287 & TRN \\
\hline CHEMBL 2094536 & 842697 & 4.3799 & 3.3133 & TST \\
\hline CHEMBL 2094906 & 842697 & 3.6813 & 3.3409 & TRN \\
\hline CHEMBL 2094627 & 842697 & 3.6813 & 4.2752 & TRN \\
\hline CHEMBL 2094722 & 842697 & 4.3799 & 3.6652 & TST \\
\hline CHEMBL2094325 & 842697 & 3.6813 & 3.8081 & TRN \\
\hline CHEMBL 2094348 & 842697 & 3.3802 & 3.8335 & TRN \\
\hline CHEMBL1372629 & 842697 & 3.6813 & 3.7625 & TRN \\
\hline CHEMBL 2094369 & 842697 & 3.6813 & 3.7101 & TRN \\
\hline CHEMBL 2094708 & 842697 & 3.3802 & 3.9258 & TRN \\
\hline CHEMBL1572415 & 842697 & 3.3802 & 3.5138 & TRN \\
\hline CHEMBL 2094554 & 842697 & 3.3802 & 3.6472 & TRN \\
\hline CHEMBL548540 & 842697 & 3.3802 & 4.0764 & TRN \\
\hline CHEMBL592116 & 842697 & 3.6813 & 4.1565 & TRN \\
\hline CHEMBL 2094795 & 842697 & 3.3802 & 3.8908 & TRN \\
\hline CHEMBL 2094468 & 842697 & 3.6813 & 3.6664 & TST \\
\hline CHEMBL 2094467 & 842697 & 4.3799 & 4.2286 & TST \\
\hline CHEMBL 2094506 & 842697 & 3.3802 & 3.9227 & TRN \\
\hline CHEMBL 2094841 & 842697 & 3.3802 & 3.6565 & TST \\
\hline CHEMBL2094817 & 842697 & 5.1255 & \multicolumn{2}{|c|}{3.9410000000000003} \\
\hline CHEMBL 2095100 & 842697 & 3.3802 & 3.7817 & TRN \\
\hline CHEMBL 2094623 & 842697 & 3.6813 & 4.0678 & TRN \\
\hline CHEMBL526240 & 842697 & 3.6813 & 3.5263 & TRN \\
\hline CHEMBL 2094865 & 842697 & 3.9821 & 4.343 & TRN \\
\hline CHEMBL 2094924 & 842697 & 3.3802 & 3.6533 & TRN \\
\hline CHEMBL 204914 & 842697 & 3.3802 & \multicolumn{2}{|c|}{3.6830000000000003} \\
\hline CHEMBL2094547 & 842697 & 3.3802 & 3.6609 & TRN \\
\hline CHEMBL 2094406 & 842697 & 3.6813 & 4.1961 & TRN \\
\hline CHEMBL 2094694 & 842697 & 3.9821 & 4.051 & TST \\
\hline CHEMBL489770 & 842697 & 3.9821 & 4.2868 & TRN \\
\hline CHEMBL 247772 & 842697 & 3.6813 & 3.5665 & TRN \\
\hline CHEMBL585655 & 842697 & 3.6813 & 3.9189 & TRN \\
\hline
\end{tabular}


Supplemental Table S2.txt

\begin{tabular}{|c|c|c|c|c|}
\hline CHEMBL 2094645 & 842697 & 3.3802 & 3.7023 & TRN \\
\hline CHEMBL 2094422 & 842697 & 3.3802 & 3.7888 & TRN \\
\hline CHEMBL2094355 & 842697 & 5.0809 & 3.6346 & TRN \\
\hline CHEMBL1339092 & 842697 & 3.6813 & 4.1611 & TRN \\
\hline CHEMBL 2094447 & 842697 & 3.6813 & 3.6902 & TRN \\
\hline CHEMBL2094641 & 842697 & 3.6813 & 3.8399 & TRN \\
\hline CHEMBL 2094633 & 842697 & 3.6813 & 3.8816 & TRN \\
\hline CHEMBL 2094526 & 842697 & 5.2351 & 3.9837 & TRN \\
\hline CHEMBL 2094323 & 842697 & 4.3799 & 3.5541 & TST \\
\hline CHEMBL 2094352 & 842697 & 3.6813 & 3.7168 & TRN \\
\hline CHEMBL2095079 & 842697 & 3.6813 & 3.718 & TRN \\
\hline CHEMBL 2094568 & 842697 & 3.3802 & 3.5973 & TRN \\
\hline CHEMBL1478755 & 842697 & 4.6819 & 4.7539 & TRN \\
\hline CHEMBL 2094767 & 842697 & 4.3799 & 4.0781 & TRN \\
\hline CHEMBL 2094416 & 842697 & 3.6813 & 3.9629 & TRN \\
\hline CHEMBL527775 & 842697 & 3.3802 & 3.6902 & TRN \\
\hline CHEMBL 2094670 & 842697 & 3.9821 & 4.5407 & TRN \\
\hline CHEMBL 2094490 & 842697 & 4.3799 & 4.1587 & TRN \\
\hline CHEMBL 2094822 & 842697 & 3.3802 & 3.6204 & TST \\
\hline CHEMBL 2094302 & 842697 & 3.6813 & 3.6353 & TRN \\
\hline CHEMBL 2094676 & 842697 & 5.2226 & 3.9091 & TST \\
\hline CHEMBL 2094737 & 842697 & 3.6813 & 3.9387 & TRN \\
\hline CHEMBL 2094686 & 842697 & 4.3799 & 4.0643 & TRN \\
\hline CHEMBL 2094532 & 842697 & 3.9821 & 4.4696 & TRN \\
\hline CHEMBL 2094290 & 842697 & 3.6813 & 3.6637 & TRN \\
\hline CHEMBL590424 & 842697 & 5.8013 & 4.4134 & TRN \\
\hline CHEMBL1504679 & 842697 & 3.6813 & 4.2001 & TRN \\
\hline CHEMBL 2094651 & 842697 & 3.3802 & 3.228999 & 99999999996 \\
\hline CHEMBL 2094698 & 842697 & 3.3802 & 3.8117 & TRN \\
\hline CHEMBL537718 & 842697 & 3.3802 & 3.8099 & TRN \\
\hline CHEMBL1568653 & 842697 & 3.6813 & 3.9965 & TRN \\
\hline CHEMBL589669 & 842697 & 4.3799 & 4.0904 & TRN \\
\hline CHEMBL1503190 & 842697 & 5.2041 & 3.6181 & TRN \\
\hline CHEMBL 2094728 & 842697 & 5.2708 & 4.3702 & TRN \\
\hline CHEMBL 2094664 & 842697 & 3.3802 & 3.6272 & TST \\
\hline CHEMBL148401 & 842697 & 6.6655 & 4.5096 & TRN \\
\hline CHEMBL 2094389 & 842697 & 3.6813 & 3.4725 & TRN \\
\hline CHEMBL599708 & 842697 & 4.6819 & 4.2895 & TRN \\
\hline CHEMBL 2094646 & 842697 & 3.3802 & 3.9774 & TRN \\
\hline CHEMBL 2094725 & 842697 & 5.3809 & 4.6439 & TRN \\
\hline CHEMBL 2094691 & 842697 & 3.3802 & 3.9226 & TRN \\
\hline CHEMBL 2094784 & 842697 & 3.3802 & 3.2352 & TRN \\
\hline CHEMBL 2094412 & 842697 & 4.8091 & 3.6303 & TRN \\
\hline CHEMBL602978 & 842697 & 4.3799 & 4.1944 & TRN \\
\hline CHEMBL 2094594 & 842697 & 3.3802 & 3.6286 & TRN \\
\hline CHEMBL 2095045 & 842697 & 3.3802 & 4.03 & TRN \\
\hline CHEMBL 2094345 & 842697 & 3.6813 & 3.9019 & TRN \\
\hline CHEMBL1390716 & 842697 & 3.6813 & 4.1411 & TST \\
\hline
\end{tabular}




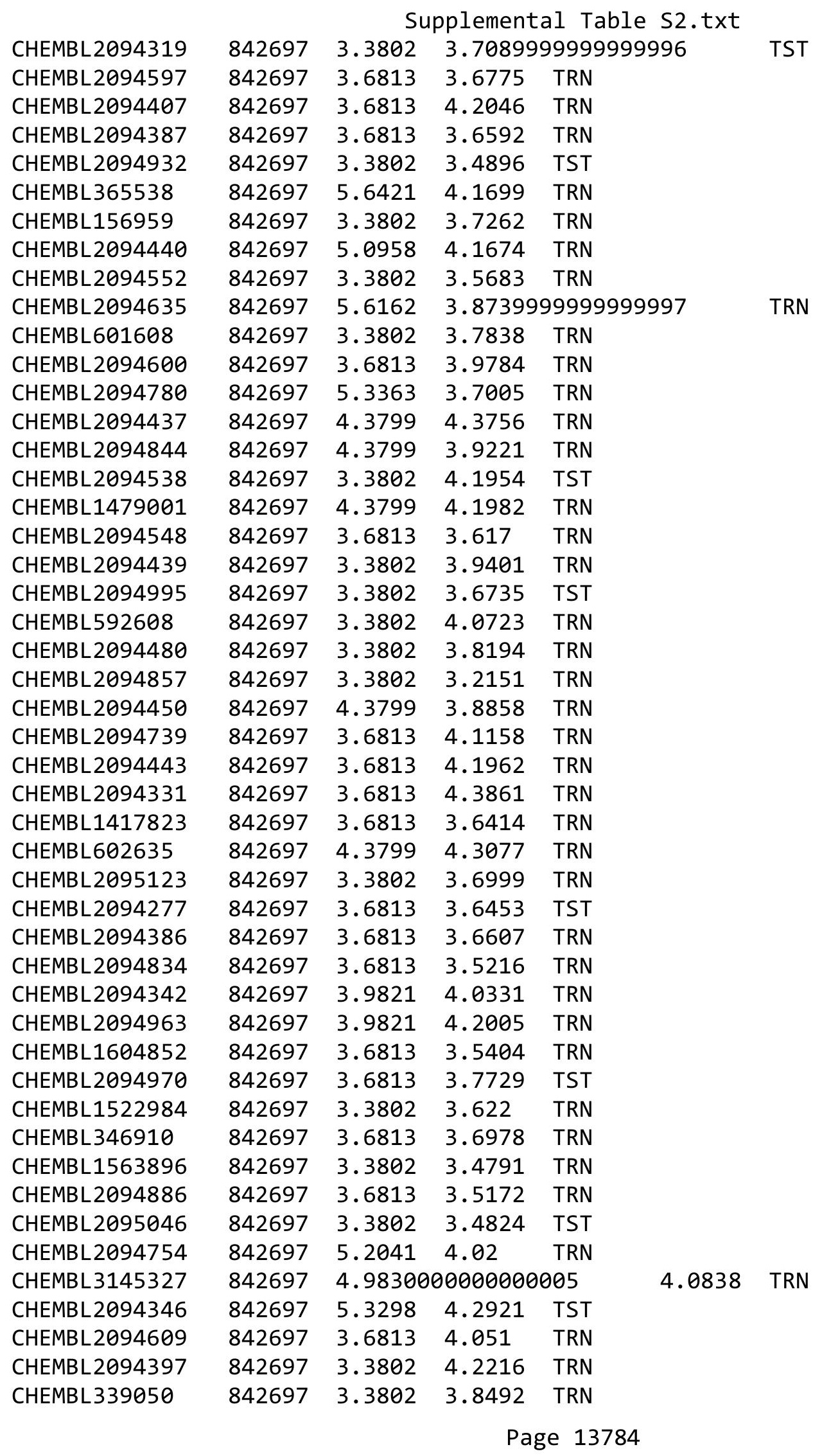




\begin{tabular}{|c|c|c|c|c|c|c|}
\hline \multicolumn{7}{|c|}{ Supplemental Table S2.txt } \\
\hline CHEMBL 2094332 & 842697 & 3.3802 & 3.947 & TST & & \\
\hline CHEMBL1903426 & 842697 & 6.1643 & 4.6055 & TRN & & \\
\hline CHEMBL428064 & 842697 & 3.6813 & 4.3389 & TRN & & \\
\hline CHEMBL 2094428 & 842697 & 4.3799 & 4.2172 & TRN & & \\
\hline CHEMBL 2094498 & 842697 & 3.6813 & 3.8058 & TRN & & \\
\hline CHEMBL1224755 & 842697 & 5.7122 & 4.4755 & TRN & & \\
\hline CHEMBL 2094704 & 842697 & 3.3802 & 3.97 & TRN & & \\
\hline CHEMBL 2094398 & 842697 & 5.2541 & 4.2482 & TRN & & \\
\hline CHEMBL 2094806 & 842697 & 5.3768 & 4.3079 & TRN & & \\
\hline CHEMBL 2094455 & 842697 & 3.6813 & 4.2837 & TRN & & \\
\hline CHEMBL 2094859 & 842697 & 3.6813 & 3.6586 & TRN & & \\
\hline CHEMBL 2094308 & 842697 & 5.3107 & 4.3226 & TRN & & \\
\hline CHEMBL1606743 & 842697 & 3.6813 & 3.9294 & TRN & & \\
\hline CHEMBL 2094501 & 842697 & 3.3802 & 3.5056 & TRN & & \\
\hline CHEMBL 2094395 & 842697 & 3.3802 & 3.4614 & TRN & & \\
\hline CHEMBL 2094334 & 842697 & 3.6813 & 4.5174 & TRN & & \\
\hline CHEMBL 2094598 & 842697 & 4.3799 & 3.9524 & TRN & & \\
\hline CHEMBL195579 & 842697 & 5.6478 & 4.1429 & TRN & & \\
\hline CHEMBL 2094792 & 842697 & 3.6813 & 3.7515 & TRN & & \\
\hline CHEMBL 2094998 & 842697 & 3.3802 & 3.6601 & TST & & \\
\hline CHEMBL 2094363 & 842697 & 3.3802 & 3.7752 & TRN & & \\
\hline CHEMBL 2094907 & 842697 & 3.3802 & 3.8686 & TRN & & \\
\hline CHEMBL 2094288 & 842697 & 3.6813 & 3.9129 & TRN & & \\
\hline CHEMBL 2094459 & 842697 & 3.6813 & 3.8055 & TRN & & \\
\hline CHEMBL 2095137 & 842697 & 3.9821 & 3.8334 & TRN & & \\
\hline CHEMBL1303587 & 842697 & 3.6813 & 3.8778 & TRN & & \\
\hline CHEMBL 2094675 & 842697 & 3.3802 & 3.6433 & TRN & & \\
\hline CHEMBL 2094453 & 842697 & 5.3242 & 3.9236 & TRN & & \\
\hline CHEMBL556398 & 842697 & 3.3802 & 3.44 & TRN & & \\
\hline CHEMBL 2094281 & 842697 & 3.9821 & 4.5698 & TRN & & \\
\hline CHEMBL589674 & 842697 & 4.3799 & 4.2042 & TRN & & \\
\hline CHEMBL582030 & 842697 & 3.3802 & 3.5833 & TRN & & \\
\hline CHEMBL577876 & 842697 & 4.3799 & 3.7982 & TRN & & \\
\hline CHEMBL1621012 & 842697 & 3.3802 & 3.6077 & TRN & & \\
\hline CHEMBL582727 & 842697 & 3.3802 & 3.6821 & TRN & & \\
\hline CHEMBL 2094798 & 842697 & 3.3802 & 3.8102 & TRN & & \\
\hline CHEMBL 2094553 & 842697 & 4.6819 & 4.4332 & TRN & & \\
\hline CHEMBL 2094379 & 842697 & 3.6813 & 3.9035 & TRN & & \\
\hline CHEMBL 2094463 & 842697 & 3.6813 & 3.8349 & TRN & & \\
\hline CHEMBL 2094550 & 842697 & 5.1726 & 3.8324 & TRN & & \\
\hline CHEMBL1503254 & 842697 & 3.3802 & 3.7096 & TRN & & \\
\hline CHEMBL 2094394 & 842697 & 3.6813 & 3.6823 & TST & & \\
\hline CHEMBL375781 & 842697 & 3.6813 & 4.0672 & TRN & & \\
\hline CHEMBL 2094558 & 842697 & 4.98300 & 30000000 & 205 & 4.763999999999999 & TRN \\
\hline CHEMBL 2094898 & 842697 & 3.3802 & 3.5424 & TST & & \\
\hline CHEMBL 2095124 & 842697 & 3.3802 & 3.6135 & TRN & & \\
\hline CHEMBL 2094315 & 842697 & 3.3802 & 3.8945 & TST & & \\
\hline CHEMBL 2094370 & 842697 & 3.6813 & 3.8551 & TRN & & \\
\hline
\end{tabular}


Supplemental Table S2.txt

\begin{tabular}{|c|c|c|c|c|}
\hline 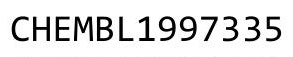 & & & & \\
\hline UГMDI & 42697 & .3802 & 4.074 & \\
\hline$-\sigma^{-1}$ & 597 & & & \\
\hline HEMBL 209 & 597 & 33 & & Ne \\
\hline AEMBL2094967 & 697 & 3802 & & \\
\hline HEMBL193528 & 42697 & 6813 & 5502 & \\
\hline 393 & 597 & 813 & 556 & \\
\hline$|F M R| 1$ & & & & \\
\hline HEMBL2094368 & 697 & 352 & & \\
\hline HEMBL2094300 & 697 & 3802 & 5786 & \\
\hline AEMBL529594 & 697 & 8813 & 62 & \\
\hline IEMBL2e & 97 & 821 & 53 & \\
\hline IEMBL2C & & & & RN \\
\hline HEMBL 209 & 597 & 802 & 4.1667 & \\
\hline HEMBL188 & 697 & 799 & & \\
\hline AEMBL 26 & 97 & 802 & 5307 & \\
\hline AEMBL2C & & 391 & 51 & \\
\hline HEMBL2C & & 802 & & \\
\hline HEMBL 20 & 97 & 802 & 505 & \\
\hline AEMBL2C & & 02 & & \\
\hline HEMBL & & 13 & & 31 \\
\hline AEMBL1 & & & & 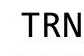 \\
\hline AEMBL2 & & 02 & 365 & \\
\hline 548 & & 802 & & \\
\hline AEMBL2C & & & & ras \\
\hline HEMBL 2 & & 802 & 259 & II \\
\hline HEMBL2 & & 799 & 16 & RN \\
\hline HFMBI 2 & & 02 & 242 & \\
\hline HEMBL2 & & 813 & & IRIV \\
\hline HEMBL 209 & & & & r \\
\hline HEMBL2C & & 821 & 967 & RN \\
\hline HEMBL & & 02 & 68 & RN \\
\hline $15 M P I A ~(15)$ & & & 375 & \\
\hline HEMBL 593 & & & 416 & IRN \\
\hline HEMBL152 & & 13 & 5408 & RN \\
\hline HEMBL 2 & & 13 & 902 & ST \\
\hline HFMRI 2 & & & & $\Gamma \mathrm{RN}$ \\
\hline & & & 419 & TRN \\
\hline HEMBL2095109 & & 802 & 7139 & TRN \\
\hline AEMBL2C & & 802 & 99 & TST \\
\hline HEMBL1 & & 306 & 817 & TRN \\
\hline HEMBL 20 & & 802 & 4027 & \\
\hline HEMBL $2 \Theta$ & & 813 & 3568 & 「RN \\
\hline HEMBL 209 & 597 & 3802 & 9759 & TS \\
\hline HEMBL1S & & 819 & & TRN \\
\hline HEMBL 2 & & 802 & & \\
\hline CHEMBL131 & & .3802 & .6572 & \\
\hline HEMBL209441€ & 842697 & 5.2154 & 3.9224 & \\
\hline
\end{tabular}

Page 13786 
Supplemental Table S2.txt

\begin{tabular}{|c|c|c|c|c|c|}
\hline CHEMBL1344912 & 842697 & 3.6813 & 3.5993 & TRN & \\
\hline CHEMBL330372 & 842697 & 3.9821 & 3.8047 & TRN & \\
\hline CHEMBL 2094474 & 842697 & 3.3802 & 3.9524 & TRN & \\
\hline CHEMBL2094949 & 842697 & 3.6813 & 3.6869 & TRN & \\
\hline CHEMBL2094771 & 842697 & 3.3802 & 3.6156 & TRN & \\
\hline CHEMBL583809 & 842697 & 3.6813 & 3.9894 & TRN & \\
\hline CHEMBL2094913 & 842697 & 3.9821 & 3.912 & TST & \\
\hline CHEMBL 2094661 & 842697 & 3.3802 & 4.6249 & TST & \\
\hline CHEMBL1446254 & 842697 & 3.3802 & 3.7901 & TST & \\
\hline CHEMBL2095110 & 842697 & 3.6813 & 3.5912 & TST & \\
\hline CHEMBL2094632 & 842697 & 3.6813 & 3.6233 & TST & \\
\hline CHEMBL2094339 & 842697 & 3.3802 & 4.1916 & TST & \\
\hline CHEMBL 2094787 & 842697 & 5.295 & 3.7529 & TST & \\
\hline CHEMBL 2094684 & 842697 & 4.3799 & 4.0028 & TST & \\
\hline CHEMBL2094954 & 842697 & 3.3802 & 3.78899 & 99999999997 & TST \\
\hline CHEMBL 2094832 & 842697 & 3.3802 & 3.6497 & TST & \\
\hline CHEMBL1373255 & 842697 & 3.3802 & 4.1175 & TST & \\
\hline CHEMBL 2094861 & 842697 & 3.3802 & 4.0962 & TST & \\
\hline CHEMBL372023 & 842697 & 3.6813 & 4.4615 & TST & \\
\hline CHEMBL 2094702 & 842697 & 3.6813 & 3.913006 & 00000000003 & TST \\
\hline CHEMBL 2094690 & 842697 & 3.3802 & 4.0497 & TST & \\
\hline CHEMBL1713477 & 842697 & 5.5421 & 3.7189 & TST & \\
\hline CHEMBL1449179 & 842697 & 3.3802 & 3.8776 & TST & \\
\hline CHEMBL 2094274 & 842697 & 5.251 & 3.8903 & TST & \\
\hline CHEMBL 2094901 & 842697 & 3.3802 & 4.2855 & TST & \\
\hline CHEMBL 2094283 & 842697 & 3.6813 & 3.7887 & TST & \\
\hline CHEMBL2094929 & 842697 & 3.6813 & 3.7807 & TST & \\
\hline CHEMBL 2094356 & 842697 & 3.6813 & 3.6161 & TST & \\
\hline CHEMBL1363249 & 842697 & 3.3802 & 3.8488 & TST & \\
\hline CHEMBL 2094365 & 842697 & 3.6813 & 3.9521 & TST & \\
\hline CHEMBL 2094287 & 842697 & 4.3799 & 5.3233 & TST & \\
\hline CHEMBL2094514 & 842697 & 3.3802 & 4.046 & TST & \\
\hline CHEMBL2094899 & 842697 & 3.3802 & 3.978 & TST & \\
\hline CHEMBL 2094629 & 842697 & 3.3802 & 3.7457 & TST & \\
\hline CHEMBL1367432 & 842697 & 3.6813 & 3.8091 & TST & \\
\hline CHEMBL1519356 & 842697 & 3.3802 & 3.6206 & TST & \\
\hline CHEMBL 2094329 & 842697 & 3.6813 & 3.8188 & TST & \\
\hline CHEMBL2094677 & 842697 & 3.6813 & 3.8377 & TST & \\
\hline CHEMBL 2094794 & 842697 & 3.6813 & 3.3285 & TST & \\
\hline CHEMBL 2094743 & 842697 & 4.3799 & 3.8408 & TST & \\
\hline CHEMBL394883 & 842697 & 3.6813 & 3.7718 & TST & \\
\hline CHEMBL 2095127 & 842697 & 3.6813 & 3.6083 & TST & \\
\hline CHEMBL1197848 & 842697 & 5.4134 & 4.3082 & TST & \\
\hline CHEMBL 2094726 & 842697 & 3.6813 & 3.8402 & TST & \\
\hline CHEMBL2094602 & 842697 & 3.3802 & 3.6551 & TST & \\
\hline CHEMBL592536 & 842697 & 3.6813 & 3.373 & TST & \\
\hline CHEMBL1422873 & 842697 & 3.3802 & 3.7755 & TST & \\
\hline CHEMBL 2094968 & 842697 & 3.3802 & 3.7871 & TST & \\
\hline
\end{tabular}




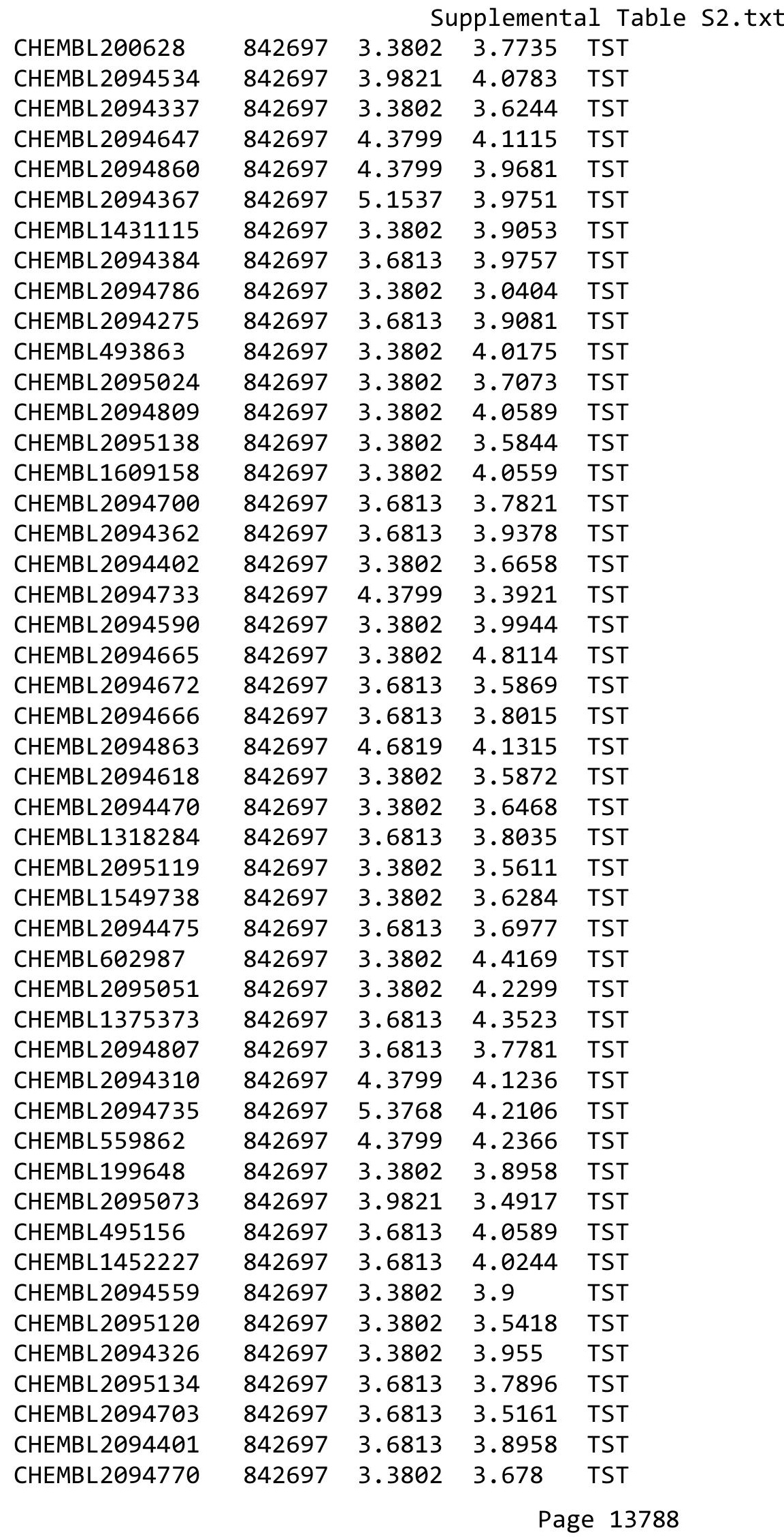




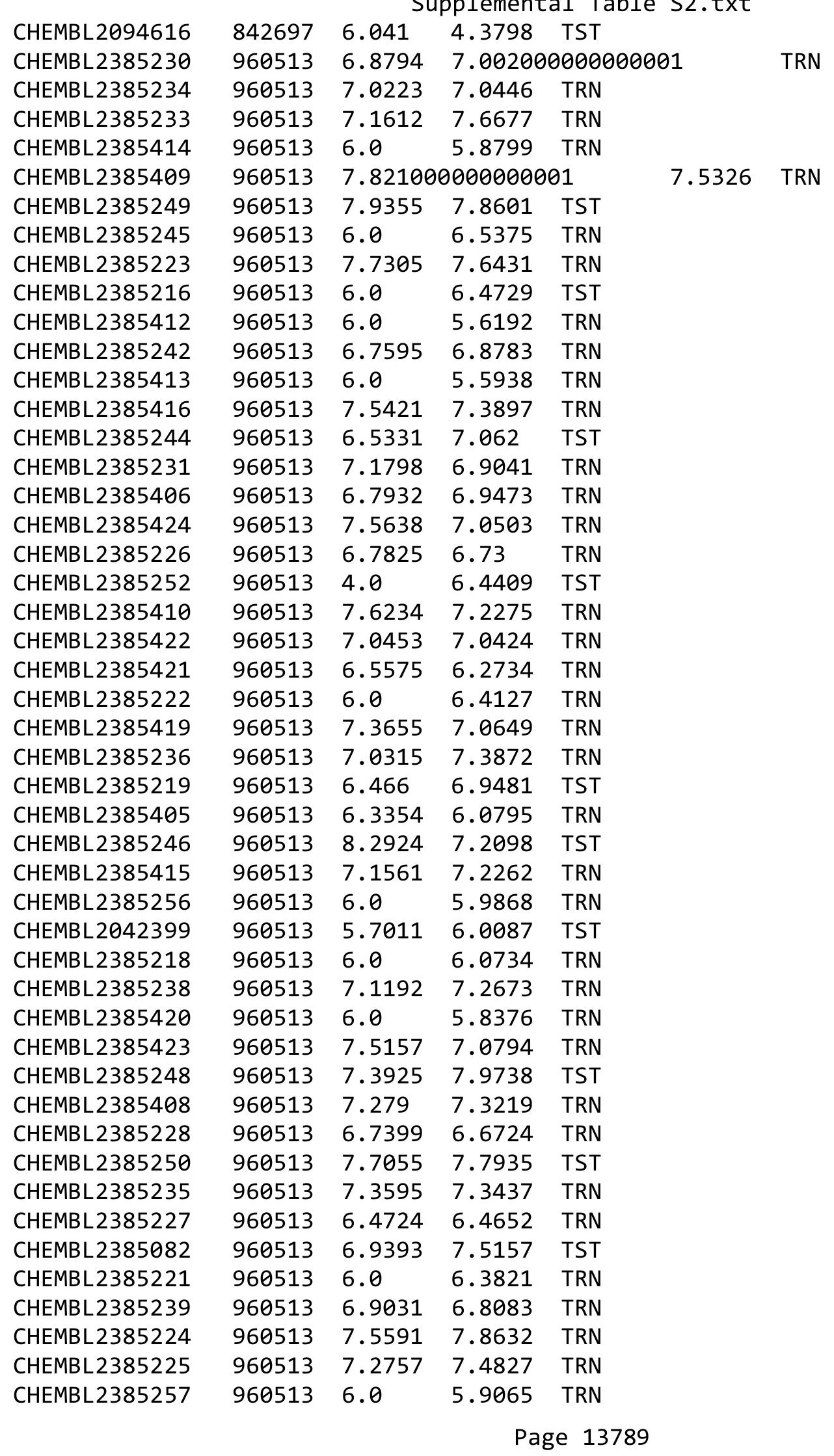




\begin{tabular}{|c|c|c|c|c|}
\hline \multicolumn{5}{|c|}{ Supplemental Table S2.txt } \\
\hline CHEMBL 2385241 & 960513 & 6.8539 & 7.2312 & TRN \\
\hline CHEMBL 2385418 & 960513 & 7.8539 & 7.2904 & TRN \\
\hline CHEMBL2385411 & 960513 & 4.0 & 5.1477 & TRN \\
\hline CHEMBL 2385232 & 960513 & 6.1851 & 7.0133 & TRN \\
\hline CHEMBL 2385255 & 960513 & 7.3665 & 7.0185 & TRN \\
\hline CHEMBL 2385247 & 960513 & 6.7932 & 7.1507 & TST \\
\hline CHEMBL 2385251 & 960513 & 7.3526 & 7.5472 & TST \\
\hline CHEMBL2385243 & 960513 & 4.0 & 6.1175 & TST \\
\hline CHEMBL 2385220 & 960513 & 7.7799 & 7.1519 & TST \\
\hline CHEMBL 2385217 & 960513 & 6.0 & 5.9925 & TRN \\
\hline CHEMBL 2385417 & 960513 & 7.3625 & 7.3748 & TST \\
\hline CHEMBL 2385254 & 960513 & 6.7375 & 7.2216 & TRN \\
\hline CHEMBL 2385229 & 960513 & 7.6021 & 7.3083 & TRN \\
\hline CHEMBL 2385407 & 960513 & 7.0297 & 6.5461 & TRN \\
\hline CHEMBL 2385237 & 960513 & 6.9431 & 6.9552 & TRN \\
\hline CHEMBL 2385240 & 960513 & 6.6162 & 6.831 & TST \\
\hline CHEMBL 2385404 & 960513 & 6.0 & 5.7959 & TRN \\
\hline CHEMBL3646022 & 1528070 & 7.0 & 7.9245 & TRN \\
\hline CHEMBL3643499 & 1528070 & 8.0 & 8.0288 & TRN \\
\hline CHEMBL 3643471 & 1528070 & 6.0 & 5.767 & TRN \\
\hline CHEMBL 3646000 & 1528070 & 7.0 & 6.7663 & TST \\
\hline CHEMBL3643453 & 1528070 & 7.0 & 7.5153 & TRN \\
\hline CHEMBL3643502 & 1528070 & 6.0 & 7.7108 & TRN \\
\hline CHEMBL3643498 & 1528070 & 7.0 & 6.9877 & TRN \\
\hline CHEMBL3645994 & 1528070 & 7.0 & 7.8326 & TRN \\
\hline CHEMBL 3643490 & 1528070 & 6.0 & 5.8114 & TRN \\
\hline CHEMBL 3643461 & 1528070 & 6.0 & 6.1518 & TRN \\
\hline CHEMBL3643493 & 1528070 & 8.0 & 7.2756 & TRN \\
\hline CHEMBL3646104 & 1528070 & 6.0 & 5.5275 & TRN \\
\hline CHEMBL3646007 & 1528070 & 8.0 & 7.9586 & TRN \\
\hline CHEMBL 3643478 & 1528070 & 5.0 & 6.7612 & TST \\
\hline CHEMBL 3646002 & 1528070 & 6.0 & 5.5587 & TRN \\
\hline CHEMBL3643491 & 1528070 & 6.0 & 6.4311 & TRN \\
\hline CHEMBL3643494 & 1528070 & 7.0 & 6.6813 & TRN \\
\hline CHEMBL3643458 & 1528070 & 7.0 & 6.4013 & TRN \\
\hline CHEMBL3646001 & 1528070 & 8.0 & 6.4445 & TST \\
\hline CHEMBL3646006 & 1528070 & 8.0 & 7.6176 & TRN \\
\hline CHEMBL 3643442 & 1528070 & 6.0 & 5.7591 & TRN \\
\hline CHEMBL3646005 & 1528070 & 8.0 & 7.2774 & TRN \\
\hline CHEMBL 3646102 & 1528070 & 6.0 & 5.3743 & TRN \\
\hline CHEMBL3645997 & 1528070 & 8.0 & 7.5982 & TRN \\
\hline CHEMBL 3643489 & 1528070 & 6.0 & 7.0878 & TRN \\
\hline CHEMBL3646037 & 1528070 & 6.0 & 6.3257 & TRN \\
\hline CHEMBL3643469 & 1528070 & 7.0 & 7.067 & TRN \\
\hline CHEMBL3646026 & 1528070 & 6.0 & 7.2539 & TRN \\
\hline CHEMBL3646083 & 1528070 & 6.0 & 6.5439 & TST \\
\hline CHEMBL3645995 & 1528070 & 6.0 & 6.6879 & TST \\
\hline CHEMBL3643468 & 1528070 & 7.0 & 6.2634 & TRN \\
\hline
\end{tabular}




\begin{tabular}{|c|c|c|c|c|}
\hline & & & & \\
\hline CHEMBL 3643460 & 1528070 & 6.0 & 5.5781 & TST \\
\hline CHEMBL3646103 & 1528070 & 5.0 & 5.0977 & TRN \\
\hline CHEMBL3643501 & 1528070 & 8.0 & 7.3579 & TRN \\
\hline CHEMBL 3645990 & 1528070 & 7.0 & 7.0739 & TRN \\
\hline CHEMBL3643444 & 1528070 & 6.0 & 5.8575 & TRN \\
\hline CHEMBL3643482 & 1528070 & 7.0 & 6.8793 & TRN \\
\hline CHEMBL3643474 & 1528070 & 8.0 & 7.4321 & TRN \\
\hline CHEMBL3643477 & 1528070 & 7.0 & 6.3169 & TST \\
\hline CHEMBL 3646028 & 1528070 & 6.0 & 7.2995 & TST \\
\hline CHEMBL3646088 & 1528070 & 6.0 & 6.1367 & TRN \\
\hline CHEMBL3646093 & 1528070 & 6.0 & 5.9214 & TRN \\
\hline CHEMBL3646024 & 1528070 & 8.0 & 7.4576 & TRN \\
\hline CHEMBL3646092 & 1528070 & 6.0 & 5.9911 & TRN \\
\hline CHEMBL 3646003 & 1528070 & 7.0 & 6.1821 & TRN \\
\hline CHEMBL3643454 & 1528070 & 8.0 & 7.9673 & TRN \\
\hline CHEMBL 3643500 & 1528070 & 8.0 & 7.6333 & TRN \\
\hline CHEMBL3643466 & 1528070 & 8.0 & 7.2584 & TRN \\
\hline CHEMBL3646077 & 1528070 & 6.0 & 6.7101 & TST \\
\hline CHEMBL3643465 & 1528070 & 7.0 & 7.0639 & TRN \\
\hline CHEMBL3639449 & 1528070 & 6.0 & 5.5035 & TRN \\
\hline CHEMBL 3643463 & 1528070 & 7.0 & 6.8682 & TRN \\
\hline CHEMBL 3643484 & 1528070 & 6.0 & 6.1118 & TST \\
\hline CHEMBL3646052 & 1528070 & 6.0 & 5.7003 & TRN \\
\hline CHEMBL3646098 & 1528070 & 6.0 & 6.0725 & TRN \\
\hline CHEMBL3643445 & 1528070 & 8.0 & 7.8162 & TRN \\
\hline CHEMBL 3643495 & 1528070 & 6.0 & 7.1406 & TRN \\
\hline CHEMBL3646075 & 1528070 & 6.0 & 7.0694 & TRN \\
\hline CHEMBL3639423 & 1528070 & 6.0 & 5.5933 & TRN \\
\hline CHEMBL3646059 & 1528070 & 8.0 & 7.96 & TRN \\
\hline CHEMBL 3643446 & 1528070 & 5.0 & 5.9546 & TRN \\
\hline CHEMBL 3643457 & 1528070 & 8.0 & 6.9744 & TRN \\
\hline CHEMBL3646089 & 1528070 & 6.0 & 6.0514 & TRN \\
\hline CHEMBL3646069 & 1528070 & 6.0 & 7.5989 & TRN \\
\hline CHEMBL3643459 & 1528070 & 6.0 & 6.4018 & TRN \\
\hline CHEMBL3643452 & 1528070 & 8.0 & 7.6147 & TRN \\
\hline CHEMBL3646036 & 1528070 & 5.0 & 6.7078 & TST \\
\hline CHEMBL3645993 & 1528070 & 7.0 & 6.2088 & TST \\
\hline CHEMBL3643473 & 1528070 & 5.0 & 5.6317 & TRN \\
\hline CHEMBL 3645991 & 1528070 & 5.0 & 5.9313 & TST \\
\hline CHEMBL3646032 & 1528070 & 6.0 & 6.5101 & TRN \\
\hline CHEMBL 3646054 & 1528070 & 5.0 & 5.7945 & TRN \\
\hline CHEMBL3646043 & 1528070 & 5.0 & 5.2134 & TRN \\
\hline CHEMBL3643492 & 1528070 & 6.0 & 6.5077 & TRN \\
\hline CHEMBL 3643483 & 1528070 & 7.0 & 6.1389 & TST \\
\hline CHEMBL3646004 & 1528070 & 5.0 & 6.2427 & TST \\
\hline CHEMBL 3643447 & 1528070 & 6.0 & 6.023 & TRN \\
\hline CHEMBL3646015 & 1528070 & 8.0 & 7.9326 & TRN \\
\hline CHEMBL 3643470 & 1528070 & 6.0 & 6.3067 & TRN \\
\hline
\end{tabular}




\begin{tabular}{|c|c|c|c|c|c|c|}
\hline \multicolumn{7}{|c|}{ Supplemental Table S2.txt } \\
\hline CHEMBL3643496 & 1528070 & 6.0 & 7.7965 & TST & & \\
\hline CHEMBL 3643485 & 1528070 & 6.0 & 5.9523 & TST & & \\
\hline CHEMBL3643462 & 1528070 & 7.0 & 6.3253 & TRN & & \\
\hline CHEMBL3643451 & 1528070 & 6.0 & 6.1304 & TRN & & \\
\hline CHEMBL 3643476 & 1528070 & 5.0 & 5.8214 & TST & & \\
\hline CHEMBL 3646106 & 1528070 & 6.0 & 6.4084 & TRN & & \\
\hline CHEMBL3643464 & 1528070 & 7.0 & 6.4338 & TRN & & \\
\hline CHEMBL 3646062 & 1528070 & 8.0 & 7.8617 & TST & & \\
\hline CHEMBL 3643480 & 1528070 & 8.0 & 7.5382 & TRN & & \\
\hline CHEMBL 3643449 & 1528070 & 8.0 & 7.3716 & TRN & & \\
\hline CHEMBL 3643488 & 1528070 & 8.0 & 7.1197 & TRN & & \\
\hline CHEMBL3645999 & 1528070 & 6.0 & 6.6145 & TST & & \\
\hline CHEMBL3643486 & 1528070 & 8.0 & 7.4961 & TRN & & \\
\hline CHEMBL3646049 & 1528070 & 5.0 & 5.7111 & TRN & & \\
\hline CHEMBL3643479 & 1528070 & 5.0 & 5.6255 & TRN & & \\
\hline CHEMBL 3646041 & 1528070 & 6.0 & 5.9267 & TRN & & \\
\hline CHEMBL3645992 & 1528070 & 7.0 & 6.5627 & TST & & \\
\hline CHEMBL3646099 & 1528070 & 5.0 & 5.9967 & TRN & & \\
\hline CHEMBL 3643456 & 1528070 & 8.0 & 7.2926 & TRN & & \\
\hline CHEMBL3646038 & 1528070 & 6.0 & 6.3607 & TRN & & \\
\hline CHEMBL 3643455 & 1528070 & 8.0 & 8.1307 & TRN & & \\
\hline CHEMBL3643443 & 1528070 & 8.0 & 7.6875 & TRN & & \\
\hline CHEMBL 3643497 & 1528070 & 8.0 & 6.9536 & TRN & & \\
\hline CHEMBL3643481 & 1528070 & 8.0 & 7.7532 & TRN & & \\
\hline CHEMBL 3643448 & 1528070 & 8.0 & 7.6941 & TST & & \\
\hline CHEMBL 3646051 & 1528070 & 6.0 & 5.8266 & TST & & \\
\hline CHEMBL3643467 & 1528070 & 7.0 & 7.1137 & TST & & \\
\hline CHEMBL3646086 & 1528070 & 5.0 & 6.3341 & TST & & \\
\hline CHEMBL 3643472 & 1528070 & 7.0 & 6.9436 & TST & & \\
\hline CHEMBL3645996 & 1528070 & 7.0 & 6.6898 & TST & & \\
\hline CHEMBL 3645998 & 1528070 & 7.0 & 6.5391 & TST & & \\
\hline CHEMBL601069 & 823827 & 4.6635 & 4.6024 & TST & & \\
\hline CHEMBL601708 & 823827 & 6.6021 & 6.4647 & TST & & \\
\hline CHEMBL2041833 & 823827 & 5.5622 & 5.0852 & TST & & \\
\hline CHEMBL 2041821 & 823827 & 7.3188 & 7.2359 & TRN & & \\
\hline CHEMBL605979 & 823827 & 4.5042 & 4.5154 & TRN & & \\
\hline CHEMBL2041820 & 823827 & 7.0506 & 7.0833 & TRN & & \\
\hline CHEMBL 2041814 & 823827 & 5.20200 & 30000000 & & 5.0984 & TRN \\
\hline CHEMBL601067 & 823827 & 5.8761 & 5.86 & TRN & & \\
\hline CHEMBL2041830 & 823827 & 7.0555 & 7.1712 & TRN & & \\
\hline CHEMBL2041811 & 823827 & 6.0555 & 6.1214 & TRN & & \\
\hline CHEMBL601065 & 823827 & 5.7545 & 5.7319 & TRN & & \\
\hline CHEMBL 2041622 & 823827 & 5.9066 & 5.9291 & TRN & & \\
\hline CHEMBL2041818 & 823827 & 7.6576 & 7.79700 & 0000000001 & & TRN \\
\hline CHEMBL2041971 & 823827 & 6.5528 & 6.5138 & TRN & & \\
\hline CHEMBL2041839 & 823827 & 6.8928 & 6.6768 & TST & & \\
\hline CHEMBL2041806 & 823827 & 7.4089 & 7.4321 & TRN & & \\
\hline CHEMBL 2041840 & 823827 & 6.0 & 6.0175 & TRN & & \\
\hline
\end{tabular}




\begin{tabular}{|c|c|c|c|c|c|}
\hline \multicolumn{6}{|c|}{ plemental } \\
\hline CHEMBL601066 & 823827 & 6.4202 & 6.4145 & TRN & \\
\hline CHEMBL2041804 & 823827 & 5.4157 & 5.4782 & TRN & \\
\hline CHEMBL596744 & 823827 & 3.0 & 3.0697 & TRN & \\
\hline CHEMBL2041616 & 823827 & 7.7696 & 7.6198 & TRN & \\
\hline CHEMBL2041796 & 823827 & 6.4815 & 6.5596 & TST & \\
\hline CHEMBL590266 & 823827 & 7.3468 & 7.3982 & TRN & \\
\hline CHEMBL 2041843 & 823827 & 8.0 & 8.125 & TRN & \\
\hline CHEMBL601706 & 823827 & 5.7878 & 5.8088 & TRN & \\
\hline CHEMBL2041844 & 823827 & 6.9586 & 6.9907 & TRN & \\
\hline CHEMBL2041846 & 823827 & 5.5638 & 5.5673 & TRN & \\
\hline CHEMBL2041838 & 823827 & 6.8539 & 6.8948 & TST & \\
\hline CHEMBL2041799 & 823827 & 6.5229 & 6.37799 & 9999999999 & TST \\
\hline CHEMBL2041829 & 823827 & 6.8861 & 6.8716 & TRN & \\
\hline CHEMBL 2041834 & 823827 & 5.1752 & 4.6528 & TST & \\
\hline CHEMBL2041831 & 823827 & 6.4815 & 6.341 & TST & \\
\hline CHEMBL2041795 & 823827 & 6.7447 & 6.6982 & TRN & \\
\hline CHEMBL2041803 & 823827 & 5.2111 & 5.24700 & 0000000001 & TRN \\
\hline CHEMBL2041970 & 823827 & 6.5528 & 6.5986 & TRN & \\
\hline CHEMBL 2041828 & 823827 & 6.5376 & 6.7864 & TST & \\
\hline CHEMBL2041801 & 823827 & 5.9626 & 6.0382 & TRN & \\
\hline CHEMBL2041807 & 823827 & 7.4559 & 7.3982 & TRN & \\
\hline CHEMBL2041832 & 823827 & 5.9872 & 5.9591 & TRN & \\
\hline CHEMBL 2041621 & 823827 & 6.6383 & 6.5733 & TRN & \\
\hline CHEMBL2041842 & 823827 & 7.9586 & 7.6052 & TRN & \\
\hline CHEMBL2041802 & 823827 & 5.7447 & 5.6965 & TRN & \\
\hline CHEMBL2041826 & 823827 & 7.6778 & 7.6347 & TRN & \\
\hline CHEMBL601707 & 823827 & 5.2007 & 5.0779 & TRN & \\
\hline CHEMBL539632 & 823827 & 6.7447 & 6.671 & TRN & \\
\hline CHEMBL 2041819 & 823827 & 4.3391 & 4.4007 & TRN & \\
\hline CHEMBL596746 & 823827 & 3.0 & 2.9837 & TRN & \\
\hline CHEMBL605561 & 823827 & 4.6099 & 4.6221 & TRN & \\
\hline CHEMBL2041800 & 823827 & 6.3665 & 6.3754 & TST & \\
\hline CHEMBL2041623 & 823827 & 6.0223 & 6.0521 & TRN & \\
\hline CHEMBL2041797 & 823827 & 6.4815 & 6.4501 & TRN & \\
\hline CHEMBL 2041812 & 823827 & 4.4365 & 4.5079 & TRN & \\
\hline CHEMBL 2041845 & 823827 & 7.3468 & 7.284 & TRN & \\
\hline CHEMBL 2041805 & 823827 & 7.3872 & 7.3032 & TRN & \\
\hline CHEMBL2041817 & 823827 & 6.8239 & 6.96299 & 9999999999 & TRN \\
\hline CHEMBL2041809 & 823827 & 4.8761 & 4.8847 & TRN & \\
\hline CHEMBL 2041835 & 823827 & 3.0 & 2.6637 & TST & \\
\hline CHEMBL598176 & 823827 & 4.819 & 4.7498 & TRN & \\
\hline CHEMBL 2041624 & 823827 & 7.1938 & 7.1871 & TRN & \\
\hline CHEMBL590505 & 823827 & 6.7375 & 6.966 & TRN & \\
\hline CHEMBL 2041619 & 823827 & 7.0969 & 7.0491 & TRN & \\
\hline CHEMBL598801 & 823827 & 4.4109 & 4.4141 & TRN & \\
\hline CHEMBL601068 & 823827 & 6.6576 & 6.654 & TRN & \\
\hline CHEMBL2041815 & 823827 & 7.0 & 7.2053 & TRN & \\
\hline CHEMBL590385 & 823827 & 6.5376 & 6.3183 & TST & \\
\hline
\end{tabular}




\begin{tabular}{|c|c|c|c|c|c|c|}
\hline & & \multicolumn{5}{|c|}{ Supplemental Table S2.txt } \\
\hline CHEMBL 2041836 & 823827 & 3.0 & 2.6978 & TST & & \\
\hline CHEMBL 2041813 & 823827 & 4.7144 & 4.6825 & TRN & & \\
\hline CHEMBL 2041827 & 823827 & 6.5686 & 6.5191 & TRN & & \\
\hline CHEMBL 2041816 & 823827 & 3.0 & 2.9495 & TRN & & \\
\hline CHEMBL 2041837 & 823827 & 6.7447 & 6.7615 & TST & & \\
\hline CHEMBL590504 & 823827 & 5.6882 & 5.678 & TRN & & \\
\hline CHEMBL 2041810 & 823827 & 5.9747 & 6.0018 & TRN & & \\
\hline CHEMBL 2041618 & 823827 & 7.1805 & 7.3654 & TST & & \\
\hline CHEMBL 2041824 & 823827 & 6.0 & 6.7159 & TST & & \\
\hline CHEMBL 2041617 & 823827 & 7.1308 & 7.2285 & TST & & \\
\hline CHEMBL 2041798 & 823827 & 6.3665 & 6.6694 & TST & & \\
\hline CHEMBL 2041620 & 823827 & 6.7212 & 6.8583 & TST & & \\
\hline CHEMBL1483335 & 688291 & 5.4868 & 5.2027 & TRN & & \\
\hline CHEMBL1353227 & 688291 & \multicolumn{3}{|c|}{5.202000000000001} & 4.9083 & TST \\
\hline CHEMBL1491919 & 688291 & 3.0 & 2.7658 & TST & & \\
\hline CHEMBL1602524 & 688291 & 3.0 & 2.7498 & TRN & & \\
\hline CHEMBL1489665 & 688291 & 3.0 & 2.6582 & TST & & \\
\hline CHEMBL1492035 & 688291 & 5.475 & 5.2422 & TRN & & \\
\hline CHEMBL1449334 & 688291 & 4.382 & 5.7261 & TST & & \\
\hline CHEMBL1606748 & 688291 & 3.0 & 3.2186 & TRN & & \\
\hline CHEMBL1603381 & 688291 & 6.2652 & 6.0121 & TRN & & \\
\hline CHEMBL1414381 & 688291 & 3.0 & 3.0277 & TRN & & \\
\hline CHEMBL1599376 & 688291 & 3.0 & 3.6154 & TST & & \\
\hline CHEMBL492894 & 688291 & 5.2182 & 5.1634 & TRN & & \\
\hline CHEMBL1403754 & 688291 & 3.0 & 3.8336 & TST & & \\
\hline CHEMBL1530046 & 688291 & 3.0 & 3.2364 & TRN & & \\
\hline CHEMBL1456035 & 688291 & 5.0164 & 4.6048 & TRN & & \\
\hline CHEMBL1328398 & 688291 & 3.0 & 4.0741 & TST & & \\
\hline CHEMBL1373509 & 688291 & 4.032 & 3.8102 & TRN & & \\
\hline CHEMBL1374065 & 688291 & 3.0 & 3.5416 & TST & & \\
\hline CHEMBL1334633 & 688291 & 5.6615 & 4.9994 & TRN & & \\
\hline CHEMBL1606056 & 688291 & 3.0 & 2.6988 & TRN & & \\
\hline CHEMBL1363824 & 688291 & 4.8894 & 4.3083 & TRN & & \\
\hline CHEMBL201289 & 688291 & 5.7878 & 5.8459 & TRN & & \\
\hline CHEMBL1452974 & 688291 & 3.0 & 3.1638 & TRN & & \\
\hline CHEMBL458328 & 688291 & 4.8125 & 4.5333 & TST & & \\
\hline CHEMBL1483741 & 688291 & 3.0 & 2.7734 & TRN & & \\
\hline CHEMBL1568844 & 688291 & 3.0 & 2.7367 & TRN & & \\
\hline CHEMBL501993 & 688291 & 6.3161 & 6.2105 & TST & & \\
\hline CHEMBL1567279 & 688291 & 3.0 & 2.8726 & TRN & & \\
\hline CHEMBL1443006 & 688291 & 3.0 & 3.2357 & TRN & & \\
\hline CHEMBL1491672 & 688291 & 4.8182 & 3.5179 & TST & & \\
\hline CHEMBL1408008 & 688291 & 3.0 & 3.7905 & TRN & & \\
\hline CHEMBL1597781 & 688291 & 3.0 & 2.9401 & TRN & & \\
\hline CHEMBL1482473 & 688291 & 3.0 & 3.1861 & TRN & & \\
\hline CHEMBL1373495 & 688291 & 5.61799 & 99999999 & 99 & 4.8724 & TRN \\
\hline CHEMBL1412998 & 688291 & 3.0 & 3.2867 & TRN & & \\
\hline CHEMBL578585 & 688291 & 5.4056 & 4.6367 & TST & & \\
\hline
\end{tabular}




\begin{tabular}{|c|c|c|c|c|c|c|}
\hline \multirow{4}{*}{$\begin{array}{l}\text { CHEMBL1334412 } \\
\text { CHEMBL244695 } \\
\text { CHEMBL1606543 }\end{array}$} & & \multicolumn{5}{|c|}{ Supplemental Table S2.txt } \\
\hline & 688291 & 3.0 & \multicolumn{3}{|c|}{3.4019999999999997} & TRN \\
\hline & 688291 & 5.6003 & \multicolumn{3}{|c|}{5.4879999999999995} & TRN \\
\hline & 688291 & 5.5528 & 5.7293 & TRN & & \\
\hline CHEMBL 2448605 & 688291 & 3.0 & 3.2372 & TRN & & \\
\hline CHEMBL1371869 & 688291 & 5.8996 & 5.8638 & TRN & & \\
\hline CHEMBL1489230 & 688291 & 5.4112 & 5.5889 & TRN & & \\
\hline CHEMBL1371777 & 688291 & \multicolumn{3}{|c|}{4.9830000000000005} & .3922 & TST \\
\hline CHEMBL1526353 & 688291 & 6.0964 & 3.221 & TST & & \\
\hline CHEMBL1557930 & 688291 & 4.5482 & 3.5179 & TST & & \\
\hline CHEMBL1410909 & 688291 & 5.58 & 4.9492 & TRN & & \\
\hline CHEMBL1493399 & 688291 & 3.0 & 3.0852 & TRN & & \\
\hline CHEMBL1331645 & 688291 & 5.2676 & \multicolumn{3}{|c|}{5.457000000000001} & TRN \\
\hline CHEMBL1491991 & 688291 & 5.4123 & 5.4347 & TRN & & \\
\hline CHEMBL1490701 & 688291 & 5.2503 & 5.4803 & TRN & & \\
\hline CHEMBL1489917 & 688291 & 3.0 & 3.0495 & TRN & & \\
\hline CHEMBL1333555 & 688291 & 5.2958 & 5.026 & TRN & & \\
\hline CHEMBL1607735 & 688291 & 5.4815 & 5.5263 & TRN & & \\
\hline CHEMBL1448629 & 688291 & 3.0 & 2.9485 & TRN & & \\
\hline CHEMBL1328309 & 688291 & 3.0 & 3.0515 & TRN & & \\
\hline CHEMBL1454310 & 688291 & 3.0 & 3.0657 & TRN & & \\
\hline CHEMBL1608225 & 688291 & 3.0 & 3.053 & TRN & & \\
\hline CHEMBL1480807 & 688291 & 3.0 & 3.08100 & 0000000000 & & TRN \\
\hline CHEMBL1528814 & 688291 & 4.9469 & 5.5382 & TRN & & \\
\hline CHEMBL1570803 & 688291 & \multicolumn{3}{|c|}{4.9830000000000005} & .9467 & TRN \\
\hline CHEMBL1376870 & 688291 & 4.8069 & 5.7749 & TRN & & \\
\hline CHEMBL1527023 & 688291 & 4.6778 & 4.441 & TRN & & \\
\hline CHEMBL1449836 & 688291 & 4.8761 & 6.2245 & TST & & \\
\hline CHEMBL1492839 & 688291 & 4.0555 & 3.6421 & TST & & \\
\hline CHEMBL1526669 & 688291 & 4.3575 & 4.5563 & TRN & & \\
\hline CHEMBL1363132 & 688291 & 4.1463 & 4.3042 & TRN & & \\
\hline CHEMBL1530080 & 688291 & 5.4401 & 5.6022 & TRN & & \\
\hline CHEMBL1608654 & 688291 & 5.6198 & 5.7078 & TRN & & \\
\hline CHEMBL1333592 & 688291 & 3.0 & 3.1084 & TRN & & \\
\hline CHEMBL1527520 & 688291 & 6.2984 & 6.4188 & TRN & & \\
\hline CHEMBL1403497 & 688291 & 5.2916 & 4.0953 & TST & & \\
\hline CHEMBL1373046 & 688291 & 4.3487 & 4.5228 & TRN & & \\
\hline CHEMBL1328061 & 688291 & 3.0 & 2.758 & TRN & & \\
\hline CHEMBL312097 & 688291 & 3.0 & 3.0848 & TRN & & \\
\hline CHEMBL1430473 & 688291 & 5.4157 & 5.5398 & TRN & & \\
\hline CHEMBL1490321 & 688291 & 4.1537 & 3.3191 & TRN & & \\
\hline CHEMBL1517389 & 688291 & 4.8633 & 4.8303 & TRN & & \\
\hline CHEMBL1451516 & 688291 & 5.091 & 5.28700 & 0000000001 & & TST \\
\hline CHEMBL1400895 & 688291 & 6.1013 & 3.5179 & TST & & \\
\hline CHEMBL1427609 & 688291 & 4.8928 & 4.6067 & TST & & \\
\hline CHEMBL1319451 & 688291 & 4.0168 & 3.5618 & TST & & \\
\hline CHEMBL1535445 & 688291 & 3.0 & 3.2952 & TRN & & \\
\hline CHEMBL1441239 & 688291 & 3.0 & 2.945 & TRN & & \\
\hline CHEMBL1407027 & 688291 & 3.0 & 3.3242 & TRN & & \\
\hline
\end{tabular}




\begin{tabular}{|c|c|c|c|c|c|}
\hline & & \multicolumn{4}{|c|}{ Supplemental Table S2.txt } \\
\hline CHEMBL1409373 & 688291 & 4.3251 & 4.5831 & TRN & \\
\hline CHEMBL1333960 & 688291 & 3.0 & 3.2873 & TST & \\
\hline CHEMBL259355 & 688291 & 4.5528 & 4.2686 & TRN & \\
\hline CHEMBL1495142 & 688291 & 3.0 & 2.9115 & TRN & \\
\hline CHEMBL1359394 & 688291 & 3.0 & 3.0505 & TRN & \\
\hline CHEMBL1608153 & 688291 & 5.6904 & 5.4304 & TRN & \\
\hline CHEMBL1566708 & 688291 & 3.0 & 2.8409 & TRN & \\
\hline CHEMBL1570401 & 688291 & 5.1203 & 5.0335 & TRN & \\
\hline CHEMBL1386069 & 688291 & 3.0 & 3.4389 & TST & \\
\hline CHEMBL1525859 & 688291 & 3.0 & 3.2461 & TST & \\
\hline CHEMBL1447461 & 688291 & 3.0 & 3.1454 & TRN & \\
\hline CHEMBL1554052 & 688291 & 3.0 & 3.5292 & TRN & \\
\hline CHEMBL1448320 & 688291 & 3.0 & 2.805 & TRN & \\
\hline CHEMBL1531431 & 688291 & 3.0 & 3.0472 & TRN & \\
\hline CHEMBL1447034 & 688291 & 5.2652 & 5.3281 & TRN & \\
\hline CHEMBL1426947 & 688291 & 3.0 & 3.66600 & 00000000004 & TST \\
\hline CHEMBL1527941 & 688291 & 4.8794 & 5.103 & TRN & \\
\hline CHEMBL1491520 & 688291 & 3.0 & 3.0355 & TRN & \\
\hline CHEMBL1526610 & 688291 & 3.0 & 4.2424 & TST & \\
\hline CHEMBL1329983 & 688291 & 3.0 & 3.1639 & TST & \\
\hline CHEMBL 271690 & 688291 & 5.5229 & 5.2512 & TRN & \\
\hline CHEMBL1368913 & 688291 & 5.6234 & 5.2292 & TRN & \\
\hline CHEMBL1452440 & 688291 & 4.9586 & 4.9977 & TRN & \\
\hline CHEMBL1565097 & 688291 & 3.0 & 2.9681 & TRN & \\
\hline CHEMBL1328729 & 688291 & 3.0 & 3.1268 & TRN & \\
\hline CHEMBL131543 & 574385 & 4.0 & 3.9127 & TRN & \\
\hline CHEMBL128907 & 574385 & 5.4 & 5.2477 & TRN & \\
\hline CHEMBL407751 & 574385 & 4.0 & 4.2394 & TRN & \\
\hline CHEMBL339140 & 574385 & 6.3 & 5.8965 & TRN & \\
\hline CHEMBL550496 & 574385 & 6.0 & 6.3866 & TRN & \\
\hline CHEMBL550167 & 574385 & 6.0 & 6.0981 & TRN & \\
\hline CHEMBL565068 & 574385 & 6.0 & 6.2952 & TRN & \\
\hline CHEMBL564535 & 574385 & 8.4 & 8.1331 & TRN & \\
\hline CHEMBL563379 & 574385 & 8.2 & 7.9435 & TRN & \\
\hline CHEMBL551377 & 574385 & 8.0 & 8.1453 & TRN & \\
\hline CHEMBL564607 & 574385 & 6.5 & 6.3591 & TRN & \\
\hline CHEMBL550902 & 574385 & 6.8 & 6.7183 & TRN & \\
\hline CHEMBL563784 & 574385 & 6.0 & 6.3268 & TRN & \\
\hline CHEMBL562690 & 574385 & 6.0 & 6.3424 & TRN & \\
\hline CHEMBL560048 & 574385 & 7.8 & 8.082 & TRN & \\
\hline CHEMBL560167 & 574385 & 7.1 & 6.6759 & TRN & \\
\hline CHEMBL562698 & 574385 & 6.0 & 5.7018 & TRN & \\
\hline CHEMBL564885 & 574385 & 6.0 & 6.0178 & TRN & \\
\hline CHEMBL550777 & 574385 & 6.0 & 6.3799 & TRN & \\
\hline CHEMBL551301 & 574385 & 8.1 & 8.2582 & TRN & \\
\hline CHEMBL562308 & 574385 & 8.0 & 7.88 & TRN & \\
\hline CHEMBL549620 & 574385 & 7.7 & 7.7583 & TRN & \\
\hline CHEMBL564366 & 574385 & 7.8 & 7.9726 & TRN & \\
\hline
\end{tabular}




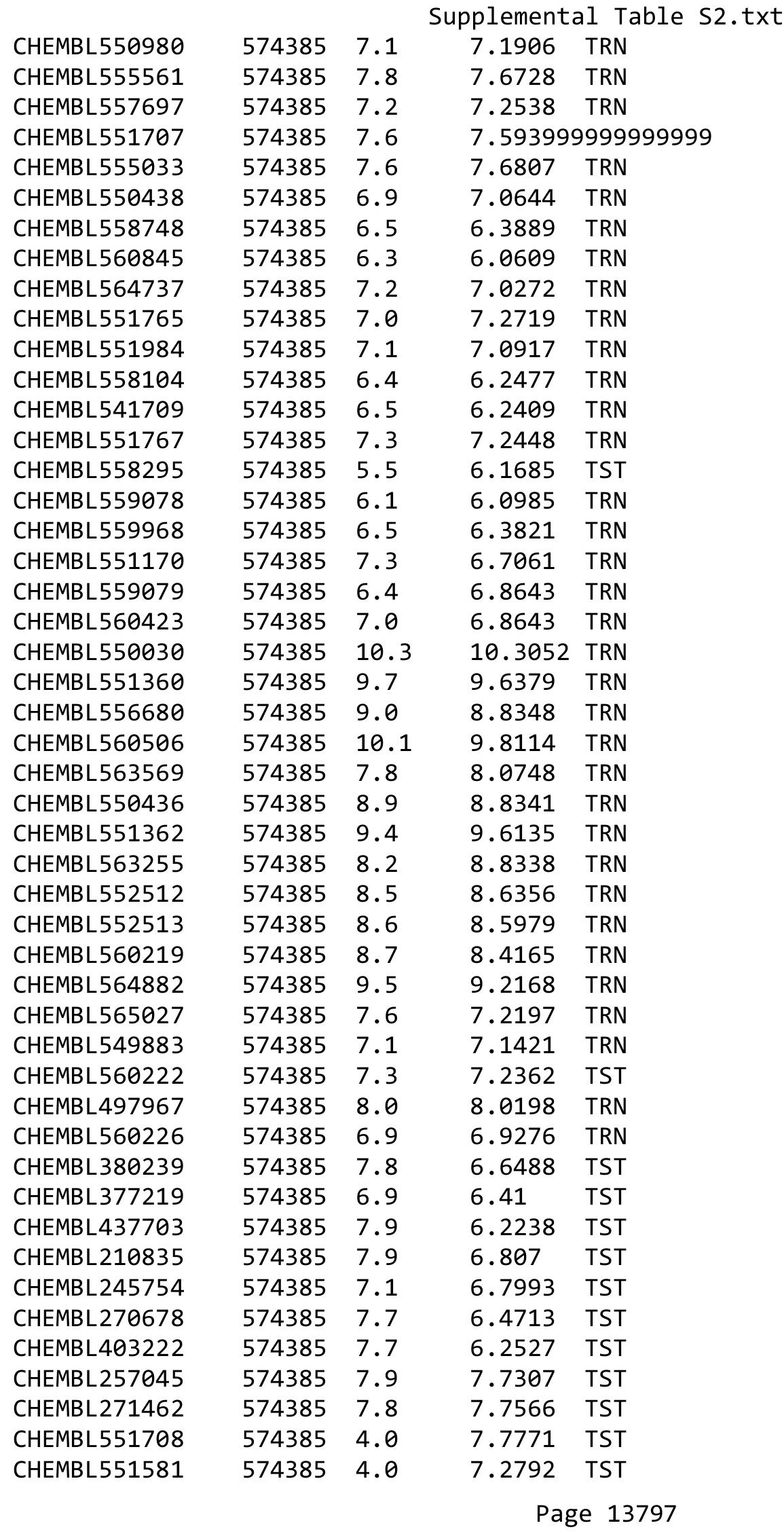




\begin{tabular}{|c|c|c|c|c|c|}
\hline \\
\hline CHEMBL551766 & 574385 & 4.0 & 7.6501 & TST & \\
\hline CHEMBL128537 & 574385 & 5.2 & 7.9414 & TST & \\
\hline CHEMBL559913 & 574385 & 4.5 & 6.6473 & TST & \\
\hline CHEMBL552515 & 574385 & 4.5 & 8.2445 & TST & \\
\hline CHEMBL561368 & 574385 & 4.5 & 6.6142 & TST & \\
\hline CHEMBL563551 & 574385 & 5.0 & 7.9003 & TST & \\
\hline CHEMBL562809 & 574385 & 5.0 & 5.3621 & TRN & \\
\hline CHEMBL 255787 & 574385 & 7.4 & 7.2797 & TST & \\
\hline CHEMBL517167 & 540742 & 7.1675 & 7.2411 & TST & \\
\hline CHEMBL471262 & 540742 & 5.8564 & 5.8634 & TRN & \\
\hline CHEMBL511161 & 540742 & 7.8539 & 7.8451 & TRN & \\
\hline CHEMBL514463 & 540742 & 7.4815 & 7.5134 & TRN & \\
\hline CHEMBL475497 & 540742 & 4.3324 & 4.1632 & TRN & \\
\hline CHEMBL510745 & 540742 & 6.6498 & 6.7664 & TRN & \\
\hline CHEMBL514662 & 540742 & 7.8861 & 7.57700 & 0000000001 & TST \\
\hline CHEMBL456225 & 540742 & 6.6073 & 6.6068 & TRN & \\
\hline CHEMBL516389 & 540742 & 7.5376 & 7.4677 & TST & \\
\hline CHEMBL472669 & 540742 & 7.6021 & 7.3439 & TST & \\
\hline CHEMBL464192 & 540742 & 6.5544 & 6.558 & TRN & \\
\hline CHEMBL516024 & 540742 & 5.7375 & 5.5385 & TRN & \\
\hline CHEMBL474283 & 540742 & 6.1838 & 6.3114 & TRN & \\
\hline CHEMBL 240657 & 540742 & 6.8633 & 6.5423 & TST & \\
\hline CHEMBL471880 & 540742 & 7.6021 & 7.5384 & TRN & \\
\hline CHEMBL 239822 & 540742 & 6.2676 & 6.4739 & TST & \\
\hline CHEMBL511649 & 540742 & 7.2518 & 7.2557 & TRN & \\
\hline CHEMBL499169 & 540742 & 6.1713 & 6.0903 & TRN & \\
\hline CHEMBL475096 & 540742 & 6.3036 & 6.5499 & TRN & \\
\hline CHEMBL473904 & 540742 & 7.8239 & 7.3416 & TST & \\
\hline CHEMBL473278 & 540742 & 6.7595 & 7.0966 & TRN & \\
\hline CHEMBL516187 & 540742 & 7.9586 & 7.9435 & TRN & \\
\hline CHEMBL510201 & 540742 & 6.8239 & 6.2027 & TST & \\
\hline CHEMBL473280 & 540742 & 7.0655 & 6.9735 & TRN & \\
\hline CHEMBL517265 & 540742 & 5.994 & 6.1185 & TRN & \\
\hline CHEMBL501088 & 540742 & 6.567 & 6.5753 & TRN & \\
\hline CHEMBL474687 & 540742 & 7.4089 & 7.2365 & TRN & \\
\hline CHEMBL472086 & 540742 & 6.8013 & 6.7973 & TRN & \\
\hline CHEMBL514965 & 540742 & 6.1586 & 6.0884 & TRN & \\
\hline CHEMBL472867 & 540742 & 6.0696 & 6.0902 & TRN & \\
\hline CHEMBL515575 & 540742 & 7.0862 & 6.8213 & TRN & \\
\hline CHEMBL475496 & 540742 & 4.0915 & 4.3738 & TRN & \\
\hline CHEMBL514489 & 540742 & 7.1675 & 7.1002 & TRN & \\
\hline CHEMBL475707 & 540742 & 7.3979 & 7.4396 & TST & \\
\hline CHEMBL472677 & 540742 & 6.1986 & 5.7848 & TRN & \\
\hline CHEMBL473884 & 540742 & 5.7577 & 5.5434 & TRN & \\
\hline CHEMBL457244 & 540742 & 6.6234 & 6.4563 & TRN & \\
\hline CHEMBL460636 & 540742 & 6.4949 & 6.6183 & TRN & \\
\hline CHEMBL474485 & 540742 & 7.3188 & 7.0965 & TRN & \\
\hline CHEMBL473068 & 540742 & 6.06 & 6.3711 & TRN & \\
\hline
\end{tabular}




\begin{tabular}{|c|c|c|c|c|c|c|}
\hline & & \multicolumn{5}{|c|}{ Supplemental Table S2.txt } \\
\hline CHEMBL515901 & 540742 & 5.7338 & 5.8619 & TRN & & \\
\hline CHEMBL516077 & 540742 & 5.6432 & 5.8439 & TRN & & \\
\hline CHEMBL240215 & 540742 & 7.284 & 6.6746 & TST & & \\
\hline CHEMBL515554 & 540742 & 5.6353 & 5.8272 & TRN & & \\
\hline CHEMBL475094 & 540742 & 6.6819 & 6.8797 & TRN & & \\
\hline CHEMBL473701 & 540742 & 7.2518 & 7.3907 & TST & & \\
\hline CHEMBL473272 & 540742 & 7.3468 & 7.1277 & TRN & & \\
\hline CHEMBL471882 & 540742 & 7.585 & 7.5067 & TRN & & \\
\hline CHEMBL474092 & 540742 & 7.3468 & 7.3314 & TRN & & \\
\hline CHEMBL475310 & 540742 & 8.0969 & 7.6899 & TST & & \\
\hline CHEMBL514606 & 540742 & 6.1118 & 5.7881 & TRN & & \\
\hline CHEMBL473700 & 540742 & 8.0 & 7.8143 & TST & & \\
\hline CHEMBL472676 & 540742 & 6.2652 & 6.1458 & TST & & \\
\hline CHEMBL515142 & 540742 & 7.2676 & 7.447 & TST & & \\
\hline CHEMBL475308 & 540742 & 5.8722 & 5.9301 & TRN & & \\
\hline CHEMBL457451 & 540742 & 6.5952 & 6.609 & TRN & & \\
\hline CHEMBL511162 & 540742 & $6.8210 e$ & 00000000 & 01 & 6.8697 & TRN \\
\hline CHEMBL515091 & 540742 & 7.3098 & 7.4611 & TRN & & \\
\hline CHEMBL473279 & 540742 & 7.1871 & 7.2838 & TRN & & \\
\hline CHEMBL241272 & 540742 & 5.2301 & 5.0803 & TST & & \\
\hline CHEMBL518325 & 540742 & 6.3288 & 6.4667 & TRN & & \\
\hline CHEMBL464191 & 540742 & 7.1938 & 6.8598 & TRN & & \\
\hline CHEMBL474091 & 540742 & 6.2958 & 6.4904 & TRN & & \\
\hline CHEMBL473898 & 540742 & 6.7721 & 6.9093 & TRN & & \\
\hline CHEMBL474096 & 540742 & 6.8601 & 7.357 & TST & & \\
\hline CHEMBL474708 & 540742 & 5.8969 & 6.0075 & TRN & & \\
\hline CHEMBL515829 & 540742 & 6.7825 & 6.5671 & TRN & & \\
\hline CHEMBL3951764 & 1642189 & 6.0 & 5.5722 & TRN & & \\
\hline CHEMBL 3908557 & 1642189 & 6.1675 & 6.3686 & TRN & & \\
\hline CHEMBL3944085 & 1642189 & 6.0 & 5.7248 & TST & & \\
\hline CHEMBL3933079 & 1642189 & 6.0 & 6.2425 & TRN & & \\
\hline CHEMBL3918703 & 1642189 & 6.0 & 6.7106 & TRN & & \\
\hline CHEMBL3899905 & 1642189 & 6.0 & 6.4808 & TRN & & \\
\hline CHEMBL3922138 & 1642189 & 6.301 & 5.0349 & TST & & \\
\hline CHEMBL3975468 & 1642189 & 8.0315 & 6.20700 & 0000000001 & & TS \\
\hline CHEMBL3918928 & 1642189 & 6.0 & 6.0637 & TST & & \\
\hline CHEMBL3955995 & 1642189 & 6.0 & 6.7771 & TRN & & \\
\hline CHEMBL 3942263 & 1642189 & 6.0 & 5.7 & TRN & & \\
\hline CHEMBL3911323 & 1642189 & 6.0 & 5.4558 & TRN & & \\
\hline CHEMBL3890585 & 1642189 & 6.0 & 6.5795 & TST & & \\
\hline CHEMBL3984958 & 1642189 & 9.4815 & 8.8965 & TRN & & \\
\hline CHEMBL3942425 & 1642189 & 5.6021 & 6.2648 & TRN & & \\
\hline CHEMBL3924667 & 1642189 & 8.4089 & 8.0025 & TRN & & \\
\hline CHEMBL3929462 & 1642189 & 6.0 & 5.7762 & TRN & & \\
\hline CHEMBL3918929 & 1642189 & 8.585 & 7.7293 & TRN & & \\
\hline CHEMBL3892986 & 1642189 & 6.0 & 7.0967 & TRN & & \\
\hline CHEMBL3913132 & 1642189 & 6.9586 & 7.2403 & TST & & \\
\hline CHEMBL3908413 & 1642189 & 6.0 & 6.6195 & TRN & & \\
\hline
\end{tabular}


Supplemental Table S2.txt

\begin{tabular}{|c|c|c|c|c|}
\hline CHEMBL3947024 & 1642189 & 7.3372 & 7.8881 & TRN \\
\hline CHEMBL3912451 & 1642189 & 6.0 & 5.9107 & TRN \\
\hline CHEMBL3986573 & 1642189 & 7.699 & 7.2322 & TST \\
\hline CHEMBL3933293 & 1642189 & 6.0 & 5.9404 & TRN \\
\hline CHEMBL3919348 & 1642189 & 7.3565 & 6.7703 & TRN \\
\hline CHEMBL3898016 & 1642189 & 6.0 & 6.2742 & TRN \\
\hline CHEMBL 3913448 & 1642189 & 6.0 & 6.6463 & TST \\
\hline CHEMBL3908920 & 1642189 & 6.0 & 6.7118 & TRN \\
\hline CHEMBL3926471 & 1642189 & 6.0 & 5.9996 & TRN \\
\hline CHEMBL3893340 & 1642189 & 6.0 & 6.2447 & TRN \\
\hline CHEMBL3907077 & 1642189 & 6.7696 & 6.7601 & TRN \\
\hline CHEMBL3959666 & 1642189 & 6.0 & 6.1884 & TRN \\
\hline CHEMBL3940391 & 1642189 & 7.9208 & 6.7489 & TRN \\
\hline CHEMBL3909473 & 1642189 & 6.0 & 6.784 & TRN \\
\hline CHEMBL3936747 & 1642189 & 8.585 & 8.2448 & TRN \\
\hline CHEMBL3940884 & 1642189 & 6.2291 & 5.6692 & TRN \\
\hline CHEMBL3898892 & 1642189 & 7.7212 & 8.0592 & TRN \\
\hline CHEMBL3934165 & 1642189 & 8.2441 & 7.3089 & TRN \\
\hline CHEMBL3948851 & 1642189 & 6.0 & 6.1832 & TST \\
\hline CHEMBL3910030 & 1642189 & 6.0 & 6.0262 & TRN \\
\hline CHEMBL3955304 & 1642189 & 8.7447 & 7.5202 & TRN \\
\hline CHEMBL3912874 & 1642189 & 6.0 & 6.3477 & TRN \\
\hline CHEMBL3982998 & 1642189 & 7.2291 & 5.2607 & TST \\
\hline CHEMBL3895641 & 1642189 & 6.0 & 5.4265 & TRN \\
\hline CHEMBL3907675 & 1642189 & 6.1871 & 5.4645 & TST \\
\hline CHEMBL3940955 & 1642189 & 7.8539 & 7.2998 & TRN \\
\hline CHEMBL3963014 & 1642189 & 6.0 & 5.5722 & TRN \\
\hline CHEMBL3898661 & 1642189 & 7.3279 & 5.0835 & TST \\
\hline CHEMBL3925277 & 1642189 & 7.9586 & 6.1229 & TRN \\
\hline CHEMBL3919308 & 1642189 & 5.4437 & 5.2984 & TRN \\
\hline CHEMBL3907209 & 1642189 & 8.8861 & 7.8544 & TRN \\
\hline CHEMBL3915521 & 1642189 & 6.0 & 6.2307 & TRN \\
\hline CHEMBL3890477 & 1642189 & 6.1308 & 6.1105 & TRN \\
\hline CHEMBL3979867 & 1642189 & 9.0506 & 8.6341 & TRN \\
\hline CHEMBL3919238 & 1642189 & 6.0 & 6.124 & TRN \\
\hline CHEMBL3893356 & 1642189 & 6.0 & 6.1062 & TRN \\
\hline CHEMBL3914424 & 1642189 & 6.0 & 6.4143 & TRN \\
\hline CHEMBL3916515 & 1642189 & 6.0 & 6.516 & TRN \\
\hline CHEMBL3892715 & 1642189 & 6.0 & 5.8561 & TRN \\
\hline CHEMBL3927844 & 1642189 & 6.0 & 7.143 & TST \\
\hline CHEMBL3963763 & 1642189 & 6.0 & 5.9715 & TRN \\
\hline CHEMBL3933533 & 1642189 & 6.0 & 6.2234 & TRN \\
\hline CHEMBL3925841 & 1642189 & 7.9586 & 8.3822 & TRN \\
\hline CHEMBL3904440 & 1642189 & 6.0 & 6.3345 & TRN \\
\hline CHEMBL3920622 & 1642189 & 6.0 & 6.2746 & TRN \\
\hline CHEMBL3910279 & 1642189 & 6.0 & 6.765 & TST \\
\hline CHEMBL3967694 & 1642189 & 5.5686 & \multicolumn{2}{|c|}{ 4. 3389999999999995} \\
\hline CHEMBL3916827 & 1642189 & 6.0 & 6.1751 & TRN \\
\hline
\end{tabular}




\begin{tabular}{|c|c|c|c|c|c|}
\hline \multicolumn{6}{|c|}{ Supplemental Table S2.txt } \\
\hline CHEMBL3931783 & 1642189 & 6.0 & 5.909 & TRN & \\
\hline CHEMBL3897751 & 1642189 & 6.4559 & 6.0542 & TRN & \\
\hline CHEMBL3939626 & 1642189 & 7.5376 & 6.9988 & TRN & \\
\hline CHEMBL3910998 & 1642189 & 6.0 & 6.8673 & TRN & \\
\hline CHEMBL 3897591 & 1642189 & 5.4089 & 5.2082 & TST & \\
\hline CHEMBL3925914 & 1642189 & 6.0 & 6.4285 & TRN & \\
\hline CHEMBL3892045 & 1642189 & 6.0 & 7.1108 & TRN & \\
\hline CHEMBL3945561 & 1642189 & 7.7696 & 7.6303 & TRN & \\
\hline CHEMBL3902080 & 1642189 & 6.0 & 6.0914 & TRN & \\
\hline CHEMBL3912259 & 1642189 & 6.1249 & 6.0094 & TRN & \\
\hline CHEMBL3909803 & 1642189 & 6.0132 & 7.6851 & TST & \\
\hline CHEMBL 3903240 & 1642189 & 5.8539 & 4.8356 & TST & \\
\hline CHEMBL3916410 & 1642189 & 6.0 & 6.4713 & TRN & \\
\hline CHEMBL3903949 & 1642189 & 6.0 & 6.1936 & TRN & \\
\hline CHEMBL3943782 & 1642189 & 6.0 & 6.5163 & TRN & \\
\hline CHEMBL3906693 & 1642189 & 6.0 & 5.5207 & TRN & \\
\hline CHEMBL3905679 & 1642189 & 5.4949 & 6.7778 & TST & \\
\hline CHEMBL3919230 & 1642189 & 6.0 & 7.3808 & TRN & \\
\hline CHEMBL3937175 & 1642189 & 6.0 & 6.41299 & 9999999999 & TRN \\
\hline CHEMBL3940256 & 1642189 & 5.9586 & 5.5728 & TRN & \\
\hline CHEMBL3918617 & 1642189 & 6.0 & 6.7036 & TRN & \\
\hline CHEMBL3974445 & 1642189 & 6.0 & 6.6328 & TRN & \\
\hline CHEMBL3924354 & 1642189 & 6.0 & 6.1259 & TRN & \\
\hline CHEMBL3941950 & 1642189 & 7.5528 & 6.5046 & TRN & \\
\hline CHEMBL3890642 & 1642189 & 6.0 & 6.6695 & TRN & \\
\hline CHEMBL3929243 & 1642189 & 8.1805 & 8.1467 & TRN & \\
\hline CHEMBL3948220 & 1642189 & 5.4202 & 5.8352 & TRN & \\
\hline CHEMBL3952712 & 1642189 & 6.0 & 6.1493 & TRN & \\
\hline CHEMBL 3913134 & 1642189 & 9.2218 & 6.7825 & TST & \\
\hline CHEMBL3962957 & 1642189 & 5.7447 & 7.71399 & 99999999995 & TST \\
\hline CHEMBL3962370 & 1642189 & 6.5086 & 6.8774 & TST & \\
\hline CHEMBL3900853 & 1642189 & 6.4815 & 5.8322 & TRN & \\
\hline CHEMBL3913299 & 1642189 & 7.8861 & 6.0427 & TST & \\
\hline CHEMBL3912349 & 1642189 & 6.0 & 6.2815 & TRN & \\
\hline CHEMBL3901156 & 1642189 & 8.0862 & 7.5113 & TRN & \\
\hline CHEMBL3975019 & 1642189 & 7.6778 & 7.3088 & TST & \\
\hline CHEMBL3932041 & 1642189 & 8.4437 & 6.7131 & TST & \\
\hline CHEMBL3923051 & 1642189 & 8.5528 & 7.1288 & TRN & \\
\hline CHEMBL 3937148 & 1642189 & 6.0 & 6.097 & TRN & \\
\hline CHEMBL3935570 & 1642189 & 6.0 & 6.2206 & TRN & \\
\hline CHEMBL3952842 & 1642189 & 5.7212 & 6.2923 & TST & \\
\hline CHEMBL3901965 & 1642189 & 6.0 & 6.4491 & TRN & \\
\hline CHEMBL3900055 & 1642189 & 6.0 & 6.8616 & TRN & \\
\hline CHEMBL3909638 & 1642189 & 6.0 & 6.2451 & TRN & \\
\hline CHEMBL3912311 & 1642189 & 6.0 & 6.57 & TRN & \\
\hline CHEMBL3969846 & 1642189 & 6.3768 & 5.2558 & TST & \\
\hline CHEMBL3917609 & 1642189 & 7.3279 & 6.6447 & TST & \\
\hline CHEMBL3924731 & 1642189 & 5.5686 & 5.0366 & TST & \\
\hline
\end{tabular}




\begin{tabular}{|c|c|c|c|c|c|c|}
\hline \multicolumn{7}{|c|}{ Supplemental Table S2.txt } \\
\hline CHEMBL 3958103 & 1642189 & 6.0 & 6.6472 & TRN & & \\
\hline CHEMBL 3953886 & 1642189 & 8.699 & 6.6654 & TST & & \\
\hline CHEMBL 3927778 & 1642189 & 7.3565 & 7.2393 & TRN & & \\
\hline CHEMBL 3897229 & 1642189 & 6.5528 & 7.1866 & TST & & \\
\hline CHEMBL 3931615 & 1642189 & 6.0 & 6.0355 & TRN & & \\
\hline CHEMBL 3949033 & 1642189 & 5.5229 & 4.4863 & TST & & \\
\hline CHEMBL 3959859 & 1642189 & 5.9208 & 5.6081 & TRN & & \\
\hline CHEMBL 3901667 & 1642189 & 6.0 & 6.3958 & TRN & & \\
\hline CHEMBL 3907553 & 1642189 & 6.0 & 5.6998 & TRN & & \\
\hline CHEMBL 3913344 & 1642189 & 9.1871 & 7.4816 & TRN & & \\
\hline CHEMBL 3920562 & 1642189 & 5.9586 & 5.7548 & TRN & & \\
\hline CHEMBL 3928959 & 1642189 & 6.0 & 5.3513 & TRN & & \\
\hline CHEMBL3931865 & 1642189 & 6.0 & 6.4849 & TRN & & \\
\hline CHEMBL 3910153 & 1642189 & 6.0 & 7.0845 & TRN & & \\
\hline CHEMBL 3918405 & 1642189 & 6.0 & 6.597 & TST & & \\
\hline CHEMBL 3958504 & 1642189 & 6.0 & 6.2678 & TRN & & \\
\hline CHEMBL3966895 & 1642189 & 6.9208 & 5.9429 & TRN & & \\
\hline CHEMBL 3904210 & 1642189 & 7.4202 & 6.8253 & TST & & \\
\hline CHEMBL 3964535 & 1642189 & 8.3979 & 8.1783 & TRN & & \\
\hline CHEMBL 3909117 & 1642189 & 6.0862 & 5.8231 & TRN & & \\
\hline CHEMBL 3920401 & 1642189 & 6.0 & 6.1259 & TRN & & \\
\hline CHEMBL 3955749 & 1642189 & 9.2757 & 6.2999 & TST & & \\
\hline CHEMBL 3890568 & 1642189 & 7.3565 & 6.4695 & TRN & & \\
\hline CHEMBL 3908077 & 1642189 & 6.0 & 7.2056 & TST & & \\
\hline CHEMBL 3235673 & 1337264 & 7.3656 & 7.2973 & TRN & & \\
\hline CHEMBL 3235667 & 1337264 & 7.1527 & 6.8772 & TRN & & \\
\hline CHEMBL 3235634 & 1337264 & 6.6183 & 6.935 & TRN & & \\
\hline CHEMBL 3235640 & 1337264 & 4.9208 & 6.7612 & TST & & \\
\hline CHEMBL 3235644 & 1337264 & 5.0969 & 6.8712 & TST & & \\
\hline CHEMBL 3235635 & 1337264 & 6.907 & 6.9512 & TRN & & \\
\hline CHEMBL 3235645 & 1337264 & 4.9208 & 7.1087 & TST & & \\
\hline CHEMBL 3235270 & 1337264 & 7.3719 & 6.7439 & TRN & & \\
\hline CHEMBL 3235655 & 1337264 & 7.3568 & 7.1967 & TST & & \\
\hline CHEMBL3235646 & 1337264 & 7.2881 & 7.0253 & TRN & & \\
\hline CHEMBL 3235666 & 1337264 & 7.4724 & 7.2141 & TRN & & \\
\hline CHEMBL 3235637 & 1337264 & 6.7582 & 6.8553 & TRN & & \\
\hline CHEMBL3235661 & 1337264 & 7.0519 & 7.194 & TRN & & \\
\hline CHEMBL 3235633 & 1337264 & 6.9862 & 6.915 & TRN & & \\
\hline CHEMBL3235665 & 1337264 & 6.6902 & 7.1987 & TRN & & \\
\hline CHEMBL 3235662 & 1337264 & 7.3045 & 7.2131 & TRN & & \\
\hline CHEMBL 3235660 & 1337264 & 7.0655 & 6.803 & TRN & & \\
\hline CHEMBL 3235647 & 1337264 & 7.12799 & 99999999 & 99 & 7.0437 & TRN \\
\hline CHEMBL3235653 & 1337264 & 7.1178 & 7.2302 & TST & & \\
\hline CHEMBL 3235642 & 1337264 & 7.6916 & 7.1168 & TRN & & \\
\hline CHEMBL 3233039 & 1337264 & 7.249 & 7.3276 & TRN & & \\
\hline CHEMBL 3235274 & 1337264 & 7.0571 & 7.0411 & TRN & & \\
\hline CHEMBL3235638 & 1337264 & 6.5421 & 6.8694 & TRN & & \\
\hline CHEMBL 3235658 & 1337264 & 5.0458 & 6.7606 & TRN & & \\
\hline
\end{tabular}


Supplemental Table S2.txt

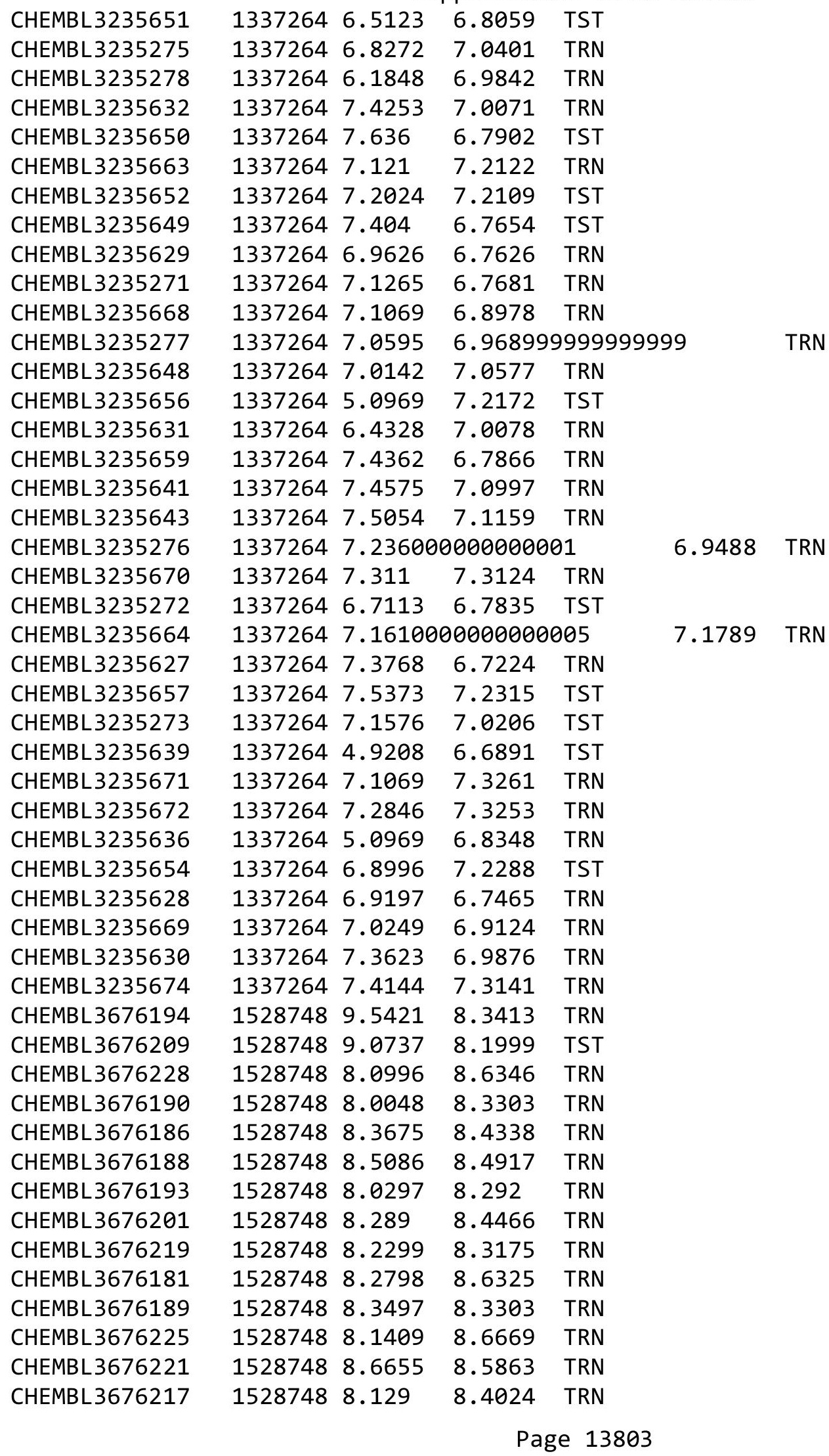


Supplemental Table S2.txt

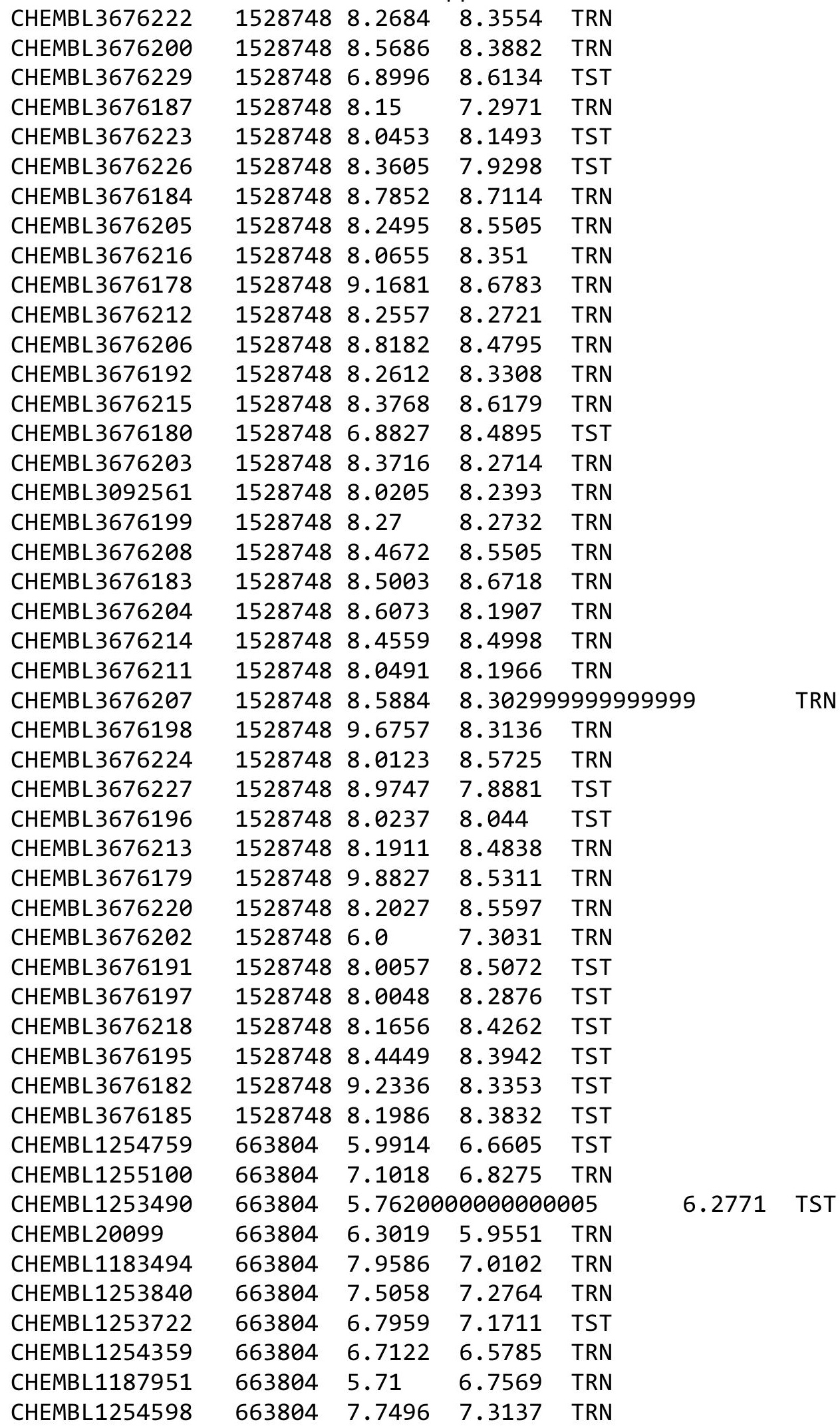

Page 13804 
Supplemental Table S2.txt

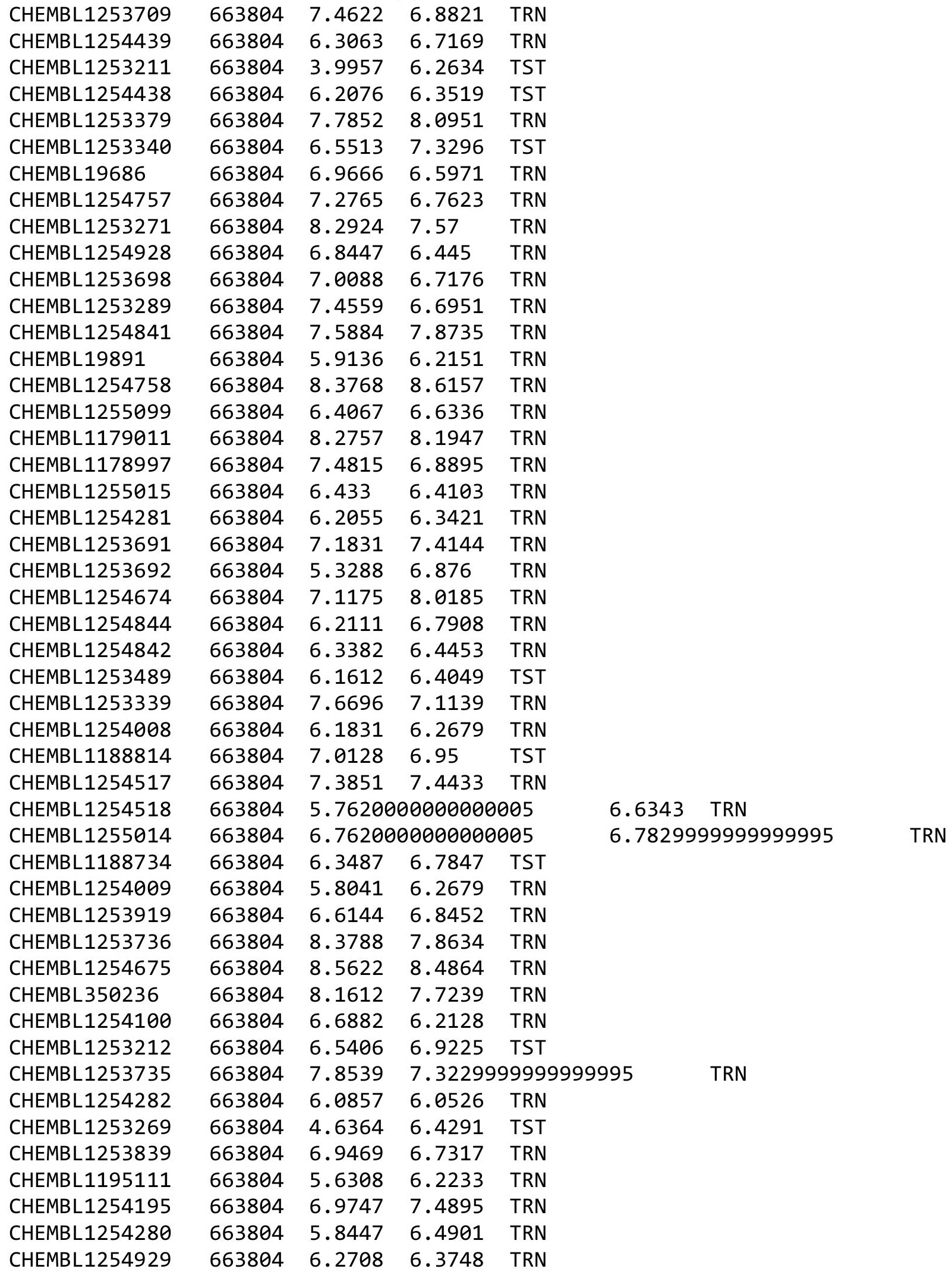

Page 13805 
Supplemental Table S2.txt

\begin{tabular}{|c|c|c|c|c|}
\hline HEMBL & 63804 & 6.5768 & 7.0092 & $\mathrm{TR}$ \\
\hline HEMBL1254596 & 63804 & .4157 & .7134 & \\
\hline HFMBI 12 & 3804 & & & 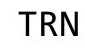 \\
\hline HEMBL118 & 3804 & 768 & 7301 & \\
\hline HEMBL1178924 & 3804 & 861 & .471 & \\
\hline HEMBL1253378 & 63804 & 8.7696 & 3.7716 & \\
\hline HEMBL125 & 53804 & 915 & .7151 & \\
\hline AEMBL125 & 63804 & & 1331 & $\mathrm{RN}$ \\
\hline HEMBL1254196 & 53804 & 5735 & 6.2697 & PN \\
\hline HEMBL1253311 & 53804 & .3925 & . 9613 & ST \\
\hline HEMBL1254360 & 63804 & 6.3747 & 6.7521 & \\
\hline AEMBL1253310 & 63804 & 77 & .4277 & \\
\hline HEMBL125 & 804 & & 6.2567 & \\
\hline HEMBL1254440 & 63804 & 697 & 7.0111 & \\
\hline HEMBL1254597 & 63804 & 53 & 7.1191 & \\
\hline AEMBL20110 & 63804 & $6.8-2 x-3$ & 6.3911 & \\
\hline HEMBL1253 & 53804 & & 3913 & ונד \\
\hline HEMBL125 & 63804 & & 3474 & \\
\hline HEMBL1253 & 63804 & 82 & 6.8818 & \\
\hline HEMBL 1253 & 804 & & 3795 & - \\
\hline HEMBL356e & 804 & 9 & 901 & II \\
\hline HEMBL3 & 19 & & & RN \\
\hline HEMBL4 & 19 & & 634 & \\
\hline HEMBL335069 & 0319 & & 5.4306 & TRN \\
\hline HEMBL3085 & & & & $\ln$ \\
\hline HEMBL 3361 & 19 & & 387 & SI \\
\hline HEMBL3 & 19 & & 379 & RN \\
\hline HEMBL 3 & 19 & 27 & 49 & 「RN \\
\hline HEMBL 284899 & 0319 & & 3927 & IR \\
\hline HEMBL336351 & 19 & & 66 & IRIN \\
\hline HEMBL132 & 9 & & 649 & $\mathrm{RN}$ \\
\hline HEMBL1 & 19 & & 389 & ST \\
\hline HEMBL1 & 19 & & 565 & 「RN \\
\hline HEMBL336117 & 19 & & 537 & ISI \\
\hline HEMBL130597 & 0319 & & 5.3771 & TST \\
\hline HEMBL 24484 & 0319 & & 479 & TRN \\
\hline HFMBI 3 & & 9 & 21 & $\Gamma \mathrm{RN}$ \\
\hline HEMBL1 & & & 323 & TRN \\
\hline HEMBL280074 & 0319 & & 5.0848 & TST \\
\hline HEMBL 3085 & 0319 & & 5.7779 & TST \\
\hline HEMBL336283 & & & 6.4344 & TRN \\
\hline CHEMBL335966 & 0319 & .3768 & & TRN \\
\hline HEMBL133477 & 0319 & & 3.8271 & TRN \\
\hline HEMBL336995 & 0319 & & 4.7106 & $\Gamma R$ \\
\hline CHEMBL 30852 & 50319 & & 4.2367 & Miv \\
\hline CHEMBL3085236 & & & 6.4597 & \\
\hline CHEMBL336537 & 50319 & .6021 & 5.8092 & \\
\hline CHEMBL 308524 & 50319 & 5.0 & 4.9473 & TRN \\
\hline
\end{tabular}

Page 13806 


\begin{tabular}{|c|c|c|c|c|c|}
\hline \multicolumn{6}{|c|}{ Supplemental Table S2.txt } \\
\hline CHEMBL 2112683 & 50319 & 6.0 & 5.9381 & TRN & \\
\hline CHEMBL 26564 & 50319 & 6.699 & 6.5536 & TRN & \\
\hline CHEMBL335938 & 50319 & 4.0458 & 4.3219 & TRN & \\
\hline CHEMBL 3085243 & 50319 & 6.5229 & 6.3656 & TRN & \\
\hline CHEMBL131083 & 50319 & 5.3665 & 5.3988 & TRN & \\
\hline CHEMBL131697 & 50319 & 6.0458 & 5.9738 & TRN & \\
\hline CHEMBL 2112678 & 50319 & 6.0 & 5.87 & TRN & \\
\hline CHEMBL130175 & 50319 & 6.0706 & 5.6122 & TRN & \\
\hline CHEMBL338924 & 50319 & 5.8861 & 5.597 & TRN & \\
\hline CHEMBL 3085248 & 50319 & 6.3665 & 6.1185 & TRN & \\
\hline CHEMBL132687 & 50319 & 5.6021 & 5.5143 & TRN & \\
\hline CHEMBL282193 & 50319 & 7.2218 & 7.063 & TRN & \\
\hline CHEMBL131031 & 50319 & 4.9586 & 5.12799 & 9999999999 & TST \\
\hline CHEMBL335743 & 50319 & 3.585 & 5.3212 & TST & \\
\hline CHEMBL334507 & 50319 & 6.5229 & 6.6227 & TRN & \\
\hline CHEMBL133242 & 50319 & 6.0 & 6.0705 & TRN & \\
\hline CHEMBL23317 & 50319 & 6.699 & 6.6258 & TRN & \\
\hline CHEMBL130161 & 50319 & 5.3768 & 5.4216 & TRN & \\
\hline CHEMBL335852 & 50319 & 5.5528 & 5.5276 & TRN & \\
\hline CHEMBL 3085241 & 50319 & 6.4815 & 6.521 & TRN & \\
\hline CHEMBL 282330 & 50319 & 6.7447 & 6.8032 & TRN & \\
\hline CHEMBL130903 & 50319 & 5.8861 & 6.2712 & TRN & \\
\hline CHEMBL440717 & 50319 & 5.1871 & 5.0366 & TRN & \\
\hline CHEMBL133740 & 50319 & 3.9586 & 5.3373 & TST & \\
\hline CHEMBL130904 & 50319 & 6.0 & 5.9462 & TRN & \\
\hline CHEMBL 3085251 & 50319 & 6.1549 & 5.2291 & TRN & \\
\hline CHEMBL133533 & 50319 & 5.0969 & 5.454 & TRN & \\
\hline CHEMBL130315 & 50319 & 5.0 & 5.1036 & TRN & \\
\hline CHEMBL337411 & 50319 & 6.4559 & 6.5847 & TRN & \\
\hline CHEMBL133461 & 50319 & 6.5229 & 6.3925 & TRN & \\
\hline CHEMBL134080 & 50319 & 6.699 & 6.6423 & TRN & \\
\hline CHEMBL23525 & 50319 & 6.8239 & 6.8992 & TRN & \\
\hline CHEMBL281525 & 50319 & 6.5229 & 6.5316 & TRN & \\
\hline CHEMBL77369 & 50319 & 6.3665 & 6.5122 & TRN & \\
\hline CHEMBL 3085242 & 50319 & 4.3979 & 4.9443 & TRN & \\
\hline CHEMBL 26513 & 50319 & 6.699 & 6.7121 & TRN & \\
\hline CHEMBL132469 & 50319 & 6.4815 & 6.5186 & TRN & \\
\hline CHEMBL336776 & 50319 & 6.301 & 6.4773 & TST & \\
\hline CHEMBL134003 & 50319 & 5.5229 & 5.5826 & TST & \\
\hline CHEMBL52387 & 50319 & 6.1871 & 6.1157 & TST & \\
\hline CHEMBL286491 & 50319 & 6.699 & 6.6092 & TST & \\
\hline CHEMBL337291 & 50319 & 3.8239 & 5.5452 & TST & \\
\hline CHEMBL440163 & 50319 & 5.8861 & 6.137006 & 00000000005 & TST \\
\hline CHEMBL132948 & 50319 & 4.1249 & 4.6171 & TST & \\
\hline CHEMBL 3085245 & 50319 & 6.3665 & 6.0669 & TST & \\
\hline CHEMBL 280623 & 50319 & 6.699 & 6.8528 & TST & \\
\hline CHEMBL134233 & 50319 & 5.5229 & 5.4054 & TST & \\
\hline CHEMBL3673127 & 1528403 & 7.1296 & 6.9974 & TRN & \\
\hline
\end{tabular}


Supplemental Table S2.txt

\begin{tabular}{|c|c|c|c|c|}
\hline CHEMBL 3673159 & 1528403 & 8.0655 & 8.1838 & TST \\
\hline CHEMBL 3673139 & 1528403 & 7.7878 & 8.1462 & TRN \\
\hline CHEMBL3673136 & 1528403 & 6.0 & 6.0593 & TST \\
\hline CHEMBL 3673134 & 1528403 & 7.7799 & 7.6348 & TRN \\
\hline CHEMBL3673141 & 1528403 & 8.585 & 8.6739 & TRN \\
\hline CHEMBL3673162 & 1528403 & 8.0088 & 8.088 & TRN \\
\hline CHEMBL 3673168 & 1528403 & 8.5229 & 8.4806 & TRN \\
\hline CHEMBL 3673174 & 1528403 & 8.6778 & 8.391 & TRN \\
\hline CHEMBL 3673167 & 1528403 & 8.3188 & 8.3901 & TRN \\
\hline CHEMBL3673146 & 1528403 & 8.28399 & 799999999 & 8.2185 \\
\hline CHEMBL3673169 & 1528403 & 8.1938 & 8.2728 & TRN \\
\hline CHEMBL3673155 & 1528403 & 8.2147 & 8.1832 & TRN \\
\hline CHEMBL 3673165 & 1528403 & 7.7235 & 8.0738 & TST \\
\hline CHEMBL 3639720 & 1528403 & 7.9626 & 7.9382 & TRN \\
\hline CHEMBL3673178 & 1528403 & 8.0969 & 8.2384 & TRN \\
\hline CHEMBL 3673170 & 1528403 & 8.1427 & 8.1157 & TRN \\
\hline CHEMBL3673154 & 1528403 & 8.3665 & 8.5088 & TRN \\
\hline CHEMBL 3673161 & 1528403 & 8.4202 & 8.5222 & TRN \\
\hline CHEMBL3673171 & 1528403 & 7.6162 & 7.4588 & TRN \\
\hline CHEMBL3673180 & 1528403 & 5.6353 & 5.701000 & 00000000005 \\
\hline CHEMBL3673173 & 1528403 & 8.0506 & 8.0337 & TRN \\
\hline CHEMBL 3673160 & 1528403 & 8.0315 & 8.5039 & TST \\
\hline CHEMBL 3673130 & 1528403 & 7.9469 & 8.0123 & TRN \\
\hline CHEMBL3673145 & 1528403 & 7.9172 & 7.927000 & 30000000005 \\
\hline CHEMBL 3673175 & 1528403 & 8.3565 & 8.3283 & TST \\
\hline CHEMBL3673163 & 1528403 & 8.301 & 8.1424 & TRN \\
\hline CHEMBL 3673172 & 1528403 & 7.6946 & 7.6176 & TRN \\
\hline CHEMBL 3673153 & 1528403 & 6.4843 & 6.4049 & TRN \\
\hline CHEMBL3673152 & 1528403 & 8.4685 & 8.5924 & TRN \\
\hline CHEMBL 3673142 & 1528403 & 8.1367 & 8.0359 & TRN \\
\hline CHEMBL 3673164 & 1528403 & 8.2291 & 8.2974 & TRN \\
\hline CHEMBL3673156 & 1528403 & 8.6383 & 8.486 & TRN \\
\hline CHEMBL 3673148 & 1528403 & 8.8239 & 8.1446 & TST \\
\hline CHEMBL 3673158 & 1528403 & 8.9208 & 8.0356 & TST \\
\hline CHEMBL 3673140 & 1528403 & 8.9586 & 8.5241 & TRN \\
\hline CHEMBL 3673157 & 1528403 & 8.3768 & 8.6143 & TST \\
\hline CHEMBL 3673129 & 1528403 & 6.0 & 6.5101 & TST \\
\hline CHEMBL 3673151 & 1528403 & 8.1427 & 8.0552 & TRN \\
\hline CHEMBL 3673128 & 1528403 & 6.901 & 6.3212 & TRN \\
\hline CHEMBL 3673132 & 1528403 & 6.0 & 6.3742 & TRN \\
\hline CHEMBL3673147 & 1528403 & 8.4685 & 8.4704 & TST \\
\hline CHEMBL3952992 & 1528403 & 7.6289 & 7.6739 & TRN \\
\hline CHEMBL 3673143 & 1528403 & 8.2757 & 8.3012 & TRN \\
\hline CHEMBL 3673149 & 1528403 & 8.1367 & 8.2049 & TST \\
\hline CHEMBL 3673177 & 1528403 & 6.0 & 6.3097 & TRN \\
\hline CHEMBL 3673150 & 1528403 & 8.1938 & 8.158 & TRN \\
\hline CHEMBL 3673133 & 1528403 & 6.0 & 6.1066 & TRN \\
\hline CHEMBL 3673138 & 1528403 & 8.1079 & 8.4605 & TRN \\
\hline
\end{tabular}

Page 13808 


\begin{tabular}{|c|c|c|c|c|c|c|}
\hline \multicolumn{7}{|c|}{ Supplemental Table S2.txt } \\
\hline CHEMBL 3673179 & 1528403 & 8.0 & 8.0255 & TRN & & \\
\hline CHEMBL3673131 & 1528403 & 7.9957 & 6.8659 & TST & & \\
\hline CHEMBL3673166 & 1528403 & 8.3279 & 7.9236 & TST & & \\
\hline CHEMBL 3673144 & 1528403 & 8.4559 & 8.5311 & TST & & \\
\hline CHEMBL1605879 & 737172 & 4.0917 & 4.2662 & TRN & & \\
\hline CHEMBL1450449 & 737172 & 5.4303 & 4.4081 & TRN & & \\
\hline CHEMBL1531766 & 737172 & 4.3897 & 4.8198 & TRN & & \\
\hline CHEMBL1522037 & 737172 & 6.3536 & 4.2849 & TRN & & \\
\hline CHEMBL1471416 & 737172 & 6.0706 & 5.3889 & TRN & & \\
\hline CHEMBL1488408 & 737172 & 5.6698 & 5.1267 & TRN & & \\
\hline CHEMBL1452981 & 737172 & 4.7875 & 4.3647 & TRN & & \\
\hline CHEMBL1711170 & 737172 & 5.2029 & 4.5223 & TST & & \\
\hline CHEMBL1529855 & 737172 & 5.13700 & 30000000 & 005 & .7166 & TRN \\
\hline CHEMBL1523260 & 737172 & 4.2294 & 4.3791 & TRN & & \\
\hline CHEMBL1430056 & 737172 & 5.4162 & 4.5653 & TRN & & \\
\hline CHEMBL1477082 & 737172 & 5.0085 & 4.7175 & TRN & & \\
\hline CHEMBL1462803 & 737172 & 4.9036 & 4.9816 & TRN & & \\
\hline CHEMBL1484025 & 737172 & 5.2677 & 4.9825 & TRN & & \\
\hline CHEMBL1334250 & 737172 & 5.3261 & 4.8199 & TRN & & \\
\hline CHEMBL1544340 & 737172 & 4.2423 & 4.4753 & TRN & & \\
\hline CHEMBL1384884 & 737172 & 4.4822 & 4.5504 & TRN & & \\
\hline CHEMBL1380642 & 737172 & 4.6061 & 4.9393 & TRN & & \\
\hline CHEMBL1414072 & 737172 & 5.1186 & 4.5047 & TRN & & \\
\hline CHEMBL1432364 & 737172 & 4.4789 & 4.6845 & TRN & & \\
\hline CHEMBL1700660 & 737172 & 4.9042 & 4.6931 & TST & & \\
\hline CHEMBL1502433 & 737172 & 4.5922 & 5.2432 & TST & & \\
\hline CHEMBL1582702 & 737172 & 5.7011 & 4.811 & TRN & & \\
\hline CHEMBL1492532 & 737172 & 4.9864 & 4.3475 & TRN & & \\
\hline CHEMBL1705193 & 737172 & 5.5714 & 5.2049 & TRN & & \\
\hline CHEMBL1411470 & 737172 & 5.5068 & 4.35800 & 00000000005 & & TRN \\
\hline CHEMBL1520624 & 737172 & 4.7927 & 4.7175 & TRN & & \\
\hline CHEMBL1522559 & 737172 & 4.9884 & 4.5314 & TRN & & \\
\hline CHEMBL1731421 & 737172 & 5.2473 & 4.9793 & TST & & \\
\hline CHEMBL1461355 & 737172 & 5.0502 & 4.7657 & TST & & \\
\hline CHEMBL1370351 & 737172 & 5.186 & 4.7388 & TRN & & \\
\hline CHEMBL1610622 & 737172 & 5.4 & 4.9809 & TRN & & \\
\hline CHEMBL1410571 & 737172 & 4.931 & 4.6591 & TRN & & \\
\hline CHEMBL1574471 & 737172 & 4.7428 & 5.28700 & 0000000001 & & TRN \\
\hline CHEMBL1595178 & 737172 & 4.6147 & 5.3103 & TRN & & \\
\hline CHEMBL1397516 & 737172 & 5.147 & 4.4162 & TRN & & \\
\hline CHEMBL1599901 & 737172 & 3.0 & 5.0157 & TRN & & \\
\hline CHEMBL1504742 & 737172 & 5.2013 & 5.3004 & TRN & & \\
\hline CHEMBL1464191 & 737172 & 5.0267 & 5.0977 & TST & & \\
\hline CHEMBL1463986 & 737172 & 3.0 & 4.8561 & TRN & & \\
\hline CHEMBL1545203 & 737172 & 3.0 & 4.2467 & TRN & & \\
\hline CHEMBL1449022 & 737172 & 5.1838 & 4.6409 & TRN & & \\
\hline CHEMBL1301092 & 737172 & 5.1131 & 5.4645 & TRN & & \\
\hline CHEMBL1602342 & 737172 & 5.9566 & 4.9361 & TST & & \\
\hline
\end{tabular}




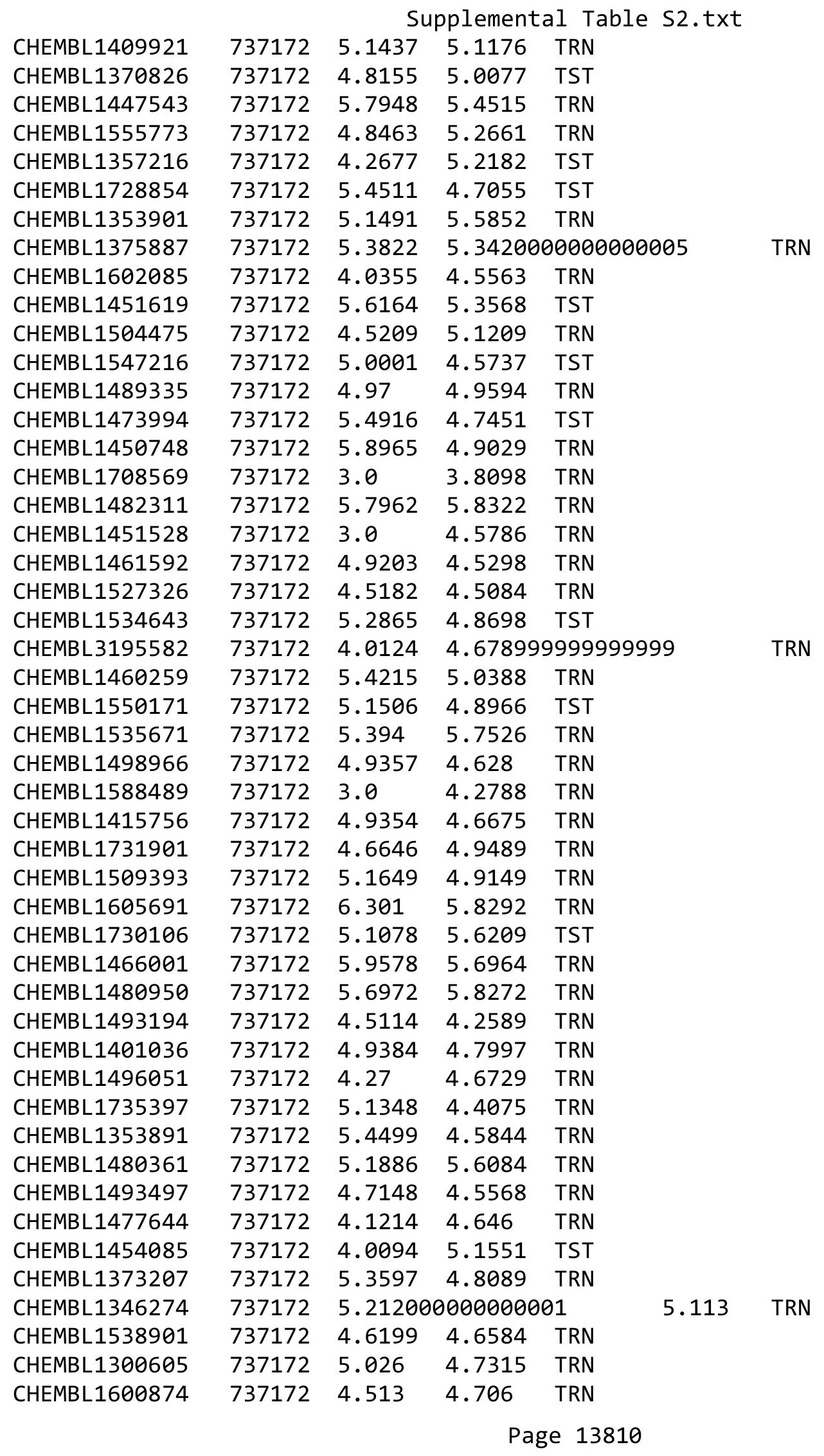


Supplemental Table S2.txt

\begin{tabular}{|c|c|c|c|c|}
\hline HEN & 172 & .1986 & & \\
\hline & 37172 & 4.3401 & 4.4693 & \\
\hline$-x^{-1}$ & .72 & & & \\
\hline AEMBL1 & 172 & & & (N) \\
\hline AEMBL1351777 & 37172 & 007 & 572 & \\
\hline HEMBL1408848 & 37172 & 25 & 6315 & \\
\hline 273 & .72 & & 16 & \\
\hline IEMBL16 & & & & DN \\
\hline AEMBL1550326 & 172 & 268 & & \\
\hline HEMBL1482006 & 37172 & 401 & 344 & \\
\hline HEMBL1407492 & 37172 & 3.0 & .74 & \\
\hline IEMBL13 & 72 & $\partial 9$ & 872 & \\
\hline IEMBL13 & & & & RN \\
\hline HEMBL1730968 & 37172 & 281 & & \\
\hline AEMBL1305969 & 72 & & & \\
\hline AEMBL1383395 & 72 & 11 & & \\
\hline IEMBL135 & 72 & & & \\
\hline HEMBL 319 & 72 & & & \\
\hline AEMBL1528007 & & & & \\
\hline IEMBL142 & & & & \\
\hline HEMBLIS & 2 & & & NIV \\
\hline HEMBL14 & & & & 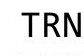 \\
\hline JEMBL14 & 72 & & & \\
\hline AEMBL1518150 & & & & \\
\hline AEMBL13 & & & & TST \\
\hline HEMBL14 & & & & KIV \\
\hline HEMBL15 & & & & RN \\
\hline HFMBI 136 & & & & \\
\hline JEMBL460508 & & & & IV \\
\hline HEMBL1716247 & & & & 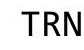 \\
\hline HEMBL159 & & & & RN \\
\hline HEMBL13 & 72 & 6 & & RN \\
\hline HEMBL14 & & & & RN \\
\hline HEMBL1449275 & & & & RIV \\
\hline HEMBL1331685 & 72 & & & TRN \\
\hline HEMBL14 & 2 & 73 & & \\
\hline HFMRI 15 & 2 & & & RN \\
\hline HEMBL171: & & & & RN \\
\hline HEMBL1532304 & 72 & & & TRN \\
\hline AEMBL1450564 & & & & TRN \\
\hline HEMBL1518307 & & 98 & & \\
\hline CHEMBL589207 & & & & TRN \\
\hline HEMBL1401707 & 72 & & 406 & TST \\
\hline HEMBL1302932 & 72 & 383 & 5267 & TRN \\
\hline MBL13 & & & & \\
\hline HEMBL154 & & & & \\
\hline CHEMBL3199709 & 72 & 4.9065 & .7666 & \\
\hline CHEMBL1568447 & 737172 & 5.171 & 4.9406 & \\
\hline
\end{tabular}

Page 13811 
Supplemental Table S2.txt

\begin{tabular}{|c|c|c|c|c|c|c|}
\hline CHEMBL1577174 & 737172 & 5.3653 & 4.7244 & TRN & & \\
\hline CHEMBL1374009 & 737172 & 4.0113 & 4.4877 & TRN & & \\
\hline CHEMBL3214587 & 737172 & 5.2241 & 5.1968 & TST & & \\
\hline CHEMBL1366230 & 737172 & 5.5772 & 5.3073 & TST & & \\
\hline CHEMBL1481107 & 737172 & 5.33899 & 9999999 & 995 & 4.8715 & I RIN \\
\hline CHEMBL1718463 & 737172 & 5.0263 & 5.3391 & TRN & & \\
\hline CHEMBL1348321 & 737172 & 3.0 & 4.6899 & TRN & & \\
\hline CHEMBL1559946 & 737172 & 4.3468 & 5.5299 & TRN & & \\
\hline CHEMBL1557592 & 737172 & 3.0 & 4.1894 & TRN & & \\
\hline CHEMBL1523811 & 737172 & 6.1739 & 4.4418 & TRN & & \\
\hline CHEMBL1382203 & 737172 & 4.9929 & 4.7022 & TRN & & \\
\hline CHEMBL1497340 & 737172 & 5.721 & 4.6968 & TST & & \\
\hline CHEMBL1327974 & 737172 & 4.3924 & 4.4208 & TRN & & \\
\hline CHEMBL1360488 & 737172 & 4.9657 & 4.9906 & TST & & \\
\hline CHEMBL1594939 & 737172 & 4.9115 & 4.5592 & TRN & & \\
\hline CHEMBL1565084 & 737172 & 4.5932 & 4.6358 & TRN & & \\
\hline CHEMBL1602539 & 737172 & 5.5038 & 4.9751 & TRN & & \\
\hline CHEMBL1508377 & 737172 & 3.0 & 4.6032 & TRN & & \\
\hline CHEMBL1603347 & 737172 & 5.9059 & 4.6146 & TRN & & \\
\hline CHEMBL1485691 & 737172 & 4.9562 & 4.4247 & TRN & & \\
\hline CHEMBL1735271 & 737172 & 4.1035 & 5.0729 & TST & & \\
\hline CHEMBL1543434 & 737172 & 5.6944 & 4.4789 & TST & & \\
\hline CHEMBL1721119 & 737172 & 4.5201 & 5.0813 & TST & & \\
\hline CHEMBL1495627 & 737172 & 4.8966 & 4.894 & TST & & \\
\hline CHEMBL1700426 & 737172 & 4.8702 & 5.0056 & TST & & \\
\hline CHEMBL1517388 & 737172 & 5.5619 & 5.2257 & TST & & \\
\hline CHEMBL1559383 & 737172 & 5.06 & 4.525 & TST & & \\
\hline CHEMBL1420574 & 737172 & 4.8831 & 5.0671 & TST & & \\
\hline CHEMBL1496322 & 737172 & 5.0433 & 4.9717 & TST & & \\
\hline CHEMBL1439648 & 737172 & 4.902 & 4.7559 & TST & & \\
\hline CHEMBL3199572 & 737172 & 5.0121 & 5.0113 & TST & & \\
\hline CHEMBL1583806 & 737172 & 5.3309 & 4.9145 & TST & & \\
\hline CHEMBL1505956 & 737172 & 4.4226 & 4.9612 & TST & & \\
\hline CHEMBL1430035 & 737172 & 4.2777 & 5.1297 & TST & & \\
\hline CHEMBL1698921 & 737172 & 3.0 & 4.3002 & TST & & \\
\hline CHEMBL1382054 & 737172 & 5.5832 & 4.9111 & TST & & \\
\hline CHEMBL1537264 & 737172 & 4.6015 & 4.8135 & TST & & \\
\hline CHEMBL1729206 & 737172 & 5.7066 & 5.1718 & TST & & \\
\hline CHEMBL1364058 & 737172 & 4.3356 & 5.227 & TST & & \\
\hline CHEMBL1588339 & 954327 & 5.1179 & 4.3457 & TRN & & \\
\hline CHEMBL1567687 & 954327 & \multicolumn{3}{|c|}{3.5239999999999996} & 4.1322 & Tार \\
\hline CHEMBL 2356071 & 954327 & 3.5241 & 3.7441 & TST & & \\
\hline CHEMBL1967046 & 954327 & 4.8952 & 4.9571 & TRN & & \\
\hline CHEMBL1490171 & 954327 & 4.7547 & 4.1356 & TRN & & \\
\hline CHEMBL 2362138 & 954327 & 3.5245 & 4.4607 & TST & & \\
\hline CHEMBL 3193221 & 954327 & 4.6055 & 4.0295 & TRN & & \\
\hline CHEMBL1405717 & 954327 & 4.5368 & 4.5433 & TRN & & \\
\hline CHEMBL1562723 & 954327 & 4.9352 & 4.7879 & TRN & & \\
\hline
\end{tabular}

Page 13812 
Supplemental Table S2.txt

\begin{tabular}{|c|c|c|c|c|c|c|}
\hline CHEMBL1368073 & 954327 & 4.6805 & 4.2126 & TRN & & \\
\hline CHEMBL1550584 & 954327 & 4.7906 & 4.7222 & TRN & & \\
\hline CHEMBL1465939 & 954327 & 5.0153 & 4.5083 & TRN & & \\
\hline CHEMBL1324111 & 954327 & 3.5241 & 4.4857 & TST & & \\
\hline CHEMBL1900893 & 954327 & 5.2101 & 4.2583 & TRN & & \\
\hline CHEMBL1421172 & 954327 & 5.5146 & 4.7332 & TRN & & \\
\hline CHEMBL1516335 & 954327 & 4.8252 & 4.8038 & TRN & & \\
\hline CHEMBL1326167 & 954327 & 4.0012 & 4.1126 & TRN & & \\
\hline CHEMBL1994935 & 954327 & 4.9118 & 4.8005 & TRN & & \\
\hline CHEMBL1571530 & 954327 & 4.5759 & 4.6342 & TRN & & \\
\hline CHEMBL1489769 & 954327 & 3.5242 & 4.0071 & TST & & \\
\hline CHEMBL1334272 & 954327 & 5.1126 & 4.6676 & TRN & & \\
\hline CHEMBL1358236 & 954327 & 4.9291 & 4.6241 & TRN & & \\
\hline CHEMBL1422340 & 954327 & 3.5244 & 4.3783 & TST & & \\
\hline CHEMBL1470869 & 954327 & 4.8375 & 4.1616 & TRN & & \\
\hline CHEMBL1314787 & 954327 & 5.1375 & 5.2682 & TRN & & \\
\hline CHEMBL1555805 & 954327 & 4.745 & 4.7912 & TRN & & \\
\hline CHEMBL1482554 & 954327 & 4.82600 & 00000000 & 05 & 4.5503 & TRN \\
\hline CHEMBL1869020 & 954327 & 3.5241 & 3.9903 & TRN & & \\
\hline CHEMBL1546959 & 954327 & 4.7337 & 4.0768 & TRN & & \\
\hline CHEMBL 1428078 & 954327 & 4.813 & 5.1136 & TRN & & \\
\hline CHEMBL1516840 & 954327 & 4.0013 & 4.1565 & TRN & & \\
\hline CHEMBL1506414 & 954327 & 4.72199 & 99999999 & 95 & 4.4589 & TRN \\
\hline CHEMBL1413495 & 954327 & 3.5241 & 4.5386 & TRN & & \\
\hline CHEMBL1474580 & 954327 & 5.4026 & 4.7031 & TRN & & \\
\hline CHEMBL 21241 & 954327 & 3.5243 & 3.5512 & TST & & \\
\hline CHEMBL 3193759 & 954327 & 4.9074 & 4.7572 & TRN & & \\
\hline CHEMBL1462153 & 954327 & 4.9395 & 4.5022 & TRN & & \\
\hline CHEMBL1340150 & 954327 & 4.6879 & 4.5297 & TRN & & \\
\hline CHEMBL1439968 & 954327 & 3.5242 & 4.765 & TRN & & \\
\hline CHEMBL1457077 & 954327 & 4.8697 & 4.9201 & TRN & & \\
\hline CHEMBL1341012 & 954327 & 5.2455 & 4.5864 & TRN & & \\
\hline CHEMBL1381149 & 954327 & 4.8326 & 5.1902 & TRN & & \\
\hline CHEMBL1380674 & 954327 & 4.8136 & 4.2729 & TRN & & \\
\hline CHEMBL1451454 & 954327 & 3.5242 & 4.6044 & TRN & & \\
\hline CHEMBL164 & 954327 & 3.5243 & 4.5961 & TST & & \\
\hline CHEMBL1461925 & 954327 & 5.0428 & 4.5204 & TRN & & \\
\hline CHEMBL1606907 & 954327 & 5.2718 & 5.34 & TRN & & \\
\hline CHEMBL1360190 & 954327 & 3.5243 & 4.1504 & TRN & & \\
\hline CHEMBL 3214350 & 954327 & \multicolumn{3}{|c|}{4.8469999999999995} & 4.9746 & TRN \\
\hline CHEMBL1524916 & 954327 & 4.7723 & 4.269 & TST & & \\
\hline CHEMBL 3195767 & 954327 & 4.8452 & 4.3467 & TST & & \\
\hline CHEMBL1396511 & 954327 & 4.7131 & 4.3357 & TRN & & \\
\hline CHEMBL1518644 & 954327 & 3.5242 & 4.0875 & TST & & \\
\hline CHEMBL1458315 & 954327 & 4.6891 & 4.4322 & TRN & & \\
\hline CHEMBL1580373 & 954327 & 4.9878 & 4.433 & TRN & & \\
\hline CHEMBL1589442 & 954327 & 3.5241 & 3.9752 & TRN & & \\
\hline CHEMBL1323994 & 954327 & 4.6831 & 4.5108 & TRN & & \\
\hline
\end{tabular}


Supplemental Table S2.txt

\begin{tabular}{|c|c|c|c|c|c|}
\hline CHEMBL1548963 & 954327 & 5.1995 & 4.6739 & TRN & \\
\hline CHEMBL1589013 & 954327 & 5.3953 & 4.9147 & TRN & \\
\hline CHEMBL1448393 & 954327 & 4.5861 & 4.4254 & TRN & \\
\hline CHEMBL1504461 & 954327 & 4.7975 & 5.0119 & TRN & \\
\hline CHEMBL1324715 & 954327 & 4.7872 & 4.6354 & TST & \\
\hline CHEMBL1380196 & 954327 & 4.7051 & 4.4196 & TRN & \\
\hline CHEMBL1528330 & 954327 & 4.7892 & 5.0149 & TRN & \\
\hline CHEMBL1896925 & 954327 & 3.5241 & 3.9021 & TRN & \\
\hline CHEMBL1529673 & 954327 & 3.5242 & 4.0556 & TRN & \\
\hline CHEMBL1999595 & 954327 & 4.7752 & 4.2512 & TRN & \\
\hline CHEMBL1895167 & 954327 & 4.7752 & 4.1727 & TRN & \\
\hline CHEMBL1489601 & 954327 & 4.9142 & 4.918 & TRN & \\
\hline CHEMBL1420007 & 954327 & 3.5243 & 3.7637 & TRN & \\
\hline CHEMBL1570929 & 954327 & 3.5243 & 3.8645 & TRN & \\
\hline CHEMBL 3194783 & 954327 & 4.8469 & 4.5446 & TRN & \\
\hline CHEMBL1465122 & 954327 & 5.2712 & 4.7095 & TRN & \\
\hline CHEMBL1343032 & 954327 & 3.5242 & 4.1867 & TRN & \\
\hline CHEMBL1310138 & 954327 & 5.0325 & 3.9308 & TST & \\
\hline CHEMBL1541862 & 954327 & 4.8467 & 4.8829 & TRN & \\
\hline CHEMBL1435818 & 954327 & 3.5237 & 3.9969 & TST & \\
\hline CHEMBL1877049 & 954327 & 3.5244 & 4.0122 & TRN & \\
\hline CHEMBL1311518 & 954327 & 3.5241 & 4.1676 & TRN & \\
\hline CHEMBL1490545 & 954327 & 3.5242 & 4.3015 & TRN & \\
\hline CHEMBL1581920 & 954327 & 3.5243 & 4.5137 & TRN & \\
\hline CHEMBL1409340 & 954327 & 4.8301 & 4.7201 & TRN & \\
\hline CHEMBL1452701 & 954327 & 3.5242 & 3.8847 & TRN & \\
\hline CHEMBL1323245 & 954327 & 5.2906 & 5.2195 & TRN & \\
\hline CHEMBL 2354667 & 954327 & 4.5674 & 4.2621 & TRN & \\
\hline CHEMBL1461513 & 954327 & 5.114 & 4.8829 & TRN & \\
\hline CHEMBL1342736 & 954327 & 4.8496 & 4.2068 & TRN & \\
\hline CHEMBL1492326 & 954327 & 3.5244 & 3.9587 & TRN & \\
\hline CHEMBL3198976 & 954327 & 5.0366 & 4.5752 & TST & \\
\hline CHEMBL1383141 & 954327 & 4.6578 & 4.9672 & TRN & \\
\hline CHEMBL1581436 & 954327 & 4.7474 & 4.3706 & TRN & \\
\hline CHEMBL1595140 & 954327 & 5.1461 & 4.4093 & TRN & \\
\hline CHEMBL1419772 & 954327 & 4.73 & 3.9654 & TST & \\
\hline CHEMBL1447162 & 954327 & 3.5242 & 4.2621 & TST & \\
\hline CHEMBL1348659 & 954327 & 4.5671 & 4.2424 & TRN & \\
\hline CHEMBL1447211 & 954327 & 4.7959 & 5.091 & TRN & \\
\hline CHEMBL1319340 & 954327 & 4.8934 & 4.6254 & TRN & \\
\hline CHEMBL1573092 & 954327 & 4.8781 & 4.3559 & TRN & \\
\hline CHEMBL1376190 & 954327 & 4.81800 & 000000000 & 305 & 4.7905 \\
\hline CHEMBL1505221 & 954327 & 4.7998 & 4.2537 & TST & \\
\hline CHEMBL1363632 & 954327 & 4.7473 & 4.4458 & TRN & \\
\hline CHEMBL3392035 & 954327 & 3.5241 & 4.1777 & TRN & \\
\hline CHEMBL1354074 & 954327 & 3.5243 & 3.6161 & TRN & \\
\hline CHEMBL1508128 & 954327 & 5.2598 & 4.9504 & TST & \\
\hline CHEMBL1555870 & 954327 & 5.1527 & 4.3422 & TRN & \\
\hline
\end{tabular}

Page 13814 
Supplemental Table S2.txt

\begin{tabular}{|c|c|c|c|c|}
\hline HEM & 327 & 242 & & \\
\hline & & .0789 & & \\
\hline AFMRI 196538 & & & & \\
\hline AEMBL15 & & 361 & & \\
\hline AEMBL1301353 & 54327 & 3646 & .7609 & \\
\hline HEMBL1470268 & 27 & 038 & 4558 & \\
\hline HEMBL137 & & & & \\
\hline HEMBL136 & & & 334 & DN \\
\hline HEMBL1310601 & 27 & 5468 & 9781 & \\
\hline HEMBL1892220 & 27 & 4.8863 & 4816 & \\
\hline HEMBL141 & & & 3215 & \\
\hline IEMBL15 & & & 897 & \\
\hline JEMBL13 & & & 398 & \\
\hline HEMBL1482957 & 27 & 351 & 0773 & \\
\hline AEMBL1972621 & & & & \\
\hline HEMBL 14 & & & 7215 & RN \\
\hline HEMBL13 & & & 896 & Niv \\
\hline HEMBL13 & & & 128 & $\mathrm{RN}$ \\
\hline HEMBL188 & & & 307 & \\
\hline HEMBL152 & & & 5376 & I KIV \\
\hline HEMBL1\& & & & 521 & RI \\
\hline AEMBL1: & & & 866 & TIV \\
\hline AEMBL13 & & & 271 & $\mathrm{RN}$ \\
\hline HEMBL132 & & & 1057 & \\
\hline HEMBL160 & & 1 & & IRN \\
\hline HEMBL13 & & & & RN \\
\hline HEMBL 1 & & & 69 & RN \\
\hline HEMP 1 & & & 272 & CRN \\
\hline HEMBL159 & & & & IK \\
\hline HEMBL170 & & & 507 & RN \\
\hline HEMBL14 & & & 637 & TRN \\
\hline HFM & & & & 「RN \\
\hline 1 & & & & RN \\
\hline HEMBL186 & & & 524 & 「RN \\
\hline HEMBL1321 & & & 015 & RN \\
\hline AEMPI 13 & & & 316 & TRN \\
\hline 10 & & & & ГRN \\
\hline HEMBL135 & & & 7804 & TRN \\
\hline HEMBL138 & & & 012 & Th \\
\hline CMIDL & & & 952 & 11 \\
\hline HFMRI 154 & & & 901 & 「RN \\
\hline & & & 37 & ו \\
\hline HEMBL1534155 & & & 0652 & TRN \\
\hline HEMBL169 & & & & TR \\
\hline CHEMPI 1287 & & & & \\
\hline HEMBL1701465 & & & .1742 & \\
\hline CHEMBL1472404 & & 4. & .3438 & RN \\
\hline LHEMBL148959e & 954327 & 4.5821 & 4.39 & 13 \\
\hline
\end{tabular}

Page 13815 
Supplemental Table S2.txt

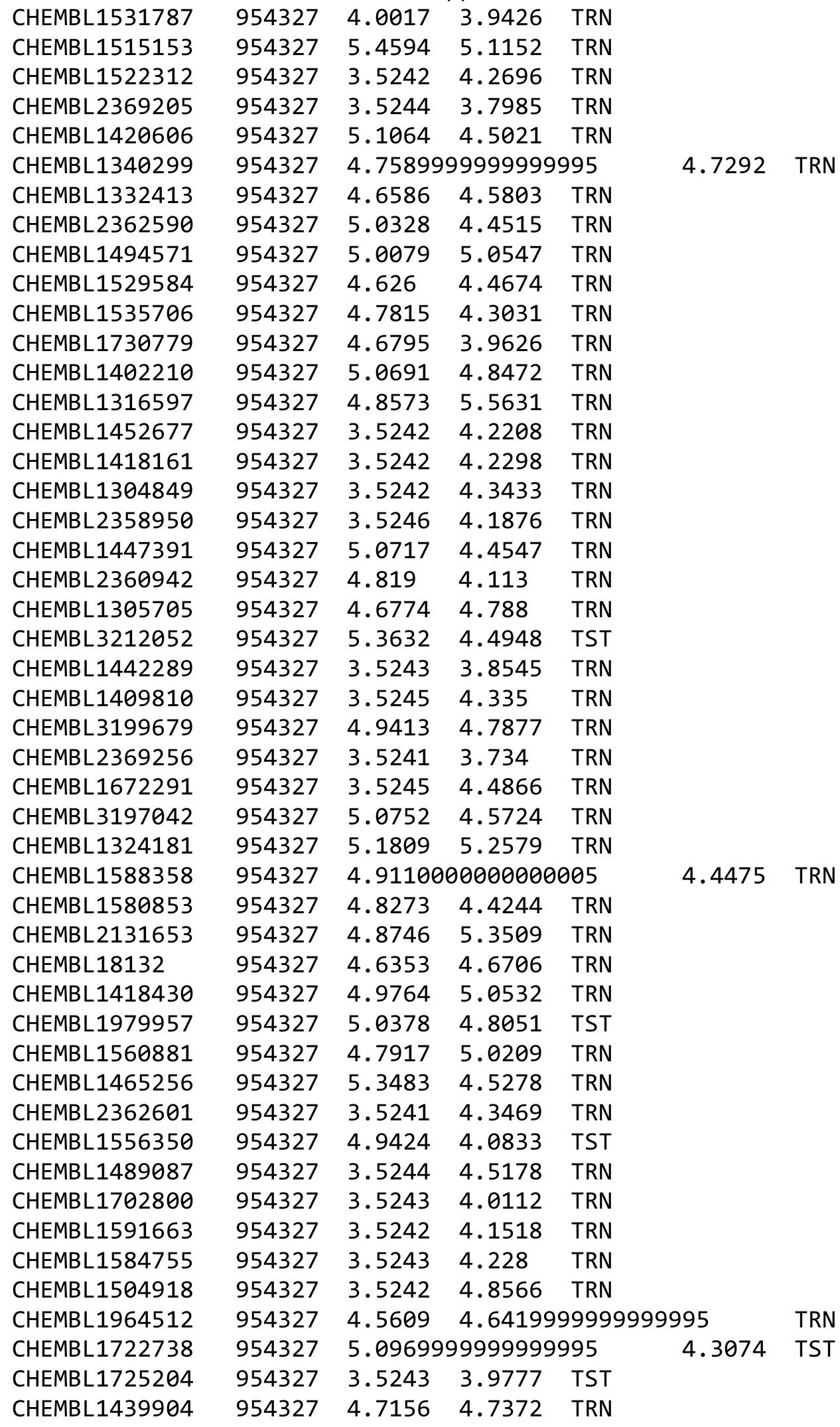

Page 13816 


\begin{tabular}{|c|c|c|c|c|c|}
\hline \multicolumn{6}{|c|}{ Supplemental Table S2.txt } \\
\hline CHEMBL1887642 & 954327 & 5.034 & 4.5199 & TRN & \\
\hline CHEMBL1478540 & 954327 & 4.9001 & 4.4817 & TRN & \\
\hline CHEMBL1878162 & 954327 & 4.7711 & 4.8107 & TRN & \\
\hline CHEMBL1587708 & 954327 & 4.6918 & 4.9687 & TRN & \\
\hline CHEMBL1704279 & 954327 & 4.7181 & 4.5864 & TRN & \\
\hline CHEMBL1730412 & 954327 & 4.7674 & 4.5918 & TRN & \\
\hline CHEMBL1599723 & 954327 & 4.6748 & 5.2488 & TST & \\
\hline CHEMBL1544896 & 954327 & 4.6779 & 4.92399 & 99999999995 & TST \\
\hline CHEMBL2356353 & 954327 & 4.7638 & 4.3443 & TST & \\
\hline CHEMBL1419357 & 954327 & 3.5241 & 5.2126 & TST & \\
\hline CHEMBL1333826 & 954327 & 4.7939 & 4.7406 & TST & \\
\hline CHEMBL1879517 & 954327 & 4.9401 & 5.0917 & TST & \\
\hline CHEMBL1410122 & 954327 & 4.7566 & 4.3885 & TST & \\
\hline CHEMBL1350332 & 954327 & 3.5242 & 4.3889 & TST & \\
\hline CHEMBL 3207440 & 954327 & 4.0013 & 4.1881 & TST & \\
\hline CHEMBL1318881 & 954327 & 4.6181 & 4.5456 & TST & \\
\hline CHEMBL1579664 & 954327 & 4.0014 & 4.1716 & TST & \\
\hline CHEMBL1459951 & 954327 & 5.0837 & 5.1142 & TST & \\
\hline CHEMBL1301386 & 954327 & 5.1309 & 4.8487 & TST & \\
\hline CHEMBL1480275 & 954327 & 4.6089 & 3.9813 & TST & \\
\hline CHEMBL1361896 & 954327 & 5.0278 & 5.1984 & TST & \\
\hline CHEMBL1490685 & 954327 & 5.0298 & 4.5507 & TST & \\
\hline CHEMBL548458 & 954327 & 4.5468 & 4.8675 & TST & \\
\hline CHEMBL1699944 & 954327 & 4.974 & 4.2026 & TST & \\
\hline CHEMBL1361817 & 954327 & 3.5243 & 4.0325 & TST & \\
\hline CHEMBL1893774 & 954327 & 3.5242 & 3.7854 & TST & \\
\hline CHEMBL 2145433 & 954327 & 5.5178 & 4.4078 & TST & \\
\hline CHEMBL3191758 & 954327 & 4.9711 & 4.9422 & TST & \\
\hline CHEMBL1328027 & 954327 & 4.6576 & 4.3971 & TST & \\
\hline CHEMBL1429917 & 954327 & 4.7405 & 4.963 & TST & \\
\hline CHEMBL1484330 & 954327 & 4.9702 & 4.7858 & TST & \\
\hline CHEMBL1702349 & 954327 & 4.6609 & 4.3495 & TST & \\
\hline CHEMBL 2002634 & 954327 & 4.7808 & 4.7376 & TST & \\
\hline CHEMBL1449712 & 954327 & 3.5241 & 4.511 & TST & \\
\hline CHEMBL1486418 & 954327 & 5.4819 & 4.9012 & TST & \\
\hline CHEMBL1714492 & 954327 & 4.935 & 4.2385 & TST & \\
\hline CHEMBL1482002 & 954327 & 4.537 & 4.2959 & TST & \\
\hline CHEMBL1884664 & 954327 & 4.8206 & 4.0586 & TST & \\
\hline CHEMBL1388892 & 954327 & 5.2245 & 4.4771 & TST & \\
\hline CHEMBL1731730 & 954327 & 3.5245 & 4.1819 & TST & \\
\hline CHEMBL1402902 & 954327 & 5.3683 & 5.0176 & TST & \\
\hline CHEMBL3980409 & 1640414 & 6.6055 & 6.3724 & TST & \\
\hline CHEMBL3972356 & 1640414 & 7.5086 & 6.4232 & TRN & \\
\hline CHEMBL3968093 & 1640414 & 6.3045 & 6.1884 & TRN & \\
\hline CHEMBL 3934981 & 1640414 & 6.3107 & 6.5718 & TRN & \\
\hline CHEMBL 3944668 & 1640414 & 6.1772 & 6.3808 & TRN & \\
\hline CHEMBL3956738 & 1640414 & 7.0915 & 7.1923 & TRN & \\
\hline CHEMBL3970345 & 1640414 & 7.7696 & 6.6244 & TRN & \\
\hline
\end{tabular}


Supplemental Table S2.txt

\begin{tabular}{|c|c|c|c|c|c|}
\hline CHEMBL 3891214 & 1640414 & 7.6383 & 6.4348 & TRN & \\
\hline CHEMBL 3966507 & 1640414 & 7.699 & 6.5169 & TRN & \\
\hline CHEMBL3934665 & 1640414 & 5.4915 & 6.7311 & TRN & \\
\hline CHEMBL3973986 & 1640414 & 7.8539 & 7.246 & TRN & \\
\hline CHEMBL 3906671 & 1640414 & 7.301 & 7.1001 & TRN & \\
\hline CHEMBL 3893175 & 1640414 & 7.2676 & 6.4546 & TRN & \\
\hline CHEMBL3939551 & 1640414 & 5.5265 & 5.3579 & TRN & \\
\hline CHEMBL3930340 & 1640414 & 6.1931 & 6.3935 & TRN & \\
\hline CHEMBL3897191 & 1640414 & 4.1765 & 4.7839 & TRN & \\
\hline CHEMBL 3972277 & 1640414 & 4.0 & 6.7224 & TRN & \\
\hline CHEMBL3906416 & 1640414 & 5.6979 & 5.9256 & TRN & \\
\hline CHEMBL 3940095 & 1640414 & 5.5207 & 6.0931 & TRN & \\
\hline CHEMBL3891999 & 1640414 & 5.4808 & 4.7265 & TRN & \\
\hline CHEMBL3954355 & 1640414 & 6.0 & 6.9738 & TRN & \\
\hline CHEMBL 3909685 & 1640414 & 6.0535 & 5.7895 & TRN & \\
\hline CHEMBL3983355 & 1640414 & 6.9101 & 6.0118 & TRN & \\
\hline CHEMBL3937316 & 1640414 & 7.7959 & 6.4593 & TRN & \\
\hline CHEMBL3928934 & 1640414 & 5.7708 & 5.6323 & TRN & \\
\hline CHEMBL 3960947 & 1640414 & 6.4559 & 6.7798 & TRN & \\
\hline CHEMBL 3890829 & 1640414 & 7.6778 & 6.5045 & TST & \\
\hline CHEMBL3912536 & 1640414 & 8.1192 & 6.58899 & 99999999995 & TRN \\
\hline CHEMBL3933896 & 1640414 & 6.4089 & 6.2494 & TST & \\
\hline CHEMBL 3956732 & 1640414 & 8.1739 & 6.9639 & TRN & \\
\hline CHEMBL3947848 & 1640414 & 7.3665 & 7.0421 & TRN & \\
\hline CHEMBL 3900280 & 1640414 & 7.1487 & 6.3743 & TRN & \\
\hline CHEMBL3929762 & 1640414 & 6.4056 & 6.0713 & TRN & \\
\hline CHEMBL 3942742 & 1640414 & 7.284 & 6.7584 & TST & \\
\hline CHEMBL 3972785 & 1640414 & 6.9872 & 6.376 & TRN & \\
\hline CHEMBL3919775 & 1640414 & 6.2381 & 5.1809 & TRN & \\
\hline CHEMBL 3906137 & 1640414 & 6.2823 & 5.8078 & TRN & \\
\hline CHEMBL 3898862 & 1640414 & 6.0 & 6.3352 & TRN & \\
\hline CHEMBL 3938295 & 1640414 & 5.6055 & 6.2522 & TRN & \\
\hline CHEMBL3969023 & 1640414 & 7.8239 & 6.9479 & TRN & \\
\hline CHEMBL3914656 & 1640414 & 6.6596 & 6.2397 & TRN & \\
\hline CHEMBL 3900441 & 1640414 & 6.0 & 6.2813 & TRN & \\
\hline CHEMBL3938223 & 1640414 & 7.1871 & 7.266 & TRN & \\
\hline CHEMBL 3980337 & 1640414 & 4.002 & 5.2496 & TST & \\
\hline CHEMBL 3948328 & 1640414 & 4.2222 & 4.9389 & TRN & \\
\hline CHEMBL 3972795 & 1640414 & 4.265 & 5.2308 & TRN & \\
\hline CHEMBL3966913 & 1640414 & 8.2518 & 7.5089 & TRN & \\
\hline CHEMBL3924934 & 1640414 & 5.706 & 6.5451 & TST & \\
\hline CHEMBL 3894319 & 1640414 & 6.2958 & 7.4217 & TRN & \\
\hline CHEMBL 3955620 & 1640414 & 6.065 & 6.973 & TRN & \\
\hline CHEMBL3942301 & 1640414 & 7.2007 & 7.0966 & TRN & \\
\hline CHEMBL3933286 & 1640414 & 5.4609 & 6.2799 & TRN & \\
\hline CHEMBL3965055 & 1640414 & 8.0458 & 7.195 & TRN & \\
\hline CHEMBL 3965863 & 1640414 & 5.8827 & 5.534 & TRN & \\
\hline CHEMBL 3912329 & 1640414 & 7.2596 & 6.3535 & TST & \\
\hline
\end{tabular}


Supplemental Table S2.txt

\begin{tabular}{|c|c|c|c|c|c|}
\hline CHEMBL 3930010 & 1640414 & 6.8761 & 6.4737 & TST & \\
\hline CHEMBL 3937302 & 1640414 & 6.4895 & 6.3121 & TRN & \\
\hline CHEMBL3895459 & 1640414 & 5.1744 & 7.0713 & TRN & \\
\hline CHEMBL 3941316 & 1640414 & 5.9935 & 6.6789 & TRN & \\
\hline CHEMBL 3985394 & 1640414 & 6.3809 & 6.393 & TRN & \\
\hline CHEMBL 3957878 & 1640414 & 7.8239 & 6.5453 & TRN & \\
\hline CHEMBL 3934119 & 1640414 & 5.9318 & 5.6211 & TRN & \\
\hline CHEMBL3959931 & 1640414 & 5.5567 & 6.2138 & TST & \\
\hline CHEMBL 3907024 & 1640414 & 5.8342 & 6.2023 & TRN & \\
\hline CHEMBL 3956984 & 1640414 & 5.0945 & 6.6337 & TRN & \\
\hline CHEMBL 3978205 & 1640414 & 5.8196 & 5.9447 & TST & \\
\hline CHEMBL 3894608 & 1640414 & 4.0752 & 6.004 & TRN & \\
\hline CHEMBL 3927943 & 1640414 & 5.9062 & 6.407 & TRN & \\
\hline CHEMBL 3897529 & 1640414 & 6.0 & 6.262000 & 30000000005 & TST \\
\hline CHEMBL 3889725 & 1640414 & 5.6117 & 5.4686 & TST & \\
\hline CHEMBL 3954192 & 1640414 & 6.82100 & 000000000 & 6.4254 & TST \\
\hline CHEMBL 3949105 & 1640414 & 8.3372 & 7.3195 & TRN & \\
\hline CHEMBL 3948202 & 1640414 & 4.2426 & 5.4097 & TST & \\
\hline CHEMBL 3921488 & 1640414 & 6.0894 & 5.1601 & TST & \\
\hline CHEMBL 3919123 & 1640414 & 6.5654 & 6.3379 & TRN & \\
\hline CHEMBL 3963084 & 1640414 & 6.0 & 6.6306 & TST & \\
\hline CHEMBL 3972434 & 1640414 & 7.0458 & 6.5601 & TRN & \\
\hline CHEMBL 3897432 & 1640414 & 5.58 & 6.2768 & TRN & \\
\hline CHEMBL3910531 & 1640414 & 5.6819 & 5.4578 & TST & \\
\hline CHEMBL 3940001 & 1640414 & 5.7282 & 5.9031 & TRN & \\
\hline CHEMBL 3953562 & 1640414 & 7.0044 & 6.77 & TRN & \\
\hline CHEMBL3895689 & 1640414 & 7.4318 & 7.0195 & TRN & \\
\hline CHEMBL 3910211 & 1640414 & 4.064 & 5.7252 & TRN & \\
\hline CHEMBL 3895200 & 1640414 & 6.6778 & 6.546 & TRN & \\
\hline CHEMBL 3918954 & 1640414 & 5.8687 & 5.4456 & TRN & \\
\hline CHEMBL 3904638 & 1640414 & 4.3207 & 6.5904 & TRN & \\
\hline CHEMBL 3958241 & 1640414 & 6.9101 & 7.2093 & TST & \\
\hline CHEMBL 3927221 & 1640414 & 6.7825 & 7.1718 & TST & \\
\hline CHEMBL3952549 & 1640414 & 6.0 & 6.8153 & TRN & \\
\hline CHEMBL 3943355 & 1640414 & 5.8617 & 5.6644 & TRN & \\
\hline CHEMBL 3948074 & 1640414 & 7.1487 & 6.7794 & TST & \\
\hline CHEMBL3977554 & 1640414 & 4.2662 & 5.0888 & TRN & \\
\hline CHEMBL 3934379 & 1640414 & 4.1894 & 4.9146 & TRN & \\
\hline CHEMBL 3946649 & 1640414 & 5.8492 & 5.9101 & TRN & \\
\hline CHEMBL 3891726 & 1640414 & 6.3251 & 5.9478 & TRN & \\
\hline CHEMBL 3937260 & 1640414 & 7.5528 & 5.8676 & TRN & \\
\hline CHEMBL 3949286 & 1640414 & 6.1079 & 5.7999 & TRN & \\
\hline CHEMBL 3947186 & 1640414 & 5.8013 & 6.6251 & TRN & \\
\hline CHEMBL3954469 & 1640414 & 5.6336 & 6.1807 & TST & \\
\hline CHEMBL 3939228 & 1640414 & 7.0362 & 6.2489 & TRN & \\
\hline CHEMBL 3982989 & 1640414 & 6.08200 & 300000000 & 6.1229 & TST \\
\hline CHEMBL 3977106 & 1640414 & 7.6778 & 7.1997 & TRN & \\
\hline CHEMBL3918695 & 1640414 & 6.6162 & 6.7601 & TRN & \\
\hline
\end{tabular}

Page 13819 
Supplemental Table S2.txt

\begin{tabular}{|c|c|c|c|c|}
\hline AEMBL 3955363 & & 1364 & & \\
\hline & 640414 & 6.0 & & \\
\hline$=M B$ & 540414 & & & \\
\hline IEMBL & 14 & 7144 & & \\
\hline HEMBL396 & 640414 & 8811 & & \\
\hline AEMBL & 14 & 6.0 & & \\
\hline AEMBL & 14 & 5.8283 & & \\
\hline IEMBL & 14 & 7.1427 & & \\
\hline AEMBL 3943555 & 14 & 5.6931 & & \\
\hline HEMBL3957938 & 414 & 6.5317 & & \\
\hline HEMBL; & 14 & 5.8979 & & \\
\hline IEMB & 14 & 4789 & & \\
\hline AEMBL & 4 & 4134 & & \\
\hline AEMBL & 14 & 7.1739 & 168 & \\
\hline HEMBL: & 14 & & & \\
\hline AEMBL. & 2 & 229 & & \\
\hline IEMBL & 7 & 198 & & 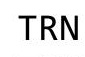 \\
\hline AEMBL & 97 & 5778 & & \\
\hline IEMBL & 97 & 7.5229 & & \\
\hline AEMBL & 97 & 1805 & & \\
\hline AEMBL & 7 & & & \\
\hline AEMBL & 7 & 229 & & 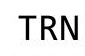 \\
\hline 282 & 7 & 7.2218 & & \\
\hline IEMBL & & 229 & & \\
\hline AEMBL & & 6. & & \\
\hline AEMBL & 2 & 949 & & 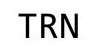 \\
\hline 265 & 7 & 49 & & $\cdots$ \\
\hline 268 & 7 & 979 & & \\
\hline IEMBL & & 916 & & $\mathrm{RI}$ \\
\hline EMBL: & 7 & & & NI \\
\hline 84 & & & & RI \\
\hline 6 & & & & T. \\
\hline & & & & . \\
\hline IEMBL & & 5. & & RI \\
\hline AEMBL: & & 778 & & $\mathrm{RI}$ \\
\hline 03 & & & & $\Gamma R$ \\
\hline 1 & & 5 & & rR \\
\hline HEMBL. & & & & RI \\
\hline AEMBL & 7 & 6 & & $\mathrm{R}$ \\
\hline IEME & $y$ & 5 . & & $\mathrm{RI}$ \\
\hline HEMBL & & 4 . & & \\
\hline HEMBL & & 7. & 67 & ST \\
\hline EMBL & & 7.1549 & & $\mathrm{RI}$ \\
\hline AEMBL & 97 & 18 & & $\mathrm{R}$ \\
\hline 5 & & 6 & & \\
\hline CHEMBL2 & & 4.6 & & \\
\hline CHEMBL 3 & 12 & & 6.7003 & \\
\hline CHEMBL 3103289 & 1285707 & 6.1675 & 6.1126 & $\mathrm{R}$ \\
\hline
\end{tabular}

Page 13820 


$$
\text { Supplemental Table S2.txt }
$$

\begin{tabular}{|c|c|c|c|c|}
\hline CHEMBL3103291 & 1285707 & 6.2518 & 5.7594 & TRN \\
\hline CHEMBL3103299 & 1285707 & 5.3063 & 5.2055 & TRN \\
\hline CHEMBL3103290 & 1285707 & 4.0 & 3.9738 & TRN \\
\hline CHEMBL3103281 & 1285707 & 4.0 & 3.7977 & TRN \\
\hline CHEMBL3103266 & 1285707 & 7.2218 & 7.3465 & TRN \\
\hline CHEMBL118883 & 1285707 & 4.0 & 2.6557 & TST \\
\hline CHEMBL3103294 & 1285707 & 5.3382 & 5.4367 & TRN \\
\hline CHEMBL3103296 & 1285707 & 5.3546 & 5.3575 & TRN \\
\hline CHEMBL326294 & 1285707 & 4.0 & 2.6718 & TST \\
\hline CHEMBL3103267 & 1285707 & 7.301 & 7.5595 & TRN \\
\hline CHEMBL3103275 & 1285707 & 6.6198 & 6.6542 & TRN \\
\hline CHEMBL3103262 & 1285707 & 6.5686 & 5.6843 & TST \\
\hline CHEMBL3103283 & 1285707 & 7.301 & 6.8862 & TST \\
\hline CHEMBL3103279 & 1285707 & 5.5058 & 4.7466 & TST \\
\hline CHEMBL3103292 & 1285707 & 6.2596 & 5.0152 & TST \\
\hline CHEMBL327012 & 1285707 & 4.0 & 2.6041 & TST \\
\hline CHEMBL3103293 & 1285707 & 5.3726 & 5.3982 & TST \\
\hline CHEMBL115897 & 1285707 & 4.0 & 2.6671 & TST \\
\hline CHEMBL1784384 & 751711 & 7.8 & 6.3066 & TRN \\
\hline CHEMBL1784387 & 751711 & 3.7 & 5.6855 & TRN \\
\hline CHEMBL1784388 & 751711 & 4.0 & 6.7731 & TST \\
\hline CHEMBL1784389 & 751711 & 5.2 & 6.0021 & TST \\
\hline CHEMBL1784390 & 751711 & 5.53 & 5.7224 & TST \\
\hline CHEMBL1784391 & 751711 & 5.0 & 5.5649 & TST \\
\hline CHEMBL1784392 & 751711 & 5.55 & 6.8143 & TST \\
\hline CHEMBL1784394 & 751711 & 5.13 & 5.7904 & TST \\
\hline CHEMBL1784395 & 751711 & 5.04 & 5.7903 & TST \\
\hline CHEMBL1784396 & 751711 & 5.9 & 5.6112 & TRN \\
\hline CHEMBL1784397 & 751711 & 5.8 & 6.2338 & TRN \\
\hline CHEMBL1784398 & 751711 & 5.7 & 5.8673 & TRN \\
\hline CHEMBL1784399 & 751711 & 5.13 & 6.904 & TRN \\
\hline CHEMBL1784400 & 751711 & 6.76 & 6.5864 & TRN \\
\hline CHEMBL1784401 & 751711 & 6.46 & 6.1865 & TRN \\
\hline CHEMBL1784402 & 751711 & 5.6 & 5.7723 & TRN \\
\hline CHEMBL1784403 & 751711 & 5.85 & 5.7419 & TRN \\
\hline CHEMBL1784404 & 751711 & 6.85 & 6.019 & TRN \\
\hline CHEMBL 1784405 & 751711 & 7.54 & 7.7836 & TST \\
\hline CHEMBL1784406 & 751711 & 7.56 & 7.8101 & TST \\
\hline CHEMBL1784407 & 751711 & 7.77 & 7.659 & TST \\
\hline CHEMBL1784408 & 751711 & 7.51 & 6.4873 & TRN \\
\hline CHEMBL1784409 & 751711 & 7.58 & 7.1142 & TRN \\
\hline CHEMBL1784465 & 751711 & 7.34 & 7.4303 & TRN \\
\hline CHEMBL1784466 & 751711 & 8.13 & 7.5543 & TRN \\
\hline CHEMBL1784467 & 751711 & 8.11 & 7.7344 & TRN \\
\hline CHEMBL1784468 & 751711 & 7.6 & 7.5812 & TRN \\
\hline CHEMBL1784469 & 751711 & 7.33 & 6.5924 & TST \\
\hline CHEMBL1784470 & 751711 & 7.53 & 7.6034 & TRN \\
\hline \multirow[t]{2}{*}{ CHEMBL1784471 } & 751711 & 7.48 & 7.04799 & 9999999999 \\
\hline & & & \multicolumn{2}{|c|}{ Page 13821} \\
\hline
\end{tabular}




\begin{tabular}{|c|c|c|c|c|c|}
\hline & & \multicolumn{4}{|c|}{ Supplemental Table S2.txt } \\
\hline CHEMBL1784472 & 751711 & 7.15 & 7.1995 & TRN & \\
\hline CHEMBL1784464 & 751711 & 7.27 & 7.0345 & TRN & \\
\hline CHEMBL1784473 & 751711 & 7.48 & 7.3922 & TRN & \\
\hline CHEMBL1784474 & 751711 & 7.04 & 6.9467 & TRN & \\
\hline CHEMBL1784475 & 751711 & 7.79 & 6.3987 & TRN & \\
\hline CHEMBL1784476 & 751711 & 7.44 & 8.0633 & TRN & \\
\hline CHEMBL1784477 & 751711 & 7.27 & 7.5761 & TRN & \\
\hline CHEMBL1784478 & 751711 & 5.0 & 6.0528 & TRN & \\
\hline CHEMBL1784479 & 751711 & 6.37 & 6.4632 & TRN & \\
\hline CHEMBL1784480 & 751711 & 5.91 & 6.3699 & TRN & \\
\hline CHEMBL1784481 & 751711 & 6.96 & 7.269 & TRN & \\
\hline CHEMBL1784482 & 751711 & 5.0 & 5.9407 & TRN & \\
\hline CHEMBL1784483 & 751711 & 6.42 & 6.7401 & TRN & \\
\hline CHEMBL1784484 & 751711 & 8.51 & 6.7717 & TRN & \\
\hline CHEMBL1784485 & 751711 & 7.35 & 6.7228 & TRN & \\
\hline CHEMBL1784486 & 751711 & 7.35 & 6.73 & TRN & \\
\hline CHEMBL1784487 & 751711 & 6.81 & 6.817 & TRN & \\
\hline CHEMBL1784488 & 751711 & 7.45 & 6.9462 & TRN & \\
\hline CHEMBL1784489 & 751711 & 7.96 & 7.24100 & 00000000005 & TRN \\
\hline CHEMBL1784490 & 751711 & 7.54 & 7.0784 & TRN & \\
\hline CHEMBL1784491 & 751711 & 6.69 & 7.0414 & TRN & \\
\hline CHEMBL1784492 & 751711 & 8.85 & 7.1172 & TRN & \\
\hline CHEMBL1784493 & 751711 & 6.21 & 6.6357 & TRN & \\
\hline CHEMBL1784494 & 751711 & 6.81 & 6.7137 & TRN & \\
\hline CHEMBL1784495 & 751711 & 7.14 & 6.73799 & 99999999995 & TRN \\
\hline CHEMBL1784496 & 751711 & 6.34 & 6.6572 & TRN & \\
\hline CHEMBL1784497 & 751711 & 6.38 & 6.5636 & TRN & \\
\hline CHEMBL1784498 & 751711 & 7.44 & 6.6397 & TRN & \\
\hline CHEMBL1784499 & 751711 & 5.36 & 6.8092 & TRN & \\
\hline CHEMBL1784501 & 751711 & 4.72 & 6.5548 & TRN & \\
\hline CHEMBL1784502 & 751711 & 6.22 & 6.6713 & TRN & \\
\hline CHEMBL1784503 & 751711 & 6.07 & 6.8513 & TRN & \\
\hline CHEMBL1784504 & 751711 & 7.75 & 6.6282 & TRN & \\
\hline CHEMBL1784505 & 751711 & 6.33 & 6.6973 & TRN & \\
\hline CHEMBL1784506 & 751711 & 6.94 & 6.8233 & TRN & \\
\hline CHEMBL1784507 & 751711 & 6.65 & 6.609 & TRN & \\
\hline CHEMBL1784508 & 751711 & 6.3 & 6.8385 & TRN & \\
\hline CHEMBL1784500 & 751711 & 6.9 & 6.847 & TRN & \\
\hline CHEMBL1784515 & 751711 & 8.16 & 8.698 & TRN & \\
\hline CHEMBL1784516 & 751711 & 8.12 & 8.5952 & TRN & \\
\hline CHEMBL1784517 & 751711 & 8.4 & 8.7291 & TRN & \\
\hline CHEMBL1784518 & 751711 & 8.6 & 8.637 & TST & \\
\hline CHEMBL1784519 & 751711 & 8.53 & 8.5284 & TST & \\
\hline CHEMBL1784520 & 751711 & 7.81 & 8.7148 & TST & \\
\hline CHEMBL1784521 & 751711 & 8.37 & 8.7294 & TST & \\
\hline CHEMBL1784522 & 751711 & 8.38 & 8.4807 & TST & \\
\hline CHEMBL1782081 & 751711 & 8.7 & 8.4625 & TST & \\
\hline CHEMBL1784523 & 751711 & 8.21 & 8.2888 & TST & \\
\hline
\end{tabular}




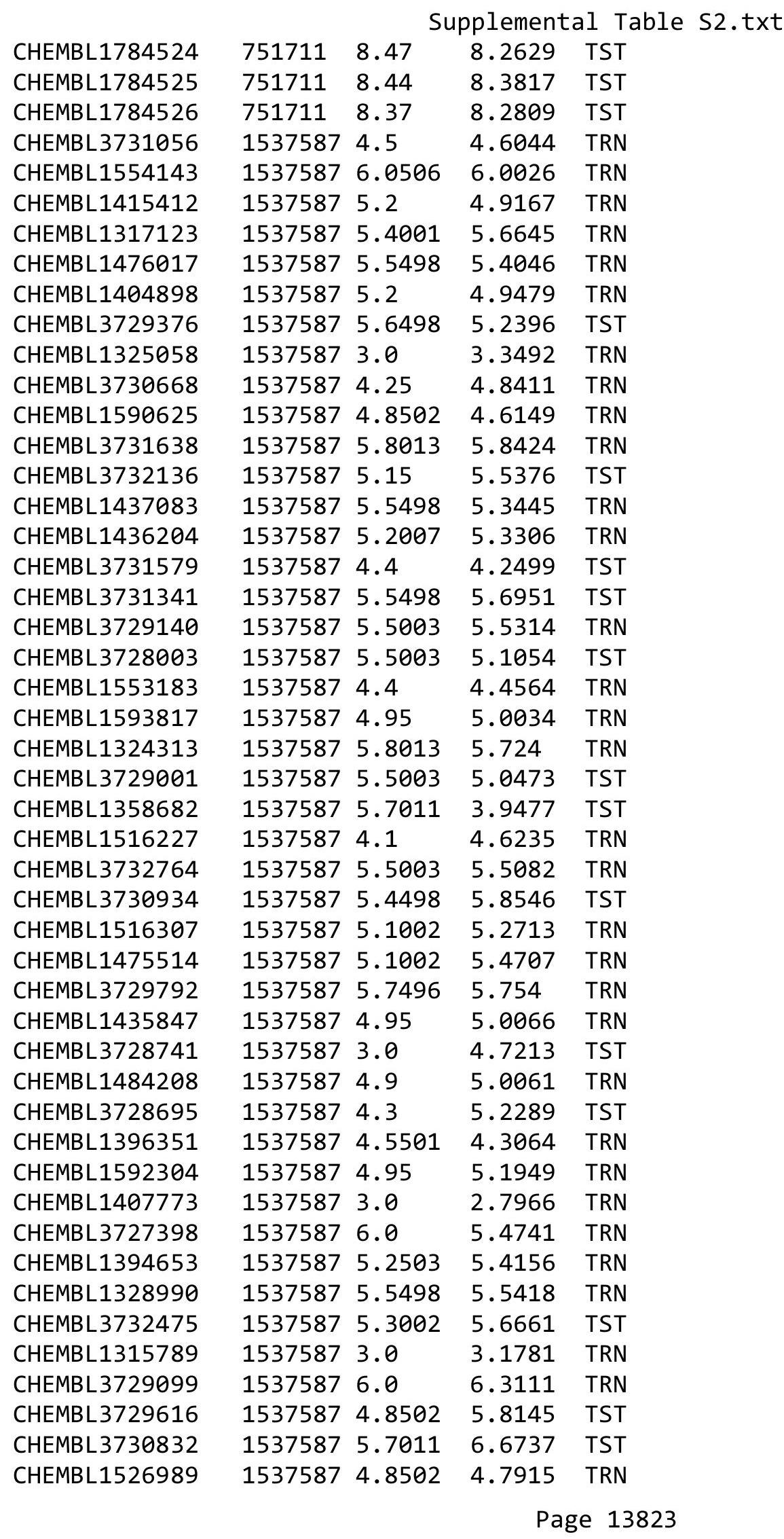


Supplemental Table S2.txt

\begin{tabular}{|c|c|c|c|c|c|}
\hline CHEMBL1371147 & 1537587 & 5.4498 & 5.0317 & TRN & \\
\hline CHEMBL1597259 & 1537587 & 5.6003 & 5.5309 & TRN & \\
\hline CHEMBL3730118 & 1537587 & 5.15 & 4.7727 & TST & \\
\hline CHEMBL3729321 & 1537587 & 5.8013 & 5.2924 & TRN & \\
\hline CHEMBL3730640 & 1537587 & 5.8013 & 6.0558 & TST & \\
\hline CHEMBL1315320 & 1537587 & 4.35 & 4.2437 & TRN & \\
\hline CHEMBL3729993 & 1537587 & 5.4023 & 5.4106 & TST & \\
\hline CHEMBL1528672 & 1537587 & 3.0 & 3.1883 & TRN & \\
\hline CHEMBL1396223 & 1537587 & 5.4001 & 5.1918 & TRN & \\
\hline CHEMBL3729186 & 1537587 & 5.2 & 5.4576 & TRN & \\
\hline CHEMBL1319866 & 1537587 & 3.0 & 2.8551 & TRN & \\
\hline CHEMBL1593156 & 1537587 & 4.2 & 4.4229 & TRN & \\
\hline CHEMBL1397580 & 1537587 & 5.2503 & 5.01699 & 99999999995 & TRN \\
\hline CHEMBL1436077 & 1537587 & 4.2 & 4.5092 & TRN & \\
\hline CHEMBL3731120 & 1537587 & 5.7011 & 5.7817 & TRN & \\
\hline CHEMBL1378851 & 1537587 & 4.9 & 4.5445 & TRN & \\
\hline CHEMBL1486329 & 1537587 & 4.95 & 4.65600 & 0000000001 & TRN \\
\hline CHEMBL3727411 & 1537587 & 5.3002 & 5.5928 & TST & \\
\hline CHEMBL1496788 & 1537587 & 5.2007 & 4.9021 & TRN & \\
\hline CHEMBL1359120 & 1537587 & 4.9 & 4.9803 & TRN & \\
\hline CHEMBL1378392 & 1537587 & 6.2007 & 5.9386 & TRN & \\
\hline CHEMBL1436389 & 1537587 & 5.9508 & 6.0092 & TRN & \\
\hline CHEMBL1490041 & 1537587 & 5.2 & 5.4774 & TRN & \\
\hline CHEMBL3730302 & 1537587 & 4.5 & 4.4346 & TRN & \\
\hline CHEMBL1456711 & 1537587 & 4.35 & 4.3657 & TRN & \\
\hline CHEMBL3731659 & 1537587 & 5.15 & 5.375 & TST & \\
\hline CHEMBL3673480 & 1528630 & 9.301 & 9.2859 & TRN & \\
\hline CHEMBL3673464 & 1528630 & 7.585 & 7.4944 & TRN & \\
\hline CHEMBL3673445 & 1528630 & 4.9547 & 5.1175 & TRN & \\
\hline CHEMBL3673468 & 1528630 & 7.4949 & 7.4406 & TRN & \\
\hline CHEMBL 3673461 & 1528630 & 8.0969 & 8.1428 & TRN & \\
\hline CHEMBL3678302 & 1528630 & 7.7696 & 8.19700 & 2000000001 & TST \\
\hline CHEMBL3673438 & 1528630 & 8.0969 & 8.1773 & TRN & \\
\hline CHEMBL3673465 & 1528630 & 6.5143 & 6.5601 & TRN & \\
\hline CHEMBL 3678283 & 1528630 & 9.699 & 9.7126 & TRN & \\
\hline CHEMBL3678290 & 1528630 & 7.2366 & 7.2344 & TRN & \\
\hline CHEMBL3678292 & 1528630 & 8.5229 & 8.35 & TST & \\
\hline CHEMBL3673439 & 1528630 & 8.5229 & 8.5679 & TRN & \\
\hline CHEMBL3673483 & 1528630 & 8.5229 & 8.5331 & TRN & \\
\hline CHEMBL 3673475 & 1528630 & 7.4949 & 7.4406 & TRN & \\
\hline CHEMBL3673473 & 1528630 & 6.4437 & 6.9967 & TST & \\
\hline CHEMBL3673470 & 1528630 & 5.2204 & 5.2279 & TRN & \\
\hline CHEMBL3673467 & 1528630 & 7.0555 & 7.13700 & 00000000005 & TST \\
\hline CHEMBL3678293 & 1528630 & 7.0706 & 7.0668 & TST & \\
\hline CHEMBL3673482 & 1528630 & 8.0458 & 8.2148 & TRN & \\
\hline CHEMBL3678303 & 1528630 & 7.4559 & 7.2062 & TST & \\
\hline CHEMBL3673446 & 1528630 & 6.1007 & 5.9971 & TRN & \\
\hline CHEMBL3673485 & 1528630 & 7.8539 & 7.7944 & TRN & \\
\hline
\end{tabular}




$$
\text { Supplemental Table S2.txt }
$$

\begin{tabular}{|c|c|c|c|c|c|}
\hline CHEMBL 3673440 & 1528630 & 8.1549 & 8.2307 & TRN & \\
\hline CHEMBL 3673453 & 1528630 & 9.301 & 9.2702 & TRN & \\
\hline CHEMBL 3673450 & 1528630 & 5.9469 & 5.9142 & TRN & \\
\hline CHEMBL3673481 & 1528630 & 8.2218 & 8.2549 & TRN & \\
\hline CHEMBL 3673444 & 1528630 & 6.3625 & 6.4013 & TRN & \\
\hline CHEMBL 3678287 & 1528630 & 9.699 & 9.7083 & TRN & \\
\hline CHEMBL3673458 & 1528630 & 6.3279 & 6.34 & TRN & \\
\hline CHEMBL 3673462 & 1528630 & 9.0 & 9.0076 & TRN & \\
\hline CHEMBL3673477 & 1528630 & 9.699 & 9.6734 & TRN & \\
\hline CHEMBL3639723 & 1528630 & 6.2291 & 6.3042 & TRN & \\
\hline CHEMBL 3678300 & 1528630 & 9.3979 & 9.386006 & 0000000001 & TRN \\
\hline CHEMBL3678299 & 1528630 & 8.1549 & 8.254 & TRN & \\
\hline CHEMBL 3673466 & 1528630 & 7.2924 & 7.1864 & TRN & \\
\hline CHEMBL3673436 & 1528630 & 9.0 & 8.8263 & TRN & \\
\hline CHEMBL3673463 & 1528630 & 9.0458 & 9.0598 & TRN & \\
\hline CHEMBL 3673484 & 1528630 & 7.2924 & 7.3917 & TRN & \\
\hline CHEMBL3673443 & 1528630 & 6.75700 & 300000006 & 6.6964 & TRN \\
\hline CHEMBL 3673452 & 1528630 & 9.5229 & 9.6951 & TRN & \\
\hline CHEMBL3673447 & 1528630 & 6.1858 & 6.2059 & TRN & \\
\hline CHEMBL 3678304 & 1528630 & 6.3478 & 6.3451 & TST & \\
\hline CHEMBL3673472 & 1528630 & 5.8297 & 6.0334 & TST & \\
\hline CHEMBL 3673488 & 1528630 & 8.3979 & 8.3667 & TRN & \\
\hline CHEMBL 3673471 & 1528630 & 6.6968 & 6.8376 & TST & \\
\hline CHEMBL3673469 & 1528630 & 6.0696 & 6.0598 & TRN & \\
\hline CHEMBL 3678305 & 1528630 & 6.7959 & 6.3028 & TST & \\
\hline CHEMBL 3673487 & 1528630 & 8.301 & 8.2094 & TRN & \\
\hline CHEMBL3678295 & 1528630 & 6.9914 & 7.1747 & TRN & \\
\hline CHEMBL 3673486 & 1528630 & 8.699 & 8.736 & TRN & \\
\hline CHEMBL3673474 & 1528630 & 5.9355 & 6.3776 & TST & \\
\hline CHEMBL 3673478 & 1528630 & 9.699 & 9.8006 & TRN & \\
\hline CHEMBL 3678294 & 1528630 & 5.9066 & 5.7631 & TRN & \\
\hline CHEMBL3678301 & 1528630 & 9.0 & 8.9477 & TRN & \\
\hline CHEMBL 3673489 & 1528630 & 9.5229 & 9.4788 & TRN & \\
\hline CHEMBL3673437 & 1528630 & 7.0655 & 7.0117 & TRN & \\
\hline CHEMBL 3678284 & 1528630 & 9.699 & 9.6151 & TRN & \\
\hline CHEMBL3673460 & 1528630 & 6.6345 & 6.6409 & TRN & \\
\hline CHEMBL3678306 & 1528630 & 6.6676 & 6.4302 & TST & \\
\hline CHEMBL 3673442 & 1528630 & 8.2218 & 8.297 & TRN & \\
\hline CHEMBL3673448 & 1528630 & 6.8697 & 6.8547 & TRN & \\
\hline CHEMBL 3673459 & 1528630 & 7.6021 & 7.6346 & TRN & \\
\hline CHEMBL 3673441 & 1528630 & 6.0778 & 6.436 & TST & \\
\hline CHEMBL3678296 & 1528630 & 6.1599 & 6.1055 & TRN & \\
\hline CHEMBL3673449 & 1528630 & 5.9872 & 5.8125 & TST & \\
\hline CHEMBL3673456 & 1528630 & 7.0458 & 7.3563 & TST & \\
\hline CHEMBL 3673479 & 1528630 & 9.699 & 9.6128 & TRN & \\
\hline CHEMBL 3678288 & 1528630 & 7.1871 & 7.1021 & TRN & \\
\hline CHEMBL 3678285 & 1528630 & 9.699 & 9.6919 & TRN & \\
\hline CHEMBL3678286 & 1528630 & 9.699 & 9.6853 & TRN & \\
\hline
\end{tabular}


Supplemental Table S2.txt

\begin{tabular}{|c|c|c|c|c|}
\hline CHEMBL3673455 & 1528630 & 7.2676 & 7.1328 & TST \\
\hline CHEMBL3678291 & 1528630 & 7.4089 & 7.5357 & TST \\
\hline CHEMBL3673457 & 1528630 & 6.9469 & 7.1063 & TST \\
\hline CHEMBL3673476 & 1528630 & 9.2218 & 9.0988 & TRN \\
\hline CHEMBL3678289 & 1528630 & 8.1549 & 8.1972 & TRN \\
\hline CHEMBL3673451 & 1528630 & 5.0467 & 5.4905 & TST \\
\hline CHEMBL379215 & 364426 & 6.0535 & 6.2208 & TST \\
\hline CHEMBL377160 & 364426 & 8.4815 & 8.5264 & TRN \\
\hline CHEMBL210716 & 364426 & 5.7011 & 5.7169 & TRN \\
\hline CHEMBL209347 & 364426 & 8.9208 & 8.6574 & TST \\
\hline CHEMBL210711 & 364426 & 4.3979 & 4.5714 & TRN \\
\hline CHEMBL210251 & 364426 & 5.8962 & 5.8921 & TRN \\
\hline CHEMBL377103 & 364426 & 6.0 & 7.4447 & TST \\
\hline CHEMBL210141 & 364426 & 6.5214 & 6.5612 & TRN \\
\hline CHEMBL381078 & 364426 & 6.0565 & 6.0637 & TRN \\
\hline CHEMBL207274 & 364426 & 7.0044 & 6.9872 & TRN \\
\hline CHEMBL210847 & 364426 & 3.3979 & 3.3683 & TRN \\
\hline CHEMBL210669 & 364426 & 7.0088 & 7.0646 & TRN \\
\hline CHEMBL210993 & 364426 & 7.5686 & 7.6867 & TST \\
\hline CHEMBL266830 & 364426 & 4.3979 & 4.354 & TRN \\
\hline CHEMBL359880 & 364426 & 6.5086 & 6.4768 & TRN \\
\hline CHEMBL209203 & 364426 & 7.4815 & 7.597 & TST \\
\hline CHEMBL209268 & 364426 & 6.8508 & 6.862 & TRN \\
\hline CHEMBL210263 & 364426 & 7.6778 & 7.6123 & TRN \\
\hline CHEMBL207535 & 364426 & 4.3979 & 4.4718 & TRN \\
\hline CHEMBL210975 & 364426 & 6.5086 & 6.4524 & TRN \\
\hline CHEMBL379703 & 364426 & 7.1612 & 7.1511 & TRN \\
\hline CHEMBL380205 & 364426 & 6.0 & 6.42299 & 9999999999 \\
\hline CHEMBL441472 & 364426 & 9.301 & 7.5818 & TST \\
\hline CHEMBL208669 & 364426 & 7.1308 & 7.232 & TRN \\
\hline CHEMBL377610 & 364426 & 3.3979 & 3.3984 & TRN \\
\hline CHEMBL 378021 & 364426 & 5.0953 & 5.0294 & TRN \\
\hline CHEMBL378187 & 364426 & 9.0 & 9.0526 & TST \\
\hline CHEMBL210623 & 364426 & 5.8508 & 5.1173 & TST \\
\hline CHEMBL379131 & 364426 & 9.1549 & 9.7461 & TST \\
\hline CHEMBL209570 & 364426 & 7.284 & 6.6292 & TST \\
\hline CHEMBL210377 & 364426 & 7.585 & 7.5074 & TRN \\
\hline CHEMBL427394 & 364426 & 6.7258 & 6.6023 & TRN \\
\hline CHEMBL210492 & 364426 & 3.3979 & 3.3369 & TRN \\
\hline CHEMBL209517 & 364426 & 6.6556 & 6.6226 & TRN \\
\hline CHEMBL210302 & 364426 & 6.0 & 6.0597 & TRN \\
\hline CHEMBL211027 & 364426 & 6.5114 & 6.4495 & TRN \\
\hline CHEMBL207715 & 364426 & 6.3915 & 6.3796 & TRN \\
\hline CHEMBL208757 & 364426 & 7.4559 & 7.40799 & 99999999995 \\
\hline CHEMBL207136 & 364426 & 3.3979 & 3.5412 & TRN \\
\hline CHEMBL210445 & 364426 & 6.9208 & 6.8383 & TRN \\
\hline CHEMBL380281 & 364426 & 6.7122 & 6.699 & TRN \\
\hline CHEMBL208580 & 364426 & 8.0458 & 6.8702 & TST \\
\hline
\end{tabular}




\begin{tabular}{|c|c|c|c|c|c|}
\hline \multirow[b]{2}{*}{ CHEMBL380215 } & \multicolumn{5}{|c|}{ Supplemental Table S2.txt } \\
\hline & 364426 & 7.3665 & 7.2225 & TRN & \\
\hline CHEMBL210698 & 364426 & 8.1739 & 8.2834 & TST & \\
\hline CHEMBL385135 & 364426 & 7.1675 & 7.1657 & TRN & \\
\hline CHEMBL209116 & 364426 & 6.6968 & 6.65600 & 0000000001 & TRN \\
\hline CHEMBL377148 & 364426 & 3.3979 & 3.3771 & TRN & \\
\hline CHEMBL208777 & 364426 & 8.9586 & 7.7814 & TST & \\
\hline CHEMBL210536 & 364426 & 6.1858 & 6.1298 & TRN & \\
\hline CHEMBL380092 & 364426 & 7.2924 & 7.2735 & TRN & \\
\hline CHEMBL207592 & 364426 & 4.7632 & 4.7305 & TRN & \\
\hline CHEMBL378565 & 364426 & 8.0362 & 7.5756 & TST & \\
\hline CHEMBL437304 & 364426 & 7.4318 & 7.5575 & TRN & \\
\hline CHEMBL377323 & 364426 & 8.4318 & 9.0279 & TST & \\
\hline CHEMBL210391 & 364426 & 4.3979 & 4.3805 & TRN & \\
\hline CHEMBL377404 & 364426 & 7.6576 & 7.6863 & TRN & \\
\hline CHEMBL379295 & 364426 & 6.3429 & 6.3659 & TRN & \\
\hline CHEMBL439152 & 364426 & 9.5229 & 7.9242 & TST & \\
\hline CHEMBL537199 & 364426 & 4.3979 & 4.4362 & TRN & \\
\hline CHEMBL208959 & 364426 & 6.0799 & 6.0393 & TRN & \\
\hline CHEMBL383988 & 364426 & 8.3979 & 8.4296 & TRN & \\
\hline CHEMBL378569 & 364426 & 3.3979 & 3.323 & TRN & \\
\hline CHEMBL208965 & 364426 & 4.3979 & 4.3761 & TRN & \\
\hline CHEMBL208795 & 364426 & 5.9431 & 5.8832 & TRN & \\
\hline CHEMBL383085 & 364426 & 4.9234 & 4.8482 & TRN & \\
\hline CHEMBL378454 & 364426 & 4.3979 & 4.4199 & TRN & \\
\hline CHEMBL210086 & 364426 & 7.6778 & 7.6338 & TRN & \\
\hline CHEMBL210412 & 364426 & 6.4547 & 6.5027 & TRN & \\
\hline CHEMBL379750 & 364426 & 9.0458 & 8.4471 & TST & \\
\hline CHEMBL208910 & 364426 & 8.7696 & 8.3055 & TST & \\
\hline CHEMBL207593 & 364426 & 6.1518 & 6.2196 & TRN & \\
\hline CHEMBL210235 & 364426 & 5.15 & 5.1807 & TRN & \\
\hline CHEMBL210442 & 364426 & 6.8539 & 6.944 & TRN & \\
\hline CHEMBL377017 & 364426 & 6.5498 & 6.528 & TRN & \\
\hline CHEMBL208692 & 364426 & 7.0915 & 7.1599 & TRN & \\
\hline CHEMBL209569 & 364426 & 9.0458 & 8.7819 & TST & \\
\hline CHEMBL210280 & 364426 & 5.5452 & 5.6866 & TRN & \\
\hline CHEMBL210214 & 364426 & 7.0223 & 7.0875 & TRN & \\
\hline CHEMBL311132 & 103276 & 5.0721 & 4.9929 & TRN & \\
\hline CHEMBL307297 & 103276 & 7.3979 & 7.2809 & TRN & \\
\hline CHEMBL 71683 & 103276 & 7.8861 & 7.7363 & TRN & \\
\hline CHEMBL419252 & 103276 & 7.0862 & 7.4915 & TRN & \\
\hline CHEMBL310247 & 103276 & 7.4318 & 7.3395 & TRN & \\
\hline CHEMBL 71042 & 103276 & 4.279 & 3.944 & TRN & \\
\hline CHEMBL70528 & 103276 & 5.7595 & 5.6865 & TRN & \\
\hline CHEMBL308091 & 103276 & 4.8097 & 4.6142 & TRN & \\
\hline CHEMBL73673 & 103276 & 7.7959 & 7.2551 & TST & \\
\hline CHEMBL431572 & 103276 & 8.5229 & 8.6612 & TST & \\
\hline CHEMBL 73250 & 103276 & 7.3979 & 7.7693 & TRN & \\
\hline CHEMBL 72529 & 103276 & 8.5229 & 9.2666 & TST & \\
\hline
\end{tabular}




\begin{tabular}{|c|c|c|c|c|c|}
\hline & & \multicolumn{4}{|c|}{ Supplemental Table S2.txt } \\
\hline CHEMBL305805 & 103276 & 7.1871 & 7.0043 & TRN & \\
\hline CHEMBL 303226 & 103276 & 8.0 & 7.28 & TRN & \\
\hline CHEMBL302538 & 103276 & 3.0 & 3.8207 & TRN & \\
\hline CHEMBL 302551 & 103276 & 7.699 & 7.6412 & TRN & \\
\hline CHEMBL72289 & 103276 & 7.2007 & 7.4353 & TRN & \\
\hline CHEMBL421114 & 103276 & 7.7696 & 7.9174 & TRN & \\
\hline CHEMBL421492 & 103276 & 5.3288 & 5.4943 & TRN & \\
\hline CHEMBL 74409 & 103276 & 6.5638 & 6.5102 & TRN & \\
\hline CHEMBL70990 & 103276 & 6.4737 & 6.3496 & TRN & \\
\hline CHEMBL70374 & 103276 & 7.9208 & 7.8328 & TRN & \\
\hline CHEMBL71728 & 103276 & 8.5229 & 9.26700 & 0000000001 & TST \\
\hline CHEMBL71521 & 103276 & 8.699 & 8.4999 & TRN & \\
\hline CHEMBL 72343 & 103276 & 6.5622 & 6.2634 & TRN & \\
\hline CHEMBL70468 & 103276 & 8.0969 & 8.2544 & TRN & \\
\hline CHEMBL71579 & 103276 & 6.6364 & 6.5897 & TRN & \\
\hline CHEMBL72011 & 103276 & 5.0 & 5.3158 & TRN & \\
\hline CHEMBL306385 & 103276 & 8.2218 & 8.8823 & TST & \\
\hline CHEMBL71750 & 103276 & 6.3979 & 6.4215 & TRN & \\
\hline CHEMBL73008 & 103276 & 8.5229 & 8.7588 & TRN & \\
\hline CHEMBL 302542 & 103276 & 8.2218 & 8.3546 & TRN & \\
\hline CHEMBL71684 & 103276 & 7.7959 & 8.0332 & TRN & \\
\hline CHEMBL 74003 & 103276 & 6.2168 & 6.34200 & 00000000005 & TRN \\
\hline CHEMBL69503 & 103276 & 8.301 & 8.0605 & TRN & \\
\hline CHEMBL 70613 & 103276 & 7.3979 & 6.6192 & TRN & \\
\hline CHEMBL 303212 & 103276 & 5.1221 & 5.1549 & TRN & \\
\hline CHEMBL 312080 & 103276 & 6.2612 & 6.5778 & TRN & \\
\hline CHEMBL 304055 & 103276 & 8.5229 & 8.1809 & TRN & \\
\hline CHEMBL268935 & 103276 & 6.279 & 6.6648 & TRN & \\
\hline CHEMBL73044 & 103276 & 8.2218 & 8.1961 & TRN & \\
\hline CHEMBL70745 & 103276 & 5.2941 & 5.0497 & TRN & \\
\hline CHEMBL70967 & 103276 & 7.0862 & 7.9146 & TST & \\
\hline CHEMBL73939 & 103276 & 8.2218 & 8.298 & TST & \\
\hline CHEMBL 307865 & 103276 & 7.0706 & 6.8235 & TRN & \\
\hline CHEMBL71659 & 103276 & 7.9586 & 7.7895 & TST & \\
\hline CHEMBL 70683 & 103276 & 6.1409 & 6.0548 & TRN & \\
\hline CHEMBL 307474 & 103276 & 7.0605 & 5.9239 & TST & \\
\hline CHEMBL305838 & 103276 & 8.0969 & 8.5164 & TST & \\
\hline CHEMBL74410 & 103276 & 7.3768 & 7.94600 & 0000000001 & TRN \\
\hline CHEMBL 71298 & 103276 & 6.6498 & 6.5249 & TST & \\
\hline CHEMBL72459 & 103276 & 7.7696 & 7.5745 & TST & \\
\hline CHEMBL 306023 & 103276 & 7.6778 & 7.67899 & 9999999999 & TRN \\
\hline CHEMBL302791 & 103276 & 8.0969 & 8.1202 & TST & \\
\hline CHEMBL72059 & 103276 & 6.8633 & 6.9615 & TRN & \\
\hline CHEMBL 74174 & 103276 & 8.699 & 8.7266 & TST & \\
\hline CHEMBL1490692 & 737534 & 5.8729 & 6.0857 & TRN & \\
\hline CHEMBL1563728 & 737534 & 5.5003 & 5.2016 & TRN & \\
\hline CHEMBL1541722 & 737534 & 5.0625 & 4.8805 & TST & \\
\hline CHEMBL1444685 & 737534 & 3.0 & 3.9141 & TRN & \\
\hline
\end{tabular}




\begin{tabular}{|c|c|c|c|c|c|}
\hline & & \multicolumn{4}{|c|}{ Supplemental Table S2.txt } \\
\hline CHEMBL1339245 & 737534 & 5.0132 & 4.3859 & TRN & \\
\hline CHEMBL1366588 & 737534 & 5.684 & 4.2158 & TST & \\
\hline CHEMBL1343658 & 737534 & 5.7122 & 5.6417 & TRN & \\
\hline CHEMBL1512568 & 737534 & 5.4202 & 5.086 & TRN & \\
\hline CHEMBL1571123 & 737534 & 5.4461 & 5.0186 & TRN & \\
\hline CHEMBL1505335 & 737534 & 4.3788 & 4.2831 & TRN & \\
\hline CHEMBL1716490 & 737534 & 4.7328 & 4.904 & TRN & \\
\hline CHEMBL1707377 & 737534 & 5.0173 & 4.7202 & TRN & \\
\hline CHEMBL3193158 & 737534 & 5.1367 & 4.6432 & TRN & \\
\hline CHEMBL1457403 & 737534 & 5.3197 & 5.218 & TRN & \\
\hline CHEMBL602526 & 737534 & 5.7905 & 5.6033 & TRN & \\
\hline CHEMBL1574982 & 737534 & 5.4522 & 5.32299 & 99999999995 & TRN \\
\hline CHEMBL1596325 & 737534 & 5.0477 & 4.7738 & TRN & \\
\hline CHEMBL1313152 & 737534 & 5.2218 & 4.1674 & TRN & \\
\hline CHEMBL1585618 & 737534 & 3.0 & 3.32899 & 99999999997 & TRN \\
\hline CHEMBL1363164 & 737534 & 4.5214 & 4.6577 & TRN & \\
\hline CHEMBL1711405 & 737534 & 4.6326 & 4.4669 & TRN & \\
\hline CHEMBL1339092 & 737534 & 4.9318 & 4.9944 & TRN & \\
\hline CHEMBL 1347185 & 737534 & 5.1805 & 5.1822 & TRN & \\
\hline CHEMBL1398317 & 737534 & 4.8633 & 4.7888 & TRN & \\
\hline CHEMBL1386774 & 737534 & 5.3089 & 4.9904 & TRN & \\
\hline CHEMBL1505307 & 737534 & 4.3625 & 4.8917 & TRN & \\
\hline CHEMBL1507547 & 737534 & 4.1158 & 4.2806 & TRN & \\
\hline CHEMBL1577062 & 737534 & 4.6055 & 5.0319 & TRN & \\
\hline CHEMBL585591 & 737534 & 5.0424 & 4.2963 & TST & \\
\hline CHEMBL1329507 & 737534 & 4.9586 & 5.0503 & TRN & \\
\hline CHEMBL1447669 & 737534 & 5.0867 & 5.3154 & TRN & \\
\hline CHEMBL3192672 & 737534 & 4.342 & 5.3251 & TRN & \\
\hline CHEMBL1549127 & 737534 & 3.0 & 3.8513 & TRN & \\
\hline CHEMBL1732520 & 737534 & 4.3851 & 4.5785 & TST & \\
\hline CHEMBL1539913 & 737534 & $4.4510 e$ & 00000000 & 4.5223 & TRN \\
\hline CHEMBL1529733 & 737534 & 4.8665 & 5.3603 & TRN & \\
\hline CHEMBL1447078 & 737534 & 4.2684 & 4.2109 & TRN & \\
\hline CHEMBL1709001 & 737534 & 4.8268 & 5.3381 & TRN & \\
\hline CHEMBL1427059 & 737534 & 5.7055 & 5.75299 & 9999999999 & TRN \\
\hline CHEMBL1412902 & 737534 & 4.9872 & 4.7876 & TRN & \\
\hline CHEMBL1727095 & 737534 & 5.3904 & 5.1421 & TRN & \\
\hline CHEMBL1331770 & 737534 & 5.9872 & 5.6924 & TRN & \\
\hline CHEMBL1580883 & 737534 & 4.0915 & 3.9922 & TRN & \\
\hline CHEMBL1381195 & 737534 & 5.3242 & 4.7544 & TRN & \\
\hline CHEMBL1530042 & 737534 & 4.3372 & 4.7089 & TRN & \\
\hline CHEMBL1388722 & 737534 & 5.0376 & 5.4441 & TRN & \\
\hline CHEMBL3191011 & 737534 & 4.6144 & 4.6139 & TRN & \\
\hline CHEMBL1334557 & 737534 & 5.2277 & 5.0229 & TRN & \\
\hline CHEMBL1532568 & 737534 & 5.0083 & 5.3267 & TRN & \\
\hline CHEMBL1596681 & 737534 & 5.0448 & 4.7109 & TRN & \\
\hline CHEMBL 2001888 & 737534 & 5.4306 & 5.0819 & TRN & \\
\hline CHEMBL1451060 & 737534 & 5.2495 & 5.3944 & TRN & \\
\hline
\end{tabular}


Supplemental Table S2.txt

\begin{tabular}{|c|c|c|c|c|c|}
\hline CHEMBL1602195 & 737534 & 5.5376 & 5.3761 & TRN & \\
\hline CHEMBL1994635 & 737534 & 4.9914 & 5.3025 & TST & \\
\hline CHEMBL 2000196 & 737534 & 5.0788 & 5.3113 & TST & \\
\hline CHEMBL1531200 & 737534 & 3.0 & 4.5105 & TST & \\
\hline CHEMBL1525362 & 737534 & 5.1331 & 5.2626 & TST & \\
\hline CHEMBL1559889 & 737534 & 4.8827 & 5.1995 & TST & \\
\hline CHEMBL1518625 & 737534 & 4.9245 & 4.9182 & TST & \\
\hline CHEMBL16312 & 737534 & 4.5086 & 4.1728 & TST & \\
\hline CHEMBL453974 & 737534 & 5.0752 & 5.6033 & TST & \\
\hline CHEMBL1703295 & 737534 & 5.8013 & 4.8038 & TST & \\
\hline CHEMBL1256359 & 737534 & 5.0958 & 5.3986 & TST & \\
\hline CHEMBL1558285 & 737534 & 4.8447 & 5.0445 & TST & \\
\hline CHEMBL1336269 & 737534 & 5.0964 & 4.3366 & TST & \\
\hline CHEMBL1411435 & 737534 & 5.1002 & 5.9255 & TST & \\
\hline CHEMBL3984169 & 1640797 & 7.0458 & 7.1668 & TRN & \\
\hline CHEMBL 3926281 & 1640797 & 6.8153 & 6.5208 & TRN & \\
\hline CHEMBL3940702 & 1640797 & 8.1549 & 7.9818 & TRN & \\
\hline CHEMBL3951026 & 1640797 & 7.3372 & 7.761 & TRN & \\
\hline CHEMBL 3898204 & 1640797 & 7.3188 & 7.4369 & TRN & \\
\hline CHEMBL3943493 & 1640797 & 6.8182 & 7.1555 & TRN & \\
\hline CHEMBL3919956 & 1640797 & 6.8097 & 6.1819 & TRN & \\
\hline CHEMBL 3949873 & 1640797 & 6.76200 & 00000000 & 7.2436 & TST \\
\hline CHEMBL 3898842 & 1640797 & 7.1249 & 7.0072 & TRN & \\
\hline CHEMBL 3903697 & 1640797 & 6.8069 & 6.9525 & TRN & \\
\hline CHEMBL 3963827 & 1640797 & 7.6198 & 7.3569 & TRN & \\
\hline CHEMBL3949477 & 1640797 & 8.5229 & 8.3798 & TRN & \\
\hline CHEMBL3952159 & 1640797 & 7.0458 & 7.1708 & TRN & \\
\hline CHEMBL3966701 & 1640797 & 7.4202 & 7.5001 & TRN & \\
\hline CHEMBL3956295 & 1640797 & 7.0862 & 7.6261 & TRN & \\
\hline CHEMBL 3923364 & 1640797 & 7.1612 & 6.9949 & TRN & \\
\hline CHEMBL 3974585 & 1640797 & 7.9208 & 7.7924 & TRN & \\
\hline CHEMBL 3952009 & 1640797 & 6.9431 & 7.0154 & TST & \\
\hline CHEMBL 3890672 & 1640797 & 7.1805 & 7.6918 & TRN & \\
\hline CHEMBL3973086 & 1640797 & 6.0 & 6.1475 & TRN & \\
\hline CHEMBL3970295 & 1640797 & 7.7696 & 7.6569 & TRN & \\
\hline CHEMBL3935180 & 1640797 & 8.0458 & 8.0932 & TRN & \\
\hline CHEMBL3941232 & 1640797 & 7.9208 & 7.36799 & 9999999999 & TRI \\
\hline CHEMBL 3970786 & 1640797 & 7.7212 & 7.8232 & TRN & \\
\hline CHEMBL3891696 & 1640797 & 7.1612 & 7.6273 & TRN & \\
\hline CHEMBL3963636 & 1640797 & 7.5686 & 7.4326 & TRN & \\
\hline CHEMBL3967392 & 1640797 & 7.8861 & 7.79799 & 9999999999 & IN \\
\hline CHEMBL3909000 & 1640797 & 6.9469 & 6.9469 & TRN & \\
\hline CHEMBL3912707 & 1640797 & 8.699 & 8.0302 & TRN & \\
\hline CHEMBL3987026 & 1640797 & 7.6576 & 7.7463 & TRN & \\
\hline CHEMBL3980052 & 1640797 & 6.9318 & 6.6259 & TST & \\
\hline CHEMBL3967769 & 1640797 & 7.4949 & 7.0604 & TST & \\
\hline CHEMBL3937689 & 1640797 & 6.9626 & 7.1026 & TRN & \\
\hline CHEMBL3936239 & 1640797 & 7.0132 & 6.8263 & TRN & \\
\hline
\end{tabular}


Supplemental Table S2.txt

\begin{tabular}{|c|c|c|c|c|c|}
\hline CHEMBL3953089 & 1640797 & 7.2366 & 7.3068 & TRN & \\
\hline CHEMBL3896585 & 1640797 & 7.1135 & 6.7761 & TST & \\
\hline CHEMBL3932237 & 1640797 & 7.4437 & 7.0645 & TRN & \\
\hline CHEMBL3905102 & 1640797 & 7.7959 & 7.5502 & TRN & \\
\hline CHEMBL3957977 & 1640797 & 8.5229 & 8.2344 & TRN & \\
\hline CHEMBL3979034 & 1640797 & 6.7595 & 6.8971 & TST & \\
\hline CHEMBL3959008 & 1640797 & 7.4949 & 7.5131 & TRN & \\
\hline CHEMBL3980874 & 1640797 & 7.8239 & 7.7526 & TRN & \\
\hline CHEMBL3903884 & 1640797 & 7.4559 & 7.7313 & TRN & \\
\hline CHEMBL3976139 & 1640797 & 6.0 & 6.307 & TRN & \\
\hline CHEMBL3979978 & 1640797 & 6.8894 & 7.0362 & TRN & \\
\hline CHEMBL3979444 & 1640797 & 6.0 & 6.1826 & TRN & \\
\hline CHEMBL3943279 & 1640797 & 6.9914 & 6.8179 & TRN & \\
\hline CHEMBL3966069 & 1640797 & 6.7959 & 7.2631 & TRN & \\
\hline CHEMBL3973012 & 1640797 & 8.5229 & 8.4786 & TRN & \\
\hline CHEMBL3925205 & 1640797 & 7.6576 & 7.629 & TST & \\
\hline CHEMBL3910416 & 1640797 & 7.0655 & 7.4823 & TST & \\
\hline CHEMBL3971118 & 1640797 & 7.7959 & 8.0366 & TST & \\
\hline CHEMBL3967508 & 1640797 & 6.9914 & 6.7648 & TST & \\
\hline CHEMBL3896150 & 1640797 & 6.7645 & 7.0712 & TST & \\
\hline CHEMBL3917379 & 1640797 & 6.9586 & 6.8646 & TST & \\
\hline CHEMBL3935023 & 1640797 & 7.3468 & 7.2868 & TST & \\
\hline CHEMBL3914356 & 1640797 & 7.0315 & 7.0838 & TST & \\
\hline CHEMBL3928863 & 1640797 & 7.6778 & 6.9 & TST & \\
\hline CHEMBL129198 & 556996 & 8.38 & 5.5969 & TST & \\
\hline CHEMBL373579 & 556996 & 9.0 & 5.5173 & TST & \\
\hline CHEMBL260549 & 556996 & 8.25 & 5.9705 & TST & \\
\hline CHEMBL261551 & 556996 & 7.4 & 5.5724 & TST & \\
\hline CHEMBL443764 & 556996 & 5.12 & 5.4473 & TRN & \\
\hline CHEMBL475331 & 556996 & 5.67 & 5.6779 & TRN & \\
\hline CHEMBL473302 & 556996 & 6.98 & 6.4817 & TRN & \\
\hline CHEMBL471712 & 556996 & 4.82 & 5.7614 & TRN & \\
\hline CHEMBL473098 & 556996 & 5.55 & 5.34 & TRN & \\
\hline CHEMBL473099 & 556996 & 5.39 & 5.3039 & TRN & \\
\hline CHEMBL515870 & 556996 & 5.07 & 5.23 & TRN & \\
\hline CHEMBL118572 & 556996 & 5.97 & 5.8609 & TRN & \\
\hline CHEMBL523617 & 556996 & 5.83 & 5.7014 & TRN & \\
\hline CHEMBL490071 & 556996 & 6.59 & \multicolumn{2}{|c|}{6.622000000000001} & TRN \\
\hline CHEMBL490072 & 556996 & 6.62 & 6.4937 & TRN & \\
\hline CHEMBL490073 & 556996 & 6.12 & 5.9993 & TRN & \\
\hline CHEMBL489060 & 556996 & 6.21 & 6.3317 & TRN & \\
\hline CHEMBL489061 & 556996 & 6.23 & 6.0264 & TRN & \\
\hline CHEMBL489062 & 556996 & 7.15 & 6.0598 & TRN & \\
\hline CHEMBL489069 & 556996 & 6.02 & 5.8971 & TRN & \\
\hline CHEMBL488885 & 556996 & 6.16 & 5.5647 & TST & \\
\hline CHEMBL489271 & 556996 & 6.25 & 6.6438 & TRN & \\
\hline CHEMBL489464 & 556996 & 6.44 & 6.5455 & TRN & \\
\hline CHEMBL489070 & 556996 & 6.98 & 6.7266 & TRN & \\
\hline
\end{tabular}




\begin{tabular}{|c|c|c|c|c|c|}
\hline \multicolumn{6}{|c|}{ Supplemental Table s2.txt } \\
\hline CHEMBL448962 & 556996 & 6.89 & 6.8 & TRN & \\
\hline CHEMBL523941 & 556996 & 6.73 & 6.7934 & TRN & \\
\hline CHEMBL489664 & 556996 & 6.24 & 6.3158 & TRN & \\
\hline CHEMBL510181 & 556996 & 6.02 & 6.1897 & TRN & \\
\hline CHEMBL452925 & 556996 & 7.05 & 7.0086 & TRN & \\
\hline CHEMBL455133 & 556996 & 6.22 & 6.1874 & TRN & \\
\hline CHEMBL454882 & 556996 & 6.65 & 6.631 & TRN & \\
\hline CHEMBL454883 & 556996 & 6.73 & 6.7491 & TRN & \\
\hline CHEMBL454890 & 556996 & 7.57 & 6.9509 & TRN & \\
\hline CHEMBL452847 & 556996 & 8.12 & 7.7718 & TRN & \\
\hline CHEMBL509142 & 556996 & 7.45 & 7.1644 & TRN & \\
\hline CHEMBL452848 & 556996 & 7.22 & 7.5344 & TRN & \\
\hline CHEMBL452849 & 556996 & 6.87 & 6.8968 & TRN & \\
\hline CHEMBL452869 & 556996 & 7.41 & 7.4487 & TRN & \\
\hline CHEMBL509852 & 556996 & 7.47 & 7.25 & TRN & \\
\hline CHEMBL452870 & 556996 & 6.43 & 6.7363 & TRN & \\
\hline CHEMBL453877 & 556996 & 6.98 & 7.2466 & TRN & \\
\hline CHEMBL454891 & 556996 & 6.97 & 7.2811 & TRN & \\
\hline CHEMBL509961 & 556996 & 6.57 & 6.9778 & TRN & \\
\hline CHEMBL461729 & 556996 & 5.0 & 4.5413 & TRN & \\
\hline CHEMBL461730 & 556996 & 5.0 & 5.206 & TRN & \\
\hline CHEMBL461731 & 556996 & 5.0 & 4.9801 & TRN & \\
\hline CHEMBL511699 & 556996 & 5.0 & 5.7882 & TRN & \\
\hline CHEMBL 3085393 & 556996 & 5.0 & 5.0094 & TST & \\
\hline CHEMBL461535 & 556996 & 5.0 & 5.6705 & TST & \\
\hline CHEMBL461536 & 556996 & 5.0 & 5.5768 & TST & \\
\hline CHEMBL505559 & 556996 & 5.0 & 4.9874 & TST & \\
\hline CHEMBL462417 & 556996 & 5.0 & 5.20799 & 9999999999 & TST \\
\hline CHEMBL462418 & 556996 & 5.0 & 5.3805 & TST & \\
\hline CHEMBL512225 & 556996 & 5.0 & 5.2146 & TST & \\
\hline CHEMBL446089 & 556996 & 5.0 & 5.4472 & TST & \\
\hline CHEMBL213912 & 556996 & 7.55 & 6.1897 & TST & \\
\hline CHEMBL612059 & 556996 & 6.57 & 6.1163 & TST & \\
\hline CHEMBL131008 & 52222 & 7.5376 & $7.2420 e$ & 0000000001 & TRN \\
\hline CHEMBL128771 & 52222 & 7.5229 & 7.83200 & 0000000001 & TST \\
\hline CHEMBL131611 & 52222 & 8.8239 & 8.0393 & TRN & \\
\hline CHEMBL127162 & 52222 & 6.7747 & 7.3394 & TST & \\
\hline CHEMBL130846 & 52222 & 8.5686 & 8.4308 & TRN & \\
\hline CHEMBL128531 & 52222 & 6.4437 & 7.1711 & TRN & \\
\hline CHEMBL128548 & 52222 & 6.6253 & 7.79299 & 9999999999 & TST \\
\hline CHEMBL128068 & 52222 & 8.2596 & 7.4188 & TRN & \\
\hline CHEMBL337195 & 52222 & 8.0757 & 7.88299 & 9999999999 & TST \\
\hline CHEMBL423333 & 52222 & 8.4685 & 7.9426 & TRN & \\
\hline CHEMBL422609 & 52222 & 8.0362 & 7.2225 & TRN & \\
\hline CHEMBL128697 & 52222 & 6.7212 & 7.1265 & TRN & \\
\hline CHEMBL434992 & 52222 & 7.8239 & 8.2803 & TST & \\
\hline CHEMBL128583 & 52222 & 8.585 & 8.5422 & TRN & \\
\hline CHEMBL131266 & 52222 & 6.9666 & 7.011 & TRN & \\
\hline
\end{tabular}




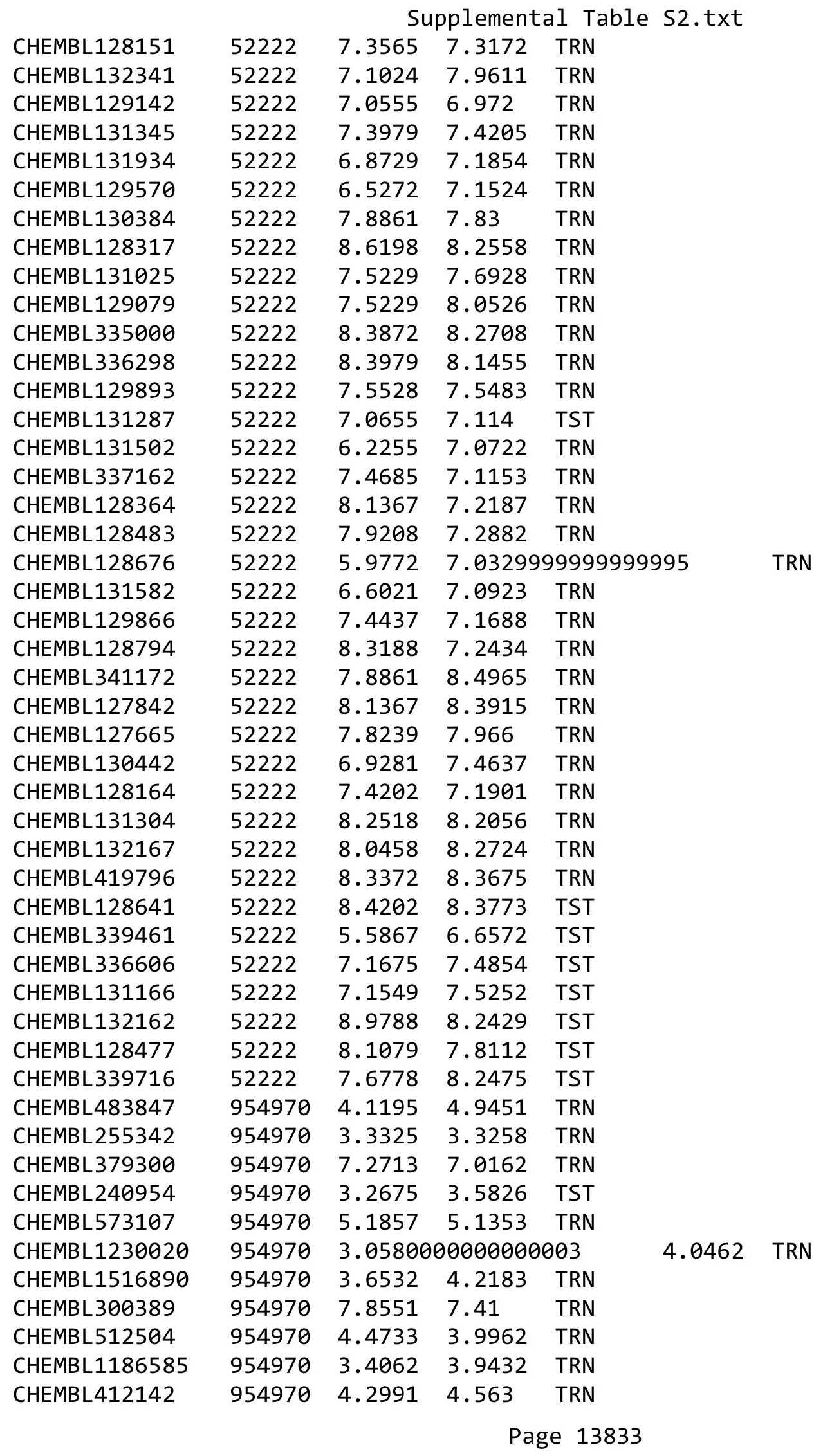




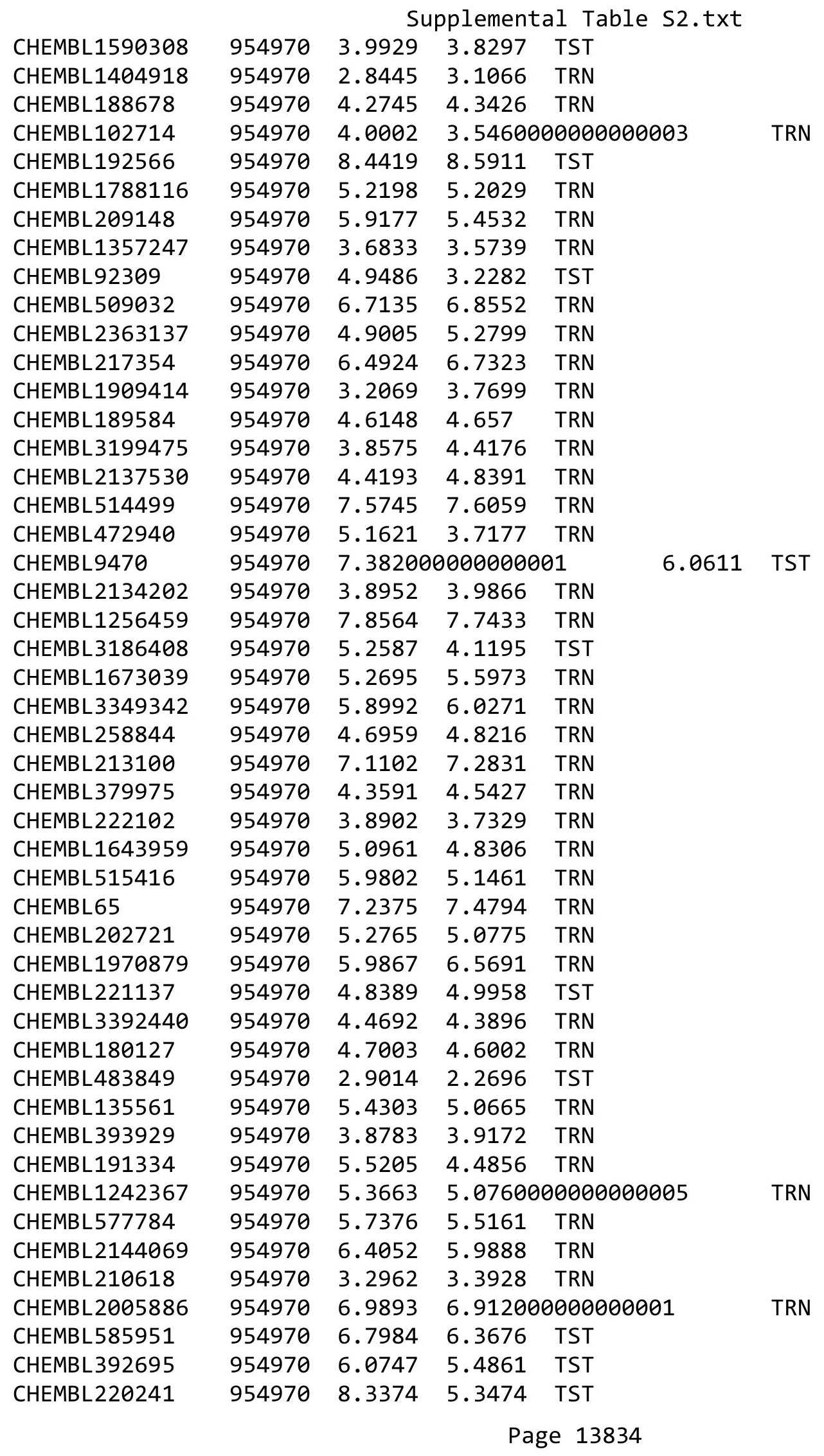




\begin{tabular}{|c|c|c|c|c|c|c|}
\hline & & \multicolumn{5}{|c|}{ Supplemental Table s2.txt } \\
\hline CHEMBL373751 & 954970 & 4.54 & 4.3413 & TST & & \\
\hline CHEMBL558642 & 954970 & 4.3589 & 4.8993 & TST & & \\
\hline CHEMBL399530 & 954970 & 3.7723 & 4.4542 & TST & & \\
\hline CHEMBL259181 & 954970 & 3.5707 & 4.9792 & TST & & \\
\hline CHEMBL449158 & 954970 & 6.3451 & 7.1779 & TST & & \\
\hline CHEMBL1190711 & 954970 & 5.5553 & 5.4114 & TST & & \\
\hline CHEMBL1643959 & 954523 & 3.3613 & 3.5136 & TRN & & \\
\hline CHEMBL220241 & 954523 & 6.4056 & 6.3462 & TRN & & \\
\hline CHEMBL217354 & 954523 & 5.9166 & 5.8837 & TRN & & \\
\hline CHEMBL573107 & 954523 & 4.6521 & 4.7019 & TRN & & \\
\hline CHEMBL1190711 & 954523 & 5.1667 & 5.1729 & TRN & & \\
\hline CHEMBL373751 & 954523 & 3.2051 & 3.2694 & TRN & & \\
\hline CHEMBL379975 & 954523 & 5.6421 & 5.732 & TRN & & \\
\hline CHEMBL1673039 & 954523 & 4.2331 & 4.6458 & TRN & & \\
\hline CHEMBL393929 & 954523 & 4.1566 & 4.118 & TRN & & \\
\hline CHEMBL3392440 & 954523 & 3.5463 & 3.4927 & TRN & & \\
\hline CHEMBL449158 & 954523 & 6.5443 & 6.8801 & TST & & \\
\hline CHEMBL 2363137 & 954523 & 3.84899 & 9999999 & 998 & 4.041 & TRN \\
\hline CHEMBL1590308 & 954523 & 2.8363 & 3.4158 & TST & & \\
\hline CHEMBL9470 & 954523 & 6.1255 & 6.0264 & TST & & \\
\hline CHEMBL483847 & 954523 & 4.0905 & 4.2213 & TRN & & \\
\hline CHEMBL135561 & 954523 & 4.5042 & 4.48 & TRN & & \\
\hline CHEMBL92309 & 954523 & 2.8994 & 3.0457 & TST & & \\
\hline CHEMBL412142 & 954523 & 4.6458 & 4.74 & TRN & & \\
\hline CHEMBL192566 & 954523 & 6.2542 & 8.1705 & TST & & \\
\hline CHEMBL472940 & 954523 & 4.1968 & 4.2145 & TRN & & \\
\hline CHEMBL512504 & 954523 & 4.2238 & 4.183 & TRN & & \\
\hline CHEMBL585951 & 954523 & 7.1748 & 7.0626 & TRN & & \\
\hline CHEMBL 2144069 & 954523 & 4.1073 & 3.9529 & TRN & & \\
\hline CHEMBL577784 & 954523 & 5.4678 & 5.5169 & TRN & & \\
\hline CHEMBL1256459 & 954523 & 7.024 & 6.9615 & TRN & & \\
\hline CHEMBL209148 & 954523 & 4.8116 & 4.5677 & TRN & & \\
\hline CHEMBL515416 & 954523 & 4.8605 & 5.0473 & TRN & & \\
\hline CHEMBL180127 & 954523 & 4.3521 & 4.3856 & TRN & & \\
\hline CHEMBL1909414 & 954523 & 3.5124 & 3.4335 & TRN & & \\
\hline CHEMBL392695 & 954523 & 5.0209 & 5.1636 & TRN & & \\
\hline CHEMBL1404918 & 954523 & 2.7009 & 2.7134 & TRN & & \\
\hline CHEMBL558642 & 954523 & 3.6816 & 3.7549 & TRN & & \\
\hline CHEMBL191334 & 954523 & 4.2898 & 4.2039 & TRN & & \\
\hline CHEMBL222102 & 954523 & 3.8916 & 3.9468 & TRN & & \\
\hline CHEMBL509032 & 954523 & 6.2534 & 5.9021 & TRN & & \\
\hline CHEMBL1788116 & 954523 & 4.8102 & 4.8339 & TRN & & \\
\hline CHEMBL 258844 & 954523 & 4.6864 & 4.4566 & TRN & & \\
\hline CHEMBL1242367 & 954523 & 3.7468 & 3.8113 & TRN & & \\
\hline CHEMBL213100 & 954523 & 6.9733 & 7.0849 & TRN & & \\
\hline CHEMBL102714 & 954523 & 3.8768 & 3.9147 & TRN & & \\
\hline CHEMBL202721 & 954523 & 5.4578 & 5.2554 & TRN & & \\
\hline CHEMBL255342 & 954523 & 4.1217 & 3.6952 & TRN & & \\
\hline
\end{tabular}




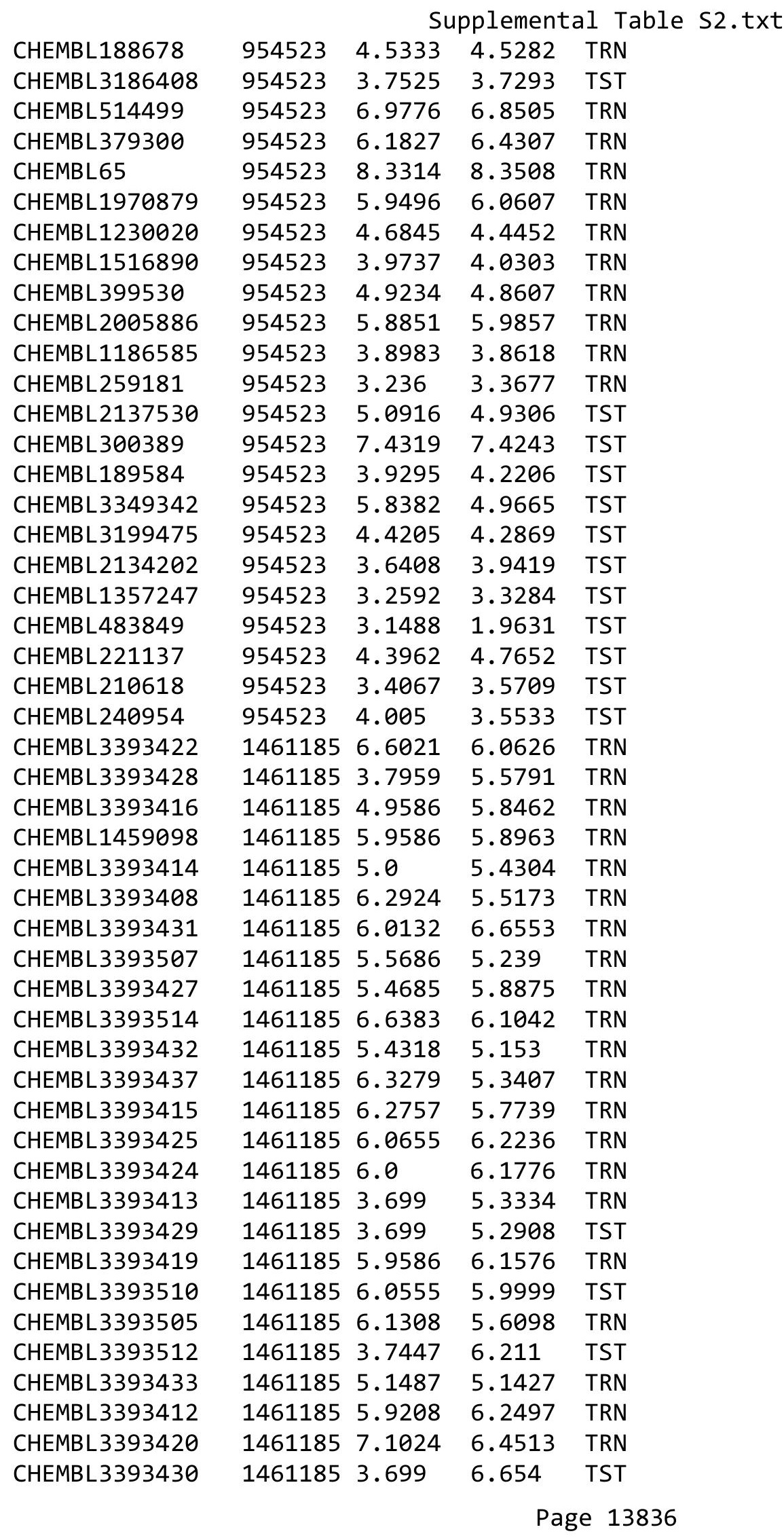


Supplemental Table S2.txt

\begin{tabular}{|c|c|c|c|c|}
\hline CHEMBL3393434 & 1461185 & 5.7959 & 4.8823 & TRN \\
\hline CHEMBL3393503 & 1461185 & 5.9208 & 5.3215 & TRN \\
\hline CHEMBL3393513 & 1461185 & 5.5686 & 6.0285 & TRN \\
\hline CHEMBL3393406 & 1461185 & 3.699 & 6.0199 & TST \\
\hline CHEMBL3393423 & 1461185 & 5.4815 & 6.0461 & TRN \\
\hline CHEMBL3393511 & 1461185 & 5.9208 & 5.9855 & TST \\
\hline CHEMBL3393506 & 1461185 & 5.3098 & 5.2773 & TRN \\
\hline CHEMBL1544205 & 1461185 & 3.699 & 5.4997 & TST \\
\hline CHEMBL1507034 & 1461185 & 5.2366 & 5.2353 & TRN \\
\hline CHEMBL3361317 & 1461185 & 3.699 & 4.8293 & TRN \\
\hline CHEMBL3393515 & 1461185 & 6.6021 & 6.6883 & TRN \\
\hline CHEMBL3393409 & 1461185 & 6.7447 & 6.1641 & TRN \\
\hline CHEMBL1378465 & 1461185 & 6.5528 & 6.2709 & TRN \\
\hline CHEMBL3393436 & 1461185 & 6.2218 & 6.7313 & TRN \\
\hline CHEMBL1350313 & 1461185 & 6.3468 & 5.1472 & TRN \\
\hline CHEMBL3102882 & 1461185 & 3.699 & 4.9234 & TRN \\
\hline CHEMBL3393504 & 1461185 & 6.0 & 5.5369 & TRN \\
\hline CHEMBL3393426 & 1461185 & 6.7212 & 6.0695 & TRN \\
\hline CHEMBL3393509 & 1461185 & 5.3468 & 5.5815 & TRN \\
\hline CHEMBL3393421 & 1461185 & 6.6198 & 6.3627 & TRN \\
\hline CHEMBL3393435 & 1461185 & 6.1367 & 5.6244 & TRN \\
\hline CHEMBL3393410 & 1461185 & 6.6778 & 6.4874 & TRN \\
\hline CHEMBL3393418 & 1461185 & 6.2007 & 6.3364 & TST \\
\hline CHEMBL3393438 & 1461185 & 6.585 & 5.34399 & 9999999999 \\
\hline CHEMBL3393407 & 1461185 & 6.1487 & 6.0368 & TST \\
\hline CHEMBL3393417 & 1461185 & 6.699 & 6.3297 & TST \\
\hline CHEMBL3393411 & 1461185 & 6.5686 & 6.4823 & TST \\
\hline CHEMBL3393508 & 1461185 & 5.3468 & 5.5549 & TST \\
\hline CHEMBL3105209 & 1461185 & 3.699 & 5.0815 & TST \\
\hline CHEMBL1802709 & 756582 & 5.6216 & 5.365 & TST \\
\hline CHEMBL1802711 & 756582 & 5.3161 & 5.4983 & TRN \\
\hline CHEMBL1802651 & 756582 & 6.2749 & 5.9465 & TRN \\
\hline CHEMBL117217 & 756582 & 7.556 & 7.2438 & TST \\
\hline CHEMBL1802722 & 756582 & 7.3478 & 7.522 & TRN \\
\hline CHEMBL1802922 & 756582 & 7.0168 & 6.2411 & TRN \\
\hline CHEMBL1802944 & 756582 & 5.3019 & 4.9792 & TRN \\
\hline CHEMBL1802656 & 756582 & 6.0814 & 6.551 & TRN \\
\hline CHEMBL1802881 & 756582 & 5.3737 & 5.7365 & TRN \\
\hline CHEMBL1802877 & 756582 & 6.6383 & 6.7804 & TRN \\
\hline CHEMBL1802706 & 756582 & 6.1355 & 6.4154 & TRN \\
\hline CHEMBL1802920 & 756582 & 4.0306 & 4.0958 & TST \\
\hline CHEMBL1802939 & 756582 & 4.0737 & 5.5319 & TRN \\
\hline CHEMBL1802668 & 756582 & 4.02 & 4.8668 & TRN \\
\hline CHEMBL1802658 & 756582 & 6.2226 & 6.0841 & TRN \\
\hline CHEMBL1802712 & 756582 & 5.6421 & 5.3243 & TRN \\
\hline CHEMBL1802713 & 756582 & 4.0159 & 4.6288 & TRN \\
\hline CHEMBL1802650 & 756582 & 5.4559 & 5.2225 & TRN \\
\hline CHEMBL1802886 & 756582 & 6.8182 & 6.4139 & TRN \\
\hline
\end{tabular}


Supplemental Table S2.txt

\begin{tabular}{|c|c|c|c|c|c|}
\hline CHEMBL1802649 & 756582 & 4.0123 & 5.3095 & TRN & \\
\hline CHEMBL1802655 & 756582 & 5.3251 & 5.1194 & TRN & \\
\hline CHEMBL1802720 & 756582 & 6.4318 & 6.2736 & TRN & \\
\hline CHEMBL1802659 & 756582 & 6.475 & 5.3796 & TRN & \\
\hline CHEMBL1802652 & 756582 & 5.7033 & 6.5934 & TRN & \\
\hline CHEMBL1802880 & 756582 & 4.3625 & 5.7365 & TRN & \\
\hline CHEMBL1802949 & 756582 & 6.8447 & 7.4253 & TRN & \\
\hline CHEMBL1802946 & 756582 & 7.1057 & 6.9256 & TRN & \\
\hline CHEMBL1802876 & 756582 & 6.8153 & 6.7804 & TRN & \\
\hline CHEMBL1802889 & 756582 & 4.0458 & 5.0179 & TRN & \\
\hline CHEMBL1802934 & 756582 & 8.2518 & 8.1048 & TRN & \\
\hline CHEMBL1802879 & 756582 & 7.7212 & 6.5742 & TRN & \\
\hline CHEMBL1802694 & 756582 & 6.1904 & 6.0371 & TRN & \\
\hline CHEMBL1802647 & 756582 & 6.2076 & 5.4568 & TRN & \\
\hline CHEMBL1802719 & 756582 & 6.1512 & 6.23600 & 0000000001 & TRN \\
\hline CHEMBL1802718 & 756582 & 5.5467 & 6.4366 & TRN & \\
\hline CHEMBL1802927 & 756582 & 7.3468 & 7.977 & TST & \\
\hline CHEMBL1802716 & 756582 & 5.4609 & 5.0683 & TRN & \\
\hline CHEMBL1802703 & 756582 & 4.0092 & 3.9339 & TRN & \\
\hline CHEMBL1802875 & 756582 & 7.0004 & 6.8907 & TRN & \\
\hline CHEMBL1802697 & 756582 & 6.0182 & 5.8423 & TST & \\
\hline CHEMBL1802710 & 756582 & 6.1146 & 5.2042 & TST & \\
\hline CHEMBL1802664 & 756582 & $5.7570 e$ & 00000000 & 5.5455 & TR \\
\hline CHEMBL1802882 & 756582 & 5.341 & 5.1374 & TRN & \\
\hline CHEMBL1802940 & 756582 & 4.0004 & 3.7349 & TST & \\
\hline CHEMBL1802723 & 756582 & 8.0605 & 7.6895 & TRN & \\
\hline CHEMBL1802937 & 756582 & 7.7905 & 7.279 & TRN & \\
\hline CHEMBL1802644 & 756582 & 7.1979 & 6.6211 & TRN & \\
\hline CHEMBL1802665 & 756582 & 6.0155 & 5.9735 & TRN & \\
\hline CHEMBL1802725 & 756582 & 6.7932 & 6.9463 & TRN & \\
\hline CHEMBL1802921 & 756582 & 4.0306 & 4.2551 & TRN & \\
\hline CHEMBL1802696 & 756582 & 5.2733 & 5.3468 & TRN & \\
\hline CHEMBL1802646 & 756582 & 6.5302 & 5.9038 & TRN & \\
\hline CHEMBL116408 & 756582 & 6.5229 & 7.0084 & TST & \\
\hline CHEMBL1802663 & 756582 & 5.3872 & 4.5033 & TRN & \\
\hline CHEMBL1802666 & 756582 & 6.4962 & 5.9417 & TRN & \\
\hline CHEMBL1802648 & 756582 & $6.7570 e$ & 00000000 & 6.7862 & mo \\
\hline CHEMBL1802919 & 756582 & 5.4698 & 5.8833 & TRN & \\
\hline CHEMBL586279 & 756582 & 6.9136 & 6.5799 & TRN & \\
\hline CHEMBL1802708 & 756582 & 7.2343 & 6.6955 & TRN & \\
\hline CHEMBL1802724 & 756582 & 7.5969 & 7.5699 & TRN & \\
\hline CHEMBL1802928 & 756582 & 6.4225 & 6.2071 & TRN & \\
\hline CHEMBL1802938 & 756582 & 7.0137 & 7.0789 & TRN & \\
\hline CHEMBL1802943 & 756582 & 5.0752 & 5.8524 & TRN & \\
\hline CHEMBL1802924 & 756582 & 6.4672 & 6.0723 & TRN & \\
\hline CHEMBL1802888 & 756582 & 5.3401 & 5.0864 & TRN & \\
\hline CHEMBL1802947 & 756582 & 7.6345 & 7.1692 & TRN & \\
\hline \multirow[t]{2}{*}{ CHEMBL1802645 } & 756582 & 6.3497 & $5.7010 €$ & 00000000005 & \\
\hline & & \multicolumn{3}{|c|}{ Page 13838} & \\
\hline
\end{tabular}


Supplemental Table S2.txt

\begin{tabular}{|c|c|c|c|c|c|c|}
\hline CHEMBL1802661 & 756582 & 6.9508 & 6.1904 & TRN & & \\
\hline CHEMBL1802935 & 756582 & 6.6459 & 7.3909 & TRN & & \\
\hline CHEMBL1802662 & 756582 & 4.0123 & 4.7173 & TRN & & \\
\hline CHEMBL1802698 & 756582 & 6.4214 & 5.6898 & TST & & \\
\hline CHEMBL1802717 & 756582 & 6.4868 & 7.6534 & TRN & & \\
\hline CHEMBL1800102 & 756582 & 6.6655 & 6.42899 & 999999995 & & TR \\
\hline CHEMBL1802704 & 756582 & 6.4881 & 6.5219 & TRN & & \\
\hline CHEMBL1802878 & 756582 & 6.3585 & 6.061 & TRN & & \\
\hline CHEMBL1802945 & 756582 & 5.0711 & 4.7315 & TRN & & \\
\hline CHEMBL1802925 & 756582 & 5.8794 & 6.4571 & TST & & \\
\hline CHEMBL1802667 & 756582 & 4.0004 & 4.462 & TRN & & \\
\hline CHEMBL1802700 & 756582 & 6.9245 & 7.0943 & TRN & & \\
\hline CHEMBL1802941 & 756582 & 7.3279 & 6.9877 & TRN & & \\
\hline CHEMBL1802726 & 756582 & 8.041 & 7.8662 & TRN & & \\
\hline CHEMBL1802699 & 756582 & 5.5361 & 6.2434 & TRN & & \\
\hline CHEMBL1802883 & 756582 & 5.5969 & 5.8202 & TRN & & \\
\hline CHEMBL1802653 & 756582 & 5.6615 & 6.1842 & TRN & & \\
\hline CHEMBL1802930 & 756582 & 7.9393 & 7.5881 & TRN & & \\
\hline CHEMBL1802715 & 756582 & 5.5867 & 4.9508 & TRN & & \\
\hline CHEMBL1802932 & 756582 & 6.983 & 7.6639 & TRN & & \\
\hline CHEMBL1802923 & 756582 & 4.0301 & 4.8745 & TRN & & \\
\hline CHEMBL1487406 & 756582 & 7.1891 & 6.0352 & TST & & \\
\hline CHEMBL1802714 & 756582 & 5.098 & 4.5128 & TRN & & \\
\hline CHEMBL1802887 & 756582 & 6.1831 & 5.9683 & TRN & & \\
\hline CHEMBL1802885 & 756582 & 6.0516 & 5.3441 & TRN & & \\
\hline CHEMBL602366 & 756582 & 6.4881 & 5.2509 & TST & & \\
\hline CHEMBL1802948 & 756582 & 7.2366 & 6.8868 & TRN & & \\
\hline CHEMBL1802942 & 756582 & 5.8665 & 6.0753 & TRN & & \\
\hline CHEMBL1802695 & 756582 & 6.2692 & 6.4484 & TST & & \\
\hline CHEMBL1802707 & 756582 & 6.6459 & 6.4029 & TST & & \\
\hline CHEMBL1802660 & 756582 & 5.6038 & 5.1083 & TST & & \\
\hline CHEMBL1802874 & 756582 & 6.2147 & 6.3878 & TST & & \\
\hline CHEMBL1802933 & 756582 & 6.8861 & 7.4381 & TST & & \\
\hline CHEMBL1802705 & 756582 & 4.0292 & 4.1949 & TST & & \\
\hline CHEMBL1802654 & 756582 & \multicolumn{3}{|c|}{5.3839999999999995} & 5.445 & ST \\
\hline CHEMBL1802926 & 756582 & 6.3925 & 6.2475 & TST & & \\
\hline CHEMBL1802931 & 756582 & 7.61799 & 99999999 & 99 & 7.6616 & ובוד \\
\hline CHEMBL1802702 & 756582 & 6.9393 & 6.309 & TST & & \\
\hline CHEMBL1802936 & 756582 & 6.4547 & 7.4241 & TST & & \\
\hline CHEMBL1802657 & 756582 & 6.9281 & 6.581 & TST & & \\
\hline CHEMBL1802701 & 756582 & 6.7773 & 5.7621 & TST & & \\
\hline CHEMBL1802884 & 756582 & 5.2262 & 5.0912 & TST & & \\
\hline CHEMBL1802721 & 756582 & 6.5331 & 6.9004 & TST & & \\
\hline CHEMBL1802929 & 756582 & 6.9281 & 7.2515 & TST & & \\
\hline CHEMBL1915912 & 787238 & 7.5229 & 7.3148 & TST & & \\
\hline CHEMBL1916094 & 787238 & 7.3915 & 7.5064 & TRN & & \\
\hline CHEMBL1916108 & 787238 & 7.8665 & 7.8405 & TRN & & \\
\hline CHEMBL1916114 & 787238 & 7.0362 & 7.1017 & TRN & & \\
\hline
\end{tabular}

Page 13839 
Supplemental Table S2.txt

\begin{tabular}{|c|c|c|c|c|c|}
\hline CHEMBL1916126 & 787238 & 6.3002 & 6.3504 & TRN & \\
\hline CHEMBL1916097 & 787238 & 7.6596 & \multicolumn{2}{|c|}{7.662999999999999} & TRN \\
\hline CHEMBL1916106 & 787238 & 7.6383 & 7.6848 & TRN & \\
\hline CHEMBL1916104 & 787238 & 7.0506 & 6.9738 & TRN & \\
\hline CHEMBL1915908 & 787238 & 6.5243 & 6.5824 & TRN & \\
\hline CHEMBL1916115 & 787238 & 6.2069 & 6.9333 & TST & \\
\hline CHEMBL1915901 & 787238 & 7.9393 & 7.9978 & TRN & \\
\hline CHEMBL1915896 & 787238 & 7.4318 & 7.5225 & TST & \\
\hline CHEMBL1915907 & 787238 & 6.5591 & 7.1851 & TST & \\
\hline CHEMBL1915905 & 787238 & 7.4486 & 7.4593 & TRN & \\
\hline CHEMBL1916113 & 787238 & 6.9666 & 6.8638 & TRN & \\
\hline CHEMBL1916131 & 787238 & 6.3862 & 6.3176 & TRN & \\
\hline CHEMBL1916101 & 787238 & 7.1249 & 7.3929 & TST & \\
\hline CHEMBL1086110 & 787238 & 6.5686 & 7.3121 & TST & \\
\hline CHEMBL1916132 & 787238 & 6.4881 & 6.5009 & TRN & \\
\hline CHEMBL1916139 & 787238 & 7.6576 & 7.359 & TST & \\
\hline CHEMBL1915906 & 787238 & 7.2076 & 7.2603 & TST & \\
\hline CHEMBL1915892 & 787238 & 7.5607 & 7.5029 & TRN & \\
\hline CHEMBL1915894 & 787238 & 6.6253 & 6.5845 & TRN & \\
\hline CHEMBL1916111 & 787238 & 6.8153 & 6.8661 & TRN & \\
\hline CHEMBL1915891 & 787238 & 7.9586 & 7.9507 & TRN & \\
\hline CHEMBL1916090 & 787238 & 7.7696 & 7.7588 & TRN & \\
\hline CHEMBL1915902 & 787238 & 8.1308 & 8.1473 & TRN & \\
\hline CHEMBL1916120 & 787238 & 6.2083 & 6.1806 & TRN & \\
\hline CHEMBL1916091 & 787238 & 7.4202 & 7.3153 & TRN & \\
\hline CHEMBL1916117 & 787238 & 7.1805 & 7.1343 & TRN & \\
\hline CHEMBL1915889 & 787238 & 6.8697 & 6.8539 & TRN & \\
\hline CHEMBL1916130 & 787238 & 6.9508 & 6.9442 & TRN & \\
\hline CHEMBL1915909 & 787238 & 7.5686 & 7.1173 & TST & \\
\hline CHEMBL1916137 & 787238 & 6.8928 & 6.8734 & TRN & \\
\hline CHEMBL1916133 & 787238 & 7.1549 & 7.1055 & TRN & \\
\hline CHEMBL1915890 & 787238 & 7.9355 & 7.9088 & TRN & \\
\hline CHEMBL1916125 & 787238 & 7.5229 & 7.55399 & 9999999999 & TRN \\
\hline CHEMBL1916124 & 787238 & 7.0809 & 7.0132 & TRN & \\
\hline CHEMBL1915897 & 787238 & 7.71 & 7.6366 & TRN & \\
\hline CHEMBL1915899 & 787238 & 8.0223 & 8.0037 & TRN & \\
\hline CHEMBL1916123 & 787238 & 6.7825 & 6.8002 & TRN & \\
\hline CHEMBL1916093 & 787238 & 7.6198 & 7.6334 & TRN & \\
\hline CHEMBL1915910 & 787238 & 7.6091 & 7.3547 & TST & \\
\hline CHEMBL1916109 & 787238 & 7.8327 & 7.8372 & TRN & \\
\hline CHEMBL1916138 & 787238 & 7.0915 & 7.0865 & TRN & \\
\hline CHEMBL1915900 & 787238 & 7.5243 & 7.5691 & TRN & \\
\hline CHEMBL1916116 & 787238 & 6.7122 & 6.9107 & TST & \\
\hline CHEMBL1916135 & 787238 & 7.6655 & 7.6218 & TRN & \\
\hline CHEMBL1916127 & 787238 & 7.3768 & 7.3147 & TRN & \\
\hline CHEMBL1915888 & 787238 & 7.3279 & 7.4199 & TRN & \\
\hline CHEMBL1916129 & 787238 & 7.1487 & 7.1693 & TRN & \\
\hline CHEMBL1916089 & 787238 & 7.4949 & 7.4866 & TRN & \\
\hline
\end{tabular}


Supplemental Table S2.txt

\begin{tabular}{|c|c|c|c|c|}
\hline CHEMBL1916096 & 787238 & 6.9355 & 7.3458 & TST \\
\hline CHEMBL1915893 & 787238 & 7.1938 & 7.2535 & TST \\
\hline CHEMBL1916103 & 787238 & 7.8539 & 7.7803 & TRN \\
\hline CHEMBL1916134 & 787238 & 7.1518 & 7.3136 & TRN \\
\hline CHEMBL1916095 & 787238 & 7.7352 & 7.5155 & TST \\
\hline CHEMBL1915898 & 787238 & 7.8827 & 7.9363 & TST \\
\hline CHEMBL1916112 & 787238 & 6.5157 & 6.6366 & TRN \\
\hline CHEMBL1916119 & 787238 & 6.5229 & 6.5501 & TRN \\
\hline CHEMBL1916118 & 787238 & 6.8601 & 6.8779 & TRN \\
\hline CHEMBL1915904 & 787238 & 8.2676 & 7.5704 & TST \\
\hline CHEMBL1916136 & 787238 & 7.4437 & 7.3801 & TRN \\
\hline CHEMBL1916102 & 787238 & 7.3979 & 7.4614 & TRN \\
\hline CHEMBL1915903 & 787238 & 6.9666 & 7.557 & TST \\
\hline CHEMBL3730725 & 1537512 & 7.2218 & 7.309 & TRN \\
\hline CHEMBL3727419 & 1537512 & 7.2218 & 7.274 & TRN \\
\hline CHEMBL3732488 & 1537512 & 7.2218 & 7.2082 & TRN \\
\hline CHEMBL3727713 & 1537512 & 4.9208 & 5.9013 & TRN \\
\hline CHEMBL3729028 & 1537512 & 7.2218 & 7.3281 & TRN \\
\hline CHEMBL3729649 & 1537512 & 7.2218 & 7.1002 & TRN \\
\hline CHEMBL3733096 & 1537512 & 7.2218 & 7.3827 & TRN \\
\hline CHEMBL3733351 & 1537512 & 7.2218 & 7.3149 & TRN \\
\hline CHEMBL3729573 & 1537512 & 7.2218 & 7.3569 & TRN \\
\hline CHEMBL3731668 & 1537512 & 7.2218 & 7.1431 & TRN \\
\hline CHEMBL3730577 & 1537512 & 7.2218 & 7.2162 & TRN \\
\hline CHEMBL3733110 & 1537512 & 7.2218 & 7.3998 & TRN \\
\hline CHEMBL3733011 & 1537512 & 7.2218 & 7.3255 & TST \\
\hline CHEMBL3732833 & 1537512 & 7.2218 & 6.9209 & TRN \\
\hline CHEMBL3732175 & 1537512 & 7.2218 & 6.6061 & TRN \\
\hline CHEMBL3728688 & 1537512 & 7.2218 & 7.4339 & TRN \\
\hline CHEMBL3727759 & 1537512 & 6.2218 & 6.7066 & TRN \\
\hline CHEMBL3731241 & 1537512 & 7.2218 & 7.2803 & TRN \\
\hline CHEMBL3728467 & 1537512 & 7.2218 & 7.2048 & TRN \\
\hline CHEMBL3728717 & 1537512 & 6.2218 & 6.2125 & TRN \\
\hline CHEMBL3729364 & 1537512 & 4.9208 & 6.0124 & TRN \\
\hline CHEMBL3731071 & 1537512 & 6.2218 & 6.3966 & TRN \\
\hline CHEMBL3728982 & 1537512 & 7.2218 & 7.2531 & TRN \\
\hline CHEMBL3730437 & 1537512 & 7.2218 & 7.1915 & TRN \\
\hline CHEMBL3729327 & 1537512 & 7.2218 & 7.3639 & TRN \\
\hline CHEMBL3731436 & 1537512 & 7.2218 & 7.2839 & TRN \\
\hline CHEMBL3727596 & 1537512 & 4.9208 & 7.0495 & TST \\
\hline CHEMBL3732454 & 1537512 & 7.2218 & 6.4547 & TRN \\
\hline CHEMBL3727723 & 1537512 & 7.2218 & 7.249 & TRN \\
\hline CHEMBL3728472 & 1537512 & 7.2218 & 7.0263 & TST \\
\hline CHEMBL3732391 & 1537512 & 7.2218 & 7.1263 & TRN \\
\hline CHEMBL3728586 & 1537512 & 7.2218 & 7.3828 & TRN \\
\hline CHEMBL3733145 & 1537512 & 7.2218 & 7.4598 & TRN \\
\hline CHEMBL3733337 & 1537512 & 7.2218 & \multicolumn{2}{|c|}{6.827000000000001} \\
\hline CHEMBL3729876 & 1537512 & 7.2218 & 6.9783 & TST \\
\hline
\end{tabular}


Supplemental Table S2.txt

\begin{tabular}{|c|c|c|c|c|}
\hline CHEMBL3732172 & 1537512 & 7.2218 & 7.3025 & TRN \\
\hline CHEMBL3731683 & 1537512 & 7.2218 & 7.4464 & TRN \\
\hline CHEMBL3729608 & 1537512 & 7.2218 & 6.9098 & TST \\
\hline CHEMBL3731335 & 1537512 & 7.2218 & 7.1311 & TRN \\
\hline CHEMBL3732356 & 1537512 & 7.2218 & 7.1695 & TRN \\
\hline CHEMBL3731956 & 1537512 & 7.2218 & 7.0545 & TST \\
\hline CHEMBL3727582 & 1537512 & 7.2218 & 7.4687 & TST \\
\hline CHEMBL3732413 & 1537512 & 7.2218 & 7.1712 & TRN \\
\hline CHEMBL3729622 & 1537512 & 7.2218 & 7.5447 & TST \\
\hline CHEMBL3728333 & 1537512 & 7.2218 & 7.5439 & TRN \\
\hline CHEMBL 3731260 & 1537512 & 7.2218 & 6.9657 & TRN \\
\hline CHEMBL3733297 & 1537512 & 7.2218 & 6.8473 & TST \\
\hline CHEMBL3727896 & 1537512 & 7.2218 & 7.2637 & TRN \\
\hline CHEMBL 3728084 & 1537512 & 7.2218 & 6.7465 & TST \\
\hline CHEMBL3730653 & 1537512 & 7.2218 & 6.6602 & TRN \\
\hline CHEMBL 3727392 & 1537512 & 7.2218 & 7.0729 & TST \\
\hline CHEMBL3728373 & 1537512 & 4.9208 & 7.4482 & TST \\
\hline CHEMBL 3732098 & 1537512 & 7.2218 & 7.1409 & TRN \\
\hline CHEMBL3732550 & 1537512 & 7.2218 & 7.1186 & TRN \\
\hline CHEMBL3727650 & 1537512 & 7.2218 & 7.1923 & TST \\
\hline CHEMBL3731997 & 1537512 & 6.2218 & 7.6476 & TST \\
\hline CHEMBL3732851 & 1537512 & 7.2218 & 6.8502 & TRN \\
\hline CHEMBL3730422 & 1537512 & 7.2218 & 7.316 & TRN \\
\hline CHEMBL3730066 & 1537512 & 7.2218 & 7.1613 & TRN \\
\hline CHEMBL3732517 & 1537512 & 7.2218 & 7.3543 & TRN \\
\hline CHEMBL3730095 & 1537512 & 7.2218 & 6.9352 & TST \\
\hline CHEMBL 3732872 & 1537512 & 7.2218 & 7.4154 & TST \\
\hline CHEMBL3732485 & 1537512 & 6.2218 & 6.6533 & TRN \\
\hline CHEMBL 3730763 & 1537512 & 7.2218 & 6.96299 & 9999999999 \\
\hline CHEMBL3732507 & 1537512 & 7.2218 & 6.4489 & TRN \\
\hline CHEMBL3728924 & 1537512 & 7.2218 & 7.03299 & 99999999995 \\
\hline CHEMBL 3730702 & 1537512 & 7.2218 & 7.1934 & TRN \\
\hline CHEMBL3730994 & 1537512 & 7.2218 & 7.0726 & TST \\
\hline CHEMBL 3727719 & 1537512 & 7.2218 & 6.6358 & TRN \\
\hline CHEMBL 3730751 & 1537512 & 7.2218 & 7.0946 & TRN \\
\hline CHEMBL3727557 & 1537512 & 7.2218 & 7.2011 & TRN \\
\hline CHEMBL 2165041 & 860330 & 5.0 & 4.7054 & TST \\
\hline CHEMBL2165017 & 860330 & 7.7959 & 7.6314 & TRN \\
\hline CHEMBL 2165040 & 860330 & 5.0 & 4.5934 & TRN \\
\hline CHEMBL 2165007 & 860330 & 7.9586 & 8.0305 & TRN \\
\hline CHEMBL2165031 & 860330 & 7.0555 & 6.9263 & TRN \\
\hline CHEMBL 2165030 & 860330 & 7.3279 & 7.6261 & TRN \\
\hline CHEMBL2165026 & 860330 & 7.0555 & 6.7506 & TRN \\
\hline CHEMBL 2165039 & 860330 & 6.5528 & 6.0459 & TST \\
\hline CHEMBL2165043 & 860330 & 5.0 & 4.7664 & TST \\
\hline CHEMBL 2165020 & 860330 & 7.2676 & 7.6647 & TRN \\
\hline CHEMBL 2165045 & 860330 & 5.0 & 5.5077 & TST \\
\hline CHEMBL 2165032 & 860330 & 7.5376 & 7.3262 & TRN \\
\hline
\end{tabular}

Page 13842 


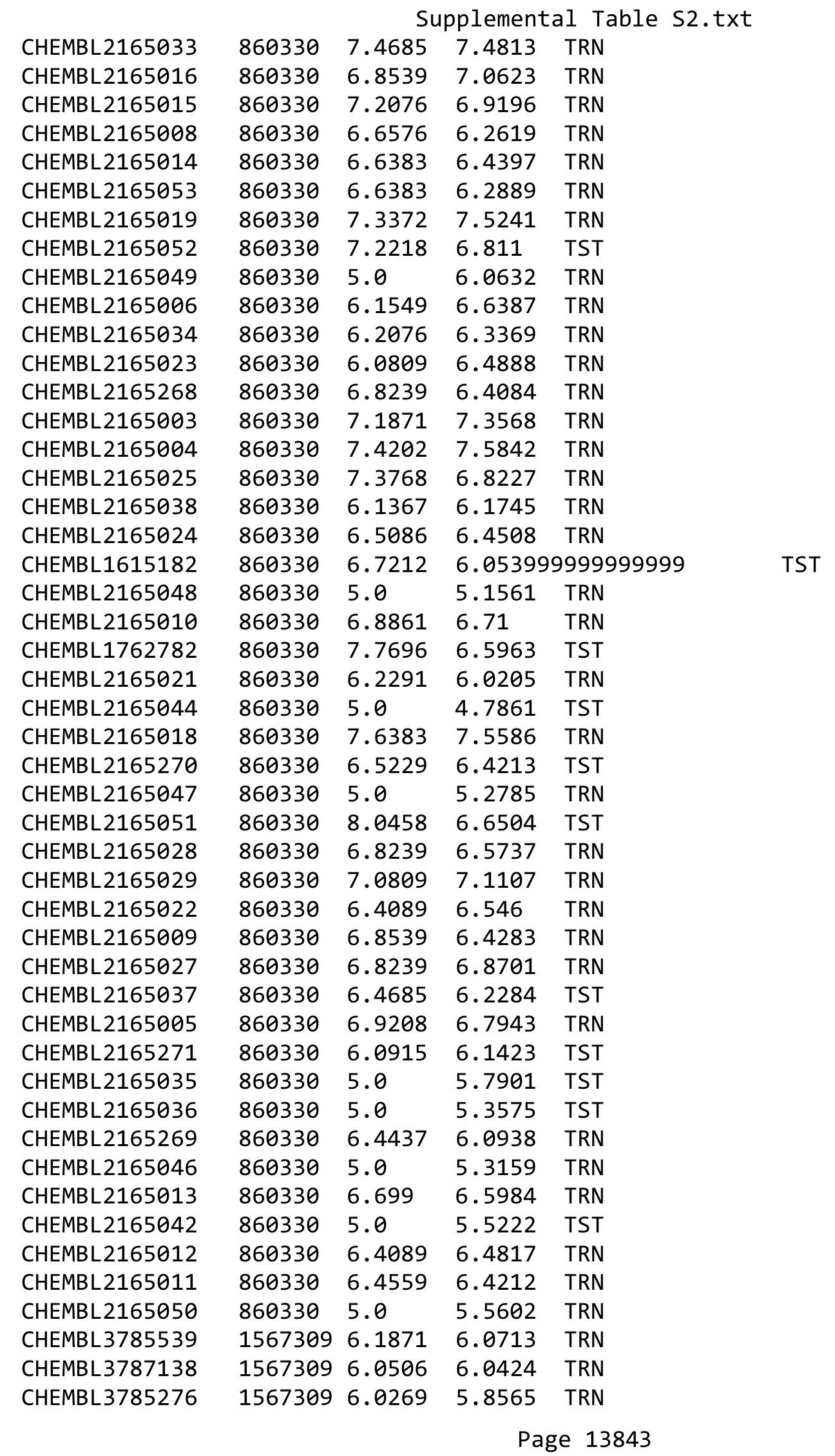


Supplemental Table S2.txt

\begin{tabular}{|c|c|c|c|c|}
\hline HEMBL & 567309 & & 5.3434 & \\
\hline & 567309 & 4.7212 & 4.85 & \\
\hline EM $>>$ & 67309 & 284 & & \\
\hline HEMBL & 67309 & 208 & 9298 & \\
\hline AEMBL3787439 & 567309 & 5.1024 & 0636 & \\
\hline HEMBL3 & 567309 & 5.3279 & .4826 & \\
\hline 867 & 309 & 4.6576 & 5415 & \\
\hline HEMBL; & 309 & 5.8239 & 8282 & \\
\hline HEMBL3785138 & 567309 & 6.0044 & .9723 & \\
\hline HEMBL3 & 567309 & 4.4815 & 4823 & \\
\hline AEMBL & 309 & & 9826 & \\
\hline AEMBL & 309 & 576 & 7214 & \\
\hline AEMBL: & 309 & & 1507 & \\
\hline HEMBL3 & 567309 & 5.7696 & .7751 & \\
\hline AEMBL3 & 567309 & 6.0 & 5815 & \\
\hline HEMBL; & 39 & 6 & 9715 & RIN \\
\hline HEMBL & & & 315 & r \\
\hline HEMBL & 309 & & 371 & \\
\hline HFMBI 3 & 309 & & 9579 & \\
\hline AEMBL3 & & & 6536 & 的 \\
\hline HEMBL & 89 & & 378 & KIV \\
\hline HEM & & & 397 & RN \\
\hline HEMBL & 309 & 21 & 621 & RN \\
\hline AFMPI : & 309 & & 153 & I RIV \\
\hline AEMBL & & & 02 & RN \\
\hline HEMBL & & & 15 & RN \\
\hline HEM & & & 95 & KIV \\
\hline HEME & 09 & 38 & 2123 & \\
\hline AEMBL & & & & |S| \\
\hline AEMBL3 & 309 & 586 & 9541 & ГST \\
\hline AEMBL & 309 & 66 & 854 & 「RN \\
\hline 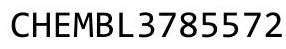 & & & 09 & 「RN \\
\hline 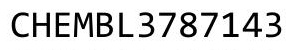 & & & 151 & TST \\
\hline HEMBL3 & & & 046 & 「RN \\
\hline HEMBL3 & 67309 & & & RN \\
\hline 71 & 309 & & 62 & ГST \\
\hline 2 & & & & TRN \\
\hline HEMBL3 & & & 5642 & TST \\
\hline HEMBL 2 & 309 & & 7712 & $\Gamma \mathrm{R}$ \\
\hline TIDL & 309 & & 409 & IST \\
\hline HEMBL3 & -0 & & 428 & TRN \\
\hline & & 28 & 458 & IST \\
\hline HEMBL3 & 567309 & 5.8539 & 1541 & TST \\
\hline HEMBL3 & 309 & 021 & 182 & $\Gamma R$ \\
\hline CHEMPI 2 & & & & RN \\
\hline HEMBL3 & 567309 & 17 & & \\
\hline CHEMBL3 & 567309 & & 981 & ST \\
\hline CHEMBL3785182 & 1567309 & 5.8239 & 5.8353 & 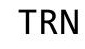 \\
\hline
\end{tabular}

Page 13844 
Supplemental Table S2.txt

\begin{tabular}{|c|c|c|c|c|}
\hline HEMBL & 567309 & 6.3979 & 6.3425 & TRN \\
\hline HEMBL178256 & 12127 & 6.0 & 6.0017 & \\
\hline HEMBL 361998 & 12127 & 4.0 & 7641 & \\
\hline HEMBL179127 & 12127 & 5.1487 & 4.5642 & CT \\
\hline HEMBL181876 & 12127 & 5.7447 & 4.1452 & \\
\hline HEMBL 361133 & 12127 & 6.0 & 5.8414 & \\
\hline HEMBL 319136 & 12127 & 5.8239 & 4.3555 & \\
\hline HEMBL181456 & 12127 & 6.0458 & 6.2746 & \\
\hline HEMBL178699 & 12127 & 3.5229 & 4.7822 & \\
\hline HEMBL433766 & 12127 & 6.1675 & 6.1358 & \\
\hline HEMBL179563 & 12127 & 6.8539 & 5.9481 & \\
\hline HEMBL180652 & 12127 & 6.1192 & 6.0912 & \\
\hline HEMBL181326 & 12127 & 6.5686 & .6548 & ST \\
\hline HEMBL 360993 & 12127 & 5.1739 & 5.3026 & \\
\hline HEMBL 361645 & 12127 & 5.0809 & 4.9698 & \\
\hline HEMBL181626 & 12127 & 5.7696 & 5.6893 & \\
\hline HEMBL427311 & 12127 & 5.8239 & 5.7757 & \\
\hline HEMBL178569 & 12127 & 4.7212 & 4.6461 & RN \\
\hline HEMBL180666 & 12127 & 5.3372 & 5.4611 & RN \\
\hline HEMBL 362828 & 12127 & 4.8861 & 5.0588 & N \\
\hline HEMBL361389 & 12127 & 5.4685 & 5.5941 & KIV \\
\hline HEMBL179132 & 12127 & 5.6021 & 4.9644 & SI \\
\hline HEMBL179368 & 12127 & 3.5229 & 4.7822 & RN \\
\hline HEMBL180757 & 12127 & 5.699 & 6.0597 & R \\
\hline HEMBL433950 & 12127 & 5.699 & 4.8594 & $\mathrm{RN}$ \\
\hline HEMBL 361780 & 12127 & 6.3872 & 6.4762 & RN \\
\hline HEMBL361006 & 12127 & 5.284 & 5.2066 & RN \\
\hline HEMBL179485 & 12127 & 3.5229 & 4.0132 & RN \\
\hline HEMBL367799 & 12127 & 5.8539 & 4.7641 & RN \\
\hline HEMBL178171 & 12127 & 5.2441 & 5.2452 & IRN \\
\hline HEMBL178253 & 12127 & 9208 & 6.0756 & RN \\
\hline HEMBL181737 & 2127 & 5.7447 & 5.5377 & $\mathrm{RN}$ \\
\hline CHEMBL181844 & 12127 & 05 & 5.864 & TRN \\
\hline HEMBL181386 & 12127 & 5.0044 & 4.6419 & IST \\
\hline HEMBL178906 & 12127 & 5.8539 & 5.6866 & TRN \\
\hline HEMBL425526 & 12127 & 5.6383 & 4.7822 & RN \\
\hline HEMBL17 & 12127 & 39 & 5.8038 & $\mathrm{RN}$ \\
\hline CHEMBL181473 & 12127 & 6.1249 & 5.8483 & TRN \\
\hline CHEMBL181553 & 12127 & 4.0 & 3.9317 & TRN \\
\hline HEMBL 360287 & 12127 & 4.0 & 4.9586 & TST \\
\hline CHEMBL362806 & 312127 & 6.1487 & 4.7822 & $\mathrm{RN}$ \\
\hline CHEMBL178288 & 312127 & 5.8539 & 5.8519 & $\mathrm{RN}$ \\
\hline CHEMBL180776 & 12127 & 5.8861 & 5.794 & TRN \\
\hline CHEMBL178524 & 12127 & 5.8861 & 5.9241 & TRN \\
\hline CHEMBL359658 & 12127 & 5.7696 & 5.8983 & RN \\
\hline CHEMBL178357 & 312127 & 5.301 & 5.3749 & RN \\
\hline CHEMBL179609 & 312127 & 5.0269 & 5.1266 & RN \\
\hline CHEMBL182239 & 312127 & 5.8539 & 5.7399 & $\mathrm{RN}$ \\
\hline
\end{tabular}

Page 13845 


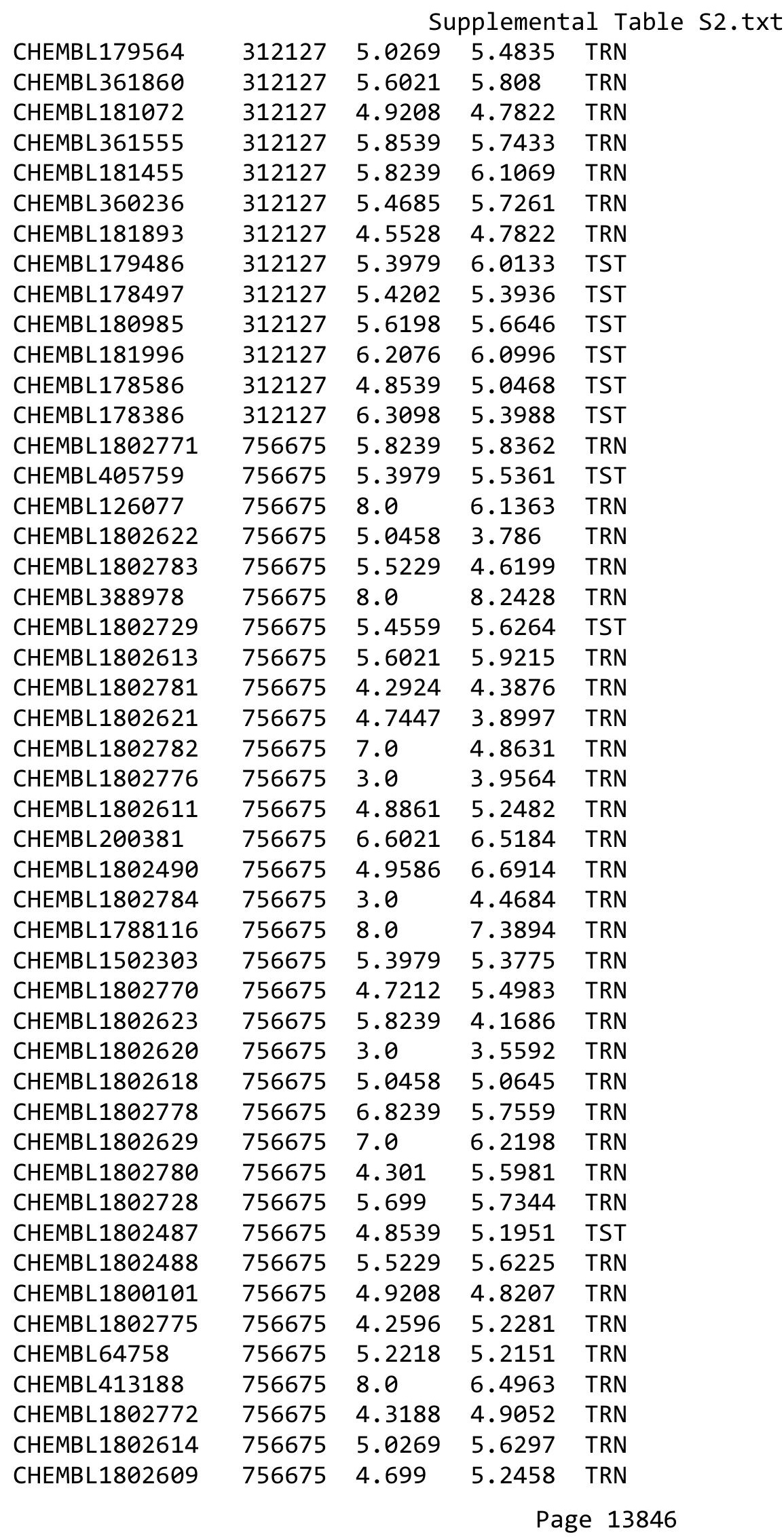




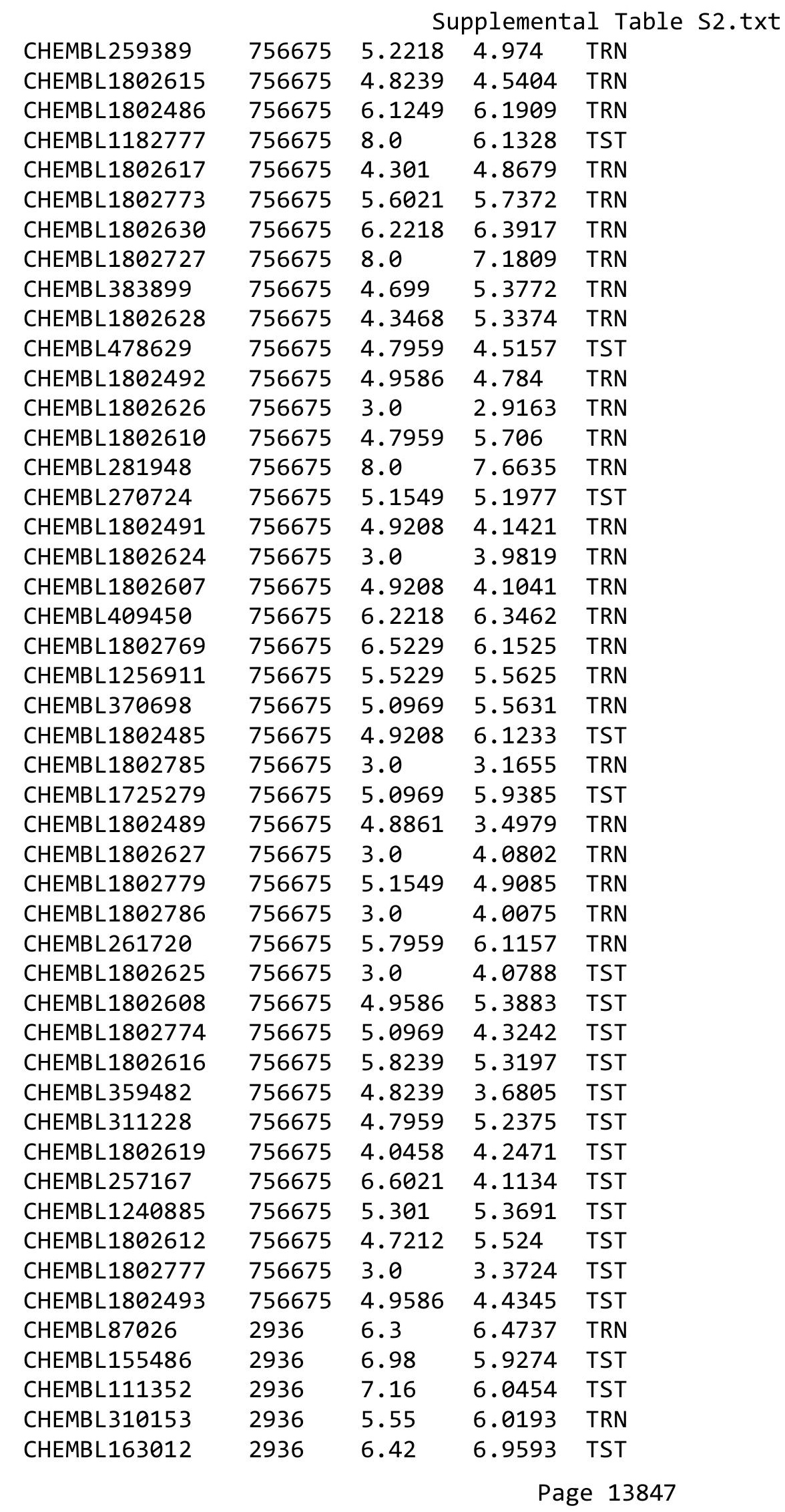




\begin{tabular}{|c|c|c|c|c|c|}
\hline \multicolumn{6}{|c|}{ Supplemental Table S2.txt } \\
\hline CHEMBL95112 & 2936 & 6.0 & 5.8153 & TRN & \\
\hline CHEMBL163180 & 2936 & 5.77 & 6.3065 & TRN & \\
\hline CHEMBL109548 & 2936 & 5.96 & 6.3331 & TRN & \\
\hline CHEMBL109528 & 2936 & 6.04 & 5.8811 & TRN & \\
\hline CHEMBL263790 & 2936 & 7.06 & 6.1015 & TST & \\
\hline CHEMBL142316 & 2936 & 6.0 & 5.8543 & TRN & \\
\hline CHEMBL87458 & 2936 & 6.08 & $6.1160 e$ & 00000000005 & TRN \\
\hline CHEMBL110847 & 2936 & 7.09 & 6.6442 & TRN & \\
\hline CHEMBL358895 & 2936 & 6.0 & 6.1128 & TRN & \\
\hline CHEMBL121744 & 2936 & 5.92 & 6.0948 & TST & \\
\hline CHEMBL325253 & 2936 & 5.4 & 5.55 & TRN & \\
\hline CHEMBL160907 & 2936 & 5.71 & 5.4409 & TRN & \\
\hline CHEMBL164471 & 2936 & 7.16 & 6.0328 & TST & \\
\hline CHEMBL87717 & 2936 & 6.78 & 6.4977 & TRN & \\
\hline CHEMBL109673 & 2936 & 6.48 & 6.5336 & TRN & \\
\hline CHEMBL159969 & 2936 & 6.38 & 6.4524 & TRN & \\
\hline CHEMBL141600 & 2936 & 6.0 & 6.1571 & TRN & \\
\hline CHEMBL142668 & 2936 & 6.0 & 5.8292 & TRN & \\
\hline CHEMBL143022 & 2936 & 6.0 & 6.2671 & TRN & \\
\hline CHEMBL161423 & 2936 & 6.55 & 6.3446 & TRN & \\
\hline CHEMBL92145 & 2936 & 6.63 & 6.5291 & TRN & \\
\hline CHEMBL357517 & 2936 & 6.0 & 6.0778 & TRN & \\
\hline CHEMBL160019 & 2936 & 6.24 & 6.4215 & TRN & \\
\hline CHEMBL159917 & 2936 & 6.0 & 6.1937 & TRN & \\
\hline CHEMBL110948 & 2936 & 6.9 & 6.153 & TST & \\
\hline CHEMBL310734 & 2936 & 6.0 & 5.8415 & TRN & \\
\hline CHEMBL111393 & 2936 & 6.03 & 5.9755 & TRN & \\
\hline CHEMBL444269 & 2936 & 6.44 & 6.1567 & TRN & \\
\hline CHEMBL159771 & 2936 & 6.07 & 6.0671 & TST & \\
\hline CHEMBL159929 & 2936 & 6.46 & 6.3641 & TRN & \\
\hline CHEMBL120903 & 2936 & 6.23 & 6.3241 & TRN & \\
\hline CHEMBL111509 & 2936 & 6.0 & 5.8774 & TRN & \\
\hline CHEMBL321682 & 2936 & 6.45 & 6.4187 & TRN & \\
\hline CHEMBL333174 & 2936 & 7.24 & 6.0528 & TST & \\
\hline CHEMBL143027 & 2936 & 6.0 & 5.9581 & TST & \\
\hline CHEMBL155006 & 2936 & 6.65 & 7.3171 & TST & \\
\hline CHEMBL143937 & 2936 & 6.64 & 6.1335 & TRN & \\
\hline CHEMBL87943 & 2936 & 6.65 & 6.5188 & TRN & \\
\hline CHEMBL111189 & 2936 & 6.4 & $5.9510 e$ & 00000000005 & TRN \\
\hline CHEMBL95098 & 2936 & 5.21 & 5.7795 & TRN & \\
\hline CHEMBL163605 & 2936 & 6.63 & 6.8794 & TRN & \\
\hline CHEMBL96781 & 2936 & 5.48 & 5.8964 & TRN & \\
\hline CHEMBL349832 & 2936 & 5.44 & 7.0117 & TST & \\
\hline CHEMBL162901 & 2936 & 7.45 & 7.3567 & TRN & \\
\hline CHEMBL159466 & 2936 & 6.0 & 5.8078 & TST & \\
\hline CHEMBL 308480 & 2936 & 6.63 & 6.3357 & TRN & \\
\hline CHEMBL94810 & 65482 & 7.6253 & 7.6729 & TRN & \\
\hline CHEMBL96347 & 65482 & 7.7645 & 7.7488 & TRN & \\
\hline
\end{tabular}




\begin{tabular}{|c|c|c|c|c|c|}
\hline & & \multicolumn{4}{|c|}{ Supplemental Table S2.txt } \\
\hline CHEMBL317589 & 65482 & 8.1938 & 8.1861 & TRN & \\
\hline CHEMBL94606 & 65482 & 6.8069 & 6.8265 & TRN & \\
\hline CHEMBL96387 & 65482 & 7.0061 & 7.0243 & TRN & \\
\hline CHEMBL316301 & 65482 & 8.1308 & 8.1446 & TRN & \\
\hline CHEMBL94212 & 65482 & 8.301 & 8.3348 & TRN & \\
\hline CHEMBL93612 & 65482 & 6.556 & 6.5229 & TRN & \\
\hline CHEMBL415010 & 65482 & 8.4559 & 8.4643 & TRN & \\
\hline CHEMBL316629 & 65482 & 7.9914 & 7.9984 & TRN & \\
\hline CHEMBL420435 & 65482 & 8.1871 & 8.1991 & TRN & \\
\hline CHEMBL 2112377 & 65482 & 7.2306 & 7.0423 & TST & \\
\hline CHEMBL314755 & 65482 & 8.2291 & 8.3004 & TRN & \\
\hline CHEMBL419148 & 65482 & 4.0 & 3.9666 & TRN & \\
\hline CHEMBL330135 & 65482 & 8.1192 & 8.0507 & TRN & \\
\hline CHEMBL 327823 & 65482 & 5.4034 & 6.8763 & TST & \\
\hline CHEMBL 317510 & 65482 & 8.2007 & 8.1224 & TRN & \\
\hline CHEMBL440507 & 65482 & 6.6757 & 6.6685 & TRN & \\
\hline CHEMBL329251 & 65482 & 8.9586 & 8.98200 & 0000000001 & TRN \\
\hline CHEMBL450628 & 65482 & 6.4123 & 6.3869 & TRN & \\
\hline CHEMBL330104 & 65482 & 8.7447 & 8.588 & TRN & \\
\hline CHEMBL92612 & 65482 & 5.8041 & 5.843 & TST & \\
\hline CHEMBL316453 & 65482 & 8.5229 & 8.3536 & TRN & \\
\hline CHEMBL95095 & 65482 & 8.041 & 8.0696 & TRN & \\
\hline CHEMBL 94962 & 65482 & 7.5884 & 7.6099 & TRN & \\
\hline CHEMBL 318270 & 65482 & 7.6882 & 7.6451 & TRN & \\
\hline CHEMBL91873 & 65482 & 8.6021 & 8.5899 & TRN & \\
\hline CHEMBL314946 & 65482 & 8.0506 & 8.002 & TRN & \\
\hline CHEMBL94602 & 65482 & 6.8894 & 6.91799 & 9999999999 & TRN \\
\hline CHEMBL96422 & 65482 & 7.9586 & 7.9861 & TRN & \\
\hline CHEMBL431460 & 65482 & 7.5186 & 7.4979 & TRN & \\
\hline CHEMBL96318 & 65482 & 8.1367 & 8.1603 & TRN & \\
\hline CHEMBL431087 & 65482 & 7.5157 & 7.3691 & TRN & \\
\hline CHEMBL96171 & 65482 & 8.4089 & 8.4064 & TRN & \\
\hline CHEMBL421184 & 65482 & 4.0 & 4.0414 & TRN & \\
\hline CHEMBL420072 & 65482 & 4.0 & 4.004 & TRN & \\
\hline CHEMBL94091 & 65482 & 6.6556 & 6.7393 & TRN & \\
\hline CHEMBL318683 & 65482 & 6.4157 & 6.0387 & TST & \\
\hline CHEMBL94964 & 65482 & 8.1805 & 7.8813 & TST & \\
\hline CHEMBL94580 & 65482 & 8.6198 & 8.5893 & TRN & \\
\hline CHEMBL96520 & 65482 & 6.0329 & 5.8209 & TST & \\
\hline CHEMBL329477 & 65482 & 8.6021 & 8.4988 & TRN & \\
\hline CHEMBL314511 & 65482 & 5.2277 & 4.0507 & TST & \\
\hline CHEMBL96351 & 65482 & 5.4157 & 6.8262 & TST & \\
\hline CHEMBL96831 & 65482 & 7.1561 & 6.9773 & TST & \\
\hline CHEMBL96114 & 65482 & 7.767 & 7.7688 & TRN & \\
\hline CHEMBL318247 & 65482 & 8.2218 & 8.2377 & TRN & \\
\hline CHEMBL94802 & 65482 & 7.6882 & 7.3932 & TST & \\
\hline CHEMBL94766 & 65482 & 7.9281 & 7.9296 & TRN & \\
\hline CHEMBL330425 & 65482 & 7.9101 & 7.8682 & TRN & \\
\hline
\end{tabular}




\begin{tabular}{|c|c|c|c|c|c|c|}
\hline & & \multicolumn{5}{|c|}{ Supplemental Table S2.txt } \\
\hline CHEMBL330359 & 65482 & 7.3382 & 7.3566 & TRN & & \\
\hline CHEMBL419136 & 65482 & 8.1739 & 8.2073 & TRN & & \\
\hline CHEMBL96154 & 65482 & 7.767 & 7.7883 & TRN & & \\
\hline CHEMBL422068 & 65482 & 8.1024 & 8.1484 & TRN & & \\
\hline CHEMBL328878 & 65482 & 8.1612 & 8.1809 & TRN & & \\
\hline CHEMBL313870 & 65482 & \multicolumn{3}{|c|}{7.7620000000000005} & \multirow[t]{25}{*}{7.7536} & TRN \\
\hline CHEMBL406551 & 65482 & 8.1675 & 8.1615 & TRN & & \\
\hline CHEMBL431286 & 65482 & 8.8539 & 8.8852 & TRN & & \\
\hline CHEMBL96125 & 65482 & 6.5817 & 7.1197 & TST & & \\
\hline CHEMBL93820 & 65482 & 8.4318 & 8.4847 & TRN & & \\
\hline CHEMBL96704 & 65482 & 7.7235 & 7.7608 & TST & & \\
\hline CHEMBL313867 & 65482 & 7.8861 & 7.8718 & TRN & & \\
\hline CHEMBL419879 & 65482 & 8.1427 & 8.1442 & TRN & & \\
\hline CHEMBL93084 & 65482 & 8.1871 & 8.1758 & TRN & & \\
\hline CHEMBL330354 & 65482 & 7.857 & 7.8935 & TRN & & \\
\hline CHEMBL 94934 & 65482 & 8.1367 & 8.1206 & TRN & & \\
\hline CHEMBL316851 & 65482 & 7.6038 & 7.6097 & TRN & & \\
\hline CHEMBL96325 & 65482 & 6.9957 & 6.4761 & TST & & \\
\hline CHEMBL329744 & 65482 & 6.4498 & 7.05 & TST & & \\
\hline CHEMBL94446 & 65482 & 6.9914 & 7.0331 & TRN & & \\
\hline CHEMBL96472 & 65482 & 7.9914 & 7.9764 & TRN & & \\
\hline CHEMBL317981 & 65482 & 4.0 & 4.262 & TST & & \\
\hline CHEMBL96932 & 65482 & 8.5086 & 8.5502 & TRN & & \\
\hline CHEMBL319754 & 65482 & 8.1024 & 8.1672 & TRN & & \\
\hline CHEMBL330629 & 65482 & 6.2182 & 6.9475 & TST & & \\
\hline CHEMBL94438 & 65482 & 8.1739 & 8.1546 & TRN & & \\
\hline CHEMBL91926 & 65482 & 7.7696 & 7.7595 & TRN & & \\
\hline CHEMBL329943 & 65482 & 7.0788 & 7.0256 & TRN & & \\
\hline CHEMBL 95013 & 65482 & 8.1938 & 8.2856 & TRN & & \\
\hline CHEMBL94488 & 65482 & 7.3354 & 7.2858 & TST & & \\
\hline CHEMBL96313 & 65482 & 7.6021 & \multicolumn{3}{|c|}{7.542000000000001} & T TRT \\
\hline CHEMBL328073 & 65482 & 6.9508 & 6.3853 & TST & & \\
\hline CHEMBL96331 & 65482 & 7.0376 & 6.7925 & TST & & \\
\hline CHEMBL330045 & 65482 & \multicolumn{3}{|c|}{6.218999999999999} & 7.3161 & TST \\
\hline CHEMBL96463 & 65482 & 6.9101 & 6.9431 & TRN & & \\
\hline CHEMBL316878 & 65482 & 8.3372 & 8.4417 & TRN & & \\
\hline CHEMBL329132 & 65482 & 6.3536 & 5.9664 & TST & & \\
\hline CHEMBL 96723 & 65482 & 8.4559 & 8.4618 & TRN & & \\
\hline CHEMBL96506 & 65482 & 6.983 & 6.9543 & TRN & & \\
\hline CHEMBL327976 & 65482 & 8.2366 & 8.2154 & TRN & & \\
\hline CHEMBL319007 & 65482 & 8.041 & 8.019 & TRN & & \\
\hline CHEMBL96906 & 65482 & 7.6308 & 7.6812 & TRN & & \\
\hline CHEMBL96746 & 65482 & 8.1739 & 8.1627 & TRN & & \\
\hline CHEMBL94370 & 65482 & 4.0 & 4.8138 & TST & & \\
\hline CHEMBL318086 & 65482 & 7.7721 & 7.9443 & TRN & & \\
\hline CHEMBL95017 & 65482 & 8.1024 & 8.1106 & TRN & & \\
\hline CHEMBL96303 & 65482 & 7.7375 & 7.6714 & TRN & & \\
\hline CHEMBL96614 & 65482 & 7.2526 & 7.4878 & TST & & \\
\hline
\end{tabular}




\begin{tabular}{|c|c|c|c|c|c|}
\hline & & \multicolumn{4}{|c|}{ Supplemental Table s2.txt } \\
\hline CHEMBL94769 & 65482 & 7.5376 & 7.4978 & TST & \\
\hline CHEMBL264625 & 65482 & 5.1805 & 5.8376 & TST & \\
\hline CHEMBL433173 & 65482 & 8.1249 & 8.1271 & TRN & \\
\hline CHEMBL94752 & 65482 & 6.8356 & 6.8263 & TRN & \\
\hline CHEMBL96193 & 65482 & 6.8996 & 7.431 & TST & \\
\hline CHEMBL140699 & 177778 & 6.0 & 5.7282 & TRN & \\
\hline CHEMBL341804 & 177778 & 5.2596 & 5.0296 & TRN & \\
\hline CHEMBL335820 & 177778 & 6.0458 & \multicolumn{2}{|c|}{6.367999999999999} & TRN \\
\hline CHEMBL138578 & 177778 & 4.8239 & 5.5903 & TRN & \\
\hline CHEMBL343552 & 177778 & 4.9586 & 4.8368 & TRN & \\
\hline CHEMBL343592 & 177778 & 6.301 & 5.7392 & TRN & \\
\hline CHEMBL336459 & 177778 & 6.0969 & 5.6388 & TRN & \\
\hline CHEMBL1203321 & 177778 & 6.0 & 6.0213 & TRN & \\
\hline CHEMBL1202005 & 177778 & 5.8861 & 6.2234 & TRN & \\
\hline CHEMBL138360 & 177778 & 5.8239 & 6.0627 & TRN & \\
\hline CHEMBL1203323 & 177778 & 6.0 & 5.9458 & TRN & \\
\hline CHEMBL138403 & 177778 & 4.6383 & 5.2808 & TRN & \\
\hline CHEMBL1908849 & 177778 & 4.7447 & 6.0213 & TST & \\
\hline CHEMBL139905 & 177778 & 5.7696 & 5.3855 & TST & \\
\hline CHEMBL138219 & 177778 & 4.3279 & 4.7825 & TRN & \\
\hline CHEMBL141752 & 177778 & 5.0605 & 4.8761 & TRN & \\
\hline CHEMBL137862 & 177778 & 5.6383 & 4.8447 & TRN & \\
\hline CHEMBL344157 & 177778 & 5.5229 & 5.818 & TST & \\
\hline CHEMBL141734 & 177778 & 5.8861 & 5.9276 & TRN & \\
\hline CHEMBL139575 & 177778 & 4.7696 & 5.7409 & TRN & \\
\hline CHEMBL141155 & 177778 & 6.0 & 5.3514 & TRN & \\
\hline CHEMBL140660 & 177778 & 6.699 & 5.4284 & TRN & \\
\hline CHEMBL336717 & 177778 & 5.2676 & 4.8235 & TRN & \\
\hline CHEMBL139681 & 177778 & 5.7447 & 4.953 & TRN & \\
\hline CHEMBL1203320 & 177778 & 6.0 & 5.7834 & TRN & \\
\hline CHEMBL1203329 & 177778 & 6.0 & 5.6503 & TRN & \\
\hline CHEMBL137908 & 177778 & 6.0 & 5.6602 & TRN & \\
\hline CHEMBL1202008 & 177778 & 6.0458 & 5.5268 & TRN & \\
\hline CHEMBL153 & 177778 & 4.3665 & 4.9518 & TRN & \\
\hline CHEMBL1202010 & 177778 & 3.752 & 5.1137 & TRN & \\
\hline CHEMBL343985 & 177778 & 6.1549 & 5.9447 & TRN & \\
\hline CHEMBL1202006 & 177778 & 4.9586 & 5.4495 & TRN & \\
\hline CHEMBL1202011 & 177778 & 4.6383 & 5.26399 & 9999999999 & TRN \\
\hline CHEMBL1203331 & 177778 & 4.7959 & 5.4238 & TRN & \\
\hline CHEMBL138529 & 177778 & 5.3872 & 5.106 & TST & \\
\hline CHEMBL 275785 & 177778 & 6.0 & 5.1657 & TST & \\
\hline CHEMBL1202009 & 177778 & 4.3188 & 5.2155 & TST & \\
\hline CHEMBL140882 & 177778 & 6.699 & 6.3653 & TRN & \\
\hline CHEMBL422467 & 177778 & 5.0 & 5.2755 & TRN & \\
\hline CHEMBL1203322 & 177778 & 6.0 & 5.7245 & TRN & \\
\hline CHEMBL142008 & 177778 & 6.1549 & 5.2079 & TST & \\
\hline CHEMBL138926 & 177778 & 5.8539 & 5.6802 & TRN & \\
\hline CHEMBL423005 & 177778 & 5.8861 & 5.0968 & TST & \\
\hline
\end{tabular}




\begin{tabular}{l} 
CHEMBL47 \\
CHEMBL141561 \\
CHEMBL1203328 \\
CHEMBL343762 \\
CHEMBL1202007 \\
CHEMBL138483 \\
CHEMBL1203327 \\
CHEMBL1203330 \\
CHEMBL3960262 \\
CHEMBL3113770 \\
CHEMBL3969685 \\
CHEMBL3984889 \\
CHEMBL3986364 \\
CHEMBL3930770 \\
CHEMBL3952476 \\
CHEMBL3962013 \\
CHEMBL3895685 \\
CHEMBL3909991 \\
CHEMBL3113751 \\
CHEMBL3889541 \\
CHEMBL3962811 \\
CHEMBL3985046 \\
CHEMBL3935599 \\
CHEMBL3928080 \\
CHEMBL3939214 \\
CHEMBL3951832 \\
CHEMBL3948982 \\
CHEMBL3917615 \\
CHEMBL3983793 \\
CHEMBL3960536 \\
CHEMBL3949744 \\
CHEMBL3965518 \\
CHEMBL3953548 \\
CHEMBL3900083 \\
CHEMBL3913300 \\
CHEMBL3966965 \\
CHEMBL3944292 \\
CHEMBL3895491 \\
CHEMBL3903513 \\
CHEMBL3966605 \\
CHEMBL3113759 \\
CHEMBL3937008 \\
CHEMBL3986684 3938814 \\
CHEMB 3921650 \\
CHEM 3925974 \\
\hline
\end{tabular}

Supplemental Table S2.txt

$\begin{array}{llll}177778 & 4.5528 & 5.5705 & \text { TST }\end{array}$

$\begin{array}{llll}177778 & 4.9208 & 5.3342 & \text { TRN }\end{array}$

$\begin{array}{llll}177778 & 6.0 & 5.5163 & \text { TST }\end{array}$

$\begin{array}{llll}177778 & 6.0969 & 5.9476 & \text { TRN }\end{array}$

$\begin{array}{llll}177778 & 6.0 & 5.5991 & \text { TST }\end{array}$

$\begin{array}{llll}177778 & 5.0 & 5.2217 & \text { TRN }\end{array}$

$\begin{array}{llll}177778 & 6.0 & 5.9636 & \text { TST }\end{array}$

$\begin{array}{llll}177778 & 6.699 & 5.5702 & \text { TST }\end{array}$

$\begin{array}{llll}1641164 & 6.8477 & 6.3119 & \text { TST }\end{array}$

$\begin{array}{llll}1641164 & 8.301 & 7.5917 & \text { TST }\end{array}$

$\begin{array}{llll}1641164 & 7.1871 & 7.2861 & \text { TRN }\end{array}$

$\begin{array}{llll}1641164 & 6.9393 & 7.2083 & \text { TRN }\end{array}$

$\begin{array}{llll}1641164 & 6.8894 & 6.6862 & \text { TRN }\end{array}$

$\begin{array}{llll}1641164 & 6.1746 & 5.7568 & \text { TRN }\end{array}$

$\begin{array}{llll}1641164 & 6.8996 & 6.2306 & \text { TRN }\end{array}$

$\begin{array}{llll}1641164 & 6.3478 & 5.9787 & \text { TRN }\end{array}$

$\begin{array}{llll}1641164 & 6.4225 & 7.1154 & \text { TST }\end{array}$

$\begin{array}{llll}1641164 & 7.5528 & 7.1379 & \text { TRN }\end{array}$

$\begin{array}{llll}1641164 & 8.301 & 7.9041 & \text { TRN }\end{array}$

$\begin{array}{llll}1641164 & 6.2069 & 6.6164 & \text { TRN }\end{array}$

$\begin{array}{llll}1641164 & 6.3675 & 6.9457 & \text { TST }\end{array}$

16411648.52298 .5966 TRN

$\begin{array}{llll}1641164 & 6.2612 & 6.055 & \text { TRN }\end{array}$

$\begin{array}{llll}1641164 & 7.1135 & 7.2712 & \text { TRN }\end{array}$

$\begin{array}{llll}1641164 & 7.0315 & 7.3157 & \text { TRN }\end{array}$

$\begin{array}{llll}1641164 & 7.5086 & 7.1585 & \text { TRN }\end{array}$

$\begin{array}{llll}1641164 & 7.9586 & 7.5879 & \text { TRN }\end{array}$

$\begin{array}{llll}1641164 & 6.153 & 6.4818 & \text { TST }\end{array}$

$\begin{array}{llll}1641164 & 7.2518 & 7.0454 & \text { TRN }\end{array}$

$\begin{array}{llll}1641164 & 6.2733 & 5.5777 & \text { TST }\end{array}$

$\begin{array}{llll}1641164 & 7.2291 & 6.4344 & \text { TRN }\end{array}$

$\begin{array}{llll}1641164 & 6.433 & 6.5342 & \text { TRN }\end{array}$

$\begin{array}{llll}1641164 & 6.5436 & 6.6328 & \text { TRN }\end{array}$

$\begin{array}{llll}1641164 & 7.5086 & 7.4066 & \text { TRN }\end{array}$

$\begin{array}{llll}1641164 & 7.7959 & 7.7445 & \text { TRN }\end{array}$

$\begin{array}{llll}1641164 & 9.0 & 7.8221 & \text { TST }\end{array}$

$\begin{array}{llll}1641164 & 8.0458 & 7.7705 & \text { TST }\end{array}$

$\begin{array}{llll}1641164 & 6.2083 & 6.1436 & \text { TRN }\end{array}$

$\begin{array}{llll}1641164 & 7.9586 & 7.9402 & \text { TRN }\end{array}$

$\begin{array}{llll}1641164 & 6.0487 & 6.8506 & \text { TRN }\end{array}$

$\begin{array}{llll}1641164 & 8.5229 & 8.133 & \text { TRN }\end{array}$

$\begin{array}{llll}1641164 & 7.0088 & 7.4688 & \text { TRN }\end{array}$

$\begin{array}{llll}1641164 & 7.2218 \quad 7.0002 & \text { TRN }\end{array}$

$16411647.0605 \quad 6.6914$ TST

$\begin{array}{llll}1641164 & 7.3279 & 7.2732 & \text { TRN }\end{array}$

$\begin{array}{llll}1641164 & 6.3242 & 6.3734 & \text { TST }\end{array}$

$\begin{array}{llll}1641164 & 7.0088 & 7.497999999999999 & \text { TST }\end{array}$

16411646.3354

6.1097 TRN

Page 13852 
Supplemental Table S2.txt

\begin{tabular}{|c|c|c|c|c|}
\hline CHEMBL 3893795 & 1641164 & 5.2613 & 5.6557 & TRN \\
\hline CHEMBL 3973202 & 1641164 & 6.0 & 5.9849 & TRN \\
\hline CHEMBL3986061 & 1641164 & 6.2248 & 5.5278 & TST \\
\hline CHEMBL 3978443 & 1641164 & 7.9208 & 7.8957 & TRN \\
\hline CHEMBL 3940180 & 1641164 & 6.7645 & 6.9486 & TRN \\
\hline CHEMBL 3955148 & 1641164 & 6.9172 & 7.1237 & TRN \\
\hline CHEMBL 3941842 & 1641164 & 6.9136 & 7.209 & TRN \\
\hline CHEMBL 3929234 & 1641164 & 7.0362 & 7.1116 & TRN \\
\hline CHEMBL 3914248 & 1641164 & 7.1938 & 7.4271 & TRN \\
\hline CHEMBL 3900701 & 1641164 & 6.767 & 7.1356 & TRN \\
\hline CHEMBL 3943680 & 1641164 & 6.7496 & 7.1227 & TST \\
\hline CHEMBL 3945078 & 1641164 & 7.8239 & 5.6942 & TST \\
\hline CHEMBL 3904976 & 1641164 & 6.3401 & 5.3817 & TST \\
\hline CHEMBL 3409860 & 1641164 & 6.0 & 6.2586 & TRN \\
\hline CHEMBL3916592 & 1641164 & 6.08299 & 999999999 & 6.0848 \\
\hline CHEMBL 3927724 & 1641164 & 7.4202 & 7.3907 & TRN \\
\hline CHEMBL 3909038 & 1641164 & 5.8633 & 5.7671 & TST \\
\hline CHEMBL 3985579 & 1641164 & 5.5748 & 5.6755 & TRN \\
\hline CHEMBL 3977087 & 1641164 & 7.7212 & 7.747000 & 0000000001 \\
\hline CHEMBL 3927897 & 1641164 & 7.5686 & 7.0977 & TRN \\
\hline CHEMBL 3919120 & 1641164 & 7.2366 & 7.4732 & TRN \\
\hline CHEMBL 3928054 & 1641164 & 6.1415 & 5.3929 & TST \\
\hline CHEMBL 3113766 & 1641164 & 6.5986 & 7.2273 & TST \\
\hline CHEMBL 3902140 & 1641164 & 7.5229 & 7.0619 & TRN \\
\hline CHEMBL 3933444 & 1641164 & 7.9586 & 6.9895 & TRN \\
\hline CHEMBL 3979225 & 1641164 & 6.2899 & 6.1531 & TRN \\
\hline CHEMBL 3980818 & 1641164 & 6.1612 & 6.8766 & TRN \\
\hline CHEMBL 3934631 & 1641164 & 6.3925 & 6.1876 & TRN \\
\hline CHEMBL3920668 & 1641164 & 7.3372 & 7.3578 & TRN \\
\hline CHEMBL3929769 & 1641164 & 7.2076 & 6.7946 & TRN \\
\hline CHEMBL 3943140 & 1641164 & 6.1798 & 6.5624 & TRN \\
\hline CHEMBL 3113749 & 1641164 & 8.0458 & 7.6524 & TRN \\
\hline CHEMBL 3949346 & 1641164 & 5.2083 & 5.4572 & TRN \\
\hline CHEMBL3113762 & 1641164 & 5.9666 & 6.2204 & TST \\
\hline CHEMBL3983392 & 1641164 & 6.0448 & 6.4488 & TRN \\
\hline CHEMBL3953804 & 1641164 & 7.8239 & 6.0098 & TST \\
\hline CHEMBL3947861 & 1641164 & 7.6778 & 8.0459 & TRN \\
\hline CHEMBL 3894604 & 1641164 & 7.3372 & 7.4532 & TRN \\
\hline CHEMBL 3894979 & 1641164 & 7.1871 & 7.3146 & TRN \\
\hline CHEMBL 3927627 & 1641164 & 6.2604 & 6.6966 & TST \\
\hline CHEMBL 3985508 & 1641164 & 6.9547 & 6.7247 & TST \\
\hline CHEMBL 3915976 & 1641164 & 5.3002 & 5.2357 & TST \\
\hline CHEMBL 3895495 & 1641164 & 6.4365 & 6.6783 & TRN \\
\hline CHEMBL 3113740 & 1641164 & 5.9991 & 6.3484 & TRN \\
\hline CHEMBL 3892186 & 1641164 & 6.0 & 6.0634 & TRN \\
\hline CHEMBL 3917173 & 1641164 & 7.6383 & 6.9493 & TST \\
\hline CHEMBL 3910868 & 1641164 & 7.0223 & 7.0215 & TRN \\
\hline CHEMBL3958111 & 1641164 & 7.5376 & 7.4362 & TST \\
\hline
\end{tabular}

Page 13853 
Supplemental Table S2.txt

\begin{tabular}{|c|c|c|c|c|c|}
\hline CHEMBL3918463 & 1641164 & 7.1549 & 7.2435 & TRN & \\
\hline CHEMBL3913002 & 1641164 & 7.0506 & 7.5782 & TRN & \\
\hline CHEMBL3915484 & 1641164 & 6.6402 & 6.03799 & 9999999999 & TRN \\
\hline CHEMBL3911828 & 1641164 & 7.4685 & 7.4455 & TRN & \\
\hline CHEMBL3910919 & 1641164 & 5.767 & 6.2572 & TRN & \\
\hline CHEMBL3113536 & 1641164 & 6.8125 & 6.5109 & TRN & \\
\hline CHEMBL3952651 & 1641164 & 5.9872 & 5.7878 & TRN & \\
\hline CHEMBL3409869 & 1641164 & 7.699 & 7.7034 & TST & \\
\hline CHEMBL3973182 & 1641164 & 7.7212 & 7.4321 & TRN & \\
\hline CHEMBL3113551 & 1641164 & 6.295 & 6.07600 & 00000000005 & TRN \\
\hline CHEMBL3897167 & 1641164 & 7.0223 & 7.1196 & TRN & \\
\hline CHEMBL3986127 & 1641164 & 7.4815 & 7.7818 & TRN & \\
\hline CHEMBL3942105 & 1641164 & 6.8477 & 6.8372 & TRN & \\
\hline CHEMBL3985172 & 1641164 & 7.2366 & 7.5939 & TRN & \\
\hline CHEMBL3933550 & 1641164 & 5.9825 & 6.3287 & TRN & \\
\hline CHEMBL3949230 & 1641164 & 7.8861 & 7.9252 & TRN & \\
\hline CHEMBL3969724 & 1641164 & 6.3706 & 6.4743 & TRN & \\
\hline CHEMBL3969627 & 1641164 & 7.2366 & 7.1643 & TRN & \\
\hline CHEMBL3950159 & 1641164 & 6.7122 & 6.6931 & TRN & \\
\hline CHEMBL3925275 & 1641164 & 7.585 & 7.4122 & TRN & \\
\hline CHEMBL3948940 & 1641164 & 7.5528 & 7.0341 & TRN & \\
\hline CHEMBL3987122 & 1641164 & 5.6556 & 6.0553 & TRN & \\
\hline CHEMBL3971715 & 1641164 & 7.7212 & 7.9778 & TST & \\
\hline CHEMBL3923424 & 1641164 & 6.4908 & \multicolumn{2}{|c|}{6.587000000000001} & TRN \\
\hline CHEMBL3925796 & 1641164 & 6.7825 & 6.7346 & TST & \\
\hline CHEMBL3981734 & 1641164 & 6.1337 & 6.3167 & TRN & \\
\hline CHEMBL3973633 & 1641164 & 7.3872 & 7.4329 & TRN & \\
\hline CHEMBL3954220 & 1641164 & 7.3372 & \multicolumn{2}{|c|}{ 7.077999999999999 } & TRN \\
\hline CHEMBL3982812 & 1641164 & 7.0915 & 7.824 & TST & \\
\hline CHEMBL3964922 & 1641164 & 5.2294 & 5.5916 & TRN & \\
\hline CHEMBL3955491 & 1641164 & 6.567 & 6.1894 & TRN & \\
\hline CHEMBL3943446 & 1641164 & 6.5918 & 6.2322 & TRN & \\
\hline CHEMBL3915110 & 1641164 & 6.3439 & 6.3101 & TRN & \\
\hline CHEMBL3939381 & 1641164 & 7.0315 & 6.0015 & TST & \\
\hline CHEMBL3964578 & 1641164 & 6.9393 & 7.2031 & TST & \\
\hline CHEMBL3945398 & 1641164 & 7.2007 & 8.307 & TST & \\
\hline CHEMBL3892961 & 1641164 & \multicolumn{3}{|c|}{6.7620000000000005} & TRN \\
\hline CHEMBL3968919 & 1641164 & 7.1135 & 5.875 & TST & \\
\hline CHEMBL3983362 & 1641164 & 7.0706 & 7.3247 & TRN & \\
\hline CHEMBL3897223 & 1641164 & 7.4815 & 7.4243 & TRN & \\
\hline CHEMBL3901353 & 1641164 & 5.857 & 6.1241 & TST & \\
\hline CHEMBL3972041 & 1641164 & 6.9469 & 7.0153 & TRN & \\
\hline CHEMBL3985696 & 1641164 & 7.6576 & 7.5524 & TRN & \\
\hline CHEMBL3904115 & 1641164 & 6.7212 & 6.5195 & TRN & \\
\hline CHEMBL3916366 & 1641164 & 5.4318 & 5.9966 & TST & \\
\hline CHEMBL3921425 & 1641164 & 8.0969 & 8.2297 & TRN & \\
\hline CHEMBL3903138 & 1641164 & 7.0177 & 6.9749 & TRN & \\
\hline CHEMBL3926227 & 1641164 & 6.8794 & 6.4065 & TRN & \\
\hline
\end{tabular}

Page 13854 
Supplemental Table S2.txt

\begin{tabular}{|c|c|c|c|c|c|}
\hline CHEMBL3938412 & 1641164 & 6.7696 & 6.5574 & TRN & \\
\hline CHEMBL3893390 & 1641164 & 8.0969 & 7.3439 & TST & \\
\hline CHEMBL3904193 & 1641164 & 7.1549 & 6.8765 & TRN & \\
\hline CHEMBL3920478 & 1641164 & 6.6364 & 6.4866 & TRN & \\
\hline CHEMBL3903348 & 1641164 & 6.3979 & 6.6243 & TRN & \\
\hline CHEMBL3948479 & 1641164 & 5.8996 & 6.5678 & TRN & \\
\hline CHEMBL3941745 & 1641164 & 6.9393 & 7.3416 & TRN & \\
\hline CHEMBL3920046 & 1641164 & 6.5361 & 6.5321 & TRN & \\
\hline CHEMBL3957144 & 1641164 & 7.1938 & 7.3138 & TRN & \\
\hline CHEMBL3892988 & 1641164 & 7.3565 & 6.6202 & TRN & \\
\hline CHEMBL3982936 & 1641164 & 6.4067 & 6.6672 & TRN & \\
\hline CHEMBL3924473 & 1641164 & 7.0362 & 7.3767 & TRN & \\
\hline CHEMBL3113742 & 1641164 & 8.3979 & 8.2758 & TST & \\
\hline CHEMBL 3935470 & 1641164 & 6.2604 & 6.2477 & TRN & \\
\hline CHEMBL3911067 & 1641164 & 6.3686 & 6.7553 & TST & \\
\hline CHEMBL3925582 & 1641164 & 6.7167 & 6.1785 & TST & \\
\hline CHEMBL3889649 & 1641164 & 5.3833 & 6.4032 & TRN & \\
\hline CHEMBL3928451 & 1641164 & 7.0862 & 7.7516 & TRN & \\
\hline CHEMBL3919179 & 1641164 & 7.5086 & 7.4162 & TRN & \\
\hline CHEMBL3911137 & 1641164 & 5.8996 & 5.6287 & TRN & \\
\hline CHEMBL3940390 & 1641164 & 7.5376 & 7.3648 & TRN & \\
\hline CHEMBL3113756 & 1641164 & 7.0655 & 6.6858 & TRN & \\
\hline CHEMBL3939364 & 1641164 & 5.6861 & 6.1948 & TRN & \\
\hline CHEMBL 3949227 & 1641164 & 6.1574 & 6.6169 & TRN & \\
\hline CHEMBL3978809 & 1641164 & 6.5361 & 6.6919 & TRN & \\
\hline CHEMBL3981203 & 1641164 & 6.9666 & 6.53 & TRN & \\
\hline CHEMBL3409870 & 1641164 & 6.0 & 7.0089 & TST & \\
\hline CHEMBL3954157 & 1641164 & 6.1296 & 6.07 & TRN & \\
\hline CHEMBL3933940 & 1641164 & 6.0 & 5.72 & TRN & \\
\hline CHEMBL3924691 & 1641164 & 6.2041 & 6.3978 & TRN & \\
\hline CHEMBL3956662 & 1641164 & 6.0665 & 6.1833 & TST & \\
\hline CHEMBL3954609 & 1641164 & 6.7282 & 7.2482 & TRN & \\
\hline CHEMBL3978321 & 1641164 & 7.8239 & 7.6312 & TRN & \\
\hline CHEMBL3941481 & 1641164 & 6.8041 & 6.7757 & TST & \\
\hline CHEMBL 3967832 & 1641164 & 7.2147 & 7.0297 & TRN & \\
\hline CHEMBL3913204 & 1641164 & 7.301 & 6.9151 & TRN & \\
\hline CHEMBL3917482 & 1641164 & 7.1675 & 7.1503 & TRN & \\
\hline CHEMBL3939066 & 1641164 & 6.6383 & 6.5353 & TRN & \\
\hline CHEMBL3985659 & 1641164 & 5.9872 & 6.3483 & TST & \\
\hline CHEMBL 3902382 & 1641164 & 7.8861 & 7.5303 & TRN & \\
\hline CHEMBL3906516 & 1641164 & 6.2581 & \multicolumn{2}{|c|}{6.571000000000001} & TRN \\
\hline CHEMBL3970006 & 1641164 & 6.26200 & 000000000 & 6.8251 & TRN \\
\hline CHEMBL3927882 & 1641164 & 7.6576 & 7.7311 & TRN & \\
\hline CHEMBL3975042 & 1641164 & 6.8697 & 7.061 & TRN & \\
\hline CHEMBL 3937707 & 1641164 & 7.7447 & 7.0628 & TRN & \\
\hline CHEMBL3970401 & 1641164 & 6.8794 & 6.5614 & TST & \\
\hline CHEMBL3113534 & 1641164 & 6.1972 & 6.2365 & TRN & \\
\hline CHEMBL3954128 & 1641164 & 6.6253 & 6.5176 & TRN & \\
\hline
\end{tabular}


Supplemental Table S2.txt

\begin{tabular}{|c|c|c|c|c|c|}
\hline CHEMBL 3931571 & 1641164 & 7.0458 & 7.3746 & TRN & \\
\hline CHEMBL3911666 & 1641164 & 7.1871 & 7.2211 & TRN & \\
\hline CHEMBL3929739 & 1641164 & 7.0969 & 7.0222 & TRN & \\
\hline CHEMBL 3113752 & 1641164 & 8.5229 & 7.9089 & TST & \\
\hline CHEMBL 3943558 & 1641164 & 5.983 & 6.3762 & TRN & \\
\hline CHEMBL3955790 & 1641164 & 6.7696 & 6.6694 & TST & \\
\hline CHEMBL3898606 & 1641164 & 6.0 & 5.4264 & TST & \\
\hline CHEMBL3985473 & 1641164 & 6.2765 & 6.1769 & TST & \\
\hline CHEMBL 3894400 & 1641164 & 7.5086 & 7.1038 & TRN & \\
\hline CHEMBL3951889 & 1641164 & 8.3979 & 8.075 & TRN & \\
\hline CHEMBL 3113550 & 1641164 & 7.9208 & 7.7502 & TRN & \\
\hline CHEMBL3969988 & 1641164 & 7.0315 & 7.3142 & TRN & \\
\hline CHEMBL3916806 & 1641164 & 7.2757 & 7.2214 & TRN & \\
\hline CHEMBL3113546 & 1641164 & 7.4559 & 7.1214 & TRN & \\
\hline CHEMBL 3957444 & 1641164 & 7.7212 & 7.57799 & 9999999999 & TRN \\
\hline CHEMBL3927062 & 1641164 & 6.1612 & 6.2906 & TST & \\
\hline CHEMBL 3895462 & 1641164 & 6.8665 & 6.614 & TST & \\
\hline CHEMBL3914823 & 1641164 & 6.341 & 5.70299 & 9999999999 & TRN \\
\hline CHEMBL3919889 & 1641164 & 6.9066 & 6.9691 & TRN & \\
\hline CHEMBL 3409858 & 1641164 & 6.0 & 6.2352 & TRN & \\
\hline CHEMBL3918050 & 1641164 & 6.8827 & 6.8309 & TRN & \\
\hline CHEMBL 3894403 & 1641164 & 8.0458 & 7.7411 & TRN & \\
\hline CHEMBL3975171 & 1641164 & 6.7423 & 6.9213 & TRN & \\
\hline CHEMBL3977119 & 1641164 & 6.9431 & 6.9183 & TRN & \\
\hline CHEMBL 3903177 & 1641164 & 7.5686 & 6.7866 & TRN & \\
\hline CHEMBL3972122 & 1641164 & 6.7258 & 6.6123 & TRN & \\
\hline CHEMBL 3959981 & 1641164 & 7.585 & 7.6661 & TRN & \\
\hline CHEMBL3986710 & 1641164 & 5.9281 & 6.3058 & TST & \\
\hline CHEMBL3958891 & 1641164 & 8.699 & 8.2473 & TRN & \\
\hline CHEMBL 3892023 & 1641164 & 6.6038 & 6.9503 & TRN & \\
\hline CHEMBL3931515 & 1641164 & 6.0362 & 6.0647 & TRN & \\
\hline CHEMBL 3113739 & 1641164 & 6.6799 & 6.4927 & TRN & \\
\hline CHEMBL3934852 & 1641164 & 6.5686 & 7.0918 & TRN & \\
\hline CHEMBL3936553 & 1641164 & 7.4815 & 7.3675 & TRN & \\
\hline CHEMBL3941716 & 1641164 & 5.9234 & 5.9632 & TRN & \\
\hline CHEMBL3113747 & 1641164 & 7.7212 & 7.4841 & TRN & \\
\hline CHEMBL 3912173 & 1641164 & 7.1367 & 7.0894 & TRN & \\
\hline CHEMBL3936973 & 1641164 & 6.2328 & 5.5749 & TST & \\
\hline CHEMBL 3891082 & 1641164 & 7.9586 & 7.1479 & TST & \\
\hline CHEMBL3925639 & 1641164 & 6.0453 & 6.1955 & TRN & \\
\hline CHEMBL 3892317 & 1641164 & 7.1249 & 6.8907 & TRN & \\
\hline CHEMBL 3957833 & 1641164 & 6.7375 & 6.6901 & TRN & \\
\hline CHEMBL 3978028 & 1641164 & 5.7747 & 6.1327 & TRN & \\
\hline CHEMBL 3969634 & 1641164 & 6.5287 & 6.5025 & TRN & \\
\hline CHEMBL3936905 & 1641164 & 7.6576 & 7.0052 & TRN & \\
\hline CHEMBL3983331 & 1641164 & 7.6778 & 7.9568 & TRN & \\
\hline CHEMBL 3912213 & 1641164 & 6.9245 & 7.1723 & TRN & \\
\hline CHEMBL 3926444 & 1641164 & 7.2924 & 6.5533 & TST & \\
\hline
\end{tabular}


Supplemental Table S2.txt

\begin{tabular}{|c|c|c|c|c|c|}
\hline CHEMBL 3940216 & 1641164 & 6.6716 & 6.7109 & TST & \\
\hline CHEMBL 3958622 & 1641164 & 6.9469 & 7.0871 & TRN & \\
\hline CHEMBL3890497 & 1641164 & 8.0969 & 7.6643 & TRN & \\
\hline CHEMBL3933036 & 1641164 & 7.585 & 7.2906 & TRN & \\
\hline CHEMBL 3896893 & 1641164 & 6.0 & \multicolumn{2}{|c|}{7.202000000000001} & TST \\
\hline CHEMBL3113539 & 1641164 & 6.4034 & 6.9302 & TRN & \\
\hline CHEMBL3941158 & 1641164 & 6.3526 & 6.347 & TRN & \\
\hline CHEMBL3965326 & 1641164 & 7.5229 & 7.4648 & TRN & \\
\hline CHEMBL3895679 & 1641164 & 7.5376 & 6.9453 & TST & \\
\hline CHEMBL3917258 & 1641164 & 7.0706 & \multicolumn{2}{|c|}{ 7.377999999999999 } & TRN \\
\hline CHEMBL3918728 & 1641164 & 6.9706 & 6.9245 & TRN & \\
\hline CHEMBL 3113535 & 1641164 & 6.5719 & 6.3663 & TRN & \\
\hline CHEMBL 3908623 & 1641164 & 7.4202 & 6.9291 & TRN & \\
\hline CHEMBL3909846 & 1641164 & 6.9666 & 6.7565 & TRN & \\
\hline CHEMBL 3899904 & 1641164 & 7.4949 & 7.5843 & TRN & \\
\hline CHEMBL3113544 & 1641164 & 8.2218 & 6.9324 & TST & \\
\hline CHEMBL3964349 & 1641164 & 8.3979 & 8.2781 & TRN & \\
\hline CHEMBL 3987155 & 1641164 & 7.0088 & 7.1095 & TRN & \\
\hline CHEMBL 3113746 & 1641164 & 8.699 & 8.1847 & TRN & \\
\hline CHEMBL3939052 & 1641164 & 6.0937 & 6.2535 & TRN & \\
\hline CHEMBL3936509 & 1641164 & 6.3625 & 6.5866 & TRN & \\
\hline CHEMBL3940994 & 1641164 & 7.1308 & 6.9387 & TST & \\
\hline CHEMBL 3897703 & 1641164 & 6.6216 & 6.7634 & TRN & \\
\hline CHEMBL3964757 & 1641164 & 7.1805 & 7.1633 & TRN & \\
\hline CHEMBL3935942 & 1641164 & 6.5607 & 6.4761 & TRN & \\
\hline CHEMBL3955473 & 1641164 & 7.0605 & 6.224 & TRN & \\
\hline CHEMBL3953208 & 1641164 & 6.0348 & 6.4749 & TRN & \\
\hline CHEMBL 3113744 & 1641164 & 7.4685 & 7.4719 & TRN & \\
\hline CHEMBL3930758 & 1641164 & 7.3979 & 7.7352 & TRN & \\
\hline CHEMBL3929583 & 1641164 & 6.1549 & 6.2431 & TRN & \\
\hline CHEMBL3903988 & 1641164 & 6.0762 & 6.8008 & TRN & \\
\hline CHEMBL3901793 & 1641164 & 6.6536 & 6.4758 & TST & \\
\hline CHEMBL 3976348 & 1641164 & 8.699 & 8.2457 & TRN & \\
\hline CHEMBL3920976 & 1641164 & 6.3851 & 6.1172 & TRN & \\
\hline CHEMBL3409871 & 1641164 & 8.301 & 7.7308 & TST & \\
\hline CHEMBL3917893 & 1641164 & 6.8327 & 7.0419 & TRN & \\
\hline CHEMBL 3922074 & 1641164 & 5.7878 & \multicolumn{2}{|c|}{6.071000000000001} & TRN \\
\hline CHEMBL3113745 & 1641164 & 8.0969 & 7.5668 & TRN & \\
\hline CHEMBL 3932504 & 1641164 & 5.6882 & 5.7523 & TST & \\
\hline CHEMBL 3898822 & 1641164 & 6.0635 & 6.0078 & TRN & \\
\hline CHEMBL3943538 & 1641164 & 6.1451 & 5.5685 & TST & \\
\hline CHEMBL 3891988 & 1641164 & 6.6345 & 6.9984 & TRN & \\
\hline CHEMBL 3113763 & 1641164 & 6.0 & 6.1073 & TRN & \\
\hline CHEMBL3983237 & 1641164 & 7.4685 & 7.3451 & TRN & \\
\hline CHEMBL 3890634 & 1641164 & 6.6198 & 6.6673 & TRN & \\
\hline CHEMBL3981188 & 1641164 & 6.5986 & 6.309 & TST & \\
\hline CHEMBL3930793 & 1641164 & 5.983 & 6.3699 & TRN & \\
\hline CHEMBL3916968 & 1641164 & 6.4318 & 6.8528 & TRN & \\
\hline
\end{tabular}

Page 13857 
Supplemental Table S2.txt

\begin{tabular}{|c|c|c|c|c|}
\hline CHEMBL3113552 & 1641164 & 7.3279 & 7.2926 & TRN \\
\hline CHEMBL3917655 & 1641164 & 6.1778 & 6.8298 & TRN \\
\hline CHEMBL3971086 & 1641164 & 6.5784 & 6.9168 & TST \\
\hline CHEMBL3937786 & 1641164 & 6.2069 & 6.569 & TRN \\
\hline CHEMBL3976100 & 1641164 & 7.1487 & 7.1744 & TST \\
\hline CHEMBL3913912 & 1641164 & 6.0 & 7.0155 & TST \\
\hline CHEMBL3963425 & 1641164 & 7.1938 & 6.8044 & TST \\
\hline CHEMBL3986272 & 1641164 & 6.9208 & 7.2507 & TRN \\
\hline CHEMBL3965895 & 1641164 & 6.0665 & 6.6571 & TRN \\
\hline CHEMBL3900745 & 1641164 & 7.1135 & 7.2256 & TRN \\
\hline CHEMBL3948062 & 1641164 & 6.8447 & 6.4637 & TRN \\
\hline CHEMBL3113547 & 1641164 & 7.5686 & 7.2582 & TRN \\
\hline CHEMBL3959670 & 1641164 & 7.3872 & 6.8792 & TST \\
\hline CHEMBL3409852 & 1641164 & 5.4425 & 6.4039 & TRN \\
\hline CHEMBL 3897884 & 1641164 & 7.1135 & 7.2081 & TST \\
\hline CHEMBL3936904 & 1641164 & 7.2007 & 6.8662 & TRN \\
\hline CHEMBL3934707 & 1641164 & 7.1805 & 6.8753 & TRN \\
\hline CHEMBL3927496 & 1641164 & 6.1096 & 5.8844 & TRN \\
\hline CHEMBL3971640 & 1641164 & 6.0 & 6.5111 & TRN \\
\hline CHEMBL3980334 & 1641164 & 7.0706 & 7.1714 & TRN \\
\hline CHEMBL3949219 & 1641164 & 6.7496 & 6.7501 & TRN \\
\hline CHEMBL3962952 & 1641164 & 7.2676 & 7.4279 & TST \\
\hline CHEMBL3113754 & 1641164 & 7.041 & 6.9393 & TRN \\
\hline CHEMBL3913461 & 1641164 & 6.6091 & 7.0401 & TRN \\
\hline CHEMBL3970150 & 1641164 & 7.9586 & 7.8239 & TRN \\
\hline CHEMBL3113771 & 1641164 & 6.9172 & 6.8118 & TST \\
\hline CHEMBL3893831 & 1641164 & 7.6021 & 7.40799 & 99999999995 \\
\hline CHEMBL3906721 & 1641164 & 6.5935 & 6.7551 & TRN \\
\hline CHEMBL3975066 & 1641164 & 8.699 & 7.5858 & TST \\
\hline CHEMBL 3935347 & 1641164 & 5.7496 & 6.0141 & TST \\
\hline CHEMBL3910216 & 1641164 & 7.2441 & 6.6568 & TRN \\
\hline CHEMBL3113774 & 1641164 & 7.6576 & 6.8465 & TRN \\
\hline CHEMBL3966972 & 1641164 & 6.0 & 6.028 & TRN \\
\hline CHEMBL3904636 & 1641164 & 6.34200 & j00000006 & 6.246 \\
\hline CHEMBL3113545 & 1641164 & 7.0269 & 7.1505 & TRN \\
\hline CHEMBL3917613 & 1641164 & 7.3979 & 7.2107 & TRN \\
\hline CHEMBL 3945256 & 1641164 & 5.9393 & 6.017 & TRN \\
\hline CHEMBL3923606 & 1641164 & 8.0969 & 7.6477 & TRN \\
\hline CHEMBL3969830 & 1641164 & 7.8861 & 7.6663 & TRN \\
\hline CHEMBL3942056 & 1641164 & 6.1158 & 6.0067 & TRN \\
\hline CHEMBL3934682 & 1641164 & 7.7696 & 7.5727 & TRN \\
\hline CHEMBL3947984 & 1641164 & 5.608 & 5.7432 & TRN \\
\hline CHEMBL3113750 & 1641164 & 7.0969 & 7.3345 & TRN \\
\hline CHEMBL3931037 & 1641164 & 6.0 & 7.1519 & TRN \\
\hline CHEMBL3954632 & 1641164 & 6.6716 & 6.9153 & TST \\
\hline CHEMBL3926581 & 1641164 & 6.4976 & 6.6099 & TST \\
\hline CHEMBL 3894788 & 1641164 & 7.6021 & 7.5864 & TRN \\
\hline CHEMBL3946040 & 1641164 & 6.8069 & 6.8619 & TRN \\
\hline
\end{tabular}


Supplemental Table S2.txt

\begin{tabular}{|c|c|c|c|c|c|c|}
\hline CHEMBL3930977 & 1641164 & 5.9318 & 6.129 & TST & & \\
\hline CHEMBL3898298 & 1641164 & 6.5317 & 6.405 & TRN & & \\
\hline CHEMBL3936096 & 1641164 & 5.4067 & 7.1164 & TRN & & \\
\hline CHEMBL3897027 & 1641164 & 6.9469 & 6.8473 & TRN & & \\
\hline CHEMBL3943155 & 1641164 & 6.9872 & 7.2407 & TRN & & \\
\hline CHEMBL3938144 & 1641164 & 7.8539 & 7.5204 & TRN & & \\
\hline CHEMBL3981092 & 1641164 & 7.4089 & 6.6067 & TRN & & \\
\hline CHEMBL3954697 & 1641164 & \multicolumn{3}{|c|}{6.3420000000000005} & 6.9723 & TRN \\
\hline CHEMBL 3978924 & 1641164 & 6.9788 & 6.9197 & TRN & & \\
\hline CHEMBL3958542 & 1641164 & 7.4815 & 7.0584 & TRN & & \\
\hline CHEMBL 3953674 & 1641164 & 7.3565 & 7.6879 & TRN & & \\
\hline CHEMBL3968171 & 1641164 & 7.2596 & 7.3405 & TRN & & \\
\hline CHEMBL3908236 & 1641164 & 7.5229 & 7.5465 & TRN & & \\
\hline CHEMBL 3890024 & 1641164 & \multicolumn{3}{|c|}{6.327000000000001} & 6.8632 & TRN \\
\hline CHEMBL3907804 & 1641164 & 6.8182 & 6.6132 & TRN & & \\
\hline CHEMBL3902815 & 1641164 & 7.699 & 7.5316 & TRN & & \\
\hline CHEMBL3984287 & 1641164 & 8.699 & 8.2879 & TRN & & \\
\hline CHEMBL 3113548 & 1641164 & 7.3768 & 7.4693 & TRN & & \\
\hline CHEMBL3113757 & 1641164 & 6.2299 & 6.1257 & TST & & \\
\hline CHEMBL3113758 & 1641164 & 6.3872 & 6.2161 & TST & & \\
\hline CHEMBL3942476 & 1641164 & 5.7435 & 6.3049 & TST & & \\
\hline CHEMBL3973773 & 1641164 & 8.2218 & 8.1089 & TRN & & \\
\hline CHEMBL3923331 & 1641164 & 5.8844 & 5.4806 & TRN & & \\
\hline CHEMBL3974803 & 1641164 & 7.2366 & 6.425 & TRN & & \\
\hline CHEMBL3980549 & 1641164 & 6.8539 & 6.8602 & TRN & & \\
\hline CHEMBL3964419 & 1641164 & 8.0458 & 7.0606 & TST & & \\
\hline CHEMBL3980990 & 1641164 & 5.6131 & 6.0636 & TRN & & \\
\hline CHEMBL3113741 & 1641164 & 7.8861 & 7.2772 & TST & & \\
\hline CHEMBL3975065 & 1641164 & 6.3152 & 6.182 & TRN & & \\
\hline CHEMBL3952013 & 1641164 & 6.2457 & 6.7466 & TRN & & \\
\hline CHEMBL3916581 & 1641164 & 6.7399 & 7.1241 & TRN & & \\
\hline CHEMBL3980118 & 1641164 & 7.3098 & 7.2416 & TST & & \\
\hline CHEMBL3963602 & 1641164 & 7.7959 & 7.2661 & TRN & & \\
\hline CHEMBL 3922634 & 1641164 & 7.7212 & 5.4107 & TST & & \\
\hline CHEMBL3938749 & 1641164 & 6.5287 & 5.7297 & TST & & \\
\hline CHEMBL3920348 & 1641164 & 6.0 & 6.8016 & TRN & & \\
\hline CHEMBL3965358 & 1641164 & 7.2291 & 8.0816 & TRN & & \\
\hline CHEMBL3931438 & 1641164 & 6.8125 & 6.9804 & TRN & & \\
\hline CHEMBL 3965481 & 1641164 & 7.0862 & 7.2412 & TST & & \\
\hline CHEMBL3957156 & 1641164 & 7.2924 & 7.6565 & TRN & & \\
\hline CHEMBL3962408 & 1641164 & 6.6289 & 6.4589 & TRN & & \\
\hline CHEMBL3917566 & 1641164 & 6.8097 & 6.92899 & 9999999999 & & TRN \\
\hline CHEMBL3113537 & 1641164 & 6.8069 & 6.954 & TRN & & \\
\hline CHEMBL 3964401 & 1641164 & 6.9031 & 7.0158 & TST & & \\
\hline CHEMBL3900899 & 1641164 & 6.9706 & 6.9915 & TRN & & \\
\hline CHEMBL3113753 & 1641164 & 8.2218 & 7.4974 & TRN & & \\
\hline CHEMBL3921925 & 1641164 & 6.0 & 6.7454 & TRN & & \\
\hline CHEMBL3983645 & 1641164 & 7.585 & 7.5819 & TRN & & \\
\hline
\end{tabular}


Supplemental Table S2.txt

\begin{tabular}{|c|c|c|c|c|c|}
\hline CHEMBL 3946703 & 1641164 & 5.9245 & 6.2898 & TST & \\
\hline CHEMBL3967901 & 1641164 & 5.9914 & 6.5307 & TRN & \\
\hline CHEMBL3904030 & 1641164 & 7.6576 & 7.8317 & TRN & \\
\hline CHEMBL3893641 & 1641164 & 7.9208 & 7.6626 & TRN & \\
\hline CHEMBL3980919 & 1641164 & 5.8153 & 6.2271 & TST & \\
\hline CHEMBL 3948876 & 1641164 & 6.0521 & 6.2376 & TRN & \\
\hline CHEMBL3951985 & 1641164 & 7.4318 & 7.3225 & TRN & \\
\hline CHEMBL3909986 & 1641164 & 8.2218 & 7.1808 & TST & \\
\hline CHEMBL 3986037 & 1641164 & 7.4685 & 7.2954 & TRN & \\
\hline CHEMBL3409857 & 1641164 & 6.8761 & 6.8955 & TST & \\
\hline CHEMBL3982929 & 1641164 & 6.7645 & 7.216 & TRN & \\
\hline CHEMBL 3908200 & 1641164 & 7.0706 & 6.4511 & TRN & \\
\hline CHEMBL3936665 & 1641164 & 7.0655 & 7.4127 & TRN & \\
\hline CHEMBL3409876 & 1641164 & 8.3979 & 7.0996 & TST & \\
\hline CHEMBL3956786 & 1641164 & 7.1079 & 7.3394 & TRN & \\
\hline CHEMBL 3915167 & 1641164 & 7.6383 & 7.028 & TRN & \\
\hline CHEMBL3113755 & 1641164 & 7.2076 & 7.2047 & TRN & \\
\hline CHEMBL3925895 & 1641164 & 6.5072 & 5.4307 & TST & \\
\hline CHEMBL3113748 & 1641164 & 7.5528 & 7.5562 & TRN & \\
\hline CHEMBL3951644 & 1641164 & 7.9208 & 7.6353 & TST & \\
\hline CHEMBL3917353 & 1641164 & 6.6517 & 6.5116 & TST & \\
\hline CHEMBL 3980751 & 1641164 & 6.4763 & 6.6028 & TST & \\
\hline CHEMBL3973879 & 1641164 & 6.9586 & 6.9736 & TRN & \\
\hline CHEMBL3918910 & 1641164 & 7.9586 & 7.9005 & TRN & \\
\hline CHEMBL3926196 & 1641164 & 5.5302 & 5.362999 & 99999999995 & TRN \\
\hline CHEMBL3972274 & 1641164 & 8.5229 & 8.2595 & TRN & \\
\hline CHEMBL 3903190 & 1641164 & 8.2218 & 8.4616 & TRN & \\
\hline CHEMBL3985834 & 1641164 & 7.8861 & 7.3978 & TST & \\
\hline CHEMBL3891471 & 1641164 & 7.301 & 7.3267 & TRN & \\
\hline CHEMBL3409872 & 1641164 & 8.3979 & 7.2655 & TST & \\
\hline CHEMBL3940457 & 1641164 & 7.0605 & 6.7571 & TRN & \\
\hline CHEMBL 3902987 & 1641164 & 6.2248 & 6.1171 & TST & \\
\hline CHEMBL3952851 & 1641164 & 7.1487 & 6.9725 & TST & \\
\hline CHEMBL3919895 & 1641164 & 6.6904 & 7.0257 & TST & \\
\hline CHEMBL3909963 & 1641164 & 6.7352 & 6.7038 & TRN & \\
\hline CHEMBL3113538 & 1641164 & 7.4318 & 7.2667 & TRN & \\
\hline CHEMBL3912462 & 1641164 & 7.1938 & 6.8344 & TRN & \\
\hline CHEMBL 3933331 & 1641164 & 7.3565 & 6.5602 & TRN & \\
\hline CHEMBL3113773 & 1641164 & 6.8013 & 6.4679 & TRN & \\
\hline CHEMBL3890906 & 1641164 & 8.699 & 8.1964 & TRN & \\
\hline CHEMBL3957500 & 1641164 & 5.8665 & 6.0661 & TRN & \\
\hline CHEMBL3946806 & 1641164 & 6.9914 & 7.2439 & TRN & \\
\hline CHEMBL3931687 & 1641164 & 6.34200 & 00000000 & 5.9392 & $\mathrm{TRI}$ \\
\hline CHEMBL3969853 & 1641164 & 7.4685 & 7.0234 & TST & \\
\hline CHEMBL3962237 & 1641164 & 7.0458 & 6.8649 & TRN & \\
\hline CHEMBL3910207 & 1641164 & 8.5229 & 8.2441 & TST & \\
\hline CHEMBL3947845 & 1641164 & 8.1549 & 7.709 & TRN & \\
\hline CHEMBL3925745 & 1641164 & 6.9872 & 6.9163 & TRN & \\
\hline
\end{tabular}


Supplemental Table S2.txt

\begin{tabular}{|c|c|c|c|c|c|}
\hline CHEMBL3113760 & 1641164 & 6.5272 & 6.479 & TRN & \\
\hline CHEMBL3113743 & 1641164 & 7.3665 & 7.5152 & TRN & \\
\hline CHEMBL3906138 & 1641164 & 7.2076 & 7.3784 & TRN & \\
\hline CHEMBL3113549 & 1641164 & 7.1427 & 6.5474 & TRN & \\
\hline CHEMBL3902652 & 1641164 & 7.1871 & 7.5302 & TRN & \\
\hline CHEMBL3929633 & 1641164 & 5.4455 & 5.5338 & TST & \\
\hline CHEMBL 3409854 & 1641164 & 6.0 & 6.1434 & TRN & \\
\hline CHEMBL3955828 & 1641164 & 7.3372 & 6.9353 & TRN & \\
\hline CHEMBL3968360 & 1641164 & 6.5884 & 6.7208 & TST & \\
\hline CHEMBL3979268 & 1641164 & 7.6198 & 7.7154 & TRN & \\
\hline CHEMBL3958937 & 1641164 & 6.4012 & 6.6334 & TRN & \\
\hline CHEMBL 3113540 & 1641164 & 6.9747 & 6.6435 & TST & \\
\hline CHEMBL3113761 & 1641164 & 5.8891 & 6.1196 & TST & \\
\hline CHEMBL 3902408 & 1641164 & 6.8794 & 7.3173 & TST & \\
\hline CHEMBL3962071 & 1641164 & 7.7696 & 7.3323 & TST & \\
\hline CHEMBL3903997 & 1641164 & 7.7696 & 7.0411 & TST & \\
\hline CHEMBL3113775 & 1641164 & 7.1805 & 6.723 & TST & \\
\hline CHEMBL1964290 & 809274 & 5.4 & 5.2262 & TRN & \\
\hline CHEMBL 213505 & 809274 & 8.0 & 7.4642 & TRN & \\
\hline CHEMBL202721 & 809274 & 4.6 & 4.5604 & TRN & \\
\hline CHEMBL1987034 & 809274 & 7.6 & 7.1911 & TRN & \\
\hline CHEMBL1993941 & 809274 & 9.4 & 8.5797 & TRN & \\
\hline CHEMBL377383 & 809274 & 5.4 & 4.9465 & TRN & \\
\hline CHEMBL 2005886 & 809274 & 6.7 & 7.527 & TRN & \\
\hline CHEMBL481491 & 809274 & 5.4 & 5.5725 & TST & \\
\hline CHEMBL1682345 & 809274 & 5.4 & 5.0875 & TRN & \\
\hline CHEMBL1973142 & 809274 & 6.4 & 5.5078 & TST & \\
\hline CHEMBL388311 & 809274 & 9.2 & 8.741 & TRN & \\
\hline CHEMBL1973145 & 809274 & 8.5 & 8.3861 & TRN & \\
\hline CHEMBL1982924 & 809274 & 5.4 & 5.9527 & TRN & \\
\hline CHEMBL 2005936 & 809274 & 5.4 & 5.0573 & TRN & \\
\hline CHEMBL1807515 & 809274 & 5.4 & 5.6301 & TRN & \\
\hline CHEMBL1964948 & 809274 & 4.4 & 3.9619 & TRN & \\
\hline CHEMBL1971141 & 809274 & 6.8 & 6.9729 & TRN & \\
\hline CHEMBL1995813 & 809274 & 5.4 & 5.2288 & TRN & \\
\hline CHEMBL206236 & 809274 & 5.4 & 5.6019 & TRN & \\
\hline CHEMBL523823 & 809274 & 5.4 & 4.9416 & TST & \\
\hline CHEMBL1973178 & 809274 & 9.2 & 8.9857 & TRN & \\
\hline CHEMBL1987430 & 809274 & 4.4 & 4.2563 & TRN & \\
\hline CHEMBL244378 & 809274 & 7.0 & 6.67399 & 99999999995 & TRN \\
\hline CHEMBL1988778 & 809274 & 9.0 & 9.2535 & TRN & \\
\hline CHEMBL2001957 & 809274 & 5.4 & 5.1344 & TRN & \\
\hline CHEMBL1969372 & 809274 & 5.4 & 5.801 & TRN & \\
\hline CHEMBL1993413 & 809274 & 4.4 & 4.6093 & TRN & \\
\hline CHEMBL1990583 & 809274 & 5.4 & 5.4484 & TRN & \\
\hline CHEMBL1986943 & 809274 & 6.8 & 6.0256 & TRN & \\
\hline CHEMBL289959 & 809274 & 3.3 & 2.8482 & TRN & \\
\hline CHEMBL1993584 & 809274 & 5.4 & 5.1037 & TRN & \\
\hline
\end{tabular}




\begin{tabular}{|c|c|c|c|c|}
\hline \multicolumn{5}{|c|}{ Supplemental Table S2.txt } \\
\hline CHEMBL1986263 & 809274 & 6.7 & 6.3583 & TRN \\
\hline CHEMBL 2000114 & 809274 & 6.4 & 5.5947 & TRN \\
\hline CHEMBL210618 & 809274 & 5.4 & 5.15 & TRN \\
\hline CHEMBL1986265 & 809274 & 4.4 & 3.8858 & TRN \\
\hline CHEMBL1975647 & 809274 & 5.4 & 5.4261 & TRN \\
\hline CHEMBL1968380 & 809274 & 5.4 & 5.9766 & TRN \\
\hline CHEMBL1991734 & 809274 & 6.4 & 6.3647 & TST \\
\hline CHEMBL1981782 & 809274 & 5.4 & 5.0265 & TRN \\
\hline CHEMBL1970142 & 809274 & 9.3 & 9.1277 & TRN \\
\hline CHEMBL1990912 & 809274 & 5.4 & 6.0859 & TRN \\
\hline CHEMBL1991782 & 809274 & 3.1 & 3.2778 & TRN \\
\hline CHEMBL 2002105 & 809274 & 4.4 & 4.7351 & TRN \\
\hline CHEMBL1983348 & 809274 & 6.2 & 6.1025 & TRN \\
\hline CHEMBL1995592 & 809274 & 6.9 & 6.1162 & TST \\
\hline CHEMBL 2000934 & 809274 & 4.4 & 4.401 & TRN \\
\hline CHEMBL1980671 & 809274 & 5.0 & 5.1521 & TRN \\
\hline CHEMBL1986177 & 809274 & 4.4 & 4.4983 & TRN \\
\hline CHEMBL1969735 & 809274 & 5.4 & 5.1759 & TRN \\
\hline CHEMBL 2002649 & 809274 & 6.5 & 6.46 & TRN \\
\hline CHEMBL1985367 & 809274 & 4.4 & 5.3778 & TST \\
\hline CHEMBL1996510 & 809274 & 4.6 & 4.6638 & TST \\
\hline CHEMBL437747 & 809274 & 5.4 & 5.7286 & TRN \\
\hline CHEMBL 2001584 & 809274 & 4.4 & 4.419 & TRN \\
\hline CHEMBL507936 & 809274 & 7.6 & 7.5146 & TRN \\
\hline CHEMBL104264 & 809274 & 5.4 & 4.9647 & TST \\
\hline CHEMBL1967998 & 809274 & 7.0 & 7.438 & TRN \\
\hline CHEMBL1994321 & 809274 & 9.1 & 8.8874 & TRN \\
\hline CHEMBL1978562 & 809274 & 4.4 & 5.4633 & TST \\
\hline CHEMBL1997129 & 809274 & 6.7 & 6.4253 & TRN \\
\hline CHEMBL1974875 & 809274 & 4.6 & 4.5577 & TST \\
\hline CHEMBL1964307 & 809274 & 8.1 & 8.2225 & TRN \\
\hline CHEMBL1989471 & 809274 & 5.6 & 6.6448 & TST \\
\hline CHEMBL 2002099 & 809274 & 4.4 & 4.9979 & TRN \\
\hline CHEMBL 2000508 & 809274 & 5.4 & 4.9371 & TRN \\
\hline CHEMBL 2001547 & 809274 & 5.4 & 5.2832 & TRN \\
\hline CHEMBL210928 & 809274 & 5.4 & 5.0698 & TRN \\
\hline CHEMBL1978195 & 809274 & 5.6 & 5.4534 & TRN \\
\hline CHEMBL1994361 & 809274 & 5.4 & 5.2038 & TRN \\
\hline CHEMBL1972840 & 809274 & 5.4 & 6.0604 & TRN \\
\hline CHEMBL1966842 & 809274 & 5.9 & 5.6416 & TRN \\
\hline CHEMBL 2003286 & 809274 & 5.4 & 5.3536 & TRN \\
\hline CHEMBL 2002165 & 809274 & 9.3 & 8.8896 & TRN \\
\hline CHEMBL1979318 & 809274 & 6.7 & 5.8179 & TRN \\
\hline CHEMBL1998585 & 809274 & 8.6 & 8.5311 & TRN \\
\hline CHEMBL519697 & 809274 & 5.4 & 6.3633 & TRN \\
\hline CHEMBL 2004934 & 809274 & 5.4 & 5.1997 & TRN \\
\hline CHEMBL 2000652 & 809274 & 9.2 & 9.1524 & TRN \\
\hline CHEMBL1996345 & 809274 & 4.4 & 5.3608 & TST \\
\hline
\end{tabular}




\begin{tabular}{|c|c|c|c|c|c|}
\hline & & & & & \\
\hline CHEMBL1975128 & 809274 & 5.4 & 5.9091 & TRN & \\
\hline CHEMBL 2004025 & 809274 & 4.4 & 4.942 & TRN & \\
\hline CHEMBL1996048 & 809274 & 5.5 & 5.1756 & TST & \\
\hline CHEMBL461876 & 809274 & 4.4 & 4.4314 & TRN & \\
\hline CHEMBL1965033 & 809274 & 4.4 & 5.0434 & TRN & \\
\hline CHEMBL 2001485 & 809274 & 8.4 & 8.4479 & TRN & \\
\hline CHEMBL1971519 & 809274 & 4.1 & 4.976 & TRN & \\
\hline CHEMBL504950 & 809274 & 5.4 & 5.3276 & TRN & \\
\hline CHEMBL1997335 & 809274 & 6.5 & 5.5031 & TRN & \\
\hline CHEMBL1984363 & 809274 & 8.3 & 8.0598 & TRN & \\
\hline CHEMBL1978099 & 809274 & 7.4 & 7.4558 & TRN & \\
\hline CHEMBL1977041 & 809274 & 8.3 & 7.983 & TRN & \\
\hline CHEMBL1968070 & 809274 & 6.4 & 6.091 & TRN & \\
\hline CHEMBL1988608 & 809274 & 5.4 & 5.2242 & TRN & \\
\hline CHEMBL184847 & 809274 & 5.4 & 6.23 & TRN & \\
\hline CHEMBL1994808 & 809274 & 4.1 & 4.9768 & TRN & \\
\hline CHEMBL1984367 & 809274 & 5.4 & 6.2523 & TRN & \\
\hline CHEMBL226898 & 809274 & 5.4 & 4.9621 & TRN & \\
\hline CHEMBL1982563 & 809274 & 5.4 & 5.2366 & TRN & \\
\hline CHEMBL539474 & 809274 & 6.5 & 5.5672 & TST & \\
\hline CHEMBL575824 & 809274 & 5.4 & 5.428 & TRN & \\
\hline CHEMBL1988387 & 809274 & 9.3 & 9.0806 & TRN & \\
\hline CHEMBL1973868 & 809274 & 4.4 & 5.1182 & TRN & \\
\hline CHEMBL1972462 & 809274 & 4.4 & 4.4807 & TRN & \\
\hline CHEMBL1990288 & 809274 & 5.4 & 5.0038 & TRN & \\
\hline CHEMBL1970074 & 809274 & 8.3 & 7.5311 & TRN & \\
\hline CHEMBL1986970 & 809274 & 5.4 & 5.0244 & TRN & \\
\hline CHEMBL1958401 & 809274 & 5.4 & 5.4643 & TRN & \\
\hline CHEMBL1966816 & 809274 & 5.4 & 5.2049 & TRN & \\
\hline CHEMBL1972584 & 809274 & 7.3 & 6.5905 & TRN & \\
\hline CHEMBL 2002992 & 809274 & 4.7 & 4.9757 & TRN & \\
\hline CHEMBL1982700 & 809274 & 4.4 & 3.7695 & TST & \\
\hline CHEMBL1968791 & 809274 & 6.9 & 6.9677 & TRN & \\
\hline CHEMBL326282 & 809274 & 5.4 & 5.2107 & TST & \\
\hline CHEMBL1977634 & 809274 & 4.4 & 3.99399 & 99999999998 & TRN \\
\hline CHEMBL1992732 & 809274 & 5.4 & 4.5981 & TST & \\
\hline CHEMBL1976872 & 809274 & 4.4 & 4.314 & TST & \\
\hline CHEMBL1973211 & 809274 & 9.1 & 8.9017 & TRN & \\
\hline CHEMBL1984700 & 809274 & 5.4 & 5.4979 & TRN & \\
\hline CHEMBL 2007151 & 809274 & 7.0 & 7.0227 & TRN & \\
\hline CHEMBL1998953 & 809274 & 4.4 & 4.4475 & TRN & \\
\hline CHEMBL1971606 & 809274 & 4.4 & 4.7934 & TRN & \\
\hline CHEMBL1972125 & 809274 & 5.4 & 5.4594 & TRN & \\
\hline CHEMBL1999120 & 809274 & 4.1 & 4.9178 & TST & \\
\hline CHEMBL1976134 & 809274 & 6.5 & 6.1893 & TRN & \\
\hline CHEMBL1972158 & 809274 & 5.4 & 5.2019 & TRN & \\
\hline CHEMBL1981215 & 809274 & 4.4 & 4.7734 & TRN & \\
\hline CHEMBL1999414 & 809274 & 8.5 & 8.1849 & TRN & \\
\hline & & & & 13863 & \\
\hline
\end{tabular}




\begin{tabular}{|c|c|c|c|c|c|}
\hline \\
\hline CHEMBL1967336 & 809274 & 4.4 & 4.641 & TRN & \\
\hline CHEMBL2001228 & 809274 & 4.4 & 5.4125 & TRN & \\
\hline CHEMBL2006581 & 809274 & 5.4 & 4.9787 & TRN & \\
\hline CHEMBL1970340 & 809274 & 4.0 & 4.5385 & TRN & \\
\hline CHEMBL1967992 & 809274 & 4.4 & 4.93199 & 99999999995 & TRN \\
\hline CHEMBL 2006450 & 809274 & 4.4 & 4.2405 & TRN & \\
\hline CHEMBL1966703 & 809274 & 5.4 & 5.3539 & TST & \\
\hline CHEMBL2001987 & 809274 & 4.4 & 4.2156 & TRN & \\
\hline CHEMBL1969561 & 809274 & 5.4 & 5.0978 & TRN & \\
\hline CHEMBL1994555 & 809274 & 4.4 & 4.6781 & TRN & \\
\hline CHEMBL1975121 & 809274 & 4.4 & 4.9172 & TRN & \\
\hline CHEMBL1983640 & 809274 & 7.3 & 8.2104 & TRN & \\
\hline CHEMBL1997023 & 809274 & 5.4 & 4.9667 & TST & \\
\hline CHEMBL1980003 & 809274 & 4.8 & 4.4759 & TST & \\
\hline CHEMBL1964687 & 809274 & 8.0 & 8.0142 & TRN & \\
\hline CHEMBL1971943 & 809274 & 4.6 & 4.3511 & TRN & \\
\hline CHEMBL1999918 & 809274 & 6.5 & 6.159 & TRN & \\
\hline CHEMBL1974254 & 809274 & 9.6 & 9.4748 & TRN & \\
\hline CHEMBL1997924 & 809274 & 7.5 & 7.6019 & TRN & \\
\hline CHEMBL1969049 & 809274 & 5.4 & 5.3705 & TRN & \\
\hline CHEMBL 2005828 & 809274 & 7.4 & 7.5569 & TRN & \\
\hline CHEMBL1978267 & 809274 & 4.4 & 4.8348 & TRN & \\
\hline CHEMBL1998611 & 809274 & 6.4 & 6.1469 & TST & \\
\hline CHEMBL485556 & 809274 & 7.3 & 6.9567 & TRN & \\
\hline CHEMBL1975900 & 809274 & 5.4 & 5.6278 & TRN & \\
\hline CHEMBL 255822 & 809274 & 5.4 & 5.3494 & TRN & \\
\hline CHEMBL1972221 & 809274 & 5.4 & 5.34200 & 00000000005 & TRN \\
\hline CHEMBL 2006778 & 809274 & 9.2 & 9.3374 & TRN & \\
\hline CHEMBL378627 & 809274 & 5.4 & 5.2595 & TRN & \\
\hline CHEMBL1996979 & 809274 & 5.4 & 6.4725 & TRN & \\
\hline CHEMBL1968406 & 809274 & 8.2 & 7.7764 & TRN & \\
\hline CHEMBL1975921 & 809274 & 5.0 & 4.6191 & TRN & \\
\hline CHEMBL1998545 & 809274 & 5.4 & 4.9641 & TRN & \\
\hline CHEMBL1975923 & 809274 & 5.7 & 5.3558 & TST & \\
\hline CHEMBL 2005449 & 809274 & 5.8 & 6.30399 & 9999999999 & TRN \\
\hline CHEMBL1987998 & 809274 & 4.4 & 4.3018 & TRN & \\
\hline CHEMBL1682558 & 809274 & 5.4 & 4.7485 & TRN & \\
\hline CHEMBL1971534 & 809274 & 5.1 & 5.3696 & TRN & \\
\hline CHEMBL1990496 & 809274 & 4.7 & 5.3517 & TRN & \\
\hline CHEMBL 242865 & 809274 & 6.1 & 5.7025 & TRN & \\
\hline CHEMBL1997623 & 809274 & 8.4 & 7.8883 & TRN & \\
\hline CHEMBL 2002479 & 809274 & 5.4 & 5.62 & TRN & \\
\hline CHEMBL1967094 & 809274 & 5.4 & 6.7502 & TRN & \\
\hline CHEMBL 2003341 & 809274 & 5.4 & 5.4678 & TRN & \\
\hline CHEMBL1998110 & 809274 & 4.4 & 4.5384 & TRN & \\
\hline CHEMBL1999590 & 809274 & 5.4 & 5.5743 & TST & \\
\hline CHEMBL1981079 & 809274 & 5.4 & 4.959 & TRN & \\
\hline CHEMBL1978166 & 809274 & 7.2 & 8.2305 & TRN & \\
\hline
\end{tabular}




\begin{tabular}{|c|c|c|c|c|c|}
\hline & & & & & \\
\hline CHEMBL1980489 & 809274 & 5.4 & 5.2713 & TRN & \\
\hline CHEMBL 2000832 & 809274 & 5.4 & 5.5412 & TRN & \\
\hline CHEMBL1967116 & 809274 & 9.7 & 9.6624 & TRN & \\
\hline CHEMBL1990590 & 809274 & 4.4 & 4.3759 & TRN & \\
\hline CHEMBL1970709 & 809274 & 5.4 & 5.1014 & TRN & \\
\hline CHEMBL1974617 & 809274 & 4.6 & 4.7803 & TRN & \\
\hline CHEMBL1965660 & 809274 & 5.4 & 5.3267 & TRN & \\
\hline CHEMBL1992125 & 809274 & 5.5 & 5.921 & TRN & \\
\hline CHEMBL1998112 & 809274 & 5.4 & 5.91799 & 9999999999 & TRN \\
\hline CHEMBL1993996 & 809274 & 10.0 & 9.6444 & TRN & \\
\hline CHEMBL1980896 & 809274 & 7.0 & 7.3253 & TRN & \\
\hline CHEMBL1970104 & 809274 & 7.1 & 6.9864 & TRN & \\
\hline CHEMBL1994040 & 809274 & 5.4 & 5.553 & TRN & \\
\hline CHEMBL388978 & 809274 & 8.3 & 7.8725 & TST & \\
\hline CHEMBL579246 & 809274 & 5.4 & 5.732 & TRN & \\
\hline CHEMBL398951 & 809274 & 4.6 & 5.4996 & TRN & \\
\hline CHEMBL2004716 & 809274 & 9.4 & 8.8 & TRN & \\
\hline CHEMBL1968127 & 809274 & 5.4 & 4.8585 & TRN & \\
\hline CHEMBL1975233 & 809274 & 5.4 & 5.7525 & TRN & \\
\hline CHEMBL1985406 & 809274 & 5.4 & 5.4639 & TRN & \\
\hline CHEMBL2007603 & 809274 & 4.4 & 4.1473 & TRN & \\
\hline CHEMBL 2000894 & 809274 & 5.4 & 5.4174 & TST & \\
\hline CHEMBL1421720 & 809274 & 5.5 & 5.2169 & TRN & \\
\hline CHEMBL1968130 & 809274 & 4.6 & 4.7557 & TST & \\
\hline CHEMBL1982135 & 809274 & 5.4 & 7.3531 & TRN & \\
\hline CHEMBL1976090 & 809274 & 5.4 & 5.1771 & TRN & \\
\hline CHEMBL1993243 & 809274 & 7.9 & 8.1446 & TRN & \\
\hline CHEMBL2004771 & 809274 & 5.4 & 5.7788 & TRN & \\
\hline CHEMBL1992922 & 809274 & 5.4 & 5.211 & TRN & \\
\hline CHEMBL399021 & 809274 & 6.4 & 6.5333 & TRN & \\
\hline CHEMBL1969537 & 809274 & 5.4 & 6.4352 & TST & \\
\hline CHEMBL1976093 & 809274 & 5.4 & 5.2596 & TRN & \\
\hline CHEMBL508928 & 809274 & 9.0 & 8.9477 & TRN & \\
\hline CHEMBL1949855 & 809274 & 5.0 & 4.4066 & TST & \\
\hline CHEMBL1990223 & 809274 & 4.4 & 4.5558 & TRN & \\
\hline CHEMBL1969879 & 809274 & 5.4 & 5.0632 & TRN & \\
\hline CHEMBL1964382 & 809274 & 4.4 & 5.0435 & TST & \\
\hline CHEMBL101311 & 809274 & 4.4 & 5.2746 & TRN & \\
\hline CHEMBL1981720 & 809274 & 5.4 & 5.3322 & TRN & \\
\hline CHEMBL419932 & 809274 & 5.4 & 5.8392 & TRN & \\
\hline CHEMBL262433 & 809274 & 8.5 & 8.3092 & TRN & \\
\hline CHEMBL373798 & 809274 & 9.8 & 9.1977 & TRN & \\
\hline CHEMBL306380 & 809274 & 6.8 & 6.8811 & TRN & \\
\hline CHEMBL1988581 & 809274 & 7.1 & 7.1895 & TST & \\
\hline CHEMBL2005699 & 809274 & 4.4 & 3.9164 & TRN & \\
\hline CHEMBL1975500 & 809274 & 5.4 & 5.5704 & TRN & \\
\hline CHEMBL1976328 & 809274 & 6.9 & 7.7134 & TRN & \\
\hline CHEMBL394619 & 809274 & 8.8 & 8.9232 & TRN & \\
\hline & & & & 1386 & \\
\hline
\end{tabular}




\begin{tabular}{|c|c|c|c|c|c|}
\hline \\
\hline CHEMBL 2006564 & 809274 & 6.7 & 6.6958 & TRN & \\
\hline CHEMBL1964399 & 809274 & 7.6 & 6.9504 & TRN & \\
\hline CHEMBL411903 & 809274 & 9.2 & 7.9785 & TRN & \\
\hline CHEMBL1978167 & 809274 & 4.4 & 5.0907 & TST & \\
\hline CHEMBL1965988 & 809274 & 9.4 & 9.0017 & TRN & \\
\hline CHEMBL418203 & 809274 & 4.7 & 4.6941 & TST & \\
\hline CHEMBL1989646 & 809274 & 5.4 & 5.4134 & TRN & \\
\hline CHEMBL1682357 & 809274 & 5.4 & 5.5774 & TRN & \\
\hline CHEMBL225519 & 809274 & 4.8 & 5.3077 & TRN & \\
\hline CHEMBL209534 & 809274 & 5.4 & 5.5719 & TRN & \\
\hline CHEMBL1978200 & 809274 & 5.4 & 5.3292 & TRN & \\
\hline CHEMBL1970522 & 809274 & 5.4 & 5.6515 & TRN & \\
\hline CHEMBL402846 & 809274 & 8.7 & 9.4675 & TRN & \\
\hline CHEMBL1964692 & 809274 & 9.1 & 8.9152 & TRN & \\
\hline CHEMBL1964413 & 809274 & 5.4 & 4.7289 & TRN & \\
\hline CHEMBL1973483 & 809274 & 5.4 & 5.0507 & TRN & \\
\hline CHEMBL1998470 & 809274 & 6.2 & 4.564 & TRN & \\
\hline CHEMBL1984432 & 809274 & 5.4 & 5.2529 & TRN & \\
\hline CHEMBL 219722 & 809274 & 8.8 & 8.147 & TRN & \\
\hline CHEMBL1975903 & 809274 & 5.5 & 5.0318 & TRN & \\
\hline CHEMBL1997340 & 809274 & 5.4 & 5.4483 & TRN & \\
\hline CHEMBL1522508 & 809274 & 3.5 & 3.6162 & TRN & \\
\hline CHEMBL1988805 & 809274 & 4.4 & 5.0108 & TST & \\
\hline CHEMBL458997 & 809274 & 5.8 & $5.6960 e$ & 0000000001 & TRN \\
\hline CHEMBL1971021 & 809274 & 5.4 & 6.0535 & TRN & \\
\hline CHEMBL227271 & 809274 & 5.4 & 5.2576 & TRN & \\
\hline CHEMBL583144 & 809274 & 5.4 & 5.2556 & TST & \\
\hline CHEMBL1969942 & 809274 & 4.4 & 4.6634 & TRN & \\
\hline CHEMBL1978567 & 809274 & 4.4 & 4.5384 & TRN & \\
\hline CHEMBL1982660 & 809274 & 6.9 & 5.8149 & TRN & \\
\hline CHEMBL1994693 & 809274 & 7.2 & 7.6465 & TRN & \\
\hline CHEMBL1982957 & 809274 & 6.9 & 7.0498 & TRN & \\
\hline CHEMBL1725279 & 809274 & 6.7 & 5.94 & TST & \\
\hline CHEMBL 2002346 & 809274 & 5.4 & 6.1501 & TRN & \\
\hline CHEMBL424872 & 809274 & 4.6 & 5.0724 & TRN & \\
\hline CHEMBL1971947 & 809274 & 8.9 & 9.1109 & TRN & \\
\hline CHEMBL412142 & 809274 & 5.4 & 5.1991 & TST & \\
\hline CHEMBL 2003271 & 809274 & 5.4 & 5.0352 & TST & \\
\hline CHEMBL1972365 & 809274 & 5.8 & 5.3626 & TRN & \\
\hline CHEMBL1966808 & 809274 & 5.4 & 5.2815 & TST & \\
\hline CHEMBL1996255 & 809274 & 9.6 & $9.3570 e$ & 0000000001 & TRN \\
\hline CHEMBL1983111 & 809274 & 8.0 & 6.7372 & TRN & \\
\hline CHEMBL260135 & 809274 & 5.4 & 5.4849 & TRN & \\
\hline CHEMBL 220241 & 809274 & 5.4 & 5.2131 & TRN & \\
\hline CHEMBL1988141 & 809274 & 4.4 & 6.2857 & TST & \\
\hline CHEMBL1977134 & 809274 & 6.6 & 6.8773 & TRN & \\
\hline CHEMBL 2006933 & 809274 & 5.4 & 5.4394 & TST & \\
\hline CHEMBL1985206 & 809274 & 4.4 & 4.9109 & TRN & \\
\hline
\end{tabular}




\begin{tabular}{|c|c|c|c|c|c|}
\hline \\
\hline CHEMBL1988300 & 809274 & 8.3 & 7.6706 & TRN & \\
\hline CHEMBL1991078 & 809274 & 6.7 & 5.8561 & TRN & \\
\hline CHEMBL1987359 & 809274 & 5.4 & 4.5298 & TST & \\
\hline CHEMBL1977749 & 809274 & 4.4 & 4.7883 & TST & \\
\hline CHEMBL1975212 & 809274 & 4.8 & 4.8771 & TRN & \\
\hline CHEMBL2000685 & 809274 & 5.4 & 4.6848 & TRN & \\
\hline CHEMBL 2001613 & 809274 & 5.1 & 4.3001 & TST & \\
\hline CHEMBL1997275 & 809274 & 4.4 & 4.5571 & TRN & \\
\hline CHEMBL1993904 & 809274 & 4.4 & 5.2055 & TRN & \\
\hline CHEMBL1967513 & 809274 & 4.4 & 4.2507 & TRN & \\
\hline CHEMBL 2000724 & 809274 & 4.4 & 4.4159 & TRN & \\
\hline CHEMBL1985311 & 809274 & 8.5 & 8.2428 & TRN & \\
\hline CHEMBL1982413 & 809274 & 4.4 & 4.8352 & TRN & \\
\hline CHEMBL1969502 & 809274 & 7.4 & 6.8119 & TST & \\
\hline CHEMBL1965910 & 809274 & 5.4 & 6.7577 & TRN & \\
\hline CHEMBL1682553 & 809274 & 5.4 & 5.0863 & TRN & \\
\hline CHEMBL1983963 & 809274 & 9.3 & 9.0698 & TRN & \\
\hline CHEMBL2000271 & 809274 & 5.4 & 5.23600 & 2000000001 & TRN \\
\hline CHEMBL1981792 & 809274 & 4.4 & 4.7595 & TRN & \\
\hline CHEMBL1987535 & 809274 & 4.4 & 4.3439 & TRN & \\
\hline CHEMBL1981410 & 809274 & 6.8 & 6.1687 & TRN & \\
\hline CHEMBL 2002586 & 809274 & 4.4 & 4.3883 & TRN & \\
\hline CHEMBL1996234 & 809274 & 5.4 & 5.8398 & TST & \\
\hline CHEMBL383264 & 809274 & 6.4 & 5.9057 & TRN & \\
\hline CHEMBL2007421 & 809274 & 5.8 & 5.8399 & TRN & \\
\hline CHEMBL1967544 & 809274 & 5.4 & 5.1416 & TRN & \\
\hline CHEMBL1973138 & 809274 & 4.4 & 4.4369 & TRN & \\
\hline CHEMBL 223367 & 809274 & 5.4 & 5.3266 & TST & \\
\hline CHEMBL1992673 & 809274 & 4.2 & 4.216 & TST & \\
\hline CHEMBL 340384 & 809274 & 5.4 & 5.9198 & TST & \\
\hline CHEMBL1969151 & 809274 & 4.4 & 4.8566 & TRN & \\
\hline CHEMBL1993335 & 809274 & 5.8 & 5.73600 & 3000000001 & TST \\
\hline CHEMBL1988692 & 809274 & 5.6 & 6.0519 & TRN & \\
\hline CHEMBL 2007574 & 809274 & 4.4 & 4.3092 & TRN & \\
\hline CHEMBL1964804 & 809274 & 5.4 & 5.5321 & TRN & \\
\hline CHEMBL443962 & 809274 & 6.8 & 5.7089 & TST & \\
\hline CHEMBL 2000354 & 809274 & 5.4 & 5.2925 & TRN & \\
\hline CHEMBL1965507 & 809274 & 5.4 & 5.6468 & TRN & \\
\hline CHEMBL 274064 & 809274 & 5.4 & 5.3907 & TRN & \\
\hline CHEMBL1998680 & 809274 & 4.4 & 4.0474 & TRN & \\
\hline CHEMBL1967564 & 809274 & 5.4 & 5.2355 & TRN & \\
\hline CHEMBL592030 & 809274 & 4.6 & 3.991 & TST & \\
\hline CHEMBL 2000071 & 809274 & 5.4 & 5.3059 & TRN & \\
\hline CHEMBL1979176 & 809274 & 5.4 & 5.6028 & TRN & \\
\hline CHEMBL1970317 & 809274 & 7.2 & 8.3255 & TRN & \\
\hline CHEMBL1985491 & 809274 & 8.6 & 8.737 & TRN & \\
\hline CHEMBL 2000408 & 809274 & 5.4 & 5.2655 & TRN & \\
\hline CHEMBL248757 & 809274 & 5.4 & 5.4296 & TST & \\
\hline
\end{tabular}




\begin{tabular}{|c|c|c|c|c|}
\hline & & & & \\
\hline CHEMBL1978014 & 809274 & 5.4 & 5.6941 & TRN \\
\hline CHEMBL1997007 & 809274 & 4.4 & 4.6377 & TRN \\
\hline CHEMBL1994538 & 809274 & 5.4 & 5.059 & TRN \\
\hline CHEMBL1964444 & 809274 & 4.7 & 4.9267 & TRN \\
\hline CHEMBL 2002690 & 809274 & 5.9 & 4.9932 & TRN \\
\hline CHEMBL1986139 & 809274 & 5.4 & 4.371 & TRN \\
\hline CHEMBL 383527 & 809274 & 5.4 & 4.9382 & TRN \\
\hline CHEMBL 278041 & 809274 & 4.4 & 4.157 & TRN \\
\hline CHEMBL1979883 & 809274 & 9.1 & 8.4798 & TRN \\
\hline CHEMBL1984162 & 809274 & 8.7 & 9.1091 & TRN \\
\hline CHEMBL1997051 & 809274 & 5.9 & 5.5424 & TRN \\
\hline CHEMBL491758 & 809274 & 6.9 & 6.347 & TRN \\
\hline CHEMBL1986590 & 809274 & 4.4 & 5.0131 & TRN \\
\hline CHEMBL1970189 & 809274 & 5.4 & 5.2745 & TRN \\
\hline CHEMBL1870106 & 809274 & 4.4 & 5.3239 & TRN \\
\hline CHEMBL1996791 & 809274 & 5.4 & 5.8191 & TRN \\
\hline CHEMBL371206 & 809274 & 7.9 & 8.3752 & TRN \\
\hline CHEMBL1974664 & 809274 & 5.4 & 6.2554 & TRN \\
\hline CHEMBL406845 & 809274 & 4.5 & 5.4415 & TRN \\
\hline CHEMBL482538 & 809274 & 4.3 & 4.8666 & TRN \\
\hline CHEMBL1974288 & 809274 & 5.4 & 5.0703 & TRN \\
\hline CHEMBL1984296 & 809274 & 5.5 & 5.1862 & TST \\
\hline CHEMBL1996837 & 809274 & 4.4 & 4.2193 & TST \\
\hline CHEMBL1190711 & 809274 & 5.4 & 6.1222 & TRN \\
\hline CHEMBL1968705 & 809274 & 4.6 & 4.5419 & TRN \\
\hline CHEMBL1964441 & 809274 & 7.4 & 8.3526 & TRN \\
\hline CHEMBL1991410 & 809274 & 4.4 & 4.3334 & TRN \\
\hline CHEMBL546797 & 809274 & 4.4 & 4.6348 & TRN \\
\hline CHEMBL404367 & 809274 & 8.7 & 9.3032 & TRN \\
\hline CHEMBL 1966343 & 809274 & 5.4 & 5.6678 & TRN \\
\hline CHEMBL1978271 & 809274 & 4.4 & 4.4369 & TRN \\
\hline CHEMBL1967887 & 809274 & 5.4 & 5.3405 & TRN \\
\hline CHEMBL 2007266 & 809274 & 5.6 & 6.6573 & TRN \\
\hline CHEMBL 2000568 & 809274 & 4.7 & 5.3441 & TRN \\
\hline CHEMBL1994308 & 809274 & 4.4 & 4.0245 & TST \\
\hline CHEMBL2000335 & 809274 & 9.6 & 8.9247 & TRN \\
\hline CHEMBL1988717 & 809274 & 9.4 & 8.5241 & TRN \\
\hline CHEMBL1974328 & 809274 & 4.7 & 5.0867 & TRN \\
\hline CHEMBL509032 & 809274 & 7.1 & 7.0329 & TRN \\
\hline CHEMBL 2000429 & 809274 & 5.4 & 5.4526 & TRN \\
\hline CHEMBL1972576 & 809274 & 5.4 & 5.4574 & TRN \\
\hline CHEMBL1992342 & 809274 & 5.4 & 5.2579 & TRN \\
\hline CHEMBL1973013 & 809274 & 4.4 & 5.5456 & TRN \\
\hline CHEMBL1164265 & 809274 & 4.4 & 6.3434 & TST \\
\hline CHEMBL1965423 & 809274 & 5.4 & 5.1404 & TRN \\
\hline CHEMBL1983025 & 809274 & 8.4 & 8.412 & TRN \\
\hline CHEMBL1975927 & 809274 & 6.6 & 6.3502 & TRN \\
\hline CHEMBL205415 & 809274 & 4.7 & 4.8072 & TRN \\
\hline
\end{tabular}




\begin{tabular}{|c|c|c|c|c|c|}
\hline CHEMBL1977135 & 809274 & 5.4 & \multicolumn{2}{|c|}{4.9830000000000005} & TRN \\
\hline CHEMBL1977138 & 809274 & 6.6 & 6.7899 & TST & \\
\hline CHEMBL1980904 & 809274 & 9.5 & 9.0568 & TRN & \\
\hline CHEMBL2002323 & 809274 & 5.4 & 5.1475 & TRN & \\
\hline CHEMBL1241473 & 809274 & 7.7 & 7.0694 & TRN & \\
\hline CHEMBL1978448 & 809274 & 4.7 & 4.0803 & TST & \\
\hline CHEMBL1969483 & 809274 & 4.4 & 5.1345 & TRN & \\
\hline CHEMBL1980329 & 809274 & 7.7 & 6.9923 & TRN & \\
\hline CHEMBL2004515 & 809274 & 5.3 & 4.708 & TRN & \\
\hline CHEMBL 2001257 & 809274 & 8.4 & 7.7117 & TRN & \\
\hline CHEMBL1992042 & 809274 & 4.4 & 4.6286 & TST & \\
\hline CHEMBL 2005548 & 809274 & 5.4 & 5.1519 & TRN & \\
\hline CHEMBL 271441 & 809274 & 9.8 & 10.0096 & TRN & \\
\hline CHEMBL21156 & 809274 & 4.4 & 5.1727 & TST & \\
\hline CHEMBL1992740 & 809274 & 5.4 & 5.524 & TRN & \\
\hline CHEMBL1994724 & 809274 & 4.4 & 4.6255 & TRN & \\
\hline CHEMBL1989267 & 809274 & 5.9 & 7.186 & TRN & \\
\hline CHEMBL1974574 & 809274 & 4.4 & 4.8319 & TST & \\
\hline CHEMBL 2006188 & 809274 & 5.4 & 4.8884 & TRN & \\
\hline CHEMBL1970290 & 809274 & 5.7 & 5.0591 & TRN & \\
\hline CHEMBL1967531 & 809274 & 7.3 & 7.4286 & TRN & \\
\hline CHEMBL1973893 & 809274 & 5.4 & 5.2632 & TRN & \\
\hline CHEMBL1978601 & 809274 & 9.6 & 8.6861 & TRN & \\
\hline CHEMBL1997534 & 809274 & 5.4 & 5.3035 & TRN & \\
\hline CHEMBL1993877 & 809274 & 5.9 & 5.9136 & TRN & \\
\hline CHEMBL1996500 & 809274 & 4.5 & 5.016999 & 99999999995 & TRN \\
\hline CHEMBL1985095 & 809274 & 5.4 & 5.465 & TST & \\
\hline CHEMBL 273187 & 809274 & 11.1 & 10.2889 & TRN & \\
\hline CHEMBL1991180 & 809274 & 5.4 & 5.0943 & TST & \\
\hline CHEMBL1682540 & 809274 & 5.4 & 5.2554 & TRN & \\
\hline CHEMBL1976420 & 809274 & 4.7 & 4.9411 & TRN & \\
\hline CHEMBL1986979 & 809274 & 10.2 & 9.5686 & TRN & \\
\hline CHEMBL1998253 & 809274 & 4.4 & 3.6888 & TST & \\
\hline CHEMBL413779 & 809274 & 5.4 & 5.298999 & 99999999995 & TST \\
\hline CHEMBL1981744 & 809274 & 4.4 & 4.681 & TRN & \\
\hline CHEMBL2002446 & 809274 & 9.4 & 9.0653 & TRN & \\
\hline CHEMBL497151 & 809274 & 5.4 & 5.3117 & TST & \\
\hline CHEMBL 2000029 & 809274 & 4.4 & 4.6885 & TRN & \\
\hline CHEMBL1973961 & 809274 & 4.4 & 4.649 & TRN & \\
\hline CHEMBL340921 & 809274 & 5.4 & 5.5089 & TST & \\
\hline CHEMBL1994977 & 809274 & 4.4 & 4.0697 & TRN & \\
\hline CHEMBL373598 & 809274 & 5.4 & 5.1339 & TST & \\
\hline CHEMBL 2001149 & 809274 & 4.4 & 4.3401 & TRN & \\
\hline CHEMBL1999718 & 809274 & 5.4 & 5.0748 & TRN & \\
\hline CHEMBL 2000078 & 809274 & 6.1 & 5.7097 & TRN & \\
\hline CHEMBL2005478 & 809274 & 4.4 & 5.6106 & TST & \\
\hline CHEMBL1276446 & 809274 & 8.0 & 7.1132 & TST & \\
\hline CHEMBL1996646 & 809274 & 7.0 & 6.495 & TRN & \\
\hline
\end{tabular}




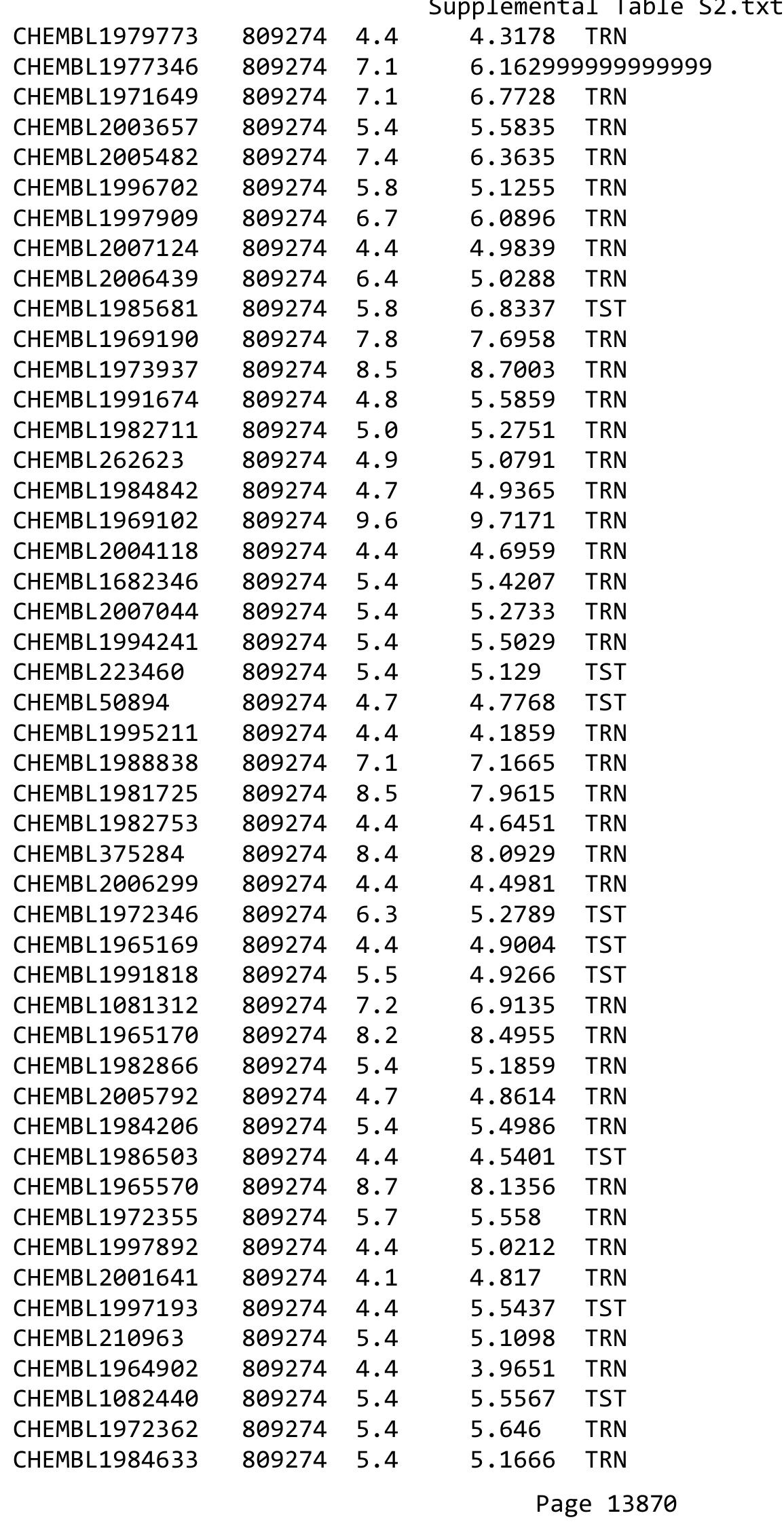

TRN 


\begin{tabular}{|c|c|c|c|c|}
\hline & & & pplement & $\mathrm{a} \perp \mathrm{Ta}$ \\
\hline CHEMBL1965845 & 809274 & 5.4 & 5.879 & TRN \\
\hline CHEMBL1983715 & 809274 & 7.1 & 7.6875 & TRN \\
\hline CHEMBL1971017 & 809274 & 6.6 & 5.8022 & TRN \\
\hline CHEMBL1990482 & 809274 & 5.4 & 5.1538 & TRN \\
\hline CHEMBL1990904 & 809274 & 5.4 & 5.7257 & TRN \\
\hline CHEMBL2005475 & 809274 & 6.5 & 7.0723 & TRN \\
\hline CHEMBL 2000104 & 809274 & 5.4 & 5.6241 & TRN \\
\hline CHEMBL183844 & 809274 & 8.1 & 7.2763 & TRN \\
\hline CHEMBL220057 & 809274 & 9.2 & 9.5827 & TRN \\
\hline CHEMBL 383541 & 809274 & 5.4 & 5.2567 & TRN \\
\hline CHEMBL 2001224 & 809274 & 5.4 & 5.59 & TRN \\
\hline CHEMBL10 & 809274 & 4.4 & 4.4746 & TRN \\
\hline CHEMBL1964937 & 809274 & 5.4 & 5.1599 & TRN \\
\hline CHEMBL1980763 & 809274 & 5.6 & 4.9648 & TRN \\
\hline CHEMBL590109 & 809274 & 6.4 & 4.5635 & TST \\
\hline CHEMBL1977931 & 809274 & 4.4 & 4.2714 & TRN \\
\hline CHEMBL1970879 & 809274 & 6.4 & 6.3333 & TRN \\
\hline CHEMBL 2005899 & 809274 & 5.4 & 6.0058 & TRN \\
\hline CHEMBL1682552 & 809274 & 5.4 & 5.2623 & TRN \\
\hline CHEMBL 259850 & 809274 & 5.4 & 5.1207 & TRN \\
\hline CHEMBL 2007479 & 809274 & 4.4 & 4.4786 & TRN \\
\hline CHEMBL229799 & 809274 & 5.4 & 5.4623 & TRN \\
\hline CHEMBL1971223 & 809274 & 4.4 & 4.6188 & TRN \\
\hline CHEMBL105739 & 809274 & 7.7 & 7.4726 & TRN \\
\hline CHEMBL1972220 & 809274 & 8.6 & 8.9807 & TRN \\
\hline CHEMBL 379300 & 809274 & 5.4 & 5.5919 & TRN \\
\hline CHEMBL 2003785 & 809274 & 4.1 & 4.1879 & TST \\
\hline CHEMBL1973720 & 809274 & 4.4 & 5.7758 & TRN \\
\hline CHEMBL1969523 & 809274 & 7.6 & 7.237 & TRN \\
\hline CHEMBL 207995 & 809274 & 5.4 & 5.5548 & TRN \\
\hline CHEMBL2001923 & 809274 & 4.7 & 4.5856 & TRN \\
\hline CHEMBL1986781 & 809274 & 5.4 & 5.2666 & TRN \\
\hline CHEMBL1983070 & 809274 & 4.4 & 4.6044 & TRN \\
\hline CHEMBL526133 & 809274 & 5.4 & 5.646 & TRN \\
\hline CHEMBL 2003514 & 809274 & 4.4 & 4.5876 & TRN \\
\hline CHEMBL1966836 & 809274 & 9.0 & 9.1161 & TRN \\
\hline CHEMBL1989043 & 809274 & 4.4 & 4.4203 & TRN \\
\hline CHEMBL1979057 & 809274 & 5.4 & 5.195 & TRN \\
\hline CHEMBL1981045 & 809274 & 5.4 & 4.9242 & TRN \\
\hline CHEMBL 387971 & 809274 & 9.3 & 8.4176 & TRN \\
\hline CHEMBL1975418 & 809274 & 5.4 & 5.6499 & TRN \\
\hline CHEMBL1164180 & 809274 & 5.8 & 6.1519 & TST \\
\hline CHEMBL223257 & 809274 & 5.4 & 5.3063 & TST \\
\hline CHEMBL1999428 & 809274 & 6.8 & 6.2053 & TRN \\
\hline CHEMBL1967560 & 809274 & 5.4 & 5.7182 & TRN \\
\hline CHEMBL1997611 & 809274 & 5.7 & 4.9637 & TST \\
\hline CHEMBL 211378 & 809274 & 8.0 & 8.4191 & TRN \\
\hline CHEMBL1982465 & 809274 & 9.0 & 8.7402 & TRN \\
\hline
\end{tabular}




\begin{tabular}{|c|c|c|c|c|}
\hline \multicolumn{5}{|c|}{ splemental T } \\
\hline CHEMBL2001751 & 809274 & 5.4 & 7.0341 & TRN \\
\hline CHEMBL1984586 & 809274 & 6.8 & 6.7209 & TRN \\
\hline CHEMBL 272938 & 809274 & 10.3 & 10.3793 & TRN \\
\hline CHEMBL 2002723 & 809274 & 5.6 & 5.6257 & TST \\
\hline CHEMBL1984632 & 809274 & 5.7 & 4.4276 & TST \\
\hline CHEMBL1973395 & 809274 & 5.4 & 4.9657 & TRN \\
\hline CHEMBL 272453 & 809274 & 9.4 & 8.3394 & TRN \\
\hline CHEMBL1987143 & 809274 & 5.7 & 4.9597 & TRN \\
\hline CHEMBL1970217 & 809274 & 5.4 & 5.3864 & TRN \\
\hline CHEMBL1984686 & 809274 & 4.4 & 4.7994 & TRN \\
\hline CHEMBL185569 & 809274 & 8.4 & 8.0283 & TRN \\
\hline CHEMBL1969843 & 809274 & 5.4 & 5.2649 & TRN \\
\hline CHEMBL 2007002 & 809274 & 5.4 & 5.2373 & TRN \\
\hline CHEMBL1973793 & 809274 & 4.4 & 4.6146 & TST \\
\hline CHEMBL1969588 & 809274 & 6.7 & 6.7207 & TRN \\
\hline CHEMBL1984711 & 809274 & 6.7 & 7.2239 & TRN \\
\hline CHEMBL1992073 & 809274 & 4.4 & 4.6832 & TRN \\
\hline CHEMBL1979252 & 809274 & 5.4 & 4.9263 & TRN \\
\hline CHEMBL1986143 & 809274 & 4.4 & 4.5434 & TRN \\
\hline CHEMBL2007559 & 809274 & 4.4 & 4.2162 & TRN \\
\hline CHEMBL1992581 & 809274 & 6.5 & 6.4831 & TRN \\
\hline CHEMBL1682341 & 809274 & 5.4 & 4.9462 & TRN \\
\hline CHEMBL 2004290 & 809274 & 8.2 & 8.6895 & TRN \\
\hline CHEMBL1986499 & 809274 & 5.4 & 4.9139 & TRN \\
\hline CHEMBL1972250 & 809274 & 5.4 & 5.9262 & TRN \\
\hline CHEMBL 2000393 & 809274 & 5.4 & 6.3676 & TST \\
\hline CHEMBL403402 & 809274 & 9.7 & 9.3172 & TRN \\
\hline CHEMBL 2004311 & 809274 & 7.1 & 6.8927 & TRN \\
\hline CHEMBL1992634 & 809274 & 6.6 & 5.9918 & TRN \\
\hline CHEMBL1242373 & 809274 & 8.2 & 8.1476 & TRN \\
\hline CHEMBL1984847 & 809274 & 4.4 & 4.7855 & TST \\
\hline CHEMBL1984402 & 809274 & 4.0 & 4.9597 & TST \\
\hline CHEMBL1988075 & 809274 & 8.9 & 8.3919 & TRN \\
\hline CHEMBL1996576 & 809274 & 4.4 & 4.0953 & TST \\
\hline CHEMBL1988076 & 809274 & 6.5 & 6.1501 & TRN \\
\hline CHEMBL1991678 & 809274 & 4.5 & 5.0018 & TRN \\
\hline CHEMBL2001239 & 809274 & 5.4 & 4.9285 & TST \\
\hline CHEMBL1988594 & 809274 & 5.4 & 4.8663 & TRN \\
\hline CHEMBL 2001288 & 809274 & 5.4 & 5.4932 & TRN \\
\hline CHEMBL 260092 & 809274 & 8.9 & 7.954 & TRN \\
\hline CHEMBL1999811 & 809274 & 5.4 & 5.4966 & TRN \\
\hline CHEMBL1965495 & 809274 & 6.7 & 6.2695 & TRN \\
\hline CHEMBL 235157 & 809274 & 5.5 & 4.3113 & TST \\
\hline CHEMBL 2000481 & 809274 & 5.4 & 5.0748 & TRN \\
\hline CHEMBL1982874 & 809274 & 5.4 & 5.5834 & TRN \\
\hline CHEMBL1991725 & 809274 & 5.4 & 5.8323 & TRN \\
\hline CHEMBL1992242 & 809274 & 7.6 & 6.9615 & TRN \\
\hline CHEMBL2007296 & 809274 & 5.4 & 5.0258 & TRN \\
\hline
\end{tabular}




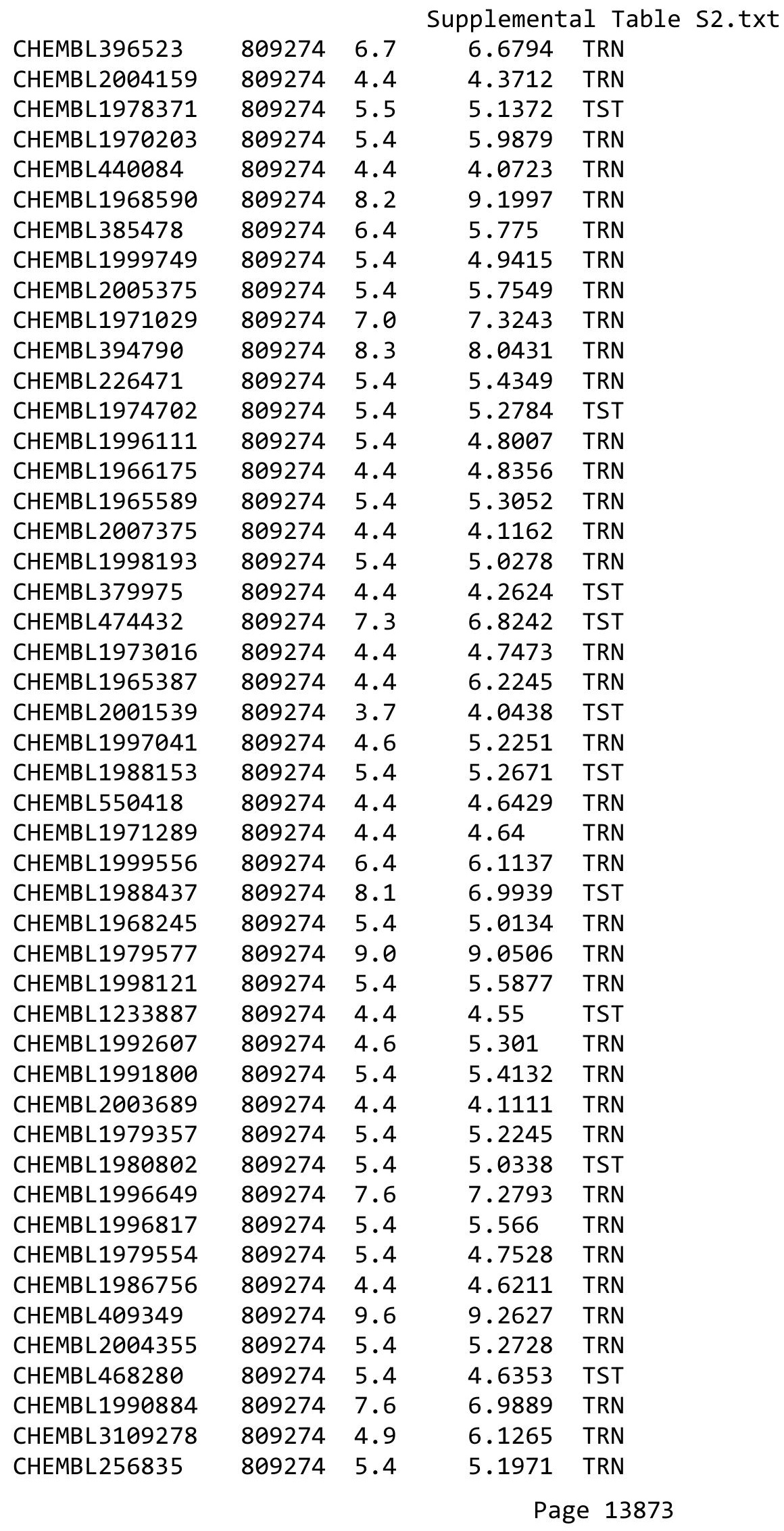




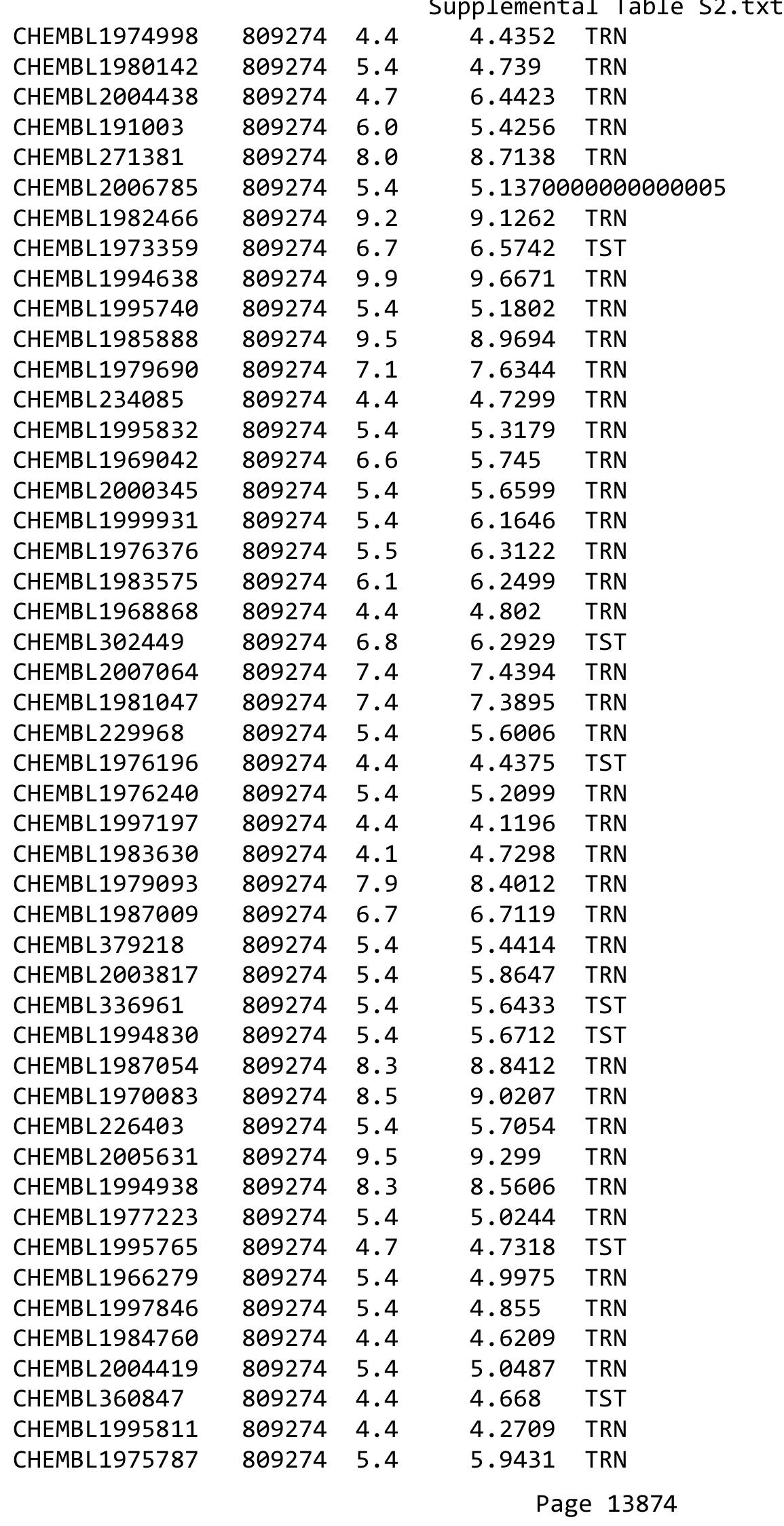




\begin{tabular}{|c|c|c|c|c|}
\hline & & & pplement & 0 \\
\hline CHEMBL2002407 & 809274 & 5.4 & 5.7621 & TRN \\
\hline CHEMBL1992937 & 809274 & 4.7 & 5.2181 & TST \\
\hline CHEMBL451401 & 809274 & 3.6 & 4.5583 & TRN \\
\hline CHEMBL1985566 & 809274 & 5.4 & 4.9262 & TRN \\
\hline CHEMBL95692 & 809274 & 5.4 & 5.1023 & TRN \\
\hline CHEMBL1090356 & 809274 & 7.7 & 6.7524 & TST \\
\hline CHEMBL1976455 & 809274 & 5.4 & 5.1917 & TST \\
\hline CHEMBL261849 & 809274 & 4.4 & 4.7237 & TST \\
\hline CHEMBL1983923 & 809274 & 7.6 & 7.6476 & TST \\
\hline CHEMBL1983534 & 809274 & 5.4 & 5.8735 & TST \\
\hline CHEMBL1999112 & 809274 & 5.4 & 6.2314 & TST \\
\hline CHEMBL1982122 & 809274 & 5.4 & 5.3427 & TST \\
\hline CHEMBL 2000801 & 809274 & 7.2 & 6.8109 & TST \\
\hline CHEMBL1991395 & 809274 & 5.4 & 5.4273 & TST \\
\hline CHEMBL1971245 & 809274 & 6.7 & 6.7036 & TST \\
\hline CHEMBL1987648 & 809274 & 5.4 & 5.1054 & TST \\
\hline CHEMBL1996780 & 809274 & 5.4 & 5.2709 & TST \\
\hline CHEMBL1972142 & 809274 & 6.8 & 5.9266 & TST \\
\hline CHEMBL1966514 & 809274 & 8.8 & 8.3043 & TST \\
\hline CHEMBL2003638 & 809274 & 5.4 & 5.5822 & TST \\
\hline CHEMBL296586 & 809274 & 6.4 & 5.4629 & TST \\
\hline CHEMBL1996066 & 809274 & 7.8 & 7.5628 & TST \\
\hline CHEMBL1983393 & 809274 & 4.4 & 4.6006 & TST \\
\hline CHEMBL516429 & 809274 & 6.5 & 6.3863 & TST \\
\hline CHEMBL1993722 & 809274 & 5.4 & 7.6716 & TST \\
\hline CHEMBL 2006674 & 809274 & 4.4 & 4.7147 & TST \\
\hline CHEMBL1984236 & 809274 & 4.4 & 4.4868 & TST \\
\hline CHEMBL1992371 & 809274 & 4.4 & 4.7365 & TST \\
\hline CHEMBL1375640 & 809274 & 5.4 & 4.8103 & TST \\
\hline CHEMBL1979970 & 809274 & 5.4 & 5.3953 & TST \\
\hline CHEMBL2002599 & 809274 & 4.4 & 5.0121 & TST \\
\hline CHEMBL 249282 & 809274 & 5.4 & 5.4937 & TST \\
\hline CHEMBL1967252 & 809274 & 4.5 & 5.5571 & TST \\
\hline CHEMBL 2004637 & 809274 & 5.5 & 4.9223 & TST \\
\hline CHEMBL1993374 & 809274 & 4.4 & 4.3666 & TST \\
\hline CHEMBL1969264 & 809274 & 5.4 & 5.8041 & TST \\
\hline CHEMBL1994318 & 809274 & 4.4 & 4.6375 & TST \\
\hline CHEMBL1973711 & 809274 & 6.4 & 5.0315 & TST \\
\hline CHEMBL1999506 & 809274 & 4.4 & 4.1106 & TST \\
\hline CHEMBL1967720 & 809274 & 9.0 & 8.9227 & TST \\
\hline CHEMBL1572266 & 809274 & 5.4 & 5.3359 & TST \\
\hline CHEMBL1979516 & 809274 & 8.8 & 8.354 & TST \\
\hline CHEMBL1605605 & 809274 & 4.4 & 5.3049 & TST \\
\hline CHEMBL1989029 & 809274 & 6.7 & 5.8632 & TST \\
\hline CHEMBL514499 & 809274 & 6.9 & 7.1957 & TST \\
\hline CHEMBL1970352 & 809274 & 4.4 & 4.704 & TST \\
\hline CHEMBL1965631 & 809274 & 5.4 & 4.7092 & TST \\
\hline CHEMBL1980144 & 809274 & 5.4 & 4.939 & TST \\
\hline
\end{tabular}




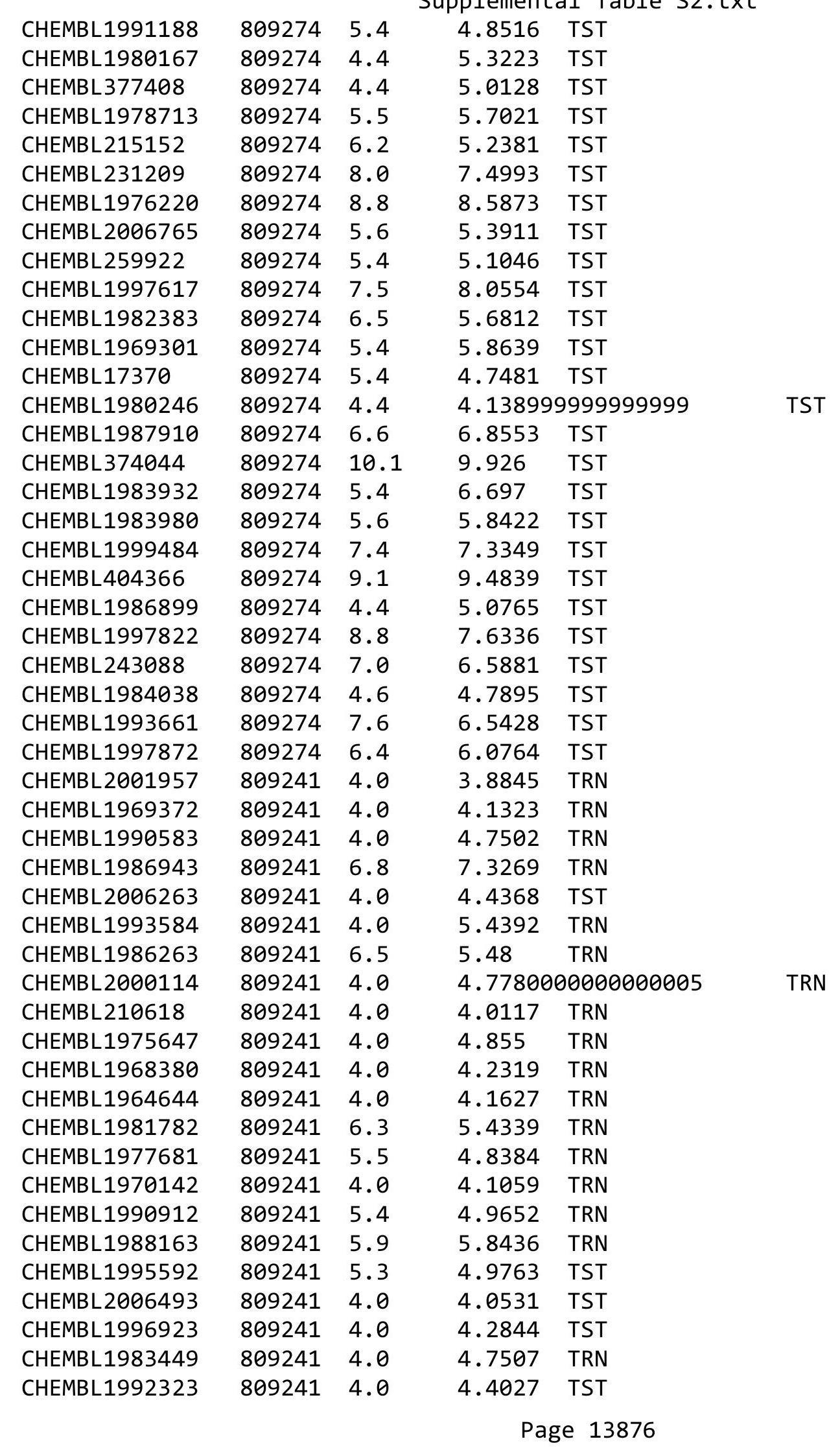




\begin{tabular}{|c|c|c|c|c|c|}
\hline \multicolumn{6}{|c|}{ Supplemental Table S2.txt } \\
\hline CHEMBL1969735 & 809241 & 4.0 & 3.8579 & TRN & \\
\hline CHEMBL 2003524 & 809241 & 4.0 & 4.5356 & TST & \\
\hline CHEMBL 2002649 & 809241 & 6.0 & 5.2154 & TRN & \\
\hline CHEMBL437747 & 809241 & 5.5 & 5.0562 & TRN & \\
\hline CHEMBL1995172 & 809241 & 4.0 & 4.1096 & TST & \\
\hline CHEMBL507936 & 809241 & 4.0 & 4.0424 & TRN & \\
\hline CHEMBL104264 & 809241 & 6.0 & 5.1122 & TST & \\
\hline CHEMBL1994321 & 809241 & 5.0 & 4.4211 & TRN & \\
\hline CHEMBL1997129 & 809241 & 6.0 & 5.7699 & TRN & \\
\hline CHEMBL1984788 & 809241 & 4.0 & 4.3072 & TRN & \\
\hline CHEMBL1996604 & 809241 & 4.0 & 4.4685 & TRN & \\
\hline CHEMBL1964307 & 809241 & 6.1 & 5.01699 & 99999999995 & TRN \\
\hline CHEMBL 2000508 & 809241 & 4.0 & 3.9367 & TRN & \\
\hline CHEMBL1971694 & 809241 & 4.0 & 4.2596 & TST & \\
\hline CHEMBL 2001547 & 809241 & 4.0 & 3.8333 & TRN & \\
\hline CHEMBL210928 & 809241 & 4.0 & 3.9114 & TRN & \\
\hline CHEMBL1986603 & 809241 & 4.0 & 4.4197 & TST & \\
\hline CHEMBL1972840 & 809241 & 6.0 & 6.2823 & TRN & \\
\hline CHEMBL1977148 & 809241 & 4.0 & 3.967 & TRN & \\
\hline CHEMBL 2003286 & 809241 & 5.4 & 4.6301 & TRN & \\
\hline CHEMBL1992306 & 809241 & 4.0 & 4.0118 & TRN & \\
\hline CHEMBL 2002165 & 809241 & 5.6 & 4.4508 & TRN & \\
\hline CHEMBL 2001668 & 809241 & 4.0 & 4.2714 & TST & \\
\hline CHEMBL1979318 & 809241 & 4.0 & 4.1478 & TRN & \\
\hline CHEMBL 206382 & 809241 & 4.0 & 5.0493 & TRN & \\
\hline CHEMBL1998585 & 809241 & 5.5 & 4.6092 & TRN & \\
\hline CHEMBL127898 & 809241 & 4.0 & 4.2699 & TST & \\
\hline CHEMBL519697 & 809241 & 4.0 & 4.6116 & TST & \\
\hline CHEMBL2004934 & 809241 & 6.5 & 5.4631 & TRN & \\
\hline CHEMBL1975128 & 809241 & 7.2 & 6.5229 & TRN & \\
\hline CHEMBL1970369 & 809241 & 4.0 & 4.2912 & TRN & \\
\hline CHEMBL 2001485 & 809241 & 4.0 & 4.1633 & TRN & \\
\hline CHEMBL504950 & 809241 & 5.5 & 4.8805 & TRN & \\
\hline CHEMBL1966425 & 809241 & 4.0 & 4.7982 & TRN & \\
\hline CHEMBL1984363 & 809241 & 5.9 & 5.0591 & TRN & \\
\hline CHEMBL1978099 & 809241 & 4.0 & 5.1962 & TRN & \\
\hline CHEMBL1977041 & 809241 & 6.2 & 4.4904 & TRN & \\
\hline CHEMBL1968070 & 809241 & 5.1 & 4.7185 & TRN & \\
\hline CHEMBL1988608 & 809241 & 6.8 & 5.7719 & TRN & \\
\hline CHEMBL184847 & 809241 & 4.0 & 4.0966 & TRN & \\
\hline CHEMBL1984367 & 809241 & 5.1 & 4.309 & TRN & \\
\hline CHEMBL178737 & 809241 & 4.0 & 4.8551 & TST & \\
\hline CHEMBL226898 & 809241 & 7.2 & 6.6503 & TRN & \\
\hline CHEMBL1982563 & 809241 & 4.0 & 3.8614 & TRN & \\
\hline CHEMBL539474 & 809241 & 4.0 & 4.4282 & TST & \\
\hline CHEMBL575824 & 809241 & 5.3 & 5.9719 & TRN & \\
\hline CHEMBL1988387 & 809241 & 4.0 & 4.3136 & TRN & \\
\hline CHEMBL1997759 & 809241 & 4.0 & 4.2078 & TRN & \\
\hline
\end{tabular}




\begin{tabular}{|c|c|c|c|c|}
\hline & & & Supplement & \\
\hline CHEMBL1989708 & 809241 & 4.0 & 4.3682 & TRN \\
\hline CHEMBL1990288 & 809241 & 4.0 & 3.9856 & TRN \\
\hline CHEMBL1974803 & 809241 & 4.0 & 4.6 & TST \\
\hline CHEMBL1970074 & 809241 & 4.0 & 4.4494 & TRN \\
\hline CHEMBL1986970 & 809241 & 5.8 & 5.7823 & TRN \\
\hline CHEMBL2005112 & 809241 & 4.0 & 4.2306 & TST \\
\hline CHEMBL1958401 & 809241 & 4.0 & 5.0776 & TRN \\
\hline CHEMBL1984044 & 809241 & 4.0 & 4.3684 & TRN \\
\hline CHEMBL2003456 & 809241 & 4.0 & 4.3427 & TRN \\
\hline CHEMBL1966816 & 809241 & 4.0 & 4.6542 & TRN \\
\hline CHEMBL2002992 & 809241 & 4.0 & 5.2715 & TRN \\
\hline CHEMBL560813 & 809241 & 4.0 & 4.317 & TRN \\
\hline CHEMBL207253 & 809241 & 4.0 & 4.1162 & TST \\
\hline CHEMBL1890036 & 809241 & 4.0 & 4.5052 & TST \\
\hline CHEMBL1968791 & 809241 & 4.0 & 4.3864 & TRN \\
\hline CHEMBL326282 & 809241 & 4.0 & 4.2822 & TST \\
\hline CHEMBL2002682 & 809241 & 4.0 & 4.5404 & TST \\
\hline CHEMBL1992732 & 809241 & 4.0 & 4.2227 & TST \\
\hline CHEMBL1971186 & 809241 & 4.0 & 4.0422 & TRN \\
\hline CHEMBL 2003482 & 809241 & 4.0 & 4.3167 & TRN \\
\hline CHEMBL1973211 & 809241 & 5.3 & 4.4495 & TRN \\
\hline CHEMBL1984700 & 809241 & 4.0 & 3.8431 & TRN \\
\hline CHEMBL 2007151 & 809241 & 4.0 & 4.4003 & TRN \\
\hline CHEMBL1998953 & 809241 & 4.2 & 5.1649 & TRN \\
\hline CHEMBL1972125 & 809241 & 4.0 & 4.6618 & TRN \\
\hline CHEMBL1461728 & 809241 & 4.0 & 4.5297 & TRN \\
\hline CHEMBL1976134 & 809241 & 5.7 & 5.2647 & TRN \\
\hline CHEMBL1965131 & 809241 & 5.5 & 5.2914 & TST \\
\hline CHEMBL1995448 & 809241 & 4.0 & 4.8693 & TRN \\
\hline CHEMBL1972158 & 809241 & 6.2 & 6.5448 & TRN \\
\hline CHEMBL1974457 & 809241 & 4.0 & 4.5293 & TRN \\
\hline CHEMBL 2006580 & 809241 & 4.0 & 4.4863 & TRN \\
\hline CHEMBL2006581 & 809241 & 4.0 & 4.1509 & TRN \\
\hline CHEMBL2006481 & 809241 & 4.0 & 4.2591 & TRN \\
\hline CHEMBL1979855 & 809241 & 4.0 & 4.1216 & TRN \\
\hline CHEMBL1970340 & 809241 & 4.0 & 4.391 & TRN \\
\hline CHEMBL 2005186 & 809241 & 4.0 & 4.6585 & TRN \\
\hline CHEMBL1995927 & 809241 & 4.0 & 4.0785 & TST \\
\hline CHEMBL1975534 & 809241 & 5.3 & 4.6793 & TRN \\
\hline CHEMBL1993424 & 809241 & 5.4 & 5.5168 & TRN \\
\hline CHEMBL1966703 & 809241 & 4.0 & 4.2771 & TST \\
\hline CHEMBL1969561 & 809241 & 6.2 & 5.8458 & TRN \\
\hline CHEMBL1997023 & 809241 & 4.0 & 4.4152 & TST \\
\hline CHEMBL1964687 & 809241 & 4.0 & 4.6371 & TRN \\
\hline CHEMBL1971943 & 809241 & 6.6 & 5.3962 & TRN \\
\hline CHEMBL1999918 & 809241 & 6.4 & 5.442 & TRN \\
\hline CHEMBL1974254 & 809241 & 4.0 & 4.1561 & TRN \\
\hline CHEMBL1988537 & 809241 & 6.4 & 5.1036 & TST \\
\hline
\end{tabular}




\begin{tabular}{|c|c|c|c|c|}
\hline & & & pplement & al $\mathrm{Ta}$ \\
\hline CHEMBL1969049 & 809241 & 6.5 & 5.3849 & TRN \\
\hline CHEMBL 2005828 & 809241 & 4.0 & 4.3713 & TRN \\
\hline CHEMBL 2002240 & 809241 & 4.0 & 4.1094 & TRN \\
\hline CHEMBL1991143 & 809241 & 4.0 & 3.9367 & TST \\
\hline CHEMBL1998611 & 809241 & 5.5 & 5.1632 & TST \\
\hline CHEMBL485556 & 809241 & 4.0 & 4.5231 & TST \\
\hline CHEMBL1975900 & 809241 & 6.3 & 5.3006 & TRN \\
\hline CHEMBL255822 & 809241 & 5.5 & 4.8258 & TRN \\
\hline CHEMBL1972221 & 809241 & 5.1 & 4.9945 & TRN \\
\hline CHEMBL 2006778 & 809241 & 5.2 & 4.4083 & TRN \\
\hline CHEMBL378627 & 809241 & 4.0 & 3.9602 & TRN \\
\hline CHEMBL1996979 & 809241 & 6.2 & 4.9828 & TRN \\
\hline CHEMBL1997025 & 809241 & 4.0 & 4.3837 & TRN \\
\hline CHEMBL1968406 & 809241 & 4.0 & 4.7898 & TRN \\
\hline CHEMBL1982476 & 809241 & 5.5 & 4.4195 & TRN \\
\hline CHEMBL1984274 & 809241 & 4.0 & 4.2843 & TST \\
\hline CHEMBL1998545 & 809241 & 5.2 & 4.7111 & TRN \\
\hline CHEMBL1986869 & 809241 & 4.0 & 4.4113 & TRN \\
\hline CHEMBL 2006010 & 809241 & 4.0 & 4.1268 & TRN \\
\hline CHEMBL1682558 & 809241 & 4.0 & 4.1786 & TRN \\
\hline CHEMBL1990496 & 809241 & 4.1 & 4.3297 & TRN \\
\hline CHEMBL1997623 & 809241 & 4.0 & 4.4231 & TRN \\
\hline CHEMBL 2002479 & 809241 & 5.3 & 5.1729 & TRN \\
\hline CHEMBL1993166 & 809241 & 4.0 & 4.9533 & TRN \\
\hline CHEMBL1967094 & 809241 & 6.0 & 4.6898 & TRN \\
\hline CHEMBL1966035 & 809241 & 4.0 & 4.4627 & TRN \\
\hline CHEMBL 2003341 & 809241 & 5.4 & 5.1011 & TRN \\
\hline CHEMBL1992645 & 809241 & 4.0 & 4.5252 & TST \\
\hline CHEMBL1982992 & 809241 & 4.0 & 4.6853 & TRN \\
\hline CHEMBL1974363 & 809241 & 4.0 & 4.2368 & TRN \\
\hline CHEMBL1999590 & 809241 & 4.0 & 4.0283 & TST \\
\hline CHEMBL1981079 & 809241 & 5.4 & 5.978 & TRN \\
\hline CHEMBL1978166 & 809241 & 5.7 & 4.936 & TRN \\
\hline CHEMBL1972276 & 809241 & 4.0 & 4.3052 & TRN \\
\hline CHEMBL1980489 & 809241 & 5.7 & 5.0373 & TRN \\
\hline CHEMBL1967116 & 809241 & 4.0 & 4.2776 & TRN \\
\hline CHEMBL 2000832 & 809241 & 4.0 & 5.2911 & TRN \\
\hline CHEMBL1977814 & 809241 & 4.0 & 4.2231 & TST \\
\hline CHEMBL513846 & 809241 & 4.0 & 4.3764 & TRN \\
\hline CHEMBL1970709 & 809241 & 6.0 & 4.7007 & TRN \\
\hline CHEMBL1965660 & 809241 & 5.8 & 6.4024 & TRN \\
\hline CHEMBL1985309 & 809241 & 4.0 & 4.4319 & TRN \\
\hline CHEMBL1998112 & 809241 & 4.0 & 4.4875 & TRN \\
\hline CHEMBL1969126 & 809241 & 4.0 & 3.9286 & TRN \\
\hline CHEMBL1980896 & 809241 & 4.0 & 4.3161 & TRN \\
\hline CHEMBL1975208 & 809241 & 4.0 & 4.0857 & TST \\
\hline CHEMBL1970104 & 809241 & 5.9 & 5.2788 & TRN \\
\hline CHEMBL1991429 & 809241 & 4.0 & 4.0594 & TRN \\
\hline
\end{tabular}




\begin{tabular}{|c|c|c|c|c|c|}
\hline \multirow[b]{2}{*}{ CHEMBL1964777 } & \multirow[b]{2}{*}{809241} & \\
\hline & & 5.1 & 5.0529 & TRN & \\
\hline CHEMBL1971149 & 809241 & 4.0 & 3.9284 & TRN & \\
\hline CHEMBL1999714 & 809241 & 4.0 & 3.8791 & TRN & \\
\hline CHEMBL1987533 & 809241 & 4.0 & 4.4714 & TRN & \\
\hline CHEMBL1994040 & 809241 & 4.0 & 3.8733 & TRN & \\
\hline CHEMBL388978 & 809241 & 8.1 & 6.8535 & TST & \\
\hline CHEMBL579246 & 809241 & 5.9 & 6.1881 & TRN & \\
\hline CHEMBL398951 & 809241 & 4.0 & 4.2614 & TST & \\
\hline CHEMBL1982506 & 809241 & 4.0 & 4.4962 & TST & \\
\hline CHEMBL 2004716 & 809241 & 5.7 & 4.4204 & TRN & \\
\hline CHEMBL1968127 & 809241 & 4.0 & 3.8553 & TRN & \\
\hline CHEMBL1975233 & 809241 & 4.0 & 4.0215 & TRN & \\
\hline CHEMBL1985406 & 809241 & 4.0 & 5.1029 & TRN & \\
\hline CHEMBL207400 & 809241 & 4.0 & 4.1153 & TST & \\
\hline CHEMBL 2000894 & 809241 & 4.0 & 5.55399 & 9999999999 & TST \\
\hline CHEMBL 2002553 & 809241 & 4.0 & 4.2294 & TST & \\
\hline CHEMBL1982135 & 809241 & 4.0 & 4.4592 & TRN & \\
\hline CHEMBL1976090 & 809241 & 6.8 & 5.1918 & TRN & \\
\hline CHEMBL1993243 & 809241 & 4.0 & 4.1105 & TRN & \\
\hline CHEMBL1992922 & 809241 & 5.1 & 5.6836 & TRN & \\
\hline CHEMBL 2004771 & 809241 & 4.0 & 4.6165 & TRN & \\
\hline CHEMBL399021 & 809241 & 4.0 & 4.3387 & TRN & \\
\hline CHEMBL1997597 & 809241 & 5.4 & 4.9826 & TRN & \\
\hline CHEMBL1969537 & 809241 & 5.8 & 4.328 & TST & \\
\hline CHEMBL1976093 & 809241 & 4.0 & 3.9852 & TRN & \\
\hline CHEMBL210032 & 809241 & 4.0 & 4.1402 & TRN & \\
\hline CHEMBL1996543 & 809241 & 4.0 & 5.4071 & TRN & \\
\hline CHEMBL1975256 & 809241 & 4.0 & 4.5758 & TST & \\
\hline CHEMBL508928 & 809241 & 5.2 & 4.3628 & TRN & \\
\hline CHEMBL1991356 & 809241 & 4.0 & 4.2328 & TST & \\
\hline CHEMBL1983309 & 809241 & 4.0 & 4.333 & TRN & \\
\hline CHEMBL 2004892 & 809241 & 6.2 & 4.9945 & TRN & \\
\hline CHEMBL1999126 & 809241 & 4.0 & 4.1073 & TST & \\
\hline CHEMBL1997503 & 809241 & 4.0 & 4.2463 & TST & \\
\hline CHEMBL116070 & 809241 & 5.7 & 5.1629 & TRN & \\
\hline CHEMBL1990821 & 809241 & 4.0 & 4.1733 & TST & \\
\hline CHEMBL1970314 & 809241 & 4.0 & 4.1818 & TRN & \\
\hline CHEMBL 2004871 & 809241 & 4.0 & 3.9187 & TRN & \\
\hline CHEMBL 2004872 & 809241 & 6.2 & 5.0422 & TRN & \\
\hline CHEMBL1727312 & 809241 & 4.0 & 3.75699 & 99999999997 & TRN \\
\hline CHEMBL1969879 & 809241 & 4.0 & 4.2164 & TRN & \\
\hline CHEMBL1981720 & 809241 & 5.9 & 4.8099 & TRN & \\
\hline CHEMBL419932 & 809241 & 5.3 & 5.2894 & TRN & \\
\hline CHEMBL262433 & 809241 & 4.0 & 4.24 & TRN & \\
\hline CHEMBL306380 & 809241 & 4.0 & 4.383 & TRN & \\
\hline CHEMBL1966722 & 809241 & 4.0 & 4.7721 & TST & \\
\hline CHEMBL1975500 & 809241 & 5.0 & 5.0723 & TRN & \\
\hline CHEMBL1976328 & 809241 & 4.0 & 4.3234 & TRN & \\
\hline & & & & 13880 & \\
\hline
\end{tabular}




\begin{tabular}{|c|c|c|c|c|}
\hline & & & Supplement & al] \\
\hline CHEMBL394619 & 809241 & 4.0 & 4.3414 & TRN \\
\hline CHEMBL1964399 & 809241 & 5.7 & 5.1709 & TRN \\
\hline CHEMBL1996831 & 809241 & 4.0 & 4.3218 & TST \\
\hline CHEMBL411903 & 809241 & 5.6 & 4.8305 & TRN \\
\hline CHEMBL1965988 & 809241 & 5.4 & 4.6255 & TRN \\
\hline CHEMBL418203 & 809241 & 4.0 & 4.9871 & TST \\
\hline CHEMBL1989646 & 809241 & 6.5 & 6.2917 & TRN \\
\hline CHEMBL1682357 & 809241 & 5.8 & 5.3079 & TRN \\
\hline CHEMBL225519 & 809241 & 5.3 & 5.8289 & TRN \\
\hline CHEMBL209534 & 809241 & 4.0 & 4.2254 & TRN \\
\hline CHEMBL1978200 & 809241 & 4.0 & 3.9357 & TRN \\
\hline CHEMBL 2006631 & 809241 & 4.0 & 4.2546 & TRN \\
\hline CHEMBL1970522 & 809241 & 5.3 & 4.7134 & TRN \\
\hline CHEMBL1990415 & 809241 & 5.8 & 4.7632 & TRN \\
\hline CHEMBL1966087 & 809241 & 4.0 & 4.8563 & TRN \\
\hline CHEMBL1964692 & 809241 & 4.0 & 4.5844 & TRN \\
\hline CHEMBL1996931 & 809241 & 4.0 & 4.5901 & TRN \\
\hline CHEMBL1964413 & 809241 & 4.0 & 4.8667 & TRN \\
\hline CHEMBL1973483 & 809241 & 4.0 & 4.2537 & TRN \\
\hline CHEMBL1984432 & 809241 & 5.5 & 5.2096 & TRN \\
\hline CHEMBL1970735 & 809241 & 4.0 & 3.9543 & TRN \\
\hline CHEMBL219722 & 809241 & 6.0 & 4.8377 & TRN \\
\hline CHEMBL1997340 & 809241 & 4.0 & 4.3323 & TRN \\
\hline CHEMBL 2004365 & 809241 & 4.0 & 4.4726 & TST \\
\hline CHEMBL1522508 & 809241 & 4.0 & 4.175 & TRN \\
\hline CHEMBL1989474 & 809241 & 4.0 & 3.947 & TRN \\
\hline CHEMBL1090360 & 809241 & 4.0 & 3.8998 & TRN \\
\hline CHEMBL210887 & 809241 & 4.0 & 4.4447 & TST \\
\hline CHEMBL458997 & 809241 & 4.1 & 5.355 & TRN \\
\hline CHEMBL1971021 & 809241 & 4.0 & 4.0307 & TRN \\
\hline CHEMBL 227271 & 809241 & 6.5 & 7.0678 & TRN \\
\hline CHEMBL583144 & 809241 & 4.0 & 4.8706 & TST \\
\hline CHEMBL1974310 & 809241 & 5.4 & 5.103 & TRN \\
\hline CHEMBL1982660 & 809241 & 4.0 & 4.7835 & TRN \\
\hline CHEMBL1994693 & 809241 & 4.0 & 4.6514 & TRN \\
\hline CHEMBL1982957 & 809241 & 6.9 & 5.7817 & TRN \\
\hline CHEMBL1725279 & 809241 & 6.6 & 5.112 & TST \\
\hline CHEMBL1975138 & 809241 & 4.0 & 4.5841 & TST \\
\hline CHEMBL424872 & 809241 & 4.2 & 4.0504 & TRN \\
\hline CHEMBL2006836 & 809241 & 4.0 & 4.1028 & TST \\
\hline CHEMBL1971947 & 809241 & 4.0 & 4.4347 & TRN \\
\hline CHEMBL412142 & 809241 & 4.0 & 4.3298 & TST \\
\hline CHEMBL1980704 & 809241 & 4.0 & 4.2152 & TST \\
\hline CHEMBL 2003271 & 809241 & 4.0 & 5.4099 & TST \\
\hline CHEMBL1966808 & 809241 & 4.0 & 4.2885 & TST \\
\hline CHEMBL 2004447 & 809241 & 4.0 & 4.0245 & TRN \\
\hline CHEMBL1983111 & 809241 & 6.4 & 5.9741 & TST \\
\hline CHEMBL1973860 & 809241 & 6.3 & 4.5582 & TRN \\
\hline
\end{tabular}




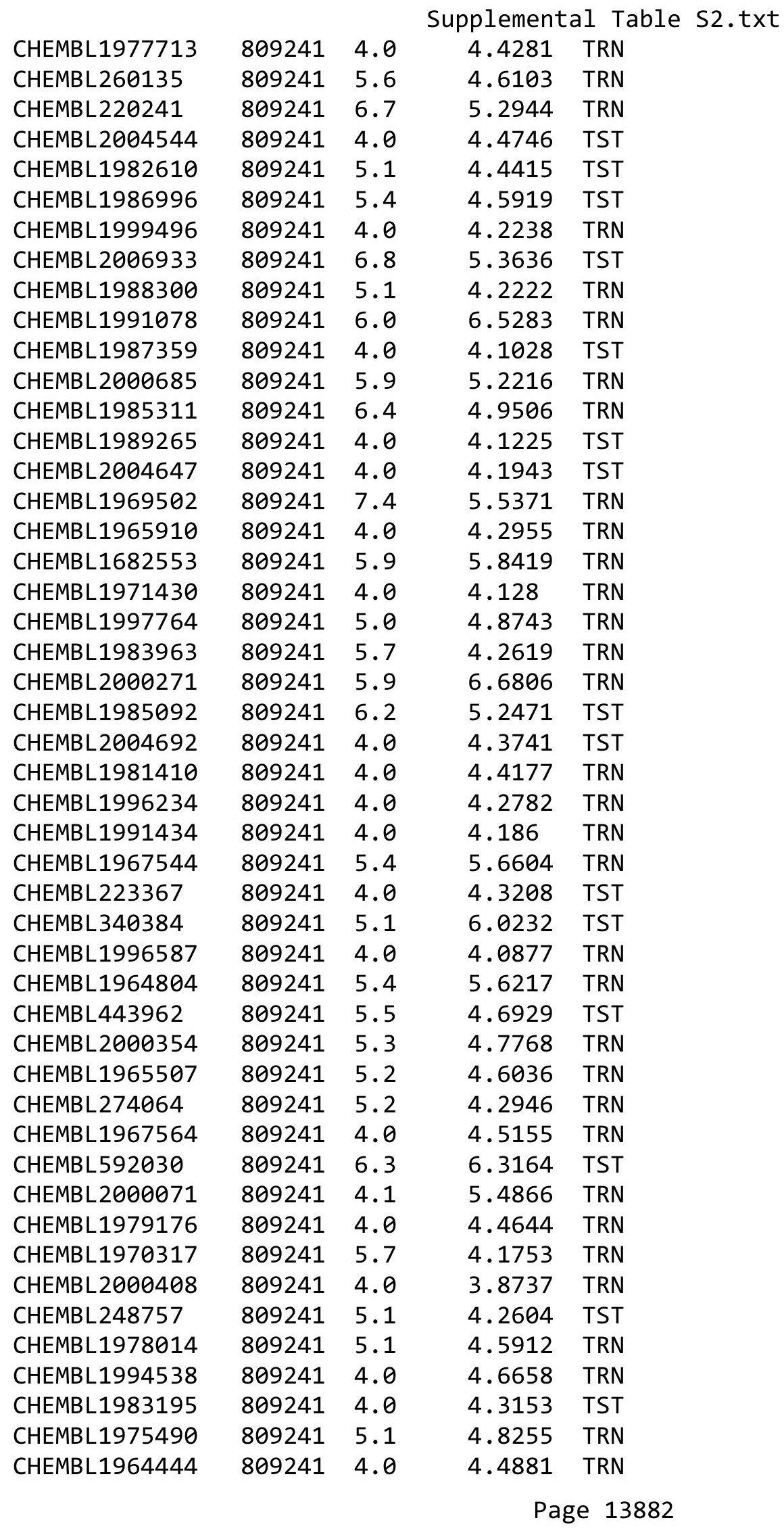




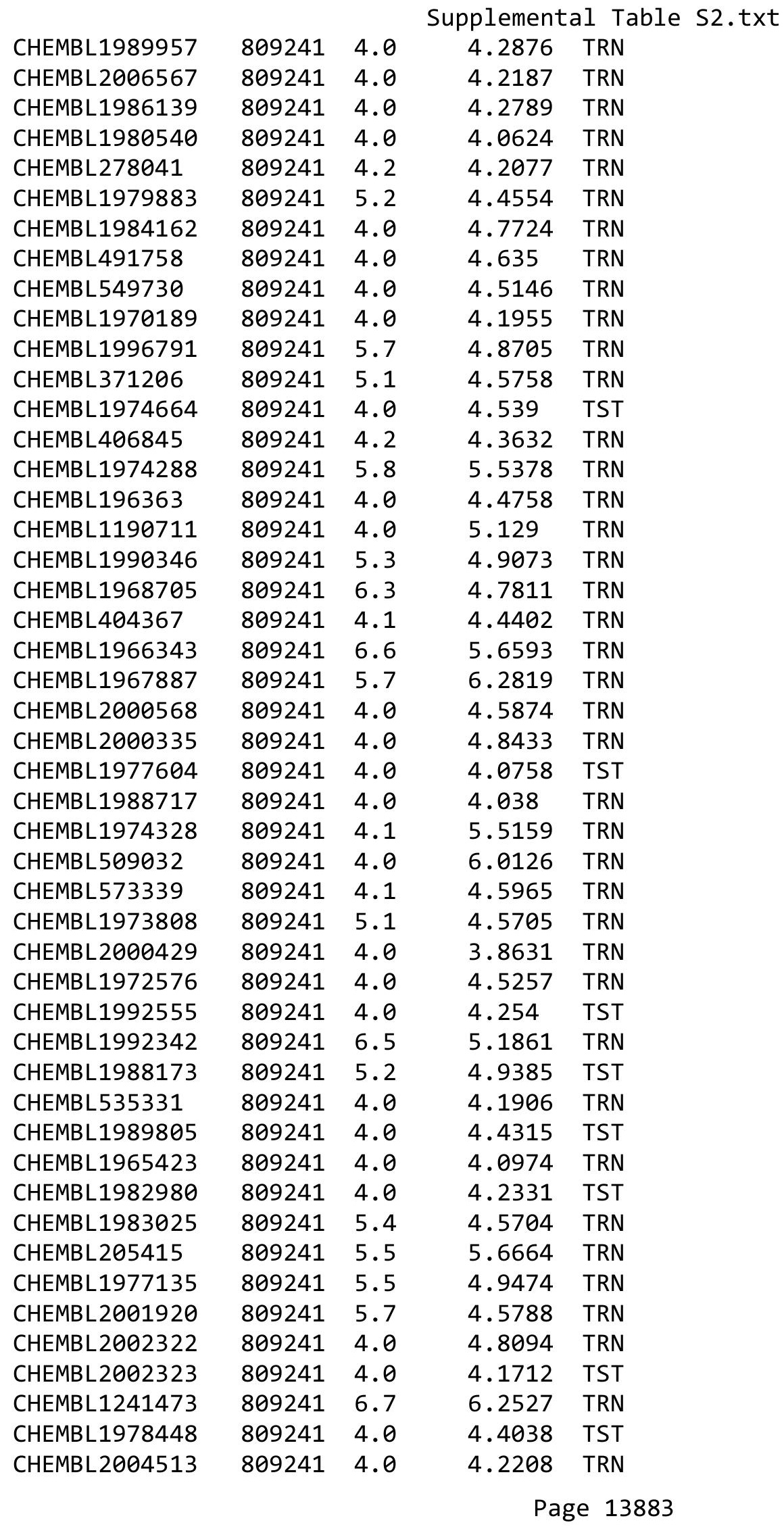




\begin{tabular}{|c|c|c|c|c|c|}
\hline \multicolumn{6}{|c|}{ Supplemental Table S2.txt } \\
\hline CHEMBL1972258 & 809241 & 4.0 & 4.917 & TRN & \\
\hline CHEMBL 2001257 & 809241 & 4.0 & 4.2736 & TRN & \\
\hline CHEMBL1992536 & 809241 & 4.0 & 4.7431 & TRN & \\
\hline CHEMBL1987793 & 809241 & 4.0 & 4.2553 & TST & \\
\hline CHEMBL1992740 & 809241 & 4.0 & 4.6931 & TRN & \\
\hline CHEMBL 2002373 & 809241 & 4.0 & 3.9615 & TRN & \\
\hline CHEMBL439340 & 809241 & 4.0 & 4.3338 & TRN & \\
\hline CHEMBL 2006188 & 809241 & 6.4 & 5.3953 & TRN & \\
\hline CHEMBL1967531 & 809241 & 5.4 & 4.51699 & 99999999995 & TRN \\
\hline CHEMBL1970913 & 809241 & 4.0 & 4.4163 & TRN & \\
\hline CHEMBL1973893 & 809241 & 4.0 & 4.9144 & TRN & \\
\hline CHEMBL1995736 & 809241 & 4.0 & 4.3502 & TRN & \\
\hline CHEMBL1997534 & 809241 & 7.3 & 5.7575 & TRN & \\
\hline CHEMBL1996500 & 809241 & 4.0 & 3.9072 & TRN & \\
\hline CHEMBL1985095 & 809241 & 4.0 & 5.9158 & TST & \\
\hline CHEMBL1998551 & 809241 & 4.0 & 3.9722 & TRN & \\
\hline CHEMBL1977374 & 809241 & 4.0 & 3.9693 & TRN & \\
\hline CHEMBL1991180 & 809241 & 5.2 & 5.1305 & TST & \\
\hline CHEMBL1682540 & 809241 & 5.9 & 5.2929 & TRN & \\
\hline CHEMBL1978656 & 809241 & 4.0 & 4.1792 & TRN & \\
\hline CHEMBL1976420 & 809241 & 4.0 & 4.4996 & TST & \\
\hline CHEMBL1994864 & 809241 & 5.4 & 4.8744 & TRN & \\
\hline CHEMBL413779 & 809241 & 4.0 & 4.4709 & TST & \\
\hline CHEMBL 2002446 & 809241 & 4.0 & 4.5131 & TST & \\
\hline CHEMBL497151 & 809241 & 6.1 & 5.1785 & TRN & \\
\hline CHEMBL246970 & 809241 & 5.3 & 5.0229 & TRN & \\
\hline CHEMBL340921 & 809241 & 4.0 & 5.5846 & TST & \\
\hline CHEMBL373598 & 809241 & 4.0 & 4.3806 & TST & \\
\hline CHEMBL1999718 & 809241 & 4.0 & 4.2917 & TRN & \\
\hline CHEMBL1276446 & 809241 & 7.8 & 5.8147 & TST & \\
\hline CHEMBL1977346 & 809241 & 5.4 & 4.5795 & TRN & \\
\hline CHEMBL1971649 & 809241 & 4.0 & 4.1712 & TRN & \\
\hline CHEMBL 2003657 & 809241 & 4.0 & 4.1529 & TRN & \\
\hline CHEMBL1998435 & 809241 & 4.0 & 4.4453 & TRN & \\
\hline CHEMBL 2006439 & 809241 & 6.1 & 6.5877 & TRN & \\
\hline CHEMBL 2006156 & 809241 & 4.0 & 4.239 & TST & \\
\hline CHEMBL1969190 & 809241 & 4.0 & 4.3026 & TRN & \\
\hline CHEMBL1973937 & 809241 & 5.3 & 4.427 & TRN & \\
\hline CHEMBL1991674 & 809241 & 6.0 & 6.4458 & TRN & \\
\hline CHEMBL1982711 & 809241 & 6.6 & 6.0116 & TRN & \\
\hline CHEMBL1987982 & 809241 & 4.0 & 4.5091 & TST & \\
\hline CHEMBL1969102 & 809241 & 4.0 & 4.4395 & TRN & \\
\hline CHEMBL 2007044 & 809241 & 4.0 & 4.1962 & TST & \\
\hline CHEMBL 2001998 & 809241 & 4.0 & 4.2281 & TST & \\
\hline CHEMBL1994241 & 809241 & 5.2 & 4.9661 & TRN & \\
\hline CHEMBL223460 & 809241 & 4.0 & 4.2261 & TST & \\
\hline CHEMBL1998829 & 809241 & 5.3 & 4.524 & TRN & \\
\hline CHEMBL50894 & 809241 & 4.0 & 5.0303 & TRN & \\
\hline
\end{tabular}




\begin{tabular}{|c|c|c|c|c|}
\hline & & & ient & al Ta \\
\hline CHEMBL1988838 & 809241 & 5.2 & 5.6176 & TRN \\
\hline CHEMBL1981725 & 809241 & 5.2 & 4.4246 & TRN \\
\hline CHEMBL1982753 & 809241 & 4.2 & 5.1126 & TRN \\
\hline CHEMBL 375284 & 809241 & 5.7 & 4.4261 & TRN \\
\hline CHEMBL1972346 & 809241 & 6.5 & 4.8733 & TST \\
\hline CHEMBL1982866 & 809241 & 4.0 & 3.9802 & TRN \\
\hline CHEMBL1968926 & 809241 & 5.1 & 4.2473 & TRN \\
\hline CHEMBL462120 & 809241 & 4.0 & 4.4813 & TST \\
\hline CHEMBL1984206 & 809241 & 4.0 & 4.1896 & TRN \\
\hline CHEMBL1991577 & 809241 & 4.0 & 4.4606 & TRN \\
\hline CHEMBL1965570 & 809241 & 4.0 & 4.3323 & TRN \\
\hline CHEMBL 2007592 & 809241 & 4.0 & 4.1108 & TST \\
\hline CHEMBL210963 & 809241 & 4.0 & 3.8833 & TRN \\
\hline CHEMBL1082440 & 809241 & 5.6 & 5.1741 & TST \\
\hline CHEMBL1614705 & 809241 & 4.0 & 4.1803 & TRN \\
\hline CHEMBL1984633 & 809241 & 6.3 & 5.1821 & TRN \\
\hline CHEMBL 2007372 & 809241 & 4.0 & 3.8595 & TRN \\
\hline CHEMBL1965845 & 809241 & 7.7 & 6.3838 & TRN \\
\hline CHEMBL1982167 & 809241 & 4.0 & 4.1994 & TRN \\
\hline CHEMBL 2006715 & 809241 & 4.0 & 4.165 & TRN \\
\hline CHEMBL1986597 & 809241 & 4.0 & 4.4567 & TRN \\
\hline CHEMBL1971017 & 809241 & 5.5 & 5.2585 & TRN \\
\hline CHEMBL1990482 & 809241 & 5.2 & 4.8668 & TRN \\
\hline CHEMBL1990904 & 809241 & 4.0 & 4.0388 & TRN \\
\hline CHEMBL 2005475 & 809241 & 5.5 & 4.7352 & TRN \\
\hline CHEMBL 2000104 & 809241 & 5.4 & 4.9024 & TRN \\
\hline CHEMBL402846 & 809241 & 4.0 & 4.422 & TRN \\
\hline CHEMBL1997349 & 809241 & 4.0 & 4.4818 & TST \\
\hline CHEMBL183844 & 809241 & 4.0 & 3.9304 & TRN \\
\hline CHEMBL 220057 & 809241 & 6.0 & 4.8183 & TRN \\
\hline CHEMBL1682545 & 809241 & 5.6 & 4.8525 & TRN \\
\hline CHEMBL 383541 & 809241 & 5.1 & 5.9452 & TRN \\
\hline CHEMBL 2001224 & 809241 & 4.0 & 4.0519 & TRN \\
\hline CHEMBL10 & 809241 & 4.1 & 4.0773 & TRN \\
\hline CHEMBL1976732 & 809241 & 4.0 & 3.9932 & TRN \\
\hline CHEMBL1969506 & 809241 & 4.0 & 4.5733 & TRN \\
\hline CHEMBL1964937 & 809241 & 6.4 & 5.9773 & TRN \\
\hline CHEMBL1980163 & 809241 & 4.0 & 4.0924 & TRN \\
\hline CHEMBL590109 & 809241 & 6.2 & 6.1501 & TST \\
\hline CHEMBL1970879 & 809241 & 4.0 & 4.495 & TRN \\
\hline CHEMBL1989856 & 809241 & 4.0 & 4.1598 & TST \\
\hline CHEMBL 2005899 & 809241 & 4.0 & 4.5449 & TRN \\
\hline CHEMBL1682552 & 809241 & 5.6 & 5.6761 & TRN \\
\hline CHEMBL 259850 & 809241 & 4.0 & 4.1769 & TRN \\
\hline CHEMBL1972568 & 809241 & 4.0 & 4.6527 & TRN \\
\hline CHEMBL1996155 & 809241 & 4.0 & 4.4697 & TRN \\
\hline CHEMBL229799 & 809241 & 6.8 & 7.2297 & TRN \\
\hline CHEMBL105739 & 809241 & 5.7 & 4.622 & TRN \\
\hline
\end{tabular}




\begin{tabular}{|c|c|c|c|c|c|}
\hline \multicolumn{6}{|c|}{ Supplemental Table S2.txt } \\
\hline CHEMBL379300 & 809241 & 7.3 & 7.0327 & TRN & \\
\hline CHEMBL203673 & 809241 & 4.0 & 5.2794 & TRN & \\
\hline CHEMBL1969523 & 809241 & 6.0 & 5.2061 & TRN & \\
\hline CHEMBL207995 & 809241 & 4.0 & 4.2466 & TRN & \\
\hline CHEMBL1988995 & 809241 & 4.0 & 3.8565 & TRN & \\
\hline CHEMBL 2001923 & 809241 & 4.0 & 4.4271 & TRN & \\
\hline CHEMBL1986781 & 809241 & 4.0 & 4.0708 & TRN & \\
\hline CHEMBL526133 & 809241 & 5.7 & 5.2166 & TRN & \\
\hline CHEMBL1979057 & 809241 & 5.3 & 4.32100 & 0000000001 & TRN \\
\hline CHEMBL1981045 & 809241 & 4.0 & 4.3518 & TRN & \\
\hline CHEMBL387971 & 809241 & 4.0 & 4.2742 & TST & \\
\hline CHEMBL1992796 & 809241 & 4.0 & 4.6538 & TST & \\
\hline CHEMBL1999428 & 809241 & 5.7 & 5.3052 & TRN & \\
\hline CHEMBL223257 & 809241 & 4.0 & 4.3674 & TST & \\
\hline CHEMBL1967560 & 809241 & 4.0 & 4.0968 & TRN & \\
\hline CHEMBL1516890 & 809241 & 5.6 & 4.8933 & TRN & \\
\hline CHEMBL211378 & 809241 & 4.0 & 4.1516 & TRN & \\
\hline CHEMBL1982465 & 809241 & 5.2 & 4.3823 & TRN & \\
\hline CHEMBL 2001751 & 809241 & 7.6 & 6.9595 & TRN & \\
\hline CHEMBL 2003420 & 809241 & 4.0 & 4.2288 & TRN & \\
\hline CHEMBL1984586 & 809241 & 5.6 & 4.13399 & 99999999995 & TRN \\
\hline CHEMBL1999774 & 809241 & 4.0 & 4.3077 & TST & \\
\hline CHEMBL1972659 & 809241 & 6.3 & 4.4022 & TST & \\
\hline CHEMBL1973395 & 809241 & 5.4 & 5.4116 & TRN & \\
\hline CHEMBL 272453 & 809241 & 4.0 & 4.2056 & TRN & \\
\hline CHEMBL1970217 & 809241 & 6.7 & 5.6397 & TRN & \\
\hline CHEMBL1971801 & 809241 & 4.0 & 4.2828 & TRN & \\
\hline CHEMBL1968850 & 809241 & 5.3 & 4.6029 & TRN & \\
\hline CHEMBL 2005528 & 809241 & 5.2 & 4.7147 & TST & \\
\hline CHEMBL185569 & 809241 & 4.0 & 4.0279 & TRN & \\
\hline CHEMBL1969843 & 809241 & 5.1 & 5.0846 & TRN & \\
\hline CHEMBL 2007002 & 809241 & 4.0 & 4.9301 & TRN & \\
\hline CHEMBL1987007 & 809241 & 5.2 & 4.4689 & TRN & \\
\hline CHEMBL1969588 & 809241 & 6.4 & 7.0204 & TRN & \\
\hline CHEMBL1984711 & 809241 & 4.0 & 4.55699 & 99999999995 & TRN \\
\hline CHEMBL1990212 & 809241 & 4.0 & 4.2429 & TRN & \\
\hline CHEMBL484390 & 809241 & 4.0 & 4.5266 & TST & \\
\hline CHEMBL1979252 & 809241 & 5.7 & 5.0864 & TRN & \\
\hline CHEMBL 2004290 & 809241 & 4.0 & 4.1467 & TRN & \\
\hline CHEMBL1986499 & 809241 & 5.6 & 6.4057 & TRN & \\
\hline CHEMBL1972937 & 809241 & 4.0 & 4.269 & TRN & \\
\hline CHEMBL1972250 & 809241 & 4.0 & 4.2809 & TST & \\
\hline CHEMBL 2000393 & 809241 & 4.0 & 5.1323 & TST & \\
\hline CHEMBL 2004072 & 809241 & 4.0 & 4.4118 & TRN & \\
\hline CHEMBL 2004311 & 809241 & 4.0 & 4.0925 & TRN & \\
\hline CHEMBL1992634 & 809241 & 5.8 & 5.1607 & TRN & \\
\hline CHEMBL1242373 & 809241 & 4.0 & 4.6775 & TRN & \\
\hline CHEMBL2000433 & 809241 & 4.0 & 4.2266 & TST & \\
\hline
\end{tabular}




\begin{tabular}{|c|c|c|c|c|c|}
\hline \multicolumn{6}{|c|}{ Supplemental Table S2.txt } \\
\hline CHEMBL56543 & 809241 & 4.0 & 4.1889 & TRN & \\
\hline CHEMBL1988075 & 809241 & 4.0 & 4.1785 & TRN & \\
\hline CHEMBL316264 & 809241 & 4.0 & 3.9772 & TRN & \\
\hline CHEMBL1991678 & 809241 & 4.0 & 3.9097 & TRN & \\
\hline CHEMBL 2001239 & 809241 & 4.0 & 4.9715 & TST & \\
\hline CHEMBL1988594 & 809241 & 4.0 & 4.6136 & TRN & \\
\hline CHEMBL 2001288 & 809241 & 4.0 & 4.677 & TRN & \\
\hline CHEMBL260092 & 809241 & 5.6 & 4.6203 & TRN & \\
\hline CHEMBL1999811 & 809241 & 6.9 & 5.0247 & TST & \\
\hline CHEMBL1965495 & 809241 & 5.4 & 4.6419 & TRN & \\
\hline CHEMBL1985074 & 809241 & 4.0 & 4.4303 & TST & \\
\hline CHEMBL1982874 & 809241 & 4.0 & 4.0723 & TRN & \\
\hline CHEMBL 2000481 & 809241 & 4.0 & 4.607 & TRN & \\
\hline CHEMBL1991725 & 809241 & 5.1 & 5.5233 & TRN & \\
\hline CHEMBL1992242 & 809241 & 4.0 & 3.9673 & TRN & \\
\hline CHEMBL 2007296 & 809241 & 5.4 & 5.2385 & TRN & \\
\hline CHEMBL 208637 & 809241 & 4.0 & 3.9224 & TRN & \\
\hline CHEMBL396523 & 809241 & 6.3 & 6.0098 & TRN & \\
\hline CHEMBL1970203 & 809241 & 4.0 & 4.2817 & TRN & \\
\hline CHEMBL1986530 & 809241 & 4.0 & 4.3966 & TST & \\
\hline CHEMBL1965351 & 809241 & 4.0 & 4.5527 & TST & \\
\hline CHEMBL1999321 & 809241 & 4.0 & 4.15 & TRN & \\
\hline CHEMBL1968590 & 809241 & 4.0 & 4.0609 & TRN & \\
\hline CHEMBL1999749 & 809241 & 4.0 & 4.3802 & TRN & \\
\hline CHEMBL 2005375 & 809241 & 4.0 & 4.1496 & TRN & \\
\hline CHEMBL1984191 & 809241 & 4.0 & 4.25899 & 99999999995 & TRN \\
\hline CHEMBL1983006 & 809241 & 4.0 & 4.0265 & TRN & \\
\hline CHEMBL1972183 & 809241 & 4.0 & 4.1582 & TRN & \\
\hline CHEMBL1971029 & 809241 & 4.0 & 5.9791 & TRN & \\
\hline CHEMBL 383527 & 809241 & 4.0 & 5.15 & TRN & \\
\hline CHEMBL394790 & 809241 & 4.0 & 4.4161 & TRN & \\
\hline CHEMBL 226471 & 809241 & 4.0 & 4.9261 & TRN & \\
\hline CHEMBL1974702 & 809241 & 4.0 & 4.5117 & TST & \\
\hline CHEMBL1996111 & 809241 & 5.7 & 5.8393 & TRN & \\
\hline CHEMBL1965589 & 809241 & 4.0 & 4.0094 & TRN & \\
\hline CHEMBL1998193 & 809241 & 4.0 & 4.0946 & TRN & \\
\hline CHEMBL474432 & 809241 & 4.0 & 4.5868 & TST & \\
\hline CHEMBL1988153 & 809241 & 4.0 & 4.7082 & TRN & \\
\hline CHEMBL1972584 & 809241 & 4.0 & 4.4629 & TRN & \\
\hline CHEMBL1999556 & 809241 & 5.3 & 5.2469 & TRN & \\
\hline CHEMBL1988437 & 809241 & 4.0 & 4.6695 & TST & \\
\hline CHEMBL1968245 & 809241 & 4.0 & 5.5198 & TRN & \\
\hline CHEMBL1998121 & 809241 & 7.7 & 6.2363 & TRN & \\
\hline CHEMBL1979577 & 809241 & 5.5 & 4.6158 & TRN & \\
\hline CHEMBL 52387 & 809241 & 4.0 & 4.7198 & TST & \\
\hline CHEMBL379835 & 809241 & 4.0 & 3.9661 & TST & \\
\hline CHEMBL1979357 & 809241 & 4.0 & 5.0415 & TRN & \\
\hline CHEMBL1980802 & 809241 & 4.0 & 4.2533 & TST & \\
\hline
\end{tabular}




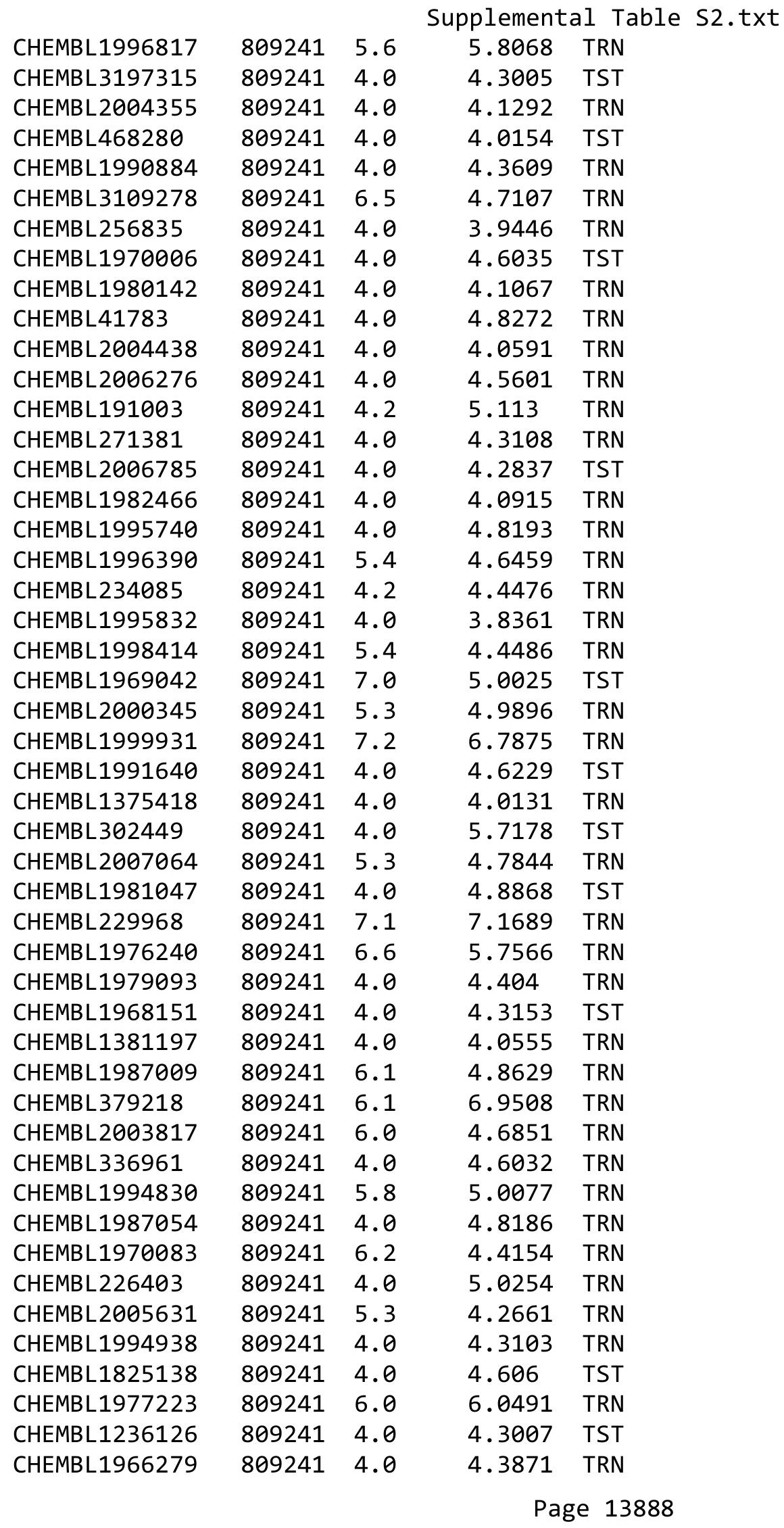




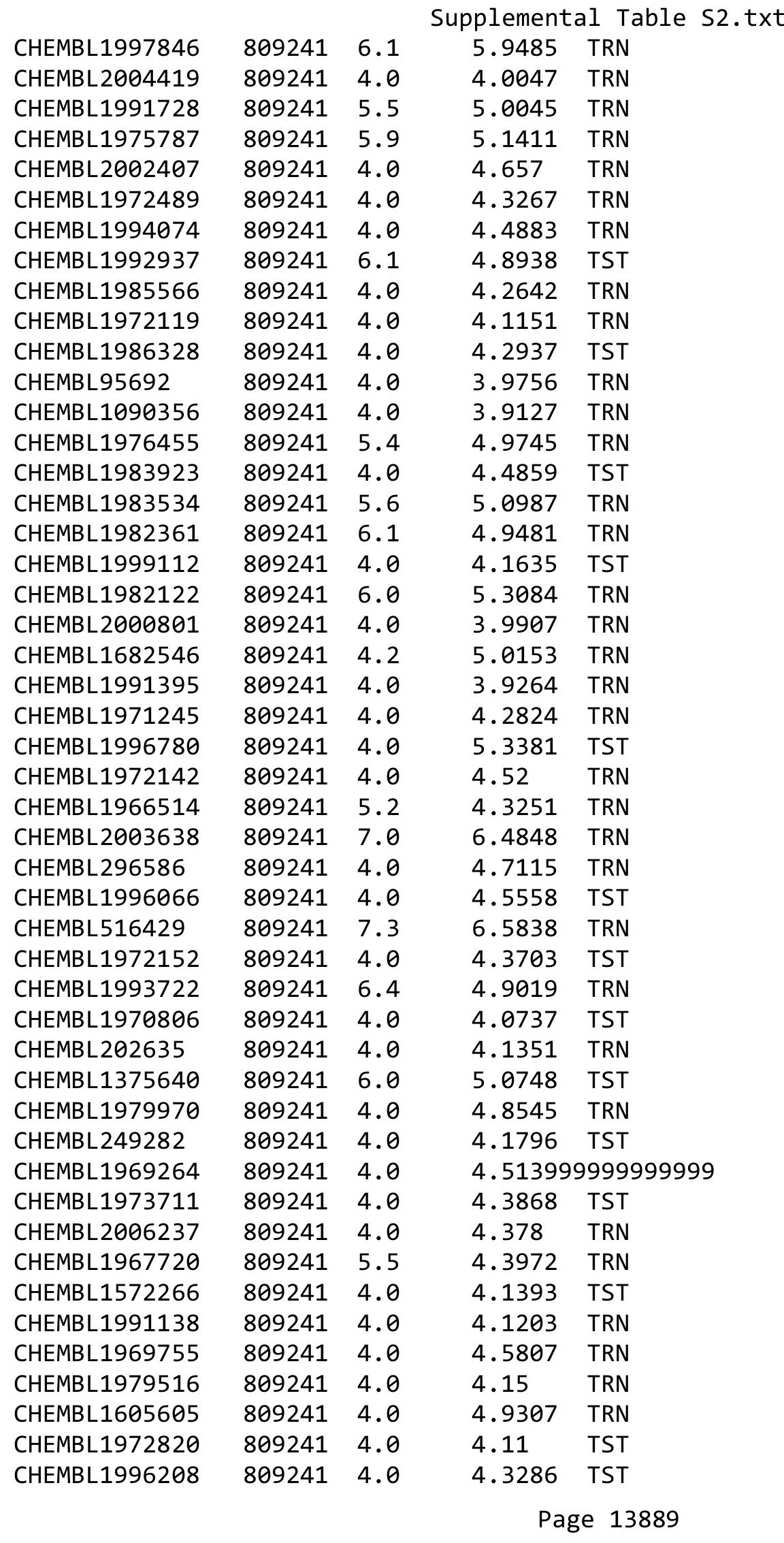




\begin{tabular}{|c|c|c|c|c|c|}
\hline \multicolumn{6}{|c|}{ Supplemental Table S2.txt } \\
\hline CHEMBL1989029 & 809241 & 4.0 & 4.3307 & TRN & \\
\hline CHEMBL392642 & 809241 & 5.2 & 5.0883 & TRN & \\
\hline CHEMBL514499 & 809241 & 4.0 & 4.378 & TST & \\
\hline CHEMBL1965631 & 809241 & 5.7 & 5.72 & TRN & \\
\hline CHEMBL1980144 & 809241 & 4.0 & 4.5244 & TRN & \\
\hline CHEMBL1991188 & 809241 & 6.2 & 5.6818 & TRN & \\
\hline CHEMBL1972849 & 809241 & 4.0 & 3.8569 & TRN & \\
\hline CHEMBL 377408 & 809241 & 4.2 & 4.1787 & TRN & \\
\hline CHEMBL231209 & 809241 & 4.0 & 4.3917 & TRN & \\
\hline CHEMBL1975357 & 809241 & 4.0 & 4.1813 & TST & \\
\hline CHEMBL1976220 & 809241 & 4.0 & 4.4707 & TRN & \\
\hline CHEMBL259922 & 809241 & 4.0 & 4.1709 & TST & \\
\hline CHEMBL1997617 & 809241 & 4.0 & 4.2972 & TRN & \\
\hline CHEMBL1982383 & 809241 & 4.0 & 3.8606 & TRN & \\
\hline CHEMBL1969301 & 809241 & 4.0 & 4.5194 & TST & \\
\hline CHEMBL17370 & 809241 & 4.0 & 4.0781 & TRN & \\
\hline CHEMBL1987910 & 809241 & 4.0 & 4.1477 & TRN & \\
\hline CHEMBL1983932 & 809241 & 4.0 & 4.7702 & TRN & \\
\hline CHEMBL1997822 & 809241 & 4.0 & 4.4392 & TRN & \\
\hline CHEMBL1991285 & 809241 & 5.2 & 4.1285 & TRN & \\
\hline CHEMBL243088 & 809241 & 6.1 & 5.5152 & TRN & \\
\hline CHEMBL1984038 & 809241 & 4.1 & 4.2102 & TRN & \\
\hline CHEMBL1993661 & 809241 & 4.3 & 6.3146 & TRN & \\
\hline CHEMBL1974416 & 809241 & 5.1 & 4.9555 & TRN & \\
\hline CHEMBL 2004615 & 809241 & 5.2 & 4.5671 & TST & \\
\hline CHEMBL1984039 & 809241 & 4.0 & 4.1736 & TST & \\
\hline CHEMBL1997872 & 809241 & 4.0 & 4.3156 & TRN & \\
\hline CHEMBL1964290 & 809241 & 4.0 & 5.8329 & TRN & \\
\hline CHEMBL2003768 & 809241 & 4.0 & 4.4911 & TRN & \\
\hline CHEMBL 213505 & 809241 & 4.0 & 4.4105 & TRN & \\
\hline CHEMBL1982880 & 809241 & 4.0 & 4.2772 & TRN & \\
\hline CHEMBL1987034 & 809241 & 6.4 & 6.2284 & TST & \\
\hline CHEMBL1993941 & 809241 & 4.0 & 4.251 & TST & \\
\hline CHEMBL377383 & 809241 & 4.0 & 4.00899 & 99999999995 & TST \\
\hline CHEMBL 2005886 & 809241 & 4.0 & 5.1726 & TST & \\
\hline CHEMBL481491 & 809241 & 4.0 & 4.2997 & TST & \\
\hline CHEMBL1682345 & 809241 & 6.6 & 5.7722 & TST & \\
\hline CHEMBL1973142 & 809241 & 5.4 & 5.2896 & TST & \\
\hline CHEMBL1973145 & 809241 & 4.0 & 4.0962 & TST & \\
\hline CHEMBL1982924 & 809241 & 5.7 & 4.992 & TST & \\
\hline CHEMBL2005936 & 809241 & 5.8 & 6.2848 & TST & \\
\hline CHEMBL1807515 & 809241 & 7.3 & 7.2246 & TST & \\
\hline CHEMBL1971141 & 809241 & 4.0 & 4.0379 & TST & \\
\hline CHEMBL1995813 & 809241 & 5.8 & 6.8745 & TST & \\
\hline CHEMBL1979718 & 809241 & 4.0 & 4.6843 & TST & \\
\hline CHEMBL206236 & 809241 & 4.0 & 5.1617 & TST & \\
\hline CHEMBL1562756 & 809241 & 4.0 & 4.5535 & TST & \\
\hline CHEMBL244378 & 809241 & 6.7 & 6.0232 & TST & \\
\hline
\end{tabular}




$$
\text { Supplemental Table S2.txt }
$$

\begin{tabular}{|c|c|c|c|c|c|}
\hline CHEMBL 3934488 & 1622038 & 5.2366 & 5.0188 & TRN & \\
\hline CHEMBL3901643 & 1622038 & 3.699 & 3.6436 & TST & \\
\hline CHEMBL3936675 & 1622038 & 5.1367 & 5.1291 & TRN & \\
\hline CHEMBL 3959584 & 1622038 & 4.2218 & 4.1936 & TRN & \\
\hline CHEMBL3891644 & 1622038 & 3.699 & 3.7035 & TRN & \\
\hline CHEMBL3985118 & 1622038 & 5.0362 & 4.3538 & TST & \\
\hline CHEMBL3909879 & 1622038 & 5.0088 & 4.8012 & TRN & \\
\hline CHEMBL3916599 & 1622038 & 5.2291 & 5.556 & TRN & \\
\hline CHEMBL 3892467 & 1622038 & 5.3372 & 5.0766 & TRN & \\
\hline CHEMBL 3947092 & 1622038 & 3.699 & 3.5172 & TRN & \\
\hline CHEMBL3891576 & 1622038 & 3.699 & 4.1001 & TRN & \\
\hline CHEMBL3917504 & 1622038 & 5.1938 & 5.1013 & TRN & \\
\hline CHEMBL 3943644 & 1622038 & 3.699 & 3.594 & TRN & \\
\hline CHEMBL 3986361 & 1622038 & 5.2518 & 5.3962 & TRN & \\
\hline CHEMBL3970636 & 1622038 & 3.699 & 3.8223 & TRN & \\
\hline CHEMBL3911524 & 1622038 & 5.4202 & 5.1342 & TRN & \\
\hline CHEMBL3968533 & 1622038 & 4.8861 & 4.5039 & TST & \\
\hline CHEMBL 3900573 & 1622038 & 4.8239 & 4.6793 & TRN & \\
\hline CHEMBL 3962757 & 1622038 & 4.8861 & 4.9887 & TRN & \\
\hline CHEMBL 3889679 & 1622038 & 5.4318 & 5.2022 & TRN & \\
\hline CHEMBL 3917847 & 1622038 & 3.699 & 3.2962 & TRN & \\
\hline CHEMBL 3902514 & 1622038 & 5.3372 & 5.6138 & TRN & \\
\hline CHEMBL3893541 & 1622038 & 5.3979 & 5.5459 & TRN & \\
\hline CHEMBL 3938408 & 1622038 & 5.4318 & 5.2263 & TRN & \\
\hline CHEMBL3917803 & 1622038 & 3.699 & 4.06 & TRN & \\
\hline CHEMBL3973515 & 1622038 & 5.4089 & 5.5567 & TRN & \\
\hline CHEMBL3928531 & 1622038 & 3.699 & 4.0683 & TRN & \\
\hline CHEMBL3973151 & 1622038 & 3.699 & 3.79399 & 99999999996 & TRN \\
\hline CHEMBL3915331 & 1622038 & 4.9586 & 4.4558 & TST & \\
\hline CHEMBL3981511 & 1622038 & 5.3768 & 5.1693 & TRN & \\
\hline CHEMBL 3899464 & 1622038 & 3.699 & 3.7468 & TRN & \\
\hline CHEMBL3908519 & 1622038 & 3.699 & 3.6568 & TRN & \\
\hline CHEMBL3926801 & 1622038 & 3.699 & 3.5213 & TST & \\
\hline CHEMBL 3898753 & 1622038 & 4.7447 & 3.9453 & TST & \\
\hline CHEMBL3963182 & 1622038 & 3.699 & 3.8904 & TST & \\
\hline CHEMBL 3906525 & 1622038 & 5.1135 & 5.0848 & TRN & \\
\hline CHEMBL3962542 & 1622038 & 6.0605 & 5.9048 & TRN & \\
\hline CHEMBL3910675 & 1622038 & 4.7959 & 4.6981 & TRN & \\
\hline CHEMBL 3908907 & 1622038 & 3.699 & 3.8832 & TST & \\
\hline CHEMBL3907779 & 1622038 & 4.7447 & 3.5973 & TST & \\
\hline CHEMBL 3935734 & 1622038 & 3.699 & 4.2918 & TST & \\
\hline CHEMBL3915504 & 1622038 & 4.9208 & 4.9609 & TRN & \\
\hline CHEMBL3980755 & 1622038 & 4.8539 & 4.5917 & TRN & \\
\hline CHEMBL3963381 & 1622038 & 3.699 & 4.5537 & TST & \\
\hline CHEMBL3919629 & 1622038 & 3.699 & 3.7066 & TRN & \\
\hline CHEMBL 3972721 & 1622038 & 3.699 & 4.0411 & TRN & \\
\hline CHEMBL 3943463 & 1622038 & 4.8861 & 4.8671 & TRN & \\
\hline CHEMBL3920459 & 1622038 & 5.0655 & 5.2108 & TRN & \\
\hline
\end{tabular}


Supplemental Table S2.txt

\begin{tabular}{|c|c|c|c|c|c|}
\hline CHEMBL3979220 & 1622038 & 3.699 & 3.8445 & TST & \\
\hline CHEMBL3978895 & 1622038 & 3.699 & 3.7016 & TST & \\
\hline CHEMBL3897524 & 1622038 & 5.3372 & 5.4359 & TRN & \\
\hline CHEMBL569077 & 1639947 & 6.1811 & 6.4114 & TRN & \\
\hline CHEMBL3948934 & 1639947 & 5.7447 & 5.7471 & TRN & \\
\hline CHEMBL3919633 & 1639947 & 3.6488 & 4.0558 & TRN & \\
\hline CHEMBL3963105 & 1639947 & 5.6767 & 5.6203 & TST & \\
\hline CHEMBL3925812 & 1639947 & 5.647 & 5.4334 & TST & \\
\hline CHEMBL3979026 & 1639947 & 3.6854 & 3.4935 & TRN & \\
\hline CHEMBL3958263 & 1639947 & 6.6676 & 6.6851 & TRN & \\
\hline CHEMBL566462 & 1639947 & 6.4089 & 6.5352 & TRN & \\
\hline CHEMBL3935110 & 1639947 & 6.6716 & 6.8106 & TRN & \\
\hline CHEMBL3897502 & 1639947 & 4.3615 & 4.7767 & TST & \\
\hline CHEMBL569932 & 1639947 & 5.9825 & 5.9385 & TRN & \\
\hline CHEMBL 3972044 & 1639947 & 6.3747 & 6.4793 & TRN & \\
\hline CHEMBL571994 & 1639947 & 5.9252 & 5.8891 & TRN & \\
\hline CHEMBL3942828 & 1639947 & 5.7438 & 5.4025 & TRN & \\
\hline CHEMBL568852 & 1639947 & 6.2069 & 6.3992 & TRN & \\
\hline CHEMBL3926473 & 1639947 & 5.034 & 5.1549 & TRN & \\
\hline CHEMBL 2018598 & 1639947 & 6.0259 & 5.96899 & 9999999999 & TRN \\
\hline CHEMBL3955823 & 1639947 & 6.7747 & 7.0569 & TRN & \\
\hline CHEMBL3895948 & 1639947 & 6.2612 & 6.0238 & TST & \\
\hline CHEMBL3889966 & 1639947 & 6.1314 & 5.7657 & TRN & \\
\hline CHEMBL3935359 & 1639947 & 5.3502 & 5.6837 & TRN & \\
\hline CHEMBL3940417 & 1639947 & 6.6038 & 6.8148 & TRN & \\
\hline CHEMBL3949019 & 1639947 & 5.9322 & 6.1601 & TRN & \\
\hline CHEMBL3941578 & 1639947 & 4.022 & 4.0298 & TST & \\
\hline CHEMBL567285 & 1639947 & 6.2832 & 6.6003 & TRN & \\
\hline CHEMBL571284 & 1639947 & 5.6442 & 5.6954 & TRN & \\
\hline CHEMBL3975657 & 1639947 & 6.0595 & 5.9183 & TRN & \\
\hline CHEMBL566676 & 1639947 & 6.1226 & 6.0033 & TRN & \\
\hline CHEMBL570194 & 1639947 & 6.0 & 5.9748 & TRN & \\
\hline CHEMBL3942535 & 1639947 & 6.3335 & 6.3483 & TRN & \\
\hline CHEMBL3893387 & 1639947 & 5.0628 & 5.0071 & TRN & \\
\hline CHEMBL 3897423 & 1639947 & 4.6306 & 5.3086 & TST & \\
\hline CHEMBL3895093 & 1639947 & 6.0146 & \multicolumn{2}{|c|}{6.093999999999999} & TRN \\
\hline CHEMBL 3979918 & 1639947 & 5.7828 & 5.6994 & TST & \\
\hline CHEMBL3939761 & 1639947 & 3.6687 & 4.8885 & TRN & \\
\hline CHEMBL570168 & 1639947 & 5.6426 & 5.5517 & TRN & \\
\hline CHEMBL3967210 & 1639947 & 6.1186 & 6.1056 & TRN & \\
\hline CHEMBL3970711 & 1639947 & 5.5315 & 5.2877 & TRN & \\
\hline CHEMBL3978646 & 1639947 & 5.5675 & 5.4929 & TRN & \\
\hline CHEMBL3930638 & 1639947 & 6.4609 & 6.5416 & TRN & \\
\hline CHEMBL3908278 & 1639947 & 6.0516 & 5.8171 & TRN & \\
\hline CHEMBL3979290 & 1639947 & 5.6998 & 5.6448 & TRN & \\
\hline CHEMBL3986685 & 1639947 & 5.7151 & 5.7571 & TRN & \\
\hline CHEMBL3945542 & 1639947 & 4.9559 & 5.1905 & TST & \\
\hline CHEMBL3896117 & 1639947 & 6.4012 & 6.3026 & TRN & \\
\hline
\end{tabular}

Page 13892 
Supplemental Table S2.txt

\begin{tabular}{|c|c|c|c|c|c|}
\hline CHEMBL3901826 & 1639947 & 6.0 & 5.8742 & TRN & \\
\hline CHEMBL566677 & 1639947 & 6.5817 & 6.5553 & TRN & \\
\hline CHEMBL3979833 & 1639947 & 6.2692 & 5.7444 & TRN & \\
\hline CHEMBL 3897759 & 1639947 & 6.7077 & 6.9115 & TRN & \\
\hline CHEMBL568799 & 1639947 & 6.8297 & 6.6447 & TRN & \\
\hline CHEMBL3971423 & 1639947 & 6.0 & 5.9804 & TST & \\
\hline CHEMBL 3977005 & 1639947 & 5.6692 & 5.7267 & TRN & \\
\hline CHEMBL569754 & 1639947 & 6.1675 & 5.8151 & TST & \\
\hline CHEMBL 3917441 & 1639947 & 6.0 & 6.0106 & TRN & \\
\hline CHEMBL 3962422 & 1639947 & 6.0625 & 6.0723 & TRN & \\
\hline CHEMBL 3900534 & 1639947 & 6.0516 & 5.9639 & TRN & \\
\hline CHEMBL 3920896 & 1639947 & 5.9252 & 5.9806 & TRN & \\
\hline CHEMBL 3933873 & 1639947 & 5.9183 & 5.6708 & TST & \\
\hline CHEMBL 2018595 & 1639947 & 5.4628 & 5.1164 & TRN & \\
\hline CHEMBL 3952412 & 1639947 & 5.8598 & 5.6579 & TRN & \\
\hline CHEMBL570418 & 1639947 & 5.6432 & 5.4068 & TRN & \\
\hline CHEMBL568825 & 1639947 & 6.1152 & 5.8188 & TRN & \\
\hline CHEMBL 3981410 & 1639947 & 6.4976 & 6.3962 & TRN & \\
\hline CHEMBL3960762 & 1639947 & 6.2175 & 5.8773 & TRN & \\
\hline CHEMBL 3965888 & 1639947 & 5.5089 & 5.5425 & TRN & \\
\hline CHEMBL3895098 & 1639947 & 3.6585 & 3.7587 & TRN & \\
\hline CHEMBL 3957422 & 1639947 & 5.7635 & 5.8236 & TST & \\
\hline CHEMBL565824 & 1639947 & 6.4283 & 6.531000 & 0000000001 & $\mathrm{TR}$ \\
\hline CHEMBL3979861 & 1639947 & 6.2291 & 6.0932 & TRN & \\
\hline CHEMBL 3977563 & 1639947 & 5.9722 & 5.6934 & TRN & \\
\hline CHEMBL3896455 & 1639947 & 5.8595 & 5.7958 & TST & \\
\hline CHEMBL 3929144 & 1639947 & 5.6349 & 5.727 & TRN & \\
\hline CHEMBL 3968876 & 1639947 & 5.7206 & 5.5897 & TST & \\
\hline CHEMBL3941067 & 1639947 & 5.2331 & 5.4583 & TRN & \\
\hline CHEMBL 3940932 & 1639947 & 4.084 & 3.748999 & 99999999997 & TRN \\
\hline CHEMBL3943536 & 1639947 & 4.5586 & 5.3874 & TRN & \\
\hline CHEMBL 3946276 & 1639947 & 5.9446 & 6.1175 & TRN & \\
\hline CHEMBL 3911971 & 1639947 & 4.2206 & 4.1592 & TST & \\
\hline CHEMBL 3961805 & 1639947 & 4.9017 & 5.5735 & TRN & \\
\hline CHEMBL3977918 & 1639947 & 5.1555 & 4.9433 & TST & \\
\hline CHEMBL3941185 & 1639947 & 5.9101 & 5.5097 & TRN & \\
\hline CHEMBL 3962235 & 1639947 & 5.6287 & 5.7355 & TRN & \\
\hline CHEMBL 3903820 & 1639947 & 6.2725 & 6.2224 & TRN & \\
\hline CHEMBL570656 & 1639947 & 6.0232 & 5.9561 & TST & \\
\hline CHEMBL585294 & 1639947 & 5.7373 & 5.635 & TRN & \\
\hline CHEMBL3979316 & 1639947 & 3.6329 & 3.7198 & TST & \\
\hline CHEMBL 3923367 & 1639947 & 5.73799 & 99999999 & 5.9167 & ST \\
\hline CHEMBL570167 & 1639947 & 5.8489 & \multicolumn{3}{|c|}{$5.712999999999999 \quad$ TRN } \\
\hline CHEMBL 3931303 & 1639947 & 6.5751 & 6.3047 & TRN & \\
\hline CHEMBL 3941106 & 1639947 & 4.2658 & 4.697 & TRN & \\
\hline CHEMBL 3893243 & 1639947 & 5.1659 & 5.5324 & TRN & \\
\hline CHEMBL568851 & 1639947 & 6.2269 & 6.2482 & TRN & \\
\hline CHEMBL577072 & 1639947 & 5.2612 & 5.3927 & TST & \\
\hline
\end{tabular}

Page 13893 
Supplemental Table S2.txt

\begin{tabular}{|c|c|c|c|c|c|}
\hline CHEMBL 3911927 & 1639947 & 5.8928 & 5.6457 & TRN & \\
\hline CHEMBL569745 & 1639947 & 6.2916 & 6.2164 & TRN & \\
\hline CHEMBL3929301 & 1639947 & 5.7647 & 5.62299 & 7999999999 & TRN \\
\hline CHEMBL565823 & 1639947 & 5.716 & 5.7758 & TRN & \\
\hline CHEMBL3946720 & 1639947 & 5.9427 & 5.9082 & TST & \\
\hline CHEMBL3948185 & 1639947 & 5.6672 & 5.8225 & TRN & \\
\hline CHEMBL 3954942 & 1639947 & 4.6759 & 5.0764 & TRN & \\
\hline CHEMBL 3955228 & 1639947 & 5.6021 & 5.687 & TST & \\
\hline CHEMBL 3923694 & 1639947 & 5.8368 & 5.706 & TRN & \\
\hline CHEMBL3897769 & 1639947 & 6.5467 & 6.5034 & TRN & \\
\hline CHEMBL582809 & 1639947 & 4.5654 & 5.3873 & TRN & \\
\hline CHEMBL 3939275 & 1639947 & 5.3774 & 5.3305 & TRN & \\
\hline CHEMBL577512 & 1639947 & 6.4101 & 6.4777 & TRN & \\
\hline CHEMBL 3977475 & 1639947 & 5.8359 & 5.4626 & TRN & \\
\hline CHEMBL3938552 & 1639947 & 5.5429 & 5.7903 & TRN & \\
\hline CHEMBL3921715 & 1639947 & 4.534 & 4.3416 & TST & \\
\hline CHEMBL3983175 & 1639947 & 5.4462 & 5.2116 & TST & \\
\hline CHEMBL 3979666 & 1639947 & 4.146 & 4.2118 & TRN & \\
\hline CHEMBL3952563 & 1639947 & 5.8033 & 5.6076 & TRN & \\
\hline CHEMBL3924167 & 1639947 & 6.2757 & 6.1287 & TRN & \\
\hline CHEMBL3936751 & 1639947 & 5.9083 & 5.8902 & TRN & \\
\hline CHEMBL569102 & 1639947 & 6.3737 & 6.1216 & TRN & \\
\hline CHEMBL 3936433 & 1639947 & 5.1447 & 5.2842 & TRN & \\
\hline CHEMBL3941869 & 1639947 & 6.0223 & \multicolumn{2}{|c|}{5.712000000000001} & TRN \\
\hline CHEMBL566887 & 1639947 & 5.8576 & 5.8518 & TRN & \\
\hline CHEMBL3921998 & 1639947 & 6.3625 & 6.2162 & TRN & \\
\hline CHEMBL585143 & 1639947 & 5.6962 & 5.7366 & TRN & \\
\hline CHEMBL 3916233 & 1639947 & 5.766 & 5.7183 & TST & \\
\hline CHEMBL569533 & 1639947 & 6.0716 & 6.0815 & TST & \\
\hline CHEMBL569962 & 1639947 & 6.3925 & \multicolumn{2}{|c|}{6.167000000000001} & TST \\
\hline CHEMBL 3905030 & 1639947 & 5.7592 & 5.6486 & TST & \\
\hline CHEMBL 3911257 & 1639947 & 5.4444 & 5.0947 & TRN & \\
\hline CHEMBL 3932651 & 1639947 & 6.0 & 5.9284 & TST & \\
\hline CHEMBL3891070 & 1639947 & 6.0501 & 5.5161 & TRN & \\
\hline CHEMBL566888 & 1639947 & 6.4597 & 6.4978 & TRN & \\
\hline CHEMBL 3983901 & 1639947 & 5.9863 & 6.0376 & TRN & \\
\hline CHEMBL3956831 & 1639947 & 6.0458 & 6.0629 & TRN & \\
\hline CHEMBL583544 & 1639947 & 6.0482 & 5.9185 & TRN & \\
\hline CHEMBL3972069 & 1639947 & 6.1129 & 6.0922 & TRN & \\
\hline CHEMBL 3925813 & 1639947 & 5.3687 & 5.345 & TRN & \\
\hline CHEMBL569682 & 1639947 & 5.1665 & 5.5005 & TRN & \\
\hline CHEMBL 3972976 & 1639947 & 5.2686 & 5.6703 & TRN & \\
\hline CHEMBL 3897766 & 1639947 & 6.1319 & 6.2163 & TRN & \\
\hline CHEMBL 3931123 & 1639947 & \multicolumn{3}{|c|}{5.837999999999999} & TRN \\
\hline CHEMBL 3985655 & 1639947 & 6.0605 & 5.9278 & TST & \\
\hline CHEMBL 3981409 & 1639947 & 4.9221 & 4.8636 & TRN & \\
\hline CHEMBL 3927222 & 1639947 & 6.4248 & 6.4013 & TST & \\
\hline CHEMBL568925 & 1639947 & 5.8008 & 5.7273 & TRN & \\
\hline
\end{tabular}

Page 13894 
Supplemental Table S2.txt

\begin{tabular}{|c|c|c|c|c|}
\hline CHEMBL 3936798 & 1639947 & 5.8834 & 6.1257 & TRN \\
\hline CHEMBL3979392 & 1639947 & 5.6975 & 5.6098 & TRN \\
\hline CHEMBL569103 & 1639947 & 6.1612 & 5.9592 & TRN \\
\hline CHEMBL 3952310 & 1639947 & 4.385 & 5.0235 & TRN \\
\hline CHEMBL568568 & 1639947 & 6.1319 & 5.9964 & TRN \\
\hline CHEMBL 3908588 & 1639947 & 4.8573 & 5.7125 & TRN \\
\hline CHEMBL569004 & 1639947 & 6.2967 & 6.4353 & TST \\
\hline CHEMBL 3960732 & 1639947 & 6.2534 & 6.3071 & TRN \\
\hline CHEMBL3910026 & 1639947 & 5.4224 & 5.7613 & TST \\
\hline CHEMBL3983378 & 1639947 & 6.0947 & 6.2143 & TST \\
\hline CHEMBL3927395 & 1639947 & 4.3456 & 5.2024 & TRN \\
\hline CHEMBL3893819 & 1639947 & 6.0367 & 5.7608 & TRN \\
\hline CHEMBL3897459 & 1639947 & 4.5252 & 4.4792 & TST \\
\hline CHEMBL3978183 & 1639947 & 6.3595 & 6.4497 & TRN \\
\hline CHEMBL3922726 & 1639947 & 5.6396 & 5.7851 & TRN \\
\hline CHEMBL3955599 & 1639947 & 6.1599 & 5.9677 & TRN \\
\hline CHEMBL2018594 & 1639947 & 5.8268 & 5.89 & TRN \\
\hline CHEMBL583242 & 1639947 & 6.1871 & 6.3062 & TRN \\
\hline CHEMBL3976271 & 1639947 & 5.7673 & 5.6529 & TRN \\
\hline CHEMBL3970788 & 1639947 & 5.9974 & 6.0445 & TST \\
\hline CHEMBL569002 & 1639947 & 5.7498 & 6.0823 & TST \\
\hline CHEMBL3893297 & 1639947 & 6.2549 & 5.9217 & TST \\
\hline CHEMBL3948625 & 1639947 & 4.6187 & 5.53 & TST \\
\hline CHEMBL3891176 & 1639947 & 6.3458 & 6.4384 & TST \\
\hline CHEMBL 3896092 & 1639947 & 5.7605 & 5.1549 & TST \\
\hline CHEMBL3939175 & 1639947 & 6.6517 & 6.6148 & TRN \\
\hline CHEMBL3986126 & 1639947 & 6.2418 & 5.9248 & TRN \\
\hline CHEMBL3899381 & 1639947 & 6.0052 & 5.879 & TST \\
\hline CHEMBL3939547 & 1639947 & 5.8008 & 6.226 & TST \\
\hline CHEMBL3911521 & 1639947 & 5.7075 & 5.5357 & TST \\
\hline CHEMBL568800 & 1639947 & 6.2807 & 6.4384 & TST \\
\hline CHEMBL565549 & 1639947 & 6.0155 & 5.9576 & TRN \\
\hline CHEMBL569230 & 1639947 & 6.4179 & 6.4599 & TRN \\
\hline CHEMBL568853 & 1639947 & 5.9872 & 6.0897 & TRN \\
\hline CHEMBL3964185 & 1639947 & 3.6665 & 3.8764 & TST \\
\hline CHEMBL584735 & 1639947 & 5.7655 & 5.8809 & TST \\
\hline CHEMBL 3962724 & 1639947 & 6.1433 & 6.1507 & TRN \\
\hline CHEMBL568569 & 1639947 & 6.2684 & \multicolumn{2}{|c|}{6.252999999999999} \\
\hline CHEMBL3963261 & 1639947 & 4.6017 & 5.4819 & TST \\
\hline CHEMBL 3982246 & 1639947 & 6.1713 & 5.9337 & TRN \\
\hline CHEMBL3987157 & 1639947 & 5.8077 & 5.4904 & TRN \\
\hline CHEMBL3955654 & 1639947 & 4.0498 & 4.2952 & TRN \\
\hline CHEMBL3934717 & 1639947 & 7.0 & 6.8259 & TRN \\
\hline CHEMBL3963724 & 1639947 & 6.6234 & \multicolumn{2}{|c|}{6.712999999999999} \\
\hline CHEMBL3919477 & 1639947 & 5.8687 & 5.7333 & TRN \\
\hline CHEMBL3986596 & 1639947 & 6.2741 & 6.2545 & TRN \\
\hline CHEMBL 3894633 & 1639947 & 6.0372 & 6.1303 & TST \\
\hline CHEMBL3933103 & 1639947 & 3.6826 & 3.2938 & TST \\
\hline
\end{tabular}

Page 13895 
Supplemental Table S2.txt

\begin{tabular}{|c|c|c|c|c|}
\hline CHEMBL3931398 & 1639947 & 6.3354 & 6.4802 & TRN \\
\hline CHEMBL3945183 & 1639947 & 5.9948 & 6.0038 & TRN \\
\hline CHEMBL585131 & 1639947 & 6.2457 & 6.5327 & TRN \\
\hline CHEMBL3962869 & 1639947 & 3.9698 & 5.2464 & TRN \\
\hline CHEMBL3924699 & 1639947 & 6.3605 & 6.1935 & TRN \\
\hline CHEMBL566021 & 1639947 & 6.1746 & 5.9832 & TRN \\
\hline CHEMBL3961169 & 1639947 & 6.3063 & 6.2273 & TRN \\
\hline CHEMBL 3896500 & 1639947 & 5.5508 & 5.4869 & TRN \\
\hline CHEMBL3983911 & 1639947 & 5.9543 & 6.0814 & TRN \\
\hline CHEMBL3970316 & 1639947 & 6.6402 & 6.0974 & TRN \\
\hline CHEMBL583050 & 1639947 & 6.4828 & 6.4508 & TRN \\
\hline CHEMBL3968980 & 1639947 & 5.9462 & 6.0557 & TRN \\
\hline CHEMBL583471 & 1639947 & 5.67 & 5.7885 & TRN \\
\hline CHEMBL3981008 & 1639947 & 5.731 & 5.4989 & TST \\
\hline CHEMBL3901294 & 1639947 & 5.8928 & 5.9371 & TST \\
\hline CHEMBL566461 & 1639947 & 6.0942 & 6.0134 & TRN \\
\hline CHEMBL3941310 & 1639947 & 6.38299 & 999999999 & 6.4333 \\
\hline CHEMBL3897819 & 1639947 & 6.3449 & 6.2973 & TRN \\
\hline CHEMBL 3925319 & 1639947 & 5.727 & 5.5701 & TST \\
\hline CHEMBL3952616 & 1639947 & 6.0348 & 5.3375 & TST \\
\hline CHEMBL3965907 & 1639947 & 6.5719 & 6.4975 & TRN \\
\hline CHEMBL 3907223 & 1639947 & 6.2588 & 6.4287 & TST \\
\hline CHEMBL3895814 & 1639947 & 6.6517 & 6.4605 & TRN \\
\hline CHEMBL 3921537 & 1639947 & 5.6596 & 5.54 & TRN \\
\hline CHEMBL568823 & 1639947 & 3.5993 & 3.7576 & TRN \\
\hline CHEMBL3948345 & 1639947 & 5.0161 & 5.1887 & TRN \\
\hline CHEMBL 3907900 & 1639947 & 6.098 & 6.0107 & TRN \\
\hline CHEMBL569098 & 1639947 & 6.091 & 5.9241 & TRN \\
\hline CHEMBL 3938608 & 1639947 & 6.2941 & 6.3099 & TRN \\
\hline CHEMBL 3904530 & 1639947 & 5.9792 & 5.1491 & TRN \\
\hline CHEMBL 3938256 & 1639947 & 5.9952 & 5.7766 & TST \\
\hline CHEMBL3900218 & 1639947 & 5.7518 & 5.5022 & TRN \\
\hline CHEMBL3955213 & 1639947 & 5.1241 & 4.2315 & TRN \\
\hline CHEMBL3970869 & 1639947 & 6.3893 & 6.4263 & TST \\
\hline CHEMBL567102 & 1639947 & 5.83 & 5.8843 & TRN \\
\hline CHEMBL3912322 & 1639947 & 5.8611 & 6.0934 & TRN \\
\hline CHEMBL3959525 & 1639947 & 6.6904 & 6.592000 & 00000000005 \\
\hline CHEMBL3928449 & 1639947 & 5.9586 & 5.84 & TST \\
\hline CHEMBL570902 & 1639947 & 6.1904 & 6.251 & TRN \\
\hline CHEMBL3980303 & 1639947 & 5.2848 & 4.9952 & TST \\
\hline CHEMBL3966823 & 1639947 & 4.6008 & 4.2374 & TST \\
\hline CHEMBL3924714 & 1639947 & 6.2916 & 6.1802 & TRN \\
\hline CHEMBL3892602 & 1639947 & 6.2111 & 6.2634 & TRN \\
\hline CHEMBL3981486 & 1639947 & 5.9408 & 6.0072 & TST \\
\hline CHEMBL3977301 & 1639947 & 4.3865 & 5.02 & TRN \\
\hline CHEMBL570417 & 1639947 & 5.9508 & 5.1482 & TRN \\
\hline CHEMBL3947971 & 1639947 & 6.0706 & 6.0338 & TST \\
\hline CHEMBL 3896011 & 1639947 & 6.1475 & 6.1608 & TRN \\
\hline
\end{tabular}


Supplemental Table S2.txt

\begin{tabular}{|c|c|c|c|c|c|}
\hline CHEMBL566879 & 1639947 & 6.1871 & 6.0079 & TRN & \\
\hline CHEMBL3953013 & 1639947 & 6.6402 & 6.0677 & TRN & \\
\hline CHEMBL3953370 & 1639947 & 6.3686 & 6.4734 & TRN & \\
\hline CHEMBL568821 & 1639947 & 5.5864 & 5.5951 & TRN & \\
\hline CHEMBL569231 & 1639947 & 6.3655 & 6.2697 & TRN & \\
\hline CHEMBL3983546 & 1639947 & 6.6676 & 6.7417 & TRN & \\
\hline CHEMBL3926054 & 1639947 & 5.9718 & 5.9156 & TRN & \\
\hline CHEMBL3927457 & 1639947 & 5.8573 & 5.9567 & TRN & \\
\hline CHEMBL576864 & 1639947 & 5.2486 & 5.2708 & TRN & \\
\hline CHEMBL565622 & 1639947 & 3.6978 & 4.1375 & TRN & \\
\hline CHEMBL3937480 & 1639947 & 5.2254 & 5.3482 & TRN & \\
\hline CHEMBL3909994 & 1639947 & 5.8745 & 5.9766 & TRN & \\
\hline CHEMBL569532 & 1639947 & 6.0814 & 6.1775 & TST & \\
\hline CHEMBL3901109 & 1639947 & 5.5249 & 5.58899 & 99999999995 & TRN \\
\hline CHEMBL569099 & 1639947 & 5.9805 & 5.7877 & TRN & \\
\hline CHEMBL3904066 & 1639947 & 6.2418 & 6.3438 & TRN & \\
\hline CHEMBL3906144 & 1639947 & 6.279 & 6.1303 & TRN & \\
\hline CHEMBL 3924750 & 1639947 & 5.6449 & 6.0497 & TRN & \\
\hline CHEMBL3903280 & 1639947 & 5.754 & 5.934 & TRN & \\
\hline CHEMBL72921 & 3907 & 7.1249 & 6.2626 & TRN & \\
\hline CHEMBL 73016 & 3907 & 6.6198 & 7.4285 & TST & \\
\hline CHEMBL69778 & 3907 & 7.1549 & 7.0602 & TRN & \\
\hline CHEMBL72906 & 3907 & 8.0458 & 7.0919 & TST & \\
\hline CHEMBL 73083 & 3907 & 7.4949 & 7.3579 & TRN & \\
\hline CHEMBL 73064 & 3907 & 5.0 & 7.0602 & TRN & \\
\hline CHEMBL 72580 & 3907 & 6.0 & 6.59399 & 9999999999 & TRN \\
\hline CHEMBL 72821 & 3907 & 7.8239 & 7.2775 & TRN & \\
\hline CHEMBL424603 & 3907 & 5.0 & 6.7447 & TRN & \\
\hline CHEMBL73186 & 3907 & 7.9586 & 6.7447 & TRN & \\
\hline CHEMBL 72020 & 3907 & 7.301 & 6.2626 & TRN & \\
\hline CHEMBL 70675 & 3907 & 7.585 & 6.7447 & TRN & \\
\hline CHEMBL 72637 & 3907 & 7.0223 & 7.224 & TST & \\
\hline CHEMBL306144 & 3907 & 7.284 & 7.5936 & TRN & \\
\hline CHEMBL 72597 & 3907 & 6.9586 & 6.9282 & TST & \\
\hline CHEMBL 72469 & 3907 & 5.0458 & 7.1097 & TRN & \\
\hline CHEMBL 70376 & 3907 & 7.0 & 7.0576 & TRN & \\
\hline CHEMBL73539 & 3907 & 5.8239 & 7.0602 & TRN & \\
\hline CHEMBL73319 & 3907 & 7.3468 & 7.6432 & TRN & \\
\hline CHEMBL 76340 & 3907 & 7.6576 & 7.0602 & TRN & \\
\hline CHEMBL 73496 & 3907 & 5.0 & 6.2626 & TRN & \\
\hline CHEMBL 75143 & 3907 & 5.0 & 6.2626 & TRN & \\
\hline CHEMBL 73400 & 3907 & 7.4559 & 7.3092 & TRN & \\
\hline CHEMBL 308070 & 3907 & 7.7696 & 7.0602 & TRN & \\
\hline CHEMBL306408 & 3907 & 7.4815 & \multicolumn{2}{|c|}{6.957000000000001} & TST \\
\hline CHEMBL420194 & 3907 & 7.5229 & 6.2626 & TRN & \\
\hline CHEMBL 72955 & 3907 & 7.5528 & 7.1097 & TRN & \\
\hline CHEMBL310474 & 3907 & 7.3768 & 6.2626 & TRN & \\
\hline CHEMBL72817 & 3907 & 7.699 & 6.7447 & TRN & \\
\hline
\end{tabular}




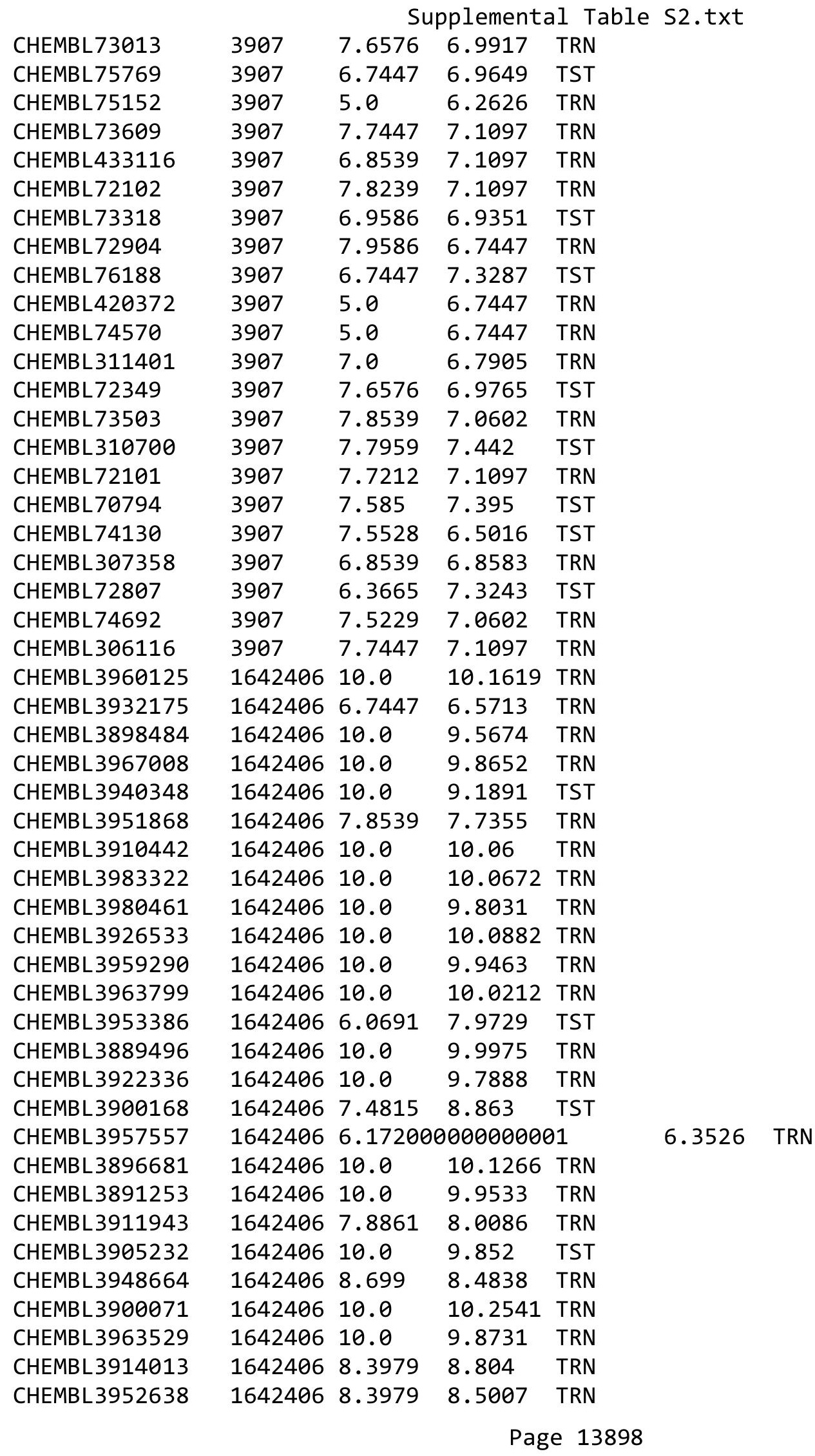


Supplemental Table S2.txt

\begin{tabular}{|c|c|c|c|c|}
\hline CHEMBL3941511 & 1642406 & 10.0 & 10.0842 & TRN \\
\hline CHEMBL3913504 & 1642406 & 10.0 & 9.6381 & TST \\
\hline CHEMBL3924624 & 1642406 & 10.0 & 9.9237 & TRN \\
\hline CHEMBL3891261 & 1642406 & 8.0 & 8.2398 & TRN \\
\hline CHEMBL 3921678 & 1642406 & 10.0 & 9.234 & TST \\
\hline CHEMBL 3956014 & 1642406 & 10.0 & 10.1055 & TRN \\
\hline CHEMBL3939295 & 1642406 & 10.0 & 9.8861 & TRN \\
\hline CHEMBL 3981394 & 1642406 & 10.0 & 10.052 & TRN \\
\hline CHEMBL 3889525 & 1642406 & 10.0 & 10.1442 & TRN \\
\hline CHEMBL 3915751 & 1642406 & 10.0 & 9.5803 & TRN \\
\hline CHEMBL3957874 & 1642406 & 10.0 & 10.1323 & TRN \\
\hline CHEMBL3932109 & 1642406 & 10.0 & 9.1458 & TST \\
\hline CHEMBL3953646 & 1642406 & 10.0 & 10.0217 & TRN \\
\hline CHEMBL3963148 & 1642406 & 10.0 & 10.1903 & TRN \\
\hline CHEMBL 3927229 & 1642406 & 7.8239 & 8.0681 & TRN \\
\hline CHEMBL3961994 & 1642406 & 10.0 & 9.4336 & TRN \\
\hline CHEMBL 3958828 & 1642406 & 10.0 & 10.1571 & TRN \\
\hline CHEMBL3957409 & 1642406 & 10.0 & 9.9943 & TST \\
\hline CHEMBL3915603 & 1642406 & 10.0 & 10.0785 & TRN \\
\hline CHEMBL 3906748 & 1642406 & 10.0 & 9.7363 & TST \\
\hline CHEMBL 3937344 & 1642406 & 10.0 & 9.9218 & TRN \\
\hline CHEMBL 3949590 & 1642406 & 10.0 & 9.9268 & TRN \\
\hline CHEMBL 3927803 & 1642406 & 10.0 & 10.0068 & TRN \\
\hline CHEMBL 3897741 & 1642406 & 10.0 & 10.0149 & TRN \\
\hline CHEMBL 3937272 & 1642406 & 10.0 & 10.203 & TRN \\
\hline CHEMBL 3892342 & 1642406 & 10.0 & 9.2432 & TST \\
\hline CHEMBL 3900286 & 1642406 & 10.0 & 9.9784 & TRN \\
\hline CHEMBL3967316 & 1642406 & 8.699 & 9.052999 & 999999999 \\
\hline CHEMBL 3959844 & 1642406 & 10.0 & 9.9692 & TRN \\
\hline CHEMBL 3968033 & 1642406 & 10.0 & 9.8834 & TRN \\
\hline CHEMBL3948944 & 1642406 & 6.4622 & 8.04 & TST \\
\hline CHEMBL 3976424 & 1642406 & 8.2218 & 8.1651 & TRN \\
\hline CHEMBL3982659 & 1642406 & 7.0506 & 8.4652 & TST \\
\hline CHEMBL3912538 & 1642406 & 10.0 & 9.2724 & TST \\
\hline CHEMBL3944659 & 1642406 & 6.6968 & 8.2783 & TST \\
\hline CHEMBL3968830 & 1642406 & 7.5686 & 8.0725 & TST \\
\hline CHEMBL1964290 & 809153 & 6.5 & 5.7228 & TRN \\
\hline CHEMBL 213505 & 809153 & 4.4 & 5.8204 & TRN \\
\hline CHEMBL1987034 & 809153 & 7.7 & 8.3459 & TRN \\
\hline CHEMBL1993941 & 809153 & 7.2 & 7.3496 & TRN \\
\hline CHEMBL377383 & 809153 & 4.4 & 4.2102 & TRN \\
\hline CHEMBL 2005886 & 809153 & 7.9 & 7.2756 & TRN \\
\hline CHEMBL481491 & 809153 & 4.4 & 5.1075 & TST \\
\hline CHEMBL1682345 & 809153 & 5.6 & 6.0095 & TRN \\
\hline CHEMBL1973142 & 809153 & 5.5 & 5.1331 & TRN \\
\hline CHEMBL1973145 & 809153 & 4.4 & 5.0369 & TRN \\
\hline CHEMBL1982924 & 809153 & 4.4 & 4.6604 & TRN \\
\hline CHEMBL2005936 & 809153 & 4.4 & 5.7469 & TRN \\
\hline
\end{tabular}




\begin{tabular}{|c|c|c|c|c|c|}
\hline & & \multicolumn{4}{|c|}{ Supplemental Table S2.txt } \\
\hline CHEMBL1807515 & 809153 & 4.4 & \multicolumn{2}{|c|}{4.9639999999999995} & TRN \\
\hline CHEMBL1971141 & 809153 & 4.4 & 4.2985 & TRN & \\
\hline CHEMBL1995813 & 809153 & 5.5 & 5.1679 & TRN & \\
\hline CHEMBL1979718 & 809153 & 5.4 & 4.397 & TRN & \\
\hline CHEMBL206236 & 809153 & 4.4 & 4.1832 & TRN & \\
\hline CHEMBL1989834 & 809153 & 4.9 & 4.644 & TRN & \\
\hline CHEMBL1562756 & 809153 & 4.4 & 4.8837 & TST & \\
\hline CHEMBL 244378 & 809153 & 8.1 & 8.6923 & TRN & \\
\hline CHEMBL 2001957 & 809153 & 4.4 & 4.6901 & TRN & \\
\hline CHEMBL1969372 & 809153 & 4.4 & 4.4062 & TRN & \\
\hline CHEMBL1986943 & 809153 & 4.4 & 5.0437 & TRN & \\
\hline CHEMBL289959 & 809153 & 3.4 & 3.8181 & TRN & \\
\hline CHEMBL 2006263 & 809153 & 6.0 & 5.4424 & TST & \\
\hline CHEMBL1993584 & 809153 & 4.4 & 4.5951 & TRN & \\
\hline CHEMBL1986263 & 809153 & 6.8 & 6.9918 & TRN & \\
\hline CHEMBL 2000114 & 809153 & 5.7 & 5.2526 & TRN & \\
\hline CHEMBL210618 & 809153 & 4.4 & 3.7968 & TRN & \\
\hline CHEMBL1975647 & 809153 & 4.4 & 4.8534 & TRN & \\
\hline CHEMBL1968380 & 809153 & 4.4 & 4.4911 & TRN & \\
\hline CHEMBL1964644 & 809153 & 4.4 & 4.105 & TRN & \\
\hline CHEMBL1981782 & 809153 & 4.4 & 4.6148 & TRN & \\
\hline CHEMBL1977681 & 809153 & 5.8 & 5.7221 & TRN & \\
\hline CHEMBL1970142 & 809153 & 7.8 & \multicolumn{2}{|c|}{7.377000000000001} & TRN \\
\hline CHEMBL1990912 & 809153 & 4.4 & 4.9684 & TRN & \\
\hline CHEMBL1995592 & 809153 & 5.9 & 5.8222 & TST & \\
\hline CHEMBL 2006493 & 809153 & 4.4 & 4.4791 & TST & \\
\hline CHEMBL1996923 & 809153 & 4.4 & 4.5765 & TST & \\
\hline CHEMBL1983449 & 809153 & 4.4 & 4.6461 & TRN & \\
\hline CHEMBL1992323 & 809153 & 4.4 & 4.2568 & TRN & \\
\hline CHEMBL1969735 & 809153 & 4.4 & 4.4301 & TRN & \\
\hline CHEMBL2003524 & 809153 & 6.4 & 5.064 & TST & \\
\hline CHEMBL 2002649 & 809153 & 6.0 & 6.3666 & TRN & \\
\hline CHEMBL1989423 & 809153 & 4.8 & 4.1879 & TRN & \\
\hline CHEMBL437747 & 809153 & 5.8 & 4.8754 & TRN & \\
\hline CHEMBL507936 & 809153 & 4.4 & 4.5353 & TRN & \\
\hline CHEMBL104264 & 809153 & 4.4 & 5.5872 & TST & \\
\hline CHEMBL1994321 & 809153 & 8.1 & 6.9338 & TRN & \\
\hline CHEMBL1997129 & 809153 & 7.5 & 7.8654 & TRN & \\
\hline CHEMBL1984788 & 809153 & 4.4 & 4.89 & TRN & \\
\hline CHEMBL1964307 & 809153 & 6.7 & 5.886 & TRN & \\
\hline CHEMBL 2000508 & 809153 & 4.4 & 4.6559 & TRN & \\
\hline CHEMBL1971694 & 809153 & 4.4 & 4.5378 & TST & \\
\hline CHEMBL 2001547 & 809153 & 4.4 & 4.3601 & TRN & \\
\hline CHEMBL210928 & 809153 & 4.4 & 3.9752 & TRN & \\
\hline CHEMBL1986603 & 809153 & 4.4 & 4.2223 & TST & \\
\hline CHEMBL1972840 & 809153 & 5.7 & 4.9777 & TRN & \\
\hline CHEMBL1977148 & 809153 & 4.4 & 5.5999 & TRN & \\
\hline CHEMBL 2003286 & 809153 & 4.4 & 5.064 & TRN & \\
\hline
\end{tabular}




\begin{tabular}{|c|c|c|c|c|}
\hline & & & ipplement & al $\mathrm{T}$ \\
\hline CHEMBL1992306 & 809153 & 6.3 & 5.0777 & TRN \\
\hline CHEMBL 2002165 & 809153 & 7.4 & 7.5904 & TRN \\
\hline CHEMBL1979318 & 809153 & 4.4 & 4.6319 & TRN \\
\hline CHEMBL 206382 & 809153 & 4.4 & 4.1382 & TRN \\
\hline CHEMBL1998585 & 809153 & 7.2 & 7.3735 & TRN \\
\hline CHEMBL127898 & 809153 & 4.4 & 4.9163 & TST \\
\hline CHEMBL519697 & 809153 & 4.4 & 5.1171 & TST \\
\hline CHEMBL2004934 & 809153 & 4.4 & 4.5318 & TRN \\
\hline CHEMBL1977619 & 809153 & 3.4 & 4.4121 & TST \\
\hline CHEMBL1975128 & 809153 & 7.4 & 7.4778 & TRN \\
\hline CHEMBL1996048 & 809153 & 6.1 & 5.1594 & TST \\
\hline CHEMBL1970369 & 809153 & 4.4 & 4.5298 & TRN \\
\hline CHEMBL461876 & 809153 & 5.7 & 5.6922 & TRN \\
\hline CHEMBL 2001485 & 809153 & 7.1 & 7.0034 & TRN \\
\hline CHEMBL504950 & 809153 & 5.5 & 5.7967 & TRN \\
\hline CHEMBL1966425 & 809153 & 5.5 & 5.1505 & TRN \\
\hline CHEMBL1984363 & 809153 & 6.3 & 5.4998 & TRN \\
\hline CHEMBL1978099 & 809153 & 7.2 & 7.3361 & TRN \\
\hline CHEMBL1977041 & 809153 & 6.9 & 6.7096 & TRN \\
\hline CHEMBL1968070 & 809153 & 6.4 & 6.1008 & TRN \\
\hline CHEMBL1988608 & 809153 & 6.1 & 5.3347 & TRN \\
\hline CHEMBL184847 & 809153 & 4.4 & 5.061 & TRN \\
\hline CHEMBL1984367 & 809153 & 4.4 & 5.5647 & TRN \\
\hline CHEMBL 226898 & 809153 & 5.6 & 5.7462 & TRN \\
\hline CHEMBL1982563 & 809153 & 4.4 & 4.3484 & TRN \\
\hline CHEMBL539474 & 809153 & 6.0 & 5.7264 & TST \\
\hline CHEMBL575824 & 809153 & 4.4 & 3.8522 & TRN \\
\hline CHEMBL1988387 & 809153 & 7.5 & 7.6537 & TRN \\
\hline CHEMBL1997759 & 809153 & 4.4 & 4.2058 & TRN \\
\hline CHEMBL1990288 & 809153 & 4.4 & 4.6004 & TRN \\
\hline CHEMBL1974803 & 809153 & 5.7 & 4.9793 & TST \\
\hline CHEMBL1970074 & 809153 & 4.4 & 4.9464 & TRN \\
\hline CHEMBL1986970 & 809153 & 6.0 & 5.7323 & TRN \\
\hline CHEMBL 2005112 & 809153 & 5.5 & 5.1771 & TST \\
\hline CHEMBL1958401 & 809153 & 4.4 & 4.8571 & TRN \\
\hline CHEMBL 2003456 & 809153 & 5.7 & 5.2988 & TRN \\
\hline CHEMBL1966816 & 809153 & 4.4 & 4.5932 & TRN \\
\hline CHEMBL1972584 & 809153 & 6.7 & 6.6499 & TRN \\
\hline CHEMBL 2002992 & 809153 & 5.8 & 4.9314 & TRN \\
\hline CHEMBL560813 & 809153 & 4.4 & 4.5027 & TRN \\
\hline CHEMBL1968791 & 809153 & 4.4 & 4.9466 & TRN \\
\hline CHEMBL326282 & 809153 & 4.4 & 4.45 & TST \\
\hline CHEMBL1992732 & 809153 & 4.4 & 4.0809 & TST \\
\hline CHEMBL1971186 & 809153 & 4.4 & 4.6618 & TRN \\
\hline CHEMBL 2003482 & 809153 & 4.4 & 4.4788 & TRN \\
\hline CHEMBL1976872 & 809153 & 3.4 & 3.6728 & TST \\
\hline CHEMBL1969156 & 809153 & 3.4 & 4.1941 & TST \\
\hline CHEMBL1973211 & 809153 & 7.0 & 6.8176 & TRN \\
\hline
\end{tabular}




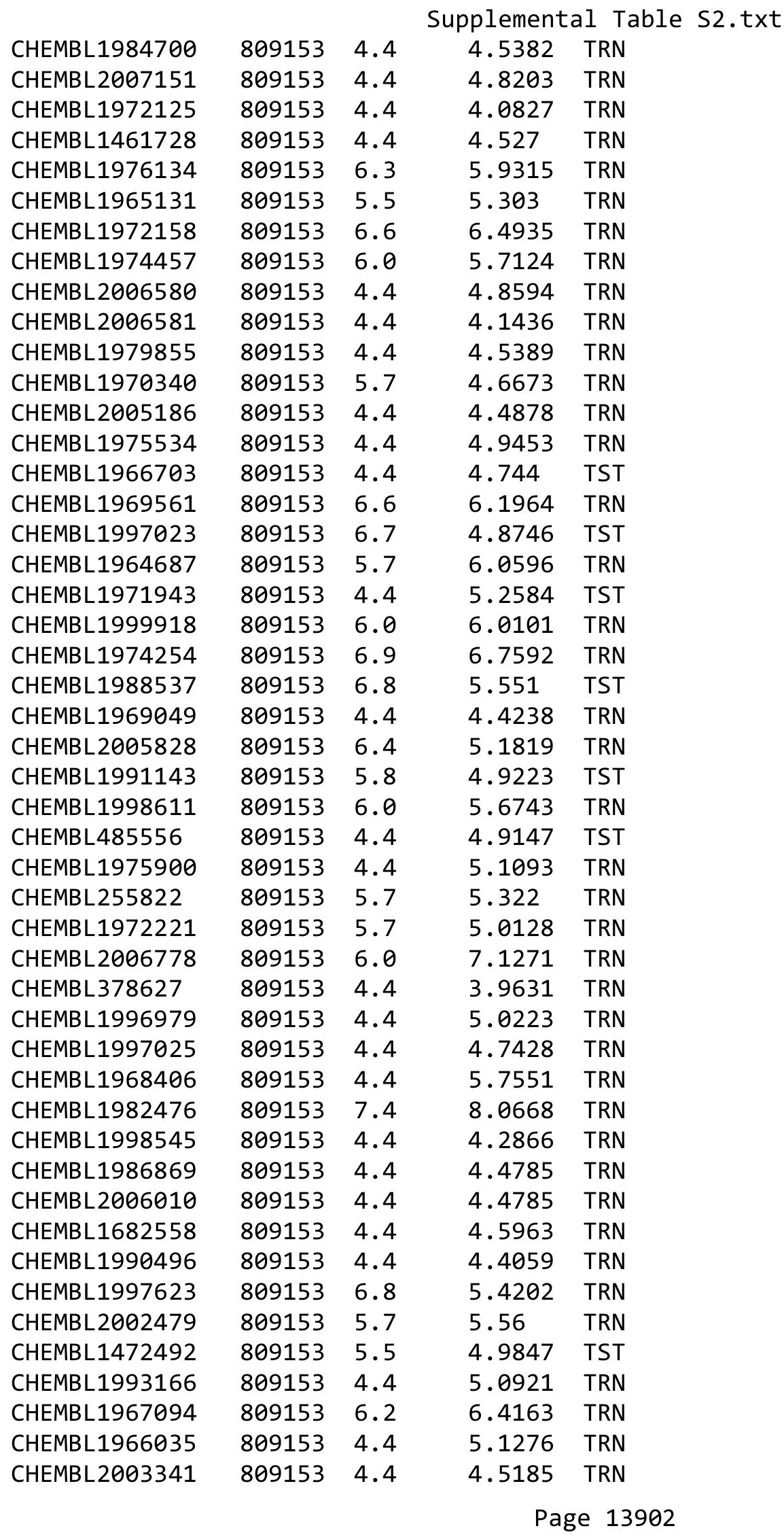




\begin{tabular}{|c|c|c|c|c|c|}
\hline \\
\hline CHEMBL1992645 & 809153 & 4.4 & 5.301 & TST & \\
\hline CHEMBL1982992 & 809153 & 4.4 & 4.8094 & TRN & \\
\hline CHEMBL1999590 & 809153 & 4.4 & 4.4739 & TST & \\
\hline CHEMBL1981079 & 809153 & 6.1 & 5.5296 & TRN & \\
\hline CHEMBL1972276 & 809153 & 4.4 & 4.6387 & TRN & \\
\hline CHEMBL1980489 & 809153 & 4.4 & 4.8771 & TRN & \\
\hline CHEMBL1967116 & 809153 & 7.9 & 8.169 & TRN & \\
\hline CHEMBL 2000832 & 809153 & 5.8 & 6.0218 & TRN & \\
\hline CHEMBL1977814 & 809153 & 4.4 & 4.1586 & TST & \\
\hline CHEMBL513846 & 809153 & 4.4 & 4.6246 & TRN & \\
\hline CHEMBL1970709 & 809153 & 4.4 & 4.1733 & TRN & \\
\hline CHEMBL1965660 & 809153 & 6.3 & 5.7356 & TRN & \\
\hline CHEMBL1998112 & 809153 & 4.4 & 5.6538 & TRN & \\
\hline CHEMBL1969126 & 809153 & 4.4 & 4.80699 & 99999999995 & TRN \\
\hline CHEMBL1980896 & 809153 & 5.9 & 5.4591 & TRN & \\
\hline CHEMBL1975208 & 809153 & 4.4 & 4.2788 & TST & \\
\hline CHEMBL1970104 & 809153 & 6.7 & 6.6254 & TRN & \\
\hline CHEMBL1964777 & 809153 & 4.4 & 4.9306 & TRN & \\
\hline CHEMBL1971149 & 809153 & 4.4 & 4.5259 & TRN & \\
\hline CHEMBL1999714 & 809153 & 4.4 & 4.4572 & TRN & \\
\hline CHEMBL1987533 & 809153 & 4.4 & 4.1636 & TRN & \\
\hline CHEMBL1994040 & 809153 & 4.4 & 4.487 & TRN & \\
\hline CHEMBL388978 & 809153 & 8.1 & 8.262 & TST & \\
\hline CHEMBL579246 & 809153 & 4.4 & 4.2235 & TRN & \\
\hline CHEMBL398951 & 809153 & 4.4 & 5.0555 & TST & \\
\hline CHEMBL1982506 & 809153 & 6.1 & 4.8937 & TST & \\
\hline CHEMBL2004716 & 809153 & 7.4 & 7.806 & TRN & \\
\hline CHEMBL1968127 & 809153 & 4.4 & 4.5521 & TRN & \\
\hline CHEMBL1975233 & 809153 & 4.4 & $3.8930 e$ & 00000000002 & TRN \\
\hline CHEMBL1985406 & 809153 & 5.4 & 4.8015 & TRN & \\
\hline CHEMBL207400 & 809153 & 4.4 & 4.1229 & TST & \\
\hline CHEMBL 2000894 & 809153 & 4.4 & 4.3463 & TST & \\
\hline CHEMBL1982135 & 809153 & 5.9 & 5.8432 & TRN & \\
\hline CHEMBL1976090 & 809153 & 6.4 & $6.4510 e$ & 00000000005 & TRN \\
\hline CHEMBL1993243 & 809153 & 6.1 & 6.4394 & TRN & \\
\hline CHEMBL1992922 & 809153 & 4.4 & 5.6921 & TRN & \\
\hline CHEMBL2004771 & 809153 & 6.3 & 5.5909 & TRN & \\
\hline CHEMBL399021 & 809153 & 6.0 & 5.2552 & TRN & \\
\hline CHEMBL1997597 & 809153 & 5.7 & 5.5649 & TRN & \\
\hline CHEMBL1969537 & 809153 & 4.4 & 5.9326 & TST & \\
\hline CHEMBL1976093 & 809153 & 4.4 & 4.4596 & TRN & \\
\hline CHEMBL1996543 & 809153 & 4.4 & 3.9171 & TRN & \\
\hline CHEMBL1975256 & 809153 & 4.4 & 4.5927 & TST & \\
\hline CHEMBL508928 & 809153 & 6.8 & 5.7179 & TRN & \\
\hline CHEMBL1991356 & 809153 & 4.4 & 4.8627 & TST & \\
\hline CHEMBL2004892 & 809153 & 6.0 & 5.6989 & TRN & \\
\hline CHEMBL1997503 & 809153 & 4.4 & 4.6568 & TST & \\
\hline CHEMBL116070 & 809153 & 4.4 & 4.3209 & TRN & \\
\hline & & & & 390 & \\
\hline
\end{tabular}




\begin{tabular}{|c|c|c|c|c|}
\hline & & & pplement & al $\mathrm{Ta}$ \\
\hline CHEMBL1990821 & 809153 & 4.4 & 5.3866 & TST \\
\hline CHEMBL1970314 & 809153 & 5.7 & 4.9304 & TRN \\
\hline CHEMBL2004871 & 809153 & 4.4 & 4.607 & TRN \\
\hline CHEMBL 2004872 & 809153 & 4.4 & 4.499 & TRN \\
\hline CHEMBL1727312 & 809153 & 3.6 & 4.1311 & TRN \\
\hline CHEMBL1969879 & 809153 & 4.4 & 4.7603 & TRN \\
\hline CHEMBL1981720 & 809153 & 5.5 & 5.0617 & TRN \\
\hline CHEMBL419932 & 809153 & 4.4 & 4.7188 & TRN \\
\hline CHEMBL 262433 & 809153 & 4.4 & 5.8991 & TRN \\
\hline CHEMBL 306380 & 809153 & 6.0 & 5.2729 & TRN \\
\hline CHEMBL1986588 & 809153 & 3.4 & 4.3472 & TRN \\
\hline CHEMBL1966722 & 809153 & 6.1 & 5.3533 & TRN \\
\hline CHEMBL1976328 & 809153 & 4.4 & 4.9605 & TRN \\
\hline CHEMBL1975500 & 809153 & 5.7 & 5.8876 & TRN \\
\hline CHEMBL394619 & 809153 & 6.0 & 5.7117 & TRN \\
\hline CHEMBL1964399 & 809153 & 8.1 & 7.9195 & TRN \\
\hline CHEMBL1996831 & 809153 & 5.6 & 4.8668 & TST \\
\hline CHEMBL411903 & 809153 & 6.9 & 7.5054 & TRN \\
\hline CHEMBL1965988 & 809153 & 6.8 & 6.99 & TRN \\
\hline CHEMBL418203 & 809153 & 5.5 & 5.0459 & TST \\
\hline CHEMBL1989646 & 809153 & 6.3 & 6.2566 & TRN \\
\hline CHEMBL1682357 & 809153 & 4.4 & 5.4181 & TRN \\
\hline CHEMBL225519 & 809153 & 6.1 & 5.6287 & TRN \\
\hline CHEMBL 209534 & 809153 & 4.4 & 4.0265 & TRN \\
\hline CHEMBL1978200 & 809153 & 4.4 & 4.5278 & TRN \\
\hline CHEMBL1970522 & 809153 & 5.7 & 5.2909 & TRN \\
\hline CHEMBL1990415 & 809153 & 4.4 & 4.6212 & TRN \\
\hline CHEMBL1966087 & 809153 & 4.4 & 4.3986 & TRN \\
\hline CHEMBL1964692 & 809153 & 4.4 & 5.1271 & TRN \\
\hline CHEMBL1996931 & 809153 & 4.4 & 4.603 & TRN \\
\hline CHEMBL1964413 & 809153 & 4.4 & 4.45 & TRN \\
\hline CHEMBL1973483 & 809153 & 4.4 & 4.7599 & TRN \\
\hline CHEMBL1984432 & 809153 & 4.4 & 4.6059 & TRN \\
\hline CHEMBL1970735 & 809153 & 4.4 & 3.9783 & TRN \\
\hline CHEMBL219722 & 809153 & 6.5 & 6.1439 & TRN \\
\hline CHEMBL1997340 & 809153 & 4.4 & 4.4371 & TRN \\
\hline CHEMBL 2004365 & 809153 & 5.4 & 5.0361 & TST \\
\hline CHEMBL1522508 & 809153 & 4.4 & 3.8716 & TRN \\
\hline CHEMBL1989474 & 809153 & 4.4 & 4.5102 & TRN \\
\hline CHEMBL210887 & 809153 & 4.4 & 4.7611 & TST \\
\hline CHEMBL458997 & 809153 & 8.4 & 7.7117 & TRN \\
\hline CHEMBL1971021 & 809153 & 5.9 & 5.2163 & TRN \\
\hline CHEMBL 227271 & 809153 & 5.6 & 5.3534 & TRN \\
\hline CHEMBL583144 & 809153 & 4.4 & 5.0619 & TRN \\
\hline CHEMBL1974310 & 809153 & 5.8 & 5.8142 & TRN \\
\hline CHEMBL1982660 & 809153 & 6.0 & 5.0412 & TRN \\
\hline CHEMBL1994693 & 809153 & 6.2 & 5.9605 & TRN \\
\hline CHEMBL1982957 & 809153 & 6.6 & 6.3034 & TRN \\
\hline
\end{tabular}




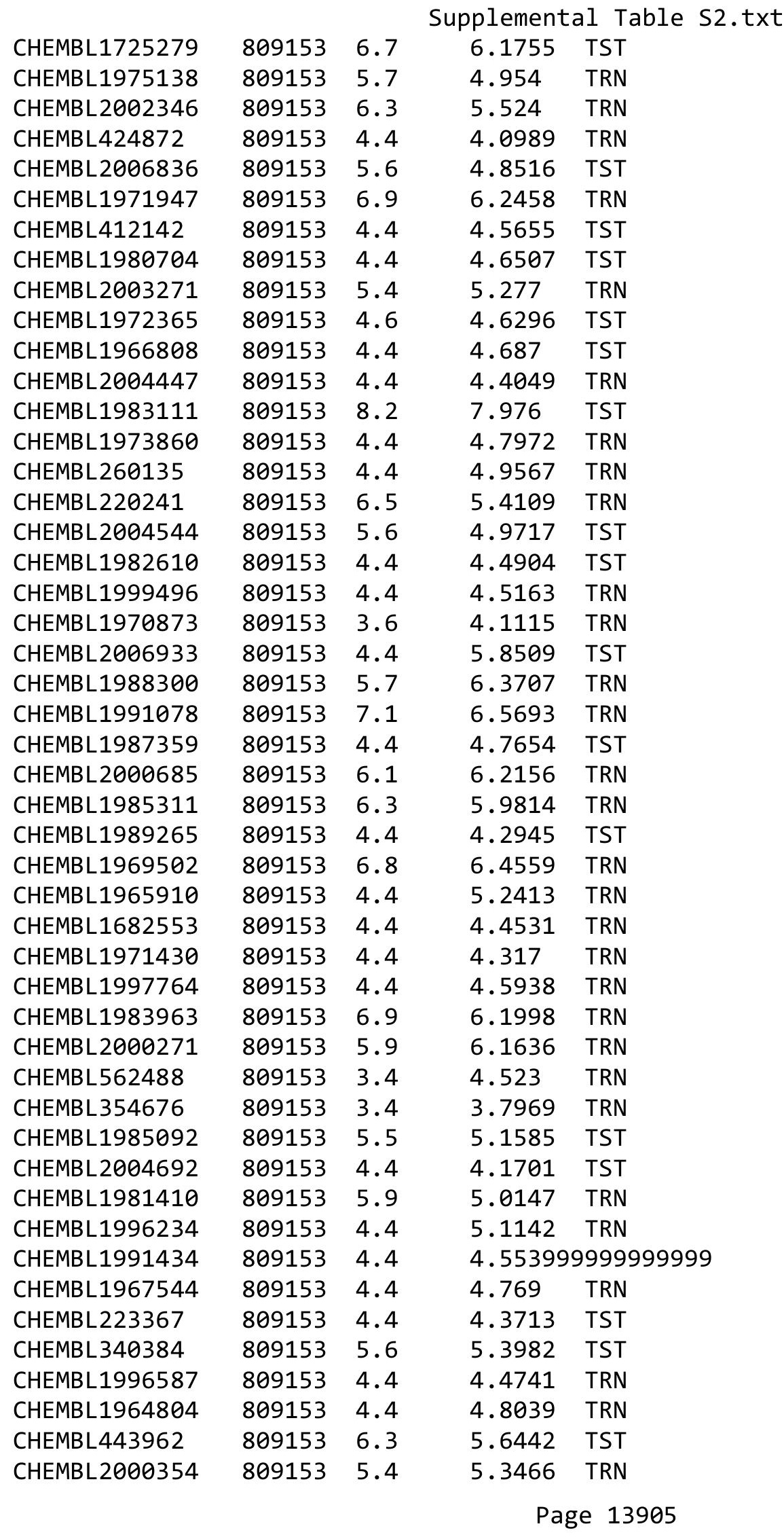




\begin{tabular}{|c|c|c|c|c|c|}
\hline \multicolumn{6}{|c|}{ Supplemental Table S2.txt } \\
\hline CHEMBL1965507 & 809153 & 7.9 & 7.8508 & TRN & \\
\hline CHEMBL274064 & 809153 & 4.4 & 4.4042 & TRN & \\
\hline CHEMBL1967564 & 809153 & 4.4 & 4.1325 & TRN & \\
\hline CHEMBL592030 & 809153 & 7.2 & 6.9506 & TST & \\
\hline CHEMBL 2000071 & 809153 & 5.9 & 5.7199 & TRN & \\
\hline CHEMBL1979176 & 809153 & 4.4 & 4.5892 & TRN & \\
\hline CHEMBL1970317 & 809153 & 7.8 & 8.166 & TRN & \\
\hline CHEMBL 2000408 & 809153 & 4.4 & 4.5278 & TRN & \\
\hline CHEMBL248757 & 809153 & 7.2 & 4.9882 & TST & \\
\hline CHEMBL1978014 & 809153 & 4.4 & 4.4269 & TRN & \\
\hline CHEMBL1994538 & 809153 & 4.4 & 4.3479 & TRN & \\
\hline CHEMBL1983195 & 809153 & 5.7 & 4.9379 & TST & \\
\hline CHEMBL1975490 & 809153 & 5.4 & 5.0507 & TRN & \\
\hline CHEMBL1964444 & 809153 & 4.4 & 4.2897 & TRN & \\
\hline CHEMBL 2006567 & 809153 & 4.4 & 4.1736 & TRN & \\
\hline CHEMBL1986139 & 809153 & 4.4 & 4.699 & TRN & \\
\hline CHEMBL383527 & 809153 & 4.4 & 4.2216 & TRN & \\
\hline CHEMBL1980540 & 809153 & 4.4 & 4.4073 & TRN & \\
\hline CHEMBL1979883 & 809153 & 7.3 & 6.7037 & TRN & \\
\hline CHEMBL1984162 & 809153 & 8.7 & 7.745 & TRN & \\
\hline CHEMBL491758 & 809153 & 7.6 & 7.234 & TRN & \\
\hline CHEMBL549730 & 809153 & 5.7 & 5.3171 & TRN & \\
\hline CHEMBL1970189 & 809153 & 4.4 & 4.7556 & TRN & \\
\hline CHEMBL1996791 & 809153 & 6.2 & 5.5588 & TRN & \\
\hline CHEMBL371206 & 809153 & 6.5 & 6.3647 & TRN & \\
\hline CHEMBL1974664 & 809153 & 4.4 & 5.2178 & TST & \\
\hline CHEMBL1974288 & 809153 & 4.4 & 4.39199 & 99999999995 & TRN \\
\hline CHEMBL196363 & 809153 & 6.8 & 6.58299 & 9999999999 & TRN \\
\hline CHEMBL1996837 & 809153 & 3.4 & 4.1268 & TRN & \\
\hline CHEMBL1190711 & 809153 & 5.8 & 5.3273 & TRN & \\
\hline CHEMBL1990346 & 809153 & 5.7 & 5.7905 & TRN & \\
\hline CHEMBL1968705 & 809153 & 5.7 & 5.1339 & TRN & \\
\hline CHEMBL404367 & 809153 & 5.7 & 5.0556 & TRN & \\
\hline CHEMBL1966343 & 809153 & 6.8 & 6.2735 & TRN & \\
\hline CHEMBL1967887 & 809153 & 4.4 & 5.0343 & TRN & \\
\hline CHEMBL 2000568 & 809153 & 5.5 & 5.4644 & TRN & \\
\hline CHEMBL 2000335 & 809153 & 7.9 & 6.8505 & TRN & \\
\hline CHEMBL1980161 & 809153 & 3.4 & 4.8532 & TRN & \\
\hline CHEMBL1988717 & 809153 & 5.5 & 5.4442 & TRN & \\
\hline CHEMBL1974328 & 809153 & 6.9 & 6.0232 & TRN & \\
\hline CHEMBL509032 & 809153 & 8.5 & 8.0878 & TRN & \\
\hline CHEMBL143703 & 809153 & 3.4 & 3.6949 & TRN & \\
\hline CHEMBL1973808 & 809153 & 4.4 & 4.294 & TRN & \\
\hline CHEMBL 2000429 & 809153 & 5.4 & 4.5407 & TRN & \\
\hline CHEMBL1972576 & 809153 & 7.8 & 7.763 & TRN & \\
\hline CHEMBL1992555 & 809153 & 4.4 & 4.9848 & TST & \\
\hline CHEMBL1990254 & 809153 & 4.4 & 4.9716 & TRN & \\
\hline CHEMBL1992342 & 809153 & 5.8 & 5.7785 & TRN & \\
\hline
\end{tabular}




\begin{tabular}{|c|c|c|c|c|c|}
\hline \multicolumn{6}{|c|}{ Supplemental Table S2.txt } \\
\hline CHEMBL1988173 & 809153 & 7.1 & 5.9276 & TRN & \\
\hline CHEMBL1164265 & 809153 & 6.3 & 6.4115 & TST & \\
\hline CHEMBL535331 & 809153 & 4.4 & 4.942 & TRN & \\
\hline CHEMBL1989805 & 809153 & 4.4 & 5.3564 & TST & \\
\hline CHEMBL1965423 & 809153 & 4.4 & 4.5077 & TRN & \\
\hline CHEMBL1983025 & 809153 & 6.6 & 6.7282 & TRN & \\
\hline CHEMBL205415 & 809153 & 4.4 & 4.5429 & TRN & \\
\hline CHEMBL1977135 & 809153 & 4.4 & 4.4164 & TRN & \\
\hline CHEMBL 2001920 & 809153 & 5.9 & 5.8373 & TRN & \\
\hline CHEMBL 2002322 & 809153 & 4.4 & 4.7175 & TRN & \\
\hline CHEMBL1241473 & 809153 & 8.0 & 7.7829 & TRN & \\
\hline CHEMBL 2002323 & 809153 & 4.4 & 4.4726 & TST & \\
\hline CHEMBL1978448 & 809153 & 6.6 & 5.4497 & TST & \\
\hline CHEMBL1972258 & 809153 & 4.4 & 4.1521 & TRN & \\
\hline CHEMBL 2001257 & 809153 & 6.6 & 6.4634 & TRN & \\
\hline CHEMBL1992536 & 809153 & 4.4 & 4.2344 & TRN & \\
\hline CHEMBL1987793 & 809153 & 4.4 & 5.2665 & TST & \\
\hline CHEMBL1992740 & 809153 & 4.4 & 4.2447 & TRN & \\
\hline CHEMBL 2002373 & 809153 & 4.4 & 4.4332 & TRN & \\
\hline CHEMBL439340 & 809153 & 4.4 & 4.2155 & TRN & \\
\hline CHEMBL 2006188 & 809153 & 4.4 & 4.533 & TRN & \\
\hline CHEMBL1967531 & 809153 & 6.6 & 6.5475 & TRN & \\
\hline CHEMBL1970913 & 809153 & 4.4 & 4.239 & TRN & \\
\hline CHEMBL1973893 & 809153 & 5.6 & 5.0484 & TRN & \\
\hline CHEMBL1995736 & 809153 & 4.4 & 4.882 & TRN & \\
\hline CHEMBL1997534 & 809153 & 4.4 & 5.3395 & TRN & \\
\hline CHEMBL1996500 & 809153 & 4.4 & 4.3441 & TRN & \\
\hline CHEMBL1985095 & 809153 & 6.7 & 6.7993 & TST & \\
\hline CHEMBL1977374 & 809153 & 4.4 & 4.6212 & TRN & \\
\hline CHEMBL1991180 & 809153 & 6.0 & 6.0194 & TST & \\
\hline CHEMBL1682540 & 809153 & 4.4 & 4.5852 & TRN & \\
\hline CHEMBL1976420 & 809153 & 7.3 & 5.8736 & TST & \\
\hline CHEMBL1994864 & 809153 & 4.4 & 4.6949 & TRN & \\
\hline CHEMBL413779 & 809153 & 4.4 & 4.7555 & TST & \\
\hline CHEMBL 2002446 & 809153 & 5.4 & 5.0726 & TST & \\
\hline CHEMBL497151 & 809153 & 6.0 & 5.6405 & TRN & \\
\hline CHEMBL1973961 & 809153 & 6.6 & 5.5594 & TRN & \\
\hline CHEMBL246970 & 809153 & 4.4 & 4.8854 & TRN & \\
\hline CHEMBL340921 & 809153 & 4.4 & 4.3746 & TST & \\
\hline CHEMBL373598 & 809153 & 4.4 & 4.3919 & TST & \\
\hline CHEMBL1999718 & 809153 & 4.4 & 4.3766 & TRN & \\
\hline CHEMBL1276446 & 809153 & 7.9 & 7.9018 & TST & \\
\hline CHEMBL1977346 & 809153 & 6.8 & 5.9377 & TRN & \\
\hline CHEMBL1971649 & 809153 & 4.4 & 4.25899 & 99999999995 & TRN \\
\hline CHEMBL 2003657 & 809153 & 4.4 & 4.6703 & TRN & \\
\hline CHEMBL 2006439 & 809153 & 4.4 & 4.7633 & TRN & \\
\hline CHEMBL 2006156 & 809153 & 5.9 & 4.9598 & TST & \\
\hline CHEMBL1969190 & 809153 & 4.4 & 6.0616 & TRN & \\
\hline
\end{tabular}




\begin{tabular}{|c|c|c|c|c|}
\hline & & & Supplement & \\
\hline CHEMBL1973937 & 809153 & 5.9 & 5.9822 & TRN \\
\hline CHEMBL1991674 & 809153 & 4.6 & 5.3906 & TRN \\
\hline CHEMBL1982711 & 809153 & 7.0 & 5.9663 & TRN \\
\hline CHEMBL1969102 & 809153 & 7.1 & 7.5512 & TRN \\
\hline CHEMBL 2007044 & 809153 & 4.4 & 4.7181 & TST \\
\hline CHEMBL 2001998 & 809153 & 4.4 & 5.5926 & TST \\
\hline CHEMBL1994241 & 809153 & 6.3 & 5.8647 & TRN \\
\hline CHEMBL223460 & 809153 & 4.4 & 4.2898 & TST \\
\hline CHEMBL1998829 & 809153 & 4.4 & 4.4357 & TRN \\
\hline CHEMBL50894 & 809153 & 6.8 & 5.9391 & TRN \\
\hline CHEMBL1988838 & 809153 & 6.9 & 7.7055 & TRN \\
\hline CHEMBL1981725 & 809153 & 7.2 & 6.9251 & TRN \\
\hline CHEMBL375284 & 809153 & 4.4 & 4.7039 & TRN \\
\hline CHEMBL1982866 & 809153 & 4.4 & 4.5043 & TRN \\
\hline CHEMBL1968926 & 809153 & 4.4 & 4.8328 & TRN \\
\hline CHEMBL462120 & 809153 & 4.4 & 4.7468 & TST \\
\hline CHEMBL1984206 & 809153 & 4.4 & 4.1462 & TRN \\
\hline CHEMBL1991577 & 809153 & 4.4 & 4.7994 & TRN \\
\hline CHEMBL1965570 & 809153 & 7.0 & 6.8913 & TRN \\
\hline CHEMBL 2007592 & 809153 & 4.4 & 4.4974 & TST \\
\hline CHEMBL210963 & 809153 & 4.4 & 3.8357 & TRN \\
\hline CHEMBL1082440 & 809153 & 6.8 & 6.3997 & TST \\
\hline CHEMBL1614705 & 809153 & 4.4 & 4.4147 & TRN \\
\hline CHEMBL1984633 & 809153 & 4.4 & 4.6263 & TRN \\
\hline CHEMBL 2007372 & 809153 & 4.4 & 4.3206 & TRN \\
\hline CHEMBL1965845 & 809153 & 5.6 & 5.7419 & TRN \\
\hline CHEMBL1982167 & 809153 & 4.4 & 4.3329 & TRN \\
\hline CHEMBL1986597 & 809153 & 5.4 & 5.0241 & TRN \\
\hline CHEMBL1971017 & 809153 & 6.7 & 6.2635 & TRN \\
\hline CHEMBL1990482 & 809153 & 5.6 & 5.0209 & TRN \\
\hline CHEMBL1990904 & 809153 & 4.4 & 4.5055 & TRN \\
\hline CHEMBL 2005475 & 809153 & 6.7 & 6.2005 & TRN \\
\hline CHEMBL 2000104 & 809153 & 5.9 & 5.3538 & TRN \\
\hline CHEMBL402846 & 809153 & 4.5 & 5.0143 & TRN \\
\hline CHEMBL1997349 & 809153 & 4.4 & 5.3156 & TST \\
\hline CHEMBL183844 & 809153 & 4.4 & 5.0282 & TRN \\
\hline CHEMBL 220057 & 809153 & 6.3 & 6.0479 & TRN \\
\hline CHEMBL1682545 & 809153 & 4.5 & 4.782 & TRN \\
\hline CHEMBL383541 & 809153 & 4.4 & 4.1551 & TRN \\
\hline CHEMBL 2001224 & 809153 & 4.4 & 3.6342 & TRN \\
\hline CHEMBL10 & 809153 & 4.4 & 4.4537 & TRN \\
\hline CHEMBL1976732 & 809153 & 4.4 & 4.6493 & TRN \\
\hline CHEMBL1969506 & 809153 & 4.4 & 4.4438 & TRN \\
\hline CHEMBL1964937 & 809153 & 4.4 & 5.2151 & TRN \\
\hline CHEMBL1980163 & 809153 & 4.4 & 4.3933 & TRN \\
\hline CHEMBL590109 & 809153 & 6.8 & 6.8429 & TST \\
\hline CHEMBL1970879 & 809153 & 6.4 & 6.0938 & TRN \\
\hline CHEMBL1989856 & 809153 & 6.1 & 4.9563 & TST \\
\hline
\end{tabular}




\begin{tabular}{|c|c|c|c|c|c|}
\hline \multirow[b]{2}{*}{ CHEMBL 2005899} & \multirow[b]{2}{*}{809153} & \\
\hline & & 5.7 & 5.3141 & TRN & \\
\hline CHEMBL1682552 & 809153 & 4.4 & 4.1565 & TRN & \\
\hline CHEMBL259850 & 809153 & 4.4 & 3.8836 & TRN & \\
\hline CHEMBL1972568 & 809153 & 4.4 & 4.3248 & TRN & \\
\hline CHEMBL1996155 & 809153 & 4.4 & 4.4258 & TRN & \\
\hline CHEMBL229799 & 809153 & 5.9 & 5.9372 & TRN & \\
\hline CHEMBL105739 & 809153 & 6.4 & 6.2876 & TRN & \\
\hline CHEMBL379300 & 809153 & 4.4 & \multicolumn{2}{|c|}{5.2989999999999995} & TRN \\
\hline CHEMBL203673 & 809153 & 4.4 & 4.0193 & TRN & \\
\hline CHEMBL1969523 & 809153 & 7.8 & 8.4571 & TRN & \\
\hline CHEMBL207995 & 809153 & 4.4 & 3.8515 & TRN & \\
\hline CHEMBL1988995 & 809153 & 4.4 & 4.5836 & TRN & \\
\hline CHEMBL2001923 & 809153 & 4.4 & 4.5353 & TRN & \\
\hline CHEMBL1986781 & 809153 & 4.4 & 4.5377 & TRN & \\
\hline CHEMBL526133 & 809153 & 4.4 & 5.351 & TRN & \\
\hline CHEMBL1967538 & 809153 & 3.4 & 4.1563 & TRN & \\
\hline CHEMBL1979057 & 809153 & 7.4 & 6.1773 & TRN & \\
\hline CHEMBL1981045 & 809153 & 4.4 & 4.7587 & TRN & \\
\hline CHEMBL387971 & 809153 & 4.4 & 4.8496 & TST & \\
\hline CHEMBL1992796 & 809153 & 4.4 & 4.4599 & TST & \\
\hline CHEMBL1999428 & 809153 & 4.4 & 4.7218 & TRN & \\
\hline CHEMBL223257 & 809153 & 4.4 & 4.2484 & TST & \\
\hline CHEMBL1967560 & 809153 & 4.4 & 4.3198 & TRN & \\
\hline CHEMBL211378 & 809153 & 4.4 & 5.3292 & TRN & \\
\hline CHEMBL1982465 & 809153 & 7.2 & 7.0916 & TRN & \\
\hline CHEMBL2001751 & 809153 & 6.7 & \multicolumn{2}{|c|}{6.252000000000001} & TRN \\
\hline CHEMBL 2003420 & 809153 & 4.4 & 4.376 & TRN & \\
\hline CHEMBL1984586 & 809153 & 6.3 & 5.7575 & TRN & \\
\hline CHEMBL1999774 & 809153 & 4.4 & 4.0954 & TST & \\
\hline CHEMBL1972659 & 809153 & 4.4 & 4.3886 & TST & \\
\hline CHEMBL1973395 & 809153 & 6.6 & 6.5018 & TRN & \\
\hline CHEMBL272453 & 809153 & 4.4 & 5.1681 & TRN & \\
\hline CHEMBL1987143 & 809153 & 3.4 & 4.467 & TST & \\
\hline CHEMBL1970217 & 809153 & 4.4 & 4.4695 & TRN & \\
\hline CHEMBL1971801 & 809153 & 6.4 & 5.2552 & TRN & \\
\hline CHEMBL1968850 & 809153 & 5.9 & 5.6463 & TRN & \\
\hline CHEMBL2005528 & 809153 & 5.5 & 5.1161 & TST & \\
\hline CHEMBL185569 & 809153 & 6.5 & \multicolumn{2}{|c|}{5.502000000000001} & TRN \\
\hline CHEMBL1969843 & 809153 & 4.4 & 4.7297 & TRN & \\
\hline CHEMBL 2007002 & 809153 & 4.4 & 4.873 & TRN & \\
\hline CHEMBL1987007 & 809153 & 4.4 & 5.1801 & TRN & \\
\hline CHEMBL1969588 & 809153 & 5.7 & 5.6256 & TRN & \\
\hline CHEMBL1984711 & 809153 & 6.4 & 6.1116 & TRN & \\
\hline CHEMBL484390 & 809153 & 4.4 & 4.7397 & TST & \\
\hline CHEMBL1979252 & 809153 & 4.4 & 4.9963 & TRN & \\
\hline CHEMBL2004290 & 809153 & 7.2 & 6.4144 & TRN & \\
\hline CHEMBL1986499 & 809153 & 6.5 & 6.4164 & TRN & \\
\hline \multirow[t]{2}{*}{ CHEMBL1972937 } & 809153 & 4.4 & 4.6363 & TRN & \\
\hline & & \multicolumn{4}{|c|}{ Page 13909} \\
\hline
\end{tabular}




\begin{tabular}{|c|c|c|c|c|c|}
\hline \multicolumn{6}{|c|}{ Supplemental Table S2.txt } \\
\hline CHEMBL1972250 & 809153 & 4.4 & 5.1319 & TST & \\
\hline CHEMBL 2000393 & 809153 & 7.1 & 6.75700 & 0000000001 & TST \\
\hline CHEMBL 2004311 & 809153 & 6.2 & 5.7482 & TRN & \\
\hline CHEMBL1992634 & 809153 & 5.8 & 5.9264 & TRN & \\
\hline CHEMBL1242373 & 809153 & 6.6 & 6.1009 & TRN & \\
\hline CHEMBL56543 & 809153 & 6.2 & 5.3957 & TRN & \\
\hline CHEMBL1988075 & 809153 & 6.8 & 6.7882 & TRN & \\
\hline CHEMBL316264 & 809153 & 4.4 & 4.6519 & TRN & \\
\hline CHEMBL1991678 & 809153 & 4.4 & 4.4068 & TRN & \\
\hline CHEMBL 2001239 & 809153 & 4.4 & 5.4965 & TST & \\
\hline CHEMBL1988594 & 809153 & 8.0 & 7.6604 & TRN & \\
\hline CHEMBL 2001288 & 809153 & 4.4 & 4.9071 & TRN & \\
\hline CHEMBL260092 & 809153 & 7.4 & 7.3774 & TRN & \\
\hline CHEMBL1999811 & 809153 & 6.3 & 5.3625 & TST & \\
\hline CHEMBL1965495 & 809153 & 6.4 & 6.07600 & 00000000005 & TRN \\
\hline CHEMBL1985074 & 809153 & 4.4 & 4.8625 & TST & \\
\hline CHEMBL1982874 & 809153 & 4.4 & 4.9002 & TRN & \\
\hline CHEMBL 2000481 & 809153 & 4.4 & 4.8465 & TRN & \\
\hline CHEMBL1991725 & 809153 & 4.4 & 4.5337 & TRN & \\
\hline CHEMBL1992242 & 809153 & 4.4 & 3.9869 & TRN & \\
\hline CHEMBL 2007296 & 809153 & 4.4 & 4.4091 & TRN & \\
\hline CHEMBL396523 & 809153 & 7.9 & 8.3728 & TRN & \\
\hline CHEMBL208637 & 809153 & 4.4 & 3.9188 & TRN & \\
\hline CHEMBL1970203 & 809153 & 7.7 & 7.6908 & TRN & \\
\hline CHEMBL1986530 & 809153 & 4.4 & 4.9991 & TST & \\
\hline CHEMBL1999321 & 809153 & 4.4 & 4.6526 & TRN & \\
\hline CHEMBL385478 & 809153 & 6.3 & 5.1272 & TRN & \\
\hline CHEMBL1968590 & 809153 & 5.6 & 6.0797 & TRN & \\
\hline CHEMBL1999749 & 809153 & 4.4 & 4.0565 & TRN & \\
\hline CHEMBL 2005375 & 809153 & 4.4 & 4.261 & TRN & \\
\hline CHEMBL1984191 & 809153 & 4.4 & 4.4558 & TRN & \\
\hline CHEMBL1983006 & 809153 & 4.4 & 4.0232 & TRN & \\
\hline CHEMBL1972183 & 809153 & 4.4 & 4.4219 & TRN & \\
\hline CHEMBL1971029 & 809153 & 7.9 & 8.0934 & TRN & \\
\hline CHEMBL394790 & 809153 & 5.9 & 5.484 & TRN & \\
\hline CHEMBL226471 & 809153 & 6.1 & 5.8944 & TRN & \\
\hline CHEMBL1974702 & 809153 & 5.4 & 5.1468 & TRN & \\
\hline CHEMBL1996111 & 809153 & 6.0 & 5.9717 & TRN & \\
\hline CHEMBL1965589 & 809153 & 4.4 & 4.5755 & TRN & \\
\hline CHEMBL1998193 & 809153 & 4.4 & 4.1262 & TRN & \\
\hline CHEMBL474432 & 809153 & 7.1 & 6.6247 & TST & \\
\hline CHEMBL 2001539 & 809153 & 4.8 & 4.7986 & TST & \\
\hline CHEMBL1988153 & 809153 & 4.4 & 4.42 & TRN & \\
\hline CHEMBL1999556 & 809153 & 6.4 & 6.1445 & TRN & \\
\hline CHEMBL1988437 & 809153 & 7.7 & 6.7266 & TST & \\
\hline CHEMBL1968245 & 809153 & 4.4 & 4.4474 & TRN & \\
\hline CHEMBL1998121 & 809153 & 6.1 & 5.9299 & TRN & \\
\hline CHEMBL1979577 & 809153 & 7.0 & 7.0825 & TRN & \\
\hline
\end{tabular}




\begin{tabular}{|c|c|c|c|c|}
\hline & & & pplement & al \\
\hline CHEMBL52387 & 809153 & 4.4 & 4.3685 & TST \\
\hline CHEMBL379835 & 809153 & 5.9 & 4.4923 & TST \\
\hline CHEMBL1979357 & 809153 & 4.4 & 4.5344 & TRN \\
\hline CHEMBL1980802 & 809153 & 4.4 & 4.2008 & TST \\
\hline CHEMBL1996817 & 809153 & 6.6 & 5.5689 & TRN \\
\hline CHEMBL3197315 & 809153 & 4.4 & 4.2987 & TST \\
\hline CHEMBL 2004355 & 809153 & 4.4 & 4.2292 & TRN \\
\hline CHEMBL468280 & 809153 & 4.4 & 4.2557 & TST \\
\hline CHEMBL1990884 & 809153 & 4.4 & 5.1467 & TRN \\
\hline CHEMBL3109278 & 809153 & 6.5 & 6.309 & TRN \\
\hline CHEMBL256835 & 809153 & 4.4 & 3.9977 & TRN \\
\hline CHEMBL1980142 & 809153 & 4.4 & 4.4154 & TRN \\
\hline CHEMBL41783 & 809153 & 4.4 & 4.148 & TRN \\
\hline CHEMBL2004438 & 809153 & 5.4 & 4.3951 & TRN \\
\hline CHEMBL 2006276 & 809153 & 4.4 & 4.9824 & TRN \\
\hline CHEMBL 271381 & 809153 & 6.3 & 5.8094 & TRN \\
\hline CHEMBL2006785 & 809153 & 4.4 & 4.3134 & TRN \\
\hline CHEMBL1982466 & 809153 & 7.6 & 7.4531 & TRN \\
\hline CHEMBL1995740 & 809153 & 4.4 & 5.3002 & TRN \\
\hline CHEMBL1996390 & 809153 & 6.4 & 5.6835 & TRN \\
\hline CHEMBL 234085 & 809153 & 4.4 & 4.8955 & TRN \\
\hline CHEMBL1995832 & 809153 & 4.4 & 4.6316 & TRN \\
\hline CHEMBL1998414 & 809153 & 5.9 & 5.4648 & TRN \\
\hline CHEMBL1969042 & 809153 & 5.5 & 5.1826 & TST \\
\hline CHEMBL 2000345 & 809153 & 6.8 & 6.1594 & TRN \\
\hline CHEMBL1999931 & 809153 & 7.4 & 6.8064 & TRN \\
\hline CHEMBL1991640 & 809153 & 4.4 & 4.8688 & TST \\
\hline CHEMBL1375418 & 809153 & 4.4 & 4.0156 & TRN \\
\hline CHEMBL302449 & 809153 & 7.7 & 6.6366 & TST \\
\hline CHEMBL 2007064 & 809153 & 7.2 & 7.2495 & TRN \\
\hline CHEMBL1981047 & 809153 & 8.2 & 7.8912 & TRN \\
\hline CHEMBL229968 & 809153 & 5.9 & 5.7497 & TRN \\
\hline CHEMBL1976240 & 809153 & 4.4 & 4.8892 & TRN \\
\hline CHEMBL1979093 & 809153 & 4.4 & 5.6431 & TRN \\
\hline CHEMBL1968151 & 809153 & 4.4 & 4.8277 & TST \\
\hline CHEMBL1381197 & 809153 & 4.4 & 3.9754 & TRN \\
\hline CHEMBL1987009 & 809153 & 6.8 & 6.4803 & TRN \\
\hline CHEMBL379218 & 809153 & 4.4 & 5.5912 & TRN \\
\hline CHEMBL2003817 & 809153 & 5.7 & 4.944 & TRN \\
\hline CHEMBL336961 & 809153 & 4.4 & 4.6717 & TRN \\
\hline CHEMBL1994830 & 809153 & 4.4 & 4.6019 & TRN \\
\hline CHEMBL1987054 & 809153 & 7.3 & 7.6355 & TRN \\
\hline CHEMBL1970083 & 809153 & 7.3 & 7.5691 & TRN \\
\hline CHEMBL226403 & 809153 & 7.2 & 6.0443 & TRN \\
\hline CHEMBL 2005631 & 809153 & 7.1 & 7.9124 & TRN \\
\hline CHEMBL1994938 & 809153 & 6.9 & 6.5373 & TRN \\
\hline CHEMBL1977223 & 809153 & 4.4 & 5.47 & TRN \\
\hline CHEMBL1236126 & 809153 & 4.4 & 4.2784 & TST \\
\hline
\end{tabular}




\begin{tabular}{|c|c|c|c|c|c|}
\hline \\
\hline CHEMBL1966279 & 809153 & 4.4 & 4.843 & TRN & \\
\hline CHEMBL1997846 & 809153 & 4.4 & 5.0828 & TRN & \\
\hline CHEMBL 2004419 & 809153 & 4.4 & 4.4239 & TRN & \\
\hline CHEMBL1991728 & 809153 & 4.4 & 5.4024 & TRN & \\
\hline CHEMBL1975787 & 809153 & 5.9 & 6.3629 & TRN & \\
\hline CHEMBL 2002407 & 809153 & 4.4 & 5.3769 & TRN & \\
\hline CHEMBL1972489 & 809153 & 4.4 & 4.3545 & TRN & \\
\hline CHEMBL1994074 & 809153 & 4.4 & 5.2056 & TRN & \\
\hline CHEMBL1992937 & 809153 & 4.4 & 5.8004 & TST & \\
\hline CHEMBL451401 & 809153 & 4.5 & 4.8227 & TRN & \\
\hline CHEMBL1985566 & 809153 & 4.4 & 4.7049 & TRN & \\
\hline CHEMBL1986328 & 809153 & 5.7 & 4.9359 & TST & \\
\hline CHEMBL95692 & 809153 & 4.4 & 4.0613 & TRN & \\
\hline CHEMBL1090356 & 809153 & 4.5 & 5.3127 & TRN & \\
\hline CHEMBL1976455 & 809153 & 4.4 & 5.24799 & 9999999999 & TRN \\
\hline CHEMBL1983923 & 809153 & 7.6 & 6.5425 & TST & \\
\hline CHEMBL1982361 & 809153 & 5.5 & 5.277 & TRN & \\
\hline CHEMBL1983534 & 809153 & 4.4 & 4.5382 & TRN & \\
\hline CHEMBL1999112 & 809153 & 4.4 & 5.1771 & TST & \\
\hline CHEMBL1982122 & 809153 & 4.4 & 4.6824 & TRN & \\
\hline CHEMBL 2000801 & 809153 & 4.4 & 4.2306 & TRN & \\
\hline CHEMBL1682546 & 809153 & 4.4 & 4.54899 & 99999999995 & TRN \\
\hline CHEMBL1991395 & 809153 & 4.4 & 4.3857 & TRN & \\
\hline CHEMBL1971245 & 809153 & 5.4 & 5.7889 & TRN & \\
\hline CHEMBL1996780 & 809153 & 4.4 & 4.0942 & TST & \\
\hline CHEMBL1972142 & 809153 & 4.4 & 5.5145 & TRN & \\
\hline CHEMBL1966514 & 809153 & 6.7 & 7.2087 & TRN & \\
\hline CHEMBL 2003638 & 809153 & 7.0 & 6.551 & TRN & \\
\hline CHEMBL296586 & 809153 & 6.4 & 5.7711 & TRN & \\
\hline CHEMBL1996066 & 809153 & 4.4 & 5.6866 & TST & \\
\hline CHEMBL516429 & 809153 & 6.2 & 5.4828 & TRN & \\
\hline CHEMBL1972152 & 809153 & 5.9 & 5.1686 & TST & \\
\hline CHEMBL1993722 & 809153 & 6.5 & 6.2248 & TRN & \\
\hline CHEMBL1970806 & 809153 & 4.4 & 4.3906 & TST & \\
\hline CHEMBL1375640 & 809153 & 5.7 & 5.12 & TST & \\
\hline CHEMBL1979970 & 809153 & 4.4 & 4.1712 & TST & \\
\hline CHEMBL 249282 & 809153 & 4.4 & 4.9494 & TST & \\
\hline CHEMBL1969264 & 809153 & 6.9 & 5.6478 & TST & \\
\hline CHEMBL1973711 & 809153 & 4.4 & 4.7652 & TST & \\
\hline CHEMBL 2006237 & 809153 & 4.4 & 4.6389 & TST & \\
\hline CHEMBL1967720 & 809153 & 7.3 & 7.6501 & TST & \\
\hline CHEMBL1572266 & 809153 & 4.4 & 4.7007 & TST & \\
\hline CHEMBL1991138 & 809153 & 4.4 & 4.2871 & TST & \\
\hline CHEMBL1969755 & 809153 & 4.4 & 4.242 & TST & \\
\hline CHEMBL1979516 & 809153 & 4.5 & 7.2562 & TST & \\
\hline CHEMBL1605605 & 809153 & 4.4 & 4.39 & TST & \\
\hline CHEMBL1972820 & 809153 & 4.4 & 5.1257 & TST & \\
\hline CHEMBL1996208 & 809153 & 4.4 & 5.0402 & TST & \\
\hline & & & & 13912 & \\
\hline
\end{tabular}




\begin{tabular}{|c|c|c|c|c|c|}
\hline \multicolumn{6}{|c|}{ Supplemental Table S2.txt } \\
\hline CHEMBL1989029 & 809153 & 5.8 & 5.144 & TST & \\
\hline CHEMBL514499 & 809153 & 6.7 & 5.1014 & TST & \\
\hline CHEMBL1965631 & 809153 & 4.4 & 4.7994 & TST & \\
\hline CHEMBL1980144 & 809153 & 8.0 & 7.49700 & 0000000001 & TST \\
\hline CHEMBL1991188 & 809153 & 4.4 & 4.712 & TST & \\
\hline CHEMBL1972849 & 809153 & 4.4 & 4.4444 & TST & \\
\hline CHEMBL 377408 & 809153 & 4.4 & 4.1448 & TST & \\
\hline CHEMBL231209 & 809153 & 4.4 & 5.3874 & TST & \\
\hline CHEMBL1976220 & 809153 & 6.3 & 5.6427 & TST & \\
\hline CHEMBL259922 & 809153 & 4.4 & 4.2234 & TST & \\
\hline CHEMBL1997617 & 809153 & 5.5 & 6.1472 & TST & \\
\hline CHEMBL1982383 & 809153 & 4.4 & 4.4911 & TST & \\
\hline CHEMBL1969301 & 809153 & 4.4 & 4.5379 & TST & \\
\hline CHEMBL17370 & 809153 & 4.4 & 4.6496 & TST & \\
\hline CHEMBL1987910 & 809153 & 5.7 & 5.3266 & TST & \\
\hline CHEMBL1983932 & 809153 & 4.4 & 4.7657 & TST & \\
\hline CHEMBL1997822 & 809153 & 4.4 & 6.369 & TST & \\
\hline CHEMBL1991285 & 809153 & 5.8 & 3.7875 & TST & \\
\hline CHEMBL1984038 & 809153 & 4.4 & 4.8782 & TST & \\
\hline CHEMBL 243088 & 809153 & 7.7 & 8.3341 & TST & \\
\hline CHEMBL1993661 & 809153 & 8.5 & 7.9341 & TST & \\
\hline CHEMBL1974416 & 809153 & 4.4 & 4.6614 & TST & \\
\hline CHEMBL 2004615 & 809153 & 6.0 & 4.9982 & TST & \\
\hline CHEMBL1997872 & 809153 & 5.7 & 5.065 & TST & \\
\hline CHEMBL3664057 & 1528940 & 7.8539 & 7.19 & TRN & \\
\hline CHEMBL 3664052 & 1528940 & 7.2757 & 7.3271 & TRN & \\
\hline CHEMBL 3664066 & 1528940 & 7.8239 & 7.8592 & TRN & \\
\hline CHEMBL 3664056 & 1528940 & 7.6021 & 7.1269 & TRN & \\
\hline CHEMBL 3664083 & 1528940 & 7.4559 & 7.2491 & TRN & \\
\hline CHEMBL 398420 & 1528940 & 6.0 & 6.7553 & TRN & \\
\hline CHEMBL3664135 & 1528940 & 6.0 & 7.3942 & TST & \\
\hline CHEMBL 3664120 & 1528940 & 7.301 & 7.3325 & TST & \\
\hline CHEMBL 3664102 & 1528940 & 6.4559 & 6.9827 & TRN & \\
\hline CHEMBL 3664140 & 1528940 & 8.0223 & 8.0799 & TST & \\
\hline CHEMBL 3664051 & 1528940 & 7.1135 & 7.2048 & TRN & \\
\hline CHEMBL3664090 & 1528940 & 6.1612 & 7.0336 & TST & \\
\hline CHEMBL 3664124 & 1528940 & 6.7447 & 7.0183 & TRN & \\
\hline CHEMBL 3664053 & 1528940 & 7.7447 & 6.9421 & TRN & \\
\hline CHEMBL3664099 & 1528940 & 7.3188 & 7.1318 & TST & \\
\hline CHEMBL3664121 & 1528940 & 7.1427 & 6.6785 & TRN & \\
\hline CHEMBL 3664041 & 1528940 & 8.2366 & 8.1429 & TRN & \\
\hline CHEMBL 3664072 & 1528940 & 8.0 & 8.1593 & TRN & \\
\hline CHEMBL 3664040 & 1528940 & 7.7696 & 7.9387 & TRN & \\
\hline CHEMBL 3664098 & 1528940 & 7.1871 & 7.13899 & 9999999999 & TST \\
\hline CHEMBL 3664115 & 1528940 & 7.4559 & 7.0497 & TRN & \\
\hline CHEMBL 3664064 & 1528940 & 7.7959 & 8.0293 & TRN & \\
\hline CHEMBL 3664065 & 1528940 & 7.7959 & 7.7369 & TRN & \\
\hline CHEMBL3664078 & 1528940 & 7.8861 & 8.238 & TRN & \\
\hline
\end{tabular}


Supplemental Table S2.txt

\begin{tabular}{|c|c|c|c|c|c|}
\hline CHEMBL 3664141 & 1528940 & 7.8861 & 7.2411 & TST & \\
\hline CHEMBL253226 & 1528940 & 6.0 & 6.8953 & TRN & \\
\hline CHEMBL 3664138 & 1528940 & 7.3768 & 7.3633 & TST & \\
\hline CHEMBL 3664123 & 1528940 & 7.0 & 7.1659 & TRN & \\
\hline CHEMBL3664047 & 1528940 & 7.3468 & 7.1219 & TRN & \\
\hline CHEMBL3664059 & 1528940 & 7.8539 & 6.8548 & TRN & \\
\hline CHEMBL 3664137 & 1528940 & 7.4685 & 7.4465 & TRN & \\
\hline CHEMBL 3967964 & 1528940 & 7.0757 & 7.8111 & TST & \\
\hline CHEMBL463788 & 1528940 & 8.0 & 7.8483 & TRN & \\
\hline CHEMBL400044 & 1528940 & 6.4949 & 6.7456 & TRN & \\
\hline CHEMBL3664110 & 1528940 & 6.4437 & \multicolumn{2}{|c|}{6.462999999999999} & TRN \\
\hline CHEMBL 3664093 & 1528940 & 6.8239 & 7.0294 & TRN & \\
\hline CHEMBL252409 & 1528940 & 7.2366 & 6.86 & TRN & \\
\hline CHEMBL 3664076 & 1528940 & 7.9208 & 7.7123 & TRN & \\
\hline CHEMBL3664088 & 1528940 & 6.7447 & 8.2496 & TST & \\
\hline CHEMBL3664128 & 1528940 & 7.6198 & 7.4466 & TRN & \\
\hline CHEMBL3664075 & 1528940 & 7.8239 & 7.5885 & TRN & \\
\hline CHEMBL3664049 & 1528940 & 7.7212 & 7.5772 & TRN & \\
\hline CHEMBL3664042 & 1528940 & 7.699 & 7.4643 & TRN & \\
\hline CHEMBL253870 & 1528940 & 6.0 & 7.0823 & TRN & \\
\hline CHEMBL399494 & 1528940 & 7.9208 & 7.4116 & TRN & \\
\hline CHEMBL3664136 & 1528940 & 6.0 & \multicolumn{2}{|c|}{7.3420000000000005} & TST \\
\hline CHEMBL 3664105 & 1528940 & 7.3565 & 6.8806 & TRN & \\
\hline CHEMBL3664092 & 1528940 & 7.0506 & 6.9642 & TRN & \\
\hline CHEMBL 3664062 & 1528940 & 6.0 & 6.8884 & TRN & \\
\hline CHEMBL3664071 & 1528940 & 7.8861 & 7.3757 & TRN & \\
\hline CHEMBL 3664045 & 1528940 & 7.5528 & 6.858 & TRN & \\
\hline CHEMBL472671 & 1528940 & 7.4949 & 7.3452 & TRN & \\
\hline CHEMBL3664067 & 1528940 & 7.9586 & 7.9832 & TRN & \\
\hline CHEMBL400929 & 1528940 & 7.4685 & 7.9789 & TRN & \\
\hline CHEMBL 3664111 & 1528940 & 6.585 & 6.8126 & TRN & \\
\hline CHEMBL 3664081 & 1528940 & 7.7696 & 7.7246 & TRN & \\
\hline CHEMBL 3664058 & 1528940 & 7.6383 & 7.335 & TRN & \\
\hline CHEMBL3664119 & 1528940 & 5.6021 & 7.1417 & TRN & \\
\hline CHEMBL 3664068 & 1528940 & 7.6198 & 7.3233 & TRN & \\
\hline CHEMBL251817 & 1528940 & 7.9208 & 7.5854 & TRN & \\
\hline CHEMBL3664126 & 1528940 & 7.3665 & 7.2186 & TST & \\
\hline CHEMBL 3664118 & 1528940 & 7.4815 & 7.6193 & TST & \\
\hline CHEMBL3664050 & 1528940 & 7.5086 & \multicolumn{2}{|c|}{7.787999999999999} & TRN \\
\hline CHEMBL 3639629 & 1528940 & 7.8239 & 7.9469 & TRN & \\
\hline CHEMBL3664131 & 1528940 & 5.3665 & 6.5444 & TST & \\
\hline CHEMBL3664073 & 1528940 & 7.7212 & 7.152 & TRN & \\
\hline CHEMBL3664039 & 1528940 & 7.0915 & 7.7588 & TRN & \\
\hline CHEMBL3664046 & 1528940 & 7.5376 & 6.8928 & TRN & \\
\hline CHEMBL 3664080 & 1528940 & 7.6198 & 7.3104 & TRN & \\
\hline CHEMBL3664113 & 1528940 & 7.7447 & 7.1595 & TST & \\
\hline CHEMBL3664082 & 1528940 & 7.7447 & 7.3694 & TST & \\
\hline CHEMBL3664070 & 1528940 & 7.7959 & 7.3623 & TRN & \\
\hline
\end{tabular}

Page 13914 
Supplemental Table S2.txt

\begin{tabular}{|c|c|c|c|c|}
\hline טלd & - & & & \\
\hline HEMBL3664089 & 528940 & 5.7447 & 6.2672 & \\
\hline & & & & \\
\hline EMBL3 & 28940 & 1 & & \\
\hline IEMBL366 & 528940 & 6.7959 & 9982 & \\
\hline EMBL3664125 & 528940 & 7.4815 & 9105 & \\
\hline HEMBL366 & 528940 & 7.9586 & & \\
\hline & 528940 & 0044 & & \\
\hline IEMBL & 528940 & 8.2218 & 91 & \\
\hline AEMBL253868 & 528940 & 8.0 & 7.6013 & \\
\hline AEMBL 3664107 & 528940 & 4685 & 36 & \\
\hline IEMBL366 & 528940 & 021 & 87 & \\
\hline EMBL: & 289 & & & \\
\hline IEMBL & 528940 & & & \\
\hline IEMBL3664109 & 528940 & 86 & 31 & \\
\hline EMBL3664139 & 528940 & 7959 & 7886 & \\
\hline IEMBL3 & 528940 & & 76 & \\
\hline IEMBL2 & 5289 & & & \\
\hline IEMBL & 528940 & 39 & & \\
\hline IEMBL 36 & 528940 & 33 & 57 & RI \\
\hline IEMBL36 & 528940 & 1 & 5744 & \\
\hline IEMBL4 & 528940 & & כל & \\
\hline IEMBL & 5289 & & & \\
\hline IEMBLC & 528940 & 36 & & \\
\hline IEMBL36 & 52 & 79 & & SI \\
\hline IEMBL366 & 528940 & & 37 & RI \\
\hline IEMBL3 & 5289 & & & RI \\
\hline EME & 528940 & 58 & & \\
\hline IEME & 528940 & & & RN \\
\hline IEMBL36 & 5289 & 8 & 6 & $S$ \\
\hline IEMBL3 & 289 & 78 & 34 & RN \\
\hline IEMBL 36 & 28940 & 7 & & 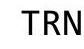 \\
\hline 6 & 10 & 8 & & RN \\
\hline EMBL36 & 528940 & & & ST \\
\hline IEMBL366 & 528940 & 39 & 4 & RN \\
\hline EMBL36 & 289 & 576 & 28 & \\
\hline 1 & 528940 & & & NIV \\
\hline & 528940 & & 84 & ST \\
\hline AEMBL 3664069 & 528940 & 7. & 7.9737 & RN \\
\hline EMBL36 & 5289 & 1 & 58 & RN \\
\hline HEMBL 366 & 528940 & 78 & 14 & \\
\hline תאר וסנזנו & & & & I \\
\hline HEMBL3664086 & 528940 & 686 & 8.1841 & RN \\
\hline IEMBL3664130 & 528940 & 6.5528 & 7.4825 & TS \\
\hline EML 36 & 5289 & 36 & & $S$ \\
\hline CHEMBL3664077 & 5289 & & 8.1284 & TR \\
\hline CHEMBL 3664043 & 528940 & 7.7959 & 7.8043 & \\
\hline CHEMBL3664048 & 1528940 & 7.7212 & 7.763 & $\mathrm{IR}$ \\
\hline
\end{tabular}

Page 13915 
Supplemental Table S2.txt

\begin{tabular}{|c|c|c|c|c|c|c|}
\hline CHEMBL 3664104 & 1528940 & 6.6021 & 7.1702 & TST & & \\
\hline CHEMBL1530410 & 954356 & 4.0005 & 4.5091 & TRN & & \\
\hline CHEMBL1875584 & 954356 & 4.0003 & 4.3614 & TST & & \\
\hline CHEMBL1459393 & 954356 & 5.4321 & 5.3605 & TRN & & \\
\hline CHEMBL1460744 & 954356 & 6.0132 & 5.8394 & TRN & & \\
\hline CHEMBL1426692 & 954356 & 5.0953 & 4.4139 & TRN & & \\
\hline CHEMBL1591599 & 954356 & 5.7978 & 5.8048 & TRN & & \\
\hline CHEMBL1419606 & 954356 & 4.9551 & 5.9463 & TRN & & \\
\hline CHEMBL1364365 & 954356 & 4.9547 & 5.5953 & TST & & \\
\hline CHEMBL1605711 & 954356 & 6.0362 & 5.9224 & TRN & & \\
\hline CHEMBL1569740 & 954356 & 5.5112 & 5.5728 & TRN & & \\
\hline CHEMBL1384403 & 954356 & 5.7265 & 5.7279 & TRN & & \\
\hline CHEMBL1451018 & 954356 & 5.9598 & 5.8931 & TRN & & \\
\hline CHEMBL1504487 & 954356 & 5.9747 & 5.8491 & TST & & \\
\hline CHEMBL 2358047 & 954356 & 5.763 & 5.7576 & TRN & & \\
\hline CHEMBL1901265 & 954356 & 5.7729 & 5.2658 & TRN & & \\
\hline CHEMBL1355971 & 954356 & 5.5827 & 5.5649 & TST & & \\
\hline CHEMBL 2141540 & 954356 & 5.4303 & 5.4717 & TRN & & \\
\hline CHEMBL1373487 & 954356 & 5.8542 & 5.2339 & TRN & & \\
\hline CHEMBL1477721 & 954356 & 5.9119 & 5.7804 & TRN & & \\
\hline CHEMBL1608811 & 954356 & 6.3146 & 5.9613 & TRN & & \\
\hline CHEMBL1452318 & 954356 & 5.8703 & 5.8874 & TRN & & \\
\hline CHEMBL1420397 & 954356 & 5.6404 & 5.5854 & TRN & & \\
\hline CHEMBL1465907 & 954356 & 5.6326 & 5.6328 & TST & & \\
\hline CHEMBL1711578 & 954356 & 5.5693 & 5.5804 & TRN & & \\
\hline CHEMBL1413355 & 954356 & 5.7314 & 5.6171 & TST & & \\
\hline CHEMBL1571018 & 954356 & 5.8781 & 5.7651 & TRN & & \\
\hline CHEMBL1595595 & 954356 & 4.9547 & 5.6809 & TRN & & \\
\hline CHEMBL 3207326 & 954356 & 4.4776 & 4.8194 & TRN & & \\
\hline CHEMBL3196476 & 954356 & 4.0004 & 4.6195 & TRN & & \\
\hline CHEMBL1576309 & 954356 & 5.2278 & 4.4451 & TST & & \\
\hline CHEMBL1717732 & 954356 & 4.0004 & 4.4895 & TRN & & \\
\hline CHEMBL1305601 & 954356 & 5.9219 & 5.2431 & TRN & & \\
\hline CHEMBL1578834 & 954356 & 5.3359 & 5.2767 & TST & & \\
\hline CHEMBL1561364 & 954356 & 5.8969 & 5.4825 & TRN & & \\
\hline CHEMBL1312740 & 954356 & 4.0004 & 4.3466 & TST & & \\
\hline CHEMBL1409396 & 954356 & 6.0796 & 6.0577 & TRN & & \\
\hline CHEMBL1526920 & 954356 & 4.0005 & 4.5347 & TRN & & \\
\hline CHEMBL1573047 & 954356 & 6.0395 & 5.8917 & TRN & & \\
\hline CHEMBL3211355 & 954356 & 4.4776 & 5.2053 & TRN & & \\
\hline CHEMBL 2144855 & 954356 & \multicolumn{3}{|c|}{5.837999999999999} & 5.2603 & TST \\
\hline CHEMBL1431253 & 954356 & 4.9543 & 4.7966 & TRN & & \\
\hline CHEMBL1327350 & 954356 & 4.0002 & 4.5627 & TRN & & \\
\hline CHEMBL1324794 & 954356 & 3.9996 & 4.5399 & TRN & & \\
\hline CHEMBL 2144387 & 954356 & 5.4315 & 5.3612 & TRN & & \\
\hline CHEMBL1366544 & 954356 & 6.0137 & 5.2554 & TRN & & \\
\hline CHEMBL1381679 & 954356 & 5.5017 & 5.3922 & TRN & & \\
\hline CHEMBL1425085 & 954356 & 5.8105 & 5.7555 & TRN & & \\
\hline
\end{tabular}

Page 13916 


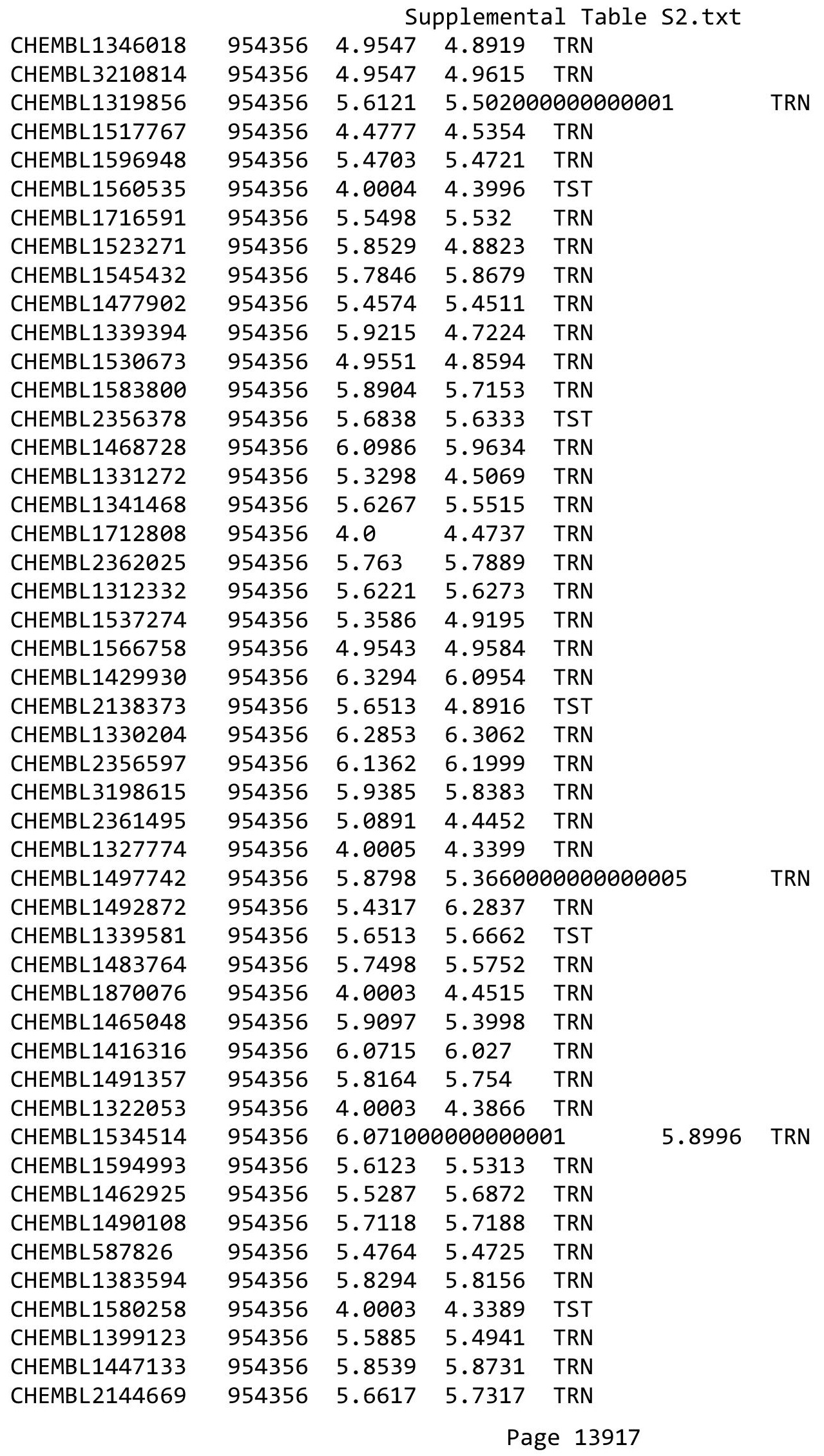




\begin{tabular}{|c|c|c|c|c|c|}
\hline & & \multicolumn{4}{|c|}{ Supplemental Table s2.txt } \\
\hline CHEMBL2359279 & 954356 & 5.5981 & 5.8024 & TRN & \\
\hline CHEMBL 3190510 & 954356 & 5.813 & 5.2945 & TRN & \\
\hline CHEMBL1332317 & 954356 & 4.0005 & 4.4325 & TRN & \\
\hline CHEMBL 2362078 & 954356 & 5.5983 & 5.5805 & TRN & \\
\hline CHEMBL1389755 & 954356 & 5.4318 & 6.2898 & TRN & \\
\hline CHEMBL1464738 & 954356 & 6.6726 & 6.5083 & TRN & \\
\hline CHEMBL1866835 & 954356 & 5.8807 & 5.8149 & TRN & \\
\hline CHEMBL1530961 & 954356 & 5.8986 & 5.3925 & TRN & \\
\hline CHEMBL611941 & 954356 & 6.04 & 5.8326 & TRN & \\
\hline CHEMBL1463935 & 954356 & 5.8162 & 5.2869 & TST & \\
\hline CHEMBL1362046 & 954356 & 5.1798 & 4.5127 & TRN & \\
\hline CHEMBL1523735 & 954356 & 4.0006 & 4.4622 & TRN & \\
\hline CHEMBL1566050 & 954356 & 6.1722 & 5.8543 & TRN & \\
\hline CHEMBL1982521 & 954356 & 6.7027 & 6.6471 & TRN & \\
\hline CHEMBL1726071 & 954356 & 5.4306 & 4.7111 & TRN & \\
\hline CHEMBL3190811 & 954356 & 4.0005 & 4.4271 & TRN & \\
\hline CHEMBL1322235 & 954356 & 6.0429 & 5.8939 & TRN & \\
\hline CHEMBL1304117 & 954356 & 4.0005 & 4.312 & TRN & \\
\hline CHEMBL1388022 & 954356 & 5.8083 & 5.616006 & 00000000005 & TRN \\
\hline CHEMBL1982831 & 954356 & 6.2519 & 6.2455 & TRN & \\
\hline CHEMBL1566701 & 954356 & 5.632999 & 99999999 & 5.6671 & TRN \\
\hline CHEMBL1709376 & 954356 & 5.87 & 5.6882 & TRN & \\
\hline CHEMBL1885760 & 954356 & 4.0005 & 4.43199 & 99999999995 & TRN \\
\hline CHEMBL1878419 & 954356 & 5.7199 & 5.7943 & TRN & \\
\hline CHEMBL1880953 & 954356 & 5.8055 & 5.5149 & TST & \\
\hline CHEMBL1709293 & 954356 & 6.3285 & 6.2089 & TRN & \\
\hline CHEMBL1331202 & 954356 & 4.9543 & 4.9074 & TRN & \\
\hline CHEMBL1396328 & 954356 & 5.9303 & 5.8787 & TRN & \\
\hline CHEMBL1474228 & 954356 & 5.586 & 5.5115 & TRN & \\
\hline CHEMBL1452334 & 954356 & 4.9547 & 5.5283 & TRN & \\
\hline CHEMBL1556319 & 954356 & 4.0008 & 4.4769 & TRN & \\
\hline CHEMBL1877038 & 954356 & 4.0005 & 4.422 & TRN & \\
\hline CHEMBL1550806 & 954356 & 6.0482 & 6.1405 & TRN & \\
\hline CHEMBL1517746 & 954356 & 5.7781 & 5.8822 & TRN & \\
\hline CHEMBL1332547 & 954356 & 5.961 & 5.9415 & TRN & \\
\hline CHEMBL1385977 & 954356 & 5.2917 & 5.4239 & TST & \\
\hline CHEMBL1306548 & 954356 & 4.0007 & 4.4784 & TRN & \\
\hline CHEMBL1586886 & 954356 & 4.0002 & 4.541 & TRN & \\
\hline CHEMBL1468514 & 954356 & 4.9543 & 5.035 & TST & \\
\hline CHEMBL1386332 & 954356 & 5.8312 & 5.6958 & TST & \\
\hline CHEMBL443510 & 954356 & 5.4313 & 6.1151 & TST & \\
\hline CHEMBL1431182 & 954356 & 4.9547 & 5.4887 & TRN & \\
\hline CHEMBL1881564 & 954356 & 5.596 & 5.5528 & TRN & \\
\hline CHEMBL1300133 & 954356 & 5.4318 & 5.9344 & TRN & \\
\hline CHEMBL1895454 & 954356 & 4.4776 & 5.5912 & TRN & \\
\hline CHEMBL 303846 & 954356 & 4.9543 & 5.536006 & 00000000005 & TRN \\
\hline CHEMBL1876674 & 954356 & 6.1848 & 6.1011 & TRN & \\
\hline CHEMBL510349 & 954356 & 5.556 & 5.559 & TRN & \\
\hline
\end{tabular}




\begin{tabular}{|c|c|c|c|c|c|c|}
\hline & & \multicolumn{5}{|c|}{ Supplemental Table s2.txt } \\
\hline CHEMBL1527163 & 954356 & 5.2355 & 4.3877 & TRN & & \\
\hline CHEMBL1342859 & 954356 & 5.3243 & 4.3176 & TRN & & \\
\hline CHEMBL1583879 & 954356 & 5.2162 & 5.4457 & TRN & & \\
\hline CHEMBL1431614 & 954356 & 5.4319 & 5.7281 & TRN & & \\
\hline CHEMBL259615 & 954356 & 5.4475 & 5.4715 & TRN & & \\
\hline CHEMBL1892379 & 954356 & 5.82299 & 99999999 & 995 & 5.7565 & TRN \\
\hline CHEMBL1315419 & 954356 & 5.8435 & 5.8536 & TRN & & \\
\hline CHEMBL2131581 & 954356 & 6.1703 & 5.9423 & TRN & & \\
\hline CHEMBL1349788 & 954356 & 5.9359 & 5.8968 & TST & & \\
\hline CHEMBL3214280 & 954356 & 4.0001 & 4.5655 & TST & & \\
\hline CHEMBL1560398 & 954356 & 5.6712 & 4.9553 & TST & & \\
\hline CHEMBL1348941 & 954356 & 5.7222 & 5.6835 & TST & & \\
\hline CHEMBL1377376 & 954356 & 5.8389 & 5.7559 & TST & & \\
\hline CHEMBL1701673 & 954356 & 5.8187 & 5.8318 & TST & & \\
\hline CHEMBL1548989 & 954356 & 6.0367 & 5.9604 & TST & & \\
\hline CHEMBL1556733 & 954356 & 5.7247 & 5.7125 & TST & & \\
\hline CHEMBL1369293 & 954356 & 5.3363 & 4.4232 & TST & & \\
\hline CHEMBL1403575 & 954356 & 6.1102 & 5.8789 & TST & & \\
\hline CHEMBL1471458 & 954356 & 6.1451 & 6.2277 & TST & & \\
\hline CHEMBL1391949 & 954356 & 4.9547 & 5.6113 & TST & & \\
\hline CHEMBL1608557 & 954356 & 5.4318 & 5.36799 & 9999999999 & & TST \\
\hline CHEMBL1889627 & 954356 & 5.8248 & 4.9746 & TST & & \\
\hline CHEMBL1404321 & 954356 & 5.782 & 5.6545 & TST & & \\
\hline CHEMBL1571914 & 954356 & 5.845 & 5.6203 & TST & & \\
\hline CHEMBL1305695 & 954356 & 6.0743 & 5.9517 & TST & & \\
\hline CHEMBL1417696 & 954356 & 6.2353 & 6.0997 & TST & & \\
\hline CHEMBL1556516 & 954356 & 5.7991 & 5.5757 & TST & & \\
\hline CHEMBL1417974 & 954356 & 6.2309 & 6.2544 & TST & & \\
\hline CHEMBL1611838 & 954356 & 5.7956 & 5.7237 & TST & & \\
\hline CHEMBL1480043 & 954356 & 4.0004 & 4.4374 & TST & & \\
\hline CHEMBL1397449 & 954356 & 5.7833 & 5.7841 & TST & & \\
\hline CHEMBL3960927 & 1642296 & 6.1079 & 6.0596 & TST & & \\
\hline CHEMBL3957607 & 1642296 & 7.9586 & 7.9037 & TRN & & \\
\hline CHEMBL3932136 & 1642296 & 7.1079 & 7.1442 & TRN & & \\
\hline CHEMBL3954079 & 1642296 & 7.3372 & 7.5776 & TRN & & \\
\hline CHEMBL3902216 & 1642296 & 7.7696 & 8.0077 & TRN & & \\
\hline CHEMBL3960241 & 1642296 & 6.0 & 6.1176 & TRN & & \\
\hline CHEMBL3935273 & 1642296 & 6.2441 & 5.9597 & TST & & \\
\hline CHEMBL3949941 & 1642296 & 6.3098 & 6.7643 & TST & & \\
\hline CHEMBL3903612 & 1642296 & 7.2007 & 7.1222 & TRN & & \\
\hline CHEMBL3954349 & 1642296 & 7.2676 & 7.0312 & TST & & \\
\hline CHEMBL3917739 & 1642296 & 7.6778 & 7.3615 & TRN & & \\
\hline CHEMBL3936037 & 1642296 & 6.0 & 6.0161 & TRN & & \\
\hline CHEMBL3974049 & 1642296 & 6.9586 & 6.9296 & TRN & & \\
\hline CHEMBL3908276 & 1642296 & 6.0 & 6.0042 & TRN & & \\
\hline CHEMBL 3984687 & 1642296 & 6.7447 & 6.827006 & 0000000001 & & TRN \\
\hline CHEMBL3937343 & 1642296 & 5.9586 & 6.1157 & TRN & & \\
\hline CHEMBL3917439 & 1642296 & 6.4949 & 6.3805 & TST & & \\
\hline
\end{tabular}




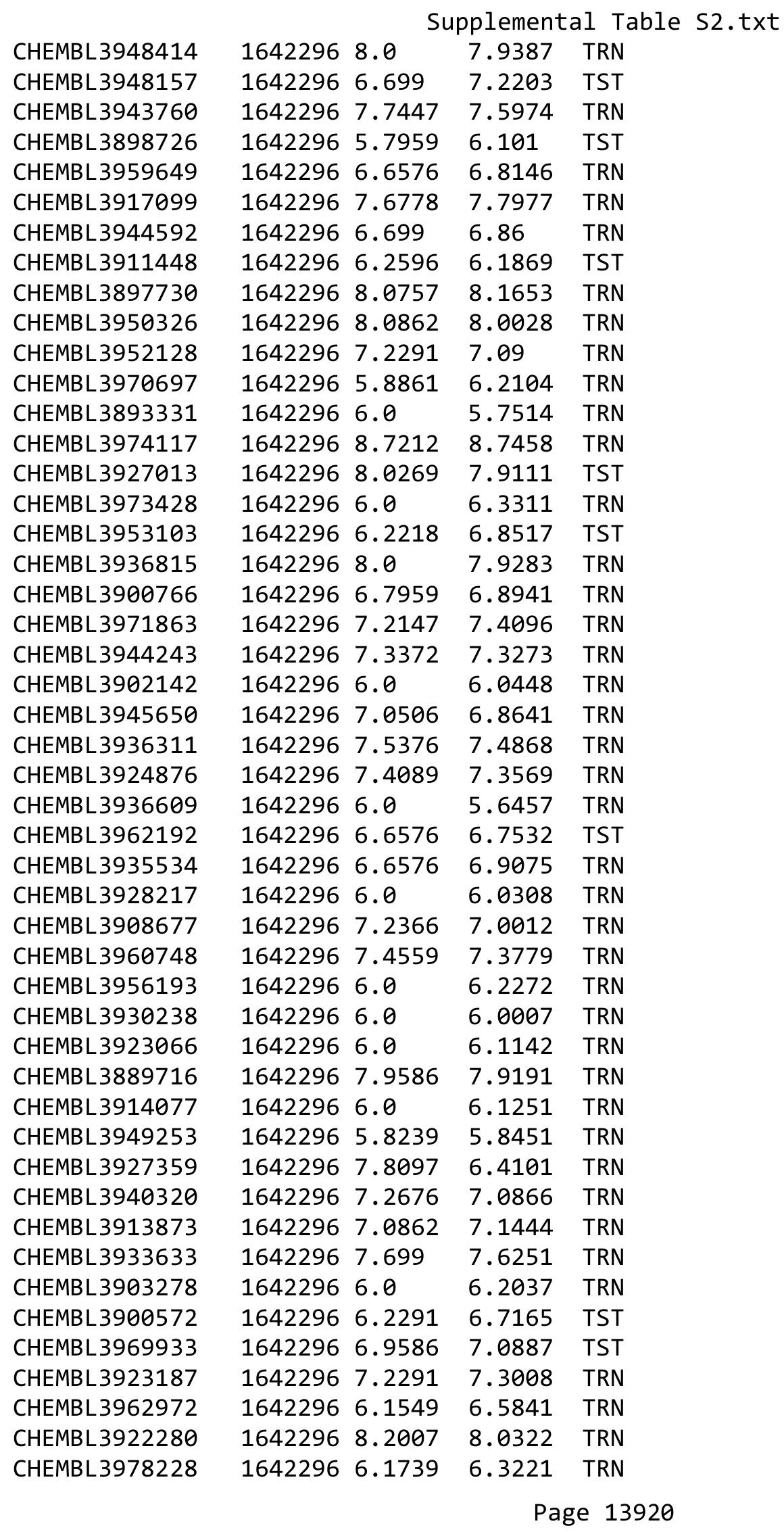


Supplemental Table S2.txt

\begin{tabular}{|c|c|c|c|c|}
\hline HEMB & 2296 & 6.4815 & 6514 & \\
\hline & 642296 & 6.6021 & & \\
\hline 95 & 296 & & & \\
\hline HEMBL 398 & 2296 & 6.0 & & \\
\hline AEMBL3928954 & 642296 & 089 & 1019 & \\
\hline HEMBL3969604 & 642296 & 7.5376 & 7322 & \\
\hline 577 & & 376 & 141 & \\
\hline AFMBI 39 & & & & \\
\hline HEMBL3934838 & 296 & 3098 & 5105 & \\
\hline HEMBL3923079 & 296 & 1938 & 7299 & ST \\
\hline HEMBL3908025 & 296 & 7.7959 & 9479 & \\
\hline IEMBL3C & 96 & 57 & 763 & \\
\hline AEMBL3E & & & & \\
\hline HEMBL39 & 296 & 959 & 7773 & \\
\hline AEMBL39 & 296 & 6.0 & 2771 & \\
\hline AEMBL393 & 62 & 6 & 06 & \\
\hline HEMBL3S & 0 & & 66 & \\
\hline HEMBL3S & & & & \\
\hline HEMBL3S & & 7. & 3627 & \\
\hline AEMBL3S & & 8 & & \\
\hline HEMBLS & 0 & 6 & 857 & II \\
\hline AEMBL & 0 & & 277 & RN \\
\hline HEMBL3S & & 6. & 372 & \\
\hline 637 & & & & \\
\hline AEMBL3S & & & & I NIV \\
\hline HEMBL3 & 6 & & 884 & RN \\
\hline HEMBL & & & & Niv \\
\hline$H F M B I=$ & 96 & 6 . & 881 & \\
\hline HEMBL3 & & & & TRIV \\
\hline HEMBL 397 & & & 084 & 15 \\
\hline HEMBL3S & 96 & 6 & 671 & RN \\
\hline HEMBL & 10 & 0 & 64 & RN \\
\hline HEMP & & 7. & 182 & 3 \\
\hline HEMBL 389 & & & 523 & is \\
\hline HEMBL3912182 & 6 & 8 . & 3782 & TST \\
\hline HEMBL38 & 96 & 7. & 5122 & RN \\
\hline HFMRI & & 6 & 797 & $\Gamma \mathrm{RN}$ \\
\hline HEMBL3 & & 6 & 896 & RN \\
\hline HEMBL3941923 & 96 & 6 & 548 & TRN \\
\hline AEMBL39 & 96 & & 556 & TST \\
\hline HEMBL 39 & 6 & 6 & 456 & \\
\hline CHEMBL 39 & & & & RN \\
\hline HEMBL3928186 & 96 & 6. & 1814 & ГST \\
\hline HEMBL3945321 & 296 & 6.5086 & 2357 & TRN \\
\hline $1=$ & & & & 13 \\
\hline HEMBL3 & & 0007 & 1177 & \\
\hline LHEMBL3919700 & & & .4253 & \\
\hline CHEMBL3956975 & 164229 & 7.4559 & 7.3213 & ГRN \\
\hline
\end{tabular}

Page 13921 
Supplemental Table S2.txt

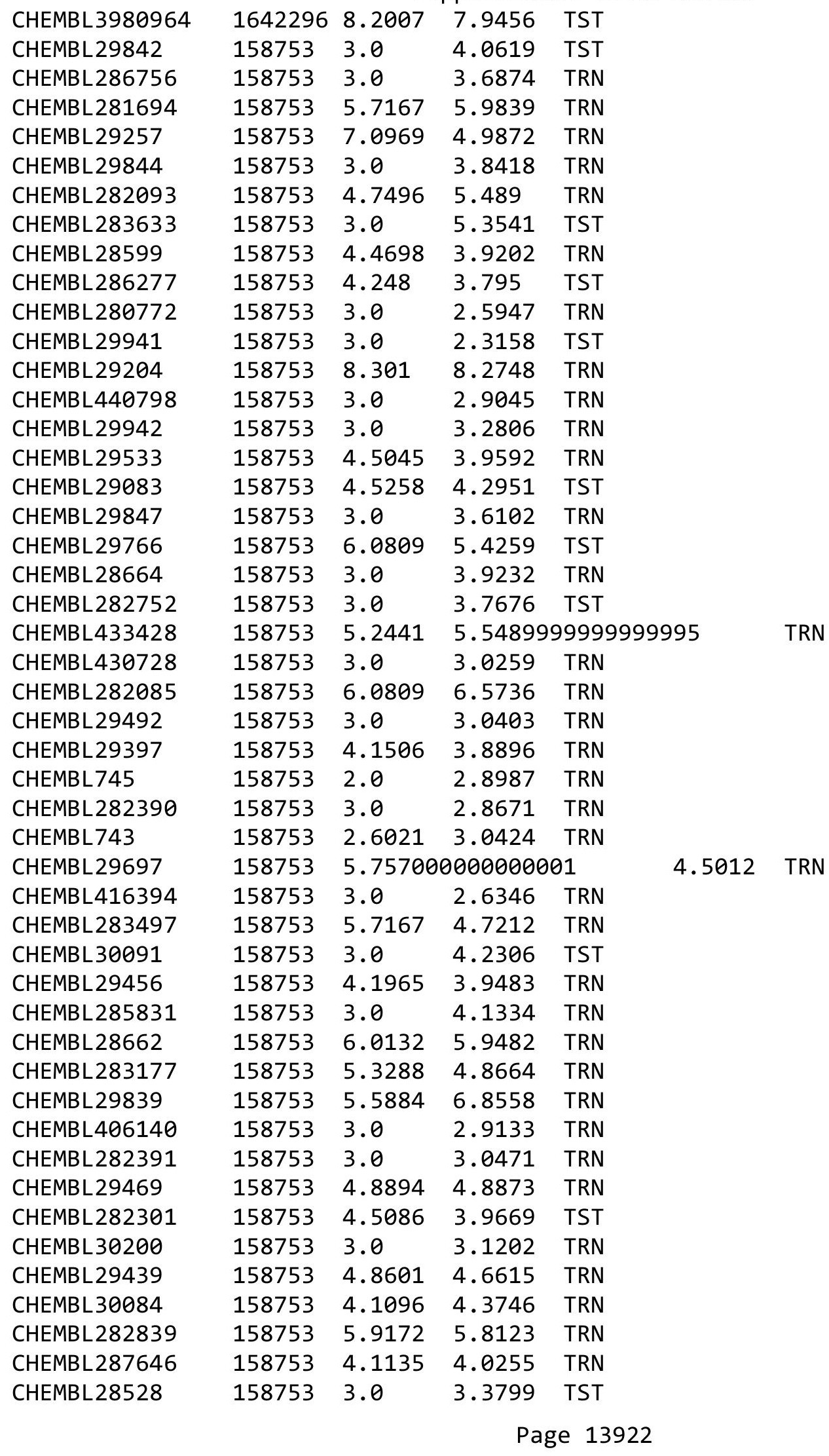




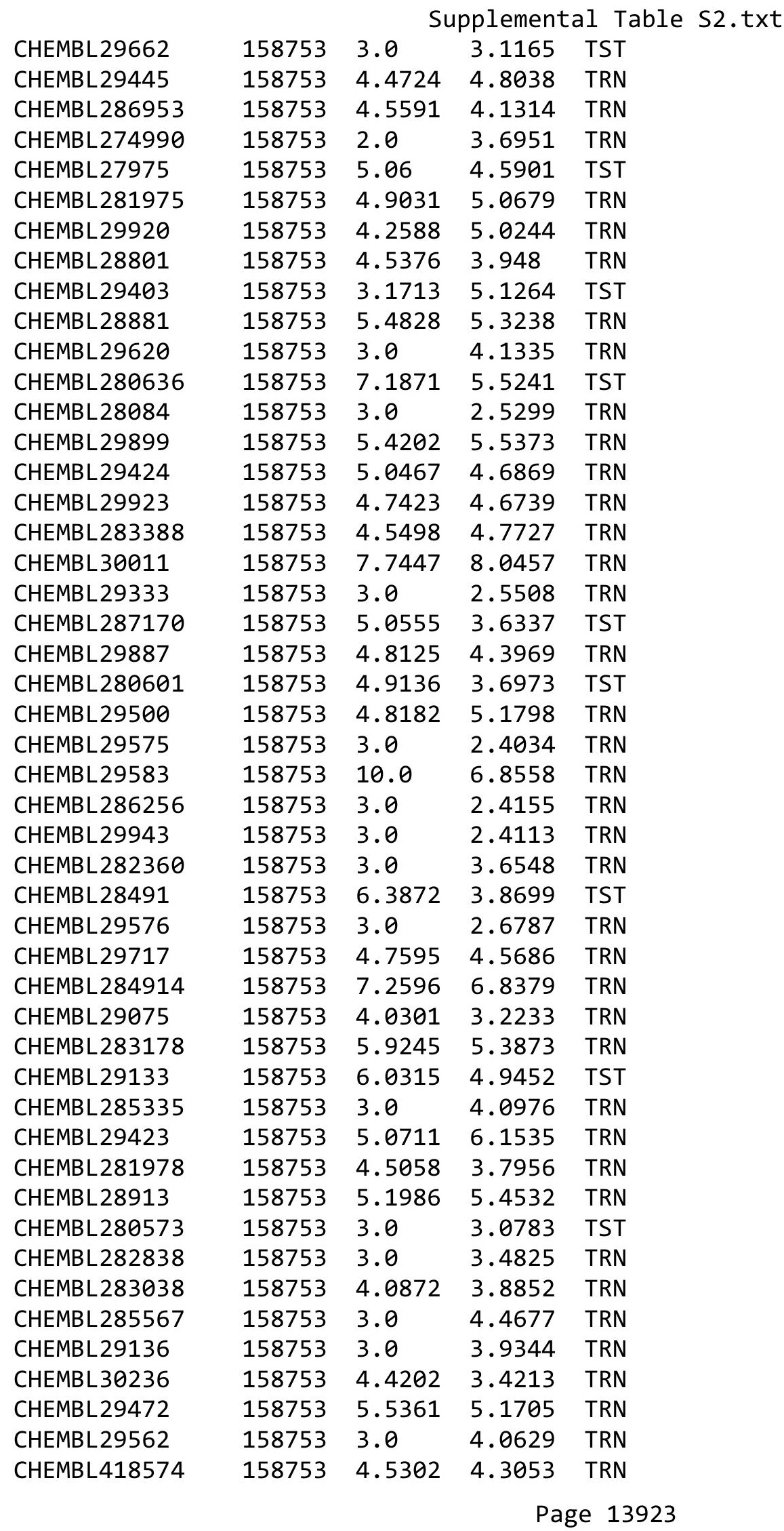




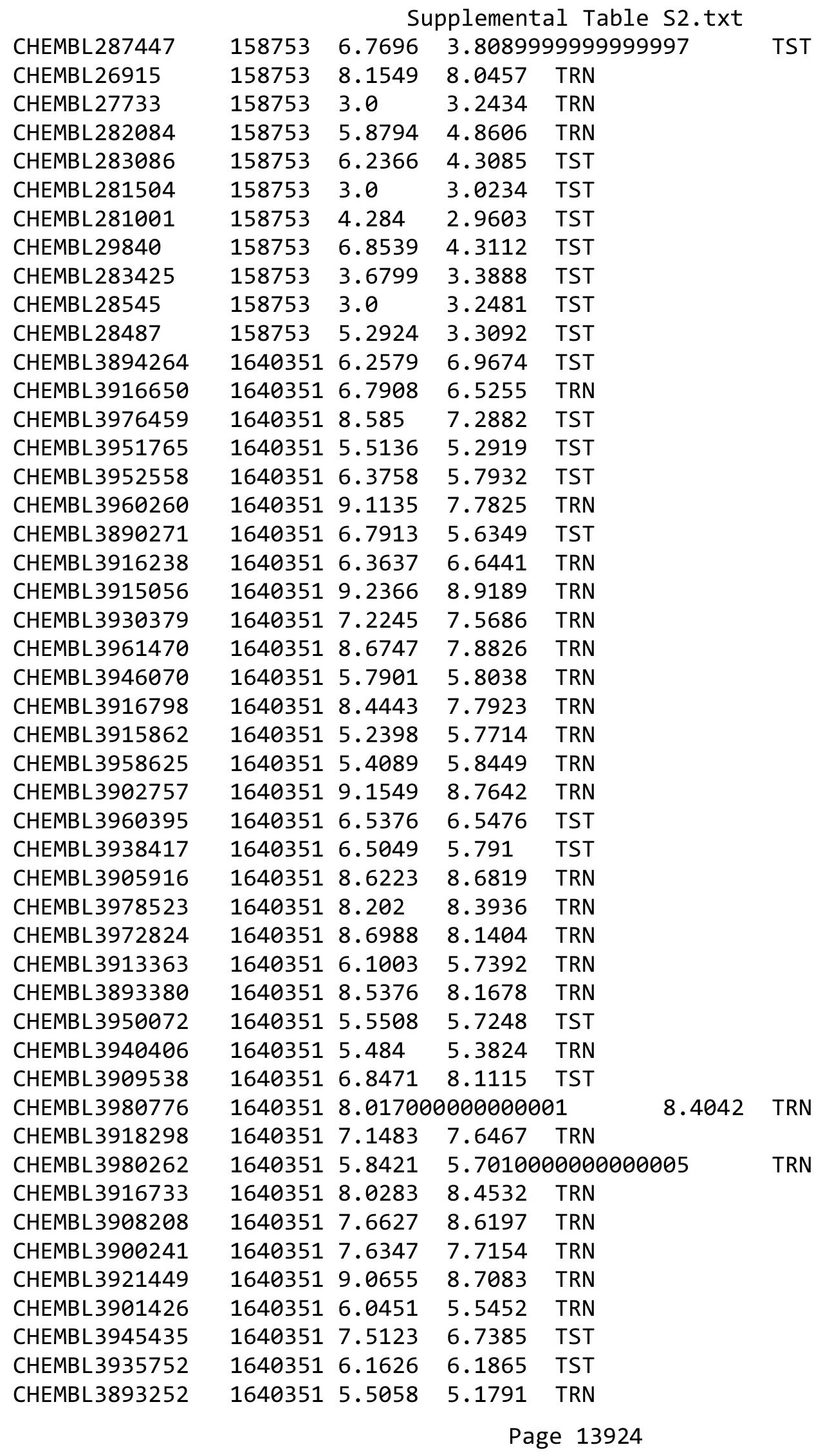


Supplemental Table S2.txt

\begin{tabular}{|c|c|c|c|c|c|}
\hline CHEMBL3981666 & 1640351 & 9.0083 & 8.4988 & TRN & \\
\hline CHEMBL 3912544 & 1640351 & 8.176 & 7.7314 & TRN & \\
\hline CHEMBL3928499 & 1640351 & 8.4424 & 7.5585 & TRN & \\
\hline CHEMBL3943814 & 1640351 & 6.0685 & 6.1546 & TST & \\
\hline CHEMBL 3894226 & 1640351 & 7.3376 & 7.4156 & TRN & \\
\hline CHEMBL3939011 & 1640351 & 6.1234 & 5.5488 & TRN & \\
\hline CHEMBL3966925 & 1640351 & 6.4219 & 6.2524 & TRN & \\
\hline CHEMBL3976418 & 1640351 & 5.4759 & 5.7818 & TRN & \\
\hline CHEMBL3906889 & 1640351 & 6.6861 & 5.9972 & TST & \\
\hline CHEMBL3963168 & 1640351 & 8.4559 & 7.8879 & TRN & \\
\hline CHEMBL 3922741 & 1640351 & 8.2105 & 7.9731 & TRN & \\
\hline CHEMBL3924929 & 1640351 & 7.1952 & 7.6544 & TST & \\
\hline CHEMBL3955465 & 1640351 & 5.7421 & 5.5868 & TRN & \\
\hline CHEMBL3943525 & 1640351 & 5.4315 & 5.1994 & TRN & \\
\hline CHEMBL 3986775 & 1640351 & 9.0039 & 8.5629 & TRN & \\
\hline CHEMBL3976640 & 1640351 & 8.67799 & 79999999 & 8.8773 & TRN \\
\hline CHEMBL 3978878 & 1640351 & 8.7296 & 8.7071 & TRN & \\
\hline CHEMBL 3923481 & 1640351 & 7.5333 & 8.0146 & TRN & \\
\hline CHEMBL3932266 & 1640351 & 9.2757 & 7.7316 & TST & \\
\hline CHEMBL3969960 & 1640351 & 5.27 & 5.4564 & TRN & \\
\hline CHEMBL 3977582 & 1640351 & 5.2494 & 5.7203 & TRN & \\
\hline CHEMBL3917178 & 1640351 & 9.5229 & 8.7409 & TRN & \\
\hline CHEMBL 3896757 & 1640351 & 6.8119 & 6.5939 & TST & \\
\hline CHEMBL 3902232 & 1640351 & 5.59399 & 79999999؟ & 5.1468 & TRN \\
\hline CHEMBL3934973 & 1640351 & 7.2916 & 7.829 & TRN & \\
\hline CHEMBL 3977388 & 1640351 & 7.8286 & 8.1903 & TRN & \\
\hline CHEMBL 3899020 & 1640351 & 7.6364 & 8.2956 & TRN & \\
\hline CHEMBL3973126 & 1640351 & 8.2427 & 7.7402 & TST & \\
\hline CHEMBL3945738 & 1640351 & 5.7204 & \multicolumn{2}{|c|}{5.452000000000001} & TRN \\
\hline CHEMBL3946088 & 1640351 & 6.064 & 6.2336 & TRN & \\
\hline CHEMBL3977102 & 1640351 & 4.8877 & 5.3166 & TRN & \\
\hline CHEMBL 3948073 & 1640351 & 5.5569 & 5.5005 & TRN & \\
\hline CHEMBL3971354 & 1640351 & 7.391 & 6.8329 & TST & \\
\hline CHEMBL3901838 & 1640351 & 7.6366 & 7.7973 & TRN & \\
\hline CHEMBL3917881 & 1640351 & 7.8156 & 8.673 & TRN & \\
\hline CHEMBL3940191 & 1640351 & 9.0458 & 8.8003 & TRN & \\
\hline CHEMBL3938910 & 1640351 & 8.1889 & 7.831 & TST & \\
\hline CHEMBL3924288 & 1640351 & 8.4608 & 8.1313 & TRN & \\
\hline CHEMBL3943314 & 1640351 & 6.2118 & 6.4986 & TRN & \\
\hline CHEMBL3913523 & 1640351 & 7.9281 & 8.4865 & TRN & \\
\hline CHEMBL 3921738 & 1640351 & 7.5378 & 6.5359 & TRN & \\
\hline CHEMBL3929615 & 1640351 & 9.5229 & 8.6413 & TRN & \\
\hline CHEMBL3954023 & 1640351 & 5.7786 & \multicolumn{2}{|c|}{6.297000000000001} & TRN \\
\hline CHEMBL3922720 & 1640351 & 7.9112 & 8.8443 & TRN & \\
\hline CHEMBL3904875 & 1640351 & 8.5892 & 8.6325 & TRN & \\
\hline CHEMBL3893299 & 1640351 & 8.219 & 7.1371 & TST & \\
\hline CHEMBL3967479 & 1640351 & 8.9314 & 8.1442 & TRN & \\
\hline CHEMBL3897963 & 1640351 & 7.0276 & 5.4824 & TST & \\
\hline
\end{tabular}


Supplemental Table S2.txt

\begin{tabular}{|c|c|c|c|c|c|c|c|}
\hline CHEMBL 3948122 & 1640351 & 8.7144 & 7.0147 & TST & & & \\
\hline CHEMBL3929315 & 1640351 & 9.0915 & 8.6355 & TRN & & & \\
\hline CHEMBL3967044 & 1640351 & 5.8776 & 5.6548 & TST & & & \\
\hline CHEMBL3983398 & 1640351 & 5.9654 & 6.3694 & TST & & & \\
\hline CHEMBL3937469 & 1640351 & 8.2217 & 7.8388 & TRN & & & \\
\hline CHEMBL 3975852 & 1640351 & 6.3981 & 7.2997 & TST & & & \\
\hline CHEMBL3923018 & 1640351 & 6.2559 & 6.2982 & TRN & & & \\
\hline CHEMBL1940181 & 1640351 & 8.5832 & 8.6744 & TRN & & & \\
\hline CHEMBL3955911 & 1640351 & 5.9 & 5.8032 & TRN & & & \\
\hline CHEMBL1779200 & 1640351 & 7.474 & 8.3582 & TRN & & & \\
\hline CHEMBL3946496 & 1640351 & 9.4949 & 8.959 & TRN & & & \\
\hline CHEMBL3953815 & 1640351 & 9.5229 & 8.7693 & TRN & & & \\
\hline CHEMBL3935006 & 1640351 & 8.0908 & 7.9157 & TRN & & & \\
\hline CHEMBL 3924183 & 1640351 & 8.5814 & 8.2425 & TST & & & \\
\hline CHEMBL3950027 & 1640351 & 4.887 & 5.8146 & TRN & & & \\
\hline CHEMBL 3985534 & 1640351 & \multicolumn{3}{|c|}{5.962000000000001} & 5.5413 & TRN & \\
\hline CHEMBL3937655 & 1640351 & 8.7501 & 8.7865 & TRN & & & \\
\hline CHEMBL3981662 & 1640351 & 9.0899 & 8.6419 & TRN & & & \\
\hline CHEMBL 3894804 & 1640351 & 8.4023 & 8.6099 & TRN & & & \\
\hline CHEMBL3943601 & 1640351 & 6.9434 & 6.6085 & TST & & & \\
\hline CHEMBL3929113 & 1640351 & 7.4851 & 8.005 & TRN & & & \\
\hline CHEMBL3943362 & 1640351 & 5.358 & 6.053999 & 9999999999 & & TST & \\
\hline CHEMBL3979107 & 1640351 & 6.2343 & 5.8561 & TST & & & \\
\hline CHEMBL 3942730 & 1640351 & 7.9248 & 7.9984 & TRN & & & \\
\hline CHEMBL 3898031 & 1640351 & 6.3821 & 5.6518 & TRN & & & \\
\hline CHEMBL3959170 & 1640351 & 6.5663 & 6.6053 & TRN & & & \\
\hline CHEMBL 3969437 & 1640351 & \multicolumn{3}{|c|}{7.757000000000001} & \multicolumn{2}{|c|}{ 7.617999999999999 } & TRN \\
\hline CHEMBL3929912 & 1640351 & 7.9893 & 7.9196 & TRN & & & \\
\hline CHEMBL3965962 & 1640351 & 6.2676 & 5.5111 & TST & & & \\
\hline CHEMBL3907916 & 1640351 & 5.6416 & 5.7214 & TRN & & & \\
\hline CHEMBL3890509 & 1640351 & 8.7359 & 8.0254 & TRN & & & \\
\hline CHEMBL3931695 & 1640351 & 7.5167 & 7.6806 & TRN & & & \\
\hline CHEMBL3921085 & 1640351 & 7.7518 & 7.947999 & 9999999999 & & TRN & \\
\hline CHEMBL 3984417 & 1640351 & 6.4667 & 6.0943 & TRN & & & \\
\hline CHEMBL 3940270 & 1640351 & 6.8038 & 5.8515 & TST & & & \\
\hline CHEMBL3958668 & 1640351 & 7.1001 & 6.7928 & TRN & & & \\
\hline CHEMBL3920411 & 1640351 & 9.0017 & 8.785 & TRN & & & \\
\hline CHEMBL3983559 & 1640351 & 7.2781 & 7.9057 & TRN & & & \\
\hline CHEMBL 3892306 & 1640351 & 8.172 & 7.8764 & TRN & & & \\
\hline CHEMBL 3975525 & 1640351 & 8.0044 & 7.5487 & TST & & & \\
\hline CHEMBL3967160 & 1640351 & 7.3728 & 7.8908 & TRN & & & \\
\hline CHEMBL3944715 & 1640351 & 9.4078 & 8.7742 & TRN & & & \\
\hline CHEMBL1823361 & 1640351 & 7.6929 & 8.6956 & TRN & & & \\
\hline CHEMBL3967916 & 1640351 & 6.7902 & 6.2719 & TST & & & \\
\hline CHEMBL 3924077 & 1640351 & 8.9614 & 8.45 & TRN & & & \\
\hline CHEMBL3945830 & 1640351 & 5.3879 & 5.2968 & TRN & & & \\
\hline CHEMBL3930736 & 1640351 & 7.8477 & 8.5594 & TRN & & & \\
\hline CHEMBL3969707 & 1640351 & 9.3064 & 8.7001 & TRN & & & \\
\hline
\end{tabular}

Page 13926 
Supplemental Table S2.txt

\begin{tabular}{|c|c|c|c|c|c|c|}
\hline CHEMBL 3962220 & 1640351 & 7.9259 & 8.1142 & TST & & \\
\hline CHEMBL3901152 & 1640351 & 8.4082 & 8.1249 & TRN & & \\
\hline CHEMBL3961889 & 1640351 & 6.2939 & 6.0247 & TRN & & \\
\hline CHEMBL3965185 & 1640351 & 8.4593 & 8.2453 & TRN & & \\
\hline CHEMBL3951779 & 1640351 & 7.9763 & 8.8083 & TRN & & \\
\hline CHEMBL1823221 & 1640351 & 8.1455 & 8.695 & TRN & & \\
\hline CHEMBL3918268 & 1640351 & 5.2257 & 6.0929 & TST & & \\
\hline CHEMBL 3931176 & 1640351 & 7.7097 & 6.5785 & TRN & & \\
\hline CHEMBL 3925752 & 1640351 & 5.936 & 5.7277 & TRN & & \\
\hline CHEMBL3962401 & 1640351 & 7.7959 & 8.029 & TRN & & \\
\hline CHEMBL3897705 & 1640351 & 8.8735 & 7.9071 & TST & & \\
\hline CHEMBL3897451 & 1640351 & 7.9205 & 8.4519 & TRN & & \\
\hline CHEMBL 3974835 & 1640351 & 8.752 & 8.844 & TRN & & \\
\hline CHEMBL 3934856 & 1640351 & 7.5306 & 7.5872 & TRN & & \\
\hline CHEMBL3895639 & 1640351 & 6.1135 & 6.4188 & TRN & & \\
\hline CHEMBL3908067 & 1640351 & 8.8239 & 8.6901 & TRN & & \\
\hline CHEMBL3901433 & 1640351 & 7.521 & 7.8299 & TRN & & \\
\hline CHEMBL 3914907 & 1640351 & 8.9454 & 8.8509 & TRN & & \\
\hline CHEMBL3961322 & 1640351 & 8.497 & 8.3206 & TRN & & \\
\hline CHEMBL3961537 & 1640351 & 8.4423 & 8.4152 & TRN & & \\
\hline CHEMBL3972222 & 1640351 & 5.3149 & 5.6883 & TRN & & \\
\hline CHEMBL3895149 & 1640351 & 5.5266 & 5.8709 & TST & & \\
\hline CHEMBL 3965090 & 1640351 & 4.6715 & 5.444 & TST & & \\
\hline CHEMBL3906593 & 1640351 & 8.7959 & 8.6063 & TRN & & \\
\hline CHEMBL 3975407 & 1640351 & 6.0467 & 7.5755 & TRN & & \\
\hline CHEMBL3931129 & 1640351 & 5.2676 & 5.8597 & TRN & & \\
\hline CHEMBL3929985 & 1640351 & 8.1686 & 8.2826 & TRN & & \\
\hline CHEMBL 3963805 & 1640351 & 7.0172 & 6.8111 & TST & & \\
\hline CHEMBL 3962326 & 1640351 & 6.444 & 6.8858 & TST & & \\
\hline CHEMBL 3910151 & 1640351 & 6.1234 & 5.6554 & TRN & & \\
\hline CHEMBL 3936102 & 1640351 & 9.2291 & 8.5729 & TRN & & \\
\hline CHEMBL3986700 & 1640351 & 9.3979 & 8.354 & TRN & & \\
\hline CHEMBL 3941123 & 1640351 & 8.7891 & 8.5818 & TRN & & \\
\hline CHEMBL3961467 & 1640351 & 8.3768 & 8.191 & TRN & & \\
\hline CHEMBL 3922510 & 1640351 & 8.0706 & 7.8853 & TRN & & \\
\hline CHEMBL 3938143 & 1640351 & 8.212 & 7.8997 & TRN & & \\
\hline CHEMBL1779195 & 1640351 & 7.58200 & $\partial 0000000$ & $\partial 1$ & 7.6419 & TRN \\
\hline CHEMBL 3929368 & 1640351 & 6.1008 & 5.3396 & TST & & \\
\hline CHEMBL3972539 & 1640351 & 7.5635 & 7.86 & TRN & & \\
\hline CHEMBL3894562 & 1640351 & 5.4318 & 5.6079 & TRN & & \\
\hline CHEMBL3936470 & 1640351 & 7.7897 & 8.3498 & TRN & & \\
\hline CHEMBL 3891393 & 1640351 & 8.8041 & 8.5325 & TRN & & \\
\hline CHEMBL3983750 & 1640351 & 7.5711 & 7.9005 & TRN & & \\
\hline CHEMBL3949427 & 1640351 & 8.0245 & 8.0505 & TRN & & \\
\hline CHEMBL 3945084 & 1640351 & 8.1249 & 8.5212 & TRN & & \\
\hline CHEMBL 3945000 & 1640351 & 9.0757 & 8.4638 & TRN & & \\
\hline CHEMBL1779202 & 1640351 & 8.8153 & 8.4574 & TRN & & \\
\hline CHEMBL 3928036 & 1640351 & 7.5711 & 8.0286 & TRN & & \\
\hline
\end{tabular}

Page 13927 
Supplemental Table S2.txt

\begin{tabular}{|c|c|c|c|c|c|c|}
\hline CHEMBL3968909 & 1640351 & 8.6421 & 8.3855 & TRN & & \\
\hline CHEMBL3966467 & 1640351 & 4.6715 & 5.784 & TST & & \\
\hline CHEMBL3937192 & 1640351 & 8.3627 & 7.9935 & TRN & & \\
\hline CHEMBL1940177 & 1640351 & 7.9024 & 8.5744 & TRN & & \\
\hline CHEMBL 3893584 & 1640351 & \multicolumn{3}{|c|}{8.306000000000001} & 7.8749 & TRN \\
\hline CHEMBL 3938280 & 1640351 & \multicolumn{3}{|c|}{9.341000000000001} & 6.7956 & TST \\
\hline CHEMBL3984781 & 1640351 & 6.5649 & 7.6404 & TRN & & \\
\hline CHEMBL3964940 & 1640351 & \multicolumn{3}{|c|}{7.138999999999999} & 8.4067 & TRN \\
\hline CHEMBL3939589 & 1640351 & 4.7579 & 5.4279 & TST & & \\
\hline CHEMBL 3904080 & 1640351 & 5.4949 & 5.9466 & TST & & \\
\hline CHEMBL 3978144 & 1640351 & 5.9043 & 5.7979 & TST & & \\
\hline CHEMBL 3985578 & 1640351 & 6.0712 & 7.0289 & TST & & \\
\hline CHEMBL 3934923 & 1640351 & 6.1549 & 5.815 & TST & & \\
\hline CHEMBL3889682 & 1640351 & 6.2403 & 5.8591 & TRN & & \\
\hline CHEMBL 3934533 & 1640351 & 5.1521 & 5.1957 & TST & & \\
\hline CHEMBL3902372 & 1640351 & 8.1163 & 7.9641 & TRN & & \\
\hline CHEMBL3939763 & 1640351 & 5.2266 & 5.1538 & TST & & \\
\hline CHEMBL 3947466 & 1640351 & 4.887 & 5.5929 & TRN & & \\
\hline CHEMBL3969762 & 1640351 & 6.8209 & 6.6507 & TST & & \\
\hline CHEMBL 3953362 & 1640351 & 6.4863 & 6.6854 & TST & & \\
\hline CHEMBL3931121 & 1640351 & 6.3718 & 6.5445 & TRN & & \\
\hline CHEMBL3943659 & 1640351 & 6.0695 & 6.1254 & TRN & & \\
\hline CHEMBL 3952250 & 1640351 & 8.3655 & 8.7565 & TRN & & \\
\hline CHEMBL3986413 & 1640351 & 6.7741 & 6.532 & TRN & & \\
\hline CHEMBL3894115 & 1640351 & 6.3838 & 6.9015 & TRN & & \\
\hline CHEMBL 3934065 & 1640351 & 6.983 & 6.4257 & TST & & \\
\hline CHEMBL3960959 & 1640351 & 5.7447 & 6.4961 & TRN & & \\
\hline CHEMBL3939751 & 1640351 & 9.2218 & 8.5922 & TRN & & \\
\hline CHEMBL3982627 & 1640351 & 7.4042 & 8.2937 & TRN & & \\
\hline CHEMBL3963068 & 1640351 & 8.8545 & 8.0307 & TRN & & \\
\hline CHEMBL 3902283 & 1640351 & 7.0799 & 6.3315 & TRN & & \\
\hline CHEMBL 3896252 & 1640351 & 9.0809 & 8.4621 & TRN & & \\
\hline CHEMBL3964766 & 1640351 & 6.723 & 6.7646 & TRN & & \\
\hline CHEMBL3903395 & 1640351 & 7.0722 & 7.6388 & TRN & & \\
\hline CHEMBL3977837 & 1640351 & 7.7657 & 7.6563 & TRN & & \\
\hline CHEMBL3919065 & 1640351 & 6.0458 & 5.7087 & TRN & & \\
\hline CHEMBL3945766 & 1640351 & 8.3343 & 8.5369 & TRN & & \\
\hline CHEMBL3981472 & 1640351 & 9.0214 & 8.7341 & TRN & & \\
\hline CHEMBL 3892424 & 1640351 & 8.6878 & 8.5136 & TRN & & \\
\hline CHEMBL3922786 & 1640351 & 8.1492 & 7.88399 & 9999999999 & & TRN \\
\hline CHEMBL 3958614 & 1640351 & 5.6201 & 6.9705 & TRN & & \\
\hline CHEMBL3912386 & 1640351 & 5.9753 & 5.775 & TST & & \\
\hline CHEMBL3904592 & 1640351 & 6.0315 & 6.16700 & 0000000001 & & TRN \\
\hline CHEMBL 3969142 & 1640351 & 6.2924 & 5.8713 & TST & & \\
\hline CHEMBL 3931742 & 1640351 & 7.9307 & 8.4686 & TRN & & \\
\hline CHEMBL3910490 & 1640351 & 7.9842 & 7.6994 & TRN & & \\
\hline CHEMBL3952637 & 1640351 & 7.8262 & 8.0222 & TRN & & \\
\hline CHEMBL3914305 & 1640351 & 5.3743 & 6.5475 & TST & & \\
\hline
\end{tabular}


Supplemental Table S2.txt

\begin{tabular}{|c|c|c|c|c|c|}
\hline CHEMBL 3920298 & 1640351 & 6.8714 & 7.6793 & TRN & \\
\hline CHEMBL 3952864 & 1640351 & 7.5528 & 5.3555 & TST & \\
\hline CHEMBL 3948508 & 1640351 & 5.1082 & 5.1891 & TST & \\
\hline CHEMBL 3979078 & 1640351 & 4.8877 & 5.6688 & TRN & \\
\hline CHEMBL3911685 & 1640351 & 8.7233 & 8.7171 & TRN & \\
\hline CHEMBL3983337 & 1640351 & 8.6576 & 8.5332 & TRN & \\
\hline CHEMBL 3951557 & 1640351 & 8.2646 & 8.4234 & TRN & \\
\hline CHEMBL 3907048 & 1640351 & 8.2964 & 8.3988 & TRN & \\
\hline CHEMBL 3939371 & 1640351 & 8.138 & 8.3585 & TRN & \\
\hline CHEMBL 3915577 & 1640351 & 9.4949 & 8.568999 & & TST \\
\hline CHEMBL 3928314 & 1640351 & 6.4096 & 5.8682 & TST & \\
\hline CHEMBL 3943227 & 1640351 & 8.7744 & 8.4958 & TRN & \\
\hline CHEMBL 3960479 & 1640351 & 7.8225 & 8.6924 & TRN & \\
\hline CHEMBL 3898277 & 1640351 & 8.0964 & 7.8765 & TRN & \\
\hline CHEMBL 3930594 & 1640351 & 5.6576 & 5.8125 & TST & \\
\hline CHEMBL 3909864 & 1640351 & 8.0578 & 8.7699 & TRN & \\
\hline CHEMBL 3892880 & 1640351 & 9.7747 & 8.7725 & TRN & \\
\hline CHEMBL 3909267 & 1640351 & 6.3074 & 6.0755 & TRN & \\
\hline CHEMBL 3936548 & 1640351 & 9.3979 & 8.7083 & TRN & \\
\hline CHEMBL 3978315 & 1640351 & 7.0091 & 7.2886 & TST & \\
\hline CHEMBL 3916287 & 1640351 & 8.2923 & 8.4351 & TRN & \\
\hline CHEMBL 3919367 & 1640351 & 9.055 & 8.83 & TRN & \\
\hline CHEMBL3931796 & 1640351 & 7.2914 & 7.6585 & TRN & \\
\hline CHEMBL 3968459 & 1640351 & 6.5218 & 7.2832 & TST & \\
\hline CHEMBL 3972083 & 1640351 & 7.0315 & 5.5326 & TST & \\
\hline CHEMBL 3934077 & 1640351 & 7.8292 & 8.1259 & TRN & \\
\hline CHEMBL 3617652 & 1517380 & 4.0 & 4.4581 & TRN & \\
\hline CHEMBL 3617512 & 1517380 & 3.5229 & 5.5467 & TRN & \\
\hline CHEMBL 3617643 & 1517380 & 5.4789 & 4.8797 & TRN & \\
\hline CHEMBL 3617631 & 1517380 & 5.224 & 5.0154 & TRN & \\
\hline CHEMBL 3617645 & 1517380 & 5.5884 & 4.8392 & TRN & \\
\hline CHEMBL 3617504 & 1517380 & 4.0 & 5.7135 & TRN & \\
\hline CHEMBL 3617628 & 1517380 & 3.5229 & 3.2794 & TRN & \\
\hline CHEMBL 3617647 & 1517380 & 4.0 & 4.8458 & TRN & \\
\hline CHEMBL 3617622 & 1517380 & 5.8601 & 5.1701 & TRN & \\
\hline CHEMBL 3617517 & 1517380 & 4.0 & 4.9174 & TST & \\
\hline CHEMBL 3617618 & 1517380 & 4.0 & 4.9975 & TRN & \\
\hline CHEMBL 3617511 & 1517380 & 5.7122 & 5.5807 & TRN & \\
\hline CHEMBL 3617520 & 1517380 & 4.0 & 5.1426 & TRN & \\
\hline CHEMBL 3617612 & 1517380 & 4.0 & 5.2338 & TRN & \\
\hline CHEMBL 3617505 & 1517380 & 6.21899 & 999999999 & 5.7706 & TRN \\
\hline CHEMBL 3617514 & 1517380 & 5.3665 & 5.159 & TST & \\
\hline CHEMBL 3617648 & 1517380 & 3.5229 & 4.9216 & TST & \\
\hline CHEMBL 3617521 & 1517380 & 5.5346 & 5.0075 & TRN & \\
\hline CHEMBL 3617500 & 1517380 & 5.8239 & 5.7633 & TRN & \\
\hline CHEMBL 3617616 & 1517380 & 6.4389 & 5.171 & TRN & \\
\hline CHEMBL 3617625 & 1517380 & 5.9101 & 5.3002 & TRN & \\
\hline CHEMBL 3617515 & 1517380 & 3.5229 & 4.9074 & TST & \\
\hline
\end{tabular}


Supplemental Table S2.txt

\begin{tabular}{|c|c|c|c|c|c|}
\hline CHEMBL3617634 & 1517380 & 5.4802 & 5.0019 & TRN & \\
\hline CHEMBL3617501 & 1517380 & 4.0 & 5.5501 & TRN & \\
\hline CHEMBL3617633 & 1517380 & 5.5421 & 4.9886 & TRN & \\
\hline CHEMBL3617617 & 1517380 & 4.0 & 5.1429 & TRN & \\
\hline CHEMBL3617626 & 1517380 & 5.4535 & 4.9619 & TRN & \\
\hline CHEMBL3617496 & 1517380 & 6.71 & 5.9663 & TRN & \\
\hline CHEMBL3617499 & 1517380 & 6.5129 & 5.7748 & TRN & \\
\hline CHEMBL3617646 & 1517380 & 5.8477 & 5.1046 & TRN & \\
\hline CHEMBL3617613 & 1517380 & 5.5654 & 5.1385 & TRN & \\
\hline CHEMBL3617649 & 1517380 & 5.9813 & 4.6795 & TRN & \\
\hline CHEMBL3617638 & 1517380 & 4.0 & 5.2281 & TRN & \\
\hline CHEMBL3617653 & 1517380 & 3.5229 & 4.3125 & TRN & \\
\hline CHEMBL3617507 & 1517380 & 5.7352 & 5.7534 & TRN & \\
\hline CHEMBL3617623 & 1517380 & 5.6757 & 5.0883 & TRN & \\
\hline CHEMBL3617620 & 1517380 & 6.5214 & 5.3594 & TRN & \\
\hline CHEMBL3617657 & 1517380 & 3.5229 & 3.9211 & TRN & \\
\hline CHEMBL3617522 & 1517380 & 5.6478 & 5.7486 & TST & \\
\hline CHEMBL3617523 & 1517380 & 3.5229 & 5.4125 & TST & \\
\hline CHEMBL 3617508 & 1517380 & 5.8729 & 5.7815 & TRN & \\
\hline CHEMBL3617659 & 1517380 & 4.0 & 4.8401 & TRN & \\
\hline CHEMBL3617641 & 1517380 & 5.3036 & 5.2058 & TST & \\
\hline CHEMBL3617498 & 1517380 & 7.0362 & 5.7271 & TRN & \\
\hline CHEMBL 3617524 & 1517380 & 4.0 & 5.8693 & TST & \\
\hline CHEMBL 3617497 & 1517380 & 7.1367 & 5.7771 & TRN & \\
\hline CHEMBL3617654 & 1517380 & 4.0 & 4.8045 & TRN & \\
\hline CHEMBL3617636 & 1517380 & 5.4437 & 4.8708 & TRN & \\
\hline CHEMBL3617518 & 1517380 & 4.0 & 4.8644 & TST & \\
\hline CHEMBL3617630 & 1517380 & 5.4895 & \multicolumn{2}{|c|}{5.127000000000001} & TRN \\
\hline CHEMBL 3617621 & 1517380 & 4.0 & 5.07 & TRN & \\
\hline CHEMBL3617509 & 1517380 & 3.5229 & 5.131 & TRN & \\
\hline CHEMBL3617503 & 1517380 & 6.3778 & 6.0197 & TRN & \\
\hline CHEMBL3617495 & 1517380 & 7.3372 & 5.9268 & TRN & \\
\hline CHEMBL3617615 & 1517380 & 5.7328 & 5.1382 & TRN & \\
\hline CHEMBL3617635 & 1517380 & 5.6421 & 5.0201 & TRN & \\
\hline CHEMBL 3617640 & 1517380 & 5.3635 & 5.0435 & TRN & \\
\hline CHEMBL3616489 & 1517380 & 4.0 & 5.1213 & TST & \\
\hline CHEMBL3617650 & 1517380 & 3.5229 & 4.7948 & TST & \\
\hline CHEMBL 3617513 & 1517380 & 3.5229 & 5.3868 & TRN & \\
\hline CHEMBL 3617651 & 1517380 & 3.5229 & 3.0697 & TRN & \\
\hline CHEMBL3617629 & 1517380 & 5.0114 & 5.0614 & TRN & \\
\hline CHEMBL3617637 & 1517380 & 4.0 & 4.6491 & TRN & \\
\hline CHEMBL3617614 & 1517380 & 5.9957 & 5.3546 & TRN & \\
\hline CHEMBL3617644 & 1517380 & 5.1752 & 4.9587 & TRN & \\
\hline CHEMBL3617516 & 1517380 & 3.5229 & 5.1537 & TST & \\
\hline CHEMBL 3617627 & 1517380 & 4.0 & 3.1512 & TRN & \\
\hline CHEMBL3617619 & 1517380 & 4.0 & 4.7539 & TRN & \\
\hline CHEMBL3617656 & 1517380 & 3.5229 & 3.2789 & TRN & \\
\hline CHEMBL3617624 & 1517380 & 4.0 & 4.9805 & TRN & \\
\hline
\end{tabular}




\begin{tabular}{|c|c|c|c|c|c|}
\hline \multicolumn{6}{|c|}{ Supplemental Table S2.txt } \\
\hline CHEMBL 3617510 & 1517380 & 5.4935 & 5.4978 & TRN & \\
\hline CHEMBL3617519 & 1517380 & 4.0 & 5.0926 & TST & \\
\hline CHEMBL3617632 & 1517380 & 5.2636 & 5.1952 & TST & \\
\hline CHEMBL3617506 & 1517380 & 4.0 & 5.9534 & TST & \\
\hline CHEMBL3617658 & 1517380 & 3.5229 & 3.9969 & TST & \\
\hline CHEMBL3617639 & 1517380 & 5.295 & 4.9138 & TST & \\
\hline CHEMBL 3617502 & 1517380 & 5.9666 & 5.3449 & TST & \\
\hline CHEMBL3617642 & 1517380 & 4.0 & 4.9269 & TST & \\
\hline CHEMBL 3617655 & 1517380 & 3.5229 & 4.4221 & TST & \\
\hline CHEMBL1407656 & 688416 & 4.7229 & 4.365 & TRN & \\
\hline CHEMBL1446290 & 688416 & 2.8239 & 2.4423 & TRN & \\
\hline CHEMBL1435719 & 688416 & 2.8239 & 2.2411 & TRN & \\
\hline CHEMBL1609332 & 688416 & 5.1772 & 4.6674 & TRN & \\
\hline CHEMBL1549651 & 688416 & 6.0511 & 5.3041 & TRN & \\
\hline CHEMBL1466614 & 688416 & 5.8671 & 5.063 & TRN & \\
\hline CHEMBL1383327 & 688416 & 5.039 & 4.3581 & TRN & \\
\hline CHEMBL1486092 & 688416 & 2.8239 & 2.9623 & TRN & \\
\hline CHEMBL1714915 & 688416 & 2.8239 & 4.6568 & TRN & \\
\hline CHEMBL1539127 & 688416 & 4.441 & 4.5438 & TRN & \\
\hline CHEMBL1398910 & 688416 & 2.8239 & 3.9297 & TRN & \\
\hline CHEMBL1516900 & 688416 & 4.8876 & 4.4496 & TRN & \\
\hline CHEMBL1533320 & 688416 & 2.8239 & 4.216 & TRN & \\
\hline CHEMBL1535443 & 688416 & 4.2214 & 4.3808 & TRN & \\
\hline CHEMBL1461661 & 688416 & 4.7457 & 5.0573 & TRN & \\
\hline CHEMBL1591445 & 688416 & 4.8775 & 4.2986 & TRN & \\
\hline CHEMBL1453857 & 688416 & 5.1927 & 5.4133 & TRN & \\
\hline CHEMBL3197008 & 688416 & 5.3116 & 4.5437 & TRN & \\
\hline CHEMBL1982010 & 688416 & 5.8867 & 4.9357 & TRN & \\
\hline CHEMBL1414059 & 688416 & 2.8239 & 4.2157 & TRN & \\
\hline CHEMBL1975652 & 688416 & 3.301 & 4.2888 & TRN & \\
\hline CHEMBL1307515 & 688416 & 4.9418 & 4.5638 & TST & \\
\hline CHEMBL1562033 & 688416 & 6.1512 & 6.4363 & TST & \\
\hline CHEMBL1463272 & 688416 & 2.8239 & 3.6073 & TRN & \\
\hline CHEMBL1546285 & 688416 & 4.6894 & 4.4656 & TRN & \\
\hline CHEMBL1971370 & 688416 & 2.8239 & 3.3084 & TRN & \\
\hline CHEMBL3192432 & 688416 & 5.1269 & 5.0838 & TRN & \\
\hline CHEMBL1300229 & 688416 & 2.8239 & 2.66899 & 99999999996 & TST \\
\hline CHEMBL1569929 & 688416 & 2.8239 & 4.0993 & TRN & \\
\hline CHEMBL1330129 & 688416 & 5.2319 & 4.9429 & TRN & \\
\hline CHEMBL1353643 & 688416 & 5.5561 & 5.0013 & TRN & \\
\hline CHEMBL463175 & 688416 & 6.0039 & 5.335 & TRN & \\
\hline CHEMBL1341979 & 688416 & 4.494 & 4.195 & TRN & \\
\hline CHEMBL1381519 & 688416 & 2.8239 & 2.3569 & TST & \\
\hline CHEMBL1411449 & 688416 & 5.4376 & 4.6568 & TRN & \\
\hline CHEMBL1390139 & 688416 & 4.9261 & 4.5331 & TRN & \\
\hline CHEMBL3189599 & 688416 & 5.2677 & 5.0684 & TRN & \\
\hline CHEMBL1332728 & 688416 & 4.7632 & 4.3141 & TRN & \\
\hline CHEMBL1965679 & 688416 & 2.8239 & 4.58899 & 99999999995 & TRN \\
\hline & & & & 13931 & \\
\hline
\end{tabular}




\begin{tabular}{|c|c|c|c|c|c|}
\hline & & \multicolumn{4}{|c|}{ Supplemental Table S2.txt } \\
\hline CHEMBL1426910 & 688416 & 4.3091 & 4.5542 & TRN & \\
\hline CHEMBL1399332 & 688416 & 4.4238 & 4.5871 & TRN & \\
\hline CHEMBL1496635 & 688416 & 2.8239 & 4.4235 & TST & \\
\hline CHEMBL1588411 & 688416 & 5.1179 & 4.5093 & TRN & \\
\hline CHEMBL1543052 & 688416 & 4.7001 & 4.0696 & TRN & \\
\hline CHEMBL1503572 & 688416 & 2.8239 & 2.8878 & TRN & \\
\hline CHEMBL 2002465 & 688416 & 5.6017 & 5.5522 & TRN & \\
\hline CHEMBL1301901 & 688416 & 2.8239 & 4.2959 & TRN & \\
\hline CHEMBL1304666 & 688416 & 5.1884 & 5.7274 & TRN & \\
\hline CHEMBL1471932 & 688416 & 4.4927 & 4.4701 & TRN & \\
\hline CHEMBL1439499 & 688416 & 2.8239 & 3.7794 & TRN & \\
\hline CHEMBL1450959 & 688416 & 2.8239 & 3.6085 & TRN & \\
\hline CHEMBL1605464 & 688416 & 4.97 & 4.3453 & TRN & \\
\hline CHEMBL1576055 & 688416 & 2.8239 & 3.9305 & TRN & \\
\hline CHEMBL498436 & 688416 & 5.1725 & 4.8601 & TST & \\
\hline CHEMBL1599173 & 688416 & 4.6928 & 4.2235 & TRN & \\
\hline CHEMBL1322496 & 688416 & 4.1149 & 3.9524 & TRN & \\
\hline CHEMBL 3197740 & 688416 & 5.2839 & 5.0653 & TRN & \\
\hline CHEMBL1518155 & 688416 & 2.8239 & 4.2479 & TRN & \\
\hline CHEMBL1456948 & 688416 & 5.8811 & 5.3565 & TRN & \\
\hline CHEMBL1606687 & 688416 & 2.8239 & 2.62100 & 300000 & TST \\
\hline CHEMBL1345195 & 688416 & 5.2045 & 4.7433 & TRN & \\
\hline CHEMBL1508058 & 688416 & 2.8239 & 4.5708 & TRN & \\
\hline CHEMBL 3213747 & 688416 & 4.9134 & 4.2115 & TST & \\
\hline CHEMBL1450872 & 688416 & 2.8239 & 4.4314 & TST & \\
\hline CHEMBL1326901 & 688416 & 2.8239 & 2.5555 & TRN & \\
\hline CHEMBL1477341 & 688416 & 5.3229 & 4.6555 & TST & \\
\hline CHEMBL39878 & 688416 & 5.4783 & 5.3186 & TRN & \\
\hline CHEMBL1501917 & 688416 & 4.7408 & 4.6971 & TRN & \\
\hline CHEMBL1334928 & 688416 & 4.8867 & 4.4203 & TRN & \\
\hline CHEMBL1507251 & 688416 & 5.5147 & 5.0269 & TRN & \\
\hline CHEMBL1400764 & 688416 & 2.8239 & 3.8749 & TRN & \\
\hline CHEMBL1609420 & 688416 & 2.8239 & 2.3515 & TRN & \\
\hline CHEMBL1456926 & 688416 & 5.1288 & 5.5855 & TRN & \\
\hline CHEMBL1535539 & 688416 & 5.2308 & 5.3765 & TST & \\
\hline CHEMBL1595276 & 688416 & 2.8239 & 2.5248 & TST & \\
\hline CHEMBL1477597 & 688416 & 2.8239 & 3.858 & TRN & \\
\hline CHEMBL1409443 & 688416 & 2.8239 & 4.7012 & TRN & \\
\hline CHEMBL1433095 & 688416 & 5.0539 & 4.3567 & TRN & \\
\hline CHEMBL1434604 & 688416 & 3.9856 & 4.0133 & TST & \\
\hline CHEMBL1544371 & 688416 & 5.4887 & 4.8762 & TRN & \\
\hline CHEMBL1480812 & 688416 & 5.2607 & 4.7438 & TRN & \\
\hline CHEMBL1492642 & 688416 & 5.0787 & 4.8441 & TRN & \\
\hline CHEMBL1345433 & 688416 & 2.8239 & 4.2154 & TST & \\
\hline CHEMBL1480252 & 688416 & 2.8239 & 4.2645 & TRN & \\
\hline CHEMBL1602902 & 688416 & 4.5094 & 4.0237 & TRN & \\
\hline CHEMBL1515251 & 688416 & 2.8239 & 4.4247 & TRN & \\
\hline CHEMBL1999166 & 688416 & 4.1612 & 4.6304 & TST & \\
\hline
\end{tabular}




\begin{tabular}{|c|c|c|c|c|c|}
\hline & & \multicolumn{4}{|c|}{ Supplemental Table S2.txt } \\
\hline CHEMBL1447853 & 688416 & 2.8239 & 3.781 & TST & \\
\hline CHEMBL1466932 & 688416 & 2.8239 & 4.2112 & TRN & \\
\hline CHEMBL1419303 & 688416 & 4.7919 & 4.5675 & TRN & \\
\hline CHEMBL1595820 & 688416 & 6.068 & 5.4737 & TRN & \\
\hline CHEMBL1578127 & 688416 & 4.8588 & 4.9798 & TST & \\
\hline CHEMBL1571096 & 688416 & 2.8239 & 2.1993 & TST & \\
\hline CHEMBL1354346 & 688416 & 2.8239 & 4.1557 & TRN & \\
\hline CHEMBL1455627 & 688416 & 5.1728 & 5.4318 & TRN & \\
\hline CHEMBL1383807 & 688416 & 4.0296 & 3.8788 & TRN & \\
\hline CHEMBL1368444 & 688416 & 5.3606 & 4.9799 & TRN & \\
\hline CHEMBL1530542 & 688416 & 2.8239 & 2.5348 & TRN & \\
\hline CHEMBL1988657 & 688416 & 2.8239 & 4.0257 & TRN & \\
\hline CHEMBL3208362 & 688416 & 4.6068 & 4.78100 & 0000000001 & TRN \\
\hline CHEMBL1335214 & 688416 & 2.8239 & 4.2154 & TRN & \\
\hline CHEMBL1162110 & 688416 & 2.8239 & 4.5048 & TRN & \\
\hline CHEMBL1479888 & 688416 & 5.1747 & 4.66100 & 00000000005 & TRN \\
\hline CHEMBL1572567 & 688416 & 2.8239 & 2.6425 & TRN & \\
\hline CHEMBL1596234 & 688416 & 2.8239 & 2.7961 & TRN & \\
\hline CHEMBL1606488 & 688416 & 2.8239 & 3.9438 & TST & \\
\hline CHEMBL1608787 & 688416 & 4.9561 & 4.1189 & TST & \\
\hline CHEMBL3195009 & 688416 & 5.0379 & 4.7464 & TRN & \\
\hline CHEMBL1344358 & 688416 & 2.8239 & 2.5136 & TRN & \\
\hline CHEMBL1422231 & 688416 & 3.9671 & 4.4534 & TRN & \\
\hline CHEMBL3191406 & 688416 & 4.926 & 4.8574 & TRN & \\
\hline CHEMBL3196941 & 688416 & 4.9465 & 4.8461 & TST & \\
\hline CHEMBL1487505 & 688416 & 2.8239 & 2.6295 & TST & \\
\hline CHEMBL1473916 & 688416 & 4.9864 & 4.091 & TST & \\
\hline CHEMBL1478237 & 688416 & 4.8427 & 4.6235 & TRN & \\
\hline CHEMBL1453837 & 688416 & 4.6491 & 4.1217 & TRN & \\
\hline CHEMBL1341100 & 688416 & 2.8239 & 3.7862 & TRN & \\
\hline CHEMBL1460624 & 688416 & 5.6949 & 5.3726 & TRN & \\
\hline CHEMBL1423338 & 688416 & 2.8239 & 4.1978 & TRN & \\
\hline CHEMBL3190621 & 688416 & 5.4988 & 4.7823 & TRN & \\
\hline CHEMBL1349635 & 688416 & 2.8239 & 3.6373 & TRN & \\
\hline CHEMBL3192727 & 688416 & 5.31 & 4.914 & TRN & \\
\hline CHEMBL1573813 & 688416 & 5.3539 & 4.9413 & TRN & \\
\hline CHEMBL1560577 & 688416 & 5.7095 & 5.1403 & TRN & \\
\hline CHEMBL193872 & 688416 & 5.5621 & 4.5759 & TST & \\
\hline CHEMBL1525775 & 688416 & 2.8239 & 2.2007 & TRN & \\
\hline CHEMBL1325258 & 688416 & 2.8239 & 3.8437 & TRN & \\
\hline CHEMBL1542349 & 688416 & 5.1478 & 4.3762 & TRN & \\
\hline CHEMBL3195943 & 688416 & 4.6629 & 4.3391 & TRN & \\
\hline CHEMBL1585321 & 688416 & 2.8239 & 2.3565 & TST & \\
\hline CHEMBL1360461 & 688416 & 4.7613 & 4.5601 & TRN & \\
\hline CHEMBL1530048 & 688416 & 2.8239 & 4.3794 & TRN & \\
\hline CHEMBL1424264 & 688416 & 4.9129 & 5.1367 & TRN & \\
\hline CHEMBL3197433 & 688416 & 5.3824 & 5.0266 & TRN & \\
\hline CHEMBL586135 & 688416 & 7.1871 & 6.2186 & TRN & \\
\hline
\end{tabular}


Supplemental Table S2.txt

\begin{tabular}{|c|c|c|c|c|c|}
\hline CHEMBL3199016 & 688416 & 4.9726 & 4.7558 & TRN & \\
\hline CHEMBL1426383 & 688416 & 5.0047 & 5.3824 & TRN & \\
\hline CHEMBL1377902 & 688416 & 2.8239 & 4.3291 & TRN & \\
\hline CHEMBL518430 & 688416 & 5.1444 & 4.4533 & TRN & \\
\hline CHEMBL1364119 & 688416 & 5.2952 & 4.8085 & TRN & \\
\hline CHEMBL3194477 & 688416 & 5.4269 & 4.6808 & TRN & \\
\hline CHEMBL1452090 & 688416 & 4.8957 & 5.1919 & TRN & \\
\hline CHEMBL591126 & 688416 & 4.9707 & 4.7383 & TRN & \\
\hline CHEMBL1377648 & 688416 & 4.3395 & 4.3689 & TRN & \\
\hline CHEMBL 2005664 & 688416 & 2.8239 & 4.0939 & TRN & \\
\hline CHEMBL1481198 & 688416 & 4.831 & 5.1679 & TRN & \\
\hline CHEMBL1315948 & 688416 & 4.9851 & 4.4118 & TRN & \\
\hline CHEMBL1421347 & 688416 & 5.8877 & 4.8942 & TRN & \\
\hline CHEMBL1497792 & 688416 & 5.1874 & 4.8498 & TST & \\
\hline CHEMBL187460 & 688416 & 4.8511 & 4.2722 & TST & \\
\hline CHEMBL1338446 & 688416 & 5.5176 & 4.8355 & TRN & \\
\hline CHEMBL1522807 & 688416 & 5.1334 & 5.1777 & TRN & \\
\hline CHEMBL1511561 & 688416 & 2.8239 & 3.2158 & TRN & \\
\hline CHEMBL1518264 & 688416 & 2.8239 & 3.9255 & TRN & \\
\hline CHEMBL1605015 & 688416 & 4.9088 & 4.9648 & TRN & \\
\hline CHEMBL1508616 & 688416 & 4.6645 & 4.5026 & TRN & \\
\hline CHEMBL45281 & 688416 & 4.819 & 4.7226 & TST & \\
\hline CHEMBL1401891 & 688416 & 2.8239 & 2.9083 & TST & \\
\hline CHEMBL1383406 & 688416 & 2.8239 & 3.9498 & TRN & \\
\hline CHEMBL1354631 & 688416 & 4.467 & 4.1826 & TRN & \\
\hline CHEMBL1344526 & 688416 & 2.8239 & 1.9219 & TRN & \\
\hline CHEMBL1426435 & 688416 & 5.6171 & 5.4556 & TRN & \\
\hline CHEMBL1595732 & 688416 & 2.8239 & 2.5168 & TST & \\
\hline CHEMBL1568827 & 688416 & 5.4415 & 4.754 & TRN & \\
\hline CHEMBL1438389 & 688416 & 2.8239 & 4.5491 & TRN & \\
\hline CHEMBL1366975 & 688416 & 5.7018 & 4.5917 & TRN & \\
\hline CHEMBL1570378 & 688416 & 2.8239 & 4.4385 & TST & \\
\hline CHEMBL610463 & 688416 & 2.8239 & 3.9877 & TRN & \\
\hline CHEMBL1300497 & 688416 & 5.2577 & 5.2743 & TRN & \\
\hline CHEMBL1315795 & 688416 & 4.5783 & 4.4416 & TRN & \\
\hline CHEMBL1556485 & 688416 & 5.0699 & 4.4408 & TRN & \\
\hline CHEMBL3197259 & 688416 & 5.66799 & 999999999 & 99 & 5.235 \\
\hline CHEMBL1588472 & 688416 & 5.6254 & 4.7344 & TRN & \\
\hline CHEMBL1422976 & 688416 & 4.7488 & 4.4088 & TRN & \\
\hline CHEMBL1596326 & 688416 & 4.702 & 4.0835 & TRN & \\
\hline CHEMBL1500128 & 688416 & 2.8239 & 3.8842 & TRN & \\
\hline CHEMBL1531454 & 688416 & 5.9727 & 4.6721 & TRN & \\
\hline CHEMBL1468672 & 688416 & 5.2488 & 4.7153 & TRN & \\
\hline CHEMBL221137 & 688416 & 5.479 & 4.8756 & TST & \\
\hline CHEMBL3194704 & 688416 & 5.5648 & 5.3329 & TRN & \\
\hline CHEMBL1387517 & 688416 & 2.8239 & 3.9997 & TST & \\
\hline CHEMBL1522582 & 688416 & 5.233 & 4.2937 & TRN & \\
\hline CHEMBL1580874 & 688416 & 4.9266 & 4.3786 & TRN & \\
\hline
\end{tabular}

Page 13934 


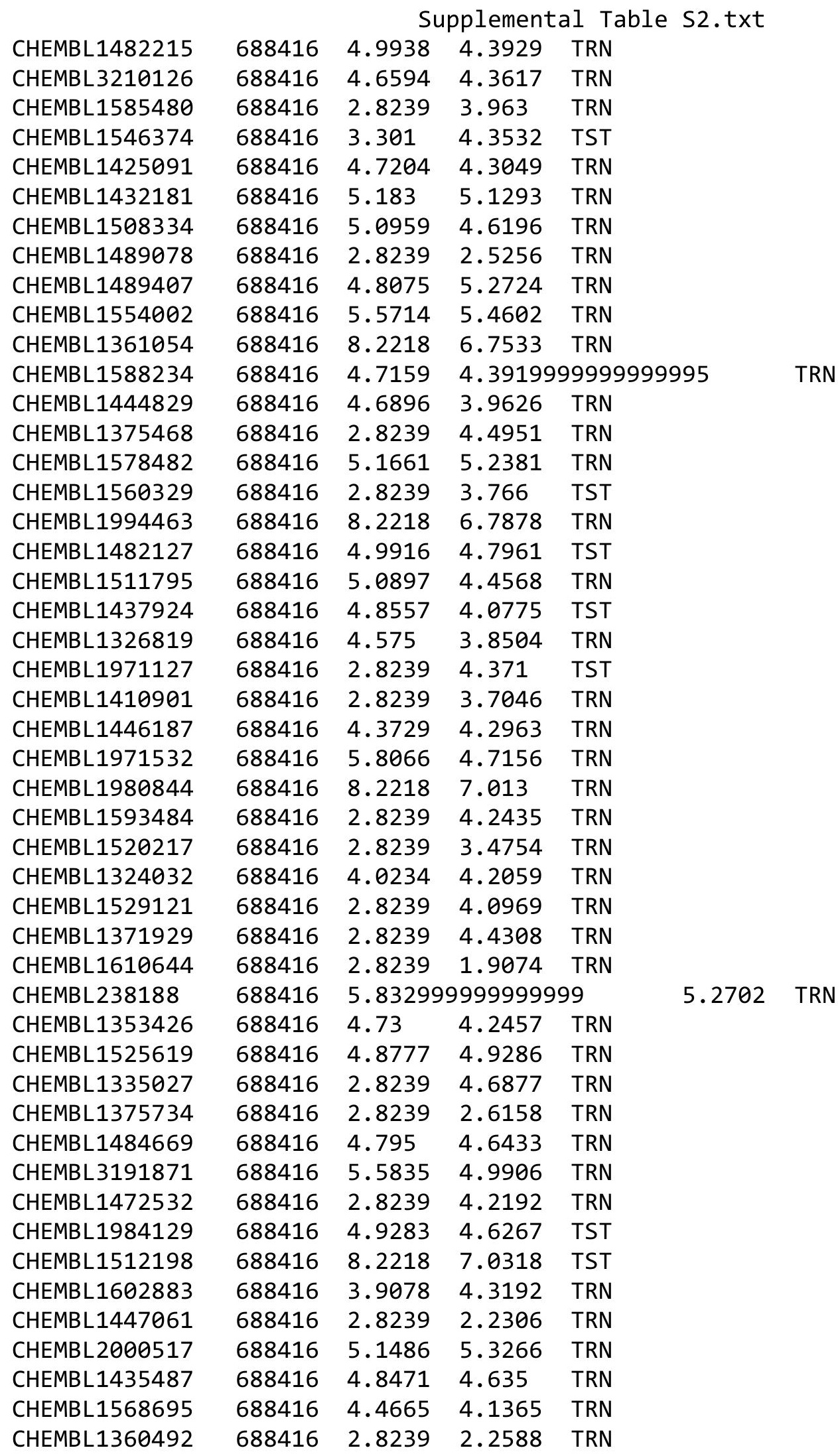

Page 13935 


\begin{tabular}{|c|c|c|c|c|c|c|}
\hline & & \multicolumn{5}{|c|}{ Supplemental Table S2.txt } \\
\hline CHEMBL1333647 & 688416 & 3.8711 & 3.2058 & TRN & & \\
\hline CHEMBL1603420 & 688416 & 4.7575 & 3.7018 & TRN & & \\
\hline CHEMBL1528933 & 688416 & 5.0835 & 4.1697 & TRN & & \\
\hline CHEMBL1506216 & 688416 & 4.8085 & 4.6903 & TRN & & \\
\hline CHEMBL3189613 & 688416 & 5.5907 & 5.0375 & TRN & & \\
\hline CHEMBL1449124 & 688416 & 4.9019 & 4.2151 & TRN & & \\
\hline CHEMBL3199217 & 688416 & 5.0457 & 4.6641 & TRN & & \\
\hline CHEMBL1407952 & 688416 & 4.4948 & 5.1692 & TRN & & \\
\hline CHEMBL1423935 & 688416 & 5.8681 & 5.0484 & TRN & & \\
\hline CHEMBL3195933 & 688416 & 4.5984 & 4.7228 & TRN & & \\
\hline CHEMBL1532303 & 688416 & 2.8239 & 4.138 & TRN & & \\
\hline CHEMBL3194133 & 688416 & 5.0893 & 5.1693 & TRN & & \\
\hline CHEMBL1467384 & 688416 & 4.7147 & 4.5781 & TST & & \\
\hline CHEMBL3195885 & 688416 & 4.7633 & 4.249 & TRN & & \\
\hline CHEMBL1391621 & 688416 & 5.032 & 4.4498 & TRN & & \\
\hline CHEMBL1340213 & 688416 & 4.7261 & 4.0118 & TRN & & \\
\hline CHEMBL3198398 & 688416 & 4.3278 & 4.4061 & TRN & & \\
\hline CHEMBL1347270 & 688416 & 4.2434 & 4.5541 & TRN & & \\
\hline CHEMBL1301717 & 688416 & 4.4647 & 4.4513 & TRN & & \\
\hline CHEMBL1401989 & 688416 & 5.1622 & 4.7487 & TRN & & \\
\hline CHEMBL1487870 & 688416 & 5.9821 & 5.3149 & TRN & & \\
\hline CHEMBL3199301 & 688416 & 5.1113 & 4.2558 & TRN & & \\
\hline CHEMBL1497196 & 688416 & 5.0946 & 4.6303 & TRN & & \\
\hline CHEMBL1498574 & 688416 & 4.8179 & 4.4948 & TRN & & \\
\hline CHEMBL1550584 & 688416 & 5.33899 & (9999999 & 995 & 5.8602 & TRN \\
\hline CHEMBL1331692 & 688416 & 2.8239 & 3.7142 & TRN & & \\
\hline CHEMBL1350169 & 688416 & 4.5676 & 4.2722 & TRN & & \\
\hline CHEMBL1462457 & 688416 & 5.7031 & 5.2883 & TRN & & \\
\hline CHEMBL1469659 & 688416 & 4.8556 & 4.1083 & TRN & & \\
\hline CHEMBL1504429 & 688416 & 5.4318 & 4.8047 & TRN & & \\
\hline CHEMBL3195760 & 688416 & 5.4316 & 5.8031 & TRN & & \\
\hline CHEMBL1566725 & 688416 & 4.324 & 4.2071 & TRN & & \\
\hline CHEMBL1995336 & 688416 & 2.8239 & 2.5888 & TRN & & \\
\hline CHEMBL1986090 & 688416 & 3.301 & 4.8959 & TRN & & \\
\hline CHEMBL1353949 & 688416 & 2.8239 & 2.4337 & TST & & \\
\hline CHEMBL1972915 & 688416 & 5.3693 & 4.9001 & TRN & & \\
\hline CHEMBL3145287 & 688416 & 5.1492 & 4.8562 & TRN & & \\
\hline CHEMBL1440743 & 688416 & 4.8463 & 4.217 & TST & & \\
\hline CHEMBL1423933 & 688416 & 2.8239 & 4.5964 & TST & & \\
\hline CHEMBL1382674 & 688416 & 6.9393 & 7.39 & TRN & & \\
\hline CHEMBL171637 & 688416 & 2.8239 & 4.7248 & TST & & \\
\hline CHEMBL1510769 & 688416 & 2.8239 & 2.6115 & TST & & \\
\hline CHEMBL1441088 & 688416 & 4.7688 & 4.2337 & TRN & & \\
\hline CHEMBL3198095 & 688416 & 4.0486 & 4.1193 & TRN & & \\
\hline CHEMBL1424234 & 688416 & 2.8239 & 2.3243 & TRN & & \\
\hline CHEMBL1527120 & 688416 & 5.099 & 4.0621 & TST & & \\
\hline CHEMBL1405968 & 688416 & 4.4054 & 5.3158 & TRN & & \\
\hline CHEMBL1557762 & 688416 & 5.2216 & 5.8415 & TRN & & \\
\hline
\end{tabular}




\begin{tabular}{|c|c|c|c|c|}
\hline \multicolumn{5}{|c|}{ Supplemental Tab. } \\
\hline CHEMBL1372606 & 688416 & 5.2003 & 5.38 & TRN \\
\hline CHEMBL3196681 & 688416 & 4.3984 & 4.2275 & TRN \\
\hline CHEMBL1336274 & 688416 & 4.8 & 4.0819 & TRN \\
\hline CHEMBL1405475 & 688416 & 4.9191 & 4.5243 & TRN \\
\hline CHEMBL1471099 & 688416 & 2.8239 & 3.7449 & TRN \\
\hline CHEMBL1464597 & 688416 & 5.008 & 4.4694 & TRN \\
\hline CHEMBL1449349 & 688416 & 2.8239 & 4.1371 & TRN \\
\hline CHEMBL1324064 & 688416 & 2.8239 & 2.2881 & TST \\
\hline CHEMBL1333387 & 688416 & 5.2048 & 4.5025 & TRN \\
\hline CHEMBL1449595 & 688416 & 2.8239 & 2.4746 & TRN \\
\hline CHEMBL1431705 & 688416 & 5.2402 & 4.8819 & TRN \\
\hline CHEMBL1612688 & 688416 & 4.3396 & 4.0204 & TRN \\
\hline CHEMBL1358861 & 688416 & 2.8239 & 2.7676 & TRN \\
\hline CHEMBL1338736 & 688416 & 5.1309 & 4.5199 & TRN \\
\hline CHEMBL530682 & 688416 & 2.8239 & 4.048 & TRN \\
\hline CHEMBL1449111 & 688416 & 3.9951 & 4.2914 & TRN \\
\hline CHEMBL 1358550 & 688416 & 2.8239 & 2.1672 & TRN \\
\hline CHEMBL1464647 & 688416 & 5.1591 & 5.2959 & TRN \\
\hline CHEMBL1503248 & 688416 & 6.0888 & 5.7805 & TRN \\
\hline CHEMBL1578607 & 688416 & 6.0915 & 5.7036 & TRN \\
\hline CHEMBL3197489 & 688416 & 2.8239 & 4.2063 & TRN \\
\hline CHEMBL1460692 & 688416 & 4.1086 & 4.3757 & TST \\
\hline CHEMBL3189289 & 688416 & 5.655 & 4.8397 & TRN \\
\hline CHEMBL1502639 & 688416 & 2.8239 & 4.1772 & TRN \\
\hline CHEMBL1495462 & 688416 & 2.8239 & 4.641 & TST \\
\hline CHEMBL3196295 & 688416 & 2.8239 & 4.6406 & TRN \\
\hline CHEMBL461820 & 688416 & 5.397 & 5.1965 & TRN \\
\hline CHEMBL1393914 & 688416 & 4.8858 & 4.9037 & TRN \\
\hline CHEMBL1564233 & 688416 & 4.5163 & 4.0596 & TRN \\
\hline CHEMBL1482387 & 688416 & 5.1213 & 4.5933 & TRN \\
\hline CHEMBL1992702 & 688416 & 5.3558 & 5.0566 & TRN \\
\hline CHEMBL1346881 & 688416 & 4.9218 & 4.1729 & TST \\
\hline CHEMBL3196731 & 688416 & 4.0209 & 4.3366 & TRN \\
\hline CHEMBL1555435 & 688416 & 2.8239 & 3.6248 & TRN \\
\hline CHEMBL1454827 & 688416 & 5.0075 & 4.459 & TRN \\
\hline CHEMBL1327172 & 688416 & 5.2651 & 4.9777 & TRN \\
\hline CHEMBL1409001 & 688416 & 5.3572 & 4.81 & TRN \\
\hline CHEMBL1975961 & 688416 & 5.1131 & 4.5814 & TRN \\
\hline CHEMBL3197766 & 688416 & 4.4864 & 4.3796 & TRN \\
\hline CHEMBL1480313 & 688416 & 2.8239 & 4.1591 & TRN \\
\hline CHEMBL1564040 & 688416 & 2.8239 & 3.8743 & TRN \\
\hline CHEMBL1336879 & 688416 & 2.8239 & 4.1759 & TRN \\
\hline CHEMBL1558397 & 688416 & 2.8239 & 2.4199 & TRN \\
\hline CHEMBL1354211 & 688416 & 2.8239 & 4.4373 & TRN \\
\hline CHEMBL1496786 & 688416 & 4.7147 & 4.3342 & TRN \\
\hline CHEMBL1600280 & 688416 & 5.1087 & 4.961 & TRN \\
\hline CHEMBL1428875 & 688416 & 4.1157 & 4.3215 & TST \\
\hline CHEMBL29097 & 688416 & 5.6582 & 4.8551 & TST \\
\hline
\end{tabular}


Supplemental Table S2.txt

\begin{tabular}{|c|c|c|c|c|}
\hline & & & & \\
\hline HEMBL1308056 & 38416 & 3473 & 953 & \\
\hline AEMBL1411897 & 16 & 683 & 66 & \\
\hline 146 & & 248 & & \\
\hline IEMBL14 & 416 & 239 & & \\
\hline AEMBL1438684 & 88416 & 239 & 128 & \\
\hline AEMBL3392057 & 88416 & 002 & 8461 & \\
\hline HEMBL1496827 & & & & \\
\hline JEMBL14 & 416 & 713 & & \\
\hline IEMBL14 & & 239 & & \\
\hline AEMBL1302367 & 416 & 155 & 5999 & \\
\hline AEMBL1593815 & & 748 & 3621 & \\
\hline AEMBL1426507 & & 72 & & \\
\hline AEMBL13 & & 39 & & \\
\hline AEMBL43 & & 06 & 697 & \\
\hline IEMBL17 & 16 & 731 & 29 & \\
\hline JEMBL16 & & 352 & & \\
\hline HEMBL14 & & 38 & & \\
\hline AEMBL13 & & 83 & & \\
\hline AEMBL15 & & & 82 & \\
\hline JEMBL14 & & 887 & 23 & \\
\hline AEMBL15 & & & & \\
\hline IEMBL58 & & 52 & & \\
\hline AEMBL1: & & & & \\
\hline 221 & & 74 & & \\
\hline 1097 & & 239 & & \\
\hline IEMBL15 & & & & \\
\hline EMBL14 & & & & \\
\hline 83 & & & & \\
\hline 21 & & 48 & 73 & \\
\hline 3408 & & & & \\
\hline HEMBL3193989 & & & & \\
\hline & & & & \\
\hline 1 & & & & \\
\hline 740 & & & & \\
\hline AEMBL3209776 & & & 981 & $\mathrm{~F}$ \\
\hline AEMBL1361740 & & 776 & & \\
\hline & & & & \\
\hline M & & & & \\
\hline HEMBL13 & & & & RI \\
\hline AEMBL3197936 & & 502 & 952 & $\mathrm{R}$ \\
\hline 07 & & 65 & & \\
\hline 907 & & & & \\
\hline HEMBL1471698 & & & .8339 & \\
\hline AEMBL13: & & 4.3337 & .2117 & RN \\
\hline IEMBL14 & 68 & 239 & .3353 & 15 \\
\hline 170 & & & & \\
\hline HEMBL140689 & & .4123 & & \\
\hline
\end{tabular}

Page 13938 


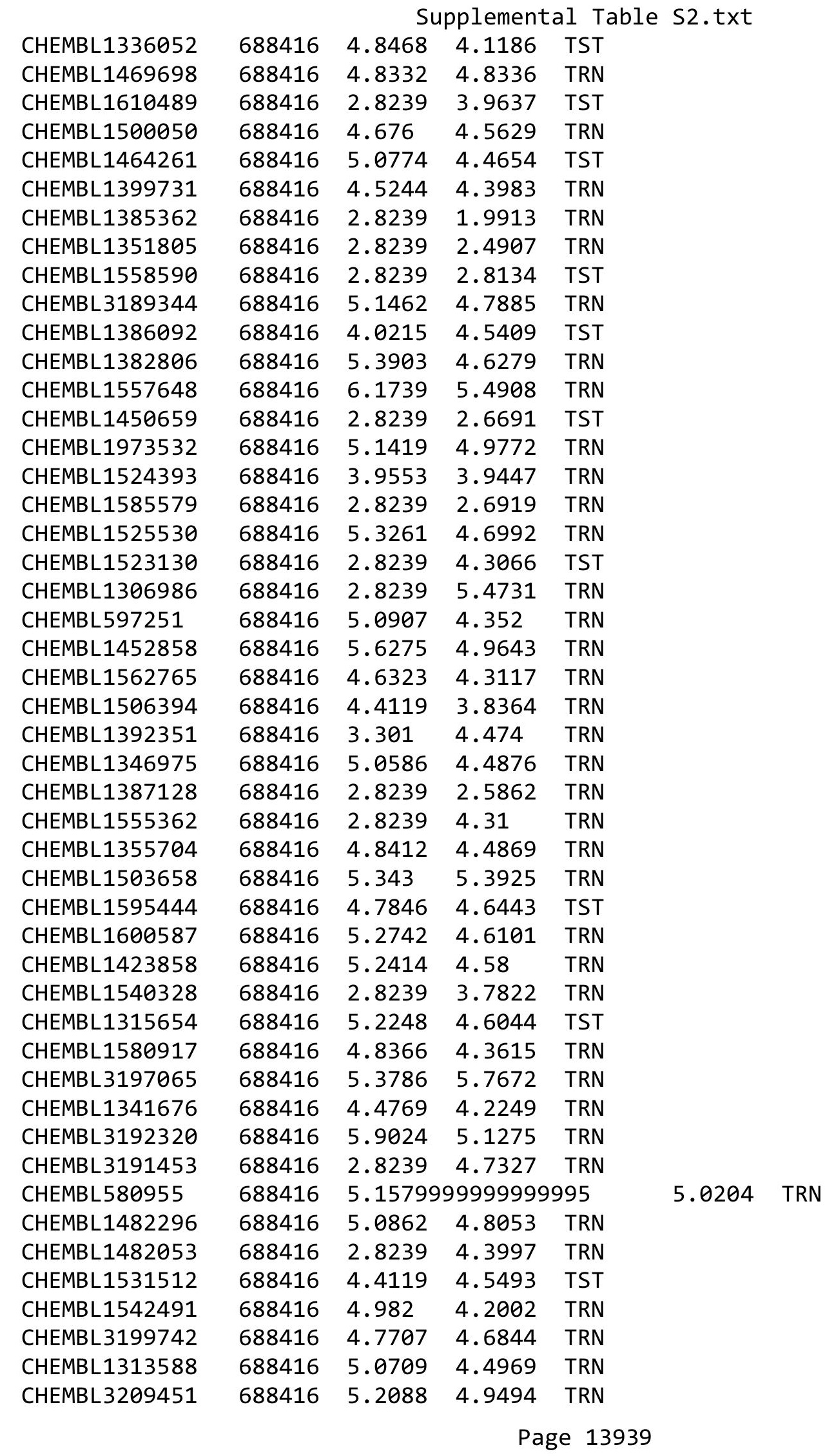




\begin{tabular}{|c|c|c|c|c|}
\hline & & & oplemen & al $\mathrm{T}$ \\
\hline CHEMBL1462041 & 688416 & 4.405 & 4.0596 & TRN \\
\hline CHEMBL1502251 & 688416 & 5.0029 & 4.565 & TRN \\
\hline CHEMBL1574271 & 688416 & 5.0869 & 4.6145 & TRN \\
\hline CHEMBL1484169 & 688416 & 5.2856 & 4.3438 & TRN \\
\hline CHEMBL1327366 & 688416 & 2.8239 & 4.2436 & TRN \\
\hline CHEMBL1344663 & 688416 & 2.8239 & 3.5775 & TRN \\
\hline CHEMBL1481616 & 688416 & 5.605 & 4.795 & TRN \\
\hline CHEMBL1536740 & 688416 & 5.2731 & 5.0084 & TRN \\
\hline CHEMBL1574982 & 688416 & 2.8239 & 3.8815 & TRN \\
\hline CHEMBL1989179 & 688416 & 4.3979 & 3.7852 & TRN \\
\hline CHEMBL268356 & 688416 & 6.2007 & 5.6365 & TRN \\
\hline CHEMBL1470446 & 688416 & 5.6457 & 4.5438 & TST \\
\hline CHEMBL1560092 & 688416 & 4.8603 & 4.5205 & TRN \\
\hline CHEMBL3190262 & 688416 & 4.7276 & 4.2342 & TRN \\
\hline CHEMBL1306283 & 688416 & 5.9404 & 5.8135 & TRN \\
\hline CHEMBL1414413 & 688416 & 2.8239 & 3.3743 & TRN \\
\hline CHEMBL1357155 & 688416 & 4.5781 & 4.2267 & TRN \\
\hline CHEMBL1517467 & 688416 & 2.8239 & 2.2921 & TRN \\
\hline CHEMBL1489358 & 688416 & 2.8239 & 4.6393 & TST \\
\hline CHEMBL3190775 & 688416 & 4.6427 & 4.7733 & TST \\
\hline CHEMBL1389315 & 688416 & 4.9204 & 4.524 & TRN \\
\hline CHEMBL494252 & 688416 & 5.484 & 4.9948 & TRN \\
\hline CHEMBL1578728 & 688416 & 4.5301 & 4.7645 & TRN \\
\hline CHEMBL1416159 & 688416 & 2.8239 & 2.5769 & TRN \\
\hline CHEMBL1985061 & 688416 & 4.9094 & 4.5816 & TST \\
\hline CHEMBL1555899 & 688416 & 2.8239 & 4.4866 & TRN \\
\hline CHEMBL 3213034 & 688416 & 5.4903 & 5.5901 & TRN \\
\hline CHEMBL 583584 & 688416 & 6.3206 & 6.5009 & TRN \\
\hline CHEMBL1989897 & 688416 & 5.2504 & 4.9707 & TRN \\
\hline CHEMBL1340114 & 688416 & 2.8239 & 3.9728 & TRN \\
\hline CHEMBL3198239 & 688416 & 5.0601 & 4.9268 & TRN \\
\hline CHEMBL1328229 & 688416 & 4.0861 & 4.1075 & TRN \\
\hline CHEMBL1368535 & 688416 & 4.5029 & 4.8758 & TRN \\
\hline CHEMBL3207920 & 688416 & 2.8239 & 4.1531 & TRN \\
\hline CHEMBL1356182 & 688416 & 4.9923 & 4.542 & TRN \\
\hline CHEMBL1588549 & 688416 & 5.7841 & 5.3525 & TRN \\
\hline CHEMBL1406942 & 688416 & 4.6728 & 4.2557 & TRN \\
\hline CHEMBL1613034 & 688416 & 2.8239 & 2.6693 & TRN \\
\hline CHEMBL1523242 & 688416 & 3.9431 & 4.2096 & TRN \\
\hline CHEMBL1470633 & 688416 & 2.8239 & 4.6564 & TRN \\
\hline CHEMBL1389982 & 688416 & 4.271 & 4.268 & TRN \\
\hline CHEMBL1532815 & 688416 & 4.9136 & 4.195 & TRN \\
\hline CHEMBL1581194 & 688416 & 2.8239 & 3.8954 & TRN \\
\hline CHEMBL1426113 & 688416 & 4.314 & 4.5186 & TRN \\
\hline CHEMBL1333965 & 688416 & 6.7399 & 6.3352 & TST \\
\hline CHEMBL1422750 & 688416 & 2.8239 & 2.396 & TRN \\
\hline CHEMBL1502724 & 688416 & 2.8239 & 4.6762 & TRN \\
\hline CHEMBL1582111 & 688416 & 5.2045 & 4.9916 & TRN \\
\hline
\end{tabular}




\begin{tabular}{|c|c|c|c|c|c|}
\hline & & \multicolumn{4}{|c|}{ Supplemental Table S2.txt } \\
\hline CHEMBL1431953 & 688416 & 4.546 & 4.5607 & TST & \\
\hline CHEMBL3208443 & 688416 & 5.6544 & 5.0328 & TRN & \\
\hline CHEMBL1336054 & 688416 & 5.1191 & 4.6684 & TRN & \\
\hline CHEMBL 3212523 & 688416 & 2.8239 & 2.5206 & TRN & \\
\hline CHEMBL1541525 & 688416 & 2.8239 & 2.78899 & 99999999997 & TRN \\
\hline CHEMBL1401984 & 688416 & 3.9427 & 3.8723 & TRN & \\
\hline CHEMBL240546 & 688416 & 5.1144 & 4.5437 & TRN & \\
\hline CHEMBL1604622 & 688416 & 2.8239 & 3.8919 & TST & \\
\hline CHEMBL1519235 & 688416 & 4.9541 & 4.3752 & TRN & \\
\hline CHEMBL1528266 & 688416 & 2.8239 & 2.6843 & TRN & \\
\hline CHEMBL1532546 & 688416 & 5.994 & 5.7628 & TRN & \\
\hline CHEMBL1520712 & 688416 & 2.8239 & 2.6057 & TST & \\
\hline CHEMBL 3199654 & 688416 & 4.3616 & 4.2676 & TRN & \\
\hline CHEMBL1344918 & 688416 & 2.8239 & 4.26399 & 9999999999 & TRN \\
\hline CHEMBL1575707 & 688416 & 2.8239 & 2.6879 & TRN & \\
\hline CHEMBL1481361 & 688416 & 5.3563 & 4.5688 & TST & \\
\hline CHEMBL1965348 & 688416 & 2.8239 & 4.8036 & TRN & \\
\hline CHEMBL1481836 & 688416 & 5.3656 & 4.4568 & TRN & \\
\hline CHEMBL1331239 & 688416 & 2.8239 & 4.2414 & TRN & \\
\hline CHEMBL1544097 & 688416 & 4.1927 & 4.7975 & TRN & \\
\hline CHEMBL1371733 & 688416 & 2.8239 & 2.7833 & TRN & \\
\hline CHEMBL1335491 & 688416 & 5.3027 & 5.4355 & TRN & \\
\hline CHEMBL1453819 & 688416 & 4.4414 & 4.7243 & TRN & \\
\hline CHEMBL1388595 & 688416 & 4.6903 & 4.3633 & TRN & \\
\hline CHEMBL1467058 & 688416 & 7.1487 & 7.3271 & TST & \\
\hline CHEMBL1553408 & 688416 & 5.0644 & 4.6222 & TRN & \\
\hline CHEMBL1607840 & 688416 & 4.3644 & 4.2475 & TST & \\
\hline CHEMBL1528835 & 688416 & 5.1458 & 4.9502 & TRN & \\
\hline CHEMBL1450648 & 688416 & 5.0339 & 4.8098 & TRN & \\
\hline CHEMBL1965791 & 688416 & 4.9695 & 4.7916 & TRN & \\
\hline CHEMBL1480647 & 688416 & 2.8239 & 2.8027 & TRN & \\
\hline CHEMBL3195171 & 688416 & 4.86 & 4.6133 & TRN & \\
\hline CHEMBL1506926 & 688416 & 4.2712 & 3.9674 & TRN & \\
\hline CHEMBL1365978 & 688416 & 8.2218 & 6.8414 & TRN & \\
\hline CHEMBL1343528 & 688416 & 2.8239 & 3.4907 & TRN & \\
\hline CHEMBL1611364 & 688416 & 5.1361 & 4.1845 & TRN & \\
\hline CHEMBL1575766 & 688416 & 5.2607 & 4.0474 & TRN & \\
\hline CHEMBL1337193 & 688416 & 5.6929 & 4.89199 & 99999999995 & TRN \\
\hline CHEMBL1388295 & 688416 & 2.8239 & 2.4802 & TRN & \\
\hline CHEMBL1599815 & 688416 & 4.9753 & 5.5817 & TRN & \\
\hline CHEMBL1537431 & 688416 & 2.8239 & 2.3584 & TRN & \\
\hline CHEMBL1587103 & 688416 & 2.8239 & 3.5518 & TRN & \\
\hline CHEMBL3195778 & 688416 & 4.7047 & 4.7553 & TRN & \\
\hline CHEMBL1350708 & 688416 & 2.8239 & 2.4088 & TRN & \\
\hline CHEMBL1604723 & 688416 & 2.8239 & 2.3578 & TRN & \\
\hline CHEMBL3191846 & 688416 & 4.8598 & 4.1914 & TRN & \\
\hline CHEMBL1376019 & 688416 & 4.8532 & 4.5024 & TRN & \\
\hline CHEMBL1483252 & 688416 & 4.8166 & 5.2053 & TRN & \\
\hline
\end{tabular}




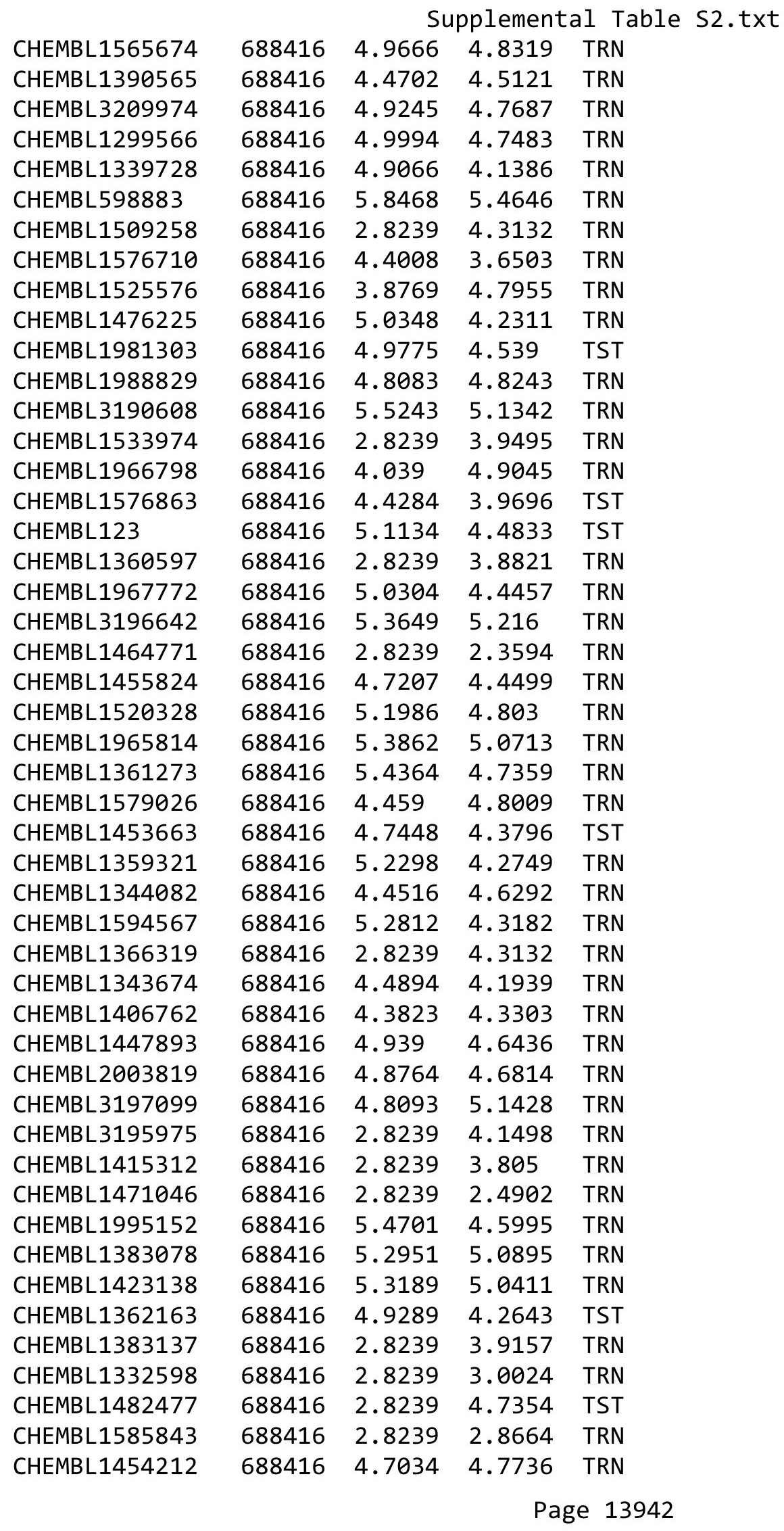




\begin{tabular}{|c|c|c|c|c|c|c|}
\hline & & \multicolumn{5}{|c|}{ Supplemental Table S2.txt } \\
\hline CHEMBL1568310 & 688416 & 2.8239 & 4.4622 & TRN & & \\
\hline CHEMBL1300385 & 688416 & 2.8239 & 3.8868 & TRN & & \\
\hline CHEMBL1548761 & 688416 & 4.1655 & 4.6036 & TRN & & \\
\hline CHEMBL1345827 & 688416 & 5.3873 & 4.33 & TRN & & \\
\hline CHEMBL1386178 & 688416 & 5.1059 & 4.6011 & TRN & & \\
\hline CHEMBL1363271 & 688416 & 2.8239 & 2.077 & TRN & & \\
\hline CHEMBL1306480 & 688416 & 4.1879 & 4.2584 & TRN & & \\
\hline CHEMBL1465980 & 688416 & 2.8239 & 2.7547 & TST & & \\
\hline CHEMBL1442884 & 688416 & 2.8239 & 4.6221 & TRN & & \\
\hline CHEMBL1487309 & 688416 & 3.301 & 4.0582 & TRN & & \\
\hline CHEMBL1521336 & 688416 & 2.8239 & 3.7526 & TRN & & \\
\hline CHEMBL355496 & 688416 & 5.4578 & 4.9204 & TRN & & \\
\hline CHEMBL1531654 & 688416 & 5.2519 & 4.4412 & TRN & & \\
\hline CHEMBL1313776 & 688416 & 2.8239 & 4.3373 & TRN & & \\
\hline CHEMBL1421905 & 688416 & 4.9684 & 5.0602 & TRN & & \\
\hline CHEMBL1510316 & 688416 & 2.8239 & 2.6981 & TST & & \\
\hline CHEMBL1302758 & 688416 & 4.515 & 3.8996 & TRN & & \\
\hline CHEMBL1488460 & 688416 & 2.8239 & 4.3853 & TRN & & \\
\hline CHEMBL1498998 & 688416 & 2.8239 & 3.6429 & TST & & \\
\hline CHEMBL1535525 & 688416 & 2.8239 & 3.8763 & TRN & & \\
\hline CHEMBL1561569 & 688416 & 2.8239 & 2.5239 & TRN & & \\
\hline CHEMBL1448732 & 688416 & 5.0903 & 4.2547 & TRN & & \\
\hline CHEMBL1399370 & 688416 & 4.6631 & 4.6163 & TRN & & \\
\hline CHEMBL1461477 & 688416 & 5.3771 & 5.2286 & TRN & & \\
\hline CHEMBL1326349 & 688416 & 2.8239 & 4.6701 & TRN & & \\
\hline CHEMBL1519764 & 688416 & 2.8239 & 4.0913 & TST & & \\
\hline CHEMBL3210497 & 688416 & 2.8239 & 3.9412 & TST & & \\
\hline CHEMBL1398268 & 688416 & 4.4861 & 2.5081 & TRN & & \\
\hline CHEMBL1412087 & 688416 & 5.4357 & 5.1616 & TRN & & \\
\hline CHEMBL1997585 & 688416 & 4.4856 & 3.5284 & TRN & & \\
\hline CHEMBL1369492 & 688416 & 5.1062 & 4.9969 & TRN & & \\
\hline CHEMBL1564821 & 688416 & 5.4238 & 4.9723 & TRN & & \\
\hline CHEMBL1598882 & 688416 & 2.8239 & 4.1008 & TRN & & \\
\hline CHEMBL1341913 & 688416 & 2.8239 & 3.8173 & TST & & \\
\hline CHEMBL1977043 & 688416 & $5.0760 e$ & 30000000 & 205 & 4.8281 & TRN \\
\hline CHEMBL1533489 & 688416 & 2.8239 & 2.6946 & TRN & & \\
\hline CHEMBL1539522 & 688416 & 4.6537 & 4.2056 & TRN & & \\
\hline CHEMBL1566130 & 688416 & 4.1804 & 4.6522 & TRN & & \\
\hline CHEMBL 2002849 & 688416 & 4.4408 & 4.938 & TRN & & \\
\hline CHEMBL1578492 & 688416 & 2.8239 & 3.7034 & TRN & & \\
\hline CHEMBL3193542 & 688416 & 2.8239 & 3.8937 & TRN & & \\
\hline CHEMBL1419536 & 688416 & 2.8239 & 4.2771 & TRN & & \\
\hline CHEMBL1495254 & 688416 & 5.3918 & 4.6111 & TRN & & \\
\hline CHEMBL1533170 & 688416 & 2.8239 & 2.7696 & TRN & & \\
\hline CHEMBL1422386 & 688416 & 5.6024 & 4.8777 & TRN & & \\
\hline CHEMBL1501558 & 688416 & 5.0336 & 4.9237 & TRN & & \\
\hline CHEMBL1303975 & 688416 & 4.6227 & 3.9015 & TRN & & \\
\hline CHEMBL1424380 & 688416 & 4.1027 & 3.8324 & TRN & & \\
\hline
\end{tabular}


Supplemental Table S2.txt

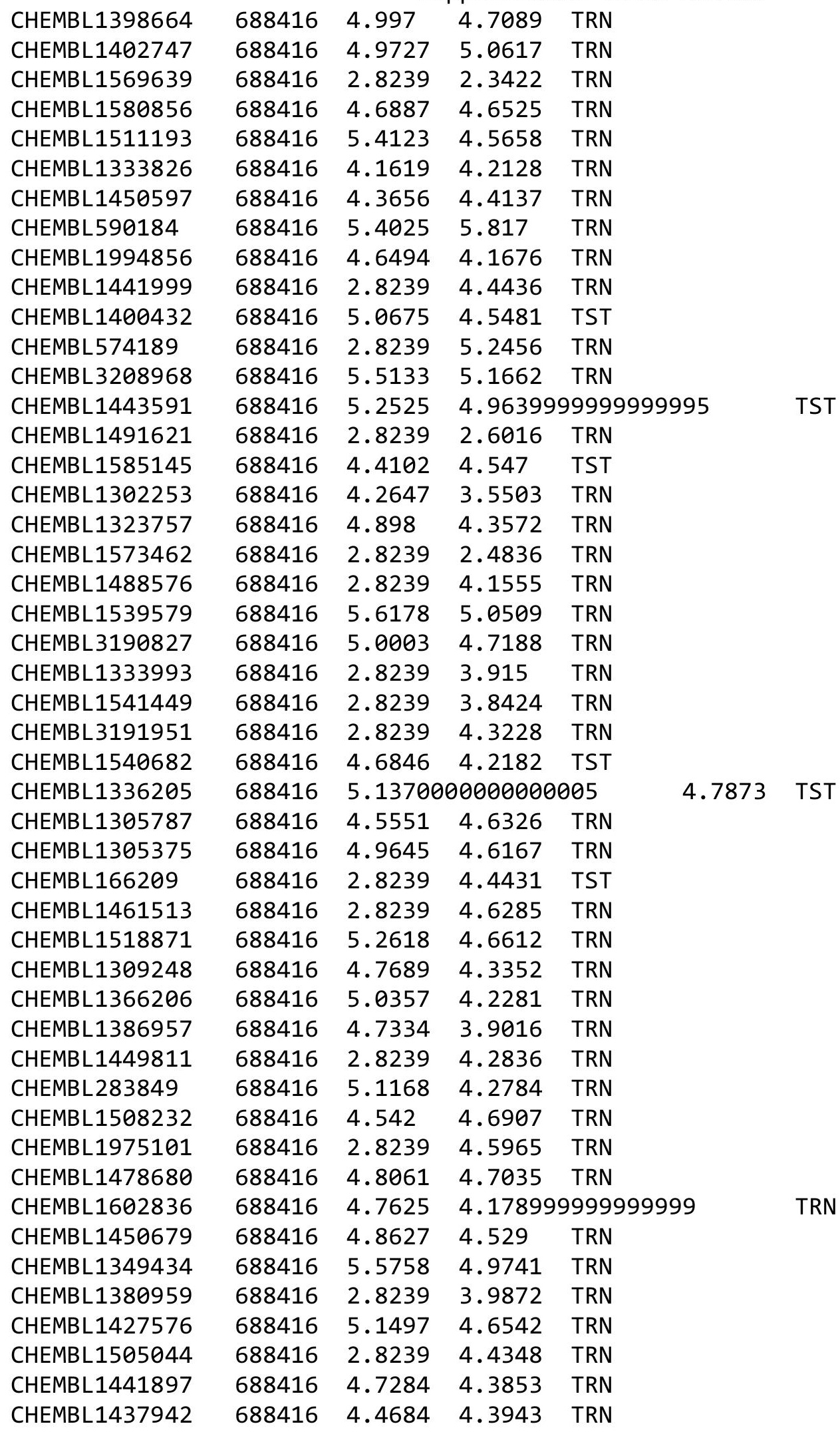

Page 13944 


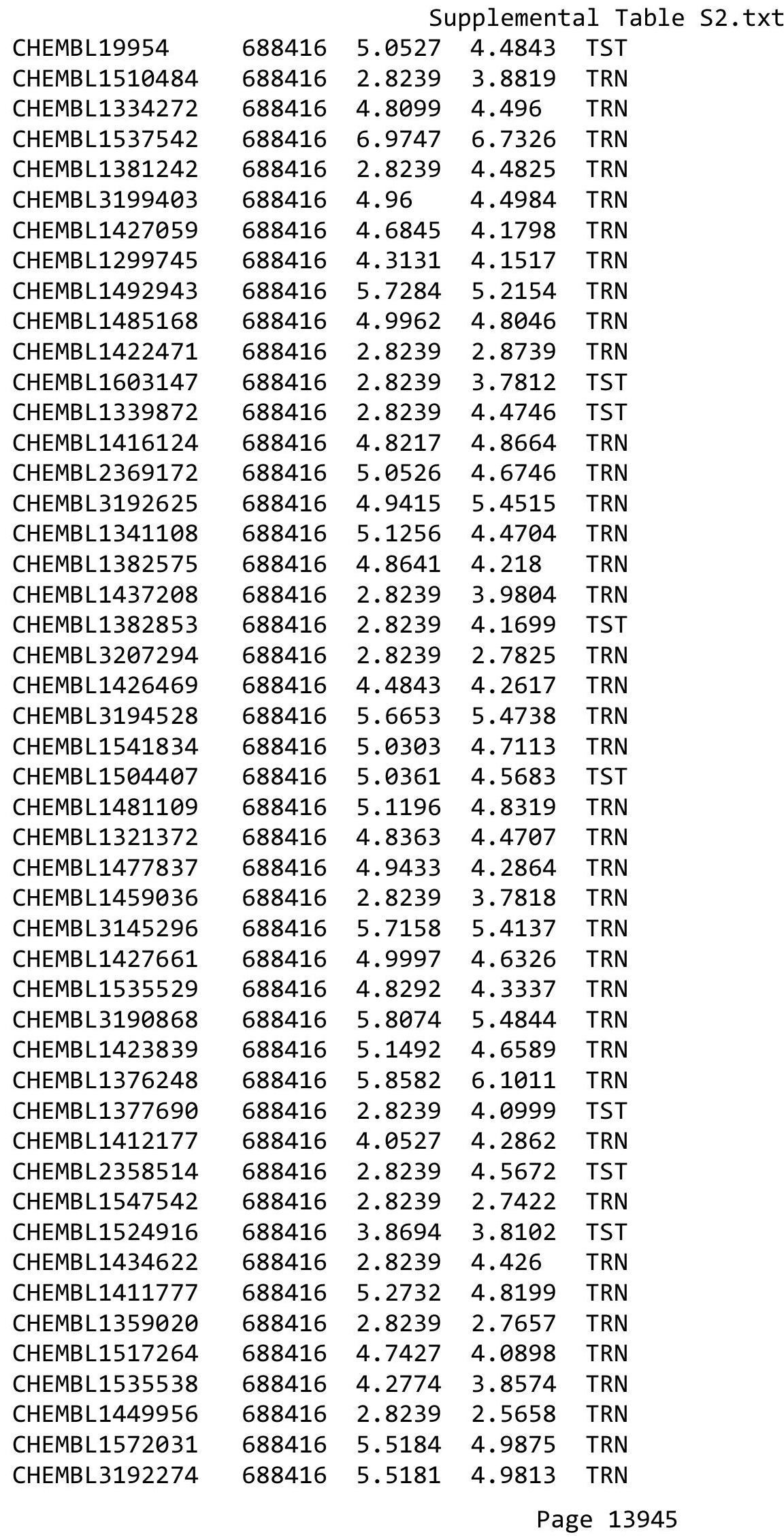




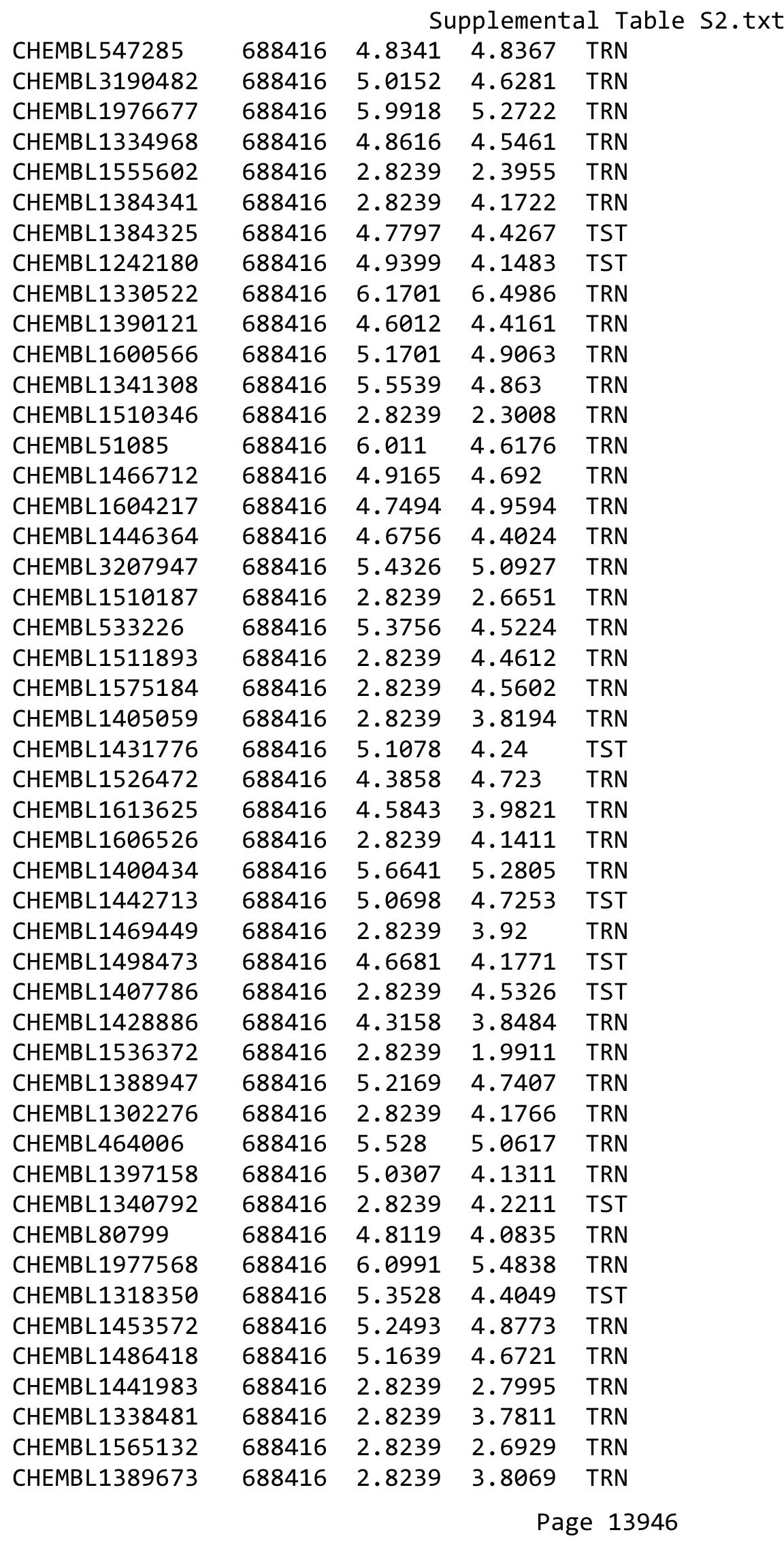


Supplemental Table S2.txt

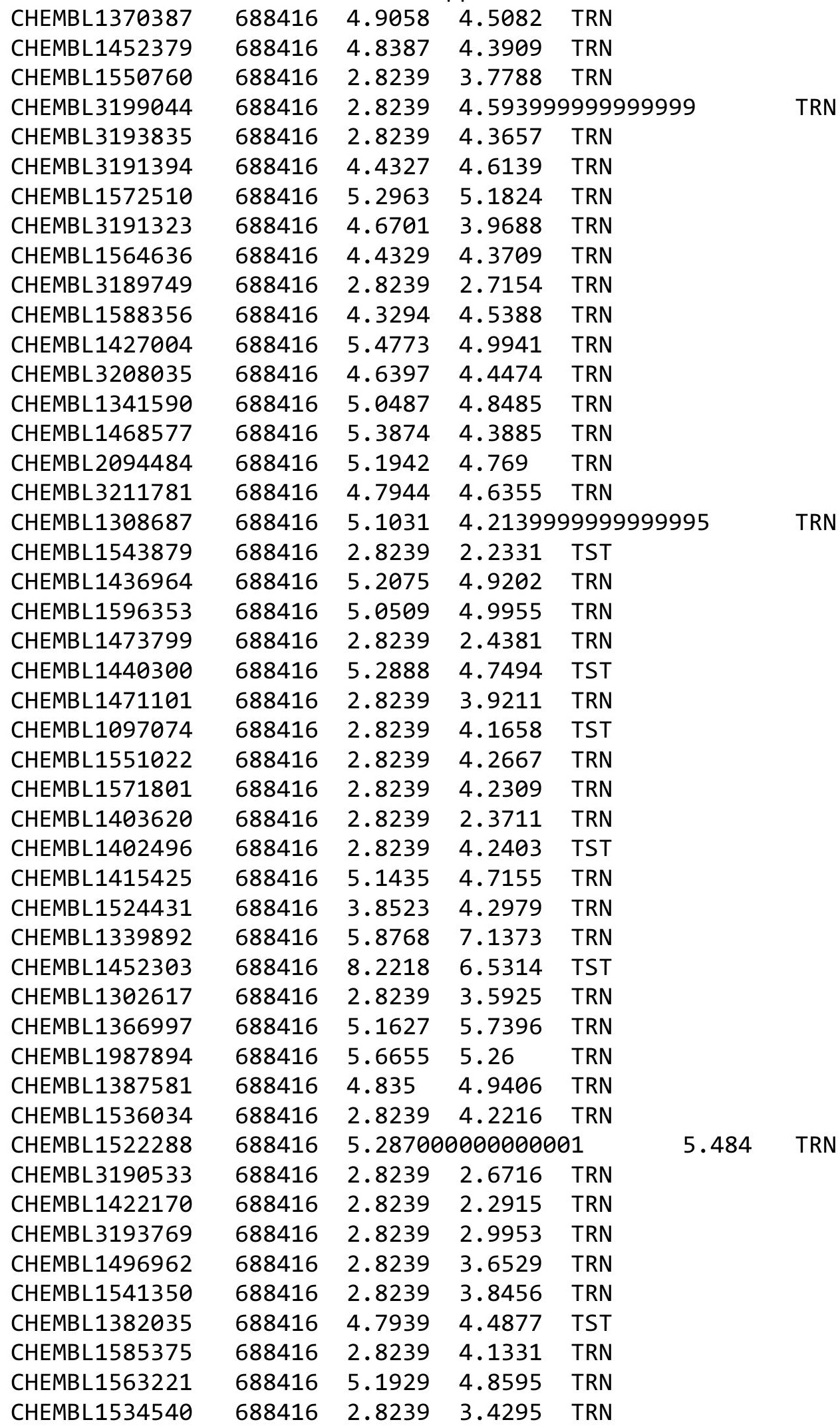

Page 13947 


\begin{tabular}{|c|c|c|c|c|c|}
\hline & & \multicolumn{4}{|c|}{ Supplemental Table S2.txt } \\
\hline CHEMBL1538328 & 688416 & 2.8239 & 5.2596 & TST & \\
\hline CHEMBL1571174 & 688416 & 4.6062 & 2.6197 & TRN & \\
\hline CHEMBL1464544 & 688416 & 4.2443 & 4.63399 & 99999999995 & TST \\
\hline CHEMBL1430104 & 688416 & 4.7165 & 4.6765 & TRN & \\
\hline CHEMBL 3194563 & 688416 & 4.967 & 4.4347 & TRN & \\
\hline CHEMBL1503034 & 688416 & 5.0195 & 5.087 & TRN & \\
\hline CHEMBL1365357 & 688416 & 2.8239 & 3.9418 & TRN & \\
\hline CHEMBL1315224 & 688416 & 5.1406 & 4.6781 & TRN & \\
\hline CHEMBL1343101 & 688416 & 5.5834 & 4.69 & TST & \\
\hline CHEMBL1395962 & 688416 & 5.3963 & 4.6742 & TST & \\
\hline CHEMBL1361033 & 688416 & 4.9659 & 4.2158 & TRN & \\
\hline CHEMBL1510680 & 688416 & 2.8239 & 3.0394 & TRN & \\
\hline CHEMBL1350867 & 688416 & 4.5067 & 4.5409 & TRN & \\
\hline CHEMBL1307769 & 688416 & 5.062 & 4.1244 & TST & \\
\hline CHEMBL586937 & 688416 & 4.9164 & 4.5847 & TRN & \\
\hline CHEMBL1398406 & 688416 & 2.8239 & 2.5723 & TRN & \\
\hline CHEMBL1443660 & 688416 & 5.6394 & 5.62200 & 0000000001 & TRN \\
\hline CHEMBL1541391 & 688416 & 5.2198 & 4.6899 & TST & \\
\hline CHEMBL1505922 & 688416 & 4.5987 & 4.1981 & TRN & \\
\hline CHEMBL1499490 & 688416 & 5.4949 & 4.8637 & TRN & \\
\hline CHEMBL1373490 & 688416 & 4.9304 & 4.435 & TRN & \\
\hline CHEMBL1521554 & 688416 & 4.8506 & 4.2973 & TRN & \\
\hline CHEMBL589351 & 688416 & 4.7322 & 4.4426 & TRN & \\
\hline CHEMBL3189791 & 688416 & 5.2229 & 5.1916 & TRN & \\
\hline CHEMBL1610002 & 688416 & 2.8239 & 4.1166 & TST & \\
\hline CHEMBL3199832 & 688416 & 4.9753 & 4.6024 & TRN & \\
\hline CHEMBL535315 & 688416 & 4.4666 & 4.6363 & TRN & \\
\hline CHEMBL1405220 & 688416 & 5.0084 & 4.6449 & TRN & \\
\hline CHEMBL1508055 & 688416 & 2.8239 & 4.2704 & TRN & \\
\hline CHEMBL1343073 & 688416 & 2.8239 & 4.6653 & TST & \\
\hline CHEMBL3213728 & 688416 & 4.7662 & 3.9331 & TRN & \\
\hline CHEMBL1604401 & 688416 & 4.0027 & 4.0392 & TRN & \\
\hline CHEMBL1422465 & 688416 & 4.9359 & 4.2581 & TST & \\
\hline CHEMBL1344875 & 688416 & 4.3475 & 4.114 & TRN & \\
\hline CHEMBL1456906 & 688416 & 8.2218 & 7.2299 & TST & \\
\hline CHEMBL1421377 & 688416 & 4.7665 & 4.4134 & TRN & \\
\hline CHEMBL1463163 & 688416 & 4.0031 & 4.0907 & TRN & \\
\hline CHEMBL1582609 & 688416 & 2.8239 & 3.912 & TRN & \\
\hline CHEMBL45152 & 688416 & 5.3798 & 4.9224 & TRN & \\
\hline CHEMBL1604156 & 688416 & 4.7569 & 5.0958 & TRN & \\
\hline CHEMBL1376130 & 688416 & 4.2094 & 3.972 & TRN & \\
\hline CHEMBL1583292 & 688416 & 6.7773 & 6.5216 & TRN & \\
\hline CHEMBL1366168 & 688416 & 5.171 & 4.8184 & TRN & \\
\hline CHEMBL1469656 & 688416 & 4.8206 & 4.6944 & TRN & \\
\hline CHEMBL1494458 & 688416 & 2.8239 & 4.2989 & TST & \\
\hline CHEMBL1505080 & 688416 & 5.087 & 4.4254 & TST & \\
\hline CHEMBL1579335 & 688416 & 2.8239 & 3.8906 & TRN & \\
\hline CHEMBL1520702 & 688416 & 2.8239 & 4.25 & TRN & \\
\hline
\end{tabular}




\begin{tabular}{|c|c|c|c|c|c|}
\hline & & \multicolumn{4}{|c|}{ Supplemental Table s2.txt } \\
\hline CHEMBL1542654 & 688416 & 4.7338 & 4.0497 & TRN & \\
\hline CHEMBL1302815 & 688416 & 4.95 & 4.783 & TRN & \\
\hline CHEMBL1384672 & 688416 & 2.8239 & 4.2199 & TST & \\
\hline CHEMBL 2003001 & 688416 & 5.1258 & 4.853 & TRN & \\
\hline CHEMBL1452261 & 688416 & 5.364 & 5.608 & TRN & \\
\hline CHEMBL1991450 & 688416 & 2.8239 & 4.3611 & TRN & \\
\hline CHEMBL1367662 & 688416 & 2.8239 & 3.9389 & TRN & \\
\hline CHEMBL209101 & 688416 & 5.15 & 4.2344 & TRN & \\
\hline CHEMBL3194892 & 688416 & 4.9293 & 4.5197 & TRN & \\
\hline CHEMBL1432380 & 688416 & 2.8239 & 2.0869 & TST & \\
\hline CHEMBL1429861 & 688416 & 2.8239 & 4.1834 & TRN & \\
\hline CHEMBL1579503 & 688416 & 2.8239 & 4.2773 & TRN & \\
\hline CHEMBL1548409 & 688416 & 4.5783 & 4.6423 & TST & \\
\hline CHEMBL1407688 & 688416 & 2.8239 & 2.6245 & TRN & \\
\hline CHEMBL1341947 & 688416 & 4.7232 & 4.3188 & TST & \\
\hline CHEMBL1494353 & 688416 & 4.9194 & 4.7453 & TRN & \\
\hline CHEMBL1969094 & 688416 & 4.1443 & 4.3081 & TRN & \\
\hline CHEMBL1528965 & 688416 & 5.2224 & 4.9653 & TRN & \\
\hline CHEMBL1536558 & 688416 & 4.4701 & 4.0016 & TRN & \\
\hline CHEMBL1996376 & 688416 & 2.8239 & 4.8288 & TRN & \\
\hline CHEMBL1304742 & 688416 & 4.7572 & 4.6906 & TST & \\
\hline CHEMBL1440974 & 688416 & 2.8239 & 2.4984 & TRN & \\
\hline CHEMBL1548396 & 688416 & 4.6748 & 4.5208 & TST & \\
\hline CHEMBL1429365 & 688416 & 4.9511 & 4.5399 & TRN & \\
\hline CHEMBL1349631 & 688416 & 5.8077 & 6.0809 & TRN & \\
\hline CHEMBL1582424 & 688416 & 2.8239 & 2.3976 & TRN & \\
\hline CHEMBL1379136 & 688416 & 5.5127 & 4.74100 & 00000000005 & TRN \\
\hline CHEMBL 2094567 & 688416 & 5.7352 & 5.9026 & TRN & \\
\hline CHEMBL1602590 & 688416 & 5.0904 & 4.4438 & TRN & \\
\hline CHEMBL1401522 & 688416 & 5.58299 & 99999999 & 4.8319 & TST \\
\hline CHEMBL1521230 & 688416 & 4.7759 & 4.5587 & TRN & \\
\hline CHEMBL1422161 & 688416 & 5.1353 & 4.5955 & TRN & \\
\hline CHEMBL1967185 & 688416 & 4.1764 & 4.7258 & TRN & \\
\hline CHEMBL1301734 & 688416 & 4.4382 & 4.3906 & TST & \\
\hline CHEMBL1479116 & 688416 & 4.6973 & 3.9184 & TST & \\
\hline CHEMBL1375254 & 688416 & 2.8239 & 3.2041 & TRN & \\
\hline CHEMBL1425166 & 688416 & 5.0274 & 4.7215 & TRN & \\
\hline CHEMBL1453089 & 688416 & 4.9356 & 4.50899 & 99999999995 & TRN \\
\hline CHEMBL1581270 & 688416 & 2.8239 & 3.8228 & TRN & \\
\hline CHEMBL1391055 & 688416 & 4.3005 & 4.5623 & TRN & \\
\hline CHEMBL1454278 & 688416 & 5.0157 & 4.5668 & TRN & \\
\hline CHEMBL1358081 & 688416 & 2.8239 & 2.26800 & 00000000002 & TRN \\
\hline CHEMBL1372388 & 688416 & 2.8239 & 3.9449 & TRN & \\
\hline CHEMBL1412412 & 688416 & 2.8239 & 3.8364 & TRN & \\
\hline CHEMBL1391272 & 688416 & 5.2136 & 4.5309 & TRN & \\
\hline CHEMBL3189161 & 688416 & 5.4424 & 4.8211 & TRN & \\
\hline CHEMBL1320562 & 688416 & 5.2384 & 4.4082 & TST & \\
\hline CHEMBL1439990 & 688416 & 4.6243 & 4.0306 & TRN & \\
\hline
\end{tabular}




\begin{tabular}{|c|c|c|c|c|c|c|}
\hline & & \multicolumn{5}{|c|}{ Supplemental Table S2.txt } \\
\hline CHEMBL1457139 & 688416 & 5.1839 & 4.9326 & TRN & & \\
\hline CHEMBL1407907 & 688416 & 4.8815 & 4.1075 & TRN & & \\
\hline CHEMBL1579548 & 688416 & 5.7042 & 4.8038 & TRN & & \\
\hline CHEMBL1438071 & 688416 & 4.5186 & 4.2899 & TRN & & \\
\hline CHEMBL1992109 & 688416 & 5.7222 & 5.3719 & TRN & & \\
\hline CHEMBL1563898 & 688416 & 4.9926 & 4.5702 & TRN & & \\
\hline CHEMBL1300446 & 688416 & 5.2619 & 5.053999 & 99999999 & & TRN \\
\hline CHEMBL1327638 & 688416 & 2.8239 & 4.2883 & TRN & & \\
\hline CHEMBL1385676 & 688416 & 5.0315 & 4.7088 & TRN & & \\
\hline CHEMBL1550132 & 688416 & 4.2704 & 4.5886 & TRN & & \\
\hline CHEMBL1570705 & 688416 & 4.859 & 5.13 & TRN & & \\
\hline CHEMBL1511380 & 688416 & 2.8239 & 2.5712 & TST & & \\
\hline CHEMBL1896972 & 688416 & 4.7951 & 4.2345 & TRN & & \\
\hline CHEMBL1362528 & 688416 & 2.8239 & 2.4226 & TRN & & \\
\hline CHEMBL1572382 & 688416 & 4.6362 & 4.4695 & TRN & & \\
\hline CHEMBL1544679 & 688416 & 5.1902 & 5.4346 & TRN & & \\
\hline CHEMBL1418469 & 688416 & 2.8239 & 3.9536 & TRN & & \\
\hline CHEMBL1445024 & 688416 & 4.4452 & 3.1475 & TRN & & \\
\hline CHEMBL1984876 & 688416 & 5.3247 & 5.1614 & TRN & & \\
\hline CHEMBL473107 & 688416 & 4.0044 & 4.3643 & TRN & & \\
\hline CHEMBL1416769 & 688416 & 5.2276 & 4.9282 & TRN & & \\
\hline CHEMBL1421446 & 688416 & 2.8239 & 2.7919 & TRN & & \\
\hline CHEMBL1603637 & 688416 & 5.4371 & 5.1333 & TRN & & \\
\hline CHEMBL1302158 & 688416 & 4.9349 & 4.5507 & TRN & & \\
\hline CHEMBL1589444 & 688416 & 2.8239 & 2.7683 & TRN & & \\
\hline CHEMBL1564958 & 688416 & 5.5302 & 4.9815 & TRN & & \\
\hline CHEMBL1536217 & 688416 & 4.8473 & 4.4861 & TRN & & \\
\hline CHEMBL1559624 & 688416 & 5.2274 & 4.6266 & TRN & & \\
\hline CHEMBL1377903 & 688416 & 4.794 & 4.4839 & TST & & \\
\hline CHEMBL1409851 & 688416 & 4.8505 & 4.3139 & TRN & & \\
\hline CHEMBL1335030 & 688416 & 4.9868 & 5.5895 & TRN & & \\
\hline CHEMBL1303651 & 688416 & 5.6003 & 5.1041 & TRN & & \\
\hline CHEMBL3191360 & 688416 & 4.3346 & 3.9908 & TRN & & \\
\hline CHEMBL1303940 & 688416 & 2.8239 & 2.4316 & TST & & \\
\hline CHEMBL1492560 & 688416 & 4.4206 & 4.3293 & TRN & & \\
\hline CHEMBL3189832 & 688416 & 5.1369 & 4.6798 & TST & & \\
\hline CHEMBL1525098 & 688416 & 5.8573 & 5.9831 & TRN & & \\
\hline CHEMBL1483261 & 688416 & 4.7104 & 4.243 & TRN & & \\
\hline CHEMBL140425 & 688416 & 5.2389 & 5.1272 & TRN & & \\
\hline CHEMBL1523997 & 688416 & $5.1560 e$ & 000000000 & 01 & 4.761 & TRN \\
\hline CHEMBL1517661 & 688416 & 2.8239 & 2.5194 & TRN & & \\
\hline CHEMBL1307746 & 688416 & 2.8239 & 2.713 & TST & & \\
\hline CHEMBL590665 & 688416 & 5.6745 & 5.3526 & TRN & & \\
\hline CHEMBL1448984 & 688416 & 2.8239 & 3.6087 & TRN & & \\
\hline CHEMBL1521482 & 688416 & 5.2502 & 4.9292 & TRN & & \\
\hline CHEMBL1387906 & 688416 & 4.6508 & 4.3657 & TRN & & \\
\hline CHEMBL1500466 & 688416 & 5.0203 & 4.3314 & TRN & & \\
\hline CHEMBL1421316 & 688416 & 2.8239 & 3.8025 & TRN & & \\
\hline
\end{tabular}




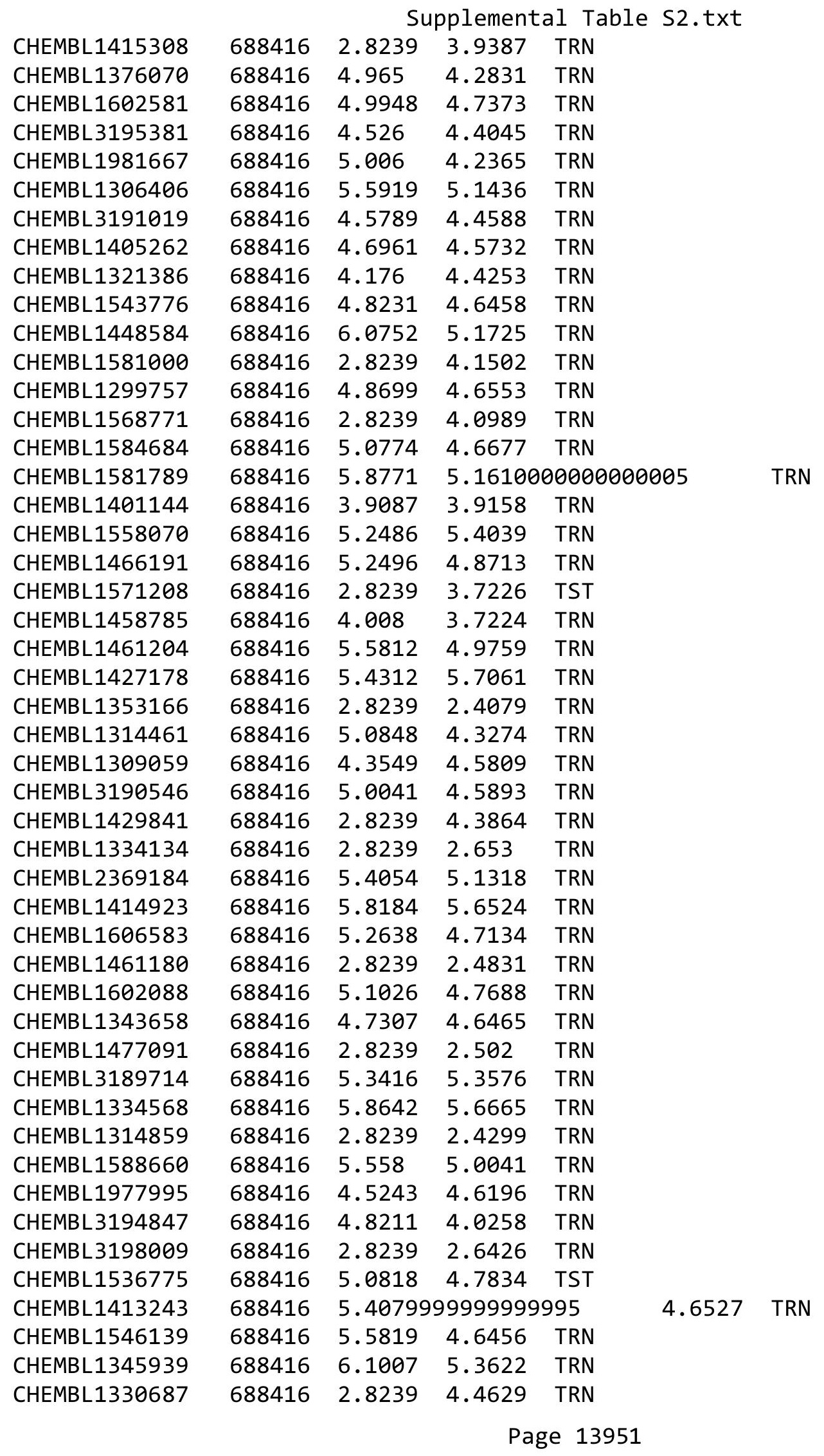


Supplemental Table S2.txt

\begin{tabular}{|c|c|c|c|c|}
\hline 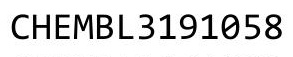 & & & & \\
\hline HEMBL1604383 & 88416 & 066 & 4.1441 & \\
\hline HEMBL1469579 & & 403 & 6635 & \\
\hline 27 & & & & \\
\hline EMBL14 & & 53 & 163 & \\
\hline AEMBL1573804 & 88416 & 849 & 1924 & \\
\hline HEMBL1504469 & 88416 & 394 & .3364 & \\
\hline HEMBL 584668 & & $\partial 24$ & 2871 & \\
\hline IEMBL: & 16 & 157 & .2276 & \\
\hline IEMBL142 & 16 & 239 & 3.9158 & \\
\hline HEMBL1533835 & 88416 & 3032 & 3619 & \\
\hline AEMBL1343581 & 6 & 3304 & 4412 & \\
\hline HEMBL143 & 16 & 478 & 9445 & \\
\hline HEMBL14 & & & 1752 & \\
\hline HEMBL 31 & 16 & 259 & 5381 & \\
\hline HEMBL1479 & 16 & 28 & 4566 & \\
\hline HEMBL1380621 & 6 & 633 & 7214 & \\
\hline HEMBL 3198 & 6 & 39 & 3818 & \\
\hline HEMBL45 & & & 904 & \\
\hline HEMBL13 & 6 & & 675 & \\
\hline HEMBL13 & 6 & & 4522 & \\
\hline AEMBL1461 & 6 & 56 & 5232 & RN \\
\hline HEMBL159 & 6 & 39 & 9062 & \\
\hline HEMBL15 & & & 313 & \\
\hline AEMBL1 14 & & & 808 & RN \\
\hline IEMBL 14 & 6 & & 839 & RN \\
\hline HEMBL134€ & 6 & 82 & 311 & ГRN \\
\hline HEMBL 200 & 16 & 81 & 377 & $\mathrm{RN}$ \\
\hline HEM & & & & RIV \\
\hline 95 & & & 019 & RN \\
\hline HEMBL150 & 6 & & 81 & RN \\
\hline HEMBL1548086 & 88416 & 406 & 3457 & ST \\
\hline HEMBL132 & 16 & 239 & 306 & ו \\
\hline 9 & & & & ST \\
\hline HEMBL 200 & & & 3062 & RN \\
\hline HEMBL1374864 & 6 & 39 & 222 & ГRN \\
\hline HEMBL3214096 & 16 & 239 & 9516 & TRN \\
\hline AFMRI 132 & 6 & 38 & 788 & N. \\
\hline HIM & & & & RN \\
\hline HEMBL138 & & & 822 & RN \\
\hline HEMBL 148 & 16 & 49 & 258 & ГRN \\
\hline HEMBL137 & 6 & 239 & 854 & $\mathrm{RI}$ \\
\hline HEMBL158 & & & 3198 & \\
\hline & & & 2165 & ГST \\
\hline HEMBL14 & & 9749 & 4721 & TST \\
\hline HEMBL152 & 88416 & 2.8239 & .3423 & $N$ \\
\hline or & & & & \\
\hline & & & & \\
\hline
\end{tabular}

Page 13952 


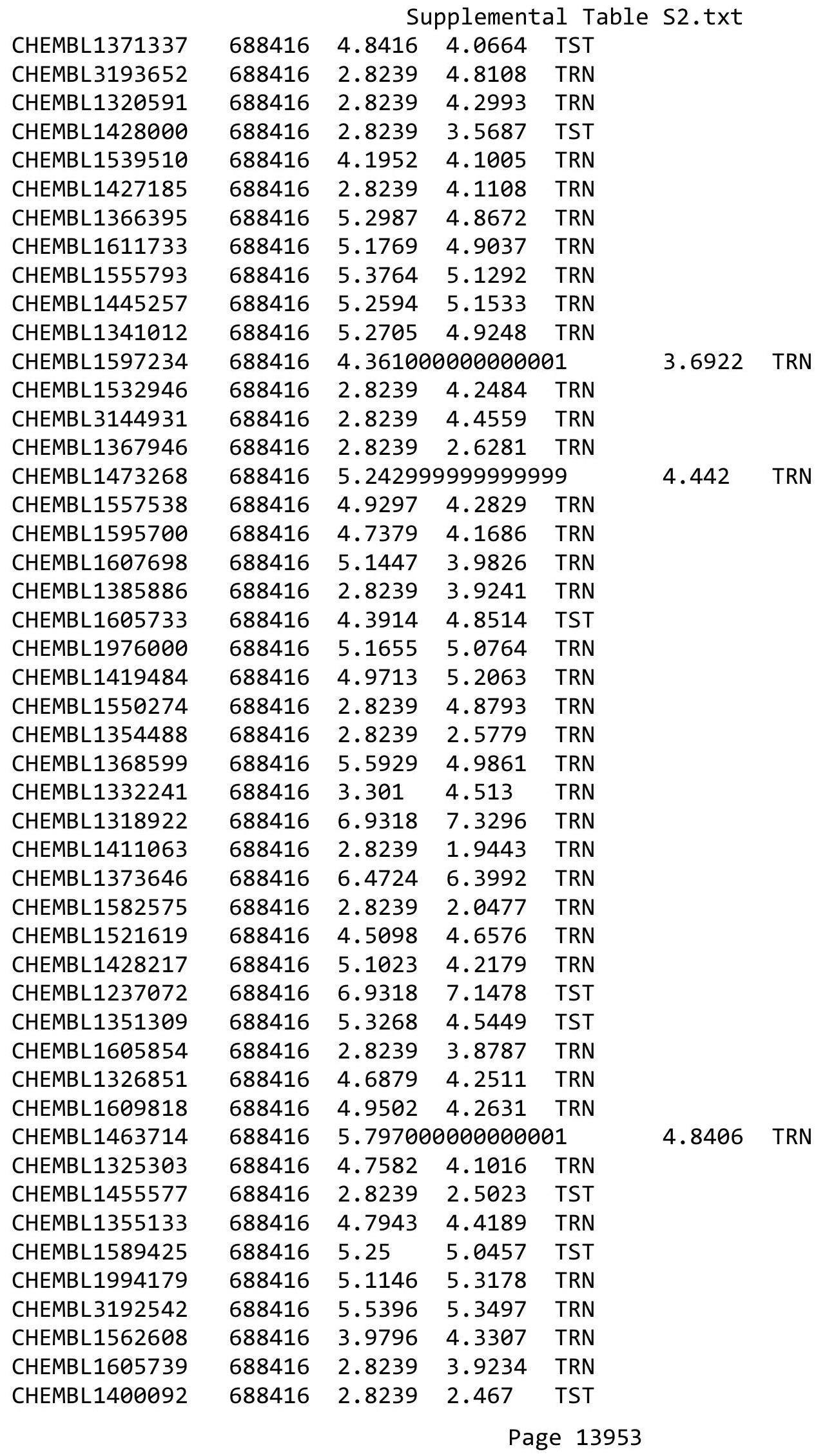




\begin{tabular}{|c|c|c|c|c|c|}
\hline \multirow[b]{2}{*}{ CHEMBL1360941 } & \multicolumn{5}{|c|}{ Supplemental Table S2.txt } \\
\hline & 688416 & 5.4123 & 4.5797 & TRN & \\
\hline CHEMBL1517469 & 688416 & 2.8239 & 2.22300 & 00000000003 & TRN \\
\hline CHEMBL1445145 & 688416 & 2.8239 & 3.9457 & TRN & \\
\hline CHEMBL1542682 & 688416 & 4.7192 & 4.0619 & TRN & \\
\hline CHEMBL1369125 & 688416 & 5.1564 & 4.4991 & TST & \\
\hline CHEMBL588804 & 688416 & 4.8232 & 5.4829 & TRN & \\
\hline CHEMBL1566254 & 688416 & 4.7732 & 4.1685 & TRN & \\
\hline CHEMBL1511495 & 688416 & 4.805 & 4.3128 & TRN & \\
\hline CHEMBL3190703 & 688416 & 4.3558 & 4.3475 & TRN & \\
\hline CHEMBL1387737 & 688416 & 2.8239 & 2.6852 & TRN & \\
\hline CHEMBL1403112 & 688416 & 5.0412 & 4.8206 & TRN & \\
\hline CHEMBL1344289 & 688416 & 2.8239 & 4.1378 & TRN & \\
\hline CHEMBL1493438 & 688416 & 4.0626 & 4.0981 & TRN & \\
\hline CHEMBL1540742 & 688416 & 4.596 & 4.2381 & TST & \\
\hline CHEMBL1240788 & 688416 & 3.8437 & 4.32600 & 00000000005 & TRN \\
\hline CHEMBL1566530 & 688416 & 5.2293 & 5.0781 & TRN & \\
\hline CHEMBL3198068 & 688416 & 4.7714 & 4.5906 & TRN & \\
\hline CHEMBL1378785 & 688416 & 5.2414 & 4.6636 & TRN & \\
\hline CHEMBL1576647 & 688416 & 5.0586 & 4.3964 & TRN & \\
\hline CHEMBL1582581 & 688416 & 4.1865 & 4.0075 & TRN & \\
\hline CHEMBL1478231 & 688416 & 2.8239 & 4.4688 & TRN & \\
\hline CHEMBL1323512 & 688416 & 4.3358 & 4.8047 & TRN & \\
\hline CHEMBL1513240 & 688416 & 4.9938 & 4.4699 & TRN & \\
\hline CHEMBL1462138 & 688416 & 2.8239 & 3.8141 & TRN & \\
\hline CHEMBL1350984 & 688416 & 2.8239 & 4.0753 & TRN & \\
\hline CHEMBL3207339 & 688416 & 4.2914 & 4.8888 & TRN & \\
\hline CHEMBL1526503 & 688416 & 4.874 & 4.4207 & TRN & \\
\hline CHEMBL1326397 & 688416 & 6.6421 & 7.6272 & TRN & \\
\hline CHEMBL1416756 & 688416 & 4.8262 & 4.039 & TRN & \\
\hline CHEMBL1337018 & 688416 & 4.198 & 4.9319 & TRN & \\
\hline CHEMBL1606740 & 688416 & 2.8239 & 4.3192 & TRN & \\
\hline CHEMBL1431676 & 688416 & 2.8239 & 4.4146 & TRN & \\
\hline CHEMBL1518515 & 688416 & 2.8239 & 4.4631 & TST & \\
\hline CHEMBL3192181 & 688416 & 5.1079 & 4.6009 & TRN & \\
\hline CHEMBL1329634 & 688416 & 2.8239 & 3.84899 & 99999999998 & TRN \\
\hline CHEMBL3198659 & 688416 & 5.1437 & 4.6121 & TST & \\
\hline CHEMBL 81782 & 688416 & 5.5233 & 4.6032 & TST & \\
\hline CHEMBL1327034 & 688416 & 4.8334 & 3.971 & TRN & \\
\hline CHEMBL1537093 & 688416 & 5.398 & 4.9459 & TRN & \\
\hline CHEMBL1414361 & 688416 & 2.8239 & 2.3417 & TST & \\
\hline CHEMBL1312303 & 688416 & 2.8239 & 4.0519 & TRN & \\
\hline CHEMBL1509762 & 688416 & 4.9356 & 4.4109 & TRN & \\
\hline CHEMBL1974063 & 688416 & 5.0421 & 4.8732 & TRN & \\
\hline CHEMBL1604044 & 688416 & 4.8418 & 4.1508 & TRN & \\
\hline CHEMBL1538502 & 688416 & 5.6912 & 4.7729 & TRN & \\
\hline CHEMBL1546634 & 688416 & 2.8239 & 4.03 & TRN & \\
\hline CHEMBL1510761 & 688416 & 5.1554 & 4.6327 & TRN & \\
\hline CHEMBL1520460 & 688416 & 4.3548 & 4.5086 & TRN & \\
\hline
\end{tabular}




\begin{tabular}{|c|c|c|c|c|c|}
\hline \multirow[b]{2}{*}{ CHEMBL1546810 } & \multicolumn{5}{|c|}{ Supplemental Table S2.txt } \\
\hline & 688416 & 5.1946 & 4.5998 & TRN & \\
\hline CHEMBL1305871 & 688416 & 2.8239 & 2.4918 & TST & \\
\hline CHEMBL1407438 & 688416 & 2.8239 & 3.7701 & TRN & \\
\hline CHEMBL1428343 & 688416 & 2.8239 & 4.2903 & TRN & \\
\hline CHEMBL1490049 & 688416 & 2.8239 & 2.8617 & TRN & \\
\hline CHEMBL1384179 & 688416 & 2.8239 & 4.8093 & TRN & \\
\hline CHEMBL1391179 & 688416 & 4.9187 & 4.1675 & TST & \\
\hline CHEMBL1334100 & 688416 & 2.8239 & 4.2353 & TST & \\
\hline CHEMBL1537722 & 688416 & 4.7956 & 4.2383 & TST & \\
\hline CHEMBL1392637 & 688416 & 4.6904 & 5.1577 & TRN & \\
\hline CHEMBL1366055 & 688416 & 5.4376 & 5.1944 & TRN & \\
\hline CHEMBL1429311 & 688416 & 5.0282 & 4.3666 & TRN & \\
\hline CHEMBL1408102 & 688416 & 4.9622 & 4.4555 & TST & \\
\hline CHEMBL1519239 & 688416 & 5.0123 & 4.6757 & TRN & \\
\hline CHEMBL1313731 & 688416 & 2.8239 & 3.8259 & TRN & \\
\hline CHEMBL3190811 & 688416 & 2.8239 & 3.5741 & TRN & \\
\hline CHEMBL1305498 & 688416 & 2.8239 & 2.551 & TST & \\
\hline CHEMBL1361520 & 688416 & 2.8239 & 2.7169 & TST & \\
\hline CHEMBL1348167 & 688416 & 2.8239 & 2.3028 & TRN & \\
\hline CHEMBL1520777 & 688416 & 4.7919 & 4.4673 & TRN & \\
\hline CHEMBL1443632 & 688416 & 5.0232 & 4.8441 & TRN & \\
\hline CHEMBL3197778 & 688416 & 2.8239 & 4.7193 & TRN & \\
\hline CHEMBL 2006856 & 688416 & 5.0692 & 4.8096 & TRN & \\
\hline CHEMBL1392200 & 688416 & 5.1565 & 5.0857 & TRN & \\
\hline CHEMBL3195036 & 688416 & 2.8239 & 4.1692 & TRN & \\
\hline CHEMBL1299577 & 688416 & 2.8239 & 4.0311 & TRN & \\
\hline CHEMBL1375741 & 688416 & 4.7406 & 4.5099 & TRN & \\
\hline CHEMBL1968842 & 688416 & 2.8239 & 4.4099 & TRN & \\
\hline CHEMBL1499320 & 688416 & 4.3906 & 5.1335 & TRN & \\
\hline CHEMBL1431276 & 688416 & 5.1955 & 4.3974 & TRN & \\
\hline CHEMBL1610738 & 688416 & 2.8239 & 2.4282 & TST & \\
\hline CHEMBL1498431 & 688416 & 5.1391 & 4.8271 & TRN & \\
\hline CHEMBL1477881 & 688416 & 4.3057 & 4.9792 & TRN & \\
\hline CHEMBL1360618 & 688416 & 4.8341 & 4.4644 & TRN & \\
\hline CHEMBL3193378 & 688416 & 5.3894 & 5.0785 & TRN & \\
\hline CHEMBL1532436 & 688416 & 4.7482 & 4.0826 & TRN & \\
\hline CHEMBL3197439 & 688416 & 2.8239 & 4.0639 & TRN & \\
\hline CHEMBL1303391 & 688416 & 4.8016 & 4.0953 & TRN & \\
\hline CHEMBL1544460 & 688416 & 4.9663 & 5.2015 & TRN & \\
\hline CHEMBL1541862 & 688416 & 4.6395 & 4.3686 & TRN & \\
\hline CHEMBL1417620 & 688416 & 5.3784 & 4.7928 & TRN & \\
\hline CHEMBL3197633 & 688416 & 4.4375 & 4.7651 & TRN & \\
\hline CHEMBL1468612 & 688416 & 2.8239 & 4.46899 & 9999999999 & TRN \\
\hline CHEMBL 3190644 & 688416 & 2.8239 & 4.4229 & TST & \\
\hline CHEMBL1371940 & 688416 & 4.6687 & 4.4269 & TRN & \\
\hline CHEMBL1611858 & 688416 & 4.7325 & 4.3477 & TRN & \\
\hline CHEMBL1573586 & 688416 & 2.8239 & 4.6169 & TST & \\
\hline CHEMBL1463734 & 688416 & 2.8239 & 2.2674 & TRN & \\
\hline
\end{tabular}




\begin{tabular}{|c|c|c|c|c|c|c|}
\hline & & \multicolumn{5}{|c|}{ Supplemental Table S2.txt } \\
\hline CHEMBL1361896 & 688416 & 4.9226 & 5.0665 & TRN & & \\
\hline CHEMBL1562570 & 688416 & 3.301 & 4.2325 & TRN & & \\
\hline CHEMBL1546382 & 688416 & 5.0737 & 4.4706 & TRN & & \\
\hline CHEMBL1407169 & 688416 & 5.5488 & 5.2437 & TST & & \\
\hline CHEMBL1459514 & 688416 & 5.0585 & 4.5038 & TRN & & \\
\hline CHEMBL1358873 & 688416 & 4.2128 & 3.9648 & TRN & & \\
\hline CHEMBL1966025 & 688416 & 4.9329 & 4.4399 & TRN & & \\
\hline CHEMBL1588500 & 688416 & 4.8647 & 4.1954 & TRN & & \\
\hline CHEMBL1367339 & 688416 & 4.8507 & 4.3625 & TRN & & \\
\hline CHEMBL1567518 & 688416 & 5.6533 & 4.9525 & TRN & & \\
\hline CHEMBL1535252 & 688416 & \multicolumn{3}{|c|}{5.071000000000001} & 4.2214 & TRN \\
\hline CHEMBL314962 & 688416 & 2.8239 & 2.5951 & TRN & & \\
\hline CHEMBL1506021 & 688416 & 2.8239 & 4.1296 & TST & & \\
\hline CHEMBL1387953 & 688416 & 2.8239 & 3.7967 & TRN & & \\
\hline CHEMBL1491019 & 688416 & 5.0502 & 5.2277 & TRN & & \\
\hline CHEMBL 276139 & 688416 & 5.4006 & 4.6361 & TST & & \\
\hline CHEMBL1312746 & 688416 & 2.8239 & 3.9652 & TRN & & \\
\hline CHEMBL1430631 & 688416 & 2.8239 & 3.1372 & TRN & & \\
\hline CHEMBL168 & 688416 & 5.687 & 4.7083 & TST & & \\
\hline CHEMBL1450554 & 688416 & 2.8239 & 2.5003 & TRN & & \\
\hline CHEMBL1339245 & 688416 & 5.1973 & 4.8648 & TRN & & \\
\hline CHEMBL1592387 & 688416 & 2.8239 & 4.1256 & TRN & & \\
\hline CHEMBL1977078 & 688416 & 5.0629 & 4.745 & TST & & \\
\hline CHEMBL1484547 & 688416 & 4.6144 & 4.9706 & TRN & & \\
\hline CHEMBL1469460 & 688416 & 2.8239 & 4.2853 & TST & & \\
\hline CHEMBL1313141 & 688416 & \multicolumn{3}{|c|}{5.053999999999999} & 4.3104 & TRN \\
\hline CHEMBL1576431 & 688416 & 2.8239 & 2.6501 & TRN & & \\
\hline CHEMBL1370922 & 688416 & 2.8239 & 2.1835 & TRN & & \\
\hline CHEMBL 2003808 & 688416 & 5.5768 & 5.3424 & TRN & & \\
\hline CHEMBL1408463 & 688416 & 5.1476 & 4.9053 & TRN & & \\
\hline CHEMBL1358236 & 688416 & 3.301 & 4.5338 & TRN & & \\
\hline CHEMBL1475524 & 688416 & 2.8239 & 3.5332 & TRN & & \\
\hline CHEMBL1584002 & 688416 & 4.6652 & 4.1139 & TRN & & \\
\hline CHEMBL1346056 & 688416 & 4.9195 & 4.8217 & TRN & & \\
\hline CHEMBL1589670 & 688416 & 5.4118 & 4.7299 & TRN & & \\
\hline CHEMBL1453753 & 688416 & 2.8239 & 4.5322 & TRN & & \\
\hline CHEMBL3196810 & 688416 & 5.1617 & 4.8772 & TRN & & \\
\hline CHEMBL1528206 & 688416 & 6.8508 & 7.1337 & TRN & & \\
\hline CHEMBL3191831 & 688416 & 5.7172 & 5.1702 & TRN & & \\
\hline CHEMBL1529276 & 688416 & 5.0977 & 4.4685 & TRN & & \\
\hline CHEMBL1500450 & 688416 & 5.3662 & 4.5704 & TRN & & \\
\hline CHEMBL1370022 & 688416 & 2.8239 & 3.9813 & TRN & & \\
\hline CHEMBL1965821 & 688416 & \multicolumn{3}{|c|}{5.172000000000001} & 4.4916 & TRN \\
\hline CHEMBL1520896 & 688416 & 4.84 & 4.8021 & TRN & & \\
\hline CHEMBL1510940 & 688416 & 2.8239 & 4.374 & TST & & \\
\hline CHEMBL3194766 & 688416 & 2.8239 & 2.9395 & TRN & & \\
\hline CHEMBL3198554 & 688416 & 5.5834 & 5.0098 & TRN & & \\
\hline CHEMBL1964793 & 688416 & 5.2105 & 4.663 & TRN & & \\
\hline
\end{tabular}




\begin{tabular}{|c|c|c|c|c|c|}
\hline \multicolumn{6}{|c|}{ Supplemental Table S2.txt } \\
\hline CHEMBL1705518 & 688416 & 5.2718 & 4.6527 & TRN & \\
\hline CHEMBL1455197 & 688416 & 5.6655 & 5.2212 & TRN & \\
\hline CHEMBL180905 & 688416 & 4.8038 & 4.2913 & TRN & \\
\hline CHEMBL1478856 & 688416 & 4.2754 & 4.3786 & TRN & \\
\hline CHEMBL570400 & 688416 & 5.4099 & 4.7887 & TRN & \\
\hline CHEMBL1338713 & 688416 & 2.8239 & 2.6899 & TRN & \\
\hline CHEMBL1535622 & 688416 & 2.8239 & 4.40600 & 0000000001 & TRN \\
\hline CHEMBL1510086 & 688416 & 5.5196 & 4.0625 & TRN & \\
\hline CHEMBL1465946 & 688416 & 5.1322 & 5.3074 & TRN & \\
\hline CHEMBL1334290 & 688416 & 2.8239 & 2.3199 & TRN & \\
\hline CHEMBL1418812 & 688416 & 6.0227 & 5.2469 & TRN & \\
\hline CHEMBL1606837 & 688416 & 2.8239 & 4.2873 & TST & \\
\hline CHEMBL3197639 & 688416 & 5.0022 & 5.4187 & TRN & \\
\hline CHEMBL1493953 & 688416 & 5.1165 & 4.5751 & TRN & \\
\hline CHEMBL1377629 & 688416 & 5.0178 & 4.4667 & TRN & \\
\hline CHEMBL1321111 & 688416 & 2.8239 & 2.3357 & TRN & \\
\hline CHEMBL1469207 & 688416 & 4.5468 & 4.5888 & TRN & \\
\hline CHEMBL1509878 & 688416 & 5.0412 & 5.3711 & TRN & \\
\hline CHEMBL1565280 & 688416 & 2.8239 & 3.7295 & TRN & \\
\hline CHEMBL1485275 & 688416 & 6.9626 & 7.0813 & TST & \\
\hline CHEMBL1332733 & 688416 & 2.8239 & 4.0441 & TST & \\
\hline CHEMBL3198440 & 688416 & 5.1413 & 4.6963 & TRN & \\
\hline CHEMBL1558175 & 688416 & 4.4193 & 4.0219 & TRN & \\
\hline CHEMBL 381033 & 688416 & 2.8239 & 4.7544 & TRN & \\
\hline CHEMBL550826 & 688416 & 2.8239 & 4.3309 & TRN & \\
\hline CHEMBL1544188 & 688416 & 4.6452 & 4.1488 & TRN & \\
\hline CHEMBL3198425 & 688416 & 4.8332 & 5.0764 & TRN & \\
\hline CHEMBL1347538 & 688416 & 2.8239 & 2.7996 & TST & \\
\hline CHEMBL1416018 & 688416 & 5.3024 & 4.9113 & TRN & \\
\hline CHEMBL1326490 & 688416 & 2.8239 & 4.2579 & TRN & \\
\hline CHEMBL1365508 & 688416 & 5.1222 & 4.7987 & TRN & \\
\hline CHEMBL1407961 & 688416 & 4.8781 & 3.6882 & TRN & \\
\hline CHEMBL1510974 & 688416 & 5.3659 & 5.0501 & TRN & \\
\hline CHEMBL1977596 & 688416 & 2.8239 & 4.0999 & TRN & \\
\hline CHEMBL1978315 & 688416 & 2.8239 & 4.5711 & TRN & \\
\hline CHEMBL1427606 & 688416 & 4.7329 & 4.5214 & TRN & \\
\hline CHEMBL 1405742 & 688416 & 4.5953 & 3.8058 & TRN & \\
\hline CHEMBL1557651 & 688416 & 2.8239 & 3.9939 & TRN & \\
\hline CHEMBL1323869 & 688416 & 2.8239 & 2.6366 & TST & \\
\hline CHEMBL1305864 & 688416 & 4.4268 & 4.1198 & TST & \\
\hline CHEMBL1310744 & 688416 & 5.0243 & 4.5907 & TRN & \\
\hline CHEMBL1511854 & 688416 & 4.76 & 3.9588 & TST & \\
\hline CHEMBL3194571 & 688416 & 5.6306 & 4.9992 & TRN & \\
\hline CHEMBL1524131 & 688416 & 4.8386 & 4.5783 & TRN & \\
\hline CHEMBL1585628 & 688416 & 4.4006 & 4.785 & TRN & \\
\hline CHEMBL3213459 & 688416 & 5.2242 & 4.6493 & TRN & \\
\hline CHEMBL1502410 & 688416 & 5.2885 & 4.5217 & TRN & \\
\hline CHEMBL1602709 & 688416 & 4.5191 & 4.1172 & TRN & \\
\hline
\end{tabular}




\begin{tabular}{|c|c|c|c|c|c|c|}
\hline \multirow[b]{2}{*}{ CHEMBL246338 } & & \multicolumn{5}{|c|}{ Supplemental Table S2.txt } \\
\hline & 688416 & 2.8239 & 2.6246 & TRN & & \\
\hline CHEMBL1423270 & 688416 & 6.11799 & 99999999 & 99 & 5.2916 & TRN \\
\hline CHEMBL1343618 & 688416 & 2.8239 & 3.0662 & TRN & & \\
\hline CHEMBL1461976 & 688416 & 5.4034 & 4.7954 & TRN & & \\
\hline CHEMBL1513192 & 688416 & 2.8239 & 2.4752 & TRN & & \\
\hline CHEMBL1470353 & 688416 & 2.8239 & 2.6461 & TST & & \\
\hline CHEMBL1417429 & 688416 & 4.5955 & 4.234 & TRN & & \\
\hline CHEMBL1381353 & 688416 & 2.8239 & 3.8253 & TRN & & \\
\hline CHEMBL1364447 & 688416 & $5.3370 e$ & 00000000 & & 5.2596 & TST \\
\hline CHEMBL1442412 & 688416 & 5.4411 & 4.5281 & TRN & & \\
\hline CHEMBL1420051 & 688416 & 4.007 & 4.6255 & TRN & & \\
\hline CHEMBL1379636 & 688416 & 5.0592 & 4.6977 & TST & & \\
\hline CHEMBL1566748 & 688416 & 2.8239 & 4.5463 & TRN & & \\
\hline CHEMBL1567899 & 688416 & 4.8069 & 5.0713 & TRN & & \\
\hline CHEMBL1303303 & 688416 & 4.1642 & 3.8195 & TRN & & \\
\hline CHEMBL1321754 & 688416 & 2.8239 & 4.2971 & TRN & & \\
\hline CHEMBL1548682 & 688416 & 2.8239 & 2.3384 & TST & & \\
\hline CHEMBL1302146 & 688416 & 2.8239 & 3.8958 & TRN & & \\
\hline CHEMBL1492565 & 688416 & 5.0562 & 5.2202 & TRN & & \\
\hline CHEMBL1491222 & 688416 & 4.9685 & 4.8519 & TRN & & \\
\hline CHEMBL1965860 & 688416 & 4.6727 & 4.533 & TRN & & \\
\hline CHEMBL1455024 & 688416 & 4.7357 & 4.1889 & TRN & & \\
\hline CHEMBL3192655 & 688416 & 5.0724 & 4.63399 & 99999 & 995 & TRN \\
\hline CHEMBL1320542 & 688416 & 4.7474 & 4.8798 & TRN & & \\
\hline CHEMBL1976312 & 688416 & 5.1169 & 5.1359 & TRN & & \\
\hline CHEMBL3191218 & 688416 & 3.8813 & 4.743 & TRN & & \\
\hline CHEMBL1594517 & 688416 & 4.0176 & 4.3224 & TRN & & \\
\hline CHEMBL1501874 & 688416 & 4.7542 & 4.2359 & TRN & & \\
\hline CHEMBL1463750 & 688416 & 5.7533 & 6.2355 & TRN & & \\
\hline CHEMBL 81935 & 688416 & 3.9917 & 4.4915 & TST & & \\
\hline CHEMBL1580583 & 688416 & 2.8239 & 4.4676 & TRN & & \\
\hline CHEMBL1338825 & 688416 & 4.6011 & 4.6131 & TRN & & \\
\hline CHEMBL1515506 & 688416 & 4.9755 & 4.7222 & TRN & & \\
\hline CHEMBL1604790 & 688416 & 4.6093 & 5.17 & TRN & & \\
\hline CHEMBL1413931 & 688416 & 4.8047 & 4.0753 & TRN & & \\
\hline CHEMBL1361866 & 688416 & 2.8239 & 3.7818 & TST & & \\
\hline CHEMBL1589298 & 688416 & 5.6438 & 5.0162 & TRN & & \\
\hline CHEMBL1451491 & 688416 & 5.2817 & 4.9542 & TRN & & \\
\hline CHEMBL 1357870 & 688416 & 2.8239 & 2.7005 & TRN & & \\
\hline CHEMBL1312122 & 688416 & 5.4281 & 4.7007 & TRN & & \\
\hline CHEMBL1599033 & 688416 & 8.2218 & 6.7811 & TST & & \\
\hline CHEMBL1322943 & 688416 & 4.9349 & 5.0078 & TRN & & \\
\hline CHEMBL1495140 & 688416 & 5.2007 & 4.4518 & TRN & & \\
\hline CHEMBL1326101 & 688416 & 5.2208 & 4.7121 & TRN & & \\
\hline CHEMBL1457515 & 688416 & 5.2278 & 4.5503 & TST & & \\
\hline CHEMBL1557920 & 688416 & 3.9567 & 4.6202 & TRN & & \\
\hline CHEMBL1447772 & 688416 & 2.8239 & 3.5894 & TST & & \\
\hline CHEMBL1315402 & 688416 & 2.8239 & 2.3685 & TRN & & \\
\hline
\end{tabular}




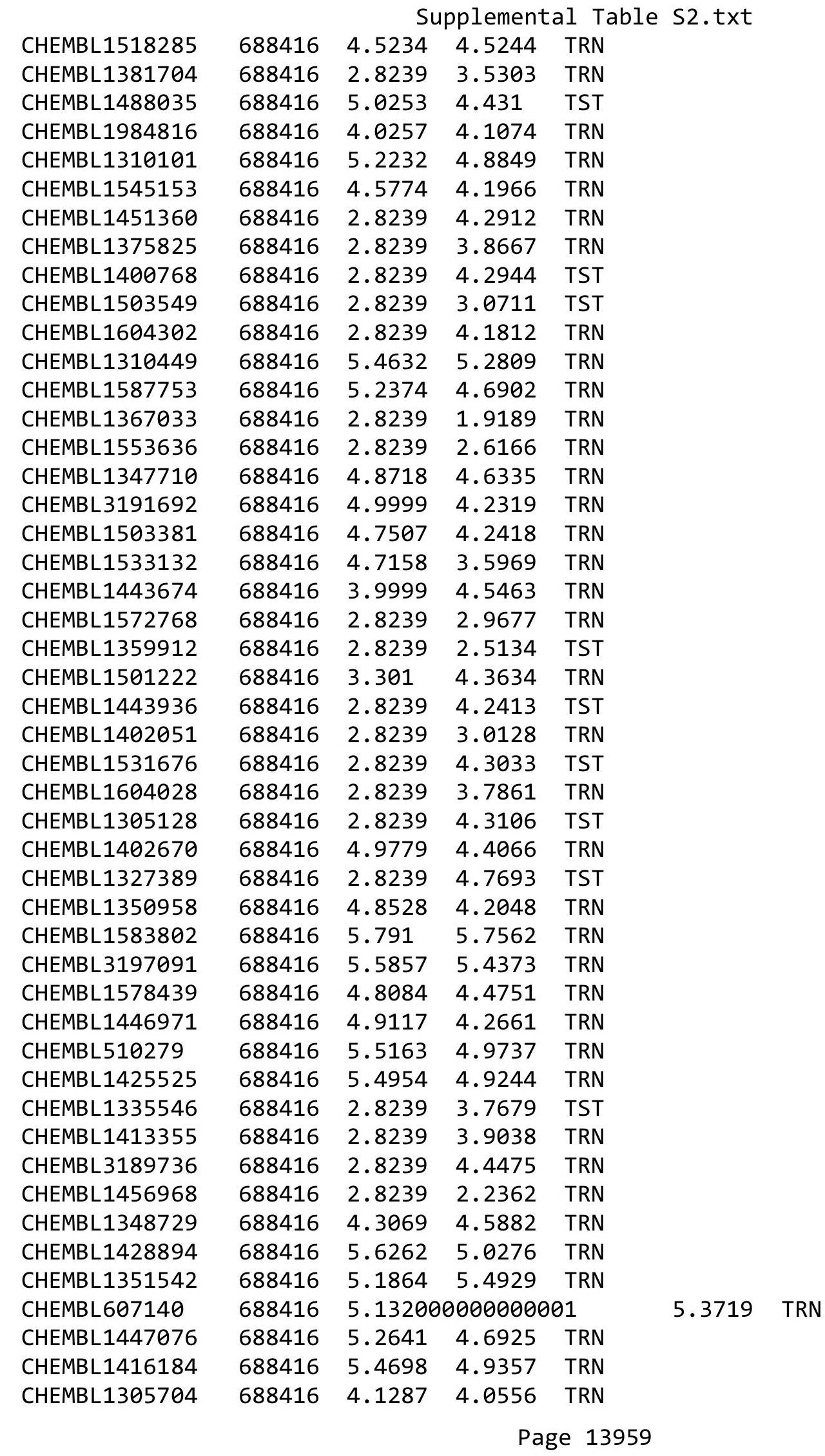




\begin{tabular}{|c|c|c|c|c|c|}
\hline & & \multicolumn{4}{|c|}{ Supplemental Table s2.txt } \\
\hline CHEMBL1420131 & 688416 & 2.8239 & 3.4593 & TRN & \\
\hline CHEMBL1332165 & 688416 & 5.1916 & 4.5495 & TRN & \\
\hline CHEMBL1510679 & 688416 & 5.4992 & 4.6023 & TRN & \\
\hline CHEMBL1459918 & 688416 & 5.2608 & 4.4063 & TRN & \\
\hline CHEMBL1436772 & 688416 & 5.761 & 5.5579 & TRN & \\
\hline CHEMBL1346995 & 688416 & 2.8239 & 5.0055 & TRN & \\
\hline CHEMBL1450690 & 688416 & 5.6231 & 5.2609 & TRN & \\
\hline CHEMBL1563827 & 688416 & 4.9132 & 4.6465 & TST & \\
\hline CHEMBL1421032 & 688416 & 5.2492 & 4.8383 & TRN & \\
\hline CHEMBL1511300 & 688416 & 5.3024 & 4.842 & TRN & \\
\hline CHEMBL1408962 & 688416 & 5.3295 & 4.7866 & TRN & \\
\hline CHEMBL1379322 & 688416 & 2.8239 & 2.7804 & TRN & \\
\hline CHEMBL1410739 & 688416 & 4.9781 & 4.7633 & TRN & \\
\hline CHEMBL1972143 & 688416 & 3.7959 & 4.9142 & TRN & \\
\hline CHEMBL1430060 & 688416 & 2.8239 & 3.7824 & TRN & \\
\hline CHEMBL1313887 & 688416 & 2.8239 & 4.2539 & TRN & \\
\hline CHEMBL1299389 & 688416 & 6.4634 & 5.4242 & TST & \\
\hline CHEMBL1538986 & 688416 & 5.093 & 4.1846 & TRN & \\
\hline CHEMBL1328544 & 688416 & 2.8239 & 4.2861 & TRN & \\
\hline CHEMBL3197344 & 688416 & 5.4795 & 5.1049 & TRN & \\
\hline CHEMBL1326559 & 688416 & 2.8239 & 2.9159 & TST & \\
\hline CHEMBL1430574 & 688416 & 5.6115 & 5.6428 & TRN & \\
\hline CHEMBL1455542 & 688416 & 5.4467 & 5.0321 & TRN & \\
\hline CHEMBL1464477 & 688416 & 4.3293 & 4.3319 & TST & \\
\hline CHEMBL1424836 & 688416 & 2.8239 & 2.65100 & 00000000002 & TRN \\
\hline CHEMBL1421884 & 688416 & 2.8239 & 3.7014 & TRN & \\
\hline CHEMBL1428730 & 688416 & 2.8239 & 4.3874 & TST & \\
\hline CHEMBL1310193 & 688416 & 5.1106 & 4.886 & TRN & \\
\hline CHEMBL1435040 & 688416 & 2.8239 & 2.5184 & TRN & \\
\hline CHEMBL1532148 & 688416 & 4.8901 & 4.4752 & TRN & \\
\hline CHEMBL1485259 & 688416 & 5.6525 & 5.045 & TRN & \\
\hline CHEMBL1416666 & 688416 & 4.2375 & 3.8478 & TRN & \\
\hline CHEMBL1373110 & 688416 & 4.8016 & 4.2021 & TRN & \\
\hline CHEMBL3195160 & 688416 & 4.6365 & 4.4862 & TRN & \\
\hline CHEMBL1580922 & 688416 & 2.8239 & 2.8732 & TRN & \\
\hline CHEMBL1346860 & 688416 & 2.8239 & 4.6976 & TRN & \\
\hline CHEMBL1376204 & 688416 & 2.8239 & 4.0578 & TRN & \\
\hline CHEMBL1457780 & 688416 & 4.5152 & 4.2054 & TRN & \\
\hline CHEMBL1504588 & 688416 & 2.8239 & 2.4031 & TRN & \\
\hline CHEMBL1431875 & 688416 & 6.5003 & 6.6118 & TRN & \\
\hline CHEMBL1597289 & 688416 & 2.8239 & 4.4067 & TRN & \\
\hline CHEMBL3190657 & 688416 & 2.8239 & 3.2487 & TRN & \\
\hline CHEMBL1486883 & 688416 & 4.7632 & 4.1208 & TRN & \\
\hline CHEMBL1585840 & 688416 & 4.8596 & 4.3824 & TRN & \\
\hline CHEMBL1394159 & 688416 & 2.8239 & 4.38899 & 9999999999 & TST \\
\hline CHEMBL1560195 & 688416 & 2.8239 & 3.6609 & TRN & \\
\hline CHEMBL1495849 & 688416 & 4.8152 & 4.3497 & TRN & \\
\hline CHEMBL1428358 & 688416 & 2.8239 & 4.0263 & TRN & \\
\hline
\end{tabular}




\begin{tabular}{|c|c|c|c|c|c|c|}
\hline & & \multicolumn{5}{|c|}{ Supplemental Table S2.txt } \\
\hline CHEMBL1312717 & 688416 & 4.4971 & 3.6115 & TRN & & \\
\hline CHEMBL1370995 & 688416 & 4.165 & 4.165 & TRN & & \\
\hline CHEMBL1332450 & 688416 & 5.5303 & 4.8432 & TRN & & \\
\hline CHEMBL1709970 & 688416 & 5.5346 & 4.7433 & TRN & & \\
\hline CHEMBL 3194327 & 688416 & 5.5119 & 5.2016 & TRN & & \\
\hline CHEMBL3190739 & 688416 & 5.1375 & 4.9171 & TRN & & \\
\hline CHEMBL1471845 & 688416 & 5.6015 & 5.1125 & TRN & & \\
\hline CHEMBL 3194940 & 688416 & 2.8239 & 4.0759 & TRN & & \\
\hline CHEMBL267225 & 688416 & 6.0164 & 5.2002 & TST & & \\
\hline CHEMBL1502127 & 688416 & 4.7794 & 4.5659 & TRN & & \\
\hline CHEMBL1522211 & 688416 & 5.6062 & 5.2775 & TRN & & \\
\hline CHEMBL1301919 & 688416 & 2.8239 & 2.2621 & TRN & & \\
\hline CHEMBL1483809 & 688416 & 2.8239 & 4.3054 & TST & & \\
\hline CHEMBL1329980 & 688416 & 4.8577 & 4.0844 & TRN & & \\
\hline CHEMBL1540469 & 688416 & 5.2447 & 4.2046 & TRN & & \\
\hline CHEMBL3189460 & 688416 & 5.5707 & 4.7741 & TRN & & \\
\hline CHEMBL1315704 & 688416 & 2.8239 & 4.3997 & TRN & & \\
\hline CHEMBL1499111 & 688416 & 5.1377 & 4.7543 & TRN & & \\
\hline CHEMBL1501277 & 688416 & 2.8239 & 3.4116 & TRN & & \\
\hline CHEMBL1383757 & 688416 & 2.8239 & 2.8681 & TRN & & \\
\hline CHEMBL1464656 & 688416 & 5.0226 & 4.3314 & TRN & & \\
\hline CHEMBL1409680 & 688416 & 5.1993 & 4.519 & TRN & & \\
\hline CHEMBL1605668 & 688416 & 2.8239 & 4.2842 & TRN & & \\
\hline CHEMBL1404312 & 688416 & 2.8239 & 4.2041 & TRN & & \\
\hline CHEMBL1588859 & 688416 & 4.7533 & 4.4475 & TST & & \\
\hline CHEMBL1383895 & 688416 & 5.0706 & 4.8301 & TRN & & \\
\hline CHEMBL3199364 & 688416 & \multicolumn{3}{|c|}{5.0280000000000005} & 4.526 & TRN \\
\hline CHEMBL3191810 & 688416 & 2.8239 & 4.1352 & TRN & & \\
\hline CHEMBL1561338 & 688416 & 2.8239 & 4.0765 & TRN & & \\
\hline CHEMBL1347076 & 688416 & 2.8239 & 3.4416 & TRN & & \\
\hline CHEMBL1299653 & 688416 & 2.8239 & 4.1295 & TST & & \\
\hline CHEMBL 2000750 & 688416 & 4.9048 & 4.8446 & TRN & & \\
\hline CHEMBL1334670 & 688416 & 4.497 & 4.5463 & TRN & & \\
\hline CHEMBL1562926 & 688416 & 5.4557 & 4.7122 & TRN & & \\
\hline CHEMBL1463331 & 688416 & 2.8239 & 3.6826 & TRN & & \\
\hline CHEMBL1995800 & 688416 & 2.8239 & 3.3877 & TRN & & \\
\hline CHEMBL1502019 & 688416 & 2.8239 & 4.1639 & TRN & & \\
\hline CHEMBL1988686 & 688416 & 2.8239 & 3.8927 & TRN & & \\
\hline CHEMBL1463571 & 688416 & 5.8407 & 5.223 & TRN & & \\
\hline CHEMBL1396209 & 688416 & 5.1017 & 4.0546 & TRN & & \\
\hline CHEMBL3199916 & 688416 & 4.9284 & 4.4755 & TRN & & \\
\hline CHEMBL1406224 & 688416 & 2.8239 & 2.6038 & TRN & & \\
\hline CHEMBL1478456 & 688416 & 4.0842 & 4.8251 & TRN & & \\
\hline CHEMBL1344296 & 688416 & 2.8239 & 3.5076 & TRN & & \\
\hline CHEMBL1578411 & 688416 & 5.1592 & 4.5947 & TRN & & \\
\hline CHEMBL1524515 & 688416 & 5.0926 & 4.9798 & TRN & & \\
\hline CHEMBL1324944 & 688416 & 5.0677 & 5.5882 & TRN & & \\
\hline CHEMBL1346628 & 688416 & 4.8005 & 4.1655 & TST & & \\
\hline
\end{tabular}




\begin{tabular}{|c|c|c|c|c|c|}
\hline & & \multicolumn{4}{|c|}{ Supplemental Table S2.txt } \\
\hline CHEMBL1313861 & 688416 & 2.8239 & 4.331 & TRN & \\
\hline CHEMBL1984120 & 688416 & 4.9649 & 4.7164 & TRN & \\
\hline CHEMBL 2006634 & 688416 & 5.7314 & 5.0704 & TRN & \\
\hline CHEMBL3209772 & 688416 & 4.6595 & 4.77 & TRN & \\
\hline CHEMBL 3196257 & 688416 & 5.0403 & 5.13299 & 9999999999 & TRN \\
\hline CHEMBL3213534 & 688416 & 2.8239 & 2.563 & TRN & \\
\hline CHEMBL1383632 & 688416 & 5.1427 & 4.7706 & TRN & \\
\hline CHEMBL1973886 & 688416 & 2.8239 & 4.4244 & TRN & \\
\hline CHEMBL1560358 & 688416 & 4.9043 & 4.0777 & TRN & \\
\hline CHEMBL1534138 & 688416 & 2.8239 & 2.36 & TRN & \\
\hline CHEMBL1470483 & 688416 & 5.6584 & 5.0468 & TRN & \\
\hline CHEMBL1603844 & 688416 & 5.4057 & 4.8961 & TST & \\
\hline CHEMBL544584 & 688416 & 5.1638 & 4.7676 & TRN & \\
\hline CHEMBL1467901 & 688416 & 2.8239 & 2.2899 & TRN & \\
\hline CHEMBL1594171 & 688416 & 4.6424 & 4.3493 & TRN & \\
\hline CHEMBL1310223 & 688416 & 2.8239 & 2.6712 & TRN & \\
\hline CHEMBL1506230 & 688416 & 2.8239 & 4.3486 & TRN & \\
\hline CHEMBL1364011 & 688416 & 6.9747 & 7.6142 & TRN & \\
\hline CHEMBL1346853 & 688416 & 2.8239 & 4.247 & TST & \\
\hline CHEMBL3189295 & 688416 & 4.9123 & 4.4231 & TRN & \\
\hline CHEMBL1583579 & 688416 & 4.2943 & 4.3211 & TRN & \\
\hline CHEMBL1390546 & 688416 & 4.4047 & 4.5104 & TRN & \\
\hline CHEMBL1575421 & 688416 & 2.8239 & 4.0496 & TRN & \\
\hline CHEMBL1612475 & 688416 & 4.3366 & 3.4939 & TRN & \\
\hline CHEMBL3144984 & 688416 & 5.1402 & 4.7635 & TRN & \\
\hline CHEMBL1494810 & 688416 & 5.0713 & 4.5962 & TRN & \\
\hline CHEMBL1520325 & 688416 & 2.8239 & 4.4374 & TRN & \\
\hline CHEMBL3212271 & 688416 & 4.6914 & 4.5371 & TRN & \\
\hline CHEMBL1532819 & 688416 & 4.8956 & 4.3995 & TRN & \\
\hline CHEMBL1447251 & 688416 & 2.8239 & 4.6314 & TRN & \\
\hline CHEMBL1504569 & 688416 & 5.5366 & 4.9708 & TRN & \\
\hline CHEMBL1365902 & 688416 & 2.8239 & 4.4465 & TRN & \\
\hline CHEMBL1584720 & 688416 & 4.9989 & 4.3488 & TRN & \\
\hline CHEMBL1386918 & 688416 & 4.8157 & 4.1531 & TRN & \\
\hline CHEMBL1605457 & 688416 & 2.8239 & 2.5984 & TST & \\
\hline CHEMBL3193441 & 688416 & 4.7872 & 4.7855 & TRN & \\
\hline CHEMBL1530694 & 688416 & 4.595 & 4.4161 & TRN & \\
\hline CHEMBL1575038 & 688416 & 4.7717 & 4.8554 & TRN & \\
\hline CHEMBL1565897 & 688416 & 2.8239 & 4.553 & TST & \\
\hline CHEMBL3199665 & 688416 & 5.4974 & 5.0191 & TRN & \\
\hline CHEMBL1978354 & 688416 & 5.0247 & 4.2963 & TRN & \\
\hline CHEMBL3193178 & 688416 & 2.8239 & 4.4747 & TRN & \\
\hline CHEMBL1469791 & 688416 & 4.8097 & 4.9587 & TRN & \\
\hline CHEMBL1539864 & 688416 & 5.2817 & 5.1452 & TRN & \\
\hline CHEMBL1488865 & 688416 & 3.9737 & 4.0429 & TRN & \\
\hline CHEMBL257286 & 688416 & 4.9099 & 4.6778 & TRN & \\
\hline CHEMBL1497721 & 688416 & 5.0179 & 5.1293 & TRN & \\
\hline CHEMBL1506791 & 688416 & 5.0965 & 4.6832 & TRN & \\
\hline
\end{tabular}




\begin{tabular}{|c|c|c|c|c|}
\hline \multicolumn{5}{|c|}{ Supplemental Tab. } \\
\hline CHEMBL1513743 & 688416 & 2.8239 & 4.4425 & TST \\
\hline CHEMBL3193092 & 688416 & 2.8239 & 4.2037 & TRN \\
\hline CHEMBL1359345 & 688416 & 2.8239 & 2.2102 & TRN \\
\hline CHEMBL3195662 & 688416 & 4.7932 & 4.6852 & TST \\
\hline CHEMBL1520763 & 688416 & 2.8239 & 4.8602 & TRN \\
\hline CHEMBL1316798 & 688416 & 4.7944 & 4.6098 & TRN \\
\hline CHEMBL1333575 & 688416 & 2.8239 & 2.4314 & TRN \\
\hline CHEMBL1440277 & 688416 & 5.3588 & 4.8387 & TRN \\
\hline CHEMBL1415442 & 688416 & 4.8467 & 4.2777 & TRN \\
\hline CHEMBL1443499 & 688416 & 2.8239 & 4.0584 & TRN \\
\hline CHEMBL1311479 & 688416 & 2.8239 & 2.3253 & TRN \\
\hline CHEMBL1537008 & 688416 & 2.8239 & 3.6719 & TRN \\
\hline CHEMBL1540477 & 688416 & 4.7517 & 4.7834 & TRN \\
\hline CHEMBL1443205 & 688416 & 5.9255 & 4.9518 & TRN \\
\hline CHEMBL1420623 & 688416 & 4.1676 & 4.6195 & TRN \\
\hline CHEMBL1304605 & 688416 & 4.7527 & 4.3324 & TRN \\
\hline CHEMBL1494274 & 688416 & 2.8239 & 2.5771 & TRN \\
\hline CHEMBL1450105 & 688416 & 5.2005 & 4.7747 & TRN \\
\hline CHEMBL1994815 & 688416 & 4.8651 & 4.5572 & TRN \\
\hline CHEMBL1460092 & 688416 & 5.6513 & 5.0646 & TRN \\
\hline CHEMBL1503359 & 688416 & 2.8239 & 4.547 & TRN \\
\hline CHEMBL1400889 & 688416 & 4.3037 & 4.8108 & TRN \\
\hline CHEMBL3199001 & 688416 & 5.8425 & 5.4908 & TRN \\
\hline CHEMBL 1447541 & 688416 & 3.9298 & 3.812 & TRN \\
\hline CHEMBL3211808 & 688416 & 4.709 & 4.1359 & TRN \\
\hline CHEMBL193627 & 688416 & 5.0462 & 4.4029 & TST \\
\hline CHEMBL1566354 & 688416 & 2.8239 & 2.5873 & TRN \\
\hline CHEMBL1354909 & 688416 & 5.8182 & 4.9961 & TRN \\
\hline CHEMBL1390716 & 688416 & 5.9678 & 5.4166 & TRN \\
\hline CHEMBL1422078 & 688416 & 6.3595 & 6.8426 & TRN \\
\hline CHEMBL1197556 & 688416 & 4.4562 & 4.4147 & TST \\
\hline CHEMBL1480944 & 688416 & 2.8239 & 2.6032 & TST \\
\hline CHEMBL1547641 & 688416 & 4.0513 & 4.1301 & TRN \\
\hline CHEMBL1402502 & 688416 & 4.8258 & 4.1503 & TRN \\
\hline CHEMBL1345663 & 688416 & 2.8239 & 4.4523 & TRN \\
\hline CHEMBL1582919 & 688416 & 5.4724 & 5.1388 & TRN \\
\hline CHEMBL1453924 & 688416 & 2.8239 & 4.0745 & TRN \\
\hline CHEMBL1400237 & 688416 & 4.6774 & 4.5315 & TRN \\
\hline CHEMBL1325551 & 688416 & 2.8239 & 3.4631 & TRN \\
\hline CHEMBL1507404 & 688416 & 2.8239 & 4.467 & TST \\
\hline CHEMBL104270 & 688416 & 6.0004 & 5.3667 & TRN \\
\hline CHEMBL591834 & 688416 & 5.0416 & 4.9779 & TST \\
\hline CHEMBL1593677 & 688416 & 4.1419 & 4.1516 & TST \\
\hline CHEMBL3144976 & 688416 & 5.6741 & 5.1925 & TRN \\
\hline CHEMBL1411435 & 688416 & 5.1115 & 4.9892 & TRN \\
\hline CHEMBL590887 & 688416 & 5.2732 & 4.7593 & TRN \\
\hline CHEMBL1551048 & 688416 & 2.8239 & 3.622 & TRN \\
\hline CHEMBL1427134 & 688416 & 2.8239 & 4.0355 & TST \\
\hline
\end{tabular}




\begin{tabular}{|c|c|c|c|c|c|}
\hline \multicolumn{6}{|c|}{ Supplemental Table S2.txt } \\
\hline CHEMBL1562776 & 688416 & 2.8239 & 2.5899 & TRN & \\
\hline CHEMBL1379894 & 688416 & 2.8239 & 4.5351 & TST & \\
\hline CHEMBL 3196175 & 688416 & 4.8196 & 4.3367 & TRN & \\
\hline CHEMBL601751 & 688416 & 2.8239 & 3.5404 & TRN & \\
\hline CHEMBL607309 & 688416 & 5.3804 & 4.7032 & TST & \\
\hline CHEMBL1429718 & 688416 & 2.8239 & 4.1908 & TST & \\
\hline CHEMBL1301129 & 688416 & 4.9247 & 4.3539 & TRN & \\
\hline CHEMBL1389601 & 688416 & 2.8239 & 4.1471 & TRN & \\
\hline CHEMBL1576333 & 688416 & 2.8239 & 4.3282 & TRN & \\
\hline CHEMBL1506533 & 688416 & 4.697 & 4.38 & TRN & \\
\hline CHEMBL1466887 & 688416 & 6.0 & 4.7891 & TST & \\
\hline CHEMBL1480524 & 688416 & 2.8239 & 2.8937 & TST & \\
\hline CHEMBL1303357 & 688416 & 4.2807 & 4.9174 & TRN & \\
\hline CHEMBL1605916 & 688416 & 4.8621 & 5.0971 & TST & \\
\hline CHEMBL 1421570 & 688416 & 2.8239 & 3.4619 & TRN & \\
\hline CHEMBL1424051 & 688416 & 2.8239 & 2.2535 & TRN & \\
\hline CHEMBL1425761 & 688416 & 2.8239 & 4.1332 & TRN & \\
\hline CHEMBL1504806 & 688416 & 2.8239 & 3.8735 & TST & \\
\hline CHEMBL1348263 & 688416 & 5.4983 & 5.0264 & TRN & \\
\hline CHEMBL 1584810 & 688416 & 4.6111 & 4.1203 & TRN & \\
\hline CHEMBL1523620 & 688416 & 4.6115 & 4.3498 & TRN & \\
\hline CHEMBL1520545 & 688416 & 4.5541 & 4.5391 & TST & \\
\hline CHEMBL1412704 & 688416 & 2.8239 & 4.2571 & TRN & \\
\hline CHEMBL1478241 & 688416 & 4.9555 & 4.228 & TRN & \\
\hline CHEMBL1563791 & 688416 & 5.4182 & 5.7465 & TRN & \\
\hline CHEMBL1991751 & 688416 & 2.8239 & 2.912 & TRN & \\
\hline CHEMBL1609946 & 688416 & 6.3665 & 5.6834 & TRN & \\
\hline CHEMBL1302894 & 688416 & 3.9879 & 4.5174 & TRN & \\
\hline CHEMBL1983939 & 688416 & 5.5474 & 5.3291 & TRN & \\
\hline CHEMBL1471592 & 688416 & 4.6805 & 4.9109 & TRN & \\
\hline CHEMBL3195963 & 688416 & 4.9519 & 4.9037 & TST & \\
\hline CHEMBL1368221 & 688416 & 3.9896 & 4.109 & TRN & \\
\hline CHEMBL1505586 & 688416 & 4.9816 & 4.7015 & TST & \\
\hline CHEMBL1468147 & 688416 & 5.0656 & 4.5982 & TRN & \\
\hline CHEMBL1553291 & 688416 & 5.0304 & 4.6833 & TRN & \\
\hline CHEMBL1376174 & 688416 & 2.8239 & 3.6427 & TST & \\
\hline CHEMBL 3189743 & 688416 & 5.4777 & 4.9534 & TRN & \\
\hline CHEMBL1450537 & 688416 & 4.1047 & 4.15600 & 2000000001 & TRN \\
\hline CHEMBL1526636 & 688416 & 5.2608 & 4.4306 & TRN & \\
\hline CHEMBL1411838 & 688416 & 2.8239 & 2.4444 & TRN & \\
\hline CHEMBL1536073 & 688416 & 4.9826 & 4.7763 & TRN & \\
\hline CHEMBL3191363 & 688416 & 5.7535 & 4.9977 & TRN & \\
\hline CHEMBL1564523 & 688416 & 4.9086 & 4.2832 & TRN & \\
\hline CHEMBL1586809 & 688416 & 2.8239 & 4.1182 & TRN & \\
\hline CHEMBL1587142 & 688416 & 2.8239 & 2.4469 & TRN & \\
\hline CHEMBL1472447 & 688416 & 4.9845 & 4.2976 & TRN & \\
\hline CHEMBL1344667 & 688416 & 4.9985 & 4.3663 & TRN & \\
\hline CHEMBL1594585 & 688416 & 2.8239 & 2.5644 & TRN & \\
\hline
\end{tabular}




\begin{tabular}{|c|c|c|c|c|c|}
\hline \multicolumn{6}{|c|}{ Supplemental Table S2.txt } \\
\hline CHEMBL1426228 & 688416 & 5.0981 & 4.4417 & TRN & \\
\hline CHEMBL1502020 & 688416 & 4.8241 & 4.367 & TRN & \\
\hline CHEMBL1402936 & 688416 & 5.2042 & 4.83 & TRN & \\
\hline CHEMBL1510905 & 688416 & 4.6347 & 4.5725 & TRN & \\
\hline CHEMBL1461142 & 688416 & 4.6758 & 5.0816 & TRN & \\
\hline CHEMBL1584486 & 688416 & 2.8239 & 3.9977 & TRN & \\
\hline CHEMBL1534716 & 688416 & 2.8239 & 4.4934 & TRN & \\
\hline CHEMBL1342028 & 688416 & 5.0514 & 4.2361 & TRN & \\
\hline CHEMBL1484658 & 688416 & 4.7972 & 4.2114 & TRN & \\
\hline CHEMBL1977376 & 688416 & 2.8239 & 2.8376 & TRN & \\
\hline CHEMBL1545247 & 688416 & 2.8239 & 2.5625 & TRN & \\
\hline CHEMBL1561190 & 688416 & 4.3072 & 4.26699 & 99999999995 & TRN \\
\hline CHEMBL1518998 & 688416 & 4.6014 & 4.7287 & TRN & \\
\hline CHEMBL1433404 & 688416 & 2.8239 & 2.1345 & TRN & \\
\hline CHEMBL1359684 & 688416 & 4.6074 & 4.5125 & TRN & \\
\hline CHEMBL1531168 & 688416 & 5.0439 & 4.7729 & TRN & \\
\hline CHEMBL1496648 & 688416 & 3.8527 & 3.9118 & TRN & \\
\hline CHEMBL1370746 & 688416 & 5.1793 & 4.1845 & TRN & \\
\hline CHEMBL1461561 & 688416 & 4.5346 & 4.2158 & TRN & \\
\hline CHEMBL1534433 & 688416 & 2.8239 & 2.5309 & TRN & \\
\hline CHEMBL1515140 & 688416 & 2.8239 & 4.3083 & TRN & \\
\hline CHEMBL1384186 & 688416 & 4.9724 & 4.533 & TRN & \\
\hline CHEMBL1530995 & 688416 & 5.2202 & 4.7852 & TST & \\
\hline CHEMBL1584143 & 688416 & 4.5799 & 4.6524 & TRN & \\
\hline CHEMBL1533770 & 688416 & 2.8239 & 4.6004 & TRN & \\
\hline CHEMBL1385499 & 688416 & 4.787 & 4.1595 & TRN & \\
\hline CHEMBL1373424 & 688416 & 2.8239 & 2.5798 & TRN & \\
\hline CHEMBL1992164 & 688416 & 5.36 & 4.8686 & TRN & \\
\hline CHEMBL1426136 & 688416 & 2.8239 & 1.8594 & TRN & \\
\hline CHEMBL1495714 & 688416 & 2.8239 & 4.7145 & TRN & \\
\hline CHEMBL1567674 & 688416 & 2.8239 & 3.9107 & TRN & \\
\hline CHEMBL3192928 & 688416 & 5.5196 & 4.8937 & TRN & \\
\hline CHEMBL1347479 & 688416 & 2.8239 & 3.9102 & TST & \\
\hline CHEMBL1355233 & 688416 & 5.2944 & 4.6995 & TST & \\
\hline CHEMBL1391280 & 688416 & 2.8239 & 2.7577 & TRN & \\
\hline CHEMBL1439833 & 688416 & 5.114 & 4.8338 & TRN & \\
\hline CHEMBL1599981 & 688416 & 2.8239 & 4.2175 & TRN & \\
\hline CHEMBL3213413 & 688416 & 4.9836 & 4.418 & TRN & \\
\hline CHEMBL1501158 & 688416 & 3.8243 & 3.6214 & TRN & \\
\hline CHEMBL1547350 & 688416 & 2.8239 & 5.0375 & TRN & \\
\hline CHEMBL1424562 & 688416 & 5.4217 & 4.8552 & TRN & \\
\hline CHEMBL1478252 & 688416 & 2.8239 & 4.288 & TST & \\
\hline CHEMBL3192299 & 688416 & 5.7921 & 4.888 & TRN & \\
\hline CHEMBL1369339 & 688416 & 5.1008 & 4.4771 & TRN & \\
\hline CHEMBL1541672 & 688416 & 4.7924 & 4.3849 & TRN & \\
\hline CHEMBL1299367 & 688416 & 4.7358 & 4.6532 & TRN & \\
\hline CHEMBL3210860 & 688416 & 4.8072 & 4.169 & TRN & \\
\hline CHEMBL1536606 & 688416 & 5.2123 & 4.4155 & TRN & \\
\hline
\end{tabular}




\begin{tabular}{|c|c|c|c|c|c|}
\hline & & \multicolumn{4}{|c|}{ Supplemental Table S2.txt } \\
\hline CHEMBL3192977 & 688416 & 4.8151 & 4.8257 & TST & \\
\hline CHEMBL1530170 & 688416 & 4.6734 & 4.6897 & TRN & \\
\hline CHEMBL1551880 & 688416 & 5.2317 & 4.1607 & TST & \\
\hline CHEMBL1493936 & 688416 & 6.6421 & 6.5579 & TRN & \\
\hline CHEMBL591361 & 688416 & 5.5672 & 5.1444 & TRN & \\
\hline CHEMBL1410625 & 688416 & 3.9048 & 4.3863 & TRN & \\
\hline CHEMBL1384359 & 688416 & 2.8239 & 4.3548 & TST & \\
\hline CHEMBL1334663 & 688416 & 2.8239 & 2.3455 & TST & \\
\hline CHEMBL1418885 & 688416 & 5.1298 & 4.9325 & TRN & \\
\hline CHEMBL1422340 & 688416 & 5.0654 & 4.6855 & TST & \\
\hline CHEMBL1377813 & 688416 & 4.7761 & 4.1258 & TRN & \\
\hline CHEMBL1371877 & 688416 & 5.0398 & 4.6447 & TRN & \\
\hline CHEMBL1372434 & 688416 & 4.7834 & 4.2126 & TRN & \\
\hline CHEMBL1529601 & 688416 & 2.8239 & 4.1 & TRN & \\
\hline CHEMBL1364216 & 688416 & 4.6284 & 4.2842 & TRN & \\
\hline CHEMBL1446095 & 688416 & 4.0013 & 4.4443 & TST & \\
\hline CHEMBL1418178 & 688416 & 2.8239 & 4.0136 & TST & \\
\hline CHEMBL1994623 & 688416 & 6.0462 & 5.4277 & TRN & \\
\hline CHEMBL1392523 & 688416 & 2.8239 & 2.7563 & TST & \\
\hline CHEMBL1525780 & 688416 & 2.8239 & 4.137 & TRN & \\
\hline CHEMBL3194209 & 688416 & 2.8239 & 3.9141 & TRN & \\
\hline CHEMBL1522645 & 688416 & 4.0992 & 3.9592 & TRN & \\
\hline CHEMBL 2005246 & 688416 & 6.3716 & 5.5516 & TRN & \\
\hline CHEMBL1964891 & 688416 & 3.301 & $4.8580 e$ & 00000000005 & TRN \\
\hline CHEMBL 2007218 & 688416 & 6.2596 & 5.7818 & TRN & \\
\hline CHEMBL1369522 & 688416 & 2.8239 & 3.3848 & TST & \\
\hline CHEMBL1560408 & 688416 & 4.8117 & 4.5245 & TRN & \\
\hline CHEMBL1322274 & 688416 & 4.2097 & 4.2501 & TST & \\
\hline CHEMBL1608907 & 688416 & 4.7382 & 4.175 & TRN & \\
\hline CHEMBL1462889 & 688416 & 2.8239 & $2.7560 e$ & 00000000002 & TRN \\
\hline CHEMBL1454738 & 688416 & 4.7781 & 4.4842 & TRN & \\
\hline CHEMBL1428514 & 688416 & 4.6999 & 4.2491 & TRN & \\
\hline CHEMBL1330453 & 688416 & 4.6903 & 3.78899 & 99999999997 & TRN \\
\hline CHEMBL1503123 & 688416 & 2.8239 & 3.9622 & TRN & \\
\hline CHEMBL1971033 & 688416 & 5.0665 & 4.87 & TRN & \\
\hline CHEMBL1598311 & 688416 & 5.1166 & 4.1896 & TRN & \\
\hline CHEMBL1359157 & 688416 & 5.1628 & 4.3692 & TST & \\
\hline CHEMBL3211464 & 688416 & 4.496 & 4.8613 & TRN & \\
\hline CHEMBL1994935 & 688416 & 4.0738 & 4.0288 & TRN & \\
\hline CHEMBL1456639 & 688416 & 2.8239 & 2.5203 & TRN & \\
\hline CHEMBL3213659 & 688416 & 5.5712 & 5.2688 & TRN & \\
\hline CHEMBL1585681 & 688416 & 4.9026 & 4.3076 & TRN & \\
\hline CHEMBL1987622 & 688416 & 5.5715 & 5.1834 & TRN & \\
\hline CHEMBL1442745 & 688416 & 5.1726 & 4.6568 & TRN & \\
\hline CHEMBL 3198886 & 688416 & 5.4272 & 4.9786 & TRN & \\
\hline CHEMBL1545578 & 688416 & 4.8327 & 4.2708 & TRN & \\
\hline CHEMBL223453 & 688416 & 5.6467 & 5.3379 & TRN & \\
\hline CHEMBL3197808 & 688416 & 5.1844 & 5.235 & TRN & \\
\hline
\end{tabular}




\begin{tabular}{|c|c|c|c|c|c|}
\hline & & \multicolumn{4}{|c|}{ Supplemental Table S2.txt } \\
\hline CHEMBL1483281 & 688416 & 2.8239 & 3.8075 & TRN & \\
\hline CHEMBL1972864 & 688416 & 4.9161 & 4.728 & TRN & \\
\hline CHEMBL1371013 & 688416 & 4.8723 & 4.6713 & TRN & \\
\hline CHEMBL1383414 & 688416 & 5.5599 & 4.9675 & TRN & \\
\hline CHEMBL1463624 & 688416 & 4.8272 & 4.39199 & 99999999995 & TRN \\
\hline CHEMBL1596460 & 688416 & 4.6654 & 3.8148 & TRN & \\
\hline CHEMBL1505053 & 688416 & 4.6674 & 4.3082 & TRN & \\
\hline CHEMBL1463761 & 688416 & 4.9829 & 4.4654 & TRN & \\
\hline CHEMBL1542604 & 688416 & 4.9541 & 4.3934 & TRN & \\
\hline CHEMBL3211496 & 688416 & 2.8239 & 2.7695 & TRN & \\
\hline CHEMBL3195074 & 688416 & 5.6299 & 4.9913 & TRN & \\
\hline CHEMBL1310234 & 688416 & 5.1361 & 4.577 & TRN & \\
\hline CHEMBL1359609 & 688416 & 4.8625 & 4.5397 & TRN & \\
\hline CHEMBL1510339 & 688416 & 5.513 & 4.8711 & TRN & \\
\hline CHEMBL1318412 & 688416 & 2.8239 & 3.9449 & TST & \\
\hline CHEMBL1430138 & 688416 & 4.6859 & 4.6044 & TRN & \\
\hline CHEMBL1452467 & 688416 & 4.87 & 5.33700 & 0000000001 & TRN \\
\hline CHEMBL1340519 & 688416 & 5.237 & 5.3767 & TRN & \\
\hline CHEMBL1256686 & 688416 & 6.8928 & 6.4829 & TST & \\
\hline CHEMBL1372397 & 688416 & 4.5781 & 4.4207 & TRN & \\
\hline CHEMBL1559100 & 688416 & 5.1317 & 4.7054 & TRN & \\
\hline CHEMBL1425743 & 688416 & 2.8239 & 4.3033 & TST & \\
\hline CHEMBL1359788 & 688416 & 4.9608 & 4.585 & TRN & \\
\hline CHEMBL1425314 & 688416 & 2.8239 & 4.2741 & TRN & \\
\hline CHEMBL1413672 & 688416 & 4.0256 & 3.9117 & TRN & \\
\hline CHEMBL1523275 & 688416 & 4.8044 & 3.8962 & TRN & \\
\hline CHEMBL1411744 & 688416 & 2.8239 & 2.481 & TRN & \\
\hline CHEMBL1350930 & 688416 & 2.8239 & 4.2329 & TRN & \\
\hline CHEMBL1426440 & 688416 & 4.7216 & 4.3772 & TST & \\
\hline CHEMBL1504993 & 688416 & 5.2251 & 4.9129 & TST & \\
\hline CHEMBL1402220 & 688416 & 2.8239 & 2.4876 & TRN & \\
\hline CHEMBL1354041 & 688416 & 4.7498 & 4.5823 & TRN & \\
\hline CHEMBL1347120 & 688416 & 2.8239 & 4.2047 & TST & \\
\hline CHEMBL1993993 & 688416 & 5.1307 & 4.8028 & TRN & \\
\hline CHEMBL1992174 & 688416 & 4.7064 & 4.5816 & TST & \\
\hline CHEMBL3196184 & 688416 & 5.4078 & 5.2764 & TRN & \\
\hline CHEMBL3196251 & 688416 & 4.7946 & 4.0543 & TRN & \\
\hline CHEMBL1536431 & 688416 & 5.756 & 4.8548 & TRN & \\
\hline CHEMBL1547867 & 688416 & 4.8122 & 4.5713 & TRN & \\
\hline CHEMBL1370838 & 688416 & 2.8239 & 4.0149 & TST & \\
\hline CHEMBL1598340 & 688416 & 5.6474 & 4.8822 & TRN & \\
\hline CHEMBL1320170 & 688416 & 2.8239 & 4.3669 & TST & \\
\hline CHEMBL1385201 & 688416 & 2.8239 & 2.5074 & TRN & \\
\hline CHEMBL1482979 & 688416 & 2.8239 & 4.7885 & TST & \\
\hline CHEMBL3189984 & 688416 & 6.0273 & 5.4672 & TRN & \\
\hline CHEMBL3199324 & 688416 & 4.9185 & 5.0429 & TRN & \\
\hline CHEMBL1567034 & 688416 & 4.1631 & 4.1143 & TST & \\
\hline CHEMBL1997052 & 688416 & 2.8239 & 4.7713 & TRN & \\
\hline
\end{tabular}




\begin{tabular}{|c|c|c|c|c|}
\hline & & & & \\
\hline CHEMBL1377978 & 688416 & 5.0668 & 4.5927 & TST \\
\hline CHEMBL1343326 & 688416 & 5.0828 & 5.1789 & TRN \\
\hline CHEMBL1395220 & 688416 & 3.878 & 4.137 & TRN \\
\hline CHEMBL1539307 & 688416 & 2.8239 & 4.2493 & ST \\
\hline CHEMBL1534683 & 688416 & 2.8239 & 3.8773 & ST \\
\hline CHEMBL1371792 & 688416 & 2.8239 & 3.9988 & RN \\
\hline CHEMBL1372805 & 688416 & 5.3323 & 4.7409 & RN \\
\hline CHEMBL 3192020 & 688416 & 5.5382 & 5.2352 & $\mathrm{RN}$ \\
\hline CHEMBL1349905 & 688416 & 5.3381 & 4.6679 & RN \\
\hline CHEMBL1372796 & 688416 & 4.9422 & 4.7107 & TRN \\
\hline CHEMBL1308201 & 688416 & 2.8239 & 3.911 & ST \\
\hline CHEMBL1572214 & 688416 & 2.8239 & 4.4075 & ST \\
\hline CHEMBL1365611 & 688416 & 4.4391 & 4.3152 & ST \\
\hline CHEMBL1173823 & 688416 & 2.8239 & 3.9685 & TRN \\
\hline CHEMBL1462381 & 688416 & 4.5728 & 4.1814 & TRN \\
\hline CHEMBL1388722 & 688416 & 5.092 & 4.6458 & TRN \\
\hline CHEMBL1499286 & 688416 & 3.9569 & 4.4719 & RN \\
\hline CHEMBL1493705 & 688416 & 4.8047 & 4.5848 & TRN \\
\hline CHEMBL1505275 & 688416 & 5.1131 & 4.5751 & TRN \\
\hline CHEMBL1532716 & 688416 & 3.8928 & 4.4801 & TST \\
\hline CHEMBL461579 & 688416 & 4.9191 & 4.4763 & TST \\
\hline CHEMBL1372421 & 688416 & 5.7642 & 4.9131 & TRN \\
\hline CHEMBL1332139 & 688416 & 5.9792 & 5.5869 & TRN \\
\hline CHEMBL1302315 & 688416 & 2.8239 & 3.4509 & TRN \\
\hline CHEMBL1511114 & 688416 & 3.8552 & 4.0976 & TRN \\
\hline CHEMBL1978479 & 688416 & 5.6066 & 5.154 & TST \\
\hline CHEMBL1541789 & 688416 & 2.8239 & 4.3394 & TRN \\
\hline CHEMBL3197599 & 688416 & 5.4346 & 5.0085 & TRN \\
\hline CHEMBL1420800 & 688416 & 4.0412 & 4.3394 & TRN \\
\hline CHEMBL1588702 & 688416 & 4.5135 & 4.1827 & TRN \\
\hline CHEMBL1606903 & 688416 & 4.9299 & 4.2215 & TRN \\
\hline CHEMBL1542959 & 688416 & 5.4852 & 4.7911 & TRN \\
\hline CHEMBL1374455 & 688416 & 2.8239 & 3.8658 & TRN \\
\hline CHEMBL1600644 & 688416 & 5.5547 & 4.7916 & TRN \\
\hline CHEMBL1575634 & 688416 & 5.9638 & 5.5409 & TRN \\
\hline CHEMBL1584229 & 688416 & 2.8239 & 3.9682 & TRN \\
\hline CHEMBL1421170 & 688416 & 5.0463 & 4.6961 & TRN \\
\hline CHEMBL1405781 & 688416 & 2.8239 & 2.9726 & TRN \\
\hline CHEMBL1486536 & 688416 & 5.3152 & 4.6475 & TRN \\
\hline CHEMBL1304169 & 688416 & 5.5287 & 5.0181 & TRN \\
\hline CHEMBL1432309 & 688416 & 4.749 & 4.5068 & TRN \\
\hline CHEMBL1374801 & 688416 & 2.8239 & 2.378 & TRN \\
\hline CHEMBL1490222 & 688416 & 5.157 & 5.2483 & TRN \\
\hline CHEMBL1472418 & 688416 & 4.711 & 4.425 & TRN \\
\hline CHEMBL1445327 & 688416 & 4.8073 & 4.3912 & TRN \\
\hline CHEMBL1378852 & 688416 & 2.8239 & 2.7069 & TRN \\
\hline CHEMBL3196386 & 688416 & 2.8239 & 4.4092 & TST \\
\hline CHEMBL1534655 & 688416 & 4.8068 & 4.6799 & 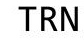 \\
\hline
\end{tabular}

Page 13968 


\begin{tabular}{|c|c|c|c|c|c|c|}
\hline \multirow{3}{*}{$\begin{array}{l}\text { CHEMBL1302569 } \\
\text { CHEMBL1612159 }\end{array}$} & & \multicolumn{5}{|c|}{ Supplemental Table S2.txt } \\
\hline & 688416 & 4.6408 & \multicolumn{3}{|c|}{4.486000000000001} & TRN \\
\hline & 688416 & 5.1529 & 4.5708 & TST & & \\
\hline CHEMBL1330429 & 688416 & 2.8239 & 3.7583 & TRN & & \\
\hline CHEMBL1468541 & 688416 & 2.8239 & 1.9591 & TRN & & \\
\hline CHEMBL1482637 & 688416 & 2.8239 & 4.7309 & TRN & & \\
\hline CHEMBL1559660 & 688416 & 3.9095 & 4.3334 & TST & & \\
\hline CHEMBL1582878 & 688416 & 2.8239 & 4.1801 & TRN & & \\
\hline CHEMBL1465097 & 688416 & 4.658 & 4.1514 & TRN & & \\
\hline CHEMBL1387036 & 688416 & 2.8239 & 2.546 & TST & & \\
\hline CHEMBL1598569 & 688416 & 5.8861 & 5.71200 & 0000000001 & & TRN \\
\hline CHEMBL1448654 & 688416 & 4.418 & 3.7034 & TRN & & \\
\hline CHEMBL1468929 & 688416 & 2.8239 & 3.8774 & TST & & \\
\hline CHEMBL1504675 & 688416 & 2.8239 & 4.4378 & TRN & & \\
\hline CHEMBL1375199 & 688416 & 4.9802 & 4.5566 & TRN & & \\
\hline CHEMBL1374950 & 688416 & 5.2293 & 4.7735 & TRN & & \\
\hline CHEMBL1568852 & 688416 & $4.9860 e$ & 30000000 & & 4.3114 & TRN \\
\hline CHEMBL1345063 & 688416 & 5.3017 & 4.6285 & TRN & & \\
\hline CHEMBL1507228 & 688416 & 5.1675 & 4.8018 & TRN & & \\
\hline CHEMBL1971379 & 688416 & 5.5583 & 5.0375 & TRN & & \\
\hline CHEMBL1980657 & 688416 & 5.5117 & 5.1315 & TRN & & \\
\hline CHEMBL1454171 & 688416 & 5.1872 & 4.7629 & TRN & & \\
\hline CHEMBL455284 & 688416 & 2.8239 & 4.7061 & TRN & & \\
\hline CHEMBL1465660 & 688416 & 2.8239 & 2.1907 & TRN & & \\
\hline CHEMBL3196139 & 688416 & 4.7445 & 4.3337 & TRN & & \\
\hline CHEMBL585591 & 688416 & 5.4104 & 4.6531 & TST & & \\
\hline CHEMBL1568277 & 688416 & 5.7525 & 5.1468 & TRN & & \\
\hline CHEMBL1496705 & 688416 & 5.1012 & 4.3494 & TRN & & \\
\hline CHEMBL1369254 & 688416 & 4.763 & 4.284 & TRN & & \\
\hline CHEMBL1400025 & 688416 & 2.8239 & 2.7947 & TRN & & \\
\hline CHEMBL1579217 & 688416 & 4.3477 & 4.5813 & TRN & & \\
\hline CHEMBL1361114 & 688416 & 2.8239 & 3.2611 & TST & & \\
\hline CHEMBL1537518 & 688416 & 2.8239 & 4.0256 & TRN & & \\
\hline CHEMBL1534816 & 688416 & 2.8239 & 3.8675 & TRN & & \\
\hline CHEMBL1588513 & 688416 & 5.2234 & 5.1939 & TRN & & \\
\hline CHEMBL1510676 & 688416 & 5.9535 & 5.1492 & TST & & \\
\hline CHEMBL1302865 & 688416 & 4.6357 & 4.3009 & TRN & & \\
\hline CHEMBL1984190 & 688416 & 5.3799 & 4.9712 & TRN & & \\
\hline CHEMBL1448529 & 688416 & 4.4296 & 4.2799 & TRN & & \\
\hline CHEMBL1365325 & 688416 & 2.8239 & 3.7632 & TRN & & \\
\hline CHEMBL1468351 & 688416 & 4.1964 & 3.8417 & TRN & & \\
\hline CHEMBL1438096 & 688416 & 2.8239 & 3.9303 & TRN & & \\
\hline CHEMBL1459494 & 688416 & 4.7845 & 4.3882 & TST & & \\
\hline CHEMBL1516534 & 688416 & 4.8778 & 4.3042 & TRN & & \\
\hline CHEMBL1607568 & 688416 & $5.4860 e$ & 00000000 & & 4.8116 & TRN \\
\hline CHEMBL1348216 & 688416 & 2.8239 & 2.7854 & TRN & & \\
\hline CHEMBL1494800 & 688416 & 2.8239 & 3.9895 & TRN & & \\
\hline CHEMBL1584456 & 688416 & 2.8239 & 2.701 & TRN & & \\
\hline CHEMBL1452612 & 688416 & 4.4941 & 4.461 & TRN & & \\
\hline
\end{tabular}




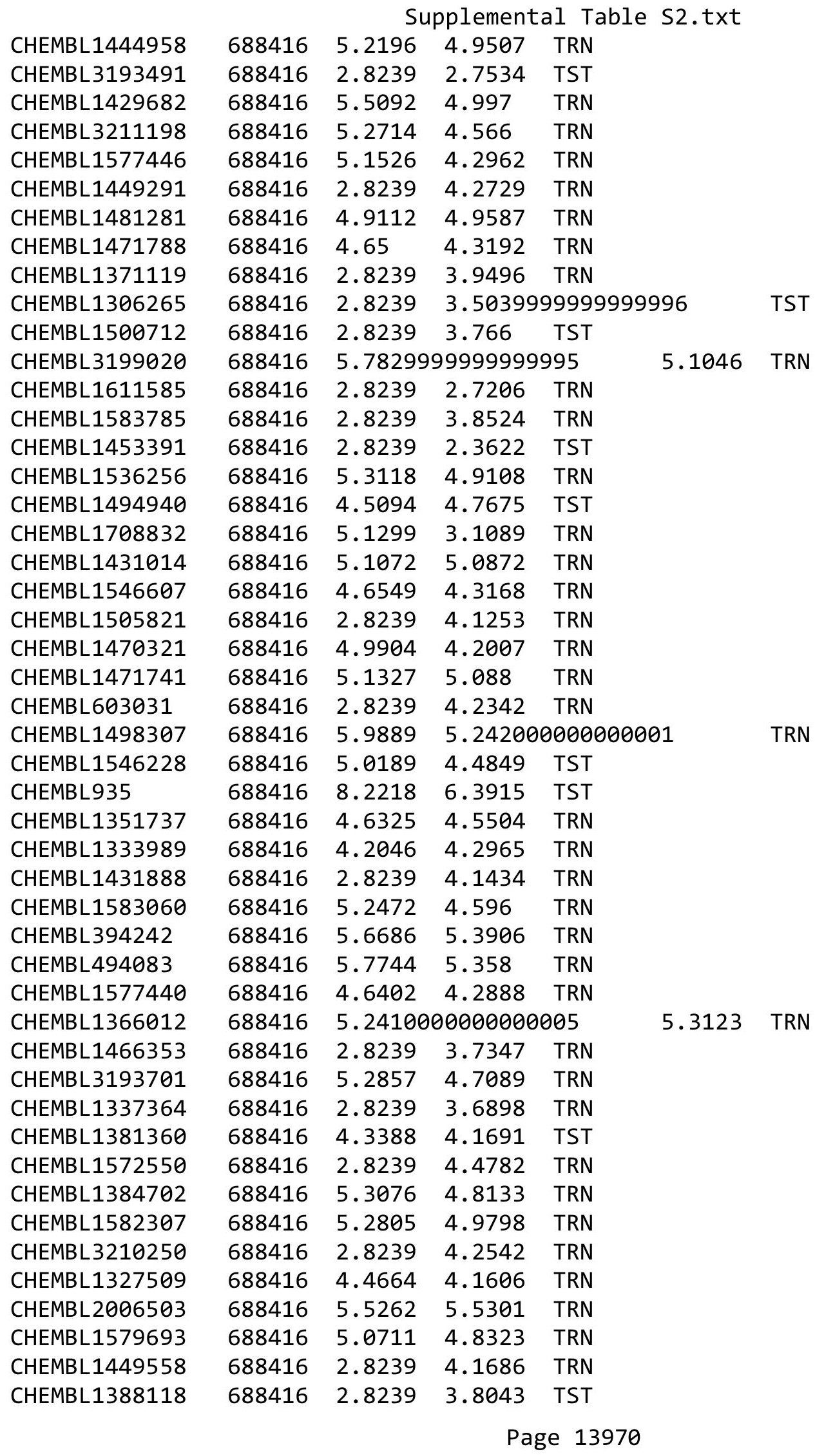




\begin{tabular}{|c|c|c|c|c|c|}
\hline \multirow[b]{2}{*}{ CHEMBL1560273 } & \multicolumn{5}{|c|}{ Supplemental Table S2.txt } \\
\hline & 688416 & 4.8125 & 4.4249 & TST & \\
\hline CHEMBL1538099 & 688416 & 5.1 & 4.4056 & TRN & \\
\hline CHEMBL1497685 & 688416 & 2.8239 & 4.0392 & TRN & \\
\hline CHEMBL1314141 & 688416 & 6.4157 & 5.6852 & TRN & \\
\hline CHEMBL 1430718 & 688416 & 4.8772 & 5.0063 & TRN & \\
\hline CHEMBL1367268 & 688416 & 4.5408 & 4.1166 & TRN & \\
\hline CHEMBL1303126 & 688416 & 2.8239 & 4.2687 & TRN & \\
\hline CHEMBL1360539 & 688416 & 5.6183 & 4.7827 & TRN & \\
\hline CHEMBL1391069 & 688416 & 2.8239 & 2.4965 & TRN & \\
\hline CHEMBL1326381 & 688416 & 3.301 & 4.3751 & TRN & \\
\hline CHEMBL1326634 & 688416 & 5.1508 & 4.487 & TST & \\
\hline CHEMBL1557756 & 688416 & 2.8239 & 4.3287 & TST & \\
\hline CHEMBL1593697 & 688416 & 6.5575 & 6.3878 & TST & \\
\hline CHEMBL517514 & 688416 & 4.5872 & 5.34200 & 00000000005 & TRN \\
\hline CHEMBL1519755 & 688416 & 4.7402 & 4.7196 & TRN & \\
\hline CHEMBL1478211 & 688416 & 4.9313 & 4.4975 & TRN & \\
\hline CHEMBL1333583 & 688416 & 2.8239 & 4.4917 & TST & \\
\hline CHEMBL1422849 & 688416 & 5.4558 & 4.8479 & TRN & \\
\hline CHEMBL1997422 & 688416 & 5.334 & 4.829 & TRN & \\
\hline CHEMBL1341945 & 688416 & 2.8239 & 3.8602 & TRN & \\
\hline CHEMBL1454039 & 688416 & 5.7366 & 4.9786 & TRN & \\
\hline CHEMBL1461196 & 688416 & 4.952 & 5.2301 & TRN & \\
\hline CHEMBL1553151 & 688416 & 2.8239 & 3.8319 & TRN & \\
\hline CHEMBL1418389 & 688416 & 6.0269 & 5.50700 & 0000000001 & TRN \\
\hline CHEMBL1599708 & 688416 & 5.6496 & 5.7461 & TRN & \\
\hline CHEMBL1374754 & 688416 & 5.4351 & 4.8658 & TRN & \\
\hline CHEMBL1580139 & 688416 & 5.4387 & 5.0573 & TRN & \\
\hline CHEMBL1607065 & 688416 & 2.8239 & 3.9524 & TST & \\
\hline CHEMBL 2006511 & 688416 & 5.5611 & 5.0284 & TRN & \\
\hline CHEMBL3208501 & 688416 & 5.4799 & 4.9965 & TRN & \\
\hline CHEMBL1368435 & 688416 & 2.8239 & 4.0992 & TRN & \\
\hline CHEMBL1361361 & 688416 & 2.8239 & 4.2389 & TRN & \\
\hline CHEMBL1402267 & 688416 & 4.3816 & 4.7634 & TRN & \\
\hline CHEMBL1393796 & 688416 & 2.8239 & 3.6868 & TRN & \\
\hline CHEMBL479765 & 688416 & 5.5369 & 5.2431 & TRN & \\
\hline CHEMBL1487004 & 688416 & 4.26 & 4.48600 & 0000000001 & TST \\
\hline CHEMBL1308319 & 688416 & 4.9284 & 4.6047 & TRN & \\
\hline CHEMBL3190880 & 688416 & 5.7212 & 5.2093 & TRN & \\
\hline CHEMBL1385808 & 688416 & 6.0 & 5.4339 & TST & \\
\hline CHEMBL1407260 & 688416 & 4.8698 & 4.138 & TRN & \\
\hline CHEMBL1496338 & 688416 & 4.8761 & 4.4576 & TRN & \\
\hline CHEMBL1604261 & 688416 & 2.8239 & 4.3121 & TST & \\
\hline CHEMBL1378131 & 688416 & 5.0403 & 5.5078 & TRN & \\
\hline CHEMBL1322304 & 688416 & 4.7459 & 4.3228 & TRN & \\
\hline CHEMBL1343705 & 688416 & 5.1468 & 4.592 & TRN & \\
\hline CHEMBL1451977 & 688416 & 5.4082 & 6.7589 & TRN & \\
\hline CHEMBL1359820 & 688416 & 2.8239 & 4.0046 & TRN & \\
\hline CHEMBL1488172 & 688416 & 4.1971 & 5.0498 & TRN & \\
\hline
\end{tabular}

Page 13971 


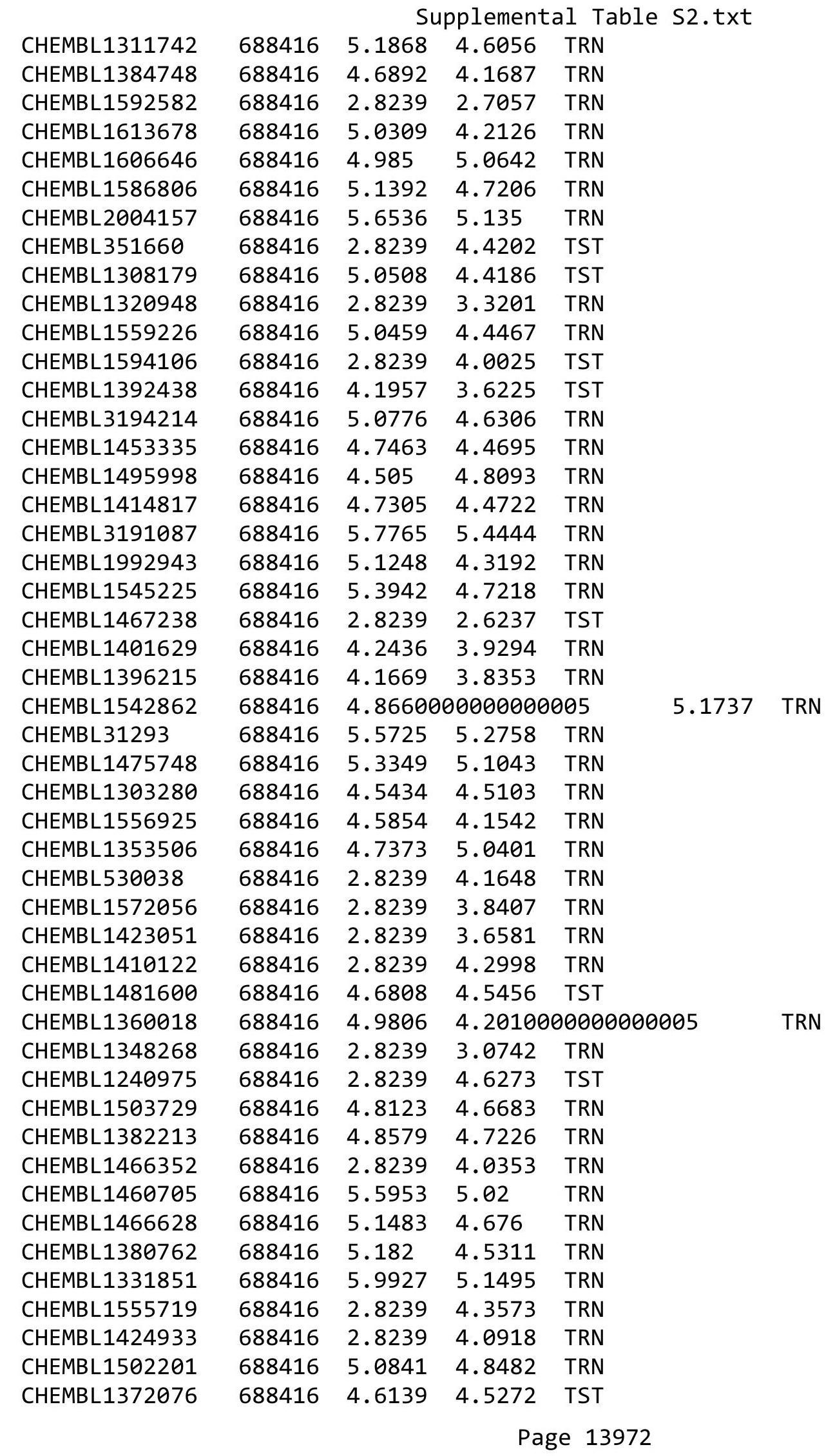


Supplemental Table S2.txt

\begin{tabular}{|c|c|c|c|c|}
\hline CHEMBL1342436 & 688416 & 6.8153 & 6.6196 & TST \\
\hline CHEMBL1557952 & 688416 & 5.1333 & 4.5337 & TRN \\
\hline CHEMBL1505760 & 688416 & 5.4289 & 4.6569 & TRN \\
\hline CHEMBL3195273 & 688416 & 2.8239 & 4.2989 & TRN \\
\hline CHEMBL1561651 & 688416 & 2.8239 & 3.858 & TRN \\
\hline CHEMBL1369724 & 688416 & 5.1022 & 4.1248 & TRN \\
\hline CHEMBL1334308 & 688416 & 2.8239 & 2.7583 & TRN \\
\hline CHEMBL1466240 & 688416 & 2.8239 & 2.4103 & TRN \\
\hline CHEMBL1428417 & 688416 & 2.8239 & 4.3333 & TRN \\
\hline CHEMBL1469901 & 688416 & 2.8239 & 2.3023 & TRN \\
\hline CHEMBL1409965 & 688416 & 2.8239 & 4.915 & TRN \\
\hline CHEMBL1392741 & 688416 & 2.8239 & 2.2556 & TRN \\
\hline CHEMBL1443649 & 688416 & 2.8239 & 4.1636 & TST \\
\hline CHEMBL1541490 & 688416 & 5.1697 & 4.4054 & TRN \\
\hline CHEMBL1313281 & 688416 & 2.8239 & 2.6827 & TST \\
\hline CHEMBL1459691 & 688416 & 5.3588 & 5.3495 & TRN \\
\hline CHEMBL1342423 & 688416 & 5.6332 & 4.9248 & TRN \\
\hline CHEMBL1519807 & 688416 & 4.9597 & 4.48600 & 0000000001 \\
\hline CHEMBL1517346 & 688416 & 2.8239 & 2.6423 & TST \\
\hline CHEMBL1478587 & 688416 & 5.1846 & 4.7992 & TRN \\
\hline CHEMBL1404750 & 688416 & 2.8239 & 4.6079 & TST \\
\hline CHEMBL1540122 & 688416 & 2.8239 & 4.0944 & TRN \\
\hline CHEMBL1426978 & 688416 & 2.8239 & 4.5729 & TRN \\
\hline CHEMBL1604283 & 688416 & 8.2218 & 7.2208 & TST \\
\hline CHEMBL1456111 & 688416 & 6.3645 & 5.9965 & TRN \\
\hline CHEMBL1501057 & 688416 & 4.8514 & 5.0421 & TRN \\
\hline CHEMBL1598442 & 688416 & 2.8239 & 3.8394 & TRN \\
\hline CHEMBL1464202 & 688416 & 3.8556 & 3.9408 & TRN \\
\hline CHEMBL1531320 & 688416 & 4.8755 & 4.2821 & TRN \\
\hline CHEMBL225963 & 688416 & 3.9112 & 4.4005 & TRN \\
\hline CHEMBL531401 & 688416 & 4.5895 & 3.9795 & TRN \\
\hline CHEMBL3145304 & 688416 & 5.0488 & 4.8825 & TRN \\
\hline CHEMBL1490689 & 688416 & 4.5982 & 4.4012 & TRN \\
\hline CHEMBL1589029 & 688416 & 2.8239 & 4.4248 & TRN \\
\hline CHEMBL1999480 & 688416 & 2.8239 & 4.6741 & TST \\
\hline CHEMBL1577983 & 688416 & 4.5968 & 5.1227 & TRN \\
\hline CHEMBL1311879 & 688416 & 4.6007 & 4.8521 & TRN \\
\hline CHEMBL1505665 & 688416 & 5.1105 & 4.631 & TRN \\
\hline CHEMBL1523842 & 688416 & 4.9378 & 5.1045 & TST \\
\hline CHEMBL1602599 & 688416 & 3.301 & 3.8041 & TRN \\
\hline CHEMBL1310411 & 688416 & 2.8239 & 2.379 & TRN \\
\hline CHEMBL1453497 & 688416 & 2.8239 & 4.2065 & TRN \\
\hline CHEMBL1544494 & 688416 & 2.8239 & 3.7945 & TST \\
\hline CHEMBL1609481 & 688416 & 4.7499 & 4.9358 & TRN \\
\hline CHEMBL1499597 & 688416 & 2.8239 & 4.1226 & TRN \\
\hline CHEMBL1611182 & 688416 & 4.9784 & 4.6706 & TRN \\
\hline CHEMBL1471170 & 688416 & 5.4832 & 4.8989 & TRN \\
\hline CHEMBL1417167 & 688416 & 5.8867 & 5.0363 & TRN \\
\hline
\end{tabular}




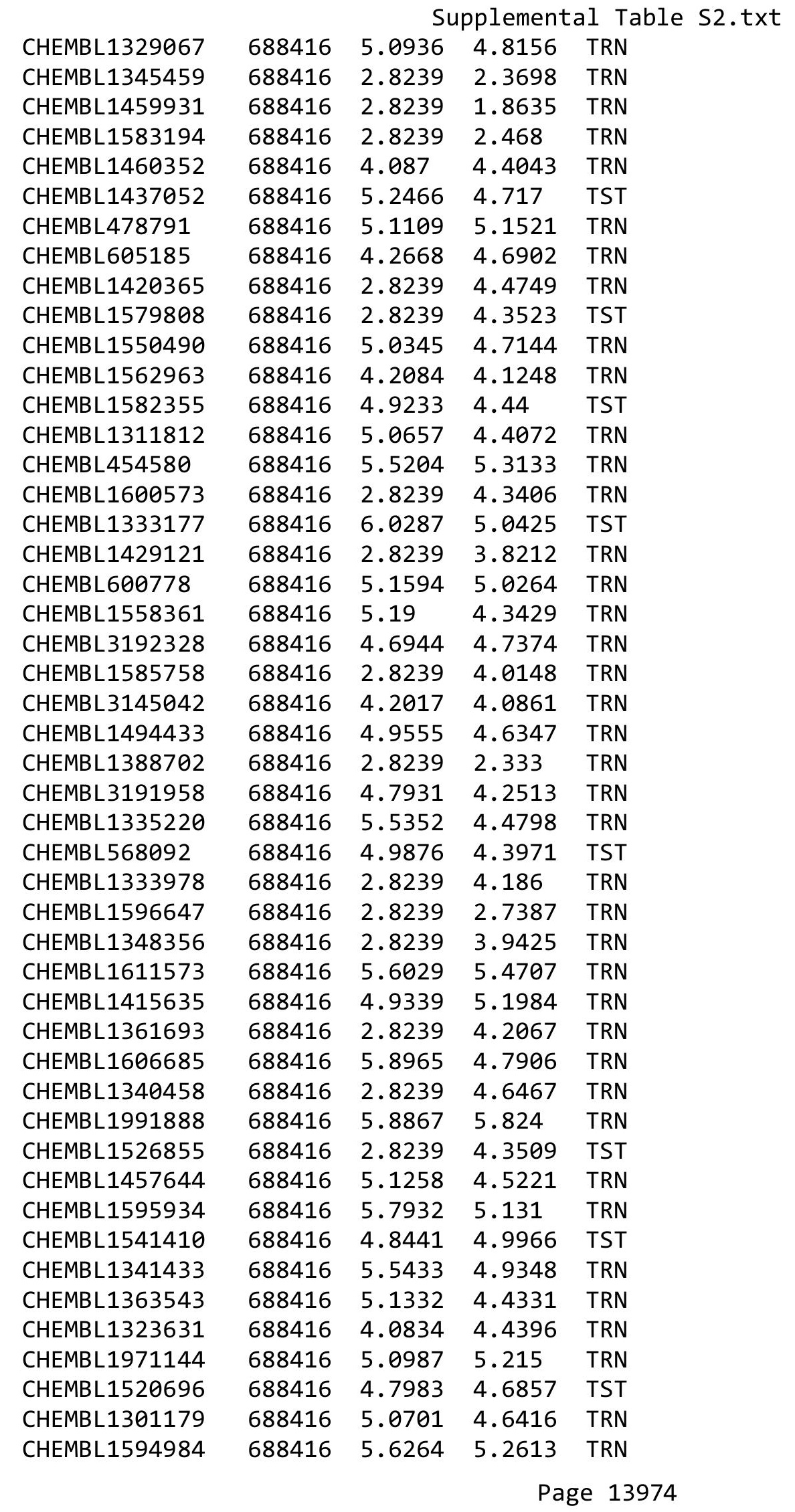


Supplemental Table S2.txt

\begin{tabular}{|c|c|c|c|c|}
\hline 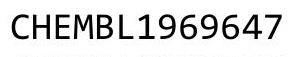 & & 729 & & \\
\hline HEMBL3199756 & 88416 & 2596 & 5.8177 & \\
\hline HEMBL1445659 & 8416 & 8315 & 49 & \\
\hline 37 & & 8239 & & \\
\hline AEMBL13 & & 2156 & & \\
\hline AEMBL197014 & 88416 & 5439 & 5668 & \\
\hline HEMBL1354074 & 88416 & 4.538 & 4.3868 & \\
\hline HEMBL14 & 16 & 2.8239 & & \\
\hline AEMBL1 & & .8239 & 28 & \\
\hline AEMBL15 & & 5.3536 & & \\
\hline HEMBL1409596 & 88416 & .8239 & 2.7349 & \\
\hline HEMBL3193204 & 88 & .8239 & 4.6132 & \\
\hline HEMBL14 & 6 & 3239 & 2 & \\
\hline HEMBL1 & & 452 & & \\
\hline HEMBL15 & & 776 & & \\
\hline HEMBL1330201 & 16 & 3526 & & \\
\hline HEMBL1405668 & & 256 & & \\
\hline HEMBL5E & 6 & 239 & 707 & \\
\hline HEM & & 969 & & \\
\hline HEMBL13 & & 239 & & \\
\hline HEMBL1545093 & & 165 & 8593 & \\
\hline AEMBL1392501 & & 69 & & \\
\hline HEMBL15 & 6 & 239 & & \\
\hline HEN & & 225 & & \\
\hline HEM & & 56 & & RN \\
\hline 706 & & & 3094 & RN \\
\hline AEMBL1518455 & & & & $\mathrm{RN}$ \\
\hline HEMBL15 & & & 366 & Iv \\
\hline HEN & & & & RN \\
\hline AEMBL5 & & 34 & 99 & RN \\
\hline 762 & & & & RN \\
\hline HEMBL1332402 & & & 3071 & RN \\
\hline AEMBL1 & & & & RN \\
\hline 6 & & & 17 & RN \\
\hline 3 & & 39 & 62 & RN \\
\hline AEMBL3190404 & & & 1093 & RN \\
\hline AEMBL1523419 & & 39 & 3023 & RN \\
\hline 7 & & & & ST \\
\hline 1 & & & 72 & RN \\
\hline HEMBL15 & & 567 & & RN \\
\hline AEMBL1970859 & 16 & & 8025 & RN \\
\hline HEMBL1: & & 05 & & RN \\
\hline & & & & \\
\hline HEMBL 15 & & & 9138 & RN \\
\hline HEMBL1481849 & & 5.0335 & 5312 & ST \\
\hline AEMBL3194816 & 16 & 2.8239 & 4182 & RN \\
\hline & & & & \\
\hline 1 & 6884 & & & \\
\hline
\end{tabular}

Page 13975 


\begin{tabular}{|c|c|c|c|c|c|c|}
\hline \multirow[b]{2}{*}{ CHEMBL1487432 } & \multirow[b]{2}{*}{688416} & \multicolumn{5}{|c|}{ Supplemental Table S2.txt } \\
\hline & & \multicolumn{2}{|c|}{$2.8239 \quad 2.6196$} & TST & & \\
\hline CHEMBL1977301 & 688416 & 5.6254 & 5.0503 & \multicolumn{3}{|l|}{ TRN } \\
\hline CHEMBL1509718 & 688416 & 5.2437 & 5.1377 & \multicolumn{3}{|l|}{ TST } \\
\hline CHEMBL1336728 & 688416 & 3.301 & \multicolumn{3}{|c|}{4.093999999999999} & TRN \\
\hline CHEMBL1458809 & 688416 & 4.3828 & 5.1378 & TRN & & \\
\hline CHEMBL1484438 & 688416 & 6.9066 & 5.8367 & TRN & & \\
\hline CHEMBL1573692 & 688416 & 4.6139 & 4.6324 & TRN & & \\
\hline CHEMBL1470925 & 688416 & \multicolumn{3}{|c|}{5.1610000000000005} & 4.7381 & TRN \\
\hline CHEMBL1532783 & 688416 & 2.8239 & 4.4966 & TRN & & \\
\hline CHEMBL1392551 & 688416 & 5.5113 & 5.1735 & TST & & \\
\hline CHEMBL1321627 & 688416 & 2.8239 & 2.9454 & TRN & & \\
\hline CHEMBL1310080 & 688416 & 4.7147 & 4.9107 & TRN & & \\
\hline CHEMBL1391560 & 688416 & 2.8239 & 4.5395 & TRN & & \\
\hline CHEMBL1416526 & 688416 & 4.4292 & 4.7652 & TRN & & \\
\hline CHEMBL1549391 & 688416 & 2.8239 & 3.9938 & TRN & & \\
\hline CHEMBL1608631 & 688416 & 2.8239 & 3.8028 & TST & & \\
\hline CHEMBL1406455 & 688416 & 2.8239 & 2.2407 & TRN & & \\
\hline CHEMBL1546249 & 688416 & 2.8239 & 4.0472 & TRN & & \\
\hline CHEMBL1466186 & 688416 & 5.3029 & 4.8324 & TRN & & \\
\hline CHEMBL1171857 & 688416 & 2.8239 & 2.7676 & TRN & & \\
\hline CHEMBL1572935 & 688416 & 2.8239 & 4.2809 & TRN & & \\
\hline CHEMBL1492378 & 688416 & 3.9596 & 3.8506 & TRN & & \\
\hline CHEMBL1583801 & 688416 & 4.8785 & 4.4335 & TRN & & \\
\hline CHEMBL1458596 & 688416 & 2.8239 & 2.3861 & TRN & & \\
\hline CHEMBL1529106 & 688416 & 3.952 & 3.8164 & TRN & & \\
\hline CHEMBL1368833 & 688416 & 5.0658 & 4.1551 & TRN & & \\
\hline CHEMBL1346232 & 688416 & 4.8406 & 4.1424 & TRN & & \\
\hline CHEMBL1525259 & 688416 & 5.4699 & 4.5825 & TRN & & \\
\hline CHEMBL1382763 & 688416 & 2.8239 & 4.2363 & TRN & & \\
\hline CHEMBL1391973 & 688416 & 2.8239 & 4.0703 & TRN & & \\
\hline CHEMBL1461674 & 688416 & 2.8239 & 2.4267 & TRN & & \\
\hline CHEMBL1410479 & 688416 & 4.4792 & 4.6898 & TRN & & \\
\hline CHEMBL1562524 & 688416 & 2.8239 & 4.1316 & TRN & & \\
\hline CHEMBL1433263 & 688416 & 4.1535 & 4.0222 & TRN & & \\
\hline CHEMBL1376578 & 688416 & 4.2815 & 4.4793 & TST & & \\
\hline CHEMBL1370217 & 688416 & 4.5729 & 3.8177 & TRN & & \\
\hline CHEMBL1983839 & 688416 & 5.3138 & 5.2178 & TRN & & \\
\hline CHEMBL1479654 & 688416 & 4.7851 & 4.1631 & TST & & \\
\hline CHEMBL1557782 & 688416 & 4.98600 & 00000000 & & 4.0777 & TRN \\
\hline CHEMBL1493101 & 688416 & 2.8239 & 3.8645 & TRN & & \\
\hline CHEMBL1990783 & 688416 & 4.92899 & 99999999 & 99 & 4.6356 & TRN \\
\hline CHEMBL1524764 & 688416 & 3.98199 & 79999999 & 998 & 3.2336 & TRN \\
\hline CHEMBL1541343 & 688416 & 5.7533 & 5.1054 & TRN & & \\
\hline CHEMBL1568686 & 688416 & 2.8239 & 3.8655 & TRN & & \\
\hline CHEMBL3192817 & 688416 & 5.166 & 4.8916 & TRN & & \\
\hline CHEMBL1346307 & 688416 & 4.5844 & 4.0819 & TRN & & \\
\hline CHEMBL1434750 & 688416 & 5.51200 & 00000000 & 005 & 5.1593 & TRN \\
\hline CHEMBL1427079 & 688416 & 4.0974 & 4.1353 & TST & & \\
\hline
\end{tabular}




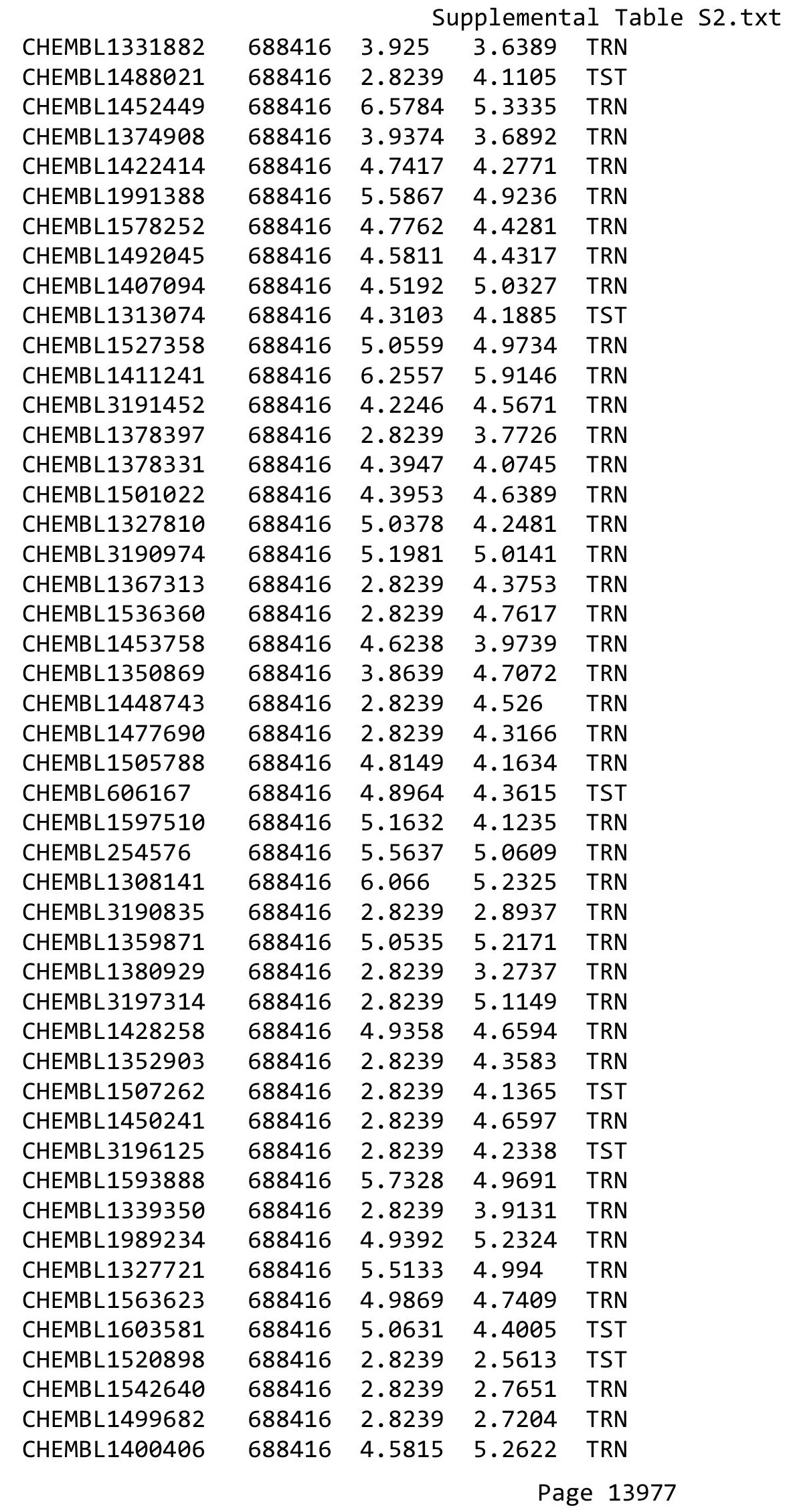




\begin{tabular}{|c|c|c|c|c|}
\hline \multicolumn{5}{|c|}{ Supplemental Tab. } \\
\hline CHEMBL1451132 & 688416 & 2.8239 & 3.9537 & TRN \\
\hline CHEMBL1506580 & 688416 & 5.229 & 4.8799 & TRN \\
\hline CHEMBL3193488 & 688416 & 2.8239 & 2.69 & TRN \\
\hline CHEMBL1506966 & 688416 & 3.9905 & 4.0828 & TST \\
\hline CHEMBL1370252 & 688416 & 4.6671 & 4.0475 & TRN \\
\hline CHEMBL1505552 & 688416 & 5.5802 & 4.9748 & TRN \\
\hline CHEMBL1519374 & 688416 & 4.8204 & 4.9711 & TST \\
\hline CHEMBL1330556 & 688416 & 5.3253 & 4.7249 & TST \\
\hline CHEMBL1404086 & 688416 & 5.3009 & 4.9447 & TRN \\
\hline CHEMBL3196980 & 688416 & 4.8718 & 4.6485 & TRN \\
\hline CHEMBL1375045 & 688416 & 5.0668 & 4.9729 & TST \\
\hline CHEMBL1597435 & 688416 & 5.6008 & 4.9925 & TRN \\
\hline CHEMBL1320128 & 688416 & 4.8351 & 4.2722 & TRN \\
\hline CHEMBL1421625 & 688416 & 4.6626 & 5.1251 & TRN \\
\hline CHEMBL1379744 & 688416 & 2.8239 & 3.9018 & TRN \\
\hline CHEMBL 2001739 & 688416 & 5.6162 & 5.1782 & TRN \\
\hline CHEMBL1475733 & 688416 & 4.1805 & 3.8643 & TRN \\
\hline CHEMBL3197039 & 688416 & 2.8239 & 3.9361 & TRN \\
\hline CHEMBL1481444 & 688416 & 4.6136 & 4.2189 & TRN \\
\hline CHEMBL1535938 & 688416 & 5.0114 & 4.0981 & TRN \\
\hline CHEMBL411070 & 688416 & 2.8239 & 2.5582 & TST \\
\hline CHEMBL482116 & 688416 & 4.8441 & 4.6357 & TRN \\
\hline CHEMBL448741 & 688416 & 5.0501 & 4.6259 & TST \\
\hline CHEMBL 1440325 & 688416 & 4.9557 & 4.7795 & TRN \\
\hline CHEMBL1472321 & 688416 & 5.7438 & 5.1773 & TRN \\
\hline CHEMBL1411001 & 688416 & 2.8239 & 3.6351 & TRN \\
\hline CHEMBL3192194 & 688416 & 5.4878 & 5.2427 & TRN \\
\hline CHEMBL1487952 & 688416 & 4.9989 & 4.3071 & TRN \\
\hline CHEMBL1596985 & 688416 & 5.1795 & 5.1533 & TRN \\
\hline CHEMBL1518844 & 688416 & 5.3548 & 4.9753 & TRN \\
\hline CHEMBL1376311 & 688416 & 4.856 & 4.4791 & TRN \\
\hline CHEMBL581257 & 688416 & 7.0706 & 6.4959 & TRN \\
\hline CHEMBL1337445 & 688416 & 5.2463 & 4.7925 & TST \\
\hline CHEMBL1478319 & 688416 & 4.6266 & 4.3749 & TST \\
\hline CHEMBL1394479 & 688416 & 3.8831 & 4.569 & TRN \\
\hline CHEMBL1540901 & 688416 & 2.8239 & 2.2003 & TRN \\
\hline CHEMBL1533366 & 688416 & 5.524 & 4.9617 & TRN \\
\hline CHEMBL1564099 & 688416 & 4.6826 & 4.0895 & TRN \\
\hline CHEMBL1301536 & 688416 & 5.402 & 4.7862 & TRN \\
\hline CHEMBL1491847 & 688416 & 5.0915 & 4.3405 & TST \\
\hline CHEMBL1526490 & 688416 & 4.6797 & 4.6042 & TRN \\
\hline CHEMBL1339368 & 688416 & 2.8239 & 4.1881 & TST \\
\hline CHEMBL1538317 & 688416 & 2.8239 & 2.7151 & TRN \\
\hline CHEMBL 1444820 & 688416 & 7.0 & 7.2021 & TRN \\
\hline CHEMBL1549816 & 688416 & 4.6916 & 3.9409 & TRN \\
\hline CHEMBL1610443 & 688416 & 5.0391 & 5.2475 & TRN \\
\hline CHEMBL1361046 & 688416 & 2.8239 & 4.7653 & TRN \\
\hline CHEMBL1540098 & 688416 & 4.7542 & 4.3848 & TRN \\
\hline
\end{tabular}




\begin{tabular}{|c|c|c|c|c|c|}
\hline & & \multicolumn{4}{|c|}{ Supplemental Table S2.txt } \\
\hline CHEMBL1430093 & 688416 & 2.8239 & 3.2038 & TRN & \\
\hline CHEMBL3196117 & 688416 & 4.7904 & 4.1632 & TRN & \\
\hline CHEMBL1330113 & 688416 & 5.6796 & 4.8634 & TST & \\
\hline CHEMBL1568457 & 688416 & 3.8494 & 3.6666 & TRN & \\
\hline CHEMBL1518085 & 688416 & 5.6334 & 4.968 & TRN & \\
\hline CHEMBL1372492 & 688416 & 5.1376 & 5.2811 & TRN & \\
\hline CHEMBL1587636 & 688416 & 2.8239 & 4.162 & TRN & \\
\hline CHEMBL1453208 & 688416 & 5.0916 & 4.6301 & TST & \\
\hline CHEMBL3193603 & 688416 & 2.8239 & 4.6148 & TRN & \\
\hline CHEMBL3193666 & 688416 & 4.833 & 4.7097 & TRN & \\
\hline CHEMBL1562454 & 688416 & 5.1376 & 4.1424 & TRN & \\
\hline CHEMBL1424907 & 688416 & 5.0579 & 4.7628 & TRN & \\
\hline CHEMBL3193184 & 688416 & 4.5041 & 4.5417 & TRN & \\
\hline CHEMBL1476264 & 688416 & 6.025 & 5.65 & TRN & \\
\hline CHEMBL1587193 & 688416 & 2.8239 & 4.3936 & TRN & \\
\hline CHEMBL169 & 688416 & 6.0555 & 5.0271 & TST & \\
\hline CHEMBL3195531 & 688416 & 5.3323 & 4.9649 & TRN & \\
\hline CHEMBL1390925 & 688416 & 4.7699 & 4.208 & TRN & \\
\hline CHEMBL1568018 & 688416 & 4.7206 & 4.0561 & TRN & \\
\hline CHEMBL1350780 & 688416 & 5.5965 & 6.0056 & TRN & \\
\hline CHEMBL1329129 & 688416 & 5.4786 & 4.8236 & TRN & \\
\hline CHEMBL1470099 & 688416 & 5.7317 & 5.3186 & TRN & \\
\hline CHEMBL1592505 & 688416 & 2.8239 & 2.3411 & TRN & \\
\hline CHEMBL1472530 & 688416 & 2.8239 & 3.4711 & TRN & \\
\hline CHEMBL1423286 & 688416 & 5.4458 & 5.4858 & TRN & \\
\hline CHEMBL1336959 & 688416 & 5.4405 & 4.9638 & TRN & \\
\hline CHEMBL1346468 & 688416 & 5.1348 & 5.12299 & 9999999999 & TRN \\
\hline CHEMBL1395972 & 688416 & 5.2691 & 4.4629 & TST & \\
\hline CHEMBL1540340 & 688416 & 2.8239 & 4.1251 & TRN & \\
\hline CHEMBL1363199 & 688416 & 2.8239 & 2.5901 & TRN & \\
\hline CHEMBL1312885 & 688416 & 5.0825 & 4.9451 & TST & \\
\hline CHEMBL1552543 & 688416 & 5.4761 & 5.0057 & TRN & \\
\hline CHEMBL3189325 & 688416 & 5.1233 & 4.8904 & TRN & \\
\hline CHEMBL1315061 & 688416 & 7.0088 & 6.1698 & TST & \\
\hline CHEMBL1574283 & 688416 & 5.1339 & 4.797 & TRN & \\
\hline CHEMBL1532755 & 688416 & 5.2599 & 4.5753 & TRN & \\
\hline CHEMBL3192725 & 688416 & 4.8008 & 4.4369 & TRN & \\
\hline CHEMBL1582831 & 688416 & 5.8502 & 5.1738 & TRN & \\
\hline CHEMBL1436666 & 688416 & 4.8507 & 4.6643 & TRN & \\
\hline CHEMBL1306359 & 688416 & 5.2463 & 5.16 & TRN & \\
\hline CHEMBL1535900 & 688416 & 4.5754 & 4.1889 & TST & \\
\hline CHEMBL1331573 & 688416 & 2.8239 & 4.7851 & TRN & \\
\hline CHEMBL1441418 & 688416 & 4.9882 & 4.2239 & TRN & \\
\hline CHEMBL1549870 & 688416 & 4.7357 & 4.4184 & TRN & \\
\hline CHEMBL3194106 & 688416 & 2.8239 & 2.9685 & TRN & \\
\hline CHEMBL1333755 & 688416 & 5.0785 & 4.5439 & TST & \\
\hline CHEMBL1380365 & 688416 & 4.7707 & 4.1265 & TRN & \\
\hline CHEMBL1596319 & 688416 & 4.6225 & 5.048 & TRN & \\
\hline
\end{tabular}


Supplemental Table S2.txt

\begin{tabular}{|c|c|c|c|c|}
\hline CHEMBL1527664 & 688416 & 5.3393 & 4.6019 & TST \\
\hline CHEMBL1329925 & 688416 & 5.3877 & 4.968 & TRN \\
\hline CHEMBL532160 & 688416 & 5.0852 & 4.5547 & TST \\
\hline CHEMBL 3198791 & 688416 & 5.082 & 4.9529 & TST \\
\hline CHEMBL1485261 & 688416 & 2.8239 & 3.7108 & TRN \\
\hline CHEMBL1360376 & 688416 & 4.8445 & 4.3676 & TRN \\
\hline CHEMBL1391911 & 688416 & 5.6672 & 4.7961 & TRN \\
\hline CHEMBL1539224 & 688416 & 5.1055 & 4.8494 & TST \\
\hline CHEMBL1495893 & 688416 & 2.8239 & 4.4491 & TST \\
\hline CHEMBL 3197243 & 688416 & 5.3025 & 5.0156 & TRN \\
\hline CHEMBL1539860 & 688416 & 5.2254 & 4.6907 & TRN \\
\hline CHEMBL1387393 & 688416 & 2.8239 & 3.4678 & TRN \\
\hline CHEMBL1426565 & 688416 & 4.7329 & 4.2183 & TRN \\
\hline CHEMBL1319984 & 688416 & 5.7862 & 5.0707 & TRN \\
\hline CHEMBL1478314 & 688416 & 2.8239 & 4.5703 & TRN \\
\hline CHEMBL1544544 & 688416 & 5.6674 & 4.9578 & TRN \\
\hline CHEMBL1417054 & 688416 & 4.1322 & 4.3346 & TRN \\
\hline CHEMBL1991441 & 688416 & 5.044 & 4.6162 & TST \\
\hline CHEMBL1598101 & 688416 & 2.8239 & 4.4419 & TRN \\
\hline CHEMBL1548513 & 688416 & 2.8239 & 2.5279 & TST \\
\hline CHEMBL1981541 & 688416 & 4.5199 & 4.4106 & TRN \\
\hline CHEMBL1990772 & 688416 & 4.9965 & 5.2087 & TRN \\
\hline CHEMBL1305393 & 688416 & 2.8239 & 2.6801 & TRN \\
\hline CHEMBL1547804 & 688416 & 5.0178 & 4.1752 & TRN \\
\hline CHEMBL1399698 & 688416 & 5.5518 & 6.7475 & TST \\
\hline CHEMBL1984315 & 688416 & 2.8239 & 3.6344 & TRN \\
\hline CHEMBL1470545 & 688416 & 4.3725 & 4.0711 & TRN \\
\hline CHEMBL1457311 & 688416 & 2.8239 & 3.8559 & TRN \\
\hline CHEMBL1336675 & 688416 & 5.4382 & 5.0005 & TRN \\
\hline CHEMBL 2007593 & 688416 & 4.6938 & 4.3519 & TRN \\
\hline CHEMBL1546791 & 688416 & 2.8239 & 4.3303 & TRN \\
\hline CHEMBL1389269 & 688416 & 2.8239 & 4.6863 & TST \\
\hline CHEMBL1999630 & 688416 & 5.3 & 5.1086 & TRN \\
\hline CHEMBL1999069 & 688416 & 5.6332 & 5.0166 & TRN \\
\hline CHEMBL1355961 & 688416 & 4.9242 & 4.4181 & TST \\
\hline CHEMBL1458833 & 688416 & 5.4426 & 4.9597 & TRN \\
\hline CHEMBL1559500 & 688416 & 2.8239 & 4.0928 & TRN \\
\hline CHEMBL458094 & 688416 & 5.5216 & 5.0304 & TRN \\
\hline CHEMBL1334456 & 688416 & 6.0237 & 5.5647 & TST \\
\hline CHEMBL 3195997 & 688416 & 5.4134 & 5.1688 & TRN \\
\hline CHEMBL1452235 & 688416 & 4.8007 & 4.9227 & TST \\
\hline CHEMBL1604272 & 688416 & 2.8239 & 4.286000 & 00000000005 \\
\hline CHEMBL1461496 & 688416 & 4.6344 & 4.0135 & TRN \\
\hline CHEMBL3190592 & 688416 & 4.3872 & 4.8782 & TRN \\
\hline CHEMBL1550591 & 688416 & 2.8239 & 4.1577 & TST \\
\hline CHEMBL1386564 & 688416 & 2.8239 & 3.9351 & TST \\
\hline CHEMBL1428911 & 688416 & 5.2095 & 5.3495 & TRN \\
\hline CHEMBL 3196614 & 688416 & 4.1434 & 4.1071 & TRN \\
\hline
\end{tabular}




\begin{tabular}{|c|c|c|c|c|c|}
\hline \multirow[b]{2}{*}{ CHEMBL3199104 } & \multicolumn{5}{|c|}{ Supplemental Table S2.txt } \\
\hline & 688416 & 5.1307 & 4.4569 & TRN & \\
\hline CHEMBL1549202 & 688416 & 4.689 & 4.658 & TRN & \\
\hline CHEMBL1533152 & 688416 & 2.8239 & 3.8165 & TRN & \\
\hline CHEMBL1497950 & 688416 & 4.734 & 4.6487 & TRN & \\
\hline CHEMBL1501475 & 688416 & 2.8239 & 4.8646 & TRN & \\
\hline CHEMBL1311826 & 688416 & 5.5727 & 5.6914 & TRN & \\
\hline CHEMBL1470520 & 688416 & 4.255 & 4.4944 & TRN & \\
\hline CHEMBL3190900 & 688416 & 5.0873 & 4.6533 & TRN & \\
\hline CHEMBL1336654 & 688416 & 2.8239 & 3.9509 & TST & \\
\hline CHEMBL1422253 & 688416 & 6.9547 & 7.124 & TRN & \\
\hline CHEMBL 256042 & 688416 & 4.7607 & 5.2017 & TRN & \\
\hline CHEMBL1519335 & 688416 & 2.8239 & 3.8058 & TRN & \\
\hline CHEMBL1464676 & 688416 & 4.0211 & 4.5065 & TRN & \\
\hline CHEMBL1385145 & 688416 & 5.2598 & 4.7881 & TRN & \\
\hline CHEMBL1982915 & 688416 & 5.0214 & 4.2589 & TRN & \\
\hline CHEMBL1603550 & 688416 & 2.8239 & 2.58600 & 00000000003 & TRN \\
\hline CHEMBL1325982 & 688416 & 2.8239 & 4.0995 & TRN & \\
\hline CHEMBL1382325 & 688416 & 4.7555 & 4.1376 & TRN & \\
\hline CHEMBL3190609 & 688416 & 5.0924 & 4.5577 & TRN & \\
\hline CHEMBL3210474 & 688416 & 5.2971 & 4.9822 & TRN & \\
\hline CHEMBL1417780 & 688416 & 4.7894 & 4.3016 & TRN & \\
\hline CHEMBL1410436 & 688416 & 2.8239 & 4.1812 & TRN & \\
\hline CHEMBL1586207 & 688416 & 2.8239 & 4.2633 & TST & \\
\hline CHEMBL1502412 & 688416 & 2.8239 & 2.6338 & TST & \\
\hline CHEMBL3196688 & 688416 & 4.4744 & 4.2038 & TRN & \\
\hline CHEMBL1349984 & 688416 & 2.8239 & 4.2519 & TRN & \\
\hline CHEMBL1433385 & 688416 & 2.8239 & 4.2972 & TRN & \\
\hline CHEMBL1463349 & 688416 & 5.1898 & 4.5285 & TRN & \\
\hline CHEMBL3183210 & 688416 & 4.9716 & 4.5348 & TRN & \\
\hline CHEMBL1403172 & 688416 & 4.7283 & 4.666 & TRN & \\
\hline CHEMBL1487657 & 688416 & 4.7276 & 4.8257 & TRN & \\
\hline CHEMBL1510981 & 688416 & 2.8239 & 4.293 & TST & \\
\hline CHEMBL3191706 & 688416 & 3.301 & 4.239 & TRN & \\
\hline CHEMBL1463088 & 688416 & 4.9741 & 4.4906 & TRN & \\
\hline CHEMBL587849 & 688416 & 5.4122 & 4.9291 & TRN & \\
\hline CHEMBL1320397 & 688416 & 5.0733 & 4.4354 & TRN & \\
\hline CHEMBL1600849 & 688416 & 5.4477 & 4.5669 & TST & \\
\hline CHEMBL1533981 & 688416 & 5.5089 & 4.6555 & TRN & \\
\hline CHEMBL1364626 & 688416 & 2.8239 & 2.3515 & TRN & \\
\hline CHEMBL1518905 & 688416 & 4.7091 & 4.2782 & TST & \\
\hline CHEMBL199405 & 688416 & 5.42299 & 99999999 & 5.2863 & TRN \\
\hline CHEMBL410525 & 688416 & 5.4866 & 4.8051 & TST & \\
\hline CHEMBL1337353 & 688416 & 4.9078 & 4.4736 & TRN & \\
\hline CHEMBL1575271 & 688416 & 2.8239 & 2.7364 & TRN & \\
\hline CHEMBL1352564 & 688416 & 5.0565 & 4.845 & TST & \\
\hline CHEMBL1509694 & 688416 & 2.8239 & 4.0947 & TRN & \\
\hline CHEMBL1580555 & 688416 & 4.8162 & 4.2898 & TRN & \\
\hline CHEMBL1405964 & 688416 & 4.8494 & 4.6572 & TRN & \\
\hline
\end{tabular}




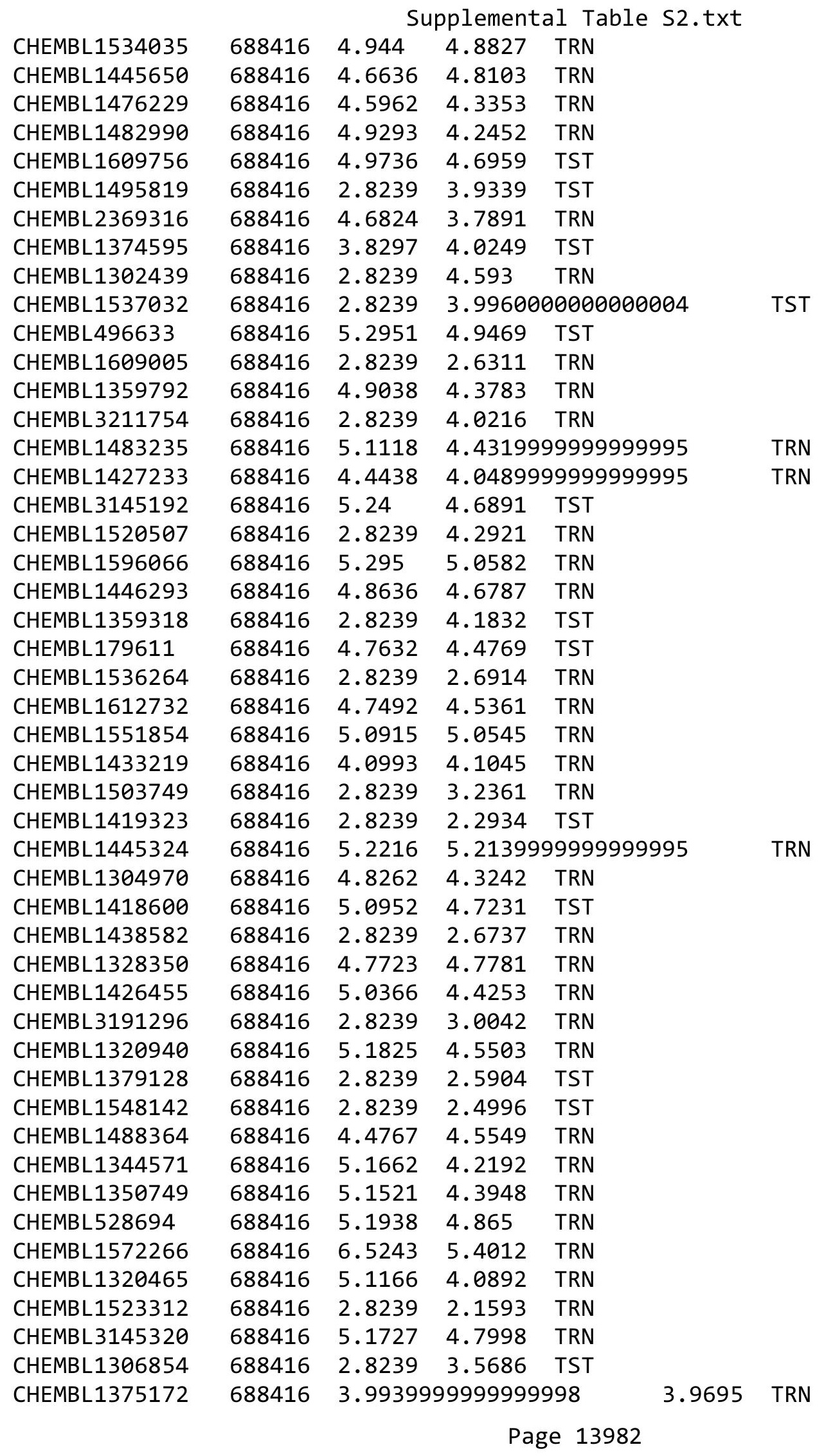




\begin{tabular}{|c|c|c|c|c|}
\hline \multicolumn{5}{|c|}{ Supplemental Table s2.txt } \\
\hline CHEMBL1504763 & 688416 & 5.2391 & 4.832 & TRN \\
\hline CHEMBL417727 & 688416 & 5.3057 & 5.2282 & TRN \\
\hline CHEMBL1998531 & 688416 & 4.9618 & 4.7959 & TRN \\
\hline CHEMBL1493766 & 688416 & 4.9362 & 4.9621 & TRN \\
\hline CHEMBL1603454 & 688416 & 2.8239 & 4.0347 & TRN \\
\hline CHEMBL1483333 & 688416 & 4.7779 & 4.2274 & TRN \\
\hline CHEMBL1331801 & 688416 & 5.1991 & 4.5532 & TST \\
\hline CHEMBL1583807 & 688416 & 4.8887 & 4.1005 & TRN \\
\hline CHEMBL1417731 & 688416 & 6.5901 & 5.5081 & TRN \\
\hline CHEMBL1504848 & 688416 & 2.8239 & 2.2304 & TRN \\
\hline CHEMBL1353013 & 688416 & 4.8625 & 3.9743 & TRN \\
\hline CHEMBL1475279 & 688416 & 2.8239 & 2.7442 & TRN \\
\hline CHEMBL1610654 & 688416 & 4.3075 & 5.096 & TRN \\
\hline CHEMBL3192972 & 688416 & 5.3434 & 4.7102 & TRN \\
\hline CHEMBL1588416 & 688416 & 2.8239 & 4.0334 & TRN \\
\hline CHEMBL1343537 & 688416 & 4.5982 & 4.5303 & TRN \\
\hline CHEMBL1354009 & 688416 & 4.0559 & 3.6662 & TRN \\
\hline CHEMBL1447284 & 688416 & 5.6022 & 6.0804 & TRN \\
\hline CHEMBL1602058 & 688416 & 4.5453 & 4.2594 & TRN \\
\hline CHEMBL1517683 & 688416 & 2.8239 & 4.3421 & TRN \\
\hline CHEMBL1572356 & 688416 & 5.6562 & 4.9951 & TRN \\
\hline CHEMBL1427991 & 688416 & 5.0193 & 4.9205 & TRN \\
\hline CHEMBL1314913 & 688416 & 5.0951 & 4.7978 & TST \\
\hline CHEMBL1300745 & 688416 & 4.6691 & 5.1417 & TRN \\
\hline CHEMBL1428153 & 688416 & 5.4951 & 5.2408 & TST \\
\hline CHEMBL1613066 & 688416 & 2.8239 & 4.2246 & TRN \\
\hline CHEMBL1323248 & 688416 & 5.4007 & 4.9128 & TRN \\
\hline CHEMBL1522803 & 688416 & 4.6774 & 4.0204 & TST \\
\hline CHEMBL3199132 & 688416 & 4.4322 & 4.4912 & TRN \\
\hline CHEMBL1500469 & 688416 & 5.4633 & 5.3062 & TRN \\
\hline CHEMBL1494569 & 688416 & 2.8239 & 2.8269 & TRN \\
\hline CHEMBL3190293 & 688416 & 5.7409 & 5.416 & TRN \\
\hline CHEMBL1428451 & 688416 & 2.8239 & 2.6765 & TRN \\
\hline CHEMBL1415338 & 688416 & 2.8239 & 3.9183 & TRN \\
\hline CHEMBL391533 & 688416 & 5.5538 & 4.8009 & TST \\
\hline CHEMBL1496534 & 688416 & 2.8239 & 4.3327 & TST \\
\hline CHEMBL1419518 & 688416 & 4.5951 & 4.7448 & TRN \\
\hline CHEMBL1459313 & 688416 & 2.8239 & 4.0646 & TRN \\
\hline CHEMBL1517362 & 688416 & 6.0565 & 6.0378 & TRN \\
\hline CHEMBL1436748 & 688416 & 5.1147 & 4.5249 & TRN \\
\hline CHEMBL1337203 & 688416 & 3.301 & 3.2658 & TRN \\
\hline CHEMBL1344556 & 688416 & 5.0433 & 4.7496 & TRN \\
\hline CHEMBL1308615 & 688416 & 4.3545 & 4.5233 & TRN \\
\hline CHEMBL1473375 & 688416 & 4.578 & 4.0899 & TRN \\
\hline CHEMBL1565526 & 688416 & 5.564 & 4.6352 & TRN \\
\hline CHEMBL1505153 & 688416 & 5.3632 & 5.1192 & TRN \\
\hline CHEMBL3195410 & 688416 & 5.2035 & 5.4476 & TRN \\
\hline CHEMBL1509433 & 688416 & 4.8811 & 4.1703 & TRN \\
\hline
\end{tabular}


Supplemental Table S2.txt

\begin{tabular}{|c|c|c|c|c|}
\hline HEMBL1342093 & & .558 & & TR \\
\hline & & .1245 & 4.6893 & \\
\hline & & & & \\
\hline IEMBL19 & & 5173 & & 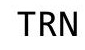 \\
\hline IEMBL1328707 & & 158 & 746 & \\
\hline HEMBL1386200 & 88416 & 523 & 1824 & \\
\hline AEMBL1533 & & 639 & & \\
\hline 58 & & & & ST \\
\hline AEMBL601768 & & 522 & & PN \\
\hline AEMBL1536017 & & 8239 & & RN \\
\hline AEMBL1584796 & 6 & 737 & & \\
\hline EMBL & & 201 & & \\
\hline EMBL & & 771 & & RN \\
\hline HEMBL 145 & & 616 & & RN \\
\hline EMBL1 & & 3239 & & \\
\hline IEMBL1 & & 793 & 67 & Niv \\
\hline IEMBL: & & 242 & & RN \\
\hline IEMBL? & & 647 & & \\
\hline AEMBL137 & & 239 & & $\lceil\mathrm{RN}$ \\
\hline EMBL158 & & 39 & & alv \\
\hline HEMB. & & 88 & & RIV \\
\hline EMBL & & 39 & & ST \\
\hline EMBL & & 93 & & \\
\hline 757 & & 239 & & ST \\
\hline IEMBL146 & & & & IRIN \\
\hline IEMBL & & 39 & & RN \\
\hline EMBL & & 67 & & RN \\
\hline 79 & & 239 & & RN \\
\hline EMBL1 & & 239 & & TRN \\
\hline HEMBL158 & & & & TST \\
\hline IEMBL1 & & 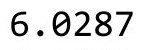 & & 「RN \\
\hline AEMBL & & 93 & & RN \\
\hline 33 & & 75 & & 「ST \\
\hline EMBL151 & & 72 & & $\lceil\mathrm{RN}$ \\
\hline AEMBL93109 & & 239 & & TRN \\
\hline AEMBL1 & & 396 & 31 & 「RN \\
\hline IFMD & & 81 & & ГST \\
\hline & & 239 & & RN \\
\hline EMBL1611483 & & 3239 & 349 & TST \\
\hline EMBL3 & & & & TRN \\
\hline EMBL2 & & 239 & 08 & TST \\
\hline & & 2.8239 & & TRN \\
\hline HEMBL148 & & 6.3757 & 163 & RN \\
\hline EMBL1609914 & & 3239 & 139 & RN \\
\hline$M P I 1$ & & 037 & & RN \\
\hline HEMBL1 & & 365 & & \\
\hline HEMBL170 & & .8239 & .9762 & RN \\
\hline SHEMBL1563370 & 688416 & 5.1968 & 4.7159 & S \\
\hline
\end{tabular}

Page 13984 


\begin{tabular}{|c|c|c|c|c|c|}
\hline & & & & & \\
\hline CHEMBL1200847 & 688416 & 2.8239 & 5.0401 & TST & \\
\hline CHEMBL1534949 & 688416 & 5.2437 & 4.8078 & TRN & \\
\hline CHEMBL1601701 & 688416 & 2.8239 & 4.1737 & TST & \\
\hline CHEMBL1514534 & 688416 & 4.9276 & 5.0079 & TRN & \\
\hline CHEMBL3212285 & 688416 & 5.1301 & 4.9893 & TRN & \\
\hline CHEMBL1304168 & 688416 & 2.8239 & 3.7888 & TRN & \\
\hline CHEMBL1518265 & 688416 & 6.068 & 4.8558 & TRN & \\
\hline CHEMBL1532727 & 688416 & 4.6713 & 3.7815 & TRN & \\
\hline CHEMBL3211356 & 688416 & 4.7293 & 5.0521 & TRN & \\
\hline CHEMBL1505450 & 688416 & 4.9083 & 4.3415 & TRN & \\
\hline CHEMBL1513407 & 688416 & 4.7171 & 4.9486 & TRN & \\
\hline CHEMBL1301650 & 688416 & 5.3091 & 5.2403 & TRN & \\
\hline CHEMBL1511042 & 688416 & 4.9208 & 4.4244 & TST & \\
\hline CHEMBL1477640 & 688416 & 3.301 & 4.4529 & TST & \\
\hline CHEMBL1549777 & 688416 & 5.0235 & 4.5271 & TRN & \\
\hline CHEMBL1404485 & 688416 & 5.4962 & 5.1071 & TRN & \\
\hline CHEMBL1376974 & 688416 & 6.1871 & 5.1293 & TST & \\
\hline CHEMBL1322356 & 688416 & 5.42399 & Э9999999 & 4.8372 & TRN \\
\hline CHEMBL1472773 & 688416 & 5.2466 & 4.7313 & TST & \\
\hline CHEMBL1404493 & 688416 & 5.053 & 4.0703 & TST & \\
\hline CHEMBL1343800 & 688416 & 5.0757 & 4.7555 & TRN & \\
\hline CHEMBL1470475 & 688416 & 2.8239 & 2.5543 & TST & \\
\hline CHEMBL1598413 & 688416 & 4.4027 & 5.0853 & TRN & \\
\hline CHEMBL1601265 & 688416 & 4.784 & 4.4782 & TRN & \\
\hline CHEMBL1442280 & 688416 & 5.8671 & 5.51399 & 9999999999 & TRN \\
\hline CHEMBL1988289 & 688416 & 5.6234 & 5.0177 & TRN & \\
\hline CHEMBL3192555 & 688416 & 5.5117 & 5.045 & TRN & \\
\hline CHEMBL1459241 & 688416 & 2.8239 & 2.6131 & TRN & \\
\hline CHEMBL1481347 & 688416 & 5.0525 & 4.2414 & TST & \\
\hline CHEMBL1454430 & 688416 & 5.3089 & 5.0898 & TRN & \\
\hline CHEMBL1308873 & 688416 & 4.6392 & 4.5694 & TRN & \\
\hline CHEMBL1610217 & 688416 & 5.2359 & 4.1976 & TRN & \\
\hline CHEMBL1448808 & 688416 & 4.8431 & 4.6197 & TRN & \\
\hline CHEMBL1463268 & 688416 & 2.8239 & 4.2634 & TRN & \\
\hline CHEMBL1499220 & 688416 & 5.0685 & 4.6878 & TRN & \\
\hline CHEMBL1555568 & 688416 & 5.5852 & 4.9789 & TRN & \\
\hline CHEMBL1441083 & 688416 & 2.8239 & 3.9747 & TST & \\
\hline CHEMBL1561240 & 688416 & 4.7541 & 4.4549 & TRN & \\
\hline CHEMBL1602964 & 688416 & 4.5635 & 4.2991 & TRN & \\
\hline CHEMBL1460903 & 688416 & 4.7949 & 4.6255 & TRN & \\
\hline CHEMBL1490336 & 688416 & 5.1334 & 4.6457 & TRN & \\
\hline CHEMBL3194562 & 688416 & 5.0587 & 5.1806 & TRN & \\
\hline CHEMBL1558952 & 688416 & 4.266 & 4.9288 & TRN & \\
\hline CHEMBL1567814 & 688416 & 4.0937 & 4.4615 & TRN & \\
\hline CHEMBL1451125 & 688416 & 2.8239 & 4.2118 & TRN & \\
\hline CHEMBL1300169 & 688416 & 4.6836 & 4.4289 & TRN & \\
\hline CHEMBL1602141 & 688416 & 4.7381 & 4.404 & TRN & \\
\hline CHEMBL1324005 & 688416 & 5.1066 & 5.4898 & TRN & \\
\hline
\end{tabular}




\begin{tabular}{|c|c|c|c|c|c|c|}
\hline \multirow[b]{2}{*}{ CHEMBL1344388 } & \multicolumn{6}{|c|}{ Supplemental Table S2.txt } \\
\hline & 688416 & 5.83 & 5.3592 & TRN & & \\
\hline CHEMBL1394121 & 688416 & 2.8239 & 4.3375 & TRN & & \\
\hline CHEMBL1311547 & 688416 & 2.8239 & 4.0781 & TRN & & \\
\hline CHEMBL3197982 & 688416 & 2.8239 & 2.8089 & TRN & & \\
\hline CHEMBL1501495 & 688416 & \multicolumn{3}{|c|}{5.156000000000001} & 4.3733 & TRN \\
\hline CHEMBL1458441 & 688416 & 4.5501 & 4.6239 & TRN & & \\
\hline CHEMBL1559999 & 688416 & 4.607 & 4.2371 & TRN & & \\
\hline CHEMBL1442742 & 688416 & 5.4216 & 4.8524 & TRN & & \\
\hline CHEMBL1379895 & 688416 & 5.7321 & 4.7534 & TRN & & \\
\hline CHEMBL3189643 & 688416 & 4.8665 & 5.0177 & TRN & & \\
\hline CHEMBL 299853 & 688416 & 5.0525 & 4.7594 & TRN & & \\
\hline CHEMBL1579058 & 688416 & 2.8239 & 4.4119 & TRN & & \\
\hline CHEMBL1326194 & 688416 & 5.1467 & 4.3263 & TRN & & \\
\hline CHEMBL1522419 & 688416 & 4.3055 & 4.2748 & TST & & \\
\hline CHEMBL1430107 & 688416 & 5.1562 & 4.3151 & TRN & & \\
\hline CHEMBL1540014 & 688416 & 2.8239 & 3.8468 & TRN & & \\
\hline CHEMBL1479271 & 688416 & 2.8239 & 2.3114 & TRN & & \\
\hline CHEMBL1581963 & 688416 & 2.8239 & \multicolumn{3}{|c|}{ 4. 388999999999999} & TRN \\
\hline CHEMBL 2004978 & 688416 & 4.9516 & 4.9204 & TRN & & \\
\hline CHEMBL1541683 & 688416 & 2.8239 & 2.9926 & TRN & & \\
\hline CHEMBL1533459 & 688416 & 4.9377 & 5.5917 & TRN & & \\
\hline CHEMBL1312788 & 688416 & 5.0279 & 4.3754 & TRN & & \\
\hline CHEMBL1427340 & 688416 & 4.7796 & 4.1377 & TRN & & \\
\hline CHEMBL1511321 & 688416 & 4.0632 & \multicolumn{3}{|c|}{3.8480000000000003} & TRN \\
\hline CHEMBL3210228 & 688416 & 2.8239 & 4.7116 & TRN & & \\
\hline CHEMBL1890591 & 688416 & 5.9944 & 5.4859 & TRN & & \\
\hline CHEMBL1969492 & 688416 & 5.5096 & 5.1792 & TST & & \\
\hline CHEMBL1606330 & 688416 & 2.8239 & 3.9175 & TST & & \\
\hline CHEMBL1557619 & 688416 & 5.0221 & 4.6287 & TRN & & \\
\hline CHEMBL1975032 & 688416 & 4.9092 & 4.6619 & TRN & & \\
\hline CHEMBL1428166 & 688416 & 5.0964 & 4.9675 & TST & & \\
\hline CHEMBL1600314 & 688416 & 5.4362 & 5.2887 & TRN & & \\
\hline CHEMBL1353666 & 688416 & \multicolumn{3}{|c|}{4.7010000000000005} & 4.0035 & TRN \\
\hline CHEMBL1432065 & 688416 & 2.8239 & 4.6382 & TST & & \\
\hline CHEMBL1538808 & 688416 & 4.7203 & 4.3709 & TRN & & \\
\hline CHEMBL3189802 & 688416 & 2.8239 & 2.6664 & TRN & & \\
\hline CHEMBL1533269 & 688416 & 4.828 & 4.5072 & TRN & & \\
\hline CHEMBL532363 & 688416 & 5.0008 & 4.663 & TRN & & \\
\hline CHEMBL1335724 & 688416 & 5.1598 & 4.4952 & TRN & & \\
\hline CHEMBL534353 & 688416 & 2.8239 & 4.6922 & TST & & \\
\hline CHEMBL1509369 & 688416 & 6.5702 & 5.8115 & TRN & & \\
\hline CHEMBL1455266 & 688416 & 4.7928 & 4.8642 & TST & & \\
\hline CHEMBL1569352 & 688416 & 2.8239 & 3.6401 & TRN & & \\
\hline CHEMBL1306690 & 688416 & \multicolumn{3}{|c|}{4.6930000000000005} & 4.1941 & TST \\
\hline CHEMBL1366577 & 688416 & 5.744 & 5.5664 & TRN & & \\
\hline CHEMBL1344339 & 688416 & 6.8327 & 5.5781 & TST & & \\
\hline CHEMBL1583127 & 688416 & 5.1151 & 4.981 & TRN & & \\
\hline CHEMBL1542263 & 688416 & 6.4647 & 6.2642 & TRN & & \\
\hline
\end{tabular}


Supplemental Table S2.txt

\begin{tabular}{|c|c|}
\hline CHEMBL1316002 & 688416 \\
\hline CHEMBL1990694 & 688416 \\
\hline CHEMBL188423 & 688416 \\
\hline CHEMBL1462007 & 688416 \\
\hline CHEMBL1452116 & 688416 \\
\hline CHEMBL1468737 & 688416 \\
\hline CHEMBL162783 & 688416 \\
\hline CHEMBL1491750 & 688416 \\
\hline CHEMBL63354 & 688416 \\
\hline CHEMBL1418598 & 688416 \\
\hline CHEMBL1300890 & 688416 \\
\hline CHEMBL1487834 & 688416 \\
\hline CHEMBL1391928 & 688416 \\
\hline CHEMBL 3195813 & 688416 \\
\hline CHEMBL1351081 & 688416 \\
\hline CHEMBL1527660 & 688416 \\
\hline CHEMBL1326060 & 688416 \\
\hline CHEMBL1481301 & 688416 \\
\hline CHEMBL1367295 & 688416 \\
\hline CHEMBL3194024 & 688416 \\
\hline CHEMBL1517741 & 688416 \\
\hline CHEMBL1412157 & 688416 \\
\hline CHEMBL1447526 & 688416 \\
\hline CHEMBL1432081 & 688416 \\
\hline CHEMBL1384368 & 688416 \\
\hline CHEMBL1534368 & 688416 \\
\hline CHEMBL1556350 & 688416 \\
\hline CHEMBL1478041 & 688416 \\
\hline CHEMBL1359037 & 688416 \\
\hline CHEMBL1504973 & 688416 \\
\hline CHEMBL1543734 & 688416 \\
\hline CHEMBL3145107 & 688416 \\
\hline CHEMBL1539624 & 688416 \\
\hline CHEMBL1547685 & 688416 \\
\hline CHEMBL1979800 & 688416 \\
\hline CHEMBL1505057 & 688416 \\
\hline CHEMBL1499084 & 688416 \\
\hline CHEMBL1509065 & 688416 \\
\hline CHEMBL1322375 & 688416 \\
\hline CHEMBL1327470 & 688416 \\
\hline CHEMBL590947 & 688416 \\
\hline CHEMBL1553969 & 688416 \\
\hline CHEMBL3197446 & 688416 \\
\hline CHEMBL1508440 & 688416 \\
\hline CHEMBL1300170 & 688416 \\
\hline CHEMBL3194623 & 688416 \\
\hline CHEMBL1345584 & 688416 \\
\hline CHEMBL1319643 & 688416 \\
\hline
\end{tabular}

$\begin{array}{lll}5.6743 & 4.7412 & \text { TRN }\end{array}$

$\begin{array}{llll}4.4513 & 4.4601 & \text { TST }\end{array}$

5.11434 .8446 TRN

$2.8239 \quad 3.7439999999999998$

$5.3498 \quad 4.8218 \quad$ TRN

$3.9348 \quad 4.5952$ TRN

$6.0146 \quad 5.5202$ TRN

$\begin{array}{lll}5.1322 & 4.9217 & \text { TST }\end{array}$

$2.8239 \quad 5.2701$ TST

$\begin{array}{lll}5.307 & 4.5921 & \text { TRN }\end{array}$

$\begin{array}{lll}5.1686 & 4.6271 & \text { TRN }\end{array}$

$\begin{array}{lll}4.4188 & 4.413 & \text { TRN }\end{array}$

$\begin{array}{lll}4.9128 & 4.2547 \quad \text { TRN }\end{array}$

$5.808 \quad 5.0906$ TRN

$\begin{array}{lll}4.8724 & 4.0249 & \text { TRN }\end{array}$

$\begin{array}{lll}2.8239 & 2.8967 & \text { TRN }\end{array}$

$\begin{array}{lll}4.7078 & 4.8141 & \text { TRN }\end{array}$

$\begin{array}{llll}4.9937 & 4.7434 & \text { TRN }\end{array}$

$4.7173 \quad 5.1169$ TRN

$\begin{array}{llll}2.8239 & 4.6474 & \text { TRN }\end{array}$

$\begin{array}{lll}5.5661 & 5.4242 & \text { TRN }\end{array}$

$\begin{array}{lll}5.4408 & 5.2087 & \text { TRN }\end{array}$

$\begin{array}{lll}4.6635 & 4.293 & \text { TRN }\end{array}$

$\begin{array}{llll}2.8239 & 2.2217 & \text { TRN }\end{array}$

$\begin{array}{lll}6.1325 & 5.5353 & \text { TRN }\end{array}$

2.82392 .5633 TRN

$\begin{array}{lll}5.4598 & 5.3723 & \text { TRN }\end{array}$

$\begin{array}{lll}4.8066 & 5.0474 & \text { TRN }\end{array}$

$4.9053 \quad 4.3475$ TRN

$\begin{array}{lll}4.4926 & 5.4757 & \text { TRN }\end{array}$

$\begin{array}{lll}5.7804 & 5.3189 & \text { TRN }\end{array}$

$\begin{array}{lll}4.9878 & 4.5199 & \text { TRN }\end{array}$

$5.6432 \quad 5.6084$ TRN

2.82394 .0913 TRN

$\begin{array}{llll}4.4849 & 5.2034 & \text { TRN }\end{array}$

$\begin{array}{lll}4.3576 & 5.1274 & \text { TRN }\end{array}$

$\begin{array}{lll}4.1908 & 4.753 & \text { TRN }\end{array}$

4.23414 .1476 TRN

$\begin{array}{lll}4.1154 & 4.3743 \text { TRN }\end{array}$

$\begin{array}{lll}5.0358 & 4.4861 & \text { TST }\end{array}$

$\begin{array}{lll}5.5712 & 5.7432 & \text { TRN }\end{array}$

$\begin{array}{lll}5.4401 & 4.7531 & \text { TRN }\end{array}$

$4.7213 \quad 4.6016 \quad$ TRN

$\begin{array}{lll}2.8239 & 4.2893 & \text { TST }\end{array}$

2.82394 .3144 TRN

$5.2134 \quad 5.1578$ TRN

$\begin{array}{lll}4.2611 & 3.9443 & \text { TRN }\end{array}$

6.61085 .7821 TRN

Page 13987 


\begin{tabular}{|c|c|c|c|c|}
\hline & & & splemen & \\
\hline CHEMBL1521990 & 688416 & 4.2254 & 4.2914 & TRN \\
\hline CHEMBL1523566 & 688416 & 5.1355 & 4.4419 & TRN \\
\hline CHEMBL1494996 & 688416 & 5.6936 & 5.2883 & TRN \\
\hline CHEMBL1596779 & 688416 & 4.4057 & 4.2121 & TST \\
\hline CHEMBL1415587 & 688416 & 2.8239 & 2.7519 & TRN \\
\hline CHEMBL1338958 & 688416 & 2.8239 & 4.0519 & TRN \\
\hline CHEMBL1509590 & 688416 & 5.5877 & 5.06 & TRN \\
\hline CHEMBL3190142 & 688416 & 4.2797 & 4.3652 & TRN \\
\hline CHEMBL1470382 & 688416 & 5.6702 & 5.2875 & TRN \\
\hline CHEMBL1378065 & 688416 & 2.8239 & 2.3216 & TRN \\
\hline CHEMBL1530378 & 688416 & 2.8239 & 2.8178 & TST \\
\hline CHEMBL1585777 & 688416 & 5.5854 & 4.9631 & TRN \\
\hline CHEMBL1300408 & 688416 & 4.8437 & 4.1974 & TRN \\
\hline CHEMBL1328493 & 688416 & 4.8099 & 4.5841 & TRN \\
\hline CHEMBL1345800 & 688416 & 5.1419 & 4.837 & TRN \\
\hline CHEMBL1527573 & 688416 & 2.8239 & 2.4541 & TRN \\
\hline CHEMBL1984298 & 688416 & 5.5913 & 5.0172 & TRN \\
\hline CHEMBL1486881 & 688416 & 5.1438 & 4.8587 & TRN \\
\hline CHEMBL1513972 & 688416 & 5.1244 & 4.4265 & TST \\
\hline CHEMBL3210343 & 688416 & 5.6611 & 4.6259 & TRN \\
\hline CHEMBL3198213 & 688416 & 6.4559 & 6.7292 & TST \\
\hline CHEMBL1378290 & 688416 & 4.0047 & 4.3235 & TRN \\
\hline CHEMBL1450825 & 688416 & 5.0683 & 4.4785 & TRN \\
\hline CHEMBL1305997 & 688416 & 5.1892 & 4.4352 & TRN \\
\hline CHEMBL1299640 & 688416 & 4.1987 & 4.3283 & TRN \\
\hline CHEMBL3214119 & 688416 & 2.8239 & 4.0936 & TST \\
\hline CHEMBL1327706 & 688416 & 5.4831 & 5.0837 & TRN \\
\hline CHEMBL6742 & 688416 & 5.8851 & 5.4546 & TRN \\
\hline CHEMBL1383809 & 688416 & 3.9125 & 4.1043 & TRN \\
\hline CHEMBL1985479 & 688416 & 4.8436 & 4.9643 & TRN \\
\hline CHEMBL1591082 & 688416 & 4.9864 & 4.5098 & TRN \\
\hline CHEMBL1531070 & 688416 & 4.6477 & 4.5842 & TST \\
\hline CHEMBL3195767 & 688416 & 6.3487 & 6.041 & TRN \\
\hline CHEMBL1986418 & 688416 & 5.2333 & 5.1098 & TRN \\
\hline CHEMBL1559496 & 688416 & 2.8239 & 4.1801 & TST \\
\hline CHEMBL1602601 & 688416 & 2.8239 & 3.4797 & TST \\
\hline CHEMBL3189407 & 688416 & 5.1146 & 4.5849 & TRN \\
\hline CHEMBL1489757 & 688416 & 4.7592 & 4.7511 & TRN \\
\hline CHEMBL1325644 & 688416 & 5.2611 & 4.4593 & TRN \\
\hline CHEMBL1580339 & 688416 & 4.9516 & 4.1387 & TRN \\
\hline CHEMBL1469266 & 688416 & 2.8239 & 2.1162 & TRN \\
\hline CHEMBL3191413 & 688416 & 2.8239 & 4.4258 & TRN \\
\hline CHEMBL1595850 & 688416 & 4.4207 & 4.9028 & TRN \\
\hline CHEMBL1534987 & 688416 & 4.8052 & 3.8539 & TRN \\
\hline CHEMBL1478826 & 688416 & 5.227 & 4.6794 & TRN \\
\hline CHEMBL1525347 & 688416 & 2.8239 & 2.1303 & TST \\
\hline CHEMBL1391287 & 688416 & 5.0888 & 5.1623 & TRN \\
\hline CHEMBL1469980 & 688416 & 4.8643 & 4.1635 & TRN \\
\hline
\end{tabular}




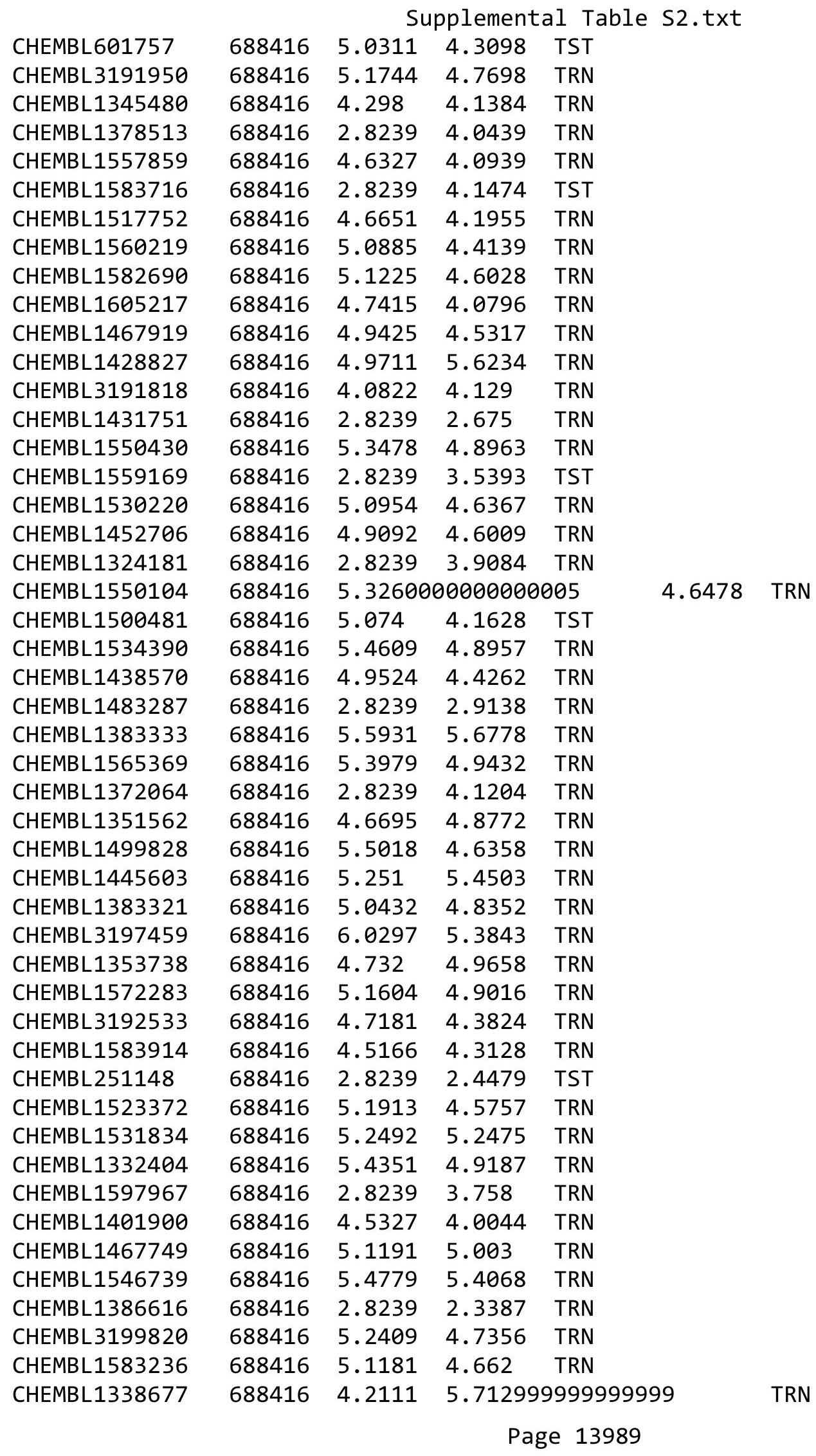




\begin{tabular}{|c|c|c|c|c|c|}
\hline \\
\hline CHEMBL1351595 & 688416 & 4.7555 & 4.2453 & TRN & \\
\hline CHEMBL1524252 & 688416 & 2.8239 & 2.9911 & TST & \\
\hline CHEMBL1599401 & 688416 & 5.1449 & 5.7055 & TRN & \\
\hline CHEMBL1409950 & 688416 & 2.8239 & 4.3358 & TRN & \\
\hline CHEMBL1345798 & 688416 & 5.4761 & 4.7232 & TRN & \\
\hline CHEMBL1559190 & 688416 & 4.7366 & 4.1193 & TRN & \\
\hline CHEMBL1357163 & 688416 & 5.0961 & 4.6586 & TST & \\
\hline CHEMBL1467377 & 688416 & 2.8239 & 2.5354 & TRN & \\
\hline CHEMBL1335732 & 688416 & 5.0851 & 4.273 & TRN & \\
\hline CHEMBL3192616 & 688416 & 5.6653 & 5.2219 & TRN & \\
\hline CHEMBL3193792 & 688416 & 4.1225 & 4.7341 & TRN & \\
\hline CHEMBL1403442 & 688416 & 4.8471 & 4.3169 & TRN & \\
\hline CHEMBL1506301 & 688416 & 5.2737 & 4.4957 & TRN & \\
\hline CHEMBL1519450 & 688416 & 2.8239 & 4.6656 & TRN & \\
\hline CHEMBL1399543 & 688416 & 5.0461 & 5.29899 & 99999999995 & TRN \\
\hline CHEMBL1467222 & 688416 & 4.3155 & 3.0236 & TRN & \\
\hline CHEMBL1407237 & 688416 & 5.5857 & 4.64199 & 99999999995 & TRN \\
\hline CHEMBL1501236 & 688416 & 2.8239 & 4.0291 & TRN & \\
\hline CHEMBL1443198 & 688416 & 2.8239 & 4.5698 & TRN & \\
\hline CHEMBL1498722 & 688416 & 2.8239 & 2.3378 & TRN & \\
\hline CHEMBL1415494 & 688416 & 2.8239 & 2.5257 & TRN & \\
\hline CHEMBL1401191 & 688416 & 2.8239 & 3.5902 & TST & \\
\hline CHEMBL3193726 & 688416 & 2.8239 & 2.715 & TRN & \\
\hline CHEMBL1569755 & 688416 & 4.9917 & 4.225 & TRN & \\
\hline CHEMBL1492135 & 688416 & 2.8239 & 2.6306 & TRN & \\
\hline CHEMBL1578856 & 688416 & 5.5774 & 4.9863 & TST & \\
\hline CHEMBL1562584 & 688416 & 5.1204 & 4.7816 & TRN & \\
\hline CHEMBL1393529 & 688416 & 4.6441 & 4.335 & TRN & \\
\hline CHEMBL1468058 & 688416 & 4.5835 & 3.8524 & TRN & \\
\hline CHEMBL1887153 & 688416 & 5.2742 & 5.0703 & TRN & \\
\hline CHEMBL3192479 & 688416 & 4.8043 & 4.1486 & TRN & \\
\hline CHEMBL1366987 & 688416 & 4.6286 & 4.4922 & TST & \\
\hline CHEMBL1483038 & 688416 & 2.8239 & 4.2334 & TRN & \\
\hline CHEMBL1500487 & 688416 & 2.8239 & 3.8316 & TRN & \\
\hline CHEMBL3193863 & 688416 & 4.4992 & 3.8523 & TRN & \\
\hline CHEMBL1494214 & 688416 & 2.8239 & 4.0127 & TRN & \\
\hline CHEMBL1374335 & 688416 & 2.8239 & 2.6929 & TRN & \\
\hline CHEMBL1594349 & 688416 & 5.1642 & 4.3437 & TRN & \\
\hline CHEMBL1587181 & 688416 & 4.8506 & 4.4761 & TRN & \\
\hline CHEMBL1528476 & 688416 & 5.6623 & 5.3169 & TRN & \\
\hline CHEMBL539027 & 688416 & 4.9655 & 3.9698 & TST & \\
\hline CHEMBL1387110 & 688416 & 3.96199 & 99999999 & 4.5896 & TRN \\
\hline CHEMBL1586416 & 688416 & 2.8239 & 4.3604 & TST & \\
\hline CHEMBL1425861 & 688416 & 5.0278 & 4.7369 & TRN & \\
\hline CHEMBL1407300 & 688416 & 2.8239 & 4.4052 & TST & \\
\hline CHEMBL1568696 & 688416 & 2.8239 & 2.6663 & TRN & \\
\hline CHEMBL1390021 & 688416 & 4.857 & 4.207 & TRN & \\
\hline CHEMBL1492510 & 688416 & 2.8239 & 3.9394 & TST & \\
\hline
\end{tabular}




\begin{tabular}{|c|c|c|c|c|c|c|}
\hline & & \multicolumn{5}{|c|}{ Supplemental Table S2.txt } \\
\hline CHEMBL1465830 & 688416 & 2.8239 & 3.4477 & TRN & & \\
\hline CHEMBL577102 & 688416 & 5.3567 & 4.6617 & TRN & & \\
\hline CHEMBL3145280 & 688416 & 5.1399 & 4.7908 & TRN & & \\
\hline CHEMBL3193765 & 688416 & 5.6912 & 5.3222 & TRN & & \\
\hline CHEMBL1477844 & 688416 & 2.8239 & 2.3571 & TRN & & \\
\hline CHEMBL1427455 & 688416 & 2.8239 & 3.8395 & TST & & \\
\hline CHEMBL1523175 & 688416 & 5.1564 & 4.69 & TRN & & \\
\hline CHEMBL1429171 & 688416 & 2.8239 & 3.8812 & TST & & \\
\hline CHEMBL1382445 & 688416 & 4.1586 & 4.2341 & TST & & \\
\hline CHEMBL1461547 & 688416 & 3.9574 & 4.8312 & TST & & \\
\hline CHEMBL1594317 & 688416 & 4.2133 & 4.3616 & TST & & \\
\hline CHEMBL1306856 & 688416 & 4.1288 & 4.1191 & TST & & \\
\hline CHEMBL1599495 & 688416 & 2.8239 & 2.5183 & TST & & \\
\hline CHEMBL1452652 & 688416 & 4.768 & 4.3901 & TST & & \\
\hline CHEMBL1511739 & 688416 & 4.8633 & 4.6542 & TST & & \\
\hline CHEMBL3193338 & 688416 & $4.3180 e$ & 00000000 & 205 & 4.9103 & TST \\
\hline CHEMBL1346621 & 688416 & 5.0282 & 4.542 & TST & & \\
\hline CHEMBL1401161 & 688416 & 2.8239 & 4.6088 & TST & & \\
\hline CHEMBL1568971 & 688416 & 2.8239 & 4.1507 & TST & & \\
\hline CHEMBL1571348 & 688416 & 4.7859 & 4.4025 & TST & & \\
\hline CHEMBL1326371 & 688416 & 5.4234 & 4.6212 & TST & & \\
\hline CHEMBL1342990 & 688416 & 4.2218 & 3.9597 & TST & & \\
\hline CHEMBL1307382 & 688416 & 2.8239 & 2.6699 & TST & & \\
\hline CHEMBL3195488 & 688416 & 5.2763 & 4.9513 & TST & & \\
\hline CHEMBL390559 & 688416 & 4.9512 & 4.6232 & TST & & \\
\hline CHEMBL1550334 & 688416 & 4.3422 & 4.2741 & TST & & \\
\hline CHEMBL 1444102 & 688416 & 2.8239 & 3.5846 & TST & & \\
\hline CHEMBL3212930 & 688416 & 4.4031 & 4.6304 & TST & & \\
\hline CHEMBL3207619 & 688416 & 5.5272 & 5.165 & TST & & \\
\hline CHEMBL1576050 & 688416 & 2.8239 & 2.3319 & TST & & \\
\hline CHEMBL1514790 & 688416 & 5.1476 & 4.5613 & TST & & \\
\hline CHEMBL1520849 & 688416 & 4.8666 & 4.3895 & TST & & \\
\hline CHEMBL1420123 & 688416 & 2.8239 & 3.9257 & TST & & \\
\hline CHEMBL1408752 & 688416 & 2.8239 & 4.2079 & TST & & \\
\hline CHEMBL1435933 & 688416 & 4.5725 & 4.6094 & TST & & \\
\hline CHEMBL1494267 & 688416 & 2.8239 & 2.6898 & TST & & \\
\hline CHEMBL 1500256 & 688416 & 5.4845 & 5.1181 & TST & & \\
\hline CHEMBL1435343 & 688416 & 5.3528 & 5.1199 & TST & & \\
\hline CHEMBL3197605 & 688416 & 4.7776 & 4.0395 & TST & & \\
\hline CHEMBL1529093 & 688416 & 5.4124 & 4.8306 & TST & & \\
\hline CHEMBL1609828 & 688416 & 5.0893 & 4.738 & TST & & \\
\hline CHEMBL1384209 & 688416 & 2.8239 & 2.9484 & TST & & \\
\hline CHEMBL1502450 & 688416 & 5.5384 & 4.9104 & TST & & \\
\hline CHEMBL1451873 & 688416 & 2.8239 & 2.734 & TST & & \\
\hline CHEMBL1479986 & 688416 & 2.8239 & 4.4575 & TST & & \\
\hline CHEMBL1390112 & 688416 & 2.8239 & 5.5244 & TST & & \\
\hline CHEMBL 1347282 & 688416 & 2.8239 & 2.5044 & TST & & \\
\hline CHEMBL1407235 & 688416 & 2.8239 & 4.2128 & TST & & \\
\hline
\end{tabular}




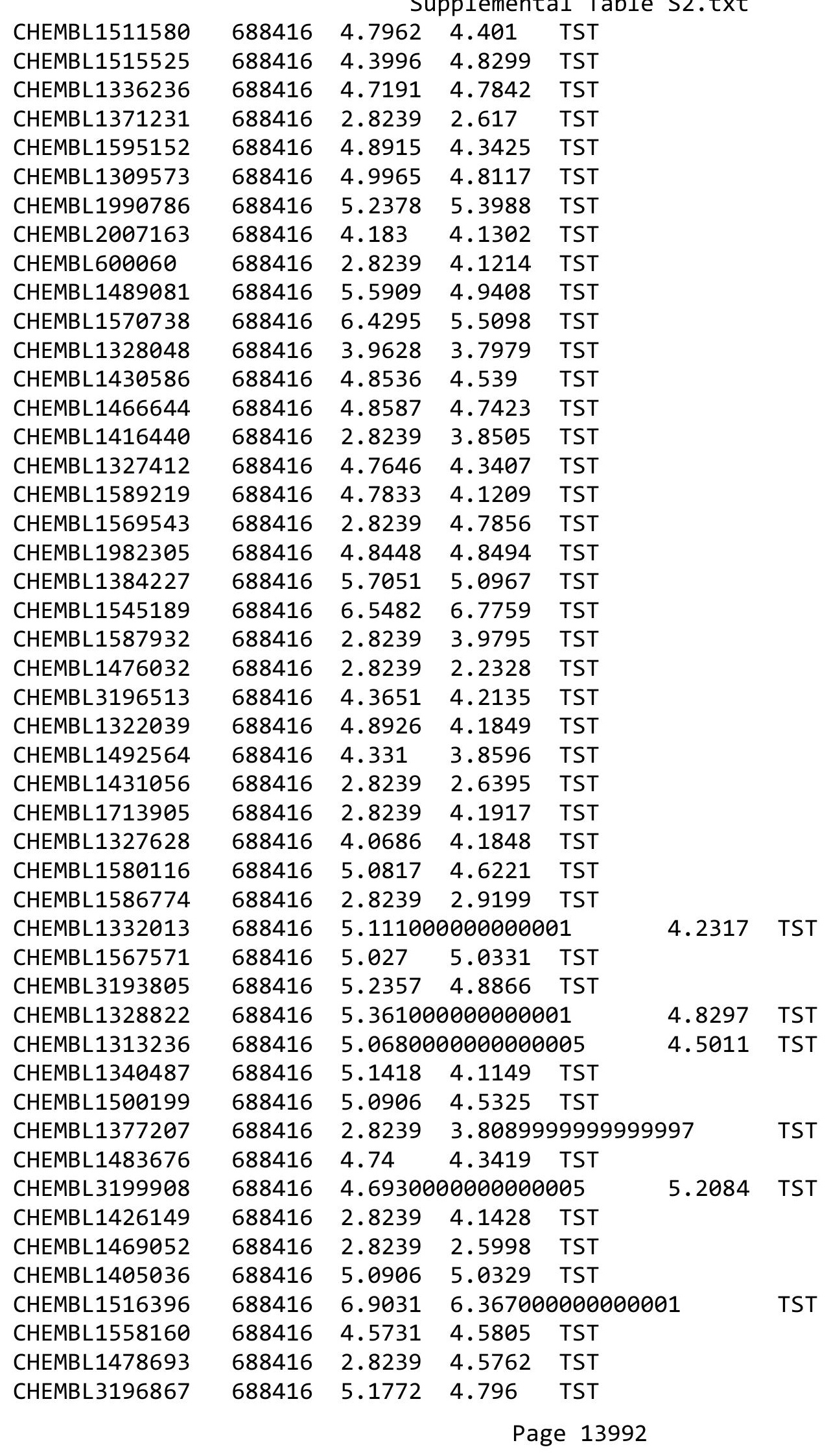


Supplemental Table S2.txt

\begin{tabular}{|c|c|c|c|c|}
\hline CHEMBL 2005895 & 688416 & 5.3505 & 4.8885 & TST \\
\hline CHEMBL1499233 & 688416 & 5.0851 & 4.9684 & TST \\
\hline CHEMBL1555769 & 688416 & 4.8322 & 4.3604 & TST \\
\hline CHEMBL1970872 & 688416 & 5.8202 & 5.2711 & TST \\
\hline CHEMBL3193419 & 688416 & 5.445 & 5.2431 & TST \\
\hline CHEMBL1508399 & 688416 & 4.4776 & 4.455 & TST \\
\hline CHEMBL1545384 & 688416 & 5.5423 & 5.0066 & TST \\
\hline CHEMBL1546381 & 688416 & 4.9196 & 4.0046 & TST \\
\hline CHEMBL1970867 & 688416 & 4.7246 & 4.9472 & TST \\
\hline CHEMBL3198313 & 688416 & 4.3351 & 4.591 & TST \\
\hline CHEMBL1454245 & 688416 & 2.8239 & 4.2713 & TST \\
\hline CHEMBL 3145088 & 688416 & 5.1781 & 4.9526 & TST \\
\hline CHEMBL1605304 & 688416 & 4.9233 & 4.1118 & TST \\
\hline CHEMBL1325639 & 688416 & 4.0209 & 3.9093 & TST \\
\hline CHEMBL1975801 & 688416 & 4.8791 & 4.0998 & TST \\
\hline CHEMBL1494782 & 688416 & 2.8239 & 2.3251 & TST \\
\hline CHEMBL391123 & 688416 & 5.7354 & 5.88399 & 99999999995 \\
\hline CHEMBL 3190468 & 688416 & 5.8251 & 5.2234 & TST \\
\hline CHEMBL1367877 & 688416 & 5.0117 & 4.5391 & TST \\
\hline CHEMBL1422105 & 688416 & 2.8239 & 4.5975 & TST \\
\hline CHEMBL1423049 & 688416 & 2.8239 & 4.1168 & TST \\
\hline CHEMBL1340150 & 688416 & 5.4438 & 4.8009 & TST \\
\hline CHEMBL1371298 & 688416 & 4.6475 & 3.7426 & TST \\
\hline CHEMBL 3197371 & 688416 & 5.0964 & 5.0185 & TST \\
\hline CHEMBL1549267 & 688416 & 5.2135 & 4.8671 & TST \\
\hline CHEMBL1303794 & 688416 & 4.8266 & 4.2117 & TST \\
\hline CHEMBL1613220 & 688416 & 4.6829 & 4.556 & TST \\
\hline CHEMBL1490966 & 688416 & 2.8239 & 2.458 & TST \\
\hline CHEMBL579318 & 688416 & 5.5918 & 4.9018 & TST \\
\hline CHEMBL1483746 & 688416 & 4.3063 & 3.8892 & TST \\
\hline CHEMBL1387643 & 688416 & 4.9542 & 4.0915 & TST \\
\hline CHEMBL 3194931 & 688416 & 4.3224 & 4.4641 & TST \\
\hline CHEMBL1350336 & 688416 & 4.9346 & 4.5551 & TST \\
\hline CHEMBL1403854 & 688416 & 5.1321 & 4.5244 & TST \\
\hline CHEMBL1504972 & 688416 & 4.5888 & 4.3093 & TST \\
\hline CHEMBL1584779 & 688416 & 2.8239 & 4.0192 & TST \\
\hline CHEMBL1603615 & 688416 & 5.0162 & 4.4405 & TST \\
\hline CHEMBL1582520 & 688416 & 2.8239 & 4.2813 & TST \\
\hline CHEMBL1569782 & 688416 & 4.4383 & 4.4406 & TST \\
\hline CHEMBL 3190103 & 688416 & 4.3837 & 4.7358 & TST \\
\hline CHEMBL 3189712 & 688416 & 5.1854 & 4.9516 & TST \\
\hline CHEMBL1461193 & 688416 & 4.7976 & 4.4264 & TST \\
\hline CHEMBL1329336 & 688416 & 4.5207 & 4.4967 & TST \\
\hline CHEMBL1391743 & 688416 & 4.5999 & 5.1774 & TST \\
\hline CHEMBL1380969 & 688416 & 4.731 & 4.206 & TST \\
\hline CHEMBL1989426 & 688416 & 4.2173 & 4.9103 & TST \\
\hline CHEMBL1524865 & 688416 & 4.8269 & 4.5299 & TST \\
\hline CHEMBL1528869 & 688416 & 2.8239 & 4.3903 & TST \\
\hline
\end{tabular}

Page 13993 


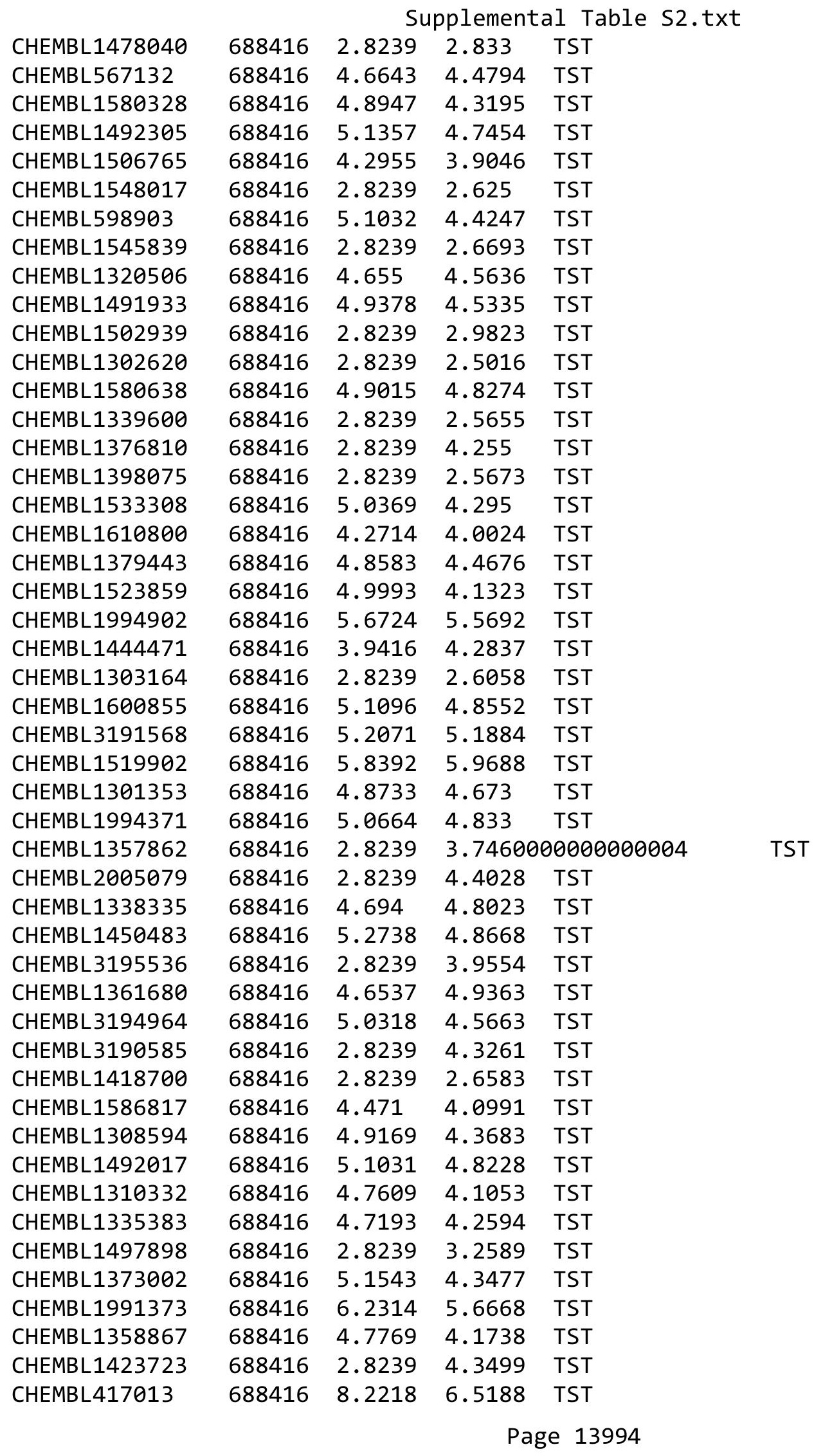




\begin{tabular}{|c|c|c|c|c|c|}
\hline & & \multicolumn{4}{|c|}{ Supplemental Table s2.txt } \\
\hline CHEMBL1505192 & 688416 & 5.0793 & 4.1504 & TST & \\
\hline CHEMBL1390437 & 688416 & 2.8239 & 2.1446 & TST & \\
\hline CHEMBL1319778 & 688416 & 5.528 & 5.6369 & TST & \\
\hline CHEMBL1550672 & 688416 & 5.2323 & 4.6393 & TST & \\
\hline CHEMBL1466844 & 688416 & 5.9674 & 5.3349 & TST & \\
\hline CHEMBL1597655 & 688416 & 4.8615 & 4.6996 & TST & \\
\hline CHEMBL3191808 & 688416 & 5.0813 & 4.5857 & TST & \\
\hline CHEMBL1576581 & 688416 & 6.6402 & 5.5422 & TST & \\
\hline CHEMBL1605393 & 688416 & 2.8239 & 4.2965 & TST & \\
\hline CHEMBL504977 & 688416 & 5.0173 & 4.8806 & TST & \\
\hline CHEMBL1418662 & 688416 & 4.9488 & 4.1919 & TST & \\
\hline CHEMBL 2002008 & 688416 & 4.9957 & 5.3168 & TST & \\
\hline CHEMBL1516308 & 688416 & 4.4646 & 3.7875 & TST & \\
\hline CHEMBL1586932 & 688416 & 2.8239 & 4.1281 & TST & \\
\hline CHEMBL1500382 & 688416 & 2.8239 & 3.6457 & TST & \\
\hline CHEMBL1528043 & 688416 & 5.1206 & 4.3492 & TST & \\
\hline CHEMBL1383799 & 688416 & 5.2376 & 4.6924 & TST & \\
\hline CHEMBL1427125 & 688416 & 3.9446 & 4.30699 & 99999999995 & TST \\
\hline CHEMBL2369228 & 688416 & 2.8239 & 4.3668 & TST & \\
\hline CHEMBL1496642 & 688416 & 2.8239 & 4.338 & TST & \\
\hline CHEMBL1345080 & 688416 & 4.1657 & 4.3322 & TST & \\
\hline CHEMBL1333275 & 688416 & 4.9461 & 4.6742 & TST & \\
\hline CHEMBL1466621 & 688416 & 5.4584 & 5.0915 & TST & \\
\hline CHEMBL1371202 & 688416 & 2.8239 & 2.6676 & TST & \\
\hline CHEMBL1404929 & 688416 & 4.6256 & 4.8883 & TST & \\
\hline CHEMBL1544859 & 688416 & 4.3927 & 4.0907 & TST & \\
\hline CHEMBL1353219 & 688416 & 2.8239 & 3.91300 & 00000000003 & TST \\
\hline CHEMBL3189459 & 688416 & 4.5523 & 4.5403 & TST & \\
\hline CHEMBL1402915 & 688416 & 2.8239 & 2.9448 & TST & \\
\hline CHEMBL1601820 & 688416 & 5.6234 & 4.7871 & TST & \\
\hline CHEMBL1466362 & 688416 & 4.8816 & 4.1696 & TST & \\
\hline CHEMBL1992276 & 688416 & 4.618 & 4.1404 & TST & \\
\hline CHEMBL1547031 & 688416 & 2.8239 & 3.8078 & TST & \\
\hline CHEMBL1320354 & 688416 & 5.2495 & 4.7016 & TST & \\
\hline CHEMBL1360393 & 688416 & 2.8239 & 4.0516 & TST & \\
\hline CHEMBL1375559 & 688416 & 2.8239 & 4.386 & TST & \\
\hline CHEMBL1387503 & 688416 & 2.8239 & 2.3153 & TST & \\
\hline CHEMBL1542568 & 688416 & 5.0656 & 4.4668 & TST & \\
\hline CHEMBL1470448 & 688416 & 5.5325 & 5.5431 & TST & \\
\hline CHEMBL3213606 & 688416 & 5.5541 & 4.98300 & 00000000005 & TST \\
\hline CHEMBL1965811 & 688416 & 5.7796 & 5.3975 & TST & \\
\hline CHEMBL1416153 & 688416 & 5.3338 & 5.2043 & TST & \\
\hline CHEMBL1537118 & 688416 & 4.0395 & 4.0794 & TST & \\
\hline CHEMBL1436608 & 688416 & 4.9577 & 4.6948 & TST & \\
\hline CHEMBL1327627 & 688416 & 5.1608 & 4.3777 & TST & \\
\hline CHEMBL1985629 & 688416 & 2.8239 & 4.7581 & TST & \\
\hline CHEMBL3189163 & 688416 & 5.9763 & 5.3052 & TST & \\
\hline CHEMBL1383511 & 688416 & 4.7082 & 4.0053 & TST & \\
\hline
\end{tabular}


Supplemental Table S2.txt

\begin{tabular}{|c|c|c|c|c|c|}
\hline CHEMBL1427928 & 688416 & 5.1976 & 5.2952 & TST & \\
\hline CHEMBL3195852 & 688416 & 4.3515 & \multicolumn{2}{|c|}{4.6419999999999995} & TST \\
\hline CHEMBL581251 & 688416 & 4.8091 & 4.5325 & TST & \\
\hline CHEMBL1378952 & 688416 & 5.4203 & 5.2401 & TST & \\
\hline CHEMBL1366790 & 688416 & 2.8239 & 2.8562 & TST & \\
\hline CHEMBL1498273 & 688416 & 2.8239 & 4.203 & TST & \\
\hline CHEMBL1430426 & 688416 & 2.8239 & 2.6899 & TST & \\
\hline CHEMBL1430636 & 688416 & 4.9153 & 4.5546 & TST & \\
\hline CHEMBL1373166 & 688416 & 4.3879 & 4.6434 & TST & \\
\hline CHEMBL1467188 & 688416 & 5.3397 & 5.2378 & TST & \\
\hline CHEMBL1487901 & 688416 & 5.2505 & 4.7953 & TST & \\
\hline CHEMBL1463856 & 688416 & 2.8239 & 2.9077 & TST & \\
\hline CHEMBL1578141 & 688416 & 4.8351 & 4.614 & TST & \\
\hline CHEMBL1430319 & 688416 & 4.7852 & 4.3501 & TST & \\
\hline CHEMBL1361533 & 688416 & 4.2483 & 4.3877 & TST & \\
\hline CHEMBL 2003651 & 688416 & 5.3929 & 4.8022 & TST & \\
\hline CHEMBL212314 & 688416 & 4.9231 & 4.5844 & TST & \\
\hline CHEMBL1564641 & 688416 & 5.0592 & 4.4522 & TST & \\
\hline CHEMBL1573962 & 688416 & 4.0399 & 4.0753 & TST & \\
\hline CHEMBL1329561 & 688416 & 4.5364 & 4.3586 & TST & \\
\hline CHEMBL 2311878 & 688416 & 5.6349 & 5.3931 & TST & \\
\hline CHEMBL 2095095 & 688416 & 5.3759 & 5.0536 & TST & \\
\hline CHEMBL1388274 & 688416 & 2.8239 & \multicolumn{2}{|c|}{4.446000000000001} & TST \\
\hline CHEMBL1323151 & 688416 & 4.5089 & 3.7934 & TST & \\
\hline CHEMBL1518955 & 688416 & 4.5463 & 3.888 & TST & \\
\hline CHEMBL51931 & 688416 & 5.6377 & 4.7329 & TST & \\
\hline CHEMBL1324715 & 688416 & 4.3795 & 3.9324 & TST & \\
\hline CHEMBL1544901 & 688416 & 5.0004 & 4.7019 & TST & \\
\hline CHEMBL1396500 & 688416 & 2.8239 & 3.8229 & TST & \\
\hline CHEMBL1413629 & 688416 & 2.8239 & 4.613 & TST & \\
\hline CHEMBL363535 & 688416 & 5.1177 & 4.4729 & TST & \\
\hline CHEMBL1445161 & 688416 & 5.0021 & 4.3158 & TST & \\
\hline CHEMBL1430495 & 688416 & 4.4994 & 4.5989 & TST & \\
\hline CHEMBL1566076 & 688416 & 4.9171 & 4.5297 & TST & \\
\hline CHEMBL1516792 & 688416 & 2.8239 & 3.7657 & TST & \\
\hline CHEMBL1345404 & 688416 & 2.8239 & 2.7839 & TST & \\
\hline CHEMBL1497894 & 688416 & 3.8514 & 5.1801 & TST & \\
\hline CHEMBL1577081 & 688416 & 2.8239 & 3.8491 & TST & \\
\hline CHEMBL 2004918 & 688416 & 4.9018 & 4.4151 & TST & \\
\hline CHEMBL1383044 & 688416 & 4.3788 & 4.1987 & TST & \\
\hline CHEMBL 2373661 & 688416 & 8.2218 & 6.5883 & TST & \\
\hline CHEMBL1332873 & 688416 & 4.4741 & 5.3229 & TST & \\
\hline CHEMBL1457175 & 688416 & 2.8239 & 4.6325 & TST & \\
\hline CHEMBL1333637 & 688416 & 2.8239 & 4.0618 & TST & \\
\hline CHEMBL1601133 & 688416 & 5.4124 & 4.9593 & TST & \\
\hline CHEMBL1384874 & 688416 & 5.0239 & 5.6215 & TST & \\
\hline CHEMBL1466495 & 688416 & 4.4149 & 4.1797 & TST & \\
\hline CHEMBL1467427 & 688416 & 5.0965 & 4.0729 & TST & \\
\hline
\end{tabular}




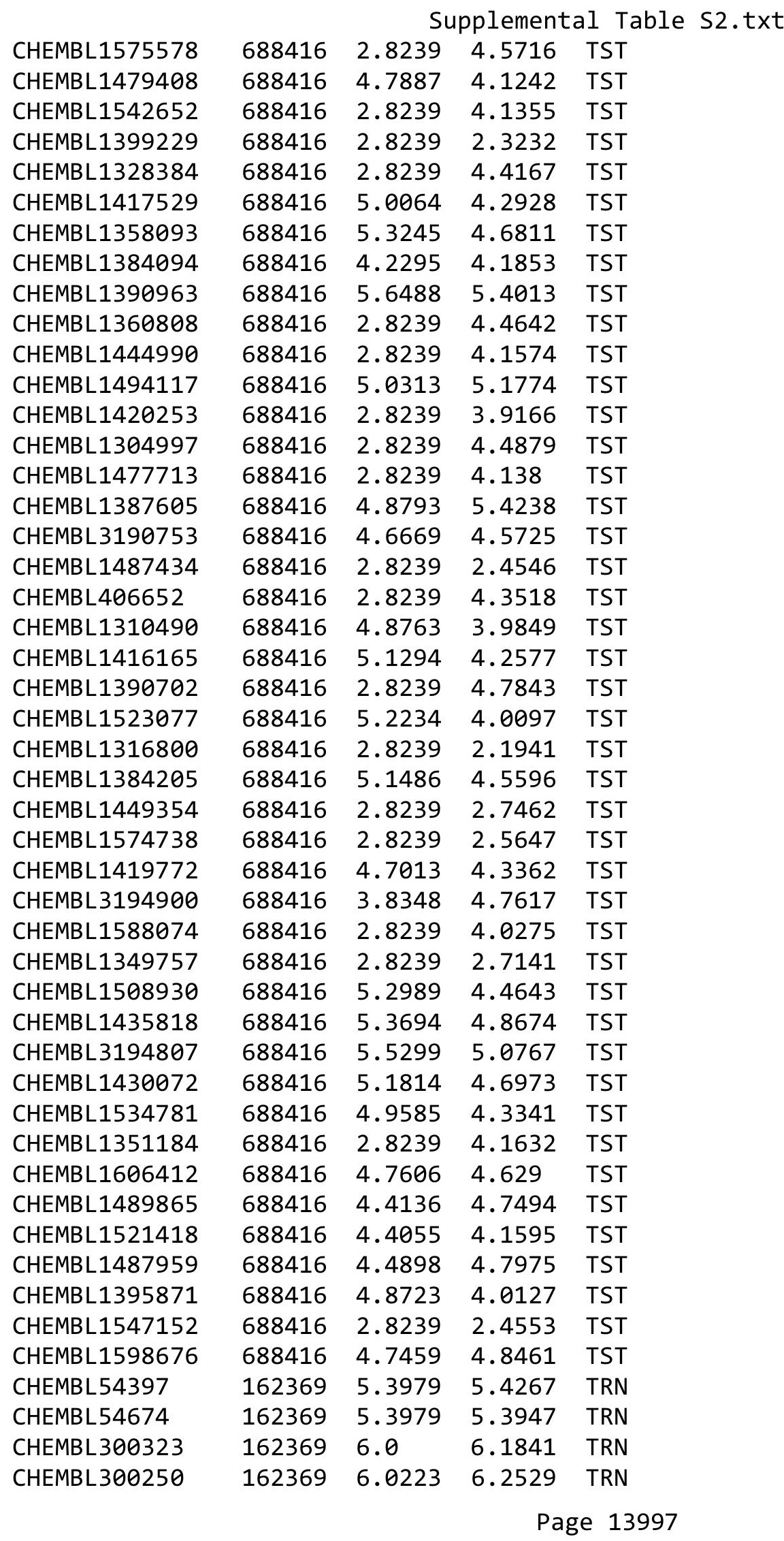




\begin{tabular}{|c|c|c|c|c|c|}
\hline \multicolumn{6}{|c|}{ Supplemental Table S2.txt } \\
\hline CHEMBL50629 & 162369 & 5.9208 & 6.2244 & TRN & \\
\hline CHEMBL299552 & 162369 & 5.7959 & 5.5716 & TRN & \\
\hline CHEMBL53873 & 162369 & 3.0 & 3.4286 & TRN & \\
\hline CHEMBL300397 & 162369 & 5.1192 & 5.0778 & TRN & \\
\hline CHEMBL 291546 & 162369 & 4.5391 & 6.0778 & TST & \\
\hline CHEMBL415945 & 162369 & 6.3565 & 6.0981 & TRN & \\
\hline CHEMBL301969 & 162369 & 5.6198 & 5.6637 & TRN & \\
\hline CHEMBL301794 & 162369 & 3.301 & 4.08899 & 99999999995 & TRN \\
\hline CHEMBL 281948 & 162369 & 6.3279 & 4.3588 & TST & \\
\hline CHEMBL52853 & 162369 & 6.1739 & 5.9583 & TRN & \\
\hline CHEMBL300207 & 162369 & 3.0 & 3.638 & TRN & \\
\hline CHEMBL293542 & 162369 & 5.0969 & 5.4454 & TRN & \\
\hline CHEMBL301389 & 162369 & 6.0915 & 6.1479 & TRN & \\
\hline CHEMBL298818 & 162369 & 4.9872 & 6.0229 & TST & \\
\hline CHEMBL 299378 & 162369 & 3.301 & 3.8386 & TRN & \\
\hline CHEMBL299015 & 162369 & 5.6576 & 6.2252 & TRN & \\
\hline CHEMBL299519 & 162369 & 5.6021 & 6.0137 & TRN & \\
\hline CHEMBL53956 & 162369 & 5.6198 & 6.3065 & TRN & \\
\hline CHEMBL53906 & 162369 & 6.2291 & 6.0979 & TRN & \\
\hline CHEMBL53495 & 162369 & 6.0 & 5.7527 & TRN & \\
\hline CHEMBL52079 & 162369 & 4.8601 & 5.0347 & TRN & \\
\hline CHEMBL431133 & 162369 & 5.6576 & 5.794 & TRN & \\
\hline CHEMBL52132 & 162369 & 5.5528 & 4.3996 & TRN & \\
\hline CHEMBL53184 & 162369 & 5.1249 & 4.614 & TRN & \\
\hline CHEMBL296150 & 162369 & 5.3979 & 5.5147 & TRN & \\
\hline CHEMBL54713 & 162369 & 6.4437 & 6.0067 & TRN & \\
\hline CHEMBL 301741 & 162369 & 4.2924 & 6.0749 & TST & \\
\hline CHEMBL 294450 & 162369 & 3.0 & 6.3967 & TST & \\
\hline CHEMBL293746 & 162369 & 6.3188 & 6.2669 & TRN & \\
\hline CHEMBL54547 & 162369 & 5.4949 & 5.8155 & TRN & \\
\hline CHEMBL52644 & 162369 & 5.5229 & 6.0698 & TRN & \\
\hline CHEMBL 388978 & 162369 & 8.0458 & 4.8976 & TST & \\
\hline CHEMBL54372 & 162369 & 4.5686 & 3.9573 & TRN & \\
\hline CHEMBL54389 & 162369 & 5.1612 & 5.4088 & TRN & \\
\hline CHEMBL299953 & 162369 & 5.5229 & 6.1215 & TST & \\
\hline CHEMBL54794 & 162369 & 6.2218 & 5.9533 & TRN & \\
\hline CHEMBL431933 & 162369 & 6.0458 & 5.732 & TRN & \\
\hline CHEMBL53695 & 162369 & 6.3279 & 6.2484 & TRN & \\
\hline CHEMBL53992 & 162369 & 5.8239 & 5.9551 & TRN & \\
\hline CHEMBL 301138 & 162369 & 5.585 & 5.9443 & TRN & \\
\hline CHEMBL53856 & 162369 & 6.6576 & 6.2065 & TRN & \\
\hline CHEMBL 291725 & 162369 & 3.0 & 5.2391 & TST & \\
\hline CHEMBL55151 & 162369 & 6.0 & 6.2347 & TRN & \\
\hline CHEMBL 300208 & 162369 & 6.0 & 5.9333 & TRN & \\
\hline CHEMBL53399 & 162369 & 5.9586 & 6.0513 & TRN & \\
\hline CHEMBL301515 & 162369 & 6.5229 & 6.1913 & TRN & \\
\hline CHEMBL 299840 & 162369 & 4.8239 & 5.3048 & TRN & \\
\hline CHEMBL52851 & 162369 & 5.5376 & 5.7355 & TRN & \\
\hline
\end{tabular}




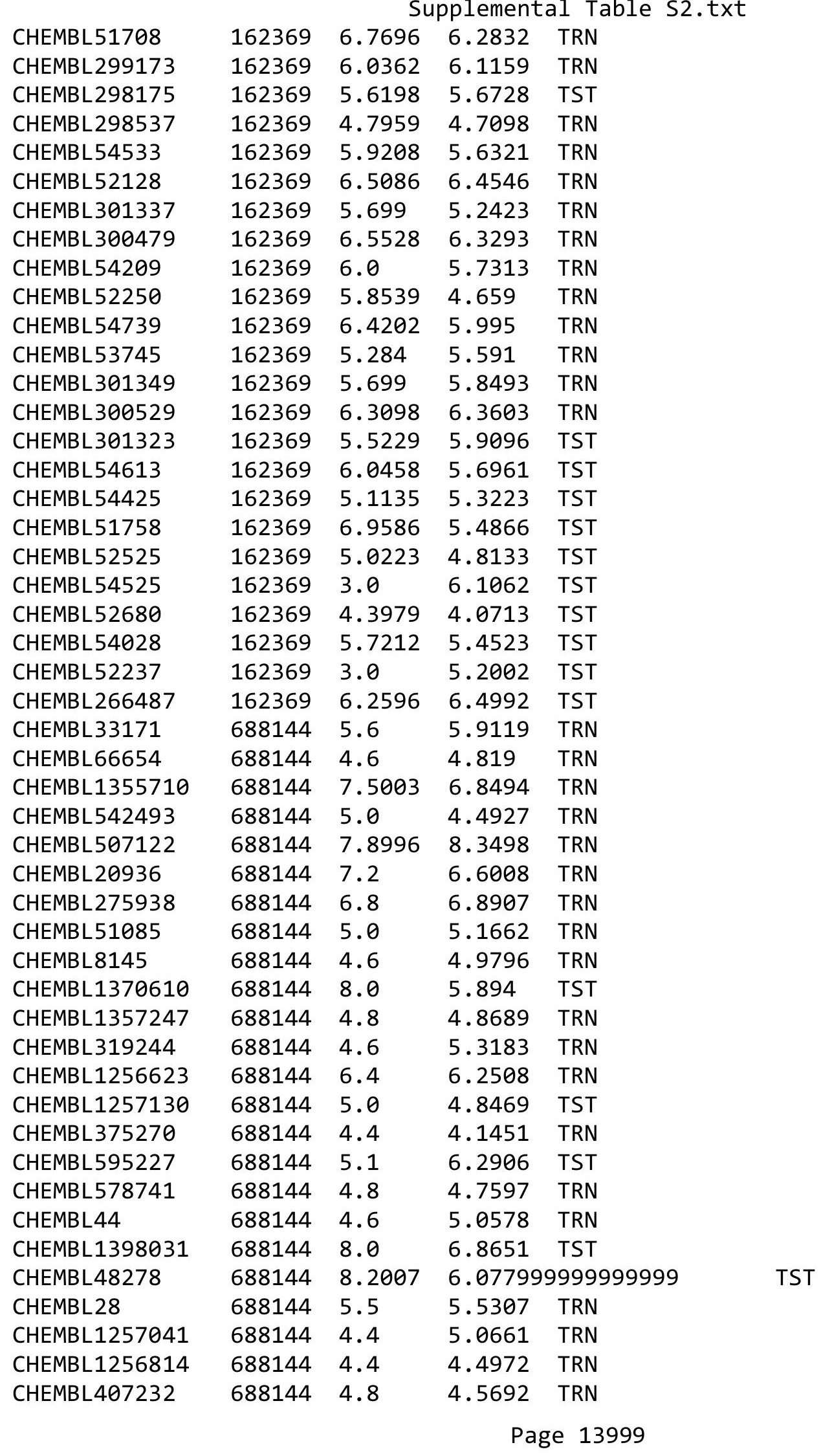




\begin{tabular}{|c|c|c|c|c|}
\hline & & & pplement & al $\mathrm{T}$ \\
\hline CHEMBL2374259 & 688144 & 5.0 & 5.027 & TRN \\
\hline CHEMBL323356 & 688144 & 4.8 & 4.3377 & TRN \\
\hline CHEMBL1256364 & 688144 & 4.6 & 4.5674 & TRN \\
\hline CHEMBL1256751 & 688144 & 4.9 & 4.8023 & TRN \\
\hline CHEMBL1256873 & 688144 & 7.5003 & 7.2344 & TRN \\
\hline CHEMBL109037 & 688144 & 6.4 & 6.9087 & TRN \\
\hline CHEMBL 328710 & 688144 & 5.5 & 5.4868 & TRN \\
\hline CHEMBL1253351 & 688144 & 4.5 & 5.2923 & TRN \\
\hline CHEMBL1972346 & 688144 & 5.6 & 4.9747 & TRN \\
\hline CHEMBL297784 & 688144 & 5.2 & 5.0796 & TRN \\
\hline CHEMBL126077 & 688144 & 4.9 & 4.4085 & TRN \\
\hline CHEMBL405358 & 688144 & 5.2 & 5.1416 & TRN \\
\hline CHEMBL1255755 & 688144 & 4.9 & 4.809 & TRN \\
\hline CHEMBL 97760 & 688144 & 5.4 & 5.3239 & TRN \\
\hline CHEMBL1255967 & 688144 & 8.4949 & 5.8269 & TST \\
\hline CHEMBL428496 & 688144 & 8.7959 & 6.3676 & TST \\
\hline CHEMBL129795 & 688144 & 4.8 & 4.8818 & TRN \\
\hline CHEMBL453066 & 688144 & 5.6 & 5.3925 & TRN \\
\hline CHEMBL1493117 & 688144 & 4.9 & 4.8527 & TRN \\
\hline CHEMBL168461 & 688144 & 8.1024 & 8.1059 & TRN \\
\hline CHEMBL296586 & 688144 & 5.5 & 5.8144 & TRN \\
\hline CHEMBL76589 & 688144 & 4.5 & 4.3664 & TRN \\
\hline CHEMBL56543 & 688144 & 8.2007 & 8.1427 & TRN \\
\hline CHEMBL1437711 & 688144 & 7.3002 & 7.7135 & TRN \\
\hline CHEMBL72631 & 688144 & 8.1024 & 7.6858 & TRN \\
\hline CHEMBL1235242 & 688144 & 4.9 & 5.3063 & TRN \\
\hline CHEMBL1256625 & 688144 & 4.8 & 5.2895 & TRN \\
\hline CHEMBL1365553 & 688144 & 4.7 & 4.5088 & TRN \\
\hline CHEMBL 305881 & 688144 & 7.8996 & 7.8428 & TRN \\
\hline CHEMBL1373007 & 688144 & 4.7 & 6.093 & TST \\
\hline CHEMBL1256996 & 688144 & 8.2007 & 8.4613 & TRN \\
\hline CHEMBL355496 & 688144 & 4.8 & 4.387 & TRN \\
\hline CHEMBL1398537 & 688144 & 4.9 & 5.8728 & TST \\
\hline CHEMBL16857 & 688144 & 7.8996 & 7.7573 & TRN \\
\hline CHEMBL56731 & 688144 & 4.6 & 5.1336 & TRN \\
\hline CHEMBL77030 & 688144 & 4.4 & 5.3559 & TRN \\
\hline CHEMBL553503 & 688144 & 8.2007 & 8.2863 & TRN \\
\hline CHEMBL85139 & 688144 & 5.5 & 5.2519 & TRN \\
\hline CHEMBL 371811 & 688144 & 5.6 & 5.1789 & TRN \\
\hline CHEMBL35482 & 688144 & 4.8 & 4.3872 & TRN \\
\hline CHEMBL269733 & 688144 & 5.4 & 5.8084 & TRN \\
\hline CHEMBL293749 & 688144 & 8.4949 & 8.036 & TRN \\
\hline CHEMBL1434950 & 688144 & 8.1024 & 7.5739 & TRN \\
\hline CHEMBL 76232 & 688144 & 8.301 & 8.1088 & TRN \\
\hline CHEMBL 2448607 & 688144 & 8.6021 & 8.4797 & TRN \\
\hline CHEMBL1336166 & 688144 & 5.3 & 5.0991 & TRN \\
\hline CHEMBL24510 & 688144 & 6.6 & 6.5859 & TRN \\
\hline CHEMBL216504 & 688144 & 4.6 & 4.6948 & TRN \\
\hline
\end{tabular}




\begin{tabular}{|c|c|c|c|c|}
\hline & & & pplement & al $\mathrm{T}$ \\
\hline CHEMBL1331383 & 688144 & 5.5 & 6.1562 & TST \\
\hline CHEMBL1461491 & 688144 & 6.7001 & 6.5812 & TST \\
\hline CHEMBL165 & 688144 & 5.5 & 4.8401 & TST \\
\hline CHEMBL1367076 & 688144 & 4.8 & 4.3129 & TST \\
\hline CHEMBL394171 & 688144 & 6.9 & 5.256 & TST \\
\hline CHEMBL1437244 & 688144 & 4.8 & 5.4399 & TST \\
\hline CHEMBL1527442 & 688144 & 4.0 & 6.3488 & TST \\
\hline CHEMBL1380684 & 688144 & 5.8 & 5.3099 & TST \\
\hline CHEMBL1490919 & 688144 & 4.9 & 4.5484 & TST \\
\hline CHEMBL68534 & 688144 & 4.7 & 5.942 & TST \\
\hline CHEMBL574181 & 688144 & 4.8 & 5.9703 & TST \\
\hline CHEMBL429711 & 688144 & 4.7 & 4.955 & TST \\
\hline CHEMBL536950 & 688144 & 4.6 & 5.2728 & TST \\
\hline CHEMBL591712 & 612285 & 8.8539 & 8.9575 & TST \\
\hline CHEMBL591185 & 612285 & 8.4318 & 7.909 & TST \\
\hline CHEMBL598999 & 612285 & 5.9245 & 6.4434 & TST \\
\hline CHEMBL598375 & 612285 & 7.3565 & 5.2341 & TST \\
\hline CHEMBL589550 & 612285 & 7.2676 & 7.5872 & TRN \\
\hline CHEMBL596732 & 612285 & 7.7447 & 6.0745 & TST \\
\hline CHEMBL598998 & 612285 & 6.4486 & 6.316 & TRN \\
\hline CHEMBL596961 & 612285 & 8.1024 & 7.9214 & TRN \\
\hline CHEMBL590262 & 612285 & 8.0088 & 8.0078 & TRN \\
\hline CHEMBL578522 & 612285 & 8.8239 & 8.5427 & TRN \\
\hline CHEMBL576331 & 612285 & 8.6021 & 8.7209 & TRN \\
\hline CHEMBL590746 & 612285 & 8.585 & 8.3594 & TRN \\
\hline CHEMBL592810 & 612285 & 8.5229 & 8.1005 & TRN \\
\hline CHEMBL603152 & 612285 & 8.5528 & 8.1614 & TRN \\
\hline CHEMBL597563 & 612285 & 6.7077 & 6.2335 & TST \\
\hline CHEMBL599606 & 612285 & 6.4283 & 6.1237 & TST \\
\hline CHEMBL578507 & 612285 & 8.7212 & 8.5684 & TRN \\
\hline CHEMBL579334 & 612285 & 8.2924 & 8.0826 & TRN \\
\hline CHEMBL591839 & 612285 & 8.2596 & 8.3839 & TRN \\
\hline CHEMBL540737 & 612285 & 7.4685 & 7.2406 & TRN \\
\hline CHEMBL599214 & 612285 & 4.4449 & 4.6343 & TRN \\
\hline CHEMBL590748 & 612285 & 8.3565 & 8.2588 & TRN \\
\hline CHEMBL590798 & 612285 & 8.4437 & 8.0402 & TST \\
\hline CHEMBL598161 & 612285 & 8.0 & 7.8481 & TRN \\
\hline CHEMBL550206 & 612285 & 7.2218 & 7.3682 & TRN \\
\hline CHEMBL549724 & 612285 & 7.5376 & 6.7913 & TST \\
\hline CHEMBL592021 & 612285 & 8.1871 & 8.1036 & TRN \\
\hline CHEMBL599399 & 612285 & 7.8239 & 5.7375 & TST \\
\hline CHEMBL598177 & 612285 & 7.0269 & 7.1716 & TRN \\
\hline CHEMBL578899 & 612285 & 8.5528 & 8.3918 & TRN \\
\hline CHEMBL599197 & 612285 & 7.3372 & 5.9937 & TST \\
\hline CHEMBL592880 & 612285 & 8.3468 & 8.2151 & TRN \\
\hline CHEMBL563183 & 612285 & 7.3768 & 7.3377 & TRN \\
\hline CHEMBL552022 & 612285 & 7.0044 & 7.1847 & TRN \\
\hline CHEMBL589519 & 612285 & 8.8239 & 8.7233 & TRN \\
\hline
\end{tabular}




\begin{tabular}{|c|c|c|c|c|c|}
\hline \multirow[b]{2}{*}{ CHEMBL569097 } & \multicolumn{5}{|c|}{ plemental } \\
\hline & 612285 & 9.0 & 7.8935 & TST & \\
\hline CHEMBL579289 & 612285 & 8.4949 & 8.5851 & TRN & \\
\hline CHEMBL589518 & 612285 & 8.3979 & 8.7588 & TRN & \\
\hline CHEMBL597980 & 612285 & 7.0605 & 6.96700 & 00000000005 & TST \\
\hline CHEMBL598167 & 612285 & 4.4202 & 4.2646 & TRN & \\
\hline CHEMBL592882 & 612285 & 7.5528 & 7.8632 & TRN & \\
\hline CHEMBL564552 & 612285 & 7.3665 & 6.5329 & TST & \\
\hline CHEMBL598612 & 612285 & 7.0269 & 5.2985 & TST & \\
\hline CHEMBL592407 & 612285 & 8.0362 & 8.4535 & TRN & \\
\hline CHEMBL597765 & 612285 & 7.2076 & 7.0992 & TRN & \\
\hline CHEMBL597766 & 612285 & 4.4449 & 4.9301 & TRN & \\
\hline CHEMBL604288 & 612285 & 8.6198 & 8.0592 & TRN & \\
\hline CHEMBL591048 & 612285 & 8.6778 & 8.1329 & TST & \\
\hline CHEMBL592535 & 612285 & 7.9586 & 8.3254 & TRN & \\
\hline CHEMBL599006 & 612285 & 5.8447 & 5.3046 & TRN & \\
\hline CHEMBL597380 & 612285 & 6.8794 & 7.2086 & TRN & \\
\hline CHEMBL592883 & 612285 & 8.7447 & 8.3599 & TST & \\
\hline CHEMBL599991 & 612285 & 4.4449 & 5.024 & TRN & \\
\hline CHEMBL 600370 & 612285 & 8.0 & 7.9825 & TRN & \\
\hline CHEMBL591226 & 612285 & 7.6576 & 8.1988 & TST & \\
\hline CHEMBL592163 & 612285 & 8.3098 & 8.0173 & TRN & \\
\hline CHEMBL598387 & 612285 & 7.9208 & 7.8549 & TRN & \\
\hline CHEMBL591691 & 612285 & 7.0506 & 7.5993 & TRN & \\
\hline CHEMBL590747 & 612285 & 8.3372 & 7.7822 & TST & \\
\hline CHEMBL560882 & 612285 & 7.0177 & 6.8845 & TRN & \\
\hline CHEMBL597772 & 612285 & 8.2441 & 7.9921 & TRN & \\
\hline CHEMBL564150 & 612285 & 7.8539 & 6.5329 & TST & \\
\hline CHEMBL597976 & 612285 & 4.4449 & 4.6058 & TRN & \\
\hline CHEMBL600577 & 612285 & 8.1308 & 8.2726 & TRN & \\
\hline CHEMBL592570 & 612285 & 8.3468 & 8.1739 & TRN & \\
\hline CHEMBL590939 & 612285 & 8.1549 & 8.3118 & TRN & \\
\hline CHEMBL598386 & 612285 & 7.3468 & 6.6323 & TST & \\
\hline CHEMBL591593 & 612285 & 7.7447 & 7.6119 & TRN & \\
\hline CHEMBL597150 & 612285 & 8.4202 & 8.0091 & TST & \\
\hline CHEMBL591991 & 612285 & 7.9586 & 8.3855 & TRN & \\
\hline CHEMBL589584 & 612285 & 8.4949 & 8.4293 & TRN & \\
\hline CHEMBL605964 & 612285 & 5.4389 & 6.3623 & TST & \\
\hline CHEMBL589554 & 612285 & 8.6198 & 8.3432 & TRN & \\
\hline CHEMBL589737 & 612285 & 7.9586 & 8.1951 & TRN & \\
\hline CHEMBL552973 & 612285 & 7.7447 & 7.4278 & TRN & \\
\hline CHEMBL599422 & 612285 & 6.9508 & 7.1514 & TRN & \\
\hline CHEMBL591874 & 612285 & 7.6021 & 7.9171 & TRN & \\
\hline CHEMBL598816 & 612285 & 6.5528 & 5.2602 & TST & \\
\hline CHEMBL589281 & 612285 & 8.3468 & 8.5196 & TRN & \\
\hline CHEMBL591227 & 612285 & 8.4815 & 7.9748 & TST & \\
\hline CHEMBL590771 & 612285 & 8.0809 & 7.8857 & TST & \\
\hline CHEMBL577454 & 612285 & 8.0269 & 7.96299 & 9999999999 & TRN \\
\hline CHEMBL555342 & 612285 & 7.7447 & 7.8268 & TRN & \\
\hline & & & & 14002 & \\
\hline
\end{tabular}




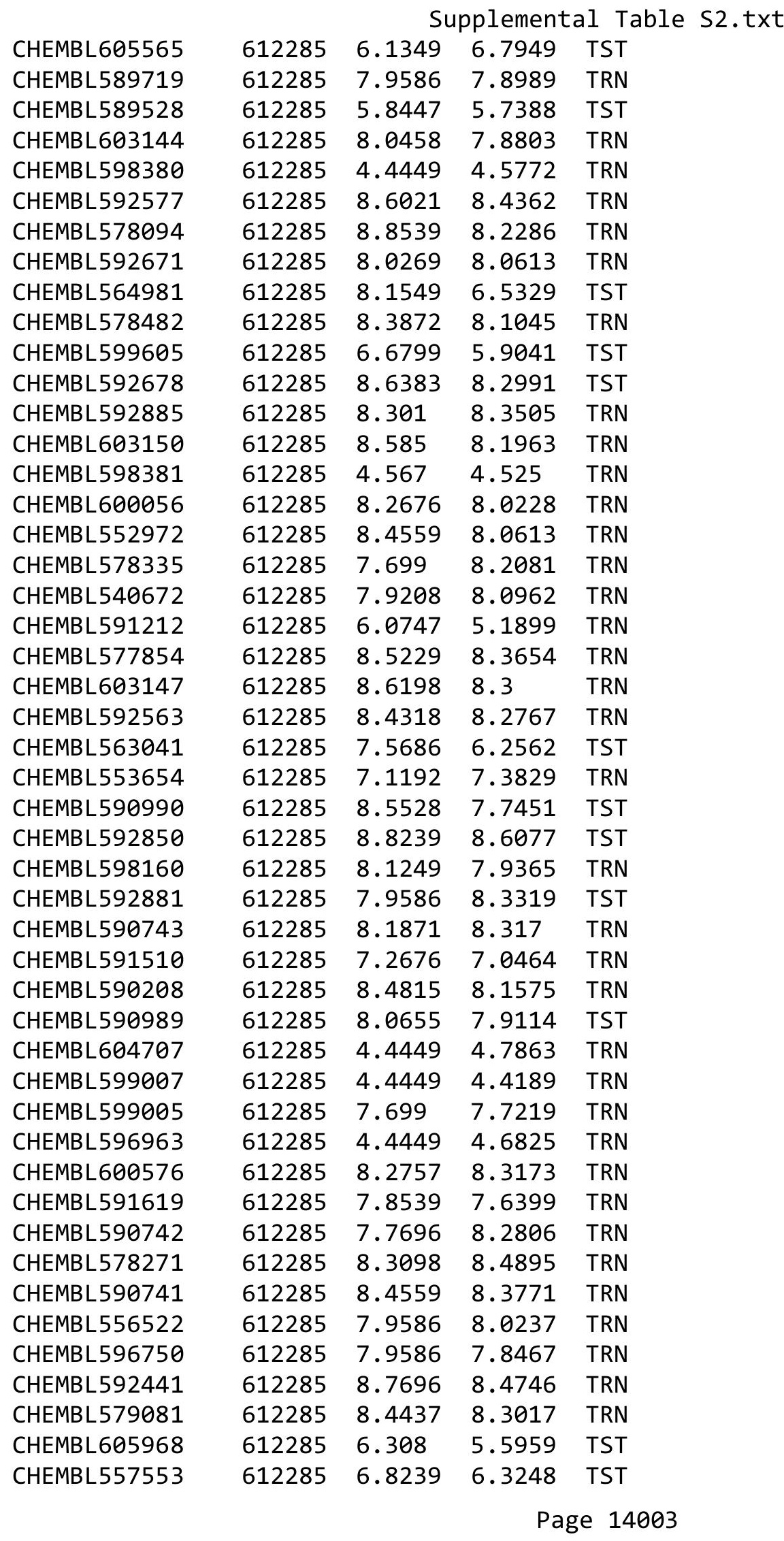




\begin{tabular}{|c|c|c|c|c|c|}
\hline & & & & & \\
\hline CHEMBL599634 & 612285 & 8.2218 & 8.4403 & TRN & \\
\hline CHEMBL600575 & 612285 & 8.8861 & 8.2535 & TRN & \\
\hline CHEMBL579094 & 612285 & 8.2366 & 8.4443 & TRN & \\
\hline CHEMBL592806 & 612285 & 8.4318 & 8.3634 & TRN & \\
\hline CHEMBL551217 & 612285 & 6.4841 & 7.2137 & TRN & \\
\hline CHEMBL592410 & 612285 & 8.7696 & 8.3988 & TST & \\
\hline CHEMBL590749 & 612285 & 8.7696 & 8.5091 & TRN & \\
\hline CHEMBL596769 & 612285 & 7.3768 & 7.69600 & 0000000001 & TRN \\
\hline CHEMBL591945 & 612285 & 7.3468 & 8.5713 & TST & \\
\hline CHEMBL590856 & 612285 & 8.0757 & 7.8648 & TST & \\
\hline CHEMBL600574 & 612285 & 8.1192 & 8.3203 & TRN & \\
\hline CHEMBL579330 & 612285 & 8.6198 & 8.6128 & TRN & \\
\hline CHEMBL592166 & 612285 & 8.3279 & 8.9383 & TST & \\
\hline CHEMBL600057 & 612285 & 8.2366 & 8.2677 & TRN & \\
\hline CHEMBL562485 & 612285 & 6.8041 & 7.05 & TRN & \\
\hline CHEMBL577630 & 612285 & 7.9586 & 8.4369 & TRN & \\
\hline CHEMBL606408 & 612285 & 7.4089 & 7.2952 & TRN & \\
\hline CHEMBL592650 & 612285 & 8.0 & 8.1214 & TRN & \\
\hline CHEMBL598821 & 612285 & 6.5575 & 6.391 & TRN & \\
\hline CHEMBL601704 & 612285 & 8.3979 & 7.2104 & TST & \\
\hline CHEMBL592581 & 612285 & 8.4318 & 8.2921 & TST & \\
\hline CHEMBL597158 & 612285 & 5.5086 & 5.1164 & TRN & \\
\hline CHEMBL592884 & 612285 & 8.6778 & 8.5445 & TRN & \\
\hline CHEMBL588492 & 612285 & 8.2757 & 8.1532 & TRN & \\
\hline CHEMBL561007 & 612285 & 7.1675 & 7.2906 & TRN & \\
\hline CHEMBL592531 & 612285 & 8.2291 & 7.9082 & TRN & \\
\hline CHEMBL600573 & 612285 & 8.585 & 8.1173 & TRN & \\
\hline CHEMBL590418 & 612285 & 8.5686 & 8.3714 & TRN & \\
\hline CHEMBL591427 & 612285 & 8.1135 & 8.3847 & TRN & \\
\hline CHEMBL589290 & 612285 & 7.1938 & 7.9951 & TRN & \\
\hline CHEMBL596939 & 612285 & 7.1612 & 7.0499 & TRN & \\
\hline CHEMBL589198 & 612285 & 7.6576 & 7.8361 & TRN & \\
\hline CHEMBL590950 & 612285 & 8.8861 & 8.59100 & 0000000001 & TRN \\
\hline CHEMBL557535 & 612285 & 7.4559 & 7.6855 & TRN & \\
\hline CHEMBL590874 & 612285 & 7.9208 & 8.5529 & TST & \\
\hline CHEMBL591536 & 612285 & 6.0747 & 5.8392 & TRN & \\
\hline CHEMBL603333 & 612285 & 7.2596 & 7.1128 & TRN & \\
\hline CHEMBL559259 & 612285 & 6.9318 & 7.2217 & TRN & \\
\hline CHEMBL590744 & 612285 & 8.585 & 7.807 & TRN & \\
\hline CHEMBL605563 & 612285 & 4.4202 & 4.3735 & TRN & \\
\hline CHEMBL599400 & 612285 & 7.4815 & 5.80200 & 00000000005 & TST \\
\hline CHEMBL592408 & 612285 & 7.3665 & 8.4549 & TRN & \\
\hline CHEMBL600371 & 612285 & 8.3468 & 7.9265 & TRN & \\
\hline CHEMBL590328 & 612285 & 8.2596 & 7.83200 & 0000000001 & TRN \\
\hline CHEMBL605773 & 612285 & 4.2441 & 6.1218 & TST & \\
\hline CHEMBL590745 & 612285 & 7.6576 & 8.17 & TRN & \\
\hline CHEMBL599816 & 612285 & 6.3152 & 6.3808 & TST & \\
\hline CHEMBL592409 & 612285 & 7.9586 & 8.5496 & TRN & \\
\hline
\end{tabular}




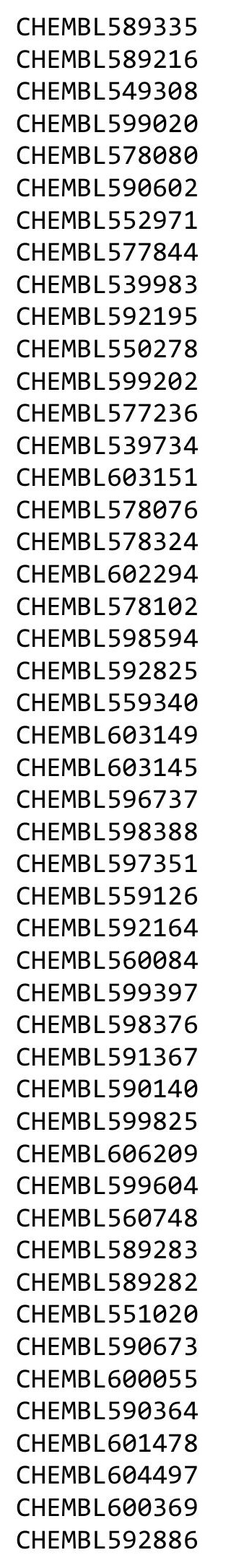

Supplemental Table S2.txt

\begin{tabular}{|c|c|c|c|c|}
\hline & & & & \\
\hline 612285 & 8.7212 & 8.3691 & TRN & \\
\hline 612285 & 7.9208 & 8.0577 & TRN & \\
\hline 612285 & 5.6126 & 5.0462 & TST & \\
\hline 612285 & 6.2125 & 6.8065 & TRN & \\
\hline 612285 & 8.5686 & 8.2956 & TRN & \\
\hline 612285 & 8.0655 & 8.1806 & TRN & \\
\hline 612285 & 8.0044 & 7.7525 & TRN & \\
\hline 612285 & 8.6021 & 8.4064 & TRN & \\
\hline 612285 & 7.4815 & 7.8842 & TRN & \\
\hline 612285 & 8.3188 & 8.3798 & TRN & \\
\hline 612285 & 7.8539 & 7.7004 & TRN & \\
\hline 612285 & 5.7932 & 5.742006 & 0000000001 & TST \\
\hline 612285 & 8.6383 & 8.5871 & TRN & \\
\hline 612285 & 7.8239 & 8.4178 & TRN & \\
\hline 612285 & 7.9586 & 8.2281 & TST & \\
\hline 612285 & 8.0 & 8.3357 & TRN & \\
\hline 612285 & 8.2218 & 8.5128 & TRN & \\
\hline 612285 & 7.7447 & 7.6734 & TRN & \\
\hline 612285 & 7.9208 & 7.8786 & TRN & \\
\hline 612285 & 7.3468 & 6.824 & TST & \\
\hline 612285 & 8.699 & 8.5036 & TRN & \\
\hline 612285 & 7.3098 & 7.7269 & TRN & \\
\hline 612285 & 8.2147 & 8.3712 & TRN & \\
\hline 612285 & 8.0 & 8.0111 & TRN & \\
\hline 612285 & 4.2676 & 5.8475 & TST & \\
\hline 612285 & 5.8827 & 6.0334 & TST & \\
\hline 612285 & 4.2457 & 4.4797 & TRN & \\
\hline 612285 & 7.1938 & 7.2338 & TRN & \\
\hline 612285 & 8.0706 & 8.1272 & TRN & \\
\hline 612285 & 4.2441 & 5.4159 & TST & \\
\hline 612285 & 8.0555 & 8.0705 & TRN & \\
\hline 612285 & 7.5528 & 5.7649 & TST & \\
\hline 612285 & 8.0757 & 7.9766 & TRN & \\
\hline 612285 & 8.6778 & 7.1486 & TST & \\
\hline 612285 & 7.5086 & 7.9193 & TRN & \\
\hline 612285 & 6.9208 & 7.064 & TRN & \\
\hline 612285 & 4.2441 & 6.6272 & TST & \\
\hline 612285 & 7.5086 & 7.7242 & TRN & \\
\hline 612285 & 8.4089 & 8.6203 & TRN & \\
\hline 612285 & 8.2596 & 8.4803 & TRN & \\
\hline 612285 & 8.0 & 7.6462 & TRN & \\
\hline 612285 & 8.301 & 7.9087 & TRN & \\
\hline 612285 & 8.4949 & 8.3348 & TRN & \\
\hline 612285 & 8.4815 & 8.0374 & TRN & \\
\hline 612285 & 8.8239 & 8.7211 & TRN & \\
\hline 612285 & 8.0969 & 8.1136 & TRN & \\
\hline 612285 & 8.2757 & 8.1015 & TRN & \\
\hline 612285 & 8.0044 & 7.8733 & TRN & \\
\hline & & Pag & 14005 & \\
\hline
\end{tabular}




\begin{tabular}{|c|c|c|c|c|c|}
\hline & & & & & \\
\hline CHEMBL578714 & 612285 & 8.1192 & 8.1754 & TRN & \\
\hline CHEMBL605847 & 612285 & 6.5406 & 6.2365 & TRN & \\
\hline CHEMBL561484 & 612285 & 6.8539 & 6.9664 & TRN & \\
\hline CHEMBL562405 & 612285 & 7.699 & 7.8493 & TRN & \\
\hline CHEMBL577433 & 612285 & 8.2076 & 8.1968 & TRN & \\
\hline CHEMBL589817 & 612285 & 7.8239 & 8.0569 & TRN & \\
\hline CHEMBL592887 & 612285 & 7.7212 & 7.7703 & TRN & \\
\hline CHEMBL560009 & 612285 & 7.9586 & 6.7827 & TST & \\
\hline CHEMBL603866 & 612285 & 7.8239 & 6.9488 & TRN & \\
\hline CHEMBL598588 & 612285 & 7.3768 & 5.3939 & TST & \\
\hline CHEMBL599843 & 612285 & 8.0458 & 7.4274 & TRN & \\
\hline CHEMBL596962 & 612285 & 5.7258 & 5.1366 & TRN & \\
\hline CHEMBL592802 & 612285 & 8.3768 & 8.3446 & TRN & \\
\hline CHEMBL562344 & 612285 & 7.1675 & 7.1198 & TRN & \\
\hline CHEMBL592165 & 612285 & 8.2441 & 8.3247 & TST & \\
\hline CHEMBL592888 & 612285 & 8.2757 & 8.6398 & TRN & \\
\hline CHEMBL601692 & 612285 & 8.9586 & 8.6638 & TRN & \\
\hline CHEMBL592737 & 612285 & 8.1612 & 8.2919 & TRN & \\
\hline CHEMBL577653 & 612285 & 8.041 & 8.0165 & TST & \\
\hline CHEMBL551620 & 612285 & 7.4559 & 7.3749 & TRN & \\
\hline CHEMBL600191 & 612285 & 4.4449 & 5.0868 & TRN & \\
\hline CHEMBL603148 & 612285 & 8.1024 & 8.2021 & TRN & \\
\hline CHEMBL603146 & 612285 & 7.8861 & 8.1572 & TRN & \\
\hline CHEMBL556330 & 612285 & 7.7447 & 8.3126 & TRN & \\
\hline CHEMBL586227 & 612285 & 8.2366 & 8.2469 & TRN & \\
\hline CHEMBL598374 & 612285 & 7.3279 & 5.183 & TST & \\
\hline CHEMBL597157 & 612285 & 4.4449 & 4.6111 & TRN & \\
\hline CHEMBL596733 & 612285 & 7.1024 & 5.7285 & TST & \\
\hline CHEMBL599637 & 612285 & 8.1612 & 7.96700 & 00000000005 & TRN \\
\hline CHEMBL1602084 & 1301436 & 4.4279 & 4.5489 & TRN & \\
\hline CHEMBL 2135758 & 1301436 & 3.284 & 4.0396 & TST & \\
\hline CHEMBL 2004445 & 1301436 & 4.4334 & 4.4667 & TST & \\
\hline CHEMBL1542378 & 1301436 & 4.4779 & 4.2537 & TRN & \\
\hline CHEMBL 2359853 & 1301436 & 4.5056 & 4.0543 & TST & \\
\hline CHEMBL1304031 & 1301436 & 4.4358 & 3.6685 & TRN & \\
\hline CHEMBL2136235 & 1301436 & 4.673 & 4.59699 & 99999999995 & TRN \\
\hline CHEMBL1419031 & 1301436 & 5.2899 & 4.4081 & TRN & \\
\hline CHEMBL429335 & 1301436 & 3.284 & 4.0779 & TRN & \\
\hline CHEMBL1439384 & 1301436 & 5.15 & 5.1353 & TRN & \\
\hline CHEMBL1528067 & 1301436 & 4.3407 & 3.58399 & 99999999996 & TRN \\
\hline CHEMBL509617 & 1301436 & 6.0246 & 5.841 & TST & \\
\hline CHEMBL1382215 & 1301436 & 3.284 & 5.113 & TRN & \\
\hline CHEMBL1505604 & 1301436 & 5.6799 & 5.2603 & TRN & \\
\hline CHEMBL 2357765 & 1301436 & 4.5596 & 4.3546 & TRN & \\
\hline CHEMBL1415374 & 1301436 & 3.284 & 3.852 & TRN & \\
\hline CHEMBL 3184385 & 1301436 & 4.5646 & 4.0933 & TST & \\
\hline CHEMBL1487964 & 1301436 & 4.3803 & 3.6036 & TRN & \\
\hline CHEMBL1391158 & 1301436 & 4.3828 & 3.8442 & TRN & \\
\hline
\end{tabular}


Supplemental Table S2.txt

\begin{tabular}{|c|c|c|c|c|c|}
\hline CHEMBL1493204 & 1301436 & 3.284 & 3.9351 & TRN & \\
\hline CHEMBL1415412 & 1301436 & 5.1518 & 5.2358 & TRN & \\
\hline CHEMBL3182996 & 1301436 & 3.284 & 3.9953 & TRN & \\
\hline CHEMBL 2362612 & 1301436 & 4.9101 & 4.4965 & TRN & \\
\hline CHEMBL1548433 & 1301436 & 5.2366 & 4.3788 & TRN & \\
\hline CHEMBL1408542 & 1301436 & 3.284 & 3.8263 & TRN & \\
\hline CHEMBL1975935 & 1301436 & 4.6603 & 4.4875 & TST & \\
\hline CHEMBL1302164 & 1301436 & 4.6919 & 3.9936 & TRN & \\
\hline CHEMBL 1444050 & 1301436 & 3.284 & 3.7278 & TRN & \\
\hline CHEMBL1556786 & 1301436 & 3.284 & 3.7058 & TRN & \\
\hline CHEMBL1404788 & 1301436 & 4.3741 & 3.7756 & TRN & \\
\hline CHEMBL1901846 & 1301436 & 3.284 & 3.6326 & TRN & \\
\hline CHEMBL1328504 & 1301436 & 5.0353 & 4.8244 & TRN & \\
\hline CHEMBL1458112 & 1301436 & 3.284 & 3.6723 & TRN & \\
\hline CHEMBL 2139358 & 1301436 & 3.284 & 4.2474 & TRN & \\
\hline CHEMBL1878940 & 1301436 & 5.1261 & 4.8963 & TST & \\
\hline CHEMBL1369200 & 1301436 & 4.9516 & 4.8361 & TRN & \\
\hline CHEMBL3183439 & 1301436 & 3.3279 & 4.4868 & TRN & \\
\hline CHEMBL3187793 & 1301436 & 4.5784 & 4.7094 & TRN & \\
\hline CHEMBL1342393 & 1301436 & 4.4159 & 4.3715 & TRN & \\
\hline CHEMBL3185075 & 1301436 & 4.4536 & 3.7683 & TRN & \\
\hline CHEMBL1871360 & 1301436 & 4.3797 & 3.9529 & TST & \\
\hline CHEMBL1459468 & 1301436 & 5.2034 & 5.5311 & TRN & \\
\hline CHEMBL1256656 & 1301436 & 5.0926 & 4.5479 & TRN & \\
\hline CHEMBL1406361 & 1301436 & 3.284 & 3.1791 & TRN & \\
\hline CHEMBL1895744 & 1301436 & 3.284 & 4.8118 & TRN & \\
\hline CHEMBL1573883 & 1301436 & 4.3043 & 3.7239 & TRN & \\
\hline CHEMBL1610597 & 1301436 & 4.5567 & 3.6819 & TST & \\
\hline CHEMBL 2358899 & 1301436 & 6.0 & \multicolumn{2}{|c|}{5.202000000000001} & TRN \\
\hline CHEMBL1345558 & 1301436 & 4.8582 & 4.5897 & TRN & \\
\hline CHEMBL1450386 & 1301436 & 4.2917 & 3.8341 & TRN & \\
\hline CHEMBL1309228 & 1301436 & 5.059 & 4.7359 & TRN & \\
\hline CHEMBL1479296 & 1301436 & 3.284 & 4.079 & TRN & \\
\hline CHEMBL1523206 & 1301436 & 4.9527 & 4.9614 & TST & \\
\hline CHEMBL1363219 & 1301436 & 6.0177 & 5.4219 & TRN & \\
\hline CHEMBL1570216 & 1301436 & 3.284 & 3.0525 & TRN & \\
\hline CHEMBL1374367 & 1301436 & 3.284 & 4.3273 & TST & \\
\hline CHEMBL1506503 & 1301436 & 3.284 & 3.6494 & TRN & \\
\hline CHEMBL1301042 & 1301436 & 3.284 & 3.799 & TRN & \\
\hline CHEMBL1351908 & 1301436 & 3.284 & 4.3394 & TRN & \\
\hline CHEMBL1486109 & 1301436 & 5.4318 & 5.2347 & TRN & \\
\hline CHEMBL1718952 & 1301436 & 5.3809 & 5.2525 & TST & \\
\hline CHEMBL1502487 & 1301436 & 3.284 & 3.7514 & TRN & \\
\hline CHEMBL3188022 & 1301436 & 4.6436 & 4.7321 & TST & \\
\hline CHEMBL 1387720 & 1301436 & 4.4639 & 4.3156 & TRN & \\
\hline CHEMBL 3183714 & 1301436 & 3.284 & 4.6086 & TRN & \\
\hline CHEMBL1577174 & 1301436 & 4.4167 & 4.3671 & TRN & \\
\hline CHEMBL1326540 & 1301436 & 3.284 & 4.1185 & TST & \\
\hline
\end{tabular}


Supplemental Table S2.txt

\begin{tabular}{|c|c|c|c|c|}
\hline CHEMBL1384167 & 1301436 & 5.7825 & 5.1964 & TRN \\
\hline CHEMBL1463659 & 1301436 & 5.6162 & 5.0591 & TRN \\
\hline CHEMBL1334090 & 1301436 & 3.284 & 3.7305 & TRN \\
\hline CHEMBL1392611 & 1301436 & 4.5965 & 4.0755 & TRN \\
\hline CHEMBL1904760 & 1301436 & 4.7815 & 4.7674 & TRN \\
\hline CHEMBL1453108 & 1301436 & 4.8877 & 4.8955 & TST \\
\hline CHEMBL3186317 & 1301436 & 5.3363 & 4.7467 & TST \\
\hline CHEMBL1329726 & 1301436 & 4.5799 & 4.05399 & 99999999999 \\
\hline CHEMBL3187852 & 1301436 & 4.9473 & 4.7845 & TRN \\
\hline CHEMBL1376674 & 1301436 & 3.284 & 3.3721 & TRN \\
\hline CHEMBL1489344 & 1301436 & 4.6592 & 3.7606 & TRN \\
\hline CHEMBL1991779 & 1301436 & 5.6055 & 5.2839 & TRN \\
\hline CHEMBL1995376 & 1301436 & 5.5421 & 4.6673 & TRN \\
\hline CHEMBL1573994 & 1301436 & 5.4389 & 4.7571 & TRN \\
\hline CHEMBL1545203 & 1301436 & 3.284 & 3.9591 & TRN \\
\hline CHEMBL1553183 & 1301436 & 5.0985 & 5.1703 & TRN \\
\hline CHEMBL1595632 & 1301436 & 5.2899 & 5.1938 & TRN \\
\hline CHEMBL1405344 & 1301436 & 4.5317 & 4.6079 & TRN \\
\hline CHEMBL1340855 & 1301436 & 3.284 & 3.3881 & TRN \\
\hline CHEMBL1612044 & 1301436 & 5.065 & 5.54299 & 9999999999 \\
\hline CHEMBL512749 & 1301436 & 4.7122 & 4.9803 & TRN \\
\hline CHEMBL1548672 & 1301436 & 3.284 & 3.3254 & TRN \\
\hline CHEMBL1435056 & 1301436 & 3.284 & 3.4199 & TST \\
\hline CHEMBL1323174 & 1301436 & 4.3451 & 3.5476 & TRN \\
\hline CHEMBL1486102 & 1301436 & 4.3653 & 3.903 & TRN \\
\hline CHEMBL1484208 & 1301436 & 5.1146 & 5.0923 & TRN \\
\hline CHEMBL3185012 & 1301436 & 4.9698 & 5.0127 & TRN \\
\hline CHEMBL 2355370 & 1301436 & 3.284 & 3.9975 & TRN \\
\hline CHEMBL3183907 & 1301436 & 4.572 & 4.172 & TST \\
\hline CHEMBL1609784 & 1301436 & 4.5717 & 4.2425 & TRN \\
\hline CHEMBL1525789 & 1301436 & 4.5945 & 3.4494 & TRN \\
\hline CHEMBL1454738 & 1301436 & 4.6282 & 4.6867 & TRN \\
\hline CHEMBL1486726 & 1301436 & 4.3146 & 4.1571 & TRN \\
\hline CHEMBL1299714 & 1301436 & 3.284 & 3.4029 & TRN \\
\hline CHEMBL1720155 & 1301436 & 4.2987 & 4.2466 & TRN \\
\hline CHEMBL591598 & 1301436 & 5.6271 & 4.5835 & TRN \\
\hline CHEMBL1299526 & 1301436 & 5.041 & 4.9706 & TRN \\
\hline CHEMBL1386689 & 1301436 & 3.284 & 3.4854 & TRN \\
\hline CHEMBL1337227 & 1301436 & 4.7867 & 4.9216 & TRN \\
\hline CHEMBL1511219 & 1301436 & 4.8392 & 5.4028 & TRN \\
\hline CHEMBL3185370 & 1301436 & 4.9622 & 4.9483 & TRN \\
\hline CHEMBL1412573 & 1301436 & 4.7959 & 4.0513 & TRN \\
\hline CHEMBL191015 & 1301436 & 3.284 & 3.6349 & TRN \\
\hline CHEMBL1595582 & 1301436 & 3.284 & 4.2091 & TRN \\
\hline CHEMBL1513654 & 1301436 & 5.0942 & 4.834 & TST \\
\hline CHEMBL1385573 & 1301436 & 3.284 & 3.975 & TRN \\
\hline CHEMBL1718787 & 1301436 & 3.284 & 5.0294 & TRN \\
\hline CHEMBL1427736 & 1301436 & 3.284 & 3.7722 & TRN \\
\hline
\end{tabular}


Supplemental Table S2.txt

\begin{tabular}{|c|c|c|c|c|c|}
\hline CHEMBL1582244 & 1301436 & 6.1175 & 4.3419 & TRN & \\
\hline CHEMBL1329974 & 1301436 & 4.9169 & 5.0254 & TRN & \\
\hline CHEMBL2355407 & 1301436 & 5.3391 & 5.4385 & TST & \\
\hline CHEMBL1597245 & 1301436 & 3.284 & 3.2922 & TRN & \\
\hline CHEMBL1399193 & 1301436 & 5.0846 & 4.779 & TRN & \\
\hline CHEMBL1475514 & 1301436 & 4.9626 & 5.0256 & TRN & \\
\hline CHEMBL1488020 & 1301436 & 4.6082 & 4.162 & TRN & \\
\hline CHEMBL1386609 & 1301436 & 4.3637 & 3.5191 & TST & \\
\hline CHEMBL1521269 & 1301436 & 4.5183 & 4.3886 & TRN & \\
\hline CHEMBL1313954 & 1301436 & 3.284 & 3.6779 & TRN & \\
\hline CHEMBL1567944 & 1301436 & 7.0182 & 6.9763 & TST & \\
\hline CHEMBL1422160 & 1301436 & 3.284 & 4.0343 & TRN & \\
\hline CHEMBL1440303 & 1301436 & 5.0123 & 4.7065 & TRN & \\
\hline CHEMBL1455421 & 1301436 & 4.8601 & 4.6721 & TRN & \\
\hline CHEMBL1361936 & 1301436 & 3.284 & 3.2638 & TRN & \\
\hline CHEMBL 3188008 & 1301436 & 3.284 & 3.9142 & TRN & \\
\hline CHEMBL1489637 & 1301436 & 3.284 & 3.331006 & 00000000004 & TRN \\
\hline CHEMBL1558021 & 1301436 & 4.7491 & 4.73600 & 0000000001 & TRN \\
\hline CHEMBL1714393 & 1301436 & 3.284 & 3.6919 & TRN & \\
\hline CHEMBL1698291 & 1301436 & 3.284 & 4.4124 & TST & \\
\hline CHEMBL1517072 & 1301436 & 4.3082 & 3.6171 & TRN & \\
\hline CHEMBL2359997 & 1301436 & 4.7317 & 4.8533 & TST & \\
\hline CHEMBL1481616 & 1301436 & 3.284 & 3.7669 & TRN & \\
\hline CHEMBL1732332 & 1301436 & 6.3747 & 6.6839 & TST & \\
\hline CHEMBL3187781 & 1301436 & 3.284 & 4.1053 & TRN & \\
\hline CHEMBL1705423 & 1301436 & 5.0841 & 4.9608 & TST & \\
\hline CHEMBL1608301 & 1301436 & 4.4715 & 3.9348 & TRN & \\
\hline CHEMBL1869875 & 1301436 & 3.284 & 3.9683 & TRN & \\
\hline CHEMBL1539400 & 1301436 & 3.284 & 3.8557 & TRN & \\
\hline CHEMBL1604245 & 1301436 & 3.284 & 4.027 & TRN & \\
\hline CHEMBL2357966 & 1301436 & 6.0 & 5.0782 & TST & \\
\hline CHEMBL1448943 & 1301436 & 4.5935 & 4.1589 & TRN & \\
\hline CHEMBL1380459 & 1301436 & 4.7528 & 4.2827 & TRN & \\
\hline CHEMBL1561956 & 1301436 & 3.284 & 3.8208 & TRN & \\
\hline CHEMBL3187421 & 1301436 & 4.7208 & 3.9537 & TST & \\
\hline CHEMBL1517002 & 1301436 & 3.284 & 3.486 & TRN & \\
\hline CHEMBL1531502 & 1301436 & 4.6722 & 4.1656 & TRN & \\
\hline CHEMBL1474280 & 1301436 & 3.284 & 3.6417 & TRN & \\
\hline CHEMBL1444124 & 1301436 & 3.284 & 4.0695 & TRN & \\
\hline CHEMBL1387923 & 1301436 & 5.0788 & 4.8293 & TRN & \\
\hline CHEMBL1456521 & 1301436 & 4.3279 & 3.8235 & TRN & \\
\hline CHEMBL1576166 & 1301436 & 3.284 & 4.2912 & TRN & \\
\hline CHEMBL1315401 & 1301436 & 4.6611 & 4.1545 & TST & \\
\hline CHEMBL1408307 & 1301436 & 4.6849 & 4.0648 & TRN & \\
\hline CHEMBL1579071 & 1301436 & 4.4531 & 4.4284 & TRN & \\
\hline CHEMBL1545865 & 1301436 & 3.284 & 3.3894 & TRN & \\
\hline CHEMBL1602614 & 1301436 & 4.501 & 4.0011 & TRN & \\
\hline CHEMBL1392228 & 1301436 & 4.5596 & 4.7667 & TRN & \\
\hline
\end{tabular}

Page 14009 
Supplemental Table S2.txt

\begin{tabular}{|c|c|c|c|c|c|}
\hline CHEMBL 3185444 & 1301436 & 4.7324 & 4.4588 & TST & \\
\hline CHEMBL1460869 & 1301436 & 5.2 & 4.9053 & TRN & \\
\hline CHEMBL2139564 & 1301436 & 5.0996 & 5.0312 & TRN & \\
\hline CHEMBL1707441 & 1301436 & 4.8626 & 4.8092 & TST & \\
\hline CHEMBL1988859 & 1301436 & 4.5664 & 4.2513 & TRN & \\
\hline CHEMBL1594126 & 1301436 & 5.0894 & 4.7218 & TST & \\
\hline CHEMBL1878853 & 1301436 & 5.1439 & 4.9016 & TRN & \\
\hline CHEMBL1533657 & 1301436 & 4.6455 & 4.4528 & TST & \\
\hline CHEMBL1732834 & 1301436 & 5.0482 & 4.4226 & TRN & \\
\hline CHEMBL1446234 & 1301436 & 4.9 & 4.7407 & TST & \\
\hline CHEMBL1338961 & 1301436 & 3.284 & 3.7115 & TRN & \\
\hline CHEMBL1277150 & 1301436 & 4.6925 & 4.1768 & TRN & \\
\hline CHEMBL460508 & 1301436 & 3.284 & 3.7088 & TRN & \\
\hline CHEMBL1468355 & 1301436 & 4.5129 & 4.351 & TRN & \\
\hline CHEMBL2136405 & 1301436 & 4.5528 & 4.4729 & TRN & \\
\hline CHEMBL3188942 & 1301436 & 4.8153 & 4.4424 & TRN & \\
\hline CHEMBL1892565 & 1301436 & 4.3448 & 4.8119 & TRN & \\
\hline CHEMBL535307 & 1301436 & 6.2211 & 6.9548 & TST & \\
\hline CHEMBL1978643 & 1301436 & 5.3595 & 4.74 & TRN & \\
\hline CHEMBL1407659 & 1301436 & 4.4598 & 3.9901 & TRN & \\
\hline CHEMBL1500923 & 1301436 & 3.284 & 3.0579 & TRN & \\
\hline CHEMBL1537106 & 1301436 & 4.3323 & 4.9654 & TRN & \\
\hline CHEMBL 2135896 & 1301436 & 4.4076 & 4.7847 & TRN & \\
\hline CHEMBL1490336 & 1301436 & 5.2351 & 4.9771 & TRN & \\
\hline CHEMBL1500112 & 1301436 & 4.5923 & 4.25 & TRN & \\
\hline CHEMBL 2355520 & 1301436 & 4.6202 & 4.5625 & TST & \\
\hline CHEMBL1546172 & 1301436 & 5.0969 & 4.766 & TST & \\
\hline CHEMBL 2130868 & 1301436 & 4.4007 & 3.5641 & TRN & \\
\hline CHEMBL367376 & 1301436 & 6.6615 & 6.5036 & TST & \\
\hline CHEMBL261123 & 1301436 & 3.284 & 3.6373 & TRN & \\
\hline CHEMBL1607086 & 1301436 & 4.4667 & 3.3322 & TRN & \\
\hline CHEMBL1438983 & 1301436 & 5.065 & \multicolumn{2}{|c|}{4.861000000000001} & TST \\
\hline CHEMBL3186447 & 1301436 & 4.4553 & 4.0256 & TRN & \\
\hline CHEMBL1997132 & 1301436 & 4.7345 & 4.6284 & TST & \\
\hline CHEMBL1527400 & 1301436 & 5.0367 & 5.2757 & TRN & \\
\hline CHEMBL1601310 & 1301436 & 5.3737 & 4.9444 & TRN & \\
\hline CHEMBL 2359438 & 1301436 & 4.6792 & 4.519 & TRN & \\
\hline CHEMBL1303280 & 1301436 & \multicolumn{3}{|c|}{4.821000000000001} & TRN \\
\hline CHEMBL3184207 & 1301436 & 4.4599 & 5.6984 & TST & \\
\hline CHEMBL1488948 & 1301436 & 4.4707 & 3.4445 & TRN & \\
\hline CHEMBL1494214 & 1301436 & 5.2628 & 4.8665 & TRN & \\
\hline CHEMBL1531169 & 1301436 & 5.1267 & 4.8745 & TST & \\
\hline CHEMBL1542560 & 1301436 & 4.9508 & 4.7042 & TST & \\
\hline CHEMBL610198 & 1301436 & 4.8425 & 5.274 & TRN & \\
\hline CHEMBL1900256 & 1301436 & 4.5387 & 4.2471 & TRN & \\
\hline CHEMBL1355823 & 1301436 & 5.4535 & 4.8893 & TRN & \\
\hline CHEMBL2360439 & 1301436 & 4.5498 & 4.2688 & TST & \\
\hline CHEMBL 2357924 & 1301436 & 4.6692 & 5.1443 & TST & \\
\hline
\end{tabular}


Supplemental Table S2.txt

\begin{tabular}{|c|c|c|c|c|c|c|}
\hline CHEMBL1608430 & 1301436 & 4.6066 & 4.3657 & TRN & & \\
\hline CHEMBL1442242 & 1301436 & 4.4656 & 4.2511 & TST & & \\
\hline CHEMBL1877321 & 1301436 & 3.284 & 3.8504 & TRN & & \\
\hline CHEMBL1497597 & 1301436 & 5.2104 & 5.1548 & TST & & \\
\hline CHEMBL1412795 & 1301436 & 3.284 & 4.1561 & TST & & \\
\hline CHEMBL1385499 & 1301436 & 3.284 & 4.3936 & TRN & & \\
\hline CHEMBL3185154 & 1301436 & 6.0 & 4.941 & TRN & & \\
\hline CHEMBL1331514 & 1301436 & 4.9069 & 4.5882 & TRN & & \\
\hline CHEMBL3188410 & 1301436 & 3.284 & 3.6042 & TRN & & \\
\hline CHEMBL3183487 & 1301436 & 3.284 & 3.7295 & TST & & \\
\hline CHEMBL1591445 & 1301436 & 4.5465 & 4.4223 & TST & & \\
\hline CHEMBL1483193 & 1301436 & 3.284 & 4.2316 & TRN & & \\
\hline CHEMBL1440781 & 1301436 & 4.3727 & 4.2012 & TST & & \\
\hline CHEMBL1470676 & 1301436 & 3.284 & 3.2826 & TRN & & \\
\hline CHEMBL1488923 & 1301436 & 4.8289 & 5.5687 & TRN & & \\
\hline CHEMBL3181899 & 1301436 & 4.6449 & 4.7211 & TRN & & \\
\hline CHEMBL1591171 & 1301436 & 5.104 & 4.9494 & TST & & \\
\hline CHEMBL1563176 & 1301436 & 5.1618 & 4.8931 & TST & & \\
\hline CHEMBL2144728 & 1301436 & 6.1198 & 5.6009 & TST & & \\
\hline CHEMBL1438614 & 1301436 & 4.3891 & 4.82 & TST & & \\
\hline CHEMBL1710184 & 1301436 & 4.98300 & 00000000 & 205 & 4.8392 & TRN \\
\hline CHEMBL3182522 & 1301436 & 5.5735 & 5.0152 & TST & & \\
\hline CHEMBL 3185003 & 1301436 & 4.71899 & 99999999 & 99 & 4.2504 & TST \\
\hline CHEMBL1602085 & 1301436 & 3.284 & 3.2411 & TRN & & \\
\hline CHEMBL1488712 & 1301436 & 4.6328 & 4.6687 & TRN & & \\
\hline CHEMBL1505044 & 1301436 & 4.7201 & 4.7825 & TRN & & \\
\hline CHEMBL1423377 & 1301436 & 3.284 & 4.6184 & TRN & & \\
\hline CHEMBL1521051 & 1301436 & 3.284 & 3.2848 & TRN & & \\
\hline CHEMBL1586425 & 1301436 & 5.1325 & 4.7759 & TRN & & \\
\hline CHEMBL1350432 & 1301436 & 4.8791 & 4.6726 & TST & & \\
\hline CHEMBL1872338 & 1301436 & 4.3528 & 4.4946 & TRN & & \\
\hline CHEMBL405317 & 1301436 & 5.3307 & 5.3203 & TRN & & \\
\hline CHEMBL1317322 & 1301436 & 4.8176 & 4.4644 & TRN & & \\
\hline CHEMBL1448774 & 1301436 & 4.3977 & 3.3764 & TRN & & \\
\hline CHEMBL3183514 & 1301436 & 3.284 & 4.129 & TST & & \\
\hline CHEMBL1516047 & 1301436 & 3.284 & 4.1845 & TRN & & \\
\hline CHEMBL1600275 & 1301436 & 4.8969 & 4.3327 & TRN & & \\
\hline CHEMBL1352223 & 1301436 & 5.7212 & 4.9614 & TRN & & \\
\hline CHEMBL1522279 & 1301436 & 5.2027 & 3.9162 & TRN & & \\
\hline CHEMBL1466997 & 1301436 & 3.284 & 4.5562 & TRN & & \\
\hline CHEMBL2355651 & 1301436 & 5.1911 & 4.9464 & TRN & & \\
\hline CHEMBL3187767 & 1301436 & 3.3279 & 4.396 & TST & & \\
\hline CHEMBL1899585 & 1301436 & 5.567 & 4.9486 & TRN & & \\
\hline CHEMBL1421941 & 1301436 & 3.284 & 3.3484 & TRN & & \\
\hline CHEMBL1383534 & 1301436 & 4.4715 & 4.2326 & TRN & & \\
\hline CHEMBL1396351 & 1301436 & 4.9176 & 5.099 & TRN & & \\
\hline CHEMBL1520753 & 1301436 & 5.1669 & 4.8442 & TRN & & \\
\hline CHEMBL1535919 & 1301436 & 4.6558 & 4.6726 & TRN & & \\
\hline
\end{tabular}




\begin{tabular}{|c|c|c|c|c|c|}
\hline \multicolumn{6}{|c|}{ Supplemental Table S2.txt } \\
\hline CHEMBL1606999 & 1301436 & 3.284 & 3.2626 & TRN & \\
\hline CHEMBL1547229 & 1301436 & 4.4829 & 3.7719 & TRN & \\
\hline CHEMBL1421255 & 1301436 & 3.284 & 3.4293 & TRN & \\
\hline CHEMBL1613147 & 1301436 & 3.284 & 4.074 & TRN & \\
\hline CHEMBL2133510 & 1301436 & 4.4991 & 4.2606 & TRN & \\
\hline CHEMBL 3187174 & 1301436 & 3.284 & 4.3313 & TST & \\
\hline CHEMBL1712850 & 1301436 & 5.1024 & 4.971 & TRN & \\
\hline CHEMBL1352995 & 1301436 & 4.738 & 4.6191 & TRN & \\
\hline CHEMBL1898104 & 1301436 & 4.6084 & 4.5473 & TRN & \\
\hline CHEMBL1539398 & 1301436 & 3.284 & 3.7713 & TRN & \\
\hline CHEMBL1872364 & 1301436 & 3.284 & 4.7747 & TRN & \\
\hline CHEMBL1597322 & 1301436 & 3.284 & 3.4462 & TRN & \\
\hline CHEMBL1391972 & 1301436 & 3.284 & 3.3029 & TRN & \\
\hline CHEMBL1736766 & 1301436 & 6.3686 & 6.2543 & TST & \\
\hline CHEMBL1438758 & 1301436 & 3.284 & 3.9333 & TRN & \\
\hline CHEMBL1524929 & 1301436 & 5.4389 & 5.0703 & TRN & \\
\hline CHEMBL1385190 & 1301436 & 4.8807 & 4.5605 & TRN & \\
\hline CHEMBL1391313 & 1301436 & 3.284 & 3.3817 & TRN & \\
\hline CHEMBL1866397 & 1301436 & 3.284 & 4.7414 & TST & \\
\hline CHEMBL1432977 & 1301436 & 3.284 & 3.4785 & TST & \\
\hline CHEMBL1478962 & 1301436 & 3.284 & 3.4439 & TRN & \\
\hline CHEMBL1539359 & 1301436 & 4.6461 & 4.6891 & TRN & \\
\hline CHEMBL3186236 & 1301436 & 4.6513 & 4.0904 & TST & \\
\hline CHEMBL1734467 & 1301436 & 4.8586 & 4.56800 & 00000000005 & TRN \\
\hline CHEMBL1527433 & 1301436 & 4.4646 & 4.0671 & TRN & \\
\hline CHEMBL261693 & 1301436 & 4.4459 & 4.4885 & TRN & \\
\hline CHEMBL2357026 & 1301436 & 4.7747 & 4.5739 & TST & \\
\hline CHEMBL1301480 & 1301436 & 5.1337 & 4.776 & TRN & \\
\hline CHEMBL 2004141 & 1301436 & 5.6861 & 5.4553 & TRN & \\
\hline CHEMBL1880578 & 1301436 & 3.284 & 4.0428 & TRN & \\
\hline CHEMBL1507537 & 1301436 & 5.0846 & 4.9188 & TRN & \\
\hline CHEMBL1995375 & 1301436 & 3.284 & 4.2342 & TRN & \\
\hline CHEMBL1379493 & 1301436 & 4.7249 & 4.738 & TRN & \\
\hline CHEMBL1441042 & 1301436 & 4.5558 & 4.3998 & TRN & \\
\hline CHEMBL1550664 & 1301436 & 3.284 & 3.516 & TRN & \\
\hline CHEMBL1360295 & 1301436 & 4.7981 & 3.7439 & TRN & \\
\hline CHEMBL1482964 & 1301436 & 3.284 & 3.4 & TRN & \\
\hline CHEMBL1903021 & 1301436 & 4.6048 & 4.9578 & TRN & \\
\hline CHEMBL1597705 & 1301436 & 4.768 & 4.3214 & TRN & \\
\hline CHEMBL 2144685 & 1301436 & 3.284 & 4.0771 & TRN & \\
\hline CHEMBL1488730 & 1301436 & 3.284 & 3.1624 & TRN & \\
\hline CHEMBL 2142817 & 1301436 & 4.7385 & 4.5464 & TRN & \\
\hline CHEMBL267099 & 1301436 & 6.6021 & 6.1048 & TST & \\
\hline CHEMBL1336848 & 1301436 & 3.284 & 4.3457 & TRN & \\
\hline CHEMBL1489293 & 1301436 & 3.284 & 3.8664 & TRN & \\
\hline CHEMBL1409883 & 1301436 & 5.1506 & 4.8943 & TRN & \\
\hline CHEMBL1472145 & 1301436 & 4.8598 & 4.4829 & TST & \\
\hline CHEMBL1579644 & 1301436 & 5.45100 & 30000000 & 5.1141 & ומנו \\
\hline
\end{tabular}




\begin{tabular}{|c|c|c|c|c|c|}
\hline \multicolumn{6}{|c|}{ Supplemental Table S2.txt } \\
\hline CHEMBL1450748 & 1301436 & 5.6615 & 4.9754 & TRN & \\
\hline CHEMBL1309573 & 1301436 & 5.0 & 5.1567 & TRN & \\
\hline CHEMBL1325945 & 1301436 & 5.4698 & 5.0314 & TRN & \\
\hline CHEMBL1310837 & 1301436 & 3.284 & 4.4027 & TRN & \\
\hline CHEMBL1540839 & 1301436 & 4.6678 & 4.244 & TRN & \\
\hline CHEMBL1978733 & 1301436 & 5.4012 & 4.9897 & TRN & \\
\hline CHEMBL1316631 & 1301436 & 3.284 & 4.0818 & TRN & \\
\hline CHEMBL1726559 & 1301436 & 4.6126 & 4.63399 & 99999999995 & TRN \\
\hline CHEMBL1421442 & 1301436 & 5.2907 & 4.1637 & TRN & \\
\hline CHEMBL1610783 & 1301436 & 3.284 & 3.4894 & TRN & \\
\hline CHEMBL2361605 & 1301436 & 5.0292 & 4.7695 & TST & \\
\hline CHEMBL137586 & 1301436 & 3.284 & 3.5933 & TRN & \\
\hline CHEMBL1499127 & 1301436 & 4.8162 & 4.4913 & TRN & \\
\hline CHEMBL1549599 & 1301436 & 3.284 & 3.8695 & TRN & \\
\hline CHEMBL1588716 & 1301436 & 3.284 & 4.2174 & TRN & \\
\hline CHEMBL 2362144 & 1301436 & 5.2306 & 5.3396 & TST & \\
\hline CHEMBL3187031 & 1301436 & 4.4355 & 4.5831 & TST & \\
\hline CHEMBL1536196 & 1301436 & 3.284 & 3.9019 & TST & \\
\hline CHEMBL125044 & 1301436 & 4.8016 & 4.406006 & 0000000001 & TRN \\
\hline CHEMBL1456271 & 1301436 & 3.284 & 4.1927 & TRN & \\
\hline CHEMBL1896073 & 1301436 & 4.5136 & 4.82100 & 0000000001 & TRN \\
\hline CHEMBL1572001 & 1301436 & 5.5513 & 5.1546 & TST & \\
\hline CHEMBL1587117 & 1301436 & 4.5084 & 4.0938 & TRN & \\
\hline CHEMBL3184527 & 1301436 & 5.0376 & 4.9821 & TST & \\
\hline CHEMBL1308273 & 1301436 & 3.284 & 3.5979 & TST & \\
\hline CHEMBL1496788 & 1301436 & 4.7865 & 5.107 & TRN & \\
\hline CHEMBL1377992 & 1301436 & 3.284 & 4.2028 & TRN & \\
\hline CHEMBL1873775 & 1301436 & 4.533 & 3.9114 & TRN & \\
\hline CHEMBL1315904 & 1301436 & 3.284 & 3.7264 & TRN & \\
\hline CHEMBL1423927 & 1301436 & 3.284 & 3.6339 & TRN & \\
\hline CHEMBL1605021 & 1301436 & 4.3964 & 4.4237 & TST & \\
\hline CHEMBL414890 & 1301436 & 5.1494 & 5.11600 & 00000000005 & TST \\
\hline CHEMBL1375966 & 1301436 & 3.284 & 4.3726 & TRN & \\
\hline CHEMBL1543215 & 1301436 & 3.284 & 3.2402 & TRN & \\
\hline CHEMBL1597627 & 1301436 & 5.0155 & 4.9024 & TRN & \\
\hline CHEMBL1710219 & 1301436 & 4.9821 & 4.1753 & TRN & \\
\hline CHEMBL1902247 & 1301436 & 4.6505 & 4.8457 & TRN & \\
\hline CHEMBL3185466 & 1301436 & 4.9772 & 4.8487 & TST & \\
\hline CHEMBL1555066 & 1301436 & 5.1445 & 4.8193 & TRN & \\
\hline CHEMBL1483331 & 1301436 & 4.8356 & 4.7165 & TST & \\
\hline CHEMBL1352521 & 1301436 & 4.7122 & 4.6755 & TRN & \\
\hline CHEMBL1325451 & 1301436 & 4.7916 & 4.7065 & TRN & \\
\hline CHEMBL1713163 & 1301436 & 4.6275 & 4.7871 & TST & \\
\hline CHEMBL 2132815 & 1301436 & 4.8219 & 4.4157 & TST & \\
\hline CHEMBL1419938 & 1301436 & 3.284 & 4.2701 & TRN & \\
\hline CHEMBL2354532 & 1301436 & 5.1192 & 4.916 & TRN & \\
\hline CHEMBL3188311 & 1301436 & 3.284 & 4.6566 & TST & \\
\hline CHEMBL1429164 & 1301436 & 4.8047 & 4.7867 & TRN & \\
\hline
\end{tabular}


Supplemental Table S2.txt

\begin{tabular}{|c|c|c|c|c|c|}
\hline CHEMBL 2359013 & 1301436 & 4.7066 & 5.0663 & TST & \\
\hline CHEMBL1348884 & 1301436 & 3.284 & 3.0338 & TRN & \\
\hline CHEMBL1601647 & 1301436 & 3.284 & 3.6271 & TRN & \\
\hline CHEMBL1575970 & 1301436 & 3.284 & 4.19 & TRN & \\
\hline CHEMBL1579902 & 1301436 & 3.284 & 3.3108 & TRN & \\
\hline CHEMBL1540513 & 1301436 & 3.284 & 3.5142 & TRN & \\
\hline CHEMBL 2137423 & 1301436 & 4.4374 & 4.7836 & TRN & \\
\hline CHEMBL1895747 & 1301436 & 4.6249 & 4.0666 & TST & \\
\hline CHEMBL 286593 & 1301436 & 7.0841 & 4.4449 & TRN & \\
\hline CHEMBL1404547 & 1301436 & 5.061 & 4.683 & TRN & \\
\hline CHEMBL 3186645 & 1301436 & 4.8431 & 4.7302 & TST & \\
\hline CHEMBL 2133546 & 1301436 & 4.6267 & 4.4203 & TST & \\
\hline CHEMBL 2131028 & 1301436 & 4.6368 & 4.5943 & TST & \\
\hline CHEMBL1573261 & 1301436 & 4.4058 & 3.6158 & TRN & \\
\hline CHEMBL 3188935 & 1301436 & 4.9817 & 5.0426 & TST & \\
\hline CHEMBL 3183033 & 1301436 & 4.8645 & 4.2079 & TST & \\
\hline CHEMBL1213608 & 1301436 & 3.284 & 3.5952 & TRN & \\
\hline CHEMBL1494038 & 1301436 & 5.2411 & 4.5377 & TRN & \\
\hline CHEMBL 3189242 & 1301436 & 3.284 & 3.3566 & TRN & \\
\hline CHEMBL1342147 & 1301436 & 4.3883 & 4.5183 & TRN & \\
\hline CHEMBL523200 & 1301436 & 5.2104 & 4.9769 & TRN & \\
\hline CHEMBL1476017 & 1301436 & 5.1325 & 5.0914 & TRN & \\
\hline CHEMBL1974563 & 1301436 & 3.284 & 4.0391 & TST & \\
\hline CHEMBL1328462 & 1301436 & 4.8972 & 4.6006 & TRN & \\
\hline CHEMBL1611128 & 1301436 & 3.284 & 3.1171 & TRN & \\
\hline CHEMBL1451470 & 1301436 & 5.0991 & 5.0315 & TST & \\
\hline CHEMBL1559713 & 1301436 & 4.4872 & 4.2474 & TRN & \\
\hline CHEMBL 2356186 & 1301436 & 5.7055 & 5.6506 & TST & \\
\hline CHEMBL1461730 & 1301436 & 3.284 & 3.3967 & TRN & \\
\hline CHEMBL1902024 & 1301436 & 5.3516 & 4.6614 & TRN & \\
\hline CHEMBL1486546 & 1301436 & 4.5913 & 4.843 & TRN & \\
\hline CHEMBL1506926 & 1301436 & 4.5445 & 4.2064 & TRN & \\
\hline CHEMBL 1877386 & 1301436 & 5.7033 & 5.2495 & TRN & \\
\hline CHEMBL1535375 & 1301436 & 5.1007 & 4.8622 & TST & \\
\hline CHEMBL1594369 & 1301436 & 4.8687 & 4.51 & TST & \\
\hline CHEMBL1900154 & 1301436 & 4.7886 & 4.6171 & TRN & \\
\hline CHEMBL 1329650 & 1301436 & 4.48600 & 000000000 & 3.1982 & TRN \\
\hline CHEMBL1396619 & 1301436 & 4.4439 & 4.4356 & TRN & \\
\hline CHEMBL1581094 & 1301436 & 3.284 & 3.7131 & TRN & \\
\hline CHEMBL1878022 & 1301436 & 3.284 & 3.731999 & 99999999998 & TRN \\
\hline CHEMBL1360928 & 1301436 & 4.5325 & 4.4368 & TRN & \\
\hline CHEMBL 1458038 & 1301436 & 4.4864 & 4.0861 & TRN & \\
\hline CHEMBL1379390 & 1301436 & 4.3605 & 4.2348 & TRN & \\
\hline CHEMBL1373194 & 1301436 & 4.3302 & 4.3097 & TRN & \\
\hline CHEMBL1479010 & 1301436 & 5.0496 & 5.1626 & TRN & \\
\hline CHEMBL1519965 & 1301436 & 5.4295 & 5.3711 & TRN & \\
\hline CHEMBL 1427072 & 1301436 & 3.284 & 4.3441 & TRN & \\
\hline CHEMBL1893675 & 1301436 & 5.6402 & 4.5588 & TST & \\
\hline
\end{tabular}


Supplemental Table S2.txt

\begin{tabular}{|c|c|c|c|c|}
\hline 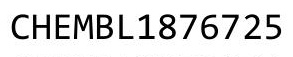 & & & & \\
\hline HEMBL2359304 & 301436 & 4.5252 & 0247 & \\
\hline HEMBL1530216 & & 4.4566 & 1496 & \\
\hline IEMBL31 & 301 & 84 & 5108 & \\
\hline IEMBL131 & 301 & 5.0721 & 1828 & \\
\hline HEMBL1995726 & 301436 & 5.2741 & .4848 & \\
\hline HEMBL1349759 & 301436 & 3.284 & 3.7792 & \\
\hline HEMBL1884029 & 301 & 3.284 & 5347 & \\
\hline IEMBL21 & 301 & 5.1215 & 0742 & \\
\hline HEMBL318 & 301 & 4.7724 & 74 & \\
\hline HEMBL3182316 & 301 & 3.6198 & 2164 & \\
\hline HEMBL1310496 & 3014 & 3.284 & 3.6762 & \\
\hline HEMBL1457060 & 301 & 3.284 & 2832 & \\
\hline HEMBL13e & 20- & 4.7124 & 43 & \\
\hline HEMBL 25 & 301 & 3.284 & 7455 & \\
\hline HEMBL171 & 301 & 5.0964 & 7234 & \\
\hline HEMBL473 & 30 & 4.3228 & 4.1876 & \\
\hline HEMBL13 & 30 & 3 & & \\
\hline HEMBL18 & & 916 & & Mrv \\
\hline HEMBL15 & 30 & 5 . & & \\
\hline HEMBL 318 & 30 & 4. & & \\
\hline HEMBL3183001 & 30 & 6.0 & 57 & ISI \\
\hline HEMBL140 & 30 & 8 & 93 & $R N$ \\
\hline HEMBL14 & & & 92 & RIV \\
\hline 353 & 30 & 3 . & & ST \\
\hline HEMBL 14 & $2 a$. & & & IST \\
\hline HEMBL 2132222 & 301 & 3.284 & 345 & SI \\
\hline HEMBL14c & 30 & 3.284 & 294 & RN \\
\hline HEMBL 14 & $30 \div-2+2$ & 3. & & ST \\
\hline HEMBL15 & 30 & 4 . & 72 & $\mathrm{RN}$ \\
\hline HEMBL 213 & 30 & & & IST \\
\hline HEMBL1468055 & 301 & 4.5948 & 3276 & ГRN \\
\hline HEMBL154 & 30 & 3.284 & 106 & RN \\
\hline 9 & $3 a$. & & & RN \\
\hline HEMBL 600 & 20 & 4. & & RN \\
\hline HEMBL93109 & 301 & 4.2958 & & 「RN \\
\hline HEMBL1317312 & 301 & 3.284 & 536 & RN \\
\hline HEMBL490 & 301 & 3. & 98 & RN \\
\hline 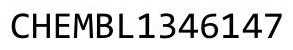 & 20 & 6. & & $\mathrm{RN}$ \\
\hline HEMBL1425919 & 1301 & 3.284 & & RN \\
\hline HEMBL1492399 & 301 & 3. & 382 & RN \\
\hline HEMBL59 & 301 & 4. & 85 & RN \\
\hline HEMBL 145 & 1301 & $5.379 \mathrm{~s}$ & & \\
\hline CHEMBL1544685 & & & & RN \\
\hline HEMBL1390421 & 1301 & 3.284 & 4625 & RN \\
\hline HEMBL1866836 & 1301 & 3.284 & 1797 & RN \\
\hline$\llcorner 14$ & 301 & & & \\
\hline 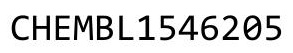 & & & & \\
\hline
\end{tabular}

Page 14015 
Supplemental Table S2.txt

\begin{tabular}{|c|c|c|c|c|c|c|}
\hline CHEMBL1590615 & 1301436 & 4.3886 & 4.3033 & TST & & \\
\hline CHEMBL3181918 & 1301436 & 3.284 & 4.4033 & TST & & \\
\hline CHEMBL3186502 & 1301436 & 3.284 & 4.0538 & TST & & \\
\hline CHEMBL1610429 & 1301436 & 3.284 & 3.4866 & TRN & & \\
\hline CHEMBL1553265 & 1301436 & 3.284 & 3.2323 & TRN & & \\
\hline CHEMBL530609 & 1301436 & 4.8894 & 4.8438 & TRN & & \\
\hline CHEMBL1896333 & 1301436 & 3.284 & 4.6438 & TRN & & \\
\hline CHEMBL1595274 & 1301436 & 3.284 & 3.1439 & TRN & & \\
\hline CHEMBL1462900 & 1301436 & 6.0762 & 5.2998 & TRN & & \\
\hline CHEMBL1891068 & 1301436 & 4.7698 & 4.7107 & TST & & \\
\hline CHEMBL 2362844 & 1301436 & 4.5667 & 4.4238 & TST & & \\
\hline CHEMBL 2131237 & 1301436 & 3.284 & 4.4595 & TRN & & \\
\hline CHEMBL1436748 & 1301436 & 4.7397 & 4.6088 & TST & & \\
\hline CHEMBL3183027 & 1301436 & 4.7089 & 5.3201 & TST & & \\
\hline CHEMBL1418175 & 1301436 & 4.9527 & 4.7945 & TRN & & \\
\hline CHEMBL1305566 & 1301436 & 3.284 & 3.2866 & TRN & & \\
\hline CHEMBL1589837 & 1301436 & 4.7089 & 4.3681 & TRN & & \\
\hline CHEMBL595825 & 1301436 & 4.5597 & 3.4945 & TRN & & \\
\hline CHEMBL607553 & 1301436 & 5.061 & 5.0915 & TRN & & \\
\hline CHEMBL1484410 & 1301436 & 4.3722 & 4.3241 & TST & & \\
\hline CHEMBL1733824 & 1301436 & 4.3368 & 4.3493 & TST & & \\
\hline CHEMBL1363706 & 1301436 & 4.8242 & 4.418 & TRN & & \\
\hline CHEMBL486569 & 1301436 & 4.5308 & 4.4767 & TRN & & \\
\hline CHEMBL 3188477 & 1301436 & 3.284 & 4.1772 & TST & & \\
\hline CHEMBL1585064 & 1301436 & 4.3788 & 3.4549 & TRN & & \\
\hline CHEMBL1378392 & 1301436 & 4.755 & 4.8049 & TRN & & \\
\hline CHEMBL3186350 & 1301436 & 4.4786 & 4.4871 & TST & & \\
\hline CHEMBL1463529 & 1301436 & \multicolumn{3}{|c|}{4.638999999999999} & 4.8632 & TRN \\
\hline CHEMBL 3189080 & 1301436 & 4.7662 & 4.3806 & TST & & \\
\hline CHEMBL 252403 & 1301436 & 4.3867 & 4.2606 & TRN & & \\
\hline CHEMBL1481849 & 1301436 & 5.4134 & 5.2039 & TST & & \\
\hline CHEMBL1467999 & 1301436 & 4.3225 & 4.2745 & TRN & & \\
\hline CHEMBL 2148124 & 1301436 & 5.4921 & 4.9578 & TRN & & \\
\hline CHEMBL1981570 & 1301436 & 5.5686 & 5.1897 & TRN & & \\
\hline CHEMBL1488371 & 1301436 & 5.2306 & 5.0045 & TRN & & \\
\hline CHEMBL1409423 & 1301436 & \multicolumn{3}{|c|}{4.486000000000001} & 4.5043 & TST \\
\hline CHEMBL1490041 & 1301436 & \multicolumn{3}{|c|}{5.172000000000001} & 5.1563 & TRN \\
\hline CHEMBL1868562 & 1301436 & 4.8567 & 4.6545 & TRN & & \\
\hline CHEMBL1538625 & 1301436 & 3.284 & 4.3438 & TRN & & \\
\hline CHEMBL1465893 & 1301436 & 3.284 & 4.5304 & TRN & & \\
\hline CHEMBL1864992 & 1301436 & 3.284 & 4.265 & TST & & \\
\hline CHEMBL1394527 & 1301436 & 3.284 & 3.9759 & TRN & & \\
\hline CHEMBL1430096 & 1301436 & 4.5728 & 4.5382 & TRN & & \\
\hline CHEMBL 3186824 & 1301436 & 4.4664 & 4.1976 & TST & & \\
\hline CHEMBL1366321 & 1301436 & 3.284 & 3.6282 & TRN & & \\
\hline CHEMBL1413454 & 1301436 & 3.284 & 3.7437 & TRN & & \\
\hline CHEMBL1573331 & 1301436 & 3.284 & 4.8213 & TRN & & \\
\hline CHEMBL1684504 & 727521 & 6.2757 & 6.4153 & TRN & & \\
\hline
\end{tabular}


Supplemental Table S2.txt

\begin{tabular}{|c|c|c|c|c|}
\hline CHEMBL1288582 & 727521 & 7.2218 & 7.3263 & TST \\
\hline CHEMBL1684501 & 727521 & 6.585 & 6.3181 & TRN \\
\hline CHEMBL1684655 & 727521 & 7.5229 & 7.5172 & TRN \\
\hline CHEMBL1684520 & 727521 & 6.6021 & 6.7593 & TRN \\
\hline CHEMBL1684661 & 727521 & 6.6778 & 7.2886 & TST \\
\hline CHEMBL1684677 & 727521 & 7.1549 & 7.6859 & TRN \\
\hline CHEMBL1684525 & 727521 & 7.3665 & 7.3704 & TRN \\
\hline CHEMBL1684668 & 727521 & 6.5229 & 6.7698 & TST \\
\hline CHEMBL1684679 & 727521 & 7.699 & 7.7174 & TRN \\
\hline CHEMBL1684526 & 727521 & 7.0706 & 7.3152 & TRN \\
\hline CHEMBL1684656 & 727521 & 7.5686 & 7.348 & TRN \\
\hline CHEMBL1684675 & 727521 & 7.0 & 6.8378 & TRN \\
\hline CHEMBL1684513 & 727521 & 6.4685 & 6.2909 & TRN \\
\hline CHEMBL1684497 & 727521 & 7.1739 & 6.70700 & 0000000001 \\
\hline CHEMBL1684521 & 727521 & 7.3372 & 6.74200 & 0000000001 \\
\hline CHEMBL1684669 & 727521 & 6.301 & 7.9397 & TST \\
\hline CHEMBL1684528 & 727521 & 7.0809 & 6.9292 & TRN \\
\hline CHEMBL1684515 & 727521 & 3.301 & 4.252 & TRN \\
\hline CHEMBL1684676 & 727521 & 7.2218 & 7.517 & TRN \\
\hline CHEMBL1684654 & 727521 & 7.0969 & 7.2883 & TRN \\
\hline CHEMBL1684538 & 727521 & 4.9208 & 5.7979 & TRN \\
\hline CHEMBL1684540 & 727521 & 6.2757 & 6.4097 & TRN \\
\hline CHEMBL1684666 & 727521 & 6.5528 & 7.7299 & TST \\
\hline CHEMBL1684672 & 727521 & 6.9208 & 7.856 & TST \\
\hline CHEMBL1684509 & 727521 & 7.0088 & 7.4011 & TRN \\
\hline CHEMBL1684506 & 727521 & 6.7959 & 7.3235 & TRN \\
\hline CHEMBL1684543 & 727521 & 7.6383 & 7.4399 & TRN \\
\hline CHEMBL1684653 & 727521 & 7.1805 & 7.419 & TRN \\
\hline CHEMBL1684662 & 727521 & 7.2218 & 6.9965 & TST \\
\hline CHEMBL1684671 & 727521 & 6.5086 & 6.081 & TRN \\
\hline CHEMBL1681817 & 727521 & 5.8239 & 5.5317 & TRN \\
\hline CHEMBL1684505 & 727521 & 6.8539 & 7.112 & TRN \\
\hline CHEMBL1684663 & 727521 & 7.0 & 7.9203 & TST \\
\hline CHEMBL1684511 & 727521 & 6.0 & 5.4065 & TRN \\
\hline CHEMBL1684508 & 727521 & 7.0605 & 7.209 & TRN \\
\hline CHEMBL1684533 & 727521 & 6.5086 & 6.8834 & TRN \\
\hline CHEMBL1684678 & 727521 & 7.1549 & 7.7397 & TST \\
\hline CHEMBL1684536 & 727521 & 6.2076 & 6.4423 & TRN \\
\hline CHEMBL1684674 & 727521 & 6.699 & 6.403 & TRN \\
\hline CHEMBL1684522 & 727521 & 5.8508 & 6.5382 & TRN \\
\hline CHEMBL1684530 & 727521 & 6.1367 & 5.8802 & TRN \\
\hline CHEMBL1684680 & 727521 & 6.9586 & 7.8632 & TST \\
\hline CHEMBL1684535 & 727521 & 6.0655 & 6.7512 & TRN \\
\hline CHEMBL1684510 & 727521 & 6.0458 & 5.8577 & TRN \\
\hline CHEMBL1684667 & 727521 & 6.9586 & 7.8592 & TST \\
\hline CHEMBL1684529 & 727521 & 6.1079 & 5.8933 & TRN \\
\hline CHEMBL1684537 & 727521 & 5.9208 & 6.0124 & TRN \\
\hline CHEMBL1684531 & 727521 & 7.1427 & 6.881 & TRN \\
\hline
\end{tabular}


Supplemental Table S2.txt

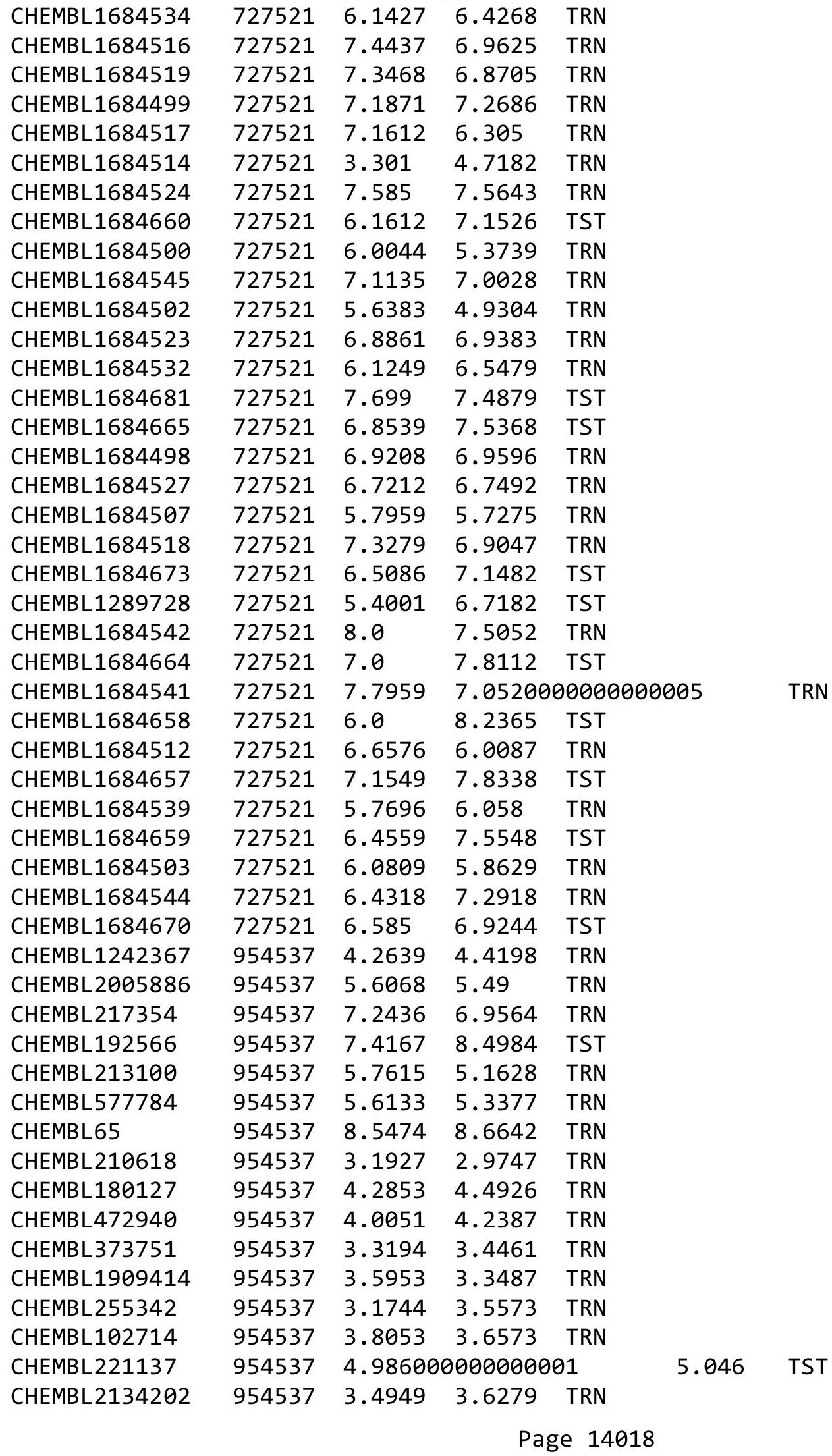


Supplemental Table S2.txt

\begin{tabular}{|c|c|c|c|c|}
\hline HEMBL5] & 7 & 276 & 23 & TRN \\
\hline HFMRI 249954 & & 3.4136 & 3.5553 & \\
\hline HEMBL3392440 & & 5171 & & \\
\hline HEMBL191334 & 54537 & 5667 & 6145 & \\
\hline HEMBL1590308 & 54537 & 7568 & 3152 & \\
\hline HEMBL189584 & 37 & 2066 & 4665 & \\
\hline HEMBL23 & & 0051 & 0777 & \\
\hline HEMBL4\& & 37 & 3295 & 8422 & \\
\hline HEMBL449158 & 37 & 5323 & 9285 & \\
\hline HEMBL1516890 & 37 & .8236 & 0907 & \\
\hline HEMBL39 & 37 & 417 & 464 & \\
\hline HEMBL12 & & & & \\
\hline HEMBL21 & 37 & 5034 & 7651 & \\
\hline HEMBL2C & 37 & 3188 & 8653 & \\
\hline HEMBL509 & 37 & 25 & 6255 & \\
\hline HEMBL1C & 37 & 54 & 73 & \\
\hline HEMBL5: & & & & \\
\hline HEMBL57 & & 033 & 9535 & \\
\hline HEMBL37 & & 076 & & \\
\hline HEMBL 39 & 7 & 11 & 553 & KIV \\
\hline HEMBL1 & & 02 & 65 & RN \\
\hline HEMBLI & & & & \\
\hline HEMBL1 & & 62 & 994 & \\
\hline HEMBL25 & & & & \\
\hline HEMBL21 & 7 & 56 & 795 & TRN \\
\hline AEMBL5: & & & 247 & RN \\
\hline $\mathrm{HEMBL}=$ & & & 64 & RN \\
\hline 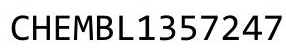 & & & & \\
\hline HEMBL16 & & & & ГRN \\
\hline AEMBL259 & 7 & 87 & 7949 & RN \\
\hline HEMBL17 & & 57 & 846 & $\mathrm{RN}$ \\
\hline HEM & & & 68 & RN \\
\hline & & & & $\mathrm{RN}$ \\
\hline HEMBL14 & & & 829 & TRN \\
\hline HEMBL 125 & & 604 & 2595 & 「RN \\
\hline HEMBL51 & & $\partial 9$ & 15 & ГRN \\
\hline גינו-1 & & & & RN \\
\hline HEMBL 22 & & & & TRN \\
\hline HEMBL 202 & & 83 & 3889 & TST \\
\hline IEMBL2: & & 69 & 5405 & TST \\
\hline HEMBL58 & & 999 & 441 & \\
\hline CHEMBL 92 & & & 2.9775 & IST \\
\hline HEMBL37 & & 5.6024 & & TST \\
\hline HEMBL 393 & 37 & 32 & 3805 & TS \\
\hline MBL3 & & & 08 & 「S \\
\hline CHEMBL9470 & & & 6.2489 & \\
\hline CHEMBL4838 & & 4.4238 & 4.3104 & SI \\
\hline CHEMBL 318640 & 954537 & 4.7294 & 3.9379 & 12 \\
\hline
\end{tabular}

Page 14019 


\begin{tabular}{|c|c|c|c|c|c|}
\hline & & & & & \\
\hline CHEMBL412142 & 954537 & 3.7461 & 3.9331 & TST & \\
\hline CHEMBL272923 & 466158 & 8.5528 & 8.4738 & TRN & \\
\hline CHEMBL403921 & 466158 & 8.8239 & 8.9736 & TRN & \\
\hline CHEMBL403666 & 466158 & 7.8861 & 7.8519 & TRN & \\
\hline CHEMBL257204 & 466158 & 8.6778 & 8.6294 & TRN & \\
\hline CHEMBL255369 & 466158 & 9.301 & 9.2307 & TRN & \\
\hline CHEMBL411457 & 466158 & 8.4685 & 8.7104 & TST & \\
\hline CHEMBL272788 & 466158 & 8.8539 & 8.7086 & TRN & \\
\hline CHEMBL271019 & 466158 & 8.6576 & 8.7619 & TRN & \\
\hline CHEMBL271221 & 466158 & 9.0969 & 9.1421 & TRN & \\
\hline CHEMBL403173 & 466158 & 7.7447 & 7.8833 & TST & \\
\hline CHEMBL409835 & 466158 & 9.0969 & 8.8616 & TRN & \\
\hline CHEMBL415099 & 466158 & 8.4318 & 8.7794 & TST & \\
\hline CHEMBL442803 & 466158 & 9.2218 & 9.2115 & TRN & \\
\hline CHEMBL273141 & 466158 & 8.6383 & 8.6544 & TST & \\
\hline CHEMBL255751 & 466158 & 5.0 & 7.9498 & TST & \\
\hline CHEMBL403334 & 466158 & 8.1739 & 8.2928 & TRN & \\
\hline CHEMBL438386 & 466158 & 8.4202 & 8.3911 & TRN & \\
\hline CHEMBL401864 & 466158 & 9.0458 & 8.8409 & TRN & \\
\hline CHEMBL256894 & 466158 & 8.8239 & 8.8768 & TRN & \\
\hline CHEMBL403762 & 466158 & 7.6576 & 8.3027 & TST & \\
\hline CHEMBL403178 & 466158 & 8.5229 & 8.2826 & TST & \\
\hline CHEMBL256161 & 466158 & 8.8539 & 8.9768 & TRN & \\
\hline CHEMBL403966 & 466158 & 8.0655 & 7.9858 & TRN & \\
\hline CHEMBL402284 & 466158 & 7.9208 & 7.8345 & TRN & \\
\hline CHEMBL257462 & 466158 & 8.7959 & 8.8302 & TRN & \\
\hline CHEMBL256383 & 466158 & 7.4685 & 8.1416 & TST & \\
\hline CHEMBL270667 & 466158 & 9.301 & 9.2942 & TRN & \\
\hline CHEMBL270575 & 466158 & 9.1549 & 9.3741 & TRN & \\
\hline CHEMBL255370 & 466158 & 8.8539 & 8.9236 & TRN & \\
\hline CHEMBL403172 & 466158 & 9.0 & 9.0212 & TRN & \\
\hline CHEMBL270568 & 466158 & 9.0969 & 8.8428 & TRN & \\
\hline CHEMBL404160 & 466158 & 8.6198 & 8.735 & TRN & \\
\hline CHEMBL257079 & 466158 & 8.3468 & 8.3789 & TRN & \\
\hline CHEMBL273143 & 466158 & 7.9208 & 7.9584 & TRN & \\
\hline CHEMBL271263 & 466158 & 8.6021 & 7.9285 & TST & \\
\hline CHEMBL257461 & 466158 & 9.2218 & 9.03399 & 9999999999 & TRN \\
\hline CHEMBL271428 & 466158 & 9.0969 & 9.1323 & TRN & \\
\hline CHEMBL403761 & 466158 & 8.7696 & 8.8125 & TRN & \\
\hline CHEMBL429592 & 466158 & 7.3872 & 7.6155 & TST & \\
\hline CHEMBL270879 & 466158 & 9.0458 & 9.1357 & TRN & \\
\hline CHEMBL255843 & 466158 & 8.585 & 8.676 & TRN & \\
\hline CHEMBL402351 & 466158 & 8.8861 & 8.9087 & TRN & \\
\hline CHEMBL255950 & 466158 & 8.9208 & 8.8132 & TRN & \\
\hline CHEMBL270588 & 466158 & 8.8861 & 8.8564 & TRN & \\
\hline CHEMBL404192 & 466158 & 7.8239 & 8.016 & TST & \\
\hline CHEMBL247234 & 466158 & 8.3979 & 8.9261 & TST & \\
\hline CHEMBL429913 & 466158 & 8.9586 & 8.8597 & TRN & \\
\hline
\end{tabular}

Page 14020 


\begin{tabular}{|c|c|c|c|c|c|}
\hline \multirow[b]{2}{*}{ CHEMBL271853 } & & \multicolumn{4}{|c|}{ Supplemental Table S2.txt } \\
\hline & 466158 & 7.585 & 7.87200 & 0000000001 & TRN \\
\hline CHEMBL410037 & 466158 & 8.7959 & 8.7592 & TRN & \\
\hline CHEMBL271502 & 466158 & 7.7696 & 8.0434 & TST & \\
\hline CHEMBL403179 & 466158 & 8.8539 & 8.8475 & TRN & \\
\hline CHEMBL271054 & 466158 & 8.0655 & 8.1769 & TRN & \\
\hline CHEMBL270143 & 466158 & 9.0 & 9.0142 & TRN & \\
\hline CHEMBL255521 & 466158 & 8.0458 & 8.3704 & TST & \\
\hline CHEMBL404183 & 466158 & 9.0969 & 9.2492 & TRN & \\
\hline CHEMBL270839 & 466158 & 8.7959 & 8.3615 & TRN & \\
\hline CHEMBL270838 & 466158 & 9.0458 & 9.0923 & TRN & \\
\hline CHEMBL257669 & 466158 & 8.0 & 8.3392 & TRN & \\
\hline CHEMBL255570 & 466158 & 7.6576 & 7.6155 & TST & \\
\hline CHEMBL272789 & 466158 & 8.9208 & 8.5596 & TST & \\
\hline CHEMBL270668 & 466158 & 9.5229 & 9.4908 & TRN & \\
\hline CHEMBL402893 & 466158 & 9.0969 & 9.0812 & TRN & \\
\hline CHEMBL257203 & 466158 & 8.9586 & 8.8193 & TRN & \\
\hline CHEMBL411852 & 466158 & 9.0969 & 9.1134 & TRN & \\
\hline CHEMBL133511 & 202590 & 3.699 & 3.8374 & TRN & \\
\hline CHEMBL337459 & 202590 & 3.6861 & 3.6926 & TRN & \\
\hline CHEMBL131768 & 202590 & 3.3107 & 3.1855 & TRN & \\
\hline CHEMBL407143 & 202590 & 4.1079 & 4.1412 & TRN & \\
\hline CHEMBL424449 & 202590 & 4.4089 & 4.202 & TRN & \\
\hline CHEMBL129842 & 202590 & 4.1675 & 4.1215 & TRN & \\
\hline CHEMBL341314 & 202590 & 2.301 & 2.4518 & TRN & \\
\hline CHEMBL339077 & 202590 & 4.5086 & 4.6518 & TRN & \\
\hline CHEMBL335284 & 202590 & 4.1871 & 4.1784 & TRN & \\
\hline CHEMBL133644 & 202590 & 3.8447 & 3.9176 & TRN & \\
\hline CHEMBL336957 & 202590 & 3.5834 & 3.9606 & TST & \\
\hline CHEMBL132007 & 202590 & 4.4949 & 4.4243 & TRN & \\
\hline CHEMBL430059 & 202590 & 3.6253 & 3.8715 & TST & \\
\hline CHEMBL336644 & 202590 & 4.301 & 4.3552 & TRN & \\
\hline CHEMBL134042 & 202590 & 4.0088 & 3.7866 & TRN & \\
\hline CHEMBL336978 & 202590 & 3.6882 & 3.628 & TRN & \\
\hline CHEMBL334891 & 202590 & 4.1805 & 4.23 & TRN & \\
\hline CHEMBL130401 & 202590 & 3.5346 & 3.6468 & TRN & \\
\hline CHEMBL336314 & 202590 & 4.0044 & 4.0148 & TRN & \\
\hline CHEMBL130871 & 202590 & 4.0177 & 3.985 & TRN & \\
\hline CHEMBL336864 & 202590 & 4.3098 & 4.0284 & TRN & \\
\hline CHEMBL 337253 & 202590 & 4.0223 & 4.0371 & TRN & \\
\hline CHEMBL340977 & 202590 & 4.3979 & 4.4936 & TRN & \\
\hline CHEMBL423330 & 202590 & 3.5867 & 3.5893 & TRN & \\
\hline CHEMBL134030 & 202590 & 3.8794 & 3.6403 & TRN & \\
\hline CHEMBL311937 & 202590 & 5.2218 & 3.8191 & TST & \\
\hline CHEMBL131229 & 202590 & 4.2076 & 4.2126 & TRN & \\
\hline CHEMBL77067 & 202590 & 4.1427 & 3.9951 & TRN & \\
\hline CHEMBL310313 & 202590 & 3.8697 & 3.77 & TRN & \\
\hline CHEMBL132006 & 202590 & 4.4318 & 4.4119 & TRN & \\
\hline CHEMBL411163 & 202590 & 4.699 & 4.1746 & TST & \\
\hline
\end{tabular}




\begin{tabular}{|c|c|c|c|c|c|}
\hline \multicolumn{6}{|c|}{ Supplemental Table S2.txt } \\
\hline CHEMBL130106 & 202590 & 3.9393 & 3.9039 & TRN & \\
\hline CHEMBL130751 & 202590 & 2.301 & 3.3862 & TST & \\
\hline CHEMBL134004 & 202590 & 3.8861 & 3.7339 & TRN & \\
\hline CHEMBL336958 & 202590 & 4.1675 & 4.1264 & TRN & \\
\hline CHEMBL103838 & 202590 & 3.6778 & 3.9854 & TRN & \\
\hline CHEMBL134191 & 202590 & 3.5058 & 3.5065 & TST & \\
\hline CHEMBL318300 & 202590 & 4.1427 & 4.2874 & TRN & \\
\hline CHEMBL76963 & 202590 & 3.8069 & 3.7885 & TRN & \\
\hline CHEMBL336949 & 202590 & 4.2218 & 4.2914 & TRN & \\
\hline CHEMBL337737 & 202590 & 3.7932 & 3.9416 & TRN & \\
\hline CHEMBL133929 & 202590 & 4.7447 & 4.6439 & TRN & \\
\hline CHEMBL334979 & 202590 & 3.5498 & 3.7706 & TRN & \\
\hline CHEMBL131361 & 202590 & 4.3468 & 4.3816 & TRN & \\
\hline CHEMBL316967 & 202590 & 4.1249 & 4.0511 & TRN & \\
\hline CHEMBL132014 & 202590 & 2.301 & 3.5712 & TST & \\
\hline CHEMBL134243 & 202590 & 3.5622 & 3.7286 & TRN & \\
\hline CHEMBL131944 & 202590 & 4.0605 & 3.9346 & TST & \\
\hline CHEMBL133185 & 202590 & 3.8268 & 3.9712 & TST & \\
\hline CHEMBL337451 & 202590 & 4.4559 & 4.235 & TST & \\
\hline CHEMBL130931 & 202590 & 3.9101 & 4.2761 & TST & \\
\hline CHEMBL334539 & 202590 & 4.0362 & 3.8619 & TST & \\
\hline CHEMBL335628 & 202590 & 4.1938 & 4.2443 & TST & \\
\hline CHEMBL132963 & 202590 & 2.301 & 3.5658 & TST & \\
\hline CHEMBL 2348950 & 949875 & 7.1938 & 7.1598 & TRN & \\
\hline CHEMBL 2348947 & 949875 & 7.4559 & 7.4074 & TRN & \\
\hline CHEMBL 2348965 & 949875 & 7.585 & 7.59200 & 00000000005 & TRN \\
\hline CHEMBL 2349090 & 949875 & 4.7447 & 5.88 & TST & \\
\hline CHEMBL 2348945 & 949875 & 7.7447 & 7.6743 & TRN & \\
\hline CHEMBL2348980 & 949875 & 4.3979 & 4.3364 & TRN & \\
\hline CHEMBL 2348952 & 949875 & 5.9901 & 5.9784 & TRN & \\
\hline CHEMBL 2348941 & 949875 & 5.8817 & 5.9494 & TRN & \\
\hline CHEMBL 2348942 & 949875 & 5.6639 & 5.6079 & TRN & \\
\hline CHEMBL 2349089 & 949875 & 5.3401 & 5.3619 & TRN & \\
\hline CHEMBL 2348968 & 949875 & 6.9957 & 7.01399 & 9999999999 & TRN \\
\hline CHEMBL 2348978 & 949875 & 6.098 & 6.6548 & TST & \\
\hline CHEMBL 2348940 & 949875 & 5.1385 & 5.1482 & TRN & \\
\hline CHEMBL 2348943 & 949875 & 8.0 & 6.4365 & TST & \\
\hline CHEMBL 2348944 & 949875 & 7.8861 & 7.8717 & TRN & \\
\hline CHEMBL 2348970 & 949875 & 6.8508 & 6.9276 & TRN & \\
\hline CHEMBL 2348964 & 949875 & 7.1135 & 7.0823 & TRN & \\
\hline CHEMBL 2346687 & 949875 & 6.2916 & 6.3135 & TRN & \\
\hline CHEMBL 2349091 & 949875 & 5.9101 & 5.9511 & TRN & \\
\hline CHEMBL 2348959 & 949875 & 4.709 & 4.7358 & TRN & \\
\hline CHEMBL 2348976 & 949875 & 5.5063 & 5.7314 & TST & \\
\hline CHEMBL 2348960 & 949875 & 5.6934 & 5.6639 & TRN & \\
\hline CHEMBL 2348938 & 949875 & 7.6383 & 7.6907 & TRN & \\
\hline CHEMBL 2348974 & 949875 & 6.7773 & 5.7419 & TST & \\
\hline CHEMBL2348981 & 949875 & 3.0 & 3.4725 & TST & \\
\hline
\end{tabular}




\begin{tabular}{|c|c|c|c|c|c|}
\hline \multicolumn{6}{|c|}{ Supplemental Table S2.txt } \\
\hline CHEMBL2348958 & 949875 & 4.6551 & 4.7007 & TRN & \\
\hline CHEMBL2348955 & 949875 & 6.7471 & 6.7577 & TRN & \\
\hline CHEMBL2348953 & 949875 & 7.2924 & 7.3127 & TRN & \\
\hline CHEMBL2348984 & 949875 & 3.0 & 2.98 & TRN & \\
\hline CHEMBL2348948 & 949875 & 6.8729 & 6.8785 & TRN & \\
\hline CHEMBL2348946 & 949875 & 7.6021 & 7.5644 & TRN & \\
\hline CHEMBL2348977 & 949875 & 6.7905 & 6.83799 & 9999999999 & TST \\
\hline CHEMBL 2348961 & 949875 & 5.6073 & 5.5774 & TRN & \\
\hline CHEMBL2348949 & 949875 & 7.3468 & 7.3634 & TRN & \\
\hline CHEMBL2348957 & 949875 & 5.6946 & 5.7125 & TRN & \\
\hline CHEMBL2348983 & 949875 & 5.8083 & 5.7659 & TRN & \\
\hline CHEMBL2348956 & 949875 & 6.51 & 6.4598 & TRN & \\
\hline CHEMBL 2348967 & 949875 & 7.1739 & 7.1677 & TRN & \\
\hline CHEMBL2348936 & 949875 & 7.301 & 7.2621 & TRN & \\
\hline CHEMBL2348954 & 949875 & 7.2596 & 7.2958 & TRN & \\
\hline CHEMBL 2348982 & 949875 & 3.0 & 3.0112 & TRN & \\
\hline CHEMBL2348975 & 949875 & 6.2358 & 6.1498 & TST & \\
\hline CHEMBL 2348962 & 949875 & 8.2218 & 8.2145 & TRN & \\
\hline CHEMBL2348951 & 949875 & 6.5969 & 6.6637 & TRN & \\
\hline CHEMBL2349092 & 949875 & 5.644 & 5.6372 & TRN & \\
\hline CHEMBL2348939 & 949875 & 7.3279 & 7.3505 & TRN & \\
\hline CHEMBL2348966 & 949875 & 7.5229 & 7.7952 & TST & \\
\hline CHEMBL 2348963 & 949875 & 8.0969 & 7.8386 & TST & \\
\hline CHEMBL2348969 & 949875 & 7.4815 & 6.6147 & TST & \\
\hline CHEMBL2348979 & 949875 & 5.6844 & 5.2385 & TST & \\
\hline CHEMBL2348971 & 949875 & 7.3188 & 6.8453 & TST & \\
\hline CHEMBL3651639 & 1527851 & 9.5528 & 9.1549 & TRN & \\
\hline CHEMBL3651612 & 1527851 & 9.301 & 9.2795 & TRN & \\
\hline CHEMBL3651691 & 1527851 & 7.0605 & 7.40799 & 99999999995 & TRN \\
\hline CHEMBL3651680 & 1527851 & 9.9586 & 8.5077 & TRN & \\
\hline CHEMBL 3651684 & 1527851 & 9.5686 & 9.4686 & TRN & \\
\hline CHEMBL3651616 & 1527851 & 6.8041 & 9.2629 & TST & \\
\hline CHEMBL 3651666 & 1527851 & 8.301 & 7.8244 & TST & \\
\hline CHEMBL3651672 & 1527851 & 9.585 & 8.5199 & TST & \\
\hline CHEMBL3651633 & 1527851 & 9.585 & 9.5176 & TRN & \\
\hline CHEMBL3651607 & 1527851 & 9.4949 & 8.9033 & TRN & \\
\hline CHEMBL 3651640 & 1527851 & 9.3372 & 9.4918 & TRN & \\
\hline CHEMBL 3651677 & 1527851 & 9.0 & 8.9801 & TRN & \\
\hline CHEMBL3651663 & 1527851 & 8.3979 & 8.1578 & TRN & \\
\hline CHEMBL3651678 & 1527851 & 9.0 & 8.51 & TRN & \\
\hline CHEMBL 3651648 & 1527851 & 8.301 & 8.0936 & TRN & \\
\hline CHEMBL3639505 & 1527851 & 7.4559 & 8.4186 & TST & \\
\hline CHEMBL 3651644 & 1527851 & 9.4089 & 8.4987 & TRN & \\
\hline CHEMBL3651673 & 1527851 & 7.9208 & 7.8312 & TRN & \\
\hline CHEMBL3651682 & 1527851 & 8.699 & 8.2455 & TST & \\
\hline CHEMBL 3651655 & 1527851 & 9.6383 & 7.6058 & TST & \\
\hline CHEMBL3651623 & 1527851 & 9.3188 & 8.9887 & TRN & \\
\hline CHEMBL3651645 & 1527851 & 9.0 & 8.9282 & TST & \\
\hline
\end{tabular}




\begin{tabular}{|c|c|c|c|c|}
\hline \multicolumn{5}{|c|}{ Supplemental Table S2.txt } \\
\hline CHEMBL 3651649 & 1527851 & 9.0 & 8.5632 & TRN \\
\hline CHEMBL3651699 & 1527851 & 8.9666 & 9.3346 & TRN \\
\hline CHEMBL3651642 & 1527851 & 9.0 & 8.9917 & TRN \\
\hline CHEMBL3651659 & 1527851 & 9.0 & 7.7658 & TST \\
\hline CHEMBL 3651690 & 1527851 & 9.0 & 8.2025 & TRN \\
\hline CHEMBL 3651617 & 1527851 & 9.2007 & 9.2139 & TRN \\
\hline CHEMBL3651613 & 1527851 & 10.0 & 9.2152 & TRN \\
\hline CHEMBL3651692 & 1527851 & 8.3979 & 8.2386 & TRN \\
\hline CHEMBL 3651700 & 1527851 & 9.2757 & 9.7318 & TRN \\
\hline CHEMBL3651698 & 1527851 & 9.0177 & 9.0289 & TRN \\
\hline CHEMBL 3651631 & 1527851 & 9.2218 & 9.6105 & TRN \\
\hline CHEMBL 3651705 & 1527851 & 8.0969 & 8.7763 & TRN \\
\hline CHEMBL3651647 & 1527851 & 7.9586 & 7.9973 & TRN \\
\hline CHEMBL3651609 & 1527851 & 10.0 & 9.4251 & TRN \\
\hline CHEMBL3651653 & 1527851 & 9.0 & 9.1187 & TRN \\
\hline CHEMBL 3651694 & 1527851 & 7.5528 & 8.1804 & TRN \\
\hline CHEMBL3651637 & 1527851 & 9.0 & 8.887 & TRN \\
\hline CHEMBL3651619 & 1527851 & 7.1726 & 9.4327 & TST \\
\hline CHEMBL 3651679 & 1527851 & 7.5086 & 7.6903 & TRN \\
\hline CHEMBL3651634 & 1527851 & 9.3665 & 9.3403 & TRN \\
\hline CHEMBL3651669 & 1527851 & 9.4318 & 9.3808 & TRN \\
\hline CHEMBL 3651701 & 1527851 & 9.8861 & 8.5929 & TST \\
\hline CHEMBL3651656 & 1527851 & 9.5376 & 7.7803 & TST \\
\hline CHEMBL 3651704 & 1527851 & 9.0 & 9.3696 & TRN \\
\hline CHEMBL3651670 & 1527851 & 8.1549 & 9.2235 & TRN \\
\hline CHEMBL 3651615 & 1527851 & 6.7235 & 8.9516 & TST \\
\hline CHEMBL 3651687 & 1527851 & 8.3979 & 7.9691 & TST \\
\hline CHEMBL3651689 & 1527851 & 9.0 & 8.6163 & TRN \\
\hline CHEMBL3651636 & 1527851 & 9.3468 & 9.6044 & TRN \\
\hline CHEMBL 3651622 & 1527851 & 7.4622 & 8.6565 & TRN \\
\hline CHEMBL 3651630 & 1527851 & 9.6198 & 9.5955 & TRN \\
\hline CHEMBL 3651627 & 1527851 & 9.0506 & 9.8325 & TRN \\
\hline CHEMBL3651635 & 1527851 & 9.5229 & 9.3692 & TRN \\
\hline CHEMBL 3651608 & 1527851 & 6.6289 & 8.9659 & TRN \\
\hline CHEMBL3651620 & 1527851 & 7.9508 & 8.7911 & TRN \\
\hline CHEMBL3651688 & 1527851 & 8.301 & 9.0652 & TRN \\
\hline CHEMBL 3651646 & 1527851 & 8.301 & 8.0476 & TRN \\
\hline CHEMBL 3651654 & 1527851 & 9.4815 & 9.5086 & TRN \\
\hline CHEMBL 3651685 & 1527851 & 9.2147 & 8.9584 & TRN \\
\hline CHEMBL3651624 & 1527851 & 9.3279 & 9.2886 & TRN \\
\hline CHEMBL3651658 & 1527851 & 9.9586 & 7.8431 & TST \\
\hline CHEMBL 3651650 & 1527851 & 7.6021 & 7.6796 & TRN \\
\hline CHEMBL3651657 & 1527851 & 9.4318 & 7.7348 & TST \\
\hline CHEMBL3651643 & 1527851 & 9.0 & 8.9255 & TRN \\
\hline CHEMBL3651662 & 1527851 & 10.0 & 8.9076 & TRN \\
\hline CHEMBL 3651703 & 1527851 & 9.9208 & 9.6426 & TRN \\
\hline CHEMBL 3651686 & 1527851 & 9.1079 & 9.1783 & TRN \\
\hline CHEMBL3651610 & 1527851 & 10.0 & 9.5115 & TRN \\
\hline
\end{tabular}


Supplemental Table S2.txt

\begin{tabular}{|c|c|c|c|c|}
\hline TLT & & & 7.7484 & . \\
\hline & & 10.0969 & 8.1775 & \\
\hline AFMRI & 27851 & 9.699 & & \\
\hline IEMBL & 27851 & 9.0 & & \\
\hline AEMBL3651702 & 527851 & 8.699 & .1027 & \\
\hline HEMBL3651661 & 851 & 9.8861 & 8.8233 & \\
\hline HEMBL & & 9.7959 & 5798 & \\
\hline AEMBL36 & & 5.6904 & & \\
\hline HEMBL3651651 & 527851 & 8.301 & 8.5012 & \\
\hline HEMBL3651641 & 527851 & 7.9586 & 2132 & \\
\hline HEMBL3651675 & 51 & 9.699 & & \\
\hline AEMBL & & 383 & 398 & \\
\hline AEMBL & & 10.0969 & 555 & \\
\hline HEMBL3651674 & 527851 & 9.7212 & 8.6539 & \\
\hline HEMBL3651606 & 851 & 9.699 & & \\
\hline AEMBL3 & ג & 447 & & \\
\hline AEMBL & & 596 & & \\
\hline AEMBL & & 6.6904 & & \\
\hline HEMBL 365 & & 10.0 & 396 & \\
\hline AEMBL3651626 & & 99 & 73 & I KIV \\
\hline HEMBL; & 1 & 202 & 57 & RIN \\
\hline HEM & & 229 & & MIV \\
\hline AEMBL & & 9.8861 & & \\
\hline HEMBL & & 576 & & IST \\
\hline HEMBL365 & & 9.7447 & 58 & RN \\
\hline HEMBL3 & & 596 & & RN \\
\hline HFM & & 58 & & RN \\
\hline HEM & & 229 & & \\
\hline AEMBL3 & & 021 & & $\Gamma \mathrm{RN}$ \\
\hline AEMBL 365 & 51 & 8.8697 & 48 & TRN \\
\hline AEMBL & & 586 & & RN \\
\hline HFM & & 2 & & RN \\
\hline ح & & 3 & & RN \\
\hline HEMBL1 & & & & 「RN \\
\hline HEMBL1186585 & & 163 & & RN \\
\hline$A F M R$ & 4 & 36 & & TRN \\
\hline 10 & & 43 & & ST \\
\hline HEMBL 189 & & 3.9392 & & TRN \\
\hline HEMBL 210 & & 5682 & & $\Gamma R$ \\
\hline Th & & 311 & & 11 \\
\hline HFMRI 1 & & 85 & 79 & 「RN \\
\hline HEMBL1 & & 7.1007 & 1843 & ST \\
\hline HEMBL 2202 & 14 & 5.1868 & 4.5039 & TRN \\
\hline HEMBL 515 & 4 & 3.7069 & & TR \\
\hline CHEMBL1404 & & & & \\
\hline HEMBL1 & & .1928 & 13 & \\
\hline CHEMBL1970879 & & 4.1414 & 4.4289 & \\
\hline CHEMBL217354 & 954414 & 6.1066 & 5.5848 & ГRN \\
\hline
\end{tabular}

Page 14025 


\begin{tabular}{|c|c|c|c|c|c|}
\hline \multicolumn{6}{|c|}{ Supplemental Table S2.txt } \\
\hline CHEMBL573107 & 954414 & 4.1339 & 4.7746 & TRN & \\
\hline CHEMBL514499 & 954414 & 7.1684 & 6.5614 & TRN & \\
\hline CHEMBL 209148 & 954414 & 4.825 & 4.2942 & TRN & \\
\hline CHEMBL1516890 & 954414 & 4.1929 & 3.80800 & 00000000003 & TRN \\
\hline CHEMBL 2137530 & 954414 & 3.656 & 4.4655 & TRN & \\
\hline CHEMBL1230020 & 954414 & 3.5028 & 3.7787 & TRN & \\
\hline CHEMBL412142 & 954414 & 3.4455 & 3.7717 & TRN & \\
\hline CHEMBL 393929 & 954414 & 3.8189 & 3.6783 & TRN & \\
\hline CHEMBL 259181 & 954414 & 3.4103 & 4.2185 & TRN & \\
\hline CHEMBL585951 & 954414 & 6.2711 & 5.7254 & TRN & \\
\hline CHEMBL 258844 & 954414 & 4.9088 & 4.1024 & TRN & \\
\hline CHEMBL 2144069 & 954414 & 4.5585 & 4.657 & TRN & \\
\hline CHEMBL379300 & 954414 & 6.5098 & 6.0086 & TRN & \\
\hline CHEMBL 3392440 & 954414 & 3.9771 & 3.6622 & TRN & \\
\hline CHEMBL 213100 & 954414 & 4.2542 & 4.6613 & TRN & \\
\hline CHEMBL135561 & 954414 & 3.8876 & 4.1778 & TRN & \\
\hline CHEMBL 222102 & 954414 & 3.9144 & 3.5772 & TRN & \\
\hline CHEMBL1909414 & 954414 & 3.4963 & 3.7357 & TRN & \\
\hline CHEMBL1256459 & 954414 & 6.9433 & 6.65600 & 0000000001 & TRN \\
\hline CHEMBL300389 & 954414 & 6.1524 & 6.3454 & TRN & \\
\hline CHEMBL483849 & 954414 & 2.59 & 2.1978 & TST & \\
\hline CHEMBL392695 & 954414 & 5.6748 & 4.8432 & TRN & \\
\hline CHEMBL483847 & 954414 & 4.4347 & 4.0104 & TRN & \\
\hline CHEMBL379975 & 954414 & 4.3063 & 4.664 & TRN & \\
\hline CHEMBL 3199475 & 954414 & 3.679 & 4.1286 & TRN & \\
\hline CHEMBL1590308 & 954414 & 2.6899 & 3.2499 & TST & \\
\hline CHEMBL1673039 & 954414 & 3.4118 & 4.4994 & TRN & \\
\hline CHEMBL558642 & 954414 & 2.8819 & 3.8901 & TRN & \\
\hline CHEMBL577784 & 954414 & 4.1363 & 4.8635 & TRN & \\
\hline CHEMBL1190711 & 954414 & 4.2018 & 4.7219 & TRN & \\
\hline CHEMBL9470 & 954414 & 4.8056 & 5.3976 & TST & \\
\hline CHEMBL 3349342 & 954414 & 5.2138 & 4.7725 & TRN & \\
\hline CHEMBL65 & 954414 & 6.7486 & 7.4174 & TRN & \\
\hline CHEMBL1357247 & 954414 & 2.9893 & 2.9592 & TRN & \\
\hline CHEMBL188678 & 954414 & 4.2037 & 4.1578 & TRN & \\
\hline CHEMBL512504 & 954414 & 4.3839 & 4.5472 & TRN & \\
\hline CHEMBL509032 & 954414 & 5.6132 & 5.2043 & TST & \\
\hline CHEMBL472940 & 954414 & 2.9208 & 3.4715 & TST & \\
\hline CHEMBL 221137 & 954414 & 4.5552 & 4.3931 & TST & \\
\hline CHEMBL449158 & 954414 & 6.2721 & 6.3331 & TST & \\
\hline CHEMBL 3186408 & 954414 & 3.6718 & 3.6071 & TST & \\
\hline CHEMBL 255342 & 954414 & 3.3114 & 3.4363 & TST & \\
\hline CHEMBL92309 & 954414 & 2.7439 & 2.8121 & TST & \\
\hline CHEMBL180127 & 954414 & 4.4242 & 3.9916 & TST & \\
\hline CHEMBL102714 & 954414 & 3.1151 & 3.3722 & TST & \\
\hline CHEMBL 2363137 & 954414 & 4.6061 & 4.4707 & TST & \\
\hline CHEMBL 2134202 & 954414 & 3.8316 & 4.1236 & TST & \\
\hline CHEMBL202721 & 954414 & 3.8387 & 4.655 & TST & \\
\hline
\end{tabular}




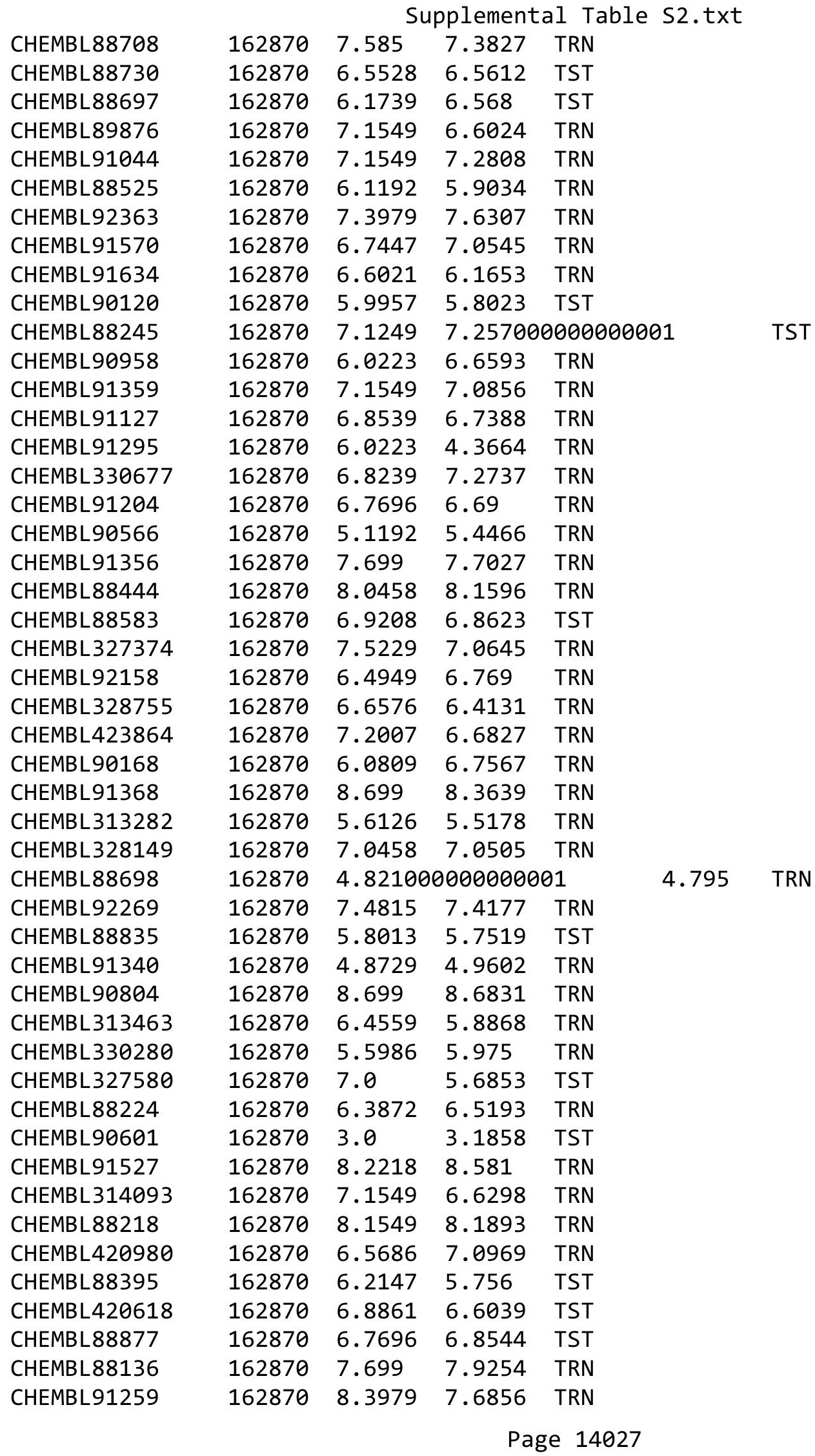




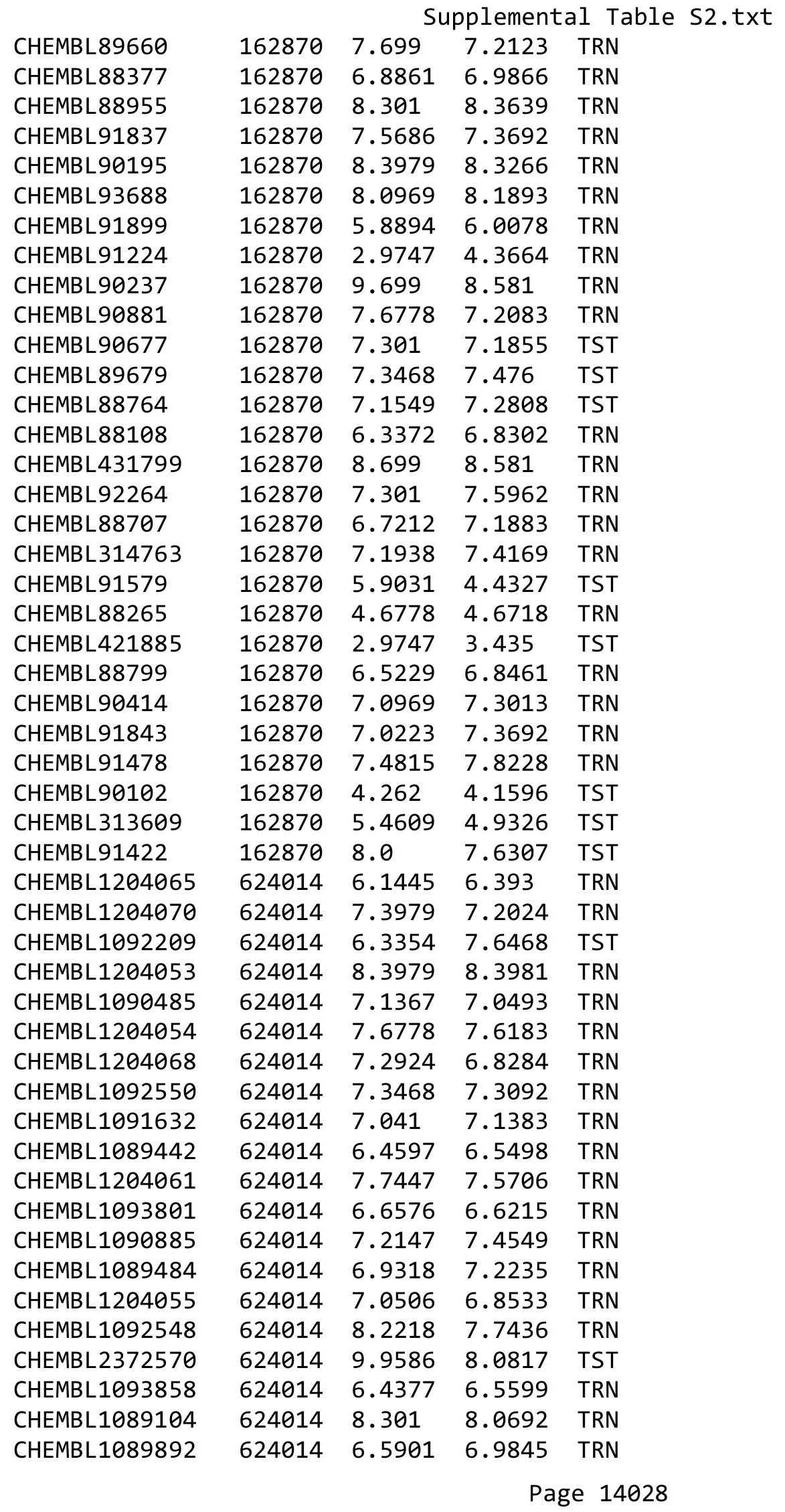


Supplemental Table S2.txt

\begin{tabular}{|c|c|c|c|c|}
\hline CHEMBL1089830 & 624014 & 7.3372 & 8.4374 & TST \\
\hline CHEMBL1090162 & 624014 & 6.2034 & 6.317 & TRN \\
\hline CHEMBL1092860 & 624014 & 8.2218 & 8.3813 & TRN \\
\hline CHEMBL1204062 & 624014 & 6.9666 & 7.4453 & TRN \\
\hline CHEMBL1089796 & 624014 & 7.7212 & 7.3066 & TRN \\
\hline CHEMBL1204063 & 624014 & 6.1911 & 6.5764 & TRN \\
\hline CHEMBL1204057 & 624014 & 7.8239 & 7.5015 & TRN \\
\hline CHEMBL1089483 & 624014 & 8.3979 & 8.0074 & TST \\
\hline CHEMBL1089797 & 624014 & 7.2596 & \multicolumn{2}{|c|}{7.2410000000000005} \\
\hline CHEMBL1090813 & 624014 & 7.2076 & 7.1907 & TRN \\
\hline CHEMBL1091633 & 624014 & 7.284 & 7.0635 & TRN \\
\hline CHEMBL1090487 & 624014 & 5.9523 & 6.7843 & TST \\
\hline CHEMBL1093855 & 624014 & 6.0168 & 6.3052 & TRN \\
\hline CHEMBL1204067 & 624014 & 6.8327 & 7.2284 & TRN \\
\hline CHEMBL1091631 & 624014 & 7.1612 & 6.9671 & TRN \\
\hline CHEMBL1090484 & 624014 & 6.9788 & 7.3457 & TRN \\
\hline CHEMBL1089487 & 624014 & 6.9547 & 8.1512 & TST \\
\hline CHEMBL1204056 & 624014 & 7.0862 & 6.961 & TST \\
\hline CHEMBL1092211 & 624014 & 6.5406 & 7.6782 & TST \\
\hline CHEMBL1204064 & 624014 & 4.9547 & 4.5601 & TRN \\
\hline CHEMBL1204069 & 624014 & 7.1612 & 7.1712 & TRN \\
\hline CHEMBL1091150 & 624014 & 7.5229 & 7.6552 & TRN \\
\hline CHEMBL1092571 & 624014 & 7.4949 & 7.1982 & TRN \\
\hline CHEMBL1092572 & 624014 & 6.4271 & 6.6588 & TRN \\
\hline CHEMBL1092573 & 624014 & 7.7447 & 7.6461 & TRN \\
\hline CHEMBL1089103 & 624014 & 7.8239 & 7.9581 & TST \\
\hline CHEMBL1090161 & 624014 & 6.8996 & 7.1501 & TST \\
\hline CHEMBL1092219 & 624014 & 7.0915 & 7.1378 & TRN \\
\hline CHEMBL1204058 & 624014 & 5.4401 & 5.5848 & TRN \\
\hline CHEMBL1089485 & 624014 & 6.6144 & \multicolumn{2}{|c|}{7.922999999999999} \\
\hline CHEMBL1204066 & 624014 & 7.0706 & 7.2303 & TRN \\
\hline CHEMBL1092733 & 624014 & 6.7986 & 7.9017 & TST \\
\hline CHEMBL1204060 & 624014 & 7.2757 & 7.1654 & TRN \\
\hline CHEMBL1093857 & 624014 & 6.8861 & 6.5378 & TRN \\
\hline CHEMBL1092210 & 624014 & 6.5935 & 7.6592 & TST \\
\hline CHEMBL1089461 & 624014 & 8.1549 & 8.4563 & TST \\
\hline CHEMBL3691555 & 1528103 & 3.8239 & 3.76899 & 99999999997 \\
\hline CHEMBL3691556 & 1528103 & 5.0737 & 5.0655 & TRN \\
\hline CHEMBL3691631 & 1528103 & 3.8239 & 3.9177 & TRN \\
\hline CHEMBL3691651 & 1528103 & 3.8239 & 4.1065 & TST \\
\hline CHEMBL3691658 & 1528103 & 3.8239 & 3.9554 & TRN \\
\hline CHEMBL3691575 & 1528103 & 3.8239 & 3.8241 & TRN \\
\hline CHEMBL3691650 & 1528103 & 4.8768 & 4.6899 & TRN \\
\hline CHEMBL3691623 & 1528103 & 6.0 & 3.1962 & TST \\
\hline CHEMBL3691548 & 1528103 & 3.8239 & 3.8387 & TRN \\
\hline CHEMBL3691602 & 1528103 & 3.8239 & 3.8439 & TRN \\
\hline CHEMBL3691680 & 1528103 & 3.8239 & 3.8892 & TST \\
\hline CHEMBL3691654 & 1528103 & 3.8239 & 3.8688 & TRN \\
\hline
\end{tabular}

Page 14029 
Supplemental Table S2.txt

\begin{tabular}{|c|c|c|c|c|}
\hline - & & & & \\
\hline & & 3.8239 & 3.8801 & \\
\hline & & & & \\
\hline AEMBL & 8103 & 6 & & \\
\hline HEMBL & 528103 & 239 & 5523 & \\
\hline HEMBL3691613 & 528103 & 3.8239 & 7616 & \\
\hline 917 & 3 & 39 & 761 & \\
\hline 606 & & & & \\
\hline AEMBL3691648 & 528103 & & 3567 & \\
\hline HEMBL3691583 & 528103 & & 8125 & \\
\hline HEMBL3691608 & 528103 & & 8397 & \\
\hline IEMBL & 03 & & 355 & \\
\hline IEMBL: & & & & \\
\hline HEMBL36 & 103 & & 4.1116 & \\
\hline AEMBL36 & 03 & & 7735 & \\
\hline AEMBL3S & 93 & 3 & 94 & \\
\hline AEMBL & 03 & & 964 & \\
\hline HEMBL & & & & \\
\hline AEMBL 3 & 03 & & 676 & \\
\hline AEMBL3 & $\partial 3$ & & & \\
\hline AEMBL: & 03 & & 03 & \\
\hline AEMBL & 13 & & 81 & S \\
\hline HEMBL; & 03 & & 77 & \\
\hline 657 & & & & \\
\hline AEMBL36 & & & & \\
\hline AEMBL: & 23 & & 917 & RN \\
\hline AEMBL & & & 67 & 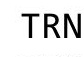 \\
\hline HFMBI : & 23 & & 97 & \\
\hline HEMBL36 & & & & 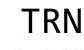 \\
\hline HEMBL3691550 & & & & s \\
\hline HEMBL36 & & & & RN \\
\hline HEMBL & & & 97 & KIN \\
\hline 18 & 33 & & 451 & RN \\
\hline HEMBL3900227 & & & 3.9274 & is \\
\hline HEMBL3691656 & 52 & & 3.8369 & TRN \\
\hline HEMBL36 & 33 & & 16 & ST \\
\hline HCMP - & & & 37 & RN \\
\hline HEMBL; & & & 235 & RN \\
\hline HEMBL3691588 & 528103 & 3 . & 3.8648 & $\Gamma \mathrm{RN}$ \\
\hline AEMBL36 & 52810 & & 7551 & RN \\
\hline HEMBL36 & $\partial 3$ & & 149 & \\
\hline HEMBL 3 & & & & TRN \\
\hline HEMBL36 & 103 & & 3.8409 & RN \\
\hline AEMBL3691562 & 528103 & 39 & 31 & RN \\
\hline HEMBL 3691 & $\partial$ & & 3.7966 & \\
\hline HEMBL36 & & & .6323 & \\
\hline HEMBL3691581 & & & 3.8685 & \\
\hline CHEMBL3986564 & 1528103 & 3.8239 & 3.8059 & ГST \\
\hline
\end{tabular}

Page 14030 
Supplemental Table S2.txt

\begin{tabular}{|c|c|c|c|c|}
\hline CHEMBL3691592 & 1528103 & 3.8239 & 3.8237 & TRN \\
\hline CHEMBL3691633 & 1528103 & 4.9675 & 4.1462 & TST \\
\hline CHEMBL3691577 & 1528103 & 3.8239 & 3.8072 & TRN \\
\hline CHEMBL3691676 & 1528103 & 3.8239 & 3.9717 & TST \\
\hline CHEMBL3691619 & 1528103 & 3.8239 & 3.8033 & TRN \\
\hline CHEMBL3691624 & 1528103 & 6.0 & 4.1831 & TST \\
\hline CHEMBL3691611 & 1528103 & 3.8239 & 3.8819 & TRN \\
\hline CHEMBL3691578 & 1528103 & 3.8239 & 3.8344 & TRN \\
\hline CHEMBL3691599 & 1528103 & 3.8239 & 3.826 & TRN \\
\hline CHEMBL3691600 & 1528103 & 3.8239 & 3.7871 & TRN \\
\hline CHEMBL3691590 & 1528103 & 3.8239 & 3.8562 & TRN \\
\hline CHEMBL3691607 & 1528103 & 3.8239 & 4.6323 & TRN \\
\hline CHEMBL3691679 & 1528103 & 3.8239 & 3.6559 & TST \\
\hline CHEMBL3691645 & 1528103 & 3.8239 & 3.8061 & TRN \\
\hline CHEMBL3691614 & 1528103 & 3.8239 & 3.8557 & TRN \\
\hline CHEMBL3691576 & 1528103 & 3.8239 & 3.8023 & TRN \\
\hline CHEMBL3691655 & 1528103 & 3.8239 & 4.5223 & TST \\
\hline CHEMBL3958281 & 1528103 & 3.8239 & 3.609 & TST \\
\hline CHEMBL3691557 & 1528103 & 3.8239 & 3.7786 & TRN \\
\hline CHEMBL3967212 & 1528103 & 3.8239 & 3.8696 & TST \\
\hline CHEMBL3908903 & 1528103 & 4.3989 & 3.8419 & TST \\
\hline CHEMBL3691594 & 1528103 & 3.8239 & 3.8591 & TRN \\
\hline CHEMBL3691661 & 1528103 & 3.8239 & 4.4284 & TST \\
\hline CHEMBL3691632 & 1528103 & 4.849 & 4.5023 & TST \\
\hline CHEMBL3691649 & 1528103 & 3.8239 & 3.8271 & TRN \\
\hline CHEMBL3691546 & 1528103 & 5.3305 & 4.8397 & TRN \\
\hline CHEMBL3691560 & 1528103 & 3.8239 & 3.8244 & TRN \\
\hline CHEMBL3691566 & 1528103 & 3.8239 & 3.7781 & TRN \\
\hline CHEMBL3691617 & 1528103 & 3.8239 & 3.8399 & TRN \\
\hline CHEMBL3691585 & 1528103 & 3.8239 & 3.7759 & TRN \\
\hline CHEMBL3691570 & 1528103 & 3.8239 & 3.6947 & TRN \\
\hline CHEMBL3691584 & 1528103 & 3.8239 & 3.8261 & TRN \\
\hline CHEMBL3691589 & 1528103 & 3.8239 & 3.8698 & TRN \\
\hline CHEMBL3914273 & 1528103 & 3.8239 & 3.1165 & TST \\
\hline CHEMBL3691597 & 1528103 & 3.8239 & 3.7666 & TRN \\
\hline CHEMBL3691563 & 1528103 & 3.8239 & 3.8182 & TRN \\
\hline CHEMBL142339 & 993484 & 5.68 & 5.7076 & TRN \\
\hline CHEMBL375988 & 993484 & 5.26 & 5.1159 & TRN \\
\hline CHEMBL2449294 & 993484 & 6.19 & 5.8202 & TST \\
\hline CHEMBL 2449295 & 993484 & 5.65 & 5.0341 & TST \\
\hline CHEMBL 2449296 & 993484 & 6.8 & 6.8733 & TRN \\
\hline CHEMBL 2449297 & 993484 & 7.15 & 7.3376 & TRN \\
\hline CHEMBL 2449302 & 993484 & 5.87 & 5.1575 & TST \\
\hline CHEMBL93496 & 993484 & 6.04 & 5.8701 & TRN \\
\hline CHEMBL319952 & 993484 & 6.22 & 6.1466 & TRN \\
\hline CHEMBL96713 & 993484 & 6.42 & 6.2861 & TRN \\
\hline CHEMBL147781 & 993484 & 4.84 & 5.3807 & TRN \\
\hline CHEMBL92889 & 993484 & 4.5 & 5.1933 & TRN \\
\hline
\end{tabular}




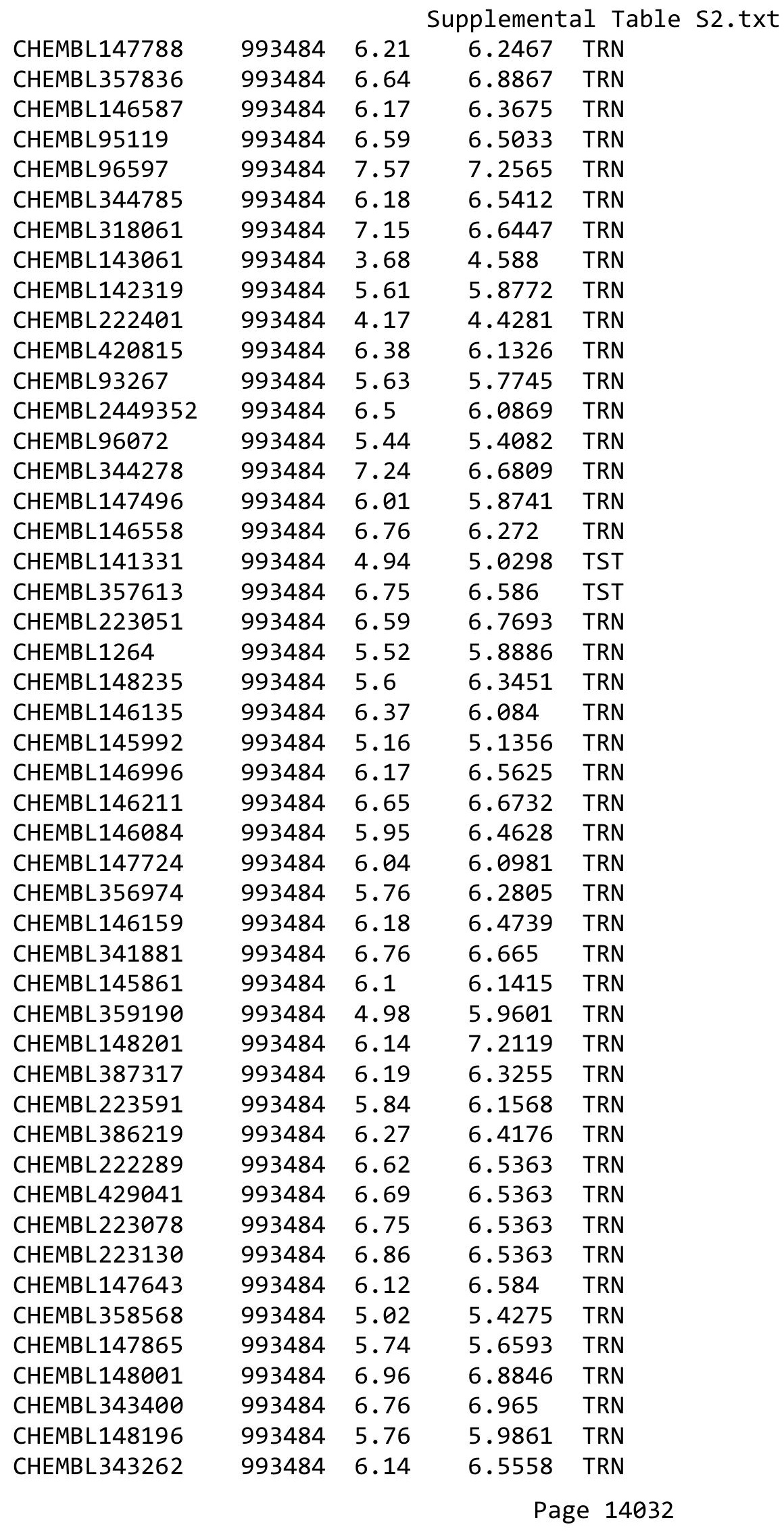




\begin{tabular}{|c|c|c|c|c|c|}
\hline \multirow[b]{2}{*}{ CHEMBL149234 } & \multirow[b]{2}{*}{993484} & \multicolumn{4}{|c|}{ Supplemental Table S2.txt } \\
\hline & & 5.19 & 5.439 & TRN & \\
\hline CHEMBL146081 & 993484 & 6.47 & \multicolumn{2}{|c|}{6.4510000000000005} & TRN \\
\hline CHEMBL149235 & 993484 & 5.98 & 6.0749 & TRN & \\
\hline CHEMBL344313 & 993484 & 7.09 & 7.0488 & TRN & \\
\hline CHEMBL144148 & 993484 & 6.94 & 7.3205 & TRN & \\
\hline CHEMBL147839 & 993484 & 6.28 & 6.3955 & TRN & \\
\hline CHEMBL436790 & 993484 & 6.34 & 6.4072 & TRN & \\
\hline CHEMBL 2449387 & 993484 & 6.4 & 6.3481 & TRN & \\
\hline CHEMBL148260 & 993484 & 6.51 & 6.5612 & TRN & \\
\hline CHEMBL148318 & 993484 & 6.83 & 6.4829 & TRN & \\
\hline CHEMBL 223408 & 993484 & 6.45 & 6.2463 & TRN & \\
\hline CHEMBL148032 & 993484 & 5.5 & 5.9545 & TRN & \\
\hline CHEMBL222232 & 993484 & 7.72 & 7.7076 & TRN & \\
\hline CHEMBL223105 & 993484 & 7.74 & \multicolumn{2}{|c|}{7.428999999999999} & TRN \\
\hline CHEMBL223886 & 993484 & 7.85 & 7.3443 & TRN & \\
\hline CHEMBL 2449395 & 993484 & 7.42 & 7.4576 & TRN & \\
\hline CHEMBL223462 & 993484 & 6.47 & 6.1315 & TRN & \\
\hline CHEMBL147852 & 993484 & 5.81 & 5.4585 & TRN & \\
\hline CHEMBL426728 & 993484 & 7.23 & 7.7475 & TRN & \\
\hline CHEMBL 375089 & 993484 & 6.75 & 7.2171 & TRN & \\
\hline CHEMBL 376083 & 993484 & 7.59 & 7.4039 & TRN & \\
\hline CHEMBL223106 & 993484 & 5.07 & 5.2183 & TRN & \\
\hline CHEMBL223463 & 993484 & 5.59 & 5.4102 & TRN & \\
\hline CHEMBL223420 & 993484 & 5.78 & 6.0377 & TRN & \\
\hline CHEMBL 375407 & 993484 & 6.0 & 5.7187 & TRN & \\
\hline CHEMBL 222276 & 993484 & 6.72 & 6.8314 & TRN & \\
\hline CHEMBL223352 & 993484 & 5.77 & 6.1066 & TRN & \\
\hline CHEMBL422315 & 993484 & 6.14 & 5.9422 & TRN & \\
\hline CHEMBL357023 & 993484 & 6.33 & 6.7705 & TRN & \\
\hline CHEMBL445381 & 993484 & 6.52 & 6.1673 & TRN & \\
\hline CHEMBL147055 & 993484 & 7.12 & 7.3153 & TRN & \\
\hline CHEMBL149548 & 993484 & 3.89 & 3.9673 & TRN & \\
\hline CHEMBL357004 & 993484 & 5.04 & 4.7219 & TRN & \\
\hline CHEMBL149228 & 993484 & 5.0 & 5.2154 & TRN & \\
\hline CHEMBL 374511 & 993484 & 6.89 & 6.505 & TRN & \\
\hline CHEMBL147997 & 993484 & 4.31 & 4.4088 & TRN & \\
\hline CHEMBL146565 & 993484 & 4.93 & 5.0719 & TRN & \\
\hline CHEMBL146671 & 993484 & 3.52 & 3.6473 & TRN & \\
\hline CHEMBL2449416 & 993484 & 5.74 & 6.4916 & TST & \\
\hline CHEMBL 2449417 & 993484 & 5.92 & 6.2752 & TST & \\
\hline CHEMBL373754 & 993484 & 6.68 & 6.2031 & TRN & \\
\hline CHEMBL221619 & 993484 & 6.84 & 6.5815 & TRN & \\
\hline CHEMBL436305 & 993484 & 7.77 & 7.6132 & TRN & \\
\hline CHEMBL2449421 & 993484 & 5.01 & 5.1191 & TRN & \\
\hline CHEMBL223409 & 993484 & 6.53 & $6.0310 e$ & 2000000001 & TRN \\
\hline CHEMBL 375528 & 993484 & 4.95 & 5.0992 & TRN & \\
\hline CHEMBL221620 & 993484 & 6.67 & 6.3215 & TRN & \\
\hline CHEMBL222964 & 993484 & 6.85 & 6.1944 & TRN & \\
\hline
\end{tabular}




\begin{tabular}{|c|c|c|c|c|c|}
\hline \\
\hline CHEMBL 2449426 & 993484 & 6.78 & 7.0522 & TRN & \\
\hline CHEMBL 2449427 & 993484 & 6.41 & 6.5705 & TRN & \\
\hline CHEMBL 2449428 & 993484 & 6.53 & 5.5991 & TRN & \\
\hline CHEMBL 223132 & 993484 & 3.75 & 5.1335 & TST & \\
\hline CHEMBL 2449430 & 993484 & 4.75 & 5.5709 & TST & \\
\hline CHEMBL 2449431 & 993484 & 5.69 & 5.8306 & TST & \\
\hline CHEMBL 2449432 & 993484 & 5.05 & 5.8297 & TST & \\
\hline CHEMBL 2449433 & 993484 & 2.9 & 4.5243 & TST & \\
\hline CHEMBL 223539 & 993484 & 4.63 & 5.6514 & TST & \\
\hline CHEMBL 223590 & 993484 & 2.8 & 5.6501 & TST & \\
\hline CHEMBL 221621 & 993484 & 5.87 & 5.6832 & TRN & \\
\hline CHEMBL 375243 & 993484 & 8.25 & 7.1699 & TRN & \\
\hline CHEMBL 221670 & 993484 & 5.81 & 6.0419 & TRN & \\
\hline CHEMBL 2449437 & 993484 & 6.42 & 5.7445 & TRN & \\
\hline CHEMBL222969 & 993484 & 5.18 & 5.5497 & TST & \\
\hline CHEMBL 222797 & 993484 & 3.98 & 4.78600 & 20000000005 & TST \\
\hline CHEMBL223736 & 993484 & 5.79 & 5.6756 & TST & \\
\hline CHEMBL 375192 & 993484 & 4.31 & 5.0339 & TST & \\
\hline CHEMBL 374861 & 993484 & 6.27 & 6.1024 & TRN & \\
\hline CHEMBL221671 & 993484 & 6.7 & 6.3022 & TRN & \\
\hline CHEMBL 375101 & 993484 & 6.64 & 6.7699 & TRN & \\
\hline CHEMBL 221936 & 993484 & 7.51 & 7.2042 & TRN & \\
\hline CHEMBL 2449446 & 993484 & 6.53 & 6.1457 & TRN & \\
\hline CHEMBL222351 & 993484 & 7.89 & 7.6225 & TRN & \\
\hline CHEMBL 221986 & 993484 & 6.07 & 6.3935 & TRN & \\
\hline CHEMBL 223858 & 993484 & 6.4 & 6.562 & TRN & \\
\hline CHEMBL 223049 & 993484 & 6.68 & 6.415 & TRN & \\
\hline CHEMBL 223488 & 993484 & 6.6 & 6.3857 & TRN & \\
\hline CHEMBL 385580 & 993484 & 6.79 & 6.6176 & TRN & \\
\hline CHEMBL 376913 & 993484 & 6.9 & 6.79899 & 99999999995 & TRN \\
\hline CHEMBL 374710 & 993484 & 7.4 & 7.5625 & TRN & \\
\hline CHEMBL 223050 & 993484 & 6.75 & 5.7722 & TRN & \\
\hline CHEMBL 223131 & 993484 & 7.13 & 6.9958 & TRN & \\
\hline CHEMBL 223489 & 993484 & 6.72 & 6.5423 & TRN & \\
\hline CHEMBL 223537 & 993484 & 6.86 & 6.9238 & TRN & \\
\hline CHEMBL 222230 & 993484 & 5.46 & 5.3518 & TRN & \\
\hline CHEMBL 374871 & 993484 & 6.3 & 6.3765 & TRN & \\
\hline CHEMBL 2449460 & 993484 & 7.07 & 7.385 & TRN & \\
\hline CHEMBL 2449461 & 993484 & 6.06 & 6.2532 & TRN & \\
\hline CHEMBL 2449462 & 993484 & 5.0 & 5.4594 & TRN & \\
\hline CHEMBL 2449463 & 993484 & 6.73 & 6.5561 & TRN & \\
\hline CHEMBL 2449464 & 993484 & 7.1 & 6.6512 & TRN & \\
\hline CHEMBL 2449465 & 993484 & 7.35 & 7.1679 & TRN & \\
\hline CHEMBL 2449466 & 993484 & 7.44 & 7.3146 & TRN & \\
\hline CHEMBL 2449467 & 993484 & 7.08 & 7.0989 & TRN & \\
\hline CHEMBL 2449468 & 993484 & 6.08 & 5.9182 & TRN & \\
\hline CHEMBL 2449469 & 993484 & 5.37 & 5.6667 & TRN & \\
\hline CHEMBL 2449470 & 993484 & 5.84 & 6.1605 & TRN & \\
\hline
\end{tabular}




\begin{tabular}{|c|c|c|c|c|c|}
\hline & & \multicolumn{4}{|c|}{ Supplemental Table S2.txt } \\
\hline CHEMBL2449471 & 993484 & 6.77 & 6.5729 & TRN & \\
\hline CHEMBL 2449472 & 993484 & 6.92 & 6.1388 & TRN & \\
\hline CHEMBL2449473 & 993484 & 4.9 & 4.3628 & TRN & \\
\hline CHEMBL 2449474 & 993484 & 5.21 & 5.4047 & TRN & \\
\hline CHEMBL 2449475 & 993484 & 5.44 & 5.6399 & TRN & \\
\hline CHEMBL 2449476 & 993484 & 6.48 & 6.2245 & TRN & \\
\hline CHEMBL 2449477 & 993484 & 6.58 & 6.3776 & TRN & \\
\hline CHEMBL 2449478 & 993484 & 5.78 & 5.6859 & TRN & \\
\hline CHEMBL 2449479 & 993484 & 6.61 & 6.8763 & TRN & \\
\hline CHEMBL 2449480 & 993484 & 7.25 & 7.3191 & TRN & \\
\hline CHEMBL 2449481 & 993484 & 6.42 & 6.5842 & TRN & \\
\hline CHEMBL2449482 & 993484 & 6.32 & 6.3703 & TRN & \\
\hline CHEMBL 2449483 & 993484 & 7.28 & 6.1257 & TRN & \\
\hline CHEMBL2449484 & 993484 & 5.02 & 6.317 & TRN & \\
\hline CHEMBL 2449485 & 993484 & 5.46 & 5.5294 & TRN & \\
\hline CHEMBL 2449486 & 993484 & 5.13 & 5.3549 & TRN & \\
\hline CHEMBL2449487 & 993484 & 5.5 & 5.4147 & TRN & \\
\hline CHEMBL 2449488 & 993484 & 6.01 & 6.1545 & TRN & \\
\hline CHEMBL 2449489 & 993484 & 6.3 & 6.5863 & TRN & \\
\hline CHEMBL 2449490 & 993484 & 6.18 & 6.5238 & TRN & \\
\hline CHEMBL 2449491 & 993484 & 5.85 & 5.8776 & TRN & \\
\hline CHEMBL1481276 & 993484 & 5.84 & 5.2711 & TRN & \\
\hline CHEMBL 2449493 & 993484 & 6.06 & 6.235 & TRN & \\
\hline CHEMBL1613332 & 993484 & 4.48 & 4.6391 & TRN & \\
\hline CHEMBL 2449495 & 993484 & 5.81 & 5.5801 & TRN & \\
\hline CHEMBL 2449496 & 993484 & 7.1 & 6.9604 & TRN & \\
\hline CHEMBL 2449497 & 993484 & 4.87 & 5.2725 & TRN & \\
\hline CHEMBL 2449498 & 993484 & 7.75 & 7.0718 & TRN & \\
\hline CHEMBL1877038 & 993484 & 5.27 & 4.8545 & TRN & \\
\hline CHEMBL 2449500 & 993484 & 5.66 & 5.5985 & TRN & \\
\hline CHEMBL 2449501 & 993484 & 5.11 & 5.0438 & TRN & \\
\hline CHEMBL2449502 & 993484 & 6.24 & 6.1437 & TRN & \\
\hline CHEMBL2449503 & 993484 & 6.76 & 6.5737 & TRN & \\
\hline CHEMBL2449504 & 993484 & 5.45 & 5.6976 & TRN & \\
\hline CHEMBL 2449505 & 993484 & 6.69 & 6.6449 & TRN & \\
\hline CHEMBL 2449506 & 993484 & 6.32 & 7.1006 & TRN & \\
\hline CHEMBL 2449507 & 993484 & 6.26 & 6.7669 & TRN & \\
\hline CHEMBL 2449508 & 993484 & 6.39 & 7.1708 & TRN & \\
\hline CHEMBL2449509 & 993484 & 6.58 & 7.2682 & TRN & \\
\hline CHEMBL 2449510 & 993484 & 6.36 & 5.8402 & TRN & \\
\hline CHEMBL 2449511 & 993484 & 4.94 & 4.9443 & TRN & \\
\hline CHEMBL 2449512 & 993484 & 6.58 & 6.3013 & TRN & \\
\hline CHEMBL2449513 & 993484 & 6.94 & 6.5375 & TRN & \\
\hline CHEMBL 2449514 & 993484 & 6.2 & 5.7856 & TRN & \\
\hline CHEMBL 2449515 & 993484 & 6.84 & 6.5013 & TRN & \\
\hline CHEMBL 2449516 & 993484 & 7.23 & 6.71399 & 99999999995 & TRN \\
\hline CHEMBL 2449517 & 993484 & 4.8 & 5.0303 & TRN & \\
\hline CHEMBL335658 & 993484 & 6.17 & 5.5883 & TST & \\
\hline
\end{tabular}




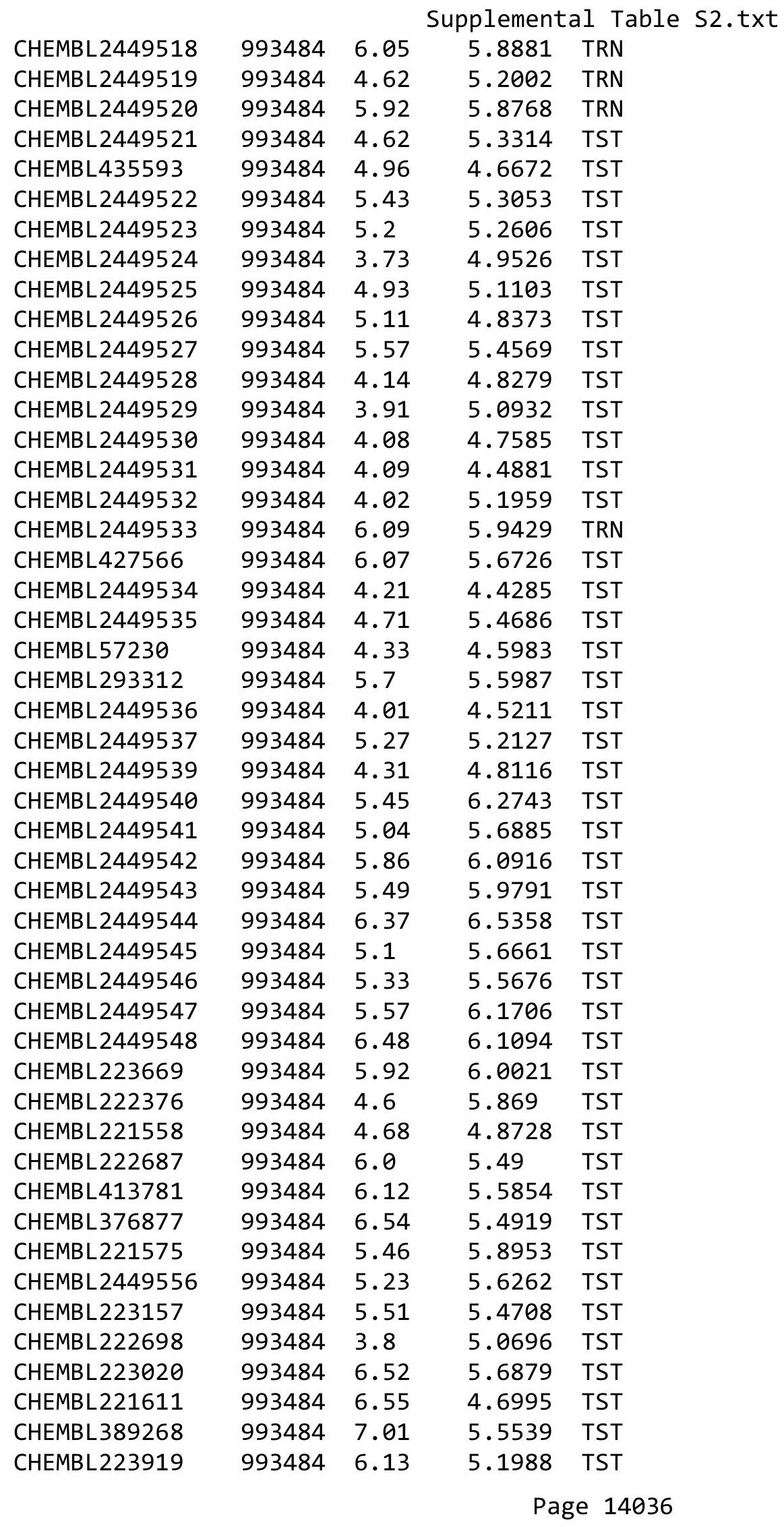




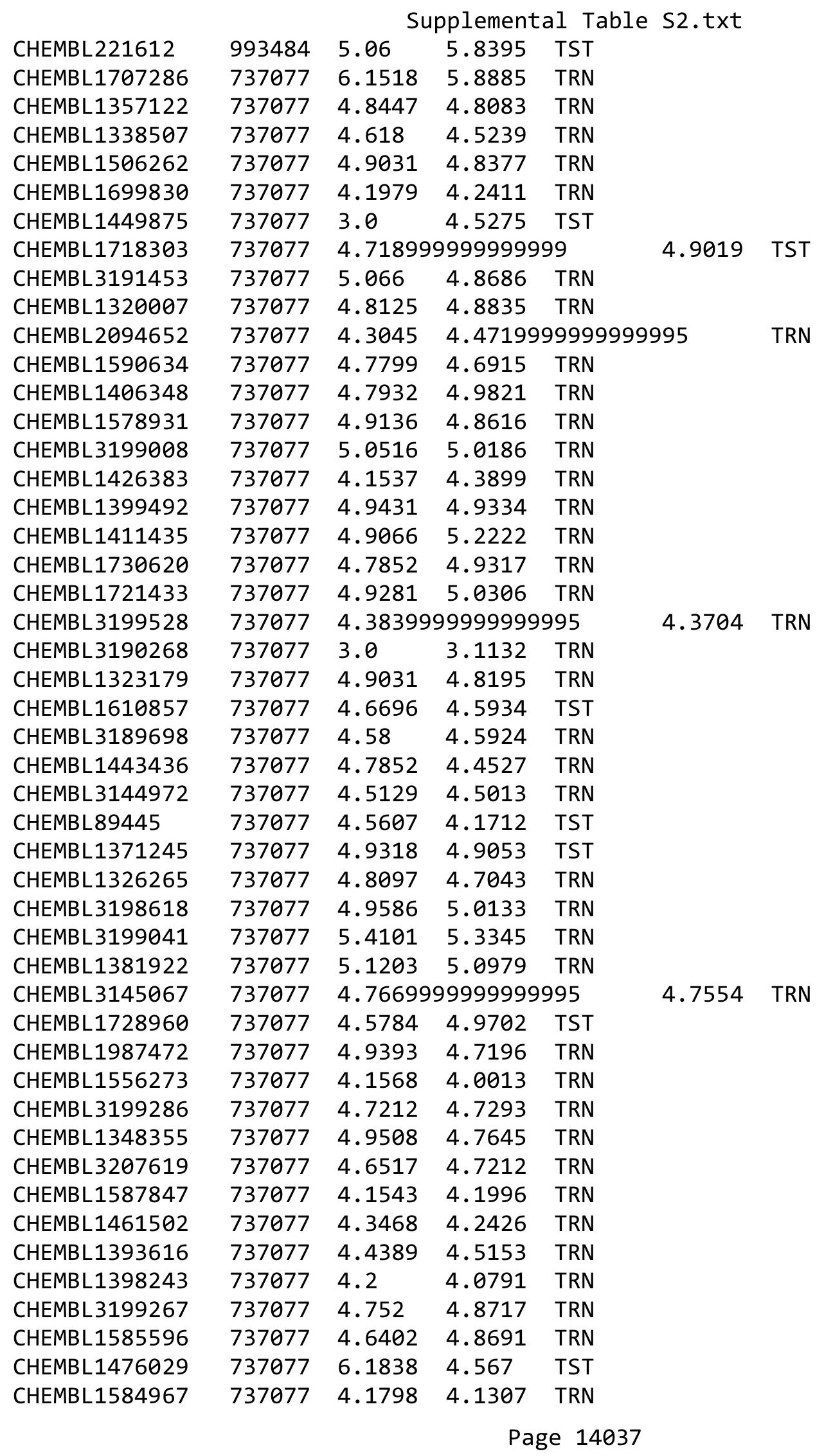




\begin{tabular}{|c|c|c|c|c|c|c|}
\hline & & \multicolumn{5}{|c|}{ Supplemental Table S2.txt } \\
\hline CHEMBL1510785 & 737077 & 4.1284 & 4.1307 & TRN & & \\
\hline CHEMBL1463851 & 737077 & 4.8861 & 4.8044 & TRN & & \\
\hline CHEMBL1386267 & 737077 & 4.6326 & 4.8907 & TST & & \\
\hline CHEMBL1721503 & 737077 & 4.1203 & 4.1511 & TRN & & \\
\hline CHEMBL1701354 & 737077 & 5.0066 & 4.8762 & TRN & & \\
\hline CHEMBL1536250 & 737077 & 4.2676 & 4.3517 & TRN & & \\
\hline CHEMBL1329826 & 737077 & 3.0 & 4.2617 & TST & & \\
\hline CHEMBL1323450 & 737077 & 4.9208 & 5.2954 & TRN & & \\
\hline CHEMBL1458290 & 737077 & 4.317 & 4.2333 & TRN & & \\
\hline CHEMBL1469921 & 737077 & 4.6757 & 4.6529 & TRN & & \\
\hline CHEMBL1352305 & 737077 & 4.7328 & 4.7941 & TRN & & \\
\hline CHEMBL1548196 & 737077 & 4.9136 & 4.8408 & TRN & & \\
\hline CHEMBL1527436 & 737077 & 4.762 & 4.7728 & TRN & & \\
\hline CHEMBL1529932 & 737077 & 3.0 & 4.462 & TST & & \\
\hline CHEMBL1510541 & 737077 & 4.857 & 4.8896 & TRN & & \\
\hline CHEMBL1505198 & 737077 & 6.1965 & 6.2278 & TRN & & \\
\hline CHEMBL1719094 & 737077 & 4.9586 & 5.0138 & TRN & & \\
\hline CHEMBL1393486 & 737077 & 4.7645 & 4.7863 & TRN & & \\
\hline CHEMBL1370217 & 737077 & 4.2069 & 4.3256 & TRN & & \\
\hline CHEMBL1544375 & 737077 & 4.8508 & 4.6745 & TRN & & \\
\hline CHEMBL1300370 & 737077 & 6.3429 & 6.2597 & TRN & & \\
\hline CHEMBL1381655 & 737077 & 4.9914 & 5.0388 & TRN & & \\
\hline CHEMBL1387581 & 737077 & 4.6345 & 4.6033 & TRN & & \\
\hline CHEMBL3195463 & 737077 & 4.4572 & 4.49 & TRN & & \\
\hline CHEMBL1328229 & 737077 & 4.2652 & 4.4287 & TRN & & \\
\hline CHEMBL1499914 & 737077 & 4.9281 & 4.8653 & TRN & & \\
\hline CHEMBL1410588 & 737077 & 4.4112 & 4.4695 & TRN & & \\
\hline CHEMBL3193098 & 737077 & 3.0 & 3.0191 & TRN & & \\
\hline CHEMBL1357672 & 737077 & 4.857 & 4.7462 & TRN & & \\
\hline CHEMBL195258 & 737077 & 5.0 & 4.7887 & TRN & & \\
\hline CHEMBL1507315 & 737077 & 4.1798 & 4.1982 & TRN & & \\
\hline CHEMBL1366575 & 737077 & 4.6946 & 4.5478 & TRN & & \\
\hline CHEMBL1583835 & 737077 & 4.5768 & 4.8928 & TRN & & \\
\hline CHEMBL1702573 & 737077 & 4.762 & 4.6323 & TRN & & \\
\hline CHEMBL1425242 & 737077 & 4.8508 & 4.8185 & TST & & \\
\hline CHEMBL1732408 & 737077 & 4.5867 & 4.783 & TRN & & \\
\hline CHEMBL1528487 & 737077 & 4.5834 & 4.1204 & TST & & \\
\hline CHEMBL1459664 & 737077 & 4.118 & 5.1475 & TST & & \\
\hline CHEMBL1370019 & 737077 & 4.2741 & 4.7946 & TST & & \\
\hline CHEMBL1375639 & 737077 & 5.6179 & 99999999 & 99 & 4.9974 & TST \\
\hline CHEMBL3211705 & 737077 & 3.0 & 4.2789 & TST & & \\
\hline CHEMBL1319190 & 737077 & 4.7905 & 4.5629 & TST & & \\
\hline CHEMBL1405239 & 737077 & 4.752 & 4.9232 & TST & & \\
\hline CHEMBL1442460 & 737077 & 3.0 & 4.3052 & TST & & \\
\hline CHEMBL1255778 & 737077 & 3.0 & 4.1374 & TST & & \\
\hline CHEMBL1474042 & 737077 & 4.7852 & 4.6874 & TST & & \\
\hline CHEMBL1969992 & 737077 & 3.0 & 4.4796 & TST & & \\
\hline CHEMBL1355012 & 737077 & 4.752 & 5.5423 & TST & & \\
\hline
\end{tabular}




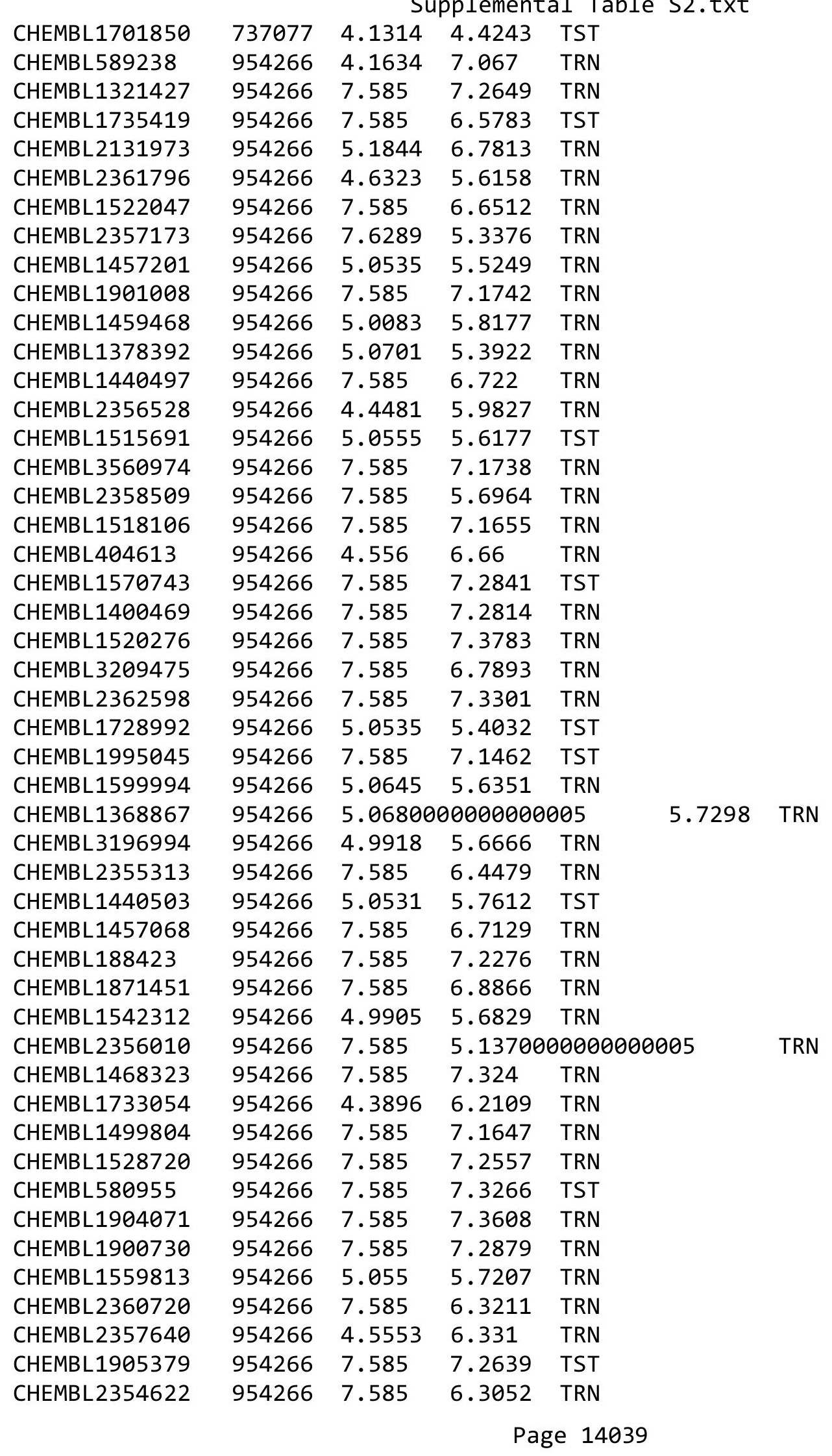




\begin{tabular}{|c|c|c|c|c|c|}
\hline & & \multicolumn{4}{|c|}{ Supplemental Table S2.txt } \\
\hline CHEMBL1589168 & 954266 & 7.585 & 7.1323 & TRN & \\
\hline CHEMBL1476017 & 954266 & 4.244 & 5.6565 & TRN & \\
\hline CHEMBL1898104 & 954266 & 5.1029 & 5.8116 & TRN & \\
\hline CHEMBL3186447 & 954266 & 7.585 & 6.1278 & TRN & \\
\hline CHEMBL1399757 & 954266 & 7.585 & 7.0777 & TST & \\
\hline CHEMBL1346506 & 954266 & \multicolumn{3}{|c|}{4.9830000000000005} & TRN \\
\hline CHEMBL 2143863 & 954266 & 5.5157 & 6.6383 & TRN & \\
\hline CHEMBL 2358490 & 954266 & 7.585 & 6.7905 & TRN & \\
\hline CHEMBL1308488 & 954266 & 7.585 & 7.13399 & 99999999995 & TRN \\
\hline CHEMBL1486546 & 954266 & 7.585 & 7.3402 & TRN & \\
\hline CHEMBL 2134576 & 954266 & 7.585 & 7.081 & TRN & \\
\hline CHEMBL1414970 & 954266 & 7.585 & 7.3131 & TRN & \\
\hline CHEMBL1731294 & 954266 & 7.585 & 7.2955 & TRN & \\
\hline CHEMBL3183033 & 954266 & 7.585 & 7.0765 & TRN & \\
\hline CHEMBL 2137524 & 954266 & 7.585 & 6.7204 & TRN & \\
\hline CHEMBL 2358011 & 954266 & 7.585 & 5.0746 & TRN & \\
\hline CHEMBL1401040 & 954266 & 7.585 & 7.3006 & TRN & \\
\hline CHEMBL1456324 & 954266 & 7.585 & 7.1275 & TST & \\
\hline CHEMBL 2358940 & 954266 & 7.585 & 6.1664 & TRN & \\
\hline CHEMBL1983234 & 954266 & 7.585 & 6.9981 & TRN & \\
\hline CHEMBL1502512 & 954266 & 5.062 & 5.4297 & TRN & \\
\hline CHEMBL 2361778 & 954266 & 4.4934 & 6.3578 & TRN & \\
\hline CHEMBL1350432 & 954266 & 7.585 & 7.3036 & TRN & \\
\hline CHEMBL 2354739 & 954266 & 7.585 & 7.2864 & TRN & \\
\hline CHEMBL1589062 & 954266 & 5.0711 & 5.3715 & TRN & \\
\hline CHEMBL 2356186 & 954266 & 7.585 & 7.224 & TRN & \\
\hline CHEMBL 2132699 & 954266 & 7.585 & 6.1692 & TRN & \\
\hline CHEMBL1595930 & 954266 & 7.585 & 6.3847 & TRN & \\
\hline CHEMBL1500335 & 954266 & 7.585 & 7.2438 & TRN & \\
\hline CHEMBL1561133 & 954266 & 5.0269 & 5.5179 & TRN & \\
\hline CHEMBL1436736 & 954266 & 4.9706 & 5.8196 & TRN & \\
\hline CHEMBL 2356725 & 954266 & 7.585 & 6.57299 & 99999999995 & TRN \\
\hline CHEMBL 2354903 & 954266 & 4.1862 & 6.5434 & TRN & \\
\hline CHEMBL1438210 & 954266 & 7.585 & 7.1563 & TRN & \\
\hline CHEMBL 2355205 & 954266 & 7.585 & 5.2267 & TRN & \\
\hline CHEMBL1873119 & 954266 & 7.585 & 7.1758 & TST & \\
\hline CHEMBL3194248 & 954266 & 4.7622 & 5.5408 & TRN & \\
\hline CHEMBL 2354849 & 954266 & 4.4622 & 6.4059 & TRN & \\
\hline CHEMBL1493437 & 954266 & 4.2359 & 6.4004 & TRN & \\
\hline CHEMBL3184535 & 954266 & 4.1816 & 6.6068 & TRN & \\
\hline CHEMBL1400861 & 954266 & 4.2028 & 6.9847 & TRN & \\
\hline CHEMBL 2356076 & 954266 & 7.585 & 6.8428 & TRN & \\
\hline CHEMBL 2358244 & 954266 & 7.585 & 6.9313 & TRN & \\
\hline CHEMBL1488060 & 954266 & 7.585 & 7.2874 & TRN & \\
\hline CHEMBL 2360303 & 954266 & 7.585 & 6.8614 & TRN & \\
\hline CHEMBL381472 & 954266 & 7.585 & 7.2831 & TRN & \\
\hline CHEMBL1486332 & 954266 & 4.9918 & 5.6072 & TRN & \\
\hline CHEMBL1478578 & 954266 & 5.0655 & 5.8093 & TST & \\
\hline
\end{tabular}




\begin{tabular}{|c|c|c|c|c|c|}
\hline & & \multicolumn{4}{|c|}{ Supplemental Table S2.txt } \\
\hline CHEMBL1376166 & 954266 & 7.585 & 7.2707 & TST & \\
\hline CHEMBL 2359110 & 954266 & 7.585 & 7.1748 & TST & \\
\hline CHEMBL 2132745 & 954266 & 7.585 & 6.7036 & TST & \\
\hline CHEMBL 2356397 & 954266 & 7.585 & 7.1141 & TST & \\
\hline CHEMBL3192873 & 954266 & 5.0022 & 5.67700 & 00000000005 & TST \\
\hline CHEMBL 2361513 & 954266 & 7.585 & 7.181 & TST & \\
\hline CHEMBL1347349 & 954266 & 7.585 & 7.2265 & TST & \\
\hline CHEMBL 26260 & 954266 & 7.585 & 7.3088 & TST & \\
\hline CHEMBL 2360775 & 954266 & 7.585 & 7.0723 & TST & \\
\hline CHEMBL 2359466 & 954266 & 7.585 & 6.1193 & TST & \\
\hline CHEMBL1430096 & 954266 & 7.585 & 7.3241 & TST & \\
\hline CHEMBL1561102 & 954266 & 5.0424 & 5.5268 & TST & \\
\hline CHEMBL1997171 & 954266 & 4.17399 & 99999999 & 6.642 & TST \\
\hline CHEMBL1873438 & 954266 & 7.585 & 7.1976 & TST & \\
\hline CHEMBL1305372 & 954266 & 4.1853 & 6.4529 & TST & \\
\hline CHEMBL1899873 & 954266 & 7.585 & 6.9088 & TST & \\
\hline CHEMBL 2420845 & 979759 & 4.4559 & 4.6815 & TRN & \\
\hline CHEMBL 2420812 & 979759 & 6.3665 & 5.9781 & TRN & \\
\hline CHEMBL 2420841 & 979759 & 4.4559 & 4.2961 & TRN & \\
\hline CHEMBL 2420855 & 979759 & 4.4559 & 4.5807 & TRN & \\
\hline CHEMBL 2420847 & 979759 & 4.4559 & 5.1556 & TRN & \\
\hline CHEMBL 2420846 & 979759 & 5.7696 & 4.6814 & TRN & \\
\hline CHEMBL 2420832 & 979759 & 5.6198 & 6.0758 & TRN & \\
\hline CHEMBL 2420830 & 979759 & 5.9586 & 5.6358 & TST & \\
\hline CHEMBL 2420823 & 979759 & 4.4559 & 4.7265 & TRN & \\
\hline CHEMBL 2420814 & 979759 & 4.4559 & 4.4474 & TST & \\
\hline CHEMBL 2420842 & 979759 & 4.4559 & 4.045 & TRN & \\
\hline CHEMBL 2420857 & 979759 & 4.4559 & 4.8816 & TRN & \\
\hline CHEMBL 2420822 & 979759 & 4.4559 & 4.4145 & TRN & \\
\hline CHEMBL 2420854 & 979759 & 5.3372 & 5.1403 & TRN & \\
\hline CHEMBL1370276 & 979759 & 5.5086 & 5.6316 & TRN & \\
\hline CHEMBL 2420819 & 979759 & 4.4559 & 4.6128 & TRN & \\
\hline CHEMBL 2420811 & 979759 & 4.4559 & 4.3871 & TRN & \\
\hline CHEMBL 2420838 & 979759 & 4.4559 & 4.3175 & TRN & \\
\hline CHEMBL 2420859 & 979759 & 4.4559 & 4.6811 & TST & \\
\hline CHEMBL 2420852 & 979759 & 5.699 & 5.375 & TRN & \\
\hline CHEMBL 2420828 & 979759 & 6.0 & 6.0968 & TRN & \\
\hline CHEMBL 2420829 & 979759 & 6.4437 & 6.4968 & TRN & \\
\hline CHEMBL 2387224 & 979759 & 7.0757 & 6.4316 & TRN & \\
\hline CHEMBL1702157 & 979759 & 4.4559 & 4.8592 & TRN & \\
\hline CHEMBL 2420848 & 979759 & 4.4559 & 4.8025 & TRN & \\
\hline CHEMBL 2420827 & 979759 & 6.699 & 6.65 & TRN & \\
\hline CHEMBL 2420836 & 979759 & 5.8239 & 5.8776 & TRN & \\
\hline CHEMBL 2420818 & 979759 & 4.4559 & 4.6398 & TST & \\
\hline CHEMBL 2420810 & 979759 & 4.4559 & 4.4151 & TRN & \\
\hline CHEMBL 2420856 & 979759 & 4.4559 & 4.3538 & TRN & \\
\hline CHEMBL 2420844 & 979759 & 5.7696 & 5.5854 & TRN & \\
\hline CHEMBL 2420834 & 979759 & 4.4559 & 4.4534 & TRN & \\
\hline
\end{tabular}


Supplemental Table S2.txt

\begin{tabular}{|c|c|c|c|c|c|c|}
\hline CHEMBL 2420817 & 979759 & 4.4559 & 4.1401 & TST & & \\
\hline CHEMBL2420815 & 979759 & 4.4559 & 4.3796 & TRN & & \\
\hline CHEMBL2420824 & 979759 & 6.0 & 5.6636 & TRN & & \\
\hline CHEMBL2420825 & 979759 & 4.4559 & 4.3987 & TRN & & \\
\hline CHEMBL2420840 & 979759 & 4.4559 & 4.8849 & TRN & & \\
\hline CHEMBL1327969 & 979759 & 5.6576 & 5.6187 & TRN & & \\
\hline CHEMBL 2420826 & 979759 & 6.3098 & 6.36100 & 0000000001 & TRN & \\
\hline CHEMBL2420813 & 979759 & 5.585 & 5.544 & TRN & & \\
\hline CHEMBL2420843 & 979759 & 4.4559 & 4.2891 & TRN & & \\
\hline CHEMBL2420851 & 979759 & 5.6778 & 5.3663 & TRN & & \\
\hline CHEMBL 2420835 & 979759 & 4.4559 & 5.3781 & TRN & & \\
\hline CHEMBL 2420816 & 979759 & 4.4559 & 3.949 & TST & & \\
\hline CHEMBL 2420821 & 979759 & 5.5376 & 5.0436 & TRN & & \\
\hline CHEMBL2420860 & 979759 & 4.4559 & 4.0871 & TST & & \\
\hline CHEMBL2420820 & 979759 & 4.4559 & 4.867 & TRN & & \\
\hline CHEMBL 2420853 & 979759 & 4.4559 & 4.569 & TRN & & \\
\hline CHEMBL 2420850 & 979759 & 4.4559 & 4.0198 & TST & & \\
\hline CHEMBL2420839 & 979759 & 4.4559 & 5.5946 & TST & & \\
\hline CHEMBL 2420837 & 979759 & 4.4559 & 5.7336 & TST & & \\
\hline CHEMBL2420833 & 979759 & 4.4559 & 4.718 & TST & & \\
\hline CHEMBL 2420831 & 979759 & 7.0 & 6.05399 & 9999999999 & TST & \\
\hline CHEMBL 2420858 & 979759 & 4.4559 & 4.5621 & TST & & \\
\hline CHEMBL 2420849 & 979759 & 4.4559 & 4.1089 & TST & & \\
\hline CHEMBL1348475 & 752507 & 4.0154 & 3.99600 & 00000000004 & TRN & \\
\hline CHEMBL1528874 & 752507 & 3.6306 & 3.6999 & TRN & & \\
\hline CHEMBL1524130 & 752507 & 2.4202 & 2.5278 & TRN & & \\
\hline CHEMBL1421513 & 752507 & 3.7857 & 3.6745 & TRN & & \\
\hline CHEMBL1557373 & 752507 & 3.6499 & 3.6447 & TRN & & \\
\hline CHEMBL1524986 & 752507 & 4.5789 & 4.4706 & TRN & & \\
\hline CHEMBL1372703 & 752507 & 4.3008 & 4.2161 & TRN & & \\
\hline CHEMBL1302198 & 752507 & 2.4202 & 3.2498 & TST & & \\
\hline CHEMBL1736345 & 752507 & 2.4202 & 2.4553 & TRN & & \\
\hline CHEMBL1888349 & 752507 & \multicolumn{3}{|c|}{ 4.1819999999999995 } & 00000000001 & TRN \\
\hline CHEMBL1479319 & 752507 & 4.0572 & 4.091 & TRN & & \\
\hline CHEMBL1383181 & 752507 & 3.5718 & 3.5444 & TRN & & \\
\hline CHEMBL1495096 & 752507 & 3.9563 & 3.9765 & TRN & & \\
\hline CHEMBL1723068 & 752507 & 3.9642 & 3.9873 & TRN & & \\
\hline CHEMBL1607242 & 752507 & 4.1304 & 4.1556 & TRN & & \\
\hline CHEMBL1442788 & 752507 & 5.5779 & 5.546 & TRN & & \\
\hline CHEMBL1507366 & 752507 & 4.1602 & 4.2215 & TRN & & \\
\hline CHEMBL1866932 & 752507 & 4.2602 & 4.2838 & TRN & & \\
\hline CHEMBL1484377 & 752507 & 4.2737 & 4.223 & TRN & & \\
\hline CHEMBL3197614 & 752507 & 4.1703 & 4.0363 & TRN & & \\
\hline CHEMBL1422619 & 752507 & 2.4202 & 2.3857 & TRN & & \\
\hline CHEMBL1522007 & 752507 & 4.7705 & 4.8228 & TRN & & \\
\hline CHEMBL1308415 & 752507 & 4.2513 & 4.1939 & TRN & & \\
\hline CHEMBL1341449 & 752507 & 4.1742 & 4.2021 & TRN & & \\
\hline CHEMBL1419145 & 752507 & 2.4202 & 2.3766 & TRN & & \\
\hline
\end{tabular}

Page 14042 


\begin{tabular}{|c|c|c|c|c|c|c|}
\hline & & \multicolumn{5}{|c|}{ Supplemental Table S2.txt } \\
\hline CHEMBL1597270 & 752507 & 4.5041 & 4.4848 & TRN & & \\
\hline CHEMBL1416766 & 752507 & 4.2429 & 4.2293 & TRN & & \\
\hline CHEMBL1325230 & 752507 & 3.8426 & 3.8654 & TRN & & \\
\hline CHEMBL1505878 & 752507 & 4.7886 & 4.8254 & TRN & & \\
\hline CHEMBL1316908 & 752507 & 4.2227 & 3.8992 & TST & & \\
\hline CHEMBL1836553 & 752507 & 4.0891 & 4.7561 & TST & & \\
\hline CHEMBL1472083 & 752507 & 4.2702 & 4.3085 & TRN & & \\
\hline CHEMBL1464769 & 752507 & 4.3187 & 4.3009 & TRN & & \\
\hline CHEMBL1456906 & 752507 & \multicolumn{3}{|c|}{ 4.7989999999999995 } & 4.6048 & TST \\
\hline CHEMBL1577402 & 752507 & 4.1775 & 4.2722 & TRN & & \\
\hline CHEMBL1385486 & 752507 & 4.2843 & 4.2922 & TRN & & \\
\hline CHEMBL1573632 & 752507 & 6.0545 & 4.2174 & TST & & \\
\hline CHEMBL1380394 & 752507 & 4.3074 & 4.4527 & TRN & & \\
\hline CHEMBL1385735 & 752507 & \multicolumn{3}{|c|}{ 4. 2989999999999995} & 4.2346 & TRN \\
\hline CHEMBL1450314 & 752507 & 4.5605 & 4.5565 & TRN & & \\
\hline CHEMBL3199393 & 752507 & 4.2076 & 4.3289 & TRN & & \\
\hline CHEMBL1577990 & 752507 & 3.7952 & 3.7339 & TRN & & \\
\hline CHEMBL1587988 & 752507 & \multicolumn{3}{|c|}{4.428999999999999} & 4.3356 & TRN \\
\hline CHEMBL1322501 & 752507 & 4.3225 & 4.373 & TRN & & \\
\hline CHEMBL1200567 & 752507 & 6.1062 & 4.1702 & TST & & \\
\hline CHEMBL 2001712 & 752507 & 3.9156 & 3.9082 & TRN & & \\
\hline CHEMBL1499330 & 752507 & 2.4202 & 2.4346 & TRN & & \\
\hline CHEMBL1741390 & 752507 & 4.7609 & 4.8058 & TRN & & \\
\hline CHEMBL1417069 & 752507 & 4.5081 & 4.3805 & TRN & & \\
\hline CHEMBL1725545 & 752507 & 3.9885 & 3.9957 & TRN & & \\
\hline CHEMBL1890604 & 752507 & 4.8598 & 4.9 & TRN & & \\
\hline CHEMBL1368945 & 752507 & 4.3287 & 4.3207 & TRN & & \\
\hline CHEMBL1978479 & 752507 & 4.9194 & 4.901 & TRN & & \\
\hline CHEMBL1480955 & 752507 & 4.1714 & 4.1893 & TRN & & \\
\hline CHEMBL1599034 & 752507 & 4.2764 & 4.4127 & TRN & & \\
\hline CHEMBL1534034 & 752507 & 3.6141 & 3.5511 & TRN & & \\
\hline CHEMBL1516191 & 752507 & 4.1193 & 4.1249 & TRN & & \\
\hline CHEMBL1562238 & 752507 & 4.4837 & 4.539 & TRN & & \\
\hline CHEMBL1883136 & 752507 & 3.9744 & 3.8895 & TRN & & \\
\hline CHEMBL3190786 & 752507 & 4.397 & 4.4027 & TRN & & \\
\hline CHEMBL1463150 & 752507 & 4.3451 & 4.3467 & TRN & & \\
\hline CHEMBL1348591 & 752507 & 4.1483 & 4.1539 & TRN & & \\
\hline CHEMBL1383138 & 752507 & 3.5588 & 3.5511 & TRN & & \\
\hline CHEMBL1556305 & 752507 & \multicolumn{3}{|c|}{3.9939999999999998} & 3.9681 & T \\
\hline CHEMBL1964361 & 752507 & 3.735 & 4.5016 & TST & & \\
\hline CHEMBL1711359 & 752507 & 4.6428 & 4.6444 & TRN & & \\
\hline CHEMBL1312101 & 752507 & 4.4543 & 4.4733 & TST & & \\
\hline CHEMBL1482539 & 752507 & 3.9188 & 3.7982 & TRN & & \\
\hline CHEMBL1356238 & 752507 & 5.0236 & 4.9229 & TRN & & \\
\hline CHEMBL1517909 & 752507 & 3.7172 & 3.6658 & TRN & & \\
\hline CHEMBL 3212682 & 752507 & 3.8323 & 3.5165 & TST & & \\
\hline CHEMBL1468813 & 752507 & 4.126 & 4.1705 & TRN & & \\
\hline CHEMBL1605055 & 752507 & 4.1334 & 4.0519 & TRN & & \\
\hline
\end{tabular}


Supplemental Table S2.txt

\begin{tabular}{|c|c|c|c|c|}
\hline CHEMBL1442917 & 752507 & 2.4202 & 2.4009 & TRN \\
\hline CHEMBL1419810 & 752507 & 4.6656 & 4.7102 & TRN \\
\hline CHEMBL1342690 & 752507 & 4.1429 & 4.2377 & TRN \\
\hline CHEMBL1362524 & 752507 & 4.0808 & 4.1076 & TRN \\
\hline CHEMBL1549948 & 752507 & 4.5652 & 2.9827 & TST \\
\hline CHEMBL1377917 & 752507 & 3.9731 & 3.9715 & TRN \\
\hline CHEMBL1347445 & 752507 & 4.4176 & 4.3628 & TRN \\
\hline CHEMBL1367332 & 752507 & 2.4202 & 2.4692 & TRN \\
\hline CHEMBL1306450 & 752507 & 4.0054 & 4.039 & TRN \\
\hline CHEMBL1485407 & 752507 & 2.4202 & 2.3196 & TRN \\
\hline CHEMBL1700479 & 752507 & 4.6816 & 4.5613 & TST \\
\hline CHEMBL1583992 & 752507 & 4.5917 & 4.579 & TRN \\
\hline CHEMBL1482127 & 752507 & 5.0508 & 3.3933 & TST \\
\hline CHEMBL1360848 & 752507 & 4.2108 & 4.1207 & TRN \\
\hline CHEMBL1532605 & 752507 & 2.4202 & 2.4643 & TRN \\
\hline CHEMBL1887922 & 752507 & 4.2386 & 4.1855 & TRN \\
\hline CHEMBL505670 & 752507 & 5.2573 & 5.2484 & TRN \\
\hline CHEMBL1520209 & 752507 & 2.4202 & 2.4452 & TRN \\
\hline CHEMBL1549270 & 752507 & 4.1479 & 4.1692 & TRN \\
\hline CHEMBL1485275 & 752507 & 6.0 & 4.525 & TST \\
\hline CHEMBL1892725 & 752507 & 3.4916 & 3.4213 & TRN \\
\hline CHEMBL1412358 & 752507 & 4.3691 & 4.3664 & TRN \\
\hline CHEMBL1407927 & 752507 & 4.5525 & 4.6026 & TRN \\
\hline CHEMBL1465605 & 752507 & 4.2458 & 4.2921 & TRN \\
\hline CHEMBL1698401 & 752507 & 3.8769 & 3.8779 & TRN \\
\hline CHEMBL1712708 & 752507 & 4.0512 & 3.9831 & TRN \\
\hline CHEMBL1388001 & 752507 & 2.4202 & 4.1274 & TST \\
\hline CHEMBL1371660 & 752507 & 4.2645 & 4.2259 & TRN \\
\hline CHEMBL1353499 & 752507 & 2.4202 & 2.4292 & TRN \\
\hline CHEMBL1558826 & 752507 & 5.8687 & 4.5365 & TST \\
\hline CHEMBL1728670 & 752507 & 4.8638 & 3.5247 & TST \\
\hline CHEMBL1555751 & 752507 & 5.659 & 4.1477 & TST \\
\hline CHEMBL1700633 & 752507 & 4.195 & 3.9826 & TRN \\
\hline CHEMBL1522925 & 752507 & 4.2308 & 4.1708 & TRN \\
\hline CHEMBL1376102 & 752507 & 4.1947 & 4.1663 & TRN \\
\hline CHEMBL1467901 & 752507 & 3.4641 & 3.4226 & TRN \\
\hline CHEMBL1409629 & 752507 & 5.138999 & 99999999 & 5.1063 \\
\hline CHEMBL1326704 & 752507 & 4.3358 & 4.383 & TRN \\
\hline CHEMBL1877367 & 752507 & 4.1624 & 4.1711 & TRN \\
\hline CHEMBL1463853 & 752507 & 3.7218 & 3.8186 & TRN \\
\hline CHEMBL1543207 & 752507 & 4.3838 & 4.4252 & TRN \\
\hline CHEMBL1720566 & 752507 & 3.4598 & 3.5036 & TRN \\
\hline CHEMBL1591969 & 752507 & 4.3162 & 4.318000 & 00000000005 \\
\hline CHEMBL1728268 & 752507 & 4.1749 & 4.1667 & TRN \\
\hline CHEMBL1511244 & 752507 & 4.5182 & 4.4956 & TRN \\
\hline CHEMBL1575803 & 752507 & 4.2167 & 4.2747 & TRN \\
\hline CHEMBL1558814 & 752507 & 4.4243 & 4.4453 & TRN \\
\hline CHEMBL1733450 & 752507 & 4.1154 & 4.2847 & TRN \\
\hline
\end{tabular}


Supplemental Table S2.txt

\begin{tabular}{|c|c|c|c|c|}
\hline-1 & & & 7983 & \\
\hline & 52507 & .8267 & & \\
\hline & 07 & & & \\
\hline AEMBL & 507 & & & \\
\hline AEMBL1418599 & 2507 & 222 & 772 & \\
\hline HEMBL1372839 & 52507 & 6738 & 5405 & \\
\hline HEMBL] & 507 & 671 & 724 & \\
\hline 711 & 507 & & 1979 & \\
\hline IEMBL1491343 & 52507 & & 4925 & \\
\hline AEMBL1337406 & 52507 & & 5431 & \\
\hline HEMBL1309596 & 52507 & 4662 & 104 & \\
\hline IEMBL1 & 507 & 02 & 06 & \\
\hline AEMBL] & 507 & & & \\
\hline AEMBL1865281 & 52507 & & .78 & \\
\hline AEMBL1878940 & 507 & & 1873 & \\
\hline AEMBL1 & 52507 & & 298 & \\
\hline AEMBL1 & 507 & & 308 & \\
\hline HEMBL1 & 07 & & & \\
\hline 13862 & 507 & & 3661 & \\
\hline AEMBLI & 07 & & & \\
\hline AEMBL: & 07 & 6 & 48 & \\
\hline AEMBL & 27 & 34 & 21 & 2 \\
\hline AEMBL & 07 & & 02 & \\
\hline 7644 & 507 & & & \\
\hline IEMBL1 & & & & \\
\hline AEMBL: & 07 & & 391 & RIV \\
\hline HEM & 77 & & 26 & Niv \\
\hline 559 & 07 & 97 & 993 & \\
\hline AEMBL1 & & & & TIV \\
\hline HEMBL1432336 & & & 508 & I RN \\
\hline HEMBL1 & 07 & & 602 & RIN \\
\hline HEMBL & 7 & & 03 & זכ \\
\hline EMBL: & 97 & & 381 & \\
\hline AEMBL1568965 & & & 16 & 15 \\
\hline HEMBL1319128 & 52507 & & 83 & TS \\
\hline HEMBL & 07 & & 91 & $\mid$ \\
\hline HFMRI & & & 72 & ГST \\
\hline & & & 373 & TST \\
\hline HEMBL1315061 & 52507 & & 208 & TST \\
\hline AEMBL3 & 52507 & & 896 & TS \\
\hline 847 & 52507 & & 527 & ISI \\
\hline HEMBL1 & & & 849 & TST \\
\hline HEMBL1537344 & 752507 & & 1406 & TST \\
\hline AEMBL1322395 & 52507 & 97 & 2363 & rS \\
\hline MBL1 & 52507 & 1 & 8334 & TS \\
\hline HEMBL1 & 07 & & & \\
\hline HEMBL3199212 & & .2736 & 7268 & \\
\hline CHEMBL141509e & 752507 & 4.2519 & 3.6711 & ГST \\
\hline
\end{tabular}

Page 14045 
Supplemental Table S2.txt

\begin{tabular}{|c|c|c|c|c|c|}
\hline CHEMBL1534204 & 752507 & 4.5023 & 4.5422 & TST & \\
\hline CHEMBL1561995 & 752507 & 4.3165 & 3.8799 & TST & \\
\hline CHEMBL1489847 & 752507 & 4.3646 & 4.1793 & TST & \\
\hline CHEMBL 96659 & 49308 & 5.8665 & 5.5439 & TRN & \\
\hline CHEMBL540898 & 49308 & 7.0862 & 7.026 & TRN & \\
\hline CHEMBL 76987 & 49308 & 6.8827 & 7.1734 & TRN & \\
\hline CHEMBL91756 & 49308 & 6.1427 & 6.4717 & TRN & \\
\hline CHEMBL420070 & 49308 & 4.2596 & 4.2941 & TRN & \\
\hline CHEMBL93316 & 49308 & 5.0 & 4.936 & TRN & \\
\hline CHEMBL552789 & 49308 & 7.301 & 7.2374 & TRN & \\
\hline CHEMBL328867 & 49308 & 5.1681 & 4.7102 & TST & \\
\hline CHEMBL92662 & 49308 & 7.8861 & 7.7384 & TST & \\
\hline CHEMBL450874 & 49308 & 5.4535 & 5.251 & TRN & \\
\hline CHEMBL327562 & 49308 & \multicolumn{2}{|c|}{6.718999999999999} & 7.0133 & TRI \\
\hline CHEMBL549688 & 49308 & 7.3979 & 7.53 & TST & \\
\hline CHEMBL316066 & 49308 & 6.0372 & 6.1378 & TRN & \\
\hline CHEMBL329418 & 49308 & 5.0 & 4.6746 & TRN & \\
\hline CHEMBL558432 & 49308 & 6.3979 & 7.0687 & TRN & \\
\hline CHEMBL327408 & 49308 & 6.6819 & 6.8893 & TRN & \\
\hline CHEMBL327986 & 49308 & 7.8239 & 7.7296 & TRN & \\
\hline CHEMBL96308 & 49308 & 5.4437 & \multicolumn{2}{|c|}{5.582000000000001} & TRN \\
\hline CHEMBL93050 & 49308 & 7.2147 & 7.4739 & TRN & \\
\hline CHEMBL91700 & 49308 & 5.1018 & 5.2844 & TRN & \\
\hline CHEMBL92090 & 49308 & 4.7607 & 4.8554 & TRN & \\
\hline CHEMBL307846 & 49308 & 6.5817 & 6.7408 & TRN & \\
\hline CHEMBL541404 & 49308 & 5.7545 & 6.1856 & TRN & \\
\hline CHEMBL96586 & 49308 & 5.808 & 5.7523 & TRN & \\
\hline CHEMBL540900 & 49308 & 7.2218 & 7.465 & TRN & \\
\hline CHEMBL316316 & 49308 & 6.0757 & 6.0993 & TRN & \\
\hline CHEMBL328307 & 49308 & 7.2924 & 6.9837 & TRN & \\
\hline CHEMBL95070 & 49308 & 5.9516 & 7.0947 & TST & \\
\hline CHEMBL96941 & 49308 & 5.0 & 5.6481 & TRN & \\
\hline CHEMBL541658 & 49308 & 6.7696 & 6.8499 & TST & \\
\hline CHEMBL541403 & 49308 & 5.4089 & 6.0315 & TST & \\
\hline CHEMBL329360 & 49308 & 5.6073 & 6.6145 & TST & \\
\hline CHEMBL540899 & 49308 & 7.0 & 6.9488 & TRN & \\
\hline CHEMBL91917 & 49308 & 5.1518 & \multicolumn{2}{|c|}{5.417000000000001} & וצנו \\
\hline CHEMBL319950 & 49308 & 7.3565 & 7.7018 & TRN & \\
\hline CHEMBL329029 & 49308 & 6.5622 & 6.4768 & TST & \\
\hline CHEMBL 96231 & 49308 & 7.0044 & 7.1558 & TRN & \\
\hline CHEMBL558150 & 49308 & 6.2218 & 5.6214 & TRN & \\
\hline CHEMBL330075 & 49308 & 5.9101 & 7.1821 & TST & \\
\hline CHEMBL328562 & 49308 & 7.1675 & \multicolumn{2}{|c|}{6.8420000000000005} & IRI \\
\hline CHEMBL96639 & 49308 & 7.0706 & 7.3265 & TST & \\
\hline CHEMBL93193 & 49308 & 5.7645 & 6.0485 & TRN & \\
\hline CHEMBL541402 & 49308 & 7.0362 & 6.8971 & TRN & \\
\hline CHEMBL 92929 & 49308 & 5.7883 & 5.7678 & TRN & \\
\hline CHEMBL329392 & 49308 & 6.4881 & 6.2978 & TRN & \\
\hline
\end{tabular}

Page 14046 


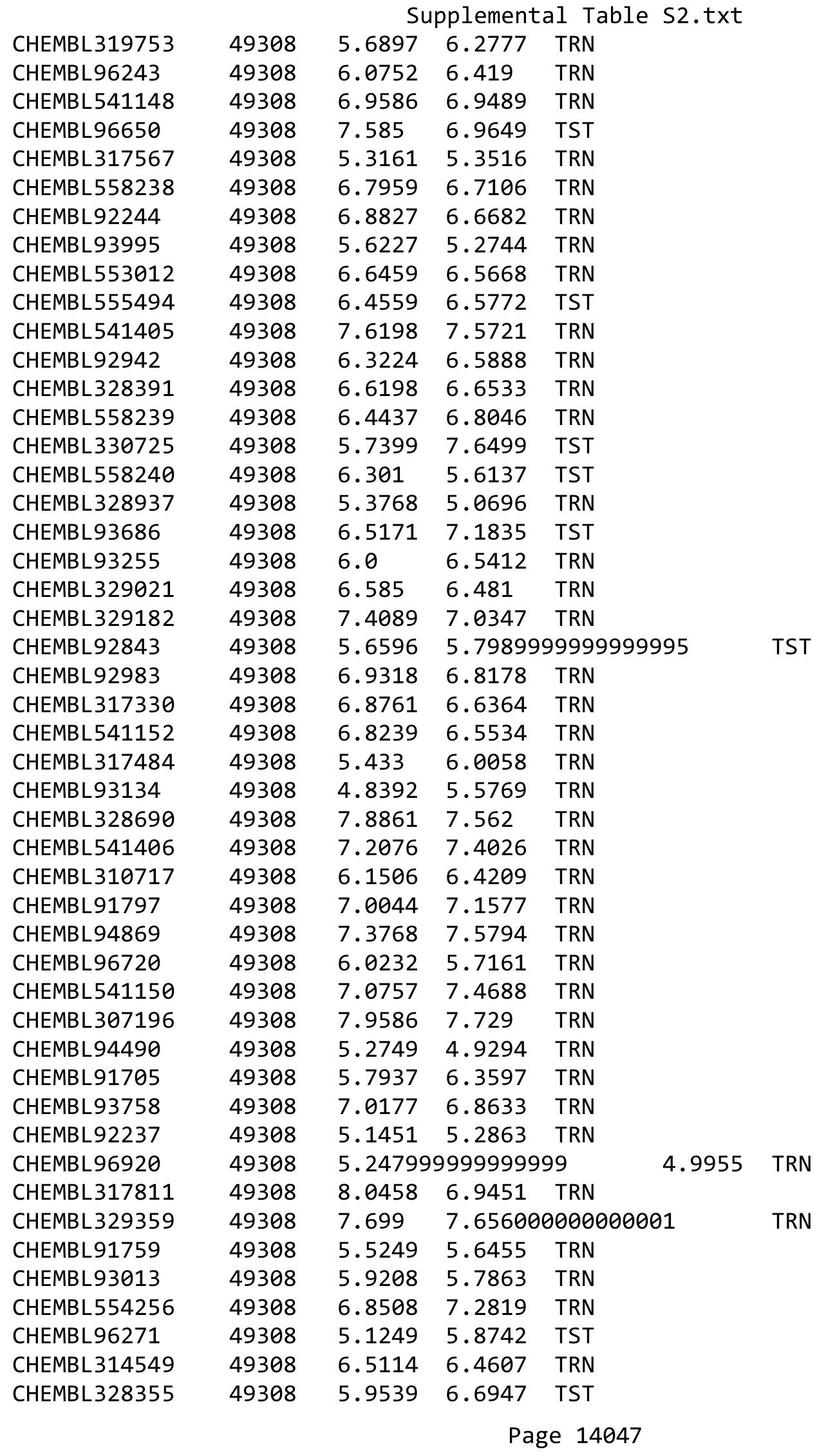




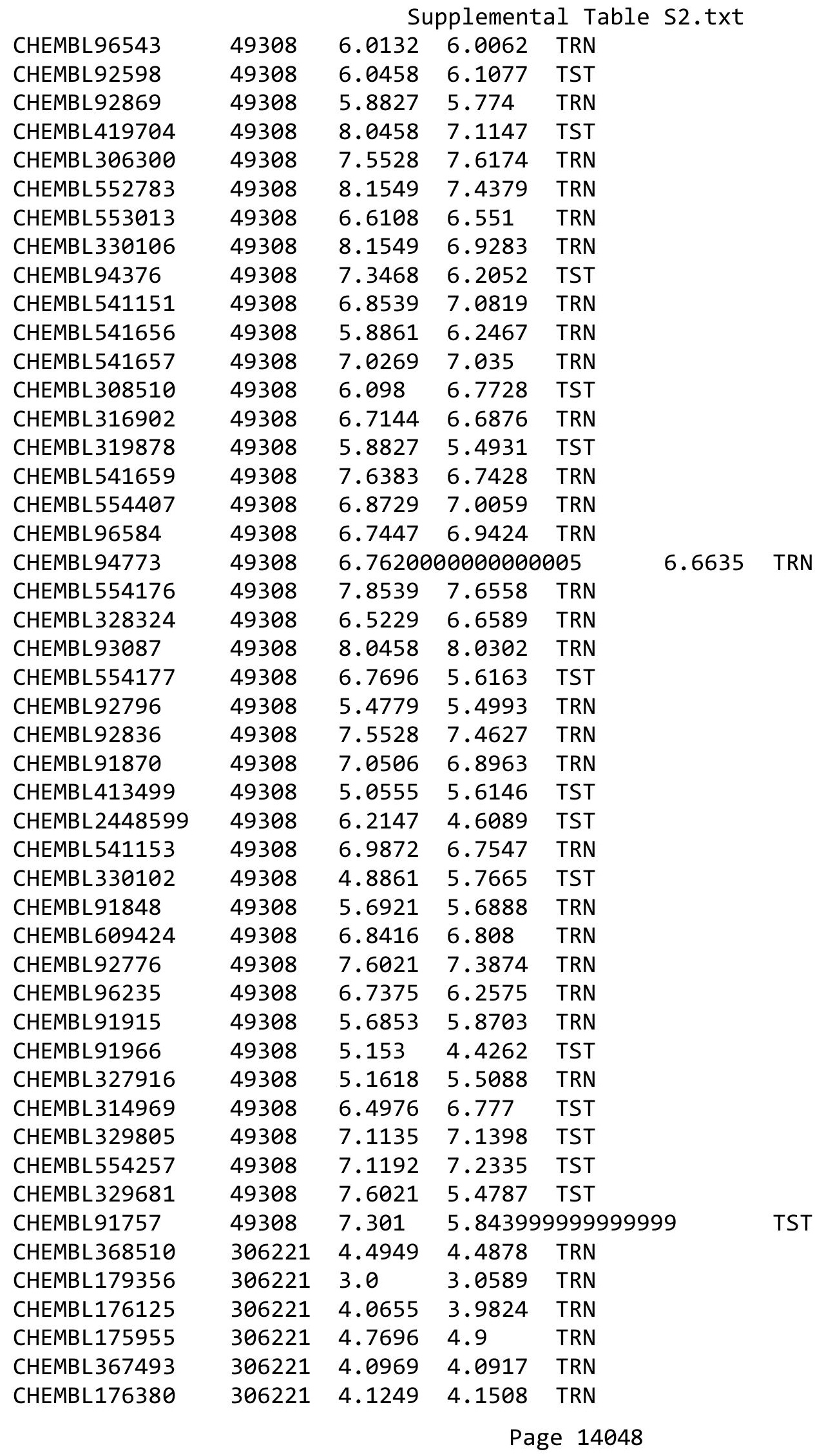




\begin{tabular}{|c|c|c|c|c|}
\hline \multicolumn{5}{|c|}{ Supplemental Table S2.txt } \\
\hline CHEMBL175563 & 306221 & 4.0315 & 3.9778 & TRN \\
\hline CHEMBL366814 & 306221 & 4.0458 & 3.9511 & TRN \\
\hline CHEMBL366397 & 306221 & 4.0706 & 4.1784 & TRN \\
\hline CHEMBL360014 & 306221 & 4.6383 & 4.6916 & TRN \\
\hline CHEMBL180113 & 306221 & 4.3565 & 4.3841 & TRN \\
\hline CHEMBL414840 & 306221 & 3.0 & 3.1004 & TRN \\
\hline CHEMBL179817 & 306221 & 4.0 & 3.9967 & TRN \\
\hline CHEMBL177335 & 306221 & 4.1249 & 4.126 & TRN \\
\hline CHEMBL175960 & 306221 & 4.5686 & 4.581 & TRN \\
\hline CHEMBL 367031 & 306221 & 3.0 & 2.9012 & TRN \\
\hline CHEMBL367845 & 306221 & 3.0 & 2.8591 & TRN \\
\hline CHEMBL179161 & 306221 & 3.0 & 3.2611 & TRN \\
\hline CHEMBL426588 & 306221 & 4.6021 & 4.4326 & TRN \\
\hline CHEMBL175758 & 306221 & 4.7696 & 4.8111 & TRN \\
\hline CHEMBL 369010 & 306221 & 3.0 & 2.8699 & TRN \\
\hline CHEMBL176150 & 306221 & 4.7696 & 4.8802 & TRN \\
\hline CHEMBL368303 & 306221 & 3.0 & 3.0622 & TRN \\
\hline CHEMBL179045 & 306221 & 3.0 & 2.9141 & TRN \\
\hline CHEMBL368526 & 306221 & 4.1612 & 4.211 & TRN \\
\hline CHEMBL175837 & 306221 & 3.0 & 3.2208 & TRN \\
\hline CHEMBL 367503 & 306221 & 4.0 & 4.2013 & TST \\
\hline CHEMBL176113 & 306221 & 4.9586 & 4.9824 & TRN \\
\hline CHEMBL179642 & 306221 & 4.4559 & 4.5026 & TRN \\
\hline CHEMBL424771 & 306221 & 4.4202 & 4.414 & TRN \\
\hline CHEMBL179221 & 306221 & 3.0 & 3.0024 & TRN \\
\hline CHEMBL177375 & 306221 & 4.4202 & 4.4289 & TRN \\
\hline CHEMBL175880 & 306221 & 5.0969 & 4.3155 & TST \\
\hline CHEMBL177242 & 306221 & 3.0 & 2.9802 & TRN \\
\hline CHEMBL369600 & 306221 & 3.0 & 2.9985 & TRN \\
\hline CHEMBL425857 & 306221 & 4.6383 & 4.5919 & TRN \\
\hline CHEMBL175521 & 306221 & 4.9586 & 4.7441 & TRN \\
\hline CHEMBL175984 & 306221 & 4.0757 & 4.0511 & TRN \\
\hline CHEMBL176083 & 306221 & 4.7447 & 4.5779 & TRN \\
\hline CHEMBL175482 & 306221 & 4.3565 & 4.0249 & TST \\
\hline CHEMBL361631 & 306221 & 3.0 & 2.9903 & TRN \\
\hline CHEMBL368194 & 306221 & 4.0 & 4.0165 & TRN \\
\hline CHEMBL3706764 & 306221 & 4.9208 & 4.3313 & TST \\
\hline CHEMBL369513 & 306221 & 3.0 & 2.6071 & TST \\
\hline CHEMBL366369 & 306221 & 4.1367 & 4.0548 & TST \\
\hline CHEMBL179024 & 306221 & 3.0 & 3.3085 & TST \\
\hline CHEMBL175822 & 306221 & 3.0 & 2.5954 & TST \\
\hline CHEMBL175480 & 306221 & 3.0 & 2.6302 & TST \\
\hline CHEMBL176084 & 306221 & 4.0 & 3.6391 & TST \\
\hline CHEMBL435309 & 306221 & 3.0 & 3.1258 & TST \\
\hline CHEMBL176129 & 306221 & 3.0 & 3.4566 & TST \\
\hline CHEMBL175828 & 306221 & 4.3665 & 4.8682 & TST \\
\hline CHEMBL185910 & 302524 & 3.7001 & 3.9332 & TRN \\
\hline CHEMBL186680 & 302524 & 7.699 & 7.1503 & TRN \\
\hline
\end{tabular}




\begin{tabular}{|c|c|c|c|c|c|}
\hline \multicolumn{6}{|c|}{ Supplemental Table S2.txt } \\
\hline CHEMBL186826 & 302524 & 3.7001 & 3.8854 & TRN & \\
\hline CHEMBL361038 & 302524 & 3.7001 & 3.5116 & TRN & \\
\hline CHEMBL189455 & 302524 & 8.0 & 8.1142 & TST & \\
\hline CHEMBL364370 & 302524 & 8.699 & 8.2188 & TRN & \\
\hline CHEMBL188303 & 302524 & 6.7212 & 7.0634 & TRN & \\
\hline CHEMBL184510 & 302524 & 9.0 & 8.5603 & TRN & \\
\hline CHEMBL184656 & 302524 & 3.7001 & 3.801 & TRN & \\
\hline CHEMBL185044 & 302524 & 3.7001 & 5.0759 & TST & \\
\hline CHEMBL186101 & 302524 & 8.5229 & 8.6562 & TRN & \\
\hline CHEMBL187139 & 302524 & 6.1024 & 6.4792 & TRN & \\
\hline CHEMBL361894 & 302524 & 8.2218 & 8.202 & TST & \\
\hline CHEMBL188247 & 302524 & 3.7001 & 3.6572 & TRN & \\
\hline CHEMBL188257 & 302524 & 3.7001 & 3.7732 & TRN & \\
\hline CHEMBL361723 & 302524 & 3.7001 & 3.8693 & TRN & \\
\hline CHEMBL188785 & 302524 & 7.0 & 6.2809 & TST & \\
\hline CHEMBL189617 & 302524 & 5.301 & 4.1122 & TRN & \\
\hline CHEMBL187287 & 302524 & 5.8996 & 5.5863 & TRN & \\
\hline CHEMBL360408 & 302524 & 5.4001 & 4.3775 & TRN & \\
\hline CHEMBL364539 & 302524 & 3.7001 & 3.8973 & TRN & \\
\hline CHEMBL185939 & 302524 & 3.7001 & 3.6745 & TRN & \\
\hline CHEMBL362155 & 302524 & 3.7001 & 4.1132 & TRN & \\
\hline CHEMBL188417 & 302524 & 6.7212 & 6.6702 & TRN & \\
\hline CHEMBL364587 & 302524 & 6.8239 & 7.0994 & TRN & \\
\hline CHEMBL 364646 & 302524 & 3.7001 & 3.7901 & TRN & \\
\hline CHEMBL182326 & 302524 & 3.7001 & 3.4591 & TRN & \\
\hline CHEMBL360206 & 302524 & 8.0 & 7.9949 & TRN & \\
\hline CHEMBL189874 & 302524 & 3.7001 & 3.7342 & TRN & \\
\hline CHEMBL188784 & 302524 & 3.7001 & 3.4291 & TRN & \\
\hline CHEMBL359999 & 302524 & 8.0 & 8.122 & TRN & \\
\hline CHEMBL189665 & 302524 & 3.7001 & 3.6529 & TRN & \\
\hline CHEMBL189415 & 302524 & 5.6021 & 5.6812 & TRN & \\
\hline CHEMBL263448 & 302524 & 3.7001 & 3.8739 & TRN & \\
\hline CHEMBL186476 & 302524 & 3.7001 & 4.0397 & TRN & \\
\hline CHEMBL 273870 & 302524 & 3.7001 & 5.3028 & TST & \\
\hline CHEMBL186606 & 302524 & 3.7001 & 5.5099 & TST & \\
\hline CHEMBL187135 & 302524 & 3.7001 & 3.8606 & TRN & \\
\hline CHEMBL189459 & 302524 & 3.7001 & 3.6473 & TRN & \\
\hline CHEMBL365229 & 302524 & 8.0 & 8.4184 & TRN & \\
\hline CHEMBL189135 & 302524 & 3.7001 & 3.55800 & 00000000003 & TRN \\
\hline CHEMBL185871 & 302524 & 6.8239 & 6.7872 & TRN & \\
\hline CHEMBL182493 & 302524 & 3.7001 & 3.708 & TRN & \\
\hline CHEMBL187006 & 302524 & 7.301 & 7.4077 & TRN & \\
\hline CHEMBL187272 & 302524 & 3.7001 & 3.6193 & TRN & \\
\hline CHEMBL359963 & 302524 & 8.0 & 7.5637 & TRN & \\
\hline CHEMBL439850 & 302524 & 3.7001 & 3.7681 & TRN & \\
\hline CHEMBL186708 & 302524 & 8.2218 & 8.1278 & TST & \\
\hline CHEMBL359794 & 302524 & 9.0 & 9.1271 & TRN & \\
\hline CHEMBL185516 & 302524 & 3.7001 & 5.3262 & TST & \\
\hline
\end{tabular}





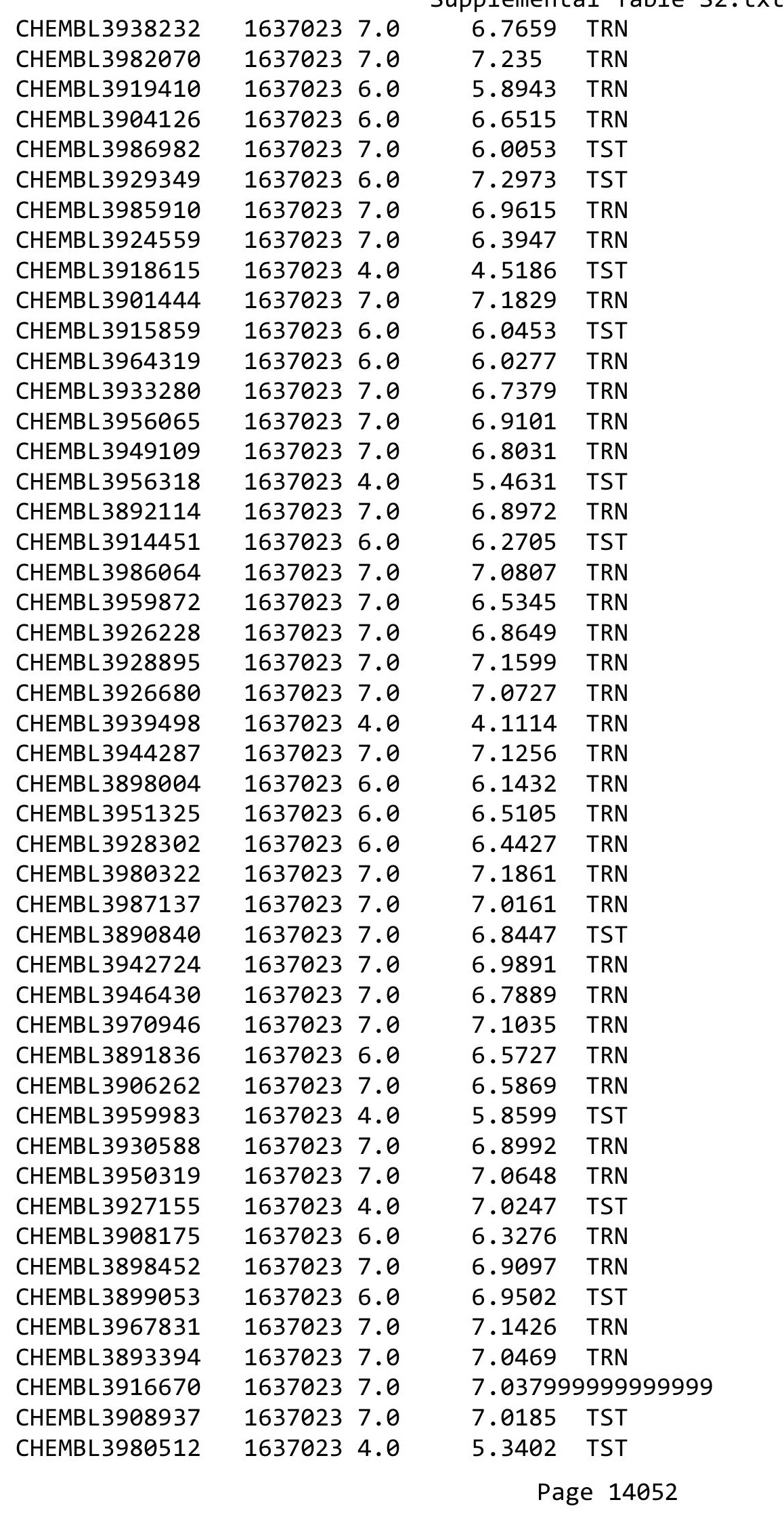

Supplemental Table S2.txt

TRN 


\begin{tabular}{|c|c|c|c|c|c|}
\hline & & & & & \\
\hline CHEMBL3929869 & 1637023 & 6.0 & 6.5186 & TST & \\
\hline CHEMBL3931058 & 1637023 & 7.0 & 7.0237 & TRN & \\
\hline CHEMBL3970691 & 1637023 & 7.0 & 6.7716 & TRN & \\
\hline CHEMBL3953463 & 1637023 & 7.0 & 6.1056 & TRN & \\
\hline CHEMBL3940071 & 1637023 & 7.0 & 6.99700 & 0000000001 & TRN \\
\hline CHEMBL3966051 & 1637023 & 7.0 & 6.8778 & TRN & \\
\hline CHEMBL3910886 & 1637023 & 7.0 & 7.0733 & TST & \\
\hline CHEMBL3960417 & 1637023 & 7.0 & 6.8283 & TRN & \\
\hline CHEMBL3925662 & 1637023 & 6.0 & 6.7089 & TRN & \\
\hline CHEMBL3963087 & 1637023 & 7.0 & 6.565 & TRN & \\
\hline CHEMBL3953598 & 1637023 & 4.0 & 6.2261 & TST & \\
\hline CHEMBL3942182 & 1637023 & 4.0 & 5.7594 & TST & \\
\hline CHEMBL3926992 & 1637023 & 7.0 & 6.8777 & TRN & \\
\hline CHEMBL485894 & 522116 & 4.2007 & 4.1958 & TRN & \\
\hline CHEMBL483987 & 522116 & 4.5686 & 4.294 & TRN & \\
\hline CHEMBL473709 & 522116 & 7.301 & 7.3167 & TRN & \\
\hline CHEMBL486518 & 522116 & 7.301 & 7.148 & TRN & \\
\hline CHEMBL521518 & 522116 & 5.699 & 5.8604 & TRN & \\
\hline CHEMBL473708 & 522116 & 7.699 & 7.6139 & TRN & \\
\hline CHEMBL475115 & 522116 & 7.1549 & 7.2099 & TST & \\
\hline CHEMBL484977 & 522116 & 4.5229 & 4.1218 & TRN & \\
\hline CHEMBL485174 & 522116 & 6.0 & 6.6397 & TST & \\
\hline CHEMBL514815 & 522116 & 8.0 & 8.06299 & 9999999999 & TRN \\
\hline CHEMBL520389 & 522116 & 6.2218 & 5.189 & TST & \\
\hline CHEMBL370902 & 522116 & 7.6021 & 7.7802 & TRN & \\
\hline CHEMBL485895 & 522116 & 4.6383 & 4.4916 & TRN & \\
\hline CHEMBL486519 & 522116 & 4.7212 & 4.7799 & TRN & \\
\hline CHEMBL486942 & 522116 & 5.3979 & 5.4702 & TRN & \\
\hline CHEMBL514181 & 522116 & 5.9208 & 5.9061 & TRN & \\
\hline CHEMBL484626 & 522116 & 4.2757 & 4.4907 & TRN & \\
\hline CHEMBL191910 & 522116 & 7.699 & 7.6778 & TRN & \\
\hline CHEMBL473707 & 522116 & 7.699 & 7.5935 & TRN & \\
\hline CHEMBL483977 & 522116 & 4.3768 & 4.3225 & TRN & \\
\hline CHEMBL486940 & 522116 & 5.0969 & 4.1297 & TST & \\
\hline CHEMBL484978 & 522116 & 5.3665 & 5.6569 & TRN & \\
\hline CHEMBL474711 & 522116 & 8.0 & 7.824 & TRN & \\
\hline CHEMBL484805 & 522116 & 5.1549 & 4.9882 & TRN & \\
\hline CHEMBL483984 & 522116 & 4.3565 & 4.69 & TST & \\
\hline CHEMBL485708 & 522116 & 3.0 & 5.1332 & TST & \\
\hline CHEMBL520203 & 522116 & 5.0458 & 5.0141 & TRN & \\
\hline CHEMBL515410 & 522116 & 5.8239 & 5.9823 & TRN & \\
\hline CHEMBL506426 & 522116 & 5.4202 & 5.5894 & TRN & \\
\hline CHEMBL485906 & 522116 & 5.0362 & 4.6673 & TST & \\
\hline CHEMBL474309 & 522116 & 7.2218 & 7.5274 & TST & \\
\hline CHEMBL484139 & 522116 & 6.699 & 6.4756 & TRN & \\
\hline CHEMBL485905 & 522116 & 4.2218 & 4.5395 & TST & \\
\hline CHEMBL453237 & 522116 & 4.585 & 4.8757 & TST & \\
\hline CHEMBL483985 & 522116 & 4.1487 & 4.1706 & TRN & \\
\hline
\end{tabular}




\begin{tabular}{|c|c|c|c|c|}
\hline & & & pplement & al $\mathrm{T}$ \\
\hline CHEMBL195161 & 522116 & 7.0 & 6.9993 & TRN \\
\hline CHEMBL484973 & 522116 & 5.0458 & 5.0597 & TRN \\
\hline CHEMBL483968 & 522116 & 4.6778 & 4.8604 & TRN \\
\hline CHEMBL514034 & 522116 & 7.5229 & 7.6867 & TRN \\
\hline CHEMBL484628 & 522116 & 4.2076 & 4.1185 & TRN \\
\hline CHEMBL191673 & 522116 & 7.5229 & 7.5105 & TRN \\
\hline CHEMBL195817 & 522116 & 7.699 & 7.7028 & TRN \\
\hline CHEMBL486097 & 522116 & 6.0969 & 5.9521 & TRN \\
\hline CHEMBL488575 & 522116 & 5.4559 & 5.4439 & TRN \\
\hline CHEMBL475526 & 522116 & 7.0 & 7.2334 & TST \\
\hline CHEMBL519064 & 522116 & 6.301 & 6.1954 & TRN \\
\hline CHEMBL521334 & 522116 & 4.5229 & 4.6656 & TRN \\
\hline CHEMBL518904 & 522116 & 5.2218 & 5.0271 & TRN \\
\hline CHEMBL473711 & 522116 & 5.6198 & 5.5111 & TRN \\
\hline CHEMBL445292 & 522116 & 5.1427 & 4.1703 & TST \\
\hline CHEMBL483976 & 522116 & 3.0 & 3.1519 & TRN \\
\hline CHEMBL487546 & 522116 & 3.0 & 5.1287 & TST \\
\hline CHEMBL473085 & 522116 & 5.0 & 4.9226 & TRN \\
\hline CHEMBL514159 & 522116 & 7.1549 & 7.2268 & TRN \\
\hline CHEMBL487684 & 522116 & 5.9586 & 4.4838 & TST \\
\hline CHEMBL475321 & 522116 & 7.5229 & 7.4924 & TRN \\
\hline CHEMBL191190 & 522116 & 7.5229 & 7.6499 & TRN \\
\hline CHEMBL485975 & 522116 & 5.0969 & 5.1919 & TRN \\
\hline CHEMBL486941 & 522116 & 4.1249 & 4.0921 & TRN \\
\hline CHEMBL520377 & 522116 & 3.0 & 2.9013 & TRN \\
\hline CHEMBL515409 & 522116 & 6.5229 & 5.7104 & TST \\
\hline CHEMBL427545 & 522116 & 7.0969 & 7.1696 & TRN \\
\hline CHEMBL484627 & 522116 & 4.3468 & 4.2077 & TRN \\
\hline CHEMBL473710 & 522116 & 6.699 & 6.7397 & TRN \\
\hline CHEMBL483797 & 522116 & 4.7959 & 4.7695 & TST \\
\hline CHEMBL487750 & 522116 & 3.0 & 5.398 & TST \\
\hline CHEMBL487135 & 522116 & 4.9586 & 5.2314 & TST \\
\hline CHEMBL520477 & 522116 & 6.3979 & 6.2427 & TRN \\
\hline CHEMBL486725 & 522116 & 4.3188 & 4.2583 & TRN \\
\hline CHEMBL484986 & 522116 & 5.1427 & 5.0221 & TST \\
\hline CHEMBL191141 & 522116 & 7.3979 & 7.4455 & TRN \\
\hline CHEMBL486170 & 522116 & 5.0 & 4.8969 & TRN \\
\hline CHEMBL520321 & 522116 & 4.0555 & 4.5892 & TST \\
\hline CHEMBL191655 & 522116 & 5.9208 & 5.8222 & TRN \\
\hline CHEMBL486169 & 522116 & 4.9586 & 5.0051 & TRN \\
\hline CHEMBL475322 & 522116 & 8.0969 & 8.0686 & TRN \\
\hline CHEMBL519871 & 522116 & 3.0 & 3.5552 & TRN \\
\hline CHEMBL519015 & 522116 & 4.2924 & 4.6717 & TST \\
\hline CHEMBL191961 & 522116 & 6.8539 & 6.7833 & TRN \\
\hline CHEMBL520017 & 522116 & 4.9208 & 5.1558 & TRN \\
\hline CHEMBL365741 & 522116 & 7.1549 & 7.1999 & TRN \\
\hline CHEMBL484804 & 522116 & 5.0969 & 5.1192 & TRN \\
\hline CHEMBL543919 & 52873 & 4.5003 & 4.5308 & TRN \\
\hline
\end{tabular}




\begin{tabular}{|c|c|c|c|c|c|c|}
\hline & & \multicolumn{5}{|c|}{ Supplemental Table s2.txt } \\
\hline CHEMBL143291 & 52873 & 4.9318 & 4.894 & TRN & & \\
\hline CHEMBL143816 & 52873 & 6.3516 & 6.3363 & TRN & & \\
\hline CHEMBL140210 & 52873 & 4.4295 & 4.3773 & TRN & & \\
\hline CHEMBL344405 & 52873 & 5.4295 & 5.4497 & TRN & & \\
\hline CHEMBL344556 & 52873 & 7.301 & 7.2451 & TRN & & \\
\hline CHEMBL344996 & 52873 & 5.6799 & 5.7544 & TRN & & \\
\hline CHEMBL357498 & 52873 & 4.6498 & 4.6229 & TRN & & \\
\hline CHEMBL143496 & 52873 & 3.0 & 2.9784 & TRN & & \\
\hline CHEMBL142705 & 52873 & 5.7496 & \multicolumn{3}{|c|}{5.752999999999999} & TRN \\
\hline CHEMBL139699 & 52873 & 5.301 & 5.3812 & TRN & & \\
\hline CHEMBL341877 & 52873 & \multicolumn{3}{|c|}{5.821000000000001} & 5.7336 & TRN \\
\hline CHEMBL139647 & 52873 & 6.2007 & 6.2347 & TRN & & \\
\hline CHEMBL142997 & 52873 & 5.0701 & 5.1099 & TRN & & \\
\hline CHEMBL143437 & 52873 & 5.1002 & 5.1691 & TRN & & \\
\hline CHEMBL141074 & 52873 & 5.6003 & 5.6826 & TRN & & \\
\hline CHEMBL141774 & 52873 & 6.7496 & 6.7393 & TRN & & \\
\hline CHEMBL140115 & 52873 & 6.2798 & 6.2884 & TRN & & \\
\hline CHEMBL143756 & 52873 & 3.0 & 3.0274 & TRN & & \\
\hline CHEMBL141195 & 52873 & 7.3768 & 7.362 & TRN & & \\
\hline CHEMBL141732 & 52873 & 7.3279 & 7.4023 & TRN & & \\
\hline CHEMBL432994 & 52873 & 3.0 & 2.9902 & TRN & & \\
\hline CHEMBL357459 & 52873 & 7.1487 & 6.0791 & TST & & \\
\hline CHEMBL143518 & 52873 & 7.4437 & 7.3108 & TRN & & \\
\hline CHEMBL342525 & 52873 & 3.0 & 2.9554 & TRN & & \\
\hline CHEMBL141126 & 52873 & 6.2007 & 6.1503 & TRN & & \\
\hline CHEMBL442489 & 52873 & 3.0 & 2.9642 & TRN & & \\
\hline CHEMBL139611 & 52873 & 5.2291 & 5.25700 & 0000000001 & & TRN \\
\hline CHEMBL139818 & 52873 & 5.4295 & 5.2051 & TST & & \\
\hline CHEMBL141086 & 52873 & 6.71 & 5.1232 & TST & & \\
\hline CHEMBL342581 & 52873 & 5.0501 & 5.0493 & TRN & & \\
\hline CHEMBL344913 & 52873 & \multicolumn{3}{|c|}{6.7620000000000005} & 6.7798 & TRN \\
\hline CHEMBL143196 & 52873 & 6.2503 & 6.2249 & TRN & & \\
\hline CHEMBL141040 & 52873 & 6.5406 & 6.5912 & TRN & & \\
\hline CHEMBL344613 & 52873 & 7.2007 & 5.8483 & TST & & \\
\hline CHEMBL141015 & 52873 & 5.5229 & 5.4943 & TRN & & \\
\hline CHEMBL334922 & 52873 & 5.4295 & 5.3881 & TRN & & \\
\hline CHEMBL140558 & 52873 & 6.8013 & 6.9006 & TST & & \\
\hline CHEMBL143116 & 52873 & 7.3979 & 7.4285 & TRN & & \\
\hline CHEMBL343081 & 52873 & 6.7496 & 6.7287 & TRN & & \\
\hline CHEMBL342124 & 52873 & 4.699 & 4.6343 & TST & & \\
\hline CHEMBL141144 & 52873 & 3.0 & 2.9777 & TRN & & \\
\hline CHEMBL143319 & 52873 & 5.4202 & 5.4387 & TRN & & \\
\hline CHEMBL141041 & 52873 & 5.8013 & 5.7847 & TRN & & \\
\hline CHEMBL143460 & 52873 & \multicolumn{3}{|c|}{4.821000000000001} & 4.8426 & TRN \\
\hline CHEMBL143052 & 52873 & 6.699 & 6.7168 & TST & & \\
\hline CHEMBL143438 & 52873 & 4.5498 & 4.6442 & TRN & & \\
\hline CHEMBL141472 & 52873 & 5.3696 & 5.1896 & TST & & \\
\hline CHEMBL141047 & 52873 & 6.7496 & 6.4869 & TST & & \\
\hline
\end{tabular}




\begin{tabular}{|c|c|c|c|c|}
\hline & & & pplement & al $\mathrm{T}$ \\
\hline CHEMBL142996 & 52873 & 5.8013 & 5.8264 & TRN \\
\hline CHEMBL358621 & 52873 & 6.3799 & 6.4286 & TRN \\
\hline CHEMBL143458 & 52873 & 4.301 & 4.6016 & TST \\
\hline CHEMBL 337130 & 52873 & 6.6799 & 6.4498 & TRN \\
\hline CHEMBL142214 & 52873 & 7.4437 & 7.4495 & TRN \\
\hline CHEMBL337546 & 52873 & 4.7799 & 4.7804 & TRN \\
\hline CHEMBL141237 & 52873 & 6.0799 & 6.1355 & TRN \\
\hline CHEMBL139954 & 52873 & 5.9508 & 5.9535 & TRN \\
\hline CHEMBL143237 & 52873 & 6.8013 & 7.1481 & TST \\
\hline CHEMBL142074 & 52873 & 7.2007 & 7.2381 & TRN \\
\hline CHEMBL356115 & 52873 & 7.0506 & 7.0431 & TST \\
\hline CHEMBL141248 & 52873 & 7.0 & 6.7266 & TST \\
\hline CHEMBL141104 & 52873 & 6.5498 & 7.0577 & TST \\
\hline CHEMBL358411 & 52873 & 7.4437 & 6.775 & TST \\
\hline CHEMBL139937 & 52873 & 6.5498 & 6.7945 & TST \\
\hline CHEMBL341721 & 52873 & 5.6498 & 4.0471 & TST \\
\hline CHEMBL1257300 & 665226 & 4.0 & 4.11 & TRN \\
\hline CHEMBL1257999 & 665226 & 4.0 & 5.2133 & TST \\
\hline CHEMBL383966 & 665226 & 5.0 & 5.8748 & TST \\
\hline CHEMBL1256437 & 665226 & 4.0 & 4.0433 & TRN \\
\hline CHEMBL452319 & 665226 & 6.0269 & 5.4577 & TRN \\
\hline CHEMBL1258797 & 665226 & 5.3872 & 5.9967 & TRN \\
\hline CHEMBL379511 & 665226 & 5.0 & 5.7624 & TST \\
\hline CHEMBL 215665 & 665226 & 4.0 & 5.3271 & TST \\
\hline CHEMBL1257771 & 665226 & 4.0 & 4.0619 & TRN \\
\hline CHEMBL215475 & 665226 & 5.0 & 6.0128 & TRN \\
\hline CHEMBL 215476 & 665226 & 6.0862 & 6.0569 & TRN \\
\hline CHEMBL1257889 & 665226 & 5.2291 & 5.2266 & TRN \\
\hline CHEMBL 212863 & 665226 & 4.0 & 5.3598 & TRN \\
\hline CHEMBL1257648 & 665226 & 4.0 & 4.2102 & TRN \\
\hline CHEMBL215083 & 665226 & 6.2757 & 5.5522 & TRN \\
\hline CHEMBL1258350 & 665226 & 6.284 & 5.6639 & TRN \\
\hline CHEMBL1257770 & 665226 & 4.8729 & 5.2039 & TRN \\
\hline CHEMBL 215487 & 665226 & 5.2596 & 5.2388 & TRN \\
\hline CHEMBL 386462 & 665226 & 5.3565 & 5.5074 & TST \\
\hline CHEMBL1256440 & 665226 & 4.0 & 4.0674 & TRN \\
\hline CHEMBL1256441 & 665226 & 5.058 & 4.0705 & TRN \\
\hline CHEMBL214659 & 665226 & 6.2007 & 5.6524 & TRN \\
\hline CHEMBL385596 & 665226 & 6.2924 & 5.5479 & TRN \\
\hline CHEMBL1258232 & 665226 & 6.2147 & 5.9589 & TRN \\
\hline CHEMBL1257416 & 665226 & 5.301 & 5.4289 & TRN \\
\hline CHEMBL 215390 & 665226 & 6.2366 & 5.5501 & TRN \\
\hline CHEMBL379869 & 665226 & 6.2218 & 5.229 & TRN \\
\hline CHEMBL 1257529 & 665226 & 4.0 & 4.2421 & TRN \\
\hline CHEMBL1257299 & 665226 & 4.0 & 5.1772 & TRN \\
\hline CHEMBL 214610 & 665226 & 6.1079 & 5.6299 & TRN \\
\hline CHEMBL1258000 & 665226 & 4.0 & 5.063 & TRN \\
\hline CHEMBL214605 & 665226 & 5.2366 & 5.5112 & TRN \\
\hline
\end{tabular}




\begin{tabular}{|c|c|c|c|c|c|}
\hline \multirow[b]{2}{*}{ CHEMBL379766 } & & \multicolumn{4}{|c|}{ Supplemental Table s2.txt } \\
\hline & 665226 & 6.2757 & 5.53600 & 00000000005 & TRN \\
\hline CHEMBL1257301 & 665226 & 4.0 & 4.5815 & TRN & \\
\hline CHEMBL215780 & 665226 & 5.1871 & 5.4019 & TRN & \\
\hline CHEMBL1256439 & 665226 & 4.0 & 4.1407 & TRN & \\
\hline CHEMBL1258351 & 665226 & 6.1612 & 5.7304 & TRN & \\
\hline CHEMBL1257890 & 665226 & 5.8665 & 5.1154 & TST & \\
\hline CHEMBL384373 & 665226 & 6.5086 & 6.0728 & TRN & \\
\hline CHEMBL214449 & 665226 & 6.2596 & 5.6516 & TRN & \\
\hline CHEMBL1256438 & 665226 & 5.0269 & 4.0297 & TRN & \\
\hline CHEMBL1258798 & 665226 & 5.2596 & 5.767 & TRN & \\
\hline CHEMBL385072 & 665226 & 4.0 & 4.0228 & TRN & \\
\hline CHEMBL 385390 & 665226 & 4.0 & 5.2075 & TRN & \\
\hline CHEMBL386292 & 665226 & 5.1367 & 5.6416 & TRN & \\
\hline CHEMBL1257647 & 665226 & 5.2147 & 5.19799 & 99999999995 & TST \\
\hline CHEMBL211989 & 665226 & 4.0 & 4.7666 & TST & \\
\hline CHEMBL 215769 & 665226 & 5.5686 & 5.71299 & 9999999999 & TST \\
\hline CHEMBL384161 & 665226 & 4.0 & 4.3577 & TST & \\
\hline CHEMBL1258682 & 665226 & 4.0 & 5.1292 & TST & \\
\hline CHEMBL1257183 & 665226 & 5.3098 & 4.4715 & TST & \\
\hline CHEMBL452318 & 665226 & 5.3372 & 5.4459 & TST & \\
\hline CHEMBL3648737 & 1527972 & 9.5751 & 7.4619 & TRN & \\
\hline CHEMBL 3648748 & 1527972 & 7.7773 & 8.0405 & TST & \\
\hline CHEMBL3648812 & 1527972 & 8.98299 & 79999999 & 8.0934 & TRN \\
\hline CHEMBL 3648760 & 1527972 & 7.4737 & 8.3052 & TRN & \\
\hline CHEMBL3648795 & 1527972 & 6.0 & 9.1098 & TRN & \\
\hline CHEMBL 3648744 & 1527972 & 9.5302 & 8.793 & TRN & \\
\hline CHEMBL3648833 & 1527972 & 6.0 & 7.2859 & TRN & \\
\hline CHEMBL3648852 & 1527972 & 10.3768 & 8.6447 & TRN & \\
\hline CHEMBL 3639476 & 1527972 & 6.0 & 6.7688 & TRN & \\
\hline CHEMBL3648819 & 1527972 & 8.5952 & 8.0057 & TRN & \\
\hline CHEMBL3648665 & 1527972 & 9.7799 & 8.1342 & TRN & \\
\hline CHEMBL3648855 & 1527972 & 10.4202 & 8.6506 & TRN & \\
\hline CHEMBL 3648805 & 1527972 & 9.7011 & 8.4788 & TRN & \\
\hline CHEMBL3648670 & 1527972 & 10.8239 & 8.4684 & TST & \\
\hline CHEMBL3648679 & 1527972 & 10.2518 & 9.4633 & TRN & \\
\hline CHEMBL3648792 & 1527972 & 10.2596 & 9.3476 & TRN & \\
\hline CHEMBL3639475 & 1527972 & 6.0 & 6.7785 & TRN & \\
\hline CHEMBL 3648785 & 1527972 & 6.0 & 6.1683 & TRN & \\
\hline CHEMBL3648708 & 1527972 & 6.0 & 7.2229 & TRN & \\
\hline CHEMBL3648858 & 1527972 & 10.0757 & 8.8517 & TRN & \\
\hline CHEMBL3648658 & 1527972 & 6.0 & 7.0881 & TRN & \\
\hline CHEMBL3648730 & 1527972 & 6.0 & 7.1563 & TRN & \\
\hline CHEMBL3648796 & 1527972 & 6.0 & 7.8539 & TRN & \\
\hline CHEMBL3648813 & 1527972 & 8.8416 & 7.8563 & TRN & \\
\hline CHEMBL3648738 & 1527972 & 10.1586 & 6.5461 & TRN & \\
\hline CHEMBL 3648710 & 1527972 & 6.0 & 7.2459 & TRN & \\
\hline CHEMBL3648830 & 1527972 & 6.0 & 8.1927 & TRN & \\
\hline CHEMBL3648754 & 1527972 & 6.0 & 7.2838 & TRN & \\
\hline
\end{tabular}




\begin{tabular}{|c|c|c|c|c|c|}
\hline \multicolumn{6}{|c|}{ Supplemental Table S2.txt } \\
\hline CHEMBL 3648793 & 1527972 & 6.0 & 7.768 & TRN & \\
\hline CHEMBL 3648815 & 1527972 & 6.0 & 6.8396 & TRN & \\
\hline CHEMBL3648804 & 1527972 & 9.4413 & 7.09399 & 9999999999 & TST \\
\hline CHEMBL 3648808 & 1527972 & 8.4318 & 8.526 & TST & \\
\hline CHEMBL 3648752 & 1527972 & 6.0 & 6.4345 & TRN & \\
\hline CHEMBL 3648772 & 1527972 & 6.0 & 5.8923 & TRN & \\
\hline CHEMBL 3648854 & 1527972 & 9.0516 & 8.14299 & 9999999999 & TRN \\
\hline CHEMBL 3648860 & 1527972 & 10.2366 & 8.1988 & TRN & \\
\hline CHEMBL 3648671 & 1527972 & 11.0 & 8.3264 & TST & \\
\hline CHEMBL 3648806 & 1527972 & 9.8416 & 8.4538 & TST & \\
\hline CHEMBL 3648765 & 1527972 & 8.1643 & 9.1005 & TRN & \\
\hline CHEMBL 3648750 & 1527972 & 10.1249 & 8.5638 & TRN & \\
\hline CHEMBL3648851 & 1527972 & 6.0 & 8.3764 & TRN & \\
\hline CHEMBL 3648811 & 1527972 & 8.9318 & 7.3853 & TRN & \\
\hline CHEMBL 3648700 & 1527972 & 11.0458 & 7.5845 & TRN & \\
\hline CHEMBL 3648803 & 1527972 & 9.4202 & 7.0155 & TRN & \\
\hline CHEMBL 3648841 & 1527972 & 10.4815 & 8.9749 & TRN & \\
\hline CHEMBL 3942484 & 1527972 & 6.0 & 6.487 & TST & \\
\hline CHEMBL 3648862 & 1527972 & 10.3279 & 7.9103 & TRN & \\
\hline CHEMBL3648802 & 1527972 & 8.3595 & 8.4905 & TST & \\
\hline CHEMBL 3648798 & 1527972 & 8.6737 & 8.2977 & TST & \\
\hline CHEMBL 3648703 & 1527972 & 6.0 & 6.7497 & TRN & \\
\hline CHEMBL 3648853 & 1527972 & 6.0 & 8.0029 & TRN & \\
\hline CHEMBL 3648687 & 1527972 & 6.0 & 7.8338 & TRN & \\
\hline CHEMBL3648829 & 1527972 & 6.0 & 7.6865 & TST & \\
\hline CHEMBL 3648857 & 1527972 & 9.8894 & 9.218 & TRN & \\
\hline CHEMBL 3648845 & 1527972 & 6.0 & 7.9741 & TRN & \\
\hline CHEMBL3648739 & 1527972 & 9.8153 & 7.9317 & TRN & \\
\hline CHEMBL 3648759 & 1527972 & 10.6576 & 9.5405 & TRN & \\
\hline CHEMBL3648693 & 1527972 & 6.0 & 5.7815 & TRN & \\
\hline CHEMBL 3648699 & 1527972 & 6.0 & 7.4478 & TRN & \\
\hline CHEMBL 3648756 & 1527972 & 6.0 & 7.2146 & TRN & \\
\hline CHEMBL 3648847 & 1527972 & 6.0 & 7.8249 & TRN & \\
\hline CHEMBL3648761 & 1527972 & 6.0 & 8.7974 & TRN & \\
\hline CHEMBL3648725 & 1527972 & 6.0 & 7.7061 & TRN & \\
\hline CHEMBL 3648722 & 1527972 & 6.0 & 5.8564 & TRN & \\
\hline CHEMBL3648859 & 1527972 & 6.0 & 7.7642 & TRN & \\
\hline CHEMBL 3648688 & 1527972 & 9.6861 & 8.7369 & TST & \\
\hline CHEMBL3648733 & 1527972 & 6.0 & 7.4736 & TRN & \\
\hline CHEMBL3648690 & 1527972 & 6.0 & 8.4516 & TRN & \\
\hline CHEMBL 3648816 & 1527972 & 6.0 & 7.3144 & TRN & \\
\hline CHEMBL 3648751 & 1527972 & 9.0168 & 8.3487 & TRN & \\
\hline CHEMBL3648773 & 1527972 & 6.0 & 7.2511 & TRN & \\
\hline CHEMBL3648824 & 1527972 & 6.0 & 7.4687 & TRN & \\
\hline CHEMBL3648777 & 1527972 & 8.5513 & 8.7929 & TRN & \\
\hline CHEMBL 3648797 & 1527972 & 6.0 & 6.4089 & TRN & \\
\hline CHEMBL3648766 & 1527972 & 9.6021 & 9.1638 & TST & \\
\hline CHEMBL3652033 & 1527972 & 6.0 & 9.0626 & TRN & \\
\hline
\end{tabular}




\begin{tabular}{|c|c|c|c|c|c|c|}
\hline \multicolumn{7}{|c|}{ Supplemental Table S2.txt } \\
\hline CHEMBL 3648742 & 1527972 & 6.0 & 7.2222 & TRN & & \\
\hline CHEMBL 3648692 & 1527972 & 6.0 & 5.7549 & TRN & & \\
\hline CHEMBL 3648720 & 1527972 & 6.0 & 7.2527 & TRN & & \\
\hline CHEMBL 3648826 & 1527972 & 10.9208 & 7.7343 & TRN & & \\
\hline CHEMBL 3648818 & 1527972 & 8.9666 & 7.5249 & TRN & & \\
\hline CHEMBL 3648707 & 1527972 & 6.0 & 7.71200 & 0000000001 & & TRN \\
\hline CHEMBL 3648839 & 1527972 & 6.0 & 7.785 & TRN & & \\
\hline CHEMBL3648675 & 1527972 & 6.0 & 8.0082 & TRN & & \\
\hline CHEMBL 3648863 & 1527972 & 10.30099 & 99999999 & 998 & 8.4088 & TRN \\
\hline CHEMBL3648736 & 1527972 & 9.0794 & 7.2227 & TRN & & \\
\hline CHEMBL 3648676 & 1527972 & 11.3979 & 7.143 & TRN & & \\
\hline CHEMBL 3648662 & 1527972 & 10.1024 & 8.226 & TRN & & \\
\hline CHEMBL3953408 & 1527972 & 9.5346 & 7.3366 & TST & & \\
\hline CHEMBL3648801 & 1527972 & 8.3716 & 8.0695 & TST & & \\
\hline CHEMBL3648835 & 1527972 & 10.5229 & 7.4024 & TRN & & \\
\hline CHEMBL 3648846 & 1527972 & 6.0 & 8.3874 & TRN & & \\
\hline CHEMBL3648778 & 1527972 & 8.4283 & 7.9424 & TST & & \\
\hline CHEMBL3648667 & 1527972 & 6.0 & 8.6712 & TST & & \\
\hline CHEMBL3957398 & 1527972 & 9.6198 & 5.21200 & 0000000001 & & TST \\
\hline CHEMBL 3648825 & 1527972 & 10.3279 & 7.7572 & TRN & & \\
\hline CHEMBL 3648764 & 1527972 & 9.4078 & 9.3365 & TRN & & \\
\hline CHEMBL 3648810 & 1527972 & 9.5017 & 7.7181 & TRN & & \\
\hline CHEMBL3648691 & 1527972 & 6.0 & 5.9204 & TRN & & \\
\hline CHEMBL3648661 & 1527972 & 10.5229 & 8.8301 & TRN & & \\
\hline CHEMBL 3648758 & 1527972 & 9.1733 & 9.1926 & TRN & & \\
\hline CHEMBL 3648820 & 1527972 & 7.451000 & 90000000 & 005 & 7.7588 & TRN \\
\hline CHEMBL 3648757 & 1527972 & 9.1481 & 8.1736 & TRN & & \\
\hline CHEMBL 3648701 & 1527972 & 10.3665 & 8.06299 & 9999999999 & & TRN \\
\hline CHEMBL 3648740 & 1527972 & 9.4157 & 7.4155 & TRN & & \\
\hline CHEMBL3648709 & 1527972 & 6.0 & 6.2897 & TRN & & \\
\hline CHEMBL 3648663 & 1527972 & 9.3665 & 7.8818 & TRN & & \\
\hline CHEMBL 3648800 & 1527972 & 9.1051 & 8.3355 & TST & & \\
\hline CHEMBL 3648684 & 1527972 & 9.9208 & 7.1788 & TRN & & \\
\hline CHEMBL 3648745 & 1527972 & 9.982999 & 99999999 & 99 & 8.9988 & TRN \\
\hline CHEMBL 3648788 & 1527972 & 9.6536 & 9.3381 & TRN & & \\
\hline CHEMBL 3648668 & 1527972 & 10.1805 & 8.8615 & TST & & \\
\hline CHEMBL3648657 & 1527972 & 6.0 & 8.4846 & TRN & & \\
\hline CHEMBL 3648747 & 1527972 & 6.0 & 6.5647 & TRN & & \\
\hline CHEMBL3648786 & 1527972 & 7.8539 & 8.4533 & TST & & \\
\hline CHEMBL 3648794 & 1527972 & 10.1612 & 7.7579 & TST & & \\
\hline CHEMBL 3648789 & 1527972 & 6.0 & 8.2033 & TRN & & \\
\hline CHEMBL 3648749 & 1527972 & 9.1688 & 7.8543 & TRN & & \\
\hline CHEMBL3648695 & 1527972 & 6.0 & 5.3679 & TRN & & \\
\hline CHEMBL3648776 & 1527972 & 9.8996 & 9.0712 & TRN & & \\
\hline CHEMBL3648729 & 1527972 & 8.6778 & 8.067 & TRN & & \\
\hline CHEMBL 3955949 & 1527972 & 9.3224 & 7.9912 & TST & & \\
\hline CHEMBL 3648741 & 1527972 & 6.0 & 7.9478 & TRN & & \\
\hline CHEMBL3648735 & 1527972 & 8.9914 & 8.8674 & TST & & \\
\hline
\end{tabular}




\begin{tabular}{|c|c|c|c|c|}
\hline \multicolumn{5}{|c|}{ Supplemental Table S2.txt } \\
\hline CHEMBL 3648717 & 1527972 & 6.0 & 6.4868 & TRN \\
\hline CHEMBL3648771 & 1527972 & 6.0 & 7.7824 & TRN \\
\hline CHEMBL3652034 & 1527972 & 6.0 & 8.9034 & TRN \\
\hline CHEMBL 3648664 & 1527972 & 6.0 & 8.3515 & TRN \\
\hline CHEMBL3648807 & 1527972 & 6.0 & 6.5654 & TRN \\
\hline CHEMBL 3648666 & 1527972 & 10.1024 & 8.4532 & TRN \\
\hline CHEMBL 3648779 & 1527972 & 9.2125 & 8.7305 & TRN \\
\hline CHEMBL 3648767 & 1527972 & 6.0 & 8.0856 & TST \\
\hline CHEMBL 3648844 & 1527972 & 10.3098 & 9.2557 & TRN \\
\hline CHEMBL3648799 & 1527972 & 8.9666 & 7.6574 & TST \\
\hline CHEMBL3648731 & 1527972 & 10.6021 & 9.2695 & TRN \\
\hline CHEMBL 3648840 & 1527972 & 6.0 & 9.0311 & TRN \\
\hline CHEMBL 3648660 & 1527972 & 10.7212 & 9.3238 & TRN \\
\hline CHEMBL 3648780 & 1527972 & 6.0 & 7.8654 & TRN \\
\hline CHEMBL3648677 & 1527972 & 6.0 & 7.5939 & TRN \\
\hline CHEMBL3648734 & 1527972 & 7.7235 & 8.3317 & TST \\
\hline CHEMBL3648768 & 1527972 & 6.0 & 7.4397 & TRN \\
\hline CHEMBL 3648698 & 1527972 & 6.0 & 7.3647 & TRN \\
\hline CHEMBL 3648809 & 1527972 & 9.0535 & 7.7984 & TRN \\
\hline CHEMBL3648787 & 1527972 & 9.3757 & 9.2669 & TRN \\
\hline CHEMBL3648746 & 1527972 & 9.7011 & 8.9099 & TRN \\
\hline CHEMBL 3648834 & 1527972 & 10.0969 & 7.407 & TRN \\
\hline CHEMBL 3648837 & 1527972 & 10.2218 & 7.8725 & TST \\
\hline CHEMBL 3648769 & 1527972 & 6.0 & 7.3386 & TST \\
\hline CHEMBL 3648831 & 1527972 & 9.5901 & 8.6366 & TST \\
\hline CHEMBL3648680 & 1527972 & 6.0 & 7.6335 & TST \\
\hline CHEMBL3648861 & 1527972 & 6.0 & 7.7057 & TST \\
\hline CHEMBL 3648817 & 1527972 & 6.0 & 7.0668 & TST \\
\hline CHEMBL 3648763 & 1527972 & 9.1062 & 8.9464 & TST \\
\hline CHEMBL 3648814 & 1527972 & 9.3215 & 7.8159 & TST \\
\hline CHEMBL3648706 & 1527972 & 6.0 & 7.0307 & TST \\
\hline CHEMBL 3648832 & 1527972 & 11.2218 & 6.9726 & TST \\
\hline CHEMBL 3648697 & 1527972 & 5.1759 & 8.1555 & TST \\
\hline CHEMBL 3648743 & 1527972 & 6.0 & 6.8766 & TST \\
\hline CHEMBL 3648656 & 1527972 & 10.3188 & 7.9616 & TST \\
\hline CHEMBL3648821 & 1527972 & 9.3507 & 7.8374 & TST \\
\hline CHEMBL568047 & 592924 & 7.2676 & 7.0236 & TST \\
\hline CHEMBL583463 & 592924 & 7.7696 & 7.6998 & TRN \\
\hline CHEMBL569890 & 592924 & 4.0655 & 4.3518 & TRN \\
\hline CHEMBL569180 & 592924 & 7.4089 & 7.4427 & TRN \\
\hline CHEMBL570825 & 592924 & 6.4949 & 6.7179 & TRN \\
\hline CHEMBL579228 & 592924 & 5.4318 & 5.3852 & TRN \\
\hline CHEMBL571471 & 592924 & 7.8239 & 7.8076 & TRN \\
\hline CHEMBL565506 & 592924 & 6.4437 & 6.6005 & TRN \\
\hline CHEMBL575020 & 592924 & 6.1079 & 7.1472 & TST \\
\hline CHEMBL565673 & 592924 & 5.8539 & 5.6942 & TRN \\
\hline CHEMBL568943 & 592924 & 4.2007 & 4.2911 & TRN \\
\hline CHEMBL568268 & 592924 & 6.8861 & 8.0872 & TST \\
\hline
\end{tabular}




\begin{tabular}{|c|c|c|c|c|c|}
\hline & & & oplementa & al Table S2. & \\
\hline CHEMBL565455 & 592924 & 5.0555 & 5.4108 & TRN & \\
\hline CHEMBL566743 & 592924 & 7.8539 & 7.6618 & TRN & \\
\hline CHEMBL585745 & 592924 & 4.9586 & 4.8802 & TRN & \\
\hline CHEMBL566744 & 592924 & 7.6383 & 8.0002 & TRN & \\
\hline CHEMBL570129 & 592924 & 7.5528 & 7.5879 & TRN & \\
\hline CHEMBL569418 & 592924 & 6.7447 & 6.7464 & TRN & \\
\hline CHEMBL585919 & 592924 & 7.3188 & 7.255 & TRN & \\
\hline CHEMBL571035 & 592924 & 7.3188 & 7.0971 & TRN & \\
\hline CHEMBL571472 & 592924 & 4.2441 & 4.3187 & TRN & \\
\hline CHEMBL565717 & 592924 & 7.4815 & 7.1172 & TRN & \\
\hline CHEMBL571251 & 592924 & 5.3468 & 5.0005 & TRN & \\
\hline CHEMBL578555 & 592924 & 6.4685 & 6.5232 & TRN & \\
\hline CHEMBL577328 & 592924 & 5.2757 & 5.2093 & TRN & \\
\hline CHEMBL571051 & 592924 & 4.0506 & 5.2881 & TST & \\
\hline CHEMBL565505 & 592924 & 5.284 & 5.2564 & TRN & \\
\hline CHEMBL576699 & 592924 & 6.5229 & 6.9836 & TST & \\
\hline CHEMBL565672 & 592924 & 5.4437 & 4.947 & TRN & \\
\hline CHEMBL566963 & 592924 & 7.0 & 6.6522 & TRN & \\
\hline CHEMBL568726 & 592924 & 5.9586 & 5.808 & TRN & \\
\hline CHEMBL570817 & 592924 & 6.1739 & 6.2659 & TRN & \\
\hline CHEMBL568969 & 592924 & 7.3872 & 7.437 & TRN & \\
\hline CHEMBL565456 & 592924 & 8.1549 & 8.0451 & TRN & \\
\hline CHEMBL577468 & 592924 & 6.4685 & 6.693 & TRN & \\
\hline CHEMBL577334 & 592924 & 4.0969 & 5.3252 & TST & \\
\hline CHEMBL575019 & 592924 & 7.2366 & 7.1854 & TRN & \\
\hline CHEMBL569417 & 592924 & 6.585 & 6.5989 & TRN & \\
\hline CHEMBL577467 & 592924 & 4.8861 & 5.1774 & TRN & \\
\hline CHEMBL570583 & 592924 & 7.2147 & 7.2879 & TRN & \\
\hline CHEMBL575017 & 592924 & 6.699 & 6.6859 & TRN & \\
\hline CHEMBL575018 & 592924 & 6.8539 & 7.0049 & TRN & \\
\hline CHEMBL569179 & 592924 & 7.2757 & 6.9763 & TRN & \\
\hline CHEMBL576463 & 592924 & 6.7447 & 6.9424 & TRN & \\
\hline CHEMBL571034 & 592924 & 6.4089 & 6.7632 & TRN & \\
\hline CHEMBL578831 & 592924 & 5.3565 & 7.2216 & TST & \\
\hline CHEMBL565457 & 592924 & 7.8861 & 7.7944 & TST & \\
\hline CHEMBL575230 & 592924 & 5.3872 & 5.7039 & TST & \\
\hline CHEMBL571256 & 592924 & 7.5528 & 7.669 & TST & \\
\hline CHEMBL583579 & 592924 & 6.7696 & 7.4579 & TST & \\
\hline CHEMBL579024 & 592924 & 5.2757 & 6.0182 & TST & \\
\hline CHEMBL585929 & 592924 & 9.0969 & 6.9357 & TST & \\
\hline CHEMBL570816 & 592924 & 7.3872 & 7.2474 & TST & \\
\hline CHEMBL 2304059 & 44576 & 3.0 & 2.6543 & TST & \\
\hline CHEMBL407356 & 44576 & 4.0809 & 3.4289 & TRN & \\
\hline CHEMBL415231 & 44576 & 2.6021 & 3.2635 & TRN & \\
\hline CHEMBL429343 & 44576 & 4.0555 & $3.56600 t$ & 00000000003 & TRN \\
\hline CHEMBL410210 & 44576 & 4.2218 & 3.7764 & TRN & \\
\hline CHEMBL415792 & 44576 & 3.0 & 2.9671 & TRN & \\
\hline CHEMBL 2370216 & 44576 & 2.301 & 1.921 & TRN & \\
\hline
\end{tabular}




\begin{tabular}{|c|c|c|c|c|c|}
\hline & & \multicolumn{4}{|c|}{ Supplemental Table S2.txt } \\
\hline CHEMBL 262586 & 44576 & 3.6162 & 3.3397 & TST & \\
\hline CHEMBL415668 & 44576 & 3.0 & 3.5002 & TRN & \\
\hline CHEMBL405267 & 44576 & 2.6021 & 2.8612 & TRN & \\
\hline CHEMBL411769 & 44576 & 2.301 & 2.3577 & TRN & \\
\hline CHEMBL 263485 & 44576 & 3.0 & 3.1059 & TRN & \\
\hline CHEMBL406634 & 44576 & 3.0 & 4.1035 & TRN & \\
\hline CHEMBL412977 & 44576 & 4.0969 & 3.444 & TRN & \\
\hline CHEMBL 267368 & 44576 & 2.6021 & 3.1592 & TRN & \\
\hline CHEMBL 263998 & 44576 & 3.6402 & 3.1097 & TRN & \\
\hline CHEMBL407397 & 44576 & 3.6576 & 3.3568 & TRN & \\
\hline CHEMBL438554 & 44576 & 2.6021 & 2.9822 & TST & \\
\hline CHEMBL 2304315 & 44576 & 4.4559 & 3.3639 & TRN & \\
\hline CHEMBL265142 & 44576 & 3.6055 & 3.06600 & 00000000003 & TRN \\
\hline CHEMBL411390 & 44576 & 2.6021 & 2.5614 & TRN & \\
\hline CHEMBL415673 & 44576 & 2.301 & 2.6785 & TRN & \\
\hline CHEMBL406690 & 44576 & 2.6021 & 2.9718 & TRN & \\
\hline CHEMBL 2370215 & 44576 & 2.301 & 1.8495 & TRN & \\
\hline CHEMBL266841 & 44576 & 2.301 & 2.2848 & TRN & \\
\hline CHEMBL441397 & 44576 & 3.0 & 3.5852 & TRN & \\
\hline CHEMBL 2370219 & 44576 & 2.6021 & 2.0439 & TRN & \\
\hline CHEMBL 2304314 & 44576 & 3.9747 & 3.0102 & TST & \\
\hline CHEMBL217475 & 44576 & 2.301 & 3.1354 & TRN & \\
\hline CHEMBL411363 & 44576 & 4.6778 & 3.8295 & TRN & \\
\hline CHEMBL 384264 & 44576 & 3.0 & 3.0338 & TRN & \\
\hline CHEMBL414553 & 44576 & 4.0915 & 3.9376 & TRN & \\
\hline CHEMBL437840 & 44576 & 3.9101 & 3.3338 & TRN & \\
\hline CHEMBL 384064 & 44576 & 2.6021 & 2.9439 & TST & \\
\hline CHEMBL405708 & 44576 & 2.6021 & 2.6729 & TRN & \\
\hline CHEMBL413864 & 44576 & 2.6021 & 3.2818 & TRN & \\
\hline CHEMBL263857 & 44576 & 2.6021 & 3.1827 & TRN & \\
\hline CHEMBL 267982 & 44576 & 3.0 & 2.6202 & TST & \\
\hline CHEMBL412204 & 44576 & 3.9431 & 3.3587 & TRN & \\
\hline CHEMBL3215340 & 44576 & 2.301 & 2.2013 & TRN & \\
\hline CHEMBL 269379 & 44576 & 2.6021 & 3.4132 & TRN & \\
\hline CHEMBL405483 & 44576 & 3.9747 & 3.656 & TRN & \\
\hline CHEMBL 266527 & 44576 & 2.301 & 2.6231 & TRN & \\
\hline CHEMBL 267424 & 44576 & 5.0655 & 3.2854 & TST & \\
\hline CHEMBL440635 & 44576 & 4.6576 & 4.2434 & TRN & \\
\hline CHEMBL 2304316 & 44576 & 4.6198 & 3.4679 & TST & \\
\hline CHEMBL439300 & 44576 & 4.1805 & 4.0458 & TRN & \\
\hline CHEMBL 267410 & 44576 & 3.0 & 3.2667 & TRN & \\
\hline CHEMBL 264829 & 44576 & 2.301 & 2.8041 & TST & \\
\hline CHEMBL 2304317 & 44576 & 2.301 & 2.5242 & TST & \\
\hline CHEMBL 2367780 & 44576 & 2.301 & 2.3252 & TST & \\
\hline CHEMBL409706 & 44576 & 2.301 & 2.9584 & TRN & \\
\hline CHEMBL415132 & 44576 & 3.6737 & 3.7456 & TRN & \\
\hline CHEMBL 387070 & 44576 & 2.301 & 3.0376 & TRN & \\
\hline CHEMBL428274 & 44576 & 3.3958 & 3.1354 & TRN & \\
\hline
\end{tabular}




\begin{tabular}{|c|c|c|c|c|c|}
\hline \multicolumn{6}{|c|}{ Supplemental Table S2.txt } \\
\hline CHEMBL437476 & 44576 & 2.6021 & 3.4338 & TRN & \\
\hline CHEMBL 267216 & 44576 & 3.6198 & 3.0939 & TST & \\
\hline CHEMBL436699 & 44576 & 4.2218 & 4.085 & TRN & \\
\hline CHEMBL3215341 & 44576 & 2.301 & 2.7201 & TST & \\
\hline CHEMBL 3215342 & 44576 & 2.301 & 2.5286 & TST & \\
\hline CHEMBL2304149 & 44576 & 4.5229 & 3.4993 & TST & \\
\hline CHEMBL411975 & 44576 & 5.0269 & 3.4998 & TST & \\
\hline CHEMBL 217364 & 44576 & 3.983 & 3.5847 & TRN & \\
\hline CHEMBL444020 & 44576 & 2.6021 & 2.8664 & TST & \\
\hline CHEMBL 264310 & 44576 & 3.9666 & 3.6013 & TRN & \\
\hline CHEMBL85637 & 221311 & 8.5229 & 8.5512 & TRN & \\
\hline CHEMBL315816 & 221311 & 6.0862 & 5.4484 & TST & \\
\hline CHEMBL 28134 & 221311 & 7.5229 & 7.4773 & TRN & \\
\hline CHEMBL 83008 & 221311 & 7.6778 & 7.6171 & TRN & \\
\hline CHEMBL433437 & 221311 & 6.4089 & 6.2493 & TRN & \\
\hline CHEMBL84877 & 221311 & 8.0458 & 8.0632 & TRN & \\
\hline CHEMBL 283212 & 221311 & 8.0458 & 8.0581 & TRN & \\
\hline CHEMBL 29457 & 221311 & 8.0458 & 7.9468 & TRN & \\
\hline CHEMBL 85824 & 221311 & 7.0 & 6.9755 & TRN & \\
\hline CHEMBL 287446 & 221311 & 5.7721 & 5.7984 & TRN & \\
\hline CHEMBL 86045 & 221311 & 8.3979 & 8.3335 & TRN & \\
\hline CHEMBL 313591 & 221311 & 7.585 & 7.6328 & TRN & \\
\hline CHEMBL 315791 & 221311 & 5.4989 & 5.6803 & TST & \\
\hline CHEMBL85835 & 221311 & 8.699 & 8.7639 & TRN & \\
\hline CHEMBL 323059 & 221311 & 7.0 & 6.9025 & TRN & \\
\hline CHEMBL 284911 & 221311 & 6.6198 & 6.58799 & э999999999 & TRN \\
\hline CHEMBL84954 & 221311 & 7.6198 & 7.5619 & TRN & \\
\hline CHEMBL 281218 & 221311 & 6.4437 & 6.4991 & TRN & \\
\hline CHEMBL 28632 & 221311 & 7.7959 & 7.785 & TRN & \\
\hline CHEMBL 28864 & 221311 & 5.8761 & 5.83899 & 99999999995 & TRN \\
\hline CHEMBL84608 & 221311 & 5.4989 & 5.6403 & TST & \\
\hline CHEMBL314819 & 221311 & 8.2076 & 8.2227 & TRN & \\
\hline CHEMBL 282607 & 221311 & 7.2218 & 7.3136 & TRN & \\
\hline CHEMBL83251 & 221311 & 7.8239 & 7.8807 & TRN & \\
\hline CHEMBL85629 & 221311 & 8.699 & 8.762 & TRN & \\
\hline CHEMBL315066 & 221311 & 8.301 & 8.3352 & TRN & \\
\hline CHEMBL 316425 & 221311 & 7.585 & 7.6589 & TRN & \\
\hline CHEMBL84046 & 221311 & 8.2218 & 8.2503 & TRN & \\
\hline CHEMBL 313798 & 221311 & 8.0269 & 6.7364 & TST & \\
\hline CHEMBL 25969 & 221311 & 7.3979 & 7.4868 & TRN & \\
\hline CHEMBL86230 & 221311 & 6.5528 & 6.5437 & TRN & \\
\hline CHEMBL 281035 & 221311 & 8.6198 & 8.5698 & TRN & \\
\hline CHEMBL29320 & 221311 & 8.699 & 8.7013 & TRN & \\
\hline CHEMBL 85886 & 221311 & 8.0 & 7.9489 & TRN & \\
\hline CHEMBL 314049 & 221311 & 8.3979 & 8.4176 & TRN & \\
\hline CHEMBL 283275 & 221311 & 7.301 & 7.3638 & TRN & \\
\hline CHEMBL28916 & 221311 & 6.7696 & 6.818 & TRN & \\
\hline CHEMBL 315272 & 221311 & 8.5229 & 8.4449 & TRN & \\
\hline
\end{tabular}




\begin{tabular}{|c|c|c|c|c|c|}
\hline \multicolumn{6}{|c|}{ Supplemental Table S2.txt } \\
\hline CHEMBL85472 & 221311 & 5.5719 & 5.2481 & TST & \\
\hline CHEMBL29764 & 221311 & 5.2581 & 5.3626 & TRN & \\
\hline CHEMBL85979 & 221311 & 7.5229 & 7.5452 & TRN & \\
\hline CHEMBL85920 & 221311 & 8.6198 & 8.5812 & TRN & \\
\hline CHEMBL 86068 & 221311 & 7.8539 & 7.8052 & TRN & \\
\hline CHEMBL85976 & 221311 & 8.0 & 8.499 & TST & \\
\hline CHEMBL313466 & 221311 & 7.9586 & 8.2265 & TST & \\
\hline CHEMBL 29185 & 221311 & 7.5229 & 7.6459 & TST & \\
\hline CHEMBL85974 & 221311 & 8.1549 & 8.2324 & TST & \\
\hline CHEMBL 29856 & 221311 & 6.0506 & 6.3161 & TST & \\
\hline CHEMBL311309 & 221311 & 8.0605 & 6.8008 & TST & \\
\hline CHEMBL281056 & 221311 & 6.7447 & 6.3355 & TST & \\
\hline CHEMBL85909 & 221311 & 7.1549 & 6.9706 & TST & \\
\hline CHEMBL 3714855 & 1536801 & 6.9788 & 6.9872 & TRN & \\
\hline CHEMBL3719041 & 1536801 & 7.6383 & 7.9957 & TRN & \\
\hline CHEMBL3715917 & 1536801 & 7.5229 & 7.7967 & TRN & \\
\hline CHEMBL 3716599 & 1536801 & 6.5544 & 7.0826 & TST & \\
\hline CHEMBL 3719043 & 1536801 & 7.1549 & 7.1955 & TRN & \\
\hline CHEMBL 3716523 & 1536801 & 7.1549 & 7.1192 & TRN & \\
\hline CHEMBL3717170 & 1536801 & 6.8928 & 6.8483 & TRN & \\
\hline CHEMBL3718389 & 1536801 & 7.9208 & 7.6819 & TRN & \\
\hline CHEMBL 3716347 & 1536801 & 7.3279 & 6.5931 & TST & \\
\hline CHEMBL3715386 & 1536801 & 6.7721 & 6.6284 & TRN & \\
\hline CHEMBL 3714810 & 1536801 & 6.8928 & 6.6846 & TST & \\
\hline CHEMBL 3719342 & 1536801 & 6.4034 & 6.5182 & TRN & \\
\hline CHEMBL 3714771 & 1536801 & 7.0915 & 7.0632 & TRN & \\
\hline CHEMBL3716175 & 1536801 & 6.7447 & 6.9446 & TRN & \\
\hline CHEMBL 3717843 & 1536801 & 6.5817 & 6.1861 & TST & \\
\hline CHEMBL 3716615 & 1536801 & 7.0969 & 6.9727 & TRN & \\
\hline CHEMBL 3716102 & 1536801 & 7.3279 & 7.4778 & TRN & \\
\hline CHEMBL 3719241 & 1536801 & 7.6576 & 7.63200 & 0000000001 & TRN \\
\hline CHEMBL 3717942 & 1536801 & 6.3487 & 6.4535 & TST & \\
\hline CHEMBL3715431 & 1536801 & 6.9066 & 6.7878 & TRN & \\
\hline CHEMBL 3716279 & 1536801 & 7.3872 & 7.3182 & TRN & \\
\hline CHEMBL3717989 & 1536801 & 7.4202 & 7.5517 & TRN & \\
\hline CHEMBL 3716850 & 1536801 & 7.2596 & 7.2849 & TRN & \\
\hline CHEMBL 3719183 & 1536801 & 7.1249 & 6.8553 & TST & \\
\hline CHEMBL 3716783 & 1536801 & 7.6778 & 7.8757 & TRN & \\
\hline CHEMBL 3717290 & 1536801 & 6.4634 & 6.0477 & TRN & \\
\hline CHEMBL 3717203 & 1536801 & 7.0044 & 6.9354 & TRN & \\
\hline CHEMBL 3719311 & 1536801 & 7.9208 & 7.9202 & TRN & \\
\hline CHEMBL3718984 & 1536801 & 7.3565 & 7.0075 & TRN & \\
\hline CHEMBL3715830 & 1536801 & 6.5901 & 6.5041 & TRN & \\
\hline CHEMBL 3716440 & 1536801 & 6.5171 & 6.8065 & TRN & \\
\hline CHEMBL3716786 & 1536801 & 9.2218 & 8.2535 & TRN & \\
\hline CHEMBL 3718047 & 1536801 & 7.0555 & 7.0383 & TRN & \\
\hline CHEMBL 3719054 & 1536801 & 6.3298 & 6.4581 & TRN & \\
\hline CHEMBL3716346 & 1536801 & 7.301 & 7.2986 & TRN & \\
\hline
\end{tabular}


Supplemental Table S2.txt

\begin{tabular}{|c|c|c|c|c|c|}
\hline CHEMBL3717019 & 1536801 & 6.8928 & 6.9912 & TRN & \\
\hline CHEMBL3716298 & 1536801 & 7.5528 & 7.67899 & 9999999999 & TRN \\
\hline CHEMBL3719091 & 1536801 & 6.4078 & 6.1579 & TRN & \\
\hline CHEMBL3718465 & 1536801 & 6.3851 & 6.63200 & 0000000001 & TRN \\
\hline CHEMBL3718553 & 1536801 & 6.8153 & 6.7585 & TRN & \\
\hline CHEMBL3716991 & 1536801 & 6.71 & 6.4766 & TST & \\
\hline CHEMBL3718495 & 1536801 & 7.4815 & 6.9012 & TST & \\
\hline CHEMBL3718849 & 1536801 & 6.9872 & 6.8888 & TRN & \\
\hline CHEMBL3716385 & 1536801 & 7.3468 & 7.3251 & TRN & \\
\hline CHEMBL 3714770 & 1536801 & 6.3872 & 6.3036 & TRN & \\
\hline CHEMBL3716975 & 1536801 & 6.7825 & 6.6454 & TRN & \\
\hline CHEMBL3715796 & 1536801 & 7.2007 & 6.7874 & TST & \\
\hline CHEMBL3715217 & 1536801 & 6.5751 & 6.5151 & TRN & \\
\hline CHEMBL3718679 & 1536801 & 6.4647 & 6.5869 & TRN & \\
\hline CHEMBL 3716427 & 1536801 & 6.4776 & 6.5906 & TRN & \\
\hline CHEMBL3718958 & 1536801 & 6.4522 & 6.2255 & TST & \\
\hline CHEMBL3716391 & 1536801 & 6.7959 & 6.7235 & TRN & \\
\hline CHEMBL3717163 & 1536801 & 6.4067 & 6.2604 & TST & \\
\hline CHEMBL3719319 & 1536801 & 6.3215 & 6.3164 & TRN & \\
\hline CHEMBL3718596 & 1536801 & 6.3696 & 6.8536 & TST & \\
\hline CHEMBL3714916 & 1536801 & 6.7328 & 6.9939 & TST & \\
\hline CHEMBL 3716244 & 1536801 & 6.4306 & 6.3706 & TRN & \\
\hline CHEMBL3714963 & 1536801 & 7.0706 & 7.271 & TRN & \\
\hline CHEMBL3718650 & 1536801 & 7.2147 & 7.3888 & TRN & \\
\hline CHEMBL3719206 & 1536801 & 6.4134 & 6.9187 & TRN & \\
\hline CHEMBL3715310 & 1536801 & 6.9031 & 6.5644 & TST & \\
\hline CHEMBL3716892 & 1536801 & 7.3565 & 7.1424 & TRN & \\
\hline CHEMBL3717041 & 1536801 & 7.6383 & 7.7611 & TRN & \\
\hline CHEMBL3716137 & 1536801 & 7.5376 & 6.8856 & TST & \\
\hline CHEMBL3716207 & 1536801 & 6.6162 & 6.6382 & TRN & \\
\hline CHEMBL3717619 & 1536801 & 6.6635 & 6.7673 & TST & \\
\hline CHEMBL3718932 & 1536801 & 6.5575 & 6.5054 & TRN & \\
\hline CHEMBL3717935 & 1536801 & 6.8729 & 7.2078 & TRN & \\
\hline CHEMBL3715951 & 1536801 & 7.2596 & 7.2201 & TST & \\
\hline CHEMBL3715481 & 1536801 & 6.4353 & 6.5716 & TRN & \\
\hline CHEMBL3717691 & 1536801 & 8.2291 & 8.0556 & TRN & \\
\hline CHEMBL3718067 & 1536801 & 6.9788 & 7.0468 & TST & \\
\hline CHEMBL3715132 & 1536801 & 6.4498 & 6.6617 & TRN & \\
\hline CHEMBL3715802 & 1536801 & 6.7595 & 6.8002 & TST & \\
\hline CHEMBL3715109 & 1536801 & 6.8041 & 6.7721 & TRN & \\
\hline CHEMBL3716422 & 1536801 & 6.4202 & 6.4026 & TRN & \\
\hline CHEMBL3715518 & 1536801 & 6.7447 & 6.8896 & TRN & \\
\hline CHEMBL3717995 & 1536801 & 8.0605 & 6.7594 & TST & \\
\hline CHEMBL3719096 & 1536801 & 7.7959 & 7.5647 & TRN & \\
\hline CHEMBL3716549 & 1536801 & 6.7878 & 6.6137 & TRN & \\
\hline CHEMBL1414832 & 737320 & 5.1487 & 5.1111 & TRN & \\
\hline CHEMBL1527361 & 737320 & 4.3179 & 4.1885 & TST & \\
\hline CHEMBL1605799 & 737320 & 3.0 & 3.3522 & TRN & \\
\hline
\end{tabular}




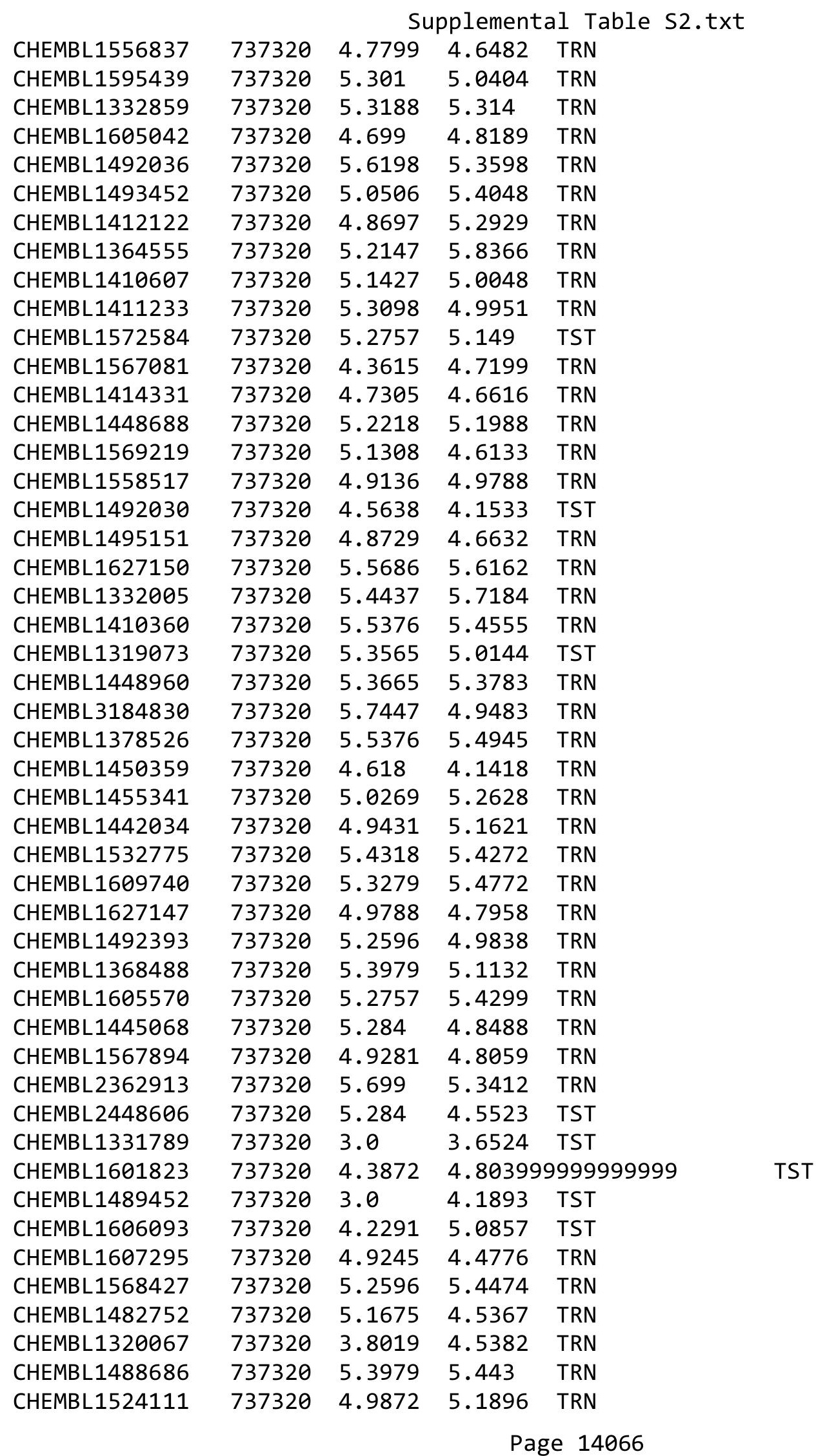




\begin{tabular}{|c|c|c|c|c|c|}
\hline & & & & & \\
\hline CHEMBL1486991 & 737320 & 3.0 & 3.5981 & TST & \\
\hline CHEMBL1337371 & 737320 & 5.4318 & 4.6801 & TRN & \\
\hline CHEMBL1371717 & 737320 & 5.0269 & 5.1491 & TRN & \\
\hline CHEMBL1450464 & 737320 & 5.0706 & 5.3179 & TRN & \\
\hline CHEMBL1374431 & 737320 & 3.0 & 5.06 & TST & \\
\hline CHEMBL1567714 & 737320 & 5.0757 & 4.9291 & TRN & \\
\hline CHEMBL1530279 & 737320 & 3.0 & 4.3454 & TST & \\
\hline CHEMBL1607541 & 737320 & 4.8356 & 4.8136 & TRN & \\
\hline CHEMBL1574672 & 737320 & 5.4089 & 4.6386 & TRN & \\
\hline CHEMBL1568407 & 737320 & 5.0555 & 4.8703 & TRN & \\
\hline CHEMBL1490324 & 737320 & 3.9431 & 4.2694 & TST & \\
\hline CHEMBL1369440 & 737320 & 3.0 & 3.1352 & TRN & \\
\hline CHEMBL1526495 & 737320 & 4.8729 & 4.7787 & TRN & \\
\hline CHEMBL1450785 & 737320 & 5.0605 & 4.7316 & TRN & \\
\hline CHEMBL1407893 & 737320 & 4.2248 & 3.589 & TST & \\
\hline CHEMBL1611493 & 737320 & 5.2218 & 5.09399 & 9999999999 & TST \\
\hline CHEMBL1449546 & 737320 & 5.0809 & 4.9441 & TRN & \\
\hline CHEMBL1604899 & 737320 & 5.2218 & 5.4279 & TRN & \\
\hline CHEMBL1531252 & 737320 & 4.1851 & 5.0092 & TST & \\
\hline CHEMBL1563442 & 737320 & 5.8861 & 5.5021 & TRN & \\
\hline CHEMBL1375065 & 737320 & 4.757 & 3.9771 & TST & \\
\hline CHEMBL1335574 & 737320 & 3.0 & 3.6576 & TST & \\
\hline CHEMBL1527319 & 737320 & 3.7395 & 3.9683 & TST & \\
\hline CHEMBL1627151 & 737320 & 5.3979 & 5.1112 & TRN & \\
\hline CHEMBL1568065 & 737320 & 4.1319 & 5.3591 & TST & \\
\hline CHEMBL1530865 & 737320 & 3.0 & 4.4204 & TRN & \\
\hline CHEMBL1531605 & 737320 & 5.5686 & 5.147 & TRN & \\
\hline CHEMBL1333419 & 737320 & 5.5086 & 5.3312 & TRN & \\
\hline CHEMBL1442157 & 737320 & 3.0 & 3.12399 & 99999999997 & TRN \\
\hline CHEMBL1413370 & 737320 & 5.3768 & 5.0709 & TST & \\
\hline CHEMBL1528339 & 737320 & 3.0 & 2.6397 & TRN & \\
\hline CHEMBL1563112 & 737320 & 3.0 & 4.1283 & TST & \\
\hline CHEMBL1600055 & 737320 & 4.7773 & 5.2537 & TRN & \\
\hline CHEMBL1490355 & 737320 & 5.041 & 5.2251 & TRN & \\
\hline CHEMBL1570446 & 737320 & 3.0 & 3.9381 & TST & \\
\hline CHEMBL1518555 & 737320 & 4.9318 & 4.6883 & TRN & \\
\hline CHEMBL1569041 & 737320 & 3.0 & 3.6261 & TRN & \\
\hline CHEMBL1329876 & 737320 & 5.4815 & 5.5187 & TRN & \\
\hline CHEMBL1372737 & 737320 & 5.4318 & 5.4536 & TRN & \\
\hline CHEMBL1565499 & 737320 & 4.0386 & 4.5815 & TRN & \\
\hline CHEMBL1411448 & 737320 & 4.4123 & 3.5259 & TST & \\
\hline CHEMBL1610703 & 737320 & 4.8386 & 4.4286 & TRN & \\
\hline CHEMBL1359629 & 737320 & 5.1487 & 5.4331 & TRN & \\
\hline CHEMBL1570483 & 737320 & 3.0 & 3.7381 & TRN & \\
\hline CHEMBL1363082 & 737320 & 3.0 & 4.2882 & TST & \\
\hline CHEMBL1367323 & 737320 & 4.5719 & 4.6578 & TRN & \\
\hline CHEMBL1330750 & 737320 & 5.3979 & 4.779 & TRN & \\
\hline CHEMBL1605665 & 737320 & 5.3188 & 5.4495 & TRN & \\
\hline
\end{tabular}


Supplemental Table S2.txt

\begin{tabular}{|c|c|c|c|c|}
\hline CHEMBL1330408 & 737320 & 5.3872 & 4.7202 & TRN \\
\hline CHEMBL1447925 & 737320 & 5.2076 & 5.3886 & TRN \\
\hline CHEMBL1412107 & 737320 & 3.0 & 4.496 & TRN \\
\hline CHEMBL1410570 & 737320 & 4.9101 & 5.4018 & TRN \\
\hline CHEMBL1322099 & 737320 & 5.0969 & 5.7821 & TST \\
\hline CHEMBL1440437 & 737320 & 5.2441 & 4.2038 & TST \\
\hline CHEMBL387316 & 424955 & 6.8125 & 5.78600 & 00000000005 \\
\hline CHEMBL220667 & 424955 & 6.2749 & 6.487 & TRN \\
\hline CHEMBL221151 & 424955 & 6.4271 & 6.4175 & TRN \\
\hline CHEMBL220719 & 424955 & 5.0691 & 5.0569 & TRN \\
\hline CHEMBL219783 & 424955 & 7.1135 & 6.9276 & TRN \\
\hline CHEMBL387314 & 424955 & 7.1427 & 7.1876 & TRN \\
\hline CHEMBL220942 & 424955 & 6.2916 & 6.2492 & TRN \\
\hline CHEMBL219994 & 424955 & 7.2518 & 7.3247 & TRN \\
\hline CHEMBL375836 & 424955 & 5.3417 & 5.3929 & TRN \\
\hline CHEMBL220823 & 424955 & 6.3344 & 6.8099 & TRN \\
\hline CHEMBL219895 & 424955 & 5.4437 & 6.1618 & TST \\
\hline CHEMBL375124 & 424955 & 8.2218 & 6.0488 & TST \\
\hline CHEMBL219717 & 424955 & 6.3675 & 6.42 & TRN \\
\hline CHEMBL 385329 & 424955 & 6.6946 & 6.0751 & TST \\
\hline CHEMBL220516 & 424955 & 5.5936 & 5.8246 & TRN \\
\hline CHEMBL374329 & 424955 & 6.9957 & 6.5627 & TRN \\
\hline CHEMBL220562 & 424955 & 6.4763 & 6.7372 & TRN \\
\hline CHEMBL387156 & 424955 & 6.1331 & 6.2826 & TRN \\
\hline CHEMBL 223345 & 424955 & 6.1898 & 6.1076 & TRN \\
\hline CHEMBL221150 & 424955 & 6.3335 & 6.2372 & TST \\
\hline CHEMBL220369 & 424955 & 6.3595 & 6.357 & TRN \\
\hline CHEMBL375310 & 424955 & 6.2411 & 6.1313 & TRN \\
\hline CHEMBL220732 & 424955 & 5.5381 & 5.9886 & TRN \\
\hline CHEMBL 375970 & 424955 & 5.5207 & 5.5639 & TRN \\
\hline CHEMBL375526 & 424955 & 6.6737 & 6.4124 & TRN \\
\hline CHEMBL375225 & 424955 & 6.5391 & 6.3895 & TRN \\
\hline CHEMBL221149 & 424955 & 6.2749 & 6.2121 & TRN \\
\hline CHEMBL220322 & 424955 & 6.3575 & 6.3173 & TRN \\
\hline CHEMBL424758 & 424955 & 5.6299 & 5.7509 & TRN \\
\hline CHEMBL375125 & 424955 & 6.7212 & 6.5908 & TRN \\
\hline CHEMBL374456 & 424955 & 6.2299 & 6.4666 & TRN \\
\hline CHEMBL375351 & 424955 & 6.7825 & 6.6374 & TRN \\
\hline CHEMBL375835 & 424955 & 5.7409 & 5.8106 & TRN \\
\hline CHEMBL387315 & 424955 & 7.041 & 7.1142 & TRN \\
\hline CHEMBL220718 & 424955 & 6.8447 & 6.8976 & TRN \\
\hline CHEMBL222722 & 424955 & 5.7185 & 5.4125 & TRN \\
\hline CHEMBL373671 & 424955 & 5.8184 & 6.3303 & TRN \\
\hline CHEMBL375169 & 424955 & 6.6498 & 6.3821 & TRN \\
\hline CHEMBL436306 & 424955 & 6.1739 & \multicolumn{2}{|c|}{6.077000000000001} \\
\hline CHEMBL219771 & 424955 & 6.7258 & 6.3876 & TRN \\
\hline CHEMBL273338 & 424955 & 6.1925 & 6.0772 & TRN \\
\hline CHEMBL219831 & 424955 & 5.2785 & 5.3314 & TRN \\
\hline
\end{tabular}




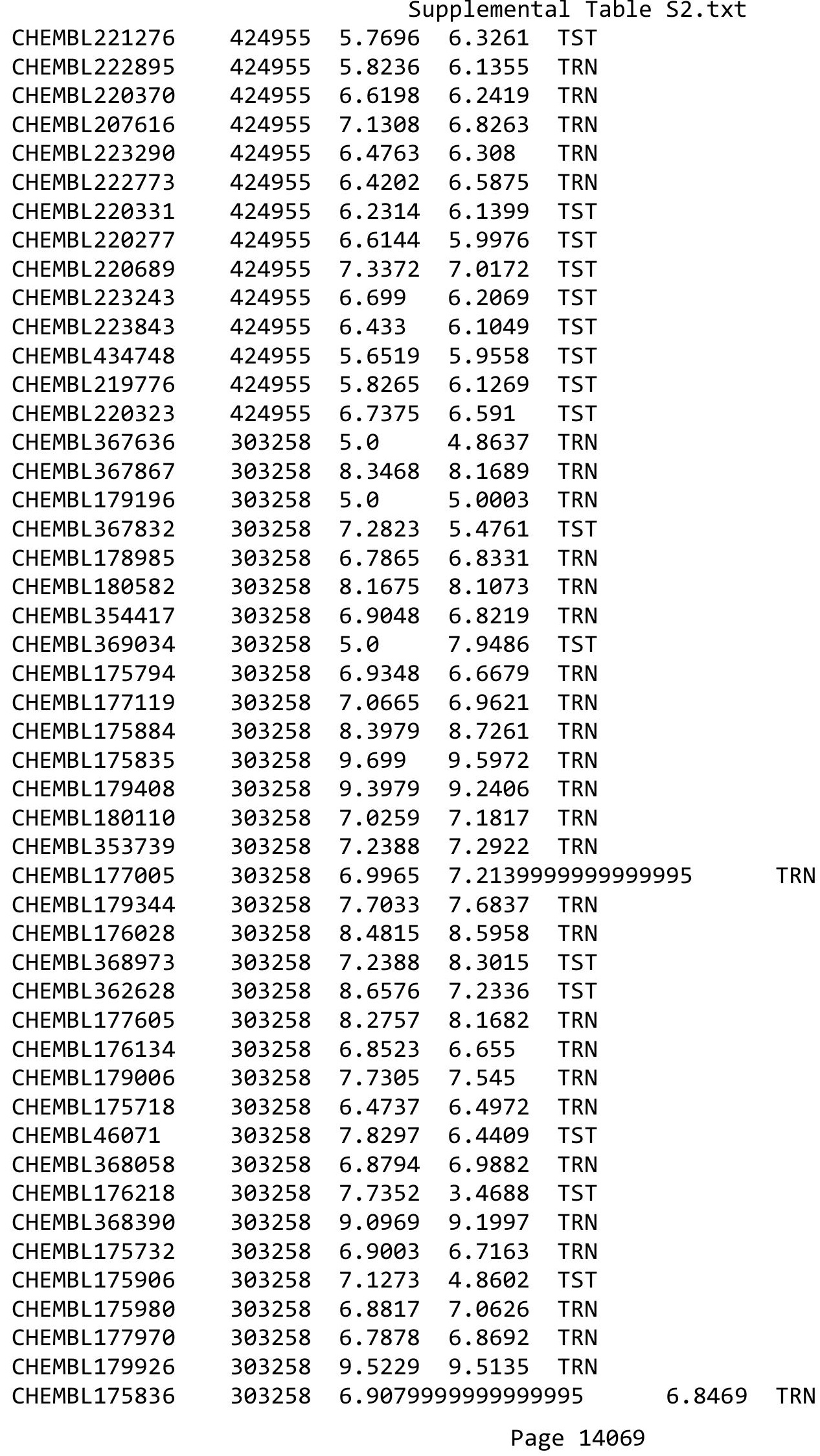




\begin{tabular}{|c|c|c|c|c|c|c|}
\hline & & \multicolumn{5}{|c|}{ Supplemental Table S2.txt } \\
\hline CHEMBL180425 & 303258 & 8.4559 & 8.6523 & TRN & & \\
\hline CHEMBL368209 & 303258 & 10.0 & 9.9812 & TRN & & \\
\hline CHEMBL176117 & 303258 & 7.8268 & 7.8444 & TRN & & \\
\hline CHEMBL431298 & 303258 & 9.0969 & 7.4174 & TST & & \\
\hline CHEMBL368557 & 303258 & 6.7802 & 6.5955 & TRN & & \\
\hline CHEMBL176162 & 303258 & 6.9634 & 7.7175 & TST & & \\
\hline CHEMBL361319 & 303258 & 5.0 & 4.8401 & TRN & & \\
\hline CHEMBL175529 & 303258 & 8.1427 & 7.8282 & TRN & & \\
\hline CHEMBL 367088 & 303258 & 8.0088 & 4.9682 & TST & & \\
\hline CHEMBL368871 & 303258 & 7.3851 & 7.4299 & TRN & & \\
\hline CHEMBL175798 & 303258 & 6.9318 & 7.0279 & TRN & & \\
\hline CHEMBL367481 & 303258 & 8.0177 & 8.083 & TRN & & \\
\hline CHEMBL361230 & 303258 & 8.3279 & 8.3147 & TRN & & \\
\hline CHEMBL354418 & 303258 & 7.2581 & 5.5149 & TST & & \\
\hline CHEMBL175940 & 303258 & 8.7212 & 5.0165 & TST & & \\
\hline CHEMBL175819 & 303258 & 7.1891 & 7.2071 & TRN & & \\
\hline CHEMBL177124 & 303258 & 8.0315 & 8.2002 & TRN & & \\
\hline CHEMBL176030 & 303258 & 5.0 & 5.4318 & TRN & & \\
\hline CHEMBL176258 & 303258 & \multicolumn{3}{|c|}{6.968999999999999} & 7.4774 & TST \\
\hline CHEMBL175488 & 303258 & 6.649 & 3.9042 & TST & & \\
\hline CHEMBL367305 & 303258 & 7.5031 & 4.9983 & TST & & \\
\hline CHEMBL369759 & 303258 & 9.0 & 8.6241 & TRN & & \\
\hline CHEMBL407860 & 303258 & 5.0 & 5.018 & TST & & \\
\hline CHEMBL 368069 & 303258 & 7.1278 & 6.9939 & TRN & & \\
\hline CHEMBL176292 & 303258 & 8.4089 & 8.5671 & TRN & & \\
\hline CHEMBL 2112986 & 303258 & 7.0119 & 4.5454 & TST & & \\
\hline CHEMBL176057 & 303258 & 5.0 & 5.0862 & TRN & & \\
\hline CHEMBL366515 & 303258 & 6.8184 & 6.8174 & TRN & & \\
\hline CHEMBL 362063 & 303258 & 9.0 & 8.9832 & TRN & & \\
\hline CHEMBL179264 & 303258 & 6.7104 & 6.8643 & TRN & & \\
\hline CHEMBL176043 & 303258 & 5.0 & 5.0243 & TRN & & \\
\hline CHEMBL433461 & 303258 & 7.3497 & 6.7733 & TST & & \\
\hline CHEMBL427134 & 303258 & 8.3665 & 8.2571 & TRN & & \\
\hline CHEMBL579981 & 303258 & 7.0448 & 7.9928 & TST & & \\
\hline CHEMBL179034 & 303258 & 7.2865 & 7.1325 & TRN & & \\
\hline CHEMBL179492 & 303258 & \multicolumn{3}{|c|}{7.821000000000001} & 7.695 & TRN \\
\hline CHEMBL368959 & 303258 & 7.6737 & 7.8827 & TRN & & \\
\hline CHEMBL433979 & 303258 & 6.6087 & 6.8363 & TRN & & \\
\hline CHEMBL367730 & 303258 & 7.6144 & 7.6696 & TRN & & \\
\hline CHEMBL179407 & 303258 & 9.301 & 9.3953 & TRN & & \\
\hline CHEMBL3718567 & 1537037 & 7.7959 & 6.7293 & TST & & \\
\hline CHEMBL3716107 & 1537037 & 6.4089 & 6.706 & TRN & & \\
\hline CHEMBL3715860 & 1537037 & 6.1135 & 6.454 & TST & & \\
\hline CHEMBL3716246 & 1537037 & 6.0 & 6.79200 & 0000000001 & & TRN \\
\hline CHEMBL3719355 & 1537037 & 5.9208 & 4.9187 & TRN & & \\
\hline CHEMBL3717583 & 1537037 & 7.3468 & 7.0066 & TST & & \\
\hline CHEMBL3719347 & 1537037 & 7.5686 & 7.1945 & TRN & & \\
\hline CHEMBL3718669 & 1537037 & 5.4802 & 5.7164 & TRN & & \\
\hline
\end{tabular}


Supplemental Table S2.txt

\begin{tabular}{|c|c|c|c|c|c|}
\hline CHEMBL3714818 & 1537037 & 5.3242 & 5.7354 & TRN & \\
\hline CHEMBL3716339 & 1537037 & 5.7328 & 5.2237 & TRN & \\
\hline CHEMBL3715022 & 1537037 & 6.0177 & 6.435 & TRN & \\
\hline CHEMBL3715595 & 1537037 & 7.2076 & 6.4696 & TRN & \\
\hline CHEMBL 3716271 & 1537037 & 5.2749 & 6.3707 & TRN & \\
\hline CHEMBL3719240 & 1537037 & 5.4935 & 4.8096 & TST & \\
\hline CHEMBL3716802 & 1537037 & 6.4202 & 5.8926 & TRN & \\
\hline CHEMBL3719236 & 1537037 & 7.6198 & 6.5838 & TRN & \\
\hline CHEMBL3717634 & 1537037 & 6.1427 & 5.0374 & TST & \\
\hline CHEMBL3716289 & 1537037 & 6.5086 & 6.4368 & TRN & \\
\hline CHEMBL3715237 & 1537037 & 5.1221 & 5.4295 & TST & \\
\hline CHEMBL3715455 & 1537037 & 6.0 & 6.6841 & TRN & \\
\hline CHEMBL3718420 & 1537037 & 5.2573 & 5.4106 & TRN & \\
\hline CHEMBL 3715188 & 1537037 & 4.997 & 5.4714 & TST & \\
\hline CHEMBL3718951 & 1537037 & 6.0 & 6.9258 & TRN & \\
\hline CHEMBL3718052 & 1537037 & 7.2518 & 6.4111 & TRN & \\
\hline CHEMBL3719262 & 1537037 & 5.7773 & 5.5736 & TRN & \\
\hline CHEMBL3718594 & 1537037 & 5.3098 & 5.9875 & TRN & \\
\hline CHEMBL3718568 & 1537037 & 6.4089 & 6.4481 & TRN & \\
\hline CHEMBL3715202 & 1537037 & 7.4949 & 6.4111 & TRN & \\
\hline CHEMBL3717669 & 1537037 & 5.7852 & 6.022 & TRN & \\
\hline CHEMBL3716412 & 1537037 & 4.9586 & 5.2568 & TRN & \\
\hline CHEMBL3718411 & 1537037 & 5.7595 & \multicolumn{2}{|c|}{5.752000000000001} & TRN \\
\hline CHEMBL3718235 & 1537037 & 7.5229 & 7.2793 & TRN & \\
\hline CHEMBL3717660 & 1537037 & 6.3206 & 6.5759 & TRN & \\
\hline CHEMBL3715409 & 1537037 & 5.3675 & 6.0202 & TST & \\
\hline CHEMBL3717824 & 1537037 & 6.0969 & 6.8022 & TRN & \\
\hline CHEMBL3718361 & 1537037 & 4.328 & 4.8488 & TRN & \\
\hline CHEMBL3716941 & 1537037 & 6.3565 & 5.9205 & TRN & \\
\hline CHEMBL 3717815 & 1537037 & 7.2676 & 7.3001 & TST & \\
\hline CHEMBL3718968 & 1537037 & 7.1079 & 5.1106 & TRN & \\
\hline CHEMBL3716194 & 1537037 & 4.099 & 4.8442 & TST & \\
\hline CHEMBL3716820 & 1537037 & 5.6402 & 5.4087 & TRN & \\
\hline CHEMBL3718285 & 1537037 & 5.3344 & 4.7386 & TST & \\
\hline CHEMBL3716373 & 1537037 & 6.9208 & \multicolumn{2}{|c|}{6.962999999999999} & TRN \\
\hline CHEMBL3716604 & 1537037 & 5.1778 & 5.3565 & TST & \\
\hline CHEMBL 3716681 & 1537037 & 7.699 & 7.3575 & TRN & \\
\hline CHEMBL3718345 & 1537037 & 7.1427 & 7.3603 & TRN & \\
\hline CHEMBL3718160 & 1537037 & 5.2197 & 5.5307 & TRN & \\
\hline CHEMBL3716101 & 1537037 & 7.7212 & 6.3428 & TRN & \\
\hline CHEMBL3715914 & 1537037 & 7.5376 & 6.5838 & TRN & \\
\hline CHEMBL3715605 & 1537037 & 7.1612 & 6.4517 & TRN & \\
\hline CHEMBL3717943 & 1537037 & 7.0088 & 6.8711 & TRN & \\
\hline CHEMBL3715372 & 1537037 & 5.1707 & 5.0962 & TRN & \\
\hline CHEMBL 3717847 & 1537037 & 4.343 & 5.4117 & TRN & \\
\hline CHEMBL3716751 & 1537037 & 7.0555 & 7.1437 & TST & \\
\hline CHEMBL3717860 & 1537037 & 5.9872 & 5.2104 & TST & \\
\hline CHEMBL 3718570 & 1537037 & 7.5376 & 7.6564 & TRN & \\
\hline
\end{tabular}


Supplemental Table S2.txt

\begin{tabular}{|c|c|c|c|c|}
\hline CHEMBL 3718447 & 1537037 & 8.0969 & 7.5843 & TRN \\
\hline CHEMBL3718510 & 1537037 & 5.6655 & 5.5777 & TRN \\
\hline CHEMBL3716890 & 1537037 & 5.2111 & 5.5535 & TST \\
\hline CHEMBL3719149 & 1537037 & 6.3979 & 6.2039 & TRN \\
\hline CHEMBL3715209 & 1537037 & 5.5768 & 5.654 & TST \\
\hline CHEMBL3718978 & 1537037 & 8.1549 & 7.4847 & TRN \\
\hline CHEMBL3715787 & 1537037 & 7.5229 & 7.2623 & TRN \\
\hline CHEMBL3718034 & 1537037 & 8.2218 & 7.393 & TRN \\
\hline CHEMBL3715878 & 1537037 & 7.7447 & 7.4231 & TRN \\
\hline CHEMBL3718107 & 1537037 & 7.8239 & 7.5783 & TRN \\
\hline CHEMBL3718817 & 1537037 & 7.0315 & 6.7013 & TST \\
\hline CHEMBL3717742 & 1537037 & 7.1805 & 6.9051 & TST \\
\hline CHEMBL3716233 & 1537037 & 5.025 & 5.6624 & TST \\
\hline CHEMBL3718199 & 1537037 & 5.7122 & 5.8871 & TRN \\
\hline CHEMBL3719318 & 1537037 & 6.0 & 7.5642 & TRN \\
\hline CHEMBL3716375 & 1537037 & 5.5402 & 5.3877 & TRN \\
\hline CHEMBL3717215 & 1537037 & 6.0 & 6.9967 & TRN \\
\hline CHEMBL3716056 & 1537037 & 7.585 & 7.5848 & TRN \\
\hline CHEMBL3715082 & 1537037 & 5.4089 & 6.5043 & TRN \\
\hline CHEMBL3714945 & 1537037 & 7.3565 & 7.3412 & TRN \\
\hline CHEMBL3716922 & 1537037 & 5.6308 & 6.3659 & TRN \\
\hline CHEMBL3718390 & 1537037 & 5.2472 & 4.7135 & TST \\
\hline CHEMBL3715505 & 1537037 & 5.5528 & 6.0081 & TRN \\
\hline CHEMBL3717745 & 1537037 & 7.5528 & 6.6156 & TST \\
\hline CHEMBL3715178 & 1537037 & 5.9469 & 6.0481 & TRN \\
\hline CHEMBL3715352 & 1537037 & 6.7696 & 6.9742 & TRN \\
\hline CHEMBL3718581 & 1537037 & 5.7167 & 5.4942 & TRN \\
\hline CHEMBL3719010 & 1537037 & 7.8539 & 7.4012 & TRN \\
\hline CHEMBL3717929 & 1537037 & 5.1152 & 4.9481 & TRN \\
\hline CHEMBL3716707 & 1537037 & 7.3979 & 7.0972 & TST \\
\hline CHEMBL3717511 & 1537037 & 4.6899 & 5.9661 & TRN \\
\hline CHEMBL3716201 & 1537037 & 5.3391 & 6.0889 & TRN \\
\hline CHEMBL3717732 & 1537037 & 5.2118 & 5.1956 & TRN \\
\hline CHEMBL3718558 & 1537037 & 6.5686 & 6.9886 & TRN \\
\hline CHEMBL3718095 & 1537037 & 6.2692 & 7.385 & TST \\
\hline CHEMBL3716946 & 1537037 & 7.5086 & 7.4441 & TRN \\
\hline CHEMBL3717455 & 1537037 & 5.4737 & 6.6421 & TRN \\
\hline CHEMBL3716800 & 1537037 & 5.4023 & 5.041 & TST \\
\hline CHEMBL3718211 & 1537037 & 7.0458 & 7.125 & TRN \\
\hline CHEMBL3714886 & 1537037 & 7.8539 & 7.2459 & TRN \\
\hline CHEMBL3715463 & 1537037 & 6.4202 & 6.6874 & TST \\
\hline CHEMBL3717615 & 1537037 & 6.585 & 7.0227 & TRN \\
\hline CHEMBL3719239 & 1537037 & 6.0 & \multicolumn{2}{|c|}{7.077999999999999} \\
\hline CHEMBL3715393 & 1537037 & 7.5376 & 6.8318 & TRN \\
\hline CHEMBL3718141 & 1537037 & 6.0 & 7.1177 & TRN \\
\hline CHEMBL3718961 & 1537037 & 5.3179 & 5.6467 & TRN \\
\hline CHEMBL3718147 & 1537037 & 7.699 & 6.9597 & TRN \\
\hline CHEMBL 3717872 & 1537037 & 7.6198 & 6.8221 & TRN \\
\hline
\end{tabular}


Supplemental Table S2.txt

\begin{tabular}{|c|c|c|c|c|c|}
\hline CHEMBL3715056 & 1537037 & 5.4001 & 5.5369 & TRN & \\
\hline CHEMBL3718030 & 1537037 & 7.4559 & 6.6151 & TRN & \\
\hline CHEMBL3716474 & 1537037 & 5.6308 & 5.8252 & TRN & \\
\hline CHEMBL 3716452 & 1537037 & 5.3206 & 5.6974 & TST & \\
\hline CHEMBL3716755 & 1537037 & 7.3372 & 6.7714 & TST & \\
\hline CHEMBL3715672 & 1537037 & 7.1427 & 6.9855 & TRN & \\
\hline CHEMBL3716065 & 1537037 & 8.301 & 7.3521 & TRN & \\
\hline CHEMBL 3714860 & 1537037 & 7.0506 & 6.0121 & TST & \\
\hline CHEMBL3716268 & 1537037 & 4.5867 & 4.7641 & TRN & \\
\hline CHEMBL3717806 & 1537037 & 5.5952 & 5.2764 & TST & \\
\hline CHEMBL3715332 & 1537037 & 6.8386 & 7.065 & TRN & \\
\hline CHEMBL3717101 & 1537037 & 6.4685 & 6.7043 & TRN & \\
\hline CHEMBL3719027 & 1537037 & 4.6619 & 4.4668 & TST & \\
\hline CHEMBL3715318 & 1537037 & 6.0757 & 5.4953 & TRN & \\
\hline CHEMBL3715157 & 1537037 & 6.5229 & 5.9505 & TST & \\
\hline CHEMBL3718003 & 1537037 & 3.977 & 4.9333 & TRN & \\
\hline CHEMBL3717038 & 1537037 & 6.5086 & 6.8155 & TRN & \\
\hline CHEMBL3716306 & 1537037 & 6.7212 & 6.1569 & TRN & \\
\hline CHEMBL3717270 & 1537037 & 6.4685 & 5.7781 & TST & \\
\hline CHEMBL3718016 & 1537037 & 7.8239 & 7.2929 & TRN & \\
\hline CHEMBL3716683 & 1537037 & 7.301 & 6.7036 & TRN & \\
\hline CHEMBL3717781 & 1537037 & 6.6021 & \multicolumn{2}{|c|}{6.196000000000001} & TRN \\
\hline CHEMBL 3716133 & 1537037 & 6.2757 & 4.6462 & TST & \\
\hline CHEMBL3719320 & 1537037 & 6.0273 & 7.1108 & TST & \\
\hline CHEMBL3719186 & 1537037 & 5.8861 & 5.9281 & TST & \\
\hline CHEMBL3715833 & 1537037 & 6.0 & 6.7409 & TRN & \\
\hline CHEMBL3718723 & 1537037 & 5.5186 & 4.8828 & TRN & \\
\hline CHEMBL3719219 & 1537037 & 5.7122 & 5.6128 & TRN & \\
\hline CHEMBL3718731 & 1537037 & 7.1487 & 6.9386 & TRN & \\
\hline CHEMBL3716960 & 1537037 & 7.585 & 6.8737 & TRN & \\
\hline CHEMBL3717381 & 1537037 & 7.699 & 7.442 & TRN & \\
\hline CHEMBL3717284 & 1537037 & 6.1871 & 5.7941 & TRN & \\
\hline CHEMBL 3716076 & 1537037 & 7.9586 & 7.1327 & TRN & \\
\hline CHEMBL3716757 & 1537037 & 7.5376 & \multicolumn{2}{|c|}{6.997000000000001} & TRN \\
\hline CHEMBL3719293 & 1537037 & 8.2218 & 7.6242 & TRN & \\
\hline CHEMBL3719166 & 1537037 & 6.8356 & 6.2529 & TRN & \\
\hline CHEMBL3717357 & 1537037 & 5.9586 & 7.1499 & TRN & \\
\hline CHEMBL 3718500 & 1537037 & 5.8447 & 7.1652 & TRN & \\
\hline CHEMBL3715955 & 1537037 & 7.2076 & 6.6036 & TRN & \\
\hline CHEMBL3718432 & 1537037 & 5.8665 & 6.0561 & TST & \\
\hline CHEMBL3717329 & 1537037 & 5.8327 & 6.8777 & TRN & \\
\hline CHEMBL3717716 & 1537037 & 6.8539 & \multicolumn{2}{|c|}{6.962999999999999} & TRN \\
\hline CHEMBL3714978 & 1537037 & 5.317 & 6.3659 & TRN & \\
\hline CHEMBL3717906 & 1537037 & 5.3382 & 5.8338 & TST & \\
\hline CHEMBL3718684 & 1537037 & 7.1871 & 7.3829 & TRN & \\
\hline CHEMBL3717670 & 1537037 & 7.1079 & 7.1839 & TRN & \\
\hline CHEMBL3718098 & 1537037 & 7.1249 & 6.716 & TRN & \\
\hline CHEMBL3718399 & 1537037 & 7.5376 & 7.0889 & TRN & \\
\hline
\end{tabular}

Page 14073 
Supplemental Table S2.txt

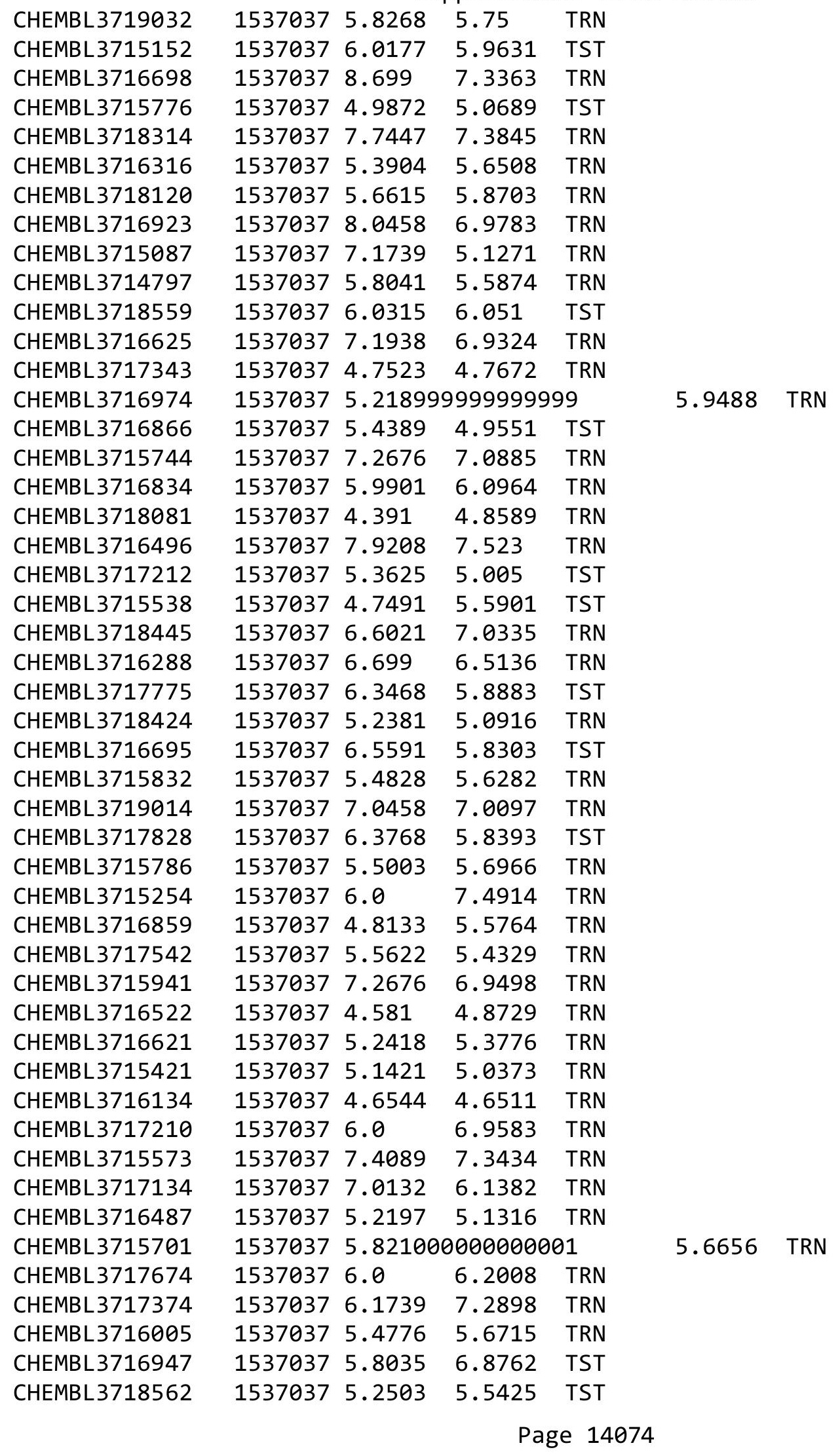


Supplemental Table S2.txt

\begin{tabular}{|c|c|c|c|c|}
\hline HEMB I & 537037 & & & \\
\hline & & & 1559 & \\
\hline-1 & & & & \\
\hline AEMBL3 & & & & \\
\hline AEMBL3717678 & 37037 & 3565 & 3398 & \\
\hline HEMBL 3716541 & 537037 & 4.8116 & 7415 & \\
\hline 221 & & 202 & 258 & \\
\hline 7950 & & & 771 & \\
\hline HEMBL3 & 337 & 9762 & 3172 & \\
\hline HEMBL37 & 37 & 7.0362 & 2543 & \\
\hline AEMBL3 & 37 & 6.8539 & 1228 & \\
\hline AEMBL3 & 37 & 3979 & & \\
\hline HEMBL & & & & \\
\hline HEMBL3 & 20 & 4.3201 & 1922 & \\
\hline AEMBL1 & 0 & 5.1765 & 076 & \\
\hline AEMBL1 & $=0$ & 5 & 3788 & \\
\hline AEMBL2 & 6 & 4 & 004 & \\
\hline HEMBLI & & & 3565 & \\
\hline HEMBL1 & & 4 & 5948 & \\
\hline AEMBL1 & & 4. & 809 & \\
\hline HEMBL & 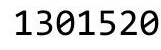 & 4 & 606 & RIV \\
\hline HEMBL & 6 & 4 . & 552 & 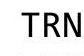 \\
\hline HEMBL & & 6 . & 908 & \\
\hline HEMBL: & & & 3829 & \\
\hline AEMBL2 & & 6. & 329 & N \\
\hline HEMBL 2 & -0 & & 769 & 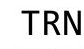 \\
\hline HEMBL & & & 405 & ST \\
\hline HFMRI & & & 738 & \\
\hline HEMBL 2 & & & 1164 & iv \\
\hline HEMBL1 & & & 693 & I NIV \\
\hline HEMBL3 & & 4. & 838 & RN \\
\hline HEMBL & $\theta$ & & 672 & RN \\
\hline HEMBL & & 986 & 069 & RN \\
\hline HEMBL1 & & & 134 & IRN \\
\hline HEMBL 2137524 & 20 & 4.758 & 226 & TRN \\
\hline HEMBL & & & 066 & \\
\hline HEMRI & & & 222 & RN \\
\hline HEMBL1 & & 4.9027 & 3699 & IST \\
\hline HEMBL2 & 30 & 6 & 5362 & TRN \\
\hline AEMBL1 & 20 & & 5702 & TST \\
\hline HEMBL1 & $-\theta$ & 4 & 3288 & \\
\hline CHEMBL 2 & & & & RN \\
\hline HEMBL2 & & 4.7003 & 5242 & $\Gamma \mathrm{RN}$ \\
\hline HEMBL1 & 20 & 4.6411 & 567 & TRN \\
\hline MBL1 & 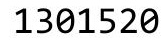 & J & 2841 & $\mathrm{~N}$ \\
\hline HEMBL2 & & & .2599 & \\
\hline HEMBL2 & & .52 & .9175 & \\
\hline LHEMBL1605224 & 1301520 & 4.7902 & 4.9467 & \\
\hline
\end{tabular}

Page 14075 
Supplemental Table S2.txt

\begin{tabular}{|c|c|c|c|c|}
\hline . & & & & \\
\hline HEMBL2134979 & 301520 & 6.0 & 5831 & \\
\hline HEMBL3181812 & 301520 & 4.3537 & & \\
\hline IEMBL: & 20 & & 263 & \\
\hline EMBL1S & 520 & & & \\
\hline HEMBL1890931 & 301520 & 4.8016 & 1198 & \\
\hline HEMBL1389886 & 301520 & 4.9863 & 9415 & \\
\hline HEMBL1586255 & 520 & 31 & 77 & \\
\hline AEMBL3185199 & 520 & 6.0 & .18 & \\
\hline AEMBL2132 & 520 & 4 & & \\
\hline HEMBL530361 & 301520 & 4. & 0025 & \\
\hline AEMBL2133366 & 520 & 5 & 379 & \\
\hline HEMBL147 & 20 & 4. & 414 & \\
\hline HEMBL 213 & & & 5044 & \\
\hline HEMBL2132942 & 20 & 4. & & \\
\hline HEMBL1487650 & 20 & 5.7747 & 7578 & \\
\hline HEMBL1883958 & 20 & 5.567 & 14 & \\
\hline HEMBL152 & 20 & 4 & 99 & \\
\hline HEMBL 318 & & & & \\
\hline HEMBL133 & 20 & & & RN \\
\hline HEMBL 235 & 20 & 6 . & & RN \\
\hline AEMBL 2139075 & 20 & 4. & 89 & ГRN \\
\hline HEMBL 3184 & 20 & & 03 & . \\
\hline HEMBL14 & & & & $2 \mathrm{~N}$ \\
\hline HEMBL318 & 20 & & & RN \\
\hline HEMBL137: & & & & RN \\
\hline HEMBL1530087 & 20 & 4. & 4 & I S \\
\hline HEMBL1563323 & 20 & & 07 & RN \\
\hline HEM & 20 & & & RN \\
\hline HEMBL139 & 20 & & & ST \\
\hline HEMBL 3187 & & & & RN \\
\hline HEMBL1327251 & 20 & 4. & & ST \\
\hline HEMBL1373761 & 20 & 4 & 53 & RN \\
\hline 6 & 20 & & & ST \\
\hline HEMBL2136465 & & 6 & & RN \\
\hline HEMBL2131028 & 20 & & & RN \\
\hline HEMBL 2144728 & 20 & & 67 & RN \\
\hline HEMBL3184167 & 30 & 4. & & RN \\
\hline 7 & & & & RN \\
\hline HEMBL1575588 & & & & ST \\
\hline HEMBL1875123 & 20 & & 51 & RN \\
\hline HEMBL1500335 & 20 & & & RN \\
\hline & 30 & & & \\
\hline HEMBL1971151 & & & & ST \\
\hline HEMBL52879 & 20 & 5.06 & 6525 & RN \\
\hline HEMBL3189712 & 20 & 5.4841 & 84 & RN \\
\hline 15 & 30 & & & \\
\hline & 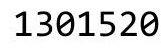 & & & \\
\hline
\end{tabular}

Page 14076 
Supplemental Table S2.txt

\begin{tabular}{|c|c|c|c|c|}
\hline 2 & & & & \\
\hline 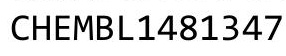 & 301520 & 5.1831 & 4.9915 & \\
\hline 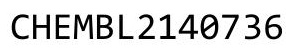 & 01520 & & & \\
\hline IEMBL2 & 20 & & 8875 & \\
\hline AEMBL1344875 & 301520 & 55 & 857 & \\
\hline HEMBL1479947 & 301520 & & 0427 & \\
\hline HEMBL2 & 20 & & 3045 & \\
\hline AEMBL15 & 520 & & 3936 & \\
\hline HEMBL1548535 & 301520 & 4.8342 & 1734 & \\
\hline HEMBL3189023 & 301520 & & 6172 & \\
\hline HEMBL 2 & 20 & & 9965 & \\
\hline HEMBL1 & 20 & & 3827 & \\
\hline AEMBL3 & 20 & & 695 & \\
\hline HEMBL1504701 & 301520 & 6.2628 & 1989 & \\
\hline AEMBL52 & 301520 & & & \\
\hline HEMBL1 & 30 & & 733 & \\
\hline HEMBL1 & 20 & & 511 & \\
\hline HEMBL 2 & 20 & & 633 & \\
\hline HFMBI 3 & 20 & & 658 & \\
\hline AEMBL13 & & & & 151 \\
\hline HEMBL1 & 20 & & 51 & RN \\
\hline HEM & 20 & & & MIV \\
\hline AEMBL 3 & 20 & & 27 & \\
\hline HEMBL1 & & & & IRIV \\
\hline AEMBL 21 & 20 & & 194 & IRN \\
\hline HEMBL3: & 20 & & 324 & RN \\
\hline HFMBI 2 & 20 & & & KIV \\
\hline 92 & 20 & & 056 & \\
\hline AEMBL3 & & & & IK \\
\hline AEMBL31 & 20 & 4. & 532 & TRN \\
\hline AEMB & 20 & & 328 & RN \\
\hline 7 & 20 & & 63 & 「RN \\
\hline 7 & & & & Ins \\
\hline HEMBL3 & & & 542 & $\mathrm{~K}$ \\
\hline HEMBL 23 & 520 & 6 & 645 & RN \\
\hline AFMRI 1 & 20 & & 976 & TRN \\
\hline 3 & 20 & & & ГRN \\
\hline HEMBL 2 & & & 5248 & TRN \\
\hline HEMBL3 & 20 & & 153 & $\Gamma R$ \\
\hline$\angle$ & 20 & & 399 & RN \\
\hline HEMBL1 & 20 & & 491 & RN \\
\hline HEMBL1 & 20 & 4.8422 & 86 & ST \\
\hline HEMBL 2: & 520 & 6 & $\partial 646$ & TS \\
\hline HEMBL 2 & 20 & & 751 & TS \\
\hline 0 & & & & $S$ \\
\hline HEMBL31 & 130 & & 2058 & \\
\hline HEMBL3] & 520 & 4.5018 & 789 & IST \\
\hline CHEMBL570399 & 1301520 & 4.7951 & 5.1652 & - \\
\hline
\end{tabular}

Page 14077 
Supplemental Table S2.txt

\begin{tabular}{|c|c|c|c|c|}
\hline CHEMBL1882125 & 1301520 & 5.3487 & 4.5101 & TST \\
\hline CHEMBL 2361807 & 1301520 & 4.8592 & 5.1362 & TST \\
\hline CHEMBL 3185040 & 1301520 & 4.6031 & 4.3119 & TST \\
\hline CHEMBL607553 & 1301520 & 5.644 & 5.5462 & TST \\
\hline CHEMBL1928491 & 1301520 & 4.7823 & \multicolumn{2}{|c|}{5.162000000000001} \\
\hline CHEMBL2132859 & 1301520 & 4.7744 & 4.7098 & TST \\
\hline CHEMBL 2134579 & 1301520 & 4.5047 & 4.3909 & TST \\
\hline CHEMBL 2138365 & 1301520 & 5.3161 & 5.5995 & TST \\
\hline CHEMBL 2355890 & 1301520 & 6.0 & 4.5401 & TST \\
\hline CHEMBL1388152 & 1301520 & 4.7667 & 4.4867 & TST \\
\hline CHEMBL1431189 & 1301520 & 5.644 & 4.8798 & TST \\
\hline CHEMBL1313978 & 1301520 & 5.2403 & 5.039 & TST \\
\hline CHEMBL 3185630 & 1301520 & 4.4324 & 4.0875 & TST \\
\hline CHEMBL 3654272 & 1536085 & 6.7447 & 6.7566 & TRN \\
\hline CHEMBL 3650885 & 1536085 & 4.5058 & 5.8797 & TST \\
\hline CHEMBL 3650894 & 1536085 & 7.0 & 7.0145 & TRN \\
\hline CHEMBL3650856 & 1536085 & 6.2366 & 6.1911 & TRN \\
\hline CHEMBL3650897 & 1536085 & 6.6778 & 6.6563 & TRN \\
\hline CHEMBL 3650917 & 1536085 & 7.4318 & 7.4516 & TRN \\
\hline CHEMBL3950564 & 1536085 & 7.6383 & 7.5907 & TRN \\
\hline CHEMBL3650890 & 1536085 & 7.3098 & 7.3342 & TRN \\
\hline CHEMBL 3654294 & 1536085 & 6.8539 & 6.8235 & TRN \\
\hline CHEMBL 3654278 & 1536085 & 6.8539 & 6.8367 & TRN \\
\hline CHEMBL 3650962 & 1536085 & 7.4685 & 7.4169 & TRN \\
\hline CHEMBL3650972 & 1536085 & 6.0 & 5.9345 & TRN \\
\hline CHEMBL3654298 & 1536085 & 7.1427 & 7.1869 & TRN \\
\hline CHEMBL3654309 & 1536085 & 6.8539 & 6.9047 & TRN \\
\hline CHEMBL 3650954 & 1536085 & 7.5686 & 7.5721 & TRN \\
\hline CHEMBL 3650883 & 1536085 & 6.1612 & 6.2009 & TRN \\
\hline CHEMBL3937587 & 1536085 & 6.0 & 5.9501 & TRN \\
\hline CHEMBL3654295 & 1536085 & 6.6576 & 7.0374 & TST \\
\hline CHEMBL 3654274 & 1536085 & 6.4815 & 6.4988 & TRN \\
\hline CHEMBL 3654319 & 1536085 & 6.5686 & 6.5281 & TST \\
\hline CHEMBL 3650893 & 1536085 & 7.041 & 7.1616 & TST \\
\hline CHEMBL 3650951 & 1536085 & 6.0 & 6.0025 & TRN \\
\hline CHEMBL3654302 & 1536085 & 7.0362 & 7.225 & TRN \\
\hline CHEMBL 3654277 & 1536085 & 6.7212 & 6.7351 & TRN \\
\hline CHEMBL3654296 & 1536085 & 7.1024 & 6.9849 & TRN \\
\hline CHEMBL 3650904 & 1536085 & 6.3188 & 6.272 & TST \\
\hline CHEMBL3650925 & 1536085 & 6.9208 & 6.8894 & TRN \\
\hline CHEMBL 3654287 & 1536085 & 7.0088 & 7.0869 & TRN \\
\hline CHEMBL 3650961 & 1536085 & 7.4437 & 7.4375 & TRN \\
\hline CHEMBL 3650903 & 1536085 & 7.0088 & 6.9681 & TRN \\
\hline CHEMBL 3654326 & 1536085 & 7.4437 & 7.3412 & TRN \\
\hline CHEMBL3650918 & 1536085 & 7.585 & 7.5321 & TRN \\
\hline CHEMBL 3654286 & 1536085 & 7.1135 & 6.9245 & TRN \\
\hline CHEMBL3650958 & 1536085 & 6.0 & 5.3661 & TST \\
\hline CHEMBL 3654283 & 1536085 & 6.9208 & 6.9271 & TRN \\
\hline
\end{tabular}


Supplemental Table S2.txt

\begin{tabular}{|c|c|c|c|c|}
\hline HEM & & 7.3279 & & \\
\hline UГMDI & & 7.0969 & 7.1493 & \\
\hline & & 959 & & \\
\hline AEMBL & 5085 & 1805 & 1773 & $2 \mathrm{~N}$ \\
\hline AEMBL3654292 & 36085 & 208 & 9323 & \\
\hline HEMBL3650939 & 536085 & 7.3468 & .4482 & \\
\hline HEMBL & & 447 & 879 & \\
\hline 91 & & & & RN \\
\hline JEMBL 36 & 5085 & 2291 & .2034 & \\
\hline HEMBL365 & 36085 & 586 & 6.9198 & \\
\hline AEMBL 365 & 6085 & 18 & .4152 & \\
\hline IEMBL36 & בל ב & & .9247 & \\
\hline AEMBL3 & & & & \\
\hline HEMBL36 & $\partial 85$ & & .0036 & \\
\hline AEMBL36 & 085 & 6 & 5.9796 & \\
\hline IEMBL365 & 36085 & 7 & .942 & \\
\hline HEMBL36 & & 12 & .77 & m \\
\hline HEMBL36 & & & 21 & \\
\hline HEMBL36 & & 7. & 7.3636 & \\
\hline AEMBL36 & 85 & 6 . & 34 & \\
\hline AEMBL3 & 36085 & 6 & 771 & $\mathrm{IRIV}$ \\
\hline HEMBL3 & & & 64 & RIN \\
\hline HEMBL & & 696 & & \\
\hline HEMBL36 & & 6 & 5.966 & \\
\hline HEMBL 365 & & 6 & & TRN \\
\hline HEMBL3 & 36085 & 6. & 15 & I RN \\
\hline HEMBL; & & & 56 & Niv \\
\hline HFMBI : & 5 & 27 & 196 & \\
\hline HEMBL3E & & & 6.6708 & IR \\
\hline HEMBL 3650 & 35 & & & is \\
\hline HEMBL 36 & 36085 & 7. & 009 & $\mathrm{RN}$ \\
\hline HEMBL & & & 357 & RN \\
\hline HEMBL & 35 & 6 & 5.8584 & 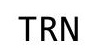 \\
\hline HEMBL365 & & 6. & 756 & IRN \\
\hline HEMBL3650878 & 360 & 6 . & 6.441 & TST \\
\hline HEMBL36 & 60 & & 8.2256 & TST \\
\hline HFMRI 3 & & 7 & 84 & $\Gamma \mathrm{RN}$ \\
\hline HEMBL3 & & & 7.5028 & 「RN \\
\hline HEMBL3650941 & 53608 & 7.2007 & 7.2044 & TRN \\
\hline HEMBL 365 & 53608 & & 6.0577 & TST \\
\hline HEMBL36 & $536 a$ & & 5.8244 & \\
\hline HEMBL 36 & & & 7.6371 & TRN \\
\hline HEMBL365 & 36085 & 6.6778 & 6.6569 & RN \\
\hline HEMBL3654304 & 536085 & 6 & 6.1775 & TR \\
\hline$M B L 3$ & & & 6.7479 & RN \\
\hline HEMBL 36 & & & 6.8977 & \\
\hline CHEMBL 365 & & .24 & 7.175 & \\
\hline CHEMBL3650886 & 153608 & 7.0223 & 7.0558 & ГRN \\
\hline
\end{tabular}

Page 14079 
Supplemental Table S2.txt

\begin{tabular}{|c|c|c|c|c|}
\hline CHEMBL 3650896 & 1536085 & 7.2218 & 7.2695 & TRN \\
\hline CHEMBL3961497 & 1536085 & 6.0 & 6.0036 & TRN \\
\hline CHEMBL3650931 & 1536085 & 6.9208 & 6.9105 & TRN \\
\hline CHEMBL3650907 & 1536085 & 6.2518 & 6.2993 & TRN \\
\hline CHEMBL 3654267 & 1536085 & 6.8539 & 6.7933 & TRN \\
\hline CHEMBL 3650881 & 1536085 & 6.0 & 5.9897 & TRN \\
\hline CHEMBL3650957 & 1536085 & 3.4318 & 2.7383 & TST \\
\hline CHEMBL 3654325 & 1536085 & 7.3768 & 7.3579 & TRN \\
\hline CHEMBL 3926752 & 1536085 & 6.8539 & 6.8417 & TRN \\
\hline CHEMBL3650892 & 1536085 & 7.1249 & 7.0826 & TST \\
\hline CHEMBL 3650935 & 1536085 & 7.1427 & 7.1398 & TRN \\
\hline CHEMBL 3650927 & 1536085 & 6.9586 & 6.9834 & TRN \\
\hline CHEMBL 3650924 & 1536085 & 7.0 & 6.979 & TRN \\
\hline CHEMBL 3654276 & 1536085 & 6.7447 & \multicolumn{2}{|c|}{6.757999999999999} \\
\hline CHEMBL 3650921 & 1536085 & 7.2218 & 7.2012 & TRN \\
\hline CHEMBL3650936 & 1536085 & 7.2218 & 7.1764 & TRN \\
\hline CHEMBL 3650905 & 1536085 & 6.0 & 6.0469 & TRN \\
\hline CHEMBL 3650974 & 1536085 & 6.0 & 6.0554 & TRN \\
\hline CHEMBL 3650906 & 1536085 & 6.5686 & 6.4623 & TRN \\
\hline CHEMBL 3650943 & 1536085 & 7.0555 & 7.1096 & TRN \\
\hline CHEMBL 3650930 & 1536085 & 7.0132 & 7.0149 & TRN \\
\hline CHEMBL3650950 & 1536085 & 6.8861 & 6.9105 & TRN \\
\hline CHEMBL 3650946 & 1536085 & 7.3665 & 7.4904 & TRN \\
\hline CHEMBL 3650966 & 1536085 & 6.0 & 6.0103 & TRN \\
\hline CHEMBL3650976 & 1536085 & 6.0 & 5.9886 & TRN \\
\hline CHEMBL 3654273 & 1536085 & 6.7447 & \multicolumn{2}{|c|}{6.787000000000001} \\
\hline CHEMBL3650914 & 1536085 & 6.6198 & 6.6875 & TRN \\
\hline CHEMBL3650959 & 1536085 & 7.4559 & 7.3983 & TST \\
\hline CHEMBL 3650887 & 1536085 & 6.8539 & 6.9575 & TST \\
\hline CHEMBL 3654270 & 1536085 & 6.7959 & 6.8006 & TST \\
\hline CHEMBL 3654305 & 1536085 & 6.9208 & 6.9152 & TST \\
\hline CHEMBL 3654308 & 1536085 & 6.0 & 5.9804 & TST \\
\hline CHEMBL3650916 & 1536085 & 7.3665 & 7.3998 & TST \\
\hline CHEMBL 3650975 & 1536085 & 7.2757 & 7.3766 & TST \\
\hline CHEMBL 3650908 & 1536085 & 6.2147 & 6.4123 & TST \\
\hline CHEMBL3650940 & 1536085 & 7.6021 & 7.8403 & TST \\
\hline CHEMBL 3654317 & 1536085 & 7.0458 & 7.017 & TST \\
\hline CHEMBL3650895 & 1536085 & 6.7696 & 6.8981 & TST \\
\hline CHEMBL 3654263 & 1536085 & 6.0 & 6.1697 & TST \\
\hline CHEMBL3650858 & 1536085 & 6.1367 & 6.3888 & TST \\
\hline CHEMBL 3650862 & 1536085 & 6.6778 & 6.7733 & TST \\
\hline CHEMBL3650915 & 1536085 & 6.7959 & 7.0487 & TST \\
\hline CHEMBL 3650884 & 1536085 & 5.9208 & 6.2178 & TST \\
\hline CHEMBL1403337 & 737064 & 3.1003 & 3.4166 & TST \\
\hline CHEMBL1505364 & 737064 & 3.1003 & 3.3622 & TRN \\
\hline CHEMBL 3198489 & 737064 & 3.1003 & 3.2831 & TRN \\
\hline CHEMBL1427304 & 737064 & 3.1003 & 2.8875 & TRN \\
\hline CHEMBL1431563 & 737064 & 3.1003 & 3.3925 & TRN \\
\hline
\end{tabular}

Page 14080 
Supplemental Table S2.txt

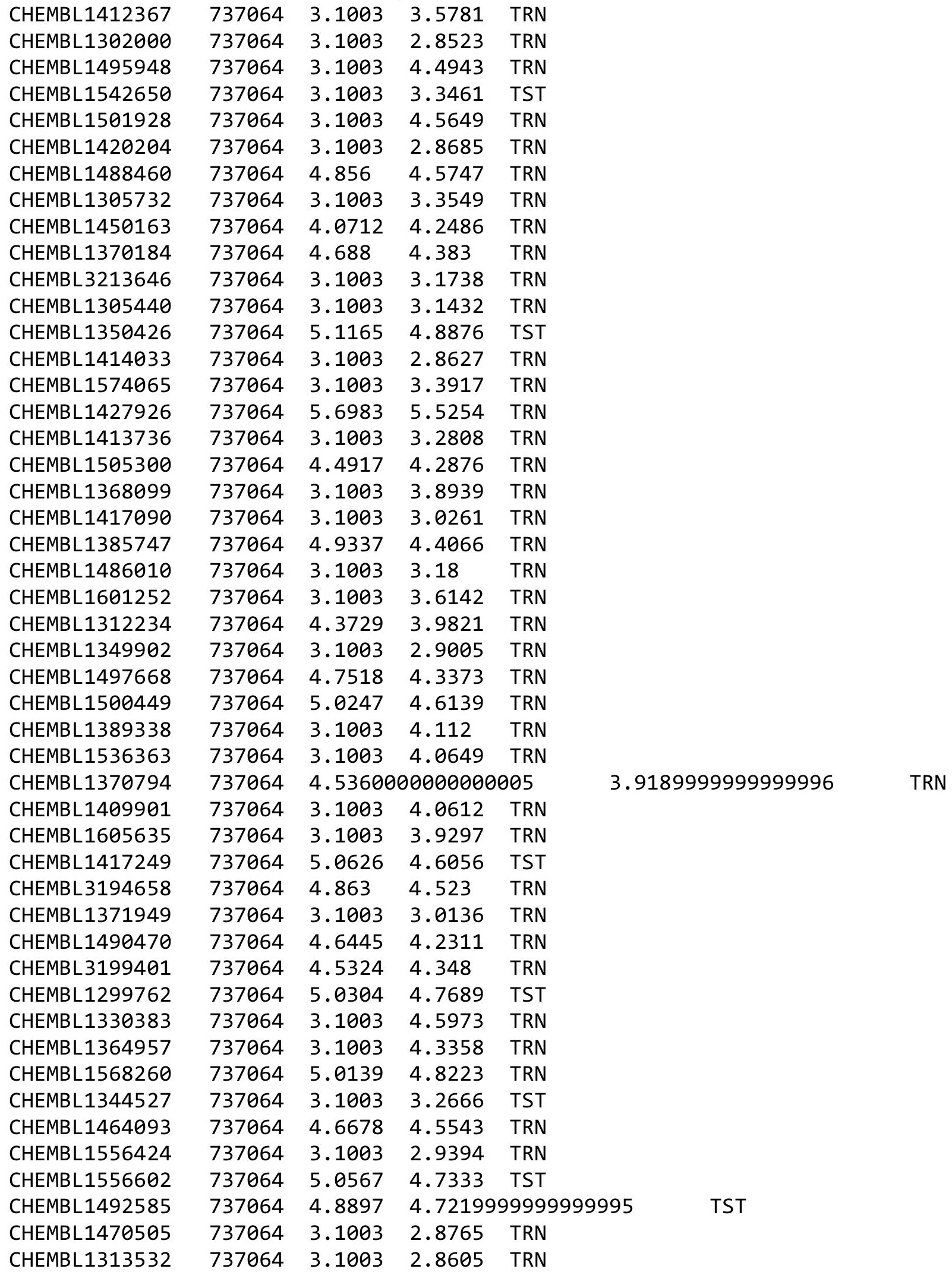

Page 14081 


\begin{tabular}{|c|c|c|c|c|c|}
\hline \multicolumn{6}{|c|}{ Supplemental Table S2.txt } \\
\hline CHEMBL1414215 & 737064 & 5.0806 & 4.8758 & TRN & \\
\hline CHEMBL1390336 & 737064 & 5.1882 & 5.1653 & TRN & \\
\hline CHEMBL1978236 & 737064 & 5.2536 & 4.8063 & TST & \\
\hline CHEMBL1510387 & 737064 & 3.1003 & 2.8642 & TRN & \\
\hline CHEMBL1596917 & 737064 & 3.1003 & 3.6674 & TRN & \\
\hline CHEMBL1374897 & 737064 & 4.498 & 4.2491 & TRN & \\
\hline CHEMBL1505452 & 737064 & 3.1003 & 2.8514 & TRN & \\
\hline CHEMBL1530807 & 737064 & 4.8784 & 4.6958 & TRN & \\
\hline CHEMBL1399076 & 737064 & 3.1003 & 2.8484 & TRN & \\
\hline CHEMBL1499884 & 737064 & 4.4693 & 3.9035 & TST & \\
\hline CHEMBL1321356 & 737064 & 5.135 & 4.9271 & TRN & \\
\hline CHEMBL1448856 & 737064 & 4.3553 & 4.2964 & TRN & \\
\hline CHEMBL1511437 & 737064 & 5.2079 & 5.2715 & TRN & \\
\hline CHEMBL1603238 & 737064 & 3.1003 & 4.0132 & TST & \\
\hline CHEMBL3194616 & 737064 & 3.1003 & 4.2193 & TRN & \\
\hline CHEMBL1411304 & 737064 & 4.8271 & 4.5187 & TRN & \\
\hline CHEMBL1449640 & 737064 & 4.4738 & 4.2718 & TRN & \\
\hline CHEMBL3192653 & 737064 & 4.7905 & 4.38899 & 9999999999 & TRN \\
\hline CHEMBL1498444 & 737064 & 3.1003 & 4.0057 & TRN & \\
\hline CHEMBL1510408 & 737064 & 5.3012 & 5.2262 & TST & \\
\hline CHEMBL1484186 & 737064 & 4.8857 & 4.4623 & TST & \\
\hline CHEMBL1547468 & 737064 & 3.1003 & 3.1792 & TST & \\
\hline CHEMBL1342815 & 737064 & 4.9918 & 4.4923 & TRN & \\
\hline CHEMBL1386916 & 737064 & 5.7421 & 5.1901 & TRN & \\
\hline CHEMBL1417231 & 737064 & 5.3915 & 5.1109 & TRN & \\
\hline CHEMBL3196830 & 737064 & 4.9136 & 4.4652 & TRN & \\
\hline CHEMBL1426003 & 737064 & 5.4336 & 5.6875 & TRN & \\
\hline CHEMBL1471229 & 737064 & 3.1003 & 3.43899 & 99999999996 & TRN \\
\hline CHEMBL1572461 & 737064 & 3.1003 & 3.1168 & TRN & \\
\hline CHEMBL1535864 & 737064 & 3.1003 & 3.165 & TRN & \\
\hline CHEMBL1360098 & 737064 & 3.5774 & 3.5623 & TRN & \\
\hline CHEMBL1425009 & 737064 & 3.1003 & 3.2262 & TRN & \\
\hline CHEMBL1347130 & 737064 & 3.5774 & 3.7964 & TRN & \\
\hline CHEMBL1450791 & 737064 & 3.8639 & 4.8385 & TRN & \\
\hline CHEMBL1380975 & 737064 & 4.4447 & 4.4961 & TRN & \\
\hline CHEMBL1556190 & 737064 & 5.0597 & 5.2059 & TRN & \\
\hline CHEMBL1465040 & 737064 & 3.1003 & 3.4978 & TRN & \\
\hline CHEMBL1499411 & 737064 & 3.1003 & 4.3073 & TRN & \\
\hline CHEMBL417727 & 737064 & 4.9083 & 4.48300 & 00000000005 & TRN \\
\hline CHEMBL1409776 & 737064 & 5.0546 & 4.2096 & TST & \\
\hline CHEMBL1491054 & 737064 & 5.0067 & 4.3366 & TRN & \\
\hline CHEMBL1456701 & 737064 & 5.0544 & 4.4868 & TRN & \\
\hline CHEMBL3198000 & 737064 & 5.5605 & 4.7687 & TRN & \\
\hline CHEMBL1498284 & 737064 & 4.1753 & 4.0936 & TRN & \\
\hline CHEMBL3196920 & 737064 & 4.3094 & 4.1762 & TRN & \\
\hline CHEMBL1304332 & 737064 & 4.8592 & 4.7389 & TRN & \\
\hline CHEMBL1461424 & 737064 & 3.1003 & 2.8839 & TRN & \\
\hline CHEMBL1441823 & 737064 & 4.9706 & 4.5846 & TRN & \\
\hline
\end{tabular}


Supplemental Table S2.txt

\begin{tabular}{|c|c|c|c|c|c|}
\hline CHEMBL1347385 & 737064 & 3.1003 & 3.8343 & TST & \\
\hline CHEMBL1374054 & 737064 & 5.4352 & 4.8452 & TRN & \\
\hline CHEMBL1365146 & 737064 & 5.3135 & 5.2172 & TRN & \\
\hline CHEMBL1402874 & 737064 & 3.1003 & 4.0808 & TRN & \\
\hline CHEMBL1501406 & 737064 & 4.4791 & 4.1829 & TRN & \\
\hline CHEMBL1331930 & 737064 & 5.794 & 5.5083 & TST & \\
\hline CHEMBL1604196 & 737064 & 4.023 & 4.2796 & TRN & \\
\hline CHEMBL3196468 & 737064 & 4.5552 & 4.2555 & TRN & \\
\hline CHEMBL1494683 & 737064 & 3.1003 & 3.5082 & TRN & \\
\hline CHEMBL1529744 & 737064 & 5.1355 & 4.8309 & TRN & \\
\hline CHEMBL1567207 & 737064 & 4.704 & 4.2449 & TRN & \\
\hline CHEMBL1332040 & 737064 & 4.3745 & 4.1339 & TST & \\
\hline CHEMBL1491688 & 737064 & 3.1003 & 3.1667 & TST & \\
\hline CHEMBL1596518 & 737064 & 3.1003 & 2.8514 & TRN & \\
\hline CHEMBL1416266 & 737064 & 5.4859 & 4.7299 & TRN & \\
\hline CHEMBL1452842 & 737064 & 3.1003 & 3.0219 & TRN & \\
\hline CHEMBL1366942 & 737064 & 4.7162 & 4.7368 & TST & \\
\hline CHEMBL1546820 & 737064 & 3.1003 & 4.1351 & TST & \\
\hline CHEMBL1538790 & 737064 & 5.5658 & 5.2603 & TRN & \\
\hline CHEMBL1537230 & 737064 & 3.1003 & 3.5135 & TRN & \\
\hline CHEMBL1408514 & 737064 & 4.5585 & 3.5811 & TRN & \\
\hline CHEMBL1378944 & 737064 & 3.1003 & 3.2083 & TRN & \\
\hline CHEMBL1328113 & 737064 & 3.1003 & 2.9083 & TRN & \\
\hline CHEMBL1601197 & 737064 & 4.2473 & 4.177 & TRN & \\
\hline CHEMBL1515768 & 737064 & 3.1003 & 3.2264 & TRN & \\
\hline CHEMBL1480312 & 737064 & 3.1003 & 3.1374 & TRN & \\
\hline CHEMBL1492686 & 737064 & 3.1003 & 3.4613 & TRN & \\
\hline CHEMBL1428877 & 737064 & 3.1003 & 2.8561 & TRN & \\
\hline CHEMBL1359009 & 737064 & 4.4304 & 4.2042 & TRN & \\
\hline CHEMBL1494589 & 737064 & 3.1003 & 2.8727 & TRN & \\
\hline CHEMBL1603319 & 737064 & 4.7055 & 3.3992 & TRN & \\
\hline CHEMBL1345018 & 737064 & 3.1003 & 2.92199 & 99999999997 & TRN \\
\hline CHEMBL1389774 & 737064 & 3.1003 & 2.8679 & TRN & \\
\hline CHEMBL3198706 & 737064 & 4.5988 & 4.2312 & TST & \\
\hline CHEMBL1450246 & 737064 & 3.1003 & 2.8659 & TRN & \\
\hline CHEMBL1494694 & 737064 & 5.0286 & 4.5739 & TRN & \\
\hline CHEMBL1589053 & 737064 & 4.8801 & 4.6186 & TRN & \\
\hline CHEMBL1452524 & 737064 & 5.3705 & 5.1075 & TST & \\
\hline CHEMBL1583070 & 737064 & 3.1003 & 2.9412 & TRN & \\
\hline CHEMBL1508025 & 737064 & 3.5774 & 3.8543 & TRN & \\
\hline CHEMBL1547257 & 737064 & 5.396 & 4.5845 & TRN & \\
\hline CHEMBL1535116 & 737064 & 3.1003 & 3.2866 & TRN & \\
\hline CHEMBL1484562 & 737064 & 5.0033 & 4.6021 & TST & \\
\hline CHEMBL1369067 & 737064 & 3.1003 & 2.8671 & TRN & \\
\hline CHEMBL1376488 & 737064 & 4.6171 & 4.627 & TRN & \\
\hline CHEMBL1605444 & 737064 & 4.5318 & 4.2477 & TRN & \\
\hline CHEMBL3193785 & 737064 & 5.3382 & 4.8718 & TST & \\
\hline CHEMBL1526553 & 737064 & 5.0197 & 4.9966 & TRN & \\
\hline
\end{tabular}


Supplemental Table S2.txt

\begin{tabular}{|c|c|c|c|c|c|}
\hline CHEMBL1307254 & 737064 & 3.1003 & 3.1903 & TRN & \\
\hline CHEMBL1569232 & 737064 & 3.1003 & 4.2403 & TRN & \\
\hline CHEMBL1545863 & 737064 & 4.9747 & 5.0765 & TRN & \\
\hline CHEMBL1363571 & 737064 & 5.2126 & 5.0662 & TRN & \\
\hline CHEMBL1485010 & 737064 & 3.1003 & 3.8406 & TRN & \\
\hline CHEMBL1388510 & 737064 & 3.1003 & 3.5125 & TST & \\
\hline CHEMBL1442411 & 737064 & 3.1003 & 3.6929 & TRN & \\
\hline CHEMBL1493043 & 737064 & 4.4382 & 4.2173 & TRN & \\
\hline CHEMBL1604187 & 737064 & 3.1003 & 3.1312 & TRN & \\
\hline CHEMBL1491062 & 737064 & 4.6409 & 4.3204 & TRN & \\
\hline CHEMBL1561641 & 737064 & 4.2284 & 4.6299 & TRN & \\
\hline CHEMBL1526978 & 737064 & 3.1003 & 3.3657 & TRN & \\
\hline CHEMBL1543169 & 737064 & 4.734 & 4.2646 & TRN & \\
\hline CHEMBL1587301 & 737064 & 4.8289 & 4.2764 & TRN & \\
\hline CHEMBL1271059 & 737064 & 4.9014 & 4.7261 & TRN & \\
\hline CHEMBL1327088 & 737064 & 3.1003 & 2.8679 & TRN & \\
\hline CHEMBL1404376 & 737064 & 3.1003 & 3.1492 & TRN & \\
\hline CHEMBL1490285 & 737064 & 3.1003 & 2.9131 & TRN & \\
\hline CHEMBL1405142 & 737064 & 5.12799 & 99999999 & 9 & 4.3165 \\
\hline CHEMBL1607932 & 737064 & 4.9314 & 4.5994 & TRN & \\
\hline CHEMBL153072 & 737064 & 4.3693 & 4.4232 & TRN & \\
\hline CHEMBL1444315 & 737064 & 4.7062 & 4.6398 & TST & \\
\hline CHEMBL1597383 & 737064 & 3.1003 & 4.162 & TRN & \\
\hline CHEMBL1448094 & 737064 & 4.2904 & 4.2336 & TRN & \\
\hline CHEMBL1328473 & 737064 & 5.1247 & 4.6576 & TRN & \\
\hline CHEMBL1416815 & 737064 & 5.319 & 5.0048 & TRN & \\
\hline CHEMBL1338781 & 737064 & 3.1003 & 2.8748 & TRN & \\
\hline CHEMBL1506268 & 737064 & 3.1003 & 3.3468 & TST & \\
\hline CHEMBL1490437 & 737064 & 3.1003 & 2.8804 & TRN & \\
\hline CHEMBL1164316 & 737064 & 4.7891 & 4.5648 & TRN & \\
\hline CHEMBL1515913 & 737064 & 3.1003 & 3.3194 & TRN & \\
\hline CHEMBL1578127 & 737064 & 4.5748 & 4.4351 & TST & \\
\hline CHEMBL1481844 & 737064 & 3.1003 & 3.5341 & TRN & \\
\hline CHEMBL504791 & 737064 & 5.055 & 4.7455 & TST & \\
\hline CHEMBL1337652 & 737064 & 4.2221 & 4.7371 & TRN & \\
\hline CHEMBL1464872 & 737064 & 3.1003 & 3.5338 & TRN & \\
\hline CHEMBL1471189 & 737064 & 5.9987 & 3.3576 & TST & \\
\hline CHEMBL1351686 & 737064 & 5.0251 & 4.7293 & TRN & \\
\hline CHEMBL1354197 & 737064 & 3.1003 & 3.3874 & TST & \\
\hline CHEMBL602163 & 737064 & 3.4447 & 3.969 & TRN & \\
\hline CHEMBL1485988 & 737064 & 3.1003 & 2.8613 & TRN & \\
\hline CHEMBL1454677 & 737064 & 4.909 & 4.6673 & TRN & \\
\hline CHEMBL1329300 & 737064 & 4.8745 & 4.823 & TRN & \\
\hline CHEMBL1604626 & 737064 & 3.1003 & 2.88 & TRN & \\
\hline CHEMBL1300912 & 737064 & 4.8891 & 4.3889 & TRN & \\
\hline CHEMBL1392806 & 737064 & 4.3445 & 4.5715 & TRN & \\
\hline CHEMBL1571111 & 737064 & 3.1003 & 4.2783 & TRN & \\
\hline CHEMBL1503047 & 737064 & 5.1241 & 4.8779 & TRN & \\
\hline
\end{tabular}

Page 14084 
Supplemental Table S2.txt

\begin{tabular}{|c|c|c|c|c|}
\hline CHEMBL1348813 & 737064 & 4.4574 & 4.2574 & TRN \\
\hline CHEMBL1426396 & 737064 & 3.1003 & 3.0517 & TRN \\
\hline CHEMBL1543903 & 737064 & 3.1003 & 2.8527 & TRN \\
\hline CHEMBL1583996 & 737064 & 3.1003 & 3.1018 & TRN \\
\hline CHEMBL1494018 & 737064 & 3.1003 & 2.8542 & TRN \\
\hline CHEMBL1467138 & 737064 & 3.1003 & 3.2609 & TST \\
\hline CHEMBL1324305 & 737064 & 3.1003 & 3.1113 & TRN \\
\hline CHEMBL1582392 & 737064 & 3.1003 & 3.1373 & TRN \\
\hline CHEMBL1426930 & 737064 & 5.2327 & 4.8147 & TRN \\
\hline CHEMBL1575003 & 737064 & 4.2763 & 3.9664 & TRN \\
\hline CHEMBL1418971 & 737064 & 3.1003 & 3.2902 & TRN \\
\hline CHEMBL1423531 & 737064 & 3.1003 & 4.1881 & TRN \\
\hline CHEMBL1352830 & 737064 & 3.1003 & 3.3441 & TRN \\
\hline CHEMBL1325591 & 737064 & 3.1003 & 3.8003 & TRN \\
\hline CHEMBL1535724 & 737064 & 3.1003 & 3.2094 & TRN \\
\hline CHEMBL1497688 & 737064 & 3.1003 & 2.8713 & TRN \\
\hline CHEMBL1587764 & 737064 & 3.5774 & 4.1793 & TRN \\
\hline CHEMBL1348824 & 737064 & 3.1003 & 2.8484 & TRN \\
\hline CHEMBL1448422 & 737064 & 3.1003 & 2.8523 & TRN \\
\hline CHEMBL1539264 & 737064 & 4.4063 & 4.1688 & TRN \\
\hline CHEMBL1573867 & 737064 & 3.1003 & 3.3372 & TRN \\
\hline CHEMBL1428882 & 737064 & 3.1003 & 3.0627 & TRN \\
\hline CHEMBL1382865 & 737064 & 4.9809 & 4.4774 & TRN \\
\hline CHEMBL1548720 & 737064 & 3.1003 & 2.9275 & TRN \\
\hline CHEMBL1305201 & 737064 & 3.1003 & 2.95 & TRN \\
\hline CHEMBL1380276 & 737064 & 3.1003 & 3.5687 & TRN \\
\hline CHEMBL1562431 & 737064 & 3.1003 & 2.8638 & TRN \\
\hline CHEMBL1338266 & 737064 & 4.3777 & 4.126 & TRN \\
\hline CHEMBL1385904 & 737064 & 5.1253 & 4.5384 & TRN \\
\hline CHEMBL1488394 & 737064 & 3.1003 & 2.9899 & TRN \\
\hline CHEMBL1462838 & 737064 & 5.0767 & 5.0167 & TRN \\
\hline CHEMBL1547272 & 737064 & 3.1003 & 3.3204 & TRN \\
\hline CHEMBL1398693 & 737064 & 3.1003 & 3.24300 & 00000000003 \\
\hline CHEMBL1322190 & 737064 & 3.1003 & 2.8514 & TRN \\
\hline CHEMBL1523661 & 737064 & 3.1003 & 3.425 & TST \\
\hline CHEMBL1489863 & 737064 & 4.669 & 4.1593 & TRN \\
\hline CHEMBL1528299 & 737064 & 3.1003 & 3.4577 & TST \\
\hline CHEMBL1557499 & 737064 & 4.6469 & 4.2829 & TRN \\
\hline CHEMBL1424191 & 737064 & 3.1003 & 3.2549 & TRN \\
\hline CHEMBL 1352840 & 737064 & 3.1003 & 3.1303 & TRN \\
\hline CHEMBL1612100 & 737064 & 5.1122 & 4.5312 & TRN \\
\hline CHEMBL1380640 & 737064 & 3.1003 & 3.4176 & TST \\
\hline CHEMBL1603373 & 737064 & 4.5088 & 4.3559 & TRN \\
\hline CHEMBL1318957 & 737064 & 4.2658 & 4.63399 & 99999999995 \\
\hline CHEMBL1362262 & 737064 & 3.1003 & 3.4522 & TRN \\
\hline CHEMBL1582769 & 737064 & 4.9706 & 4.4547 & TRN \\
\hline CHEMBL1559168 & 737064 & 4.8768 & 4.5307 & TRN \\
\hline CHEMBL1498247 & 737064 & 3.1003 & 3.2089 & TRN \\
\hline
\end{tabular}




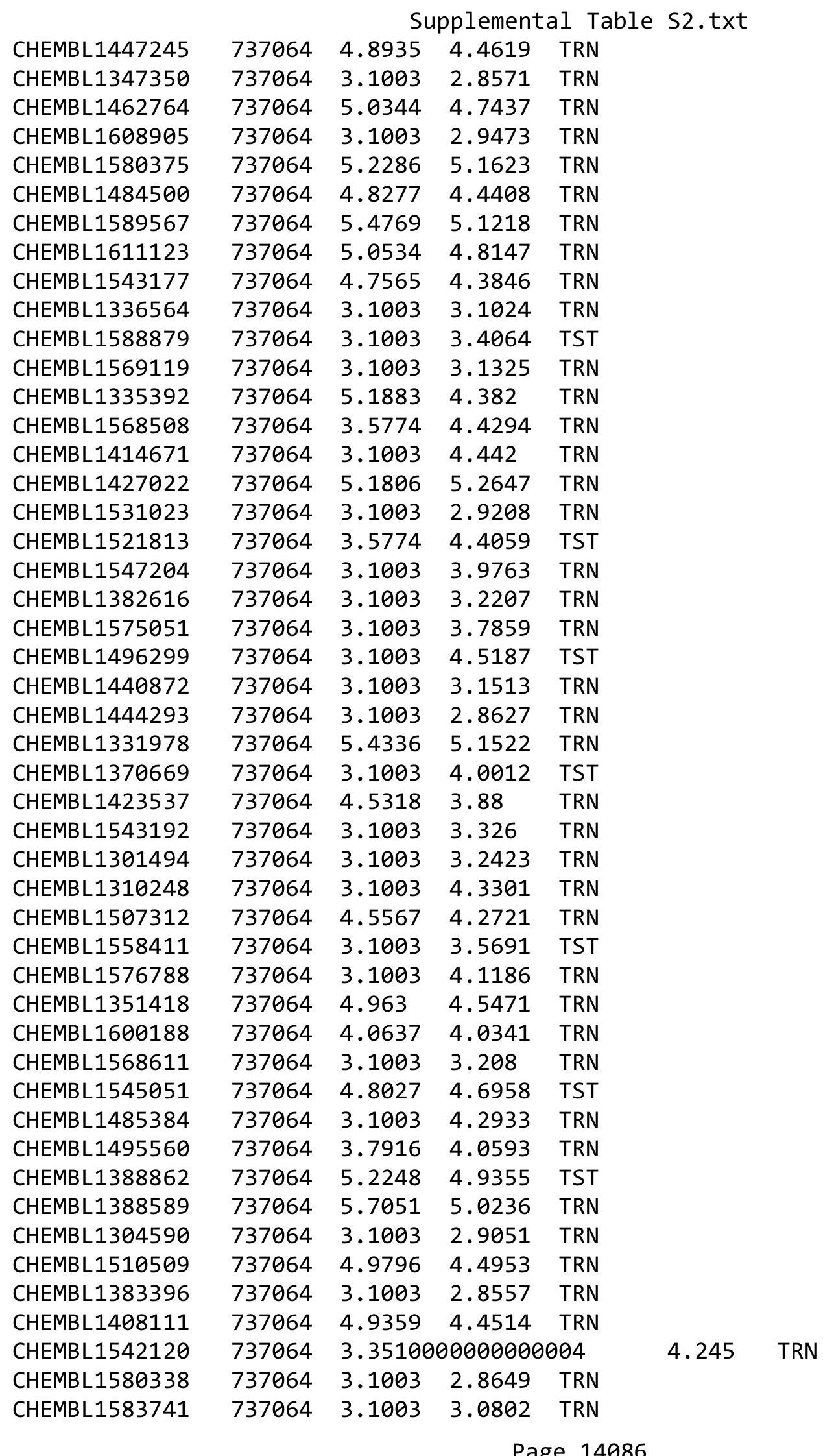

Page 14086 
Supplemental Table S2.txt

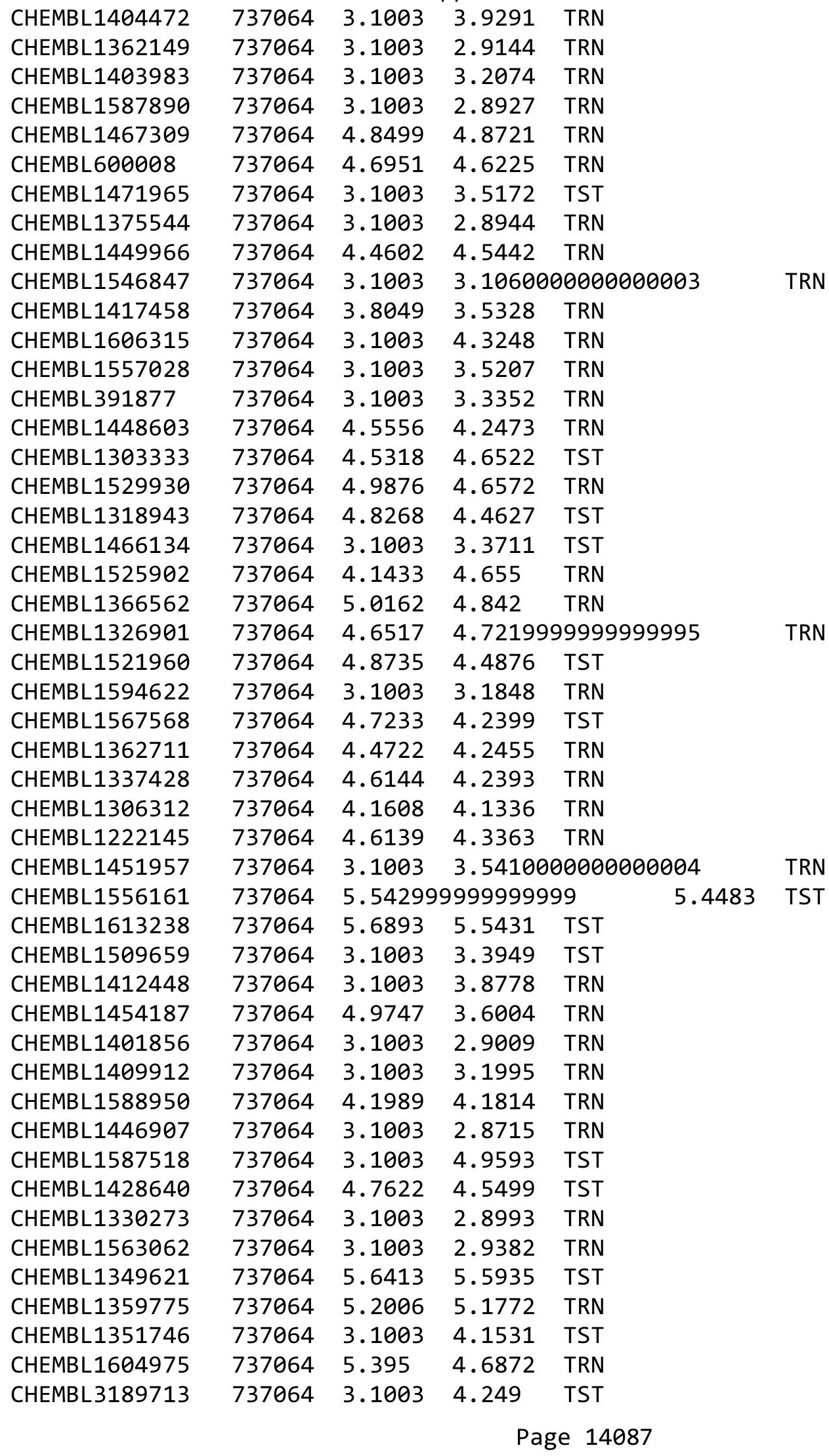


Supplemental Table S2.txt

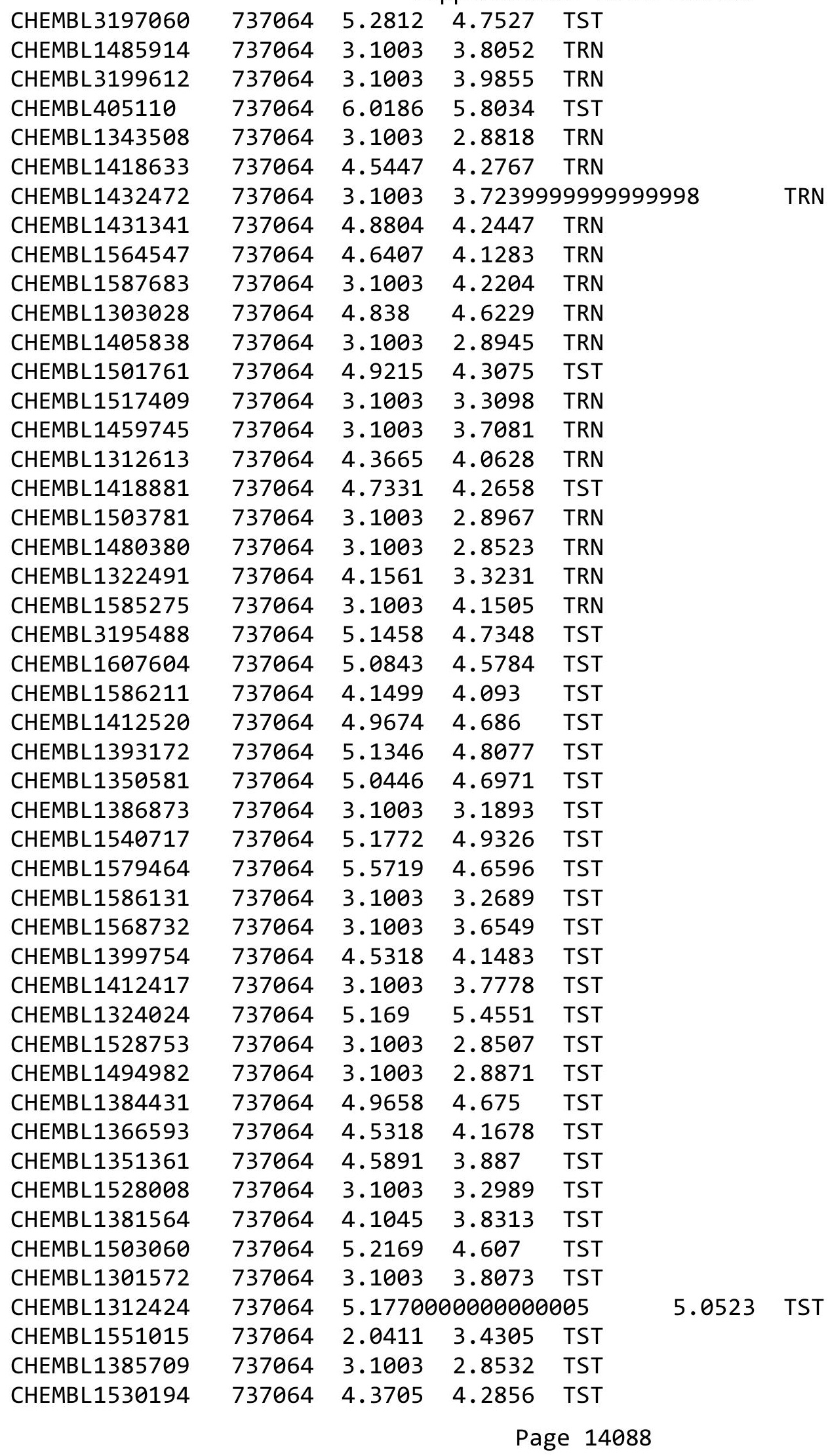


Supplemental Table S2.txt

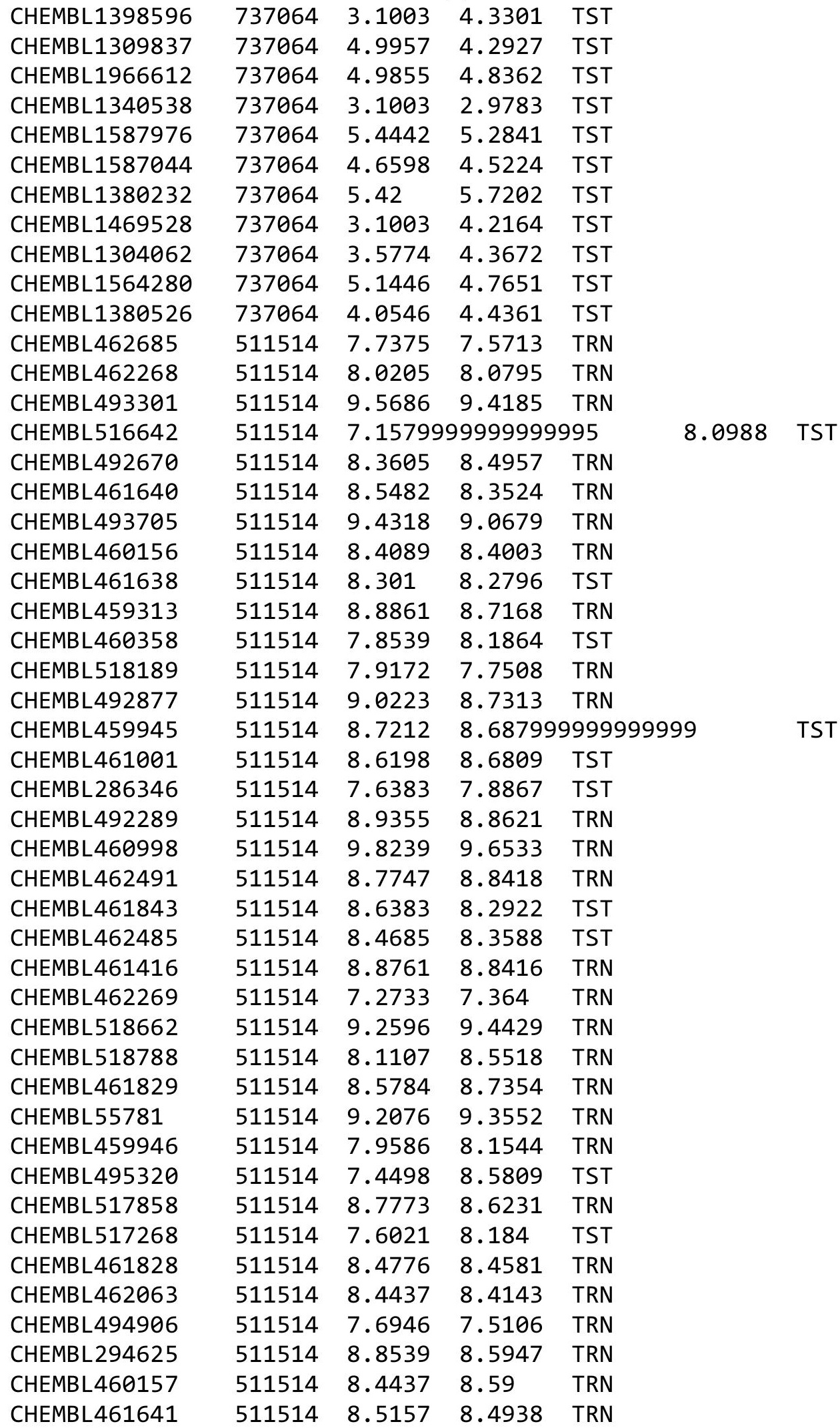

Page 14089 


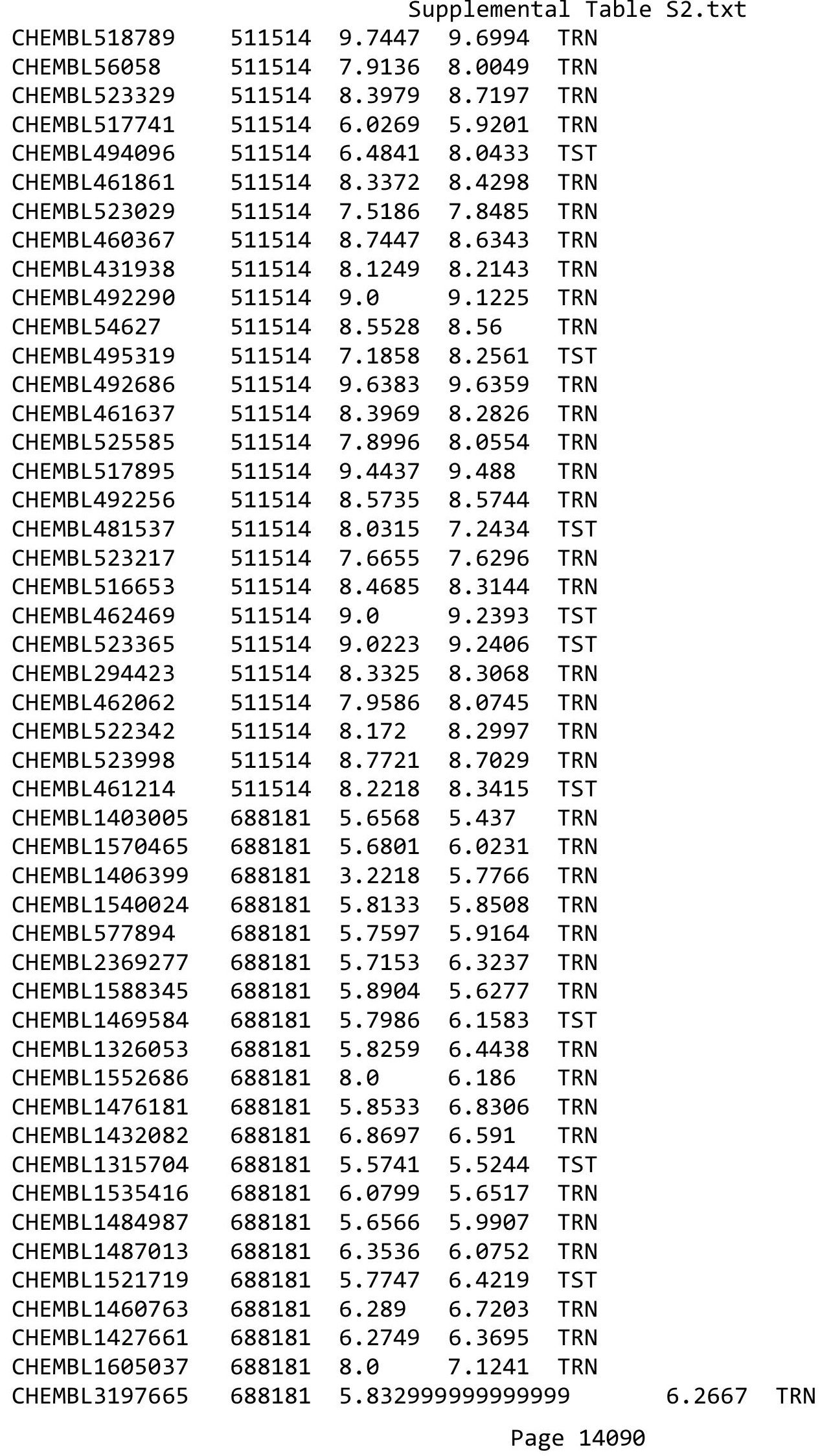




\begin{tabular}{|c|c|c|c|c|c|c|}
\hline & & \multicolumn{5}{|c|}{ Supplemental Table S2.txt } \\
\hline CHEMBL1507864 & 688181 & 5.4794 & 5.7079 & TRN & & \\
\hline CHEMBL1309228 & 688181 & 5.3056 & 5.6713 & TRN & & \\
\hline CHEMBL1399502 & 688181 & 8.0 & 7.3645 & TRN & & \\
\hline CHEMBL1311181 & 688181 & 5.761 & 5.9466 & TRN & & \\
\hline CHEMBL1434502 & 688181 & 5.3053 & 5.4001 & TRN & & \\
\hline CHEMBL1370172 & 688181 & 5.6813 & 5.7561 & TRN & & \\
\hline CHEMBL1513753 & 688181 & 6.2692 & 6.3858 & TRN & & \\
\hline CHEMBL1544633 & 688181 & 6.2526 & 6.11 & TRN & & \\
\hline CHEMBL1409486 & 688181 & 6.1129 & 6.7003 & TRN & & \\
\hline CHEMBL1312833 & 688181 & 6.38399 & 99999999 & 995 & 6.0071 & TRN \\
\hline CHEMBL1540057 & 688181 & 5.5904 & 5.7197 & TST & & \\
\hline CHEMBL3193276 & 688181 & 6.0665 & 5.9656 & TRN & & \\
\hline CHEMBL1562340 & 688181 & 5.5643 & 5.8777 & TRN & & \\
\hline CHEMBL579742 & 688181 & 5.7817 & 6.2277 & TRN & & \\
\hline CHEMBL1599558 & 688181 & 5.7314 & 5.4977 & TRN & & \\
\hline CHEMBL1323274 & 688181 & 6.1904 & 5.6806 & TRN & & \\
\hline CHEMBL1406484 & 688181 & 6.6861 & 6.3612 & TRN & & \\
\hline CHEMBL1456950 & 688181 & 6.2807 & 6.1859 & TRN & & \\
\hline CHEMBL3195863 & 688181 & 5.6722 & 5.7941 & TRN & & \\
\hline CHEMBL1600295 & 688181 & 5.54299 & 99999999 & 99 & 6.0714 & TRN \\
\hline CHEMBL1324203 & 688181 & 5.8077 & 5.3866 & TST & & \\
\hline CHEMBL1970082 & 688181 & 6.3002 & 5.7541 & TRN & & \\
\hline CHEMBL3199868 & 688181 & 6.4908 & 6.1485 & TRN & & \\
\hline CHEMBL1979106 & 688181 & 5.8085 & 6.0145 & TRN & & \\
\hline CHEMBL1583752 & 688181 & 5.072 & 4.8344 & TRN & & \\
\hline CHEMBL1315169 & 688181 & 6.4976 & 5.9513 & TRN & & \\
\hline CHEMBL1612393 & 688181 & 8.0 & 7.2072 & TRN & & \\
\hline CHEMBL1561133 & 688181 & 5.8066 & 6.6166 & TRN & & \\
\hline CHEMBL1548492 & 688181 & 6.3188 & 6.4918 & TRN & & \\
\hline CHEMBL1340458 & 688181 & 5.9678 & 5.3207 & TRN & & \\
\hline CHEMBL1383015 & 688181 & 5.6371 & 5.7155 & TST & & \\
\hline CHEMBL1519935 & 688181 & 5.5255 & 5.4186 & TRN & & \\
\hline CHEMBL1501217 & 688181 & 5.6362 & 6.1908 & TRN & & \\
\hline CHEMBL1375245 & 688181 & 5.0762 & 5.5676 & TRN & & \\
\hline CHEMBL3212271 & 688181 & 5.857 & 6.322 & TRN & & \\
\hline CHEMBL1548500 & 688181 & 5.83 & 5.9686 & TRN & & \\
\hline CHEMBL1996749 & 688181 & 6.2097 & 6.1079 & TRN & & \\
\hline CHEMBL1500169 & 688181 & 6.056 & 5.8937 & TRN & & \\
\hline CHEMBL1988829 & 688181 & 6.2161 & 6.3126 & TRN & & \\
\hline CHEMBL1968356 & 688181 & 5.7064 & 6.0549 & TRN & & \\
\hline CHEMBL1308088 & 688181 & 5.9344 & 6.0982 & TRN & & \\
\hline CHEMBL1495352 & 688181 & 5.9662 & 5.9448 & TRN & & \\
\hline CHEMBL1982304 & 688181 & 6.1226 & 6.0238 & TRN & & \\
\hline CHEMBL1428827 & 688181 & 5.6849 & 5.2944 & TST & & \\
\hline CHEMBL1458277 & 688181 & 6.1391 & 6.2505 & TST & & \\
\hline CHEMBL1572896 & 688181 & 6.5719 & 6.7635 & TRN & & \\
\hline CHEMBL1521418 & 688181 & 5.6308 & 5.5187 & TRN & & \\
\hline CHEMBL1468513 & 688181 & 5.7951 & 5.8754 & TRN & & \\
\hline
\end{tabular}


Supplemental Table S2.txt

\begin{tabular}{|c|c|c|c|c|c|c|}
\hline CHEMBL 3211754 & 688181 & 5.7807 & 5.7432 & TST & & \\
\hline CHEMBL1605960 & 688181 & 6.4237 & 6.5292 & TRN & & \\
\hline CHEMBL1305477 & 688181 & 5.9706 & 6.2911 & TRN & & \\
\hline CHEMBL1365247 & 688181 & 5.9205 & 6.0611 & TRN & & \\
\hline CHEMBL1467247 & 688181 & 5.7156 & 6.1678 & TRN & & \\
\hline CHEMBL1610820 & 688181 & 8.0 & 6.1576 & TRN & & \\
\hline CHEMBL1527540 & 688181 & 5.8242 & 6.1569 & TST & & \\
\hline CHEMBL1464788 & 688181 & 6.2807 & 6.1888 & TRN & & \\
\hline CHEMBL1403654 & 688181 & 6.4145 & 6.7635 & TRN & & \\
\hline CHEMBL1524733 & 688181 & 5.6805 & 6.1533 & TRN & & \\
\hline CHEMBL1391128 & 688181 & 6.0458 & 6.5593 & TRN & & \\
\hline CHEMBL1380645 & 688181 & 6.556 & 6.6466 & TST & & \\
\hline CHEMBL1299566 & 688181 & 6.9914 & 6.4141 & TRN & & \\
\hline CHEMBL1522988 & 688181 & 5.6028 & 6.091 & TRN & & \\
\hline CHEMBL1407122 & 688181 & 6.1746 & 5.7939 & TRN & & \\
\hline CHEMBL1307861 & 688181 & 8.0 & 7.0961 & TRN & & \\
\hline CHEMBL1387773 & 688181 & 6.7282 & 6.4464 & TRN & & \\
\hline CHEMBL1504020 & 688181 & 5.9183 & 5.5192 & TRN & & \\
\hline CHEMBL1337424 & 688181 & 5.9872 & 6.4685 & TST & & \\
\hline CHEMBL3198269 & 688181 & 6.7645 & 6.9142 & TRN & & \\
\hline CHEMBL1597655 & 688181 & 6.2765 & 5.9274 & TRN & & \\
\hline CHEMBL1558306 & 688181 & 5.8162 & 5.6941 & TRN & & \\
\hline CHEMBL1535712 & 688181 & 5.5522 & 5.7566 & TRN & & \\
\hline CHEMBL3199820 & 688181 & 6.3947 & 5.9649 & TRN & & \\
\hline CHEMBL1565600 & 688181 & 6.1965 & 6.4441 & TRN & & \\
\hline CHEMBL1400298 & 688181 & 6.32700 & 00000000 & 31 & 5.8077 & TRN \\
\hline CHEMBL1543982 & 688181 & 5.9872 & 6.2941 & TRN & & \\
\hline CHEMBL1478612 & 688181 & 5.6276 & 5.6148 & TRN & & \\
\hline CHEMBL1342293 & 688181 & 5.7395 & 5.8933 & TRN & & \\
\hline CHEMBL1605568 & 688181 & 5.5126 & 6.05 & TRN & & \\
\hline CHEMBL1342069 & 688181 & 5.7962 & 5.6984 & TRN & & \\
\hline CHEMBL1340257 & 688181 & 5.8228 & 5.8411 & TRN & & \\
\hline CHEMBL1361674 & 688181 & 6.2807 & 6.19 & TRN & & \\
\hline CHEMBL1576374 & 688181 & 5.8492 & 6.1792 & TRN & & \\
\hline CHEMBL1503475 & 688181 & 5.7812 & 6.8795 & TST & & \\
\hline CHEMBL1341761 & 688181 & 6.6108 & 6.6594 & TRN & & \\
\hline CHEMBL1528798 & 688181 & 5.8986 & 6.6536 & TRN & & \\
\hline CHEMBL1574116 & 688181 & 5.8099 & 5.6037 & TRN & & \\
\hline CHEMBL581257 & 688181 & \multicolumn{3}{|c|}{6.752000000000001} & 6.1757 & TST \\
\hline CHEMBL1443990 & 688181 & 6.025 & 5.7757 & TST & & \\
\hline CHEMBL1542402 & 688181 & 5.8395 & 6.0382 & TRN & & \\
\hline CHEMBL1396320 & 688181 & 5.5328 & 5.5837 & TRN & & \\
\hline CHEMBL1347339 & 688181 & 6.5171 & 6.4254 & TRN & & \\
\hline CHEMBL1609419 & 688181 & 5.6068 & 6.0792 & TRN & & \\
\hline CHEMBL1506580 & 688181 & 5.731 & 5.684 & TRN & & \\
\hline CHEMBL1347724 & 688181 & 6.0937 & 6.3481 & TRN & & \\
\hline CHEMBL1524363 & 688181 & 6.0762 & 5.9769 & TST & & \\
\hline CHEMBL1340002 & 688181 & 6.1858 & 6.5443 & TRN & & \\
\hline
\end{tabular}

Page 14092 
Supplemental Table S2.txt

\begin{tabular}{|c|c|c|c|c|c|}
\hline CHEMBL1427859 & 688181 & 5.7084 & 5.4349 & TRN & \\
\hline CHEMBL1350432 & 688181 & 5.6457 & 5.8223 & TST & \\
\hline CHEMBL1340381 & 688181 & 6.7399 & 7.1129 & TRN & \\
\hline CHEMBL1349172 & 688181 & 6.8386 & 5.8349 & TST & \\
\hline CHEMBL1587218 & 688181 & 5.6033 & 5.5925 & TRN & \\
\hline CHEMBL1359655 & 688181 & 5.6535 & 5.6492 & TRN & \\
\hline CHEMBL1975652 & 688181 & 6.1549 & 5.8833 & TRN & \\
\hline CHEMBL1458468 & 688181 & 6.0996 & 5.6327 & TST & \\
\hline CHEMBL1437683 & 688181 & 6.0395 & 5.6951 & TRN & \\
\hline CHEMBL1564032 & 688181 & 5.7075 & 5.7896 & TRN & \\
\hline CHEMBL1510724 & 688181 & 5.6772 & 5.9182 & TRN & \\
\hline CHEMBL 2006221 & 688181 & 5.6171 & 5.8338 & TRN & \\
\hline CHEMBL1422217 & 688181 & 5.309 & 5.91700 & 000000001 & TR \\
\hline CHEMBL1608065 & 688181 & 6.0696 & 6.0789 & TRN & \\
\hline CHEMBL1588104 & 688181 & 6.0074 & 5.7904 & TST & \\
\hline CHEMBL1492998 & 688181 & 6.4056 & 6.01200 & 0000000005 & \\
\hline CHEMBL1534659 & 688181 & 6.0022 & 6.17700 & 0000000005 & \\
\hline CHEMBL1440993 & 688181 & 6.1612 & 7.482 & TRN & \\
\hline CHEMBL3194005 & 688181 & 5.7097 & 6.2731 & TST & \\
\hline CHEMBL1496808 & 688181 & 6.9393 & 6.7253 & TRN & \\
\hline CHEMBL1563809 & 688181 & 6.3497 & 6.3849 & TRN & \\
\hline CHEMBL1343371 & 688181 & 5.7878 & 5.3819 & TRN & \\
\hline CHEMBL1399720 & 688181 & 6.1871 & 6.2549 & TRN & \\
\hline CHEMBL1349539 & 688181 & 5.6653 & 5.5943 & TST & \\
\hline CHEMBL1351519 & 688181 & \multicolumn{3}{|c|}{5.757000000000001} & TR \\
\hline CHEMBL1341008 & 688181 & 5.516 & 5.8268 & TST & \\
\hline CHEMBL 237424 & 688181 & 5.2797 & 6.0072 & TRN & \\
\hline CHEMBL1313559 & 688181 & 6.1688 & 6.3936 & TRN & \\
\hline CHEMBL1607015 & 688181 & 5.7617 & 5.5716 & TST & \\
\hline CHEMBL 3192084 & 688181 & 6.0867 & 6.3983 & TRN & \\
\hline CHEMBL516194 & 688181 & 6.9547 & 6.2475 & TRN & \\
\hline CHEMBL1306817 & 688181 & 5.6077 & 6.1611 & TRN & \\
\hline CHEMBL1393034 & 688181 & 5.71 & 5.7059 & TRN & \\
\hline CHEMBL3192922 & 688181 & 5.4925 & 6.2468 & TST & \\
\hline CHEMBL1324917 & 688181 & 6.2218 & 6.2061 & TRN & \\
\hline CHEMBL1408337 & 688181 & 5.9598 & 6.2677 & TRN & \\
\hline CHEMBL1353285 & 688181 & 6.6799 & 6.4897 & TRN & \\
\hline CHEMBL1531919 & 688181 & 5.6635 & 5.3952 & TRN & \\
\hline CHEMBL1394270 & 688181 & 8.0 & 7.0894 & TRN & \\
\hline CHEMBL1414338 & 688181 & 6.0953 & 6.3405 & TRN & \\
\hline CHEMBL3196726 & 688181 & 6.0975 & 6.5396 & TRN & \\
\hline CHEMBL1496187 & 688181 & 6.8041 & 6.4573 & TST & \\
\hline CHEMBL1509365 & 688181 & 6.3233 & 6.1271 & TRN & \\
\hline CHEMBL1311185 & 688181 & 5.8821 & 5.7715 & TRN & \\
\hline CHEMBL1548871 & 688181 & 5.9488 & 5.9586 & TRN & \\
\hline CHEMBL1452320 & 688181 & 5.5426 & 5.5875 & TST & \\
\hline CHEMBL 3194943 & 688181 & 6.2596 & 5.9495 & TRN & \\
\hline CHEMBL1457321 & 688181 & 5.8768 & 6.1082 & TRN & \\
\hline
\end{tabular}

Page 14093 


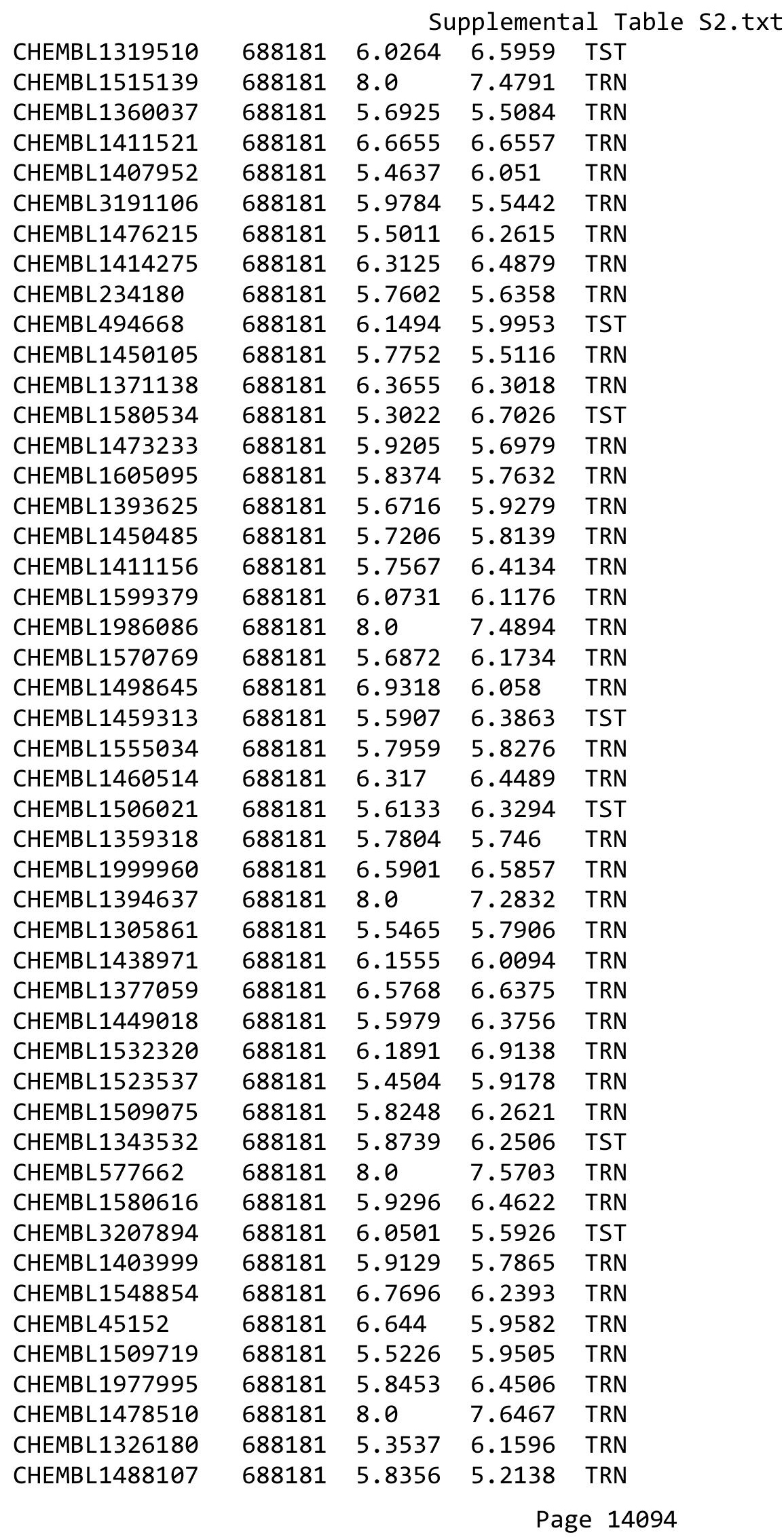




\begin{tabular}{|c|c|c|c|c|c|c|c|}
\hline \multicolumn{8}{|c|}{ Supplemental Table S2.txt } \\
\hline CHEMBL1532349 & 688181 & 3.5229 & 6.0073 & TRN & & & \\
\hline CHEMBL1391923 & 688181 & 5.9446 & 5.6315 & TRN & & & \\
\hline CHEMBL1412548 & 688181 & 6.5243 & 5.524 & TRN & & & \\
\hline CHEMBL1398888 & 688181 & 6.8069 & 6.5775 & TST & & & \\
\hline CHEMBL572994 & 688181 & 5.9602 & 6.2076 & TRN & & & \\
\hline CHEMBL1995078 & 688181 & 5.8567 & 5.7847 & TRN & & & \\
\hline CHEMBL1545271 & 688181 & 5.5722 & 5.2067 & TRN & & & \\
\hline CHEMBL1364729 & 688181 & 6.8962 & 6.63399 & 9999999999 & 95 & TST & \\
\hline CHEMBL1412488 & 688181 & 5.6607 & 5.8926 & TRN & & & \\
\hline CHEMBL1443767 & 688181 & 5.6465 & 6.0622 & TRN & & & \\
\hline CHEMBL1330803 & 688181 & 6.1765 & 5.7672 & TRN & & & \\
\hline CHEMBL1366187 & 688181 & 6.02 & 6.3829 & TRN & & & \\
\hline CHEMBL3199347 & 688181 & 5.6878 & 5.5867 & TRN & & & \\
\hline CHEMBL591370 & 688181 & 5.937 & 6.0002 & TRN & & & \\
\hline CHEMBL1508616 & 688181 & 5.4456 & 5.7682 & TRN & & & \\
\hline CHEMBL1439269 & 688181 & 5.7635 & 5.8355 & TST & & & \\
\hline CHEMBL1519902 & 688181 & 6.1871 & 5.6558 & TRN & & & \\
\hline CHEMBL1429755 & 688181 & 8.0 & 6.7079 & TRN & & & \\
\hline CHEMBL1301171 & 688181 & 6.3233 & 6.7799 & TRN & & & \\
\hline CHEMBL3199822 & 688181 & 5.5412 & 5.6149 & TRN & & & \\
\hline CHEMBL 2001139 & 688181 & 5.54 & 5.834 & TRN & & & \\
\hline CHEMBL1322772 & 688181 & 6.15799 & 99999999 & 995 & 6.3843 & TRN & \\
\hline CHEMBL1985759 & 688181 & 6.0788 & 5.6488 & TRN & & & \\
\hline CHEMBL1464666 & 688181 & 6.8827 & 6.6513 & TRN & & & \\
\hline CHEMBL1401402 & 688181 & 8.0 & 6.7966 & TRN & & & \\
\hline CHEMBL1427684 & 688181 & 5.1913 & 5.7758 & TST & & & \\
\hline CHEMBL1334036 & 688181 & 5.5405 & 5.88899 & 9999999999 & & TRN & \\
\hline CHEMBL1355046 & 688181 & 5.8202 & 5.3805 & TRN & & & \\
\hline CHEMBL1575786 & 688181 & 6.38200 & 20000000 & $\partial 1$ & 6.46299 & 9999999999 & TRN \\
\hline CHEMBL1478187 & 688181 & 6.7055 & 5.9728 & TRN & & & \\
\hline CHEMBL1533151 & 688181 & 6.7986 & 6.3554 & TRN & & & \\
\hline CHEMBL1451721 & 688181 & 5.794 & 5.6309 & TRN & & & \\
\hline CHEMBL3192651 & 688181 & 8.0 & 7.0881 & TRN & & & \\
\hline CHEMBL1378814 & 688181 & 6.3536 & 6.1719 & TRN & & & \\
\hline CHEMBL1464161 & 688181 & 6.3947 & 6.3279 & TRN & & & \\
\hline CHEMBL1404792 & 688181 & 8.0 & 8.25 & TRN & & & \\
\hline CHEMBL1464261 & 688181 & 5.9237 & 6.1913 & TRN & & & \\
\hline CHEMBL1557913 & 688181 & 5.1653 & 5.79 & TRN & & & \\
\hline CHEMBL1380129 & 688181 & 8.0 & 6.2462 & TRN & & & \\
\hline CHEMBL1446830 & 688181 & 5.9674 & 5.9637 & TRN & & & \\
\hline CHEMBL1564442 & 688181 & 6.2941 & 6.3485 & TRN & & & \\
\hline CHEMBL1444212 & 688181 & 5.6643 & 5.6452 & TRN & & & \\
\hline CHEMBL1421143 & 688181 & 5.5597 & 5.9754 & TRN & & & \\
\hline CHEMBL3145019 & 688181 & 4.7867 & 6.0992 & TST & & & \\
\hline CHEMBL374107 & 688181 & 8.0 & 6.1774 & TST & & & \\
\hline CHEMBL3207905 & 688181 & 6.0482 & 5.7065 & TRN & & & \\
\hline CHEMBL1342053 & 688181 & 5.7238 & 6.0688 & TRN & & & \\
\hline CHEMBL1367706 & 688181 & 6.1385 & 6.8142 & TRN & & & \\
\hline
\end{tabular}




\begin{tabular}{|c|c|c|c|c|c|}
\hline & & \multicolumn{4}{|c|}{ Supplemental Table S2.txt } \\
\hline CHEMBL573226 & 688181 & 6.2644 & 6.1254 & TRN & \\
\hline CHEMBL3197508 & 688181 & 5.8248 & 6.4874 & TRN & \\
\hline CHEMBL1415650 & 688181 & 5.7165 & 5.94 & TST & \\
\hline CHEMBL1347055 & 688181 & 5.5972 & 5.7017 & TRN & \\
\hline CHEMBL1418463 & 688181 & 6.2076 & 5.9286 & TRN & \\
\hline CHEMBL1417730 & 688181 & 5.8245 & 5.9282 & TRN & \\
\hline CHEMBL3193178 & 688181 & 5.4855 & 5.7847 & TRN & \\
\hline CHEMBL607140 & 688181 & 6.9914 & 6.6115 & TRN & \\
\hline CHEMBL1563835 & 688181 & 6.6737 & 6.4614 & TRN & \\
\hline CHEMBL1538817 & 688181 & 5.8389 & 5.71899 & 9999999999 & TRN \\
\hline CHEMBL586135 & 688181 & 8.0 & 7.057 & TRN & \\
\hline CHEMBL1566671 & 688181 & 5.6586 & 5.4889 & TRN & \\
\hline CHEMBL1443756 & 688181 & 6.7055 & 7.1516 & TRN & \\
\hline CHEMBL3197024 & 688181 & 5.7807 & 5.7736 & TRN & \\
\hline CHEMBL1304963 & 688181 & 5.7997 & 5.3559 & TRN & \\
\hline CHEMBL1366588 & 688181 & 5.5071 & 5.6509 & TRN & \\
\hline CHEMBL1382633 & 688181 & 6.0278 & 5.9452 & TRN & \\
\hline CHEMBL1435987 & 688181 & 6.3045 & 6.1925 & TRN & \\
\hline CHEMBL1422741 & 688181 & 5.58299 & 9999999 & 5.4723 & TRN \\
\hline CHEMBL1393490 & 688181 & 5.4881 & 6.5244 & TRN & \\
\hline CHEMBL1606975 & 688181 & 6.3862 & 6.2073 & TRN & \\
\hline CHEMBL1579650 & 688181 & 5.8207 & 5.8218 & TRN & \\
\hline CHEMBL1415310 & 688181 & 5.6803 & 5.4729 & TRN & \\
\hline CHEMBL1312788 & 688181 & 5.7066 & 5.6519 & TRN & \\
\hline CHEMBL1510455 & 688181 & 5.4235 & 5.2932 & TRN & \\
\hline CHEMBL3196836 & 688181 & 5.942 & 5.8899 & TRN & \\
\hline CHEMBL1401358 & 688181 & 5.4629 & 5.9555 & TST & \\
\hline CHEMBL3197064 & 688181 & 6.266 & 7.0175 & TRN & \\
\hline CHEMBL1484893 & 688181 & 5.6521 & 5.1866 & TRN & \\
\hline CHEMBL1495589 & 688181 & 5.6375 & 6.2706 & TRN & \\
\hline CHEMBL1426659 & 688181 & 5.5704 & 5.5707 & TRN & \\
\hline CHEMBL1546392 & 688181 & 5.6533 & 5.8654 & TRN & \\
\hline CHEMBL1460613 & 688181 & 6.4908 & 6.5471 & TRN & \\
\hline CHEMBL1389053 & 688181 & 6.3655 & 6.4708 & TRN & \\
\hline CHEMBL1309183 & 688181 & 5.7962 & 5.42 & TRN & \\
\hline CHEMBL1973669 & 688181 & 5.6874 & 6.5814 & TRN & \\
\hline CHEMBL1518337 & 688181 & 6.9747 & 7.0229 & TRN & \\
\hline CHEMBL1517103 & 688181 & 6.7352 & 7.564 & TRN & \\
\hline CHEMBL1608375 & 688181 & 5.608 & 6.1696 & TST & \\
\hline CHEMBL1998516 & 688181 & 6.3242 & 6.6114 & TRN & \\
\hline CHEMBL1300881 & 688181 & 5.5756 & 5.5441 & TRN & \\
\hline CHEMBL1972216 & 688181 & 6.0696 & 6.0834 & TRN & \\
\hline CHEMBL1314709 & 688181 & 5.8827 & 6.5657 & TRN & \\
\hline CHEMBL1515292 & 688181 & 5.9431 & 5.9269 & TRN & \\
\hline CHEMBL1307456 & 688181 & 6.0899 & 6.099 & TRN & \\
\hline CHEMBL1453857 & 688181 & 5.5921 & 6.0024 & TRN & \\
\hline CHEMBL1503426 & 688181 & 5.654 & 5.9677 & TRN & \\
\hline CHEMBL1410160 & 688181 & 5.7102 & 5.7134 & TRN & \\
\hline
\end{tabular}




\begin{tabular}{|c|c|c|c|c|c|c|}
\hline & & \multicolumn{5}{|c|}{ Supplemental Table S2.txt } \\
\hline CHEMBL1405111 & 688181 & 5.8428 & 5.9646 & TRN & & \\
\hline CHEMBL1550763 & 688181 & 5.6544 & 6.0323 & TRN & & \\
\hline CHEMBL1384942 & 688181 & 5.73799 & 79999999 & 995 & 5.956 & TRN \\
\hline CHEMBL1370929 & 688181 & 5.8935 & 6.0639 & TRN & & \\
\hline CHEMBL1531172 & 688181 & 5.4836 & 6.2085 & TRN & & \\
\hline CHEMBL1300840 & 688181 & 6.067 & 5.6022 & TRN & & \\
\hline CHEMBL1403587 & 688181 & 6.6198 & 6.3617 & TRN & & \\
\hline CHEMBL1597604 & 688181 & 5.6643 & 5.8789 & TRN & & \\
\hline CHEMBL1482679 & 688181 & 6.2396 & 6.688 & TRN & & \\
\hline CHEMBL1304704 & 688181 & 6.3391 & 6.0523 & TRN & & \\
\hline CHEMBL1388922 & 688181 & 5.7138 & 5.7073 & TRN & & \\
\hline CHEMBL1354075 & 688181 & 6.0146 & 6.2493 & TRN & & \\
\hline CHEMBL1405052 & 688181 & 5.5095 & 5.8661 & TRN & & \\
\hline CHEMBL 3193284 & 688181 & 5.5779 & 5.8391 & TRN & & \\
\hline CHEMBL3197275 & 688181 & 6.2976 & 6.388 & TRN & & \\
\hline CHEMBL1368998 & 688181 & 5.8441 & 6.0539 & TRN & & \\
\hline CHEMBL1432378 & 688181 & 5.4475 & 5.5884 & TST & & \\
\hline CHEMBL1330307 & 688181 & 5.9136 & 5.855 & TRN & & \\
\hline CHEMBL1424855 & 688181 & 8.0 & 7.1379 & TRN & & \\
\hline CHEMBL1592881 & 688181 & 6.6968 & 6.4338 & TRN & & \\
\hline CHEMBL1412708 & 688181 & 6.2083 & 6.12700 & 0000000001 & & TRN \\
\hline CHEMBL1497167 & 688181 & 8.0 & 6.5292 & TRN & & \\
\hline CHEMBL1413445 & 688181 & 5.6619 & 5.942 & TRN & & \\
\hline CHEMBL1340153 & 688181 & 5.83799 & 79999999 & & 6.5537 & TST \\
\hline CHEMBL1588177 & 688181 & 6.129 & 6.4013 & TRN & & \\
\hline CHEMBL1338994 & 688181 & 5.6124 & 5.6199 & TRN & & \\
\hline CHEMBL1484618 & 688181 & 5.9846 & 6.1065 & TRN & & \\
\hline CHEMBL1606583 & 688181 & 6.0259 & 6.0583 & TRN & & \\
\hline CHEMBL1349360 & 688181 & 5.3415 & 5.8475 & TRN & & \\
\hline CHEMBL1581277 & 688181 & 5.6167 & 5.8349 & TRN & & \\
\hline CHEMBL1300532 & 688181 & 5.71899 & 99999999 & 99 & 5.8548 & TRN \\
\hline CHEMBL1326782 & 688181 & 6.2373 & 6.6071 & TRN & & \\
\hline CHEMBL1444725 & 688181 & 6.6819 & 6.3338 & TRN & & \\
\hline CHEMBL1323722 & 688181 & 5.575 & 5.862 & TRN & & \\
\hline CHEMBL1546577 & 688181 & 5.035 & 6.0077 & TRN & & \\
\hline CHEMBL1506210 & 688181 & 5.4712 & 5.4157 & TST & & \\
\hline CHEMBL547175 & 688181 & 6.3316 & 6.1417 & TRN & & \\
\hline CHEMBL1471341 & 688181 & 5.6356 & 5.4802 & TRN & & \\
\hline CHEMBL1477243 & 688181 & 5.5286 & 5.9503 & TRN & & \\
\hline CHEMBL1372058 & 688181 & 5.7916 & 5.5627 & TRN & & \\
\hline CHEMBL1535365 & 688181 & 3.2218 & 5.0328 & TRN & & \\
\hline CHEMBL1324005 & 688181 & 5.6182 & 6.2044 & TST & & \\
\hline CHEMBL1456276 & 688181 & 6.8386 & 6.2758 & TRN & & \\
\hline CHEMBL1479560 & 688181 & 5.7169 & 6.4094 & TRN & & \\
\hline CHEMBL1347001 & 688181 & 5.7031 & 6.2566 & TRN & & \\
\hline CHEMBL1498519 & 688181 & 6.0545 & 6.3088 & TRN & & \\
\hline CHEMBL1535872 & 688181 & 6.6536 & 7.3464 & TRN & & \\
\hline CHEMBL3213876 & 688181 & 6.5143 & 6.0249 & TRN & & \\
\hline
\end{tabular}




\begin{tabular}{|c|c|c|c|c|c|}
\hline & & \multicolumn{4}{|c|}{ Supplemental Table S2.txt } \\
\hline CHEMBL1585894 & 688181 & 5.4662 & 6.0828 & TRN & \\
\hline CHEMBL1416569 & 688181 & 5.3847 & 5.3368 & TRN & \\
\hline CHEMBL1612512 & 688181 & 8.0 & 7.2208 & TRN & \\
\hline CHEMBL1986073 & 688181 & 5.9796 & 6.0862 & TRN & \\
\hline CHEMBL1372230 & 688181 & 6.6556 & 6.8047 & TRN & \\
\hline CHEMBL1417823 & 688181 & 6.0227 & 6.4086 & TRN & \\
\hline CHEMBL1380395 & 688181 & 5.5032 & 5.7718 & TRN & \\
\hline CHEMBL1338012 & 688181 & 6.2518 & 6.095 & TRN & \\
\hline CHEMBL1545515 & 688181 & 5.6533 & 5.6663 & TRN & \\
\hline CHEMBL1383873 & 688181 & 6.266 & 6.2533 & TST & \\
\hline CHEMBL1564737 & 688181 & 6.0482 & 5.7659 & TRN & \\
\hline CHEMBL3208763 & 688181 & 5.6463 & 5.8265 & TRN & \\
\hline CHEMBL1322516 & 688181 & 5.4077 & 5.9991 & TRN & \\
\hline CHEMBL1429418 & 688181 & 5.4689 & 6.005 & TRN & \\
\hline CHEMBL1535730 & 688181 & 6.8386 & 6.1532 & TRN & \\
\hline CHEMBL1366389 & 688181 & 5.8745 & 5.7091 & TST & \\
\hline CHEMBL1403638 & 688181 & 5.7293 & 6.0004 & TRN & \\
\hline CHEMBL1546694 & 688181 & 5.5797 & 6.0249 & TRN & \\
\hline CHEMBL 1438240 & 688181 & 5.3026 & 5.7485 & TRN & \\
\hline CHEMBL1309290 & 688181 & 6.0009 & 5.7396 & TRN & \\
\hline CHEMBL1430098 & 688181 & 8.0 & 6.5628 & TRN & \\
\hline CHEMBL1387729 & 688181 & 5.8044 & 6.8308 & TST & \\
\hline CHEMBL1454384 & 688181 & 5.6572 & 5.9258 & TRN & \\
\hline CHEMBL1507231 & 688181 & 6.1249 & 6.1431 & TRN & \\
\hline CHEMBL1444246 & 688181 & 5.6373 & 5.5067 & TRN & \\
\hline CHEMBL1375345 & 688181 & 8.0 & 6.1341 & TST & \\
\hline CHEMBL1449142 & 688181 & 5.626 & 5.6596 & TRN & \\
\hline CHEMBL1420524 & 688181 & 5.8022 & 5.9247 & TST & \\
\hline CHEMBL1439058 & 688181 & 5.8199 & 6.9135 & TRN & \\
\hline CHEMBL1506757 & 688181 & 6.9957 & 6.2542 & TST & \\
\hline CHEMBL1391028 & 688181 & 5.9574 & 6.074 & TRN & \\
\hline CHEMBL1331877 & 688181 & 5.8881 & 6.6456 & TRN & \\
\hline CHEMBL1339071 & 688181 & 6.1302 & 5.9389 & TRN & \\
\hline CHEMBL1411104 & 688181 & 5.9755 & 5.9613 & TRN & \\
\hline CHEMBL1347673 & 688181 & 5.7713 & 6.24799 & 9999999999 & TST \\
\hline CHEMBL1605374 & 688181 & 5.9914 & 5.5888 & TRN & \\
\hline CHEMBL1348534 & 688181 & 5.6953 & 5.6604 & TRN & \\
\hline CHEMBL1391330 & 688181 & 5.8248 & 6.0334 & TST & \\
\hline CHEMBL1383044 & 688181 & 6.6144 & 6.416 & TRN & \\
\hline CHEMBL1452258 & 688181 & 5.9658 & 6.2643 & TRN & \\
\hline CHEMBL600734 & 688181 & 6.4989 & 6.4086 & TST & \\
\hline CHEMBL1439642 & 688181 & 5.5139 & 5.4511 & TRN & \\
\hline CHEMBL1342452 & 688181 & 6.0391 & 7.2038 & TRN & \\
\hline CHEMBL1611777 & 688181 & 6.0958 & 6.4146 & TRN & \\
\hline CHEMBL1327455 & 688181 & 8.0 & 7.4366 & TRN & \\
\hline CHEMBL602400 & 688181 & 6.1688 & 6.0107 & TST & \\
\hline CHEMBL1343971 & 688181 & 6.0031 & 6.1853 & TRN & \\
\hline CHEMBL602730 & 688181 & 5.8176 & 6.5221 & TRN & \\
\hline
\end{tabular}


Supplemental Table S2.txt

\begin{tabular}{|c|c|c|c|c|c|}
\hline CHEMBL1572059 & 688181 & 6.0783 & 6.3994 & TRN & \\
\hline CHEMBL1360539 & 688181 & 5.7537 & 5.749 & TST & \\
\hline CHEMBL1505555 & 688181 & 5.8453 & 6.1168 & TRN & \\
\hline CHEMBL1352127 & 688181 & 5.716 & 6.308 & TST & \\
\hline CHEMBL1344934 & 688181 & 6.6635 & 5.8529 & TRN & \\
\hline CHEMBL1561229 & 688181 & 6.2111 & 6.4823 & TRN & \\
\hline CHEMBL1508047 & 688181 & 5.6254 & 5.6424 & TRN & \\
\hline CHEMBL1327702 & 688181 & 6.3107 & 6.104 & TRN & \\
\hline CHEMBL1399928 & 688181 & 6.0283 & 5.9557 & TST & \\
\hline CHEMBL1338528 & 688181 & 5.6714 & 5.6559 & TRN & \\
\hline CHEMBL1343101 & 688181 & 5.4638 & 6.044 & TST & \\
\hline CHEMBL305686 & 688181 & 6.2749 & 5.8558 & TST & \\
\hline CHEMBL 3210267 & 688181 & 5.6276 & 5.6785 & TRN & \\
\hline CHEMBL1359186 & 688181 & 5.6256 & 5.7118 & TRN & \\
\hline CHEMBL1448681 & 688181 & 5.4072 & 5.8134 & TRN & \\
\hline CHEMBL1560331 & 688181 & 6.2388 & 5.869 & TRN & \\
\hline CHEMBL1608757 & 688181 & 5.6994 & 5.3199 & TST & \\
\hline CHEMBL1576718 & 688181 & 6.3883 & 6.4808 & TRN & \\
\hline CHEMBL1526016 & 688181 & 6.2725 & 6.0011 & TRN & \\
\hline CHEMBL 3197597 & 688181 & 6.3893 & 6.2506 & TRN & \\
\hline CHEMBL 3194410 & 688181 & 6.4622 & 5.9911 & TRN & \\
\hline CHEMBL601135 & 688181 & 5.6908 & 5.8613 & TRN & \\
\hline CHEMBL1428840 & 688181 & 5.79700 & 00000000 & 31 & 5.8791 \\
\hline CHEMBL1423872 & 688181 & 5.8514 & 5.5989 & TRN & \\
\hline CHEMBL1374222 & 688181 & 8.0 & 6.8055 & TRN & \\
\hline CHEMBL1338638 & 688181 & 6.0921 & 6.1164 & TRN & \\
\hline CHEMBL1361820 & 688181 & 5.7547 & 6.2614 & TRN & \\
\hline CHEMBL1411318 & 688181 & 5.5897 & 6.1088 & TRN & \\
\hline CHEMBL 2094789 & 688181 & 5.7807 & 6.3209 & TST & \\
\hline CHEMBL1493788 & 688181 & 6.0287 & 6.475 & TRN & \\
\hline CHEMBL 3194256 & 688181 & 6.2495 & 6.6173 & TRN & \\
\hline CHEMBL1460345 & 688181 & 5.7345 & 5.4391 & TST & \\
\hline CHEMBL1501464 & 688181 & 6.8069 & 6.8421 & TST & \\
\hline CHEMBL1325908 & 688181 & 5.9863 & 6.5446 & TRN & \\
\hline CHEMBL600121 & 688181 & 6.8182 & 6.8428 & TRN & \\
\hline CHEMBL1563484 & 688181 & 6.7932 & 6.1891 & TRN & \\
\hline CHEMBL163428 & 688181 & 6.4225 & 6.7871 & TRN & \\
\hline CHEMBL1328795 & 688181 & 6.8069 & 6.3447 & TRN & \\
\hline CHEMBL 3197818 & 688181 & 6.2299 & 6.631 & TRN & \\
\hline CHEMBL1459296 & 688181 & 6.0362 & 6.2799 & TRN & \\
\hline CHEMBL1529190 & 688181 & 5.8327 & 5.8251 & TRN & \\
\hline CHEMBL1327278 & 688181 & 5.4402 & 5.3618 & TST & \\
\hline CHEMBL1446405 & 688181 & 5.6428 & 5.7797 & TRN & \\
\hline CHEMBL1575414 & 688181 & 4.954 & 5.471 & TRN & \\
\hline CHEMBL1540705 & 688181 & 6.3726 & 5.9665 & TRN & \\
\hline CHEMBL1334887 & 688181 & 5.6678 & 6.18 & TRN & \\
\hline CHEMBL1452831 & 688181 & 6.4535 & 5.5291 & TST & \\
\hline CHEMBL1336882 & 688181 & 6.1463 & 5.4897 & TST & \\
\hline
\end{tabular}

Page 14099 


\begin{tabular}{|c|c|c|c|c|c|c|c|}
\hline \multicolumn{8}{|c|}{ Supplemental Table S2.txt } \\
\hline CHEMBL1519558 & 688181 & 6.2882 & 5.94 & TRN & & & \\
\hline CHEMBL 1459740 & 688181 & 6.2749 & 5.5222 & TRN & & & \\
\hline CHEMBL1586531 & 688181 & 5.70200 & 00000000 & & $5.2810 e$ & 0000000001 & TST \\
\hline CHEMBL1577558 & 688181 & 6.2832 & 6.415 & TRN & & & \\
\hline CHEMBL1327756 & 688181 & 5.9094 & 6.4416 & TRN & & & \\
\hline CHEMBL1340694 & 688181 & 5.731 & 5.7073 & TRN & & & \\
\hline CHEMBL1589014 & 688181 & 5.99700 & 00000000 & & 5.6269 & TRN & \\
\hline CHEMBL1313191 & 688181 & 5.6521 & 5.6488 & TST & & & \\
\hline CHEMBL1468333 & 688181 & 5.7595 & 5.6398 & TST & & & \\
\hline CHEMBL1425849 & 688181 & 5.766 & 5.6766 & TST & & & \\
\hline CHEMBL1325994 & 688181 & 6.34200 & 00000000 & 005 & 6.5022 & TRN & \\
\hline CHEMBL1596985 & 688181 & 5.6633 & 5.5972 & TRN & & & \\
\hline CHEMBL1542864 & 688181 & 6.0975 & 6.0255 & TRN & & & \\
\hline CHEMBL3190702 & 688181 & 5.6385 & 5.47 & TRN & & & \\
\hline CHEMBL1422398 & 688181 & 3.2218 & 5.4805 & TRN & & & \\
\hline CHEMBL 2095095 & 688181 & 5.9416 & 6.1543 & TST & & & \\
\hline CHEMBL1386387 & 688181 & 6.4078 & 6.16700 & 000000000 & & TRN & \\
\hline CHEMBL1532622 & 688181 & 6.8827 & 7.2784 & TRN & & & \\
\hline CHEMBL1442145 & 688181 & 6.0269 & 6.6438 & TRN & & & \\
\hline CHEMBL1522824 & 688181 & 5.7778 & 6.1121 & TRN & & & \\
\hline CHEMBL1389740 & 688181 & 5.7007 & 5.9733 & TST & & & \\
\hline CHEMBL1425921 & 688181 & 5.5686 & 5.9687 & TRN & & & \\
\hline CHEMBL1459155 & 688181 & 5.6077 & 5.8795 & TRN & & & \\
\hline CHEMBL1419582 & 688181 & 6.2958 & 5.3766 & TRN & & & \\
\hline CHEMBL1461939 & 688181 & 6.1512 & 5.7596 & TRN & & & \\
\hline CHEMBL1399277 & 688181 & 5.7508 & 5.7587 & TRN & & & \\
\hline CHEMBL1402576 & 688181 & 5.4561 & 5.6498 & TRN & & & \\
\hline CHEMBL1499094 & 688181 & 5.99100 & 00000000 & 005 & 6.2396 & TRN & \\
\hline CHEMBL1508501 & 688181 & 6.3706 & 6.8012 & TRN & & & \\
\hline CHEMBL1307207 & 688181 & 5.6607 & 5.6942 & TRN & & & \\
\hline CHEMBL1431173 & 688181 & 6.1325 & 6.0006 & TRN & & & \\
\hline CHEMBL1433858 & 688181 & 5.6666 & 6.0152 & TRN & & & \\
\hline CHEMBL1462795 & 688181 & 6.4622 & 6.1337 & TRN & & & \\
\hline CHEMBL3211539 & 688181 & 5.7153 & 6.4353 & TRN & & & \\
\hline CHEMBL1368428 & 688181 & 6.1409 & 6.4468 & TRN & & & \\
\hline CHEMBL1529783 & 688181 & 5.5035 & 6.1941 & TRN & & & \\
\hline CHEMBL1488150 & 688181 & 5.5521 & 5.8813 & TRN & & & \\
\hline CHEMBL1467798 & 688181 & 6.1169 & 5.8387 & TRN & & & \\
\hline CHEMBL1491932 & 688181 & 5.6047 & 5.4856 & TST & & & \\
\hline CHEMBL1340919 & 688181 & 6.062 & 5.81 & TST & & & \\
\hline CHEMBL3195997 & 688181 & 6.2487 & 6.0986 & TRN & & & \\
\hline CHEMBL1366651 & 688181 & 5.3939 & 6.345 & TRN & & & \\
\hline CHEMBL1351388 & 688181 & 5.6964 & 6.1287 & TRN & & & \\
\hline CHEMBL1536074 & 688181 & 6.6459 & 6.5052 & TRN & & & \\
\hline CHEMBL1401989 & 688181 & 6.02 & 5.9934 & TRN & & & \\
\hline CHEMBL1544979 & 688181 & 5.6824 & 5.88399 & 999999999 & 995 & TRN & \\
\hline CHEMBL1419659 & 688181 & 6.0762 & 6.3211 & TRN & & & \\
\hline CHEMBL1308225 & 688181 & 6.3458 & 5.8234 & TRN & & & \\
\hline
\end{tabular}




\begin{tabular}{|c|c|c|c|c|c|}
\hline & & \multicolumn{4}{|c|}{ Supplemental Table S2.txt } \\
\hline CHEMBL1462321 & 688181 & 5.5667 & 6.335 & TST & \\
\hline CHEMBL1467293 & 688181 & 5.7047 & 5.4444 & TRN & \\
\hline CHEMBL1481717 & 688181 & 6.1798 & 7.6469 & TRN & \\
\hline CHEMBL1410009 & 688181 & 5.6373 & 5.5208 & TRN & \\
\hline CHEMBL1528425 & 688181 & 5.6735 & 6.2927 & TRN & \\
\hline CHEMBL1576431 & 688181 & 6.1568 & 6.0767 & TRN & \\
\hline CHEMBL1588842 & 688181 & 6.1051 & 5.9823 & TRN & \\
\hline CHEMBL1607320 & 688181 & 5.8639 & 6.0404 & TRN & \\
\hline CHEMBL600968 & 688181 & 5.8489 & 5.835 & TRN & \\
\hline CHEMBL1480289 & 688181 & 8.0 & 7.4313 & TRN & \\
\hline CHEMBL1497141 & 688181 & 6.0804 & 5.434 & TST & \\
\hline CHEMBL1320638 & 688181 & 5.5555 & 5.8506 & TRN & \\
\hline CHEMBL1449965 & 688181 & 6.4353 & 6.2131 & TRN & \\
\hline CHEMBL1337639 & 688181 & 5.7688 & 5.7856 & TRN & \\
\hline CHEMBL1302863 & 688181 & 6.0227 & 5.7706 & TRN & \\
\hline CHEMBL1386599 & 688181 & 8.0 & 7.8977 & TRN & \\
\hline CHEMBL1599642 & 688181 & 6.8386 & 6.1124 & TRN & \\
\hline CHEMBL1557727 & 688181 & 5.2232 & 6.1516 & TRN & \\
\hline CHEMBL1542066 & 688181 & 6.1549 & 5.8864 & TRN & \\
\hline CHEMBL3212029 & 688181 & 6.4473 & 5.83799 & 9999999999 & TRN \\
\hline CHEMBL333767 & 688181 & 6.8861 & 6.3504 & TRN & \\
\hline CHEMBL1352488 & 688181 & 6.2708 & 5.9458 & TRN & \\
\hline CHEMBL1359156 & 688181 & 6.1409 & 5.9288 & TRN & \\
\hline CHEMBL1566514 & 688181 & 5.9767 & 5.8521 & TRN & \\
\hline CHEMBL1336856 & 688181 & 5.6966 & 5.8569 & TRN & \\
\hline CHEMBL1544998 & 688181 & 5.71200 & 00000000 & 5.8805 & TRN \\
\hline CHEMBL1325957 & 688181 & 8.0 & 6.4948 & TRN & \\
\hline CHEMBL1419909 & 688181 & 5.3392 & 5.766 & TRN & \\
\hline CHEMBL1515696 & 688181 & 5.6855 & 6.5392 & TRN & \\
\hline CHEMBL1557945 & 688181 & 6.2716 & 6.80399 & 9999999999 & TRN \\
\hline CHEMBL1611004 & 688181 & 5.8928 & 6.0333 & TRN & \\
\hline CHEMBL1447988 & 688181 & 5.4852 & 5.9836 & TRN & \\
\hline CHEMBL1533459 & 688181 & 5.7471 & 6.1405 & TRN & \\
\hline CHEMBL1404308 & 688181 & 8.0 & 7.2303 & TRN & \\
\hline CHEMBL534353 & 688181 & 8.0 & 6.0873 & TRN & \\
\hline CHEMBL3191452 & 688181 & 4.3494 & 5.1952 & TRN & \\
\hline CHEMBL1501995 & 688181 & 6.3325 & 6.7137 & TRN & \\
\hline CHEMBL1492096 & 688181 & 5.7493 & 6.7204 & TRN & \\
\hline CHEMBL609438 & 688181 & 8.0 & 7.0713 & TRN & \\
\hline CHEMBL1352651 & 688181 & 5.8983 & 6.01200 & 00000000005 & TS \\
\hline CHEMBL1380969 & 688181 & 5.7828 & 5.8128 & TRN & \\
\hline CHEMBL 3194214 & 688181 & 6.0137 & 6.3462 & TST & \\
\hline CHEMBL1454008 & 688181 & 6.8539 & 6.8627 & TRN & \\
\hline CHEMBL1375627 & 688181 & 5.8579 & 5.8839 & TRN & \\
\hline CHEMBL1556892 & 688181 & 5.8642 & 6.3492 & TRN & \\
\hline CHEMBL1556382 & 688181 & 6.3883 & 6.1083 & TRN & \\
\hline CHEMBL1514711 & 688181 & 6.0405 & 6.8357 & TST & \\
\hline CHEMBL1541441 & 688181 & 5.6501 & 5.9371 & TST & \\
\hline
\end{tabular}




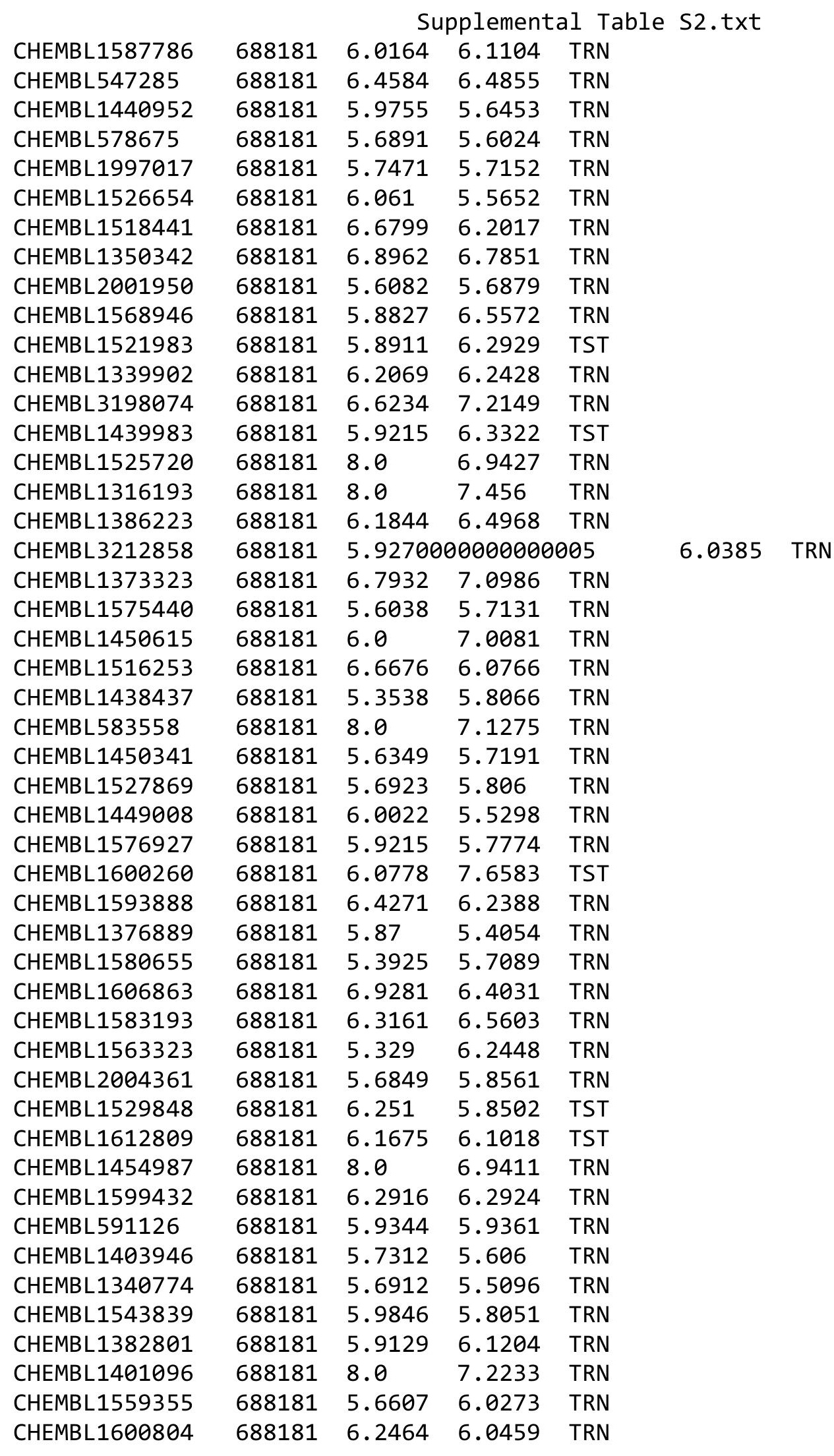

Page 14102 
Supplemental Table S2.txt

\begin{tabular}{|c|c|c|c|c|}
\hline HEMBL & 8181 & .7828 & 5.279 & 皮 \\
\hline UГMDI 1961171 & & & $5.917 €$ & \\
\hline 10 & & & & \\
\hline AEMBL3190978 & & 339 & & \\
\hline AEMBL3190293 & 181 & & & \\
\hline HEMBL1351106 & 88181 & 6392 & 1114 & \\
\hline HEMBL1389131 & 181 & & 3934 & \\
\hline IFMBI 1613478 & & & & \\
\hline AEMBL1358680 & 181 & & 9272 & \\
\hline HEMBL1573977 & 88181 & 2725 & 8978 & \\
\hline HEMBL1500188 & 88181 & 8.0 & 6634 & \\
\hline AEMBL319942ع & 181 & 89 & 9699 & \\
\hline JEMBL 59 & & & & \\
\hline HEMBL 137240 & 181 & & 4134 & \\
\hline AEMBL602135 & & & & \\
\hline IEMBL14 & 81 & 23 & & \\
\hline HEMBL13 & & & & \\
\hline HEMBL15 & & & & \\
\hline HEMBL15 & & & 9066 & \\
\hline AEMBL13 & & & 3224 & \\
\hline AEMBLIS & & & 96 & RIV \\
\hline AEMBL1C & & & 66 & 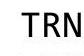 \\
\hline HEMBL15 & & & & \\
\hline AEMBL15 & & & & \\
\hline AEMBL14 & & & & r \\
\hline HEMBL1C & & & 045 & $\cdot$ \\
\hline HEMBL1C & & & 69 & ST \\
\hline HFMBI 17 & & & 104 & RN \\
\hline AEMBL14 & & & & זער \\
\hline HEMBL1477352 & & & 249 & I RIV \\
\hline HEMBL13 & & & 866 & SI \\
\hline HEMBL3 & & & 52 & RN \\
\hline HFMRI 1 & & & 141 & RN \\
\hline HEMBL1301355 & & & 456 & IR \\
\hline HEMBL1519798 & & & 5649 & TRN \\
\hline HEMBL1 & & & 567 & $\mathrm{RN}$ \\
\hline HᄃMPI 1 & & & 273 & $\Gamma \mathrm{RN}$ \\
\hline HEMBL1568279 & & & 529 & RN \\
\hline HEMBL1314809 & 88181 & & 5.8481 & TST \\
\hline JEMBL14 & & & 2028 & $\Gamma \mathrm{RN}$ \\
\hline HEMBL15 & 31 & & 3609 & \\
\hline CHEMBL13 & & & 5.1979 & TRN \\
\hline HEMBL14 & & & 4857 & RN \\
\hline IEMBL146922 & 81 & & 6584 & ГRN \\
\hline AEMBL14 & & & 2143 & \\
\hline CHEMBL14 & & & 2624 & \\
\hline CHEMBL146736 & & 8.0 & .8334 & \\
\hline LHEMBL1331384 & 688181 & 8.0 & 7.9498 & ГRN \\
\hline
\end{tabular}

Page 14103 


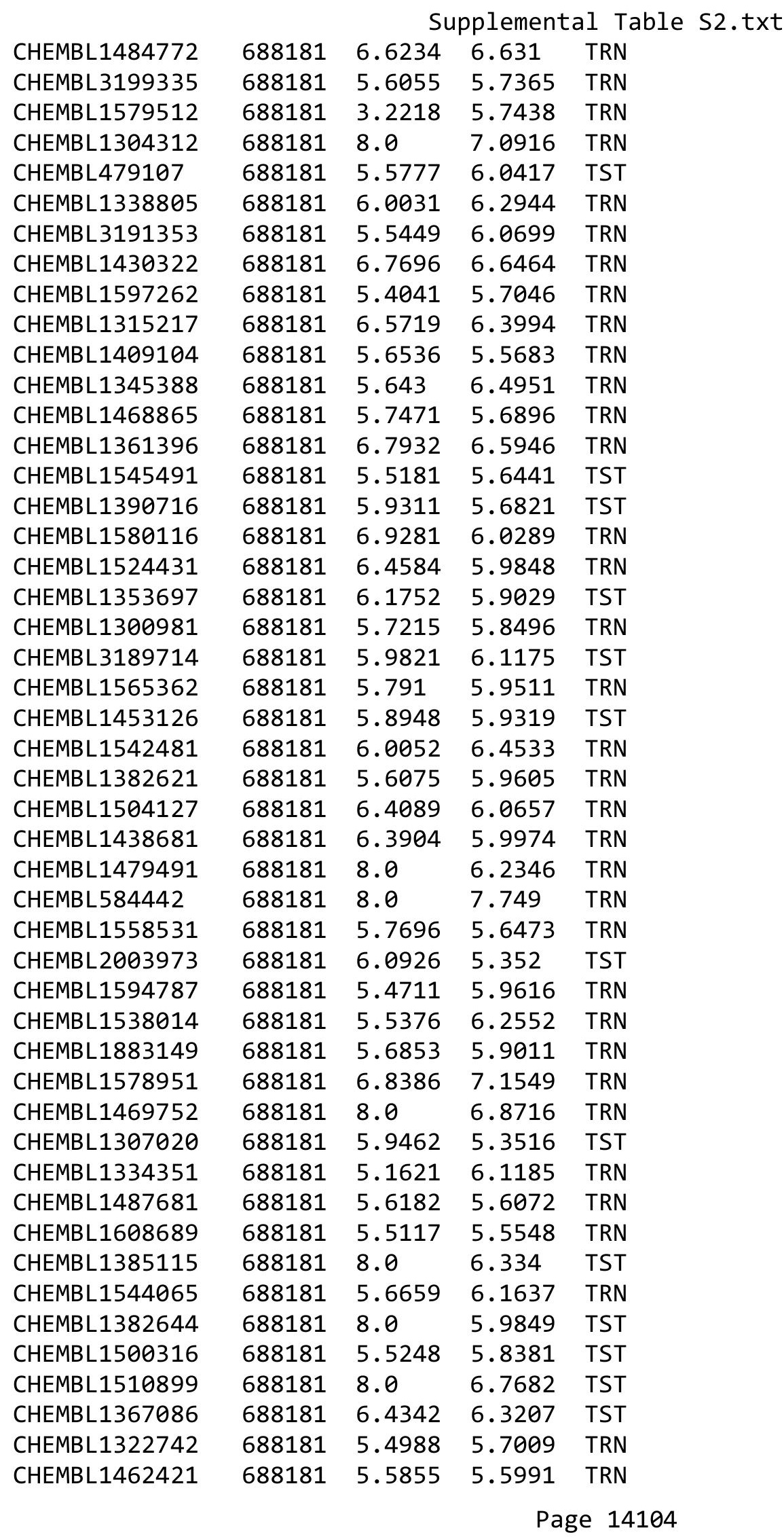


Supplemental Table S2.txt

\begin{tabular}{|c|c|c|c|c|}
\hline CHEMBL1389077 & 688181 & 5.9076 & 6.0894 & TRN \\
\hline CHEMBL1343778 & 688181 & 5.5481 & 5.5449 & TRN \\
\hline CHEMBL1335915 & 688181 & 5.6174 & 5.9375 & TRN \\
\hline CHEMBL1505371 & 688181 & 6.1002 & 6.5237 & TRN \\
\hline CHEMBL1458569 & 688181 & 5.9718 & 6.4381 & TRN \\
\hline CHEMBL2369184 & 688181 & 5.8784 & 6.3174 & TRN \\
\hline CHEMBL585622 & 688181 & 5.8456 & 6.7836 & TRN \\
\hline CHEMBL1400809 & 688181 & 6.1203 & 6.4484 & TRN \\
\hline CHEMBL581870 & 688181 & 5.6815 & 6.0514 & TRN \\
\hline CHEMBL3208834 & 688181 & 5.6857 & 5.8533 & TRN \\
\hline CHEMBL3199132 & 688181 & 5.8297 & 5.8383 & TRN \\
\hline CHEMBL1583911 & 688181 & 8.0 & 6.0363 & TST \\
\hline CHEMBL1511962 & 688181 & 5.6778 & 6.0971 & TRN \\
\hline CHEMBL1455796 & 688181 & 5.845 & 5.3157 & TST \\
\hline CHEMBL1604735 & 688181 & 3.5229 & 6.2366 & TRN \\
\hline CHEMBL1478356 & 688181 & 6.1249 & 6.3326 & TRN \\
\hline CHEMBL1375511 & 688181 & 5.6031 & 5.9348 & TRN \\
\hline CHEMBL1602182 & 688181 & 6.2725 & 6.3873 & TRN \\
\hline CHEMBL1544097 & 688181 & 5.761 & 5.4088 & TRN \\
\hline CHEMBL1595820 & 688181 & 6.0996 & 5.8029 & TRN \\
\hline CHEMBL1328878 & 688181 & 8.0 & 7.8202 & TRN \\
\hline CHEMBL1372102 & 688181 & 6.2848 & 5.7934 & TRN \\
\hline CHEMBL1501558 & 688181 & 5.7844 & 5.9025 & TRN \\
\hline CHEMBL1577446 & 688181 & 5.4621 & 5.9087 & TRN \\
\hline CHEMBL1446052 & 688181 & 5.7383 & 6.2178 & TST \\
\hline CHEMBL1457884 & 688181 & 5.515 & 5.8476 & TRN \\
\hline CHEMBL452409 & 688181 & 6.279 & 5.981 & TRN \\
\hline CHEMBL1563955 & 688181 & 6.8356 & 6.892 & TRN \\
\hline CHEMBL1329349 & 688181 & 5.61799 & 99999999 & 5.6339999999999995 \\
\hline CHEMBL1473507 & 688181 & 8.0 & 6.747006 & $0000000001 \quad$ TRN \\
\hline CHEMBL1559713 & 688181 & 5.8557 & 6.164 & TRN \\
\hline CHEMBL1521674 & 688181 & 5.3788 & 5.7782 & TRN \\
\hline CHEMBL1566645 & 688181 & 5.7144 & 5.6483 & TST \\
\hline CHEMBL1607722 & 688181 & 8.0 & 6.8337 & TRN \\
\hline CHEMBL1449336 & 688181 & 8.0 & 6.3628 & TST \\
\hline CHEMBL3197447 & 688181 & 6.2518 & 5.7145 & TRN \\
\hline CHEMBL1571452 & 688181 & 6.1192 & 6.7117 & TST \\
\hline CHEMBL1429930 & 688181 & 5.6659 & 5.7964 & TRN \\
\hline CHEMBL1368437 & 688181 & 5.688 & 5.9632 & TRN \\
\hline CHEMBL1366608 & 688181 & 6.9318 & 7.1579 & TRN \\
\hline CHEMBL600971 & 688181 & 5.8517 & 5.5834 & TRN \\
\hline CHEMBL142816 & 688181 & 5.9658 & 6.1537 & TST \\
\hline CHEMBL1522224 & 688181 & 5.9614 & 6.1628 & TRN \\
\hline CHEMBL1327816 & 688181 & 5.4515 & 6.1584 & TST \\
\hline CHEMBL1518678 & 688181 & 6.5186 & 6.3115 & TRN \\
\hline CHEMBL1987472 & 688181 & 5.8309 & 5.8086 & TRN \\
\hline CHEMBL578257 & 688181 & 8.0 & 7.6052 & TRN \\
\hline CHEMBL1427637 & 688181 & 5.4689 & 6.0253 & TST \\
\hline
\end{tabular}


Supplemental Table S2.txt

CHEMBL1541973
CHEMBL3195599
CHEMBL1526744
CHEMBL1402621
CHEMBL1388543
CHEMBL3191763
CHEMBL1313978
CHEMBL248847
CHEMBL1559098
CHEMBL1385062
CHEMBL1346127
CHEMBL1313495
CHEMBL1324831
CHEMBL578294
CHEMBL1364803
CHEMBL1389254
CHEMBL1507682
CHEMBL1532766
CHEMBL1378644
CHEMBL1996724
CHEMBL1404130
CHEMBL1326290
CHEMBL1455181
CHEMBL1430772
CHEMBL1547414
CHEMBL1327678
CHEMBL1547129
CHEMBL1326939
CHEMBL1379252
CHEMBL1353899
CHEMBL583351
CHEMBL1352195
CHEMBL1498979
CHEMBL1422433
CHEMBL1450446
CHEMBL1594274
CHEMBL1303440
CHEMBL1476688
CHEMBL1556705
CHEMBL1527336
CHEMBL1596956
CHEMBL1521101
CHEMBL1379694

$\begin{array}{llll}688181 & 6.2933 & 6.2278 & \text { TRN } \\ 688181 & 4.9693 & 5.8197 & \text { TST } \\ 688181 & 6.7352 & 6.2747 & \text { TRN } \\ 688181 & 6.0487 & 6.4001 & \text { TRN } \\ 688181 & 5.8901 & 5.8575 & \text { TRN } \\ 688181 & 6.2083 & 6.0818 & \text { TRN } \\ 688181 & 5.7781 & 5.659 & \text { TRN } \\ 688181 & 6.3054 & 6.3521 & \text { TRN } \\ 688181 & 6.2596 & 6.1563 & \text { TRN } \\ 688181 & 5.5869 & 6.2001 & \text { TST } \\ 688181 & 5.7575 & 6.5599 & \text { TRN } \\ 688181 & 5.7615 & 5.7097 & \text { TRN } \\ 688181 & 5.9266 & 5.9762 & \text { TST } \\ 688181 & 6.9208 & 6.6364 & \text { TRN } \\ 688181 & 6.1785 & 5.9537 & \text { TRN } \\ 688181 & 6.1355 & 6.4896 & \text { TRN } \\ 688181 & 5.7106 & 6.0822 & \text { TST } \\ 688181 & 6.2644 & 5.9183 & \text { TRN } \\ 688181 & 5.6936 & 5.6741 & \text { TRN } \\ 688181 & 5.4634 & 5.9962 & \text { TST } \\ 688181 & 5.5683 & 5.5428 & \text { TST } \\ 688181 & 8.0 & 6.1884 & \text { TRN } \\ 688181 & 5.9481 & 6.155 & \text { TRN } \\ 688181 & 5.6598 & 6.127999999999999 \\ 688181 & 5.7501 & 5.8456 & \text { TRN } \\ 688181 & 6.9136 & 7.4988 & \text { TRN } \\ 688181 & 6.8297 & 6.3124 & \text { TRN } \\ 688181 & 6.2526 & 6.3411 & \text { TRN } \\ 688181 & 6.1331 & 6.0044 & \text { TRN } \\ 688181 & 6.067 & 5.9567 & \text { TRN } \\ 688181 & 6.5498 & 6.5381 & \text { TRN } \\ 688181 & 5.6767 & 5.7354 & \text { TRN } \\ 688181 & 5.8024 & 5.8414 & \text { TST } \\ 688181 & 5.7567 & 6.1274 & \text { TRN } \\ 688181 & 5.7409 & 5.7079 & \text { TRN } \\ 688181 & 8.0 & 7.1585 & \text { TRN } \\ 688181 & 5.9952 & 5.9202 & \text { TRN } \\ 688181 & 6.767 & 6.1574 & \text { TRN } \\ 688181 & 5.7642 & 5.8791 & \text { TRN } \\ 688181 & 5.7064 & 5.5652 & \text { TRN } \\ 688181 & 5.9674 & 5.9325 & \text { TST } \\ 688181 & 8.0 & 7.5191 & \text { TRN } \\ 688181 & 6.4365 & 6.5192 & \text { TRN } \\ 688181 & 6.4789 & 6.357 & \text { TRN } \\ 688181 & 5.8887 & 6.0416 & \text { TRN } \\ 688181 & 5.7934 & 6.3889 & \text { TRN } \\ 688181 & 5.8097 & 5.8625 & \text { TRN } \\ 688181 & 3.5229 & 5.11 & \text { TRN }\end{array}$


Supplemental Table S2.txt

\begin{tabular}{|c|c|c|c|c|c|}
\hline CHEMBL1503342 & 688181 & 6.0851 & 6.0216 & TRN & \\
\hline CHEMBL1355165 & 688181 & 6.5952 & 6.1498 & TRN & \\
\hline CHEMBL1503375 & 688181 & 5.7768 & 6.3532 & TRN & \\
\hline CHEMBL1363275 & 688181 & 5.6364 & 5.6234 & TRN & \\
\hline CHEMBL1363834 & 688181 & 5.6015 & 5.551 & TRN & \\
\hline CHEMBL1374388 & 688181 & 5.6936 & 5.9575 & TRN & \\
\hline CHEMBL1490750 & 688181 & 6.1785 & 6.0781 & TRN & \\
\hline CHEMBL1469600 & 688181 & 5.4357 & 6.1807 & TST & \\
\hline CHEMBL1528110 & 688181 & 5.6698 & 6.2739 & TRN & \\
\hline CHEMBL1371831 & 688181 & 5.5812 & 5.8209 & TRN & \\
\hline CHEMBL1329222 & 688181 & 5.4987 & 5.9751 & TRN & \\
\hline CHEMBL1361161 & 688181 & 6.1506 & 6.1815 & TST & \\
\hline CHEMBL1561313 & 688181 & 6.82100 & 00000000 & 6.3828 & \\
\hline CHEMBL1351458 & 688181 & 5.7442 & 6.0767 & TRN & \\
\hline CHEMBL1348964 & 688181 & 5.3164 & 5.8889 & TST & \\
\hline CHEMBL1304179 & 688181 & 6.0283 & 6.0628 & TRN & \\
\hline CHEMBL3209165 & 688181 & 6.0565 & 6.2949 & TRN & \\
\hline CHEMBL 3193419 & 688181 & 6.1013 & 5.8987 & TRN & \\
\hline CHEMBL1457083 & 688181 & 6.4949 & 6.2114 & TRN & \\
\hline CHEMBL523200 & 688181 & 5.8952 & 5.9589 & TRN & \\
\hline CHEMBL1327783 & 688181 & 5.7331 & 5.5525 & TST & \\
\hline CHEMBL1496585 & 688181 & 5.6519 & 5.9991 & TST & \\
\hline CHEMBL1336926 & 688181 & 5.8327 & 6.0329 & TRN & \\
\hline CHEMBL1310527 & 688181 & 6.0292 & 5.902 & TST & \\
\hline CHEMBL1344533 & 688181 & 5.7652 & 5.1089 & TRN & \\
\hline CHEMBL1540313 & 688181 & 6.1079 & 6.3591 & TRN & \\
\hline CHEMBL1475194 & 688181 & 6.1925 & 6.0669 & TRN & \\
\hline CHEMBL1514530 & 688181 & 6.5719 & 6.193 & TRN & \\
\hline CHEMBL1395305 & 688181 & 5.942 & 6.6173 & TRN & \\
\hline CHEMBL1355541 & 688181 & 6.4815 & 6.6188 & TST & \\
\hline CHEMBL1382659 & 688181 & 6.6421 & 6.419 & TRN & \\
\hline CHEMBL 3197910 & 688181 & 6.3809 & \multicolumn{2}{|c|}{6.497000000000001} & TRN \\
\hline CHEMBL1399982 & 688181 & 6.2248 & 5.9487 & TRN & \\
\hline CHEMBL1522064 & 688181 & 5.6942 & 5.8284 & TRN & \\
\hline CHEMBL 3191962 & 688181 & 6.0809 & 5.6569 & TRN & \\
\hline CHEMBL1506837 & 688181 & 4.4014 & 6.1467 & TST & \\
\hline CHEMBL1527929 & 688181 & 5.5337 & 6.1111 & TST & \\
\hline CHEMBL1462697 & 688181 & 6.3197 & 7.0747 & TRN & \\
\hline CHEMBL1579710 & 688181 & 6.098 & 6.0974 & TRN & \\
\hline CHEMBL1526859 & 688181 & 5.5741 & 5.795 & TRN & \\
\hline CHEMBL1527809 & 688181 & 8.0 & \multicolumn{2}{|c|}{7.542999999999999} & $1 \mathrm{~m}$ \\
\hline CHEMBL1388072 & 688181 & 5.9416 & 6.3302 & TRN & \\
\hline CHEMBL1581902 & 688181 & 6.1884 & 6.2918 & TRN & \\
\hline CHEMBL2369168 & 688181 & 6.2684 & 6.5183 & TRN & \\
\hline CHEMBL1566928 & 688181 & 5.5294 & 6.1158 & TST & \\
\hline CHEMBL1497463 & 688181 & 8.0 & 6.1012 & TRN & \\
\hline CHEMBL1334906 & 688181 & 5.8877 & 5.8666 & TRN & \\
\hline CHEMBL1530315 & 688181 & 6.5575 & 6.5071 & TRN & \\
\hline
\end{tabular}

Page 14107 
Supplemental Table S2.txt

\begin{tabular}{|c|c|c|c|c|c|}
\hline CHEMBL1457240 & 688181 & 5.7176 & 5.9314 & TRN & \\
\hline CHEMBL1417213 & 688181 & 5.9263 & 6.1252 & TRN & \\
\hline CHEMBL1493415 & 688181 & 5.3534 & 5.5371 & TRN & \\
\hline CHEMBL1404718 & 688181 & 6.2874 & 6.0135 & TRN & \\
\hline CHEMBL1377336 & 688181 & 5.7147 & 5.0631 & TRN & \\
\hline CHEMBL1551823 & 688181 & 6.0013 & 6.4918 & TRN & \\
\hline CHEMBL1524531 & 688181 & 6.1811 & 6.8538 & TST & \\
\hline CHEMBL 3198503 & 688181 & 5.9893 & 5.8101 & TRN & \\
\hline CHEMBL1479432 & 688181 & 5.6176 & 5.7442 & TRN & \\
\hline CHEMBL1340188 & 688181 & 6.5969 & 6.0866 & TRN & \\
\hline CHEMBL1411665 & 688181 & 5.7208 & 6.2543 & TRN & \\
\hline CHEMBL1606726 & 688181 & 6.0516 & 6.5726 & TRN & \\
\hline CHEMBL1570958 & 688181 & 5.7064 & 6.2394 & TRN & \\
\hline CHEMBL1377321 & 688181 & 5.6686 & 6.1372 & TRN & \\
\hline CHEMBL1423920 & 688181 & 6.7055 & 7.0354 & TRN & \\
\hline CHEMBL1347509 & 688181 & 5.62 & 6.2186 & TRN & \\
\hline CHEMBL1398630 & 688181 & 5.6889 & 5.5296 & TRN & \\
\hline CHEMBL 3211624 & 688181 & 5.782 & 6.4931 & TRN & \\
\hline CHEMBL 3192284 & 688181 & 6.2055 & 6.1268 & TRN & \\
\hline CHEMBL1503190 & 688181 & 5.8404 & 6.3392 & TST & \\
\hline CHEMBL1386828 & 688181 & 6.266 & 6.6965 & TRN & \\
\hline CHEMBL1344831 & 688181 & 5.9435 & 6.1711 & TRN & \\
\hline CHEMBL1320354 & 688181 & 5.6114 & 5.7749 & TRN & \\
\hline CHEMBL1504429 & 688181 & 5.8611 & 6.032999 & 79999999995 & TRN \\
\hline CHEMBL1505799 & 688181 & 5.8069 & 5.9812 & TRN & \\
\hline CHEMBL1544409 & 688181 & 6.0278 & 6.2345 & TRN & \\
\hline CHEMBL1588034 & 688181 & 6.9706 & 6.0976 & TRN & \\
\hline CHEMBL1358777 & 688181 & \multicolumn{2}{|c|}{5.5489999999999995} & 6.4403 & TST \\
\hline CHEMBL1482740 & 688181 & 5.5514 & 6.1433 & TRN & \\
\hline CHEMBL1409186 & 688181 & 6.2668 & 6.6202 & TRN & \\
\hline CHEMBL1402909 & 688181 & 5.8871 & 6.5493 & TST & \\
\hline CHEMBL1575557 & 688181 & 6.2967 & 5.9104 & TRN & \\
\hline CHEMBL1366622 & 688181 & 6.4547 & 6.4436 & TRN & \\
\hline CHEMBL1424738 & 688181 & 6.2351 & 6.0187 & TRN & \\
\hline CHEMBL 3190564 & 688181 & \multicolumn{3}{|c|}{5.757999999999999} & TST \\
\hline CHEMBL1485299 & 688181 & 6.3372 & 6.4783 & TRN & \\
\hline CHEMBL 3210550 & 688181 & 5.6882 & 5.8057 & TRN & \\
\hline CHEMBL1378686 & 688181 & 6.068 & 5.4472 & TRN & \\
\hline CHEMBL1533772 & 688181 & 6.3696 & 6.4706 & TRN & \\
\hline CHEMBL1587027 & 688181 & 5.185 & 6.4776 & TRN & \\
\hline CHEMBL1471951 & 688181 & 6.0458 & 6.0637 & TRN & \\
\hline CHEMBL1424307 & 688181 & 6.3809 & 6.4771 & TRN & \\
\hline CHEMBL1433403 & 688181 & 5.7235 & 5.5922 & TRN & \\
\hline CHEMBL609027 & 688181 & 6.2351 & 7.2826 & TRN & \\
\hline CHEMBL1455508 & 688181 & 6.9066 & 6.3262 & TRN & \\
\hline CHEMBL1537115 & 688181 & 4.9004 & 5.7417 & TST & \\
\hline CHEMBL1363249 & 688181 & 5.6714 & 5.9321 & TRN & \\
\hline CHEMBL1500500 & 688181 & 6.0731 & 6.428 & TRN & \\
\hline
\end{tabular}




\begin{tabular}{|c|c|c|c|c|c|c|}
\hline \multirow[b]{2}{*}{ CHEMBL1518506 } & \multirow[b]{2}{*}{688181} & \multicolumn{5}{|c|}{ Supplemental Table S2.txt } \\
\hline & & 5.8945 & 6.454 & TRN & & \\
\hline CHEMBL1580259 & 688181 & 5.7557 & 5.8784 & TST & & \\
\hline CHEMBL3209776 & 688181 & 5.8745 & 5.7618 & TRN & & \\
\hline CHEMBL1327683 & 688181 & 5.8844 & 6.1509 & TRN & & \\
\hline CHEMBL 2000342 & 688181 & 5.8395 & 6.0369 & TST & & \\
\hline CHEMBL1367702 & 688181 & 5.4016 & 5.4289 & TRN & & \\
\hline CHEMBL1368748 & 688181 & 6.6364 & 6.5231 & TRN & & \\
\hline CHEMBL1415135 & 688181 & 5.6107 & 5.6214 & TST & & \\
\hline CHEMBL1393349 & 688181 & 5.794 & 6.0722 & TRN & & \\
\hline CHEMBL1587013 & 688181 & \multicolumn{3}{|c|}{5.797000000000001} & 6.6562 & TRN \\
\hline CHEMBL1315948 & 688181 & 5.8681 & 6.5412 & TST & & \\
\hline CHEMBL1609946 & 688181 & 6.0155 & 6.0989 & TRN & & \\
\hline CHEMBL162347 & 688181 & 5.9278 & 6.5674 & TRN & & \\
\hline CHEMBL1583479 & 688181 & 5.8921 & 5.4939 & TRN & & \\
\hline CHEMBL1452421 & 688181 & 6.3615 & 6.0469 & TRN & & \\
\hline CHEMBL1556468 & 688181 & 5.5943 & 6.0197 & TRN & & \\
\hline CHEMBL1432707 & 688181 & 5.6315 & 5.9626 & TST & & \\
\hline CHEMBL1372380 & 688181 & 6.2874 & 6.2015 & TRN & & \\
\hline CHEMBL1997413 & 688181 & 5.7852 & 5.7502 & TST & & \\
\hline CHEMBL602363 & 688181 & 5.7298 & 5.7083 & TRN & & \\
\hline CHEMBL1524605 & 688181 & 5.5962 & 6.1759 & TRN & & \\
\hline CHEMBL1496053 & 688181 & 6.1518 & 6.3753 & TRN & & \\
\hline CHEMBL1490365 & 688181 & 6.0472 & 6.6715 & TRN & & \\
\hline CHEMBL394242 & 688181 & 6.3116 & 5.9395 & TRN & & \\
\hline CHEMBL534214 & 688181 & 6.5952 & 6.1368 & TRN & & \\
\hline CHEMBL1414994 & 688181 & 6.2716 & 5.9146 & TST & & \\
\hline CHEMBL3191242 & 688181 & 5.6882 & 5.6632 & TRN & & \\
\hline CHEMBL1342525 & 688181 & 5.744 & 5.9411 & TRN & & \\
\hline CHEMBL1447166 & 688181 & 5.6417 & 5.8045 & TRN & & \\
\hline CHEMBL1347533 & 688181 & 5.7018 & 6.3594 & TRN & & \\
\hline CHEMBL1386133 & 688181 & 8.0 & 6.9023 & TRN & & \\
\hline CHEMBL1532890 & 688181 & 5.6135 & 5.4316 & TRN & & \\
\hline CHEMBL1333386 & 688181 & 6.38206 & 30000000 & & 5.8101 & TRN \\
\hline CHEMBL1600766 & 688181 & 6.1445 & 6.2432 & TRN & & \\
\hline CHEMBL1533447 & 688181 & 6.2604 & 5.6813 & TRN & & \\
\hline CHEMBL1391835 & 688181 & 5.4288 & 6.8295 & TRN & & \\
\hline CHEMBL1522802 & 688181 & 5.8016 & 6.0994 & TRN & & \\
\hline CHEMBL1971154 & 688181 & 5.7122 & 5.8633 & TRN & & \\
\hline CHEMBL1521380 & 688181 & 6.4672 & 6.4203 & TST & & \\
\hline CHEMBL1550184 & 688181 & 6.7986 & 7.0001 & TRN & & \\
\hline CHEMBL3212652 & 688181 & 8.0 & 7.0146 & TRN & & \\
\hline CHEMBL1470648 & 688181 & 5.7962 & 6.0762 & TRN & & \\
\hline CHEMBL1544131 & 688181 & 5.6517 & 6.0174 & TRN & & \\
\hline CHEMBL1531936 & 688181 & 5.8024 & 6.2927 & TRN & & \\
\hline CHEMBL1461290 & 688181 & 6.6478 & 6.4214 & TRN & & \\
\hline CHEMBL1418200 & 688181 & 5.7924 & 5.9271 & TRN & & \\
\hline CHEMBL1460030 & 688181 & 6.1124 & 6.4056 & TST & & \\
\hline CHEMBL1499015 & 688181 & 5.6554 & 5.7365 & TRN & & \\
\hline
\end{tabular}




\begin{tabular}{|c|c|c|c|c|}
\hline & & & oplement & al $\mathrm{Ta}$ \\
\hline CHEMBL1509954 & 688181 & 6.0969 & 6.1233 & TRN \\
\hline CHEMBL1444877 & 688181 & 6.3449 & 6.8524 & TRN \\
\hline CHEMBL1401860 & 688181 & 8.0 & 6.5882 & TRN \\
\hline CHEMBL1312303 & 688181 & 5.4892 & 5.621 & TRN \\
\hline CHEMBL1540239 & 688181 & 6.1433 & 6.7388 & TRN \\
\hline CHEMBL1608825 & 688181 & 6.1798 & 6.025 & TRN \\
\hline CHEMBL1391551 & 688181 & 6.0132 & 6.2665 & TRN \\
\hline CHEMBL1509509 & 688181 & 5.7138 & 5.7347 & TRN \\
\hline CHEMBL1459090 & 688181 & 8.0 & 7.2178 & TRN \\
\hline CHEMBL1466926 & 688181 & 5.4752 & 6.1881 & TRN \\
\hline CHEMBL1342790 & 688181 & 6.433 & 6.4884 & TRN \\
\hline CHEMBL1309888 & 688181 & 6.9281 & 5.98 & TRN \\
\hline CHEMBL3207674 & 688181 & 6.1669 & 5.56 & TRN \\
\hline CHEMBL3195405 & 688181 & 5.5733 & 5.5691 & TST \\
\hline CHEMBL1558925 & 688181 & 6.2277 & 6.2031 & TRN \\
\hline CHEMBL1330516 & 688181 & 5.5124 & 5.8081 & TRN \\
\hline CHEMBL530499 & 688181 & 5.9735 & 6.0309 & TRN \\
\hline CHEMBL1383334 & 688181 & 6.1013 & 5.7476 & TRN \\
\hline CHEMBL1549333 & 688181 & 6.27 & 5.7995 & TRN \\
\hline CHEMBL1455636 & 688181 & 6.1765 & 6.0701 & TRN \\
\hline CHEMBL1349441 & 688181 & 6.1057 & 6.211 & TRN \\
\hline CHEMBL1401727 & 688181 & 5.8083 & 5.9597 & TRN \\
\hline CHEMBL1445171 & 688181 & 6.0757 & 5.5118 & TRN \\
\hline CHEMBL3190712 & 688181 & 5.9307 & 6.2086 & TRN \\
\hline CHEMBL162057 & 688181 & 3.5229 & 5.3674 & TRN \\
\hline CHEMBL1371761 & 688181 & 6.1506 & 5.9625 & TRN \\
\hline CHEMBL1503683 & 688181 & 5.937 & 6.4719 & TRN \\
\hline CHEMBL1374191 & 688181 & 5.8831 & 6.2559 & TST \\
\hline CHEMBL1360030 & 688181 & 5.6919 & 5.6542 & TRN \\
\hline CHEMBL1463485 & 688181 & 5.7235 & 5.8759 & TRN \\
\hline CHEMBL1530515 & 688181 & 6.3546 & 6.4841 & TRN \\
\hline CHEMBL1558075 & 688181 & 6.2211 & 7.0977 & TST \\
\hline CHEMBL1305471 & 688181 & 5.6227 & 6.3512 & TRN \\
\hline CHEMBL1302283 & 688181 & 6.2676 & 6.7356 & TRN \\
\hline CHEMBL1398431 & 688181 & 6.7905 & 6.059 & TRN \\
\hline CHEMBL1338825 & 688181 & 5.5619 & 5.4173 & TRN \\
\hline CHEMBL1573175 & 688181 & 5.7703 & 5.7935 & TRN \\
\hline CHEMBL1469791 & 688181 & 6.1018 & 5.7084 & TRN \\
\hline CHEMBL1608985 & 688181 & 6.6737 & 6.3337 & TRN \\
\hline CHEMBL1550090 & 688181 & 5.5396 & 6.0759 & TRN \\
\hline CHEMBL1490222 & 688181 & 6.1838 & 6.1521 & TRN \\
\hline CHEMBL1607938 & 688181 & 6.15 & 5.9327 & TRN \\
\hline CHEMBL605753 & 688181 & 6.9318 & 6.7202 & TRN \\
\hline CHEMBL1465450 & 688181 & 5.7277 & 5.3298 & TST \\
\hline CHEMBL587849 & 688181 & 5.6753 & 6.0143 & TST \\
\hline CHEMBL1412904 & 688181 & 6.1898 & 5.5713 & TRN \\
\hline CHEMBL1392878 & 688181 & 5.9416 & 5.6872 & TST \\
\hline CHEMBL1388469 & 688181 & 5.6566 & 5.4583 & TRN \\
\hline
\end{tabular}


Supplemental Table S2.txt

\begin{tabular}{|c|c|c|c|c|c|}
\hline CHEMBL1391958 & 688181 & 5.7036 & 5.9128 & TRN & \\
\hline CHEMBL1435670 & 688181 & 5.7846 & 6.2138 & TRN & \\
\hline CHEMBL3210984 & 688181 & 5.6191 & 5.8667 & TRN & \\
\hline CHEMBL171289 & 688181 & 8.0 & 6.4544 & TRN & \\
\hline CHEMBL1418073 & 688181 & 5.6882 & 5.5696 & TRN & \\
\hline CHEMBL1414110 & 688181 & 5.9401 & 6.4843 & TRN & \\
\hline CHEMBL1525808 & 688181 & 6.5935 & 6.5555 & TRN & \\
\hline CHEMBL1446268 & 688181 & 6.6819 & 5.9857 & TRN & \\
\hline CHEMBL 239275 & 688181 & 5.9194 & 5.9077 & TRN & \\
\hline CHEMBL599924 & 688181 & 6.1029 & 5.8429 & TST & \\
\hline CHEMBL 3210051 & 688181 & 5.5005 & 5.5868 & TRN & \\
\hline CHEMBL598679 & 688181 & 6.5935 & 6.643 & TRN & \\
\hline CHEMBL1360865 & 688181 & 5.6398 & 6.1033 & TRN & \\
\hline CHEMBL1391965 & 688181 & 6.2321 & \multicolumn{2}{|c|}{6.2410000000000005} & TRN \\
\hline CHEMBL1339909 & 688181 & 5.528 & 5.5298 & TRN & \\
\hline CHEMBL1511029 & 688181 & 6.4976 & 6.2971 & TRN & \\
\hline CHEMBL3199462 & 688181 & 5.4324 & 6.3859 & TST & \\
\hline CHEMBL1575043 & 688181 & 5.8716 & 6.1151 & TRN & \\
\hline CHEMBL1329678 & 688181 & 6.6144 & \multicolumn{2}{|c|}{5.882000000000001} & TRN \\
\hline CHEMBL1423463 & 688181 & 6.4473 & 6.0781 & TST & \\
\hline CHEMBL1326623 & 688181 & 8.0 & 6.7186 & TRN & \\
\hline CHEMBL2094567 & 688181 & 6.9031 & 6.7928 & TRN & \\
\hline CHEMBL1974269 & 688181 & 6.6615 & 6.4873 & TRN & \\
\hline CHEMBL1588899 & 688181 & 6.1073 & \multicolumn{2}{|c|}{6.452000000000001} & TRN \\
\hline CHEMBL1510342 & 688181 & 5.8486 & 6.2161 & TRN & \\
\hline CHEMBL1588774 & 688181 & 8.0 & 7.4644 & TRN & \\
\hline CHEMBL1405679 & 688181 & 5.6617 & 5.6248 & TRN & \\
\hline CHEMBL1431331 & 688181 & 5.9957 & 6.2476 & TRN & \\
\hline CHEMBL1311109 & 688181 & 5.6946 & 5.5518 & TST & \\
\hline CHEMBL1445324 & 688181 & 5.5621 & 5.5434 & TST & \\
\hline CHEMBL1563140 & 688181 & 6.3778 & \multicolumn{2}{|c|}{6.247000000000001} & TRN \\
\hline CHEMBL1390770 & 688181 & 6.3706 & 6.2281 & TRN & \\
\hline CHEMBL1534203 & 688181 & 8.0 & 6.5438 & TST & \\
\hline CHEMBL1345510 & 688181 & 5.5309 & 5.7593 & TST & \\
\hline CHEMBL1482308 & 688181 & 5.4235 & 6.2158 & TRN & \\
\hline CHEMBL1367691 & 688181 & 5.8356 & 5.9193 & TRN & \\
\hline CHEMBL1416618 & 688181 & 8.0 & 5.5576 & TST & \\
\hline CHEMBL1310848 & 688181 & 5.8162 & 6.135 & TRN & \\
\hline CHEMBL1599467 & 688181 & 5.6405 & 6.0314 & TRN & \\
\hline CHEMBL1437928 & 688181 & 6.9788 & 6.445 & TRN & \\
\hline CHEMBL3210126 & 688181 & 5.694 & 5.9493 & TRN & \\
\hline CHEMBL1417223 & 688181 & 5.5761 & 5.879 & TRN & \\
\hline CHEMBL1467233 & 688181 & 5.4313 & 5.7742 & TRN & \\
\hline CHEMBL1486546 & 688181 & 5.6761 & 6.2643 & TRN & \\
\hline CHEMBL1977659 & 688181 & 5.9038 & 6.2899 & TRN & \\
\hline CHEMBL1589882 & 688181 & 5.6353 & 5.5509 & TST & \\
\hline CHEMBL1382160 & 688181 & 6.5272 & 7.3118 & TRN & \\
\hline CHEMBL1325564 & 688181 & 6.2857 & 6.1019 & TRN & \\
\hline
\end{tabular}




\begin{tabular}{|c|c|c|c|c|c|c|}
\hline \multicolumn{7}{|c|}{ Supplemental Table S2.txt } \\
\hline CHEMBL1472773 & 688181 & 8.0 & 7.0846 & TST & & \\
\hline CHEMBL1357288 & 688181 & 6.0726 & 5.6157 & TRN & & \\
\hline CHEMBL3194715 & 688181 & 5.5528 & 6.5254 & TST & & \\
\hline CHEMBL583305 & 688181 & 6.1463 & 6.04700 & 0000000001 & & TRN \\
\hline CHEMBL1531615 & 688181 & 6.5031 & 6.4323 & TRN & & \\
\hline CHEMBL1372492 & 688181 & 6.466 & 5.7895 & TRN & & \\
\hline CHEMBL1454346 & 688181 & 5.7862 & 5.6627 & TRN & & \\
\hline CHEMBL1389078 & 688181 & 8.0 & 7.0124 & TRN & & \\
\hline CHEMBL1561638 & 688181 & 5.9809 & 5.8174 & TRN & & \\
\hline CHEMBL1999137 & 688181 & 6.4101 & 6.8596 & TRN & & \\
\hline CHEMBL1565991 & 688181 & 5.9112 & 6.1644 & TRN & & \\
\hline CHEMBL1455046 & 688181 & 5.7455 & 6.2165 & TST & & \\
\hline CHEMBL1444044 & 688181 & 5.7471 & 6.9274 & TRN & & \\
\hline CHEMBL1309292 & 688181 & 5.7755 & 5.9731 & TRN & & \\
\hline CHEMBL1345355 & 688181 & 6.0132 & 6.7712 & TRN & & \\
\hline CHEMBL1386648 & 688181 & 5.6857 & 5.6673 & TST & & \\
\hline CHEMBL1366850 & 688181 & 5.6265 & 5.8697 & TRN & & \\
\hline CHEMBL1329918 & 688181 & 5.7978 & 6.0342 & TRN & & \\
\hline CHEMBL1495939 & 688181 & 5.6114 & 5.7842 & TRN & & \\
\hline CHEMBL1419536 & 688181 & 5.3956 & 5.7057 & TRN & & \\
\hline CHEMBL1507137 & 688181 & 5.6855 & 5.8216 & TRN & & \\
\hline CHEMBL1519338 & 688181 & 5.7484 & 5.3382 & TRN & & \\
\hline CHEMBL1474925 & 688181 & 6.2013 & 6.3641 & TRN & & \\
\hline CHEMBL1375462 & 688181 & 6.5421 & 6.5321 & TRN & & \\
\hline CHEMBL1321758 & 688181 & 5.6499 & 5.6118 & TST & & \\
\hline CHEMBL1326728 & 688181 & 6.1605 & 6.0433 & TRN & & \\
\hline CHEMBL1468446 & 688181 & 6.0985 & 6.4827 & TRN & & \\
\hline CHEMBL1322673 & 688181 & 5.5516 & 6.0099 & TRN & & \\
\hline CHEMBL1506663 & 688181 & 8.0 & 6.4447 & TRN & & \\
\hline CHEMBL536166 & 688181 & 8.0 & 8.2039 & TRN & & \\
\hline CHEMBL1563709 & 688181 & 6.0357 & 5.9752 & TRN & & \\
\hline CHEMBL1534096 & 688181 & 6.6925 & 7.3631 & TRN & & \\
\hline CHEMBL1404397 & 688181 & 6.0555 & 6.63200 & 0000000001 & & TRN \\
\hline CHEMBL3196728 & 688181 & 6.9914 & 6.0666 & TRN & & \\
\hline CHEMBL1308687 & 688181 & 5.7967 & 6.5566 & TRN & & \\
\hline CHEMBL1495094 & 688181 & 5.4403 & 5.7936 & TRN & & \\
\hline CHEMBL1315993 & 688181 & 7.0 & 6.1865 & TRN & & \\
\hline CHEMBL1458338 & 688181 & 5.6492 & 6.0646 & TST & & \\
\hline CHEMBL1995715 & 688181 & 5.6447 & 5.9618 & TRN & & \\
\hline CHEMBL1588903 & 688181 & 3.5229 & 6.5005 & TST & & \\
\hline CHEMBL1458840 & 688181 & 6.3116 & 5.9087 & TRN & & \\
\hline CHEMBL1511166 & 688181 & 6.7258 & 6.6728 & TRN & & \\
\hline CHEMBL1440608 & 688181 & 6.3615 & 6.6122 & TRN & & \\
\hline CHEMBL3195037 & 688181 & 5.57299 & 79999999 & 995 & 6.3621 & TRN \\
\hline CHEMBL1990786 & 688181 & 5.425 & 5.8219 & TRN & & \\
\hline CHEMBL1433394 & 688181 & 6.0605 & 6.2754 & TRN & & \\
\hline CHEMBL1329637 & 688181 & 5.7359 & 5.5731 & TRN & & \\
\hline CHEMBL1546827 & 688181 & 6.9666 & 6.2832 & TRN & & \\
\hline
\end{tabular}

Page 14112 
Supplemental Table S2.txt

\begin{tabular}{|c|c|c|c|c|}
\hline CHEMBL482116 & 688181 & 6.1427 & 6.1935 & TRN \\
\hline CHEMBL1597731 & 688181 & 5.5077 & 5.6959 & TRN \\
\hline CHEMBL1445650 & 688181 & 6.2807 & 5.5683 & TRN \\
\hline CHEMBL1373415 & 688181 & 5.7572 & 6.1678 & TRN \\
\hline CHEMBL560579 & 688181 & 8.0 & 6.4324 & TST \\
\hline CHEMBL1382265 & 688181 & 5.7474 & 6.4045 & TRN \\
\hline CHEMBL1428354 & 688181 & 8.0 & 7.4061 & TRN \\
\hline CHEMBL1992689 & 688181 & 3.2218 & 5.5318 & TRN \\
\hline CHEMBL1605956 & 688181 & 5.6861 & 6.0482 & TRN \\
\hline CHEMBL1485078 & 688181 & 5.6803 & 5.5866 & TRN \\
\hline CHEMBL1438205 & 688181 & 6.6556 & 5.8459 & TRN \\
\hline CHEMBL1341581 & 688181 & 5.5156 & 6.0026 & TRN \\
\hline CHEMBL602218 & 688181 & 5.5025 & 5.9196 & TRN \\
\hline CHEMBL1600678 & 688181 & 6.5436 & 6.8278 & TST \\
\hline CHEMBL1406457 & 688181 & 5.5309 & 6.0184 & TST \\
\hline CHEMBL1563708 & 688181 & 5.5077 & 5.8558 & TRN \\
\hline CHEMBL1599053 & 688181 & 6.3363 & 6.3943 & TRN \\
\hline CHEMBL1500410 & 688181 & 5.691 & 6.1588 & TRN \\
\hline CHEMBL1579895 & 688181 & 5.9212 & 6.2906 & TRN \\
\hline CHEMBL1330788 & 688181 & 5.6672 & 5.8876 & TRN \\
\hline CHEMBL1990071 & 688181 & 5.5278 & 5.7041 & TRN \\
\hline CHEMBL1577829 & 688181 & 6.0467 & 5.6961 & TRN \\
\hline CHEMBL1328118 & 688181 & 5.9318 & 6.1536 & TRN \\
\hline CHEMBL1329235 & 688181 & 5.3936 & 6.1244 & TRN \\
\hline CHEMBL1527604 & 688181 & 6.5143 & 6.5974 & TRN \\
\hline CHEMBL1368909 & 688181 & 5.7878 & 5.7812 & TRN \\
\hline CHEMBL 3198253 & 688181 & 6.8125 & 6.9489 & TRN \\
\hline CHEMBL1407068 & 688181 & 6.9101 & 6.434 & TRN \\
\hline CHEMBL1353998 & 688181 & 8.0 & 6.8246 & TRN \\
\hline CHEMBL1437822 & 688181 & 8.0 & \multicolumn{2}{|c|}{6.747999999999999} \\
\hline CHEMBL1538325 & 688181 & 5.7486 & 6.0006 & TST \\
\hline CHEMBL1593656 & 688181 & 5.8024 & 5.4473 & TRN \\
\hline CHEMBL1598299 & 688181 & 6.3487 & 6.1174 & TST \\
\hline CHEMBL1313959 & 688181 & 5.643 & 6.2598 & TRN \\
\hline CHEMBL1503033 & 688181 & 4.6636 & 5.9677 & TST \\
\hline CHEMBL1310068 & 688181 & 6.4089 & 6.3377 & TRN \\
\hline CHEMBL1304177 & 688181 & 5.9935 & 5.7836 & TRN \\
\hline CHEMBL1365183 & 688181 & 6.6459 & 6.1441 & TST \\
\hline CHEMBL1385581 & 688181 & 6.3288 & 6.1492 & TRN \\
\hline CHEMBL1531841 & 688181 & 5.8979 & 5.8377 & TRN \\
\hline CHEMBL1431608 & 688181 & 5.624 & \multicolumn{2}{|c|}{5.587999999999999} \\
\hline CHEMBL1383333 & 688181 & 5.8693 & 5.6093 & TRN \\
\hline CHEMBL1514810 & 688181 & 5.6981 & 5.4338 & TST \\
\hline CHEMBL 3199423 & 688181 & 5.3376 & 5.8727 & TST \\
\hline CHEMBL1391048 & 688181 & 6.2411 & 6.2456 & TRN \\
\hline CHEMBL1608575 & 688181 & 6.6861 & 6.4113 & TRN \\
\hline CHEMBL1524234 & 688181 & 6.7375 & 6.9304 & TRN \\
\hline CHEMBL1525567 & 688181 & 6.4045 & 5.9547 & TRN \\
\hline
\end{tabular}

Page 14113 


\begin{tabular}{|c|c|c|c|c|c|c|}
\hline & & \multicolumn{5}{|c|}{ Supplemental Table S2.txt } \\
\hline CHEMBL1525103 & 688181 & 5.9169 & 5.5589 & TRN & & \\
\hline CHEMBL1382698 & 688181 & 5.8318 & 6.431 & TRN & & \\
\hline CHEMBL1522473 & 688181 & 8.0 & 6.5003 & TRN & & \\
\hline CHEMBL1497658 & 688181 & 5.4412 & 5.7936 & TRN & & \\
\hline CHEMBL1542506 & 688181 & 6.15 & 5.9233 & TRN & & \\
\hline CHEMBL3193604 & 688181 & 6.6696 & 6.3381 & TRN & & \\
\hline CHEMBL3193305 & 688181 & 6.2027 & 6.276 & TRN & & \\
\hline CHEMBL1414364 & 688181 & 8.0 & 6.0147 & TRN & & \\
\hline CHEMBL1461792 & 688181 & 6.0458 & 5.8647 & TRN & & \\
\hline CHEMBL1377644 & 688181 & 6.4168 & 6.2465 & TRN & & \\
\hline CHEMBL1341517 & 688181 & 8.0 & 7.0191 & TRN & & \\
\hline CHEMBL1384414 & 688181 & 5.9469 & 6.0148 & TRN & & \\
\hline CHEMBL1423197 & 688181 & 6.6198 & 6.3294 & TST & & \\
\hline CHEMBL1372575 & 688181 & 8.0 & 6.9299 & TRN & & \\
\hline CHEMBL1388616 & 688181 & 8.0 & 6.0105 & TST & & \\
\hline CHEMBL3195896 & 688181 & 5.6258 & 5.4716 & TST & & \\
\hline CHEMBL1550144 & 688181 & 5.9527 & 6.1711 & TRN & & \\
\hline CHEMBL1999900 & 688181 & 5.5842 & 5.9412 & TRN & & \\
\hline CHEMBL1527057 & 688181 & 6.7011 & 7.2146 & TRN & & \\
\hline CHEMBL1562009 & 688181 & 5.6755 & 6.0151 & TRN & & \\
\hline CHEMBL405857 & 688181 & 6.0311 & 6.2077 & TRN & & \\
\hline CHEMBL3199324 & 688181 & 6.0625 & 6.0227 & TRN & & \\
\hline CHEMBL1483481 & 688181 & 6.61799 & 99999999 & 99 & 5.8233 & TRN \\
\hline CHEMBL1606342 & 688181 & 6.1518 & 5.8029 & TST & & \\
\hline CHEMBL1602449 & 688181 & 8.0 & 6.4071 & TRN & & \\
\hline CHEMBL1393054 & 688181 & 5.5638 & 6.026 & TRN & & \\
\hline CHEMBL1401984 & 688181 & 5.6643 & 5.8387 & TRN & & \\
\hline CHEMBL1503479 & 688181 & 6.4559 & 6.2732 & TST & & \\
\hline CHEMBL1517864 & 688181 & 5.8887 & 6.1172 & TRN & & \\
\hline CHEMBL1490351 & 688181 & 5.8444 & 5.7781 & TRN & & \\
\hline CHEMBL1430413 & 688181 & 6.3575 & 6.3071 & TRN & & \\
\hline CHEMBL1994963 & 688181 & 5.9352 & 6.0279 & TRN & & \\
\hline CHEMBL1370513 & 688181 & 6.3188 & 6.1605 & TRN & & \\
\hline CHEMBL1345564 & 688181 & 6.4179 & 6.085 & TRN & & \\
\hline CHEMBL1596245 & 688181 & 5.5872 & 5.6179 & TST & & \\
\hline CHEMBL1409362 & 688181 & 8.0 & 7.0276 & TRN & & \\
\hline CHEMBL312032 & 688181 & 5.8557 & 5.972 & TST & & \\
\hline CHEMBL1414681 & 688181 & 5.8722 & 6.0142 & TRN & & \\
\hline CHEMBL1558598 & 688181 & 5.8428 & 6.0176 & TRN & & \\
\hline CHEMBL1490430 & 688181 & 5.9884 & 6.278 & TRN & & \\
\hline CHEMBL1599032 & 688181 & 4.8752 & 6.1665 & TRN & & \\
\hline CHEMBL3192656 & 688181 & 5.6975 & 6.0337 & TRN & & \\
\hline CHEMBL1607875 & 688181 & 6.1911 & 5.6342 & TRN & & \\
\hline CHEMBL1332689 & 688181 & 4.8649 & 5.2395 & TST & & \\
\hline CHEMBL1581020 & 688181 & 6.6478 & 6.2037 & TRN & & \\
\hline CHEMBL1609009 & 688181 & 5.4448 & 6.0827 & TRN & & \\
\hline CHEMBL3194114 & 688181 & 5.8407 & 6.0312 & TRN & & \\
\hline CHEMBL1463257 & 688181 & 5.7254 & 5.7176 & TST & & \\
\hline
\end{tabular}


Supplemental Table S2.txt

\begin{tabular}{|c|c|c|c|c|c|c|}
\hline CHEMBL1377273 & 688181 & 5.7133 & 5.9998 & TRN & & \\
\hline CHEMBL1540026 & 688181 & 6.3242 & 6.1089 & TRN & & \\
\hline CHEMBL1492017 & 688181 & 5.7291 & 6.0576 & TRN & & \\
\hline CHEMBL1345979 & 688181 & 6.3125 & 6.0439 & TST & & \\
\hline CHEMBL1427431 & 688181 & 5.791 & 5.62299 & 9999999999 & & TRN \\
\hline CHEMBL1427474 & 688181 & 3.2218 & 5.0959 & TRN & & \\
\hline CHEMBL1368429 & 688181 & 6.7721 & 6.0097 & TRN & & \\
\hline CHEMBL 305469 & 688181 & 6.8928 & 6.4937 & TRN & & \\
\hline CHEMBL 603020 & 688181 & 8.0 & 6.9927 & TRN & & \\
\hline CHEMBL1542180 & 688181 & 6.6655 & 7.3909 & TRN & & \\
\hline CHEMBL1577081 & 688181 & \multicolumn{3}{|c|}{5.6770000000000005} & 5.9189 & TRN \\
\hline CHEMBL1352381 & 688181 & 5.6983 & 5.5184 & TRN & & \\
\hline CHEMBL1393829 & 688181 & 6.3107 & 6.1234 & TRN & & \\
\hline CHEMBL1338304 & 688181 & 5.7655 & 5.4024 & TRN & & \\
\hline CHEMBL486706 & 688181 & 5.7752 & 6.3998 & TRN & & \\
\hline CHEMBL1561245 & 688181 & 6.1972 & 6.0241 & TRN & & \\
\hline CHEMBL1416323 & 688181 & 3.2218 & 5.5577 & TRN & & \\
\hline CHEMBL1571801 & 688181 & 5.5981 & 6.13200 & 0000000001 & & TRN \\
\hline CHEMBL1403514 & 688181 & 8.0 & 6.1418 & TRN & & \\
\hline CHEMBL1302137 & 688181 & 6.1805 & 6.4814 & TST & & \\
\hline CHEMBL578515 & 688181 & \multicolumn{3}{|c|}{6.752000000000001} & 6.6091 & TRN \\
\hline CHEMBL1410618 & 688181 & 5.9578 & 5.6561 & TRN & & \\
\hline CHEMBL1483331 & 688181 & 5.5776 & 5.5779 & TST & & \\
\hline CHEMBL1430872 & 688181 & \multicolumn{3}{|c|}{5.513999999999999} & 5.8324 & TRN \\
\hline CHEMBL1718568 & 688181 & 6.6946 & 6.216 & TRN & & \\
\hline CHEMBL1432149 & 688181 & 6.8386 & 6.6714 & TRN & & \\
\hline CHEMBL3194760 & 688181 & 6.4101 & 5.6476 & TRN & & \\
\hline CHEMBL1540265 & 688181 & 5.5567 & 5.9567 & TRN & & \\
\hline CHEMBL1454557 & 688181 & 8.0 & 6.7486 & TRN & & \\
\hline CHEMBL3195621 & 688181 & 5.8831 & 6.20100 & 0000000000 & & TRN \\
\hline CHEMBL1306998 & 688181 & 5.6708 & 5.6442 & TRN & & \\
\hline CHEMBL1351455 & 688181 & 5.6672 & 5.1527 & TRN & & \\
\hline CHEMBL1511748 & 688181 & 5.6151 & 5.5769 & TRN & & \\
\hline CHEMBL1420768 & 688181 & 5.4667 & 5.4084 & TRN & & \\
\hline CHEMBL1571289 & 688181 & 6.2013 & 6.1878 & TRN & & \\
\hline CHEMBL1544525 & 688181 & 6.8508 & 6.3043 & TRN & & \\
\hline CHEMBL585481 & 688181 & 3.2218 & 5.4294 & TRN & & \\
\hline CHEMBL1486739 & 688181 & \multicolumn{3}{|c|}{5.667000000000001} & 5.5002 & TRN \\
\hline CHEMBL1348909 & 688181 & 5.9974 & 6.5051 & TRN & & \\
\hline CHEMBL1457275 & 688181 & 8.0 & 7.4078 & TRN & & \\
\hline CHEMBL1516689 & 688181 & 8.0 & 6.3509 & TRN & & \\
\hline CHEMBL1557917 & 688181 & 8.0 & 6.479 & TRN & & \\
\hline CHEMBL1336823 & 688181 & 6.8297 & 5.7581 & TST & & \\
\hline CHEMBL1581149 & 688181 & 5.8948 & 5.4918 & TRN & & \\
\hline CHEMBL1498173 & 688181 & 6.2457 & 6.0311 & TRN & & \\
\hline CHEMBL1534781 & 688181 & 5.7238 & 5.7619 & TRN & & \\
\hline CHEMBL1561936 & 688181 & 5.7964 & 5.7314 & TRN & & \\
\hline CHEMBL527586 & 688181 & 5.2245 & 6.1367 & TST & & \\
\hline
\end{tabular}

Page 14115 
Supplemental Table S2.txt

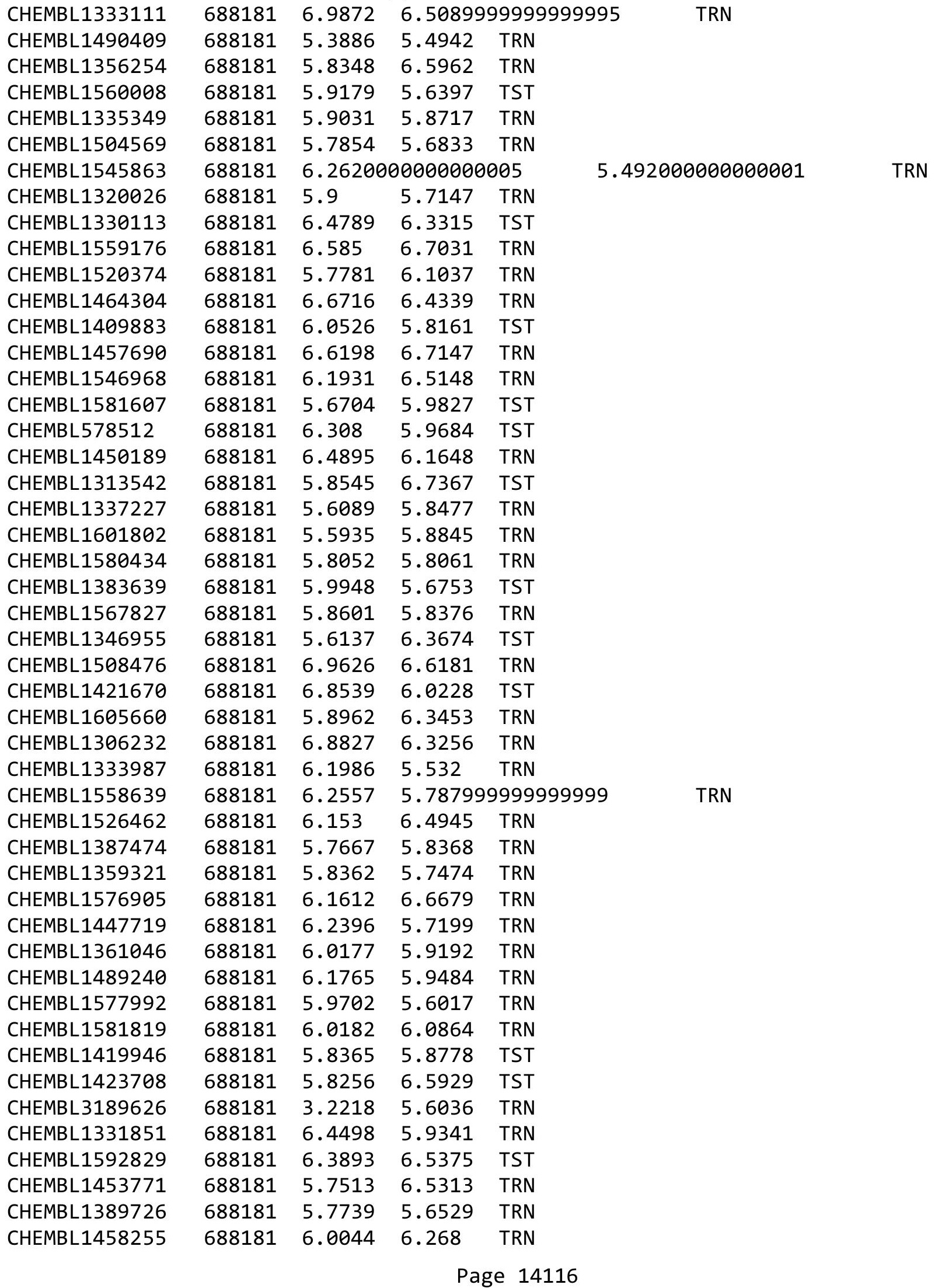




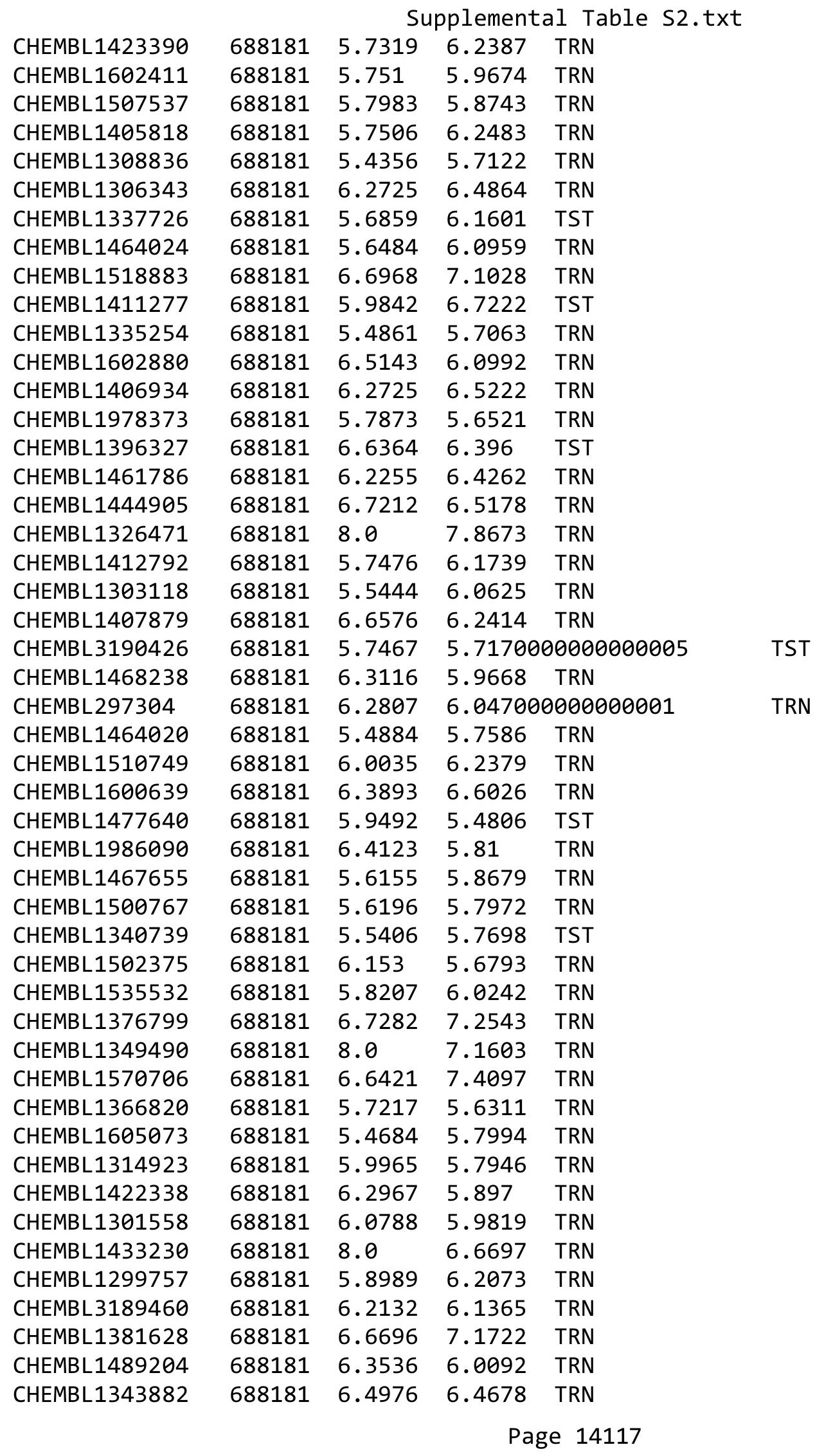


Supplemental Table S2.txt

\begin{tabular}{|c|c|c|c|c|c|}
\hline CHEMBL1578482 & 688181 & 6.2604 & 6.1079 & TRN & \\
\hline CHEMBL1300848 & 688181 & 6.9281 & 7.4799 & TRN & \\
\hline CHEMBL1304172 & 688181 & 5.9208 & $6.36700 t$ & 0000000001 & TRN \\
\hline CHEMBL1570989 & 688181 & 5.3601 & 5.3954 & TRN & \\
\hline CHEMBL1389194 & 688181 & 5.7364 & 5.6475 & TRN & \\
\hline CHEMBL1525949 & 688181 & 5.5114 & 5.4596 & TRN & \\
\hline CHEMBL1388583 & 688181 & 5.9996 & 6.0584 & TRN & \\
\hline CHEMBL1517625 & 688181 & 5.6653 & 6.1535 & TRN & \\
\hline CHEMBL1505182 & 688181 & 5.7347 & 6.029 & TRN & \\
\hline CHEMBL1596097 & 688181 & 5.5216 & 5.4242 & TRN & \\
\hline CHEMBL1583585 & 688181 & 8.0 & 7.4604 & TRN & \\
\hline CHEMBL1365771 & 688181 & 5.9062 & 5.5495 & TST & \\
\hline CHEMBL1375788 & 688181 & 6.9872 & 6.4403 & TRN & \\
\hline CHEMBL 2369290 & 688181 & 6.0362 & 6.3809 & TRN & \\
\hline CHEMBL1371264 & 688181 & 5.3088 & 6.0916 & TST & \\
\hline CHEMBL1537990 & 688181 & 6.6073 & 6.3754 & TRN & \\
\hline CHEMBL1385421 & 688181 & 5.6712 & 5.88899 & 9999999999 & TRN \\
\hline CHEMBL1347480 & 688181 & 5.7256 & 5.3969 & TRN & \\
\hline CHEMBL1965403 & 688181 & 6.1643 & 6.1584 & TRN & \\
\hline CHEMBL1971458 & 688181 & 5.5525 & 5.7031 & TRN & \\
\hline CHEMBL1975756 & 688181 & 5.6609 & 5.7494 & TRN & \\
\hline CHEMBL1543791 & 688181 & 3.2218 & 5.4211 & TRN & \\
\hline CHEMBL548458 & 688181 & 5.4139 & 5.5286 & TRN & \\
\hline CHEMBL1516781 & 688181 & 5.6782 & 6.6315 & TRN & \\
\hline CHEMBL1497838 & 688181 & 6.1618 & 6.7531 & TST & \\
\hline CHEMBL591137 & 688181 & 6.3072 & 6.068 & TRN & \\
\hline CHEMBL1333262 & 688181 & 5.8477 & 6.0888 & TST & \\
\hline CHEMBL1977424 & 688181 & 5.5998 & 6.4111 & TRN & \\
\hline CHEMBL1466305 & 688181 & 5.8608 & 6.3101 & TRN & \\
\hline CHEMBL1525672 & 688181 & 5.5265 & 5.4522 & TRN & \\
\hline CHEMBL580609 & 688181 & 6.7773 & 6.9768 & TRN & \\
\hline CHEMBL1392171 & 688181 & 5.7069 & 5.3596 & TRN & \\
\hline CHEMBL1460315 & 688181 & 6.585 & 6.8531 & TRN & \\
\hline CHEMBL1404493 & 688181 & 8.0 & 8.3437 & TRN & \\
\hline CHEMBL3194060 & 688181 & 5.4244 & 6.2415 & TRN & \\
\hline CHEMBL1470728 & 688181 & 6.1675 & 6.6043 & TST & \\
\hline CHEMBL1510761 & 688181 & 5.7812 & 6.2555 & TRN & \\
\hline CHEMBL1512652 & 688181 & 8.0 & 7.6494 & TRN & \\
\hline CHEMBL1421564 & 688181 & 6.1925 & 6.354 & TRN & \\
\hline CHEMBL1585988 & 688181 & 5.8374 & 5.6815 & TRN & \\
\hline CHEMBL1451569 & 688181 & 5.9739 & 5.6465 & TRN & \\
\hline CHEMBL1373082 & 688181 & 6.3045 & 5.8374 & TST & \\
\hline CHEMBL1351620 & 688181 & 6.5513 & 6.0734 & TRN & \\
\hline CHEMBL1309059 & 688181 & 5.9481 & 6.6951 & TST & \\
\hline CHEMBL1386293 & 688181 & 5.6598 & 6.0372 & TRN & \\
\hline CHEMBL1531536 & 688181 & 5.7011 & 5.2985 & TRN & \\
\hline CHEMBL1506706 & 688181 & 5.643 & 5.6133 & TRN & \\
\hline CHEMBL1438636 & 688181 & 5.9076 & 5.9688 & TRN & \\
\hline
\end{tabular}

Page 14118 
Supplemental Table S2.txt

\begin{tabular}{|c|c|c|c|c|}
\hline CHEMBL3198627 & 688181 & 5.7542 & 5.9285 & TRN \\
\hline CHEMBL1582357 & 688181 & 5.8874 & 5.995 & TRN \\
\hline CHEMBL1564759 & 688181 & 6.015 & 5.9589 & TRN \\
\hline CHEMBL1304308 & 688181 & 6.3261 & 6.0528 & TRN \\
\hline CHEMBL1488591 & 688181 & 6.7144 & 5.5265 & TST \\
\hline CHEMBL1333600 & 688181 & 8.0 & 7.3163 & TST \\
\hline CHEMBL1398183 & 688181 & 6.2495 & 6.2254 & TRN \\
\hline CHEMBL1385989 & 688181 & 6.266 & 6.0971 & TST \\
\hline CHEMBL602954 & 688181 & 5.6876 & 6.0779 & TRN \\
\hline CHEMBL1309799 & 688181 & 6.0926 & 6.0395 & TRN \\
\hline CHEMBL1334247 & 688181 & 8.0 & 6.6482 & TRN \\
\hline CHEMBL1424169 & 688181 & 5.6455 & 6.0822 & TST \\
\hline CHEMBL1346447 & 688181 & 6.1681 & 6.6029 & TRN \\
\hline CHEMBL1323545 & 688181 & 6.9393 & 6.2562 & TRN \\
\hline CHEMBL1440623 & 688181 & 6.0531 & 6.3344 & TRN \\
\hline CHEMBL1465741 & 688181 & 3.2218 & 4.8164 & TRN \\
\hline CHEMBL1452645 & 688181 & 5.5408 & 5.4041 & TST \\
\hline CHEMBL1524865 & 688181 & 5.9296 & 5.8254 & TRN \\
\hline CHEMBL1331197 & 688181 & 5.8184 & 6.4287 & TRN \\
\hline CHEMBL1465458 & 688181 & 6.5017 & 6.143 & TRN \\
\hline CHEMBL1964702 & 688181 & 6.0482 & 6.1409 & TRN \\
\hline CHEMBL229150 & 688181 & 6.1135 & 6.9827 & TRN \\
\hline CHEMBL1600095 & 688181 & 6.4949 & 5.9893 & TRN \\
\hline CHEMBL1532372 & 688181 & 5.5829 & 5.6372 & TRN \\
\hline CHEMBL1340358 & 688181 & 8.0 & 7.4838 & TRN \\
\hline CHEMBL1380760 & 688181 & 6.3458 & 6.5162 & TST \\
\hline CHEMBL1313522 & 688181 & 6.2027 & 6.2967 & TRN \\
\hline CHEMBL596633 & 688181 & 6.0921 & 6.3584 & TRN \\
\hline CHEMBL1528103 & 688181 & 6.4802 & 5.9754 & TRN \\
\hline CHEMBL1319018 & 688181 & 5.7338 & 6.1763 & TRN \\
\hline CHEMBL1606969 & 688181 & 5.8841 & 6.4634 & TRN \\
\hline CHEMBL1299962 & 688181 & 5.6957 & 5.7884 & TRN \\
\hline CHEMBL581346 & 688181 & 8.0 & 7.0099 & TRN \\
\hline CHEMBL1497588 & 688181 & 5.7849 & 7.2124 & TST \\
\hline CHEMBL1575070 & 688181 & 5.9496 & 6.1641 & TRN \\
\hline CHEMBL1598611 & 688181 & 6.317 & 6.2394 & TRN \\
\hline CHEMBL1625031 & 688181 & 6.8182 & 6.34 & TRN \\
\hline CHEMBL1583226 & 688181 & 6.2628 & 6.3335 & TRN \\
\hline CHEMBL1491222 & 688181 & 6.3325 & 6.435 & TRN \\
\hline CHEMBL1496972 & 688181 & 5.5756 & 5.9077 & TRN \\
\hline CHEMBL1432792 & 688181 & 5.8614 & 6.2753 & TRN \\
\hline CHEMBL1503859 & 688181 & 5.6349 & 5.683 & TST \\
\hline CHEMBL1602006 & 688181 & 6.9914 & 7.2244 & TRN \\
\hline CHEMBL1311220 & 688181 & 5.6853 & 5.8071 & TRN \\
\hline CHEMBL1411787 & 688181 & 5.6536 & 5.7455 & TRN \\
\hline CHEMBL1444859 & 688181 & 5.7918 & 5.5182 & TRN \\
\hline CHEMBL1332873 & 688181 & 6.1349 & \multicolumn{2}{|c|}{5.6770000000000005} \\
\hline CHEMBL1583365 & 688181 & 5.7402 & 5.3859 & TRN \\
\hline
\end{tabular}




\begin{tabular}{|c|c|c|c|c|c|c|}
\hline \multirow[b]{2}{*}{ CHEMBL1609910 } & \multicolumn{6}{|c|}{ Supplemental Table S2.txt } \\
\hline & 688181 & 5.6019 & 5.8744 & TRN & & \\
\hline CHEMBL1388234 & 688181 & 6.7077 & 6.681 & TRN & & \\
\hline CHEMBL1417027 & 688181 & 5.9602 & 6.192 & TRN & & \\
\hline CHEMBL1543324 & 688181 & 5.6942 & 5.6937 & TRN & & \\
\hline CHEMBL1494867 & 688181 & 5.95700 & 30000000 & $\partial 1$ & 5.7983 & TRN \\
\hline CHEMBL1303653 & 688181 & 5.3915 & 5.5232 & TRN & & \\
\hline CHEMBL1363376 & 688181 & 5.63700 & 00000000 & 205 & 5.8574 & TRN \\
\hline CHEMBL1303552 & 688181 & 5.806 & 6.1569 & TRN & & \\
\hline CHEMBL1582891 & 688181 & 5.7069 & 5.7559 & TRN & & \\
\hline CHEMBL1546922 & 688181 & 5.7238 & 5.9841 & TRN & & \\
\hline CHEMBL 3211473 & 688181 & 5.1691 & 5.397 & TRN & & \\
\hline CHEMBL1370205 & 688181 & 5.6078 & 6.3999 & TRN & & \\
\hline CHEMBL1581166 & 688181 & 6.3107 & 5.9755 & TRN & & \\
\hline CHEMBL1500059 & 688181 & 5.8348 & 6.3143 & TRN & & \\
\hline CHEMBL3196370 & 688181 & 6.1146 & 6.1105 & TRN & & \\
\hline CHEMBL1464157 & 688181 & 3.2218 & 5.9908 & TST & & \\
\hline CHEMBL1580532 & 688181 & 5.4698 & 5.771 & TRN & & \\
\hline CHEMBL1558058 & 688181 & 6.7375 & 6.5756 & TRN & & \\
\hline CHEMBL3190585 & 688181 & 8.0 & 7.482 & TRN & & \\
\hline CHEMBL1424146 & 688181 & 8.0 & 7.2393 & TRN & & \\
\hline CHEMBL1349631 & 688181 & 6.1637 & 5.8718 & TRN & & \\
\hline CHEMBL1343003 & 688181 & 8.0 & 6.6407 & TRN & & \\
\hline CHEMBL1579424 & 688181 & 5.6317 & 5.8868 & TRN & & \\
\hline CHEMBL1489926 & 688181 & 5.8362 & 6.4836 & TRN & & \\
\hline CHEMBL1420056 & 688181 & 5.5418 & 5.7911 & TST & & \\
\hline CHEMBL1519553 & 688181 & 5.7151 & 5.2829 & TRN & & \\
\hline CHEMBL1323770 & 688181 & 5.6404 & 5.5793 & TRN & & \\
\hline CHEMBL3211050 & 688181 & 5.4916 & 6.1621 & TRN & & \\
\hline CHEMBL1414836 & 688181 & 5.6914 & 6.0089 & TRN & & \\
\hline CHEMBL1417431 & 688181 & 8.0 & 7.8884 & TRN & & \\
\hline CHEMBL1376183 & 688181 & 5.7077 & 5.6984 & TST & & \\
\hline CHEMBL1569910 & 688181 & 6.21899 & 99999999 & 99 & 6.6718 & TRN \\
\hline CHEMBL1502402 & 688181 & 5.6191 & 5.5668 & TRN & & \\
\hline CHEMBL 2006503 & 688181 & 5.7967 & 6.1193 & TST & & \\
\hline CHEMBL1377682 & 688181 & 5.6586 & 5.7729 & TRN & & \\
\hline CHEMBL1369642 & 688181 & 8.0 & 7.0927 & TRN & & \\
\hline CHEMBL3213212 & 688181 & 5.9212 & 5.7759 & TRN & & \\
\hline CHEMBL1319478 & 688181 & 6.3107 & 6.1477 & TRN & & \\
\hline CHEMBL1574049 & 688181 & 3.2218 & 5.9792 & TST & & \\
\hline CHEMBL1460800 & 688181 & 8.0 & 7.1193 & TRN & & \\
\hline CHEMBL1350245 & 688181 & 8.0 & 7.1398 & TRN & & \\
\hline CHEMBL1321070 & 688181 & 6.0467 & 6.4699 & TST & & \\
\hline CHEMBL1393563 & 688181 & 6.9101 & 6.6927 & TRN & & \\
\hline CHEMBL1467833 & 688181 & 6.2388 & 6.4824 & TRN & & \\
\hline CHEMBL1505727 & 688181 & 8.0 & 6.5575 & TRN & & \\
\hline CHEMBL1300928 & 688181 & 5.4648 & 6.2041 & TRN & & \\
\hline CHEMBL3191334 & 688181 & 5.4717 & 5.8065 & TST & & \\
\hline CHEMBL1338272 & 688181 & 6.1811 & 6.2704 & TRN & & \\
\hline
\end{tabular}




\begin{tabular}{|c|c|c|c|c|c|}
\hline \multicolumn{6}{|c|}{ Supplemental Table S2.txt } \\
\hline CHEMBL1549686 & 688181 & 8.0 & 7.6412 & TRN & \\
\hline CHEMBL1392643 & 688181 & 6.1249 & 5.9758 & TRN & \\
\hline CHEMBL1390121 & 688181 & 5.7228 & 6.0023 & TRN & \\
\hline CHEMBL3208191 & 688181 & 6.4935 & 6.6656 & TRN & \\
\hline CHEMBL1987108 & 688181 & 8.0 & 7.081 & TRN & \\
\hline CHEMBL1421724 & 688181 & 6.2984 & 6.6123 & TRN & \\
\hline CHEMBL1421700 & 688181 & 5.4443 & 5.3167 & TRN & \\
\hline CHEMBL1430621 & 688181 & 6.6819 & 6.70200 & 0000000001 & \\
\hline CHEMBL1497409 & 688181 & 5.8598 & 5.9961 & TRN & \\
\hline CHEMBL1604813 & 688181 & 5.6882 & 5.8677 & TRN & \\
\hline CHEMBL3211295 & 688181 & 5.9884 & 6.3191 & TRN & \\
\hline CHEMBL1547208 & 688181 & 6.7496 & 6.9694 & TRN & \\
\hline CHEMBL1444886 & 688181 & 6.1945 & 6.8118 & TST & \\
\hline CHEMBL 3192648 & 688181 & 5.8085 & 5.9863 & TRN & \\
\hline CHEMBL1431917 & 688181 & 6.2628 & 6.3513 & TRN & \\
\hline CHEMBL3189867 & 688181 & 6.4776 & 6.9047 & TRN & \\
\hline CHEMBL1348403 & 688181 & 6.5129 & 5.8889 & TRN & \\
\hline CHEMBL1457870 & 688181 & 5.937 & 6.3794 & TRN & \\
\hline CHEMBL1559953 & 688181 & 6.0137 & 6.15600 & 0000000001 & \\
\hline CHEMBL1575964 & 688181 & 5.8013 & 6.3694 & TRN & \\
\hline CHEMBL1538913 & 688181 & 5.6594 & 6.0983 & TRN & \\
\hline CHEMBL1419470 & 688181 & 8.0 & 7.4769 & TRN & \\
\hline CHEMBL1440829 & 688181 & 6.0742 & 5.5992 & TRN & \\
\hline CHEMBL1498731 & 688181 & 6.6536 & 6.9163 & TRN & \\
\hline CHEMBL1305357 & 688181 & 5.74299 & 99999999 & 5.6399 & \\
\hline CHEMBL1301971 & 688181 & 6.2182 & 6.3967 & TRN & \\
\hline CHEMBL1437660 & 688181 & 6.4283 & 6.4964 & TRN & \\
\hline CHEMBL1304715 & 688181 & 6.5969 & 7.1211 & TRN & \\
\hline CHEMBL1385766 & 688181 & 6.1818 & 7.0095 & TST & \\
\hline CHEMBL1374340 & 688181 & 5.9759 & 6.0019 & TRN & \\
\hline CHEMBL1571734 & 688181 & 6.068 & 5.3272 & TRN & \\
\hline CHEMBL1531377 & 688181 & 8.0 & 7.3513 & TRN & \\
\hline CHEMBL1433021 & 688181 & 5.6535 & 5.8972 & TRN & \\
\hline CHEMBL1585212 & 688181 & 6.2984 & 6.04200 & 0000000001 & \\
\hline CHEMBL1600245 & 688181 & 8.0 & 7.3956 & TRN & \\
\hline CHEMBL1381780 & 688181 & 5.7488 & 6.2581 & TRN & \\
\hline CHEMBL1302735 & 688181 & 8.0 & 6.4323 & TRN & \\
\hline CHEMBL1569162 & 688181 & 6.109 & 5.8181 & TRN & \\
\hline CHEMBL600862 & 688181 & 8.0 & 6.3587 & TRN & \\
\hline CHEMBL1392785 & 688181 & 3.5229 & 5.2747 & TRN & \\
\hline CHEMBL1331573 & 688181 & 6.2924 & 5.5302 & TST & \\
\hline CHEMBL1421106 & 688181 & 8.0 & 6.4599 & TRN & \\
\hline CHEMBL1415084 & 688181 & 8.0 & 7.0312 & TRN & \\
\hline CHEMBL1366269 & 688181 & 6.7878 & 7.0526 & TRN & \\
\hline CHEMBL3199288 & 688181 & 5.7357 & 5.9041 & TRN & \\
\hline CHEMBL1455794 & 688181 & 6.301 & 6.7565 & TRN & \\
\hline CHEMBL1595850 & 688181 & 6.2573 & 5.3918 & TRN & \\
\hline CHEMBL1559422 & 688181 & 5.7981 & 6.0403 & TRN & \\
\hline
\end{tabular}

Page 14121 
Supplemental Table S2.txt

\begin{tabular}{|c|c|c|c|c|c|c|}
\hline CHEMBL1439007 & 688181 & 6.6003 & 5.7685 & TRN & & \\
\hline CHEMBL1428228 & 688181 & 5.7937 & 5.9695 & TRN & & \\
\hline CHEMBL1334574 & 688181 & 5.7187 & 5.5849 & TRN & & \\
\hline CHEMBL1388053 & 688181 & 5.7637 & 6.6404 & TRN & & \\
\hline CHEMBL1450762 & 688181 & 6.1643 & 6.3248 & TST & & \\
\hline CHEMBL1353891 & 688181 & 6.2062 & 6.4384 & TRN & & \\
\hline CHEMBL1558538 & 688181 & 5.8703 & 6.2012 & TRN & & \\
\hline CHEMBL1430328 & 688181 & 5.8821 & 5.5792 & TRN & & \\
\hline CHEMBL1316691 & 688181 & 6.1543 & 5.8386 & TRN & & \\
\hline CHEMBL1499652 & 688181 & 5.9682 & 6.0905 & TRN & & \\
\hline CHEMBL1337675 & 688181 & 5.6728 & 5.9523 & TRN & & \\
\hline CHEMBL1365519 & 688181 & 5.7873 & 5.7784 & TST & & \\
\hline CHEMBL1458483 & 688181 & 5.751 & 6.6485 & TST & & \\
\hline CHEMBL1342420 & 688181 & 6.1129 & 6.9945 & TRN & & \\
\hline CHEMBL1564500 & 688181 & 6.9245 & 5.8322 & TRN & & \\
\hline CHEMBL1495283 & 688181 & \multicolumn{3}{|c|}{5.547000000000001} & 5.6675 & TRN \\
\hline CHEMBL1544063 & 688181 & 6.3737 & 6.1573 & TST & & \\
\hline CHEMBL1304058 & 688181 & 6.6253 & 5.9296 & TRN & & \\
\hline CHEMBL1351116 & 688181 & \multicolumn{3}{|c|}{6.327000000000001} & 6.011 & TRN \\
\hline CHEMBL 3197634 & 688181 & 8.0 & 7.1856 & TRN & & \\
\hline CHEMBL1321841 & 688181 & 5.4178 & 6.4195 & TST & & \\
\hline CHEMBL1329757 & 688181 & 6.4908 & 6.4697 & TRN & & \\
\hline CHEMBL1498161 & 688181 & 5.5741 & 5.6055 & TST & & \\
\hline CHEMBL1472369 & 688181 & 6.3605 & 6.0098 & TRN & & \\
\hline CHEMBL1516772 & 688181 & 6.1675 & 5.8616 & TRN & & \\
\hline CHEMBL1440600 & 688181 & 5.9208 & 6.1172 & TRN & & \\
\hline CHEMBL1485422 & 688181 & \multicolumn{3}{|c|}{5.122999999999999} & 5.8027 & ונדו \\
\hline CHEMBL604321 & 688181 & 5.9097 & 6.2911 & TST & & \\
\hline CHEMBL3199314 & 688181 & 4.9711 & 6.4798 & TST & & \\
\hline CHEMBL1485727 & 688181 & 6.475 & 6.4194 & TST & & \\
\hline CHEMBL1479340 & 688181 & 5.6633 & 5.7139 & TRN & & \\
\hline CHEMBL1318149 & 688181 & 5.5953 & 5.3618 & TRN & & \\
\hline CHEMBL1421010 & 688181 & 5.6668 & 5.6647 & TRN & & \\
\hline CHEMBL1311899 & 688181 & 6.7825 & 5.8568 & TST & & \\
\hline CHEMBL1566789 & 688181 & 5.556 & 5.7651 & TRN & & \\
\hline CHEMBL1361462 & 688181 & 5.8386 & 6.1633 & TRN & & \\
\hline CHEMBL1567619 & 688181 & 5.5079 & 5.5753 & TRN & & \\
\hline CHEMBL1573697 & 688181 & 5.8636 & 5.7946 & TRN & & \\
\hline CHEMBL64391 & 688181 & 7.0 & 6.2366 & TST & & \\
\hline CHEMBL1462872 & 688181 & 5.7948 & 6.447 & TST & & \\
\hline CHEMBL1390905 & 688181 & 5.6832 & 5.5592 & TRN & & \\
\hline CHEMBL1369547 & 688181 & 6.1656 & 6.3148 & TRN & & \\
\hline CHEMBL1480738 & 688181 & 5.659 & 5.835 & TST & & \\
\hline CHEMBL1450652 & 688181 & 5.5701 & 5.7095 & TST & & \\
\hline CHEMBL1328792 & 688181 & 5.5602 & 6.0875 & TRN & & \\
\hline CHEMBL1556670 & 688181 & 5.7102 & 6.205 & TST & & \\
\hline CHEMBL1329638 & 688181 & 8.0 & 5.86 & TRN & & \\
\hline CHEMBL1999862 & 688181 & 5.8576 & 5.9096 & TRN & & \\
\hline
\end{tabular}

Page 14122 


\begin{tabular}{|c|c|c|c|c|c|c|}
\hline & & \multicolumn{5}{|c|}{ Supplemental Table S2.txt } \\
\hline CHEMBL1561080 & 688181 & 5.6035 & 5.6489 & TRN & & \\
\hline CHEMBL1451015 & 688181 & 6.1898 & 5.769 & TRN & & \\
\hline CHEMBL1575901 & 688181 & 6.7773 & 7.284 & TRN & & \\
\hline CHEMBL1543341 & 688181 & 5.6936 & 5.8813 & TRN & & \\
\hline CHEMBL577709 & 688181 & 6.4828 & 5.9961 & TRN & & \\
\hline CHEMBL1545240 & 688181 & 6.2411 & 6.3749 & TRN & & \\
\hline CHEMBL1320178 & 688181 & 5.8986 & 5.9559 & TRN & & \\
\hline CHEMBL1586770 & 688181 & 5.6923 & 5.9726 & TST & & \\
\hline CHEMBL1468682 & 688181 & 6.8794 & 6.4943 & TRN & & \\
\hline CHEMBL1527789 & 688181 & 6.6038 & 5.8284 & TRN & & \\
\hline CHEMBL1617452 & 688181 & 5.3645 & 6.2726 & TRN & & \\
\hline CHEMBL1422158 & 688181 & 5.8589 & 5.8432 & TRN & & \\
\hline CHEMBL3196667 & 688181 & 5.8887 & 5.5076 & TST & & \\
\hline CHEMBL1327443 & 688181 & 5.6062 & 5.5453 & TST & & \\
\hline CHEMBL1598374 & 688181 & 5.4492 & 6.0042 & TRN & & \\
\hline CHEMBL1467533 & 688181 & 5.9983 & 5.8625 & TRN & & \\
\hline CHEMBL1525538 & 688181 & 8.0 & 6.8605 & TRN & & \\
\hline CHEMBL1488321 & 688181 & 5.669 & 5.4401 & TRN & & \\
\hline CHEMBL1543203 & 688181 & 6.5784 & 7.2405 & TRN & & \\
\hline CHEMBL1312654 & 688181 & 5.7411 & 6.0406 & TRN & & \\
\hline CHEMBL1421558 & 688181 & 5.765 & 5.9872 & TST & & \\
\hline CHEMBL1521395 & 688181 & 6.4271 & 6.1529 & TRN & & \\
\hline CHEMBL1467294 & 688181 & 5.8511 & 6.3213 & TRN & & \\
\hline CHEMBL1439532 & 688181 & 5.6994 & 5.7119 & TRN & & \\
\hline CHEMBL1502121 & 688181 & 6.7986 & 6.7259 & TRN & & \\
\hline CHEMBL1576088 & 688181 & 8.0 & 7.0958 & TRN & & \\
\hline CHEMBL1599458 & 688181 & 6.3054 & 6.0302 & TRN & & \\
\hline CHEMBL1599994 & 688181 & 6.983 & 6.7393 & TRN & & \\
\hline CHEMBL1369945 & 688181 & 6.0218 & 5.9392 & TRN & & \\
\hline CHEMBL469036 & 688181 & 6.0691 & 6.5587 & TST & & \\
\hline CHEMBL1567646 & 688181 & 5.8681 & 5.7194 & TRN & & \\
\hline CHEMBL1348555 & 688181 & 6.3536 & 6.7572 & TRN & & \\
\hline CHEMBL1470634 & 688181 & 5.1009 & 5.7912 & TRN & & \\
\hline CHEMBL1499436 & 688181 & 6.0044 & 5.7195 & TST & & \\
\hline CHEMBL1592251 & 688181 & 5.5635 & 6.1985 & TRN & & \\
\hline CHEMBL1363712 & 688181 & 6.8447 & 6.9125 & TRN & & \\
\hline CHEMBL1312486 & 688181 & 5.6811 & 5.8464 & TST & & \\
\hline CHEMBL3189613 & 688181 & 6.16299 & 99999999 & 99 & 5.9885 & TRN \\
\hline CHEMBL1415769 & 688181 & 8.0 & 7.8346 & TRN & & \\
\hline CHEMBL1300339 & 688181 & 4.9469 & 6.017 & TRN & & \\
\hline CHEMBL1422038 & 688181 & 5.5787 & 5.4561 & TRN & & \\
\hline CHEMBL1407258 & 688181 & 5.66700 & 00000000 & 01 & 5.8784 & TRN \\
\hline CHEMBL1561001 & 688181 & 5.6872 & 6.0014 & TST & & \\
\hline CHEMBL1603602 & 688181 & 5.6859 & 5.4762 & TRN & & \\
\hline CHEMBL1542356 & 688181 & 5.9562 & 5.6046 & TRN & & \\
\hline CHEMBL1356472 & 688181 & 8.0 & 7.3843 & TRN & & \\
\hline CHEMBL1384306 & 688181 & 5.5919 & 5.7251 & TRN & & \\
\hline CHEMBL1506283 & 688181 & 5.8844 & 6.176 & TRN & & \\
\hline
\end{tabular}




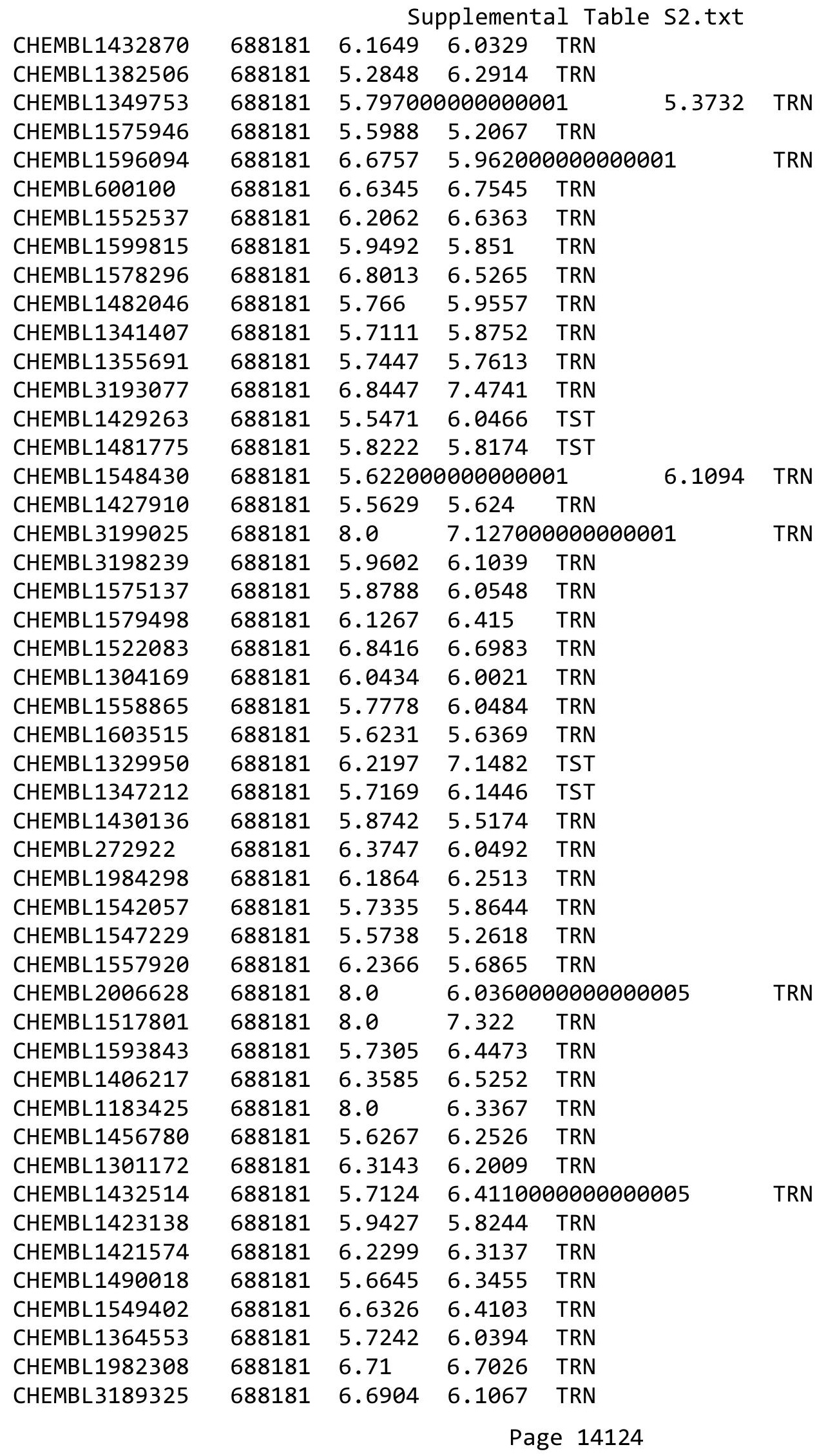


Supplemental Table S2.txt

\begin{tabular}{|c|c|c|c|c|c|}
\hline CHEMBL1312038 & 688181 & 6.6459 & 5.9944 & TRN & \\
\hline CHEMBL1440235 & 688181 & 5.9003 & 6.0893 & TRN & \\
\hline CHEMBL1405704 & 688181 & 5.8722 & 6.3761 & TRN & \\
\hline CHEMBL1311878 & 688181 & 6.5467 & 5.9486 & TRN & \\
\hline CHEMBL1520753 & 688181 & 5.724 & 5.7807 & TRN & \\
\hline CHEMBL1408058 & 688181 & 5.8586 & 5.8655 & TST & \\
\hline CHEMBL1604779 & 688181 & 5.8125 & 5.8403 & TRN & \\
\hline CHEMBL1443205 & 688181 & 6.0731 & 5.606 & TRN & \\
\hline CHEMBL1448078 & 688181 & 5.8719 & 5.9931 & TRN & \\
\hline CHEMBL1517971 & 688181 & 6.3439 & 6.2516 & TRN & \\
\hline CHEMBL1568298 & 688181 & 8.0 & 6.7481 & TRN & \\
\hline CHEMBL1605870 & 688181 & 6.0097 & 5.8557 & TRN & \\
\hline CHEMBL 3194186 & 688181 & 5.6714 & 6.1867 & TST & \\
\hline CHEMBL607309 & 688181 & 5.4795 & 6.1957 & TRN & \\
\hline CHEMBL1455808 & 688181 & 5.8005 & 6.3053 & TST & \\
\hline CHEMBL1533362 & 688181 & 5.6262 & 5.1783 & TRN & \\
\hline CHEMBL1343079 & 688181 & 8.0 & 6.6144 & TRN & \\
\hline CHEMBL1462133 & 688181 & 3.5229 & 5.9995 & TRN & \\
\hline CHEMBL1482998 & 688181 & 5.7883 & 5.5521 & TST & \\
\hline CHEMBL530049 & 688181 & 5.95 & 5.8443 & TRN & \\
\hline CHEMBL1433443 & 688181 & 5.7064 & 6.2302 & TRN & \\
\hline CHEMBL1327264 & 688181 & 6.6478 & 6.2875 & TRN & \\
\hline CHEMBL1424546 & 688181 & 6.3224 & 6.0564 & TRN & \\
\hline CHEMBL1347699 & 688181 & 6.0799 & 6.0868 & TRN & \\
\hline CHEMBL1332334 & 688181 & 5.9642 & 5.5825 & TRN & \\
\hline CHEMBL1601100 & 688181 & 5.7027 & 6.0299 & TRN & \\
\hline CHEMBL1302055 & 688181 & 6.7878 & 5.9997 & TRN & \\
\hline CHEMBL1558327 & 688181 & 5.9626 & 5.7369 & TRN & \\
\hline CHEMBL1559985 & 688181 & 6.767 & 6.0089 & TST & \\
\hline CHEMBL1328004 & 688181 & 6.6737 & 6.4036 & TRN & \\
\hline CHEMBL1566063 & 688181 & 5.766 & 5.8356 & TRN & \\
\hline CHEMBL1473119 & 688181 & 8.0 & 7.1849 & TRN & \\
\hline CHEMBL1333248 & 688181 & 5.9208 & 5.9029 & TRN & \\
\hline CHEMBL1976839 & 688181 & \multicolumn{3}{|c|}{5.4879999999999995} & TRN \\
\hline CHEMBL1445085 & 688181 & 6.2725 & 5.8971 & TRN & \\
\hline CHEMBL580955 & 688181 & 6.644 & 6.5588 & TRN & \\
\hline CHEMBL1598069 & 688181 & 3.2218 & 5.5215 & TRN & \\
\hline CHEMBL1522033 & 688181 & 5.4358 & 6.1676 & TRN & \\
\hline CHEMBL1409539 & 688181 & 8.0 & 7.2083 & TRN & \\
\hline CHEMBL1518868 & 688181 & 6.0675 & 6.4955 & TST & \\
\hline CHEMBL1522066 & 688181 & 5.4685 & 5.8884 & TRN & \\
\hline CHEMBL1500696 & 688181 & 6.4737 & 5.467006 & 00000000005 & TST \\
\hline CHEMBL601768 & 688181 & 6.6459 & 6.4871 & TRN & \\
\hline CHEMBL1563818 & 688181 & 5.5505 & 5.809 & TST & \\
\hline CHEMBL 3213476 & 688181 & 6.567 & 6.5151 & TRN & \\
\hline CHEMBL1500194 & 688181 & 6.0804 & 5.4966 & TRN & \\
\hline CHEMBL1508560 & 688181 & 5.8407 & 5.6492 & TRN & \\
\hline CHEMBL1369984 & 688181 & 5.7981 & 6.0228 & TRN & \\
\hline
\end{tabular}

Page 14125 
Supplemental Table S2.txt

\begin{tabular}{|c|c|c|c|c|c|}
\hline CHEMBL1576413 & 688181 & 5.8765 & 5.6804 & TST & \\
\hline CHEMBL1510014 & 688181 & 6.1238 & 6.2218 & TRN & \\
\hline CHEMBL1449930 & 688181 & 6.1118 & 5.8449 & TRN & \\
\hline CHEMBL581225 & 688181 & 5.6474 & 5.8364 & TST & \\
\hline CHEMBL1393210 & 688181 & 5.8817 & 6.0072 & TRN & \\
\hline CHEMBL1591393 & 688181 & 6.3516 & 6.8919 & TRN & \\
\hline CHEMBL1403049 & 688181 & 5.1186 & 5.5842 & TRN & \\
\hline CHEMBL1453673 & 688181 & 6.0535 & 6.282999 & 99999999995 & TST \\
\hline CHEMBL3189925 & 688181 & 5.8091 & 6.3472 & TRN & \\
\hline CHEMBL1408197 & 688181 & 6.5243 & 6.2416 & TRN & \\
\hline CHEMBL1481444 & 688181 & 5.6876 & 5.6601 & TRN & \\
\hline CHEMBL1471790 & 688181 & 5.704 & 6.2749 & TRN & \\
\hline CHEMBL1986956 & 688181 & 5.9303 & 6.1682 & TRN & \\
\hline CHEMBL1380091 & 688181 & 5.4163 & 6.088999 & 99999999995 & TRN \\
\hline CHEMBL1578962 & 688181 & 5.4817 & 5.2105 & TST & \\
\hline CHEMBL 3194794 & 688181 & 8.0 & 6.612999 & 99999999995 & TRN \\
\hline CHEMBL1159655 & 688181 & 5.4657 & 5.568 & TST & \\
\hline CHEMBL1462215 & 688181 & 8.0 & 7.6751 & TRN & \\
\hline CHEMBL1410560 & 688181 & 5.8164 & 5.6614 & TRN & \\
\hline CHEMBL1545434 & 688181 & 5.5769 & 5.9958 & TST & \\
\hline CHEMBL1301226 & 688181 & 8.0 & 7.3568 & TRN & \\
\hline CHEMBL1410929 & 688181 & 5.8459 & 5.8175 & TRN & \\
\hline CHEMBL1527580 & 688181 & 5.768 & 5.5821 & TRN & \\
\hline CHEMBL1546166 & 688181 & 6.3516 & 7.1101 & TRN & \\
\hline CHEMBL1333527 & 688181 & 6.9957 & 5.5107 & TRN & \\
\hline CHEMBL1607305 & 688181 & 6.5918 & 6.7165 & TRN & \\
\hline CHEMBL1565624 & 688181 & 5.9846 & 6.3528 & TRN & \\
\hline CHEMBL3190849 & 688181 & 5.8716 & 6.0705 & TRN & \\
\hline CHEMBL1371339 & 688181 & 5.5011 & 6.4266 & TRN & \\
\hline CHEMBL1455242 & 688181 & 6.3497 & 5.568 & TRN & \\
\hline CHEMBL3192845 & 688181 & 5.7115 & 6.2334 & TST & \\
\hline CHEMBL1493012 & 688181 & 5.5583 & 5.6534 & TST & \\
\hline CHEMBL67212 & 688181 & 6.2765 & 5.855 & TRN & \\
\hline CHEMBL1458485 & 688181 & 6.699 & 6.3967 & TRN & \\
\hline CHEMBL1501777 & 688181 & 5.5567 & 5.7044 & TRN & \\
\hline CHEMBL2006909 & 688181 & 5.9987 & 6.0271 & TRN & \\
\hline CHEMBL409906 & 688181 & 5.5355 & 5.3768 & TRN & \\
\hline CHEMBL597251 & 688181 & 6.2733 & 6.1223 & TRN & \\
\hline CHEMBL1458752 & 688181 & 5.5453 & 5.9092 & TRN & \\
\hline CHEMBL1509707 & 688181 & 6.0022 & 6.0077 & TRN & \\
\hline CHEMBL1588945 & 688181 & \multicolumn{2}{|c|}{5.6770000000000005} & 6.0187 & TRN \\
\hline CHEMBL1312586 & 688181 & \multicolumn{3}{|c|}{5.582999999999999} & TRN \\
\hline CHEMBL1442542 & 688181 & 5.9055 & 6.0389 & TRN & \\
\hline CHEMBL3197272 & 688181 & 5.9735 & 6.2217 & TRN & \\
\hline CHEMBL1570435 & 688181 & 5.8965 & 6.1843 & TRN & \\
\hline CHEMBL1365461 & 688181 & 5.7873 & 5.881 & TRN & \\
\hline CHEMBL1605977 & 688181 & 5.7392 & 5.9572 & TRN & \\
\hline CHEMBL 391123 & 688181 & 6.2807 & 5.5016 & TST & \\
\hline
\end{tabular}


Supplemental Table S2.txt

\begin{tabular}{|c|c|c|c|c|c|}
\hline CHEMBL3197394 & 688181 & 5.6659 & 6.0598 & TST & \\
\hline CHEMBL1513198 & 688181 & 5.9017 & 5.9893 & TRN & \\
\hline CHEMBL1507774 & 688181 & 6.5229 & \multicolumn{2}{|c|}{6.117000000000001} & TRN \\
\hline CHEMBL1429312 & 688181 & 5.8502 & 6.0376 & TRN & \\
\hline CHEMBL1465422 & 688181 & 5.9755 & 5.9108 & TRN & \\
\hline CHEMBL1574982 & 688181 & 5.5732 & 5.966 & TRN & \\
\hline CHEMBL1572951 & 688181 & 8.0 & 6.5813 & TST & \\
\hline CHEMBL1348172 & 688181 & 6.1124 & 6.1625 & TRN & \\
\hline CHEMBL1408596 & 688181 & 8.0 & 7.3202 & TRN & \\
\hline CHEMBL1432670 & 688181 & 5.776 & 5.4831 & TRN & \\
\hline CHEMBL1519411 & 688181 & 5.6774 & 5.8243 & TRN & \\
\hline CHEMBL1360870 & 688181 & 5.6739 & 6.2884 & TRN & \\
\hline CHEMBL3213034 & 688181 & 5.7357 & 6.3964 & TRN & \\
\hline CHEMBL1317657 & 688181 & 5.9416 & 5.9053 & TST & \\
\hline CHEMBL1382529 & 688181 & 8.0 & 7.2496 & TRN & \\
\hline CHEMBL1570587 & 688181 & 5.6724 & 5.395 & TRN & \\
\hline CHEMBL1557316 & 688181 & 6.58 & 6.6719 & TRN & \\
\hline CHEMBL2365737 & 688181 & 6.6904 & 6.3927 & TRN & \\
\hline CHEMBL1326032 & 688181 & 5.6908 & 6.2771 & TST & \\
\hline CHEMBL590949 & 688181 & 5.9187 & \multicolumn{2}{|c|}{6.4239999999999995} & TRN \\
\hline CHEMBL3191683 & 688181 & 5.5738 & 5.7582 & TRN & \\
\hline CHEMBL1415640 & 688181 & 5.9108 & 5.6822 & TRN & \\
\hline CHEMBL3197098 & 688181 & 6.2055 & 6.1963 & TRN & \\
\hline CHEMBL1437258 & 688181 & 8.0 & 6.2251 & TRN & \\
\hline CHEMBL1302033 & 688181 & 6.1986 & 6.5448 & TRN & \\
\hline CHEMBL1446560 & 688181 & 5.8742 & 5.6327 & TRN & \\
\hline CHEMBL1358406 & 688181 & 5.7986 & 6.0106 & TST & \\
\hline CHEMBL1386472 & 688181 & 6.1079 & 5.9453 & TRN & \\
\hline CHEMBL1504859 & 688181 & 6.5003 & 5.974 & TST & \\
\hline CHEMBL1506948 & 688181 & 8.0 & 6.3497 & TRN & \\
\hline CHEMBL 3856089 & 688181 & 3.5229 & 5.7906 & TST & \\
\hline CHEMBL1417605 & 688181 & 5.983 & 5.9233 & TRN & \\
\hline CHEMBL1300695 & 688181 & 5.5996 & 6.1138 & TST & \\
\hline CHEMBL3197671 & 688181 & 5.7016 & 6.0011 & TRN & \\
\hline CHEMBL1491724 & 688181 & 8.0 & 6.6088 & TST & \\
\hline CHEMBL1383799 & 688181 & 5.6552 & 5.6359 & TRN & \\
\hline CHEMBL1303468 & 688181 & 5.9226 & 6.66 & TRN & \\
\hline CHEMBL1449040 & 688181 & 5.7001 & 6.1071 & TRN & \\
\hline CHEMBL1379493 & 688181 & 5.3605 & 6.1468 & TRN & \\
\hline CHEMBL1310479 & 688181 & 8.0 & 6.7513 & TRN & \\
\hline CHEMBL1471200 & 688181 & 6.3536 & 6.5535 & TRN & \\
\hline CHEMBL1978733 & 688181 & 6.1427 & 5.8782 & TRN & \\
\hline CHEMBL1401114 & 688181 & 6.3233 & 6.2039 & TST & \\
\hline CHEMBL1557166 & 688181 & 5.6451 & 5.7612 & TST & \\
\hline CHEMBL1430812 & 688181 & 6.1844 & 5.6449 & TRN & \\
\hline CHEMBL1567824 & 688181 & 5.961 & 5.8182 & TRN & \\
\hline CHEMBL1567465 & 688181 & 6.6308 & 6.7953 & TRN & \\
\hline CHEMBL1323553 & 688181 & 5.6334 & 5.7463 & TRN & \\
\hline
\end{tabular}

Page 14127 


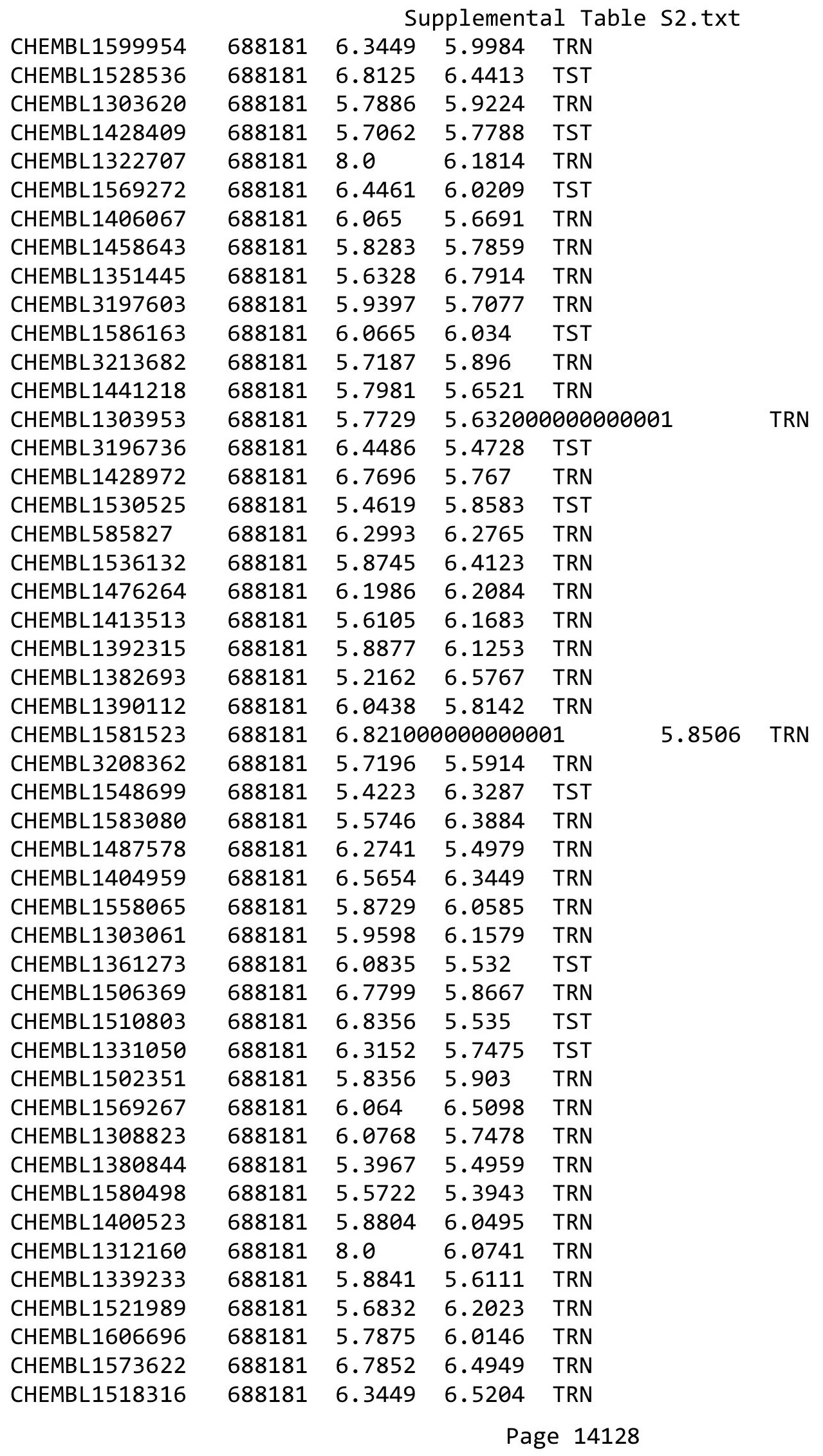


Supplemental Table S2.txt

\begin{tabular}{|c|c|c|c|c|c|}
\hline CHEMBL1495454 & 688181 & 5.7572 & 6.0831 & TRN & \\
\hline CHEMBL1340421 & 688181 & 6.3206 & 6.7608 & TRN & \\
\hline CHEMBL1333375 & 688181 & 6.2832 & 6.3742 & TRN & \\
\hline CHEMBL1325549 & 688181 & 5.6351 & 6.0362 & TST & \\
\hline CHEMBL1521061 & 688181 & 5.9867 & 6.1763 & TRN & \\
\hline CHEMBL1600372 & 688181 & 5.6101 & 6.2939 & TST & \\
\hline CHEMBL1335637 & 688181 & 8.0 & 7.3192 & TRN & \\
\hline CHEMBL1385128 & 688181 & 6.9431 & 6.5991 & TRN & \\
\hline CHEMBL1366764 & 688181 & 5.5036 & 6.0032 & TRN & \\
\hline CHEMBL1513910 & 688181 & 6.0458 & 6.8076 & TST & \\
\hline CHEMBL1361509 & 688181 & 5.5403 & 5.2605 & TRN & \\
\hline CHEMBL1330830 & 688181 & 6.9508 & 6.9806 & TRN & \\
\hline CHEMBL1369698 & 688181 & 6.1649 & 6.5932 & TRN & \\
\hline CHEMBL1383654 & 688181 & 5.5438 & 5.2846 & TRN & \\
\hline CHEMBL1484174 & 688181 & 6.2411 & 6.715 & TRN & \\
\hline CHEMBL1440558 & 688181 & 5.433 & 5.5853 & TRN & \\
\hline CHEMBL1458071 & 688181 & 5.7411 & 6.2342 & TRN & \\
\hline CHEMBL1613054 & 688181 & 5.6183 & 5.9172 & TRN & \\
\hline CHEMBL1383987 & 688181 & 5.9266 & 5.7737 & TRN & \\
\hline CHEMBL1537588 & 688181 & 5.5875 & 6.183 & TST & \\
\hline CHEMBL1350765 & 688181 & 5.7972 & 5.4947 & TRN & \\
\hline CHEMBL1438803 & 688181 & 5.7174 & 5.4411 & TRN & \\
\hline CHEMBL1478316 & 688181 & 5.841 & 6.1447 & TRN & \\
\hline CHEMBL1412271 & 688181 & 5.6538 & 6.0659 & TRN & \\
\hline CHEMBL1509840 & 688181 & 6.8508 & 6.3366 & TRN & \\
\hline CHEMBL1399754 & 688181 & 5.7865 & 5.2148 & TRN & \\
\hline CHEMBL1556010 & 688181 & 6.2581 & 6.2728 & TRN & \\
\hline CHEMBL1438500 & 688181 & 5.6639 & 5.4775 & TRN & \\
\hline CHEMBL1527622 & 688181 & 5.5635 & 5.961 & TRN & \\
\hline CHEMBL1581901 & 688181 & 6.1379 & 6.224 & TRN & \\
\hline CHEMBL1574469 & 688181 & 6.5243 & 6.5591 & TRN & \\
\hline CHEMBL1418007 & 688181 & 6.0092 & 5.6307 & TRN & \\
\hline CHEMBL1518625 & 688181 & 8.0 & 7.5703 & TRN & \\
\hline CHEMBL1531073 & 688181 & 6.0872 & 5.9327 & TST & \\
\hline CHEMBL1534094 & 688181 & 6.8508 & 6.3593 & TRN & \\
\hline CHEMBL1413334 & 688181 & 5.9147 & 5.8916 & TRN & \\
\hline CHEMBL1500974 & 688181 & 5.8013 & 6.085 & TRN & \\
\hline CHEMBL1729277 & 688181 & 8.0 & 7.3344 & TRN & \\
\hline CHEMBL1612409 & 688181 & 5.7812 & 6.3427 & TST & \\
\hline CHEMBL1341301 & 688181 & 5.8514 & 5.7413 & TRN & \\
\hline CHEMBL1548234 & 688181 & 6.2487 & 6.2819 & TRN & \\
\hline CHEMBL1471108 & 688181 & 5.7284 & 5.9957 & TST & \\
\hline CHEMBL1335899 & 688181 & 5.961 & 5.7812 & TRN & \\
\hline CHEMBL1414059 & 688181 & 5.6299 & 5.6201 & TRN & \\
\hline CHEMBL1588211 & 688181 & 6.9281 & 6.4791 & TRN & \\
\hline CHEMBL1411856 & 688181 & 6.157999 & 99999999 & 995 & 6.1146 \\
\hline CHEMBL1301480 & 688181 & 8.0 & 6.7926 & TRN & \\
\hline CHEMBL3196241 & 688181 & 6.2248 & 6.4601 & TRN & \\
\hline
\end{tabular}

Page 14129 


\begin{tabular}{|c|c|c|c|c|c|c|}
\hline & & \multicolumn{5}{|c|}{ Supplemental Table S2.txt } \\
\hline CHEMBL1582320 & 688181 & 6.8665 & 6.6161 & TRN & & \\
\hline CHEMBL 2369200 & 688181 & 5.9212 & 6.2773 & TRN & & \\
\hline CHEMBL1311589 & 688181 & 5.5321 & 6.3208 & TST & & \\
\hline CHEMBL1345336 & 688181 & 6.1152 & 6.1163 & TST & & \\
\hline CHEMBL3189272 & 688181 & 8.0 & 6.3746 & TST & & \\
\hline CHEMBL1374620 & 688181 & 5.3908 & 5.6336 & TRN & & \\
\hline CHEMBL1452119 & 688181 & 5.6653 & 5.6069 & TRN & & \\
\hline CHEMBL3190608 & 688181 & 8.0 & 6.9654 & TRN & & \\
\hline CHEMBL1419306 & 688181 & 5.731 & 6.3702 & TST & & \\
\hline CHEMBL1988686 & 688181 & 8.0 & 5.9221 & TST & & \\
\hline CHEMBL1452782 & 688181 & 5.8668 & 6.2964 & TRN & & \\
\hline CHEMBL1338780 & 688181 & 6.1612 & 6.3076 & TRN & & \\
\hline CHEMBL1418742 & 688181 & 5.6805 & 5.7744 & TRN & & \\
\hline CHEMBL1525481 & 688181 & 5.4981 & 5.8364 & TRN & & \\
\hline CHEMBL3193688 & 688181 & 6.1726 & 6.1105 & TRN & & \\
\hline CHEMBL1387605 & 688181 & 6.6655 & 5.8017 & TRN & & \\
\hline CHEMBL1346694 & 688181 & 5.9408 & 6.471 & TRN & & \\
\hline CHEMBL1580339 & 688181 & 6.0044 & 5.4514 & TRN & & \\
\hline CHEMBL1430889 & 688181 & 5.8069 & 6.2429 & TRN & & \\
\hline CHEMBL1570765 & 688181 & 5.9686 & 5.7737 & TRN & & \\
\hline CHEMBL1445047 & 688181 & 6.6861 & 5.9129 & TRN & & \\
\hline CHEMBL1497906 & 688181 & 5.9183 & 6.7708 & TRN & & \\
\hline CHEMBL3193072 & 688181 & 5.6819 & 5.9063 & TRN & & \\
\hline CHEMBL1399269 & 688181 & 5.6842 & 5.6118 & TRN & & \\
\hline CHEMBL1549267 & 688181 & 5.82799 & 99999999 & 99 & 5.5462 & TRN \\
\hline CHEMBL1402502 & 688181 & 8.0 & 6.0909 & TST & & \\
\hline CHEMBL1382389 & 688181 & 5.9024 & 5.7295 & TRN & & \\
\hline CHEMBL1478087 & 688181 & 5.9416 & 5.5778 & TRN & & \\
\hline CHEMBL 1453314 & 688181 & 5.8333 & 6.8935 & TRN & & \\
\hline CHEMBL1521990 & 688181 & 5.75899 & 99999999 & 995 & 5.9729 & TRN \\
\hline CHEMBL1592239 & 688181 & 5.95 & 6.4302 & TRN & & \\
\hline CHEMBL1406194 & 688181 & 8.0 & 6.8824 & TRN & & \\
\hline CHEMBL1338064 & 688181 & 5.4574 & 5.7908 & TRN & & \\
\hline CHEMBL1415357 & 688181 & 5.4162 & 5.8252 & TRN & & \\
\hline CHEMBL1541594 & 688181 & 5.6906 & 6.4859 & TRN & & \\
\hline CHEMBL1613375 & 688181 & 5.6678 & 5.8426 & TRN & & \\
\hline CHEMBL1366055 & 688181 & 5.9606 & 5.9639 & TRN & & \\
\hline CHEMBL1549657 & 688181 & 5.7042 & 5.5237 & TRN & & \\
\hline CHEMBL3195985 & 688181 & 5.608 & 5.9853 & TRN & & \\
\hline CHEMBL585213 & 688181 & 5.6409 & 5.3469 & TRN & & \\
\hline CHEMBL1354447 & 688181 & 6.1798 & 6.1218 & TRN & & \\
\hline CHEMBL1479940 & 688181 & 8.0 & 7.4478 & TRN & & \\
\hline CHEMBL1500614 & 688181 & 6.1891 & 5.7357 & TRN & & \\
\hline CHEMBL1495419 & 688181 & 6.6073 & 6.1557 & TRN & & \\
\hline CHEMBL1430378 & 688181 & 5.7296 & 5.8378 & TRN & & \\
\hline CHEMBL1412143 & 688181 & 5.8292 & 5.7449 & TRN & & \\
\hline CHEMBL1370879 & 688181 & 8.0 & 6.7154 & TRN & & \\
\hline CHEMBL1309463 & 688181 & 5.421 & 6.0985 & TRN & & \\
\hline
\end{tabular}




\begin{tabular}{|c|c|c|c|c|c|}
\hline & & \multicolumn{4}{|c|}{ Supplemental Table S2.txt } \\
\hline CHEMBL1502115 & 688181 & 6.3045 & 6.3928 & TRN & \\
\hline CHEMBL1499684 & 688181 & 5.5064 & 5.5595 & TST & \\
\hline CHEMBL1358098 & 688181 & 6.6289 & 6.0059 & TRN & \\
\hline CHEMBL1325077 & 688181 & 6.1314 & 5.5039 & TRN & \\
\hline CHEMBL1351963 & 688181 & 5.9266 & 5.3633 & TRN & \\
\hline CHEMBL1380943 & 688181 & 8.0 & 6.5021 & TRN & \\
\hline CHEMBL1606575 & 688181 & 6.6861 & 7.0198 & TRN & \\
\hline CHEMBL3195222 & 688181 & 6.2749 & 6.0382 & TRN & \\
\hline CHEMBL1991388 & 688181 & 6.7122 & 6.9013 & TRN & \\
\hline CHEMBL1360033 & 688181 & 6.2565 & 6.4635 & TRN & \\
\hline CHEMBL3207955 & 688181 & 5.5414 & 5.5846 & TRN & \\
\hline CHEMBL3197349 & 688181 & 5.8814 & 6.04299 & 9999999999 & TST \\
\hline CHEMBL1441595 & 688181 & 8.0 & 6.5238 & TRN & \\
\hline CHEMBL1415264 & 688181 & 5.5297 & 6.2986 & TRN & \\
\hline CHEMBL3198456 & 688181 & 6.2741 & 6.8128 & TRN & \\
\hline CHEMBL1603270 & 688181 & 6.3665 & 6.2474 & TRN & \\
\hline CHEMBL1601344 & 688181 & 5.8353 & 5.4967 & TRN & \\
\hline CHEMBL520275 & 688181 & 5.8222 & 6.3816 & TST & \\
\hline CHEMBL1305849 & 688181 & 6.06 & 5.4866 & TRN & \\
\hline CHEMBL1401821 & 688181 & 6.0311 & 6.4319 & TRN & \\
\hline CHEMBL1332266 & 688181 & 6.0516 & 6.1336 & TRN & \\
\hline CHEMBL1491019 & 688181 & 6.0535 & 5.54899 & 99999999995 & TST \\
\hline CHEMBL1392079 & 688181 & 5.7899 & 6.3395 & TRN & \\
\hline CHEMBL1427739 & 688181 & 8.0 & 6.5206 & TST & \\
\hline CHEMBL1314125 & 688181 & 5.6805 & 5.8918 & TRN & \\
\hline CHEMBL3190047 & 688181 & 6.8633 & 6.8877 & TRN & \\
\hline CHEMBL1489356 & 688181 & 5.819 & $6.1110 e$ & 0000000001 & TRN \\
\hline CHEMBL1402679 & 688181 & 8.0 & 6.61799 & 9999999999 & TRN \\
\hline CHEMBL22062 & 688181 & 6.2549 & 6.3795 & TRN & \\
\hline CHEMBL1495807 & 688181 & 6.1605 & 5.7954 & TST & \\
\hline CHEMBL1532309 & 688181 & 5.6291 & 5.6364 & TRN & \\
\hline CHEMBL1381574 & 688181 & 6.5498 & 6.3324 & TRN & \\
\hline CHEMBL1360206 & 688181 & 8.0 & 6.4432 & TRN & \\
\hline CHEMBL3208086 & 688181 & 5.5629 & 5.8021 & TRN & \\
\hline CHEMBL1525098 & 688181 & 5.7875 & 5.6193 & TRN & \\
\hline CHEMBL1419859 & 688181 & 5.7115 & 5.82 & TRN & \\
\hline CHEMBL1580286 & 688181 & 6.1273 & 6.1215 & TRN & \\
\hline CHEMBL1424867 & 688181 & 5.841 & 6.0149 & TRN & \\
\hline CHEMBL1304254 & 688181 & 5.8914 & 6.2688 & TRN & \\
\hline CHEMBL1550238 & 688181 & 5.5438 & 6.3938 & TRN & \\
\hline CHEMBL1503962 & 688181 & 6.2336 & 6.3413 & TST & \\
\hline CHEMBL3195171 & 688181 & 6.1325 & 6.3217 & TRN & \\
\hline CHEMBL1522928 & 688181 & 6.0996 & 5.8428 & TRN & \\
\hline CHEMBL1595704 & 688181 & 5.8274 & 5.9155 & TRN & \\
\hline CHEMBL1594820 & 688181 & 5.7886 & 5.8512 & TRN & \\
\hline CHEMBL1592477 & 688181 & 5.9488 & 6.1609 & TRN & \\
\hline CHEMBL1509629 & 688181 & 6.2604 & 6.395 & TRN & \\
\hline CHEMBL1520936 & 688181 & 5.9104 & 5.9287 & TRN & \\
\hline
\end{tabular}


Supplemental Table S2.txt

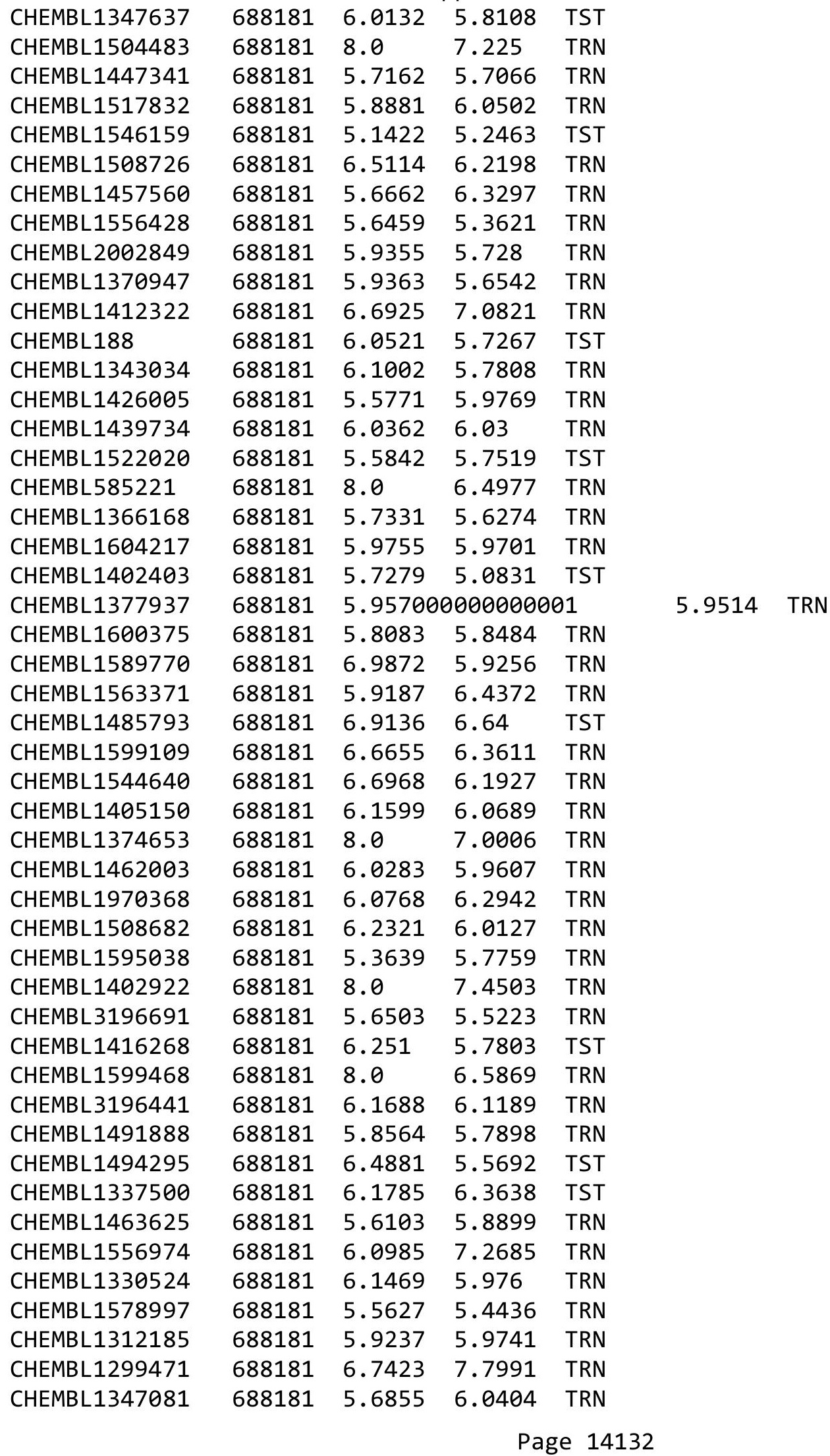


Supplemental Table S2.txt

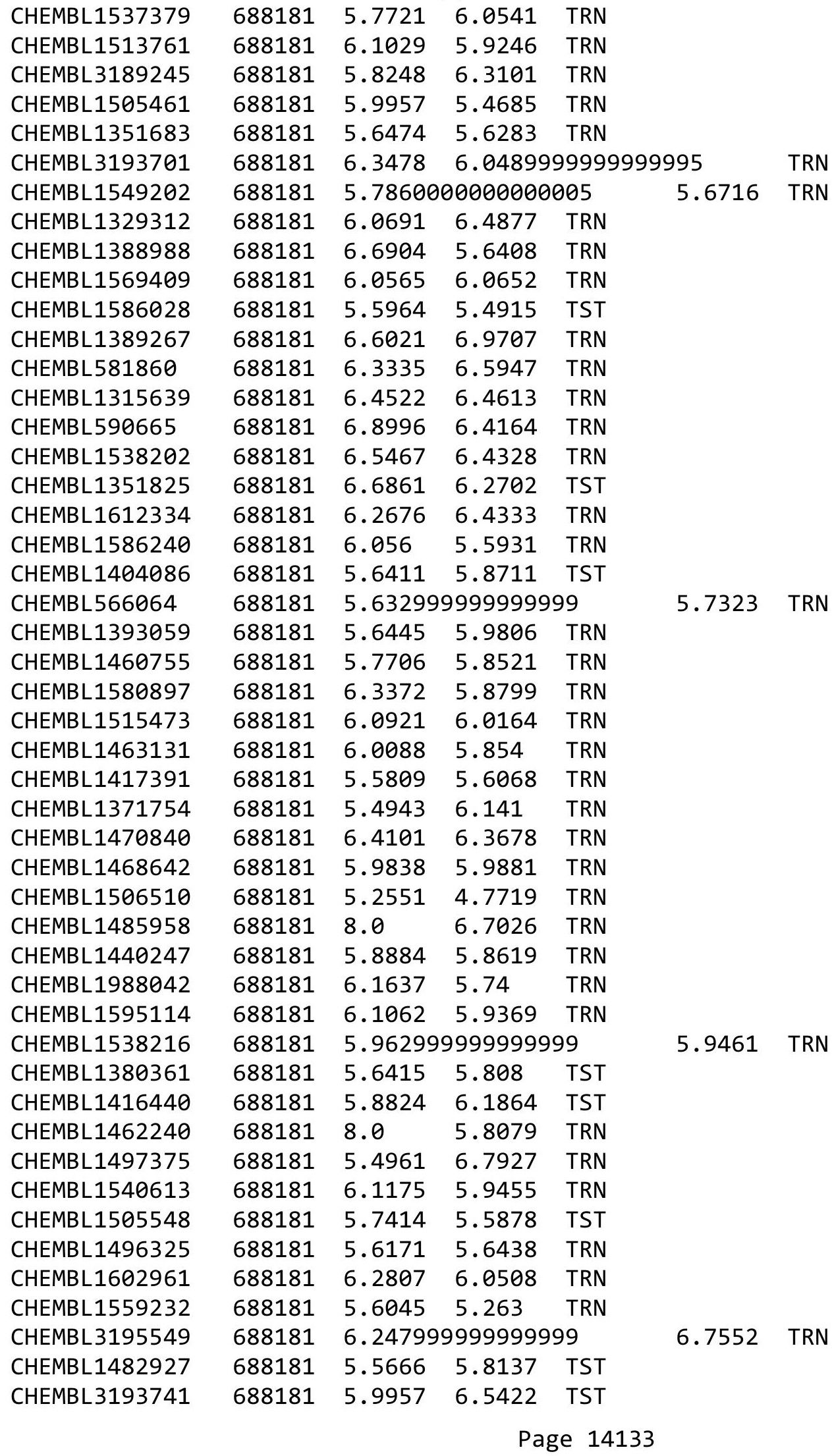




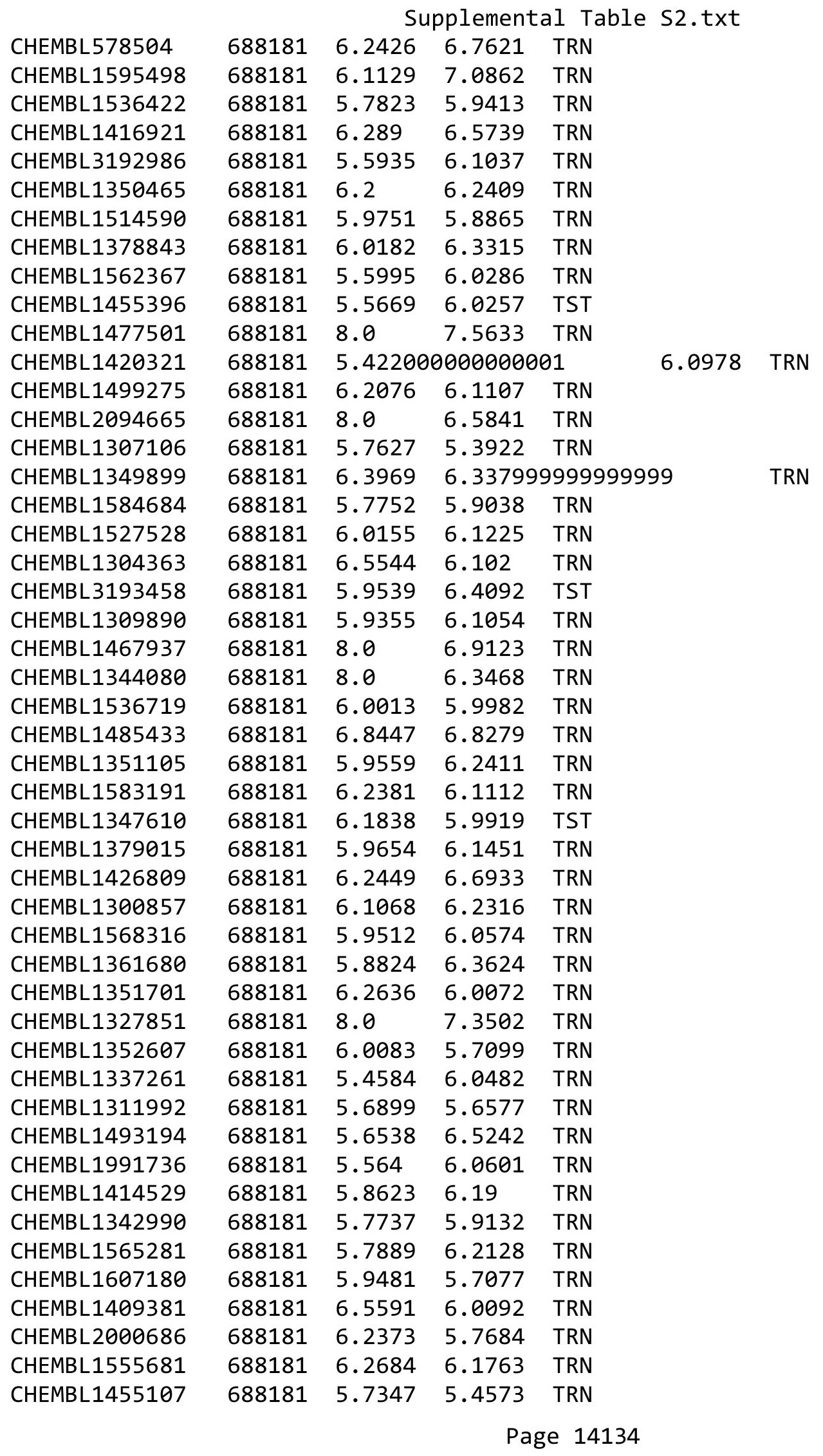




\begin{tabular}{|c|c|c|c|c|c|c|}
\hline & & \multicolumn{5}{|c|}{ Supplemental Table S2.txt } \\
\hline CHEMBL1501413 & 688181 & 6.6576 & 6.5459 & TRN & & \\
\hline CHEMBL1464095 & 688181 & 5.8814 & 5.8067 & TST & & \\
\hline CHEMBL1310690 & 688181 & 5.3758 & 5.8207 & TRN & & \\
\hline CHEMBL3194618 & 688181 & 5.6576 & 5.8022 & TRN & & \\
\hline CHEMBL1579548 & 688181 & 5.9614 & 5.9285 & TRN & & \\
\hline CHEMBL1437823 & 688181 & 8.0 & 7.4556 & TRN & & \\
\hline CHEMBL1498801 & 688181 & 5.3764 & 5.6269 & TST & & \\
\hline CHEMBL1530308 & 688181 & 8.0 & 6.8802 & TRN & & \\
\hline CHEMBL1608731 & 688181 & 6.3215 & 6.0376 & TRN & & \\
\hline CHEMBL1344013 & 688181 & \multicolumn{3}{|c|}{5.656000000000001} & 5.9584 & TRN \\
\hline CHEMBL1543833 & 688181 & 5.9226 & 6.4114 & TRN & & \\
\hline CHEMBL1454738 & 688181 & 6.0575 & 5.7743 & TRN & & \\
\hline CHEMBL1548005 & 688181 & 5.767 & 5.6378 & TST & & \\
\hline CHEMBL3190827 & 688181 & 5.5879 & 5.7313 & TST & & \\
\hline CHEMBL1369594 & 688181 & 5.9851 & 6.2303 & TRN & & \\
\hline CHEMBL1551385 & 688181 & 5.8935 & 6.1441 & TRN & & \\
\hline CHEMBL1566345 & 688181 & 5.8677 & 6.0498 & TRN & & \\
\hline CHEMBL1375155 & 688181 & 5.7749 & 5.6148 & TRN & & \\
\hline CHEMBL1603615 & 688181 & 6.1433 & 5.4242 & TRN & & \\
\hline CHEMBL1492754 & 688181 & 6.1938 & 6.1678 & TRN & & \\
\hline CHEMBL1988416 & 688181 & 5.8564 & 5.91200 & 0000000001 & & TST \\
\hline CHEMBL1542674 & 688181 & 5.3816 & 5.9498 & TRN & & \\
\hline CHEMBL1519827 & 688181 & 6.9547 & 6.1008 & TST & & \\
\hline CHEMBL1352919 & 688181 & 5.7158 & 5.8267 & TST & & \\
\hline CHEMBL1580472 & 688181 & 6.6716 & 6.8619 & TRN & & \\
\hline CHEMBL547833 & 688181 & 5.6755 & 5.9929 & TRN & & \\
\hline CHEMBL1504841 & 688181 & 8.0 & 6.7826 & TRN & & \\
\hline CHEMBL1369986 & 688181 & 8.0 & 6.3167 & TRN & & \\
\hline CHEMBL 2000517 & 688181 & 6.2596 & 6.0051 & TST & & \\
\hline CHEMBL1536905 & 688181 & 8.0 & 6.4285 & TRN & & \\
\hline CHEMBL1550106 & 688181 & 5.7022 & 6.1391 & TRN & & \\
\hline CHEMBL1380330 & 688181 & \multicolumn{3}{|c|}{5.587000000000001} & 5.9706 & TRN \\
\hline CHEMBL1487401 & 688181 & 5.6664 & 6.0737 & TRN & & \\
\hline CHEMBL3195567 & 688181 & 5.9219 & 5.7079 & TRN & & \\
\hline CHEMBL1323306 & 688181 & 5.7471 & 5.8077 & TST & & \\
\hline CHEMBL1461175 & 688181 & 5.751 & 6.2848 & TRN & & \\
\hline CHEMBL2369159 & 688181 & 6.3615 & 6.3401 & TRN & & \\
\hline CHEMBL1468483 & 688181 & 6.6383 & 5.9766 & TRN & & \\
\hline CHEMBL1326819 & 688181 & 5.7187 & 5.9487 & TRN & & \\
\hline CHEMBL1536437 & 688181 & 6.2907 & 6.0248 & TST & & \\
\hline CHEMBL1411889 & 688181 & 6.7235 & 6.096 & TRN & & \\
\hline CHEMBL1302158 & 688181 & 5.58 & 6.0814 & TRN & & \\
\hline CHEMBL1355120 & 688181 & 6.4437 & 6.1219 & TRN & & \\
\hline CHEMBL1460853 & 688181 & 5.934 & 5.9974 & TRN & & \\
\hline CHEMBL1498301 & 688181 & 6.062 & 6.0341 & TRN & & \\
\hline CHEMBL1577085 & 688181 & 5.3218 & 5.9586 & TST & & \\
\hline CHEMBL1420558 & 688181 & 3.2218 & 5.7489 & TRN & & \\
\hline CHEMBL1414813 & 688181 & 6.0477 & 5.8307 & TRN & & \\
\hline
\end{tabular}




\begin{tabular}{|c|c|c|c|c|c|c|}
\hline & & \multicolumn{5}{|c|}{ Supplemental Table S2.txt } \\
\hline CHEMBL1994815 & 688181 & 5.4339 & 5.936 & TRN & & \\
\hline CHEMBL1580683 & 688181 & 5.8617 & 5.9754 & TRN & & \\
\hline CHEMBL1391672 & 688181 & 5.6906 & 5.5618 & TRN & & \\
\hline CHEMBL1441481 & 688181 & 6.3002 & 5.8385 & TRN & & \\
\hline CHEMBL1315433 & 688181 & 5.6981 & 6.1999 & TRN & & \\
\hline CHEMBL1375247 & 688181 & 5.601 & 5.6538 & TRN & & \\
\hline CHEMBL1503689 & 688181 & 5.8142 & 5.9308 & TST & & \\
\hline CHEMBL1312619 & 688181 & 5.8567 & 5.8909 & TRN & & \\
\hline CHEMBL1349055 & 688181 & 6.0132 & 6.1626 & TRN & & \\
\hline CHEMBL1215474 & 688181 & 5.8928 & 5.9804 & TRN & & \\
\hline CHEMBL1343758 & 688181 & 5.7192 & 5.7572 & TRN & & \\
\hline CHEMBL1360154 & 688181 & 5.3306 & 5.7655 & TRN & & \\
\hline CHEMBL1353330 & 688181 & 6.0381 & 6.0041 & TRN & & \\
\hline CHEMBL1491626 & 688181 & \multicolumn{3}{|c|}{5.7860000000000005} & .8574 & TRN \\
\hline CHEMBL1350062 & 688181 & 6.6271 & 7.2795 & TRN & & \\
\hline CHEMBL1524141 & 688181 & 5.6686 & 6.0327 & TRN & & \\
\hline CHEMBL1563777 & 688181 & 5.655 & 5.5941 & TRN & & \\
\hline CHEMBL1532608 & 688181 & 8.0 & 7.1731 & TRN & & \\
\hline CHEMBL3193676 & 688181 & 6.0888 & 5.8109 & TRN & & \\
\hline CHEMBL1307607 & 688181 & 5.7064 & 5.8989 & TRN & & \\
\hline CHEMBL3197504 & 688181 & 6.3279 & 6.3384 & TRN & & \\
\hline CHEMBL1325039 & 688181 & 5.73 & 6.062 & TRN & & \\
\hline CHEMBL1320566 & 688181 & 5.8456 & 6.4586 & TRN & & \\
\hline CHEMBL1611966 & 688181 & 4.5756 & 5.7235 & TRN & & \\
\hline CHEMBL589694 & 688181 & 5.8499 & 5.9122 & TRN & & \\
\hline CHEMBL1523254 & 688181 & 8.0 & 6.3032 & TRN & & \\
\hline CHEMBL1423951 & 688181 & 6.0888 & 6.0262 & TRN & & \\
\hline CHEMBL1604326 & 688181 & 5.6708 & \multicolumn{3}{|c|}{6.0120000000000005} & TRN \\
\hline CHEMBL 1310876 & 688181 & 5.7637 & 6.1044 & TRN & & \\
\hline CHEMBL1492590 & 688181 & 5.7989 & 5.9886 & TRN & & \\
\hline CHEMBL1454611 & 688181 & 5.6972 & 5.8663 & TRN & & \\
\hline CHEMBL1442253 & 688181 & 8.0 & 6.4225 & TRN & & \\
\hline CHEMBL1458565 & 688181 & 6.0004 & 5.9926 & TRN & & \\
\hline CHEMBL1498473 & 688181 & 5.3847 & 5.987 & TST & & \\
\hline CHEMBL1406337 & 688181 & 6.8761 & 6.4084 & TRN & & \\
\hline CHEMBL1453858 & 688181 & 6.3316 & 6.7012 & TST & & \\
\hline CHEMBL1423277 & 688181 & 5.6704 & 5.8237 & TRN & & \\
\hline CHEMBL1490953 & 688181 & 5.9983 & 5.8677 & TRN & & \\
\hline CHEMBL1369226 & 688181 & 6.2757 & 5.6643 & TRN & & \\
\hline CHEMBL1511464 & 688181 & 5.7918 & 5.5948 & TRN & & \\
\hline CHEMBL1402496 & 688181 & 5.3988 & 5.7235 & TST & & \\
\hline CHEMBL1994623 & 688181 & 6.3054 & 6.3876 & TRN & & \\
\hline CHEMBL1446348 & 688181 & 6.1018 & 7.0835 & TRN & & \\
\hline CHEMBL1324481 & 688181 & 8.0 & 6.2722 & TRN & & \\
\hline CHEMBL3196917 & 688181 & 6.6478 & 6.4815 & TRN & & \\
\hline CHEMBL 2001712 & 688181 & 6.2457 & 6.2481 & TRN & & \\
\hline CHEMBL1541981 & 688181 & 5.9978 & 6.5657 & TRN & & \\
\hline CHEMBL1360505 & 688181 & 5.8739 & 6.1069 & TRN & & \\
\hline
\end{tabular}




\begin{tabular}{|c|c|c|c|c|c|}
\hline & & \multicolumn{4}{|c|}{ Supplemental Table S2.txt } \\
\hline CHEMBL1534270 & 688181 & 5.9485 & 5.5777 & TRN & \\
\hline CHEMBL1367226 & 688181 & 5.5236 & 5.3856 & TRN & \\
\hline CHEMBL1345313 & 688181 & 5.3442 & 5.7178 & TRN & \\
\hline CHEMBL1579010 & 688181 & 5.5245 & 6.185 & TST & \\
\hline CHEMBL1353790 & 688181 & 5.6447 & 6.3126 & TRN & \\
\hline CHEMBL1458944 & 688181 & 5.2739 & 5.8511 & TST & \\
\hline CHEMBL3192732 & 688181 & 5.4763 & 5.596 & TST & \\
\hline CHEMBL3189237 & 688181 & 6.0119 & 5.9194 & TRN & \\
\hline CHEMBL1519873 & 688181 & 5.8377 & 5.7872 & TRN & \\
\hline CHEMBL1581347 & 688181 & 6.1249 & 6.0697 & TRN & \\
\hline CHEMBL1964464 & 688181 & 6.1972 & 6.4245 & TRN & \\
\hline CHEMBL1599708 & 688181 & 6.0414 & 6.1759 & TRN & \\
\hline CHEMBL1991516 & 688181 & 6.2774 & 6.1349 & TST & \\
\hline CHEMBL584840 & 688181 & 8.0 & 7.0584 & TRN & \\
\hline CHEMBL1486803 & 688181 & 5.7708 & 5.9236 & TRN & \\
\hline CHEMBL1562606 & 688181 & 8.0 & 7.1479 & TRN & \\
\hline CHEMBL1518491 & 688181 & 5.6749 & 5.5501 & TRN & \\
\hline CHEMBL1534832 & 688181 & 6.8041 & 6.5565 & TRN & \\
\hline CHEMBL1349378 & 688181 & 5.4739 & 5.4071 & TRN & \\
\hline CHEMBL1557906 & 688181 & 6.5186 & 6.7767 & TRN & \\
\hline CHEMBL1572982 & 688181 & 8.0 & 7.4064 & TRN & \\
\hline CHEMBL1299591 & 688181 & 5.6332 & 6.3247 & TST & \\
\hline CHEMBL1489334 & 688181 & 8.0 & 6.2989 & TST & \\
\hline CHEMBL1367639 & 688181 & 5.8052 & 5.6167 & TRN & \\
\hline CHEMBL1601462 & 688181 & 6.3152 & 6.40600 & 0000000001 & TST \\
\hline CHEMBL1339150 & 688181 & 5.9578 & 6.1184 & TRN & \\
\hline CHEMBL1340022 & 688181 & 5.5889 & 5.3345 & TRN & \\
\hline CHEMBL1586230 & 688181 & 5.6038 & 6.1363 & TRN & \\
\hline CHEMBL1607453 & 688181 & 5.5251 & 5.8881 & TRN & \\
\hline CHEMBL1573309 & 688181 & 5.9187 & 6.4571 & TRN & \\
\hline CHEMBL1560678 & 688181 & 8.0 & 7.0387 & TRN & \\
\hline CHEMBL1306912 & 688181 & 5.8857 & 6.3704 & TST & \\
\hline CHEMBL1300193 & 688181 & 5.7242 & 5.7451 & TRN & \\
\hline CHEMBL1466481 & 688181 & 5.6509 & 6.0087 & TRN & \\
\hline CHEMBL1415768 & 688181 & 5.7562 & 5.7832 & TRN & \\
\hline CHEMBL1409908 & 688181 & 5.7178 & 6.0027 & TRN & \\
\hline CHEMBL1433248 & 688181 & 5.7272 & 6.5543 & TST & \\
\hline CHEMBL1997747 & 688181 & 6.9788 & 7.0003 & TRN & \\
\hline CHEMBL1511950 & 688181 & 6.7423 & 5.5803 & TRN & \\
\hline CHEMBL1344559 & 688181 & 6.644 & 6.7162 & TRN & \\
\hline CHEMBL1332089 & 688181 & 6.2676 & 6.0572 & TRN & \\
\hline CHEMBL586031 & 688181 & 6.2518 & 6.097 & TRN & \\
\hline CHEMBL1502931 & 688181 & 6.0079 & 6.2932 & TRN & \\
\hline CHEMBL1309200 & 688181 & 6.71899 & 99999999 & 6.8282 & TRN \\
\hline CHEMBL1429512 & 688181 & 6.2526 & 6.4257 & TRN & \\
\hline CHEMBL1340602 & 688181 & 6.5391 & 6.907 & TRN & \\
\hline CHEMBL1319618 & 688181 & 5.6931 & 6.1345 & TRN & \\
\hline CHEMBL3198142 & 688181 & 6.5143 & 5.4883 & TRN & \\
\hline
\end{tabular}


Supplemental Table S2.txt

\begin{tabular}{|c|c|c|c|c|}
\hline IE & 1 & & & TR \\
\hline 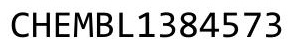 & & .7104 & 5.6095 & \\
\hline & & & & \\
\hline HEMBL 321 & & 796 & 9669 & \\
\hline AEMBL1442300 & & 184 & 3018 & \\
\hline HEMBL1319858 & 88181 & .7642 & 965 & \\
\hline HEMBL1 & 181 & 156 & 3946 & \\
\hline IEMBL157 & & & & \\
\hline HEMBL1501 & 181 & 593 & 6572 & \\
\hline HEMBL1390501 & 88181 & 761 & 1271 & \\
\hline HEMBL1558805 & 88181 & 102 & 9296 & \\
\hline IEMBL150 & 181 & 26 & 058 & \\
\hline HEMBL157 & & & & \\
\hline AEMBL1558506 & & 801 & 9158 & \\
\hline AEMBL160 & & 271 & 952 & ST \\
\hline AEMBL153e & 31 & 31 & 526 & \\
\hline HEMBL142 & & 84 & 123 & \\
\hline HEMBL156 & & & & \\
\hline HEMBL1383777 & & & 5099 & \\
\hline IEMBL141 & & & 503 & \\
\hline HEMBLS & & 94 & 85 & \\
\hline HEMBL1 & & & 305 & \\
\hline HEMBL1 & & & & \\
\hline AEMBL1391 & & & & \\
\hline AEMBL133 & & & & RIN \\
\hline HEMBL1 & & & 004 & RIV \\
\hline AEMBL1 & & & 695 & RN \\
\hline AFMRI 1 & & & 18 & RN \\
\hline HEMBL198 & & & & $2 \mathrm{~N}$ \\
\hline HEMBL1578651 & & & 519 & IRN \\
\hline HEMBL159 & & & 1922 & \\
\hline AFMBI 1 & & & 279 & זות \\
\hline 58 & & & 29 & RN \\
\hline HEMBL1536803 & & & 3863 & RN \\
\hline HEMBL1399486 & & 586 & 2392 & RN \\
\hline HEMBL152 & & & 1906 & DMU \\
\hline HᄃMDI - & & & 764 & RN \\
\hline HEMBL1 & & & 135 & RN \\
\hline HEMBL3189599 & 88181 & 59 & 138 & $\Gamma \mathrm{RN}$ \\
\hline EMBL1 & & 57 & 248 & RN \\
\hline HEMBL1332 & & 264 & 521 & \\
\hline HEMBL1386097 & & & & RN \\
\hline HEMBL1472 & & .3188 & 4156 & $\Gamma \mathrm{RN}$ \\
\hline AEMBL1541331 & 38181 & & 9929 & ГST \\
\hline MBL1 & & 0 & 7386 & \\
\hline CHEMBL1321140 & & & 1994 & \\
\hline CHEMBL137367e & & & 5799 & \\
\hline HEMBL1428004 & 688181 & 6.1107 & 5.7967 & ГRN \\
\hline
\end{tabular}

Page 14138 


\begin{tabular}{|c|c|c|c|c|c|c|}
\hline \multirow[b]{2}{*}{ CHEMBL1560092 } & \multirow[b]{2}{*}{688181} & \multicolumn{5}{|c|}{ Supplemental Table S2.txt } \\
\hline & & \multicolumn{2}{|c|}{5.74816 .1051} & TRN & & \\
\hline CHEMBL1339973 & 688181 & 6.1331 & 6.4312 & TRN & & \\
\hline CHEMBL1401052 & 688181 & \multicolumn{3}{|c|}{6.162999999999999} & 6.2958 & TRN \\
\hline CHEMBL1602043 & 688181 & 6.0017 & 6.6963 & TRN & & \\
\hline CHEMBL1990036 & 688181 & 6.0074 & \multicolumn{3}{|c|}{6.1370000000000005} & TRN \\
\hline CHEMBL1426147 & 688181 & 5.647 & 5.4073 & TRN & & \\
\hline CHEMBL580727 & 688181 & 5.7062 & 6.0821 & TRN & & \\
\hline CHEMBL1522721 & 688181 & 5.5158 & 6.0787 & TRN & & \\
\hline CHEMBL1516976 & 688181 & 5.7126 & 5.5372 & TRN & & \\
\hline CHEMBL3194778 & 688181 & 5.9622 & 6.2599 & TRN & & \\
\hline CHEMBL1447188 & 688181 & 5.9727 & 5.8617 & TRN & & \\
\hline CHEMBL1356454 & 688181 & 5.644 & 5.7615 & TRN & & \\
\hline CHEMBL1989315 & 688181 & 5.7231 & 6.0944 & TRN & & \\
\hline CHEMBL1463351 & 688181 & 5.8047 & 6.1904 & TRN & & \\
\hline CHEMBL1423251 & 688181 & 5.3481 & 6.2939 & TRN & & \\
\hline CHEMBL1496534 & 688181 & 6.0092 & 5.8168 & TRN & & \\
\hline CHEMBL1341097 & 688181 & 5.3469 & 6.7873 & TST & & \\
\hline CHEMBL1427895 & 688181 & 6.1226 & 6.0028 & TRN & & \\
\hline CHEMBL1323631 & 688181 & 5.7345 & 5.6578 & TRN & & \\
\hline CHEMBL609628 & 688181 & 8.0 & 6.7387 & TRN & & \\
\hline CHEMBL1386066 & 688181 & 6.4191 & 6.6527 & TRN & & \\
\hline CHEMBL1519697 & 688181 & 5.6625 & 6.1723 & TRN & & \\
\hline CHEMBL1571445 & 688181 & 6.6478 & 6.7435 & TRN & & \\
\hline CHEMBL1312502 & 688181 & \multicolumn{3}{|c|}{5.638999999999999} & 5.5214 & TRN \\
\hline CHEMBL1466585 & 688181 & 6.0177 & 6.6234 & TRN & & \\
\hline CHEMBL1599262 & 688181 & 5.8019 & 6.3041 & TRN & & \\
\hline CHEMBL1489229 & 688181 & 5.3401 & 5.5904 & TRN & & \\
\hline CHEMBL3190934 & 688181 & 5.7959 & 6.0376 & TRN & & \\
\hline CHEMBL1586170 & 688181 & 5.6904 & 5.6576 & TRN & & \\
\hline CHEMBL1496327 & 688181 & 5.8219 & 5.9399 & TRN & & \\
\hline CHEMBL1370630 & 688181 & 5.5484 & 5.4341 & TRN & & \\
\hline CHEMBL1586276 & 688181 & 6.301 & 6.1666 & TRN & & \\
\hline CHEMBL1464171 & 688181 & 5.8441 & 6.232 & TRN & & \\
\hline CHEMBL 2001433 & 688181 & 6.2076 & 6.2563 & TRN & & \\
\hline CHEMBL1566464 & 688181 & 6.6968 & 6.2301 & TRN & & \\
\hline CHEMBL1574263 & 688181 & \multicolumn{3}{|c|}{6.162999999999999} & 5.978 & TRN \\
\hline CHEMBL1405968 & 688181 & 5.7823 & 6.1354 & TRN & & \\
\hline CHEMBL1451287 & 688181 & 6.7825 & 6.336 & TRN & & \\
\hline CHEMBL2369174 & 688181 & 6.9666 & 6.2217 & TRN & & \\
\hline CHEMBL1532068 & 688181 & 6.5287 & 6.4492 & TRN & & \\
\hline CHEMBL1346272 & 688181 & 5.9851 & \multicolumn{3}{|c|}{5.757000000000001} & TRN \\
\hline CHEMBL3198812 & 688181 & 6.0057 & 6.1106 & TRN & & \\
\hline CHEMBL1302527 & 688181 & 5.6951 & 5.6881 & TST & & \\
\hline CHEMBL1400048 & 688181 & 6.1302 & 6.1301 & TRN & & \\
\hline CHEMBL1594475 & 688181 & 5.9702 & 6.1866 & TRN & & \\
\hline CHEMBL1386918 & 688181 & 5.46 & 6.3377 & TRN & & \\
\hline CHEMBL1500144 & 688181 & 6.2503 & \multicolumn{3}{|c|}{6.417000000000001} & TRN \\
\hline CHEMBL1385823 & 688181 & 5.5319 & 5.4575 & TRN & & \\
\hline
\end{tabular}




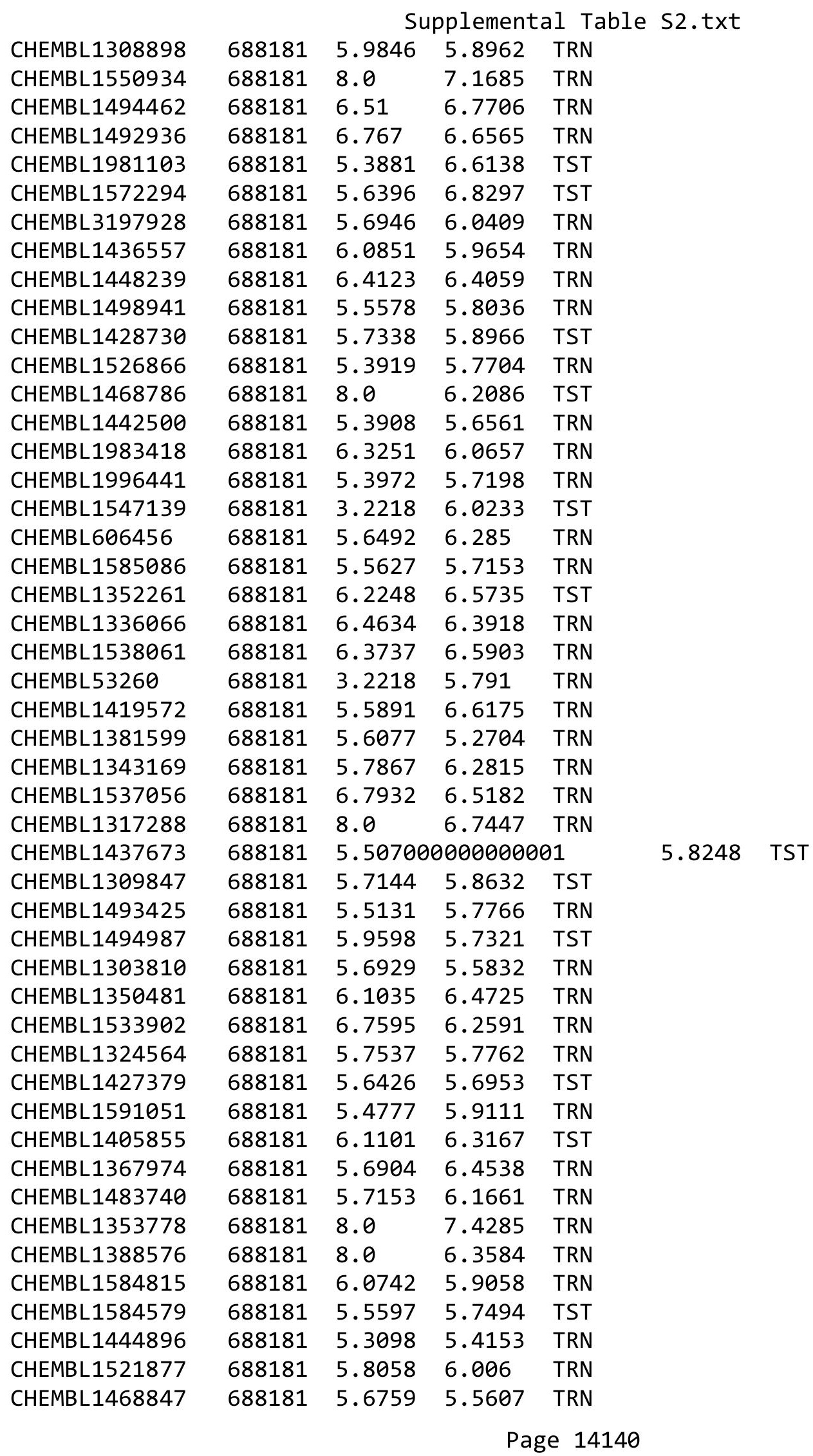


Supplemental Table S2.txt

\begin{tabular}{|c|c|c|c|c|}
\hline CHEMBL1378467 & 688181 & 6.1931 & 5.6039 & TRN \\
\hline CHEMBL1392318 & 688181 & 6.1864 & 6.2118 & TRN \\
\hline CHEMBL1404731 & 688181 & 5.8573 & 6.1345 & TRN \\
\hline CHEMBL1543822 & 688181 & 5.8864 & 5.9568 & TRN \\
\hline CHEMBL1580409 & 688181 & 5.9727 & 6.2778 & TRN \\
\hline CHEMBL1541490 & 688181 & 5.3751 & 5.7486 & TRN \\
\hline CHEMBL1505006 & 688181 & 5.6613 & 5.564 & TRN \\
\hline CHEMBL1563257 & 688181 & 3.5229 & 5.4666 & TRN \\
\hline CHEMBL3190508 & 688181 & 6.38299 & 99999999 & 5.907 \\
\hline CHEMBL1577826 & 688181 & 5.8687 & 6.6358 & TST \\
\hline CHEMBL1433185 & 688181 & 5.8752 & 5.609 & TRN \\
\hline CHEMBL1535032 & 688181 & 5.7989 & 5.7828 & TST \\
\hline CHEMBL1535975 & 688181 & 6.5735 & 5.9546 & TRN \\
\hline CHEMBL1606890 & 688181 & 5.6513 & 5.7128 & TRN \\
\hline CHEMBL1509653 & 688181 & 5.8489 & 6.0029 & TRN \\
\hline CHEMBL1491124 & 688181 & 5.8102 & 6.41700 & 2000000001 \\
\hline CHEMBL1555655 & 688181 & 5.6036 & 6.2464 & TST \\
\hline CHEMBL1578286 & 688181 & 5.6089 & 5.9488 & TRN \\
\hline CHEMBL1323541 & 688181 & 3.2218 & 5.761 & TST \\
\hline CHEMBL1400118 & 688181 & 6.4001 & 6.0314 & TRN \\
\hline CHEMBL1424032 & 688181 & 8.0 & 6.9029 & TRN \\
\hline CHEMBL1483462 & 688181 & 6.6517 & 5.8263 & TRN \\
\hline CHEMBL3213112 & 688181 & 8.0 & 6.0154 & TST \\
\hline CHEMBL1570930 & 688181 & 5.7326 & 6.11100 & $\partial 000000001$ \\
\hline CHEMBL1408009 & 688181 & 6.0605 & 6.086 & TRN \\
\hline CHEMBL511979 & 688181 & 5.4916 & 5.4197 & TRN \\
\hline CHEMBL1381159 & 688181 & 8.0 & 6.5827 & TRN \\
\hline CHEMBL1469579 & 688181 & 5.7375 & 5.7667 & TST \\
\hline CHEMBL1349711 & 688181 & 8.0 & 7.3152 & TRN \\
\hline CHEMBL1461417 & 688181 & 6.8928 & 6.4638 & TRN \\
\hline CHEMBL1471807 & 688181 & 6.8182 & 6.0608 & TRN \\
\hline CHEMBL1976834 & 688181 & 6.8508 & 6.3857 & TRN \\
\hline CHEMBL1533231 & 688181 & 6.6882 & 6.855 & TRN \\
\hline CHEMBL1429091 & 688181 & 8.0 & 7.6503 & TRN \\
\hline CHEMBL1484425 & 688181 & 6.0799 & 6.0994 & TST \\
\hline CHEMBL1301150 & 688181 & 5.9519 & 6.7698 & TRN \\
\hline CHEMBL1426561 & 688181 & 6.0329 & 6.4227 & TRN \\
\hline CHEMBL1500469 & 688181 & 5.9154 & 5.5295 & TRN \\
\hline CHEMBL1468874 & 688181 & 6.1612 & 6.4839 & TRN \\
\hline CHEMBL1524985 & 688181 & 6.7721 & 5.7035 & TRN \\
\hline CHEMBL1518073 & 688181 & 5.6776 & 5.6077 & TRN \\
\hline CHEMBL1485598 & 688181 & 5.8162 & 5.6646 & TRN \\
\hline CHEMBL3198693 & 688181 & 5.648 & 5.987 & TRN \\
\hline CHEMBL1596287 & 688181 & 8.0 & 7.0906 & TRN \\
\hline CHEMBL1420206 & 688181 & 5.5988 & 5.646 & TRN \\
\hline CHEMBL1308218 & 688181 & 6.7077 & 6.4242 & TRN \\
\hline CHEMBL1603838 & 688181 & 6.1421 & 6.1174 & TRN \\
\hline CHEMBL1322395 & 688181 & 6.6946 & 6.5474 & TRN \\
\hline
\end{tabular}




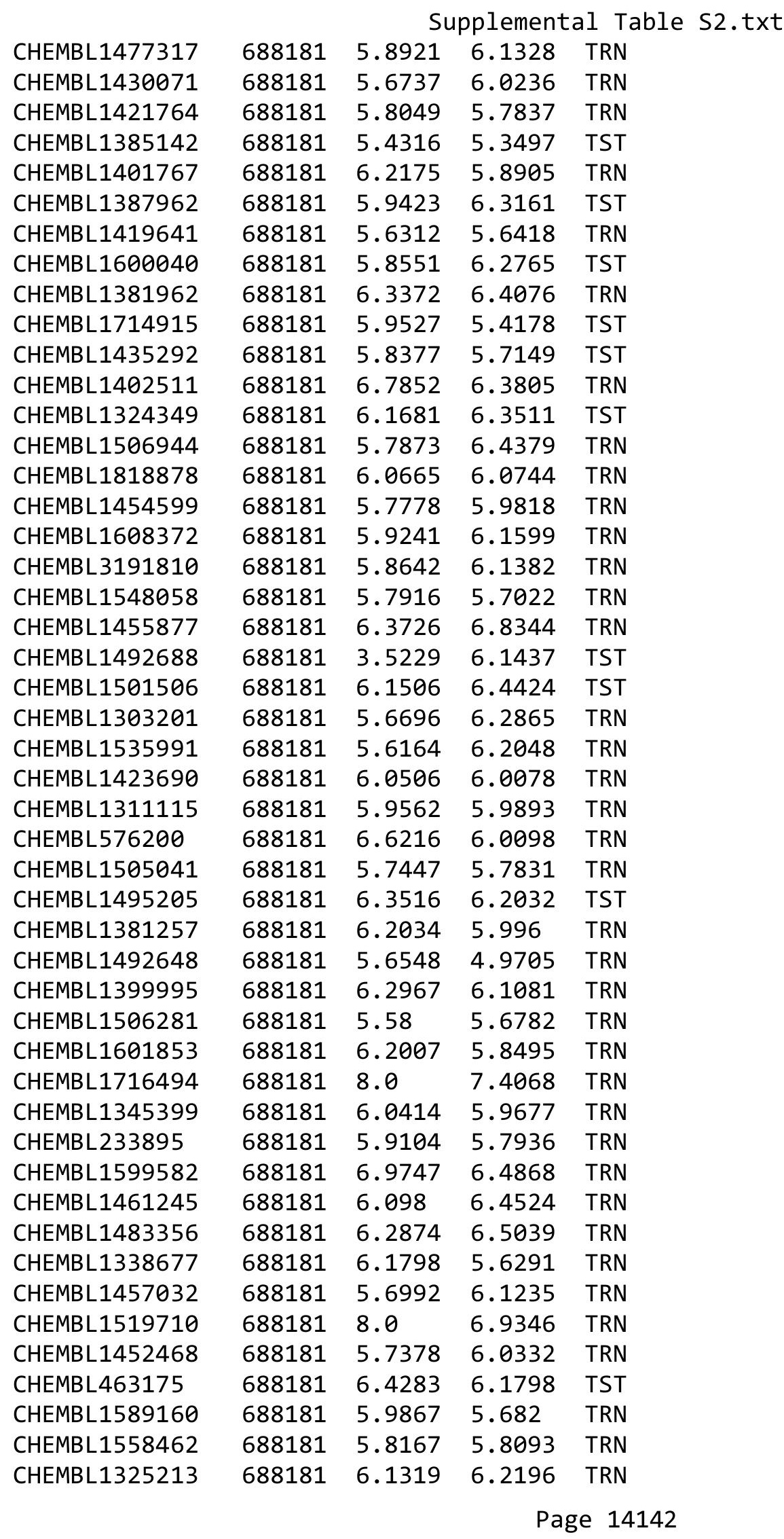


Supplemental Table S2.txt

\begin{tabular}{|c|c|c|c|c|c|c|}
\hline CHEMBL1382628 & 688181 & 5.6799 & 5.939 & TRN & & \\
\hline CHEMBL1733454 & 688181 & 6.7375 & 6.9486 & TRN & & \\
\hline CHEMBL1582997 & 688181 & 5.9274 & 6.1388 & TRN & & \\
\hline CHEMBL1430211 & 688181 & 5.5906 & 5.6798 & TRN & & \\
\hline CHEMBL1383144 & 688181 & 6.1945 & 6.2328 & TRN & & \\
\hline CHEMBL1351537 & 688181 & 8.0 & 6.0905 & TRN & & \\
\hline CHEMBL1329197 & 688181 & 6.9136 & 6.4353 & TRN & & \\
\hline CHEMBL1427779 & 688181 & 5.8781 & 6.8086 & TST & & \\
\hline CHEMBL1347451 & 688181 & 6.7496 & 5.6667 & TST & & \\
\hline CHEMBL1509539 & 688181 & \multicolumn{3}{|c|}{5.821000000000001} & 5.8726 & TRN \\
\hline CHEMBL1432681 & 688181 & 6.4855 & 6.3717 & TRN & & \\
\hline CHEMBL1498044 & 688181 & 5.7249 & 5.8515 & TRN & & \\
\hline CHEMBL1393511 & 688181 & 5.9527 & 6.3972 & TRN & & \\
\hline CHEMBL3196591 & 688181 & 5.7338 & 5.7466 & TRN & & \\
\hline CHEMBL1494677 & 688181 & 8.0 & 6.8186 & TRN & & \\
\hline CHEMBL1513401 & 688181 & 5.7533 & 6.0884 & TRN & & \\
\hline CHEMBL1504286 & 688181 & 5.7817 & 5.5999 & TRN & & \\
\hline CHEMBL1343868 & 688181 & 5.9594 & 5.8707 & TST & & \\
\hline CHEMBL1477838 & 688181 & 5.7095 & 5.6806 & TRN & & \\
\hline CHEMBL3197039 & 688181 & 6.4056 & 5.9803 & TRN & & \\
\hline CHEMBL1443747 & 688181 & 8.0 & 6.6931 & TRN & & \\
\hline CHEMBL1567438 & 688181 & 5.7385 & 5.7544 & TRN & & \\
\hline CHEMBL1517422 & 688181 & 6.8794 & 7.46299 & 9999999999 & & TRN \\
\hline CHEMBL1407015 & 688181 & 5.6568 & 5.6175 & TRN & & \\
\hline CHEMBL1440037 & 688181 & 5.6059 & 6.3045 & TRN & & \\
\hline CHEMBL1606886 & 688181 & 5.8854 & 5.7487 & TRN & & \\
\hline CHEMBL1500801 & 688181 & 5.6619 & 6.1595 & TRN & & \\
\hline CHEMBL1299343 & 688181 & 6.5452 & 6.3923 & TRN & & \\
\hline CHEMBL 3210428 & 688181 & 6.0726 & 6.0519 & TRN & & \\
\hline CHEMBL1525619 & 688181 & 5.6592 & 5.5796 & TRN & & \\
\hline CHEMBL1338466 & 688181 & 5.48 & 5.6791 & TST & & \\
\hline CHEMBL1492024 & 688181 & 6.2565 & 5.8648 & TRN & & \\
\hline CHEMBL1546248 & 688181 & 5.5585 & 5.1272 & TRN & & \\
\hline CHEMBL1424826 & 688181 & 8.0 & 6.4966 & TRN & & \\
\hline CHEMBL1458824 & 688181 & 5.5702 & 5.9638 & TRN & & \\
\hline CHEMBL1571301 & 688181 & 5.8576 & 6.3224 & TRN & & \\
\hline CHEMBL1377889 & 688181 & 5.5571 & 6.0036 & TST & & \\
\hline CHEMBL1566084 & 688181 & 6.1624 & 5.7038 & TRN & & \\
\hline CHEMBL1493120 & 688181 & 5.7481 & 6.4425 & TST & & \\
\hline CHEMBL3191149 & 688181 & 5.9423 & 5.8316 & TRN & & \\
\hline CHEMBL355318 & 688181 & 6.1073 & 6.0715 & TRN & & \\
\hline CHEMBL1386607 & 688181 & 5.5948 & 5.9542 & TRN & & \\
\hline CHEMBL1500161 & 688181 & 5.4063 & 6.2497 & TRN & & \\
\hline CHEMBL1376225 & 688181 & 6.2541 & 6.1175 & TRN & & \\
\hline CHEMBL1517879 & 688181 & 6.0501 & 5.8026 & TRN & & \\
\hline CHEMBL1351508 & 688181 & 6.45100 & 000000006 & 005 & $5.6620 e$ & 0000000001 \\
\hline CHEMBL1538267 & 688181 & 5.8348 & 6.1946 & TRN & & \\
\hline CHEMBL1390546 & 688181 & 5.4588 & 5.6868 & TST & & \\
\hline
\end{tabular}




\begin{tabular}{|c|c|c|c|c|c|c|c|}
\hline \multicolumn{8}{|c|}{ Supplemental Table s2.txt } \\
\hline CHEMBL1601578 & 688181 & 8.0 & 7.5653 & TRN & & & \\
\hline CHEMBL1430339 & 688181 & 6.8827 & 6.9214 & TRN & & & \\
\hline CHEMBL1555809 & 688181 & 5.7506 & 5.9046 & TST & & & \\
\hline CHEMBL1568501 & 688181 & 5.8162 & 5.7649 & TST & & & \\
\hline CHEMBL1376605 & 688181 & 5.9698 & 6.2826 & TST & & & \\
\hline CHEMBL1500256 & 688181 & 5.9439 & 5.6183 & TRN & & & \\
\hline CHEMBL1603578 & 688181 & 8.0 & 7.4855 & TRN & & & \\
\hline CHEMBL3208866 & 688181 & 5.6286 & 6.01 & TRN & & & \\
\hline CHEMBL1534574 & 688181 & 6.1669 & 6.4671 & TRN & & & \\
\hline CHEMBL1406635 & 688181 & 5.7038 & 6.1527 & TST & & & \\
\hline CHEMBL1518478 & 688181 & 8.0 & 7.7107 & TRN & & & \\
\hline CHEMBL1580926 & 688181 & 5.7607 & 5.8853 & TRN & & & \\
\hline CHEMBL1577399 & 688181 & 6.08299 & 99999999 & 99 & .3013 & TRN & \\
\hline CHEMBL1519453 & 688181 & 6.0899 & 6.5478 & TRN & & & \\
\hline CHEMBL1439562 & 688181 & 6.1925 & 5.9416 & TRN & & & \\
\hline CHEMBL1306287 & 688181 & 6.2055 & 6.1687 & TRN & & & \\
\hline CHEMBL1447425 & 688181 & 5.4241 & 6.5782 & TST & & & \\
\hline CHEMBL1594637 & 688181 & 5.4528 & 5.7084 & TST & & & \\
\hline CHEMBL3195074 & 688181 & 6.7055 & 6.4815 & TRN & & & \\
\hline CHEMBL1364345 & 688181 & 5.8063 & 5.8066 & TST & & & \\
\hline CHEMBL1446462 & 688181 & 6.9666 & 7.1742 & TRN & & & \\
\hline CHEMBL1427040 & 688181 & 6.9586 & 7.3432 & TRN & & & \\
\hline CHEMBL1326404 & 688181 & 5.9241 & 5.9886 & TRN & & & \\
\hline CHEMBL1472122 & 688181 & 5.6482 & 5.3291 & TRN & & & \\
\hline CHEMBL3194441 & 688181 & 5.9574 & 6.1057 & TRN & & & \\
\hline CHEMBL1977568 & 688181 & 6.8928 & 6.8013 & TRN & & & \\
\hline CHEMBL1392603 & 688181 & 5.8377 & 6.2809 & TRN & & & \\
\hline CHEMBL1612647 & 688181 & 5.0802 & 6.12200 & 0000000001 & & TRN & \\
\hline CHEMBL1535558 & 688181 & 6.0301 & 6.28299 & 99999999995 & & TRN & \\
\hline CHEMBL3197816 & 688181 & 5.9408 & 6.0902 & TRN & & & \\
\hline CHEMBL1563291 & 688181 & 5.8649 & 5.9714 & TRN & & & \\
\hline CHEMBL1489071 & 688181 & 5.605 & 5.6877 & TRN & & & \\
\hline CHEMBL1503772 & 688181 & 6.0799 & 6.086 & TRN & & & \\
\hline CHEMBL3208560 & 688181 & 5.70200 & 30000000 & & .11799 & 9999999999 & TRN \\
\hline CHEMBL1503688 & 688181 & 6.9431 & 7.0282 & TRN & & & \\
\hline CHEMBL1530259 & 688181 & 8.0 & 6.5397 & TRN & & & \\
\hline CHEMBL1399543 & 688181 & 5.8857 & 5.9724 & TST & & & \\
\hline CHEMBL1548869 & 688181 & 5.7129 & 5.5176 & TRN & & & \\
\hline CHEMBL1436964 & 688181 & 8.0 & 7.1601 & TRN & & & \\
\hline CHEMBL1419514 & 688181 & 6.6696 & 7.4692 & TRN & & & \\
\hline CHEMBL1507510 & 688181 & 6.02 & 6.2023 & TRN & & & \\
\hline CHEMBL3193093 & 688181 & 6.0343 & 5.9934 & TRN & & & \\
\hline CHEMBL1499819 & 688181 & 6.0867 & 6.6443 & TRN & & & \\
\hline CHEMBL1489017 & 688181 & 6.3925 & 6.5098 & TRN & & & \\
\hline CHEMBL1581208 & 688181 & 8.0 & 7.4438 & TRN & & & \\
\hline CHEMBL1564144 & 688181 & 8.0 & 7.0644 & TRN & & & \\
\hline CHEMBL28324 & 688181 & 6.3979 & 6.1613 & TST & & & \\
\hline CHEMBL1501557 & 688181 & 8.0 & 7.8611 & TRN & & & \\
\hline
\end{tabular}


Supplemental Table S2.txt

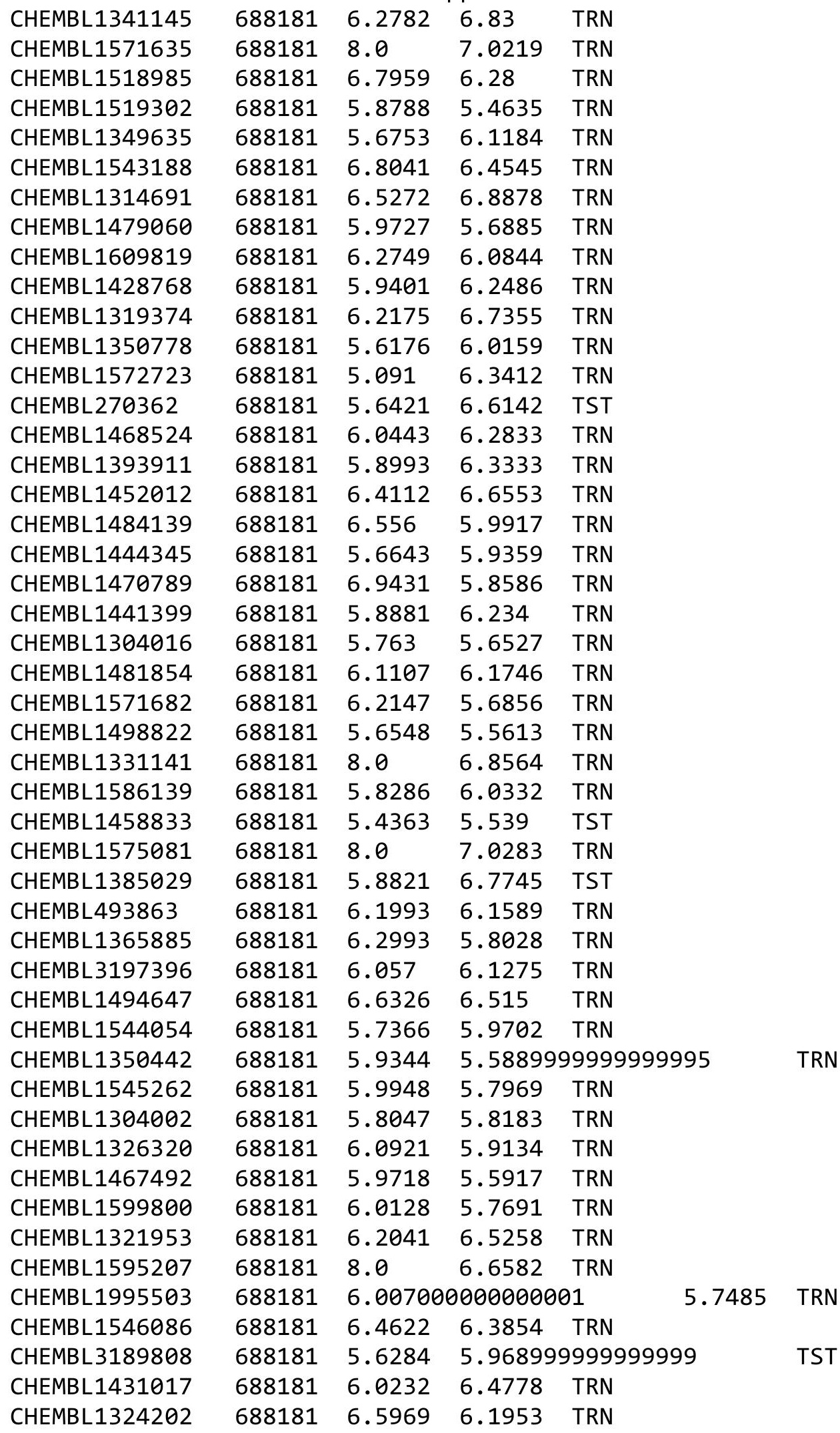

Page 14145 


\begin{tabular}{|c|c|c|c|c|c|}
\hline \multirow[b]{2}{*}{ CHEMBL3191808 } & \multicolumn{5}{|c|}{ Supplemental Table S2.txt } \\
\hline & 688181 & 6.2549 & 6.6128 & TRN & \\
\hline CHEMBL1455913 & 688181 & 5.6358 & 5.8022 & TRN & \\
\hline CHEMBL1558402 & 688181 & 5.6778 & 5.6488 & TST & \\
\hline CHEMBL1523343 & 688181 & 5.5984 & 5.66799 & 9999999999 & TRN \\
\hline CHEMBL1394019 & 688181 & 5.5524 & 5.6618 & TRN & \\
\hline CHEMBL 2005737 & 688181 & 5.8703 & 6.4319 & TRN & \\
\hline CHEMBL1446829 & 688181 & 6.3197 & 5.4354 & TST & \\
\hline CHEMBL1448282 & 688181 & 6.3179 & 6.2389 & TRN & \\
\hline CHEMBL1567571 & 688181 & 5.6962 & 6.2626 & TST & \\
\hline CHEMBL1497561 & 688181 & 5.6531 & 5.8693 & TRN & \\
\hline CHEMBL1548882 & 688181 & 5.3707 & 5.9036 & TST & \\
\hline CHEMBL1440687 & 688181 & 3.2218 & 5.9874 & TST & \\
\hline CHEMBL1545168 & 688181 & 5.4833 & 6.6913 & TRN & \\
\hline CHEMBL1608531 & 688181 & 6.5331 & 7.0036 & TRN & \\
\hline CHEMBL3193649 & 688181 & 6.1186 & 6.0928 & TRN & \\
\hline CHEMBL1486146 & 688181 & 8.0 & 6.6217 & TRN & \\
\hline CHEMBL1584055 & 688181 & 8.0 & 6.6937 & TRN & \\
\hline CHEMBL1452116 & 688181 & 5.9318 & 6.1322 & TST & \\
\hline CHEMBL1366536 & 688181 & 6.6055 & 6.4795 & TRN & \\
\hline CHEMBL1569900 & 688181 & 6.0205 & 5.8753 & TRN & \\
\hline CHEMBL1565895 & 688181 & 5.7385 & 6.1649 & TRN & \\
\hline CHEMBL1511143 & 688181 & 6.4001 & 7.204 & TRN & \\
\hline CHEMBL1965975 & 688181 & 5.6343 & 6.0299 & TRN & \\
\hline CHEMBL1540973 & 688181 & 6.4034 & 6.3295 & TRN & \\
\hline CHEMBL1455689 & 688181 & 5.6664 & 5.5681 & TRN & \\
\hline CHEMBL1465999 & 688181 & 5.6964 & 6.2934 & TRN & \\
\hline CHEMBL1612977 & 688181 & 6.4157 & 6.7566 & TRN & \\
\hline CHEMBL1470620 & 688181 & 8.0 & 6.9686 & TRN & \\
\hline CHEMBL1581822 & 688181 & 5.6784 & 6.2512 & TRN & \\
\hline CHEMBL1510199 & 688181 & 5.9562 & 5.9392 & TST & \\
\hline CHEMBL193627 & 688181 & 8.0 & 7.7829 & TRN & \\
\hline CHEMBL1481836 & 688181 & 5.4689 & 5.6975 & TRN & \\
\hline CHEMBL1539600 & 688181 & 5.7131 & 6.0711 & TRN & \\
\hline CHEMBL1353925 & 688181 & 6.0846 & 6.1567 & TRN & \\
\hline CHEMBL1547262 & 688181 & 5.5567 & 6.2972 & TRN & \\
\hline CHEMBL1986418 & 688181 & 6.3851 & 5.9381 & TRN & \\
\hline CHEMBL1545797 & 688181 & 5.8324 & 5.3791 & TRN & \\
\hline CHEMBL1528870 & 688181 & 5.6598 & 5.8133 & TRN & \\
\hline CHEMBL1460077 & 688181 & 5.6887 & 6.2088 & TST & \\
\hline CHEMBL1452711 & 688181 & 5.6026 & 5.7881 & TRN & \\
\hline CHEMBL1382799 & 688181 & 8.0 & 7.0634 & TRN & \\
\hline CHEMBL1385622 & 688181 & 5.9598 & 5.7087 & TRN & \\
\hline CHEMBL3190901 & 688181 & 5.766 & 6.1386 & TRN & \\
\hline CHEMBL1494144 & 688181 & 6.0297 & 6.3307 & TRN & \\
\hline CHEMBL1314661 & 688181 & 6.5986 & 6.4901 & TRN & \\
\hline CHEMBL1603471 & 688181 & 6.8386 & 7.0327 & TRN & \\
\hline CHEMBL1608294 & 688181 & 5.971 & 6.5936 & TRN & \\
\hline CHEMBL1442280 & 688181 & 6.5969 & 5.8895 & TRN & \\
\hline
\end{tabular}


Supplemental Table S2.txt

\begin{tabular}{|c|c|c|c|c|c|c|}
\hline CHEMBL1483235 & 688181 & 5.9983 & 6.4602 & TRN & & \\
\hline CHEMBL1360998 & 688181 & 6.0655 & 6.0662 & TST & & \\
\hline CHEMBL1342523 & 688181 & 8.0 & 6.9474 & TRN & & \\
\hline CHEMBL1580066 & 688181 & 5.3595 & 5.8457 & TST & & \\
\hline CHEMBL1523126 & 688181 & 5.6859 & 5.5396 & TRN & & \\
\hline CHEMBL1412300 & 688181 & 5.9817 & 5.9856 & TST & & \\
\hline CHEMBL1314578 & 688181 & 5.8447 & 5.7999 & TRN & & \\
\hline CHEMBL1461679 & 688181 & 6.0915 & 5.472 & TRN & & \\
\hline CHEMBL1415154 & 688181 & 5.7208 & 6.0877 & TRN & & \\
\hline CHEMBL3189428 & 688181 & 6.0259 & 5.6992 & TRN & & \\
\hline CHEMBL1478420 & 688181 & 6.063 & 6.45 & TRN & & \\
\hline CHEMBL1466191 & 688181 & 6.4089 & 6.3417 & TRN & & \\
\hline CHEMBL1565500 & 688181 & 5.4499 & 5.5794 & TST & & \\
\hline CHEMBL1409554 & 688181 & 5.6392 & 6.5982 & TRN & & \\
\hline CHEMBL1503091 & 688181 & 5.8617 & 5.6843 & TRN & & \\
\hline CHEMBL1521114 & 688181 & 8.0 & 7.2009 & TRN & & \\
\hline CHEMBL1467678 & 688181 & 6.1146 & 6.5577 & TST & & \\
\hline CHEMBL3194489 & 688181 & 5.768 & 5.8171 & TRN & & \\
\hline CHEMBL1576984 & 688181 & 5.7918 & 6.1019 & TRN & & \\
\hline CHEMBL1370471 & 688181 & 6.1675 & 6.5181 & TRN & & \\
\hline CHEMBL1734063 & 688181 & 6.9136 & 7.1716 & TRN & & \\
\hline CHEMBL1969543 & 688181 & 6.4437 & 6.9912 & TRN & & \\
\hline CHEMBL1467646 & 688181 & 5.7194 & 5.779 & TRN & & \\
\hline CHEMBL1508753 & 688181 & 5.7552 & 5.7196 & TRN & & \\
\hline CHEMBL1341771 & 688181 & 5.4517 & 5.8692 & TRN & & \\
\hline CHEMBL1584502 & 688181 & 5.4442 & 5.9694 & TRN & & \\
\hline CHEMBL1390057 & 688181 & 5.54899 & 99999999 & 95 & 6.0854 & TRN \\
\hline CHEMBL1451774 & 688181 & 5.9003 & 5.9284 & TRN & & \\
\hline CHEMBL1340282 & 688181 & 5.9359 & 5.7009 & TST & & \\
\hline CHEMBL1358906 & 688181 & 5.5045 & 6.0216 & TST & & \\
\hline CHEMBL1530438 & 688181 & 6.3401 & 5.7411 & TRN & & \\
\hline CHEMBL1323186 & 688181 & 6.9586 & 6.359 & TRN & & \\
\hline CHEMBL1459537 & 688181 & 6.8125 & 5.7186 & TST & & \\
\hline CHEMBL1406953 & 688181 & 6.8928 & 6.0371 & TRN & & \\
\hline CHEMBL1589432 & 688181 & 5.9446 & 5.7453 & TRN & & \\
\hline CHEMBL1373316 & 688181 & 5.2661 & 6.0896 & TST & & \\
\hline CHEMBL1302488 & 688181 & 5.6432 & 5.425 & TRN & & \\
\hline CHEMBL1468680 & 688181 & 5.7176 & 6.1703 & TRN & & \\
\hline CHEMBL1561609 & 688181 & 6.4881 & 6.2734 & TRN & & \\
\hline CHEMBL1483558 & 688181 & 6.1226 & 6.0648 & TRN & & \\
\hline CHEMBL1609264 & 688181 & 5.7314 & 6.2843 & TRN & & \\
\hline CHEMBL1318190 & 688181 & 5.7838 & 6.5196 & TRN & & \\
\hline CHEMBL1593567 & 688181 & 5.5685 & 6.3559 & TRN & & \\
\hline CHEMBL1423649 & 688181 & 5.4751 & 5.7577 & TRN & & \\
\hline CHEMBL1534134 & 688181 & 6.6253 & 6.6111 & TRN & & \\
\hline CHEMBL1556555 & 688181 & 6.0942 & 5.8228 & TRN & & \\
\hline CHEMBL1508738 & 688181 & 5.8874 & 6.2178 & TST & & \\
\hline CHEMBL1424344 & 688181 & 5.3304 & 5.6406 & TST & & \\
\hline
\end{tabular}


Supplemental Table S2.txt

\begin{tabular}{|c|c|c|c|c|c|c|}
\hline CHEMBL1391450 & 688181 & 5.6499 & 5.9911 & TRN & & \\
\hline CHEMBL1472130 & 688181 & 6.9706 & 6.1457 & TRN & & \\
\hline CHEMBL1570797 & 688181 & 6.6459 & 6.4045 & TRN & & \\
\hline CHEMBL1426831 & 688181 & 6.1355 & \multicolumn{3}{|c|}{6.867000000000001} & TRN \\
\hline CHEMBL602718 & 688181 & 6.0218 & 6.0119 & TRN & & \\
\hline CHEMBL1433286 & 688181 & 5.7625 & 5.9457 & TST & & \\
\hline CHEMBL1407833 & 688181 & 5.4702 & 5.3288 & TRN & & \\
\hline CHEMBL1491513 & 688181 & 6.0545 & 5.7577 & TRN & & \\
\hline CHEMBL1586425 & 688181 & 5.9052 & \multicolumn{3}{|c|}{5.622000000000001} & TST \\
\hline CHEMBL1461209 & 688181 & 6.3344 & 6.553 & TRN & & \\
\hline CHEMBL1341810 & 688181 & 6.1079 & 6.4401 & TRN & & \\
\hline CHEMBL1390857 & 688181 & 5.9007 & 5.9263 & TRN & & \\
\hline CHEMBL1382687 & 688181 & 6.0026 & 6.1562 & TRN & & \\
\hline CHEMBL1341890 & 688181 & 6.062 & 5.4867 & TRN & & \\
\hline CHEMBL1432747 & 688181 & \multicolumn{3}{|c|}{6.327000000000001} & 6.3507 & Tr \\
\hline CHEMBL1539682 & 688181 & 5.8091 & 5.6899 & TRN & & \\
\hline CHEMBL1503173 & 688181 & 5.2153 & 6.0211 & TRN & & \\
\hline CHEMBL 3189165 & 688181 & 5.9112 & 5.8166 & TST & & \\
\hline CHEMBL1405869 & 688181 & \multicolumn{3}{|c|}{5.962999999999999} & 5.7429 & 1. \\
\hline CHEMBL1526969 & 688181 & 5.4947 & 5.9252 & TRN & & \\
\hline CHEMBL1441527 & 688181 & 6.129 & 5.6953 & TRN & & \\
\hline CHEMBL1541692 & 688181 & 6.1979 & 6.5152 & TRN & & \\
\hline CHEMBL3197179 & 688181 & 6.4841 & 5.8597 & TRN & & \\
\hline CHEMBL1483975 & 688181 & 6.2299 & 6.1884 & TRN & & \\
\hline CHEMBL1377340 & 688181 & 5.6838 & 5.6594 & TST & & \\
\hline CHEMBL1391606 & 688181 & 5.9772 & 6.1591 & TRN & & \\
\hline CHEMBL584444 & 688181 & 5.6684 & 5.7877 & TRN & & \\
\hline CHEMBL1547328 & 688181 & 5.648 & 5.6283 & TRN & & \\
\hline CHEMBL1607901 & 688181 & 6.2899 & 6.3568 & TST & & \\
\hline CHEMBL 3196941 & 688181 & 5.6548 & 6.2761 & TST & & \\
\hline CHEMBL1372156 & 688181 & 5.8517 & 5.9898 & TRN & & \\
\hline CHEMBL1376053 & 688181 & 4.771 & 6.249 & TST & & \\
\hline CHEMBL1489344 & 688181 & 6.2211 & 6.0447 & TRN & & \\
\hline CHEMBL1419329 & 688181 & \multicolumn{3}{|c|}{6.3839999999999995} & 5.968 & r. \\
\hline CHEMBL1525666 & 688181 & 8.0 & 6.8881 & TRN & & \\
\hline CHEMBL1348126 & 688181 & 6.2581 & 6.7354 & TRN & & \\
\hline CHEMBL1973500 & 688181 & 5.3775 & 5.4373 & TST & & \\
\hline CHEMBL1593023 & 688181 & 5.6861 & 5.8925 & TST & & \\
\hline CHEMBL1608354 & 688181 & 6.1007 & 6.265 & TRN & & \\
\hline CHEMBL1332670 & 688181 & 5.7296 & 5.5768 & TRN & & \\
\hline CHEMBL1365141 & 688181 & 5.6639 & 6.0031 & TRN & & \\
\hline CHEMBL1368433 & 688181 & 6.0778 & 5.6152 & TRN & & \\
\hline CHEMBL1333119 & 688181 & 6.2161 & 6.2643 & TRN & & \\
\hline CHEMBL1425518 & 688181 & 8.0 & 6.2939 & TST & & \\
\hline CHEMBL1464802 & 688181 & 6.7852 & 6.4947 & TRN & & \\
\hline CHEMBL1538511 & 688181 & 6.2277 & 6.6432 & TRN & & \\
\hline CHEMBL1498430 & 688181 & \multicolumn{3}{|c|}{5.4239999999999995} & 6.4005 & וכל \\
\hline CHEMBL1532368 & 688181 & 5.7913 & 5.9781 & TRN & & \\
\hline
\end{tabular}




\begin{tabular}{|c|c|c|c|c|c|}
\hline \multicolumn{6}{|c|}{ Supplemental Table S2.txt } \\
\hline CHEMBL1521491 & 688181 & 8.0 & 7.4167 & TRN & \\
\hline CHEMBL1438109 & 688181 & 6.3188 & 6.2767 & TRN & \\
\hline CHEMBL1993522 & 688181 & 5.8824 & 6.0867 & TRN & \\
\hline CHEMBL1513856 & 688181 & 6.9031 & 6.3468 & TRN & \\
\hline CHEMBL1505781 & 688181 & 5.9435 & 6.3078 & TRN & \\
\hline CHEMBL3198425 & 688181 & 6.224 & 5.9525 & TRN & \\
\hline CHEMBL1600694 & 688181 & 6.1421 & 5.9834 & TRN & \\
\hline CHEMBL1316717 & 688181 & 5.5913 & 5.7629 & TRN & \\
\hline CHEMBL 3192460 & 688181 & 6.2857 & 6.0255 & TST & \\
\hline CHEMBL3197607 & 688181 & 6.7352 & 6.4826 & TRN & \\
\hline CHEMBL1450314 & 688181 & 6.2118 & 6.1606 & TRN & \\
\hline CHEMBL1505248 & 688181 & 5.6085 & $6.3210 e$ & 0000000001 & TST \\
\hline CHEMBL1504221 & 688181 & 5.5556 & 5.5794 & TST & \\
\hline CHEMBL1359302 & 688181 & 5.9045 & 6.2341 & TRN & \\
\hline CHEMBL1575023 & 688181 & 5.8871 & 6.5842 & TRN & \\
\hline CHEMBL504977 & 688181 & 5.6755 & 5.9149 & TST & \\
\hline CHEMBL1440203 & 688181 & 5.8262 & 5.8066 & TRN & \\
\hline CHEMBL1425204 & 688181 & 3.5229 & 5.38299 & 9999999999 & TRN \\
\hline CHEMBL1545435 & 688181 & 5.6269 & 5.6118 & TRN & \\
\hline CHEMBL1535187 & 688181 & 5.369 & 6.1375 & TST & \\
\hline CHEMBL1564403 & 688181 & 5.4868 & 5.5977 & TRN & \\
\hline CHEMBL1401790 & 688181 & 6.1979 & 6.2856 & TRN & \\
\hline CHEMBL1495833 & 688181 & 8.0 & 6.996 & TRN & \\
\hline CHEMBL1542513 & 688181 & 5.9809 & 5.5425 & TST & \\
\hline CHEMBL1538919 & 688181 & 6.6421 & 6.4519 & TRN & \\
\hline CHEMBL1439199 & 688181 & 5.4866 & 5.8346 & TRN & \\
\hline CHEMBL1542029 & 688181 & 4.4895 & 5.40799 & 99999999995 & TRN \\
\hline CHEMBL1989294 & 688181 & 6.1203 & 6.12 & TRN & \\
\hline CHEMBL1359154 & 688181 & 5.7612 & 5.7189 & TST & \\
\hline CHEMBL1528186 & 688181 & 6.109 & 5.8598 & TRN & \\
\hline CHEMBL582980 & 688181 & 5.6284 & 6.1583 & TRN & \\
\hline CHEMBL1601701 & 688181 & 5.9397 & 6.0039 & TST & \\
\hline CHEMBL1569989 & 688181 & 5.8996 & 6.0687 & TRN & \\
\hline CHEMBL1384550 & 688181 & 6.5129 & 5.9653 & TRN & \\
\hline CHEMBL1381724 & 688181 & 5.556 & 5.9966 & TST & \\
\hline CHEMBL1990545 & 688181 & 6.7545 & 6.6986 & TRN & \\
\hline CHEMBL1372201 & 688181 & 6.0975 & 6.0183 & TRN & \\
\hline CHEMBL1395454 & 688181 & 5.4791 & 5.5569 & TRN & \\
\hline CHEMBL1606239 & 688181 & 5.5916 & 6.0608 & TST & \\
\hline CHEMBL1471351 & 688181 & 5.8386 & 5.7461 & TRN & \\
\hline CHEMBL1570959 & 688181 & 8.0 & 7.3396 & TRN & \\
\hline CHEMBL1609301 & 688181 & 8.0 & 6.5699 & TRN & \\
\hline CHEMBL1448733 & 688181 & 5.8173 & 6.3974 & TRN & \\
\hline CHEMBL1305827 & 688181 & 5.6182 & 6.2121 & TRN & \\
\hline CHEMBL1595133 & 688181 & 5.1123 & 5.8666 & TST & \\
\hline CHEMBL1590892 & 688181 & 6.8297 & 6.7432 & TRN & \\
\hline CHEMBL1352337 & 688181 & 8.0 & 6.9004 & TRN & \\
\hline CHEMBL1411488 & 688181 & 6.1649 & 5.9471 & TRN & \\
\hline
\end{tabular}


Supplemental Table S2.txt

\begin{tabular}{|c|c|c|c|c|c|c|}
\hline CHEMBL1462774 & 688181 & 5.7231 & 5.5027 & TRN & & \\
\hline CHEMBL1473337 & 688181 & 5.7373 & 5.6874 & TRN & & \\
\hline CHEMBL1532997 & 688181 & 6.6946 & 6.2844 & TRN & & \\
\hline CHEMBL1431912 & 688181 & 5.7899 & 6.4439 & TRN & & \\
\hline CHEMBL1494214 & 688181 & 5.61299 & 99999999 & 995 & 5.2304 & TRN \\
\hline CHEMBL1521122 & 688181 & 5.6576 & 5.8313 & TRN & & \\
\hline CHEMBL1477061 & 688181 & 5.6386 & 5.6975 & TRN & & \\
\hline CHEMBL1344557 & 688181 & 6.5884 & 6.4893 & TRN & & \\
\hline CHEMBL1403185 & 688181 & 6.0255 & 6.0509 & TRN & & \\
\hline CHEMBL1557781 & 688181 & 6.5935 & 6.1256 & TRN & & \\
\hline CHEMBL1362490 & 688181 & 6.767 & 6.8832 & TRN & & \\
\hline CHEMBL1413416 & 688181 & 5.487 & 6.0963 & TRN & & \\
\hline CHEMBL1542883 & 688181 & 6.0942 & 5.7937 & TRN & & \\
\hline CHEMBL1576407 & 688181 & 6.1391 & 6.2955 & TRN & & \\
\hline CHEMBL1467164 & 688181 & 5.8864 & 6.1789 & TRN & & \\
\hline CHEMBL1532127 & 688181 & 6.0915 & 6.2455 & TRN & & \\
\hline CHEMBL1565189 & 688181 & 6.2581 & 6.4806 & TST & & \\
\hline CHEMBL1320243 & 688181 & 6.3595 & 5.5535 & TRN & & \\
\hline CHEMBL1510244 & 688181 & 6.2358 & 6.3463 & TRN & & \\
\hline CHEMBL1451696 & 688181 & 5.6927 & 5.9707 & TRN & & \\
\hline CHEMBL1494100 & 688181 & 5.5479 & 5.3357 & TRN & & \\
\hline CHEMBL1532303 & 688181 & 5.6868 & 5.9459 & TRN & & \\
\hline CHEMBL1606330 & 688181 & 5.4572 & 5.4975 & TST & & \\
\hline CHEMBL1380914 & 688181 & 5.8904 & 5.7687 & TRN & & \\
\hline CHEMBL1578834 & 688181 & 5.3594 & 5.5729 & TST & & \\
\hline CHEMBL1468684 & 688181 & 5.7438 & 5.6345 & TRN & & \\
\hline CHEMBL602828 & 688181 & 6.5436 & 6.9266 & TST & & \\
\hline CHEMBL1603936 & 688181 & 6.4895 & 7.5921 & TST & & \\
\hline CHEMBL3193663 & 688181 & 6.4895 & 5.812 & TRN & & \\
\hline CHEMBL1364072 & 688181 & 6.0283 & 6.5135 & TRN & & \\
\hline CHEMBL1352004 & 688181 & 6.2541 & 6.8029 & TRN & & \\
\hline CHEMBL3210310 & 688181 & 6.1785 & 5.9762 & TST & & \\
\hline CHEMBL3210588 & 688181 & 5.5564 & 5.3756 & TST & & \\
\hline CHEMBL1589219 & 688181 & 5.555 & 5.755 & TST & & \\
\hline CHEMBL1387790 & 688181 & 5.7368 & 5.7715 & TRN & & \\
\hline CHEMBL1490247 & 688181 & 6.3224 & 6.1799 & TRN & & \\
\hline CHEMBL3207397 & 688181 & 8.0 & 6.9908 & TRN & & \\
\hline CHEMBL1545406 & 688181 & 6.0306 & 5.6293 & TRN & & \\
\hline CHEMBL1494154 & 688181 & 6.8508 & 6.6665 & TRN & & \\
\hline CHEMBL1342145 & 688181 & 6.684 & 6.3671 & TRN & & \\
\hline CHEMBL1384438 & 688181 & 5.5829 & 5.9324 & TRN & & \\
\hline CHEMBL1352981 & 688181 & 6.9031 & 6.5385 & TRN & & \\
\hline CHEMBL1505746 & 688181 & 6.2741 & 6.4153 & TRN & & \\
\hline CHEMBL1596747 & 688181 & 5.6882 & 5.7343 & TST & & \\
\hline CHEMBL1586169 & 688181 & \multicolumn{3}{|c|}{6.247999999999999} & 6.8766 & TRN \\
\hline CHEMBL1501121 & 688181 & 5.7279 & 5.9196 & TRN & & \\
\hline CHEMBL1597693 & 688181 & 5.9285 & 6.6412 & TRN & & \\
\hline CHEMBL1430895 & 688181 & 5.5901 & 5.2134 & TRN & & \\
\hline
\end{tabular}




\begin{tabular}{|c|c|c|c|c|c|c|}
\hline \multicolumn{7}{|c|}{ Supplemental Table S2.txt } \\
\hline CHEMBL1610386 & 688181 & 8.0 & 6.5135 & TRN & & \\
\hline CHEMBL1353980 & 688181 & 8.0 & 6.2926 & TST & & \\
\hline CHEMBL1596149 & 688181 & 8.0 & 7.1953 & TRN & & \\
\hline CHEMBL1967586 & 688181 & 5.7058 & 6.1807 & TST & & \\
\hline CHEMBL1451911 & 688181 & 6.6904 & 5.6872 & TRN & & \\
\hline CHEMBL3197532 & 688181 & 5.8732 & 6.854 & TRN & & \\
\hline CHEMBL1593551 & 688181 & 5.9289 & 5.9133 & TRN & & \\
\hline CHEMBL1445206 & 688181 & 5.4437 & 5.6939 & TRN & & \\
\hline CHEMBL3196495 & 688181 & 6.4437 & 6.3811 & TRN & & \\
\hline CHEMBL1480827 & 688181 & 5.6092 & 5.1214 & TRN & & \\
\hline CHEMBL590927 & 688181 & 6.2782 & 6.2795 & TRN & & \\
\hline CHEMBL1494922 & 688181 & 6.0585 & 6.084 & TST & & \\
\hline CHEMBL1338004 & 688181 & 6.1163 & 6.5085 & TRN & & \\
\hline CHEMBL1383709 & 688181 & 6.0209 & 6.3425 & TRN & & \\
\hline CHEMBL1393813 & 688181 & 5.8755 & 6.1737 & TRN & & \\
\hline CHEMBL3189322 & 688181 & 6.9431 & 5.9614 & TRN & & \\
\hline CHEMBL1508826 & 688181 & 5.6582 & 5.9714 & TRN & & \\
\hline CHEMBL1576004 & 688181 & 6.0762 & 5.9955 & TRN & & \\
\hline CHEMBL1534967 & 688181 & 6.6402 & 6.1305 & TRN & & \\
\hline CHEMBL3213920 & 688181 & 5.76399 & 99999995 & & 5.9876 & TRN \\
\hline CHEMBL3194226 & 688181 & 5.74299 & 99999995 & 99 & 6.2966 & TRN \\
\hline CHEMBL1390786 & 688181 & 5.8539 & 5.934 & TRN & & \\
\hline CHEMBL1584308 & 688181 & 6.1421 & 5.6044 & TRN & & \\
\hline CHEMBL1335491 & 688181 & 5.9151 & 5.6856 & TRN & & \\
\hline CHEMBL1541409 & 688181 & 6.2967 & 5.7766 & TRN & & \\
\hline CHEMBL1378719 & 688181 & 6.279 & 6.4095 & TRN & & \\
\hline CHEMBL1535696 & 688181 & 6.3429 & 6.968 & TRN & & \\
\hline CHEMBL 3211420 & 688181 & 6.3497 & 6.3767 & TRN & & \\
\hline CHEMBL1413689 & 688181 & 5.5923 & 5.9007 & TRN & & \\
\hline CHEMBL1361507 & 688181 & 5.83799 & 99999995 & 99 & 5.956 & TST \\
\hline CHEMBL1481521 & 688181 & 5.7387 & 6.0214 & TRN & & \\
\hline CHEMBL533542 & 688181 & 5.7402 & 6.0829 & TRN & & \\
\hline CHEMBL1391094 & 688181 & 5.5455 & 5.2463 & TRN & & \\
\hline CHEMBL1460273 & 688181 & 5.8726 & 6.4578 & TST & & \\
\hline CHEMBL1349314 & 688181 & 6.6038 & 6.6169 & TRN & & \\
\hline CHEMBL1535252 & 688181 & 5.6137 & 6.0232 & TRN & & \\
\hline CHEMBL1379112 & 688181 & 5.8948 & 5.7993 & TRN & & \\
\hline CHEMBL1452090 & 688181 & 5.8739 & 5.9964 & TRN & & \\
\hline CHEMBL1426189 & 688181 & 5.8333 & 5.4652 & TRN & & \\
\hline CHEMBL1364193 & 688181 & 5.3419 & 6.0122 & TRN & & \\
\hline CHEMBL1340890 & 688181 & 5.4594 & 5.9193 & TRN & & \\
\hline CHEMBL1413459 & 688181 & 6.6364 & 6.5531 & TRN & & \\
\hline CHEMBL1499282 & 688181 & 5.7582 & 6.106 & TRN & & \\
\hline CHEMBL3193826 & 688181 & 5.7956 & 6.5382 & TRN & & \\
\hline CHEMBL1335286 & 688181 & 6.6308 & 5.6686 & TST & & \\
\hline CHEMBL3196547 & 688181 & 6.3675 & 7.0231 & TRN & & \\
\hline CHEMBL1389316 & 688181 & 5.8365 & 6.5969 & TRN & & \\
\hline CHEMBL1499059 & 688181 & 6.0931 & 5.4109 & TRN & & \\
\hline
\end{tabular}


Supplemental Table S2.txt

\begin{tabular}{|c|c|c|c|c|c|}
\hline CHEMBL1325631 & 688181 & 5.8213 & 5.5325 & TST & \\
\hline CHEMBL1549336 & 688181 & 6.7077 & 7.0818 & TRN & \\
\hline CHEMBL1516792 & 688181 & 5.6556 & 5.5588 & TRN & \\
\hline CHEMBL1543470 & 688181 & 5.7625 & 5.8695 & TRN & \\
\hline CHEMBL1602684 & 688181 & 5.8306 & 5.5479 & TRN & \\
\hline CHEMBL1539286 & 688181 & 6.9066 & 7.0518 & TRN & \\
\hline CHEMBL1401845 & 688181 & 6.8069 & 6.0742 & TRN & \\
\hline CHEMBL1468734 & 688181 & 6.3206 & 6.6861 & TRN & \\
\hline CHEMBL1584157 & 688181 & 6.4157 & 6.2261 & TRN & \\
\hline CHEMBL1572967 & 688181 & 5.9374 & 5.9108 & TRN & \\
\hline CHEMBL1458403 & 688181 & 6.8041 & 5.9748 & TRN & \\
\hline CHEMBL1441035 & 688181 & 6.2314 & 6.975 & TRN & \\
\hline CHEMBL1514131 & 688181 & 6.0706 & 6.3516 & TRN & \\
\hline CHEMBL1412887 & 688181 & 6.5901 & 6.7449 & TRN & \\
\hline CHEMBL1561119 & 688181 & 5.8441 & 6.3271 & TRN & \\
\hline CHEMBL1454385 & 688181 & 5.6488 & 6.2787 & TRN & \\
\hline CHEMBL1506248 & 688181 & 5.6996 & 5.9412 & TRN & \\
\hline CHEMBL1511640 & 688181 & 6.1851 & 6.0754 & TRN & \\
\hline CHEMBL1428016 & 688181 & 5.3288 & 5.6114 & TRN & \\
\hline CHEMBL1606254 & 688181 & 6.8697 & 6.6254 & TST & \\
\hline CHEMBL1540768 & 688181 & 5.9702 & 5.7065 & TRN & \\
\hline CHEMBL1376864 & 688181 & 6.3045 & 6.2458 & TRN & \\
\hline CHEMBL1484388 & 688181 & 6.5287 & 7.2125 & TRN & \\
\hline CHEMBL1529180 & 688181 & 5.7007 & 5.79799 & 9999999999 & TRN \\
\hline CHEMBL1421267 & 688181 & 8.0 & 7.6696 & TRN & \\
\hline CHEMBL1566203 & 688181 & 5.6276 & 5.4863 & TST & \\
\hline CHEMBL1404536 & 688181 & 6.0405 & 6.901 & TRN & \\
\hline CHEMBL 3209453 & 688181 & 6.4685 & 6.031006 & 0000000001 & TRN \\
\hline CHEMBL1410701 & 688181 & 5.8147 & 6.3178 & TRN & \\
\hline CHEMBL1386577 & 688181 & 6.8069 & 6.2669 & TST & \\
\hline CHEMBL1386031 & 688181 & 6.7352 & 6.3035 & TRN & \\
\hline CHEMBL1502523 & 688181 & 5.6923 & 5.5186 & TRN & \\
\hline CHEMBL1473001 & 688181 & 6.4895 & 6.3131 & TRN & \\
\hline CHEMBL1300244 & 688181 & 5.8837 & 6.9662 & TST & \\
\hline CHEMBL1599283 & 688181 & 3.2218 & 5.7312 & TST & \\
\hline CHEMBL1501300 & 688181 & 8.0 & 6.7922 & TRN & \\
\hline CHEMBL 3194048 & 688181 & 5.6287 & 5.54899 & 99999999995 & TST \\
\hline CHEMBL 3192795 & 688181 & 6.8182 & 6.4041 & TST & \\
\hline CHEMBL 3197177 & 688181 & 8.0 & 6.0247 & TRN & \\
\hline CHEMBL1557674 & 688181 & 5.8874 & 6.093 & TRN & \\
\hline CHEMBL1461084 & 688181 & 3.2218 & 5.4098 & TRN & \\
\hline CHEMBL1581410 & 688181 & 5.5281 & 6.4539 & TRN & \\
\hline CHEMBL1408619 & 688181 & 5.4323 & 5.8132 & TST & \\
\hline CHEMBL1481335 & 688181 & 5.9311 & 6.0473 & TRN & \\
\hline CHEMBL1435226 & 688181 & 5.862 & 5.7596 & TRN & \\
\hline CHEMBL3196117 & 688181 & 5.4646 & 6.0173 & TRN & \\
\hline CHEMBL1460032 & 688181 & 5.5774 & 6.1738 & TST & \\
\hline CHEMBL1517374 & 688181 & 5.3595 & 5.6432 & TST & \\
\hline
\end{tabular}




\begin{tabular}{|c|c|c|c|c|c|c|}
\hline & & \multicolumn{5}{|c|}{ Supplemental Table S2.txt } \\
\hline CHEMBL1452858 & 688181 & 5.6059 & 5.816 & TRN & & \\
\hline CHEMBL1304951 & 688181 & 5.9442 & 5.6268 & TRN & & \\
\hline CHEMBL1343069 & 688181 & 6.0585 & 6.0127 & TRN & & \\
\hline CHEMBL1405379 & 688181 & 5.9666 & 6.2998 & TRN & & \\
\hline CHEMBL 3196538 & 688181 & 5.6108 & 5.3996 & TST & & \\
\hline CHEMBL1385250 & 688181 & \multicolumn{3}{|c|}{6.082000000000001} & 6.6839 & TRN \\
\hline CHEMBL1557849 & 688181 & 8.0 & 6.0238 & TST & & \\
\hline CHEMBL1518850 & 688181 & 6.7055 & 6.8638 & TRN & & \\
\hline CHEMBL1550862 & 688181 & 6.1221 & 5.9892 & TRN & & \\
\hline CHEMBL1547627 & 688181 & 5.7719 & 6.3925 & TST & & \\
\hline CHEMBL1411474 & 688181 & 6.1959 & 6.3444 & TRN & & \\
\hline CHEMBL1523432 & 688181 & 5.5722 & 5.8453 & TRN & & \\
\hline CHEMBL1393788 & 688181 & 6.0585 & 5.6646 & TRN & & \\
\hline CHEMBL1416252 & 688181 & 6.2351 & 6.4013 & TRN & & \\
\hline CHEMBL1528519 & 688181 & 6.0123 & 6.4176 & TRN & & \\
\hline CHEMBL1998592 & 688181 & 5.4381 & 5.9388 & TST & & \\
\hline CHEMBL1611426 & 688181 & \multicolumn{3}{|c|}{6.617999999999999} & 5.9475 & TRN \\
\hline CHEMBL1546247 & 688181 & 3.2218 & 5.6938 & TRN & & \\
\hline CHEMBL1461748 & 688181 & 5.965 & 5.7828 & TRN & & \\
\hline CHEMBL1404209 & 688181 & 5.6755 & 5.5002 & TRN & & \\
\hline CHEMBL1517535 & 688181 & 5.6716 & \multicolumn{3}{|c|}{5.742000000000001} & TRN \\
\hline CHEMBL1612163 & 688181 & \multicolumn{3}{|c|}{6.117999999999999} & 6.1787 & TRN \\
\hline CHEMBL1546468 & 688181 & 6.2069 & 5.8323 & TST & & \\
\hline CHEMBL1465021 & 688181 & 5.8693 & 6.2443 & TRN & & \\
\hline CHEMBL1486862 & 688181 & 5.8055 & 6.1104 & TRN & & \\
\hline CHEMBL1414508 & 688181 & 6.098 & 5.7474 & TRN & & \\
\hline CHEMBL1300618 & 688181 & 5.8083 & 5.9052 & TRN & & \\
\hline CHEMBL1479266 & 688181 & 8.0 & 7.4697 & TRN & & \\
\hline CHEMBL1306666 & 688181 & 5.914 & 5.8067 & TRN & & \\
\hline CHEMBL1583933 & 688181 & 6.983 & 7.3178 & TRN & & \\
\hline CHEMBL1482730 & 688181 & 5.7091 & 5.8404 & TRN & & \\
\hline CHEMBL1606040 & 688181 & 6.2343 & 6.0927 & TRN & & \\
\hline CHEMBL1534949 & 688181 & 5.6077 & 5.7609 & TRN & & \\
\hline CHEMBL1595226 & 688181 & 6.3401 & 6.749 & TRN & & \\
\hline CHEMBL1374678 & 688181 & 5.6546 & 5.7086 & TST & & \\
\hline CHEMBL1329490 & 688181 & 5.6424 & 5.6985 & TRN & & \\
\hline CHEMBL3197981 & 688181 & 6.0264 & 5.731 & TST & & \\
\hline CHEMBL1386511 & 688181 & 8.0 & 6.5889 & TRN & & \\
\hline CHEMBL3211771 & 688181 & 6.0742 & 6.2441 & TRN & & \\
\hline CHEMBL1380419 & 688181 & 6.4157 & 6.7608 & TST & & \\
\hline CHEMBL1379600 & 688181 & 5.4861 & 6.2038 & TRN & & \\
\hline CHEMBL1423881 & 688181 & 6.1415 & 5.8887 & TRN & & \\
\hline CHEMBL1354027 & 688181 & \multicolumn{3}{|c|}{5.5329999999999995} & 5.4594 & TST \\
\hline CHEMBL586937 & 688181 & 6.5129 & 5.9485 & TRN & & \\
\hline CHEMBL1326349 & 688181 & 5.9307 & 5.6486 & TST & & \\
\hline CHEMBL1527565 & 688181 & 5.6245 & 5.608 & TST & & \\
\hline CHEMBL1539905 & 688181 & 6.9101 & 5.9543 & TRN & & \\
\hline CHEMBL1377903 & 688181 & 5.7523 & 5.9556 & TRN & & \\
\hline
\end{tabular}




\begin{tabular}{|c|c|c|c|c|c|c|}
\hline \multirow[b]{2}{*}{ CHEMBL1610565 } & & \multicolumn{5}{|c|}{ Supplemental Table S2.txt } \\
\hline & 688181 & 5.7009 & 6.4841 & TRN & & \\
\hline CHEMBL3199937 & 688181 & 5.32799 & 99999999 & 99 & 5.4852 & TRN \\
\hline CHEMBL1476995 & 688181 & 6.1669 & 6.2515 & TRN & & \\
\hline CHEMBL1459491 & 688181 & 3.2218 & 6.2719 & TRN & & \\
\hline CHEMBL1388262 & 688181 & 5.468 & 5.9352 & TRN & & \\
\hline CHEMBL1338599 & 688181 & 6.2984 & 6.4599 & TRN & & \\
\hline CHEMBL1468750 & 688181 & 5.6407 & 5.8683 & TRN & & \\
\hline CHEMBL3191812 & 688181 & 5.6377 & 6.0056 & TRN & & \\
\hline CHEMBL1465112 & 688181 & 8.0 & 7.1403 & TRN & & \\
\hline CHEMBL1515913 & 688181 & 5.8719 & 6.0903 & TRN & & \\
\hline CHEMBL527584 & 688181 & 5.5306 & 5.7023 & TRN & & \\
\hline CHEMBL1401011 & 688181 & 5.4161 & 5.7634 & TRN & & \\
\hline CHEMBL530291 & 688181 & 8.0 & 8.2288 & TRN & & \\
\hline CHEMBL1513196 & 688181 & 6.6778 & 5.8675 & TRN & & \\
\hline CHEMBL493691 & 688181 & 6.8477 & 6.221 & TST & & \\
\hline CHEMBL1584573 & 688181 & 8.0 & 6.9729 & TRN & & \\
\hline CHEMBL1401325 & 688181 & 6.9626 & 6.3213 & TRN & & \\
\hline CHEMBL1562557 & 688181 & 6.3915 & 5.9435 & TRN & & \\
\hline CHEMBL3192725 & 688181 & 6.8239 & 6.0408 & TRN & & \\
\hline CHEMBL1494718 & 688181 & 6.21899 & 99999999 & 99 & 6.4095 & TRN \\
\hline CHEMBL1312033 & 688181 & 6.0264 & 5.6186 & TRN & & \\
\hline CHEMBL1470115 & 688181 & 6.0731 & 6.6825 & TRN & & \\
\hline CHEMBL1543347 & 688181 & 6.1669 & 5.8784 & TRN & & \\
\hline CHEMBL3198299 & 688181 & 5.9884 & 6.197 & TRN & & \\
\hline CHEMBL1358038 & 688181 & 5.6964 & 6.4185 & TST & & \\
\hline CHEMBL1327693 & 688181 & 5.5193 & 5.8552 & TRN & & \\
\hline CHEMBL1440904 & 688181 & 5.5913 & 6.6752 & TRN & & \\
\hline CHEMBL1583668 & 688181 & 5.9292 & 5.4826 & TRN & & \\
\hline CHEMBL1347246 & 688181 & 5.7203 & 5.9751 & TRN & & \\
\hline CHEMBL1419954 & 688181 & 5.6169 & 5.3642 & TRN & & \\
\hline CHEMBL1578876 & 688181 & 6.08200 & 30000000 & $\partial 1$ & 6.5881 & TRN \\
\hline CHEMBL1348336 & 688181 & 5.5137 & 5.3111 & TST & & \\
\hline CHEMBL1388509 & 688181 & 5.7414 & 5.7172 & TST & & \\
\hline CHEMBL1557079 & 688181 & 8.0 & 7.3092 & TRN & & \\
\hline CHEMBL1528097 & 688181 & 4.6699 & 5.8235 & TRN & & \\
\hline CHEMBL1307435 & 688181 & 5.9401 & 6.0548 & TRN & & \\
\hline CHEMBL1585288 & 688181 & 4.9527 & 5.3905 & TRN & & \\
\hline CHEMBL1523938 & 688181 & 5.4931 & 5.9678 & TST & & \\
\hline CHEMBL1523566 & 688181 & 5.7729 & 5.8491 & TRN & & \\
\hline CHEMBL1427185 & 688181 & 5.5555 & 6.1538 & TST & & \\
\hline CHEMBL1605450 & 688181 & 6.0017 & 5.8386 & TST & & \\
\hline CHEMBL586465 & 688181 & 8.0 & 6.9866 & TRN & & \\
\hline CHEMBL1510627 & 688181 & 6.1891 & 5.7609 & TRN & & \\
\hline CHEMBL1574497 & 688181 & 5.7799 & 6.152 & TST & & \\
\hline CHEMBL 1406270 & 688181 & 8.0 & 5.9092 & TRN & & \\
\hline CHEMBL1410751 & 688181 & 6.7144 & 6.3699 & TRN & & \\
\hline CHEMBL1431335 & 688181 & 5.5707 & 5.7176 & TRN & & \\
\hline CHEMBL1589364 & 688181 & 6.3344 & 6.2807 & TST & & \\
\hline
\end{tabular}


Supplemental Table S2.txt

\begin{tabular}{|c|c|c|c|c|}
\hline 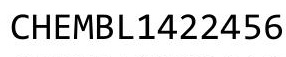 & & & & \\
\hline HEMBL3193010 & 88181 & 9027 & 5528 & \\
\hline HEMBL1583419 & 88181 & 7959 & 1888 & \\
\hline IEMBL1: & & & & \\
\hline EMBL14 & & & 5519 & \\
\hline AEMBL1400434 & 88181 & 1215 & .7769 & \\
\hline HEMBL1403575 & 88181 & .6137 & .3767 & \\
\hline HEMBL31972 & 81 & & 2009 & \\
\hline IEMBL: & 81 & 14 & .2878 & \\
\hline IEMBL13 & 81 & & .8098 & \\
\hline HEMBL1512725 & 88181 & 431 & .8719 & \\
\hline HEMBL1502346 & 88181 & .776 & .9706 & \\
\hline HEMBL1550397 & 88 & 58 & .8994 & \\
\hline HEMBL1426 & 81 & & 5857 & \\
\hline HEMBL136 & 81 & & 9301 & \\
\hline HEMBL1363887 & 88181 & & 2178 & \\
\hline HEMBL1545484 & 88181 & & .5845 & \\
\hline HEMBL156 & 31 & & 209 & \\
\hline HEMBL15 & 31 & & & \\
\hline HEMBL14 & 81 & & 348 & RN \\
\hline HEMBL15 & 81 & & 1227 & \\
\hline HEMBL1501645 & 31 & & 5.6641 & \\
\hline HEMBL15€ & 31 & & 7.3555 & RIV \\
\hline HEMBL13 & & & 2233 & RN \\
\hline HEM & 31 & & 6.0299 & $\mathrm{RN}$ \\
\hline HEMBL 319 & 31 & & 5.3938 & 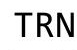 \\
\hline HEMBL 321 & 31 & & 5.9374 & SI \\
\hline HEMBL19 & 31 & & 897 & RN \\
\hline HEM & 31 & & 55 & RN \\
\hline HEM & 31 & & 6.8623 & RN \\
\hline HEMBL154 & 31 & & & RN \\
\hline HEMBL1299672 & 31 & & 5.7283 & RN \\
\hline AEMBL1: & & & 29 & RN \\
\hline HEM & 31 & & 45 & RN \\
\hline HEN & & & & $\mathrm{RN}$ \\
\hline HEMBL1606685 & 31 & & & RN \\
\hline HEMBL1389471 & 81 & & 5.6798 & RN \\
\hline LTT & & & 7753 & RN \\
\hline IIM & 31 & & .6362 & $\mathrm{RN}$ \\
\hline HEMBL140 & & & & ST \\
\hline HEMBL3190825 & 88181 & & 093 & RN \\
\hline HEMBL 319442 & 81 & & 546 & \\
\hline HEM & & & 5.9303 & \\
\hline HEMBL1399938 & 81 & & .4797 & RN \\
\hline HEMBL1361407 & & & 6.8095 & RN \\
\hline HEMBL14267 & 88181 & & 6.2775 & $N$ \\
\hline HEMBL13782 & & & & \\
\hline -1 1 & & & & \\
\hline
\end{tabular}

Page 14155 


\begin{tabular}{|c|c|c|c|c|c|c|}
\hline & & \multicolumn{5}{|c|}{ Supplemental Table S2.txt } \\
\hline CHEMBL1339538 & 688181 & 5.4421 & 6.1132 & TST & & \\
\hline CHEMBL1580663 & 688181 & 6.1884 & 6.3255 & TRN & & \\
\hline CHEMBL1333742 & 688181 & \multicolumn{3}{|c|}{5.656000000000001} & 6.046 & TRN \\
\hline CHEMBL1312606 & 688181 & 6.2426 & 5.7951 & TRN & & \\
\hline CHEMBL1393475 & 688181 & 5.669 & 6.0276 & TST & & \\
\hline CHEMBL1471188 & 688181 & 5.6602 & 6.228 & TRN & & \\
\hline CHEMBL1465142 & 688181 & 5.3896 & 5.5895 & TRN & & \\
\hline CHEMBL1477200 & 688181 & \multicolumn{3}{|c|}{5.4270000000000005} & 6.0604 & TRN \\
\hline CHEMBL1382744 & 688181 & 8.0 & 7.4334 & TRN & & \\
\hline CHEMBL1594815 & 688181 & 6.8386 & 6.4201 & TRN & & \\
\hline CHEMBL1324135 & 688181 & 5.5756 & 5.5869 & TRN & & \\
\hline CHEMBL1974613 & 688181 & 5.7804 & 5.8821 & TRN & & \\
\hline CHEMBL1561187 & 688181 & 5.5211 & 6.3708 & TRN & & \\
\hline CHEMBL1562386 & 688181 & 6.1568 & 6.7526 & TRN & & \\
\hline CHEMBL1595675 & 688181 & 6.6904 & 5.9701 & TRN & & \\
\hline CHEMBL1468779 & 688181 & 5.7815 & 6.0586 & TRN & & \\
\hline CHEMBL1329129 & 688181 & 5.815 & 6.3031 & TRN & & \\
\hline CHEMBL1312371 & 688181 & 5.5508 & 6.4001 & TST & & \\
\hline CHEMBL 1460700 & 688181 & 6.6716 & 6.8752 & TRN & & \\
\hline CHEMBL1487443 & 688181 & 5.6953 & 5.6353 & TRN & & \\
\hline CHEMBL1458736 & 688181 & 8.0 & 7.4963 & TRN & & \\
\hline CHEMBL1493490 & 688181 & 6.0026 & 6.1097 & TRN & & \\
\hline CHEMBL1414078 & 688181 & 5.5436 & 6.114 & TRN & & \\
\hline CHEMBL1490311 & 688181 & 6.1637 & 6.0117 & TRN & & \\
\hline CHEMBL1457139 & 688181 & 6.0799 & 5.8911 & TRN & & \\
\hline CHEMBL1486900 & 688181 & 6.9355 & 7.1589 & TRN & & \\
\hline CHEMBL1524333 & 688181 & 5.7025 & 6.2355 & TST & & \\
\hline CHEMBL1373654 & 688181 & 5.5479 & 6.1751 & TST & & \\
\hline CHEMBL1418062 & 688181 & 3.2218 & 6.2169 & TST & & \\
\hline CHEMBL1459681 & 688181 & 5.6137 & 5.581 & TST & & \\
\hline CHEMBL1535811 & 688181 & 6.1146 & 6.045 & TST & & \\
\hline CHEMBL1342070 & 688181 & 5.5103 & 6.0069 & TST & & \\
\hline CHEMBL1382191 & 688181 & 8.0 & 6.79700 & 0000000001 & & TRN \\
\hline CHEMBL3196365 & 688181 & 5.6611 & 5.4704 & TRN & & \\
\hline CHEMBL1390538 & 688181 & 5.0788 & 6.0688 & TRN & & \\
\hline CHEMBL1365484 & 688181 & 5.9961 & 5.7824 & TRN & & \\
\hline CHEMBL1324397 & 688181 & 6.644 & 6.6011 & TRN & & \\
\hline CHEMBL1330269 & 688181 & 5.3248 & 5.7892 & TRN & & \\
\hline CHEMBL1403090 & 688181 & 6.1068 & 6.0239 & TRN & & \\
\hline CHEMBL1488269 & 688181 & 6.1002 & 6.3945 & TRN & & \\
\hline CHEMBL1466872 & 688181 & 6.9914 & 6.3498 & TRN & & \\
\hline CHEMBL1371896 & 688181 & 6.2381 & 6.1738 & TRN & & \\
\hline CHEMBL3211221 & 688181 & 5.6866 & 6.3174 & TST & & \\
\hline CHEMBL1564958 & 688181 & 6.1891 & 6.0109 & TRN & & \\
\hline CHEMBL1583892 & 688181 & 6.8268 & 7.271 & TRN & & \\
\hline CHEMBL1347793 & 688181 & 5.7433 & 6.0268 & TRN & & \\
\hline CHEMBL1500417 & 688181 & 6.7011 & 6.0291 & TRN & & \\
\hline CHEMBL3212436 & 688181 & 6.0685 & 5.8841 & TRN & & \\
\hline
\end{tabular}




\begin{tabular}{|c|c|c|c|c|c|}
\hline \multicolumn{6}{|c|}{ Supplemental Table S2.txt } \\
\hline CHEMBL578689 & 688181 & 8.0 & 6.6458 & TRN & \\
\hline CHEMBL1600830 & 688181 & 8.0 & 7.0992 & TRN & \\
\hline CHEMBL1335443 & 688181 & 6.1945 & 6.6006 & TRN & \\
\hline CHEMBL1457644 & 688181 & 5.731 & 5.4865 & TRN & \\
\hline CHEMBL1994402 & 688181 & 5.7637 & 5.7725 & TRN & \\
\hline CHEMBL1363108 & 688181 & 5.8864 & 6.5886 & TRN & \\
\hline CHEMBL1560506 & 688181 & 6.1851 & 6.534 & TRN & \\
\hline CHEMBL1604690 & 688181 & 5.7533 & 5.57799 & 9999999999 & TRN \\
\hline CHEMBL1374947 & 688181 & 6.0841 & 6.1655 & TRN & \\
\hline CHEMBL1611486 & 688181 & 8.0 & 6.8519 & TRN & \\
\hline CHEMBL1522648 & 688181 & 5.9747 & 6.0157 & TRN & \\
\hline CHEMBL1491864 & 688181 & 6.3325 & 6.1711 & TRN & \\
\hline CHEMBL 3192432 & 688181 & 8.0 & 6.7957 & TRN & \\
\hline CHEMBL1580381 & 688181 & 5.9389 & 6.1844 & TRN & \\
\hline CHEMBL1520276 & 688181 & 5.4309 & 5.5201 & TRN & \\
\hline CHEMBL1540776 & 688181 & 6.4157 & 6.2004 & TRN & \\
\hline CHEMBL1385771 & 688181 & 5.6605 & 5.8001 & TRN & \\
\hline CHEMBL1354909 & 688181 & 5.9154 & 5.57600 & 00000000005 & TRN \\
\hline CHEMBL1334937 & 688181 & 5.495 & 5.3379 & TRN & \\
\hline CHEMBL1337204 & 688181 & 5.5017 & 5.4419 & TRN & \\
\hline CHEMBL1409903 & 688181 & 5.4777 & 6.3743 & TRN & \\
\hline CHEMBL3197856 & 688181 & 6.21399 & 99999999 & 6.0504 & TRN \\
\hline CHEMBL1564542 & 688181 & 5.7883 & 6.6024 & TRN & \\
\hline CHEMBL3191556 & 688181 & 6.7986 & 6.5499 & TST & \\
\hline CHEMBL1462449 & 688181 & 6.0696 & 6.2958 & TRN & \\
\hline CHEMBL1468147 & 688181 & 5.6128 & 6.4746 & TST & \\
\hline CHEMBL1543510 & 688181 & 6.2823 & 5.3877 & TRN & \\
\hline CHEMBL1550290 & 688181 & 5.7567 & 5.6709 & TRN & \\
\hline CHEMBL1468457 & 688181 & 8.0 & 6.6874 & TRN & \\
\hline CHEMBL1353563 & 688181 & 6.0501 & 6.6474 & TST & \\
\hline CHEMBL1561091 & 688181 & 5.6919 & 5.6715 & TRN & \\
\hline CHEMBL1351081 & 688181 & 5.697 & 5.37 & TRN & \\
\hline CHEMBL523375 & 688181 & 6.9101 & 6.7893 & TRN & \\
\hline CHEMBL1530499 & 688181 & 5.6662 & 5.8563 & TRN & \\
\hline CHEMBL1332003 & 688181 & 5.7637 & 5.959 & TRN & \\
\hline CHEMBL1477538 & 688181 & 5.6216 & 5.8953 & TRN & \\
\hline CHEMBL1544733 & 688181 & 5.5378 & 5.6246 & TRN & \\
\hline CHEMBL 1452840 & 688181 & 6.0386 & 5.8638 & TST & \\
\hline CHEMBL1425806 & 688181 & 8.0 & 7.4209 & TRN & \\
\hline CHEMBL1315176 & 688181 & 6.2306 & 5.9008 & TRN & \\
\hline CHEMBL1365653 & 688181 & 6.9136 & 6.5952 & TRN & \\
\hline CHEMBL1364364 & 688181 & 6.0872 & 6.9402 & TRN & \\
\hline CHEMBL1550370 & 688181 & 6.9066 & 6.7473 & TRN & \\
\hline CHEMBL1362366 & 688181 & 6.0283 & 6.89 & TRN & \\
\hline CHEMBL3212517 & 688181 & 6.1918 & 6.03 & TRN & \\
\hline CHEMBL1332927 & 688181 & 6.1379 & 5.9531 & TRN & \\
\hline CHEMBL1393032 & 688181 & 5.2019 & 5.6083 & TRN & \\
\hline CHEMBL1462341 & 688181 & 5.1557 & 6.0143 & TRN & \\
\hline
\end{tabular}




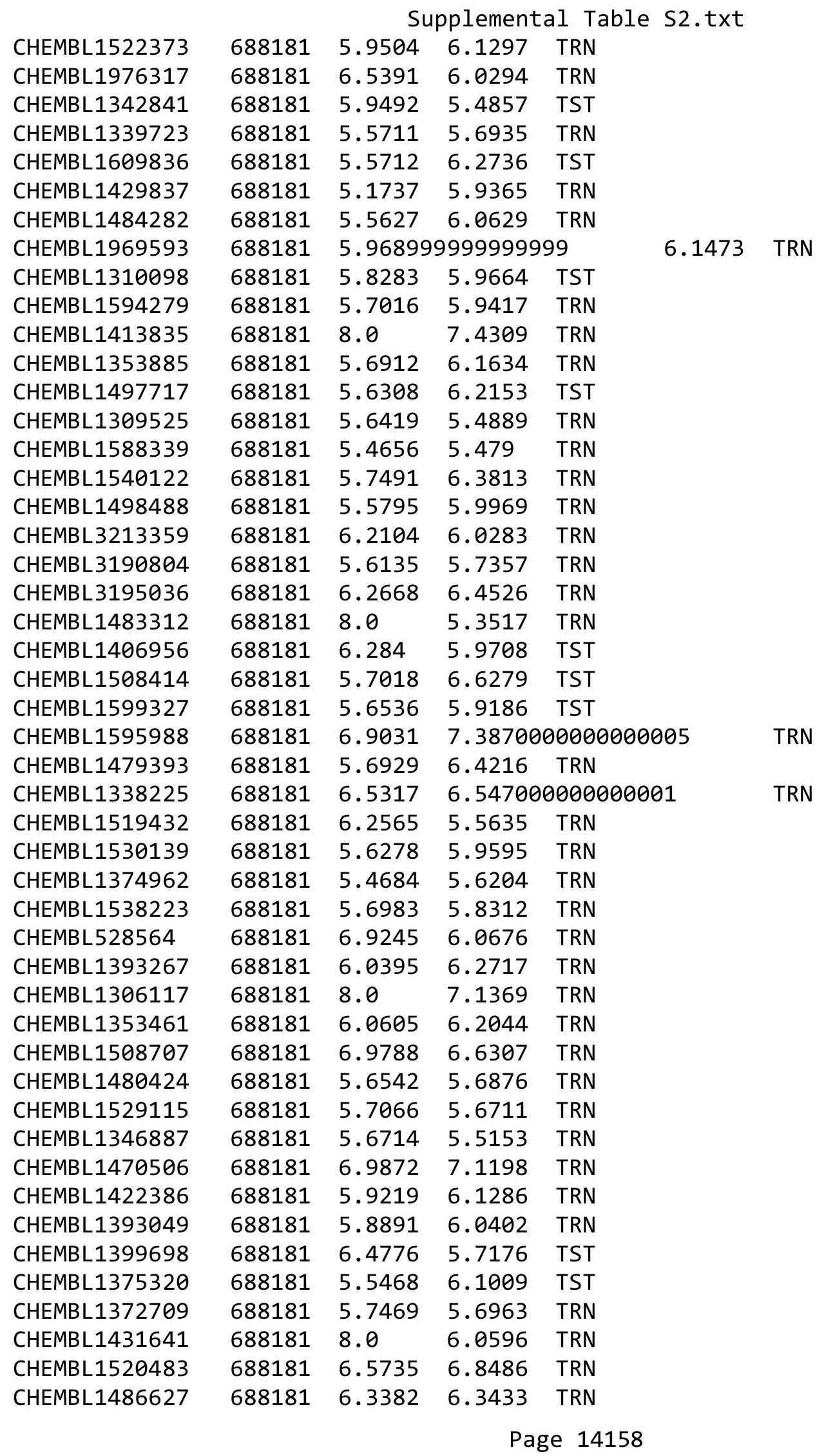


Supplemental Table S2.txt

\begin{tabular}{|c|c|c|c|c|}
\hline CHEMBL1607349 & 688181 & 5.6712 & 6.6662 & TST \\
\hline CHEMBL1424665 & 688181 & 6.5302 & 6.2677 & TRN \\
\hline CHEMBL1318143 & 688181 & 6.7328 & 7.0138 & TRN \\
\hline CHEMBL1578702 & 688181 & 6.2967 & 6.5399 & TRN \\
\hline CHEMBL1329502 & 688181 & 5.6996 & 6.0204 & TST \\
\hline CHEMBL1567282 & 688181 & 5.744 & 6.6029 & TRN \\
\hline CHEMBL1321181 & 688181 & 5.6811 & 5.76200 & 00000000005 \\
\hline CHEMBL1606234 & 688181 & 6.5157 & 5.8714 & TRN \\
\hline CHEMBL1534362 & 688181 & 6.426 & 6.2596 & TRN \\
\hline CHEMBL1539624 & 688181 & 6.041 & 5.7463 & TRN \\
\hline CHEMBL3197761 & 688181 & 5.5148 & 6.0446 & TRN \\
\hline CHEMBL1579831 & 688181 & 5.9496 & 5.3678 & TRN \\
\hline CHEMBL1389509 & 688181 & 5.6649 & 6.0226 & TRN \\
\hline CHEMBL1382038 & 688181 & 6.1163 & 6.0678 & TRN \\
\hline CHEMBL1429497 & 688181 & 6.8447 & 6.4782 & TRN \\
\hline CHEMBL1359520 & 688181 & 6.1739 & 6.0146 & TRN \\
\hline CHEMBL1494201 & 688181 & 5.6336 & 5.8779 & TST \\
\hline CHEMBL1479681 & 688181 & 5.8133 & 5.8159 & TRN \\
\hline CHEMBL1427574 & 688181 & 5.6108 & 5.1454 & TRN \\
\hline CHEMBL601957 & 688181 & 6.9172 & 6.351 & TRN \\
\hline CHEMBL3195226 & 688181 & 5.6463 & 6.3647 & TRN \\
\hline CHEMBL1471189 & 688181 & 5.6515 & 5.4323 & TST \\
\hline CHEMBL1378097 & 688181 & 8.0 & 6.7774 & TRN \\
\hline CHEMBL1446762 & 688181 & 8.0 & 6.2259 & TRN \\
\hline CHEMBL3198191 & 688181 & 6.0511 & 6.2952 & TRN \\
\hline CHEMBL1714669 & 688181 & 5.6988 & 6.0557 & TRN \\
\hline CHEMBL1409471 & 688181 & 6.1952 & 6.1127 & TRN \\
\hline CHEMBL1570521 & 688181 & 5.9017 & 5.8774 & TRN \\
\hline CHEMBL1611583 & 688181 & 5.6531 & 5.3657 & TRN \\
\hline CHEMBL1454957 & 688181 & 6.9788 & 6.5852 & TRN \\
\hline CHEMBL1553881 & 688181 & 6.857 & 7.2142 & TRN \\
\hline CHEMBL1510954 & 688181 & 5.71 & 5.8455 & TRN \\
\hline CHEMBL3212850 & 688181 & 5.8811 & 6.2932 & TRN \\
\hline CHEMBL3213394 & 688181 & 6.4012 & 6.2175 & TRN \\
\hline CHEMBL1549833 & 688181 & 5.8989 & 5.6381 & TRN \\
\hline CHEMBL1327470 & 688181 & 6.6498 & 6.5587 & TST \\
\hline CHEMBL1483355 & 688181 & 6.7471 & 6.5307 & TRN \\
\hline CHEMBL3211962 & 688181 & 6.3915 & 6.1278 & TRN \\
\hline CHEMBL3189416 & 688181 & 5.9488 & 5.6895 & TRN \\
\hline CHEMBL1989760 & 688181 & 6.5017 & 5.8057 & TRN \\
\hline CHEMBL3209063 & 688181 & 3.2218 & 5.7845 & TST \\
\hline CHEMBL1453552 & 688181 & 5.745 & 6.28299 & 99999999995 \\
\hline CHEMBL1337833 & 688181 & 6.2573 & 6.5175 & TRN \\
\hline CHEMBL1506351 & 688181 & 5.3329 & 5.6352 & TRN \\
\hline CHEMBL1562359 & 688181 & 5.3166 & 6.4954 & TST \\
\hline CHEMBL1504216 & 688181 & 6.1494 & 5.6746 & TRN \\
\hline CHEMBL1503394 & 688181 & 8.0 & 7.3421 & TRN \\
\hline CHEMBL1403351 & 688181 & 5.8153 & 5.9224 & TRN \\
\hline
\end{tabular}




\begin{tabular}{|c|c|c|c|c|c|}
\hline & & \multicolumn{4}{|c|}{ Supplemental Table s2.txt } \\
\hline CHEMBL1342468 & 688181 & 5.7665 & 6.059 & TRN & \\
\hline CHEMBL477139 & 688181 & 5.697 & 5.56 & TRN & \\
\hline CHEMBL1355284 & 688181 & 5.6868 & 5.8778 & TST & \\
\hline CHEMBL 3212126 & 688181 & 5.8492 & 6.2055 & TRN & \\
\hline CHEMBL1501375 & 688181 & 6.1555 & 5.2829 & TST & \\
\hline CHEMBL1509857 & 688181 & 8.0 & 7.0271 & TRN & \\
\hline CHEMBL1316845 & 688181 & 5.7192 & 5.4414 & TRN & \\
\hline CHEMBL1328653 & 688181 & 6.8928 & 6.5028 & TRN & \\
\hline CHEMBL588250 & 688181 & 6.7122 & 6.5588 & TRN & \\
\hline CHEMBL1472012 & 688181 & 6.0372 & 6.1153 & TRN & \\
\hline CHEMBL1570555 & 688181 & 5.691 & 6.3926 & TRN & \\
\hline CHEMBL1574894 & 688181 & 5.9041 & 6.0263 & TRN & \\
\hline CHEMBL1477071 & 688181 & 5.6863 & 6.5093 & TST & \\
\hline CHEMBL1382838 & 688181 & 5.9759 & 5.7837 & TRN & \\
\hline CHEMBL1441093 & 688181 & 5.971 & 6.01200 & 00000000005 & TRN \\
\hline CHEMBL1381355 & 688181 & 6.0273 & 6.16 & TRN & \\
\hline CHEMBL1964793 & 688181 & 6.6144 & 6.5538 & TRN & \\
\hline CHEMBL1554367 & 688181 & 5.7665 & 5.348 & TRN & \\
\hline CHEMBL1541113 & 688181 & 6.3161 & 5.806 & TRN & \\
\hline CHEMBL1335703 & 688181 & 8.0 & 6.039 & TRN & \\
\hline CHEMBL1333271 & 688181 & 6.9031 & 6.5842 & TRN & \\
\hline CHEMBL585112 & 688181 & 5.8861 & 6.2145 & TRN & \\
\hline CHEMBL1558309 & 688181 & 8.0 & 7.0589 & TRN & \\
\hline CHEMBL1424996 & 688181 & 6.7799 & 6.29299 & 9999999999 & TRN \\
\hline CHEMBL1465342 & 688181 & 6.4283 & 6.358 & TRN & \\
\hline CHEMBL3189959 & 688181 & 6.308 & 5.9547 & TST & \\
\hline CHEMBL1997062 & 688181 & 5.7361 & 6.063 & TRN & \\
\hline CHEMBL3193259 & 688181 & 5.5542 & 5.6814 & TRN & \\
\hline CHEMBL1302563 & 688181 & 6.5214 & 5.66 & TRN & \\
\hline CHEMBL1539527 & 688181 & 5.7174 & 5.77 & TRN & \\
\hline CHEMBL1430193 & 688181 & 5.9834 & 5.8062 & TRN & \\
\hline CHEMBL1382320 & 688181 & 5.8005 & 5.5042 & TRN & \\
\hline CHEMBL1509804 & 688181 & 5.74299 & و9999999 & 5.8479 & TST \\
\hline CHEMBL1366934 & 688181 & 5.7342 & 5.9215 & TRN & \\
\hline CHEMBL1353913 & 688181 & 6.5591 & 6.3147 & TRN & \\
\hline CHEMBL1359097 & 688181 & 5.6819 & 5.7924 & TST & \\
\hline CHEMBL1453895 & 688181 & 5.9259 & 5.8437 & TRN & \\
\hline CHEMBL1593292 & 688181 & 8.0 & 7.1309 & TRN & \\
\hline CHEMBL1573428 & 688181 & 5.8798 & 5.7231 & TRN & \\
\hline CHEMBL1513831 & 688181 & 6.3625 & 6.0522 & TRN & \\
\hline CHEMBL1413584 & 688181 & 5.5482 & 5.7265 & TRN & \\
\hline CHEMBL1611658 & 688181 & 5.6304 & 5.3144 & TRN & \\
\hline CHEMBL1370221 & 688181 & 5.5119 & 5.8412 & TRN & \\
\hline CHEMBL1440191 & 688181 & 5.9169 & 5.7335 & TST & \\
\hline CHEMBL1441053 & 688181 & 6.9747 & 6.749 & TRN & \\
\hline CHEMBL1476738 & 688181 & 6.9136 & 6.4522 & TRN & \\
\hline CHEMBL1428809 & 688181 & 5.4878 & 5.6707 & TRN & \\
\hline CHEMBL3209511 & 688181 & 6.475 & 6.0698 & TST & \\
\hline
\end{tabular}




\begin{tabular}{|c|c|c|c|c|c|c|}
\hline & & \multicolumn{5}{|c|}{ Supplemental Table S2.txt } \\
\hline CHEMBL1301490 & 688181 & 6.091 & 7.0015 & TRN & & \\
\hline CHEMBL1407452 & 688181 & 6.1249 & 6.0643 & TRN & & \\
\hline CHEMBL3194756 & 688181 & 5.7838 & 5.9236 & TRN & & \\
\hline CHEMBL1597597 & 688181 & 5.6942 & 6.4984 & TRN & & \\
\hline CHEMBL1602759 & 688181 & 6.0264 & 6.0667 & TST & & \\
\hline CHEMBL1420234 & 688181 & 5.4053 & 5.8997 & TRN & & \\
\hline CHEMBL1410957 & 688181 & 5.5802 & 5.6463 & TRN & & \\
\hline CHEMBL1496236 & 688181 & 5.4963 & 5.27 & TRN & & \\
\hline CHEMBL1580265 & 688181 & 5.8038 & 5.4813 & TRN & & \\
\hline CHEMBL1485786 & 688181 & 5.7737 & 6.3644 & TRN & & \\
\hline CHEMBL1409950 & 688181 & 5.7426 & 5.9925 & TRN & & \\
\hline CHEMBL1459266 & 688181 & 5.2328 & 6.2265 & TRN & & \\
\hline CHEMBL3191951 & 688181 & 5.6666 & 5.9825 & TRN & & \\
\hline CHEMBL1403800 & 688181 & 6.2612 & 6.2139 & TRN & & \\
\hline CHEMBL1556687 & 688181 & 5.7042 & 6.1036 & TRN & & \\
\hline CHEMBL1510550 & 688181 & 5.7307 & 6.2091 & TRN & & \\
\hline CHEMBL1362499 & 688181 & 5.8901 & 6.0012 & TRN & & \\
\hline CHEMBL1333006 & 688181 & 8.0 & 6.4506 & TRN & & \\
\hline CHEMBL1338802 & 688181 & 4.7839 & 5.9123 & TRN & & \\
\hline CHEMBL1548142 & 688181 & 5.6977 & 5.9751 & TST & & \\
\hline CHEMBL3211531 & 688181 & 5.8196 & 6.183 & TRN & & \\
\hline CHEMBL1530018 & 688181 & 5.9957 & 5.6682 & TRN & & \\
\hline CHEMBL1581655 & 688181 & 5.4582 & 6.4598 & TST & & \\
\hline CHEMBL1594604 & 688181 & 6.2 & 5.9692 & TRN & & \\
\hline CHEMBL1304427 & 688181 & 6.8356 & 6.8674 & TRN & & \\
\hline CHEMBL1404766 & 688181 & 6.9208 & 6.8558 & TRN & & \\
\hline CHEMBL601547 & 688181 & 8.0 & 6.78 & TRN & & \\
\hline CHEMBL1993103 & 688181 & 8.0 & 6.6741 & TRN & & \\
\hline CHEMBL1358722 & 688181 & 8.0 & 6.6545 & TST & & \\
\hline CHEMBL1320204 & 688181 & 5.8477 & 5.7375 & TRN & & \\
\hline CHEMBL1299526 & 688181 & 5.6209 & 5.8297 & TRN & & \\
\hline CHEMBL1502165 & 688181 & 8.0 & 6.5138 & TRN & & \\
\hline CHEMBL3192555 & 688181 & 6.1433 & 5.9547 & TST & & \\
\hline CHEMBL1562771 & 688181 & 6.7011 & 6.3499 & TRN & & \\
\hline CHEMBL1481385 & 688181 & 6.7352 & 6.9536 & TRN & & \\
\hline CHEMBL1450526 & 688181 & 6.2708 & 6.0969 & TRN & & \\
\hline CHEMBL1446369 & 688181 & 5.7321 & 5.9568 & TRN & & \\
\hline CHEMBL1558458 & 688181 & 5.9412 & 6.0388 & TRN & & \\
\hline CHEMBL3190520 & 688181 & 5.7997 & 5.9937 & TRN & & \\
\hline CHEMBL1609900 & 688181 & 6.399 & 5.7129 & TRN & & \\
\hline CHEMBL1543586 & 688181 & 5.8321 & 6.8317 & TRN & & \\
\hline CHEMBL1528898 & 688181 & 5.7577 & 5.6236 & TRN & & \\
\hline CHEMBL1326561 & 688181 & 5.7435 & 6.2393 & TRN & & \\
\hline CHEMBL1440668 & 688181 & 6.21399 & 99999999 & 995 & 5.9901 & TRN \\
\hline CHEMBL1426138 & 688181 & 6.0039 & 6.5831 & TRN & & \\
\hline CHEMBL1412700 & 688181 & 6.3143 & 6.1848 & TRN & & \\
\hline CHEMBL1445602 & 688181 & 6.76200 & 30000000 & 005 & 5.9009 & TRN \\
\hline CHEMBL1409120 & 688181 & 5.6442 & 6.24200 & 000000001 & & TST \\
\hline & & & & 14161 & & \\
\hline
\end{tabular}


Supplemental Table S2.txt

\begin{tabular}{|c|c|c|c|c|c|c|}
\hline CHEMBL1381360 & 688181 & 5.5275 & 5.7823 & TRN & & \\
\hline CHEMBL1492769 & 688181 & 6.3363 & 6.4864 & TRN & & \\
\hline CHEMBL1578547 & 688181 & 5.61799 & 799999999 & 6.3035 & TRN & \\
\hline CHEMBL1392478 & 688181 & 5.6613 & 6.0784 & TRN & & \\
\hline CHEMBL1306394 & 688181 & 6.2041 & 6.1499 & TRN & & \\
\hline CHEMBL1567410 & 688181 & 5.8962 & 6.3872 & TRN & & \\
\hline CHEMBL1535817 & 688181 & 8.0 & 6.2271 & TRN & & \\
\hline CHEMBL1600754 & 688181 & 6.1561 & 6.1505 & TRN & & \\
\hline CHEMBL3198154 & 688181 & 5.7612 & 6.3927 & TRN & & \\
\hline CHEMBL1401319 & 688181 & 6.1284 & 6.3821 & TRN & & \\
\hline CHEMBL3195459 & 688181 & 6.3675 & 6.3904 & TRN & & \\
\hline CHEMBL1612383 & 688181 & 5.9322 & 6.072999 & 99999999995 & TRN & \\
\hline CHEMBL1348135 & 688181 & 6.08299 & 799999999 & 5.7263 & TRN & \\
\hline CHEMBL1330670 & 688181 & 6.1675 & 6.302000 & 00000000005 & TRN & \\
\hline CHEMBL1418631 & 688181 & 6.1073 & 6.4076 & TRN & & \\
\hline CHEMBL1442515 & 688181 & 6.3125 & 6.3007 & TRN & & \\
\hline CHEMBL1501444 & 688181 & 3.2218 & 5.5891 & TST & & \\
\hline CHEMBL1497295 & 688181 & 6.3851 & 5.6932 & TST & & \\
\hline CHEMBL1335477 & 688181 & 6.3958 & 6.5793 & TRN & & \\
\hline CHEMBL3193931 & 688181 & 6.8416 & 6.0124 & TRN & & \\
\hline CHEMBL1563478 & 688181 & 5.6144 & 6.1602 & TRN & & \\
\hline CHEMBL1328537 & 688181 & 8.0 & 7.1757 & TRN & & \\
\hline CHEMBL1321912 & 688181 & 8.0 & 5.7941 & TRN & & \\
\hline CHEMBL1501486 & 688181 & 6.4389 & 5.5934 & TST & & \\
\hline CHEMBL1351542 & 688181 & 5.8807 & 5.9393 & TRN & & \\
\hline CHEMBL1573374 & 688181 & 6.301 & 5.6074 & TRN & & \\
\hline CHEMBL1453582 & 688181 & 5.5829 & 6.4336 & TRN & & \\
\hline CHEMBL1339925 & 688181 & 5.9234 & 6.3657 & TRN & & \\
\hline CHEMBL1349058 & 688181 & 6.5045 & 6.2344 & TRN & & \\
\hline CHEMBL565269 & 688181 & 6.8125 & 5.9401 & TRN & & \\
\hline CHEMBL3196619 & 688181 & 6.9136 & 6.2794 & TRN & & \\
\hline CHEMBL1401231 & 688181 & 5.53299 & 999999999 & 6.0470 & 0000000001 & TRN \\
\hline CHEMBL1503034 & 688181 & 5.914 & 5.8219 & TST & & \\
\hline CHEMBL1459626 & 688181 & 5.8019 & 6.4026 & TRN & & \\
\hline CHEMBL1304120 & 688181 & 6.0506 & 5.9925 & TRN & & \\
\hline CHEMBL1352295 & 688181 & 6.0218 & 6.5039 & TRN & & \\
\hline CHEMBL1359166 & 688181 & 5.9374 & 6.2167 & TRN & & \\
\hline CHEMBL482687 & 688181 & 5.501 & 6.0863 & TRN & & \\
\hline CHEMBL1242180 & 688181 & 8.0 & 7.3162 & TRN & & \\
\hline CHEMBL1504978 & 688181 & 5.8035 & 6.3439 & TRN & & \\
\hline CHEMBL1373289 & 688181 & 6.3002 & 6.6153 & TRN & & \\
\hline CHEMBL1444041 & 688181 & 5.7926 & 5.9368 & TST & & \\
\hline CHEMBL1326851 & 688181 & 5.6891 & 5.729 & TRN & & \\
\hline CHEMBL1578436 & 688181 & 6.8665 & 6.2421 & TRN & & \\
\hline CHEMBL1556978 & 688181 & 5.5839 & 6.127999 & 9999999999 & TST & \\
\hline CHEMBL1328240 & 688181 & 6.2832 & 5.6946 & TRN & & \\
\hline CHEMBL1340215 & 688181 & 5.7095 & 6.3214 & TRN & & \\
\hline CHEMBL3193095 & 688181 & 5.7409 & 6.225 & TRN & & \\
\hline
\end{tabular}




\begin{tabular}{|c|c|c|c|c|c|c|}
\hline & & \multicolumn{5}{|c|}{ Supplemental Table S2.txt } \\
\hline CHEMBL1537508 & 688181 & 6.2984 & 6.0983 & TRN & & \\
\hline CHEMBL 3145137 & 688181 & 6.1746 & 5.7609 & TST & & \\
\hline CHEMBL1322532 & 688181 & 6.3468 & 5.6676 & TST & & \\
\hline CHEMBL1336489 & 688181 & 5.57299 & Э9999999 & 995 & 5.9613 & TST \\
\hline CHEMBL1377193 & 688181 & 5.6684 & 5.7577 & TRN & & \\
\hline CHEMBL1432611 & 688181 & 5.6182 & 5.819 & TRN & & \\
\hline CHEMBL1423724 & 688181 & 5.7742 & 5.572 & TRN & & \\
\hline CHEMBL1410498 & 688181 & 5.6077 & 5.8566 & TRN & & \\
\hline CHEMBL1386824 & 688181 & 5.6813 & 6.4545 & TST & & \\
\hline CHEMBL1388405 & 688181 & 5.66799 & 999999995 & 99 & 5.5011 & II \\
\hline CHEMBL1487849 & 688181 & 5.7833 & 5.8228 & TRN & & \\
\hline CHEMBL1549732 & 688181 & 8.0 & 6.1458 & TRN & & \\
\hline CHEMBL1321294 & 688181 & 6.1002 & 5.9791 & TRN & & \\
\hline CHEMBL1562159 & 688181 & 8.0 & 6.8165 & TRN & & \\
\hline CHEMBL3214537 & 688181 & 8.0 & 7.3359 & TRN & & \\
\hline CHEMBL1339881 & 688181 & 4.7389 & 5.6526 & TST & & \\
\hline CHEMBL1384286 & 688181 & 5.9017 & 5.4112 & TRN & & \\
\hline CHEMBL1575372 & 688181 & 5.4658 & 6.1399 & TRN & & \\
\hline CHEMBL1475884 & 688181 & 8.0 & 6.5219 & TST & & \\
\hline CHEMBL1346837 & 688181 & 8.0 & 7.8097 & TRN & & \\
\hline CHEMBL1337365 & 688181 & 6.2306 & 6.0964 & TRN & & \\
\hline CHEMBL532239 & 688181 & 6.0964 & 6.8134 & TRN & & \\
\hline CHEMBL1525167 & 688181 & 5.7533 & 6.4011 & TST & & \\
\hline CHEMBL1442730 & 688181 & 5.8986 & 5.6703 & TRN & & \\
\hline CHEMBL1361493 & 688181 & 5.5412 & 6.2747 & TRN & & \\
\hline CHEMBL1610821 & 688181 & 8.0 & 7.4153 & TRN & & \\
\hline CHEMBL1583262 & 688181 & 5.8102 & 5.9477 & TST & & \\
\hline CHEMBL1418230 & 688181 & 5.7592 & 5.8393 & TRN & & \\
\hline CHEMBL1448157 & 688181 & 6.1818 & 5.7481 & TRN & & \\
\hline CHEMBL1587643 & 688181 & 5.7075 & 6.0978 & TST & & \\
\hline CHEMBL1385886 & 688181 & 5.8804 & 5.8042 & TRN & & \\
\hline CHEMBL1425875 & 688181 & 5.8993 & 5.9951 & TRN & & \\
\hline CHEMBL1456768 & 688181 & 6.8633 & 7.0253 & TRN & & \\
\hline CHEMBL1559371 & 688181 & 8.0 & 6.7534 & TRN & & \\
\hline CHEMBL1299258 & 688181 & 6.0737 & 6.3155 & TRN & & \\
\hline CHEMBL1539970 & 688181 & 5.721 & 5.8983 & TRN & & \\
\hline CHEMBL1489815 & 688181 & 7.0 & 7.0429 & TRN & & \\
\hline CHEMBL1421570 & 688181 & 5.6737 & 6.202006 & 0000000001 & & \\
\hline CHEMBL3190292 & 688181 & 5.845 & 5.9975 & TST & & \\
\hline CHEMBL1488473 & 688181 & 5.6041 & 5.8351 & TRN & & \\
\hline CHEMBL1522807 & 688181 & 5.9562 & 5.8938 & TRN & & \\
\hline CHEMBL1465813 & 688181 & 6.2565 & 6.1267 & TRN & & \\
\hline CHEMBL3195031 & 688181 & 5.8362 & 5.7813 & TRN & & \\
\hline CHEMBL1583317 & 688181 & 6.3354 & 6.3916 & TRN & & \\
\hline CHEMBL1349747 & 688181 & 5.7106 & 5.7869 & TST & & \\
\hline CHEMBL1361797 & 688181 & 5.6191 & 5.7189 & TRN & & \\
\hline CHEMBL1590153 & 688181 & 5.6396 & 6.056 & TRN & & \\
\hline CHEMBL1496338 & 688181 & 5.6863 & 5.9347 & TRN & & \\
\hline
\end{tabular}




\begin{tabular}{|c|c|c|c|c|c|}
\hline \multirow[b]{2}{*}{ CHEMBL1500719 } & \multicolumn{5}{|c|}{ Supplemental Table S2.txt } \\
\hline & 688181 & 5.6688 & 5.1049 & TRN & \\
\hline CHEMBL1326995 & 688181 & 5.7445 & 5.9162 & TRN & \\
\hline CHEMBL1377028 & 688181 & 5.7187 & 6.7824 & TRN & \\
\hline CHEMBL1329742 & 688181 & 6.3936 & 6.1686 & TRN & \\
\hline CHEMBL1480313 & 688181 & 5.8989 & 6.3629 & TST & \\
\hline CHEMBL1473837 & 688181 & 5.6899 & 5.6828 & TST & \\
\hline CHEMBL35228 & 688181 & 6.2314 & 6.1848 & TRN & \\
\hline CHEMBL3210057 & 688181 & 5.6026 & 6.0005 & TRN & \\
\hline CHEMBL570399 & 688181 & 5.9914 & 6.1893 & TRN & \\
\hline CHEMBL1344586 & 688181 & 5.9602 & 6.4141 & TST & \\
\hline CHEMBL1370704 & 688181 & 5.857 & 5.67299 & 9999999999 & TRN \\
\hline CHEMBL1500172 & 688181 & 6.1864 & 6.3807 & TRN & \\
\hline CHEMBL1389268 & 688181 & 6.5638 & 6.7076 & TRN & \\
\hline CHEMBL3199850 & 688181 & 6.2426 & 5.7204 & TRN & \\
\hline CHEMBL1385263 & 688181 & 6.5513 & 6.0141 & TRN & \\
\hline CHEMBL1351290 & 688181 & 5.978 & 5.9574 & TST & \\
\hline CHEMBL1468556 & 688181 & 8.0 & 6.8896 & TRN & \\
\hline CHEMBL578719 & 688181 & 6.4306 & 5.9984 & TST & \\
\hline CHEMBL1511522 & 688181 & 5.9523 & 6.1962 & TRN & \\
\hline CHEMBL1343490 & 688181 & 6.3045 & 6.7711 & TRN & \\
\hline CHEMBL1474782 & 688181 & 6.3288 & 6.87299 & 9999999999 & TRN \\
\hline CHEMBL1583505 & 688181 & 5.4427 & 5.7692 & TRN & \\
\hline CHEMBL1523690 & 688181 & 5.9423 & 6.0878 & TRN & \\
\hline CHEMBL1385608 & 688181 & 5.8877 & 6.3833 & TST & \\
\hline CHEMBL1415035 & 688181 & 6.0788 & 6.0419 & TRN & \\
\hline CHEMBL1456311 & 688181 & 5.2569 & 6.1213 & TRN & \\
\hline CHEMBL1539673 & 688181 & 6.6716 & 7.1885 & TRN & \\
\hline CHEMBL1529005 & 688181 & 6.983 & 7.3765 & TRN & \\
\hline CHEMBL 3212702 & 688181 & 5.9626 & 6.3456 & TST & \\
\hline CHEMBL1448321 & 688181 & 5.6847 & 6.2599 & TRN & \\
\hline CHEMBL1470008 & 688181 & 5.9259 & 5.8832 & TRN & \\
\hline CHEMBL1537043 & 688181 & 8.0 & 7.653 & TRN & \\
\hline CHEMBL1496582 & 688181 & 6.0788 & 6.0548 & TRN & \\
\hline CHEMBL1891759 & 688181 & 5.8817 & 5.9932 & TST & \\
\hline CHEMBL1460487 & 688181 & 8.0 & 7.3942 & TRN & \\
\hline CHEMBL1428905 & 688181 & 6.3391 & 6.3257 & TRN & \\
\hline CHEMBL1576090 & 688181 & 5.7135 & 5.8032 & TRN & \\
\hline CHEMBL1497771 & 688181 & $5.9570 e$ & 30000000 & 5.3164 & TRN \\
\hline CHEMBL1593220 & 688181 & 3.2218 & 5.3888 & TRN & \\
\hline CHEMBL1530144 & 688181 & 5.5947 & 5.63700 & 00000000005 & TRN \\
\hline CHEMBL1386291 & 688181 & 5.5227 & 5.8837 & TRN & \\
\hline CHEMBL1373096 & 688181 & 6.5143 & 6.3984 & TRN & \\
\hline CHEMBL1470502 & 688181 & 5.7701 & 5.5797 & TRN & \\
\hline CHEMBL1516586 & 688181 & 5.5498 & 5.6027 & TRN & \\
\hline CHEMBL1535915 & 688181 & 6.1163 & 6.1615 & TRN & \\
\hline CHEMBL3199944 & 688181 & 8.0 & 6.4854 & TRN & \\
\hline CHEMBL1422978 & 688181 & 5.7696 & 5.6182 & TRN & \\
\hline CHEMBL1532028 & 688181 & 5.7459 & 6.2211 & TRN & \\
\hline
\end{tabular}


Supplemental Table S2.txt

\begin{tabular}{|c|c|c|c|c|c|c|}
\hline CHEMBL1568848 & 688181 & 6.7496 & 6.5587 & TST & & \\
\hline CHEMBL1516721 & 688181 & 6.4976 & 6.1282 & TRN & & \\
\hline CHEMBL1501748 & 688181 & 5.76399 & 99999999 & 99 & 5.5073 & TRN \\
\hline CHEMBL1583669 & 688181 & 5.8371 & 6.0096 & TRN & & \\
\hline CHEMBL1569370 & 688181 & 5.6356 & 6.0242 & TRN & & \\
\hline CHEMBL1346437 & 688181 & 5.6509 & 6.5057 & TRN & & \\
\hline CHEMBL1479642 & 688181 & 6.2941 & 7.1974 & TRN & & \\
\hline CHEMBL1495992 & 688181 & 6.7852 & 6.4827 & TRN & & \\
\hline CHEMBL1343511 & 688181 & 5.7199 & 5.8621 & TST & & \\
\hline CHEMBL1312953 & 688181 & 8.0 & 7.4419 & TST & & \\
\hline CHEMBL1608758 & 688181 & 5.7918 & 5.5441 & TRN & & \\
\hline CHEMBL592842 & 688181 & 5.7462 & 6.0434 & TRN & & \\
\hline CHEMBL1469281 & 688181 & 5.6564 & 5.3682 & TRN & & \\
\hline CHEMBL1609529 & 688181 & 5.7122 & 6.075 & TRN & & \\
\hline CHEMBL1309132 & 688181 & 7.0 & 6.4005 & TRN & & \\
\hline CHEMBL 3197008 & 688181 & 5.856 & 5.8764 & TRN & & \\
\hline CHEMBL1431408 & 688181 & 5.9416 & 6.5662 & TRN & & \\
\hline CHEMBL1582535 & 688181 & 6.0942 & 5.6501 & TRN & & \\
\hline CHEMBL1321238 & 688181 & 5.4051 & 6.0765 & TRN & & \\
\hline CHEMBL1492965 & 688181 & 8.0 & 6.9009 & TRN & & \\
\hline CHEMBL1516456 & 688181 & 5.6588 & 5.5585 & TRN & & \\
\hline CHEMBL1547350 & 688181 & 6.1701 & 6.2078 & TRN & & \\
\hline CHEMBL1399175 & 688181 & 8.0 & 6.595 & TST & & \\
\hline CHEMBL1502883 & 688181 & 6.2534 & 6.2619 & TRN & & \\
\hline CHEMBL1349113 & 688181 & 5.3079 & 6.0923 & TRN & & \\
\hline CHEMBL1341601 & 688181 & 5.8477 & 6.2743 & TRN & & \\
\hline CHEMBL1310190 & 688181 & 5.519 & 5.7684 & TRN & & \\
\hline CHEMBL1392178 & 688181 & 5.8655 & 5.7225 & TRN & & \\
\hline CHEMBL1541967 & 688181 & 6.2774 & 6.0539 & TRN & & \\
\hline CHEMBL1596102 & 688181 & 8.0 & 7.3771 & TRN & & \\
\hline CHEMBL1529206 & 688181 & 8.0 & 7.6678 & TRN & & \\
\hline CHEMBL1438141 & 688181 & 5.8259 & 5.8835 & TRN & & \\
\hline CHEMBL1378626 & 688181 & 6.1141 & 5.9989 & TRN & & \\
\hline CHEMBL1449617 & 688181 & 5.6981 & 5.5325 & TST & & \\
\hline CHEMBL1367596 & 688181 & 5.7242 & 5.5601 & TRN & & \\
\hline CHEMBL1332667 & 688181 & 5.7943 & 6.3779 & TST & & \\
\hline CHEMBL1586416 & 688181 & 6.16299 & 79999999 & 99 & 6.6269 & J \\
\hline CHEMBL1373678 & 688181 & 6.0894 & 6.1077 & TRN & & \\
\hline CHEMBL1596712 & 688181 & 8.0 & 6.6103 & TRN & & \\
\hline CHEMBL1465730 & 688181 & 6.6126 & 6.8401 & TRN & & \\
\hline CHEMBL1517889 & 688181 & 6.9914 & 6.939 & TRN & & \\
\hline CHEMBL1307342 & 688181 & 5.9918 & 6.3997 & TRN & & \\
\hline CHEMBL1461496 & 688181 & 5.9694 & 6.5759 & TRN & & \\
\hline CHEMBL1526966 & 688181 & 5.8468 & 5.3898 & TRN & & \\
\hline CHEMBL1314461 & 688181 & 5.9201 & 5.9696 & TRN & & \\
\hline CHEMBL1486139 & 688181 & 6.7545 & 6.2225 & TRN & & \\
\hline CHEMBL1495072 & 688181 & 5.8633 & 6.4925 & TRN & & \\
\hline CHEMBL1341209 & 688181 & 6.1118 & 6.3457 & TRN & & \\
\hline
\end{tabular}

Page 14165 
Supplemental Table S2.txt

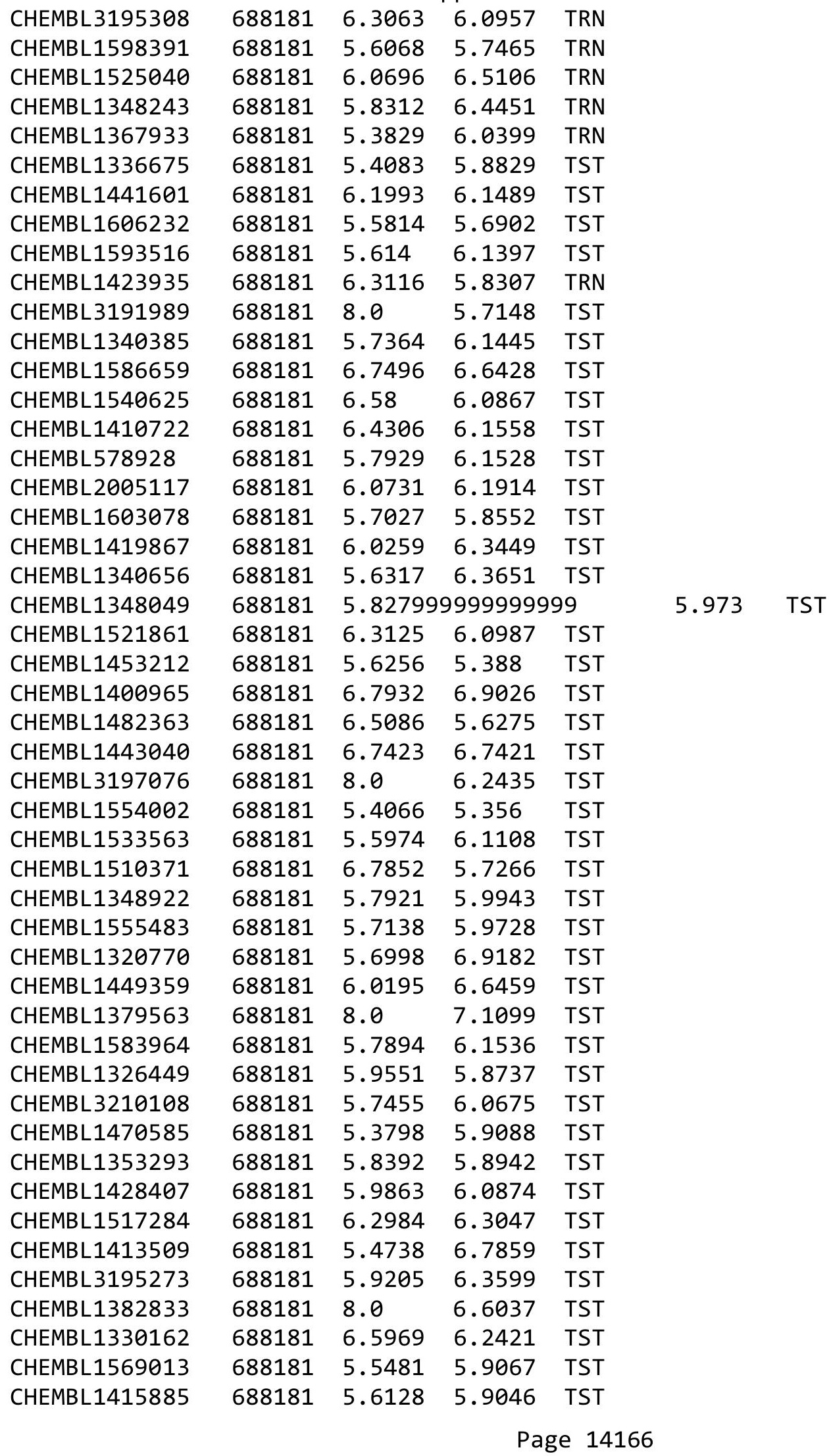


Supplemental Table S2.txt

\begin{tabular}{|c|c|c|c|c|c|}
\hline CHEMBL1537553 & 688181 & 3.5229 & 6.3273 & TST & \\
\hline CHEMBL1547364 & 688181 & 5.6872 & 5.6877 & TST & \\
\hline CHEMBL1383625 & 688181 & 6.3325 & 6.5409 & TST & \\
\hline CHEMBL1573817 & 688181 & 8.0 & 7.0446 & TST & \\
\hline CHEMBL1577917 & 688181 & 5.4634 & 5.6904 & TST & \\
\hline CHEMBL1325969 & 688181 & 5.5227 & 5.731 & TST & \\
\hline CHEMBL1536305 & 688181 & 6.0511 & 6.0231 & TST & \\
\hline CHEMBL1414335 & 688181 & 6.6162 & 6.8319 & TST & \\
\hline CHEMBL1588531 & 688181 & 7.0 & 6.7404 & TST & \\
\hline CHEMBL1300226 & 688181 & 5.4725 & 5.141 & TST & \\
\hline CHEMBL1424596 & 688181 & 5.7007 & 5.7287 & TST & \\
\hline CHEMBL1440303 & 688181 & 6.0101 & 5.7836 & TST & \\
\hline CHEMBL1526737 & 688181 & 6.3325 & 5.9129 & TST & \\
\hline CHEMBL1363597 & 688181 & 5.6788 & 5.7411 & TST & \\
\hline CHEMBL1469056 & 688181 & 5.605 & 5.8608 & TST & \\
\hline CHEMBL1420074 & 688181 & 5.7688 & 5.6104 & TST & \\
\hline CHEMBL3213787 & 688181 & 5.7073 & 5.5361 & TST & \\
\hline CHEMBL1598571 & 688181 & 3.2218 & 5.855 & TST & \\
\hline CHEMBL1507840 & 688181 & 5.8259 & 5.9049 & TST & \\
\hline CHEMBL1479786 & 688181 & 5.5112 & 7.0721 & TST & \\
\hline CHEMBL1329473 & 688181 & 6.056 & 6.1551 & TST & \\
\hline CHEMBL1522472 & 688181 & 6.71899 & 999999999 & 99 & 6.0023 \\
\hline CHEMBL1499951 & 688181 & 5.7284 & 6.1317 & TST & \\
\hline CHEMBL1537810 & 688181 & 6.7696 & 5.687 & TST & \\
\hline CHEMBL1511171 & 688181 & 8.0 & 6.1253 & TST & \\
\hline CHEMBL1602962 & 688181 & 5.9423 & 5.8169 & TST & \\
\hline CHEMBL1386112 & 688181 & 5.8844 & 6.1043 & TST & \\
\hline CHEMBL1397224 & 688181 & 5.8582 & 5.7102 & TST & \\
\hline CHEMBL1384193 & 688181 & 5.6811 & 5.8299 & TST & \\
\hline CHEMBL1581249 & 688181 & 5.2657 & 6.1355 & TST & \\
\hline CHEMBL1491816 & 688181 & 6.1113 & 6.3184 & TST & \\
\hline CHEMBL1542798 & 688181 & 5.6368 & 5.3377 & TST & \\
\hline CHEMBL1542936 & 688181 & 5.731 & 6.1989 & TST & \\
\hline CHEMBL 3211430 & 688181 & 5.5812 & 6.5072 & TST & \\
\hline CHEMBL1556358 & 688181 & 6.2076 & 6.7832 & TST & \\
\hline CHEMBL1521766 & 688181 & 5.6332 & 5.6498 & TST & \\
\hline CHEMBL1431754 & 688181 & 5.87 & 7.0896 & TST & \\
\hline CHEMBL1439675 & 688181 & 5.6951 & 5.5819 & TST & \\
\hline CHEMBL1320407 & 688181 & 3.2218 & 5.5099 & TST & \\
\hline CHEMBL2005743 & 688181 & 5.4804 & 6.626 & TST & \\
\hline CHEMBL587801 & 688181 & 5.6946 & 6.3079 & TST & \\
\hline CHEMBL3195168 & 688181 & 6.9281 & 6.0949 & TST & \\
\hline CHEMBL1548862 & 688181 & 5.6546 & 5.6958 & TST & \\
\hline CHEMBL1527447 & 688181 & 5.6299 & 6.3757 & TST & \\
\hline CHEMBL1378654 & 688181 & 5.8193 & 5.944 & TST & \\
\hline CHEMBL1443656 & 688181 & 6.3458 & 6.7005 & TST & \\
\hline CHEMBL1351755 & 688181 & 6.7799 & 5.1603 & TST & \\
\hline CHEMBL1402518 & 688181 & 8.0 & 6.1854 & TST & \\
\hline
\end{tabular}




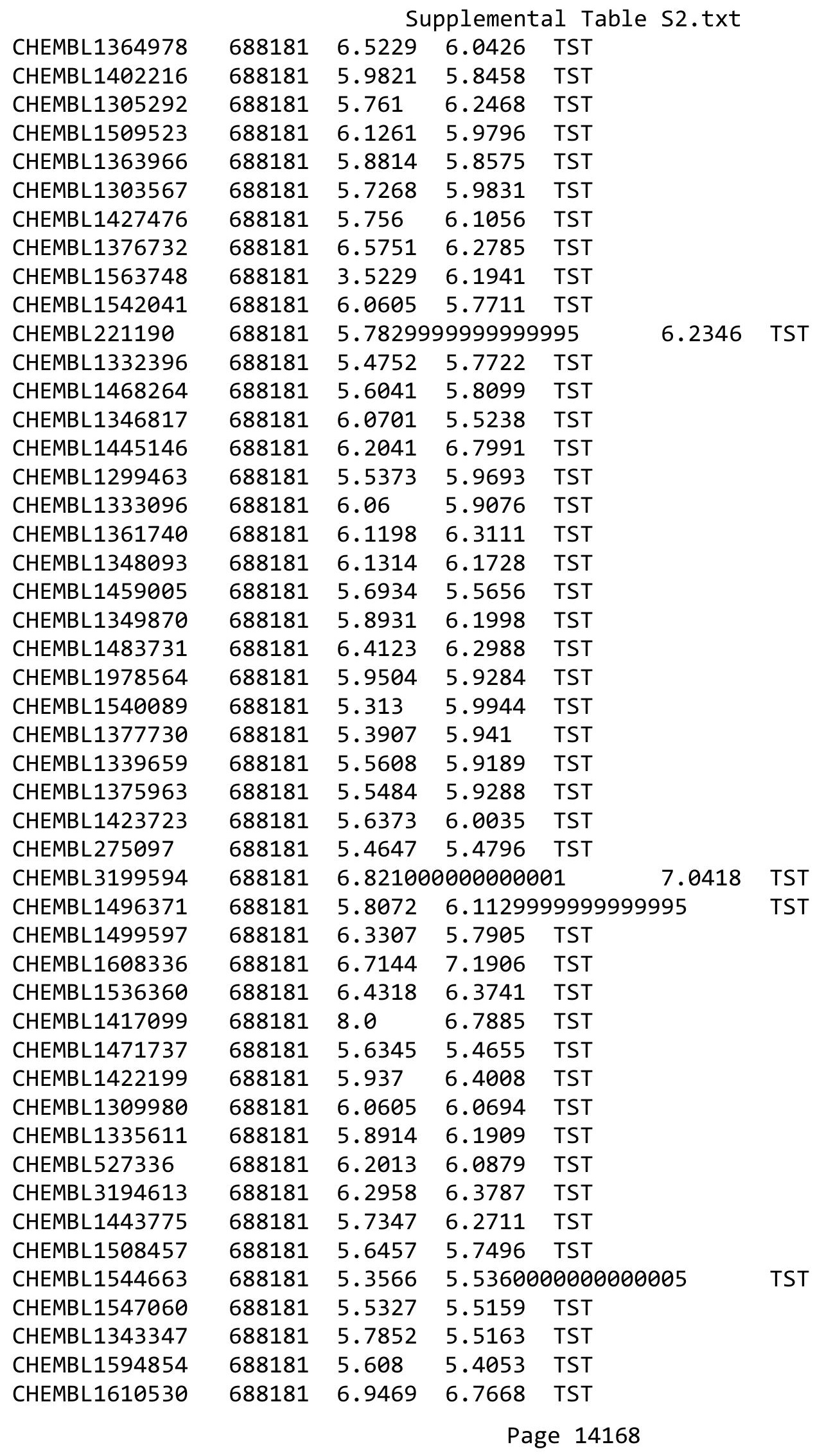


Supplemental Table S2.txt

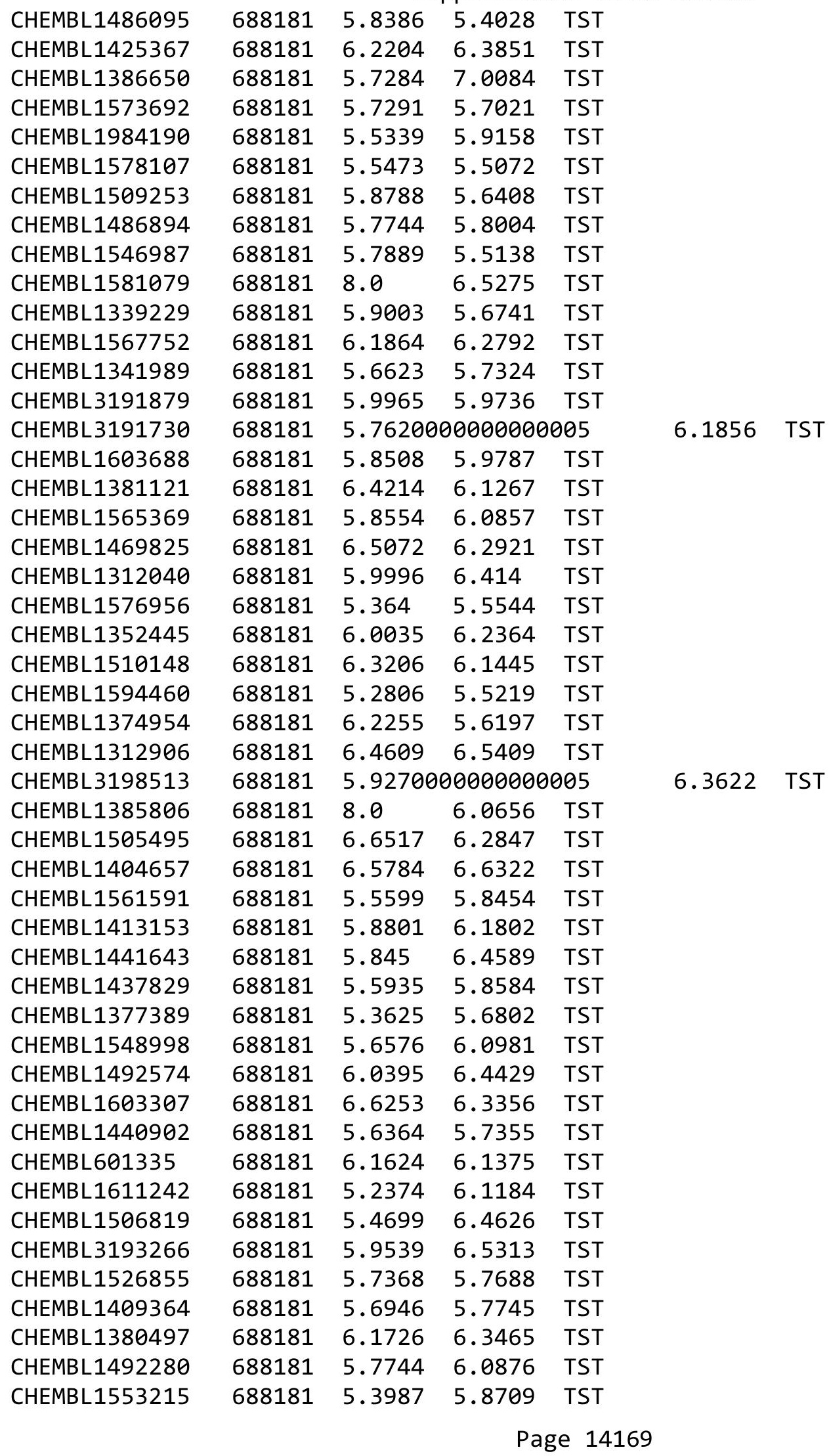




\begin{tabular}{|c|c|c|c|c|c|}
\hline \multicolumn{6}{|c|}{ Supplemental Table S2.txt } \\
\hline CHEMBL1383806 & 688181 & 5.3761 & 5.7286 & TST & \\
\hline CHEMBL1361962 & 688181 & 5.9248 & 5.7934 & TST & \\
\hline CHEMBL1569005 & 688181 & 5.654 & 6.547999 & 9999999999 & TST \\
\hline CHEMBL349417 & 688181 & 5.5887 & 5.9515 & TST & \\
\hline CHEMBL1447783 & 688181 & 5.6735 & 5.4603 & TST & \\
\hline CHEMBL1435876 & 688181 & 6.9914 & 7.0489 & TST & \\
\hline CHEMBL1394145 & 688181 & 3.7959 & 6.3704 & TST & \\
\hline CHEMBL1610249 & 688181 & 5.8871 & 6.3365 & TST & \\
\hline CHEMBL1982484 & 688181 & 6.6498 & 6.0468 & TST & \\
\hline CHEMBL1320328 & 688181 & 5.6453 & 6.4518 & TST & \\
\hline CHEMBL1332165 & 688181 & 5.8377 & 5.7733 & TST & \\
\hline CHEMBL1553717 & 688181 & 8.0 & 7.4646 & TST & \\
\hline CHEMBL1550449 & 688181 & 5.4512 & 6.0489 & TST & \\
\hline CHEMBL1430107 & 688181 & 5.6847 & 5.8576 & TST & \\
\hline CHEMBL1497123 & 688181 & 5.5372 & 5.5356 & TST & \\
\hline CHEMBL1466404 & 688181 & 5.6641 & 5.7205 & TST & \\
\hline CHEMBL1392846 & 688181 & 5.7375 & 5.7529 & TST & \\
\hline CHEMBL1339023 & 688181 & 5.6033 & 5.5836 & TST & \\
\hline CHEMBL1505189 & 688181 & 6.011 & 6.7146 & TST & \\
\hline CHEMBL1602160 & 688181 & 5.6807 & 5.7483 & TST & \\
\hline CHEMBL1328686 & 688181 & 5.8356 & 5.9519 & TST & \\
\hline CHEMBL1598383 & 688181 & 5.7467 & 6.12799 & 9999999999 & TST \\
\hline CHEMBL1584937 & 688181 & 6.2441 & 6.233 & TST & \\
\hline CHEMBL585502 & 688181 & 8.0 & 7.7097 & TST & \\
\hline CHEMBL1450188 & 688181 & 8.0 & 7.5024 & TST & \\
\hline CHEMBL1370877 & 688181 & 5.2145 & 5.9276 & TST & \\
\hline CHEMBL1353840 & 688181 & 5.7286 & 6.5235 & TST & \\
\hline CHEMBL591412 & 688181 & 6.2741 & 6.1968 & TST & \\
\hline CHEMBL1424408 & 688181 & 6.7852 & 6.6874 & TST & \\
\hline CHEMBL3191420 & 688181 & 5.5981 & 5.7158 & TST & \\
\hline CHEMBL1547990 & 688181 & 6.585 & 5.9704 & TST & \\
\hline CHEMBL1491927 & 688181 & 6.2041 & 5.9856 & TST & \\
\hline CHEMBL1568095 & 688181 & 6.066 & 5.5691 & TST & \\
\hline CHEMBL1517609 & 688181 & 6.1397 & 6.2097 & TST & \\
\hline CHEMBL1511893 & 688181 & 5.6592 & 5.1597 & TST & \\
\hline CHEMBL1371298 & 688181 & 5.42 & 6.2762 & TST & \\
\hline CHEMBL1421411 & 688181 & 4.3155 & 5.7853 & TST & \\
\hline CHEMBL1420664 & 688181 & 6.7122 & 6.8948 & TST & \\
\hline CHEMBL600778 & 688181 & 6.7878 & 6.5936 & TST & \\
\hline CHEMBL1430882 & 688181 & 6.5045 & 6.3062 & TST & \\
\hline CHEMBL1540341 & 688181 & 5.7251 & 6.7726 & TST & \\
\hline CHEMBL586602 & 688181 & 8.0 & 8.2039 & TST & \\
\hline CHEMBL1490602 & 688181 & 6.011 & 5.9122 & TST & \\
\hline CHEMBL1467958 & 688181 & 5.9385 & 6.7209 & TST & \\
\hline CHEMBL1559629 & 688181 & 6.5406 & 6.0781 & TST & \\
\hline CHEMBL1349976 & 688181 & 6.7878 & 7.23799 & 99999999995 & TST \\
\hline CHEMBL1541107 & 688181 & 5.8176 & 5.9352 & TST & \\
\hline CHEMBL1502723 & 688181 & 5.6708 & 6.0079 & TST & \\
\hline
\end{tabular}




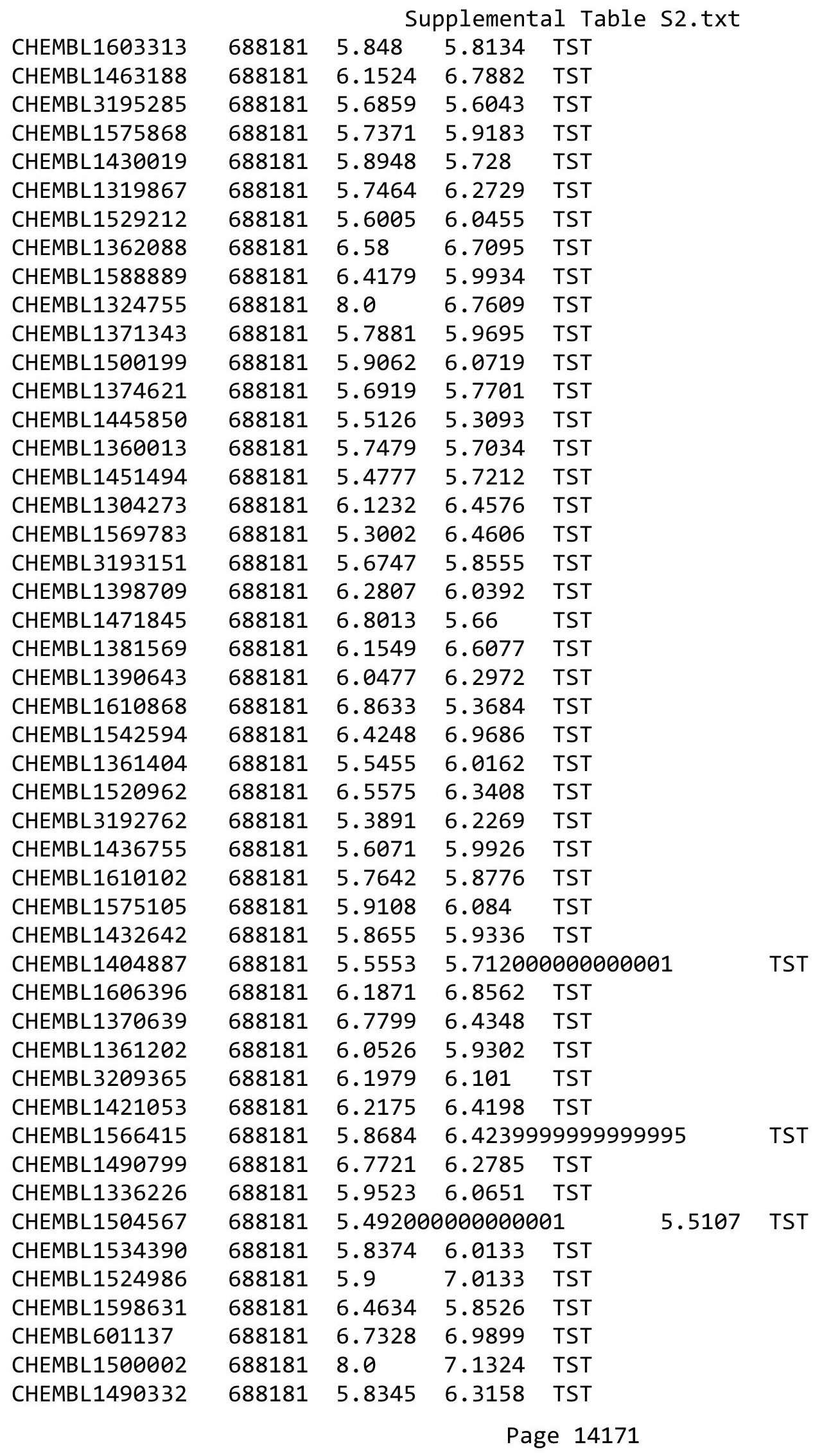


Supplemental Table S2.txt

\begin{tabular}{lllll} 
CHEMBL1388545 & 688181 & 6.5157 & 6.0972 & TST \\
CHEMBL1327706 & 688181 & 5.8052 & 5.9546 & TST \\
CHEMBL3196108 & 688181 & 5.7683 & 5.8984 & TST \\
CHEMBL581152 & 688181 & 5.4755 & 6.1061 & TST \\
CHEMBL586000 & 688181 & 5.8965 & 6.4811 & TST \\
CHEMBL1559157 & 688181 & 8.0 & 5.8556 & TST \\
CHEMBL1358591 & 688181 & 6.0039 & 6.5564 & TST \\
CHEMBL1606450 & 688181 & 6.1013 & 5.8717 & TST \\
CHEMBL1430826 & 688181 & 5.7479 & 5.9189 & TST \\
CHEMBL3190547 & 688181 & 6.1772 & 7.0549 & TST \\
CHEMBL1368752 & 688181 & 5.7442 & 5.8044 & TST \\
CHEMBL1458178 & 688181 & 6.0491 & 5.9768 & TST \\
CHEMBL1597523 & 688181 & 6.0706 & 6.4092 & TST \\
CHEMBL1473676 & 688181 & 8.0 & 6.5598 & TST \\
CHEMBL1397537 & 688181 & 5.6682 & 5.7654 & TST \\
CHEMBL1505040 & 688181 & 6.8697 & 5.8698 & TST \\
CHEMBL1540097 & 688181 & 5.8407 & 6.3122 & TST \\
CHEMBL1494338 & 688181 & 5.7215 & 5.5048 & TST \\
CHEMBL1431496 & 688181 & 5.5751 & 5.3081 & TST \\
CHEMBL1504716 & 688181 & 5.8321 & 6.626 & TST \\
CHEMBL1546205 & 688181 & 5.9382 & 6.2961 & TST \\
CHEMBL1337374 & 688181 & 6.0214 & 6.1713 & TST \\
CHEMBL1424003 & 688181 & 5.856 & 6.7632 & TST \\
CHEMBL1976567 & 688181 & 6.1979 & 6.2361 & TST \\
CHEMBL1425696 & 688181 & 5.4132 & 5.7045 & TST \\
CHEMBL365161 & 688181 & 6.2076 & 6.3633 & TST \\
CHEMBL1459735 & 688181 & 6.2644 & 5.9116 & TST \\
CHEMBL1329908 & 688181 & 6.8794 & 6.4194 & TST \\
CHEMBL1565254 & 688181 & 6.0009 & 6.3979 & TST \\
CHEMBL1602669 & 688181 & 6.3372 & 6.9163 & TST \\
CHEMBL1325192 & 688181 & 6.2306 & 6.9208 & TST \\
CHEMBL1499233 & 688181 & 5.7192 & 5.9943 & TST \\
CHEMBL1517945 & 688181 & 5.5224 & 6.131 & TST \\
CHEMBE1575766 & 688181 & 5.734 & 5.7289 & TST \\
CHEMBL1498307 & 688181 & 6.1314 & 6.1246 & TST \\
CHEMBL1349570 & 688181 & 5.4833 & 6.5185 & TST \\
CHEMB1488960 & 688181 & 6.3947 & 7.0608 & TST \\
CHEMBL1493211 & 688181 & 6.3851 & 7.7479 & TST \\
CHEMBL585594 & 688181 & 8.0 & 6.7271 & TST \\
CHEMBL1597539 & 688181 & 6.2865 & 6.8484 & TST \\
CHEMBL1495053 & 688181 & 5.9454 & 6.6105 & TST \\
CHEM 3209581 & 68818181 & 5.7841 & 5.9192 & TST \\
\hline
\end{tabular}

Page 14172 
Supplemental Table S2.txt

\begin{tabular}{|c|c|c|c|c|}
\hline CHEMBL1362105 & 688181 & 5.769 & 6.1197 & TST \\
\hline CHEMBL1432867 & 688181 & 6.0329 & 5.445 & TST \\
\hline CHEMBL1406312 & 688181 & 6.9872 & 6.1465 & TST \\
\hline CHEMBL1371146 & 688181 & 6.0937 & 6.3466 & TST \\
\hline CHEMBL1379201 & 688181 & 5.8256 & 5.6697 & TST \\
\hline CHEMBL1383998 & 688181 & 5.4643 & 5.943 & TST \\
\hline CHEMBL1307602 & 688181 & 6.1972 & 6.0329 & TST \\
\hline CHEMBL1387181 & 688181 & 8.0 & 6.7442 & TST \\
\hline CHEMBL1462433 & 688181 & 5.6396 & 5.7282 & TST \\
\hline CHEMBL1546120 & 688181 & 5.4816 & 5.7583 & TST \\
\hline CHEMBL1312140 & 688181 & 5.7635 & 6.3607 & TST \\
\hline CHEMBL585267 & 688181 & 6.5346 & 5.8776 & TST \\
\hline CHEMBL1582517 & 688181 & 5.6542 & 6.1362 & TST \\
\hline CHEMBL249987 & 688181 & 6.9788 & 6.3722 & TST \\
\hline CHEMBL1864040 & 688181 & 6.1135 & 5.6212 & TST \\
\hline CHEMBL304291 & 688181 & 8.0 & 6.6617 & TST \\
\hline CHEMBL3192153 & 688181 & 5.8573 & 6.3464 & TST \\
\hline CHEMBL1506692 & 688181 & 5.909 & 6.0631 & TST \\
\hline CHEMBL1338669 & 688181 & 5.9578 & 6.4175 & TST \\
\hline CHEMBL1502222 & 688181 & 5.8533 & 6.5651 & TST \\
\hline CHEMBL1336959 & 688181 & 6.4425 & 6.0288 & TST \\
\hline CHEMBL1375041 & 688181 & 6.4609 & 6.0057 & TST \\
\hline CHEMBL1521617 & 688181 & 5.647 & 6.2863 & TST \\
\hline CHEMBL1307069 & 688181 & 5.9119 & 5.9843 & TST \\
\hline CHEMBL3208118 & 688181 & 5.6617 & 5.5887 & TST \\
\hline CHEMBL1562186 & 688181 & 5.9133 & 6.2567 & TST \\
\hline CHEMBL1556420 & 688181 & 6.4935 & 6.2205 & TST \\
\hline CHEMBL1557973 & 688181 & 6.3497 & 6.4857 & TST \\
\hline CHEMBL1531197 & 688181 & 8.0 & 6.11799 & 9999999999 \\
\hline CHEMBL1466735 & 688181 & 5.4985 & 5.8373 & TST \\
\hline CHEMBL1352375 & 688181 & 5.5056 & 5.8333 & TST \\
\hline CHEMBL1359342 & 688181 & 8.0 & 6.3621 & TST \\
\hline CHEMBL1612159 & 688181 & 5.6151 & 5.6986 & TST \\
\hline CHEMBL3197662 & 688181 & 6.857 & 6.5079 & TST \\
\hline CHEMBL1491334 & 688181 & 5.8857 & 5.8289 & TST \\
\hline CHEMBL1613629 & 688181 & 5.9935 & 6.0712 & TST \\
\hline CHEMBL1378502 & 688181 & 6.2062 & 6.2576 & TST \\
\hline CHEMBL1320454 & 688181 & 8.0 & 6.5684 & TST \\
\hline CHEMBL1464407 & 688181 & 6.1427 & 5.8694 & TST \\
\hline CHEMBL1444729 & 688181 & 6.1494 & 7.0468 & TST \\
\hline CHEMBL1993291 & 688181 & 6.9914 & 6.6212 & TST \\
\hline CHEMBL1374393 & 688181 & 5.7435 & 6.0477 & TST \\
\hline CHEMBL1552445 & 688181 & 8.0 & 7.1634 & TST \\
\hline CHEMBL1405075 & 688181 & 6.4895 & 6.1602 & TST \\
\hline CHEMBL1581541 & 688181 & 6.6073 & 6.1058 & TST \\
\hline CHEMBL1978150 & 688181 & 5.7042 & 6.0137 & TST \\
\hline CHEMBL1398621 & 688181 & 8.0 & 6.106 & TST \\
\hline CHEMBL1545598 & 688181 & 5.5989 & 5.9953 & TST \\
\hline
\end{tabular}


Supplemental Table S2.txt

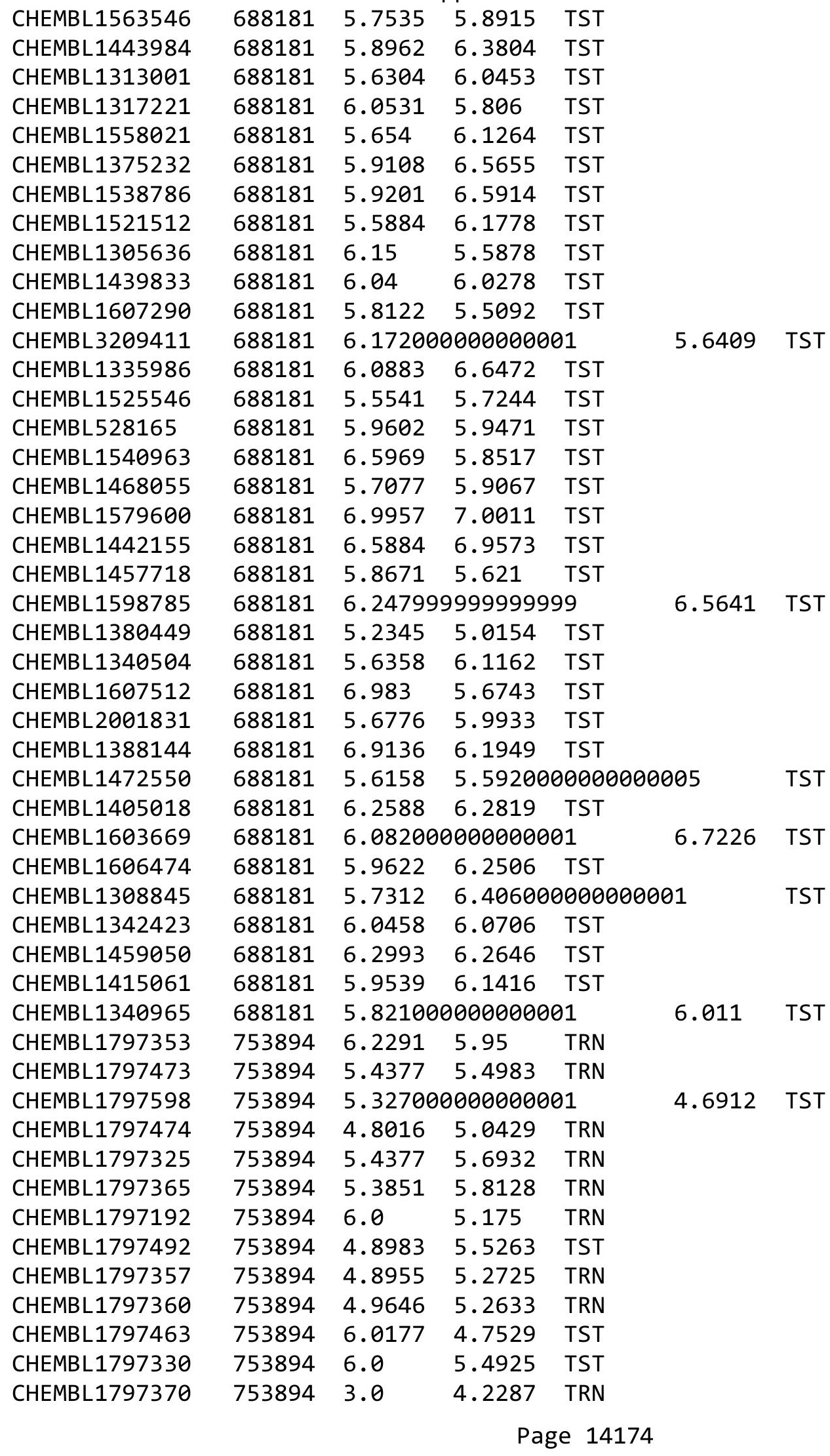




\begin{tabular}{|c|c|c|c|c|c|c|}
\hline \multirow[b]{2}{*}{ CHEMBL1797369 } & & \multicolumn{5}{|c|}{ Supplemental Table S2.txt } \\
\hline & 753894 & 4.817 & 4.4966 & TRN & & \\
\hline CHEMBL1797458 & 753894 & 5.20200 & 00000000 & $\partial 1$ & 4.4235 & TRN \\
\hline CHEMBL1797343 & 753894 & 5.2676 & 4.9511 & TST & & \\
\hline CHEMBL1797457 & 753894 & 5.2823 & 4.6918 & TST & & \\
\hline CHEMBL1797486 & 753894 & 6.9586 & 5.9196 & TRN & & \\
\hline CHEMBL1797361 & 753894 & 5.2782 & 5.0069 & TRN & & \\
\hline CHEMBL1797362 & 753894 & 5.9136 & 5.8812 & TRN & & \\
\hline CHEMBL1797489 & 753894 & 4.8033 & 5.0406 & TRN & & \\
\hline CHEMBL1797469 & 753894 & 6.2366 & 6.0275 & TRN & & \\
\hline CHEMBL1797471 & 753894 & 5.426 & 5.3772 & TRN & & \\
\hline CHEMBL1797465 & 753894 & 5.4935 & 5.3487 & TRN & & \\
\hline CHEMBL1797491 & 753894 & 4.927 & 5.8016 & TST & & \\
\hline CHEMBL1797354 & 753894 & 5.8239 & 5.6887 & TRN & & \\
\hline CHEMBL1797476 & 753894 & 3.0 & 4.8177 & TRN & & \\
\hline CHEMBL1797359 & 753894 & 5.4711 & 5.5219 & TRN & & \\
\hline CHEMBL1797363 & 753894 & 5.7496 & 5.6248 & TRN & & \\
\hline CHEMBL1797479 & 753894 & 5.3215 & 4.9413 & TRN & & \\
\hline CHEMBL1797456 & 753894 & 5.1772 & 4.9055 & TST & & \\
\hline CHEMBL1797356 & 753894 & 5.52 & 5.5289 & TRN & & \\
\hline CHEMBL1797194 & 753894 & 6.0 & 5.5791 & TRN & & \\
\hline CHEMBL1652176 & 753894 & 5.9788 & 5.0283 & TRN & & \\
\hline CHEMBL1797478 & 753894 & 5.4498 & 4.9891 & TRN & & \\
\hline CHEMBL1797466 & 753894 & 5.8239 & 5.4292 & TRN & & \\
\hline CHEMBL1797483 & 753894 & 4.8351 & 5.2014 & TRN & & \\
\hline CHEMBL1797488 & 753894 & 5.6253 & 5.1574 & TRN & & \\
\hline CHEMBL1797493 & 753894 & 5.8327 & 5.2665 & TST & & \\
\hline CHEMBL1797329 & 753894 & 5.2725 & 5.5681 & TRN & & \\
\hline CHEMBL1797481 & 753894 & 5.8665 & 5.0378 & TRN & & \\
\hline CHEMBL1795365 & 753894 & 5.3696 & 5.4523 & TST & & \\
\hline CHEMBL1797190 & 753894 & 5.6402 & 5.4046 & TRN & & \\
\hline CHEMBL1797327 & 753894 & 5.3261 & 5.1989 & TRN & & \\
\hline CHEMBL1797368 & 753894 & 3.0 & 4.715 & TST & & \\
\hline CHEMBL1797323 & 753894 & 5.1688 & 5.3339 & TRN & & \\
\hline CHEMBL1797352 & 753894 & 6.1487 & 5.9784 & TRN & & \\
\hline CHEMBL1797366 & 753894 & 5.3233 & 5.5487 & TRN & & \\
\hline CHEMBL1797472 & 753894 & 5.2676 & 5.2667 & TRN & & \\
\hline CHEMBL1797333 & 753894 & 5.9066 & 5.8038 & TRN & & \\
\hline CHEMBL1797198 & 753894 & 4.9393 & 5.2986 & TRN & & \\
\hline CHEMBL1797324 & 753894 & 5.3316 & 5.0922 & TRN & & \\
\hline CHEMBL1797350 & 753894 & 5.0246 & 5.1441 & TRN & & \\
\hline CHEMBL 1797348 & 753894 & 5.3098 & 5.6753 & TRN & & \\
\hline CHEMBL1797487 & 753894 & 5.3161 & 5.1542 & TRN & & \\
\hline CHEMBL 1797480 & 753894 & 4.8945 & 4.8553 & TRN & & \\
\hline CHEMBL1797344 & 753894 & 6.0458 & 5.7234 & TST & & \\
\hline CHEMBL1797461 & 753894 & 5.32700 & 90000000 & 21 & 4.4069 & TST \\
\hline CHEMBL1797355 & 753894 & 5.3288 & 5.4231 & TRN & & \\
\hline CHEMBL1797459 & 753894 & 4.4259 & 4.8863 & TST & & \\
\hline CHEMBL1797339 & 753894 & 5.8013 & 5.817 & TRN & & \\
\hline
\end{tabular}




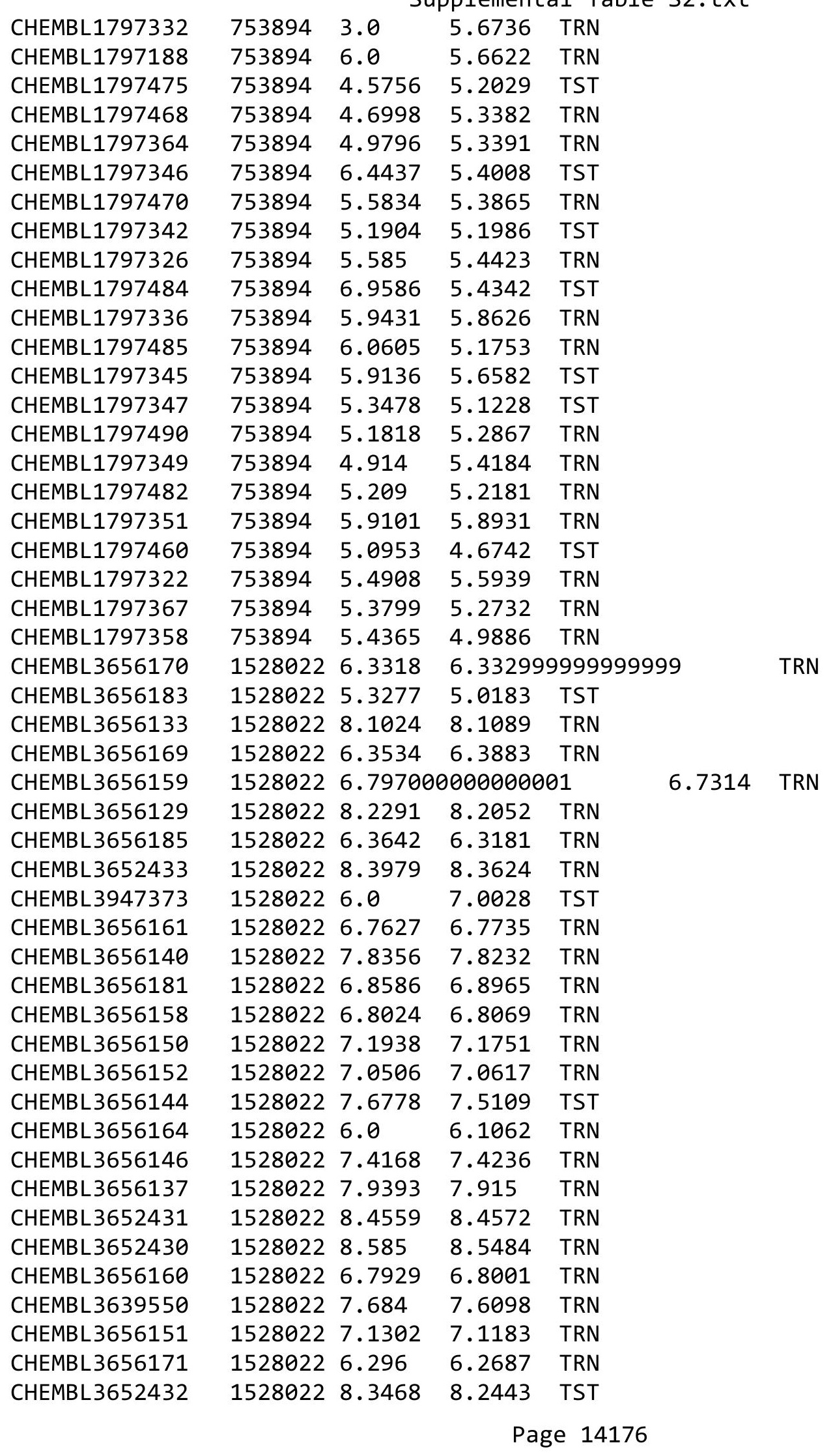


Supplemental Table S2.txt

\begin{tabular}{|c|c|c|c|c|c|}
\hline CHEMBL 3656132 & 1528022 & 8.1079 & 8.1307 & TRN & \\
\hline CHEMBL 3656131 & 1528022 & 8.1308 & 8.175 & TRN & \\
\hline CHEMBL3656153 & 1528022 & 7.0301 & 7.0213 & TRN & \\
\hline CHEMBL 3656134 & 1528022 & 8.0555 & 8.0816 & TRN & \\
\hline CHEMBL 3968267 & 1528022 & 6.0 & 6.8259 & TST & \\
\hline CHEMBL 3656139 & 1528022 & 7.7747 & 7.7612 & TRN & \\
\hline CHEMBL3656149 & 1528022 & 7.2104 & 7.2172 & TRN & \\
\hline CHEMBL 3656157 & 1528022 & 6.8847 & 6.8886 & TRN & \\
\hline CHEMBL 3656135 & 1528022 & 7.9547 & 7.9887 & TRN & \\
\hline CHEMBL3656163 & 1528022 & 6.7233 & 6.6998 & TRN & \\
\hline CHEMBL 3970197 & 1528022 & 7.3799 & 7.3553 & TRN & \\
\hline CHEMBL 3656130 & 1528022 & 8.1549 & 8.1625 & TRN & \\
\hline CHEMBL 3656167 & 1528022 & 6.4222 & 6.4373 & TRN & \\
\hline CHEMBL 3656172 & 1528022 & 6.2091 & 6.1748 & TRN & \\
\hline CHEMBL3656168 & 1528022 & 7.3799 & 7.2742 & TST & \\
\hline CHEMBL 3656177 & 1528022 & 5.8083 & 5.8054 & TRN & \\
\hline CHEMBL3656136 & 1528022 & 7.9508 & 7.99200 & 2000000001 & TRN \\
\hline CHEMBL 3656165 & 1528022 & 6.5333 & 6.4902 & TRN & \\
\hline CHEMBL 3656145 & 1528022 & 7.5817 & 7.695 & TRN & \\
\hline CHEMBL3898229 & 1528022 & 6.1737 & 6.8548 & TST & \\
\hline CHEMBL 3656162 & 1528022 & 6.7486 & 6.7722 & TRN & \\
\hline CHEMBL 3656138 & 1528022 & 7.9172 & 7.8434 & TRN & \\
\hline CHEMBL3656155 & 1528022 & 6.9147 & 6.935 & TRN & \\
\hline CHEMBL 3656143 & 1528022 & 7.7144 & 7.6854 & TRN & \\
\hline CHEMBL 3652434 & 1528022 & 8.3468 & 8.3711 & TRN & \\
\hline CHEMBL 3656142 & 1528022 & 7.7235 & 7.74200 & 3000000001 & TRN \\
\hline CHEMBL 3652435 & 1528022 & 8.3188 & 8.3342 & TST & \\
\hline CHEMBL 3656184 & 1528022 & 8.6778 & 8.792 & TST & \\
\hline CHEMBL3656141 & 1528022 & 7.7282 & 7.6801 & TST & \\
\hline CHEMBL3656156 & 1528022 & 6.901 & 7.0109 & TST & \\
\hline CHEMBL 3656154 & 1528022 & 6.9805 & 7.1314 & TST & \\
\hline CHEMBL 3656182 & 1528022 & 5.7499 & 5.9416 & TST & \\
\hline CHEMBL 3656179 & 1528022 & 5.2964 & 6.2888 & TST & \\
\hline CHEMBL3656128 & 1528022 & 8.2291 & 8.1475 & TST & \\
\hline CHEMBL 383498 & 336476 & 7.4685 & 7.2717 & TRN & \\
\hline CHEMBL381266 & 336476 & 6.8239 & 6.9163 & TRN & \\
\hline CHEMBL 206808 & 336476 & 6.7496 & 6.7047 & TRN & \\
\hline CHEMBL203516 & 336476 & 6.6073 & 6.8158 & TRN & \\
\hline CHEMBL204960 & 336476 & 7.1024 & 7.2219 & TRN & \\
\hline CHEMBL203991 & 336476 & 7.4318 & 7.4443 & TRN & \\
\hline CHEMBL206570 & 336476 & 6.2366 & 6.2749 & TRN & \\
\hline CHEMBL205016 & 336476 & 6.75700 & 00000000 & 6.8133 & $1 \mathrm{~K}$ \\
\hline CHEMBL383478 & 336476 & 7.3872 & 7.3359 & TRN & \\
\hline CHEMBL381580 & 336476 & 6.9788 & 6.94600 & 0000000001 & TRN \\
\hline CHEMBL 206341 & 336476 & 6.4935 & 6.6757 & TRN & \\
\hline CHEMBL382794 & 336476 & 7.0223 & 6.8897 & TRN & \\
\hline CHEMBL 203444 & 336476 & 6.2027 & 6.5741 & TRN & \\
\hline CHEMBL382221 & 336476 & 5.9935 & 6.0845 & TRN & \\
\hline
\end{tabular}




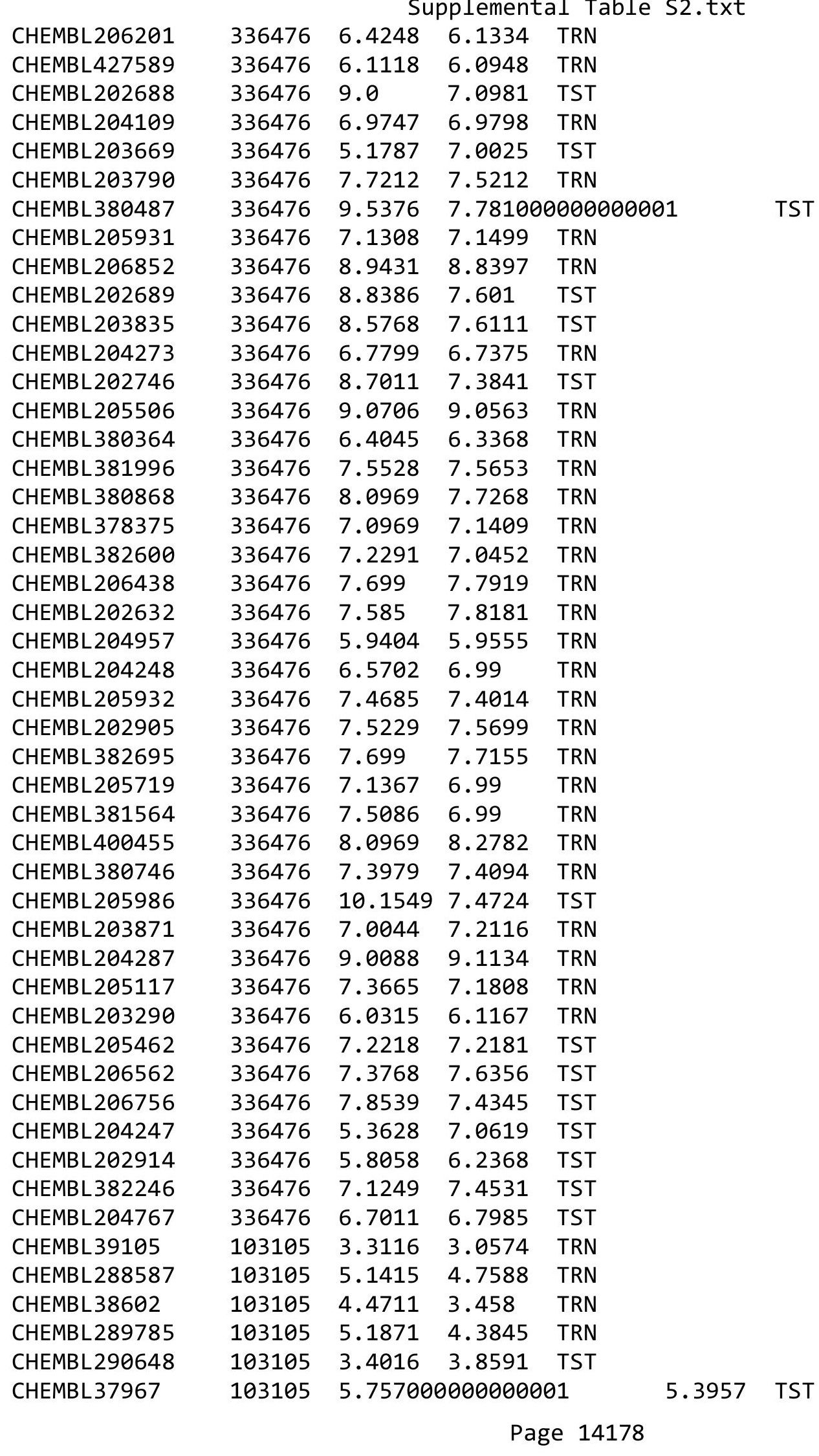




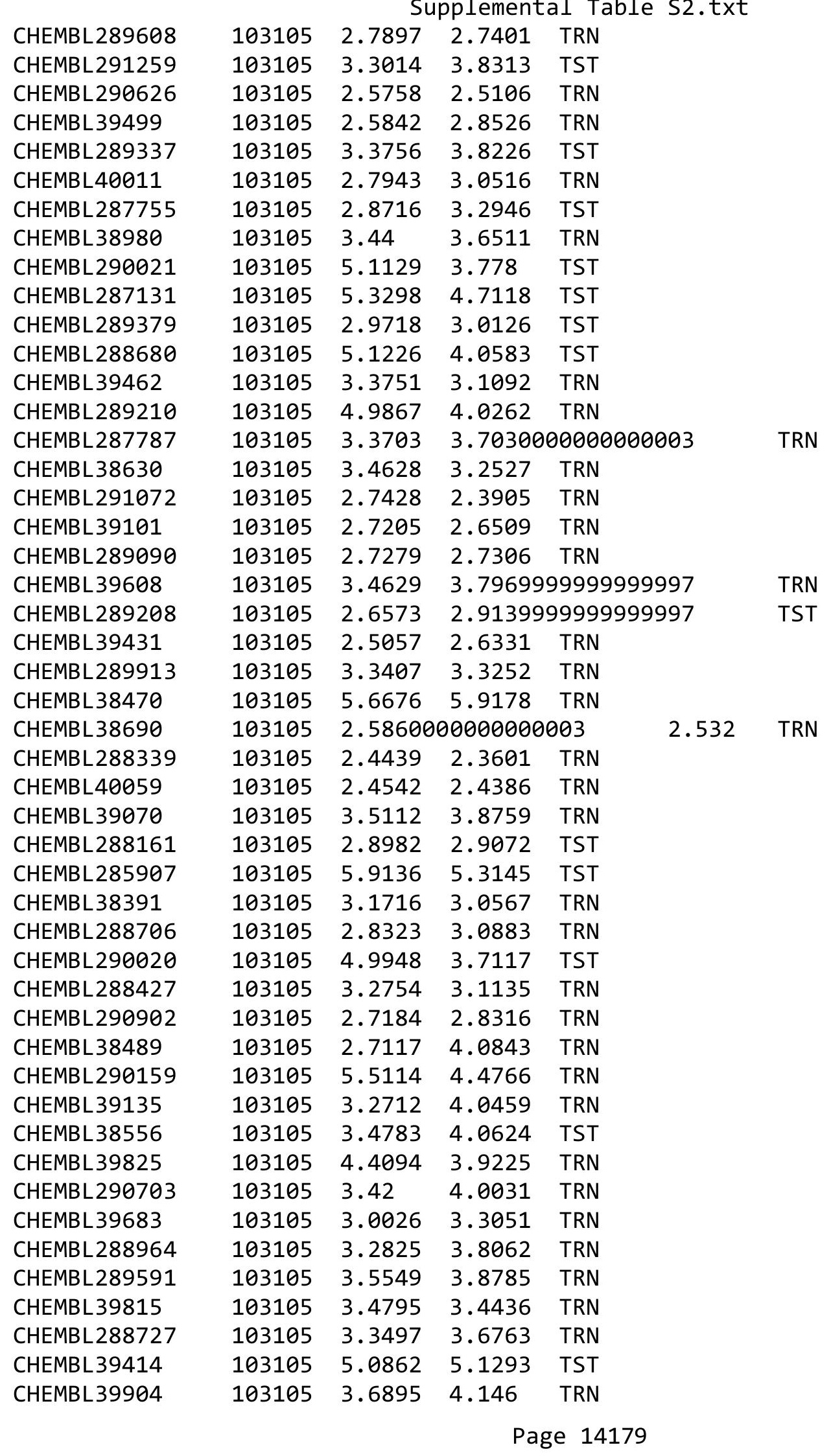




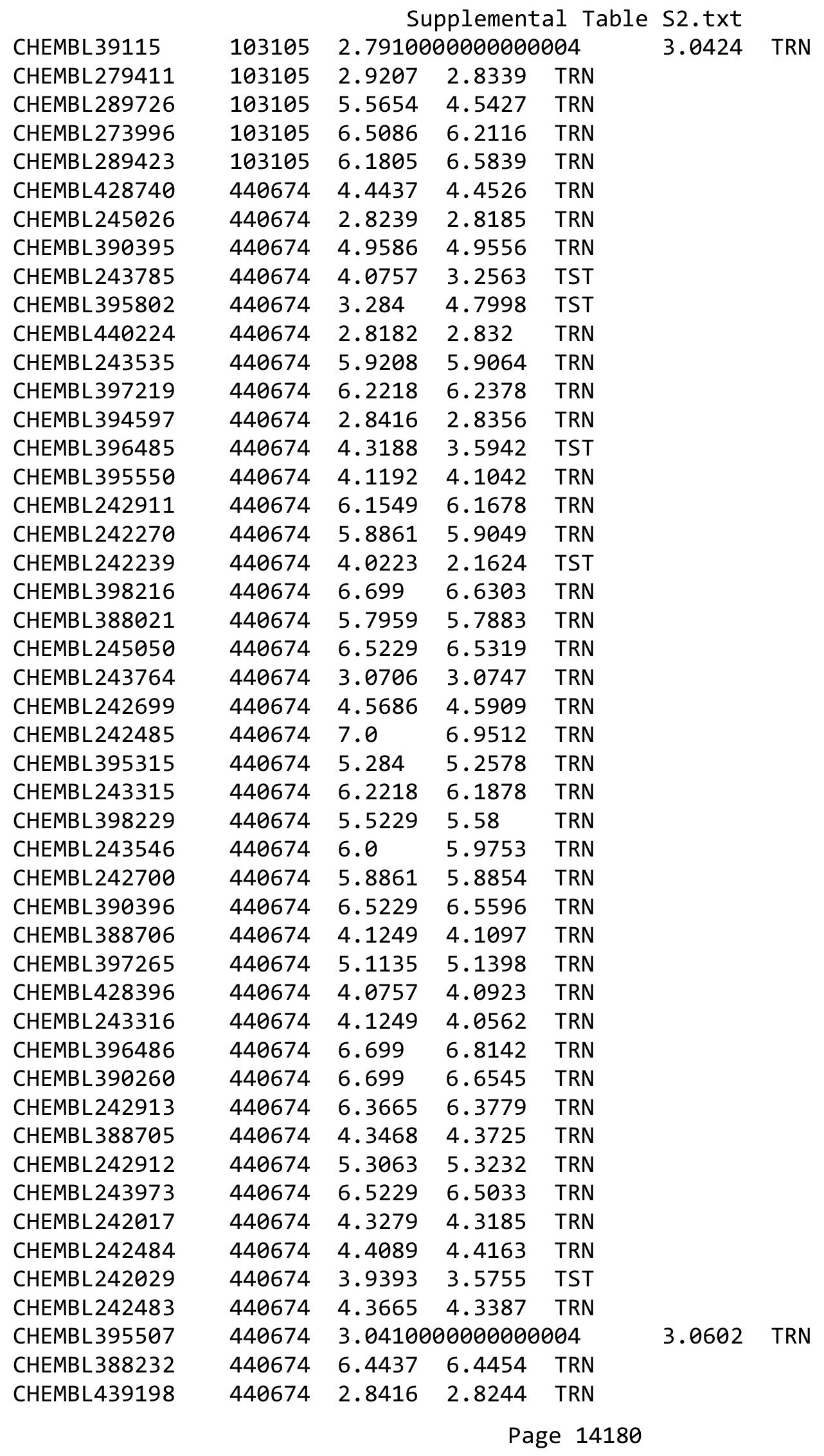


Supplemental Table S2.txt

\begin{tabular}{|c|c|c|c|c|}
\hline CHEMBL 243534 & 440674 & 4.1612 & 4.1982 & TRN \\
\hline CHEMBL390178 & 440674 & 2.7852 & 3.5168 & TST \\
\hline CHEMBL390397 & 440674 & 6.5229 & 6.5065 & TRN \\
\hline CHEMBL242269 & 440674 & 6.301 & 6.3012 & TRN \\
\hline CHEMBL 242238 & 440674 & 2.7905 & 2.7868 & TRN \\
\hline CHEMBL 243972 & 440674 & 7.0969 & $5.9170 €$ & 0000 \\
\hline CHEMBL 245275 & 440674 & 4.2757 & 5.0448 & TST \\
\hline CHEMBL242698 & 440674 & 4.7959 & 5.1051 & TST \\
\hline CHEMBL 243783 & 440674 & 2.7852 & 3.1358 & TST \\
\hline CHEMBL428043 & 440674 & 6.5229 & 4.6179 & TST \\
\hline CHEMBL 244810 & 440674 & 6.699 & 6.5168 & TST \\
\hline CHEMBL394364 & 440674 & 3.9706 & 4.6492 & TST \\
\hline CHEMBL390215 & 440674 & 2.9172 & 3.5157 & TST \\
\hline CHEMBL 182725 & 311591 & 6.8239 & 7.3062 & TRN \\
\hline CHEMBL189030 & 311591 & 6.6021 & 6.4637 & TRN \\
\hline CHEMBL182299 & 311591 & 7.0 & 6.9364 & TRN \\
\hline CHEMBL186390 & 311591 & 7.301 & 7.5525 & TRN \\
\hline CHEMBL186129 & 311591 & 5.8013 & 5.7012 & TRN \\
\hline CHEMBL362435 & 311591 & 6.9208 & 7.0543 & TRN \\
\hline CHEMBL185715 & 311591 & 8.699 & 8.2973 & TRN \\
\hline CHEMBL188223 & 311591 & 7.699 & 7.6014 & TRN \\
\hline CHEMBL426242 & 311591 & 6.301 & 6.6961 & TRN \\
\hline CHEMBL187832 & 311591 & 4.9 & 4.9587 & TRN \\
\hline CHEMBL366692 & 311591 & 8.0 & 7.269 & TST \\
\hline CHEMBL 187515 & 311591 & 5.7011 & 5.2437 & TRN \\
\hline CHEMBL184934 & 311591 & 6.5086 & 5.6657 & TRN \\
\hline CHEMBL359749 & 311591 & 6.9208 & 7.0268 & TRN \\
\hline CHEMBL188877 & 311591 & 7.5229 & 6.9412 & TRN \\
\hline CHEMBL338047 & 311591 & 7.5229 & 7.0357 & TST \\
\hline CHEMBL185487 & 311591 & 7.3979 & 7.5147 & TRN \\
\hline CHEMBL181683 & 311591 & 6.6021 & 6.2433 & TST \\
\hline CHEMBL188489 & 311591 & 7.699 & 7.501 & TRN \\
\hline CHEMBL181747 & 311591 & 6.4089 & 6.0003 & TRN \\
\hline CHEMBL361839 & 311591 & 5.7011 & 5.9385 & TST \\
\hline CHEMBL 188580 & 311591 & 8.2218 & 7.9727 & TRN \\
\hline CHEMBL188941 & 311591 & 8.0 & 7.7001 & TRN \\
\hline CHEMBL361479 & 311591 & 7.2218 & 7.5423 & TRN \\
\hline CHEMBL184880 & 311591 & 4.1 & 4.7615 & TRN \\
\hline CHEMBL361069 & 311591 & 7.699 & 7.0632 & TRN \\
\hline CHEMBL187513 & 311591 & 5.0 & 5.0046 & TRN \\
\hline CHEMBL188995 & 311591 & 6.4089 & 7.2316 & TRN \\
\hline CHEMBL184026 & 311591 & 5.0 & 5.0098 & TRN \\
\hline CHEMBL189760 & 311591 & 7.699 & 7.6713 & TST \\
\hline CHEMBL184294 & 311591 & 7.699 & 7.1815 & TRN \\
\hline CHEMBL189458 & 311591 & 7.301 & 6.7815 & TST \\
\hline CHEMBL183249 & 311591 & 8.0 & 7.5908 & TST \\
\hline CHEMBL185622 & 311591 & 6.4089 & 6.4959 & TRN \\
\hline CHEMBL363066 & 311591 & 6.0 & 6.0507 & TRN \\
\hline
\end{tabular}

Page 14181 


\begin{tabular}{|c|c|c|c|c|c|}
\hline \multicolumn{6}{|c|}{ Supplemental Table S2.txt } \\
\hline CHEMBL184175 & 311591 & 4.0 & 4.4696 & TRN & \\
\hline CHEMBL363952 & 311591 & 8.5229 & 8.1052 & TST & \\
\hline CHEMBL182580 & 311591 & 8.0969 & 7.6837 & TST & \\
\hline CHEMBL434518 & 311591 & 8.2218 & 7.9526 & TST & \\
\hline CHEMBL188365 & 311591 & 5.0 & 4.8724 & TRN & \\
\hline CHEMBL364403 & 311591 & 6.4089 & 6.6492 & TRN & \\
\hline CHEMBL366120 & 311591 & 6.699 & 6.353 & TRN & \\
\hline CHEMBL182846 & 311591 & 7.5229 & 7.3013 & TST & \\
\hline CHEMBL188547 & 311591 & 8.0 & 7.8127 & TST & \\
\hline CHEMBL187786 & 311591 & 7.699 & 7.4792 & TRN & \\
\hline CHEMBL181497 & 311591 & 6.4437 & 6.8876 & TST & \\
\hline CHEMBL185865 & 311591 & 7.0 & 7.8205 & TRN & \\
\hline CHEMBL188745 & 311591 & 5.9031 & 5.8231 & TRN & \\
\hline CHEMBL186128 & 311591 & 5.0 & 5.0031 & TRN & \\
\hline CHEMBL 361250 & 311591 & 7.301 & 6.7253 & TST & \\
\hline CHEMBL188595 & 311591 & 5.6003 & 5.86600 & 00000000005 & TRN \\
\hline CHEMBL187305 & 311591 & 7.3979 & 7.6856 & TRN & \\
\hline CHEMBL188878 & 311591 & 7.0 & 7.1788 & TRN & \\
\hline CHEMBL398554 & 455329 & 6.3979 & 6.4081 & TRN & \\
\hline CHEMBL438524 & 455329 & 6.6778 & 6.6233 & TRN & \\
\hline CHEMBL399065 & 455329 & 5.8539 & 5.0746 & TRN & \\
\hline CHEMBL249314 & 455329 & 3.5229 & 4.7445 & TST & \\
\hline CHEMBL428757 & 455329 & 6.1871 & 5.5602 & TRN & \\
\hline CHEMBL399376 & 455329 & 3.5229 & 4.0054 & TRN & \\
\hline CHEMBL427707 & 455329 & 4.5528 & 4.8786 & TRN & \\
\hline CHEMBL401090 & 455329 & 3.5229 & 4.9887 & TRN & \\
\hline CHEMBL 251141 & 455329 & 6.0969 & 6.6444 & TRN & \\
\hline CHEMBL249512 & 455329 & 5.8861 & 4.6626 & TRN & \\
\hline CHEMBL248901 & 455329 & 4.7447 & 5.2167 & TRN & \\
\hline CHEMBL250939 & 455329 & 6.2218 & 6.4476 & TRN & \\
\hline CHEMBL249926 & 455329 & 3.5229 & 4.9543 & TST & \\
\hline CHEMBL249718 & 455329 & 6.0458 & 5.1121 & TRN & \\
\hline CHEMBL400121 & 455329 & 5.7423 & 6.0694 & TRN & \\
\hline CHEMBL399266 & 455329 & 5.9355 & 4.9223 & TRN & \\
\hline CHEMBL 248900 & 455329 & 5.8239 & 5.4367 & TRN & \\
\hline CHEMBL250741 & 455329 & 6.0177 & 5.7655 & TRN & \\
\hline CHEMBL400122 & 455329 & 6.699 & 6.5183 & TRN & \\
\hline CHEMBL400937 & 455329 & 6.1739 & 6.4314 & TST & \\
\hline CHEMBL251531 & 455329 & 6.3279 & 6.8249 & TRN & \\
\hline CHEMBL 251530 & 455329 & 6.7212 & 6.6899 & TRN & \\
\hline CHEMBL251532 & 455329 & 6.2757 & 6.8642 & TRN & \\
\hline CHEMBL399115 & 455329 & 7.2218 & 6.6083 & TRN & \\
\hline CHEMBL251736 & 455329 & 5.8239 & 6.3137 & TRN & \\
\hline CHEMBL59030 & 455329 & 7.4559 & 5.1149 & TST & \\
\hline CHEMBL 398680 & 455329 & 6.3372 & 6.1953 & TRN & \\
\hline CHEMBL 250940 & 455329 & 5.475 & 5.9723 & TRN & \\
\hline CHEMBL399453 & 455329 & 4.585 & 5.1151 & TRN & \\
\hline CHEMBL400702 & 455329 & 3.5229 & 4.4593 & TST & \\
\hline
\end{tabular}




\begin{tabular}{|c|c|c|c|c|c|}
\hline \multirow[b]{2}{*}{ CHEMBL251332 } & \multicolumn{5}{|c|}{ Supplemental Table S2.txt } \\
\hline & 455329 & 6.1192 & 6.5427 & TRN & \\
\hline CHEMBL 249717 & 455329 & 3.5229 & 4.863 & TST & \\
\hline CHEMBL251331 & 455329 & 7.0458 & 6.75899 & 99999999995 & TRN \\
\hline CHEMBL403130 & 455329 & 3.5229 & 3.8248 & TRN & \\
\hline CHEMBL399452 & 455329 & 3.5229 & 4.9852 & TRN & \\
\hline CHEMBL 250129 & 455329 & 4.0 & 4.4473 & TST & \\
\hline CHEMBL62136 & 455329 & 7.8239 & 5.4908 & TST & \\
\hline CHEMBL400701 & 455329 & 5.6778 & 4.5781 & TRN & \\
\hline CHEMBL249513 & 455329 & 3.5229 & 4.4592 & TRN & \\
\hline CHEMBL 251140 & 455329 & 6.2218 & 6.4254 & TRN & \\
\hline CHEMBL428051 & 455329 & 5.7959 & 4.9421 & TRN & \\
\hline CHEMBL 250332 & 455329 & 5.9355 & 6.1662 & TRN & \\
\hline CHEMBL 249924 & 455329 & 3.5229 & 5.02800 & 00000000005 & TRN \\
\hline CHEMBL 249105 & 455329 & 6.1739 & 5.0507 & TRN & \\
\hline CHEMBL399116 & 455329 & 7.0 & 6.7935 & TRN & \\
\hline CHEMBL 251130 & 455329 & 3.5229 & 3.7538 & TRN & \\
\hline CHEMBL 250333 & 455329 & 6.3665 & 6.0009 & TRN & \\
\hline CHEMBL 251538 & 455329 & 6.9586 & 6.5377 & TRN & \\
\hline CHEMBL429117 & 455329 & 6.8861 & 6.4608 & TRN & \\
\hline CHEMBL 250537 & 455329 & 6.1367 & 6.2871 & TRN & \\
\hline CHEMBL 250742 & 455329 & 6.3372 & 5.9567 & TRN & \\
\hline CHEMBL 251539 & 455329 & 6.284 & 5.626 & TRN & \\
\hline CHEMBL 250538 & 455329 & 5.8761 & 6.03 & TRN & \\
\hline CHEMBL 249315 & 455329 & 5.7959 & 4.9264 & TST & \\
\hline CHEMBL401089 & 455329 & 6.5229 & 5.3063 & TST & \\
\hline CHEMBL 248711 & 455329 & 3.5229 & 4.9791 & TST & \\
\hline CHEMBL399428 & 455329 & 6.7696 & 7.2351 & TST & \\
\hline CHEMBL 250128 & 455329 & 3.5229 & 4.1029 & TST & \\
\hline CHEMBL437773 & 455329 & 3.5229 & 4.3411 & TST & \\
\hline CHEMBL 249925 & 455329 & 3.5229 & 4.9398 & TST & \\
\hline CHEMBL 250241 & 455329 & 5.6778 & 5.3786 & TST & \\
\hline CHEMBL2376496 & 956489 & 8.39 & 7.5942 & TST & \\
\hline CHEMBL2376495 & 956489 & 7.68 & 7.6289 & TST & \\
\hline CHEMBL516110 & 956489 & 7.19 & 7.5319 & TST & \\
\hline CHEMBL1981047 & 956489 & 7.6 & 7.5805 & TST & \\
\hline CHEMBL484609 & 956489 & 6.22 & 6.6149 & TST & \\
\hline CHEMBL 206319 & 956489 & 7.77 & 7.8803 & TRN & \\
\hline CHEMBL2376494 & 956489 & 7.96 & 8.1132 & TRN & \\
\hline CHEMBL1614711 & 956489 & 8.4 & 8.2414 & TRN & \\
\hline CHEMBL205723 & 956489 & 8.4 & 8.2679 & TRN & \\
\hline CHEMBL 203343 & 956489 & 8.3 & 8.1284 & TRN & \\
\hline CHEMBL 203071 & 956489 & 8.0 & 7.9329 & TRN & \\
\hline CHEMBL383010 & 956489 & 8.15 & 8.1316 & TRN & \\
\hline CHEMBL 382605 & 956489 & 8.0 & 7.9561 & TRN & \\
\hline CHEMBL 205409 & 956489 & 7.2 & 7.5074 & TRN & \\
\hline CHEMBL185901 & 956489 & 5.0 & 4.9078 & TRN & \\
\hline CHEMBL365673 & 956489 & 6.0 & 5.9179 & TRN & \\
\hline CHEMBL185834 & 956489 & 5.3 & 5.2093 & TRN & \\
\hline
\end{tabular}




\begin{tabular}{|c|c|c|c|c|c|}
\hline \multicolumn{6}{|c|}{ Supplemental Table S2.txt } \\
\hline CHEMBL184742 & 956489 & 6.14 & 6.0693 & TRN & \\
\hline CHEMBL184709 & 956489 & 5.0 & 5.0147 & TRN & \\
\hline CHEMBL434335 & 956489 & 6.24 & 6.0803 & TRN & \\
\hline CHEMBL2376497 & 956489 & 6.0 & 6.0708 & TRN & \\
\hline CHEMBL363926 & 956489 & 5.05 & 5.0641 & TRN & \\
\hline CHEMBL185775 & 956489 & 5.0 & 4.8385 & TRN & \\
\hline CHEMBL113534 & 956489 & 4.76 & 4.9837 & TRN & \\
\hline CHEMBL 230286 & 956489 & 5.5 & 5.4924 & TRN & \\
\hline CHEMBL109329 & 956489 & 5.66 & 5.5475 & TRN & \\
\hline CHEMBL2376501 & 956489 & 4.479 & 4.622 & TRN & \\
\hline CHEMBL326753 & 956489 & 4.17 & 4.7292 & TRN & \\
\hline CHEMBL113302 & 956489 & 5.01 & 4.7306 & TRN & \\
\hline CHEMBL2376500 & 956489 & 5.0 & 6.3313 & TST & \\
\hline CHEMBL2376499 & 956489 & 5.27 & 5.9926 & TST & \\
\hline CHEMBL55662 & 956489 & 4.0 & 5.8820 & 0000000001 & TST \\
\hline CHEMBL55683 & 956489 & 4.21 & 4.2731 & TRN & \\
\hline CHEMBL 2376498 & 956489 & 4.3 & 6.6473 & TST & \\
\hline CHEMBL56081 & 956489 & 4.47 & 4.3543 & TRN & \\
\hline CHEMBL57556 & 956489 & 5.1 & 5.0536 & TRN & \\
\hline CHEMBL56671 & 956489 & 5.29 & 5.2007 & TRN & \\
\hline CHEMBL 291963 & 956489 & 5.48 & 5.6851 & TRN & \\
\hline CHEMBL327907 & 956489 & 5.74 & 6.0072 & TRN & \\
\hline CHEMBL 300817 & 956489 & 5.82 & 5.9703 & TRN & \\
\hline CHEMBL 278103 & 956489 & 5.82 & 5.6311 & TRN & \\
\hline CHEMBL60816 & 956489 & 5.92 & 5.829 & TRN & \\
\hline CHEMBL58436 & 956489 & 6.0 & 6.0770 & 0000000001 & TRN \\
\hline CHEMBL1204212 & 956489 & 6.15 & 6.0709 & TRN & \\
\hline CHEMBL57443 & 956489 & 6.22 & 6.1629 & 9999999999 & TRN \\
\hline CHEMBL 2376502 & 956489 & 6.4 & 6.4989 & TRN & \\
\hline CHEMBL55379 & 956489 & 6.43 & 7.0951 & TST & \\
\hline CHEMBL 293991 & 956489 & 6.46 & 7.0318 & TST & \\
\hline CHEMBL423288 & 956489 & 5.24 & 5.1958 & TRN & \\
\hline CHEMBL 292866 & 956489 & 5.42 & 5.4834 & TRN & \\
\hline CHEMBL55742 & 956489 & 5.7 & 5.4592 & TRN & \\
\hline CHEMBL299707 & 956489 & 5.72 & 5.8924 & TRN & \\
\hline CHEMBL58580 & 956489 & 5.89 & 5.9614 & TRN & \\
\hline CHEMBL59036 & 956489 & 6.0 & 5.9594 & TRN & \\
\hline CHEMBL 21162 & 956489 & 6.1 & 5.9344 & TRN & \\
\hline CHEMBL418010 & 956489 & 6.1 & 6.0187 & TRN & \\
\hline CHEMBL55592 & 956489 & 6.3 & 5.9449 & TRN & \\
\hline CHEMBL58142 & 956489 & 6.35 & 6.6383 & TRN & \\
\hline CHEMBL20926 & 956489 & 6.4 & 6.5416 & TRN & \\
\hline CHEMBL277931 & 956489 & 6.4 & 6.468 & TRN & \\
\hline CHEMBL 2376503 & 956489 & 6.52 & 6.4998 & TRN & \\
\hline CHEMBL418279 & 956489 & 6.7 & 5.8548 & TST & \\
\hline CHEMBL 20252 & 956489 & 6.7 & 6.7426 & TST & \\
\hline CHEMBL2376633 & 956489 & 6.7 & 5.7642 & TST & \\
\hline CHEMBL20867 & 956489 & 6.7 & 5.9505 & TST & \\
\hline
\end{tabular}




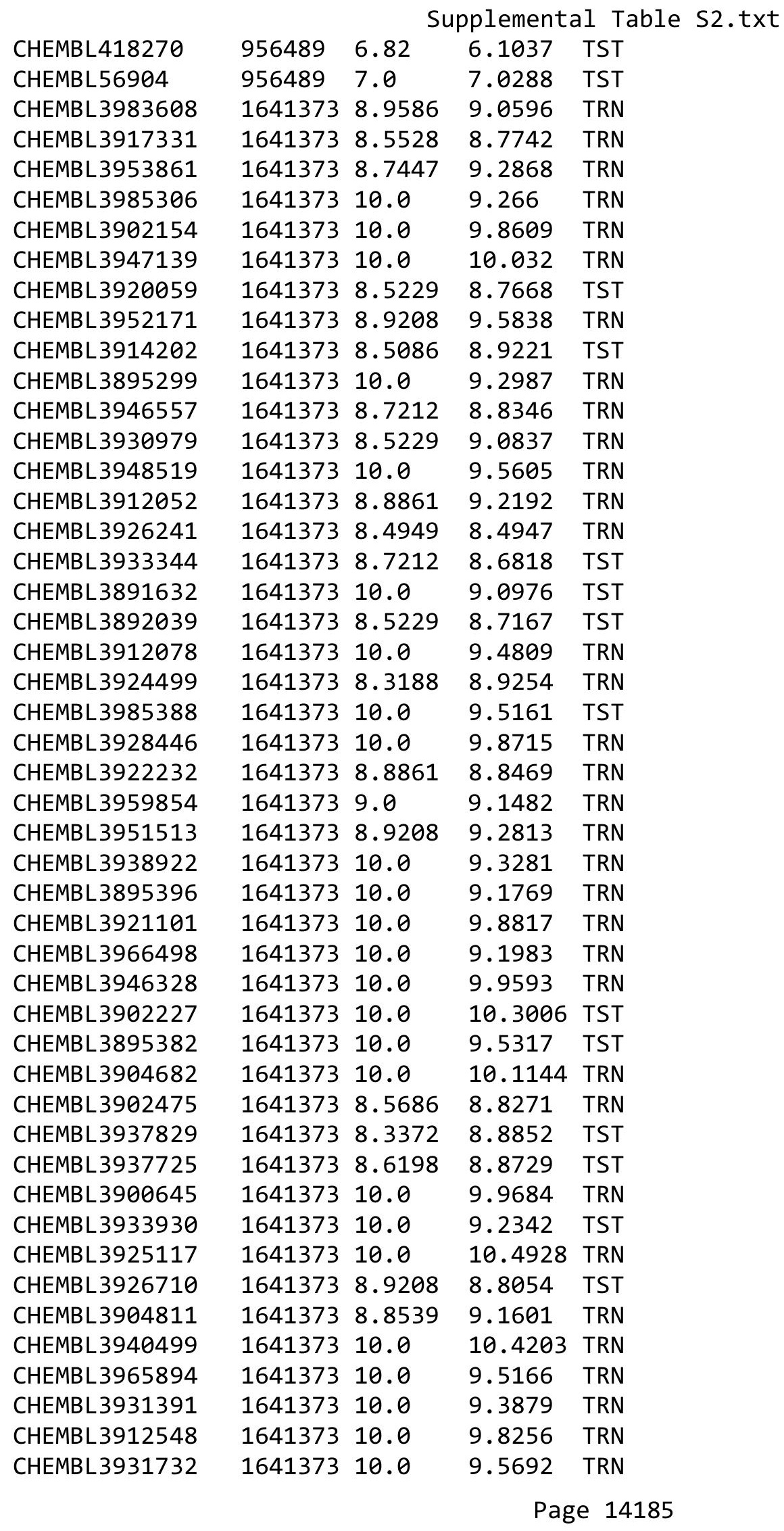




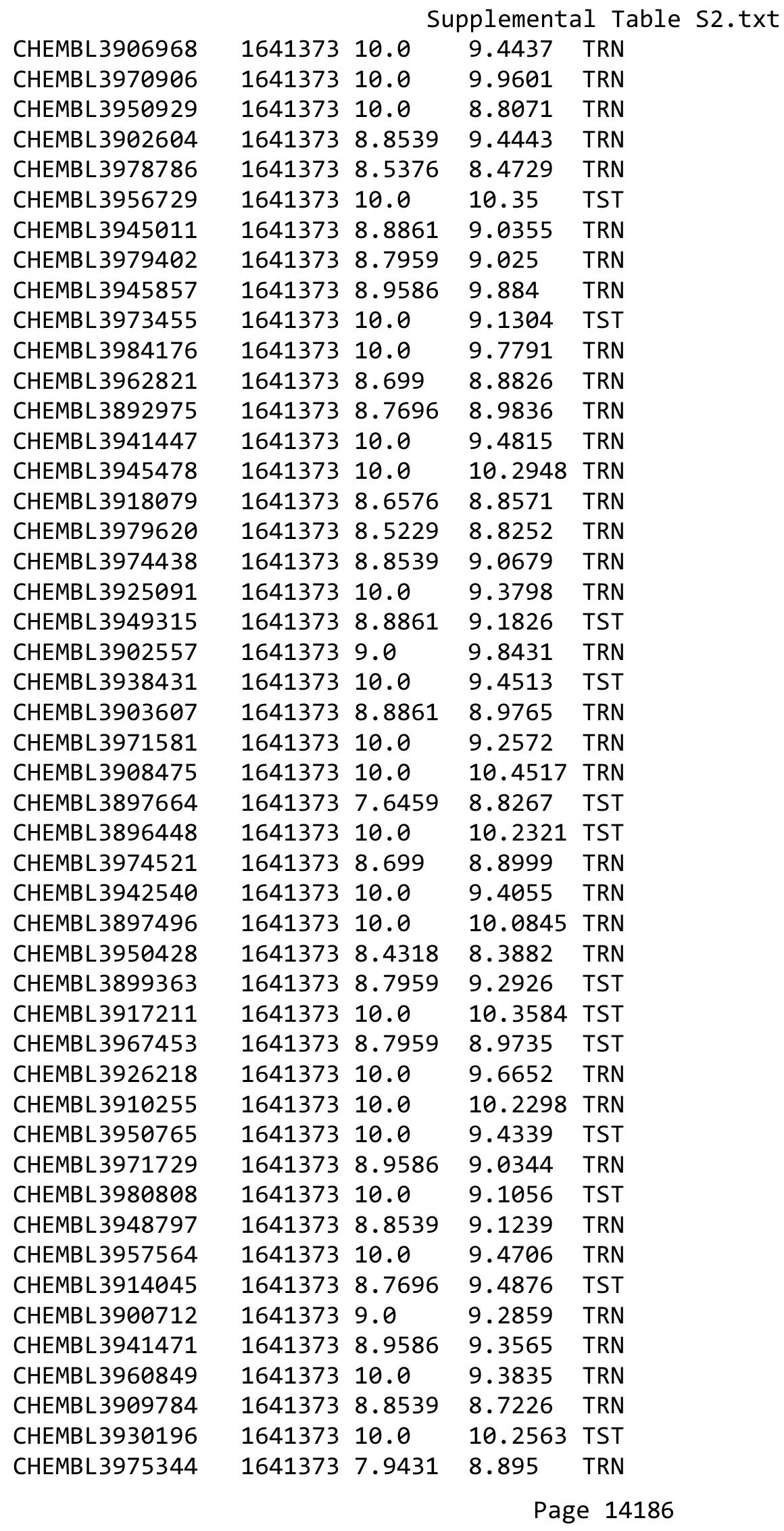


Supplemental Table S2.txt

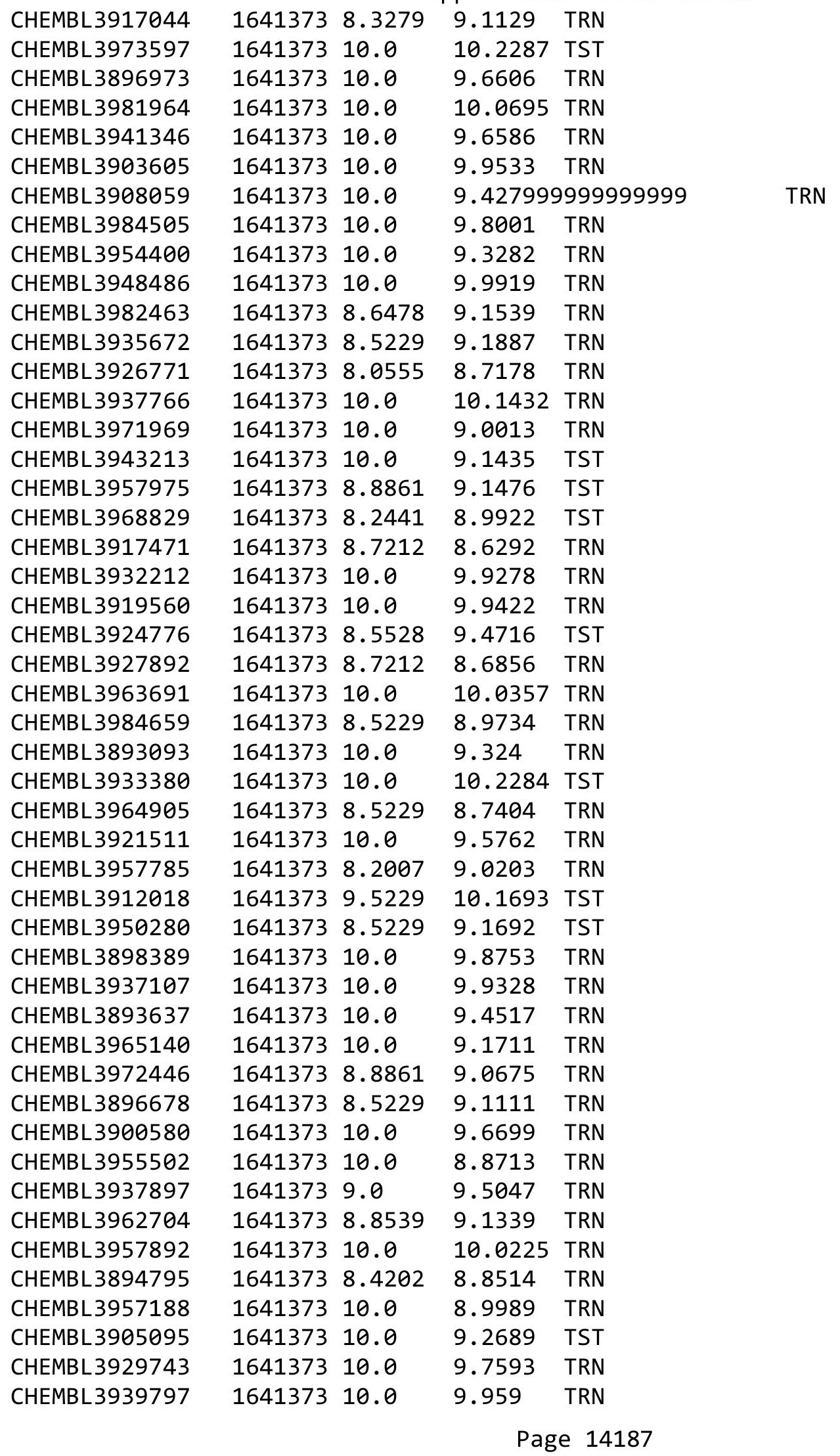


Supplemental Table S2.txt

\begin{tabular}{|c|c|c|c|c|}
\hline 34 & 373 & & & $\cdot$ \\
\hline HEMBL3 & 641373 & 10.0 & 9.6346 & \\
\hline & 373 & & & \\
\hline 628 & 373 & & & \\
\hline IEMBL3980996 & 641373 & 8.34 & & \\
\hline AEMBL3938673 & 641373 & 10.0 & 7066 & \\
\hline EMBL38S & 373 & & 352 & \\
\hline 955 & 373 & 9.0 & & \\
\hline IEMBL & 373 & 8.522 & & \\
\hline AEMBL3975505 & 373 & 10.0 & 516 & \\
\hline AEMBL3978526 & 373 & 10.0 & & \\
\hline IEMBL 3957274 & 373 & 8.4056 & 07 & \\
\hline 196 & 73 & & & \\
\hline IEMBL: & 373 & 10.0 & & \\
\hline IEMBL 3958982 & 373 & 8.3188 & & \\
\hline IEMBL 3975966 & 73 & & 02 & TST \\
\hline IEMBL39 & 73 & $\theta$ & & RN \\
\hline IEMBL39 & 73 & .0 & & RN \\
\hline IEMBL3 & 73 & 8.275 & & $\mathrm{ST}$ \\
\hline IEMBL 39 & 73 & & & \\
\hline IEMBL 3905380 & 73 & 9.8861 & 24 & KIV \\
\hline EMBL39 & 73 & 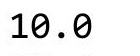 & & RN \\
\hline EMBL3C & 73 & & & RN \\
\hline 554 & & & & RN \\
\hline IEMBL3 & 73 & & & TST \\
\hline IEMBL 3940323 & 73 & 8.522 & & $\mathrm{RN}$ \\
\hline EMBL3S & 73 & & & ST \\
\hline 029 & 73 & & & \\
\hline 047 & 73 & 8 & & Tho \\
\hline EMBL3 & 73 & & & TS \\
\hline IEMBL3S & 73 & & 005 & TRN \\
\hline 514 & 73 & 0 & & rRN \\
\hline 173 & 73 & 676 & & ST \\
\hline EMBL3967157 & & 8.3872 & & TRN \\
\hline IEMBL 3917970 & 73 & & & TRN \\
\hline IEMBL3E & 73 & & & RN \\
\hline 026 & 73 & 8. & & rRN \\
\hline 775 & 73 & 8.7447 & & TRN \\
\hline AEMBL3932348 & 373 & 10.0 & 237 & TRN \\
\hline EMBL3973902 & 73 & 8.6383 & & TS \\
\hline HEMBL3946063 & 16 & 10.0 & & STT \\
\hline HEMBL 3890051 & & & & rRN \\
\hline HEMBL3918701 & 373 & 8.9586 & & ST \\
\hline EMBL3899180 & 373 & 10.0 & 86 & RN \\
\hline MBL39 & 73 & 10.0 & & miv \\
\hline HEMBL 14 & & 3.39 & & rRN \\
\hline CHEMBL1511291 & 46 & 3.3997 & 3.3962 & ST \\
\hline CHEMBL1407014 & 688846 & 3.3997 & 3.4682 & RN \\
\hline
\end{tabular}

Page 14188 


\begin{tabular}{|c|c|c|c|c|c|}
\hline & & \\
\hline CHEMBL578512 & 688846 & 3.3997 & 4.3461 & TST & \\
\hline CHEMBL1433074 & 688846 & 6.4813 & 6.4443 & TRN & \\
\hline CHEMBL1373811 & 688846 & 5.7862 & 5.3251 & TRN & \\
\hline CHEMBL1423531 & 688846 & 3.3997 & 2.9942 & TRN & \\
\hline CHEMBL1521729 & 688846 & 3.3997 & 3.3296 & TRN & \\
\hline CHEMBL1465171 & 688846 & 3.3997 & 3.5656 & TRN & \\
\hline CHEMBL1313195 & 688846 & 3.3997 & 4.5358 & TST & \\
\hline CHEMBL1452125 & 688846 & 3.3997 & 3.47399 & 99999999998 & TRN \\
\hline CHEMBL1346015 & 688846 & 3.3997 & 3.407 & TRN & \\
\hline CHEMBL1352306 & 688846 & 3.3997 & 3.5778 & TRN & \\
\hline CHEMBL1394096 & 688846 & 3.3997 & 4.0037 & TRN & \\
\hline CHEMBL1488092 & 688846 & 3.3997 & 3.625 & TRN & \\
\hline CHEMBL1381980 & 688846 & 3.3997 & 3.5327 & TRN & \\
\hline CHEMBL1543331 & 688846 & 5.8474 & 4.4677 & TST & \\
\hline CHEMBL51931 & 688846 & 3.3997 & 3.3668 & TST & \\
\hline CHEMBL1386595 & 688846 & 4.482 & 4.7675 & TST & \\
\hline CHEMBL1415156 & 688846 & 3.3997 & 3.14899 & 99999999996 & TRN \\
\hline CHEMBL1610242 & 688846 & 3.3997 & 3.2754 & TRN & \\
\hline CHEMBL1391748 & 688846 & 3.3997 & 3.6888 & TRN & \\
\hline CHEMBL1391385 & 688846 & 5.9763 & 5.5183 & TRN & \\
\hline CHEMBL1569119 & 688846 & 3.3997 & 3.6799 & TRN & \\
\hline CHEMBL1334062 & 688846 & 3.3997 & 4.6605 & TST & \\
\hline CHEMBL1327274 & 688846 & 3.3997 & 3.4763 & TRN & \\
\hline CHEMBL1575389 & 688846 & 6.7498 & 5.9387 & TST & \\
\hline CHEMBL1580962 & 688846 & 5.7206 & 5.851 & TRN & \\
\hline CHEMBL1347130 & 688846 & 3.3997 & 3.2974 & TRN & \\
\hline CHEMBL1307433 & 688846 & 4.8309 & 4.4383 & TRN & \\
\hline CHEMBL1353643 & 688846 & 3.3997 & 2.7417 & TRN & \\
\hline CHEMBL1414306 & 688846 & 3.3997 & 3.2428 & TRN & \\
\hline CHEMBL1336910 & 688846 & 5.6794 & 5.2371 & TRN & \\
\hline CHEMBL1565261 & 688846 & 3.3997 & 3.6567 & TRN & \\
\hline CHEMBL1508847 & 688846 & 3.3997 & 3.3164 & TST & \\
\hline CHEMBL1388002 & 688846 & 3.3997 & 3.305 & TRN & \\
\hline CHEMBL1535636 & 688846 & 3.3997 & 3.0941 & TRN & \\
\hline CHEMBL1499411 & 688846 & 5.8608 & 5.6526 & TRN & \\
\hline CHEMBL1600749 & 688846 & 3.3997 & 3.2886 & TRN & \\
\hline CHEMBL450135 & 688846 & 3.3997 & 3.1801 & TRN & \\
\hline CHEMBL1577894 & 688846 & 3.3997 & 3.3626 & TRN & \\
\hline CHEMBL1579576 & 688846 & 3.3997 & 3.5197 & TRN & \\
\hline CHEMBL1312189 & 688846 & 4.8309 & 5.4739 & TRN & \\
\hline CHEMBL1380975 & 688846 & 3.3997 & 3.29100 & 00000000004 & TRN \\
\hline CHEMBL1601179 & 688846 & 3.3997 & 3.72399 & 99999999998 & TRN \\
\hline CHEMBL1232381 & 688846 & 6.8265 & 6.6783 & TRN & \\
\hline CHEMBL1536779 & 688846 & 5.8262 & 5.857 & TRN & \\
\hline CHEMBL1379684 & 688846 & 5.6906 & 5.6619 & TRN & \\
\hline CHEMBL1455509 & 688846 & 4.9076 & 4.1171 & TRN & \\
\hline CHEMBL1564075 & 688846 & 3.3997 & 3.2289 & TRN & \\
\hline CHEMBL1326814 & 688846 & 6.7317 & 6.2581 & TRN & \\
\hline & & & & 14189 & \\
\hline
\end{tabular}




\begin{tabular}{|c|c|c|c|c|c|}
\hline \multicolumn{6}{|c|}{ Supplemental Table S2.txt } \\
\hline CHEMBL1457535 & 688846 & 3.3997 & 3.813 & TRN & \\
\hline CHEMBL1488696 & 688846 & 3.3997 & 3.092 & TRN & \\
\hline CHEMBL1573867 & 688846 & 3.3997 & 3.0835 & TRN & \\
\hline CHEMBL1563863 & 688846 & 3.3997 & 3.2224 & TRN & \\
\hline CHEMBL1369512 & 688846 & 5.4143 & 5.5656 & TRN & \\
\hline CHEMBL1402874 & 688846 & 3.3997 & 3.3087 & TRN & \\
\hline CHEMBL1520797 & 688846 & 3.3997 & 3.6859 & TRN & \\
\hline CHEMBL1503060 & 688846 & 3.3997 & 3.3244 & TRN & \\
\hline CHEMBL1306480 & 688846 & 3.3997 & 4.72 & TST & \\
\hline CHEMBL1306635 & 688846 & 3.3997 & 4.0019 & TRN & \\
\hline CHEMBL1384281 & 688846 & 6.7499 & 6.3387 & TST & \\
\hline CHEMBL1544403 & 688846 & 6.5181 & 6.5069 & TRN & \\
\hline CHEMBL1347701 & 688846 & 3.3997 & 3.3258 & TRN & \\
\hline CHEMBL1480178 & 688846 & 5.6345 & 5.34200 & 00000000005 & TRN \\
\hline CHEMBL1609827 & 688846 & 5.2919 & 5.5183 & TRN & \\
\hline CHEMBL1418370 & 688846 & 3.3997 & 3.4218 & TRN & \\
\hline CHEMBL1541029 & 688846 & 3.3997 & 3.7563 & TRN & \\
\hline CHEMBL1425600 & 688846 & 3.3997 & 3.7739 & TRN & \\
\hline CHEMBL1581437 & 688846 & 3.3997 & 3.4859 & TRN & \\
\hline CHEMBL1393131 & 688846 & 3.3997 & 2.9781 & TRN & \\
\hline CHEMBL1330383 & 688846 & 3.3997 & 3.6238 & TRN & \\
\hline CHEMBL1514625 & 688846 & 3.3997 & 3.3425 & TRN & \\
\hline CHEMBL1566010 & 688846 & 5.9626 & 5.5133 & TRN & \\
\hline CHEMBL1549101 & 688846 & 5.515 & 5.2098 & TRN & \\
\hline CHEMBL1319204 & 688846 & 3.3997 & 3.4275 & TRN & \\
\hline CHEMBL1550435 & 688846 & 5.416 & 4.9605 & TST & \\
\hline CHEMBL1370669 & 688846 & 3.3997 & 3.3682 & TRN & \\
\hline CHEMBL1576064 & 688846 & 3.3997 & 3.6449 & TRN & \\
\hline CHEMBL1454614 & 688846 & 3.3997 & 3.4555 & TST & \\
\hline CHEMBL1601448 & 688846 & 3.3997 & 3.5958 & TRN & \\
\hline CHEMBL1427088 & 688846 & 3.3997 & 3.8015 & TRN & \\
\hline CHEMBL1477452 & 688846 & 3.3997 & 4.458 & TRN & \\
\hline CHEMBL1479469 & 688846 & 3.3997 & 4.0728 & TRN & \\
\hline CHEMBL1608748 & 688846 & 3.3997 & 3.3188 & TRN & \\
\hline CHEMBL 601757 & 688846 & 3.3997 & 4.0773 & TST & \\
\hline CHEMBL1402650 & 688846 & 3.3997 & 3.3902 & TRN & \\
\hline CHEMBL1329826 & 688846 & 3.3997 & 3.5429 & TRN & \\
\hline CHEMBL1592326 & 688846 & 5.2416 & 4.6255 & TRN & \\
\hline CHEMBL1463659 & 688846 & 3.3997 & 4.3467 & TST & \\
\hline CHEMBL1343308 & 688846 & 5.2384 & 4.9521 & TRN & \\
\hline CHEMBL1431571 & 688846 & 3.3997 & 3.6416 & TRN & \\
\hline CHEMBL1470378 & 688846 & 3.3997 & 3.1555 & TRN & \\
\hline CHEMBL1341012 & 688846 & 3.3997 & 3.5279 & TRN & \\
\hline CHEMBL1430235 & 688846 & 3.3997 & 3.4961 & TST & \\
\hline CHEMBL1307313 & 688846 & 3.3997 & 3.1869 & TRN & \\
\hline CHEMBL1330042 & 688846 & 3.3997 & 3.833 & TRN & \\
\hline CHEMBL1343936 & 688846 & 3.3997 & 3.6453 & TRN & \\
\hline CHEMBL1306166 & 688846 & 3.3997 & 3.4868 & TRN & \\
\hline
\end{tabular}




\begin{tabular}{|c|c|c|c|c|}
\hline & & & oplement & al $\mathrm{T}$ \\
\hline CHEMBL1385074 & 688846 & 3.3997 & 3.4768 & TRN \\
\hline CHEMBL1501734 & 688846 & 5.3237 & 5.4887 & TRN \\
\hline CHEMBL1303255 & 688846 & 5.0754 & 4.8229 & TST \\
\hline CHEMBL1382928 & 688846 & 3.3997 & 3.3946 & TRN \\
\hline CHEMBL1464821 & 688846 & 3.3997 & 3.1057 & TRN \\
\hline CHEMBL1475400 & 688846 & 3.3997 & 4.479 & TST \\
\hline CHEMBL1324779 & 688846 & 6.6572 & 5.8198 & TST \\
\hline CHEMBL1306565 & 688846 & 3.3997 & 5.1762 & TST \\
\hline CHEMBL1432707 & 688846 & 3.3997 & 4.8171 & TST \\
\hline CHEMBL1505221 & 688846 & 3.3997 & 5.3818 & TST \\
\hline CHEMBL1349484 & 688846 & 3.3997 & 3.3014 & TRN \\
\hline CHEMBL1329797 & 688846 & 3.3997 & 3.6517 & TRN \\
\hline CHEMBL1536665 & 688846 & 5.3861 & 5.7352 & TRN \\
\hline CHEMBL1517409 & 688846 & 3.3997 & 3.9759 & TST \\
\hline CHEMBL1600566 & 688846 & 3.3997 & 3.0366 & TRN \\
\hline CHEMBL1446248 & 688846 & 3.3997 & 5.0488 & TST \\
\hline CHEMBL1486010 & 688846 & 3.3997 & 3.263 & TST \\
\hline CHEMBL1407788 & 688846 & 5.9996 & 4.621 & TST \\
\hline CHEMBL1542646 & 688846 & 3.3997 & 3.3891 & TST \\
\hline CHEMBL1462380 & 688846 & 5.1933 & 4.4372 & TST \\
\hline CHEMBL1409901 & 688846 & 3.3997 & 2.3262 & TST \\
\hline CHEMBL1598762 & 688846 & 3.3997 & 3.6174 & TST \\
\hline CHEMBL1162443 & 688846 & 3.3997 & 2.7999 & TST \\
\hline CHEMBL173325 & 70261 & 7.0804 & 7.5064 & TST \\
\hline CHEMBL132529 & 70261 & 7.3468 & 7.6296 & TRN \\
\hline CHEMBL339172 & 70261 & 6.8239 & 7.018 & TRN \\
\hline CHEMBL314804 & 70261 & 5.5229 & 5.1402 & TRN \\
\hline CHEMBL52030 & 70261 & 7.5622 & 7.5916 & TRN \\
\hline CHEMBL341398 & 70261 & 7.8861 & 8.1071 & TRN \\
\hline CHEMBL 298561 & 70261 & 6.9031 & 6.9369 & TRN \\
\hline CHEMBL133219 & 70261 & 7.5686 & 7.9479 & TRN \\
\hline CHEMBL87331 & 70261 & 4.5229 & 4.6048 & TRN \\
\hline CHEMBL368768 & 70261 & 8.0315 & 7.5453 & TRN \\
\hline CHEMBL 307783 & 70261 & 7.8239 & 7.7195 & TRN \\
\hline CHEMBL 79945 & 70261 & 7.983 & 7.8297 & TRN \\
\hline CHEMBL173339 & 70261 & 7.8794 & 7.9196 & TRN \\
\hline CHEMBL415293 & 70261 & 7.6655 & 7.4898 & TRN \\
\hline CHEMBL85539 & 70261 & 5.5229 & 4.9852 & TRN \\
\hline CHEMBL 84668 & 70261 & 4.5229 & 4.9792 & TRN \\
\hline CHEMBL47853 & 70261 & 4.5229 & 4.706 & TRN \\
\hline CHEMBL 78766 & 70261 & 6.301 & 6.8674 & TST \\
\hline CHEMBL130416 & 70261 & 7.2218 & 7.1766 & TRN \\
\hline CHEMBL173329 & 70261 & 8.5376 & 8.6179 & TRN \\
\hline CHEMBL66902 & 70261 & 6.7122 & 6.6856 & TRN \\
\hline CHEMBL133705 & 70261 & 7.0555 & 6.999 & TRN \\
\hline CHEMBL45174 & 70261 & 5.5376 & 5.6945 & TRN \\
\hline CHEMBL177076 & 70261 & 7.7595 & 7.8791 & TRN \\
\hline CHEMBL416450 & 70261 & 7.4437 & 7.7346 & TRN \\
\hline
\end{tabular}




\begin{tabular}{|c|c|c|c|c|c|}
\hline & & \multicolumn{4}{|c|}{ Supplemental Table S2.txt } \\
\hline CHEMBL408797 & 70261 & 7.5086 & 7.6259 & TST & \\
\hline CHEMBL431973 & 70261 & 5.5229 & 6.0122 & TRN & \\
\hline CHEMBL85716 & 70261 & 5.0 & 4.8128 & TRN & \\
\hline CHEMBL172866 & 70261 & 6.9281 & 7.4784 & TST & \\
\hline CHEMBL336728 & 70261 & 7.9208 & 7.8982 & TRN & \\
\hline CHEMBL 275115 & 70261 & 6.5086 & 6.5037 & TRN & \\
\hline CHEMBL368171 & 70261 & 6.6882 & 6.6854 & TRN & \\
\hline CHEMBL174535 & 70261 & 7.3757 & 7.207999 & 9999999999 & TRN \\
\hline CHEMBL11709 & 70261 & 8.3098 & 8.2262 & TRN & \\
\hline CHEMBL10195 & 70261 & 8.2676 & 8.2744 & TRN & \\
\hline CHEMBL366789 & 70261 & 4.5229 & 5.2411 & TST & \\
\hline CHEMBL435550 & 70261 & 6.5361 & 6.4673 & TRN & \\
\hline CHEMBL335960 & 70261 & 6.4123 & 6.1202 & TRN & \\
\hline CHEMBL 295277 & 70261 & 5.5229 & 4.9993 & TRN & \\
\hline CHEMBL369358 & 70261 & 6.6676 & 6.7081 & TST & \\
\hline CHEMBL141039 & 70261 & 7.9318 & 7.8495 & TRN & \\
\hline CHEMBL368919 & 70261 & 8.7696 & 8.7444 & TST & \\
\hline CHEMBL337166 & 70261 & 7.2518 & 7.242000 & 3000000001 & TRN \\
\hline CHEMBL45346 & 70261 & 5.5229 & 5.0853 & TRN & \\
\hline CHEMBL73096 & 70261 & 6.8601 & 6.5904 & TST & \\
\hline CHEMBL10534 & 70261 & 8.5544 & 8.4757 & TRN & \\
\hline CHEMBL133272 & 70261 & 7.9914 & 8.2088 & TRN & \\
\hline CHEMBL6814 & 70261 & 7.4724 & 7.5172 & TRN & \\
\hline CHEMBL1269093 & 70261 & 6.9066 & 7.0584 & TST & \\
\hline CHEMBL84921 & 70261 & 6.2676 & 6.6812 & TRN & \\
\hline CHEMBL87641 & 70261 & 4.5229 & 4.7779 & TRN & \\
\hline CHEMBL6421 & 70261 & 7.6556 & 7.8882 & TRN & \\
\hline CHEMBL10597 & 70261 & 6.7721 & 6.9295 & TRN & \\
\hline CHEMBL3144697 & 70261 & 10.0969 & 11.5496 & TST & \\
\hline CHEMBL 3144841 & 70261 & 10.0 & 10.7829 & TST & \\
\hline CHEMBL57655 & 70261 & 8.1427 & 8.327 & TRN & \\
\hline CHEMBL 286594 & 70261 & 7.6696 & 7.5994 & TRN & \\
\hline CHEMBL1518572 & 70261 & 8.3768 & 8.1636 & TRN & \\
\hline CHEMBL58757 & 70261 & 7.58 & 7.5758 & TRN & \\
\hline CHEMBL85861 & 70261 & 7.7282 & 8.0683 & TRN & \\
\hline CHEMBL13458 & 70261 & 6.6326 & 6.3823 & TST & \\
\hline CHEMBL176307 & 70261 & 5.5229 & 5.7462 & TST & \\
\hline CHEMBL 307202 & 70261 & 8.6819 & 8.9357 & TST & \\
\hline CHEMBL 10483 & 70261 & 8.9245 & 8.8716 & TRN & \\
\hline CHEMBL84842 & 70261 & 4.5229 & 4.6974 & TRN & \\
\hline CHEMBL 299250 & 70261 & 7.6003 & 7.021 & TRN & \\
\hline CHEMBL 268262 & 70261 & 7.52 & 7.2971 & TRN & \\
\hline CHEMBL 273464 & 70261 & 7.1062 & 7.3245 & TRN & \\
\hline CHEMBL420044 & 70261 & 6.9788 & 6.5475 & TRN & \\
\hline CHEMBL415290 & 70261 & 7.7878 & 7.9396 & TRN & \\
\hline CHEMBL43725 & 70261 & 4.4711 & 4.9215 & TRN & \\
\hline CHEMBL59180 & 70261 & 7.6536 & 7.5694 & TRN & \\
\hline CHEMBL44784 & 70261 & 5.5229 & 5.1805 & TRN & \\
\hline
\end{tabular}




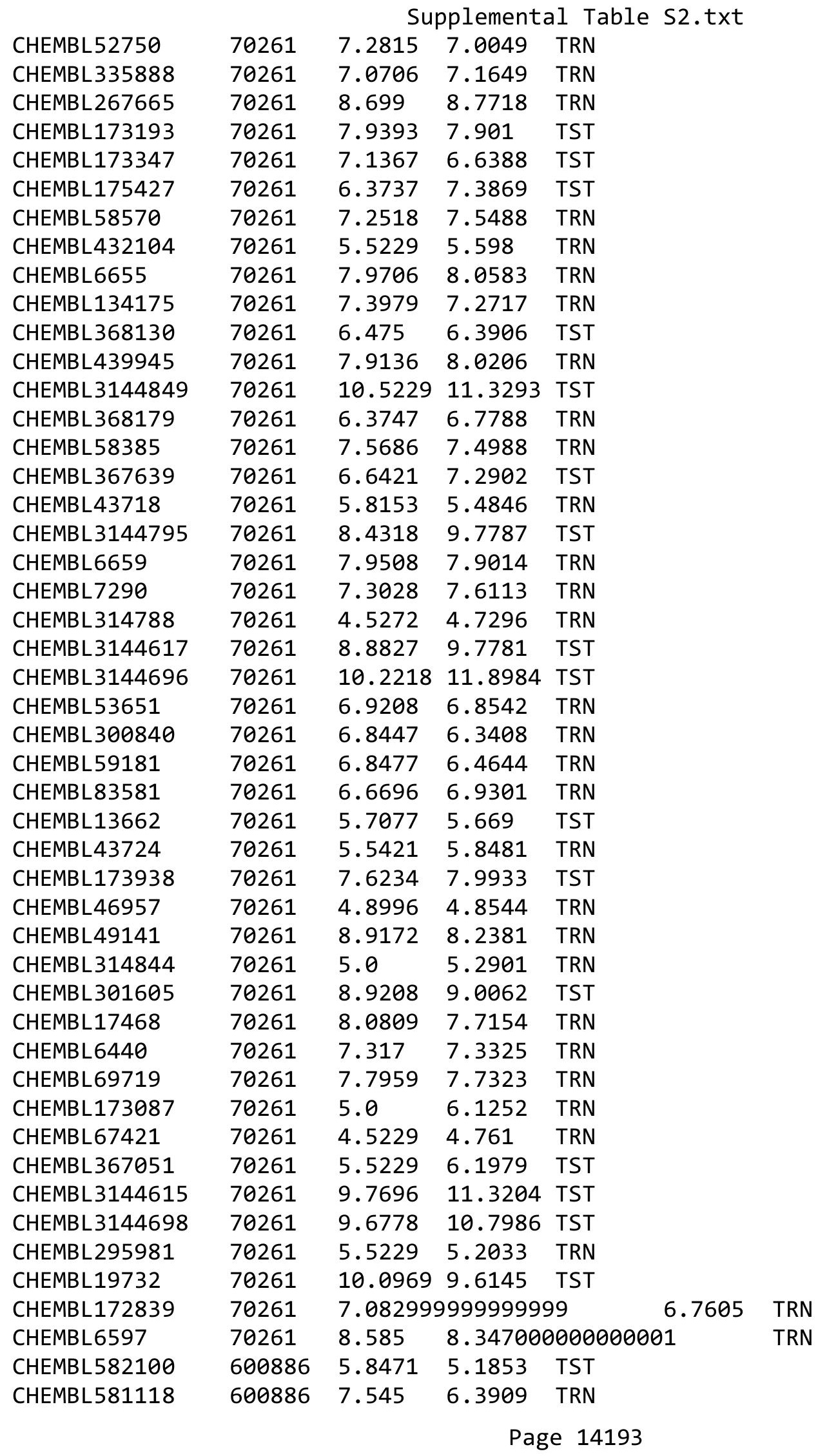




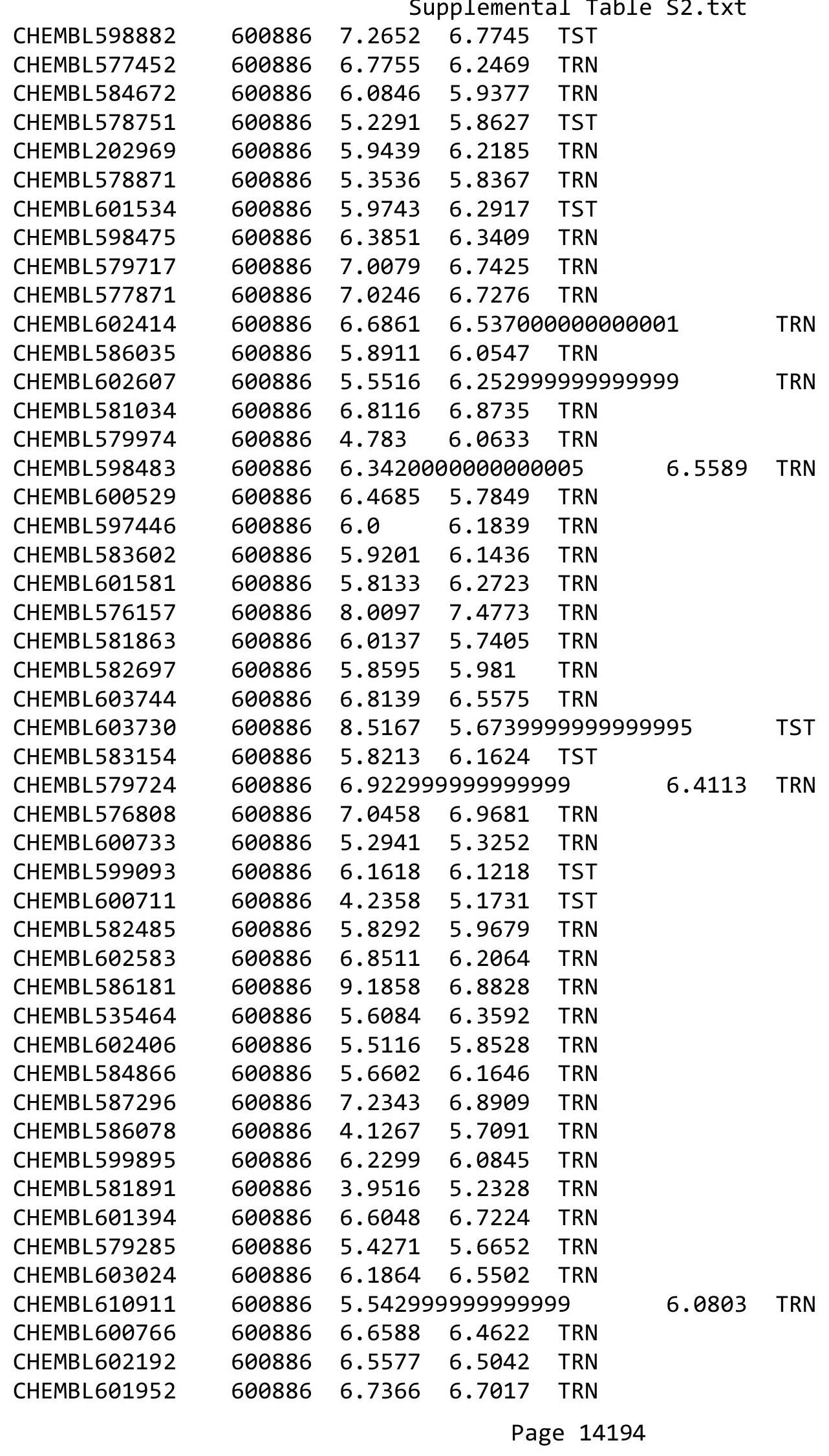




\begin{tabular}{|c|c|c|c|c|c|c|}
\hline \multirow[b]{2}{*}{ CHEMBL600547 } & \multicolumn{6}{|c|}{$p \perp$} \\
\hline & 600886 & 5.8545 & 6.4675 & TRN & & \\
\hline CHEMBL603003 & 600886 & 5.4486 & 5.8034 & TST & & \\
\hline CHEMBL578494 & 600886 & 5.4045 & 6.0373 & TST & & \\
\hline CHEMBL585631 & 600886 & 6.567 & 6.4247 & TRN & & \\
\hline CHEMBL583844 & 600886 & 6.0867 & 5.9059 & TRN & & \\
\hline CHEMBL586635 & 600886 & \multicolumn{3}{|c|}{7.082000000000001} & 6.5399 & TRN \\
\hline CHEMBL534566 & 600886 & 5.2204 & 5.6971 & TRN & & \\
\hline CHEMBL586075 & 600886 & 6.1035 & 5.5964 & TST & & \\
\hline CHEMBL599920 & 600886 & 7.0306 & 6.9593 & TRN & & \\
\hline CHEMBL597673 & 600886 & 5.9784 & 6.3088 & TRN & & \\
\hline CHEMBL600162 & 600886 & 6.4498 & 6.0934 & TRN & & \\
\hline CHEMBL586650 & 600886 & 6.0757 & 5.6801 & TRN & & \\
\hline CHEMBL597665 & 600886 & 3.9031 & 5.7749 & TRN & & \\
\hline CHEMBL600523 & 600886 & 7.1518 & 5.1877 & TRN & & \\
\hline CHEMBL606450 & 600886 & 5.6133 & 5.9245 & TST & & \\
\hline CHEMBL584448 & 600886 & 6.8576 & 6.994 & TRN & & \\
\hline CHEMBL577852 & 600886 & 6.5188 & 6.65 & TRN & & \\
\hline CHEMBL601987 & 600886 & 7.2857 & 6.7609 & TRN & & \\
\hline CHEMBL583449 & 600886 & \multicolumn{3}{|c|}{6.2620000000000005} & 6.6965 & TRN \\
\hline CHEMBL582465 & 600886 & 6.1101 & 6.2573 & TRN & & \\
\hline CHEMBL601754 & 600886 & \multicolumn{3}{|c|}{8.341000000000001} & 6.7784 & TST \\
\hline CHEMBL602381 & 600886 & 5.7665 & 5.6292 & TRN & & \\
\hline CHEMBL602383 & 600886 & 5.9296 & 6.2354 & TRN & & \\
\hline CHEMBL582253 & 600886 & 5.3107 & 6.0605 & TRN & & \\
\hline CHEMBL588291 & 600886 & 4.1739 & 5.2557 & TRN & & \\
\hline CHEMBL577446 & 600886 & 6.0 & 6.2307 & TRN & & \\
\hline CHEMBL598903 & 600886 & 6.1062 & 6.3711 & TST & & \\
\hline CHEMBL579763 & 600886 & 5.768 & 4.9497 & TRN & & \\
\hline CHEMBL578334 & 600886 & 6.8196 & 6.8622 & TST & & \\
\hline CHEMBL527700 & 600886 & 6.4248 & 6.805 & TRN & & \\
\hline CHEMBL577418 & 600886 & 6.3936 & 5.5498 & TRN & & \\
\hline CHEMBL601162 & 600886 & 4.9031 & 5.9057 & TRN & & \\
\hline CHEMBL586004 & 600886 & 6.7199 & 6.7462 & TRN & & \\
\hline CHEMBL597466 & 600886 & 6.1681 & 5.8787 & TRN & & \\
\hline CHEMBL581466 & 600886 & 5.8398 & 5.0457 & TRN & & \\
\hline CHEMBL600157 & 600886 & 5.9219 & 6.145 & TRN & & \\
\hline CHEMBL580849 & 600886 & 5.9027 & 6.1597 & TRN & & \\
\hline CHEMBL579149 & 600886 & 6.5727 & 5.54899 & 99999 & 995 & TRN \\
\hline CHEMBL585056 & 600886 & 5.0372 & 5.5777 & TRN & & \\
\hline CHEMBL 600160 & 600886 & 4.9927 & 5.6203 & TRN & & \\
\hline CHEMBL585028 & 600886 & 8.6227 & 6.3814 & TRN & & \\
\hline CHEMBL602359 & 600886 & 6.0535 & 6.2589 & TST & & \\
\hline CHEMBL528486 & 600886 & 6.0535 & 6.1871 & TRN & & \\
\hline CHEMBL581469 & 600886 & 5.7937 & 5.5002 & TRN & & \\
\hline CHEMBL602027 & 600886 & 7.1203 & 6.9058 & TRN & & \\
\hline CHEMBL582077 & 600886 & 5.78700 & 30000000 & $\partial 1$ & 5.2688 & TST \\
\hline CHEMBL530445 & 600886 & 6.2741 & 6.1161 & TRN & & \\
\hline \multirow[t]{2}{*}{ CHEMBL585256 } & 600886 & 4.9031 & 6.3038 & TST & & \\
\hline & & \multicolumn{5}{|c|}{ Page 14195} \\
\hline
\end{tabular}




\begin{tabular}{|c|c|c|c|c|c|}
\hline & & & oplement & al Table S & \\
\hline CHEMBL601964 & 600886 & 5.2526 & 5.8355 & TRN & \\
\hline CHEMBL577667 & 600886 & 9.2007 & 6.62799 & 9999999999 & TRN \\
\hline CHEMBL582491 & 600886 & 6.3872 & 6.3551 & TRN & \\
\hline CHEMBL582722 & 600886 & 6.5222 & 6.0069 & TRN & \\
\hline CHEMBL581047 & 600886 & 6.0675 & 6.2696 & TRN & \\
\hline CHEMBL597245 & 600886 & 6.1192 & 6.0881 & TST & \\
\hline CHEMBL600939 & 600886 & 7.4855 & 6.4144 & TRN & \\
\hline CHEMBL581649 & 600886 & 6.1959 & 6.4346 & TRN & \\
\hline CHEMBL580139 & 600886 & 7.751 & 7.3302 & TRN & \\
\hline CHEMBL527976 & 600886 & 6.1878 & 4.7655 & TRN & \\
\hline CHEMBL579136 & 600886 & 6.0841 & 6.6027 & TRN & \\
\hline CHEMBL577007 & 600886 & 6.1379 & 6.3311 & TRN & \\
\hline CHEMBL582080 & 600886 & 6.426 & 6.5822 & TRN & \\
\hline CHEMBL602572 & 600886 & 6.2366 & 6.21 & TRN & \\
\hline CHEMBL581684 & 600886 & 5.8176 & 5.1825 & TRN & \\
\hline CHEMBL598692 & 600886 & 6.2807 & 6.46200 & 0000000001 & TRN \\
\hline CHEMBL584254 & 600886 & 7.1343 & 7.2403 & TRN & \\
\hline CHEMBL598275 & 600886 & 7.1925 & 6.3188 & TRN & \\
\hline CHEMBL526034 & 600886 & 7.2291 & 6.4785 & TST & \\
\hline CHEMBL602211 & 600886 & 5.7778 & 6.5397 & TRN & \\
\hline CHEMBL597447 & 600886 & 6.062 & 6.5084 & TRN & \\
\hline CHEMBL1576338 & 600886 & 3.9031 & 5.5168 & TST & \\
\hline CHEMBL583364 & 600886 & 5.1864 & 5.6792 & TRN & \\
\hline CHEMBL530023 & 600886 & 3.9516 & 5.0363 & TRN & \\
\hline CHEMBL578512 & 600886 & 6.3179 & 5.1497 & TRN & \\
\hline CHEMBL578711 & 600886 & 5.6286 & 5.7216 & TST & \\
\hline CHEMBL582265 & 600886 & 6.6696 & 6.74200 & 0000000001 & TRN \\
\hline CHEMBL578719 & 600886 & 6.3536 & 6.5669 & TRN & \\
\hline CHEMBL586982 & 600886 & 7.1871 & 6.0834 & TRN & \\
\hline CHEMBL602588 & 600886 & 6.6467 & 6.3653 & TST & \\
\hline CHEMBL602213 & 600886 & 5.869 & 5.105 & TST & \\
\hline CHEMBL585043 & 600886 & 6.4168 & 6.3901 & TRN & \\
\hline CHEMBL577013 & 600886 & 8.8716 & 6.6072 & TRN & \\
\hline CHEMBL579142 & 600886 & 5.569 & 5.2058 & TRN & \\
\hline CHEMBL585058 & 600886 & 4.9031 & 5.6046 & TRN & \\
\hline CHEMBL578087 & 600886 & 5.8468 & 5.9983 & TST & \\
\hline CHEMBL602564 & 600886 & 7.5532 & 6.1485 & TRN & \\
\hline CHEMBL587452 & 600886 & 6.8228 & 6.0394 & TRN & \\
\hline CHEMBL600916 & 600886 & 5.7203 & 5.0854 & TRN & \\
\hline CHEMBL585587 & 600886 & 6.8804 & 6.6043 & TRN & \\
\hline CHEMBL585267 & 600886 & 6.1656 & 6.2972 & TRN & \\
\hline CHEMBL599937 & 600886 & 7.3862 & 7.5468 & TRN & \\
\hline CHEMBL583819 & 600886 & 5.9555 & 6.6407 & TRN & \\
\hline CHEMBL579333 & 600886 & 5.5355 & 5.092 & TRN & \\
\hline CHEMBL601955 & 600886 & 4.9031 & 5.6673 & TRN & \\
\hline CHEMBL530973 & 600886 & 7.5728 & 6.5996 & TST & \\
\hline CHEMBL599939 & 600886 & 6.2168 & 6.2914 & TRN & \\
\hline CHEMBL477328 & 600886 & 6.4353 & 6.3899 & TRN & \\
\hline
\end{tabular}




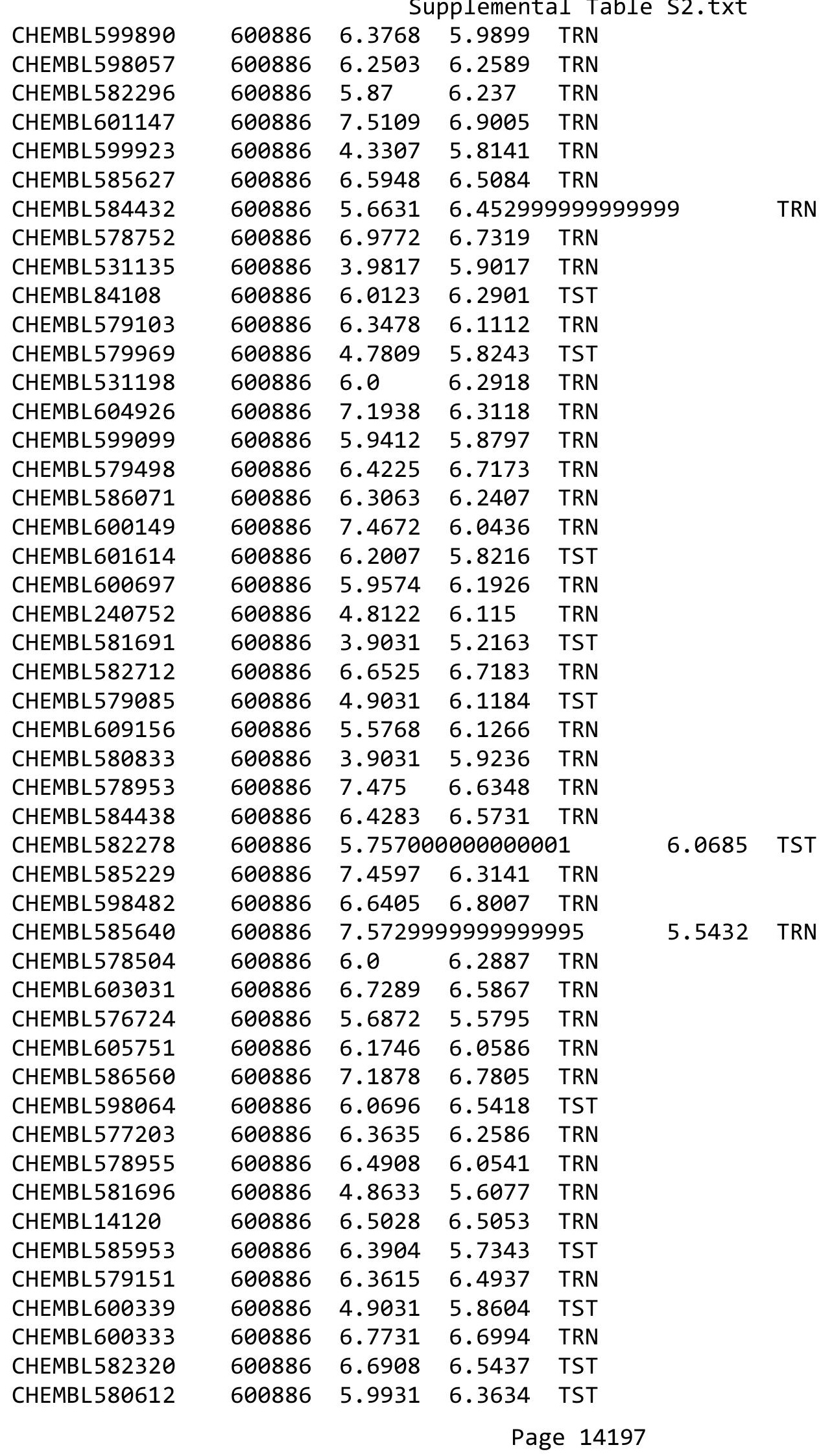




\begin{tabular}{|c|c|c|c|c|c|c|}
\hline & & \multicolumn{5}{|c|}{ Supplemental Table S2.txt } \\
\hline CHEMBL587671 & 600886 & 5.209 & 6.2689 & TRN & & \\
\hline CHEMBL338094 & 600886 & 5.7231 & 5.559 & TRN & & \\
\hline CHEMBL584712 & 600886 & 6.9876 & 6.6091 & TRN & & \\
\hline CHEMBL596653 & 600886 & 8.5029 & 7.4016 & TST & & \\
\hline CHEMBL601396 & 600886 & 6.6182 & 6.1518 & TRN & & \\
\hline CHEMBL582645 & 600886 & 7.2097 & 6.9783 & TRN & & \\
\hline CHEMBL602621 & 600886 & 6.6645 & 6.4888 & TRN & & \\
\hline CHEMBL600498 & 600886 & 7.1107 & 5.5519 & TRN & & \\
\hline CHEMBL597855 & 600886 & 6.3072 & 6.3226 & TRN & & \\
\hline CHEMBL582119 & 600886 & 4.9031 & 5.9732 & TRN & & \\
\hline CHEMBL601316 & 600886 & 6.4935 & 6.3544 & TRN & & \\
\hline CHEMBL536605 & 600886 & 6.2284 & 6.2568 & TRN & & \\
\hline CHEMBL576525 & 600886 & 6.1494 & 5.6942 & TST & & \\
\hline CHEMBL581700 & 600886 & 5.8814 & 6.149 & TRN & & \\
\hline CHEMBL585036 & 600886 & 6.6351 & 6.5752 & TST & & \\
\hline CHEMBL597655 & 600886 & 6.2692 & 5.8943 & TRN & & \\
\hline CHEMBL585423 & 600886 & 5.9927 & 5.6205 & TRN & & \\
\hline CHEMBL584639 & 600886 & 4.0164 & 5.1544 & TST & & \\
\hline CHEMBL600485 & 600886 & 4.9031 & 5.7466 & TST & & \\
\hline CHEMBL582516 & 600886 & 5.7242 & 6.2778 & TRN & & \\
\hline CHEMBL584242 & 600886 & 6.4413 & 6.3951 & TRN & & \\
\hline CHEMBL588811 & 600886 & 6.0726 & 5.9588 & TRN & & \\
\hline CHEMBL579161 & 600886 & 6.0742 & 6.4797 & TRN & & \\
\hline CHEMBL597659 & 600886 & 5.96899 & 9999999 & 99 & 6.3745 & TRN \\
\hline CHEMBL585590 & 600886 & 5.9788 & 6.165 & TRN & & \\
\hline CHEMBL582694 & 600886 & 5.644 & 5.8582 & TRN & & \\
\hline CHEMBL598278 & 600886 & 7.3215 & 6.3096 & TRN & & \\
\hline CHEMBL578103 & 600886 & 6.0013 & 5.1595 & TRN & & \\
\hline CHEMBL578115 & 600886 & 5.1688 & 5.5296 & TRN & & \\
\hline CHEMBL528186 & 600886 & 6.2832 & 6.6813 & TRN & & \\
\hline CHEMBL585833 & 600886 & 6.6238 & 6.3589 & TRN & & \\
\hline CHEMBL601978 & 600886 & 6.7027 & 6.6201 & TRN & & \\
\hline CHEMBL600736 & 600886 & 5.3497 & 5.2047 & TRN & & \\
\hline CHEMBL578531 & 600886 & 7.1337 & 6.9257 & TRN & & \\
\hline CHEMBL578043 & 600886 & 5.5805 & 6.4497 & TRN & & \\
\hline CHEMBL584428 & 600886 & 6.6014 & 6.6766 & TRN & & \\
\hline CHEMBL1744493 & 600886 & 4.9031 & 5.6189 & TRN & & \\
\hline CHEMBL601336 & 600886 & 5.1226 & 5.275 & TRN & & \\
\hline CHEMBL586608 & 600886 & 7.0177 & 6.1389 & TRN & & \\
\hline CHEMBL601747 & 600886 & 8.7335 & 6.2976 & TRN & & \\
\hline CHEMBL529315 & 600886 & 7.2013 & 6.9183 & TRN & & \\
\hline CHEMBL584218 & 600886 & 5.9889 & 6.4106 & TRN & & \\
\hline CHEMBL600105 & 600886 & 5.3778 & 5.1665 & TST & & \\
\hline CHEMBL600494 & 600886 & 5.0685 & 5.6849 & TST & & \\
\hline CHEMBL579350 & 600886 & 5.6525 & 5.6455 & TRN & & \\
\hline CHEMBL604978 & 600886 & 5.8058 & 5.9714 & TRN & & \\
\hline CHEMBL585455 & 600886 & 6.4868 & 6.4365 & TRN & & \\
\hline CHEMBL1197554 & 600886 & 6.1397 & 6.3956 & TRN & & \\
\hline
\end{tabular}




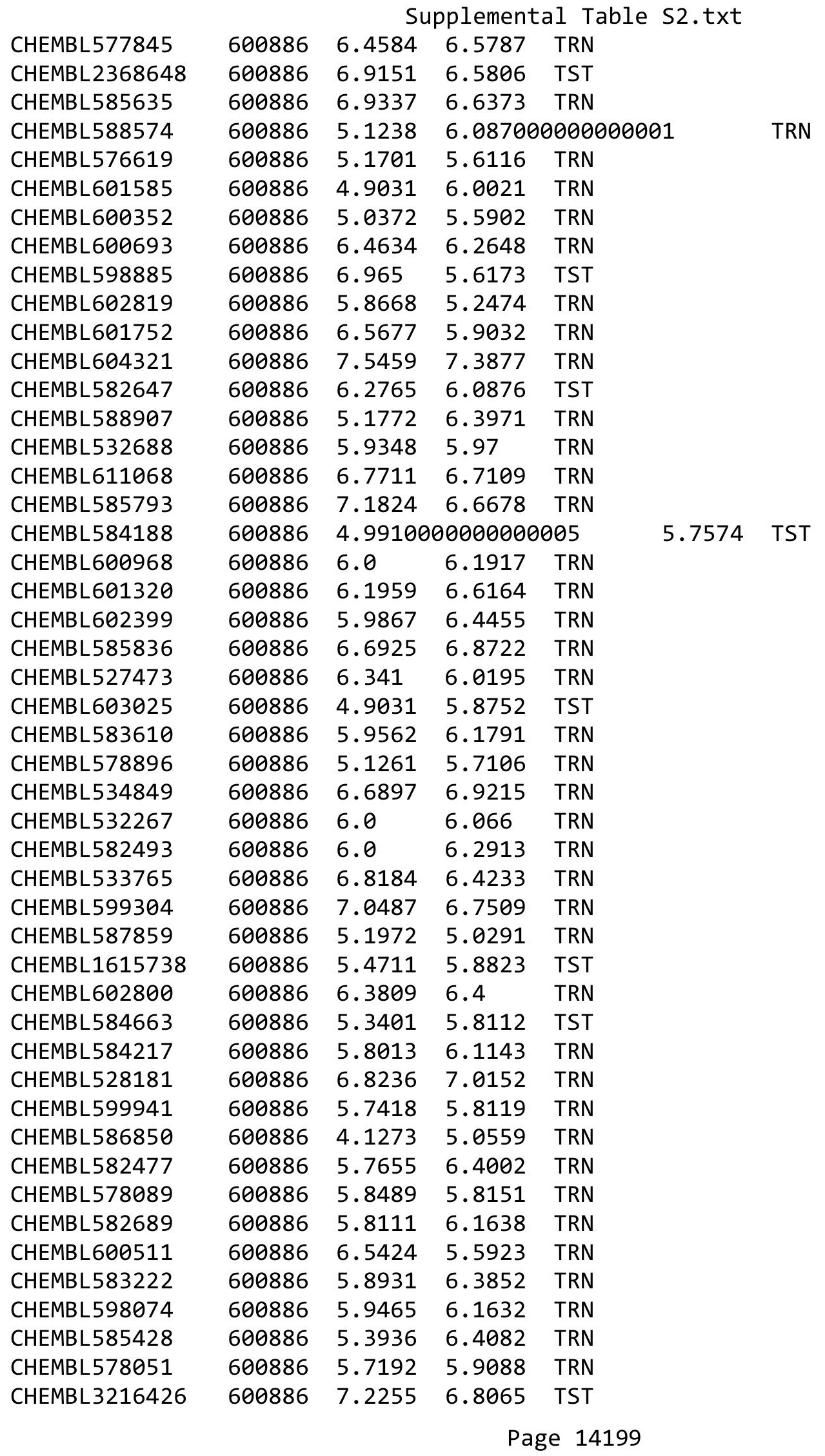




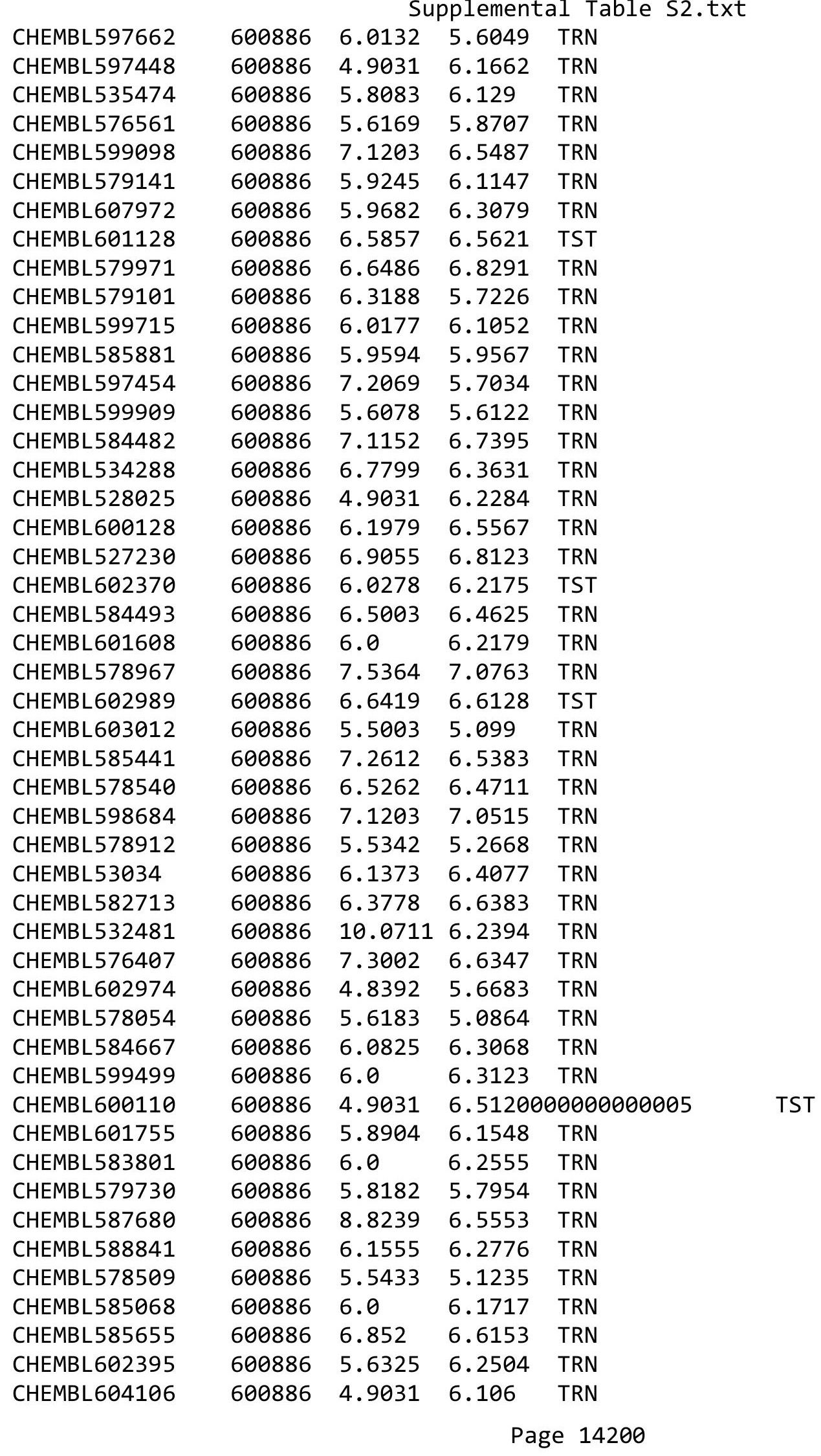




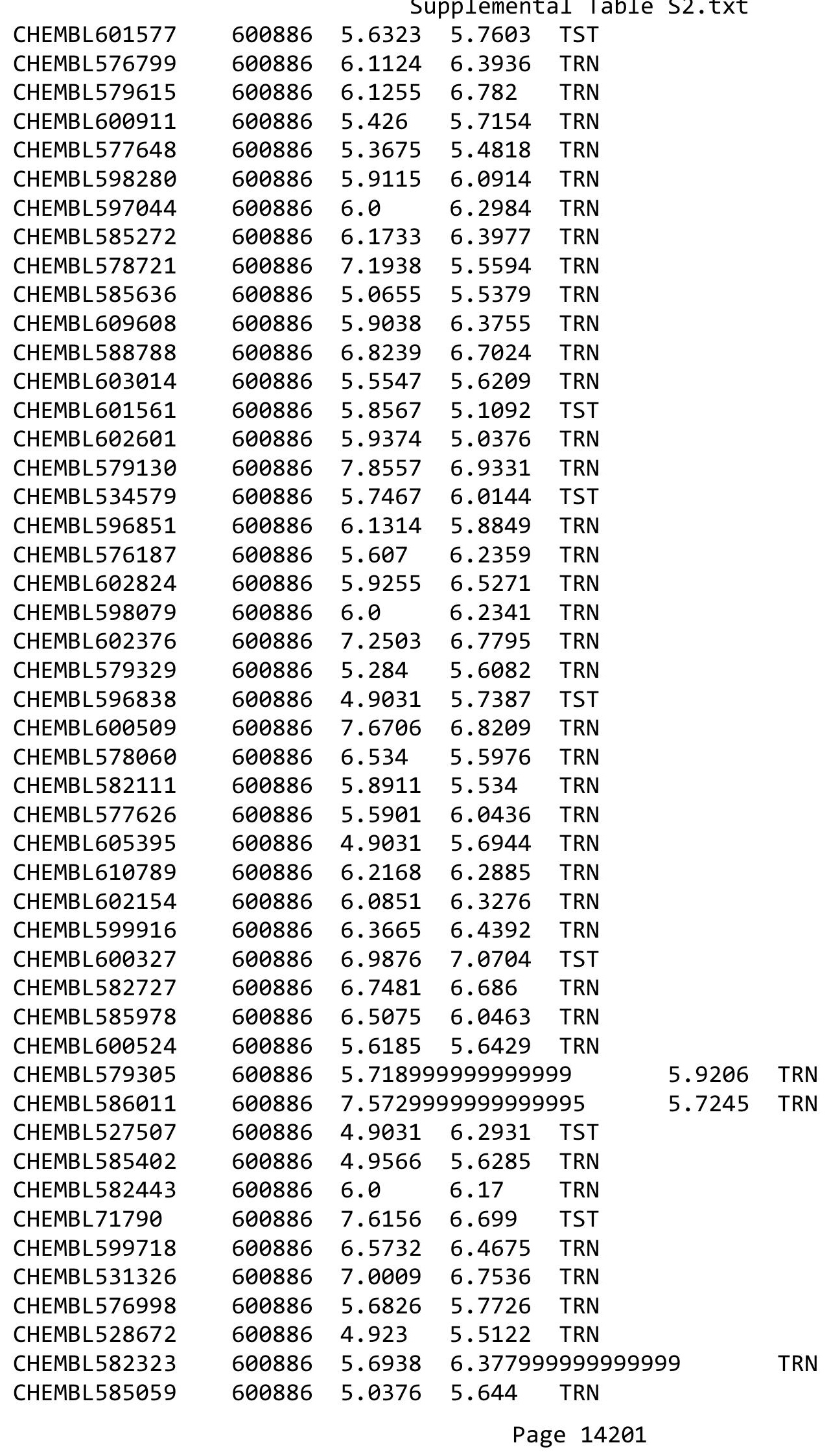




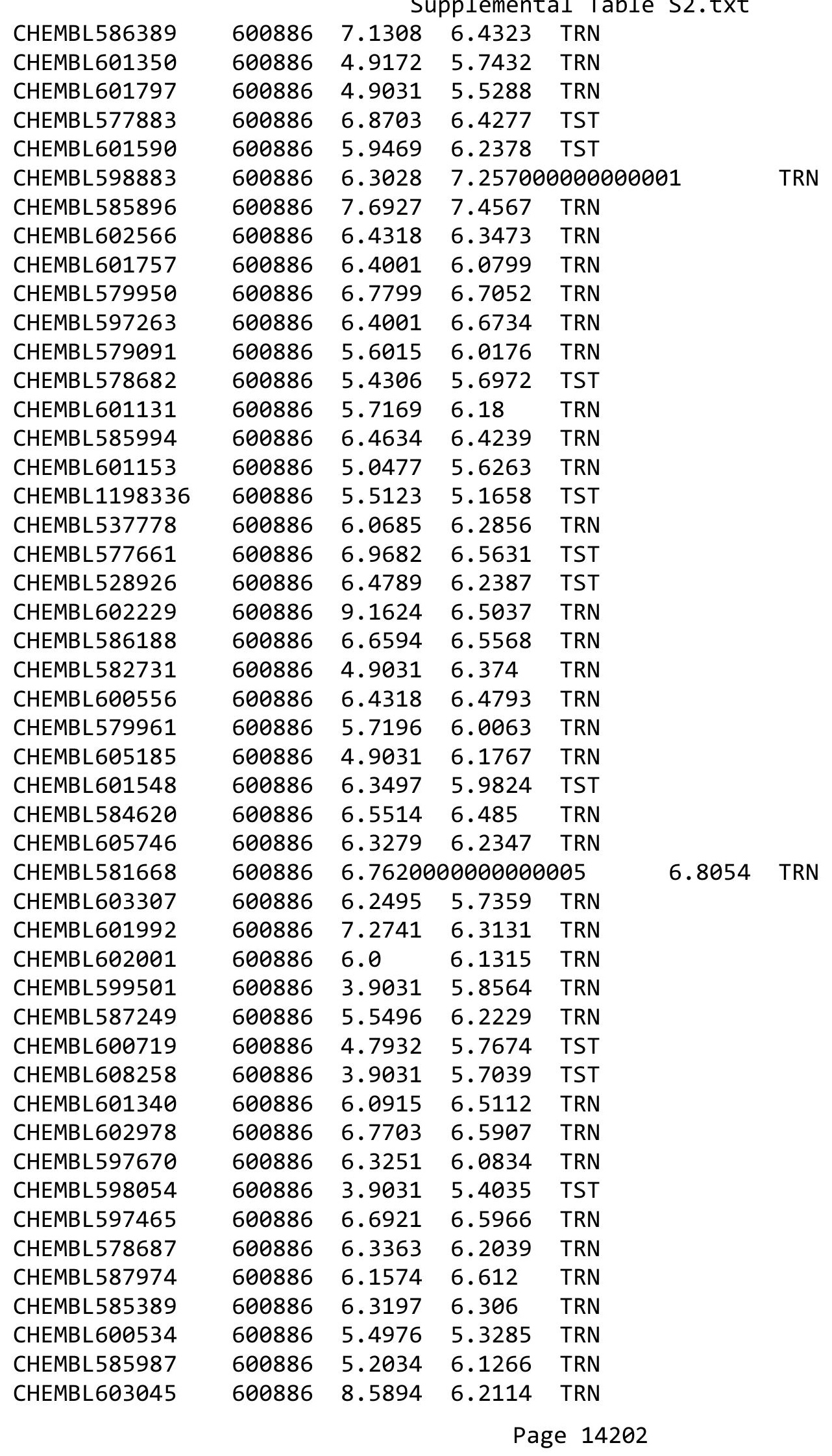




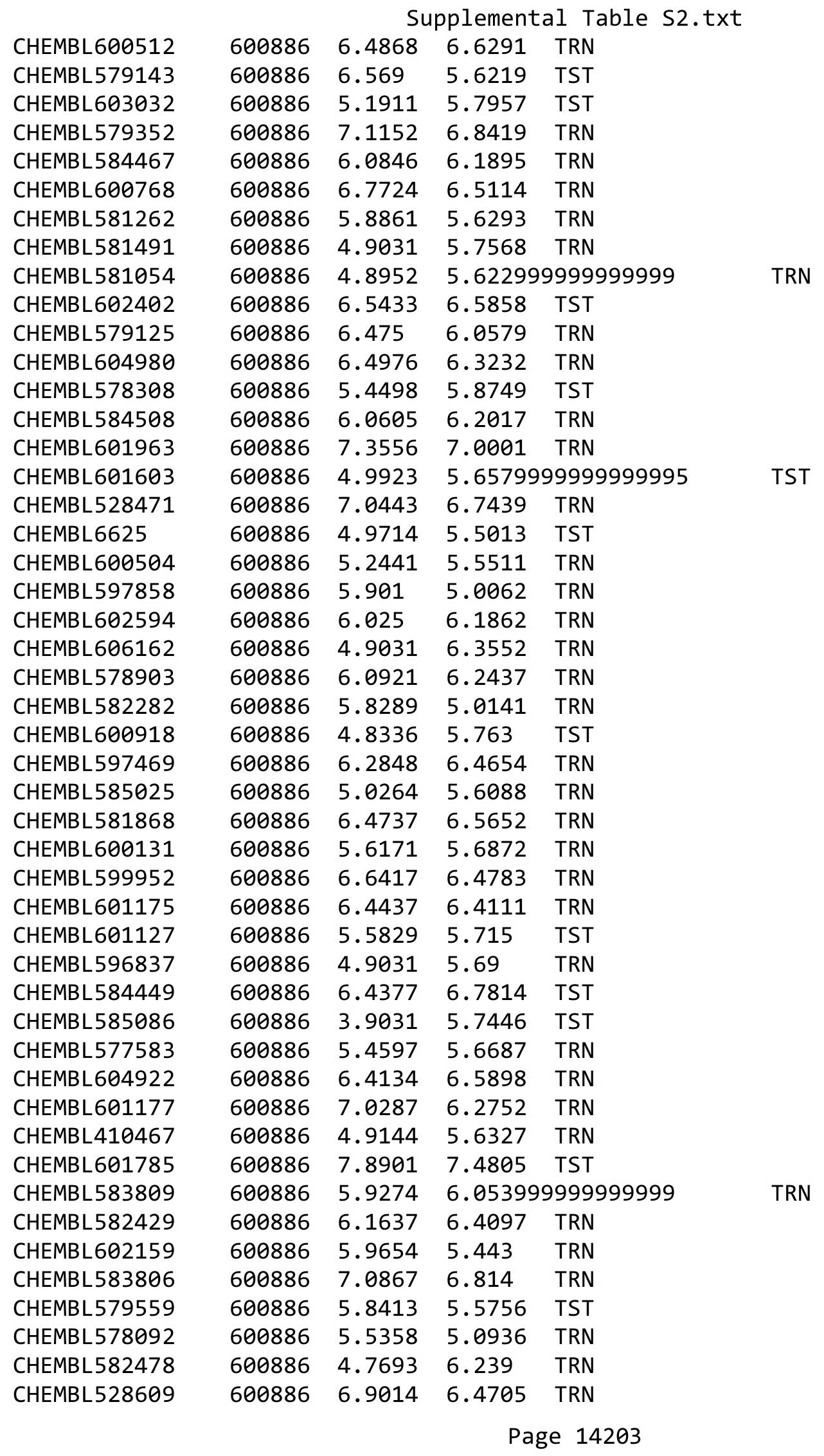




\begin{tabular}{|c|c|c|c|c|}
\hline & & Su & pplement & \\
\hline CHEMBL584615 & 600886 & 5.9389 & 6.3622 & TRN \\
\hline CHEMBL602171 & 600886 & 5.3298 & 5.7508 & TST \\
\hline CHEMBL602808 & 600886 & 6.1805 & 6.4535 & TRN \\
\hline CHEMBL601397 & 600886 & 6.9855 & 6.4349 & TRN \\
\hline CHEMBL585593 & 600886 & 8.5003 & 5.5289 & TRN \\
\hline CHEMBL583597 & 600886 & 4.9329 & 5.52 & TRN \\
\hline CHEMBL584436 & 600886 & 6.4711 & 6.3525 & TRN \\
\hline CHEMBL602403 & 600886 & 7.308 & 7.1803 & TRN \\
\hline CHEMBL579970 & 600886 & 5.7812 & 6.2058 & TRN \\
\hline CHEMBL601768 & 600886 & 6.7683 & 6.5968 & TRN \\
\hline CHEMBL607577 & 600886 & 5.9735 & 5.7039 & TST \\
\hline CHEMBL602997 & 600886 & 6.2154 & 6.2925 & TRN \\
\hline CHEMBL578875 & 600886 & 6.4012 & 6.1879 & TRN \\
\hline CHEMBL585597 & 600886 & 6.3716 & 6.2632 & TRN \\
\hline CHEMBL600293 & 600886 & 6.3915 & 6.1291 & TRN \\
\hline CHEMBL602388 & 600886 & 5.0931 & 5.1772 & TRN \\
\hline CHEMBL582679 & 600886 & 4.8292 & 5.5902 & TRN \\
\hline CHEMBL530565 & 600886 & 6.4001 & 6.7697 & TST \\
\hline CHEMBL582449 & 600886 & 7.9226 & 7.2908 & TRN \\
\hline CHEMBL583820 & 600886 & 6.0 & 6.1605 & TST \\
\hline CHEMBL599293 & 600886 & 6.1226 & 6.0717 & TRN \\
\hline CHEMBL582487 & 600886 & 5.0325 & 5.0554 & TRN \\
\hline CHEMBL601144 & 600886 & 7.5882 & 6.6778 & TST \\
\hline CHEMBL601349 & 600886 & 5.1135 & 5.5254 & TRN \\
\hline CHEMBL581249 & 600886 & 5.7975 & 6.0365 & TRN \\
\hline CHEMBL529615 & 600886 & 5.0232 & 5.5896 & TRN \\
\hline CHEMBL606160 & 600886 & 6.2013 & 6.5198 & TST \\
\hline CHEMBL580160 & 600886 & 6.6916 & 6.8472 & TRN \\
\hline CHEMBL581874 & 600886 & 5.8684 & 5.9434 & TRN \\
\hline CHEMBL584841 & 600886 & 7.0013 & 6.359 & TST \\
\hline CHEMBL587229 & 600886 & 6.4698 & 6.392 & TRN \\
\hline CHEMBL 604777 & 600886 & 5.7804 & 6.2079 & TRN \\
\hline CHEMBL602605 & 600886 & 6.1457 & 5.6015 & TRN \\
\hline CHEMBL585656 & 600886 & 7.7406 & 7.5325 & TRN \\
\hline CHEMBL606166 & 600886 & 6.4559 & 6.7195 & TRN \\
\hline CHEMBL578030 & 600886 & 6.1791 & 6.4476 & TRN \\
\hline CHEMBL534037 & 600886 & 6.1904 & 6.3224 & TRN \\
\hline CHEMBL582271 & 600886 & 6.0975 & 6.869 & TRN \\
\hline CHEMBL 602428 & 600886 & 6.0227 & 5.5829 & TRN \\
\hline CHEMBL579924 & 600886 & 5.1778 & 5.1716 & TRN \\
\hline CHEMBL600973 & 600886 & 5.9817 & 6.1914 & TRN \\
\hline CHEMBL580846 & 600886 & 5.0477 & 5.8236 & TST \\
\hline CHEMBL585072 & 600886 & 10.2426 & 8.5751 & TST \\
\hline CHEMBL585466 & 600886 & 6.66 & 6.4228 & TRN \\
\hline CHEMBL531569 & 600886 & 6.0106 & 6.5258 & TRN \\
\hline CHEMBL577441 & 600886 & 6.1884 & 6.2472 & TRN \\
\hline CHEMBL610913 & 600886 & 5.8579 & 5.9625 & TRN \\
\hline CHEMBL598062 & 600886 & 6.0123 & 6.4456 & TRN \\
\hline
\end{tabular}




\begin{tabular}{|c|c|c|c|c|c|c|}
\hline & & & pplement & al Tabl & & \\
\hline CHEMBL580168 & 600886 & 5.6747 & 6.0939 & TRN & & \\
\hline CHEMBL602836 & 600886 & 7.57299 & 99999999 & 995 & 5.5621 & TRN \\
\hline CHEMBL531947 & 600886 & 6.466 & 6.2892 & TRN & & \\
\hline CHEMBL585266 & 600886 & 6.9034 & 6.527 & TRN & & \\
\hline CHEMBL 609748 & 600886 & 7.7652 & 7.436 & TRN & & \\
\hline CHEMBL 31734 & 600886 & 4.9031 & 6.3109 & TRN & & \\
\hline CHEMBL586032 & 600886 & 5.8891 & 6.2569 & TRN & & \\
\hline CHEMBL581486 & 600886 & 4.9031 & 6.3135 & TRN & & \\
\hline CHEMBL581259 & 600886 & 5.7765 & 5.8913 & TRN & & \\
\hline CHEMBL579562 & 600886 & 4.8801 & 6.0022 & TRN & & \\
\hline CHEMBL578542 & 600886 & 6.2815 & 6.6604 & TST & & \\
\hline CHEMBL582256 & 600886 & 6.2175 & 5.615 & TRN & & \\
\hline CHEMBL578902 & 600886 & 5.5325 & 5.1728 & TRN & & \\
\hline CHEMBL527541 & 600886 & 6.289 & 6.3961 & TRN & & \\
\hline CHEMBL585964 & 600886 & 6.6171 & 6.5037 & TRN & & \\
\hline CHEMBL586875 & 600886 & 6.6657 & 6.6812 & TRN & & \\
\hline CHEMBL585457 & 600886 & 7.2581 & 7.1793 & TRN & & \\
\hline CHEMBL585830 & 600886 & 7.57299 & 99999999 & 995 & 5.6181 & TST \\
\hline CHEMBL582118 & 600886 & 4.9031 & 6.1673 & TRN & & \\
\hline CHEMBL585444 & 600886 & 6.5659 & 6.2295 & TST & & \\
\hline CHEMBL602822 & 600886 & 4.8931 & 6.0929 & TST & & \\
\hline CHEMBL577208 & 600886 & 6.3726 & 5.5181 & TST & & \\
\hline CHEMBL605947 & 600886 & 6.7867 & 5.914 & TRN & & \\
\hline CHEMBL576376 & 600886 & 7.5677 & 7.0502 & TRN & & \\
\hline CHEMBL593483 & 600886 & 6.0 & 6.1782 & TRN & & \\
\hline CHEMBL601170 & 600886 & 7.2118 & 6.2767 & TRN & & \\
\hline CHEMBL583434 & 600886 & 5.9872 & 6.2491 & TRN & & \\
\hline CHEMBL582084 & 600886 & 5.76200 & 00000000 & 005 & 5.7584 & TRN \\
\hline CHEMBL602170 & 600886 & 7.7518 & 7.0438 & TRN & & \\
\hline CHEMBL600093 & 600886 & 5.919 & 5.5727 & TRN & & \\
\hline CHEMBL577016 & 600886 & 7.4584 & 6.724 & TRN & & \\
\hline CHEMBL601124 & 600886 & 6.0737 & 6.3637 & TRN & & \\
\hline CHEMBL597450 & 600886 & 4.9031 & 6.3739 & TRN & & \\
\hline CHEMBL585319 & 600886 & 6.0883 & 5.9775 & TRN & & \\
\hline CHEMBL 2372413 & 600886 & 7.2865 & 6.8815 & TST & & \\
\hline CHEMBL582573 & 600886 & 5.025 & 6.0691 & TRN & & \\
\hline CHEMBL602632 & 600886 & 6.17200 & 20000000 & 01 & 6.0031 & TRN \\
\hline CHEMBL602185 & 600886 & 6.3179 & 6.1651 & TST & & \\
\hline CHEMBL576997 & 600886 & 6.0 & 6.496 & TST & & \\
\hline CHEMBL581196 & 600886 & 6.1798 & 6.1159 & TRN & & \\
\hline CHEMBL582461 & 600886 & 6.24799 & 99999999 & & 6.5461 & TRN \\
\hline CHEMBL582445 & 600886 & 5.20200 & 00000000 & $\partial 1$ & 5.7181 & TRN \\
\hline CHEMBL531478 & 600886 & 6.1555 & 6.3258 & TRN & & \\
\hline CHEMBL535079 & 600886 & 8.0737 & 6.5023 & TRN & & \\
\hline CHEMBL582101 & 600886 & 4.8041 & 5.9223 & TRN & & \\
\hline CHEMBL578681 & 600886 & 6.2757 & 6.4274 & TRN & & \\
\hline CHEMBL486232 & 600886 & 7.4237 & 6.3922 & TST & & \\
\hline CHEMBL600163 & 600886 & 6.4045 & 6.2707 & TRN & & \\
\hline
\end{tabular}




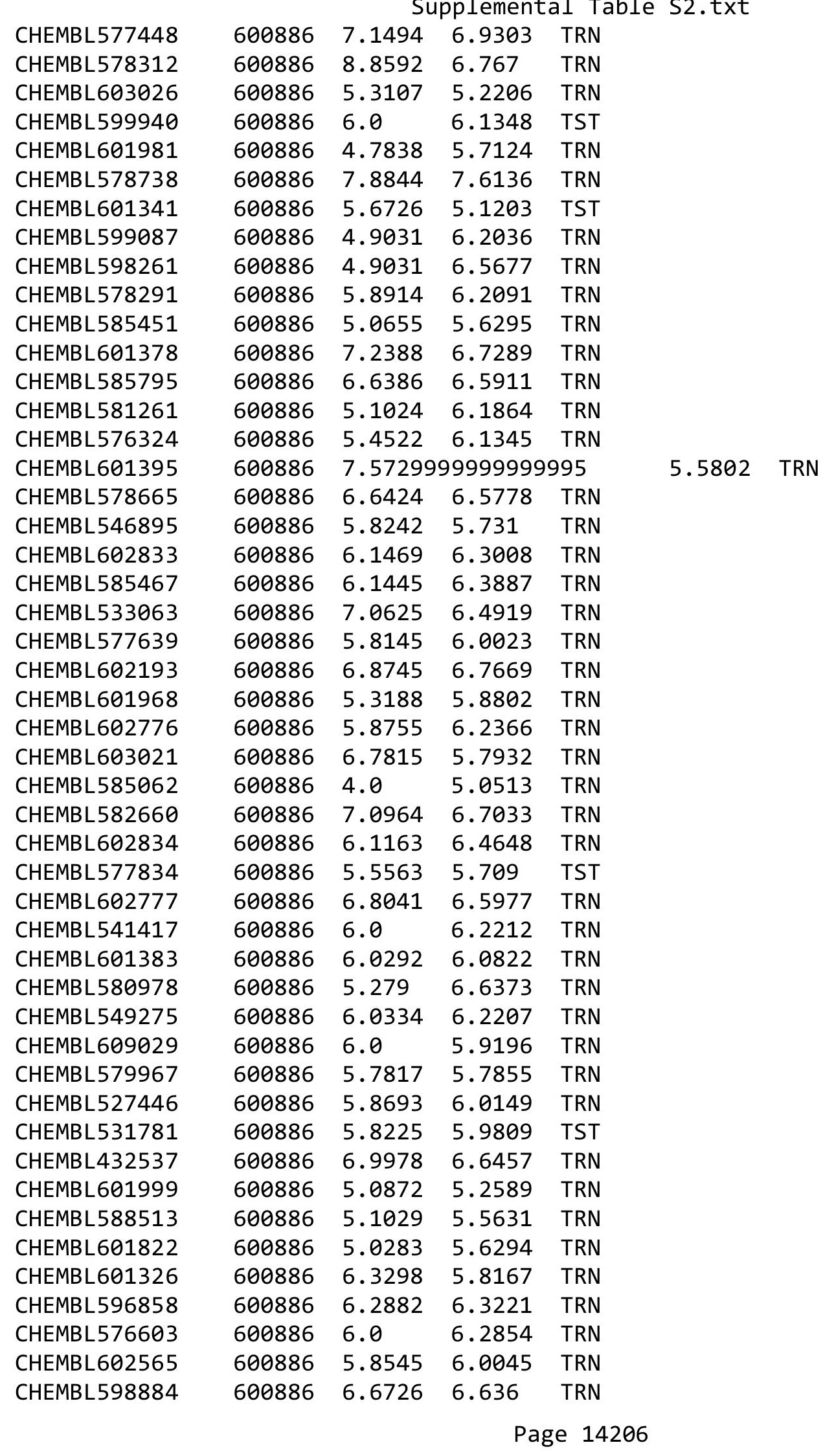




\begin{tabular}{|c|c|c|c|c|c|}
\hline \multirow[b]{2}{*}{ CHEMBL579134 } & \\
\hline & 600886 & 7.5615 & 7.0943 & TRN & \\
\hline CHEMBL579489 & 600886 & 5.2441 & 5.6523 & TRN & \\
\hline CHEMBL581657 & 600886 & 6.1118 & 6.6858 & TRN & \\
\hline CHEMBL582670 & 600886 & 6.1073 & 6.1141 & TRN & \\
\hline CHEMBL582466 & 600886 & 6.7501 & 6.5408 & TRN & \\
\hline CHEMBL578078 & 600886 & 5.5075 & \multicolumn{2}{|c|}{6.077000000000001} & TRN \\
\hline CHEMBL588802 & 600886 & 7.3487 & 7.3041 & TRN & \\
\hline CHEMBL533909 & 600886 & 5.9918 & 6.1573 & TRN & \\
\hline CHEMBL586007 & 600886 & 6.9052 & 6.6266 & TRN & \\
\hline CHEMBL585409 & 600886 & 5.9378 & 5.8713 & TRN & \\
\hline CHEMBL577668 & 600886 & 6.5317 & 6.3247 & TRN & \\
\hline CHEMBL304291 & 600886 & 6.0 & 6.1707 & TST & \\
\hline CHEMBL582695 & 600886 & 6.8582 & 5.7092 & TRN & \\
\hline CHEMBL578234 & 600886 & 7.2848 & 7.0237 & TRN & \\
\hline CHEMBL597250 & 600886 & 6.1851 & 6.1678 & TRN & \\
\hline CHEMBL599502 & 600886 & 4.9031 & 5.8021 & TRN & \\
\hline CHEMBL599910 & 600886 & 5.7899 & 6.52 & TRN & \\
\hline CHEMBL577214 & 600886 & 5.3429 & 5.5754 & TRN & \\
\hline CHEMBL524251 & 600886 & 6.8413 & 6.7199 & TRN & \\
\hline CHEMBL584034 & 600886 & 5.9965 & 6.1147 & TRN & \\
\hline CHEMBL585225 & 600886 & 6.7022 & 5.5897 & TST & \\
\hline CHEMBL577641 & 600886 & 6.0 & 6.3065 & TRN & \\
\hline CHEMBL602636 & 600886 & 7.6174 & 6.3017 & TRN & \\
\hline CHEMBL582327 & 600886 & 4.9031 & 5.7171 & TRN & \\
\hline CHEMBL601770 & 600886 & 5.7981 & 5.8439 & TST & \\
\hline CHEMBL576777 & 600886 & 6.3233 & 5.4996 & TRN & \\
\hline CHEMBL610249 & 600886 & 6.0 & 6.1356 & TST & \\
\hline CHEMBL579287 & 600886 & 5.5502 & 5.2261 & TRN & \\
\hline CHEMBL582740 & 600886 & 5.8794 & 6.3281 & TRN & \\
\hline CHEMBL578922 & 600886 & 5.3307 & 5.1655 & TST & \\
\hline CHEMBL 373330 & 600886 & 5.8742 & 6.3574 & TRN & \\
\hline CHEMBL585426 & 600886 & 4.9412 & 5.71 & TST & \\
\hline CHEMBL510650 & 600886 & 6.2807 & 6.7623 & TST & \\
\hline CHEMBL584828 & 600886 & 4.9763 & 5.7013 & TRN & \\
\hline CHEMBL584703 & 600886 & 6.4622 & 6.3194 & TRN & \\
\hline CHEMBL1583585 & 600886 & 7.626 & 7.0996 & TRN & \\
\hline CHEMBL585607 & 600886 & 5.919 & 5.6729 & TRN & \\
\hline CHEMBL601787 & 600886 & 7.3107 & 6.7319 & TST & \\
\hline CHEMBL579116 & 600886 & 6.6366 & 6.11799 & 9999999999 & TRN \\
\hline CHEMBL579891 & 600886 & 6.8739 & 6.7224 & TRN & \\
\hline CHEMBL600321 & 600886 & 7.7783 & 7.2813 & TRN & \\
\hline CHEMBL582441 & 600886 & 6.1051 & 6.4993 & TRN & \\
\hline CHEMBL578064 & 600886 & 9.5039 & 5.8338 & TST & \\
\hline CHEMBL583813 & 600886 & 4.9296 & 5.6362 & TST & \\
\hline CHEMBL586697 & 600886 & 5.2396 & 5.7231 & TST & \\
\hline CHEMBL581910 & 600886 & 6.0 & 6.1485 & TRN & \\
\hline CHEMBL578881 & 600886 & 6.1918 & 6.1188 & TRN & \\
\hline CHEMBL598053 & 600886 & 3.9031 & 5.46399 & 99999999995 & TRN \\
\hline & & & & 14207 & \\
\hline
\end{tabular}




CHEMBL582023
CHEMBL578692
CHEMBL513104
CHEMBL579294
CHEMBL597867
CHEMBL600765
CHEMBL529833
CHEMBL584447
CHEMBL528683
CHEMBL601179
CHEMBL602166
CHEMBL599300
CHEMBL535265
CHEMBL596844
CHEMBL601795
CHEMBL579731
CHEMBL579360
CHEMBL598699
CHEMBL598476
CHEMBL583831
CHEMBL530562
CHEMBL611069
CHEMBL582255
CHEMBL582108
CHEMBL577005
CHEMBL579675
CHEMBL576392
CHEMBL528000
CHEMBL578726
CHEMBL584883
CHEMBL585329
CHEMBL578468
CHEMBL589027
CHEMBL582315
CHEMBL599894
CHEMBL602625
CHEMBL579362
CHEMBL599509
CHEMBL586782
CHEMBL578541
CHEMBL 5314485786895
6

\begin{tabular}{llll} 
& \multicolumn{3}{c}{ Supplemental Tabl } \\
600886 & 7.1427 & 6.727 & TST \\
600886 & 6.3536 & 6.6463 & TRN \\
600886 & 6.1851 & 5.8044 & TRN \\
600886 & 6.4634 & 6.5583 & TRN \\
600886 & 3.9031 & 6.506 & TST \\
600886 & 6.0 & 6.3231 & TST \\
600886 & 6.1864 & 6.4508 & TST \\
600886 & 7.3152 & 6.8957 & TRN \\
600886 & 4.9739 & 5.4266 & TRN \\
600886 & 6.0841 & 6.1696 & TRN \\
600886 & 5.4225 & 5.6327 & TST \\
600886 & 6.4237 & 6.9086 & TRN \\
600886 & 6.0477 & 6.2759 & TRN \\
600886 & 6.0106 & 6.2375 & TRN \\
600886 & 6.971 & 6.4096 & TRN \\
600886 & 6.0 & 6.3263 & TRN \\
600886 & 5.5993 & 5.1313 & TRN \\
600886 & 7.2874 & 6.1638 & TRN \\
600886 & 6.3054 & 6.2059 & TRN \\
600886 & 5.9825 & 6.2262 & TRN \\
600886 & 6.4498 & 6.2964 & TST \\
600886 & 6.4962 & 6.9109 & TRN \\
600886 & 8.8016 & 5.8004 & TRN \\
600886 & 4.8847 & 5.7862 & TST \\
600886 & 5.5071 & 5.0686 & TRN \\
600886 & 5.2426 & 5.5186 & TST \\
600886 & 5.3134 & 5.102 & TRN \\
600886 & 6.3354 & 6.6689 & TST \\
600886 & 6.4841 & 6.4581 & TRN \\
600886 & 6.4597 & 6.4615 & TRN \\
600886 & 5.8969 & 6.149 & TRN \\
600886 & 5.3788 & 5.562 & TST \\
600886 & 6.1561 & 6.3139 & TRN \\
600886 & 5.8798 & 5.6719 & TRN \\
600886 & 4.9855 & 5.6428 & TRN \\
600886 & 5.2848 & 5.0716 & TST \\
600886 & 4.9031 & 5.7318 & TRN \\
600886 & 6.8262 & 6.3148 & TRN \\
600886 & 6.2048 & 6.5311 & TRN \\
600886 & 7.6183 & 6.8335 & TRN \\
600886 & 6.2269 & 6.2117 & TRN \\
600886 & 7.0496 & 6.5028 & TRN \\
600886 & 9.0443 & 6.3699 & TRN \\
600886 & 6.1238 & 6.2692 & TRN \\
6008886 & 5.1367 & 6.3535 & TRN \\
6.1331 & 6.4898 & TRN \\
6.0857 & 6.4973 & TRN \\
\hline 6 & 5.9864 & TST
\end{tabular}

Page 14208 


\begin{tabular}{|c|c|c|c|c|c|c|}
\hline & & & & & & \\
\hline CHEMBL602999 & 600886 & 6.1481 & $6.11700 t$ & 0000000001 & & TRN \\
\hline CHEMBL601172 & 600886 & 5.8894 & 6.0202 & TRN & & \\
\hline CHEMBL600349 & 600886 & 6.4724 & 6.2337 & TST & & \\
\hline CHEMBL578073 & 600886 & 5.5364 & 5.9036 & TRN & & \\
\hline CHEMBL578884 & 600886 & 7.8386 & 7.6422 & TRN & & \\
\hline CHEMBL603939 & 600886 & 6.1118 & 6.5808 & TRN & & \\
\hline CHEMBL576995 & 600886 & 6.7226 & 5.647 & TST & & \\
\hline CHEMBL585270 & 600886 & 7.1726 & 6.7265 & TRN & & \\
\hline CHEMBL587592 & 600886 & 5.9208 & 5.9345 & TRN & & \\
\hline CHEMBL585052 & 600886 & 7.2848 & 6.3375 & TRN & & \\
\hline CHEMBL584631 & 600886 & 5.0691 & 5.7764 & TST & & \\
\hline CHEMBL582657 & 600886 & 6.4473 & 6.5875 & TRN & & \\
\hline CHEMBL388886 & 600886 & 5.5024 & 6.0348 & TRN & & \\
\hline CHEMBL601812 & 600886 & 6.2041 & 6.4224 & TRN & & \\
\hline CHEMBL585022 & 600886 & 4.9144 & 5.7293 & TRN & & \\
\hline CHEMBL588332 & 600886 & 5.0762 & 5.5161 & TRN & & \\
\hline CHEMBL601572 & 600886 & 6.0841 & 6.376 & TRN & & \\
\hline CHEMBL602032 & 600886 & 5.5067 & 5.0483 & TRN & & \\
\hline CHEMBL576410 & 600886 & 6.5637 & 6.7151 & TST & & \\
\hline CHEMBL585641 & 600886 & 7.57299 & 99999999 & 995 & 5.5439 & TRN \\
\hline CHEMBL577011 & 600886 & 6.8771 & 6.341 & TRN & & \\
\hline CHEMBL600923 & 600886 & 5.7484 & 6.1136 & TRN & & \\
\hline CHEMBL604309 & 600886 & 6.1278 & 6.3408 & TRN & & \\
\hline CHEMBL530173 & 600886 & 6.0453 & 6.17899 & 9999999999 & & TRN \\
\hline CHEMBL579372 & 600886 & 6.1169 & 6.3804 & TRN & & \\
\hline CHEMBL581274 & 600886 & 5.1085 & 5.079 & TRN & & \\
\hline CHEMBL581457 & 600886 & 7.3565 & 6.2936 & TRN & & \\
\hline CHEMBL578893 & 600886 & 5.6434 & 5.7389 & TRN & & \\
\hline CHEMBL582646 & 600886 & 8.2111 & 6.2937 & TRN & & \\
\hline CHEMBL584425 & 600886 & 8.7665 & 6.3577 & TRN & & \\
\hline CHEMBL584846 & 600886 & 5.0716 & 5.6605 & TST & & \\
\hline CHEMBL598076 & 600886 & 6.08200 & 0000000 & & 5.4715 & TRN \\
\hline CHEMBL600958 & 600886 & 5.9952 & 6.2177 & TRN & & \\
\hline CHEMBL600751 & 600886 & 6.8289 & 5.5458 & TRN & & \\
\hline CHEMBL585772 & 600886 & 6.2557 & 6.4899 & TRN & & \\
\hline CHEMBL597467 & 600886 & 6.1952 & 5.9594 & TRN & & \\
\hline CHEMBL579368 & 600886 & 6.7585 & 6.6774 & TRN & & \\
\hline CHEMBL578712 & 600886 & 6.6306 & 6.516 & TRN & & \\
\hline CHEMBL596642 & 600886 & 5.9714 & 6.3645 & TRN & & \\
\hline CHEMBL577010 & 600886 & 6.5452 & 5.6895 & TRN & & \\
\hline CHEMBL604361 & 600886 & 5.8582 & 5.5795 & TST & & \\
\hline CHEMBL583805 & 600886 & 6.0 & 6.2609 & TRN & & \\
\hline CHEMBL604801 & 600886 & 4.9031 & 6.2276 & TST & & \\
\hline CHEMBL600971 & 600886 & 6.2503 & 5.202006 & 0000000001 & & TRN \\
\hline CHEMBL582056 & 600886 & 4.1851 & 5.1477 & TRN & & \\
\hline CHEMBL581873 & 600886 & 6.6745 & 6.9021 & TRN & & \\
\hline CHEMBL587560 & 600886 & 6.1993 & 5.6322 & TST & & \\
\hline CHEMBL576160 & 600886 & 5.6207 & 5.6853 & TRN & & \\
\hline
\end{tabular}




\begin{tabular}{|c|c|c|c|c|c|}
\hline \multirow[b]{2}{*}{ CHEMBL578455 } & \multicolumn{5}{|c|}{ su } \\
\hline & 600886 & 6.0804 & 5.9149 & TST & \\
\hline CHEMBL582098 & 600886 & 6.6315 & 6.9533 & TRN & \\
\hline CHEMBL601129 & 600886 & 5.0762 & 5.6572 & TRN & \\
\hline CHEMBL582737 & 600886 & 4.9031 & 5.5359 & TRN & \\
\hline CHEMBL579168 & 600886 & 5.2277 & 5.7826 & TRN & \\
\hline CHEMBL578467 & 600886 & 5.6119 & 5.5786 & TRN & \\
\hline CHEMBL579919 & 600886 & 6.4763 & 6.6286 & TRN & \\
\hline CHEMBL604157 & 600886 & 5.0535 & 5.5718 & TRN & \\
\hline CHEMBL602775 & 600886 & 6.1013 & 6.2815 & TST & \\
\hline CHEMBL601763 & 600886 & 6.4763 & 6.5258 & TRN & \\
\hline CHEMBL587111 & 600886 & 5.1707 & 5.5712 & TRN & \\
\hline CHEMBL583119 & 600886 & 8.2774 & 6.3843 & TRN & \\
\hline CHEMBL585960 & 600886 & 7.1284 & 6.7938 & TRN & \\
\hline CHEMBL603002 & 600886 & 6.2197 & 6.0307 & TRN & \\
\hline CHEMBL601135 & 600886 & 6.1314 & 5.9758 & TRN & \\
\hline CHEMBL596631 & 600886 & 6.0372 & 6.2112 & TRN & \\
\hline CHEMBL587899 & 600886 & 5.9165 & 6.3969 & TRN & \\
\hline CHEMBL588667 & 600886 & 6.2807 & 6.4361 & TRN & \\
\hline CHEMBL600738 & 600886 & 5.8775 & 6.08200 & 0000000001 & TRN \\
\hline CHEMBL609312 & 600886 & 7.0074 & 6.4971 & TRN & \\
\hline CHEMBL597868 & 600886 & 6.2418 & 6.2952 & TRN & \\
\hline CHEMBL602768 & 600886 & 4.9389 & 5.6151 & TRN & \\
\hline CHEMBL 2079780 & 600886 & 6.0278 & 6.3491 & TST & \\
\hline CHEMBL579154 & 600886 & 7.4413 & 6.4584 & TRN & \\
\hline CHEMBL610790 & 600886 & 6.8601 & 6.6198 & TST & \\
\hline CHEMBL585809 & 600886 & 5.9446 & 6.3015 & TRN & \\
\hline CHEMBL588350 & 600886 & 5.1772 & 5.4855 & TRN & \\
\hline CHEMBL236695 & 600886 & 6.8798 & 6.6618 & TRN & \\
\hline CHEMBL585657 & 600886 & 6.2069 & 5.6267 & TRN & \\
\hline CHEMBL528024 & 600886 & 4.8368 & 5.52 & TRN & \\
\hline CHEMBL582688 & 600886 & 5.7698 & 5.3959 & TRN & \\
\hline CHEMBL584660 & 600886 & 6.4815 & 6.2755 & TRN & \\
\hline CHEMBL582529 & 600886 & 5.8993 & 6.4247 & TRN & \\
\hline CHEMBL601563 & 600886 & 6.0 & 6.2296 & TRN & \\
\hline CHEMBL7199 & 600886 & 6.0947 & 6.4157 & TST & \\
\hline CHEMBL584439 & 600886 & 8.6737 & 5.6647 & TRN & \\
\hline CHEMBL585991 & 600886 & 5.994 & 5.5328 & TST & \\
\hline CHEMBL601328 & 600886 & 6.129 & 5.6861 & TST & \\
\hline CHEMBL 373292 & 600886 & 6.647 & 6.4642 & TRN & \\
\hline CHEMBL578261 & 600886 & 5.3516 & 5.037 & TRN & \\
\hline CHEMBL601119 & 600886 & 5.2916 & 5.9253 & TRN & \\
\hline CHEMBL600752 & 600886 & 5.9706 & 5.9978 & TRN & \\
\hline CHEMBL584824 & 600886 & 6.0273 & 6.2953 & TRN & \\
\hline CHEMBL601762 & 600886 & 5.6639 & 6.2302 & TRN & \\
\hline CHEMBL600559 & 600886 & 5.0214 & 6.3057 & TST & \\
\hline CHEMBL530144 & 600886 & 5.8894 & 5.9049 & TRN & \\
\hline CHEMBL601973 & 600886 & 5.0794 & 5.57 & TRN & \\
\hline CHEMBL585253 & 600886 & 4.0386 & 5.1615 & TST & \\
\hline & & & & 14210 & \\
\hline
\end{tabular}




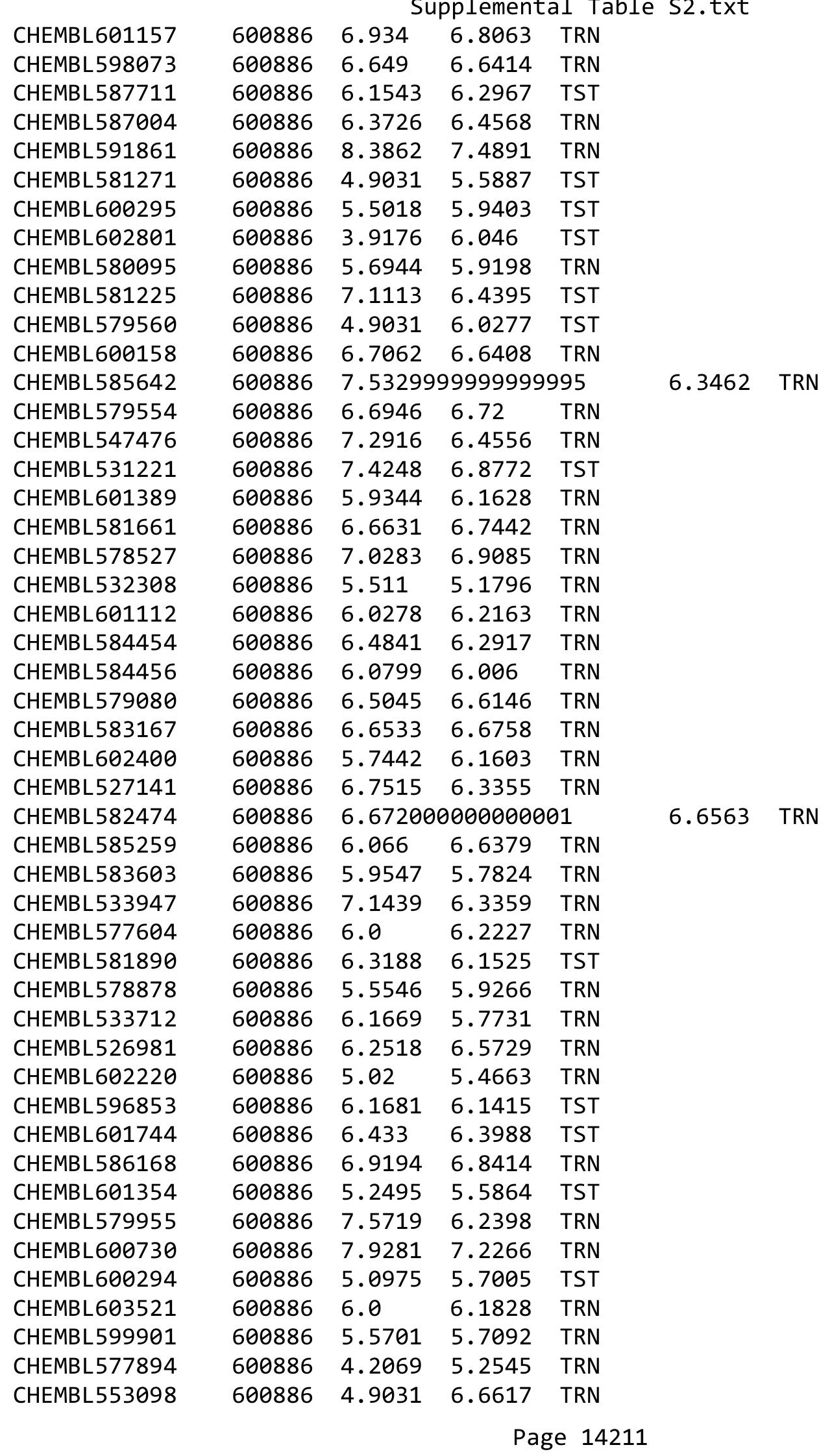




\begin{tabular}{|c|c|c|c|c|c|c|}
\hline & & & & & & \\
\hline CHEMBL576788 & 600886 & 6.4214 & 6.5864 & TRN & & \\
\hline CHEMBL598286 & 600886 & 7.1215 & 6.9004 & TRN & & \\
\hline CHEMBL579553 & 600886 & 6.6592 & 6.5235 & TRN & & \\
\hline CHEMBL1744500 & 600886 & 6.209 & 6.1532 & TRN & & \\
\hline CHEMBL529062 & 600886 & 6.0996 & 6.3592 & TST & & \\
\hline CHEMBL582717 & 600886 & 6.2306 & 6.4399 & TRN & & \\
\hline CHEMBL578748 & 600886 & 6.3585 & 6.5669 & TRN & & \\
\hline CHEMBL546464 & 600886 & 6.2984 & 5.8031 & TRN & & \\
\hline CHEMBL600735 & 600886 & 6.7321 & 6.7233 & TRN & & \\
\hline CHEMBL578705 & 600886 & 7.5154 & 7.3572 & TRN & & \\
\hline CHEMBL579077 & 600886 & 6.0 & 6.3019 & TRN & & \\
\hline CHEMBL580172 & 600886 & 6.2882 & 6.5903 & TRN & & \\
\hline CHEMBL582673 & 600886 & 8.8573 & 6.5961 & TST & & \\
\hline CHEMBL578058 & 600886 & 6.3197 & 6.1845 & TRN & & \\
\hline CHEMBL583883 & 600886 & 6.2984 & 6.1808 & TRN & & \\
\hline CHEMBL577841 & 600886 & 6.32700 & 30000000 & 01 & 5.6237 & TRN \\
\hline CHEMBL532641 & 600886 & 6.4672 & 6.697 & TRN & & \\
\hline CHEMBL600153 & 600886 & 5.95 & 6.1434 & TRN & & \\
\hline CHEMBL585816 & 600886 & 7.0044 & 6.6763 & TRN & & \\
\hline CHEMBL585596 & 600886 & 6.3716 & 6.4301 & TRN & & \\
\hline CHEMBL602196 & 600886 & 5.2118 & 5.5098 & TRN & & \\
\hline CHEMBL582440 & 600886 & 6.3072 & 6.4521 & TRN & & \\
\hline CHEMBL582475 & 600886 & 6.5229 & 6.1006 & TST & & \\
\hline CHEMBL585815 & 600886 & 7.6533 & 6.9387 & TRN & & \\
\hline CHEMBL597037 & 600886 & 6.0915 & 5.2194 & TRN & & \\
\hline CHEMBL577672 & 600886 & 5.0904 & 5.5639 & TRN & & \\
\hline CHEMBL534063 & 600886 & 5.4134 & 6.0713 & TRN & & \\
\hline CHEMBL585097 & 600886 & 6.067 & 6.3503 & TRN & & \\
\hline CHEMBL600550 & 600886 & 5.8854 & 5.9609 & TST & & \\
\hline CHEMBL578688 & 600886 & 6.4685 & 6.4044 & TRN & & \\
\hline CHEMBL579318 & 600886 & 5.75700 & 00000000 & & 6.1477 & TRN \\
\hline CHEMBL609628 & 600886 & 6.3747 & 6.58799 & 9999999999 & & TRN \\
\hline CHEMBL581245 & 600886 & 5.7142 & 5.601 & TRN & & \\
\hline CHEMBL579172 & 600886 & 7.9626 & 6.2782 & TRN & & \\
\hline CHEMBL585496 & 600886 & 6.1778 & 6.0154 & TRN & & \\
\hline CHEMBL586249 & 600886 & 6.909 & 6.6039 & TRN & & \\
\hline CHEMBL578304 & 600886 & 4.2381 & 6.1791 & TRN & & \\
\hline CHEMBL598060 & 600886 & 5.902 & 5.2727 & TRN & & \\
\hline CHEMBL609025 & 600886 & 6.0 & 6.1642 & TRN & & \\
\hline CHEMBL581674 & 600886 & 5.7513 & 5.8818 & TRN & & \\
\hline CHEMBL601806 & 600886 & 5.2007 & 5.8144 & TST & & \\
\hline CHEMBL588987 & 600886 & 6.3565 & 6.4426 & TRN & & \\
\hline CHEMBL603009 & 600886 & 8.1057 & 7.5525 & TRN & & \\
\hline CHEMBL578934 & 600886 & 6.5955 & 6.4805 & TRN & & \\
\hline CHEMBL579378 & 600886 & 7.7418 & 7.2237 & TRN & & \\
\hline CHEMBL530030 & 600886 & 6.7036 & 6.8976 & TRN & & \\
\hline CHEMBL601760 & 600886 & 6.5024 & 6.2588 & TRN & & \\
\hline CHEMBL584520 & 600886 & 6.2993 & 6.1406 & TST & & \\
\hline
\end{tabular}




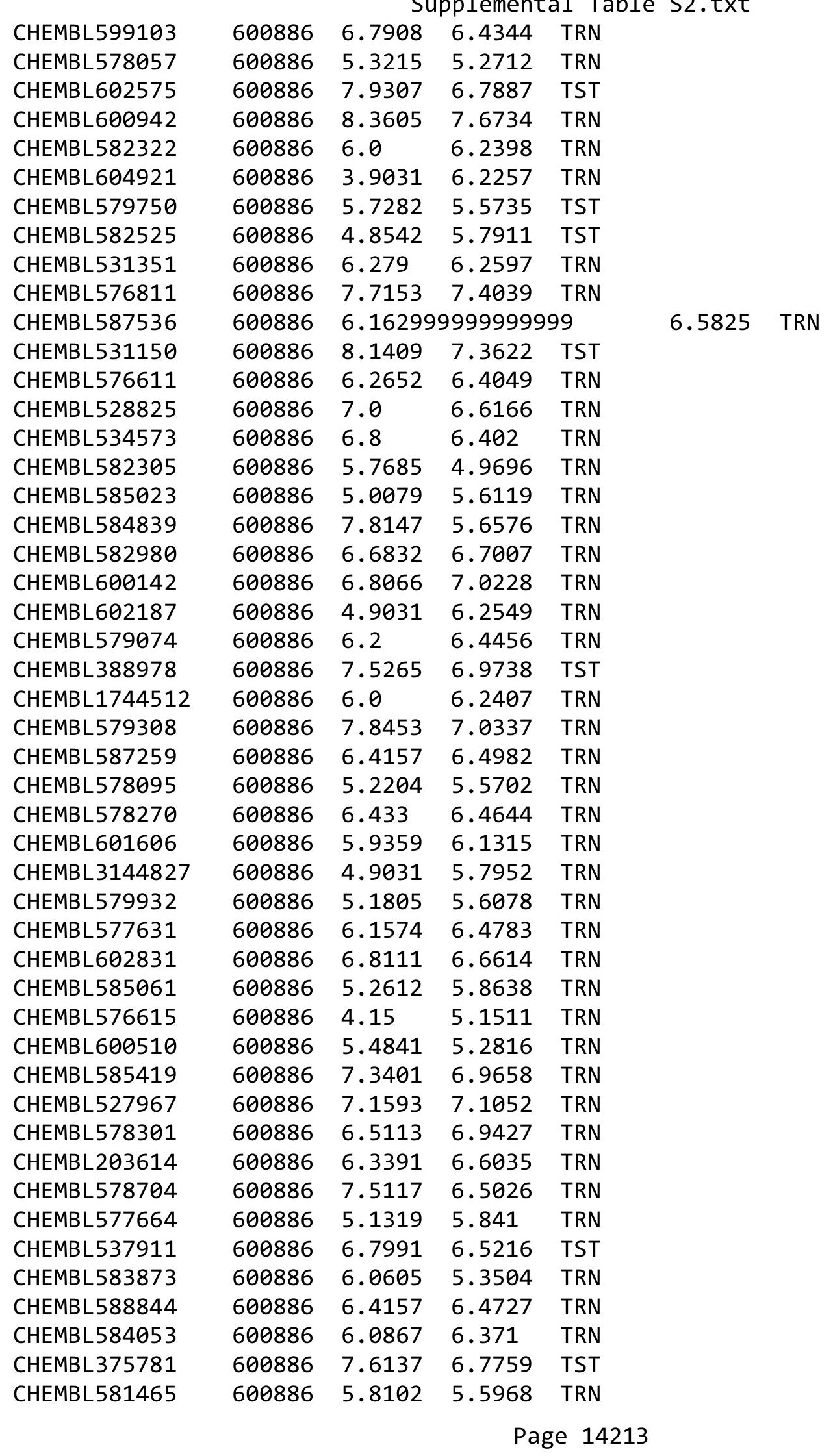




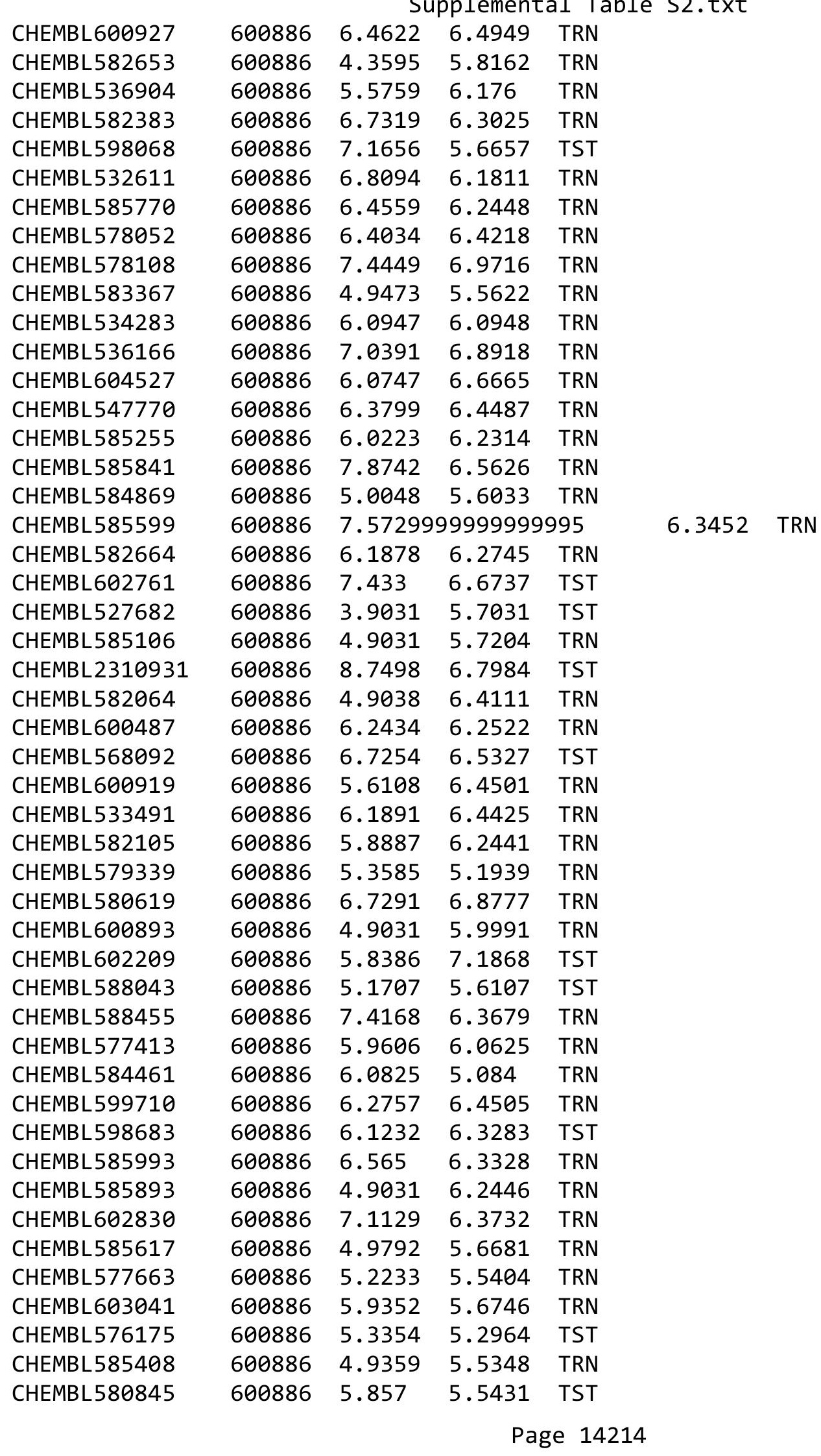




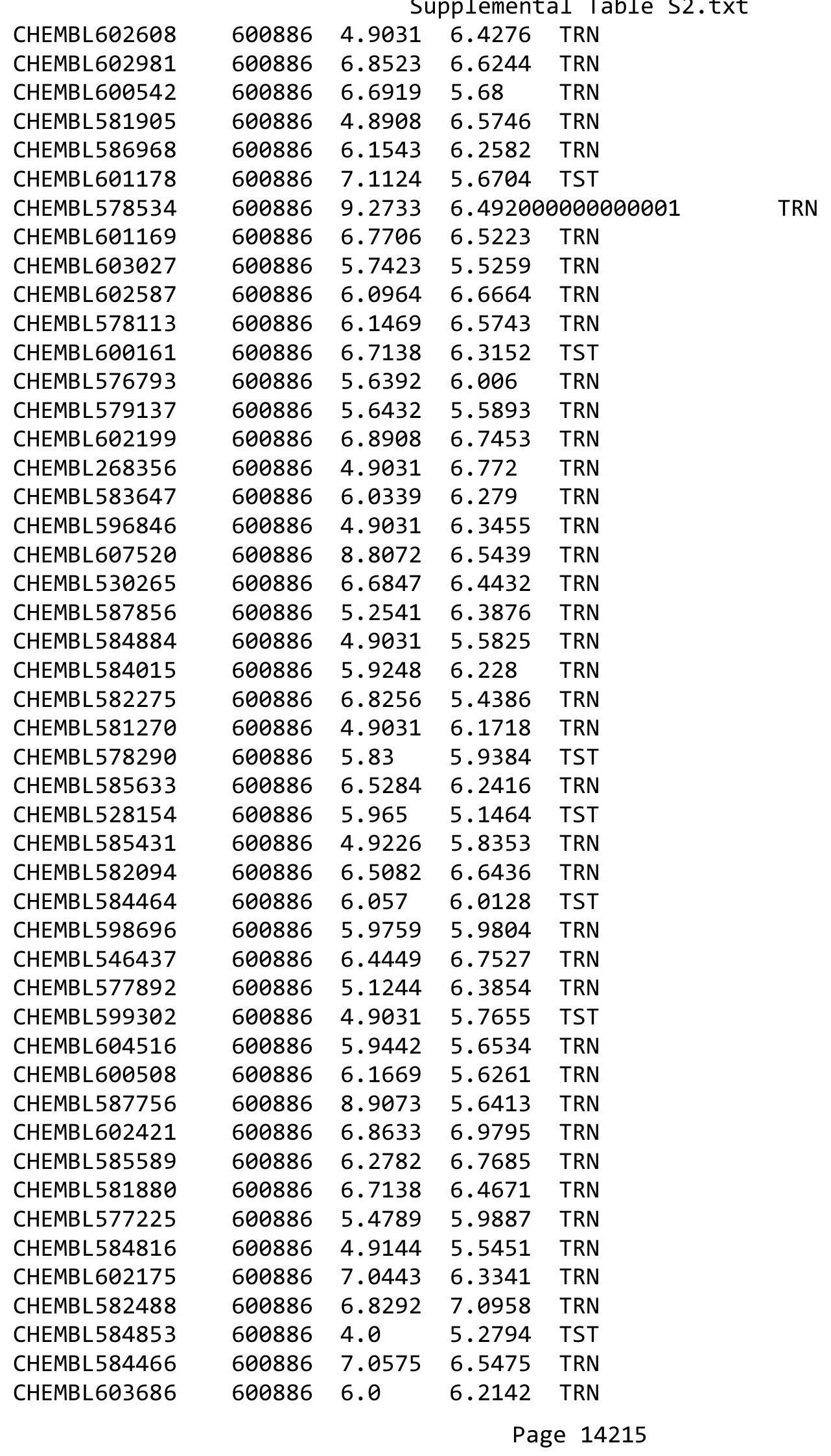




\begin{tabular}{|c|c|c|c|c|c|c|}
\hline & & \multicolumn{5}{|c|}{ Supplemental Table s2.txt } \\
\hline CHEMBL577391 & 600886 & 7.8778 & 7.2614 & TRN & & \\
\hline CHEMBL579332 & 600886 & 6.3635 & 6.2139 & TST & & \\
\hline CHEMBL598681 & 600886 & 6.426 & 6.7868 & TRN & & \\
\hline CHEMBL585606 & 600886 & 5.845 & 6.2811 & TRN & & \\
\hline CHEMBL577856 & 600886 & 5.4802 & 5.2125 & TRN & & \\
\hline CHEMBL601364 & 600886 & 6.0 & 6.3132 & TRN & & \\
\hline CHEMBL601182 & 600886 & 4.9031 & 5.9731 & TST & & \\
\hline CHEMBL579376 & 600886 & 6.2565 & 5.6386 & TRN & & \\
\hline CHEMBL582302 & 600886 & 5.6874 & 6.0135 & TRN & & \\
\hline CHEMBL578495 & 600886 & 5.3288 & 6.5023 & TRN & & \\
\hline CHEMBL600537 & 600886 & \multicolumn{3}{|c|}{6.787000000000001} & 6.6172 & TRN \\
\hline CHEMBL579959 & 600886 & 6.54 & 6.7051 & TRN & & \\
\hline CHEMBL605335 & 600886 & 3.9031 & 5.9611 & TRN & & \\
\hline CHEMBL602155 & 600886 & 6.1593 & 6.1948 & TRN & & \\
\hline CHEMBL585972 & 600886 & 6.1506 & 6.1391 & TRN & & \\
\hline CHEMBL54804 & 600886 & 5.0862 & 5.6577 & TST & & \\
\hline CHEMBL582066 & 600886 & 4.8359 & 6.1125 & TRN & & \\
\hline CHEMBL582483 & 600886 & 6.1713 & 6.2275 & TRN & & \\
\hline CHEMBL546930 & 600886 & 7.3595 & 7.2263 & TRN & & \\
\hline CHEMBL588461 & 600886 & 6.0742 & 6.4605 & TRN & & \\
\hline CHEMBL585648 & 600886 & 6.4377 & 6.416 & TST & & \\
\hline CHEMBL593252 & 600886 & 6.845 & 6.8511 & TST & & \\
\hline CHEMBL578872 & 600886 & 5.3556 & 6.7843 & TST & & \\
\hline CHEMBL587636 & 600886 & 8.9813 & 7.0134 & TRN & & \\
\hline CHEMBL585435 & 600886 & 7.3487 & 6.3446 & TRN & & \\
\hline CHEMBL585826 & 600886 & 8.6176 & 6.4272 & TRN & & \\
\hline CHEMBL602427 & 600886 & 5.0022 & 5.606 & TST & & \\
\hline CHEMBL583900 & 600886 & 5.6008 & 5.7433 & TRN & & \\
\hline CHEMBL580637 & 600886 & 6.0 & 6.2472 & TRN & & \\
\hline CHEMBL579380 & 600886 & 6.2668 & 6.3485 & TRN & & \\
\hline CHEMBL605548 & 600886 & 6.1024 & 6.3985 & TRN & & \\
\hline CHEMBL597035 & 600886 & 6.1232 & 6.1488 & TRN & & \\
\hline CHEMBL583399 & 600886 & 5.8914 & 5.0749 & TST & & \\
\hline CHEMBL578533 & 600886 & \multicolumn{3}{|c|}{7.2620000000000005} & 6.8245 & TRN \\
\hline CHEMBL586021 & 600886 & 6.7371 & 6.4101 & TST & & \\
\hline CHEMBL577382 & 600886 & 7.2815 & 6.4836 & TRN & & \\
\hline CHEMBL581030 & 600886 & 6.683 & 6.8489 & TRN & & \\
\hline CHEMBL597669 & 600886 & 6.8539 & 6.65 & TST & & \\
\hline CHEMBL585812 & 600886 & 7.3507 & 6.4282 & TRN & & \\
\hline CHEMBL581236 & 600886 & 5.7053 & 5.8866 & TST & & \\
\hline CHEMBL579133 & 600886 & 7.5455 & 7.0917 & TRN & & \\
\hline CHEMBL584013 & 600886 & 4.9634 & 6.0165 & TRN & & \\
\hline CHEMBL585838 & 600886 & 6.2899 & 5.9108 & TRN & & \\
\hline CHEMBL576773 & 600886 & 6.6979 & 6.71200 & 0000000001 & & TRN \\
\hline CHEMBL578315 & 600886 & 6.8649 & 6.4679 & TRN & & \\
\hline CHEMBL600924 & 600886 & 5.8321 & 6.2629 & TRN & & \\
\hline CHEMBL580146 & 600886 & 7.8483 & 7.5172 & TRN & & \\
\hline CHEMBL598287 & 600886 & 7.0526 & 6.6508 & TRN & & \\
\hline
\end{tabular}




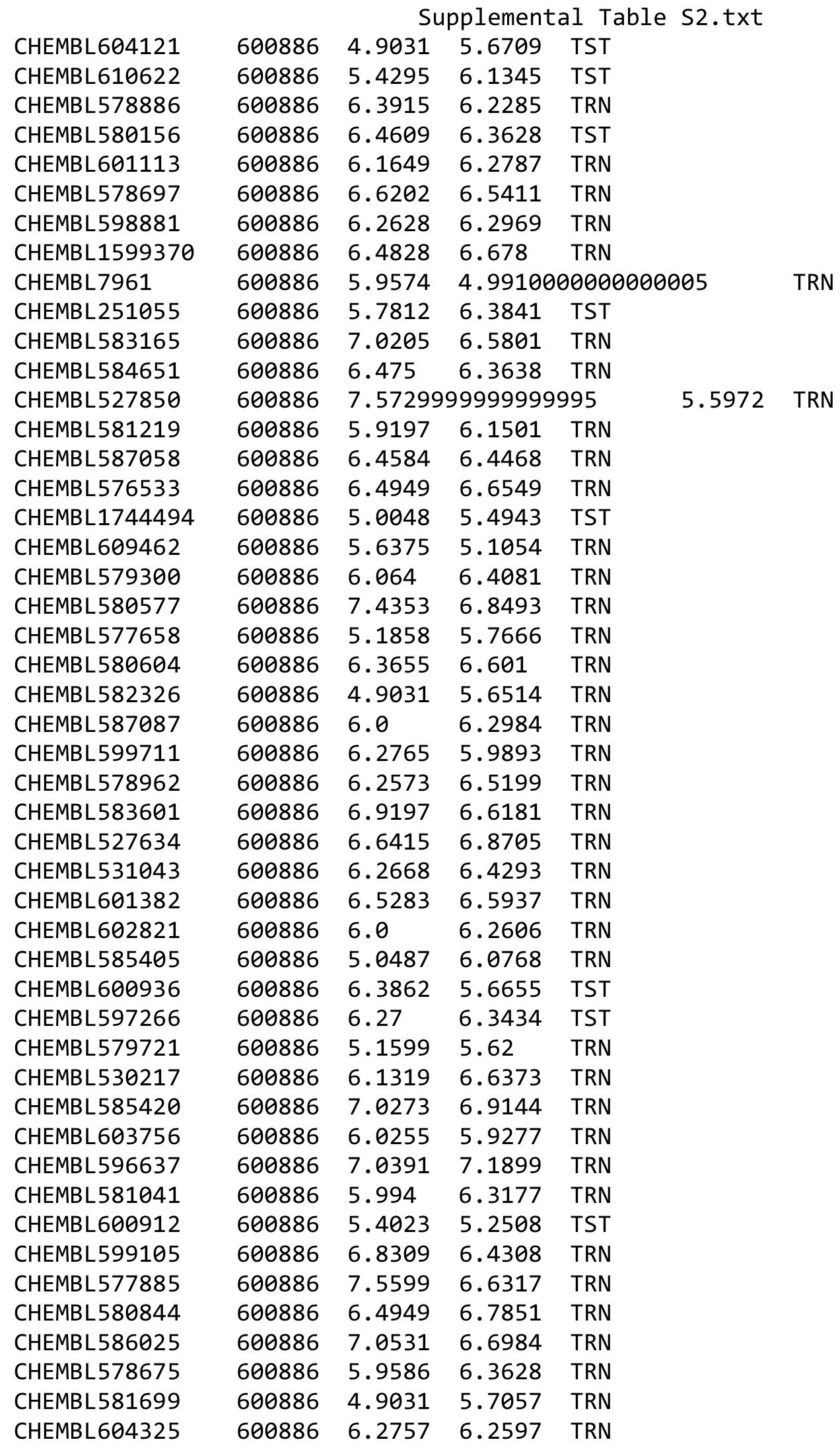

Page 14217 


\begin{tabular}{|c|c|c|c|c|c|}
\hline \multicolumn{6}{|c|}{ 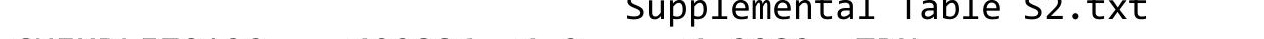 } \\
\hline CHEMBL579120 & 600886 & 6.0 & 6.2982 & TRN & \\
\hline CHEMBL579132 & 600886 & 10.2426 & 6.3947 & TST & \\
\hline CHEMBL583592 & 600886 & 4.9307 & 5.6452 & TST & \\
\hline CHEMBL532518 & 600886 & 4.9031 & 5.6941 & TST & \\
\hline CHEMBL579934 & 600886 & 7.1255 & 6.6041 & TRN & \\
\hline CHEMBL578328 & 600886 & 5.1688 & 5.5543 & TRN & \\
\hline CHEMBL576800 & 600886 & 6.7565 & 6.4976 & TRN & \\
\hline CHEMBL582508 & 600886 & 5.7399 & 6.1002 & TRN & \\
\hline CHEMBL601983 & 600886 & 6.1113 & 6.1433 & TRN & \\
\hline CHEMBL578503 & 600886 & 4.9031 & 7.3855 & TRN & \\
\hline CHEMBL597457 & 600886 & 5.9337 & 6.5232 & TRN & \\
\hline CHEMBL610251 & 600886 & 6.3468 & 6.4201 & TST & \\
\hline CHEMBL585285 & 600886 & 5.9872 & 5.91700 & 0000000001 & TRN \\
\hline CHEMBL610250 & 600886 & 6.2958 & 6.3386 & TRN & \\
\hline CHEMBL579054 & 600886 & 5.4597 & 6.1655 & TRN & \\
\hline CHEMBL600902 & 600886 & 3.9031 & 5.2318 & TRN & \\
\hline CHEMBL602018 & 600886 & 4.9292 & 5.664 & TRN & \\
\hline CHEMBL306147 & 600886 & 8.6381 & 5.5368 & TST & \\
\hline CHEMBL581346 & 600886 & 6.8164 & 6.5204 & TRN & \\
\hline CHEMBL547833 & 600886 & 6.0334 & 6.4618 & TRN & \\
\hline CHEMBL600723 & 600886 & 5.0958 & 6.3075 & TRN & \\
\hline CHEMBL600317 & 600886 & 6.8914 & 6.2169 & TRN & \\
\hline CHEMBL584281 & 600886 & 6.1487 & 6.1076 & TRN & \\
\hline CHEMBL583595 & 600886 & 4.9314 & 5.6236 & TRN & \\
\hline CHEMBL530412 & 600886 & 7.1331 & 6.8928 & TRN & \\
\hline CHEMBL579233 & 600886 & 6.1952 & 6.2488 & TRN & \\
\hline CHEMBL580340 & 600886 & 6.4868 & 6.7595 & TRN & \\
\hline CHEMBL579977 & 600886 & 5.6517 & 5.0908 & TRN & \\
\hline CHEMBL579175 & 600886 & 5.266 & 6.3265 & TRN & \\
\hline CHEMBL578951 & 600886 & 7.4597 & 6.9292 & TRN & \\
\hline CHEMBL584671 & 600886 & 6.0835 & 5.1538 & TST & \\
\hline CHEMBL488757 & 600886 & 6.2434 & 6.7138 & TRN & \\
\hline CHEMBL588495 & 600886 & 5.7825 & 5.9968 & TST & \\
\hline CHEMBL584040 & 600886 & 7.2782 & 5.5693 & TRN & \\
\hline CHEMBL599494 & 600886 & 7.0 & 6.495 & TRN & \\
\hline CHEMBL602222 & 600886 & 7.433 & 6.8604 & TRN & \\
\hline CHEMBL609606 & 600886 & 6.5436 & 6.49 & TRN & \\
\hline CHEMBL582274 & 600886 & 6.8551 & 6.7222 & TRN & \\
\hline CHEMBL582728 & 600886 & 5.8726 & 6.1966 & TRN & \\
\hline CHEMBL583352 & 600886 & 6.0132 & 5.7231 & TRN & \\
\hline CHEMBL582082 & 600886 & 6.704 & 6.5329 & TRN & \\
\hline CHEMBL524786 & 600886 & 6.0381 & 6.4066 & TRN & \\
\hline CHEMBL578671 & 600886 & 6.5532 & 6.0399 & TRN & \\
\hline CHEMBL578083 & 600886 & 5.4815 & 5.9883 & TRN & \\
\hline CHEMBL582725 & 600886 & 5.6668 & 6.0074 & TRN & \\
\hline CHEMBL581655 & 600886 & 5.7053 & 5.209 & TRN & \\
\hline CHEMBL586946 & 600886 & 9.0696 & 5.7465 & TST & \\
\hline CHEMBL581190 & 600886 & 6.3063 & 6.0537 & TRN & \\
\hline
\end{tabular}




\begin{tabular}{|c|c|c|c|c|c|c|}
\hline \multirow[b]{2}{*}{ CHEMBL578674 } & \multicolumn{6}{|c|}{ Supplemental Ta } \\
\hline & 600886 & 5.3468 & 5.7428 & TRN & & \\
\hline CHEMBL579374 & 600886 & 6.2284 & 5.7258 & TRN & & \\
\hline CHEMBL585269 & 600886 & 6.17200 & 30000000 & $\partial 1$ & 6.0474 & TRN \\
\hline CHEMBL608736 & 600886 & 7.0009 & 6.0522 & TST & & \\
\hline CHEMBL584012 & 600886 & 6.556 & 7.017 & TRN & & \\
\hline CHEMBL578516 & 600886 & 6.0017 & 6.2618 & TST & & \\
\hline CHEMBL582512 & 600886 & 5.8614 & 6.0505 & TRN & & \\
\hline CHEMBL585801 & 600886 & 3.9813 & 5.0673 & TRN & & \\
\hline CHEMBL 270726 & 600886 & 6.6985 & 6.2663 & TRN & & \\
\hline CHEMBL598691 & 600886 & 6.279 & 5.7039 & TST & & \\
\hline CHEMBL583162 & 600886 & 6.3665 & 6.5274 & TRN & & \\
\hline CHEMBL585234 & 600886 & 6.3468 & 6.4537 & TRN & & \\
\hline CHEMBL602431 & 600886 & 6.5653 & 6.5074 & TRN & & \\
\hline CHEMBL532383 & 600886 & 6.2 & 6.3775 & TRN & & \\
\hline CHEMBL534600 & 600886 & 6.7894 & 6.5466 & TRN & & \\
\hline CHEMBL601369 & 600886 & 5.78299 & 99999999 & 995 & 5.1763 & TST \\
\hline CHEMBL585957 & 600886 & 5.5427 & 5.6514 & TRN & & \\
\hline CHEMBL 600748 & 600886 & 6.8871 & 6.294 & TRN & & \\
\hline CHEMBL581264 & 600886 & 6.1891 & 6.2904 & TRN & & \\
\hline CHEMBL581690 & 600886 & 4.9031 & 6.3547 & TRN & & \\
\hline CHEMBL602434 & 600886 & 6.62799 & 99999999 & 99 & 6.4035 & TRN \\
\hline CHEMBL579259 & 600886 & 6.5555 & 6.9071 & TST & & \\
\hline CHEMBL600101 & 600886 & 6.6153 & 6.3276 & TRN & & \\
\hline CHEMBL597058 & 600886 & 6.2882 & 6.1451 & TRN & & \\
\hline CHEMBL585588 & 600886 & 6.0 & 6.3288 & TRN & & \\
\hline CHEMBL581247 & 600886 & 6.9194 & 7.0476 & TRN & & \\
\hline CHEMBL583619 & 600886 & 6.2262 & 6.3013 & TRN & & \\
\hline CHEMBL600112 & 600886 & 5.6747 & 5.2589 & TRN & & \\
\hline CHEMBL599308 & 600886 & 3.9031 & 5.7089 & TRN & & \\
\hline CHEMBL582675 & 600886 & 5.1113 & 5.2751 & TRN & & \\
\hline CHEMBL547227 & 600886 & 6.9512 & 6.6675 & TRN & & \\
\hline CHEMBL600301 & 600886 & 6.2725 & 6.5487 & TRN & & \\
\hline CHEMBL598262 & 600886 & 7.57299 & 99999999 & 995 & 5.5989 & TST \\
\hline CHEMBL601979 & 600886 & 6.7719 & 6.6712 & TRN & & \\
\hline CHEMBL 600124 & 600886 & 5.0794 & 5.9242 & TRN & & \\
\hline CHEMBL602827 & 600886 & 6.7203 & 6.2451 & TRN & & \\
\hline CHEMBL581263 & 600886 & 4.8428 & 6.0678 & TRN & & \\
\hline CHEMBL587291 & 600886 & 5.0883 & 5.5472 & TRN & & \\
\hline CHEMBL585425 & 600886 & 5.9931 & 5.5806 & TRN & & \\
\hline CHEMBL576605 & 600886 & 6.055 & 6.3708 & TRN & & \\
\hline CHEMBL535281 & 600886 & 7.8526 & 7.147 & TRN & & \\
\hline CHEMBL601605 & 600886 & 4.9147 & 5.6256 & TST & & \\
\hline CHEMBL583210 & 600886 & 4.9031 & 5.6662 & TRN & & \\
\hline CHEMBL579381 & 600886 & 6.2668 & 6.5174 & TST & & \\
\hline CHEMBL602218 & 600886 & 6.4283 & 6.1856 & TRN & & \\
\hline CHEMBL587611 & 600886 & 6.6659 & 6.3851 & TRN & & \\
\hline CHEMBL601778 & 600886 & 5.8874 & 6.4109 & TRN & & \\
\hline CHEMBL533926 & 600886 & 6.1267 & 6.3382 & TRN & & \\
\hline
\end{tabular}




\begin{tabular}{|c|c|c|c|c|c|}
\hline & & \multicolumn{4}{|c|}{ Supplemental Table S2.txt } \\
\hline CHEMBL1416605 & 600886 & 5.0269 & 5.7435 & TST & \\
\hline CHEMBL604565 & 600886 & 7.4962 & 7.0789 & TRN & \\
\hline CHEMBL577669 & 600886 & 6.1965 & 6.2619 & TST & \\
\hline CHEMBL576797 & 600886 & 6.0809 & 5.4205 & TRN & \\
\hline CHEMBL585798 & 600886 & 6.0 & 6.1938 & TRN & \\
\hline CHEMBL600146 & 600886 & 4.8038 & 6.1277 & TST & \\
\hline CHEMBL582714 & 600886 & 5.6842 & 5.0993 & TST & \\
\hline CHEMBL578464 & 600886 & 6.4295 & 6.5378 & TST & \\
\hline CHEMBL585612 & 600886 & 6.0119 & 5.6566 & TRN & \\
\hline CHEMBL533783 & 600886 & 9.1238 & 6.7394 & TRN & \\
\hline CHEMBL583828 & 600886 & 6.9813 & 6.5849 & TRN & \\
\hline CHEMBL608557 & 600886 & 5.3143 & 5.2549 & TRN & \\
\hline CHEMBL584882 & 600886 & 3.9031 & 5.6589 & TRN & \\
\hline CHEMBL601769 & 600886 & 6.5283 & 6.1426 & TST & \\
\hline CHEMBL582953 & 600886 & 6.7328 & 6.2169 & TST & \\
\hline CHEMBL584697 & 600886 & 4.9031 & 5.8686 & TST & \\
\hline CHEMBL605752 & 600886 & 4.9031 & 6.2397 & TRN & \\
\hline CHEMBL585434 & 600886 & 7.57299 & 99999999 & 5.5051 & TR \\
\hline CHEMBL600564 & 600886 & 7.7007 & 6.3401 & TRN & \\
\hline CHEMBL578706 & 600886 & 8.383 & 7.6539 & TRN & \\
\hline CHEMBL580152 & 600886 & 6.8499 & 6.3871 & TRN & \\
\hline CHEMBL579139 & 600886 & 5.9397 & 5.6087 & TRN & \\
\hline CHEMBL585594 & 600886 & 6.8008 & 6.4798 & TRN & \\
\hline CHEMBL527307 & 600886 & 6.2403 & 6.50299 & 9999999999 & TRN \\
\hline CHEMBL573710 & 600886 & 6.4112 & 6.3384 & TST & \\
\hline CHEMBL585796 & 600886 & 6.6392 & 6.1217 & TRN & \\
\hline CHEMBL585592 & 600886 & 6.5002 & 6.2933 & TRN & \\
\hline CHEMBL585118 & 600886 & 6.2967 & 5.1601 & TST & \\
\hline CHEMBL604099 & 600886 & 3.9031 & 5.7819 & TST & \\
\hline CHEMBL605396 & 600886 & 7.3893 & 7.1537 & TRN & \\
\hline CHEMBL581480 & 600886 & 4.9031 & 6.0701 & TST & \\
\hline CHEMBL581474 & 600886 & 5.7711 & 5.9082 & TST & \\
\hline CHEMBL585216 & 600886 & 6.5035 & 6.6828 & TRN & \\
\hline CHEMBL582486 & 600886 & 5.8614 & 5.79 & TRN & \\
\hline CHEMBL602409 & 600886 & 4.8508 & 6.2722 & TRN & \\
\hline CHEMBL604154 & 600886 & 5.649 & 6.246 & TRN & \\
\hline CHEMBL600316 & 600886 & 6.0 & 6.2727 & TRN & \\
\hline CHEMBL587984 & 600886 & 6.1772 & 6.0034 & TRN & \\
\hline CHEMBL578280 & 600886 & 6.4365 & 6.2674 & TRN & \\
\hline CHEMBL584867 & 600886 & 6.4815 & 6.40600 & 0000000001 & 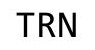 \\
\hline CHEMBL598890 & 600886 & 4.9031 & 6.4138 & TRN & \\
\hline CHEMBL601805 & 600886 & 6.1273 & 6.5565 & TST & \\
\hline CHEMBL578931 & 600886 & 6.3098 & 6.4962 & TRN & \\
\hline CHEMBL597257 & 600886 & 6.0453 & 5.0605 & TRN & \\
\hline CHEMBL579357 & 600886 & 5.6375 & 6.1191 & TRN & \\
\hline CHEMBL582046 & 600886 & 6.2062 & 6.4469 & TRN & \\
\hline CHEMBL1358722 & 600886 & 6.0 & 6.3152 & TST & \\
\hline CHEMBL586006 & 600886 & 6.7235 & 6.4668 & TRN & \\
\hline
\end{tabular}




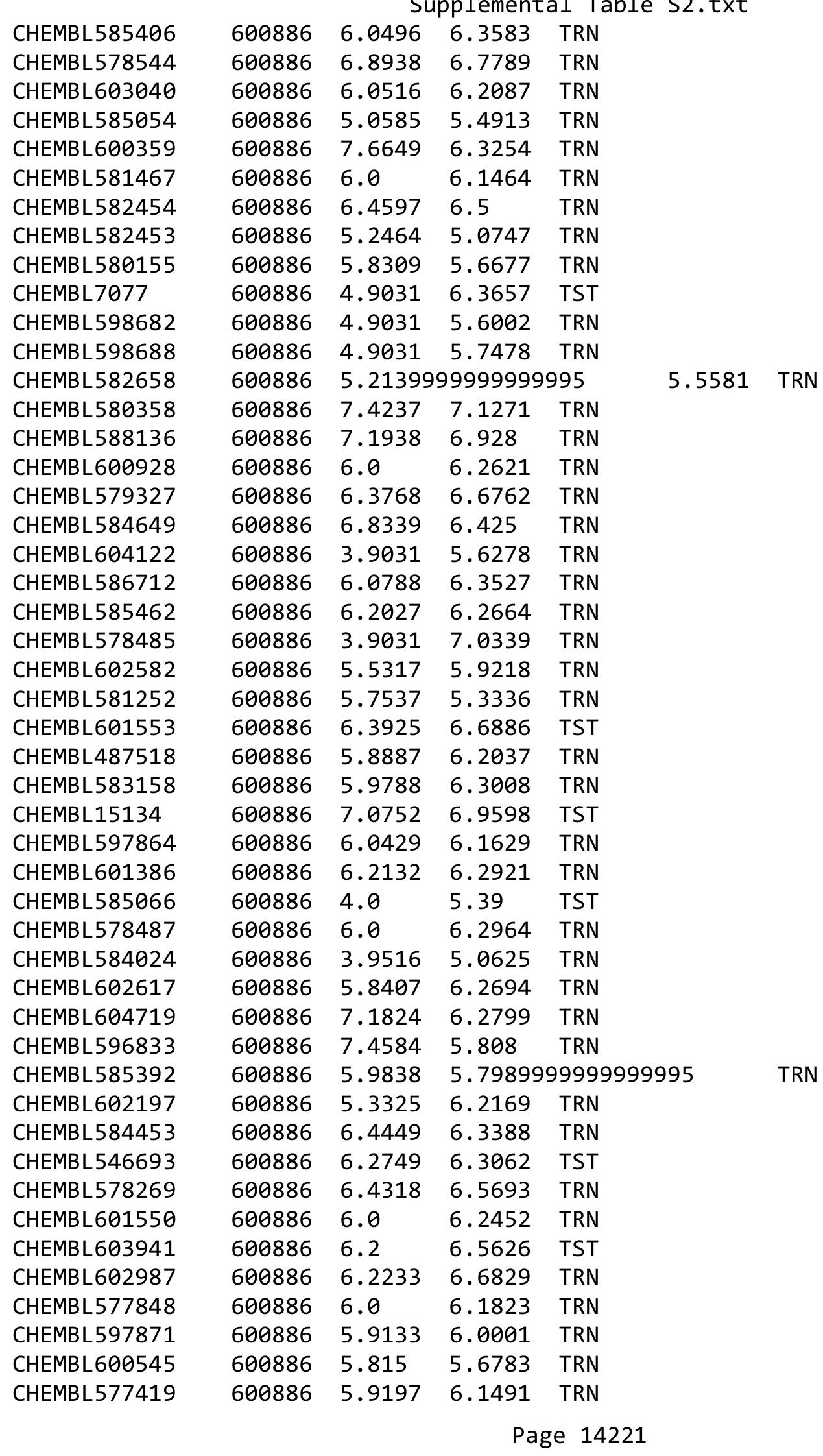




\begin{tabular}{|c|c|c|c|c|c|c|c|}
\hline \multirow{3}{*}{$\begin{array}{l}\text { CHEMBL584228 } \\
\text { CHEMBL599516 }\end{array}$} & \multicolumn{6}{|c|}{ nental } & \\
\hline & 600886 & 6.0 & \multicolumn{3}{|c|}{6.202000000000001} & TRN & \\
\hline & 600886 & 4.9076 & 6.0456 & TRN & & & \\
\hline CHEMBL577869 & 600886 & 6.9223 & 6.6918 & TRN & & & \\
\hline CHEMBL587884 & 600886 & 7.3487 & 6.7751 & TST & & & \\
\hline CHEMBL601977 & 600886 & 6.7106 & 6.6046 & TST & & & \\
\hline CHEMBL1197790 & 600886 & 6.9543 & 6.5488 & TST & & & \\
\hline CHEMBL584622 & 600886 & 6.2716 & 6.5144 & TRN & & & \\
\hline CHEMBL601114 & 600886 & 6.1649 & 6.4323 & TRN & & & \\
\hline CHEMBL604981 & 600886 & 6.3556 & 6.4321 & TRN & & & \\
\hline CHEMBL576606 & 600886 & \multicolumn{3}{|c|}{6.202000000000001} & \multicolumn{2}{|c|}{6.367999999999999} & TST \\
\hline CHEMBL601142 & 600886 & 4.9031 & 5.8543 & TRN & & & \\
\hline CHEMBL588954 & 600886 & 6.0453 & 6.144 & TRN & & & \\
\hline CHEMBL598679 & 600886 & 6.8798 & 6.9668 & TRN & & & \\
\hline CHEMBL582076 & 600886 & 5.7867 & 5.5869 & TRN & & & \\
\hline CHEMBL581472 & 600886 & 5.7457 & 5.7557 & TRN & & & \\
\hline CHEMBL584630 & 600886 & 6.6426 & 6.1259 & TST & & & \\
\hline CHEMBL597053 & 600886 & 3.9031 & 5.3089 & TST & & & \\
\hline CHEMBL586788 & 600886 & 9.0773 & 6.4047 & TRN & & & \\
\hline CHEMBL597853 & 600886 & 6.1586 & 5.7355 & TRN & & & \\
\hline CHEMBL601342 & 600886 & 6.2366 & 6.0459 & TRN & & & \\
\hline CHEMBL579121 & 600886 & 6.5594 & 6.7368 & TRN & & & \\
\hline CHEMBL529270 & 600886 & 4.9031 & 5.6731 & TRN & & & \\
\hline CHEMBL531543 & 600886 & 6.4685 & 6.3371 & TRN & & & \\
\hline CHEMBL597857 & 600886 & 6.8167 & 6.8686 & TRN & & & \\
\hline CHEMBL581969 & 600886 & 7.57299 & 99999999 & 995 & 5.6369 & TST & \\
\hline CHEMBL582078 & 600886 & 5.7873 & 6.2161 & TST & & & \\
\hline CHEMBL1312953 & 600886 & 6.0 & 6.28600 & 0000000000 & & TRN & \\
\hline CHEMBL601362 & 600886 & 7.9469 & 7.0441 & TRN & & & \\
\hline CHEMBL583021 & 600886 & 4.9031 & 5.8148 & TRN & & & \\
\hline CHEMBL533779 & 600886 & 7.3605 & 6.5584 & TST & & & \\
\hline CHEMBL599904 & 600886 & 6.1267 & 6.2694 & TRN & & & \\
\hline CHEMBL585834 & 600886 & 6.8861 & 6.7788 & TRN & & & \\
\hline CHEMBL602585 & 600886 & 5.4145 & 6.74 & TRN & & & \\
\hline CHEMBL585469 & 600886 & 6.1739 & 6.1357 & TRN & & & \\
\hline CHEMBL585965 & 600886 & 6.4473 & 6.256 & TRN & & & \\
\hline CHEMBL584253 & 600886 & 6.0297 & 6.8289 & TRN & & & \\
\hline CHEMBL602973 & 600886 & 7.57299 & 99999999 & 995 & 5.5654 & TRN & \\
\hline CHEMBL601107 & 600886 & 6.1549 & 6.1048 & TRN & & & \\
\hline CHEMBL577846 & 600886 & 6.8658 & 6.5592 & TST & & & \\
\hline CHEMBL534372 & 600886 & 5.6722 & 5.8761 & TRN & & & \\
\hline CHEMBL582532 & 600886 & 5.8854 & 6.3035 & TRN & & & \\
\hline CHEMBL598260 & 600886 & 3.9031 & 5.9554 & TRN & & & \\
\hline CHEMBL578107 & 600886 & 8.8462 & 5.6545 & TRN & & & \\
\hline CHEMBL598904 & 600886 & 7.1062 & 6.2752 & TRN & & & \\
\hline CHEMBL600976 & 600886 & 6.2941 & 6.04299 & 9999999999 & & TST & \\
\hline CHEMBL579325 & 600886 & 7.9363 & 7.489 & TRN & & & \\
\hline CHEMBL576939 & 600886 & 5.3747 & 6.1556 & TRN & & & \\
\hline CHEMBL581437 & 600886 & 6.0 & 6.2357 & TRN & & & \\
\hline
\end{tabular}




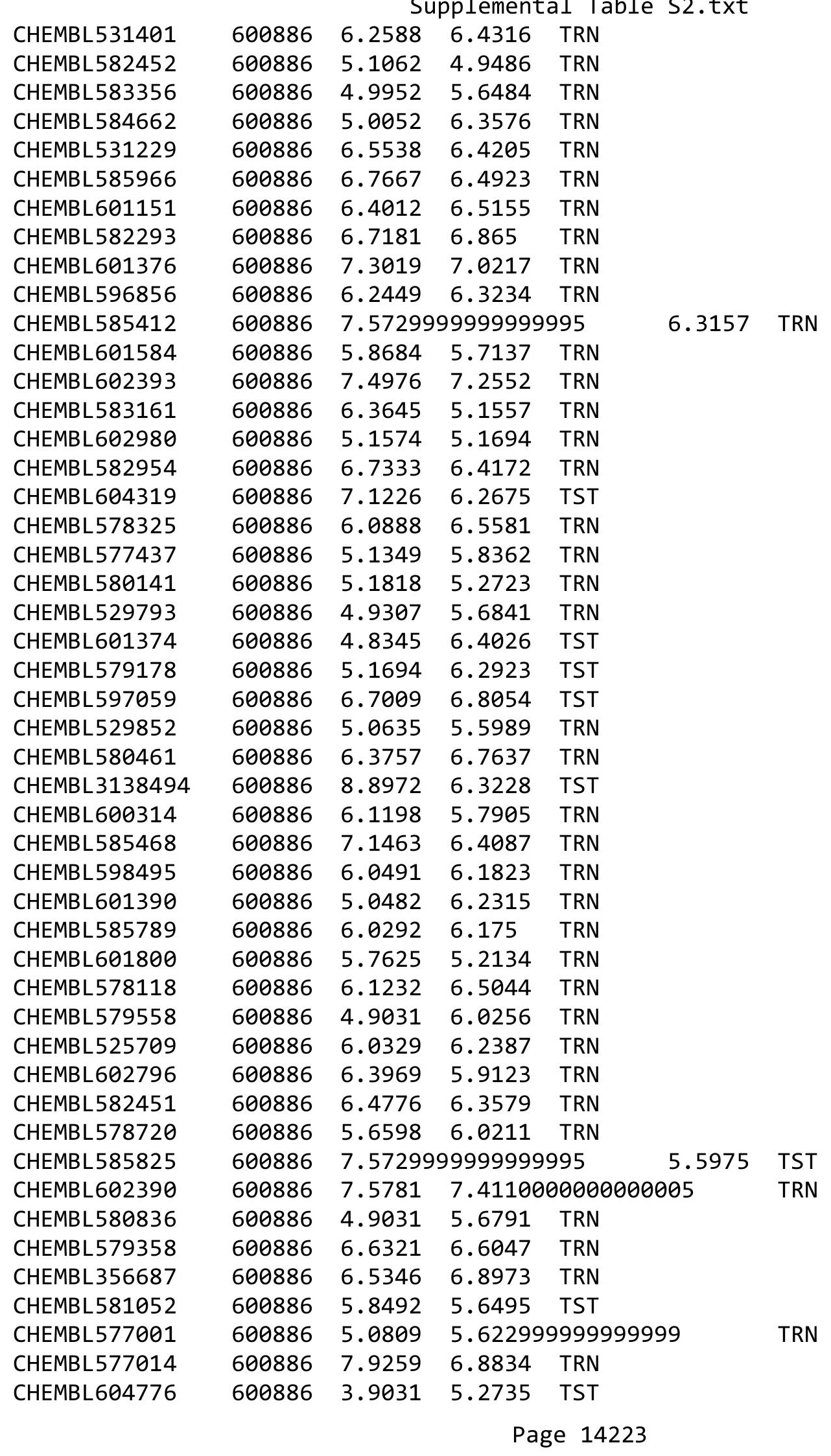




\begin{tabular}{|c|c|c|c|c|c|}
\hline CHEMBL585644 & 600886 & \multicolumn{3}{|c|}{ Supplemental Table S2.txt } & TRN \\
\hline CHEMBL581251 & 600886 & 5.1959 & 6.041 & TRN & \\
\hline CHEMBL599962 & 600886 & 5.9594 & 6.1342 & TRN & \\
\hline CHEMBL597054 & 600886 & 3.9031 & 5.7697 & TRN & \\
\hline CHEMBL581166 & 600886 & 4.0083 & 5.7076 & TRN & \\
\hline CHEMBL587782 & 600886 & 6.0757 & 6.2676 & TRN & \\
\hline CHEMBL579359 & 600886 & 6.0655 & 6.4015 & TRN & \\
\hline CHEMBL585055 & 600886 & 6.5197 & 5.9998 & TST & \\
\hline CHEMBL582504 & 600886 & 6.6185 & 6.8343 & TRN & \\
\hline CHEMBL598492 & 600886 & 5.9446 & 6.0799 & TRN & \\
\hline CHEMBL601351 & 600886 & 6.7162 & 6.6505 & TST & \\
\hline CHEMBL577865 & 600886 & 6.0 & 6.2878 & TRN & \\
\hline CHEMBL578950 & 600886 & 7.7178 & 7.0646 & TRN & \\
\hline CHEMBL579747 & 600886 & 4.7791 & 5.557 & TST & \\
\hline CHEMBL586764 & 600886 & 5.3045 & 5.2562 & TRN & \\
\hline CHEMBL581870 & 600886 & 6.6501 & 7.1615 & TRN & \\
\hline CHEMBL601126 & 600886 & 4.5191 & 5.2627 & TRN & \\
\hline CHEMBL193528 & 600886 & 6.0 & 6.2162 & TRN & \\
\hline CHEMBL525826 & 600886 & 6.5061 & 6.8746 & TRN & \\
\hline CHEMBL600745 & 600886 & 5.794 & 5.5841 & TRN & \\
\hline CHEMBL596633 & 600886 & 6.4949 & 6.8861 & TRN & \\
\hline CHEMBL113999 & 600886 & 4.9031 & 6.0114 & TRN & \\
\hline CHEMBL582106 & 600886 & 4.8392 & 5.57299 & 99999999995 & 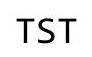 \\
\hline CHEMBL585277 & 600886 & 6.1469 & 6.2268 & TRN & \\
\hline CHEMBL578689 & 600886 & 6.2765 & 6.5332 & TRN & \\
\hline CHEMBL578683 & 600886 & 5.4306 & 6.2364 & TST & \\
\hline CHEMBL606163 & 600886 & 6.2464 & 6.2806 & TRN & \\
\hline CHEMBL6229 & 600886 & 6.2676 & 6.3314 & TRN & \\
\hline CHEMBL577873 & 600886 & 5.2197 & 5.1893 & TRN & \\
\hline CHEMBL526069 & 600886 & 4.9594 & 6.3588 & TRN & \\
\hline CHEMBL582665 & 600886 & 5.1314 & 5.6242 & TRN & \\
\hline CHEMBL582521 & 600886 & 4.9031 & 5.6846 & TRN & \\
\hline CHEMBL580144 & 600886 & 8.3054 & 6.6448 & TRN & \\
\hline CHEMBL600947 & 600886 & 6.066 & 6.3976 & TRN & \\
\hline CHEMBL532209 & 600886 & 7.4023 & 6.5773 & TRN & \\
\hline CHEMBL576408 & 600886 & 7.301 & 6.6321 & TRN & \\
\hline CHEMBL584237 & 600886 & 6.399 & 6.6408 & TRN & \\
\hline CHEMBL601574 & 600886 & 4.9031 & 5.4924 & TRN & \\
\hline CHEMBL585060 & 600886 & 6.0376 & 6.32299 & 99999999995 & S \\
\hline CHEMBL585813 & 600886 & 6.9363 & 6.9656 & TRN & \\
\hline CHEMBL585824 & 600886 & 7.5315 & 6.8781 & TST & \\
\hline CHEMBL582114 & 600886 & 4.9031 & 5.6077 & TRN & \\
\hline CHEMBL472879 & 600886 & 5.8216 & 6.3054 & TRN & \\
\hline CHEMBL581672 & 600886 & 6.6544 & 6.4947 & TRN & \\
\hline CHEMBL585437 & 600886 & 6.5629 & 6.306 & TRN & \\
\hline CHEMBL582446 & 600886 & 8.7921 & 6.5456 & TRN & \\
\hline CHEMBL579968 & 600886 & 5.6558 & 5.8625 & TRN & \\
\hline CHEMBL601184 & 600886 & 6.2055 & 6.5093 & TRN & \\
\hline
\end{tabular}




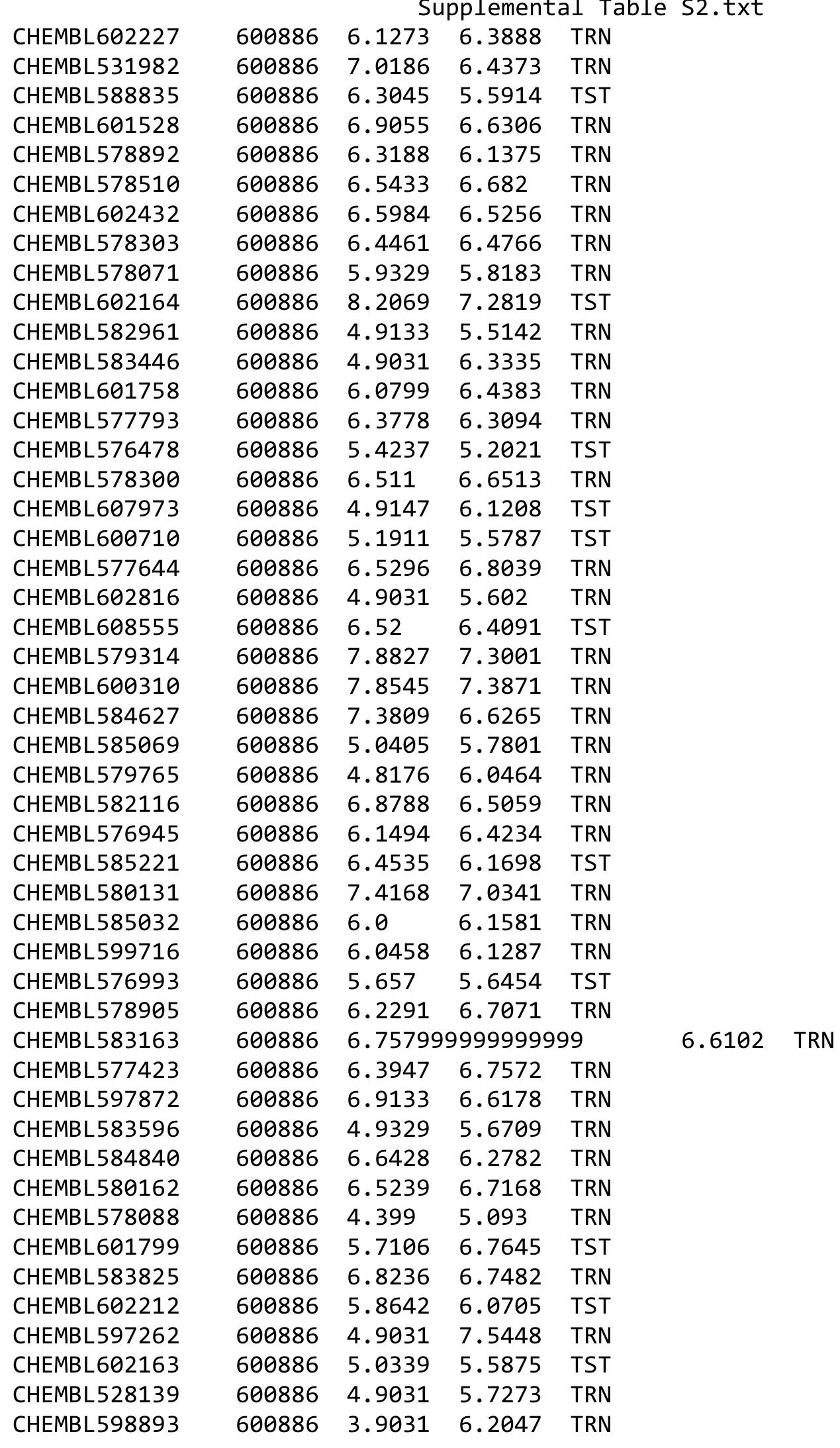

Page 14225 


\begin{tabular}{|c|c|c|c|c|c|c|}
\hline \multirow[b]{2}{*}{ CHEMBL578729 } & \multicolumn{6}{|c|}{ 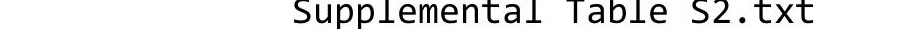 } \\
\hline & 600886 & 6.5209 & 6.5811 & TRN & & \\
\hline CHEMBL227959 & 600886 & 6.0 & 6.2097 & TRN & & \\
\hline CHEMBL602157 & 600886 & 5.9252 & 6.3256 & TRN & & \\
\hline CHEMBL588864 & 600886 & 6.9948 & 6.7399 & TRN & & \\
\hline CHEMBL585063 & 600886 & 6.0214 & 6.4569 & TRN & & \\
\hline CHEMBL530610 & 600886 & 5.0114 & 5.2087 & TST & & \\
\hline CHEMBL582743 & 600886 & 4.9867 & 5.5654 & TRN & & \\
\hline CHEMBL578264 & 600886 & 5.5564 & 5.7416 & TST & & \\
\hline CHEMBL597654 & 600886 & 6.6317 & 6.1284 & TST & & \\
\hline CHEMBL585136 & 600886 & 7.2321 & 7.0007 & TRN & & \\
\hline CHEMBL581660 & 600886 & \multicolumn{3}{|c|}{5.757999999999999} & 6.1099 & TRN \\
\hline CHEMBL582254 & 600886 & 6.2612 & 6.36 & TRN & & \\
\hline CHEMBL584820 & 600886 & 6.6981 & 6.3418 & TRN & & \\
\hline CHEMBL582273 & 600886 & 6.5488 & 5.7744 & TRN & & \\
\hline CHEMBL602792 & 600886 & 6.1898 & 6.4578 & TRN & & \\
\hline CHEMBL587142 & 600886 & \multicolumn{3}{|c|}{6.082999999999999} & 6.6452 & TRN \\
\hline CHEMBL601957 & 600886 & 5.9446 & 6.4203 & TRN & & \\
\hline CHEMBL578894 & 600886 & 4.9031 & 6.1037 & TRN & & \\
\hline CHEMBL605750 & 600886 & 6.2518 & 6.2019 & TRN & & \\
\hline CHEMBL585643 & 600886 & 6.5331 & 6.3668 & TRN & & \\
\hline CHEMBL586830 & 600886 & 6.0 & 6.2949 & TRN & & \\
\hline CHEMBL604100 & 600886 & 6.2204 & \multicolumn{3}{|c|}{5.792999999999999} & TRN \\
\hline CHEMBL608855 & 600886 & 5.4045 & 6.075 & TRN & & \\
\hline CHEMBL578926 & 600886 & 5.6371 & 5.4932 & TRN & & \\
\hline CHEMBL579265 & 600886 & 5.5485 & 5.9525 & TRN & & \\
\hline CHEMBL585499 & 600886 & 6.2104 & 6.1086 & TRN & & \\
\hline CHEMBL580559 & 600886 & 6.0 & 6.2202 & TST & & \\
\hline CHEMBL583358 & 600886 & 4.9842 & 5.601 & TRN & & \\
\hline CHEMBL600772 & 600886 & 4.9586 & \multicolumn{3}{|c|}{5.7410000000000005} & TST \\
\hline CHEMBL584032 & 600886 & 4.9718 & 5.5857 & TRN & & \\
\hline CHEMBL587731 & 600886 & 5.0742 & 5.6478 & TRN & & \\
\hline CHEMBL599883 & 600886 & 6.6594 & 6.5048 & TST & & \\
\hline CHEMBL580397 & 600886 & 5.7662 & 6.3346 & TRN & & \\
\hline CHEMBL601387 & 600886 & 6.3737 & 7.04 & TRN & & \\
\hline CHEMBL579150 & 600886 & 5.5733 & 6.2872 & TRN & & \\
\hline CHEMBL576990 & 600886 & 6.0429 & 6.3459 & TRN & & \\
\hline CHEMBL588631 & 600886 & \multicolumn{3}{|c|}{6.172000000000001} & 6.3522 & TRN \\
\hline CHEMBL597047 & 600886 & 6.0 & 6.3171 & TRN & & \\
\hline CHEMBL586548 & 600886 & 6.2351 & 6.2038 & TRN & & \\
\hline CHEMBL604720 & 600886 & 6.3116 & 6.2747 & TST & & \\
\hline CHEMBL602219 & 600886 & 6.4306 & 6.2135 & TST & & \\
\hline CHEMBL602629 & 600886 & 6.0035 & 6.2685 & TRN & & \\
\hline CHEMBL602368 & 600886 & 6.1739 & 6.3018 & TRN & & \\
\hline CHEMBL576608 & 600886 & 6.9574 & 6.3328 & TRN & & \\
\hline CHEMBL585933 & 600886 & 5.8356 & 5.5645 & TRN & & \\
\hline CHEMBL580959 & 600886 & 7.6275 & 6.8227 & TRN & & \\
\hline CHEMBL600713 & 600886 & 4.2182 & 5.2571 & TST & & \\
\hline \multirow[t]{2}{*}{ CHEMBL582072 } & 600886 & 6.6082 & 6.56 & TRN & & \\
\hline & & \multicolumn{5}{|c|}{ Page 14226} \\
\hline
\end{tabular}




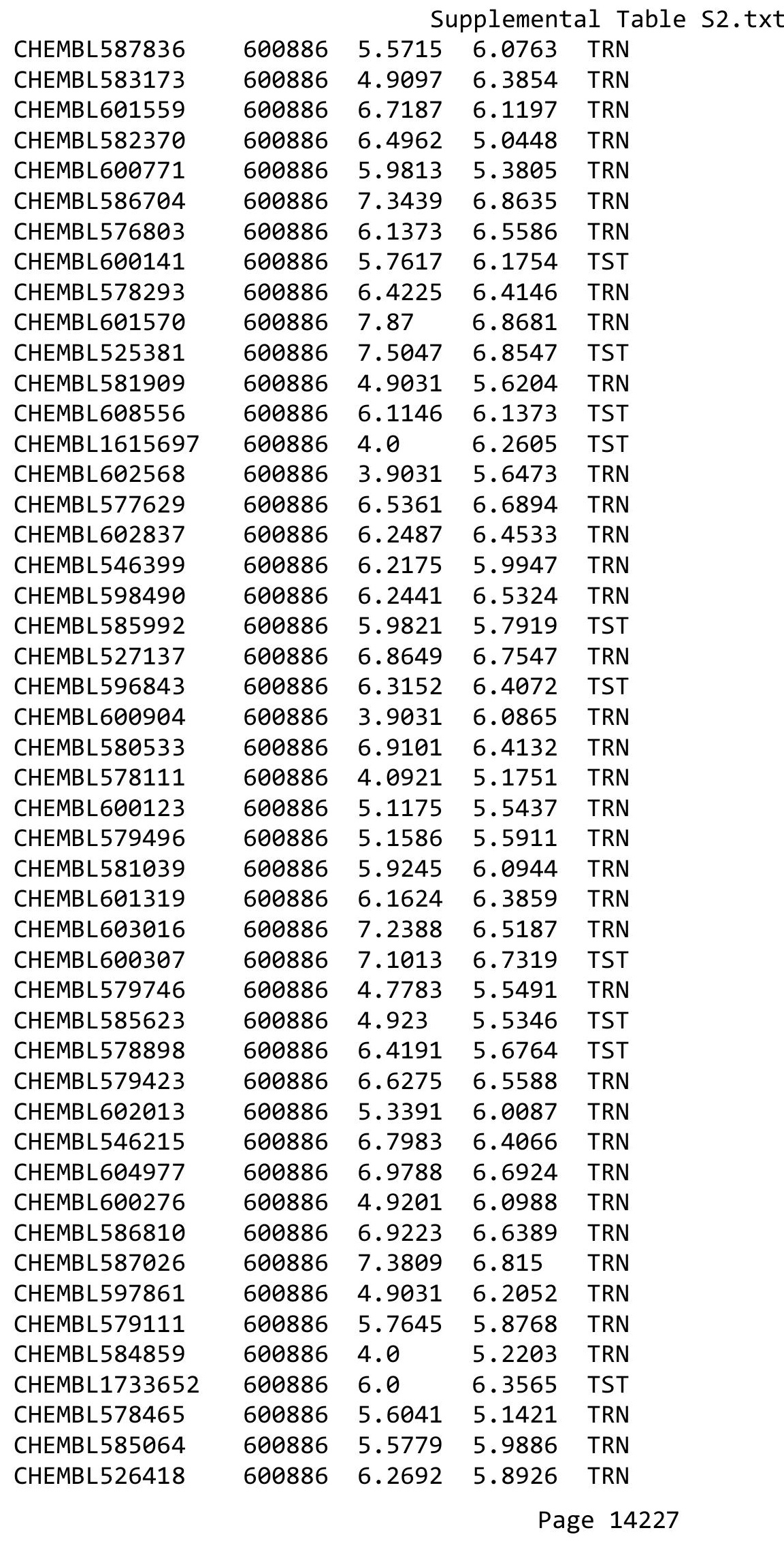




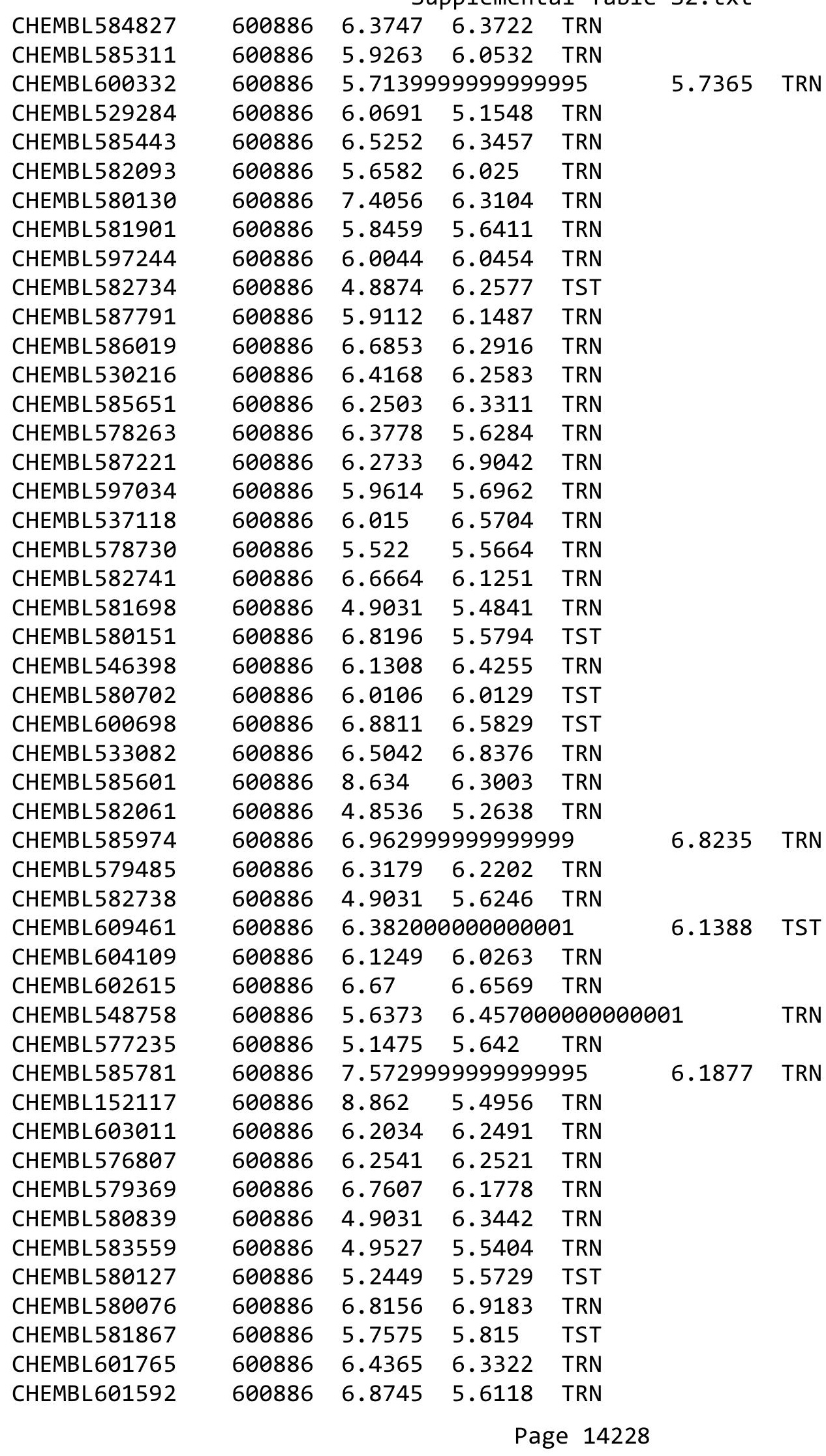




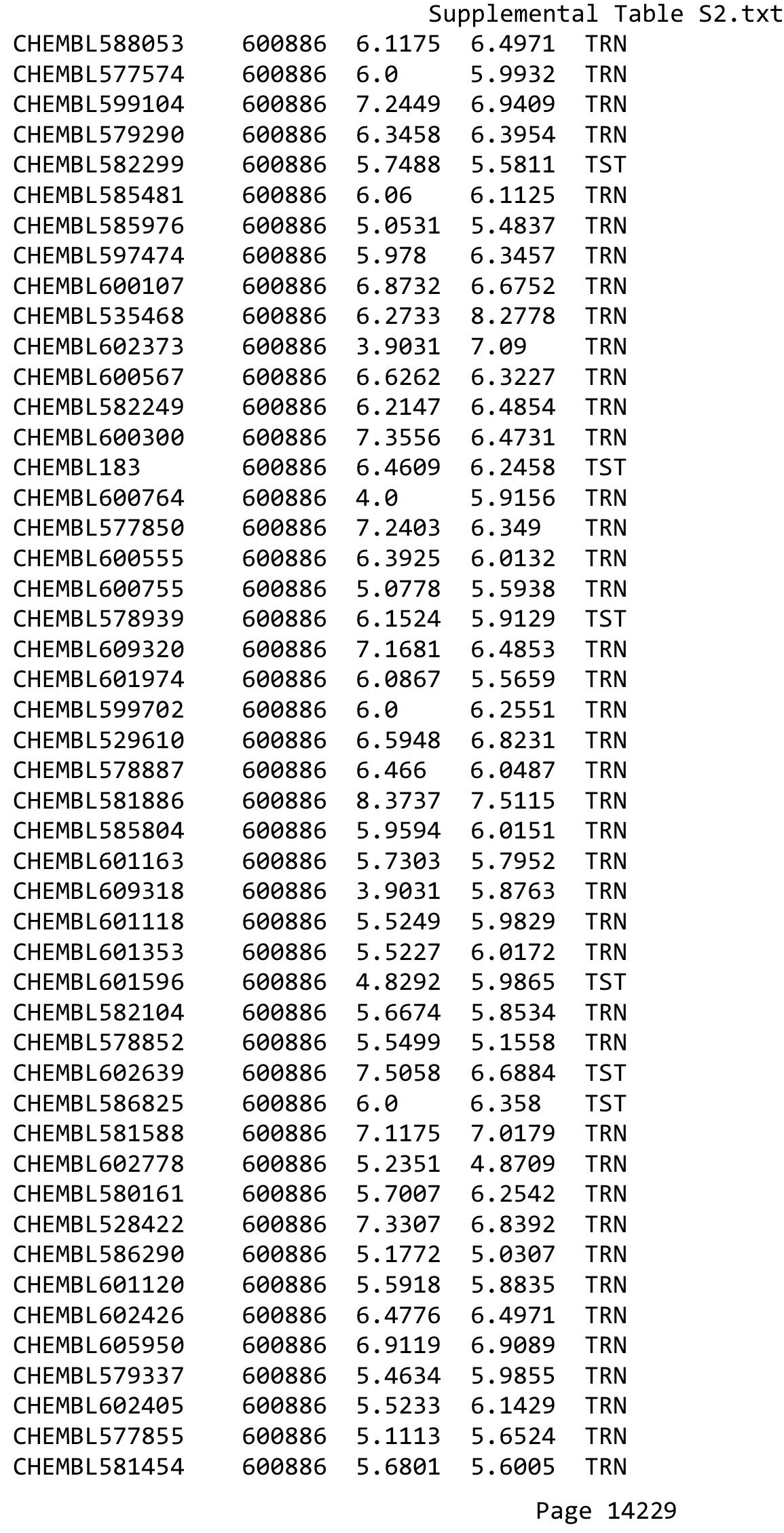




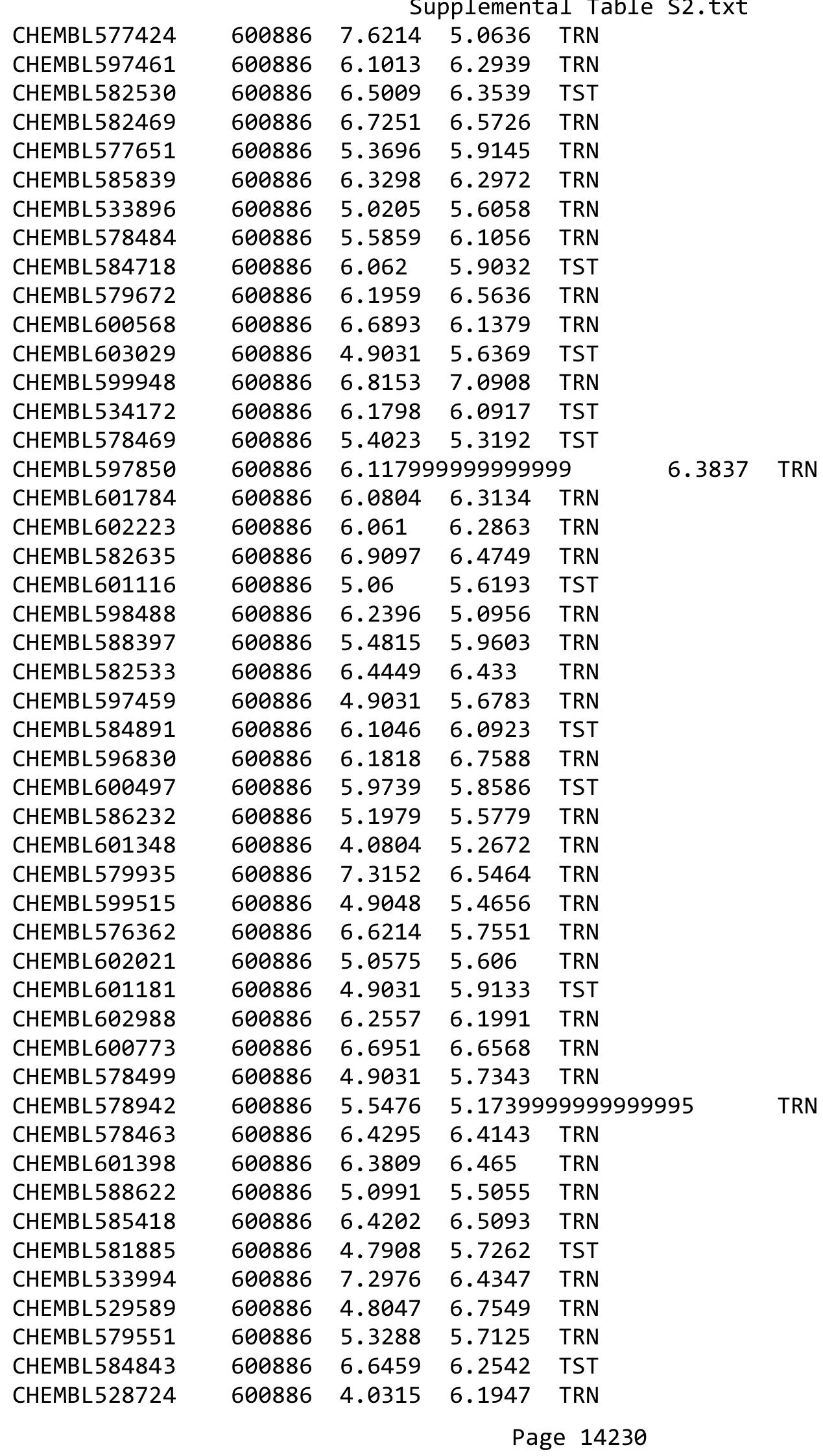




\begin{tabular}{|c|c|c|c|c|c|}
\hline & & & & & \\
\hline CHEMBL597268 & 600886 & 6.4389 & 6.4136 & TRN & \\
\hline CHEMBL585228 & 600886 & 6.3497 & 6.2868 & TRN & \\
\hline CHEMBL585039 & 600886 & 5.0301 & 5.6687 & TRN & \\
\hline CHEMBL530729 & 600886 & 6.27 & 5.3063 & TRN & \\
\hline CHEMBL547947 & 600886 & 5.8551 & 6.3839 & TRN & \\
\hline CHEMBL600279 & 600886 & 4.1965 & 5.0813 & TRN & \\
\hline CHEMBL532141 & 600886 & 5.082 & 5.9077 & TRN & \\
\hline CHEMBL547606 & 600886 & 6.3747 & 6.5605 & TRN & \\
\hline CHEMBL601547 & 600886 & 6.5438 & 6.7503 & TRN & \\
\hline CHEMBL578286 & 600886 & 6.5854 & 6.5795 & TST & \\
\hline CHEMBL576812 & 600886 & 6.7815 & 6.5703 & TRN & \\
\hline CHEMBL581049 & 600886 & 4.9031 & 5.7151 & TRN & \\
\hline CHEMBL534116 & 600886 & 6.4179 & 6.4095 & TRN & \\
\hline CHEMBL582110 & 600886 & 5.4401 & 6.2362 & TST & \\
\hline CHEMBL581652 & 600886 & 5.7018 & 5.1535 & TRN & \\
\hline CHEMBL602968 & 600886 & 4.032 & 5.0157 & TRN & \\
\hline CHEMBL579119 & 600886 & 7.4908 & 7.11299 & 99999999995 & TRN \\
\hline CHEMBL603008 & 600886 & 6.4067 & 6.5431 & TRN & \\
\hline CHEMBL528647 & 600886 & 6.9289 & 6.8464 & TRN & \\
\hline CHEMBL579048 & 600886 & 6.3862 & 6.9909 & TRN & \\
\hline CHEMBL601323 & 600886 & 6.5635 & 6.5361 & TRN & \\
\hline CHEMBL600959 & 600886 & 5.6012 & 6.0283 & TST & \\
\hline CHEMBL585471 & 600886 & 6.4413 & 6.5403 & TRN & \\
\hline CHEMBL597251 & 600886 & 7.0044 & 6.4893 & TRN & \\
\hline CHEMBL600898 & 600886 & 7.5009 & 5.6251 & TST & \\
\hline CHEMBL585450 & 600886 & 6.0 & 6.3043 & TRN & \\
\hline CHEMBL580001 & 600886 & 6.0 & 6.3499 & TRN & \\
\hline CHEMBL576612 & 600886 & 6.2652 & 6.5161 & TRN & \\
\hline CHEMBL597254 & 600886 & 6.0 & 6.1504 & TRN & \\
\hline CHEMBL580008 & 600886 & 5.9867 & 5.6824 & TRN & \\
\hline CHEMBL601344 & 600886 & 7.4134 & 7.0918 & TRN & \\
\hline CHEMBL582682 & 600886 & 6.5977 & 6.6964 & TRN & \\
\hline CHEMBL602356 & 600886 & 6.2104 & 6.3749 & TRN & \\
\hline CHEMBL578099 & 600886 & 6.2495 & 5.5592 & TST & \\
\hline CHEMBL581671 & 600886 & 5.7662 & 6.2363 & TRN & \\
\hline CHEMBL585800 & 600886 & 5.9792 & 6.4516 & TST & \\
\hline CHEMBL587370 & 600886 & 6.1024 & 6.2355 & TRN & \\
\hline CHEMBL596855 & 600886 & 6.1694 & 6.3589 & TST & \\
\hline CHEMBL584626 & 600886 & 6.4895 & 6.4801 & TRN & \\
\hline CHEMBL577218 & 600886 & 5.1343 & 5.6959 & TST & \\
\hline CHEMBL584864 & 600886 & 5.0017 & 5.7741 & TRN & \\
\hline CHEMBL585995 & 600886 & 6.466 & 6.2708 & TRN & \\
\hline CHEMBL602017 & 600886 & 4.9274 & 6.2369 & TRN & \\
\hline CHEMBL577231 & 600886 & 6.0 & 6.2707 & TRN & \\
\hline CHEMBL587449 & 600886 & 6.041 & 6.2376 & TRN & \\
\hline CHEMBL528716 & 600886 & 6.0057 & 5.5743 & TRN & \\
\hline CHEMBL578109 & 600886 & 7.0367 & 6.3232 & TRN & \\
\hline CHEMBL604778 & 600886 & 6.20200 & 30000000 & 5.9491 & TS \\
\hline & & & & 14231 & \\
\hline
\end{tabular}




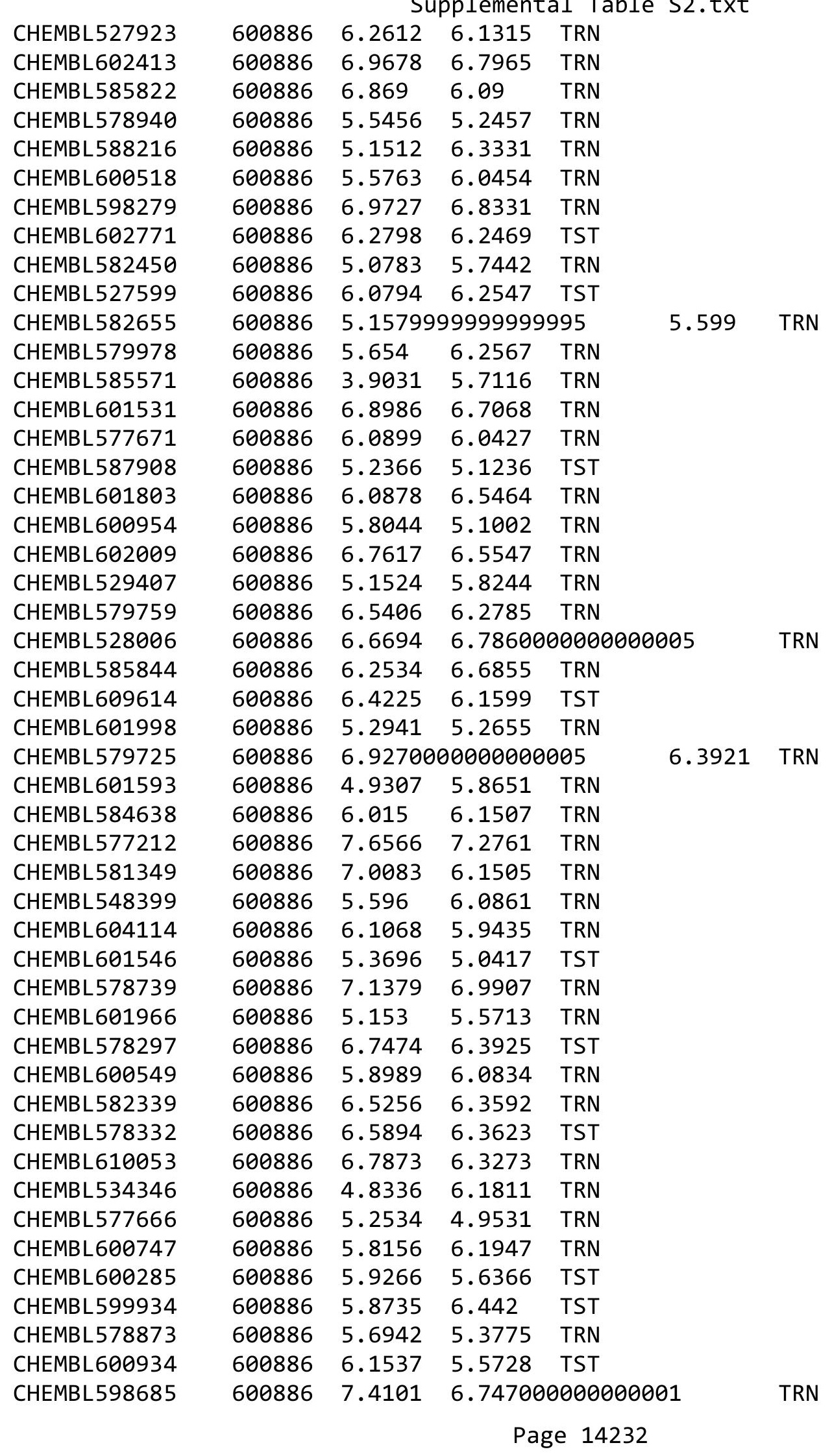




\begin{tabular}{|c|c|c|c|c|c|c|}
\hline & & & & & & \\
\hline CHEMBL527838 & 600886 & 6.1791 & 6.5282 & TRN & & \\
\hline CHEMBL577632 & 600886 & 5.9574 & 6.2073 & TST & & \\
\hline CHEMBL585261 & 600886 & 4.9031 & 6.1401 & TRN & & \\
\hline CHEMBL599945 & 600886 & 6.7335 & 6.7144 & TRN & & \\
\hline CHEMBL585845 & 600886 & 7.2549 & 6.0298 & TRN & & \\
\hline CHEMBL577634 & 600886 & 6.569 & 6.1704 & TRN & & \\
\hline CHEMBL579382 & 600886 & 5.2993 & 5.0447 & TST & & \\
\hline CHEMBL596848 & 600886 & 7.0141 & 6.9447 & TST & & \\
\hline CHEMBL582250 & 600886 & 6.0 & 5.9616 & TRN & & \\
\hline CHEMBL601330 & 600886 & 6.4012 & 6.4465 & TRN & & \\
\hline CHEMBL528178 & 600886 & 6.0862 & 5.5599 & TRN & & \\
\hline CHEMBL579338 & 600886 & 8.2668 & 7.7136 & TRN & & \\
\hline CHEMBL582686 & 600886 & 5.7001 & 5.9645 & TRN & & \\
\hline CHEMBL584418 & 600886 & 5.9212 & 6.1555 & TRN & & \\
\hline CHEMBL602016 & 600886 & 5.8517 & 5.9155 & TRN & & \\
\hline CHEMBL600964 & 600886 & 6.0 & 6.2167 & TRN & & \\
\hline CHEMBL602007 & 600886 & 6.4306 & 6.9137 & TRN & & \\
\hline CHEMBL586563 & 600886 & 7.4976 & 6.8094 & TST & & \\
\hline CHEMBL585780 & 600886 & 7.57299 & 79999999 & 995 & .5851 & TRN \\
\hline CHEMBL582481 & 600886 & 5.0857 & 6.0752 & TRN & & \\
\hline CHEMBL585828 & 600886 & 6.6809 & 6.5926 & TRN & & \\
\hline CHEMBL598677 & 600886 & 6.3556 & 5.0509 & TST & & \\
\hline CHEMBL599100 & 600886 & 6.0794 & 6.0297 & TRN & & \\
\hline CHEMBL581489 & 600886 & 6.8775 & 6.2567 & TRN & & \\
\hline CHEMBL588640 & 600886 & 8.9007 & 6.4803 & TRN & & \\
\hline CHEMBL587064 & 600886 & 5.7402 & 5.9959 & TRN & & \\
\hline CHEMBL582307 & 600886 & 5.75799 & 99999999 & 99 & 5.581 & TST \\
\hline CHEMBL578019 & 600886 & 5.3439 & 5.5272 & TST & & \\
\hline CHEMBL579090 & 600886 & 6.6815 & 6.6582 & TRN & & \\
\hline CHEMBL587620 & 600886 & 6.2314 & 6.5801 & TRN & & \\
\hline CHEMBL605550 & 600886 & 6.3261 & 5.9687 & TRN & & \\
\hline CHEMBL578319 & 600886 & 6.9446 & 6.6317 & TRN & & \\
\hline CHEMBL586026 & 600886 & 5.9172 & 6.2205 & TST & & \\
\hline CHEMBL582701 & 600886 & 6.6863 & 5.4967 & TRN & & \\
\hline CHEMBL532965 & 600886 & 6.0 & 6.1681 & TRN & & \\
\hline CHEMBL605754 & 600886 & 6.0 & 6.2811 & TRN & & \\
\hline CHEMBL533105 & 600886 & 7.1752 & 6.7424 & TST & & \\
\hline CHEMBL600156 & 600886 & 5.6178 & 5.8787 & TRN & & \\
\hline CHEMBL588099 & 600886 & 7.1878 & 6.607 & TRN & & \\
\hline CHEMBL534131 & 600886 & 6.1561 & 6.2206 & TRN & & \\
\hline CHEMBL590647 & 600886 & 7.4001 & 7.0507 & TRN & & \\
\hline CHEMBL602382 & 600886 & 5.7192 & 5.129 & TST & & \\
\hline CHEMBL581892 & 600886 & 6.0 & 6.3163 & TRN & & \\
\hline CHEMBL534382 & 600886 & 5.716 & 5.5436 & TRN & & \\
\hline CHEMBL 601370 & 600886 & 6.7027 & 6.277 & TRN & & \\
\hline CHEMBL602781 & 600886 & 7.8681 & 6.5891 & TRN & & \\
\hline CHEMBL548348 & 600886 & 6.6059 & 6.6851 & TRN & & \\
\hline CHEMBL577880 & 600886 & 6.251 & 5.5726 & TRN & & \\
\hline
\end{tabular}




\begin{tabular}{|c|c|c|c|c|c|c|}
\hline \multirow[b]{2}{*}{ CHEMBL597859 } & \multicolumn{6}{|c|}{ Supplemental Table S2.txt } \\
\hline & 600886 & 3.9031 & 5.7147 & TRN & & \\
\hline CHEMBL600541 & 600886 & 5.7357 & 5.5907 & TRN & & \\
\hline CHEMBL586013 & 600886 & 6.8536 & 6.7089 & TRN & & \\
\hline CHEMBL584874 & 600886 & 4.9031 & 5.63700 & 0000000006 & 05 & TST \\
\hline CHEMBL583159 & 600886 & 6.9404 & 6.6706 & TRN & & \\
\hline CHEMBL584645 & 600886 & 8.4724 & 5.596 & TRN & & \\
\hline CHEMBL586545 & 600886 & 5.2097 & 5.6804 & TRN & & \\
\hline CHEMBL603727 & 600886 & 6.78299 & 79999999 & 995 & 6.1474 & TRN \\
\hline CHEMBL582301 & 600886 & 6.6007 & 6.6772 & TRN & & \\
\hline CHEMBL600299 & 600886 & 6.4609 & 6.8575 & TRN & & \\
\hline CHEMBL582924 & 600886 & 4.9948 & 5.6771 & TRN & & \\
\hline CHEMBL585840 & 600886 & 6.2907 & 6.2284 & TRN & & \\
\hline CHEMBL577414 & 600886 & 6.4425 & 5.5399 & TRN & & \\
\hline CHEMBL585811 & 600886 & 6.7167 & 6.4635 & TST & & \\
\hline CHEMBL581665 & 600886 & 5.7109 & 6.0411 & TRN & & \\
\hline CHEMBL577836 & 600886 & 6.4711 & 6.5686 & TRN & & \\
\hline CHEMBL531726 & 600886 & 6.0 & 6.3484 & TRN & & \\
\hline CHEMBL530359 & 600886 & 4.9031 & 6.0733 & TRN & & \\
\hline CHEMBL582492 & 600886 & 5.8309 & 5.7909 & TRN & & \\
\hline CHEMBL6742 & 600886 & 6.0052 & 7.1833 & TRN & & \\
\hline CHEMBL604326 & 600886 & 5.9076 & 6.2273 & TRN & & \\
\hline CHEMBL601367 & 600886 & 6.6951 & 6.6796 & TRN & & \\
\hline CHEMBL261693 & 600886 & 6.0975 & 6.0514 & TRN & & \\
\hline CHEMBL606024 & 600886 & 7.3325 & 6.9835 & TRN & & \\
\hline CHEMBL583682 & 600886 & 6.67299 & 99999999 & 99 & 6.5055 & TRN \\
\hline CHEMBL579171 & 600886 & 6.9622 & 6.6444 & TRN & & \\
\hline CHEMBL603044 & 600886 & 6.54700 & 90000000 & & 6.2784 & TRN \\
\hline CHEMBL578895 & 600886 & 6.1918 & 6.5755 & TRN & & \\
\hline CHEMBL578266 & 600886 & 5.5822 & 5.1109 & TRN & & \\
\hline CHEMBL604110 & 600886 & 5.9094 & 6.0095 & TRN & & \\
\hline CHEMBL582524 & 600886 & 4.8539 & 5.721 & TRN & & \\
\hline CHEMBL527461 & 600886 & 4.9031 & 6.0852 & TST & & \\
\hline CHEMBL586344 & 600886 & 6.5318 & 6.4701 & TST & & \\
\hline CHEMBL577810 & 600886 & 5.6073 & 6.2677 & TRN & & \\
\hline CHEMBL579113 & 600886 & 5.7812 & 6.0569 & TRN & & \\
\hline CHEMBL598894 & 600886 & 6.1643 & 6.0363 & TRN & & \\
\hline CHEMBL577643 & 600886 & 5.3665 & 5.12700 & 0000000001 & & TRN \\
\hline CHEMBL600291 & 600886 & 6.4271 & 6.3293 & TRN & & \\
\hline CHEMBL579354 & 600886 & 4.091 & 5.0177 & TRN & & \\
\hline CHEMBL599291 & 600886 & 6.0958 & 6.1245 & TRN & & \\
\hline CHEMBL585251 & 600886 & 4.0227 & 5.121 & TST & & \\
\hline CHEMBL 608260 & 600886 & 6.6014 & 6.1437 & TRN & & \\
\hline CHEMBL578907 & 600886 & 6.3072 & 6.4055 & TRN & & \\
\hline CHEMBL578086 & 600886 & 5.4202 & 5.6163 & TRN & & \\
\hline CHEMBL600348 & 600886 & 5.99700 & 30000000 & 01 & 6.3106 & TRN \\
\hline CHEMBL535684 & 600886 & 5.7786 & 5.9811 & TRN & & \\
\hline CHEMBL579690 & 600886 & 9.0926 & 6.3765 & TST & & \\
\hline CHEMBL268584 & 600886 & 5.7673 & 6.8765 & TRN & & \\
\hline
\end{tabular}




\begin{tabular}{|c|c|c|c|c|c|c|}
\hline & & & oplementa & al Ta & s2.txt & \\
\hline CHEMBL579045 & 600886 & 5.8665 & 6.0149 & TRN & & \\
\hline CHEMBL577148 & 600886 & 4.4597 & 6.0802 & TRN & & \\
\hline CHEMBL494668 & 600886 & 5.9326 & 6.0624 & TRN & & \\
\hline CHEMBL600717 & 600886 & 5.73 & 5.5268 & TRN & & \\
\hline CHEMBL609153 & 600886 & 10.2426 & 6.671 & TRN & & \\
\hline CHEMBL600304 & 600886 & 5.7022 & 6.0356 & TRN & & \\
\hline CHEMBL600357 & 600886 & 7.572999 & 99999999 & 995 & 5.5829 & TST \\
\hline CHEMBL585415 & 600886 & 4.93 & 6.1618 & TRN & & \\
\hline CHEMBL584657 & 600886 & 6.0013 & 5.6374 & TRN & & \\
\hline CHEMBL529361 & 600886 & 7.3915 & 6.2309 & TRN & & \\
\hline CHEMBL579082 & 600886 & 6.4908 & 6.6217 & TST & & \\
\hline CHEMBL583598 & 600886 & 6.9176 & 6.5513 & TRN & & \\
\hline CHEMBL578949 & 600886 & 7.262006 & 0000000 & 205 & 6.5175 & TRN \\
\hline CHEMBL577210 & 600886 & 7.6267 & 6.9848 & TRN & & \\
\hline CHEMBL602430 & 600886 & 5.0453 & 5.6495 & TRN & & \\
\hline CHEMBL602190 & 600886 & 6.0 & 6.4174 & TST & & \\
\hline CHEMBL578678 & 600886 & 4.9031 & 5.7194 & TST & & \\
\hline CHEMBL532872 & 600886 & 6.5079 & 6.6204 & TRN & & \\
\hline CHEMBL1348555 & 600886 & 6.9031 & 6.9042 & TRN & & \\
\hline CHEMBL580785 & 600886 & 7.9165 & 7.0737 & TRN & & \\
\hline CHEMBL599927 & 600886 & 5.4001 & 5.9108 & TRN & & \\
\hline CHEMBL577204 & 600886 & 5.6101 & 6.5002 & TRN & & \\
\hline CHEMBL602030 & 600886 & 4.9792 & 5.5936 & TRN & & \\
\hline CHEMBL579291 & 600886 & 5.7934 & 5.2683 & TST & & \\
\hline CHEMBL600691 & 600886 & 6.0 & 6.336 & TRN & & \\
\hline CHEMBL581173 & 600886 & 6.9104 & 6.7026 & TRN & & \\
\hline CHEMBL601826 & 600886 & 6.2565 & 6.1354 & TRN & & \\
\hline CHEMBL599943 & 600886 & 6.153 & 6.6758 & TRN & & \\
\hline CHEMBL583607 & 600886 & 6.1911 & 5.3931 & TRN & & \\
\hline CHEMBL585067 & 600886 & 5.0004 & 5.5401 & TRN & & \\
\hline CHEMBL578096 & 600886 & 6.2204 & 6.2565 & TST & & \\
\hline CHEMBL581537 & 600886 & 8.8874 & 5.7174 & TRN & & \\
\hline CHEMBL583431 & 600886 & 6.9776 & 6.0713 & TRN & & \\
\hline CHEMBL584442 & 600886 & 6.9234 & 6.8789 & TRN & & \\
\hline CHEMBL579098 & 600886 & 5.5286 & 5.7483 & TRN & & \\
\hline CHEMBL601558 & 600886 & 6.0996 & 6.1568 & TST & & \\
\hline CHEMBL600913 & 600886 & 8.4498 & 7.6634 & TST & & \\
\hline CHEMBL582652 & 600886 & 6.1046 & 6.0851 & TST & & \\
\hline CHEMBL583604 & 600886 & 6.8765 & 6.7134 & TRN & & \\
\hline CHEMBL531160 & 600886 & 6.3625 & 6.2577 & TRN & & \\
\hline CHEMBL581645 & 600886 & 5.8202 & 6.3462 & TST & & \\
\hline CHEMBL585779 & 600886 & 6.5468 & 6.4847 & TRN & & \\
\hline CHEMBL600106 & 600886 & 5.1925 & 5.0163 & TRN & & \\
\hline CHEMBL579104 & 600886 & 6.0106 & 6.4423 & TRN & & \\
\hline CHEMBL258137 & 600886 & 6.0164 & 5.9615 & TRN & & \\
\hline CHEMBL585308 & 600886 & 6.2967 & 6.3437 & TRN & & \\
\hline CHEMBL602986 & 600886 & 6.2464 & 6.4436 & TST & & \\
\hline CHEMBL582784 & 600886 & 6.7501 & 6.1612 & TRN & & \\
\hline
\end{tabular}




\begin{tabular}{|c|c|c|c|c|c|c|}
\hline \multirow[b]{2}{*}{ CHEMBL578333 } & \multicolumn{6}{|c|}{ Supplemental Table s2.txt } \\
\hline & 600886 & 6.2604 & 5.5171 & TRN & & \\
\hline CHEMBL606165 & 600886 & 6.3125 & 6.2203 & TRN & & \\
\hline CHEMBL601823 & 600886 & 5.9393 & 5.61799 & 9999999999 & & TRN \\
\hline CHEMBL586034 & 600886 & 6.8911 & 6.6472 & TRN & & \\
\hline CHEMBL602023 & 600886 & 5.0353 & 5.6321 & TST & & \\
\hline CHEMBL579761 & 600886 & 5.7383 & 5.6908 & TST & & \\
\hline CHEMBL528241 & 600886 & 5.9626 & 6.2744 & TRN & & \\
\hline CHEMBL602420 & 600886 & 5.7673 & 5.6102 & TST & & \\
\hline CHEMBL602191 & 600886 & 5.3233 & 6.0433 & TRN & & \\
\hline CHEMBL577456 & 600886 & 5.1688 & 5.7235 & TRN & & \\
\hline CHEMBL217665 & 600886 & 6.6247 & 6.7759 & TRN & & \\
\hline CHEMBL586310 & 600886 & 6.4737 & 6.5418 & TST & & \\
\hline CHEMBL582291 & 600886 & 6.1215 & 6.4834 & TRN & & \\
\hline CHEMBL578928 & 600886 & 6.4389 & 6.5914 & TRN & & \\
\hline CHEMBL 2021322 & 600886 & 6.1135 & 6.4286 & TRN & & \\
\hline CHEMBL583360 & 600886 & 6.4237 & 5.1879 & TST & & \\
\hline CHEMBL601802 & 600886 & 6.1325 & 6.5799 & TRN & & \\
\hline CHEMBL583810 & 600886 & 5.9278 & 6.0496 & TRN & & \\
\hline CHEMBL584310 & 600886 & 7.2055 & 6.5997 & TRN & & \\
\hline CHEMBL581057 & 600886 & 4.9031 & 5.702006 & 0000000001 & & TST \\
\hline CHEMBL583594 & 600886 & 4.9311 & 6.2636 & TST & & \\
\hline CHEMBL582654 & 600886 & 5.129 & 5.0412 & TRN & & \\
\hline CHEMBL534338 & 600886 & 5.7953 & 5.8394 & TRN & & \\
\hline CHEMBL602201 & 600886 & 4.9031 & 6.0319 & TRN & & \\
\hline CHEMBL578727 & 600886 & 6.0 & 6.2525 & TRN & & \\
\hline CHEMBL600126 & 600886 & 6.4365 & 6.4007 & TST & & \\
\hline CHEMBL578702 & 600886 & 6.0 & 6.3085 & TRN & & \\
\hline CHEMBL598267 & 600886 & 6.2147 & 6.1444 & TST & & \\
\hline CHEMBL602208 & 600886 & 4.8377 & 5.2108 & TRN & & \\
\hline CHEMBL596835 & 600886 & 6.0635 & 6.0551 & TRN & & \\
\hline CHEMBL534547 & 600886 & 5.78299 & 79999999 & 995 & 5.6365 & TRN \\
\hline CHEMBL583605 & 600886 & 5.9223 & 5.0779 & TRN & & \\
\hline CHEMBL580133 & 600886 & 6.0 & 6.28100 & 0000000001 & & TRN \\
\hline CHEMBL577417 & 600886 & 5.5297 & 5.8343 & TST & & \\
\hline CHEMBL602634 & 600886 & 6.5688 & 5.1029 & TRN & & \\
\hline CHEMBL579966 & 600886 & 5.648 & 5.864 & TRN & & \\
\hline CHEMBL528712 & 600886 & 6.3706 & 6.6736 & TRN & & \\
\hline CHEMBL596629 & 600886 & 6.00700 & 00000000 & $\partial 1$ & 5.5912 & TRN \\
\hline CHEMBL602626 & 600886 & 4.9634 & 6.4915 & TST & & \\
\hline CHEMBL530869 & 600886 & 6.9834 & 6.8918 & TRN & & \\
\hline CHEMBL600138 & 600886 & 5.8761 & 5.8768 & TRN & & \\
\hline CHEMBL596857 & 600886 & 7.2865 & 6.9542 & TST & & \\
\hline CHEMBL581478 & 600886 & 6.0 & 5.7682 & TRN & & \\
\hline CHEMBL600278 & 600886 & 7.6326 & 5.6324 & TRN & & \\
\hline CHEMBL578275 & 600886 & 5.5574 & 6.0261 & TRN & & \\
\hline CHEMBL579345 & 600886 & 5.3354 & 5.1129 & TRN & & \\
\hline CHEMBL599307 & 600886 & 3.9031 & 5.8875 & TRN & & \\
\hline CHEMBL532858 & 600886 & 6.54700 & 00000000 & & 6.4066 & TRN \\
\hline & & & & 14236 & & \\
\hline
\end{tabular}




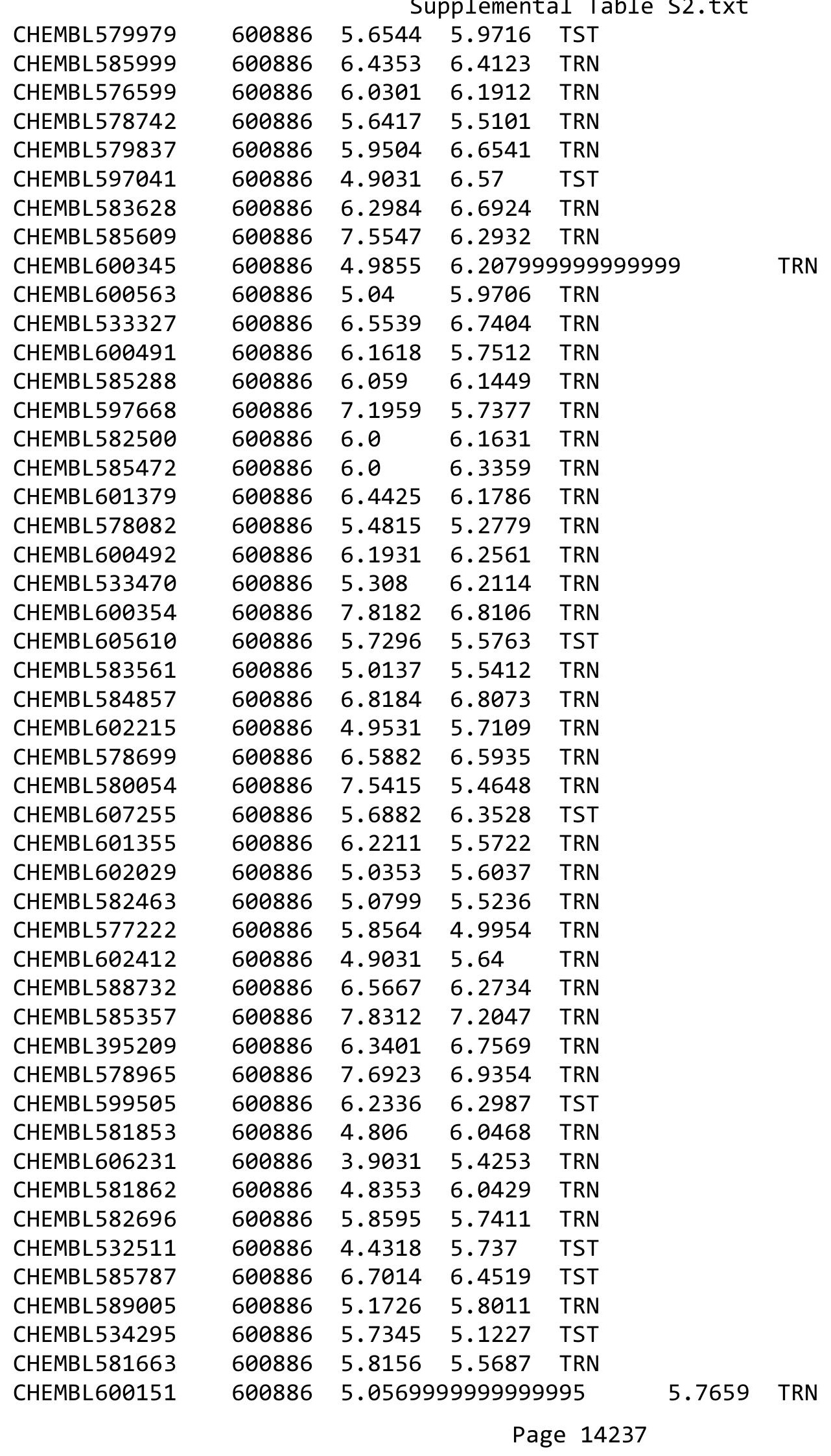




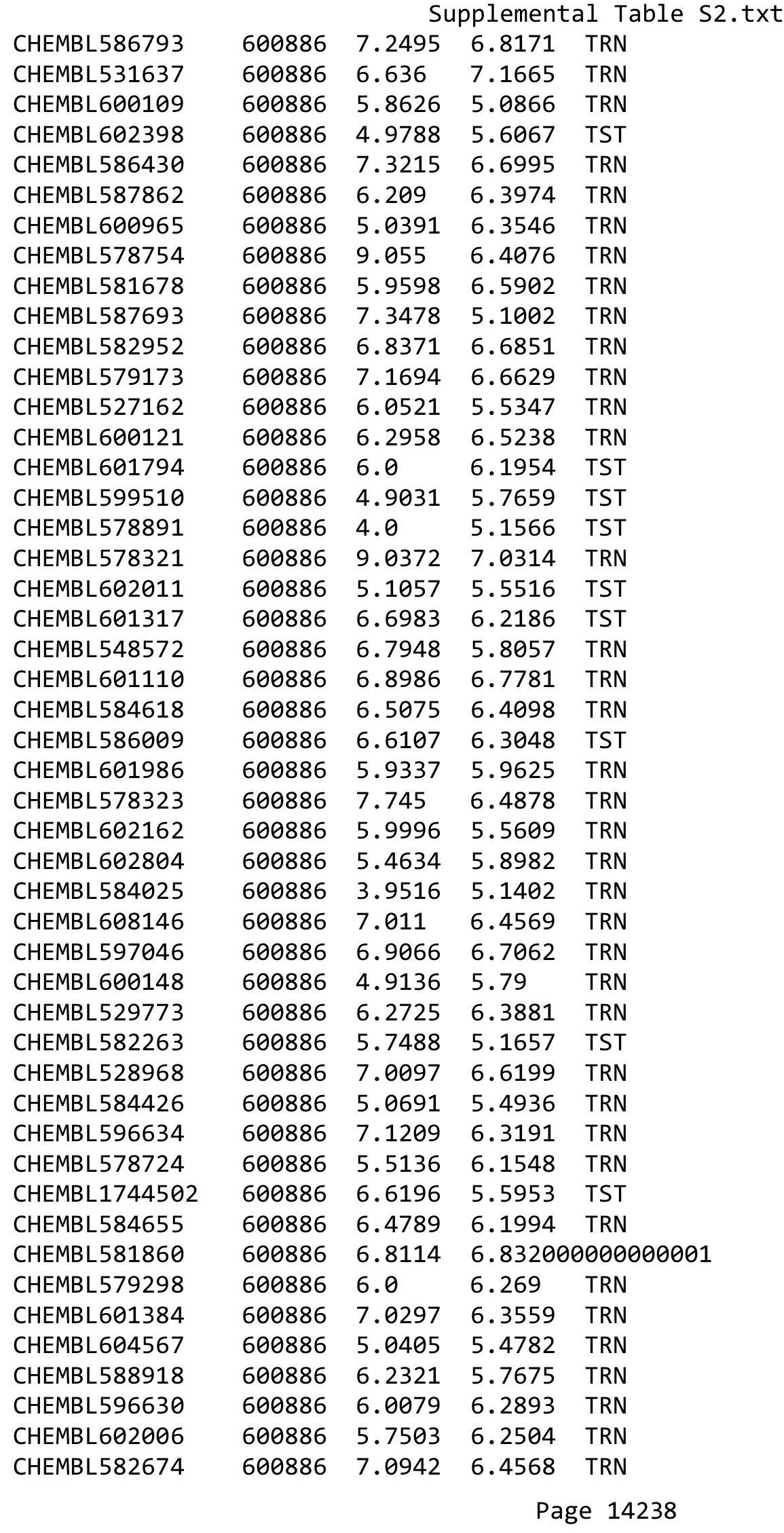

TRN 


\begin{tabular}{|c|c|c|c|c|c|}
\hline \multicolumn{6}{|c|}{ Supplemental Table S2.txt } \\
\hline CHEMBL577015 & 600886 & 7.2882 & 6.9436 & TRN & \\
\hline CHEMBL601776 & 600886 & 6.3635 & 6.6253 & TRN & \\
\hline CHEMBL596636 & 600886 & 6.2984 & 6.5775 & TRN & \\
\hline CHEMBL602825 & 600886 & 3.9516 & 5.2009 & TRN & \\
\hline CHEMBL577665 & 600886 & 6.2262 & 6.2748 & TST & \\
\hline CHEMBL581898 & 600886 & 4.9031 & 5.61799 & 9999999999 & TRN \\
\hline CHEMBL602031 & 600886 & 5.9427 & 6.1339 & TRN & \\
\hline CHEMBL578106 & 600886 & 5.3516 & 5.59 & TRN & \\
\hline CHEMBL581900 & 600886 & 5.8447 & 6.1775 & TRN & \\
\hline CHEMBL1301480 & 600886 & 6.6664 & 6.8785 & TRN & \\
\hline CHEMBL604780 & 600886 & 6.2118 & 6.3187 & TRN & \\
\hline CHEMBL605630 & 600886 & 5.9473 & 6.1054 & TRN & \\
\hline CHEMBL585065 & 600886 & 4.0 & 5.078 & TRN & \\
\hline CHEMBL603729 & 600886 & 5.1361 & 5.6728 & TRN & \\
\hline CHEMBL546917 & 600886 & 7.0706 & 6.3669 & TRN & \\
\hline CHEMBL1567944 & 600886 & 6.0 & 6.5701 & TRN & \\
\hline CHEMBL585624 & 600886 & 6.5943 & 6.2215 & TST & \\
\hline CHEMBL602180 & 600886 & 6.1884 & 6.4184 & TRN & \\
\hline CHEMBL579118 & 600886 & 9.4841 & 7.1052 & TRN & \\
\hline CHEMBL 235891 & 600886 & 5.6776 & 6.0224 & TST & \\
\hline CHEMBL604119 & 600886 & 6.4157 & 6.5747 & TST & \\
\hline CHEMBL602569 & 600886 & 3.9031 & 6.2542 & TRN & \\
\hline CHEMBL586015 & 600886 & 7.1244 & 6.3376 & TRN & \\
\hline CHEMBL581659 & 600886 & 5.9792 & 6.3568 & TRN & \\
\hline CHEMBL578913 & 600886 & 6.2013 & 7.0431 & TRN & \\
\hline CHEMBL582649 & 600886 & 6.3915 & 6.2626 & TRN & \\
\hline CHEMBL579282 & 600886 & 5.4089 & 5.8433 & TRN & \\
\hline CHEMBL597475 & 600886 & 5.9784 & 6.3912 & TRN & \\
\hline CHEMBL581911 & 600886 & 5.871 & 5.7537 & TRN & \\
\hline CHEMBL601160 & 600886 & 5.7293 & 5.0641 & TRN & \\
\hline CHEMBL578257 & 600886 & 6.0 & 6.3029 & TRN & \\
\hline CHEMBL602580 & 600886 & 6.0737 & 6.5536 & TST & \\
\hline CHEMBL582672 & 600886 & 6.8548 & 6.5549 & TRN & \\
\hline CHEMBL600320 & 600886 & 6.7696 & 6.9411 & TRN & \\
\hline CHEMBL275177 & 600886 & 6.6347 & 6.4467 & TST & \\
\hline CHEMBL581109 & 600886 & 8.5771 & 5.8968 & TRN & \\
\hline CHEMBL602561 & 600886 & 6.0 & 6.0678 & TRN & \\
\hline CHEMBL602216 & 600886 & 5.9559 & 6.13899 & 9999999999 & TRN \\
\hline CHEMBL531888 & 600886 & 5.6164 & 5.1711 & TST & \\
\hline CHEMBL600933 & 600886 & 6.5262 & 5.6799 & TRN & \\
\hline CHEMBL584868 & 600886 & 6.4815 & 6.8079 & TRN & \\
\hline CHEMBL586023 & 600886 & 6.7418 & 6.8104 & TRN & \\
\hline CHEMBL584214 & 600886 & 6.5126 & 6.3041 & TRN & \\
\hline CHEMBL584009 & 600886 & 4.9622 & 5.4848 & TRN & \\
\hline CHEMBL600753 & 600886 & 6.767 & 6.2021 & TRN & \\
\hline CHEMBL601385 & 600886 & 6.7003 & 6.6366 & TRN & \\
\hline CHEMBL579320 & 600886 & 6.5444 & 5.9322 & TRN & \\
\hline CHEMBL532496 & 600886 & 5.5366 & 5.8859 & TRN & \\
\hline
\end{tabular}




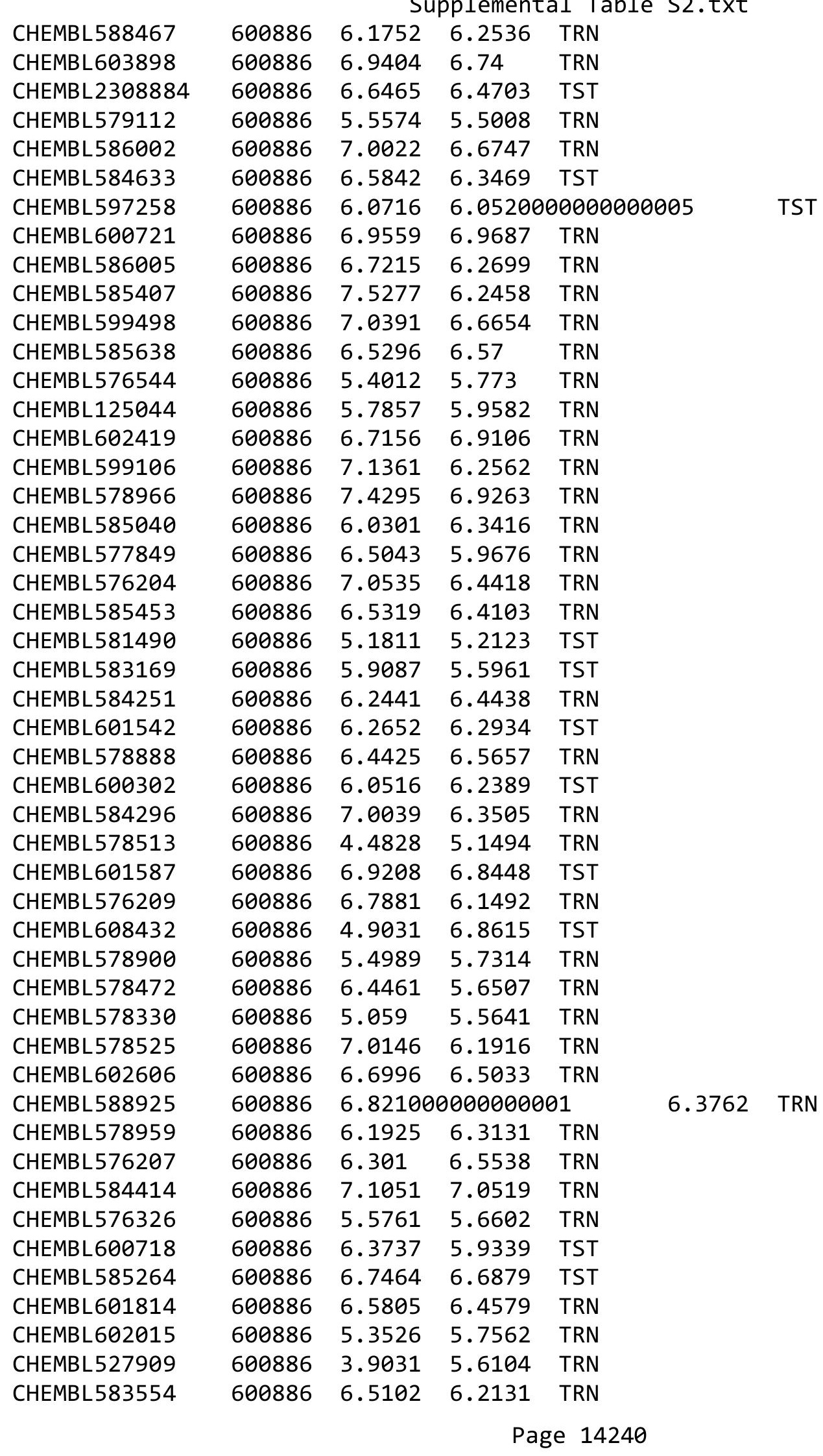




\begin{tabular}{|c|c|c|c|c|c|}
\hline & & & & & \\
\hline CHEMBL588400 & 600886 & 5.1965 & 5.6265 & TRN & \\
\hline CHEMBL602764 & 600886 & 6.2924 & 5.8774 & TRN & \\
\hline CHEMBL585954 & 600886 & 6.4123 & 5.7538 & TRN & \\
\hline CHEMBL602838 & 600886 & 4.9772 & 5.6791 & TST & \\
\hline CHEMBL578937 & 600886 & 6.6457 & 6.9188 & TRN & \\
\hline CHEMBL585843 & 600886 & 6.9578 & 6.8233 & TRN & \\
\hline CHEMBL579108 & 600886 & 6.3197 & 6.5489 & TRN & \\
\hline CHEMBL582251 & 600886 & 4.2457 & 6.1492 & TRN & \\
\hline CHEMBL585252 & 600886 & 5.0386 & 5.63200 & 0000000001 & TRN \\
\hline CHEMBL600341 & 600886 & 6.2441 & 6.0251 & TRN & \\
\hline CHEMBL576610 & 600886 & 7.2815 & 6.4625 & TRN & \\
\hline CHEMBL576796 & 600886 & 6.3134 & 5.5673 & TRN & \\
\hline CHEMBL598686 & 600886 & 6.2291 & 6.5424 & TRN & \\
\hline CHEMBL579459 & 600886 & 5.9978 & 6.345 & TST & \\
\hline CHEMBL531507 & 600886 & 6.6077 & 6.468 & TRN & \\
\hline CHEMBL579315 & 600886 & 6.0 & 6.2392 & TRN & \\
\hline CHEMBL582480 & 600886 & 5.1203 & 5.6506 & TRN & \\
\hline CHEMBL585446 & 600886 & 6.0 & 6.2406 & TRN & \\
\hline CHEMBL586029 & 600886 & 6.9884 & 6.6691 & TRN & \\
\hline CHEMBL579517 & 600886 & 6.7286 & 6.2568 & TRN & \\
\hline CHEMBL586203 & 600886 & 7.5977 & 6.9415 & TRN & \\
\hline CHEMBL600914 & 600886 & 6.7331 & 6.8385 & TRN & \\
\hline CHEMBL578295 & 600886 & 6.5388 & 6.0053 & TST & \\
\hline CHEMBL586200 & 600886 & 6.1255 & 6.3216 & TRN & \\
\hline CHEMBL585276 & 600886 & 4.9031 & 5.8377 & TRN & \\
\hline CHEMBL599953 & 600886 & 8.4353 & 5.9928 & TRN & \\
\hline CHEMBL527297 & 600886 & 5.9747 & 6.3683 & TRN & \\
\hline CHEMBL602797 & 600886 & 6.6981 & 5.5341 & TRN & \\
\hline CHEMBL581267 & 600886 & 5.8904 & 6.1845 & TRN & \\
\hline CHEMBL576951 & 600886 & 5.5791 & 5.8691 & TRN & \\
\hline CHEMBL600308 & 600886 & 7.2976 & 6.9056 & TRN & \\
\hline CHEMBL579550 & 600886 & 6.0501 & 6.2294 & TRN & \\
\hline CHEMBL586694 & 600886 & 7.9784 & 7.1254 & TRN & \\
\hline CHEMBL600561 & 600886 & 6.0 & 6.0268 & TRN & \\
\hline CHEMBL586504 & 600886 & 9.057 & 6.2207 & TRN & \\
\hline CHEMBL296622 & 600886 & 4.9031 & 7.2463 & TRN & \\
\hline CHEMBL584232 & 600886 & 5.9485 & 6.0168 & TST & \\
\hline CHEMBL584236 & 600886 & 6.4401 & 6.4019 & TRN & \\
\hline CHEMBL578947 & 600886 & 7.2366 & 7.0125 & TRN & \\
\hline CHEMBL578933 & 600886 & 5.7862 & 6.1974 & TRN & \\
\hline CHEMBL601380 & 600886 & 6.5571 & 6.407 & TRN & \\
\hline CHEMBL527949 & 600886 & 6.9154 & 6.2801 & TRN & \\
\hline CHEMBL600906 & 600886 & 6.3675 & 6.3383 & TRN & \\
\hline CHEMBL607688 & 600886 & 5.1568 & 5.6969 & TST & \\
\hline CHEMBL528492 & 600886 & 3.9031 & 7.194 & TRN & \\
\hline CHEMBL582455 & 600886 & 6.8508 & 6.4021 & TRN & \\
\hline CHEMBL605745 & 600886 & 6.0376 & 5.91200 & 2000000001 & TRN \\
\hline CHEMBL577571 & 600886 & 5.5995 & 5.1971 & TRN & \\
\hline & & & & 14241 & \\
\hline
\end{tabular}




\begin{tabular}{|c|c|c|c|c|c|c|}
\hline & & & & & & \\
\hline CHEMBL535252 & 600886 & 5.8153 & 5.8264 & TRN & & \\
\hline CHEMBL602210 & 600886 & 5.1096 & 5.6344 & TRN & & \\
\hline CHEMBL582283 & 600886 & 5.8289 & 6.1496 & TRN & & \\
\hline CHEMBL529844 & 600886 & 5.3429 & 5.7257 & TRN & & \\
\hline CHEMBL581043 & 600886 & 6.7467 & 5.6267 & TRN & & \\
\hline CHEMBL604736 & 600886 & 3.9031 & 5.9189 & TRN & & \\
\hline CHEMBL602014 & 600886 & 5.7747 & 5.8171 & TRN & & \\
\hline CHEMBL577163 & 600886 & 6.4012 & 6.933 & TRN & & \\
\hline CHEMBL602195 & 600886 & 10.2426 & 5.7305 & TRN & & \\
\hline CHEMBL602610 & 600886 & 4.9031 & 5.5911 & TST & & \\
\hline CHEMBL583823 & 600886 & 6.4908 & 6.6929 & TRN & & \\
\hline CHEMBL577428 & 600886 & 7.6388 & 7.20100 & 0000000000 & & TRN \\
\hline CHEMBL583811 & 600886 & 4.9108 & 6.3641 & TRN & & \\
\hline CHEMBL600091 & 600886 & 3.9031 & 6.0047 & TRN & & \\
\hline CHEMBL579262 & 600886 & 6.2218 & 6.0454 & TST & & \\
\hline CHEMBL580166 & 600886 & 6.8049 & 6.9205 & TRN & & \\
\hline CHEMBL582284 & 600886 & 6.4908 & 6.11100 & 0000000001 & & TRN \\
\hline CHEMBL599955 & 600886 & 7.0237 & 6.7335 & TRN & & \\
\hline CHEMBL529630 & 600886 & 7.507006 & 90000000 & & 6.3108 & TRN \\
\hline CHEMBL585413 & 600886 & 7.572999 & 79999999 & 995 & 6.4183 & TRN \\
\hline CHEMBL582661 & 600886 & 7.098 & 6.95799 & 9999999999 & & TRN \\
\hline CHEMBL600758 & 600886 & 5.0137 & 5.0081 & TRN & & \\
\hline CHEMBL598063 & 600886 & 6.4855 & 6.4126 & TRN & & \\
\hline CHEMBL585271 & 600886 & 6.1733 & 6.1748 & TRN & & \\
\hline CHEMBL579307 & 600886 & 5.3487 & 5.6007 & TRN & & \\
\hline CHEMBL 3143972 & 600886 & 6.856 & 6.1653 & TST & & \\
\hline CHEMBL588108 & 600886 & 6.4789 & 6.1964 & TRN & & \\
\hline CHEMBL578958 & 600886 & 5.1925 & 5.6964 & TST & & \\
\hline CHEMBL576169 & 600886 & 6.3904 & 5.5458 & TRN & & \\
\hline CHEMBL599083 & 600886 & 5.8986 & 5.1207 & TRN & & \\
\hline CHEMBL583397 & 600886 & 5.9208 & 6.2596 & TRN & & \\
\hline CHEMBL577675 & 600886 & 6.0259 & 5.6044 & TRN & & \\
\hline CHEMBL587519 & 600886 & 5.3036 & 5.0494 & TRN & & \\
\hline CHEMBL578919 & 600886 & 8.1319 & 7.2223 & TRN & & \\
\hline CHEMBL582644 & 600886 & 7.0872 & 6.8172 & TRN & & \\
\hline CHEMBL588436 & 600886 & 6.0991 & 5.5194 & TRN & & \\
\hline CHEMBL585214 & 600886 & 4.9582 & 5.9915 & TRN & & \\
\hline CHEMBL600969 & 600886 & 5.0462 & 5.5676 & TST & & \\
\hline CHEMBL533423 & 600886 & 5.4989 & 5.1682 & TRN & & \\
\hline CHEMBL588643 & 600886 & 6.9901 & 6.7715 & TRN & & \\
\hline CHEMBL577859 & 600886 & 5.4449 & 6.3623 & TRN & & \\
\hline CHEMBL600282 & 600886 & 5.8726 & 5.6164 & TRN & & \\
\hline CHEMBL530067 & 600886 & 6.5624 & 6.4495 & TST & & \\
\hline CHEMBL528316 & 600886 & 7.5894 & 7.0265 & TRN & & \\
\hline CHEMBL602630 & 600886 & 6.7948 & 6.2607 & TST & & \\
\hline CHEMBL602635 & 600886 & 6.0 & 6.2734 & TRN & & \\
\hline CHEMBL584026 & 600886 & 6.0752 & 6.401 & TRN & & \\
\hline CHEMBL585077 & 600886 & 3.9031 & 5.3469 & TRN & & \\
\hline
\end{tabular}




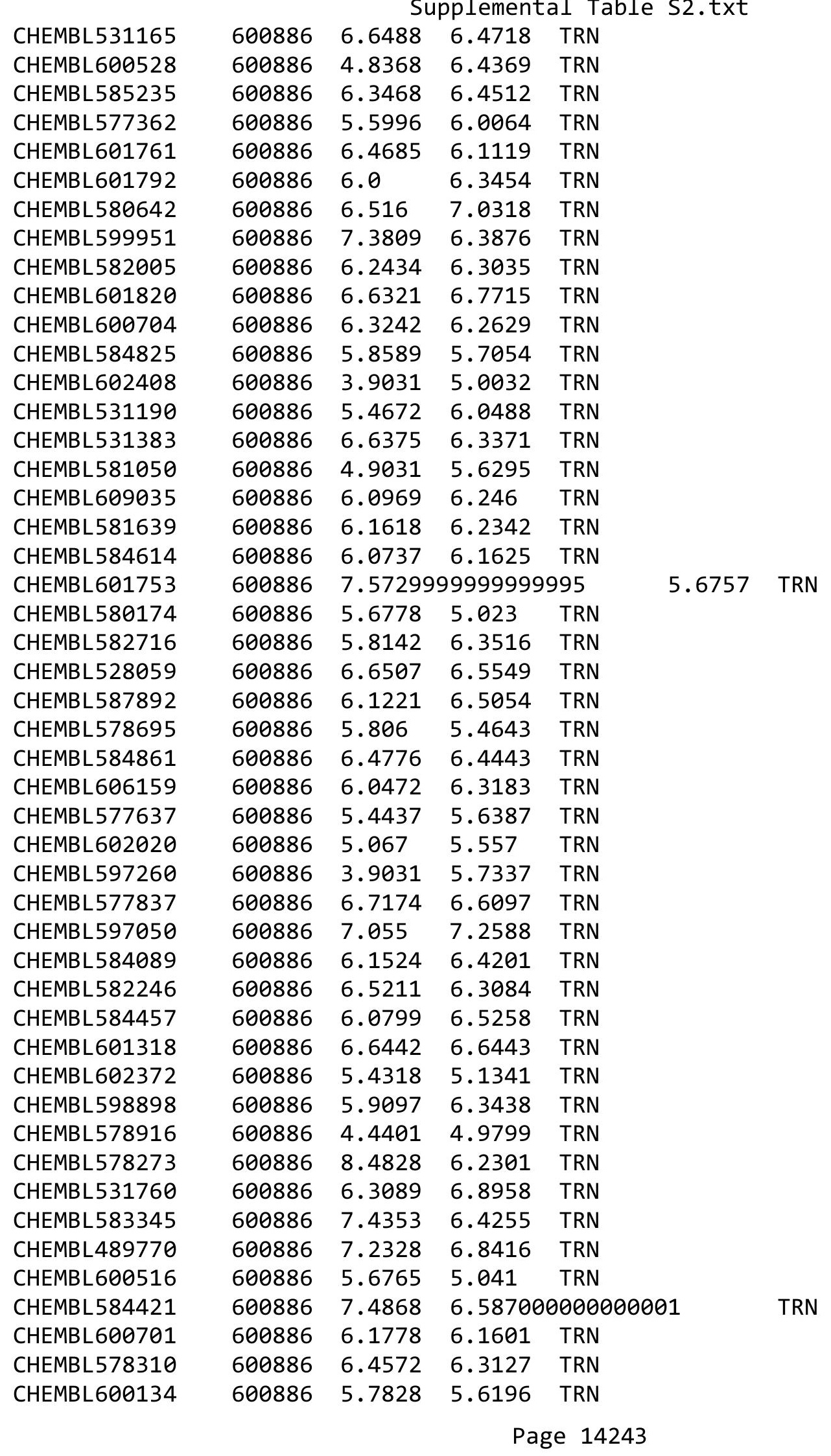




\begin{tabular}{|c|c|c|c|c|c|c|}
\hline \multicolumn{7}{|c|}{ Supplemental Table S2.txt } \\
\hline CHEMBL603731 & 600886 & 7.0857 & 5.5092 & TRN & & \\
\hline CHEMBL578065 & 600886 & 7.506 & 6.5468 & TRN & & \\
\hline CHEMBL529351 & 600886 & 6.38399 & 99999999 & 995 & 6.4471 & TRN \\
\hline CHEMBL597854 & 600886 & 6.1824 & 6.1979 & TST & & \\
\hline CHEMBL579102 & 600886 & 6.0 & 6.2116 & TRN & & \\
\hline CHEMBL534243 & 600886 & 6.1726 & 6.3113 & TRN & & \\
\hline CHEMBL586105 & 600886 & 5.2336 & 5.5833 & TRN & & \\
\hline CHEMBL577388 & 600886 & 6.5802 & 5.5915 & TST & & \\
\hline CHEMBL576323 & 600886 & 6.4522 & 6.644 & TRN & & \\
\hline CHEMBL582704 & 600886 & 4.8649 & 6.2229 & TRN & & \\
\hline CHEMBL600103 & 600886 & 5.2464 & 5.1733 & TST & & \\
\hline CHEMBL600319 & 600886 & 6.7291 & 6.8386 & TRN & & \\
\hline CHEMBL600946 & 600886 & 7.4572 & 6.3416 & TRN & & \\
\hline CHEMBL583351 & 600886 & 6.5096 & 6.5009 & TRN & & \\
\hline CHEMBL584233 & 600886 & 4.9485 & 5.5955 & TRN & & \\
\hline CHEMBL582182 & 600886 & 7.7423 & 6.5562 & TRN & & \\
\hline CHEMBL579720 & 600886 & 6.1325 & 6.4522 & TRN & & \\
\hline CHEMBL581055 & 600886 & 5.8962 & 5.53700 & 0000000001 & & TRN \\
\hline CHEMBL577881 & 600886 & 5.2518 & 5.4902 & TRN & & \\
\hline CHEMBL581680 & 600886 & 5.7713 & 5.6592 & TRN & & \\
\hline CHEMBL601373 & 600886 & 5.7673 & 5.6561 & TRN & & \\
\hline CHEMBL374744 & 600886 & 5.6164 & 6.2489 & TRN & & \\
\hline CHEMBL578915 & 600886 & 6.3526 & 6.1131 & TRN & & \\
\hline CHEMBL599096 & 600886 & 6.2358 & 6.5159 & TRN & & \\
\hline CHEMBL604155 & 600886 & 6.5196 & 6.4879 & TRN & & \\
\hline CHEMBL582700 & 600886 & 6.0 & 6.2575 & TRN & & \\
\hline CHEMBL602976 & 600886 & 5.475 & 5.9598 & TRN & & \\
\hline CHEMBL609154 & 600886 & 6.27 & 6.2738 & TST & & \\
\hline CHEMBL584444 & 600886 & 6.1018 & 6.5013 & TST & & \\
\hline CHEMBL599888 & 600886 & 7.056 & 5.6569 & TRN & & \\
\hline CHEMBL585775 & 600886 & 7.6927 & 5.8843 & TRN & & \\
\hline CHEMBL582090 & 600886 & 6.3143 & 6.2736 & TRN & & \\
\hline CHEMBL600129 & 600886 & 6.3449 & 6.4386 & TST & & \\
\hline CHEMBL585478 & 600886 & 5.9996 & 5.7853 & TRN & & \\
\hline CHEMBL528954 & 600886 & 5.3655 & 6.0104 & TST & & \\
\hline CHEMBL584621 & 600886 & 7.2757 & 7.1452 & TRN & & \\
\hline CHEMBL584041 & 600886 & 5.9987 & 5.0895 & TRN & & \\
\hline CHEMBL588749 & 600886 & 7.3391 & 6.9494 & TRN & & \\
\hline CHEMBL534589 & 600886 & 5.8283 & 5.1747 & TRN & & \\
\hline CHEMBL576798 & 600886 & 5.083 & 5.6378 & TST & & \\
\hline CHEMBL604979 & 600886 & 5.8697 & 5.1727 & TRN & & \\
\hline CHEMBL584894 & 600886 & 6.0325 & 5.0094 & TST & & \\
\hline CHEMBL578523 & 600886 & 7.2573 & 6.6334 & TST & & \\
\hline CHEMBL582950 & 600886 & 7.1296 & 6.4543 & TRN & & \\
\hline CHEMBL600489 & 600886 & 5.9431 & 5.1756 & TRN & & \\
\hline CHEMBL578056 & 600886 & 5.2882 & 6.7959 & TRN & & \\
\hline CHEMBL584245 & 600886 & 6.0535 & 6.1884 & TRN & & \\
\hline CHEMBL587714 & 600886 & 6.5479 & 6.6712 & TST & & \\
\hline
\end{tabular}




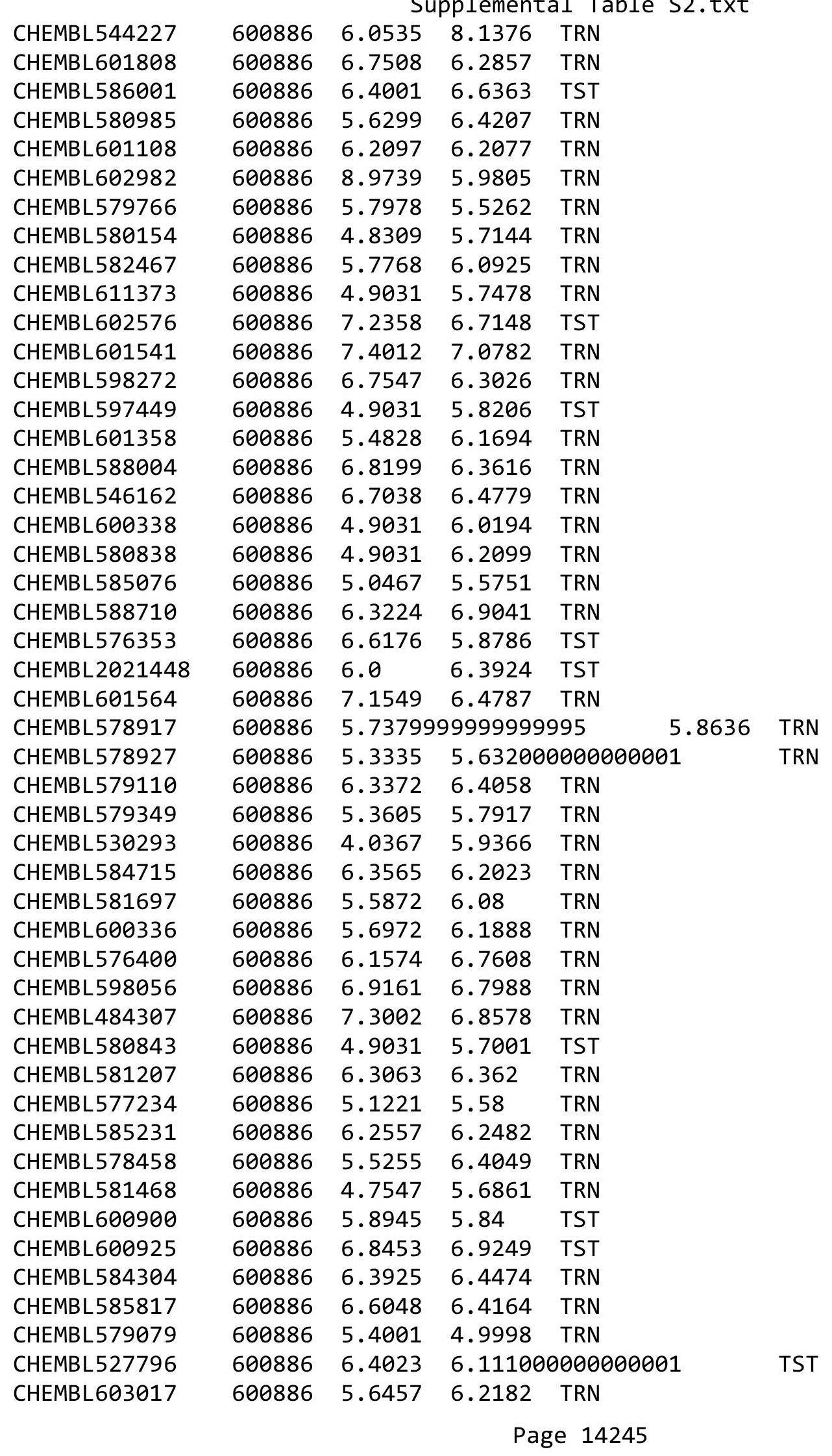




\begin{tabular}{|c|c|c|c|c|c|c|}
\hline & & \multicolumn{5}{|c|}{ Supplemental Table s2.txt } \\
\hline CHEMBL277148 & 600886 & $6.2620 e$ & 00000000 & 005 & 6.3026 & TRN \\
\hline CHEMBL579126 & 600886 & 6.3575 & 6.3423 & TRN & & \\
\hline CHEMBL582086 & 600886 & 6.8083 & 6.3531 & TST & & \\
\hline CHEMBL585233 & 600886 & 5.9412 & 5.7842 & TRN & & \\
\hline CHEMBL581683 & 600886 & 5.8167 & 5.7813 & TRN & & \\
\hline CHEMBL587159 & 600886 & 5.1972 & 6.7191 & TRN & & \\
\hline CHEMBL599706 & 600886 & 4.9031 & 6.3701 & TRN & & \\
\hline CHEMBL585977 & 600886 & 6.0531 & 6.4279 & TST & & \\
\hline CHEMBL588602 & 600886 & 7.9863 & 6.5372 & TRN & & \\
\hline CHEMBL581673 & 600886 & 6.841 & 6.4068 & TRN & & \\
\hline CHEMBL598494 & 600886 & 7.0237 & 6.8478 & TRN & & \\
\hline CHEMBL583396 & 600886 & 5.8908 & 6.1896 & TRN & & \\
\hline CHEMBL601595 & 600886 & 4.1605 & 5.1363 & TST & & \\
\hline CHEMBL578320 & 600886 & 7.0311 & 6.555 & TRN & & \\
\hline CHEMBL581208 & 600886 & 6.1713 & 6.6179 & TRN & & \\
\hline CHEMBL602000 & 600886 & 8.8392 & 5.8405 & TRN & & \\
\hline CHEMBL600284 & 600886 & 4.9031 & 5.638 & TST & & \\
\hline CHEMBL577860 & 600886 & 5.7605 & 5.7839 & TRN & & \\
\hline CHEMBL579286 & 600886 & 5.5253 & 5.9332 & TST & & \\
\hline CHEMBL602186 & 600886 & 7.289 & 6.7335 & TRN & & \\
\hline CHEMBL604511 & 600886 & 5.9759 & 6.3388 & TST & & \\
\hline CHEMBL579169 & 600886 & 6.05399 & 99999999 & 99 & 6.1102 & TRN \\
\hline CHEMBL530572 & 600886 & 5.8642 & 6.2919 & TST & & \\
\hline CHEMBL584215 & 600886 & 4.0146 & 5.1066 & TST & & \\
\hline CHEMBL602019 & 600886 & 5.9303 & 6.3659 & TST & & \\
\hline CHEMBL530840 & 600886 & 6.2396 & 5.7082 & TRN & & \\
\hline CHEMBL535514 & 600886 & 5.6421 & 5.9498 & TRN & & \\
\hline CHEMBL598897 & 600886 & 6.7027 & 6.5347 & TRN & & \\
\hline CHEMBL577201 & 600886 & 9.5224 & 6.6199 & TRN & & \\
\hline CHEMBL585785 & 600886 & 6.9215 & 6.3922 & TRN & & \\
\hline CHEMBL579640 & 600886 & 6.596 & 6.6548 & TRN & & \\
\hline CHEMBL599932 & 600886 & 6.2069 & 5.115 & TRN & & \\
\hline CHEMBL605952 & 600886 & 7.0726 & 6.0893 & TST & & \\
\hline CHEMBL598680 & 600886 & 5.9007 & 6.0059 & TRN & & \\
\hline CHEMBL601158 & 600886 & 5.6749 & 6.1626 & TRN & & \\
\hline CHEMBL601388 & 600886 & 4.9031 & 5.8348 & TRN & & \\
\hline CHEMBL600329 & 600886 & 6.7924 & 6.0885 & TST & & \\
\hline CHEMBL578101 & 600886 & 5.2503 & 4.9361 & TRN & & \\
\hline CHEMBL587049 & 600886 & 6.2933 & 6.2743 & TRN & & \\
\hline CHEMBL602165 & 600886 & 5.3516 & 5.8528 & TRN & & \\
\hline CHEMBL584019 & 600886 & 4.9255 & 6.3997 & TRN & & \\
\hline CHEMBL583532 & 600886 & 6.9115 & 6.3276 & TRN & & \\
\hline CHEMBL581265 & 600886 & 5.8844 & 5.6813 & TRN & & \\
\hline CHEMBL 602600 & 600886 & 5.5661 & 5.6432 & TST & & \\
\hline CHEMBL582951 & 600886 & 6.6805 & 6.3727 & TRN & & \\
\hline CHEMBL580135 & 600886 & 5.1811 & 5.59 & TRN & & \\
\hline CHEMBL579321 & 600886 & 5.8133 & 5.5321 & TRN & & \\
\hline CHEMBL585458 & 600886 & 6.5342 & 5.9226 & TRN & & \\
\hline
\end{tabular}




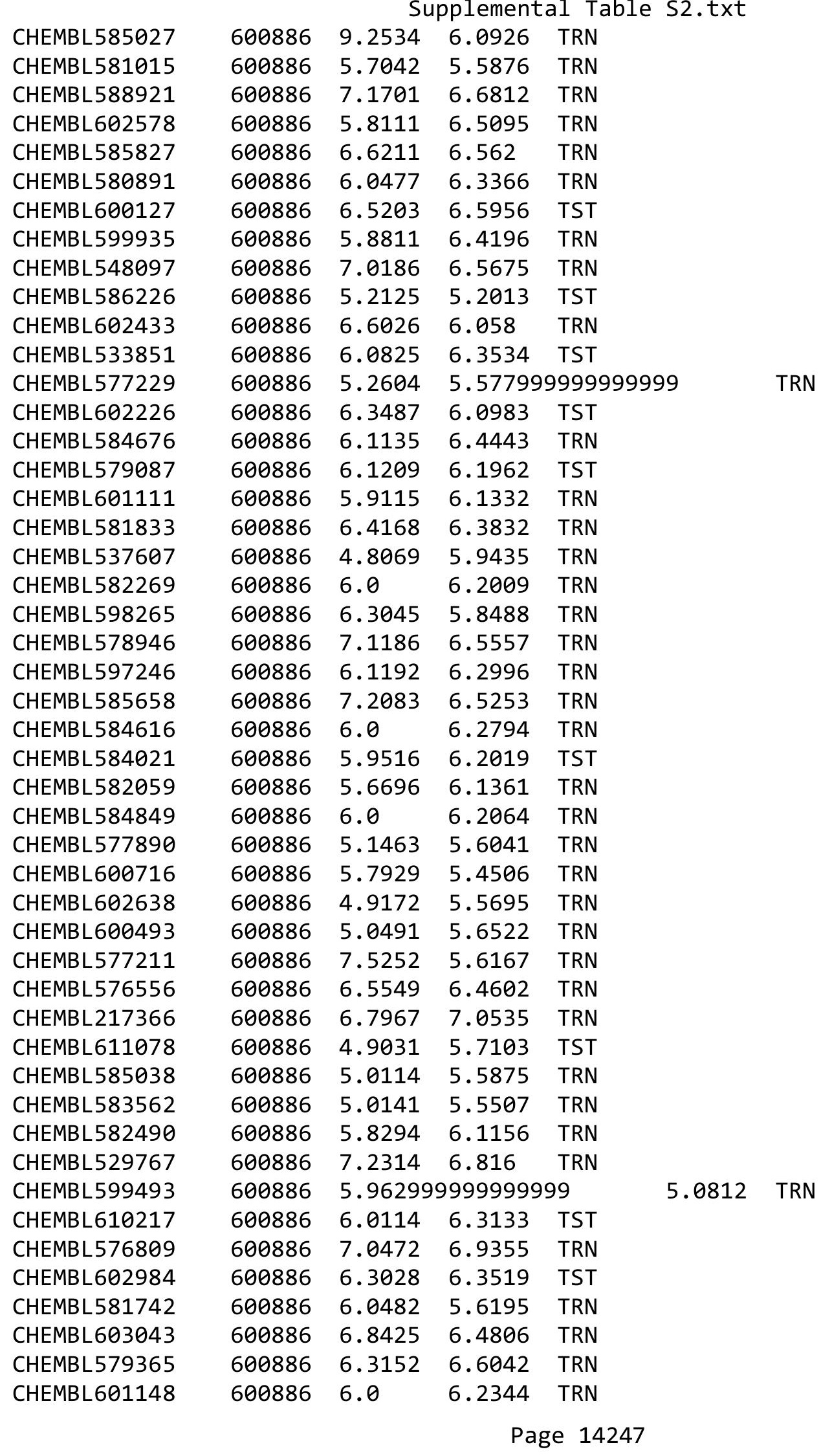




\begin{tabular}{|c|c|c|c|c|c|c|}
\hline & & & & & & \\
\hline CHEMBL549170 & 600886 & 6.5027 & 6.5412 & TST & & \\
\hline CHEMBL600096 & 600886 & 6.1057 & 6.2784 & TRN & & \\
\hline CHEMBL584613 & 600886 & 5.6692 & 6.1068 & TRN & & \\
\hline CHEMBL529349 & 600886 & 6.0 & 6.3966 & TST & & \\
\hline CHEMBL611382 & 600886 & 6.0511 & 6.4941 & TRN & & \\
\hline CHEMBL580062 & 600886 & 7.57299 & 99999999 & 995 & 5.5765 & TRN \\
\hline CHEMBL577807 & 600886 & 5.6101 & 5.0457 & TRN & & \\
\hline CHEMBL588543 & 600886 & 6.2083 & 6.3371 & TST & & \\
\hline CHEMBL601984 & 600886 & 6.1662 & 5.3342 & TRN & & \\
\hline CHEMBL605946 & 600886 & 6.3335 & 6.50700 & 0000000001 & & TRN \\
\hline CHEMBL583362 & 600886 & 4.9454 & 5.6225 & TRN & & \\
\hline CHEMBL585628 & 600886 & 6.5948 & 6.5787 & TRN & & \\
\hline CHEMBL579956 & 600886 & 6.1415 & 6.1146 & TST & & \\
\hline CHEMBL602391 & 600886 & 5.5007 & 5.0739 & TRN & & \\
\hline CHEMBL581458 & 600886 & 6.0 & 6.1576 & TST & & \\
\hline CHEMBL577893 & 600886 & 6.2069 & 5.6408 & TRN & & \\
\hline CHEMBL600500 & 600886 & 6.1713 & 6.1042 & TRN & & \\
\hline CHEMBL600920 & 600886 & 6.5385 & 6.6691 & TRN & & \\
\hline CHEMBL600094 & 600886 & 6.9385 & 6.8316 & TRN & & \\
\hline CHEMBL602363 & 600886 & 8.5913 & 6.4203 & TRN & & \\
\hline CHEMBL580752 & 600886 & 7.2076 & 6.6372 & TRN & & \\
\hline CHEMBL585821 & 600886 & 6.5719 & 6.5719 & TRN & & \\
\hline CHEMBL579377 & 600886 & 6.9642 & 6.3485 & TRN & & \\
\hline CHEMBL578443 & 600886 & 6.3439 & 6.5974 & TRN & & \\
\hline CHEMBL599922 & 600886 & 7.5148 & 7.226 & TRN & & \\
\hline CHEMBL529555 & 600886 & 6.2933 & 5.8008 & TRN & & \\
\hline CHEMBL604528 & 600886 & 4.9031 & 5.6865 & TRN & & \\
\hline CHEMBL600102 & 600886 & 6.0 & 6.28100 & 0000000001 & & TRN \\
\hline CHEMBL602204 & 600886 & 5.8864 & 5.0981 & TRN & & \\
\hline CHEMBL584220 & 600886 & 6.4248 & 6.2126 & TRN & & \\
\hline CHEMBL583827 & 600886 & 5.9551 & 5.7734 & TST & & \\
\hline CHEMBL581242 & 600886 & 6.7597 & 6.4603 & TRN & & \\
\hline CHEMBL531495 & 600886 & 6.5081 & 6.5299 & TRN & & \\
\hline CHEMBL578311 & 600886 & 5.2495 & 5.6063 & TRN & & \\
\hline CHEMBL601327 & 600886 & 6.6003 & 6.3778 & TST & & \\
\hline CHEMBL576616 & 600886 & 5.1506 & 5.6826 & TRN & & \\
\hline CHEMBL124006 & 600886 & 6.4123 & 7.1454 & TRN & & \\
\hline CHEMBL577633 & 600886 & 6.0 & 6.1831 & TRN & & \\
\hline CHEMBL604530 & 600886 & 7.0467 & 5.5952 & TRN & & \\
\hline CHEMBL578904 & 600886 & 6.5144 & 6.4809 & TRN & & \\
\hline CHEMBL584037 & 600886 & 5.9978 & 6.4018 & TRN & & \\
\hline CHEMBL585244 & 600886 & 6.2321 & 6.4236 & TST & & \\
\hline CHEMBL597242 & 600886 & 6.0768 & 5.0434 & TST & & \\
\hline CHEMBL584619 & 600886 & 6.5078 & 6.3319 & TRN & & \\
\hline CHEMBL601164 & 600886 & 6.7986 & 6.45700 & 0000000001 & & TRN \\
\hline CHEMBL584420 & 600886 & 4.9412 & 5.581 & TRN & & \\
\hline CHEMBL593484 & 600886 & 6.8359 & 6.3615 & TRN & & \\
\hline CHEMBL577444 & 600886 & 6.8182 & 6.4443 & TRN & & \\
\hline
\end{tabular}




\begin{tabular}{|c|c|c|c|c|c|}
\hline & & & & & \\
\hline CHEMBL 588176 & 600886 & 6.0526 & 6.6233 & TRN & \\
\hline CHEMBL588167 & 600886 & 6.0716 & 6.1727 & TRN & \\
\hline CHEMBL585078 & 600886 & 4.9031 & 5.8714 & TST & \\
\hline CHEMBL602627 & 600886 & 6.4401 & 6.187 & TRN & \\
\hline CHEMBL600754 & 600886 & 6.8965 & 6.4255 & TRN & \\
\hline CHEMBL581866 & 600886 & 6.3979 & 6.4551 & TRN & \\
\hline CHEMBL576792 & 600886 & 5.6075 & 6.3762 & TRN & \\
\hline CHEMBL 394752 & 600886 & 6.1765 & 6.4719 & TST & \\
\hline CHEMBL579316 & 600886 & 6.4179 & 6.4085 & TRN & \\
\hline CHEMBL602429 & 600886 & 6.4868 & 6.1418 & TST & \\
\hline CHEMBL 600530 & 600886 & 8.1244 & 5.7387 & TRN & \\
\hline CHEMBL602774 & 600886 & 5.4034 & 5.3671 & TST & \\
\hline CHEMBL 588796 & 600886 & 7.9606 & 7.1235 & TRN & \\
\hline CHEMBL597471 & 600886 & 6.511 & 5.9822 & TRN & \\
\hline CHEMBL581455 & 600886 & 6.706 & 6.8621 & TRN & \\
\hline CHEMBL 585145 & 600886 & 7.1605 & 7.41200 & 0000000001 & TRN \\
\hline CHEMBL598273 & 600886 & 7.0996 & 6.3469 & TRN & \\
\hline CHEMBL600756 & 600886 & 6.0022 & 6.4913 & TST & \\
\hline CHEMBL599720 & 600886 & 6.1343 & 6.1912 & TRN & \\
\hline CHEMBL588450 & 600886 & 6.8312 & 6.3351 & TRN & \\
\hline CHEMBL 343286 & 600886 & 7.57299 & 79999999 & 6.4303 & TST \\
\hline CHEMBL577884 & 600886 & 6.8739 & 6.5625 & TRN & \\
\hline CHEMBL586008 & 600886 & 6.9041 & 6.6018 & TRN & \\
\hline CHEMBL600737 & 600886 & 6.5571 & 6.2516 & TRN & \\
\hline CHEMBL582103 & 600886 & 6.6674 & 6.398 & TST & \\
\hline CHEMBL582107 & 600886 & 7.4078 & 6.8502 & TRN & \\
\hline CHEMBL532466 & 600886 & 6.0 & 6.2263 & TST & \\
\hline CHEMBL600501 & 600886 & 4.1192 & 5.1117 & TRN & \\
\hline CHEMBL581872 & 600886 & 6.6323 & 6.4893 & TRN & \\
\hline CHEMBL 600744 & 600886 & 4.7007 & 5.0561 & TST & \\
\hline CHEMBL534144 & 600886 & 6.4962 & 5.5251 & TRN & \\
\hline CHEMBL601530 & 600886 & 6.058 & 5.80200 & 00000000005 & TRN \\
\hline CHEMBL 581393 & 600886 & 7.0825 & 5.9738 & TRN & \\
\hline CHEMBL597650 & 600886 & 6.3072 & 6.5401 & TRN & \\
\hline CHEMBL577862 & 600886 & 6.0 & 5.8307 & TRN & \\
\hline CHEMBL584415 & 600886 & 6.4572 & 6.13 & TRN & \\
\hline CHEMBL602966 & 600886 & 6.0106 & 5.2958 & TST & \\
\hline CHEMBL604517 & 600886 & 8.0969 & 6.3405 & TRN & \\
\hline CHEMBL597874 & 600886 & 7.2069 & 6.603 & TRN & \\
\hline CHEMBL578715 & 600886 & 5.5941 & 6.0764 & TRN & \\
\hline CHEMBL529984 & 600886 & 6.4597 & 6.6954 & TRN & \\
\hline CHEMBL531956 & 600886 & 5.2457 & 5.8149 & TRN & \\
\hline CHEMBL579858 & 600886 & 6.6276 & 6.1675 & TRN & \\
\hline CHEMBL585046 & 600886 & 5.5494 & 6.0808 & TRN & \\
\hline CHEMBL577226 & 600886 & 6.8801 & 6.2015 & TRN & \\
\hline CHEMBL578740 & 600886 & 7.2495 & 6.3121 & TRN & \\
\hline CHEMBL581685 & 600886 & 7.2197 & 5.5932 & TST & \\
\hline CHEMBL581896 & 600886 & 5.8038 & 6.5517 & TRN & \\
\hline
\end{tabular}




\begin{tabular}{|c|c|c|c|c|c|}
\hline \multirow[b]{2}{*}{ CHEMBL532671 } & \multicolumn{5}{|c|}{ Supplemental Table S2.txt } \\
\hline & 600886 & 6.3206 & 6.7871 & TRN & \\
\hline CHEMBL584018 & 600886 & 4.9255 & 5.5681 & TRN & \\
\hline CHEMBL601315 & 600886 & 9.0991 & 5.5659 & TRN & \\
\hline CHEMBL599891 & 600886 & 4.9031 & 6.16100 & 00000000005 & TRN \\
\hline CHEMBL532552 & 600886 & 6.5473 & 6.2509 & TRN & \\
\hline CHEMBL602570 & 600886 & 3.9031 & 6.2313 & TRN & \\
\hline CHEMBL530300 & 600886 & 5.066 & 5.7642 & TRN & \\
\hline CHEMBL603036 & 600886 & 4.9389 & 5.5439 & TRN & \\
\hline CHEMBL602618 & 600886 & 5.4647 & 5.9143 & TRN & \\
\hline CHEMBL577195 & 600886 & 5.4134 & 5.4871 & TRN & \\
\hline CHEMBL611663 & 600886 & 6.8539 & 6.67299 & 9999999999 & TRN \\
\hline CHEMBL582801 & 600886 & 4.9031 & 5.6407 & TRN & \\
\hline CHEMBL578700 & 600886 & 6.4377 & 6.5879 & TRN & \\
\hline CHEMBL601356 & 600886 & 6.5933 & 6.7813 & TRN & \\
\hline CHEMBL584871 & 600886 & 6.0246 & 5.6019 & TRN & \\
\hline CHEMBL581875 & 600886 & 6.1255 & 6.4059 & TRN & \\
\hline CHEMBL604362 & 600886 & 6.4584 & 5.3725 & TRN & \\
\hline CHEMBL577882 & 600886 & 6.0 & 6.2675 & TRN & \\
\hline CHEMBL600731 & 600886 & 5.8595 & 6.5376 & TRN & \\
\hline CHEMBL579503 & 600886 & 6.3862 & 6.4798 & TRN & \\
\hline CHEMBL583584 & 600886 & 6.506 & 6.9303 & TRN & \\
\hline CHEMBL586455 & 600886 & 5.5899 & 6.1186 & TRN & \\
\hline CHEMBL601793 & 600886 & 7.451006 & 30000000 & 6.619 & TRN \\
\hline CHEMBL577436 & 600886 & 6.0 & 6.2635 & TRN & \\
\hline CHEMBL585767 & 600886 & 5.5661 & 5.7174 & TRN & \\
\hline CHEMBL599899 & 600886 & 6.8861 & 6.9399 & TST & \\
\hline CHEMBL602189 & 600886 & 5.1938 & 5.5837 & TRN & \\
\hline CHEMBL600953 & 600886 & 5.8038 & 6.0955 & TRN & \\
\hline CHEMBL584873 & 600886 & 6.1385 & 6.0004 & TRN & \\
\hline CHEMBL602221 & 600886 & 4.0 & 5.2297 & TST & \\
\hline CHEMBL531808 & 600886 & 10.2426 & 5.7295 & TRN & \\
\hline CHEMBL586883 & 600886 & 6.9796 & 6.9022 & TRN & \\
\hline CHEMBL601813 & 600886 & 5.2262 & 5.8354 & TRN & \\
\hline CHEMBL602637 & 600886 & 6.4123 & 6.2293 & TRN & \\
\hline CHEMBL602811 & 600886 & 4.9031 & 5.6255 & TRN & \\
\hline CHEMBL527465 & 600886 & 5.8908 & 5.1129 & TRN & \\
\hline CHEMBL597051 & 600886 & 7.0438 & 6.6148 & TRN & \\
\hline CHEMBL579556 & 600886 & 5.8735 & 5.807 & TRN & \\
\hline CHEMBL584834 & 600886 & 6.0114 & 5.5553 & TRN & \\
\hline CHEMBL195024 & 600886 & 5.059 & 5.7109 & TRN & \\
\hline CHEMBL585835 & 600886 & 6.6271 & 6.4078 & TRN & \\
\hline CHEMBL602794 & 600886 & 6.0 & 6.2985 & TRN & \\
\hline CHEMBL531387 & 600886 & 4.3655 & 5.2359 & TRN & \\
\hline CHEMBL585608 & 600886 & 4.9393 & 5.7165 & TRN & \\
\hline CHEMBL586146 & 600886 & 5.1537 & 5.6731 & TRN & \\
\hline CHEMBL582781 & 600886 & 6.0255 & 5.7342 & TRN & \\
\hline CHEMBL585502 & 600886 & 6.0 & 6.24 & TRN & \\
\hline CHEMBL602581 & 600886 & 6.2132 & 6.2977 & TRN & \\
\hline
\end{tabular}




\begin{tabular}{|c|c|c|c|c|c|}
\hline \multirow[b]{2}{*}{ CHEMBL601137 } & \multicolumn{5}{|c|}{ Supplemental Table S2.txt } \\
\hline & 600886 & 6.0 & 6.2624 & TRN & \\
\hline CHEMBL598284 & 600886 & 5.994 & 5.4832 & TST & \\
\hline CHEMBL603046 & 600886 & 6.5092 & 6.2709 & TRN & \\
\hline CHEMBL581651 & 600886 & 6.1884 & 6.6384 & TRN & \\
\hline CHEMBL582067 & 600886 & 5.8368 & 6.3256 & TRN & \\
\hline CHEMBL578741 & 600886 & 7.2549 & 6.7243 & TRN & \\
\hline CHEMBL579569 & 600886 & 4.9031 & 6.2876 & TRN & \\
\hline CHEMBL601361 & 600886 & 6.0223 & 6.1717 & TRN & \\
\hline CHEMBL581858 & 600886 & 7.2403 & 7.0163 & TRN & \\
\hline CHEMBL602418 & 600886 & 5.7696 & 5.5624 & TRN & \\
\hline CHEMBL560918 & 600886 & 5.8614 & 6.2324 & TRN & \\
\hline CHEMBL599301 & 600886 & 5.9735 & 6.4096 & TRN & \\
\hline CHEMBL185912 & 600886 & 6.2503 & 6.1741 & TRN & \\
\hline CHEMBL581448 & 600886 & 5.7042 & 6.3162 & TRN & \\
\hline CHEMBL579100 & 600886 & 5.5294 & 6.0108 & TRN & \\
\hline CHEMBL601159 & 600886 & 6.6375 & 6.7734 & TRN & \\
\hline CHEMBL578673 & 600886 & 5.3468 & 5.2849 & TST & \\
\hline CHEMBL577006 & 600886 & 5.1367 & 5.7196 & TRN & \\
\hline CHEMBL577200 & 600886 & 8.4078 & 7.6912 & TRN & \\
\hline CHEMBL596842 & 600886 & 7.2306 & 6.3054 & TRN & \\
\hline CHEMBL586206 & 600886 & 5.1972 & 5.6475 & TRN & \\
\hline CHEMBL596646 & 600886 & 6.0 & 6.141 & TRN & \\
\hline CHEMBL599511 & 600886 & 6.0173 & 6.3343 & TRN & \\
\hline CHEMBL588250 & 600886 & 5.803 & 6.351 & TRN & \\
\hline CHEMBL611499 & 600886 & 6.3143 & 5.7626 & TRN & \\
\hline CHEMBL601598 & 600886 & 5.9531 & 5.9818 & TRN & \\
\hline CHEMBL600760 & 600886 & 4.968999 & 999999999 & 5.6139 & TRN \\
\hline CHEMBL584441 & 600886 & 6.3936 & 6.497000 & 0000000001 & TRN \\
\hline CHEMBL599902 & 600886 & 6.0405 & 6.2492 & TRN & \\
\hline CHEMBL598486 & 600886 & 4.9031 & 6.457999 & 9999999999 & TRN \\
\hline CHEMBL584523 & 600886 & 6.3585 & 5.9632 & TRN & \\
\hline CHEMBL597265 & 600886 & 6.2441 & 6.1357 & TRN & \\
\hline CHEMBL581871 & 600886 & 6.8539 & 6.8815 & TRN & \\
\hline CHEMBL530620 & 600886 & 7.475 & 6.8148 & TRN & \\
\hline CHEMBL602612 & 600886 & 5.6815 & 6.6843 & TRN & \\
\hline CHEMBL578954 & 600886 & 7.4789 & 6.8151 & TRN & \\
\hline CHEMBL582699 & 600886 & 5.4776 & 5.8023 & TRN & \\
\hline CHEMBL580794 & 600886 & 6.1599 & 6.1972 & TST & \\
\hline CHEMBL530405 & 600886 & 7.1062 & 6.8545 & TRN & \\
\hline CHEMBL597455 & 600886 & 4.9031 & 6.3836 & TRN & \\
\hline CHEMBL585797 & 600886 & 5.383999 & 999999999 & 5.0501 & TRN \\
\hline CHEMBL582308 & 600886 & 4.758 & 6.3111 & TRN & \\
\hline CHEMBL578938 & 600886 & 6.56 & 6.3924 & TRN & \\
\hline CHEMBL577224 & 600886 & 6.1898 & 6.1341 & TST & \\
\hline CHEMBL598896 & 600886 & 5.9087 & 6.1613 & TRN & \\
\hline CHEMBL599905 & 600886 & 5.1439 & 6.548999 & 99999999995 & TST \\
\hline CHEMBL600532 & 600886 & 6.1543 & 6.397 & TRN & \\
\hline CHEMBL528589 & 600886 & 6.6407 & 6.3257 & TRN & \\
\hline
\end{tabular}




\begin{tabular}{|c|c|c|c|c|c|c|}
\hline \multicolumn{7}{|c|}{ Supplemental Table S2.txt } \\
\hline CHEMBL599095 & 600886 & 7.2351 & 7.3055 & TRN & & \\
\hline CHEMBL602832 & 600886 & 6.1445 & 5.7068 & TRN & & \\
\hline CHEMBL578285 & 600886 & 6.0 & 6.3509 & TRN & & \\
\hline CHEMBL584637 & 600886 & 6.5191 & 6.5528 & TRN & & \\
\hline CHEMBL602354 & 600886 & 6.1605 & 6.2176 & TRN & & \\
\hline CHEMBL578735 & 600886 & 8.118 & 7.2508 & TST & & \\
\hline CHEMBL581614 & 600886 & 6.1051 & 6.1743 & TRN & & \\
\hline CHEMBL531121 & 600886 & 6.7178 & 6.7326 & TRN & & \\
\hline CHEMBL601117 & 600886 & 6.4711 & 6.5053 & TRN & & \\
\hline CHEMBL579312 & 600886 & 5.5306 & 5.2593 & TST & & \\
\hline CHEMBL603896 & 600886 & 6.1649 & 6.4492 & TRN & & \\
\hline CHEMBL482160 & 600886 & 6.3625 & 6.2211 & TRN & & \\
\hline CHEMBL584226 & 600886 & 7.3893 & 6.1218 & TRN & & \\
\hline CHEMBL526027 & 600886 & 6.0205 & 6.5852 & TRN & & \\
\hline CHEMBL579424 & 600886 & 6.2933 & 6.6994 & TRN & & \\
\hline CHEMBL580158 & 600886 & 5.7525 & 5.2156 & TST & & \\
\hline CHEMBL585659 & 600886 & 6.2097 & 6.2941 & TRN & & \\
\hline CHEMBL585236 & 600886 & 4.9223 & 6.0969 & TRN & & \\
\hline CHEMBL579304 & 600886 & 6.5297 & 5.6639 & TRN & & \\
\hline CHEMBL584496 & 600886 & 6.2604 & 5.7971 & TRN & & \\
\hline CHEMBL607974 & 600886 & 4.9031 & 5.9234 & TRN & & \\
\hline CHEMBL583821 & 600886 & 6.0 & 6.0362 & TRN & & \\
\hline CHEMBL405668 & 600886 & 6.0 & 6.2638 & TRN & & \\
\hline CHEMBL599513 & 600886 & 6.1046 & 6.3565 & TRN & & \\
\hline CHEMBL580827 & 600886 & 5.8116 & 5.7177 & TRN & & \\
\hline CHEMBL599517 & 600886 & 4.908 & 5.6056 & TST & & \\
\hline CHEMBL1615695 & 600886 & 4.914 & 6.8104 & TRN & & \\
\hline CHEMBL347645 & 600886 & 5.0223 & 5.1511 & TST & & \\
\hline CHEMBL600948 & 600886 & 5.8775 & 6.1541 & TRN & & \\
\hline CHEMBL600324 & 600886 & 4.61100 & 00000000 & 01 & 6.0828 TRN & \\
\hline CHEMBL582659 & 600886 & 6.0 & 6.2529 & TRN & & \\
\hline CHEMBL577589 & 600886 & 5.3757 & 5.1104 & TRN & & \\
\hline CHEMBL582698 & 600886 & 5.7217 & 5.5907 & TRN & & \\
\hline CHEMBL585454 & 600886 & 7.57299 & 99999999 & 995 & 5.4879999999999995 & TRN \\
\hline CHEMBL600531 & 600886 & 7.1385 & 6.4022 & TRN & & \\
\hline CHEMBL585459 & 600886 & 6.5342 & 6.1572 & TRN & & \\
\hline CHEMBL602161 & 600886 & 5.9987 & 6.1504 & TST & & \\
\hline CHEMBL587826 & 600886 & 7.0625 & 6.6692 & TRN & & \\
\hline CHEMBL603030 & 600886 & 6.7562 & 5.0432 & TRN & & \\
\hline CHEMBL533302 & 600886 & 6.2565 & 6.5275 & TST & & \\
\hline CHEMBL422330 & 600886 & 6.2857 & 6.3175 & TRN & & \\
\hline CHEMBL532935 & 600886 & 5.9952 & 5.9966 & TRN & & \\
\hline CHEMBL526240 & 600886 & 7.2958 & 6.7289 & TRN & & \\
\hline CHEMBL578268 & 600886 & 6.4034 & 6.6262 & TRN & & \\
\hline CHEMBL601544 & 600886 & 5.3354 & 6.0949 & TRN & & \\
\hline CHEMBL599286 & 600886 & 6.9303 & 6.348 & TRN & & \\
\hline CHEMBL602769 & 600886 & 6.7678 & 6.5689 & TST & & \\
\hline CHEMBL579165 & 600886 & 6.0872 & 5.454 & TRN & & \\
\hline
\end{tabular}




\begin{tabular}{|c|c|c|c|c|c|}
\hline \multirow[b]{2}{*}{ CHEMBL605944 } & \multicolumn{5}{|c|}{ supp } \\
\hline & 600886 & 6.1612 & 6.3009 & TST & \\
\hline CHEMBL14435 & 600886 & 6.0186 & 6.135 & TRN & \\
\hline CHEMBL582482 & 600886 & 6.0 & 6.1856 & TST & \\
\hline CHEMBL587581 & 600886 & 9.0809 & 6.9641 & TRN & \\
\hline CHEMBL600328 & 600886 & 7.4202 & 6.9143 & TRN & \\
\hline CHEMBL585776 & 600886 & 4.9739 & 5.6054 & TRN & \\
\hline CHEMBL600144 & 600886 & 6.3125 & 5.625 & TRN & \\
\hline CHEMBL 366240 & 600886 & 6.9813 & 6.7185 & TRN & \\
\hline CHEMBL599908 & 600886 & 5.6405 & 6.1771 & TRN & \\
\hline CHEMBL582718 & 600886 & 6.7673 & 6.4174 & TRN & \\
\hline CHEMBL602772 & 600886 & 5.3354 & 5.8647 & TST & \\
\hline CHEMBL601782 & 600886 & 6.9481 & 6.3252 & TRN & \\
\hline CHEMBL578519 & 600886 & 6.0942 & 6.2675 & TRN & \\
\hline CHEMBL610912 & 600886 & 6.0467 & 6.0629 & TRN & \\
\hline CHEMBL579123 & 600886 & 5.4737 & 5.1506 & TRN & \\
\hline CHEMBL585639 & 600886 & \multicolumn{2}{|c|}{7.5729999999999995} & 5.5673 & TRN \\
\hline CHEMBL586012 & 600886 & 8.6108 & 6.146 & TST & \\
\hline CHEMBL600901 & 600886 & 6.1203 & 6.1002 & TST & \\
\hline CHEMBL598271 & 600886 & 7.068 & 5.5367 & TRN & \\
\hline CHEMBL600759 & 600886 & 5.9488 & 5.6174 & TRN & \\
\hline CHEMBL602224 & 600886 & 5.063 & 5.5349 & TST & \\
\hline CHEMBL585401 & 600886 & 4.9562 & 5.5871 & TRN & \\
\hline CHEMBL603518 & 600886 & 5.3575 & 5.5896 & TRN & \\
\hline CHEMBL578749 & 600886 & 5.8745 & 6.0471 & TRN & \\
\hline CHEMBL602411 & 600886 & 5.848 & 4.9896 & TRN & \\
\hline CHEMBL577000 & 600886 & 6.2774 & \multicolumn{2}{|c|}{6.712000000000001} & TRN \\
\hline CHEMBL577220 & 600886 & 6.1574 & 5.6202 & TRN & \\
\hline CHEMBL601775 & 600886 & 5.7577 & 5.6338 & TRN & \\
\hline CHEMBL577438 & 600886 & 6.1624 & \multicolumn{2}{|c|}{6.3660000000000005} & TRN \\
\hline CHEMBL588276 & 600886 & 6.9855 & 7.0123 & TRN & \\
\hline CHEMBL602360 & 600886 & 6.5894 & 6.5086 & TRN & \\
\hline CHEMBL600484 & 600886 & 4.9031 & 5.62 & TRN & \\
\hline CHEMBL585790 & 600886 & 5.0301 & 5.6284 & TST & \\
\hline CHEMBL602970 & 600886 & 5.9003 & 5.4271 & TRN & \\
\hline CHEMBL586668 & 600886 & 9.6077 & 7.0304 & TRN & \\
\hline CHEMBL611075 & 600886 & 6.9326 & 5.7458 & TRN & \\
\hline CHEMBL600769 & 600886 & 6.5387 & 6.2885 & TST & \\
\hline CHEMBL602614 & 600886 & 4.9739 & 5.5308 & TRN & \\
\hline CHEMBL582460 & 600886 & 6.2472 & 5.6203 & TST & \\
\hline CHEMBL579356 & 600886 & 5.6375 & 5.9289 & TRN & \\
\hline CHEMBL547775 & 600886 & 6.5725 & \multicolumn{2}{|c|}{6.832000000000001} & TRN \\
\hline CHEMBL1615698 & 600886 & 5.7731 & 6.1552 & TST & \\
\hline CHEMBL596839 & 600886 & 4.9031 & 5.8087 & TRN & \\
\hline CHEMBL527131 & 600886 & 6.4498 & 6.3755 & TRN & \\
\hline CHEMBL529496 & 600886 & 4.9031 & 6.2107 & TRN & \\
\hline CHEMBL600727 & 600886 & 9.9731 & 5.5538 & TRN & \\
\hline CHEMBL599942 & 600886 & 5.8182 & 5.6169 & TST & \\
\hline CHEMBL585807 & 600886 & 5.9176 & 5.9746 & TST & \\
\hline & & & & 14253 & \\
\hline
\end{tabular}




\begin{tabular}{|c|c|c|c|c|c|c|}
\hline & & \multicolumn{5}{|c|}{ Supplemental Table S2.txt } \\
\hline CHEMBL601352 & 600886 & 5.6385 & 5.7869 & TRN & & \\
\hline CHEMBL597664 & 600886 & 7.1308 & 6.3114 & TRN & & \\
\hline CHEMBL602012 & 600886 & 7.1733 & 6.5918 & TRN & & \\
\hline CHEMBL546707 & 600886 & 5.937 & 6.3106 & TRN & & \\
\hline CHEMBL581257 & 600886 & \multicolumn{3}{|c|}{6.202000000000001} & 7.3401 & TRN \\
\hline CHEMBL532167 & 600886 & 5.2076 & 5.6879 & TRN & & \\
\hline CHEMBL199659 & 600886 & 4.9031 & 5.5881 & TRN & & \\
\hline CHEMBL578279 & 600886 & 5.9147 & 6.7786 & TRN & & \\
\hline CHEMBL600929 & 600886 & \multicolumn{3}{|c|}{5.327000000000001} & 5.77 & TRN \\
\hline CHEMBL580841 & 600886 & 4.9031 & 5.5975 & TRN & & \\
\hline CHEMBL586031 & 600886 & 7.3969 & 7.1849 & TRN & & \\
\hline CHEMBL602380 & 600886 & 5.7513 & 5.6568 & TST & & \\
\hline CHEMBL585803 & 600886 & 5.9582 & 6.0797 & TRN & & \\
\hline CHEMBL611070 & 600886 & 6.1959 & 6.0823 & TRN & & \\
\hline CHEMBL602597 & 600886 & 5.4802 & 5.1103 & TRN & & \\
\hline CHEMBL597036 & 600886 & 5.9893 & 5.9451 & TRN & & \\
\hline CHEMBL585986 & 600886 & 6.0 & 6.3866 & TST & & \\
\hline CHEMBL585239 & 600886 & 6.7102 & 6.4639 & TRN & & \\
\hline CHEMBL585654 & 600886 & 6.1739 & 6.404 & TST & & \\
\hline CHEMBL600903 & 600886 & 4.9031 & 5.7014 & TRN & & \\
\hline CHEMBL602826 & 600886 & 6.0804 & 6.1212 & TRN & & \\
\hline CHEMBL371218 & 600886 & 6.4389 & 6.4139 & TRN & & \\
\hline CHEMBL585808 & 600886 & 4.9234 & 5.636 & TRN & & \\
\hline CHEMBL582310 & 600886 & 6.669 & 5.7421 & TRN & & \\
\hline CHEMBL580640 & 600886 & 4.8693 & 6.3428 & TRN & & \\
\hline CHEMBL531018 & 600886 & 6.6308 & 6.5017 & TRN & & \\
\hline CHEMBL470514 & 600886 & 6.4342 & 6.5528 & TRN & & \\
\hline CHEMBL599960 & 600886 & 6.8589 & 6.2021 & TRN & & \\
\hline CHEMBL602620 & 600886 & 5.8626 & 5.8516 & TRN & & \\
\hline CHEMBL537724 & 600886 & 6.9504 & 6.5412 & TRN & & \\
\hline CHEMBL600315 & 600886 & 6.1463 & 6.2801 & TST & & \\
\hline CHEMBL582707 & 600886 & 6.4078 & 6.6922 & TRN & & \\
\hline CHEMBL607687 & 600886 & 6.1175 & 6.4212 & TST & & \\
\hline CHEMBL579479 & 600886 & 6.3063 & 6.5182 & TRN & & \\
\hline CHEMBL583558 & 600886 & 6.0 & 6.2747 & TRN & & \\
\hline CHEMBL582479 & 600886 & 5.118 & 5.8091 & TRN & & \\
\hline CHEMBL605747 & 600886 & 6.063 & 6.3425 & TRN & & \\
\hline CHEMBL599699 & 600886 & 4.9031 & 6.2831 & TRN & & \\
\hline CHEMBL598266 & 600886 & 6.0 & 6.1419 & TRN & & \\
\hline CHEMBL605423 & 600886 & 6.3487 & 6.1511 & TRN & & \\
\hline CHEMBL600522 & 600886 & 6.2248 & 6.3351 & TRN & & \\
\hline CHEMBL588539 & 600886 & 6.0 & 6.2573 & TRN & & \\
\hline CHEMBL605188 & 600886 & 7.0731 & 6.3507 & TRN & & \\
\hline CHEMBL588571 & 600886 & 6.0721 & 6.67 & TRN & & \\
\hline CHEMBL581473 & 600886 & 5.7459 & 5.227 & TRN & & \\
\hline CHEMBL545872 & 600886 & 6.5409 & 6.4736 & TRN & & \\
\hline CHEMBL598058 & 600886 & 5.9678 & 6.1365 & TST & & \\
\hline CHEMBL582702 & 600886 & 6.8636 & 6.2656 & TRN & & \\
\hline
\end{tabular}




\begin{tabular}{|c|c|c|c|c|}
\hline & & & pplement & al $\mathrm{T}$ \\
\hline CHEMBL527728 & 600886 & 4.9031 & 5.7478 & TRN \\
\hline CHEMBL584836 & 600886 & 4.9784 & 5.4985 & TRN \\
\hline CHEMBL582117 & 600886 & 5.8722 & 6.3162 & TRN \\
\hline CHEMBL599090 & 600886 & 7.0953 & 6.3114 & TRN \\
\hline CHEMBL602410 & 600886 & 5.8952 & 5.5871 & TRN \\
\hline CHEMBL581675 & 600886 & 5.8122 & 6.6341 & TRN \\
\hline CHEMBL577199 & 600886 & 6.3925 & 6.4114 & TRN \\
\hline CHEMBL578911 & 600886 & 6.5016 & 5.5106 & TRN \\
\hline CHEMBL527416 & 600886 & 7.6407 & 6.2802 & TRN \\
\hline CHEMBL602198 & 600886 & 4.399 & 5.2339 & TRN \\
\hline CHEMBL610623 & 600886 & 5.5933 & 5.233 & TST \\
\hline CHEMBL603006 & 600886 & 8.8611 & 6.745 & TRN \\
\hline CHEMBL597473 & 600886 & 6.9519 & 6.3423 & TRN \\
\hline CHEMBL585074 & 600886 & 4.9662 & 5.5879 & TST \\
\hline CHEMBL601529 & 600886 & 4.9031 & 5.6308 & TST \\
\hline CHEMBL581662 & 600886 & 5.7095 & 6.0825 & TRN \\
\hline CHEMBL583600 & 600886 & 6.0 & 6.1308 & TST \\
\hline CHEMBL584246 & 600886 & 6.4935 & 6.8055 & TST \\
\hline CHEMBL579930 & 600886 & 5.4179 & 5.82 & TST \\
\hline CHEMBL597667 & 600886 & 6.8312 & 6.4209 & TRN \\
\hline CHEMBL577866 & 600886 & 6.0 & 6.2994 & TRN \\
\hline CHEMBL581244 & 600886 & 6.6819 & 6.6069 & TST \\
\hline CHEMBL582496 & 600886 & 5.8336 & 6.2535 & TRN \\
\hline CHEMBL579095 & 600886 & 6.3497 & 5.7033 & TST \\
\hline CHEMBL583168 & 600886 & 6.3706 & 6.1591 & TRN \\
\hline CHEMBL576181 & 600886 & 5.9851 & 6.2762 & TRN \\
\hline CHEMBL600111 & 600886 & 5.7724 & 5.8764 & TRN \\
\hline CHEMBL577002 & 600886 & 4.9031 & 6.9206 & TRN \\
\hline CHEMBL584505 & 600886 & 6.0325 & 6.3996 & TRN \\
\hline CHEMBL598887 & 600886 & 7.1986 & 7.2308 & TRN \\
\hline CHEMBL576334 & 600886 & 5.4935 & 5.5397 & TRN \\
\hline CHEMBL601150 & 600886 & 5.6957 & 5.4944 & TRN \\
\hline CHEMBL597462 & 600886 & 6.1018 & 6.0644 & TRN \\
\hline CHEMBL375673 & 600886 & 5.4535 & 6.124 & TRN \\
\hline CHEMBL584410 & 600886 & 6.0 & 6.2755 & TRN \\
\hline CHEMBL576527 & 600886 & 6.3737 & 6.2474 & TRN \\
\hline CHEMBL580134 & 600886 & 6.279 & 6.3043 & TRN \\
\hline CHEMBL602153 & 600886 & 6.3799 & 6.2366 & TRN \\
\hline CHEMBL603022 & 600886 & 5.9439 & 6.2496 & TRN \\
\hline CHEMBL596651 & 600886 & 6.1993 & 6.0564 & TRN \\
\hline CHEMBL603732 & 600886 & 4.9031 & 6.0889 & TRN \\
\hline CHEMBL583550 & 600886 & 6.4112 & 6.2095 & TRN \\
\hline CHEMBL586658 & 600886 & 5.1273 & 5.6638 & TST \\
\hline CHEMBL585245 & 600886 & 6.061 & 5.5554 & TRN \\
\hline CHEMBL578530 & 600886 & 7.0329 & 6.7192 & TST \\
\hline CHEMBL583815 & 600886 & 3.9516 & 4.9535 & TRN \\
\hline CHEMBL599719 & 600886 & 6.0 & 6.2852 & TRN \\
\hline CHEMBL581897 & 600886 & 4.9031 & 6.0184 & TRN \\
\hline
\end{tabular}




\begin{tabular}{|c|c|c|c|c|c|}
\hline \multicolumn{6}{|c|}{30} \\
\hline CHEMBL587760 & 600886 & 6.9905 & 6.4661 & TRN & \\
\hline CHEMBL585200 & 600886 & 6.4389 & 6.5221 & TRN & \\
\hline CHEMBL597851 & 600886 & 4.9031 & 6.4643 & TRN & \\
\hline CHEMBL604320 & 600886 & 6.7438 & 6.4494 & TST & \\
\hline CHEMBL599918 & 600886 & 5.251 & 5.0701 & TRN & \\
\hline CHEMBL596639 & 600886 & 6.3143 & 6.4233 & TRN & \\
\hline CHEMBL584222 & 600886 & 7.3851 & 6.5164 & TRN & \\
\hline CHEMBL602200 & 600886 & 6.7199 & 6.5328 & TRN & \\
\hline CHEMBL546828 & 600886 & 5.8548 & 6.1651 & TRN & \\
\hline CHEMBL585411 & 600886 & 7.5488 & 6.8012 & TST & \\
\hline CHEMBL604515 & 600886 & 6.2684 & 6.374 & TRN & \\
\hline CHEMBL602799 & 600886 & 6.4572 & 6.5733 & TRN & \\
\hline CHEMBL584826 & 600886 & 6.3737 & 6.5501 & TRN & \\
\hline CHEMBL582514 & 600886 & 6.1798 & 6.3536 & TRN & \\
\hline CHEMBL585243 & 600886 & 6.5224 & 6.5726 & TST & \\
\hline CHEMBL599290 & 600886 & 7.0092 & 6.2097 & TRN & \\
\hline CHEMBL584632 & 600886 & 6.584 & 6.5122 & TRN & \\
\hline CHEMBL600113 & 600886 & 6.4112 & 6.2914 & TRN & \\
\hline CHEMBL602619 & 600886 & 5.9897 & 6.1641 & TRN & \\
\hline CHEMBL582091 & 600886 & 5.5776 & 6.0437 & TRN & \\
\hline CHEMBL578535 & 600886 & 5.8136 & 5.5374 & TRN & \\
\hline CHEMBL365324 & 600886 & 6.0 & 6.2958 & TRN & \\
\hline CHEMBL600331 & 600886 & 6.6503 & 6.735 & TST & \\
\hline CHEMBL597264 & 600886 & 7.2441 & 6.3354 & TRN & \\
\hline CHEMBL577004 & 600886 & 5.1141 & 5.4861 & TRN & \\
\hline CHEMBL603689 & 600886 & 6.067 & 6.2049 & TRN & \\
\hline CHEMBL581856 & 600886 & 6.8508 & 6.697 & TRN & \\
\hline CHEMBL599707 & 600886 & 4.9031 & 6.5449 & TST & \\
\hline CHEMBL536846 & 600886 & 6.9427 & 6.148 & TRN & \\
\hline CHEMBL600154 & 600886 & 6.5862 & 6.4992 & TRN & \\
\hline CHEMBL3216654 & 600886 & 6.3788 & 6.6993 & TRN & \\
\hline CHEMBL603020 & 600886 & 6.7721 & 6.8285 & TRN & \\
\hline CHEMBL599288 & 600886 & 7.0079 & 6.7854 & TRN & \\
\hline CHEMBL585619 & 600886 & 5.1373 & 5.8267 & TRN & \\
\hline CHEMBL582085 & 600886 & 5.791 & 5.7766 & TST & \\
\hline CHEMBL601375 & 600886 & 5.7585 & 6.19799 & 99999999995 & TST \\
\hline CHEMBL600525 & 600886 & 6.109 & 6.807 & TRN & \\
\hline CHEMBL593487 & 600886 & 6.5735 & 5.6989 & TST & \\
\hline CHEMBL196573 & 600886 & 6.0 & 6.268 & TRN & \\
\hline CHEMBL581464 & 600886 & 5.7652 & 5.3889 & TRN & \\
\hline CHEMBL578901 & 600886 & 5.5324 & 5.7209 & TRN & \\
\hline CHEMBL602598 & 600886 & 5.9512 & 5.8965 & TST & \\
\hline CHEMBL582690 & 600886 & 6.6728 & 6.8785 & TRN & \\
\hline CHEMBL584465 & 600886 & 6.8874 & 6.6734 & TRN & \\
\hline CHEMBL577842 & 600886 & 6.32700 & 000000006 & 5.5971 & TRN \\
\hline CHEMBL579762 & 600886 & 6.2449 & 6.1265 & TRN & \\
\hline CHEMBL579144 & 600886 & 5.5962 & 5.941 & TST & \\
\hline CHEMBL582286 & 600886 & 5.8024 & 6.2694 & TRN & \\
\hline
\end{tabular}




\begin{tabular}{|c|c|c|c|c|c|}
\hline \multirow[b]{2}{*}{ CHEMBL580648 } & \multicolumn{5}{|c|}{ Supplemental Table S2.txt } \\
\hline & 600886 & 4.9031 & 6.2291 & TRN & \\
\hline CHEMBL581656 & 600886 & 4.8122 & 5.631 & TST & \\
\hline CHEMBL601190 & 600886 & 8.0605 & 6.326006 & 00000000005 & TRN \\
\hline CHEMBL604363 & 600886 & 6.6498 & 6.1126 & TST & \\
\hline CHEMBL578492 & 600886 & 5.3862 & 6.0781 & TRN & \\
\hline CHEMBL579371 & 600886 & 6.1169 & 5.6224 & TRN & \\
\hline CHEMBL579297 & 600886 & 6.3936 & 6.4354 & TRN & \\
\hline CHEMBL585665 & 600886 & 8.9003 & 7.8442 & TRN & \\
\hline CHEMBL582416 & 600886 & 5.2132 & 5.6794 & TST & \\
\hline CHEMBL529166 & 600886 & 5.02 & 5.6782 & TRN & \\
\hline CHEMBL530051 & 600886 & 7.3516 & 6.6001 & TRN & \\
\hline CHEMBL605943 & 600886 & 6.1203 & 6.3087 & TRN & \\
\hline CHEMBL583817 & 600886 & 6.0 & 6.359 & TRN & \\
\hline CHEMBL581492 & 600886 & 4.9031 & 6.068 & TRN & \\
\hline CHEMBL530252 & 600886 & 4.978 & 5.7943 & TST & \\
\hline CHEMBL579561 & 600886 & 4.8422 & 6.2354 & TRN & \\
\hline CHEMBL583560 & 600886 & 5.9957 & 6.1658 & TRN & \\
\hline CHEMBL582692 & 600886 & 3.9031 & 6.4225 & TST & \\
\hline CHEMBL578091 & 600886 & 6.4225 & 6.2545 & TRN & \\
\hline CHEMBL600506 & 600886 & 5.0942 & 5.261 & TRN & \\
\hline CHEMBL578723 & 600886 & 6.7555 & 6.7845 & TRN & \\
\hline CHEMBL585600 & 600886 & 8.6336 & 6.3209 & TRN & \\
\hline CHEMBL601766 & 600886 & 5.7307 & 7.5894 & TRN & \\
\hline CHEMBL602784 & 600886 & 5.7251 & 5.9384 & TRN & \\
\hline CHEMBL580609 & 600886 & 6.4225 & 6.3845 & TRN & \\
\hline CHEMBL600899 & 600886 & 5.8511 & 6.1487 & TRN & \\
\hline CHEMBL599299 & 600886 & 6.0 & 6.1283 & TRN & \\
\hline CHEMBL593255 & 600886 & 4.9255 & 5.3763 & TRN & \\
\hline CHEMBL579295 & 600886 & 5.4634 & 6.3216 & TRN & \\
\hline CHEMBL582055 & 600886 & 5.1838 & 6.2321 & TRN & \\
\hline CHEMBL583164 & 600886 & 9.4647 & 6.36299 & 99999999995 & TRN \\
\hline CHEMBL579552 & 600886 & 4.7567 & 6.3089 & TRN & \\
\hline CHEMBL602573 & 600886 & 7.6832 & 7.0403 & TST & \\
\hline CHEMBL582680 & 600886 & 6.8179 & 6.3203 & TRN & \\
\hline CHEMBL578528 & 600886 & 7.308 & 6.9474 & TRN & \\
\hline CHEMBL10835 & 600886 & 6.3372 & 6.192 & TRN & \\
\hline CHEMBL587642 & 600886 & 7.3288 & 7.2925 & TRN & \\
\hline CHEMBL584641 & 600886 & 7.466 & 7.3602 & TRN & \\
\hline CHEMBL585823 & 600886 & 7.1198 & 6.6277 & TRN & \\
\hline CHEMBL581036 & 600886 & 7.1612 & 6.5508 & TRN & \\
\hline CHEMBL524376 & 600886 & 6.2034 & 6.7987 & TRN & \\
\hline CHEMBL597048 & 600886 & 5.9535 & 6.254 & TRN & \\
\hline CHEMBL579361 & 600886 & 7.4547 & 6.8877 & TRN & \\
\hline CHEMBL585217 & 600886 & 6.5043 & 6.4711 & TST & \\
\hline CHEMBL578251 & 600886 & 6.2277 & 6.7029 & TRN & \\
\hline CHEMBL583593 & 600886 & 5.9311 & 6.0896 & TRN & \\
\hline CHEMBL602358 & 600886 & 6.0453 & 6.1726 & TRN & \\
\hline CHEMBL524603 & 600886 & 5.6407 & 5.7788 & TRN & \\
\hline & & & & 14257 & \\
\hline
\end{tabular}




\begin{tabular}{|c|c|c|c|c|c|}
\hline \multirow[b]{2}{*}{ CHEMBL584017 } & \multicolumn{5}{|c|}{ Supplemental Table S2.txt } \\
\hline & 600886 & 7.3019 & 5.6957 & TRN & \\
\hline CHEMBL600544 & 600886 & 5.8225 & 5.5019 & TRN & \\
\hline CHEMBL586912 & 600886 & 6.1249 & 6.2655 & TRN & \\
\hline CHEMBL600136 & 600886 & 5.7962 & 5.8398 & TRN & \\
\hline CHEMBL582501 & 600886 & 4.7857 & 6.9568 & TRN & \\
\hline CHEMBL585618 & 600886 & 5.9435 & 6.3732 & TRN & \\
\hline CHEMBL537500 & 600886 & 4.8162 & 5.7495 & TST & \\
\hline CHEMBL585786 & 600886 & 6.8548 & 6.7076 & TRN & \\
\hline CHEMBL600155 & 600886 & 6.015 & 5.6529 & TRN & \\
\hline CHEMBL529934 & 600886 & 5.9161 & 5.2026 & TRN & \\
\hline CHEMBL611381 & 600886 & 4.9031 & 5.744 & TRN & \\
\hline CHEMBL578963 & 600886 & 6.2581 & 6.4382 & TRN & \\
\hline CHEMBL611212 & 600886 & 6.4962 & 6.2833 & TRN & \\
\hline CHEMBL585625 & 600886 & 7.065 & 6.5739 & TRN & \\
\hline CHEMBL580414 & 600886 & 7.0315 & 6.8328 & TRN & \\
\hline CHEMBL610216 & 600886 & 6.9329 & 5.6307 & TRN & \\
\hline CHEMBL578294 & 600886 & 6.3696 & 6.8925 & TRN & \\
\hline CHEMBL585768 & 600886 & 6.3625 & 5.6815 & TRN & \\
\hline CHEMBL531119 & 600886 & 4.2749 & 4.9875 & TRN & \\
\hline CHEMBL584452 & 600886 & 6.4389 & 6.2965 & TRN & \\
\hline CHEMBL600938 & 600886 & 5.3028 & 5.7875 & TRN & \\
\hline CHEMBL582495 & 600886 & 5.8321 & 5.1571 & TRN & \\
\hline CHEMBL580571 & 600886 & 7.4237 & 7.1796 & TRN & \\
\hline CHEMBL579749 & 600886 & 5.7265 & 5.8188 & TRN & \\
\hline CHEMBL602365 & 600886 & 6.0665 & 6.3592 & TRN & \\
\hline CHEMBL536002 & 600886 & 5.6751 & 5.4162 & TST & \\
\hline CHEMBL579301 & 600886 & 6.0506 & 6.20700 & 0000000001 & TRN \\
\hline CHEMBL585262 & 600886 & 5.0429 & 5.1178 & TST & \\
\hline CHEMBL585207 & 600886 & 5.9144 & 6.4106 & TRN & \\
\hline CHEMBL600700 & 600886 & 7.0731 & 6.3408 & TRN & \\
\hline CHEMBL585430 & 600886 & 4.9226 & 5.6145 & TRN & \\
\hline CHEMBL576983 & 600886 & 6.0851 & 6.5673 & TRN & \\
\hline CHEMBL597656 & 600886 & 6.426 & 6.2897 & TRN & \\
\hline CHEMBL599084 & 600886 & 6.6931 & 6.9059 & TRN & \\
\hline CHEMBL601751 & 600886 & 6.6036 & 6.4367 & TRN & \\
\hline CHEMBL577868 & 600886 & 5.399 & 5.75200 & 0000000001 & TRN \\
\hline CHEMBL577154 & 600886 & 5.3757 & 5.2367 & TRN & \\
\hline CHEMBL599086 & 600886 & 4.9031 & 5.7084 & TRN & \\
\hline CHEMBL576327 & 600886 & 6.0259 & 6.25799 & 9999999999 & TRN \\
\hline CHEMBL598694 & 600886 & 6.433 & 6.2181 & TRN & \\
\hline CHEMBL610621 & 600886 & 5.4584 & 5.5783 & TRN & \\
\hline CHEMBL579310 & 600886 & 6.5302 & 6.1386 & TRN & \\
\hline CHEMBL600152 & 600886 & 6.0348 & 5.5835 & TST & \\
\hline CHEMBL584257 & 600886 & 6.0306 & 6.6992 & TRN & \\
\hline CHEMBL585399 & 600886 & 8.0395 & 6.78799 & 9999999999 & TRN \\
\hline CHEMBL581799 & 600886 & 5.2426 & 6.6156 & TST & \\
\hline CHEMBL584643 & 600886 & 4.9974 & 5.591 & TRN & \\
\hline CHEMBL532582 & 600886 & 5.1209 & 6.0828 & TRN & \\
\hline
\end{tabular}




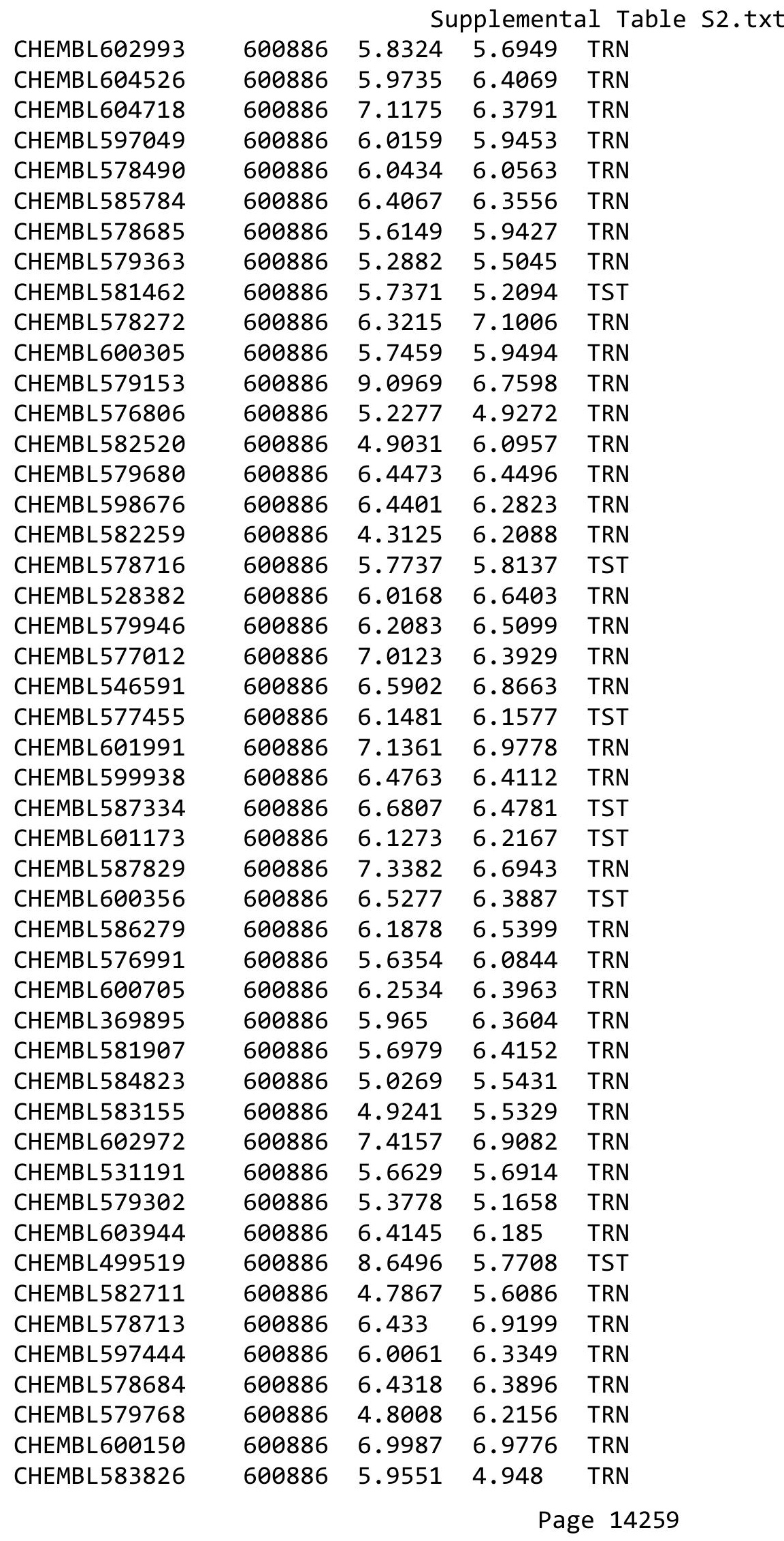




\begin{tabular}{|c|c|c|c|c|c|c|}
\hline & & & 西 & & & \\
\hline CHEMBL585583 & 600886 & 6.0 & 6.17 & TRN & & \\
\hline CHEMBL525864 & 600886 & 5.4949 & 6.1948 & TRN & & \\
\hline CHEMBL597252 & 600886 & 5.9027 & 6.1745 & TST & & \\
\hline CHEMBL528121 & 600886 & 4.8425 & 5.6932 & TST & & \\
\hline CHEMBL602392 & 600886 & 6.5865 & 6.1853 & TRN & & \\
\hline CHEMBL599926 & 600886 & 7.8508 & 6.6601 & TRN & & \\
\hline CHEMBL599944 & 600886 & 5.9094 & 5.6768 & TRN & & \\
\hline CHEMBL529057 & 600886 & 7.025 & 6.396 & TRN & & \\
\hline CHEMBL527981 & 600886 & 6.2204 & 5.9227 & TRN & & \\
\hline CHEMBL585615 & 600886 & 4.9574 & 5.6137 & TRN & & \\
\hline CHEMBL529403 & 600886 & 5.0496 & 5.6745 & TRN & & \\
\hline CHEMBL577457 & 600886 & 6.1688 & 6.42700 & 00000000005 & TRN & \\
\hline CHEMBL578690 & 600886 & 6.4989 & 5.5287 & TRN & & \\
\hline CHEMBL581460 & 600886 & 5.7338 & 5.2624 & TRN & & \\
\hline CHEMBL603010 & 600886 & 6.7652 & 6.398 & TRN & & \\
\hline CHEMBL600311 & 600886 & 5.7565 & 5.5667 & TRN & & \\
\hline CHEMBL588308 & 600886 & 6.9531 & 6.631 & TRN & & \\
\hline CHEMBL606252 & 600886 & 5.9119 & 5.9859 & TRN & & \\
\hline CHEMBL547603 & 600886 & 6.4089 & 6.3424 & TRN & & \\
\hline CHEMBL602633 & 600886 & 6.1733 & 6.1445 & TST & & \\
\hline CHEMBL581903 & 600886 & 4.8526 & 5.7593 & TRN & & \\
\hline CHEMBL602985 & 600886 & 6.4828 & 5.6475 & TST & & \\
\hline CHEMBL548230 & 600886 & 6.1007 & 6.4735 & TRN & & \\
\hline CHEMBL601588 & 600886 & 6.1096 & 6.4588 & TST & & \\
\hline CHEMBL587717 & 600886 & 6.2358 & 5.4324 & TRN & & \\
\hline CHEMBL272093 & 600886 & 6.8831 & 6.0334 & TST & & \\
\hline CHEMBL585973 & 600886 & 6.3363 & 5.5387 & TRN & & \\
\hline CHEMBL585247 & 600886 & 7.2495 & 6.6324 & TRN & & \\
\hline CHEMBL580639 & 600886 & 6.0146 & 6.3834 & TRN & & \\
\hline CHEMBL579939 & 600886 & 6.9285 & 6.4558 & TRN & & \\
\hline CHEMBL598281 & 600886 & 6.4776 & 6.3247 & TRN & & \\
\hline CHEMBL604512 & 600886 & 7.0516 & 6.3114 & TRN & & \\
\hline CHEMBL597464 & 600886 & 6.5166 & 7.0084 & TRN & & \\
\hline CHEMBL583530 & 600886 & 6.9454 & 7.00700 & 0000000001 & TST & \\
\hline CHEMBL533772 & 600886 & 7.9481 & 6.1695 & TST & & \\
\hline CHEMBL582075 & 600886 & 5.8008 & 5.1341 & TRN & & \\
\hline CHEMBL531562 & 600886 & 6.0 & 6.2862 & TRN & & \\
\hline CHEMBL583653 & 600886 & 6.1524 & 6.4659 & TRN & & \\
\hline CHEMBL599954 & 600886 & 4.9767 & 5.6123 & TRN & & \\
\hline CHEMBL524594 & 600886 & 6.3429 & 6.3055 & TRN & & \\
\hline CHEMBL578329 & 600886 & 6.1931 & 5.3478 & TST & & \\
\hline CHEMBL581658 & 600886 & 5.3526 & 5.1391 & TRN & & \\
\hline CHEMBL585626 & 600886 & 6.6511 & 6.5373 & TRN & & \\
\hline CHEMBL603039 & 600886 & 6.75299 & 99999999 & 6.6 & 99999999995 & TRN \\
\hline CHEMBL244023 & 600886 & 6.0 & 6.1562 & TST & & \\
\hline CHEMBL577430 & 600886 & 7.6876 & 7.2846 & TRN & & \\
\hline CHEMBL604779 & 600886 & 7.0448 & 6.6784 & TRN & & \\
\hline CHEMBL611211 & 600886 & 5.6757 & 5.7315 & TST & & \\
\hline
\end{tabular}




\begin{tabular}{|c|c|c|c|c|}
\hline & & & pple & $\mathrm{a} \perp$ \\
\hline CHEMBL579293 & 600886 & 5.4547 & 6.602 & TRN \\
\hline CHEMBL582470 & 600886 & 6.433 & 6.7114 & TRN \\
\hline CHEMBL605945 & 600886 & 6.1871 & 6.3489 & TRN \\
\hline CHEMBL582102 & 600886 & 6.3487 & 6.483 & TRN \\
\hline CHEMBL578879 & 600886 & 5.5764 & 5.9798 & TRN \\
\hline CHEMBL577136 & 600886 & 6.5748 & 5.4301 & TRN \\
\hline CHEMBL 600280 & 600886 & 4.9031 & 5.7479 & TRN \\
\hline CHEMBL601347 & 600886 & 5.64 & 6.0398 & TRN \\
\hline CHEMBL529901 & 600886 & 6.4157 & 6.3073 & TRN \\
\hline CHEMBL600742 & 600886 & 4.8564 & 5.9815 & TRN \\
\hline CHEMBL588032 & 600886 & 6.0 & 6.0708 & TST \\
\hline CHEMBL 600726 & 600886 & 6.0942 & 6.4598 & TRN \\
\hline CHEMBL600539 & 600886 & 7.2343 & 6.8222 & TRN \\
\hline CHEMBL578322 & 600886 & 9.1024 & 6.4036 & TRN \\
\hline CHEMBL596832 & 600886 & 5.9281 & 5.8515 & TRN \\
\hline CHEMBL610330 & 600886 & 5.6275 & 5.8746 & TRN \\
\hline CHEMBL597060 & 600886 & 6.6024 & 6.7228 & TRN \\
\hline CHEMBL600139 & 600886 & 5.8703 & 5.5581 & TRN \\
\hline CHEMBL579159 & 600886 & 6.2899 & 6.4606 & TRN \\
\hline CHEMBL600318 & 600886 & 5.6043 & 5.2551 & TRN \\
\hline CHEMBL599917 & 600886 & 6.9122 & 6.8614 & TRN \\
\hline CHEMBL577209 & 600886 & 6.0477 & 5.6197 & TRN \\
\hline CHEMBL578498 & 600886 & 6.0 & 6.2681 & TRN \\
\hline CHEMBL527516 & 600886 & 5.9073 & 5.9153 & TRN \\
\hline CHEMBL580848 & 600886 & 6.6457 & 6.7487 & TRN \\
\hline CHEMBL598895 & 600886 & 6.1891 & 5.0183 & TRN \\
\hline CHEMBL601337 & 600886 & 6.1373 & 6.2181 & TRN \\
\hline CHEMBL576404 & 600886 & 6.8857 & 6.7117 & TRN \\
\hline CHEMBL577219 & 600886 & 5.1343 & 5.2414 & TRN \\
\hline CHEMBL599500 & 600886 & 4.9031 & 5.8104 & TST \\
\hline CHEMBL584023 & 600886 & 5.9686 & 5.5851 & TST \\
\hline CHEMBL577216 & 600886 & 7.7314 & 6.8227 & TRN \\
\hline CHEMBL600905 & 600886 & 7.3675 & 6.89 & TRN \\
\hline CHEMBL 588394 & 600886 & 6.1427 & 6.568 & TRN \\
\hline CHEMBL582955 & 600886 & 4.9097 & 6.4152 & TRN \\
\hline CHEMBL585398 & 600886 & 6.0857 & 6.5597 & TRN \\
\hline CHEMBL 271556 & 600886 & 4.7752 & 6.2735 & TRN \\
\hline CHEMBL 578737 & 600886 & 7.2426 & 6.8317 & TRN \\
\hline CHEMBL 585749 & 600886 & 6.7595 & 6.4698 & TRN \\
\hline CHEMBL576980 & 600886 & 6.3429 & 6.5555 & TRN \\
\hline CHEMBL580834 & 600886 & 4.9031 & 5.9147 & TRN \\
\hline CHEMBL584845 & 600886 & 5.0711 & 5.5739 & TST \\
\hline CHEMBL 578746 & 600886 & 6.1675 & 6.3353 & TRN \\
\hline CHEMBL 584027 & 600886 & 5.9714 & 6.2856 & TRN \\
\hline CHEMBL495496 & 600886 & 6.062 & 6.4296 & TRN \\
\hline CHEMBL587147 & 600886 & 6.0218 & 6.1139 & TST \\
\hline CHEMBL581881 & 600886 & 5.794 & 5.8854 & TRN \\
\hline CHEMBL612130 & 600886 & 7.4191 & 6.5255 & TRN \\
\hline
\end{tabular}




\begin{tabular}{|c|c|c|c|c|c|}
\hline \multicolumn{6}{|c|}{ Supplemental Table S } \\
\hline CHEMBL584250 & 600886 & 6.055 & 6.2394 & TRN & \\
\hline CHEMBL599296 & 600886 & 6.1878 & 6.0224 & TRN & \\
\hline CHEMBL598892 & 600886 & 4.9031 & 5.7895 & TRN & \\
\hline CHEMBL585814 & 600886 & 7.6519 & 6.8645 & TRN & \\
\hline CHEMBL580145 & 600886 & 7.4389 & 6.9518 & TRN & \\
\hline CHEMBL578462 & 600886 & 5.4295 & 5.82100 & 0000000001 & TRN \\
\hline CHEMBL584462 & 600886 & 6.4486 & 6.4634 & TRN & \\
\hline CHEMBL600962 & 600886 & 5.971 & 5.78799 & 9999999999 & TRN \\
\hline CHEMBL587918 & 600886 & 5.7328 & 5.9598 & TRN & \\
\hline CHEMBL585212 & 600886 & 5.0487 & 5.71 & TST & \\
\hline CHEMBL583327 & 600886 & 6.1232 & 6.3278 & TRN & \\
\hline CHEMBL585417 & 600886 & 6.3382 & 5.2231 & TRN & \\
\hline CHEMBL529033 & 600886 & 5.9154 & 6.0791 & TRN & \\
\hline CHEMBL600323 & 600886 & 5.6031 & 5.0342 & TST & \\
\hline CHEMBL597261 & 600886 & 4.9031 & 6.3938 & TRN & \\
\hline CHEMBL586580 & 600886 & 5.1255 & 5.296 & TST & \\
\hline CHEMBL530719 & 600886 & 6.3799 & 6.4494 & TRN & \\
\hline CHEMBL533670 & 600886 & 5.5972 & 5.9708 & TRN & \\
\hline CHEMBL576526 & 600886 & 5.3737 & 5.1672 & TST & \\
\hline CHEMBL579135 & 600886 & 7.5662 & 6.7037 & TRN & \\
\hline CHEMBL582442 & 600886 & 5.1273 & 5.8885 & TST & \\
\hline CHEMBL583606 & 600886 & 5.9555 & 5.9669 & TRN & \\
\hline CHEMBL601594 & 600886 & 6.8573 & 6.5714 & TRN & \\
\hline CHEMBL601133 & 600886 & 5.7752 & 5.6045 & TRN & \\
\hline CHEMBL597873 & 600886 & 5.9446 & 6.3162 & TRN & \\
\hline CHEMBL576573 & 600886 & 6.3768 & 5.6587 & TST & \\
\hline CHEMBL597865 & 600886 & 3.9031 & 5.9166 & TRN & \\
\hline CHEMBL535432 & 600886 & 7.1805 & 6.5236 & TRN & \\
\hline CHEMBL601331 & 600886 & 5.2874 & 5.8119 & TST & \\
\hline CHEMBL598072 & 600886 & 8.8136 & 6.2048 & TRN & \\
\hline CHEMBL584835 & 600886 & 7.1612 & 6.4756 & TRN & \\
\hline CHEMBL587500 & 600886 & 6.8233 & 6.3284 & TST & \\
\hline CHEMBL585996 & 600886 & 4.9454 & 5.7868 & TRN & \\
\hline CHEMBL576602 & 600886 & 6.1141 & 5.5214 & TRN & \\
\hline CHEMBL1744505 & 600886 & 6.0 & 6.2089 & TRN & \\
\hline CHEMBL601335 & 600886 & 6.1057 & 6.4033 & TRN & \\
\hline CHEMBL582081 & 600886 & 5.7889 & 6.114 & TRN & \\
\hline CHEMBL584459 & 600886 & 6.0555 & 6.25799 & 9999999999 & TRN \\
\hline CHEMBL586000 & 600886 & 6.8703 & 6.9076 & TST & \\
\hline CHEMBL583402 & 600886 & 5.9237 & 5.3826 & TRN & \\
\hline CHEMBL600689 & 600886 & 6.4597 & 6.4656 & TRN & \\
\hline CHEMBL581487 & 600886 & 5.8771 & 5.1937 & TRN & \\
\hline CHEMBL601995 & 600886 & 6.5349 & 6.1446 & TRN & \\
\hline CHEMBL578105 & 600886 & 8.8697 & 6.9421 & TRN & \\
\hline CHEMBL611660 & 600886 & 6.4191 & 5.1907 & TRN & \\
\hline CHEMBL586017 & 600886 & 6.7319 & 6.0596 & TRN & \\
\hline CHEMBL600088 & 600886 & 5.0013 & 5.5567 & TRN & \\
\hline CHEMBL579281 & 600886 & 4.9031 & 5.8658 & TRN & \\
\hline
\end{tabular}




\begin{tabular}{|c|c|c|c|c|c|}
\hline \\
\hline CHEMBL535261 & 600886 & 6.4776 & 6.4391 & TRN & \\
\hline CHEMBL529551 & 600886 & 6.3036 & 6.1351 & TST & \\
\hline CHEMBL601801 & 600886 & 5.7964 & 5.6571 & TRN & \\
\hline CHEMBL597243 & 600886 & 7.2125 & 6.8979 & TRN & \\
\hline CHEMBL578288 & 600886 & 5.6216 & 6.3046 & TST & \\
\hline CHEMBL598477 & 600886 & 5.8996 & 5.1303 & TRN & \\
\hline CHEMBL581821 & 600886 & 6.3072 & 6.3029 & TRN & \\
\hline CHEMBL601774 & 600886 & 6.3595 & 6.5054 & TRN & \\
\hline CHEMBL579408 & 600886 & 7.0173 & 6.524 & TRN & \\
\hline CHEMBL526199 & 600886 & 6.3507 & 6.2822 & TRN & \\
\hline CHEMBL528258 & 600886 & 6.3904 & 6.4521 & TRN & \\
\hline CHEMBL582052 & 600886 & 5.2823 & 5.676 & TRN & \\
\hline CHEMBL547194 & 600886 & 6.0343 & 6.0365 & TRN & \\
\hline CHEMBL534997 & 600886 & 6.1409 & 5.9788 & TRN & \\
\hline CHEMBL603001 & 600886 & 5.7183 & 5.9166 & TRN & \\
\hline CHEMBL600714 & 600886 & 7.3883 & 6.4701 & TST & \\
\hline CHEMBL584030 & 600886 & 5.8545 & 6.4642 & TRN & \\
\hline CHEMBL578117 & 600886 & 6.2069 & 5.7504 & TRN & \\
\hline CHEMBL602992 & 600886 & 5.7713 & 5.3112 & TRN & \\
\hline CHEMBL583753 & 600886 & 4.988 & 5.6534 & TRN & \\
\hline CHEMBL576329 & 600886 & 4.7791 & 6.1562 & TRN & \\
\hline CHEMBL579084 & 600886 & 6.5249 & 6.3502 & TRN & \\
\hline CHEMBL597671 & 600886 & 6.3261 & 6.1123 & TRN & \\
\hline CHEMBL606449 & 600886 & 6.6983 & 6.8474 & TRN & \\
\hline CHEMBL579311 & 600886 & 6.5305 & 6.4878 & TRN & \\
\hline CHEMBL585213 & 600886 & 5.9151 & 6.2836 & TST & \\
\hline CHEMBL598274 & 600886 & 6.1267 & 5.3339 & TRN & \\
\hline CHEMBL579146 & 600886 & 6.5693 & 6.5074 & TRN & \\
\hline CHEMBL601825 & 600886 & 6.2518 & 6.2319 & TRN & \\
\hline CHEMBL577660 & 600886 & 6.8164 & 6.6807 & TRN & \\
\hline CHEMBL582281 & 600886 & 6.1035 & 6.4851 & TRN & \\
\hline CHEMBL600553 & 600886 & 7.3904 & 5.6521 & TRN & \\
\hline CHEMBL600135 & 600886 & 5.7849 & 5.6593 & TRN & \\
\hline CHEMBL582068 & 600886 & 5.8245 & 5.1779 & TRN & \\
\hline CHEMBL601783 & 600886 & 8.7721 & 6.4698 & TRN & \\
\hline CHEMBL602378 & 600886 & 6.2941 & 6.471 & TRN & \\
\hline CHEMBL583363 & 600886 & 5.9458 & 5.5132 & TRN & \\
\hline CHEMBL582721 & 600886 & 5.8453 & 5.8065 & TRN & \\
\hline CHEMBL585990 & 600886 & 5.9935 & 5.5737 & TST & \\
\hline CHEMBL579905 & 600886 & 8.3179 & 7.4298 & TRN & \\
\hline CHEMBL583556 & 600886 & 6.5685 & 6.5803 & TRN & \\
\hline CHEMBL576359 & 600886 & 5.3536 & 6.03299 & 99999999995 & TRN \\
\hline CHEMBL579331 & 600886 & 6.3468 & 6.4195 & TRN & \\
\hline CHEMBL599705 & 600886 & 4.9031 & 5.7121 & TRN & \\
\hline CHEMBL582710 & 600886 & 4.7862 & 5.7502 & TRN & \\
\hline CHEMBL596650 & 600886 & 4.9034 & 5.6327 & TRN & \\
\hline CHEMBL581243 & 600886 & 5.9389 & 6.4492 & TRN & \\
\hline CHEMBL585033 & 600886 & 6.4067 & 6.4393 & TRN & \\
\hline
\end{tabular}




\begin{tabular}{|c|c|c|c|c|c|}
\hline & & \multicolumn{4}{|c|}{ Supplemental Table S2.txt } \\
\hline CHEMBL601365 & 600886 & 5.3134 & 5.112 & TRN & \\
\hline CHEMBL580253 & 600886 & 5.0477 & 5.7023 & TST & \\
\hline CHEMBL584822 & 600886 & 6.7003 & 6.5023 & TST & \\
\hline CHEMBL530796 & 600886 & 4.1267 & 5.1423 & TRN & \\
\hline CHEMBL579846 & 600886 & 6.5427 & 6.1946 & TRN & \\
\hline CHEMBL582089 & 600886 & 6.0 & 6.1264 & TRN & \\
\hline CHEMBL600120 & 600886 & 6.8703 & 6.2841 & TRN & \\
\hline CHEMBL579557 & 600886 & 4.9031 & 6.0431 & TST & \\
\hline CHEMBL584856 & 600886 & 6.0209 & 6.4569 & TRN & \\
\hline CHEMBL579379 & 600886 & 7.0516 & 6.7361 & TRN & \\
\hline CHEMBL582531 & 600886 & 6.0 & 6.2356 & TRN & \\
\hline CHEMBL606474 & 600886 & 6.0788 & 5.8691 & TRN & \\
\hline CHEMBL579028 & 600886 & 5.1701 & 6.0981 & TRN & \\
\hline CHEMBL584450 & 600886 & 7.4001 & 6.0831 & TRN & \\
\hline CHEMBL579326 & 600886 & 7.9496 & 7.2016 & TRN & \\
\hline CHEMBL603897 & 600886 & 4.9031 & 6.6144 & TRN & \\
\hline CHEMBL598693 & 600886 & 6.3188 & 6.0726 & TST & \\
\hline CHEMBL600750 & 600886 & 5.8536 & 6.0914 & TRN & \\
\hline CHEMBL576614 & 600886 & 5.1221 & 6.1023 & TRN & \\
\hline CHEMBL532239 & 600886 & 6.2472 & 6.6116 & TRN & \\
\hline CHEMBL601132 & 600886 & 5.7742 & 5.5693 & TRN & \\
\hline CHEMBL601962 & 600886 & 6.0348 & 6.1189 & TRN & \\
\hline CHEMBL578062 & 600886 & 6.4056 & 6.5152 & TST & \\
\hline CHEMBL532857 & 600886 & \multicolumn{4}{|c|}{6.4510000000000005} \\
\hline CHEMBL531672 & 600886 & 6.5082 & 5.5826 & TRN & \\
\hline CHEMBL586785 & 600886 & 6.9893 & 6.812 & TRN & \\
\hline CHEMBL531108 & 600886 & 7.8122 & 7.1436 & TST & \\
\hline CHEMBL577870 & 600886 & 5.4225 & 5.1525 & TRN & \\
\hline CHEMBL584434 & 600886 & 6.4248 & 6.3747 & TRN & \\
\hline CHEMBL585810 & 600886 & 7.4001 & 6.5184 & TRN & \\
\hline CHEMBL531777 & 600886 & 5.2668 & 5.0674 & TRN & \\
\hline CHEMBL603306 & 600886 & 6.7905 & 6.8407 & TRN & \\
\hline CHEMBL583353 & 600886 & 5.0137 & 6.0415 & TST & \\
\hline CHEMBL602977 & 600886 & 6.4776 & \multicolumn{2}{|c|}{6.537000000000001} & TRN \\
\hline CHEMBL582294 & 600886 & 5.8362 & 6.3828 & TRN & \\
\hline CHEMBL601985 & 600886 & 5.2218 & 5.7513 & TRN & \\
\hline CHEMBL22148 & 600886 & 4.9031 & 6.2037 & TST & \\
\hline CHEMBL577853 & 600886 & 6.5075 & 6.7142 & TRN & \\
\hline CHEMBL604153 & 600886 & 5.5213 & 5.8209 & TRN & \\
\hline CHEMBL600706 & 600886 & 6.9401 & 6.517 & TRN & \\
\hline CHEMBL578703 & 600886 & 6.4078 & 5.6294 & TRN & \\
\hline CHEMBL578307 & 600886 & 6.4486 & 6.1669 & TRN & \\
\hline CHEMBL578883 & 600886 & 5.3478 & 5.5596 & TRN & \\
\hline CHEMBL589010 & 600886 & 5.5686 & 5.7086 & TRN & \\
\hline CHEMBL602937 & 600886 & 7.3335 & 6.8281 & TST & \\
\hline CHEMBL584225 & 600886 & 6.7256 & 5.9616 & TST & \\
\hline CHEMBL599714 & 600886 & 5.9374 & 6.5031 & TRN & \\
\hline CHEMBL530361 & 600886 & 5.9914 & 6.3543 & TRN & \\
\hline
\end{tabular}




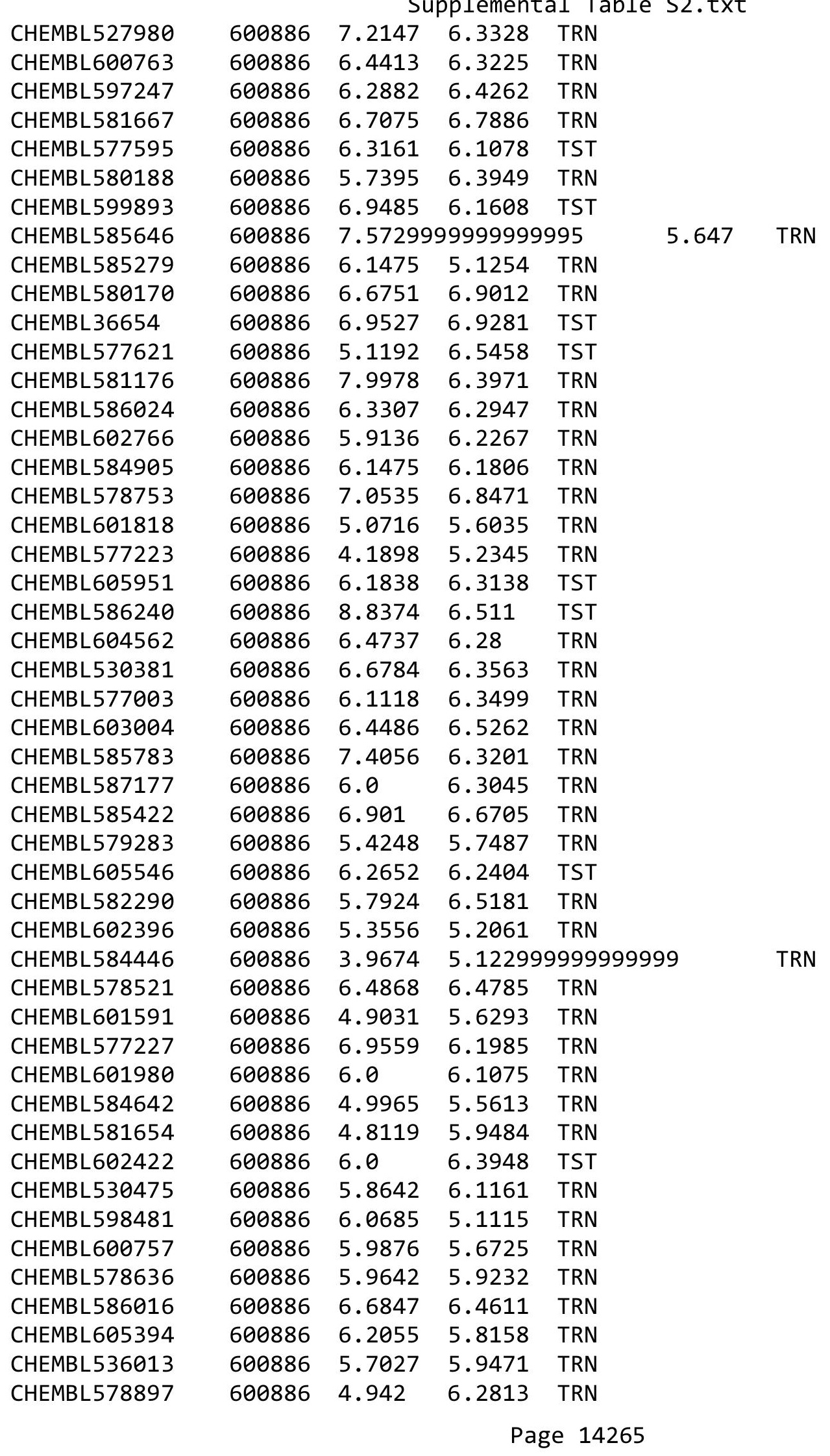




\begin{tabular}{|c|c|c|c|c|c|c|}
\hline & & & & & & \\
\hline CHEMBL601324 & 600886 & 5.9024 & 6.0395 & TRN & & \\
\hline CHEMBL579764 & 600886 & 5.7989 & 5.7319 & TRN & & \\
\hline CHEMBL577636 & 600886 & 5.4437 & 5.6768 & TST & & \\
\hline CHEMBL581679 & 600886 & 4.9031 & 5.6229 & TST & & \\
\hline CHEMBL600287 & 600886 & 6.4698 & 6.669 & TRN & & \\
\hline CHEMBL578479 & 600886 & 7.9066 & 7.4594 & TRN & & \\
\hline CHEMBL581456 & 600886 & 6.0 & 6.2399 & TRN & & \\
\hline CHEMBL 317364 & 600886 & 8.2211 & 7.5542 & TRN & & \\
\hline CHEMBL588616 & 600886 & 5.6778 & 5.8857 & TST & & \\
\hline CHEMBL602595 & 600886 & 7.7082 & 6.8221 & TRN & & \\
\hline CHEMBL576205 & 600886 & 8.1643 & 7.2599 & TRN & & \\
\hline CHEMBL589018 & 600886 & 7.1904 & 6.9557 & TST & & \\
\hline CHEMBL601189 & 600886 & 6.837999 & 99999999 & 99 & 6.6767 & TST \\
\hline CHEMBL 585424 & 600886 & 5.9927 & 5.6121 & TRN & & \\
\hline CHEMBL585778 & 600886 & 7.4724 & 6.1008 & TRN & & \\
\hline CHEMBL577656 & 600886 & 7.8094 & 6.6245 & TRN & & \\
\hline CHEMBL600966 & 600886 & 6.9172 & 7.0099 & TST & & \\
\hline CHEMBL 588153 & 600886 & 4.1267 & 4.8911 & TRN & & \\
\hline CHEMBL528790 & 600886 & 6.9158 & 6.3174 & TRN & & \\
\hline CHEMBL 606046 & 600886 & 6.6202 & 6.4577 & TRN & & \\
\hline CHEMBL601325 & 600886 & 6.8164 & 6.6069 & TST & & \\
\hline CHEMBL588091 & 600886 & 6.0 & 6.263 & TRN & & \\
\hline CHEMBL 577674 & 600886 & 6.3316 & 6.4113 & TRN & & \\
\hline CHEMBL609319 & 600886 & 7.0343 & 6.9204 & TRN & & \\
\hline CHEMBL585084 & 600886 & 4.9031 & 6.192 & TRN & & \\
\hline CHEMBL600343 & 600886 & 4.9245 & 5.6347 & TRN & & \\
\hline CHEMBL579973 & 600886 & 3.9031 & 5.8581 & TRN & & \\
\hline CHEMBL 585706 & 600886 & 6.2111 & 6.32 & TRN & & \\
\hline CHEMBL582518 & 600886 & 5.8801 & 5.5538 & TRN & & \\
\hline CHEMBL530391 & 600886 & 6.007006 & 00000000 & $\partial 1$ & 5.5677 & TRN \\
\hline CHEMBL602026 & 600886 & 4.9223 & 5.6867 & TRN & & \\
\hline CHEMBL581459 & 600886 & 5.7131 & 5.8554 & TRN & & \\
\hline CHEMBL 582498 & 600886 & 5.7414 & 5.6238 & TRN & & \\
\hline CHEMBL585224 & 600886 & 6.7022 & 6.2077 & TST & & \\
\hline CHEMBL 227704 & 600886 & 6.3969 & 6.8963 & TRN & & \\
\hline CHEMBL578480 & 600886 & 7.9237 & 7.2399 & TRN & & \\
\hline CHEMBL583539 & 600886 & 6.6321 & 6.2708 & TRN & & \\
\hline CHEMBL601134 & 600886 & 5.6325 & 5.1097 & TRN & & \\
\hline CHEMBL587819 & 600886 & 5.67 & 5.1219 & TRN & & \\
\hline CHEMBL611659 & 600886 & 3.9031 & 5.3121 & TRN & & \\
\hline CHEMBL603233 & 600886 & 7.0013 & 6.4131 & TRN & & \\
\hline CHEMBL577425 & 600886 & 11.1512 & 7.656006 & 0000000001 & & TRN \\
\hline CHEMBL584238 & 600886 & 5.9702 & 6.2188 & TRN & & \\
\hline CHEMBL533293 & 600886 & 6.2381 & 5.6379 & TRN & & \\
\hline CHEMBL581879 & 600886 & 6.3969 & 6.6391 & TRN & & \\
\hline CHEMBL597042 & 600886 & 6.1586 & 6.0381 & TRN & & \\
\hline CHEMBL609026 & 600886 & 6.0926 & 6.2871 & TRN & & \\
\hline CHEMBL578536 & 600886 & 5.2218 & 5.1044 & TRN & & \\
\hline
\end{tabular}




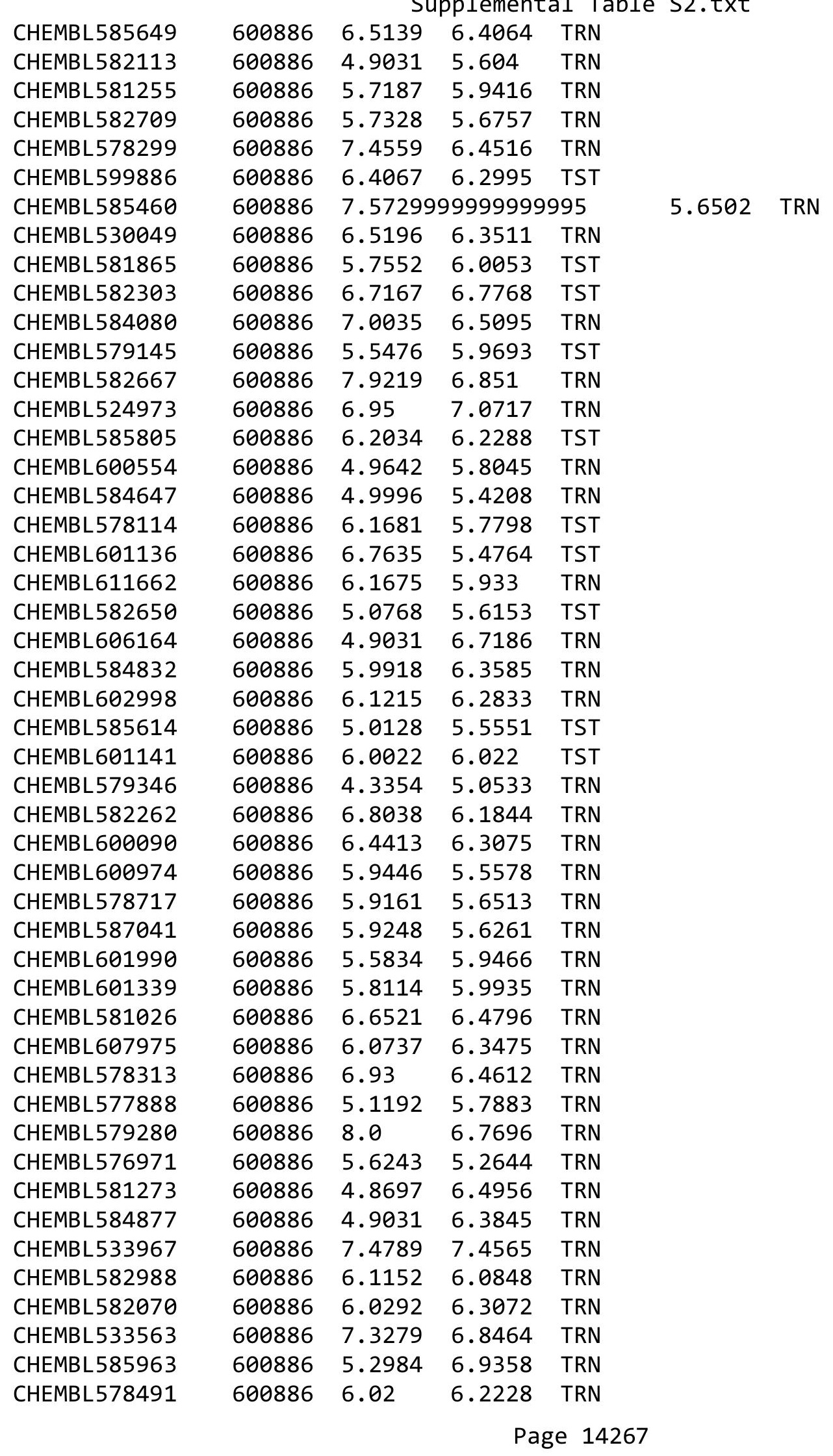




\begin{tabular}{|c|c|c|c|c|c|c|}
\hline & & \multicolumn{5}{|c|}{ Supplemental Table S2.txt } \\
\hline CHEMBL608259 & 600886 & 7.57299 & 999999999 & 995 & 5.7888 & TRN \\
\hline CHEMBL588288 & 600886 & 6.1267 & 6.7227 & TRN & & \\
\hline CHEMBL300389 & 600886 & 6.7296 & 6.584 & TRN & & \\
\hline CHEMBL582671 & 600886 & 6.1314 & 6.376 & TST & & \\
\hline CHEMBL607976 & 600886 & 6.683 & 5.5155 & TRN & & \\
\hline CHEMBL586761 & 600886 & 6.2716 & 6.4205 & TST & & \\
\hline CHEMBL579128 & 600886 & 5.5418 & 5.1235 & TRN & & \\
\hline CHEMBL611983 & 600886 & 7.5635 & 6.7886 & TRN & & \\
\hline CHEMBL581904 & 600886 & 5.8529 & 6.1391 & TRN & & \\
\hline CHEMBL577857 & 600886 & 5.8483 & 6.2983 & TRN & & \\
\hline CHEMBL600930 & 600886 & 5.5892 & 6.0625 & TRN & & \\
\hline CHEMBL533195 & 600886 & 6.26200 & 000000000 & 005 & 6.0696 & \\
\hline CHEMBL582325 & 600886 & 4.9031 & 6.1446 & TST & & \\
\hline CHEMBL587942 & 600886 & 6.9059 & 5.1574 & TRN & & \\
\hline CHEMBL600715 & 600886 & 8.4802 & 7.3337 & TST & & \\
\hline CHEMBL583830 & 600886 & 5.9821 & 5.0727 & TRN & & \\
\hline CHEMBL578093 & 600886 & 6.0675 & 6.302000 & 0000000 & 205 & \\
\hline CHEMBL493863 & 600886 & 6.5583 & 7.1148 & TRN & & \\
\hline CHEMBL583150 & 600886 & 5.9602 & 5.5696 & TRN & & \\
\hline CHEMBL578515 & 600886 & 6.2168 & 7.1028 & TRN & & \\
\hline CHEMBL587436 & 600886 & 5.2 & 5.077 & TST & & \\
\hline CHEMBL598069 & 600886 & 6.8441 & 6.5361 & TRN & & \\
\hline CHEMBL602990 & 600886 & 6.1487 & 6.143 & TRN & & \\
\hline CHEMBL585968 & 600886 & 6.6287 & 6.2289 & TRN & & \\
\hline CHEMBL600513 & 600886 & 3.9031 & 6.3221 & TRN & & \\
\hline CHEMBL578731 & 600886 & 5.5229 & 6.2735 & TST & & \\
\hline CHEMBL577620 & 600886 & 5.7007 & 5.9263 & TRN & & \\
\hline CHEMBL583650 & 600886 & 6.3768 & 5.8711 & TRN & & \\
\hline CHEMBL603000 & 600886 & 5.3969 & 6.0834 & TRN & & \\
\hline CHEMBL529837 & 600886 & 6.0 & 6.2306 & TRN & & \\
\hline CHEMBL579367 & 600886 & 7.0195 & 6.8917 & TST & & \\
\hline CHEMBL588589 & 600886 & 6.2097 & 5.591 & TRN & & \\
\hline CHEMBL579086 & 600886 & 4.9031 & 6.1852 & TST & & \\
\hline CHEMBL534971 & 600886 & 5.7199 & 5.1143 & TRN & & \\
\hline CHEMBL582526 & 600886 & 6.2373 & 6.4968 & TST & & \\
\hline CHEMBL602964 & 600886 & 3.9031 & 5.2084 & TST & & \\
\hline CHEMBL481505 & 600886 & 6.0372 & 5.9034 & TRN & & \\
\hline CHEMBL588178 & 600886 & 6.26200 & 000000000 & 005 & 6.4566 & \\
\hline CHEMBL530195 & 600886 & 3.9031 & 6.1823 & TRN & & \\
\hline CHEMBL582459 & 600886 & 6.21899 & 999999999 & 99 & 5.6684 & 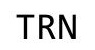 \\
\hline CHEMBL601779 & 600886 & 6.3098 & 6.5736 & TRN & & \\
\hline CHEMBL604982 & 600886 & 5.8891 & 6.3614 & TRN & & \\
\hline CHEMBL600707 & 600886 & 9.0114 & 6.3899 & TRN & & \\
\hline CHEMBL601372 & 600886 & 6.6694 & 6.3121 & TRN & & \\
\hline CHEMBL598283 & 600886 & 6.9935 & 6.9633 & TRN & & \\
\hline CHEMBL579940 & 600886 & 7.0128 & 6.9134 & TRN & & \\
\hline CHEMBL602404 & 600886 & 6.4881 & 5.6541 & TRN & & \\
\hline CHEMBL530263 & 600886 & 5.7307 & 6.4001 & TRN & & \\
\hline
\end{tabular}




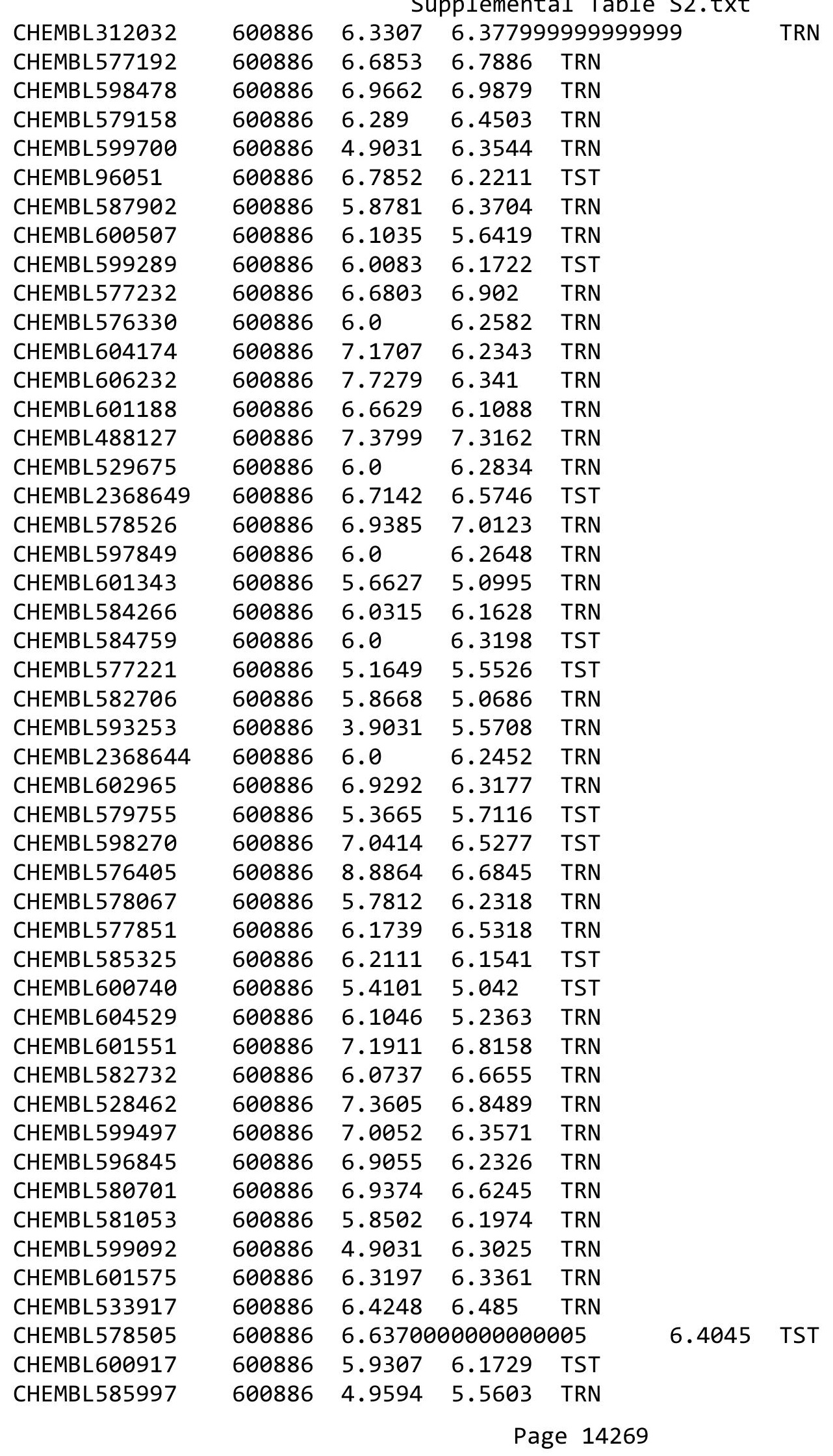




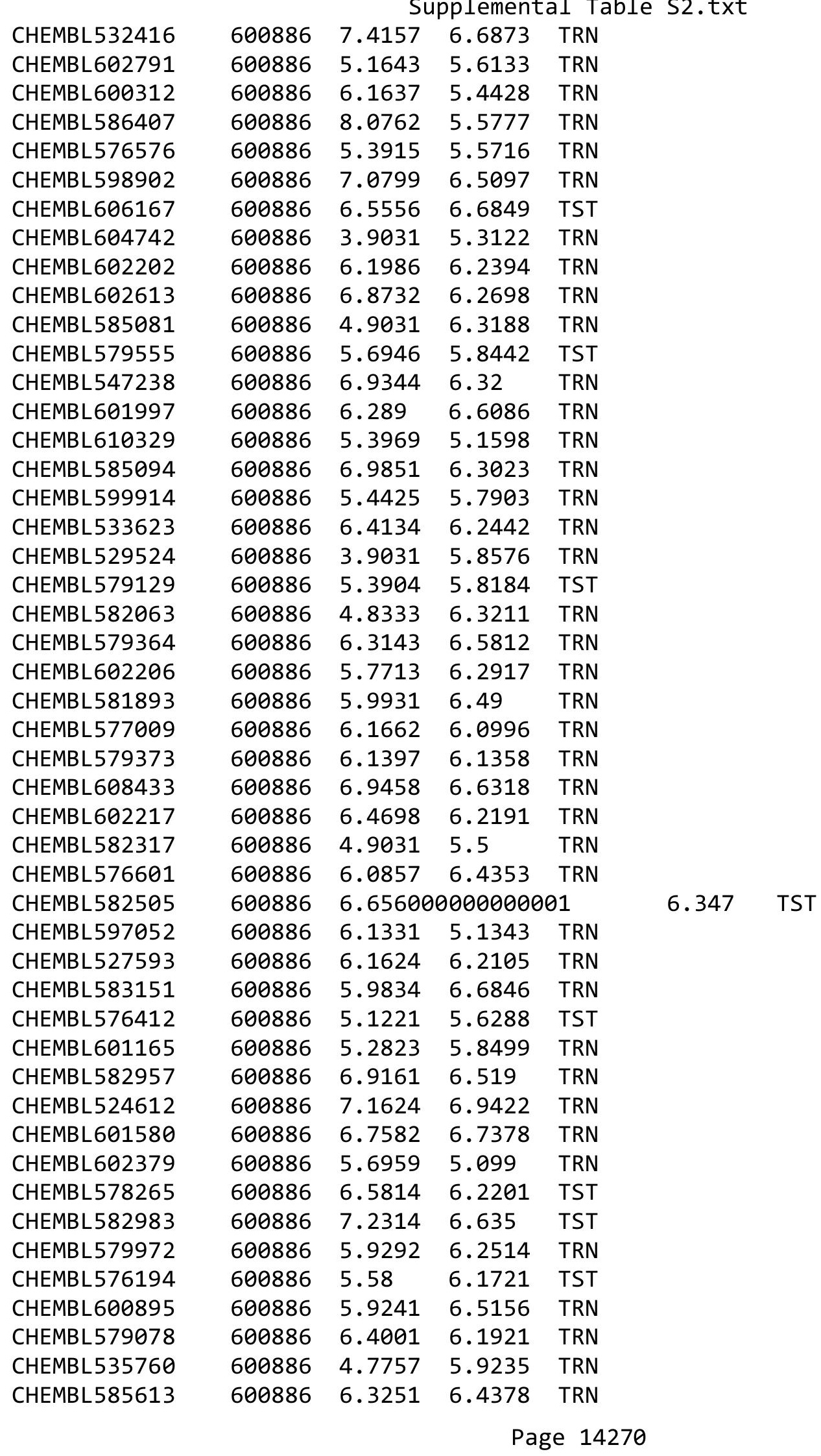




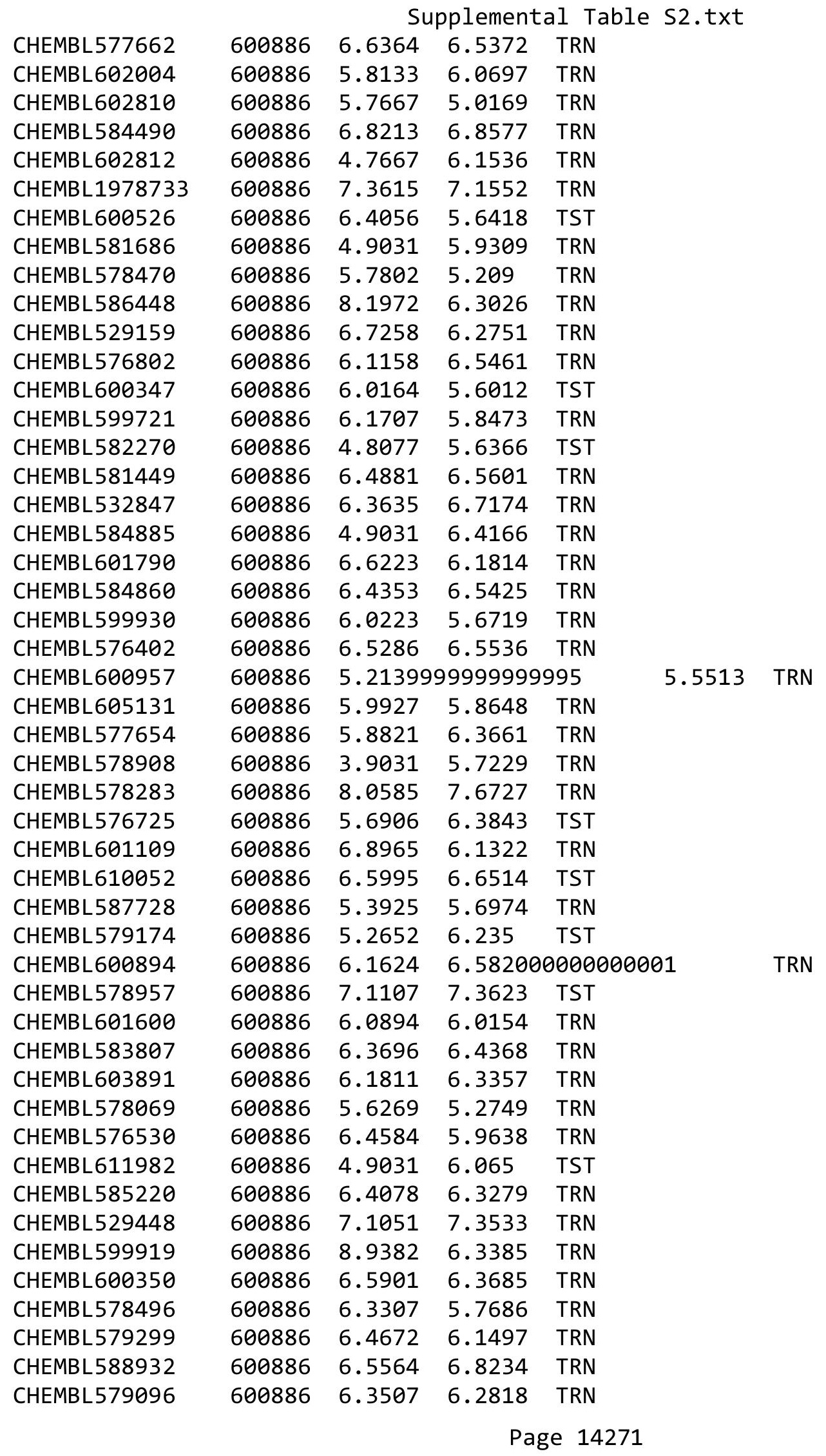




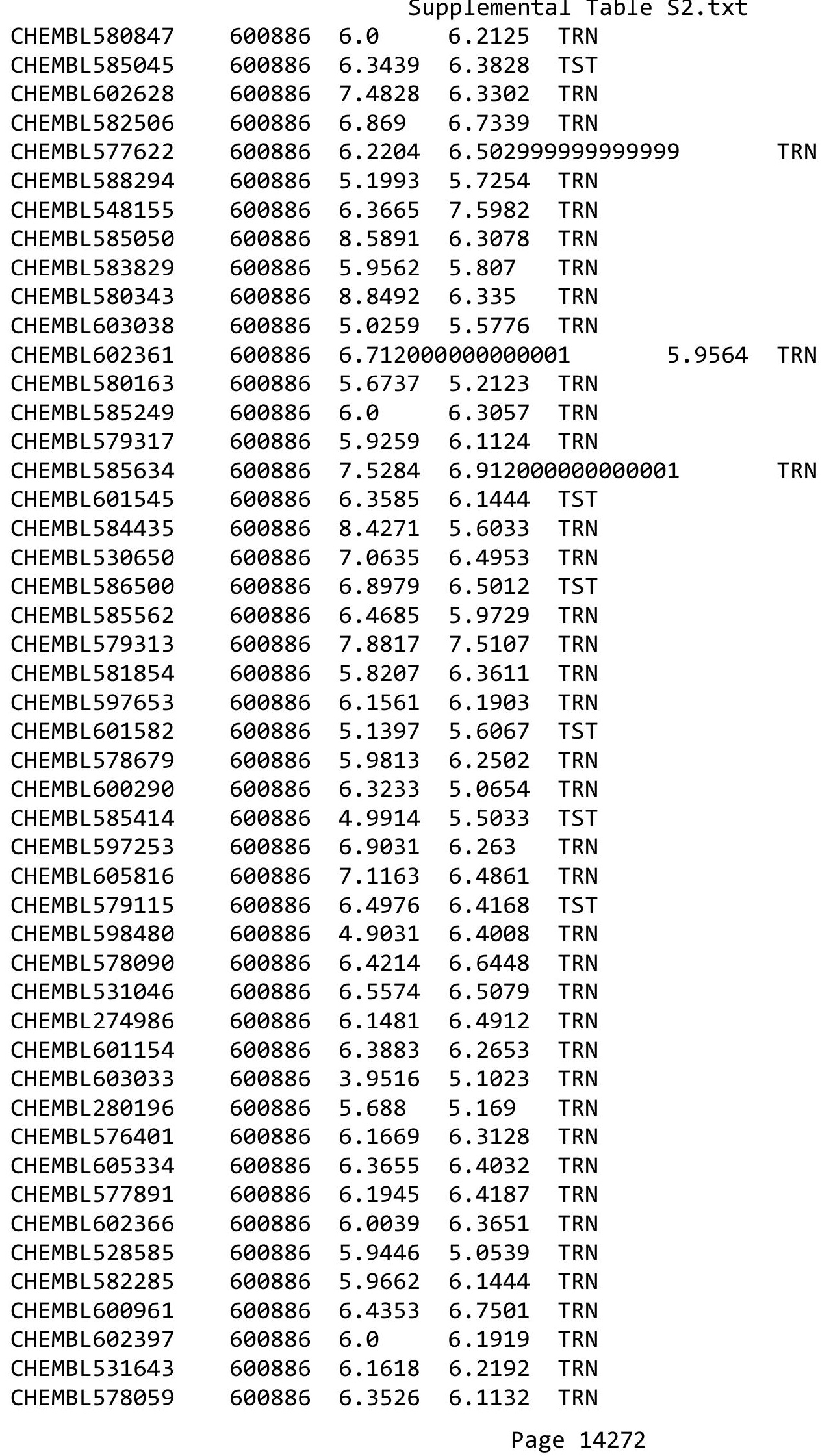




\begin{tabular}{|c|c|c|c|c|c|}
\hline \multicolumn{6}{|c|}{ supplementa } \\
\hline CHEMBL599295 & 600886 & 6.1878 & 6.2852 & TRN & \\
\hline CHEMBL582719 & 600886 & 5.8147 & 6.1531 & TRN & \\
\hline CHEMBL601535 & 600886 & 5.0061 & 6.0009 & TRN & \\
\hline CHEMBL578696 & 600886 & 6.3696 & 6.0919 & TRN & \\
\hline CHEMBL579323 & 600886 & 5.4698 & 5.6553 & TRN & \\
\hline CHEMBL601567 & 600886 & 6.3696 & 6.1304 & TRN & \\
\hline CHEMBL584878 & 600886 & 4.9031 & 5.6754 & TST & \\
\hline CHEMBL578956 & 600886 & 6.2958 & 6.3002 & TST & \\
\hline CHEMBL586184 & 600886 & 7.3344 & 6.8198 & TRN & \\
\hline CHEMBL603035 & 600886 & 6.3716 & 6.6129 & TRN & \\
\hline CHEMBL529858 & 600886 & 6.4486 & 6.659 & TRN & \\
\hline CHEMBL605817 & 600886 & 5.9212 & 6.5461 & TRN & \\
\hline CHEMBL577645 & 600886 & 5.3675 & 5.5565 & TRN & \\
\hline CHEMBL601391 & 600886 & 6.2612 & 6.3522 & TRN & \\
\hline CHEMBL579923 & 600886 & 6.5642 & 6.459 & TRN & \\
\hline CHEMBL584028 & 600886 & 6.4023 & 6.3556 & TST & \\
\hline CHEMBL582733 & 600886 & 5.8483 & 6.0621 & TST & \\
\hline CHEMBL585222 & 600886 & 6.8911 & 6.65600 & 0000000001 & TRN \\
\hline CHEMBL612129 & 600886 & 4.055 & 5.1027 & TRN & \\
\hline CHEMBL582687 & 600886 & 5.7277 & 6.2837 & TRN & \\
\hline CHEMBL581889 & 600886 & 7.1878 & 7.4295 & TRN & \\
\hline CHEMBL599703 & 600886 & 6.7602 & 6.6427 & TRN & \\
\hline CHEMBL586516 & 600886 & 6.3019 & 6.3498 & TRN & \\
\hline CHEMBL581452 & 600886 & 5.7069 & 5.6983 & TRN & \\
\hline CHEMBL599723 & 600886 & 6.1707 & 6.3549 & TRN & \\
\hline CHEMBL486081 & 600886 & 7.011 & 6.8849 & TRN & \\
\hline CHEMBL578061 & 600886 & 5.7153 & 6.4044 & TRN & \\
\hline CHEMBL585777 & 600886 & 6.694 & 6.5783 & TRN & \\
\hline CHEMBL585782 & 600886 & 6.0 & 6.1728 & TRN & \\
\hline CHEMBL609036 & 600886 & 6.3536 & 6.4991 & TRN & \\
\hline CHEMBL584623 & 600886 & 4.9918 & 5.6345 & TRN & \\
\hline CHEMBL530636 & 600886 & 3.9031 & 5.9531 & TRN & \\
\hline CHEMBL581482 & 600886 & 4.9031 & 5.5759 & TRN & \\
\hline CHEMBL577416 & 600886 & 6.4425 & 6.4365 & TRN & \\
\hline CHEMBL578880 & 600886 & 6.5768 & 6.4905 & TRN & \\
\hline CHEMBL602179 & 600886 & 5.8462 & 6.5156 & TRN & \\
\hline CHEMBL601786 & 600886 & 6.9355 & 6.3559 & TRN & \\
\hline CHEMBL579162 & 600886 & 4.584 & 5.9493 & TRN & \\
\hline CHEMBL584479 & 600886 & 6.1152 & 5.7056 & TRN & \\
\hline CHEMBL585842 & 600886 & 8.7397 & 6.2048 & TRN & \\
\hline CHEMBL604305 & 600886 & 6.3206 & 6.4328 & TRN & \\
\hline CHEMBL577835 & 600886 & 6.4935 & 6.4665 & TRN & \\
\hline CHEMBL536918 & 600886 & 7.2798 & 6.3993 & TRN & \\
\hline CHEMBL602760 & 600886 & 8.5787 & 6.153 & TRN & \\
\hline CHEMBL600897 & 600886 & 6.4248 & 6.4047 & TST & \\
\hline CHEMBL 580140 & 600886 & 6.3125 & 6.6889 & TRN & \\
\hline CHEMBL584451 & 600886 & 6.4498 & 5.7119 & TRN & \\
\hline CHEMBL578010 & 600886 & 6.574 & 6.5538 & TRN & \\
\hline
\end{tabular}




\begin{tabular}{|c|c|c|c|c|c|c|}
\hline \multirow[b]{2}{*}{ CHEMBL528533 } & \multicolumn{6}{|c|}{ Supplemental Table S2.txt } \\
\hline & 600886 & 5.5711 & 6.3762 & TRN & & \\
\hline CHEMBL588407 & 600886 & 5.2343 & 5.5004 & TRN & & \\
\hline CHEMBL597657 & 600886 & 6.2708 & 6.4598 & TRN & & \\
\hline CHEMBL578506 & 600886 & 6.2807 & 6.4605 & TRN & & \\
\hline CHEMBL585219 & 600886 & 7.3809 & 6.9051 & TRN & & \\
\hline CHEMBL583361 & 600886 & 6.4237 & 6.1122 & TST & & \\
\hline CHEMBL603688 & 600886 & \multicolumn{3}{|c|}{6.712000000000001} & 5.4973 & TRN \\
\hline CHEMBL585037 & 600886 & \multicolumn{3}{|c|}{7.2620000000000005} & 7.0289 & TRN \\
\hline CHEMBL582054 & 600886 & 5.1831 & 5.6838 & TRN & & \\
\hline CHEMBL599097 & 600886 & 6.301 & 6.3181 & TRN & & \\
\hline CHEMBL536695 & 600886 & 3.9031 & 5.6685 & TRN & & \\
\hline CHEMBL527626 & 600886 & 6.5995 & 6.4007 & TST & & \\
\hline CHEMBL585686 & 600886 & 6.2104 & 6.0719 & TST & & \\
\hline CHEMBL585769 & 600886 & 5.0297 & 5.5901 & TRN & & \\
\hline CHEMBL599885 & 600886 & 6.2941 & 6.1624 & TRN & & \\
\hline CHEMBL528900 & 600886 & 4.9481 & 6.0124 & TRN & & \\
\hline CHEMBL584476 & 600886 & 6.4559 & 6.4821 & TRN & & \\
\hline CHEMBL588079 & 600886 & 6.0731 & 6.4188 & TRN & & \\
\hline CHEMBL585647 & 600886 & 7.0904 & 6.5567 & TRN & & \\
\hline CHEMBL578870 & 600886 & 5.4908 & 5.6805 & TRN & & \\
\hline CHEMBL586033 & 600886 & 6.4949 & 6.4907 & TRN & & \\
\hline CHEMBL581045 & 600886 & 5.8861 & 5.5985 & TST & & \\
\hline CHEMBL598889 & 600886 & 6.0 & 6.0603 & TRN & & \\
\hline CHEMBL603047 & 600886 & 6.4634 & 5.7743 & TRN & & \\
\hline CHEMBL582306 & 600886 & 7.4377 & 6.3138 & TRN & & \\
\hline CHEMBL1967497 & 600886 & 7.6293 & 7.1924 & TRN & & \\
\hline CHEMBL578081 & 600886 & 6.0477 & 5.6255 & TRN & & \\
\hline CHEMBL601338 & 600886 & 4.2277 & 5.2406 & TRN & & \\
\hline CHEMBL528390 & 600886 & 6.062 & 6.1655 & TRN & & \\
\hline CHEMBL584463 & 600886 & 6.0565 & 5.5351 & TRN & & \\
\hline CHEMBL585057 & 600886 & 5.0372 & 5.6757 & TRN & & \\
\hline CHEMBL596841 & 600886 & 6.2299 & 6.0778 & TRN & & \\
\hline CHEMBL584673 & 600886 & 6.1124 & 6.5515 & TRN & & \\
\hline CHEMBL580314 & 600886 & 8.8447 & 6.2584 & TRN & & \\
\hline CHEMBL576208 & 600886 & 7.1013 & 6.6068 & TRN & & \\
\hline CHEMBL576604 & 600886 & 5.1911 & 5.6485 & TRN & & \\
\hline CHEMBL1197556 & 600886 & 6.0 & 6.2789 & TRN & & \\
\hline CHEMBL584666 & 600886 & 6.1101 & 6.1862 & TRN & & \\
\hline CHEMBL534001 & 600886 & 7.0696 & 6.8578 & TRN & & \\
\hline CHEMBL585652 & 600886 & 7.2503 & 6.6591 & TST & & \\
\hline CHEMBL600767 & 600886 & 6.5322 & 6.6162 & TRN & & \\
\hline CHEMBL588768 & 600886 & 6.0334 & 6.263 & TRN & & \\
\hline CHEMBL579340 & 600886 & 5.3585 & 6.0241 & TRN & & \\
\hline CHEMBL586571 & 600886 & 5.4461 & 5.0598 & TRN & & \\
\hline CHEMBL531222 & 600886 & 6.9846 & 6.8102 & TRN & & \\
\hline CHEMBL578935 & 600886 & 5.607 & 5.95299 & 9999999999 & & TRN \\
\hline CHEMBL609027 & 600886 & 6.1965 & 6.2635 & TRN & & \\
\hline CHEMBL548176 & 600886 & 6.2573 & 6.82700 & 3000000 & & TRN \\
\hline & & & & 14274 & & \\
\hline
\end{tabular}




\begin{tabular}{|c|c|c|c|c|c|c|}
\hline \multicolumn{7}{|c|}{ Supplemental Tab } \\
\hline CHEMBL579256 & 600886 & 6.27 & 6.6254 & TRN & & \\
\hline CHEMBL584234 & 600886 & 4.95 & 6.5372 & TRN & & \\
\hline CHEMBL601975 & 600886 & 5.8008 & 6.0069 & TRN & & \\
\hline CHEMBL588086 & 600886 & 5.1707 & 5.0751 & TST & & \\
\hline CHEMBL585982 & 600886 & 6.7467 & 6.725 & TRN & & \\
\hline CHEMBL584074 & 600886 & 6.6586 & 6.7999 & TRN & & \\
\hline CHEMBL584664 & 600886 & 6.1073 & 6.3282 & TRN & & \\
\hline CHEMBL599936 & 600886 & 6.7862 & 5.7576 & TST & & \\
\hline CHEMBL602624 & 600886 & 5.9614 & 6.4035 & TRN & & \\
\hline CHEMBL582678 & 600886 & 3.997 & 5.0726 & TRN & & \\
\hline CHEMBL598264 & 600886 & 7.2676 & 6.2645 & TRN & & \\
\hline CHEMBL604739 & 600886 & 5.5879 & 5.9375 & TRN & & \\
\hline CHEMBL 7070 & 600886 & 7.2774 & 7.4299 & TRN & & \\
\hline CHEMBL588583 & 600886 & 5.1972 & 5.1058 & TST & & \\
\hline CHEMBL597852 & 600886 & 7.0443 & 6.379 & TRN & & \\
\hline CHEMBL600309 & 600886 & 6.7836 & 6.5617 & TST & & \\
\hline CHEMBL581687 & 600886 & 4.9031 & 6.1351 & TRN & & \\
\hline CHEMBL585645 & 600886 & 7.57299 & 999999995 & 995 & 5.6125 & TRN \\
\hline CHEMBL531123 & 600886 & 6.0 & 6.2757 & TRN & & \\
\hline CHEMBL601381 & 600886 & 4.9133 & 6.0986 & TST & & \\
\hline CHEMBL601956 & 600886 & 5.8386 & 5.6517 & TRN & & \\
\hline CHEMBL587655 & 600886 & $5.7020 e$ & 000000006 & 01 & 5.2296 & TST \\
\hline CHEMBL581861 & 600886 & 5.8351 & 6.5397 & TRN & & \\
\hline CHEMBL582248 & 600886 & 6.0783 & 6.3306 & TRN & & \\
\hline CHEMBL578529 & 600886 & 9.032 & 6.4234 & TRN & & \\
\hline CHEMBL585227 & 600886 & 6.3696 & 6.1862 & TRN & & \\
\hline CHEMBL581666 & 600886 & 6.7314 & 6.5447 & TRN & & \\
\hline CHEMBL578050 & 600886 & 6.3788 & 6.4678 & TRN & & \\
\hline CHEMBL599887 & 600886 & 6.0804 & 5.7343 & TRN & & \\
\hline CHEMBL581727 & 600886 & 5.0329 & 6.1788 & TRN & & \\
\hline CHEMBL600743 & 600886 & 5.7513 & 5.8895 & TRN & & \\
\hline CHEMBL581864 & 600886 & 5.7552 & 5.0393 & TRN & & \\
\hline CHEMBL586779 & 600886 & 5.1391 & 5.6919 & TRN & & \\
\hline CHEMBL602609 & 600886 & 5.7867 & 6.0193 & TRN & & \\
\hline CHEMBL602389 & 600886 & 8.4962 & 7.7138 & TRN & & \\
\hline CHEMBL588746 & 600886 & 9.0645 & 6.8312 & TRN & & \\
\hline CHEMBL601166 & 600886 & 6.0 & 6.2006 & TST & & \\
\hline CHEMBL599915 & 600886 & 5.4134 & 5.8042 & TRN & & \\
\hline CHEMBL578925 & 600886 & 5.6315 & 5.5904 & TRN & & \\
\hline CHEMBL601586 & 600886 & 4.9031 & 5.6135 & TST & & \\
\hline CHEMBL584035 & 600886 & 7.109 & 6.2906 & TRN & & \\
\hline CHEMBL602803 & 600886 & 7.4572 & 6.7674 & TRN & & \\
\hline CHEMBL584240 & 600886 & 7.0159 & 6.5879 & TRN & & \\
\hline CHEMBL584269 & 600886 & 6.9952 & 6.8468 & TRN & & \\
\hline CHEMBL 306946 & 600886 & 6.5597 & 6.6317 & TRN & & \\
\hline CHEMBL585083 & 600886 & 4.9031 & 5.7239 & TRN & & \\
\hline CHEMBL585031 & 600886 & 6.0516 & 6.2849 & TRN & & \\
\hline CHEMBL2368645 & 600886 & 6.2069 & 6.5124 & TRN & & \\
\hline
\end{tabular}




\begin{tabular}{|c|c|c|c|c|c|}
\hline & & & & & \\
\hline CHEMBL580167 & 600886 & 6.1062 & 6.2967 & TRN & \\
\hline CHEMBL 2000517 & 600886 & 6.5267 & 6.437 & TRN & \\
\hline CHEMBL586396 & 600886 & 5.1972 & 5.7395 & TST & \\
\hline CHEMBL585087 & 600886 & 4.9031 & 6.3697 & TRN & \\
\hline CHEMBL587267 & 600886 & 6.3487 & 6.6649 & TRN & \\
\hline CHEMBL583553 & 600886 & 4.9212 & 5.8142 & TRN & \\
\hline CHEMBL600118 & 600886 & 7.7018 & 6.7444 & TRN & \\
\hline CHEMBL600538 & 600886 & 7.4012 & 6.5884 & TRN & \\
\hline CHEMBL608858 & 600886 & 6.8794 & 6.6981 & TRN & \\
\hline CHEMBL576054 & 600886 & 5.3372 & 5.1196 & TRN & \\
\hline CHEMBL528984 & 600886 & 6.7075 & 6.3512 & TRN & \\
\hline CHEMBL581841 & 600886 & 6.1864 & 6.79200 & 0000000001 & TRN \\
\hline CHEMBL581463 & 600886 & 5.7642 & 6.2972 & TRN & \\
\hline CHEMBL600130 & 600886 & 5.4535 & 5.1135 & TRN & \\
\hline CHEMBL600741 & 600886 & 6.0301 & 7.0474 & TRN & \\
\hline CHEMBL578473 & 600886 & 6.6139 & 6.4006 & TRN & \\
\hline CHEMBL577858 & 600886 & 5.4437 & 6.1535 & TST & \\
\hline CHEMBL582503 & 600886 & 6.6554 & 6.6503 & TRN & \\
\hline CHEMBL600125 & 600886 & 5.5683 & 6.07299 & 99999999995 & TRN \\
\hline CHEMBL527237 & 600886 & 4.9031 & 5.6662 & TST & \\
\hline CHEMBL603037 & 600886 & 6.3716 & 6.2851 & TRN & \\
\hline CHEMBL584290 & 600886 & 5.9252 & 5.1414 & TRN & \\
\hline CHEMBL600910 & 600886 & 5.301 & 5.6542 & TRN & \\
\hline CHEMBL601537 & 600886 & 6.251 & 6.0793 & TRN & \\
\hline CHEMBL604310 & 600886 & 6.2396 & 6.3778 & TRN & \\
\hline CHEMBL587277 & 600886 & 6.2668 & 6.5122 & TRN & \\
\hline CHEMBL581887 & 600886 & 5.7926 & 6.4259 & TRN & \\
\hline CHEMBL598479 & 600886 & 4.9031 & 5.7307 & TST & \\
\hline CHEMBL600940 & 600886 & 5.3261 & 5.8494 & TRN & \\
\hline CHEMBL584239 & 600886 & 5.9512 & 6.0701 & TRN & \\
\hline CHEMBL582318 & 600886 & 4.9031 & 6.0904 & TRN & \\
\hline CHEMBL606381 & 600886 & 6.9352 & 6.7378 & TRN & \\
\hline CHEMBL579160 & 600886 & 6.5433 & 6.4947 & TRN & \\
\hline CHEMBL587210 & 600886 & 7.3799 & 6.7855 & TRN & \\
\hline CHEMBL577018 & 600886 & 6.0915 & 6.0534 & TRN & \\
\hline CHEMBL581272 & 600886 & 6.8814 & 5.6389 & TST & \\
\hline CHEMBL578707 & 600886 & 5.9508 & 6.1746 & TRN & \\
\hline CHEMBL582115 & 600886 & 4.9031 & 5.686 & TRN & \\
\hline CHEMBL578941 & 600886 & 6.9041 & 6.8608 & TRN & \\
\hline CHEMBL579083 & 600886 & 6.0278 & 6.7018 & TST & \\
\hline CHEMBL532723 & 600886 & 6.3615 & 6.5409 & TST & \\
\hline CHEMBL602807 & 600886 & 5.6613 & 5.8807 & TST & \\
\hline CHEMBL585985 & 600886 & 5.0555 & 6.6061 & TRN & \\
\hline CHEMBL600565 & 600886 & 7.4976 & 7.1478 & TRN & \\
\hline CHEMBL600695 & 600886 & 5.3363 & 4.9344 & TRN & \\
\hline CHEMBL577368 & 600886 & 5.3747 & 5.0915 & TST & \\
\hline CHEMBL602818 & 600886 & 6.0511 & 6.1394 & TRN & \\
\hline CHEMBL585439 & 600886 & 6.5239 & 6.428 & TRN & \\
\hline
\end{tabular}




\begin{tabular}{|c|c|c|c|c|c|}
\hline \multirow[b]{2}{*}{ CHEMBL529143 } & \multicolumn{5}{|c|}{ Supplemental Table S2.txt } \\
\hline & 600886 & 6.4498 & 7.0372 & TRN & \\
\hline CHEMBL578718 & 600886 & 6.5678 & 6.4452 & TRN & \\
\hline CHEMBL578743 & 600886 & 6.0246 & 6.4028 & TRN & \\
\hline CHEMBL581882 & 600886 & 6.0429 & 6.2433 & TRN & \\
\hline CHEMBL598891 & 600886 & 4.9031 & 6.3884 & TRN & \\
\hline CHEMBL596850 & 600886 & 6.0 & 6.2018 & TRN & \\
\hline CHEMBL578066 & 600886 & 8.04 & 6.4341 & TRN & \\
\hline CHEMBL584256 & 600886 & 6.2976 & 6.4929 & TRN & \\
\hline CHEMBL579892 & 600886 & 6.475 & 6.301 & TRN & \\
\hline CHEMBL585133 & 600886 & 6.1175 & 5.6846 & TRN & \\
\hline CHEMBL581035 & 600886 & 6.0 & 5.9797 & TST & \\
\hline CHEMBL602603 & 600886 & 5.5459 & 5.8701 & TRN & \\
\hline CHEMBL612128 & 600886 & 7.6957 & 6.3521 & TRN & \\
\hline CHEMBL584736 & 600886 & 6.6925 & 6.2948 & TRN & \\
\hline CHEMBL584837 & 600886 & 4.9788 & 5.6346 & TRN & \\
\hline CHEMBL582079 & 600886 & 6.4976 & 6.6939 & TRN & \\
\hline CHEMBL601371 & 600886 & 5.8122 & 5.6192 & TST & \\
\hline CHEMBL582097 & 600886 & 5.7438 & 5.5318 & TRN & \\
\hline CHEMBL578921 & 600886 & 5.3575 & 5.1417 & TRN & \\
\hline CHEMBL598268 & 600886 & 6.1938 & 5.9968 & TRN & \\
\hline CHEMBL579933 & 600886 & 7.0101 & 6.4861 & TRN & \\
\hline CHEMBL581859 & 600886 & 6.7823 & 6.4409 & TST & \\
\hline CHEMBL529295 & 600886 & 6.1284 & 6.254 & TRN & \\
\hline CHEMBL577635 & 600886 & 6.0 & 6.2521 & TST & \\
\hline CHEMBL588763 & 600886 & 5.1238 & 5.6598 & TST & \\
\hline CHEMBL598697 & 600886 & 6.5131 & 6.38 & TRN & \\
\hline CHEMBL602586 & 600886 & 6.6282 & 6.61700 & 0000000001 & TST \\
\hline CHEMBL582681 & 600886 & 5.7508 & 6.2309 & TRN & \\
\hline CHEMBL602369 & 600886 & 6.5246 & 6.4005 & TST & \\
\hline CHEMBL584275 & 600886 & 4.9031 & 5.5751 & TRN & \\
\hline CHEMBL588661 & 600886 & 5.2111 & 5.2331 & TRN & \\
\hline CHEMBL585026 & 600886 & 6.7506 & 6.5178 & TRN & \\
\hline CHEMBL600297 & 600886 & 5.4342 & 5.8517 & TRN & \\
\hline CHEMBL578287 & 600886 & 6.4724 & 6.36299 & 99999999995 & TRN \\
\hline CHEMBL584625 & 600886 & 6.3788 & 6.4832 & TRN & \\
\hline CHEMBL585237 & 600886 & 8.6914 & 6.5031 & TRN & \\
\hline CHEMBL3191855 & 600886 & 6.9638 & 6.7933 & TRN & \\
\hline CHEMBL582499 & 600886 & 5.7428 & 5.7791 & TRN & \\
\hline CHEMBL578084 & 600886 & 6.4179 & 6.4742 & TST & \\
\hline CHEMBL596834 & 600886 & 6.063 & 5.8794 & TST & \\
\hline CHEMBL602809 & 600886 & 6.7371 & 5.5057 & TRN & \\
\hline CHEMBL585209 & 600886 & 4.9337 & 5.5932 & TRN & \\
\hline CHEMBL583357 & 600886 & 5.9952 & 6.2537 & TRN & \\
\hline CHEMBL582739 & 600886 & 4.9031 & 5.6326 & TST & \\
\hline CHEMBL548646 & 600886 & 6.1002 & 6.3308 & TRN & \\
\hline CHEMBL601602 & 600886 & 6.5784 & 5.274 & TRN & \\
\hline CHEMBL579328 & 600886 & 5.5884 & 5.0582 & TRN & \\
\hline CHEMBL 600535 & 600886 & 5.5889 & 6.3753 & TST & \\
\hline
\end{tabular}




\begin{tabular}{|c|c|c|c|c|c|}
\hline \\
\hline CHEMBL600770 & 600886 & 5.032 & 5.6031 & TST & \\
\hline CHEMBL530679 & 600886 & 4.9393 & 5.6811 & TRN & \\
\hline CHEMBL599933 & 600886 & 6.4202 & 6.6086 & TRN & \\
\hline CHEMBL582502 & 600886 & 4.7905 & 6.0559 & TRN & \\
\hline CHEMBL578276 & 600886 & 5.5585 & 6.2 & TRN & \\
\hline CHEMBL581260 & 600886 & 4.8383 & 5.6045 & TRN & \\
\hline CHEMBL584221 & 600886 & 6.4698 & 6.4018 & TRN & \\
\hline CHEMBL600505 & 600886 & 5.5745 & 5.7715 & TST & \\
\hline CHEMBL609030 & 600886 & 3.9031 & 5.8467 & TST & \\
\hline CHEMBL602780 & 600886 & 6.9788 & 6.5955 & TRN & \\
\hline CHEMBL600346 & 600886 & 7.4248 & 7.0094 & TST & \\
\hline CHEMBL581451 & 600886 & 6.7062 & 6.2856 & TST & \\
\hline CHEMBL582048 & 600886 & 4.1831 & 5.0563 & TRN & \\
\hline CHEMBL584879 & 600886 & 3.9031 & 5.2084 & TRN & \\
\hline CHEMBL488954 & 600886 & 6.6857 & 6.79299 & 9999999999 & TRN \\
\hline CHEMBL577374 & 600886 & 6.6091 & 6.9908 & TRN & \\
\hline CHEMBL584648 & 600886 & 5.0 & 5.5577 & TRN & \\
\hline CHEMBL1989853 & 600886 & 6.6436 & 6.5876 & TRN & \\
\hline CHEMBL582663 & 600886 & 5.3449 & 5.1643 & TRN & \\
\hline CHEMBL585302 & 600886 & 6.1772 & 6.1906 & TRN & \\
\hline CHEMBL602579 & 600886 & 6.2013 & 6.4901 & TST & \\
\hline CHEMBL582668 & 600886 & 8.0048 & 6.4643 & TRN & \\
\hline CHEMBL585956 & 600886 & 5.5935 & 5.092 & TRN & \\
\hline CHEMBL582260 & 600886 & 5.2373 & 5.7723 & TRN & \\
\hline CHEMBL588133 & 600886 & 9.0814 & 6.3067 & TRN & \\
\hline CHEMBL601788 & 600886 & 6.4045 & 6.2466 & TST & \\
\hline CHEMBL599101 & 600886 & 6.2366 & 6.4299 & TST & \\
\hline CHEMBL601138 & 600886 & 6.9594 & 6.6721 & TRN & \\
\hline CHEMBL596640 & 600886 & 6.3152 & 6.1425 & TRN & \\
\hline CHEMBL585622 & 600886 & 7.5006 & 6.8987 & TRN & \\
\hline CHEMBL600775 & 600886 & 5.9187 & 5.005 & TRN & \\
\hline CHEMBL581471 & 600886 & 4.794 & 5.7718 & TST & \\
\hline CHEMBL584865 & 600886 & 5.0227 & 6.1487 & TRN & \\
\hline CHEMBL587853 & 600886 & 5.1701 & 5.3 & TRN & \\
\hline CHEMBL596652 & 600886 & 6.2013 & 6.4109 & TRN & \\
\hline CHEMBL578929 & 600886 & 4.9031 & 6.8293 & TST & \\
\hline CHEMBL599889 & 600886 & 6.0315 & 5.9301 & TRN & \\
\hline CHEMBL586410 & 600886 & 7.3686 & 6.9284 & TRN & \\
\hline CHEMBL598066 & 600886 & 6.0991 & 6.0542 & TRN & \\
\hline CHEMBL579292 & 600886 & 7.8204 & 7.4123 & TST & \\
\hline CHEMBL600277 & 600886 & 6.6474 & 6.136 & TRN & \\
\hline CHEMBL528661 & 600886 & 6.3063 & 6.2797 & TRN & \\
\hline CHEMBL577019 & 600886 & 6.0915 & 6.355 & TRN & \\
\hline CHEMBL601573 & 600886 & 5.4855 & 5.5709 & TRN & \\
\hline CHEMBL580598 & 600886 & 5.7038 & 6.0569 & TRN & \\
\hline CHEMBL579341 & 600886 & 8.3179 & 7.3677 & TRN & \\
\hline CHEMBL582095 & 600886 & 5.7181 & 6.084 & TRN & \\
\hline CHEMBL602828 & 600886 & 6.0 & 6.3298 & TRN & \\
\hline
\end{tabular}




\begin{tabular}{|c|c|c|c|c|c|c|}
\hline \\
\hline CHEMBL600945 & 600886 & 6.7007 & 6.5688 & TST & & \\
\hline CHEMBL528080 & 600886 & 8.5277 & 5.7952 & TRN & & \\
\hline CHEMBL604514 & 600886 & 6.7802 & 6.546 & TRN & & \\
\hline CHEMBL582088 & 600886 & 6.9129 & 7.1463 & TRN & & \\
\hline CHEMBL577864 & 600886 & 5.3686 & 5.5362 & TRN & & \\
\hline CHEMBL584301 & 600886 & 6.4572 & 5.5017 & TRN & & \\
\hline CHEMBL579322 & 600886 & 6.0 & 6.2877 & TRN & & \\
\hline CHEMBL586424 & 600886 & 5.2388 & 6.6124 & TRN & & \\
\hline CHEMBL585621 & 600886 & 6.3487 & 5.8741 & TRN & & \\
\hline CHEMBL600527 & 600886 & 7.2832 & 6.9343 & TST & & \\
\hline CHEMBL581048 & 600886 & 3.9031 & 5.3018 & TRN & & \\
\hline CHEMBL579980 & 600886 & 6.08299 & 99999999 & 99 & 6.2045 & TST \\
\hline CHEMBL583225 & 600886 & 5.961 & 6.2376 & TRN & & \\
\hline CHEMBL600941 & 600886 & 6.6951 & 6.7335 & TRN & & \\
\hline CHEMBL576994 & 600886 & 5.9333 & 6.596 & TRN & & \\
\hline CHEMBL528950 & 600886 & 5.0472 & 5.8596 & TRN & & \\
\hline CHEMBL580159 & 600886 & 6.1146 & 6.3225 & TRN & & \\
\hline CHEMBL581044 & 600886 & 6.0 & 6.228 & TST & & \\
\hline CHEMBL601791 & 600886 & 6.5722 & 5.5746 & TST & & \\
\hline CHEMBL586022 & 600886 & 6.7373 & 5.9093 & TST & & \\
\hline CHEMBL600536 & 600886 & 6.5036 & 6.2199 & TST & & \\
\hline CHEMBL533376 & 600886 & 8.4413 & 7.3315 & TST & & \\
\hline CHEMBL585421 & 600886 & 7.6904 & 7.0958 & TRN & & \\
\hline CHEMBL581670 & 600886 & 5.7652 & 6.2785 & TRN & & \\
\hline CHEMBL578245 & 600886 & 5.7275 & 5.2115 & TRN & & \\
\hline CHEMBL532079 & 600886 & 7.1688 & 6.6828 & TRN & & \\
\hline CHEMBL582708 & 600886 & 6.9987 & 6.8345 & TRN & & \\
\hline CHEMBL582392 & 600886 & 6.7455 & 6.6681 & TRN & & \\
\hline CHEMBL579929 & 600886 & 9.2314 & 6.7886 & TRN & & \\
\hline CHEMBL1765 & 600886 & 6.5777 & 6.9326 & TST & & \\
\hline CHEMBL588728 & 600886 & 6.209 & 5.6269 & TRN & & \\
\hline CHEMBL596854 & 600886 & 6.1694 & 5.7274 & TRN & & \\
\hline CHEMBL604359 & 600886 & 4.8877 & 5.9242 & TRN & & \\
\hline CHEMBL 577878 & 600886 & 5.2464 & 5.7334 & TRN & & \\
\hline CHEMBL582515 & 600886 & 6.0448 & 6.3904 & TRN & & \\
\hline CHEMBL582314 & 600886 & 5.8788 & 5.6285 & TST & & \\
\hline CHEMBL530907 & 600886 & 5.3188 & 5.0755 & TST & & \\
\hline CHEMBL580128 & 600886 & 5.8099 & 6.0465 & TRN & & \\
\hline CHEMBL601139 & 600886 & 6.7757 & 6.8037 & TRN & & \\
\hline CHEMBL494669 & 600886 & 7.0915 & 6.9953 & TRN & & \\
\hline CHEMBL600729 & 600886 & 6.6584 & 6.2446 & TRN & & \\
\hline CHEMBL600972 & 600886 & 6.1733 & 6.2872 & TRN & & \\
\hline CHEMBL528586 & 600886 & 6.6788 & 6.3702 & TST & & \\
\hline CHEMBL585630 & 600886 & 8.567 & 5.5462 & TRN & & \\
\hline CHEMBL133276 & 600886 & 6.5516 & 6.5058 & TST & & \\
\hline CHEMBL584819 & 600886 & 4.9884 & 5.1313 & TRN & & \\
\hline CHEMBL577625 & 600886 & 5.9512 & 5.9098 & TRN & & \\
\hline CHEMBL581488 & 600886 & 5.8775 & 5.0829 & TRN & & \\
\hline
\end{tabular}




\begin{tabular}{|c|c|c|c|c|c|}
\hline \multirow[b]{2}{*}{ CHEMBL525333 } & \multicolumn{5}{|c|}{$x$} \\
\hline & 600886 & 6.9378 & 6.8255 & TRN & \\
\hline CHEMBL206540 & 600886 & 6.2798 & 6.3472 & TRN & \\
\hline CHEMBL586041 & 600886 & 7.0013 & $6.66100 t$ & 00000000005 & TRN \\
\hline CHEMBL579114 & 600886 & 6.0 & 6.3656 & TRN & \\
\hline CHEMBL580840 & 600886 & 4.8881 & 5.7433 & TRN & \\
\hline CHEMBL575039 & 600886 & 5.5965 & 5.6168 & TRN & \\
\hline CHEMBL603023 & 600886 & 6.7557 & 6.0913 & TRN & \\
\hline CHEMBL582268 & 600886 & 6.0 & 6.1659 & TST & \\
\hline CHEMBL577439 & 600886 & 5.6568 & 5.772 & TRN & \\
\hline CHEMBL604323 & 600886 & 6.2343 & 6.0588 & TRN & \\
\hline CHEMBL601609 & 600886 & 8.633 & 6.3551 & TRN & \\
\hline CHEMBL578517 & 600886 & 6.3224 & 6.4334 & TRN & \\
\hline CHEMBL579960 & 600886 & 5.7192 & 5.6273 & TRN & \\
\hline CHEMBL599292 & 600886 & 6.0964 & 6.1934 & TRN & \\
\hline CHEMBL611500 & 600886 & 6.5375 & 6.1822 & TRN & \\
\hline CHEMBL602593 & 600886 & 5.3382 & 5.7752 & TRN & \\
\hline CHEMBL106525 & 600886 & 7.02 & 7.0399 & TRN & \\
\hline CHEMBL599506 & 600886 & 7.1726 & 7.0001 & TRN & \\
\hline CHEMBL607578 & 600886 & 6.8739 & 6.7702 & TRN & \\
\hline CHEMBL601180 & 600886 & 6.6985 & 6.4859 & TRN & \\
\hline CHEMBL529107 & 600886 & 6.3134 & 6.3192 & TRN & \\
\hline CHEMBL585616 & 600886 & 5.9578 & 6.2098 & TRN & \\
\hline CHEMBL527181 & 600886 & 5.8837 & 5.8527 & TRN & \\
\hline CHEMBL611380 & 600886 & 6.3188 & 6.2924 & TRN & \\
\hline CHEMBL602207 & 600886 & 5.8083 & 5.9302 & TRN & \\
\hline CHEMBL577405 & 600886 & 5.7047 & 6.1348 & TST & \\
\hline CHEMBL530038 & 600886 & 6.4179 & 6.196006 & 0000000001 & TST \\
\hline CHEMBL586018 & 600886 & 6.624 & 6.3852 & TRN & \\
\hline CHEMBL581857 & 600886 & 5.7815 & 6.1802 & TST & \\
\hline CHEMBL602571 & 600886 & 3.9031 & 5.896 & TRN & \\
\hline CHEMBL584039 & 600886 & 5.983 & 6.0943 & TRN & \\
\hline CHEMBL600950 & 600886 & 4.9031 & 5.5562 & TRN & \\
\hline CHEMBL529205 & 600886 & 6.7734 & 6.1369 & TRN & \\
\hline CHEMBL600303 & 600886 & 6.0 & 6.2147 & TST & \\
\hline CHEMBL598061 & 600886 & 6.011 & 6.1443 & TRN & \\
\hline CHEMBL598052 & 600886 & 4.9031 & 6.3994 & TRN & \\
\hline CHEMBL601176 & 600886 & 6.0545 & 5.0409 & TRN & \\
\hline CHEMBL578524 & 600886 & 6.9344 & 6.6759 & TRN & \\
\hline CHEMBL601366 & 600886 & 6.0343 & 6.7925 & TRN & \\
\hline CHEMBL577365 & 600886 & 5.3439 & 5.05699 & 99999999995 & TST \\
\hline CHEMBL578309 & 600886 & 5.4572 & 5.2728 & TRN & \\
\hline CHEMBL579355 & 600886 & 6.3197 & 6.199 & TRN & \\
\hline CHEMBL579944 & 600886 & 6.1612 & 5.4162 & TRN & \\
\hline CHEMBL602436 & 600886 & 4.9905 & 5.5806 & TST & \\
\hline CHEMBL579375 & 600886 & 5.2557 & 5.8517 & TRN & \\
\hline CHEMBL583366 & 600886 & 5.9245 & 6.4315 & TRN & \\
\hline CHEMBL604563 & 600886 & 5.794 & 5.9035 & TRN & \\
\hline CHEMBL581877 & 600886 & 5.7321 & 6.1819 & TRN & \\
\hline & & & & 14280 & \\
\hline
\end{tabular}




\begin{tabular}{|c|c|c|c|c|c|c|}
\hline \multicolumn{7}{|c|}{ sup } \\
\hline CHEMBL581461 & 600886 & 5.734 & 5.8335 & TRN & & \\
\hline CHEMBL586220 & 600886 & 7.3585 & 6.6795 & TRN & & \\
\hline CHEMBL529640 & 600886 & 6.7345 & 6.3635 & TST & & \\
\hline CHEMBL600499 & 600886 & 3.9031 & 5.7488 & TRN & & \\
\hline CHEMBL581266 & 600886 & 4.7625 & 6.1664 & TRN & & \\
\hline CHEMBL602160 & 600886 & 6.4202 & 6.3819 & TRN & & \\
\hline CHEMBL579122 & 600886 & 6.5872 & 6.1488 & TRN & & \\
\hline CHEMBL600728 & 600886 & 6.0 & 6.2503 & TRN & & \\
\hline CHEMBL585771 & 600886 & 5.6842 & 5.5068 & TRN & & \\
\hline CHEMBL600132 & 600886 & 6.1007 & 5.6591 & TST & & \\
\hline CHEMBL578693 & 600886 & 5.38200 & 00000000 & 01 & 5.8585 & TRN \\
\hline CHEMBL585241 & 600886 & 6.5211 & 6.454 & TRN & & \\
\hline CHEMBL600342 & 600886 & 3.9241 & 5.0894 & TRN & & \\
\hline CHEMBL577838 & 600886 & 6.3556 & 6.0684 & TRN & & \\
\hline CHEMBL584427 & 600886 & 5.05699 & 99999999 & 995 & 5.5503 & TRN \\
\hline CHEMBL530683 & 600886 & 6.3726 & 4.8128 & TRN & & \\
\hline CHEMBL584460 & 600886 & 6.0814 & 6.2396 & TRN & & \\
\hline CHEMBL600896 & 600886 & 5.978 & 5.1176 & TRN & & \\
\hline CHEMBL584875 & 600886 & 4.9031 & 5.6892 & TRN & & \\
\hline CHEMBL602783 & 600886 & 6.1209 & 6.3055 & TRN & & \\
\hline CHEMBL579099 & 600886 & 6.5501 & 6.749 & TRN & & \\
\hline CHEMBL99 & 600886 & 6.7675 & 6.5159 & TRN & & \\
\hline CHEMBL596641 & 600886 & 5.9714 & 6.1722 & TRN & & \\
\hline CHEMBL578677 & 600886 & 6.0 & 6.2632 & TRN & & \\
\hline CHEMBL584244 & 600886 & 7.0535 & 6.3114 & TRN & & \\
\hline CHEMBL585773 & 600886 & 6.2534 & 6.4268 & TRN & & \\
\hline CHEMBL583824 & 600886 & 6.2161 & 6.3211 & TRN & & \\
\hline CHEMBL600932 & 600886 & 5.5646 & 5.8447 & TRN & & \\
\hline CHEMBL602616 & 600886 & 5.8049 & 5.7241 & TRN & & \\
\hline CHEMBL600165 & 600886 & 6.7194 & 6.6344 & TRN & & \\
\hline CHEMBL580173 & 600886 & 5.808 & 5.8888 & TRN & & \\
\hline CHEMBL585959 & 600886 & 5.2211 & 5.9811 & TRN & & \\
\hline CHEMBL600977 & 600886 & 6.1007 & 6.2933 & TRN & & \\
\hline CHEMBL601960 & 600886 & 4.9031 & 5.8747 & TRN & & \\
\hline CHEMBL581884 & 600886 & 5.8091 & 5.8276 & TRN & & \\
\hline CHEMBL601357 & 600886 & 6.4145 & 6.4585 & TRN & & \\
\hline CHEMBL606023 & 600886 & 4.9129 & 5.6322 & TRN & & \\
\hline CHEMBL577649 & 600886 & 5.5916 & 6.0501 & TRN & & \\
\hline CHEMBL601333 & 600886 & 5.3546 & 5.0401 & TST & & \\
\hline CHEMBL193627 & 600886 & 6.0 & 6.3328 & TRN & & \\
\hline CHEMBL579941 & 600886 & 9.1475 & 5.7521 & TRN & & \\
\hline CHEMBL601532 & 600886 & 6.7501 & 6.244 & TRN & & \\
\hline CHEMBL596635 & 600886 & 6.1605 & 6.4544 & TRN & & \\
\hline CHEMBL576406 & 600886 & 7.2652 & 5.6359 & TRN & & \\
\hline CHEMBL601533 & 600886 & 4.9473 & 6.0142 & TRN & & \\
\hline CHEMBL599287 & 600886 & 6.7899 & 6.3422 & TRN & & \\
\hline CHEMBL601171 & 600886 & 6.0 & 6.1995 & TRN & & \\
\hline CHEMBL602793 & 600886 & 6.9531 & 6.5941 & TST & & \\
\hline
\end{tabular}




\begin{tabular}{|c|c|c|c|c|c|c|}
\hline & & & ello & & & \\
\hline CHEMBL576613 & 600886 & 6.5084 & 6.7827 & TRN & & \\
\hline CHEMBL585788 & 600886 & 5.0287 & 5.6355 & TST & & \\
\hline CHEMBL602805 & 600886 & 6.66799 & 99999999 & 99 & 6.5087 & TST \\
\hline CHEMBL584419 & 600886 & 4.9408 & 5.5986 & TRN & & \\
\hline CHEMBL602375 & 600886 & 6.0 & 6.2913 & TST & & \\
\hline CHEMBL580956 & 600886 & 6.9974 & 6.6191 & TRN & & \\
\hline CHEMBL585464 & 600886 & 6.5727 & 6.3501 & TRN & & \\
\hline CHEMBL582729 & 600886 & 4.9031 & 6.1451 & TST & & \\
\hline CHEMBL603007 & 600886 & 6.4737 & 6.1303 & TRN & & \\
\hline CHEMBL600351 & 600886 & 5.0585 & 5.5858 & TRN & & \\
\hline CHEMBL584252 & 600886 & 6.0292 & 5.2518 & TRN & & \\
\hline CHEMBL601821 & 600886 & 6.7029 & 6.6898 & TRN & & \\
\hline CHEMBL582132 & 600886 & 6.4045 & 6.2333 & TRN & & \\
\hline CHEMBL582677 & 600886 & 6.1331 & 6.2758 & TST & & \\
\hline CHEMBL584445 & 600886 & 5.96700 & 300000006 & 205 & 6.3932 & TRN \\
\hline CHEMBL611372 & 600886 & 3.9031 & 6.4146 & TRN & & \\
\hline CHEMBL582288 & 600886 & 5.8035 & 5.5546 & TST & & \\
\hline CHEMBL1448140 & 600886 & 4.9031 & 5.8236 & TRN & & \\
\hline CHEMBL601589 & 600886 & 6.2291 & 6.3907 & TST & & \\
\hline CHEMBL596638 & 600886 & 6.2774 & 6.2144 & TRN & & \\
\hline CHEMBL527336 & 600886 & 7.1107 & 6.8981 & TRN & & \\
\hline CHEMBL604112 & 600886 & 6.0794 & 5.7561 & TRN & & \\
\hline CHEMBL598263 & 600886 & 6.0 & 6.2052 & TST & & \\
\hline CHEMBL599950 & 600886 & 6.5508 & 6.5788 & TRN & & \\
\hline CHEMBL602174 & 600886 & 6.8623 & 6.5885 & TRN & & \\
\hline CHEMBL578945 & 600886 & 5.5482 & 5.0284 & TRN & & \\
\hline CHEMBL578110 & 600886 & 6.7716 & 6.6508 & TRN & & \\
\hline CHEMBL584212 & 600886 & 5.0565 & 6.6175 & TRN & & \\
\hline CHEMBL534535 & 600886 & 6.5907 & 7.099 & TRN & & \\
\hline CHEMBL524403 & 600886 & 7.0545 & 6.4263 & TRN & & \\
\hline CHEMBL585962 & 600886 & 7.16299 & 99999999 & 99 & 6.4129 & TST \\
\hline CHEMBL578476 & 600886 & 5.9574 & 5.734 & TRN & & \\
\hline CHEMBL531730 & 600886 & 6.5728 & 6.7799 & TRN & & \\
\hline CHEMBL609749 & 600886 & 6.1267 & 5.9649 & TRN & & \\
\hline CHEMBL600696 & 600886 & 4.8592 & 5.6855 & TST & & \\
\hline CHEMBL583339 & 600886 & 5.9172 & 6.2027 & TRN & & \\
\hline CHEMBL602407 & 600886 & 5.7268 & 5.9969 & TST & & \\
\hline CHEMBL584008 & 600886 & 5.961 & 6.355 & TRN & & \\
\hline CHEMBL603013 & 600886 & 6.3382 & 6.3529 & TRN & & \\
\hline CHEMBL599088 & 600886 & 6.067 & 5.9733 & TRN & & \\
\hline CHEMBL601819 & 600886 & 6.4522 & 6.3232 & TRN & & \\
\hline CHEMBL577650 & 600886 & 6.7215 & 6.3766 & TRN & & \\
\hline CHEMBL602814 & 600886 & 5.8867 & 5.3777 & TRN & & \\
\hline CHEMBL604564 & 600886 & 7.38200 & 30000000 & $\partial 1$ & 7.4682 & TRN \\
\hline CHEMBL581669 & 600886 & 6.0665 & 6.4807 & TRN & & \\
\hline CHEMBL584650 & 600886 & 6.4318 & 6.3162 & TRN & & \\
\hline CHEMBL531250 & 600886 & 5.648 & 5.9623 & TRN & & \\
\hline CHEMBL601146 & 600886 & 6.3706 & 6.5562 & TRN & & \\
\hline
\end{tabular}




\begin{tabular}{|c|c|c|c|c|c|c|c|}
\hline \multicolumn{7}{|c|}{ Supplemental Table s2.txt } & \\
\hline CHEMBL527397 & 600886 & 6.5436 & 6.4515 & TST & & & \\
\hline CHEMBL584659 & 600886 & 7.4815 & 6.4261 & TRN & & & \\
\hline CHEMBL 7892 & 600886 & 5.059 & 5.5799 & TRN & & & \\
\hline CHEMBL601105 & 600886 & 6.1255 & 6.3543 & TRN & & & \\
\hline CHEMBL582528 & 600886 & 5.4802 & 5.7631 & TRN & & & \\
\hline CHEMBL582060 & 600886 & 5.8523 & 5.8213 & TRN & & & \\
\hline CHEMBL587468 & 600886 & 7.7905 & 5.6381 & TRN & & & \\
\hline CHEMBL579324 & 600886 & 7.4976 & 6.4118 & TRN & & & \\
\hline CHEMBL580820 & 600886 & 5.091 & 6.2369 & TRN & & & \\
\hline CHEMBL602782 & 600886 & 5.6826 & 6.1857 & TRN & & & \\
\hline CHEMBL599495 & 600886 & 5.9642 & 5.6587 & TRN & & & \\
\hline CHEMBL600956 & 600886 & 6.15799 & 99999999 & 995 & 6.3431 & TRN & \\
\hline CHEMBL600552 & 600886 & 7.7303 & 6.3022 & TRN & & & \\
\hline CHEMBL602823 & 600886 & 5.9248 & 7.2717 & TRN & & & \\
\hline CHEMBL604927 & 600886 & 5.9101 & 5.7461 & TST & & & \\
\hline CHEMBL548286 & 600886 & 6.959 & 6.3229 & TRN & & & \\
\hline CHEMBL585079 & 600886 & 4.908 & 5.6008 & TRN & & & \\
\hline CHEMBL611370 & 600886 & 6.9027 & 6.5334 & TRN & & & \\
\hline CHEMBL579719 & 600886 & 5.1319 & 5.4459 & TRN & & & \\
\hline CHEMBL531932 & 600886 & 6.4522 & 6.5582 & TRN & & & \\
\hline CHEMBL582258 & 600886 & 6.0 & 6.206 & TRN & & & \\
\hline CHEMBL582656 & 600886 & 6.15799 & 99999999 & 995 & 6.5735 & TRN & \\
\hline CHEMBL588655 & 600886 & 4.1267 & 5.1178 & TRN & & & \\
\hline CHEMBL576607 & 600886 & 6.0 & 6.1632 & TRN & & & \\
\hline CHEMBL600952 & 600886 & 5.8719 & 5.7096 & TRN & & & \\
\hline CHEMBL602205 & 600886 & 5.6602 & 5.0331 & TRN & & & \\
\hline CHEMBL598687 & 600886 & 6.7886 & 6.659 & TRN & & & \\
\hline CHEMBL600344 & 600886 & 7.4685 & 6.372999 & 9999999999 & & TRN & \\
\hline CHEMBL582669 & 600886 & 6.1068 & 6.1957 & TRN & & & \\
\hline CHEMBL600540 & 600886 & 5.8492 & 6.1192 & TRN & & & \\
\hline CHEMBL578961 & 600886 & 4.2573 & 4.9718 & TRN & & & \\
\hline CHEMBL579106 & 600886 & 6.4976 & 6.3632 & TRN & & & \\
\hline CHEMBL584241 & 600886 & 6.4023 & 6.5572 & TRN & & & \\
\hline CHEMBL584838 & 600886 & 6.7042 & 6.5509 & TRN & & & \\
\hline CHEMBL528933 & 600886 & 5.9129 & 6.5277 & TRN & & & \\
\hline CHEMBL600097 & 600886 & 7.1361 & 6.2693 & TRN & & & \\
\hline CHEMBL579851 & 600886 & 6.6385 & 6.4066 & TST & & & \\
\hline CHEMBL600915 & 600886 & 5.38399 & 99999999 & 995 & $5.5760 e$ & 00000000005 & TST \\
\hline CHEMBL578909 & 600886 & 6.4012 & 6.5889 & TRN & & & \\
\hline CHEMBL585260 & 600886 & 5.067 & 5.5273 & TST & & & \\
\hline CHEMBL601972 & 600886 & 6.5916 & 5.6697 & TST & & & \\
\hline CHEMBL602817 & 600886 & 6.8315 & 6.1838 & TRN & & & \\
\hline CHEMBL597856 & 600886 & 6.3116 & 6.282 & TRN & & & \\
\hline CHEMBL609152 & 600886 & 5.5597 & 5.9664 & TRN & & & \\
\hline CHEMBL605333 & 600886 & 6.2255 & 5.9675 & TRN & & & \\
\hline CHEMBL604322 & 600886 & 6.466 & 6.2805 & TRN & & & \\
\hline CHEMBL593486 & 600886 & 5.4078 & 5.7482 & TRN & & & \\
\hline CHEMBL597663 & 600886 & 6.0191 & 6.6441 & TRN & & & \\
\hline
\end{tabular}




\begin{tabular}{|c|c|c|c|c|c|c|}
\hline & & & oplement & al lable & t> & \\
\hline CHEMBL578079 & 600886 & 5.5081 & 5.2925 & TRN & & \\
\hline CHEMBL581682 & 600886 & 4.82100 & 00000000 & 01 & 5.6131 & TRN \\
\hline CHEMBL582444 & 600886 & 6.0 & 6.3724 & TST & & \\
\hline CHEMBL582509 & 600886 & 6.7708 & 6.6076 & TRN & & \\
\hline CHEMBL605753 & 600886 & 6.1952 & 6.4729 & TRN & & \\
\hline CHEMBL603034 & 600886 & 4.971 & 5.5846 & TRN & & \\
\hline CHEMBL580169 & 600886 & 5.648 & 6.1171 & TRN & & \\
\hline CHEMBL600943 & 600886 & 5.3354 & 5.5818 & TRN & & \\
\hline CHEMBL586027 & 600886 & 6.9952 & 6.7129 & TRN & & \\
\hline CHEMBL602425 & 600886 & 7.4389 & 6.6658 & TRN & & \\
\hline CHEMBL584235 & 600886 & 7.4908 & 6.6102 & TRN & & \\
\hline CHEMBL578952 & 600886 & 7.2549 & 6.9753 & TRN & & \\
\hline CHEMBL536655 & 600886 & 6.782 & 6.66700 & 0000000001 & & TRN \\
\hline CHEMBL44789 & 600886 & 7.2396 & 6.5232 & TRN & & \\
\hline CHEMBL582312 & 600886 & 5.697 & 6.2189 & TRN & & \\
\hline CHEMBL602991 & 600886 & 5.7187 & 5.5812 & TRN & & \\
\hline CHEMBL605611 & 600886 & 5.6666 & 6.0924 & TRN & & \\
\hline CHEMBL600975 & 600886 & 6.2916 & 6.7148 & TRN & & \\
\hline CHEMBL601183 & 600886 & 4.9031 & 6.2552 & TRN & & \\
\hline CHEMBL582087 & 600886 & 6.2765 & 6.2996 & TRN & & \\
\hline CHEMBL602604 & 600886 & 6.5478 & 6.1872 & TRN & & \\
\hline CHEMBL529241 & 600886 & 4.9031 & 6.1092 & TST & & \\
\hline CHEMBL600724 & 600886 & 7.284 & 6.8702 & TRN & & \\
\hline CHEMBL602225 & 600886 & 5.0391 & 5.6041 & TST & & \\
\hline CHEMBL600690 & 600886 & 8.8013 & 6.3052 & TST & & \\
\hline CHEMBL598059 & 600886 & 5.9017 & 5.1807 & TST & & \\
\hline CHEMBL194986 & 600886 & 6.4134 & 6.3504 & TRN & & \\
\hline CHEMBL602773 & 600886 & 6.3526 & 6.4452 & TRN & & \\
\hline CHEMBL602971 & 600886 & 3.9031 & 5.5726 & TRN & & \\
\hline CHEMBL576600 & 600886 & 6.08299 & 79999999 & 99 & 5.5888 & TRN \\
\hline CHEMBL585448 & 600886 & 5.0395 & 5.6062 & TRN & & \\
\hline CHEMBL601967 & 600886 & 4.2197 & 5.1209 & TST & & \\
\hline CHEMBL578680 & 600886 & 5.6133 & 5.1061 & TRN & & \\
\hline CHEMBL533577 & 600886 & 6.1463 & 6.3187 & TRN & & \\
\hline CHEMBL577171 & 600886 & 5.5564 & 5.6346 & TST & & \\
\hline CHEMBL586214 & 600886 & 6.9034 & 6.5938 & TRN & & \\
\hline CHEMBL584844 & 600886 & 6.3449 & 6.37799 & 9999999999 & & TRN \\
\hline CHEMBL585246 & 600886 & 7.523 & 6.7761 & TRN & & \\
\hline CHEMBL578420 & 600886 & 5.4597 & 5.8648 & TRN & & \\
\hline CHEMBL585747 & 600886 & 5.7929 & 6.37299 & 9999999999 & & TST \\
\hline CHEMBL527494 & 600886 & 6.055 & 6.1524 & TRN & & \\
\hline CHEMBL532987 & 600886 & 7.0186 & 6.6049 & TRN & & \\
\hline CHEMBL611811 & 600886 & 7.7891 & 7.2219 & TRN & & \\
\hline CHEMBL586171 & 600886 & 7.9 & 7.2046 & TRN & & \\
\hline CHEMBL598474 & 600886 & 6.308 & 6.2377 & TRN & & \\
\hline CHEMBL582297 & 600886 & 5.7392 & 6.0158 & TRN & & \\
\hline CHEMBL527773 & 600886 & 6.7314 & 6.5565 & TRN & & \\
\hline CHEMBL533556 & 600886 & 7.7335 & 7.0764 & TRN & & \\
\hline
\end{tabular}




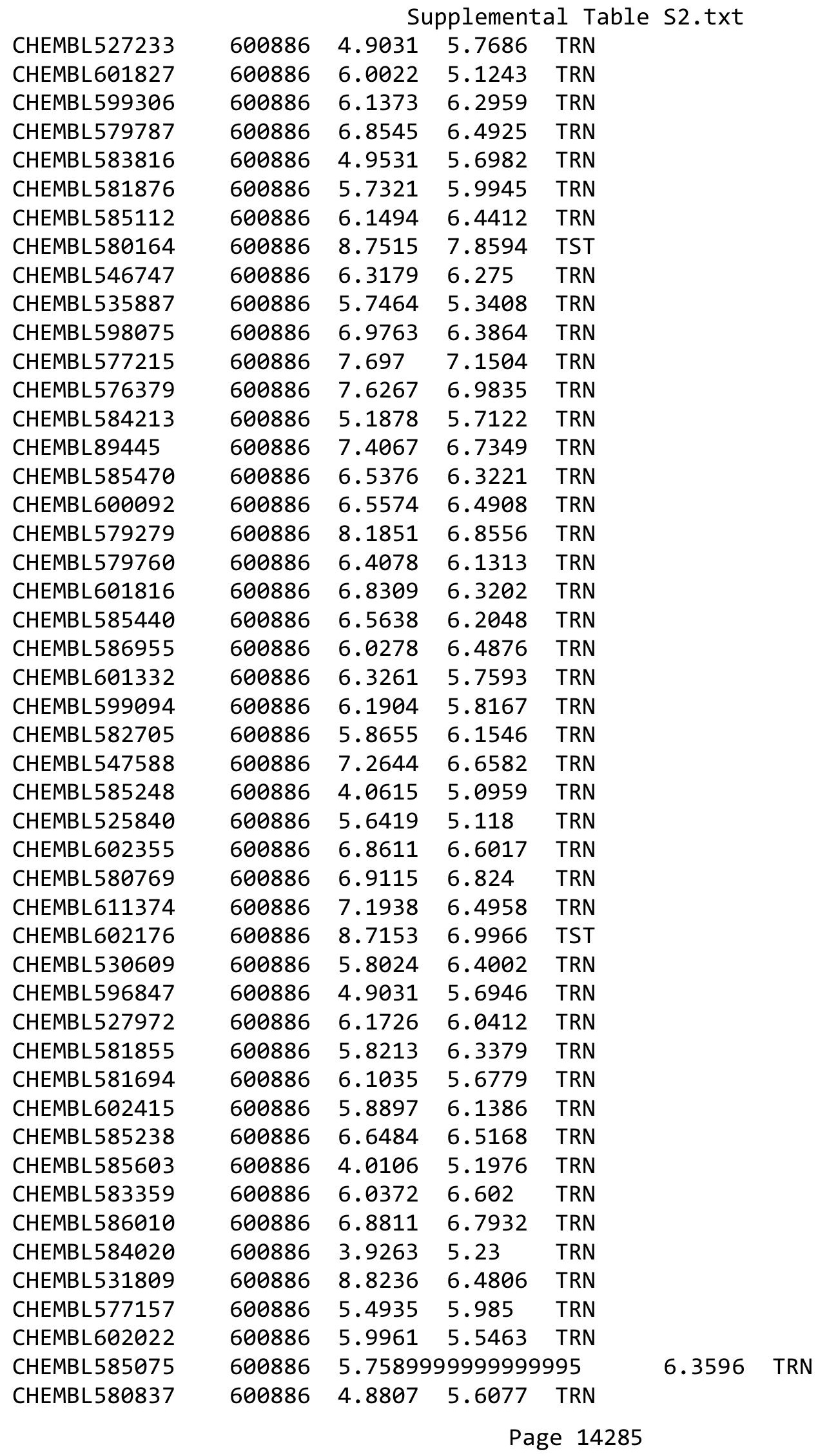




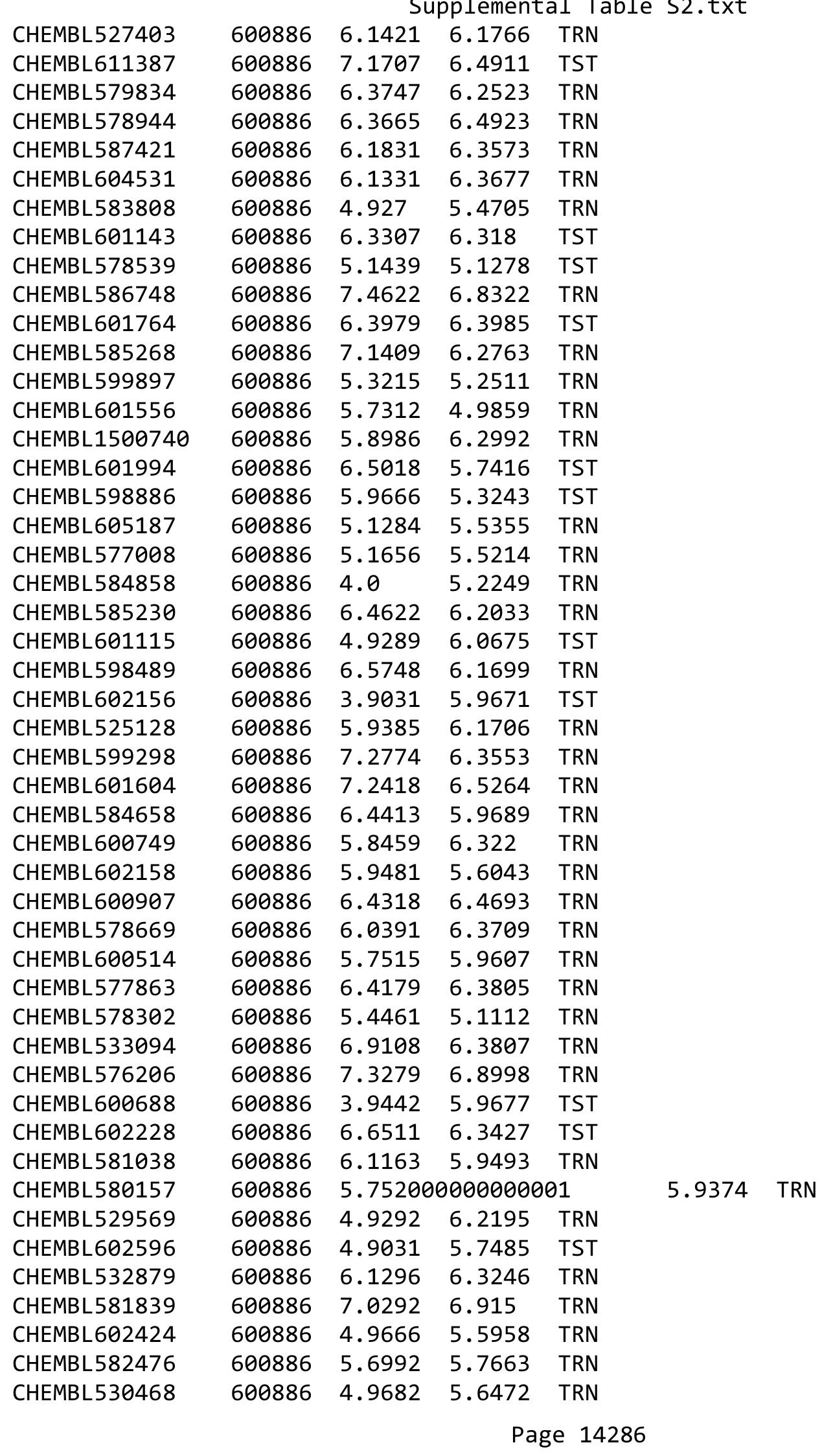




\begin{tabular}{|c|c|c|c|c|c|c|}
\hline \multirow[b]{2}{*}{ CHEMBL578119 } & \multicolumn{6}{|c|}{ PL } \\
\hline & 600886 & 5.3958 & 4.9968 & TRN & & \\
\hline CHEMBL583542 & 600886 & 6.2518 & 6.192 & TRN & & \\
\hline CHEMBL585429 & 600886 & 6.4763 & 6.7451 & TRN & & \\
\hline CHEMBL583818 & 600886 & 4.9539 & 5.5128 & TRN & & \\
\hline CHEMBL582264 & 600886 & 6.7491 & 6.7432 & TST & & \\
\hline CHEMBL585637 & 600886 & 5.5494 & 6.3245 & TRN & & \\
\hline CHEMBL49055 & 600886 & 6.0867 & 6.5251 & TRN & & \\
\hline CHEMBL602152 & 600886 & 5.9614 & 5.9677 & TRN & & \\
\hline CHEMBL600159 & 600886 & 6.5527 & 6.4398 & TRN & & \\
\hline CHEMBL577421 & 600886 & 6.0 & 6.0949 & TRN & & \\
\hline CHEMBL585049 & 600886 & 6.5261 & 6.5814 & TRN & & \\
\hline CHEMBL583166 & 600886 & 6.7421 & 6.6358 & TRN & & \\
\hline CHEMBL600147 & 600886 & 5.7233 & 6.0471 & TRN & & \\
\hline CHEMBL579963 & 600886 & 4.7762 & 5.7655 & TRN & & \\
\hline CHEMBL602829 & 600886 & 6.1379 & 5.7428 & TRN & & \\
\hline CHEMBL578327 & 600886 & \multicolumn{3}{|c|}{6.117999999999999} & 6.3686 & TRN \\
\hline CHEMBL581258 & 600886 & 5.7721 & 5.2993 & TST & & \\
\hline CHEMBL600095 & 600886 & \multicolumn{3}{|c|}{6.9910000000000005} & 7.1631 & TRN \\
\hline CHEMBL603042 & 600886 & 6.6398 & 6.5902 & TRN & & \\
\hline CHEMBL597259 & 600886 & 6.0721 & 6.3497 & TRN & & \\
\hline CHEMBL578068 & 600886 & 6.6249 & 6.2794 & TRN & & \\
\hline CHEMBL585983 & 600886 & 7.2857 & 7.2833 & TRN & & \\
\hline CHEMBL601583 & 600886 & 6.9759 & 6.5704 & TRN & & \\
\hline CHEMBL598888 & 600886 & 6.0405 & 6.4049 & TRN & & \\
\hline CHEMBL579088 & 600886 & 6.6321 & 6.7242 & TST & & \\
\hline CHEMBL581869 & 600886 & 5.7857 & 5.9415 & TRN & & \\
\hline CHEMBL600546 & 600886 & 6.1979 & 5.6178 & TRN & & \\
\hline CHEMBL578508 & 600886 & 6.5116 & 6.6795 & TRN & & \\
\hline CHEMBL586014 & 600886 & \multicolumn{3}{|c|}{6.672000000000001} & 6.6311 & TST \\
\hline CHEMBL602584 & 600886 & 5.6627 & 6.2586 & TRN & & \\
\hline CHEMBL599102 & 600886 & 6.0472 & 6.3454 & TRN & & \\
\hline CHEMBL600361 & 600886 & 6.6162 & 6.1482 & TRN & & \\
\hline CHEMBL581037 & 600886 & 5.8419 & 5.7051 & TRN & & \\
\hline CHEMBL602983 & 600886 & 5.7124 & 5.5609 & TRN & & \\
\hline CHEMBL602975 & 600886 & 6.0 & 6.2642 & TRN & & \\
\hline CHEMBL585232 & 600886 & 5.9412 & 6.23 & TRN & & \\
\hline CHEMBL527800 & 600886 & 6.4342 & 6.4778 & TRN & & \\
\hline CHEMBL578694 & 600886 & 5.7825 & 5.7826 & TST & & \\
\hline CHEMBL531798 & 600886 & 6.4698 & 6.6647 & TRN & & \\
\hline CHEMBL 3189145 & 600886 & 6.5134 & 6.6551 & TRN & & \\
\hline CHEMBL585837 & 600886 & 6.289 & 6.2211 & TRN & & \\
\hline CHEMBL578501 & 600886 & 5.791 & 5.9862 & TRN & & \\
\hline CHEMBL529517 & 600886 & 7.3487 & 6.9696 & TST & & \\
\hline CHEMBL579284 & 600886 & 5.426 & 5.2496 & TRN & & \\
\hline CHEMBL578242 & 600886 & 5.4609 & 5.5846 & TRN & & \\
\hline CHEMBL596852 & 600886 & 6.1107 & 6.6204 & TRN & & \\
\hline CHEMBL593488 & 600886 & 6.7058 & 5.6219 & TRN & & \\
\hline \multirow[t]{2}{*}{ CHEMBL581677 } & 600886 & 5.9914 & 6.0017 & TRN & & \\
\hline & & \multicolumn{5}{|c|}{ Page 14287} \\
\hline
\end{tabular}




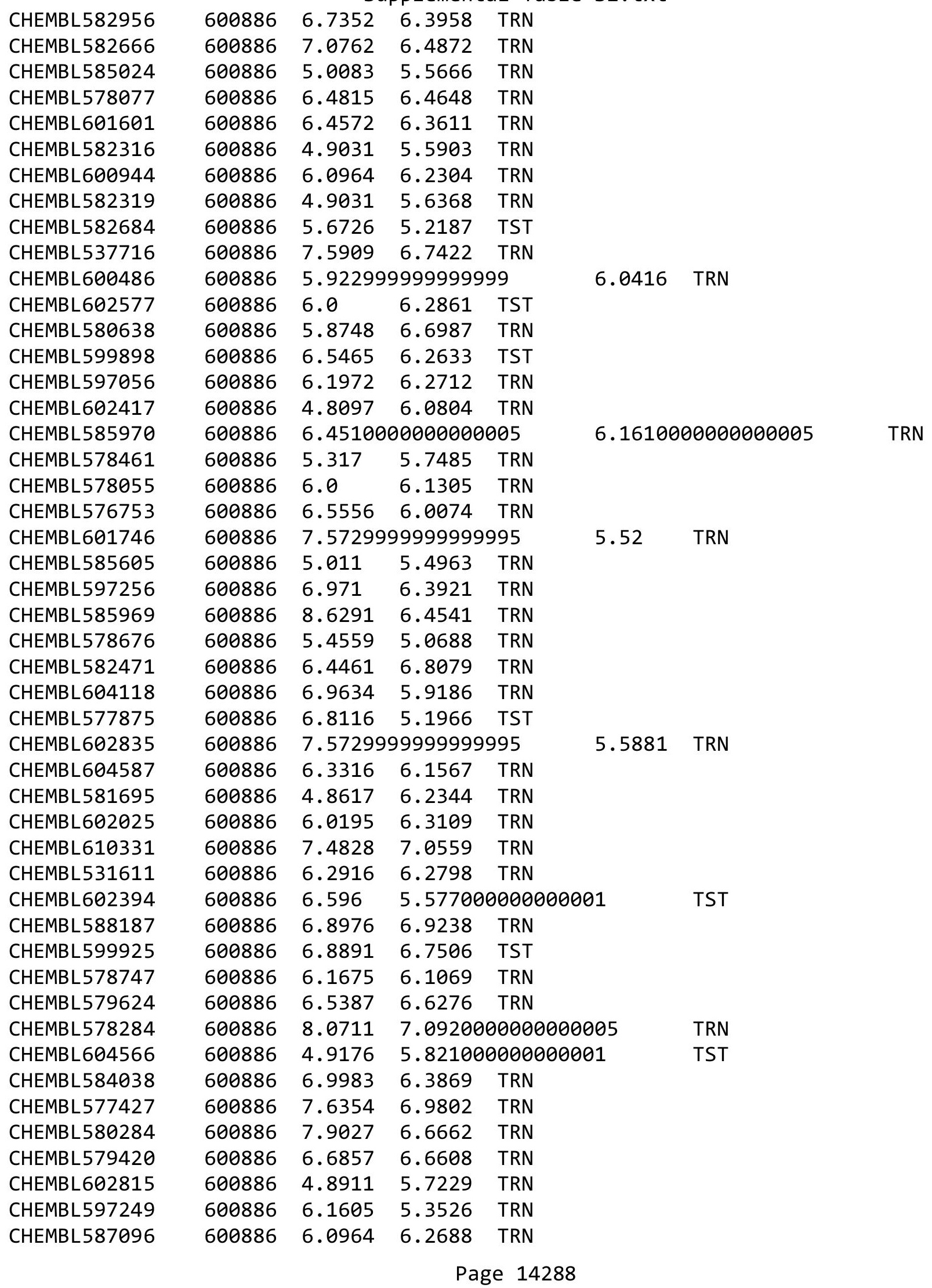




\begin{tabular}{|c|c|c|c|c|c|}
\hline \multicolumn{6}{|c|}{ Supplemental Table S2.txt } \\
\hline CHEMBL597674 & 600886 & 5.9788 & 5.1994 & TRN & \\
\hline CHEMBL605818 & 600886 & 6.0329 & 5.6087 & TST & \\
\hline CHEMBL1493528 & 600886 & 7.2487 & 6.5807 & TRN & \\
\hline CHEMBL588102 & 600886 & 6.2725 & 5.6122 & TRN & \\
\hline CHEMBL585442 & 600886 & 7.5248 & 6.2122 & TRN & \\
\hline CHEMBL587356 & 600886 & 9.0386 & 6.3208 & TRN & \\
\hline CHEMBL597666 & 600886 & 3.9031 & 5.7965 & TRN & \\
\hline CHEMBL580004 & 600886 & 6.3726 & 6.6624 & TRN & \\
\hline CHEMBL601334 & 600886 & 6.3546 & 6.4342 & TRN & \\
\hline CHEMBL585511 & 600886 & 6.0339 & 6.1757 & TRN & \\
\hline CHEMBL599931 & 600886 & 4.7749 & 5.6839 & TRN & \\
\hline CHEMBL602562 & 600886 & 5.983 & 6.29299 & 9999999999 & TRN \\
\hline CHEMBL601578 & 600886 & 5.6323 & 6.2862 & TRN & \\
\hline CHEMBL319952 & 600886 & 6.8416 & 6.2674 & TRN & \\
\hline CHEMBL577659 & 600886 & 6.3028 & 6.6787 & TST & \\
\hline CHEMBL533955 & 600886 & 6.1331 & 6.777 & TRN & \\
\hline CHEMBL597661 & 600886 & 7.0128 & 6.7835 & TST & \\
\hline CHEMBL585971 & 600886 & 4.9893 & 5.8414 & TRN & \\
\hline CHEMBL585322 & 600886 & 4.9031 & 5.7024 & TST & \\
\hline CHEMBL608145 & 600886 & 4.9031 & 5.5838 & TRN & \\
\hline CHEMBL584443 & 600886 & 4.9662 & 5.6042 & TST & \\
\hline CHEMBL605547 & 600886 & 4.9031 & 5.5296 & TRN & \\
\hline CHEMBL602169 & 600886 & 7.2449 & 6.5594 & TRN & \\
\hline CHEMBL582464 & 600886 & 6.1079 & 6.5786 & TRN & \\
\hline CHEMBL600337 & 600886 & 5.2211 & 5.6936 & TRN & \\
\hline CHEMBL609607 & 600886 & 6.1029 & 4.8889 & TST & \\
\hline CHEMBL601346 & 600886 & 5.3468 & 5.0823 & TRN & \\
\hline CHEMBL602168 & 600886 & 9.1864 & 5.5835 & TST & \\
\hline CHEMBL600087 & 600886 & 4.9923 & 6.1626 & TST & \\
\hline CHEMBL582517 & 600886 & 6.5508 & 6.3745 & TRN & \\
\hline CHEMBL582676 & 600886 & 6.1878 & 6.1153 & TRN & \\
\hline CHEMBL586414 & 600886 & 4.0788 & 5.2743 & TRN & \\
\hline CHEMBL610788 & 600886 & 6.2154 & 6.2523 & TRN & \\
\hline CHEMBL588026 & 600886 & 5.0721 & 5.6569 & TRN & \\
\hline CHEMBL582807 & 600886 & 6.2976 & 6.346 & TRN & \\
\hline CHEMBL578943 & 600886 & 6.5476 & 6.0906 & TST & \\
\hline CHEMBL604389 & 600886 & 4.9307 & 5.4685 & TRN & \\
\hline CHEMBL579644 & 600886 & 6.7498 & 6.824 & TRN & \\
\hline CHEMBL578722 & 600886 & 6.5009 & 6.5974 & TRN & \\
\hline CHEMBL602371 & 600886 & 6.8499 & 6.5054 & TRN & \\
\hline CHEMBL602010 & 600886 & 6.7913 & 6.6985 & TRN & \\
\hline CHEMBL578502 & 600886 & 6.5399 & 6.7715 & TRN & \\
\hline CHEMBL601569 & 600886 & 6.8658 & 6.3849 & TRN & \\
\hline CHEMBL585436 & 600886 & 6.5611 & 5.8357 & TRN & \\
\hline CHEMBL533366 & 600886 & 7.5229 & 6.7082 & TRN & \\
\hline CHEMBL602214 & 600886 & 4.7875 & 5.7425 & TRN & \\
\hline CHEMBL578483 & 600886 & 6.0 & 6.235 & TST & \\
\hline CHEMBL576996 & 600886 & 5.6749 & 6.2515 & TST & \\
\hline
\end{tabular}




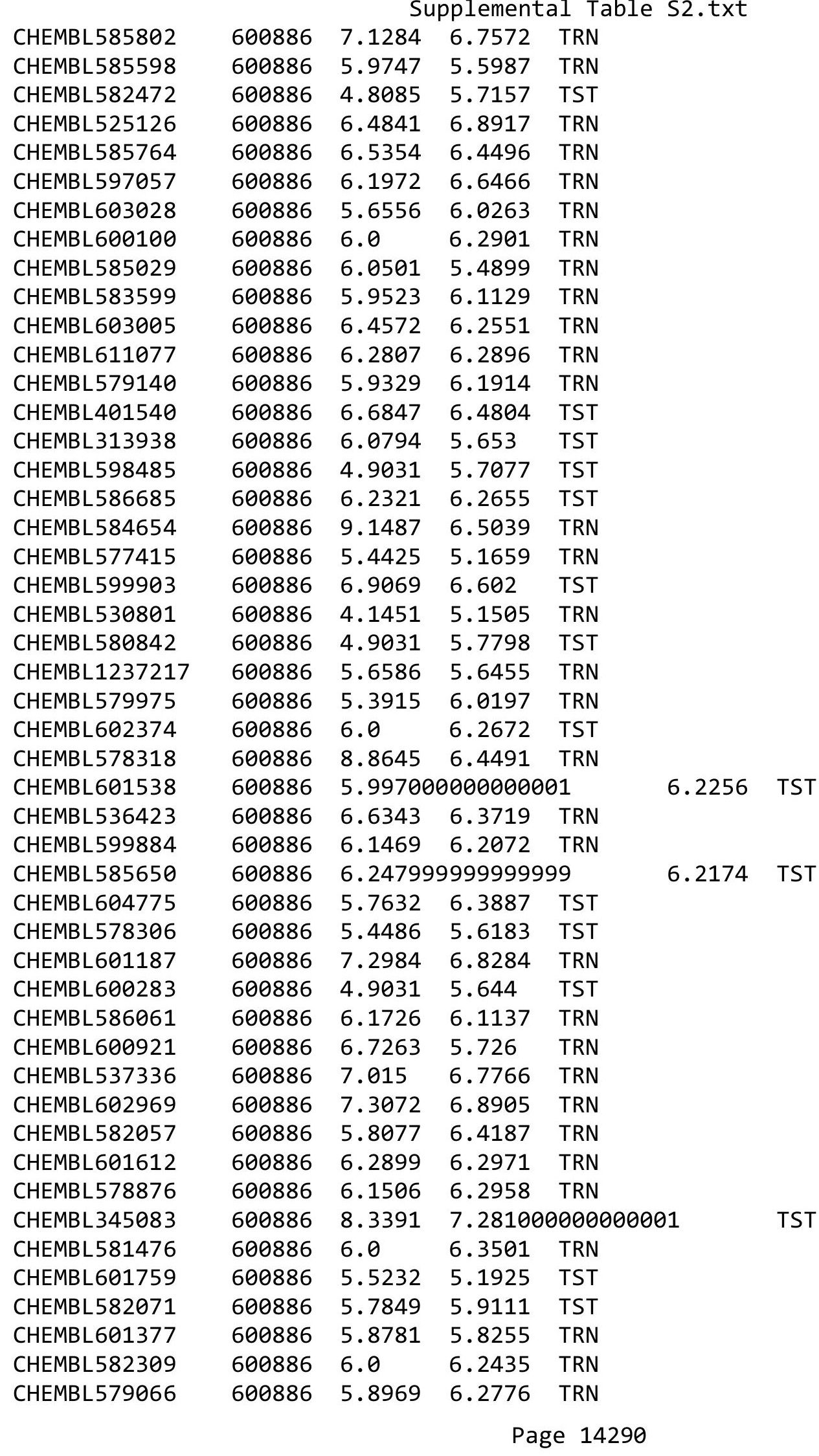




\begin{tabular}{|c|c|c|c|c|c|}
\hline \multirow[b]{2}{*}{ CHEMBL527520 } & \multicolumn{5}{|c|}{ Supplemental Table S2.txt } \\
\hline & 600886 & 7.1543 & 6.5546 & TST & \\
\hline CHEMBL581912 & 600886 & 4.871 & 5.9125 & TRN & \\
\hline CHEMBL577889 & 600886 & 5.1451 & 5.5197 & TRN & \\
\hline CHEMBL601363 & 600886 & 9.5481 & 5.558 & TRN & \\
\hline CHEMBL577861 & 600886 & 6.2557 & 6.4581 & TST & \\
\hline CHEMBL587633 & 600886 & 6.8941 & 6.5962 & TRN & \\
\hline CHEMBL577628 & 600886 & 5.0232 & 5.6189 & TST & \\
\hline CHEMBL601993 & 600886 & 6.1415 & 5.7419 & TST & \\
\hline CHEMBL598071 & 600886 & 6.2823 & 6.649 & TRN & \\
\hline CHEMBL598695 & 600886 & 6.0 & 6.2266 & TRN & \\
\hline CHEMBL586684 & 600886 & 7.301 & 6.9412 & TRN & \\
\hline CHEMBL597869 & 600886 & 6.2426 & 6.4351 & TRN & \\
\hline CHEMBL602567 & 600886 & 7.0991 & 5.7949 & TRN & \\
\hline CHEMBL600960 & 600886 & 4.9473 & 5.5165 & TRN & \\
\hline CHEMBL602230 & 600886 & 6.2314 & 6.1979 & TRN & \\
\hline CHEMBL582049 & 600886 & 6.7972 & 6.5206 & TRN & \\
\hline CHEMBL532674 & 600886 & 6.2636 & 6.2329 & TRN & \\
\hline CHEMBL606022 & 600886 & 6.0137 & 5.7489 & TRN & \\
\hline CHEMBL577627 & 600886 & 4.9031 & 6.20299 & 9999999999 & TRN \\
\hline CHEMBL584847 & 600886 & 6.0915 & 6.2855 & TRN & \\
\hline CHEMBL172 & 600886 & 8.6249 & 6.8225 & TST & \\
\hline CHEMBL584851 & 600886 & 5.0186 & 5.595 & TST & \\
\hline CHEMBL582096 & 600886 & 5.7187 & 5.7731 & TRN & \\
\hline CHEMBL602005 & 600886 & 5.691 & 5.7696 & TRN & \\
\hline CHEMBL580945 & 600886 & 5.2426 & 5.5414 & TRN & \\
\hline CHEMBL577453 & 600886 & 8.7783 & 6.4144 & TRN & \\
\hline CHEMBL601780 & 600886 & 8.8069 & 6.6688 & TRN & \\
\hline CHEMBL604117 & 600886 & 7.1765 & 6.1239 & TRN & \\
\hline CHEMBL588690 & 600886 & 8.7921 & 5.5049 & TRN & \\
\hline CHEMBL534139 & 600886 & 6.4634 & 6.5696 & TRN & \\
\hline CHEMBL577440 & 600886 & 4.1878 & 6.301 & TRN & \\
\hline CHEMBL577233 & 600886 & 5.1198 & 5.3461 & TST & \\
\hline CHEMBL582703 & 600886 & 5.7251 & 5.7713 & TRN & \\
\hline CHEMBL579943 & 600886 & 5.1612 & 5.66799 & 9999999999 & TRN \\
\hline CHEMBL584022 & 600886 & 3.9516 & 5.0964 & TRN & \\
\hline CHEMBL529493 & 600886 & 6.8979 & 6.4941 & TRN & \\
\hline CHEMBL527704 & 600886 & 5.9923 & 6.0736 & TRN & \\
\hline CHEMBL3216427 & 600886 & 7.2857 & 7.3936 & TRN & \\
\hline CHEMBL578890 & 600886 & 5.8837 & 6.2524 & TRN & \\
\hline CHEMBL585967 & 600886 & 7.572999 & 99999999 & 6.3228 & TRN \\
\hline CHEMBL584014 & 600886 & 6.1938 & 6.2796 & TRN & \\
\hline CHEMBL579767 & 600886 & 4.7983 & 5.711 & TST & \\
\hline CHEMBL601554 & 600886 & 5.6936 & 5.1985 & TST & \\
\hline CHEMBL598900 & 600886 & 4.9031 & 5.7483 & TRN & \\
\hline CHEMBL599924 & 600886 & 4.0 & 5.3434 & TRN & \\
\hline CHEMBL601958 & 600886 & 5.9991 & 5.1446 & TST & \\
\hline CHEMBL576350 & 600886 & 8.0372 & 7.9564 & TST & \\
\hline CHEMBL611661 & 600886 & 6.1314 & 6.3342 & TRN & \\
\hline
\end{tabular}




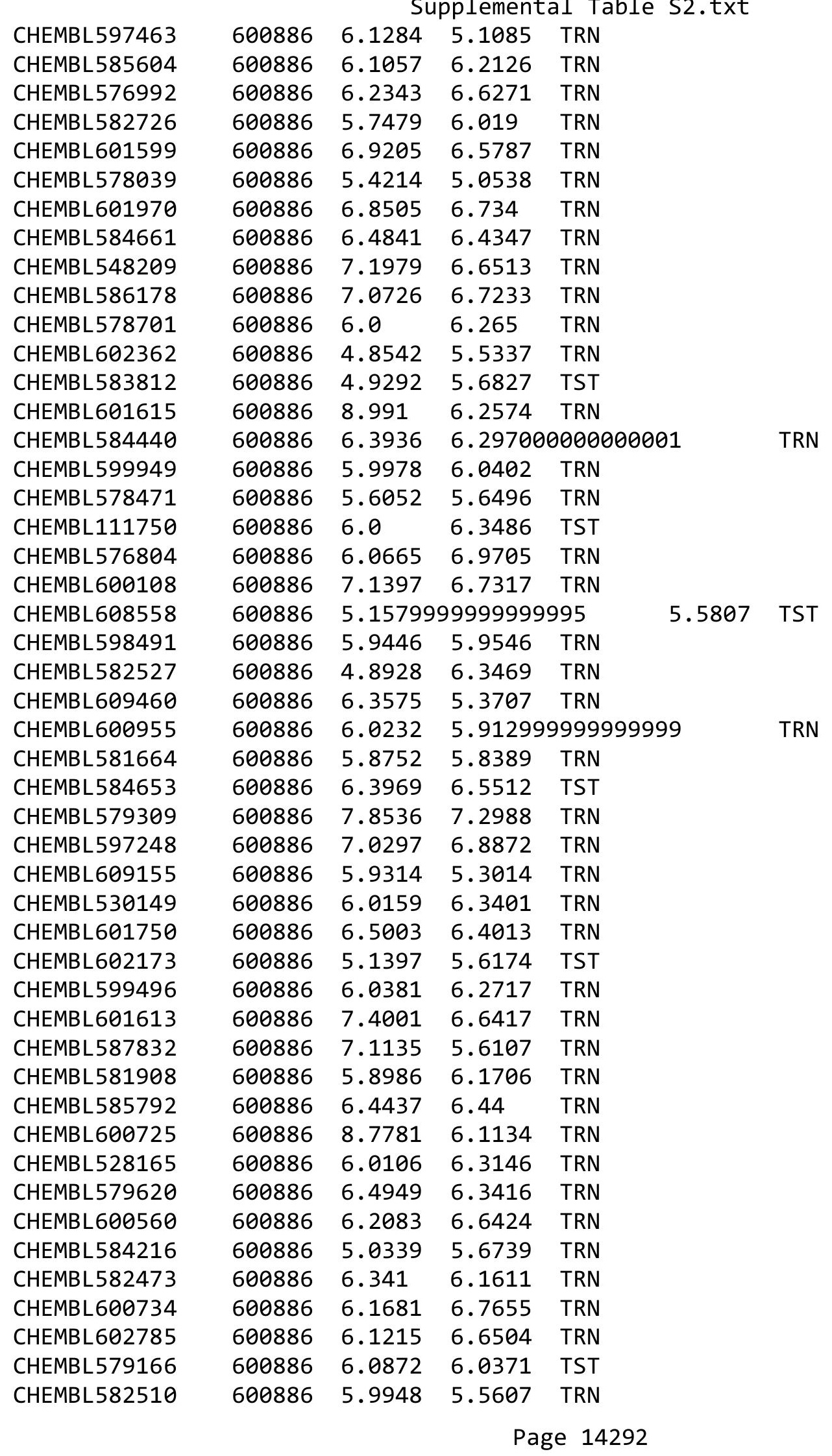




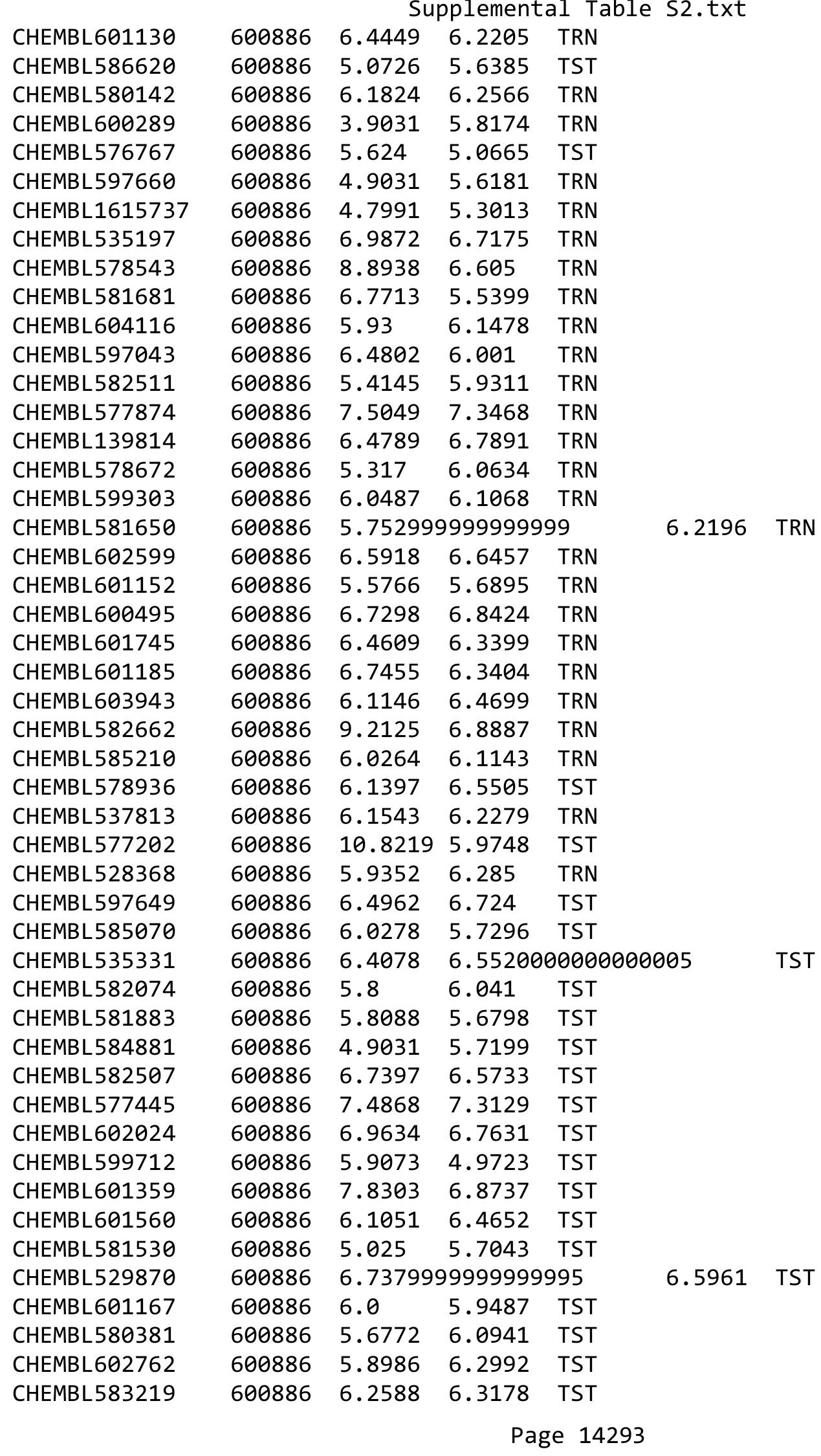




\begin{tabular}{|c|c|c|c|c|}
\hline \multicolumn{5}{|c|}{ Supplemental Table S2.txt } \\
\hline CHEMBL580171 & 600886 & 6.6765 & 7.0386 & TST \\
\hline CHEMBL526955 & 600886 & 7.3915 & 6.5565 & TST \\
\hline CHEMBL579542 & 600886 & 6.819 & 6.5646 & TST \\
\hline CHEMBL578736 & 600886 & 7.2549 & 7.0532 & TST \\
\hline CHEMBL528150 & 600886 & 6.6476 & 6.3972 & TST \\
\hline CHEMBL582277 & 600886 & 6.6826 & 6.6555 & TST \\
\hline CHEMBL601540 & 600886 & 6.0241 & 6.2337 & TST \\
\hline CHEMBL579958 & 600886 & 6.3851 & 6.5527 & TST \\
\hline CHEMBL599507 & 600886 & 7.2132 & 7.115 & TST \\
\hline CHEMBL421088 & 600886 & 6.4067 & 6.3728 & TST \\
\hline CHEMBL599906 & 600886 & 6.1785 & 6.1489 & TST \\
\hline CHEMBL581058 & 600886 & 4.9031 & 5.5943 & TST \\
\hline CHEMBL602435 & 600886 & 7.067 & 6.6674 & TST \\
\hline CHEMBL588470 & 600886 & 5.4855 & 5.2404 & TST \\
\hline CHEMBL599709 & 600886 & 6.0 & 5.8515 & TST \\
\hline CHEMBL596645 & 600886 & 6.0472 & 6.0185 & TST \\
\hline CHEMBL582456 & 600886 & 7.1844 & 6.6401 & TST \\
\hline CHEMBL600926 & 600886 & 6.3242 & 5.775 & TST \\
\hline CHEMBL578075 & 600886 & 5.5375 & 4.9747 & TST \\
\hline CHEMBL583160 & 600886 & 6.6212 & 6.7205 & TST \\
\hline CHEMBL601125 & 600886 & 6.4123 & 6.7752 & TST \\
\hline CHEMBL597039 & 600886 & 6.777 & 6.0439 & TST \\
\hline CHEMBL533167 & 600886 & 6.3799 & 6.981 & TST \\
\hline CHEMBL602377 & 600886 & 9.3072 & 6.4787 & TST \\
\hline CHEMBL601552 & 600886 & 7.2132 & 6.1568 & TST \\
\hline CHEMBL585447 & 600886 & 6.0655 & 6.1647 & TST \\
\hline CHEMBL579336 & 600886 & 5.8877 & 6.2397 & TST \\
\hline CHEMBL579092 & 600886 & 6.6036 & 6.8082 & TST \\
\hline CHEMBL585379 & 600886 & 6.3526 & 5.5287 & TST \\
\hline CHEMBL587779 & 600886 & 6.0 & 6.2223 & TST \\
\hline CHEMBL585820 & 600886 & 6.5719 & 6.0891 & TST \\
\hline CHEMBL598484 & 600886 & 6.1273 & 5.8886 & TST \\
\hline CHEMBL579344 & 600886 & 6.058 & 6.3152 & TST \\
\hline CHEMBL578670 & 600886 & 6.2782 & 5.8433 & TST \\
\hline CHEMBL584675 & 600886 & 7.1135 & 6.9199 & TST \\
\hline CHEMBL576783 & 600886 & 7.5733 & 7.1821 & TST \\
\hline CHEMBL602008 & 600886 & 6.9158 & 6.5213 & TST \\
\hline CHEMBL586602 & 600886 & 6.7333 & 6.8918 & TST \\
\hline CHEMBL580373 & 600886 & 4.8425 & 6.2754 & TST \\
\hline CHEMBL586162 & 600886 & 5.2351 & 5.5434 & TST \\
\hline CHEMBL598493 & 600886 & 6.1409 & 6.0366 & TST \\
\hline CHEMBL605186 & 600886 & 4.9031 & 6.1604 & TST \\
\hline CHEMBL578511 & 600886 & 5.1713 & 5.7553 & TST \\
\hline CHEMBL578924 & 600886 & 8.6108 & 6.8164 & TST \\
\hline CHEMBL597040 & 600886 & 4.9031 & 6.4239 & TST \\
\hline CHEMBL533536 & 600886 & 6.9821 & 6.496 & TST \\
\hline CHEMBL584031 & 600886 & 4.9718 & 5.5413 & TST \\
\hline CHEMBL598277 & 600886 & 6.5928 & 6.0116 & TST \\
\hline
\end{tabular}




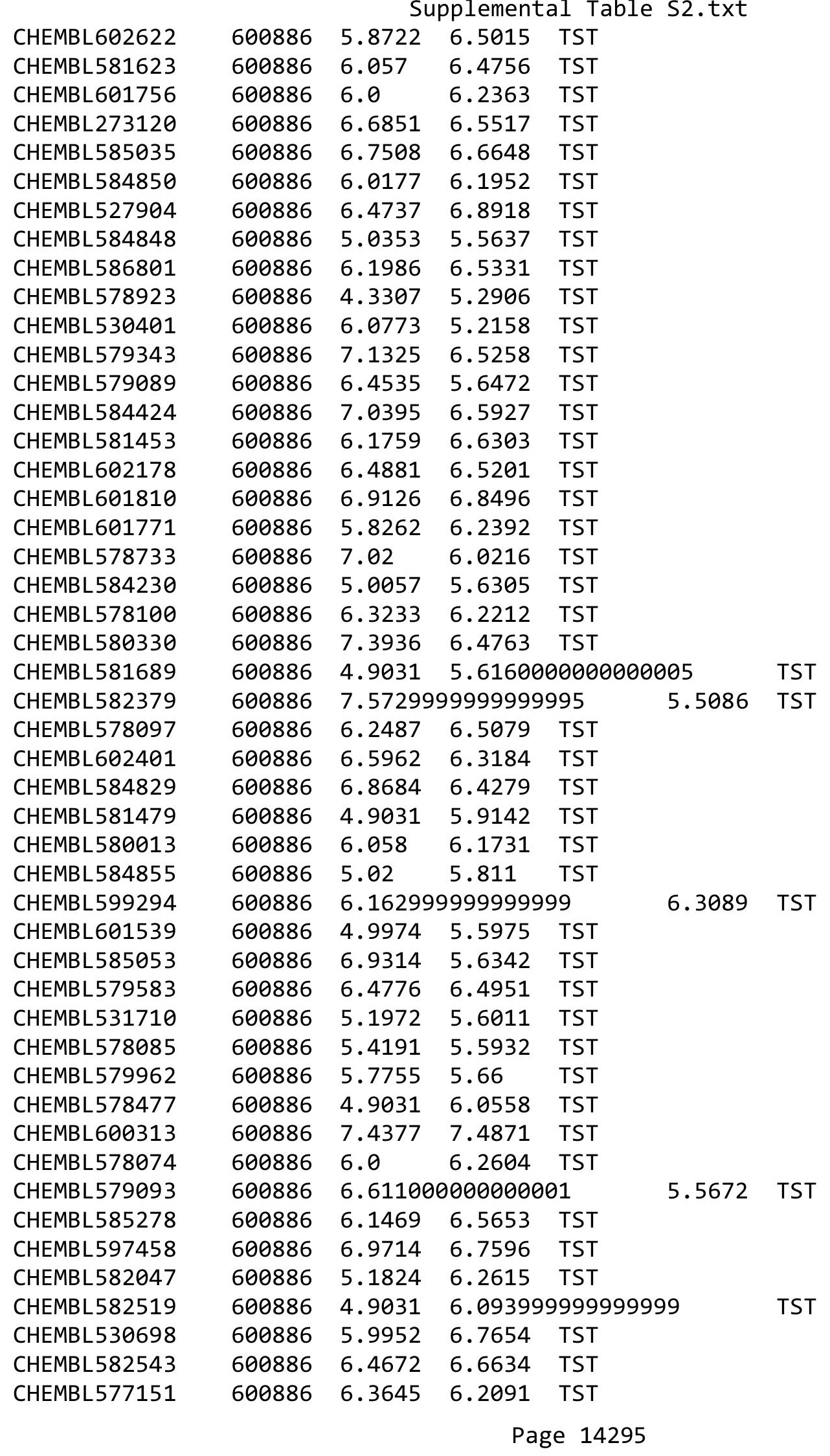




\begin{tabular}{|c|c|c|c|c|c|c|}
\hline \multicolumn{7}{|c|}{$\pi$} \\
\hline CHEMBL529111 & 600886 & 6.3439 & 6.5048 & TST & & \\
\hline CHEMBL530736 & 600886 & 6.4724 & 6.3711 & TST & & \\
\hline CHEMBL528644 & 600886 & 6.2299 & 5.9739 & TST & & \\
\hline CHEMBL601145 & 600886 & 5.4191 & 6.1013 & TST & & \\
\hline CHEMBL601121 & 600886 & 6.1013 & 6.7417 & TST & & \\
\hline CHEMBL602979 & 600886 & 6.5354 & 5.9277 & TST & & \\
\hline CHEMBL584888 & 600886 & 5.95700 & 00000000 & 01 & 6.3205 & TST \\
\hline CHEMBL579348 & 600886 & 6.4724 & 6.3711 & TST & & \\
\hline CHEMBL596648 & 600886 & 4.9031 & 6.3964 & TST & & \\
\hline CHEMBL577843 & 600886 & 7.4989 & 7.0246 & TST & & \\
\hline CHEMBL577435 & 600886 & 6.0 & 6.3234 & TST & & \\
\hline CHEMBL577652 & 600886 & 6.3706 & 6.3753 & TST & & \\
\hline CHEMBL600922 & 600886 & 5.7272 & 6.2954 & TST & & \\
\hline CHEMBL602779 & 600886 & 6.1367 & 5.6536 & TST & & \\
\hline CHEMBL583401 & 600886 & 7.4949 & 7.4727 & TST & & \\
\hline CHEMBL584706 & 600886 & 7.2604 & 6.9005 & TST & & \\
\hline CHEMBL604723 & 600886 & 6.9666 & 6.2348 & TST & & \\
\hline CHEMBL582065 & 600886 & 5.8225 & 5.8003 & TST & & \\
\hline CHEMBL581852 & 600886 & 4.7665 & 6.3356 & TST & & \\
\hline CHEMBL529171 & 600886 & 4.0329 & 5.0273 & TST & & \\
\hline CHEMBL584668 & 600886 & 6.704 & 6.1409 & TST & & \\
\hline CHEMBL577876 & 600886 & 6.0 & 6.3406 & TST & & \\
\hline CHEMBL577020 & 600886 & 5.1198 & 6.4905 & TST & & \\
\hline CHEMBL601557 & 600886 & 5.7314 & 5.0738 & TST & & \\
\hline CHEMBL584249 & 600886 & 6.055 & 5.9801 & TST & & \\
\hline CHEMBL585595 & 600886 & 7.5464 & 6.35 & TST & & \\
\hline CHEMBL593485 & 600886 & 8.8726 & 5.5983 & TST & & \\
\hline CHEMBL582715 & 600886 & 5.6861 & 5.9884 & TST & & \\
\hline CHEMBL584821 & 600886 & 6.9045 & 6.44600 & 0000000001 & & 13 \\
\hline CHEMBL577442 & 600886 & 6.1891 & 6.3217 & TST & & \\
\hline CHEMBL600503 & 600886 & 6.2154 & 6.4035 & TST & & \\
\hline CHEMBL600746 & 600886 & 6.2255 & 6.3445 & TST & & \\
\hline CHEMBL582058 & 600886 & 4.8077 & 6.3105 & TST & & \\
\hline CHEMBL582177 & 600886 & 7.15799 & 99999999 & 995 & 6.5484 & TS \\
\hline CHEMBL581042 & 600886 & 5.7222 & 6.1757 & TST & & \\
\hline CHEMBL527454 & 600886 & 4.9031 & 6.0885 & TST & & \\
\hline CHEMBL583196 & 600886 & 5.9842 & 5.7426 & TST & & \\
\hline CHEMBL582448 & 600886 & 7.0726 & 6.732 & TST & & \\
\hline CHEMBL600488 & 600886 & 5.8739 & 6.1081 & TST & & \\
\hline CHEMBL578488 & 600886 & 4.7989 & 5.97 & TST & & \\
\hline CHEMBL578500 & 600886 & 6.6236 & 6.5197 & TST & & \\
\hline CHEMBL585265 & 600886 & 6.4921 & 5.3608 & TST & & \\
\hline CHEMBL529464 & 600886 & 3.9031 & 5.8131 & TST & & \\
\hline CHEMBL577205 & 600886 & 6.3372 & 6.7825 & TST & & \\
\hline CHEMBL580071 & 600886 & 4.9031 & 6.0824 & TST & & \\
\hline CHEMBL547101 & 600886 & 4.9031 & 7.5769 & TST & & \\
\hline CHEMBL577887 & 600886 & 5.8908 & 6.5711 & TST & & \\
\hline CHEMBL582685 & 600886 & 6.6994 & 5.8549 & TST & & \\
\hline
\end{tabular}




\begin{tabular}{|c|c|c|c|c|c|c|}
\hline \multicolumn{7}{|c|}{ s2.txt } \\
\hline CHEMBL602765 & 600886 & 6.3125 & 6.3322 & TST & & \\
\hline CHEMBL602423 & 600886 & 5.9559 & 5.9953 & TST & & \\
\hline CHEMBL601579 & 600886 & 7.5168 & 6.3492 & TST & & \\
\hline CHEMBL579109 & 600886 & 6.3487 & 6.2964 & TST & & \\
\hline CHEMBL535101 & 600886 & 6.6828 & 6.3316 & TST & & \\
\hline CHEMBL584669 & 600886 & 7.1118 & 6.2832 & TST & & \\
\hline CHEMBL582300 & 600886 & 6.1605 & 6.0867 & TST & & \\
\hline CHEMBL600296 & 600886 & 6.0173 & 6.1664 & TST & & \\
\hline CHEMBL583416 & 600886 & 7.1152 & 6.7895 & TST & & \\
\hline CHEMBL602188 & 600886 & 6.091 & 6.2373 & TST & & \\
\hline CHEMBL600140 & 600886 & 6.0867 & 5.9744 & TST & & \\
\hline CHEMBL599896 & 600886 & 7.8374 & 6.6197 & TST & & \\
\hline CHEMBL600286 & 600886 & 4.9504 & 5.5439 & TST & & \\
\hline CHEMBL1744498 & 600886 & 6.7219 & 5.8071 & TST & & \\
\hline CHEMBL577847 & 600886 & 5.2013 & 5.1205 & TST & & \\
\hline CHEMBL577451 & 600886 & 6.0809 & 6.3589 & TST & & \\
\hline CHEMBL577640 & 600886 & 6.7975 & 6.7689 & TST & & \\
\hline CHEMBL584624 & 600886 & 4.9412 & 6.205 & TST & & \\
\hline CHEMBL578930 & 600886 & 5.6312 & 5.5857 & TST & & \\
\hline CHEMBL609313 & 600886 & 6.3152 & 6.3066 & TST & & \\
\hline CHEMBL601809 & 600886 & 5.6992 & 5.8552 & TST & & \\
\hline CHEMBL601360 & 600886 & 6.4962 & 6.4277 & TST & & \\
\hline CHEMBL600089 & 600886 & 5.0391 & 6.3301 & TST & & \\
\hline CHEMBL527732 & 600886 & 3.9031 & 5.8836 & TST & & \\
\hline CHEMBL585799 & 600886 & 5.055 & 6.3914 & TST & & \\
\hline CHEMBL580353 & 600886 & 7.5327 & 7.3864 & TST & & \\
\hline CHEMBL582109 & 600886 & 4.8864 & 6.2349 & TST & & \\
\hline CHEMBL600490 & 600886 & 6.4498 & 6.4546 & TST & & \\
\hline CHEMBL585984 & 600886 & 5.9205 & 6.4402 & TST & & \\
\hline CHEMBL603232 & 600886 & 3.9031 & 5.7914 & TST & & \\
\hline CHEMBL601106 & 600886 & 3.9031 & 7.1068 & TST & & \\
\hline CHEMBL579366 & 600886 & 6.0 & 6.1643 & TST & & \\
\hline CHEMBL530308 & 600886 & 6.53700 & 20000000 & $\partial 1$ & 6.4510000000000005 & TST \\
\hline CHEMBL578423 & 600886 & 6.4881 & 6.2914 & TST & & \\
\hline CHEMBL588634 & 600886 & 6.1765 & 6.2695 & TST & & \\
\hline CHEMBL600722 & 600886 & 6.2652 & 6.3448 & TST & & \\
\hline CHEMBL600099 & 600886 & 7.8486 & 6.6735 & TST & & \\
\hline CHEMBL602798 & 600886 & 5.4828 & 5.0613 & TST & & \\
\hline CHEMBL603895 & 600886 & 6.0395 & 5.9041 & TST & & \\
\hline CHEMBL601965 & 600886 & 6.5433 & 6.9921 & TST & & \\
\hline CHEMBL600145 & 600886 & 8.8063 & 6.4996 & TST & & \\
\hline CHEMBL605422 & 600886 & 6.0 & 6.3073 & TST & & \\
\hline CHEMBL582073 & 600886 & 5.7865 & 6.4395 & TST & & \\
\hline CHEMBL530733 & 600886 & 6.9923 & 6.5513 & TST & & \\
\hline CHEMBL585791 & 600886 & 4.9397 & 5.7452 & TST & & \\
\hline CHEMBL585047 & 600886 & 7.7097 & 6.3573 & TST & & \\
\hline CHEMBL583555 & 600886 & 6.5112 & 6.5697 & TST & & \\
\hline CHEMBL534578 & 600886 & 5.6 & 5.8463 & TST & & \\
\hline
\end{tabular}




\begin{tabular}{|c|c|c|c|c|c|c|}
\hline & & & & & & \\
\hline CHEMBL586554 & 600886 & 6.7484 & 6.3066 & TST & & \\
\hline CHEMBL576547 & 600886 & 6.5782 & 5.8693 & TST & & \\
\hline CHEMBL585071 & 600886 & 6.0 & 6.1746 & TST & & \\
\hline CHEMBL581253 & 600886 & 4.7542 & 5.7185 & TST & & \\
\hline CHEMBL580480 & 600886 & 7.572999 & 99999999 & 995 & 5.6241 & TST \\
\hline CHEMBL578072 & 600886 & 5.5643 & 5.791 & TST & & \\
\hline CHEMBL584612 & 600886 & 5.2958 & 5.6712 & TST & & \\
\hline CHEMBL585774 & 600886 & 6.7781 & 6.5704 & TST & & \\
\hline CHEMBL610503 & 600886 & 6.3298 & 6.0781 & TST & & \\
\hline CHEMBL582298 & 600886 & 5.7464 & 5.5545 & TST & & \\
\hline CHEMBL601610 & 600886 & 6.7185 & 6.5554 & TST & & \\
\hline CHEMBL582468 & 600886 & 6.6033 & 6.617006 & 000000000 & & TST \\
\hline CHEMBL600515 & 600886 & 4.056999 & 99999999 & 995 & 5.2399 & TST \\
\hline CHEMBL582960 & 600886 & 4.9133 & 6.084 & TST & & \\
\hline CHEMBL599928 & 600886 & 6.8649 & 6.3014 & TST & & \\
\hline CHEMBL528197 & 600886 & 6.1463 & 5.9425 & TST & & \\
\hline CHEMBL601149 & 600886 & 4.0004 & 6.0618 & TST & & \\
\hline CHEMBL528734 & 600886 & 5.1409 & 5.8347 & TST & & \\
\hline CHEMBL579157 & 600886 & 6.2882 & 6.2877 & TST & & \\
\hline CHEMBL600334 & 600886 & 5.7921 & 5.513 & TST & & \\
\hline CHEMBL600137 & 600886 & 5.1124 & 5.4864 & TST & & \\
\hline CHEMBL587658 & 600886 & 6.2941 & 6.712006 & 000000000 & & 31 \\
\hline CHEMBL601798 & 600886 & 5.7022 & 6.7186 & TST & & \\
\hline CHEMBL601781 & 600886 & 6.8111 & 6.2869 & TST & & \\
\hline CHEMBL601954 & 600886 & 4.9031 & 5.6982 & TST & & \\
\hline CHEMBL535958 & 600886 & 6.6293 & 6.3389 & TST & & \\
\hline CHEMBL598269 & 600886 & 6.0414 & 5.6965 & TST & & \\
\hline CHEMBL533855 & 600886 & 5.5715 & 6.0472 & TST & & \\
\hline CHEMBL 577230 & 600886 & 6.262000 & 00000000 & 205 & 6.251 & TST \\
\hline CHEMBL599959 & 600886 & 5.957000 & 00000006 & & 5.9655 & TST \\
\hline CHEMBL581692 & 600886 & 5.8713 & 5.1626 & TST & & \\
\hline CHEMBL602623 & 600886 & 4.9031 & 5.7278 & TST & & \\
\hline CHEMBL577180 & 600886 & 5.4711 & 6.9654 & TST & & \\
\hline CHEMBL528723 & 600886 & 5.0273 & 5.6829 & TST & & \\
\hline CHEMBL583141 & 600886 & 6.5096 & 6.3253 & TST & & \\
\hline CHEMBL531990 & 600886 & 10.0615 & 7.5311 & TST & & \\
\hline CHEMBL604311 & 600886 & 3.9031 & 6.2309 & TST & & \\
\hline CHEMBL599089 & 600886 & 6.0953 & 6.4213 & TST & & \\
\hline CHEMBL 586235 & 600886 & 6.2118 & 6.2131 & TST & & \\
\hline CHEMBL605551 & 600886 & 6.2741 & 6.4 & TST & & \\
\hline CHEMBL585048 & 600886 & 6.7097 & 6.0744 & TST & & \\
\hline CHEMBL600970 & 600886 & 6.3809 & 6.5791 & TST & & \\
\hline CHEMBL602602 & 600886 & 6.1871 & 6.449 & TST & & \\
\hline CHEMBL 585465 & 600886 & 6.2041 & 5.1086 & TST & & \\
\hline CHEMBL578545 & 600886 & 6.971 & 6.7237 & TST & & \\
\hline CHEMBL533134 & 600886 & 5.9547 & 6.9461 & TST & & \\
\hline CHEMBL584036 & 600886 & 5.9978 & 6.0147 & TST & & \\
\hline CHEMBL579105 & 600886 & 6.1778 & 7.0641 & TST & & \\
\hline
\end{tabular}




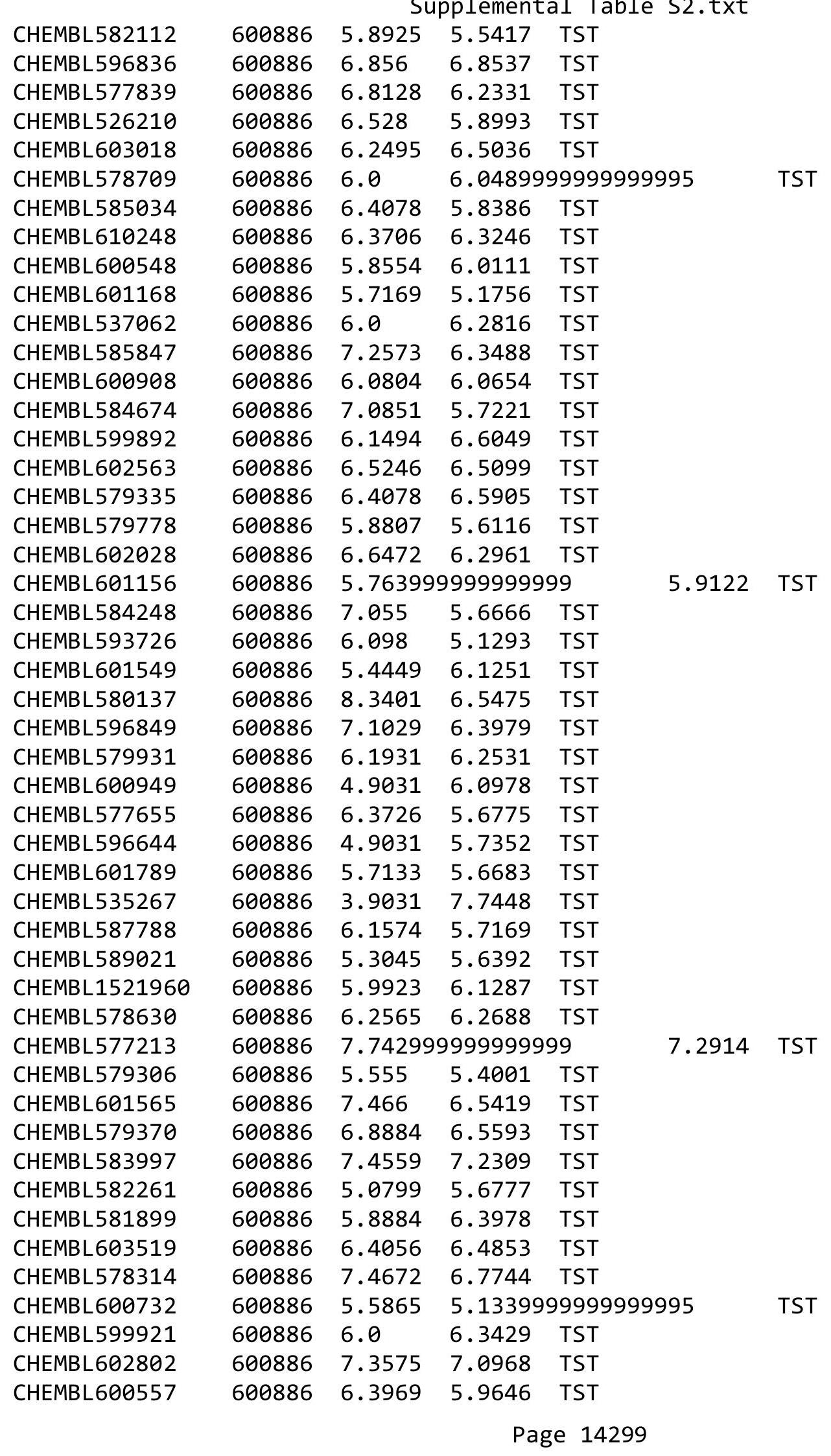




\begin{tabular}{|c|c|c|c|c|c|c|c|}
\hline \multicolumn{7}{|c|}{ 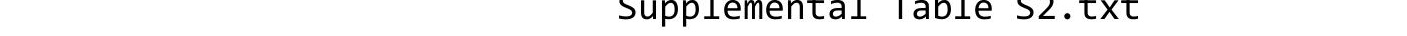 } & \\
\hline CHEMBL585082 & 600886 & 6.4962 & 5.9728 & TST & & & \\
\hline CHEMBL603728 & 600886 & 5.3401 & 5.8259 & TST & & & \\
\hline CHEMBL601122 & 600886 & 6.7402 & 6.6513 & TST & & & \\
\hline CHEMBL584223 & 600886 & 6.3862 & 6.4204 & TST & & & \\
\hline CHEMBL578537 & 600886 & 6.1186 & 5.5995 & TST & & & \\
\hline CHEMBL604324 & 600886 & 6.6173 & 6.3775 & TST & & & \\
\hline CHEMBL585226 & 600886 & 7.3382 & 7.0057 & TST & & & \\
\hline CHEMBL607519 & 600886 & 6.2725 & 5.8956 & TST & & & \\
\hline CHEMBL598078 & 600886 & 6.0264 & 6.0193 & TST & & & \\
\hline CHEMBL579288 & 600886 & 5.5527 & 5.7887 & TST & & & \\
\hline CHEMBL597860 & 600886 & 4.9031 & 5.5878 & TST & & & \\
\hline CHEMBL599958 & 600886 & 4.9739 & 5.6349 & TST & & & \\
\hline CHEMBL599508 & 600886 & 6.317 & 6.2747 & TST & & & \\
\hline CHEMBL604105 & 600886 & 6.5799 & 6.2607 & TST & & & \\
\hline CHEMBL580835 & 600886 & 4.9031 & 6.271 & TST & & & \\
\hline CHEMBL604111 & 600886 & 5.9914 & 6.0667 & TST & & & \\
\hline CHEMBL602631 & 600886 & 6.4949 & 6.2144 & TST & & & \\
\hline CHEMBL581851 & 600886 & 4.76399 & 99999999 & 99 & .8454 & TST & \\
\hline CHEMBL601393 & 600886 & 6.5455 & 6.4259 & TST & & & \\
\hline CHEMBL604156 & 600886 & 4.9031 & 6.346 & TST & & & \\
\hline CHEMBL581046 & 600886 & 6.7361 & 7.0711 & TST & & & \\
\hline CHEMBL602203 & 600886 & 5.7464 & 5.9959 & TST & & & \\
\hline CHEMBL585044 & 600886 & 6.3439 & 6.0497 & TST & & & \\
\hline CHEMBL582050 & 600886 & 5.7899 & 6.2544 & TST & & & \\
\hline CHEMBL577872 & 600886 & 6.8102 & 6.4433 & TST & & & \\
\hline CHEMBL587924 & 600886 & 6.1024 & 6.3464 & TST & & & \\
\hline CHEMBL580767 & 600886 & 6.0904 & 6.3242 & TST & & & \\
\hline CHEMBL602003 & 600886 & 5.9007 & 6.0373 & TST & & & \\
\hline CHEMBL582099 & 600886 & 6.5735 & 6.5104 & TST & & & \\
\hline CHEMBL582267 & 600886 & 5.699 & 5.2387 & TST & & & \\
\hline CHEMBL576999 & 600886 & 5.34200 & 00000000 & 205 & .63700 & 30000000005 & TST \\
\hline CHEMBL601796 & 600886 & 6.3002 & 5.912006 & 0000000001 & & TST & \\
\hline CHEMBL582252 & 600886 & 5.2815 & 5.6767 & TST & & & \\
\hline CHEMBL579147 & 600886 & 6.3526 & 6.6205 & TST & & & \\
\hline CHEMBL578277 & 600886 & 6.289 & 6.6786 & TST & & & \\
\hline CHEMBL599503 & 600886 & 6.1878 & 6.2033 & TST & & & \\
\hline CHEMBL601576 & 600886 & 6.5318 & 6.2862 & TST & & & \\
\hline CHEMBL599722 & 600886 & 6.1707 & 5.5231 & TST & & & \\
\hline CHEMBL585254 & 600886 & 5.0391 & 5.092 & TST & & & \\
\hline CHEMBL580138 & 600886 & 7.2291 & 6.87799 & 9999999999 & & TST & \\
\hline CHEMBL600937 & 600886 & 6.9747 & 6.5896 & TST & & & \\
\hline CHEMBL586889 & 600886 & 7.1811 & 6.8637 & TST & & & \\
\hline CHEMBL529626 & 600886 & 5.062 & 5.6981 & TST & & & \\
\hline CHEMBL587533 & 600886 & 6.2154 & 6.4712 & TST & & & \\
\hline CHEMBL582324 & 600886 & 4.8652 & 5.5065 & TST & & & \\
\hline CHEMBL577145 & 600886 & 5.3747 & 5.684 & TST & & & \\
\hline CHEMBL600502 & 600886 & 6.1319 & 6.1963 & TST & & & \\
\hline CHEMBL1615700 & 600886 & 6.7956 & 7.1153 & TST & & & \\
\hline
\end{tabular}




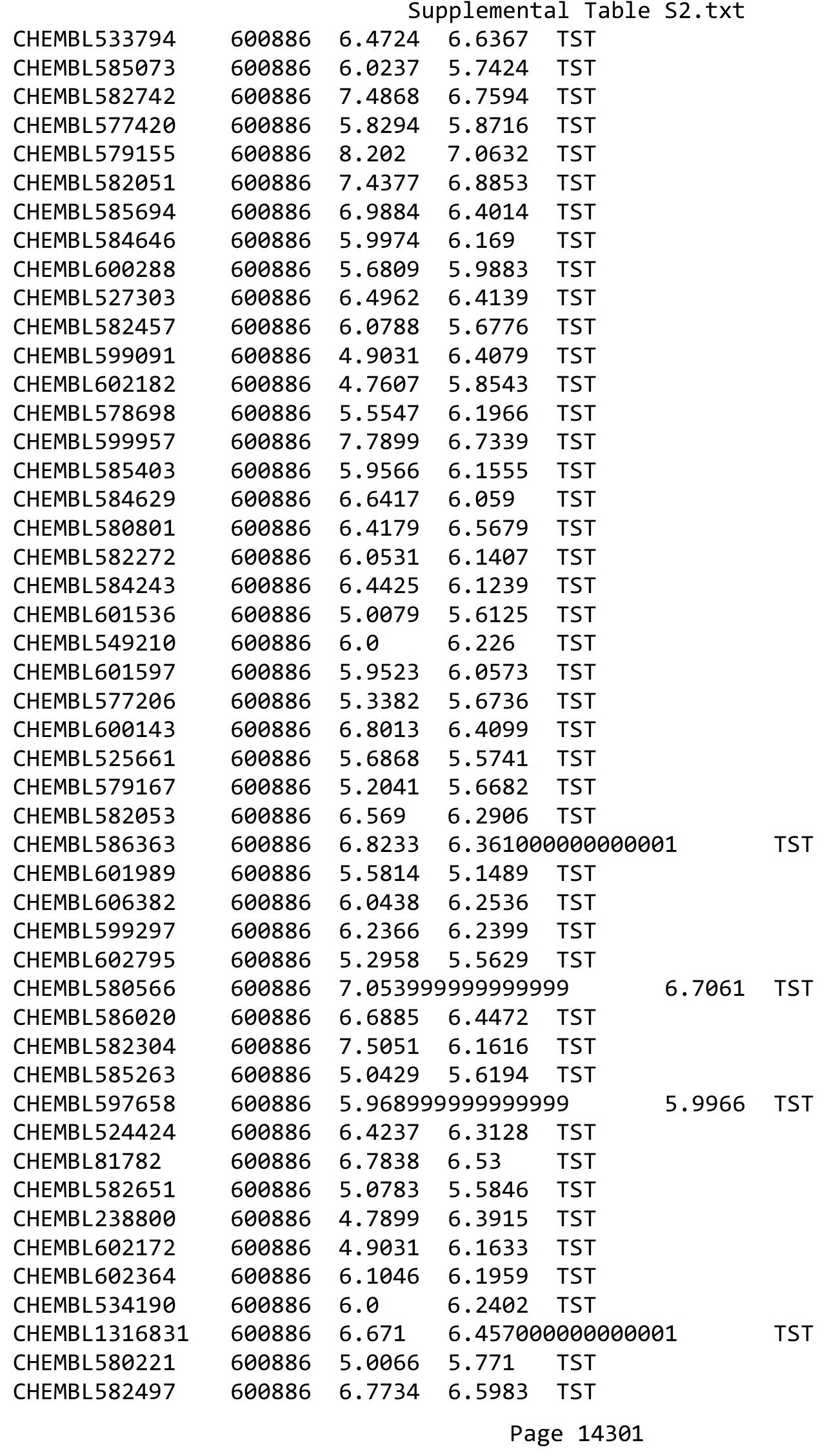




\begin{tabular}{|c|c|c|c|c|c|}
\hline & & & & & \\
\hline CHEMBL368715 & 600886 & 5.9634 & 6.14 & TST & \\
\hline CHEMBL579353 & 600886 & 6.0 & 6.3153 & TST & \\
\hline CHEMBL274189 & 600886 & 6.1158 & 6.4244 & TST & \\
\hline CHEMBL602839 & 600886 & 6.341 & 6.1876 & TST & \\
\hline CHEMBL119315 & 600886 & 4.9031 & 7.0689 & TST & \\
\hline CHEMBL605629 & 600886 & 6.0343 & 5.9899 & TST & \\
\hline CHEMBL582276 & 600886 & 5.8564 & 6.17299 & 9999999999 & TST \\
\hline CHEMBL577879 & 600886 & 4.224 & 5.24799 & 9999999999 & TST \\
\hline CHEMBL600340 & 600886 & 7.0783 & 7.16 & TST & \\
\hline CHEMBL597452 & 600886 & 6.2255 & 6.4254 & TST & \\
\hline CHEMBL585088 & 600886 & 4.9031 & 6.2737 & TST & \\
\hline CHEMBL586483 & 600886 & 6.1993 & 6.5441 & TST & \\
\hline CHEMBL598065 & 600886 & 6.4377 & 6.3057 & TST & \\
\hline CHEMBL601815 & 600886 & 8.5835 & 6.3503 & TST & \\
\hline CHEMBL581595 & 600886 & 6.99700 & 30000000 & 6.6559 & TST \\
\hline CHEMBL585208 & 600886 & 5.9329 & 6.5148 & TST & \\
\hline CHEMBL601817 & 600886 & 8.6315 & 5.9483 & TST & \\
\hline CHEMBL582458 & 600886 & 6.5036 & 6.6814 & TST & \\
\hline CHEMBL598678 & 600886 & 6.2168 & 6.2452 & TST & \\
\hline CHEMBL578728 & 600886 & 6.2565 & 5.8973 & TST & \\
\hline CHEMBL600521 & 600886 & 6.8162 & 6.7458 & TST & \\
\hline CHEMBL578281 & 600886 & 5.6637 & 5.69600 & 0000000001 & TST \\
\hline CHEMBL588827 & 600886 & 6.9014 & 6.525 & TST & \\
\hline CHEMBL578316 & 600886 & 6.9363 & 6.7362 & TST & \\
\hline CHEMBL582245 & 600886 & 8.9165 & 6.5481 & TST & \\
\hline CHEMBL599305 & 600886 & 6.0757 & 6.188 & TST & \\
\hline CHEMBL532640 & 600886 & 7.0 & 6.6937 & TST & \\
\hline CHEMBL585258 & 600886 & 4.066 & 5.0368 & TST & \\
\hline CHEMBL530432 & 600886 & 7.0434 & 6.8292 & TST & \\
\hline CHEMBL588060 & 600886 & 8.8745 & 6.3608 & TST & \\
\hline CHEMBL581475 & 600886 & 3.9031 & 6.2724 & TST & \\
\hline CHEMBL582735 & 600886 & 6.2899 & 6.1889 & TST & \\
\hline CHEMBL596831 & 600886 & 6.9278 & 6.8812 & TST & \\
\hline CHEMBL584219 & 600886 & 6.4237 & 6.105 & TST & \\
\hline CHEMBL597468 & 600886 & 6.561 & 5.3569 & TST & \\
\hline CHEMBL582730 & 600886 & 4.9031 & 6.2989 & TST & \\
\hline CHEMBL584830 & 600886 & 6.5737 & 6.4803 & TST & \\
\hline CHEMBL579138 & 600886 & 5.6469 & 5.6688 & TST & \\
\hline CHEMBL576403 & 600886 & 6.8811 & 6.6593 & TST & \\
\hline CHEMBL600330 & 600886 & 5.7086 & 5.5523 & TST & \\
\hline CHEMBL581481 & 600886 & 4.9031 & 6.045 & TST & \\
\hline CHEMBL584636 & 600886 & 7.8814 & 7.481 & TST & \\
\hline CHEMBL578292 & 600886 & 6.5654 & 6.5873 & TST & \\
\hline CHEMBL585211 & 600886 & 6.0264 & 5.7777 & TST & \\
\hline CHEMBL577657 & 600886 & 5.224 & 5.1819 & TST & \\
\hline CHEMBL500142 & 600886 & 5.848 & 6.335 & TST & \\
\hline CHEMBL578708 & 600886 & 5.2518 & 6.7973 & TST & \\
\hline CHEMBL582313 & 600886 & 5.7326 & 6.0755 & TST & \\
\hline
\end{tabular}




\begin{tabular}{|c|c|c|c|c|c|}
\hline \multicolumn{6}{|c|}{ Supplemental Table S2.txt } \\
\hline CHEMBL532918 & 600886 & 6.1355 & 6.3568 & TST & \\
\hline CHEMBL581074 & 600886 & 7.27 & 6.5059 & TST & \\
\hline CHEMBL602763 & 600886 & 6.2588 & 6.33 & TST & \\
\hline CHEMBL597675 & 600886 & 6.994 & 6.6154 & TST & \\
\hline CHEMBL602167 & 600886 & 6.0555 & 6.1563 & TST & \\
\hline CHEMBL578948 & 600886 & 8.2581 & \multicolumn{2}{|c|}{6.832999999999999} & TST \\
\hline CHEMBL581653 & 600886 & 6.0 & 6.1847 & TST & \\
\hline CHEMBL379386 & 600886 & 6.7156 & 6.8067 & TST & \\
\hline CHEMBL578686 & 600886 & 4.869 & 6.1406 & TST & \\
\hline CHEMBL604101 & 600886 & 6.2343 & 6.2755 & TST & \\
\hline CHEMBL576810 & 600886 & 7.4179 & 7.044 & TST & \\
\hline CHEMBL599514 & 600886 & 7.9731 & 7.5548 & TST & \\
\hline CHEMBL600098 & 600886 & 6.0 & 6.2546 & TST & \\
\hline CHEMBL605549 & 600886 & 5.9698 & 5.9433 & TST & \\
\hline CHEMBL586271 & 600886 & 4.9622 & 6.0969 & TST & \\
\hline CHEMBL581484 & 600886 & 4.9031 & 5.4669 & TST & \\
\hline CHEMBL601140 & 600886 & 5.6899 & 6.4368 & TST & \\
\hline CHEMBL579170 & 600886 & 6.8897 & 6.4607 & TST & \\
\hline CHEMBL582683 & 600886 & 5.8976 & 6.2075 & TST & \\
\hline CHEMBL600702 & 600886 & 6.3536 & 6.4652 & TST & \\
\hline CHEMBL 307370 & 75463 & 4.7447 & 4.8602 & TRN & \\
\hline CHEMBL70593 & 75463 & 6.2596 & 5.8971 & TRN & \\
\hline CHEMBL73522 & 75463 & 6.0 & \multicolumn{2}{|c|}{5.968999999999999} & TRN \\
\hline CHEMBL306958 & 75463 & 4.0 & 3.7231 & TRN & \\
\hline CHEMBL72616 & 75463 & 3.7447 & 3.9177 & TRN & \\
\hline CHEMBL72546 & 75463 & 5.8861 & 6.1813 & TRN & \\
\hline CHEMBL1907663 & 75463 & 3.8861 & 3.7678 & TRN & \\
\hline CHEMBL 308404 & 75463 & 3.0 & 3.7115 & TST & \\
\hline CHEMBL 74181 & 75463 & 4.7696 & 4.3503 & TRN & \\
\hline CHEMBL308297 & 75463 & 3.0 & 2.8022 & TRN & \\
\hline CHEMBL70405 & 75463 & 3.0 & \multicolumn{2}{|c|}{3.4760000000000004} & TRN \\
\hline CHEMBL306806 & 75463 & 5.3372 & 5.4211 & TRN & \\
\hline CHEMBL 302825 & 75463 & 5.6198 & 5.2538 & TST & \\
\hline CHEMBL422951 & 75463 & 4.8539 & 4.9941 & TRN & \\
\hline CHEMBL73510 & 75463 & 5.301 & 5.1313 & TRN & \\
\hline CHEMBL74125 & 75463 & 4.7212 & 4.4008 & TRN & \\
\hline CHEMBL70550 & 75463 & 4.0 & 4.0339 & TRN & \\
\hline CHEMBL 2092866 & 75463 & 6.0 & 5.9648 & TRN & \\
\hline CHEMBL 72550 & 75463 & 4.0 & 4.1324 & TRN & \\
\hline CHEMBL 2114102 & 75463 & 6.0 & 4.9599 & TST & \\
\hline CHEMBL 307878 & 75463 & 4.0 & 4.3941 & TRN & \\
\hline CHEMBL70728 & 75463 & 4.5229 & 3.4809 & TST & \\
\hline CHEMBL72057 & 75463 & 3.3979 & 3.7287 & TRN & \\
\hline CHEMBL73561 & 75463 & 5.0223 & 4.9266 & TRN & \\
\hline CHEMBL 303386 & 75463 & 4.585 & 4.4912 & TST & \\
\hline CHEMBL 303724 & 75463 & 4.0 & 4.0089 & TRN & \\
\hline CHEMBL 72841 & 75463 & 4.284 & 4.3249 & TRN & \\
\hline CHEMBL72073 & 75463 & 5.1739 & 5.523 & TRN & \\
\hline
\end{tabular}




\begin{tabular}{|c|c|c|c|c|c|}
\hline \multicolumn{6}{|c|}{ Supplemental Table S2.txt } \\
\hline CHEMBL73563 & 75463 & 5.4089 & 4.6827 & TST & \\
\hline CHEMBL72491 & 75463 & 3.3979 & 3.6688 & TRN & \\
\hline CHEMBL72894 & 75463 & 4.0 & 3.7832 & TRN & \\
\hline CHEMBL 70896 & 75463 & 4.0 & 4.0102 & TRN & \\
\hline CHEMBL70549 & 75463 & 4.0 & 4.4017 & TST & \\
\hline CHEMBL1907854 & 75463 & 6.0 & 5.3125 & TRN & \\
\hline CHEMBL72738 & 75463 & 4.6021 & 5.3134 & TST & \\
\hline CHEMBL71079 & 75463 & 5.699 & 5.7638 & TRN & \\
\hline CHEMBL72300 & 75463 & 4.8539 & 4.9795 & TRN & \\
\hline CHEMBL 74580 & 75463 & 5.0862 & 4.4543 & TRN & \\
\hline CHEMBL 74515 & 75463 & 4.6021 & 4.4072 & TRN & \\
\hline CHEMBL 74066 & 75463 & 4.5376 & 4.4656 & TRN & \\
\hline CHEMBL70499 & 75463 & 3.0 & 3.7458 & TRN & \\
\hline CHEMBL 309017 & 75463 & 4.5376 & 5.0468 & TRN & \\
\hline CHEMBL73272 & 75463 & 4.6021 & 4.4174 & TRN & \\
\hline CHEMBL 310250 & 75463 & 4.5086 & 4.2609 & TRN & \\
\hline CHEMBL72570 & 75463 & 5.1549 & 5.0832 & TRN & \\
\hline CHEMBL1907852 & 75463 & 6.0 & 5.7316 & TRN & \\
\hline CHEMBL308111 & 75463 & 4.0 & 4.4962 & TRN & \\
\hline CHEMBL1907847 & 75463 & 5.0458 & 5.5202 & TRN & \\
\hline CHEMBL72667 & 75463 & 4.0 & 4.1925 & TRN & \\
\hline CHEMBL431185 & 75463 & 3.0 & 4.0658 & TST & \\
\hline CHEMBL13095 & 75463 & 3.0 & 3.5746 & TST & \\
\hline CHEMBL1907839 & 75463 & 4.4202 & 5.1459 & TRN & \\
\hline CHEMBL39263 & 75463 & 6.0 & 6.2202 & TRN & \\
\hline CHEMBL 306271 & 75463 & 3.0 & 2.7686 & TST & \\
\hline CHEMBL 74170 & 75463 & 3.0 & 2.7937 & TRN & \\
\hline CHEMBL73885 & 75463 & 5.2007 & 5.2464 & TRN & \\
\hline CHEMBL 308769 & 75463 & 3.0 & 4.044 & TST & \\
\hline CHEMBL 306760 & 75463 & 5.3979 & 5.2533 & TRN & \\
\hline CHEMBL72599 & 75463 & 5.2676 & 4.7142 & TRN & \\
\hline CHEMBL1907849 & 75463 & 6.0 & 5.9004 & TRN & \\
\hline CHEMBL302282 & 75463 & 4.3979 & 4.3972 & TRN & \\
\hline CHEMBL419997 & 75463 & 4.0 & 3.8574 & TRN & \\
\hline CHEMBL 70456 & 75463 & 6.1871 & 6.1249 & TRN & \\
\hline CHEMBL443009 & 75463 & 5.4202 & $6.0870 e$ & 0000000001 & TRN \\
\hline CHEMBL307661 & 75463 & 6.4089 & 6.2449 & TRN & \\
\hline CHEMBL73621 & 75463 & 5.0862 & 5.6388 & TRN & \\
\hline CHEMBL 306396 & 75463 & 3.0 & 2.6529 & TST & \\
\hline CHEMBL1907661 & 75463 & 6.7447 & 6.4673 & TRN & \\
\hline CHEMBL72727 & 75463 & 3.3979 & 3.5113 & TRN & \\
\hline CHEMBL40668 & 75463 & 6.1612 & 6.2196 & TRN & \\
\hline CHEMBL422411 & 75463 & 4.4949 & 4.9383 & TRN & \\
\hline CHEMBL1907848 & 75463 & 6.2757 & 6.2511 & TRN & \\
\hline CHEMBL73745 & 75463 & 3.0 & 3.3179 & TRN & \\
\hline CHEMBL1907660 & 75463 & 4.8861 & 4.6092 & TRN & \\
\hline CHEMBL1907851 & 75463 & 6.1249 & 5.9794 & TRN & \\
\hline CHEMBL306369 & 75463 & 3.9586 & 3.9903 & TST & \\
\hline
\end{tabular}




\begin{tabular}{|c|c|c|c|c|c|}
\hline & & \multicolumn{4}{|c|}{ Supplemental Table S2.txt } \\
\hline CHEMBL 306394 & 75463 & 5.0269 & 4.5537 & TRN & \\
\hline CHEMBL70883 & 75463 & 6.9208 & 6.8013 & TRN & \\
\hline CHEMBL72710 & 75463 & 4.6576 & 3.9857 & TRN & \\
\hline CHEMBL1907850 & 75463 & 6.1675 & 6.1883 & TRN & \\
\hline CHEMBL 304768 & 75463 & 4.9586 & 5.2328 & TRN & \\
\hline CHEMBL73892 & 75463 & 4.7447 & 4.3958 & TRN & \\
\hline CHEMBL 307659 & 75463 & 4.5528 & 4.5912 & TRN & \\
\hline CHEMBL 309575 & 75463 & 5.0969 & 4.4842 & TRN & \\
\hline CHEMBL1907841 & 75463 & 6.0 & 5.8894 & TRN & \\
\hline CHEMBL1907846 & 75463 & 6.0 & 5.678 & TRN & \\
\hline CHEMBL 308414 & 75463 & 4.699 & 4.3161 & TRN & \\
\hline CHEMBL 72670 & 75463 & 3.0 & 3.801 & TRN & \\
\hline CHEMBL70856 & 75463 & 4.9586 & 4.8661 & TST & \\
\hline CHEMBL 308756 & 75463 & 4.0969 & 3.6481 & TST & \\
\hline CHEMBL1907665 & 75463 & 4.1367 & 4.3171 & TST & \\
\hline CHEMBL72428 & 75463 & 5.7212 & 5.6023 & TST & \\
\hline CHEMBL1907667 & 75463 & 5.4318 & 5.5915 & TST & \\
\hline CHEMBL 72151 & 75463 & 3.0 & 3.8839 & TST & \\
\hline CHEMBL 303227 & 75463 & 5.7959 & 6.3402 & TST & \\
\hline CHEMBL302359 & 75463 & 4.4437 & 4.5211 & TST & \\
\hline CHEMBL1907842 & 75463 & 6.0 & 5.7002 & TST & \\
\hline CHEMBL73096 & 75463 & 4.0269 & 3.3421 & TST & \\
\hline CHEMBL 2092869 & 75463 & 6.0 & 5.5072 & TST & \\
\hline CHEMBL281627 & 79581 & 3.0 & 3.0334 & TRN & \\
\hline CHEMBL513232 & 79581 & 3.6234 & 4.9876 & TST & \\
\hline CHEMBL 277221 & 79581 & 3.0 & 2.9417 & TRN & \\
\hline CHEMBL 277486 & 79581 & 3.0 & 2.9627 & TRN & \\
\hline CHEMBL22503 & 79581 & 4.4318 & 4.5165 & TRN & \\
\hline CHEMBL25329 & 79581 & 3.0 & 2.87899 & 99999999996 & TRN \\
\hline CHEMBL 284016 & 79581 & 3.0 & 2.9186 & TRN & \\
\hline CHEMBL22209 & 79581 & 4.4815 & 3.4088 & TST & \\
\hline CHEMBL22263 & 79581 & 4.4949 & 4.6224 & TRN & \\
\hline CHEMBL282937 & 79581 & 3.0 & 2.9868 & TRN & \\
\hline CHEMBL 25100 & 79581 & 3.0 & 3.0991 & TST & \\
\hline CHEMBL23020 & 79581 & 3.0 & 3.0358 & TRN & \\
\hline CHEMBL22402 & 79581 & 3.0 & 3.0583 & TRN & \\
\hline CHEMBL 280131 & 79581 & 3.0 & 3.0154 & TRN & \\
\hline CHEMBL22264 & 79581 & 3.0 & 2.9812 & TRN & \\
\hline CHEMBL 283158 & 79581 & 3.0 & 2.9948 & TRN & \\
\hline CHEMBL 277233 & 79581 & 3.0 & 3.0659 & TRN & \\
\hline CHEMBL 278997 & 79581 & 3.0 & 2.9775 & TRN & \\
\hline CHEMBL 25044 & 79581 & 3.0 & 3.0668 & TRN & \\
\hline CHEMBL25270 & 79581 & 4.4949 & 4.5509 & TRN & \\
\hline CHEMBL22997 & 79581 & 4.0 & 3.4711 & TRN & \\
\hline CHEMBL281111 & 79581 & 3.0 & 3.0241 & TRN & \\
\hline CHEMBL22941 & 79581 & 4.4949 & 4.3853 & TRN & \\
\hline CHEMBL 279744 & 79581 & 3.0 & 3.0555 & TST & \\
\hline CHEMBL 277866 & 79581 & 3.0 & 3.0879 & TRN & \\
\hline
\end{tabular}




\begin{tabular}{|c|c|c|c|c|}
\hline \multicolumn{5}{|c|}{ Supplemental Table S2.txt } \\
\hline CHEMBL 22262 & 79581 & 3.0 & 3.1711 & TST \\
\hline CHEMBL 278766 & 79581 & 3.0 & 3.1104 & TRN \\
\hline CHEMBL278162 & 79581 & 4.2366 & 4.0021 & TRN \\
\hline CHEMBL 282023 & 79581 & 3.0 & 3.5688 & TRN \\
\hline CHEMBL 23023 & 79581 & 3.0 & 2.9689 & TRN \\
\hline CHEMBL276979 & 79581 & 3.0 & 3.0057 & TRN \\
\hline CHEMBL435567 & 79581 & 4.6576 & 4.1194 & TST \\
\hline CHEMBL 282268 & 79581 & 3.0 & 3.1079 & TRN \\
\hline CHEMBL22681 & 79581 & 3.0 & 3.0301 & TST \\
\hline CHEMBL 22887 & 79581 & 3.0 & 2.9342 & TRN \\
\hline CHEMBL 25388 & 79581 & 3.0 & 3.0323 & TRN \\
\hline CHEMBL 23032 & 79581 & 4.4949 & 3.7944 & TRN \\
\hline CHEMBL 22368 & 79581 & 3.0 & 3.0778 & TST \\
\hline CHEMBL 22792 & 79581 & 4.4949 & 4.62 & TRN \\
\hline CHEMBL2093921 & 79581 & 3.9281 & 5.1615 & TST \\
\hline CHEMBL 22714 & 79581 & 3.0 & 3.0784 & TRN \\
\hline CHEMBL 22289 & 79581 & 3.0 & 2.9826 & TRN \\
\hline CHEMBL 22658 & 79581 & 3.0 & 3.4921 & TRN \\
\hline CHEMBL 22787 & 79581 & 3.0 & 2.9438 & TST \\
\hline CHEMBL 281171 & 79581 & 4.4949 & 3.5928 & TST \\
\hline CHEMBL 277222 & 79581 & 3.0 & 2.9505 & TRN \\
\hline CHEMBL 22850 & 79581 & 4.4949 & 4.4318 & TRN \\
\hline CHEMBL 25607 & 79581 & 3.0 & 3.0223 & TRN \\
\hline CHEMBL 280386 & 79581 & 3.0 & 2.9585 & TRN \\
\hline CHEMBL22954 & 79581 & 3.0 & 3.1214 & TST \\
\hline CHEMBL 22995 & 79581 & 4.4949 & 4.1751 & TST \\
\hline CHEMBL2286418 & 925676 & 4.26 & 3.4571 & TST \\
\hline CHEMBL2286412 & 925676 & 5.0 & 4.9477 & TST \\
\hline CHEMBL 2286411 & 925676 & 4.45 & 6.8679 & TST \\
\hline CHEMBL2286410 & 925676 & 5.9 & 6.4885 & TST \\
\hline CHEMBL2286409 & 925676 & 6.72 & 6.3723 & TST \\
\hline CHEMBL55108 & 925676 & 7.11 & 5.7433 & TST \\
\hline CHEMBL2286448 & 925676 & 8.36 & 5.3116 & TST \\
\hline CHEMBL 2286716 & 925676 & 3.0 & 4.9876 & TST \\
\hline CHEMBL2286715 & 925676 & 3.0 & 3.8449 & TST \\
\hline CHEMBL 2286714 & 925676 & 5.77 & 3.6475 & TST \\
\hline CHEMBL2286713 & 925676 & 6.05 & 3.5432 & TST \\
\hline CHEMBL1579486 & 925676 & 4.59 & 4.5639 & TRN \\
\hline CHEMBL 2286712 & 925676 & 5.54 & 4.3506 & TST \\
\hline CHEMBL2286711 & 925676 & 5.15 & 4.2711 & TST \\
\hline CHEMBL 27602 & 925676 & 3.0 & 3.0233 & TRN \\
\hline CHEMBL 2286710 & 925676 & 5.81 & 6.4058 & TRN \\
\hline CHEMBL2285684 & 925676 & 7.01 & 6.4058 & TRN \\
\hline CHEMBL2286709 & 925676 & 7.04 & 7.0722 & TRN \\
\hline CHEMBL2286708 & 925676 & 7.1 & 6.9962 & TRN \\
\hline CHEMBL2286707 & 925676 & 5.73 & 5.7891 & TRN \\
\hline CHEMBL2286706 & 925676 & 6.13 & 6.1692 & TRN \\
\hline CHEMBL2286705 & 925676 & 5.03 & 5.0396 & TRN \\
\hline
\end{tabular}




\begin{tabular}{|c|c|c|c|c|c|}
\hline \multicolumn{6}{|c|}{ Supplemental Table S2.txt } \\
\hline CHEMBL2286704 & 925676 & 6.0 & 6.0418 & TRN & \\
\hline CHEMBL 2286703 & 925676 & 7.88 & 7.8355 & TRN & \\
\hline CHEMBL2286466 & 925676 & 4.93 & 5.0155 & TRN & \\
\hline CHEMBL2286465 & 925676 & 6.08 & 5.9999 & TRN & \\
\hline CHEMBL2286735 & 925676 & 5.55 & 5.5525 & TRN & \\
\hline CHEMBL 2286734 & 925676 & 3.0 & 2.9289 & TRN & \\
\hline CHEMBL 2286733 & 925676 & 4.84 & 4.9651 & TRN & \\
\hline CHEMBL2286732 & 925676 & 5.06 & 5.0667 & TRN & \\
\hline CHEMBL2286731 & 925676 & 5.14 & 5.0507 & TRN & \\
\hline CHEMBL2286730 & 925676 & 4.33 & 4.2723 & TRN & \\
\hline CHEMBL2286437 & 925676 & 5.93 & 5.9402 & TRN & \\
\hline CHEMBL2286436 & 925676 & 5.54 & 5.5563 & TRN & \\
\hline CHEMBL226969 & 925676 & 7.06 & 7.1189 & TRN & \\
\hline CHEMBL 2286431 & 925676 & 8.31 & 8.2963 & TRN & \\
\hline CHEMBL2286729 & 925676 & 7.28 & 7.2837 & TRN & \\
\hline CHEMBL55772 & 925676 & 8.22 & 8.2119 & TRN & \\
\hline CHEMBL2228859 & 925676 & 7.72 & 7.6558 & TRN & \\
\hline CHEMBL226968 & 925676 & 8.91 & 8.8805 & TRN & \\
\hline CHEMBL2286728 & 925676 & 7.92 & 7.9055 & TRN & \\
\hline CHEMBL 2286727 & 925676 & 7.18 & 7.1773 & TRN & \\
\hline CHEMBL 2286726 & 925676 & 7.06 & 7.0562 & TRN & \\
\hline CHEMBL2286725 & 925676 & 5.79 & 5.7888 & TRN & \\
\hline CHEMBL 2286724 & 925676 & 6.79 & 6.8411 & TRN & \\
\hline CHEMBL2286723 & 925676 & 7.81 & 7.8048 & TRN & \\
\hline CHEMBL 2286722 & 925676 & 7.7 & 7.654 & TRN & \\
\hline CHEMBL 2286721 & 925676 & 8.03 & 8.0662 & TRN & \\
\hline CHEMBL2286429 & 925676 & 7.29 & 7.2196 & TRN & \\
\hline CHEMBL 2286428 & 925676 & 7.61 & 7.6309 & TRN & \\
\hline CHEMBL 2286427 & 925676 & 8.04 & 8.0489 & TRN & \\
\hline CHEMBL 2286720 & 925676 & 8.24 & 8.3176 & TRN & \\
\hline CHEMBL 2286719 & 925676 & 7.73 & 7.6418 & TRN & \\
\hline CHEMBL2286718 & 925676 & 6.22 & 6.1868 & TRN & \\
\hline CHEMBL 2286946 & 925676 & 8.12 & 8.1291 & TRN & \\
\hline CHEMBL2286426 & 925676 & 7.47 & 7.4771 & TRN & \\
\hline CHEMBL2286752 & 925676 & 6.94 & 6.9542 & TRN & \\
\hline CHEMBL2286751 & 925676 & 6.41 & 6.4054 & TRN & \\
\hline CHEMBL 2286750 & 925676 & 7.28 & 7.2833 & TRN & \\
\hline CHEMBL2286749 & 925676 & 6.22 & 6.2024 & TRN & \\
\hline CHEMBL2286748 & 925676 & 6.02 & 6.0395 & TRN & \\
\hline CHEMBL 2286747 & 925676 & 6.72 & 6.7696 & TRN & \\
\hline CHEMBL 2286425 & 925676 & 6.81 & 6.8332 & TRN & \\
\hline CHEMBL 2286746 & 925676 & 7.16 & 7.1658 & TRN & \\
\hline CHEMBL2286423 & 925676 & 7.14 & 7.1324 & TRN & \\
\hline CHEMBL2286745 & 925676 & 5.89 & 5.8579 & TRN & \\
\hline CHEMBL 2286744 & 925676 & 6.5 & 6.4837 & TRN & \\
\hline CHEMBL 2286743 & 925676 & 6.48 & 6.4437 & TRN & \\
\hline CHEMBL 2286422 & 925676 & 7.29 & 7.2778 & TRN & \\
\hline CHEMBL 2228438 & 925676 & 7.16 & 7.25700 & 0000000001 & TRN \\
\hline & & & & 14307 & \\
\hline
\end{tabular}




\begin{tabular}{|c|c|c|c|c|c|}
\hline \multirow{3}{*}{$\begin{array}{l}\text { CHEMBL } 2286742 \\
\text { CHFMBI } 2228437\end{array}$} & \multirow[b]{2}{*}{925676} & \multicolumn{4}{|c|}{ Supplemental Table s2.txt } \\
\hline & & 6.93 & 6.92899 & 9999999999 & TRN \\
\hline & 925676 & 6.28 & 6.3323 & TRN & \\
\hline CHEMBL 2286741 & 925676 & 6.23 & 6.229 & TRN & \\
\hline CHEMBL 2286740 & 925676 & 6.65 & 6.0636 & TST & \\
\hline CHEMBL 2286739 & 925676 & 6.65 & 6.138 & TST & \\
\hline CHEMBL 2286420 & 925676 & 6.2 & 7.0524 & TST & \\
\hline CHEMBL 2286738 & 925676 & 6.98 & 5.3819 & TST & \\
\hline CHEMBL 2286737 & 925676 & 6.77 & 5.5477 & TST & \\
\hline CHEMBL 2228435 & 925676 & 7.12 & 7.2049 & TST & \\
\hline CHEMBL 2286736 & 925676 & 6.51 & 6.6312 & TST & \\
\hline CHEMBL387744 & 925676 & 6.37 & 6.6623 & TST & \\
\hline CHEMBL6623 & 157 & 11.1 & 10.7454 & TRN & \\
\hline CHEMBL294534 & 157 & 8.43 & 8.5149 & TRN & \\
\hline CHEMBL63325 & 157 & 8.81 & 8.8555 & TRN & \\
\hline CHEMBL444049 & 157 & 8.02 & 8.3391 & TRN & \\
\hline CHEMBL291399 & 157 & 8.05 & 8.0302 & TRN & \\
\hline CHEMBL301901 & 157 & 10.35 & 10.6098 & TRN & \\
\hline CHEMBL305325 & 157 & 8.1 & 7.3667 & TRN & \\
\hline CHEMBL62858 & 157 & 10.77 & 10.6356 & TRN & \\
\hline CHEMBL303358 & 157 & 7.91 & 9.0524 & TST & \\
\hline CHEMBL65237 & 157 & 5.78 & 5.7697 & TRN & \\
\hline CHEMBL65324 & 157 & 8.6 & 8.6646 & TRN & \\
\hline CHEMBL444572 & 157 & 10.29 & 10.0773 & TRN & \\
\hline CHEMBL293185 & 157 & 10.55 & 10.4779 & TRN & \\
\hline CHEMBL292301 & 157 & 8.68 & 8.9698 & TRN & \\
\hline CHEMBL63078 & 157 & 7.5 & 7.5207 & TRN & \\
\hline CHEMBL 64779 & 157 & 8.12 & 9.5056 & TST & \\
\hline CHEMBL302691 & 157 & 4.21 & 7.2427 & TST & \\
\hline CHEMBL61843 & 157 & 9.28 & 8.5487 & TRN & \\
\hline CHEMBL64672 & 157 & 6.67 & 5.1853 & TST & \\
\hline CHEMBL64850 & 157 & 6.58 & 6.7108 & TRN & \\
\hline CHEMBL 302380 & 157 & 8.0 & 8.1014 & TRN & \\
\hline CHEMBL424226 & 157 & 8.7 & 8.5242 & TRN & \\
\hline CHEMBL62975 & 157 & 8.8 & 8.9535 & TRN & \\
\hline CHEMBL303289 & 157 & 6.68 & 6.36600 & 00000000005 & TRN \\
\hline CHEMBL62346 & 157 & 5.7 & 7.6145 & TST & \\
\hline CHEMBL406216 & 157 & 5.61 & 7.818 & TST & \\
\hline CHEMBL 66262 & 157 & 6.0 & 8.4188 & TST & \\
\hline CHEMBL292266 & 157 & 9.26 & 9.0607 & TRN & \\
\hline CHEMBL305106 & 157 & 11.0 & 10.7912 & TRN & \\
\hline CHEMBL291398 & 157 & 9.28 & 8.9345 & TRN & \\
\hline CHEMBL54586 & 157 & 10.6 & 10.7049 & TRN & \\
\hline CHEMBL 302237 & 157 & 7.72 & 8.418 & TRN & \\
\hline CHEMBL56682 & 157 & 10.55 & 10.4743 & TRN & \\
\hline CHEMBL63102 & 157 & 9.77 & 9.9139 & TRN & \\
\hline CHEMBL292030 & 157 & 7.51 & 7.6117 & TRN & \\
\hline CHEMBL64138 & 157 & 9.85 & 9.5645 & TRN & \\
\hline CHEMBL497939 & 157 & 9.91 & 9.6467 & TRN & \\
\hline
\end{tabular}




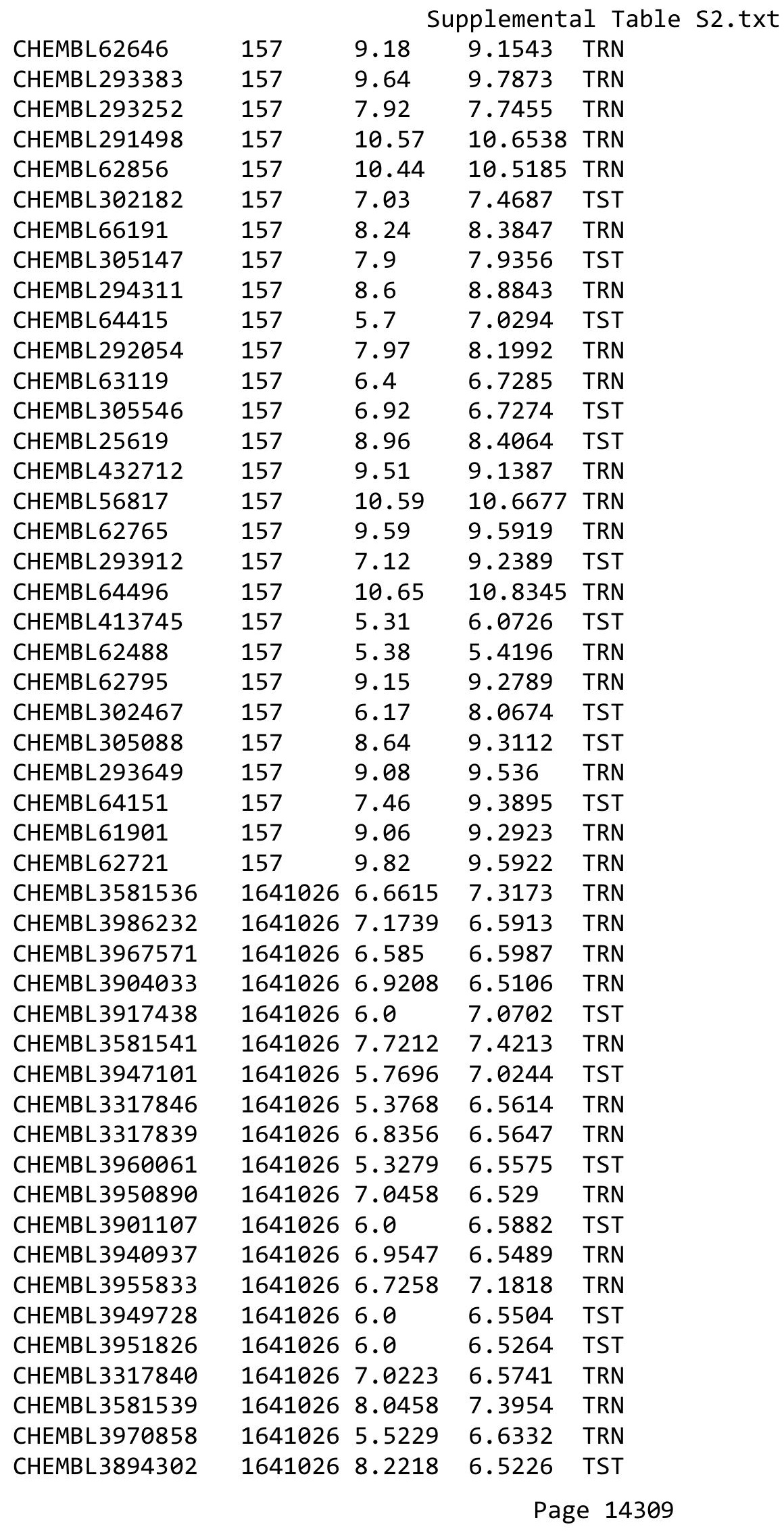


Supplemental Table S2.txt

\begin{tabular}{|c|c|c|c|c|}
\hline 829 & 541026 & & & \\
\hline & 641026 & 7.0969 & & \\
\hline & 026 & & & \\
\hline IEMBL: & 1026 & 2518 & & \\
\hline AEMBL & $0410<6$ & 7595 & & \\
\hline AEMBL3581529 & 541026 & 6.6038 & 465 & \\
\hline AEMBL & 26 & 361 & & \\
\hline 83 & 026 & & & RN \\
\hline AEMBL33 & 026 & 7.2218 & & \\
\hline AEMBL3317733 & 026 & 6.9281 & & \\
\hline IEMBL395 & $\partial 26$ & 14 & & \\
\hline IEMBL & 26 & 688 & & \\
\hline IEMBL & 26 & & & \\
\hline AEMBL39] & 026 & 2757 & & \\
\hline IEMBL: & 26 & 7.3098 & & \\
\hline AEMBL. & 16 & & & \\
\hline AEMBL & v & 8 & & \\
\hline AEMBL & 6 & & & \\
\hline IEMBL & 26 & 7.1739 & & \\
\hline IEMBL & & 36 & & \\
\hline IEMBL & 6 & r & & \\
\hline EMB & 6 & & & \\
\hline EMB & 6 & 98 & & \\
\hline 85 & & & & \\
\hline IEMBL: & & 2 & & Q| \\
\hline IEMBL & 16 & & & $\cdots$ \\
\hline EMBL & 16 & & & 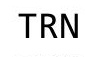 \\
\hline$\theta 0$ & 16 & & & \\
\hline IEMBL & & & & \\
\hline IEMBL 331 & 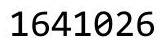 & & & 「R \\
\hline AEMBL & 16 & 61 & & 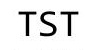 \\
\hline 30 & 16 & 77 & & \\
\hline 31 & 6 & 18 & & \\
\hline IEMBL & 16 & & & RN \\
\hline AEMBL3925502 & 64 & 229 & & ГRN \\
\hline IEMBL & 16 & 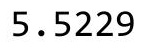 & & J \\
\hline 39 & & & & \\
\hline & & 6 & & 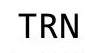 \\
\hline HEMBL331 & 16 & 6.9208 & & $\mathrm{RI}$ \\
\hline IEMBL: & 026 & 6.8041 & & RI \\
\hline HEMBL & 6 & 7.0362 & & TS \\
\hline 43 & & & & \\
\hline HEMBL & & 6.6655 & & $\mathrm{RA}$ \\
\hline AEMBL392 & 62 & 6.857 & 514 & $R$ \\
\hline HEMBL395 & 6 & 7.4559 & & $\mathrm{~K}$ \\
\hline CHEMBL & & & & \\
\hline CHEMBL394 & & & 6.5502 & \\
\hline CHEMBL3581531 & 1641026 & 6.9747 & 7.0834 & TR \\
\hline
\end{tabular}

Page 14310 
Supplemental Table S2.txt

\begin{tabular}{|c|c|c|c|c|}
\hline CHEMBL 3960274 & 1641026 & 6.1192 & 6.5941 & TRN \\
\hline CHEMBL3895658 & 1641026 & 6.7496 & 7.2684 & TRN \\
\hline CHEMBL3911860 & 1641026 & 7.9208 & 7.2592 & TRN \\
\hline CHEMBL3964828 & 1641026 & 6.0315 & 6.5473 & TRN \\
\hline CHEMBL 3924598 & 1641026 & 7.0 & 6.9317 & TST \\
\hline CHEMBL3930001 & 1641026 & 5.4559 & 6.6586 & TST \\
\hline CHEMBL3581549 & 1641026 & 6.9393 & 7.2032 & TRN \\
\hline CHEMBL3926261 & 1641026 & 7.3565 & 6.9582 & TST \\
\hline CHEMBL 3948593 & 1641026 & 7.8861 & 7.3854 & TRN \\
\hline CHEMBL3317826 & 1641026 & 6.4123 & 6.5155 & TRN \\
\hline CHEMBL3317828 & 1641026 & 6.6289 & 6.5373 & TRN \\
\hline CHEMBL3581550 & 1641026 & 7.1192 & 7.4982 & TRN \\
\hline CHEMBL3956592 & 1641026 & 8.3979 & 6.5213 & TST \\
\hline CHEMBL3912971 & 1641026 & 5.3188 & 6.529 & TST \\
\hline CHEMBL 3934849 & 1641026 & 6.8539 & 6.5603 & TRN \\
\hline CHEMBL3965604 & 1641026 & 6.0 & 6.9366 & TRN \\
\hline CHEMBL3925361 & 1641026 & 7.1612 & 6.5455 & TRN \\
\hline CHEMBL 3897930 & 1641026 & 5.9208 & 6.5112 & TRN \\
\hline CHEMBL 3960641 & 1641026 & 6.8539 & 6.5281 & TRN \\
\hline CHEMBL 3581534 & 1641026 & 7.1871 & 7.3318 & TRN \\
\hline CHEMBL 3925457 & 1641026 & 6.8861 & 6.523 & TRN \\
\hline CHEMBL3925822 & 1641026 & 7.2676 & 6.5102 & TST \\
\hline CHEMBL3581535 & 1641026 & 7.6021 & 7.2869 & TRN \\
\hline CHEMBL 3962870 & 1641026 & 6.52 & 6.5318 & TRN \\
\hline CHEMBL 3897495 & 1641026 & 6.5575 & \multicolumn{2}{|c|}{7.327999999999999} \\
\hline CHEMBL3949119 & 1641026 & 7.4559 & 6.6085 & TST \\
\hline CHEMBL3317832 & 1641026 & 5.9586 & 6.5551 & TRN \\
\hline CHEMBL3986080 & 1641026 & 6.0 & 6.6615 & TST \\
\hline CHEMBL3929058 & 1641026 & 6.0 & 6.6821 & TST \\
\hline CHEMBL3969808 & 1641026 & 6.1871 & 6.5293 & TRN \\
\hline CHEMBL3920006 & 1641026 & 6.0 & 6.5474 & TRN \\
\hline CHEMBL3908990 & 1641026 & 6.7696 & 6.5722 & TST \\
\hline CHEMBL3950048 & 1641026 & 7.1135 & 7.2586 & TRN \\
\hline CHEMBL3314036 & 1641026 & 8.2218 & \multicolumn{2}{|c|}{6.537999999999999} \\
\hline CHEMBL 3925847 & 1641026 & 7.1739 & 6.5809 & TRN \\
\hline CHEMBL3919743 & 1641026 & 7.2441 & 6.6518 & TST \\
\hline CHEMBL 3902901 & 1641026 & 7.2518 & 6.6015 & TRN \\
\hline CHEMBL3982977 & 1641026 & 6.7696 & 6.5806 & TRN \\
\hline CHEMBL 3920010 & 1641026 & 7.1938 & 6.5421 & TRN \\
\hline CHEMBL 3909233 & 1641026 & 5.9586 & 6.5327 & TST \\
\hline CHEMBL 3962482 & 1641026 & 5.4949 & 6.5538 & TRN \\
\hline CHEMBL 3943476 & 1641026 & 6.0 & 6.523 & TRN \\
\hline CHEMBL3581552 & 1641026 & 6.0 & 7.2434 & TRN \\
\hline CHEMBL3939317 & 1641026 & 6.9957 & 6.5548 & TRN \\
\hline CHEMBL 3317833 & 1641026 & 7.3279 & 6.5389 & TRN \\
\hline CHEMBL 3581533 & 1641026 & 8.0 & 7.2588 & TRN \\
\hline CHEMBL3910176 & 1641026 & 6.2233 & 6.5681 & TRN \\
\hline CHEMBL3986915 & 1641026 & 6.2518 & 6.5897 & TRN \\
\hline
\end{tabular}

Page 14311 
Supplemental Table S2.txt

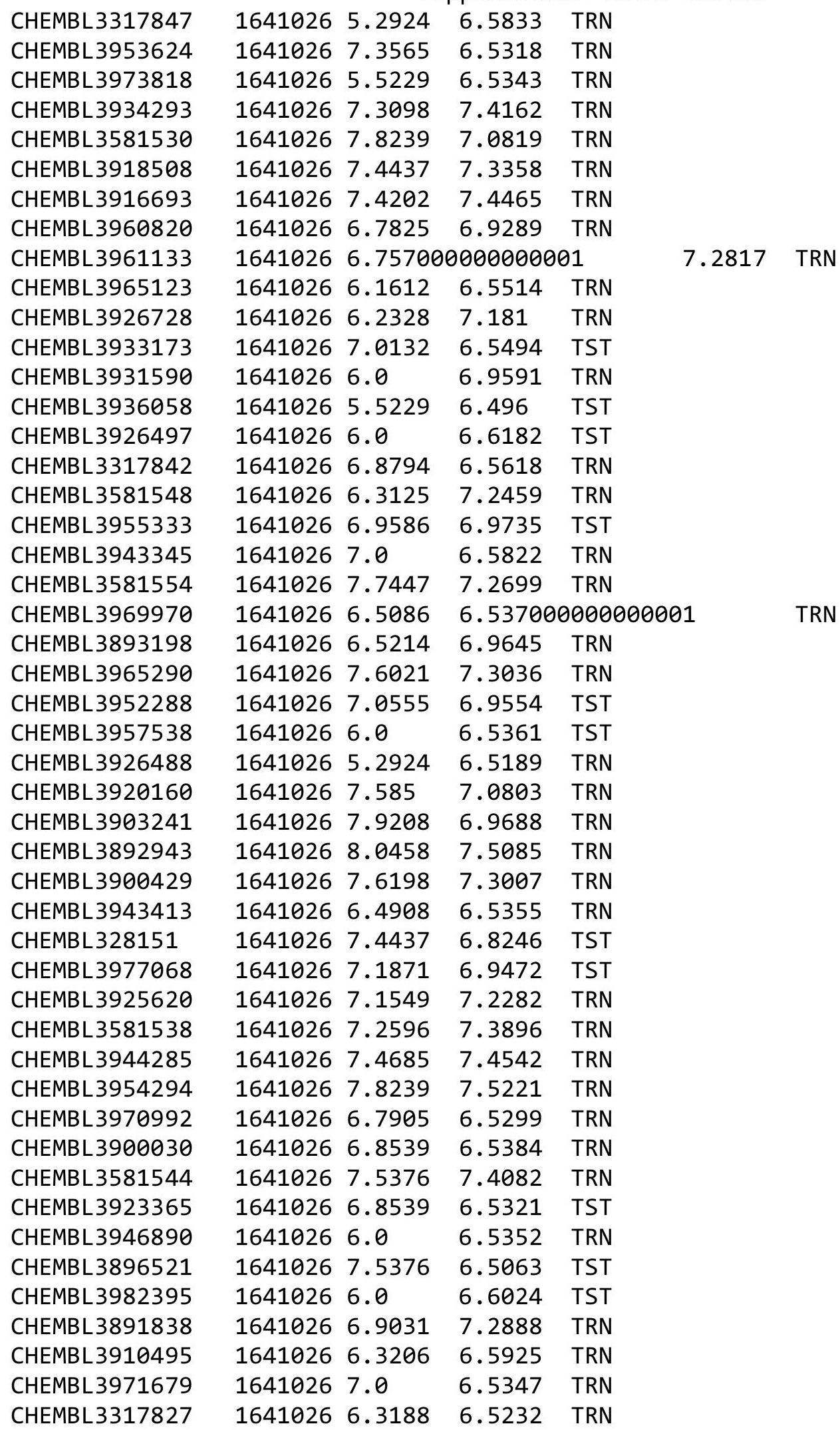

Page 14312 


$$
\text { Supplemental Table S2.txt }
$$

\begin{tabular}{|c|c|c|c|c|c|}
\hline CHEMBL3916357 & 1641026 & 7.4815 & 7.2973 & TRN & \\
\hline CHEMBL3956585 & 1641026 & 6.0467 & 6.5319 & TRN & \\
\hline CHEMBL3581546 & 1641026 & 7.4437 & 7.2322 & TRN & \\
\hline CHEMBL3933459 & 1641026 & 7.2291 & 6.5719 & TRN & \\
\hline CHEMBL3984806 & 1641026 & 6.0 & 6.5466 & TRN & \\
\hline CHEMBL3946626 & 1641026 & 5.3979 & 6.5159 & TRN & \\
\hline CHEMBL3581540 & 1641026 & 7.6576 & 7.4691 & TRN & \\
\hline CHEMBL3924732 & 1641026 & 6.6904 & 6.9559 & TRN & \\
\hline CHEMBL3916870 & 1641026 & 6.4815 & 6.5932 & TRN & \\
\hline CHEMBL3979092 & 1641026 & 5.284 & 6.5498 & TRN & \\
\hline CHEMBL3314035 & 1641026 & 8.1549 & 7.4412 & TRN & \\
\hline CHEMBL3937233 & 1641026 & 7.2291 & 6.6057 & TRN & \\
\hline CHEMBL 3895167 & 1641026 & 6.3565 & 6.5035 & TRN & \\
\hline CHEMBL3581537 & 1641026 & 7.7696 & 7.2823 & TRN & \\
\hline CHEMBL3936911 & 1641026 & 8.1549 & 6.9303 & TRN & \\
\hline CHEMBL3921287 & 1641026 & 6.9872 & 6.6887 & TRN & \\
\hline CHEMBL3976081 & 1641026 & 7.0315 & 6.59200 & 00000000005 & TRN \\
\hline CHEMBL 3984452 & 1641026 & 6.0 & 7.17700 & 00000000005 & TST \\
\hline CHEMBL3904032 & 1641026 & 7.2924 & 6.5302 & TRN & \\
\hline CHEMBL94371 & 1641026 & 8.2218 & 7.2699 & TST & \\
\hline CHEMBL3317844 & 1641026 & 6.1549 & 6.5442 & TRN & \\
\hline CHEMBL 3960982 & 1641026 & 6.7932 & 7.3051 & TST & \\
\hline CHEMBL1224683 & 688509 & 4.7 & 4.4937 & TRN & \\
\hline CHEMBL3192285 & 688509 & 4.9 & 4.9957 & TRN & \\
\hline CHEMBL1403877 & 688509 & 4.1 & 4.0546 & TRN & \\
\hline CHEMBL1390333 & 688509 & 3.0 & 4.3437 & TRN & \\
\hline CHEMBL 1455110 & 688509 & 4.0 & 4.2226 & TRN & \\
\hline CHEMBL1367879 & 688509 & 4.2 & 4.3622 & TST & \\
\hline CHEMBL1416049 & 688509 & 4.4 & 4.7092 & TST & \\
\hline CHEMBL3190169 & 688509 & 4.2 & 4.3105 & TRN & \\
\hline CHEMBL1587145 & 688509 & 4.2 & 3.7428 & TRN & \\
\hline CHEMBL1495170 & 688509 & 4.4 & 4.447 & TRN & \\
\hline CHEMBL1388922 & 688509 & 4.1 & 4.0941 & TRN & \\
\hline CHEMBL1334300 & 688509 & 4.7 & 4.5325 & TRN & \\
\hline CHEMBL3192506 & 688509 & 4.0 & 3.8934 & TRN & \\
\hline CHEMBL1992211 & 688509 & 3.7 & 4.4812 & TRN & \\
\hline CHEMBL 1347567 & 688509 & 4.5 & 4.5542 & TST & \\
\hline CHEMBL1397706 & 688509 & 5.35 & 5.1569 & TST & \\
\hline CHEMBL1503961 & 688509 & 4.3 & 4.6787 & TST & \\
\hline CHEMBL1579564 & 688509 & 4.2 & 4.5817 & TRN & \\
\hline CHEMBL3198956 & 688509 & 5.0367 & 5.0826 & TRN & \\
\hline CHEMBL3199294 & 688509 & 4.1 & 3.8297 & TRN & \\
\hline CHEMBL1608402 & 688509 & 4.4 & 4.4537 & TRN & \\
\hline CHEMBL1483015 & 688509 & 4.1 & 3.8147 & TRN & \\
\hline CHEMBL1456371 & 688509 & 4.6 & 3.9654 & TST & \\
\hline CHEMBL3199045 & 688509 & 4.45 & 3.9646 & TRN & \\
\hline CHEMBL527584 & 688509 & 4.2 & 4.627 & TRN & \\
\hline CHEMBL1377051 & 688509 & 4.2 & 4.4657 & TRN & \\
\hline
\end{tabular}




\begin{tabular}{|c|c|c|c|c|c|}
\hline \multicolumn{6}{|c|}{ Supplemental Table S2.txt } \\
\hline CHEMBL3192276 & 688509 & 4.2 & 4.1387 & TRN & \\
\hline CHEMBL1597177 & 688509 & 5.0 & 4.6991 & TRN & \\
\hline CHEMBL1342429 & 688509 & 5.05 & 4.2036 & TRN & \\
\hline CHEMBL505670 & 688509 & 5.2 & 4.7532 & TST & \\
\hline CHEMBL3198697 & 688509 & 4.2 & 4.3397 & TRN & \\
\hline CHEMBL1384370 & 688509 & 4.4 & 4.4754 & TRN & \\
\hline CHEMBL449392 & 688509 & 4.2 & 4.4532 & TST & \\
\hline CHEMBL1379103 & 688509 & 4.4 & 4.4765 & TRN & \\
\hline CHEMBL1421970 & 688509 & 4.4 & 4.6281 & TRN & \\
\hline CHEMBL1480480 & 688509 & 4.2 & 4.5433 & TRN & \\
\hline CHEMBL3199800 & 688509 & 4.4 & 4.4309 & TRN & \\
\hline CHEMBL1608959 & 688509 & 4.1 & $4.4460 e$ & 0000000001 & TRN \\
\hline CHEMBL1361504 & 688509 & 4.0 & 4.9171 & TST & \\
\hline CHEMBL1518227 & 688509 & 4.2 & 4.1086 & TRN & \\
\hline CHEMBL1979954 & 688509 & 4.2 & 4.3394 & TRN & \\
\hline CHEMBL429095 & 688509 & 5.4 & 5.4115 & TRN & \\
\hline CHEMBL1555585 & 688509 & 4.5 & 4.1737 & TRN & \\
\hline CHEMBL1536432 & 688509 & 4.8 & 4.7334 & TRN & \\
\hline CHEMBL1353825 & 688509 & 4.7 & 4.4743 & TRN & \\
\hline CHEMBL1579143 & 688509 & 4.2 & 4.3617 & TRN & \\
\hline CHEMBL1557332 & 688509 & 4.1 & 4.4162 & TRN & \\
\hline CHEMBL1416045 & 688509 & 4.1 & 4.3735 & TRN & \\
\hline CHEMBL3191104 & 688509 & 6.25 & 4.918 & TRN & \\
\hline CHEMBL1574945 & 688509 & 4.6 & 4.3722 & TRN & \\
\hline CHEMBL3199203 & 688509 & 3.6 & 4.2823 & TRN & \\
\hline CHEMBL3392041 & 688509 & 4.5 & 4.2532 & TRN & \\
\hline CHEMBL1330232 & 688509 & 5.0 & 4.7626 & TRN & \\
\hline CHEMBL3199679 & 688509 & 4.1 & 3.9835 & TRN & \\
\hline CHEMBL3207423 & 688509 & 4.7867 & 4.6836 & TRN & \\
\hline CHEMBL3198124 & 688509 & 4.1 & 4.2548 & TRN & \\
\hline CHEMBL1304979 & 688509 & 4.4 & 4.7648 & TRN & \\
\hline CHEMBL1446929 & 688509 & 5.4367 & 5.4504 & TRN & \\
\hline CHEMBL3195038 & 688509 & 4.1 & 4.6017 & TRN & \\
\hline CHEMBL1322542 & 688509 & 4.4 & 4.9167 & TST & \\
\hline CHEMBL1362221 & 688509 & 5.45 & 4.4649 & TRN & \\
\hline CHEMBL1505857 & 688509 & 6.35 & 4.6527 & TST & \\
\hline CHEMBL112597 & 688509 & 4.2 & 4.1722 & TRN & \\
\hline CHEMBL1519313 & 688509 & 5.4 & 5.1244 & TST & \\
\hline CHEMBL3198979 & 688509 & 5.1867 & 5.2711 & TRN & \\
\hline CHEMBL1983530 & 688509 & 4.0 & 4.3693 & TRN & \\
\hline CHEMBL1365988 & 688509 & 4.1 & 4.2033 & TRN & \\
\hline CHEMBL1482740 & 688509 & 4.6867 & 4.3974 & TRN & \\
\hline CHEMBL1581518 & 688509 & 4.2 & 4.3284 & TRN & \\
\hline CHEMBL1331149 & 688509 & 4.4 & 4.3465 & TRN & \\
\hline CHEMBL1465240 & 688509 & 4.2 & 4.4242 & TRN & \\
\hline CHEMBL1333181 & 688509 & 4.0 & 4.092 & TRN & \\
\hline CHEMBL1586360 & 688509 & 4.4 & 4.5509 & TRN & \\
\hline CHEMBL3189834 & 688509 & 4.0 & 4.1853 & TRN & \\
\hline
\end{tabular}




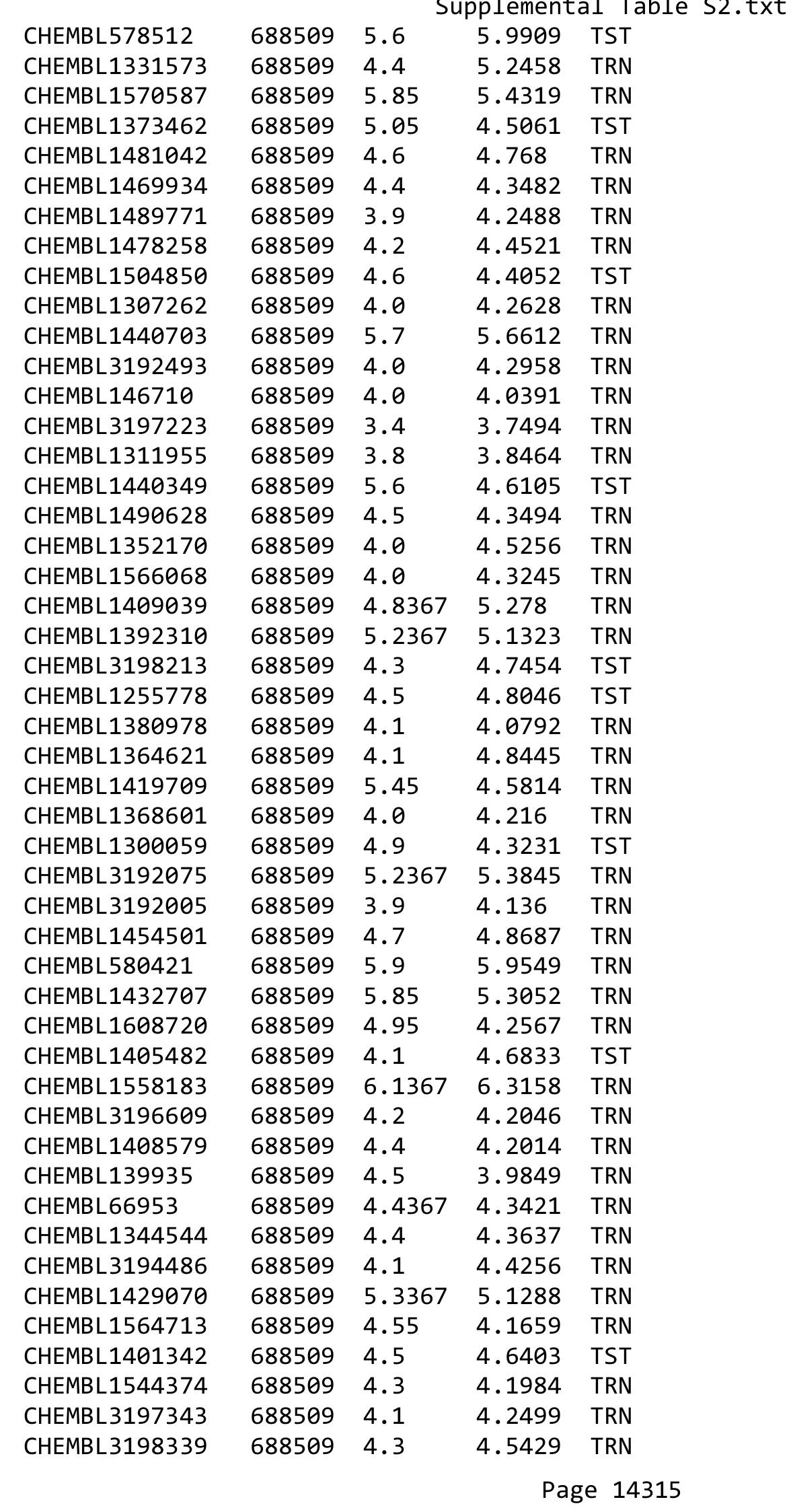




\begin{tabular}{|c|c|c|c|c|}
\hline \multicolumn{5}{|c|}{ Supplemental Table S2.txt } \\
\hline CHEMBL1392084 & 688509 & 4.3367 & 4.896 & TST \\
\hline CHEMBL1543129 & 688509 & 4.3 & 4.4321 & TRN \\
\hline CHEMBL1337734 & 688509 & 4.7 & 4.4886 & TRN \\
\hline CHEMBL1969548 & 688509 & 5.4867 & 5.2234 & TRN \\
\hline CHEMBL3208936 & 688509 & 4.5 & 4.4922 & TST \\
\hline CHEMBL1966224 & 688509 & 4.2 & 4.3012 & TRN \\
\hline CHEMBL1454890 & 688509 & 4.0 & 3.9305 & TRN \\
\hline CHEMBL406341 & 688509 & 5.7867 & 4.7755 & TRN \\
\hline CHEMBL380979 & 688509 & 4.1 & 4.2977 & TRN \\
\hline CHEMBL1506538 & 688509 & 6.9 & 4.9696 & TRN \\
\hline CHEMBL1984001 & 688509 & 4.5 & 4.3967 & TRN \\
\hline CHEMBL1301488 & 688509 & 4.5 & 4.262 & TRN \\
\hline CHEMBL1368092 & 688509 & 4.0 & 4.7074 & TST \\
\hline CHEMBL1581251 & 688509 & 3.7 & 4.0164 & TRN \\
\hline CHEMBL1590378 & 688509 & 5.5 & 5.1896 & TST \\
\hline CHEMBL457665 & 688509 & 4.65 & 5.2037 & TST \\
\hline CHEMBL1464383 & 688509 & 4.1 & 4.5349 & TRN \\
\hline CHEMBL1606433 & 688509 & 4.6 & 4.7993 & TRN \\
\hline CHEMBL1348582 & 688509 & 4.8867 & 4.6795 & TRN \\
\hline CHEMBL1451772 & 688509 & 5.4367 & 5.6637 & TRN \\
\hline CHEMBL3212055 & 688509 & 4.45 & 4.2671 & TRN \\
\hline CHEMBL1477845 & 688509 & 4.4 & 4.7383 & TRN \\
\hline CHEMBL1421542 & 688509 & 4.1 & 4.5711 & TRN \\
\hline CHEMBL1392651 & 688509 & 4.8867 & 5.0362 & TRN \\
\hline CHEMBL1406389 & 688509 & 4.4 & 4.6424 & TRN \\
\hline CHEMBL1964535 & 688509 & 4.2 & 4.3034 & TRN \\
\hline CHEMBL1613270 & 688509 & 4.85 & 4.6637 & TRN \\
\hline CHEMBL1426115 & 688509 & 4.6 & 4.4161 & TRN \\
\hline CHEMBL1370567 & 688509 & 4.0 & 4.1241 & TRN \\
\hline CHEMBL1412043 & 688509 & 5.5867 & 5.7498 & TRN \\
\hline CHEMBL1721986 & 688509 & 5.45 & 5.13 & TRN \\
\hline CHEMBL1400439 & 688509 & 4.6367 & 4.5211 & TRN \\
\hline CHEMBL3209306 & 688509 & 3.9 & 4.0196 & TRN \\
\hline CHEMBL 2003806 & 688509 & 5.3 & 5.2387 & TRN \\
\hline CHEMBL1375858 & 688509 & 6.2867 & 4.9731 & TRN \\
\hline CHEMBL1998643 & 688509 & 5.1867 & 4.585 & TRN \\
\hline CHEMBL3392240 & 688509 & 4.0 & 4.1975 & TRN \\
\hline CHEMBL 1334670 & 688509 & 4.4 & 4.3642 & TRN \\
\hline CHEMBL3194449 & 688509 & 4.1 & 4.0403 & TRN \\
\hline CHEMBL1402473 & 688509 & 5.05 & 4.5221 & TRN \\
\hline CHEMBL1347832 & 688509 & 4.7867 & 4.9315 & TRN \\
\hline CHEMBL1463248 & 688509 & 4.7 & 4.9383 & TRN \\
\hline CHEMBL3192970 & 688509 & 5.2 & 5.4214 & TRN \\
\hline CHEMBL1464106 & 688509 & 4.4 & 4.5524 & TRN \\
\hline CHEMBL1542693 & 688509 & 5.2 & 5.3951 & TRN \\
\hline CHEMBL 1461413 & 688509 & 4.2 & 4.252 & TRN \\
\hline CHEMBL1350793 & 688509 & 3.8 & 4.3407 & TRN \\
\hline CHEMBL1540266 & 688509 & 4.0 & 4.0539 & TRN \\
\hline
\end{tabular}




\begin{tabular}{|c|c|c|c|c|c|}
\hline \multicolumn{6}{|c|}{ Supplemental Table S2.txt } \\
\hline CHEMBL1351412 & 688509 & 4.1 & 4.3503 & TRN & \\
\hline CHEMBL1561062 & 688509 & 4.8 & 4.6031 & TRN & \\
\hline CHEMBL592552 & 688509 & 4.4367 & 4.3386 & TRN & \\
\hline CHEMBL1350231 & 688509 & 5.1867 & 4.8837 & TST & \\
\hline CHEMBL1429228 & 688509 & 4.1 & 4.3138 & TRN & \\
\hline CHEMBL 3190218 & 688509 & 4.4 & 4.3308 & TRN & \\
\hline CHEMBL1386684 & 688509 & 4.9 & 4.302 & TRN & \\
\hline CHEMBL1458422 & 688509 & 4.3 & 4.2353 & TRN & \\
\hline CHEMBL1383025 & 688509 & 4.1 & 4.1764 & TRN & \\
\hline CHEMBL1559336 & 688509 & 4.2 & 4.0261 & TRN & \\
\hline CHEMBL1531579 & 688509 & 4.7367 & 4.8072 & TST & \\
\hline CHEMBL 3194044 & 688509 & 4.6 & 4.4221 & TRN & \\
\hline CHEMBL1414890 & 688509 & 4.55 & 4.6056 & TRN & \\
\hline CHEMBL3197134 & 688509 & 4.7 & 4.6441 & TRN & \\
\hline CHEMBL1569135 & 688509 & 6.5 & 4.6019 & TST & \\
\hline CHEMBL1454079 & 688509 & 4.0 & 3.9179 & TST & \\
\hline CHEMBL3190181 & 688509 & 5.6 & 5.4816 & TST & \\
\hline CHEMBL1382559 & 688509 & 4.0 & 4.7655 & TST & \\
\hline CHEMBL1359871 & 688509 & 5.2367 & 4.4176 & TST & \\
\hline CHEMBL51931 & 688509 & 5.95 & 5.5156 & TST & \\
\hline CHEMBL1402056 & 688509 & 4.3 & 4.4973 & TST & \\
\hline CHEMBL1331139 & 688509 & 4.4 & 4.3666 & TST & \\
\hline CHEMBL3196881 & 688509 & 5.5 & 5.0233 & TST & \\
\hline CHEMBL 3189879 & 688509 & 4.4 & 4.0313 & TST & \\
\hline CHEMBL1344075 & 688509 & 4.3 & 4.352 & TST & \\
\hline CHEMBL601757 & 688509 & 5.65 & 5.5835 & TST & \\
\hline CHEMBL1410997 & 688509 & 4.1 & 4.6092 & TST & \\
\hline CHEMBL1568805 & 688509 & 4.0 & 4.351 & TST & \\
\hline CHEMBL1968732 & 688509 & 5.5 & 5.1142 & TST & \\
\hline CHEMBL1511834 & 688509 & 4.3 & 4.3412 & TST & \\
\hline CHEMBL1499701 & 688509 & 4.4867 & 4.8871 & TST & \\
\hline CHEMBL1576815 & 688509 & 5.35 & 5.21700 & 00000000005 & \\
\hline CHEMBL1403112 & 688509 & 4.0 & 4.2374 & TST & \\
\hline CHEMBL1335945 & 688509 & 4.9 & 4.5938 & TST & \\
\hline CHEMBL1497651 & 688509 & 4.6867 & 4.5356 & TST & \\
\hline CHEMBL3190603 & 688509 & 4.3 & 4.4671 & TST & \\
\hline CHEMBL 234338 & 688509 & 5.0867 & 4.4118 & TST & \\
\hline CHEMBL1582210 & 688509 & 5.1 & 4.7038 & TST & \\
\hline CHEMBL3190339 & 688509 & 4.8367 & 4.9146 & TST & \\
\hline CHEMBL434945 & 327489 & 6.983 & 6.9989 & TRN & \\
\hline CHEMBL 200943 & 327489 & 6.5317 & 6.5223 & TRN & \\
\hline CHEMBL199928 & 327489 & 7.4685 & 7.4819 & TRN & \\
\hline CHEMBL200043 & 327489 & 6.8665 & 6.8472 & TRN & \\
\hline CHEMBL199339 & 327489 & 4.0 & 3.9886 & TRN & \\
\hline CHEMBL199855 & 327489 & 6.4023 & 6.4003 & TRN & \\
\hline CHEMBL 382982 & 327489 & 7.3665 & 7.3848 & TRN & \\
\hline CHEMBL199814 & 327489 & 6.1993 & 6.1651 & TRN & \\
\hline CHEMBL 380961 & 327489 & 6.6073 & 6.6242 & TRN & \\
\hline
\end{tabular}




\begin{tabular}{|c|c|c|c|c|c|c|}
\hline & & \multicolumn{5}{|c|}{ Supplemental Table S2.txt } \\
\hline CHEMBL199782 & 327489 & 5.7305 & 5.7169 & TRN & & \\
\hline CHEMBL199819 & 327489 & 7.284 & 7.2752 & TRN & & \\
\hline CHEMBL200746 & 327489 & 6.5143 & 6.5066 & TRN & & \\
\hline CHEMBL383398 & 327489 & 6.6861 & 6.7145 & TRN & & \\
\hline CHEMBL372825 & 327489 & 7.0706 & 6.1536 & TST & & \\
\hline CHEMBL201632 & 327489 & 4.0 & 4.295 & TST & & \\
\hline CHEMBL382718 & 327489 & 6.9469 & 6.9503 & TRN & & \\
\hline CHEMBL202137 & 327489 & 4.0 & 4.0269 & TRN & & \\
\hline CHEMBL200045 & 327489 & 6.7747 & 6.7523 & TRN & & \\
\hline CHEMBL200207 & 327489 & \multicolumn{3}{|c|}{6.117999999999999} & 6.1302 & TRN \\
\hline CHEMBL381891 & 327489 & 6.4815 & 6.4691 & TRN & & \\
\hline CHEMBL199449 & 327489 & 7.3468 & 7.3274 & TRN & & \\
\hline CHEMBL200811 & 327489 & 4.0 & 3.9845 & TST & & \\
\hline CHEMBL198288 & 327489 & 6.2815 & 6.2764 & TRN & & \\
\hline CHEMBL200610 & 327489 & 6.2097 & 6.2077 & TRN & & \\
\hline CHEMBL199846 & 327489 & 4.0 & 4.0122 & TRN & & \\
\hline CHEMBL426108 & 327489 & 4.0 & 5.2936 & TST & & \\
\hline CHEMBL199509 & 327489 & 6.9066 & 6.9369 & TRN & & \\
\hline CHEMBL202087 & 327489 & 6.4597 & 6.4415 & TRN & & \\
\hline CHEMBL371760 & 327489 & 6.4342 & 6.4236 & TRN & & \\
\hline CHEMBL370186 & 327489 & 7.4949 & \multicolumn{3}{|c|}{7.5120000000000005} & TRN \\
\hline CHEMBL197866 & 327489 & 7.8539 & 7.8525 & TRN & & \\
\hline CHEMBL200840 & 327489 & 7.3468 & 7.3492 & TRN & & \\
\hline CHEMBL370809 & 327489 & 7.1675 & 7.1895 & TRN & & \\
\hline CHEMBL381468 & 327489 & 4.0 & 3.9768 & TRN & & \\
\hline CHEMBL372519 & 327489 & 6.7959 & 6.8091 & TRN & & \\
\hline CHEMBL440758 & 327489 & 6.6882 & 6.6663 & TRN & & \\
\hline CHEMBL382928 & 327489 & 5.4976 & 5.4767 & TRN & & \\
\hline CHEMBL370407 & 327489 & 5.0195 & 5.0206 & TRN & & \\
\hline CHEMBL383789 & 327489 & 7.2147 & 7.1971 & TRN & & \\
\hline CHEMBL200138 & 327489 & 8.2218 & 8.2424 & TRN & & \\
\hline CHEMBL200916 & 327489 & 7.4318 & 7.445 & TRN & & \\
\hline CHEMBL436113 & 327489 & 7.9208 & 7.9145 & TRN & & \\
\hline CHEMBL371041 & 327489 & 7.7959 & 7.8132 & TRN & & \\
\hline CHEMBL200810 & 327489 & 4.0 & 3.9749 & TRN & & \\
\hline CHEMBL199362 & 327489 & 4.0 & 4.0177 & TRN & & \\
\hline CHEMBL200611 & 327489 & 4.0 & 4.6361 & TST & & \\
\hline CHEMBL199526 & 327489 & 4.0 & 4.4009 & TST & & \\
\hline CHEMBL 382525 & 327489 & 4.0 & 4.0127 & TRN & & \\
\hline CHEMBL198023 & 327489 & 7.3665 & 7.3429 & TRN & & \\
\hline CHEMBL369930 & 327489 & 7.7959 & 7.8138 & TRN & & \\
\hline CHEMBL199530 & 327489 & 4.0 & 4.0367 & TRN & & \\
\hline CHEMBL382957 & 327489 & 7.6576 & 7.6297 & TRN & & \\
\hline CHEMBL197971 & 327489 & 7.0757 & 7.0612 & TRN & & \\
\hline CHEMBL199579 & 327489 & 7.7212 & 7.6959 & TRN & & \\
\hline CHEMBL200760 & 327489 & 7.3372 & 7.3496 & TRN & & \\
\hline CHEMBL199459 & 327489 & \multicolumn{3}{|c|}{6.752000000000001} & 6.7513 & TRN \\
\hline CHEMBL200305 & 327489 & 6.7077 & 5.5085 & TST & & \\
\hline
\end{tabular}


Supplemental Table S2.txt

\begin{tabular}{|c|c|c|c|c|c|c|}
\hline CHEMBL199432 & 327489 & 7.3098 & 7.3323 & TRN & & \\
\hline CHEMBL199794 & 327489 & 9.0 & 7.2728 & TST & & \\
\hline CHEMBL201280 & 327489 & 6.5376 & 6.67399 & 999999999 & 995 & TST \\
\hline CHEMBL199372 & 327489 & 6.1319 & 6.5946 & TST & & \\
\hline CHEMBL199645 & 327489 & 7.1135 & 7.146 & TST & & \\
\hline CHEMBL438979 & 327489 & 6.8153 & 7.68 & TST & & \\
\hline CHEMBL 200122 & 327489 & 7.3768 & 7.1806 & TST & & \\
\hline CHEMBL199559 & 327489 & 7.6778 & 6.6713 & TST & & \\
\hline CHEMBL 371764 & 327489 & 6.983 & 6.3487 & TST & & \\
\hline CHEMBL199703 & 327489 & 7.3979 & 7.2708 & TST & & \\
\hline CHEMBL199823 & 327489 & 5.2487 & 6.2216 & TST & & \\
\hline CHEMBL 200071 & 327489 & 6.6737 & 6.715 & TST & & \\
\hline CHEMBL55308 & 102784 & 6.2218 & 6.3195 & TRN & & \\
\hline CHEMBL53684 & 102784 & 5.5229 & 5.5726 & TRN & & \\
\hline CHEMBL55998 & 102784 & 7.0969 & 6.8982 & TRN & & \\
\hline CHEMBL55187 & 102784 & 7.301 & 7.0362 & TRN & & \\
\hline CHEMBL 297956 & 102784 & 5.4789 & 5.5051 & TRN & & \\
\hline CHEMBL415959 & 102784 & 5.6576 & 3.1938 & TST & & \\
\hline CHEMBL56324 & 102784 & 5.7545 & 5.6947 & TRN & & \\
\hline CHEMBL 57064 & 102784 & 6.3665 & 6.3677 & TRN & & \\
\hline CHEMBL 293331 & 102784 & 5.3188 & 5.3763 & TRN & & \\
\hline CHEMBL 292464 & 102784 & 5.3665 & 5.5356 & TST & & \\
\hline CHEMBL55007 & 102784 & 4.7959 & 4.9165 & TRN & & \\
\hline CHEMBL55997 & 102784 & 6.2218 & 6.1713 & TRN & & \\
\hline CHEMBL54318 & 102784 & 6.4685 & 6.4654 & TRN & & \\
\hline CHEMBL57223 & 102784 & 4.699 & 4.7291 & TRN & & \\
\hline CHEMBL 299781 & 102784 & 4.4067 & 4.6311 & TST & & \\
\hline CHEMBL 293780 & 102784 & 5.301 & 5.2591 & TRN & & \\
\hline CHEMBL432327 & 102784 & 3.301 & 4.9229 & TST & & \\
\hline CHEMBL52458 & 102784 & 4.5017 & 4.4528 & TRN & & \\
\hline CHEMBL55747 & 102784 & 3.4948 & 3.7357 & TRN & & \\
\hline CHEMBL293989 & 102784 & 6.2676 & 6.3543 & TRN & & \\
\hline CHEMBL55758 & 102784 & 2.699 & 4.7052 & TST & & \\
\hline CHEMBL 296376 & 102784 & 5.2147 & 5.3641 & TRN & & \\
\hline CHEMBL 301086 & 102784 & 5.3872 & 5.439 & TRN & & \\
\hline CHEMBL53893 & 102784 & 4.5342 & 5.7033 & TST & & \\
\hline CHEMBL55387 & 102784 & 5.684 & 5.6177 & TST & & \\
\hline CHEMBL56895 & 102784 & 4.0292 & 2.6747 & TST & & \\
\hline CHEMBL 292644 & 102784 & 4.3979 & 5.3357 & TST & & \\
\hline CHEMBL 293806 & 102784 & \multicolumn{3}{|c|}{5.7620000000000005} & 5.8624 & $\mathrm{TR}$ \\
\hline CHEMBL 299001 & 102784 & 8.0 & 8.3384 & TRN & & \\
\hline CHEMBL55951 & 102784 & 7.1549 & 7.1393 & TRN & & \\
\hline CHEMBL54166 & 102784 & 5.8239 & 5.5793 & TRN & & \\
\hline CHEMBL55043 & 102784 & 4.6021 & 4.6854 & TRN & & \\
\hline CHEMBL54111 & 102784 & 3.9208 & 4.8833 & TST & & \\
\hline CHEMBL 300934 & 102784 & 4.3098 & 3.9202 & TST & & \\
\hline CHEMBL 292012 & 102784 & 5.0066 & 5.7507 & TST & & \\
\hline CHEMBL 300757 & 102784 & 5.3872 & 5.1903 & TRN & & \\
\hline
\end{tabular}

Page 14319 


\begin{tabular}{|c|c|c|c|c|c|}
\hline \multicolumn{6}{|c|}{ Supplemental Table s2.txt } \\
\hline CHEMBL53043 & 102784 & 7.301 & 7.325 & TRN & \\
\hline CHEMBL 292436 & 102784 & 4.0969 & 4.4729 & TRN & \\
\hline CHEMBL301055 & 102784 & 6.5229 & 6.4791 & TRN & \\
\hline CHEMBL55186 & 102784 & 7.0458 & 7.2042 & TRN & \\
\hline CHEMBL53896 & 102784 & 5.0223 & 4.9307 & TRN & \\
\hline CHEMBL54970 & 102784 & 5.2924 & 5.2652 & TRN & \\
\hline CHEMBL56178 & 102784 & 4.6944 & 4.8732 & TST & \\
\hline CHEMBL433488 & 102784 & 5.5229 & 5.3416 & TRN & \\
\hline CHEMBL55862 & 102784 & 6.4949 & 5.8228 & TST & \\
\hline CHEMBL 293963 & 102784 & 4.8928 & 4.8638 & TRN & \\
\hline CHEMBL294627 & 102784 & 6.3665 & 6.2736 & TRN & \\
\hline CHEMBL56465 & 102784 & 5.2924 & 5.2925 & TRN & \\
\hline CHEMBL 291558 & 102784 & 5.0655 & 3.0131 & TST & \\
\hline CHEMBL 299014 & 102784 & 4.7959 & 4.7983 & TRN & \\
\hline CHEMBL55599 & 102784 & 5.1308 & 5.3301 & TRN & \\
\hline CHEMBL 300851 & 102784 & 7.2218 & 7.1918 & TRN & \\
\hline CHEMBL54487 & 102784 & 2.699 & 3.8811 & TST & \\
\hline CHEMBL56135 & 102784 & 7.699 & 7.7394 & TRN & \\
\hline CHEMBL 293298 & 102784 & 4.0315 & 4.635 & TST & \\
\hline CHEMBL291983 & 102784 & 7.5229 & 7.5381 & TRN & \\
\hline CHEMBL58988 & 102784 & 5.5229 & 5.6288 & TRN & \\
\hline CHEMBL449041 & 102784 & 5.0088 & 4.8348 & TRN & \\
\hline CHEMBL 292891 & 102784 & 5.699 & 5.7939 & TRN & \\
\hline CHEMBL 299271 & 102784 & 5.6198 & 5.5404 & TRN & \\
\hline CHEMBL432894 & 102784 & 5.4559 & 5.38399 & 99999999995 & TRN \\
\hline CHEMBL54444 & 102784 & 5.6383 & 5.7062 & TRN & \\
\hline CHEMBL301855 & 102784 & 2.699 & 5.001 & TST & \\
\hline CHEMBL51912 & 102784 & 3.9393 & 3.9524 & TRN & \\
\hline CHEMBL56841 & 102784 & 4.3585 & 4.0371 & TRN & \\
\hline CHEMBL55199 & 102784 & 6.0458 & 6.0858 & TRN & \\
\hline CHEMBL55625 & 102784 & 4.3768 & 4.3697 & TRN & \\
\hline CHEMBL54698 & 102784 & 5.0969 & 5.1172 & TRN & \\
\hline CHEMBL 293553 & 102784 & 4.8477 & 5.671 & TST & \\
\hline CHEMBL 291532 & 102784 & 6.2291 & 6.0919 & TRN & \\
\hline CHEMBL55271 & 102784 & 5.699 & 5.5125 & TRN & \\
\hline CHEMBL54600 & 102784 & 6.3979 & 6.3428 & TRN & \\
\hline CHEMBL54793 & 102784 & 4.5229 & 4.4688 & TRN & \\
\hline CHEMBL52068 & 102784 & 4.8356 & 4.8735 & TRN & \\
\hline CHEMBL 298823 & 102784 & 5.2676 & 5.117 & TRN & \\
\hline CHEMBL51738 & 102784 & 5.2218 & 5.1766 & TRN & \\
\hline CHEMBL59586 & 102784 & 4.1938 & 4.40600 & 0000000001 & TRN \\
\hline CHEMBL 292381 & 102784 & 4.2924 & 4.4124 & TRN & \\
\hline CHEMBL294212 & 102784 & 5.4089 & 4.7347 & TST & \\
\hline CHEMBL55757 & 102784 & 7.2218 & 7.1629 & TRN & \\
\hline CHEMBL3966080 & 1641454 & 2.3979 & 2.2855 & TRN & \\
\hline CHEMBL3930808 & 1641454 & 3.1965 & 3.1051 & TRN & \\
\hline CHEMBL3971100 & 1641454 & 2.3979 & 2.7797 & TRN & \\
\hline CHEMBL3956399 & 1641454 & 2.6536 & 2.9154 & TRN & \\
\hline
\end{tabular}


Supplemental Table S2.txt

\begin{tabular}{|c|c|c|c|c|c|}
\hline CHEMBL3933312 & 1641454 & 2.3979 & 2.9073 & TRN & \\
\hline CHEMBL3915529 & 1641454 & 3.2917 & 3.1757 & TRN & \\
\hline CHEMBL3911484 & 1641454 & 2.3979 & 3.2416 & TST & \\
\hline CHEMBL3891585 & 1641454 & 2.3979 & 2.2539 & TRN & \\
\hline CHEMBL3927002 & 1641454 & 2.3979 & 2.773 & TRN & \\
\hline CHEMBL3979143 & 1641454 & 3.2565 & 3.1957 & TRN & \\
\hline CHEMBL3926914 & 1641454 & 2.3979 & 2.363 & TRN & \\
\hline CHEMBL 3898408 & 1641454 & 2.3979 & 2.7494 & TST & \\
\hline CHEMBL3949737 & 1641454 & 2.3979 & 2.6433 & TRN & \\
\hline CHEMBL3908288 & 1641454 & 3.2154 & 3.1211 & TRN & \\
\hline CHEMBL 3976045 & 1641454 & 3.6946 & 2.8082 & TRN & \\
\hline CHEMBL3936327 & 1641454 & 2.3979 & 2.8748 & TRN & \\
\hline CHEMBL 3944240 & 1641454 & 3.6778 & 3.0709 & TST & \\
\hline CHEMBL 3944430 & 1641454 & 3.0012 & 3.1012 & TRN & \\
\hline CHEMBL3969602 & 1641454 & 3.0737 & 2.7045 & TST & \\
\hline CHEMBL3940796 & 1641454 & 2.3979 & 2.775 & TRN & \\
\hline CHEMBL3900583 & 1641454 & 2.6234 & 2.3853 & TRN & \\
\hline CHEMBL3915277 & 1641454 & 2.3979 & 2.7424 & TRN & \\
\hline CHEMBL3948355 & 1641454 & 2.3979 & 2.2711 & TRN & \\
\hline CHEMBL3969211 & 1641454 & 2.4425 & 2.8037 & TST & \\
\hline CHEMBL3910073 & 1641454 & 3.3726 & 3.3584 & TRN & \\
\hline CHEMBL3943708 & 1641454 & 3.2381 & 2.6427 & TST & \\
\hline CHEMBL3902460 & 1641454 & 2.3979 & 2.8316 & TRN & \\
\hline CHEMBL3985686 & 1641454 & 2.9512 & 2.763 & TRN & \\
\hline CHEMBL3949268 & 1641454 & 3.983 & 3.2106 & TST & \\
\hline CHEMBL3965566 & 1641454 & 2.8761 & 2.9819 & TRN & \\
\hline CHEMBL3943888 & 1641454 & 3.3526 & 2.7416 & TST & \\
\hline CHEMBL3904438 & 1641454 & 2.3979 & 2.5598 & TRN & \\
\hline CHEMBL3958521 & 1641454 & 2.3979 & 2.9759 & TRN & \\
\hline CHEMBL3913544 & 1641454 & 3.1183 & 3.2392 & TRN & \\
\hline CHEMBL3965367 & 1641454 & 3.3117 & 3.0914 & TRN & \\
\hline CHEMBL3960610 & 1641454 & 2.3979 & 2.59899 & 99999999998 & TRN \\
\hline CHEMBL3961630 & 1641454 & 2.3979 & 2.7383 & TST & \\
\hline CHEMBL 3924137 & 1641454 & 3.3429 & 2.6402 & TST & \\
\hline CHEMBL3964122 & 1641454 & 2.3979 & 2.4131 & TST & \\
\hline CHEMBL3957027 & 1641454 & 3.1107 & 2.72600 & 00000000004 & TRN \\
\hline CHEMBL3942282 & 1641454 & 2.3979 & 2.7394 & TST & \\
\hline CHEMBL3916241 & 1641454 & 2.9747 & 2.7721 & TST & \\
\hline CHEMBL3921965 & 1641454 & 2.3979 & 2.6757 & TRN & \\
\hline CHEMBL3898955 & 1641454 & 2.3979 & 2.8804 & TRN & \\
\hline CHEMBL3973889 & 1641454 & 2.7665 & 3.0681 & TRN & \\
\hline CHEMBL3943162 & 1641454 & 2.3979 & 2.6761 & TRN & \\
\hline CHEMBL3971569 & 1641454 & 3.1076 & 2.674 & TRN & \\
\hline CHEMBL3964029 & 1641454 & 3.2456 & 2.6331 & TRN & \\
\hline CHEMBL3895405 & 1641454 & 2.6861 & 3.1307 & TRN & \\
\hline CHEMBL3957032 & 1641454 & 2.3979 & 2.5656 & TST & \\
\hline CHEMBL3965056 & 1641454 & 2.3979 & 2.7555 & TRN & \\
\hline CHEMBL3909660 & 1641454 & 2.3979 & 2.5697 & TST & \\
\hline
\end{tabular}

Page 14321 
Supplemental Table S2.txt

\begin{tabular}{|c|c|c|c|c|c|}
\hline CHEMBL3972614 & 1641454 & 2.3979 & 2.6207 & TRN & \\
\hline CHEMBL3915749 & 1641454 & 2.3979 & 2.499 & TST & \\
\hline CHEMBL3951561 & 1641454 & 2.3979 & 2.1448 & TRN & \\
\hline CHEMBL3971064 & 1641454 & 2.3979 & 2.65 & TST & \\
\hline CHEMBL3981436 & 1641454 & 2.6216 & 2.296 & TRN & \\
\hline CHEMBL3897736 & 1641454 & 3.8297 & 2.678 & TST & \\
\hline CHEMBL3905422 & 1641454 & 3.219 & 2.9083 & TRN & \\
\hline CHEMBL3939817 & 1641454 & 3.1475 & 2.975 & TRN & \\
\hline CHEMBL3986682 & 1641454 & 2.3979 & 2.9488 & TRN & \\
\hline CHEMBL3957556 & 1641454 & 2.3979 & 2.6802 & TRN & \\
\hline CHEMBL3962299 & 1641454 & 2.4572 & 2.425 & TST & \\
\hline CHEMBL3979965 & 1641454 & 3.3288 & 2.8549 & TST & \\
\hline CHEMBL3955707 & 1641454 & 3.7122 & 2.9563 & TRN & \\
\hline CHEMBL3968711 & 1641454 & 2.9318 & 2.6714 & TRN & \\
\hline CHEMBL3921416 & 1641454 & 2.7144 & 2.9836 & TRN & \\
\hline CHEMBL3985831 & 1641454 & 3.056 & 2.7775 & TST & \\
\hline CHEMBL3955892 & 1641454 & 2.3979 & 2.9888 & TRN & \\
\hline CHEMBL 3913444 & 1641454 & 2.3979 & 2.7973 & TST & \\
\hline CHEMBL3897411 & 1641454 & 2.3979 & 2.5348 & TRN & \\
\hline CHEMBL3927382 & 1641454 & 3.8239 & 2.9152 & TRN & \\
\hline CHEMBL3899306 & 1641454 & 3.2848 & 3.3068 & TRN & \\
\hline CHEMBL3898875 & 1641454 & 2.3979 & 2.7734 & TRN & \\
\hline CHEMBL3933535 & 1641454 & 3.3894 & 3.1563 & TRN & \\
\hline CHEMBL3972152 & 1641454 & 2.3979 & 3.2168 & TRN & \\
\hline CHEMBL3955255 & 1641454 & 2.9809 & 2.9862 & TRN & \\
\hline CHEMBL3960749 & 1641454 & 2.3979 & 2.95 & TRN & \\
\hline CHEMBL3953251 & 1641454 & 2.3979 & 2.9735 & TST & \\
\hline CHEMBL3892657 & 1641454 & 3.3809 & 3.0471 & TRN & \\
\hline CHEMBL3908807 & 1641454 & 2.3979 & 2.6058 & TST & \\
\hline CHEMBL3942544 & 1641454 & 3.0036 & 2.6252 & TRN & \\
\hline CHEMBL3952357 & 1641454 & 3.1203 & 2.6373 & TST & \\
\hline CHEMBL3984503 & 1641454 & 2.9957 & 2.9628 & TRN & \\
\hline CHEMBL3954714 & 1641454 & 6.0 & 3.2326 & TRN & \\
\hline CHEMBL2347208 & 1641454 & 2.3979 & 2.5423 & TST & \\
\hline CHEMBL3924932 & 1641454 & 2.3979 & 2.3192 & TRN & \\
\hline CHEMBL3908739 & 1641454 & 2.3979 & 2.7192 & TST & \\
\hline CHEMBL3899615 & 1641454 & 2.8761 & 2.6956 & TST & \\
\hline CHEMBL3945149 & 1641454 & 2.3979 & 2.8594 & TRN & \\
\hline CHEMBL3894515 & 1641454 & 3.0942 & 2.5 & TRN & \\
\hline CHEMBL3934414 & 1641454 & 3.1818 & 2.9466 & TRN & \\
\hline CHEMBL3945996 & 1641454 & 3.4139 & 3.12899 & 99999999996 & TRN \\
\hline CHEMBL3969182 & 1641454 & 2.9666 & 2.5656 & TST & \\
\hline CHEMBL3966600 & 1641454 & 2.3979 & 2.7054 & TRN & \\
\hline CHEMBL3923890 & 1641454 & 2.3979 & 2.3397 & TRN & \\
\hline CHEMBL3968817 & 1641454 & 2.5607 & 2.6489 & TRN & \\
\hline CHEMBL3964525 & 1641454 & 2.3979 & 2.3584 & TRN & \\
\hline CHEMBL3905535 & 1641454 & 2.4535 & 2.6619 & TRN & \\
\hline CHEMBL3923494 & 1641454 & 2.3915 & 2.3315 & TRN & \\
\hline
\end{tabular}


Supplemental Table S2.txt

\begin{tabular}{|c|c|c|c|c|}
\hline HEMBL39 & 641454 & 2.3979 & 2.7559 & \\
\hline HEMBL3926156 & 641454 & 2.3979 & 2.8159 & \\
\hline HEMBL3939374 & 454 & 2.5901 & & \\
\hline AEMBL3911117 & & 2.3979 & 9356 & \\
\hline HEMBL3930384 & 64 & 2.3979 & 5106 & \\
\hline AEMBL3954148 & 641454 & 2.3979 & . 3187 & \\
\hline HEMBL3922335 & 4 & 2.3979 & .938 & \\
\hline HEMBL3909033 & & & 8792 & \\
\hline HEMBL3920732 & 164 & 2.3979 & 2.4089 & \\
\hline HEMBL3928092 & 64 & 2.3979 & 2.8243 & \\
\hline HEMBL3930009 & 64 & 3.2023 & .0994 & \\
\hline HEMBL3926622 & 4 & 2.3979 & 6836 & \\
\hline AEMBL3952065 & & & .7988 & \\
\hline HEMBL3961045 & 164 & 2.3979 & 3.2318 & \\
\hline HEMBL3934218 & 64 & 2.8761 & .6968 & \\
\hline HEMBL 3985357 & 164 & 2.3979 & 2.78 & \\
\hline AEMBL3929456 & 4 & 79 & 2.8071 & \\
\hline HEMBL3952931 & 4 & 79 & 2.5815 & \\
\hline HEMBL3935479 & 16 & 2.3979 & 3.2203 & \\
\hline AEMBL3915646 & 6 & 2 . & 8848 & \\
\hline HEMBL3940163 & 16 & 2. & 525 & \\
\hline HEMBL39 & 10 & 2. & 044 & \\
\hline HEMBL3963410 & 16 & 2 . & 2.8332 & \\
\hline HEMBL3926112 & & & 2.9417 & \\
\hline HEMBL3960890 & & & 304 & \\
\hline HEMBL3938609 & 16 & 2 . & 2.6942 & \\
\hline HEMBL3972761 & 16 & 72 & 5226 & \\
\hline HEMBL3893892 & 16 & 79 & 407 & \\
\hline HEMBL3906965 & & & 2.7209 & \\
\hline HEMBL3924515 & 16 & & 3.3381 & \\
\hline HEMBL3927936 & 16 & 471 & 2.3515 & \\
\hline HEMBL3S & 16 & 79 & 2.3794 & \\
\hline HEMBL 3 & 16 & 98 & 3.1328 & \\
\hline HEMBL3940040 & 164 & 6. & 3.5185 & \\
\hline HEMBL3921212 & 164 & 3. & 2.6913 & \\
\hline HEMBL3944783 & 64 & 79 & 2.6396 & \\
\hline HEMBL 39 & 16 & 79 & 2.7177 & \\
\hline HEMBL3906242 & 16 & 3. & 2.8235 & \\
\hline HEMBL3931128 & 16 & 2.8697 & 3.1375 & \\
\hline HEMBL3929911 & 64 & 2.3979 & 2.8892 & \\
\hline HEMBL3963645 & 164 & 3.2062 & 3.236 & \\
\hline CHEMBL3941417 & & 2.3979 & 2.88 & \\
\hline CHEMBL3957666 & 164 & 2.3979 & 2.5656 & \\
\hline HEMBL3948514 & 16 & 2.3979 & 2.8346 & \\
\hline EMBL3972899 & 62 & 2.9 & 3.1677 & \\
\hline CHEMBL3957970 & 164 & 2.3979 & 2.4918 & \\
\hline CHEMBL3901216 & 164 & 2.4737 & 2.4782 & \\
\hline CHEMBL3923385 & 1641454 & 3.4045 & 2.8508 & \\
\hline
\end{tabular}

Page 14323 
Supplemental Table S2.txt

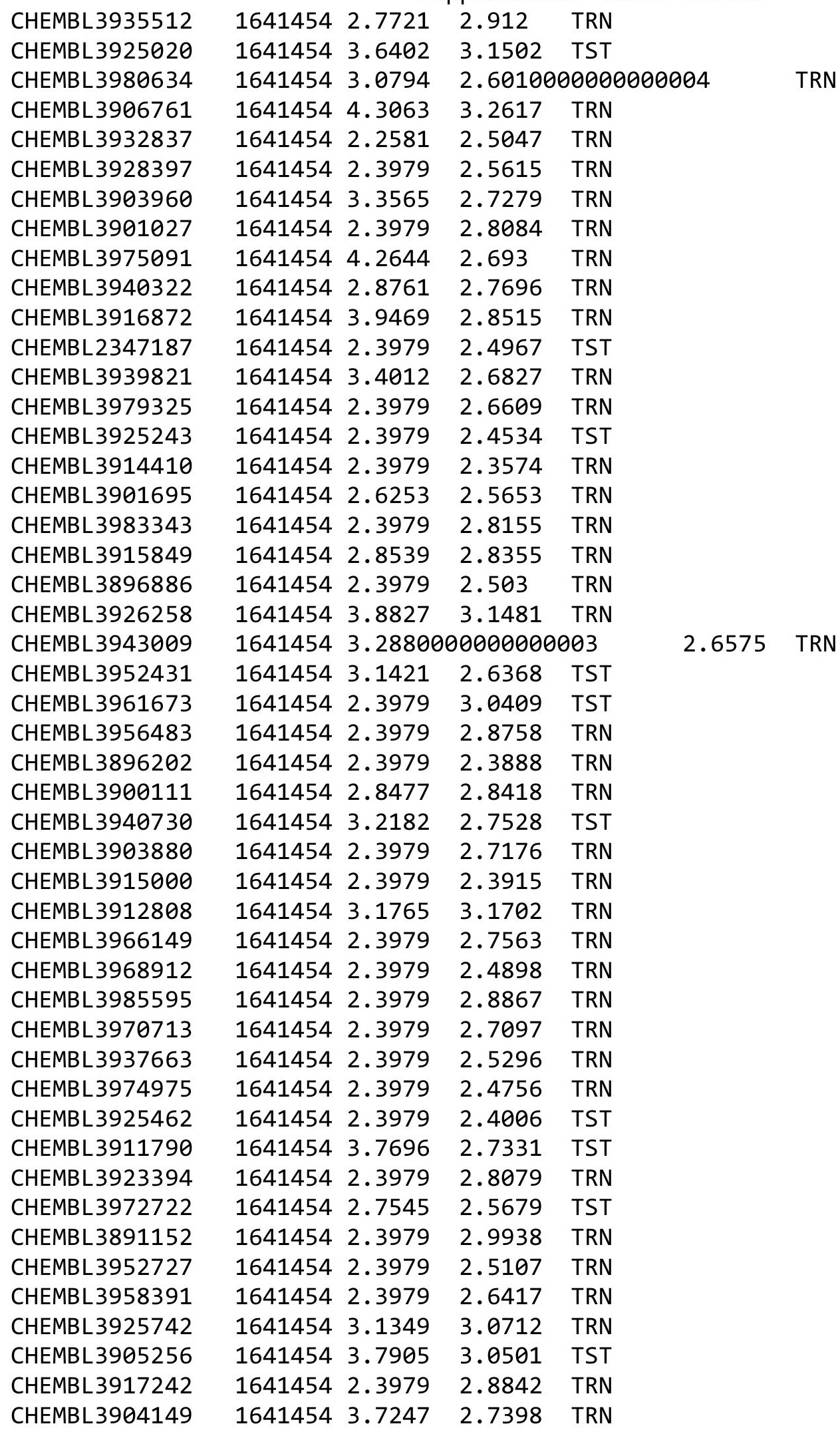

Page 14324 
Supplemental Table S2.txt

\begin{tabular}{|c|c|c|c|c|c|}
\hline CHEMBL3968489 & 1641454 & 2.3979 & 2.9142 & TRN & \\
\hline CHEMBL3934911 & 1641454 & 3.8894 & 2.6579 & TST & \\
\hline CHEMBL3966537 & 1641454 & 3.1979 & 2.3883 & TRN & \\
\hline CHEMBL3902829 & 1641454 & $3.3080 e$ & 00000000 & 203 & 3.1180000000000003 \\
\hline CHEMBL3919193 & 1641454 & 3.0325 & 2.984 & TRN & \\
\hline CHEMBL3961455 & 1641454 & 3.9431 & 3.0876 & TRN & \\
\hline CHEMBL3958580 & 1641454 & 2.3979 & 2.6093 & TRN & \\
\hline CHEMBL3892989 & 1641454 & 2.3979 & 2.9149 & TRN & \\
\hline CHEMBL3975793 & 1641454 & 2.5243 & 2.3819 & TRN & \\
\hline CHEMBL3923927 & 1641454 & 2.3979 & 2.6339 & TRN & \\
\hline CHEMBL3982006 & 1641454 & 2.3979 & 2.8681 & TRN & \\
\hline CHEMBL3961329 & 1641454 & 2.3979 & 2.3276 & TRN & \\
\hline CHEMBL3953730 & 1641454 & 2.3979 & 3.0469 & TRN & \\
\hline CHEMBL3951840 & 1641454 & 2.3979 & 2.8661 & TST & \\
\hline CHEMBL3977392 & 1641454 & 2.3979 & 2.1256 & TRN & \\
\hline CHEMBL3951015 & 1641454 & 3.8297 & 2.8422 & TRN & \\
\hline CHEMBL3980894 & 1641454 & 2.3979 & 2.2632 & TRN & \\
\hline CHEMBL 3894342 & 1641454 & 2.7878 & 2.7653 & TST & \\
\hline CHEMBL3946502 & 1641454 & 2.8761 & 2.7662 & TRN & \\
\hline CHEMBL3966981 & 1641454 & 3.4049 & 2.9667 & TRN & \\
\hline CHEMBL3952503 & 1641454 & 2.3979 & 3.1696 & TST & \\
\hline CHEMBL3972147 & 1641454 & 3.58 & 2.7354 & TRN & \\
\hline CHEMBL3986014 & 1641454 & 2.7399 & 3.0179 & TST & \\
\hline CHEMBL3950109 & 1641454 & 3.1314 & 3.3554 & TRN & \\
\hline CHEMBL3930667 & 1641454 & 3.0915 & 2.6624 & TST & \\
\hline CHEMBL1715729 & 737116 & 4.9547 & 4.8127 & TRN & \\
\hline CHEMBL1731106 & 737116 & 4.6271 & 4.4462 & TRN & \\
\hline CHEMBL1711505 & 737116 & 4.7721 & 4.6365 & TRN & \\
\hline CHEMBL568739 & 737116 & 4.3546 & 3.013 & TST & \\
\hline CHEMBL1703311 & 737116 & 5.4535 & 5.7739 & TRN & \\
\hline CHEMBL1726776 & 737116 & 5.5186 & 5.5745 & TRN & \\
\hline CHEMBL1391552 & 737116 & 5.5768 & 5.8736 & TRN & \\
\hline CHEMBL1734915 & 737116 & 4.8416 & 4.4594 & TRN & \\
\hline CHEMBL1520143 & 737116 & 5.8268 & 5.9176 & TRN & \\
\hline CHEMBL1708115 & 737116 & 5.0665 & 5.1789 & TRN & \\
\hline CHEMBL1735003 & 737116 & 3.301 & 3.3766 & TRN & \\
\hline CHEMBL1728993 & 737116 & 4.7305 & 5.0629 & TRN & \\
\hline CHEMBL1562260 & 737116 & 3.301 & 3.5093 & TST & \\
\hline CHEMBL1570441 & 737116 & 4.2111 & 4.1944 & TRN & \\
\hline CHEMBL1306415 & 737116 & 3.301 & 2.7076 & TST & \\
\hline CHEMBL1709105 & 737116 & 4.618 & 4.8897 & TRN & \\
\hline CHEMBL1701478 & 737116 & 4.644 & 4.6659 & TRN & \\
\hline CHEMBL1733176 & 737116 & 3.0 & 3.3724 & TRN & \\
\hline CHEMBL1724133 & 737116 & 3.301 & 3.1665 & TRN & \\
\hline CHEMBL1727048 & 737116 & 5.0052 & 4.7545 & TRN & \\
\hline CHEMBL1479664 & 737116 & 3.0 & 3.7294 & TST & \\
\hline CHEMBL1700715 & 737116 & 5.2765 & 5.1314 & TRN & \\
\hline CHEMBL3192684 & 737116 & 4.5072 & 2.7427 & TST & \\
\hline
\end{tabular}




\begin{tabular}{|c|c|c|c|c|c|c|}
\hline \multicolumn{7}{|c|}{ splemental Table s2.txt } \\
\hline CHEMBL1397665 & 737116 & 6.0 & 5.7556 & TRN & & \\
\hline CHEMBL1701846 & 737116 & \multicolumn{3}{|c|}{5.752000000000001} & .5981 & TRN \\
\hline CHEMBL51085 & 737116 & 6.7212 & 6.6972 & TRN & & \\
\hline CHEMBL1717022 & 737116 & 5.6696 & 5.7128 & TRN & & \\
\hline CHEMBL1318817 & 737116 & 5.5058 & 5.5185 & TRN & & \\
\hline CHEMBL1704396 & 737116 & 3.0 & 2.8858 & TRN & & \\
\hline CHEMBL1603385 & 737116 & 3.301 & 4.0057 & TST & & \\
\hline CHEMBL1725446 & 737116 & 3.0 & 4.0715 & TST & & \\
\hline CHEMBL 77534 & 737116 & 4.4353 & 4.7964 & TRN & & \\
\hline CHEMBL1406130 & 737116 & 5.9031 & 5.3459 & TRN & & \\
\hline CHEMBL1723958 & 737116 & 4.0083 & 3.9218 & TRN & & \\
\hline CHEMBL1710748 & 737116 & 4.8097 & 4.8888 & TRN & & \\
\hline CHEMBL1698074 & 737116 & 4.5607 & 4.3623 & TRN & & \\
\hline CHEMBL1724427 & 737116 & 4.5214 & 4.6674 & TRN & & \\
\hline CHEMBL1325232 & 737116 & 3.301 & 3.2825 & TST & & \\
\hline CHEMBL1422255 & 737116 & 3.301 & 4.0445 & TST & & \\
\hline CHEMBL1706897 & 737116 & 5.1851 & 5.0098 & TRN & & \\
\hline CHEMBL1724945 & 737116 & 5.2262 & 5.1763 & TRN & & \\
\hline CHEMBL1708335 & 737116 & 4.9508 & 4.8175 & TRN & & \\
\hline CHEMBL1709252 & 737116 & 3.301 & 3.2563 & TRN & & \\
\hline CHEMBL1734992 & 737116 & 4.5834 & 4.6354 & TRN & & \\
\hline CHEMBL1712193 & 737116 & 4.9245 & 4.9676 & TRN & & \\
\hline CHEMBL1706034 & 737116 & 4.4711 & 4.53600 & 00000000005 & & TRN \\
\hline CHEMBL1374283 & 737116 & 5.4101 & 3.1192 & TST & & \\
\hline CHEMBL1734392 & 737116 & 3.0 & 2.9331 & TRN & & \\
\hline CHEMBL1731796 & 737116 & 4.0555 & 4.0398 & TRN & & \\
\hline CHEMBL1347373 & 737116 & 5.0074 & 4.4369 & TST & & \\
\hline CHEMBL1334768 & 737116 & 5.2111 & 4.08899 & 99999999995 & & TST \\
\hline CHEMBL1720939 & 737116 & 4.6271 & 4.6033 & TRN & & \\
\hline CHEMBL3196067 & 737116 & 4.7932 & 4.97199 & 99999999995 & & TST \\
\hline CHEMBL1558672 & 737116 & 3.301 & 3.1084 & TST & & \\
\hline CHEMBL1447470 & 737116 & 4.4248 & 4.4197 & TST & & \\
\hline CHEMBL1605045 & 737116 & 3.301 & 3.7104 & TST & & \\
\hline CHEMBL1733695 & 737116 & 3.301 & 3.2184 & TRN & & \\
\hline CHEMBL 1707546 & 737116 & 4.644 & 4.305 & TRN & & \\
\hline CHEMBL1708710 & 737116 & 4.6253 & 4.3855 & TRN & & \\
\hline CHEMBL1712748 & 737116 & 3.0 & 3.2824 & TRN & & \\
\hline CHEMBL 74497 & 737116 & 4.8041 & 4.8322 & TRN & & \\
\hline CHEMBL1698721 & 737116 & 3.0 & 2.7476 & TRN & & \\
\hline CHEMBL1712029 & 737116 & 3.301 & 3.3394 & TRN & & \\
\hline CHEMBL1333813 & 737116 & 3.0 & 3.2756 & TST & & \\
\hline CHEMBL1700152 & 737116 & 4.4881 & 4.6815 & TRN & & \\
\hline CHEMBL1449845 & 737116 & 5.7773 & 5.5303 & TRN & & \\
\hline CHEMBL1573550 & 737116 & 3.301 & 5.3232 & TST & & \\
\hline CHEMBL1499314 & 737116 & 3.301 & 3.0954 & TST & & \\
\hline CHEMBL1300370 & 737116 & 3.0 & 3.4501 & TST & & \\
\hline CHEMBL1609086 & 737116 & 3.0 & 3.035 & TRN & & \\
\hline CHEMBL1601716 & 737116 & 5.7258 & 5.7338 & TRN & & \\
\hline
\end{tabular}




\begin{tabular}{|c|c|c|c|c|c|c|}
\hline \multicolumn{7}{|c|}{ Supplemental Table S2.txt } \\
\hline CHEMBL1336959 & 737116 & 6.0 & 5.6709 & TRN & & \\
\hline CHEMBL1705022 & 737116 & 3.301 & 3.0841 & TRN & & \\
\hline CHEMBL1712661 & 737116 & 4.5834 & 4.9631 & TRN & & \\
\hline CHEMBL1728676 & 737116 & 4.6383 & 4.606 & TRN & & \\
\hline CHEMBL1721020 & 737116 & 4.2916 & 4.1867 & TRN & & \\
\hline CHEMBL1734684 & 737116 & 4.3019 & 4.3648 & TRN & & \\
\hline CHEMBL1706310 & 737116 & 4.9245 & 4.7437 & TRN & & \\
\hline CHEMBL1556634 & 737116 & \multicolumn{3}{|c|}{5.382999999999999} & 5.2424 & TRN \\
\hline CHEMBL1589626 & 737116 & 3.301 & 3.4349 & TST & & \\
\hline CHEMBL1702227 & 737116 & 3.301 & 3.2751 & TRN & & \\
\hline CHEMBL1730714 & 737116 & 3.0 & 3.2487 & TRN & & \\
\hline CHEMBL1704299 & 737116 & 3.301 & 3.4998 & TRN & & \\
\hline CHEMBL1732571 & 737116 & 3.301 & 3.5905 & TRN & & \\
\hline CHEMBL1728270 & 737116 & 4.6271 & 4.806 & TRN & & \\
\hline CHEMBL1725457 & 737116 & 4.9208 & 4.8434 & TRN & & \\
\hline CHEMBL1725977 & 737116 & 5.7986 & 5.7932 & TRN & & \\
\hline CHEMBL1354431 & 737116 & 5.4828 & 5.7288 & TRN & & \\
\hline CHEMBL1712495 & 737116 & 4.4067 & 4.7369 & TRN & & \\
\hline CHEMBL1699421 & 737116 & 3.0 & 3.4429 & TRN & & \\
\hline CHEMBL1722737 & 737116 & 3.301 & 3.6353 & TRN & & \\
\hline CHEMBL1482621 & 737116 & 3.301 & 3.5825 & TST & & \\
\hline CHEMBL1711919 & 737116 & 5.3778 & 5.43 & TRN & & \\
\hline CHEMBL1338317 & 737116 & 5.1244 & 5.1435 & TRN & & \\
\hline CHEMBL1698123 & 737116 & 5.4647 & 5.6319 & TRN & & \\
\hline CHEMBL1605787 & 737116 & 4.4101 & 4.8973 & TST & & \\
\hline CHEMBL1392315 & 737116 & 3.301 & 3.2065 & TRN & & \\
\hline CHEMBL1558816 & 737116 & 3.301 & 2.4971 & TST & & \\
\hline CHEMBL1714415 & 737116 & 5.3615 & 5.0406 & TRN & & \\
\hline CHEMBL1371792 & 737116 & 5.585 & 5.1987 & TRN & & \\
\hline CHEMBL45152 & 737116 & 5.1772 & 5.6209 & TRN & & \\
\hline CHEMBL1333250 & 737116 & 6.1506 & 5.94 & TRN & & \\
\hline CHEMBL1448063 & 737116 & 3.301 & 4.1544 & TST & & \\
\hline CHEMBL1712882 & 737116 & 4.3851 & 4.2262 & TRN & & \\
\hline CHEMBL608699 & 737116 & 5.3536 & 5.2101 & TRN & & \\
\hline CHEMBL1707406 & 737116 & 4.4461 & 4.4873 & TRN & & \\
\hline CHEMBL1720245 & 737116 & 3.301 & 2.9738 & TRN & & \\
\hline CHEMBL1550861 & 737116 & 3.301 & 4.0377 & TST & & \\
\hline CHEMBL1732801 & 737116 & 3.301 & 3.4889 & TST & & \\
\hline CHEMBL1699075 & 737116 & 4.5258 & 4.5821 & TRN & & \\
\hline CHEMBL1698318 & 737116 & 3.0 & 3.4594 & TRN & & \\
\hline CHEMBL1732009 & 737116 & 3.301 & 3.2981 & TRN & & \\
\hline CHEMBL1703790 & 737116 & 3.0 & 3.0625 & TRN & & \\
\hline CHEMBL1704102 & 737116 & 5.1325 & 5.1911 & TRN & & \\
\hline CHEMBL1531603 & 737116 & 3.0 & 3.4671 & TST & & \\
\hline CHEMBL1321356 & 737116 & 3.301 & 3.6075 & TST & & \\
\hline CHEMBL1571309 & 737116 & 4.7447 & 4.8527 & TST & & \\
\hline CHEMBL1410147 & 737116 & 6.5686 & 4.7007 & TST & & \\
\hline CHEMBL1369613 & 737116 & 5.3072 & 5.32799 & 999999 & & \\
\hline & & & & 14327 & & \\
\hline
\end{tabular}




\begin{tabular}{|c|c|c|c|c|c|}
\hline \multicolumn{6}{|c|}{ Supplemental Table S2.txt } \\
\hline CHEMBL1569077 & 737116 & 4.0615 & 4.0111 & TRN & \\
\hline CHEMBL1720377 & 737116 & 4.4248 & 4.6292 & TRN & \\
\hline CHEMBL1530439 & 737116 & 3.301 & 3.0032 & TRN & \\
\hline CHEMBL1701021 & 737116 & 3.301 & 3.41600 & 00000000004 & TRN \\
\hline CHEMBL 1720777 & 737116 & 5.3507 & 5.2874 & TRN & \\
\hline CHEMBL75913 & 737116 & 5.5361 & 5.0764 & TRN & \\
\hline CHEMBL1520471 & 737116 & 3.0 & 3.1637 & TST & \\
\hline CHEMBL1719803 & 737116 & 4.3478 & 3.9975 & TRN & \\
\hline CHEMBL1715772 & 737116 & 5.0101 & 4.8152 & TRN & \\
\hline CHEMBL1714207 & 737116 & 3.301 & 3.2621 & TRN & \\
\hline CHEMBL98386 & 737116 & 5.6108 & 5.7141 & TRN & \\
\hline CHEMBL1714438 & 737116 & 4.6696 & 4.6706 & TRN & \\
\hline CHEMBL1314602 & 737116 & 5.9872 & 5.9892 & TRN & \\
\hline CHEMBL1708334 & 737116 & 5.1379 & 4.8346 & TRN & \\
\hline CHEMBL1725175 & 737116 & 3.301 & 3.5511 & TRN & \\
\hline CHEMBL1404277 & 737116 & 5.9706 & 5.6623 & TRN & \\
\hline CHEMBL1732623 & 737116 & 5.8386 & 5.6021 & TRN & \\
\hline CHEMBL1443661 & 737116 & 3.0 & 2.6454 & TRN & \\
\hline CHEMBL1496326 & 737116 & 4.3788 & 3.8076 & TST & \\
\hline CHEMBL1702821 & 737116 & 4.9706 & 5.2038 & TRN & \\
\hline CHEMBL3197242 & 737116 & 4.7645 & 4.7039 & TRN & \\
\hline CHEMBL1718784 & 737116 & 3.0 & 2.9941 & TRN & \\
\hline CHEMBL1606954 & 737116 & 3.0 & 4.2224 & TST & \\
\hline CHEMBL1608601 & 737116 & 4.5376 & 5.291 & TST & \\
\hline CHEMBL1701599 & 737116 & 5.2757 & 5.5257 & TRN & \\
\hline CHEMBL1727194 & 737116 & 5.3526 & 5.1799 & TRN & \\
\hline CHEMBL1423690 & 737116 & 5.5143 & 5.801 & TRN & \\
\hline CHEMBL1602859 & 737116 & 3.301 & 2.60100 & 00000000004 & TST \\
\hline CHEMBL1733472 & 737116 & 4.3478 & 4.8422 & TRN & \\
\hline CHEMBL1715058 & 737116 & 5.4881 & 5.2742 & TRN & \\
\hline CHEMBL1704576 & 737116 & 6.0 & 6.2033 & TRN & \\
\hline CHEMBL1709285 & 737116 & 4.8827 & 4.7677 & TRN & \\
\hline CHEMBL1329850 & 737116 & 4.433 & 3.1969 & TST & \\
\hline CHEMBL1703573 & 737116 & 3.0 & 3.3849 & TRN & \\
\hline CHEMBL1606007 & 737116 & 4.9136 & 5.0815 & TRN & \\
\hline CHEMBL1524838 & 737116 & 3.301 & 3.6641 & TST & \\
\hline CHEMBL1527869 & 737116 & 4.3363 & 2.4496 & TST & \\
\hline CHEMBL1734048 & 737116 & 3.0 & 2.9161 & TRN & \\
\hline CHEMBL1727796 & 737116 & 3.301 & 3.3328 & TRN & \\
\hline CHEMBL1728593 & 737116 & 3.301 & 3.3416 & TRN & \\
\hline CHEMBL1718499 & 737116 & 5.0255 & 5.1673 & TRN & \\
\hline CHEMBL1328836 & 737116 & 3.301 & 2.0155 & TST & \\
\hline CHEMBL1411202 & 737116 & 5.6478 & 5.7778 & TRN & \\
\hline CHEMBL1553163 & 737116 & 5.5719 & 5.6587 & TRN & \\
\hline CHEMBL1731467 & 737116 & 3.301 & 3.2782 & TRN & \\
\hline CHEMBL1711440 & 737116 & 4.5436 & 4.4389 & TRN & \\
\hline CHEMBL297304 & 737116 & 3.301 & 4.0442 & TST & \\
\hline CHEMBL1730721 & 737116 & 3.0 & 3.4853 & TRN & \\
\hline
\end{tabular}




\begin{tabular}{|c|c|c|c|c|}
\hline \multicolumn{5}{|c|}{ Supplemental Table S2.txt } \\
\hline CHEMBL1736848 & 737116 & 4.6819 & 4.6575 & TRN \\
\hline CHEMBL1352830 & 737116 & 5.7122 & 4.8984 & TST \\
\hline CHEMBL1708860 & 737116 & 3.301 & 2.9915 & TRN \\
\hline CHEMBL1718068 & 737116 & 3.0 & 2.8324 & TRN \\
\hline CHEMBL1730307 & 737116 & 4.9066 & 4.7331 & TRN \\
\hline CHEMBL1734202 & 737116 & 4.4855 & 4.4151 & TRN \\
\hline CHEMBL1712384 & 737116 & 4.9031 & 4.953 & TRN \\
\hline CHEMBL1334528 & 737116 & 4.3002 & 5.141 & TST \\
\hline CHEMBL1732887 & 737116 & 4.6478 & 4.7404 & TRN \\
\hline CHEMBL1575600 & 737116 & 3.301 & 3.9604 & TST \\
\hline CHEMBL1713178 & 737116 & 4.2083 & 4.1968 & TRN \\
\hline CHEMBL1567359 & 737116 & 4.4078 & 4.7549 & TST \\
\hline CHEMBL1725043 & 737116 & 4.1726 & 4.2193 & TRN \\
\hline CHEMBL1712016 & 737116 & 6.0 & 5.8495 & TRN \\
\hline CHEMBL1714665 & 737116 & 6.1494 & 5.9665 & TRN \\
\hline CHEMBL1737005 & 737116 & 3.301 & 3.697 & TRN \\
\hline CHEMBL1721184 & 737116 & 4.8508 & 4.6276 & TRN \\
\hline CHEMBL1412731 & 737116 & 3.301 & 3.2461 & TRN \\
\hline CHEMBL1699167 & 737116 & 4.8069 & 4.8756 & TRN \\
\hline CHEMBL1471698 & 737116 & 3.301 & 4.636 & TST \\
\hline CHEMBL1700881 & 737116 & 4.4685 & 4.7222 & TRN \\
\hline CHEMBL1322803 & 737116 & 3.301 & 3.2812 & TST \\
\hline CHEMBL1731974 & 737116 & 4.9355 & 5.2235 & TST \\
\hline CHEMBL1711106 & 737116 & 3.301 & 3.3512 & TRN \\
\hline CHEMBL476373 & 766669 & 8.961 & 9.2912 & TRN \\
\hline CHEMBL392573 & 766669 & 9.6198 & 9.6064 & TRN \\
\hline CHEMBL1085800 & 766669 & 9.1549 & 9.1925 & TRN \\
\hline CHEMBL453653 & 766669 & 9.8063 & 9.0049 & TST \\
\hline CHEMBL1822866 & 766669 & 8.4559 & 8.7284 & TRN \\
\hline CHEMBL1822861 & 766669 & 7.983 & 8.4852 & TST \\
\hline CHEMBL562629 & 766669 & 8.8 & 8.657 & TRN \\
\hline CHEMBL574837 & 766669 & 7.2007 & 7.4147 & TRN \\
\hline CHEMBL575685 & 766669 & 7.6021 & 7.5467 & TRN \\
\hline CHEMBL442242 & 766669 & 9.301 & 9.4897 & TRN \\
\hline CHEMBL1082488 & 766669 & 8.7696 & 9.1108 & TRN \\
\hline CHEMBL1823339 & 766669 & 7.4318 & 8.4556 & TST \\
\hline CHEMBL1823051 & 766669 & 8.37 & 8.5149 & TRN \\
\hline CHEMBL1091834 & 766669 & 7.7959 & 8.2182 & TRN \\
\hline CHEMBL476322 & 766669 & 9.1627 & 9.1181 & TRN \\
\hline CHEMBL1822858 & 766669 & 8.4437 & 8.5823 & TRN \\
\hline CHEMBL575241 & 766669 & 7.7959 & 7.4691 & TRN \\
\hline CHEMBL1823047 & 766669 & 8.3979 & 8.6779 & TST \\
\hline CHEMBL1085398 & 766669 & 10.0 & 9.9225 & TRN \\
\hline CHEMBL1084384 & 766669 & 9.0458 & 8.8109 & TRN \\
\hline CHEMBL477363 & 766669 & 9.3913 & 9.3464 & TRN \\
\hline CHEMBL393581 & 766669 & 9.585 & 9.8292 & TRN \\
\hline CHEMBL1823340 & 766669 & 8.5229 & 8.3936 & TRN \\
\hline CHEMBL549433 & 766669 & 8.2218 & 8.7249 & TST \\
\hline
\end{tabular}




\begin{tabular}{|c|c|c|c|c|c|}
\hline \multicolumn{6}{|c|}{ Supplemental Table s2.txt } \\
\hline CHEMBL1823054 & 766669 & 8.3 & 8.4909 & TRN & \\
\hline CHEMBL1086561 & 766669 & 9.2518 & 9.0705 & TRN & \\
\hline CHEMBL550517 & 766669 & 9.7959 & 8.9499 & TST & \\
\hline CHEMBL554506 & 766669 & 9.2 & 8.8748 & TRN & \\
\hline CHEMBL1822856 & 766669 & 8.283999 & 99999999 & 8.5301 & TRN \\
\hline CHEMBL 573034 & 766669 & 8.3979 & 7.7017 & TRN & \\
\hline CHEMBL1086514 & 766669 & 10.0 & 10.037 & TRN & \\
\hline CHEMBL1822855 & 766669 & 8.3098 & 8.3934 & TRN & \\
\hline CHEMBL573493 & 766669 & 7.1805 & 7.6103 & TRN & \\
\hline CHEMBL488248 & 766669 & 9.66 & 9.3155 & TRN & \\
\hline CHEMBL561279 & 766669 & 8.2 & 8.5892 & TRN & \\
\hline CHEMBL1822688 & 766669 & 8.8539 & 8.6516 & TRN & \\
\hline CHEMBL1086032 & 766669 & 8.1308 & 7.9929 & TRN & \\
\hline CHEMBL575453 & 766669 & 7.7696 & 7.9023 & TRN & \\
\hline CHEMBL1822854 & 766669 & 8.5528 & 8.422 & TRN & \\
\hline CHEMBL1083447 & 766669 & 9.3979 & 9.3605 & TRN & \\
\hline CHEMBL479036 & 766669 & 9.6021 & 9.5206 & TRN & \\
\hline CHEMBL478616 & 766669 & 9.2041 & 9.2558 & TRN & \\
\hline CHEMBL1822853 & 766669 & 8.7959 & 8.3792 & TRN & \\
\hline CHEMBL1085828 & 766669 & 9.699 & 9.7359 & TRN & \\
\hline CHEMBL478406 & 766669 & 8.9031 & 9.0824 & TRN & \\
\hline CHEMBL575023 & 766669 & 7.4559 & 7.4941 & TRN & \\
\hline CHEMBL565007 & 766669 & 9.3979 & 8.7476 & TST & \\
\hline CHEMBL1822852 & 766669 & 8.4437 & 8.2094 & TST & \\
\hline CHEMBL1823053 & 766669 & 8.6 & 8.8337 & TRN & \\
\hline CHEMBL263101 & 766669 & 9.5229 & 9.3765 & TRN & \\
\hline CHEMBL1085326 & 766669 & 8.301 & 8.4581 & TRN & \\
\hline CHEMBL1085142 & 766669 & 9.3979 & 9.7953 & TRN & \\
\hline CHEMBL487060 & 766669 & 9.301 & 9.2488 & TRN & \\
\hline CHEMBL1085124 & 766669 & 7.6778 & 7.9719 & TRN & \\
\hline CHEMBL1823180 & 766669 & 8.3979 & 8.8735 & TST & \\
\hline CHEMBL575474 & 766669 & 8.0 & 7.35 & TRN & \\
\hline CHEMBL487230 & 766669 & 9.8063 & 9.4245 & TRN & \\
\hline CHEMBL1084878 & 766669 & 8.1675 & 7.9478 & TRN & \\
\hline CHEMBL1085829 & 766669 & 9.0 & 9.1119 & TRN & \\
\hline CHEMBL562870 & 766669 & 9.7932 & 8.69399 & 9999999999 & TST \\
\hline CHEMBL1084385 & 766669 & 10.0 & 9.75 & TRN & \\
\hline CHEMBL1083406 & 766669 & 9.6576 & 9.6255 & TRN & \\
\hline CHEMBL488249 & 766669 & 10.1627 & 9.1446 & TST & \\
\hline CHEMBL1082606 & 766669 & 9.4559 & 9.702 & TRN & \\
\hline CHEMBL584766 & 766669 & 7.6383 & 7.65799 & 99999999995 & 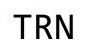 \\
\hline CHEMBL1084559 & 766669 & 9.699 & 9.5492 & TRN & \\
\hline CHEMBL561324 & 766669 & 9.5229 & 8.8214 & TST & \\
\hline CHEMBL556100 & 766669 & 9.0458 & 8.8641 & TST & \\
\hline CHEMBL1091836 & 766669 & 8.5229 & 7.8675 & TRN & \\
\hline CHEMBL477991 & 766669 & 9.5051 & 9.1916 & TRN & \\
\hline CHEMBL1092109 & 766669 & 8.0 & 7.91 & TRN & \\
\hline CHEMBL1822857 & 766669 & 8.0809 & 8.6083 & TRN & \\
\hline
\end{tabular}




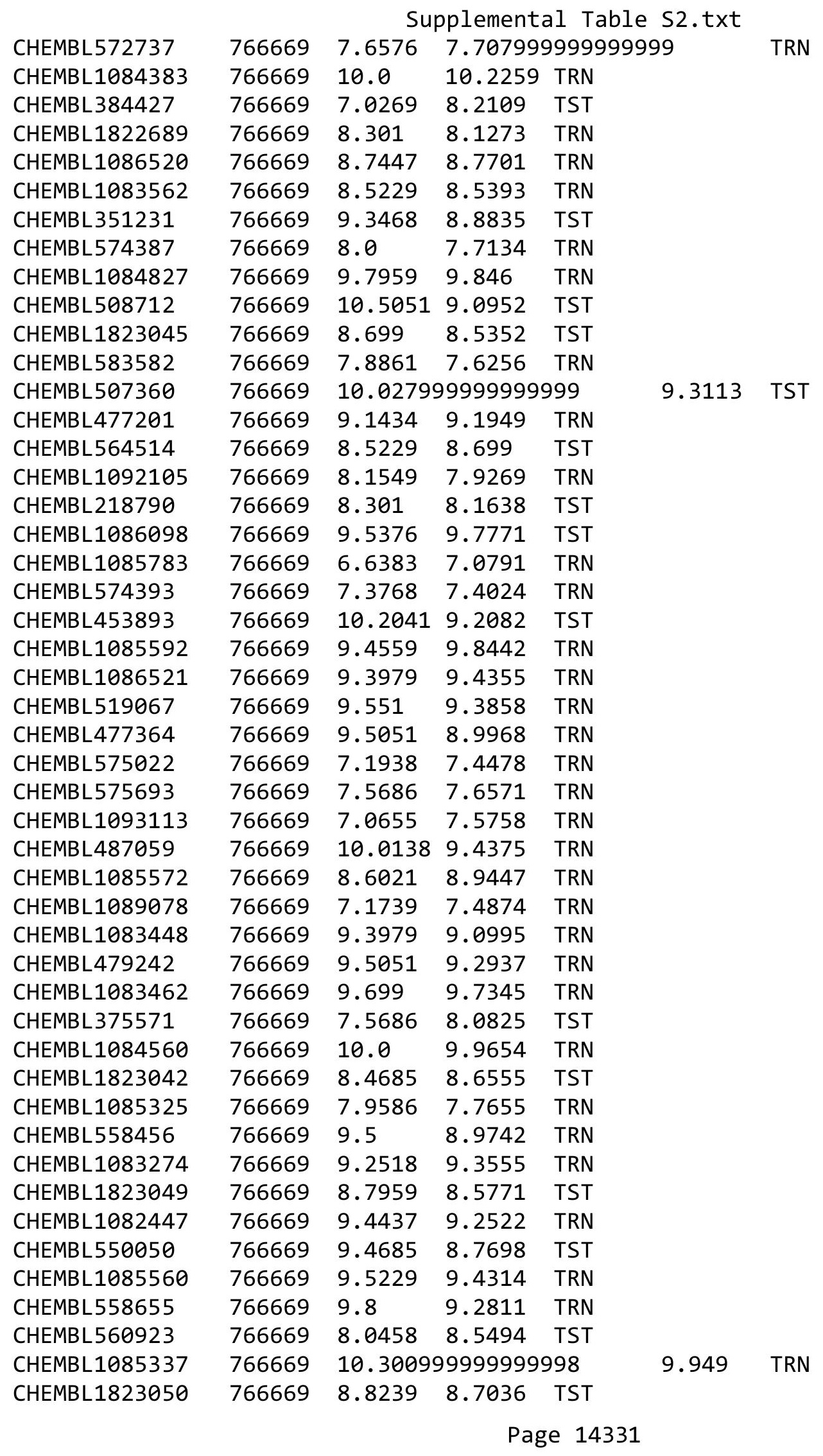




\begin{tabular}{|c|c|c|c|c|c|c|}
\hline \multicolumn{7}{|c|}{ Supplemental Table S2.txt } \\
\hline CHEMBL564380 & 766669 & 8.8 & 8.7736 & TRN & & \\
\hline CHEMBL1085964 & 766669 & 9.9586 & 10.0023 & TRN & & \\
\hline CHEMBL1084581 & 766669 & 8.4949 & 8.575 & TRN & & \\
\hline CHEMBL477152 & 766669 & 8.93700 & 00000000 & 01 & 9.3226 & TRN \\
\hline CHEMBL453894 & 766669 & 9.66 & 8.8914 & TST & & \\
\hline CHEMBL550405 & 766669 & 8.5 & 8.7078 & TRN & & \\
\hline CHEMBL1094030 & 766669 & 8.1549 & 7.77 & TRN & & \\
\hline CHEMBL575234 & 766669 & 7.6021 & 7.6171 & TRN & & \\
\hline CHEMBL1084877 & 766669 & 8.9586 & 9.0401 & TRN & & \\
\hline CHEMBL518431 & 766669 & 8.961 & 9.3535 & TRN & & \\
\hline CHEMBL575476 & 766669 & 7.6021 & 7.7756 & TRN & & \\
\hline CHEMBL373860 & 766669 & 7.3468 & 7.745 & TST & & \\
\hline CHEMBL1822859 & 766669 & 8.6576 & 8.3614 & TRN & & \\
\hline CHEMBL1085591 & 766669 & 8.4202 & 8.5584 & TRN & & \\
\hline CHEMBL1822865 & 766669 & 9.1549 & 8.9126 & TRN & & \\
\hline CHEMBL582876 & 766669 & 7.699 & 7.4672 & TRN & & \\
\hline CHEMBL572559 & 766669 & 6.983 & 7.5244 & TRN & & \\
\hline CHEMBL1085336 & 766669 & 9.0 & 9.0332 & TRN & & \\
\hline CHEMBL 218836 & 766669 & 6.7905 & 8.1733 & TST & & \\
\hline CHEMBL1822862 & 766669 & 9.699 & 8.7315 & TRN & & \\
\hline CHEMBL1084294 & 766669 & 7.5528 & 7.688 & TRN & & \\
\hline CHEMBL1086513 & 766669 & 8.9586 & 8.9124 & TRN & & \\
\hline CHEMBL515004 & 766669 & 9.66 & 9.3863 & TRN & & \\
\hline CHEMBL552279 & 766669 & 8.7001 & 8.4376 & TRN & & \\
\hline CHEMBL216666 & 766669 & 6.5513 & 8.3517 & TST & & \\
\hline CHEMBL488251 & 766669 & 9.551 & 9.4433 & TRN & & \\
\hline CHEMBL1084314 & 766669 & 9.699 & 9.4957 & TRN & & \\
\hline CHEMBL1823043 & 766669 & 8.6021 & 8.3218 & TST & & \\
\hline CHEMBL1823048 & 766669 & 8.7959 & 8.4987 & TST & & \\
\hline CHEMBL 220407 & 766669 & 7.7696 & 8.2719 & TST & & \\
\hline CHEMBL479241 & 766669 & 9.66 & 9.3651 & TRN & & \\
\hline CHEMBL1082496 & 766669 & 9.0969 & 8.8787 & TRN & & \\
\hline CHEMBL 219074 & 766669 & 7.8539 & 8.7657 & TST & & \\
\hline CHEMBL575483 & 766669 & 7.0315 & 7.3848 & TRN & & \\
\hline CHEMBL1822690 & 766669 & 8.0458 & 8.54 & TRN & & \\
\hline CHEMBL1094029 & 766669 & 7.8539 & 7.895 & TRN & & \\
\hline CHEMBL1082489 & 766669 & 9.699 & 9.7501 & TRN & & \\
\hline CHEMBL1082781 & 766669 & 9.8239 & 9.9337 & TRN & & \\
\hline CHEMBL1085396 & 766669 & 9.7959 & 9.7536 & TRN & & \\
\hline CHEMBL1092106 & 766669 & 7.3872 & 8.1584 & TST & & \\
\hline CHEMBL1822849 & 766669 & 8.3188 & 8.4202 & TRN & & \\
\hline CHEMBL1085782 & 766669 & 9.0 & 8.9909 & TRN & & \\
\hline CHEMBL1823046 & 766669 & 8.6198 & 8.7885 & TST & & \\
\hline CHEMBL558923 & 766669 & 8.3 & 8.3746 & TRN & & \\
\hline CHEMBL477356 & 766669 & 9.1627 & 9.2441 & TRN & & \\
\hline CHEMBL578834 & 766669 & 8.0969 & 7.5003 & TRN & & \\
\hline CHEMBL1086072 & 766669 & 8.7696 & 8.5946 & TRN & & \\
\hline CHEMBL1085841 & 766669 & 9.5229 & 9.7037 & TRN & & \\
\hline
\end{tabular}

Page 14332 


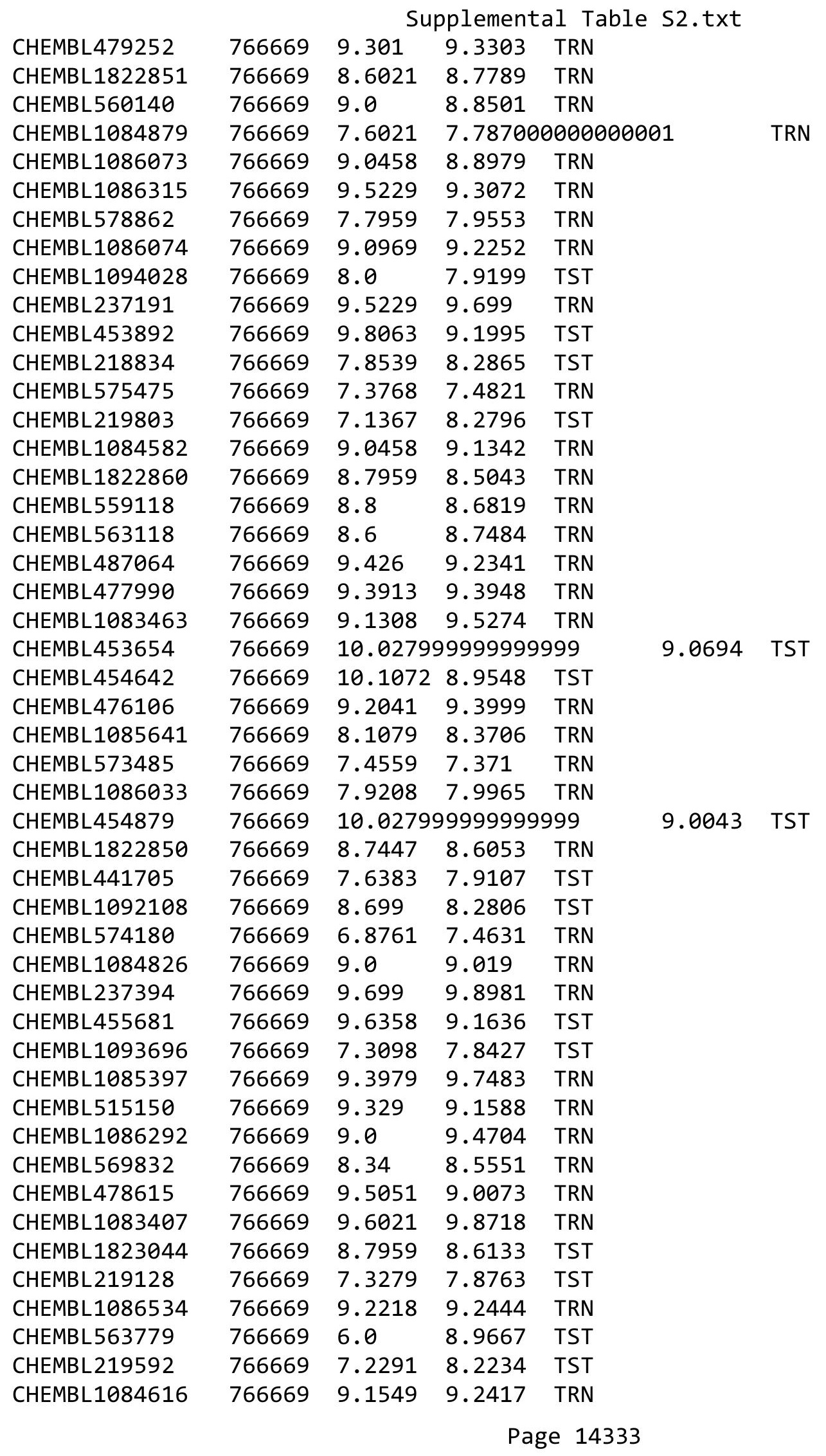




\begin{tabular}{|c|c|c|c|c|}
\hline & & & olement & \\
\hline CHEMBL1085866 & 766669 & 9.4685 & 9.3774 & TRN \\
\hline CHEMBL218992 & 766669 & 7.7959 & 7.9502 & TST \\
\hline CHEMBL572558 & 766669 & 7.5528 & 7.7191 & TRN \\
\hline CHEMBL1086034 & 766669 & 8.1308 & 7.9287 & TRN \\
\hline CHEMBL 374493 & 766669 & 7.0655 & 8.4091 & TST \\
\hline CHEMBL558260 & 766669 & 8.6 & 8.7243 & TRN \\
\hline CHEMBL549639 & 766669 & 9.301 & 8.783 & TST \\
\hline CHEMBL476723 & 766669 & 9.301 & 9.2906 & TRN \\
\hline CHEMBL1823052 & 766669 & 8.2 & 8.5414 & TRN \\
\hline CHEMBL574826 & 766669 & 7.3565 & 7.4295 & TRN \\
\hline CHEMBL 218410 & 766669 & 7.6021 & 8.0539 & TST \\
\hline CHEMBL239187 & 454273 & 5.7447 & 5.268 & TRN \\
\hline CHEMBL 393482 & 454273 & 3.0 & 3.67 & TRN \\
\hline CHEMBL437759 & 454273 & 3.0 & 3.4299 & TST \\
\hline CHEMBL395466 & 454273 & 5.4949 & 5.0671 & TRN \\
\hline CHEMBL246242 & 454273 & 5.2596 & 4.9952 & TST \\
\hline CHEMBL442422 & 454273 & 3.0 & 4.0897 & TRN \\
\hline CHEMBL 394730 & 454273 & 5.7212 & 4.8575 & TRN \\
\hline CHEMBL245818 & 454273 & 4.3098 & 4.1776 & TRN \\
\hline CHEMBL443582 & 454273 & 3.0 & 3.7722 & TRN \\
\hline CHEMBL395469 & 454273 & 3.0 & 4.1925 & TRN \\
\hline CHEMBL239381 & 454273 & 5.4685 & 5.6911 & TRN \\
\hline CHEMBL246865 & 454273 & 3.0 & 3.1352 & TRN \\
\hline CHEMBL392210 & 454273 & 3.0 & 3.4208 & TRN \\
\hline CHEMBL245617 & 454273 & 4.585 & 3.9334 & TRN \\
\hline CHEMBL246864 & 454273 & 3.0 & 4.055 & TST \\
\hline CHEMBL245817 & 454273 & 4.9586 & 5.1352 & TRN \\
\hline CHEMBL401033 & 454273 & 3.0 & 3.4518 & TRN \\
\hline CHEMBL239582 & 454273 & 5.3872 & 5.7327 & TRN \\
\hline CHEMBL248485 & 454273 & 3.0 & 2.8694 & TRN \\
\hline CHEMBL391898 & 454273 & 5.8861 & 5.2156 & TRN \\
\hline CHEMBL264032 & 454273 & 5.8861 & 4.8732 & TRN \\
\hline CHEMBL 245438 & 454273 & 5.2924 & 4.8732 & TRN \\
\hline CHEMBL246447 & 454273 & 4.1024 & 4.4055 & TST \\
\hline CHEMBL 248308 & 454273 & 5.4318 & 5.268 & TRN \\
\hline CHEMBL 245418 & 454273 & 5.3372 & 6.4595 & TRN \\
\hline CHEMBL412246 & 454273 & 3.0 & 3.2588 & TRN \\
\hline CHEMBL 266152 & 454273 & 3.0 & 3.0559 & TRN \\
\hline CHEMBL245437 & 454273 & 6.1612 & 5.1045 & TST \\
\hline CHEMBL248103 & 454273 & 4.7696 & 4.9662 & TST \\
\hline CHEMBL246448 & 454273 & 4.3979 & 4.235 & TST \\
\hline CHEMBL245439 & 454273 & 3.0 & 4.043 & TST \\
\hline CHEMBL263615 & 454273 & 5.3872 & 6.4595 & TRN \\
\hline CHEMBL 241530 & 454273 & 6.2218 & 5.9408 & TRN \\
\hline CHEMBL392119 & 454273 & 5.7447 & 5.1901 & TST \\
\hline CHEMBL392338 & 454273 & 5.7959 & 5.1901 & TST \\
\hline CHEMBL273563 & 454273 & 5.7696 & 5.2511 & TRN \\
\hline CHEMBL399009 & 454273 & 4.8239 & 4.3934 & TRN \\
\hline
\end{tabular}




\begin{tabular}{|c|c|c|c|c|c|}
\hline \multicolumn{6}{|c|}{ Supplemental Table S2.txt } \\
\hline CHEMBL239382 & 454273 & 5.7959 & 5.6911 & TRN & \\
\hline CHEMBL248146 & 454273 & 5.2596 & 4.6567 & TRN & \\
\hline CHEMBL241727 & 454273 & 5.3372 & 5.7327 & TST & \\
\hline CHEMBL246446 & 454273 & 4.7696 & 4.1998 & TST & \\
\hline CHEMBL398048 & 454273 & 4.2757 & 4.3695 & TRN & \\
\hline CHEMBL239588 & 454273 & 5.8861 & 5.7046 & TRN & \\
\hline CHEMBL248278 & 454273 & 4.1427 & 4.2214 & TRN & \\
\hline CHEMBL245436 & 454273 & 5.6576 & 5.329 & TRN & \\
\hline CHEMBL239589 & 454273 & 5.2147 & 5.0434 & TRN & \\
\hline CHEMBL247069 & 454273 & 4.4815 & 4.1822 & TRN & \\
\hline CHEMBL436994 & 454273 & 4.7959 & 4.9431 & TRN & \\
\hline CHEMBL395278 & 454273 & 4.4318 & 4.21399 & 99999999995 & TST \\
\hline CHEMBL395470 & 454273 & 5.9208 & 5.0799 & TST & \\
\hline CHEMBL239188 & 454273 & 5.301 & 5.9408 & TRN & \\
\hline CHEMBL247287 & 454273 & 4.8239 & 4.1904 & TRN & \\
\hline CHEMBL396626 & 454273 & 4.0 & 4.3096 & TRN & \\
\hline CHEMBL398049 & 454273 & 5.0655 & 4.3115 & TRN & \\
\hline CHEMBL1531118 & 688540 & 3.4559 & 3.2791 & TRN & \\
\hline CHEMBL1376342 & 688540 & 3.4559 & 3.8292 & TRN & \\
\hline CHEMBL1482513 & 688540 & 3.4559 & 3.5445 & TST & \\
\hline CHEMBL1531251 & 688540 & 3.4559 & 2.9901 & TRN & \\
\hline CHEMBL1386178 & 688540 & 3.4559 & 3.6368 & TRN & \\
\hline CHEMBL1550015 & 688540 & 4.5791 & 4.1907 & TRN & \\
\hline CHEMBL1377690 & 688540 & 3.4559 & 4.3066 & TRN & \\
\hline CHEMBL1556933 & 688540 & 3.4559 & 3.0941 & TRN & \\
\hline CHEMBL1326298 & 688540 & 3.4559 & 3.3574 & TRN & \\
\hline CHEMBL1562842 & 688540 & 3.4559 & 3.64300 & 00000000002 & TRN \\
\hline CHEMBL1336318 & 688540 & 5.0351 & 4.8057 & TRN & \\
\hline CHEMBL1421312 & 688540 & 3.4559 & 3.36800 & 00000000003 & TRN \\
\hline CHEMBL1533962 & 688540 & 3.4559 & 3.7462 & TRN & \\
\hline CHEMBL1545205 & 688540 & 3.4559 & 3.9137 & TRN & \\
\hline CHEMBL1550184 & 688540 & 3.4559 & 3.9699 & TST & \\
\hline CHEMBL530291 & 688540 & 4.8365 & 4.2926 & TST & \\
\hline CHEMBL1427664 & 688540 & 3.4559 & 3.2978 & TST & \\
\hline CHEMBL1328017 & 688540 & 3.4559 & 3.4935 & TRN & \\
\hline CHEMBL1312220 & 688540 & 5.353 & 5.0136 & TRN & \\
\hline CHEMBL 1412538 & 688540 & 5.4559 & 4.46 & TRN & \\
\hline CHEMBL1383077 & 688540 & 3.4559 & 3.5125 & TRN & \\
\hline CHEMBL 2004475 & 688540 & 5.3224 & 4.2639 & TRN & \\
\hline CHEMBL1381600 & 688540 & 5.229 & 4.9256 & TRN & \\
\hline CHEMBL1468639 & 688540 & 3.4559 & 3.6804 & TRN & \\
\hline CHEMBL1407634 & 688540 & 4.9662 & 4.8356 & TRN & \\
\hline CHEMBL1359108 & 688540 & 3.4559 & 3.6235 & TRN & \\
\hline CHEMBL1360997 & 688540 & 3.4559 & 3.281 & TRN & \\
\hline CHEMBL1342624 & 688540 & 3.4559 & 3.7718 & TRN & \\
\hline CHEMBL1452153 & 688540 & 5.0964 & 5.0457 & TRN & \\
\hline CHEMBL1608455 & 688540 & 3.4559 & 3.8773 & TRN & \\
\hline CHEMBL1555711 & 688540 & 5.0032 & 4.8333 & TRN & \\
\hline
\end{tabular}




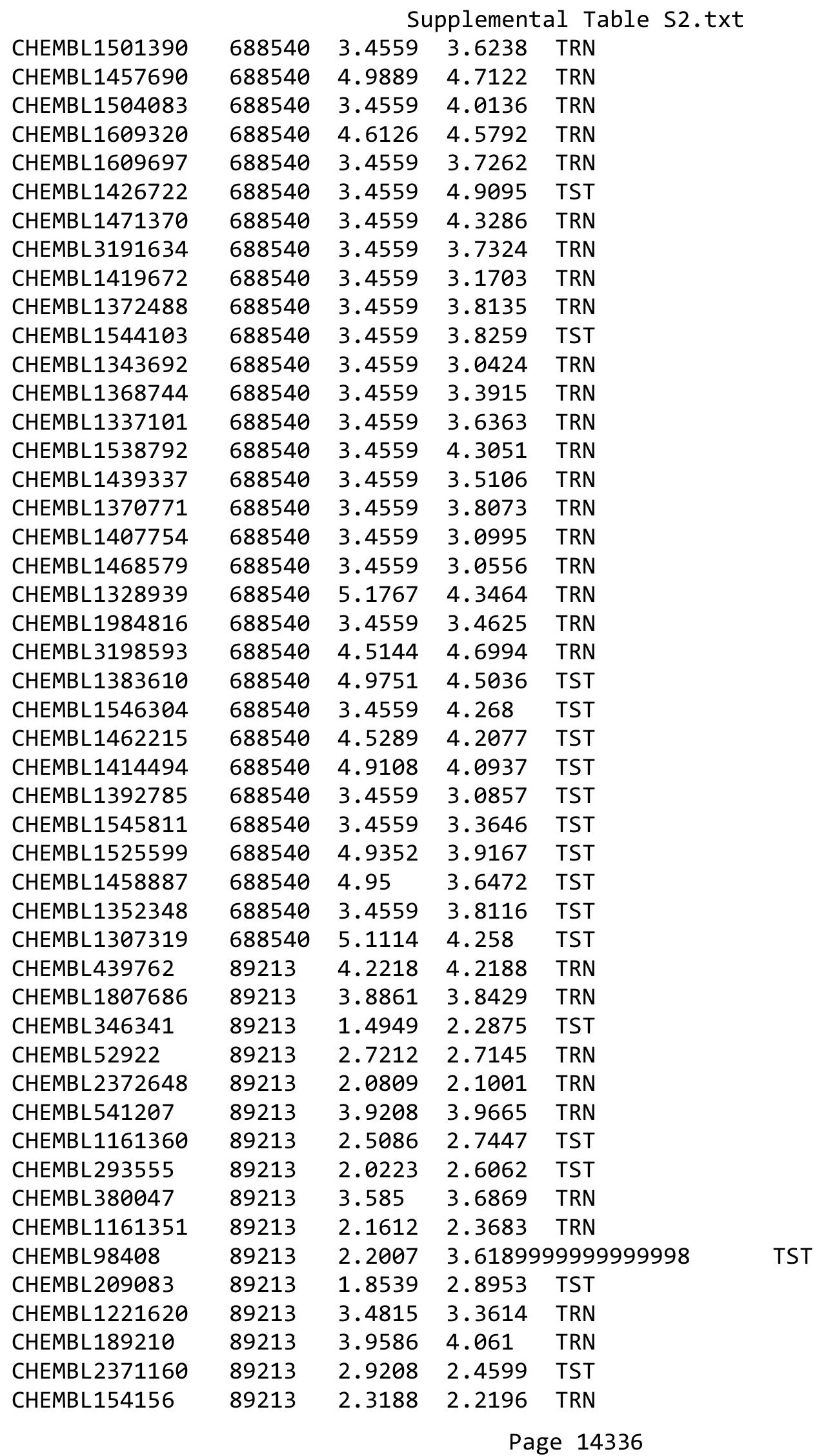




\begin{tabular}{|c|c|c|c|c|}
\hline & & & oplement & al $\mathrm{T}$ \\
\hline CHEMBL 2371842 & 89213 & 3.0088 & 2.9885 & TRN \\
\hline CHEMBL1161361 & 89213 & 3.3372 & 3.2916 & TRN \\
\hline CHEMBL2371142 & 89213 & 0.5229 & 0.5321 & TRN \\
\hline CHEMBL55523 & 89213 & 4.0458 & 4.0079 & TRN \\
\hline CHEMBL93127 & 89213 & 3.0 & 3.0645 & TRN \\
\hline CHEMBL59426 & 89213 & 1.6576 & 2.2564 & TST \\
\hline CHEMBL90074 & 89213 & 3.6021 & 3.7256 & TRN \\
\hline CHEMBL1161359 & 89213 & 3.0506 & 3.0517 & TRN \\
\hline CHEMBL 298979 & 89213 & 3.1367 & 2.9351 & TST \\
\hline CHEMBL 2371148 & 89213 & 4.699 & 4.4456 & TRN \\
\hline CHEMBL2371149 & 89213 & 3.3188 & 3.3539 & TRN \\
\hline CHEMBL17171 & 89213 & 3.3872 & 3.4866 & TRN \\
\hline CHEMBL371579 & 89213 & 3.699 & 3.8421 & TRN \\
\hline CHEMBL2372592 & 89213 & 0.5229 & 0.5151 & TRN \\
\hline CHEMBL17503 & 89213 & 3.4948 & 3.2931 & TRN \\
\hline CHEMBL1161354 & 89213 & 3.3872 & 3.3097 & TRN \\
\hline CHEMBL2371151 & 89213 & 2.7447 & 2.6132 & TRN \\
\hline CHEMBL 2371145 & 89213 & 4.1549 & 4.1458 & TRN \\
\hline CHEMBL1161347 & 89213 & 2.1079 & 2.1061 & TRN \\
\hline CHEMBL56119 & 89213 & 3.7959 & 3.8582 & TRN \\
\hline CHEMBL292467 & 89213 & 3.0 & 2.8357 & TST \\
\hline CHEMBL1161346 & 89213 & 2.6383 & 1.9163 & TST \\
\hline CHEMBL157008 & 89213 & 2.041 & 2.2654 & TRN \\
\hline CHEMBL91241 & 89213 & 3.4202 & 3.3916 & TRN \\
\hline CHEMBL2371152 & 89213 & 3.9208 & 4.0868 & TRN \\
\hline CHEMBL 2371154 & 89213 & 3.8539 & 3.8781 & TRN \\
\hline CHEMBL2371159 & 89213 & 3.6778 & 3.194 & TST \\
\hline CHEMBL 2372590 & 89213 & 3.8539 & 3.7975 & TRN \\
\hline CHEMBL175737 & 89213 & 3.0809 & 2.408 & TST \\
\hline CHEMBL1814488 & 89213 & 4.0458 & 3.8402 & TRN \\
\hline CHEMBL2371157 & 89213 & 3.6021 & 3.4548 & TST \\
\hline CHEMBL316103 & 89213 & 4.0458 & 3.9485 & TRN \\
\hline CHEMBL190869 & 89213 & 4.699 & 4.8264 & TRN \\
\hline CHEMBL347510 & 89213 & 3.4815 & 3.412 & TRN \\
\hline CHEMBL2371155 & 89213 & 3.8861 & 3.8546 & TRN \\
\hline CHEMBL55868 & 89213 & 3.9586 & 3.9473 & TRN \\
\hline CHEMBL191532 & 89213 & 2.2676 & 2.1661 & TRN \\
\hline CHEMBL190027 & 89213 & 1.699 & 2.591 & TST \\
\hline CHEMBL1161345 & 89213 & 2.5376 & 2.6633 & TRN \\
\hline CHEMBL192867 & 89213 & 3.8539 & 3.9273 & TRN \\
\hline CHEMBL 293494 & 89213 & 3.3279 & 3.1297 & TST \\
\hline CHEMBL2371139 & 89213 & 2.7959 & 2.7775 & TRN \\
\hline CHEMBL94250 & 89213 & 3.8539 & 3.88 & TRN \\
\hline CHEMBL318725 & 89213 & 1.8508 & 1.8495 & TRN \\
\hline CHEMBL1161356 & 89213 & 2.2676 & 1.9407 & TST \\
\hline CHEMBL83418 & 89213 & 2.2503 & 3.5551 & TST \\
\hline CHEMBL2371153 & 89213 & 3.8861 & 3.9533 & TRN \\
\hline CHEMBL1161352 & 89213 & 3.4685 & 3.5553 & TRN \\
\hline
\end{tabular}




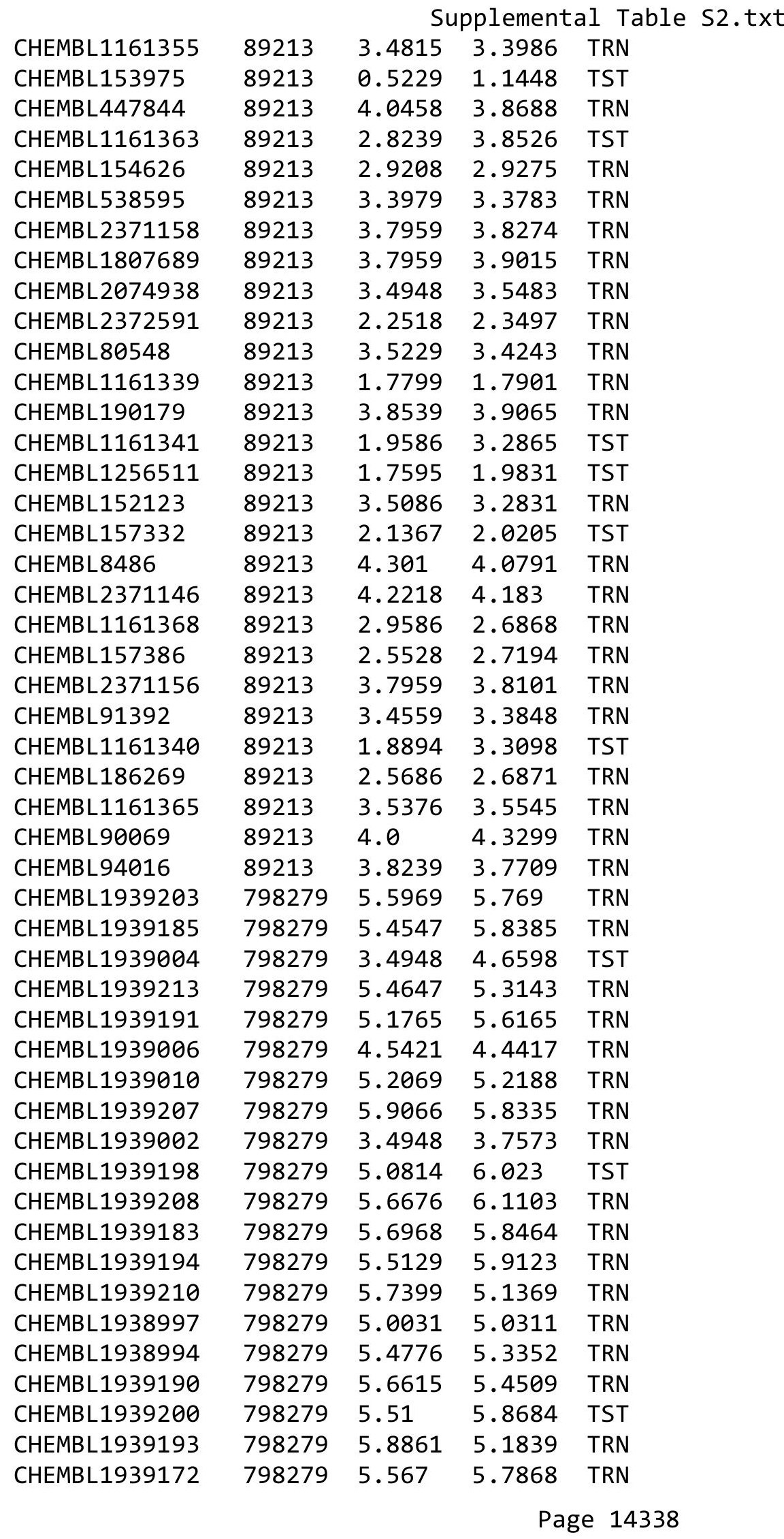




\begin{tabular}{|c|c|c|c|c|c|c|}
\hline & & \multicolumn{4}{|c|}{ Supplemental Table S2.txt } & \\
\hline CHEMBL1939216 & 798279 & $5.2020 €$ & 0000000 & 01 & 4.9487 & TST \\
\hline CHEMBL1939192 & 798279 & 5.3883 & 5.2187 & TRN & & \\
\hline CHEMBL1939176 & 798279 & 5.6536 & 5.4802 & TRN & & \\
\hline CHEMBL1939219 & 798279 & 6.1549 & 6.1578 & TRN & & \\
\hline CHEMBL1939182 & 798279 & 5.9101 & 5.9935 & TRN & & \\
\hline CHEMBL1939218 & 798279 & 5.5768 & 5.472 & TRN & & \\
\hline CHEMBL1939008 & 798279 & 5.6198 & 5.8045 & TRN & & \\
\hline CHEMBL1939173 & 798279 & 5.4949 & 5.1439 & TRN & & \\
\hline CHEMBL1939215 & 798279 & 6.1549 & 5.5911 & TRN & & \\
\hline CHEMBL1939181 & 798279 & 5.6216 & 5.2981 & TRN & & \\
\hline CHEMBL1939178 & 798279 & 5.4698 & 5.1944 & TRN & & \\
\hline CHEMBL1939209 & 798279 & 5.6904 & 5.5352 & TRN & & \\
\hline CHEMBL1939001 & 798279 & 3.4948 & 3.9066 & TRN & & \\
\hline CHEMBL1939206 & 798279 & 5.9586 & 6.0574 & TRN & & \\
\hline CHEMBL1939189 & 798279 & 5.9355 & 5.3535 & TRN & & \\
\hline CHEMBL1939217 & 798279 & 6.1549 & 5.8465 & TST & & \\
\hline CHEMBL1938992 & 798279 & 5.1858 & 5.1242 & TRN & & \\
\hline CHEMBL1939199 & 798279 & 5.284 & 5.7685 & TRN & & \\
\hline CHEMBL1939179 & 798279 & 5.5003 & 5.1332 & TRN & & \\
\hline CHEMBL1939000 & 798279 & 5.0862 & 5.0837 & TRN & & \\
\hline CHEMBL1938998 & 798279 & 5.1543 & 5.0425 & TRN & & \\
\hline CHEMBL1939175 & 798279 & 5.6536 & 5.3788 & TRN & & \\
\hline CHEMBL1939003 & 798279 & 3.4948 & 4.2865 & TRN & & \\
\hline CHEMBL1939186 & 798279 & 5.6253 & 5.3917 & TRN & & \\
\hline CHEMBL1939005 & 798279 & 3.4948 & 3.8486 & TRN & & \\
\hline CHEMBL1939174 & 798279 & 6.1549 & 5.528 & TRN & & \\
\hline CHEMBL1939201 & 798279 & 5.5918 & 5.5833 & TRN & & \\
\hline CHEMBL1939221 & 798279 & 6.1549 & 6.2658 & TRN & & \\
\hline CHEMBL1939204 & 798279 & 6.1367 & 6.1766 & TRN & & \\
\hline CHEMBL1939220 & 798279 & 5.8508 & 5.9714 & TRN & & \\
\hline CHEMBL1581755 & 798279 & 3.4948 & 3.9799 & TRN & & \\
\hline CHEMBL1939007 & 798279 & 4.6144 & 4.1531 & TRN & & \\
\hline CHEMBL1939195 & 798279 & 5.8069 & 4.9576 & TRN & & \\
\hline CHEMBL1939205 & 798279 & 5.8069 & 6.3582 & TRN & & \\
\hline CHEMBL1939211 & 798279 & 6.0458 & 6.351 & TRN & & \\
\hline CHEMBL1939180 & 798279 & 5.3179 & 5.5592 & TRN & & \\
\hline CHEMBL1939214 & 798279 & 3.4948 & 4.627 & TRN & & \\
\hline CHEMBL1939212 & 798279 & 5.2328 & 5.5331 & TST & & \\
\hline CHEMBL1938993 & 798279 & 5.0809 & 4.8511 & TRN & & \\
\hline CHEMBL1939184 & 798279 & 5.8013 & 5.7005 & TST & & \\
\hline CHEMBL1938991 & 798279 & 5.3401 & 4.5594 & TST & & \\
\hline CHEMBL1939188 & 798279 & 5.4437 & 5.6079 & TST & & \\
\hline CHEMBL1939009 & 798279 & 5.6289 & 5.2008 & TST & & \\
\hline CHEMBL1938999 & 798279 & 3.4948 & 4.8518 & TST & & \\
\hline CHEMBL1938996 & 798279 & 3.4948 & 5.9021 & TST & & \\
\hline CHEMBL1938995 & 798279 & 3.4948 & 4.677 & TST & & \\
\hline CHEMBL1939197 & 798279 & 5.8268 & 5.6984 & TST & & \\
\hline CHEMBL1939187 & 798279 & 5.5406 & 5.0116 & TST & & \\
\hline
\end{tabular}




$$
\text { Supplemental Table S2.txt }
$$

\begin{tabular}{|c|c|c|c|c|c|}
\hline CHEMBL1939202 & 798279 & 5.567 & 6.064 & TST & \\
\hline CHEMBL1939196 & 798279 & 5.399 & 5.0564 & TST & \\
\hline CHEMBL1939177 & 798279 & 5.5686 & 5.2332 & TST & \\
\hline CHEMBL1407368 & 737315 & 6.0953 & 6.0306 & TRN & \\
\hline CHEMBL1721448 & 737315 & 4.1831 & 3.3472 & TST & \\
\hline CHEMBL 3210218 & 737315 & 3.0 & 2.9278 & TRN & \\
\hline CHEMBL1589694 & 737315 & 3.0 & 3.0118 & TRN & \\
\hline CHEMBL1715328 & 737315 & 4.0768 & 3.4815 & TST & \\
\hline CHEMBL1724547 & 737315 & 4.5143 & 4.5316 & TRN & \\
\hline CHEMBL1729688 & 737315 & 4.4949 & 4.3688 & TRN & \\
\hline CHEMBL1732016 & 737315 & 4.9101 & 5.1575 & TRN & \\
\hline CHEMBL1672292 & 737315 & 5.5622 & 5.565 & TRN & \\
\hline CHEMBL1425801 & 737315 & 3.0 & 2.9655 & TRN & \\
\hline CHEMBL1409987 & 737315 & 3.0 & 2.9356 & TRN & \\
\hline CHEMBL1730304 & 737315 & 4.9508 & 4.9887 & TRN & \\
\hline CHEMBL1572439 & 737315 & 5.1593 & 5.1041 & TRN & \\
\hline CHEMBL1373210 & 737315 & 5.3883 & 5.5652 & TRN & \\
\hline CHEMBL601167 & 737315 & 5.4698 & 5.4332 & TRN & \\
\hline CHEMBL1719458 & 737315 & 3.0 & 3.2084 & TRN & \\
\hline CHEMBL1320181 & 737315 & 5.7595 & 5.8358 & TRN & \\
\hline CHEMBL1367928 & 737315 & 3.0 & 3.0691 & TRN & \\
\hline CHEMBL1408081 & 737315 & 6.2204 & 6.2661 & TRN & \\
\hline CHEMBL1439815 & 737315 & 5.2083 & 4.7048 & TST & \\
\hline CHEMBL1706168 & 737315 & 4.2132 & 4.0959 & TRN & \\
\hline CHEMBL1438889 & 737315 & 5.5317 & 5.3775 & TRN & \\
\hline CHEMBL1721385 & 737315 & 4.1959 & 2.9927 & TST & \\
\hline CHEMBL1701224 & 737315 & 6.433 & 6.29799 & 9999999999 & TRN \\
\hline CHEMBL1487870 & 737315 & 4.327 & 4.2008 & TRN & \\
\hline CHEMBL1719149 & 737315 & 5.4559 & 5.599 & TRN & \\
\hline CHEMBL1529781 & 737315 & 4.0706 & 4.1142 & TRN & \\
\hline CHEMBL1532025 & 737315 & 4.3279 & 4.3534 & TRN & \\
\hline CHEMBL1724311 & 737315 & 4.52 & 4.5524 & TRN & \\
\hline CHEMBL1371816 & 737315 & 5.1965 & 4.9669 & TRN & \\
\hline CHEMBL1574614 & 737315 & 3.0 & 2.95600 & 00000000004 & TRN \\
\hline CHEMBL1709810 & 737315 & 4.4672 & 4.3607 & TRN & \\
\hline CHEMBL1721258 & 737315 & 3.0 & 2.9758 & TRN & \\
\hline CHEMBL1713374 & 737315 & 2.699 & 2.5525 & TST & \\
\hline CHEMBL1735637 & 737315 & 3.0 & 2.3879 & TST & \\
\hline CHEMBL1526088 & 737315 & 5.1713 & 5.2276 & TRN & \\
\hline CHEMBL1718018 & 737315 & 4.3307 & 4.0979 & TRN & \\
\hline CHEMBL3193786 & 737315 & 5.289 & 5.2081 & TRN & \\
\hline CHEMBL1413629 & 737315 & 4.1192 & 4.1872 & TRN & \\
\hline CHEMBL3209371 & 737315 & 3.0 & 2.9031 & TRN & \\
\hline CHEMBL1552304 & 737315 & 4.2328 & 4.2843 & TRN & \\
\hline CHEMBL2000167 & 737315 & 5.3696 & 5.3239 & TRN & \\
\hline CHEMBL1721618 & 737315 & 5.433 & 5.5984 & TRN & \\
\hline CHEMBL1478943 & 737315 & 3.0 & 2.8481 & TRN & \\
\hline \multirow[t]{2}{*}{ CHEMBL1373132 } & 737315 & 5.71899 & 79999999 & 5.6955 & TRN \\
\hline & & \multicolumn{4}{|c|}{ Page 14340} \\
\hline
\end{tabular}




\begin{tabular}{|c|c|c|c|c|c|}
\hline \multicolumn{6}{|c|}{ Supplemental Table S2.txt } \\
\hline CHEMBL1714966 & 737315 & 3.0 & 3.3942 & TRN & \\
\hline CHEMBL1700415 & 737315 & 3.0 & 3.2086 & TRN & \\
\hline CHEMBL1443268 & 737315 & 5.3134 & 4.931 & TRN & \\
\hline CHEMBL1732186 & 737315 & 3.0 & 2.9647 & TRN & \\
\hline CHEMBL408702 & 737315 & 3.0 & 2.176 & TST & \\
\hline CHEMBL1550429 & 737315 & 5.1811 & 5.3561 & TRN & \\
\hline CHEMBL1323221 & 737315 & 4.0511 & 4.1928 & TRN & \\
\hline CHEMBL1417070 & 737315 & 4.3279 & 4.6675 & TST & \\
\hline CHEMBL1343331 & 737315 & 4.8894 & 4.7809 & TRN & \\
\hline CHEMBL1704862 & 737315 & 5.4572 & 5.4853 & TRN & \\
\hline CHEMBL1488869 & 737315 & 3.0 & 2.8848 & TRN & \\
\hline CHEMBL1729772 & 737315 & 4.3487 & 4.4942 & TRN & \\
\hline CHEMBL1672291 & 737315 & 5.4401 & 5.3678 & TRN & \\
\hline CHEMBL3194119 & 737315 & 4.5901 & 4.5801 & TRN & \\
\hline CHEMBL1710150 & 737315 & 5.0706 & 3.1658 & TST & \\
\hline CHEMBL1411988 & 737315 & 3.0 & 3.1061 & TRN & \\
\hline CHEMBL1589711 & 737315 & 4.1361 & 4.1905 & TRN & \\
\hline CHEMBL1327648 & 737315 & 5.0491 & 5.0954 & TRN & \\
\hline CHEMBL1390354 & 737315 & 5.4724 & 5.4526 & TRN & \\
\hline CHEMBL1734920 & 737315 & 3.0 & 3.0727 & TRN & \\
\hline CHEMBL1387413 & 737315 & 4.4089 & 4.3658 & TRN & \\
\hline CHEMBL1710376 & 737315 & 3.0 & 3.0645 & TRN & \\
\hline CHEMBL1698734 & 737315 & 3.0 & 2.8358 & TST & \\
\hline CHEMBL1407963 & 737315 & 3.0 & 2.8486 & TRN & \\
\hline CHEMBL1444708 & 737315 & 4.1391 & 4.2081 & TRN & \\
\hline CHEMBL1722719 & 737315 & 4.6904 & 4.665 & TRN & \\
\hline CHEMBL1724482 & 737315 & 4.8013 & 4.9379 & TST & \\
\hline CHEMBL1492305 & 737315 & 5.4023 & 5.1574 & TST & \\
\hline CHEMBL1708751 & 737315 & 3.0 & 2.7209 & TST & \\
\hline CHEMBL1333032 & 737315 & 4.0996 & 4.1823 & TST & \\
\hline CHEMBL1732934 & 737315 & 3.0 & 3.2756 & TST & \\
\hline CHEMBL1715912 & 737315 & 3.0 & 2.7504 & TST & \\
\hline CHEMBL1718472 & 737315 & 4.266 & 4.1611 & TST & \\
\hline CHEMBL1487024 & 737315 & 4.0182 & 3.8402 & TST & \\
\hline CHEMBL1716861 & 737315 & 3.0 & 2.8453 & TST & \\
\hline CHEMBL1727280 & 737315 & 3.0 & 2.9883 & TST & \\
\hline CHEMBL1560901 & 737315 & 4.2027 & 3.8265 & TST & \\
\hline CHEMBL3963317 & 1528851 & 8.301 & 8.353 & TRN & \\
\hline CHEMBL 3649859 & 1528851 & 8.0969 & 8.2281 & TRN & \\
\hline CHEMBL3649876 & 1528851 & 7.3872 & 7.4896 & TRN & \\
\hline CHEMBL3650011 & 1528851 & 10.0 & 10.209 & TRN & \\
\hline CHEMBL3649991 & 1528851 & 6.0 & 6.3402 & TRN & \\
\hline CHEMBL 3649870 & 1528851 & 8.5229 & 8.5418 & TRN & \\
\hline CHEMBL3649828 & 1528851 & 8.699 & 8.957 & TRN & \\
\hline CHEMBL3649912 & 1528851 & 8.301 & 8.1593 & TRN & \\
\hline CHEMBL3649917 & 1528851 & 7.3768 & 7.61299 & 99999999995 & TRN \\
\hline CHEMBL 3647061 & 1528851 & 8.699 & 8.6943 & TRN & \\
\hline CHEMBL 3650021 & 1528851 & 8.5229 & 6.9706 & TST & \\
\hline
\end{tabular}




\begin{tabular}{|c|c|c|c|c|c|}
\hline \multicolumn{6}{|c|}{ Supplemental Table S2.txt } \\
\hline CHEMBL 3649823 & 1528851 & 6.0 & 6.6564 & TRN & \\
\hline CHEMBL 3957580 & 1528851 & 6.0 & 5.9903 & TRN & \\
\hline CHEMBL3949194 & 1528851 & 8.5229 & 8.4169 & TRN & \\
\hline CHEMBL 3649854 & 1528851 & 7.9586 & 8.0533 & TRN & \\
\hline CHEMBL3649873 & 1528851 & 7.7212 & 7.8358 & TST & \\
\hline CHEMBL 3653329 & 1528851 & 7.1427 & 7.0751 & TRN & \\
\hline CHEMBL 3649907 & 1528851 & 6.0 & 6.1978 & TRN & \\
\hline CHEMBL3923676 & 1528851 & 8.3979 & 8.3954 & TRN & \\
\hline CHEMBL3649849 & 1528851 & 9.0 & 8.9326 & TRN & \\
\hline CHEMBL3649964 & 1528851 & 8.5229 & 7.9418 & TRN & \\
\hline CHEMBL 3971741 & 1528851 & 8.699 & 9.2031 & TST & \\
\hline CHEMBL3653334 & 1528851 & 8.1549 & 8.2622 & TRN & \\
\hline CHEMBL3649915 & 1528851 & 6.0 & 6.4175 & TRN & \\
\hline CHEMBL3957470 & 1528851 & 8.699 & 9.2515 & TST & \\
\hline CHEMBL3909594 & 1528851 & 9.0 & 9.0212 & TRN & \\
\hline CHEMBL 3649865 & 1528851 & 9.0 & 8.7429 & TRN & \\
\hline CHEMBL3650015 & 1528851 & 7.5528 & 7.4264 & TST & \\
\hline CHEMBL3649898 & 1528851 & 9.0 & 9.045 & TRN & \\
\hline CHEMBL3954821 & 1528851 & 6.6021 & 6.7957 & TST & \\
\hline CHEMBL3653315 & 1528851 & 6.0 & 6.037006 & 0000000001 & TRN \\
\hline CHEMBL 3647051 & 1528851 & 9.0 & 9.1215 & TRN & \\
\hline CHEMBL3647047 & 1528851 & 9.0 & 8.7463 & TRN & \\
\hline CHEMBL3649998 & 1528851 & 8.301 & 8.3365 & TRN & \\
\hline CHEMBL 3649848 & 1528851 & 8.0 & 6.1453 & TRN & \\
\hline CHEMBL 3946174 & 1528851 & 8.5229 & 8.441 & TRN & \\
\hline CHEMBL 3649960 & 1528851 & 6.0 & 6.1749 & TRN & \\
\hline CHEMBL3649921 & 1528851 & 7.0655 & 6.7119 & TST & \\
\hline CHEMBL3649961 & 1528851 & 6.0 & 6.0427 & TRN & \\
\hline CHEMBL3649869 & 1528851 & 9.0 & 8.811 & TRN & \\
\hline CHEMBL3907252 & 1528851 & 6.0 & 6.1022 & TRN & \\
\hline CHEMBL 3653336 & 1528851 & 7.1549 & 8.2038 & TST & \\
\hline CHEMBL3986537 & 1528851 & 8.5229 & 8.5641 & TRN & \\
\hline CHEMBL 3927925 & 1528851 & 6.4522 & 6.6323 & TRN & \\
\hline CHEMBL3649926 & 1528851 & 9.0 & 8.8449 & TRN & \\
\hline CHEMBL3911237 & 1528851 & 9.0 & 8.6276 & TRN & \\
\hline CHEMBL3979791 & 1528851 & 6.0 & 6.215 & TRN & \\
\hline CHEMBL3649896 & 1528851 & 8.0458 & 8.1846 & TRN & \\
\hline CHEMBL 3653337 & 1528851 & 7.4318 & 7.6118 & TST & \\
\hline CHEMBL3649990 & 1528851 & 8.699 & 8.7403 & TST & \\
\hline CHEMBL3938767 & 1528851 & 8.2218 & 8.0306 & TRN & \\
\hline CHEMBL3952603 & 1528851 & 7.9586 & 7.8773 & TRN & \\
\hline CHEMBL3969880 & 1528851 & 6.0 & 6.0397 & TRN & \\
\hline CHEMBL 3907671 & 1528851 & 8.2218 & 8.1624 & TRN & \\
\hline CHEMBL3649891 & 1528851 & 9.0 & 9.2271 & TRN & \\
\hline CHEMBL3971736 & 1528851 & 6.0 & $6.66100 t$ & 00000000005 & TST \\
\hline CHEMBL3647069 & 1528851 & 6.0 & 6.2913 & TRN & \\
\hline CHEMBL3933957 & 1528851 & 6.0 & 6.1735 & TST & \\
\hline CHEMBL3649890 & 1528851 & 7.8539 & 7.6676 & TRN & \\
\hline
\end{tabular}


Supplemental Table S2.txt

\begin{tabular}{|c|c|c|c|c|}
\hline HEM & 528851 & & 5501 & \\
\hline HEMPI 2510050 & 528851 & 7.9208 & 3.1014 & \\
\hline & 851 & & & \\
\hline HEMBL 39 & 28851 & 6.0 & & $2 \mathrm{~N}$ \\
\hline HEMBL3968578 & 528851 & & 5768 & \\
\hline HEMBL3639487 & 528851 & 6.0 & .1455 & \\
\hline HEMBL396 & 528851 & & .679 & \\
\hline AEMBL36 & 528851 & & & RN \\
\hline AEMBL3649879 & 528851 & & 3.5133 & \\
\hline HEMBL391 & 528851 & 6.9136 & .7037 & \\
\hline HEMBL393. & 528851 & 9.0 & 9.2984 & \\
\hline AEMBL36 & 528851 & & .9387 & \\
\hline AEMBL39 & 8851 & & & RN \\
\hline HEMBL 394 & 528851 & & 7.6655 & \\
\hline AEMBL 365 & 528851 & & & \\
\hline AEMBL364 & 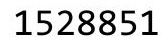 & 6. & .5044 & \\
\hline HEMBL 39 & 28051 & & & \\
\hline HEMBL 39 & 8851 & & & \\
\hline HEMBL36 & 528851 & & & \\
\hline AEMBL36 & 851 & & & \\
\hline AEMBL36 & D. & 10 & 76 & $\mathrm{IRIV}$ \\
\hline HEMBL36 & DI & & & Niv \\
\hline HEMBL3 & 51 & & & \\
\hline HEMBL36 & & & & TRN \\
\hline AEMBL39e & & & & Iد \\
\hline HEMBL36 & 8851 & 6. & 65 & RN \\
\hline HEMBL3S & $b 1$ & 9. & 26 & RN \\
\hline HFMBI 36 & 3851 & 6 . & 277 & \\
\hline HEMBL 364 & 8851 & & & $\ln$ \\
\hline HEMBL 364 & 528851 & & & is \\
\hline HEMBL 36 & 8851 & 9 & 369 & $\mathrm{RN}$ \\
\hline HEMBL; & 51 & & & ST \\
\hline HEMBL; & 51 & 6 . & 39 & 「RN \\
\hline HEMBL 364 & $=000$ - & & & IRN \\
\hline HEMBL 395 & 528851 & 8. & 98 & TRN \\
\hline HEMBL36 & 8851 & & 59 & TRN \\
\hline HFMRI $=2$ & 1 & 9 & 49 & $\Gamma \mathrm{RN}$ \\
\hline HEMBL3 & & & & TRN \\
\hline HEMBL392 & 528851 & & 7.2012 & TST \\
\hline AEMBL39 & 528851 & & 636 & TRN \\
\hline HEMBL39 & 528851 & & & RN \\
\hline CHEMBL364 & 528851 & 7.8861 & & TRN \\
\hline HEMBL39 & 528851 & 9.0 & 9.3784 & TST \\
\hline HEMBL 364 & 528851 & 10.0 & 6534 & $\Gamma R$ \\
\hline$=2+3$ & 851 & & & $\mathrm{~N}$ \\
\hline HEMBL 36 & 528851 & 69 & . 9146 & \\
\hline CHEMBL 36 & 528851 & 7.1675 & 7.0924 & \\
\hline CHEMBL3649911 & 1528851 & 8.5229 & 7.8532 & ГRN \\
\hline
\end{tabular}

Page 14343 


$$
\text { Supplemental Table S2.txt }
$$

\begin{tabular}{|c|c|c|c|c|}
\hline$\partial$ & 51 & & & TRN \\
\hline HEMBI & 851 & 7.7447 & & \\
\hline IEMBL: & 28851 & 9.0 & & \\
\hline IEMBL 3971319 & 528851 & 9.0 & 1024 & \\
\hline AEMBL3 & 528851 & & 74 & \\
\hline & 528851 & 6.0 & 57 & \\
\hline IEMBL & 528851 & & .718 & \\
\hline AEMBL & 528851 & & 2504 & \\
\hline AEMBL: & 528851 & 8.301 & 5404 & \\
\hline AEMBL & 528851 & 9.0 & 394 & \\
\hline $5 \mathrm{MC}$ & 528851 & 8.0 & 526 & \\
\hline IEMBL & L528851 & 6.0 & 849 & \\
\hline IEMBL & 528851 & & 9605 & \\
\hline IEMBL & 528851 & $7 . \varepsilon$ & 817 & \\
\hline 8 & 528851 & 8. & 89 & \\
\hline & 528851 & & & \\
\hline IEMB & 1528851 & & 66 & \\
\hline IEMBL & 528851 & & 04 & \\
\hline 7 & 528851 & 8. & 673 & \\
\hline$\theta$ & 528851 & 7. & 61 & \\
\hline & 528851 & 8. & & \\
\hline 93 & 1528851 & 6.0 & & \\
\hline 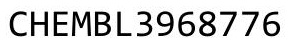 & 528851 & & & \\
\hline It & 1528851 & 8 . & 38 & \\
\hline 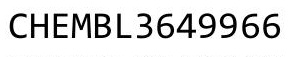 & 528851 & 8 . & & \\
\hline 2 & 528851 & 6. & & \\
\hline 06 & 851 & 7. & & \\
\hline 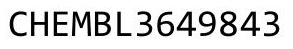 & 851 & & & \\
\hline EMBL & 528851 & 9. & 72 & \\
\hline 4 & 528851 & 6. & 62 & \\
\hline 1 & 851 & 9. & 17 & \\
\hline & 1528851 & 7. & & \\
\hline & 528851 & & 141 & \\
\hline HEMBL & 528851 & 8. & & \\
\hline 9 & 51 & 6.6 & 17 & \\
\hline & & 7. & 23 & \\
\hline & 1528851 & 6.0 & & \\
\hline & 528851 & 9. & & \\
\hline $\mathrm{CH}$ & 851 & 8.5229 & 815 & 13 \\
\hline & 1528851 & 6. & & \\
\hline & 1528851 & 8.69 & & \\
\hline IEMBL: & 1528851 & 6.0 & .8131 & TS \\
\hline 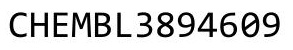 & 1528851 & 6.29 & 1051 & $\mathrm{~T}$ \\
\hline $\mathrm{CH}$ & 1528851 & 10.0 & 1776 & \\
\hline & 1528851 & 7.537 & & \\
\hline CHEMBL & 1528851 & 8.699 & 8.6812 & TR \\
\hline AEMBL: & 1528851 & 9.0 & 8.8956 & TR \\
\hline CHEMBL3649979 & 1528851 & 8.699 & 8.5205 & \\
\hline
\end{tabular}

Page 14344 


$$
\text { Supplemental Table S2.txt }
$$

CHEMBL3649919

CHEMBL 3650012

CHEMBL3649959

CHEMBL3984635

CHEMBL 3909218

CHEMBL 3649846

CHEMBL 3927923

CHEMBL3649983

CHEMBL 3894245

CHEMBL3649892

CHEMBL3942694

CHEMBL3653318

CHEMBL3941748

CHEMBL3649968

CHEMBL3933691

CHEMBL 3649841

CHEMBL3929391

CHEMBL 3649914

CHEMBL3649905

CHEMBL3926337

CHEMBL3914761

CHEMBL3653333

CHEMBL 3649875

CHEMBL 3647067

CHEMBL 3649816

CHEMBL3649965

CHEMBL 3649877

CHEMBL3647049

CHEMBL3945283

CHEMBL3647057

CHEMBL3890287

CHEMBL3649817

CHEMBL3654193

CHEMBL3649918

CHEMBL3649989

CHEMBL3647056

CHEMBL3649818

CHEMBL3952519

CHEMBL3650020

CHEMBL 3649970

CHEMBL3647066

CHEMBL 3959078

CHEMBL3959820

CHEMBL3895119

CHEMBL3649971

CHEMBL 3958237

CHEMBL 3653330

CHEMBL3952705 $\begin{array}{llll}1528851 & 7.3979 & 7.1105 & \text { TST }\end{array}$

$\begin{array}{llll}1528851 & 7.699 & 7.6942 & \text { TRN }\end{array}$

$\begin{array}{llll}15288516.0 & 7.9129 & \text { TRN }\end{array}$

$\begin{array}{llll}1528851 & 8.3979 & 7.999 & \text { TRN }\end{array}$

$\begin{array}{llll}1528851 & 8.301 & 8.3575 & \text { TRN }\end{array}$

15288518.2218

15288516.0

15288516.0

15288516.0

15288518.5229

15288518.5229

8. 232000000000001

6.4835 TST

5.9227 TST

6.0457 TRN

8.6591 TRN

8.5557 TRN

$\begin{array}{llll}15288516.0 & 6.0847 & \text { TRN }\end{array}$

$\begin{array}{lll}15288519.0 & 9.4264 & \text { TST }\end{array}$

$\begin{array}{llll}1528851 & 6.0 & 5.8348 & \text { TRN }\end{array}$

$\begin{array}{llll}1528851 & 8.3979 & 8.3536 & \text { TRN }\end{array}$

$\begin{array}{llll}1528851 & 8.1549 & 8.2125 & \text { TRN }\end{array}$

$\begin{array}{llll}1528851 & 6.0 & 7.6353 & \text { TRN }\end{array}$

$\begin{array}{llll}1528851 & 7.7212 & 7.6 & \text { TRN }\end{array}$

$\begin{array}{llll}1528851 & 9.0 & 9.1689 & \text { TRN }\end{array}$

$\begin{array}{llll}1528851 & 6.8894 & 6.9606 & \text { TST }\end{array}$

$\begin{array}{llll}1528851 & 7.7959 & 8.1506 & \text { TST }\end{array}$

$\begin{array}{llll}1528851 & 8.699 & 8.7631 & \text { TRN }\end{array}$

$\begin{array}{lll}15288519.0 & 9.1789 & \text { TRN }\end{array}$

$\begin{array}{lll}15288519.0 & 8.4173 & \text { TST }\end{array}$

$\begin{array}{llll}1528851 & 7.3665 & 7.2938 & \text { TRN }\end{array}$

$\begin{array}{llll}1528851 & 7.8239 & 7.6914 & \text { TRN }\end{array}$

$\begin{array}{llll}1528851 & 7.9586 & 7.8858 & \text { TRN }\end{array}$

$\begin{array}{llll}1528851 & 8.5229 & 8.5969 & \text { TRN }\end{array}$

$\begin{array}{llll}1528851 & 6.0 & 6.3208 & \text { TRN }\end{array}$

$\begin{array}{ll}15288519.0 & 9.1086 \text { TRN }\end{array}$

$\begin{array}{llll}1528851 & 8.699 & 9.0208 & \text { TST }\end{array}$

$\begin{array}{llll}1528851 & 6.0 & 6.0854 & \text { TRN }\end{array}$

$\begin{array}{llll}1528851 & 7.2757 & 7.2597 & \text { TST }\end{array}$

$\begin{array}{llll}1528851 & 7.6383 & 7.5161 & \text { TRN }\end{array}$

$\begin{array}{llll}1528851 & 8.699 & 8.5161 & \text { TRN }\end{array}$

$\begin{array}{llll}1528851 & 6.0 & 6.1044 & \text { TRN }\end{array}$

$\begin{array}{llll}1528851 & 7.7959 & 7.8181 & \text { TRN }\end{array}$

$\begin{array}{llll}1528851 & 8.3979 & 8.3639 & \text { TRN }\end{array}$

$\begin{array}{llll}1528851 & 8.301 & 6.4447 & \text { TRN }\end{array}$

$\begin{array}{lll}15288516.0 & 6.0973 & \text { TRN }\end{array}$

$\begin{array}{llll}1528851 & 8.699 & 8.849 & \text { TRN }\end{array}$

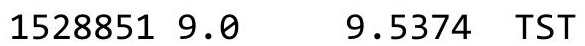

$\begin{array}{lll}15288519.0 & 8.5738 \text { TST }\end{array}$

$\begin{array}{llll}1528851 & 8.3979 & 8.5028 & \text { TST }\end{array}$

$\begin{array}{llll}1528851 & 7.7212 & 8.0336 & \text { TST }\end{array}$

$\begin{array}{llll}15288519.0 & 8.7711 & \text { TRN }\end{array}$

$\begin{array}{llll}1528851 & 6.9508 & 6.9637 & \text { TRN }\end{array}$

$\begin{array}{lll}1528851 & 10.0 & 9.6844\end{array}$ 
Supplemental Table S2.txt

\begin{tabular}{|c|c|c|c|c|c|c|}
\hline CHEMBL 3649987 & 1528851 & 8.3979 & 8.22 & TST & & \\
\hline CHEMBL3934510 & 1528851 & 7.6198 & 8.2365 & TST & & \\
\hline CHEMBL3649977 & 1528851 & 8.5229 & 8.112 & TRN & & \\
\hline CHEMBL 3949967 & 1528851 & 9.0 & 8.8346 & TRN & & \\
\hline CHEMBL3647059 & 1528851 & 6.0 & 5.9075 & TRN & & \\
\hline CHEMBL 3650009 & 1528851 & $6.7570 e$ & 00000000 & $\partial 1$ & 6.8151 & TST \\
\hline CHEMBL 3649851 & 1528851 & 7.6778 & 7.9113 & TRN & & \\
\hline CHEMBL 3649881 & 1528851 & 8.699 & 8.7301 & TRN & & \\
\hline CHEMBL3931087 & 1528851 & 8.1549 & 7.9446 & TST & & \\
\hline CHEMBL3654187 & 1528851 & 7.4559 & 5.8213 & TRN & & \\
\hline CHEMBL 3653326 & 1528851 & 9.0 & 8.9126 & TRN & & \\
\hline CHEMBL 3649878 & 1528851 & 8.0458 & 7.943 & TRN & & \\
\hline CHEMBL 3649974 & 1528851 & 6.0 & 6.0555 & TRN & & \\
\hline CHEMBL 3649834 & 1528851 & 6.0 & 5.7707 & TRN & & \\
\hline CHEMBL3939191 & 1528851 & 9.0 & 9.0345 & TRN & & \\
\hline CHEMBL 3653327 & 1528851 & 7.1871 & 7.4047 & TRN & & \\
\hline CHEMBL3916078 & 1528851 & 8.3979 & 8.2807 & TRN & & \\
\hline CHEMBL 3649981 & 1528851 & 8.699 & 7.8938 & TST & & \\
\hline CHEMBL 3650018 & 1528851 & 6.0 & 6.2209 & TRN & & \\
\hline CHEMBL 3650013 & 1528851 & 8.0 & 8.0455 & TRN & & \\
\hline CHEMBL 3650019 & 1528851 & 6.0 & 6.1493 & TRN & & \\
\hline CHEMBL3649819 & 1528851 & 9.0 & 8.9352 & TRN & & \\
\hline CHEMBL 3649988 & 1528851 & 8.3979 & 8.4243 & TST & & \\
\hline CHEMBL3649815 & 1528851 & 8.5229 & 8.7555 & TRN & & \\
\hline CHEMBL 3649963 & 1528851 & 6.0 & 6.2077 & TRN & & \\
\hline CHEMBL 3653321 & 1528851 & 6.0 & 6.2452 & TRN & & \\
\hline CHEMBL 3649860 & 1528851 & 6.0 & 6.3693 & TRN & & \\
\hline CHEMBL 3966472 & 1528851 & 6.0 & 6.2765 & TST & & \\
\hline CHEMBL3979460 & 1528851 & 8.5229 & 8.4434 & TRN & & \\
\hline CHEMBL 3649845 & 1528851 & 6.0 & 6.4235 & TRN & & \\
\hline CHEMBL3981115 & 1528851 & 10.0 & 10.0331 & TRN & & \\
\hline CHEMBL3978215 & 1528851 & 8.301 & 8.3046 & TRN & & \\
\hline CHEMBL3649996 & 1528851 & 8.2218 & 8.1536 & TRN & & \\
\hline CHEMBL3649976 & 1528851 & 6.0 & 6.145 & TRN & & \\
\hline CHEMBL 3650008 & 1528851 & 6.7959 & 6.8768 & TST & & \\
\hline CHEMBL3971691 & 1528851 & 9.0 & 9.0567 & TRN & & \\
\hline CHEMBL 3894230 & 1528851 & 8.5229 & 8.3816 & TRN & & \\
\hline CHEMBL 3649969 & 1528851 & 6.0 & 5.9753 & TRN & & \\
\hline CHEMBL 3649853 & 1528851 & 8.699 & 8.7135 & TRN & & \\
\hline CHEMBL 3649872 & 1528851 & 9.0 & 8.9211 & TRN & & \\
\hline CHEMBL3649997 & 1528851 & 8.0969 & 8.129 & TRN & & \\
\hline CHEMBL3653335 & 1528851 & 8.301 & 8.4043 & TRN & & \\
\hline CHEMBL3649863 & 1528851 & 9.0 & 9.0635 & TRN & & \\
\hline CHEMBL3650017 & 1528851 & 10.0 & 6.9511 & TST & & \\
\hline CHEMBL 3649920 & 1528851 & 6.8794 & 6.7819 & TRN & & \\
\hline CHEMBL 3647053 & 1528851 & 9.0 & 9.1275 & TRN & & \\
\hline CHEMBL 3639488 & 1528851 & 6.0 & 6.3167 & TRN & & \\
\hline CHEMBL3649826 & 1528851 & 8.5229 & 8.7987 & TRN & & \\
\hline
\end{tabular}

Page 14346 


\begin{tabular}{|c|c|c|c|c|}
\hline & & & & \\
\hline EMBL494630 & 764847 & 8.1549 & 6.6439 & TS \\
\hline CHEMBL462232 & 764847 & 7.6383 & 7.0364 & \\
\hline CHEMBL1822366 & 64847 & 1549 & 498 & \\
\hline CHEMBL508403 & 64847 & 6.3279 & 2022 & \\
\hline CHEMBL256920 & 764847 & 6.8861 & 006 & \\
\hline HEMBL1822556 & 64847 & 7.0655 & 06 & \\
\hline CHEMBL1822374 & 64847 & 5.3279 & 469 & \\
\hline CHEMBL517469 & 64847 & 7.6778 & 365 & \\
\hline CHEMBL458874 & 764847 & 5.301 & 5.3615 & \\
\hline CHEMBL1822550 & 764847 & 135 & 748 & \\
\hline CHEMBL503090 & 764 & 6.9586 & 102 & \\
\hline CHEMBL1822549 & 764 & 239 & 309 & \\
\hline CHEMBL252213 & 47 & 6.585 & 996 & \\
\hline CHEMBL1822764 & 764 & 7. & 851 & \\
\hline CHEMBL4 & 764 & 8.7212 & 7.4685 & \\
\hline CHEMBL 5 & 47 & 212 & 325 & \\
\hline CHEMBL 1 & 47 & 114 & 398 & \\
\hline CHEMBL1822001 & 47 & 7.3468 & 821 & \\
\hline CHEMBL460791 & 76 & 596 & 329 & \\
\hline CHEMBL1 & 764 & 7.3372 & 75 & \\
\hline CHEMBL & 764 & 239 & 45 & \\
\hline CHEMBL: & 47 & 212 & 17 & \\
\hline CHEMBL1822376 & 764 & 7471 & 817 & \\
\hline CHEMBL1822548 & 76 & 21 & & \\
\hline CHEMBL 5 & 764 & 7.1938 & 211 & \\
\hline CHEMBL & 47 & 979 & 826 & \\
\hline CHEMBL & 47 & $\partial 89$ & 11 & \\
\hline HEMBL462357 & 764 & 969 & 586 & \\
\hline CHEMBL253444 & 764 & 6.3565 & 6.6235 & \\
\hline CHEMBL456720 & 764 & 6.1871 & 327 & 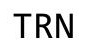 \\
\hline CHEMBL & 47 & 676 & & \\
\hline CHEMBL: & 76 & 949 & 333 & $\mathrm{TR}$ \\
\hline CHEMBL493313 & 764 & 6.4815 & 596 & TR \\
\hline CHEMBL445 & 764 & 8.5686 & 866 & TS \\
\hline CHEMBL5 & 764 & 5.5114 & 54 & IJ \\
\hline CHEMBL & 764 & 7.5686 & 239 & TRN \\
\hline CHEMBL: & 764 & 8.7447 & 066 & $\mathrm{TR}$ \\
\hline CHEMBL444560 & 764847 & 7.7696 & 7.9645 & $\mathrm{TR}$ \\
\hline CHEMBL1822972 & 764 & 7.1871 & 607 & $T R$ \\
\hline CHEMBL & 764 & 539 & & או \\
\hline CHEMBL 5 & 764 & 8.699 & 8.1452 & $\mathrm{TR}$ \\
\hline CHEMBL1822757 & 764847 & 7.7696 & 7.1876 & TRI \\
\hline CHEMBL1822582 & 764847 & 5.8386 & 6.303 & $\mathrm{TR}$ \\
\hline CHEMBL556837 & 764 & 7.6576 & 278 & TS \\
\hline CHEMBL5 & 764 & 8.4685 & 8.6204 & K \\
\hline CHEMBL448993 & 764847 & 6.699 & 6.8805 & $\mathrm{TR}$ \\
\hline CHEMBL503139 & 764847 & 8.6383 & 7.9552 & $\mathrm{TR}$ \\
\hline CHEMBL518656 & 764847 & 8.5686 & 8.5988 & $\mathrm{TR}$ \\
\hline
\end{tabular}

Page 14347 


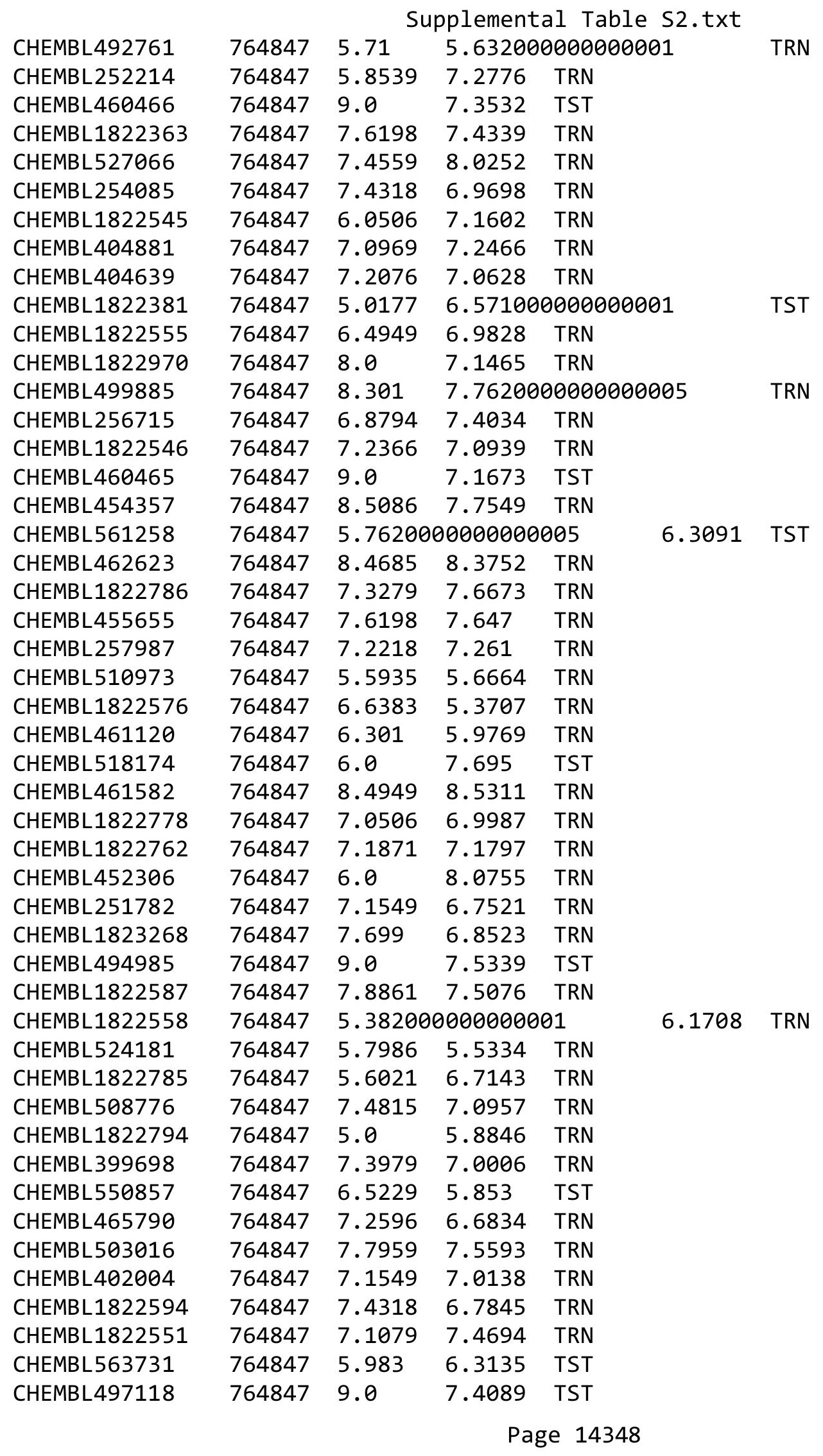




\begin{tabular}{|c|c|c|c|c|c|}
\hline & & & & & \\
\hline CHEMBL1822544 & 764847 & 6.301 & 6.9733 & TRN & \\
\hline CHEMBL492760 & 764847 & 5.6799 & 5.2844 & TST & \\
\hline CHEMBL430027 & 764847 & 6.0 & 6.7925 & TRN & \\
\hline CHEMBL561180 & 764847 & 5.3565 & 6.1715 & TST & \\
\hline CHEMBL1823269 & 764847 & 7.7959 & 7.2781 & TRN & \\
\hline CHEMBL454356 & 764847 & 8.5528 & 7.7683 & TRN & \\
\hline CHEMBL1822761 & 764847 & 7.3468 & 6.7604 & TRN & \\
\hline CHEMBL564904 & 764847 & 7.9586 & 6.4727 & TST & \\
\hline CHEMBL459948 & 764847 & 7.1427 & 7.3284 & TRN & \\
\hline CHEMBL252415 & 764847 & 6.3872 & 6.7627 & TRN & \\
\hline CHEMBL 256972 & 764847 & 6.9469 & 7.2393 & TRN & \\
\hline CHEMBL1822547 & 764847 & 6.3665 & 6.3543 & TRN & \\
\hline CHEMBL461293 & 764847 & 8.8861 & 7.6301 & TST & \\
\hline CHEMBL258396 & 764847 & 7.1612 & 7.2809 & TRN & \\
\hline CHEMBL1822759 & 764847 & 7.6778 & 6.7253 & TRN & \\
\hline CHEMBL 254907 & 764847 & 6.8539 & 6.9025 & TRN & \\
\hline CHEMBL456722 & 764847 & 5.2757 & 5.239 & TST & \\
\hline CHEMBL1822367 & 764847 & 8.301 & 8.0637 & TRN & \\
\hline CHEMBL457338 & 764847 & 5.8239 & 6.1165 & TRN & \\
\hline CHEMBL453613 & 764847 & 7.6021 & 7.2829 & TRN & \\
\hline CHEMBL 253223 & 764847 & 6.1079 & 6.664 & TRN & \\
\hline CHEMBL399674 & 764847 & 6.7212 & 6.8788 & TRN & \\
\hline CHEMBL1822377 & 764847 & 6.6576 & 6.6606 & TST & \\
\hline CHEMBL1822588 & 764847 & 6.6198 & 6.7091 & TRN & \\
\hline CHEMBL518209 & 764847 & 7.4559 & 6.8828 & TRN & \\
\hline CHEMBL502331 & 764847 & 7.5376 & 7.6465 & TRN & \\
\hline CHEMBL459325 & 764847 & 6.2676 & 6.3871 & TRN & \\
\hline CHEMBL561660 & 764847 & 7.0862 & 6.2983 & TST & \\
\hline CHEMBL1822573 & 764847 & 5.1765 & 5.6342 & TRN & \\
\hline CHEMBL454101 & 764847 & 8.0 & 7.49299 & 9999999999 & TRN \\
\hline CHEMBL518208 & 764847 & 7.2007 & 7.126 & TRN & \\
\hline CHEMBL508006 & 764847 & 6.0 & 7.1307 & TRN & \\
\hline CHEMBL1822385 & 764847 & 5.9747 & 7.5515 & TRN & \\
\hline CHEMBL457339 & 764847 & 5.7447 & 5.803 & TRN & \\
\hline CHEMBL1823249 & 764847 & 7.6198 & 7.3367 & TRN & \\
\hline CHEMBL459478 & 764847 & 7.4089 & 6.9434 & TRN & \\
\hline CHEMBL1822384 & 764847 & 7.1079 & 7.0459 & TRN & \\
\hline CHEMBL459647 & 764847 & 8.0969 & 7.4244 & TST & \\
\hline CHEMBL462711 & 764847 & 5.301 & 6.0584 & TRN & \\
\hline CHEMBL253657 & 764847 & 6.0 & 6.7609 & TRN & \\
\hline CHEMBL516790 & 764847 & 8.3468 & 8.1655 & TRN & \\
\hline CHEMBL489326 & 764847 & 7.6778 & 7.44600 & 2000000001 & TST \\
\hline CHEMBL1822580 & 764847 & 5.1972 & 6.4403 & TRN & \\
\hline CHEMBL500536 & 764847 & 7.284 & 7.23 & TRN & \\
\hline CHEMBL465791 & 764847 & 6.4949 & 6.8417 & TRN & \\
\hline CHEMBL498769 & 764847 & 8.2218 & 6.3281 & TST & \\
\hline CHEMBL495899 & 764847 & 6.2147 & 6.2289 & TST & \\
\hline CHEMBL1822575 & 764847 & 5.2457 & 5.8172 & TRN & \\
\hline
\end{tabular}




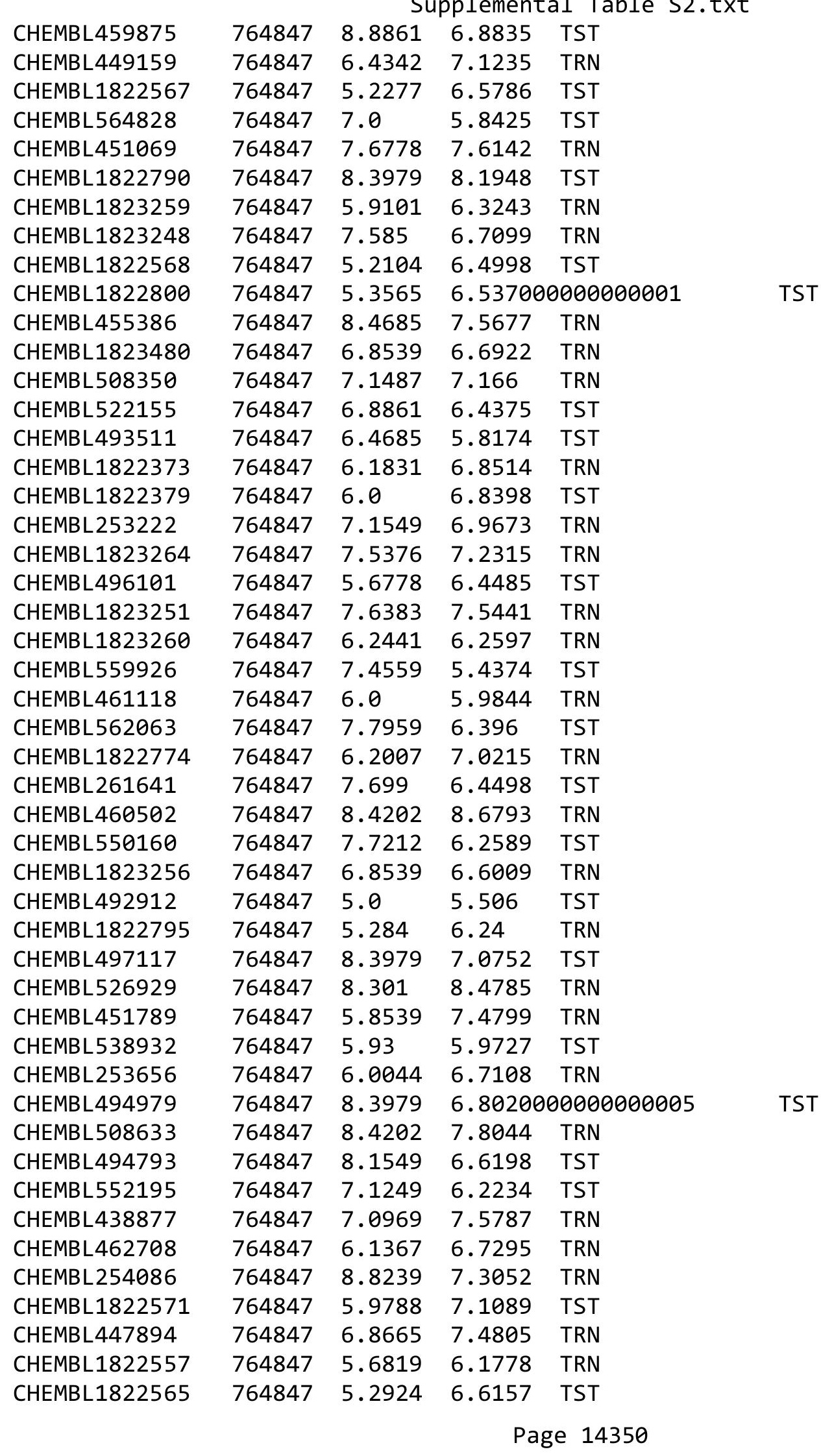




\begin{tabular}{|c|c|c|c|c|c|}
\hline \\
\hline CHEMBL 251980 & 764847 & 6.7959 & 7.0299 & TRN & \\
\hline CHEMBL505896 & 764847 & 7.7696 & 7.5978 & TRN & \\
\hline CHEMBL518676 & 764847 & 7.6198 & 7.2098 & TRN & \\
\hline CHEMBL448276 & 764847 & 7.6576 & 7.557 & TRN & \\
\hline CHEMBL1822796 & 764847 & 5.0159 & 6.0118 & TRN & \\
\hline CHEMBL518357 & 764847 & 5.5528 & 5.9327 & TRN & \\
\hline CHEMBL461583 & 764847 & 8.585 & 8.8032 & TRN & \\
\hline CHEMBL400726 & 764847 & 6.7447 & 7.1885 & TRN & \\
\hline CHEMBL1822371 & 764847 & 8.7959 & 7.7481 & TRN & \\
\hline CHEMBL402042 & 764847 & 6.8996 & 7.2693 & TRN & \\
\hline CHEMBL551998 & 764847 & 6.699 & 6.7563 & TST & \\
\hline CHEMBL1822566 & 764847 & 6.1308 & 6.63399 & 99999999995 & TRN \\
\hline CHEMBL445958 & 764847 & 7.4815 & 7.5678 & TRN & \\
\hline CHEMBL549980 & 764847 & 7.9208 & 6.3271 & TST & \\
\hline CHEMBL549571 & 764847 & 7.6383 & 6.4324 & TST & \\
\hline CHEMBL467574 & 764847 & 6.4815 & 5.947 & TRN & \\
\hline CHEMBL258185 & 764847 & 7.3098 & 7.1808 & TRN & \\
\hline CHEMBL550651 & 764847 & 6.3188 & 5.6487 & TST & \\
\hline CHEMBL1822207 & 764847 & 6.7423 & 6.9737 & TRN & \\
\hline CHEMBL400332 & 764847 & 7.5229 & 6.9339 & TRN & \\
\hline CHEMBL500834 & 764847 & 7.5229 & 7.2327 & TRN & \\
\hline CHEMBL1822768 & 764847 & 7.8239 & 7.13 & TRN & \\
\hline CHEMBL1822801 & 764847 & 6.5229 & 6.7208 & TRN & \\
\hline CHEMBL1822365 & 764847 & 8.301 & 7.7396 & TRN & \\
\hline CHEMBL402550 & 764847 & 7.1871 & 7.2527 & TRN & \\
\hline CHEMBL1822552 & 764847 & 6.4089 & 7.2004 & TRN & \\
\hline CHEMBL1822758 & 764847 & 6.6778 & 6.7945 & TRN & \\
\hline CHEMBL464510 & 764847 & 7.5528 & 6.9613 & TRN & \\
\hline CHEMBL556215 & 764847 & 5.3372 & 5.7397 & TST & \\
\hline CHEMBL462023 & 764847 & 6.5229 & 7.2536 & TRN & \\
\hline CHEMBL458217 & 764847 & 5.5528 & 5.3846 & TRN & \\
\hline CHEMBL 254761 & 764847 & 6.7144 & 7.3107 & TRN & \\
\hline CHEMBL1822570 & 764847 & 6.0088 & 6.871 & TST & \\
\hline CHEMBL503524 & 764847 & 7.4559 & 7.3946 & TRN & \\
\hline CHEMBL512616 & 764847 & 5.7212 & 6.0893 & TRN & \\
\hline CHEMBL403747 & 764847 & 7.1308 & 7.2011 & TRN & \\
\hline CHEMBL558306 & 764847 & 8.0 & 5.9847 & TST & \\
\hline CHEMBL1823254 & 764847 & 6.7696 & 6.4826 & TST & \\
\hline CHEMBL1822766 & 764847 & 6.7696 & 7.1182 & TRN & \\
\hline CHEMBL499618 & 764847 & 7.0 & 7.7422 & TRN & \\
\hline CHEMBL1822789 & 764847 & 7.6576 & 7.6967 & TST & \\
\hline CHEMBL1822767 & 764847 & 7.0458 & 6.3031 & TRN & \\
\hline CHEMBL1822561 & 764847 & 6.3665 & 6.0152 & TRN & \\
\hline CHEMBL492705 & 764847 & 5.2541 & 6.2779 & TST & \\
\hline CHEMBL1823123 & 764847 & 6.8861 & 7.0846 & TRN & \\
\hline CHEMBL459876 & 764847 & 8.7447 & 7.2906 & TST & \\
\hline CHEMBL402504 & 764847 & 6.9431 & 7.2751 & TRN & \\
\hline CHEMBL460586 & 764847 & 6.9706 & 6.976 & TRN & \\
\hline
\end{tabular}




\begin{tabular}{|c|c|c|c|c|c|}
\hline \multicolumn{6}{|c|}{ Supplemental Table S2.txt } \\
\hline CHEMBL456502 & 764847 & 5.8861 & 5.3398 & TRN & \\
\hline CHEMBL255091 & 764847 & 7.3979 & 6.8101 & TRN & \\
\hline CHEMBL499878 & 764847 & 7.3565 & 7.984 & TRN & \\
\hline CHEMBL508142 & 764847 & 7.9586 & 7.7834 & TRN & \\
\hline CHEMBL 1822763 & 764847 & 7.0555 & 7.6479 & TRN & \\
\hline CHEMBL494794 & 764847 & 7.1739 & 6.4726 & TST & \\
\hline CHEMBL460795 & 764847 & 6.3107 & 7.2906 & TRN & \\
\hline CHEMBL254964 & 764847 & 7.2676 & 7.1931 & TRN & \\
\hline CHEMBL500422 & 764847 & 8.301 & 8.2077 & TRN & \\
\hline CHEMBL453849 & 764847 & 7.5229 & 7.666 & TRN & \\
\hline CHEMBL1823253 & 764847 & 6.8239 & 6.1891 & TST & \\
\hline CHEMBL1822791 & 764847 & 6.0 & 7.7203 & TRN & \\
\hline CHEMBL1822562 & 764847 & 5.8861 & 6.1058 & TRN & \\
\hline CHEMBL459892 & 764847 & 6.0 & 5.9696 & TRN & \\
\hline CHEMBL429490 & 764847 & 6.8239 & 6.6396 & TRN & \\
\hline CHEMBL510316 & 764847 & 7.1549 & 7.74299 & 9999999999 & TRN \\
\hline CHEMBL502531 & 764847 & 8.699 & 8.1312 & TRN & \\
\hline CHEMBL1822589 & 764847 & $5.7520 e$ & 00000000 & 6.4042 & TRN \\
\hline CHEMBL1822974 & 764847 & 8.3979 & 6.4716 & TST & \\
\hline CHEMBL462171 & 764847 & 5.1938 & 5.9452 & TRN & \\
\hline CHEMBL518516 & 764847 & 7.4559 & 6.7761 & TRN & \\
\hline CHEMBL1822579 & 764847 & 6.284 & 6.6278 & TRN & \\
\hline CHEMBL1822560 & 764847 & 6.9586 & 6.919 & TRN & \\
\hline CHEMBL1822378 & 764847 & 6.7959 & 6.086 & TST & \\
\hline CHEMBL1822362 & 764847 & 7.699 & 5.916 & TST & \\
\hline CHEMBL1822787 & 764847 & 6.699 & 6.4522 & TRN & \\
\hline CHEMBL1823476 & 764847 & 5.7905 & 6.6563 & TRN & \\
\hline CHEMBL495898 & 764847 & 6.9208 & 6.6188 & TST & \\
\hline CHEMBL551458 & 764847 & 7.8239 & 6.3698 & TST & \\
\hline CHEMBL450209 & 764847 & 7.9208 & 7.5224 & TRN & \\
\hline CHEMBL510676 & 764847 & 7.585 & 7.2478 & TRN & \\
\hline CHEMBL1823124 & 764847 & 7.5376 & 6.99100 & 00000000005 & TRN \\
\hline CHEMBL462667 & 764847 & 6.0 & 7.1161 & TRN & \\
\hline CHEMBL1823475 & 764847 & 7.2676 & 6.5881 & TRN & \\
\hline CHEMBL 257802 & 764847 & 6.9355 & 7.0882 & TRN & \\
\hline CHEMBL1823270 & 764847 & 7.8861 & 6.6083 & TRN & \\
\hline CHEMBL497119 & 764847 & 7.5376 & 7.171 & TST & \\
\hline CHEMBL254280 & 764847 & 7.5229 & 6.9904 & TRN & \\
\hline CHEMBL461119 & 764847 & 6.301 & 5.9917 & TRN & \\
\hline CHEMBL462624 & 764847 & 9.0 & 8.3696 & TRN & \\
\hline CHEMBL1822784 & 764847 & 5.4763 & 6.0593 & TRN & \\
\hline CHEMBL447616 & 764847 & 7.5376 & 7.6104 & TRN & \\
\hline CHEMBL1822572 & 764847 & 5.1175 & 5.7345 & TRN & \\
\hline CHEMBL1822375 & 764847 & 6.8013 & 7.396 & TRN & \\
\hline CHEMBL399920 & 764847 & 7.0458 & 6.7887 & TRN & \\
\hline CHEMBL1822797 & 764847 & 5.1805 & 6.8312 & TST & \\
\hline CHEMBL1823265 & 764847 & 5.6676 & 6.0036 & TRN & \\
\hline CHEMBL449833 & 764847 & 8.0362 & 7.7315 & TRN & \\
\hline
\end{tabular}


Supplemental Table S2.txt

\begin{tabular}{|c|c|c|c|c|}
\hline 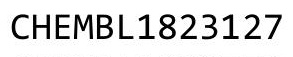 & & 29 & . & \\
\hline HEMBL1822770 & 847 & 8239 & 2306 & \\
\hline HEMBL1822382 & 54847 & .1549 & .438 & \\
\hline AEMBL5 & 47 & & 8136 & \\
\hline AEMBL1822578 & 4847 & & 7964 & \\
\hline HEMBL402792 & 64847 & 198 & 1968 & \\
\hline HEMBL 525260 & 64847 & .699 & 8297 & \\
\hline HEMBL 256786 & 54847 & 007 & 1714 & \\
\hline HEMBL 18 & 54847 & & .0124 & \\
\hline AEMBL46 & & & .6139 & \\
\hline HEMBL1823261 & 64847 & .585 & 6398 & \\
\hline HEMBL449757 & 64847 & 6778 & 5654 & \\
\hline HEMBL49 & 64847 & 3979 & 7755 & \\
\hline HEMBL1\& & & & .2209 & \\
\hline HEMBL1\& & 47 & 36 & .2311 & \\
\hline HEMBL182 & 64847 & 08 & 5231 & ST \\
\hline HEMBL1823250 & 64847 & 69 & 7.1599 & \\
\hline HEMBL1\& & 47 & 586 & 1648 & \\
\hline HEMBL5 & & & 1767 & \\
\hline HEMBL5E & 17 & 29 & 128 & RN \\
\hline HEMBL182 & 47 & & 992 & RN \\
\hline HEMBL401\& & 17 & 31 & 2144 & RN \\
\hline HEMBL4 & 47 & 862 & 7765 & \\
\hline HEMBL & & & 191 & \\
\hline HEMBL & 17 & & 192 & RN \\
\hline HEMBL18 & & & 645 & ST \\
\hline HEMBL182 & 64847 & 27 & 598 & $\mathrm{RN}$ \\
\hline HEMBL5 5 & 7 & & 423 & I \\
\hline HEM & 7 & & & RN \\
\hline HEMBL1\& & & & 082 & RN \\
\hline HEMBL462 & & & 243 & RN \\
\hline HEMBL554 & 54847 & & 6572 & ST \\
\hline HEMBL4 & 17 & 39 & 1819 & RN \\
\hline$A F N$ & 7 & & 887 & RN \\
\hline HEMBL 523 & & & 8211 & ST \\
\hline HEMBL182276e & 648 & & 227 & RN \\
\hline HEMBL 51 & $64 \varepsilon$ & & 9688 & RN \\
\hline HEMBL18 & 17 & & 431 & RN \\
\hline HEMBL18 & & & 563 & RN \\
\hline HEMBL 182 & & & 369 & RN \\
\hline HEMBL182 & 17 & & 3222 & RN \\
\hline HEMBL 46 & & & 7986 & RN \\
\hline HEMBL18 & & & 7.7891 & \\
\hline CHEMBL182 & & & 7.5821 & RN \\
\hline HEMBL18 & & .2676 & .7924 & RN \\
\hline HEMBL497968 & 64847 & 7.9208 & .7281 & ST \\
\hline HEMBL18 & & & 3778 & \\
\hline $\mathrm{HEI}$ & 7648 & 6.06 & & \\
\hline
\end{tabular}

Page 14353 
Supplemental Table S2.txt

\begin{tabular}{|c|c|c|c|c|}
\hline CHEMBL502621 & 764847 & 7.3768 & 7.3512 & TRN \\
\hline CHEMBL1823267 & 764847 & 7.4437 & 6.4471 & TRN \\
\hline CHEMBL1822771 & 764847 & 7.2291 & 7.444 & TRN \\
\hline CHEMBL462914 & 764847 & 6.0969 & 6.3335 & TRN \\
\hline CHEMBL1822383 & 764847 & 6.0458 & 6.8451 & TRN \\
\hline CHEMBL502283 & 764847 & 8.1549 & 8.6196 & TRN \\
\hline CHEMBL465130 & 764847 & 7.3665 & 6.9713 & TRN \\
\hline CHEMBL1822006 & 764847 & 6.7696 & 6.6545 & TST \\
\hline CHEMBL554497 & 764847 & 8.0458 & 6.3181 & TST \\
\hline CHEMBL462712 & 764847 & 6.0458 & 5.9848 & TRN \\
\hline CHEMBL1823125 & 764847 & 8.2218 & 6.9448 & TST \\
\hline CHEMBL1822564 & 764847 & 6.6383 & 7.1246 & TRN \\
\hline CHEMBL461832 & 764847 & 7.4202 & 7.4798 & TRN \\
\hline CHEMBL1822782 & 764847 & 6.1024 & 7.0995 & TRN \\
\hline CHEMBL401344 & 764847 & 6.8861 & 6.9565 & TRN \\
\hline CHEMBL540744 & 764847 & 6.6021 & 5.4768 & TST \\
\hline CHEMBL563356 & 764847 & 7.1549 & 6.1226 & TST \\
\hline CHEMBL1822585 & 764847 & 7.8239 & 7.5202 & TRN \\
\hline CHEMBL1822780 & 764847 & 6.7212 & 7.3798 & TRN \\
\hline CHEMBL1822591 & 764847 & 7.6576 & 7.1494 & TRN \\
\hline CHEMBL1822975 & 764847 & 7.301 & 5.7907 & TST \\
\hline CHEMBL1822005 & 764847 & 7.5528 & 8.0902 & TRN \\
\hline CHEMBL258453 & 764847 & 7.284 & 7.2041 & TRN \\
\hline CHEMBL1822973 & 764847 & 7.6778 & 7.718 & TRN \\
\hline CHEMBL399710 & 764847 & 6.1192 & 6.2541 & TRN \\
\hline CHEMBL205372 & 764847 & 8.699 & 6.9936 & TRN \\
\hline CHEMBL567908 & 764847 & 8.5229 & 6.812 & TST \\
\hline CHEMBL518511 & 764847 & 6.3979 & 6.1596 & TRN \\
\hline CHEMBL438696 & 764847 & 7.3979 & 7.2596 & TRN \\
\hline CHEMBL550305 & 764847 & 7.699 & 5.6079 & TST \\
\hline CHEMBL1823258 & 764847 & 6.6383 & 5.8872 & TRN \\
\hline CHEMBL502232 & 764847 & 7.9586 & 8.0499 & TRN \\
\hline CHEMBL507573 & 764847 & 6.0 & 7.4349 & TRN \\
\hline CHEMBL1822775 & 764847 & 5.2226 & 6.1497 & TRN \\
\hline CHEMBL515858 & 764847 & 8.2291 & 8.3921 & TRN \\
\hline CHEMBL461648 & 764847 & 7.4089 & 7.2676 & TRN \\
\hline CHEMBL521639 & 764847 & 6.7447 & 5.6972 & TST \\
\hline CHEMBL253882 & 764847 & 6.0458 & 6.6 & TRN \\
\hline CHEMBL1822772 & 764847 & 7.041 & 6.4177 & TRN \\
\hline CHEMBL1822554 & 764847 & 6.8861 & 6.0244 & TRN \\
\hline CHEMBL522196 & 764847 & 8.0458 & 6.5659 & TST \\
\hline CHEMBL1822002 & 764847 & 7.2518 & 6.6758 & TST \\
\hline CHEMBL462493 & 764847 & 7.3468 & 7.19600 & 0000000001 \\
\hline CHEMBL1823477 & 764847 & 7.2596 & 7.1542 & TRN \\
\hline CHEMBL1823126 & 764847 & 7.8861 & 5.9181 & TST \\
\hline CHEMBL462622 & 764847 & 9.0 & 8.2366 & TRN \\
\hline CHEMBL525049 & 764847 & 8.3979 & 8.3056 & TRN \\
\hline CHEMBL430026 & 764847 & 6.2924 & 6.7113 & TRN \\
\hline
\end{tabular}




\begin{tabular}{|c|c|c|c|c|}
\hline \multicolumn{5}{|c|}{ Supplemental Table S2.txt } \\
\hline CHEMBL1822777 & 764847 & 6.4949 & 7.4989 & TRN \\
\hline CHEMBL465131 & 764847 & 7.5528 & 6.9862 & TRN \\
\hline CHEMBL413996 & 764847 & 7.301 & 7.2402 & TRN \\
\hline CHEMBL1823479 & 764847 & 6.3665 & 6.2243 & TRN \\
\hline CHEMBL254879 & 764847 & 7.0458 & 6.7432 & TRN \\
\hline CHEMBL564371 & 764847 & 8.0458 & 5.8346 & TST \\
\hline CHEMBL1822799 & 764847 & 6.6383 & 6.7876 & TRN \\
\hline CHEMBL453737 & 764847 & 8.3098 & 8.0315 & TRN \\
\hline CHEMBL1822004 & 764847 & 8.0458 & 6.4134 & TST \\
\hline CHEMBL494984 & 764847 & 8.5229 & 7.4304 & TST \\
\hline CHEMBL510459 & 764847 & 5.8861 & 5.3844 & TRN \\
\hline CHEMBL458216 & 764847 & 5.4089 & 5.3547 & TRN \\
\hline CHEMBL1822380 & 764847 & 5.9393 & 6.3287 & TST \\
\hline CHEMBL561583 & 764847 & 6.5086 & 5.4755 & TST \\
\hline CHEMBL1822563 & 764847 & 5.2336 & 6.9371 & TST \\
\hline CHEMBL468787 & 764847 & 6.7696 & 5.9688 & TRN \\
\hline CHEMBL1822586 & 764847 & 7.6576 & 7.1666 & TRN \\
\hline CHEMBL462835 & 764847 & 7.585 & 7.4884 & TRN \\
\hline CHEMBL462505 & 764847 & 5.1487 & 5.9998 & TRN \\
\hline CHEMBL1823263 & 764847 & 5.2314 & 5.7404 & TRN \\
\hline CHEMBL515659 & 764847 & 7.5086 & 6.5221 & TRN \\
\hline CHEMBL499886 & 764847 & 8.3979 & 7.9496 & TRN \\
\hline CHEMBL490965 & 764847 & 7.6021 & 7.0788 & TRN \\
\hline CHEMBL1823128 & 764847 & 9.0 & 7.9135 & TRN \\
\hline CHEMBL561461 & 764847 & 5.0915 & 6.2834 & TST \\
\hline CHEMBL452680 & 764847 & 8.0177 & 7.8446 & TRN \\
\hline CHEMBL255092 & 764847 & 7.5229 & 6.9549 & TRN \\
\hline CHEMBL472552 & 764847 & 6.3188 & 5.9377 & TRN \\
\hline CHEMBL1766507 & 764847 & 7.2441 & 7.0784 & TST \\
\hline CHEMBL562958 & 764847 & 5.2464 & 5.7144 & TST \\
\hline CHEMBL402036 & 764847 & 7.3188 & 7.3699 & TRN \\
\hline CHEMBL1822779 & 764847 & 7.3468 & 7.3835 & TRN \\
\hline CHEMBL1823262 & 764847 & 6.699 & 7.3456 & TST \\
\hline CHEMBL1822372 & 764847 & 7.1871 & 6.8185 & TRN \\
\hline CHEMBL462504 & 764847 & 5.9586 & 6.0426 & TRN \\
\hline CHEMBL1823478 & 764847 & 8.6021 & 7.5207 & TST \\
\hline CHEMBL1822569 & 764847 & 6.2676 & 6.9022 & TRN \\
\hline CHEMBL461998 & 764847 & 7.0969 & 6.4465 & TRN \\
\hline CHEMBL445871 & 764847 & 7.4685 & 7.2856 & TRN \\
\hline CHEMBL253881 & 764847 & 7.3468 & 6.7831 & TRN \\
\hline CHEMBL1822003 & 764847 & 6.0809 & 7.1446 & TST \\
\hline CHEMBL1822783 & 764847 & 6.3768 & 6.8754 & TRN \\
\hline CHEMBL256974 & 764847 & 7.1871 & 7.5468 & TRN \\
\hline CHEMBL462231 & 764847 & 7.1739 & 7.0151 & TRN \\
\hline CHEMBL456456 & 764847 & 6.4202 & 6.4582 & TRN \\
\hline CHEMBL1822553 & 764847 & 7.6198 & 6.9607 & TRN \\
\hline CHEMBL561058 & 764847 & 7.8239 & 6.1346 & TST \\
\hline CHEMBL1822364 & 764847 & 7.5528 & 7.652 & TRN \\
\hline
\end{tabular}




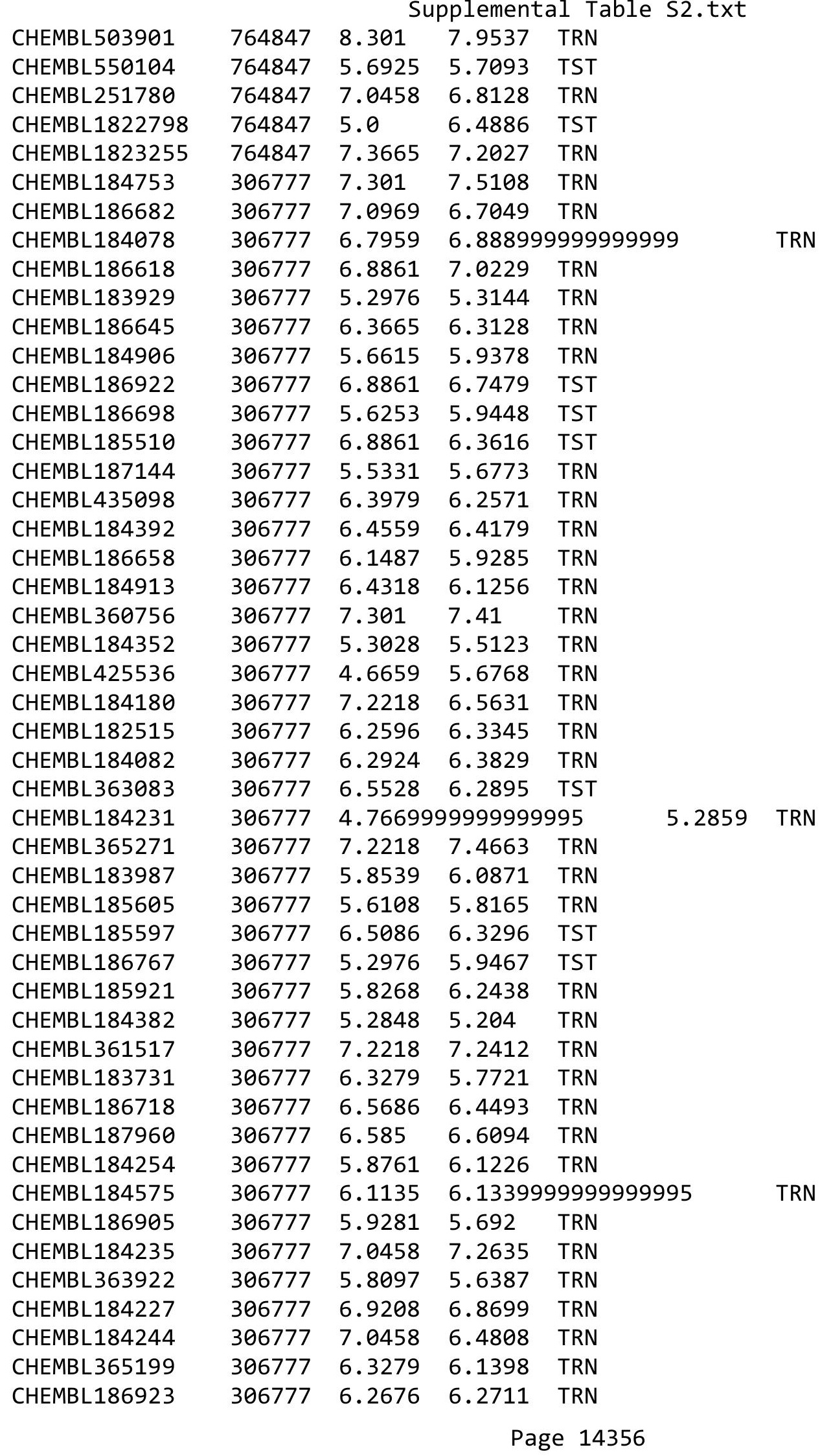




\begin{tabular}{|c|c|c|c|c|c|}
\hline & & \multicolumn{4}{|c|}{ Supplemental Table S2.txt } \\
\hline CHEMBL187280 & 306777 & 7.2218 & 7.2636 & TRN & \\
\hline CHEMBL186851 & 306777 & 6.8239 & 6.659 & TRN & \\
\hline CHEMBL183923 & 306777 & 6.1308 & 6.1226 & TRN & \\
\hline CHEMBL186719 & 306777 & 6.9208 & 6.6801 & TST & \\
\hline CHEMBL184118 & 306777 & 5.9747 & 6.022 & TRN & \\
\hline CHEMBL364601 & 306777 & 8.0 & 7.1027 & TST & \\
\hline CHEMBL363057 & 306777 & 5.3497 & 6.1473 & TST & \\
\hline CHEMBL184414 & 306777 & 6.4949 & 6.6437 & TRN & \\
\hline CHEMBL363901 & 306777 & 6.2596 & 5.9921 & TRN & \\
\hline CHEMBL186850 & 306777 & 6.2291 & 6.0061 & TRN & \\
\hline CHEMBL363085 & 306777 & 5.4449 & 5.4567 & TRN & \\
\hline CHEMBL184188 & 306777 & 6.0132 & 5.6811 & TRN & \\
\hline CHEMBL186550 & 306777 & 6.3468 & 6.7246 & TST & \\
\hline CHEMBL186889 & 306777 & 5.7471 & 5.6775 & TST & \\
\hline CHEMBL187688 & 306777 & 6.4089 & 6.16700 & 3000000001 & TST \\
\hline CHEMBL184129 & 306777 & 7.0458 & 6.8367 & TST & \\
\hline CHEMBL186612 & 306777 & 6.6383 & 6.8695 & TST & \\
\hline CHEMBL184642 & 306777 & 7.0 & 6.8032 & TST & \\
\hline CHEMBL184699 & 306777 & 7.0 & 6.9648 & TST & \\
\hline CHEMBL429419 & 470054 & 7.3979 & 7.4025 & TRN & \\
\hline CHEMBL256271 & 470054 & 6.5528 & 6.5552 & TRN & \\
\hline CHEMBL429591 & 470054 & 6.284 & 6.2814 & TRN & \\
\hline CHEMBL256887 & 470054 & 6.4815 & 6.5051 & TST & \\
\hline CHEMBL427834 & 470054 & 6.0 & 5.9945 & TRN & \\
\hline CHEMBL256272 & 470054 & 6.9208 & 6.9132 & TRN & \\
\hline CHEMBL257509 & 470054 & 7.0 & 7.01 & TRN & \\
\hline CHEMBL258359 & 470054 & 6.7447 & 6.7446 & TRN & \\
\hline CHEMBL270253 & 470054 & 6.8861 & 6.8861 & TRN & \\
\hline CHEMBL255338 & 470054 & 6.9586 & 6.9543 & TRN & \\
\hline CHEMBL270631 & 470054 & 7.0458 & 7.03299 & 99999999995 & TRN \\
\hline CHEMBL270433 & 470054 & 6.7447 & 6.7476 & TRN & \\
\hline CHEMBL257508 & 470054 & 4.0 & 3.9966 & TRN & \\
\hline CHEMBL271903 & 470054 & 6.7447 & 6.7419 & TRN & \\
\hline CHEMBL411477 & 470054 & 6.4437 & 6.42700 & 00000000005 & TRN \\
\hline CHEMBL257039 & 470054 & 3.5229 & 3.5263 & TRN & \\
\hline CHEMBL256404 & 470054 & 7.5229 & 7.5227 & TRN & \\
\hline CHEMBL404757 & 470054 & 6.2147 & 6.2175 & TRN & \\
\hline CHEMBL404195 & 470054 & 4.0 & 3.99399 & 99999999998 & TRN \\
\hline CHEMBL272097 & 470054 & 7.1549 & 7.1534 & TRN & \\
\hline CHEMBL256264 & 470054 & 5.7825 & 6.5005 & TST & \\
\hline CHEMBL270564 & 470054 & 6.4145 & 6.4223 & TRN & \\
\hline CHEMBL403692 & 470054 & 5.1349 & 4.7542 & TST & \\
\hline CHEMBL257853 & 470054 & 5.3325 & 5.6566 & TST & \\
\hline CHEMBL270419 & 470054 & 5.9066 & 5.9055 & TRN & \\
\hline CHEMBL403665 & 470054 & 5.6459 & 5.6507 & TST & \\
\hline CHEMBL258362 & 470054 & 5.4377 & 5.4321 & TRN & \\
\hline CHEMBL 270358 & 470054 & 5.9031 & 5.90600 & 3000000001 & TRN \\
\hline CHEMBL258369 & 470054 & 6.1739 & 6.175 & TRN & \\
\hline
\end{tabular}




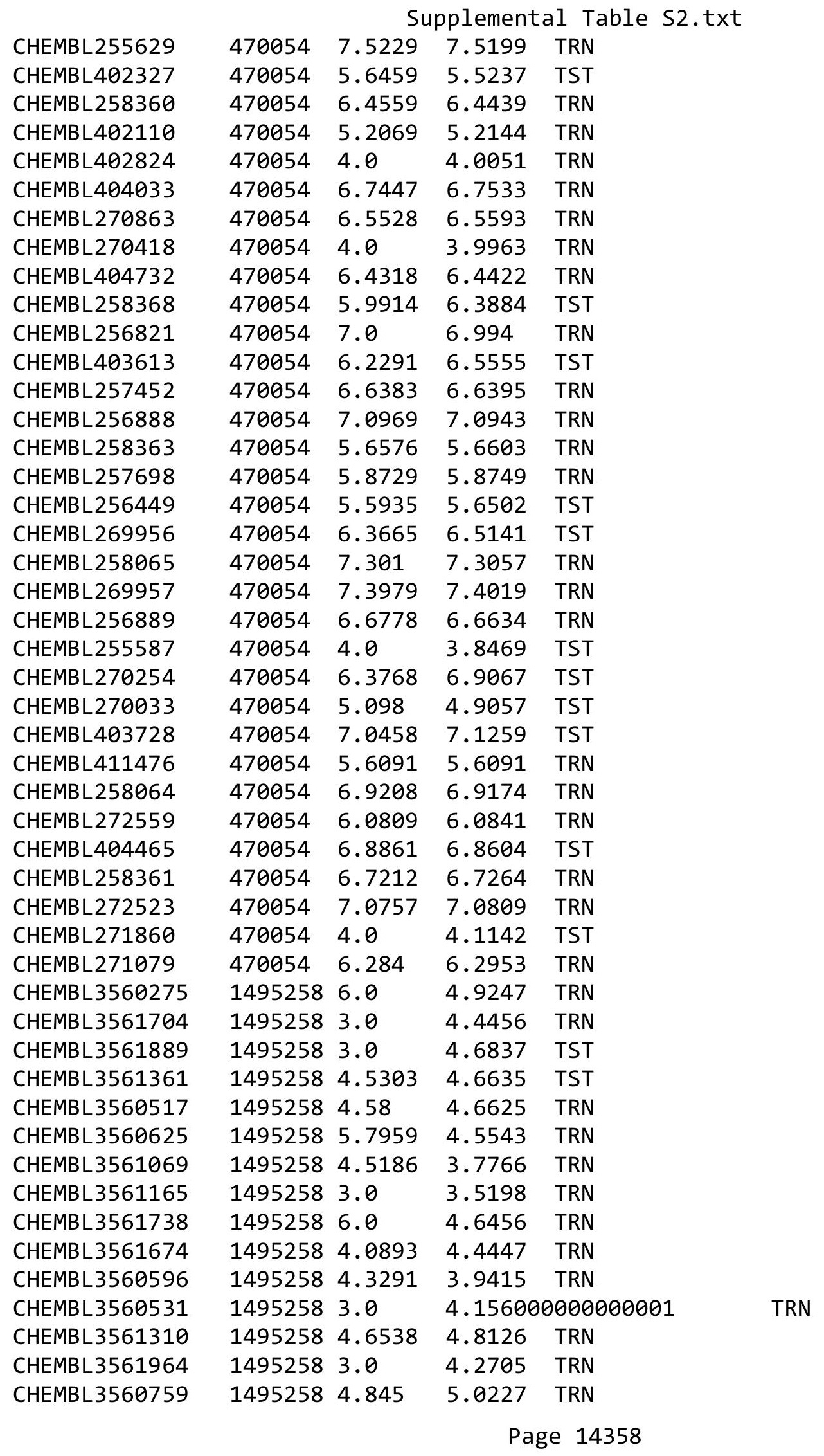


Supplemental Table S2.txt

\begin{tabular}{|c|c|c|c|c|c|}
\hline CHEMBL3559752 & 1495258 & 5.9172 & 4.6338 & TRN & \\
\hline CHEMBL2357924 & 1495258 & 3.0 & 4.5968 & TRN & \\
\hline CHEMBL3560652 & 1495258 & 4.4791 & 4.6393 & TRN & \\
\hline CHEMBL3560189 & 1495258 & 4.5906 & \multicolumn{2}{|c|}{4.6530000000000005} & TRN \\
\hline CHEMBL3561886 & 1495258 & 3.0 & 4.2022 & TST & \\
\hline CHEMBL2357075 & 1495258 & 4.6527 & 3.7429 & TRN & \\
\hline CHEMBL3561625 & 1495258 & 3.0 & 3.3143 & TRN & \\
\hline CHEMBL3561050 & 1495258 & 4.6153 & 4.9944 & TRN & \\
\hline CHEMBL3560766 & 1495258 & 4.1912 & \multicolumn{2}{|c|}{ 4. 361000000000001} & TST \\
\hline CHEMBL3560816 & 1495258 & 6.0 & 4.789 & TST & \\
\hline CHEMBL3560902 & 1495258 & 4.6765 & 4.7296 & TRN & \\
\hline CHEMBL3560177 & 1495258 & 3.0 & 3.5965 & TRN & \\
\hline CHEMBL3560440 & 1495258 & 3.0 & 4.3162 & TST & \\
\hline CHEMBL3560665 & 1495258 & 4.7354 & \multicolumn{2}{|c|}{4.2010000000000005} & TRN \\
\hline CHEMBL3561276 & 1495258 & 4.7104 & 4.6639 & TRN & \\
\hline CHEMBL3561779 & 1495258 & 6.0 & 4.8895 & TRN & \\
\hline CHEMBL3187467 & 1495258 & 4.3421 & 4.7303 & TRN & \\
\hline CHEMBL3560984 & 1495258 & 4.6149 & \multicolumn{2}{|c|}{ 4. 361000000000001} & TST \\
\hline CHEMBL3561332 & 1495258 & 4.73 & 4.0675 & TST & \\
\hline CHEMBL3561693 & 1495258 & 4.206 & 3.6484 & TRN & \\
\hline CHEMBL3560034 & 1495258 & 3.0 & 4.0191 & TRN & \\
\hline CHEMBL3560834 & 1495258 & 4.5161 & 3.9644 & TST & \\
\hline CHEMBL3561438 & 1495258 & 5.0186 & 4.9021 & TRN & \\
\hline CHEMBL3560425 & 1495258 & 6.0 & 4.417 & TST & \\
\hline CHEMBL3559805 & 1495258 & 3.0 & 4.4516 & TRN & \\
\hline CHEMBL3561210 & 1495258 & 4.0863 & 4.5742 & TRN & \\
\hline CHEMBL 3188022 & 1495258 & 3.0 & 4.7027 & TRN & \\
\hline CHEMBL3561900 & 1495258 & 5.4365 & 4.3335 & TRN & \\
\hline CHEMBL3561864 & 1495258 & 3.0 & 3.6982 & TRN & \\
\hline CHEMBL3560224 & 1495258 & 6.0 & 4.4209 & TST & \\
\hline CHEMBL3561709 & 1495258 & 6.0 & 4.2079 & TST & \\
\hline CHEMBL3560348 & 1495258 & 6.0 & 4.9401 & TST & \\
\hline CHEMBL3561411 & 1495258 & 3.0 & \multicolumn{2}{|c|}{ 4. 303999999999999} & TRN \\
\hline CHEMBL2358261 & 1495258 & 4.33 & 4.162 & TRN & \\
\hline CHEMBL3560196 & 1495258 & 4.3814 & 4.7881 & TRN & \\
\hline CHEMBL3561010 & 1495258 & 6.0 & 3.8796 & TRN & \\
\hline CHEMBL2135917 & 1495258 & 4.9751 & 4.2073 & TRN & \\
\hline CHEMBL3561713 & 1495258 & 4.1815 & 4.4336 & TRN & \\
\hline CHEMBL3560222 & 1495258 & 4.3605 & 4.9724 & TST & \\
\hline CHEMBL3561832 & 1495258 & 4.6126 & 4.3537 & TRN & \\
\hline CHEMBL3561177 & 1495258 & 4.5433 & 4.6172 & TRN & \\
\hline CHEMBL3561485 & 1495258 & 4.4864 & 4.7921 & TST & \\
\hline CHEMBL3560549 & 1495258 & 4.2929 & 4.711 & TRN & \\
\hline CHEMBL3561599 & 1495258 & 6.0 & 4.4259 & TRN & \\
\hline CHEMBL3186588 & 1495258 & 3.0 & 3.8919 & TST & \\
\hline CHEMBL 2359013 & 1495258 & 4.63399 & 99999999 & 4.5758 & TRN \\
\hline CHEMBL2361207 & 1495258 & 5.1244 & 3.8267 & TRN & \\
\hline CHEMBL 2357642 & 1495258 & 3.0 & 4.6463 & TRN & \\
\hline
\end{tabular}


Supplemental Table S2.txt

\begin{tabular}{|c|c|c|c|c|}
\hline HEM & & 3555 & 4.4072 & TS \\
\hline & 495258 & 3.0 & 4.2046 & \\
\hline HEMBL & 258 & 3.0 & 3346 & \\
\hline AEMBL & 258 & 8935 & & \\
\hline HEMBL 2355498 & 495258 & 3.0 & 2051 & \\
\hline HEMBL2359541 & 58 & 4.0701 & 9491 & \\
\hline 0294 & & 3987 & & \\
\hline AEMBL 3561044 & & 4.5774 & & \\
\hline HEMBL1891222 & 495258 & 6.0 & 4.9237 & \\
\hline HEMBL3560974 & 495258 & 4.013 & .1814 & \\
\hline HEMBL3561043 & 58 & 4.3111 & 3.9243 & \\
\hline AEMBL3 & 58 & 6 . & 214 & \\
\hline HEMBL3561837 & & 742 & & \\
\hline HEMBL3560281 & 258 & 4.0497 & 4.7783 & \\
\hline HEMBL3560412 & & 4.7011 & & \\
\hline AEMBL3560060 & & 4.5877 & 44 & KIV \\
\hline HEMBL; & & 3. & & 政 \\
\hline HEMBL & 58 & & & \\
\hline HEMBL3560476 & & 885 & & \\
\hline AEMBL3561765 & 58 & 4.1014 & 51 & $I$ KIV \\
\hline HEMBL2355930 & & 3. & 76 & RN \\
\hline HEMBL & & 3 & & NIV \\
\hline HEMBL & & 4.2732 & & RN \\
\hline 61181 & & 4 . & & I RIV \\
\hline HEMBL 2359510 & 58 & 3. & 12 & RN \\
\hline HEMBL3561629 & & & 41 & RN \\
\hline HEM & & & 06 & $\mathrm{RN}$ \\
\hline 503 & & 88 & & RN \\
\hline AEMBL3 & & 6 & & $\mathrm{R}$ \\
\hline HEMBL2361179 & 49 & 4 . & 69 & ГRN \\
\hline HEMBL3 & 58 & 6 & 99 & RN \\
\hline 4 & & & & RN \\
\hline & & 4. & & RN \\
\hline AEMBL3561115 & & 3. & & TST \\
\hline HEMBL2356002 & 58 & 3 & 606 & TRN \\
\hline 034 & 58 & 6 & 89 & TRN \\
\hline & & & & RIN \\
\hline HEMBL3 & & 4.8931 & 7716 & ГRN \\
\hline HEMBL3561517 & & 6. & 376 & TRN \\
\hline HEMBL3 & & 3 & & $\mathrm{n}$ \\
\hline HEMBL3 & & 6 & 54 & TRN \\
\hline HEMBL3560030 & & 4.0276 & 3117 & 「RN \\
\hline HEMBL2361222 & & 3 . & & $\Gamma R$ \\
\hline HEMBL 318251 & 58 & 6 . & 973 & TR \\
\hline HEMBL 356 & & 6 & 5271 & ST \\
\hline HEMBL3 & & & .1462 & \\
\hline CHEMBL2144022 & 1495258 & 4.3 & 3.8012 & RN \\
\hline CHEMBL 2359667 & 1495258 & 4.7844 & 4.6407 & 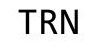 \\
\hline
\end{tabular}

Page 14360 
Supplemental Table S2.txt

\begin{tabular}{|c|c|c|c|c|c|c|}
\hline CHEMBL 3561018 & 1495258 & 4.1375 & 4.0163 & TRN & & \\
\hline CHEMBL 3561442 & 1495258 & 4.1105 & 4.2222 & TRN & & \\
\hline CHEMBL3561404 & 1495258 & 3.0 & 3.6009 & TRN & & \\
\hline CHEMBL 3561078 & 1495258 & 4.2501 & 4.3911 & TRN & & \\
\hline CHEMBL 3559913 & 1495258 & 4.1991 & 4.2024 & TST & & \\
\hline CHEMBL1864597 & 1495258 & 4.6231 & 4.2475 & TRN & & \\
\hline CHEMBL 3560392 & 1495258 & 6.0 & 4.3117 & TRN & & \\
\hline CHEMBL 3187821 & 1495258 & 4.2663 & 4.7349 & TRN & & \\
\hline CHEMBL 3561793 & 1495258 & 4.5369 & 4.0461 & TST & & \\
\hline CHEMBL 2362260 & 1495258 & 4.6398 & 4.6105 & TRN & & \\
\hline CHEMBL 3561288 & 1495258 & 3.0 & 3.5183 & TRN & & \\
\hline CHEMBL 3185314 & 1495258 & 4.4462 & 4.8531 & TST & & \\
\hline CHEMBL 3560441 & 1495258 & 6.0 & 4.8482 & TRN & & \\
\hline CHEMBL3560681 & 1495258 & 4.6461 & 4.1343 & TST & & \\
\hline CHEMBL 2355635 & 1495258 & 6.0 & 4.7487 & TRN & & \\
\hline CHEMBL 2136462 & 1495258 & 4.1504 & 3.9562 & TRN & & \\
\hline CHEMBL3561549 & 1495258 & 4.3341 & 4.7536 & TRN & & \\
\hline CHEMBL 2360127 & 1495258 & 4.7066 & 4.8877 & TRN & & \\
\hline CHEMBL 3561420 & 1495258 & 3.0 & 4.2609 & TRN & & \\
\hline CHEMBL 3561333 & 1495258 & 4.2664 & 3.8806 & TRN & & \\
\hline CHEMBL3183001 & 1495258 & 6.0 & 4.7693 & TRN & & \\
\hline CHEMBL 3561521 & 1495258 & 3.0 & 3.515 & TRN & & \\
\hline CHEMBL 3561895 & 1495258 & 3.0 & 3.9436 & TRN & & \\
\hline CHEMBL 3561715 & 1495258 & 4.6765 & 4.5292 & TRN & & \\
\hline CHEMBL 3561655 & 1495258 & 3.0 & 4.7008 & TST & & \\
\hline CHEMBL 2361534 & 1495258 & 4.3285 & 4.409 & TST & & \\
\hline CHEMBL3559806 & 1495258 & 4.5038 & 4.0022 & TST & & \\
\hline CHEMBL 3560250 & 1495258 & 4.1146 & 4.2566 & TRN & & \\
\hline CHEMBL3560169 & 1495258 & 4.0989 & 4.8227 & TRN & & \\
\hline CHEMBL3561593 & 1495258 & 3.0 & 3.7458 & TRN & & \\
\hline CHEMBL 3560351 & 1495258 & 4.5948 & 4.4147 & TST & & \\
\hline CHEMBL3561511 & 1495258 & 4.1607 & 5.0251 & TST & & \\
\hline CHEMBL 3185444 & 1495258 & 4.59399 & 999999999 & 99 & 4.6966 & TRN \\
\hline CHEMBL 3561785 & 1495258 & 4.7445 & 4.9366 & TRN & & \\
\hline CHEMBL 3183458 & 1495258 & 4.4173 & 3.5632 & TRN & & \\
\hline CHEMBL3561252 & 1495258 & 4.0995 & 4.5258 & TRN & & \\
\hline CHEMBL 3560423 & 1495258 & 4.23 & 3.6886 & TRN & & \\
\hline CHEMBL 2358924 & 1495258 & 4.1781 & 4.8966 & TRN & & \\
\hline CHEMBL 3560198 & 1495258 & 4.6826 & 4.7307 & TRN & & \\
\hline CHEMBL 3560452 & 1495258 & 4.6678 & 4.8606 & TRN & & \\
\hline CHEMBL 2143055 & 1495258 & 4.1754 & 3.8548 & TST & & \\
\hline CHEMBL2358899 & 1495258 & 6.0 & 4.9581 & TRN & & \\
\hline CHEMBL3560599 & 1495258 & 4.7577 & 4.8095 & TST & & \\
\hline CHEMBL3561099 & 1495258 & 3.0 & 3.5991 & TRN & & \\
\hline CHEMBL 2355407 & 1495258 & 4.4903 & 4.6817 & TRN & & \\
\hline CHEMBL 2140610 & 1495258 & 3.0 & 3.8719 & TRN & & \\
\hline CHEMBL 3560551 & 1495258 & 6.0 & 4.6042 & TRN & & \\
\hline CHEMBL 3560061 & 1495258 & 4.5317 & 4.1437 & TST & & \\
\hline
\end{tabular}

Page 14361 
Supplemental Table S2.txt

\begin{tabular}{|c|c|c|c|c|c|}
\hline CHEMBL3561818 & 1495258 & 4.3146 & 3.6992 & TRN & \\
\hline CHEMBL 3560408 & 1495258 & 4.8677 & 4.436 & TRN & \\
\hline CHEMBL3559982 & 1495258 & 3.0 & 3.5955 & TRN & \\
\hline CHEMBL 3560821 & 1495258 & 4.1789 & 4.2113 & TST & \\
\hline CHEMBL 3561666 & 1495258 & 4.7296 & 5.038 & TRN & \\
\hline CHEMBL 2362144 & 1495258 & 5.5467 & 4.6366 & TRN & \\
\hline CHEMBL 3560428 & 1495258 & 4.71399 & 79999999ऽ & 995 & 3.7882 \\
\hline CHEMBL3559891 & 1495258 & 6.0 & 4.5823 & TST & \\
\hline CHEMBL 3561831 & 1495258 & 4.3708 & 4.092 & TRN & \\
\hline CHEMBL 3560353 & 1495258 & 4.6341 & 4.6904 & TST & \\
\hline CHEMBL 3561876 & 1495258 & 4.6402 & 4.2137 & TST & \\
\hline CHEMBL 3561071 & 1495258 & 4.745 & 5.0764 & TRN & \\
\hline CHEMBL 3561915 & 1495258 & 4.6212 & 4.7394 & TST & \\
\hline CHEMBL3561601 & 1495258 & 4.1445 & 3.7221 & TRN & \\
\hline CHEMBL3561461 & 1495258 & 6.0 & 4.7287 & TRN & \\
\hline CHEMBL 3561386 & 1495258 & 4.6743 & 4.6055 & TRN & \\
\hline CHEMBL3559957 & 1495258 & 4.3633 & 4.5856 & TRN & \\
\hline CHEMBL 3560554 & 1495258 & 3.0 & 4.5024 & TST & \\
\hline CHEMBL 3561860 & 1495258 & 3.0 & 4.2275 & TRN & \\
\hline CHEMBL 3560647 & 1495258 & 4.0846 & 4.8679 & TRN & \\
\hline CHEMBL 3560062 & 1495258 & 3.0 & 3.4936 & TRN & \\
\hline CHEMBL 3560269 & 1495258 & 4.7474 & 4.6625 & TST & \\
\hline CHEMBL 3560715 & 1495258 & 3.0 & 4.4853 & TRN & \\
\hline CHEMBL3187889 & 1495258 & 4.7102 & 4.9128 & TRN & \\
\hline CHEMBL 3560302 & 1495258 & 4.1183 & 3.6924 & TRN & \\
\hline CHEMBL 2356186 & 1495258 & 5.8508 & 4.7388 & TRN & \\
\hline CHEMBL 3561937 & 1495258 & 4.6021 & 4.053 & TRN & \\
\hline CHEMBL 2361967 & 1495258 & 3.0 & 4.4736 & TRN & \\
\hline CHEMBL3560116 & 1495258 & 4.1418 & 4.6042 & TST & \\
\hline CHEMBL 3560215 & 1495258 & 3.0 & 3.1978 & TRN & \\
\hline CHEMBL 2359728 & 1495258 & 4.4283 & 4.7369 & TRN & \\
\hline CHEMBL 2362817 & 1495258 & 4.7918 & 4.3061 & TST & \\
\hline CHEMBL 2361979 & 1495258 & 4.0952 & \multicolumn{3}{|c|}{4.031000000000001} \\
\hline CHEMBL 3561320 & 1495258 & 3.0 & 4.2081 & TRN & \\
\hline CHEMBL3561459 & 1495258 & 4.007 & 4.6324 & TRN & \\
\hline CHEMBL3561126 & 1495258 & 4.3075 & 4.7417 & TST & \\
\hline CHEMBL 3561850 & 1495258 & 4.1203 & 3.7346 & TRN & \\
\hline CHEMBL 3560583 & 1495258 & 4.6021 & 3.7926 & TRN & \\
\hline CHEMBL3560946 & 1495258 & 4.5733 & 3.5269 & TRN & \\
\hline CHEMBL 3561923 & 1495258 & 4.3743 & 3.6055 & TRN & \\
\hline CHEMBL 3560954 & 1495258 & 3.0 & 3.5848 & TST & \\
\hline CHEMBL 3561199 & 1495258 & 3.0 & 3.9098 & TRN & \\
\hline CHEMBL 3560920 & 1495258 & 4.6098 & 4.8886 & TRN & \\
\hline CHEMBL3561716 & 1495258 & 4.3153 & 4.0427 & TST & \\
\hline CHEMBL 3561401 & 1495258 & 4.0379 & 4.1986 & TST & \\
\hline CHEMBL 3561772 & 1495258 & 4.6176 & 3.7523 & TST & \\
\hline CHEMBL 3560677 & 1495258 & 4.4357 & 4.5995 & TRN & \\
\hline CHEMBL2354995 & 1495258 & 3.0 & 4.3502 & TRN & \\
\hline
\end{tabular}




\begin{tabular}{|c|c|c|c|c|c|c|}
\hline \multicolumn{7}{|c|}{ Supplemental Table S2.txt } \\
\hline CHEMBL 2358156 & 1495258 & 3.0 & 4.7432 & TRN & & \\
\hline CHEMBL3561300 & 1495258 & 4.67899 & 99999999 & 99 & 4.3791 & TST \\
\hline CHEMBL3561830 & 1495258 & 6.0 & 4.8594 & TRN & & \\
\hline CHEMBL 3189030 & 1495258 & 3.0 & 3.3393 & TRN & & \\
\hline CHEMBL3560649 & 1495258 & 4.6753 & 4.7526 & TST & & \\
\hline CHEMBL3560126 & 1495258 & 3.0 & 3.7233 & TRN & & \\
\hline CHEMBL 2357966 & 1495258 & 4.3478 & 4.7312 & TRN & & \\
\hline CHEMBL3561970 & 1495258 & 4.0104 & 4.4446 & TRN & & \\
\hline CHEMBL 2356893 & 1495258 & 4.9547 & 4.4407 & TST & & \\
\hline CHEMBL3560110 & 1495258 & 5.129 & 4.97 & TRN & & \\
\hline CHEMBL3559884 & 1495258 & 4.1894 & 3.8902 & TRN & & \\
\hline CHEMBL3561742 & 1495258 & 4.3451 & 3.6205 & TST & & \\
\hline CHEMBL3559852 & 1495258 & 4.0622 & 3.8497 & TRN & & \\
\hline CHEMBL3561311 & 1495258 & 4.2457 & 4.5926 & TRN & & \\
\hline CHEMBL3560271 & 1495258 & 6.0 & 4.7229 & TRN & & \\
\hline CHEMBL3561954 & 1495258 & 4.7261 & 4.8844 & TRN & & \\
\hline CHEMBL3561409 & 1495258 & 3.0 & 4.9233 & TST & & \\
\hline CHEMBL3561652 & 1495258 & 6.0 & 3.9816 & TST & & \\
\hline CHEMBL3561718 & 1495258 & 4.0695 & 4.0998 & TST & & \\
\hline CHEMBL 3182224 & 1495258 & 5.0031 & 4.8322 & TRN & & \\
\hline CHEMBL3561607 & 1495258 & 6.0 & 4.8711 & TRN & & \\
\hline CHEMBL3560233 & 1495258 & 4.3135 & 4.6169 & TRN & & \\
\hline CHEMBL3560160 & 1495258 & 4.4828 & 4.3354 & TST & & \\
\hline CHEMBL3560246 & 1495258 & 3.0 & 3.8651 & TRN & & \\
\hline CHEMBL 2361970 & 1495258 & 4.4642 & 4.5014 & TRN & & \\
\hline CHEMBL3560983 & 1495258 & 4.1478 & 4.5351 & TST & & \\
\hline CHEMBL3559779 & 1495258 & 4.6584 & 3.8964 & TRN & & \\
\hline CHEMBL 2355506 & 1495258 & 6.0 & 4.6052 & TRN & & \\
\hline CHEMBL3561784 & 1495258 & 4.1459 & 4.6128 & TST & & \\
\hline CHEMBL 2361002 & 1495258 & 4.47199 & 99999999 & 995 & 3.9245 & TRN \\
\hline CHEMBL3560704 & 1495258 & 4.1984 & 4.5405 & TRN & & \\
\hline CHEMBL3559979 & 1495258 & 4.2977 & 4.0012 & TRN & & \\
\hline CHEMBL3561497 & 1495258 & 3.0 & 3.7936 & TST & & \\
\hline CHEMBL3561578 & 1495258 & 3.0 & 4.6809 & TST & & \\
\hline CHEMBL591876 & 752326 & 5.523 & 5.6967 & TRN & & \\
\hline CHEMBL1384771 & 752326 & 4.5079 & 4.7776 & TST & & \\
\hline CHEMBL1300250 & 752326 & 4.2424 & 4.4215 & TRN & & \\
\hline CHEMBL1547261 & 752326 & 4.4023 & 4.2378 & TRN & & \\
\hline CHEMBL1700106 & 752326 & 4.8586 & 4.8571 & TRN & & \\
\hline CHEMBL1342837 & 752326 & 4.4694 & 4.1653 & TST & & \\
\hline CHEMBL 2006168 & 752326 & 5.9115 & 4.8062 & TST & & \\
\hline CHEMBL1987820 & 752326 & 5.4893 & 5.2004 & TRN & & \\
\hline CHEMBL1400298 & 752326 & 5.4655 & 4.9023 & TRN & & \\
\hline CHEMBL3194964 & 752326 & 5.7713 & 5.0432 & TRN & & \\
\hline CHEMBL1532863 & 752326 & 4.4776 & 4.2507 & TRN & & \\
\hline CHEMBL1979954 & 752326 & 4.7467 & 4.6709 & TRN & & \\
\hline CHEMBL 2004978 & 752326 & 4.4872 & 4.8279 & TRN & & \\
\hline CHEMBL1503689 & 752326 & 4.8072 & 4.3619 & TRN & & \\
\hline
\end{tabular}




\begin{tabular}{|c|c|c|c|c|c|c|}
\hline & & \multicolumn{5}{|c|}{ Supplemental Table S2.txt } \\
\hline CHEMBL1404522 & 752326 & 3.74399 & 9999999 & 998 & 3.8985 & TRN \\
\hline CHEMBL547285 & 752326 & 5.3512 & 5.669 & TRN & & \\
\hline CHEMBL1504701 & 752326 & 4.5358 & 4.9158 & TRN & & \\
\hline CHEMBL1532595 & 752326 & 4.0212 & 4.2485 & TRN & & \\
\hline CHEMBL1713163 & 752326 & 5.1714 & 4.5495 & TRN & & \\
\hline CHEMBL1880417 & 752326 & 5.3412 & 5.8246 & TRN & & \\
\hline CHEMBL1583665 & 752326 & 4.9285 & 4.8465 & TRN & & \\
\hline CHEMBL1541177 & 752326 & 5.3451 & 4.2904 & TRN & & \\
\hline CHEMBL1980018 & 752326 & 4.4153 & 5.1189 & TRN & & \\
\hline CHEMBL1360977 & 752326 & 4.314 & 4.4033 & TRN & & \\
\hline CHEMBL1450526 & 752326 & 5.0325 & 5.013 & TRN & & \\
\hline CHEMBL1335944 & 752326 & 5.5899 & 4.7346 & TRN & & \\
\hline CHEMBL1528669 & 752326 & 2.585 & 4.0345 & TRN & & \\
\hline CHEMBL1486726 & 752326 & 4.6746 & 4.234 & TRN & & \\
\hline CHEMBL1900376 & 752326 & 4.4712 & 4.3484 & TRN & & \\
\hline CHEMBL1524403 & 752326 & 4.1533 & 4.1964 & TRN & & \\
\hline CHEMBL1541260 & 752326 & 2.585 & 4.0921 & TRN & & \\
\hline CHEMBL3198912 & 752326 & 5.3804 & 5.1857 & TRN & & \\
\hline CHEMBL1458376 & 752326 & 4.9296 & 4.3049 & TRN & & \\
\hline CHEMBL3195997 & 752326 & 5.4535 & 4.9927 & TRN & & \\
\hline CHEMBL1989897 & 752326 & 5.4593 & 5.3709 & TRN & & \\
\hline CHEMBL1878035 & 752326 & 5.8595 & 4.3876 & TRN & & \\
\hline CHEMBL3189519 & 752326 & 5.5513 & 4.9634 & TRN & & \\
\hline CHEMBL3210088 & 752326 & 2.585 & 4.6044 & TRN & & \\
\hline CHEMBL1894615 & 752326 & 4.928 & 4.7578 & TRN & & \\
\hline CHEMBL1363032 & 752326 & 3.6123 & 4.0933 & TRN & & \\
\hline CHEMBL1448442 & 752326 & 4.2981 & 4.3759 & TST & & \\
\hline CHEMBL1896407 & 752326 & 2.585 & 4.5357 & TST & & \\
\hline CHEMBL1526148 & 752326 & 4.5791 & 4.3952 & TRN & & \\
\hline CHEMBL1893379 & 752326 & 3.6208 & 4.2824 & TRN & & \\
\hline CHEMBL3196134 & 752326 & 5.3859 & 4.6508 & TRN & & \\
\hline CHEMBL1587624 & 752326 & 3.7203 & 4.215 & TRN & & \\
\hline CHEMBL1417731 & 752326 & 2.585 & 4.0206 & TRN & & \\
\hline CHEMBL1698608 & 752326 & 5.4528 & 5.2019 & TRN & & \\
\hline CHEMBL1998863 & 752326 & 5.4911 & 5.1083 & TRN & & \\
\hline CHEMBL1373096 & 752326 & 5.8784 & 5.8753 & TRN & & \\
\hline CHEMBL1488020 & 752326 & 4.8596 & 4.2033 & TRN & & \\
\hline CHEMBL1431189 & 752326 & 4.5458 & 4.3083 & TRN & & \\
\hline CHEMBL1497295 & 752326 & 5.9241 & 4.5858 & TRN & & \\
\hline CHEMBL1547169 & 752326 & 4.0154 & 3.9012 & TRN & & \\
\hline CHEMBL1474014 & 752326 & 4.2464 & 4.8321 & TRN & & \\
\hline CHEMBL1866510 & 752326 & 3.9789 & 4.9531 & TRN & & \\
\hline CHEMBL1527400 & 752326 & 5.1042 & 4.7578 & TRN & & \\
\hline CHEMBL1460705 & 752326 & 4.5862 & 4.4446 & TRN & & \\
\hline CHEMBL1599290 & 752326 & 2.585 & 4.3957 & TRN & & \\
\hline CHEMBL1332756 & 752326 & 5.437 & 5.7294 & TRN & & \\
\hline CHEMBL3208365 & 752326 & 5.8768 & 4.6368 & TRN & & \\
\hline CHEMBL1339433 & 752326 & 4.7189 & 4.7388 & TRN & & \\
\hline
\end{tabular}


Supplemental Table S2.txt

\begin{tabular}{|c|c|c|c|c|c|}
\hline CHEMBL1422176 & 752326 & 3.9042 & 4.4261 & TRN & \\
\hline CHEMBL199194 & 752326 & 4.1755 & 4.2763 & TRN & \\
\hline CHEMBL3198332 & 752326 & 5.4934 & 5.0694 & TRN & \\
\hline CHEMBL1301164 & 752326 & 4.5536 & 4.306 & TRN & \\
\hline CHEMBL1902169 & 752326 & 4.6379 & 4.8045 & TRN & \\
\hline CHEMBL1449083 & 752326 & 4.0331 & 4.3152 & TRN & \\
\hline CHEMBL1408952 & 752326 & 3.9356 & 4.2077 & TRN & \\
\hline CHEMBL512749 & 752326 & 5.2497 & 4.6704 & TRN & \\
\hline CHEMBL1558462 & 752326 & 5.4947 & 4.3775 & TRN & \\
\hline CHEMBL1888076 & 752326 & 4.1255 & 5.6649 & TRN & \\
\hline CHEMBL 3192181 & 752326 & 5.3461 & 5.2937 & TRN & \\
\hline CHEMBL492267 & 752326 & 4.1842 & 4.5084 & TRN & \\
\hline CHEMBL1394624 & 752326 & 5.3311 & 5.09399 & 9999999999 & TRN \\
\hline CHEMBL1256737 & 752326 & 4.812 & 4.8043 & TST & \\
\hline CHEMBL1532068 & 752326 & 5.0859 & 5.6641 & TRN & \\
\hline CHEMBL1341936 & 752326 & 4.6786 & 4.2412 & TST & \\
\hline CHEMBL1544917 & 752326 & 2.585 & 4.3534 & TST & \\
\hline CHEMBL1305312 & 752326 & 4.1209 & 4.1981 & TRN & \\
\hline CHEMBL1527600 & 752326 & 4.0715 & 4.1261 & TRN & \\
\hline CHEMBL3192616 & 752326 & 5.1221 & 4.8382 & TRN & \\
\hline CHEMBL1572496 & 752326 & 4.1456 & 4.2059 & TRN & \\
\hline CHEMBL1577983 & 752326 & 4.1534 & 4.4931 & TRN & \\
\hline CHEMBL455284 & 752326 & 5.6866 & 5.6771 & TRN & \\
\hline CHEMBL530049 & 752326 & 5.0503 & 5.2022 & TRN & \\
\hline CHEMBL 3190805 & 752326 & 4.0395 & 5.0549 & TRN & \\
\hline CHEMBL585266 & 752326 & 5.445 & 5.6242 & TRN & \\
\hline CHEMBL1969934 & 752326 & 5.4329 & 4.8115 & TRN & \\
\hline CHEMBL1441042 & 752326 & 4.3955 & 4.3684 & TRN & \\
\hline CHEMBL534423 & 752326 & 6.0353 & 5.76200 & 00000000005 & TRN \\
\hline CHEMBL429335 & 752326 & 2.585 & 4.6841 & TRN & \\
\hline CHEMBL 3145303 & 752326 & 5.5779 & 5.4574 & TRN & \\
\hline CHEMBL1545435 & 752326 & 4.727 & 4.6461 & TRN & \\
\hline CHEMBL1308201 & 752326 & 4.143 & 4.2225 & TRN & \\
\hline CHEMBL1588024 & 752326 & 4.4536 & 4.0304 & TRN & \\
\hline CHEMBL 2000750 & 752326 & 5.3047 & 5.2364 & TRN & \\
\hline CHEMBL1576166 & 752326 & 4.8516 & 4.2156 & TRN & \\
\hline CHEMBL1505474 & 752326 & 4.3678 & 4.7148 & TRN & \\
\hline CHEMBL1366321 & 752326 & 3.986 & 4.5821 & TRN & \\
\hline CHEMBL1091556 & 752326 & 4.4048 & 5.1069 & TRN & \\
\hline CHEMBL1318556 & 752326 & 4.0409 & 4.2058 & TRN & \\
\hline CHEMBL1485358 & 752326 & 2.585 & 4.3628 & TST & \\
\hline CHEMBL1392509 & 752326 & 4.275 & 3.8561 & TRN & \\
\hline CHEMBL1596270 & 752326 & 3.6802 & 4.6 & TRN & \\
\hline CHEMBL592600 & 752326 & 5.9226 & 5.8023 & TRN & \\
\hline CHEMBL1865393 & 752326 & 4.9326 & 4.6942 & TRN & \\
\hline CHEMBL2359467 & 752326 & 4.113 & 4.9698 & TRN & \\
\hline CHEMBL1594286 & 752326 & 4.1628 & 4.2742 & TRN & \\
\hline CHEMBL1354085 & 752326 & 4.6187 & 4.5984 & TST & \\
\hline
\end{tabular}




\begin{tabular}{|c|c|c|c|c|c|}
\hline \multicolumn{6}{|c|}{ Supplemental Table S2.txt } \\
\hline CHEMBL 225903 & 752326 & 5.6445 & 4.5456 & TRN & \\
\hline CHEMBL1611182 & 752326 & 5.3574 & 4.9952 & TST & \\
\hline CHEMBL1479393 & 752326 & 4.5636 & 4.535 & TRN & \\
\hline CHEMBL 3198588 & 752326 & 4.4055 & 4.7309 & TRN & \\
\hline CHEMBL1595015 & 752326 & 5.3865 & 4.4331 & TRN & \\
\hline CHEMBL1717138 & 752326 & 5.6615 & 5.6649 & TRN & \\
\hline CHEMBL1360295 & 752326 & 4.4386 & 4.3215 & TRN & \\
\hline CHEMBL1529190 & 752326 & 5.3115 & 5.1459 & TRN & \\
\hline CHEMBL1597777 & 752326 & 3.8002 & 4.4899 & TRN & \\
\hline CHEMBL1902131 & 752326 & 3.6001 & 4.6691 & TST & \\
\hline CHEMBL1316074 & 752326 & 4.0879 & 4.0626 & TRN & \\
\hline CHEMBL1399478 & 752326 & 5.8874 & 4.5481 & TRN & \\
\hline CHEMBL1708568 & 752326 & 5.5058 & 4.8827 & TRN & \\
\hline CHEMBL 3195241 & 752326 & 5.0264 & 4.937 & TRN & \\
\hline CHEMBL1460869 & 752326 & 5.6178 & 4.5153 & TRN & \\
\hline CHEMBL1893344 & 752326 & 5.2431 & 4.5946 & TST & \\
\hline CHEMBL1466844 & 752326 & 3.6575 & 4.3648 & TRN & \\
\hline CHEMBL582099 & 752326 & 5.4053 & 5.4157 & TRN & \\
\hline CHEMBL590665 & 752326 & 5.4999 & 5.5538 & TRN & \\
\hline CHEMBL1979727 & 752326 & 4.4238 & 4.9481 & TRN & \\
\hline CHEMBL3145296 & 752326 & 3.6216 & 4.8256 & TRN & \\
\hline CHEMBL1317322 & 752326 & 5.1107 & 4.2827 & TRN & \\
\hline CHEMBL1440588 & 752326 & 4.3928 & 4.2287 & TST & \\
\hline CHEMBL1462938 & 752326 & 8.9586 & 5.5184 & TST & \\
\hline CHEMBL1996281 & 752326 & 4.6925 & 4.8191 & TRN & \\
\hline CHEMBL1492729 & 752326 & 4.4831 & 4.4582 & TST & \\
\hline CHEMBL1971144 & 752326 & 4.1965 & 5.2016 & TRN & \\
\hline CHEMBL1980322 & 752326 & 5.3883 & 4.8746 & TRN & \\
\hline CHEMBL1605795 & 752326 & 4.2644 & 4.1459 & TRN & \\
\hline CHEMBL3195168 & 752326 & 4.3289 & 4.26699 & 99999999995 & TST \\
\hline CHEMBL1894539 & 752326 & 4.6151 & 4.5453 & TRN & \\
\hline CHEMBL1991388 & 752326 & 3.7565 & 4.3112 & TRN & \\
\hline CHEMBL591363 & 752326 & 5.9363 & 5.8812 & TRN & \\
\hline CHEMBL3196324 & 752326 & 5.4715 & 5.3717 & TRN & \\
\hline CHEMBL1531895 & 752326 & 5.0308 & 5.0271 & TRN & \\
\hline CHEMBL3197431 & 752326 & 3.9392 & 4.4983 & TRN & \\
\hline CHEMBL 1372760 & 752326 & 3.6293 & 4.0013 & TRN & \\
\hline CHEMBL1510652 & 752326 & 3.8633 & 4.2794 & TRN & \\
\hline CHEMBL1484158 & 752326 & 2.585 & 3.7667 & TRN & \\
\hline CHEMBL1609219 & 752326 & 4.5778 & 4.3991 & TST & \\
\hline CHEMBL1464448 & 752326 & 2.585 & 4.3373 & TRN & \\
\hline CHEMBL1417732 & 752326 & 4.9477 & 4.0119 & TRN & \\
\hline CHEMBL225951 & 752326 & 5.0105 & 4.3916 & TRN & \\
\hline CHEMBL1597459 & 752326 & 5.4766 & 4.3147 & TST & \\
\hline CHEMBL1365689 & 752326 & 2.585 & 4.1192 & TRN & \\
\hline CHEMBL1307933 & 752326 & 4.3864 & 4.2013 & TRN & \\
\hline CHEMBL1726705 & 752326 & 4.445 & 4.2612 & TST & \\
\hline CHEMBL1312788 & 752326 & 5.1502 & 4.1248 & TRN & \\
\hline
\end{tabular}




\begin{tabular}{|c|c|c|c|c|c|}
\hline \multirow[b]{2}{*}{ CHEMBL1864040 } & \\
\hline & 752326 & 5.3519 & 4.9788 & TRN & \\
\hline CHEMBL607553 & 752326 & 5.2842 & 5.022 & TRN & \\
\hline CHEMBL3197978 & 752326 & 5.8508 & 4.9999 & TRN & \\
\hline CHEMBL1864760 & 752326 & 5.1384 & 4.6356 & TST & \\
\hline CHEMBL1323139 & 752326 & 4.7493 & 4.416 & TRN & \\
\hline CHEMBL1366310 & 752326 & 4.1657 & 4.2505 & TRN & \\
\hline CHEMBL1608757 & 752326 & 5.3765 & 4.3635 & TST & \\
\hline CHEMBL1338961 & 752326 & 4.0022 & 4.3892 & TRN & \\
\hline CHEMBL1570364 & 752326 & 4.5463 & 4.5331 & TRN & \\
\hline CHEMBL1441122 & 752326 & 4.4475 & 4.6532 & TRN & \\
\hline CHEMBL3190155 & 752326 & 4.3849 & 4.2414 & TRN & \\
\hline CHEMBL600862 & 752326 & 5.813 & 5.256 & TRN & \\
\hline CHEMBL1521187 & 752326 & 2.585 & 3.6768 & TRN & \\
\hline CHEMBL1502883 & 752326 & 2.585 & 4.6129 & TRN & \\
\hline CHEMBL1348501 & 752326 & 4.2053 & 4.2528 & TRN & \\
\hline CHEMBL1440685 & 752326 & 4.6269 & 4.3006 & TRN & \\
\hline CHEMBL1343490 & 752326 & 5.0248 & 4.7083 & TST & \\
\hline CHEMBL1880333 & 752326 & 4.3096 & 4.1829 & TRN & \\
\hline CHEMBL1889367 & 752326 & 4.791 & 5.2269 & TRN & \\
\hline CHEMBL3191921 & 752326 & 4.357 & 4.8573 & TRN & \\
\hline CHEMBL1730953 & 752326 & 4.1789 & 4.303 & TST & \\
\hline CHEMBL1410758 & 752326 & 5.3636 & 5.6313 & TRN & \\
\hline CHEMBL89445 & 752326 & 5.7533 & 5.4811 & TRN & \\
\hline CHEMBL1585578 & 752326 & 4.4172 & 3.9019 & TRN & \\
\hline CHEMBL1360505 & 752326 & 4.2518 & 3.9512 & TRN & \\
\hline CHEMBL1518085 & 752326 & 5.9473 & 4.612 & TRN & \\
\hline CHEMBL1706381 & 752326 & 5.334 & 5.3384 & TRN & \\
\hline CHEMBL1527433 & 752326 & 4.6665 & 4.6607 & TRN & \\
\hline CHEMBL590643 & 752326 & 5.3627 & 5.4135 & TRN & \\
\hline CHEMBL1491194 & 752326 & 4.7282 & 4.3744 & TRN & \\
\hline CHEMBL601119 & 752326 & 4.4921 & 4.7513 & TRN & \\
\hline CHEMBL1984876 & 752326 & 5.4447 & 5.3712 & TRN & \\
\hline CHEMBL1256751 & 752326 & 4.3677 & 4.4402 & TRN & \\
\hline CHEMBL1708343 & 752326 & 2.585 & 5.1326 & TRN & \\
\hline CHEMBL1580774 & 752326 & 4.9174 & 4.6041 & TST & \\
\hline CHEMBL1964614 & 752326 & 5.4935 & 4.9444 & TRN & \\
\hline CHEMBL1339283 & 752326 & 4.0247 & 4.4296 & TRN & \\
\hline CHEMBL3189416 & 752326 & 4.5772 & 5.0336 & TRN & \\
\hline CHEMBL1607568 & 752326 & 5.0089 & 4.3194 & TST & \\
\hline CHEMBL1455993 & 752326 & 4.2505 & 4.2448 & TRN & \\
\hline CHEMBL1581396 & 752326 & 4.3016 & 4.3938 & TRN & \\
\hline CHEMBL1573883 & 752326 & 4.6383 & 4.4771 & TRN & \\
\hline CHEMBL1568213 & 752326 & 4.0995 & 3.9953 & TRN & \\
\hline CHEMBL1880661 & 752326 & 5.29200 & 000000006 & 4.3297 & TRN \\
\hline CHEMBL1731017 & 752326 & 5.4116 & 4.588 & TRN & \\
\hline CHEMBL1299470 & 752326 & 4.9146 & 4.6412 & TRN & \\
\hline CHEMBL1887233 & 752326 & 4.3764 & 4.438 & TRN & \\
\hline CHEMBL1724732 & 752326 & 3.8601 & 5.04899 & 99999999995 & TRN \\
\hline & & & & $1450 \%$ & \\
\hline
\end{tabular}




\begin{tabular}{|c|c|c|c|c|c|c|}
\hline \multicolumn{7}{|c|}{ Supplemental Table S2.txt } \\
\hline CHEMBL3189405 & 752326 & 5.4482 & 4.8653 & TRN & & \\
\hline CHEMBL1698316 & 752326 & 6.2048 & 5.5891 & TRN & & \\
\hline CHEMBL1415882 & 752326 & 4.2432 & 4.1306 & TRN & & \\
\hline CHEMBL1591222 & 752326 & 4.4431 & 4.23300 & 00000000005 & TRN & \\
\hline CHEMBL1981002 & 752326 & 4.4306 & 4.3916 & TST & & \\
\hline CHEMBL1991779 & 752326 & 5.4209 & 5.1604 & TRN & & \\
\hline CHEMBL1599458 & 752326 & 2.585 & 4.1352 & TRN & & \\
\hline CHEMBL1500966 & 752326 & 5.0797 & 4.5472 & TRN & & \\
\hline CHEMBL1372947 & 752326 & 4.1077 & 4.3289 & TST & & \\
\hline CHEMBL1606999 & 752326 & 4.1305 & 4.3521 & TRN & & \\
\hline CHEMBL1481444 & 752326 & 4.4409 & 4.4123 & TRN & & \\
\hline CHEMBL1987419 & 752326 & 5.2788 & 4.9904 & TRN & & \\
\hline CHEMBL1580272 & 752326 & 4.1976 & 4.6493 & TRN & & \\
\hline CHEMBL1595473 & 752326 & 2.585 & 4.2692 & TRN & & \\
\hline CHEMBL1898104 & 752326 & 5.7607 & 4.3927 & TRN & & \\
\hline CHEMBL3190911 & 752326 & 5.3986 & 4.9314 & TRN & & \\
\hline CHEMBL1882125 & 752326 & 5.388 & 4.454 & TRN & & \\
\hline CHEMBL1342147 & 752326 & 5.1015 & 4.3265 & TRN & & \\
\hline CHEMBL1389177 & 752326 & 4.3939 & 4.5654 & TRN & & \\
\hline CHEMBL1343448 & 752326 & 4.6516 & 4.282 & TRN & & \\
\hline CHEMBL602218 & 752326 & 5.0597 & 4.9663 & TRN & & \\
\hline CHEMBL1459140 & 752326 & 5.44 & 4.7099 & TRN & & \\
\hline CHEMBL1525735 & 752326 & 4.3329 & 4.2052 & TRN & & \\
\hline CHEMBL1544114 & 752326 & 5.5406 & 5.1174 & TRN & & \\
\hline CHEMBL1611300 & 752326 & 2.585 & 3.83399 & 99999999996 & TST & \\
\hline CHEMBL1577174 & 752326 & 4.794 & 4.192 & TRN & & \\
\hline CHEMBL1311453 & 752326 & 4.4134 & 4.5154 & TRN & & \\
\hline CHEMBL1400132 & 752326 & 4.9073 & 3.8596 & TRN & & \\
\hline CHEMBL1393813 & 752326 & 5.3932 & 4.6681 & TRN & & \\
\hline CHEMBL1302241 & 752326 & 2.585 & 4.6276 & TRN & & \\
\hline CHEMBL1699228 & 752326 & 4.9473 & 4.4686 & TST & & \\
\hline CHEMBL494326 & 752326 & 3.8714 & 3.9008 & TRN & & \\
\hline CHEMBL1559383 & 752326 & 4.4282 & 4.3457 & TST & & \\
\hline CHEMBL1542378 & 752326 & 3.7481 & 4.431 & TRN & & \\
\hline CHEMBL1406208 & 752326 & 3.8177 & 4.2689 & TST & & \\
\hline CHEMBL1891517 & 752326 & 4.3749 & 4.1517 & TRN & & \\
\hline CHEMBL1311208 & 752326 & 4.3142 & 4.1529 & TRN & & \\
\hline CHEMBL1725990 & 752326 & 6.16299 & و9999999 & 99 & 000000001 & TRN \\
\hline CHEMBL1983939 & 752326 & 5.3503 & 4.9504 & TRN & & \\
\hline CHEMBL1900730 & 752326 & 5.3342 & 4.6938 & TST & & \\
\hline CHEMBL42178 & 752326 & 4.4832 & 4.3911 & TRN & & \\
\hline CHEMBL1491279 & 752326 & 4.2393 & 4.1654 & TRN & & \\
\hline CHEMBL1883309 & 752326 & 5.3516 & 4.461 & TST & & \\
\hline CHEMBL1473464 & 752326 & 4.0091 & 4.2627 & TRN & & \\
\hline CHEMBL1899528 & 752326 & 5.3048 & 4.6655 & TRN & & \\
\hline CHEMBL1537781 & 752326 & 4.5919 & 4.4609 & TRN & & \\
\hline CHEMBL1593484 & 752326 & 4.8461 & 4.2872 & TRN & & \\
\hline CHEMBL1701797 & 752326 & 6.5986 & 5.3582 & TRN & & \\
\hline
\end{tabular}


Supplemental Table S2.txt

\begin{tabular}{|c|c|c|c|c|c|}
\hline CHEMBL1883210 & 752326 & 5.8173 & 5.0895 & TRN & \\
\hline CHEMBL1582999 & 752326 & 4.4125 & 4.4993 & TRN & \\
\hline CHEMBL1718568 & 752326 & 4.6692 & 4.8316 & TRN & \\
\hline CHEMBL1555271 & 752326 & $5.3610 e$ & 0000000 & 91 & 5.6691 \\
\hline CHEMBL1899451 & 752326 & 6.3915 & 4.5957 & TST & \\
\hline CHEMBL1448282 & 752326 & 5.3634 & 5.5497 & TRN & \\
\hline CHEMBL1731367 & 752326 & 4.2658 & 4.3039 & TRN & \\
\hline CHEMBL1717079 & 752326 & 6.3947 & 5.561 & TRN & \\
\hline CHEMBL1986514 & 752326 & 4.7249 & 4.6431 & TRN & \\
\hline CHEMBL 2354875 & 752326 & 4.3082 & 4.6015 & TST & \\
\hline CHEMBL1990258 & 752326 & 4.5689 & 4.3126 & TST & \\
\hline CHEMBL1487901 & 752326 & 4.1557 & 4.4722 & TST & \\
\hline CHEMBL1978733 & 752326 & 5.2978 & 4.6907 & TST & \\
\hline CHEMBL1487619 & 752326 & 5.0061 & 5.0211 & TST & \\
\hline CHEMBL1699099 & 752326 & 2.585 & 4.378 & TST & \\
\hline CHEMBL1394581 & 752326 & 4.1863 & 4.4237 & TST & \\
\hline CHEMBL1571157 & 752326 & 5.0012 & 4.5602 & TST & \\
\hline CHEMBL1705854 & 752326 & 4.5401 & 4.7326 & TST & \\
\hline CHEMBL 26320 & 752326 & 4.7833 & 4.4287 & TST & \\
\hline CHEMBL1390386 & 752326 & 3.8058 & 4.5938 & TST & \\
\hline CHEMBL3194777 & 752326 & 2.585 & 4.3198 & TST & \\
\hline CHEMBL1720801 & 752326 & 4.7966 & 5.2244 & TST & \\
\hline CHEMBL1602614 & 752326 & 4.6798 & 4.3888 & TST & \\
\hline CHEMBL1986418 & 752326 & 5.6343 & 4.9012 & TST & \\
\hline CHEMBL1993020 & 752326 & 4.4612 & 3.9104 & TST & \\
\hline CHEMBL1531914 & 752326 & 4.3657 & 4.3892 & TST & \\
\hline CHEMBL3199168 & 752326 & 4.1176 & 4.3525 & TST & \\
\hline CHEMBL3192341 & 752326 & 4.4702 & 4.2787 & TST & \\
\hline CHEMBL1466352 & 752326 & 4.5814 & 4.3097 & TST & \\
\hline CHEMBL1423060 & 752326 & 4.3029 & 4.0099 & TST & \\
\hline CHEMBL1713327 & 752326 & 5.474 & 5.0613 & TST & \\
\hline CHEMBL1421559 & 752326 & 5.3591 & 4.6183 & TST & \\
\hline CHEMBL1899001 & 752326 & 5.2466 & 4.9665 & TST & \\
\hline CHEMBL1544409 & 752326 & 4.1289 & 4.4193 & TST & \\
\hline CHEMBL1558310 & 752326 & 3.7668 & 4.1505 & TST & \\
\hline CHEMBL1535532 & 752326 & 4.8261 & 4.6099 & TST & \\
\hline CHEMBL412355 & 752326 & 4.4449 & 4.6421 & TST & \\
\hline CHEMBL600778 & 752326 & 5.7867 & 5.8839 & TST & \\
\hline CHEMBL1414273 & 752326 & 4.4079 & 4.1682 & TST & \\
\hline CHEMBL 1875746 & 752326 & 5.3876 & 4.882 & TST & \\
\hline CHEMBL1867591 & 752326 & 5.8069 & 5.7897 & TST & \\
\hline CHEMBL 3198754 & 752326 & 2.585 & 5.2724 & TST & \\
\hline CHEMBL3194991 & 752326 & 4.2222 & 4.3709 & TST & \\
\hline CHEMBL1315948 & 752326 & 4.9511 & 4.5477 & TST & \\
\hline CHEMBL1514530 & 752326 & 5.3616 & 5.5633 & TST & \\
\hline CHEMBL1510399 & 752326 & 4.499 & 4.272 & TST & \\
\hline CHEMBL1316462 & 752326 & 4.1892 & 4.0198 & TST & \\
\hline CHEMBL259615 & 752326 & 4.398 & 4.1484 & TST & \\
\hline
\end{tabular}


Supplemental Table S2.txt

\begin{tabular}{|c|c|c|c|c|}
\hline HEMBL3213419 & 52326 & 4.2784 & ככעו & 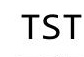 \\
\hline CHEMBL1376974 & 752326 & 7.7959 & 4.6767 & TST \\
\hline HEMBL522176 & 3414 & 3.5229 & 3.8186 & \\
\hline HEMBL522346 & 3414 & .5229 & 4.0987 & {$[R N$} \\
\hline HEMBL493839 & 23414 & 3.5229 & 3.4628 & \\
\hline HEMBL493823 & 23414 & 3.5229 & 3.8049 & \\
\hline HEMBL582971 & 23414 & 4.5229 & 4.3436 & \\
\hline CHEMBL496226 & 23414 & 4.5229 & 4.0788 & \\
\hline HEMBL492791 & 23414 & 4.5229 & 3.9555 & \\
\hline HEMBL493824 & 23414 & 3.5229 & 3.5558 & \\
\hline HEMBL467253 & 23414 & 4.5229 & 4.211 & \\
\hline HEMBL493988 & 23414 & 3.5229 & 3.395 & \\
\hline HEMBL493835 & 523414 & 3.5229 & 3.8913 & \\
\hline HEMBL 522873 & 23414 & 3.5229 & 3.4778 & \\
\hline HEMBL496404 & 3414 & 3.5229 & 3.8312 & \\
\hline HEMBL468291 & 23414 & 3.5229 & 3.7918 & \\
\hline HEMBL495016 & 23414 & 3.5229 & 2575 & \\
\hline HEMBL402465 & 523414 & 3.5229 & 3.7117 & \\
\hline HEMBL493832 & 23414 & 3.5229 & 3.6544 & \\
\hline HEMBL 524049 & 3414 & 4.5229 & 4.7439 & \\
\hline JEMBL497435 & 23414 & 3.5229 & 3.8914 & RN \\
\hline HEMBL467880 & 23414 & 3.5229 & 993 & \\
\hline CHEMBL500021 & 23414 & 4.5229 & 3.9834 & \\
\hline HEMBL49 & 3414 & 3.5229 & 4.1319 & \\
\hline HEMBL501878 & 23414 & 4.5229 & 3.9317 & \\
\hline AEMBL523733 & 23414 & 3.5229 & 4.1458 & RI \\
\hline CHEMBL521727 & 23414 & 4.5229 & 4.2213 & ST \\
\hline CHEMBL495178 & 3414 & 4.5229 & 4.1838 & KIV \\
\hline HEMBL4C & 414 & 3.5 & 3.5512 & NIV \\
\hline HEMBL 495803 & 3414 & 3.5229 & 3.7611 & RN \\
\hline AEMBL450123 & 3414 & 3.5229 & 3.537 & RN \\
\hline CHEMBL495177 & 23414 & 3.5229 & 3.8143 & TRN \\
\hline CHEMBL524006 & 14 & 4. & 84 & $\mathbf{M I}$ \\
\hline HEMBL49 & 14 & 3.5 & 09 & Niv \\
\hline HEMBL493994 & 414 & 3.5 & 3.852 & $\mathrm{RN}$ \\
\hline HEMBL522008 & 3414 & 3.5229 & 3.7826 & RN \\
\hline CHEMBL522389 & 3414 & 4.5229 & 4.0827 & \\
\hline CHEMBL4 & & & & TRN \\
\hline HEMBL 52 & 14 & 3.5 & 67 & r \\
\hline CHEMBL497008 & 3414 & 5.2218 & 4.4329 & $\mathrm{RN}$ \\
\hline CHEMBL495591 & 23414 & 4.9208 & 4.0503 & RN \\
\hline CHEMBL467879 & 23414 & 3.5229 & 3.0576 & RI \\
\hline CHEMBL524803 & & 4.5 & 4.4601 & \\
\hline CHEMBL497234 & 23414 & 4.5229 & 3.9089 & \\
\hline CHEMBL493993 & 23414 & 3.5229 & 3.5931 & $\mathrm{RN}$ \\
\hline CHEMBL523363 & 23414 & 4.5229 & 4.2889 & RI \\
\hline CHEMBL495015 & 23414 & 3.5229 & 4.1309 & \\
\hline CHEMBL497237 & 523414 & 3.5229 & 3.812 & \\
\hline
\end{tabular}

Page 14370 
Supplemental Table S2.txt

\begin{tabular}{|c|c|c|c|c|}
\hline 235 & 3414 & 229 & 3.9078 & 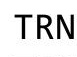 \\
\hline CHEMBL496199 & 3414 & 3.5229 & 7262 & \\
\hline HEMBL493840 & 23414 & 4.5229 & 4371 & \\
\hline AEMBL5 & 3414 & 5229 & .6848 & \\
\hline AEMBL4 & 3414 & 5229 & 4.1927 & \\
\hline HEMBL523526 & 23414 & 3.5229 & 3.4182 & \\
\hline HEMBL494830 & 23414 & 3.5229 & 3.7826 & \\
\hline HEMBL493841 & 23414 & .5229 & .2519 & \\
\hline AEMBL4 & 23414 & 4.5229 & .3756 & \\
\hline HEMBL4 & 414 & 3.5229 & 3.8043 & \\
\hline HEMBL493995 & 23414 & 3.5229 & 6337 & \\
\hline HEMBL 522212 & 23414 & 4.8539 & 4.1645 & \\
\hline HEMBL494829 & 3414 & 3.5229 & .2854 & \\
\hline HEMBL4 & 414 & & .3611 & \\
\hline HEMBL4 & 414 & 29 & 4.0328 & \\
\hline HEMBL507577 & 414 & 229 & 4.1204 & \\
\hline HEMBL497019 & 23414 & 229 & 3.7693 & ST \\
\hline HEMBL5 & 414 & 29 & 4.3689 & 西 \\
\hline HEMBL 5 & 414 & & 3.6329 & \\
\hline HEMBL4 & 414 & & 3.6142 & RN \\
\hline HEMBL4 & 414 & 29 & 363 & ST \\
\hline HEMBL494841 & 23414 & 29 & 4.728 & $\mathrm{RN}$ \\
\hline HEMBL5 & 414 & 29 & 7685 & ST \\
\hline HEMBL4 & 14 & & 2413 & RN \\
\hline HEMBL4 & 414 & 29 & 3539 & ST \\
\hline HEMBL574590 & & & 1688 & ST \\
\hline HEMBL181504 & 3414 & 29 & 4.2086 & ST \\
\hline HEMBL4 & 414 & 29 & 3.5573 & $\mathrm{RN}$ \\
\hline HEMBL & 14 & 29 & 1005 & RN \\
\hline HEMBL4 & 14 & 29 & 9574 & ST \\
\hline HEMBL495614 & & & 3.8673 & ST \\
\hline HEMBL524075 & 23414 & 29 & 3.6258 & TST \\
\hline HEMBL523210 & 414 & 29 & 1049 & $\mathrm{RN}$ \\
\hline CHEM & 4 & 29 & 013 & ST \\
\hline CHEMBL512103 & 14 & & 3.964 & RN \\
\hline CHEMBL521904 & & 29 & 3.8437 & TST \\
\hline HEMBL497620 & 414 & 229 & 4.2483 & TST \\
\hline HEMBL447021 & 14 & 29 & 4.2046 & ST \\
\hline CHEMBL 5 & & & 3.9764 & ST \\
\hline CHEMBL468091 & 23414 & & 3.5329 & $\Gamma \mathrm{RN}$ \\
\hline CHEMBL494840 & 3414 & 29 & 4.1287 & IRN \\
\hline CHEMBL3892389 & 1619734 & $\partial 21$ & 5.5771 & RN \\
\hline CHEMBL3905097 & 1619734 & 6.699 & 6.5917 & \\
\hline CHEMBL3613194 & 1619734 & 5.2007 & 5.2536 & RN \\
\hline CHEMBL3952136 & 1619734 & 6.3979 & 7.5992 & ST \\
\hline CHEMBL 3813871 & 1619734 & 7.1024 & 7.8292 & ST \\
\hline CHEMBL 3 & 9734 & 6. & 7.1796 & \\
\hline CHEMBL 3909313 & 1619734 & 7.699 & 7.7152 & \\
\hline
\end{tabular}

Page 14371 
Supplemental Table S2.txt

\begin{tabular}{|c|c|c|c|c|}
\hline HEMB I & 619734 & & & \\
\hline UГMDI & 619734 & 5.6021 & 5.8174 & \\
\hline 14 & & & & \\
\hline AEMBL3973875 & 619734 & 301 & & $2 \mathrm{~N}$ \\
\hline AEMBL3915155 & $619 / 34$ & 2969 & 0274 & \\
\hline HEMBL3984331 & 619734 & 8.0 & 9175 & \\
\hline HEMBL393. & 519734 & 07 & & \\
\hline IEMBL 392 & & & & \\
\hline AEMBL3896147 & 619734 & 6.6021 & & \\
\hline HEMBL3929992 & 619734 & 5.301 & 5 & \\
\hline HEMBL3895839 & 619734 & 9.0 & & \\
\hline AEMBL395 & 01 & 01 & 02 & \\
\hline AEMBL39 & & & & \\
\hline HEMBL391 & 619 & 6.699 & .5778 & \\
\hline HEMBL391 & 34 & 021 & & \\
\hline AEMBL381 & 61 & 7.301 & 82 & \\
\hline HEMBL39 & $0 \perp$ & 1 & & m \\
\hline HEMBL 36 & & & & \\
\hline HEMBL 361 & $61+2-1$ & 007 & & \\
\hline AEMBL39 & 4 & 6. & & \\
\hline HEMBL3\& & 6. & 6 & 58 & 151 \\
\hline HEMBL3 & 4 & $\sigma_{5}+2$ & & ST \\
\hline HEMBL36 & 4 & & & \\
\hline HEMBL 39 & & 6 & & \\
\hline AEMBL39 & & & & $\Gamma \mathrm{RN}$ \\
\hline HEMBL3S & 61 & 7.79 & 51 & I RN \\
\hline HEMBL; & & 9 & & ST \\
\hline$H F M B I=$ & 4 & 5 & & $\mathrm{RN}$ \\
\hline HEMBL39 & & & & I \\
\hline HEMBL 389 & & 7.60 & & IK \\
\hline HEMBL36 & 61 & & & ST \\
\hline HEMBL & & & & RN \\
\hline HEMBL3 & 4 & 6 & & RN \\
\hline HEMBL395 & 61 & 7. & & IRN \\
\hline HEMBL3958807 & 61 & 5 . & 5 . & TRN \\
\hline HEMBL39 & $61+2>3$ & & 63 & TRN \\
\hline HFMRI 3 & & & 25 & $\Gamma \mathrm{RN}$ \\
\hline HEMBL3 & & 7. & & RN \\
\hline HEMBL3815093 & 619 & 7.6021 & 7.9875 & TST \\
\hline HEMBL396 & 61 & 7.3979 & 7.8005 & TRN \\
\hline HEMBL 381 & $61+2-2$ & 6.699 & 67 & \\
\hline CHEMBL395 & & & & TRN \\
\hline HEMBL39 & 1619734 & 6.8861 & 6.9259 & TRN \\
\hline HEMBL3964772 & 6197 & 7.0 & 33 & P \\
\hline MBL3 & & & & \\
\hline HEMBL 39 & & & & \\
\hline CHEMBL 392 & 161973 & - & .7515 & \\
\hline CHEMBL3894005 & 1619734 & 7.0969 & 7.1039 & \\
\hline
\end{tabular}

Page 14372 
Supplemental Table S2.txt

\begin{tabular}{|c|c|c|c|c|c|}
\hline CHEMBL3982684 & 1619734 & 7.3979 & 7.5233 & TRN & \\
\hline CHEMBL 3814121 & 1619734 & 7.4949 & 7.1607 & TST & \\
\hline CHEMBL3912429 & 1619734 & 7.0969 & 7.2317 & TST & \\
\hline CHEMBL3946992 & 1619734 & 5.8861 & 6.6027 & TST & \\
\hline CHEMBL3924164 & 1619734 & 6.8861 & 6.7535 & TRN & \\
\hline CHEMBL3815116 & 1619734 & 7.6021 & 7.6355 & TRN & \\
\hline CHEMBL3938338 & 1619734 & 7.3979 & 7.2369 & TRN & \\
\hline CHEMBL78627 & 46818 & 1.74 & 1.8062 & TRN & \\
\hline CHEMBL 81683 & 46818 & 1.07 & 1.0712 & TRN & \\
\hline CHEMBL 79204 & 46818 & 1.67 & 1.7409 & TRN & \\
\hline CHEMBL302948 & 46818 & 1.61 & 1.5514 & TST & \\
\hline CHEMBL307073 & 46818 & 1.67 & 1.7424 & TRN & \\
\hline CHEMBL78701 & 46818 & 2.65 & 2.9051 & TST & \\
\hline CHEMBL 78815 & 46818 & 1.94 & 2.0008 & TRN & \\
\hline CHEMBL309700 & 46818 & 2.6 & \multicolumn{2}{|c|}{2.5140000000000002} & TRN \\
\hline CHEMBL312259 & 46818 & 2.47 & 2.4619 & TRN & \\
\hline CHEMBL13272 & 46818 & 2.8 & 2.6772 & TRN & \\
\hline CHEMBL 82361 & 46818 & 0.44 & 0.5251 & TRN & \\
\hline CHEMBL 80938 & 46818 & 2.34 & 2.3792 & TRN & \\
\hline CHEMBL273606 & 46818 & 2.49 & 2.432 & TRN & \\
\hline CHEMBL310751 & 46818 & 3.06 & \multicolumn{2}{|c|}{3.7910000000000004} & TST \\
\hline CHEMBL81473 & 46818 & 0.04 & 0.1006 & TRN & \\
\hline CHEMBL78359 & 46818 & 0.74 & 0.7695 & TRN & \\
\hline CHEMBL310741 & 46818 & 2.61 & 3.5299 & TST & \\
\hline CHEMBL302251 & 46818 & 0.38 & 1.3653 & TST & \\
\hline CHEMBL68641 & 46818 & 0.02 & 1.3918 & TST & \\
\hline CHEMBL 78710 & 46818 & 2.82 & 2.8566 & TRN & \\
\hline CHEMBL81911 & 46818 & 2.45 & 2.3962 & TRN & \\
\hline CHEMBL 78415 & 46818 & 0.9 & 0.9129 & TRN & \\
\hline CHEMBL 309763 & 46818 & 0.67 & 0.6798 & TRN & \\
\hline CHEMBL 78992 & 46818 & 2.59 & 2.4812 & TRN & \\
\hline CHEMBL 77445 & 46818 & 2.35 & 2.4732 & TRN & \\
\hline CHEMBL80311 & 46818 & 3.37 & 3.3031 & TRN & \\
\hline CHEMBL80984 & 46818 & 2.48 & 2.4638 & TRN & \\
\hline CHEMBL 67652 & 46818 & 2.59 & 3.0052 & TST & \\
\hline CHEMBL 70952 & 46818 & 0.72 & 1.401 & TST & \\
\hline CHEMBL 78752 & 46818 & 2.38 & 2.5495 & TRN & \\
\hline CHEMBL 78994 & 46818 & 0.94 & 0.8836 & TRN & \\
\hline CHEMBL 78308 & 46818 & 1.44 & 1.5131 & TRN & \\
\hline CHEMBL 78550 & 46818 & 2.69 & 3.1866 & TST & \\
\hline CHEMBL309605 & 46818 & 0.43 & 0.3881 & TRN & \\
\hline CHEMBL310995 & 46818 & 2.15 & 2.0935 & TRN & \\
\hline CHEMBL274833 & 46818 & 1.18 & 1.2229 & TRN & \\
\hline CHEMBL 78940 & 46818 & 0.9 & 0.9396 & TRN & \\
\hline CHEMBL 78763 & 46818 & 2.01 & 1.9439 & TRN & \\
\hline CHEMBL 80214 & 46818 & 0.35 & 0.184 & TRN & \\
\hline CHEMBL 309756 & 46818 & 2.38 & 2.4068 & TRN & \\
\hline CHEMBL311560 & 46818 & 1.48 & 1.4815 & TST & \\
\hline
\end{tabular}




\begin{tabular}{|c|c|c|c|c|}
\hline & & \multicolumn{3}{|c|}{ Supplemental Table S2.txt } \\
\hline CHEMBL431589 & 46818 & 2.52 & 2.4727 & TRN \\
\hline CHEMBL68533 & 46818 & 0.71 & 1.7242 & TST \\
\hline CHEMBL310539 & 46818 & 3.17 & 3.8256 & TST \\
\hline CHEMBL311328 & 46818 & 2.17 & 2.134 & TRN \\
\hline CHEMBL78713 & 46818 & 0.9 & 0.8806 & TRN \\
\hline CHEMBL12914 & 46818 & 2.68 & 2.6848 & TRN \\
\hline CHEMBL312057 & 46818 & 1.64 & 1.4966 & TRN \\
\hline CHEMBL441060 & 46818 & 2.95 & 2.9104 & TRN \\
\hline CHEMBL311065 & 46818 & 2.42 & 2.3876 & TRN \\
\hline CHEMBL80337 & 46818 & 1.28 & 1.1959 & TRN \\
\hline CHEMBL78376 & 46818 & 3.02 & 3.07 & TRN \\
\hline CHEMBL310538 & 46818 & 3.08 & 3.1669 & TST \\
\hline CHEMBL 275242 & 46818 & 3.15 & 3.2047 & TRN \\
\hline CHEMBL68642 & 46818 & 0.63 & 1.7025 & TST \\
\hline CHEMBL78995 & 46818 & 2.04 & 2.057 & TRN \\
\hline CHEMBL311667 & 46818 & 2.04 & 2.1386 & TRN \\
\hline CHEMBL69593 & 46818 & 0.88 & 2.4904 & TST \\
\hline CHEMBL13078 & 46818 & 0.78 & 0.8402 & TRN \\
\hline CHEMBL311645 & 46818 & 1.47 & 1.4739 & TRN \\
\hline CHEMBL421497 & 46818 & 2.74 & 2.9457 & TST \\
\hline CHEMBL3976226 & 1639948 & 7.301 & 7.4622 & TRN \\
\hline CHEMBL 3986404 & 1639948 & 6.0 & 6.6944 & TST \\
\hline CHEMBL 3966040 & 1639948 & 7.301 & 7.5208 & TRN \\
\hline CHEMBL3896044 & 1639948 & 6.0 & 5.7979 & TST \\
\hline CHEMBL3958466 & 1639948 & 7.301 & 7.5222 & TRN \\
\hline CHEMBL3928180 & 1639948 & 7.301 & 7.6167 & TRN \\
\hline CHEMBL3948661 & 1639948 & 6.0 & 5.8325 & TST \\
\hline CHEMBL3938621 & 1639948 & 7.301 & 7.3781 & TST \\
\hline CHEMBL3904510 & 1639948 & 6.0 & 6.5428 & TST \\
\hline CHEMBL3986123 & 1639948 & 7.301 & 7.0946 & TRN \\
\hline CHEMBL3925935 & 1639948 & 8.301 & 7.7678 & TRN \\
\hline CHEMBL 3924998 & 1639948 & 8.301 & 7.8571 & TRN \\
\hline CHEMBL3961472 & 1639948 & 8.301 & 7.4337 & TRN \\
\hline CHEMBL3909596 & 1639948 & 7.301 & 7.1777 & TST \\
\hline CHEMBL3942161 & 1639948 & 7.301 & 7.6684 & TRN \\
\hline CHEMBL3959038 & 1639948 & 7.301 & 7.1328 & TRN \\
\hline CHEMBL3979728 & 1639948 & 7.301 & 7.4282 & TRN \\
\hline CHEMBL3930406 & 1639948 & 7.301 & 7.2295 & TRN \\
\hline CHEMBL3955083 & 1639948 & 7.301 & 7.4399 & TRN \\
\hline CHEMBL3984213 & 1639948 & 6.0 & 6.6224 & TST \\
\hline CHEMBL3959857 & 1639948 & 8.301 & 7.3837 & TST \\
\hline CHEMBL3926038 & 1639948 & 7.301 & 7.4854 & TRN \\
\hline CHEMBL 3897215 & 1639948 & 6.0 & 7.29299 & 9999999999 \\
\hline CHEMBL3933398 & 1639948 & 6.0 & 6.8613 & TRN \\
\hline CHEMBL3960016 & 1639948 & 8.301 & 7.8918 & TST \\
\hline CHEMBL3964536 & 1639948 & 7.301 & 7.9348 & TRN \\
\hline CHEMBL3968522 & 1639948 & 8.301 & 8.0809 & TRN \\
\hline CHEMBL 3924442 & 1639948 & 6.0 & 5.7309 & TST \\
\hline
\end{tabular}

TRN 
Supplemental Table S2.txt

\begin{tabular}{|c|c|c|c|c|}
\hline CHEMBL 3909626 & 1639948 & 7.301 & 6.9863 & TST \\
\hline CHEMBL 3952805 & 1639948 & 7.301 & 7.4069 & TRN \\
\hline CHEMBL 3916828 & 1639948 & 6.0 & 6.145 & TST \\
\hline CHEMBL 3976896 & 1639948 & 6.0 & 6.8639 & TRN \\
\hline CHEMBL 3891130 & 1639948 & 7.301 & 7.1194 & TST \\
\hline CHEMBL 3917294 & 1639948 & 7.301 & 7.527 & TRN \\
\hline CHEMBL 3907764 & 1639948 & 7.301 & 7.0602 & TRN \\
\hline CHEMBL 3969472 & 1639948 & 7.301 & 7.3983 & TRN \\
\hline CHEMBL 3983201 & 1639948 & 6.0 & 5.8769 & TRN \\
\hline CHEMBL 3955873 & 1639948 & 6.0 & 5.9603 & TST \\
\hline CHEMBL3951099 & 1639948 & 6.0 & 5.8609 & TST \\
\hline CHEMBL 3952493 & 1639948 & 6.0 & 5.9752 & TST \\
\hline CHEMBL 3983466 & 1639948 & 7.301 & 7.4977 & TST \\
\hline CHEMBL 3923692 & 1639948 & 7.301 & 7.4051 & TRN \\
\hline CHEMBL 3943734 & 1639948 & 6.0 & 6.0468 & TRN \\
\hline CHEMBL 3957171 & 1639948 & 8.301 & 7.4408 & TST \\
\hline CHEMBL 3944780 & 1639948 & 7.301 & 7.119 & TRN \\
\hline CHEMBL 3939717 & 1639948 & 6.0 & 6.7231 & TRN \\
\hline CHEMBL 3976788 & 1639948 & 6.0 & 6.0835 & TRN \\
\hline CHEMBL 3982666 & 1639948 & 7.301 & 7.0954 & TRN \\
\hline CHEMBL 3986082 & 1639948 & 6.0 & 5.6888 & TRN \\
\hline CHEMBL 3952048 & 1639948 & 7.301 & 6.5012 & TRN \\
\hline CHEMBL 3893032 & 1639948 & 7.301 & 7.1895 & TRN \\
\hline CHEMBL 3895645 & 1639948 & 7.301 & 7.0509 & TRN \\
\hline CHEMBL 3979317 & 1639948 & 6.0 & 6.8639 & TRN \\
\hline CHEMBL 3985116 & 1639948 & 6.0 & 5.8122 & TST \\
\hline CHEMBL 3906715 & 1639948 & 7.301 & 7.48 & TRN \\
\hline CHEMBL 3971864 & 1639948 & 6.0 & 6.0421 & TRN \\
\hline CHEMBL 3896122 & 1639948 & 8.301 & 8.0631 & TRN \\
\hline CHEMBL 3914394 & 1639948 & 7.301 & 7.2201 & TRN \\
\hline CHEMBL 3916759 & 1639948 & 7.301 & 7.402 & TRN \\
\hline CHEMBL 3951403 & 1639948 & 7.301 & 7.1387 & TRN \\
\hline CHEMBL 3939874 & 1639948 & 7.301 & 7.5146 & TST \\
\hline CHEMBL 3916485 & 1639948 & 6.0 & 5.8336 & TST \\
\hline CHEMBL 3900296 & 1639948 & 6.0 & 6.3124 & TST \\
\hline CHEMBL 3923449 & 1639948 & 8.301 & 7.9787 & TRN \\
\hline CHEMBL 3949400 & 1639948 & 7.301 & 7.2505 & TRN \\
\hline CHEMBL 3933130 & 1639948 & 7.301 & 7.24299 & 9999999999 \\
\hline CHEMBL 3900858 & 1639948 & 6.0 & 6.1061 & TST \\
\hline CHEMBL 3906789 & 1639948 & 7.301 & 7.5366 & TST \\
\hline CHEMBL 3942671 & 1639948 & 7.301 & 6.9682 & TRN \\
\hline CHEMBL 3953606 & 1639948 & 7.301 & 7.0331 & TRN \\
\hline CHEMBL 3923013 & 1639948 & 7.301 & 7.4727 & TRN \\
\hline CHEMBL 3955824 & 1639948 & 7.301 & 7.3159 & TRN \\
\hline CHEMBL 3946590 & 1639948 & 6.0 & 6.3712 & TST \\
\hline CHEMBL 3945062 & 1639948 & 7.301 & 7.0239 & TRN \\
\hline CHEMBL 3901787 & 1639948 & 7.301 & 6.9529 & TRN \\
\hline CHEMBL 3977030 & 1639948 & 8.301 & 7.6555 & TRN \\
\hline
\end{tabular}


Supplemental Table S2.txt

\begin{tabular}{|c|c|c|c|c|}
\hline HEMBL 3932218 & 639948 & 7.301 & 7.1096 & $\mathrm{TR}$ \\
\hline HEMBL3955359 & 639948 & 6.0 & 6.0869 & $T$ \\
\hline HFMBL & 539948 & 7.301 & & $2 \mathrm{~N}$ \\
\hline HEMBL3929942 & 639948 & 7.301 & 0481 & RN \\
\hline HEMBL3965901 & 639948 & 7.301 & 4946 & ST \\
\hline HEMBL3932115 & 639948 & 6.0 & .8345 & \\
\hline HEMBL3940839 & 539948 & 7.301 & 6637 & RN \\
\hline AEMBL3921861 & 639948 & 6.0 & 1645 & $\mathrm{RN}$ \\
\hline HEMBL3986135 & 639948 & 7.301 & .7904 & ST \\
\hline HEMBL3937598 & 639948 & 7.301 & .129 & \\
\hline HEMBL3929002 & 639948 & 6.0 & .9328 & \\
\hline HEMBL3912646 & 639948 & 7.301 & 6348 & $\mathrm{RN}$ \\
\hline HEMBL3890300 & 639948 & 6.0 & 7544 & ST \\
\hline HEMBL3925803 & 639948 & 7.301 & .5511 & RN \\
\hline HEMBL3944791 & 639948 & 8.301 & .8731 & \\
\hline HEMBL3893416 & 1639948 & 6.0 & .8952 & NIV \\
\hline HEMBL3959638 & 639948 & 8.301 & 9966 & RIV \\
\hline HEMBL3965160 & 639948 & 7.301 & 8972 & \\
\hline HEMBL3895123 & 639948 & 7.301 & 7.4405 & RN \\
\hline HEMBL3927549 & 639948 & 7.301 & 06 & TRN \\
\hline HEMBL 389 & 639948 & 7.301 & 9851 & SIN \\
\hline HEMBL 390 & 639948 & 7.301 & 957 & ST \\
\hline HEMBL 398 & 639948 & 7.301 & 5883 & $\mathrm{RN}$ \\
\hline HEMBL3985840 & 639948 & 6.0 & .7556 & TST \\
\hline HEMBL3956056 & 639 & 7.301 & 2544 & ISI \\
\hline HEMBL3911207 & 6399 & 7.301 & 2045 & TRN \\
\hline HEMBL39 & 539948 & 7.301 & 177 & RN \\
\hline HEMBL3896067 & 639948 & 6.0 & 8852 & 「RN \\
\hline HEMBL3945353 & 639948 & 7.301 & 9475 & TS \\
\hline HEMBL3946018 & 639948 & 6.0 & 5757 & TST \\
\hline HEMBL3955495 & 6399 & 8 . & .7728 & TRN \\
\hline HEMBL39 & 9948 & 7. & 3931 & ST \\
\hline HEMBL3S & 48 & 7.301 & 2494 & TRN \\
\hline HEMBL3895458 & 639948 & 6.0 & 9335 & TRN \\
\hline HEMBL3985254 & 639948 & 7.301 & .4648 & TRN \\
\hline HEMBL3893575 & 639948 & 7.301 & 1637 & RN \\
\hline HEMBL 38 & 18 & 7.301 & 523 & TRN \\
\hline HEMBL3923250 & 1639948 & 6.0 & .8719 & TRN \\
\hline HEMBL3959774 & 639948 & 8.301 & 0353 & TRN \\
\hline HEMBL3892117 & 639948 & 7.301 & 1633 & TRN \\
\hline HEMBL3979687 & 1639948 & 6.0 & 0854 & $\Gamma \mathrm{RN}$ \\
\hline CHEMBL3912287 & 1639948 & 7.301 & 7.1468 & TRN \\
\hline CHEMBL 3922630 & 1639948 & 6.0 & 5.8229 & TST \\
\hline HEMBL3942082 & 1639948 & 7.301 & . 4905 & $T R$ \\
\hline HEMBL3910102 & 639948 & 7.301 & 0719 & I KIV \\
\hline CHEMBL3919501 & 1639948 & 6.0 & .5656 & \\
\hline CHEMBL 3939671 & 1639948 & 8.301 & 8.0861 & \\
\hline CHEMBL3968322 & 1639948 & 7.301 & 6.6813 & ГST \\
\hline
\end{tabular}

Page 14376 
Supplemental Table S2.txt

\begin{tabular}{|c|c|c|c|c|c|}
\hline CHEMBL3904192 & 1639948 & 7.301 & 7.2297 & TRN & \\
\hline CHEMBL3944857 & 1639948 & 7.301 & 7.8994 & TRN & \\
\hline CHEMBL3895424 & 1639948 & 6.0 & 6.4151 & TST & \\
\hline CHEMBL3935265 & 1639948 & 8.301 & 7.7411 & TRN & \\
\hline CHEMBL3916953 & 1639948 & 6.0 & 6.0585 & TRN & \\
\hline CHEMBL3927849 & 1639948 & 6.0 & 6.1693 & TRN & \\
\hline CHEMBL3916567 & 1639948 & 7.301 & 7.4084 & TRN & \\
\hline CHEMBL3905501 & 1639948 & 7.301 & 7.4432 & TRN & \\
\hline CHEMBL3958898 & 1639948 & 7.301 & 7.7506 & TST & \\
\hline CHEMBL3958778 & 1639948 & 6.0 & 7.0076 & TRN & \\
\hline CHEMBL3921390 & 1639948 & 7.301 & 7.5463 & TRN & \\
\hline CHEMBL3909744 & 1639948 & 8.301 & 7.941 & TRN & \\
\hline CHEMBL3968030 & 1639948 & 7.301 & 6.6504 & TRN & \\
\hline CHEMBL3933359 & 1639948 & 6.0 & 6.0645 & TRN & \\
\hline CHEMBL 3898627 & 1639948 & 7.301 & 7.46899 & 9999999999 & TST \\
\hline CHEMBL3964605 & 1639948 & 6.0 & 6.3801 & TST & \\
\hline CHEMBL3916297 & 1639948 & 6.0 & 7.005 & TRN & \\
\hline CHEMBL3939133 & 1639948 & 6.0 & 7.0527 & TRN & \\
\hline CHEMBL3909572 & 1639948 & 6.0 & 6.4904 & TRN & \\
\hline CHEMBL3931427 & 1639948 & 7.301 & 7.0219 & TRN & \\
\hline CHEMBL3905012 & 1639948 & 7.301 & 7.0574 & TRN & \\
\hline CHEMBL3900567 & 1639948 & 6.0 & 5.8156 & TRN & \\
\hline CHEMBL3918761 & 1639948 & 8.301 & 8.122 & TRN & \\
\hline CHEMBL3895890 & 1639948 & 7.301 & 7.3498 & TRN & \\
\hline CHEMBL 3896927 & 1639948 & 8.301 & 7.392 & TRN & \\
\hline CHEMBL3907215 & 1639948 & 7.301 & 7.1475 & TRN & \\
\hline CHEMBL3934095 & 1639948 & 7.301 & 7.2121 & TRN & \\
\hline CHEMBL3898808 & 1639948 & 8.301 & 7.9741 & TRN & \\
\hline CHEMBL3931393 & 1639948 & 7.301 & 7.1753 & TST & \\
\hline CHEMBL 3954731 & 1639948 & 6.0 & 6.5587 & TRN & \\
\hline CHEMBL3967776 & 1639948 & 7.301 & 7.3666 & TRN & \\
\hline CHEMBL3904460 & 1639948 & 7.301 & 7.5962 & TRN & \\
\hline CHEMBL3985896 & 1639948 & 7.301 & 7.1215 & TRN & \\
\hline CHEMBL3895129 & 1639948 & 8.301 & 7.7956 & TRN & \\
\hline CHEMBL3921482 & 1639948 & 8.301 & 8.131 & TRN & \\
\hline CHEMBL3952188 & 1639948 & 8.301 & 7.8162 & TRN & \\
\hline CHEMBL3923153 & 1639948 & 7.301 & 7.9208 & TRN & \\
\hline CHEMBL3977221 & 1639948 & 7.301 & 7.5075 & TRN & \\
\hline CHEMBL3929966 & 1639948 & 7.301 & 7.125 & TRN & \\
\hline CHEMBL3983450 & 1639948 & 6.0 & 6.305 & TRN & \\
\hline CHEMBL3914180 & 1639948 & 7.301 & 7.9768 & TRN & \\
\hline CHEMBL3929188 & 1639948 & 7.301 & 6.8983 & TRN & \\
\hline CHEMBL3937857 & 1639948 & 6.0 & 5.9349 & TST & \\
\hline CHEMBL3893058 & 1639948 & 6.0 & 5.8667 & TST & \\
\hline CHEMBL3910031 & 1639948 & 6.0 & 6.0764 & TRN & \\
\hline CHEMBL3958721 & 1639948 & 6.0 & 5.7015 & TRN & \\
\hline CHEMBL3952315 & 1639948 & 7.301 & 7.4067 & TRN & \\
\hline CHEMBL3974328 & 1639948 & 6.0 & 6.0667 & TRN & \\
\hline
\end{tabular}




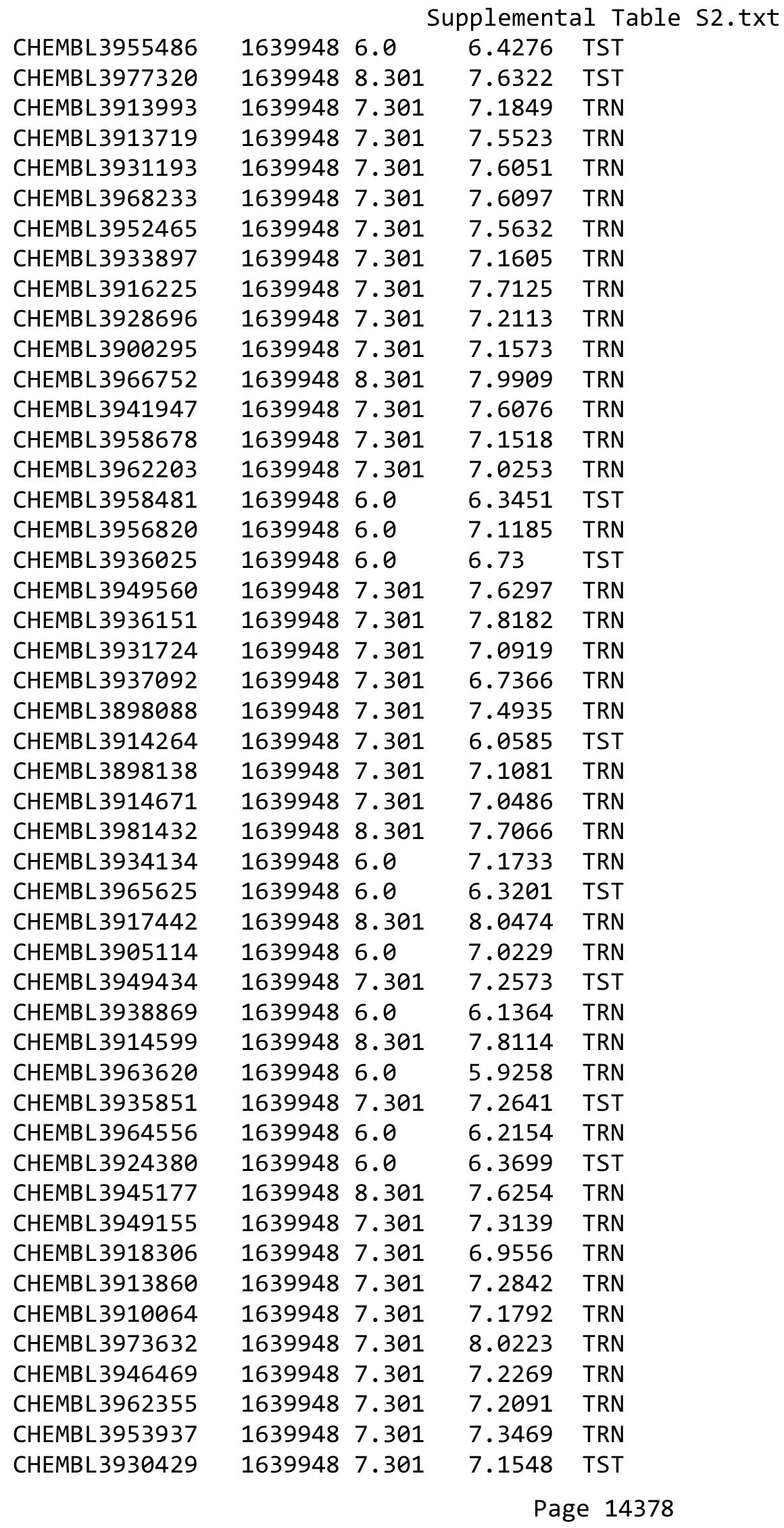


Supplemental Table S2.txt

\begin{tabular}{|c|c|c|c|c|c|}
\hline CHEMBL3896699 & 1639948 & 8.301 & 7.7182 & TRN & \\
\hline CHEMBL3955447 & 1639948 & 7.301 & 7.2542 & TRN & \\
\hline CHEMBL3966429 & 1639948 & 7.301 & 7.4544 & TRN & \\
\hline CHEMBL3960730 & 1639948 & 6.0 & 6.6932 & TST & \\
\hline CHEMBL 3945860 & 1639948 & 7.301 & 7.1694 & TST & \\
\hline CHEMBL3913496 & 1639948 & 7.301 & 7.7266 & TST & \\
\hline CHEMBL3893176 & 1639948 & 7.301 & 7.1866 & TRN & \\
\hline CHEMBL3941402 & 1639948 & 8.301 & 7.8967 & TRN & \\
\hline CHEMBL 3941200 & 1639948 & 6.0 & 7.0487 & TRN & \\
\hline CHEMBL3977503 & 1639948 & 7.301 & 7.5327 & TRN & \\
\hline CHEMBL 3959495 & 1639948 & 7.301 & 7.1722 & TRN & \\
\hline CHEMBL3933123 & 1639948 & 7.301 & 7.1942 & TST & \\
\hline CHEMBL 3907230 & 1639948 & 6.0 & 6.2219 & TRN & \\
\hline CHEMBL3904481 & 1639948 & 7.301 & 7.7889 & TST & \\
\hline CHEMBL3971560 & 1639948 & 6.0 & 6.8576 & TST & \\
\hline CHEMBL3928439 & 1639948 & 7.301 & 7.2549 & TRN & \\
\hline CHEMBL3943632 & 1639948 & 6.0 & 5.7132 & TST & \\
\hline CHEMBL 3891059 & 1639948 & 7.301 & 7.5707 & TRN & \\
\hline CHEMBL3965938 & 1639948 & 7.301 & 7.1472 & TRN & \\
\hline CHEMBL3959195 & 1639948 & 7.301 & 7.4268 & TST & \\
\hline CHEMBL3947700 & 1639948 & 7.301 & 7.3943 & TRN & \\
\hline CHEMBL 3918670 & 1639948 & 7.301 & \multicolumn{2}{|c|}{7.196000000000001} & TRN \\
\hline CHEMBL 3971050 & 1639948 & 8.301 & 7.671 & TRN & \\
\hline CHEMBL3951755 & 1639948 & 7.301 & 7.5806 & TRN & \\
\hline CHEMBL3983938 & 1639948 & 8.301 & 7.9074 & TRN & \\
\hline CHEMBL3945028 & 1639948 & 6.0 & 6.0376 & TRN & \\
\hline CHEMBL3986102 & 1639948 & 7.301 & 7.6287 & TRN & \\
\hline CHEMBL 3932578 & 1639948 & 8.301 & 7.6666 & TRN & \\
\hline CHEMBL3933848 & 1639948 & 6.0 & 5.8271 & TST & \\
\hline CHEMBL3943570 & 1639948 & 7.301 & 7.7637 & TRN & \\
\hline CHEMBL3942387 & 1639948 & 7.301 & 7.1365 & TRN & \\
\hline CHEMBL 3894418 & 1639948 & 6.0 & \multicolumn{2}{|c|}{6.992000000000001} & TRN \\
\hline CHEMBL3981613 & 1639948 & 7.301 & 7.3513 & TRN & \\
\hline CHEMBL3978177 & 1639948 & 8.301 & 7.6964 & TRN & \\
\hline CHEMBL3959254 & 1639948 & 8.301 & 7.8866 & TST & \\
\hline CHEMBL3970332 & 1639948 & 6.0 & 6.7204 & TRN & \\
\hline CHEMBL3906936 & 1639948 & 8.301 & 8.0317 & TRN & \\
\hline CHEMBL3972940 & 1639948 & 6.0 & 6.2368 & TRN & \\
\hline CHEMBL 3897256 & 1639948 & 8.301 & 7.8523 & TRN & \\
\hline CHEMBL3983179 & 1639948 & 7.301 & 6.7315 & TRN & \\
\hline CHEMBL3961982 & 1639948 & 6.0 & 5.9306 & TST & \\
\hline CHEMBL 3893128 & 1639948 & 6.0 & 5.8682 & TST & \\
\hline CHEMBL3972712 & 1639948 & 8.301 & 8.1077 & TRN & \\
\hline CHEMBL3983245 & 1639948 & 7.301 & 7.7703 & TRN & \\
\hline CHEMBL3944502 & 1639948 & 6.0 & 5.8649 & TST & \\
\hline CHEMBL3907879 & 1639948 & 7.301 & 7.1247 & TRN & \\
\hline CHEMBL3939828 & 1639948 & 6.0 & 6.7319 & TST & \\
\hline CHEMBL 3890263 & 1639948 & 7.301 & 6.8513 & TRN & \\
\hline
\end{tabular}




\begin{tabular}{|c|c|c|c|c|c|}
\hline & & & pplementa & al Table S2 & \\
\hline CHEMBL3895848 & 1639948 & 6.0 & 5.9187 & TST & \\
\hline CHEMBL3923645 & 1639948 & 6.0 & 6.171 & TRN & \\
\hline CHEMBL 3922278 & 1639948 & 8.301 & 7.713999 & 99999999995 & TRN \\
\hline CHEMBL 3899440 & 1639948 & 7.301 & 7.2555 & TRN & \\
\hline CHEMBL3921689 & 1639948 & 6.0 & 6.175 & TRN & \\
\hline CHEMBL3968519 & 1639948 & 8.301 & 7.9055 & TST & \\
\hline CHEMBL3952693 & 1639948 & 7.301 & 7.721 & TST & \\
\hline CHEMBL 3947769 & 1639948 & 7.301 & 7.2865 & TRN & \\
\hline CHEMBL3979195 & 1639948 & 7.301 & 7.2524 & TRN & \\
\hline CHEMBL3893846 & 1639948 & 7.301 & 7.4728 & TRN & \\
\hline CHEMBL3962487 & 1639948 & 8.301 & 8.0259 & TRN & \\
\hline CHEMBL3958507 & 1639948 & 7.301 & 6.838999 & 99999999995 & TST \\
\hline CHEMBL 3947643 & 1639948 & 6.0 & 6.1946 & TRN & \\
\hline CHEMBL3920114 & 1639948 & 7.301 & 7.5141 & TRN & \\
\hline CHEMBL3961417 & 1639948 & 6.0 & 6.0635 & TRN & \\
\hline CHEMBL 3937297 & 1639948 & 8.301 & 7.8705 & TRN & \\
\hline CHEMBL3932698 & 1639948 & 7.301 & 6.8639 & TRN & \\
\hline CHEMBL 3951527 & 1639948 & 7.301 & 7.0935 & TRN & \\
\hline CHEMBL3947408 & 1639948 & 7.301 & 7.2537 & TRN & \\
\hline CHEMBL3976826 & 1639948 & 6.0 & 5.7976 & TST & \\
\hline CHEMBL3897525 & 1639948 & 8.301 & 7.9211 & TRN & \\
\hline CHEMBL3959160 & 1639948 & 6.0 & 4.9626 & TRN & \\
\hline CHEMBL 3937048 & 1639948 & 6.0 & 6.1985 & TRN & \\
\hline CHEMBL3968843 & 1639948 & 7.301 & 6.937 & TRN & \\
\hline CHEMBL3968956 & 1639948 & 7.301 & 7.7147 & TRN & \\
\hline CHEMBL3963821 & 1639948 & 7.301 & 7.831 & TRN & \\
\hline CHEMBL3961005 & 1639948 & 6.0 & 6.821000 & 0000000001 & TST \\
\hline CHEMBL 3892030 & 1639948 & 8.301 & 7.4929 & TRN & \\
\hline CHEMBL3951258 & 1639948 & 7.301 & 7.9121 & TRN & \\
\hline CHEMBL 3903022 & 1639948 & 7.301 & 6.6892 & TST & \\
\hline CHEMBL 3919051 & 1639948 & 7.301 & 7.6567 & TRN & \\
\hline CHEMBL3965096 & 1639948 & 8.301 & 7.5715 & TRN & \\
\hline CHEMBL 3944702 & 1639948 & 7.301 & 6.9323 & TRN & \\
\hline CHEMBL3921228 & 1639948 & 7.301 & 7.1615 & TRN & \\
\hline CHEMBL3949535 & 1639948 & 7.301 & 6.9002 & TRN & \\
\hline CHEMBL3919493 & 1639948 & 7.301 & 7.2497 & TRN & \\
\hline CHEMBL3899410 & 1639948 & 7.301 & 7.4997 & TRN & \\
\hline CHEMBL3651510 & 1527786 & 9.8097 & 10.2038 & TRN & \\
\hline CHEMBL3651499 & 1527786 & 9.8239 & 9.9376 & TRN & \\
\hline CHEMBL3651531 & 1527786 & 7.9739 & 8.1577 & TRN & \\
\hline CHEMBL3651483 & 1527786 & 9.0292 & 8.9164 & TRN & \\
\hline CHEMBL3651537 & 1527786 & 7.4016 & 7.3481 & TRN & \\
\hline CHEMBL3651524 & 1527786 & 8.5017 & 8.3026 & TRN & \\
\hline CHEMBL3651523 & 1527786 & 8.5607 & 8.5245 & TST & \\
\hline CHEMBL 3651540 & 1527786 & 6.3121 & 6.6295 & TRN & \\
\hline CHEMBL3651492 & 1527786 & 9.054 & 9.1706 & TRN & \\
\hline CHEMBL3651528 & 1527786 & 8.3593 & 8.6856 & TRN & \\
\hline CHEMBL3651522 & 1527786 & 8.5686 & 7.3562 & TRN & \\
\hline
\end{tabular}


Supplemental Table S2.txt

\begin{tabular}{|c|c|c|c|c|c|c|}
\hline CHEMBL 3651481 & 1527786 & 9.2007 & 9.1888 & TRN & & \\
\hline CHEMBL 3651526 & 1527786 & 8.4498 & 8.9694 & TRN & & \\
\hline CHEMBL 3651541 & 1527786 & 9.4949 & 9.0256 & TRN & & \\
\hline CHEMBL 3651515 & 1527786 & 9.0246 & 9.0146 & TST & & \\
\hline CHEMBL3651507 & 1527786 & 6.0 & 6.7246 & TRN & & \\
\hline CHEMBL3651539 & 1527786 & 5.1639 & 5.1146 & TRN & & \\
\hline CHEMBL 3651506 & 1527786 & 10.5376 & 10.5094 & TRN & & \\
\hline CHEMBL 3651512 & 1527786 & 9.301 & 9.1232 & TRN & & \\
\hline CHEMBL 3651490 & 1527786 & 8.0588 & 8.3268 & TRN & & \\
\hline CHEMBL3651488 & 1527786 & 8.3039 & 8.376 & TRN & & \\
\hline CHEMBL3651486 & 1527786 & 9.1367 & 8.7612 & TRN & & \\
\hline CHEMBL 3651489 & 1527786 & 8.8438 & 8.7573 & TRN & & \\
\hline CHEMBL 3651493 & 1527786 & 9.6882 & 8.9807 & TST & & \\
\hline CHEMBL 3651500 & 1527786 & 9.4498 & 9.8981 & TST & & \\
\hline CHEMBL3651530 & 1527786 & 8.0403 & 8.0708 & TRN & & \\
\hline CHEMBL 3651467 & 1527786 & 7.1707 & 6.9951 & TRN & & \\
\hline CHEMBL3651498 & 1527786 & 9.382 & 9.8505 & TST & & \\
\hline CHEMBL 3651473 & 1527786 & 9.5086 & 9.2634 & TRN & & \\
\hline CHEMBL 3651461 & 1527786 & 7.2924 & 6.3406 & TST & & \\
\hline CHEMBL3651478 & 1527786 & 7.4437 & 7.5342 & TRN & & \\
\hline CHEMBL3651496 & 1527786 & 9.283999 & 99999999 & 99 & 9.4654 & TRN \\
\hline CHEMBL3651534 & 1527786 & 7.7022 & 7.4671 & TRN & & \\
\hline CHEMBL 3651532 & 1527786 & 7.8389 & 7.933 & TRN & & \\
\hline CHEMBL3651462 & 1527786 & 6.5017 & 6.0813 & TST & & \\
\hline CHEMBL 3651466 & 1527786 & 7.058 & 6.4533 & TST & & \\
\hline CHEMBL3651533 & 1527786 & 7.8041 & 8.0578 & TRN & & \\
\hline CHEMBL3651511 & 1527786 & 9.5157 & 8.9508 & TRN & & \\
\hline CHEMBL 3651519 & 1527786 & 8.6735 & 8.5998 & TRN & & \\
\hline CHEMBL3651505 & 1527786 & 9.8861 & 8.4719 & TST & & \\
\hline CHEMBL 3651516 & 1527786 & 8.9208 & 9.1923 & TRN & & \\
\hline CHEMBL 3651521 & 1527786 & 8.6289 & 9.1906 & TRN & & \\
\hline CHEMBL 3651518 & 1527786 & 8.7447 & 8.8241 & TRN & & \\
\hline CHEMBL 3651520 & 1527786 & 8.6572 & 8.8045 & TRN & & \\
\hline CHEMBL 3651485 & 1527786 & 9.1772 & 8.5741 & TRN & & \\
\hline CHEMBL 3651474 & 1527786 & 7.757000 & 00000000 & 11 & 8.2685 & TRN \\
\hline CHEMBL 3651460 & 1527786 & 6.0 & 5.8006 & TST & & \\
\hline CHEMBL3651529 & 1527786 & 8.2952 & 8.1322 & TRN & & \\
\hline CHEMBL 3651494 & 1527786 & 9.2596 & 9.0458 & TRN & & \\
\hline CHEMBL 3651468 & 1527786 & 7.2007 & 7.1143 & TRN & & \\
\hline CHEMBL 3651517 & 1527786 & 8.7696 & 8.085 & TST & & \\
\hline CHEMBL3651479 & 1527786 & 8.4437 & 8.3381 & TRN & & \\
\hline CHEMBL3651484 & 1527786 & 8.7825 & 8.4515 & TRN & & \\
\hline CHEMBL 3651472 & 1527786 & 8.1079 & 8.2005 & TST & & \\
\hline CHEMBL 3651514 & 1527786 & 9.1805 & 9.327 & TRN & & \\
\hline CHEMBL 3651513 & 1527786 & 9.2007 & 9.7545 & TRN & & \\
\hline CHEMBL3651471 & 1527786 & 8.8239 & 8.2615 & TRN & & \\
\hline CHEMBL3639503 & 1527786 & 8.1549 & 8.2874 & TRN & & \\
\hline CHEMBL 3651477 & 1527786 & 8.3979 & 8.1273 & TRN & & \\
\hline
\end{tabular}

Page 14381 
Supplemental Table S2.txt

\begin{tabular}{|c|c|c|c|c|c|}
\hline CHEMBL3651463 & 1527786 & 6.8643 & 7.1328 & TST & \\
\hline CHEMBL3651476 & 1527786 & 5.7057 & 6.6228 & TRN & \\
\hline CHEMBL3651502 & 1527786 & 10.284 & 9.8377 & TST & \\
\hline CHEMBL3651508 & 1527786 & 10.2147 & 9.3389 & TRN & \\
\hline CHEMBL3651501 & 1527786 & 8.7696 & 8.2339 & TST & \\
\hline CHEMBL3651487 & 1527786 & 8.8239 & 8.6586 & TRN & \\
\hline CHEMBL3651527 & 1527786 & 8.3979 & 8.3527 & TRN & \\
\hline CHEMBL3651538 & 1527786 & 6.9154 & 6.7933 & TRN & \\
\hline CHEMBL3651535 & 1527786 & 7.7001 & 7.981 & TRN & \\
\hline CHEMBL3651482 & 1527786 & 8.2518 & 9.994 & TST & \\
\hline CHEMBL3651497 & 1527786 & 9.475 & 8.712 & TST & \\
\hline CHEMBL3651464 & 1527786 & 6.6079 & 6.432 & TST & \\
\hline CHEMBL3651491 & 1527786 & 8.6383 & 9.2232 & TRN & \\
\hline CHEMBL3651495 & 1527786 & 9.7773 & 9.8643 & TRN & \\
\hline CHEMBL3651480 & 1527786 & 8.2716 & 8.629 & TRN & \\
\hline CHEMBL3651536 & 1527786 & 7.4483 & 7.4297 & TRN & \\
\hline CHEMBL3651504 & 1527786 & 9.2716 & 8.8356 & TST & \\
\hline CHEMBL3651509 & 1527786 & 9.9586 & 9.7 & TST & \\
\hline CHEMBL 3651525 & 1527786 & 8.4949 & 8.4018 & TRN & \\
\hline CHEMBL3651475 & 1527786 & 9.1871 & 8.5957 & TRN & \\
\hline CHEMBL483849 & 955058 & 2.4619 & 2.4103 & TRN & \\
\hline CHEMBL1909414 & 955058 & 4.6799 & 4.6206 & TRN & \\
\hline CHEMBL3186408 & 955058 & 4.5097 & 3.9266 & TST & \\
\hline CHEMBL2363137 & 955058 & 5.2904 & 5.2753 & TRN & \\
\hline CHEMBL 9470 & 955058 & 5.5586 & 7.0247 & TST & \\
\hline CHEMBL213100 & 955058 & 3.3587 & 3.3536 & TRN & \\
\hline CHEMBL192566 & 955058 & 8.3445 & 9.1764 & TST & \\
\hline CHEMBL1357247 & 955058 & 3.5247 & 3.5183 & TRN & \\
\hline CHEMBL 2144069 & 955058 & 4.4946 & 4.4988 & TRN & \\
\hline CHEMBL221137 & 955058 & 4.9238 & 5.2437 & TST & \\
\hline CHEMBL1673039 & 955058 & 5.567 & 5.6085 & TRN & \\
\hline CHEMBL573107 & 955058 & 5.0378 & 5.0551 & TRN & \\
\hline CHEMBL188678 & 955058 & 3.9694 & 3.9228 & TRN & \\
\hline CHEMBL1590308 & 955058 & 3.9789 & 3.9106 & TST & \\
\hline CHEMBL135561 & 955058 & 3.7205 & 3.7139 & TRN & \\
\hline CHEMBL412142 & 955058 & 5.4105 & 5.4171 & TRN & \\
\hline CHEMBL393929 & 955058 & 4.2916 & 4.3124 & TRN & \\
\hline CHEMBL483847 & 955058 & 3.7642 & 3.7958 & TRN & \\
\hline CHEMBL1516890 & 955058 & 3.6926 & 3.6394 & TRN & \\
\hline CHEMBL259181 & 955058 & 4.678 & 4.7308 & TRN & \\
\hline CHEMBL240954 & 955058 & 3.2962 & 4.2208 & TST & \\
\hline CHEMBL1230020 & 955058 & 3.9078 & 3.9145 & TRN & \\
\hline CHEMBL577784 & 955058 & 5.4987 & 5.5245 & TRN & \\
\hline CHEMBL3349342 & 955058 & 3.4968 & 3.4969 & TRN & \\
\hline CHEMBL514499 & 955058 & \multicolumn{3}{|c|}{7.502000000000001} & 7.4917 \\
\hline CHEMBL1643959 & 955058 & 3.8153 & 3.8234 & TRN & \\
\hline CHEMBL509032 & 955058 & 6.0576 & 6.0337 & TRN & \\
\hline CHEMBL512504 & 955058 & 7.2082 & 7.2515 & TRN & \\
\hline
\end{tabular}




\begin{tabular}{|c|c|c|c|c|c|}
\hline \multirow[b]{2}{*}{ CHEMBL191334 } & \multicolumn{5}{|c|}{ Supplemental } \\
\hline & 955058 & 5.7481 & 5.7627 & TRN & \\
\hline CHEMBL 210618 & 955058 & 3.5953 & 3.6265 & TRN & \\
\hline CHEMBL585951 & 955058 & 6.1347 & 6.1247 & TRN & \\
\hline CHEMBL392695 & 955058 & 5.7237 & 5.7361 & TRN & \\
\hline CHEMBL1256459 & 955058 & 7.7899 & 7.8117 & TRN & \\
\hline CHEMBL92309 & 955058 & 3.8951 & 3.2628 & TST & \\
\hline CHEMBL558642 & 955058 & 5.454 & 5.3992 & TRN & \\
\hline CHEMBL1242367 & 955058 & 4.7437 & 4.7474 & TRN & \\
\hline CHEMBL65 & 955058 & 9.1356 & 9.1137 & TRN & \\
\hline CHEMBL1190711 & 955058 & 6.2435 & 6.2133 & TRN & \\
\hline CHEMBL1404918 & 955058 & 2.7719 & \multicolumn{2}{|c|}{2.7560000000000002} & TRN \\
\hline CHEMBL449158 & 955058 & 5.7753 & 6.8352 & TST & \\
\hline CHEMBL180127 & 955058 & 4.8549 & 4.8501 & TRN & \\
\hline CHEMBL1970879 & 955058 & 3.5072 & 3.5113 & TRN & \\
\hline CHEMBL 222102 & 955058 & \multicolumn{2}{|c|}{3.0989999999999998} & 3.1523 & TRN \\
\hline CHEMBL 2005886 & 955058 & 5.2995 & \multicolumn{2}{|c|}{5.292000000000001} & TRN \\
\hline CHEMBL1788116 & 955058 & 5.8587 & 5.8756 & TRN & \\
\hline CHEMBL189584 & 955058 & 4.9219 & 4.9174 & TRN & \\
\hline CHEMBL 220241 & 955058 & 5.386 & 5.41 & TRN & \\
\hline CHEMBL3199475 & 955058 & 4.577 & 4.5829 & TRN & \\
\hline CHEMBL373751 & 955058 & 3.0146 & 3.0482 & TRN & \\
\hline CHEMBL515416 & 955058 & 4.5755 & 4.5902 & TRN & \\
\hline CHEMBL 209148 & 955058 & 5.3232 & 5.2806 & TRN & \\
\hline CHEMBL 379300 & 955058 & 7.0772 & 7.0525 & TRN & \\
\hline CHEMBL 379975 & 955058 & 5.8464 & 5.9255 & TST & \\
\hline CHEMBL300389 & 955058 & 5.5216 & 7.5799 & TST & \\
\hline CHEMBL3392440 & 955058 & 3.6345 & 3.7554 & TST & \\
\hline CHEMBL 202721 & 955058 & 6.2149 & 5.603 & TST & \\
\hline CHEMBL102714 & 955058 & 4.0114 & 4.3498 & TST & \\
\hline CHEMBL 258844 & 955058 & 5.4748 & 4.6218 & TST & \\
\hline CHEMBL472940 & 955058 & 3.8532 & 4.9526 & TST & \\
\hline CHEMBL 2315802 & 934533 & 5.5436 & 5.1424 & TST & \\
\hline CHEMBL 2315451 & 934533 & 7.0555 & \multicolumn{2}{|c|}{6.747000000000001} & TRN \\
\hline CHEMBL 2315463 & 934533 & 6.0177 & 5.155 & TRN & \\
\hline CHEMBL 2315781 & 934533 & 5.5702 & 5.2462 & TRN & \\
\hline CHEMBL2315439 & 934533 & 6.1656 & 6.6676 & TRN & \\
\hline CHEMBL 2315425 & 934533 & 7.1739 & 6.9867 & TRN & \\
\hline CHEMBL 2315440 & 934533 & 6.0106 & 6.7035 & TRN & \\
\hline CHEMBL2315450 & 934533 & 7.1487 & 6.5902 & TRN & \\
\hline CHEMBL2315789 & 934533 & 3.5229 & 5.3515 & TRN & \\
\hline CHEMBL2315764 & 934533 & 5.7055 & 4.9648 & TRN & \\
\hline CHEMBL2315768 & 934533 & 5.4622 & \multicolumn{2}{|c|}{5.0760000000000005} & TRN \\
\hline CHEMBL2315467 & 934533 & 3.5229 & 4.4927 & TRN & \\
\hline CHEMBL 2315457 & 934533 & 6.6478 & 6.5075 & TRN & \\
\hline CHEMBL2315813 & 934533 & 3.5229 & 4.5403 & TRN & \\
\hline CHEMBL2315797 & 934533 & 3.5229 & 4.1044 & TRN & \\
\hline CHEMBL2315423 & 934533 & 7.2676 & 7.1647 & TRN & \\
\hline CHEMBL2315765 & 934533 & 5.3665 & 4.9921 & TRN & \\
\hline & & & & 14383 & \\
\hline
\end{tabular}


Supplemental Table S2.txt

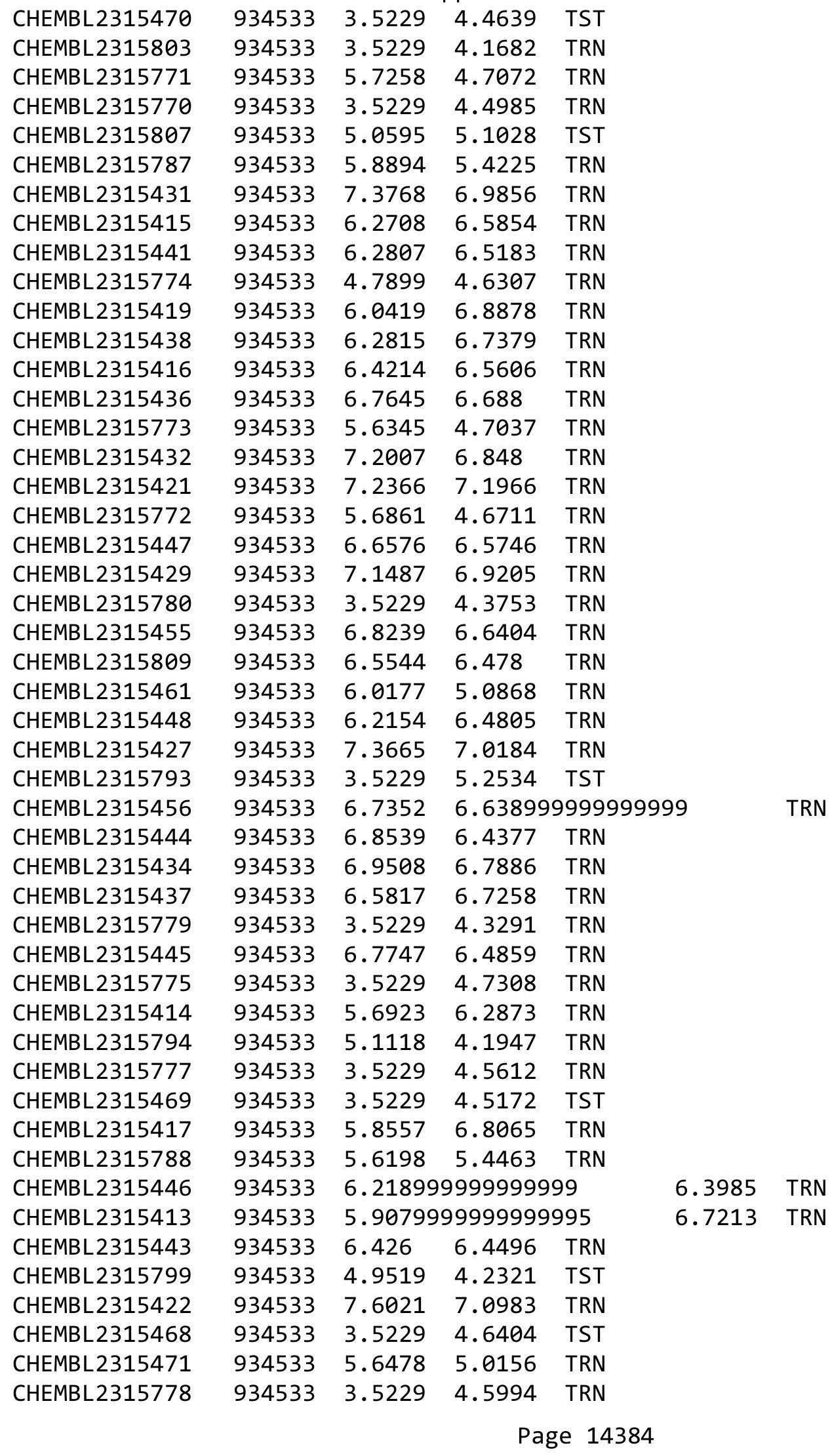


Supplemental Table S2.txt

\begin{tabular}{|c|c|c|c|c|}
\hline CHEMBL2315791 & 934533 & 3.5229 & 5.2806 & TRN \\
\hline CHEMBL2315449 & 934533 & 6.2314 & 6.4209 & TRN \\
\hline CHEMBL2315806 & 934533 & 5.7122 & 5.2401 & TST \\
\hline CHEMBL2315785 & 934533 & 5.5513 & 5.6048 & TRN \\
\hline CHEMBL2315812 & 934533 & 5.5702 & 4.4046 & TRN \\
\hline CHEMBL 2315430 & 934533 & 7.3872 & 6.9592 & TRN \\
\hline CHEMBL 2315767 & 934533 & 5.5452 & 5.0494 & TRN \\
\hline CHEMBL2315454 & 934533 & 6.8729 & 6.5617 & TRN \\
\hline CHEMBL2315796 & 934533 & 4.5732 & 4.1685 & TRN \\
\hline CHEMBL2315801 & 934533 & 4.7296 & 5.3212 & TST \\
\hline CHEMBL2315466 & 934533 & 5.4214 & 4.56800 & 00000000005 \\
\hline CHEMBL2315805 & 934533 & 5.2549 & 5.1905 & TRN \\
\hline CHEMBL2315426 & 934533 & 6.3536 & 6.5925 & TRN \\
\hline CHEMBL2315465 & 934533 & 3.5229 & 5.0756 & TRN \\
\hline CHEMBL2315792 & 934533 & 6.3279 & 5.9333 & TRN \\
\hline CHEMBL2315424 & 934533 & 7.2757 & 7.0925 & TRN \\
\hline CHEMBL2315460 & 934533 & 5.8894 & 4.5271 & TRN \\
\hline CHEMBL2315453 & 934533 & 7.0 & 6.6408 & TRN \\
\hline CHEMBL2315782 & 934533 & 6.1308 & 5.4036 & TRN \\
\hline CHEMBL2315769 & 934533 & 4.7115 & 4.4581 & TRN \\
\hline CHEMBL 2311578 & 934533 & 7.6198 & 7.0361 & TRN \\
\hline CHEMBL2315808 & 934533 & 5.8938 & 6.1792 & TRN \\
\hline CHEMBL2315811 & 934533 & 6.4214 & 6.4319 & TRN \\
\hline CHEMBL2315776 & 934533 & 4.7077 & 4.5132 & TRN \\
\hline CHEMBL2315783 & 934533 & 6.0177 & 5.4 & TRN \\
\hline CHEMBL2315458 & 934533 & 6.5901 & 6.4596 & TRN \\
\hline CHEMBL 2315418 & 934533 & 6.3458 & 7.0311 & TRN \\
\hline CHEMBL2315435 & 934533 & 6.7905 & 6.8631 & TRN \\
\hline CHEMBL2315810 & 934533 & 6.5482 & 6.5063 & TST \\
\hline CHEMBL2315462 & 934533 & 6.1427 & 5.1277 & TST \\
\hline CHEMBL2315433 & 934533 & 7.1871 & 6.9092 & TST \\
\hline CHEMBL1379971 & 934533 & 3.5229 & 4.4105 & TST \\
\hline CHEMBL2315428 & 934533 & 7.3188 & 6.9262 & TST \\
\hline CHEMBL2315442 & 934533 & 5.5046 & 6.4892 & TST \\
\hline CHEMBL2315464 & 934533 & 5.9393 & 5.0125 & TST \\
\hline CHEMBL2315420 & 934533 & 7.1487 & 6.9424 & TST \\
\hline CHEMBL2315804 & 934533 & 3.5229 & 4.789 & TST \\
\hline CHEMBL2315795 & 934533 & 4.9289 & 4.0962 & TST \\
\hline CHEMBL2315798 & 934533 & 3.5229 & 4.3583 & TST \\
\hline CHEMBL2315786 & 934533 & 3.5229 & 5.3901 & TST \\
\hline CHEMBL2315459 & 934533 & 5.0035 & 4.5939 & TST \\
\hline CHEMBL2315766 & 934533 & 3.5229 & 4.5701 & TST \\
\hline CHEMBL2315784 & 934533 & 5.556 & 5.3761 & TST \\
\hline CHEMBL2315790 & 934533 & 3.5229 & 5.306 & TST \\
\hline CHEMBL2315452 & 934533 & 7.0458 & 6.5675 & TST \\
\hline CHEMBL 2315763 & 934533 & 5.7077 & 5.0431 & TST \\
\hline CHEMBL2315800 & 934533 & 6.3565 & 5.2917 & TST \\
\hline CHEMBL219944 & 428015 & 8.6383 & 8.5556 & TRN \\
\hline
\end{tabular}

Page 14385 


\begin{tabular}{|c|c|c|c|c|c|c|}
\hline & & \multicolumn{5}{|c|}{ Supplemental Table S2.txt } \\
\hline CHEMBL436514 & 428015 & 8.6383 & 8.6306 & TRN & & \\
\hline CHEMBL426529 & 428015 & 6.8861 & 8.138 & TST & & \\
\hline CHEMBL 222248 & 428015 & 8.3872 & 8.3867 & TRN & & \\
\hline CHEMBL424939 & 428015 & \multicolumn{3}{|c|}{8.283999999999999} & 8.2721 & TRN \\
\hline CHEMBL220836 & 428015 & 8.7212 & 8.5867 & TRN & & \\
\hline CHEMBL223629 & 428015 & 7.3979 & 8.0789 & TST & & \\
\hline CHEMBL 220508 & 428015 & 8.1367 & 8.0238 & TRN & & \\
\hline CHEMBL 223247 & 428015 & \multicolumn{3}{|c|}{6.082000000000001} & 8.1548 & TST \\
\hline CHEMBL220785 & 428015 & 8.3372 & 8.3201 & TRN & & \\
\hline CHEMBL426883 & 428015 & 8.2218 & 8.4498 & TRN & & \\
\hline CHEMBL220627 & 428015 & 8.1739 & 8.0091 & TRN & & \\
\hline CHEMBL 375098 & 428015 & 8.6198 & 8.6079 & TRN & & \\
\hline CHEMBL220117 & 428015 & 7.9586 & 7.9444 & TRN & & \\
\hline CHEMBL 219686 & 428015 & 8.7959 & 8.8154 & TRN & & \\
\hline CHEMBL219817 & 428015 & 6.4353 & 6.6409 & TST & & \\
\hline CHEMBL 219668 & 428015 & 7.7447 & 7.6181 & TRN & & \\
\hline CHEMBL 220060 & 428015 & 8.1249 & 8.2313 & TRN & & \\
\hline CHEMBL 375427 & 428015 & 8.8861 & 8.8542 & TRN & & \\
\hline CHEMBL 376418 & 428015 & 8.4202 & 8.611 & TRN & & \\
\hline CHEMBL 374234 & 428015 & 7.3565 & 7.8982 & TRN & & \\
\hline CHEMBL 375812 & 428015 & 8.6576 & 8.7039 & TRN & & \\
\hline CHEMBL 219617 & 428015 & 8.4815 & 8.4225 & TRN & & \\
\hline CHEMBL 219669 & 428015 & 8.5229 & 8.5797 & TRN & & \\
\hline CHEMBL 220124 & 428015 & 9.2366 & 8.9752 & TRN & & \\
\hline CHEMBL 373791 & 428015 & 8.4949 & 8.4266 & TRN & & \\
\hline CHEMBL 374346 & 428015 & 7.7212 & 7.7531 & TRN & & \\
\hline CHEMBL 220893 & 428015 & 8.8239 & 8.1722 & TRN & & \\
\hline CHEMBL 375373 & 428015 & 7.7959 & 7.7928 & TRN & & \\
\hline CHEMBL 220894 & 428015 & 8.4685 & 8.617 & TRN & & \\
\hline CHEMBL219609 & 428015 & 8.2676 & 8.3877 & TRN & & \\
\hline CHEMBL220628 & 428015 & 7.2518 & 7.1866 & TRN & & \\
\hline CHEMBL220635 & 428015 & 8.3565 & 8.5628 & TRN & & \\
\hline CHEMBL 219610 & 428015 & 7.1739 & 7.6845 & TST & & \\
\hline CHEMBL 223748 & 428015 & 8.9208 & 8.8911 & TRN & & \\
\hline CHEMBL 222508 & 428015 & 8.5229 & 8.7297 & TRN & & \\
\hline CHEMBL 220173 & 428015 & 8.6778 & 8.5551 & TRN & & \\
\hline CHEMBL220681 & 428015 & 8.5686 & 8.754 & TRN & & \\
\hline CHEMBL427237 & 428015 & 8.2076 & 7.8009 & TRN & & \\
\hline CHEMBL 220388 & 428015 & 7.3665 & 8.2388 & TST & & \\
\hline CHEMBL 376537 & 428015 & 7.1739 & 7.1314 & TRN & & \\
\hline CHEMBL 223356 & 428015 & 7.1739 & 7.0558 & TRN & & \\
\hline CHEMBL 374901 & 428015 & 8.7959 & 8.9498 & TRN & & \\
\hline CHEMBL220151 & 428015 & 8.4685 & 8.1499 & TRN & & \\
\hline CHEMBL 2113263 & 428015 & 8.7212 & 8.6507 & TRN & & \\
\hline CHEMBL221101 & 428015 & 8.8861 & 8.8166 & TRN & & \\
\hline CHEMBL 374682 & 428015 & 6.6615 & 7.4799 & TRN & & \\
\hline CHEMBL 220152 & 428015 & 8.2218 & 8.3392 & TRN & & \\
\hline CHEMBL219935 & 428015 & 6.5436 & 7.3211 & TRN & & \\
\hline
\end{tabular}




\begin{tabular}{|c|c|c|c|c|c|}
\hline \multicolumn{6}{|c|}{ Supplemental Table S2.txt } \\
\hline CHEMBL 373605 & 428015 & 7.8861 & 7.925 & TRN & \\
\hline CHEMBL220059 & 428015 & 8.5686 & 8.6282 & TRN & \\
\hline CHEMBL220325 & 428015 & 8.6576 & 8.5282 & TRN & \\
\hline CHEMBL 220990 & 428015 & 5.6517 & 6.1254 & TST & \\
\hline CHEMBL222247 & 428015 & 7.3372 & 7.1472 & TRN & \\
\hline CHEMBL220422 & 428015 & 8.3768 & 8.3284 & TRN & \\
\hline CHEMBL 220662 & 428015 & 8.3565 & 8.2678 & TRN & \\
\hline CHEMBL 220204 & 428015 & 8.6778 & 8.3337 & TRN & \\
\hline CHEMBL220223 & 428015 & 8.4559 & 8.5089 & TRN & \\
\hline CHEMBL375747 & 428015 & 7.8539 & 7.8309 & TRN & \\
\hline CHEMBL427080 & 428015 & 7.5528 & 7.3899 & TRN & \\
\hline CHEMBL221044 & 428015 & 8.3979 & 8.3683 & TST & \\
\hline CHEMBL374925 & 428015 & 8.3979 & 8.3328 & TRN & \\
\hline CHEMBL 219688 & 428015 & 8.4685 & 8.3706 & TST & \\
\hline CHEMBL374545 & 428015 & 8.1612 & 7.9803 & TRN & \\
\hline CHEMBL219687 & 428015 & 8.5376 & 8.4622 & TRN & \\
\hline CHEMBL220837 & 428015 & 8.5376 & 8.4154 & TRN & \\
\hline CHEMBL 387350 & 428015 & 8.699 & 8.7148 & TRN & \\
\hline CHEMBL 220224 & 428015 & 8.8861 & 9.0241 & TRN & \\
\hline CHEMBL 219723 & 428015 & 8.0969 & 7.6368 & TRN & \\
\hline CHEMBL425116 & 428015 & 8.2518 & 8.2226 & TRN & \\
\hline CHEMBL219661 & 428015 & 7.6021 & 7.7661 & TRN & \\
\hline CHEMBL220421 & 428015 & 8.0506 & 8.1807 & TRN & \\
\hline CHEMBL220431 & 428015 & 7.9586 & 7.83799 & 9999999999 & TST \\
\hline CHEMBL220557 & 428015 & 8.6021 & 8.7384 & TRN & \\
\hline CHEMBL 221100 & 428015 & 7.6198 & 7.5876 & TRN & \\
\hline CHEMBL220448 & 428015 & 7.9586 & 8.2229 & TRN & \\
\hline CHEMBL 374090 & 428015 & 8.4815 & 8.3393 & TST & \\
\hline CHEMBL220507 & 428015 & 8.1805 & 8.1845 & TST & \\
\hline CHEMBL 220430 & 428015 & 8.6576 & 8.5612 & TST & \\
\hline CHEMBL373591 & 428015 & 7.5376 & 8.5394 & TST & \\
\hline CHEMBL 375072 & 428015 & 8.3372 & 8.3537 & TST & \\
\hline CHEMBL 220205 & 428015 & 8.0915 & 8.0305 & TST & \\
\hline CHEMBL 220058 & 428015 & 7.3665 & 8.2937 & TST & \\
\hline CHEMBL373554 & 428015 & 6.9318 & 7.0736 & TST & \\
\hline CHEMBL 220570 & 428015 & 9.0223 & 8.3691 & TST & \\
\hline CHEMBL424933 & 428015 & 7.9208 & 7.4312 & TST & \\
\hline CHEMBL 219872 & 428015 & 7.7447 & 7.5398 & TST & \\
\hline CHEMBL 375748 & 428015 & 8.2291 & 8.3385 & TST & \\
\hline CHEMBL 373813 & 428015 & 7.9586 & 8.1836 & TST & \\
\hline CHEMBL3797256 & 1573232 & 4.0 & 5.02 & TST & \\
\hline CHEMBL3797647 & 1573232 & 7.3468 & 7.3023 & TRN & \\
\hline CHEMBL 3800430 & 1573232 & 5.8539 & 5.8523 & TRN & \\
\hline CHEMBL3799260 & 1573232 & 6.2441 & 6.6803 & TRN & \\
\hline CHEMBL3798420 & 1573232 & 5.4949 & 5.5099 & TRN & \\
\hline CHEMBL3799748 & 1573232 & 5.9031 & 6.1314 & TRN & \\
\hline CHEMBL3798293 & 1573232 & 4.0 & 4.2089 & TRN & \\
\hline CHEMBL 3797541 & 1573232 & 5.3665 & 6.3893 & TST & \\
\hline
\end{tabular}


Supplemental Table S2.txt

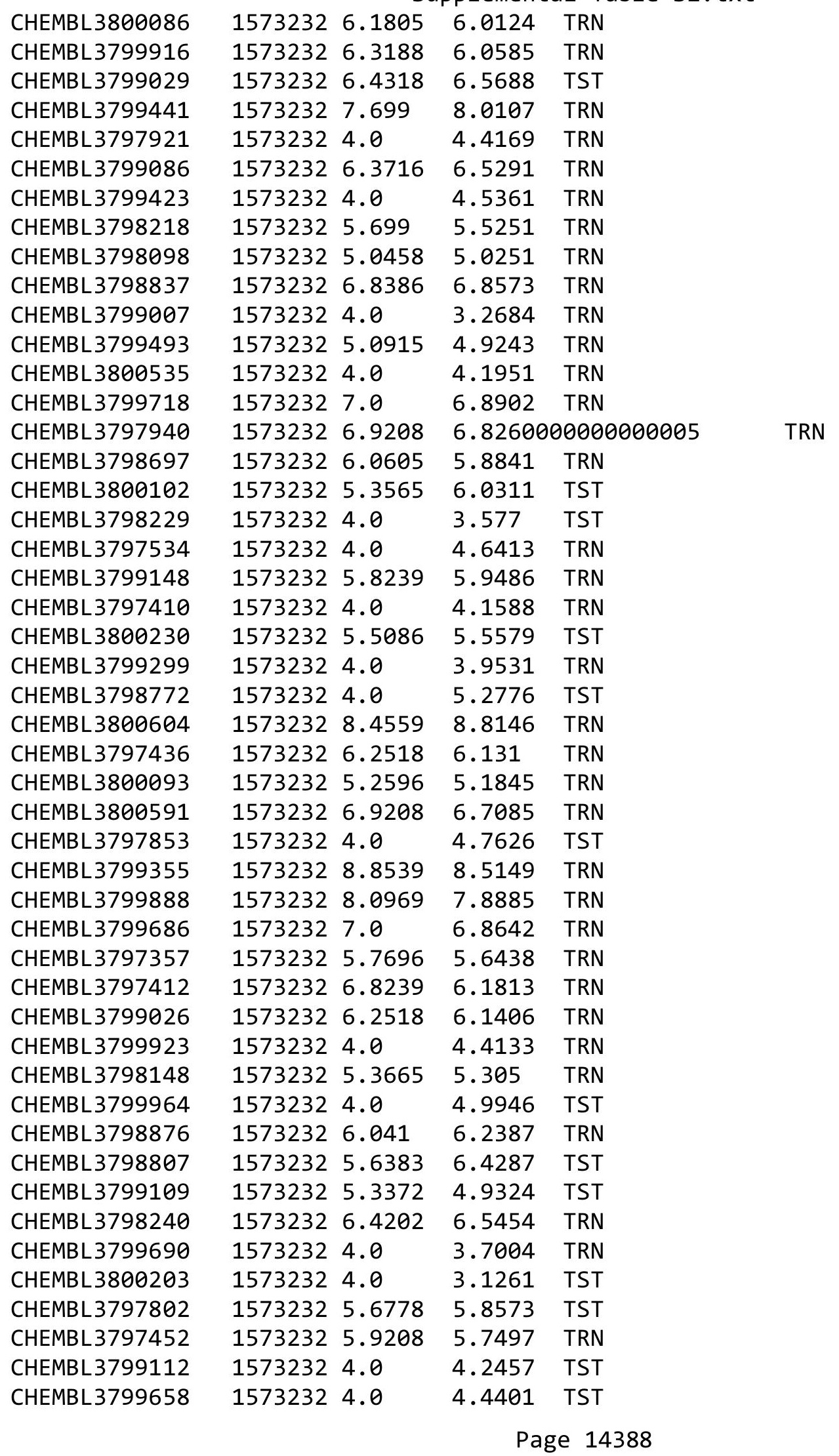


Supplemental Table S2.txt

\begin{tabular}{|c|c|c|c|c|c|c|}
\hline CHEMBL3798068 & 1573232 & 6.4559 & 6.666 & TRN & & \\
\hline CHEMBL3798181 & 1573232 & 4.0 & 3.9261 & TRN & & \\
\hline CHEMBL3798722 & 1573232 & 5.5376 & 5.3237 & TRN & & \\
\hline CHEMBL3797596 & 1573232 & 6.6778 & 6.7102 & TRN & & \\
\hline CHEMBL373003 & 331194 & 6.4089 & 6.3746 & TRN & & \\
\hline CHEMBL199825 & 331194 & 7.2366 & 7.2441 & TRN & & \\
\hline CHEMBL199667 & 331194 & 6.7471 & 6.835 & TRN & & \\
\hline CHEMBL201474 & 331194 & 7.1612 & 7.1806 & TRN & & \\
\hline CHEMBL382523 & 331194 & 6.4815 & 6.4907 & TRN & & \\
\hline CHEMBL203209 & 331194 & 7.0177 & 6.9762 & TRN & & \\
\hline CHEMBL201052 & 331194 & 6.857 & 6.814 & TRN & & \\
\hline CHEMBL324519 & 331194 & 4.9136 & 6.1142 & TST & & \\
\hline CHEMBL201235 & 331194 & 6.4067 & 6.4315 & TRN & & \\
\hline CHEMBL381968 & 331194 & 6.9281 & 6.9465 & TRN & & \\
\hline CHEMBL31661 & 331194 & \multicolumn{3}{|c|}{6.821000000000001} & 6.1642 & TST \\
\hline CHEMBL371445 & 331194 & 5.8962 & 5.8983 & TRN & & \\
\hline CHEMBL203300 & 331194 & 7.4318 & 7.4257 & TRN & & \\
\hline CHEMBL203144 & 331194 & 5.3233 & 5.3146 & TRN & & \\
\hline CHEMBL380963 & 331194 & \multicolumn{3}{|c|}{5.3420000000000005} & 5.2656 & TRN \\
\hline CHEMBL201549 & 331194 & 5.0223 & 7.4611 & TST & & \\
\hline CHEMBL201059 & 331194 & 7.4437 & 7.3886 & TRN & & \\
\hline CHEMBL203203 & 331194 & 4.011 & 4.8879 & TST & & \\
\hline CHEMBL201058 & 331194 & 5.3665 & 5.3351 & TRN & & \\
\hline CHEMBL202989 & 331194 & 6.0506 & 6.0973 & TRN & & \\
\hline CHEMBL202927 & 331194 & 8.0506 & 8.1905 & TRN & & \\
\hline CHEMBL201795 & 331194 & 8.699 & 8.6579 & TRN & & \\
\hline CHEMBL201174 & 331194 & 4.585 & 5.5804 & TST & & \\
\hline CHEMBL379891 & 331194 & 7.6383 & 7.6555 & TRN & & \\
\hline CHEMBL203141 & 331194 & 5.0809 & 5.0562 & TRN & & \\
\hline CHEMBL202829 & 331194 & 6.2757 & 6.2398 & TRN & & \\
\hline CHEMBL198234 & 331194 & 5.8153 & 5.8876 & TRN & & \\
\hline CHEMBL381748 & 331194 & 6.0269 & 6.0423 & TRN & & \\
\hline CHEMBL383662 & 331194 & 6.4342 & 6.435 & TRN & & \\
\hline CHEMBL 381030 & 331194 & 4.644 & 5.9742 & TST & & \\
\hline CHEMBL370772 & 331194 & 8.7959 & 8.7842 & TRN & & \\
\hline CHEMBL199848 & 331194 & 8.3851 & 8.394 & TRN & & \\
\hline CHEMBL 201440 & 331194 & 8.8356 & 8.8734 & TRN & & \\
\hline CHEMBL202705 & 331194 & 3.5229 & 3.5159 & TRN & & \\
\hline CHEMBL31741 & 331194 & 8.8539 & 6.7604 & TST & & \\
\hline CHEMBL202412 & 331194 & 8.4815 & 8.5073 & TRN & & \\
\hline CHEMBL382307 & 331194 & 7.0969 & 7.1033 & TRN & & \\
\hline CHEMBL263962 & 331194 & 7.7799 & 7.8288 & TRN & & \\
\hline CHEMBL200079 & 331194 & \multicolumn{3}{|c|}{5.752000000000001} & 6.6399 & TS \\
\hline CHEMBL 370669 & 331194 & 5.5086 & 7.6913 & TST & & \\
\hline CHEMBL201294 & 331194 & 8.1805 & 8.1138 & TRN & & \\
\hline CHEMBL382779 & 331194 & 8.2366 & 8.2832 & TRN & & \\
\hline CHEMBL381520 & 331194 & 4.4685 & 4.4844 & TRN & & \\
\hline CHEMBL383627 & 331194 & 6.5735 & 6.5458 & TRN & & \\
\hline
\end{tabular}


Supplemental Table S2.txt

\begin{tabular}{|c|c|c|c|c|}
\hline CHEMBL202126 & 331194 & 4.7825 & 4.842 & TRN \\
\hline CHEMBL414672 & 331194 & 4.7852 & 4.7504 & TRN \\
\hline CHEMBL 383226 & 31194 & 8.9547 & 8.789 & $\mathrm{RN}$ \\
\hline HEMBL 202933 & 31194 & 7.9788 & 7.7077 & 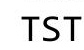 \\
\hline CHEMBL 378817 & 31194 & 5.7033 & 3.37 & \\
\hline HEMBL 200082 & 31194 & 8.0223 & 7.2743 & II \\
\hline CHEMBL 372309 & 331194 & 4.6364 & 4.124 & 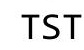 \\
\hline CHEMBL 305173 & 34232 & 6.5528 & 6.6165 & IIV \\
\hline HEMBL66965 & 34232 & 7.6253 & 6.769 & \\
\hline CHEMBL 70173 & 34232 & 7.0 & 5.9309 & ST \\
\hline CHEMBL303017 & 34232 & 6.1024 & 5.1913 & TST \\
\hline CHEMBL 67882 & 34232 & 6.5952 & 6.5855 & TRN \\
\hline CHEMBL67639 & 34232 & 6.6108 & 6.5479 & \\
\hline HEMBL431721 & 34232 & 6.6596 & 6.6989 & \\
\hline CHEMBL 303130 & 34232 & 6.3883 & 6.3217 & RN \\
\hline CHEMBL66118 & 34232 & 5.8993 & 5.8768 & $\Gamma \mathrm{RN}$ \\
\hline CHEMBL 302857 & 34232 & 7.6289 & 6.769 & ST \\
\hline CHEMBL 303895 & 34232 & 7.4056 & 7.1241 & RIN \\
\hline CHEMBL46172 & 34232 & 6.284 & 7.1753 & RN \\
\hline CHEMBL 303347 & 34232 & 7.5986 & 7.7824 & RN \\
\hline CHEMBL 302554 & 34232 & 7.3391 & 7.2303 & TRN \\
\hline CHEMBL417565 & 34232 & 6.9788 & 6.769 & ST \\
\hline CHEMBL 302268 & 34232 & 7.6108 & 7.1753 & RN \\
\hline CHEMBL 67856 & 34232 & .5935 & 5.9309 & ST \\
\hline CHEMBL417745 & 34232 & 7.6198 & 6.2855 & TST \\
\hline CHEMBL10347 & 34232 & 8.3979 & 6.8295 & ST \\
\hline CHEMBL66272 & 34232 & 7.0706 & 7.0074 & TRN \\
\hline CHEMBL67379 & 34232 & 6.8239 & 6.7861 & RN \\
\hline HEMBL 68447 & 34232 & 7.1805 & 7.4682 & RN \\
\hline CHEMBL 302051 & 34232 & 6.857 & 6.8338 & RN \\
\hline CHEMBL65963 & 34232 & 7.7447 & 7.4682 & TRN \\
\hline CHEMBL65887 & 34232 & 7.279 & 6.0773 & TST \\
\hline CHEMBL67132 & 34232 & 1308 & 7.7824 & TRN \\
\hline CHEMBL66 & 34232 & 42 & 6.5555 & TRN \\
\hline CHEMBL 66747 & 34232 & 6.6383 & 7.0259 & TRN \\
\hline CHEMBL67773 & 34232 & 7.1439 & 7.2303 & TRN \\
\hline CHEMBL 304783 & 34232 & 7.8239 & 8.0004 & TRN \\
\hline CHEMBL67162 & 34232 & .0605 & 5.9723 & TRN \\
\hline CHEMBL63876 & 34232 & 6.585 & 6.4222 & TST \\
\hline CHEMBL 66607 & 34232 & 6.2 & 5.4959 & TST \\
\hline CHEMBL67478 & 34232 & 6.3565 & 6.4806 & TRN \\
\hline CHEMBL63781 & 34232 & 6.4318 & 6.4164 & TRN \\
\hline CHEMBL66172 & 34232 & 8.4559 & 8.0004 & TRN \\
\hline CHEMBL67681 & 34232 & 6.5003 & 6.6231 & TRN \\
\hline CHEMBL 66748 & 34232 & 7.1561 & 7.2303 & TRN \\
\hline CHEMBL49152 & 34232 & 8.3372 & 8.0004 & TRN \\
\hline CHEMBL 303894 & 34232 & 7.5376 & 7.7824 & Tro \\
\hline CHEMBL 306440 & 34232 & 6.8576 & 6.8338 & \\
\hline
\end{tabular}

Page 14390 


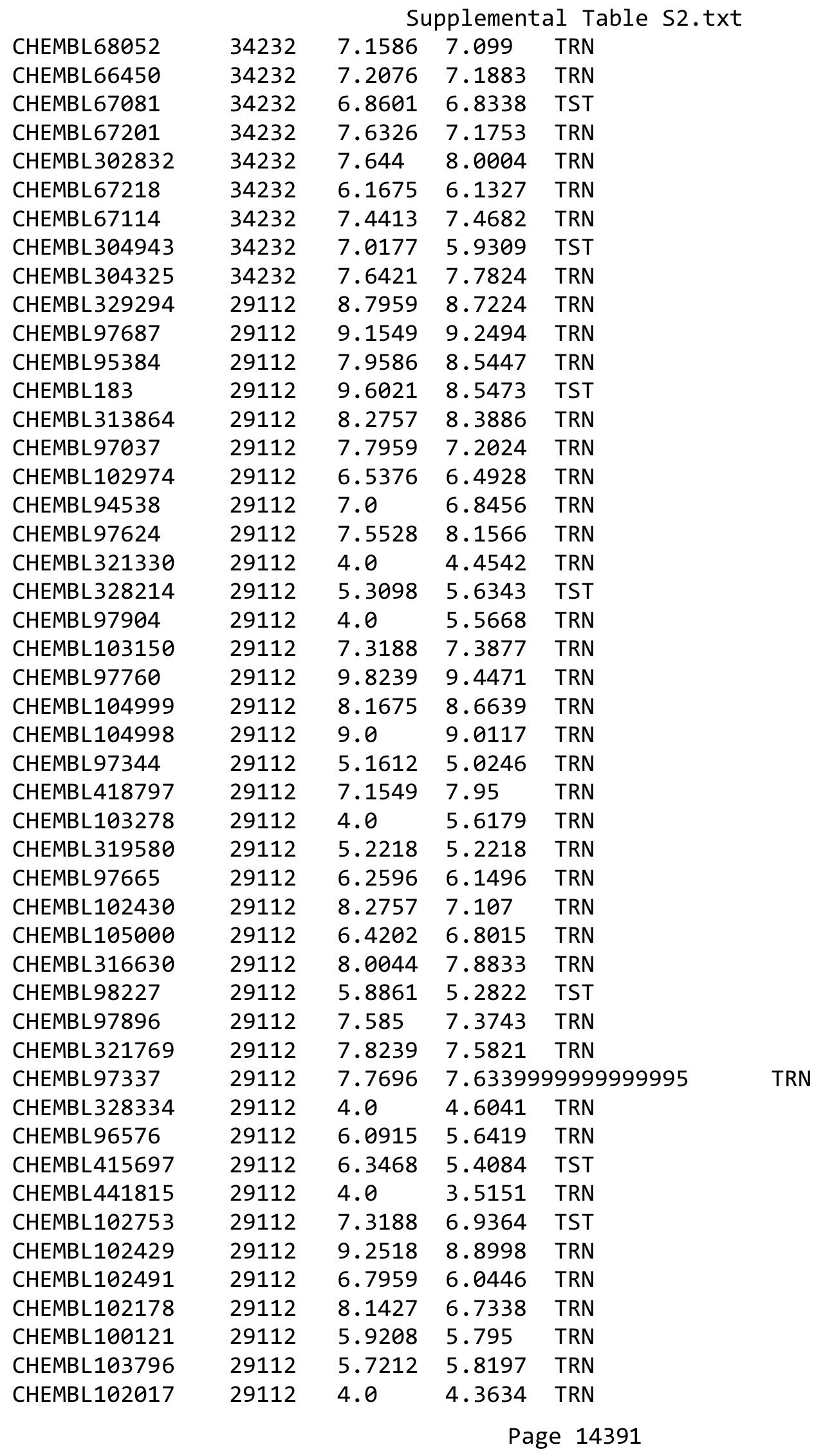




\begin{tabular}{|c|c|c|c|c|c|c|}
\hline & & \multicolumn{5}{|c|}{ Supplemental Table S2.txt } \\
\hline CHEMBL97778 & 29112 & 6.0 & 5.9864 & TRN & & \\
\hline CHEMBL96617 & 29112 & 5.0605 & 4.0449 & TRN & & \\
\hline CHEMBL329293 & 29112 & 7.0969 & 7.21 & TRN & & \\
\hline CHEMBL97549 & 29112 & 8.2757 & 8.3551 & TRN & & \\
\hline CHEMBL97895 & 29112 & 8.28399 & 99999999 & 99 & 8.2051 & TRN \\
\hline CHEMBL323303 & 29112 & 7.6383 & 7.6682 & TST & & \\
\hline CHEMBL102126 & 29112 & 4.0 & 4.4579 & TST & & \\
\hline CHEMBL97757 & 29112 & 8.3872 & 8.56 & TST & & \\
\hline CHEMBL323288 & 29112 & 5.3279 & 6.3027 & TST & & \\
\hline CHEMBL103553 & 29112 & 5.1549 & 4.7047 & TST & & \\
\hline CHEMBL103559 & 29112 & 7.301 & 8.1121 & TST & & \\
\hline CHEMBL103588 & 29112 & 6.6778 & 6.1894 & TST & & \\
\hline CHEMBL317411 & 29112 & 6.4685 & 6.7698 & TST & & \\
\hline CHEMBL17127 & 29112 & 6.4473 & 8.0798 & TST & & \\
\hline CHEMBL3338005 & 1435305 & 4.4934 & 4.6186 & TST & & \\
\hline CHEMBL3338017 & 1435305 & 4.9352 & 4.5312 & TRN & & \\
\hline CHEMBL3338052 & 1435305 & 6.1024 & 6.2062 & TRN & & \\
\hline CHEMBL3338019 & 1435305 & 4.9355 & 5.0054 & TRN & & \\
\hline CHEMBL3338055 & 1435305 & 3.1938 & 3.5676 & TST & & \\
\hline CHEMBL3338021 & 1435305 & 5.3497 & 4.0632 & TRN & & \\
\hline CHEMBL3338048 & 1435305 & 5.284 & 4.8148 & TRN & & \\
\hline CHEMBL3338035 & 1435305 & 3.1938 & 3.758 & TRN & & \\
\hline CHEMBL3338027 & 1435305 & 6.2291 & 6.0298 & TRN & & \\
\hline CHEMBL3338049 & 1435305 & 5.4535 & 5.9101 & TRN & & \\
\hline CHEMBL3338020 & 1435305 & 5.2111 & 5.6402 & TRN & & \\
\hline CHEMBL3338040 & 1435305 & 5.2857 & 5.0121 & TRN & & \\
\hline CHEMBL3338008 & 1435305 & 4.3397 & 4.9183 & TRN & & \\
\hline CHEMBL3338026 & 1435305 & 5.3497 & 5.419 & TRN & & \\
\hline CHEMBL3337999 & 1435305 & 3.1938 & 4.4547 & TST & & \\
\hline CHEMBL3338009 & 1435305 & 6.6778 & 6.2654 & TRN & & \\
\hline CHEMBL3337998 & 1435305 & 5.1433 & 4.4408 & TST & & \\
\hline CHEMBL71659 & 1435305 & 6.1079 & 6.1379 & TRN & & \\
\hline CHEMBL3338042 & 1435305 & 5.3872 & 5.4679 & TRN & & \\
\hline CHEMBL3338032 & 1435305 & 6.3768 & 6.4588 & TRN & & \\
\hline CHEMBL72529 & 1435305 & 6.0177 & 5.8329 & TRN & & \\
\hline CHEMBL3338033 & 1435305 & 5.7747 & 5.9074 & TRN & & \\
\hline CHEMBL3338002 & 1435305 & 3.4948 & 3.4473 & TRN & & \\
\hline CHEMBL3338018 & 1435305 & 5.3809 & 4.9812 & TRN & & \\
\hline CHEMBL3338039 & 1435305 & 5.8386 & 5.9592 & TRN & & \\
\hline CHEMBL3338043 & 1435305 & 5.2741 & 5.5812 & TRN & & \\
\hline CHEMBL3338024 & 1435305 & 5.1911 & 5.4372 & TRN & & \\
\hline CHEMBL3338047 & 1435305 & 4.8136 & 4.9753 & TRN & & \\
\hline CHEMBL421114 & 1435305 & 5.9469 & 5.695 & TRN & & \\
\hline CHEMBL71521 & 1435305 & 5.9318 & 6.0458 & TRN & & \\
\hline CHEMBL3338003 & 1435305 & 3.4948 & 3.4195 & TRN & & \\
\hline CHEMBL54893 & 1435305 & 3.1938 & 4.2409 & TST & & \\
\hline CHEMBL3338029 & 1435305 & 5.8125 & 5.9475 & TRN & & \\
\hline CHEMBL3338036 & 1435305 & 4.2963 & 3.8167 & TRN & & \\
\hline
\end{tabular}


Supplemental Table S2.txt

\begin{tabular}{|c|c|c|c|c|c|}
\hline CHEMBL3338015 & 1435305 & 5.0937 & 5.2883 & TRN & \\
\hline CHEMBL3338045 & 1435305 & 5.284 & 5.5686 & TRN & \\
\hline CHEMBL3338001 & 1435305 & 3.4948 & 3.7505 & TRN & \\
\hline CHEMBL3338010 & 1435305 & 5.5436 & 5.4822 & TRN & \\
\hline CHEMBL 74174 & 1435305 & 5.3152 & 5.2671 & TRN & \\
\hline CHEMBL3338046 & 1435305 & 5.04 & 5.231 & TRN & \\
\hline CHEMBL3338037 & 1435305 & 3.1938 & 3.7053 & TRN & \\
\hline CHEMBL3338051 & 1435305 & 5.6925 & 5.86799 & 9999999999 & TRN \\
\hline CHEMBL3338053 & 1435305 & 7.8239 & 6.8357 & TRN & \\
\hline CHEMBL3338028 & 1435305 & 5.8125 & 5.7437 & TRN & \\
\hline CHEMBL3338006 & 1435305 & 3.1938 & 3.2139 & TRN & \\
\hline CHEMBL3338007 & 1435305 & 5.6326 & 5.6047 & TRN & \\
\hline CHEMBL3338041 & 1435305 & 5.2588 & 4.9385 & TRN & \\
\hline CHEMBL3337461 & 1435305 & 3.4948 & 3.437 & TRN & \\
\hline CHEMBL578061 & 1435305 & 5.1385 & 4.9221 & TST & \\
\hline CHEMBL3338038 & 1435305 & 5.6737 & 5.7074 & TRN & \\
\hline CHEMBL470025 & 1435305 & 6.9208 & 6.6113 & TRN & \\
\hline CHEMBL3338011 & 1435305 & 3.4948 & 3.3309 & TRN & \\
\hline CHEMBL71728 & 1435305 & 4.6423 & 4.9395 & TRN & \\
\hline CHEMBL302791 & 1435305 & 6.284 & 6.2594 & TRN & \\
\hline CHEMBL3338025 & 1435305 & 5.1649 & 5.8201 & TRN & \\
\hline CHEMBL3338004 & 1435305 & 3.4948 & 3.3251 & TRN & \\
\hline CHEMBL3338044 & 1435305 & 5.5834 & 5.6289 & TRN & \\
\hline CHEMBL3338016 & 1435305 & 3.4948 & 3.8732 & TRN & \\
\hline CHEMBL3338000 & 1435305 & 3.1938 & 4.3236 & TST & \\
\hline CHEMBL3338013 & 1435305 & 5.7011 & 4.8581 & TST & \\
\hline CHEMBL3338050 & 1435305 & 7.301 & 6.607 & TST & \\
\hline CHEMBL69503 & 1435305 & 5.8633 & 6.3322 & TST & \\
\hline CHEMBL3338034 & 1435305 & 5.7258 & 5.9999 & TST & \\
\hline CHEMBL3338022 & 1435305 & 4.7883 & 4.7114 & TST & \\
\hline CHEMBL3338014 & 1435305 & 3.4948 & 3.9896 & TST & \\
\hline CHEMBL3338031 & 1435305 & 4.9151 & 4.9353 & TST & \\
\hline CHEMBL3338023 & 1435305 & 5.1543 & 4.9388 & TST & \\
\hline CHEMBL3338030 & 1435305 & 5.6882 & 6.1557 & TST & \\
\hline CHEMBL3338012 & 1435305 & 4.4887 & 4.5959 & TST & \\
\hline CHEMBL3338054 & 1435305 & 6.6778 & 6.1837 & TST & \\
\hline CHEMBL91249 & 89859 & 6.1249 & 5.756 & TRN & \\
\hline CHEMBL89810 & 89859 & 5.6126 & \multicolumn{2}{|c|}{5.617000000000001} & TRN \\
\hline CHEMBL92169 & 89859 & 4.945 & 5.399 & TRN & \\
\hline CHEMBL329173 & 89859 & 7.2676 & 6.2849 & TRN & \\
\hline CHEMBL91088 & 89859 & 6.1427 & 6.7104 & TRN & \\
\hline CHEMBL90380 & 89859 & 7.2076 & 6.7049 & TRN & \\
\hline CHEMBL330240 & 89859 & 5.2007 & 4.6108 & TRN & \\
\hline CHEMBL313021 & 89859 & 6.3665 & 5.9037 & TRN & \\
\hline CHEMBL90877 & 89859 & 6.5376 & 6.4555 & TRN & \\
\hline CHEMBL431085 & 89859 & 5.4318 & 6.3665 & TRN & \\
\hline CHEMBL89277 & 89859 & 5.4535 & 4.9489 & TST & \\
\hline CHEMBL329344 & 89859 & 5.6925 & 4.978 & TRN & \\
\hline
\end{tabular}




\begin{tabular}{|c|c|c|c|c|c|c|}
\hline & & \multicolumn{5}{|c|}{ Supplemental Table S2.txt } \\
\hline CHEMBL91014 & 89859 & 6.4815 & 6.2615 & TRN & & \\
\hline CHEMBL90515 & 89859 & 4.9066 & 5.6799 & TST & & \\
\hline CHEMBL329573 & 89859 & 5.6946 & 5.9867 & TRN & & \\
\hline CHEMBL330086 & 89859 & 6.4202 & 6.2463 & TRN & & \\
\hline CHEMBL89820 & 89859 & 6.1739 & 6.1897 & TRN & & \\
\hline CHEMBL328543 & 89859 & 6.5686 & 5.9696 & TRN & & \\
\hline CHEMBL91720 & 89859 & 5.8477 & 4.5485 & TST & & \\
\hline CHEMBL90183 & 89859 & 6.0458 & 5.0846 & TRN & & \\
\hline CHEMBL90647 & 89859 & 6.8861 & 6.2783 & TRN & & \\
\hline CHEMBL91010 & 89859 & 5.0506 & 5.2864 & TRN & & \\
\hline CHEMBL89395 & 89859 & 3.4318 & 4.9551 & TST & & \\
\hline CHEMBL328987 & 89859 & 4.4209 & 5.0091 & TST & & \\
\hline CHEMBL91503 & 89859 & 6.9586 & 7.2546 & TRN & & \\
\hline CHEMBL 327808 & 89859 & \multicolumn{3}{|c|}{5.382000000000001} & 6.6697 & TST \\
\hline CHEMBL 327882 & 89859 & 6.284 & 5.8613 & TRN & & \\
\hline CHEMBL89276 & 89859 & 6.5528 & 4.7715 & TST & & \\
\hline CHEMBL91715 & 89859 & 6.1487 & 6.7112 & TRN & & \\
\hline CHEMBL 330737 & 89859 & 6.7696 & 6.1697 & TRN & & \\
\hline CHEMBL316367 & 89859 & 3.248 & 5.541 & TRN & & \\
\hline CHEMBL90546 & 89859 & 6.2757 & 6.1847 & TRN & & \\
\hline CHEMBL90876 & 89859 & 6.4202 & 5.9941 & TRN & & \\
\hline CHEMBL90230 & 89859 & 4.6821 & 5.3552 & TRN & & \\
\hline CHEMBL327786 & 89859 & 5.1409 & 6.0506 & TST & & \\
\hline CHEMBL92165 & 89859 & 5.8861 & 6.325 & TRN & & \\
\hline CHEMBL279859 & 89859 & 5.0937 & 5.5032 & TST & & \\
\hline CHEMBL432057 & 89859 & 6.2924 & 6.4555 & TRN & & \\
\hline CHEMBL 93730 & 89859 & 6.7212 & 6.7458 & TRN & & \\
\hline CHEMBL 88182 & 89859 & 4.5193 & 5.2306 & TST & & \\
\hline CHEMBL90176 & 89859 & 5.6144 & 5.9589 & TRN & & \\
\hline CHEMBL329412 & 89859 & 5.9136 & 5.8165 & TRN & & \\
\hline CHEMBL 329788 & 89859 & 6.1675 & 6.0585 & TRN & & \\
\hline CHEMBL314949 & 89859 & 6.0362 & 6.4067 & TRN & & \\
\hline CHEMBL329248 & 89859 & 6.6021 & 5.0107 & TST & & \\
\hline CHEMBL90849 & 89859 & 5.1662 & 5.7293 & TST & & \\
\hline CHEMBL92205 & 89859 & 7.301 & 6.7906 & TRN & & \\
\hline CHEMBL 88787 & 89859 & 7.3279 & 7.3592 & TRN & & \\
\hline CHEMBL 328279 & 89859 & 4.098 & 4.6352 & TRN & & \\
\hline CHEMBL328711 & 89859 & 5.3468 & 5.0384 & TRN & & \\
\hline CHEMBL 92202 & 89859 & 3.2284 & 6.5157 & TST & & \\
\hline CHEMBL327234 & 89859 & 7.2924 & 6.7112 & TRN & & \\
\hline CHEMBL91724 & 89859 & 4.2702 & 4.9132 & TRN & & \\
\hline CHEMBL 88797 & 89859 & 5.0915 & 5.8443 & TST & & \\
\hline CHEMBL91388 & 89859 & 5.6757 & 6.3248 & TRN & & \\
\hline CHEMBL92381 & 89859 & 4.9066 & 4.7869 & TRN & & \\
\hline CHEMBL171632 & 1301747 & 4.6291 & 5.0143 & TST & & \\
\hline CHEMBL1998302 & 1301747 & 5.9867 & 5.7143 & TRN & & \\
\hline CHEMBL 1495700 & 1301747 & 3.9569 & 3.7807 & TST & & \\
\hline CHEMBL1327596 & 1301747 & 4.587 & 2.6614 & TST & & \\
\hline
\end{tabular}


Supplemental Table S2.txt

\begin{tabular}{|c|c|c|}
\hline 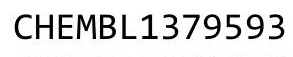 & & \\
\hline HEMBL1330558 & 301747 & 4 \\
\hline HEMBL1484549 & 301747 & 4.4227 \\
\hline AEMBL1454614 & 301747 & 4.923 \\
\hline IEMBL1334670 & 301747 & \\
\hline AEMBL1210769 & 301747 & \\
\hline AEMBL3193343 & 301747 & 4.44 \\
\hline HEMBL1378508 & 747 & \\
\hline HEMBL599924 & 747 & \\
\hline IEMBL1899341 & 747 & \\
\hline AEMBL1546172 & L301747 & \\
\hline AEMBL1591913 & 747 & \\
\hline HEMBL1464949 & 747 & 4. \\
\hline AEMBL1535503 & 47 & 2. \\
\hline AEMBL1475961 & 47 & \\
\hline AEMBL1524233 & 747 & \\
\hline HEMBL1509380 & 47 & \\
\hline AEMBL1506031 & 47 & \\
\hline HEMBL198 & 47 & \\
\hline AEMBL 145 & 47 & \\
\hline AEMBL3197091 & 47 & \\
\hline AEMBL578905 & & \\
\hline AEMBL1564699 & 47 & \\
\hline AEMBL1734 & 47 & \\
\hline HEMBL1380801 & 47 & \\
\hline AEMBL1542693 & 47 & \\
\hline AEMBL1713009 & 47 & \\
\hline AEMBL1451327 & 13 & \\
\hline AEMBL1362 & 7 & \\
\hline HEMBL1344702 & 47 & \\
\hline HEMBL 3191474 & 47 & \\
\hline AEMBL1361173 & 47 & \\
\hline HEMBL1351 & 7 & \\
\hline $146=2+3$ & 17 & \\
\hline HEMBL1504853 & 47 & \\
\hline HEMBL1735496 & 47 & \\
\hline HEMBL1530767 & 136 & \\
\hline 2 & 47 & \\
\hline 1421 & 47 & \\
\hline HEMBL1383503 & 747 & 2.940 \\
\hline AEMBL3191855 & 136 & 5.874 \\
\hline HEMBL1707222 & 136 & 4.467 \\
\hline CHEMBL1988648 & 130 & \\
\hline CHEMBL1355280 & 747 & \\
\hline CHEMBL1980681 & 1301747 & 4.61 \\
\hline HEMBL1402117 & 1301747 & $4.66 e$ \\
\hline HEMBL 140 & 1301747 & 2010 C \\
\hline 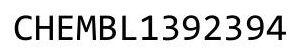 & & 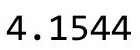 \\
\hline
\end{tabular}

4.2851 TRN

4.2551 TRN

4.4832 TRN

4.9792 TRN

4.7832 TRN

5.7257 TRN

4.196000000000001

4.0997 TST

5.9646 TST

4.3065 TRN

5.6137 TRN

4.5225 TRN

4.5296 TRN

3.9679 TRN

4.5896 TRN

4.5836 TRN

4.396 TST

4.0203 TRN

5.9236 TRN

5.1467 TRN

5.6564 TRN

4.9142 TRN

4.8908 TRN

4.9619 TRN

4.4601 TRN

5.081 TRN

5.2785 TRN

4.2046 TST

4.8088 TRN

4.6306 TRN

4.2735 TRN

4.8873 TRN

4.2652 TST

5.7925 TST

4.4921 TRN

4.6061 TST

4.1181 TRN

4.7944 TRN

4.4305 TST

4.5809 TRN

6.1271 TRN

4.8216 TRN

5.1266 TRN

4.4633 TRN

4.2762 TRN

4.4292 TST

2.3061 TRN

4.3363 TRN 
Supplemental Table S2.txt

\begin{tabular}{|c|c|c|c|c|}
\hline CHEMBL1881345 & 1301747 & 4.779 & 4.7886 & TRN \\
\hline CHEMBL1377824 & 1301747 & 2.9408 & 3.8304 & TRN \\
\hline CHEMBL1719244 & 1301747 & 5.8649 & 5.5252 & TRN \\
\hline CHEMBL1530670 & 1301747 & 4.5888 & 4.5758 & TRN \\
\hline CHEMBL1487660 & 1301747 & 2.9406 & 3.8043 & TRN \\
\hline CHEMBL1733422 & 1301747 & 5.8259 & 5.2656 & TRN \\
\hline CHEMBL586029 & 1301747 & 4.21 & 4.3256 & TRN \\
\hline CHEMBL1497838 & 1301747 & 4.6206 & 4.5327 & TRN \\
\hline CHEMBL1335953 & 1301747 & 4.8237 & 4.7573 & TRN \\
\hline CHEMBL1711432 & 1301747 & 5.2239 & 4.966 & TRN \\
\hline CHEMBL1409603 & 1301747 & 4.8015 & 4.4762 & TRN \\
\hline CHEMBL1735482 & 1301747 & 5.9602 & 5.8451 & TRN \\
\hline CHEMBL1524916 & 1301747 & 4.4495 & 4.4141 & TRN \\
\hline CHEMBL1598762 & 1301747 & 5.9465 & 6.0099 & TRN \\
\hline CHEMBL429095 & 1301747 & 5.1341 & 5.2247 & TRN \\
\hline CHEMBL1526391 & 1301747 & 5.0844 & 4.7457 & TRN \\
\hline CHEMBL3196451 & 1301747 & 5.7467 & 6.2543 & TRN \\
\hline CHEMBL1235966 & 1301747 & 4.9032 & 4.6526 & TST \\
\hline CHEMBL1392911 & 1301747 & 5.1612 & 4.5757 & TRN \\
\hline CHEMBL 3199312 & 1301747 & 4.4404 & 4.5005 & TRN \\
\hline CHEMBL1302524 & 1301747 & 5.3217 & 5.0556 & TRN \\
\hline CHEMBL51931 & 1301747 & 5.4262 & 5.1958 & TRN \\
\hline CHEMBL1893320 & 1301747 & 4.145 & 4.2634 & TST \\
\hline CHEMBL1877709 & 1301747 & 5.8536 & 6.206 & TRN \\
\hline CHEMBL1505552 & 1301747 & 4.6723 & 4.6561 & TST \\
\hline CHEMBL3187596 & 1301747 & 4.9929 & 5.006 & TRN \\
\hline CHEMBL3194415 & 1301747 & 4.3359 & 4.5039 & TRN \\
\hline CHEMBL156174 & 1301747 & 5.3063 & 5.3603 & TRN \\
\hline CHEMBL3191689 & 1301747 & 5.7416 & 5.5488 & TRN \\
\hline CHEMBL592115 & 1301747 & 4.8131 & 4.9063 & TRN \\
\hline CHEMBL1360435 & 1301747 & 2.9406 & 3.8128 & TST \\
\hline CHEMBL1728280 & 1301747 & 6.0689 & 5.8197 & TRN \\
\hline CHEMBL1502234 & 1301747 & 4.8125 & 4.2344 & TRN \\
\hline CHEMBL1302170 & 1301747 & 5.119 & 4.9256 & TRN \\
\hline CHEMBL3190880 & 1301747 & 5.6005 & 5.8916 & TRN \\
\hline CHEMBL1417929 & 1301747 & 4.8476 & 4.9887 & TRN \\
\hline CHEMBL1308936 & 1301747 & 4.1172 & 4.0936 & TRN \\
\hline CHEMBL1331106 & 1301747 & 2.9408 & 4.1776 & TRN \\
\hline CHEMBL1714348 & 1301747 & 4.8592 & 5.1305 & TRN \\
\hline CHEMBL1331912 & 1301747 & 5.8225 & 5.6403 & TRN \\
\hline CHEMBL3190083 & 1301747 & 4.6253 & 4.9472 & TRN \\
\hline CHEMBL 3189714 & 1301747 & 5.9817 & 6.3786 & TRN \\
\hline CHEMBL1698877 & 1301747 & 5.2389 & 4.7402 & TRN \\
\hline CHEMBL1402879 & 1301747 & 4.5074 & 4.4677 & TST \\
\hline CHEMBL3144856 & 1301747 & 2.9406 & 4.1122 & TRN \\
\hline CHEMBL3194086 & 1301747 & 5.1316 & 4.9911 & TRN \\
\hline CHEMBL1359236 & 1301747 & 5.9722 & 5.38899 & 9999999999 \\
\hline CHEMBL1717890 & 1301747 & 4.9076 & 4.993 & TRN \\
\hline
\end{tabular}


Supplemental Table S2.txt

\begin{tabular}{|c|c|c|c|c|}
\hline CHEMBL1373577 & 1301747 & 4.9122 & 4.8105 & TRN \\
\hline CHEMBL1734083 & 1301747 & 6.4118 & 6.0916 & TRN \\
\hline CHEMBL1504710 & 1301747 & 5.0586 & 4.6328 & TRN \\
\hline CHEMBL1724452 & 1301747 & 5.3832 & 4.5005 & TRN \\
\hline CHEMBL1304979 & 1301747 & 2.9406 & 2.5267 & TRN \\
\hline CHEMBL1706454 & 1301747 & 5.2874 & 5.3191 & TRN \\
\hline CHEMBL1458448 & 1301747 & 4.1516 & 4.1291 & TST \\
\hline CHEMBL600175 & 1301747 & 4.8369 & 4.8737 & TRN \\
\hline CHEMBL1451931 & 1301747 & 4.8106 & 4.8523 & TRN \\
\hline CHEMBL1535375 & 1301747 & 4.9038 & 4.8348 & TRN \\
\hline CHEMBL1890961 & 1301747 & 5.0917 & 5.1187 & TRN \\
\hline CHEMBL1468658 & 1301747 & 4.6377 & 4.293 & TRN \\
\hline CHEMBL1163377 & 1301747 & 5.9686 & 6.0263 & TRN \\
\hline CHEMBL1383632 & 1301747 & 4.7464 & 4.845 & TRN \\
\hline CHEMBL1999630 & 1301747 & 6.2711 & 6.261 & TRN \\
\hline CHEMBL1969046 & 1301747 & 5.6273 & 5.8008 & TRN \\
\hline CHEMBL1469728 & 1301747 & 4.9457 & 4.3867 & TRN \\
\hline CHEMBL175434 & 1301747 & 4.9389 & 4.9566 & TRN \\
\hline CHEMBL1331211 & 1301747 & 4.9496 & 4.944 & TRN \\
\hline CHEMBL1438567 & 1301747 & 4.5773 & 4.3415 & TRN \\
\hline CHEMBL 3187033 & 1301747 & 4.9639 & 4.21399 & 99999999995 \\
\hline CHEMBL3192701 & 1301747 & 4.8982 & 4.5128 & TRN \\
\hline CHEMBL 2000196 & 1301747 & 4.1369 & 4.4435 & TRN \\
\hline CHEMBL1473955 & 1301747 & 4.6631 & 4.7321 & TRN \\
\hline CHEMBL1709354 & 1301747 & 4.6974 & 4.8948 & TRN \\
\hline CHEMBL1330787 & 1301747 & 2.9406 & 4.2317 & TRN \\
\hline CHEMBL1496231 & 1301747 & 4.6164 & 5.024 & TRN \\
\hline CHEMBL 299853 & 1301747 & 4.8084 & 4.8255 & TRN \\
\hline CHEMBL1384339 & 1301747 & 4.6218 & 4.5468 & TRN \\
\hline CHEMBL1485159 & 1301747 & 4.9154 & 4.6968 & TRN \\
\hline CHEMBL1326863 & 1301747 & 4.8464 & 4.4721 & TRN \\
\hline CHEMBL1311500 & 1301747 & 4.3956 & 4.0635 & TST \\
\hline CHEMBL1471498 & 1301747 & 5.3936 & 5.6331 & TRN \\
\hline CHEMBL3198994 & 1301747 & 4.4768 & 4.4873 & TRN \\
\hline CHEMBL1589737 & 1301747 & 5.2839 & 4.8537 & TRN \\
\hline CHEMBL1456440 & 1301747 & 4.9973 & 4.6023 & TRN \\
\hline CHEMBL1983033 & 1301747 & 4.7909 & 4.7984 & TST \\
\hline CHEMBL1384253 & 1301747 & 6.1789 & 5.808 & TRN \\
\hline CHEMBL1702473 & 1301747 & 5.3025 & 5.354 & TRN \\
\hline CHEMBL1701533 & 1301747 & 4.7902 & 5.0162 & TST \\
\hline CHEMBL2137294 & 1301747 & 4.8874 & 4.7525 & TRN \\
\hline CHEMBL1709883 & 1301747 & 5.2642 & 4.9945 & TST \\
\hline CHEMBL1698715 & 1301747 & 4.7234 & 4.784 & TRN \\
\hline CHEMBL1582771 & 1301747 & 4.6576 & 4.4994 & TRN \\
\hline CHEMBL1438627 & 1301747 & 4.6052 & 4.7361 & TRN \\
\hline CHEMBL1706438 & 1301747 & 4.5823 & 4.851 & TRN \\
\hline CHEMBL1403154 & 1301747 & 4.9156 & 4.8243 & TRN \\
\hline CHEMBL1468954 & 1301747 & 5.1772 & 5.0955 & TRN \\
\hline
\end{tabular}


Supplemental Table S2.txt

\begin{tabular}{|c|c|c|c|c|}
\hline CHEMBL1505544 & 1301747 & 5.8748 & 5.5727 & TRN \\
\hline CHEMBL1986381 & 1301747 & 4.5463 & 4.3659 & TRN \\
\hline CHEMBL1339245 & 1301747 & 4.8883 & 4.6703 & TRN \\
\hline CHEMBL1721855 & 1301747 & 5.2684 & 5.4131 & TRN \\
\hline CHEMBL1466516 & 1301747 & 5.8844 & 5.5992 & TRN \\
\hline CHEMBL1301243 & 1301747 & 5.2647 & 4.9282 & TRN \\
\hline CHEMBL1470701 & 1301747 & 4.9583 & 4.8413 & TRN \\
\hline CHEMBL1699398 & 1301747 & 4.5933 & 4.752 & TRN \\
\hline CHEMBL1324826 & 1301747 & 4.3653 & 4.5076 & TRN \\
\hline CHEMBL1727228 & 1301747 & 5.245 & 4.6031 & TRN \\
\hline CHEMBL1508357 & 1301747 & 4.2164 & 4.1317 & TST \\
\hline CHEMBL1541408 & 1301747 & 4.6073 & 4.4867 & TRN \\
\hline CHEMBL 3216654 & 1301747 & 5.3376 & 5.0802 & TRN \\
\hline CHEMBL1511226 & 1301747 & 4.6099 & 4.4472 & TST \\
\hline CHEMBL604321 & 1301747 & 3.8946 & 4.4648 & TRN \\
\hline CHEMBL1445776 & 1301747 & 5.2003 & 5.1073 & TRN \\
\hline CHEMBL1438078 & 1301747 & 4.5063 & 4.0555 & TRN \\
\hline CHEMBL1605599 & 1301747 & 4.6902 & 4.852 & TRN \\
\hline CHEMBL1335844 & 1301747 & 5.6662 & 5.5196 & TRN \\
\hline CHEMBL1329974 & 1301747 & 5.1186 & 5.0761 & TRN \\
\hline CHEMBL994 & 1301747 & 4.7589 & 4.3073 & TRN \\
\hline CHEMBL 2000633 & 1301747 & 4.5357 & 4.5738 & TRN \\
\hline CHEMBL1491417 & 1301747 & 4.0187 & 4.0559 & TRN \\
\hline CHEMBL1723968 & 1301747 & 5.3397 & 5.0456 & TRN \\
\hline CHEMBL590186 & 1301747 & 4.6391 & 4.724 & TRN \\
\hline CHEMBL1506756 & 1301747 & 4.5561 & 4.5953 & TRN \\
\hline CHEMBL1589837 & 1301747 & 4.9981 & 4.821000 & 0000000001 \\
\hline CHEMBL339561 & 1301747 & 5.6515 & 5.8226 & TRN \\
\hline CHEMBL1472773 & 1301747 & 4.9337 & 5.0335 & TRN \\
\hline CHEMBL 3197208 & 1301747 & 4.2575 & 4.4736 & TRN \\
\hline CHEMBL1415312 & 1301747 & 2.9406 & 4.1318 & TRN \\
\hline CHEMBL1527008 & 1301747 & 5.20200 & 000000000 & 5.0298 \\
\hline CHEMBL1438881 & 1301747 & 5.3772 & 4.4748 & TST \\
\hline CHEMBL1698802 & 1301747 & 5.364 & 5.3677 & TRN \\
\hline CHEMBL527336 & 1301747 & 4.694 & 4.9028 & TRN \\
\hline CHEMBL1389066 & 1301747 & 4.5565 & 4.1613 & TRN \\
\hline CHEMBL1578029 & 1301747 & 4.3917 & 4.5995 & TRN \\
\hline CHEMBL1395907 & 1301747 & 4.652 & 4.8045 & TRN \\
\hline CHEMBL1607263 & 1301747 & 4.6889 & 4.7997 & TRN \\
\hline CHEMBL1389315 & 1301747 & 2.9406 & 2.4319 & TRN \\
\hline CHEMBL1412077 & 1301747 & 4.4452 & 4.6017 & TRN \\
\hline CHEMBL 235504 & 1301747 & 4.9115 & 5.0638 & TST \\
\hline CHEMBL1729804 & 1301747 & 4.9239 & 5.0033 & TST \\
\hline CHEMBL1329140 & 1301747 & 4.8488 & 4.9577 & TST \\
\hline CHEMBL1448592 & 1301747 & 5.1511 & 4.2952 & TST \\
\hline CHEMBL1453503 & 1301747 & 5.8398 & 5.4688 & TST \\
\hline CHEMBL1709564 & 1301747 & 5.3633 & 4.3607 & TST \\
\hline CHEMBL1964407 & 1301747 & 5.3364 & 5.2494 & TST \\
\hline
\end{tabular}


Supplemental Table S2.txt

\begin{tabular}{|c|c|c|c|c|c|c|}
\hline CHEMBL1569238 & 1301747 & 4.4924 & 4.5033 & TST & & \\
\hline CHEMBL1555938 & 1301747 & 5.2919 & 4.5137 & TST & & \\
\hline CHEMBL1526855 & 1301747 & 4.8943 & 4.9828 & TST & & \\
\hline CHEMBL 2003651 & 1301747 & 5.9069 & 6.1574 & TST & & \\
\hline CHEMBL1361392 & 1301747 & 4.6895 & 4.6598 & TST & & \\
\hline CHEMBL1473428 & 1301747 & 4.5844 & 4.6238 & TST & & \\
\hline CHEMBL1430005 & 1301747 & 4.9715 & 4.6473 & TST & & \\
\hline CHEMBL1458444 & 1301747 & 4.5374 & 4.6098 & TST & & \\
\hline CHEMBL1570497 & 1301747 & 5.1571 & 4.7418 & TST & & \\
\hline CHEMBL1212972 & 1301747 & 4.8495 & 4.977 & TST & & \\
\hline CHEMBL1713097 & 1301747 & 2.9403 & 4.0148 & TST & & \\
\hline CHEMBL1376622 & 1301747 & 3.8951 & 4.5419 & TST & & \\
\hline CHEMBL1716155 & 1301747 & 5.4382 & 4.7318 & TST & & \\
\hline CHEMBL57013 & 1301747 & 5.5887 & 5.5872 & TST & & \\
\hline CHEMBL1482180 & 1301747 & 4.2691 & 2.9825 & TST & & \\
\hline CHEMBL1723945 & 1301747 & 4.9607 & 4.9158 & TST & & \\
\hline CHEMBL1542809 & 1301747 & 4.0222 & 4.2935 & TST & & \\
\hline CHEMBL1989853 & 1301747 & 4.9396 & 5.0694 & TST & & \\
\hline CHEMBL2141749 & 1301747 & 5.2703 & 5.0802 & TST & & \\
\hline CHEMBL1732365 & 1301747 & 5.0039 & 5.1738 & TST & & \\
\hline CHEMBL1700996 & 1301747 & 5.0292 & 5.0195 & TST & & \\
\hline CHEMBL1401717 & 688661 & 5.4 & 6.4498 & TST & & \\
\hline CHEMBL1591871 & 688661 & 7.2472 & 7.2358 & TRN & & \\
\hline CHEMBL1082457 & 688661 & 7.5969 & 7.4273 & TRN & & \\
\hline CHEMBL1088762 & 688661 & 7.0969 & 7.36799 & 999999999 & TRN & \\
\hline CHEMBL1083728 & 688661 & 6.9469 & 7.1026 & TRN & & \\
\hline CHEMBL1331234 & 688661 & 5.1 & 6.135 & TST & & \\
\hline CHEMBL1404208 & 688661 & 4.9 & 6.6934 & TST & & \\
\hline CHEMBL1089603 & 688661 & 7.1972 & 7.1332 & TRN & & \\
\hline CHEMBL1091055 & 688661 & \multicolumn{3}{|c|}{6.497000000000001} & 6.662999999999999 & TRN \\
\hline CHEMBL1085874 & 688661 & 7.4078 & 7.3574 & TRN & & \\
\hline CHEMBL1086565 & 688661 & 7.8477 & 7.5395 & TRN & & \\
\hline CHEMBL1308027 & 688661 & 5.3 & 5.3486 & TST & & \\
\hline CHEMBL1083475 & 688661 & \multicolumn{3}{|c|}{6.497000000000001} & 6.9422 TRN & \\
\hline CHEMBL1086538 & 688661 & 7.5969 & 7.2096 & TRN & & \\
\hline CHEMBL1086566 & 688661 & 7.7959 & 7.5058 & TRN & & \\
\hline CHEMBL1084058 & 688661 & 4.5971 & 5.7164 & TRN & & \\
\hline CHEMBL1093687 & 688661 & 6.8972 & 6.7533 & TRN & & \\
\hline CHEMBL1085873 & 688661 & 6.0 & 7.057 & TRN & & \\
\hline CHEMBL1085647 & 688661 & 8.1487 & 7.2584 & TRN & & \\
\hline CHEMBL1094007 & 688661 & 6.9469 & 6.2753 & TRN & & \\
\hline CHEMBL1435175 & 688661 & 7.6968 & 6.9404 & TRN & & \\
\hline CHEMBL1093688 & 688661 & 5.6971 & 6.6541 & TRN & & \\
\hline CHEMBL1083165 & 688661 & 7.1972 & 7.2357 & TRN & & \\
\hline CHEMBL1092121 & 688661 & 5.5971 & 5.1252 & TRN & & \\
\hline CHEMBL1089366 & 688661 & 7.2472 & 7.6592 & TRN & & \\
\hline CHEMBL1509101 & 688661 & 6.7867 & 5.3903 & TST & & \\
\hline CHEMBL1093092 & 688661 & 5.3971 & 5.3899 & TRN & & \\
\hline
\end{tabular}

Page 14399 


\begin{tabular}{|c|c|c|c|c|c|c|c|}
\hline \multicolumn{8}{|c|}{ splemental Ia } \\
\hline CHEMBL1084899 & 688661 & 8.1487 & 7.3377 & TRN & & & \\
\hline CHEMBL1091078 & 688661 & 7.7471 & 7.4881 & TRN & & & \\
\hline CHEMBL1323190 & 688661 & 5.3471 & 5.7806 & TRN & & & \\
\hline CHEMBL1086349 & 688661 & 7.8962 & 7.4791 & TRN & & & \\
\hline CHEMBL1092462 & 688661 & 7.1972 & 7.2146 & TRN & & & \\
\hline CHEMBL1085340 & 688661 & 4.7971 & 6.5596 & TRN & & & \\
\hline CHEMBL1085147 & 688661 & 6.9469 & 7.314 & TRN & & & \\
\hline CHEMBL1091501 & 688661 & 6.7471 & 6.6807 & TRN & & & \\
\hline CHEMBL1090776 & 688661 & 7.2472 & 7.0644 & TRN & & & \\
\hline CHEMBL1093996 & 688661 & 7.2472 & 6.7571 & TRN & & & \\
\hline CHEMBL1093049 & 688661 & 5.4471 & 5.1455 & TRN & & & \\
\hline CHEMBL1360157 & 688661 & 4.8471 & 6.142 & TRN & & & \\
\hline CHEMBL1599610 & 688661 & 4.9 & 5.9256 & TST & & & \\
\hline CHEMBL1083166 & 688661 & 6.99700 & 00000000 & $\partial 1$ & 7.13299 & 9999999999 & TRN \\
\hline CHEMBL1091457 & 688661 & 6.2471 & 6.6455 & TRN & & & \\
\hline CHEMBL1086320 & 688661 & 6.99700 & 00000000 & $\partial 1$ & 6.5969 & TRN & \\
\hline CHEMBL1091504 & 688661 & 7.2472 & 6.7887 & TRN & & & \\
\hline CHEMBL1090756 & 688661 & 7.0969 & 6.7066 & TRN & & & \\
\hline CHEMBL1093091 & 688661 & 5.6971 & 5.3899 & TRN & & & \\
\hline CHEMBL1083136 & 688661 & 4.6471 & 5.2924 & TRN & & & \\
\hline CHEMBL1082796 & 688661 & 6.1471 & 6.975 & TRN & & & \\
\hline CHEMBL1084625 & 688661 & 7.3969 & 7.3699 & TRN & & & \\
\hline CHEMBL1093369 & 688661 & 7.2967 & 6.9361 & TRN & & & \\
\hline CHEMBL1315562 & 688661 & 6.0971 & 5.8807 & TRN & & & \\
\hline CHEMBL1091795 & 688661 & 5.2971 & 5.2279 & TRN & & & \\
\hline CHEMBL1085215 & 688661 & 6.697 & 6.8165 & TRN & & & \\
\hline CHEMBL1524808 & 688661 & 7.1972 & 6.5363 & TRN & & & \\
\hline CHEMBL1089365 & 688661 & 4.1471 & 6.1845 & TRN & & & \\
\hline CHEMBL1089059 & 688661 & 7.0472 & 6.0535 & TRN & & & \\
\hline CHEMBL1560192 & 688661 & 4.8 & 5.8368 & TST & & & \\
\hline CHEMBL1089031 & 688661 & 5.0471 & 6.2327 & TRN & & & \\
\hline CHEMBL1090777 & 688661 & 7.4473 & 6.6367 & TRN & & & \\
\hline CHEMBL1092463 & 688661 & 6.2971 & 6.2765 & TRN & & & \\
\hline CHEMBL1352854 & 688661 & 6.2 & 6.7155 & TST & & & \\
\hline CHEMBL1085648 & 688661 & 7.5467 & 7.6276 & TRN & & & \\
\hline CHEMBL1084029 & 688661 & 7.3969 & 7.3288 & TRN & & & \\
\hline CHEMBL1091502 & 688661 & 6.8471 & 7.42299 & 9999999999 & & TRN & \\
\hline CHEMBL1083882 & 688661 & 7.3969 & 7.8299 & TRN & & & \\
\hline CHEMBL1086350 & 688661 & 4.7471 & 6.0773 & TRN & & & \\
\hline CHEMBL1089364 & 688661 & 6.697 & 6.0658 & TRN & & & \\
\hline CHEMBL1090753 & 688661 & 7.4976 & 6.9457 & TRN & & & \\
\hline CHEMBL1086539 & 688661 & 6.9469 & 7.3549 & TST & & & \\
\hline CHEMBL1092472 & 688661 & 4.7471 & 4.7032 & TRN & & & \\
\hline CHEMBL1082454 & 688661 & 6.647 & 6.6757 & TST & & & \\
\hline CHEMBL1091057 & 688661 & 6.1471 & 5.9538 & TRN & & & \\
\hline CHEMBL1091458 & 688661 & 4.6971 & 5.3091 & TRN & & & \\
\hline CHEMBL1091794 & 688661 & 5.5471 & 5.2102 & TRN & & & \\
\hline CHEMBL1488030 & 688661 & 4.6 & 5.7149 & TST & & & \\
\hline
\end{tabular}


Supplemental Table S2.txt

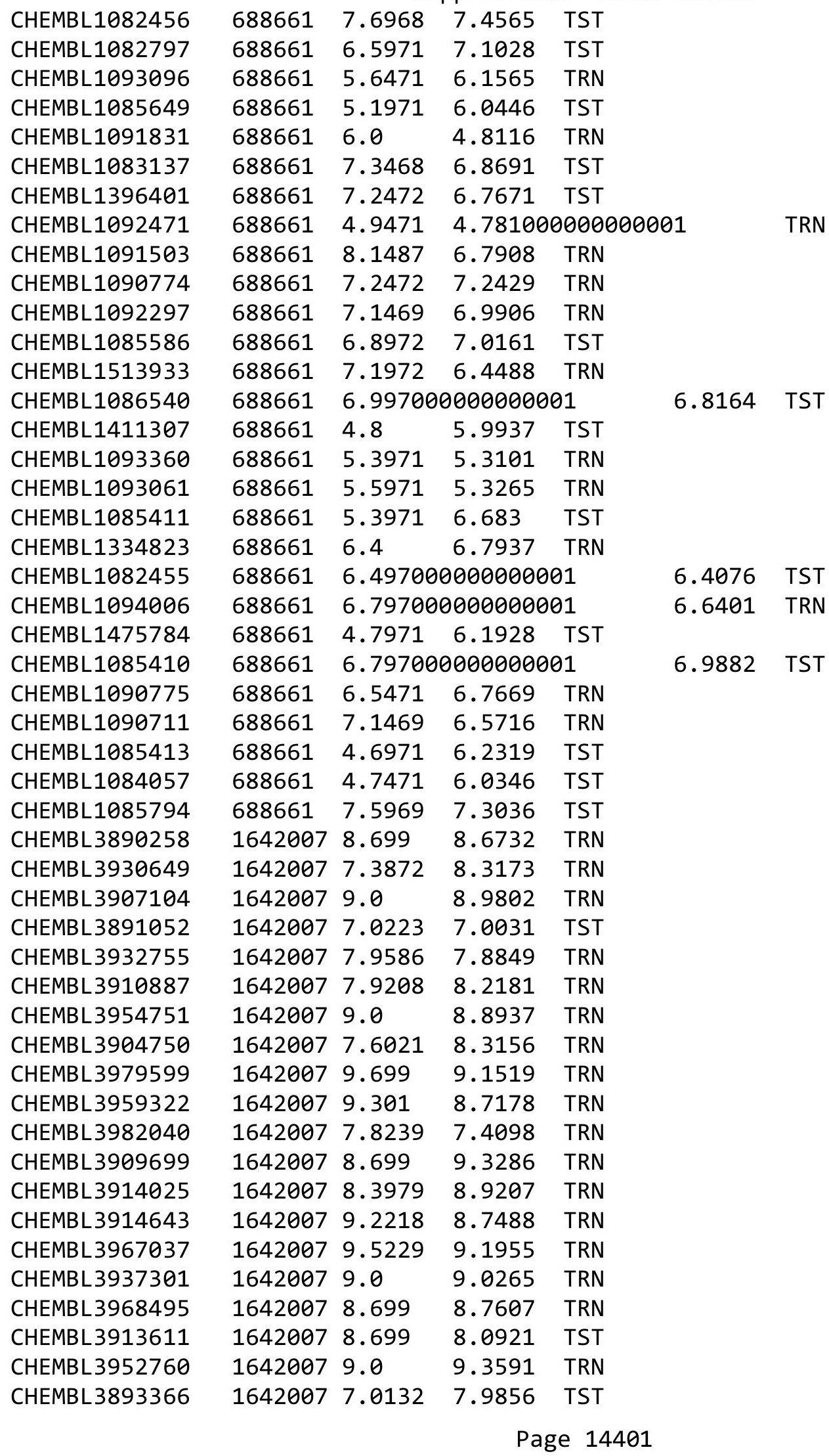




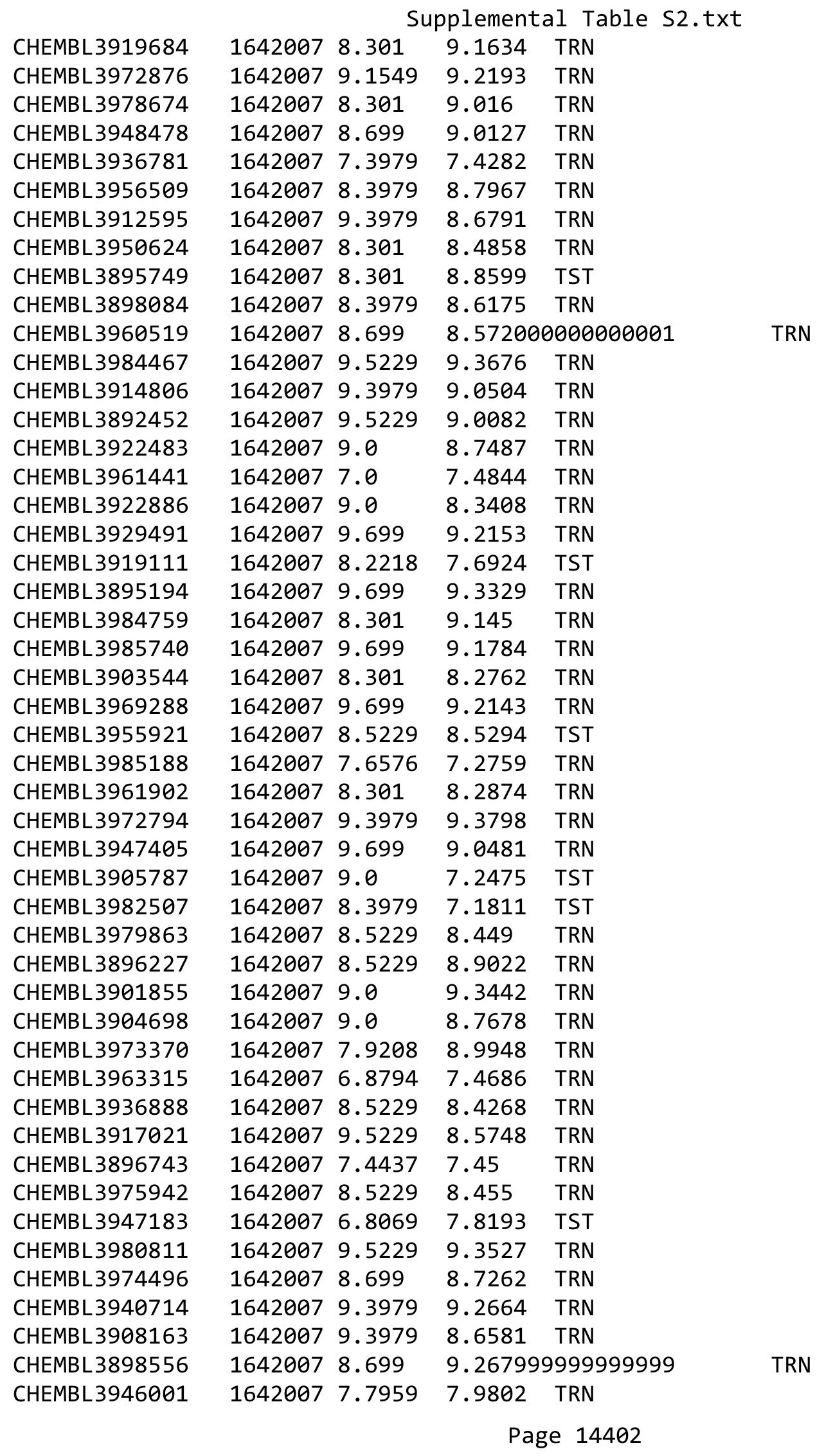


Supplemental Table S2.txt

\begin{tabular}{lllll} 
CHEMBL3896378 & 1642007 & 7.5229 & 7.4395 & TRN \\
CHEMBL3905176 & 1642007 & 9.0969 & 9.1471 & TST \\
CHEMBL3910322 & 1642007 & 7.7696 & 7.7125 & TST \\
CHEMBL3967455 & 1642007 & 9.699 & 8.63 & TST \\
CHEMBL3949490 & 1642007 & 9.3979 & 8.7991 & TST \\
CHEMBL3910737 & 1642007 & 9.3979 & 8.8276 & TST \\
CHEMBL3976670 & 1642007 & 9.3979 & 9.0514 & TST \\
CHEMBL3928013 & 1642007 & 8.5229 & 8.3953 & TST \\
CHEMBL3984124 & 1642007 & 8.301 & 8.708 & TST \\
CHEMBL3925216 & 1642007 & 9.1549 & 9.8326 & TST \\
CHEMBL3936115 & 1642007 & 9.0969 & 9.366 & TST \\
CHEMBL3905026 & 1642007 & 9.0 & 8.4525 & TST \\
CHEMBL3894468 & 1642007 & 8.0 & 8.0883 & TST \\
CHEMBL2058422 & 829594 & 4.5713 & 4.6374 & TRN \\
CHEMBL1170237 & 829594 & 5.5686 & 5.6736 & TRN \\
CHEMBL2058420 & 829594 & 5.5063 & 5.3069 & TRN \\
CHEMBL2058412 & 829594 & 5.3665 & 5.2435 & TRN \\
CHEMBL2058426 & 829594 & 5.2826 & 5.1337 & TRN \\
CHEMBL2058704 & 829594 & 5.699 & 5.404 & TRN \\
CHEMBL508657 & 829594 & 4.4707 & 4.3722 & TRN \\
CHEMBL541474 & 829594 & 4.6138 & 4.8689 & TRN \\
CHEMBL2058417 & 829594 & 5.574 & 5.5933 & TRN \\
CHEMBL2058413 & 829594 & 5.4202 & 5.3176 & TRN \\
CHEMBL2058414 & 829594 & 4.8457 & 5.0663 & TRN \\
CHEMBL2058151 & 829594 & 4.5477 & 4.4802 & TST \\
CHEMBL2058409 & 829594 & 4.4643 & 4.2547 & TRN \\
CHEMBL2058408 & 829594 & 4.4477 & 4.6668 & TRN \\
CHEMBL1173331 & 829594 & 4.6108 & 4.5176 & TRN \\
CHEMBL1173525 & 829594 & 4.3648 & 3.9403 & TRN \\
CHEMBL2058703 & 829594 & 5.1529 & 5.0843 & TST \\
CHEMBL2058428 & 829594 & 6.684 & 6.7337 & TRN \\
CHEMBL2058702 & 829594 & 5.2218 & 5.1669 & TRN \\
CHEMBL2058152 & 829594 & 4.9457 & 4.9421 & TRN \\
CHEMB2058429 & 829594 & 5.5502 & 5.7568 & TRN \\
CHEMBL2058153 & 829594 & 4.5963 & 4.5214 & TRN \\
CHEMBL2058705 & 829594 & 4.684 & 4.7588 & TRN \\
CHEMBEMLML2058407 & 829594 & 3.0 & 3.4074 & TRN \\
CHEMBL20586967 & 829594 & 4.585 & 5.4216 & TST \\
CHEMBL2058419 & 829594 & 5.9076 & 5.586 & TST \\
CHEMBL2058150 & 829594 & 4.291 & 4.2319 & TRN \\
CHEMB2058701 & 829594 & 4.4815 & 4.5951 & TRN \\
\hline & 829594 & 6.3468 & 5.643 & TST \\
\hline
\end{tabular}

Page 14403 


\begin{tabular}{|c|c|c|c|c|c|}
\hline & & & & & \\
\hline CHEMBL463249 & 829594 & 6.3497 & 6.2897 & TRN & \\
\hline CHEMBL2058700 & 829594 & 5.8486 & 5.3503 & TST & \\
\hline CHEMBL2058424 & 829594 & 4.5895 & 4.837 & TRN & \\
\hline CHEMBL 2058698 & 829594 & 5.4279 & 5.2024 & TST & \\
\hline CHEMBL2058425 & 829594 & 5.3706 & 5.1846 & TRN & \\
\hline CHEMBL2058699 & 829594 & 5.058 & 5.1131 & TST & \\
\hline CHEMBL2058695 & 829594 & 5.5906 & 5.4755 & TST & \\
\hline CHEMBL2058154 & 829594 & 4.556 & 4.8638 & TST & \\
\hline CHEMBL 2058696 & 829594 & 5.5906 & 4.9623 & TST & \\
\hline CHEMBL2058410 & 829594 & 4.4643 & 4.6044 & TRN & \\
\hline CHEMBL404232 & 829594 & 4.9993 & 4.9425 & TRN & \\
\hline CHEMBL2058423 & 829594 & 4.7755 & 4.6492 & TRN & \\
\hline CHEMBL2058415 & 829594 & 4.5795 & 4.4177 & TRN & \\
\hline CHEMBL 2058411 & 829594 & 4.4318 & 4.4638 & TRN & \\
\hline CHEMBL2058416 & 829594 & 4.9343 & 5.2019 & TRN & \\
\hline CHEMBL1563898 & 1495391 & 3.0152 & 4.0206 & TRN & \\
\hline CHEMBL3560853 & 1495391 & 3.0152 & 2.9478 & TRN & \\
\hline CHEMBL3560907 & 1495391 & 3.0152 & 2.9291 & TRN & \\
\hline CHEMBL1736648 & 1495391 & 4.909 & 4.8767 & TRN & \\
\hline CHEMBL1325945 & 1495391 & 6.3061 & 4.4924 & TST & \\
\hline CHEMBL3560422 & 1495391 & 3.0152 & 3.0499 & TRN & \\
\hline CHEMBL3561241 & 1495391 & 3.0152 & 2.9732 & TRN & \\
\hline CHEMBL3561543 & 1495391 & 3.0152 & 2.7284 & TRN & \\
\hline CHEMBL1313485 & 1495391 & 3.0152 & 2.9989 & TRN & \\
\hline CHEMBL1504738 & 1495391 & 4.7463 & 4.7867 & TRN & \\
\hline CHEMBL3560220 & 1495391 & 3.0152 & 2.9708 & TRN & \\
\hline CHEMBL1381017 & 1495391 & 4.1966 & 4.3441 & TST & \\
\hline CHEMBL3561794 & 1495391 & 3.0152 & 2.924 & TRN & \\
\hline CHEMBL1324517 & 1495391 & 3.0152 & 2.9959 & TRN & \\
\hline CHEMBL3560044 & 1495391 & 3.0152 & 2.9796 & TST & \\
\hline CHEMBL522983 & 1495391 & 4.2892 & 3.8585 & TRN & \\
\hline CHEMBL1412999 & 1495391 & 3.0152 & 3.2104 & TRN & \\
\hline CHEMBL3561922 & 1495391 & 5.3873 & 3.8789 & TST & \\
\hline CHEMBL1464200 & 1495391 & 5.302006 & 000000006 & 4.78 & TRN \\
\hline CHEMBL3561372 & 1495391 & 3.0152 & 2.8412 & TRN & \\
\hline CHEMBL3561808 & 1495391 & 3.0152 & 2.98100 & 00000000003 & TRN \\
\hline CHEMBL1560833 & 1495391 & 4.6396 & 4.1432 & TRN & \\
\hline CHEMBL1401488 & 1495391 & 3.0152 & 3.3731 & TRN & \\
\hline CHEMBL1426865 & 1495391 & 4.6409 & 4.1336 & TRN & \\
\hline CHEMBL3561736 & 1495391 & 3.0152 & 3.0715 & TRN & \\
\hline CHEMBL1480043 & 1495391 & 4.2951 & 2.9102 & TST & \\
\hline CHEMBL1424607 & 1495391 & 3.0152 & 3.0406 & TRN & \\
\hline CHEMBL1613004 & 1495391 & 3.0152 & 3.072 & TRN & \\
\hline CHEMBL1581216 & 1495391 & 4.2102 & 3.9761 & TRN & \\
\hline CHEMBL1500850 & 1495391 & 4.1084 & 4.2138 & TRN & \\
\hline CHEMBL1869220 & 1495391 & 3.0152 & 2.9544 & TRN & \\
\hline CHEMBL3561562 & 1495391 & 3.0152 & 3.0957 & TRN & \\
\hline CHEMBL3560433 & 1495391 & 3.0152 & 3.2065 & TRN & \\
\hline
\end{tabular}




\begin{tabular}{|c|c|c|c|c|c|}
\hline \multirow[b]{2}{*}{ CHEMBL71466 } & \multicolumn{5}{|c|}{ Supplemental Table S2.txt } \\
\hline & 1495391 & 4.5484 & 4.9323 & TRN & \\
\hline CHEMBL1420037 & 1495391 & 3.0152 & 3.63199 & 99999999997 & TST \\
\hline CHEMBL1531443 & 1495391 & 4.706 & 4.1211 & TST & \\
\hline CHEMBL1315463 & 1495391 & 3.0152 & 2.9191 & TRN & \\
\hline CHEMBL1429070 & 1495391 & 5.5592 & 4.275 & TST & \\
\hline CHEMBL3561204 & 1495391 & 3.0152 & 3.0864 & TRN & \\
\hline CHEMBL 3560774 & 1495391 & 3.0152 & 3.0734 & TRN & \\
\hline CHEMBL1361023 & 1495391 & 4.1953 & 3.9316 & TRN & \\
\hline CHEMBL1369478 & 1495391 & 4.4456 & 4.3992 & TRN & \\
\hline CHEMBL1470135 & 1495391 & 4.9856 & 4.7924 & TRN & \\
\hline CHEMBL3196993 & 1495391 & 3.0152 & 2.7023 & TRN & \\
\hline CHEMBL 3559781 & 1495391 & 3.0152 & 3.092 & TRN & \\
\hline CHEMBL3559960 & 1495391 & 3.0152 & 3.1031 & TRN & \\
\hline CHEMBL1493100 & 1495391 & 3.0152 & 3.7537 & TRN & \\
\hline CHEMBL1474387 & 1495391 & 3.0152 & 3.157 & TST & \\
\hline CHEMBL3191780 & 1495391 & 3.0152 & 2.9116 & TRN & \\
\hline CHEMBL3560270 & 1495391 & 3.0152 & 2.93300 & 00000000003 & TRN \\
\hline CHEMBL1335685 & 1495391 & 3.0152 & 3.2495 & TRN & \\
\hline CHEMBL3560451 & 1495391 & 3.0152 & 2.9795 & TRN & \\
\hline CHEMBL3560741 & 1495391 & 3.0152 & 3.3914 & TRN & \\
\hline CHEMBL1438480 & 1495391 & 3.0152 & 2.9209 & TRN & \\
\hline CHEMBL3196591 & 1495391 & 3.0152 & 3.0682 & TRN & \\
\hline CHEMBL3561494 & 1495391 & 3.0152 & 2.8107 & TRN & \\
\hline CHEMBL1873535 & 1495391 & 3.0152 & 3.11800 & 00000000003 & TRN \\
\hline CHEMBL3559950 & 1495391 & 3.0152 & 3.0307 & TRN & \\
\hline CHEMBL1491374 & 1495391 & 3.0152 & 3.0639 & TRN & \\
\hline CHEMBL3559993 & 1495391 & 3.0152 & 3.23199 & 99999999998 & TRN \\
\hline CHEMBL3561759 & 1495391 & 3.0152 & 2.8543 & TRN & \\
\hline CHEMBL1722358 & 1495391 & 3.0152 & 3.5592 & TRN & \\
\hline CHEMBL3560071 & 1495391 & 3.0152 & 3.2104 & TRN & \\
\hline CHEMBL3561273 & 1495391 & 3.0152 & 2.9961 & TRN & \\
\hline CHEMBL1501990 & 1495391 & 4.864 & 5.2465 & TRN & \\
\hline CHEMBL1978925 & 1495391 & 4.3872 & 3.8363 & TST & \\
\hline CHEMBL3559954 & 1495391 & 3.0152 & 2.9255 & TRN & \\
\hline CHEMBL1409603 & 1495391 & 4.5468 & 4.1576 & TRN & \\
\hline CHEMBL1417815 & 1495391 & 4.8212 & 4.7404 & TRN & \\
\hline CHEMBL1729269 & 1495391 & 3.0152 & 3.2216 & TRN & \\
\hline CHEMBL316034 & 1495391 & 3.0152 & 4.3537 & TRN & \\
\hline CHEMBL 3186243 & 1495391 & 3.0152 & 2.99899 & 99999999997 & TRN \\
\hline CHEMBL3561513 & 1495391 & 3.0152 & 3.1485 & TRN & \\
\hline CHEMBL3560784 & 1495391 & 3.0152 & 3.0803 & TRN & \\
\hline CHEMBL 172350 & 1495391 & 3.0152 & 3.3053 & TRN & \\
\hline CHEMBL1404277 & 1495391 & 4.1024 & 4.127 & TST & \\
\hline CHEMBL1530899 & 1495391 & 3.0152 & 3.1654 & TRN & \\
\hline CHEMBL1479759 & 1495391 & 4.468 & 3.7355 & TST & \\
\hline CHEMBL3560717 & 1495391 & 3.0152 & 3.1396 & TRN & \\
\hline CHEMBL1489131 & 1495391 & 3.0152 & 2.9257 & TRN & \\
\hline CHEMBL1314408 & 1495391 & 3.0152 & 3.0983 & TRN & \\
\hline
\end{tabular}


Supplemental Table S2.txt

\begin{tabular}{|c|c|c|c|c|}
\hline CHEMBL3560519 & 1495391 & 3.0152 & 2.9384 & TRN \\
\hline CHEMBL3561222 & 1495391 & 4.3727 & 4.288 & TRN \\
\hline CHEMBL1384387 & 1495391 & 3.0152 & 3.85600 & 30000000003 \\
\hline CHEMBL1493010 & 1495391 & 4.4492 & 3.26899 & 99999999997 \\
\hline CHEMBL 3561215 & 1495391 & 3.0152 & 3.1681 & TRN \\
\hline CHEMBL1436443 & 1495391 & 3.0152 & 3.2476 & TRN \\
\hline CHEMBL1313554 & 1495391 & 4.5572 & 4.5022 & TRN \\
\hline CHEMBL1371194 & 1495391 & 3.0152 & 3.055 & TRN \\
\hline CHEMBL 3561017 & 1495391 & 3.0152 & 2.9352 & TRN \\
\hline CHEMBL235504 & 1495391 & 5.4547 & 5.2162 & TRN \\
\hline CHEMBL1437516 & 1495391 & 3.0152 & 2.8544 & TRN \\
\hline CHEMBL 3560058 & 1495391 & 3.0152 & 3.1622 & TRN \\
\hline CHEMBL601757 & 1495391 & 6.3864 & 4.7772 & TST \\
\hline CHEMBL 3560475 & 1495391 & 3.0152 & 2.8516 & TRN \\
\hline CHEMBL3561341 & 1495391 & 3.0152 & 2.8433 & TRN \\
\hline CHEMBL3561748 & 1495391 & 3.0152 & 2.8353 & TRN \\
\hline CHEMBL1368302 & 1495391 & 4.6747 & 4.4652 & TRN \\
\hline CHEMBL1365833 & 1495391 & 4.8315 & 4.115 & TRN \\
\hline CHEMBL1602055 & 1495391 & 4.5111 & 4.7747 & TRN \\
\hline CHEMBL1403664 & 1495391 & 4.7936 & 4.0937 & TRN \\
\hline CHEMBL3195177 & 1495391 & 3.0152 & 2.7917 & TRN \\
\hline CHEMBL1981657 & 1495391 & 4.673 & 3.9857 & TRN \\
\hline CHEMBL1557323 & 1495391 & 3.0152 & 3.1175 & TRN \\
\hline CHEMBL1532828 & 1495391 & 3.0152 & 2.8544 & TRN \\
\hline CHEMBL 3560315 & 1495391 & 3.0152 & 3.1971 & TRN \\
\hline CHEMBL1568356 & 1495391 & 4.6938 & 3.8802 & TST \\
\hline CHEMBL1594766 & 1495391 & 3.0152 & 3.0372 & TST \\
\hline CHEMBL1896928 & 1495391 & 3.0152 & 2.9729 & TRN \\
\hline CHEMBL1892749 & 1495391 & 3.0152 & 3.0355 & TRN \\
\hline CHEMBL3561782 & 1495391 & 3.0152 & 2.9539 & TRN \\
\hline CHEMBL1463829 & 1495391 & 4.6623 & 4.2952 & TRN \\
\hline CHEMBL1578027 & 1495391 & 3.0152 & 3.5521 & TRN \\
\hline CHEMBL 3560570 & 1495391 & 4.7051 & 4.0277 & TST \\
\hline CHEMBL3561454 & 1495391 & 3.0152 & 2.9463 & TST \\
\hline CHEMBL 3560487 & 1495391 & 3.0152 & 3.2681 & TST \\
\hline CHEMBL3560882 & 1495391 & 3.0152 & 2.9089 & TST \\
\hline CHEMBL3560099 & 1495391 & 3.0152 & 2.8215 & TST \\
\hline CHEMBL1467971 & 1495391 & 3.0152 & 3.1599 & TST \\
\hline CHEMBL 3560645 & 1495391 & 3.0152 & 2.7057 & TST \\
\hline CHEMBL 3559885 & 1495391 & 3.0152 & 3.0387 & TST \\
\hline CHEMBL3560498 & 1495391 & 3.0152 & 3.0791 & TST \\
\hline CHEMBL1308845 & 1495391 & 3.0152 & 3.0698 & TST \\
\hline CHEMBL 3560495 & 1495391 & 3.0152 & 2.8149 & TST \\
\hline CHEMBL1499873 & 1495391 & 3.0152 & 3.216 & TST \\
\hline CHEMBL3559908 & 1495391 & 3.0152 & 3.0343 & TST \\
\hline CHEMBL1382439 & 1495391 & 3.0152 & 3.2084 & TST \\
\hline CHEMBL1489074 & 1495391 & 4.3366 & 4.5401 & TST \\
\hline CHEMBL586157 & 751786 & 6.6576 & 7.2571 & TRN \\
\hline
\end{tabular}




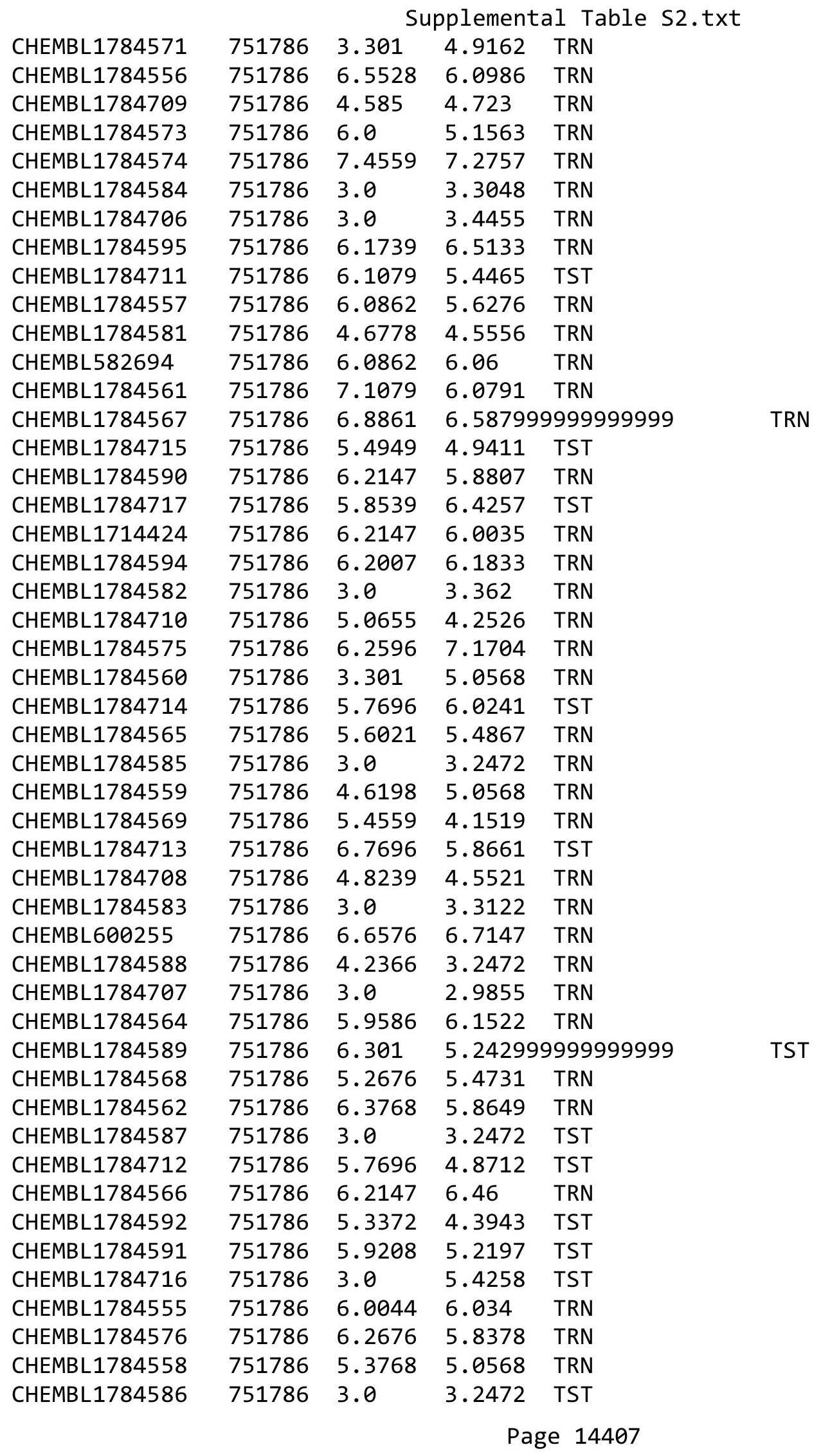




\begin{tabular}{|c|c|c|c|c|}
\hline & & & & \\
\hline CHEMBL1784577 & 751786 & 6.7212 & 6.2459 & TRN \\
\hline CHEMBL1784593 & 751786 & 6.2676 & 5.5258 & TST \\
\hline CHEMBL1784572 & 751786 & 4.3565 & 4.6389 & TRN \\
\hline CHEMBL1784596 & 751786 & 3.0 & 4.4894 & TST \\
\hline CHEMBL1784579 & 751786 & 5.7959 & 5.5751 & TRN \\
\hline CHEMBL1784563 & 751786 & 6.0969 & 6.3925 & TRN \\
\hline CHEMBL1784570 & 751786 & 3.0 & 3.3596 & TRN \\
\hline CHEMBL1529387 & 751786 & 3.0 & 3.2069 & TRN \\
\hline CHEMBL1784578 & 751786 & 7.1938 & 7.2908 & TRN \\
\hline CHEMBL1784580 & 751786 & 7.0458 & 7.0694 & TST \\
\hline CHEMBL100483 & 69840 & 6.8539 & 7.0582 & TRN \\
\hline CHEMBL294191 & 69840 & 7.3979 & 7.7047 & TRN \\
\hline CHEMBL298771 & 69840 & 6.3768 & 6.4412 & TRN \\
\hline CHEMBL301065 & 69840 & 7.8239 & 7.4308 & TRN \\
\hline CHEMBL55352 & 69840 & 6.0458 & 6.2921 & TRN \\
\hline CHEMBL55837 & 69840 & 6.2076 & 6.1993 & TRN \\
\hline CHEMBL434024 & 69840 & 7.8539 & 8.0306 & TRN \\
\hline CHEMBL301244 & 69840 & 7.5229 & 7.4544 & TRN \\
\hline CHEMBL54004 & 69840 & 6.6383 & 6.1993 & TRN \\
\hline CHEMBL55959 & 69840 & 6.9208 & 7.0334 & TRN \\
\hline CHEMBL280463 & 69840 & 6.0362 & 6.4786 & TRN \\
\hline CHEMBL55856 & 69840 & 7.3279 & 7.0045 & TRN \\
\hline CHEMBL316844 & 69840 & 7.3665 & 7.3923 & TRN \\
\hline CHEMBL 292224 & 69840 & 5.4089 & 6.6912 & TST \\
\hline CHEMBL431735 & 69840 & 6.0 & 6.8433 & TRN \\
\hline CHEMBL56255 & 69840 & 7.4815 & 7.1245 & TRN \\
\hline CHEMBL55886 & 69840 & 6.8861 & 6.8839 & TRN \\
\hline CHEMBL299717 & 69840 & 6.7959 & 6.9603 & TRN \\
\hline CHEMBL291727 & 69840 & 7.3872 & 7.3483 & TRN \\
\hline CHEMBL298547 & 69840 & 5.7212 & 6.1993 & TRN \\
\hline CHEMBL 294478 & 69840 & 7.1249 & 7.0804 & TRN \\
\hline CHEMBL55464 & 69840 & 7.6198 & 7.1402 & TRN \\
\hline CHEMBL55608 & 69840 & 7.699 & 7.1934 & TRN \\
\hline CHEMBL58830 & 69840 & 7.284 & 6.9349 & TST \\
\hline CHEMBL149321 & 69840 & 5.3872 & 7.0783 & TST \\
\hline CHEMBL54480 & 69840 & 6.9586 & 6.8652 & TRN \\
\hline CHEMBL299563 & 69840 & 5.1367 & 6.2779 & TST \\
\hline CHEMBL291736 & 69840 & 7.699 & 7.7235 & TRN \\
\hline CHEMBL417549 & 69840 & 7.0655 & 6.9683 & TRN \\
\hline CHEMBL54344 & 69840 & 5.7696 & 5.7276 & TRN \\
\hline CHEMBL55557 & 69840 & 7.7696 & 7.4861 & TRN \\
\hline CHEMBL54472 & 69840 & 7.3098 & 6.7192 & TST \\
\hline CHEMBL55572 & 69840 & 6.1938 & 6.1993 & TRN \\
\hline CHEMBL56011 & 69840 & 7.4685 & 7.0839 & TRN \\
\hline CHEMBL55140 & 69840 & 7.9586 & 8.0246 & TRN \\
\hline CHEMBL54714 & 69840 & 7.6383 & 7.365 & TRN \\
\hline CHEMBL54747 & 69840 & 6.1871 & 6.4643 & TRN \\
\hline CHEMBL294192 & 69840 & 7.7959 & 7.7036 & TST \\
\hline
\end{tabular}

Page 14408 


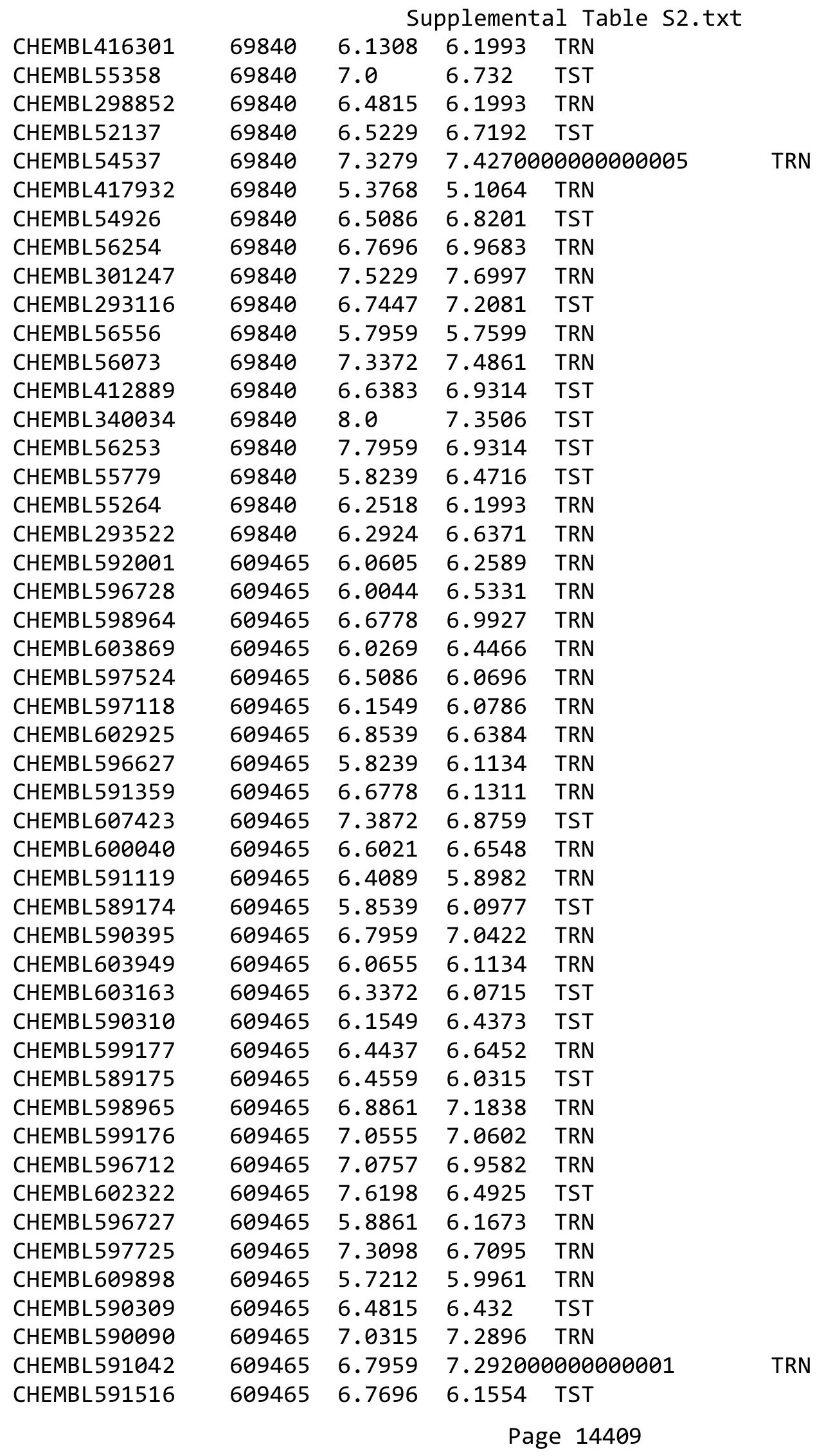




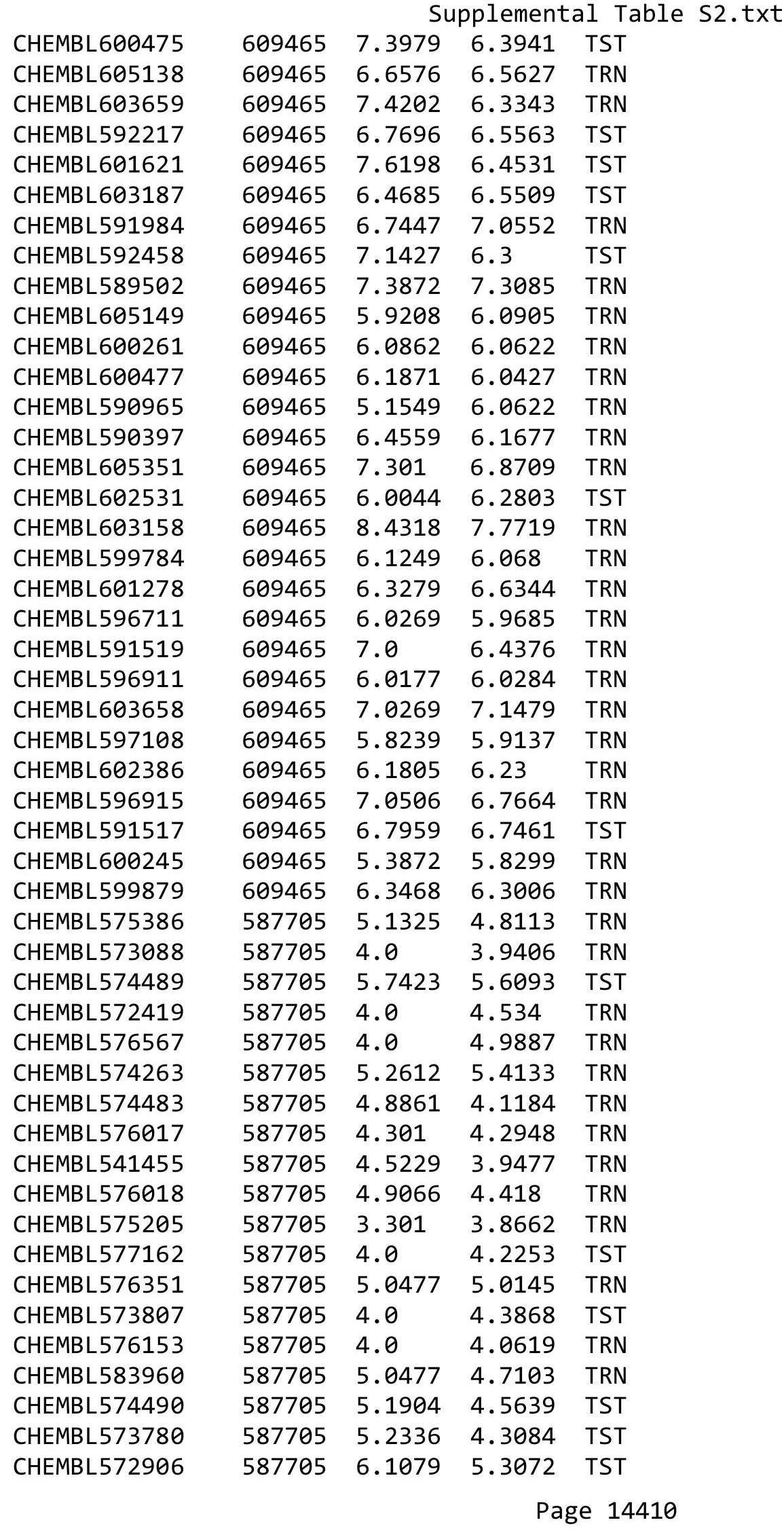




\begin{tabular}{|c|c|c|c|c|}
\hline \multicolumn{5}{|c|}{ Supplemental Table S2.txt } \\
\hline CHEMBL573360 & 587705 & 5.064 & 4.7247 & TRN \\
\hline CHEMBL575605 & 587705 & 3.301 & 3.6222 & TRN \\
\hline CHEMBL578008 & 587705 & 4.9842 & 4.2648 & TRN \\
\hline CHEMBL573594 & 587705 & 3.301 & 4.1292 & TRN \\
\hline CHEMBL574775 & 587705 & 6.3089 & 5.0425 & TST \\
\hline CHEMBL572601 & 587705 & 6.0429 & 5.8505 & TRN \\
\hline CHEMBL575204 & 587705 & 4.0 & 3.9348 & TRN \\
\hline CHEMBL574323 & 587705 & 4.0 & 3.625 & TRN \\
\hline CHEMBL574484 & 587705 & 3.301 & 3.6953 & TRN \\
\hline CHEMBL578224 & 587705 & 6.4401 & 4.2927 & TST \\
\hline CHEMBL572653 & 587705 & 3.301 & 4.0219 & TRN \\
\hline CHEMBL576369 & 587705 & 4.8633 & 4.5278 & TRN \\
\hline CHEMBL575825 & 587705 & 4.0 & 3.6545 & TRN \\
\hline CHEMBL578005 & 587705 & 5.2958 & 5.4924 & TRN \\
\hline CHEMBL572386 & 587705 & 5.041 & 4.7588 & TRN \\
\hline CHEMBL577588 & 587705 & 4.0 & 4.9786 & TST \\
\hline CHEMBL572654 & 587705 & 3.301 & 4.0617 & TRN \\
\hline CHEMBL577135 & 587705 & 5.27 & 4.6033 & TRN \\
\hline CHEMBL575855 & 587705 & 4.0 & 4.1338 & TST \\
\hline CHEMBL576185 & 587705 & 5.857 & 6.13 & TRN \\
\hline CHEMBL573327 & 587705 & 5.9136 & 5.7326 & TRN \\
\hline CHEMBL575604 & 587705 & 4.0 & 4.0463 & TRN \\
\hline CHEMBL575198 & 587705 & 5.0283 & 5.0523 & TRN \\
\hline CHEMBL575197 & 587705 & 4.0 & 4.3873 & TRN \\
\hline CHEMBL573593 & 587705 & 4.0 & 4.3662 & TRN \\
\hline CHEMBL573089 & 587705 & 5.8416 & 5.8859 & TRN \\
\hline CHEMBL573771 & 587705 & 4.9547 & 3.9399 & TRN \\
\hline CHEMBL335950 & 587705 & 3.0 & 3.3813 & TRN \\
\hline CHEMBL576538 & 587705 & 4.0 & 4.06 & TRN \\
\hline CHEMBL573779 & 587705 & 4.8239 & 4.891 & TST \\
\hline CHEMBL572602 & 587705 & 3.0 & 3.6048 & TST \\
\hline CHEMBL578649 & 587705 & 4.0 & 4.1003 & TST \\
\hline CHEMBL606159 & 817939 & 6.0246 & 5.9282 & TRN \\
\hline CHEMBL319952 & 817939 & 6.7399 & 6.4394 & TRN \\
\hline CHEMBL584240 & 817939 & 6.6861 & 6.9605 & TRN \\
\hline CHEMBL494669 & 817939 & 6.2449 & 6.0607 & TRN \\
\hline CHEMBL580381 & 817939 & 5.9508 & 6.3279 & TST \\
\hline CHEMBL532597 & 817939 & 6.2351 & 6.2161 & TST \\
\hline CHEMBL530308 & 817939 & 6.1403 & 6.1932 & TST \\
\hline CHEMBL591362 & 817939 & 5.8013 & 5.8762 & TRN \\
\hline CHEMBL470514 & 817939 & 7.0851 & 6.6599 & TRN \\
\hline CHEMBL106525 & 817939 & 6.3125 & 6.0076 & TRN \\
\hline CHEMBL525692 & 817939 & 5.9318 & 6.5002 & TRN \\
\hline CHEMBL601534 & 817939 & 5.9245 & 6.561 & TST \\
\hline CHEMBL590201 & 817939 & 6.1864 & 6.7232 & TRN \\
\hline CHEMBL548334 & 817939 & 6.2993 & 6.2487 & TST \\
\hline CHEMBL583682 & 817939 & 6.1518 & 6.3077 & TRN \\
\hline CHEMBL591637 & 817939 & 6.2503 & 6.0907 & TRN \\
\hline
\end{tabular}




\begin{tabular}{|c|c|c|c|c|c|}
\hline & & & & & \\
\hline CHEMBL533017 & 817939 & 6.71 & 6.4908 & TST & \\
\hline CHEMBL530438 & 817939 & 6.8447 & 6.9786 & TRN & \\
\hline CHEMBL577014 & 817939 & 6.284 & 6.6862 & TRN & \\
\hline CHEMBL591393 & 817939 & 5.6716 & 5.7626 & TRN & \\
\hline CHEMBL598881 & 817939 & 5.9706 & 6.0644 & TRN & \\
\hline CHEMBL589205 & 817939 & 6.7747 & 6.8356 & TRN & \\
\hline CHEMBL537087 & 817939 & 6.2403 & 6.3278 & TRN & \\
\hline CHEMBL591128 & 817939 & 6.0491 & 6.7273 & TRN & \\
\hline CHEMBL600305 & 817939 & 6.6498 & 6.5465 & TRN & \\
\hline CHEMBL588481 & 817939 & 6.5258 & 6.192 & TRN & \\
\hline CHEMBL587022 & 817939 & 8.1675 & 7.1896 & TRN & \\
\hline CHEMBL535514 & 817939 & 6.4634 & 6.2353 & TRN & \\
\hline CHEMBL584841 & 817939 & 6.2798 & 6.2243 & TRN & \\
\hline CHEMBL586033 & 817939 & 5.9706 & 6.0229 & TRN & \\
\hline CHEMBL338094 & 817939 & 6.098 & 6.4186 & TST & \\
\hline CHEMBL608855 & 817939 & 6.0841 & 6.2688 & TST & \\
\hline CHEMBL546799 & 817939 & 6.0325 & 5.8391 & TRN & \\
\hline CHEMBL548469 & 817939 & 5.82100 & 000000000 & 6.0597 & TRN \\
\hline CHEMBL529919 & 817939 & 6.3778 & 6.012000 & 00000000005 & TRN \\
\hline CHEMBL605751 & 817939 & 7.3188 & 6.4142 & TRN & \\
\hline CHEMBL601378 & 817939 & 6.0173 & 6.501 & TST & \\
\hline CHEMBL528245 & 817939 & 6.0061 & 6.0002 & TRN & \\
\hline CHEMBL602580 & 817939 & 6.0 & 6.2699 & TST & \\
\hline CHEMBL585839 & 817939 & 5.8962 & 6.7458 & TRN & \\
\hline CHEMBL600444 & 817939 & 6.0462 & 6.6504 & TRN & \\
\hline CHEMBL585243 & 817939 & 6.9957 & 6.8679 & TRN & \\
\hline CHEMBL602946 & 817939 & 5.9469 & 5.4988 & TRN & \\
\hline CHEMBL534283 & 817939 & 6.1518 & 5.9831 & TST & \\
\hline CHEMBL596852 & 817939 & 6.1124 & 5.9333 & TRN & \\
\hline CHEMBL601814 & 817939 & 5.9706 & 6.0284 & TRN & \\
\hline CHEMBL582495 & 817939 & 6.3279 & 6.4096 & TRN & \\
\hline CHEMBL600706 & 817939 & 6.295 & 6.468 & TRN & \\
\hline CHEMBL533563 & 817939 & 6.5406 & 6.3106 & TST & \\
\hline CHEMBL579315 & 817939 & 6.0835 & 6.3723 & TRN & \\
\hline CHEMBL601580 & 817939 & 5.7144 & 6.3831 & TST & \\
\hline CHEMBL586344 & 817939 & 7.0931 & 6.8095 & TRN & \\
\hline CHEMBL600030 & 817939 & 6.1029 & 6.4804 & TRN & \\
\hline CHEMBL525519 & 817939 & 6.426 & 6.451000 & 00000000005 & TRN \\
\hline CHEMBL601566 & 817939 & 6.8268 & 6.7938 & TRN & \\
\hline CHEMBL261693 & 817939 & 6.7825 & 6.7686 & TST & \\
\hline CHEMBL599886 & 817939 & 6.1656 & 6.4317 & TST & \\
\hline CHEMBL599885 & 817939 & 6.5834 & 6.8773 & TRN & \\
\hline CHEMBL589946 & 817939 & 6.341 & 6.383999 & 99999999995 & IRIV \\
\hline CHEMBL577011 & 817939 & 5.9469 & 6.421 & TRN & \\
\hline CHEMBL548209 & 817939 & 5.8894 & 6.2601 & TRN & \\
\hline CHEMBL601771 & 817939 & 7.5591 & 6.8162 & TRN & \\
\hline CHEMBL585622 & 817939 & 6.1752 & 6.3697 & TRN & \\
\hline CHEMBL124006 & 817939 & 5.8069 & 5.824 & TRN & \\
\hline
\end{tabular}




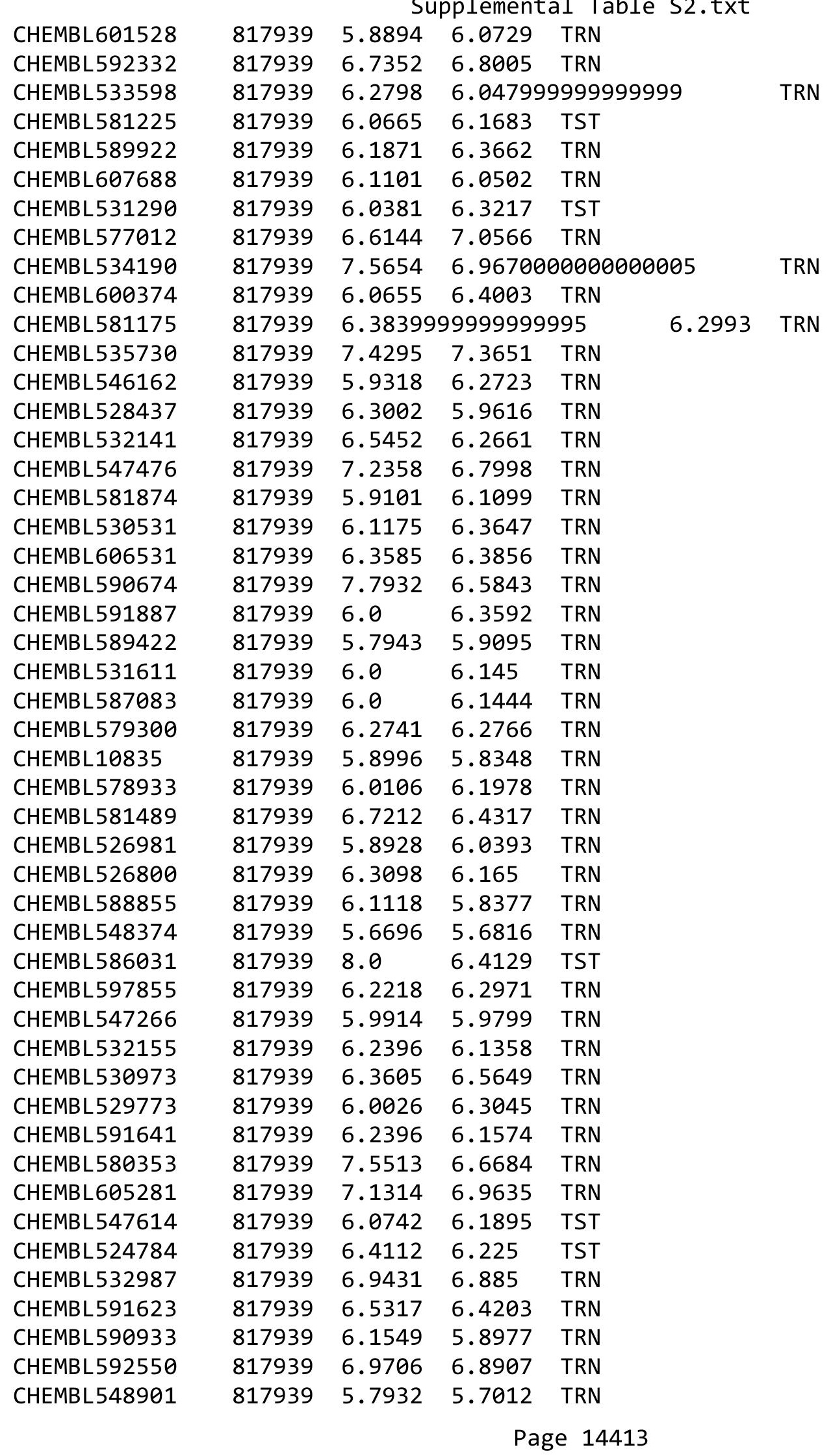


Supplemental Table S2.txt

\begin{tabular}{|c|c|c|c|c|}
\hline CHEMBL534288 & 817939 & 6.6925 & 6.6312 & TRN \\
\hline CHEMBL584655 & 817939 & 5.7959 & 6.1208 & TRN \\
\hline CHEMBL584235 & 817939 & 6.6778 & 6.5825 & TRN \\
\hline CHEMBL588155 & 817939 & 5.8386 & 5.8261 & TRN \\
\hline CHEMBL609628 & 817939 & 5.8013 & 5.9896 & TRN \\
\hline CHEMBL586178 & 817939 & 6.1475 & 6.3547 & TRN \\
\hline CHEMBL590212 & 817939 & 6.6216 & 6.3441 & TRN \\
\hline CHEMBL587989 & 817939 & 6.1765 & 6.4752 & TRN \\
\hline CHEMBL587410 & 817939 & 6.3979 & 6.0639 & TST \\
\hline CHEMBL582180 & 817939 & 5.7773 & 6.2508 & TRN \\
\hline CHEMBL590919 & 817939 & 5.9666 & 6.2985 & TST \\
\hline CHEMBL586704 & 817939 & 7.4078 & 7.2578 & TRN \\
\hline CHEMBL604389 & 817939 & 5.983 & 6.5161 & TRN \\
\hline CHEMBL590435 & 817939 & 6.8962 & 6.494 & TRN \\
\hline CHEMBL585264 & 817939 & 7.0287 & 6.6972 & TST \\
\hline CHEMBL534589 & 817939 & 6.7258 & 6.5307 & TRN \\
\hline CHEMBL578952 & 817939 & 7.2941 & 7.1054 & TRN \\
\hline CHEMBL600356 & 817939 & 6.3307 & 6.6019 & TRN \\
\hline CHEMBL599100 & 817939 & 6.153 & 6.1981 & TRN \\
\hline CHEMBL524930 & 817939 & 6.5719 & 6.7575 & TRN \\
\hline CHEMBL529640 & 817939 & 6.4001 & 6.3384 & TRN \\
\hline CHEMBL603686 & 817939 & 6.0841 & 6.5683 & TRN \\
\hline CHEMBL579443 & 817939 & 6.1811 & 6.2435 & TRN \\
\hline CHEMBL537778 & 817939 & 6.3036 & 6.2149 & TRN \\
\hline CHEMBL1615697 & 817939 & 6.7645 & 6.0957 & TST \\
\hline CHEMBL585966 & 817939 & 6.2676 & 6.1938 & TRN \\
\hline CHEMBL534319 & 817939 & 5.8697 & 5.777 & TRN \\
\hline CHEMBL530223 & 817939 & 6.6925 & 6.1068 & TRN \\
\hline CHEMBL 2021322 & 817939 & 5.9586 & 6.4502 & TST \\
\hline CHEMBL529732 & 817939 & 6.4023 & 6.7381 & TRN \\
\hline CHEMBL602234 & 817939 & 5.9031 & 5.9239 & TRN \\
\hline CHEMBL531222 & 817939 & 5.8297 & 6.21399 & 99999999995 \\
\hline CHEMBL529968 & 817939 & 6.1379 & 6.135 & TRN \\
\hline CHEMBL592808 & 817939 & 5.8153 & 6.0506 & TRN \\
\hline CHEMBL537505 & 817939 & 5.8665 & 6.2136 & TRN \\
\hline CHEMBL582666 & 817939 & 6.2874 & 6.0306 & TRN \\
\hline CHEMBL591183 & 817939 & 5.9431 & 5.8888 & TRN \\
\hline CHEMBL582767 & 817939 & 5.7905 & 5.8257 & TRN \\
\hline CHEMBL532079 & 817939 & 7.3391 & 6.8685 & TRN \\
\hline CHEMBL546168 & 817939 & 7.8508 & 6.1489 & TST \\
\hline CHEMBL531060 & 817939 & 6.5229 & 5.8282 & TST \\
\hline CHEMBL590683 & 817939 & 6.2782 & 5.9812 & TST \\
\hline CHEMBL533917 & 817939 & 5.8386 & 5.9018 & TST \\
\hline CHEMBL586026 & 817939 & 5.9747 & 6.3048 & TST \\
\hline CHEMBL601612 & 817939 & 5.5735 & 6.3775 & TST \\
\hline CHEMBL592123 & 817939 & 6.4413 & 5.8614 & TST \\
\hline CHEMBL581240 & 817939 & 6.7282 & 6.5893 & TST \\
\hline \multirow[t]{2}{*}{ CHEMBL546994 } & 817939 & 7.4413 & 6.67200 & $\partial 000000001$ \\
\hline & & \multicolumn{3}{|c|}{ Page 14414} \\
\hline
\end{tabular}




\begin{tabular}{|c|c|c|c|c|c|c|}
\hline \multicolumn{7}{|c|}{ Supplemental Table S2.txt } \\
\hline CHEMBL587288 & 817939 & 6.8239 & 6.4488 & TST & & \\
\hline CHEMBL582286 & 817939 & 5.983 & 6.2611 & TST & & \\
\hline CHEMBL535079 & 817939 & 6.9431 & 6.6682 & TST & & \\
\hline CHEMBL586310 & 817939 & 6.5867 & 6.0337 & TST & & \\
\hline CHEMBL529874 & 817939 & 5.983 & 6.4126 & TST & & \\
\hline CHEMBL590888 & 817939 & 6.2596 & 6.2809 & TST & & \\
\hline CHEMBL601567 & 817939 & 6.1512 & 6.529 & TST & & \\
\hline CHEMBL549210 & 817939 & 6.16299 & 99999999 & 99 & 6.3307 & TST \\
\hline CHEMBL525106 & 817939 & 5.8539 & 5.8709 & TST & & \\
\hline CHEMBL393929 & 954868 & 4.3065 & 4.3118 & TRN & & \\
\hline CHEMBL573107 & 954868 & 4.947 & 4.9676 & TRN & & \\
\hline CHEMBL1242367 & 954868 & 3.909 & 3.9009 & TRN & & \\
\hline CHEMBL65 & 954868 & 9.1543 & 9.1572 & TRN & & \\
\hline CHEMBL1788116 & 954868 & 4.8576 & 4.8607 & TRN & & \\
\hline CHEMBL1590308 & 954868 & 3.278 & 3.3162 & TST & & \\
\hline CHEMBL221137 & 954868 & 5.2367 & 5.2703 & TST & & \\
\hline CHEMBL213100 & 954868 & 3.1652 & 3.1821 & TRN & & \\
\hline CHEMBL220241 & 954868 & 4.8604 & 4.8781 & TRN & & \\
\hline CHEMBL 300389 & 954868 & 6.7593 & 6.7533 & TRN & & \\
\hline CHEMBL 2144069 & 954868 & 3.6699 & 3.6748 & TRN & & \\
\hline CHEMBL1673039 & 954868 & 5.1145 & 5.0727 & TRN & & \\
\hline CHEMBL189584 & 954868 & 4.9021 & 4.897 & TRN & & \\
\hline CHEMBL483847 & 954868 & 3.7703 & 3.7509 & TRN & & \\
\hline CHEMBL222102 & 954868 & 3.4576 & 3.47 & TRN & & \\
\hline CHEMBL 259181 & 954868 & 5.2592 & 5.2447 & TRN & & \\
\hline CHEMBL3199475 & 954868 & 5.1394 & 5.1491 & TRN & & \\
\hline CHEMBL373751 & 954868 & 3.3351 & 3.3451 & TRN & & \\
\hline CHEMBL3186408 & 954868 & 4.0479 & 3.9548 & TST & & \\
\hline CHEMBL509032 & 954868 & 5.8577 & 5.8929 & TRN & & \\
\hline CHEMBL 9470 & 954868 & 6.9906 & 6.3554 & TST & & \\
\hline CHEMBL1230020 & 954868 & 4.558 & 4.5607 & TRN & & \\
\hline CHEMBL1256459 & 954868 & 7.5759 & 7.5619 & TRN & & \\
\hline CHEMBL191334 & 954868 & 4.4888 & 4.4949 & TRN & & \\
\hline CHEMBL180127 & 954868 & 4.1491 & 4.1293 & TRN & & \\
\hline CHEMBL512504 & 954868 & 6.6623 & 6.6604 & TRN & & \\
\hline CHEMBL577784 & 954868 & 5.3029 & 5.297006 & 0000000001 & & TRN \\
\hline CHEMBL202721 & 954868 & 4.377 & 4.3615 & TRN & & \\
\hline CHEMBL558642 & 954868 & 4.789 & 4.7972 & TRN & & \\
\hline CHEMBL514499 & 954868 & 7.0758 & 7.0639 & TRN & & \\
\hline CHEMBL 2005886 & 954868 & 5.4852 & 5.4775 & TRN & & \\
\hline CHEMBL1909414 & 954868 & 4.1955 & 4.215 & TRN & & \\
\hline CHEMBL3349342 & 954868 & 3.3355 & 3.3588 & TRN & & \\
\hline CHEMBL392695 & 954868 & 5.5279 & 5.516 & TRN & & \\
\hline CHEMBL585951 & 954868 & 6.1888 & 6.1946 & TRN & & \\
\hline CHEMBL412142 & 954868 & 3.3867 & 3.4009 & TRN & & \\
\hline CHEMBL515416 & 954868 & 4.4633 & 4.4652 & TRN & & \\
\hline CHEMBL2363137 & 954868 & 4.988 & 4.9961 & TRN & & \\
\hline CHEMBL379975 & 954868 & 6.0109 & 6.0161 & TRN & & \\
\hline
\end{tabular}




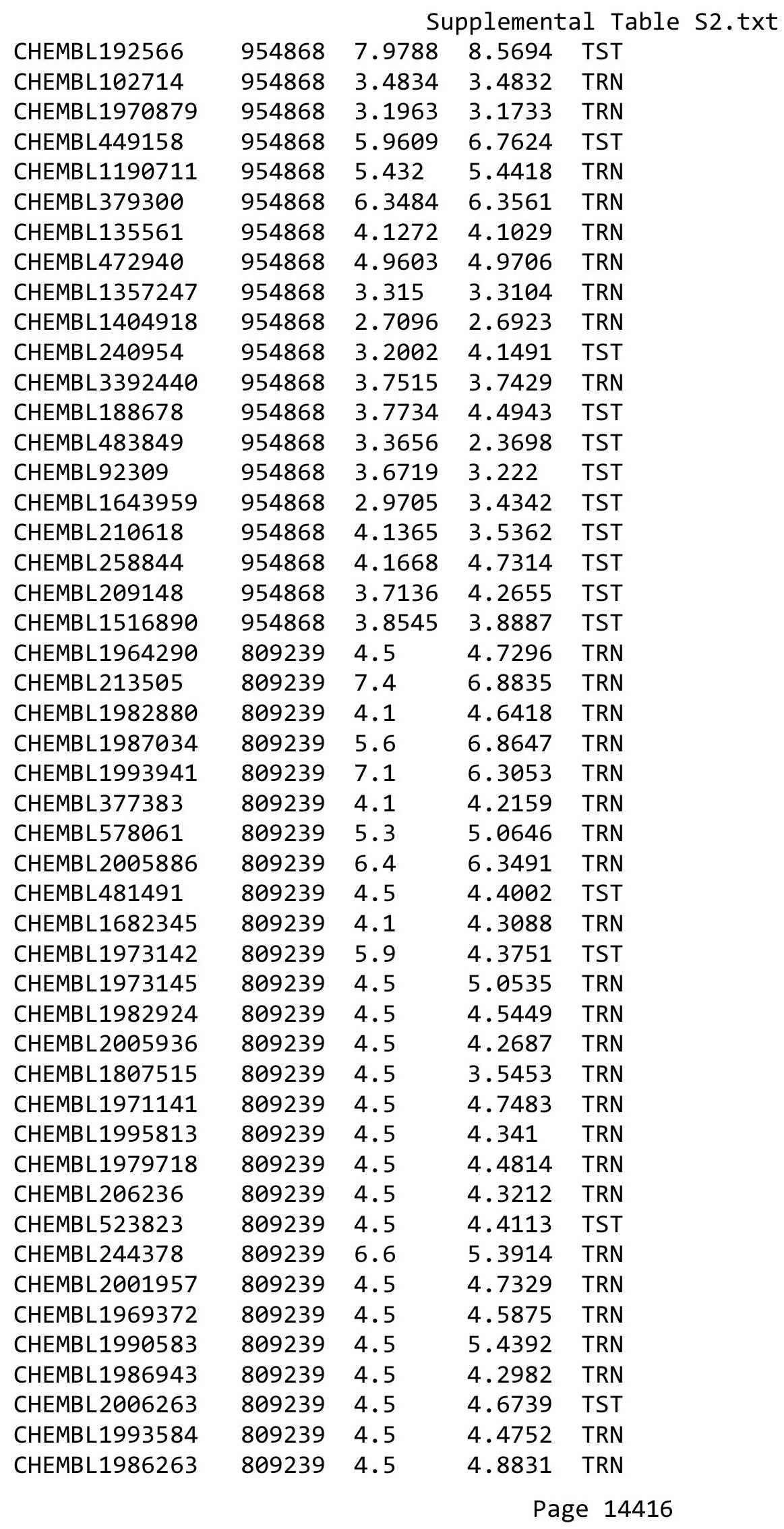




\begin{tabular}{|c|c|c|c|c|c|}
\hline \multicolumn{6}{|c|}{ Supplemental Table S2.txt } \\
\hline CHEMBL 2000114 & 809239 & 4.5 & 4.2408 & TRN & \\
\hline CHEMBL210618 & 809239 & 4.5 & 4.3375 & TRN & \\
\hline CHEMBL1975647 & 809239 & 4.5 & 4.5776 & TRN & \\
\hline CHEMBL1968380 & 809239 & 4.5 & 4.4929 & TRN & \\
\hline CHEMBL1964644 & 809239 & 4.5 & 4.2617 & TRN & \\
\hline CHEMBL1981782 & 809239 & 4.5 & 4.6078 & TRN & \\
\hline CHEMBL1977681 & 809239 & 4.5 & 4.2624 & TRN & \\
\hline CHEMBL1970142 & 809239 & 5.8 & 6.8538 & TRN & \\
\hline CHEMBL1990912 & 809239 & 4.5 & 4.2882 & TRN & \\
\hline CHEMBL1988163 & 809239 & 7.0 & 6.0126 & TRN & \\
\hline CHEMBL1995592 & 809239 & 4.1 & 4.5859 & TST & \\
\hline CHEMBL 2006493 & 809239 & 4.5 & 4.3536 & TST & \\
\hline CHEMBL1982541 & 809239 & 4.1 & 4.4353 & TRN & \\
\hline CHEMBL1983449 & 809239 & 4.5 & 4.4366 & TRN & \\
\hline CHEMBL1992323 & 809239 & 4.1 & 4.3942 & TST & \\
\hline CHEMBL1969735 & 809239 & 4.5 & 4.626 & TRN & \\
\hline CHEMBL 2003524 & 809239 & 4.1 & 4.0844 & TST & \\
\hline CHEMBL 2002649 & 809239 & 4.5 & 5.5523 & TRN & \\
\hline CHEMBL437747 & 809239 & 4.1 & 4.4018 & TRN & \\
\hline CHEMBL1995172 & 809239 & 4.5 & 4.512 & TST & \\
\hline CHEMBL507936 & 809239 & 4.5 & 4.7094 & TRN & \\
\hline CHEMBL104264 & 809239 & 4.5 & 4.7211 & TST & \\
\hline CHEMBL1994321 & 809239 & 7.0 & 6.905 & TRN & \\
\hline CHEMBL1997129 & 809239 & 4.1 & 4.2778 & TRN & \\
\hline CHEMBL1984788 & 809239 & 4.5 & 3.9763 & TRN & \\
\hline CHEMBL451964 & 809239 & 4.5 & 4.4414 & TRN & \\
\hline CHEMBL1964307 & 809239 & 4.5 & 5.2468 & TRN & \\
\hline CHEMBL 2000508 & 809239 & 4.5 & 4.6073 & TRN & \\
\hline CHEMBL1971694 & 809239 & 4.1 & 4.5279 & TST & \\
\hline CHEMBL 2001547 & 809239 & 4.5 & 4.5393 & TRN & \\
\hline CHEMBL210928 & 809239 & 4.5 & 4.3056 & TRN & \\
\hline CHEMBL1994361 & 809239 & 4.5 & 4.3908 & TRN & \\
\hline CHEMBL1986603 & 809239 & 4.5 & 4.70100 & 00000000005 & TST \\
\hline CHEMBL1972840 & 809239 & 4.5 & 4.6824 & TRN & \\
\hline CHEMBL1977148 & 809239 & 4.5 & 5.6904 & TRN & \\
\hline CHEMBL 2003286 & 809239 & 4.5 & 4.2112 & TRN & \\
\hline CHEMBL1992306 & 809239 & 7.7 & 6.5902 & TRN & \\
\hline CHEMBL 2002165 & 809239 & 7.0 & 6.2106 & TRN & \\
\hline CHEMBL1979318 & 809239 & 4.5 & 4.2747 & TRN & \\
\hline CHEMBL 206382 & 809239 & 4.5 & 4.2802 & TRN & \\
\hline CHEMBL1998585 & 809239 & 7.4 & 6.8907 & TRN & \\
\hline CHEMBL127898 & 809239 & 4.5 & 4.8468 & TST & \\
\hline CHEMBL519697 & 809239 & 4.5 & 4.6591 & TST & \\
\hline CHEMBL 2004934 & 809239 & 4.5 & 4.4287 & TRN & \\
\hline CHEMBL1975128 & 809239 & 4.5 & 4.1258 & TRN & \\
\hline CHEMBL1996048 & 809239 & 4.5 & 4.7213 & TST & \\
\hline CHEMBL461876 & 809239 & 4.5 & 5.0098 & TST & \\
\hline CHEMBL2001485 & 809239 & 6.1 & 6.649 & TRN & \\
\hline
\end{tabular}




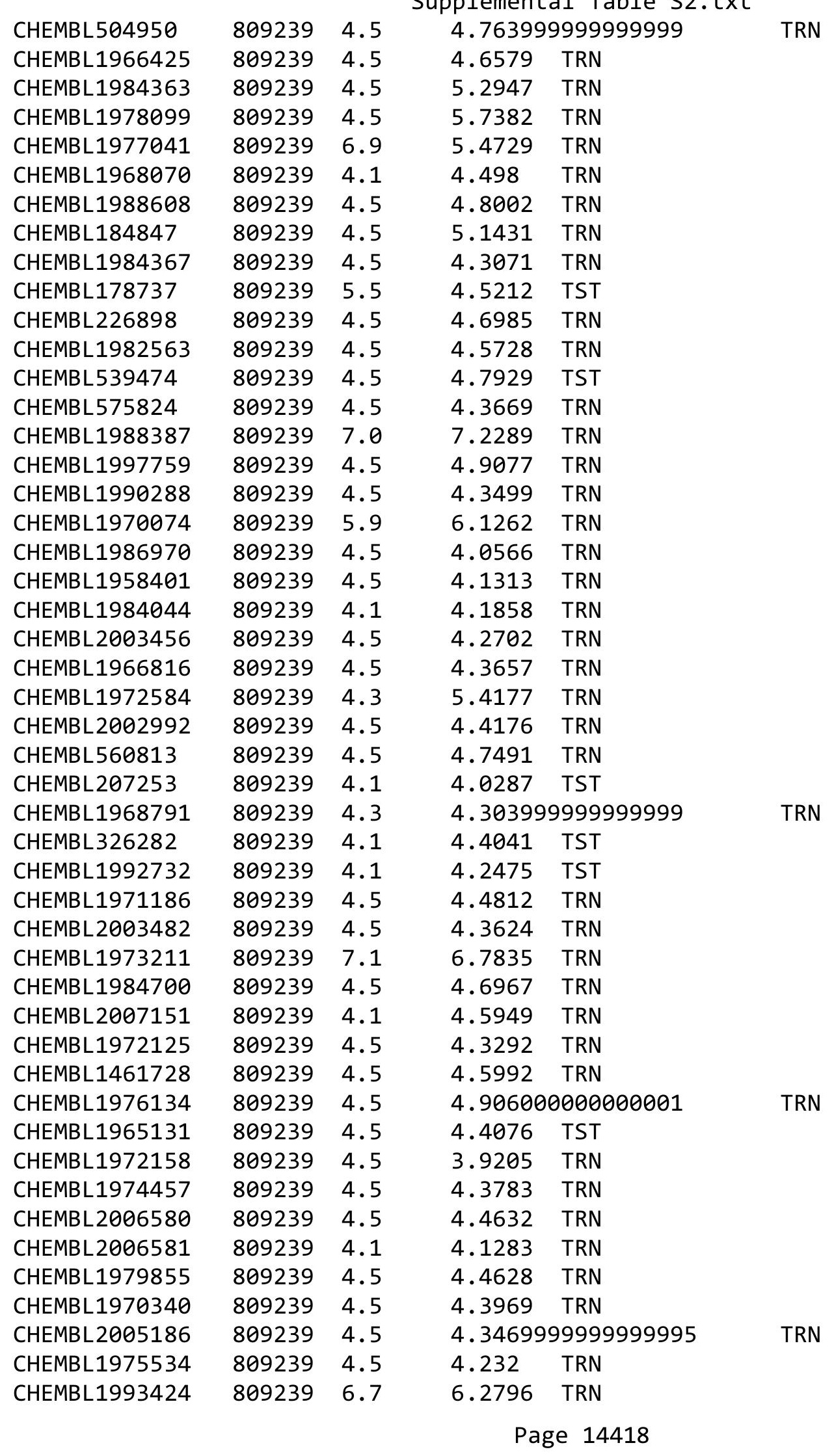




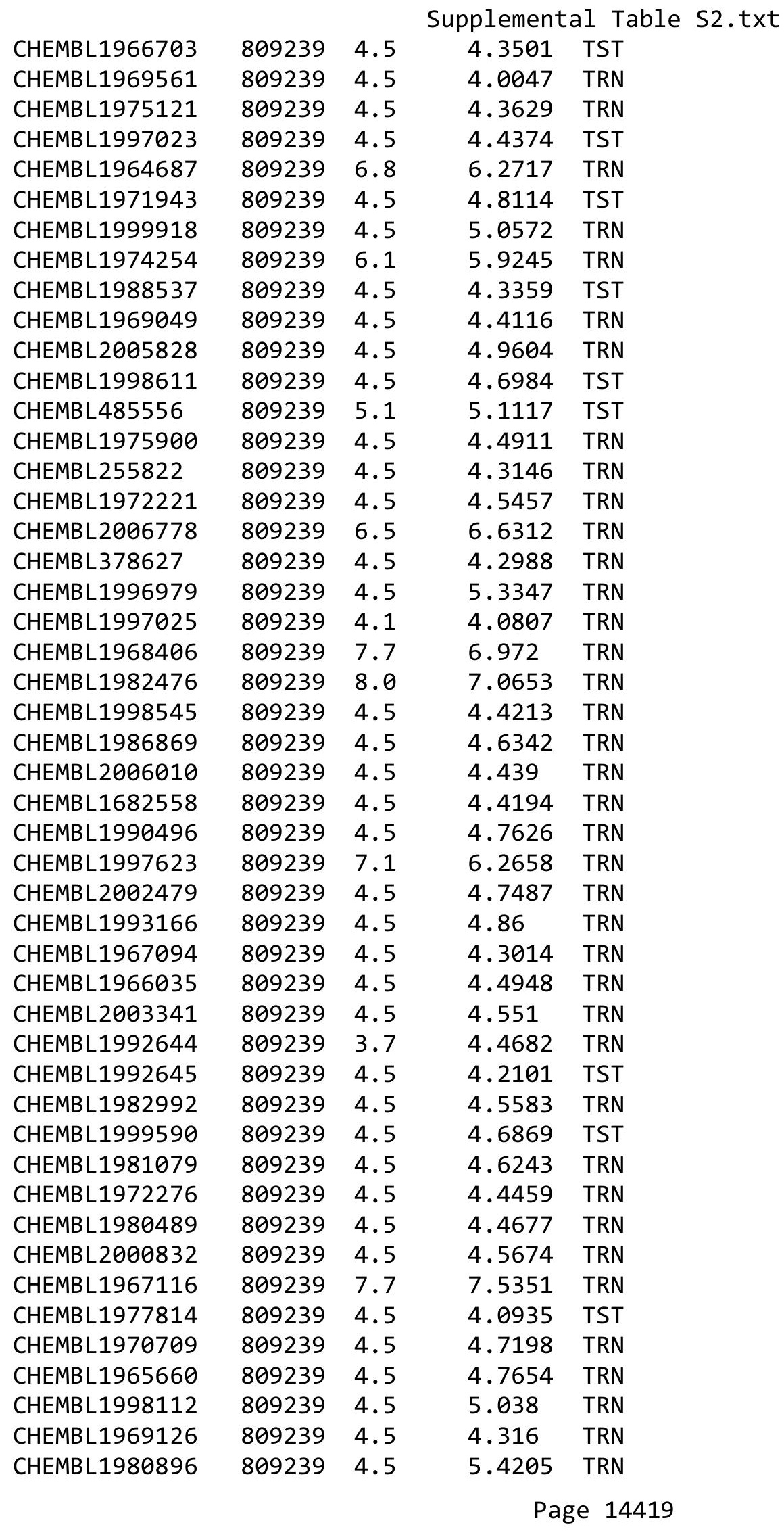




\begin{tabular}{|c|c|c|c|c|c|}
\hline & & & & & \\
\hline CHEMBL1975208 & 809239 & 4.5 & 4.4205 & TST & \\
\hline CHEMBL1970104 & 809239 & 4.5 & 5.2379 & TRN & \\
\hline CHEMBL1991429 & 809239 & 7.0 & 6.1832 & TRN & \\
\hline CHEMBL1964777 & 809239 & 4.5 & 4.442 & TRN & \\
\hline CHEMBL1971149 & 809239 & 4.5 & 4.4616 & TRN & \\
\hline CHEMBL1999714 & 809239 & 4.5 & 4.51699 & 99999999995 & TRN \\
\hline CHEMBL1987533 & 809239 & 4.5 & 4.5517 & TRN & \\
\hline CHEMBL1994040 & 809239 & 4.5 & 4.3881 & TRN & \\
\hline CHEMBL 388978 & 809239 & 6.6 & 5.6109 & TST & \\
\hline CHEMBL579246 & 809239 & 4.5 & 4.5073 & TRN & \\
\hline CHEMBL398951 & 809239 & 4.5 & 4.4088 & TST & \\
\hline CHEMBL1982506 & 809239 & 4.1 & 4.1054 & TST & \\
\hline CHEMBL 2004716 & 809239 & 7.7 & 7.3921 & TRN & \\
\hline CHEMBL1968127 & 809239 & 4.5 & 4.313 & TRN & \\
\hline CHEMBL1975233 & 809239 & 4.5 & 4.4979 & TRN & \\
\hline CHEMBL1985406 & 809239 & 4.5 & 4.50899 & 99999999995 & TRN \\
\hline CHEMBL 207400 & 809239 & 4.5 & 4.2056 & TST & \\
\hline CHEMBL 2000894 & 809239 & 4.5 & 4.4405 & TST & \\
\hline CHEMBL1982135 & 809239 & 4.5 & 4.5691 & TRN & \\
\hline CHEMBL1976090 & 809239 & 4.5 & 4.763 & TRN & \\
\hline CHEMBL1993243 & 809239 & 7.7 & 6.4359 & TRN & \\
\hline CHEMBL1992922 & 809239 & 4.1 & 4.8442 & TRN & \\
\hline CHEMBL 2004771 & 809239 & 4.5 & 4.5387 & TRN & \\
\hline CHEMBL399021 & 809239 & 4.1 & 4.3377 & TRN & \\
\hline CHEMBL1997597 & 809239 & 4.5 & 4.3989 & TRN & \\
\hline CHEMBL1969537 & 809239 & 4.5 & 4.7448 & TST & \\
\hline CHEMBL1976093 & 809239 & 4.5 & 4.372 & TRN & \\
\hline CHEMBL1996543 & 809239 & 4.5 & 4.4476 & TRN & \\
\hline CHEMBL1975256 & 809239 & 4.5 & 4.6364 & TST & \\
\hline CHEMBL508928 & 809239 & 7.1 & 6.8008 & TRN & \\
\hline CHEMBL1991356 & 809239 & 4.5 & 4.3101 & TST & \\
\hline CHEMBL 2004892 & 809239 & 4.5 & 4.4669 & TRN & \\
\hline CHEMBL1997503 & 809239 & 4.5 & 4.5402 & TST & \\
\hline CHEMBL116070 & 809239 & 4.5 & 4.5075 & TRN & \\
\hline CHEMBL1990821 & 809239 & 4.5 & 4.5918 & TST & \\
\hline CHEMBL1970314 & 809239 & 4.5 & 4.1926 & TRN & \\
\hline CHEMBL 2004871 & 809239 & 4.5 & 4.4984 & TRN & \\
\hline CHEMBL 2004872 & 809239 & 4.5 & 4.3473 & TRN & \\
\hline CHEMBL1727312 & 809239 & 4.1 & 4.2972 & TRN & \\
\hline CHEMBL1969879 & 809239 & 4.5 & 4.4551 & TRN & \\
\hline CHEMBL1981720 & 809239 & 4.5 & 4.545 & TRN & \\
\hline CHEMBL419932 & 809239 & 4.5 & 4.3153 & TRN & \\
\hline CHEMBL262433 & 809239 & 7.0 & 6.0973 & TRN & \\
\hline CHEMBL 306380 & 809239 & 6.9 & 6.1261 & TRN & \\
\hline CHEMBL1966722 & 809239 & 4.5 & 4.8773 & TST & \\
\hline CHEMBL1975500 & 809239 & 4.5 & 4.3875 & TRN & \\
\hline CHEMBL1976328 & 809239 & 4.5 & 5.319 & TRN & \\
\hline CHEMBL394619 & 809239 & 6.1 & 5.8893 & TRN & \\
\hline & & & & 14420 & \\
\hline
\end{tabular}




\begin{tabular}{|c|c|c|c|c|c|}
\hline & & & & & \\
\hline CHEMBL1964399 & 809239 & 4.1 & 4.921 & TRN & \\
\hline CHEMBL1996831 & 809239 & 4.5 & 4.4615 & TST & \\
\hline CHEMBL411903 & 809239 & 7.2 & 6.7439 & TRN & \\
\hline CHEMBL1965988 & 809239 & 6.7 & 6.7301 & TRN & \\
\hline CHEMBL418203 & 809239 & 5.7 & 4.3498 & TST & \\
\hline CHEMBL1989646 & 809239 & 4.5 & 4.1953 & TRN & \\
\hline CHEMBL1682357 & 809239 & 4.1 & 4.3974 & TRN & \\
\hline CHEMBL225519 & 809239 & 4.5 & 4.515 & TRN & \\
\hline CHEMBL209534 & 809239 & 4.1 & 4.1438 & TRN & \\
\hline CHEMBL1978200 & 809239 & 6.1 & 4.6754 & TRN & \\
\hline CHEMBL1970522 & 809239 & 4.1 & 4.1091 & TRN & \\
\hline CHEMBL402846 & 809239 & 6.2 & 5.6477 & TRN & \\
\hline CHEMBL1990415 & 809239 & 4.5 & 4.4223 & TRN & \\
\hline CHEMBL1966087 & 809239 & 4.5 & 4.3657 & TRN & \\
\hline CHEMBL1964692 & 809239 & 7.8 & 7.7058 & TRN & \\
\hline CHEMBL1996931 & 809239 & 4.5 & 4.54899 & 99999999995 & TRN \\
\hline CHEMBL1964413 & 809239 & 4.1 & 4.5215 & TRN & \\
\hline CHEMBL1973483 & 809239 & 4.5 & 4.7421 & TRN & \\
\hline CHEMBL1984432 & 809239 & 4.1 & 4.3806 & TRN & \\
\hline CHEMBL1970735 & 809239 & 4.5 & 4.2138 & TRN & \\
\hline CHEMBL219722 & 809239 & 4.5 & 5.5086 & TRN & \\
\hline CHEMBL1997340 & 809239 & 4.5 & 4.4291 & TRN & \\
\hline CHEMBL1522508 & 809239 & 4.5 & 4.4167 & TRN & \\
\hline CHEMBL1989474 & 809239 & 4.5 & 4.3814 & TRN & \\
\hline CHEMBL1090360 & 809239 & 7.0 & 5.9551 & TRN & \\
\hline CHEMBL210887 & 809239 & 4.5 & 4.2704 & TST & \\
\hline CHEMBL458997 & 809239 & 4.5 & 4.9942 & TRN & \\
\hline CHEMBL1971021 & 809239 & 6.4 & 5.7579 & TRN & \\
\hline CHEMBL227271 & 809239 & 4.5 & 4.5364 & TRN & \\
\hline CHEMBL583144 & 809239 & 4.1 & 4.8045 & TST & \\
\hline CHEMBL1974310 & 809239 & 4.5 & 4.5822 & TRN & \\
\hline CHEMBL1982660 & 809239 & 4.5 & 5.0494 & TRN & \\
\hline CHEMBL1994693 & 809239 & 4.5 & 5.5357 & TRN & \\
\hline CHEMBL1982957 & 809239 & 4.5 & 5.2565 & TRN & \\
\hline CHEMBL1725279 & 809239 & 4.5 & 5.0337 & TST & \\
\hline CHEMBL1975138 & 809239 & 4.5 & 4.829 & TST & \\
\hline CHEMBL424872 & 809239 & 4.1 & 4.0171 & TRN & \\
\hline CHEMBL 2006836 & 809239 & 4.5 & 4.4633 & TST & \\
\hline CHEMBL1971947 & 809239 & 7.0 & 7.3821 & TRN & \\
\hline CHEMBL412142 & 809239 & 4.5 & 4.4392 & TST & \\
\hline CHEMBL1980704 & 809239 & 4.5 & 4.4052 & TST & \\
\hline CHEMBL 2003271 & 809239 & 4.5 & 4.4938 & TST & \\
\hline CHEMBL1966808 & 809239 & 4.5 & 4.4128 & TST & \\
\hline CHEMBL 2004447 & 809239 & 4.5 & 4.3121 & TRN & \\
\hline CHEMBL1983111 & 809239 & 6.0 & 6.29799 & 9999999999 & TST \\
\hline CHEMBL1973860 & 809239 & 4.5 & 4.3628 & TRN & \\
\hline CHEMBL 260135 & 809239 & 4.1 & 4.3856 & TRN & \\
\hline CHEMBL220241 & 809239 & 4.5 & 4.42399 & 99999999995 & TST \\
\hline & & & & 14421 & \\
\hline
\end{tabular}




\begin{tabular}{|c|c|c|c|c|}
\hline & & & pplement & al $\mathrm{Ta}$ \\
\hline CHEMBL 2004544 & 809239 & 4.5 & 4.4814 & TST \\
\hline CHEMBL1982610 & 809239 & 4.5 & 4.7419 & TST \\
\hline CHEMBL1999496 & 809239 & 4.5 & 4.7849 & TRN \\
\hline CHEMBL 2006933 & 809239 & 4.5 & 4.5006 & TST \\
\hline CHEMBL1988300 & 809239 & 4.5 & 5.4773 & TRN \\
\hline CHEMBL1991078 & 809239 & 4.5 & 5.0342 & TRN \\
\hline CHEMBL1987359 & 809239 & 5.7 & 4.342 & TST \\
\hline CHEMBL 2000685 & 809239 & 4.5 & 4.8051 & TRN \\
\hline CHEMBL1985311 & 809239 & 4.1 & 5.1148 & TRN \\
\hline CHEMBL1989265 & 809239 & 4.5 & 4.4821 & TST \\
\hline CHEMBL1969502 & 809239 & 5.8 & 5.8534 & TRN \\
\hline CHEMBL1965910 & 809239 & 4.1 & 4.3838 & TRN \\
\hline CHEMBL1682553 & 809239 & 4.3 & 4.5612 & TRN \\
\hline CHEMBL1971430 & 809239 & 4.5 & 4.7147 & TRN \\
\hline CHEMBL1997764 & 809239 & 4.5 & 4.0898 & TRN \\
\hline CHEMBL1983963 & 809239 & 6.6 & 5.9159 & TRN \\
\hline CHEMBL2000271 & 809239 & 4.1 & 4.2244 & TRN \\
\hline CHEMBL1985092 & 809239 & 4.5 & 4.6196 & TST \\
\hline CHEMBL 2004692 & 809239 & 4.5 & 4.4987 & TST \\
\hline CHEMBL1981410 & 809239 & 4.5 & 5.7077 & TRN \\
\hline CHEMBL1996234 & 809239 & 4.5 & 4.3635 & TRN \\
\hline CHEMBL1991434 & 809239 & 4.5 & 4.2932 & TST \\
\hline CHEMBL1967544 & 809239 & 4.5 & 4.5361 & TRN \\
\hline CHEMBL 223367 & 809239 & 4.5 & 4.0187 & TST \\
\hline CHEMBL340384 & 809239 & 5.7 & 4.3078 & TST \\
\hline CHEMBL1996587 & 809239 & 4.5 & 4.4568 & TRN \\
\hline CHEMBL1964804 & 809239 & 4.5 & 4.5258 & TRN \\
\hline CHEMBL443962 & 809239 & 4.1 & 4.489 & TST \\
\hline CHEMBL 2000354 & 809239 & 4.5 & 4.2779 & TRN \\
\hline CHEMBL1965507 & 809239 & 4.5 & 4.8718 & TRN \\
\hline CHEMBL1981107 & 809239 & 3.7 & 4.5434 & TST \\
\hline CHEMBL 274064 & 809239 & 4.1 & 4.3801 & TRN \\
\hline CHEMBL1967564 & 809239 & 4.5 & 4.3919 & TRN \\
\hline CHEMBL592030 & 809239 & 4.5 & 3.9385 & TST \\
\hline CHEMBL 2000071 & 809239 & 4.3 & 4.4268 & TRN \\
\hline CHEMBL1979176 & 809239 & 4.5 & 4.6554 & TRN \\
\hline CHEMBL1970317 & 809239 & 6.6 & 6.1514 & TRN \\
\hline CHEMBL 2000408 & 809239 & 4.5 & 4.6137 & TRN \\
\hline CHEMBL 248757 & 809239 & 4.1 & 3.8031 & TST \\
\hline CHEMBL1978014 & 809239 & 4.5 & 4.4448 & TRN \\
\hline CHEMBL1994538 & 809239 & 4.5 & 4.511 & TRN \\
\hline CHEMBL1983195 & 809239 & 4.5 & 4.8837 & TST \\
\hline CHEMBL1975490 & 809239 & 5.9 & 4.6785 & TRN \\
\hline CHEMBL1964444 & 809239 & 4.5 & 4.3293 & TRN \\
\hline CHEMBL 2006567 & 809239 & 4.5 & 4.4816 & TRN \\
\hline CHEMBL1986139 & 809239 & 4.5 & 4.494 & TRN \\
\hline CHEMBL 383527 & 809239 & 4.5 & 4.7365 & TRN \\
\hline CHEMBL1980540 & 809239 & 4.5 & 4.2954 & TRN \\
\hline
\end{tabular}




\begin{tabular}{|c|c|c|c|c|}
\hline & & & pplement & al $\mathrm{Ta}$ \\
\hline CHEMBL1979883 & 809239 & 7.0 & 6.7818 & TRN \\
\hline CHEMBL1984162 & 809239 & 7.5 & 6.8581 & TRN \\
\hline CHEMBL491758 & 809239 & 4.5 & 5.3053 & TRN \\
\hline CHEMBL549730 & 809239 & 4.5 & 4.3622 & TRN \\
\hline CHEMBL1682360 & 809239 & 4.5 & 4.2753 & TRN \\
\hline CHEMBL1970189 & 809239 & 4.5 & 4.1524 & TRN \\
\hline CHEMBL1996791 & 809239 & 6.0 & 4.393 & TRN \\
\hline CHEMBL371206 & 809239 & 7.1 & 6.5088 & TRN \\
\hline CHEMBL1974664 & 809239 & 7.9 & 4.795 & TST \\
\hline CHEMBL1974288 & 809239 & 4.5 & 4.4711 & TRN \\
\hline CHEMBL196363 & 809239 & 7.0 & 6.0988 & TRN \\
\hline CHEMBL1190711 & 809239 & 4.5 & 4.4391 & TRN \\
\hline CHEMBL1990346 & 809239 & 4.5 & 4.6146 & TRN \\
\hline CHEMBL1968705 & 809239 & 4.5 & 4.4089 & TRN \\
\hline CHEMBL404367 & 809239 & 6.1 & 5.7866 & TRN \\
\hline CHEMBL1966343 & 809239 & 4.5 & 4.335 & TRN \\
\hline CHEMBL1967887 & 809239 & 4.5 & 4.2923 & TRN \\
\hline CHEMBL 2000568 & 809239 & 4.5 & 4.073 & TRN \\
\hline CHEMBL 2000335 & 809239 & 6.5 & 6.369 & TRN \\
\hline CHEMBL1988717 & 809239 & 7.9 & 7.1346 & TRN \\
\hline CHEMBL1974328 & 809239 & 4.5 & 5.5501 & TST \\
\hline CHEMBL509032 & 809239 & 5.5 & 5.5926 & TRN \\
\hline CHEMBL1973808 & 809239 & 4.5 & 4.573 & TRN \\
\hline CHEMBL 2000429 & 809239 & 4.5 & 4.709 & TRN \\
\hline CHEMBL1972576 & 809239 & 4.5 & 4.4518 & TRN \\
\hline CHEMBL1992555 & 809239 & 4.5 & 4.2493 & TST \\
\hline CHEMBL1990254 & 809239 & 4.5 & 4.5821 & TRN \\
\hline CHEMBL1992342 & 809239 & 4.5 & 4.4705 & TRN \\
\hline CHEMBL1988173 & 809239 & 4.5 & 4.7639 & TST \\
\hline CHEMBL1164265 & 809239 & 4.5 & 4.9892 & TST \\
\hline CHEMBL1989805 & 809239 & 5.5 & 4.7341 & TST \\
\hline CHEMBL1965423 & 809239 & 4.3 & 4.565 & TRN \\
\hline CHEMBL1983025 & 809239 & 6.5 & 6.5137 & TRN \\
\hline CHEMBL 205415 & 809239 & 4.5 & 4.7037 & TRN \\
\hline CHEMBL1977135 & 809239 & 4.5 & 4.3291 & TRN \\
\hline CHEMBL 2001920 & 809239 & 4.5 & 4.3266 & TST \\
\hline CHEMBL 2002322 & 809239 & 4.5 & 4.4913 & TRN \\
\hline CHEMBL 2002323 & 809239 & 4.5 & 4.9773 & TST \\
\hline CHEMBL1241473 & 809239 & 6.9 & 6.5851 & TRN \\
\hline CHEMBL1978448 & 809239 & 4.5 & 4.5495 & TST \\
\hline CHEMBL1972258 & 809239 & 4.5 & 4.3467 & TRN \\
\hline CHEMBL 2001257 & 809239 & 6.5 & 6.5571 & TRN \\
\hline CHEMBL 2005548 & 809239 & 4.5 & 4.5889 & TRN \\
\hline CHEMBL1992536 & 809239 & 4.5 & 4.253 & TRN \\
\hline CHEMBL1987793 & 809239 & 4.5 & 4.6574 & TST \\
\hline CHEMBL1992740 & 809239 & 4.1 & 4.8082 & TRN \\
\hline CHEMBL 2002373 & 809239 & 4.5 & 4.4744 & TRN \\
\hline CHEMBL439340 & 809239 & 4.5 & 4.3812 & TRN \\
\hline
\end{tabular}




\begin{tabular}{|c|c|c|c|c|}
\hline & & & Supplement & \\
\hline CHEMBL2006188 & 809239 & 4.5 & 4.4961 & TRN \\
\hline CHEMBL1967531 & 809239 & 4.5 & 5.0289 & TRN \\
\hline CHEMBL1970913 & 809239 & 4.1 & 4.3178 & TRN \\
\hline CHEMBL1973893 & 809239 & 4.5 & 4.619 & TRN \\
\hline CHEMBL1997534 & 809239 & 4.5 & 4.5558 & TRN \\
\hline CHEMBL1996500 & 809239 & 4.5 & 4.3921 & TRN \\
\hline CHEMBL1985095 & 809239 & 4.5 & 4.2737 & TST \\
\hline CHEMBL1991180 & 809239 & 4.5 & 4.3863 & TST \\
\hline CHEMBL1682540 & 809239 & 4.5 & 4.5167 & TRN \\
\hline CHEMBL1976420 & 809239 & 5.6 & 5.0799 & TST \\
\hline CHEMBL1994864 & 809239 & 4.5 & 4.4844 & TRN \\
\hline CHEMBL413779 & 809239 & 4.5 & 3.9312 & TST \\
\hline CHEMBL 2002446 & 809239 & 4.5 & 5.29 & TST \\
\hline CHEMBL497151 & 809239 & 4.5 & 4.2822 & TRN \\
\hline CHEMBL1973961 & 809239 & 4.5 & 4.5266 & TRN \\
\hline CHEMBL 246970 & 809239 & 4.5 & 4.3143 & TRN \\
\hline CHEMBL340921 & 809239 & 4.5 & 4.4824 & TST \\
\hline CHEMBL 373598 & 809239 & 4.5 & 3.9424 & TST \\
\hline CHEMBL1999718 & 809239 & 4.5 & 4.5708 & TRN \\
\hline CHEMBL1276446 & 809239 & 6.1 & 6.0356 & TST \\
\hline CHEMBL1977346 & 809239 & 4.5 & 4.4036 & TRN \\
\hline CHEMBL1971649 & 809239 & 4.5 & 4.5252 & TRN \\
\hline CHEMBL 2003657 & 809239 & 4.5 & 4.6462 & TRN \\
\hline CHEMBL2006439 & 809239 & 4.5 & 4.1495 & TRN \\
\hline CHEMBL 2006156 & 809239 & 4.1 & 4.9196 & TST \\
\hline CHEMBL1969190 & 809239 & 4.5 & 6.0533 & TRN \\
\hline CHEMBL1973937 & 809239 & 5.9 & 6.1811 & TRN \\
\hline CHEMBL1991674 & 809239 & 4.5 & 4.0502 & TRN \\
\hline CHEMBL1982711 & 809239 & 5.8 & 4.6982 & TRN \\
\hline CHEMBL1984842 & 809239 & 4.5 & 4.5518 & TRN \\
\hline CHEMBL1969102 & 809239 & 7.2 & 7.1547 & TRN \\
\hline CHEMBL1682346 & 809239 & 4.5 & 4.2253 & TRN \\
\hline CHEMBL 2007044 & 809239 & 4.5 & 4.3327 & TST \\
\hline CHEMBL2001998 & 809239 & 4.1 & 4.3517 & TST \\
\hline CHEMBL1994241 & 809239 & 4.5 & 4.1721 & TRN \\
\hline CHEMBL 223460 & 809239 & 4.5 & 4.0472 & TST \\
\hline CHEMBL1998829 & 809239 & 4.5 & 4.3253 & TRN \\
\hline CHEMBL50894 & 809239 & 4.1 & 4.3338 & TRN \\
\hline CHEMBL1988838 & 809239 & 5.9 & 6.5767 & TRN \\
\hline CHEMBL1981725 & 809239 & 7.0 & 5.8157 & TRN \\
\hline CHEMBL375284 & 809239 & 4.5 & 4.8189 & TRN \\
\hline CHEMBL1982866 & 809239 & 4.5 & 4.3211 & TRN \\
\hline CHEMBL2005792 & 809239 & 4.5 & 4.5425 & TRN \\
\hline CHEMBL1968926 & 809239 & 4.5 & 4.3284 & TRN \\
\hline CHEMBL462120 & 809239 & 5.6 & 4.0364 & TST \\
\hline CHEMBL1984206 & 809239 & 4.1 & 4.4185 & TRN \\
\hline CHEMBL1991577 & 809239 & 4.5 & 4.4286 & TRN \\
\hline CHEMBL1965570 & 809239 & 5.6 & 5.9158 & TRN \\
\hline
\end{tabular}




\begin{tabular}{|c|c|c|c|c|c|}
\hline \multicolumn{6}{|c|}{ Supplemental Table S2.txt } \\
\hline CHEMBL 2007592 & 809239 & 4.1 & 4.3223 & TST & \\
\hline CHEMBL210963 & 809239 & 4.5 & 4.2698 & TRN & \\
\hline CHEMBL1082440 & 809239 & 5.3 & 4.2019 & TST & \\
\hline CHEMBL1614705 & 809239 & 4.3 & 4.4799 & TRN & \\
\hline CHEMBL1972362 & 809239 & 4.5 & 4.5127 & TRN & \\
\hline CHEMBL1984633 & 809239 & 4.5 & 4.6676 & TRN & \\
\hline CHEMBL 2007372 & 809239 & 4.5 & 4.6234 & TRN & \\
\hline CHEMBL1965845 & 809239 & 4.5 & 4.34 & TRN & \\
\hline CHEMBL 2006715 & 809239 & 4.5 & 6.1189 & TRN & \\
\hline CHEMBL1986597 & 809239 & 4.5 & 4.2732 & TRN & \\
\hline CHEMBL1971017 & 809239 & 4.5 & 4.7344 & TRN & \\
\hline CHEMBL1990482 & 809239 & 4.3 & 4.4552 & TRN & \\
\hline CHEMBL1990904 & 809239 & 4.5 & 4.5274 & TRN & \\
\hline CHEMBL 2005475 & 809239 & 4.5 & 4.24100 & 00000000005 & TRN \\
\hline CHEMBL 2000104 & 809239 & 4.5 & 4.3437 & TRN & \\
\hline CHEMBL1997349 & 809239 & 4.5 & 4.6034 & TST & \\
\hline CHEMBL183844 & 809239 & 6.6 & 5.6909 & TRN & \\
\hline CHEMBL220057 & 809239 & 4.7 & 5.8683 & TRN & \\
\hline CHEMBL1682545 & 809239 & 4.5 & 4.8012 & TRN & \\
\hline CHEMBL 383541 & 809239 & 4.5 & 4.6348 & TRN & \\
\hline CHEMBL 2001224 & 809239 & 4.5 & 4.4268 & TRN & \\
\hline CHEMBL10 & 809239 & 4.2 & 4.3239 & TRN & \\
\hline CHEMBL1976732 & 809239 & 4.5 & 4.4864 & TRN & \\
\hline CHEMBL1969506 & 809239 & 4.5 & 4.8264 & TRN & \\
\hline CHEMBL1964937 & 809239 & 4.5 & 4.5403 & TRN & \\
\hline CHEMBL1980163 & 809239 & 4.5 & 4.2736 & TRN & \\
\hline CHEMBL590109 & 809239 & 4.1 & 3.9949 & TST & \\
\hline CHEMBL1970879 & 809239 & 4.1 & 5.1256 & TRN & \\
\hline CHEMBL1989856 & 809239 & 4.5 & 4.3022 & TST & \\
\hline CHEMBL 2005899 & 809239 & 4.5 & 4.4651 & TRN & \\
\hline CHEMBL1682552 & 809239 & 4.3 & 4.5044 & TRN & \\
\hline CHEMBL 259850 & 809239 & 4.5 & 4.2945 & TRN & \\
\hline CHEMBL1996155 & 809239 & 4.5 & 4.4694 & TRN & \\
\hline CHEMBL229799 & 809239 & 4.5 & 4.3189 & TRN & \\
\hline CHEMBL1682359 & 809239 & 4.5 & 4.2874 & TRN & \\
\hline CHEMBL105739 & 809239 & 4.5 & 4.7777 & TRN & \\
\hline CHEMBL379300 & 809239 & 4.5 & 4.0762 & TRN & \\
\hline CHEMBL203673 & 809239 & 4.5 & 4.4098 & TRN & \\
\hline CHEMBL1969523 & 809239 & 4.1 & 4.7365 & TRN & \\
\hline CHEMBL207995 & 809239 & 4.5 & 4.2964 & TRN & \\
\hline CHEMBL 2001923 & 809239 & 4.5 & 4.3124 & TRN & \\
\hline CHEMBL1986781 & 809239 & 4.5 & 4.5497 & TRN & \\
\hline CHEMBL526133 & 809239 & 4.5 & 4.3997 & TRN & \\
\hline CHEMBL1979057 & 809239 & 4.5 & 4.1302 & TRN & \\
\hline CHEMBL1981045 & 809239 & 4.5 & 4.4554 & TRN & \\
\hline CHEMBL387971 & 809239 & 4.5 & 5.0348 & TST & \\
\hline CHEMBL1975418 & 809239 & 4.5 & 4.2651 & TRN & \\
\hline CHEMBL1992796 & 809239 & 4.5 & 4.1292 & TST & \\
\hline
\end{tabular}




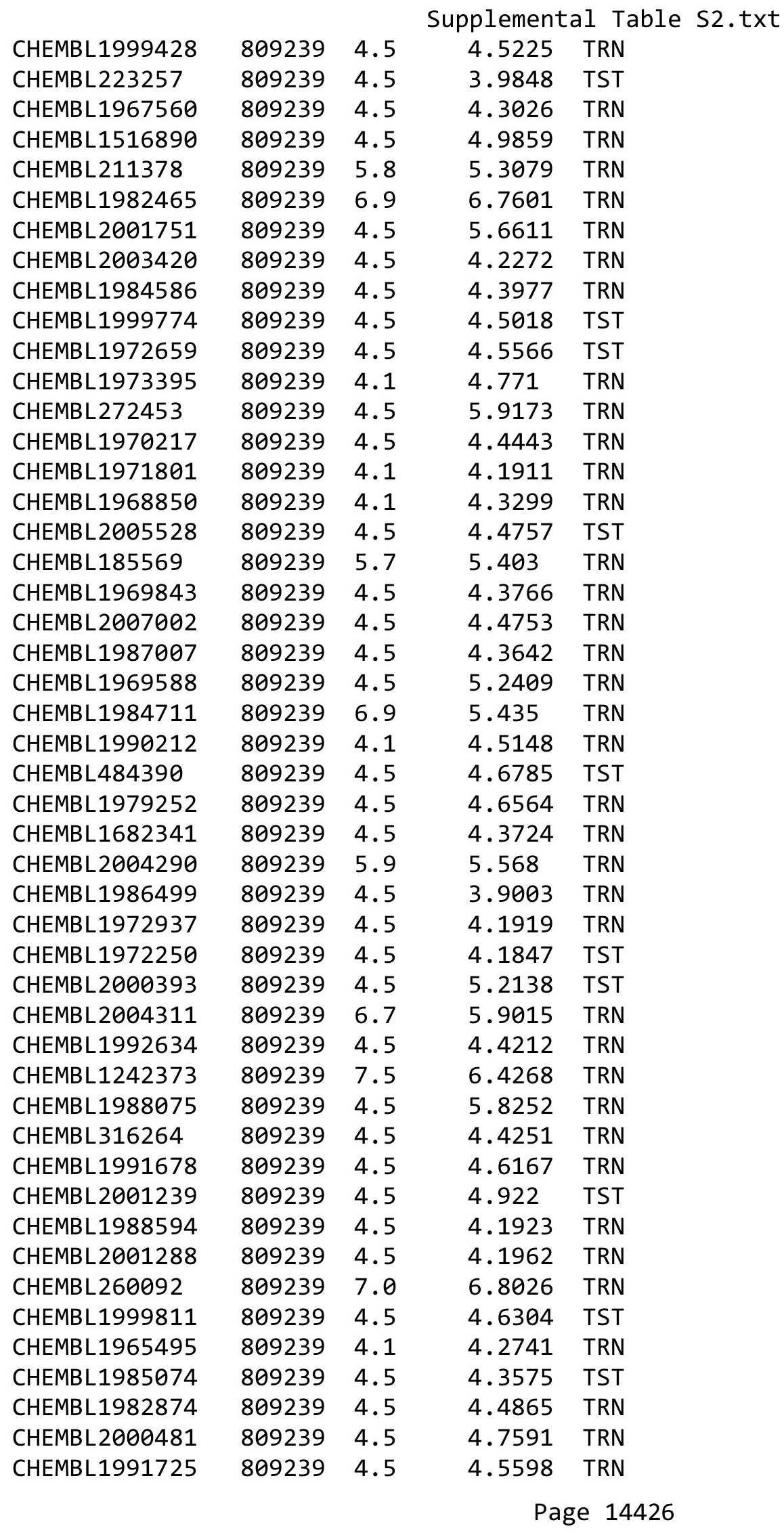




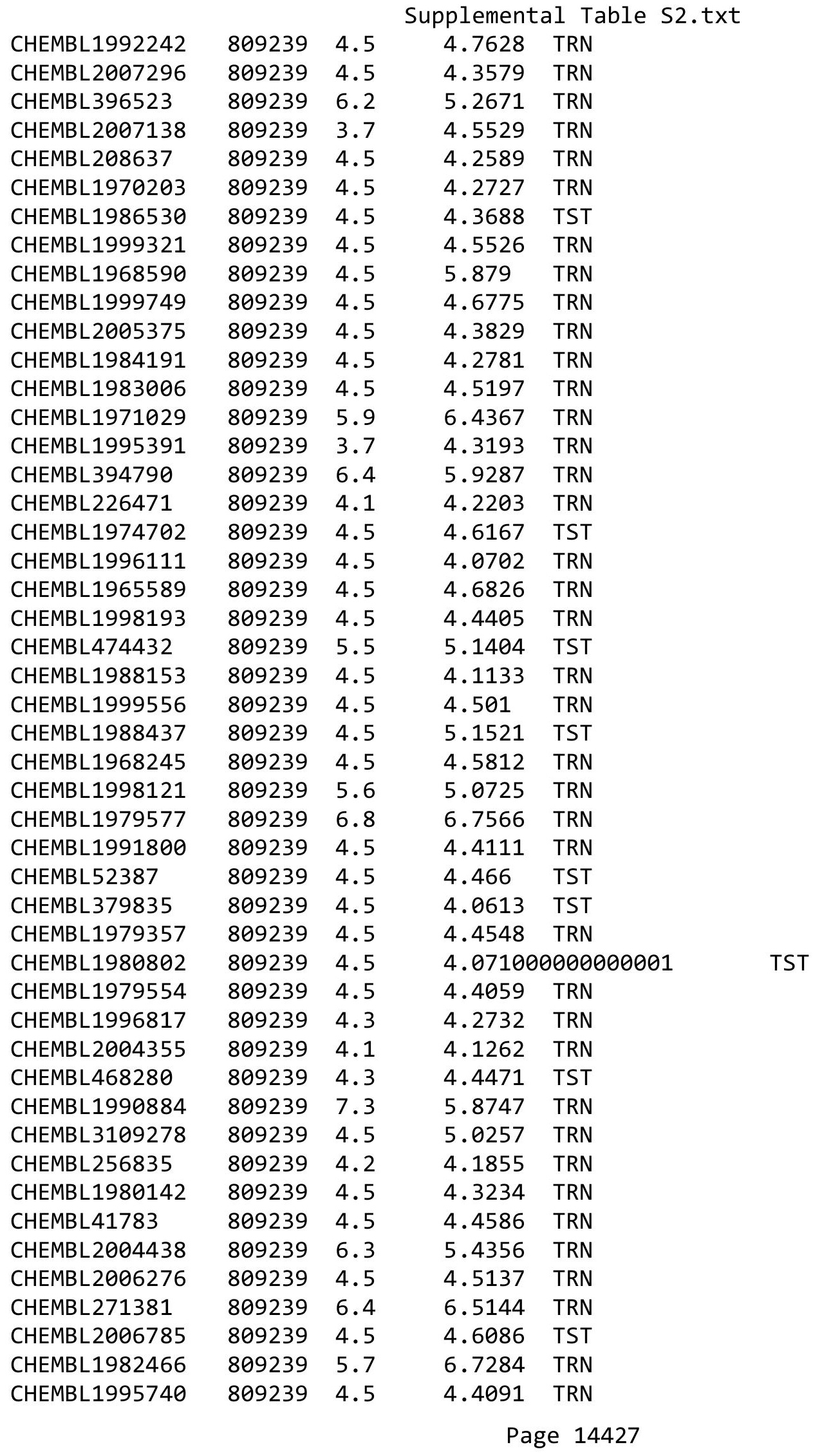




\begin{tabular}{|c|c|c|c|c|}
\hline & & & Lement & al Ta \\
\hline CHEMBL1996390 & 809239 & 4.5 & 4.2205 & TRN \\
\hline CHEMBL 234085 & 809239 & 4.5 & 4.4494 & TRN \\
\hline CHEMBL1995832 & 809239 & 4.5 & 4.7528 & TRN \\
\hline CHEMBL1969042 & 809239 & 4.5 & 4.6739 & TST \\
\hline CHEMBL 2000345 & 809239 & 4.5 & 4.2033 & TRN \\
\hline CHEMBL1999931 & 809239 & 4.5 & 4.8174 & TRN \\
\hline CHEMBL1991640 & 809239 & 4.1 & 4.4051 & TST \\
\hline CHEMBL1375418 & 809239 & 4.5 & 4.5521 & TRN \\
\hline CHEMBL 302449 & 809239 & 4.5 & 4.5453 & TST \\
\hline CHEMBL 2007064 & 809239 & 4.5 & 4.8834 & TRN \\
\hline CHEMBL1981047 & 809239 & 7.5 & 6.5812 & TRN \\
\hline CHEMBL 229968 & 809239 & 4.5 & 4.1814 & TRN \\
\hline CHEMBL1976240 & 809239 & 4.5 & 4.61 & TRN \\
\hline CHEMBL1979093 & 809239 & 5.7 & 6.1752 & TRN \\
\hline CHEMBL1968151 & 809239 & 4.5 & 4.4352 & TST \\
\hline CHEMBL1381197 & 809239 & 4.1 & 4.6737 & TRN \\
\hline CHEMBL1987009 & 809239 & 4.5 & 4.3739 & TRN \\
\hline CHEMBL379218 & 809239 & 4.5 & 4.2867 & TRN \\
\hline CHEMBL 2003817 & 809239 & 4.1 & 4.6994 & TRN \\
\hline CHEMBL336961 & 809239 & 4.5 & 4.3356 & TRN \\
\hline CHEMBL1994830 & 809239 & 4.5 & 4.3014 & TRN \\
\hline CHEMBL1987054 & 809239 & 7.0 & 6.8135 & TRN \\
\hline CHEMBL1970083 & 809239 & 7.3 & 7.1638 & TRN \\
\hline CHEMBL226403 & 809239 & 4.3 & 4.2999 & TRN \\
\hline CHEMBL 2005631 & 809239 & 7.7 & 7.3857 & TRN \\
\hline CHEMBL1994938 & 809239 & 8.5 & 6.8356 & TRN \\
\hline CHEMBL1977223 & 809239 & 4.1 & 4.3283 & TRN \\
\hline CHEMBL1236126 & 809239 & 4.1 & 4.1075 & TST \\
\hline CHEMBL1966279 & 809239 & 4.5 & 4.5623 & TRN \\
\hline CHEMBL1997846 & 809239 & 4.5 & 4.0886 & TRN \\
\hline CHEMBL2004419 & 809239 & 4.5 & 4.4722 & TRN \\
\hline CHEMBL1991728 & 809239 & 4.5 & 4.6869 & TRN \\
\hline CHEMBL1975787 & 809239 & 4.1 & 4.6765 & TRN \\
\hline CHEMBL 2002407 & 809239 & 4.5 & 4.4891 & TRN \\
\hline CHEMBL1972489 & 809239 & 4.5 & 4.5896 & TRN \\
\hline CHEMBL1994074 & 809239 & 4.5 & 3.9243 & TRN \\
\hline CHEMBL1992937 & 809239 & 4.1 & 4.1998 & TST \\
\hline CHEMBL1985566 & 809239 & 4.5 & 4.4796 & TRN \\
\hline CHEMBL1972119 & 809239 & 4.5 & 4.4104 & TRN \\
\hline CHEMBL1986328 & 809239 & 4.5 & 4.9681 & TST \\
\hline CHEMBL 95692 & 809239 & 4.5 & 4.1917 & TRN \\
\hline CHEMBL1090356 & 809239 & 4.5 & 5.5489 & TRN \\
\hline CHEMBL1976455 & 809239 & 4.5 & 4.7776 & TRN \\
\hline CHEMBL1991874 & 809239 & 5.7 & 4.9161 & TRN \\
\hline CHEMBL1983923 & 809239 & 5.6 & 5.5087 & TST \\
\hline CHEMBL1983534 & 809239 & 4.5 & 4.499 & TRN \\
\hline CHEMBL1982361 & 809239 & 4.5 & 4.3999 & TRN \\
\hline CHEMBL1999112 & 809239 & 4.5 & 4.6024 & TST \\
\hline
\end{tabular}




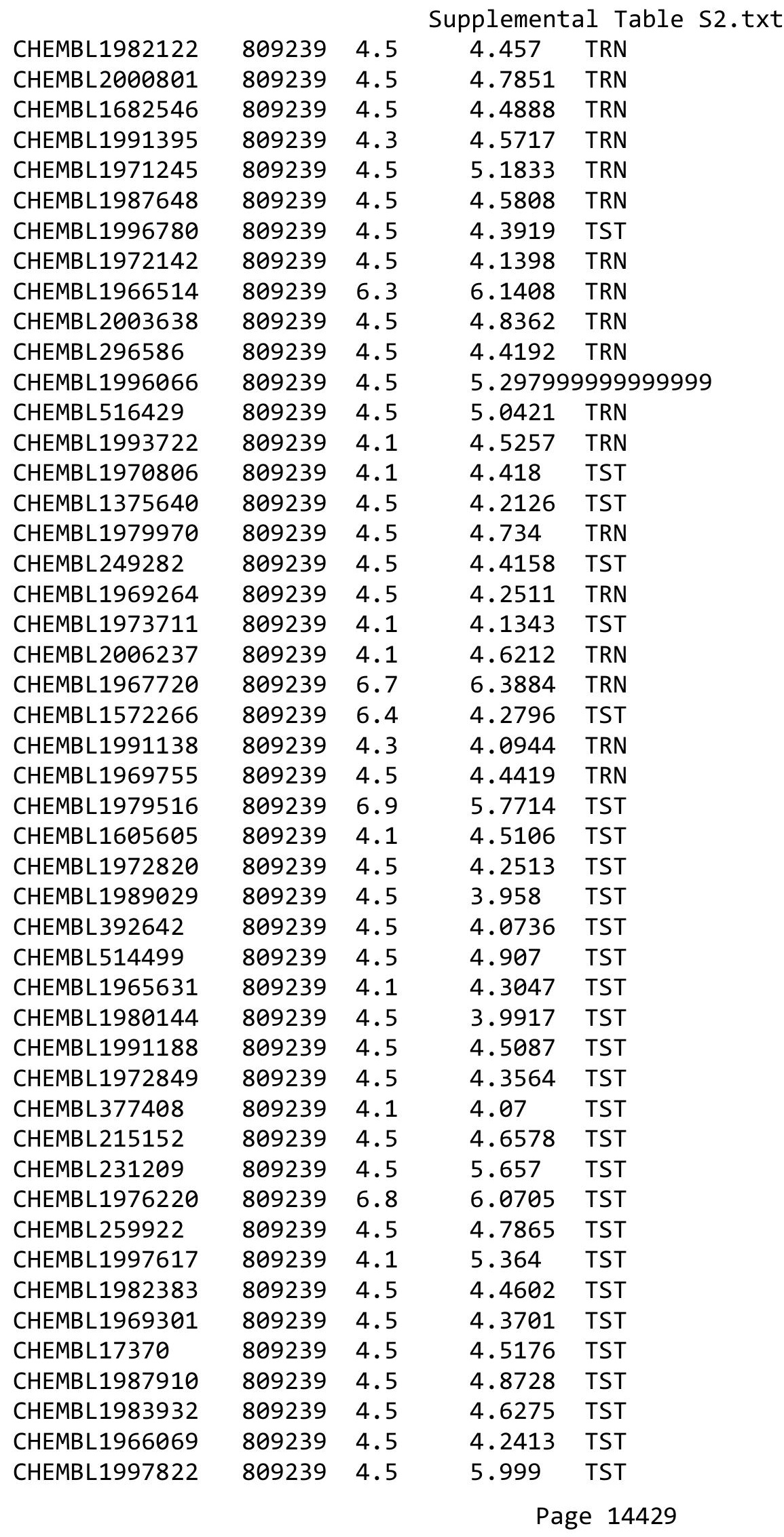




\begin{tabular}{|c|c|c|c|c|c|}
\hline \\
\hline CHEMBL1991285 & 809239 & 4.5 & 4.2813 & TST & \\
\hline CHEMBL243088 & 809239 & 6.5 & 5.218 & TST & \\
\hline CHEMBL1984038 & 809239 & 4.5 & 5.018 & TST & \\
\hline CHEMBL1993661 & 809239 & 8.2 & 6.3056 & TST & \\
\hline CHEMBL1974416 & 809239 & 4.5 & 4.6462 & TST & \\
\hline CHEMBL1997872 & 809239 & 4.5 & 4.221 & TST & \\
\hline CHEMBL 3644909 & 1527722 & 7.9208 & 7.9753 & TRN & \\
\hline CHEMBL3644875 & 1527722 & 6.71 & 6.9442 & TRN & \\
\hline CHEMBL3644887 & 1527722 & 6.7959 & 7.0166 & TRN & \\
\hline CHEMBL3644931 & 1527722 & 6.2147 & 6.4458 & TRN & \\
\hline CHEMBL3644925 & 1527722 & 6.0269 & 7.7043 & TST & \\
\hline CHEMBL3644881 & 1527722 & 8.301 & 8.43100 & 0000000001 & TRN \\
\hline CHEMBL3644905 & 1527722 & 8.0458 & 8.0804 & TRN & \\
\hline CHEMBL3644900 & 1527722 & 6.1938 & 6.12299 & 9999999999 & TRN \\
\hline CHEMBL3644902 & 1527722 & 7.7212 & 8.1076 & TRN & \\
\hline CHEMBL3644935 & 1527722 & 7.699 & 7.7418 & TRN & \\
\hline CHEMBL3644908 & 1527722 & 8.699 & 7.7951 & TRN & \\
\hline CHEMBL3644940 & 1527722 & 6.2147 & 6.2476 & TST & \\
\hline CHEMBL3644892 & 1527722 & 7.5528 & 7.511 & TRN & \\
\hline CHEMBL3644890 & 1527722 & 7.1675 & 6.8151 & TST & \\
\hline CHEMBL 3644883 & 1527722 & 7.8539 & 7.7229 & TRN & \\
\hline CHEMBL3644917 & 1527722 & 7.3468 & 7.4514 & TRN & \\
\hline CHEMBL3644918 & 1527722 & 7.3979 & 7.5275 & TRN & \\
\hline CHEMBL3644897 & 1527722 & 8.2218 & 8.4497 & TRN & \\
\hline CHEMBL3644877 & 1527722 & 7.2441 & 6.7903 & TRN & \\
\hline CHEMBL3644903 & 1527722 & 7.3872 & 7.7755 & TRN & \\
\hline CHEMBL 3644937 & 1527722 & 5.8447 & 7.0743 & TST & \\
\hline CHEMBL3644899 & 1527722 & 7.8539 & 7.5123 & TRN & \\
\hline CHEMBL3644878 & 1527722 & 7.6778 & 6.4493 & TST & \\
\hline CHEMBL3644911 & 1527722 & 7.9208 & 7.7103 & TRN & \\
\hline CHEMBL3644913 & 1527722 & 7.6778 & 7.4887 & TRN & \\
\hline CHEMBL 3644885 & 1527722 & 7.6576 & 7.7796 & TRN & \\
\hline CHEMBL3644893 & 1527722 & 8.699 & 8.3779 & TRN & \\
\hline CHEMBL3644886 & 1527722 & 6.7696 & 6.9128 & TRN & \\
\hline CHEMBL3644896 & 1527722 & 8.699 & 8.5064 & TRN & \\
\hline CHEMBL3644891 & 1527722 & 7.7959 & 7.6219 & TRN & \\
\hline CHEMBL3644938 & 1527722 & 5.9393 & 7.0639 & TST & \\
\hline CHEMBL3644920 & 1527722 & 7.1805 & 7.3341 & TRN & \\
\hline CHEMBL3644904 & 1527722 & 7.8861 & 7.7091 & TRN & \\
\hline CHEMBL3644898 & 1527722 & 8.5229 & 8.6586 & TRN & \\
\hline CHEMBL3644933 & 1527722 & 8.699 & 8.7449 & TRN & \\
\hline CHEMBL3644882 & 1527722 & 7.9586 & 7.994 & TRN & \\
\hline CHEMBL3644906 & 1527722 & 8.0 & 7.9461 & TRN & \\
\hline CHEMBL 3644934 & 1527722 & 8.699 & 7.8013 & TST & \\
\hline CHEMBL3644924 & 1527722 & 8.5229 & 8.6721 & TRN & \\
\hline CHEMBL3644912 & 1527722 & 8.301 & 8.3786 & TRN & \\
\hline CHEMBL3644939 & 1527722 & 6.0223 & 7.0795 & TST & \\
\hline CHEMBL3644929 & 1527722 & 5.9626 & 6.9646 & TST & \\
\hline
\end{tabular}


Supplemental Table S2.txt

\begin{tabular}{|c|c|c|c|c|}
\hline CHEMBL 3644921 & 1527722 & 6.9586 & 7.0516 & TRN \\
\hline CHEMBL 3644922 & 1527722 & 7.5528 & 7.5571 & TRN \\
\hline CHEMBL 3644889 & 1527722 & 7.4949 & 7.6093 & TRN \\
\hline CHEMBL 3644915 & 1527722 & 7.4089 & 7.4257 & TRN \\
\hline CHEMBL3644936 & 1527722 & 5.8477 & 6.9491 & TST \\
\hline CHEMBL3644888 & 1527722 & 8.699 & 8.3158 & TRN \\
\hline CHEMBL3644901 & 1527722 & 7.2147 & 7.0516 & TRN \\
\hline CHEMBL 3644876 & 1527722 & 6.3098 & \multicolumn{2}{|c|}{6.3420000000000005} \\
\hline CHEMBL 3644923 & 1527722 & 4.7959 & 4.755 & TRN \\
\hline CHEMBL3644879 & 1527722 & 7.8861 & 7.4247 & TRN \\
\hline CHEMBL3644932 & 1527722 & 8.301 & 8.5142 & TRN \\
\hline CHEMBL3644928 & 1527722 & 6.0 & 6.956 & TST \\
\hline CHEMBL 3644914 & 1527722 & 7.4685 & 7.6144 & TRN \\
\hline CHEMBL 3644916 & 1527722 & 7.0862 & 7.0707 & TRN \\
\hline CHEMBL3644907 & 1527722 & 8.0458 & 8.0571 & TRN \\
\hline CHEMBL3644910 & 1527722 & 7.7959 & 7.8727 & TRN \\
\hline CHEMBL3644919 & 1527722 & 4.3468 & 4.5849 & TRN \\
\hline CHEMBL 3644927 & 1527722 & 6.301 & 8.3471 & TST \\
\hline CHEMBL 3644884 & 1527722 & 8.3979 & 8.7295 & TRN \\
\hline CHEMBL3644880 & 1527722 & 6.3947 & 7.0504 & TST \\
\hline CHEMBL3644894 & 1527722 & 8.2218 & 8.7412 & TST \\
\hline CHEMBL3644895 & 1527722 & 8.3979 & 8.7745 & TST \\
\hline CHEMBL 3644926 & 1527722 & 5.3768 & 6.1542 & TST \\
\hline CHEMBL3644930 & 1527722 & 5.4685 & 6.7921 & TST \\
\hline CHEMBL 3978628 & 1641201 & 7.2757 & 7.0679 & TRN \\
\hline CHEMBL3946504 & 1641201 & 9.0 & 8.705 & TRN \\
\hline CHEMBL 3943738 & 1641201 & 7.0223 & 7.0552 & TST \\
\hline CHEMBL3969043 & 1641201 & 8.5229 & 8.6219 & TRN \\
\hline CHEMBL3946388 & 1641201 & 9.0 & 8.2315 & TRN \\
\hline CHEMBL3944851 & 1641201 & 9.0 & 8.6178 & TRN \\
\hline CHEMBL3983236 & 1641201 & 6.3686 & 6.7904 & TRN \\
\hline CHEMBL3931529 & 1641201 & 5.9255 & \multicolumn{2}{|c|}{7.071000000000001} \\
\hline CHEMBL3928237 & 1641201 & 9.0 & 8.7305 & TRN \\
\hline CHEMBL3975877 & 1641201 & 9.0 & 8.7037 & TRN \\
\hline CHEMBL3929533 & 1641201 & 5.1983 & 6.0447 & TRN \\
\hline CHEMBL3958644 & 1641201 & 7.5528 & 6.8295 & TRN \\
\hline CHEMBL3975889 & 1641201 & 9.0 & 8.3866 & TRN \\
\hline CHEMBL3935993 & 1641201 & 9.0 & 8.8806 & TRN \\
\hline CHEMBL3923211 & 1641201 & 9.0 & 8.2779 & TRN \\
\hline CHEMBL3935909 & 1641201 & 9.0 & 8.8191 & TRN \\
\hline CHEMBL3937672 & 1641201 & 9.0 & 8.7978 & TRN \\
\hline CHEMBL3898998 & 1641201 & 8.699 & 8.4501 & TRN \\
\hline CHEMBL 3901338 & 1641201 & 7.301 & 8.0952 & TRN \\
\hline CHEMBL3949256 & 1641201 & 5.3064 & 6.2028 & TRN \\
\hline CHEMBL3945899 & 1641201 & 6.289 & 5.9756 & TRN \\
\hline CHEMBL3923542 & 1641201 & 9.0 & 8.1047 & TRN \\
\hline CHEMBL3983891 & 1641201 & 7.5086 & 6.9461 & TRN \\
\hline CHEMBL3957993 & 1641201 & 6.7696 & 6.6436 & TRN \\
\hline
\end{tabular}

Page 14431 


\begin{tabular}{|c|c|c|c|c|c|}
\hline \multicolumn{6}{|c|}{ Supplemental Table S2.txt } \\
\hline CHEMBL3906797 & 1641201 & 9.0 & 8.6387 & TRN & \\
\hline CHEMBL 3932220 & 1641201 & 7.284 & 6.5479 & TRN & \\
\hline CHEMBL 3941154 & 1641201 & 6.983 & 6.1752 & TRN & \\
\hline CHEMBL 3913142 & 1641201 & 6.8794 & 6.0594 & TRN & \\
\hline CHEMBL 3960445 & 1641201 & 8.5229 & 8.60799 & 9999999999 & TRN \\
\hline CHEMBL3952463 & 1641201 & 6.6478 & 7.9274 & TRN & \\
\hline CHEMBL3927049 & 1641201 & 8.5229 & 8.4644 & TRN & \\
\hline CHEMBL 3915777 & 1641201 & 9.0 & 8.8135 & TRN & \\
\hline CHEMBL 3971543 & 1641201 & 8.1549 & 8.5607 & TRN & \\
\hline CHEMBL3959026 & 1641201 & 5.5845 & 6.7577 & TRN & \\
\hline CHEMBL3932969 & 1641201 & 8.699 & 8.6518 & TRN & \\
\hline CHEMBL3986011 & 1641201 & 6.2233 & 6.1634 & TRN & \\
\hline CHEMBL3936420 & 1641201 & 7.9586 & 7.9955 & TRN & \\
\hline CHEMBL 3951871 & 1641201 & 8.5229 & 8.676 & TRN & \\
\hline CHEMBL3959727 & 1641201 & 7.4437 & 6.9431 & TRN & \\
\hline CHEMBL3926020 & 1641201 & 7.5528 & 8.4756 & TRN & \\
\hline CHEMBL3970113 & 1641201 & 6.153 & 6.9511 & TRN & \\
\hline CHEMBL3929227 & 1641201 & 7.2596 & 8.7508 & TRN & \\
\hline CHEMBL 3937728 & 1641201 & 7.2291 & 6.9294 & TRN & \\
\hline CHEMBL3953439 & 1641201 & 9.0 & 8.32 & TST & \\
\hline CHEMBL3929299 & 1641201 & 8.301 & 8.5566 & TRN & \\
\hline CHEMBL3916269 & 1641201 & 9.0 & 8.6613 & TST & \\
\hline CHEMBL3924954 & 1641201 & 5.4963 & 6.7179 & TST & \\
\hline CHEMBL 3946563 & 1641201 & 7.7447 & 8.4021 & TST & \\
\hline CHEMBL3967322 & 1641201 & 9.0 & 8.4799 & TST & \\
\hline CHEMBL3969548 & 1641201 & 7.3468 & 8.4038 & TST & \\
\hline CHEMBL 3975253 & 1641201 & 6.2573 & 5.9685 & TST & \\
\hline CHEMBL3930490 & 1641201 & 6.3757 & 7.7811 & TST & \\
\hline CHEMBL 3957995 & 1641201 & 5.3375 & 7.1819 & TST & \\
\hline CHEMBL3889562 & 1641201 & 6.4584 & 7.3039 & TST & \\
\hline CHEMBL3963989 & 1641201 & 5.272 & 7.4483 & TST & \\
\hline CHEMBL 3959673 & 1641201 & 7.7696 & 8.4257 & TST & \\
\hline CHEMBL3955142 & 1641201 & 8.0 & 8.4583 & TST & \\
\hline CHEMBL3932853 & 1641201 & 9.0 & 8.704 & TST & \\
\hline CHEMBL1497214 & 809094 & 6.2147 & 6.1491 & TRN & \\
\hline CHEMBL1903217 & 809094 & 5.2636 & 5.3709 & TRN & \\
\hline CHEMBL1353179 & 809094 & 9.0458 & 7.4375 & TRN & \\
\hline CHEMBL1572115 & 809094 & 6.0 & 5.3596 & TRN & \\
\hline CHEMBL1965752 & 809094 & 6.0 & 5.1246 & TRN & \\
\hline CHEMBL1402451 & 809094 & 6.4248 & 5.4008 & TRN & \\
\hline CHEMBL1964469 & 809094 & 4.71 & 4.9495 & TRN & \\
\hline CHEMBL1702895 & 809094 & 4.71 & 5.5406 & TRN & \\
\hline CHEMBL1601501 & 809094 & 9.0458 & 5.6011 & TRN & \\
\hline CHEMBL1894896 & 809094 & 9.0458 & 5.3199 & TST & \\
\hline CHEMBL522983 & 809094 & 5.0088 & 5.06 & TRN & \\
\hline CHEMBL1705320 & 809094 & 6.0 & 5.1828 & TRN & \\
\hline CHEMBL 1455056 & 809094 & 4.8063 & 4.7537 & TRN & \\
\hline CHEMBL1581874 & 809094 & 5.2197 & 6.3471 & TRN & \\
\hline
\end{tabular}




\begin{tabular}{|c|c|c|c|c|c|}
\hline \multicolumn{6}{|c|}{ Supplemental Table S2.txt } \\
\hline CHEMBL1312212 & 809094 & 4.8016 & 5.2469 & TRN & \\
\hline CHEMBL1865583 & 809094 & 4.71 & 5.4202 & TRN & \\
\hline CHEMBL1602222 & 809094 & 5.3925 & 6.1468 & TST & \\
\hline CHEMBL1589639 & 809094 & 9.0458 & 4.5386 & TST & \\
\hline CHEMBL1419228 & 809094 & 5.4547 & 5.4021 & TRN & \\
\hline CHEMBL1314522 & 809094 & 4.9905 & 4.6786 & TRN & \\
\hline CHEMBL1466367 & 809094 & 4.9923 & 5.7968 & TRN & \\
\hline CHEMBL1986012 & 809094 & 9.0458 & 6.8433 & TRN & \\
\hline CHEMBL1365256 & 809094 & 4.71 & 5.575 & TRN & \\
\hline CHEMBL1385209 & 809094 & 4.71 & 5.7389 & TRN & \\
\hline CHEMBL1700809 & 809094 & 5.1871 & 5.9855 & TRN & \\
\hline CHEMBL1350520 & 809094 & 5.0625 & 5.97 & TRN & \\
\hline CHEMBL1336749 & 809094 & 6.0867 & 5.1576 & TRN & \\
\hline CHEMBL1967856 & 809094 & 9.0458 & 6.9282 & TRN & \\
\hline CHEMBL1377048 & 809094 & 4.71 & 5.3315 & TRN & \\
\hline CHEMBL1325366 & 809094 & 5.3686 & 5.1002 & TRN & \\
\hline CHEMBL1997716 & 809094 & 9.0458 & 6.2326 & TRN & \\
\hline CHEMBL1975589 & 809094 & 5.0953 & 4.8032 & TST & \\
\hline CHEMBL1318895 & 809094 & 4.71 & 5.0276 & TRN & \\
\hline CHEMBL1719426 & 809094 & 5.3716 & 5.4576 & TRN & \\
\hline CHEMBL1445410 & 809094 & 9.0458 & 4.7919 & TST & \\
\hline CHEMBL1528546 & 809094 & 4.71 & 6.149 & TRN & \\
\hline CHEMBL1317415 & 809094 & 4.7713 & 4.2808 & TRN & \\
\hline CHEMBL1711359 & 809094 & 4.7455 & 4.0353 & TRN & \\
\hline CHEMBL1388418 & 809094 & 4.71 & 5.2046 & TRN & \\
\hline CHEMBL32579 & 809094 & 5.118 & 5.2706 & TRN & \\
\hline CHEMBL1407485 & 809094 & 4.71 & 5.7252 & TRN & \\
\hline CHEMBL1599703 & 809094 & 9.0458 & 7.5412 & TRN & \\
\hline CHEMBL1459949 & 809094 & 6.3747 & 5.1275 & TRN & \\
\hline CHEMBL1496563 & 809094 & 4.71 & 6.2544 & TRN & \\
\hline CHEMBL1882710 & 809094 & 4.71 & 4.4556 & TST & \\
\hline CHEMBL1472008 & 809094 & 4.9731 & 6.726 & TRN & \\
\hline CHEMBL1711509 & 809094 & 5.0991 & 5.5872 & TRN & \\
\hline CHEMBL1730958 & 809094 & 5.0182 & 5.4982 & TST & \\
\hline CHEMBL1593882 & 809094 & 4.71 & 5.2826 & TRN & \\
\hline CHEMBL1369482 & 809094 & 4.8041 & 4.9705 & TRN & \\
\hline CHEMBL1575149 & 809094 & 5.2299 & 5.763 & TRN & \\
\hline CHEMBL1326263 & 809094 & 4.71 & 5.038 & TRN & \\
\hline CHEMBL1429017 & 809094 & 4.71 & 6.4442 & TRN & \\
\hline CHEMBL1544290 & 809094 & 4.71 & 5.0756 & TRN & \\
\hline CHEMBL1346813 & 809094 & 5.6655 & 5.5877 & TRN & \\
\hline CHEMBL1532097 & 809094 & 4.71 & 4.0541 & TRN & \\
\hline CHEMBL1472472 & 809094 & 4.7773 & 5.5465 & TRN & \\
\hline CHEMBL1097687 & 809094 & 4.8342 & 5.2865 & TRN & \\
\hline CHEMBL1598643 & 809094 & 4.9427 & 6.0218 & TRN & \\
\hline CHEMBL1544797 & 809094 & 5.5258 & 5.9614 & TRN & \\
\hline CHEMBL579956 & 809094 & 4.7997 & 5.62700 & 0000000001 & TRN \\
\hline CHEMBL511995 & 809094 & 4.8074 & 4.6889 & TRN & \\
\hline
\end{tabular}




\begin{tabular}{|c|c|c|c|c|c|}
\hline & & \multicolumn{4}{|c|}{ Supplemental Table S2.txt } \\
\hline CHEMBL1877342 & 809094 & 5.1599 & 5.2337 & TRN & \\
\hline CHEMBL1987920 & 809094 & 6.9031 & 4.7524 & TRN & \\
\hline CHEMBL1459881 & 809094 & 4.71 & 5.7229 & TRN & \\
\hline CHEMBL1536119 & 809094 & 6.2226 & 6.8304 & TST & \\
\hline CHEMBL1377464 & 809094 & 5.1701 & 5.6235 & TST & \\
\hline CHEMBL1321340 & 809094 & 4.8114 & 5.8173 & TST & \\
\hline CHEMBL1341750 & 809094 & 4.71 & 6.2618 & TST & \\
\hline CHEMBL1437405 & 809094 & 4.71 & 5.0433 & TST & \\
\hline CHEMBL1567225 & 809094 & 4.7263 & 5.6303 & TST & \\
\hline CHEMBL1502590 & 809094 & 4.9281 & 6.2107 & TST & \\
\hline CHEMBL 250450 & 809094 & 5.0496 & 5.2179 & TST & \\
\hline CHEMBL 82242 & 809094 & 6.0 & 5.0262 & TST & \\
\hline CHEMBL1560033 & 809094 & 4.71 & 5.9615 & TST & \\
\hline CHEMBL1459953 & 809094 & 4.8094 & 5.7525 & TST & \\
\hline CHEMBL1362479 & 809094 & 4.71 & 6.5434 & TST & \\
\hline CHEMBL1975853 & 809094 & 4.71 & 6.4303 & TST & \\
\hline CHEMBL1520096 & 688867 & 4.4697 & 5.5321 & TRN & \\
\hline CHEMBL1535460 & 688867 & 4.9398 & 4.9407 & TRN & \\
\hline CHEMBL1605565 & 688867 & 6.9914 & 4.8217 & TRN & \\
\hline CHEMBL1395051 & 688867 & 4.9531 & 4.6065 & TRN & \\
\hline CHEMBL1460749 & 688867 & 2.9208 & 4.1287 & TRN & \\
\hline CHEMBL1372616 & 688867 & 5.2901 & 3.77100 & 00000000004 & TRN \\
\hline CHEMBL1445361 & 688867 & 4.2812 & 4.9866 & TST & \\
\hline CHEMBL1388701 & 688867 & 4.7108 & 4.3073 & TRN & \\
\hline CHEMBL1406346 & 688867 & 6.4976 & 6.1315 & TRN & \\
\hline CHEMBL1353437 & 688867 & 4.5547 & 4.6985 & TRN & \\
\hline CHEMBL1331356 & 688867 & 4.9023 & 4.9598 & TRN & \\
\hline CHEMBL1461809 & 688867 & 6.8996 & 4.9534 & TRN & \\
\hline CHEMBL1550861 & 688867 & 4.0553 & 5.8264 & TRN & \\
\hline CHEMBL1325593 & 688867 & 4.9406 & 4.8031 & TRN & \\
\hline CHEMBL1534465 & 688867 & 4.7316 & 4.7477 & TRN & \\
\hline CHEMBL1347694 & 688867 & 4.6403 & 4.1968 & TRN & \\
\hline CHEMBL1307635 & 688867 & 6.2306 & 4.8267 & TRN & \\
\hline CHEMBL1479114 & 688867 & 5.6745 & 4.9818 & TRN & \\
\hline CHEMBL1611417 & 688867 & 5.0845 & 4.257 & TRN & \\
\hline CHEMBL1392554 & 688867 & 4.95 & 4.5636 & TRN & \\
\hline CHEMBL1531389 & 688867 & 4.6436 & 5.008 & TRN & \\
\hline CHEMBL1353499 & 688867 & 6.7852 & 5.6023 & TRN & \\
\hline CHEMBL1582073 & 688867 & 4.3502 & 4.8247 & TST & \\
\hline CHEMBL1453539 & 688867 & 5.0795 & 4.8804 & TRN & \\
\hline CHEMBL1390899 & 688867 & 4.5958 & 4.5181 & TRN & \\
\hline CHEMBL1561135 & 688867 & 8.0 & 5.5584 & TRN & \\
\hline CHEMBL1462713 & 688867 & 6.7545 & 6.5273 & TRN & \\
\hline CHEMBL3190926 & 688867 & 4.5308 & 4.2393 & TRN & \\
\hline CHEMBL1443936 & 688867 & 5.6486 & 6.4613 & TRN & \\
\hline CHEMBL1362558 & 688867 & 5.1484 & 5.282 & TRN & \\
\hline CHEMBL1556289 & 688867 & 2.9208 & 6.1536 & TRN & \\
\hline CHEMBL3197234 & 688867 & 8.0 & 6.6049 & TRN & \\
\hline
\end{tabular}




\begin{tabular}{|c|c|c|c|c|c|}
\hline \multicolumn{6}{|c|}{ oplemental Table S } \\
\hline CHEMBL1414419 & 688867 & 4.4835 & 5.0115 & TST & \\
\hline CHEMBL3212376 & 688867 & 6.7932 & 4.9975 & TRN & \\
\hline CHEMBL1564332 & 688867 & 8.0 & 5.5645 & TRN & \\
\hline CHEMBL1557320 & 688867 & 4.6109 & 5.3538 & TRN & \\
\hline CHEMBL1448605 & 688867 & 6.7212 & 5.8998 & TRN & \\
\hline CHEMBL1423940 & 688867 & 4.3235 & 4.5599 & TRN & \\
\hline CHEMBL1495908 & 688867 & 4.3404 & 5.1023 & TRN & \\
\hline CHEMBL1529438 & 688867 & 5.0915 & 4.3923 & TST & \\
\hline CHEMBL1414223 & 688867 & 5.0882 & 4.773 & TST & \\
\hline CHEMBL1584711 & 688867 & 5.0356 & 4.8859 & TRN & \\
\hline CHEMBL1369483 & 688867 & 8.0 & 5.8435 & TRN & \\
\hline CHEMBL495063 & 688867 & 5.5043 & 5.3216 & TST & \\
\hline CHEMBL1415813 & 688867 & 4.4341 & 5.0723 & TRN & \\
\hline CHEMBL1304199 & 688867 & 4.8432 & 5.006 & TRN & \\
\hline CHEMBL1504204 & 688867 & 5.0747 & 3.83 & TRN & \\
\hline CHEMBL1369590 & 688867 & 3.2218 & 4.7709 & TRN & \\
\hline CHEMBL1443564 & 688867 & 4.4328 & 5.1255 & TRN & \\
\hline CHEMBL3211069 & 688867 & 4.3115 & 4.9223 & TRN & \\
\hline CHEMBL1354346 & 688867 & 2.9208 & 4.0755 & TRN & \\
\hline CHEMBL1344475 & 688867 & 5.2421 & 5.7205 & TRN & \\
\hline CHEMBL1530653 & 688867 & 4.9626 & 4.4227 & TRN & \\
\hline CHEMBL1524702 & 688867 & 5.0641 & 4.38399 & 99999999995 & TST \\
\hline CHEMBL1445899 & 688867 & 2.9208 & 3.6503 & TRN & \\
\hline CHEMBL1576496 & 688867 & 4.3098 & 4.5966 & TRN & \\
\hline CHEMBL1551926 & 688867 & 5.0786 & 4.9682 & TST & \\
\hline CHEMBL1321322 & 688867 & 4.6064 & 4.7149 & TRN & \\
\hline CHEMBL1549665 & 688867 & 6.9666 & 5.478 & TRN & \\
\hline CHEMBL3212041 & 688867 & 4.4015 & 5.4829 & TRN & \\
\hline CHEMBL1998940 & 688867 & 2.9208 & 4.6539 & TST & \\
\hline CHEMBL1498632 & 688867 & 2.9208 & 5.0686 & TRN & \\
\hline CHEMBL1446387 & 688867 & 2.9208 & 3.61800 & 30000000003 & TRN \\
\hline CHEMBL469058 & 688867 & 4.163 & 4.4539 & TRN & \\
\hline CHEMBL1441613 & 688867 & 5.4449 & 4.9489 & TRN & \\
\hline CHEMBL1536236 & 688867 & 4.4259 & 4.3853 & TRN & \\
\hline CHEMBL 1302780 & 688867 & 5.0277 & 4.4569 & TRN & \\
\hline CHEMBL3190074 & 688867 & 4.474 & 5.4082 & TRN & \\
\hline CHEMBL1999595 & 688867 & 4.898 & 4.7512 & TRN & \\
\hline CHEMBL1401381 & 688867 & 4.4475 & 4.6033 & TRN & \\
\hline CHEMBL1581554 & 688867 & 4.7531 & 4.7173 & TRN & \\
\hline CHEMBL1601751 & 688867 & 6.8097 & 4.7464 & TRN & \\
\hline CHEMBL1601835 & 688867 & 4.2078 & 4.1147 & TRN & \\
\hline CHEMBL1589770 & 688867 & 5.1241 & 3.9298 & TRN & \\
\hline CHEMBL1521723 & 688867 & 4.8599 & 4.8529 & TRN & \\
\hline CHEMBL1600400 & 688867 & 2.9208 & 4.0478 & TST & \\
\hline CHEMBL476190 & 688867 & 5.3309 & 4.7813 & TRN & \\
\hline CHEMBL1998648 & 688867 & 3.2218 & 4.4533 & TRN & \\
\hline CHEMBL1357281 & 688867 & 5.1185 & 4.7903 & TRN & \\
\hline CHEMBL1452993 & 688867 & 4.5199 & 4.7629 & TRN & \\
\hline
\end{tabular}




\begin{tabular}{|c|c|c|c|c|c|c|}
\hline \multirow[b]{2}{*}{ CHEMBL1413839 } & \multirow[b]{2}{*}{688867} & \multicolumn{5}{|c|}{ Supplemental Table S2.txt } \\
\hline & & 3.9407 & 4.1675 & TRN & & \\
\hline CHEMBL3197115 & 688867 & 5.9776 & 5.7586 & TRN & & \\
\hline CHEMBL1496960 & 688867 & 5.1148 & 5.7797 & TRN & & \\
\hline CHEMBL3196904 & 688867 & 4.8005 & 5.1081 & TRN & & \\
\hline CHEMBL3207968 & 688867 & \multicolumn{3}{|c|}{4.428999999999999} & 6.5626 & TST \\
\hline CHEMBL1547901 & 688867 & 8.0 & 4.1119 & TRN & & \\
\hline CHEMBL1400744 & 688867 & 4.6999 & 4.8558 & TRN & & \\
\hline CHEMBL1454225 & 688867 & 4.8398 & 4.7936 & TRN & & \\
\hline CHEMBL1463023 & 688867 & 4.3077 & 4.3759 & TRN & & \\
\hline CHEMBL1536507 & 688867 & 8.0 & 5.3567 & TRN & & \\
\hline CHEMBL1384659 & 688867 & 3.2218 & 3.9715 & TST & & \\
\hline CHEMBL 2004918 & 688867 & 6.4401 & 5.5513 & TRN & & \\
\hline CHEMBL1609010 & 688867 & 4.689 & 5.3606 & TRN & & \\
\hline CHEMBL3191975 & 688867 & 6.0448 & 5.8531 & TST & & \\
\hline CHEMBL1353405 & 688867 & 4.8195 & 4.3815 & TRN & & \\
\hline CHEMBL1522037 & 688867 & 5.1392 & 4.3684 & TRN & & \\
\hline CHEMBL1488893 & 688867 & 4.4079 & 5.3915 & TRN & & \\
\hline CHEMBL1585789 & 688867 & 2.9208 & 4.1542 & TRN & & \\
\hline CHEMBL1406155 & 688867 & 6.8041 & 5.0848 & TRN & & \\
\hline CHEMBL1412908 & 688867 & 6.6126 & 6.0268 & TRN & & \\
\hline CHEMBL 252901 & 688867 & 5.1826 & 5.7274 & TRN & & \\
\hline CHEMBL1383664 & 688867 & 4.8529 & 3.8421 & TRN & & \\
\hline CHEMBL1698283 & 688867 & 2.9208 & 4.4526 & TRN & & \\
\hline CHEMBL1462378 & 688867 & 2.9208 & 4.6941 & TRN & & \\
\hline CHEMBL1447912 & 688867 & 4.7213 & 4.5624 & TRN & & \\
\hline CHEMBL1374459 & 688867 & 2.9208 & 3.7787 & TRN & & \\
\hline CHEMBL1321519 & 688867 & 8.0 & 5.4581 & TRN & & \\
\hline CHEMBL1564468 & 688867 & 5.0722 & 4.0975 & TRN & & \\
\hline CHEMBL1563664 & 688867 & 5.2597 & 5.4926 & TRN & & \\
\hline CHEMBL1364646 & 688867 & 6.7167 & 6.6548 & TRN & & \\
\hline CHEMBL1484963 & 688867 & 4.018 & 4.7473 & TRN & & \\
\hline CHEMBL1494524 & 688867 & 8.0 & 4.2718 & TRN & & \\
\hline CHEMBL3195974 & 688867 & 4.3295 & 5.1641 & TRN & & \\
\hline CHEMBL1598240 & 688867 & 5.3158 & 5.4672 & TRN & & \\
\hline CHEMBL1361268 & 688867 & 3.9743 & 6.1074 & TRN & & \\
\hline CHEMBL1527546 & 688867 & 4.8011 & 4.7413 & TRN & & \\
\hline CHEMBL3190070 & 688867 & 4.9544 & 5.2843 & TRN & & \\
\hline CHEMBL1440341 & 688867 & 4.4169 & 5.7116 & TRN & & \\
\hline CHEMBL1574074 & 688867 & 4.5343 & 5.4798 & TRN & & \\
\hline CHEMBL1337770 & 688867 & 4.923 & 5.4848 & TST & & \\
\hline CHEMBL1301421 & 688867 & 6.0477 & 5.0847 & TRN & & \\
\hline CHEMBL1545363 & 688867 & 5.4426 & 4.6655 & TST & & \\
\hline CHEMBL1393333 & 688867 & 4.0857 & 4.5427 & TRN & & \\
\hline CHEMBL1395615 & 688867 & 5.9586 & 5.5861 & TST & & \\
\hline CHEMBL1422230 & 688867 & 8.0 & 6.7246 & TST & & \\
\hline CHEMBL1411474 & 688867 & 2.9208 & 4.2077 & TRN & & \\
\hline CHEMBL1536621 & 688867 & 4.4799 & 4.6661 & TRN & & \\
\hline CHEMBL1358960 & 688867 & 4.9952 & 4.8548 & TRN & & \\
\hline
\end{tabular}




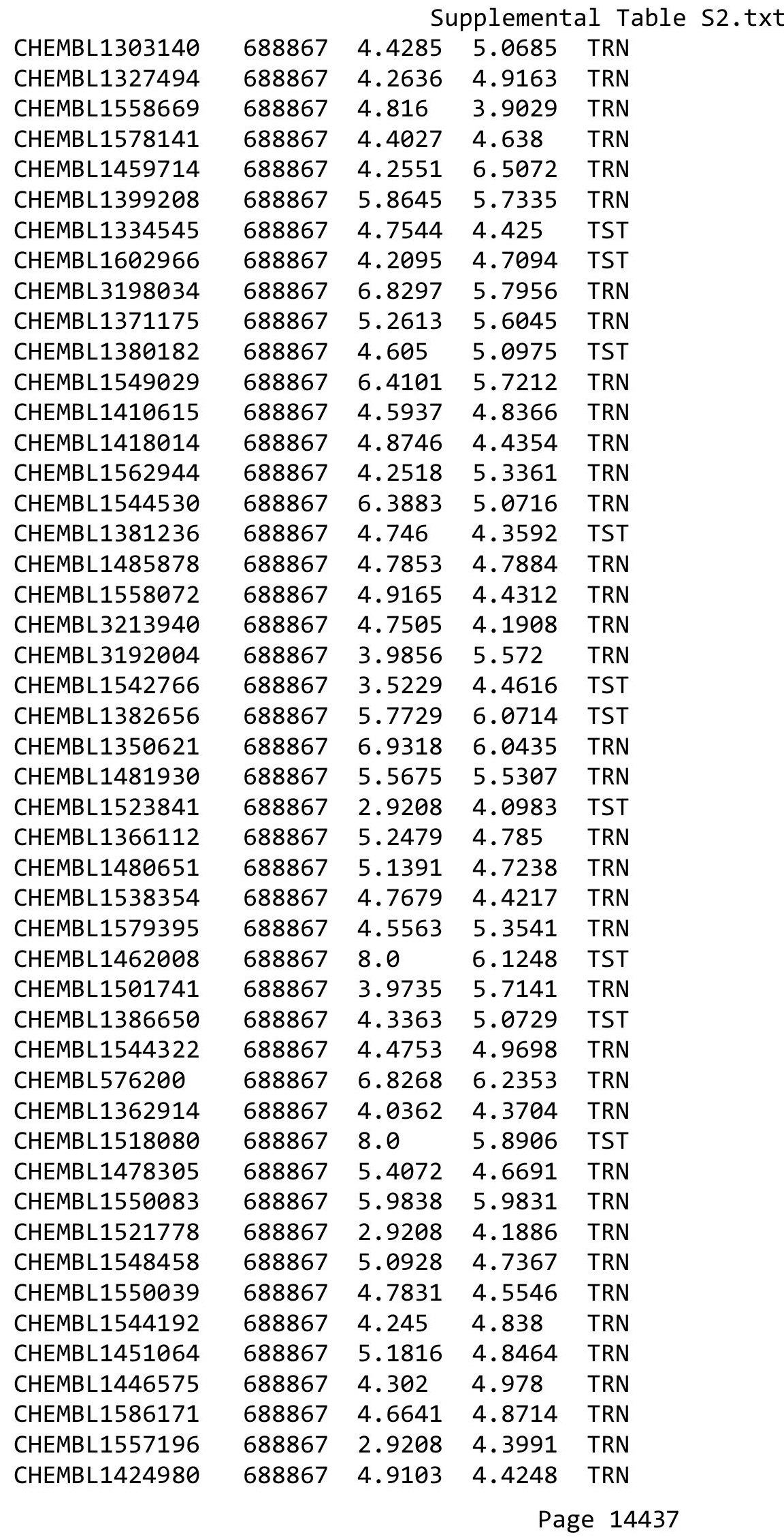




\begin{tabular}{|c|c|c|c|c|c|c|}
\hline & & \multicolumn{5}{|c|}{ Supplemental Table S2.txt } \\
\hline CHEMBL1513271 & 688867 & 2.9208 & 4.5835 & TRN & & \\
\hline CHEMBL1422468 & 688867 & 5.0946 & 5.2634 & TRN & & \\
\hline CHEMBL1383152 & 688867 & 4.7828 & 4.3475 & TRN & & \\
\hline CHEMBL3190711 & 688867 & 4.4373 & 5.9748 & TRN & & \\
\hline CHEMBL 1454860 & 688867 & 5.9488 & 5.1946 & TRN & & \\
\hline CHEMBL3211158 & 688867 & \multicolumn{3}{|c|}{6.7620000000000005} & 5.8215 & TRN \\
\hline CHEMBL1422056 & 688867 & 4.8282 & 5.0699 & TRN & & \\
\hline CHEMBL1502286 & 688867 & 5.1581 & 4.7069 & TST & & \\
\hline CHEMBL3192016 & 688867 & 4.9938 & 4.8147 & TRN & & \\
\hline CHEMBL1418678 & 688867 & 4.9547 & 4.4393 & TRN & & \\
\hline CHEMBL1490429 & 688867 & 8.0 & 6.6448 & TRN & & \\
\hline CHEMBL1388766 & 688867 & 2.9208 & 4.1444 & TRN & & \\
\hline CHEMBL1438797 & 688867 & 2.9208 & 3.8315 & TRN & & \\
\hline CHEMBL 1357756 & 688867 & 6.6326 & 4.2993 & TRN & & \\
\hline CHEMBL1493135 & 688867 & 5.0296 & 4.516 & TRN & & \\
\hline CHEMBL1492232 & 688867 & 4.0232 & 4.8103 & TRN & & \\
\hline CHEMBL1534523 & 688867 & 4.5577 & 4.5943 & TST & & \\
\hline CHEMBL1443457 & 688867 & 4.9415 & 4.7249 & TRN & & \\
\hline CHEMBL1428684 & 688867 & 5.93 & 5.2513 & TRN & & \\
\hline CHEMBL3195088 & 688867 & 4.7228 & 5.8919 & TRN & & \\
\hline CHEMBL1566003 & 688867 & 8.0 & 5.5655 & TRN & & \\
\hline CHEMBL1997288 & 688867 & 5.0188 & 3.6364 & TRN & & \\
\hline CHEMBL1582035 & 688867 & 4.9639 & 4.9331 & TRN & & \\
\hline CHEMBL 3210474 & 688867 & \multicolumn{3}{|c|}{5.127999999999999} & 5.0641 & TRN \\
\hline CHEMBL1374559 & 688867 & 2.9208 & 4.4659 & TRN & & \\
\hline CHEMBL1317919 & 688867 & 2.9208 & 3.4766 & TRN & & \\
\hline CHEMBL3191856 & 688867 & 5.3907 & 6.0595 & TRN & & \\
\hline CHEMBL3197987 & 688867 & 5.183 & 5.1752 & TRN & & \\
\hline CHEMBL1511008 & 688867 & 8.0 & 5.3883 & TRN & & \\
\hline CHEMBL1413214 & 688867 & 4.1883 & 4.5595 & TRN & & \\
\hline CHEMBL1360431 & 688867 & 6.9431 & 5.7999 & TRN & & \\
\hline CHEMBL1483680 & 688867 & 5.9743 & 5.1692 & TRN & & \\
\hline CHEMBL1421807 & 688867 & 4.3085 & 5.5272 & TRN & & \\
\hline CHEMBL1599365 & 688867 & 2.9208 & 4.0525 & TST & & \\
\hline CHEMBL585622 & 688867 & 5.3132 & 3.5125 & TRN & & \\
\hline CHEMBL1376590 & 688867 & 4.8901 & 5.2783 & TST & & \\
\hline CHEMBL1323910 & 688867 & 4.9129 & 4.7998 & TST & & \\
\hline CHEMBL1547533 & 688867 & 4.4718 & 5.0319 & TST & & \\
\hline CHEMBL1992801 & 688867 & 6.1586 & 6.0799 & TRN & & \\
\hline CHEMBL1403377 & 688867 & 4.7584 & 4.4099 & TRN & & \\
\hline CHEMBL1987798 & 688867 & 8.0 & 7.0813 & TRN & & \\
\hline CHEMBL1365216 & 688867 & 6.9031 & 5.8043 & TRN & & \\
\hline CHEMBL3189901 & 688867 & 4.851 & 6.0816 & TRN & & \\
\hline CHEMBL1563027 & 688867 & 2.9208 & 4.0186 & TST & & \\
\hline CHEMBL1353881 & 688867 & 4.0477 & 4.5164 & TRN & & \\
\hline CHEMBL1308386 & 688867 & 3.9248 & 5.1067 & TRN & & \\
\hline CHEMBL1594893 & 688867 & 4.7942 & 3.8569 & TST & & \\
\hline CHEMBL1586474 & 688867 & 5.1651 & 4.8217 & TRN & & \\
\hline
\end{tabular}


Supplemental Table S2.txt

\begin{tabular}{|c|c|c|c|c|}
\hline CHEMBL1613430 & 688867 & 4.9917 & 4.7231 & TRN \\
\hline CHEMBL1565061 & 688867 & 4.9076 & 4.8993 & TRN \\
\hline CHEMBL1556655 & 688867 & 4.7813 & 4.7083 & TST \\
\hline CHEMBL1542242 & 688867 & 6.7799 & 5.6079 & TRN \\
\hline CHEMBL3192101 & 688867 & 5.2515 & 5.1855 & TRN \\
\hline CHEMBL1535665 & 688867 & 2.9208 & 3.9079 & TRN \\
\hline CHEMBL1301373 & 688867 & 6.857 & 4.7557 & TRN \\
\hline CHEMBL1432814 & 688867 & 4.3184 & 4.8368 & TRN \\
\hline CHEMBL1488930 & 688867 & 4.8098 & 4.105 & TRN \\
\hline CHEMBL1449473 & 688867 & 4.4171 & 5.6187 & TRN \\
\hline CHEMBL1501121 & 688867 & 4.3774 & 5.8011 & TRN \\
\hline CHEMBL1375202 & 688867 & 4.6344 & 4.9245 & TRN \\
\hline CHEMBL1441328 & 688867 & 5.0444 & 4.7396 & TST \\
\hline CHEMBL1303649 & 688867 & 4.4396 & 4.8148 & TRN \\
\hline CHEMBL1576462 & 688867 & 2.9208 & 4.999 & TRN \\
\hline CHEMBL1531245 & 688867 & 2.9208 & 3.7069 & TRN \\
\hline CHEMBL3191413 & 688867 & 4.2896 & 5.4731 & TRN \\
\hline CHEMBL1393143 & 688867 & 6.0878 & 6.0876 & TRN \\
\hline CHEMBL 3213703 & 688867 & 4.6235 & 4.3922 & TST \\
\hline CHEMBL1365808 & 688867 & 6.5884 & 5.1453 & TRN \\
\hline CHEMBL1364267 & 688867 & 5.0371 & 4.8895 & TRN \\
\hline CHEMBL240333 & 688867 & 5.4619 & 6.3667 & TRN \\
\hline CHEMBL1536255 & 688867 & 4.7034 & 5.46299 & 9999999999 \\
\hline CHEMBL1567309 & 688867 & 2.9208 & 4.7682 & TRN \\
\hline CHEMBL1466758 & 688867 & 4.3229 & 5.5425 & TRN \\
\hline CHEMBL1480985 & 688867 & 2.9208 & 3.91899 & 99999999996 \\
\hline CHEMBL1312308 & 688867 & 2.9208 & 4.1733 & TST \\
\hline CHEMBL1595573 & 688867 & 4.6173 & 4.8207 & TRN \\
\hline CHEMBL1309788 & 688867 & 8.0 & 5.706 & TRN \\
\hline CHEMBL 3199242 & 688867 & 4.5436 & 5.5243 & TRN \\
\hline CHEMBL1422337 & 688867 & 4.6704 & 5.5237 & TRN \\
\hline CHEMBL1390335 & 688867 & 4.3734 & 5.1239 & TRN \\
\hline CHEMBL492116 & 688867 & 4.4158 & 4.7651 & TRN \\
\hline CHEMBL1433770 & 688867 & 5.1369 & 4.9623 & TRN \\
\hline CHEMBL1468383 & 688867 & 5.1674 & 5.0249 & TRN \\
\hline CHEMBL3211626 & 688867 & 2.9208 & 4.8578 & TST \\
\hline CHEMBL1610276 & 688867 & 4.8011 & 4.7297 & TRN \\
\hline CHEMBL1550851 & 688867 & 2.9208 & 4.5695 & TRN \\
\hline CHEMBL1370754 & 688867 & 4.5089 & 4.3341 & TRN \\
\hline CHEMBL 1302420 & 688867 & 4.8819 & 4.7138 & TRN \\
\hline CHEMBL1323437 & 688867 & 2.9208 & 4.2636 & TST \\
\hline CHEMBL1391486 & 688867 & 4.6738 & 5.3721 & TRN \\
\hline CHEMBL1362757 & 688867 & 2.9208 & 4.112 & TRN \\
\hline CHEMBL1607208 & 688867 & 8.0 & 5.8339 & TRN \\
\hline CHEMBL1336959 & 688867 & 4.6323 & 4.0688 & TRN \\
\hline CHEMBL1392472 & 688867 & 4.9465 & 4.1081 & TRN \\
\hline CHEMBL1368165 & 688867 & 4.5487 & 5.2885 & TST \\
\hline CHEMBL1539263 & 688867 & 4.7738 & 4.3287 & TRN \\
\hline
\end{tabular}

Page 14439 


\begin{tabular}{|c|c|c|c|c|c|c|}
\hline & & \multicolumn{5}{|c|}{ Supplemental Table S2.txt } \\
\hline CHEMBL1509227 & 688867 & 5.3291 & 5.2194 & TRN & & \\
\hline CHEMBL1525073 & 688867 & 2.9208 & 4.7475 & TRN & & \\
\hline CHEMBL567829 & 688867 & 2.9208 & 3.9657 & TST & & \\
\hline CHEMBL1510400 & 688867 & 8.0 & 5.9775 & TRN & & \\
\hline CHEMBL1420870 & 688867 & 5.0726 & 3.822 & TRN & & \\
\hline CHEMBL1448066 & 688867 & 6.9469 & 6.2099 & TRN & & \\
\hline CHEMBL1606705 & 688867 & 6.3429 & 3.9656 & TRN & & \\
\hline CHEMBL1510630 & 688867 & 4.9129 & 3.9751 & TRN & & \\
\hline CHEMBL1392365 & 688867 & 4.3468 & 4.0829 & TRN & & \\
\hline CHEMBL1387546 & 688867 & 4.6994 & 5.0016 & TRN & & \\
\hline CHEMBL1305288 & 688867 & 6.5331 & 4.668 & TRN & & \\
\hline CHEMBL1520703 & 688867 & 5.8286 & 6.2333 & TRN & & \\
\hline CHEMBL1333661 & 688867 & 4.1996 & 4.7044 & TRN & & \\
\hline CHEMBL139250 & 688867 & 2.9208 & 4.988 & TRN & & \\
\hline CHEMBL1446574 & 688867 & 6.6716 & 6.2429 & TRN & & \\
\hline CHEMBL1542533 & 688867 & 6.4123 & 6.774 & TRN & & \\
\hline CHEMBL1407407 & 688867 & 4.7992 & 5.1909 & TST & & \\
\hline CHEMBL1373917 & 688867 & 4.9232 & 4.9252 & TST & & \\
\hline CHEMBL1467438 & 688867 & 4.9838 & 4.3828 & TRN & & \\
\hline CHEMBL1378700 & 688867 & 2.9208 & 5.4916 & TST & & \\
\hline CHEMBL3197123 & 688867 & 4.9559 & 6.2461 & TRN & & \\
\hline CHEMBL1300675 & 688867 & 2.9208 & 4.7213 & TRN & & \\
\hline CHEMBL1580472 & 688867 & 3.2218 & 3.819 & TRN & & \\
\hline CHEMBL1381436 & 688867 & 2.9208 & 3.8078 & TRN & & \\
\hline CHEMBL1583989 & 688867 & 5.1568 & 5.1374 & TRN & & \\
\hline CHEMBL1410469 & 688867 & 4.8759 & 5.3294 & TRN & & \\
\hline CHEMBL1422573 & 688867 & 8.0 & 5.5672 & TRN & & \\
\hline CHEMBL1366559 & 688867 & 5.0156 & 4.9209 & TRN & & \\
\hline CHEMBL1317605 & 688867 & 4.9268 & 4.6641 & TRN & & \\
\hline CHEMBL1609490 & 688867 & 4.9438 & 3.8854 & TRN & & \\
\hline CHEMBL1603448 & 688867 & 4.4172 & 5.4679 & TRN & & \\
\hline CHEMBL1468965 & 688867 & 4.3967 & 3.9536 & TRN & & \\
\hline CHEMBL1579931 & 688867 & 4.9664 & 4.5536 & TRN & & \\
\hline CHEMBL1424754 & 688867 & 6.6289 & 6.1694 & TRN & & \\
\hline CHEMBL1418134 & 688867 & 5.0843 & 5.3605 & TRN & & \\
\hline CHEMBL1450777 & 688867 & 4.4959 & 4.8045 & TRN & & \\
\hline CHEMBL1364689 & 688867 & 5.0906 & 4.5771 & TST & & \\
\hline CHEMBL1420382 & 688867 & 5.3784 & 4.9189 & TRN & & \\
\hline CHEMBL1491745 & 688867 & 2.9208 & 6.2304 & TRN & & \\
\hline CHEMBL1415834 & 688867 & 4.7165 & 5.199 & TRN & & \\
\hline CHEMBL1611998 & 688867 & 5.437 & 5.3844 & TRN & & \\
\hline CHEMBL1088589 & 688867 & 6.6925 & 6.0159 & TRN & & \\
\hline CHEMBL1439895 & 688867 & 5.0038 & 4.9273 & TRN & & \\
\hline CHEMBL1450952 & 688867 & 5.6434 & 4.7233 & TRN & & \\
\hline CHEMBL1353660 & 688867 & 4.6217 & 4.2987 & TRN & & \\
\hline CHEMBL1508085 & 688867 & 2.9208 & 4.0185 & TRN & & \\
\hline CHEMBL1603708 & 688867 & 4.51699 & 99999999 & 995 & 4.8565 & TRN \\
\hline CHEMBL1489593 & 688867 & 4.047 & 5.3244 & TRN & & \\
\hline
\end{tabular}




\begin{tabular}{|c|c|c|c|c|}
\hline & & & pplement & al $\mathrm{T}$ \\
\hline CHEMBL1518811 & 688867 & 4.7939 & 4.5156 & TRN \\
\hline CHEMBL1572722 & 688867 & 4.5271 & 5.9439 & TRN \\
\hline CHEMBL1484081 & 688867 & 5.044 & 5.1331 & TRN \\
\hline CHEMBL1347160 & 688867 & 4.5178 & 5.1895 & TRN \\
\hline CHEMBL104728 & 688867 & 6.4841 & 5.7789 & TRN \\
\hline CHEMBL1488333 & 688867 & 4.4208 & 6.0088 & TRN \\
\hline CHEMBL1347002 & 688867 & 4.8228 & 4.3793 & TRN \\
\hline CHEMBL1369424 & 688867 & 4.4499 & 6.0467 & TRN \\
\hline CHEMBL1480104 & 688867 & 4.0526 & 4.9132 & TRN \\
\hline CHEMBL1388416 & 688867 & 4.2906 & 4.5168 & TRN \\
\hline CHEMBL1557519 & 688867 & 4.2524 & 4.7034 & TRN \\
\hline CHEMBL1581941 & 688867 & 8.0 & 5.5189 & TRN \\
\hline CHEMBL1599411 & 688867 & 6.8894 & 6.8414 & TRN \\
\hline CHEMBL1357288 & 688867 & 8.0 & 5.3337 & TRN \\
\hline CHEMBL1445482 & 688867 & 2.9208 & 3.6438 & TRN \\
\hline CHEMBL1456985 & 688867 & 5.5122 & 4.6733 & TRN \\
\hline CHEMBL3197870 & 688867 & 8.0 & 5.9261 & TRN \\
\hline CHEMBL1390595 & 688867 & 4.8285 & 4.6982 & TRN \\
\hline CHEMBL1304553 & 688867 & 4.6437 & 5.5006 & TRN \\
\hline CHEMBL1343740 & 688867 & 4.4196 & 5.0074 & TRN \\
\hline CHEMBL1502465 & 688867 & 5.3323 & 6.7017 & TRN \\
\hline CHEMBL1305924 & 688867 & 4.7641 & 5.2204 & TRN \\
\hline CHEMBL1612547 & 688867 & 2.9208 & 4.0492 & TRN \\
\hline CHEMBL1327517 & 688867 & 2.9208 & 4.1074 & TRN \\
\hline CHEMBL1567107 & 688867 & 4.479 & 5.0989 & TRN \\
\hline CHEMBL512649 & 688867 & 4.7274 & 4.2623 & TST \\
\hline CHEMBL1596076 & 688867 & 4.7886 & 4.8977 & TRN \\
\hline CHEMBL1424478 & 688867 & 6.9914 & 5.1039 & TRN \\
\hline CHEMBL3194933 & 688867 & 4.7577 & 5.5198 & TRN \\
\hline CHEMBL1563844 & 688867 & 2.9208 & 4.1727 & TRN \\
\hline CHEMBL1429268 & 688867 & 6.3605 & 5.9758 & TRN \\
\hline CHEMBL 2001794 & 688867 & 3.2218 & 4.123 & TRN \\
\hline CHEMBL3211758 & 688867 & 2.9208 & 4.1266 & TRN \\
\hline CHEMBL1490718 & 688867 & 6.5482 & 5.8241 & TRN \\
\hline CHEMBL1570507 & 688867 & 5.0991 & 4.6468 & TRN \\
\hline CHEMBL1976271 & 688867 & 2.9208 & 5.3236 & TRN \\
\hline CHEMBL1416015 & 688867 & 4.7605 & 4.8516 & TRN \\
\hline CHEMBL1517426 & 688867 & 2.9208 & 3.7359 & TST \\
\hline CHEMBL1584686 & 688867 & 4.8605 & 4.0789 & TRN \\
\hline CHEMBL1572878 & 688867 & 4.792 & 4.073 & TRN \\
\hline CHEMBL601070 & 688867 & 2.9208 & 4.2846 & TRN \\
\hline CHEMBL1585189 & 688867 & 4.6213 & 4.2445 & TST \\
\hline CHEMBL1534249 & 688867 & 4.2964 & 4.726 & TST \\
\hline CHEMBL1399126 & 688867 & 2.9208 & 4.646 & TRN \\
\hline CHEMBL312032 & 688867 & 4.8875 & 4.7417 & TRN \\
\hline CHEMBL1612542 & 688867 & 4.8907 & 5.4891 & TRN \\
\hline CHEMBL1978063 & 688867 & 8.0 & 6.0805 & TRN \\
\hline CHEMBL1471693 & 688867 & 4.6644 & 4.7676 & TRN \\
\hline
\end{tabular}




\begin{tabular}{|c|c|c|c|c|c|c|}
\hline \\
\hline CHEMBL1501925 & 688867 & 4.9667 & 4.9263 & TRN & & \\
\hline CHEMBL1558301 & 688867 & 4.6994 & 5.0238 & TST & & \\
\hline CHEMBL1391282 & 688867 & 4.7246 & 4.581 & TRN & & \\
\hline CHEMBL1610220 & 688867 & 4.346 & 4.9255 & TRN & & \\
\hline CHEMBL1384739 & 688867 & 5.3984 & 5.5978 & TRN & & \\
\hline CHEMBL1377335 & 688867 & 5.2455 & 5.0352 & TST & & \\
\hline CHEMBL 3195592 & 688867 & 5.0753 & 4.8303 & TRN & & \\
\hline CHEMBL3197411 & 688867 & 6.7595 & 5.0098 & TRN & & \\
\hline CHEMBL1507676 & 688867 & 8.0 & 6.8153 & TRN & & \\
\hline CHEMBL1530257 & 688867 & 4.7286 & 4.8 & TRN & & \\
\hline CHEMBL1439775 & 688867 & 5.2052 & 4.8913 & TRN & & \\
\hline CHEMBL1367908 & 688867 & 8.0 & 4.8073 & TST & & \\
\hline CHEMBL1588752 & 688867 & 5.0009 & 4.6809 & TRN & & \\
\hline CHEMBL1387251 & 688867 & 5.2468 & 6.3616 & TRN & & \\
\hline CHEMBL1575033 & 688867 & 4.9291 & 5.6403 & TRN & & \\
\hline CHEMBL3193613 & 688867 & 6.4949 & 6.0042 & TRN & & \\
\hline CHEMBL1449093 & 688867 & 4.6495 & 4.9757 & TRN & & \\
\hline CHEMBL3211169 & 688867 & 2.9208 & 4.0368 & TRN & & \\
\hline CHEMBL1307237 & 688867 & 6.3788 & 4.5244 & TRN & & \\
\hline CHEMBL1371198 & 688867 & 2.9208 & 5.5355 & TRN & & \\
\hline CHEMBL1302741 & 688867 & 6.2403 & 6.7262 & TRN & & \\
\hline CHEMBL1335068 & 688867 & 2.9208 & 3.5406 & TRN & & \\
\hline CHEMBL1387465 & 688867 & 4.44300 & 00000000 & 205 & 5.2411 & TRN \\
\hline CHEMBL1477333 & 688867 & 5.8019 & 5.7297 & TRN & & \\
\hline CHEMBL1609788 & 688867 & 4.0925 & 4.8272 & TST & & \\
\hline CHEMBL1383500 & 688867 & 4.4797 & 4.8701 & TRN & & \\
\hline CHEMBL1511429 & 688867 & 2.9208 & 4.6165 & TRN & & \\
\hline CHEMBL1525529 & 688867 & 6.75700 & 00000000 & & 5.6767 & TRN \\
\hline CHEMBL1476282 & 688867 & 5.0231 & 4.5943 & TRN & & \\
\hline CHEMBL1501051 & 688867 & 3.9951 & 5.0446 & TRN & & \\
\hline CHEMBL3199635 & 688867 & 4.9194 & 4.4346 & TRN & & \\
\hline CHEMBL1560251 & 688867 & 4.6151 & 4.4836 & TRN & & \\
\hline CHEMBL1533679 & 688867 & 4.5008 & 5.1632 & TRN & & \\
\hline CHEMBL1511487 & 688867 & 4.3344 & 5.1358 & TRN & & \\
\hline CHEMBL 3189738 & 688867 & 4.9816 & 5.3007 & TRN & & \\
\hline CHEMBL 2007400 & 688867 & 4.8313 & 3.8061 & TRN & & \\
\hline CHEMBL1336874 & 688867 & 5.2887 & 4.2568 & TRN & & \\
\hline CHEMBL1435486 & 688867 & 4.8655 & 5.8311 & TRN & & \\
\hline CHEMBL1534832 & 688867 & 2.9208 & 4.4373 & TRN & & \\
\hline CHEMBL1483951 & 688867 & 6.4377 & 6.1313 & TRN & & \\
\hline CHEMBL1612481 & 688867 & 4.6564 & 5.3218 & TRN & & \\
\hline CHEMBL1390438 & 688867 & 6.3161 & 5.9113 & TRN & & \\
\hline CHEMBL1308593 & 688867 & 4.9138 & 5.3376 & TRN & & \\
\hline CHEMBL1431044 & 688867 & 4.9644 & 5.164 & TRN & & \\
\hline CHEMBL1492469 & 688867 & 6.3516 & 5.4737 & TRN & & \\
\hline CHEMBL1306554 & 688867 & 4.7702 & 5.0455 & TRN & & \\
\hline CHEMBL1369567 & 688867 & 4.7732 & 4.8157 & TST & & \\
\hline CHEMBL1575609 & 688867 & 2.9208 & 3.9573 & TRN & & \\
\hline
\end{tabular}




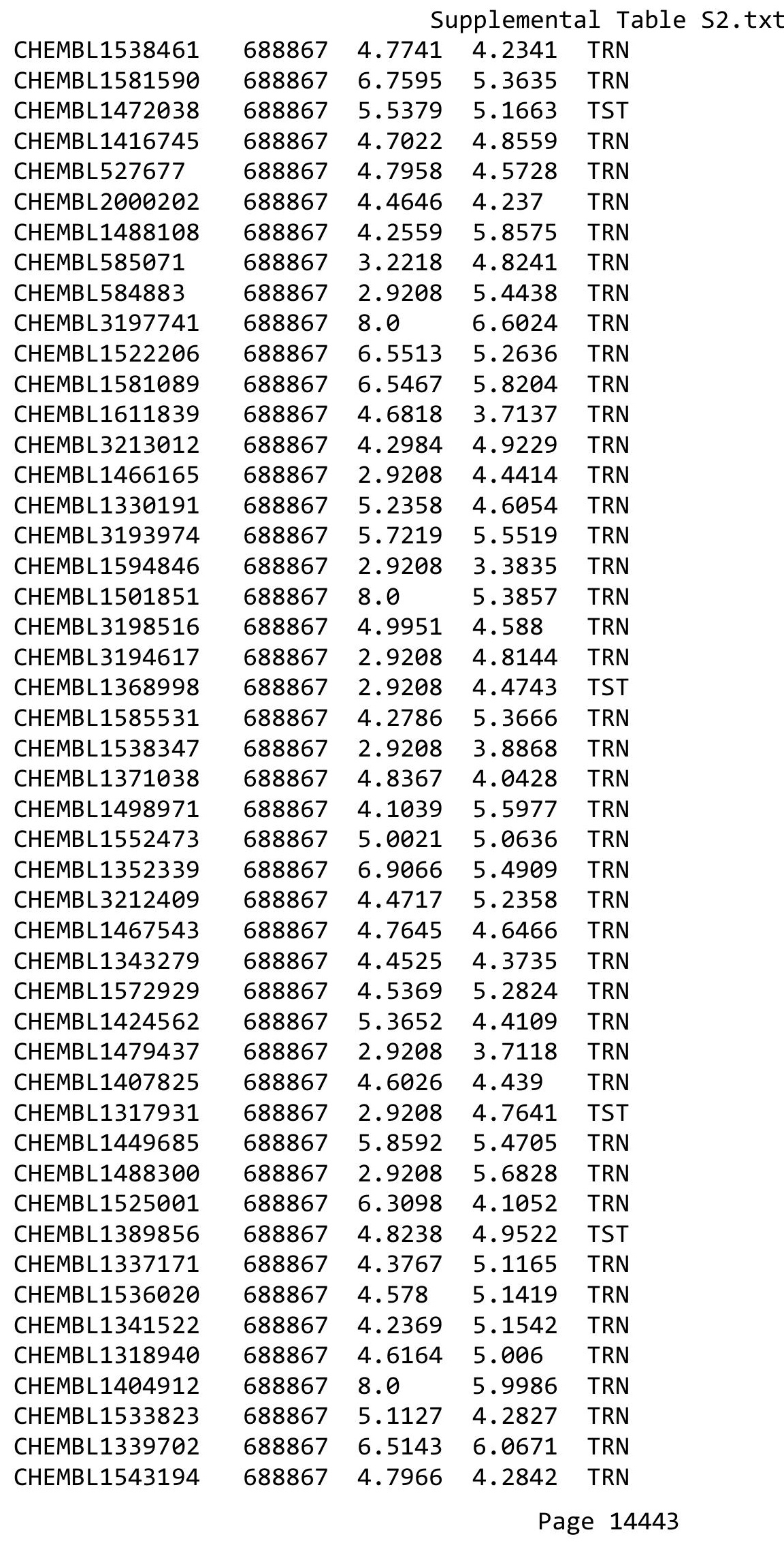





\begin{tabular}{|c|c|c|c|c|}
\hline & & & oplement & al $\mathrm{T}$ \\
\hline CHEMBL1421394 & 688867 & 4.9577 & 4.0586 & TRN \\
\hline CHEMBL1468717 & 688867 & 4.362 & 4.5117 & TRN \\
\hline CHEMBL1368552 & 688867 & 4.7623 & 4.2819 & TRN \\
\hline CHEMBL1510805 & 688867 & 4.9212 & 4.7809 & TRN \\
\hline CHEMBL1556666 & 688867 & 4.9677 & 4.0651 & TRN \\
\hline CHEMBL1376011 & 688867 & 6.8827 & 5.3566 & TRN \\
\hline CHEMBL1589378 & 688867 & 5.1246 & 5.2674 & TRN \\
\hline CHEMBL1577893 & 688867 & 6.1494 & 5.1068 & TRN \\
\hline CHEMBL3211273 & 688867 & 4.7072 & 5.7714 & TRN \\
\hline CHEMBL1326044 & 688867 & 4.9303 & 3.8534 & TRN \\
\hline CHEMBL1577623 & 688867 & 4.458 & 5.0443 & TRN \\
\hline CHEMBL 3190273 & 688867 & 8.0 & 5.5912 & TRN \\
\hline CHEMBL1396533 & 688867 & 4.0394 & 5.8124 & TRN \\
\hline CHEMBL3193751 & 688867 & 4.5776 & 4.7894 & TRN \\
\hline CHEMBL 3195749 & 688867 & 2.9208 & 4.2327 & TRN \\
\hline CHEMBL1558211 & 688867 & 5.2929 & 5.8065 & TRN \\
\hline CHEMBL560553 & 688867 & 4.7823 & 4.4277 & TRN \\
\hline CHEMBL1402596 & 688867 & 4.7668 & 5.1403 & TRN \\
\hline CHEMBL1578622 & 688867 & 4.8707 & 4.3718 & TRN \\
\hline CHEMBL1577289 & 688867 & 4.882 & 5.0451 & TRN \\
\hline CHEMBL1439137 & 688867 & 4.9793 & 4.9827 & TRN \\
\hline CHEMBL1376118 & 688867 & 6.1278 & 6.4116 & TRN \\
\hline CHEMBL1367297 & 688867 & 4.4562 & 4.2059 & TST \\
\hline CHEMBL1494178 & 688867 & 6.289 & 5.3107 & TRN \\
\hline CHEMBL1596598 & 688867 & 4.8114 & 4.8162 & TRN \\
\hline CHEMBL1366133 & 688867 & 4.5097 & 4.9403 & TRN \\
\hline CHEMBL1491863 & 688867 & 4.298 & 4.5911 & TRN \\
\hline CHEMBL3208161 & 688867 & 8.0 & 5.5982 & TRN \\
\hline CHEMBL1457445 & 688867 & 4.4747 & 5.1179 & TRN \\
\hline CHEMBL1511456 & 688867 & 4.2169 & 5.6563 & TST \\
\hline CHEMBL1399096 & 688867 & 5.0734 & 4.0922 & TRN \\
\hline CHEMBL 3193521 & 688867 & 4.8362 & 4.837 & TRN \\
\hline CHEMBL1575402 & 688867 & 8.0 & 5.4213 & TRN \\
\hline CHEMBL1565500 & 688867 & 6.4498 & 5.6627 & TST \\
\hline CHEMBL116569 & 688867 & 4.5754 & 6.2951 & TRN \\
\hline CHEMBL1450173 & 688867 & 4.939 & 4.9964 & TRN \\
\hline CHEMBL1320349 & 688867 & 4.8045 & 4.0759 & TRN \\
\hline CHEMBL1396872 & 688867 & 5.2738 & 4.7644 & TRN \\
\hline CHEMBL1305131 & 688867 & 4.3654 & 5.0618 & TST \\
\hline CHEMBL1309143 & 688867 & 4.7698 & 4.5177 & TST \\
\hline CHEMBL1376944 & 688867 & 4.8626 & 4.3314 & TRN \\
\hline CHEMBL1403575 & 688867 & 4.5703 & 3.7005 & TRN \\
\hline CHEMBL1324703 & 688867 & 6.9393 & 7.0224 & TRN \\
\hline CHEMBL1451470 & 688867 & 2.9208 & 4.0244 & TRN \\
\hline CHEMBL1489535 & 688867 & 2.9208 & 4.7212 & TST \\
\hline CHEMBL1525320 & 688867 & 4.9205 & 4.5805 & TRN \\
\hline CHEMBL131037 & 688867 & 3.2218 & 3.8188 & TRN \\
\hline CHEMBL1984052 & 688867 & 8.0 & 5.4281 & TRN \\
\hline
\end{tabular}




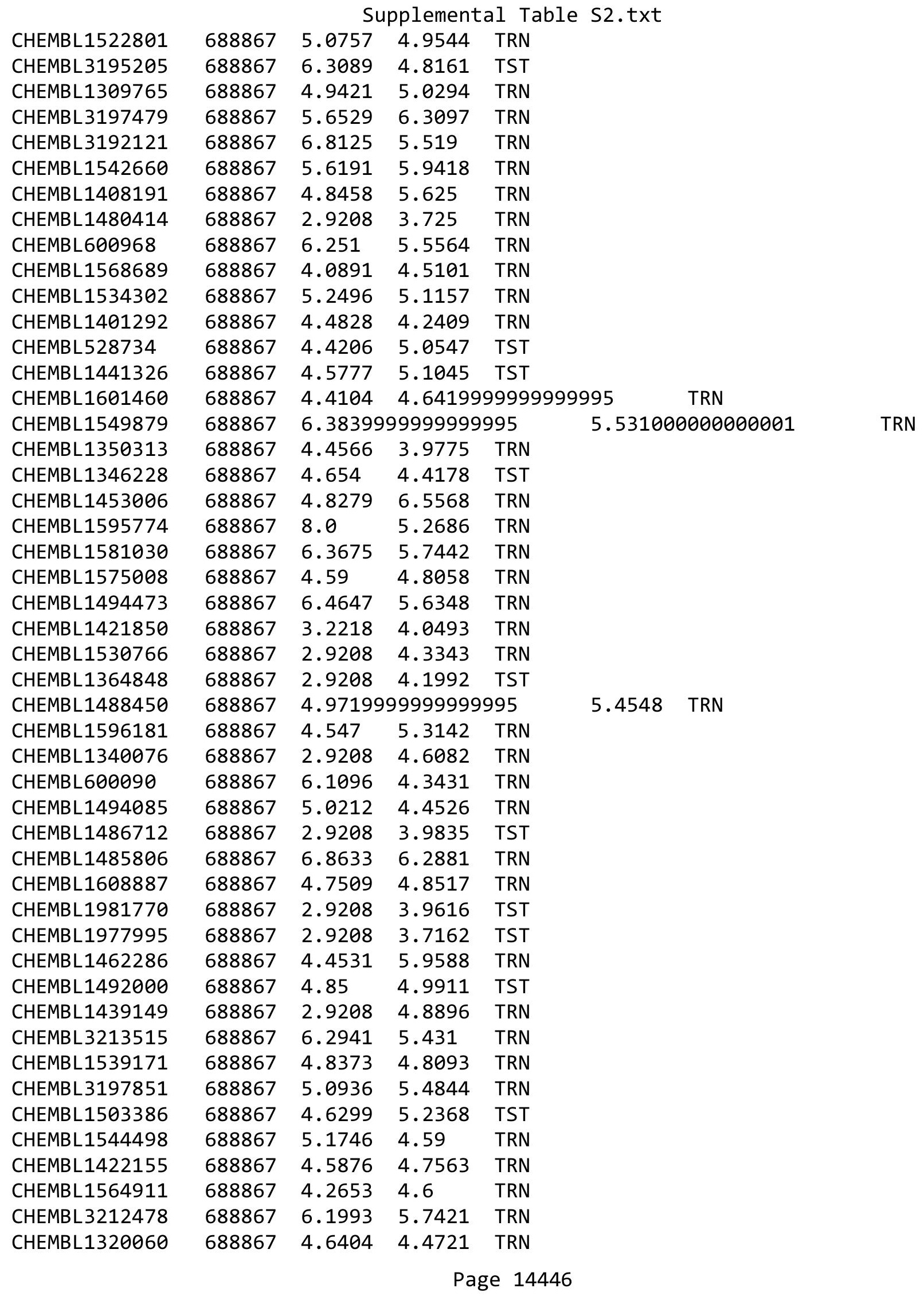




\begin{tabular}{|c|c|c|c|c|c|}
\hline \\
\hline CHEMBL1586026 & 688867 & 8.0 & 4.2118 & TRN & \\
\hline CHEMBL3213784 & 688867 & 5.2343 & 5.5071 & TRN & \\
\hline CHEMBL1510937 & 688867 & 5.1718 & 6.0343 & TRN & \\
\hline CHEMBL1449911 & 688867 & 6.8928 & 6.0185 & TRN & \\
\hline CHEMBL1470875 & 688867 & 5.7064 & 5.295 & TRN & \\
\hline CHEMBL1342491 & 688867 & 2.9208 & 5.6543 & TST & \\
\hline CHEMBL1335434 & 688867 & 2.9208 & 4.836 & TRN & \\
\hline CHEMBL1387034 & 688867 & 4.6068 & 4.2759 & TRN & \\
\hline CHEMBL1301035 & 688867 & 4.6207 & 4.2032 & TST & \\
\hline CHEMBL1588860 & 688867 & 8.0 & 5.769 & TRN & \\
\hline CHEMBL1308206 & 688867 & 4.5157 & 4.8024 & TRN & \\
\hline CHEMBL1613483 & 688867 & 6.4498 & 5.4946 & TRN & \\
\hline CHEMBL1531035 & 688867 & 4.8836 & 4.6878 & TRN & \\
\hline CHEMBL1382183 & 688867 & 2.9208 & 3.79399 & 99999999996 & TRN \\
\hline CHEMBL1570977 & 688867 & 4.0258 & 5.4801 & TRN & \\
\hline CHEMBL1504256 & 688867 & 6.556 & 5.8108 & TRN & \\
\hline CHEMBL1342766 & 688867 & 4.752 & 5.4206 & TST & \\
\hline CHEMBL1351765 & 688867 & 5.2325 & 4.3432 & TRN & \\
\hline CHEMBL1566477 & 688867 & 4.9114 & 4.2644 & TRN & \\
\hline CHEMBL1379768 & 688867 & 4.7373 & 4.6278 & TRN & \\
\hline CHEMBL1598190 & 688867 & 4.6484 & 3.7665 & TRN & \\
\hline CHEMBL1527045 & 688867 & 4.2241 & 4.8503 & TRN & \\
\hline CHEMBL1338990 & 688867 & 2.9208 & 4.0556 & TST & \\
\hline CHEMBL3196868 & 688867 & 6.9136 & 5.9772 & TRN & \\
\hline CHEMBL1334134 & 688867 & 4.8911 & 4.1182 & TRN & \\
\hline CHEMBL1438259 & 688867 & 5.9606 & 5.13899 & 9999999999 & TRN \\
\hline CHEMBL1530182 & 688867 & 4.7919 & 5.7805 & TRN & \\
\hline CHEMBL1491707 & 688867 & 4.8309 & 4.4295 & TRN & \\
\hline CHEMBL1305886 & 688867 & 6.067 & 5.0773 & TRN & \\
\hline CHEMBL1427062 & 688867 & 8.0 & 5.6483 & TRN & \\
\hline CHEMBL1568702 & 688867 & 4.4132 & 6.3186 & TST & \\
\hline CHEMBL1491031 & 688867 & 4.7694 & 5.5485 & TRN & \\
\hline CHEMBL1567793 & 688867 & 8.0 & 5.2794 & TRN & \\
\hline CHEMBL3196035 & 688867 & 2.9208 & 4.5259 & TST & \\
\hline CHEMBL1502176 & 688867 & 2.9208 & 4.2348 & TRN & \\
\hline CHEMBL1477949 & 688867 & 4.2486 & 4.8439 & TRN & \\
\hline CHEMBL1502542 & 688867 & 4.7944 & 5.5392 & TRN & \\
\hline CHEMBL1324465 & 688867 & 4.5712 & 5.5482 & TRN & \\
\hline CHEMBL1409944 & 688867 & 4.4982 & 4.8327 & TRN & \\
\hline CHEMBL1597878 & 688867 & 5.0888 & 5.3956 & TRN & \\
\hline CHEMBL1409330 & 688867 & 4.2727 & 5.7096 & TRN & \\
\hline CHEMBL1414244 & 688867 & 4.0809 & 3.9021 & TRN & \\
\hline CHEMBL1518669 & 688867 & 2.9208 & 4.2691 & TRN & \\
\hline CHEMBL1610086 & 688867 & 5.1276 & 4.415 & TRN & \\
\hline CHEMBL1541791 & 688867 & 4.8901 & 4.7496 & TRN & \\
\hline CHEMBL 2000947 & 688867 & 4.8856 & 4.1344 & TRN & \\
\hline CHEMBL1457749 & 688867 & 4.0884 & 4.681 & TRN & \\
\hline CHEMBL1382847 & 688867 & 5.318 & 5.5432 & TRN & \\
\hline
\end{tabular}




\begin{tabular}{|c|c|c|c|c|c|}
\hline \multicolumn{6}{|c|}{ splemental lable s2 } \\
\hline CHEMBL1335404 & 688867 & 8.0 & 6.1467 & TRN & \\
\hline CHEMBL1308374 & 688867 & 2.9208 & 5.2608 & TST & \\
\hline CHEMBL1530938 & 688867 & 4.4963 & 5.096 & TRN & \\
\hline CHEMBL1410151 & 688867 & 4.9023 & 4.5944 & TRN & \\
\hline CHEMBL1328903 & 688867 & 4.6428 & 4.6422 & TRN & \\
\hline CHEMBL1524916 & 688867 & 4.8624 & 4.24100 & 00000000005 & TST \\
\hline CHEMBL3208511 & 688867 & 2.9208 & 4.9577 & TRN & \\
\hline CHEMBL1578816 & 688867 & 4.7246 & 4.7668 & TRN & \\
\hline CHEMBL1303281 & 688867 & 2.9208 & 3.5508 & TST & \\
\hline CHEMBL1462109 & 688867 & 6.4776 & 6.1359 & TRN & \\
\hline CHEMBL1352590 & 688867 & 4.5604 & 4.9378 & TRN & \\
\hline CHEMBL1525755 & 688867 & 4.1532 & 5.8652 & TST & \\
\hline CHEMBL1343527 & 688867 & 8.0 & 6.5625 & TRN & \\
\hline CHEMBL1330446 & 688867 & 6.7258 & 6.0863 & TRN & \\
\hline CHEMBL1451747 & 688867 & 2.9208 & 3.9126 & TRN & \\
\hline CHEMBL1398665 & 688867 & 4.9785 & 5.2858 & TRN & \\
\hline CHEMBL1609703 & 688867 & 2.9208 & 4.4542 & TST & \\
\hline CHEMBL1339785 & 688867 & 4.1964 & 5.9879 & TST & \\
\hline CHEMBL1579339 & 688867 & 6.7212 & 7.3511 & TRN & \\
\hline CHEMBL1344216 & 688867 & 6.71 & 5.4678 & TRN & \\
\hline CHEMBL1410857 & 688867 & 2.9208 & 3.9343 & TRN & \\
\hline CHEMBL1559251 & 688867 & 8.0 & 6.6031 & TRN & \\
\hline CHEMBL1491320 & 688867 & 5.0171 & 4.5809 & TRN & \\
\hline CHEMBL1444341 & 688867 & 5.0957 & 4.3523 & TRN & \\
\hline CHEMBL1428012 & 688867 & 2.9208 & 4.4486 & TRN & \\
\hline CHEMBL1421506 & 688867 & 2.9208 & 3.9077 & TRN & \\
\hline CHEMBL1310403 & 688867 & 4.5596 & 4.6422 & TRN & \\
\hline CHEMBL1548929 & 688867 & 5.9 & 5.4077 & TRN & \\
\hline CHEMBL1331362 & 688867 & 6.0942 & 4.6271 & TRN & \\
\hline CHEMBL1967184 & 688867 & 4.4063 & 4.6427 & TST & \\
\hline CHEMBL1392461 & 688867 & 4.4758 & 4.4214 & TRN & \\
\hline CHEMBL1321786 & 688867 & 2.9208 & 4.8775 & TRN & \\
\hline CHEMBL1371624 & 688867 & 5.8778 & 5.371 & TRN & \\
\hline CHEMBL1586145 & 688867 & 8.0 & 6.5243 & TRN & \\
\hline CHEMBL1526676 & 688867 & 4.7064 & 5.544 & TST & \\
\hline CHEMBL1556906 & 688867 & 4.6826 & 4.8852 & TRN & \\
\hline CHEMBL1380397 & 688867 & 2.9208 & 4.7891 & TRN & \\
\hline CHEMBL1403215 & 688867 & 4.208 & 4.7661 & TRN & \\
\hline CHEMBL1523458 & 688867 & 8.0 & 5.9498 & TST & \\
\hline CHEMBL1489931 & 688867 & 4.0113 & 4.9811 & TRN & \\
\hline CHEMBL1528180 & 688867 & 4.8388 & 4.7528 & TRN & \\
\hline CHEMBL1977683 & 688867 & 4.8878 & 5.3362 & TRN & \\
\hline CHEMBL1465534 & 688867 & 5.1316 & 3.9757 & TRN & \\
\hline CHEMBL1581345 & 688867 & 4.8781 & 5.9827 & TRN & \\
\hline CHEMBL1362566 & 688867 & 3.9756 & 4.905 & TST & \\
\hline CHEMBL1531764 & 688867 & 6.7447 & 5.5507 & TRN & \\
\hline CHEMBL1350667 & 688867 & 4.2939 & 4.5582 & TRN & \\
\hline CHEMBL1505540 & 688867 & 2.9208 & 3.9166 & TRN & \\
\hline
\end{tabular}




\begin{tabular}{|c|c|c|c|c|c|}
\hline & & \multicolumn{4}{|c|}{ Supplemental Table S2.txt } \\
\hline CHEMBL1421119 & 688867 & 2.9208 & 4.6673 & TRN & \\
\hline CHEMBL1502638 & 688867 & 4.711 & 4.4804 & TRN & \\
\hline CHEMBL1587805 & 688867 & 8.0 & 5.4462 & TRN & \\
\hline CHEMBL1541650 & 688867 & 4.7992 & 4.0419 & TRN & \\
\hline CHEMBL3197286 & 688867 & 5.2203 & 4.5213 & TST & \\
\hline CHEMBL1337152 & 688867 & 2.9208 & 4.9268 & TRN & \\
\hline CHEMBL1409789 & 688867 & 4.6472 & 5.5446 & TRN & \\
\hline CHEMBL1402437 & 688867 & 8.0 & 4.9129 & TRN & \\
\hline CHEMBL1503609 & 688867 & 5.0275 & 4.5352 & TRN & \\
\hline CHEMBL1377682 & 688867 & 2.9208 & 3.6717 & TRN & \\
\hline CHEMBL1597773 & 688867 & 2.9208 & 3.7886 & TRN & \\
\hline CHEMBL1572118 & 688867 & 6.0287 & 5.3154 & TRN & \\
\hline CHEMBL3208320 & 688867 & 4.6089 & 3.9696 & TRN & \\
\hline CHEMBL1414067 & 688867 & 4.5182 & 5.9283 & TRN & \\
\hline CHEMBL1578674 & 688867 & 4.8761 & 4.6814 & TRN & \\
\hline CHEMBL3208065 & 688867 & 4.9124 & 5.0122 & TRN & \\
\hline CHEMBL1977589 & 688867 & 8.0 & 7.0723 & TRN & \\
\hline CHEMBL1311838 & 688867 & 5.3179 & 5.1548 & TRN & \\
\hline CHEMBL1401270 & 688867 & 4.0747 & 4.5268 & TRN & \\
\hline CHEMBL1364392 & 688867 & 5.4995 & 5.1172 & TRN & \\
\hline CHEMBL1353083 & 688867 & 4.2557 & 5.0713 & TRN & \\
\hline CHEMBL1600749 & 688867 & 8.0 & 5.9421 & TRN & \\
\hline CHEMBL1557161 & 688867 & 4.7301 & 4.8597 & TRN & \\
\hline CHEMBL1310486 & 688867 & 4.516 & 3.9697 & TRN & \\
\hline CHEMBL1306090 & 688867 & 4.572 & 5.5768 & TRN & \\
\hline CHEMBL1490778 & 688867 & 4.6607 & 4.8277 & TRN & \\
\hline CHEMBL1550249 & 688867 & 4.9957 & 4.6222 & TRN & \\
\hline CHEMBL1306033 & 688867 & 6.9469 & 5.3623 & TST & \\
\hline CHEMBL1306147 & 688867 & 2.9208 & 4.5327 & TRN & \\
\hline CHEMBL3212959 & 688867 & 2.9208 & 5.38200 & 0000000001 & TRN \\
\hline CHEMBL1341023 & 688867 & 2.9208 & 4.1634 & TRN & \\
\hline CHEMBL3192482 & 688867 & 4.992 & 4.6122 & TRN & \\
\hline CHEMBL3196175 & 688867 & 4.5446 & 4.9291 & TRN & \\
\hline CHEMBL1491264 & 688867 & 6.71899 & 99999999 & 6.1464 & TRN \\
\hline CHEMBL1329655 & 688867 & 4.7042 & 5.0207 & TRN & \\
\hline CHEMBL1359250 & 688867 & 5.0125 & 4.1891 & TRN & \\
\hline CHEMBL1337145 & 688867 & 4.9235 & 5.4195 & TRN & \\
\hline CHEMBL1483754 & 688867 & 4.5224 & 5.16799 & 9999999999 & TST \\
\hline CHEMBL1386412 & 688867 & 2.9208 & 3.5325 & TRN & \\
\hline CHEMBL1551741 & 688867 & 4.6021 & 4.5636 & TRN & \\
\hline CHEMBL1558144 & 688867 & 2.9208 & 3.8816 & TRN & \\
\hline CHEMBL1400312 & 688867 & 4.5908 & 5.3475 & TRN & \\
\hline CHEMBL1545721 & 688867 & 4.5422 & 4.8947 & TRN & \\
\hline CHEMBL1469054 & 688867 & 8.0 & 4.6846 & TRN & \\
\hline CHEMBL3197003 & 688867 & 2.9208 & 4.1347 & TRN & \\
\hline CHEMBL1319483 & 688867 & 4.3993 & 4.7246 & TRN & \\
\hline CHEMBL1566939 & 688867 & 6.9066 & 5.3565 & TRN & \\
\hline CHEMBL1490976 & 688867 & 8.0 & 5.7199 & TRN & \\
\hline
\end{tabular}




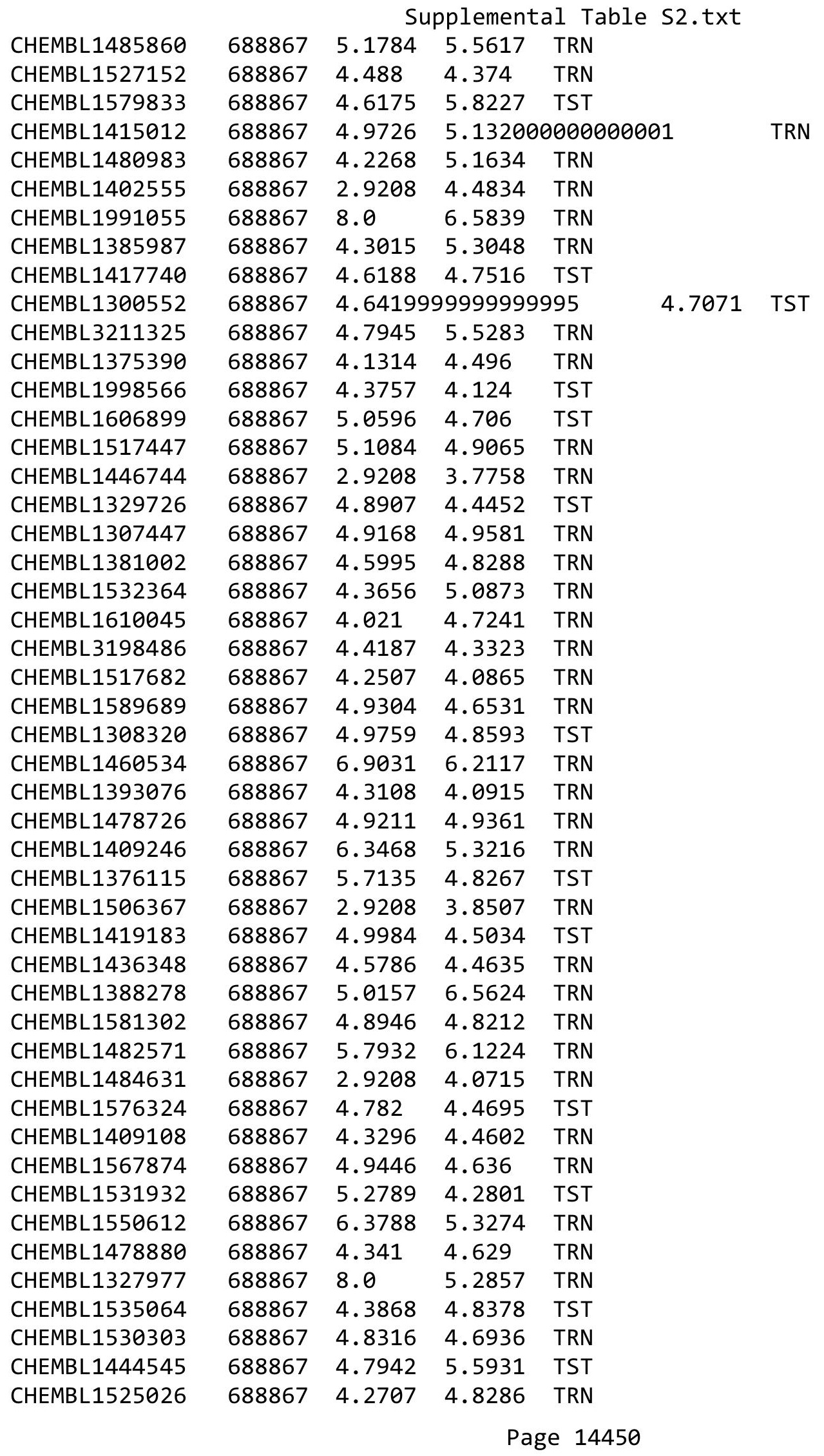




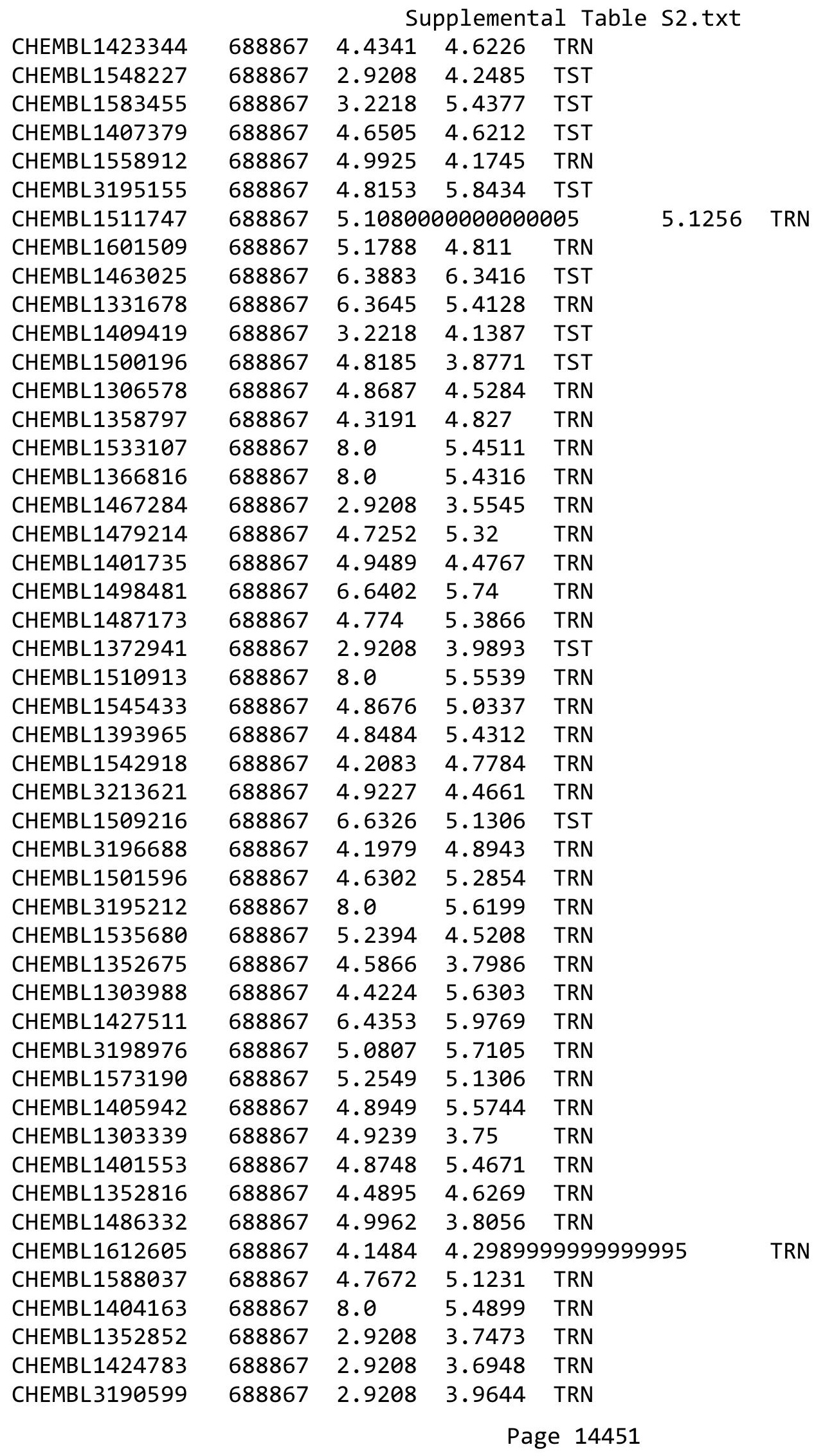




\begin{tabular}{|c|c|c|c|c|c|c|}
\hline & & \multicolumn{5}{|c|}{ Supplemental Table S2.txt } \\
\hline CHEMBL1974926 & 688867 & 5.7289 & 5.2098 & TRN & & \\
\hline CHEMBL3196102 & 688867 & 8.0 & 6.1078 & TRN & & \\
\hline CHEMBL1530943 & 688867 & 6.8447 & 6.6106 & TRN & & \\
\hline CHEMBL1450420 & 688867 & 4.5289 & 4.8358 & TRN & & \\
\hline CHEMBL1440361 & 688867 & 2.9208 & 3.89 & TRN & & \\
\hline CHEMBL1374706 & 688867 & 8.0 & 4.7767 & TST & & \\
\hline CHEMBL1585599 & 688867 & 5.1754 & 4.7452 & TRN & & \\
\hline CHEMBL1977963 & 688867 & 2.9208 & 4.4197 & TRN & & \\
\hline CHEMBL1464329 & 688867 & 4.6972 & 4.2162 & TRN & & \\
\hline CHEMBL1464980 & 688867 & 5.0419 & 4.3574 & TRN & & \\
\hline CHEMBL1351823 & 688867 & 3.2218 & 3.4421 & TRN & & \\
\hline CHEMBL1463302 & 688867 & 4.9206 & 4.1831 & TRN & & \\
\hline CHEMBL1391325 & 688867 & 5.3615 & 5.9447 & TRN & & \\
\hline CHEMBL1885024 & 688867 & 8.0 & 3.8052 & TRN & & \\
\hline CHEMBL1505173 & 688867 & 4.7854 & 5.0206 & TRN & & \\
\hline CHEMBL1579176 & 688867 & 4.7317 & 4.6735 & TRN & & \\
\hline CHEMBL1586319 & 688867 & 4.6134 & 3.8869 & TRN & & \\
\hline CHEMBL1477760 & 688867 & 4.5577 & 5.2014 & TST & & \\
\hline CHEMBL1421415 & 688867 & \multicolumn{3}{|c|}{ 4.763999999999999 } & .4976 & TRN \\
\hline CHEMBL1343099 & 688867 & 5.3479 & 5.6033 & TST & & \\
\hline CHEMBL1587454 & 688867 & 4.7851 & 4.448 & TRN & & \\
\hline CHEMBL1328025 & 688867 & 6.8097 & 4.9449 & TRN & & \\
\hline CHEMBL1363543 & 688867 & 2.9208 & 4.4992 & TRN & & \\
\hline CHEMBL1578490 & 688867 & 4.9615 & 4.8866 & TRN & & \\
\hline CHEMBL1530721 & 688867 & 4.5325 & 4.6626 & TRN & & \\
\hline CHEMBL1427637 & 688867 & 2.9208 & 3.4901 & TST & & \\
\hline CHEMBL1377687 & 688867 & 6.8827 & 6.0784 & TRN & & \\
\hline CHEMBL1604106 & 688867 & 4.9778 & 4.2271 & TST & & \\
\hline CHEMBL3192388 & 688867 & 5.1285 & 4.1487 & TRN & & \\
\hline CHEMBL1533752 & 688867 & 5.0562 & 4.3574 & TST & & \\
\hline CHEMBL1383379 & 688867 & 8.0 & 5.3362 & TRN & & \\
\hline CHEMBL1450961 & 688867 & 4.7472 & 4.5592 & TRN & & \\
\hline CHEMBL1471700 & 688867 & 8.0 & 5.5946 & TST & & \\
\hline CHEMBL1440560 & 688867 & 8.0 & 4.3023 & TST & & \\
\hline CHEMBL1520326 & 688867 & 4.8643 & 3.8171 & TRN & & \\
\hline CHEMBL1343030 & 688867 & 4.5683 & 4.1738 & TRN & & \\
\hline CHEMBL1377858 & 688867 & 6.9066 & 5.7433 & TRN & & \\
\hline CHEMBL1501969 & 688867 & 4.5651 & 4.3944 & TRN & & \\
\hline CHEMBL1449627 & 688867 & 6.8827 & 6.8349 & TRN & & \\
\hline CHEMBL1302976 & 688867 & 4.7284 & 4.7123 & TRN & & \\
\hline CHEMBL1442956 & 688867 & 4.8431 & 5.0408 & TRN & & \\
\hline CHEMBL1305810 & 688867 & 6.7282 & 5.5606 & TRN & & \\
\hline CHEMBL1366110 & 688867 & 2.9208 & 3.9689 & TRN & & \\
\hline CHEMBL1405384 & 688867 & 2.9208 & 4.15600 & 0000000001 & & TRN \\
\hline CHEMBL1449655 & 688867 & 2.9208 & 5.6864 & TRN & & \\
\hline CHEMBL1523917 & 688867 & 4.2677 & 4.843 & TRN & & \\
\hline CHEMBL1573309 & 688867 & 4.6775 & 4.4023 & TST & & \\
\hline CHEMBL1328527 & 688867 & 8.0 & 6.6917 & TRN & & \\
\hline
\end{tabular}




\begin{tabular}{|c|c|c|c|c|c|}
\hline & & \multicolumn{4}{|c|}{ Supplemental Table S2.txt } \\
\hline CHEMBL1459415 & 688867 & 2.9208 & 3.8366 & TRN & \\
\hline CHEMBL 3191398 & 688867 & 5.7144 & 6.5507 & TRN & \\
\hline CHEMBL201039 & 688867 & 2.9208 & 3.878 & TRN & \\
\hline CHEMBL1388901 & 688867 & 8.0 & 5.6722 & TRN & \\
\hline CHEMBL1361693 & 688867 & 8.0 & 5.8475 & TST & \\
\hline CHEMBL1477375 & 688867 & 8.0 & 5.4012 & TRN & \\
\hline CHEMBL1549877 & 688867 & 4.4797 & 5.0567 & TRN & \\
\hline CHEMBL1428992 & 688867 & 4.0598 & 5.7122 & TRN & \\
\hline CHEMBL1534478 & 688867 & 4.6866 & 4.516 & TRN & \\
\hline CHEMBL1443303 & 688867 & 2.9208 & 4.0435 & TRN & \\
\hline CHEMBL 3194650 & 688867 & 4.8791 & 4.8405 & TRN & \\
\hline CHEMBL1467750 & 688867 & 2.9208 & 4.1249 & TST & \\
\hline CHEMBL1347288 & 688867 & 4.6243 & 6.1502 & TRN & \\
\hline CHEMBL1543843 & 688867 & 4.5441 & 4.8691 & TRN & \\
\hline CHEMBL1521031 & 688867 & 4.5723 & 4.8672 & TST & \\
\hline CHEMBL1537737 & 688867 & 4.1361 & 5.42200 & 0000000001 & TRN \\
\hline CHEMBL1520975 & 688867 & 4.9872 & 4.3547 & TRN & \\
\hline CHEMBL1373336 & 688867 & 5.0367 & 4.6798 & TRN & \\
\hline CHEMBL1313750 & 688867 & 4.9763 & 4.9789 & TST & \\
\hline CHEMBL1459112 & 688867 & 4.9483 & 4.8926 & TRN & \\
\hline CHEMBL1347104 & 688867 & 2.9208 & 4.4386 & TRN & \\
\hline CHEMBL1562955 & 688867 & 4.7173 & 5.2488 & TRN & \\
\hline CHEMBL1371851 & 688867 & 4.7712 & 4.7867 & TRN & \\
\hline CHEMBL1579841 & 688867 & 4.8008 & 6.1191 & TRN & \\
\hline CHEMBL 3191741 & 688867 & 4.9088 & 5.3879 & TRN & \\
\hline CHEMBL1574394 & 688867 & 4.7978 & 4.6397 & TRN & \\
\hline CHEMBL1390021 & 688867 & 4.6392 & 5.5076 & TRN & \\
\hline CHEMBL1466699 & 688867 & 5.0587 & 3.6925 & TRN & \\
\hline CHEMBL1467999 & 688867 & 5.2102 & 4.7105 & TRN & \\
\hline CHEMBL 3194251 & 688867 & 2.9208 & 4.5551 & TRN & \\
\hline CHEMBL1402339 & 688867 & 4.6782 & 4.7792 & TRN & \\
\hline CHEMBL1503325 & 688867 & 6.857 & 6.4678 & TRN & \\
\hline CHEMBL1570344 & 688867 & 6.7545 & 5.8361 & TRN & \\
\hline CHEMBL1588880 & 688867 & 5.3758 & 6.6384 & TRN & \\
\hline CHEMBL1349012 & 688867 & 6.2534 & 6.0838 & TRN & \\
\hline CHEMBL1367860 & 688867 & 4.8387 & 4.4046 & TST & \\
\hline CHEMBL1383700 & 688867 & 4.5813 & 5.7111 & TRN & \\
\hline CHEMBL1373061 & 688867 & 4.9686 & 5.0618 & TRN & \\
\hline CHEMBL1531960 & 688867 & 4.9095 & 4.4017 & TRN & \\
\hline CHEMBL1577430 & 688867 & 4.7817 & 5.6734 & TRN & \\
\hline CHEMBL 3198603 & 688867 & 4.8842 & 5.2253 & TST & \\
\hline CHEMBL1393834 & 688867 & 5.6131 & 5.9874 & TRN & \\
\hline CHEMBL1466288 & 688867 & 2.9208 & 5.4299 & TRN & \\
\hline CHEMBL1587263 & 688867 & 5.4175 & 5.7393 & TRN & \\
\hline CHEMBL1603512 & 688867 & 4.8138 & 5.2942 & TST & \\
\hline CHEMBL1527038 & 688867 & 8.0 & 5.1764 & TRN & \\
\hline CHEMBL1320633 & 688867 & 2.9208 & 4.4597 & TST & \\
\hline CHEMBL1389746 & 688867 & 4.7324 & 4.5441 & TRN & \\
\hline
\end{tabular}




\begin{tabular}{|c|c|c|c|c|c|}
\hline & & \multicolumn{4}{|c|}{ Supplemental Table s2.txt } \\
\hline CHEMBL1364200 & 688867 & 5.0251 & 4.7568 & TRN & \\
\hline CHEMBL1405401 & 688867 & 8.0 & 6.0463 & TRN & \\
\hline CHEMBL1574660 & 688867 & 4.9933 & 4.2736 & TRN & \\
\hline CHEMBL1326068 & 688867 & 5.0567 & 5.2963 & TRN & \\
\hline CHEMBL1315908 & 688867 & 6.3788 & 5.0845 & TRN & \\
\hline CHEMBL1541948 & 688867 & 8.0 & 5.9158 & TRN & \\
\hline CHEMBL1544075 & 688867 & 5.0909 & 4.4618 & TST & \\
\hline CHEMBL1528899 & 688867 & 2.9208 & 4.4556 & TRN & \\
\hline CHEMBL1564117 & 688867 & 2.9208 & 3.8659 & TRN & \\
\hline CHEMBL1483686 & 688867 & 4.4767 & 4.95100 & 00000000005 & TRN \\
\hline CHEMBL1603695 & 688867 & 4.3242 & 4.9384 & TRN & \\
\hline CHEMBL1397547 & 688867 & 2.9208 & 5.4668 & TRN & \\
\hline CHEMBL1482199 & 688867 & 4.5175 & 4.2951 & TRN & \\
\hline CHEMBL1299663 & 688867 & 4.5474 & 4.7825 & TST & \\
\hline CHEMBL1568905 & 688867 & 4.8113 & 5.5148 & TRN & \\
\hline CHEMBL1531774 & 688867 & 4.7785 & 4.9018 & TRN & \\
\hline CHEMBL1330543 & 688867 & 4.8996 & 5.0312 & TRN & \\
\hline CHEMBL1555260 & 688867 & 2.9208 & 4.8626 & TRN & \\
\hline CHEMBL1455567 & 688867 & 2.9208 & 4.596 & TST & \\
\hline CHEMBL547833 & 688867 & 4.8882 & 4.211 & TRN & \\
\hline CHEMBL1402159 & 688867 & 4.5209 & 5.4593 & TRN & \\
\hline CHEMBL1542043 & 688867 & 5.7011 & 4.1644 & TRN & \\
\hline CHEMBL1311825 & 688867 & 4.0335 & 5.2743 & TRN & \\
\hline CHEMBL1338750 & 688867 & 8.0 & 6.0204 & TRN & \\
\hline CHEMBL1344387 & 688867 & 4.5421 & 5.41299 & 9999999999 & TRN \\
\hline CHEMBL1326481 & 688867 & 5.251 & 5.9619 & TRN & \\
\hline CHEMBL1516764 & 688867 & 4.8654 & 4.6784 & TRN & \\
\hline CHEMBL1464721 & 688867 & 8.0 & 4.8695 & TRN & \\
\hline CHEMBL1987082 & 688867 & 8.0 & 6.7671 & TRN & \\
\hline CHEMBL1392667 & 688867 & 4.4771 & 5.5542 & TRN & \\
\hline CHEMBL1532369 & 688867 & 2.9208 & 3.8376 & TRN & \\
\hline CHEMBL1327643 & 688867 & 5.0397 & 4.963 & TRN & \\
\hline CHEMBL1454540 & 688867 & 4.9998 & 4.5977 & TRN & \\
\hline CHEMBL1522903 & 688867 & 4.4563 & 5.9426 & TRN & \\
\hline CHEMBL1602826 & 688867 & 4.9544 & 4.897 & TRN & \\
\hline CHEMBL1320994 & 688867 & 2.9208 & 3.4669 & TRN & \\
\hline CHEMBL1374228 & 688867 & 4.9168 & 4.4487 & TRN & \\
\hline CHEMBL1349916 & 688867 & 4.7904 & 3.8715 & TRN & \\
\hline CHEMBL1588778 & 688867 & 5.1708 & 4.3121 & TRN & \\
\hline CHEMBL1425046 & 688867 & 6.1713 & 6.3611 & TRN & \\
\hline CHEMBL588683 & 688867 & 6.1884 & 5.7671 & TRN & \\
\hline CHEMBL1331513 & 688867 & 5.7129 & 5.7554 & TRN & \\
\hline CHEMBL1530830 & 688867 & 5.019 & 4.5253 & TRN & \\
\hline CHEMBL1570117 & 688867 & 5.3231 & 4.7183 & TRN & \\
\hline CHEMBL1318394 & 688867 & 6.11799 & 99999999 & 4.7373 & TRN \\
\hline CHEMBL1458725 & 688867 & 4.501 & 4.2946 & TRN & \\
\hline CHEMBL1526136 & 688867 & 4.7226 & 4.4649 & TRN & \\
\hline CHEMBL1484374 & 688867 & 4.2507 & 4.4521 & TRN & \\
\hline
\end{tabular}




\begin{tabular}{|c|c|c|c|c|c|}
\hline \multicolumn{6}{|c|}{ Supplemental Table S2.txt } \\
\hline CHEMBL1514916 & 688867 & 3.2218 & 4.1937 & TST & \\
\hline CHEMBL1327780 & 688867 & 6.0506 & 6.0751 & TRN & \\
\hline CHEMBL1602105 & 688867 & 2.9208 & 3.9405 & TRN & \\
\hline CHEMBL1604264 & 688867 & 4.6716 & 4.9384 & TRN & \\
\hline CHEMBL1472807 & 688867 & 4.9535 & 5.1575 & TRN & \\
\hline CHEMBL1462522 & 688867 & 4.9579 & 5.3675 & TRN & \\
\hline CHEMBL372840 & 688867 & 2.9208 & 4.8363 & TST & \\
\hline CHEMBL1509078 & 688867 & 2.9208 & 3.8752 & TRN & \\
\hline CHEMBL1442140 & 688867 & 4.1414 & 5.4532 & TRN & \\
\hline CHEMBL1569442 & 688867 & 8.0 & 6.3168 & TRN & \\
\hline CHEMBL1549548 & 688867 & 4.3877 & 3.988 & TRN & \\
\hline CHEMBL1339266 & 688867 & 2.9208 & 4.4885 & TRN & \\
\hline CHEMBL1534933 & 688867 & 4.162 & 4.0754 & TRN & \\
\hline CHEMBL3198668 & 688867 & 4.4777 & 6.2807 & TRN & \\
\hline CHEMBL1531116 & 688867 & 2.9208 & 3.9118 & TRN & \\
\hline CHEMBL1393395 & 688867 & 2.9208 & 5.444 & TRN & \\
\hline CHEMBL1392796 & 688867 & 2.9208 & 3.92199 & 99999999997 & TRN \\
\hline CHEMBL1328052 & 688867 & 2.9208 & 4.9047 & TRN & \\
\hline CHEMBL1561202 & 688867 & 2.9208 & 4.8324 & TRN & \\
\hline CHEMBL1404510 & 688867 & 4.53 & 4.8343 & TRN & \\
\hline CHEMBL3198019 & 688867 & 4.6064 & 5.0523 & TRN & \\
\hline CHEMBL1574741 & 688867 & 4.9906 & 4.7808 & TRN & \\
\hline CHEMBL1524235 & 688867 & 4.2692 & 5.03100 & 0000000001 & TRN \\
\hline CHEMBL1384726 & 688867 & 2.9208 & 3.9168 & TRN & \\
\hline CHEMBL1455218 & 688867 & 5.278 & 5.114 & TRN & \\
\hline CHEMBL1417043 & 688867 & 4.6655 & 5.4832 & TRN & \\
\hline CHEMBL1585251 & 688867 & 2.9208 & 4.2906 & TRN & \\
\hline CHEMBL1603268 & 688867 & 6.9136 & 4.8534 & TST & \\
\hline CHEMBL1312512 & 688867 & 4.4999 & 4.7725 & TRN & \\
\hline CHEMBL1485736 & 688867 & 4.6201 & 4.7532 & TRN & \\
\hline CHEMBL1411542 & 688867 & 6.9355 & 5.2352 & TRN & \\
\hline CHEMBL1377181 & 688867 & 5.0095 & 4.4496 & TST & \\
\hline CHEMBL1385806 & 688867 & 4.8882 & 4.0118 & TRN & \\
\hline CHEMBL1527192 & 688867 & 4.4872 & 5.0236 & TRN & \\
\hline CHEMBL1607064 & 688867 & 2.9208 & 3.9245 & TRN & \\
\hline CHEMBL1440263 & 688867 & 4.9766 & 4.3608 & TRN & \\
\hline CHEMBL1427522 & 688867 & 4.9286 & 4.6912 & TRN & \\
\hline CHEMBL1478382 & 688867 & 4.71 & 4.9193 & TST & \\
\hline CHEMBL1342518 & 688867 & 2.9208 & 5.0059 & TST & \\
\hline CHEMBL1733957 & 688867 & 2.9208 & 4.2627 & TRN & \\
\hline CHEMBL1518828 & 688867 & 5.1028 & 5.3246 & TST & \\
\hline CHEMBL1377753 & 688867 & 4.3725 & 5.7741 & TST & \\
\hline CHEMBL3198916 & 688867 & 5.124 & 4.7598 & TRN & \\
\hline CHEMBL1469904 & 688867 & 2.9208 & 6.0161 & TRN & \\
\hline CHEMBL1432488 & 688867 & 4.2836 & 4.4802 & TRN & \\
\hline CHEMBL 3211742 & 688867 & 4.5216 & 4.9653 & TRN & \\
\hline CHEMBL1565105 & 688867 & 4.5301 & 4.2986 & TRN & \\
\hline CHEMBL1323478 & 688867 & 4.727 & 5.0576 & TRN & \\
\hline
\end{tabular}




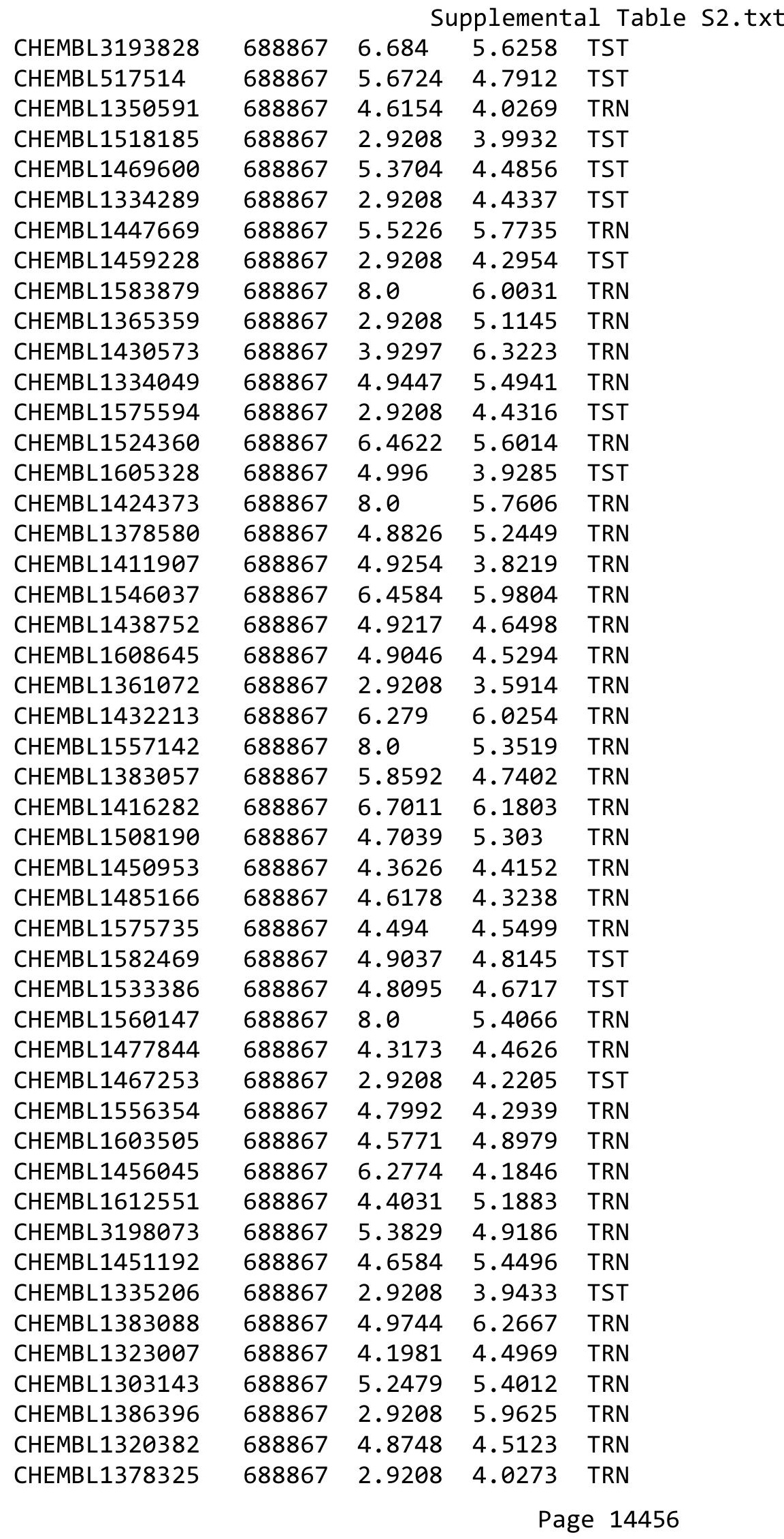




\begin{tabular}{|c|c|c|c|c|c|c|c|}
\hline \multicolumn{7}{|c|}{ Supplemental Table s2.txt } & \\
\hline CHEMBL1423459 & 688867 & 4.9543 & 3.928 & TRN & & & \\
\hline CHEMBL1546205 & 688867 & 2.9208 & 3.4568 & TRN & & & \\
\hline CHEMBL1494242 & 688867 & 4.8961 & 4.5869 & TRN & & & \\
\hline CHEMBL1371660 & 688867 & 4.17 & 4.6275 & TST & & & \\
\hline CHEMBL1315161 & 688867 & 4.9686 & 3.6661 & TRN & & & \\
\hline CHEMBL1305128 & 688867 & 2.9208 & 5.2439 & TRN & & & \\
\hline CHEMBL1418545 & 688867 & 4.0166 & 5.119 & TRN & & & \\
\hline CHEMBL1485099 & 688867 & 4.3909 & 4.6897 & TRN & & & \\
\hline CHEMBL1459418 & 688867 & 4.9059 & 5.2107 & TRN & & & \\
\hline CHEMBL1506291 & 688867 & 5.1681 & 4.6803 & TRN & & & \\
\hline CHEMBL1550657 & 688867 & 5.48600 & 00000000 & & .6072 & TRN & \\
\hline CHEMBL1442123 & 688867 & 4.8229 & 5.8003 & TRN & & & \\
\hline CHEMBL1561777 & 688867 & 4.4328 & 5.4343 & TST & & & \\
\hline CHEMBL1378837 & 688867 & 4.5952 & 4.2025 & TRN & & & \\
\hline CHEMBL1520661 & 688867 & 4.86 & 4.6206 & TST & & & \\
\hline CHEMBL1596117 & 688867 & 6.7905 & 5.4397 & TRN & & & \\
\hline CHEMBL483137 & 688867 & 5.4338 & 4.1591 & TRN & & & \\
\hline CHEMBL3193288 & 688867 & 4.6848 & 5.2726 & TST & & & \\
\hline CHEMBL1335336 & 688867 & 5.0981 & 5.1152 & TRN & & & \\
\hline CHEMBL3190857 & 688867 & 4.8994 & 4.1478 & TRN & & & \\
\hline CHEMBL1572244 & 688867 & 5.1006 & 4.0091 & TRN & & & \\
\hline CHEMBL1466147 & 688867 & 6.9586 & 5.7885 & TRN & & & \\
\hline CHEMBL1347452 & 688867 & 4.9395 & 3.83399 & 99999999996 & & TRN & \\
\hline CHEMBL1321895 & 688867 & 4.3174 & 4.3259 & TRN & & & \\
\hline CHEMBL1542537 & 688867 & 4.82600 & 20000000 & 005 & .89300 & 00000000002 & TRN \\
\hline CHEMBL1573986 & 688867 & 4.1741 & 5.1839 & TRN & & & \\
\hline CHEMBL1375907 & 688867 & 4.3769 & 4.9233 & TRN & & & \\
\hline CHEMBL1403078 & 688867 & 6.7212 & 5.6575 & TST & & & \\
\hline CHEMBL1544548 & 688867 & 6.7033 & 5.6434 & TRN & & & \\
\hline CHEMBL1304057 & 688867 & 4.0537 & 4.9006 & TRN & & & \\
\hline CHEMBL3210009 & 688867 & 4.8311 & 5.1971 & TRN & & & \\
\hline CHEMBL1367639 & 688867 & 2.9208 & 3.8474 & TRN & & & \\
\hline CHEMBL1605898 & 688867 & 4.7606 & 3.8291 & TST & & & \\
\hline CHEMBL1322336 & 688867 & 4.5199 & 5.024 & TRN & & & \\
\hline CHEMBL1478232 & 688867 & 6.5719 & 6.4704 & TRN & & & \\
\hline CHEMBL3213109 & 688867 & 5.2055 & 4.5075 & TST & & & \\
\hline CHEMBL1307120 & 688867 & 4.9104 & 5.3401 & TRN & & & \\
\hline CHEMBL1343552 & 688867 & 5.0166 & 4.7902 & TRN & & & \\
\hline CHEMBL1525437 & 688867 & 4.2856 & 4.3193 & TRN & & & \\
\hline CHEMBL1441799 & 688867 & 3.9467 & 4.9834 & TRN & & & \\
\hline CHEMBL1387969 & 688867 & 2.9208 & 5.11100 & 0000000001 & & TST & \\
\hline CHEMBL1350043 & 688867 & 8.0 & 5.3673 & TRN & & & \\
\hline CHEMBL1343460 & 688867 & 5.1512 & 5.7756 & TRN & & & \\
\hline CHEMBL1470349 & 688867 & 4.6005 & 4.3837 & TRN & & & \\
\hline CHEMBL1521872 & 688867 & 4.6425 & 5.5672 & TST & & & \\
\hline CHEMBL1350563 & 688867 & 4.5073 & 4.1294 & TRN & & & \\
\hline CHEMBL1516666 & 688867 & 5.7397 & 6.5138 & TRN & & & \\
\hline CHEMBL1575467 & 688867 & 4.876 & 4.5296 & TST & & & \\
\hline
\end{tabular}




\begin{tabular}{|c|c|c|c|c|c|}
\hline \multicolumn{6}{|c|}{ Supplemental Table S2.txt } \\
\hline CHEMBL 3213101 & 688867 & 8.0 & 6.3019 & TRN & \\
\hline CHEMBL1600748 & 688867 & 5.0122 & 3.9334 & TRN & \\
\hline CHEMBL1530528 & 688867 & 4.5738 & 5.1743 & TRN & \\
\hline CHEMBL1352038 & 688867 & 6.7986 & 6.515 & TRN & \\
\hline CHEMBL1392187 & 688867 & 4.5801 & 5.1036 & TRN & \\
\hline CHEMBL1422053 & 688867 & 6.6108 & 5.9171 & TRN & \\
\hline CHEMBL1501255 & 688867 & 8.0 & 5.72 & TRN & \\
\hline CHEMBL1358035 & 688867 & 4.1783 & 5.9788 & TRN & \\
\hline CHEMBL1452106 & 688867 & 5.5591 & 4.9161 & TRN & \\
\hline CHEMBL1305077 & 688867 & 2.9208 & 4.007 & TRN & \\
\hline CHEMBL1462785 & 688867 & 2.9208 & 3.8954 & TRN & \\
\hline CHEMBL1377341 & 688867 & 4.7481 & 6.0831 & TRN & \\
\hline CHEMBL3198130 & 688867 & 5.2337 & 5.3113 & TRN & \\
\hline CHEMBL1542591 & 688867 & 4.9812 & 4.8658 & TRN & \\
\hline CHEMBL1490334 & 688867 & 8.0 & 6.7284 & TRN & \\
\hline CHEMBL1581738 & 688867 & 4.7044 & 4.5866 & TRN & \\
\hline CHEMBL1488548 & 688867 & 3.9227 & 4.5295 & TRN & \\
\hline CHEMBL1342054 & 688867 & 2.9208 & 3.438 & TRN & \\
\hline CHEMBL1400463 & 688867 & 4.1495 & 4.7306 & TRN & \\
\hline CHEMBL1565691 & 688867 & 8.0 & 4.9062 & TRN & \\
\hline CHEMBL1360965 & 688867 & 4.6742 & 4.7486 & TRN & \\
\hline CHEMBL1549222 & 688867 & 5.0834 & 4.8366 & TRN & \\
\hline CHEMBL1984523 & 688867 & 4.325 & 4.643 & TRN & \\
\hline CHEMBL1462502 & 688867 & 2.9208 & 3.7412 & TRN & \\
\hline CHEMBL1487137 & 688867 & 4.6766 & 4.2762 & TRN & \\
\hline CHEMBL1986090 & 688867 & 8.0 & 5.6404 & TRN & \\
\hline CHEMBL1423521 & 688867 & 4.4352 & 5.2487 & TRN & \\
\hline CHEMBL1582517 & 688867 & 4.7891 & 4.51699 & 99999999995 & TRN \\
\hline CHEMBL1613264 & 688867 & 5.978 & 5.0716 & TST & \\
\hline CHEMBL3195196 & 688867 & 8.0 & 5.2269 & TRN & \\
\hline CHEMBL1520035 & 688867 & 6.8665 & 6.2579 & TRN & \\
\hline CHEMBL1324332 & 688867 & 4.3007 & 5.1682 & TRN & \\
\hline CHEMBL1324770 & 688867 & 4.5656 & 5.2414 & TRN & \\
\hline CHEMBL1491252 & 688867 & 2.9208 & 3.9222 & TST & \\
\hline CHEMBL1331497 & 688867 & 5.3696 & 4.6298 & TRN & \\
\hline CHEMBL1462179 & 688867 & 5.0103 & 5.1244 & TRN & \\
\hline CHEMBL1419764 & 688867 & 4.3342 & 4.8874 & TRN & \\
\hline CHEMBL1463674 & 688867 & 5.0786 & 4.6624 & TRN & \\
\hline CHEMBL1568474 & 688867 & 4.2983 & 5.6433 & TST & \\
\hline CHEMBL1571801 & 688867 & 5.2327 & 5.1649 & TST & \\
\hline CHEMBL1548613 & 688867 & 6.75200 & 20000000 & 6.4719 & TRN \\
\hline CHEMBL1371482 & 688867 & 5.0926 & 5.0079 & TRN & \\
\hline CHEMBL1342148 & 688867 & 4.6143 & 5.3546 & TRN & \\
\hline CHEMBL1607650 & 688867 & 4.7232 & 4.175 & TRN & \\
\hline CHEMBL580324 & 688867 & 5.211 & 5.5731 & TRN & \\
\hline CHEMBL1322183 & 688867 & 4.7724 & 5.1833 & TRN & \\
\hline CHEMBL1574508 & 688867 & 4.2242 & 4.8266 & TRN & \\
\hline CHEMBL1496902 & 688867 & 5.0376 & 4.1981 & TRN & \\
\hline
\end{tabular}




\begin{tabular}{|c|c|c|c|c|c|}
\hline \multicolumn{6}{|c|}{ Supplemental Table s2.txt } \\
\hline CHEMBL41384 & 688867 & 8.0 & 4.9265 & TRN & \\
\hline CHEMBL1415109 & 688867 & 4.7751 & 4.2401 & TRN & \\
\hline CHEMBL1491779 & 688867 & 3.2218 & 4.5492 & TRN & \\
\hline CHEMBL1584117 & 688867 & 2.9208 & 3.9825 & TST & \\
\hline CHEMBL1342952 & 688867 & 4.6196 & 5.5415 & TRN & \\
\hline CHEMBL1445389 & 688867 & 5.2877 & 4.5089 & TRN & \\
\hline CHEMBL1390469 & 688867 & 5.0633 & 3.8084 & TST & \\
\hline CHEMBL3210221 & 688867 & 4.2118 & 3.7172 & TST & \\
\hline CHEMBL1532225 & 688867 & 4.931 & 3.6405 & TRN & \\
\hline CHEMBL1391573 & 688867 & 4.5539 & 5.3287 & TRN & \\
\hline CHEMBL1360086 & 688867 & 8.0 & 5.8129 & TRN & \\
\hline CHEMBL3210132 & 688867 & 4.9719 & 4.7036 & TRN & \\
\hline CHEMBL3209992 & 688867 & 6.5719 & 4.9193 & TRN & \\
\hline CHEMBL1405274 & 688867 & 2.9208 & 4.1292 & TRN & \\
\hline CHEMBL1575391 & 688867 & 5.7226 & 5.0519 & TRN & \\
\hline CHEMBL1549899 & 688867 & 5.1153 & 4.5346 & TRN & \\
\hline CHEMBL1412392 & 688867 & 6.7399 & 5.3284 & TRN & \\
\hline CHEMBL1471358 & 688867 & 4.8251 & 4.4292 & TRN & \\
\hline CHEMBL3208275 & 688867 & 4.7691 & 5.311 & TRN & \\
\hline CHEMBL1556113 & 688867 & 4.4499 & 4.8352 & TRN & \\
\hline CHEMBL1568672 & 688867 & 4.6028 & 4.0213 & TRN & \\
\hline CHEMBL1385055 & 688867 & 2.9208 & 4.6735 & TRN & \\
\hline CHEMBL1305698 & 688867 & 4.7235 & 5.1046 & TRN & \\
\hline CHEMBL1341336 & 688867 & 4.8186 & 4.7155 & TRN & \\
\hline CHEMBL1333794 & 688867 & 4.4834 & 6.2753 & TRN & \\
\hline CHEMBL1381492 & 688867 & 4.8682 & 4.6779 & TST & \\
\hline CHEMBL1327688 & 688867 & 4.902 & 6.0901 & TRN & \\
\hline CHEMBL1466824 & 688867 & 4.7199 & 4.8646 & TRN & \\
\hline CHEMBL1313467 & 688867 & 5.1587 & 4.2876 & TRN & \\
\hline CHEMBL1564952 & 688867 & 4.1065 & 5.43 & TRN & \\
\hline CHEMBL1420308 & 688867 & 6.5391 & 5.0037 & TRN & \\
\hline CHEMBL1590783 & 688867 & 4.893 & 4.2766 & TRN & \\
\hline CHEMBL1506611 & 688867 & 4.7424 & 4.75899 & 99999999995 & TRN \\
\hline CHEMBL1600446 & 688867 & 4.6747 & 4.5057 & TRN & \\
\hline CHEMBL1461878 & 688867 & 5.8297 & 5.5247 & TRN & \\
\hline CHEMBL3195612 & 688867 & 8.0 & 5.4018 & TRN & \\
\hline CHEMBL1611833 & 688867 & 5.2112 & 5.3926 & TRN & \\
\hline CHEMBL1443354 & 688867 & 4.7942 & 5.2445 & TRN & \\
\hline CHEMBL1439444 & 688867 & 2.9208 & 4.7775 & TRN & \\
\hline CHEMBL1326724 & 688867 & 6.6126 & 5.1215 & TRN & \\
\hline CHEMBL1452245 & 688867 & 5.1824 & 5.6478 & TRN & \\
\hline CHEMBL1329152 & 688867 & 4.6699 & 4.8078 & TRN & \\
\hline CHEMBL1341924 & 688867 & 4.6118 & 5.0621 & TRN & \\
\hline CHEMBL3211514 & 688867 & 2.9208 & 4.6597 & TRN & \\
\hline CHEMBL1465386 & 688867 & 4.6504 & 4.7541 & TRN & \\
\hline CHEMBL1402878 & 688867 & 2.9208 & 4.5702 & TRN & \\
\hline CHEMBL1571228 & 688867 & 4.79 & 4.4201 & TRN & \\
\hline CHEMBL1568646 & 688867 & 5.9278 & 6.07700 & 0000000001 & TRN \\
\hline & & & & 14459 & \\
\hline
\end{tabular}




\begin{tabular}{|c|c|c|c|c|}
\hline \multicolumn{5}{|c|}{ Supplemental Table s2.txt } \\
\hline CHEMBL1553636 & 688867 & 2.9208 & 5.2386 & TRN \\
\hline CHEMBL1569728 & 688867 & 5.0976 & 4.8436 & TRN \\
\hline CHEMBL1424179 & 688867 & 4.2549 & 4.2004 & TRN \\
\hline CHEMBL1364610 & 688867 & 4.3321 & 4.7925 & TRN \\
\hline CHEMBL1531900 & 688867 & 4.8157 & 4.6796 & TRN \\
\hline CHEMBL1549611 & 688867 & 6.2916 & 3.9766 & TRN \\
\hline CHEMBL1548850 & 688867 & 4.4358 & 4.3716 & TRN \\
\hline CHEMBL1517690 & 688867 & 4.0194 & 3.6168 & TST \\
\hline CHEMBL1460013 & 688867 & 4.7747 & 5.2519 & TRN \\
\hline CHEMBL1321104 & 688867 & 8.0 & 6.7388 & TRN \\
\hline CHEMBL1481951 & 688867 & 4.4852 & 4.7442 & TST \\
\hline CHEMBL1481541 & 688867 & 5.3593 & 5.7061 & TRN \\
\hline CHEMBL1487531 & 688867 & 3.9317 & 4.1569 & TST \\
\hline CHEMBL1473601 & 688867 & 4.7842 & 3.909 & TST \\
\hline CHEMBL1536258 & 688867 & 6.5935 & 5.3821 & TST \\
\hline CHEMBL1335321 & 688867 & 4.8795 & 4.346 & TRN \\
\hline CHEMBL1428141 & 688867 & 4.9338 & 4.6192 & TRN \\
\hline CHEMBL3207928 & 688867 & 4.9275 & 4.774 & TRN \\
\hline CHEMBL1386310 & 688867 & 8.0 & 6.5335 & TRN \\
\hline CHEMBL1443669 & 688867 & 4.8514 & 4.4813 & TRN \\
\hline CHEMBL1596703 & 688867 & 5.1266 & 4.4333 & TRN \\
\hline CHEMBL1389025 & 688867 & 5.0272 & 4.7279 & TRN \\
\hline CHEMBL1352868 & 688867 & 4.8799 & 4.5279 & TRN \\
\hline CHEMBL1565236 & 688867 & 4.5533 & 6.0846 & TRN \\
\hline CHEMBL1492589 & 688867 & 4.8491 & 4.6893 & TST \\
\hline CHEMBL1493792 & 688867 & 4.7507 & 4.4777 & TRN \\
\hline CHEMBL3189326 & 688867 & 2.9208 & 4.3457 & TST \\
\hline CHEMBL1363818 & 688867 & 2.9208 & 3.7588 & TRN \\
\hline CHEMBL1412848 & 688867 & 4.2484 & 4.8838 & TRN \\
\hline CHEMBL1501303 & 688867 & 4.8038 & 5.1884 & TRN \\
\hline CHEMBL1579898 & 688867 & 4.1759 & 5.0295 & TRN \\
\hline CHEMBL1586234 & 688867 & 5.1814 & 5.7068 & TRN \\
\hline CHEMBL1551808 & 688867 & 2.9208 & 5.0074 & TRN \\
\hline CHEMBL1535290 & 688867 & 6.3002 & 4.9038 & TRN \\
\hline CHEMBL1555525 & 688867 & 4.3886 & 5.5121 & TRN \\
\hline CHEMBL1319703 & 688867 & 5.5855 & 6.3841 & TRN \\
\hline CHEMBL1336834 & 688867 & 5.218 & 4.6433 & TRN \\
\hline CHEMBL 3212690 & 688867 & 4.7405 & 5.1556 & TRN \\
\hline CHEMBL1410766 & 688867 & 6.3125 & 6.19 & TRN \\
\hline CHEMBL1304189 & 688867 & 5.0679 & 4.5886 & TST \\
\hline CHEMBL1349626 & 688867 & 2.9208 & 5.1397 & TRN \\
\hline CHEMBL1345630 & 688867 & 4.416 & 5.1152 & TRN \\
\hline CHEMBL1310278 & 688867 & 4.8507 & 4.5082 & TRN \\
\hline CHEMBL1499905 & 688867 & 6.6126 & 6.3288 & TRN \\
\hline CHEMBL1453532 & 688867 & 4.4845 & 4.4936 & TRN \\
\hline CHEMBL 2007227 & 688867 & 5.6223 & 6.7146 & TRN \\
\hline CHEMBL1389557 & 688867 & 4.9774 & 4.2329 & TST \\
\hline CHEMBL3211285 & 688867 & 2.9208 & 5.556 & TRN \\
\hline
\end{tabular}




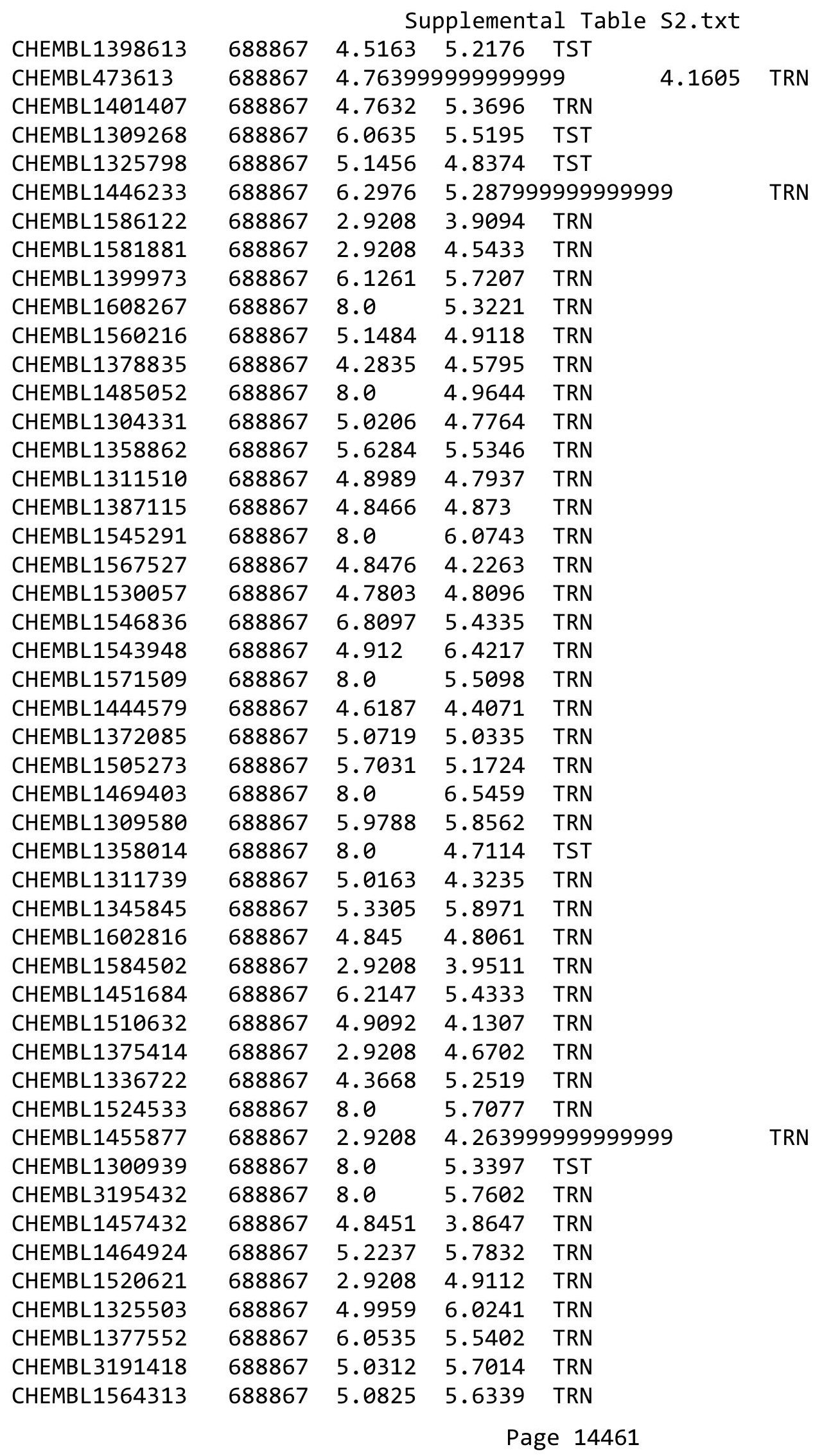




\begin{tabular}{|c|c|c|c|c|c|}
\hline \multicolumn{6}{|c|}{ Supplemental Table S2.txt } \\
\hline CHEMBL1448583 & 688867 & 4.8826 & 4.5418 & TRN & \\
\hline CHEMBL1477280 & 688867 & 6.857 & 5.0769 & TRN & \\
\hline CHEMBL1562079 & 688867 & 6.1169 & 5.3039 & TRN & \\
\hline CHEMBL1585145 & 688867 & 5.0495 & 5.5932 & TRN & \\
\hline CHEMBL1478376 & 688867 & 4.7003 & 5.0437 & TRN & \\
\hline CHEMBL1583715 & 688867 & 4.8405 & 4.6399 & TRN & \\
\hline CHEMBL1410519 & 688867 & 4.4584 & 3.6895 & TRN & \\
\hline CHEMBL1528931 & 688867 & 5.2059 & 4.4136 & TRN & \\
\hline CHEMBL1487005 & 688867 & 4.2944 & 4.9551 & TRN & \\
\hline CHEMBL1350429 & 688867 & 4.6996 & 5.2813 & TRN & \\
\hline CHEMBL1501848 & 688867 & 5.4393 & 4.8405 & TRN & \\
\hline CHEMBL1363291 & 688867 & 6.6635 & 6.2602 & TRN & \\
\hline CHEMBL1410134 & 688867 & 4.6014 & 5.2457 & TRN & \\
\hline CHEMBL1417225 & 688867 & 6.5918 & 5.3399 & TRN & \\
\hline CHEMBL1523424 & 688867 & 2.9208 & 5.6463 & TRN & \\
\hline CHEMBL1313911 & 688867 & 2.9208 & 4.9393 & TRN & \\
\hline CHEMBL1546043 & 688867 & 4.7774 & 4.9813 & TRN & \\
\hline CHEMBL1519624 & 688867 & 5.3427 & 4.9376 & TRN & \\
\hline CHEMBL1325354 & 688867 & 6.5918 & 6.0079 & TST & \\
\hline CHEMBL 249931 & 688867 & 4.7873 & 4.9993 & TRN & \\
\hline CHEMBL1419597 & 688867 & 5.5748 & 5.6297 & TRN & \\
\hline CHEMBL1597510 & 688867 & 4.4886 & 4.4407 & TST & \\
\hline CHEMBL1443948 & 688867 & 5.1718 & 5.5037 & TRN & \\
\hline CHEMBL1332894 & 688867 & 4.758 & 5.4839 & TRN & \\
\hline CHEMBL1540320 & 688867 & 2.9208 & 4.9007 & TRN & \\
\hline CHEMBL1556013 & 688867 & 4.5099 & 4.0825 & TRN & \\
\hline CHEMBL1311047 & 688867 & 2.9208 & 5.1959 & TRN & \\
\hline CHEMBL1476311 & 688867 & 5.3726 & 6.3165 & TRN & \\
\hline CHEMBL1380549 & 688867 & 2.9208 & 4.1562 & TST & \\
\hline CHEMBL1444483 & 688867 & 5.2222 & 5.6905 & TRN & \\
\hline CHEMBL1428107 & 688867 & 4.35 & 5.0783 & TRN & \\
\hline CHEMBL1308658 & 688867 & 6.9706 & 6.40799 & 99999999995 & TRN \\
\hline CHEMBL1549398 & 688867 & 5.614 & 5.9428 & TRN & \\
\hline CHEMBL1387916 & 688867 & 2.9208 & 5.0506 & TRN & \\
\hline CHEMBL1306086 & 688867 & 2.9208 & 4.2028 & TRN & \\
\hline CHEMBL1559721 & 688867 & 5.018 & 4.9404 & TRN & \\
\hline CHEMBL1368839 & 688867 & 5.0744 & 4.6726 & TRN & \\
\hline CHEMBL1530113 & 688867 & 5.4198 & 5.5991 & TRN & \\
\hline CHEMBL1340374 & 688867 & 6.3429 & 5.0205 & TRN & \\
\hline CHEMBL 3212742 & 688867 & 4.2846 & 4.5715 & TST & \\
\hline CHEMBL1566141 & 688867 & 6.9101 & 5.765 & TRN & \\
\hline CHEMBL1583114 & 688867 & 2.9208 & 5.08 & TRN & \\
\hline CHEMBL579380 & 688867 & 2.9208 & 4.8606 & TRN & \\
\hline CHEMBL1560206 & 688867 & 6.4214 & 5.436 & TRN & \\
\hline CHEMBL1446545 & 688867 & 6.4078 & 4.4649 & TRN & \\
\hline CHEMBL1460850 & 688867 & 5.2023 & 5.2301 & TST & \\
\hline CHEMBL1330965 & 688867 & 4.8392 & 5.6273 & TRN & \\
\hline CHEMBL1569976 & 688867 & 4.3749 & 5.0227 & TRN & \\
\hline
\end{tabular}




\begin{tabular}{|c|c|c|c|c|c|c|}
\hline & & \multicolumn{5}{|c|}{ Supplemental Table S2.txt } \\
\hline CHEMBL1307534 & 688867 & 2.9208 & 3.8546 & TRN & & \\
\hline CHEMBL1560260 & 688867 & 4.21899 & 99999999 & 99 & 4.4073 & TST \\
\hline CHEMBL1511867 & 688867 & 4.7916 & 3.5237 & TRN & & \\
\hline CHEMBL1571645 & 688867 & 4.6641 & 5.1225 & TRN & & \\
\hline CHEMBL1343994 & 688867 & 4.5758 & 5.3504 & TRN & & \\
\hline CHEMBL449336 & 688867 & 4.3333 & 5.148 & TST & & \\
\hline CHEMBL3208019 & 688867 & 4.8534 & 4.9883 & TRN & & \\
\hline CHEMBL1320798 & 688867 & 4.1698 & 3.7547 & TRN & & \\
\hline CHEMBL1410534 & 688867 & 4.3778 & 5.2227 & TRN & & \\
\hline CHEMBL1364299 & 688867 & 4.8097 & 4.5209 & TST & & \\
\hline CHEMBL1517251 & 688867 & 5.0607 & 5.2202 & TRN & & \\
\hline CHEMBL1599076 & 688867 & 5.7291 & 5.6235 & TRN & & \\
\hline CHEMBL1387204 & 688867 & 2.9208 & 4.3256 & TST & & \\
\hline CHEMBL1582426 & 688867 & 2.9208 & 4.4944 & TRN & & \\
\hline CHEMBL1308307 & 688867 & 5.0566 & 5.0907 & TRN & & \\
\hline CHEMBL1539830 & 688867 & 2.9208 & 4.96899 & 9999999999 & & TRN \\
\hline CHEMBL1547757 & 688867 & 4.7445 & 4.9827 & TRN & & \\
\hline CHEMBL1493546 & 688867 & 2.9208 & 5.0476 & TST & & \\
\hline CHEMBL1336531 & 688867 & 8.0 & 5.4393 & TRN & & \\
\hline CHEMBL1445762 & 688867 & 4.7586 & 4.5401 & TRN & & \\
\hline CHEMBL1381681 & 688867 & 2.9208 & 4.4538 & TRN & & \\
\hline CHEMBL1965956 & 688867 & 4.3889 & 4.8814 & TRN & & \\
\hline CHEMBL1329106 & 688867 & 4.2568 & 4.673 & TRN & & \\
\hline CHEMBL1586235 & 688867 & 5.0562 & 5.2389 & TRN & & \\
\hline CHEMBL1562098 & 688867 & 4.8494 & 3.8083 & TRN & & \\
\hline CHEMBL1323422 & 688867 & 8.0 & 5.6481 & TRN & & \\
\hline CHEMBL1508330 & 688867 & 5.2021 & 3.7914 & TRN & & \\
\hline CHEMBL1575523 & 688867 & 4.8962 & 3.7554 & TRN & & \\
\hline CHEMBL1332476 & 688867 & 4.7489 & 4.7962 & TRN & & \\
\hline CHEMBL1447078 & 688867 & 6.8996 & 5.20700 & 0000000001 & & TRN \\
\hline CHEMBL1349194 & 688867 & 5.0895 & 3.7042 & TRN & & \\
\hline CHEMBL1359565 & 688867 & 6.983 & 5.7808 & TRN & & \\
\hline CHEMBL1446875 & 688867 & 4.5332 & 5.5666 & TST & & \\
\hline CHEMBL3196435 & 688867 & 5.1438 & 4.8469 & TRN & & \\
\hline CHEMBL3190953 & 688867 & 6.7212 & 6.155 & TRN & & \\
\hline CHEMBL1375658 & 688867 & 6.585 & 5.2009 & TRN & & \\
\hline CHEMBL1519102 & 688867 & 4.775 & 4.8035 & TST & & \\
\hline CHEMBL1499023 & 688867 & 4.4399 & 4.8509 & TRN & & \\
\hline CHEMBL1501871 & 688867 & 5.0881 & 3.9756 & TRN & & \\
\hline CHEMBL1589458 & 688867 & 4.7969 & 4.7065 & TRN & & \\
\hline CHEMBL1403844 & 688867 & 4.6404 & 4.4652 & TRN & & \\
\hline CHEMBL1427857 & 688867 & 4.5834 & 5.3868 & TRN & & \\
\hline CHEMBL1439902 & 688867 & 6.8153 & 5.3839 & TST & & \\
\hline CHEMBL1445723 & 688867 & 4.836 & 6.1831 & TRN & & \\
\hline CHEMBL1454113 & 688867 & 4.7149 & 5.9784 & TST & & \\
\hline CHEMBL3197088 & 688867 & 2.9208 & 3.9708 & TRN & & \\
\hline CHEMBL1473575 & 688867 & 4.0242 & 5.0639 & TRN & & \\
\hline CHEMBL1365247 & 688867 & 4.4621 & 3.9342 & TRN & & \\
\hline
\end{tabular}




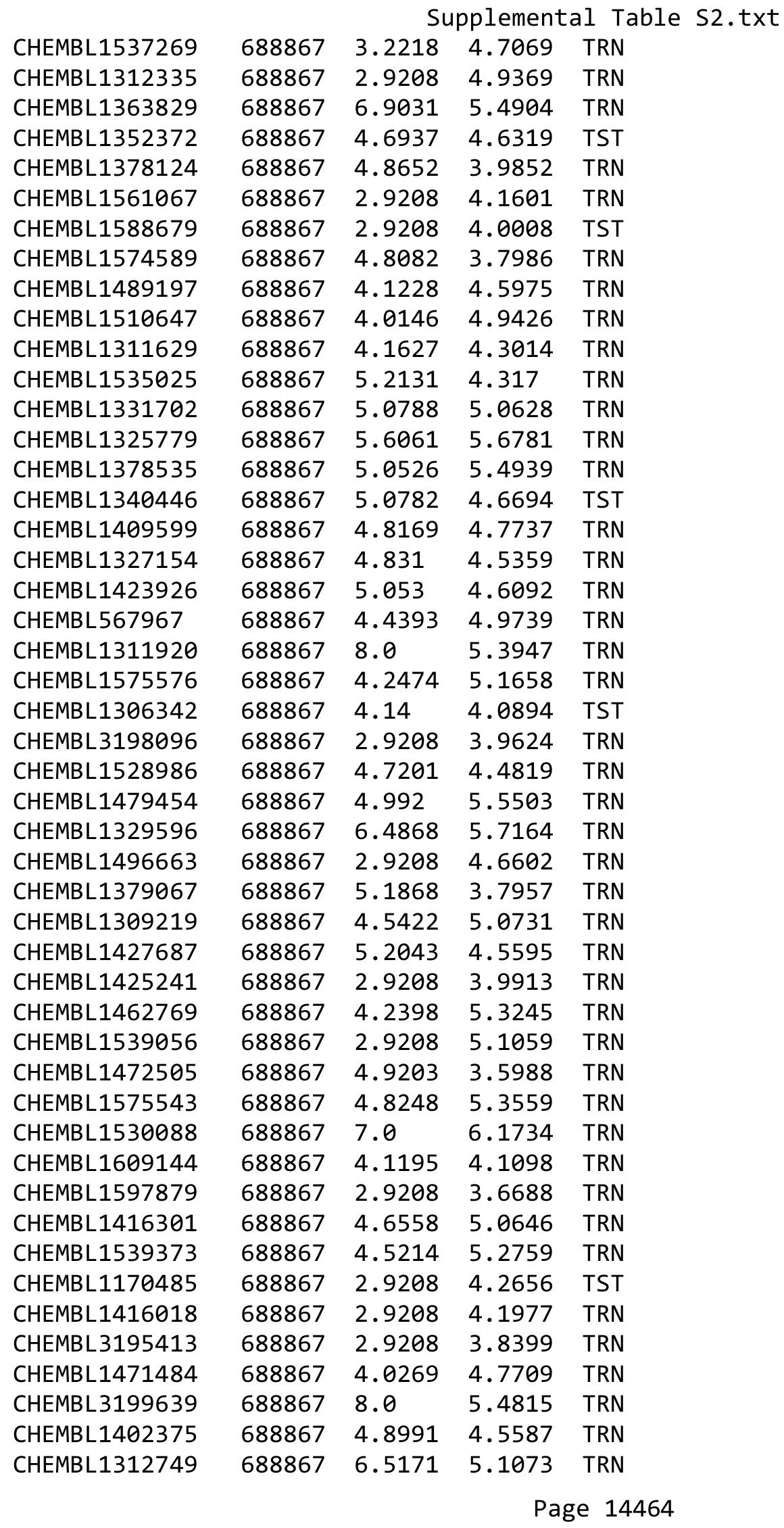


Supplemental Table S2.txt

\begin{tabular}{|c|c|c|c|c|}
\hline CHEMBL3194985 & 688867 & 6.4763 & 5.7156 & TRN \\
\hline CHEMBL1538034 & 688867 & 4.4539 & 4.3908 & TRN \\
\hline CHEMBL1453005 & 688867 & 5.0586 & 5.1863 & TRN \\
\hline CHEMBL1389832 & 688867 & 2.9208 & 4.2593 & TST \\
\hline CHEMBL1561900 & 688867 & 2.9208 & \multicolumn{2}{|c|}{5.111000000000001} \\
\hline CHEMBL1584746 & 688867 & 5.0357 & 5.1195 & TRN \\
\hline CHEMBL1327417 & 688867 & 2.9208 & 3.8002 & TRN \\
\hline CHEMBL1313565 & 688867 & 2.9208 & 5.9261 & TRN \\
\hline CHEMBL1335650 & 688867 & 4.5285 & 3.9187 & TST \\
\hline CHEMBL1368046 & 688867 & 2.9208 & 3.6643 & TRN \\
\hline CHEMBL117813 & 688867 & 2.9208 & 4.3997 & TRN \\
\hline CHEMBL1383996 & 688867 & 6.6253 & 5.2551 & TRN \\
\hline CHEMBL1349436 & 688867 & 8.0 & 5.3119 & TRN \\
\hline CHEMBL1401099 & 688867 & 6.2874 & 5.7939 & TRN \\
\hline CHEMBL1488590 & 688867 & 2.9208 & 3.9424 & TRN \\
\hline CHEMBL1498440 & 688867 & 5.8517 & 5.8364 & TRN \\
\hline CHEMBL 3210095 & 688867 & 8.0 & 5.774 & TST \\
\hline CHEMBL1393134 & 688867 & 2.9208 & 4.0915 & TRN \\
\hline CHEMBL 3190842 & 688867 & 4.329 & 4.4555 & TRN \\
\hline CHEMBL546475 & 688867 & 4.9571 & 3.8466 & TRN \\
\hline CHEMBL1612424 & 688867 & 4.9586 & 4.5564 & TRN \\
\hline CHEMBL1574154 & 688867 & 4.6708 & 5.1083 & TRN \\
\hline CHEMBL1401683 & 688867 & 4.6758 & 4.9665 & TRN \\
\hline CHEMBL1490792 & 688867 & 5.4992 & 5.4117 & TRN \\
\hline CHEMBL1571239 & 688867 & 6.8794 & 6.9186 & TRN \\
\hline CHEMBL1581155 & 688867 & 4.1406 & 4.5127 & TST \\
\hline CHEMBL1520665 & 688867 & 2.9208 & 3.8163 & TRN \\
\hline CHEMBL1494477 & 688867 & 4.5566 & 4.8229 & TRN \\
\hline CHEMBL1410076 & 688867 & 2.9208 & 4.5462 & TRN \\
\hline CHEMBL1526996 & 688867 & 4.2615 & 5.0036 & TST \\
\hline CHEMBL1508105 & 688867 & 4.2974 & 4.5658 & TRN \\
\hline CHEMBL1375823 & 688867 & 5.029 & 4.6734 & TRN \\
\hline CHEMBL1574562 & 688867 & 4.2926 & 5.5313 & TRN \\
\hline CHEMBL1458318 & 688867 & 4.5608 & 4.7317 & TST \\
\hline CHEMBL1346191 & 688867 & 4.6249 & 5.3743 & TRN \\
\hline CHEMBL1478644 & 688867 & 6.0904 & 6.8378 & TRN \\
\hline CHEMBL1536326 & 688867 & 6.9101 & 4.1724 & TRN \\
\hline CHEMBL1535087 & 688867 & 6.3143 & 5.8251 & TRN \\
\hline CHEMBL1323133 & 688867 & 8.0 & 5.4376 & TRN \\
\hline CHEMBL 3208442 & 688867 & 4.3364 & 4.8603 & TST \\
\hline CHEMBL1325363 & 688867 & 2.9208 & 4.4072 & TRN \\
\hline CHEMBL1415140 & 688867 & 4.5787 & 5.6993 & TRN \\
\hline CHEMBL1467146 & 688867 & 4.6805 & 4.4541 & TST \\
\hline CHEMBL1399142 & 688867 & 2.9208 & 3.813 & TRN \\
\hline CHEMBL1379181 & 688867 & 4.9027 & 4.7883 & TRN \\
\hline CHEMBL1606193 & 688867 & 5.7791 & 5.3262 & TRN \\
\hline CHEMBL1608506 & 688867 & 8.0 & 5.6481 & TRN \\
\hline CHEMBL 3212230 & 688867 & 5.2951 & 5.065 & TRN \\
\hline
\end{tabular}




\begin{tabular}{|c|c|c|c|c|c|c|}
\hline & & \multicolumn{5}{|c|}{ Supplemental Table S2.txt } \\
\hline CHEMBL1352917 & 688867 & 4.8149 & 4.9226 & TST & & \\
\hline CHEMBL 3193057 & 688867 & 5.1052 & 4.6695 & TRN & & \\
\hline CHEMBL1468618 & 688867 & 4.7562 & 6.0231 & TRN & & \\
\hline CHEMBL1549700 & 688867 & 4.6922 & 5.5429 & TRN & & \\
\hline CHEMBL1545467 & 688867 & 4.6669 & 6.4705 & TRN & & \\
\hline CHEMBL1461433 & 688867 & 4.8175 & 4.918 & TRN & & \\
\hline CHEMBL1337580 & 688867 & 5.9274 & 3.8519 & TRN & & \\
\hline CHEMBL1328281 & 688867 & 4.3141 & 3.6846 & TRN & & \\
\hline CHEMBL1424555 & 688867 & 6.8447 & 5.7927 & TRN & & \\
\hline CHEMBL1583898 & 688867 & 4.6961 & 5.0397 & TRN & & \\
\hline CHEMBL1408762 & 688867 & 5.687 & 5.5181 & TRN & & \\
\hline CHEMBL1469668 & 688867 & 6.6383 & 5.4978 & TRN & & \\
\hline CHEMBL1389445 & 688867 & 4.6639 & 5.2252 & TRN & & \\
\hline CHEMBL1597187 & 688867 & 4.8136 & 4.9608 & TRN & & \\
\hline CHEMBL 3191360 & 688867 & 5.0822 & 4.8922 & TRN & & \\
\hline CHEMBL1431361 & 688867 & 8.0 & 6.1815 & TRN & & \\
\hline CHEMBL1467994 & 688867 & 4.867 & 3.8986 & TST & & \\
\hline CHEMBL1419233 & 688867 & 8.0 & 5.5653 & TRN & & \\
\hline CHEMBL1310825 & 688867 & 5.1821 & 5.2972 & TRN & & \\
\hline CHEMBL1374534 & 688867 & 4.5359 & 4.4943 & TRN & & \\
\hline CHEMBL1499697 & 688867 & 2.9208 & 5.2973 & TRN & & \\
\hline CHEMBL1360493 & 688867 & 4.9958 & 4.7114 & TST & & \\
\hline CHEMBL1488263 & 688867 & 4.5965 & 5.6515 & TRN & & \\
\hline CHEMBL1543100 & 688867 & 2.9208 & 4.0317 & TRN & & \\
\hline CHEMBL1401361 & 688867 & 6.9914 & 6.7352 & TRN & & \\
\hline CHEMBL1523967 & 688867 & 4.8299 & 5.4735 & TRN & & \\
\hline CHEMBL1374157 & 688867 & 4.5196 & 5.3342 & TRN & & \\
\hline CHEMBL1601967 & 688867 & 4.9241 & 4.7788 & TST & & \\
\hline CHEMBL1386822 & 688867 & 6.1701 & 6.2045 & TRN & & \\
\hline CHEMBL 3199347 & 688867 & $6.1720 e$ & 00000000 & $\partial 1$ & 5.2326 & TRN \\
\hline CHEMBL1331973 & 688867 & 2.9208 & 4.0947 & TRN & & \\
\hline CHEMBL 3190627 & 688867 & 8.0 & 6.3857 & TRN & & \\
\hline CHEMBL1499004 & 688867 & 4.0272 & 4.8153 & TRN & & \\
\hline CHEMBL 3192253 & 688867 & 4.8303 & 5.5988 & TRN & & \\
\hline CHEMBL1393056 & 688867 & 4.5558 & 5.1415 & TST & & \\
\hline CHEMBL1501185 & 688867 & 8.0 & 5.4435 & TRN & & \\
\hline CHEMBL1540417 & 688867 & 6.2083 & 6.5274 & TRN & & \\
\hline CHEMBL1507946 & 688867 & 4.8338 & 4.5179 & TST & & \\
\hline CHEMBL222759 & 688867 & 4.7955 & 5.0889 & TRN & & \\
\hline CHEMBL1555544 & 688867 & 4.1987 & 4.334 & TRN & & \\
\hline CHEMBL1574671 & 688867 & 8.0 & 5.7506 & TST & & \\
\hline CHEMBL1577017 & 688867 & 4.6483 & 4.7206 & TST & & \\
\hline CHEMBL1601249 & 688867 & 4.2312 & 5.4732 & TRN & & \\
\hline CHEMBL1487591 & 688867 & 5.8811 & 4.8723 & TRN & & \\
\hline CHEMBL1486606 & 688867 & 4.4816 & 4.0951 & TRN & & \\
\hline CHEMBL1454438 & 688867 & 5.1561 & 3.8297 & TRN & & \\
\hline CHEMBL1359655 & 688867 & 3.2218 & 3.7059 & TRN & & \\
\hline CHEMBL 3208063 & 688867 & 4.9084 & 4.8049 & TRN & & \\
\hline
\end{tabular}




\begin{tabular}{|c|c|c|c|c|c|}
\hline \multicolumn{6}{|c|}{ Supplemental Table s2.txt } \\
\hline CHEMBL1428673 & 688867 & 8.0 & 5.8133 & TRN & \\
\hline CHEMBL1373880 & 688867 & 2.9208 & 3.7774 & TST & \\
\hline CHEMBL199925 & 688867 & 4.6089 & 6.1984 & TRN & \\
\hline CHEMBL1496585 & 688867 & 5.0052 & 4.5671 & TRN & \\
\hline CHEMBL1488336 & 688867 & 2.9208 & 3.9641 & TRN & \\
\hline CHEMBL1412704 & 688867 & 4.1851 & 5.4884 & TRN & \\
\hline CHEMBL1382069 & 688867 & 2.9208 & 4.5716 & TST & \\
\hline CHEMBL1535599 & 688867 & 4.7432 & 4.6853 & TRN & \\
\hline CHEMBL1587328 & 688867 & 3.9716 & 4.6322 & TRN & \\
\hline CHEMBL3198682 & 688867 & 4.8128 & 4.0916 & TST & \\
\hline CHEMBL1392596 & 688867 & 5.9136 & 5.4383 & TRN & \\
\hline CHEMBL 3214547 & 688867 & 6.3116 & 6.0861 & TRN & \\
\hline CHEMBL1431253 & 688867 & 6.8297 & 6.1408 & TRN & \\
\hline CHEMBL 256202 & 688867 & 5.2917 & 4.4118 & TRN & \\
\hline CHEMBL1409532 & 688867 & 5.5782 & 4.7422 & TRN & \\
\hline CHEMBL1376768 & 688867 & 4.5409 & 4.6008 & TRN & \\
\hline CHEMBL1303994 & 688867 & 4.9623 & 4.9207 & TRN & \\
\hline CHEMBL1392445 & 688867 & 4.3743 & 5.7565 & TRN & \\
\hline CHEMBL3194597 & 688867 & 4.4986 & 4.686 & TRN & \\
\hline CHEMBL1381195 & 688867 & 8.0 & 4.5734 & TST & \\
\hline CHEMBL1339672 & 688867 & 5.3064 & 5.2658 & TRN & \\
\hline CHEMBL1378756 & 688867 & 5.7158 & 4.9716 & TRN & \\
\hline CHEMBL1302851 & 688867 & 3.5229 & 4.7336 & TRN & \\
\hline CHEMBL1437043 & 688867 & 5.0248 & 4.7136 & TRN & \\
\hline CHEMBL1311224 & 688867 & 4.9271 & 5.1853 & TST & \\
\hline CHEMBL1335318 & 688867 & 8.0 & 6.2613 & TRN & \\
\hline CHEMBL1502859 & 688867 & 4.7451 & 3.9257 & TRN & \\
\hline CHEMBL1362093 & 688867 & 2.9208 & 4.1066 & TRN & \\
\hline CHEMBL1536561 & 688867 & 4.33 & 3.91 & TRN & \\
\hline CHEMBL1423707 & 688867 & 4.6696 & 4.6134 & TRN & \\
\hline CHEMBL1534639 & 688867 & 4.837 & 4.8268 & TRN & \\
\hline CHEMBL1550457 & 688867 & 4.2289 & 5.6191 & TST & \\
\hline CHEMBL3193579 & 688867 & 4.5088 & 4.5346 & TRN & \\
\hline CHEMBL1564290 & 688867 & 4.8068 & 4.5832 & TRN & \\
\hline CHEMBL1405940 & 688867 & 6.8153 & 6.1829 & TRN & \\
\hline CHEMBL1534490 & 688867 & 2.9208 & 3.9229 & TST & \\
\hline CHEMBL1369984 & 688867 & 2.9208 & 5.9929 & TRN & \\
\hline CHEMBL1391219 & 688867 & 4.9297 & 4.8813 & TRN & \\
\hline CHEMBL1583182 & 688867 & 4.5414 & 4.6078 & TRN & \\
\hline CHEMBL1464300 & 688867 & 5.1133 & $4.8610 e$ & 0000000001 & TRN \\
\hline CHEMBL1385946 & 688867 & 5.7402 & 5.8857 & TRN & \\
\hline CHEMBL1463032 & 688867 & 5.0665 & 4.8488 & TRN & \\
\hline CHEMBL1573487 & 688867 & 4.8215 & 4.1225 & TRN & \\
\hline CHEMBL1452771 & 688867 & 4.1767 & 5.2599 & TRN & \\
\hline CHEMBL1560307 & 688867 & 2.9208 & 4.0844 & TRN & \\
\hline CHEMBL1495905 & 688867 & 6.9706 & 5.8489 & TRN & \\
\hline CHEMBL1340348 & 688867 & 5.6121 & 5.9 & TRN & \\
\hline CHEMBL1508470 & 688867 & 5.3051 & 4.7244 & TRN & \\
\hline
\end{tabular}




\begin{tabular}{|c|c|c|c|c|}
\hline \multicolumn{5}{|c|}{ Supplemental Tab. } \\
\hline CHEMBL 3192267 & 688867 & 4.6634 & 5.0231 & TRN \\
\hline CHEMBL1401589 & 688867 & 4.9047 & 4.8094 & TRN \\
\hline CHEMBL1540638 & 688867 & 5.3913 & 5.0656 & TRN \\
\hline CHEMBL1479324 & 688867 & 5.095 & 4.2894 & TRN \\
\hline CHEMBL1299603 & 688867 & 4.6754 & 4.768 & TRN \\
\hline CHEMBL1447118 & 688867 & 4.6268 & 4.8593 & TRN \\
\hline CHEMBL1585607 & 688867 & 5.3555 & 4.9546 & TRN \\
\hline CHEMBL1609109 & 688867 & 4.8086 & 4.1176 & TRN \\
\hline CHEMBL1401958 & 688867 & 4.6022 & 3.7209 & TRN \\
\hline CHEMBL1420871 & 688867 & 5.7016 & 6.9306 & TRN \\
\hline CHEMBL1580910 & 688867 & 2.9208 & 3.3975 & TST \\
\hline CHEMBL1481384 & 688867 & 6.0453 & 6.265 & TRN \\
\hline CHEMBL1537753 & 688867 & 4.3403 & 4.251 & TRN \\
\hline CHEMBL1321472 & 688867 & 5.3344 & 5.3853 & TRN \\
\hline CHEMBL1555575 & 688867 & 5.0068 & 4.3317 & TRN \\
\hline CHEMBL1344382 & 688867 & 4.8305 & 4.1183 & TST \\
\hline CHEMBL1378090 & 688867 & 5.2154 & 5.1189 & TRN \\
\hline CHEMBL1534798 & 688867 & 4.5113 & 4.9239 & TRN \\
\hline CHEMBL3194711 & 688867 & 4.8557 & 4.5409 & TRN \\
\hline CHEMBL1299462 & 688867 & 4.6924 & 3.9381 & TST \\
\hline CHEMBL1513595 & 688867 & 5.2013 & 4.9395 & TST \\
\hline CHEMBL1600990 & 688867 & 4.2032 & 4.0241 & TRN \\
\hline CHEMBL1389228 & 688867 & 5.0911 & 4.1407 & TRN \\
\hline CHEMBL1351353 & 688867 & 5.6826 & 5.092 & TRN \\
\hline CHEMBL1334962 & 688867 & 4.1925 & 5.2225 & TRN \\
\hline CHEMBL1498996 & 688867 & 4.3155 & 4.9623 & TRN \\
\hline CHEMBL1531533 & 688867 & 4.6513 & 5.5522 & TRN \\
\hline CHEMBL3207881 & 688867 & 2.9208 & 4.1111 & TRN \\
\hline CHEMBL1550661 & 688867 & 4.0829 & 4.6552 & TRN \\
\hline CHEMBL1431210 & 688867 & 8.0 & 5.3648 & TRN \\
\hline CHEMBL1545149 & 688867 & 4.7548 & 5.1232 & TRN \\
\hline CHEMBL1377188 & 688867 & 2.9208 & 6.2538 & TRN \\
\hline CHEMBL1560476 & 688867 & 4.8192 & 4.7481 & TRN \\
\hline CHEMBL1452680 & 688867 & 4.9273 & 4.9052 & TRN \\
\hline CHEMBL 3207793 & 688867 & 4.7788 & 5.1468 & TST \\
\hline CHEMBL1340584 & 688867 & 4.5129 & 4.4537 & TRN \\
\hline CHEMBL1301226 & 688867 & 4.8071 & 3.7803 & TRN \\
\hline CHEMBL1446080 & 688867 & 4.573 & 4.2071 & TRN \\
\hline CHEMBL1416732 & 688867 & 4.4179 & 4.7874 & TRN \\
\hline CHEMBL1405368 & 688867 & 4.8435 & 5.2895 & TRN \\
\hline CHEMBL1517544 & 688867 & 4.8298 & 4.1975 & TRN \\
\hline CHEMBL1448972 & 688867 & 4.4022 & 5.3731 & TRN \\
\hline CHEMBL1604258 & 688867 & 5.0461 & 4.865 & TRN \\
\hline CHEMBL1385904 & 688867 & 8.0 & 5.8711 & TRN \\
\hline CHEMBL1517603 & 688867 & 6.7878 & 6.4616 & TRN \\
\hline CHEMBL3199114 & 688867 & 5.0929 & 5.9436 & TRN \\
\hline CHEMBL1459195 & 688867 & 4.6026 & 4.6843 & TRN \\
\hline CHEMBL3211529 & 688867 & 2.9208 & 3.7191 & TRN \\
\hline
\end{tabular}




\begin{tabular}{|c|c|c|c|c|c|c|}
\hline \multirow[b]{2}{*}{ CHEMBL1339310 } & \multirow[b]{2}{*}{688867} & \multicolumn{5}{|c|}{ Supplemental Table S2.txt } \\
\hline & & 5.0043 & 4.9679 & TRN & & \\
\hline CHEMBL1584476 & 688867 & 8.0 & 5.4255 & TRN & & \\
\hline CHEMBL1491767 & 688867 & 4.80399 & 99999999 & 99 & 5.4409 & TRN \\
\hline CHEMBL1461102 & 688867 & 4.0591 & 4.4107 & TRN & & \\
\hline CHEMBL1480309 & 688867 & 4.5921 & 4.6242 & TRN & & \\
\hline CHEMBL1417174 & 688867 & 5.7268 & 6.2892 & TRN & & \\
\hline CHEMBL1432801 & 688867 & 4.5116 & 5.6334 & TRN & & \\
\hline CHEMBL1334136 & 688867 & 8.0 & 6.3019 & TRN & & \\
\hline CHEMBL1530139 & 688867 & 4.2724 & 5.2252 & TRN & & \\
\hline CHEMBL1414311 & 688867 & 2.9208 & 4.112 & TRN & & \\
\hline CHEMBL1599460 & 688867 & 5.0088 & 4.8846 & TRN & & \\
\hline CHEMBL1539579 & 688867 & 4.4626 & 4.5213 & TRN & & \\
\hline CHEMBL1977867 & 688867 & 4.1566 & 4.5255 & TRN & & \\
\hline CHEMBL1479116 & 688867 & 4.7959 & 4.756 & TRN & & \\
\hline CHEMBL1602119 & 688867 & 4.5661 & 4.8176 & TRN & & \\
\hline CHEMBL1509760 & 688867 & 4.5103 & 4.2437 & TRN & & \\
\hline CHEMBL1432072 & 688867 & 4.8138 & 4.8199 & TRN & & \\
\hline CHEMBL1971282 & 688867 & 5.096 & 5.1331 & TRN & & \\
\hline CHEMBL3196718 & 688867 & 6.3862 & 5.7184 & TRN & & \\
\hline CHEMBL1435015 & 688867 & 5.033 & 4.3403 & TRN & & \\
\hline CHEMBL1367788 & 688867 & 5.8784 & 4.9719 & TRN & & \\
\hline CHEMBL1597587 & 688867 & 2.9208 & 3.8829 & TRN & & \\
\hline CHEMBL1345705 & 688867 & 4.6141 & 4.1566 & TRN & & \\
\hline CHEMBL3199580 & 688867 & 6.7423 & 5.9543 & TRN & & \\
\hline CHEMBL1393784 & 688867 & 8.0 & 4.5301 & TST & & \\
\hline CHEMBL1548782 & 688867 & 4.6028 & 4.9421 & TST & & \\
\hline CHEMBL1336269 & 688867 & 4.4867 & 6.0547 & TRN & & \\
\hline CHEMBL1347564 & 688867 & 5.1407 & 4.5659 & TRN & & \\
\hline CHEMBL1505790 & 688867 & 2.9208 & 3.8704 & TRN & & \\
\hline CHEMBL1421436 & 688867 & 5.1561 & 4.7005 & TST & & \\
\hline CHEMBL1416594 & 688867 & 4.3774 & 4.8925 & TRN & & \\
\hline CHEMBL1554017 & 688867 & 2.9208 & 3.7771 & TRN & & \\
\hline CHEMBL1423670 & 688867 & 4.9206 & 4.9484 & TRN & & \\
\hline CHEMBL1376513 & 688867 & 4.1756 & 5.5012 & TRN & & \\
\hline CHEMBL1610786 & 688867 & 6.5884 & 5.0843 & TRN & & \\
\hline CHEMBL1605162 & 688867 & 4.098 & 4.7422 & TRN & & \\
\hline CHEMBL3209422 & 688867 & 2.9208 & 4.4411 & TST & & \\
\hline CHEMBL1529647 & 688867 & 5.7303 & 6.1971 & TRN & & \\
\hline CHEMBL1547182 & 688867 & 4.1565 & 4.6203 & TST & & \\
\hline CHEMBL1439783 & 688867 & 3.2218 & 4.1373 & TRN & & \\
\hline CHEMBL1310007 & 688867 & 4.9852 & 4.8495 & TRN & & \\
\hline CHEMBL1526806 & 688867 & 5.1866 & 4.4233 & TRN & & \\
\hline CHEMBL1308898 & 688867 & 4.8223 & 5.7046 & TRN & & \\
\hline CHEMBL1462536 & 688867 & 4.7254 & 4.7389 & TRN & & \\
\hline CHEMBL3189244 & 688867 & 2.9208 & 4.6239 & TRN & & \\
\hline CHEMBL3192618 & 688867 & 5.3392 & 5.3538 & TRN & & \\
\hline CHEMBL1494066 & 688867 & 4.9153 & 4.9349 & TRN & & \\
\hline CHEMBL1422858 & 688867 & 5.1341 & 4.846 & TRN & & \\
\hline
\end{tabular}




\begin{tabular}{|c|c|c|c|c|}
\hline \multicolumn{5}{|c|}{ Supplemental Tabl } \\
\hline CHEMBL1602676 & 688867 & 4.5355 & 4.8078 & TST \\
\hline CHEMBL1341673 & 688867 & 5.0426 & 5.3976 & TRN \\
\hline CHEMBL1599602 & 688867 & 5.1318 & 5.0062 & TRN \\
\hline CHEMBL 3212000 & 688867 & 6.6003 & 5.5559 & TRN \\
\hline CHEMBL1416166 & 688867 & 4.2089 & 5.7974 & TST \\
\hline CHEMBL 3212747 & 688867 & 2.9208 & 4.1461 & TST \\
\hline CHEMBL1605528 & 688867 & 8.0 & 5.3548 & TRN \\
\hline CHEMBL1523560 & 688867 & 5.0116 & 3.8572 & TRN \\
\hline CHEMBL1493226 & 688867 & 5.1539 & 5.7609 & TRN \\
\hline CHEMBL1383194 & 688867 & 2.9208 & 5.3446 & TRN \\
\hline CHEMBL1549607 & 688867 & 4.7707 & 4.4236 & TRN \\
\hline CHEMBL3211206 & 688867 & 4.2196 & 4.9109 & TRN \\
\hline CHEMBL1539723 & 688867 & 4.2624 & 4.6998 & TRN \\
\hline CHEMBL1349074 & 688867 & 4.5024 & 4.7052 & TRN \\
\hline CHEMBL1349964 & 688867 & 6.8697 & 6.1104 & TRN \\
\hline CHEMBL1312289 & 688867 & 8.0 & 5.2478 & TRN \\
\hline CHEMBL1483099 & 688867 & 4.4888 & 4.5509 & TRN \\
\hline CHEMBL1403922 & 688867 & 8.0 & 6.0477 & TRN \\
\hline CHEMBL1544693 & 688867 & 2.9208 & 4.0646 & TST \\
\hline CHEMBL1389755 & 688867 & 2.9208 & 4.4625 & TRN \\
\hline CHEMBL1491711 & 688867 & 2.9208 & 4.2393 & TRN \\
\hline CHEMBL1477847 & 688867 & 4.3652 & 4.9699 & TRN \\
\hline CHEMBL1509230 & 688867 & 6.9872 & 5.5117 & TRN \\
\hline CHEMBL1971532 & 688867 & 6.7799 & 5.6792 & TRN \\
\hline CHEMBL1484894 & 688867 & 4.8257 & 4.4776 & TRN \\
\hline CHEMBL1527438 & 688867 & 4.5917 & 4.9327 & TRN \\
\hline CHEMBL1588715 & 688867 & 4.8011 & 4.7427 & TRN \\
\hline CHEMBL1472137 & 688867 & 4.8373 & 4.4051 & TRN \\
\hline CHEMBL1448415 & 688867 & 4.5453 & 4.3617 & TRN \\
\hline CHEMBL1603132 & 688867 & 4.7338 & 4.7518 & TRN \\
\hline CHEMBL 1449261 & 688867 & 4.5359 & 4.0996 & TRN \\
\hline CHEMBL1559258 & 688867 & 2.9208 & 4.5969 & TRN \\
\hline CHEMBL1315795 & 688867 & 4.2 & 5.2218 & TST \\
\hline CHEMBL1499853 & 688867 & 8.0 & 4.5595 & TRN \\
\hline CHEMBL1603170 & 688867 & 7.0 & 6.686 & TRN \\
\hline CHEMBL1582836 & 688867 & 2.9208 & 4.2 & TRN \\
\hline CHEMBL1540631 & 688867 & 4.1927 & 5.0667 & TST \\
\hline CHEMBL1575925 & 688867 & 4.6282 & 3.8387 & TST \\
\hline CHEMBL1381275 & 688867 & 4.3917 & 4.3363 & TRN \\
\hline CHEMBL1605642 & 688867 & 4.6833 & 5.0548 & TRN \\
\hline CHEMBL1609019 & 688867 & 4.7688 & 4.8049 & TRN \\
\hline CHEMBL1308677 & 688867 & 3.9251 & 5.1205 & TRN \\
\hline CHEMBL1566459 & 688867 & 6.1701 & 5.7889 & TRN \\
\hline CHEMBL1522298 & 688867 & 4.8215 & 5.0104 & TRN \\
\hline CHEMBL1566881 & 688867 & 5.3082 & 5.8695 & TRN \\
\hline CHEMBL1370259 & 688867 & 4.7483 & 5.7548 & TRN \\
\hline CHEMBL1305388 & 688867 & 4.6125 & 4.9621 & TRN \\
\hline CHEMBL1603658 & 688867 & 4.6416 & 4.71 & TRN \\
\hline
\end{tabular}




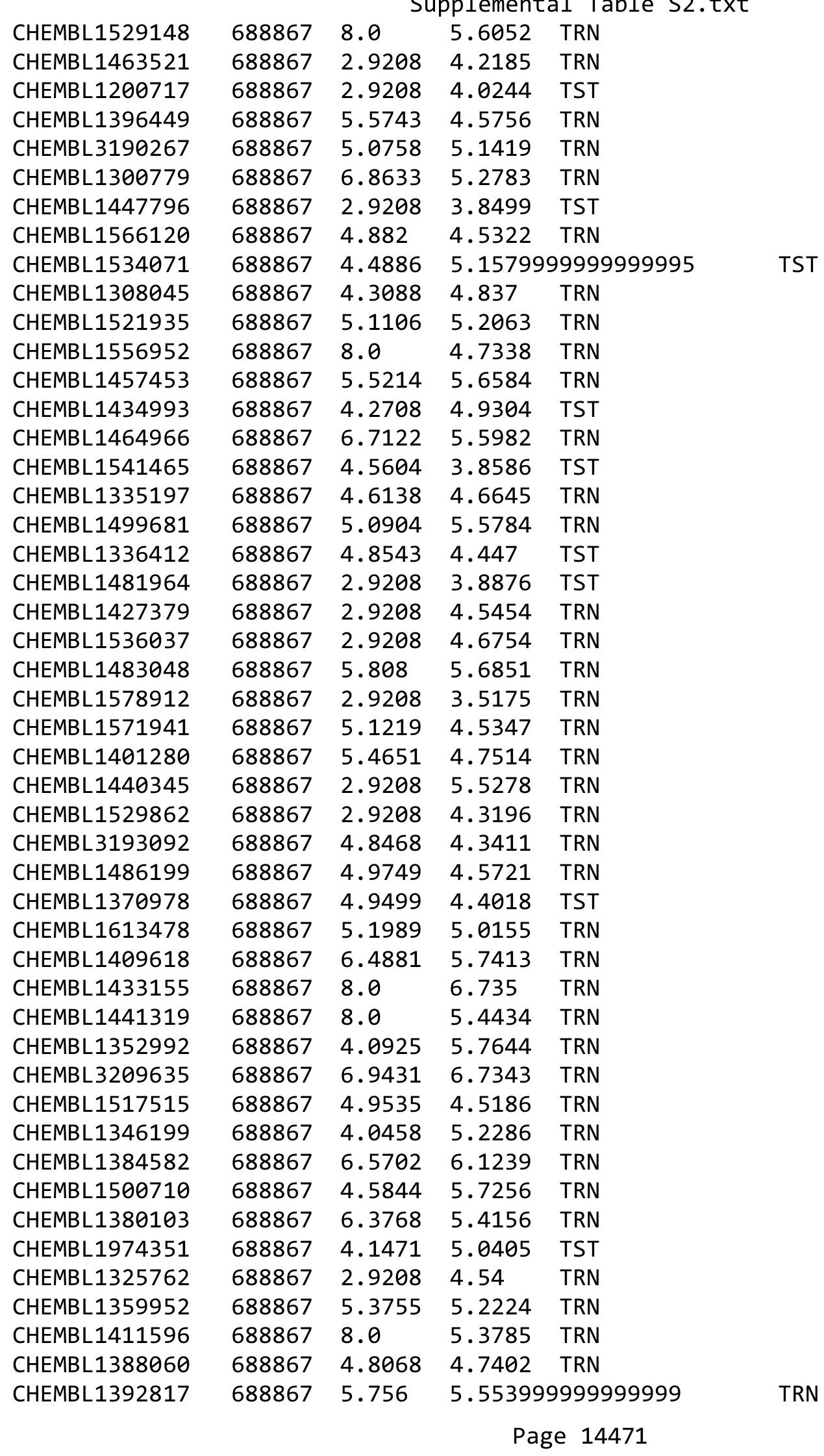


Supplemental Table S2.txt

\begin{tabular}{|c|c|c|c|c|}
\hline . & & & & \\
\hline HEMBL1597364 & 38867 & 2597 & 3445 & \\
\hline HEMBL1576454 & 88867 & 2536 & & \\
\hline 2505 & & & 803 & \\
\hline EMBL32 & 867 & & 531 & \\
\hline HEMBL1411342 & 88867 & 711 & 9578 & \\
\hline HEMBL1470281 & 88867 & 2.9208 & .1672 & \\
\hline HEMBL1340291 & 88867 & & 54 & \\
\hline 329 & 8867 & & 5223 & \\
\hline IEMBL14 & 867 & & 4801 & \\
\hline HEMBL1337140 & 88867 & 638 & 4.7411 & \\
\hline HEMBL1348831 & 88867 & .419 & & \\
\hline HEMBL14 & 88867 & 213 & 732 & \\
\hline HEMBL3: & & & 1771 & \\
\hline HEMBL1 & 67 & & 5.6359 & \\
\hline AEMBL1C & 88867 & 709 & 4134 & \\
\hline HEMBL1387889 & 88867 & 11 & 4.2603 & \\
\hline HEMBL1C & 88867 & 208 & 4.0784 & \\
\hline HEMBL1: & & & 918 & \\
\hline 991 & 57 & 208 & 3805 & RN \\
\hline HEMBL1: & 867 & $\partial 8$ & 316 & RN \\
\hline HEMBL1303960 & 88867 & 29 & 853 & RN \\
\hline HEMBL15 & 867 & 208 & 564 & 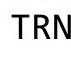 \\
\hline 310 & & & 491 & RN \\
\hline 471 & & & 9076 & RN \\
\hline 456 & 67 & & 3938 & RN \\
\hline HEMBL13 & 38867 & 208 & 2601 & RN \\
\hline HEMBL1C & 867 & 477 & 3249 & 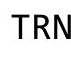 \\
\hline 31 & & 81 & & RN \\
\hline 38 & & & 781 & RN \\
\hline AEMBL13 & & & 641 & RN \\
\hline HEMBL1322536 & 88867 & 08 & 8303 & RN \\
\hline HEMBL15 & 8867 & 21 & 3213 & RN \\
\hline 5 & 7 & & 49 & ST \\
\hline HEMBL137 & & & 363 & ST \\
\hline HEMBL1390359 & 67 & & 5722 & RN \\
\hline HEMBL14 & 88867 & 12 & 2616 & RN \\
\hline HEMBL13 & 38867 & 27 & 874 & RIV \\
\hline 3 & & & & ST \\
\hline HEMBL13 & & 801 & 9777 & RN \\
\hline HEMBL15 & 88867 & & 3116 & RN \\
\hline HEMBL1: & 88867 & 518 & 458 & ST \\
\hline HEMBL1: & 88867 & & 2789 & \\
\hline & & & 156 & ST \\
\hline HEMBL13 & & 9208 & 6266 & RN \\
\hline HEMBL1305278 & 38867 & 3.2218 & 6071 & RN \\
\hline 2 & & & & \\
\hline & & & & \\
\hline
\end{tabular}

Page 14472 
Supplemental Table S2.txt

\begin{tabular}{|c|c|c|c|c|}
\hline CHEMBL1323962 & 688867 & 4.7766 & 5.0422 & TST \\
\hline CHEMBL1485369 & 688867 & 2.9208 & 3.9631 & TRN \\
\hline CHEMBL1501282 & 688867 & 6.0434 & 5.5564 & TRN \\
\hline CHEMBL1424732 & 688867 & 2.9208 & 4.58899 & 99999999995 \\
\hline CHEMBL1997978 & 688867 & 5.2381 & 4.5437 & TRN \\
\hline CHEMBL1389262 & 688867 & 6.8297 & 4.8897 & TRN \\
\hline CHEMBL1381292 & 688867 & 4.8268 & 4.6404 & TRN \\
\hline CHEMBL1528629 & 688867 & 2.9208 & 3.96199 & 99999999997 \\
\hline CHEMBL1528404 & 688867 & 5.3143 & 4.4072 & TRN \\
\hline CHEMBL1520273 & 688867 & 6.3152 & 7.0939 & TRN \\
\hline CHEMBL1336661 & 688867 & 6.9914 & 4.6722 & TRN \\
\hline CHEMBL1301732 & 688867 & 8.0 & 5.6925 & TRN \\
\hline CHEMBL1362521 & 688867 & 2.9208 & 4.5323 & TRN \\
\hline CHEMBL1562193 & 688867 & 5.1341 & 5.4026 & TRN \\
\hline CHEMBL1371059 & 688867 & 4.6293 & 6.2495 & TRN \\
\hline CHEMBL3197511 & 688867 & 2.9208 & 4.2982 & TRN \\
\hline CHEMBL1565737 & 688867 & 5.1514 & 6.3907 & TRN \\
\hline CHEMBL1427221 & 688867 & 5.5265 & 6.1415 & TRN \\
\hline CHEMBL1493059 & 688867 & 4.0439 & 5.0975 & TRN \\
\hline CHEMBL1583812 & 688867 & 2.9208 & 4.015 & TRN \\
\hline CHEMBL1508071 & 688867 & 4.4287 & 4.4911 & TRN \\
\hline CHEMBL1351722 & 688867 & 4.7486 & 5.0213 & TRN \\
\hline CHEMBL1595926 & 688867 & 4.6219 & 4.7716 & TST \\
\hline CHEMBL1499250 & 688867 & 8.0 & 4.5489 & TRN \\
\hline CHEMBL1342667 & 688867 & 8.0 & 5.2416 & TRN \\
\hline CHEMBL1488035 & 688867 & 3.5229 & 3.4345 & TRN \\
\hline CHEMBL1555816 & 688867 & 4.559 & 4.8333 & TRN \\
\hline CHEMBL1443597 & 688867 & 5.3766 & 4.6635 & TRN \\
\hline CHEMBL1350122 & 688867 & 4.8628 & 4.1339 & TST \\
\hline CHEMBL1364203 & 688867 & 4.8276 & 4.2065 & TST \\
\hline CHEMBL1362125 & 688867 & 2.9208 & 4.3166 & TST \\
\hline CHEMBL1549871 & 688867 & 5.2106 & 4.9535 & TST \\
\hline CHEMBL1578551 & 688867 & 4.8442 & 3.7125 & TST \\
\hline CHEMBL1428009 & 688867 & 2.9208 & 3.438 & TST \\
\hline CHEMBL1310628 & 688867 & 4.6906 & 4.6051 & TST \\
\hline CHEMBL1531037 & 688867 & 8.0 & 5.4659 & TST \\
\hline CHEMBL1328741 & 688867 & 5.0813 & 4.4736 & TST \\
\hline CHEMBL1588285 & 688867 & 8.0 & 5.5916 & TST \\
\hline CHEMBL3213546 & 688867 & 6.3449 & 5.1841 & TST \\
\hline CHEMBL1367627 & 688867 & 2.9208 & 3.91899 & 99999999996 \\
\hline CHEMBL1462073 & 688867 & 5.1025 & 4.4056 & TST \\
\hline CHEMBL1613402 & 688867 & 4.7945 & 4.445 & TST \\
\hline CHEMBL1389637 & 688867 & 4.8934 & 4.9286 & TST \\
\hline CHEMBL1460831 & 688867 & 2.9208 & 3.7658 & TST \\
\hline CHEMBL1370907 & 688867 & 5.2347 & 4.5782 & TST \\
\hline CHEMBL1326529 & 688867 & 4.6288 & 4.7946 & TST \\
\hline CHEMBL1530542 & 688867 & 5.0494 & 5.2714 & TST \\
\hline CHEMBL1507421 & 688867 & 4.7223 & 4.5715 & TST \\
\hline
\end{tabular}




\begin{tabular}{|c|c|c|c|c|c|}
\hline & & & & & \\
\hline CHEMBL1390789 & 688867 & 8.0 & 5.1431 & TST & \\
\hline CHEMBL1477080 & 688867 & 6.8697 & 4.5185 & TST & \\
\hline CHEMBL1527590 & 688867 & 4.8322 & 4.6341 & TST & \\
\hline CHEMBL 3207847 & 688867 & 5.1117 & 4.4644 & TST & \\
\hline CHEMBL1342363 & 688867 & 2.9208 & 3.8384 & TST & \\
\hline CHEMBL1461372 & 688867 & 5.0936 & 4.4404 & TST & \\
\hline CHEMBL1495566 & 688867 & 4.8854 & 5.3073 & TST & \\
\hline CHEMBL1600643 & 688867 & 2.9208 & 3.9771 & TST & \\
\hline CHEMBL1428897 & 688867 & 6.8297 & 5.851 & TST & \\
\hline CHEMBL1497725 & 688867 & 2.9208 & 5.6312 & TST & \\
\hline CHEMBL1304741 & 688867 & 4.455 & 3.8181 & TST & \\
\hline CHEMBL1424249 & 688867 & 4.1981 & 5.1328 & TST & \\
\hline CHEMBL1568555 & 688867 & 3.9759 & 5.6465 & TST & \\
\hline CHEMBL3191391 & 688867 & 4.6936 & 4.7645 & TST & \\
\hline CHEMBL1427219 & 688867 & 5.1133 & 4.0885 & TST & \\
\hline CHEMBL1605779 & 688867 & 4.5016 & 5.9305 & TST & \\
\hline CHEMBL1532352 & 688867 & 2.9208 & 5.41200 & 2000000001 & TST \\
\hline CHEMBL1331200 & 688867 & 4.556 & 4.934 & TST & \\
\hline CHEMBL1395312 & 688867 & 4.3425 & 5.29 & TST & \\
\hline CHEMBL1328740 & 688867 & 4.7259 & 5.1608 & TST & \\
\hline CHEMBL1374465 & 688867 & 4.5617 & 4.6635 & TST & \\
\hline CHEMBL1583892 & 688867 & 4.4964 & 4.711 & TST & \\
\hline CHEMBL1344260 & 688867 & 4.4344 & 5.28600 & 00000000005 & TST \\
\hline CHEMBL1523761 & 688867 & 4.0359 & 4.6063 & TST & \\
\hline CHEMBL1571896 & 688867 & 6.2848 & 4.7662 & TST & \\
\hline CHEMBL1486214 & 688867 & 2.9208 & 4.4702 & TST & \\
\hline CHEMBL1384623 & 688867 & 4.8641 & 4.9774 & TST & \\
\hline CHEMBL1446641 & 688867 & 5.3281 & 4.2812 & TST & \\
\hline CHEMBL1594327 & 688867 & 4.1461 & 4.1016 & TST & \\
\hline CHEMBL1506183 & 688867 & 2.9208 & 4.0031 & TST & \\
\hline CHEMBL223496 & 688867 & 4.1206 & 4.6175 & TST & \\
\hline CHEMBL1544748 & 688867 & 4.7631 & 3.9888 & TST & \\
\hline CHEMBL1308668 & 688867 & 4.3726 & 5.7247 & TST & \\
\hline CHEMBL1384906 & 688867 & 4.7903 & 4.8698 & TST & \\
\hline CHEMBL1367400 & 688867 & 4.7941 & 5.1237 & TST & \\
\hline CHEMBL1529331 & 688867 & 4.7526 & 4.3324 & TST & \\
\hline CHEMBL1428180 & 688867 & 4.9863 & 6.00299 & 9999999999 & TST \\
\hline CHEMBL1425445 & 688867 & 4.6304 & 4.2776 & TST & \\
\hline CHEMBL1566972 & 688867 & 4.5268 & 5.3537 & TST & \\
\hline CHEMBL1383533 & 688867 & 2.9208 & 4.8198 & TST & \\
\hline CHEMBL1503105 & 688867 & 4.2741 & 4.9772 & TST & \\
\hline CHEMBL1508882 & 688867 & 4.8675 & 4.4438 & TST & \\
\hline CHEMBL1331466 & 688867 & 5.1722 & 4.4793 & TST & \\
\hline CHEMBL1543054 & 688867 & 8.0 & 5.1581 & TST & \\
\hline CHEMBL1489440 & 688867 & 5.5865 & 5.9189 & TST & \\
\hline CHEMBL1382658 & 688867 & 6.8539 & 5.6239 & TST & \\
\hline CHEMBL1332868 & 688867 & 4.7444 & 4.5448 & TST & \\
\hline CHEMBL1597227 & 688867 & 4.8833 & 4.6287 & TST & \\
\hline
\end{tabular}




\begin{tabular}{|c|c|c|c|c|}
\hline & & \multicolumn{3}{|c|}{ Supplemental Table S } \\
\hline CHEMBL1559477 & 688867 & 4.92 & 4.3237 & TST \\
\hline CHEMBL1561296 & 688867 & 4.9251 & 4.9716 & TST \\
\hline CHEMBL3195471 & 688867 & 5.1171 & 5.6015 & TST \\
\hline CHEMBL1470903 & 688867 & 7.71 & 6.3383 & TST \\
\hline CHEMBL1577624 & 688867 & 6.6459 & 5.0131 & TST \\
\hline CHEMBL1253586 & 688867 & 4.9176 & 5.1211 & TST \\
\hline CHEMBL1402372 & 688867 & 4.5358 & 4.8842 & TST \\
\hline CHEMBL1342306 & 688867 & 4.9381 & 4.8713 & TST \\
\hline CHEMBL3211496 & 688867 & 4.8445 & 4.5529 & TST \\
\hline CHEMBL1598916 & 688867 & 5.0465 & 4.6323 & TST \\
\hline CHEMBL1601639 & 688867 & 4.9553 & 4.754 & TST \\
\hline CHEMBL1464193 & 688867 & 5.0157 & 4.7027 & TST \\
\hline CHEMBL1528010 & 688867 & 4.4088 & 4.9976 & TST \\
\hline CHEMBL1495198 & 688867 & 4.8 & 5.5506 & TST \\
\hline CHEMBL1582862 & 688867 & 8.0 & 6.6143 & TST \\
\hline CHEMBL1480762 & 688867 & 4.8108 & 4.4258 & TST \\
\hline CHEMBL1305543 & 688867 & 3.5229 & 4.1624 & TST \\
\hline CHEMBL1586872 & 688867 & 4.57 & 5.2162 & TST \\
\hline CHEMBL1539301 & 688867 & 4.7026 & 4.4915 & TST \\
\hline CHEMBL3198303 & 688867 & 8.0 & 5.9354 & TST \\
\hline CHEMBL1382098 & 688867 & 4.0269 & 5.1186 & TST \\
\hline CHEMBL578716 & 688867 & 2.9208 & 4.1706 & TST \\
\hline CHEMBL3192157 & 688867 & 4.7096 & 4.9703 & TST \\
\hline CHEMBL1471595 & 688867 & 2.9208 & 3.9496 & TST \\
\hline CHEMBL1588575 & 688867 & 4.2466 & 6.3105 & TST \\
\hline CHEMBL3192269 & 688867 & 4.7786 & 4.9953 & TST \\
\hline CHEMBL1524528 & 688867 & 6.6271 & 5.4114 & TST \\
\hline CHEMBL1412792 & 688867 & 2.9208 & 4.9392 & TST \\
\hline CHEMBL1519639 & 688867 & 6.9281 & 6.4435 & TST \\
\hline CHEMBL1991311 & 688867 & 5.1724 & 5.1902 & TST \\
\hline CHEMBL3195910 & 688867 & 2.9208 & 4.9753 & TST \\
\hline CHEMBL1461600 & 688867 & 6.7144 & 5.9968 & TST \\
\hline CHEMBL1482145 & 688867 & 4.9307 & 4.8896 & TST \\
\hline CHEMBL3192922 & 688867 & 4.2611 & 5.1412 & TST \\
\hline CHEMBL1581385 & 688867 & 5.124 & 5.0843 & TST \\
\hline CHEMBL1484314 & 688867 & 4.7434 & 4.3148 & TST \\
\hline CHEMBL1509837 & 688867 & 4.8518 & 3.9445 & TST \\
\hline CHEMBL 3211892 & 688867 & 2.9208 & 4.2475 & TST \\
\hline CHEMBL1607544 & 688867 & 4.5124 & 5.2596 & TST \\
\hline CHEMBL1599636 & 688867 & 4.566 & 4.9394 & TST \\
\hline CHEMBL1455144 & 688867 & 4.1577 & 5.1691 & TST \\
\hline CHEMBL1518652 & 688867 & 4.1183 & 4.8702 & TST \\
\hline CHEMBL 1457697 & 688867 & 5.2245 & 4.3969 & TST \\
\hline CHEMBL1373344 & 688867 & 4.981 & 5.1883 & TST \\
\hline CHEMBL1535700 & 688867 & 5.1263 & 5.16799 & 9999999999 \\
\hline CHEMBL1464256 & 688867 & 4.5941 & 5.7946 & TST \\
\hline CHEMBL 3184145 & 688867 & 2.9208 & 4.5587 & TST \\
\hline CHEMBL1509816 & 688867 & 4.5727 & 4.9884 & TST \\
\hline
\end{tabular}




\begin{tabular}{|c|c|c|c|c|}
\hline \multicolumn{5}{|c|}{ Supplemental Table s2.txt } \\
\hline CHEMBL1445085 & 688867 & 2.9208 & 4.4987 & TST \\
\hline CHEMBL1489179 & 688867 & 8.0 & 5.9256 & TST \\
\hline CHEMBL1595927 & 688867 & 5.2662 & 5.357 & TST \\
\hline CHEMBL1361242 & 688867 & 6.109 & 5.5566 & TST \\
\hline CHEMBL1080213 & 688867 & 6.6421 & 5.6354 & TST \\
\hline CHEMBL1602646 & 688867 & 2.9208 & 4.0881 & TST \\
\hline CHEMBL1449896 & 688867 & 4.2259 & 5.4778 & TST \\
\hline CHEMBL1349795 & 688867 & 4.6117 & 4.8102 & TST \\
\hline CHEMBL1499860 & 688867 & 4.7712 & 4.3616 & TST \\
\hline CHEMBL1563059 & 688867 & 5.226 & 4.4406 & TST \\
\hline CHEMBL1586605 & 688867 & 2.9208 & 4.6965 & TST \\
\hline CHEMBL1326031 & 688867 & 4.9514 & 5.2353 & TST \\
\hline CHEMBL1459184 & 688867 & 4.8131 & 4.364 & TST \\
\hline CHEMBL1309378 & 688867 & 8.0 & 5.9753 & TST \\
\hline CHEMBL3193472 & 688867 & 2.9208 & 4.5178 & TST \\
\hline CHEMBL1361637 & 688867 & 4.1386 & 4.832 & TST \\
\hline CHEMBL1378221 & 688867 & 4.9516 & 5.0294 & TST \\
\hline CHEMBL1520533 & 688867 & 4.3157 & 4.3032 & TST \\
\hline CHEMBL1403313 & 688867 & 4.5927 & 3.8478 & TST \\
\hline CHEMBL1517230 & 688867 & 4.2543 & 4.4734 & TST \\
\hline CHEMBL1524817 & 688867 & 6.0878 & 5.0993 & TST \\
\hline CHEMBL1518032 & 688867 & 6.5272 & 6.4689 & TST \\
\hline CHEMBL1458423 & 688867 & 5.061 & 4.5848 & TST \\
\hline CHEMBL1373732 & 688867 & 5.0172 & 4.8907 & TST \\
\hline CHEMBL1340162 & 688867 & 6.4353 & 5.2412 & TST \\
\hline CHEMBL1497338 & 688867 & 2.9208 & 4.2302 & TST \\
\hline CHEMBL1359482 & 688867 & 6.9508 & 5.8122 & TST \\
\hline CHEMBL1465725 & 688867 & 4.6778 & 6.0411 & TST \\
\hline CHEMBL1565407 & 688867 & 5.7562 & 4.7735 & TST \\
\hline CHEMBL1450360 & 688867 & 5.2212 & 5.1334 & TST \\
\hline CHEMBL1607974 & 688867 & 4.8856 & 4.1774 & TST \\
\hline CHEMBL1588123 & 688867 & 4.5096 & 5.4468 & TST \\
\hline CHEMBL1589285 & 688867 & 4.4057 & 4.3534 & TST \\
\hline CHEMBL1539762 & 688867 & 4.7321 & 5.3155 & TST \\
\hline CHEMBL1570217 & 688867 & 6.9318 & 6.2432 & TST \\
\hline CHEMBL1339768 & 688867 & 5.3712 & 5.1939 & TST \\
\hline CHEMBL1582707 & 688867 & 5.9245 & 5.3824 & TST \\
\hline CHEMBL1554847 & 688867 & 6.9066 & 6.1981 & TST \\
\hline CHEMBL1351967 & 688867 & 4.7505 & 4.5385 & TST \\
\hline CHEMBL1507040 & 688867 & 2.9208 & 5.2334 & TST \\
\hline CHEMBL1508749 & 688867 & 4.4373 & 4.6708 & TST \\
\hline CHEMBL1502624 & 688867 & 5.9062 & 5.5392 & TST \\
\hline CHEMBL3196976 & 688867 & 2.9208 & 4.0201 & TST \\
\hline CHEMBL1387150 & 688867 & 6.9508 & 4.0743 & TST \\
\hline CHEMBL1513113 & 688867 & 4.8896 & 4.942 & TST \\
\hline CHEMBL1541933 & 688867 & 5.195 & 6.2781 & TST \\
\hline CHEMBL1450011 & 688867 & 4.7826 & 4.5976 & TST \\
\hline CHEMBL1345184 & 688867 & 4.0364 & 4.1322 & TST \\
\hline
\end{tabular}


Supplemental Table S2.txt

\begin{tabular}{|c|c|c|c|c|}
\hline CHEMBL1549571 & 688867 & 5.0124 & 5.0705 & TST \\
\hline CHEMBL3208571 & 688867 & 5.0224 & 4.5519 & TST \\
\hline CHEMBL1361053 & 688867 & 4.2638 & 5.44600 & 0000000001 \\
\hline CHEMBL1498536 & 688867 & 4.5078 & 4.5849 & TST \\
\hline CHEMBL1520731 & 688867 & 5.7698 & 6.2666 & TST \\
\hline CHEMBL1438073 & 688867 & 5.5315 & 4.9844 & TST \\
\hline CHEMBL1561715 & 688867 & 4.8449 & 5.0886 & TST \\
\hline CHEMBL1425110 & 688867 & 4.5943 & 4.6591 & TST \\
\hline CHEMBL1592550 & 688867 & 4.7854 & 5.8464 & TST \\
\hline CHEMBL1414633 & 688867 & 5.4149 & 5.8482 & TST \\
\hline CHEMBL1610870 & 688867 & 4.3833 & 5.0331 & TST \\
\hline CHEMBL1424944 & 688867 & 4.6785 & 4.5944 & TST \\
\hline CHEMBL1404286 & 688867 & 4.9008 & 5.1531 & TST \\
\hline CHEMBL1531352 & 688867 & 4.5145 & 4.8042 & TST \\
\hline CHEMBL 3190048 & 688867 & 4.8857 & 5.3506 & TST \\
\hline CHEMBL1547409 & 688867 & 5.0266 & 4.8885 & TST \\
\hline CHEMBL1518379 & 688867 & 4.6347 & 4.6401 & TST \\
\hline CHEMBL1372066 & 688867 & 4.754 & 5.5102 & TST \\
\hline CHEMBL1092508 & 688867 & 4.8224 & 5.0561 & TST \\
\hline CHEMBL1302081 & 688867 & 4.1861 & 5.6611 & TST \\
\hline CHEMBL1365203 & 688867 & 2.9208 & 4.412 & TST \\
\hline CHEMBL1408969 & 688867 & 8.0 & 6.3464 & TST \\
\hline CHEMBL1443086 & 688867 & 4.5432 & 5.4362 & TST \\
\hline CHEMBL 3198658 & 688867 & 4.9215 & 5.2161 & TST \\
\hline CHEMBL3199337 & 688867 & 4.3459 & 4.8044 & TST \\
\hline CHEMBL1557898 & 688867 & 6.8097 & 6.7258 & TST \\
\hline CHEMBL1601903 & 688867 & 5.2291 & 4.8163 & TST \\
\hline CHEMBL1405704 & 688867 & 2.9208 & 4.2856 & TST \\
\hline CHEMBL1606344 & 688867 & 8.0 & 5.5584 & TST \\
\hline CHEMBL1543615 & 688867 & 3.9253 & 5.67299 & 9999999999 \\
\hline CHEMBL1570658 & 688867 & 4.2503 & 5.4171 & TST \\
\hline CHEMBL1447341 & 688867 & 2.9208 & 4.0388 & TST \\
\hline CHEMBL1522322 & 688867 & 4.9911 & 4.4356 & TST \\
\hline CHEMBL1574581 & 688867 & 2.9208 & 3.9943 & TST \\
\hline CHEMBL1561328 & 688867 & 2.9208 & 4.2146 & TST \\
\hline CHEMBL1469170 & 688867 & 2.9208 & 3.8434 & TST \\
\hline CHEMBL1335236 & 688867 & 4.1558 & 3.93 & TST \\
\hline CHEMBL 3197566 & 688867 & 2.9208 & 4.3008 & TST \\
\hline CHEMBL1427533 & 688867 & 5.1762 & 4.5005 & TST \\
\hline CHEMBL1481769 & 688867 & 4.1041 & 5.5549 & TST \\
\hline CHEMBL1602693 & 688867 & 8.0 & 4.5791 & TST \\
\hline CHEMBL1496209 & 688867 & 4.7088 & 4.4238 & TST \\
\hline CHEMBL1357259 & 688867 & 4.9663 & 4.3137 & TST \\
\hline CHEMBL1306816 & 688867 & 2.9208 & 4.9544 & TST \\
\hline CHEMBL473162 & 688867 & 6.4437 & 6.6151 & TST \\
\hline CHEMBL1305221 & 688867 & 3.9579 & 4.4842 & TST \\
\hline CHEMBL1570236 & 688867 & 4.7923 & 4.7185 & TST \\
\hline CHEMBL1490486 & 688867 & 2.9208 & 4.1199 & TST \\
\hline
\end{tabular}




\begin{tabular}{|c|c|c|c|c|c|}
\hline \multicolumn{6}{|c|}{ Supplemental Table S2.txt } \\
\hline CHEMBL 3212098 & 688867 & 5.0018 & 4.8763 & TST & \\
\hline CHEMBL1537451 & 688867 & 4.7628 & 4.9789 & TST & \\
\hline CHEMBL1418909 & 688867 & 6.0114 & 5.4537 & TST & \\
\hline CHEMBL1531080 & 688867 & 5.5458 & 5.551 & TST & \\
\hline CHEMBL1306817 & 688867 & 5.1141 & 5.1096 & TST & \\
\hline CHEMBL1307720 & 688867 & 5.5339 & 3.7589 & TST & \\
\hline CHEMBL1345839 & 688867 & 5.0791 & 4.4734 & TST & \\
\hline CHEMBL1577922 & 688867 & 8.0 & 5.4177 & TST & \\
\hline CHEMBL1481805 & 688867 & 2.9208 & 4.5547 & TST & \\
\hline CHEMBL3194314 & 688867 & 4.7557 & 5.3092 & TST & \\
\hline CHEMBL1350769 & 688867 & 4.7453 & 4.4975 & TST & \\
\hline CHEMBL1543038 & 688867 & 4.2343 & 4.9711 & TST & \\
\hline CHEMBL1565794 & 688867 & 4.8403 & 4.8247 & TST & \\
\hline CHEMBL1447771 & 688867 & 6.4271 & 5.4315 & TST & \\
\hline CHEMBL1448363 & 688867 & 4.5879 & 5.0775 & TST & \\
\hline CHEMBL1421266 & 688867 & 5.9551 & 4.9714 & TST & \\
\hline CHEMBL1465298 & 688867 & 4.4956 & 5.4403 & TST & \\
\hline CHEMBL1534724 & 688867 & 4.2919 & 5.3544 & TST & \\
\hline CHEMBL1569541 & 688867 & 4.3901 & 5.4217 & TST & \\
\hline CHEMBL1304209 & 688867 & 4.5271 & 4.3809 & TST & \\
\hline CHEMBL1605139 & 688867 & 4.9282 & 4.6649 & TST & \\
\hline CHEMBL1515973 & 688867 & 4.3856 & 4.2802 & TST & \\
\hline CHEMBL3197079 & 688867 & 6.6003 & 5.3073 & TST & \\
\hline CHEMBL1340051 & 688867 & 2.9208 & 3.9024 & TST & \\
\hline CHEMBL3194157 & 688867 & 4.9373 & 4.735 & TST & \\
\hline CHEMBL1373309 & 688867 & 5.5071 & 5.414 & TST & \\
\hline CHEMBL1488090 & 688867 & 4.8792 & 5.9218 & TST & \\
\hline CHEMBL1312428 & 688867 & 4.7291 & 5.2552 & TST & \\
\hline CHEMBL1600243 & 688867 & 5.4191 & 5.456 & TST & \\
\hline CHEMBL1583427 & 688867 & 4.8675 & 4.7961 & TST & \\
\hline CHEMBL1326037 & 688867 & 5.1223 & 4.9409 & TST & \\
\hline CHEMBL1497673 & 688867 & 4.3386 & 5.16799 & 9999999999 & TST \\
\hline CHEMBL1543489 & 688867 & 6.2048 & 5.1266 & TST & \\
\hline CHEMBL3189879 & 688867 & 4.6475 & 4.4906 & TST & \\
\hline CHEMBL1355755 & 688867 & 8.0 & 7.4242 & TST & \\
\hline CHEMBL3199616 & 688867 & 4.6811 & 4.4237 & TST & \\
\hline CHEMBL3211314 & 688867 & 4.575 & 4.7596 & TST & \\
\hline CHEMBL1343061 & 688867 & 5.1194 & 4.6949 & TST & \\
\hline CHEMBL1378851 & 688867 & 6.9355 & 4.2457 & TST & \\
\hline CHEMBL1403095 & 688867 & 4.294 & 4.8878 & TST & \\
\hline CHEMBL1357542 & 688867 & 4.8007 & 4.9197 & TST & \\
\hline CHEMBL1327719 & 688867 & 4.9023 & 4.7639 & TST & \\
\hline CHEMBL1969332 & 688867 & 5.9439 & 5.5557 & TST & \\
\hline CHEMBL1377690 & 688867 & 2.9208 & 4.9955 & TST & \\
\hline CHEMBL1381979 & 688867 & 5.0857 & 4.6716 & TST & \\
\hline CHEMBL1319024 & 688867 & 4.8349 & 4.437 & TST & \\
\hline CHEMBL1505083 & 688867 & 4.2756 & 5.426 & TST & \\
\hline CHEMBL1197872 & 688867 & 5.0138 & 3.6383 & TST & \\
\hline
\end{tabular}




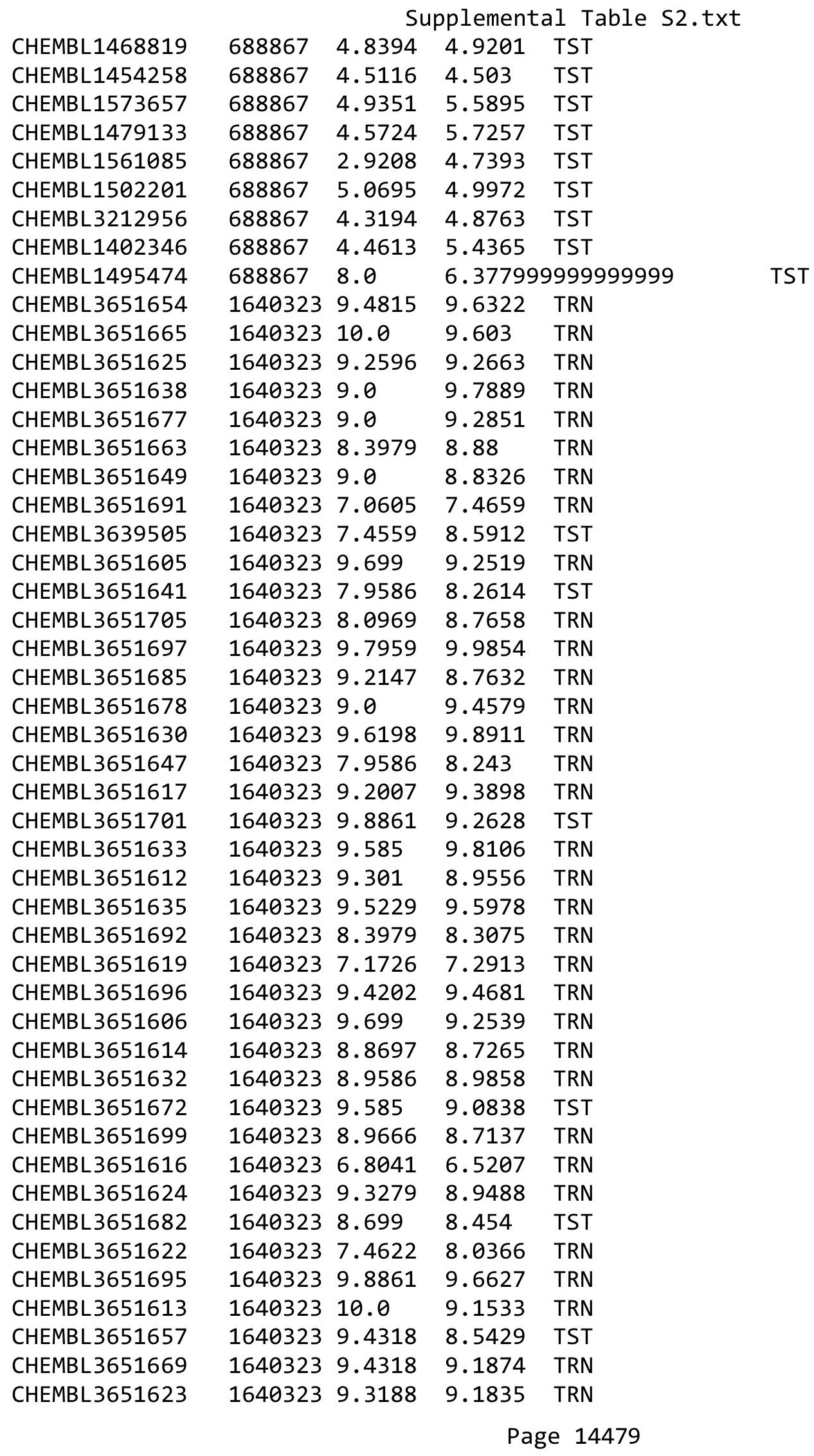


Supplemental Table S2.txt

\begin{tabular}{|c|c|c|c|c|}
\hline CHEMBL3651631 & 1640323 & 9.2218 & 9.0775 & TRN \\
\hline CHEMBL3651609 & 1640323 & 10.0 & 9.3232 & TRN \\
\hline CHEMBL 3651687 & 1640323 & 8.3979 & 8.454 & TST \\
\hline CHEMBL 3651680 & 1640323 & 9.9586 & 9.4061 & TRN \\
\hline CHEMBL3651704 & 1640323 & 9.0 & 9.5228 & TRN \\
\hline CHEMBL 3651689 & 1640323 & 9.0 & 9.0963 & TRN \\
\hline CHEMBL 3651658 & 1640323 & 9.9586 & 8.6349 & TST \\
\hline CHEMBL 3651694 & 1640323 & 7.5528 & 7.8158 & TRN \\
\hline CHEMBL 3651653 & 1640323 & 9.0 & 8.6203 & TRN \\
\hline CHEMBL3651667 & 1640323 & 9.6576 & \multicolumn{2}{|c|}{8.761000000000001} \\
\hline CHEMBL 3651645 & 1640323 & 9.0 & 8.8141 & TST \\
\hline CHEMBL3651661 & 1640323 & 9.8861 & 9.0904 & TST \\
\hline CHEMBL 3651637 & 1640323 & 9.0 & 9.0482 & TRN \\
\hline CHEMBL 3651698 & 1640323 & 9.0177 & 8.8862 & TRN \\
\hline CHEMBL3651644 & 1640323 & 9.4089 & 9.273 & TRN \\
\hline CHEMBL 3651670 & 1640323 & 8.1549 & 8.6546 & TRN \\
\hline CHEMBL3651676 & 1640323 & 9.6383 & 9.344 & TRN \\
\hline CHEMBL 3651640 & 1640323 & 9.3372 & 9.5422 & TRN \\
\hline CHEMBL 3651627 & 1640323 & 9.0506 & 10.0089 & TRN \\
\hline CHEMBL3651650 & 1640323 & 7.6021 & 7.7521 & TRN \\
\hline CHEMBL3651693 & 1640323 & 6.2381 & 8.52 & TST \\
\hline CHEMBL3651636 & 1640323 & 9.3468 & 9.4418 & TRN \\
\hline CHEMBL 3651675 & 1640323 & 9.699 & 9.1998 & TRN \\
\hline CHEMBL 3651703 & 1640323 & 9.9208 & 9.974 & TRN \\
\hline CHEMBL 3651643 & 1640323 & 9.0 & 9.3052 & TRN \\
\hline CHEMBL 3651648 & 1640323 & 8.301 & 8.572000 & 0000000001 \\
\hline CHEMBL 3651690 & 1640323 & 9.0 & 8.4047 & TRN \\
\hline CHEMBL 3651628 & 1640323 & 9.7447 & 8.9646 & TRN \\
\hline CHEMBL 3651620 & 1640323 & 7.9508 & 8.2585 & TRN \\
\hline CHEMBL3651629 & 1640323 & 9.7447 & 9.6271 & TRN \\
\hline CHEMBL 3651674 & 1640323 & 9.7212 & 9.4064 & TRN \\
\hline CHEMBL3651664 & 1640323 & 10.0969 & 9.3174 & TST \\
\hline CHEMBL 3651618 & 1640323 & 6.6904 & 7.244 & TRN \\
\hline CHEMBL 3651660 & 1640323 & 8.5229 & 8.7372 & TST \\
\hline CHEMBL3651611 & 1640323 & 9.5229 & 9.3616 & TRN \\
\hline CHEMBL3651651 & 1640323 & 8.301 & 8.3496 & TRN \\
\hline CHEMBL3651662 & 1640323 & 10.0 & 9.5784 & TST \\
\hline CHEMBL 3651688 & 1640323 & 8.301 & 8.8914 & TRN \\
\hline CHEMBL 3651656 & 1640323 & 9.5376 & 8.3201 & TST \\
\hline CHEMBL3651659 & 1640323 & 9.0 & 8.3726 & TST \\
\hline CHEMBL3651621 & 1640323 & 8.5058 & 8.3483 & TRN \\
\hline CHEMBL 3651686 & 1640323 & 9.1079 & 9.1735 & TRN \\
\hline CHEMBL3651668 & 1640323 & 7.2596 & 8.2925 & TST \\
\hline CHEMBL3651610 & 1640323 & 10.0 & 9.274 & TRN \\
\hline CHEMBL 3651679 & 1640323 & 7.5086 & 8.6597 & TST \\
\hline CHEMBL3651607 & 1640323 & 9.4949 & 8.4077 & TRN \\
\hline CHEMBL 3651702 & 1640323 & 8.699 & 8.1994 & TST \\
\hline CHEMBL3651700 & 1640323 & 9.2757 & 9.622 & TRN \\
\hline
\end{tabular}


Supplemental Table S2.txt

\begin{tabular}{|c|c|c|c|c|c|}
\hline CHEMBL3651683 & 1640323 & 10.0969 & 8.6395 & TST & \\
\hline CHEMBL3651684 & 1640323 & 9.5686 & 9.2171 & TRN & \\
\hline CHEMBL3651681 & 1640323 & 5.6904 & 8.8488 & TST & \\
\hline CHEMBL 3651615 & 1640323 & 6.7235 & 6.5132 & TRN & \\
\hline CHEMBL3651634 & 1640323 & 9.3665 & 9.8776 & TRN & \\
\hline CHEMBL3651671 & 1640323 & 9.6021 & 9.7189 & TRN & \\
\hline CHEMBL 3651673 & 1640323 & 7.9208 & 8.6111 & TST & \\
\hline CHEMBL 3651646 & 1640323 & 8.301 & 8.6343 & TST & \\
\hline CHEMBL3651639 & 1640323 & 9.5528 & 8.9029 & TRN & \\
\hline CHEMBL3651655 & 1640323 & 9.6383 & 8.5092 & TST & \\
\hline CHEMBL3651608 & 1640323 & 6.6289 & 8.3979 & TRN & \\
\hline CHEMBL 3651626 & 1640323 & 9.699 & \multicolumn{2}{|c|}{9.177999999999999} & TRN \\
\hline CHEMBL3651666 & 1640323 & 8.301 & 8.6509 & TST & \\
\hline CHEMBL 3651642 & 1640323 & 9.0 & 9.3134 & TRN & \\
\hline CHEMBL3973225 & 1640561 & 7.6198 & 7.5621 & TRN & \\
\hline CHEMBL3931184 & 1640561 & 5.6198 & 6.568 & TST & \\
\hline CHEMBL3935327 & 1640561 & 7.1612 & 7.1482 & TRN & \\
\hline CHEMBL3901195 & 1640561 & 6.011 & 6.2194 & TST & \\
\hline CHEMBL3914004 & 1640561 & 7.8861 & 7.8741 & TRN & \\
\hline CHEMBL3970375 & 1640561 & 7.0177 & 6.9896 & TRN & \\
\hline CHEMBL3912635 & 1640561 & 6.3372 & 6.3018 & TRN & \\
\hline CHEMBL3965344 & 1640561 & 7.7212 & 7.6574 & TRN & \\
\hline CHEMBL3939244 & 1640561 & 7.8239 & 7.8471 & TRN & \\
\hline CHEMBL3949009 & 1640561 & 6.5017 & 6.8744 & TST & \\
\hline CHEMBL 3907389 & 1640561 & 6.7328 & 6.7422 & TRN & \\
\hline CHEMBL3953683 & 1640561 & 7.3565 & 6.4164 & TST & \\
\hline CHEMBL3915190 & 1640561 & 8.699 & 8.6719 & TRN & \\
\hline CHEMBL3944297 & 1640561 & 7.2924 & 7.2939 & TRN & \\
\hline CHEMBL3974970 & 1640561 & 7.6576 & 7.6606 & TRN & \\
\hline CHEMBL 3946211 & 1640561 & 7.6576 & 7.688 & TRN & \\
\hline CHEMBL 3943712 & 1640561 & 7.5086 & 7.5791 & TRN & \\
\hline CHEMBL3906637 & 1640561 & 7.0177 & 6.9313 & TST & \\
\hline CHEMBL3929599 & 1640561 & 7.4685 & 7.4633 & TRN & \\
\hline CHEMBL3958675 & 1640561 & 7.4318 & 7.4359 & TRN & \\
\hline CHEMBL3941645 & 1640561 & 8.2218 & 8.1921 & TRN & \\
\hline CHEMBL3966372 & 1640561 & 6.3716 & 6.3926 & TRN & \\
\hline CHEMBL3978598 & 1640561 & 6.3468 & 6.3489 & TRN & \\
\hline CHEMBL3928399 & 1640561 & 7.585 & 7.6031 & TRN & \\
\hline CHEMBL3912126 & 1640561 & 7.0655 & 6.5345 & TST & \\
\hline CHEMBL 3940127 & 1640561 & 6.8861 & 6.8918 & TRN & \\
\hline CHEMBL3938496 & 1640561 & 7.2147 & 7.2446 & TRN & \\
\hline CHEMBL3924595 & 1640561 & 5.9031 & 5.8981 & TRN & \\
\hline CHEMBL3967862 & 1640561 & 6.5935 & 6.3439 & TST & \\
\hline CHEMBL3937776 & 1640561 & 8.3979 & 8.3503 & TRN & \\
\hline CHEMBL3892827 & 1640561 & 7.3372 & 7.3063 & TRN & \\
\hline CHEMBL3917054 & 1640561 & 5.9666 & 6.0033 & TRN & \\
\hline CHEMBL3939539 & 1640561 & 7.7212 & 7.7404 & TRN & \\
\hline CHEMBL3954662 & 1640561 & 7.7696 & 7.8443 & TRN & \\
\hline
\end{tabular}


Supplemental Table S2.txt

\begin{tabular}{|c|c|c|c|c|}
\hline 8 & & & & \\
\hline & & & & \\
\hline HFMRI & 61 & & & \\
\hline IEMBL & 561 & 539 & & \\
\hline AEMBL3960604 & 561 & 437 & 4572 & \\
\hline HEMBL3 & 561 & 8.1549 & 1909 & \\
\hline 547 & & & & \\
\hline IEMBL & & & & DN \\
\hline HEMBL3961839 & 561 & 7.2518 & 7.3121 & \\
\hline HEMBL3889926 & 561 & 76 & 5.9467 & ГST \\
\hline HEMBL; & 61 & & .7714 & \\
\hline 386 & 61 & & .1005 & \\
\hline AEMBL3 & & & 976 & \\
\hline HEMBL3899189 & 561 & 76 & .9471 & - \\
\hline AEMBL3909843 & 561 & & & \\
\hline AEMBL3 & 51 & & .9884 & RIN \\
\hline AEMBL & & & 5616 & RIV \\
\hline AEMBL3 & & & 595 & \\
\hline 5855 & 61 & & $\partial 992$ & 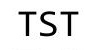 \\
\hline AEMBL3 & 61 & & 7.8601 & I KIV \\
\hline AEMBL. & 1 & & 7.4031 & RN \\
\hline HEN & & & & RN \\
\hline AEMBL & 61 & & 189 & $\mathrm{RN}$ \\
\hline 157 & & & 297 & (2) \\
\hline AEMBL3 & & 9 & 362 & IRN \\
\hline HEMBL3 & & & 7766 & 「RN \\
\hline 831 & & & 329 & ST \\
\hline 212 & & & 7.1156 & RN \\
\hline HEMBL392 & & & & IRN \\
\hline HEMBL3919903 & 61 & 6. & 5927 & RN \\
\hline AEMBL & & & 918 & ST \\
\hline 1 & & & & ГST \\
\hline 492 & & & 6.7626 & 「RN \\
\hline HEMBL3929147 & & & 221 & TST \\
\hline HEMBL3949518 & 61 & & 5.7103 & ГST \\
\hline 908 & & & & TRN \\
\hline 07 & & & 901 & ГRN \\
\hline HEMBL3931931 & & & 7.8232 & TRN \\
\hline HEMBL3943899 & & & 89 & $\Gamma R$ \\
\hline 900 & & & & RN \\
\hline HFMRI 3 & & & 916 & RN \\
\hline HEMBL3 & & & 7.5157 & 「RN \\
\hline HEMBL3920688 & & 7.0915 & 6.9478 & TST \\
\hline HEMBL3934847 & 61 & & 54 & $\mathrm{R}$ \\
\hline 681 & & & & \\
\hline HEMBL3929877 & & - & 6.4832 & \\
\hline HEMBL611393 & 30 & 8.64 & 8.654 & RN \\
\hline IHEMBL607067 & 304038 & 8.05 & 8.0799 & TRN \\
\hline
\end{tabular}

Page 14482 


\begin{tabular}{|c|c|c|c|c|c|}
\hline \multirow[b]{2}{*}{ CHEMBL607118 } & \multicolumn{5}{|c|}{ Supplemental Table S2.txt } \\
\hline & 304038 & 8.64 & 8.5593 & TRN & \\
\hline CHEMBL179679 & 304038 & 7.03 & $6.9920 e$ & 0000000001 & TST \\
\hline CHEMBL359917 & 304038 & 6.29 & 6.6567 & TST & \\
\hline CHEMBL178829 & 304038 & 8.15 & 6.4786 & TST & \\
\hline CHEMBL606673 & 304038 & 8.08 & 8.1388 & TRN & \\
\hline CHEMBL607484 & 304038 & 7.8 & 7.4529 & TRN & \\
\hline CHEMBL606738 & 304038 & 7.59 & 7.4529 & TRN & \\
\hline CHEMBL606608 & 304038 & 7.1 & 7.4529 & TRN & \\
\hline CHEMBL607485 & 304038 & 7.48 & 7.4641 & TRN & \\
\hline CHEMBL606676 & 304038 & 8.42 & 8.4368 & TRN & \\
\hline CHEMBL606607 & 304038 & 8.42 & 8.4577 & TRN & \\
\hline CHEMBL606798 & 304038 & 8.13 & 8.2173 & TRN & \\
\hline CHEMBL606675 & 304038 & 8.33 & 8.1415 & TRN & \\
\hline CHEMBL606606 & 304038 & 7.6 & 7.5121 & TRN & \\
\hline CHEMBL610618 & 304038 & 7.28 & 7.255 & TRN & \\
\hline CHEMBL610617 & 304038 & 7.17 & 7.2818 & TRN & \\
\hline CHEMBL611397 & 304038 & 7.83 & 7.7878 & TRN & \\
\hline CHEMBL610878 & 304038 & 7.8 & 7.7989 & TRN & \\
\hline CHEMBL611399 & 304038 & 7.75 & 7.8225 & TRN & \\
\hline CHEMBL611132 & 304038 & 8.36 & $8.2770 e$ & 0000000001 & TRN \\
\hline CHEMBL611133 & 304038 & 7.74 & 7.8073 & TRN & \\
\hline CHEMBL611396 & 304038 & 8.19 & 7.9985 & TRN & \\
\hline CHEMBL610616 & 304038 & 8.17 & 8.297 & TRN & \\
\hline CHEMBL611131 & 304038 & 8.68 & 8.7134 & TRN & \\
\hline CHEMBL611398 & 304038 & 9.15 & 9.0252 & TRN & \\
\hline CHEMBL610620 & 304038 & 8.51 & 8.6486 & TRN & \\
\hline CHEMBL610880 & 304038 & 8.43 & 8.4449 & TRN & \\
\hline CHEMBL610881 & 304038 & 7.46 & 7.4516 & TRN & \\
\hline CHEMBL610879 & 304038 & 7.15 & 7.1042 & TRN & \\
\hline CHEMBL610882 & 304038 & 7.21 & 7.1801 & TRN & \\
\hline CHEMBL611130 & 304038 & 6.02 & 5.9862 & TRN & \\
\hline CHEMBL610877 & 304038 & 4.98 & 4.9507 & TRN & \\
\hline CHEMBL610619 & 304038 & 5.79 & 5.8571 & TRN & \\
\hline CHEMBL606797 & 304038 & 7.02 & 7.0026 & TRN & \\
\hline CHEMBL606848 & 304038 & 7.57 & 7.6053 & TRN & \\
\hline CHEMBL606605 & 304038 & 6.43 & 6.3508 & TRN & \\
\hline CHEMBL606741 & 304038 & 8.62 & 8.6242 & TRN & \\
\hline CHEMBL606795 & 304038 & 9.15 & 9.1667 & TRN & \\
\hline CHEMBL606674 & 304038 & 7.66 & 7.7374 & TRN & \\
\hline CHEMBL363631 & 304038 & 6.66 & 7.2976 & TST & \\
\hline CHEMBL193877 & 304038 & 6.16 & 7.0029 & TST & \\
\hline CHEMBL370897 & 304038 & 7.66 & 7.2535 & TST & \\
\hline CHEMBL195784 & 304038 & 9.11 & 9.0528 & TRN & \\
\hline CHEMBL370544 & 304038 & 8.75 & 8.7907 & TRN & \\
\hline CHEMBL192443 & 304038 & 9.06 & 9.0399 & TRN & \\
\hline CHEMBL195684 & 304038 & 8.66 & 8.7608 & TRN & \\
\hline CHEMBL194021 & 304038 & 7.14 & 7.0984 & TRN & \\
\hline CHEMBL364055 & 304038 & 6.9 & 6.8906 & TRN & \\
\hline
\end{tabular}




\begin{tabular}{|c|c|c|c|c|c|}
\hline & & \multicolumn{4}{|c|}{ Supplemental Table S2.txt } \\
\hline CHEMBL 2112568 & 304038 & 7.07 & 7.1005 & TRN & \\
\hline CHEMBL 2112573 & 304038 & 7.14 & 7.1442 & TRN & \\
\hline CHEMBL195770 & 304038 & 8.46 & 8.4137 & TRN & \\
\hline CHEMBL363601 & 304038 & 7.64 & 7.6508 & TRN & \\
\hline CHEMBL363348 & 304038 & 7.8 & 7.7593 & TRN & \\
\hline CHEMBL 2112570 & 304038 & 6.64 & 6.6875 & TRN & \\
\hline CHEMBL371565 & 304038 & 6.49 & 6.4916 & TRN & \\
\hline CHEMBL 2112578 & 304038 & 7.0 & 6.9743 & TRN & \\
\hline CHEMBL 2112577 & 304038 & 6.46 & 6.4604 & TRN & \\
\hline CHEMBL606796 & 304038 & 6.3 & 6.58899 & 99999999995 & TRN \\
\hline CHEMBL317536 & 304038 & 7.8 & 7.8122 & TRN & \\
\hline CHEMBL318957 & 304038 & 6.59 & 6.5757 & TRN & \\
\hline CHEMBL192133 & 304038 & 7.39 & 7.3517 & TST & \\
\hline CHEMBL194938 & 304038 & 6.68 & 6.6782 & TRN & \\
\hline CHEMBL194995 & 304038 & 5.47 & 5.46 & TRN & \\
\hline CHEMBL316930 & 304038 & 7.4 & 7.3406 & TRN & \\
\hline CHEMBL95847 & 304038 & 5.62 & 5.6959 & TRN & \\
\hline CHEMBL329719 & 304038 & 8.09 & 8.3223 & TRN & \\
\hline CHEMBL95408 & 304038 & 7.36 & 7.0873 & TRN & \\
\hline CHEMBL364937 & 304038 & 8.09 & 8.019 & TRN & \\
\hline CHEMBL427546 & 304038 & 8.54 & 8.6187 & TRN & \\
\hline CHEMBL194033 & 304038 & 8.41 & 8.3464 & TRN & \\
\hline CHEMBL193586 & 304038 & 8.4 & 8.4211 & TRN & \\
\hline CHEMBL195756 & 304038 & 8.31 & 8.3649 & TST & \\
\hline CHEMBL265033 & 304038 & 8.36 & 8.4411 & TST & \\
\hline CHEMBL425728 & 304038 & 8.3 & 8.4005 & TST & \\
\hline CHEMBL195879 & 304038 & 8.43 & 8.2017 & TST & \\
\hline CHEMBL363777 & 304038 & 8.96 & 7.6787 & TST & \\
\hline CHEMBL 364247 & 304038 & 8.59 & 8.1965 & TST & \\
\hline CHEMBL610798 & 304038 & 9.1 & 8.0572 & TST & \\
\hline CHEMBL195082 & 304038 & 7.97 & 7.3697 & TST & \\
\hline CHEMBL608246 & 304038 & 8.24 & 7.8578 & TST & \\
\hline CHEMBL322796 & 304038 & 6.38 & 6.3595 & TRN & \\
\hline CHEMBL611144 & 304038 & 6.12 & 6.1431 & TRN & \\
\hline CHEMBL195411 & 304038 & 6.08 & 6.0812 & TRN & \\
\hline CHEMBL370759 & 304038 & 5.85 & 5.7949 & TRN & \\
\hline CHEMBL372439 & 304038 & 6.67 & 6.7299 & TRN & \\
\hline CHEMBL194825 & 304038 & 5.93 & 5.9615 & TRN & \\
\hline CHEMBL370966 & 304038 & 8.3 & 7.9323 & TST & \\
\hline CHEMBL370735 & 304038 & 7.77 & 6.6532 & TST & \\
\hline CHEMBL190978 & 304038 & 6.63 & 6.1053 & TST & \\
\hline CHEMBL371845 & 304038 & 7.34 & 6.7028 & TST & \\
\hline CHEMBL195477 & 304038 & 7.83 & 6.3785 & TST & \\
\hline CHEMBL195562 & 304038 & 5.84 & 6.0576 & TST & \\
\hline CHEMBL425735 & 304038 & 7.25 & 5.6916 & TST & \\
\hline CHEMBL195316 & 304038 & 7.4 & 8.94399 & 9999999999 & TST \\
\hline CHEMBL195040 & 304038 & 5.76 & 5.684 & TST & \\
\hline CHEMBL567175 & 304038 & 9.66 & 9.5993 & TRN & \\
\hline
\end{tabular}




\begin{tabular}{|c|c|c|c|c|c|}
\hline \\
\hline CHEMBL606739 & 304038 & 8.3 & 8.2962 & TRN & \\
\hline CHEMBL 606740 & 304038 & 8.7 & 8.7173 & TRN & \\
\hline CHEMBL3701025 & 1528883 & 6.0 & 5.9828 & TST & \\
\hline CHEMBL 3697483 & 1528883 & 6.0 & 6.0611 & TRN & \\
\hline CHEMBL3697452 & 1528883 & 6.0 & 5.86100 & 0000000001 & TRN \\
\hline CHEMBL 3697422 & 1528883 & 6.0 & 6.4067 & TRN & \\
\hline CHEMBL3701009 & 1528883 & 6.0 & 6.1295 & TRN & \\
\hline CHEMBL3701008 & 1528883 & 6.0 & 6.0943 & TRN & \\
\hline CHEMBL 3697485 & 1528883 & 6.0 & 5.6878 & TRN & \\
\hline CHEMBL3701038 & 1528883 & 6.0 & 6.1358 & TRN & \\
\hline CHEMBL 3697421 & 1528883 & 6.0 & 6.4285 & TST & \\
\hline CHEMBL 3697425 & 1528883 & 6.9233 & 6.8297 & TRN & \\
\hline CHEMBL3697445 & 1528883 & 6.0 & 5.9076 & TRN & \\
\hline CHEMBL3701015 & 1528883 & 6.0 & 6.0965 & TRN & \\
\hline CHEMBL3697409 & 1528883 & 7.4162 & 7.2115 & TRN & \\
\hline CHEMBL 3701026 & 1528883 & 6.0 & 5.9689 & TRN & \\
\hline CHEMBL3701045 & 1528883 & 8.007 & 8.0719 & TRN & \\
\hline CHEMBL 3701020 & 1528883 & 6.0 & 6.0795 & TRN & \\
\hline CHEMBL 3697419 & 1528883 & 6.0 & 6.6452 & TRN & \\
\hline CHEMBL 3697415 & 1528883 & 6.0 & 6.026 & TRN & \\
\hline CHEMBL3697428 & 1528883 & 6.0 & 6.2159 & TRN & \\
\hline CHEMBL 3697489 & 1528883 & 6.0 & 5.8678 & TRN & \\
\hline CHEMBL3697455 & 1528883 & 6.0 & 6.3178 & TRN & \\
\hline CHEMBL3701037 & 1528883 & 6.0 & 6.1505 & TRN & \\
\hline CHEMBL 3701022 & 1528883 & 6.0 & 6.0377 & TRN & \\
\hline CHEMBL3701005 & 1528883 & 6.0 & 5.8506 & TRN & \\
\hline CHEMBL 3697404 & 1528883 & 6.0 & 7.4142 & TST & \\
\hline CHEMBL3697407 & 1528883 & 7.8511 & 6.7778 & TRN & \\
\hline CHEMBL 3701032 & 1528883 & 6.0 & 6.1426 & TRN & \\
\hline CHEMBL 3697491 & 1528883 & 6.0 & 6.1887 & TRN & \\
\hline CHEMBL 3701007 & 1528883 & 6.0 & 5.9973 & TRN & \\
\hline CHEMBL 3701050 & 1528883 & 8.4921 & 6.7844 & TST & \\
\hline CHEMBL3701033 & 1528883 & 6.0 & 6.0408 & TRN & \\
\hline CHEMBL 3697490 & 1528883 & 6.0 & 6.369 & TRN & \\
\hline CHEMBL 3701049 & 1528883 & 6.0 & 6.0602 & TRN & \\
\hline CHEMBL3697411 & 1528883 & 7.2222 & 7.22 & TRN & \\
\hline CHEMBL 3697479 & 1528883 & 6.0 & 6.2144 & TRN & \\
\hline CHEMBL 3697417 & 1528883 & 6.0 & 5.7189 & TST & \\
\hline CHEMBL 3697465 & 1528883 & 6.0 & 6.0497 & TRN & \\
\hline CHEMBL 3701017 & 1528883 & 6.0 & 5.7693 & TRN & \\
\hline CHEMBL3697434 & 1528883 & 6.0 & 6.4801 & TRN & \\
\hline CHEMBL 3697412 & 1528883 & 7.6863 & 7.2252 & TRN & \\
\hline CHEMBL3697480 & 1528883 & 6.0 & 6.0739 & TRN & \\
\hline CHEMBL 3697460 & 1528883 & 6.0 & 6.0422 & TRN & \\
\hline CHEMBL 3701030 & 1528883 & 6.0 & 6.8885 & TST & \\
\hline CHEMBL 3697398 & 1528883 & 7.2604 & 7.3047 & TRN & \\
\hline CHEMBL 3701046 & 1528883 & 7.9504 & 7.7342 & TST & \\
\hline CHEMBL3697413 & 1528883 & 6.9357 & 7.5564 & TST & \\
\hline
\end{tabular}




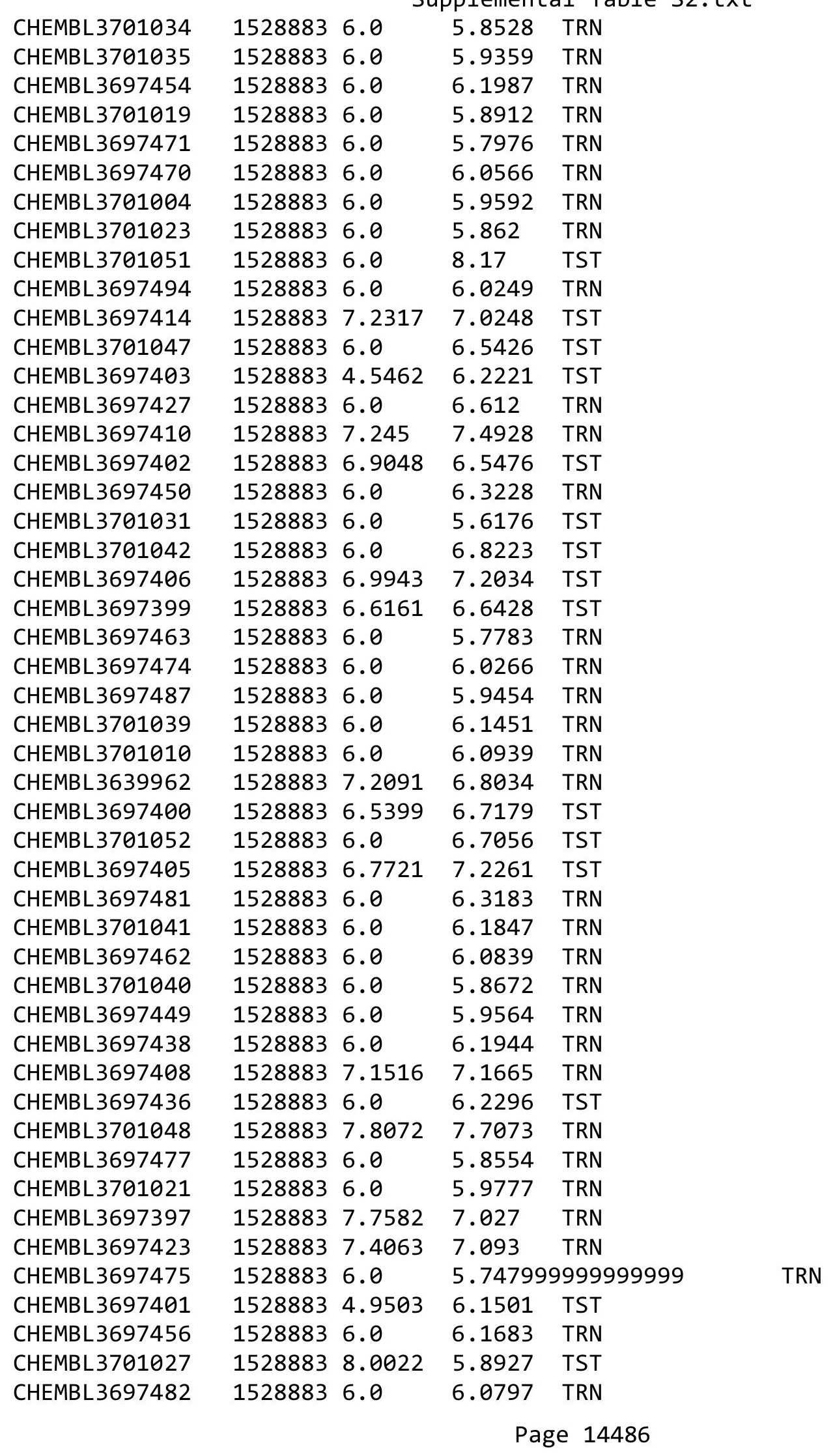




\begin{tabular}{|c|c|c|c|c|c|}
\hline CHEMBL 3697429 & 1528883 & 6.0 & 6.2931 & TST & \\
\hline CHEMBL3701018 & 1528883 & 6.0 & 5.956 & TST & \\
\hline CHEMBL3701044 & 1528883 & 6.0 & 7.5657 & TST & \\
\hline CHEMBL 3697493 & 1528883 & 6.0 & 6.0482 & TRN & \\
\hline CHEMBL3700996 & 1528883 & 6.0 & 5.9317 & TST & \\
\hline CHEMBL3701028 & 1528883 & 6.0 & 6.0833 & TST & \\
\hline CHEMBL3697486 & 1528883 & 6.0 & 6.1255 & TRN & \\
\hline CHEMBL 3697440 & 1528883 & 6.0 & 6.4146 & TRN & \\
\hline CHEMBL 3697500 & 1528883 & 6.0 & 6.3505 & TRN & \\
\hline CHEMBL 3697443 & 1528883 & 6.0 & 5.7818 & TRN & \\
\hline CHEMBL 3697459 & 1528883 & 6.0 & 5.8866 & TRN & \\
\hline CHEMBL3697453 & 1528883 & 6.0 & 6.0182 & TRN & \\
\hline CHEMBL 3697424 & 1528883 & 7.0367 & 7.3189 & TRN & \\
\hline CHEMBL3701014 & 1528883 & 6.0 & 5.96 & TRN & \\
\hline CHEMBL3701016 & 1528883 & 6.0 & 5.8928 & TRN & \\
\hline CHEMBL 3697458 & 1528883 & 6.0 & 5.5828 & TST & \\
\hline CHEMBL3701006 & 1528883 & 6.0 & 5.6871 & TRN & \\
\hline CHEMBL 3697420 & 1528883 & 7.2552 & 7.0122 & TST & \\
\hline CHEMBL3701013 & 1528883 & 6.0 & 6.1159 & TST & \\
\hline CHEMBL3697473 & 1528883 & 6.0 & 5.9229 & TRN & \\
\hline CHEMBL 3701012 & 1528883 & 6.0 & 6.1299 & TRN & \\
\hline CHEMBL 3697451 & 1528883 & 6.0 & 5.8993 & TRN & \\
\hline CHEMBL 3697426 & 1528883 & 7.3468 & 7.4151 & TRN & \\
\hline CHEMBL3701011 & 1528883 & 6.0 & 5.9568 & TRN & \\
\hline CHEMBL 3697478 & 1528883 & 8.2628 & 7.6988 & TRN & \\
\hline CHEMBL 3701029 & 1528883 & 6.0 & 6.3887 & TST & \\
\hline CHEMBL 3697469 & 1528883 & 6.0 & 5.7401 & TRN & \\
\hline CHEMBL3697433 & 1528883 & 6.0 & 5.9631 & TRN & \\
\hline CHEMBL3414621 & 1528883 & 6.0 & 6.0741 & TRN & \\
\hline CHEMBL 3697472 & 1528883 & 6.0 & 5.9184 & TRN & \\
\hline CHEMBL 3701043 & 1528883 & 9.0362 & 6.1335 & TST & \\
\hline CHEMBL 3697492 & 1528883 & 6.0 & 5.7705 & TRN & \\
\hline CHEMBL 3697488 & 1528883 & 6.0 & 5.9423 & TRN & \\
\hline CHEMBL 3697466 & 1528883 & 6.0 & 5.9157 & TRN & \\
\hline CHEMBL 3701024 & 1528883 & 6.0 & 5.874 & TRN & \\
\hline CHEMBL 3697468 & 1528883 & 6.0 & 5.9842 & TRN & \\
\hline CHEMBL3697476 & 1528883 & 6.0 & 6.0646 & TRN & \\
\hline CHEMBL1475400 & 688391 & 4.7793 & 5.3588 & TST & \\
\hline CHEMBL1598762 & 688391 & 3.3997 & 4.8608 & TRN & \\
\hline CHEMBL1477452 & 688391 & 5.2028 & 4.7836 & TRN & \\
\hline CHEMBL1452125 & 688391 & 5.1734 & 5.4265 & TRN & \\
\hline CHEMBL1336910 & 688391 & 5.3765 & \multicolumn{2}{|c|}{5.417000000000001} & TRN \\
\hline CHEMBL1520797 & 688391 & 5.2726 & 5.6431 & TRN & \\
\hline CHEMBL1600749 & 688391 & 5.567 & 5.6295 & TRN & \\
\hline CHEMBL1535636 & 688391 & 5.7064 & 5.7023 & TRN & \\
\hline CHEMBL1508847 & 688391 & 3.3997 & 5.1198 & TST & \\
\hline CHEMBL1334062 & 688391 & 4.3539 & 5.4262 & TST & \\
\hline CHEMBL1346015 & 688391 & 5.3867 & 5.3936 & TRN & \\
\hline
\end{tabular}

Page 14487 
Supplemental Table S2.txt

\begin{tabular}{|c|c|c|c|c|}
\hline . & & 5297 & & \\
\hline & 88391 & .0297 & & \\
\hline 874 & & & & \\
\hline IEMBL1324779 & 391 & & & \\
\hline AEMBL1581437 & 391 & & & \\
\hline HEMBL1418370 & 38391 & 0288 & 918 & \\
\hline HEMBL16 & 3391 & & & \\
\hline IEMBL14 & 391 & & & \\
\hline HEMBL1423531 & 8391 & & .5012 & \\
\hline HEMBL1430235 & 8391 & & & \\
\hline AEMBL1381 & 3391 & & & \\
\hline IEMBL14 & 391 & & & \\
\hline IEMBL16 & & & & \\
\hline HEMBL160 & 391 & & & \\
\hline AEMBL15 & 391 & & & \\
\hline AEMBL134 & 391 & 23 & & \\
\hline AEMBL13 & 391 & & & \\
\hline HEMBL15 & & & & \\
\hline HEMBL 16 & 391 & & & \\
\hline AEMBL132 & 391 & & & \\
\hline 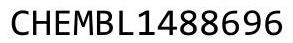 & 91 & & & NIV \\
\hline AEMBL13 & 91 & & & RN \\
\hline HEMBL13 & 91 & & & \\
\hline 89 & 391 & & & \\
\hline AEMBL13. & & & & (2) \\
\hline HEMBL1 & 91 & & & KIV \\
\hline HEMBLI & 91 & & & 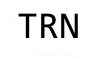 \\
\hline HFMBI 1 & 91 & & & \\
\hline AEMBL1: & & & & I RIV \\
\hline HEMBL14 & & & & IRN \\
\hline HEMBL57 & 91 & & & SI \\
\hline HEMBL: & & & & RN \\
\hline HAMRI & 91 & & & 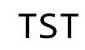 \\
\hline HEMBL141 & 391 & & & IRN \\
\hline HEMBL1517409 & 88391 & & & TS \\
\hline HEMBL: & 391 & & & I RIV \\
\hline 1 & & & & ГST \\
\hline HEMBL13 & & & & IST \\
\hline HEMBL1542646 & 88391 & & & TRN \\
\hline AEMBL15 & 38391 & & & TRN \\
\hline HEMBL1 14 & 88391 & & 21 & \\
\hline CHEMBL13 & & & 44 & \\
\hline HEMBL15 & 391 & & 5.4408 & IST \\
\hline AEMBL152 & 8391 & & 5 . & TR \\
\hline HEMBL13€ & 391 & & & 「RN \\
\hline HEMBL1 & & & & \\
\hline CHEMBL157 & 88391 & 5191 & 4.8853 & \\
\hline SHEMBL1385074 & 688391 & 5.5642 & 5.5452 & ГRN \\
\hline
\end{tabular}

Page 14488 
Supplemental Table S2.txt

\begin{tabular}{|c|c|c|c|c|c|}
\hline CHEMBL1544403 & 688391 & 7.2556 & 5.949 & TRN & \\
\hline CHEMBL1415156 & 688391 & 5.2942 & 5.3802 & TRN & \\
\hline CHEMBL1579576 & 688391 & 5.6269 & 5.3709 & TRN & \\
\hline CHEMBL1329826 & 688391 & 3.3997 & 4.6006 & TRN & \\
\hline CHEMBL1592326 & 688391 & 5.6085 & 5.2886 & TRN & \\
\hline CHEMBL1455509 & 688391 & 5.2284 & 4.9557 & TRN & \\
\hline CHEMBL1503060 & 688391 & 5.2973 & 5.3271 & TRN & \\
\hline CHEMBL1347130 & 688391 & 4.8155 & 5.5273 & TRN & \\
\hline CHEMBL1162443 & 688391 & 4.6921 & 5.2026 & TRN & \\
\hline CHEMBL1329797 & 688391 & 5.3312 & 5.3406 & TRN & \\
\hline CHEMBL1343936 & 688391 & 5.6476 & 4.9254 & TRN & \\
\hline CHEMBL450135 & 688391 & 6.4037 & 6.1338 & TRN & \\
\hline CHEMBL1601448 & 688391 & 4.863 & 4.979 & TRN & \\
\hline CHEMBL1488092 & 688391 & 5.7535 & 6.035 & TRN & \\
\hline CHEMBL1382928 & 688391 & 3.3997 & 5.1681 & TRN & \\
\hline CHEMBL1413474 & 688391 & 5.6336 & 6.1213 & TRN & \\
\hline CHEMBL1369512 & 688391 & 3.3997 & 4.6068 & TRN & \\
\hline CHEMBL1465171 & 688391 & 5.0036 & 5.3175 & TRN & \\
\hline CHEMBL1319204 & 688391 & 5.8871 & 4.9812 & TRN & \\
\hline CHEMBL1432707 & 688391 & 3.3997 & 5.1608 & TST & \\
\hline CHEMBL1232381 & 688391 & 5.8608 & 4.9961 & TRN & \\
\hline CHEMBL1353643 & 688391 & 5.5343 & 5.7221 & TRN & \\
\hline CHEMBL1569119 & 688391 & 5.4002 & 5.3062 & TRN & \\
\hline CHEMBL1306635 & 688391 & 5.5564 & 4.7067 & TRN & \\
\hline CHEMBL601757 & 688391 & 3.3997 & 5.192 & TST & \\
\hline CHEMBL1303255 & 688391 & 5.49200 & 00000000 & 31 & 5.5241 \\
\hline CHEMBL1550435 & 688391 & 5.6236 & 5.4103 & TST & \\
\hline CHEMBL1454614 & 688391 & 3.3997 & 5.3876 & TST & \\
\hline CHEMBL1330383 & 688391 & 5.857 & 5.3714 & TRN & \\
\hline CHEMBL1327274 & 688391 & 5.2768 & 5.0472 & TRN & \\
\hline CHEMBL1370669 & 688391 & 5.3563 & 5.5323 & TRN & \\
\hline CHEMBL1479469 & 688391 & 5.4525 & 4.4247 & TRN & \\
\hline CHEMBL1446248 & 688391 & 4.4861 & 4.9228 & TST & \\
\hline CHEMBL1541029 & 688391 & 5.4793 & 5.439 & TRN & \\
\hline CHEMBL1380975 & 688391 & 5.3033 & 5.3886 & TRN & \\
\hline CHEMBL1306480 & 688391 & 5.6059 & 5.8096 & TST & \\
\hline CHEMBL1514625 & 688391 & 4.5316 & 4.2235 & TRN & \\
\hline CHEMBL1462380 & 688391 & 5.1351 & 5.1971 & TRN & \\
\hline CHEMBL1536779 & 688391 & 5.694 & 4.9878 & TRN & \\
\hline CHEMBL1564075 & 688391 & 3.3997 & 3.9259 & TRN & \\
\hline CHEMBL1394096 & 688391 & 4.776 & 4.905 & TRN & \\
\hline CHEMBL1349484 & 688391 & 3.3997 & 4.4684 & TRN & \\
\hline CHEMBL1409901 & 688391 & 5.6536 & 5.2468 & TRN & \\
\hline CHEMBL1511291 & 688391 & 5.614 & 4.905 & TST & \\
\hline CHEMBL1536665 & 688391 & 5.1187 & 5.3963 & TRN & \\
\hline CHEMBL1563863 & 688391 & 5.7364 & 5.6559 & TRN & \\
\hline CHEMBL1464821 & 688391 & 5.4527 & 5.1388 & TRN & \\
\hline CHEMBL1307313 & 688391 & 5.7113 & 5.604 & TRN & \\
\hline
\end{tabular}




\begin{tabular}{|c|c|c|c|c|c|c|}
\hline & & \multicolumn{5}{|c|}{ Supplemental Table S2.txt } \\
\hline CHEMBL1330042 & 688391 & 5.4056 & 5.8527 & TRN & & \\
\hline CHEMBL1384281 & 688391 & 6.6804 & 5.4444 & TST & & \\
\hline CHEMBL1566010 & 688391 & 5.76399 & 99999999 & 99 & 5.1815 & TRN \\
\hline CHEMBL1549101 & 688391 & 5.002 & 5.6206 & TRN & & \\
\hline CHEMBL1486010 & 688391 & 5.5539 & 5.0711 & TRN & & \\
\hline CHEMBL1373811 & 688391 & 5.96299 & 99999999 & 99 & 6.1122 & TRN \\
\hline CHEMBL51931 & 688391 & 5.7354 & 5.4117 & TST & & \\
\hline CHEMBL1457535 & 688391 & 5.2889 & 5.3403 & TST & & \\
\hline CHEMBL1433074 & 688391 & 6.1088 & 5.2505 & TST & & \\
\hline CHEMBL1505221 & 688391 & 5.3279 & 5.5487 & TST & & \\
\hline CHEMBL1499411 & 688391 & 6.21899 & 79999999 & 99 & 5.3623 & TST \\
\hline CHEMBL1610242 & 688391 & 5.3709 & 4.6084 & TST & & \\
\hline CHEMBL1391748 & 688391 & 5.3106 & 5.4073 & TST & & \\
\hline CHEMBL1379684 & 688391 & 5.794 & 4.8147 & TST & & \\
\hline CHEMBL1573867 & 688391 & 5.6474 & 5.3276 & TST & & \\
\hline CHEMBL197242 & 1638062 & 6.4318 & 6.3265 & TRN & & \\
\hline CHEMBL315954 & 1638062 & 6.3925 & 6.4625 & TRN & & \\
\hline CHEMBL194235 & 1638062 & 7.2366 & 7.398 & TRN & & \\
\hline CHEMBL93960 & 1638062 & 6.4522 & 6.8058 & TRN & & \\
\hline CHEMBL 330110 & 1638062 & 6.9872 & 7.0632 & TRN & & \\
\hline CHEMBL3895160 & 1638062 & 5.8928 & 6.2016 & TRN & & \\
\hline CHEMBL 3907290 & 1638062 & 6.6946 & 7.2396 & TRN & & \\
\hline CHEMBL316101 & 1638062 & 5.9547 & 5.93 & TRN & & \\
\hline CHEMBL3910303 & 1638062 & 7.0269 & 7.1676 & TRN & & \\
\hline CHEMBL91236 & 1638062 & 7.1739 & 6.9147 & TRN & & \\
\hline CHEMBL3961549 & 1638062 & 7.3665 & 7.6552 & TRN & & \\
\hline CHEMBL91423 & 1638062 & 7.8539 & 7.7202 & TRN & & \\
\hline CHEMBL 3947447 & 1638062 & 6.8894 & 6.6846 & TRN & & \\
\hline CHEMBL327207 & 1638062 & 6.4101 & 6.308 & TRN & & \\
\hline CHEMBL3917051 & 1638062 & 5.9547 & 6.3122 & TRN & & \\
\hline CHEMBL 3950285 & 1638062 & 6.8962 & 6.747006 & 0000000001 & & TRN \\
\hline CHEMBL3983710 & 1638062 & 6.7932 & 6.9816 & TRN & & \\
\hline CHEMBL 3966591 & 1638062 & 7.2147 & 7.2255 & TRN & & \\
\hline CHEMBL3968852 & 1638062 & 7.301 & 7.1396 & TST & & \\
\hline CHEMBL3977587 & 1638062 & 7.8861 & 7.7152 & TRN & & \\
\hline CHEMBL262735 & 1638062 & 7.6198 & 7.4053 & TRN & & \\
\hline CHEMBL3926784 & 1638062 & 7.6576 & 7.4676 & TRN & & \\
\hline CHEMBL316102 & 1638062 & 6.7144 & 6.5289 & TRN & & \\
\hline CHEMBL1199895 & 1638062 & 4.5834 & 4.7393 & TRN & & \\
\hline CHEMBL88540 & 1638062 & 7.3372 & 7.2531 & TRN & & \\
\hline CHEMBL 3928643 & 1638062 & 7.5376 & 7.08700 & 0000000001 & & TRN \\
\hline CHEMBL3934331 & 1638062 & 7.4949 & 7.7258 & TRN & & \\
\hline CHEMBL 3917557 & 1638062 & 7.8861 & 8.0371 & TRN & & \\
\hline CHEMBL91305 & 1638062 & 7.1938 & 6.9225 & TRN & & \\
\hline CHEMBL88795 & 1638062 & 7.7212 & 7.7219 & TRN & & \\
\hline CHEMBL194207 & 1638062 & 7.4559 & 7.6644 & TRN & & \\
\hline CHEMBL3981787 & 1638062 & 6.983 & 6.6174 & TST & & \\
\hline CHEMBL 372185 & 1638062 & 7.1487 & 7.371 & TRN & & \\
\hline
\end{tabular}


Supplemental Table S2.txt

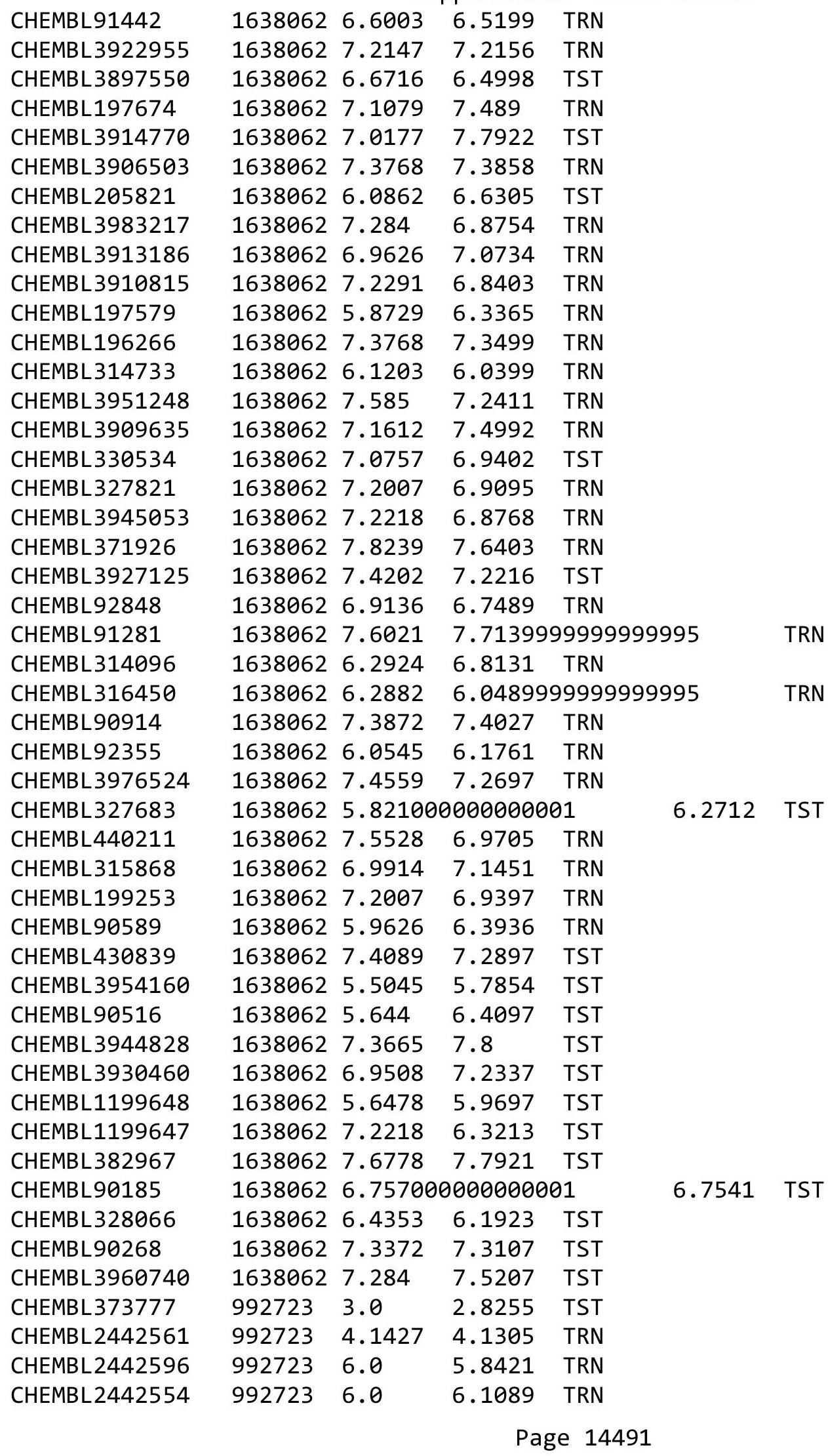




\begin{tabular}{|c|c|c|c|c|}
\hline \multicolumn{5}{|c|}{ Supplemental Table S2.txt } \\
\hline CHEMBL 2442555 & 992723 & 4.0 & 4.2498 & TRN \\
\hline CHEMBL 2442598 & 992723 & 6.0 & 5.7715 & TRN \\
\hline CHEMBL 2442546 & 992723 & 6.0 & 6.3527 & TRN \\
\hline CHEMBL67 & 992723 & 8.6021 & 4.0439 & TST \\
\hline CHEMBL2442583 & 992723 & 5.0315 & 4.9674 & TRN \\
\hline CHEMBL 2442544 & 992723 & 4.6799 & 4.7103 & TRN \\
\hline CHEMBL 2442550 & 992723 & 6.0 & 6.0493 & TRN \\
\hline CHEMBL2442594 & 992723 & 6.0 & 6.0128 & TRN \\
\hline CHEMBL 2442575 & 992723 & 3.0 & 3.2857 & TRN \\
\hline CHEMBL 2442592 & 992723 & 6.0 & 6.289 & TRN \\
\hline CHEMBL2442579 & 992723 & 4.5591 & 4.8604 & TRN \\
\hline CHEMBL 2442562 & 992723 & 4.5003 & 4.5239 & TRN \\
\hline CHEMBL 2440143 & 992723 & 4.2588 & 4.5053 & TST \\
\hline CHEMBL 2442566 & 992723 & 4.5421 & 4.0327 & TRN \\
\hline CHEMBL 2442588 & 992723 & 4.6676 & 4.6743 & TRN \\
\hline CHEMBL 2442564 & 992723 & 4.4711 & 4.4882 & TRN \\
\hline CHEMBL 2442578 & 992723 & 5.0706 & 5.313 & TRN \\
\hline CHEMBL2442587 & 992723 & 3.0 & 2.9989 & TRN \\
\hline CHEMBL 2442570 & 992723 & 4.4123 & 4.3362 & TST \\
\hline CHEMBL2442569 & 992723 & 4.4473 & 4.3656 & TST \\
\hline CHEMBL 2442580 & 992723 & 5.0655 & 5.4056 & TRN \\
\hline CHEMBL 2442574 & 992723 & 4.4306 & 4.5883 & TST \\
\hline CHEMBL 2442586 & 992723 & 3.0 & 2.9656 & TRN \\
\hline CHEMBL 2442600 & 992723 & 6.0 & 5.7677 & TRN \\
\hline CHEMBL 2442572 & 992723 & 4.3645 & 4.3816 & TST \\
\hline CHEMBL 2442567 & 992723 & 4.4935 & 4.0803 & TST \\
\hline CHEMBL 2442557 & 992723 & 6.0 & 5.9617 & TRN \\
\hline CHEMBL 2442582 & 992723 & 4.5229 & 4.6239 & TRN \\
\hline CHEMBL 2442581 & 992723 & 4.0362 & 4.3035 & TRN \\
\hline CHEMBL 2442584 & 992723 & 5.4559 & 5.5217 & TRN \\
\hline CHEMBL 2442589 & 992723 & 3.0 & 3.4023 & TRN \\
\hline CHEMBL 2442571 & 992723 & 4.0223 & 3.93 & TST \\
\hline CHEMBL 2442558 & 992723 & 4.5622 & 4.6959 & TRN \\
\hline CHEMBL 2442538 & 992723 & 4.5058 & 4.3889 & TRN \\
\hline CHEMBL466267 & 992723 & 6.0 & 5.6725 & TRN \\
\hline CHEMBL 2442590 & 992723 & 3.0 & 2.9214 & TRN \\
\hline CHEMBL 2442576 & 992723 & 4.6383 & 4.2201 & TRN \\
\hline CHEMBL 2442573 & 992723 & 4.1918 & 4.7076 & TST \\
\hline CHEMBL 2442577 & 992723 & 6.1427 & 5.2643 & TRN \\
\hline CHEMBL 2442565 & 992723 & 4.5229 & 4.0848 & TST \\
\hline CHEMBL 2442552 & 992723 & 6.0 & 6.1184 & TRN \\
\hline CHEMBL 2442585 & 992723 & 5.4559 & 5.3081 & TRN \\
\hline CHEMBL2442563 & 992723 & 4.5258 & 4.5041 & TST \\
\hline CHEMBL 2442541 & 992723 & 4.4815 & 4.3158 & TRN \\
\hline CHEMBL 2442560 & 992723 & 6.0 & 6.0128 & TRN \\
\hline CHEMBL 2442568 & 992723 & 5.1135 & 3.9469 & TST \\
\hline CHEMBL1242367 & 954836 & 3.7738 & 3.8411 & TRN \\
\hline CHEMBL2363137 & 954836 & 4.9552 & 4.7304 & TRN \\
\hline
\end{tabular}




\begin{tabular}{|c|c|c|c|c|c|c|}
\hline \multirow[b]{2}{*}{ CHEMBL 217354} & \multirow[b]{2}{*}{954836} & \multicolumn{5}{|c|}{ Supplemental Table S2.txt } \\
\hline & & 6.5681 & 6.4355 & TRN & & \\
\hline CHEMBL188678 & 954836 & 5.46 & 5.4409 & TRN & & \\
\hline CHEMBL515416 & 954836 & 3.526999 & 999999999 & 997 & 3.5419 & TRN \\
\hline CHEMBL 220241 & 954836 & 5.2814 & 5.4813 & TRN & & \\
\hline CHEMBL1516890 & 954836 & 4.791 & 4.7284 & TRN & & \\
\hline CHEMBL1186585 & 954836 & 4.9438 & 5.0828 & TRN & & \\
\hline CHEMBL509032 & 954836 & 3.3737 & 3.36 & TRN & & \\
\hline CHEMBL 2144069 & 954836 & 3.8232 & 4.1422 & TRN & & \\
\hline CHEMBL392695 & 954836 & 3.3472 & 3.3447 & TRN & & \\
\hline CHEMBL210618 & 954836 & 3.3861 & 3.563 & TRN & & \\
\hline CHEMBL399530 & 954836 & 4.9517 & 5.095 & TRN & & \\
\hline CHEMBL1788116 & 954836 & 5.5182 & 5.4359 & TRN & & \\
\hline CHEMBL1643959 & 954836 & 3.5505 & 3.5956 & TRN & & \\
\hline CHEMBL1673039 & 954836 & 4.5612 & 4.4293 & TRN & & \\
\hline CHEMBL222102 & 954836 & 4.9286 & 4.7877 & TRN & & \\
\hline CHEMBL449158 & 954836 & 6.0285 & 7.9626 & TST & & \\
\hline CHEMBL 2137530 & 954836 & 4.6864 & 5.0873 & TRN & & \\
\hline CHEMBL300389 & 954836 & 6.1358 & 6.0259 & TRN & & \\
\hline CHEMBL92309 & 954836 & 3.3208 & 2.8119 & TST & & \\
\hline CHEMBL412142 & 954836 & 3.6678 & 3.6232 & TRN & & \\
\hline CHEMBL135561 & 954836 & 4.3298 & 4.3411 & TRN & & \\
\hline CHEMBL65 & 954836 & 10.5947 & 10.6242 & TRN & & \\
\hline CHEMBL3349342 & 954836 & 3.5162 & 3.639 & TRN & & \\
\hline CHEMBL577784 & 954836 & 6.077999 & 999999999 & & 6.2236 & TRN \\
\hline CHEMBL379975 & 954836 & 5.5207 & 5.3905 & TRN & & \\
\hline CHEMBL 213100 & 954836 & 3.4404 & 3.4424 & TRN & & \\
\hline CHEMBL189584 & 954836 & 3.766 & 3.8399 & TRN & & \\
\hline CHEMBL192566 & 954836 & 7.6753 & 8.642999 & 9999999999 & & TST \\
\hline CHEMBL1230020 & 954836 & 3.6628 & 3.6863 & TRN & & \\
\hline CHEMBL 2134202 & 954836 & 4.441 & 4.3186 & TRN & & \\
\hline CHEMBL3199475 & 954836 & 5.1713 & 5.0443 & TRN & & \\
\hline CHEMBL191334 & 954836 & 3.7757 & 3.6767 & TRN & & \\
\hline CHEMBL1590308 & 954836 & 2.7867 & 3.5237 & TST & & \\
\hline CHEMBL1909414 & 954836 & 3.6306 & 3.2537 & TRN & & \\
\hline CHEMBL180127 & 954836 & 4.3007 & 4.4241 & TRN & & \\
\hline CHEMBL483849 & 954836 & 2.6233 & 2.3655 & TST & & \\
\hline CHEMBL1190711 & 954836 & 5.9636 & 5.468 & TRN & & \\
\hline CHEMBL1357247 & 954836 & 4.3276 & 3.9546 & TRN & & \\
\hline CHEMBL102714 & 954836 & 3.2656 & 3.3453 & TRN & & \\
\hline CHEMBL 255342 & 954836 & 3.5977 & 3.9564 & TRN & & \\
\hline CHEMBL1256459 & 954836 & 5.1939 & 5.2993 & TRN & & \\
\hline CHEMBL393929 & 954836 & 4.2387 & 4.0756 & TRN & & \\
\hline CHEMBL259181 & 954836 & 4.7119 & 4.7706 & TRN & & \\
\hline CHEMBL514499 & 954836 & 4.6008 & 4.4404 & TRN & & \\
\hline CHEMBL3392440 & 954836 & 4.2398 & 4.4265 & TRN & & \\
\hline CHEMBL558642 & 954836 & 2.9302 & 3.0034 & TRN & & \\
\hline CHEMBL 2005886 & 954836 & 3.8564 & 3.872 & TRN & & \\
\hline CHEMBL1404918 & 954836 & 3.9143 & 3.8105 & TRN & & \\
\hline
\end{tabular}




\begin{tabular}{|c|c|c|c|c|c|c|}
\hline \multirow[b]{2}{*}{ CHEMBL373751 } & & \multicolumn{5}{|c|}{ Supplemental Table s2.txt } \\
\hline & 954836 & 3.5921 & 3.7128 & TRN & & \\
\hline CHEMBL585951 & 954836 & 6.4887 & \multicolumn{3}{|c|}{6.656000000000001} & TRN \\
\hline CHEMBL258844 & 954836 & 5.8712 & 5.7833 & \multicolumn{2}{|l|}{ TRN } & \\
\hline CHEMBL1970879 & 954836 & 3.8115 & 3.3595 & \multicolumn{2}{|l|}{ TST } & \\
\hline CHEMBL9470 & 954836 & 6.2608 & 6.4088 & \multicolumn{2}{|l|}{ TST } & \\
\hline CHEMBL512504 & 954836 & 4.2143 & 5.5391 & \multicolumn{2}{|l|}{ TST } & \\
\hline CHEMBL202721 & 954836 & 5.1655 & 5.5335 & \multicolumn{2}{|l|}{ TST } & \\
\hline CHEMBL3186408 & 954836 & 3.3666 & 3.6565 & \multicolumn{2}{|l|}{ TST } & \\
\hline CHEMBL 240954 & 954836 & 3.3437 & 3.7848 & \multicolumn{2}{|l|}{ TST } & \\
\hline CHEMBL221137 & 954836 & 5.1804 & 4.8176 & \multicolumn{2}{|l|}{ TST } & \\
\hline CHEMBL 209148 & 954836 & 4.2871 & 4.338 & \multicolumn{2}{|l|}{ TST } & \\
\hline CHEMBL573107 & 954836 & 6.0381 & 6.0942 & \multicolumn{2}{|l|}{ TST } & \\
\hline CHEMBL472940 & 954836 & 3.9924 & 4.7123 & \multicolumn{2}{|l|}{ TST } & \\
\hline CHEMBL483847 & 954836 & 4.5263 & 4.3912 & \multicolumn{2}{|l|}{ TST } & \\
\hline CHEMBL379300 & 954836 & 4.1092 & 5.1305 & \multicolumn{2}{|l|}{ TST } & \\
\hline CHEMBL99779 & 52665 & 4.456 & 4.7595 & \multicolumn{2}{|l|}{ TST } & \\
\hline CHEMBL121543 & 52665 & 6.523 & 6.7675 & \multicolumn{2}{|l|}{ TRN } & \\
\hline CHEMBL316485 & 52665 & 4.699 & 4.7893 & \multicolumn{2}{|l|}{ TST } & \\
\hline CHEMBL318208 & 52665 & \multicolumn{3}{|c|}{5.207999999999999} & 4.93 & TRN \\
\hline CHEMBL430574 & 52665 & 5.155 & 5.6093 & TRN & & \\
\hline CHEMBL317964 & 52665 & 5.699 & 5.7494 & \multicolumn{3}{|l|}{ TRN } \\
\hline CHEMBL120030 & 52665 & 5.194 & 5.1922 & TST & & \\
\hline CHEMBL331722 & 52665 & 4.638 & 4.2066 & TRN & & \\
\hline CHEMBL331120 & 52665 & 3.638 & 4.0821 & TST & & \\
\hline CHEMBL95477 & 52665 & 4.398 & 4.5486 & TRN & & \\
\hline CHEMBL545053 & 52665 & 6.155 & 5.8404 & TST & & \\
\hline CHEMBL97844 & 52665 & 3.32800 & 30000000 & 003 & 4.476 & TST \\
\hline CHEMBL121958 & 52665 & 5.36700 & 30000000 & & 5.9692 & TRN \\
\hline CHEMBL 325403 & 52665 & 7.097 & 6.9624 & TRN & & \\
\hline CHEMBL 98360 & 52665 & 6.523 & 6.08899 & 99999 & 995 & TRN \\
\hline CHEMBL98554 & 52665 & 5.886 & 5.9264 & TRN & & \\
\hline CHEMBL332678 & 52665 & 5.854 & 5.0255 & TST & & \\
\hline CHEMBL121957 & 52665 & 6.155 & 6.1516 & TRN & & \\
\hline CHEMBL99037 & 52665 & 5.796 & 6.278 & TRN & & \\
\hline CHEMBL328194 & 52665 & 6.553 & 6.5707 & TRN & & \\
\hline CHEMBL324064 & 52665 & 4.22199 & 99999999 & 995 & 4.7652 & TST \\
\hline CHEMBL98153 & 52665 & 6.222 & 6.1746 & TRN & & \\
\hline CHEMBL319373 & 52665 & 6.699 & 6.4526 & TRN & & \\
\hline CHEMBL116545 & 52665 & 6.0 & 6.7232 & TRN & & \\
\hline CHEMBL331000 & 52665 & 6.222 & 6.6397 & TRN & & \\
\hline CHEMBL318471 & 52665 & 5.854 & 5.7418 & TRN & & \\
\hline CHEMBL331190 & 52665 & 7.62 & 7.2131 & TRN & & \\
\hline CHEMBL334084 & 52665 & 6.155 & 6.2373 & TRN & & \\
\hline CHEMBL121492 & 52665 & 7.32799 & 99999999 & & 7.4792 & TRN \\
\hline CHEMBL329063 & 52665 & 5.523 & 6.1659 & TRN & & \\
\hline CHEMBL 316940 & 52665 & 5.481 & 5.6865 & TRN & & \\
\hline CHEMBL431634 & 52665 & 5.36700 & 00000000 & & 5.4966 & TRN \\
\hline CHEMBL99803 & 52665 & 5.523 & 5.0886 & TST & & \\
\hline
\end{tabular}




\begin{tabular}{|c|c|c|c|c|c|c|}
\hline & & \multicolumn{5}{|c|}{ Supplemental Table S2.txt } \\
\hline CHEMBL116832 & 52665 & 5.432 & 5.5842 & TRN & & \\
\hline CHEMBL120355 & 52665 & 4.699 & 5.6008 & TRN & & \\
\hline CHEMBL331783 & 52665 & 5.65799 & 79999999 & 995 & 5.1662 & TRN \\
\hline CHEMBL334031 & 52665 & 6.301 & 6.0597 & TRN & & \\
\hline CHEMBL100309 & 52665 & 6.62 & 6.4393 & TRN & & \\
\hline CHEMBL317150 & 52665 & 5.42 & 5.4091 & TRN & & \\
\hline CHEMBL120137 & 52665 & 4.046 & 3.813 & TRN & & \\
\hline CHEMBL121953 & 52665 & 3.699 & 3.7933 & TRN & & \\
\hline CHEMBL120941 & 52665 & 5.886 & 5.6724 & TRN & & \\
\hline CHEMBL120078 & 52665 & 5.222 & 4.8952 & TRN & & \\
\hline CHEMBL329505 & 52665 & 6.398 & 6.7041 & TRN & & \\
\hline CHEMBL316512 & 52665 & 5.602 & 5.0679 & TRN & & \\
\hline CHEMBL331502 & 52665 & 4.481 & 3.4792 & TST & & \\
\hline CHEMBL333894 & 52665 & 6.699 & 6.8225 & TRN & & \\
\hline CHEMBL50894 & 52665 & 7.456 & 6.8981 & TRN & & \\
\hline CHEMBL318911 & 52665 & 5.886 & 5.8541 & TRN & & \\
\hline CHEMBL317562 & 52665 & 3.0 & 3.9534 & TST & & \\
\hline CHEMBL299756 & 52665 & 7.62 & 7.2543 & TRN & & \\
\hline CHEMBL 98501 & 52665 & 5.523 & 5.472 & TRN & & \\
\hline CHEMBL52551 & 52665 & 5.638 & 5.0328 & TST & & \\
\hline CHEMBL328164 & 52665 & 4.367 & 4.5731 & TST & & \\
\hline CHEMBL323657 & 52665 & 6.222 & 6.2843 & TRN & & \\
\hline CHEMBL296586 & 52665 & 6.398 & 6.1415 & TRN & & \\
\hline CHEMBL95827 & 52665 & 6.046 & 5.6937 & TRN & & \\
\hline CHEMBL 99423 & 52665 & 3.367 & 3.6126 & TRN & & \\
\hline CHEMBL333006 & 52665 & 7.276 & 7.1508 & TRN & & \\
\hline CHEMBL332359 & 52665 & 5.921 & 6.621 & TRN & & \\
\hline CHEMBL120497 & 52665 & 5.886 & 5.6526 & TST & & \\
\hline CHEMBL100312 & 52665 & 4.155 & 4.6523 & TST & & \\
\hline CHEMBL419054 & 52665 & 6.569 & 6.4688 & TRN & & \\
\hline CHEMBL333066 & 52665 & 6.495 & 5.8186 & TRN & & \\
\hline CHEMBL325654 & 52665 & 7.357 & 7.0653 & TRN & & \\
\hline CHEMBL119989 & 52665 & 6.495 & 5.9226 & TRN & & \\
\hline CHEMBL331759 & 52665 & 4.292 & 4.2654 & TST & & \\
\hline CHEMBL119932 & 52665 & 5.481 & 5.734 & TRN & & \\
\hline CHEMBL120547 & 52665 & 3.886 & 3.9896 & TST & & \\
\hline CHEMBL119963 & 52665 & 7.097 & 7.1292 & TRN & & \\
\hline CHEMBL328627 & 52665 & 4.638 & 4.9334 & TST & & \\
\hline CHEMBL330398 & 52665 & 3.602 & 4.2135 & TRN & & \\
\hline CHEMBL118406 & 52665 & 5.398 & 5.4492 & TRN & & \\
\hline CHEMBL120664 & 52665 & 5.495 & 6.3449 & TST & & \\
\hline CHEMBL118162 & 52665 & 7.125 & 6.9041 & TRN & & \\
\hline CHEMBL3134519 & 1298621 & 9.5229 & 9.3717 & TRN & & \\
\hline CHEMBL 3134550 & 1298621 & 8.0555 & 8.2491 & TRN & & \\
\hline CHEMBL 3134526 & 1298621 & 8.9586 & 8.5435 & TST & & \\
\hline CHEMBL 3134548 & 1298621 & 6.7545 & 7.2393 & TRN & & \\
\hline CHEMBL3134563 & 1298621 & 8.1739 & 8.055 & TRN & & \\
\hline CHEMBL3134518 & 1298621 & 8.3565 & 8.3078 & TRN & & \\
\hline
\end{tabular}


Supplemental Table S2.txt

\begin{tabular}{|c|c|c|c|c|}
\hline 8 & & 6.7423 & & \\
\hline & & 8.5528 & & \\
\hline HFMRI 3 & 21 & & & \\
\hline HEMBL & 98621 & 9.301 & 02 & \\
\hline AEMBL3134542 & 298621 & 7.3706 & 4349 & \\
\hline HEMBL 313 & 298621 & 7.4389 & 097 & \\
\hline HEM & 98621 & & & \\
\hline AEMBL & 8621 & & & \\
\hline HEMBL3134539 & 298621 & 7.4535 & .5808 & \\
\hline HEMBL3134 & 298621 & 7.6289 & 931 & \\
\hline HEMBL3 & 298621 & & & \\
\hline IEME & 298621 & & & \\
\hline AEMBL: & 621 & & & \\
\hline HEMBL3134 & 298621 & 6.8125 & 6.681 & \\
\hline HEMBL 313 & 298621 & & & \\
\hline HEMBL3 & 21 & 7 & 8888 & KIN \\
\hline HEMBL & 21 & & 2771 & \\
\hline HEMBL; & 21 & & 3861 & \\
\hline HEMBL3 & 298621 & & & \\
\hline AEMBL3 & & & 2976 & Thiv \\
\hline HEMBL & 1 & 9 & 95 & RN \\
\hline HEM & & & & ונס \\
\hline HEMBL & 21 & & & \\
\hline HEMPI & & & & 151 \\
\hline AEMBL3 & & & 63 & RN \\
\hline HEMBL & 21 & & 144 & RI \\
\hline HEM & 21 & & & KIV \\
\hline 9 & & & & \\
\hline AEMBLI & & & & IRN \\
\hline AEMBL3 & 98621 & 9. & 889 & TRN \\
\hline AEMBL & 21 & & 78 & RN \\
\hline JEN & & & 78 & RN \\
\hline נ & & & & RN \\
\hline HEMBL3 & & & & 「RN \\
\hline HEMBL3 & 298621 & 7. & 687 & ГST \\
\hline JEMPI & 20: & 9 & 68 & TRN \\
\hline 4 & & & & RN \\
\hline HEMBL3 & & & 561 & TST \\
\hline HEMBL3 & 98621 & & 739 & $\Gamma R$ \\
\hline 3 & & & & IST \\
\hline HEMBL; & 1 & & & TRN \\
\hline HEMBL & & 7. & 107 & RN \\
\hline HEMBL3 & 298621 & 8.7 & 0852 & {$[R$} \\
\hline HEMBL3 & 98621 & 9. & 97 & TR \\
\hline 0 & & & & \\
\hline HEMBL3 & & & & \\
\hline CHEMBL3 & 1298621 & .0655 & 8.5026 & ST \\
\hline CHEMBL3134557 & 1298621 & 8.1427 & 8.1048 & ב \\
\hline
\end{tabular}

Page 14496 
Supplemental Table S2.txt

\begin{tabular}{|c|c|c|c|c|}
\hline CHEMBL 3134562 & 1298621 & 6.0625 & 5.9392 & TST \\
\hline CHEMBL224135 & 430992 & 3.0 & 3.873 & TRN \\
\hline CHEMBL389655 & 430992 & 6.1871 & 6.3167 & TRN \\
\hline CHEMBL386565 & 430992 & 6.466 & 3.9472 & TST \\
\hline CHEMBL 225124 & 430992 & 4.9469 & 5.0261 & TRN \\
\hline CHEMBL 375439 & 430992 & 3.0 & 2.8691 & TRN \\
\hline CHEMBL389918 & 430992 & 3.0 & 3.1668 & TRN \\
\hline CHEMBL426018 & 430992 & 5.6904 & 6.2 & TRN \\
\hline CHEMBL 224375 & 430992 & 3.0 & 2.7836 & TRN \\
\hline CHEMBL387687 & 430992 & 5.3354 & 4.676 & TRN \\
\hline CHEMBL225126 & 430992 & 3.0 & 2.9717 & TRN \\
\hline CHEMBL 224322 & 430992 & 6.8125 & 3.94 & TST \\
\hline CHEMBL 224672 & 430992 & 3.0 & 3.4173 & TRN \\
\hline CHEMBL 374167 & 430992 & \multicolumn{2}{|c|}{5.4510000000000005} & 5.7425 \\
\hline CHEMBL223819 & 430992 & 3.0 & 4.1189 & TST \\
\hline CHEMBL223399 & 430992 & 6.7471 & 6.3167 & TRN \\
\hline CHEMBL 223868 & 430992 & 3.0 & 3.0511 & TRN \\
\hline CHEMBL 374180 & 430992 & 6.0883 & 6.3486 & TRN \\
\hline CHEMBL 224898 & 430992 & 3.0 & 2.8229 & TRN \\
\hline CHEMBL 224356 & 430992 & 3.0 & 2.82 & TRN \\
\hline CHEMBL 225438 & 430992 & 3.0 & 2.9365 & TRN \\
\hline CHEMBL 225125 & 430992 & 3.0 & 2.8517 & TRN \\
\hline CHEMBL224798 & 430992 & 5.6655 & 5.5629 & TRN \\
\hline CHEMBL225589 & 430992 & 5.7423 & 5.9315 & TRN \\
\hline CHEMBL 224315 & 430992 & 6.2277 & 4.5681 & TRN \\
\hline CHEMBL223869 & 430992 & 5.3936 & 5.5307 & TRN \\
\hline CHEMBL385336 & 430992 & 6.3546 & 6.1791 & TRN \\
\hline CHEMBL 224200 & 430992 & 6.0453 & 4.312 & TST \\
\hline CHEMBL 374815 & 430992 & 5.2248 & 5.5206 & TRN \\
\hline CHEMBL386935 & 430992 & 3.0 & 2.7995 & TRN \\
\hline CHEMBL385776 & 430992 & 3.0 & 4.3241 & TRN \\
\hline CHEMBL389897 & 430992 & 3.0 & 2.9024 & TRN \\
\hline CHEMBL 224673 & 430992 & 6.4634 & 5.9265 & TRN \\
\hline CHEMBL 223496 & 430992 & 6.0506 & 5.754 & TRN \\
\hline CHEMBL 374135 & 430992 & 3.0 & 3.4682 & TRN \\
\hline CHEMBL388087 & 430992 & 3.0 & 2.7655 & TRN \\
\hline CHEMBL 224615 & 430992 & 3.0 & 3.6918 & TRN \\
\hline CHEMBL 224084 & 430992 & 3.0 & 2.7287 & TRN \\
\hline CHEMBL 225032 & 430992 & 6.8327 & 6.3167 & TRN \\
\hline CHEMBL 225201 & 430992 & 5.3439 & 5.5997 & TRN \\
\hline CHEMBL389870 & 430992 & 3.0 & 3.0142 & TRN \\
\hline CHEMBL 387976 & 430992 & 6.0453 & 6.1461 & TRN \\
\hline CHEMBL224617 & 430992 & 5.9355 & 5.5846 & TRN \\
\hline CHEMBL 225590 & 430992 & 5.9031 & 6.124 & TRN \\
\hline CHEMBL386408 & 430992 & 3.0 & 2.99399 & 99999999998 \\
\hline CHEMBL 223543 & 430992 & 5.5901 & 5.0784 & TST \\
\hline CHEMBL 388827 & 430992 & 5.6655 & 3.6235 & TST \\
\hline CHEMBL224377 & 430992 & 3.0 & 4.4902 & TST \\
\hline
\end{tabular}




\begin{tabular}{|c|c|c|c|c|c|}
\hline & & & & & \\
\hline CHEMBL 376372 & 430992 & 3.0 & 4.0729 & TST & \\
\hline CHEMBL 224088 & 430992 & 3.0 & 5.4161 & TST & \\
\hline CHEMBL 225439 & 430992 & 3.0 & 2.8885 & TST & \\
\hline CHEMBL426190 & 430992 & 5.6778 & 4.9919 & TST & \\
\hline CHEMBL 390391 & 430992 & 3.0 & 4.4496 & TST & \\
\hline CHEMBL 29858 & 468975 & 8.1308 & 8.1387 & TRN & \\
\hline CHEMBL 107183 & 468975 & 6.6198 & 6.6204 & TRN & \\
\hline CHEMBL 323059 & 468975 & 7.0 & 7.0294 & TRN & \\
\hline CHEMBL 320967 & 468975 & 8.3979 & 8.4979 & TRN & \\
\hline CHEMBL106482 & 468975 & 8.0 & 8.0008 & TRN & \\
\hline CHEMBL106457 & 468975 & 8.6198 & 8.0207 & TRN & \\
\hline CHEMBL 84046 & 468975 & 8.2218 & 8.1278 & TRN & \\
\hline CHEMBL 322745 & 468975 & 7.585 & 7.5856 & TRN & \\
\hline CHEMBL418580 & 468975 & 5.4989 & 4.8328 & TST & \\
\hline CHEMBL 285805 & 468975 & 3.9031 & 3.9216 & TRN & \\
\hline CHEMBL 29764 & 468975 & 5.2581 & 5.2602 & TRN & \\
\hline CHEMBL108907 & 468975 & 9.0 & 9.0324 & TRN & \\
\hline CHEMBL 29531 & 468975 & 6.0862 & 6.097 & TRN & \\
\hline CHEMBL321862 & 468975 & 8.301 & 8.3136 & TRN & \\
\hline CHEMBL 283212 & 468975 & 8.0458 & 8.06899 & 9999999999 & TRN \\
\hline CHEMBL319199 & 468975 & 8.1549 & 8.15299 & 9999999999 & TRN \\
\hline CHEMBL110783 & 468975 & 8.0458 & 8.0349 & TRN & \\
\hline CHEMBL 315272 & 468975 & 6.5528 & 6.5692 & TRN & \\
\hline CHEMBL322598 & 468975 & 8.2676 & 8.3126 & TRN & \\
\hline CHEMBL106304 & 468975 & 7.1549 & 7.1238 & TRN & \\
\hline CHEMBL106378 & 468975 & 8.0269 & 8.0166 & TRN & \\
\hline CHEMBL 30023 & 468975 & 5.3575 & 5.3437 & TST & \\
\hline CHEMBL 321869 & 468975 & 7.8239 & 7.8604 & TRN & \\
\hline CHEMBL110220 & 468975 & 8.3979 & 8.3778 & TRN & \\
\hline CHEMBL 86068 & 468975 & 7.8539 & 7.8273 & TRN & \\
\hline CHEMBL 28728 & 468975 & 8.0 & 8.003 & TRN & \\
\hline CHEMBL108841 & 468975 & 7.4437 & 8.0207 & TRN & \\
\hline CHEMBL106654 & 468975 & 8.1549 & 8.1207 & TRN & \\
\hline CHEMBL28632 & 468975 & 7.7959 & 7.8036 & TRN & \\
\hline CHEMBL85629 & 468975 & 8.699 & 8.7214 & TRN & \\
\hline CHEMBL28134 & 468975 & 7.5229 & 7.4796 & TST & \\
\hline CHEMBL110394 & 468975 & 8.0458 & 8.0499 & TRN & \\
\hline CHEMBL110932 & 468975 & 8.0 & 7.9861 & TRN & \\
\hline CHEMBL28787 & 468975 & 6.6234 & 6.6256 & TRN & \\
\hline CHEMBL 321464 & 468975 & 7.585 & 7.5911 & TRN & \\
\hline CHEMBL84877 & 468975 & 8.0458 & 8.0921 & TRN & \\
\hline CHEMBL 29462 & 468975 & 5.5719 & 5.5737 & TRN & \\
\hline CHEMBL29320 & 468975 & 8.699 & 8.6966 & TRN & \\
\hline CHEMBL 281218 & 468975 & 6.4437 & 6.4156 & TRN & \\
\hline CHEMBL 281056 & 468975 & 6.7447 & 6.3005 & TST & \\
\hline CHEMBL29185 & 468975 & 7.5229 & 7.5036 & TRN & \\
\hline CHEMBL 86230 & 468975 & 8.5229 & 8.5031 & TRN & \\
\hline CHEMBL108686 & 468975 & 8.699 & 8.6759 & TRN & \\
\hline
\end{tabular}




\begin{tabular}{|c|c|c|c|c|c|}
\hline \multicolumn{6}{|c|}{ Supplemental Table S2.txt } \\
\hline CHEMBL29742 & 468975 & 3.9031 & 3.8981 & TRN & \\
\hline CHEMBL271759 & 468975 & 7.2218 & 5.3603 & TST & \\
\hline CHEMBL282607 & 468975 & 7.2218 & 7.2106 & TRN & \\
\hline CHEMBL313466 & 468975 & 7.9586 & 7.9483 & TRN & \\
\hline CHEMBL28864 & 468975 & 5.8761 & 5.8984 & TRN & \\
\hline CHEMBL281035 & 468975 & 8.6198 & 8.6086 & TRN & \\
\hline CHEMBL85920 & 468975 & 8.6198 & 8.6227 & TRN & \\
\hline CHEMBL283275 & 468975 & 7.301 & 7.2958 & TRN & \\
\hline CHEMBL85979 & 468975 & 7.5229 & 7.5367 & TRN & \\
\hline CHEMBL284911 & 468975 & 6.6198 & 6.5988 & TRN & \\
\hline CHEMBL 283215 & 468975 & 3.9031 & 3.9019 & TRN & \\
\hline CHEMBL29191 & 468975 & 8.3665 & 8.3494 & TRN & \\
\hline CHEMBL107826 & 468975 & 7.6198 & 7.6159 & TRN & \\
\hline CHEMBL418392 & 468975 & 3.9031 & 4.59 & TST & \\
\hline CHEMBL 29936 & 468975 & 3.9031 & 3.8872 & TRN & \\
\hline CHEMBL107048 & 468975 & 8.699 & 8.6842 & TRN & \\
\hline CHEMBL29856 & 468975 & 6.0506 & 6.0272 & TRN & \\
\hline CHEMBL110654 & 468975 & 8.2218 & 8.2638 & TRN & \\
\hline CHEMBL 322600 & 468975 & 7.8861 & 7.9845 & TRN & \\
\hline CHEMBL 30250 & 468975 & 3.9031 & 5.8462 & TST & \\
\hline CHEMBL106822 & 468975 & 7.9586 & 7.95200 & 0000000001 & TRN \\
\hline CHEMBL25969 & 468975 & 7.3979 & 7.4129 & TRN & \\
\hline CHEMBL109157 & 468975 & 8.5229 & 8.4313 & TRN & \\
\hline CHEMBL29105 & 468975 & 6.1772 & 6.1772 & TRN & \\
\hline CHEMBL108362 & 468975 & 8.7696 & 8.7031 & TRN & \\
\hline CHEMBL 29457 & 468975 & 8.0458 & 8.0499 & TRN & \\
\hline CHEMBL29549 & 468975 & 3.9031 & 6.15 & TST & \\
\hline CHEMBL433437 & 468975 & 6.4089 & 6.4452 & TRN & \\
\hline CHEMBL 83008 & 468975 & 7.6778 & 7.6564 & TRN & \\
\hline CHEMBL423321 & 468975 & 7.0 & 6.9959 & TRN & \\
\hline CHEMBL 287214 & 468975 & 5.4318 & 4.9098 & TST & \\
\hline CHEMBL326476 & 468975 & 8.301 & 8.3092 & TRN & \\
\hline CHEMBL421600 & 468975 & 8.0 & 7.9888 & TRN & \\
\hline CHEMBL 30160 & 468975 & 3.9031 & 6.6982 & TST & \\
\hline CHEMBL 286032 & 468975 & 5.4989 & 5.4418 & TST & \\
\hline CHEMBL311309 & 468975 & 8.0605 & 8.0867 & TRN & \\
\hline CHEMBL 30222 & 468975 & 3.9031 & 3.8959 & TRN & \\
\hline CHEMBL 280546 & 468975 & 8.2076 & 8.2147 & TRN & \\
\hline CHEMBL322651 & 468975 & 7.7447 & 8.4411 & TST & \\
\hline CHEMBL110622 & 468975 & 8.5229 & 8.3394 & TST & \\
\hline CHEMBL 287446 & 468975 & 5.7721 & 6.1698 & TST & \\
\hline CHEMBL405503 & 468975 & 6.0915 & 6.9527 & TST & \\
\hline CHEMBL110732 & 468975 & 8.5229 & 8.2505 & TST & \\
\hline CHEMBL 320280 & 468975 & 8.3979 & 8.0062 & TST & \\
\hline CHEMBL405020 & 468975 & 3.9031 & 5.7917 & TST & \\
\hline CHEMBL108044 & 468975 & 8.0969 & 8.6355 & TST & \\
\hline CHEMBL29794 & 468975 & 7.1612 & 7.521 & TST & \\
\hline CHEMBL325986 & 468975 & 8.5229 & 7.9208 & TST & \\
\hline
\end{tabular}


Supplemental Table S2.txt

\begin{tabular}{|c|c|c|c|c|c|}
\hline CHEMBL282741 & 468975 & 7.2757 & 7.0201 & TST & \\
\hline CHEMBL110550 & 468975 & 8.0458 & 8.5416 & TST & \\
\hline CHEMBL28916 & 468975 & 6.7696 & 6.1629 & TST & \\
\hline CHEMBL3944712 & 1642440 & 6.5986 & 6.1255 & TRN & \\
\hline CHEMBL3933294 & 1642440 & 6.2373 & 6.0465 & TRN & \\
\hline CHEMBL3910010 & 1642440 & 5.7011 & 5.9235 & TRN & \\
\hline CHEMBL3944878 & 1642440 & 6.0 & 6.5792 & TRN & \\
\hline CHEMBL3940004 & 1642440 & 7.3439 & 7.2299 & TRN & \\
\hline CHEMBL3973834 & 1642440 & 6.4737 & 5.8592 & TRN & \\
\hline CHEMBL3931062 & 1642440 & 7.0315 & 6.6298 & TRN & \\
\hline CHEMBL3894733 & 1642440 & 5.4855 & 5.6905 & TRN & \\
\hline CHEMBL3912605 & 1642440 & 5.0 & 5.4069 & TRN & \\
\hline CHEMBL3958563 & 1642440 & 5.0 & 5.1475 & TRN & \\
\hline CHEMBL3925064 & 1642440 & 7.2757 & 6.5725 & TRN & \\
\hline CHEMBL3904072 & 1642440 & 5.0 & 4.8605 & TRN & \\
\hline CHEMBL3944360 & 1642440 & 5.0 & 5.2907 & TRN & \\
\hline CHEMBL3924355 & 1642440 & 5.0 & 5.1128 & TRN & \\
\hline CHEMBL3937117 & 1642440 & 6.0 & 5.9061 & TRN & \\
\hline CHEMBL3936804 & 1642440 & 6.0926 & 6.4328 & TRN & \\
\hline CHEMBL 3942322 & 1642440 & 6.5544 & 6.6015 & TRN & \\
\hline CHEMBL3907457 & 1642440 & 5.7399 & 5.8831 & TRN & \\
\hline CHEMBL3909202 & 1642440 & 6.7122 & 6.088999 & 99999999995 & TST \\
\hline CHEMBL3945123 & 1642440 & 5.0 & 4.9064 & TRN & \\
\hline CHEMBL3908347 & 1642440 & 6.0 & 6.2607 & TRN & \\
\hline CHEMBL3912026 & 1642440 & 7.0031 & 6.5104 & TRN & \\
\hline CHEMBL3929932 & 1642440 & 6.0 & 5.7163 & TRN & \\
\hline CHEMBL3943001 & 1642440 & 6.0685 & 5.581 & TRN & \\
\hline CHEMBL3971270 & 1642440 & 6.6289 & 6.0689 & TRN & \\
\hline CHEMBL3962490 & 1642440 & 5.2161 & 5.2719 & TRN & \\
\hline CHEMBL 3980140 & 1642440 & 7.2366 & 6.6977 & TRN & \\
\hline CHEMBL3985140 & 1642440 & 6.644 & 6.6391 & TRN & \\
\hline CHEMBL3951757 & 1642440 & 6.2967 & 6.1591 & TRN & \\
\hline CHEMBL3900163 & 1642440 & 5.7905 & 6.0269 & TST & \\
\hline CHEMBL3955986 & 1642440 & 6.9318 & 6.019 & TRN & \\
\hline CHEMBL3941268 & 1642440 & 5.7144 & 5.5727 & TRN & \\
\hline CHEMBL3907738 & 1642440 & 6.4191 & 5.987999 & 99999999995 & TST \\
\hline CHEMBL3968531 & 1642440 & 6.82100 & 000000000 & 5.8952 & TRN \\
\hline CHEMBL3981377 & 1642440 & 5.9066 & 5.6373 & TRN & \\
\hline CHEMBL3930790 & 1642440 & 6.6498 & 6.0069 & TRN & \\
\hline CHEMBL3933962 & 1642440 & 4.0 & 6.1251 & TST & \\
\hline CHEMBL3943875 & 1642440 & 5.4672 & 4.9251 & TRN & \\
\hline CHEMBL 3897015 & 1642440 & 7.4202 & 7.3353 & TRN & \\
\hline CHEMBL3948778 & 1642440 & 6.8182 & 5.7994 & TRN & \\
\hline CHEMBL3897391 & 1642440 & 5.6819 & 5.8665 & TRN & \\
\hline CHEMBL3928856 & 1642440 & 6.0696 & 6.4175 & TST & \\
\hline CHEMBL3928755 & 1642440 & 5.6289 & 6.1205 & TST & \\
\hline CHEMBL3910925 & 1642440 & 5.2534 & 6.4541 & TRN & \\
\hline CHEMBL3938953 & 1642440 & 6.0 & 6.5434 & TRN & \\
\hline
\end{tabular}


Supplemental Table S2.txt

\begin{tabular}{|c|c|c|c|c|}
\hline HEMBL3918930 & 1642440 & 5.7399 & 5.8023 & TRN \\
\hline HEMBL3941839 & L642440 & 5.0 & 5.6593 & TRN \\
\hline AEMBL3919855 & 642440 & 5.3565 & & RN \\
\hline AEMBL 3934434 & 642440 & 7.3279 & 22 & $\mathrm{~N}$ \\
\hline HEMBL3952134 & 642440 & 5.0 & . 9919 & $\mathrm{~N}$ \\
\hline HEMBL 3913852 & 642440 & 6.0 & 6.5976 & TRN \\
\hline HEMBL3983971 & 642440 & 6.3002 & .557 & ST \\
\hline AEMBL3978765 & 642440 & 5.51 & 5.4423 & ST \\
\hline AEMBL3957443 & 642440 & 5.2557 & 5.4416 & ST \\
\hline HEMBL3901984 & 642440 & 6.0 & 5.604 & STT \\
\hline HEMBL3969134 & 642440 & 6.0357 & . 1649 & TST \\
\hline HEMBL3968026 & 642440 & 5.0 & .0213 & ST \\
\hline AEMBL3914324 & 140 & 5.9066 & 6.2986 & ST \\
\hline HEMBL3898993 & 1642440 & 5.1675 & 5.2617 & ST \\
\hline HEMBL3951056 & L642440 & 6.0 & 6.6688 & TRN \\
\hline HEMBL3932194 & 1642440 & 6.3851 & 6.1812 & TRN \\
\hline HEMBL3931669 & 1642440 & 6.0 & 6.2117 & IST \\
\hline HEMBL3950397 & 164 & 5.6073 & 5.8739 & IST \\
\hline HEMBL3916419 & 164 & 6.0 & 6.0956 & rRN \\
\hline AEMBL3956323 & 164 & & .7553 & rRN \\
\hline HEMBL3907358 & 164 & 4.0 & 5.8017 & RN \\
\hline HEMBL3973389 & 164 & 5.7986 & 5.9279 & 「ST \\
\hline HEMBL3893482 & 164 & 5.3487 & 4.9639 & TST \\
\hline HEMBL3908893 & 40 & 5.0 & 5.0282 & TRN \\
\hline AEMBL86631 & 87 & & 054 & TST \\
\hline HEMBL89363 & 787 & 3 & .9589 & $\mathrm{RN}$ \\
\hline HEMBL89697 & 1 & & 3.0921 & $\Gamma \mathrm{RN}$ \\
\hline HEMBL89721 & 1 & & 3.1755 & TRN \\
\hline HEMBL86837 & 187 & & 2491 & TRN \\
\hline HEMBL 87783 & 87 & & .0637 & TRN \\
\hline HEMBL86921 & 87 & & 3.2599 & TST \\
\hline HEMBL316008 & 8751 & & 3.1636 & TRN \\
\hline AEMBL431025 & 1 & 0 & .8246 & TRN \\
\hline HEMBL86480 & 87 & & 3.3576 & TRN \\
\hline HEMBL 87208 & 8751 & & 2.978 & TRN \\
\hline HEMBL 86755 & 787 & & 2.7344 & rRN \\
\hline HEMBL86 & 1 & 2 & 5.1264 & TRN \\
\hline HEMBL 86432 & 78751 & 4.0391 & 3.2858 & TRN \\
\hline HEMBL314217 & 78751 & 3.0 & 3.3207 & TRN \\
\hline HEMBL 316020 & 8751 & & 2.9772 & TST \\
\hline CHEMBL85403 & 78751 & 3. & 2.9513 & TRN \\
\hline CHEMBL85021 & 78751 & 5.1549 & 4.0159 & TRN \\
\hline CHEMBL314146 & 78751 & 3.0 & 3.2266 & TST \\
\hline CHEMBL89646 & 78751 & 3.0 & 3.6968 & TST \\
\hline ZHEMBL 33032 & 787 & 3 & 3.1968 & TRN \\
\hline CHEMBL 88405 & 78751 & 3.301 & 3.8695 & IRN \\
\hline CHEMBL312826 & 78751 & 3.0 & 3.1947 & TST \\
\hline CHEMBL315701 & 78751 & 4.0334 & 3.3341 & rRN \\
\hline
\end{tabular}

Page 14501 


\begin{tabular}{|c|c|c|c|c|c|}
\hline \multicolumn{6}{|c|}{ Supplemental Table S2.txt } \\
\hline CHEMBL89483 & 78751 & 3.0 & 3.3187 & TRN & \\
\hline CHEMBL313433 & 78751 & 3.0 & 2.99399 & 99999999998 & TST \\
\hline CHEMBL316268 & 78751 & 3.0 & 3.2781 & TRN & \\
\hline CHEMBL48760 & 78751 & 4.7721 & 3.7769 & TRN & \\
\hline CHEMBL313259 & 78751 & 3.0 & 3.2466 & TRN & \\
\hline CHEMBL86943 & 78751 & 3.0 & 3.0795 & TST & \\
\hline CHEMBL86326 & 78751 & 4.7905 & 5.2084 & TRN & \\
\hline CHEMBL313578 & 78751 & 3.0 & 3.0793 & TRN & \\
\hline CHEMBL316009 & 78751 & 3.0 & 3.2869 & TST & \\
\hline CHEMBL86945 & 78751 & 4.8794 & 4.3309 & TRN & \\
\hline CHEMBL328452 & 78751 & 3.0 & 3.2498 & TST & \\
\hline CHEMBL89809 & 78751 & 3.0 & 3.0172 & TRN & \\
\hline CHEMBL89723 & 78751 & 5.0862 & 4.9206 & TRN & \\
\hline CHEMBL 90277 & 78751 & 4.1765 & 3.4755 & TRN & \\
\hline CHEMBL315546 & 78751 & 4.0448 & 3.3195 & TRN & \\
\hline CHEMBL 89040 & 78751 & 3.0 & 3.3735 & TRN & \\
\hline CHEMBL314798 & 78751 & 3.0 & 3.5456 & TST & \\
\hline CHEMBL328710 & 78751 & 3.0 & 2.95600 & 00000000004 & TRN \\
\hline CHEMBL87402 & 78751 & 3.0 & 3.4817 & TST & \\
\hline CHEMBL420411 & 78751 & 3.0 & 3.0493 & TST & \\
\hline CHEMBL87810 & 78751 & 3.0 & 3.5058 & TRN & \\
\hline CHEMBL 314021 & 78751 & 4.6478 & 3.5914 & TST & \\
\hline CHEMBL87080 & 78751 & 4.0 & 3.9853 & TRN & \\
\hline CHEMBL 87746 & 78751 & 4.7212 & 4.3151 & TRN & \\
\hline CHEMBL89505 & 78751 & 4.1884 & 3.9954 & TRN & \\
\hline CHEMBL421548 & 78751 & 4.0 & 4.4593 & TRN & \\
\hline CHEMBL 87324 & 78751 & 3.0 & 3.2469 & TRN & \\
\hline CHEMBL 87325 & 78751 & 3.0 & 3.2012 & TRN & \\
\hline CHEMBL329367 & 78751 & 3.0 & 3.2974 & TRN & \\
\hline CHEMBL1869506 & 752508 & 5.6819 & 5.2604 & TST & \\
\hline CHEMBL1883614 & 752508 & 3.0044 & 2.5663 & TST & \\
\hline CHEMBL1904381 & 752508 & 3.0044 & 3.0865 & TRN & \\
\hline CHEMBL1577231 & 752508 & 5.8697 & 6.0172 & TRN & \\
\hline CHEMBL1904269 & 752508 & 3.0044 & 2.9878 & TST & \\
\hline CHEMBL1869393 & 752508 & 5.9355 & 5.9009 & TRN & \\
\hline CHEMBL1889468 & 752508 & 3.0044 & 3.1103 & TRN & \\
\hline CHEMBL1878043 & 752508 & 5.109 & 5.1468 & TRN & \\
\hline CHEMBL1898996 & 752508 & 3.0044 & 3.0295 & TRN & \\
\hline CHEMBL1885333 & 752508 & 3.0044 & 3.0781 & TRN & \\
\hline CHEMBL1871228 & 752508 & 6.0057 & 6.0018 & TRN & \\
\hline CHEMBL1903348 & 752508 & 5.6716 & 5.4294 & TRN & \\
\hline CHEMBL1316867 & 752508 & 6.2299 & 5.8378 & TRN & \\
\hline CHEMBL1866613 & 752508 & 5.8125 & 5.5702 & TRN & \\
\hline CHEMBL1864520 & 752508 & 3.0044 & 3.1385 & TRN & \\
\hline CHEMBL1899813 & 752508 & 4.0516 & 3.8194 & TRN & \\
\hline CHEMBL566295 & 752508 & 3.0044 & 2.9034 & TRN & \\
\hline CHEMBL 1705186 & 752508 & 5.7328 & 5.7242 & TRN & \\
\hline CHEMBL1899989 & 752508 & 5.6536 & 5.5933 & TRN & \\
\hline
\end{tabular}




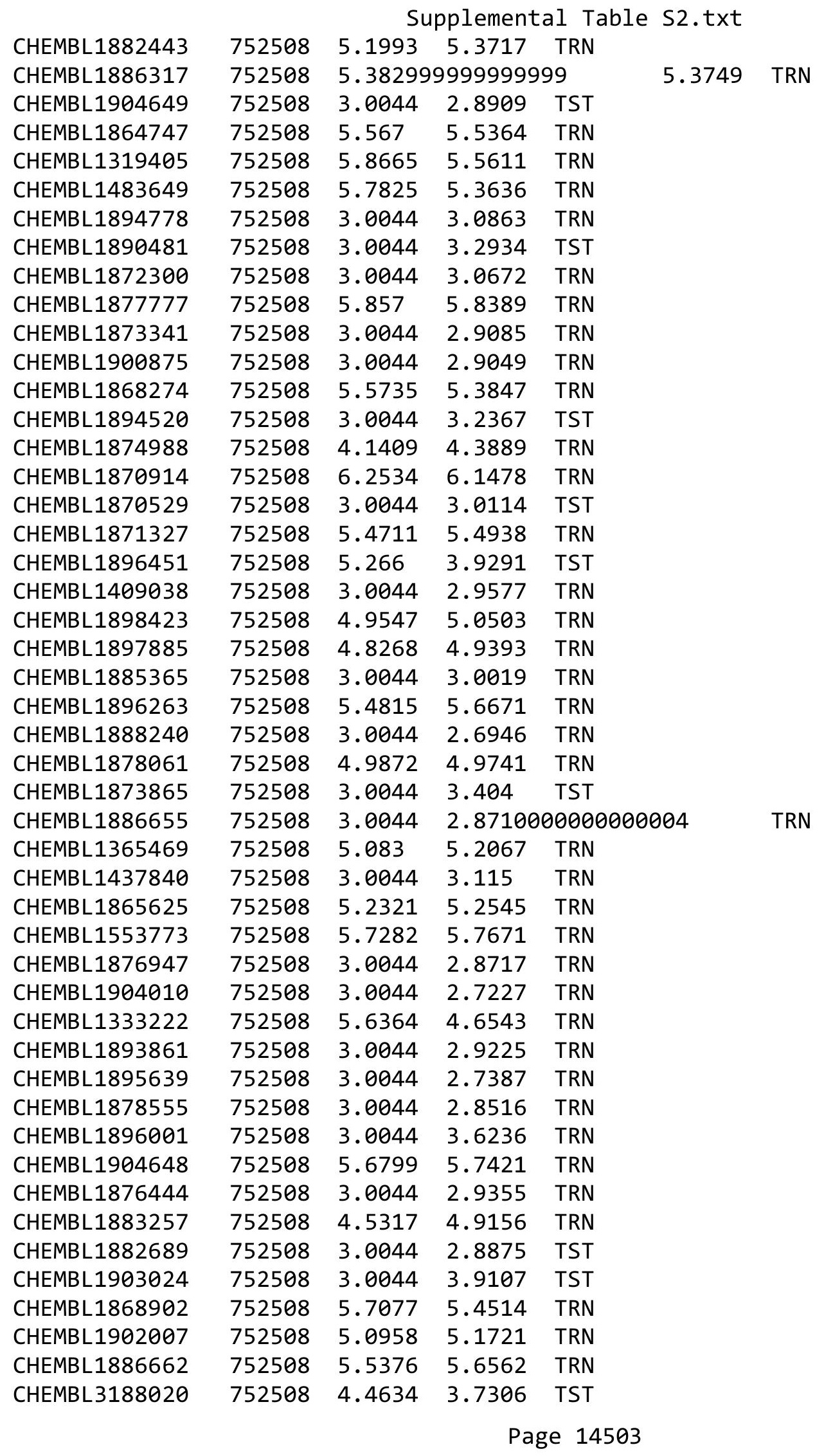




\begin{tabular}{|c|c|c|c|c|c|}
\hline \multicolumn{6}{|c|}{ Supplemental Table s2.txt } \\
\hline CHEMBL1877394 & 752508 & 3.0044 & 2.8656 & TST & \\
\hline CHEMBL1884442 & 752508 & 5.2175 & 5.5933 & TRN & \\
\hline CHEMBL1905960 & 752508 & 3.0044 & 3.1436 & TST & \\
\hline CHEMBL1864230 & 752508 & 3.0044 & 2.763 & TST & \\
\hline CHEMBL1883713 & 752508 & 3.0044 & 3.2544 & TRN & \\
\hline CHEMBL1404762 & 752508 & 3.0044 & 3.0803 & TRN & \\
\hline CHEMBL1904728 & 752508 & 3.0044 & 3.3018 & TST & \\
\hline CHEMBL1413278 & 752508 & 4.3585 & 4.4005 & TRN & \\
\hline CHEMBL1302779 & 752508 & 5.9101 & 6.0096 & TRN & \\
\hline CHEMBL1874506 & 752508 & 4.7167 & 4.7028 & TRN & \\
\hline CHEMBL1897348 & 752508 & 3.0044 & 2.6486 & TRN & \\
\hline CHEMBL1899595 & 752508 & 5.5686 & 5.3945 & TRN & \\
\hline CHEMBL1879719 & 752508 & 3.0044 & 3.2088 & TRN & \\
\hline CHEMBL1901952 & 752508 & 5.6819 & 5.9276 & TRN & \\
\hline CHEMBL1885482 & 752508 & 3.0044 & 3.6191 & TRN & \\
\hline CHEMBL1891206 & 752508 & 5.9172 & 5.7095 & TRN & \\
\hline CHEMBL1877480 & 752508 & 3.0044 & 3.0168 & TRN & \\
\hline CHEMBL1699684 & 752508 & 3.0044 & 3.2325 & TRN & \\
\hline CHEMBL1883149 & 752508 & 3.0044 & 2.9331 & TST & \\
\hline CHEMBL1865073 & 752508 & 3.0044 & 3.0309 & TST & \\
\hline CHEMBL1865901 & 752508 & 3.0044 & 3.1537 & TRN & \\
\hline CHEMBL1564500 & 752508 & 5.1273 & 5.0921 & TRN & \\
\hline CHEMBL1875484 & 752508 & 3.0044 & 3.0095 & TST & \\
\hline CHEMBL1899871 & 752508 & 3.0044 & 2.4296 & TST & \\
\hline CHEMBL1905421 & 752508 & 3.0044 & 2.615 & TST & \\
\hline CHEMBL1890960 & 752508 & 4.0191 & 3.4817 & TST & \\
\hline CHEMBL1881032 & 752508 & 3.0044 & 3.2721 & TST & \\
\hline CHEMBL1903767 & 752508 & 3.0044 & 3.339 & TST & \\
\hline CHEMBL1872841 & 752508 & 4.9136 & 5.1201 & TRN & \\
\hline CHEMBL1887272 & 752508 & 5.0757 & 5.4136 & TRN & \\
\hline CHEMBL1878966 & 752508 & 3.0044 & 2.6895 & TST & \\
\hline CHEMBL1870753 & 752508 & 3.0044 & 3.0379 & TRN & \\
\hline CHEMBL1901621 & 752508 & 3.0044 & 2.9196 & TST & \\
\hline CHEMBL145850 & 752508 & 3.0044 & 3.0866 & TRN & \\
\hline CHEMBL2402152 & 969260 & 6.2518 & 6.1459 & TRN & \\
\hline CHEMBL 2402258 & 969260 & 7.0655 & 7.2339 & TRN & \\
\hline CHEMBL1784201 & 969260 & 5.8539 & 5.9842 & TRN & \\
\hline CHEMBL 2402145 & 969260 & 5.5376 & 5.50799 & 9999999999 & TRN \\
\hline CHEMBL1784208 & 969260 & 6.2218 & 6.0687 & TRN & \\
\hline CHEMBL2402244 & 969260 & 7.1024 & 7.4012 & TRN & \\
\hline CHEMBL2402264 & 969260 & 7.3768 & 7.6673 & TRN & \\
\hline CHEMBL 2402265 & 969260 & 6.8539 & 6.8832 & TRN & \\
\hline CHEMBL2402263 & 969260 & 7.0555 & 7.1245 & TRN & \\
\hline CHEMBL 2402144 & 969260 & 7.1938 & 7.2282 & TRN & \\
\hline CHEMBL1782536 & 969260 & 6.0506 & 5.8062 & TRN & \\
\hline CHEMBL2402252 & 969260 & 6.0605 & 6.3933 & TRN & \\
\hline CHEMBL 2402259 & 969260 & 7.1024 & 7.2469 & TRN & \\
\hline CHEMBL 2402253 & 969260 & 6.284 & 6.5277 & TRN & \\
\hline
\end{tabular}

Page 14504 


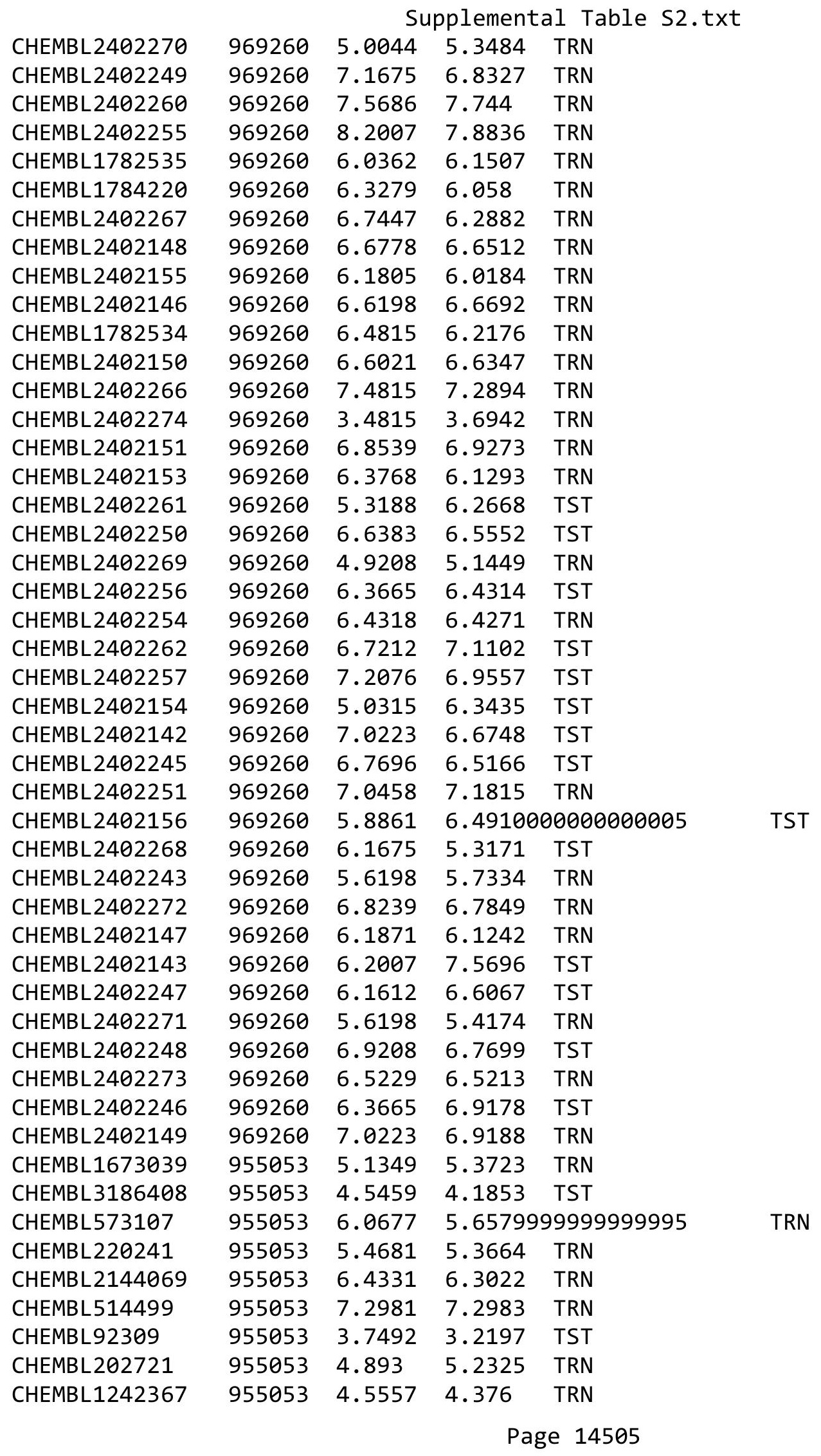




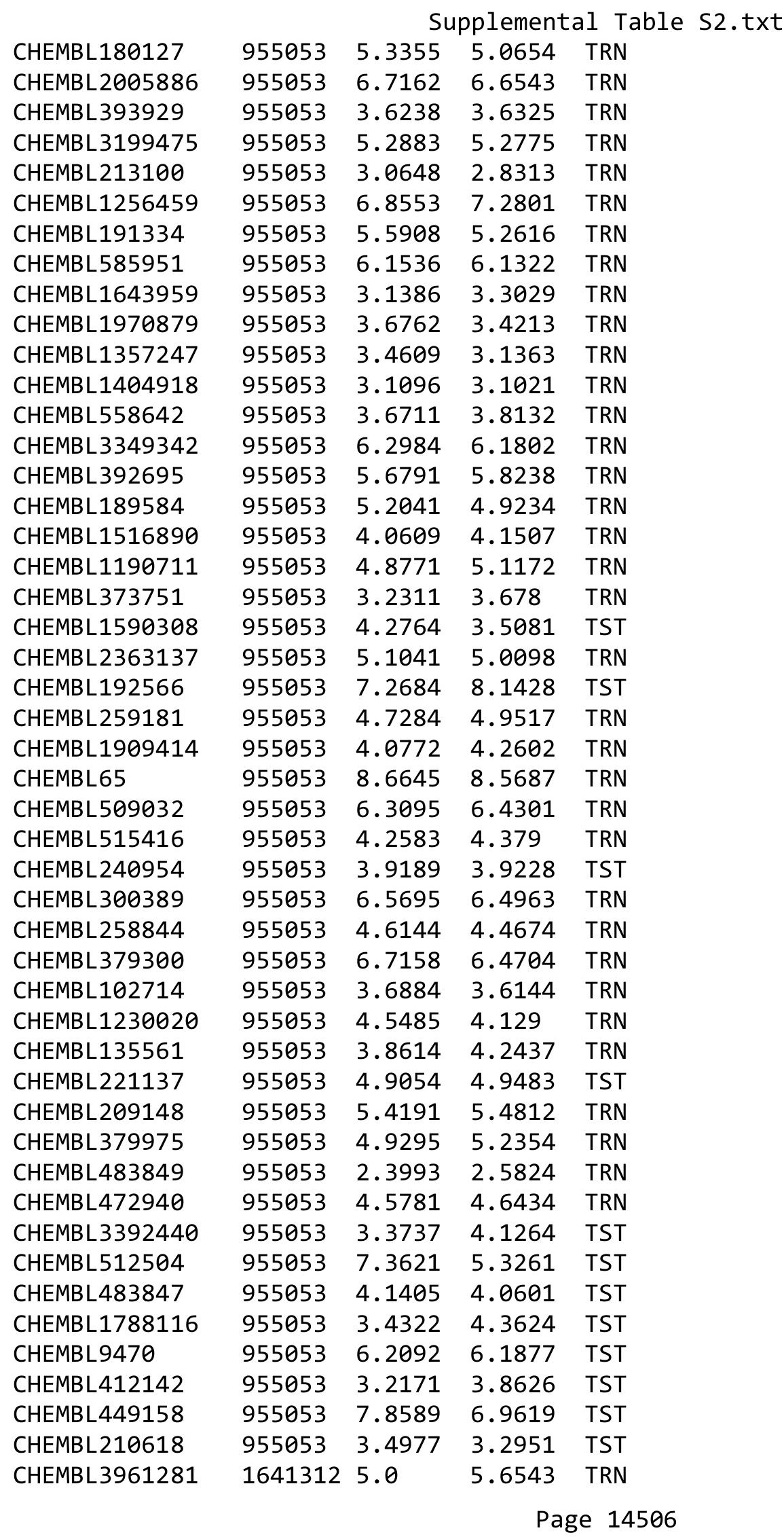




\begin{tabular}{|c|c|c|c|c|c|}
\hline \multicolumn{6}{|c|}{ Supplemental Table s2.txt } \\
\hline CHEMBL 3923008 & 1641312 & 8.0 & 7.1636 & TRN & \\
\hline CHEMBL 3942778 & 1641312 & 5.0 & 5.336 & TST & \\
\hline CHEMBL3970591 & 1641312 & 5.0 & 6.1884 & TRN & \\
\hline CHEMBL 3806195 & 1641312 & 8.0 & 7.6513 & TRN & \\
\hline CHEMBL3985786 & 1641312 & 6.2596 & 6.4718 & TRN & \\
\hline CHEMBL3894743 & 1641312 & 8.0 & 7.9561 & TRN & \\
\hline CHEMBL 3964884 & 1641312 & 8.0 & 8.7421 & TRN & \\
\hline CHEMBL 3984727 & 1641312 & 5.0 & 4.8145 & TST & \\
\hline CHEMBL3946382 & 1641312 & 5.0 & 4.7648 & TRN & \\
\hline CHEMBL3985129 & 1641312 & 5.0 & 5.1819 & TRN & \\
\hline CHEMBL3936315 & 1641312 & 5.0 & 5.0793 & TST & \\
\hline CHEMBL 3962520 & 1641312 & 6.2596 & 7.2055 & TRN & \\
\hline CHEMBL3805019 & 1641312 & 6.2596 & 5.7528 & TRN & \\
\hline CHEMBL 3909896 & 1641312 & 5.0 & 4.947 & TRN & \\
\hline CHEMBL3938430 & 1641312 & 6.2596 & 6.7904 & TST & \\
\hline CHEMBL3945844 & 1641312 & 6.2596 & 6.2517 & TRN & \\
\hline CHEMBL3984593 & 1641312 & 6.2596 & 5.7119 & TRN & \\
\hline CHEMBL3954063 & 1641312 & 5.0 & 4.9011 & TRN & \\
\hline CHEMBL3955573 & 1641312 & 5.0 & 5.2216 & TRN & \\
\hline CHEMBL3915305 & 1641312 & 6.2596 & 5.8911 & TRN & \\
\hline CHEMBL3951359 & 1641312 & 5.0 & 5.3073 & TRN & \\
\hline CHEMBL 3919714 & 1641312 & 5.0 & 4.8812 & TRN & \\
\hline CHEMBL3908201 & 1641312 & 5.0 & 5.2085 & TRN & \\
\hline CHEMBL3961942 & 1641312 & 8.0 & 8.3392 & TRN & \\
\hline CHEMBL3900762 & 1641312 & 5.0 & 4.5617 & TRN & \\
\hline CHEMBL3907367 & 1641312 & 8.0 & 7.7689 & TRN & \\
\hline CHEMBL3916345 & 1641312 & 6.2596 & 6.3262 & TRN & \\
\hline CHEMBL3945447 & 1641312 & 8.0 & 6.7424 & TRN & \\
\hline CHEMBL 3905764 & 1641312 & 6.2596 & 5.9019 & TRN & \\
\hline CHEMBL3949799 & 1641312 & 5.0 & 5.2201 & TRN & \\
\hline CHEMBL3960130 & 1641312 & 5.0 & 5.87200 & 0000000001 & TRN \\
\hline CHEMBL3963832 & 1641312 & 6.2596 & 5.7294 & TST & \\
\hline CHEMBL3960871 & 1641312 & 5.0 & 5.6303 & TRN & \\
\hline CHEMBL3935980 & 1641312 & 6.2596 & 6.0207 & TRN & \\
\hline CHEMBL3902512 & 1641312 & 5.0 & 4.9494 & TRN & \\
\hline CHEMBL3908658 & 1641312 & 5.0 & 4.9891 & TRN & \\
\hline CHEMBL3906875 & 1641312 & 5.0 & 6.0242 & TRN & \\
\hline CHEMBL3964862 & 1641312 & 6.2596 & 5.3451 & TRN & \\
\hline CHEMBL3805061 & 1641312 & 8.0 & 7.5633 & TRN & \\
\hline CHEMBL3901264 & 1641312 & 5.0 & 5.6665 & TST & \\
\hline CHEMBL3957723 & 1641312 & 5.0 & 5.0357 & TRN & \\
\hline CHEMBL3936046 & 1641312 & 8.0 & 5.01 & TST & \\
\hline CHEMBL3935531 & 1641312 & 6.2596 & 7.7791 & TST & \\
\hline CHEMBL3943986 & 1641312 & 8.0 & 7.57700 & 0000000001 & TRN \\
\hline CHEMBL3907068 & 1641312 & 5.0 & 5.2649 & TRN & \\
\hline CHEMBL3950633 & 1641312 & 6.2596 & 5.5627 & TRN & \\
\hline CHEMBL3925201 & 1641312 & 6.2596 & 5.3898 & TRN & \\
\hline CHEMBL3958476 & 1641312 & 8.0 & 7.6486 & TRN & \\
\hline
\end{tabular}


Supplemental Table S2.txt

\begin{tabular}{|c|c|c|c|c|c|}
\hline CHEMBL3937838 & 1641312 & 6.2596 & 6.0564 & TRN & \\
\hline CHEMBL3896111 & 1641312 & 6.2596 & 6.1071 & TST & \\
\hline CHEMBL3943827 & 1641312 & 8.0 & 7.9578 & TRN & \\
\hline CHEMBL3929687 & 1641312 & 6.2596 & 5.563 & TRN & \\
\hline CHEMBL3922036 & 1641312 & 8.0 & 7.8801 & TRN & \\
\hline CHEMBL3805337 & 1641312 & 6.2596 & 6.9636 & TRN & \\
\hline CHEMBL3928621 & 1641312 & 5.0 & 4.8332 & TRN & \\
\hline CHEMBL3913035 & 1641312 & 5.0 & 4.6298 & TRN & \\
\hline CHEMBL3906822 & 1641312 & 5.0 & 5.2386 & TRN & \\
\hline CHEMBL3922602 & 1641312 & 8.0 & 6.9254 & TRN & \\
\hline CHEMBL3919058 & 1641312 & 5.0 & 5.2299 & TRN & \\
\hline CHEMBL3917559 & 1641312 & 8.0 & 7.2348 & TRN & \\
\hline CHEMBL3959013 & 1641312 & 5.0 & 5.5947 & TST & \\
\hline CHEMBL3965130 & 1641312 & 6.2596 & 5.7435 & TST & \\
\hline CHEMBL3959531 & 1641312 & 6.2596 & 6.2033 & TST & \\
\hline CHEMBL3911495 & 1641312 & 8.0 & 7.6981 & TRN & \\
\hline CHEMBL3944491 & 1641312 & 5.0 & 5.7128 & TRN & \\
\hline CHEMBL 3952804 & 1641312 & 5.0 & 4.8104 & TRN & \\
\hline CHEMBL3931327 & 1641312 & 6.2596 & 6.9459 & TRN & \\
\hline CHEMBL3891821 & 1641312 & 5.0 & 6.21299 & 9999999999 & TRN \\
\hline CHEMBL3934086 & 1641312 & 6.2596 & 6.3824 & TRN & \\
\hline CHEMBL3951402 & 1641312 & 6.2596 & 7.48 & TST & \\
\hline CHEMBL3890805 & 1641312 & 5.0 & 4.5968 & TRN & \\
\hline CHEMBL3906328 & 1641312 & 6.2596 & 6.9126 & TRN & \\
\hline CHEMBL3922409 & 1641312 & 5.0 & 4.9477 & TRN & \\
\hline CHEMBL3924120 & 1641312 & 5.0 & 5.5561 & TST & \\
\hline CHEMBL 3895810 & 1641312 & 5.0 & 5.0163 & TRN & \\
\hline CHEMBL3914621 & 1641312 & 6.2596 & 5.9066 & TRN & \\
\hline CHEMBL3960691 & 1641312 & 5.0 & 5.5728 & TRN & \\
\hline CHEMBL3910328 & 1641312 & 5.0 & 5.3549 & TRN & \\
\hline CHEMBL3962518 & 1641312 & 5.0 & 4.7139 & TRN & \\
\hline CHEMBL3920650 & 1641312 & 5.0 & 5.1998 & TRN & \\
\hline CHEMBL3946520 & 1641312 & 6.2596 & 5.8995 & TRN & \\
\hline CHEMBL3943275 & 1641312 & 8.0 & 8.5965 & TRN & \\
\hline CHEMBL3899091 & 1641312 & 5.0 & 5.7339 & TRN & \\
\hline CHEMBL3903827 & 1641312 & 6.2596 & 5.3364 & TST & \\
\hline CHEMBL 3909257 & 1641312 & 5.0 & 5.0354 & TRN & \\
\hline CHEMBL3917126 & 1641312 & 5.0 & 6.9307 & TST & \\
\hline CHEMBL3923649 & 1641312 & 6.2596 & 4.9237 & TST & \\
\hline CHEMBL3955690 & 1641312 & 5.0 & 5.8037 & TST & \\
\hline CHEMBL3908612 & 1641312 & 5.0 & 5.8278 & TST & \\
\hline CHEMBL 3930845 & 1641312 & 8.0 & 8.6274 & TRN & \\
\hline CHEMBL3946867 & 1641312 & 5.0 & 5.6167 & TRN & \\
\hline CHEMBL3901439 & 1641312 & 5.0 & 5.4192 & TST & \\
\hline CHEMBL3806228 & 1641312 & 5.0 & 6.1967 & TRN & \\
\hline CHEMBL3937519 & 1641312 & 8.0 & 8.1661 & TST & \\
\hline CHEMBL3892650 & 1641312 & 5.0 & 5.0039 & TRN & \\
\hline CHEMBL 3945040 & 1641312 & 5.0 & 5.6713 & TRN & \\
\hline
\end{tabular}


Supplemental Table S2.txt

\begin{tabular}{|c|c|c|c|c|c|}
\hline CHEMBL3931513 & 1641312 & 5.0 & 4.6243 & TRN & \\
\hline CHEMBL3950928 & 1641312 & 5.0 & 5.2578 & TRN & \\
\hline CHEMBL3979594 & 1641312 & 5.0 & 4.5331 & TRN & \\
\hline CHEMBL 3953484 & 1641312 & 6.2596 & 6.4077 & TRN & \\
\hline CHEMBL3919255 & 1641312 & 8.0 & 7.4841 & TRN & \\
\hline CHEMBL3914201 & 1641312 & 5.0 & 5.0982 & TRN & \\
\hline CHEMBL3947550 & 1641312 & 5.0 & 5.1428 & TRN & \\
\hline CHEMBL 3976500 & 1641312 & 5.0 & 6.5931 & TST & \\
\hline CHEMBL 3976222 & 1641312 & 8.0 & 6.9544 & TRN & \\
\hline CHEMBL3900390 & 1641312 & 6.2596 & 5.6302 & TRN & \\
\hline CHEMBL 3984444 & 1641312 & 6.2596 & 5.3193 & TST & \\
\hline CHEMBL 3908064 & 1641312 & 6.2596 & 6.0457 & TRN & \\
\hline CHEMBL3924491 & 1641312 & 8.0 & 7.1153 & TRN & \\
\hline CHEMBL3973117 & 1641312 & 5.0 & 5.6476 & TST & \\
\hline CHEMBL3944692 & 1641312 & 6.2596 & 5.99100 & 00000000005 & TRN \\
\hline CHEMBL3956195 & 1641312 & 6.2596 & 6.0267 & TRN & \\
\hline CHEMBL3915079 & 1641312 & 5.0 & 5.7069 & TRN & \\
\hline CHEMBL3907586 & 1641312 & 5.0 & 4.5784 & TRN & \\
\hline CHEMBL3981331 & 1641312 & 5.0 & 5.9601 & TRN & \\
\hline CHEMBL3954547 & 1641312 & 6.2596 & 6.5304 & TRN & \\
\hline CHEMBL3915903 & 1641312 & 5.0 & 4.9382 & TRN & \\
\hline CHEMBL3959485 & 1641312 & 5.0 & 4.9855 & TRN & \\
\hline CHEMBL3902091 & 1641312 & 5.0 & 5.1595 & TST & \\
\hline CHEMBL3932612 & 1641312 & 5.0 & 5.6613 & TRN & \\
\hline CHEMBL 3926413 & 1641312 & 6.2596 & 6.6219 & TRN & \\
\hline CHEMBL3969543 & 1641312 & 5.0 & 5.7869 & TRN & \\
\hline CHEMBL 3898042 & 1641312 & 5.0 & 4.9436 & TRN & \\
\hline CHEMBL3946133 & 1641312 & 5.0 & 4.9846 & TRN & \\
\hline CHEMBL 3972988 & 1641312 & 6.2596 & 5.5533 & TRN & \\
\hline CHEMBL 3915257 & 1641312 & 6.2596 & 5.692 & TRN & \\
\hline CHEMBL3891379 & 1641312 & 5.0 & 5.1807 & TRN & \\
\hline CHEMBL 3935121 & 1641312 & 6.2596 & 6.4516 & TRN & \\
\hline CHEMBL3892931 & 1641312 & 8.0 & 6.9373 & TRN & \\
\hline CHEMBL3986194 & 1641312 & 6.2596 & 6.8043 & TRN & \\
\hline CHEMBL3908150 & 1641312 & 5.0 & 6.0784 & TST & \\
\hline CHEMBL3983189 & 1641312 & 5.0 & 5.4454 & TRN & \\
\hline CHEMBL3967978 & 1641312 & 8.0 & 7.5247 & TRN & \\
\hline CHEMBL3961581 & 1641312 & 5.0 & 5.2692 & TRN & \\
\hline CHEMBL3914780 & 1641312 & 5.0 & 5.9053 & TST & \\
\hline CHEMBL3948382 & 1641312 & 5.0 & 5.1879 & TRN & \\
\hline CHEMBL3983551 & 1641312 & 5.0 & 4.9644 & TRN & \\
\hline CHEMBL3973482 & 1641312 & 6.2596 & 6.695 & TRN & \\
\hline CHEMBL3977922 & 1641312 & 8.0 & 6.8629 & TRN & \\
\hline CHEMBL3804882 & 1641312 & 8.0 & 6.4771 & TRN & \\
\hline CHEMBL3971322 & 1641312 & 5.0 & 4.9924 & TRN & \\
\hline CHEMBL3896991 & 1641312 & 6.2596 & 6.3608 & TRN & \\
\hline CHEMBL3940834 & 1641312 & 5.0 & 5.4312 & TRN & \\
\hline CHEMBL3952571 & 1641312 & 5.0 & 4.7487 & TRN & \\
\hline
\end{tabular}




\begin{tabular}{|c|c|c|c|c|c|}
\hline \multicolumn{6}{|c|}{ Supplemental Table S2.txt } \\
\hline CHEMBL3969032 & 1641312 & 5.0 & 5.3161 & TRN & \\
\hline CHEMBL 3916948 & 1641312 & 5.0 & 4.7825 & TST & \\
\hline CHEMBL3893512 & 1641312 & 6.2596 & 6.2583 & TRN & \\
\hline CHEMBL3902489 & 1641312 & 8.0 & 7.4778 & TST & \\
\hline CHEMBL3919742 & 1641312 & 5.0 & 5.5657 & TST & \\
\hline CHEMBL3923690 & 1641312 & 8.0 & 8.52 & TST & \\
\hline CHEMBL 3894395 & 1641312 & 5.0 & 5.0347 & TST & \\
\hline CHEMBL3901914 & 1641312 & 6.2596 & 6.6425 & TST & \\
\hline CHEMBL3970101 & 1641312 & 6.2596 & 5.9647 & TST & \\
\hline CHEMBL3922388 & 1641312 & 5.0 & 5.1607 & TST & \\
\hline CHEMBL3908091 & 1641312 & 5.0 & 5.7711 & TST & \\
\hline CHEMBL3972643 & 1641312 & 5.0 & \multicolumn{2}{|c|}{5.4239999999999995} & TST \\
\hline CHEMBL3963325 & 1641312 & 6.2596 & 5.9177 & TST & \\
\hline CHEMBL3967711 & 1641312 & 6.2596 & 4.9766 & TST & \\
\hline CHEMBL3961122 & 1641312 & 6.2596 & 7.0844 & TST & \\
\hline CHEMBL138535 & 104726 & 5.0 & 5.069 & TRN & \\
\hline CHEMBL343392 & 104726 & 7.699 & 7.1356 & TRN & \\
\hline CHEMBL138613 & 104726 & 7.699 & 7.72 & TRN & \\
\hline CHEMBL335118 & 104726 & 7.301 & 6.3908 & TRN & \\
\hline CHEMBL434446 & 104726 & 7.5229 & 7.5507 & TRN & \\
\hline CHEMBL142134 & 104726 & 7.699 & 7.6581 & TRN & \\
\hline CHEMBL443478 & 104726 & 5.699 & 5.9826 & TST & \\
\hline CHEMBL142071 & 104726 & 6.301 & 6.4343 & TRN & \\
\hline CHEMBL141471 & 104726 & 6.3979 & 6.3868 & TRN & \\
\hline CHEMBL294680 & 104726 & 6.5229 & 6.2891 & TST & \\
\hline CHEMBL336243 & 104726 & 7.699 & 7.7187 & TRN & \\
\hline CHEMBL140863 & 104726 & 7.5229 & 7.3944 & TRN & \\
\hline CHEMBL140454 & 104726 & 6.1549 & 6.025 & TRN & \\
\hline CHEMBL138696 & 104726 & 6.301 & 6.4849 & TRN & \\
\hline CHEMBL344587 & 104726 & 5.0 & 5.5791 & TRN & \\
\hline CHEMBL140335 & 104726 & 6.0 & 5.3572 & TRN & \\
\hline CHEMBL141470 & 104726 & 6.2218 & 5.7111 & TRN & \\
\hline CHEMBL334709 & 104726 & 6.1549 & 6.3278 & TRN & \\
\hline CHEMBL294167 & 104726 & 6.0 & 6.1431 & TRN & \\
\hline CHEMBL424106 & 104726 & 5.0 & 4.8066 & TRN & \\
\hline CHEMBL 341604 & 104726 & 7.699 & 7.8741 & TRN & \\
\hline CHEMBL141589 & 104726 & 6.0 & 6.3175 & TRN & \\
\hline CHEMBL142095 & 104726 & 6.301 & 6.5226 & TRN & \\
\hline CHEMBL139542 & 104726 & 8.0 & 7.8434 & TRN & \\
\hline CHEMBL141675 & 104726 & 6.5229 & 6.5524 & TRN & \\
\hline CHEMBL140602 & 104726 & 7.699 & 6.7958 & TST & \\
\hline CHEMBL137966 & 104726 & 5.0 & 5.0146 & TRN & \\
\hline CHEMBL140543 & 104726 & 7.0 & 7.2021 & TRN & \\
\hline CHEMBL138181 & 104726 & 5.699 & 5.4919 & TST & \\
\hline CHEMBL141475 & 104726 & 7.0 & 6.5587 & TRN & \\
\hline CHEMBL140439 & 104726 & 6.699 & 6.7285 & TRN & \\
\hline CHEMBL344827 & 104726 & 6.301 & 6.46399 & 99999999995 & TST \\
\hline CHEMBL291757 & 104726 & 7.2218 & 7.0979 & TST & \\
\hline
\end{tabular}




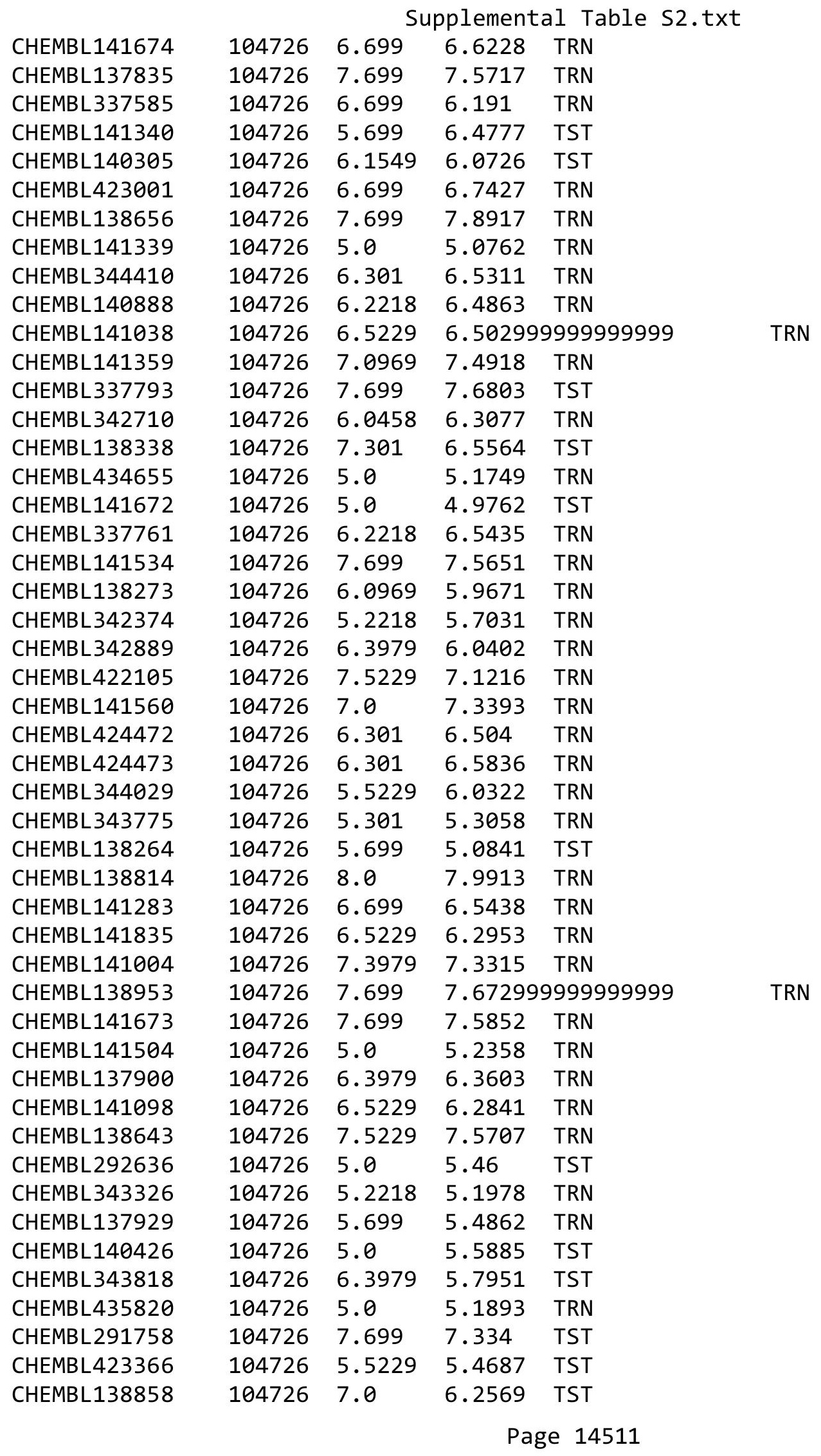




\begin{tabular}{|c|c|c|c|c|c|}
\hline \multicolumn{6}{|c|}{ Supplemental Table S2.txt } \\
\hline CHEMBL140368 & 104726 & 6.0 & 6.7327 & TST & \\
\hline CHEMBL138400 & 104726 & 7.699 & 7.7182 & TST & \\
\hline CHEMBL343547 & 104726 & 5.0 & 5.1367 & TST & \\
\hline CHEMBL57725 & 104726 & 7.699 & 7.49706 & $\partial 000000001$ & TST \\
\hline CHEMBL1318643 & 688603 & 4.6 & 6.7115 & TRN & \\
\hline CHEMBL1976489 & 688603 & 4.9 & 4.9488 & TRN & \\
\hline CHEMBL1393783 & 688603 & 5.3 & 5.2089 & TRN & \\
\hline CHEMBL1315725 & 688603 & 5.0 & 5.0987 & TRN & \\
\hline CHEMBL429095 & 688603 & 5.2 & 5.0272 & TRN & \\
\hline CHEMBL1391136 & 688603 & 5.0 & 4.7891 & TRN & \\
\hline CHEMBL1322597 & 688603 & 4.9 & 4.9605 & TRN & \\
\hline CHEMBL1374763 & 688603 & 4.9 & 4.97199 & 99999999995 & TRN \\
\hline CHEMBL1551254 & 688603 & 5.2 & 5.056 & TST & \\
\hline CHEMBL1476170 & 688603 & 4.9 & 4.8314 & TST & \\
\hline CHEMBL512908 & 688603 & 4.8 & 5.0237 & TRN & \\
\hline CHEMBL1402049 & 688603 & 5.1 & 5.0871 & TRN & \\
\hline CHEMBL1391184 & 688603 & 4.7 & 4.7262 & TRN & \\
\hline CHEMBL1547481 & 688603 & 4.8 & 4.8999 & TRN & \\
\hline CHEMBL1352895 & 688603 & 5.8 & 5.0211 & TRN & \\
\hline CHEMBL1317415 & 688603 & 5.2 & 5.2342 & TRN & \\
\hline CHEMBL546257 & 688603 & 4.9 & 4.9054 & TRN & \\
\hline CHEMBL605003 & 688603 & 5.6 & 5.0969 & TST & \\
\hline CHEMBL18238 & 688603 & 5.3 & 5.9961 & TRN & \\
\hline CHEMBL1229712 & 688603 & 5.2 & 4.8401 & TRN & \\
\hline CHEMBL1608811 & 688603 & 4.8 & 4.7189 & 9999999999 & TRN \\
\hline CHEMBL1495685 & 688603 & 4.9 & 4.9668 & TRN & \\
\hline CHEMBL1577982 & 688603 & 4.9 & 4.9032 & TRN & \\
\hline CHEMBL1362157 & 688603 & 4.8 & 4.9052 & TRN & \\
\hline CHEMBL 3212923 & 688603 & 4.8 & 4.9035 & TRN & \\
\hline CHEMBL1497991 & 688603 & 5.0 & 5.0062 & TRN & \\
\hline CHEMBL1359564 & 688603 & 4.6 & 4.8982 & TRN & \\
\hline CHEMBL1324032 & 688603 & 5.8 & 5.0509 & TST & \\
\hline CHEMBL1488420 & 688603 & 4.5 & 4.8422 & TRN & \\
\hline CHEMBL1316980 & 688603 & 5.1 & 6.1161 & TRN & \\
\hline CHEMBL1421908 & 688603 & 4.6 & 4.7137 & TRN & \\
\hline CHEMBL1434042 & 688603 & 4.8 & 5.5699 & TRN & \\
\hline CHEMBL3186408 & 688603 & 6.0 & 5.28299 & 99999999995 & TST \\
\hline CHEMBL1471205 & 688603 & 4.2 & 4.6939 & TRN & \\
\hline CHEMBL 23327 & 688603 & 5.3 & 5.0583 & TRN & \\
\hline CHEMBL516616 & 688603 & 5.1 & 5.1821 & TST & \\
\hline CHEMBL1379686 & 688603 & 4.9 & 4.8867 & TRN & \\
\hline CHEMBL1481974 & 688603 & 5.0 & 5.1846 & TRN & \\
\hline CHEMBL1574278 & 688603 & 4.6 & 4.8459 & TRN & \\
\hline CHEMBL72365 & 688603 & 4.9 & 5.2773 & TST & \\
\hline CHEMBL1496363 & 688603 & 5.6 & 5.5552 & TRN & \\
\hline CHEMBL1407886 & 688603 & 5.3 & 5.0354 & TST & \\
\hline CHEMBL1374334 & 688603 & 4.8 & 5.1004 & TRN & \\
\hline CHEMBL1352733 & 688603 & 5.4 & 5.0017 & TRN & \\
\hline
\end{tabular}




\begin{tabular}{|c|c|c|c|c|c|}
\hline & & & & & \\
\hline CHEMBL1552708 & 688603 & 5.4 & 6.0722 & TRN & \\
\hline CHEMBL1469584 & 688603 & 5.0 & 5.0982 & TRN & \\
\hline CHEMBL1523150 & 688603 & 4.6 & 4.9503 & TRN & \\
\hline CHEMBL1327989 & 688603 & 4.6 & 4.9883 & TRN & \\
\hline CHEMBL584759 & 688603 & 4.9 & 5.2555 & TRN & \\
\hline CHEMBL1358065 & 688603 & 5.0 & 4.8507 & TRN & \\
\hline CHEMBL1398608 & 688603 & 4.6 & 4.9814 & TRN & \\
\hline CHEMBL1533917 & 688603 & 5.0 & 4.8817 & TRN & \\
\hline CHEMBL1173475 & 688603 & 5.6 & 5.45200 & 2000000001 & TRN \\
\hline CHEMBL1505922 & 688603 & 4.8 & 4.8317 & TRN & \\
\hline CHEMBL1530216 & 688603 & 5.0 & 4.7365 & TRN & \\
\hline CHEMBL1521681 & 688603 & 5.0 & 4.9566 & TRN & \\
\hline CHEMBL1366680 & 688603 & 4.9 & 4.7552 & TRN & \\
\hline CHEMBL1320482 & 688603 & 5.9 & 5.066 & TRN & \\
\hline CHEMBL404613 & 688603 & 6.7001 & 5.0864 & TST & \\
\hline CHEMBL1596619 & 688603 & 4.5 & 5.0879 & TST & \\
\hline CHEMBL1422158 & 688603 & 4.8 & 4.8586 & TRN & \\
\hline CHEMBL1530314 & 688603 & 6.4 & 5.0771 & TST & \\
\hline CHEMBL1370146 & 688603 & 4.8 & 4.8485 & TRN & \\
\hline CHEMBL1414842 & 688603 & 4.9 & 4.7523 & TRN & \\
\hline CHEMBL1304582 & 688603 & 4.8 & 5.0117 & TRN & \\
\hline CHEMBL1310964 & 688603 & 5.0 & 4.9157 & TRN & \\
\hline CHEMBL363332 & 688603 & 6.0 & 5.4284 & TRN & \\
\hline CHEMBL1570111 & 688603 & 5.1 & 4.84699 & 99999999995 & TRN \\
\hline CHEMBL1256911 & 688603 & 5.4 & 5.2437 & TRN & \\
\hline CHEMBL1236872 & 688603 & 10.5 & 6.8632 & TRN & \\
\hline CHEMBL1255737 & 688603 & 4.9 & 4.8778 & TRN & \\
\hline CHEMBL1439172 & 688603 & 4.9 & 5.5094 & TRN & \\
\hline CHEMBL1499183 & 688603 & 4.8 & 5.102 & TRN & \\
\hline CHEMBL1430325 & 688603 & 4.8 & 5.0655 & TRN & \\
\hline CHEMBL65 & 688603 & 4.6 & 4.2994 & TRN & \\
\hline CHEMBL3304020 & 688603 & 4.9 & 5.2577 & TRN & \\
\hline CHEMBL1544947 & 688603 & 5.5 & 4.9631 & TRN & \\
\hline CHEMBL1445121 & 688603 & 5.5 & 5.1833 & TRN & \\
\hline CHEMBL1517669 & 688603 & 4.9 & 4.76 & TRN & \\
\hline CHEMBL1515691 & 688603 & 6.1 & 5.1879 & TRN & \\
\hline CHEMBL1524631 & 688603 & 5.4 & 4.9274 & TRN & \\
\hline CHEMBL1431091 & 688603 & 5.2 & 4.9162 & TST & \\
\hline CHEMBL 340807 & 688603 & 4.8 & 5.1813 & TST & \\
\hline CHEMBL1529647 & 688603 & 5.1 & 4.90300 & 20000000005 & TST \\
\hline CHEMBL1601218 & 688603 & 4.7 & 5.1646 & TST & \\
\hline CHEMBL 1256775 & 688603 & 4.4 & 5.0027 & TST & \\
\hline CHEMBL1557811 & 688603 & 4.8 & 4.8579 & TST & \\
\hline CHEMBL 275516 & 688603 & 5.0 & 5.1839 & TST & \\
\hline CHEMBL1329597 & 688603 & 4.8 & 5.061 & TST & \\
\hline CHEMBL1409990 & 688603 & 4.8 & 4.8775 & TST & \\
\hline CHEMBL60662 & 688603 & 6.4 & 5.9495 & TST & \\
\hline CHEMBL1530638 & 688603 & 4.8 & 5.0334 & TST & \\
\hline & & & & 14513 & \\
\hline
\end{tabular}




\begin{tabular}{|c|c|c|c|c|c|}
\hline \\
\hline CHEMBL365739 & 688603 & 4.8 & 5.099 & TST & \\
\hline CHEMBL1414867 & 688603 & 4.8 & 4.8089 & TST & \\
\hline CHEMBL1242574 & 654922 & 5.301 & 5.3662 & TRN & \\
\hline CHEMBL1241269 & 654922 & 4.301 & 4.7509 & TST & \\
\hline CHEMBL1242199 & 654922 & 6.4647 & 5.9486 & TRN & \\
\hline CHEMBL1242112 & 654922 & 5.6778 & 6.1033 & TRN & \\
\hline CHEMBL1241770 & 654922 & 6.0168 & 5.14 & TRN & \\
\hline CHEMBL1241586 & 654922 & 5.0362 & 4.9764 & TRN & \\
\hline CHEMBL1242209 & 654922 & 6.3224 & 5.6883 & TRN & \\
\hline CHEMBL1241490 & 654922 & 4.1726 & 5.4446 & TRN & \\
\hline CHEMBL1241860 & 654922 & 5.2291 & 5.4266 & TRN & \\
\hline CHEMBL1242567 & 654922 & 6.4389 & 5.6187 & TRN & \\
\hline CHEMBL1242119 & 654922 & 5.9586 & 5.8109 & TRN & \\
\hline CHEMBL1241485 & 654922 & 5.4559 & 5.6036 & TRN & \\
\hline CHEMBL1242850 & 654922 & 4.0 & 3.3126 & TST & \\
\hline CHEMBL1242471 & 654922 & 5.317 & 5.1577 & TST & \\
\hline CHEMBL1241482 & 654922 & 4.0 & 4.3507 & TST & \\
\hline CHEMBL1242382 & 654922 & 4.301 & 3.9235 & TRN & \\
\hline CHEMBL1241771 & 654922 & 4.0 & 4.9308 & TRN & \\
\hline CHEMBL1241680 & 654922 & 4.0 & 4.6757 & TRN & \\
\hline CHEMBL1242383 & 654922 & 4.0 & 4.4181 & TRN & \\
\hline CHEMBL1242286 & 654922 & 5.3372 & 5.4756 & TRN & \\
\hline CHEMBL1230790 & 654922 & 5.0655 & 5.4556 & TRN & \\
\hline CHEMBL1242034 & 654922 & 4.9208 & 4.90300 & 00000000005 & TRN \\
\hline CHEMBL1240567 & 654922 & 4.5229 & 4.4595 & TST & \\
\hline CHEMBL1242204 & 654922 & 4.0 & 3.62600 & 00000000003 & TST \\
\hline CHEMBL1242751 & 654922 & 4.0 & 3.95600 & 00000000004 & TRN \\
\hline CHEMBL1233881 & 654922 & 6.8861 & 6.9477 & TRN & \\
\hline CHEMBL1241240 & 654922 & 4.0 & 3.9837 & TST & \\
\hline CHEMBL1241945 & 654922 & 5.8386 & 6.0162 & TRN & \\
\hline CHEMBL1240594 & 654922 & 4.8239 & 5.0009 & TST & \\
\hline CHEMBL1242031 & 654922 & 5.6778 & 5.3389 & TRN & \\
\hline CHEMBL1241389 & 654922 & 4.0 & 4.1934 & TST & \\
\hline CHEMBL1242469 & 654922 & 6.3179 & 5.4691 & TST & \\
\hline CHEMBL1241864 & 654922 & 4.0 & 3.7872 & TRN & \\
\hline CHEMBL1241859 & 654922 & 5.5686 & 5.2548 & TRN & \\
\hline CHEMBL1242026 & 654922 & 5.7645 & 5.7554 & TRN & \\
\hline CHEMBL1233882 & 654922 & 6.6198 & 6.5921 & TRN & \\
\hline CHEMBL1241585 & 654922 & 4.301 & 3.7604 & TRN & \\
\hline CHEMBL1242202 & 654922 & 6.0227 & 6.4236 & TRN & \\
\hline CHEMBL1242114 & 654922 & 6.1568 & 6.0503 & TRN & \\
\hline CHEMBL1242378 & 654922 & 6.0 & 5.4455 & TRN & \\
\hline CHEMBL1241484 & 654922 & 6.1805 & 6.2958 & TRN & \\
\hline CHEMBL1242032 & 654922 & 5.284 & 5.2121 & TRN & \\
\hline CHEMBL1242027 & 654922 & 5.8928 & 5.28600 & 00000000005 & TRN \\
\hline CHEMBL1241491 & 654922 & 4.5421 & 5.482 & TRN & \\
\hline CHEMBL1241947 & 654922 & 4.0969 & 5.4097 & TST & \\
\hline CHEMBL1242206 & 654922 & 4.0 & 3.8226 & TST & \\
\hline
\end{tabular}




\begin{tabular}{|c|c|c|c|c|c|c|}
\hline & & \multicolumn{5}{|c|}{ Supplemental Table S2.txt } \\
\hline CHEMBL1241271 & 654922 & 5.5045 & 5.7393 & TRN & & \\
\hline CHEMBL1242756 & 654922 & 5.8539 & 6.2448 & TRN & & \\
\hline CHEMBL1241355 & 654922 & 4.0 & 3.4761 & TST & & \\
\hline CHEMBL1242477 & 654922 & 6.0 & 6.0514 & TRN & & \\
\hline CHEMBL1241578 & 654922 & 6.6198 & 6.5289 & TRN & & \\
\hline CHEMBL1241486 & 654922 & 4.0 & 4.8105 & TRN & & \\
\hline CHEMBL1242476 & 654922 & 6.1818 & 6.004 & TRN & & \\
\hline CHEMBL1242290 & 654922 & 6.6383 & 6.1491 & TRN & & \\
\hline CHEMBL1242845 & 654922 & 5.5498 & 5.2601 & TST & & \\
\hline CHEMBL1241299 & 654922 & \multicolumn{3}{|c|}{6.7620000000000005} & .6082 & TRN \\
\hline CHEMBL1241775 & 654922 & 5.1871 & 4.912 & TRN & & \\
\hline CHEMBL1242657 & 654922 & 6.0 & 5.371 & TRN & & \\
\hline CHEMBL1241144 & 654922 & 4.0 & 3.7491 & TST & & \\
\hline CHEMBL1241581 & 654922 & 5.5406 & 5.966 & TRN & & \\
\hline CHEMBL1240566 & 654922 & 5.5376 & 5.2617 & TRN & & \\
\hline CHEMBL1242754 & 654922 & 4.7959 & 5.0451 & TRN & & \\
\hline CHEMBL1242111 & 654922 & 5.251 & 5.4102 & TST & & \\
\hline CHEMBL1242662 & 654922 & 5.4949 & 5.6282 & TRN & & \\
\hline CHEMBL1242203 & 654922 & 5.5735 & 5.7461 & TRN & & \\
\hline CHEMBL1242758 & 654922 & 4.9747 & 5.1396 & TST & & \\
\hline CHEMBL1241488 & 654922 & 4.301 & 4.4727 & TRN & & \\
\hline CHEMBL1241143 & 654922 & 4.6383 & 4.4743 & TST & & \\
\hline CHEMBL1241681 & 654922 & 5.5686 & 5.99799 & 9999999999 & & TRN \\
\hline CHEMBL1241300 & 654922 & 5.8665 & 5.4867 & TST & & \\
\hline CHEMBL1241481 & 654922 & 3.301 & 4.6924 & TRN & & \\
\hline CHEMBL1242109 & 654922 & 5.2765 & 5.4364 & TRN & & \\
\hline CHEMBL1241242 & 654922 & 4.6021 & 4.5826 & TST & & \\
\hline CHEMBL1242200 & 654922 & 4.2984 & 4.8532 & TRN & & \\
\hline CHEMBL1241675 & 654922 & 4.8239 & 4.9029 & TST & & \\
\hline CHEMBL1242475 & 654922 & 5.8239 & 6.07100 & 0000000001 & & TRN \\
\hline CHEMBL1242846 & 654922 & 5.7932 & 4.9623 & TST & & \\
\hline CHEMBL1242381 & 654922 & 6.0 & 5.4233 & TRN & & \\
\hline CHEMBL1242661 & 654922 & 5.2757 & 4.6103 & TRN & & \\
\hline CHEMBL1241489 & 654922 & 4.4949 & 4.7511 & TRN & & \\
\hline CHEMBL1242117 & 654922 & 5.0915 & 4.8742 & TRN & & \\
\hline CHEMBL1242748 & 654922 & 6.0 & 5.3844 & TRN & & \\
\hline CHEMBL1242573 & 654922 & 6.2612 & 5.8155 & TRN & & \\
\hline CHEMBL1242028 & 654922 & 5.5969 & 6.0169 & TRN & & \\
\hline CHEMBL1241950 & 654922 & 5.3372 & 5.3881 & TRN & & \\
\hline CHEMBL1242292 & 654922 & 4.0 & 3.3584 & TST & & \\
\hline CHEMBL1242288 & 654922 & 5.644 & 5.4608 & TRN & & \\
\hline CHEMBL1241587 & 654922 & 4.3298 & 5.2869 & TST & & \\
\hline CHEMBL1242033 & 654922 & 5.0506 & 4.7612 & TRN & & \\
\hline CHEMBL1241683 & 654922 & 5.2596 & 5.7535 & TRN & & \\
\hline CHEMBL1241682 & 654922 & 5.7959 & 5.9173 & TRN & & \\
\hline CHEMBL1241241 & 654922 & 6.4202 & 5.6837 & TRN & & \\
\hline CHEMBL1242849 & 654922 & 4.0 & 3.7625 & TRN & & \\
\hline CHEMBL1241301 & 654922 & 6.6655 & 6.0399 & TRN & & \\
\hline
\end{tabular}




\begin{tabular}{|c|c|c|c|c|c|}
\hline \multicolumn{6}{|c|}{ Supplemental Table S2.txt } \\
\hline CHEMBL1241483 & 654922 & 5.4935 & 5.6012 & TRN & \\
\hline CHEMBL1242379 & 654922 & 6.2798 & 5.6314 & TRN & \\
\hline CHEMBL1242294 & 654922 & 5.4921 & 5.6589 & TRN & \\
\hline CHEMBL1242291 & 654922 & 4.0 & 3.8254 & TST & \\
\hline CHEMBL1234815 & 654922 & 4.7959 & 5.0365 & TRN & \\
\hline CHEMBL1242118 & 654922 & 4.6021 & 5.0188 & TRN & \\
\hline CHEMBL1241487 & 654922 & 5.2815 & 5.6126 & TRN & \\
\hline CHEMBL1241270 & 654922 & 5.2314 & 5.0507 & TST & \\
\hline CHEMBL 1242110 & 654922 & 5.2358 & 5.1864 & TRN & \\
\hline CHEMBL1242852 & 654922 & 4.3468 & 4.8666 & TRN & \\
\hline CHEMBL1242472 & 654922 & 5.7773 & 5.7526 & TRN & \\
\hline CHEMBL1241773 & 654922 & 5.4815 & 5.3212 & TRN & \\
\hline CHEMBL1242750 & 654922 & 4.0 & 5.9445 & TRN & \\
\hline CHEMBL1242289 & 654922 & 5.4976 & 5.8298 & TRN & \\
\hline CHEMBL1242198 & 654922 & 6.4559 & 6.0573 & TRN & \\
\hline CHEMBL1241104 & 654922 & 4.0 & 3.81100 & 00000000004 & TST \\
\hline CHEMBL1241584 & 654922 & 4.301 & 4.4719 & TRN & \\
\hline CHEMBL1242844 & 654922 & 5.2449 & 4.9052 & TRN & \\
\hline CHEMBL1240545 & 654922 & 4.0 & 4.6203 & TRN & \\
\hline CHEMBL1241684 & 654922 & 4.301 & 5.0376 & TST & \\
\hline CHEMBL1242755 & 654922 & 5.5686 & 5.1541 & TRN & \\
\hline CHEMBL1242656 & 654922 & 5.9066 & 6.0798 & TRN & \\
\hline CHEMBL1242566 & 654922 & 5.8013 & 5.6756 & TRN & \\
\hline CHEMBL1242569 & 654922 & 5.6108 & 5.5827 & TRN & \\
\hline CHEMBL1241357 & 654922 & 4.0 & 3.9857 & TST & \\
\hline CHEMBL1242024 & 654922 & 5.0655 & 5.5577 & TRN & \\
\hline CHEMBL1241769 & 654922 & 5.1561 & 4.8466 & TRN & \\
\hline CHEMBL1242025 & 654922 & 4.0 & 4.1915 & TST & \\
\hline CHEMBL1241588 & 654922 & 5.8539 & 5.1227 & TST & \\
\hline CHEMBL1241583 & 654922 & 5.1427 & 4.9229 & TRN & \\
\hline CHEMBL1242660 & 654922 & 4.0 & 4.4516 & TRN & \\
\hline CHEMBL1241774 & 654922 & 6.011 & 5.9452 & TRN & \\
\hline CHEMBL1242664 & 654922 & 5.1549 & 5.2306 & TRN & \\
\hline CHEMBL1241677 & 654922 & 6.0635 & 5.7141 & TRN & \\
\hline CHEMBL1242115 & 654922 & 5.2366 & 5.0251 & TST & \\
\hline CHEMBL1241358 & 654922 & 4.0 & 3.3861 & TST & \\
\hline CHEMBL1241946 & 654922 & 5.0969 & 5.1402 & TRN & \\
\hline CHEMBL1241943 & 654922 & 5.5784 & 5.1398 & TRN & \\
\hline CHEMBL1242293 & 654922 & 6.0 & 5.7753 & TRN & \\
\hline CHEMBL1241441 & 654922 & 4.0 & 4.6176 & TST & \\
\hline CHEMBL1242295 & 654922 & 5.3872 & 5.5707 & TRN & \\
\hline CHEMBL1241492 & 654922 & 6.3565 & 5.0033 & TRN & \\
\hline CHEMBL1242384 & 654922 & 6.0685 & 5.6749 & TRN & \\
\hline CHEMBL1242853 & 654922 & 4.0 & 4.7264 & TRN & \\
\hline CHEMBL1242848 & 654922 & 4.8477 & 5.3335 & TRN & \\
\hline CHEMBL1242207 & 654922 & 4.0 & 4.458 & TRN & \\
\hline CHEMBL1241580 & 654922 & 5.8697 & 6.0982 & TRN & \\
\hline CHEMBL1242473 & 654922 & 4.0 & 4.5251 & TRN & \\
\hline
\end{tabular}




\begin{tabular}{|c|c|c|c|c|c|}
\hline \multicolumn{6}{|c|}{ Supplemental Table S2.txt } \\
\hline CHEMBL1231371 & 654922 & 4.0 & 3.6811 & TRN & \\
\hline CHEMBL1241391 & 654922 & 4.0 & 3.9278 & TRN & \\
\hline CHEMBL1242568 & 654922 & 5.9914 & 5.9095 & TRN & \\
\hline CHEMBL1241676 & 654922 & 6.0264 & 6.1397 & TRN & \\
\hline CHEMBL1242285 & 654922 & 6.5935 & 5.8143 & TRN & \\
\hline CHEMBL1242470 & 654922 & 6.7721 & 5.5369 & TST & \\
\hline CHEMBL1242663 & 654922 & 4.0 & 4.4251 & TST & \\
\hline CHEMBL1242376 & 654922 & 6.4949 & 6.4141 & TRN & \\
\hline CHEMBL 1242386 & 654922 & 6.2596 & 6.1265 & TRN & \\
\hline CHEMBL1240565 & 654922 & 5.7959 & 5.7489 & TRN & \\
\hline CHEMBL1241858 & 654922 & 4.0 & 4.3684 & TRN & \\
\hline CHEMBL1242753 & 654922 & 4.0 & 5.2484 & TRN & \\
\hline CHEMBL1241582 & 654922 & 5.2147 & 5.0754 & TRN & \\
\hline CHEMBL1241949 & 654922 & 6.301 & 5.8515 & TRN & \\
\hline CHEMBL1242287 & 654922 & 6.6289 & 6.5432 & TRN & \\
\hline CHEMBL1241145 & 654922 & 4.301 & 4.0254 & TST & \\
\hline CHEMBL1242116 & 654922 & 4.6021 & 3.4263 & TST & \\
\hline CHEMBL1241861 & 654922 & 5.1427 & 4.9222 & TRN & \\
\hline CHEMBL1241772 & 654922 & 5.2147 & 4.5963 & TRN & \\
\hline CHEMBL1242113 & 654922 & 6.0921 & 5.9605 & TRN & \\
\hline CHEMBL1242752 & 654922 & 6.308 & 5.7882 & TRN & \\
\hline CHEMBL1081312 & 654922 & 5.8539 & 5.7981 & TRN & \\
\hline CHEMBL1241944 & 654922 & 6.1296 & $6.1670 e$ & 0000000001 & TRN \\
\hline CHEMBL1241390 & 654922 & 4.301 & 4.7002 & TRN & \\
\hline CHEMBL1241776 & 654922 & 6.3307 & 5.9193 & TRN & \\
\hline CHEMBL1242847 & 654922 & 5.8239 & 5.2989 & TRN & \\
\hline CHEMBL1242665 & 654922 & 4.284 & 3.9895 & TST & \\
\hline CHEMBL1242208 & 654922 & 5.8861 & 5.5787 & TRN & \\
\hline CHEMBL1242474 & 654922 & 4.0 & 4.0719 & TRN & \\
\hline CHEMBL1240553 & 654922 & 6.6345 & 6.4409 & TRN & \\
\hline CHEMBL1241863 & 654922 & 4.8239 & 3.6484 & TRN & \\
\hline CHEMBL1242385 & 654922 & 5.9586 & 5.1999 & TRN & \\
\hline CHEMBL1242201 & 654922 & 6.5834 & 6.4965 & TRN & \\
\hline CHEMBL1240554 & 654922 & 6.5317 & 6.3827 & TRN & \\
\hline CHEMBL1241440 & 654922 & 4.0 & 3.4381 & TST & \\
\hline CHEMBL1242205 & 654922 & 4.0 & 3.2421 & TST & \\
\hline CHEMBL1241356 & 654922 & 4.0 & 4.0928 & TST & \\
\hline CHEMBL1242572 & 654922 & 5.7212 & 5.9221 & TRN & \\
\hline CHEMBL1241942 & 654922 & 4.0 & 4.3372 & TRN & \\
\hline CHEMBL1242029 & 654922 & 4.0 & 5.0383 & TRN & \\
\hline CHEMBL1241862 & 654922 & 5.1549 & 5.3717 & TRN & \\
\hline CHEMBL1242659 & 654922 & 5.0061 & 5.9905 & TST & \\
\hline CHEMBL1242757 & 654922 & 5.3233 & 4.7774 & TST & \\
\hline CHEMBL1241767 & 654922 & 6.1739 & 5.4347 & TST & \\
\hline CHEMBL1241142 & 654922 & 4.301 & 4.2156 & TST & \\
\hline CHEMBL1242377 & 654922 & 6.2125 & 6.0366 & TST & \\
\hline CHEMBL1241674 & 654922 & 5.6576 & 5.3479 & TST & \\
\hline CHEMBL414162 & 159742 & 5.7959 & 6.8426 & TST & \\
\hline
\end{tabular}




\begin{tabular}{|c|c|c|c|c|c|}
\hline \multicolumn{6}{|c|}{ Supplemental Table S2.txt } \\
\hline CHEMBL44924 & 159742 & 5.2299 & 5.2097 & TRN & \\
\hline CHEMBL44468 & 159742 & 6.4559 & 6.3823 & TRN & \\
\hline CHEMBL298476 & 159742 & 8.5229 & 8.4686 & TRN & \\
\hline CHEMBL46637 & 159742 & 3.0 & 6.7584 & TST & \\
\hline CHEMBL43654 & 159742 & 3.0 & 5.5459 & TST & \\
\hline CHEMBL42225 & 159742 & 6.9208 & 6.8436 & TRN & \\
\hline CHEMBL416250 & 159742 & 6.1805 & 6.2375 & TRN & \\
\hline CHEMBL264300 & 159742 & 6.2441 & 6.1864 & TRN & \\
\hline CHEMBL42996 & 159742 & 6.1549 & 6.1172 & TRN & \\
\hline CHEMBL45197 & 159742 & 6.7959 & 6.9175 & TRN & \\
\hline CHEMBL42674 & 159742 & 8.0 & 8.05299 & 9999999999 & TRN \\
\hline CHEMBL295752 & 159742 & 6.0177 & 6.0392 & TRN & \\
\hline CHEMBL46712 & 159742 & 7.2218 & 7.3681 & TRN & \\
\hline CHEMBL294969 & 159742 & 3.0 & 6.0009 & TST & \\
\hline CHEMBL44516 & 159742 & 6.9586 & 7.309 & TRN & \\
\hline CHEMBL291129 & 159742 & 3.0 & 4.9218 & TST & \\
\hline CHEMBL42119 & 159742 & 6.7696 & 6.9432 & TRN & \\
\hline CHEMBL46667 & 159742 & 6.0362 & 6.0727 & TRN & \\
\hline CHEMBL42398 & 159742 & 7.5229 & 7.6841 & TRN & \\
\hline CHEMBL42651 & 159742 & 6.8239 & 6.8655 & TRN & \\
\hline CHEMBL44829 & 159742 & 5.4949 & 5.4333 & TRN & \\
\hline CHEMBL43103 & 159742 & 5.8327 & 5.7529 & TRN & \\
\hline CHEMBL43317 & 159742 & 7.5229 & 7.4209 & TRN & \\
\hline CHEMBL43645 & 159742 & 6.3979 & 6.4025 & TRN & \\
\hline CHEMBL43553 & 159742 & 6.8539 & 6.8356 & TRN & \\
\hline CHEMBL295707 & 159742 & 4.1669 & 4.1666 & TRN & \\
\hline CHEMBL42277 & 159742 & 7.3979 & 7.3137 & TRN & \\
\hline CHEMBL295032 & 159742 & 7.0969 & 7.20100 & 00000000005 & TRN \\
\hline CHEMBL44926 & 159742 & 7.0 & 6.9766 & TRN & \\
\hline CHEMBL45090 & 159742 & 6.7696 & 6.5809 & TRN & \\
\hline CHEMBL42549 & 159742 & 6.2366 & 6.2141 & TRN & \\
\hline CHEMBL42709 & 159742 & 7.3979 & 7.3446 & TRN & \\
\hline CHEMBL42074 & 159742 & 4.9136 & 4.9371 & TRN & \\
\hline CHEMBL43217 & 159742 & 3.0 & 6.0014 & TST & \\
\hline CHEMBL43672 & 159742 & 7.5229 & 7.6412 & TRN & \\
\hline CHEMBL296662 & 159742 & 7.5229 & 7.5631 & TRN & \\
\hline CHEMBL45192 & 159742 & 8.0 & 7.9716 & TRN & \\
\hline CHEMBL294967 & 159742 & 6.699 & 6.6194 & TRN & \\
\hline CHEMBL44977 & 159742 & 6.4815 & 6.5299 & TRN & \\
\hline CHEMBL46761 & 159742 & 6.6198 & 6.4988 & TRN & \\
\hline CHEMBL42174 & 159742 & 5.983 & 5.9342 & TRN & \\
\hline CHEMBL43089 & 159742 & 6.3372 & 6.4525 & TRN & \\
\hline CHEMBL43265 & 159742 & 6.3872 & 5.2789 & TST & \\
\hline CHEMBL45383 & 159742 & 5.0783 & 5.4817 & TST & \\
\hline CHEMBL43282 & 159742 & 6.9208 & 6.7698 & TRN & \\
\hline CHEMBL43640 & 159742 & 3.0 & 2.9693 & TRN & \\
\hline CHEMBL298269 & 159742 & 8.0969 & 8.0358 & TRN & \\
\hline CHEMBL43270 & 159742 & 3.0 & 3.343 & TRN & \\
\hline
\end{tabular}


Supplemental Table S2.txt

\begin{tabular}{|c|c|c|c|c|}
\hline CHEMBL296571 & 9742 & 7.5229 & 7.6533 & Th \\
\hline CHEMBL42175 & 159742 & 7.2218 & 7.3834 & \\
\hline HEMBL 290945 & 59742 & 7.0458 & 0341 & \\
\hline HEMBL43331 & 59742 & 6.1427 & 1654 & \\
\hline CHEMBL432112 & 59742 & 7.0 & 5.9783 & \\
\hline CHEMBL43149 & 59742 & 6.8861 & .8061 & \\
\hline HEMBL42180 & 59742 & 6.9586 & 6.899 & \\
\hline HEMBL 289561 & 59742 & 7.699 & 7.5737 & \\
\hline CHEMBL42408 & 59742 & 6.8539 & 6.691 & \\
\hline CHEMBL43493 & 59742 & 6.4815 & 4332 & \\
\hline CHEMBL43933 & 59742 & 6.4949 & 6.4248 & \\
\hline CHEMBL 2 & 59742 & 7.301 & 085 & \\
\hline CHEMBL 296673 & 159742 & 7.5229 & 761 & \\
\hline HEMBL42884 & 159742 & 6.9586 & 506 & \\
\hline CHEMBL4 & 59742 & 7.5229 & 536 & \\
\hline CHEMBL 4 & 159742 & 5.2328 & 783 & \\
\hline CHEMBL & 159 & 7.0458 & 006 & \\
\hline CHEMBL 4 & 159742 & 7.5229 & 692 & \\
\hline HEMBL46623 & 159742 & 8.0 & 599 & \\
\hline CHEMBL4 & 12 & 5.8125 & 088 & \\
\hline $\mathrm{CHE}$ & 159 & 6.6 & 932 & \\
\hline 66 & 12 & 969 & 601 & \\
\hline CHEMBL $\angle$ & 159 & 7.0969 & 117 & \\
\hline CHEMBL 4 & 59742 & 6.4559 & 612 & \\
\hline CHEMBL4 & 2 & 6.6021 & 43 & \\
\hline $\mathrm{CHE}$ & 159 & 7.3 & 34 & \\
\hline $\mathrm{CHE}$ & 2 & 6.7 & 69 & \\
\hline 3296 & 159 & 198 & 908 & \\
\hline CHEMBL & 59742 & & 142 & \\
\hline CHEMBL 4 & 12 & 6. & 341 & \\
\hline $\mathrm{CHE}$ & +2 & 6. & 99 & \\
\hline $\mathrm{CHE}$ & 2 & 8 & 05 & \\
\hline CHEMBL $\angle$ & 12 & 6.2147 & & \\
\hline CHEMBL45139 & 59742 & 4. & 058 & $1 \mathrm{~K}$ \\
\hline CHEMBL29779 & 159742 & 6.76 & 826 & \\
\hline $\mathrm{CH}$ & +2 & 3. & 45 & \\
\hline $\mathrm{CH}$ & 159 & 7.3979 & 6 & \\
\hline CHEMBL4 & 159742 & 5.4295 & 253 & \\
\hline CHEMBL417170 & 159742 & 7.5229 & 048 & TS \\
\hline CHEMBL 2 & 159742 & 6.7696 & 749 & \\
\hline CHEMBL2 & 159742 & 7.699 & 543 & 3 \\
\hline CHEMBL4 & 159742 & 6.6778 & 4.7686 & \\
\hline CHEMBL296515 & 159742 & 5.2441 & 5.8742 & TS \\
\hline CHEMBL295654 & 159742 & 3.0 & 7.3225 & TS \\
\hline CHEMBL296318 & 159742 & 3. & 5.4381 & TS \\
\hline CHEMBL289484 & 159742 & 5.2441 & 5.018 & \\
\hline CHEMBL1645090 & 698147 & 5.7496 & 5.3908 & \\
\hline CHEMBL1645053 & 698147 & 3.5986 & 3.6051 & \\
\hline
\end{tabular}

Page 14519 


\begin{tabular}{|c|c|c|c|c|c|c|}
\hline & & \multicolumn{5}{|c|}{ Supplemental Table S2.txt } \\
\hline CHEMBL1645067 & 698147 & 5.104 & 4.2074 & TRN & & \\
\hline CHEMBL1645051 & 698147 & 3.6271 & 4.2136 & TRN & & \\
\hline CHEMBL1645071 & 698147 & 5.301 & 4.9867 & TRN & & \\
\hline CHEMBL1645043 & 698147 & 5.9747 & 4.7471 & TRN & & \\
\hline CHEMBL1645056 & 698147 & 3.6055 & 4.1476 & TRN & & \\
\hline CHEMBL1645045 & 698147 & 5.6655 & 4.2619 & TRN & & \\
\hline CHEMBL1645078 & 698147 & 4.9066 & 4.3884 & TRN & & \\
\hline CHEMBL1645062 & 698147 & 3.4101 & 5.3896 & TST & & \\
\hline CHEMBL1645083 & 698147 & 5.2366 & 5.0927 & TRN & & \\
\hline CHEMBL1645057 & 698147 & \multicolumn{3}{|c|}{3.6180000000000003} & 3.98 & TRN \\
\hline CHEMBL1645076 & 698147 & 3.8239 & 4.0977 & TRN & & \\
\hline CHEMBL1645086 & 698147 & 5.1675 & 5.1445 & TST & & \\
\hline CHEMBL1645089 & 698147 & 5.1612 & 5.6774 & TST & & \\
\hline CHEMBL1645087 & 698147 & 4.4785 & 5.5453 & TST & & \\
\hline CHEMBL1645072 & 698147 & 5.0655 & 5.3857 & TRN & & \\
\hline CHEMBL1645092 & 698147 & 3.4948 & 5.1947 & TST & & \\
\hline CHEMBL1645093 & 698147 & 3.7825 & 5.1012 & TST & & \\
\hline CHEMBL1645044 & 698147 & 3.7773 & 3.5454 & TRN & & \\
\hline CHEMBL1645074 & 698147 & 5.2147 & 5.1989 & TRN & & \\
\hline CHEMBL1645055 & 698147 & 3.6596 & 4.2849 & TRN & & \\
\hline CHEMBL1645082 & 698147 & 5.1938 & 4.7793 & TRN & & \\
\hline CHEMBL1645081 & 698147 & 5.51 & 4.8463 & TRN & & \\
\hline CHEMBL1645052 & 698147 & 5.1487 & 4.5085 & TRN & & \\
\hline CHEMBL1645039 & 698147 & 5.3958 & 5.0203 & TRN & & \\
\hline CHEMBL1645085 & 698147 & 5.1746 & 5.2184 & TST & & \\
\hline CHEMBL1645048 & 698147 & 3.6108 & 4.0348 & TRN & & \\
\hline CHEMBL1645084 & 698147 & 4.475 & 5.2047 & TST & & \\
\hline CHEMBL1645066 & 698147 & 3.8861 & 4.3901 & TRN & & \\
\hline CHEMBL1645065 & 698147 & 4.9101 & 4.7073 & TRN & & \\
\hline CHEMBL1645047 & 698147 & 3.5607 & 4.1751 & TRN & & \\
\hline CHEMBL1645049 & 698147 & 3.5918 & 4.1984 & TRN & & \\
\hline CHEMBL1645060 & 698147 & 5.3279 & 4.6132 & TRN & & \\
\hline CHEMBL1645091 & 698147 & 3.5143 & 5.0602 & TST & & \\
\hline CHEMBL1645069 & 698147 & 4.9281 & 5.1263 & TRN & & \\
\hline CHEMBL1645061 & 698147 & 3.6556 & 3.8358 & TRN & & \\
\hline CHEMBL1645064 & 698147 & 3.85699 & 99999999 & 998 & 4.5125 & TRN \\
\hline CHEMBL1645042 & 698147 & 5.5735 & 4.7614 & TRN & & \\
\hline CHEMBL1645040 & 698147 & 5.3737 & 5.1605 & TRN & & \\
\hline CHEMBL1645079 & 698147 & 3.7905 & 3.9809 & TRN & & \\
\hline CHEMBL1645073 & 698147 & 5.1024 & 5.2394 & TRN & & \\
\hline CHEMBL1645063 & 698147 & 5.0329 & 5.6298 & TST & & \\
\hline CHEMBL1645054 & 698147 & 5.0862 & 4.7951 & TRN & & \\
\hline CHEMBL1645059 & 698147 & 3.5751 & 3.6862 & TRN & & \\
\hline CHEMBL1645041 & 698147 & 5.1397 & 5.5098 & TRN & & \\
\hline CHEMBL1645046 & 698147 & 5.0325 & 4.2737 & TRN & & \\
\hline CHEMBL1645077 & 698147 & 3.7747 & 4.223 & TRN & & \\
\hline CHEMBL1645075 & 698147 & 3.8356 & 3.9905 & TRN & & \\
\hline CHEMBL1645068 & 698147 & 4.9318 & 5.1143 & TRN & & \\
\hline
\end{tabular}


Supplemental Table S2.txt

\begin{tabular}{|c|c|c|c|c|}
\hline CHEMBL1550421 & 698147 & 3.5901 & 4.2774 & TST \\
\hline CHEMBL1645070 & 698147 & 3.8894 & 5.0018 & TRN \\
\hline CHEMBL1578760 & 698147 & 3.7825 & 4.9718 & TST \\
\hline CHEMBL1645088 & 698147 & 4.5229 & 4.9985 & TST \\
\hline CHEMBL1645080 & 698147 & 5.4449 & 6.1573 & TRN \\
\hline CHEMBL1645058 & 698147 & 3.6271 & 4.1472 & TRN \\
\hline CHEMBL1645050 & 698147 & 5.0362 & 4.226 & TST \\
\hline CHEMBL1521297 & 752581 & 5.9179 & 5.597 & TRN \\
\hline CHEMBL1534520 & 752581 & 2.7959 & 2.675 & TRN \\
\hline CHEMBL1520556 & 752581 & 2.7959 & 3.2781 & TRN \\
\hline CHEMBL1487639 & 752581 & 4.9494 & 5.9297 & TRN \\
\hline CHEMBL3199452 & 752581 & 4.7234 & 3.7354 & TST \\
\hline CHEMBL3189845 & 752581 & 2.7959 & 3.67199 & 79999999997 \\
\hline CHEMBL1520157 & 752581 & 2.8239 & 3.4663 & TRN \\
\hline CHEMBL1348448 & 752581 & 4.7808 & 4.2881 & TRN \\
\hline CHEMBL1522211 & 752581 & 4.6976 & 3.3276 & TRN \\
\hline CHEMBL1574132 & 752581 & 5.3259 & 4.5966 & TRN \\
\hline CHEMBL1468024 & 752581 & 2.8239 & 2.6551 & TRN \\
\hline CHEMBL 334707 & 752581 & 5.4356 & 4.4753 & TRN \\
\hline CHEMBL1469362 & 752581 & 2.8239 & 2.9711 & TRN \\
\hline CHEMBL1503033 & 752581 & 2.8239 & 4.3394 & TST \\
\hline CHEMBL1416601 & 752581 & 5.284 & 3.9181 & TRN \\
\hline CHEMBL1475477 & 752581 & 2.7959 & 3.5659 & TRN \\
\hline CHEMBL3193010 & 752581 & 2.7959 & 3.3309 & TRN \\
\hline CHEMBL1350245 & 752581 & 2.7959 & 3.6754 & TST \\
\hline CHEMBL1789998 & 752581 & 2.7959 & 3.9749 & TST \\
\hline CHEMBL1330558 & 752581 & 4.732 & 4.1548 & TRN \\
\hline CHEMBL1404792 & 752581 & 2.7959 & 3.6662 & TRN \\
\hline CHEMBL 3190648 & 752581 & 4.6248 & 3.2219 & TRN \\
\hline CHEMBL1420628 & 752581 & 4.5276 & 3.8532 & TRN \\
\hline CHEMBL588804 & 752581 & 4.6839 & 3.98 & TRN \\
\hline CHEMBL1609759 & 752581 & 2.7959 & 3.4267 & TRN \\
\hline CHEMBL1596066 & 752581 & 4.7844 & 4.7472 & TRN \\
\hline CHEMBL3198912 & 752581 & 4.7434 & 5.1828 & TRN \\
\hline CHEMBL1449883 & 752581 & 2.7959 & 3.0064 & TRN \\
\hline CHEMBL1451169 & 752581 & 2.7959 & 3.5469 & TRN \\
\hline CHEMBL590927 & 752581 & 2.7959 & 2.6668 & TRN \\
\hline CHEMBL1534035 & 752581 & 2.8239 & 3.5864 & TRN \\
\hline CHEMBL1362096 & 752581 & 2.7959 & 3.1652 & TRN \\
\hline CHEMBL1609663 & 752581 & 2.7959 & 3.0589 & TRN \\
\hline CHEMBL1491815 & 752581 & 4.5502 & 3.7935 & TRN \\
\hline CHEMBL3198836 & 752581 & 4.6843 & 4.5383 & TRN \\
\hline CHEMBL1340519 & 752581 & 4.8936 & 4.8442 & TRN \\
\hline CHEMBL585591 & 752581 & 4.6265 & 4.7003 & TST \\
\hline CHEMBL1377316 & 752581 & 4.6087 & 3.9694 & TRN \\
\hline CHEMBL1306256 & 752581 & 2.8239 & 4.1451 & TRN \\
\hline CHEMBL1524956 & 752581 & 2.8239 & 3.5471 & TRN \\
\hline CHEMBL1490481 & 752581 & 5.102 & 4.0406 & TRN \\
\hline
\end{tabular}


Supplemental Table S2.txt

\begin{tabular}{|c|c|c|c|c|c|}
\hline CHEMBL1311007 & 752581 & 2.7959 & 2.5743 & TRN & \\
\hline CHEMBL1446034 & 752581 & 2.8239 & 2.9303 & TRN & \\
\hline CHEMBL1392455 & 752581 & 2.8239 & 4.1646 & TST & \\
\hline CHEMBL1499233 & 752581 & 2.7959 & 3.3255 & TRN & \\
\hline CHEMBL 3195142 & 752581 & 4.5295 & 4.5029 & TRN & \\
\hline CHEMBL1390303 & 752581 & 4.9028 & 3.8304 & TRN & \\
\hline CHEMBL1514530 & 752581 & 4.5356 & 4.5962 & TRN & \\
\hline CHEMBL1363249 & 752581 & 2.8239 & 3.6406 & TRN & \\
\hline CHEMBL1544423 & 752581 & 5.9017 & 4.1275 & TRN & \\
\hline CHEMBL1332450 & 752581 & 4.6712 & 3.9499 & TRN & \\
\hline CHEMBL1308052 & 752581 & 5.3938 & 6.1454 & TRN & \\
\hline CHEMBL1525081 & 752581 & 4.8551 & 3.3362 & TRN & \\
\hline CHEMBL585827 & 752581 & 4.6154 & 3.0053 & TRN & \\
\hline CHEMBL1348582 & 752581 & 2.8239 & 3.6998 & TRN & \\
\hline CHEMBL1478797 & 752581 & 2.8239 & 3.2947 & TRN & \\
\hline CHEMBL3198729 & 752581 & 4.448 & 3.8522 & TRN & \\
\hline CHEMBL3392051 & 752581 & 2.8239 & 3.283 & TST & \\
\hline CHEMBL1500188 & 752581 & 4.4509 & 4.1954 & TRN & \\
\hline CHEMBL 3196726 & 752581 & 2.7959 & 3.4155 & TRN & \\
\hline CHEMBL1382191 & 752581 & 4.7317 & 4.4554 & TST & \\
\hline CHEMBL1350780 & 752581 & 5.31 & 4.8002 & TRN & \\
\hline CHEMBL1386774 & 752581 & 5.5913 & 6.3166 & TRN & \\
\hline CHEMBL1576118 & 752581 & 2.7959 & 3.2733 & TRN & \\
\hline CHEMBL1504569 & 752581 & 4.8524 & 3.9628 & TRN & \\
\hline CHEMBL1438970 & 752581 & 2.7959 & 3.3475 & TRN & \\
\hline CHEMBL1481132 & 752581 & 4.6276 & 3.648 & TRN & \\
\hline CHEMBL1307255 & 752581 & 2.7959 & 3.3568 & TRN & \\
\hline CHEMBL1606685 & 752581 & 4.7971 & 4.5888 & TRN & \\
\hline CHEMBL1578127 & 752581 & 4.6386 & 3.7645 & TST & \\
\hline CHEMBL1452090 & 752581 & 2.8239 & 3.2747 & TRN & \\
\hline CHEMBL1460705 & 752581 & 5.3039 & 4.3462 & TRN & \\
\hline CHEMBL1359871 & 752581 & 4.869 & 4.1672 & TRN & \\
\hline CHEMBL1585527 & 752581 & 2.7959 & 3.7527 & TRN & \\
\hline CHEMBL1568848 & 752581 & 4.5137 & 3.2594 & TST & \\
\hline CHEMBL1511029 & 752581 & 2.8239 & 3.4532 & TRN & \\
\hline CHEMBL1310176 & 752581 & 2.7959 & 2.7786 & TRN & \\
\hline CHEMBL547285 & 752581 & 2.8239 & 2.9361 & TRN & \\
\hline CHEMBL1517325 & 752581 & 2.8239 & 4.2492 & TRN & \\
\hline CHEMBL3197024 & 752581 & \multicolumn{4}{|c|}{4.6530000000000005} \\
\hline CHEMBL1582831 & 752581 & 4.647 & 4.2924 & TRN & \\
\hline CHEMBL1612118 & 752581 & 2.8239 & 2.5997 & TST & \\
\hline CHEMBL586031 & 752581 & 2.7959 & 3.2726 & TRN & \\
\hline CHEMBL1576945 & 752581 & 2.7959 & 3.5136 & TST & \\
\hline CHEMBL1393700 & 752581 & 4.6691 & $3.99300 t$ & 00000000003 & TRN \\
\hline CHEMBL1317657 & 752581 & 2.8239 & 3.5775 & TRN & \\
\hline CHEMBL 3213034 & 752581 & 4.6451 & 3.8331 & TRN & \\
\hline CHEMBL1492378 & 752581 & 2.8239 & 2.9612 & TRN & \\
\hline CHEMBL1979784 & 752581 & 2.7959 & 3.5049 & TRN & \\
\hline
\end{tabular}

Page 14522 
Supplemental Table S2.txt

\begin{tabular}{|c|c|c|c|c|c|}
\hline CHEMBL1588660 & 752581 & 5.1625 & 5.0866 & TRN & \\
\hline CHEMBL3197761 & 752581 & 4.6226 & 4.2333 & TRN & \\
\hline CHEMBL1304950 & 752581 & 2.8239 & 3.5165 & TRN & \\
\hline CHEMBL1595088 & 752581 & 4.8329 & 3.231006 & 00000000003 & TRN \\
\hline CHEMBL1611301 & 752581 & 2.7959 & 3.7181 & TRN & \\
\hline CHEMBL1472105 & 752581 & 5.0231 & 4.8711 & TRN & \\
\hline CHEMBL1579999 & 752581 & 2.7959 & 3.8914 & TRN & \\
\hline CHEMBL 3196754 & 752581 & 4.7529 & 4.4458 & TRN & \\
\hline CHEMBL1318943 & 752581 & 2.8239 & 3.6964 & TST & \\
\hline CHEMBL548615 & 752581 & 5.3654 & 4.5063 & TRN & \\
\hline CHEMBL1547347 & 752581 & 4.6131 & 3.7912 & TRN & \\
\hline CHEMBL1545105 & 752581 & 2.8239 & 3.8004 & TRN & \\
\hline CHEMBL1534596 & 752581 & 2.7959 & 2.8947 & TRN & \\
\hline CHEMBL1588513 & 752581 & 4.4764 & 4.27 & TRN & \\
\hline CHEMBL 3192165 & 752581 & 4.5488 & 4.0427 & TRN & \\
\hline CHEMBL1994623 & 752581 & 4.6135 & 4.5094 & TRN & \\
\hline CHEMBL1331790 & 752581 & 4.5059 & 3.8166 & TRN & \\
\hline CHEMBL1299903 & 752581 & 4.7808 & 3.4199 & TRN & \\
\hline CHEMBL1323512 & 752581 & 2.7959 & 3.7236 & TRN & \\
\hline CHEMBL1376904 & 752581 & 2.8239 & 2.8293 & TST & \\
\hline CHEMBL1447219 & 752581 & 2.7959 & 3.9404 & TRN & \\
\hline CHEMBL1484777 & 752581 & 5.7585 & 5.7388 & TRN & \\
\hline CHEMBL1570820 & 752581 & 5.3997 & 3.8899 & TRN & \\
\hline CHEMBL595700 & 752581 & 2.8239 & 3.3776 & TRN & \\
\hline CHEMBL 3196241 & 752581 & 2.7959 & 3.1909 & TRN & \\
\hline CHEMBL 3191808 & 752581 & 2.7959 & 3.2841 & TRN & \\
\hline CHEMBL1380975 & 752581 & 4.7655 & 4.1142 & TRN & \\
\hline CHEMBL1424665 & 752581 & 4.745 & 3.7844 & TRN & \\
\hline CHEMBL1317642 & 752581 & 4.6632 & 2.6285 & TRN & \\
\hline CHEMBL602363 & 752581 & 4.9702 & 4.197 & TRN & \\
\hline CHEMBL3193098 & 752581 & 4.7433 & \multicolumn{2}{|c|}{3.8760000000000003} & TRN \\
\hline CHEMBL1242180 & 752581 & 4.2693 & 4.1846 & TRN & \\
\hline CHEMBL1430893 & 752581 & 2.7959 & 3.9513 & TRN & \\
\hline CHEMBL1392564 & 752581 & 4.7395 & 3.3997 & TRN & \\
\hline CHEMBL1437579 & 752581 & 2.7959 & 3.8491 & TRN & \\
\hline CHEMBL1581042 & 752581 & 2.7959 & 3.3007 & TRN & \\
\hline CHEMBL1349566 & 752581 & 2.8239 & 3.4427 & TRN & \\
\hline CHEMBL1469579 & 752581 & 5.6794 & 5.9409 & TRN & \\
\hline CHEMBL1319079 & 752581 & 2.7959 & 3.8261 & TRN & \\
\hline CHEMBL1602855 & 752581 & 2.8239 & 3.5098 & TRN & \\
\hline CHEMBL1372734 & 752581 & 2.8239 & 3.8011 & TRN & \\
\hline CHEMBL1997747 & 752581 & 2.7959 & 3.5671 & TRN & \\
\hline CHEMBL193872 & 752581 & 4.7374 & 4.4036 & TRN & \\
\hline CHEMBL 3212271 & 752581 & 2.8239 & 3.2146 & TRN & \\
\hline CHEMBL1349146 & 752581 & 2.7959 & 3.8523 & TRN & \\
\hline CHEMBL518252 & 752581 & 2.7959 & 3.9827 & TST & \\
\hline CHEMBL1420556 & 752581 & 6.08299 & 99999999 & 5.8763 & RI \\
\hline CHEMBL1462215 & 752581 & 2.8239 & 4.0221 & TRN & \\
\hline
\end{tabular}




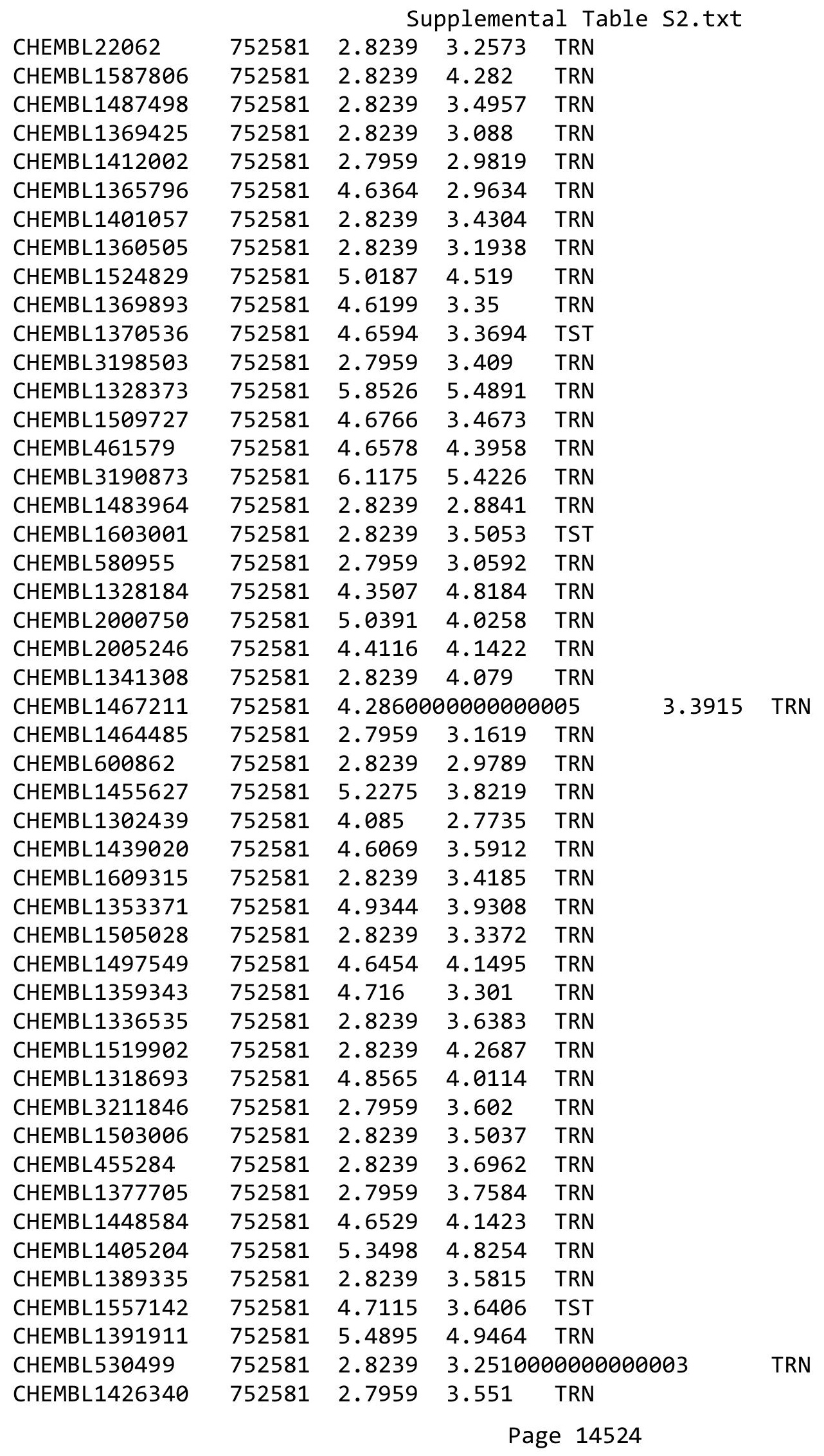


Supplemental Table S2.txt

\begin{tabular}{|c|c|c|c|c|c|}
\hline CHEMBL1428240 & 752581 & 2.8239 & 3.2318 & TRN & \\
\hline CHEMBL1306283 & 752581 & 4.8932 & 4.9037 & TRN & \\
\hline CHEMBL1485579 & 752581 & 4.2637 & 3.5938 & TRN & \\
\hline CHEMBL1594071 & 752581 & 2.7959 & 3.3154 & TRN & \\
\hline CHEMBL1581627 & 752581 & 2.7959 & 3.4384 & TRN & \\
\hline CHEMBL1311826 & 752581 & 5.5348 & 5.0048 & TRN & \\
\hline CHEMBL1364071 & 752581 & 4.7826 & 3.2586 & TRN & \\
\hline CHEMBL3199428 & 752581 & 2.8239 & 3.7482 & TRN & \\
\hline CHEMBL1571370 & 752581 & 2.7959 & 3.2238 & TRN & \\
\hline CHEMBL1524014 & 752581 & 2.8239 & 2.4894 & TST & \\
\hline CHEMBL1309890 & 752581 & 4.3944 & 3.6469 & TRN & \\
\hline CHEMBL1472418 & 752581 & 2.8239 & 3.4703 & TRN & \\
\hline CHEMBL1548492 & 752581 & 2.7959 & 2.7558 & TRN & \\
\hline CHEMBL1342093 & 752581 & 4.6086 & 4.1436 & TRN & \\
\hline CHEMBL1362036 & 752581 & 2.7959 & 3.1323 & TRN & \\
\hline CHEMBL1488279 & 752581 & 2.7959 & 3.0726 & TRN & \\
\hline CHEMBL1383706 & 752581 & 2.7959 & 3.7696 & TRN & \\
\hline CHEMBL1403955 & 752581 & 4.3883 & 3.2886 & TRN & \\
\hline CHEMBL 2004978 & 752581 & \multicolumn{2}{|c|}{4.656000000000001} & 4.3497 & \\
\hline CHEMBL1517151 & 752581 & 2.8239 & 3.2446 & TRN & \\
\hline CHEMBL590665 & 752581 & 2.8239 & 3.7142 & TRN & \\
\hline CHEMBL591412 & 752581 & 4.5862 & 2.9328 & TRN & \\
\hline CHEMBL1561050 & 752581 & 2.7959 & 3.3507 & TRN & \\
\hline CHEMBL1401645 & 752581 & 5.3546 & 3.3497 & TST & \\
\hline CHEMBL1352025 & 752581 & 4.5126 & 3.5024 & TST & \\
\hline CHEMBL3189966 & 752581 & 2.8239 & 3.2535 & TRN & \\
\hline CHEMBL193627 & 752581 & 4.4289 & 4.4388 & TRN & \\
\hline CHEMBL1414734 & 752581 & 4.716 & 3.6304 & TST & \\
\hline CHEMBL1346226 & 752581 & 4.6327 & 3.7512 & TRN & \\
\hline CHEMBL1387710 & 752581 & 4.6974 & 3.7998 & TRN & \\
\hline CHEMBL1301513 & 752581 & 2.8239 & 2.6307 & TRN & \\
\hline CHEMBL1544114 & 752581 & 4.8678 & 4.98600 & 0000000001 & TRN \\
\hline CHEMBL1537190 & 752581 & 2.8239 & 3.4245 & TRN & \\
\hline CHEMBL1556805 & 752581 & 4.6781 & 4.149 & TRN & \\
\hline CHEMBL1483620 & 752581 & 4.8058 & 3.5842 & TRN & \\
\hline CHEMBL225963 & 752581 & 2.7959 & 3.8925 & TST & \\
\hline CHEMBL1563323 & 752581 & 2.7959 & 3.1124 & TRN & \\
\hline CHEMBL1426693 & 752581 & 2.8239 & 3.4298 & TRN & \\
\hline CHEMBL1490555 & 752581 & 4.2046 & 4.3214 & TST & \\
\hline CHEMBL1466179 & 752581 & 2.8239 & 3.2951 & TST & \\
\hline CHEMBL1347656 & 752581 & 4.7605 & 3.2689 & TST & \\
\hline CHEMBL1988042 & 752581 & 5.0297 & 4.0915 & TRN & \\
\hline CHEMBL1587683 & 752581 & 4.6656 & 3.90199 & 99999999997 & RN \\
\hline CHEMBL1521991 & 752581 & 5.3375 & 4.8902 & TRN & \\
\hline CHEMBL1391737 & 752581 & 5.1799 & 3.7918 & TRN & \\
\hline CHEMBL1555271 & 752581 & 2.8239 & 3.2222 & TRN & \\
\hline CHEMBL1491222 & 752581 & 2.7959 & 3.8571 & TRN & \\
\hline CHEMBL1322052 & 752581 & 4.3103 & 3.3179 & TRN & \\
\hline
\end{tabular}

Page 14525 
Supplemental Table S2.txt

\begin{tabular}{|c|c|c|c|c|c|}
\hline CHEMBL1320281 & 752581 & 2.7959 & 3.4582 & TRN & \\
\hline CHEMBL1539624 & 752581 & 4.9311 & 4.7222 & TRN & \\
\hline CHEMBL1329507 & 752581 & 4.8075 & 4.9631 & TRN & \\
\hline CHEMBL1550278 & 752581 & 2.7959 & 3.1648 & TRN & \\
\hline CHEMBL1451060 & 752581 & 2.7959 & 4.0136 & TRN & \\
\hline CHEMBL 3190585 & 752581 & 2.7959 & 2.9655 & TRN & \\
\hline CHEMBL1533353 & 752581 & 4.1616 & 3.2056 & TRN & \\
\hline CHEMBL1557243 & 752581 & 2.8239 & 3.8261 & TST & \\
\hline CHEMBL1349480 & 752581 & 4.8453 & 3.5588 & TRN & \\
\hline CHEMBL1433075 & 752581 & 4.97 & 3.6783 & TST & \\
\hline CHEMBL580727 & 752581 & 2.8239 & 3.4378 & TRN & \\
\hline CHEMBL1546228 & 752581 & 6.0521 & 5.6566 & TST & \\
\hline CHEMBL1979455 & 752581 & 2.8239 & 4.2251 & TRN & \\
\hline CHEMBL1610563 & 752581 & 2.8239 & 3.7889 & TRN & \\
\hline CHEMBL1476264 & 752581 & 2.8239 & 4.4495 & TRN & \\
\hline CHEMBL1502020 & 752581 & 2.7959 & 4.6825 & TRN & \\
\hline CHEMBL1468776 & 752581 & 4.7488 & 3.4064 & TRN & \\
\hline CHEMBL1986418 & 752581 & 5.4915 & 3.5708 & TRN & \\
\hline CHEMBL600315 & 752581 & 4.6255 & 3.3455 & TST & \\
\hline CHEMBL1310713 & 752581 & 4.9243 & 4.4658 & TRN & \\
\hline CHEMBL601768 & 752581 & 2.7959 & 4.1497 & TRN & \\
\hline CHEMBL1547468 & 752581 & 4.0818 & 4.3824 & TST & \\
\hline CHEMBL1406031 & 752581 & 2.7959 & 2.4977 & TRN & \\
\hline CHEMBL140425 & 752581 & 5.8297 & 4.428 & TRN & \\
\hline CHEMBL375781 & 752581 & 2.8239 & 3.6553 & TST & \\
\hline CHEMBL1538246 & 752581 & 2.8239 & 3.6409 & TRN & \\
\hline CHEMBL1969300 & 752581 & 4.9751 & 3.8403 & TRN & \\
\hline CHEMBL1389318 & 752581 & 2.7959 & 3.8399 & TRN & \\
\hline CHEMBL1431710 & 752581 & 2.8239 & 3.3106 & TRN & \\
\hline CHEMBL1470382 & 752581 & 4.7917 & 4.6047 & TRN & \\
\hline CHEMBL1595820 & 752581 & 2.8239 & 3.8997 & TRN & \\
\hline CHEMBL1550442 & 752581 & 2.7959 & 3.2445 & TRN & \\
\hline CHEMBL1789993 & 752581 & 2.8239 & 3.8943 & TST & \\
\hline CHEMBL3195036 & 752581 & 2.8239 & 3.1189 & TRN & \\
\hline CHEMBL1365988 & 752581 & 2.8239 & 3.02699 & 99999999997 & TRN \\
\hline CHEMBL1312049 & 752581 & 2.8239 & 3.513 & TRN & \\
\hline CHEMBL1319004 & 752581 & 2.8239 & 3.0075 & TRN & \\
\hline CHEMBL1368410 & 752581 & 2.8239 & 3.7575 & TST & \\
\hline CHEMBL1527022 & 752581 & 2.8239 & 3.6405 & TRN & \\
\hline CHEMBL1373577 & 752581 & 4.3906 & 4.0957 & TRN & \\
\hline CHEMBL3195688 & 752581 & 2.7959 & 3.5129 & TRN & \\
\hline CHEMBL1500266 & 752581 & 4.7395 & 3.9587 & TRN & \\
\hline CHEMBL1498830 & 752581 & 2.8239 & 3.735 & TRN & \\
\hline CHEMBL1528425 & 752581 & 4.816 & 4.3316 & TRN & \\
\hline CHEMBL1222385 & 752581 & 4.6045 & 3.5141 & TRN & \\
\hline CHEMBL1422472 & 752581 & 2.7959 & 3.6338 & TRN & \\
\hline CHEMBL1970872 & 752581 & 4.7566 & 4.5165 & TRN & \\
\hline CHEMBL1424331 & 752581 & 2.7959 & 3.5964 & TST & \\
\hline
\end{tabular}


Supplemental Table S2.txt

\begin{tabular}{|c|c|c|c|c|}
\hline CHEMBL1393829 & 752581 & 2.8239 & 3.3467 & TRN \\
\hline CHEMBL1598785 & 752581 & 2.7959 & 2.8674 & TRN \\
\hline CHEMBL1361307 & 752581 & 2.7959 & 3.3065 & TRN \\
\hline CHEMBL1500742 & 752581 & 2.7959 & 3.05899 & 99999999997 \\
\hline CHEMBL1383721 & 752581 & 4.7303 & 4.0428 & TST \\
\hline CHEMBL1599674 & 752581 & 2.8239 & 4.0354 & TST \\
\hline CHEMBL584442 & 752581 & 4.2527 & 4.9061 & TST \\
\hline CHEMBL1352792 & 752581 & 4.6216 & 3.4017 & TST \\
\hline CHEMBL1545702 & 752581 & 2.7959 & 4.6133 & TST \\
\hline CHEMBL1405150 & 752581 & 2.8239 & 3.4617 & TST \\
\hline CHEMBL1484227 & 752581 & 4.7276 & 3.4132 & TST \\
\hline CHEMBL1468661 & 752581 & 4.7228 & 4.3607 & TST \\
\hline CHEMBL1480836 & 752581 & 2.7959 & 3.3367 & TST \\
\hline CHEMBL1595934 & 752581 & 5.4973 & 4.2376 & TST \\
\hline CHEMBL1542594 & 752581 & 2.7959 & 3.9811 & TST \\
\hline CHEMBL1602088 & 752581 & 4.7443 & 3.9451 & TST \\
\hline CHEMBL1455523 & 752581 & 5.352 & 3.5732 & TST \\
\hline CHEMBL1327172 & 752581 & 2.8239 & 4.1262 & TST \\
\hline CHEMBL1462283 & 752581 & 4.7719 & 2.8893 & TST \\
\hline CHEMBL1318350 & 752581 & 4.4951 & 4.1253 & TST \\
\hline CHEMBL1541834 & 752581 & 2.7959 & 4.0214 & TST \\
\hline CHEMBL1334557 & 752581 & 4.6358 & 3.2499 & TST \\
\hline CHEMBL1408965 & 752581 & 2.7959 & 3.6814 & TST \\
\hline CHEMBL1477033 & 752581 & 2.7959 & 3.0736 & TST \\
\hline CHEMBL1602947 & 752581 & 2.8239 & 4.0005 & TST \\
\hline CHEMBL1506580 & 752581 & 4.7871 & 4.0211 & TST \\
\hline CHEMBL1519450 & 752581 & 4.2811 & 2.9351 & TST \\
\hline CHEMBL1433124 & 752581 & 4.6621 & 4.5161 & TST \\
\hline CHEMBL1392918 & 752581 & 2.8239 & 3.2978 & TST \\
\hline CHEMBL1990174 & 752581 & 5.3891 & 4.4177 & TST \\
\hline CHEMBL1543255 & 752581 & 2.7959 & 2.8952 & TST \\
\hline CHEMBL1478041 & 752581 & 2.8239 & 3.862 & TST \\
\hline CHEMBL1995550 & 752581 & 5.2242 & 3.9708 & TST \\
\hline CHEMBL1585127 & 752581 & 2.8239 & 4.0803 & TST \\
\hline CHEMBL 1385760 & 752581 & 2.8239 & 3.1264 & TST \\
\hline CHEMBL1351542 & 752581 & 5.1726 & 4.2136 & TST \\
\hline CHEMBL1303401 & 752581 & 2.8239 & 3.1187 & TST \\
\hline CHEMBL1374462 & 752581 & 2.8239 & 4.0459 & TST \\
\hline CHEMBL3197825 & 752581 & 2.7959 & 3.7019 & TST \\
\hline CHEMBL 1300080 & 752581 & 4.7017 & 3.273 & TST \\
\hline CHEMBL3197343 & 752581 & 2.7959 & 4.0868 & TST \\
\hline CHEMBL1440514 & 752581 & 2.8239 & 3.1703 & TST \\
\hline CHEMBL1383916 & 752581 & 2.8239 & 3.0218 & TST \\
\hline CHEMBL3190230 & 752581 & 2.7959 & 3.6085 & TST \\
\hline CHEMBL3145031 & 752581 & 2.7959 & 3.3452 & TST \\
\hline CHEMBL1304603 & 752581 & 4.4704 & 3.4606 & TST \\
\hline CHEMBL1371081 & 752581 & 2.8239 & 3.3327 & TST \\
\hline CHEMBL3190697 & 752581 & 2.8239 & 3.3505 & TST \\
\hline
\end{tabular}


Supplemental Table S2.txt

\begin{tabular}{|c|c|c|c|c|c|}
\hline CHEMBL87285 & 752581 & 4.6169 & 3.9066 & TST & \\
\hline CHEMBL1330453 & 752581 & 4.5053 & 3.4051 & TST & \\
\hline CHEMBL1329129 & 752581 & 2.8239 & 4.1211 & TST & \\
\hline CHEMBL1545677 & 752581 & 4.7092 & 3.201 & TST & \\
\hline CHEMBL1784196 & 752182 & 5.6383 & 5.6684 & TRN & \\
\hline CHEMBL1784224 & 752182 & 6.4815 & 6.4706 & TRN & \\
\hline CHEMBL1784231 & 752182 & 5.3372 & 5.50200 & 0000000001 & TRN \\
\hline CHEMBL1784233 & 752182 & 6.0223 & 6.074 & TRN & \\
\hline CHEMBL1784194 & 752182 & 5.9586 & 6.1105 & TRN & \\
\hline CHEMBL1784200 & 752182 & 5.5686 & 5.5011 & TRN & \\
\hline CHEMBL1784201 & 752182 & 5.8539 & 5.8056 & TRN & \\
\hline CHEMBL1784204 & 752182 & 6.7696 & 6.5026 & TRN & \\
\hline CHEMBL1784241 & 752182 & 5.0 & 4.3008 & TST & \\
\hline CHEMBL1784183 & 752182 & 3.4815 & 3.6421 & TST & \\
\hline CHEMBL1784228 & 752182 & 5.7696 & 5.7793 & TRN & \\
\hline CHEMBL1784206 & 752182 & 5.7696 & 5.7227 & TRN & \\
\hline CHEMBL1784190 & 752182 & 6.6778 & 6.6245 & TRN & \\
\hline CHEMBL1784210 & 752182 & 5.2676 & 5.4707 & TRN & \\
\hline CHEMBL1784188 & 752182 & 5.7696 & 5.7244 & TRN & \\
\hline CHEMBL1784191 & 752182 & 5.7447 & 5.75 & TRN & \\
\hline CHEMBL1782537 & 752182 & 5.7447 & 5.9688 & TRN & \\
\hline CHEMBL1784238 & 752182 & 5.7212 & 5.9062 & TRN & \\
\hline CHEMBL1784185 & 752182 & 5.7447 & 5.8342 & TRN & \\
\hline CHEMBL1784181 & 752182 & 3.4815 & 3.4071 & TRN & \\
\hline CHEMBL1784227 & 752182 & 5.5686 & 5.5843 & TRN & \\
\hline CHEMBL1784229 & 752182 & 5.7959 & 5.6371 & TRN & \\
\hline CHEMBL1784222 & 752182 & 6.3665 & 5.9606 & TRN & \\
\hline CHEMBL1784193 & 752182 & 6.5086 & \multicolumn{2}{|c|}{6.412999999999999} & TRN \\
\hline CHEMBL1782536 & 752182 & 6.0555 & 5.9892 & TRN & \\
\hline CHEMBL1784179 & 752182 & 3.4815 & 3.5124 & TRN & \\
\hline CHEMBL1784240 & 752182 & 5.2518 & 5.3421 & TRN & \\
\hline CHEMBL1784205 & 752182 & 6.6198 & 6.4939 & TRN & \\
\hline CHEMBL1782540 & 752182 & 3.4815 & 3.4908 & TRN & \\
\hline CHEMBL1784223 & 752182 & 6.3188 & 6.4028 & TRN & \\
\hline CHEMBL1782535 & 752182 & 6.0362 & 6.1871 & TRN & \\
\hline CHEMBL1784182 & 752182 & 3.4815 & 3.4961 & TRN & \\
\hline CHEMBL1784198 & 752182 & 6.7212 & 6.6358 & TRN & \\
\hline CHEMBL1784207 & 752182 & 6.2218 & 6.1321 & TRN & \\
\hline CHEMBL1784217 & 752182 & 6.2924 & 6.29 & TRN & \\
\hline CHEMBL1784199 & 752182 & 5.5086 & 5.5478 & TRN & \\
\hline CHEMBL1784189 & 752182 & 6.3098 & 6.6454 & TRN & \\
\hline CHEMBL1782538 & 752182 & 5.3872 & 5.4826 & TST & \\
\hline CHEMBL1784236 & 752182 & 3.4815 & 3.455 & TRN & \\
\hline CHEMBL1784215 & 752182 & 6.2366 & 6.1981 & TRN & \\
\hline CHEMBL1784221 & 752182 & 6.4949 & 6.4795 & TRN & \\
\hline CHEMBL1782542 & 752182 & 5.6198 & 5.49 & TRN & \\
\hline CHEMBL1784212 & 752182 & 6.9586 & 6.7856 & TRN & \\
\hline CHEMBL1784218 & 752182 & 6.0862 & 6.0915 & TRN & \\
\hline
\end{tabular}


Supplemental Table S2.txt

\begin{tabular}{|c|c|c|c|c|}
\hline CHEMBL1784226 & 752182 & 5.9586 & 5.9812 & TRN \\
\hline CHEMBL1784186 & 752182 & 5.6383 & 6.0093 & TST \\
\hline CHEMBL1784203 & 752182 & 5.4949 & 5.5394 & TRN \\
\hline CHEMBL1784235 & 752182 & 6.0 & 5.8746 & TST \\
\hline CHEMBL1784214 & 752182 & 5.2441 & 5.1655 & TRN \\
\hline CHEMBL1784187 & 752182 & 5.7212 & 6.0315 & TST \\
\hline CHEMBL1782539 & 752182 & 3.4815 & 4.0693 & TST \\
\hline CHEMBL1784209 & 752182 & 5.1805 & 5.3821 & TRN \\
\hline CHEMBL1784220 & 752182 & 6.3279 & 6.1148 & TST \\
\hline CHEMBL1784195 & 752182 & 5.1675 & 5.4643 & TST \\
\hline CHEMBL1784213 & 752182 & 6.4202 & 6.432 & TRN \\
\hline CHEMBL1784208 & 752182 & 6.2218 & \multicolumn{2}{|c|}{6.0489999999999995} \\
\hline CHEMBL1784197 & 752182 & 6.7212 & 6.1555 & TST \\
\hline CHEMBL1782078 & 752182 & 5.6198 & 5.7215 & TRN \\
\hline CHEMBL1784225 & 752182 & 6.2291 & 5.8545 & TST \\
\hline CHEMBL1784216 & 752182 & 6.301 & 6.145 & TST \\
\hline CHEMBL1784230 & 752182 & 6.0132 & 6.2129 & TRN \\
\hline CHEMBL1784178 & 752182 & 5.5686 & 5.4329 & TST \\
\hline CHEMBL1784202 & 752182 & 5.8539 & 5.7964 & TRN \\
\hline CHEMBL1784180 & 752182 & 3.4815 & 3.3549 & TRN \\
\hline CHEMBL1782541 & 752182 & 5.0088 & 5.1197 & TRN \\
\hline CHEMBL1784184 & 752182 & 5.0177 & 5.4007 & TST \\
\hline CHEMBL1784219 & 752182 & 6.1249 & \multicolumn{2}{|c|}{6.077999999999999} \\
\hline CHEMBL1784234 & 752182 & 6.2147 & 5.5407 & TST \\
\hline CHEMBL1784192 & 752182 & 6.1135 & 5.9579 & TST \\
\hline CHEMBL1784237 & 752182 & 3.4815 & 5.5226 & TST \\
\hline CHEMBL1782534 & 752182 & 6.4949 & 6.2107 & TST \\
\hline CHEMBL1784211 & 752182 & 5.9208 & 5.8606 & TRN \\
\hline CHEMBL 1784232 & 752182 & 6.1079 & 6.0465 & TRN \\
\hline CHEMBL 2313792 & 934451 & 5.9208 & 5.4365 & TST \\
\hline CHEMBL 2313454 & 934451 & 3.3979 & 3.4367 & TRN \\
\hline CHEMBL 2313462 & 934451 & 6.0269 & 5.9672 & TRN \\
\hline CHEMBL 2313817 & 934451 & 5.4815 & 5.5006 & TRN \\
\hline CHEMBL 2313798 & 934451 & 5.5686 & 5.3476 & TRN \\
\hline CHEMBL 2313457 & 934451 & 5.5528 & 4.9189 & TST \\
\hline CHEMBL 2313460 & 934451 & 3.699 & 5.0922 & TST \\
\hline CHEMBL 2313470 & 934451 & 5.8861 & 5.9095 & TRN \\
\hline CHEMBL 2313816 & 934451 & 5.0269 & 4.9678 & TRN \\
\hline CHEMBL 2313474 & 934451 & 3.3979 & 3.3686 & TRN \\
\hline CHEMBL 2313796 & 934451 & 5.1871 & 5.1425 & TRN \\
\hline CHEMBL 2313793 & 934451 & 5.7212 & 5.6913 & TRN \\
\hline CHEMBL 2313487 & 934451 & 3.3979 & 3.3634 & TRN \\
\hline CHEMBL2313459 & 934451 & 5.3979 & 4.9869 & TST \\
\hline CHEMBL 2313803 & 934451 & 5.3468 & 5.3463 & TRN \\
\hline CHEMBL 2313794 & 934451 & 5.1675 & 5.2417 & TRN \\
\hline CHEMBL 2313809 & 934451 & 6.0269 & 6.0155 & TRN \\
\hline CHEMBL 2313815 & 934451 & 5.7447 & 5.7517 & TRN \\
\hline CHEMBL 2313453 & 934451 & 5.7696 & 5.7479 & TRN \\
\hline
\end{tabular}

Page 14529 
Supplemental Table S2.txt

\begin{tabular}{|c|c|c|c|c|c|}
\hline CHEMBL2313479 & 934451 & 3.3979 & 5.6677 & TST & \\
\hline CHEMBL 2313471 & 934451 & 5.2007 & 5.2562 & TRN & \\
\hline CHEMBL2313787 & 934451 & 5.7696 & 5.5698 & TRN & \\
\hline CHEMBL2313820 & 934451 & 5.7447 & 5.9332 & TRN & \\
\hline CHEMBL2313799 & 934451 & 6.0177 & 5.9815 & TRN & \\
\hline CHEMBL 2313790 & 934451 & 5.8861 & 5.5285 & TST & \\
\hline CHEMBL 2313812 & 934451 & 5.6778 & 5.7461 & TRN & \\
\hline CHEMBL2313473 & 934451 & 5.2218 & 5.1859 & TRN & \\
\hline CHEMBL2313807 & 934451 & 5.2441 & 5.1699 & TRN & \\
\hline CHEMBL2313814 & 934451 & 5.1192 & 5.092 & TRN & \\
\hline CHEMBL2313489 & 934451 & 6.0362 & 6.1749 & TRN & \\
\hline CHEMBL 2313458 & 934451 & 5.585 & 5.1488 & TST & \\
\hline CHEMBL2313482 & 934451 & 5.5086 & 5.551 & TRN & \\
\hline CHEMBL2313805 & 934451 & 3.3979 & 3.4069 & TRN & \\
\hline CHEMBL 2313463 & 934451 & 3.3979 & 3.4373 & TRN & \\
\hline CHEMBL2313485 & 934451 & 5.7447 & 6.7434 & TST & \\
\hline CHEMBL2313797 & 934451 & 5.6778 & 5.8064 & TRN & \\
\hline CHEMBL2313475 & 934451 & 3.3979 & 3.3774 & TRN & \\
\hline CHEMBL 2313461 & 934451 & 3.699 & 4.9503 & TST & \\
\hline CHEMBL 2313811 & 934451 & 5.7696 & 5.7447 & TRN & \\
\hline CHEMBL2313468 & 934451 & 5.8239 & 5.83200 & 0000000001 & TRN \\
\hline CHEMBL2313477 & 934451 & 6.0 & 5.8857 & TRN & \\
\hline CHEMBL 2313476 & 934451 & 3.3979 & 3.4415 & TRN & \\
\hline CHEMBL2313789 & 934451 & 5.3372 & 5.3502 & TRN & \\
\hline CHEMBL2313452 & 934451 & 5.8239 & 5.7617 & TRN & \\
\hline CHEMBL2313464 & 934451 & 5.9586 & 5.9625 & TRN & \\
\hline CHEMBL 2313483 & 934451 & 5.7447 & 5.6884 & TRN & \\
\hline CHEMBL 2313480 & 934451 & 3.3979 & 3.5102 & TRN & \\
\hline CHEMBL2313484 & 934451 & 4.5376 & 4.5184 & TRN & \\
\hline CHEMBL 2313800 & 934451 & 5.4815 & 5.4685 & TRN & \\
\hline CHEMBL2313467 & 934451 & 3.3979 & 3.5986 & TRN & \\
\hline CHEMBL 2313465 & 934451 & 3.3979 & 3.3511 & TRN & \\
\hline CHEMBL2313819 & 934451 & 5.8539 & 5.8583 & TRN & \\
\hline CHEMBL2313456 & 934451 & 5.699 & 5.0731 & TST & \\
\hline CHEMBL 2313486 & 934451 & 5.0458 & 5.0838 & TRN & \\
\hline CHEMBL2313488 & 934451 & 5.5229 & 5.3672 & TRN & \\
\hline CHEMBL 2313802 & 934451 & 5.0269 & 5.0422 & TRN & \\
\hline CHEMBL2313466 & 934451 & 5.3872 & 4.9913 & TST & \\
\hline CHEMBL2313481 & 934451 & 5.3979 & 5.3441 & TRN & \\
\hline CHEMBL2313791 & 934451 & 5.4559 & 5.7545 & TST & \\
\hline CHEMBL2313478 & 934451 & 3.3979 & 4.8808 & TST & \\
\hline CHEMBL 2313788 & 934451 & 5.9208 & 6.0036 & TRN & \\
\hline CHEMBL2313469 & 934451 & 3.699 & 5.7636 & TST & \\
\hline CHEMBL 2313818 & 934451 & 5.4437 & 5.4111 & TRN & \\
\hline CHEMBL2313808 & 934451 & 5.4318 & 4.0461 & TST & \\
\hline CHEMBL2313795 & 934451 & 5.9586 & 5.8578 & TST & \\
\hline CHEMBL 2313810 & 934451 & 5.7447 & 5.7842 & TRN & \\
\hline CHEMBL67 & 934451 & 6.0 & 7.0489 & TST & \\
\hline
\end{tabular}


Supplemental Table S2.txt

\begin{tabular}{|c|c|c|c|c|}
\hline 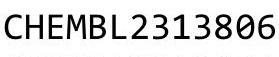 & & & 5.6603 & \\
\hline CHEMBL 2313804 & 34451 & .4685 & 5.4211 & \\
\hline HEMBL2313801 & 34451 & .8539 & 3044 & \\
\hline EMBL2 & 4451 & & & \\
\hline EMBL23 & 34451 & . 3979 & & \\
\hline AEMBL2313813 & 34451 & 7696 & 747 & \\
\hline HEMBL 2418177 & 78481 & .6021 & & \\
\hline HEMBL 241 & 81 & 021 & & \\
\hline IEMBL2 & 81 & .6021 & 701 & \\
\hline AEMBL24 & 81 & & & \\
\hline HEMBL2418188 & 81 & .6021 & 126 & \\
\hline AEMBL2418151 & 31 & .6021 & 53 & \\
\hline JEMBL 24 & 31 & .6021 & 338 & \\
\hline AEMBL 24 & & .6021 & & \\
\hline HEMBL2 & 31 & 3.6021 & & \\
\hline IEMBL 24 & 31 & .4437 & 98 & \\
\hline HEMBL 241 & $7 \varepsilon$ & .6021 & 77 & \\
\hline AEMBL24 & 31 & 4.9066 & & \\
\hline AEMBL24 & & 3.6021 & & \\
\hline AEMBL2 & & 6.0 & & \\
\hline IEMBL24 & & 21 & & \\
\hline IEMBL24 & 1 & 3.6021 & & \\
\hline AEMBL24 & 1 & .6021 & 33 & \\
\hline IEMBL & & & & \\
\hline IEMBL & & 794 & & \\
\hline IEMBL2 24 & & 021 & & \\
\hline HEMBL24 & 1 & 3.6021 & 21 & RI \\
\hline AEMBL24 & & 3.6021 & & \\
\hline EMB & & 21 & & \\
\hline AEMBL 2 & & 21 & & RN \\
\hline IEMBL24 & & & & RI \\
\hline AEMBL24 & 31 & 3.6021 & & S \\
\hline HEMBL2 & 1 & $\partial 21$ & & \\
\hline I M & & & & $R / N$ \\
\hline AEMBL2 & & & & \\
\hline IEMBL24 & & & & \\
\hline IEMBL24 & 1 & 3.6021 & & RI \\
\hline AEMBL2 & 1 & 59 & & \\
\hline 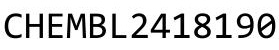 & & & & $R / N$ \\
\hline AEMBL2 & & & & RN \\
\hline IEMBL2 24 & & 3.6021 & & \\
\hline IEMBL & & & & \\
\hline HEMBL & & & & \\
\hline & & & & \\
\hline HEMBL 2 & & .6021 & 3.5721 & \\
\hline HEMBL2 2 & 31 & .6021 & & $\mathrm{R}$ \\
\hline CHEME & & 3.6 & & \\
\hline CHEMBL2 & & & 3.5246 & \\
\hline
\end{tabular}

Page 14531 
Supplemental Table S2.txt

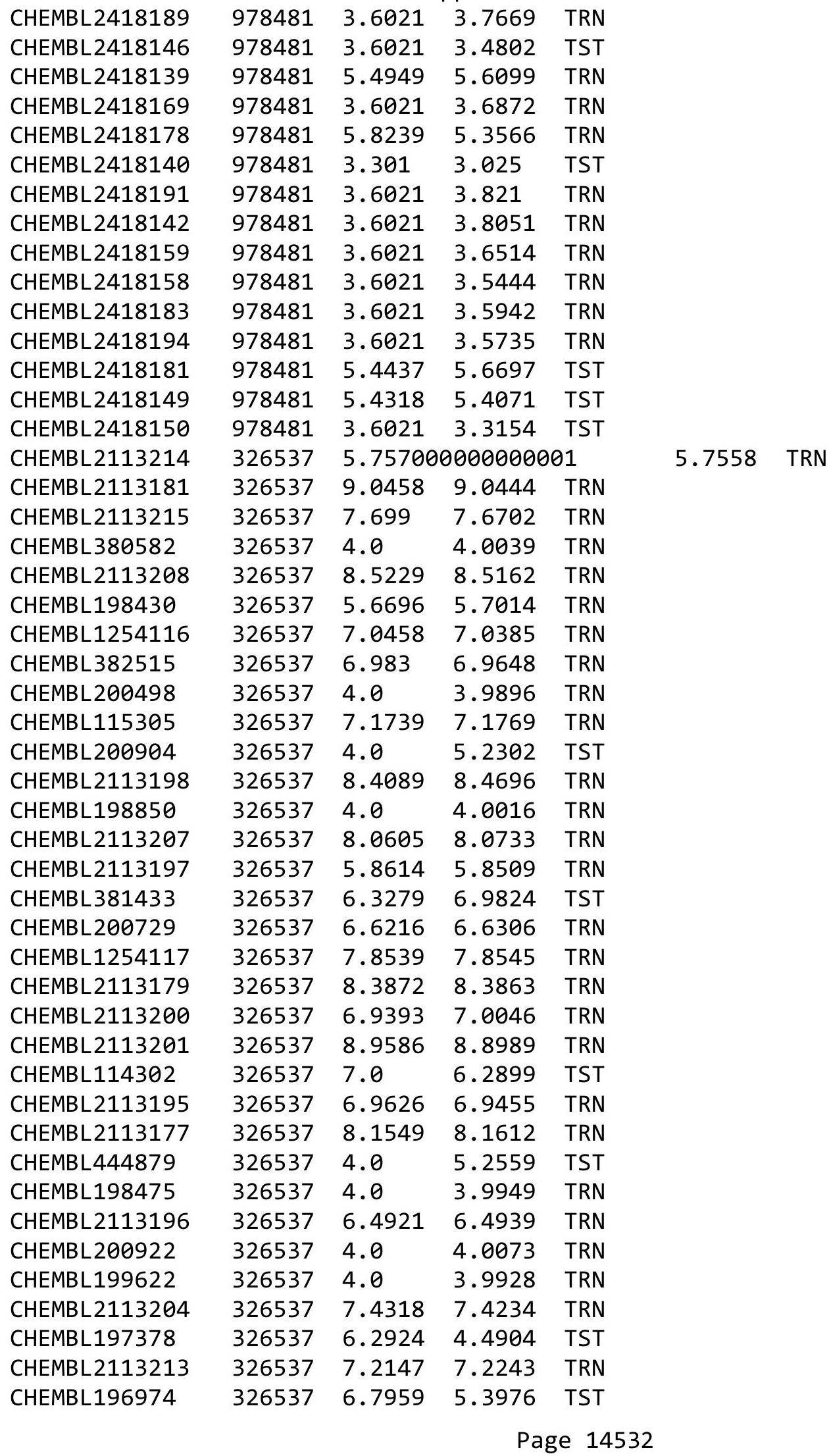




\begin{tabular}{|c|c|c|c|c|c|}
\hline & & \multicolumn{4}{|c|}{ Supplemental Table S2.txt } \\
\hline CHEMBL371223 & 326537 & 7.7447 & 7.7428 & TRN & \\
\hline CHEMBL 2113205 & 326537 & 6.9547 & 6.96 & TRN & \\
\hline CHEMBL2113216 & 326537 & 7.6778 & 7.6891 & TRN & \\
\hline CHEMBL 200682 & 326537 & 6.0969 & 6.5635 & TST & \\
\hline CHEMBL 381448 & 326537 & 4.0 & 4.01399 & 9999999999 & TRN \\
\hline CHEMBL 2113185 & 326537 & 9.0458 & 9.0424 & TRN & \\
\hline CHEMBL382071 & 326537 & 4.0 & 4.0044 & TRN & \\
\hline CHEMBL200738 & 326537 & 4.0 & 3.9862 & TRN & \\
\hline CHEMBL 2113189 & 326537 & 8.7959 & 8.7996 & TRN & \\
\hline CHEMBL200329 & 326537 & 7.2218 & 7.2229 & TRN & \\
\hline CHEMBL2113194 & 326537 & 6.3487 & 6.3452 & TRN & \\
\hline CHEMBL2113209 & 326537 & 8.0 & 8.0298 & TRN & \\
\hline CHEMBL2113211 & 326537 & 8.1549 & 8.1583 & TRN & \\
\hline CHEMBL200368 & 326537 & 5.5607 & 5.5572 & TRN & \\
\hline CHEMBL198780 & 326537 & 6.2076 & 6.7275 & TST & \\
\hline CHEMBL2113203 & 326537 & 8.6778 & 8.6992 & TRN & \\
\hline CHEMBL200282 & 326537 & 4.0 & 4.71899 & 9999999999 & TST \\
\hline CHEMBL199078 & 326537 & 4.0 & 3.9981 & TRN & \\
\hline CHEMBL373167 & 326537 & 6.7959 & 5.9903 & TST & \\
\hline CHEMBL 200415 & 326537 & 7.0315 & 6.2139 & TST & \\
\hline CHEMBL 2113210 & 326537 & 7.7447 & 7.729 & TRN & \\
\hline CHEMBL198630 & 326537 & 6.6253 & 4.3282 & TST & \\
\hline CHEMBL 383149 & 326537 & 6.1135 & 3.4339 & TST & \\
\hline CHEMBL 372122 & 326537 & 7.8239 & 7.829 & TRN & \\
\hline CHEMBL 200403 & 326537 & 7.4437 & 4.5714 & TST & \\
\hline CHEMBL196816 & 326537 & 5.3098 & 6.5049 & TST & \\
\hline CHEMBL 2113206 & 326537 & 6.7595 & 6.7671 & TRN & \\
\hline CHEMBL 2113212 & 326537 & 7.4437 & 7.4397 & TRN & \\
\hline CHEMBL198622 & 326537 & 6.4949 & 4.3924 & TST & \\
\hline CHEMBL 200792 & 326537 & 7.1739 & 7.1597 & TRN & \\
\hline CHEMBL445816 & 326537 & 9.1871 & 9.1791 & TRN & \\
\hline CHEMBL427190 & 326537 & 6.301 & 5.4002 & TST & \\
\hline CHEMBL 2113202 & 326537 & 7.1938 & 7.1255 & TRN & \\
\hline CHEMBL578814 & 787657 & 5.3401 & 5.683 & TRN & \\
\hline CHEMBL1917830 & 787657 & 3.0 & 3.1379 & TST & \\
\hline CHEMBL1917837 & 787657 & 3.0 & 3.3512 & TST & \\
\hline CHEMBL571359 & 787657 & 5.3391 & 3.8534 & TRN & \\
\hline CHEMBL1917664 & 787657 & 3.0 & 3.2153 & TRN & \\
\hline CHEMBL1917667 & 787657 & 3.0 & 3.659 & TRN & \\
\hline CHEMBL1917660 & 787657 & 4.6953 & 4.631 & TRN & \\
\hline CHEMBL583335 & 787657 & 4.8608 & 4.7253 & TRN & \\
\hline CHEMBL1917670 & 787657 & 3.0 & 3.5821 & TRN & \\
\hline CHEMBL1917666 & 787657 & 4.2665 & 4.5207 & TRN & \\
\hline CHEMBL584953 & 787657 & 5.0711 & 4.4979 & TRN & \\
\hline CHEMBL1917836 & 787657 & 3.0 & 3.3958 & TST & \\
\hline CHEMBL1917662 & 787657 & 3.0 & 3.0315 & TRN & \\
\hline CHEMBL1917655 & 787657 & 5.1701 & 4.8319 & TRN & \\
\hline CHEMBL1917663 & 787657 & 4.8794 & 4.5656 & TRN & \\
\hline
\end{tabular}




\begin{tabular}{|c|c|c|c|c|c|}
\hline & & \multicolumn{4}{|c|}{ Supplemental Table S2.txt } \\
\hline CHEMBL569557 & 787657 & 4.1578 & 3.7353 & TRN & \\
\hline CHEMBL1917661 & 787657 & 4.162 & 4.2479 & TRN & \\
\hline CHEMBL1917668 & 787657 & 3.0 & 2.9023 & TRN & \\
\hline CHEMBL569115 & 787657 & 5.6757 & 5.6863 & TRN & \\
\hline CHEMBL1917657 & 787657 & 5.8447 & 5.4619 & TRN & \\
\hline CHEMBL1917654 & 787657 & 5.7144 & 5.3942 & TRN & \\
\hline CHEMBL1917835 & 787657 & 3.0 & 4.4702 & TST & \\
\hline CHEMBL572024 & 787657 & 5.6615 & 5.7486 & TRN & \\
\hline CHEMBL1917671 & 787657 & 4.0921 & 3.7666 & TRN & \\
\hline CHEMBL1917832 & 787657 & 4.4186 & 4.1297 & TST & \\
\hline CHEMBL569338 & 787657 & 5.0079 & 4.6263 & TRN & \\
\hline CHEMBL1917839 & 787657 & 3.0 & 3.0665 & TST & \\
\hline CHEMBL1917658 & 787657 & 3.0 & 3.3136 & TRN & \\
\hline CHEMBL1917834 & 787657 & 3.0 & 2.9319 & TST & \\
\hline CHEMBL571146 & 787657 & 5.2874 & 4.7129 & TRN & \\
\hline CHEMBL570510 & 787657 & 4.2264 & 4.5095 & TRN & \\
\hline CHEMBL570465 & 787657 & 3.0 & 3.0376 & TRN & \\
\hline CHEMBL570511 & 787657 & 3.0 & 3.6887 & TRN & \\
\hline CHEMBL570466 & 787657 & 5.4622 & 4.7638 & TRN & \\
\hline CHEMBL1917838 & 787657 & 3.0 & 3.1839 & TST & \\
\hline CHEMBL570059 & 787657 & 4.7027 & 5.4184 & TRN & \\
\hline CHEMBL569558 & 787657 & 3.0 & 3.8534 & TRN & \\
\hline CHEMBL1914493 & 787657 & 4.704 & 4.6339 & TST & \\
\hline CHEMBL1917831 & 787657 & 3.0 & 3.2031 & TST & \\
\hline CHEMBL576070 & 787657 & 3.0 & 4.614 & TRN & \\
\hline CHEMBL1917828 & 787657 & 4.8608 & 4.5369 & TRN & \\
\hline CHEMBL1917833 & 787657 & 4.5948 & 4.3358 & TST & \\
\hline CHEMBL572026 & 787657 & 4.4542 & 3.7299 & TRN & \\
\hline CHEMBL1917656 & 787657 & 4.5393 & 4.5489 & TRN & \\
\hline CHEMBL1917827 & 787657 & 3.0 & 2.7869 & TRN & \\
\hline CHEMBL1917665 & 787657 & 3.0 & 3.02 & TRN & \\
\hline CHEMBL1917829 & 787657 & 3.0 & 3.4554 & TST & \\
\hline CHEMBL1917659 & 787657 & 4.4193 & 4.9635 & TRN & \\
\hline CHEMBL572236 & 787657 & 3.0 & 3.02600 & 00000000002 & TRN \\
\hline CHEMBL1917669 & 787657 & 3.0 & 3.1831 & TST & \\
\hline CHEMBL346371 & 71130 & 3.8508 & 3.9429 & TRN & \\
\hline CHEMBL158885 & 71130 & 4.284 & 4.648 & TRN & \\
\hline CHEMBL160938 & 71130 & 3.3497 & 3.5617 & TRN & \\
\hline CHEMBL160373 & 71130 & 3.3261 & 3.5034 & TRN & \\
\hline CHEMBL346721 & 71130 & 4.0809 & 3.7809 & TRN & \\
\hline CHEMBL155680 & 71130 & 3.9101 & 4.1784 & TRN & \\
\hline CHEMBL160743 & 71130 & 3.2741 & 3.5175 & TRN & \\
\hline CHEMBL156263 & 71130 & 3.6655 & 3.4624 & TRN & \\
\hline CHEMBL157348 & 71130 & 3.8477 & 3.8352 & TRN & \\
\hline CHEMBL156506 & 71130 & 3.71 & 3.8649 & TRN & \\
\hline CHEMBL434484 & 71130 & 3.3936 & 3.321 & TRN & \\
\hline CHEMBL156277 & 71130 & 3.9431 & 3.6742 & TRN & \\
\hline CHEMBL156801 & 71130 & 2.8545 & 3.9874 & TST & \\
\hline
\end{tabular}




\begin{tabular}{|c|c|c|c|c|c|c|}
\hline \multirow[b]{2}{*}{ CHEMBL350029 } & & \multicolumn{5}{|c|}{ Supplemental 1} \\
\hline & 71130 & 4.5229 & 3.8851 & TST & & \\
\hline CHEMBL156218 & 71130 & 3.6696 & \multicolumn{3}{|c|}{3.4010000000000002} & TRN \\
\hline CHEMBL322970 & 71130 & 6.983 & 4.777 & TRN & & \\
\hline CHEMBL 345364 & 71130 & 3.8729 & 3.6887 & TRN & & \\
\hline CHEMBL156524 & 71130 & 2.8502 & 3.5492 & TST & & \\
\hline CHEMBL 345212 & 71130 & 4.1308 & 4.0745 & TRN & & \\
\hline CHEMBL 347580 & 71130 & 3.1586 & 3.3244 & TST & & \\
\hline CHEMBL 346523 & 71130 & 4.301 & 3.8056 & TST & & \\
\hline CHEMBL158526 & 71130 & 3.6925 & 3.3376 & TRN & & \\
\hline CHEMBL347857 & 71130 & 3.8268 & 3.9418 & TRN & & \\
\hline CHEMBL158559 & 71130 & 3.6271 & 4.1264 & TRN & & \\
\hline CHEMBL 347681 & 71130 & 4.1487 & 4.4451 & TRN & & \\
\hline CHEMBL 348505 & 71130 & 3.5361 & 3.552 & TRN & & \\
\hline CHEMBL160231 & 71130 & 3.5867 & 3.6798 & TRN & & \\
\hline CHEMBL 349540 & 71130 & 3.9586 & 3.4854 & TRN & & \\
\hline CHEMBL 346066 & 71130 & 3.983 & 4.2926 & TRN & & \\
\hline CHEMBL155967 & 71130 & 3.4724 & 3.8118 & TST & & \\
\hline CHEMBL435045 & 71130 & 2.6411 & 3.4944 & TST & & \\
\hline CHEMBL351356 & 71130 & 3.5214 & 3.5698 & TRN & & \\
\hline CHEMBL346996 & 71130 & 3.8182 & 3.9165 & TRN & & \\
\hline CHEMBL156807 & 71130 & 3.4089 & 3.1855 & TRN & & \\
\hline CHEMBL345801 & 71130 & 4.1549 & 4.1252 & TRN & & \\
\hline CHEMBL156563 & 71130 & 3.7932 & 3.7303 & TRN & & \\
\hline CHEMBL 349810 & 71130 & 4.0706 & 3.7708 & TRN & & \\
\hline CHEMBL 345800 & 71130 & 4.0862 & 4.0244 & TRN & & \\
\hline CHEMBL156808 & 71130 & 3.4989 & 3.708 & TRN & & \\
\hline CHEMBL156987 & 71130 & 4.1192 & 3.8933 & TRN & & \\
\hline CHEMBL160876 & 71130 & 3.9626 & 3.8553 & TRN & & \\
\hline CHEMBL 350702 & 71130 & 3.8665 & 3.9225 & TRN & & \\
\hline CHEMBL160251 & 71130 & 3.8447 & 3.8827 & TRN & & \\
\hline CHEMBL 347647 & 71130 & 3.6655 & 3.7551 & TRN & & \\
\hline CHEMBL158719 & 71130 & 3.8827 & 4.1143 & TST & & \\
\hline CHEMBL155904 & 71130 & 1.3468 & 3.4242 & TST & & \\
\hline CHEMBL159149 & 71130 & 4.1024 & 4.079 & TRN & & \\
\hline CHEMBL 351334 & 71130 & 2.5829 & 3.4259 & TST & & \\
\hline CHEMBL157089 & 71130 & 3.85699 & 9999999 & 998 & 4.145 & TRN \\
\hline CHEMBL160937 & 71130 & 3.4271 & 3.98 & TRN & & \\
\hline CHEMBL 346829 & 71130 & 3.5901 & 3.5074 & TRN & & \\
\hline CHEMBL157141 & 71130 & 3.8182 & 4.2922 & TRN & & \\
\hline CHEMBL 345348 & 71130 & 4.2291 & 4.5715 & TRN & & \\
\hline CHEMBL422714 & 71130 & 4.2366 & 3.9717 & TRN & & \\
\hline CHEMBL 351342 & 71130 & 3.2765 & 3.4234 & TRN & & \\
\hline CHEMBL 351801 & 71130 & 2.8303 & 3.7261 & TRN & & \\
\hline CHEMBL160968 & 71130 & 3.28899 & 9999999 & 997 & 3.4234 & TRN \\
\hline CHEMBL157258 & 71130 & 4.0315 & 4.1624 & TRN & & \\
\hline CHEMBL160333 & 71130 & 4.0269 & 4.1003 & TRN & & \\
\hline CHEMBL 352222 & 71130 & 4.699 & 4.4546 & TRN & & \\
\hline CHEMBL158835 & 71130 & 3.4067 & 3.8454 & TRN & & \\
\hline
\end{tabular}




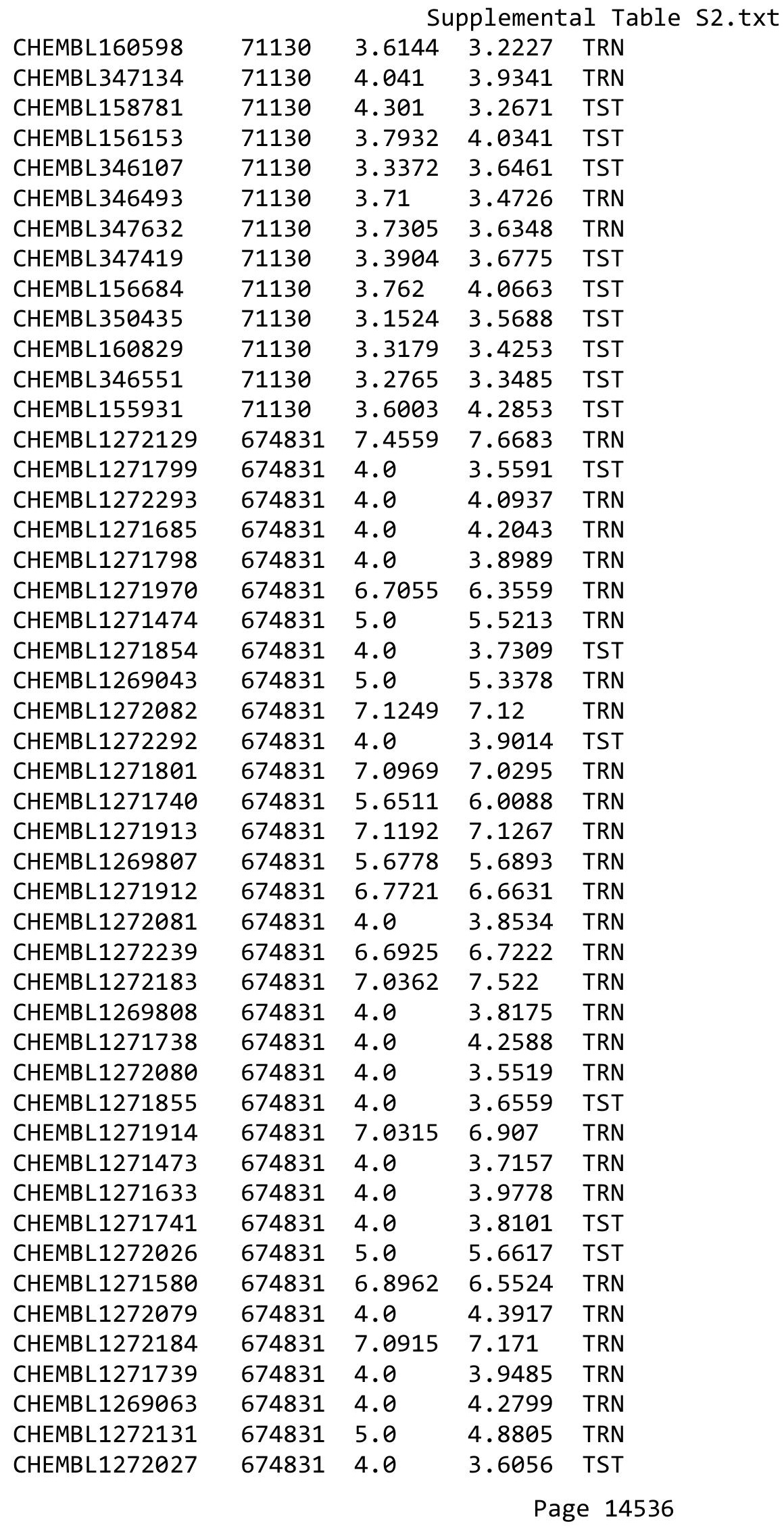




\begin{tabular}{|c|c|c|c|c|c|c|}
\hline \multicolumn{7}{|c|}{ Supplemental Table S2.txt } \\
\hline CHEMBL1269065 & 674831 & 4.0 & 3.6958 & TST & & \\
\hline CHEMBL1271581 & 674831 & 4.0 & 3.79 & TRN & & \\
\hline CHEMBL1272130 & 674831 & 7.0915 & 6.7851 & TRN & & \\
\hline CHEMBL1271800 & 674831 & 7.4815 & 7.2342 & TST & & \\
\hline CHEMBL1271969 & 674831 & 7.0809 & 7.3797 & TST & & \\
\hline CHEMBL1272024 & 674831 & 7.1871 & 6.6992 & TRN & & \\
\hline CHEMBL1271856 & 674831 & 4.0 & 4.0026 & TST & & \\
\hline CHEMBL1272023 & 674831 & 8.0458 & 8.0868 & TRN & & \\
\hline CHEMBL1271857 & 674831 & 4.0 & 3.7541 & TST & & \\
\hline CHEMBL1271967 & 674831 & 7.3468 & 7.5845 & TRN & & \\
\hline CHEMBL1271684 & 674831 & 4.0 & 3.7365 & TST & & \\
\hline CHEMBL1271525 & 674831 & 7.1024 & 6.605 & TRN & & \\
\hline CHEMBL1271579 & 674831 & 4.0 & 4.449 & TRN & & \\
\hline CHEMBL1269064 & 674831 & 4.0 & 4.0804 & TRN & & \\
\hline CHEMBL1271797 & 674831 & 5.4949 & 5.4366 & TRN & & \\
\hline CHEMBL1271968 & 674831 & 7.5086 & 7.3063 & TRN & & \\
\hline CHEMBL1271737 & 674831 & 6.5376 & 6.575 & TRN & & \\
\hline CHEMBL1271911 & 674831 & 4.0 & 3.5855 & TST & & \\
\hline CHEMBL 309700 & 46624 & 6.3019 & 6.3169 & TRN & & \\
\hline CHEMBL 309605 & 46624 & 8.4685 & 8.4572 & TRN & & \\
\hline CHEMBL310995 & 46624 & \multicolumn{3}{|c|}{6.752000000000001} & 6.7224 & TRN \\
\hline CHEMBL80311 & 46624 & 5.528 & 5.5278 & TRN & & \\
\hline CHEMBL78763 & 46624 & 6.8928 & 6.8892 & TRN & & \\
\hline CHEMBL 78815 & 46624 & 6.9586 & 6.9541 & TRN & & \\
\hline CHEMBL78713 & 46624 & 8.0 & 8.0156 & TRN & & \\
\hline CHEMBL79204 & 46624 & 7.2291 & 7.1982 & TRN & & \\
\hline CHEMBL 78710 & 46624 & \multicolumn{3}{|c|}{6.082000000000001} & 6.1418 & TRN \\
\hline CHEMBL319464 & 46624 & 6.9066 & 7.6778 & TST & & \\
\hline CHEMBL80214 & 46624 & 8.5528 & 8.59100 & 0000000001 & & TRN \\
\hline CHEMBL309763 & 46624 & 8.2291 & 8.1649 & TRN & & \\
\hline CHEMBL78627 & 46624 & 7.1549 & 7.1703 & TRN & & \\
\hline CHEMBL 78992 & 46624 & 6.3089 & 6.2888 & TRN & & \\
\hline CHEMBL81911 & 46624 & 6.4473 & 6.4475 & TRN & & \\
\hline CHEMBL 81473 & 46624 & 8.8539 & 8.8426 & TRN & & \\
\hline CHEMBL431589 & 46624 & 6.3809 & 6.3608 & TRN & & \\
\hline CHEMBL80984 & 46624 & 6.4157 & 6.4141 & TRN & & \\
\hline CHEMBL273606 & 46624 & 6.4089 & 6.41 & TRN & & \\
\hline CHEMBL 311560 & 46624 & 7.4202 & 7.1478 & TST & & \\
\hline CHEMBL12914 & 46624 & 6.2175 & 6.1991 & TRN & & \\
\hline CHEMBL13272 & 46624 & 6.0969 & 6.068 & TRN & & \\
\hline CHEMBL310539 & 46624 & 5.7251 & 5.0042 & TST & & \\
\hline CHEMBL107136 & 46624 & 7.1487 & 7.1843 & TRN & & \\
\hline CHEMBL78359 & 46624 & 8.1612 & 8.2029 & TRN & & \\
\hline CHEMBL 310741 & 46624 & 6.2882 & 5.5124 & TST & & \\
\hline CHEMBL309756 & 46624 & 6.5171 & 6.5395 & TRN & & \\
\hline CHEMBL 78940 & 46624 & 8.0 & 8.0504 & TRN & & \\
\hline CHEMBL 323501 & 46624 & 7.3665 & 7.3645 & TRN & & \\
\hline CHEMBL307073 & 46624 & 7.2291 & 7.2343 & TRN & & \\
\hline
\end{tabular}




\begin{tabular}{|c|c|c|c|c|c|}
\hline \multicolumn{6}{|c|}{ Supplemental Table S2.txt } \\
\hline CHEMBL 78752 & 46624 & 6.5143 & 6.5257 & TRN & \\
\hline CHEMBL78375 & 46624 & 7.7447 & 7.7265 & TRN & \\
\hline CHEMBL78995 & 46624 & 6.8539 & 6.8968 & TRN & \\
\hline CHEMBL80337 & 46624 & 7.6198 & 7.6061 & TRN & \\
\hline CHEMBL78994 & 46624 & 7.9586 & 7.9367 & TRN & \\
\hline CHEMBL431862 & 46624 & 6.8239 & 6.8535 & TRN & \\
\hline CHEMBL311065 & 46624 & 6.4802 & 6.4749 & TRN & \\
\hline CHEMBL104688 & 46624 & 5.9454 & 5.9234 & TRN & \\
\hline CHEMBL80938 & 46624 & 6.5622 & 6.5792 & TRN & \\
\hline CHEMBL77445 & 46624 & 6.5482 & 6.5295 & TRN & \\
\hline CHEMBL104412 & 46624 & 5.8811 & 5.8764 & TRN & \\
\hline CHEMBL104841 & 46624 & 7.8861 & 7.542000 & 0000000001 & TST \\
\hline CHEMBL312057 & 46624 & 7.2596 & 7.2635 & TRN & \\
\hline CHEMBL78308 & 46624 & 7.4559 & 7.4504 & TRN & \\
\hline CHEMBL311667 & 46624 & 6.8601 & 6.8466 & TRN & \\
\hline CHEMBL310751 & 46624 & 5.8383 & 5.1326 & TST & \\
\hline CHEMBL311328 & 46624 & 6.7305 & 6.7336 & TRN & \\
\hline CHEMBL274833 & 46624 & 7.7212 & 7.6681 & TRN & \\
\hline CHEMBL 275242 & 46624 & 5.7513 & 5.7663 & TRN & \\
\hline CHEMBL81683 & 46624 & 7.8239 & 7.9548 & TST & \\
\hline CHEMBL 78550 & 46624 & 6.2062 & 5.7152 & TST & \\
\hline CHEMBL13078 & 46624 & 8.1079 & 8.0393 & TST & \\
\hline CHEMBL310538 & 46624 & 5.8145 & 5.6016 & TST & \\
\hline CHEMBL312259 & 46624 & 6.4283 & 6.5656 & TST & \\
\hline CHEMBL82361 & 46624 & 8.4559 & 8.5381 & TST & \\
\hline CHEMBL311645 & 46624 & 7.4318 & 7.2277 & TST & \\
\hline CHEMBL 78415 & 46624 & 8.0 & 7.3966 & TST & \\
\hline CHEMBL78701 & 46624 & 6.2434 & 5.8983 & TST & \\
\hline CHEMBL270121 & 464617 & 4.7258 & 4.9557 & TRN & \\
\hline CHEMBL3216323 & 464617 & 7.6021 & 7.0802 & TRN & \\
\hline CHEMBL272259 & 464617 & 4.7986 & 4.8854 & TRN & \\
\hline CHEMBL186961 & 464617 & 3.7404 & 3.8936 & TRN & \\
\hline CHEMBL3216997 & 464617 & 7.4437 & 7.1728 & TRN & \\
\hline CHEMBL390246 & 464617 & 4.3316 & 4.1944 & TRN & \\
\hline CHEMBL77633 & 464617 & 6.7932 & 6.7022 & TRN & \\
\hline CHEMBL271808 & 464617 & 4.3028 & 4.1858 & TRN & \\
\hline CHEMBL431961 & 464617 & 6.6421 & 5.9059 & TST & \\
\hline CHEMBL77670 & 464617 & 5.585 & 4.909 & TST & \\
\hline CHEMBL539632 & 464617 & 6.38299 & 999999999 & 5.2502 & TST \\
\hline CHEMBL1162155 & 464617 & 4.4828 & 4.486000 & 0000000001 & TRN \\
\hline CHEMBL1162156 & 464617 & 4.3429 & 4.8909 & TRN & \\
\hline CHEMBL404606 & 464617 & 7.3468 & 7.4544 & TRN & \\
\hline CHEMBL271534 & 464617 & 5.3188 & 5.5342 & TRN & \\
\hline CHEMBL242839 & 464617 & 3.8245 & 4.5262 & TST & \\
\hline CHEMBL538590 & 464617 & 4.8416 & 4.3127 & TRN & \\
\hline CHEMBL 270500 & 464617 & 4.2976 & 4.1967 & TRN & \\
\hline CHEMBL 270330 & 464617 & 5.3098 & 5.0777 & TRN & \\
\hline CHEMBL424238 & 464617 & 4.4895 & 4.623 & TRN & \\
\hline
\end{tabular}




\begin{tabular}{|c|c|c|c|c|c|c|}
\hline \multirow[b]{2}{*}{ CHEMBL405745 } & & \multicolumn{5}{|c|}{ Supplemental Table S2.txt } \\
\hline & 464617 & 6.3279 & 6.0966 & TST & & \\
\hline CHEMBL 271578 & 464617 & 3.581006 & 30000000 & 004 & 3.7287 & TRN \\
\hline CHEMBL1162154 & 464617 & 5.8861 & 5.1544 & TRN & & \\
\hline CHEMBL 267337 & 464617 & 6.5003 & 5.4761 & TST & & \\
\hline CHEMBL537246 & 464617 & 5.0269 & 4.895 & TRN & & \\
\hline CHEMBL532729 & 464617 & 6.9136 & 6.7648 & TRN & & \\
\hline CHEMBL43415 & 464617 & 3.786 & 3.8267 & TRN & & \\
\hline CHEMBL423676 & 464617 & 5.3665 & 5.3765 & TRN & & \\
\hline CHEMBL271995 & 464617 & 4.0747 & 4.0866 & TRN & & \\
\hline CHEMBL407777 & 464617 & 6.5686 & 6.8834 & TST & & \\
\hline CHEMBL 270533 & 464617 & 7.301 & 7.9497 & TST & & \\
\hline CHEMBL556563 & 464617 & 6.2692 & 6.8865 & TRN & & \\
\hline CHEMBL9441 & 464617 & 5.1367 & 5.0009 & TRN & & \\
\hline CHEMBL44100 & 464617 & 3.8356 & 3.9112 & TST & & \\
\hline CHEMBL430286 & 464617 & 5.7212 & 5.459 & TRN & & \\
\hline CHEMBL 261388 & 464617 & 4.3134 & 4.6719 & TST & & \\
\hline CHEMBL443320 & 464617 & 4.399 & 4.2522 & TRN & & \\
\hline CHEMBL 270752 & 464617 & 5.0362 & 4.9709 & TRN & & \\
\hline CHEMBL537021 & 464617 & 4.0237 & 4.0945 & TRN & & \\
\hline CHEMBL244986 & 464617 & 6.3307 & 6.4209 & TRN & & \\
\hline CHEMBL271996 & 464617 & 6.9281 & 6.7595 & TRN & & \\
\hline CHEMBL230861 & 464617 & 4.3969 & 4.7298 & TRN & & \\
\hline CHEMBL537247 & 464617 & 3.9147 & 4.3544 & TRN & & \\
\hline CHEMBL1203959 & 464617 & 7.4202 & 7.4855 & TRN & & \\
\hline CHEMBL42139 & 464617 & 4.1649 & 4.1658 & TRN & & \\
\hline CHEMBL 270122 & 464617 & 5.301 & 5.1142 & TRN & & \\
\hline CHEMBL1203960 & 464617 & 4.2628 & 4.3792 & TRN & & \\
\hline CHEMBL272681 & 464617 & 5.6198 & 5.5223 & TRN & & \\
\hline CHEMBL553649 & 464617 & 4.0585 & 4.4331 & TRN & & \\
\hline CHEMBL557382 & 464617 & 6.6635 & 7.569 & TST & & \\
\hline CHEMBL407518 & 464617 & 6.0044 & 5.4524 & TST & & \\
\hline CHEMBL271749 & 464617 & 7.2218 & 7.6774 & TRN & & \\
\hline CHEMBL428395 & 464617 & 6.9914 & 6.7815 & TRN & & \\
\hline CHEMBL548436 & 464617 & 6.7282 & 6.2118 & TRN & & \\
\hline CHEMBL73758 & 464617 & 5.6882 & 6.2052 & TRN & & \\
\hline CHEMBL404605 & 464617 & 4.3401 & 4.3231 & TRN & & \\
\hline CHEMBL243288 & 464617 & 6.7077 & 6.8096 & TRN & & \\
\hline CHEMBL242759 & 464617 & 7.6576 & 7.6024 & TRN & & \\
\hline CHEMBL405429 & 464617 & 5.9208 & 5.61299 & 99999 & 995 & TRN \\
\hline CHEMBL308767 & 464617 & 6.6861 & 6.9696 & TRN & & \\
\hline CHEMBL536556 & 464617 & 4.3675 & 4.2049 & TRN & & \\
\hline CHEMBL243061 & 464617 & 4.0292 & 3.8819 & TRN & & \\
\hline CHEMBL 270352 & 464617 & 5.2291 & 5.0506 & TST & & \\
\hline CHEMBL42751 & 464617 & 3.6253 & 3.9108 & TST & & \\
\hline CHEMBL231585 & 464617 & 4.6968 & 4.6101 & TST & & \\
\hline CHEMBL 271404 & 464617 & 3.506999 & 99999999 & 997 & 4.9161 & TST \\
\hline CHEMBL271809 & 464617 & 8.3098 & 8.0829 & TRN & & \\
\hline CHEMBL1162153 & 464617 & 5.585 & 5.8725 & TRN & & \\
\hline
\end{tabular}




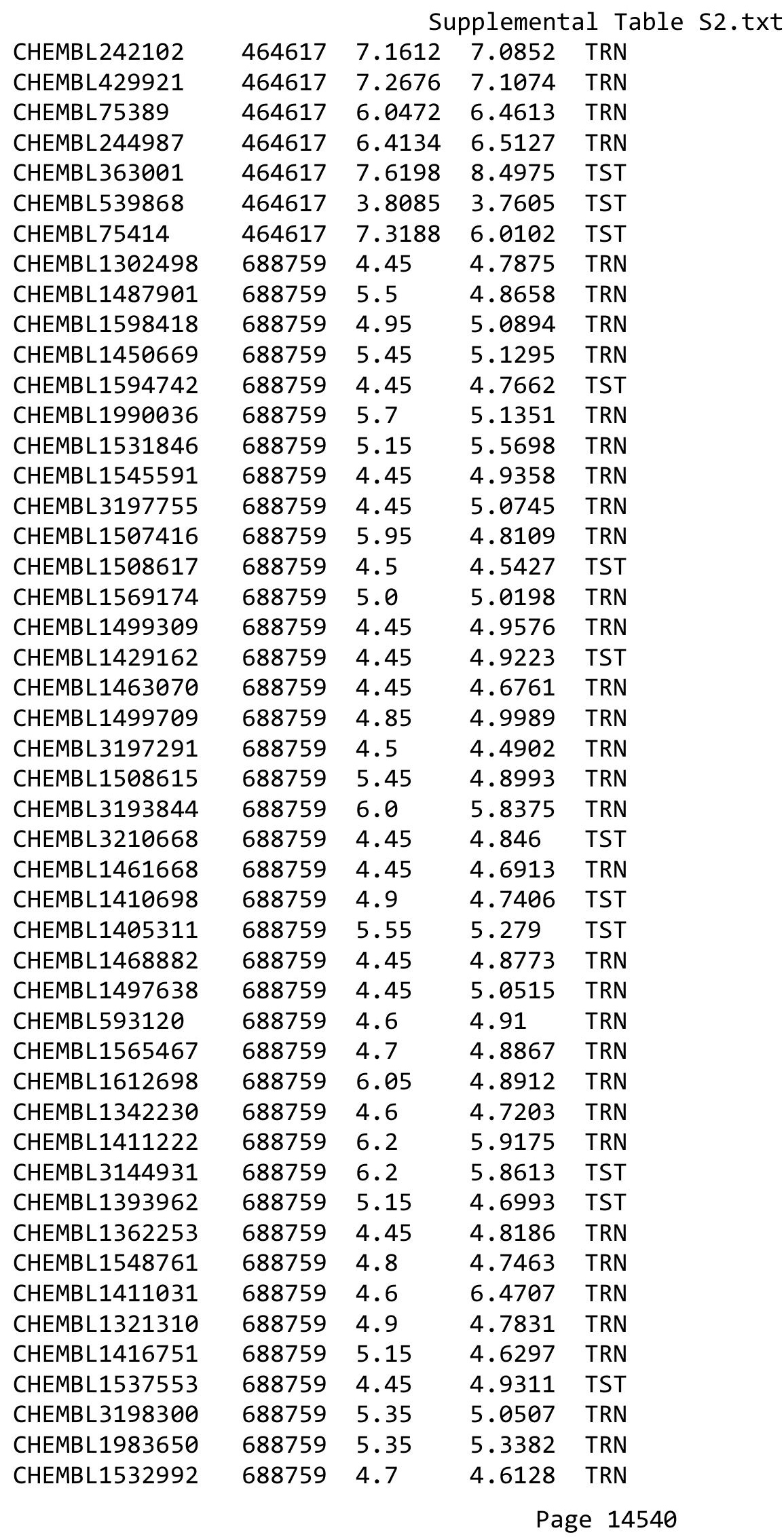




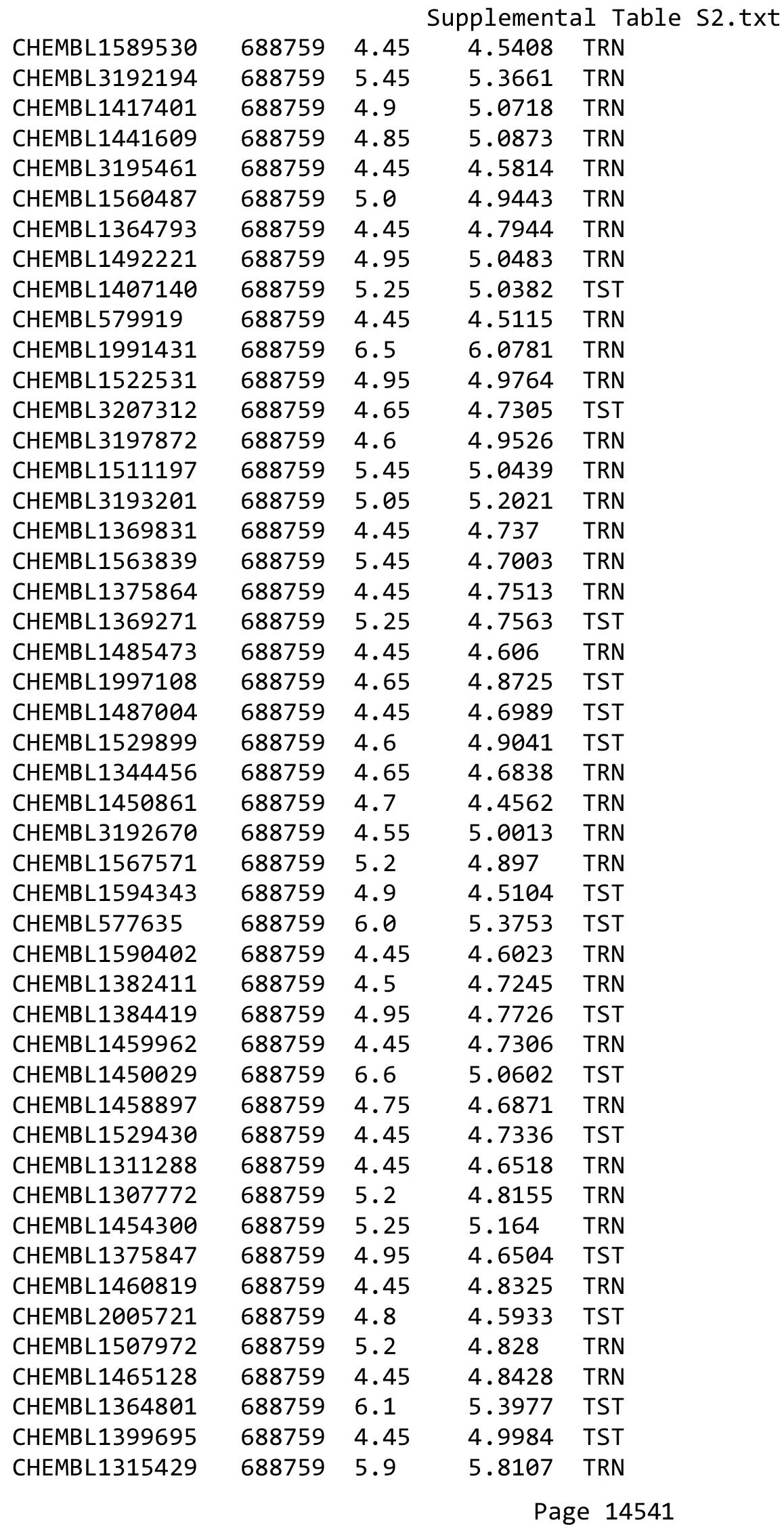




\begin{tabular}{|c|c|c|c|c|c|}
\hline & & \multicolumn{4}{|c|}{ Supplemental Table S2.txt } \\
\hline CHEMBL1362503 & 688759 & 4.7 & 4.7532 & TRN & \\
\hline CHEMBL1392538 & 688759 & 4.45 & 5.0852 & TRN & \\
\hline CHEMBL1364962 & 688759 & 5.1 & 4.9026 & TST & \\
\hline CHEMBL1469806 & 688759 & 5.2 & 4.8747 & TST & \\
\hline CHEMBL1467991 & 688759 & 4.95 & 4.8744 & TRN & \\
\hline CHEMBL1533563 & 688759 & 4.65 & 4.7652 & TRN & \\
\hline CHEMBL1443694 & 688759 & 4.45 & 4.6758 & TST & \\
\hline CHEMBL1325665 & 688759 & 4.45 & 4.8988 & TRN & \\
\hline CHEMBL1579315 & 688759 & 4.45 & 4.599 & TRN & \\
\hline CHEMBL3198503 & 688759 & 5.4 & 5.4054 & TRN & \\
\hline CHEMBL1420422 & 688759 & 4.8 & 4.9049 & TST & \\
\hline CHEMBL1366281 & 688759 & 4.8 & 4.9734 & TRN & \\
\hline CHEMBL1543956 & 688759 & 4.9 & 5.0531 & TST & \\
\hline CHEMBL1967121 & 688759 & 4.55 & 4.573 & TRN & \\
\hline CHEMBL3198902 & 688759 & 4.7 & 4.9244 & TRN & \\
\hline CHEMBL1467761 & 688759 & 4.5 & 4.5165 & TRN & \\
\hline CHEMBL1420286 & 688759 & 4.45 & 4.6769 & TRN & \\
\hline CHEMBL1577873 & 688759 & 5.1 & 5.1091 & TRN & \\
\hline CHEMBL1431906 & 688759 & 4.95 & 4.7502 & TRN & \\
\hline CHEMBL3189873 & 688759 & 4.75 & 4.8241 & TST & \\
\hline CHEMBL1458541 & 688759 & 4.45 & 4.7573 & TRN & \\
\hline CHEMBL1596460 & 688759 & 4.8 & 4.7101 & TST & \\
\hline CHEMBL1321494 & 688759 & 4.45 & 5.0598 & TRN & \\
\hline CHEMBL3196320 & 688759 & 4.45 & 4.9682 & TST & \\
\hline CHEMBL1351356 & 688759 & 4.6 & 4.7664 & TRN & \\
\hline CHEMBL1592885 & 688759 & 5.65 & 4.9852 & TRN & \\
\hline CHEMBL1495821 & 688759 & 4.5 & 4.7912 & TST & \\
\hline CHEMBL1308122 & 688759 & 4.45 & 4.5572 & TRN & \\
\hline CHEMBL 1387710 & 688759 & 4.45 & 4.8466 & TST & \\
\hline CHEMBL1483819 & 688759 & 5.3 & $5.2410 e$ & 00000000005 & TRN \\
\hline CHEMBL1449057 & 688759 & 5.0 & 4.6542 & TRN & \\
\hline CHEMBL1325550 & 688759 & 4.45 & 4.7622 & TRN & \\
\hline CHEMBL560579 & 688759 & 4.75 & 4.5092 & TST & \\
\hline CHEMBL1972029 & 688759 & 5.35 & 5.3489 & TRN & \\
\hline CHEMBL1544877 & 688759 & 5.1 & 5.1457 & TRN & \\
\hline CHEMBL1365457 & 688759 & 6.0 & 4.5962 & TRN & \\
\hline CHEMBL1965654 & 688759 & 6.0 & 6.074 & TRN & \\
\hline CHEMBL1405352 & 688759 & 5.45 & 4.851 & TRN & \\
\hline CHEMBL1464242 & 688759 & 4.45 & 4.9633 & TRN & \\
\hline CHEMBL1418920 & 688759 & 4.9 & 5.0684 & TRN & \\
\hline CHEMBL1426296 & 688759 & 5.1 & 4.6311 & TST & \\
\hline CHEMBL1332849 & 688759 & 4.95 & 4.7789 & TRN & \\
\hline CHEMBL1353643 & 688759 & 4.5 & 4.5492 & TRN & \\
\hline CHEMBL1465165 & 688759 & 4.85 & 5.4673 & TST & \\
\hline CHEMBL1460111 & 688759 & 4.8 & 4.9009 & TRN & \\
\hline CHEMBL1423257 & 688759 & 5.3 & 5.0709 & TRN & \\
\hline CHEMBL1359093 & 688759 & 6.4 & 4.9184 & TRN & \\
\hline CHEMBL3192927 & 688759 & 4.6 & 4.7831 & TRN & \\
\hline
\end{tabular}




\begin{tabular}{|c|c|c|c|c|}
\hline \multicolumn{5}{|c|}{ Supplemental Table } \\
\hline CHEMBL1530063 & 688759 & 4.55 & 4.8884 & TRN \\
\hline CHEMBL1383944 & 688759 & 4.45 & 4.9984 & TRN \\
\hline CHEMBL3194495 & 688759 & 4.45 & 4.6916 & TRN \\
\hline CHEMBL1535198 & 688759 & 4.45 & 4.6374 & TRN \\
\hline CHEMBL1344618 & 688759 & 5.15 & 5.3532 & TRN \\
\hline CHEMBL578161 & 688759 & 4.45 & 4.8384 & TRN \\
\hline CHEMBL1410641 & 688759 & 4.75 & 4.6643 & TST \\
\hline CHEMBL1973780 & 688759 & 5.65 & 4.9678 & TRN \\
\hline CHEMBL1309559 & 688759 & 5.25 & 4.7132 & TRN \\
\hline CHEMBL1999069 & 688759 & 4.45 & 5.7703 & TRN \\
\hline CHEMBL3194785 & 688759 & 5.35 & 5.0325 & TRN \\
\hline CHEMBL1352444 & 688759 & 4.45 & 5.1272 & TST \\
\hline CHEMBL1550184 & 688759 & 5.3 & 5.0353 & TRN \\
\hline CHEMBL3196656 & 688759 & 4.6 & 5.1156 & TRN \\
\hline CHEMBL1481390 & 688759 & 4.6 & 4.8353 & TRN \\
\hline CHEMBL1393775 & 688759 & 5.2 & 5.1407 & TRN \\
\hline CHEMBL592712 & 688759 & 4.55 & 4.8502 & TST \\
\hline CHEMBL1448729 & 688759 & 5.1 & 4.9916 & TRN \\
\hline CHEMBL1489318 & 688759 & 4.9 & 4.7306 & TRN \\
\hline CHEMBL1360250 & 688759 & 4.45 & 4.8213 & TRN \\
\hline CHEMBL1969293 & 688759 & 4.85 & 4.8462 & TRN \\
\hline CHEMBL1496441 & 688759 & 6.45 & 5.0665 & TRN \\
\hline CHEMBL1501060 & 688759 & 5.3 & 4.9046 & TRN \\
\hline CHEMBL 2436520 & 688759 & 5.5 & 4.7361 & TRN \\
\hline CHEMBL3193578 & 688759 & 5.0 & 4.8676 & TRN \\
\hline CHEMBL1447203 & 688759 & 4.9 & 4.9579 & TRN \\
\hline CHEMBL 2004185 & 688759 & 5.85 & 5.3656 & TRN \\
\hline CHEMBL533602 & 688759 & 5.4 & 5.0274 & TST \\
\hline CHEMBL1433216 & 688759 & 4.45 & 4.7269 & TRN \\
\hline CHEMBL1348584 & 688759 & 4.85 & 5.0644 & TRN \\
\hline CHEMBL1524390 & 688759 & 4.55 & 4.6238 & TST \\
\hline CHEMBL1505571 & 688759 & 4.45 & 4.9451 & TST \\
\hline CHEMBL1412188 & 688759 & 5.0 & 5.2924 & TRN \\
\hline CHEMBL1586625 & 688759 & 5.3 & 5.0575 & TST \\
\hline CHEMBL579837 & 688759 & 4.65 & 4.3872 & TRN \\
\hline CHEMBL1529404 & 688759 & 5.05 & 5.1933 & TRN \\
\hline CHEMBL1585557 & 688759 & 5.45 & 5.2276 & TRN \\
\hline CHEMBL1404911 & 688759 & 4.9 & 4.4424 & TRN \\
\hline CHEMBL1374398 & 688759 & 5.25 & 5.003 & TRN \\
\hline CHEMBL1506537 & 688759 & 6.3 & 4.7123 & TST \\
\hline CHEMBL1401425 & 688759 & 4.55 & 5.0291 & TRN \\
\hline CHEMBL1310662 & 688759 & 4.45 & 4.9303 & TRN \\
\hline CHEMBL3191296 & 688759 & 4.85 & 4.8956 & TRN \\
\hline CHEMBL1479205 & 688759 & 4.95 & 4.8208 & TST \\
\hline CHEMBL1457311 & 688759 & 5.1 & 4.8648 & TRN \\
\hline CHEMBL1386431 & 688759 & 4.8 & 5.0741 & TRN \\
\hline CHEMBL1494959 & 688759 & 4.45 & 4.8083 & TRN \\
\hline CHEMBL3189469 & 688759 & 4.8 & 5.0707 & TRN \\
\hline
\end{tabular}




\begin{tabular}{|c|c|c|c|c|}
\hline \multicolumn{5}{|c|}{ Supplemental Table S2.txt } \\
\hline CHEMBL1421080 & 688759 & 4.45 & 4.5264 & TRN \\
\hline CHEMBL1304478 & 688759 & 4.6 & 4.6073 & TRN \\
\hline CHEMBL1452159 & 688759 & 5.8 & 5.7552 & TRN \\
\hline CHEMBL1360435 & 688759 & 4.45 & 4.6057 & TRN \\
\hline CHEMBL1440709 & 688759 & 7.699 & 4.926 & TRN \\
\hline CHEMBL1594541 & 688759 & 5.0 & 4.8092 & TRN \\
\hline CHEMBL1369137 & 688759 & 4.9 & 4.5624 & TRN \\
\hline CHEMBL1303543 & 688759 & 5.2 & 4.8011 & TST \\
\hline CHEMBL1539860 & 688759 & 5.3 & 5.2759 & TRN \\
\hline CHEMBL1311900 & 688759 & 5.15 & 4.7325 & TST \\
\hline CHEMBL1425545 & 688759 & 5.5 & 4.8325 & TST \\
\hline CHEMBL1582691 & 688759 & 4.45 & 4.7305 & TRN \\
\hline CHEMBL3193313 & 688759 & 4.45 & 4.9594 & TRN \\
\hline CHEMBL1459004 & 688759 & 4.5 & 5.0376 & TRN \\
\hline CHEMBL1500425 & 688759 & 4.65 & 4.8883 & TRN \\
\hline CHEMBL3207727 & 688759 & 5.25 & 4.8094 & TRN \\
\hline CHEMBL1426814 & 688759 & 4.45 & 4.8514 & TRN \\
\hline CHEMBL1460564 & 688759 & 4.95 & 4.7492 & TRN \\
\hline CHEMBL1567639 & 688759 & 4.5 & 4.7118 & TRN \\
\hline CHEMBL1308862 & 688759 & 5.35 & 4.7539 & TRN \\
\hline CHEMBL1534865 & 688759 & 5.55 & 4.94 & TST \\
\hline CHEMBL1500327 & 688759 & 4.9 & 4.9027 & TRN \\
\hline CHEMBL1392327 & 688759 & 7.3497 & 6.1113 & TRN \\
\hline CHEMBL1478401 & 688759 & 4.5 & 4.6894 & TRN \\
\hline CHEMBL1306125 & 688759 & 4.7 & 4.6158 & TRN \\
\hline CHEMBL1497937 & 688759 & 4.75 & 4.9546 & TRN \\
\hline CHEMBL1337364 & 688759 & 6.25 & 5.0756 & TRN \\
\hline CHEMBL1429331 & 688759 & 4.45 & 4.8266 & TRN \\
\hline CHEMBL1359521 & 688759 & 6.1 & 5.1842 & TRN \\
\hline CHEMBL1612112 & 688759 & 4.6 & 4.7041 & TRN \\
\hline CHEMBL1405754 & 688759 & 5.9 & 4.9839 & TRN \\
\hline CHEMBL1509975 & 688759 & 5.15 & 4.6 & TRN \\
\hline CHEMBL1494527 & 688759 & 5.1 & 4.4961 & TRN \\
\hline CHEMBL1470558 & 688759 & 4.45 & 4.8567 & TRN \\
\hline CHEMBL1415312 & 688759 & 5.55 & 5.1216 & TRN \\
\hline CHEMBL1325241 & 688759 & 4.55 & 4.7717 & TST \\
\hline CHEMBL 1478175 & 688759 & 4.45 & 4.6773 & TRN \\
\hline CHEMBL125044 & 688759 & 5.55 & 5.3762 & TRN \\
\hline CHEMBL1321721 & 688759 & 5.15 & 4.9239 & TRN \\
\hline CHEMBL1502098 & 688759 & 4.45 & 4.7977 & TRN \\
\hline CHEMBL1601116 & 688759 & 4.45 & 4.7984 & TRN \\
\hline CHEMBL 2004475 & 688759 & 4.95 & 4.9564 & TST \\
\hline CHEMBL1360126 & 688759 & 5.05 & 4.9811 & TST \\
\hline CHEMBL1352116 & 688759 & 4.45 & 4.7288 & TST \\
\hline CHEMBL1506641 & 688759 & 5.0 & 4.6843 & TRN \\
\hline CHEMBL1527183 & 688759 & 4.45 & 4.7587 & TRN \\
\hline CHEMBL1549952 & 688759 & 5.2 & 4.7582 & TST \\
\hline CHEMBL1402954 & 688759 & 4.95 & 5.6826 & TST \\
\hline
\end{tabular}




\begin{tabular}{|c|c|c|c|c|c|}
\hline \multicolumn{6}{|c|}{ Supplemental Table S2.txt } \\
\hline CHEMBL1591543 & 688759 & 4.45 & 4.7974 & TRN & \\
\hline CHEMBL586061 & 688759 & 5.9 & 5.0465 & TRN & \\
\hline CHEMBL1495234 & 688759 & 5.45 & 5.0054 & TRN & \\
\hline CHEMBL1532941 & 688759 & 5.3 & 5.3538 & TRN & \\
\hline CHEMBL1309169 & 688759 & 4.45 & 4.9885 & TST & \\
\hline CHEMBL 3214435 & 688759 & 4.95 & 4.8265 & TRN & \\
\hline CHEMBL1405279 & 688759 & 4.6 & 4.9656 & TST & \\
\hline CHEMBL 3208587 & 688759 & 4.75 & 4.8465 & TRN & \\
\hline CHEMBL1489201 & 688759 & 5.0 & 4.7892 & TRN & \\
\hline CHEMBL1573697 & 688759 & 5.55 & 5.2861 & TRN & \\
\hline CHEMBL1523463 & 688759 & 4.6 & 4.7031 & TRN & \\
\hline CHEMBL1481422 & 688759 & 4.45 & 4.7012 & TST & \\
\hline CHEMBL1387499 & 688759 & 4.5 & 4.4616 & TRN & \\
\hline CHEMBL 3214515 & 688759 & 6.0 & 5.3807 & TRN & \\
\hline CHEMBL1345299 & 688759 & 5.15 & 5.1322 & TRN & \\
\hline CHEMBL1531523 & 688759 & 4.45 & 4.8592 & TRN & \\
\hline CHEMBL1577776 & 688759 & 4.45 & 4.5613 & TST & \\
\hline CHEMBL 2000945 & 688759 & 5.85 & 5.6387 & TRN & \\
\hline CHEMBL1465621 & 688759 & 4.75 & 4.7985 & TRN & \\
\hline CHEMBL1503689 & 688759 & 4.45 & 4.631 & TRN & \\
\hline CHEMBL1323186 & 688759 & 4.65 & 4.7069 & TRN & \\
\hline CHEMBL1319889 & 688759 & 4.45 & 4.7887 & TRN & \\
\hline CHEMBL1348606 & 688759 & 4.9 & 4.993 & TRN & \\
\hline CHEMBL1401424 & 688759 & 7.0501 & 4.9171 & TRN & \\
\hline CHEMBL1483038 & 688759 & 5.65 & 5.4595 & TRN & \\
\hline CHEMBL1311730 & 688759 & 5.4 & 4.9173 & TST & \\
\hline CHEMBL407817 & 688759 & 6.1 & 5.3396 & TST & \\
\hline CHEMBL1613164 & 688759 & 6.25 & $4.9830 e$ & 00000000005 & TRN \\
\hline CHEMBL 3189381 & 688759 & 4.45 & 4.8068 & TRN & \\
\hline CHEMBL1499845 & 688759 & 4.45 & 4.9152 & TRN & \\
\hline CHEMBL1611476 & 688759 & 4.45 & 4.7218 & TRN & \\
\hline CHEMBL1366478 & 688759 & 6.5 & 5.5468 & TRN & \\
\hline CHEMBL1971072 & 688759 & 4.6 & 4.7552 & TRN & \\
\hline CHEMBL1528905 & 688759 & 5.0 & 4.9262 & TRN & \\
\hline CHEMBL1452379 & 688759 & 5.5 & 5.1136 & TST & \\
\hline CHEMBL 3212735 & 688759 & 5.0 & 5.1607 & TRN & \\
\hline CHEMBL1587259 & 688759 & 4.45 & 4.8275 & TRN & \\
\hline CHEMBL1341160 & 688759 & 5.45 & 4.9166 & TRN & \\
\hline CHEMBL1413495 & 688759 & 4.45 & 4.6644 & TRN & \\
\hline CHEMBL1456825 & 688759 & 4.45 & 4.8692 & TRN & \\
\hline CHEMBL1394341 & 688759 & 5.05 & 4.6795 & TST & \\
\hline CHEMBL1423331 & 688759 & 5.15 & 5.1435 & TRN & \\
\hline CHEMBL1609569 & 688759 & 4.45 & 4.8981 & TST & \\
\hline CHEMBL 3198332 & 688759 & 5.25 & 5.3919 & TRN & \\
\hline CHEMBL1381965 & 688759 & 5.55 & 5.651 & TRN & \\
\hline CHEMBL1608596 & 688759 & 5.25 & 5.1833 & TRN & \\
\hline CHEMBL1373987 & 688759 & 4.95 & 4.731 & TRN & \\
\hline CHEMBL1609373 & 688759 & 4.75 & 4.9473 & TRN & \\
\hline
\end{tabular}




\begin{tabular}{|c|c|c|c|c|}
\hline & & & oplement & al $\mathrm{Ta}$ \\
\hline CHEMBL1500395 & 688759 & 6.3 & 5.0565 & TRN \\
\hline CHEMBL1413672 & 688759 & 4.7 & 4.7983 & TRN \\
\hline CHEMBL1423004 & 688759 & 8.6576 & 4.6918 & TST \\
\hline CHEMBL599291 & 688759 & 5.1 & 4.6976 & TRN \\
\hline CHEMBL 3193235 & 688759 & 4.9 & 5.3767 & TRN \\
\hline CHEMBL1485443 & 688759 & 4.75 & 4.6421 & TRN \\
\hline CHEMBL1518905 & 688759 & 5.4 & 5.7751 & TRN \\
\hline CHEMBL1489786 & 688759 & 4.45 & 5.0169 & TRN \\
\hline CHEMBL1413623 & 688759 & 4.85 & 4.8389 & TST \\
\hline CHEMBL1501751 & 688759 & 5.35 & 5.1249 & TRN \\
\hline CHEMBL1379008 & 688759 & 4.45 & 4.5924 & TRN \\
\hline CHEMBL1563198 & 688759 & 4.85 & 4.4389 & TRN \\
\hline CHEMBL1339221 & 688759 & 5.4 & 4.9493 & TRN \\
\hline CHEMBL3197193 & 688759 & 5.0 & 4.6957 & TRN \\
\hline CHEMBL236685 & 688759 & 4.45 & 4.8754 & TST \\
\hline CHEMBL 2000517 & 688759 & 4.9 & 5.1089 & TRN \\
\hline CHEMBL1446353 & 688759 & 5.15 & 4.7457 & TRN \\
\hline CHEMBL1405400 & 688759 & 5.25 & 4.9271 & TRN \\
\hline CHEMBL1529876 & 688759 & 4.6 & 5.1236 & TRN \\
\hline CHEMBL1380279 & 688759 & 4.45 & 4.5862 & TRN \\
\hline CHEMBL1390891 & 688759 & 5.25 & 5.0228 & TST \\
\hline CHEMBL1497127 & 688759 & 4.45 & 4.7974 & TRN \\
\hline CHEMBL1528475 & 688759 & 5.55 & 4.942 & TRN \\
\hline CHEMBL1362271 & 688759 & 4.5 & 4.6427 & TRN \\
\hline CHEMBL1350693 & 688759 & 4.45 & 4.8259 & TST \\
\hline CHEMBL3212594 & 688759 & 4.8 & 4.8473 & TRN \\
\hline CHEMBL1459125 & 688759 & 4.45 & 4.6122 & TRN \\
\hline CHEMBL1424862 & 688759 & 4.45 & 4.835 & TST \\
\hline CHEMBL1549231 & 688759 & 5.35 & 5.1164 & TRN \\
\hline CHEMBL1455588 & 688759 & 4.45 & 5.0268 & TRN \\
\hline CHEMBL1423129 & 688759 & 5.1 & 5.0224 & TRN \\
\hline CHEMBL1477357 & 688759 & 4.95 & 4.8795 & TRN \\
\hline CHEMBL1594512 & 688759 & 5.15 & 4.9475 & TRN \\
\hline CHEMBL3194818 & 688759 & 4.9 & 4.9211 & TRN \\
\hline CHEMBL1464022 & 688759 & 4.9 & 4.9774 & TRN \\
\hline CHEMBL1359315 & 688759 & 5.45 & 5.1097 & TRN \\
\hline CHEMBL1458881 & 688759 & 4.45 & 4.6848 & TRN \\
\hline CHEMBL3198440 & 688759 & 4.45 & 4.579 & TRN \\
\hline CHEMBL1570479 & 688759 & 4.8 & 4.9691 & TRN \\
\hline CHEMBL1461551 & 688759 & 4.65 & 4.5626 & TST \\
\hline CHEMBL1332188 & 688759 & 5.9 & 5.0336 & TRN \\
\hline CHEMBL1524022 & 688759 & 4.45 & 4.9923 & TRN \\
\hline CHEMBL1523841 & 688759 & 4.9 & 4.8942 & TST \\
\hline CHEMBL1457388 & 688759 & 5.2 & 5.1072 & TST \\
\hline CHEMBL1578853 & 688759 & 6.7001 & 4.9456 & TRN \\
\hline CHEMBL3211905 & 688759 & 4.45 & 4.743 & TRN \\
\hline CHEMBL477139 & 688759 & 4.45 & 4.9919 & TRN \\
\hline CHEMBL1484260 & 688759 & 4.45 & 4.5971 & TRN \\
\hline
\end{tabular}




\begin{tabular}{|c|c|c|c|c|c|}
\hline \multicolumn{6}{|c|}{ Supplemental Table S2.txt } \\
\hline CHEMBL 3214426 & 688759 & 4.6 & 4.7385 & TRN & \\
\hline CHEMBL1457402 & 688759 & 4.95 & 4.9676 & TRN & \\
\hline CHEMBL1558216 & 688759 & 4.95 & 4.883 & TST & \\
\hline CHEMBL1425919 & 688759 & 4.7 & 4.898 & TRN & \\
\hline CHEMBL1468164 & 688759 & 5.25 & 4.909 & TST & \\
\hline CHEMBL1573250 & 688759 & 6.45 & 5.3717 & TRN & \\
\hline CHEMBL1365808 & 688759 & 5.5 & 4.8706 & TST & \\
\hline CHEMBL1305605 & 688759 & 5.0 & 5.1009 & TRN & \\
\hline CHEMBL1576858 & 688759 & 4.55 & 4.6838 & TRN & \\
\hline CHEMBL1596599 & 688759 & 4.6 & 4.4648 & TRN & \\
\hline CHEMBL1440926 & 688759 & 4.7 & 4.9275 & TRN & \\
\hline CHEMBL1532068 & 688759 & 4.65 & 5.41299 & 9999999999 & TRN \\
\hline CHEMBL3194503 & 688759 & 4.6 & 4.8013 & TRN & \\
\hline CHEMBL1589670 & 688759 & 5.7 & 5.5861 & TRN & \\
\hline CHEMBL1422340 & 688759 & 5.9 & 5.6451 & TRN & \\
\hline CHEMBL1488020 & 688759 & 5.0 & 5.0494 & TRN & \\
\hline CHEMBL1599767 & 688759 & 4.45 & 5.1361 & TRN & \\
\hline CHEMBL3199906 & 688759 & 4.5 & 4.6544 & TRN & \\
\hline CHEMBL1365069 & 688759 & 5.2 & 5.2635 & TRN & \\
\hline CHEMBL1509579 & 688759 & 4.8 & 4.9511 & TRN & \\
\hline CHEMBL3197362 & 688759 & 4.9 & 4.9219 & TRN & \\
\hline CHEMBL1984688 & 688759 & 5.15 & 5.5547 & TRN & \\
\hline CHEMBL1572296 & 688759 & 4.75 & 4.9606 & TRN & \\
\hline CHEMBL1463769 & 688759 & 4.7 & 4.5632 & TRN & \\
\hline CHEMBL1304514 & 688759 & 4.65 & 4.6474 & TRN & \\
\hline CHEMBL1550586 & 688759 & 5.25 & 4.8444 & TRN & \\
\hline CHEMBL1429289 & 688759 & 4.45 & 4.772 & TRN & \\
\hline CHEMBL1431795 & 688759 & 4.95 & 4.8745 & TRN & \\
\hline CHEMBL3145362 & 688759 & 6.4 & 6.1006 & TRN & \\
\hline CHEMBL1497625 & 688759 & 5.85 & 4.675 & TRN & \\
\hline CHEMBL1490871 & 688759 & 5.05 & 5.0023 & TRN & \\
\hline CHEMBL1575214 & 688759 & 4.8 & 4.827 & TRN & \\
\hline CHEMBL1550509 & 688759 & 4.45 & 4.9405 & TST & \\
\hline CHEMBL1467133 & 688759 & 4.45 & 4.8932 & TRN & \\
\hline CHEMBL1494843 & 688759 & 4.45 & 4.8285 & TRN & \\
\hline CHEMBL1419030 & 688759 & 4.55 & 4.8921 & TRN & \\
\hline CHEMBL1327366 & 688759 & 4.45 & 4.7337 & TST & \\
\hline CHEMBL1412013 & 688759 & 6.1 & 4.8081 & TRN & \\
\hline CHEMBL1351501 & 688759 & 4.45 & 4.698 & TRN & \\
\hline CHEMBL3191302 & 688759 & 5.15 & 5.1096 & TRN & \\
\hline CHEMBL1390986 & 688759 & 4.45 & 4.8364 & TRN & \\
\hline CHEMBL1373897 & 688759 & 5.85 & 4.9463 & TRN & \\
\hline CHEMBL1359650 & 688759 & 5.25 & 4.7624 & TRN & \\
\hline CHEMBL1462265 & 688759 & 4.45 & 4.925 & TST & \\
\hline CHEMBL1381034 & 688759 & 4.65 & 4.8043 & TRN & \\
\hline CHEMBL1367316 & 688759 & 5.3 & 5.117 & TST & \\
\hline CHEMBL1456670 & 688759 & 5.0 & 4.9229 & TST & \\
\hline CHEMBL1457272 & 688759 & 4.8 & 4.8451 & TRN & \\
\hline
\end{tabular}




\begin{tabular}{|c|c|c|c|c|}
\hline \multicolumn{5}{|c|}{ Supplemental Table S2.txt } \\
\hline CHEMBL1524722 & 688759 & 4.45 & 4.8168 & TRN \\
\hline CHEMBL1300082 & 688759 & 4.45 & 5.0325 & TST \\
\hline CHEMBL1552163 & 688759 & 4.8 & 4.967 & TRN \\
\hline CHEMBL1340454 & 688759 & 5.0 & 4.547 & TRN \\
\hline CHEMBL1429967 & 688759 & 4.8 & 4.92899 & 9999999999 \\
\hline CHEMBL1541987 & 688759 & 5.0 & 5.0048 & TST \\
\hline CHEMBL1441404 & 688759 & 5.4 & 4.7817 & TRN \\
\hline CHEMBL1309466 & 688759 & 5.1 & 4.978 & TRN \\
\hline CHEMBL1370177 & 688759 & 4.85 & 4.8729 & TRN \\
\hline CHEMBL1607793 & 688759 & 4.8 & 4.7936 & TST \\
\hline CHEMBL1511404 & 688759 & 4.45 & 4.7703 & TRN \\
\hline CHEMBL1351166 & 688759 & 5.15 & 4.8184 & TRN \\
\hline CHEMBL1995681 & 688759 & 4.45 & 4.7509 & TRN \\
\hline CHEMBL1372732 & 688759 & 4.45 & 4.8038 & TST \\
\hline CHEMBL1317588 & 688759 & 6.05 & 5.1049 & TST \\
\hline CHEMBL1420268 & 688759 & 4.65 & 4.6952 & TST \\
\hline CHEMBL1431685 & 688759 & 4.6 & 4.782 & TRN \\
\hline CHEMBL1606709 & 688759 & 5.75 & 5.5176 & TRN \\
\hline CHEMBL1508649 & 688759 & 4.6 & 4.9826 & TRN \\
\hline CHEMBL1399269 & 688759 & 4.45 & 4.9402 & TRN \\
\hline CHEMBL1531728 & 688759 & 4.6 & 4.7684 & TRN \\
\hline CHEMBL1319432 & 688759 & 4.45 & 4.6682 & TST \\
\hline CHEMBL1362188 & 688759 & 4.45 & 5.0993 & TRN \\
\hline CHEMBL1525157 & 688759 & 4.9 & 4.9473 & TST \\
\hline CHEMBL1415675 & 688759 & 4.45 & 4.8667 & TRN \\
\hline CHEMBL1368758 & 688759 & 4.8 & 4.8619 & TST \\
\hline CHEMBL1555845 & 688759 & 4.75 & 4.7012 & TRN \\
\hline CHEMBL1485898 & 688759 & 4.45 & 4.9052 & TRN \\
\hline CHEMBL1345053 & 688759 & 4.65 & 4.6288 & TRN \\
\hline CHEMBL1432210 & 688759 & 4.65 & 4.6617 & TRN \\
\hline CHEMBL1569414 & 688759 & 4.45 & 4.5551 & TRN \\
\hline CHEMBL224869 & 688759 & 5.35 & 4.9163 & TRN \\
\hline CHEMBL1352573 & 688759 & 4.6 & 4.8851 & TRN \\
\hline CHEMBL3194772 & 688759 & 4.9 & 4.9095 & TRN \\
\hline CHEMBL1405433 & 688759 & 4.65 & 4.6503 & TRN \\
\hline CHEMBL1467284 & 688759 & 4.45 & 4.8889 & TRN \\
\hline CHEMBL1424636 & 688759 & 4.7 & 4.9465 & TRN \\
\hline CHEMBL1412094 & 688759 & 4.8 & 4.9325 & TRN \\
\hline CHEMBL3192970 & 688759 & 4.45 & 4.9702 & TST \\
\hline CHEMBL3207760 & 688759 & 5.4 & 4.9317 & TRN \\
\hline CHEMBL1363565 & 688759 & 4.65 & 4.5926 & TRN \\
\hline CHEMBL1381082 & 688759 & 4.5 & 4.7168 & TRN \\
\hline CHEMBL1468075 & 688759 & 5.0 & 4.8301 & TRN \\
\hline CHEMBL1341850 & 688759 & 4.85 & 4.9855 & TRN \\
\hline CHEMBL1391047 & 688759 & 5.2 & 5.0412 & TRN \\
\hline CHEMBL1573754 & 688759 & 4.6 & 5.1637 & TST \\
\hline CHEMBL1992283 & 688759 & 4.45 & 4.4621 & TRN \\
\hline CHEMBL1546196 & 688759 & 4.95 & 5.0741 & TRN \\
\hline
\end{tabular}




\begin{tabular}{|c|c|c|c|c|c|}
\hline & & \multicolumn{4}{|c|}{ Supplemental Table S2.txt } \\
\hline CHEMBL1506141 & 688759 & 6.15 & 4.865 & TRN & \\
\hline CHEMBL1359879 & 688759 & 5.35 & 5.6871 & TRN & \\
\hline CHEMBL1323135 & 688759 & 4.65 & 4.9193 & TST & \\
\hline CHEMBL1304291 & 688759 & 5.0 & 5.5297 & TRN & \\
\hline CHEMBL3212655 & 688759 & 5.2 & 4.9907 & TRN & \\
\hline CHEMBL 2006848 & 688759 & 5.4 & 4.9797 & TRN & \\
\hline CHEMBL3190433 & 688759 & 5.7 & 5.6247 & TRN & \\
\hline CHEMBL1403041 & 688759 & 5.05 & 5.1403 & TRN & \\
\hline CHEMBL1432186 & 688759 & 5.15 & 4.8364 & TRN & \\
\hline CHEMBL1603655 & 688759 & 6.35 & 4.8985 & TRN & \\
\hline CHEMBL1510116 & 688759 & 5.15 & 5.0261 & TRN & \\
\hline CHEMBL1570776 & 688759 & 4.95 & 4.7117 & TRN & \\
\hline CHEMBL1517542 & 688759 & 4.65 & 4.9832 & TRN & \\
\hline CHEMBL1504970 & 688759 & 4.95 & 4.9797 & TRN & \\
\hline CHEMBL1575590 & 688759 & 4.45 & 4.5949 & TRN & \\
\hline CHEMBL 260311 & 688759 & 4.9 & 5.4981 & TRN & \\
\hline CHEMBL1370839 & 688759 & 4.6 & 4.9701 & TRN & \\
\hline CHEMBL1359848 & 688759 & 5.2 & 5.142 & TRN & \\
\hline CHEMBL1389268 & 688759 & 6.0 & 5.2838 & TRN & \\
\hline CHEMBL1468982 & 688759 & 4.5 & 4.8181 & TRN & \\
\hline CHEMBL1373655 & 688759 & 5.0 & 5.1387 & TRN & \\
\hline CHEMBL1461168 & 688759 & 4.55 & 4.9429 & TRN & \\
\hline CHEMBL1439624 & 688759 & 4.6 & 5.2291 & TST & \\
\hline CHEMBL1527503 & 688759 & 5.95 & 4.9567 & TST & \\
\hline CHEMBL1319439 & 688759 & 4.45 & 4.8286 & TRN & \\
\hline CHEMBL1466310 & 688759 & 4.45 & 4.7395 & TST & \\
\hline CHEMBL1485466 & 688759 & 4.95 & 4.596 & TRN & \\
\hline CHEMBL3197275 & 688759 & 4.45 & 5.0666 & TRN & \\
\hline CHEMBL1481095 & 688759 & 4.85 & 5.011 & TST & \\
\hline CHEMBL1506477 & 688759 & 4.45 & 4.8583 & TRN & \\
\hline CHEMBL1571464 & 688759 & 4.55 & 4.7492 & TRN & \\
\hline CHEMBL1420415 & 688759 & 4.45 & 4.6849 & TRN & \\
\hline CHEMBL3193623 & 688759 & 6.25 & 5.4247 & TST & \\
\hline CHEMBL3192479 & 688759 & 4.65 & 4.7699 & TRN & \\
\hline CHEMBL1368484 & 688759 & 4.45 & 4.6732 & TRN & \\
\hline CHEMBL1496819 & 688759 & 4.45 & 4.625 & TRN & \\
\hline CHEMBL1445599 & 688759 & 4.9 & 4.7811 & TST & \\
\hline CHEMBL1522096 & 688759 & 4.45 & 4.7233 & TRN & \\
\hline CHEMBL1572664 & 688759 & 4.6 & 4.9555 & TRN & \\
\hline CHEMBL1517756 & 688759 & 4.85 & 4.7167 & TRN & \\
\hline CHEMBL1384559 & 688759 & 4.45 & $4.5280 e$ & 00000000005 & TRN \\
\hline CHEMBL1304399 & 688759 & 4.45 & 4.5953 & TRN & \\
\hline CHEMBL1546120 & 688759 & 4.45 & 4.7752 & TRN & \\
\hline CHEMBL3190818 & 688759 & 5.2 & 4.8915 & TST & \\
\hline CHEMBL1486191 & 688759 & 5.3 & 5.5722 & TST & \\
\hline CHEMBL1357180 & 688759 & 4.9 & 5.0 & TST & \\
\hline CHEMBL1537369 & 688759 & 4.75 & 5.113 & TRN & \\
\hline CHEMBL1341529 & 688759 & 7.15 & 5.0395 & TRN & \\
\hline
\end{tabular}




\begin{tabular}{|c|c|c|c|c|c|}
\hline & & \multicolumn{4}{|c|}{ Supplemental Table S2.txt } \\
\hline CHEMBL1366059 & 688759 & 5.25 & 4.9206 & TST & \\
\hline CHEMBL1329018 & 688759 & 4.45 & 4.6398 & TRN & \\
\hline CHEMBL592184 & 688759 & 4.7 & 4.8798 & TST & \\
\hline CHEMBL525826 & 688759 & 4.45 & 4.7415 & TST & \\
\hline CHEMBL1432330 & 688759 & 4.9 & 4.9618 & TRN & \\
\hline CHEMBL3194361 & 688759 & 4.9 & 5.0757 & TRN & \\
\hline CHEMBL1358820 & 688759 & 4.45 & 5.0732 & TRN & \\
\hline CHEMBL1523864 & 688759 & 5.5 & 5.146 & TST & \\
\hline CHEMBL1428765 & 688759 & 5.6 & 4.7462 & TRN & \\
\hline CHEMBL1525615 & 688759 & 4.7 & 4.6078 & TRN & \\
\hline CHEMBL1600901 & 688759 & 4.95 & 5.6469 & TRN & \\
\hline CHEMBL1423992 & 688759 & 5.05 & 5.2993 & TRN & \\
\hline CHEMBL1526981 & 688759 & 4.45 & 4.9285 & TRN & \\
\hline CHEMBL1410075 & 688759 & 4.95 & 5.0367 & TST & \\
\hline CHEMBL587579 & 688759 & 4.65 & 4.8122 & TRN & \\
\hline CHEMBL1330854 & 688759 & 4.65 & 4.7828 & TRN & \\
\hline CHEMBL1484885 & 688759 & 4.45 & 4.6545 & TRN & \\
\hline CHEMBL1610128 & 688759 & 4.45 & 4.7316 & TST & \\
\hline CHEMBL1594948 & 688759 & 4.45 & 4.8959 & TST & \\
\hline CHEMBL1375086 & 688759 & 4.75 & 4.7947 & TST & \\
\hline CHEMBL1511603 & 688759 & 4.45 & 4.9204 & TST & \\
\hline CHEMBL1331199 & 688759 & 4.65 & 5.0427 & TRN & \\
\hline CHEMBL1364777 & 688759 & 4.75 & 4.7572 & TRN & \\
\hline CHEMBL1516583 & 688759 & 4.45 & 4.5949 & TRN & \\
\hline CHEMBL1505142 & 688759 & 4.95 & 4.6524 & TRN & \\
\hline CHEMBL1478651 & 688759 & 4.6 & 4.5954 & TRN & \\
\hline CHEMBL1485452 & 688759 & 4.75 & 4.9389 & TRN & \\
\hline CHEMBL1429000 & 688759 & 4.8 & 4.5176 & TRN & \\
\hline CHEMBL1540716 & 688759 & 4.95 & 4.9813 & TRN & \\
\hline CHEMBL1312306 & 688759 & 4.45 & 4.6164 & TRN & \\
\hline CHEMBL1567495 & 688759 & 4.8 & 4.7503 & TRN & \\
\hline CHEMBL1435118 & 688759 & 4.6 & 4.7626 & TST & \\
\hline CHEMBL1447656 & 688759 & 4.45 & 4.7279 & TRN & \\
\hline CHEMBL1559115 & 688759 & 4.65 & 5.20299 & 7999999999 & TST \\
\hline CHEMBL1592914 & 688759 & 4.7 & 4.7692 & TST & \\
\hline CHEMBL3199020 & 688759 & 5.15 & 5.4418 & TRN & \\
\hline CHEMBL1349080 & 688759 & 5.05 & 5.0878 & TRN & \\
\hline CHEMBL1314042 & 688759 & 5.15 & 4.8734 & TRN & \\
\hline CHEMBL3190125 & 688759 & 5.95 & 5.1615 & TRN & \\
\hline CHEMBL1412674 & 688759 & 4.7 & 4.7804 & TST & \\
\hline CHEMBL1523465 & 688759 & 5.3 & 4.561 & TRN & \\
\hline CHEMBL166486 & 688759 & 4.65 & 4.9089 & TRN & \\
\hline CHEMBL1577782 & 688759 & 5.3 & 5.0368 & TRN & \\
\hline CHEMBL1605724 & 688759 & 5.95 & 5.801 & TRN & \\
\hline CHEMBL1495782 & 688759 & 4.75 & 4.7944 & TRN & \\
\hline CHEMBL3198047 & 688759 & 4.45 & 4.942 & TRN & \\
\hline CHEMBL1600519 & 688759 & 4.45 & 4.7345 & TRN & \\
\hline CHEMBL1602699 & 688759 & 5.25 & 4.9666 & TST & \\
\hline
\end{tabular}




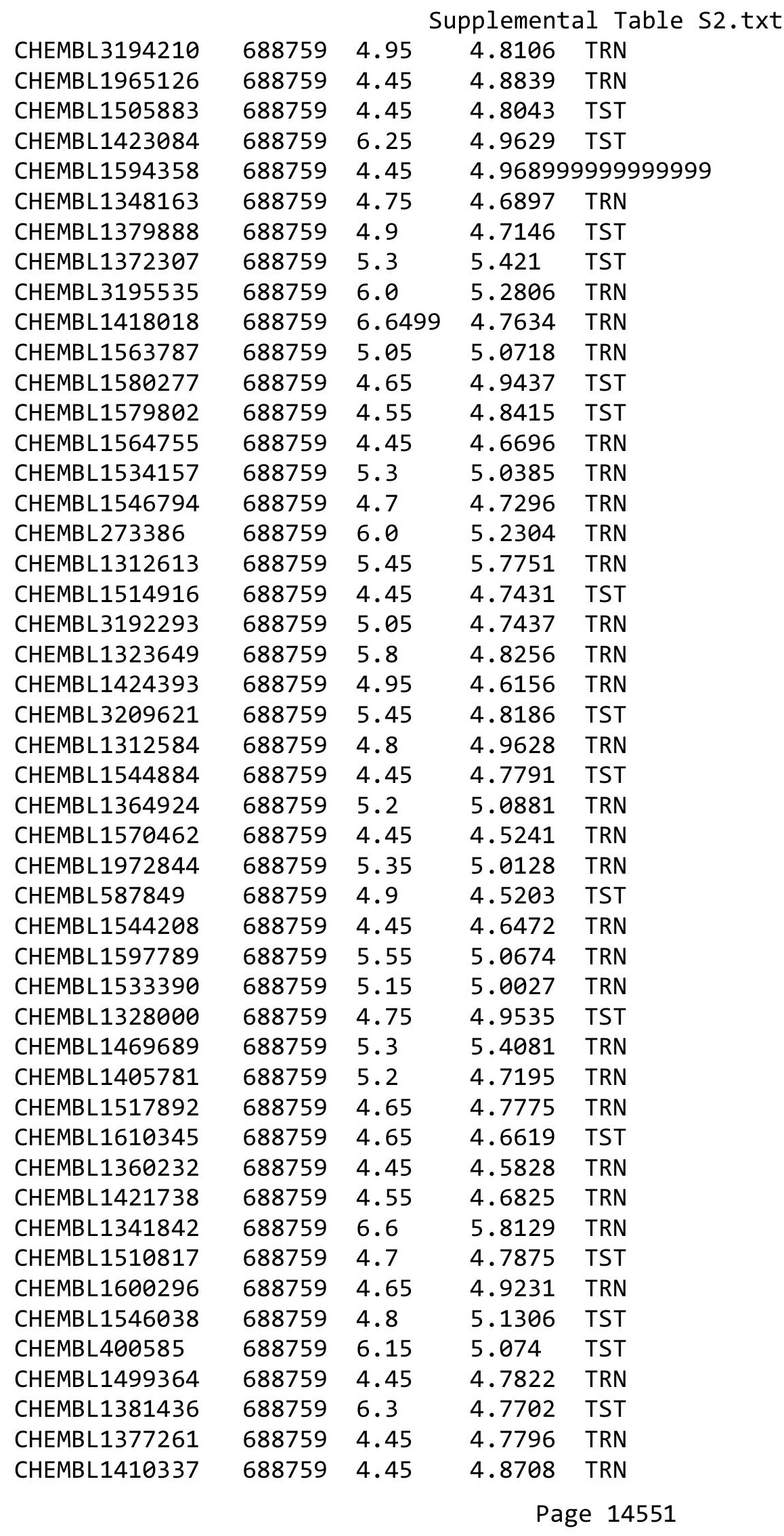

TRN 


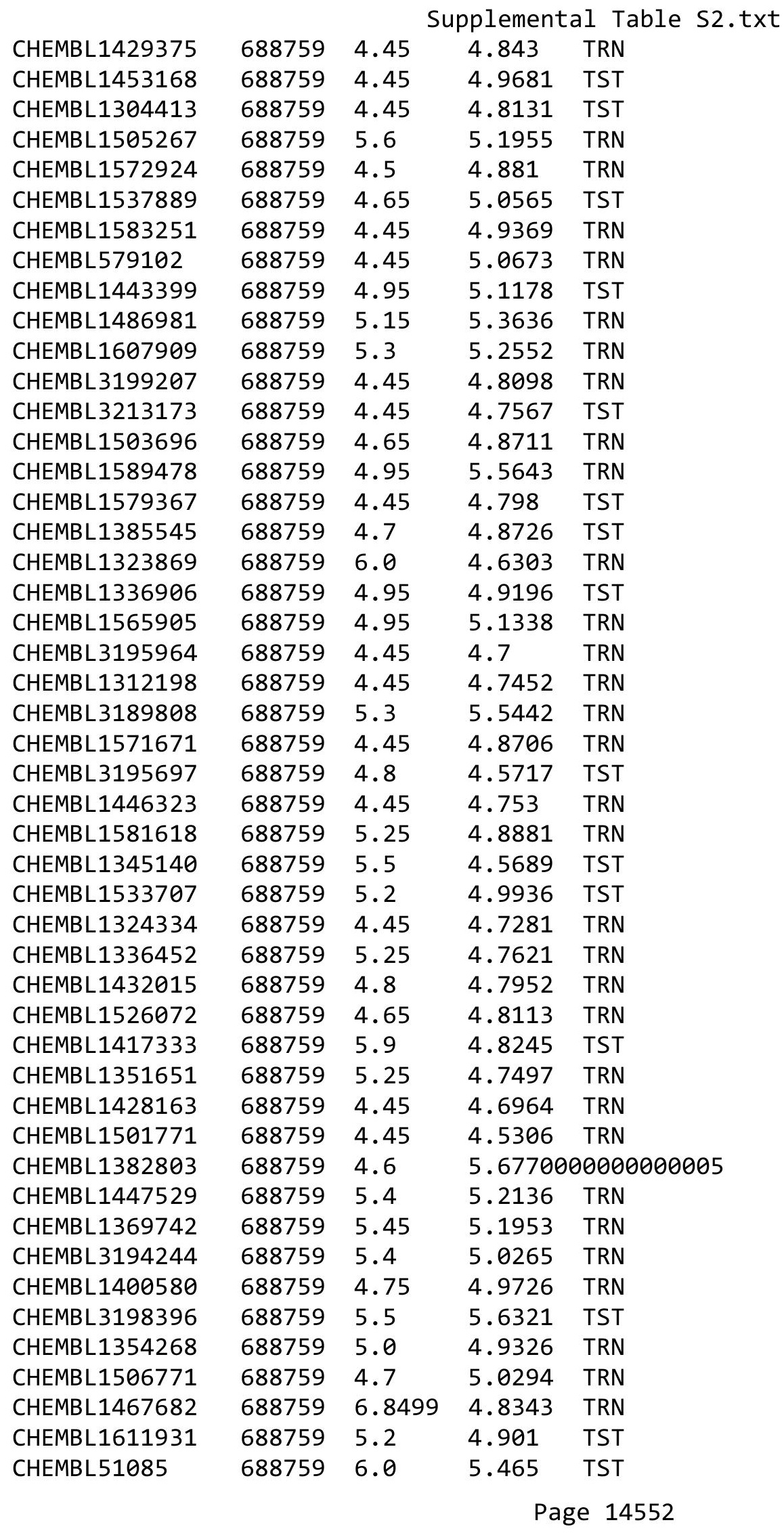




\begin{tabular}{|c|c|c|c|c|}
\hline \multicolumn{5}{|c|}{ Supplemental Table } \\
\hline CHEMBL1534587 & 688759 & 4.45 & 4.875 & TST \\
\hline CHEMBL1480241 & 688759 & 5.0 & 4.5365 & TRN \\
\hline CHEMBL1606036 & 688759 & 4.7 & 4.8728 & TST \\
\hline CHEMBL1362689 & 688759 & 4.65 & 4.6853 & TST \\
\hline CHEMBL1577923 & 688759 & 4.5 & 4.922 & TRN \\
\hline CHEMBL1327750 & 688759 & 4.9 & 4.7522 & TRN \\
\hline CHEMBL1417851 & 688759 & 6.05 & 5.1432 & TRN \\
\hline CHEMBL1995097 & 688759 & 4.95 & 4.9766 & TRN \\
\hline CHEMBL1595601 & 688759 & 4.45 & 4.874 & TRN \\
\hline CHEMBL1374966 & 688759 & 5.1 & 4.9107 & TRN \\
\hline CHEMBL1531226 & 688759 & 4.9 & 4.7436 & TRN \\
\hline CHEMBL1574826 & 688759 & 5.05 & 5.166 & TRN \\
\hline CHEMBL1485861 & 688759 & 4.45 & 4.8408 & TRN \\
\hline CHEMBL1501444 & 688759 & 4.95 & 4.8248 & TRN \\
\hline CHEMBL1538040 & 688759 & 4.7 & 5.0581 & TST \\
\hline CHEMBL1451381 & 688759 & 4.95 & 4.7269 & TRN \\
\hline CHEMBL1455285 & 688759 & 4.65 & 4.8587 & TST \\
\hline CHEMBL1467999 & 688759 & 5.1 & 4.7681 & TRN \\
\hline CHEMBL1588452 & 688759 & 5.35 & 5.5323 & TRN \\
\hline CHEMBL1396713 & 688759 & 6.3 & 4.9306 & TRN \\
\hline CHEMBL1503229 & 688759 & 4.45 & 4.7932 & TST \\
\hline CHEMBL1326819 & 688759 & 4.45 & 4.7346 & TRN \\
\hline CHEMBL338407 & 688759 & 5.3 & 4.9427 & TST \\
\hline CHEMBL1426415 & 688759 & 4.75 & 5.1034 & TST \\
\hline CHEMBL 343002 & 688759 & 4.9 & 5.3695 & TRN \\
\hline CHEMBL1190455 & 688759 & 4.7 & 4.8076 & TST \\
\hline CHEMBL1580176 & 688759 & 5.15 & 4.9837 & TRN \\
\hline CHEMBL1574280 & 688759 & 4.75 & 4.7861 & TST \\
\hline CHEMBL1340321 & 688759 & 4.45 & 4.7184 & TRN \\
\hline CHEMBL1414718 & 688759 & 5.2 & 4.8296 & TRN \\
\hline CHEMBL3198994 & 688759 & 5.4 & 4.9414 & TRN \\
\hline CHEMBL 3199486 & 688759 & 4.6 & 4.6538 & TRN \\
\hline CHEMBL1493396 & 688759 & 4.45 & 4.7018 & TST \\
\hline CHEMBL1310690 & 688759 & 5.1 & 5.0538 & TRN \\
\hline CHEMBL1344814 & 688759 & 4.45 & 4.7369 & TRN \\
\hline CHEMBL1393886 & 688759 & 4.45 & 4.9136 & TST \\
\hline CHEMBL1499314 & 688759 & 5.35 & 5.2615 & TRN \\
\hline CHEMBL1610067 & 688759 & 4.6 & 4.7196 & TRN \\
\hline CHEMBL1539880 & 688759 & 4.65 & 4.835 & TRN \\
\hline CHEMBL1337260 & 688759 & 5.25 & 4.7885 & TST \\
\hline CHEMBL1341727 & 688759 & 4.45 & 4.7111 & TRN \\
\hline CHEMBL1491322 & 688759 & 4.45 & 4.6007 & TST \\
\hline CHEMBL1354829 & 688759 & 4.45 & 4.6709 & TRN \\
\hline CHEMBL1445233 & 688759 & 4.45 & 4.7203 & TRN \\
\hline CHEMBL1461051 & 688759 & 4.45 & 5.0934 & TST \\
\hline CHEMBL1312690 & 688759 & 5.25 & 4.6699 & TRN \\
\hline CHEMBL1465257 & 688759 & 4.9 & 5.0974 & TRN \\
\hline CHEMBL1976099 & 688759 & 5.7 & 5.8649 & TRN \\
\hline
\end{tabular}




\begin{tabular}{|c|c|c|c|c|c|}
\hline \multicolumn{6}{|c|}{ Supplemental Table S2.txt } \\
\hline CHEMBL1505328 & 688759 & 4.95 & 4.7647 & TST & \\
\hline CHEMBL3211264 & 688759 & 5.15 & 5.1063 & TRN & \\
\hline CHEMBL1463198 & 688759 & 4.65 & 4.9996 & TRN & \\
\hline CHEMBL1477697 & 688759 & 4.45 & 4.7672 & TRN & \\
\hline CHEMBL1580588 & 688759 & 4.7 & 4.8513 & TRN & \\
\hline CHEMBL1422109 & 688759 & 4.6 & 4.8394 & TRN & \\
\hline CHEMBL1502200 & 688759 & 4.65 & 4.6354 & TST & \\
\hline CHEMBL1409135 & 688759 & 5.35 & 4.8802 & TST & \\
\hline CHEMBL1312902 & 688759 & 4.45 & 5.0967 & TRN & \\
\hline CHEMBL1594218 & 688759 & 4.5 & 4.8943 & TRN & \\
\hline CHEMBL1401510 & 688759 & 5.4 & 5.1704 & TRN & \\
\hline CHEMBL1302510 & 688759 & 4.55 & 4.7966 & TST & \\
\hline CHEMBL1329385 & 688759 & 5.0 & 4.8267 & TRN & \\
\hline CHEMBL1335687 & 688759 & 5.0 & 5.086 & TRN & \\
\hline CHEMBL1462710 & 688759 & 4.75 & 4.7982 & TRN & \\
\hline CHEMBL1346303 & 688759 & 4.45 & 4.65600 & 0000000001 & TRN \\
\hline CHEMBL1338895 & 688759 & 4.45 & 4.6785 & TRN & \\
\hline CHEMBL1367820 & 688759 & 7.0 & 5.0262 & TRN & \\
\hline CHEMBL1487658 & 688759 & 5.75 & 5.65799 & 99999999995 & TRN \\
\hline CHEMBL3209370 & 688759 & 4.45 & 4.675 & TRN & \\
\hline CHEMBL1559982 & 688759 & 7.6498 & 5.3701 & TRN & \\
\hline CHEMBL1495292 & 688759 & 5.2 & 4.6241 & TRN & \\
\hline CHEMBL 2007403 & 688759 & 5.45 & 5.0004 & TRN & \\
\hline CHEMBL1372414 & 688759 & 6.25 & 5.008 & TRN & \\
\hline CHEMBL1577010 & 688759 & 4.65 & 4.8868 & TRN & \\
\hline CHEMBL371523 & 688759 & 5.1 & 4.9491 & TRN & \\
\hline CHEMBL1534888 & 688759 & 5.3 & 5.155 & TRN & \\
\hline CHEMBL3213665 & 688759 & 5.15 & 5.3765 & TRN & \\
\hline CHEMBL3191243 & 688759 & 5.4 & 5.655 & TRN & \\
\hline CHEMBL1410609 & 688759 & 4.8 & 5.0205 & TRN & \\
\hline CHEMBL3212443 & 688759 & 5.1 & 5.2853 & TRN & \\
\hline CHEMBL1351387 & 688759 & 4.7 & 5.21700 & 00000000005 & TRN \\
\hline CHEMBL1488916 & 688759 & 4.8 & 5.1138 & TST & \\
\hline CHEMBL1428507 & 688759 & 4.45 & 4.7895 & TRN & \\
\hline CHEMBL1385683 & 688759 & 4.45 & 4.7153 & TRN & \\
\hline CHEMBL265686 & 688759 & 5.65 & 5.3872 & TRN & \\
\hline CHEMBL1386403 & 688759 & 4.7 & 5.0024 & TRN & \\
\hline CHEMBL1533431 & 688759 & 5.0 & 5.0846 & TRN & \\
\hline CHEMBL1484158 & 688759 & 4.45 & 5.1508 & TRN & \\
\hline CHEMBL1530953 & 688759 & 5.15 & 5.0662 & TRN & \\
\hline CHEMBL1590360 & 688759 & 4.7 & 4.8722 & TRN & \\
\hline CHEMBL1600576 & 688759 & 5.0 & 4.9411 & TRN & \\
\hline CHEMBL1389688 & 688759 & 4.45 & 4.914 & TRN & \\
\hline CHEMBL1580404 & 688759 & 4.65 & 4.9228 & TRN & \\
\hline CHEMBL1588476 & 688759 & 4.5 & 4.5739 & TRN & \\
\hline CHEMBL1392625 & 688759 & 4.45 & 4.7648 & TST & \\
\hline CHEMBL1393379 & 688759 & 4.45 & 4.8851 & TRN & \\
\hline CHEMBL1330076 & 688759 & 5.0 & 5.1139 & TRN & \\
\hline
\end{tabular}




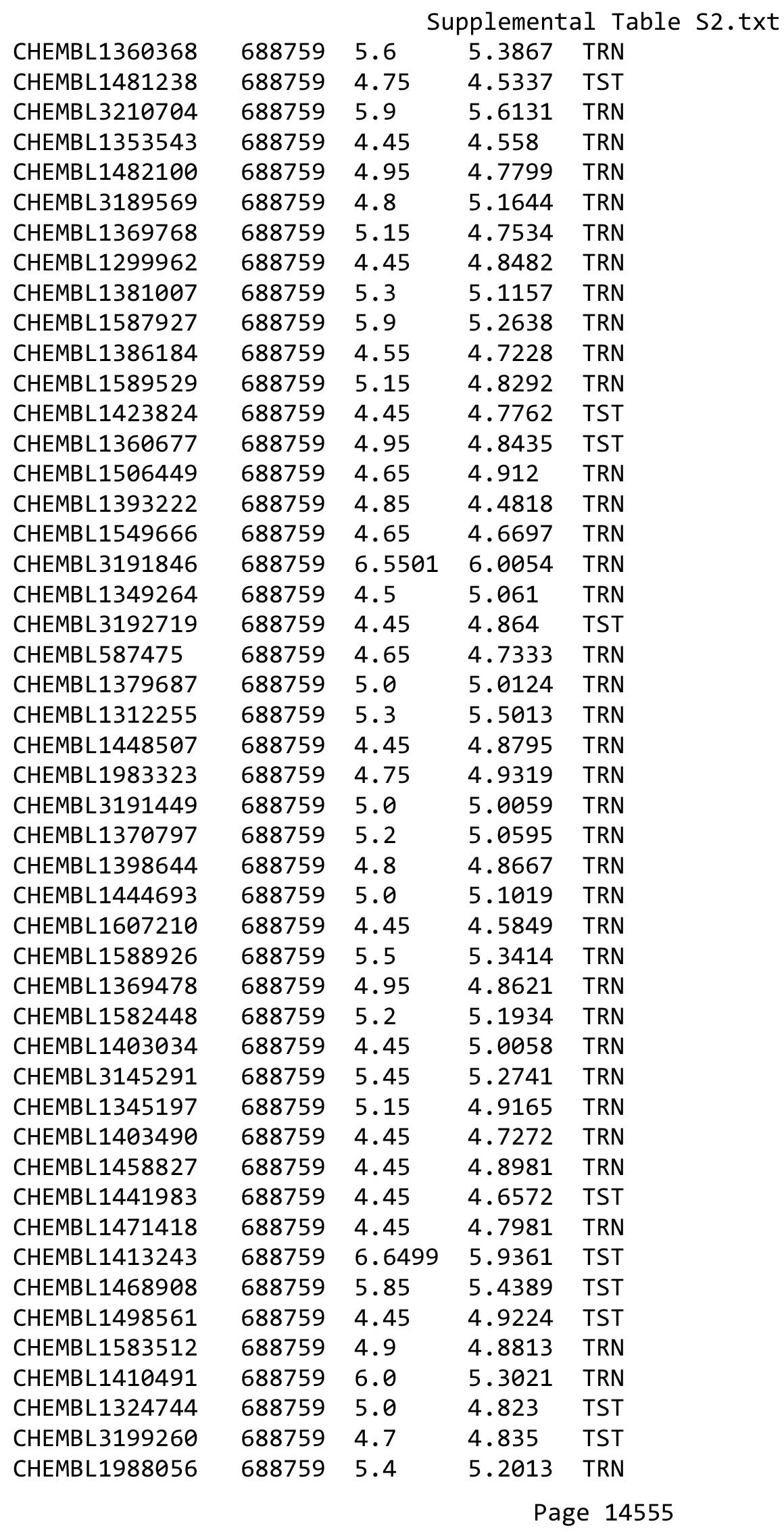




\begin{tabular}{|c|c|c|c|c|c|}
\hline \\
\hline CHEMBL1441799 & 688759 & 6.8 & 4.9206 & TST & \\
\hline CHEMBL1994594 & 688759 & 5.25 & 4.9329 & TRN & \\
\hline CHEMBL1968166 & 688759 & 5.0 & 4.8281 & TRN & \\
\hline CHEMBL1973785 & 688759 & 4.45 & 4.7773 & TRN & \\
\hline CHEMBL533293 & 688759 & 5.15 & 5.2366 & TST & \\
\hline CHEMBL1532237 & 688759 & 5.25 & 4.9842 & TRN & \\
\hline CHEMBL1489067 & 688759 & 4.75 & 4.5112 & TRN & \\
\hline CHEMBL1492304 & 688759 & 4.45 & 4.9292 & TRN & \\
\hline CHEMBL1371315 & 688759 & 4.6 & 4.8092 & TST & \\
\hline CHEMBL1352098 & 688759 & 4.45 & 4.6573 & TRN & \\
\hline CHEMBL1449208 & 688759 & 5.05 & 4.8978 & TRN & \\
\hline CHEMBL1372539 & 688759 & 4.45 & 4.7419 & TRN & \\
\hline CHEMBL1522084 & 688759 & 5.15 & 4.9696 & TRN & \\
\hline CHEMBL3191322 & 688759 & 6.0 & 4.7805 & TRN & \\
\hline CHEMBL1374746 & 688759 & 5.05 & 4.8905 & TST & \\
\hline CHEMBL1606890 & 688759 & 4.45 & 4.9798 & TRN & \\
\hline CHEMBL1497399 & 688759 & 4.8 & 4.7447 & TRN & \\
\hline CHEMBL1486214 & 688759 & 5.7 & 5.4191 & TRN & \\
\hline CHEMBL1425348 & 688759 & 5.3 & 5.2477 & TRN & \\
\hline CHEMBL1543907 & 688759 & 5.45 & 5.1236 & TRN & \\
\hline CHEMBL3195237 & 688759 & 5.3 & 5.2608 & TRN & \\
\hline CHEMBL1470910 & 688759 & 4.45 & 4.8663 & TRN & \\
\hline CHEMBL1590423 & 688759 & 4.9 & 4.8209 & TST & \\
\hline CHEMBL1442546 & 688759 & 4.65 & 4.886 & TRN & \\
\hline CHEMBL1541251 & 688759 & 4.45 & $5.2120 e$ & 0000000001 & TRN \\
\hline CHEMBL1353089 & 688759 & 4.45 & 4.7171 & TRN & \\
\hline CHEMBL1351763 & 688759 & 4.45 & 4.8915 & TRN & \\
\hline CHEMBL3191235 & 688759 & 5.2 & 5.2771 & TRN & \\
\hline CHEMBL3193524 & 688759 & 4.9 & 5.2321 & TRN & \\
\hline CHEMBL1482551 & 688759 & 4.5 & 4.8644 & TRN & \\
\hline CHEMBL1504097 & 688759 & 5.4 & 5.3955 & TRN & \\
\hline CHEMBL1451459 & 688759 & 4.6 & 4.5384 & TRN & \\
\hline CHEMBL1567384 & 688759 & 4.85 & 5.0322 & TRN & \\
\hline CHEMBL1572788 & 688759 & 6.15 & 5.022 & TRN & \\
\hline CHEMBL1586938 & 688759 & 5.4 & 5.1304 & TRN & \\
\hline CHEMBL1423575 & 688759 & 4.45 & 4.6356 & TST & \\
\hline CHEMBL1427530 & 688759 & 4.7 & 4.8409 & TRN & \\
\hline CHEMBL3189688 & 688759 & 4.85 & 4.7541 & TST & \\
\hline CHEMBL3189998 & 688759 & 5.5 & 4.8592 & TRN & \\
\hline CHEMBL3193405 & 688759 & 4.85 & $4.9110 e$ & 00000000005 & TST \\
\hline CHEMBL1353090 & 688759 & 4.45 & 4.8223 & TRN & \\
\hline CHEMBL1577210 & 688759 & 5.0 & 5.13 & TRN & \\
\hline CHEMBL1486702 & 688759 & 5.15 & 5.1916 & TRN & \\
\hline CHEMBL3210231 & 688759 & 5.25 & 4.8676 & TRN & \\
\hline CHEMBL1323560 & 688759 & 5.2 & 4.7859 & TRN & \\
\hline CHEMBL1571861 & 688759 & 4.7 & 5.088 & TRN & \\
\hline CHEMBL1496936 & 688759 & 4.45 & 4.7963 & TST & \\
\hline CHEMBL1526757 & 688759 & 5.35 & 5.0464 & TRN & \\
\hline
\end{tabular}




\begin{tabular}{|c|c|c|c|c|c|}
\hline & & \multicolumn{4}{|c|}{ Supplemental Table S2.txt } \\
\hline CHEMBL1423241 & 688759 & 4.9 & 4.8548 & TST & \\
\hline CHEMBL1368752 & 688759 & 4.5 & 4.8147 & TRN & \\
\hline CHEMBL1417731 & 688759 & 4.95 & 4.7216 & TST & \\
\hline CHEMBL1301924 & 688759 & 4.9 & 4.8746 & TRN & \\
\hline CHEMBL1304323 & 688759 & 4.75 & 4.8834 & TRN & \\
\hline CHEMBL1539975 & 688759 & 4.65 & 4.5852 & TRN & \\
\hline CHEMBL1449463 & 688759 & 4.65 & 4.7525 & TST & \\
\hline CHEMBL1469973 & 688759 & 5.45 & 4.58 & TRN & \\
\hline CHEMBL3192012 & 688759 & 5.35 & 5.1637 & TRN & \\
\hline CHEMBL1351284 & 688759 & 4.45 & 4.6696 & TRN & \\
\hline CHEMBL1477515 & 688759 & 5.15 & 4.9857 & TRN & \\
\hline CHEMBL1406208 & 688759 & 6.0 & 5.0183 & TRN & \\
\hline CHEMBL1570643 & 688759 & 4.45 & 4.3923 & TRN & \\
\hline CHEMBL1562679 & 688759 & 5.75 & 5.2349 & TRN & \\
\hline CHEMBL3193006 & 688759 & 4.7 & 4.6118 & TRN & \\
\hline CHEMBL3193389 & 688759 & 5.3 & 5.6022 & TRN & \\
\hline CHEMBL1413135 & 688759 & 5.25 & 4.8596 & TRN & \\
\hline CHEMBL1501184 & 688759 & 4.45 & 4.666 & TRN & \\
\hline CHEMBL1604809 & 688759 & 5.8 & 5.3416 & TRN & \\
\hline CHEMBL 2003872 & 688759 & 5.1 & 5.249 & TRN & \\
\hline CHEMBL1446416 & 688759 & 4.85 & 4.7009 & TRN & \\
\hline CHEMBL1319717 & 688759 & 4.45 & 4.6427 & TST & \\
\hline CHEMBL1396595 & 688759 & 4.9 & 4.817 & TRN & \\
\hline CHEMBL1424380 & 688759 & 6.0 & 5.9504 & TRN & \\
\hline CHEMBL1488659 & 688759 & 4.55 & 4.7011 & TRN & \\
\hline CHEMBL1554542 & 688759 & 6.5 & 4.7225 & TRN & \\
\hline CHEMBL1470769 & 688759 & 5.15 & 4.607 & TRN & \\
\hline CHEMBL1348611 & 688759 & 4.65 & 5.0943 & TRN & \\
\hline CHEMBL1589524 & 688759 & 4.95 & 4.8242 & TRN & \\
\hline CHEMBL1537716 & 688759 & 4.45 & 4.7363 & TRN & \\
\hline CHEMBL1508848 & 688759 & 5.5 & 4.9477 & TST & \\
\hline CHEMBL1321064 & 688759 & 5.45 & 5.0546 & TRN & \\
\hline CHEMBL1351835 & 688759 & 4.45 & 4.4559 & TRN & \\
\hline CHEMBL1449818 & 688759 & 5.45 & 4.8695 & TRN & \\
\hline CHEMBL 243677 & 688759 & 4.9 & 4.7517 & TRN & \\
\hline CHEMBL1312215 & 688759 & 4.6 & 4.646 & TRN & \\
\hline CHEMBL1604215 & 688759 & 5.25 & 4.88899 & 9999999999 & TRN \\
\hline CHEMBL1519210 & 688759 & 4.95 & 5.2444 & TRN & \\
\hline CHEMBL1607877 & 688759 & 4.45 & 4.4801 & TRN & \\
\hline CHEMBL1967070 & 688759 & 5.35 & 5.2015 & TRN & \\
\hline CHEMBL1497900 & 688759 & 4.7 & 4.9029 & TRN & \\
\hline CHEMBL3197769 & 688759 & 4.45 & 4.7787 & TST & \\
\hline CHEMBL1525429 & 688759 & 4.6 & 4.5237 & TRN & \\
\hline CHEMBL3198031 & 688759 & 4.45 & 4.9189 & TRN & \\
\hline CHEMBL1501400 & 688759 & 4.55 & 4.8678 & TRN & \\
\hline CHEMBL1370461 & 688759 & 4.9 & 5.1664 & TRN & \\
\hline CHEMBL1580723 & 688759 & 4.95 & 4.732 & TRN & \\
\hline CHEMBL1419847 & 688759 & 6.15 & 5.5729 & TRN & \\
\hline
\end{tabular}




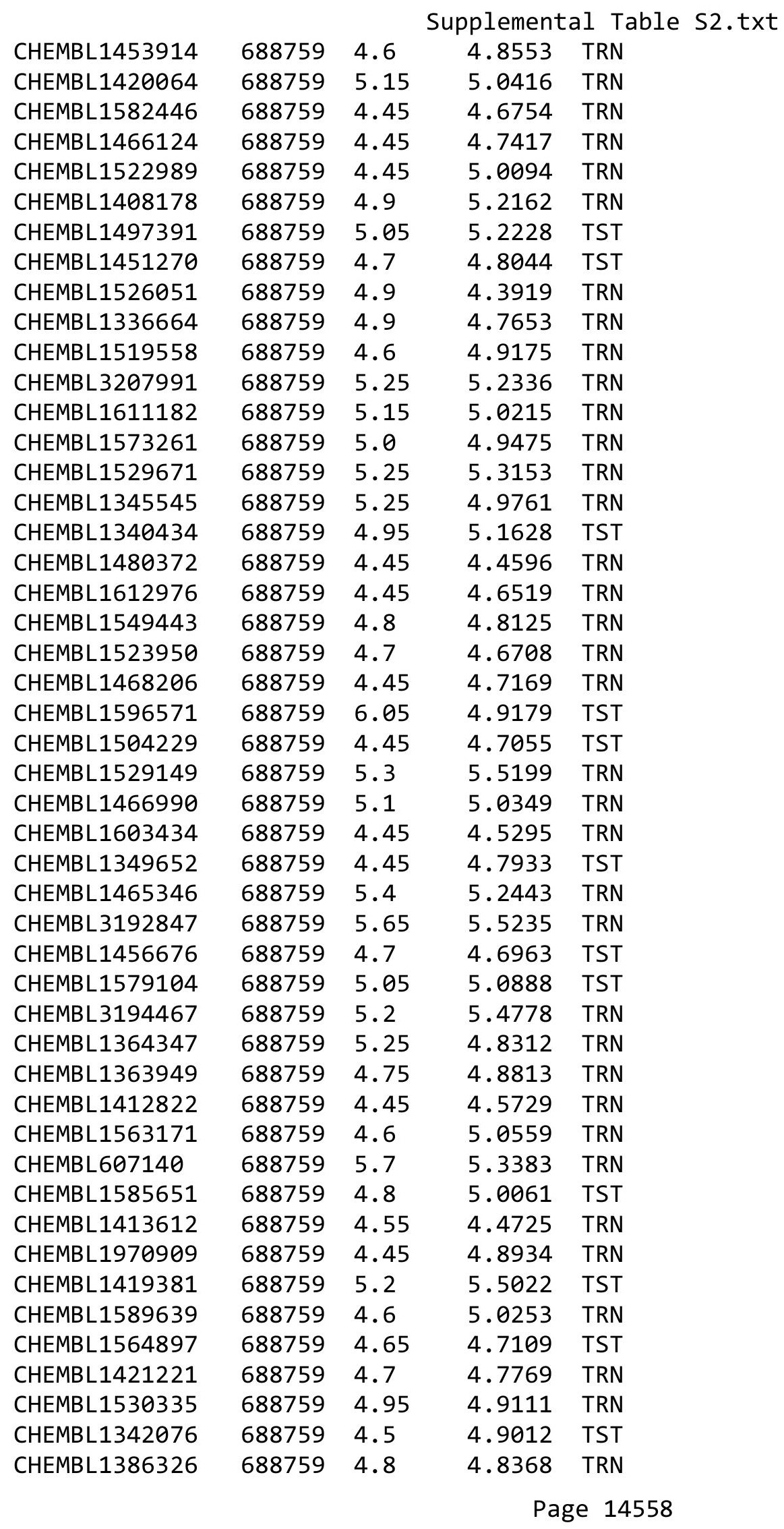




\begin{tabular}{|c|c|c|c|c|}
\hline \multicolumn{5}{|c|}{ Supplemental Table S2.txt } \\
\hline CHEMBL1358973 & 688759 & 4.45 & 4.8285 & TRN \\
\hline CHEMBL1313140 & 688759 & 4.45 & 4.9445 & TRN \\
\hline CHEMBL1410412 & 688759 & 5.15 & 5.1433 & TRN \\
\hline CHEMBL1487616 & 688759 & 4.45 & 4.5584 & TRN \\
\hline CHEMBL1391974 & 688759 & 5.35 & 5.3631 & TRN \\
\hline CHEMBL1466851 & 688759 & 4.45 & 4.8474 & TST \\
\hline CHEMBL1488010 & 688759 & 6.0 & 4.9376 & TST \\
\hline CHEMBL1302075 & 688759 & 4.9 & 4.5942 & TRN \\
\hline CHEMBL1611342 & 688759 & 5.15 & 4.6516 & TRN \\
\hline CHEMBL1345195 & 688759 & 4.45 & 4.7308 & TRN \\
\hline CHEMBL1301636 & 688759 & 4.9 & 4.8122 & TRN \\
\hline CHEMBL1516884 & 688759 & 5.3 & 5.0854 & TRN \\
\hline CHEMBL1345248 & 688759 & 4.45 & 4.813 & TST \\
\hline CHEMBL586946 & 688759 & 4.8 & 4.7592 & TST \\
\hline CHEMBL1576164 & 688759 & 4.45 & 4.5079 & TRN \\
\hline CHEMBL1430980 & 688759 & 5.15 & 5.0127 & TRN \\
\hline CHEMBL1332704 & 688759 & 4.85 & 4.7496 & TST \\
\hline CHEMBL1429207 & 688759 & 4.45 & 4.7834 & TRN \\
\hline CHEMBL3195565 & 688759 & 4.45 & 4.9897 & TRN \\
\hline CHEMBL1353796 & 688759 & 4.5 & 4.8579 & TRN \\
\hline CHEMBL1427576 & 688759 & 5.1 & 4.64 & TST \\
\hline CHEMBL1583799 & 688759 & 5.6 & 5.4706 & TRN \\
\hline CHEMBL1469241 & 688759 & 6.5501 & 5.0559 & TRN \\
\hline CHEMBL1575003 & 688759 & 5.0 & 4.595 & TRN \\
\hline CHEMBL1432523 & 688759 & 6.7501 & 4.8635 & TRN \\
\hline CHEMBL1583801 & 688759 & 4.9 & 5.0409 & TRN \\
\hline CHEMBL1509896 & 688759 & 5.4 & 4.8263 & TRN \\
\hline CHEMBL3195720 & 688759 & 5.3 & 4.9052 & TST \\
\hline CHEMBL3194995 & 688759 & 4.45 & 4.9294 & TRN \\
\hline CHEMBL1429074 & 688759 & 4.65 & 4.817 & TRN \\
\hline CHEMBL1331011 & 688759 & 4.45 & 4.8055 & TRN \\
\hline CHEMBL1438733 & 688759 & 6.1 & 5.0954 & TST \\
\hline CHEMBL1379666 & 688759 & 6.1 & 4.9834 & TRN \\
\hline CHEMBL1540770 & 688759 & 5.95 & 5.0406 & TRN \\
\hline CHEMBL1466547 & 688759 & 4.85 & 4.8701 & TST \\
\hline CHEMBL1319428 & 688759 & 4.45 & 4.4673 & TST \\
\hline CHEMBL1570916 & 688759 & 4.7 & 4.7422 & TRN \\
\hline CHEMBL3213748 & 688759 & 4.45 & 5.21299 & 9999999999 \\
\hline CHEMBL1523135 & 688759 & 5.45 & 4.8367 & TRN \\
\hline CHEMBL1448681 & 688759 & 5.6 & 5.5417 & TRN \\
\hline CHEMBL1304996 & 688759 & 5.2 & 5.0824 & TRN \\
\hline CHEMBL3210389 & 688759 & 4.45 & 4.9255 & TRN \\
\hline CHEMBL3190505 & 688759 & 4.45 & 4.7036 & TRN \\
\hline CHEMBL1478241 & 688759 & 4.85 & 5.04 & TST \\
\hline CHEMBL1342545 & 688759 & 5.6 & 5.7076 & TRN \\
\hline CHEMBL1453002 & 688759 & 4.45 & 4.7472 & TST \\
\hline CHEMBL1164862 & 688759 & 4.95 & 5.043 & TRN \\
\hline CHEMBL1563972 & 688759 & 4.5 & 4.8728 & TST \\
\hline
\end{tabular}




\begin{tabular}{|c|c|c|c|c|c|}
\hline \multicolumn{6}{|c|}{ Supplemental Table S2.txt } \\
\hline CHEMBL1609099 & 688759 & 5.4 & 5.135 & TRN & \\
\hline CHEMBL3197528 & 688759 & 4.45 & 4.813 & TRN & \\
\hline CHEMBL3183210 & 688759 & 5.2 & 5.0166 & TRN & \\
\hline CHEMBL1458203 & 688759 & 4.45 & 4.4284 & TRN & \\
\hline CHEMBL1383513 & 688759 & 4.45 & 4.8729 & TRN & \\
\hline CHEMBL1528514 & 688759 & 4.45 & 4.9121 & TRN & \\
\hline CHEMBL1472464 & 688759 & 4.95 & 4.8296 & TST & \\
\hline CHEMBL1343263 & 688759 & 5.95 & 4.9569 & TST & \\
\hline CHEMBL1406091 & 688759 & 4.45 & 4.9058 & TRN & \\
\hline CHEMBL1500728 & 688759 & 5.3 & 4.9869 & TRN & \\
\hline CHEMBL282489 & 688759 & 6.0 & 5.3151 & TST & \\
\hline CHEMBL1388405 & 688759 & 4.45 & 4.3962 & TRN & \\
\hline CHEMBL1405254 & 688759 & 5.15 & 4.7279 & TRN & \\
\hline CHEMBL1428061 & 688759 & 5.55 & 4.8612 & TST & \\
\hline CHEMBL1344697 & 688759 & 5.3 & 5.06800 & 00000000005 & TST \\
\hline CHEMBL1320141 & 688759 & 5.45 & 4.8709 & TRN & \\
\hline CHEMBL1520337 & 688759 & 4.45 & 4.8489 & TRN & \\
\hline CHEMBL1350958 & 688759 & 4.95 & 5.1289 & TRN & \\
\hline CHEMBL1313321 & 688759 & 4.45 & 4.5991 & TST & \\
\hline CHEMBL3214552 & 688759 & 4.45 & 4.8268 & TRN & \\
\hline CHEMBL1425248 & 688759 & 5.15 & 5.0257 & TRN & \\
\hline CHEMBL 74497 & 688759 & 4.45 & 4.7135 & TRN & \\
\hline CHEMBL1311810 & 688759 & 5.25 & 4.6004 & TRN & \\
\hline CHEMBL1379761 & 688759 & 5.25 & 5.1091 & TST & \\
\hline CHEMBL1499923 & 688759 & 8.5528 & 4.93199 & 99999999995 & TRN \\
\hline CHEMBL1442164 & 688759 & 4.85 & 4.7648 & TST & \\
\hline CHEMBL1559614 & 688759 & 4.95 & 4.8971 & TRN & \\
\hline CHEMBL1347324 & 688759 & 5.15 & 5.1962 & TST & \\
\hline CHEMBL1469857 & 688759 & 4.7 & 4.8707 & TST & \\
\hline CHEMBL1322203 & 688759 & 4.65 & 4.6342 & TRN & \\
\hline CHEMBL1472645 & 688759 & 4.85 & 4.8641 & TRN & \\
\hline CHEMBL1300980 & 688759 & 4.5 & 4.7199 & TRN & \\
\hline CHEMBL1499213 & 688759 & 4.45 & 4.7121 & TRN & \\
\hline CHEMBL1315727 & 688759 & 4.85 & 4.8068 & TRN & \\
\hline CHEMBL1583184 & 688759 & 4.6 & 4.7138 & TRN & \\
\hline CHEMBL3196898 & 688759 & 5.35 & 5.2554 & TRN & \\
\hline CHEMBL1373289 & 688759 & 4.8 & 5.0366 & TST & \\
\hline CHEMBL1600508 & 688759 & 5.55 & 5.1937 & TRN & \\
\hline CHEMBL 3214372 & 688759 & 4.9 & 4.7796 & TST & \\
\hline CHEMBL1535575 & 688759 & 4.45 & 5.117 & TRN & \\
\hline CHEMBL1422275 & 688759 & 4.55 & 4.69 & TRN & \\
\hline CHEMBL1578267 & 688759 & 5.95 & 5.5819 & TRN & \\
\hline CHEMBL1376905 & 688759 & 4.95 & 4.5752 & TRN & \\
\hline CHEMBL1337997 & 688759 & 4.75 & 4.5575 & TRN & \\
\hline CHEMBL1422378 & 688759 & 5.2 & 4.886 & TST & \\
\hline CHEMBL1576063 & 688759 & 5.9 & 4.93 & TRN & \\
\hline CHEMBL1374834 & 688759 & 4.9 & 4.7319 & TRN & \\
\hline CHEMBL1365741 & 688759 & 6.0 & 5.1632 & TRN & \\
\hline
\end{tabular}




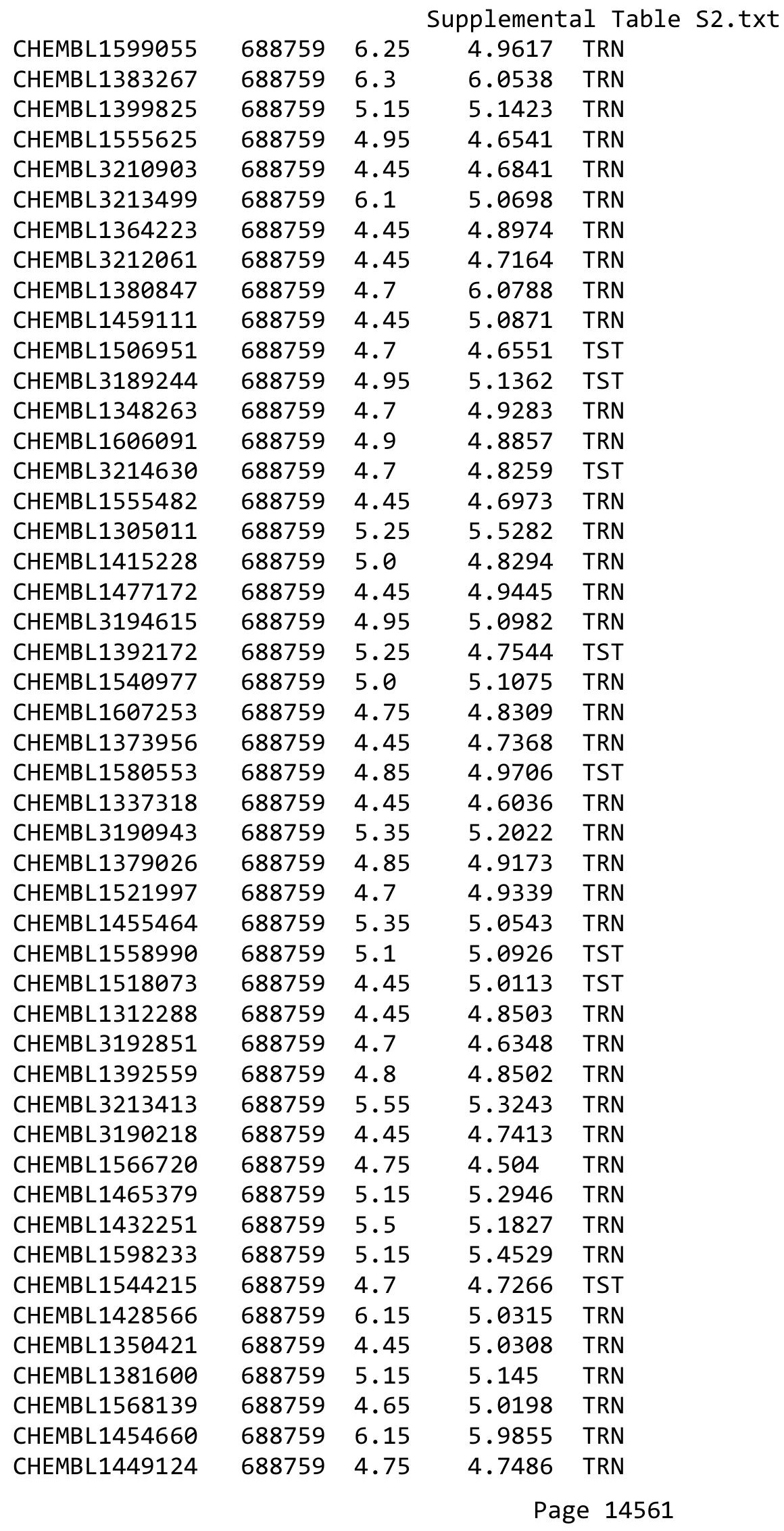




\begin{tabular}{|c|c|c|c|c|c|}
\hline & & \multicolumn{4}{|c|}{ Supplemental Table S2.txt } \\
\hline CHEMBL1579644 & 688759 & 4.45 & 4.5237 & TRN & \\
\hline CHEMBL1612153 & 688759 & 5.4 & 4.9028 & TST & \\
\hline CHEMBL1403214 & 688759 & 4.55 & 4.6428 & TRN & \\
\hline CHEMBL1478876 & 688759 & 6.05 & 4.6993 & TRN & \\
\hline CHEMBL271673 & 688759 & 4.7 & 4.8046 & TST & \\
\hline CHEMBL1459106 & 688759 & 4.6 & 4.8135 & TRN & \\
\hline CHEMBL1502209 & 688759 & 4.95 & 4.8523 & TRN & \\
\hline CHEMBL1346906 & 688759 & 4.45 & 4.6561 & TRN & \\
\hline CHEMBL1368784 & 688759 & 4.45 & 4.8981 & TST & \\
\hline CHEMBL1308357 & 688759 & 4.45 & 4.7503 & TRN & \\
\hline CHEMBL1477097 & 688759 & 4.45 & 4.6163 & TST & \\
\hline CHEMBL1300301 & 688759 & 4.45 & 4.8634 & TRN & \\
\hline CHEMBL1324027 & 688759 & 5.1 & 5.32799 & 9999999999 & TRN \\
\hline CHEMBL3214506 & 688759 & 4.45 & 5.1211 & TST & \\
\hline CHEMBL1426475 & 688759 & 5.6 & 5.2825 & TST & \\
\hline CHEMBL1365179 & 688759 & 4.95 & 5.0163 & TRN & \\
\hline CHEMBL1548076 & 688759 & 4.45 & 4.5364 & TRN & \\
\hline CHEMBL 583578 & 688759 & 4.85 & 5.4544 & TRN & \\
\hline CHEMBL 1467322 & 688759 & 4.45 & 4.9018 & TRN & \\
\hline CHEMBL1521404 & 688759 & 5.0 & 5.3263 & TRN & \\
\hline CHEMBL1969037 & 688759 & 5.3 & 5.1844 & TRN & \\
\hline CHEMBL1461679 & 688759 & 5.0 & 4.808 & TRN & \\
\hline CHEMBL1585499 & 688759 & 4.6 & 4.5474 & TRN & \\
\hline CHEMBL1315467 & 688759 & 4.45 & 4.8752 & TRN & \\
\hline CHEMBL1327747 & 688759 & 4.45 & 4.7595 & TRN & \\
\hline CHEMBL1573230 & 688759 & 4.45 & 4.6458 & TST & \\
\hline CHEMBL1363543 & 688759 & 5.35 & 5.1712 & TST & \\
\hline CHEMBL1461496 & 688759 & 5.0 & 5.1452 & TRN & \\
\hline CHEMBL1362077 & 688759 & 5.1 & 5.2543 & TRN & \\
\hline CHEMBL1428789 & 688759 & 4.75 & 4.7587 & TST & \\
\hline CHEMBL90181 & 688759 & 5.3 & 5.3501 & TST & \\
\hline CHEMBL1544407 & 688759 & 4.5 & 4.6849 & TRN & \\
\hline CHEMBL1402767 & 688759 & 5.2 & 5.0713 & TRN & \\
\hline CHEMBL1331875 & 688759 & 5.15 & 5.1392 & TRN & \\
\hline CHEMBL1406703 & 688759 & 4.45 & 4.716 & TST & \\
\hline CHEMBL1415585 & 688759 & 4.95 & 4.9152 & TST & \\
\hline CHEMBL1337593 & 688759 & 5.35 & 4.8316 & TRN & \\
\hline CHEMBL1323237 & 688759 & 5.4 & 4.8038 & TST & \\
\hline CHEMBL3198558 & 688759 & 6.0 & 5.6163 & TRN & \\
\hline CHEMBL1580774 & 688759 & 4.9 & 4.8196 & TRN & \\
\hline CHEMBL1334903 & 688759 & 4.45 & 4.5883 & TST & \\
\hline CHEMBL1609146 & 688759 & 4.45 & 5.182 & TRN & \\
\hline CHEMBL1580860 & 688759 & 6.05 & 5.7366 & TRN & \\
\hline CHEMBL1562432 & 688759 & 4.45 & 4.8046 & TST & \\
\hline CHEMBL1592095 & 688759 & 4.7 & 5.2255 & TRN & \\
\hline CHEMBL1300364 & 688759 & 4.45 & 4.6016 & TRN & \\
\hline CHEMBL1491806 & 688759 & 4.45 & 4.6761 & TRN & \\
\hline CHEMBL1426371 & 688759 & 4.65 & 4.7498 & TST & \\
\hline
\end{tabular}




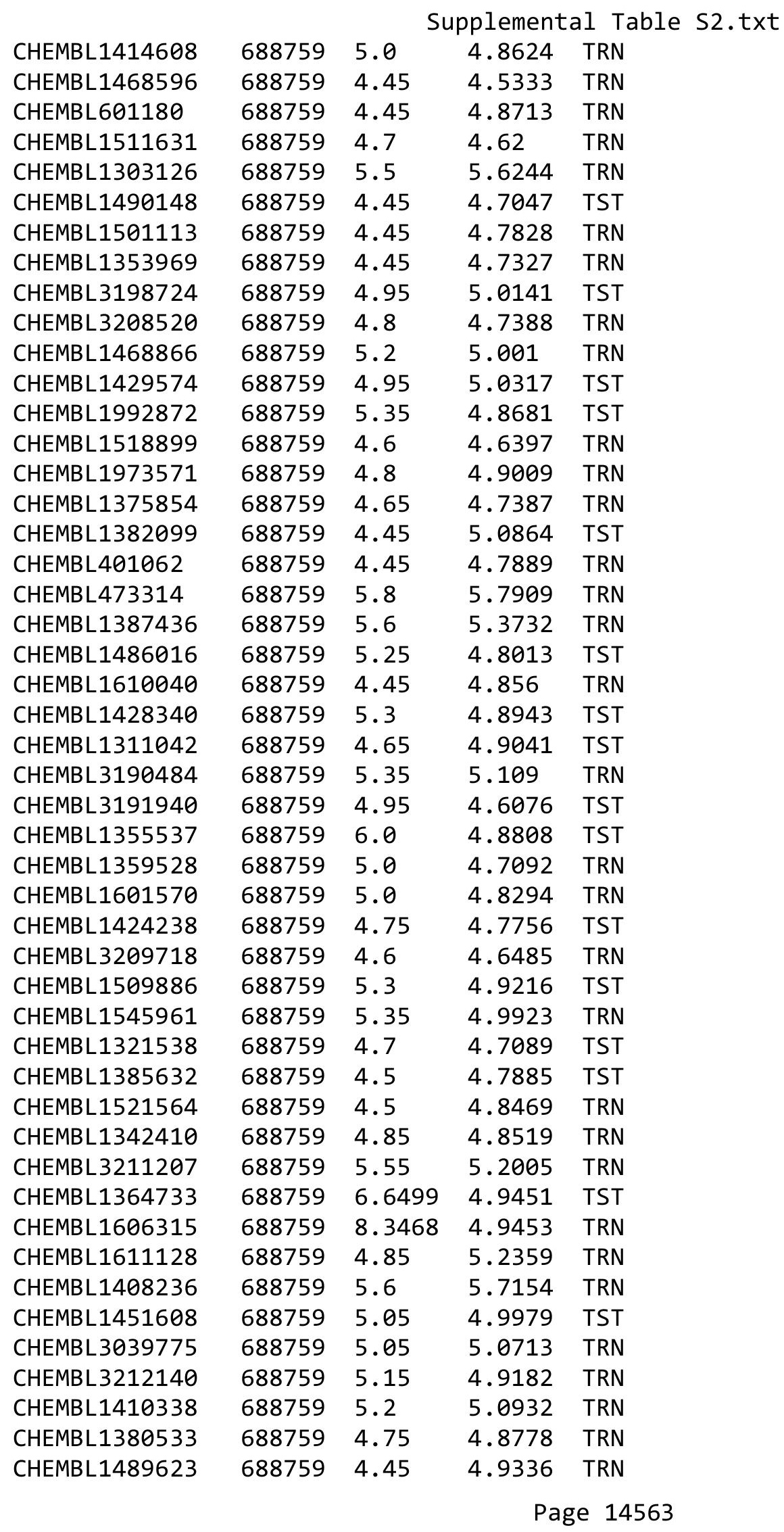




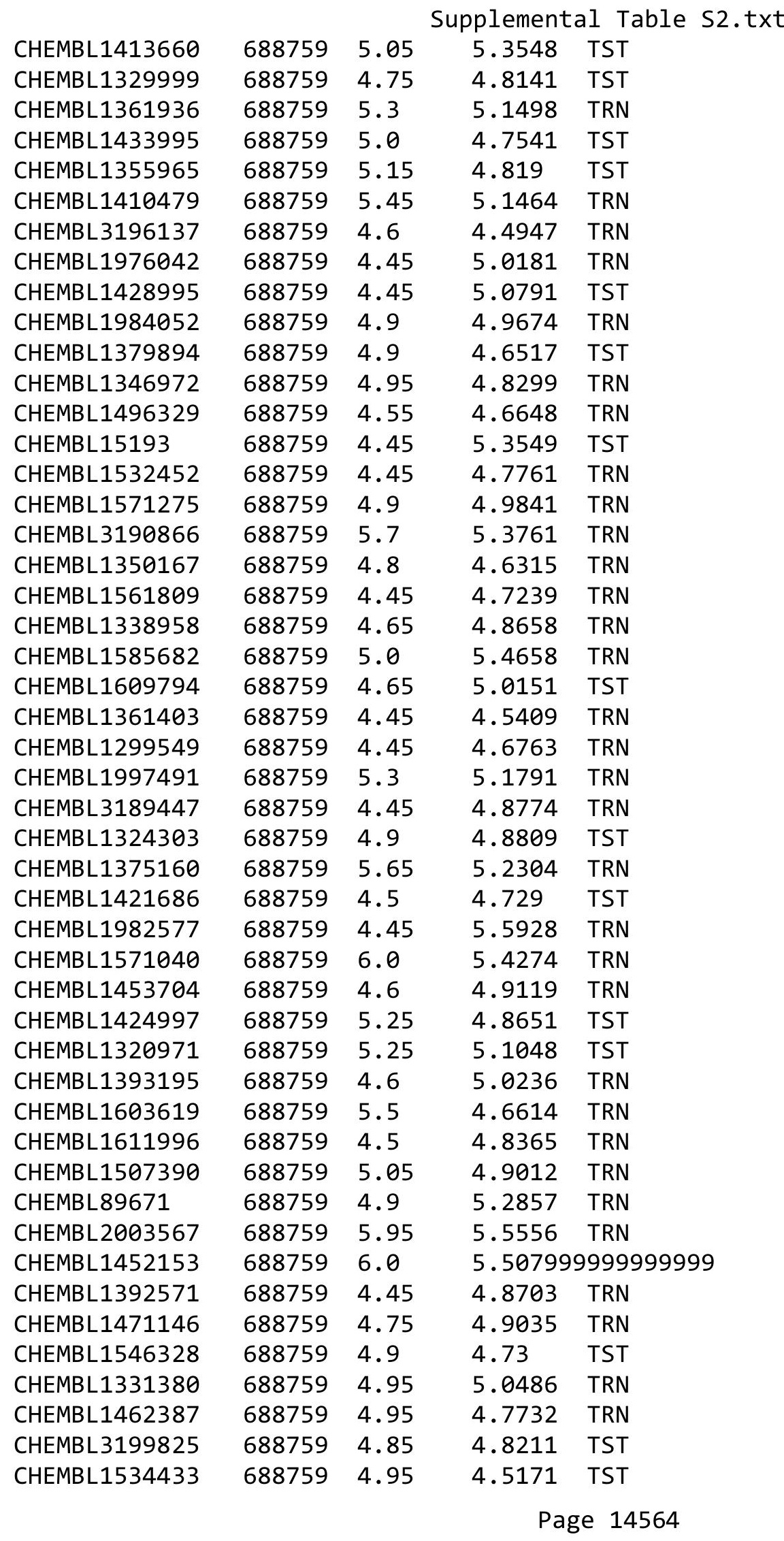




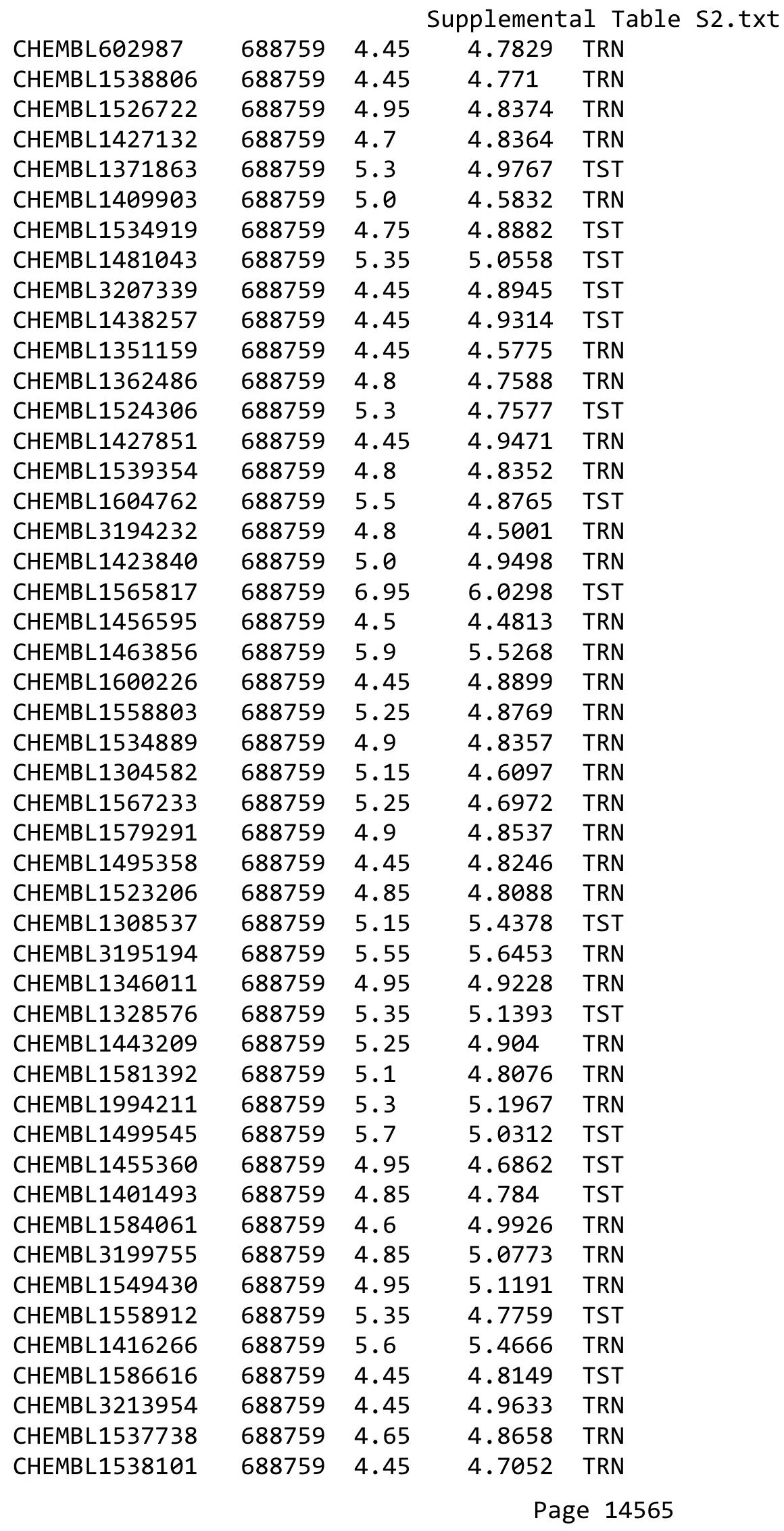




\begin{tabular}{|c|c|c|c|c|}
\hline \multicolumn{5}{|c|}{ Supplemental Table S2.txt } \\
\hline CHEMBL1537867 & 688759 & 5.0 & 4.4113 & TRN \\
\hline CHEMBL3196674 & 688759 & 4.9 & 4.984 & TRN \\
\hline CHEMBL1471282 & 688759 & 4.8 & 4.748 & TRN \\
\hline CHEMBL1423440 & 688759 & 5.35 & 5.1619 & TRN \\
\hline CHEMBL1442582 & 688759 & 5.25 & 4.8761 & TST \\
\hline CHEMBL1411779 & 688759 & 4.45 & 4.63899 & 9999999999 \\
\hline CHEMBL1524030 & 688759 & 4.65 & 5.0522 & TST \\
\hline CHEMBL 3196616 & 688759 & 4.6 & 4.8405 & TRN \\
\hline CHEMBL1417842 & 688759 & 4.9 & 4.5775 & TRN \\
\hline CHEMBL3190375 & 688759 & 4.45 & 4.6221 & TST \\
\hline CHEMBL1361292 & 688759 & 4.7 & 4.9088 & TST \\
\hline CHEMBL1373949 & 688759 & 5.25 & 5.1269 & TRN \\
\hline CHEMBL1352747 & 688759 & 4.45 & 4.8584 & TRN \\
\hline CHEMBL1497624 & 688759 & 4.65 & 4.8065 & TRN \\
\hline CHEMBL1373467 & 688759 & 6.0 & 4.7307 & TST \\
\hline CHEMBL1421010 & 688759 & 4.65 & 4.7876 & TRN \\
\hline CHEMBL1310496 & 688759 & 5.0 & 5.0421 & TRN \\
\hline CHEMBL1303068 & 688759 & 4.45 & 4.7369 & TRN \\
\hline CHEMBL1443125 & 688759 & 5.45 & 5.399 & TRN \\
\hline CHEMBL1384764 & 688759 & 4.6 & 4.8456 & TRN \\
\hline CHEMBL1381992 & 688759 & 4.6 & 4.8125 & TRN \\
\hline CHEMBL3193119 & 688759 & 4.65 & 4.8396 & TRN \\
\hline CHEMBL1550553 & 688759 & 4.45 & 4.645 & TRN \\
\hline CHEMBL1496051 & 688759 & 4.45 & 4.9532 & TRN \\
\hline CHEMBL1501127 & 688759 & 6.15 & 5.5726 & TRN \\
\hline CHEMBL1599621 & 688759 & 5.15 & 4.9739 & TRN \\
\hline CHEMBL1426273 & 688759 & 4.7 & 4.7505 & TRN \\
\hline CHEMBL 3193060 & 688759 & 4.6 & 4.8378 & TRN \\
\hline CHEMBL1300201 & 688759 & 4.45 & 4.6222 & TRN \\
\hline CHEMBL3194311 & 688759 & 4.65 & 4.9193 & TRN \\
\hline CHEMBL1513524 & 688759 & 4.95 & 5.0448 & TRN \\
\hline CHEMBL1536569 & 688759 & 4.45 & 4.6068 & TST \\
\hline CHEMBL1387758 & 688759 & 4.45 & 5.0468 & TRN \\
\hline CHEMBL1470668 & 688759 & 5.35 & 5.2415 & TRN \\
\hline CHEMBL1387194 & 688759 & 4.45 & 4.5667 & TST \\
\hline CHEMBL1345705 & 688759 & 5.05 & 5.1889 & TRN \\
\hline CHEMBL1343502 & 688759 & 4.45 & 4.5867 & TRN \\
\hline CHEMBL1584795 & 688759 & 4.45 & 4.7842 & TRN \\
\hline CHEMBL1326464 & 688759 & 5.85 & 5.2539 & TST \\
\hline CHEMBL1557939 & 688759 & 6.0 & 5.3951 & TRN \\
\hline CHEMBL1524767 & 688759 & 5.25 & 4.8998 & TST \\
\hline CHEMBL1555801 & 688759 & 4.45 & 4.5999 & TRN \\
\hline CHEMBL1570784 & 688759 & 4.45 & 4.9268 & TRN \\
\hline CHEMBL1582859 & 688759 & 4.45 & 4.4523 & TRN \\
\hline CHEMBL1314584 & 688759 & 4.65 & 5.08 & TRN \\
\hline CHEMBL1488608 & 688759 & 4.95 & 4.737 & TRN \\
\hline CHEMBL3210713 & 688759 & 7.0 & 4.8009 & TRN \\
\hline CHEMBL1549604 & 688759 & 4.45 & 5.1507 & TRN \\
\hline
\end{tabular}




\begin{tabular}{|c|c|c|c|c|c|}
\hline \multicolumn{6}{|c|}{ Supplemental Table S2.txt } \\
\hline CHEMBL1416519 & 688759 & 5.5 & 4.7802 & TRN & \\
\hline CHEMBL1972436 & 688759 & 4.75 & 6.1266 & TRN & \\
\hline CHEMBL1385235 & 688759 & 4.6 & 4.7108 & TRN & \\
\hline CHEMBL1343770 & 688759 & 4.45 & 4.7454 & TRN & \\
\hline CHEMBL3196772 & 688759 & 6.1 & 5.5106 & TRN & \\
\hline CHEMBL1604158 & 688759 & 4.65 & 4.7781 & TRN & \\
\hline CHEMBL1361464 & 688759 & 5.4 & 4.8158 & TRN & \\
\hline CHEMBL3196437 & 688759 & 5.1 & 4.6867 & TRN & \\
\hline CHEMBL1584694 & 688759 & 5.55 & 5.1901 & TST & \\
\hline CHEMBL3196810 & 688759 & 5.5 & 5.5211 & TRN & \\
\hline CHEMBL1581725 & 688759 & 5.55 & 5.0858 & TST & \\
\hline CHEMBL1444273 & 688759 & 4.45 & 5.0814 & TRN & \\
\hline CHEMBL1588880 & 688759 & 5.15 & 5.20100 & 00000000005 & TRN \\
\hline CHEMBL1385145 & 688759 & 4.8 & 4.7555 & TRN & \\
\hline CHEMBL1366471 & 688759 & 4.9 & 4.872 & TRN & \\
\hline CHEMBL1309710 & 688759 & 4.65 & 5.1098 & TST & \\
\hline CHEMBL1362961 & 688759 & 4.65 & 4.6357 & TRN & \\
\hline CHEMBL1509711 & 688759 & 5.2 & 5.3506 & TRN & \\
\hline CHEMBL1594951 & 688759 & 5.1 & 5.246 & TRN & \\
\hline CHEMBL1568173 & 688759 & 4.45 & 4.5541 & TRN & \\
\hline CHEMBL1422443 & 688759 & 4.9 & 4.8797 & TRN & \\
\hline CHEMBL1372396 & 688759 & 4.95 & 4.8855 & TRN & \\
\hline CHEMBL1530247 & 688759 & 5.25 & 4.8604 & TRN & \\
\hline CHEMBL1500973 & 688759 & 5.35 & 4.7269 & TST & \\
\hline CHEMBL1550187 & 688759 & 5.45 & 4.9819 & TRN & \\
\hline CHEMBL1331928 & 688759 & 4.65 & 5.1607 & TRN & \\
\hline CHEMBL3212695 & 688759 & 4.45 & 5.0105 & TRN & \\
\hline CHEMBL1366988 & 688759 & 5.2 & 4.9119 & TRN & \\
\hline CHEMBL1424898 & 688759 & 4.9 & 4.6309 & TST & \\
\hline CHEMBL1533798 & 688759 & 4.6 & 4.8333 & TST & \\
\hline CHEMBL1498618 & 688759 & 4.45 & 4.9581 & TST & \\
\hline CHEMBL1557811 & 688759 & 4.45 & 4.7089 & TST & \\
\hline CHEMBL1441761 & 688759 & 4.95 & 4.6502 & TRN & \\
\hline CHEMBL1353409 & 688759 & 4.9 & 4.9683 & TST & \\
\hline CHEMBL493032 & 688759 & 4.45 & 4.7952 & TST & \\
\hline CHEMBL1460050 & 688759 & 4.8 & 4.7233 & TRN & \\
\hline CHEMBL1413963 & 688759 & 5.25 & 4.9585 & TRN & \\
\hline CHEMBL1419783 & 688759 & 4.45 & 4.793 & TST & \\
\hline CHEMBL1605830 & 688759 & 5.15 & 5.1805 & TRN & \\
\hline CHEMBL1536196 & 688759 & 5.15 & 4.7171 & TRN & \\
\hline CHEMBL1362734 & 688759 & 4.8 & 4.8815 & TRN & \\
\hline CHEMBL1451727 & 688759 & 5.45 & 5.4127 & TRN & \\
\hline CHEMBL1524109 & 688759 & 4.5 & 4.6303 & TRN & \\
\hline CHEMBL1446871 & 688759 & 5.7 & 4.8412 & TRN & \\
\hline CHEMBL1486619 & 688759 & 4.45 & 4.6284 & TRN & \\
\hline CHEMBL1340112 & 688759 & 5.4 & 4.5953 & TRN & \\
\hline CHEMBL1458332 & 688759 & 4.45 & 4.6084 & TST & \\
\hline CHEMBL1405989 & 688759 & 4.75 & 4.8841 & TRN & \\
\hline
\end{tabular}




\begin{tabular}{|c|c|c|c|c|c|}
\hline \multicolumn{6}{|c|}{ Supplemental Table S2.txt } \\
\hline CHEMBL3145285 & 688759 & 4.95 & 5.1772 & TST & \\
\hline CHEMBL3213012 & 688759 & 4.45 & 4.8894 & TRN & \\
\hline CHEMBL1523375 & 688759 & 4.45 & 4.9941 & TRN & \\
\hline CHEMBL1599092 & 688759 & 4.6 & 4.7664 & TRN & \\
\hline CHEMBL1365971 & 688759 & 4.45 & 4.643 & TST & \\
\hline CHEMBL1543818 & 688759 & 4.95 & 5.1795 & TST & \\
\hline CHEMBL3193345 & 688759 & 4.75 & 4.7756 & TRN & \\
\hline CHEMBL1384167 & 688759 & 5.5 & 5.4891 & TRN & \\
\hline CHEMBL1588753 & 688759 & 5.3 & 5.0604 & TST & \\
\hline CHEMBL1597039 & 688759 & 6.0 & 4.9052 & TRN & \\
\hline CHEMBL1600352 & 688759 & 4.6 & 4.7995 & TST & \\
\hline CHEMBL3194106 & 688759 & 4.95 & 4.8697 & TRN & \\
\hline CHEMBL1349347 & 688759 & 4.8 & 4.5706 & TST & \\
\hline CHEMBL1560329 & 688759 & 4.45 & 5.8775 & TST & \\
\hline CHEMBL1523835 & 688759 & 4.45 & 4.7181 & TRN & \\
\hline CHEMBL1417893 & 688759 & 4.6 & 4.67899 & 9999999999 & TRN \\
\hline CHEMBL1452914 & 688759 & 4.45 & 4.8403 & TRN & \\
\hline CHEMBL1465706 & 688759 & 5.85 & 4.8988 & TRN & \\
\hline CHEMBL1559916 & 688759 & 4.45 & 4.7048 & TRN & \\
\hline CHEMBL1412334 & 688759 & 4.45 & 4.5862 & TRN & \\
\hline CHEMBL1322031 & 688759 & 4.5 & 4.9018 & TST & \\
\hline CHEMBL1518107 & 688759 & 4.45 & 4.805 & TRN & \\
\hline CHEMBL1378739 & 688759 & 4.7 & 4.8896 & TRN & \\
\hline CHEMBL1379350 & 688759 & 5.35 & 5.1141 & TST & \\
\hline CHEMBL1517119 & 688759 & 5.4 & 4.7658 & TRN & \\
\hline CHEMBL1554240 & 688759 & 4.5 & 5.0951 & TRN & \\
\hline CHEMBL1452063 & 688759 & 4.95 & 4.9155 & TRN & \\
\hline CHEMBL3214152 & 688759 & 4.95 & 4.8859 & TRN & \\
\hline CHEMBL 3211743 & 688759 & 6.25 & 4.8678 & TRN & \\
\hline CHEMBL1526249 & 688759 & 6.8499 & 5.1321 & TRN & \\
\hline CHEMBL1517675 & 688759 & 4.45 & 4.8437 & TST & \\
\hline CHEMBL1532973 & 688759 & 4.45 & 4.9201 & TST & \\
\hline CHEMBL1581070 & 688759 & 5.25 & 5.24100 & 00000000005 & TRN \\
\hline CHEMBL1488416 & 688759 & 4.9 & 5.0722 & TRN & \\
\hline CHEMBL1450770 & 688759 & 5.4 & 4.9527 & TST & \\
\hline CHEMBL1571631 & 688759 & 4.8 & 5.2067 & TRN & \\
\hline CHEMBL3191830 & 688759 & 4.6 & 4.7781 & TRN & \\
\hline CHEMBL1441634 & 688759 & 4.45 & 4.7597 & TRN & \\
\hline CHEMBL1541300 & 688759 & 4.65 & 4.8766 & TRN & \\
\hline CHEMBL1422426 & 688759 & 4.55 & 4.6843 & TRN & \\
\hline CHEMBL1336286 & 688759 & 5.15 & 4.7126 & TRN & \\
\hline CHEMBL1300234 & 688759 & 4.8 & 4.8397 & TRN & \\
\hline CHEMBL1570705 & 688759 & 5.85 & 5.8189 & TRN & \\
\hline CHEMBL1560610 & 688759 & 4.45 & 4.7385 & TST & \\
\hline CHEMBL1462059 & 688759 & 4.45 & 4.6951 & TRN & \\
\hline CHEMBL1386810 & 688759 & 5.25 & 5.4059 & TRN & \\
\hline CHEMBL3212969 & 688759 & 5.25 & 4.6451 & TST & \\
\hline CHEMBL1388967 & 688759 & 4.45 & 4.6386 & TRN & \\
\hline
\end{tabular}




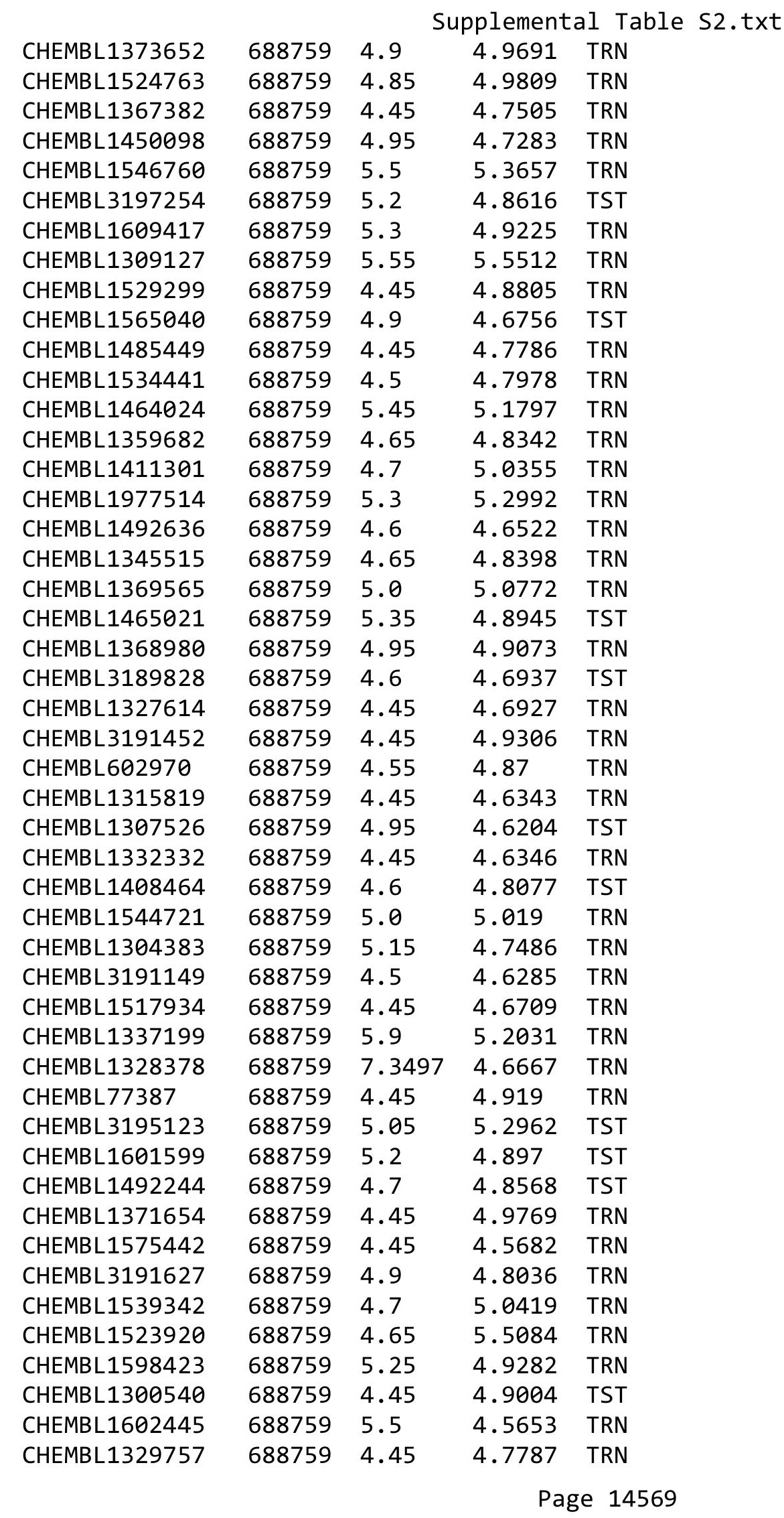




\begin{tabular}{|c|c|c|c|c|c|}
\hline \\
\hline CHEMBL1323872 & 688759 & 5.7 & 5.8622 & TRN & \\
\hline CHEMBL1506855 & 688759 & 4.45 & 4.8213 & TRN & \\
\hline CHEMBL1370257 & 688759 & 4.55 & 4.8363 & TST & \\
\hline CHEMBL1461439 & 688759 & 4.7 & 4.6687 & TRN & \\
\hline CHEMBL1481069 & 688759 & 5.4 & 5.7154 & TRN & \\
\hline CHEMBL1349631 & 688759 & 2.35 & 6.4052 & TRN & \\
\hline CHEMBL1541842 & 688759 & 4.65 & 5.1265 & TRN & \\
\hline CHEMBL1485296 & 688759 & 5.3 & 5.42200 & 0000000001 & TRN \\
\hline CHEMBL3210453 & 688759 & 4.45 & 4.6379 & TST & \\
\hline CHEMBL1998566 & 688759 & 4.45 & 4.931 & TST & \\
\hline CHEMBL1595182 & 688759 & 4.45 & 4.9758 & TRN & \\
\hline CHEMBL1319713 & 688759 & 4.75 & 4.8944 & TRN & \\
\hline CHEMBL1535439 & 688759 & 4.45 & 4.9409 & TRN & \\
\hline CHEMBL1490017 & 688759 & 4.95 & 4.7889 & TRN & \\
\hline CHEMBL1439925 & 688759 & 4.45 & 4.488 & TRN & \\
\hline CHEMBL1509438 & 688759 & 5.3 & 5.0826 & TST & \\
\hline CHEMBL1557719 & 688759 & 4.65 & 4.7847 & TRN & \\
\hline CHEMBL3193424 & 688759 & 4.85 & 4.9801 & TRN & \\
\hline CHEMBL1302524 & 688759 & 4.45 & 4.8824 & TST & \\
\hline CHEMBL1564028 & 688759 & 4.45 & 4.828 & TST & \\
\hline CHEMBL1555584 & 688759 & 5.25 & 5.25799 & 9999999999 & TST \\
\hline CHEMBL1392425 & 688759 & 4.75 & 4.9413 & TRN & \\
\hline CHEMBL1300169 & 688759 & 4.65 & 4.9338 & TRN & \\
\hline CHEMBL1563012 & 688759 & 5.5 & 4.6587 & TRN & \\
\hline CHEMBL1567803 & 688759 & 4.45 & 4.9189 & TRN & \\
\hline CHEMBL1408789 & 688759 & 4.75 & 5.4496 & TRN & \\
\hline CHEMBL1518557 & 688759 & 4.45 & 4.6911 & TST & \\
\hline CHEMBL3191995 & 688759 & 5.05 & 5.0581 & TRN & \\
\hline CHEMBL1558462 & 688759 & 5.9 & 5.2021 & TRN & \\
\hline CHEMBL3199344 & 688759 & 4.95 & 5.0243 & TRN & \\
\hline CHEMBL1449563 & 688759 & 4.6 & 4.7792 & TRN & \\
\hline CHEMBL3145201 & 688759 & 4.75 & 5.0334 & TRN & \\
\hline CHEMBL3197668 & 688759 & 5.0 & 4.7297 & TRN & \\
\hline CHEMBL1497010 & 688759 & 4.6 & 4.8516 & TRN & \\
\hline CHEMBL1528944 & 688759 & 4.45 & 4.9913 & TRN & \\
\hline CHEMBL1438881 & 688759 & 5.55 & 5.0604 & TRN & \\
\hline CHEMBL1417267 & 688759 & 4.45 & 4.7029 & TRN & \\
\hline CHEMBL1508691 & 688759 & 4.45 & 5.0047 & TRN & \\
\hline CHEMBL1557357 & 688759 & 4.45 & 4.8518 & TST & \\
\hline CHEMBL1443069 & 688759 & 4.95 & 4.9354 & TRN & \\
\hline CHEMBL1353189 & 688759 & 6.2 & 4.9235 & TRN & \\
\hline CHEMBL1362163 & 688759 & 4.45 & 4.7403 & TST & \\
\hline CHEMBL1308275 & 688759 & 5.2 & 4.9045 & TRN & \\
\hline CHEMBL1342790 & 688759 & 5.55 & 4.8917 & TRN & \\
\hline CHEMBL1569984 & 688759 & 5.05 & 5.1464 & TRN & \\
\hline CHEMBL1322764 & 688759 & 4.7 & 4.7843 & TST & \\
\hline CHEMBL1459144 & 688759 & 4.7 & 5.0972 & TST & \\
\hline CHEMBL1325958 & 688759 & 4.45 & 4.6415 & TRN & \\
\hline
\end{tabular}




\begin{tabular}{|c|c|c|c|c|c|}
\hline \multicolumn{6}{|c|}{ Supplemental Table S2.txt } \\
\hline CHEMBL1532318 & 688759 & 4.65 & 4.7437 & TRN & \\
\hline CHEMBL3194385 & 688759 & 4.45 & 4.7683 & TRN & \\
\hline CHEMBL3196673 & 688759 & 4.9 & 5.0343 & TRN & \\
\hline CHEMBL1307610 & 688759 & 4.6 & 4.6216 & TRN & \\
\hline CHEMBL1306565 & 688759 & 4.75 & 4.9833 & TST & \\
\hline CHEMBL3145036 & 688759 & 5.95 & 5.6741 & TRN & \\
\hline CHEMBL1613268 & 688759 & 5.0 & 4.5947 & TRN & \\
\hline CHEMBL1384984 & 688759 & 5.55 & 5.57799 & 9999999999 & TRN \\
\hline CHEMBL1490158 & 688759 & 4.8 & 4.7741 & TRN & \\
\hline CHEMBL1374291 & 688759 & 4.7 & 4.8212 & TST & \\
\hline CHEMBL1299757 & 688759 & 5.05 & 5.1958 & TST & \\
\hline CHEMBL1540237 & 688759 & 5.25 & 4.9071 & TRN & \\
\hline CHEMBL1430335 & 688759 & 4.95 & 4.7483 & TRN & \\
\hline CHEMBL1583171 & 688759 & 4.45 & 4.7366 & TRN & \\
\hline CHEMBL1492958 & 688759 & 4.5 & 4.9484 & TST & \\
\hline CHEMBL3196591 & 688759 & 4.6 & 4.769 & TRN & \\
\hline CHEMBL1463446 & 688759 & 4.45 & 4.7168 & TST & \\
\hline CHEMBL3192895 & 688759 & 4.85 & 4.7685 & TRN & \\
\hline CHEMBL1588097 & 688759 & 4.45 & 4.788 & TRN & \\
\hline CHEMBL3197238 & 688759 & 5.85 & 5.4042 & TRN & \\
\hline CHEMBL1423902 & 688759 & 5.5 & 4.823 & TST & \\
\hline CHEMBL1299371 & 688759 & 4.45 & 4.8896 & TRN & \\
\hline CHEMBL1504677 & 688759 & 4.45 & 4.7687 & TRN & \\
\hline CHEMBL1349632 & 688759 & 5.3 & 4.9052 & TRN & \\
\hline CHEMBL1523610 & 688759 & 4.6 & 4.8096 & TST & \\
\hline CHEMBL1461661 & 688759 & 6.0 & 4.7297 & TRN & \\
\hline CHEMBL1588465 & 688759 & 4.55 & 5.0181 & TRN & \\
\hline CHEMBL1438570 & 688759 & 5.45 & 5.5834 & TRN & \\
\hline CHEMBL1492323 & 688759 & 6.0 & 5.4146 & TRN & \\
\hline CHEMBL1416688 & 688759 & 4.45 & 5.09399 & 9999999999 & TST \\
\hline CHEMBL3199203 & 688759 & 4.45 & 4.7164 & TRN & \\
\hline CHEMBL1457755 & 688759 & 4.65 & 4.585 & TRN & \\
\hline CHEMBL1464930 & 688759 & 4.45 & 4.5531 & TRN & \\
\hline CHEMBL1595185 & 688759 & 4.45 & 4.735 & TRN & \\
\hline CHEMBL1611604 & 688759 & 4.45 & 4.5162 & TRN & \\
\hline CHEMBL1549433 & 688759 & 4.45 & 4.6456 & TRN & \\
\hline CHEMBL1582453 & 688759 & 4.7 & 4.8316 & TRN & \\
\hline CHEMBL1527109 & 688759 & 4.7 & 5.1408 & TRN & \\
\hline CHEMBL1570127 & 688759 & 5.0 & 4.7738 & TRN & \\
\hline CHEMBL1452295 & 688759 & 5.15 & 4.8488 & TRN & \\
\hline CHEMBL1455840 & 688759 & 5.3 & 4.7488 & TRN & \\
\hline CHEMBL1447051 & 688759 & 4.8 & 4.7559 & TST & \\
\hline CHEMBL118009 & 688759 & 5.0 & 4.8278 & TRN & \\
\hline CHEMBL3189885 & 688759 & 5.05 & 5.0481 & TRN & \\
\hline CHEMBL1564229 & 688759 & 4.45 & 4.9186 & TST & \\
\hline CHEMBL 2003063 & 688759 & 5.4 & 5.0667 & TRN & \\
\hline CHEMBL1528168 & 688759 & 5.4 & 4.86100 & 0000000001 & TRN \\
\hline CHEMBL1551808 & 688759 & 5.8 & 5.6359 & TRN & \\
\hline
\end{tabular}




\begin{tabular}{|c|c|c|c|c|}
\hline & & & pplement & al $\mathrm{Ta}$ \\
\hline CHEMBL1490840 & 688759 & 5.4 & 4.8271 & TST \\
\hline CHEMBL1496902 & 688759 & 5.0 & 4.9378 & TRN \\
\hline CHEMBL1506827 & 688759 & 4.45 & 4.7348 & TRN \\
\hline CHEMBL3195459 & 688759 & 5.15 & 5.0079 & TRN \\
\hline CHEMBL1360255 & 688759 & 4.5 & 4.9959 & TRN \\
\hline CHEMBL 3191171 & 688759 & 4.85 & 5.1241 & TRN \\
\hline CHEMBL3195876 & 688759 & 4.45 & 4.8047 & TST \\
\hline CHEMBL1585037 & 688759 & 4.9 & 4.8337 & TRN \\
\hline CHEMBL1498178 & 688759 & 4.5 & 4.9018 & TRN \\
\hline CHEMBL1449849 & 688759 & 4.95 & 4.753 & TRN \\
\hline CHEMBL1538334 & 688759 & 5.05 & 4.6837 & TRN \\
\hline CHEMBL1381005 & 688759 & 4.85 & 4.8388 & TRN \\
\hline CHEMBL1417099 & 688759 & 5.3 & 4.9437 & TST \\
\hline CHEMBL1604774 & 688759 & 5.1 & 4.8128 & TRN \\
\hline CHEMBL1490031 & 688759 & 5.7 & 4.715 & TST \\
\hline CHEMBL1609973 & 688759 & 4.6 & 4.9249 & TST \\
\hline CHEMBL1429590 & 688759 & 5.25 & 4.8029 & TRN \\
\hline CHEMBL1465068 & 688759 & 4.45 & 4.7908 & TST \\
\hline CHEMBL1427774 & 688759 & 4.95 & 4.7006 & TRN \\
\hline CHEMBL1485360 & 688759 & 5.05 & 5.2073 & TST \\
\hline CHEMBL1312836 & 688759 & 4.45 & 4.5074 & TRN \\
\hline CHEMBL1393260 & 688759 & 5.0 & 4.9887 & TST \\
\hline CHEMBL1607369 & 688759 & 4.45 & 4.8165 & TST \\
\hline CHEMBL1341239 & 688759 & 5.45 & 4.5215 & TRN \\
\hline CHEMBL1500992 & 688759 & 4.75 & 5.3905 & TRN \\
\hline CHEMBL1557564 & 688759 & 4.45 & 4.5675 & TRN \\
\hline CHEMBL1505902 & 688759 & 5.15 & 4.8473 & TST \\
\hline CHEMBL1487255 & 688759 & 6.5501 & 4.7451 & TRN \\
\hline CHEMBL1393397 & 688759 & 6.45 & 5.8685 & TRN \\
\hline CHEMBL1324493 & 688759 & 8.301 & 5.1727 & TRN \\
\hline CHEMBL1602768 & 688759 & 5.45 & 4.905 & TRN \\
\hline CHEMBL1550800 & 688759 & 4.9 & 5.1041 & TRN \\
\hline CHEMBL1299725 & 688759 & 5.0 & 5.0543 & TRN \\
\hline CHEMBL1567092 & 688759 & 4.65 & 4.6481 & TRN \\
\hline CHEMBL1487761 & 688759 & 4.8 & 4.5894 & TRN \\
\hline CHEMBL1986907 & 688759 & 4.9 & 5.0189 & TRN \\
\hline CHEMBL391533 & 688759 & 4.45 & 4.9755 & TRN \\
\hline CHEMBL1308224 & 688759 & 4.45 & 4.6643 & TST \\
\hline CHEMBL1563483 & 688759 & 6.05 & 5.5443 & TST \\
\hline CHEMBL1311028 & 688759 & 4.7 & 4.7103 & TRN \\
\hline CHEMBL1328289 & 688759 & 4.9 & 5.2444 & TRN \\
\hline CHEMBL1388351 & 688759 & 4.85 & 5.1057 & TST \\
\hline CHEMBL1435301 & 688759 & 4.45 & 4.5582 & TRN \\
\hline CHEMBL1374014 & 688759 & 4.55 & 4.9133 & TST \\
\hline CHEMBL1336526 & 688759 & 5.65 & 4.6733 & TRN \\
\hline CHEMBL1498164 & 688759 & 5.25 & 4.8207 & TRN \\
\hline CHEMBL1467760 & 688759 & 5.4 & 4.7762 & TST \\
\hline CHEMBL3210611 & 688759 & 4.45 & 4.8797 & TRN \\
\hline
\end{tabular}




\begin{tabular}{|c|c|c|c|c|c|}
\hline \multicolumn{6}{|c|}{ Supplemental Table S2.txt } \\
\hline CHEMBL1478531 & 688759 & 5.2 & 5.0033 & TRN & \\
\hline CHEMBL362994 & 688759 & 5.5 & 5.4505 & TRN & \\
\hline CHEMBL1330492 & 688759 & 5.1 & 4.8097 & TRN & \\
\hline CHEMBL1556779 & 688759 & 4.45 & 4.7633 & TRN & \\
\hline CHEMBL 3213274 & 688759 & 4.85 & 4.8797 & TRN & \\
\hline CHEMBL1346771 & 688759 & 6.05 & 5.5593 & TRN & \\
\hline CHEMBL1305312 & 688759 & 4.7 & 4.6906 & TST & \\
\hline CHEMBL 271023 & 688759 & 6.15 & 5.4525 & TST & \\
\hline CHEMBL3196643 & 688759 & 4.45 & 5.311 & TRN & \\
\hline CHEMBL1464503 & 688759 & 4.65 & 4.7152 & TST & \\
\hline CHEMBL1448690 & 688759 & 5.35 & 4.8644 & TRN & \\
\hline CHEMBL1426113 & 688759 & 4.9 & 4.9 & TST & \\
\hline CHEMBL175434 & 688759 & 4.45 & 4.7814 & TRN & \\
\hline CHEMBL1445254 & 688759 & 4.8 & 4.9293 & TRN & \\
\hline CHEMBL1320389 & 688759 & 4.65 & 4.8388 & TRN & \\
\hline CHEMBL1526889 & 688759 & 6.35 & 5.0134 & TRN & \\
\hline CHEMBL1459662 & 688759 & 5.05 & 4.877 & TST & \\
\hline CHEMBL1407386 & 688759 & 4.6 & 4.9176 & TST & \\
\hline CHEMBL1393417 & 688759 & 4.7 & 4.7546 & TRN & \\
\hline CHEMBL3194664 & 688759 & 4.6 & 4.6819 & TRN & \\
\hline CHEMBL1572026 & 688759 & 4.9 & 4.6442 & TRN & \\
\hline CHEMBL1410274 & 688759 & 4.65 & 4.9789 & TRN & \\
\hline CHEMBL1429134 & 688759 & 4.5 & 4.7743 & TRN & \\
\hline CHEMBL1536852 & 688759 & 4.8 & 4.9454 & TST & \\
\hline CHEMBL3211742 & 688759 & 4.9 & 4.9718 & TST & \\
\hline CHEMBL1359508 & 688759 & 4.65 & 4.6751 & TST & \\
\hline CHEMBL1501057 & 688759 & 5.45 & 5.5293 & TRN & \\
\hline CHEMBL3199228 & 688759 & 4.45 & 4.8992 & TRN & \\
\hline CHEMBL1309529 & 688759 & 5.15 & 4.7498 & TRN & \\
\hline CHEMBL1443934 & 688759 & 4.8 & 5.0752 & TRN & \\
\hline CHEMBL1977867 & 688759 & 5.35 & 5.2314 & TRN & \\
\hline CHEMBL3192357 & 688759 & 5.55 & 5.3463 & TRN & \\
\hline CHEMBL1379713 & 688759 & 7.3497 & 5.9262 & TRN & \\
\hline CHEMBL1588393 & 688759 & 5.4 & 4.7095 & TRN & \\
\hline CHEMBL1343483 & 688759 & 4.45 & 4.8282 & TRN & \\
\hline CHEMBL3145280 & 688759 & 5.9 & 5.6804 & TRN & \\
\hline CHEMBL1577590 & 688759 & 4.65 & 4.7243 & TRN & \\
\hline CHEMBL3195852 & 688759 & 4.6 & 4.9549 & TRN & \\
\hline CHEMBL1480467 & 688759 & 4.5 & 4.8666 & TRN & \\
\hline CHEMBL1371052 & 688759 & 4.9 & 5.13299 & 9999999999 & TRN \\
\hline CHEMBL1345103 & 688759 & 5.55 & $4.9030 e$ & 00000000005 & TST \\
\hline CHEMBL1557142 & 688759 & 4.6 & 4.8201 & TST & \\
\hline CHEMBL1384904 & 688759 & 4.7 & 4.8499 & TST & \\
\hline CHEMBL1351019 & 688759 & 5.5 & 5.0796 & TRN & \\
\hline CHEMBL1316447 & 688759 & 4.7 & 4.6689 & TRN & \\
\hline CHEMBL1547707 & 688759 & 5.15 & 4.6789 & TST & \\
\hline CHEMBL1499806 & 688759 & 4.45 & 4.8347 & TST & \\
\hline CHEMBL1308241 & 688759 & 4.65 & 4.4685 & TRN & \\
\hline
\end{tabular}




\begin{tabular}{|c|c|c|c|c|c|}
\hline \multicolumn{6}{|c|}{ Supplemental Table S2.txt } \\
\hline CHEMBL 3192734 & 688759 & 4.45 & 4.8562 & TRN & \\
\hline CHEMBL148296 & 688759 & 4.5 & 4.7287 & TST & \\
\hline CHEMBL3197911 & 688759 & 5.2 & 4.9587 & TRN & \\
\hline CHEMBL1504661 & 688759 & 4.45 & 4.75899 & 99999999995 & TST \\
\hline CHEMBL1301614 & 688759 & 5.3 & 5.5158 & TRN & \\
\hline CHEMBL1418919 & 688759 & 5.1 & 4.91100 & 00000000005 & TST \\
\hline CHEMBL1582277 & 688759 & 4.65 & 4.953 & TRN & \\
\hline CHEMBL1428019 & 688759 & 6.95 & 4.7965 & TST & \\
\hline CHEMBL3197007 & 688759 & 4.65 & 4.8091 & TRN & \\
\hline CHEMBL1423726 & 688759 & 4.65 & 4.7282 & TRN & \\
\hline CHEMBL1314989 & 688759 & 4.45 & 4.9246 & TST & \\
\hline CHEMBL1478146 & 688759 & 4.45 & 4.7045 & TRN & \\
\hline CHEMBL1342379 & 688759 & 4.7 & 4.6394 & TST & \\
\hline CHEMBL1487862 & 688759 & 5.05 & 5.2202 & TRN & \\
\hline CHEMBL1507741 & 688759 & 4.8 & 5.4832 & TRN & \\
\hline CHEMBL1570377 & 688759 & 4.45 & 4.9802 & TRN & \\
\hline CHEMBL3198857 & 688759 & 5.1 & 4.9852 & TST & \\
\hline CHEMBL1348823 & 688759 & 4.95 & 4.8405 & TRN & \\
\hline CHEMBL1403612 & 688759 & 4.45 & 4.8356 & TRN & \\
\hline CHEMBL1383362 & 688759 & 6.0 & 4.8452 & TST & \\
\hline CHEMBL1544794 & 688759 & 4.45 & 4.8801 & TST & \\
\hline CHEMBL1300632 & 688759 & 4.6 & 4.7772 & TRN & \\
\hline CHEMBL1535940 & 688759 & 4.65 & 4.9294 & TST & \\
\hline CHEMBL1611613 & 688759 & 4.8 & 4.6599 & TRN & \\
\hline CHEMBL1353389 & 688759 & 4.8 & 4.7942 & TRN & \\
\hline CHEMBL1527216 & 688759 & 6.0 & 5.42299 & 9999999999 & TRN \\
\hline CHEMBL1303272 & 688759 & 4.7 & 5.1151 & TRN & \\
\hline CHEMBL1606820 & 688759 & 4.6 & 5.0636 & TRN & \\
\hline CHEMBL1489179 & 688759 & 4.45 & 4.843 & TST & \\
\hline CHEMBL1606360 & 688759 & 5.25 & 4.9859 & TRN & \\
\hline CHEMBL1582556 & 688759 & 5.25 & 4.7924 & TST & \\
\hline CHEMBL1350008 & 688759 & 4.65 & 4.7294 & TST & \\
\hline CHEMBL 3196441 & 688759 & 6.05 & 5.5421 & TRN & \\
\hline CHEMBL1362635 & 688759 & 4.45 & 4.6809 & TRN & \\
\hline CHEMBL1570841 & 688759 & 4.85 & 4.4094 & TRN & \\
\hline CHEMBL1377978 & 688759 & 4.65 & 4.8321 & TST & \\
\hline CHEMBL1598517 & 688759 & 4.6 & 4.4953 & TRN & \\
\hline CHEMBL1567409 & 688759 & 4.65 & 4.8256 & TST & \\
\hline CHEMBL1967385 & 688759 & 4.45 & 4.5878 & TRN & \\
\hline CHEMBL1524115 & 688759 & 4.45 & 4.7717 & TRN & \\
\hline CHEMBL1520245 & 688759 & 4.45 & 4.5232 & TRN & \\
\hline CHEMBL3208232 & 688759 & 4.65 & 4.7479 & TRN & \\
\hline CHEMBL1403965 & 688759 & 5.0 & 5.0133 & TRN & \\
\hline CHEMBL 2296993 & 688759 & 4.95 & 4.9801 & TRN & \\
\hline CHEMBL1465360 & 688759 & 4.45 & 4.7004 & TRN & \\
\hline CHEMBL1422876 & 688759 & 4.45 & 4.8341 & TRN & \\
\hline CHEMBL1372326 & 688759 & 4.65 & 4.9916 & TRN & \\
\hline CHEMBL1310093 & 688759 & 4.65 & 4.7655 & TST & \\
\hline
\end{tabular}




\begin{tabular}{|c|c|c|c|c|c|}
\hline \multicolumn{6}{|c|}{ Supplemental Table s2.txt } \\
\hline CHEMBL1311615 & 688759 & 5.25 & 4.626 & TST & \\
\hline CHEMBL1413291 & 688759 & 4.95 & 4.8803 & TRN & \\
\hline CHEMBL1418430 & 688759 & 4.5 & 4.8095 & TRN & \\
\hline CHEMBL1432057 & 688759 & 5.2 & 4.907 & TRN & \\
\hline CHEMBL1601325 & 688759 & 5.7 & 5.2538 & TRN & \\
\hline CHEMBL1498044 & 688759 & 5.85 & 4.8553 & TST & \\
\hline CHEMBL1535660 & 688759 & 4.75 & 4.8977 & TRN & \\
\hline CHEMBL1425833 & 688759 & 4.65 & 4.9003 & TST & \\
\hline CHEMBL1303880 & 688759 & 4.65 & 4.51699 & 99999999995 & TS \\
\hline CHEMBL1513046 & 688759 & 5.3 & 5.3207 & TRN & \\
\hline CHEMBL1328628 & 688759 & 4.45 & 5.2056 & TRN & \\
\hline CHEMBL1342522 & 688759 & 4.6 & 4.8495 & TRN & \\
\hline CHEMBL1433058 & 688759 & 4.55 & 4.8381 & TST & \\
\hline CHEMBL1333617 & 688759 & 4.45 & 4.7061 & TST & \\
\hline CHEMBL1530503 & 688759 & 4.5 & 4.6298 & TST & \\
\hline CHEMBL1386067 & 688759 & 5.8 & 4.9339 & TRN & \\
\hline CHEMBL1582213 & 688759 & 4.45 & 4.6335 & TRN & \\
\hline CHEMBL1584595 & 688759 & 4.9 & 4.879 & TRN & \\
\hline CHEMBL1441304 & 688759 & 5.45 & 5.1041 & TRN & \\
\hline CHEMBL 281948 & 688759 & 6.0 & 5.5517 & TST & \\
\hline CHEMBL1567847 & 688759 & 4.9 & 5.1596 & TRN & \\
\hline CHEMBL1405047 & 688759 & 4.65 & 4.6311 & TRN & \\
\hline CHEMBL1607720 & 688759 & 5.4 & 4.9502 & TRN & \\
\hline CHEMBL1488374 & 688759 & 4.45 & 4.8187 & TRN & \\
\hline CHEMBL1332265 & 688759 & 5.45 & 4.9831 & TRN & \\
\hline CHEMBL1371460 & 688759 & 5.55 & 5.0049 & TRN & \\
\hline CHEMBL1517880 & 688759 & 4.6 & 5.003 & TRN & \\
\hline CHEMBL486706 & 688759 & 5.2 & 4.7033 & TST & \\
\hline CHEMBL1416800 & 688759 & 4.45 & 4.647 & TRN & \\
\hline CHEMBL1968361 & 688759 & 4.45 & 4.8092 & TRN & \\
\hline CHEMBL1517460 & 688759 & 5.5 & 4.9476 & TRN & \\
\hline CHEMBL1517624 & 688759 & 5.35 & 5.3372 & TRN & \\
\hline CHEMBL1600851 & 688759 & 5.25 & 4.8388 & TRN & \\
\hline CHEMBL1519630 & 688759 & 4.45 & 4.8573 & TRN & \\
\hline CHEMBL1464122 & 688759 & 4.45 & 4.5309 & TRN & \\
\hline CHEMBL1406948 & 688759 & 4.65 & 4.9786 & TRN & \\
\hline CHEMBL1569945 & 688759 & 5.5 & 5.9769 & TRN & \\
\hline CHEMBL1369879 & 688759 & 4.45 & 4.8671 & TRN & \\
\hline CHEMBL1557762 & 688759 & 5.5 & 5.3339 & TRN & \\
\hline CHEMBL1344833 & 688759 & 4.8 & 4.7422 & TRN & \\
\hline CHEMBL1536725 & 688759 & 4.9 & 4.833 & TST & \\
\hline CHEMBL1312884 & 688759 & 4.9 & 4.9896 & TST & \\
\hline CHEMBL1582712 & 688759 & 4.55 & 4.85 & TST & \\
\hline CHEMBL1340587 & 688759 & 4.95 & 4.8209 & TST & \\
\hline CHEMBL1508457 & 688759 & 4.45 & 5.0581 & TRN & \\
\hline CHEMBL1890591 & 688759 & 4.45 & 4.939 & TRN & \\
\hline CHEMBL1344484 & 688759 & 4.8 & 4.6097 & TST & \\
\hline CHEMBL1981002 & 688759 & 4.45 & 4.9231 & TST & \\
\hline
\end{tabular}




\begin{tabular}{|c|c|c|c|c|c|}
\hline \\
\hline CHEMBL1547869 & 688759 & 6.0 & 5.0235 & TRN & \\
\hline CHEMBL1585075 & 688759 & 5.35 & 4.7907 & TRN & \\
\hline CHEMBL1361809 & 688759 & 4.45 & 5.0039 & TRN & \\
\hline CHEMBL1331775 & 688759 & 5.3 & 5.1298 & TRN & \\
\hline CHEMBL496324 & 688759 & 5.45 & 5.2569 & TRN & \\
\hline CHEMBL1467867 & 688759 & 6.0 & 5.4093 & TRN & \\
\hline CHEMBL1498887 & 688759 & 6.0 & 4.8637 & TRN & \\
\hline CHEMBL1517852 & 688759 & 4.65 & 4.6577 & TRN & \\
\hline CHEMBL1515703 & 688759 & 4.6 & 4.5448 & TRN & \\
\hline CHEMBL1301122 & 688759 & 4.45 & 5.1191 & TST & \\
\hline CHEMBL1399698 & 688759 & 5.3 & 5.2552 & TRN & \\
\hline CHEMBL1501726 & 688759 & 4.65 & 4.4005 & TRN & \\
\hline CHEMBL1414869 & 688759 & 5.0 & 4.6377 & TRN & \\
\hline CHEMBL1584634 & 688759 & 5.6 & 4.8101 & TRN & \\
\hline CHEMBL1541350 & 688759 & 5.6 & 5.75899 & 99999999995 & TRN \\
\hline CHEMBL1579286 & 688759 & 5.3 & 5.0806 & TRN & \\
\hline CHEMBL1443814 & 688759 & 5.15 & 5.5123 & TRN & \\
\hline CHEMBL1968628 & 688759 & 5.85 & 5.359 & TRN & \\
\hline CHEMBL1315868 & 688759 & 4.75 & 4.5939 & TST & \\
\hline CHEMBL1484832 & 688759 & 4.45 & 4.745 & TRN & \\
\hline CHEMBL1309954 & 688759 & 5.0 & 4.8588 & TST & \\
\hline CHEMBL1455877 & 688759 & 5.2 & 4.853 & TRN & \\
\hline CHEMBL1478525 & 688759 & 4.45 & 4.7796 & TRN & \\
\hline CHEMBL1558162 & 688759 & 4.65 & 5.2021 & TRN & \\
\hline CHEMBL1581360 & 688759 & 5.4 & 5.0631 & TRN & \\
\hline CHEMBL1996858 & 688759 & 5.15 & 4.6254 & TRN & \\
\hline CHEMBL3198742 & 688759 & 6.9 & 4.842 & TST & \\
\hline CHEMBL1468954 & 688759 & 4.45 & 4.9357 & TRN & \\
\hline CHEMBL1339505 & 688759 & 5.95 & 5.4091 & TRN & \\
\hline CHEMBL1429502 & 688759 & 4.85 & 4.8257 & TRN & \\
\hline CHEMBL1418937 & 688759 & 4.65 & 4.8511 & TRN & \\
\hline CHEMBL1408323 & 688759 & 5.15 & 5.1884 & TRN & \\
\hline CHEMBL578944 & 688759 & 4.95 & 4.6588 & TRN & \\
\hline CHEMBL1339953 & 688759 & 4.45 & 4.9265 & TST & \\
\hline CHEMBL1530349 & 688759 & 4.45 & 4.8714 & TRN & \\
\hline CHEMBL1503757 & 688759 & 5.15 & 5.1112 & TRN & \\
\hline CHEMBL3193413 & 688759 & 5.35 & 4.9412 & TRN & \\
\hline CHEMBL1563360 & 688759 & 4.45 & 4.6156 & TRN & \\
\hline CHEMBL1996922 & 688759 & 6.3 & 5.79299 & 9999999999 & TRN \\
\hline CHEMBL1560229 & 688759 & 4.55 & 4.5419 & TRN & \\
\hline CHEMBL1484156 & 688759 & 4.5 & 4.6598 & TRN & \\
\hline CHEMBL1328184 & 688759 & 4.75 & 4.8329 & TRN & \\
\hline CHEMBL1423956 & 688759 & 4.65 & 4.7487 & TRN & \\
\hline CHEMBL1608666 & 688759 & 5.35 & 5.1161 & TRN & \\
\hline CHEMBL1523796 & 688759 & 4.45 & 4.8135 & TRN & \\
\hline CHEMBL1465813 & 688759 & 4.6 & 4.5579 & TRN & \\
\hline CHEMBL1564866 & 688759 & 4.6 & 4.9059 & TST & \\
\hline CHEMBL1377824 & 688759 & 5.15 & 4.8689 & TRN & \\
\hline
\end{tabular}




\begin{tabular}{|c|c|c|c|c|}
\hline & & & upplement & al $\mathrm{Ta}$ \\
\hline CHEMBL1580993 & 688759 & 4.45 & 4.7759 & TST \\
\hline CHEMBL1522106 & 688759 & 5.95 & 5.0255 & TST \\
\hline CHEMBL1345585 & 688759 & 5.5 & 5.1327 & TRN \\
\hline CHEMBL131199 & 688759 & 5.35 & 5.0473 & TRN \\
\hline CHEMBL1497659 & 688759 & 4.45 & 4.7921 & TRN \\
\hline CHEMBL1410494 & 688759 & 4.45 & 4.8575 & TRN \\
\hline CHEMBL1511739 & 688759 & 5.45 & 4.9863 & TRN \\
\hline CHEMBL1594188 & 688759 & 4.45 & 4.8842 & TRN \\
\hline CHEMBL470266 & 688759 & 4.9 & 4.9353 & TRN \\
\hline CHEMBL3192146 & 688759 & 4.95 & 4.6221 & TRN \\
\hline CHEMBL1510632 & 688759 & 4.95 & 4.9812 & TRN \\
\hline CHEMBL1444604 & 688759 & 4.45 & 4.879 & TST \\
\hline CHEMBL1332049 & 688759 & 4.9 & 5.0838 & TRN \\
\hline CHEMBL1423091 & 688759 & 4.55 & 4.9887 & TRN \\
\hline CHEMBL1326118 & 688759 & 4.45 & 4.8026 & TRN \\
\hline CHEMBL1519471 & 688759 & 6.5 & 4.7614 & TST \\
\hline CHEMBL 2007318 & 688759 & 5.05 & 4.6564 & TST \\
\hline CHEMBL1323123 & 688759 & 5.15 & 4.6886 & TRN \\
\hline CHEMBL3214029 & 688759 & 4.45 & 4.5192 & TRN \\
\hline CHEMBL1528875 & 688759 & 5.25 & 4.7152 & TST \\
\hline CHEMBL1482025 & 688759 & 4.75 & 4.7555 & TRN \\
\hline CHEMBL1524881 & 688759 & 5.15 & 5.0379 & TRN \\
\hline CHEMBL1503922 & 688759 & 4.45 & 4.6689 & TRN \\
\hline CHEMBL1329012 & 688759 & 4.45 & 4.7673 & TST \\
\hline CHEMBL1392176 & 688759 & 4.9 & 4.6323 & TST \\
\hline CHEMBL1364960 & 688759 & 4.45 & 4.5536 & TRN \\
\hline CHEMBL1511925 & 688759 & 4.85 & 5.2235 & TRN \\
\hline CHEMBL1987894 & 688759 & 4.95 & 4.9016 & TRN \\
\hline CHEMBL1329724 & 688759 & 4.45 & 4.8335 & TST \\
\hline CHEMBL1502348 & 688759 & 4.7 & 4.627 & TST \\
\hline CHEMBL1596903 & 688759 & 5.0 & 4.7362 & TST \\
\hline CHEMBL3198178 & 688759 & 4.6 & 4.5671 & TRN \\
\hline CHEMBL1519694 & 688759 & 4.55 & 5.2728 & TRN \\
\hline CHEMBL1449042 & 688759 & 5.2 & 5.1769 & TRN \\
\hline CHEMBL1477884 & 688759 & 5.3 & 4.8444 & TRN \\
\hline CHEMBL1387334 & 688759 & 4.45 & 4.7716 & TST \\
\hline CHEMBL 1471078 & 688759 & 6.1 & 5.1194 & TRN \\
\hline CHEMBL1502375 & 688759 & 4.8 & 4.8658 & TRN \\
\hline CHEMBL1376794 & 688759 & 4.45 & 4.5932 & TRN \\
\hline CHEMBL1508450 & 688759 & 4.45 & 4.7607 & TRN \\
\hline CHEMBL1600335 & 688759 & 4.65 & 4.8759 & TST \\
\hline CHEMBL1611695 & 688759 & 4.45 & 4.5464 & TRN \\
\hline CHEMBL1536360 & 688759 & 4.45 & 4.9269 & TRN \\
\hline CHEMBL1305752 & 688759 & 4.8 & 4.9504 & TRN \\
\hline CHEMBL1386172 & 688759 & 5.55 & 5.3593 & TRN \\
\hline CHEMBL1402245 & 688759 & 4.8 & 4.9678 & TRN \\
\hline CHEMBL1319850 & 688759 & 4.8 & 5.0318 & TRN \\
\hline CHEMBL3192762 & 688759 & 4.75 & 4.841 & TRN \\
\hline
\end{tabular}




\begin{tabular}{|c|c|c|c|c|}
\hline \multicolumn{5}{|c|}{ Supplemental Table S2.txt } \\
\hline CHEMBL1489531 & 688759 & 5.7 & 5.2196 & TRN \\
\hline CHEMBL1332353 & 688759 & 4.6 & 4.6813 & TRN \\
\hline CHEMBL1461119 & 688759 & 5.0 & 4.6169 & TRN \\
\hline CHEMBL 3213340 & 688759 & 4.45 & 4.7263 & TRN \\
\hline CHEMBL 1607143 & 688759 & 5.55 & 4.8909 & TRN \\
\hline CHEMBL 255068 & 688759 & 4.45 & 5.0391 & TRN \\
\hline CHEMBL1389269 & 688759 & 4.9 & 5.1509 & TRN \\
\hline CHEMBL1507297 & 688759 & 5.3 & 4.9948 & TRN \\
\hline CHEMBL3210983 & 688759 & 4.95 & 5.0131 & TRN \\
\hline CHEMBL1322114 & 688759 & 4.45 & 4.9121 & TRN \\
\hline CHEMBL1570002 & 688759 & 5.0 & 5.1408 & TRN \\
\hline CHEMBL1458622 & 688759 & 4.95 & 5.4903 & TRN \\
\hline CHEMBL1576113 & 688759 & 5.25 & 5.18 & TST \\
\hline CHEMBL1303767 & 688759 & 4.45 & 4.8032 & TST \\
\hline CHEMBL1548745 & 688759 & 5.25 & 4.5237 & TRN \\
\hline CHEMBL3192465 & 688759 & 4.45 & 4.6848 & TRN \\
\hline CHEMBL584668 & 688759 & 4.7 & 5.1626 & TRN \\
\hline CHEMBL1503528 & 688759 & 5.0 & 4.8701 & TRN \\
\hline CHEMBL 3190625 & 688759 & 5.5 & 4.6422 & TST \\
\hline CHEMBL1378190 & 688759 & 4.45 & 4.6909 & TST \\
\hline CHEMBL582355 & 688759 & 4.85 & 4.9595 & TST \\
\hline CHEMBL603945 & 688759 & 4.45 & 4.8476 & TRN \\
\hline CHEMBL1349317 & 688759 & 6.15 & 5.0059 & TRN \\
\hline CHEMBL1603182 & 688759 & 4.45 & 4.9105 & TRN \\
\hline CHEMBL1455524 & 688759 & 4.7 & 5.0291 & TRN \\
\hline CHEMBL1430765 & 688759 & 4.95 & 5.0092 & TRN \\
\hline CHEMBL1579471 & 688759 & 4.45 & 4.3204 & TRN \\
\hline CHEMBL1428211 & 688759 & 4.45 & 5.3534 & TRN \\
\hline CHEMBL1383493 & 688759 & 4.65 & 4.776 & TST \\
\hline CHEMBL1412475 & 688759 & 4.95 & 5.0114 & TST \\
\hline CHEMBL1362799 & 688759 & 4.45 & 4.7973 & TRN \\
\hline CHEMBL1423635 & 688759 & 4.45 & 4.8894 & TRN \\
\hline CHEMBL1330279 & 688759 & 5.55 & 5.474 & TRN \\
\hline CHEMBL1270082 & 688759 & 4.7 & 4.771 & TRN \\
\hline CHEMBL1369916 & 688759 & 4.75 & 4.9346 & TRN \\
\hline CHEMBL1363788 & 688759 & 4.9 & 5.1237 & TRN \\
\hline CHEMBL1611827 & 688759 & 4.45 & 4.7893 & TRN \\
\hline CHEMBL1969492 & 688759 & 4.45 & 4.7501 & TST \\
\hline CHEMBL154580 & 688759 & 6.15 & 5.4365 & TST \\
\hline CHEMBL1418605 & 688759 & 4.45 & 4.5008 & TRN \\
\hline CHEMBL1341705 & 688759 & 5.2 & 4.9752 & TRN \\
\hline CHEMBL 1350380 & 688759 & 5.25 & 4.9445 & TRN \\
\hline CHEMBL1339661 & 688759 & 4.45 & 4.9417 & TRN \\
\hline CHEMBL1437654 & 688759 & 4.8 & 4.8987 & TRN \\
\hline CHEMBL1611507 & 688759 & 6.5 & 4.9235 & TRN \\
\hline CHEMBL1469323 & 688759 & 4.45 & 4.5827 & TRN \\
\hline CHEMBL1449793 & 688759 & 5.0 & 4.849 & TRN \\
\hline CHEMBL1330713 & 688759 & 4.45 & 4.9057 & TRN \\
\hline
\end{tabular}




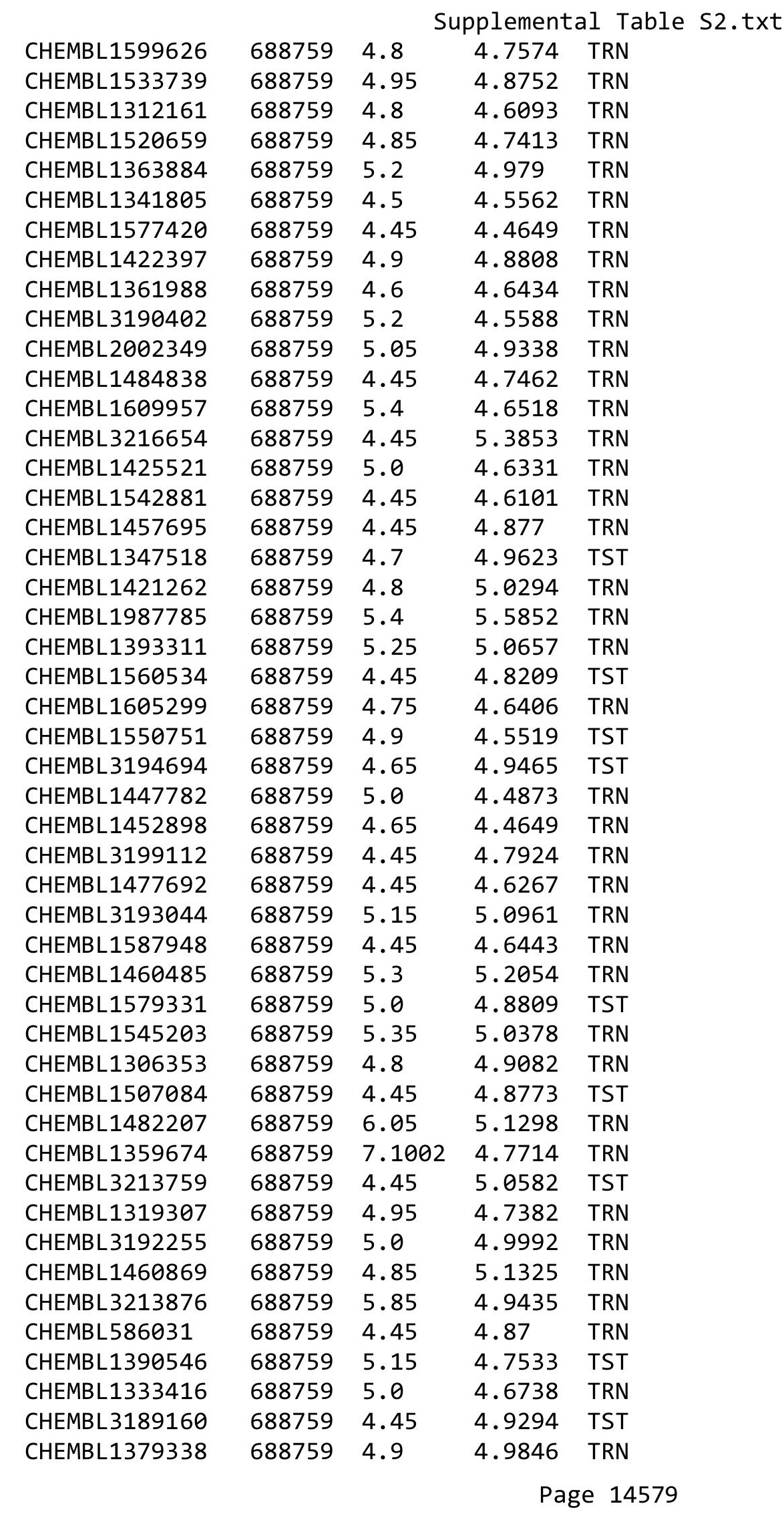




\begin{tabular}{|c|c|c|c|c|}
\hline \multicolumn{5}{|c|}{ Supplemental Table S2.txt } \\
\hline CHEMBL1531898 & 688759 & 5.4 & 4.9227 & TRN \\
\hline CHEMBL1482647 & 688759 & 4.6 & 4.7342 & TRN \\
\hline CHEMBL1609735 & 688759 & 5.25 & 5.0343 & TRN \\
\hline CHEMBL1385323 & 688759 & 4.75 & 4.9671 & TST \\
\hline CHEMBL1388194 & 688759 & 5.05 & 5.0707 & TRN \\
\hline CHEMBL1540633 & 688759 & 4.45 & 4.8671 & TRN \\
\hline CHEMBL1305196 & 688759 & 5.2 & 5.1792 & TRN \\
\hline CHEMBL1536892 & 688759 & 4.9 & 4.7305 & TST \\
\hline CHEMBL1424063 & 688759 & 4.55 & 4.6721 & TRN \\
\hline CHEMBL1343775 & 688759 & 4.9 & 4.7515 & TST \\
\hline CHEMBL1472066 & 688759 & 5.1 & 4.9757 & TRN \\
\hline CHEMBL1427966 & 688759 & 4.6 & 4.9214 & TST \\
\hline CHEMBL1470098 & 688759 & 4.95 & 4.9747 & TRN \\
\hline CHEMBL1544369 & 688759 & 5.8 & 5.5709 & TRN \\
\hline CHEMBL3196693 & 688759 & 4.45 & 4.8471 & TRN \\
\hline CHEMBL1591251 & 688759 & 4.55 & 5.0205 & TST \\
\hline CHEMBL1389046 & 688759 & 4.45 & 4.9512 & TRN \\
\hline CHEMBL1392810 & 688759 & 4.65 & 4.6887 & TRN \\
\hline CHEMBL1313383 & 688759 & 5.5 & 4.887 & TST \\
\hline CHEMBL1546023 & 688759 & 4.85 & 4.8456 & TST \\
\hline CHEMBL1542886 & 688759 & 6.25 & 6.231 & TRN \\
\hline CHEMBL1454532 & 688759 & 4.45 & 4.5679 & TRN \\
\hline CHEMBL1483014 & 688759 & 4.9 & 4.8041 & TST \\
\hline CHEMBL1467814 & 688759 & 5.45 & 4.8987 & TRN \\
\hline CHEMBL1546906 & 688759 & 5.1 & 5.2549 & TRN \\
\hline CHEMBL1375177 & 688759 & 5.35 & 4.8331 & TST \\
\hline CHEMBL1525219 & 688759 & 5.15 & 4.7229 & TRN \\
\hline CHEMBL1368778 & 688759 & 5.5 & 4.8341 & TST \\
\hline CHEMBL1539817 & 688759 & 4.85 & 5.4331 & TRN \\
\hline CHEMBL1454555 & 688759 & 4.45 & 4.9044 & TRN \\
\hline CHEMBL1582490 & 688759 & 4.95 & 4.8593 & TST \\
\hline CHEMBL1967938 & 688759 & 4.45 & 4.7851 & TRN \\
\hline CHEMBL1574026 & 688759 & 4.9 & 5.1435 & TRN \\
\hline CHEMBL584826 & 688759 & 5.5 & 4.8434 & TRN \\
\hline CHEMBL1580944 & 688759 & 4.65 & 4.7771 & TRN \\
\hline CHEMBL1559937 & 688759 & 4.45 & 4.7487 & TRN \\
\hline CHEMBL1603366 & 688759 & 4.45 & 4.7819 & TST \\
\hline CHEMBL1589738 & 688759 & 6.6 & 4.7842 & TRN \\
\hline CHEMBL1303203 & 688759 & 4.45 & 4.8543 & TRN \\
\hline CHEMBL117966 & 688759 & 5.8 & 5.1427 & TRN \\
\hline CHEMBL1301471 & 688759 & 6.15 & 5.8634 & TRN \\
\hline CHEMBL1508128 & 688759 & 4.45 & 4.6181 & TRN \\
\hline CHEMBL1479284 & 688759 & 4.45 & 4.9072 & TRN \\
\hline CHEMBL3192649 & 688759 & 4.45 & 4.8551 & TRN \\
\hline CHEMBL1483191 & 688759 & 6.8499 & 5.0828 & TRN \\
\hline CHEMBL1467554 & 688759 & 4.45 & 4.8832 & TST \\
\hline CHEMBL1579696 & 688759 & 4.85 & 5.7306 & TRN \\
\hline CHEMBL1588366 & 688759 & 5.55 & 5.3703 & TRN \\
\hline
\end{tabular}




\begin{tabular}{|c|c|c|c|c|}
\hline \multicolumn{5}{|c|}{ Supplemental Table S2.txt } \\
\hline CHEMBL1312665 & 688759 & 5.2 & 4.8682 & TRN \\
\hline CHEMBL1388346 & 688759 & 4.5 & 4.7146 & TST \\
\hline CHEMBL3193226 & 688759 & 4.5 & 4.7034 & TRN \\
\hline CHEMBL1375250 & 688759 & 4.45 & 4.9084 & TST \\
\hline CHEMBL1349682 & 688759 & 5.5 & 5.4257 & TRN \\
\hline CHEMBL1490562 & 688759 & 5.0 & 5.1826 & TRN \\
\hline CHEMBL1548309 & 688759 & 4.6 & 4.9166 & TRN \\
\hline CHEMBL1349261 & 688759 & 4.65 & 4.6825 & TST \\
\hline CHEMBL 3190644 & 688759 & 4.95 & 4.994 & TRN \\
\hline CHEMBL235658 & 688759 & 5.35 & 5.2638 & TST \\
\hline CHEMBL1378752 & 688759 & 4.6 & 4.7975 & TRN \\
\hline CHEMBL1416184 & 688759 & 5.3 & 5.285 & TRN \\
\hline CHEMBL1454243 & 688759 & 4.9 & 4.9168 & TST \\
\hline CHEMBL1489585 & 688759 & 4.45 & 4.7879 & TRN \\
\hline CHEMBL1366196 & 688759 & 4.7 & 4.6559 & TST \\
\hline CHEMBL1428940 & 688759 & 4.45 & 5.0717 & TRN \\
\hline CHEMBL1602174 & 688759 & 5.3 & 4.7135 & TST \\
\hline CHEMBL1400247 & 688759 & 4.65 & 5.0829 & TST \\
\hline CHEMBL1431877 & 688759 & 5.6 & 5.069 & TRN \\
\hline CHEMBL1582735 & 688759 & 5.3 & 5.4687 & TRN \\
\hline CHEMBL1525735 & 688759 & 5.15 & 4.4895 & TRN \\
\hline CHEMBL1417408 & 688759 & 4.45 & 5.0902 & TST \\
\hline CHEMBL1453534 & 688759 & 5.25 & 5.0508 & TST \\
\hline CHEMBL1716038 & 688759 & 4.45 & 4.7243 & TRN \\
\hline CHEMBL1537615 & 688759 & 5.15 & 5.0532 & TST \\
\hline CHEMBL35228 & 688759 & 4.8 & 4.8377 & TST \\
\hline CHEMBL1536406 & 688759 & 4.85 & 4.7279 & TRN \\
\hline CHEMBL1365906 & 688759 & 4.65 & 4.5826 & TRN \\
\hline CHEMBL1541173 & 688759 & 4.75 & 4.6223 & TRN \\
\hline CHEMBL1368865 & 688759 & 4.75 & 4.7267 & TRN \\
\hline CHEMBL1529127 & 688759 & 4.45 & 4.5854 & TST \\
\hline CHEMBL1568453 & 688759 & 4.6 & 5.0028 & TST \\
\hline CHEMBL1386913 & 688759 & 6.0 & 5.4114 & TRN \\
\hline CHEMBL3208482 & 688759 & 4.75 & 4.5987 & TRN \\
\hline CHEMBL1368806 & 688759 & 4.95 & 5.0534 & TRN \\
\hline CHEMBL1373222 & 688759 & 4.95 & 4.6687 & TST \\
\hline CHEMBL1524678 & 688759 & 4.45 & 4.6671 & TRN \\
\hline CHEMBL1310471 & 688759 & 4.95 & 5.0706 & TRN \\
\hline CHEMBL3192547 & 688759 & 4.75 & 5.2238 & TRN \\
\hline CHEMBL1387884 & 688759 & 4.9 & 4.8473 & TRN \\
\hline CHEMBL1374323 & 688759 & 4.75 & 4.7939 & TRN \\
\hline CHEMBL1540401 & 688759 & 4.45 & 4.7609 & TST \\
\hline CHEMBL3189286 & 688759 & 5.1 & 5.3786 & TST \\
\hline CHEMBL1338427 & 688759 & 4.8 & 5.2216 & TST \\
\hline CHEMBL1337208 & 688759 & 4.45 & 5.0819 & TRN \\
\hline CHEMBL3195663 & 688759 & 5.2 & 4.822 & TST \\
\hline CHEMBL1470180 & 688759 & 4.75 & 5.0957 & TRN \\
\hline CHEMBL1382360 & 688759 & 4.75 & 4.7306 & TRN \\
\hline
\end{tabular}




\begin{tabular}{|c|c|c|c|c|c|}
\hline \multicolumn{6}{|c|}{ Supplemental Table S2.txt } \\
\hline CHEMBL1377944 & 688759 & 5.2 & 4.8846 & TRN & \\
\hline CHEMBL1596003 & 688759 & 4.45 & 4.5312 & TRN & \\
\hline CHEMBL3194807 & 688759 & 5.95 & 5.7055 & TRN & \\
\hline CHEMBL1457235 & 688759 & 6.6 & 4.83 & TRN & \\
\hline CHEMBL3189415 & 688759 & 5.2 & 4.77 & TST & \\
\hline CHEMBL1431808 & 688759 & 5.8 & 4.9445 & TRN & \\
\hline CHEMBL1344528 & 688759 & 4.45 & 4.7681 & TRN & \\
\hline CHEMBL1407461 & 688759 & 4.65 & 4.9585 & TRN & \\
\hline CHEMBL1471460 & 688759 & 5.65 & 5.5859 & TRN & \\
\hline CHEMBL1611408 & 688759 & 4.45 & 5.2654 & TRN & \\
\hline CHEMBL1324397 & 688759 & 4.45 & 4.6727 & TRN & \\
\hline CHEMBL1983125 & 688759 & 6.05 & 5.3504 & TRN & \\
\hline CHEMBL1371364 & 688759 & 5.4 & 5.0155 & TRN & \\
\hline CHEMBL1427614 & 688759 & 4.6 & 4.5433 & TRN & \\
\hline CHEMBL1463157 & 688759 & 4.95 & 6.13299 & 9999999999 & TST \\
\hline CHEMBL1458500 & 688759 & 4.45 & 4.7751 & TST & \\
\hline CHEMBL1381809 & 688759 & 4.45 & 4.5896 & TST & \\
\hline CHEMBL1317919 & 688759 & 5.1 & 4.9063 & TRN & \\
\hline CHEMBL1301920 & 688759 & 5.45 & 5.03100 & 2000000001 & TST \\
\hline CHEMBL1567983 & 688759 & 4.45 & 4.4936 & TST & \\
\hline CHEMBL1389441 & 688759 & 4.45 & 4.7958 & TST & \\
\hline CHEMBL1543556 & 688759 & 4.7 & 4.8119 & TRN & \\
\hline CHEMBL1523643 & 688759 & 4.65 & 5.6894 & TRN & \\
\hline CHEMBL1491095 & 688759 & 4.45 & 4.8089 & TRN & \\
\hline CHEMBL1401965 & 688759 & 4.45 & 4.8097 & TRN & \\
\hline CHEMBL1348747 & 688759 & 4.45 & 4.7845 & TRN & \\
\hline CHEMBL1467927 & 688759 & 4.45 & 4.6341 & TRN & \\
\hline CHEMBL3199792 & 688759 & 5.0 & 4.8075 & TRN & \\
\hline CHEMBL1384383 & 688759 & 4.7 & 4.5911 & TRN & \\
\hline CHEMBL3209657 & 688759 & 4.45 & 4.5861 & TRN & \\
\hline CHEMBL1418673 & 688759 & 4.65 & 4.7121 & TRN & \\
\hline CHEMBL1995177 & 688759 & 5.5 & 5.4858 & TST & \\
\hline CHEMBL3196288 & 688759 & 5.05 & 4.9792 & TRN & \\
\hline CHEMBL1352608 & 688759 & 4.45 & 4.9768 & TRN & \\
\hline CHEMBL1490050 & 688759 & 4.65 & 4.6464 & TRN & \\
\hline CHEMBL1352080 & 688759 & 4.75 & 4.6012 & TRN & \\
\hline CHEMBL1510706 & 688759 & 5.25 & 4.9803 & TRN & \\
\hline CHEMBL1530718 & 688759 & 6.05 & 4.9792 & TST & \\
\hline CHEMBL1329705 & 688759 & 4.85 & 6.0451 & TST & \\
\hline CHEMBL1571157 & 688759 & 4.55 & 4.7036 & TRN & \\
\hline CHEMBL546257 & 688759 & 6.0 & 4.6039 & TST & \\
\hline CHEMBL1331447 & 688759 & 4.45 & 4.8729 & TRN & \\
\hline CHEMBL1499843 & 688759 & 5.2 & 5.1932 & TRN & \\
\hline CHEMBL1461640 & 688759 & 4.75 & 5.3808 & TST & \\
\hline CHEMBL1475194 & 688759 & 5.0 & 5.048 & TRN & \\
\hline CHEMBL1458309 & 688759 & 5.0 & 4.9472 & TRN & \\
\hline CHEMBL1511193 & 688759 & 5.15 & 5.2265 & TRN & \\
\hline CHEMBL1380222 & 688759 & 5.6 & 4.8719 & TST & \\
\hline
\end{tabular}




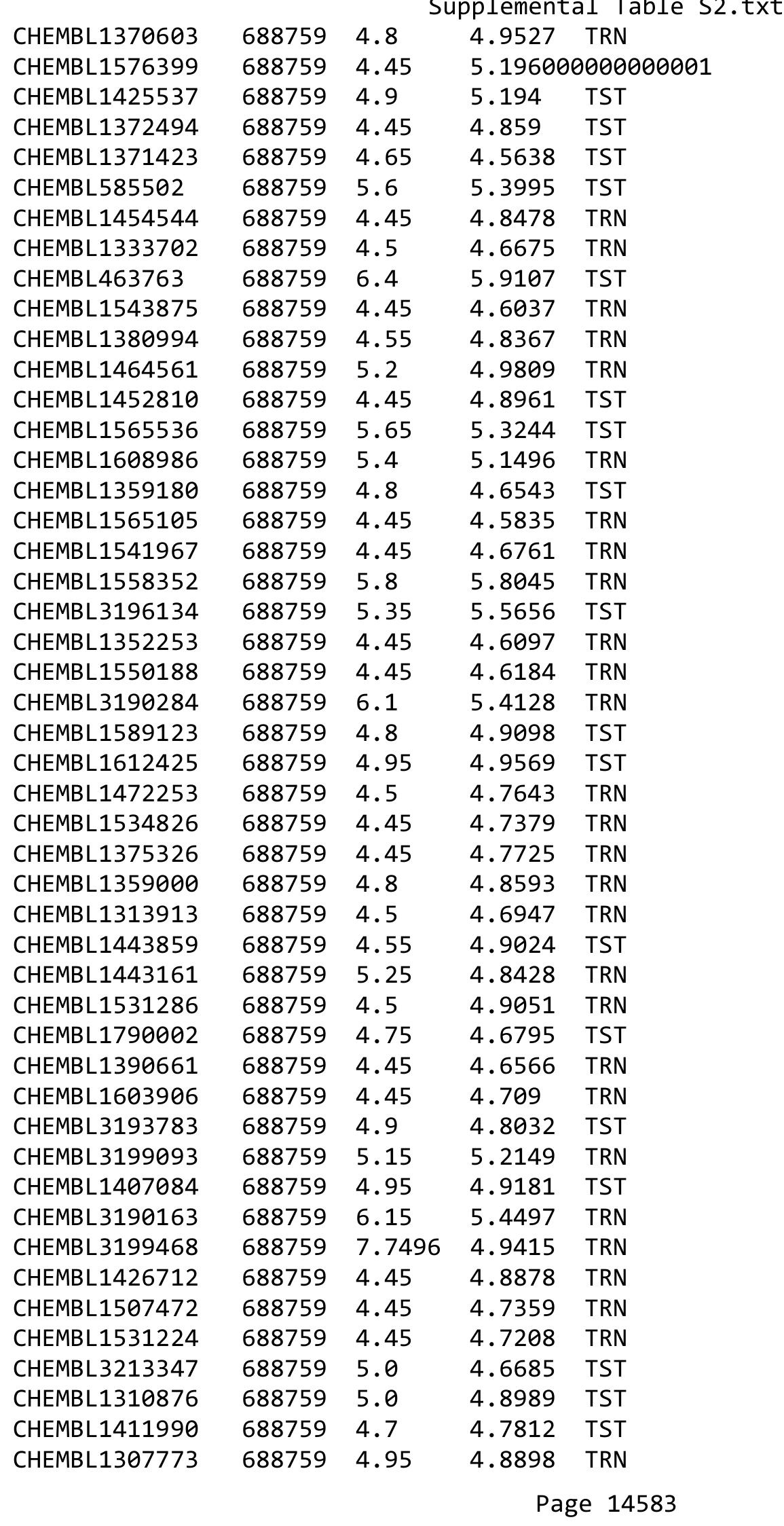

TRN 


\begin{tabular}{|c|c|c|c|c|c|}
\hline & & \multicolumn{4}{|c|}{ Supplemental Table S2.txt } \\
\hline CHEMBL1525073 & 688759 & 4.85 & 4.8626 & TRN & \\
\hline CHEMBL1573648 & 688759 & 5.5 & 4.9285 & TRN & \\
\hline CHEMBL1495442 & 688759 & 4.6 & 4.7426 & TRN & \\
\hline CHEMBL1561202 & 688759 & 4.45 & 4.7263 & TRN & \\
\hline CHEMBL1507898 & 688759 & 4.65 & 4.9151 & TST & \\
\hline CHEMBL1290138 & 688759 & 4.95 & 4.8017 & TRN & \\
\hline CHEMBL1526511 & 688759 & 5.05 & 5.1112 & TRN & \\
\hline CHEMBL3194093 & 688759 & 4.45 & 5.0041 & TRN & \\
\hline CHEMBL1611183 & 688759 & 5.45 & 5.2071 & TRN & \\
\hline CHEMBL1790016 & 688759 & 4.85 & 5.0248 & TRN & \\
\hline CHEMBL1542113 & 688759 & 5.25 & 4.7508 & TRN & \\
\hline CHEMBL1491916 & 688759 & 5.1 & 4.9065 & TRN & \\
\hline CHEMBL1301857 & 688759 & 4.45 & 4.9029 & TRN & \\
\hline CHEMBL1566877 & 688759 & 6.5 & 5.3421 & TRN & \\
\hline CHEMBL1308799 & 688759 & 4.45 & 4.8717 & TST & \\
\hline CHEMBL3197805 & 688759 & 4.8 & 5.2644 & TRN & \\
\hline CHEMBL1335792 & 688759 & 5.25 & 4.9694 & TRN & \\
\hline CHEMBL3208216 & 688759 & 5.55 & 5.2395 & TRN & \\
\hline CHEMBL1526654 & 688759 & 4.75 & 4.8643 & TRN & \\
\hline CHEMBL1341725 & 688759 & 5.2 & 4.9294 & TRN & \\
\hline CHEMBL1428384 & 688759 & 4.45 & 4.9452 & TRN & \\
\hline CHEMBL1597813 & 688759 & 5.15 & 4.8692 & TST & \\
\hline CHEMBL3194567 & 688759 & 4.95 & 4.9839 & TRN & \\
\hline CHEMBL3193709 & 688759 & 5.25 & 4.6389 & TST & \\
\hline CHEMBL1463386 & 688759 & 4.45 & 5.0256 & TRN & \\
\hline CHEMBL1382296 & 688759 & 5.3 & 5.2148 & TRN & \\
\hline CHEMBL1308605 & 688759 & 4.8 & 4.7799 & TST & \\
\hline CHEMBL1466202 & 688759 & 4.45 & 4.5416 & TST & \\
\hline CHEMBL1561460 & 688759 & 4.45 & 4.8558 & TRN & \\
\hline CHEMBL3193157 & 688759 & 4.45 & 4.8994 & TST & \\
\hline CHEMBL3190289 & 688759 & 5.2 & 4.9138 & TRN & \\
\hline CHEMBL1520214 & 688759 & 5.35 & 5.2096 & TRN & \\
\hline CHEMBL1425851 & 688759 & 5.2 & 4.9198 & TRN & \\
\hline CHEMBL1543734 & 688759 & 5.45 & 5.1919 & TRN & \\
\hline CHEMBL3198073 & 688759 & 6.0 & 5.6367 & TRN & \\
\hline CHEMBL3208211 & 688759 & 6.1 & 5.4166 & TRN & \\
\hline CHEMBL1510111 & 688759 & 4.85 & 5.3349 & TRN & \\
\hline CHEMBL1528582 & 688759 & 4.45 & 4.6536 & TRN & \\
\hline CHEMBL1500119 & 688759 & 4.45 & 4.7912 & TRN & \\
\hline CHEMBL1516627 & 688759 & 4.45 & 4.7624 & TRN & \\
\hline CHEMBL1542354 & 688759 & 4.55 & 4.92399 & 99999999995 & TRN \\
\hline CHEMBL3199738 & 688759 & 4.45 & 4.7833 & TST & \\
\hline CHEMBL1329277 & 688759 & 4.65 & 4.8781 & TRN & \\
\hline CHEMBL1569671 & 688759 & 4.9 & 4.6916 & TRN & \\
\hline CHEMBL1989225 & 688759 & 5.05 & 5.3755 & TRN & \\
\hline CHEMBL531710 & 688759 & 5.15 & 5.2538 & TRN & \\
\hline CHEMBL1479752 & 688759 & 4.55 & 4.6355 & TST & \\
\hline CHEMBL1400375 & 688759 & 4.65 & 4.8616 & TRN & \\
\hline
\end{tabular}




\begin{tabular}{|c|c|c|c|c|c|}
\hline & & \multicolumn{4}{|c|}{ Supplemental Table S2.txt } \\
\hline CHEMBL1436345 & 688759 & 5.45 & 4.8488 & TST & \\
\hline CHEMBL1585304 & 688759 & 4.45 & 4.8143 & TRN & \\
\hline CHEMBL1599632 & 688759 & 5.05 & 4.8194 & TST & \\
\hline CHEMBL 3199511 & 688759 & 4.55 & 4.7416 & TST & \\
\hline CHEMBL1554721 & 688759 & 4.9 & 4.6484 & TRN & \\
\hline CHEMBL1598561 & 688759 & 4.65 & 4.8218 & TST & \\
\hline CHEMBL1511882 & 688759 & 5.35 & 5.018 & TST & \\
\hline CHEMBL1576283 & 688759 & 4.9 & 4.7032 & TRN & \\
\hline CHEMBL3193191 & 688759 & 4.45 & 4.6753 & TRN & \\
\hline CHEMBL1407390 & 688759 & 4.45 & 5.2839 & TRN & \\
\hline CHEMBL1375247 & 688759 & 5.4 & 5.40799 & 99999999995 & TRN \\
\hline CHEMBL 3144874 & 688759 & 4.45 & 4.7032 & TRN & \\
\hline CHEMBL3193801 & 688759 & 5.5 & 5.3458 & TRN & \\
\hline CHEMBL1373960 & 688759 & 4.8 & 4.7462 & TRN & \\
\hline CHEMBL1586819 & 688759 & 4.45 & 4.8594 & TRN & \\
\hline CHEMBL1353324 & 688759 & 5.2 & 4.6778 & TRN & \\
\hline CHEMBL1256816 & 688759 & 4.85 & 4.9199 & TST & \\
\hline CHEMBL1609034 & 688759 & 4.65 & 4.8192 & TST & \\
\hline CHEMBL1543683 & 688759 & 4.9 & 4.8602 & TRN & \\
\hline CHEMBL1455485 & 688759 & 6.2 & 5.7362 & TRN & \\
\hline CHEMBL1579592 & 688759 & 6.3 & 5.9906 & TRN & \\
\hline CHEMBL1412534 & 688759 & 4.6 & 4.6554 & TRN & \\
\hline CHEMBL1543510 & 688759 & 4.45 & 4.8285 & TRN & \\
\hline CHEMBL1524807 & 688759 & 4.45 & 4.7488 & TRN & \\
\hline CHEMBL1329907 & 688759 & 4.8 & 4.6718 & TRN & \\
\hline CHEMBL1572006 & 688759 & 4.5 & 4.8322 & TST & \\
\hline CHEMBL1508337 & 688759 & 4.8 & 4.5848 & TST & \\
\hline CHEMBL1575970 & 688759 & 5.3 & 5.2545 & TRN & \\
\hline CHEMBL1331842 & 688759 & 4.5 & 5.1273 & TRN & \\
\hline CHEMBL1532143 & 688759 & 5.3 & 4.6628 & TRN & \\
\hline CHEMBL1497773 & 688759 & 4.65 & 4.8897 & TRN & \\
\hline CHEMBL1415953 & 688759 & 4.45 & 4.6893 & TRN & \\
\hline CHEMBL1470979 & 688759 & 5.2 & 5.0504 & TRN & \\
\hline CHEMBL1597195 & 688759 & 4.45 & 4.5872 & TST & \\
\hline CHEMBL1529768 & 688759 & 4.7 & 5.0979 & TST & \\
\hline CHEMBL1574541 & 688759 & 5.1 & 5.0178 & TRN & \\
\hline CHEMBL1498574 & 688759 & 5.2 & 4.68199 & 99999999995 & TRN \\
\hline CHEMBL1441657 & 688759 & 5.25 & 4.8184 & TRN & \\
\hline CHEMBL1492152 & 688759 & 4.6 & 4.8083 & TRN & \\
\hline CHEMBL1459468 & 688759 & 6.3 & 5.7831 & TRN & \\
\hline CHEMBL1380786 & 688759 & 4.5 & 5.003 & TST & \\
\hline CHEMBL1367734 & 688759 & 4.6 & 4.7845 & TRN & \\
\hline CHEMBL1598610 & 688759 & 5.25 & 5.0663 & TRN & \\
\hline CHEMBL1526081 & 688759 & 5.9 & 5.5078 & TRN & \\
\hline CHEMBL1964398 & 688759 & 5.15 & 4.8164 & TST & \\
\hline CHEMBL1340855 & 688759 & 5.35 & 5.2193 & TRN & \\
\hline CHEMBL1303785 & 688759 & 5.5 & 5.1018 & TST & \\
\hline CHEMBL1464512 & 688759 & 4.45 & 5.0054 & TRN & \\
\hline
\end{tabular}




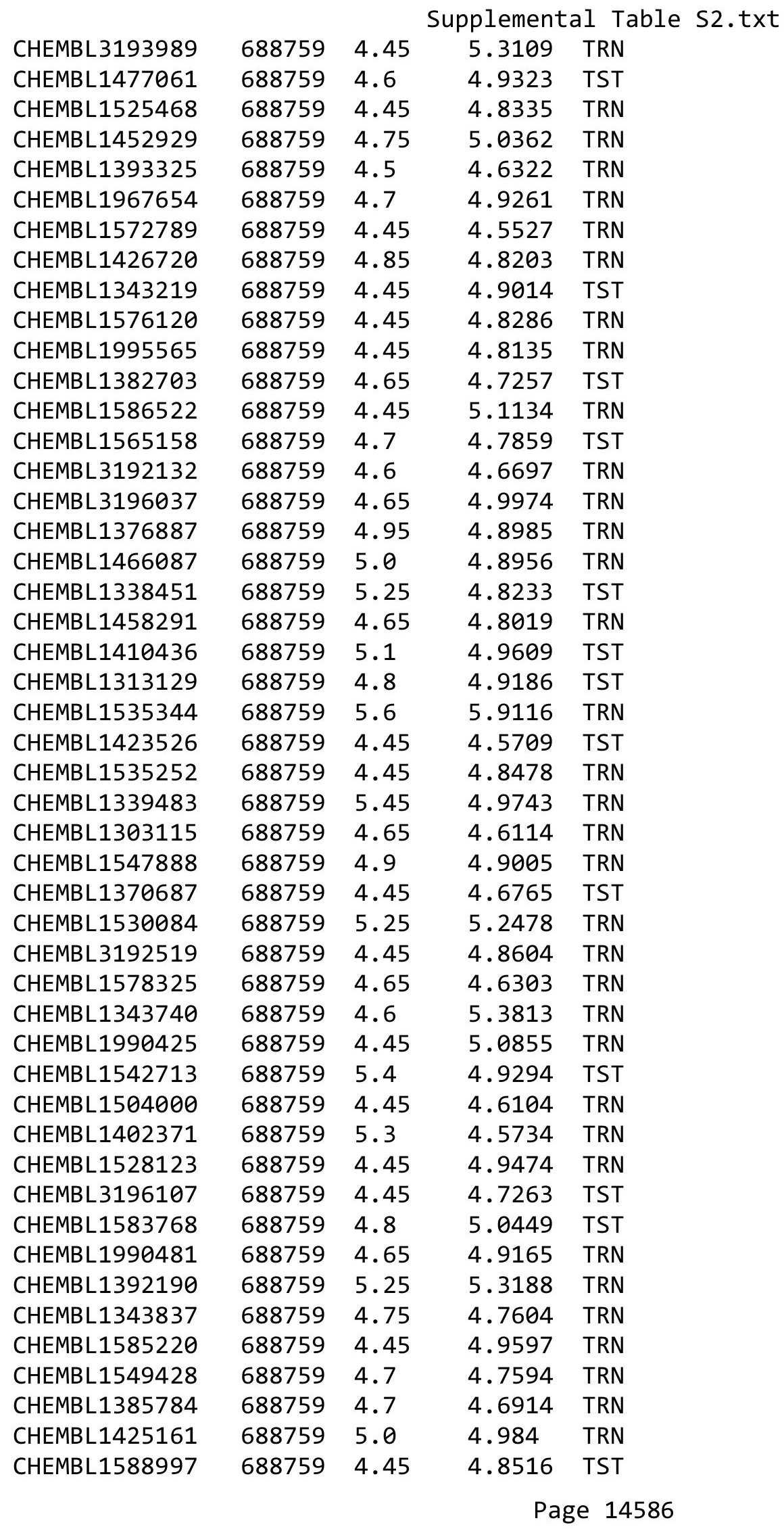




\begin{tabular}{|c|c|c|c|c|c|}
\hline \multicolumn{6}{|c|}{ Supplemental Table S2.txt } \\
\hline CHEMBL1348931 & 688759 & 4.75 & 4.7192 & TRN & \\
\hline CHEMBL412927 & 688759 & 5.3 & 5.1695 & TST & \\
\hline CHEMBL1577380 & 688759 & 4.45 & 4.8403 & TST & \\
\hline CHEMBL1403741 & 688759 & 4.85 & 4.9809 & TST & \\
\hline CHEMBL1387054 & 688759 & 4.95 & 4.7995 & TRN & \\
\hline CHEMBL3195163 & 688759 & 4.45 & 4.698 & TST & \\
\hline CHEMBL1606581 & 688759 & 4.65 & 4.9017 & TRN & \\
\hline CHEMBL1549250 & 688759 & 4.65 & 4.7171 & TRN & \\
\hline CHEMBL1378438 & 688759 & 4.85 & 4.80699 & 99999999995 & TST \\
\hline CHEMBL1422597 & 688759 & 4.95 & 4.8357 & TRN & \\
\hline CHEMBL1492534 & 688759 & 4.8 & 4.5599 & TRN & \\
\hline CHEMBL1511663 & 688759 & 4.45 & 4.6652 & TRN & \\
\hline CHEMBL1531068 & 688759 & 4.5 & 4.8657 & TRN & \\
\hline CHEMBL1368774 & 688759 & 4.9 & 4.7838 & TRN & \\
\hline CHEMBL1598514 & 688759 & 5.15 & 4.9813 & TST & \\
\hline CHEMBL1417674 & 688759 & 4.6 & 4.8161 & TRN & \\
\hline CHEMBL1442243 & 688759 & 4.95 & 5.0096 & TRN & \\
\hline CHEMBL1609703 & 688759 & 4.45 & 4.9373 & TST & \\
\hline CHEMBL1431004 & 688759 & 4.45 & 4.5133 & TRN & \\
\hline CHEMBL1333149 & 688759 & 4.95 & 4.8181 & TRN & \\
\hline CHEMBL1329616 & 688759 & 4.45 & 4.9195 & TST & \\
\hline CHEMBL1602590 & 688759 & 4.8 & 4.6756 & TRN & \\
\hline CHEMBL1305038 & 688759 & 5.9 & 5.6318 & TRN & \\
\hline CHEMBL1406968 & 688759 & 5.2 & 5.1264 & TST & \\
\hline CHEMBL1501215 & 688759 & 4.45 & 4.5998 & TRN & \\
\hline CHEMBL1500188 & 688759 & 5.3 & 5.0465 & TST & \\
\hline CHEMBL1299954 & 688759 & 4.7 & 5.0487 & TRN & \\
\hline CHEMBL1408453 & 688759 & 4.45 & 4.8306 & TRN & \\
\hline CHEMBL1302732 & 688759 & 4.45 & 5.0451 & TST & \\
\hline CHEMBL1407380 & 688759 & 5.45 & 5.6453 & TRN & \\
\hline CHEMBL1562294 & 688759 & 5.15 & 4.8204 & TRN & \\
\hline CHEMBL1321574 & 688759 & 5.2 & 5.1925 & TRN & \\
\hline CHEMBL1347798 & 688759 & 6.7501 & 5.1178 & TST & \\
\hline CHEMBL1300267 & 688759 & 4.65 & 4.987 & TRN & \\
\hline CHEMBL1560714 & 688759 & 4.6 & 4.9105 & TST & \\
\hline CHEMBL1346078 & 688759 & 4.45 & 4.7149 & TRN & \\
\hline CHEMBL3197096 & 688759 & 5.0 & 5.38299 & 9999999999 & TRN \\
\hline CHEMBL1516746 & 688759 & 5.25 & 5.2602 & TST & \\
\hline CHEMBL3199437 & 688759 & 5.45 & 4.9745 & TRN & \\
\hline CHEMBL3192017 & 688759 & 4.45 & 4.5786 & TRN & \\
\hline CHEMBL1541205 & 688759 & 5.0 & 4.8389 & TRN & \\
\hline CHEMBL1400659 & 688759 & 5.25 & 4.7694 & TST & \\
\hline CHEMBL1446667 & 688759 & 4.45 & 4.7873 & TST & \\
\hline CHEMBL1473755 & 688759 & 4.75 & 4.842 & TRN & \\
\hline CHEMBL1308888 & 688759 & 4.75 & 4.7261 & TRN & \\
\hline CHEMBL 2369193 & 688759 & 5.3 & 5.7909 & TRN & \\
\hline CHEMBL1565795 & 688759 & 5.2 & 4.8149 & TST & \\
\hline CHEMBL1524528 & 688759 & 5.7 & 4.8757 & TRN & \\
\hline
\end{tabular}




\begin{tabular}{|c|c|c|c|c|}
\hline \multicolumn{5}{|c|}{ Supplemental Table } \\
\hline CHEMBL3198806 & 688759 & 4.75 & 4.8957 & TRN \\
\hline CHEMBL1565204 & 688759 & 5.5 & 5.1031 & TST \\
\hline CHEMBL1580360 & 688759 & 5.6 & 4.7641 & TRN \\
\hline CHEMBL504256 & 688759 & 4.45 & 4.9895 & TRN \\
\hline CHEMBL1305304 & 688759 & 4.9 & 5.7984 & TRN \\
\hline CHEMBL1349929 & 688759 & 4.45 & 4.9179 & TRN \\
\hline CHEMBL1324462 & 688759 & 4.7 & 4.7664 & TST \\
\hline CHEMBL1504221 & 688759 & 4.75 & 4.8357 & TRN \\
\hline CHEMBL306783 & 688759 & 5.5 & 4.7978 & TST \\
\hline CHEMBL486094 & 688759 & 4.8 & 4.5181 & TRN \\
\hline CHEMBL1361388 & 688759 & 4.5 & 4.645 & TRN \\
\hline CHEMBL1411002 & 688759 & 4.65 & 4.7443 & TRN \\
\hline CHEMBL1463846 & 688759 & 5.45 & 4.9792 & TRN \\
\hline CHEMBL1596457 & 688759 & 4.6 & 4.8484 & TRN \\
\hline CHEMBL1510643 & 688759 & 4.45 & 4.7168 & TST \\
\hline CHEMBL1408307 & 688759 & 5.2 & 5.1189 & TRN \\
\hline CHEMBL1447990 & 688759 & 4.6 & 4.8281 & TST \\
\hline CHEMBL1548815 & 688759 & 4.45 & 4.7257 & TST \\
\hline CHEMBL 3190754 & 688759 & 4.75 & 4.6607 & TST \\
\hline CHEMBL1462123 & 688759 & 4.85 & 4.9147 & TRN \\
\hline CHEMBL1971324 & 688759 & 4.45 & 5.4092 & TRN \\
\hline CHEMBL1541082 & 688759 & 4.45 & 4.8818 & TRN \\
\hline CHEMBL1340965 & 688759 & 4.65 & 4.4123 & TRN \\
\hline CHEMBL1573529 & 688759 & 6.0 & 5.4808 & TST \\
\hline CHEMBL1361757 & 688759 & 4.45 & 4.6276 & TRN \\
\hline CHEMBL1594536 & 688759 & 4.65 & 4.8667 & TRN \\
\hline CHEMBL1466705 & 688759 & 4.75 & 5.053 & TRN \\
\hline CHEMBL1171338 & 688759 & 4.55 & 4.8573 & TRN \\
\hline CHEMBL1495394 & 688759 & 4.95 & 4.8307 & TRN \\
\hline CHEMBL1416497 & 688759 & 4.9 & 4.7021 & TRN \\
\hline CHEMBL1442280 & 688759 & 6.15 & 5.7925 & TRN \\
\hline CHEMBL1400423 & 688759 & 5.25 & 4.9173 & TRN \\
\hline CHEMBL1308013 & 688759 & 4.8 & 5.5274 & TRN \\
\hline CHEMBL1479418 & 688759 & 4.45 & 5.0082 & TRN \\
\hline CHEMBL1398687 & 688759 & 5.5 & 5.1656 & TRN \\
\hline CHEMBL1541227 & 688759 & 4.45 & 4.7089 & TST \\
\hline CHEMBL1559013 & 688759 & 5.55 & 4.9531 & TRN \\
\hline CHEMBL3192210 & 688759 & 6.4 & 5.8663 & TRN \\
\hline CHEMBL 3197624 & 688759 & 4.45 & 4.8025 & TRN \\
\hline CHEMBL1344417 & 688759 & 5.5 & 5.5549 & TRN \\
\hline CHEMBL528451 & 688759 & 4.5 & 4.8171 & TRN \\
\hline CHEMBL1356336 & 688759 & 4.45 & 4.6474 & TRN \\
\hline CHEMBL53268 & 688759 & 4.45 & 5.0312 & TST \\
\hline CHEMBL1467200 & 688759 & 4.45 & 5.1302 & TST \\
\hline CHEMBL3208510 & 688759 & 4.9 & 4.752 & TRN \\
\hline CHEMBL1351600 & 688759 & 5.35 & 5.0682 & TRN \\
\hline CHEMBL1425613 & 688759 & 4.45 & 4.73 & TRN \\
\hline CHEMBL1384468 & 688759 & 4.9 & 4.6407 & TRN \\
\hline
\end{tabular}




\begin{tabular}{|c|c|c|c|c|c|}
\hline \multicolumn{6}{|c|}{ Supplemental Table S2.txt } \\
\hline CHEMBL1497162 & 688759 & 4.45 & 4.8625 & TRN & \\
\hline CHEMBL1498236 & 688759 & 4.45 & 4.7452 & TRN & \\
\hline CHEMBL 3189736 & 688759 & 4.45 & 4.8074 & TST & \\
\hline CHEMBL1431669 & 688759 & 4.45 & 5.0244 & TST & \\
\hline CHEMBL1493976 & 688759 & 4.65 & 4.7075 & TRN & \\
\hline CHEMBL1530571 & 688759 & 5.65 & 5.5233 & TRN & \\
\hline CHEMBL1538677 & 688759 & 4.45 & 4.7519 & TRN & \\
\hline CHEMBL1442281 & 688759 & 4.75 & 4.9671 & TST & \\
\hline CHEMBL1374583 & 688759 & 4.85 & 4.5453 & TRN & \\
\hline CHEMBL1587609 & 688759 & 5.9 & 5.5192 & TRN & \\
\hline CHEMBL1303411 & 688759 & 4.45 & 4.6661 & TRN & \\
\hline CHEMBL1602317 & 688759 & 4.45 & 4.7854 & TRN & \\
\hline CHEMBL1443902 & 688759 & 6.3 & 5.4503 & TRN & \\
\hline CHEMBL1532993 & 688759 & 4.55 & 5.0331 & TRN & \\
\hline CHEMBL1595882 & 688759 & 4.45 & 4.9821 & TRN & \\
\hline CHEMBL1356207 & 688759 & 4.45 & 4.9484 & TRN & \\
\hline CHEMBL1416591 & 688759 & 4.45 & 4.7361 & TRN & \\
\hline CHEMBL1966151 & 688759 & 5.7 & 5.2301 & TRN & \\
\hline CHEMBL1462341 & 688759 & 4.45 & 4.5031 & TRN & \\
\hline CHEMBL3190198 & 688759 & 6.1 & 5.6474 & TRN & \\
\hline CHEMBL1544543 & 688759 & 4.65 & 4.9563 & TRN & \\
\hline CHEMBL1443495 & 688759 & 5.65 & 5.1269 & TRN & \\
\hline CHEMBL1430707 & 688759 & 5.5 & 4.9202 & TRN & \\
\hline CHEMBL1383423 & 688759 & 5.4 & 4.8093 & TRN & \\
\hline CHEMBL1393529 & 688759 & 4.45 & 4.8368 & TRN & \\
\hline CHEMBL1602907 & 688759 & 4.45 & 4.8017 & TRN & \\
\hline CHEMBL1386270 & 688759 & 6.9 & 5.7747 & TRN & \\
\hline CHEMBL1430421 & 688759 & 4.65 & 4.7874 & TRN & \\
\hline CHEMBL 3210625 & 688759 & 4.45 & 4.8212 & TST & \\
\hline CHEMBL1517235 & 688759 & 4.45 & 4.5705 & TRN & \\
\hline CHEMBL1466815 & 688759 & 4.8 & 4.93199 & 99999999995 & TRN \\
\hline CHEMBL1508461 & 688759 & 4.65 & 4.8322 & TST & \\
\hline CHEMBL1582378 & 688759 & 4.45 & 4.7617 & TRN & \\
\hline CHEMBL1558757 & 688759 & 4.45 & 4.5732 & TST & \\
\hline CHEMBL1470728 & 688759 & 5.3 & 5.3145 & TST & \\
\hline CHEMBL 2369209 & 688759 & 4.9 & 5.4089 & TRN & \\
\hline CHEMBL1339702 & 688759 & 4.45 & 4.876 & TRN & \\
\hline CHEMBL1468522 & 688759 & 4.45 & 4.6934 & TST & \\
\hline CHEMBL1535276 & 688759 & 4.95 & 4.6667 & TRN & \\
\hline CHEMBL1459912 & 688759 & 4.85 & 4.8604 & TRN & \\
\hline CHEMBL1462131 & 688759 & 4.75 & 4.575 & TRN & \\
\hline CHEMBL1375998 & 688759 & 4.65 & 4.6736 & TRN & \\
\hline CHEMBL1481819 & 688759 & 4.45 & 4.6653 & TRN & \\
\hline CHEMBL1556493 & 688759 & 4.9 & 4.7609 & TRN & \\
\hline CHEMBL3194437 & 688759 & 5.0 & 4.8919 & TRN & \\
\hline CHEMBL1454476 & 688759 & 4.45 & 4.8483 & TRN & \\
\hline CHEMBL1299751 & 688759 & 4.9 & 4.7153 & TRN & \\
\hline CHEMBL1454102 & 688759 & 4.75 & 4.6615 & TRN & \\
\hline
\end{tabular}




\begin{tabular}{|c|c|c|c|c|}
\hline \multicolumn{5}{|c|}{ Supplemental Table S2.txt } \\
\hline CHEMBL1579379 & 688759 & 5.0 & 4.9157 & TRN \\
\hline CHEMBL1558811 & 688759 & 4.45 & 4.7728 & TRN \\
\hline CHEMBL1587373 & 688759 & 4.45 & 4.5541 & TRN \\
\hline CHEMBL 3194454 & 688759 & 4.85 & 4.9305 & TRN \\
\hline CHEMBL1599889 & 688759 & 5.15 & 5.078 & TRN \\
\hline CHEMBL3196073 & 688759 & 4.9 & 4.8999 & TST \\
\hline CHEMBL1564666 & 688759 & 5.3 & 5.0644 & TRN \\
\hline CHEMBL1581221 & 688759 & 4.85 & 4.6771 & TRN \\
\hline CHEMBL1310704 & 688759 & 4.45 & 4.8214 & TRN \\
\hline CHEMBL1540053 & 688759 & 5.25 & 5.027 & TST \\
\hline CHEMBL1312248 & 688759 & 4.85 & 4.9307 & TST \\
\hline CHEMBL1328035 & 688759 & 4.45 & 4.6106 & TRN \\
\hline CHEMBL1419066 & 688759 & 4.45 & 4.8438 & TRN \\
\hline CHEMBL1392234 & 688759 & 4.45 & 5.0556 & TRN \\
\hline CHEMBL1993165 & 688759 & 5.95 & 5.8099 & TRN \\
\hline CHEMBL1380177 & 688759 & 4.45 & 4.6733 & TRN \\
\hline CHEMBL1452090 & 688759 & 5.55 & 5.5007 & TRN \\
\hline CHEMBL3191645 & 688759 & 4.45 & 4.9482 & TRN \\
\hline CHEMBL3196600 & 688759 & 5.3 & 5.4825 & TRN \\
\hline CHEMBL1391213 & 688759 & 4.9 & 4.9248 & TST \\
\hline CHEMBL1311612 & 688759 & 4.85 & 4.6356 & TST \\
\hline CHEMBL1370130 & 688759 & 4.45 & 4.7572 & TRN \\
\hline CHEMBL1607843 & 688759 & 4.45 & 5.0058 & TRN \\
\hline CHEMBL1462692 & 688759 & 4.45 & 4.7634 & TST \\
\hline CHEMBL1498022 & 688759 & 4.6 & 4.8284 & TST \\
\hline CHEMBL1351833 & 688759 & 4.9 & 4.8708 & TRN \\
\hline CHEMBL1580578 & 688759 & 4.9 & 5.0702 & TST \\
\hline CHEMBL1375129 & 688759 & 4.75 & 4.835 & TST \\
\hline CHEMBL1336235 & 688759 & 4.5 & 4.5595 & TRN \\
\hline CHEMBL1385487 & 688759 & 4.7 & 4.6135 & TST \\
\hline CHEMBL3208179 & 688759 & 5.05 & 4.4167 & TST \\
\hline CHEMBL1305239 & 688759 & 4.95 & 5.1669 & TRN \\
\hline CHEMBL3195824 & 688759 & 4.45 & 4.6831 & TRN \\
\hline CHEMBL1418066 & 688759 & 5.95 & 5.1854 & TRN \\
\hline CHEMBL1340962 & 688759 & 4.45 & 4.6191 & TRN \\
\hline CHEMBL1361461 & 688759 & 4.95 & 4.9757 & TRN \\
\hline CHEMBL1600744 & 688759 & 4.6 & 4.9305 & TST \\
\hline CHEMBL1447273 & 688759 & 4.5 & 4.7175 & TST \\
\hline CHEMBL1327298 & 688759 & 5.9 & 5.048 & TRN \\
\hline CHEMBL1455146 & 688759 & 5.45 & 5.6665 & TRN \\
\hline CHEMBL1577763 & 688759 & 5.45 & 5.0458 & TRN \\
\hline CHEMBL1418261 & 688759 & 4.75 & 4.6359 & TRN \\
\hline CHEMBL1488633 & 688759 & 4.65 & 5.194 & TRN \\
\hline CHEMBL1585953 & 688759 & 4.75 & 4.8722 & TST \\
\hline CHEMBL1380444 & 688759 & 6.3 & 4.9845 & TST \\
\hline CHEMBL3193753 & 688759 & 4.45 & 4.6534 & TRN \\
\hline CHEMBL3197452 & 688759 & 5.9 & 5.4352 & TRN \\
\hline CHEMBL1307726 & 688759 & 4.65 & 4.5228 & TRN \\
\hline
\end{tabular}




\begin{tabular}{|c|c|c|c|c|c|}
\hline \multicolumn{6}{|c|}{ Supplemental Table S2.txt } \\
\hline CHEMBL1271764 & 688759 & 4.6 & 4.7027 & TRN & \\
\hline CHEMBL1523369 & 688759 & 4.95 & 4.9125 & TST & \\
\hline CHEMBL284861 & 688759 & 5.2 & 5.0888 & TST & \\
\hline CHEMBL1410042 & 688759 & 6.15 & 5.227 & TRN & \\
\hline CHEMBL1419080 & 688759 & 4.45 & 5.9931 & TRN & \\
\hline CHEMBL1393336 & 688759 & 4.5 & 4.9305 & TST & \\
\hline CHEMBL3190712 & 688759 & 5.2 & 5.1296 & TRN & \\
\hline CHEMBL1419762 & 688759 & 5.2 & 5.1834 & TRN & \\
\hline CHEMBL 366884 & 688759 & 4.45 & 4.8141 & TRN & \\
\hline CHEMBL3198172 & 688759 & 4.65 & 4.975 & TST & \\
\hline CHEMBL1378167 & 688759 & 4.45 & 5.11100 & 0000000001 & TST \\
\hline CHEMBL1490656 & 688759 & 5.2 & 5.2901 & TRN & \\
\hline CHEMBL1333477 & 688759 & 4.8 & 4.6331 & TRN & \\
\hline CHEMBL1400924 & 688759 & 4.45 & 4.6706 & TRN & \\
\hline CHEMBL1389066 & 688759 & 5.2 & 4.9093 & TST & \\
\hline CHEMBL3196034 & 688759 & 5.05 & 4.8499 & TRN & \\
\hline CHEMBL1330067 & 688759 & 4.65 & 4.9592 & TRN & \\
\hline CHEMBL1305968 & 688759 & 4.65 & 4.82 & TRN & \\
\hline CHEMBL1425369 & 688759 & 4.95 & 4.734 & TRN & \\
\hline CHEMBL1579067 & 688759 & 4.45 & 5.2603 & TRN & \\
\hline CHEMBL3196080 & 688759 & 5.25 & 5.2295 & TRN & \\
\hline CHEMBL1489111 & 688759 & 4.45 & 4.6055 & TRN & \\
\hline CHEMBL1448346 & 688759 & 4.65 & 4.7744 & TRN & \\
\hline CHEMBL1533215 & 688759 & 4.95 & 4.8382 & TRN & \\
\hline CHEMBL1536452 & 688759 & 5.4 & 5.223 & TRN & \\
\hline CHEMBL1471198 & 688759 & 4.5 & 4.8757 & TRN & \\
\hline CHEMBL1399489 & 688759 & 4.5 & 4.7879 & TRN & \\
\hline CHEMBL494252 & 688759 & 4.5 & 5.455 & TST & \\
\hline CHEMBL 3145137 & 688759 & 6.2 & 5.6688 & TST & \\
\hline CHEMBL1562633 & 688759 & 4.45 & 4.5022 & TRN & \\
\hline CHEMBL1972652 & 688759 & 5.05 & 4.6376 & TRN & \\
\hline CHEMBL 2005602 & 688759 & 4.45 & 4.9849 & TRN & \\
\hline CHEMBL1477958 & 688759 & 6.4 & 5.2338 & TST & \\
\hline CHEMBL1375099 & 688759 & 4.95 & 4.9924 & TST & \\
\hline CHEMBL1379149 & 688759 & 5.15 & 4.5568 & TRN & \\
\hline CHEMBL1342212 & 688759 & 5.45 & 4.8001 & TRN & \\
\hline CHEMBL1600360 & 688759 & 4.65 & 4.766 & TRN & \\
\hline CHEMBL1520842 & 688759 & 4.45 & 4.9462 & TRN & \\
\hline CHEMBL1528163 & 688759 & 4.85 & 5.2282 & TRN & \\
\hline CHEMBL1987895 & 688759 & 5.0 & 5.1075 & TRN & \\
\hline CHEMBL1506406 & 688759 & 4.9 & 4.8111 & TRN & \\
\hline CHEMBL1559256 & 688759 & 5.45 & 5.2366 & TRN & \\
\hline CHEMBL1503326 & 688759 & 5.2 & 4.8081 & TRN & \\
\hline CHEMBL1488035 & 688759 & 5.9 & 5.6254 & TRN & \\
\hline CHEMBL1445960 & 688759 & 4.7 & 5.0452 & TST & \\
\hline CHEMBL3194833 & 688759 & 4.7 & 5.1367 & TRN & \\
\hline CHEMBL1504117 & 688759 & 4.45 & 4.5918 & TRN & \\
\hline CHEMBL1489605 & 688759 & 4.55 & 4.879 & TST & \\
\hline
\end{tabular}




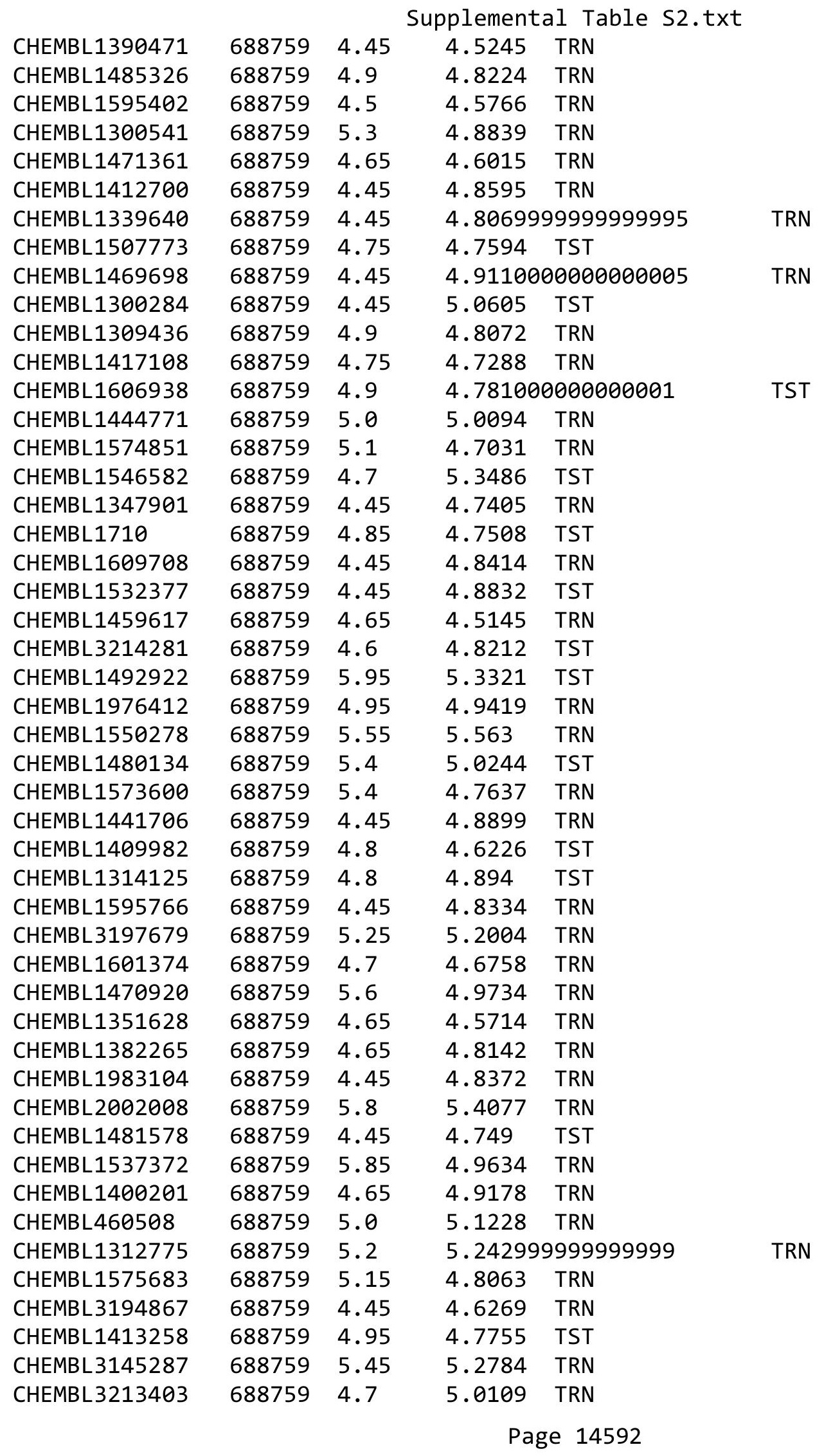




\begin{tabular}{|c|c|c|c|c|c|}
\hline \multicolumn{6}{|c|}{ Supplemental Table S2.txt } \\
\hline CHEMBL1459273 & 688759 & 4.45 & 4.8198 & TRN & \\
\hline CHEMBL1376787 & 688759 & 4.75 & 4.7587 & TST & \\
\hline CHEMBL1096706 & 688759 & 4.8 & 5.1013 & TRN & \\
\hline CHEMBL1346295 & 688759 & 4.45 & 4.54 & TST & \\
\hline CHEMBL1338854 & 688759 & 4.5 & 4.8932 & TRN & \\
\hline CHEMBL1460151 & 688759 & 4.45 & 4.7014 & TRN & \\
\hline CHEMBL1321448 & 688759 & 4.7 & 4.9376 & TST & \\
\hline CHEMBL1600906 & 688759 & 6.45 & 5.0585 & TRN & \\
\hline CHEMBL1385747 & 688759 & 4.8 & 5.0085 & TRN & \\
\hline CHEMBL1569585 & 688759 & 6.0 & 5.3372 & TRN & \\
\hline CHEMBL1322151 & 688759 & 4.45 & 4.5248 & TRN & \\
\hline CHEMBL1374475 & 688759 & 4.7 & 4.801 & TRN & \\
\hline CHEMBL1574573 & 688759 & 4.45 & 4.7101 & TRN & \\
\hline CHEMBL1464317 & 688759 & 4.6 & 5.0109 & TRN & \\
\hline CHEMBL1461781 & 688759 & 4.7 & 4.7835 & TRN & \\
\hline CHEMBL1543527 & 688759 & 4.45 & 4.9847 & TRN & \\
\hline CHEMBL1428623 & 688759 & 4.9 & 5.2794 & TRN & \\
\hline CHEMBL1588831 & 688759 & 4.6 & 4.9765 & TST & \\
\hline CHEMBL1326911 & 688759 & 4.45 & 4.6629 & TRN & \\
\hline CHEMBL1523419 & 688759 & 4.45 & 4.9073 & TRN & \\
\hline CHEMBL1379619 & 688759 & 5.05 & 5.2268 & TRN & \\
\hline CHEMBL1574009 & 688759 & 4.45 & 4.6863 & TRN & \\
\hline CHEMBL1501292 & 688759 & 5.1 & 4.9773 & TRN & \\
\hline CHEMBL1340366 & 688759 & 5.1 & 4.8896 & TRN & \\
\hline CHEMBL1568506 & 688759 & 4.45 & 4.8847 & TRN & \\
\hline CHEMBL1578237 & 688759 & 4.65 & 4.5806 & TRN & \\
\hline CHEMBL3198186 & 688759 & 5.2 & 4.977 & TRN & \\
\hline CHEMBL1535919 & 688759 & 5.45 & 5.15799 & 99999999995 & TRN \\
\hline CHEMBL1503085 & 688759 & 4.45 & 4.9837 & TST & \\
\hline CHEMBL1980322 & 688759 & 5.85 & 5.3057 & TRN & \\
\hline CHEMBL1531357 & 688759 & 4.45 & 4.665 & TRN & \\
\hline CHEMBL1343925 & 688759 & 4.9 & 4.7677 & TRN & \\
\hline CHEMBL1484332 & 688759 & 5.15 & $4.9830 e$ & 00000000005 & TRN \\
\hline CHEMBL 2005001 & 688759 & 6.0 & 6.2334 & TRN & \\
\hline CHEMBL1469536 & 688759 & 4.45 & 4.7505 & TRN & \\
\hline CHEMBL528373 & 688759 & 5.0 & 4.8246 & TRN & \\
\hline CHEMBL1457597 & 688759 & 4.95 & 4.6959 & TRN & \\
\hline CHEMBL1464281 & 688759 & 4.65 & 4.7318 & TST & \\
\hline CHEMBL1586168 & 688759 & 5.0 & 4.9567 & TRN & \\
\hline CHEMBL1299457 & 688759 & 5.4 & 4.9059 & TRN & \\
\hline CHEMBL1368384 & 688759 & 4.65 & 4.6969 & TST & \\
\hline CHEMBL1327870 & 688759 & 5.5 & 4.8016 & TRN & \\
\hline CHEMBL1343825 & 688759 & 5.35 & 4.9222 & TRN & \\
\hline CHEMBL3198567 & 688759 & 5.25 & 4.6009 & TRN & \\
\hline CHEMBL1589665 & 688759 & 4.8 & 5.0695 & TRN & \\
\hline CHEMBL1602709 & 688759 & 5.2 & 5.0344 & TRN & \\
\hline CHEMBL1544786 & 688759 & 4.95 & 4.67899 & 9999999999 & TST \\
\hline CHEMBL1611037 & 688759 & 4.75 & 4.6161 & TRN & \\
\hline
\end{tabular}




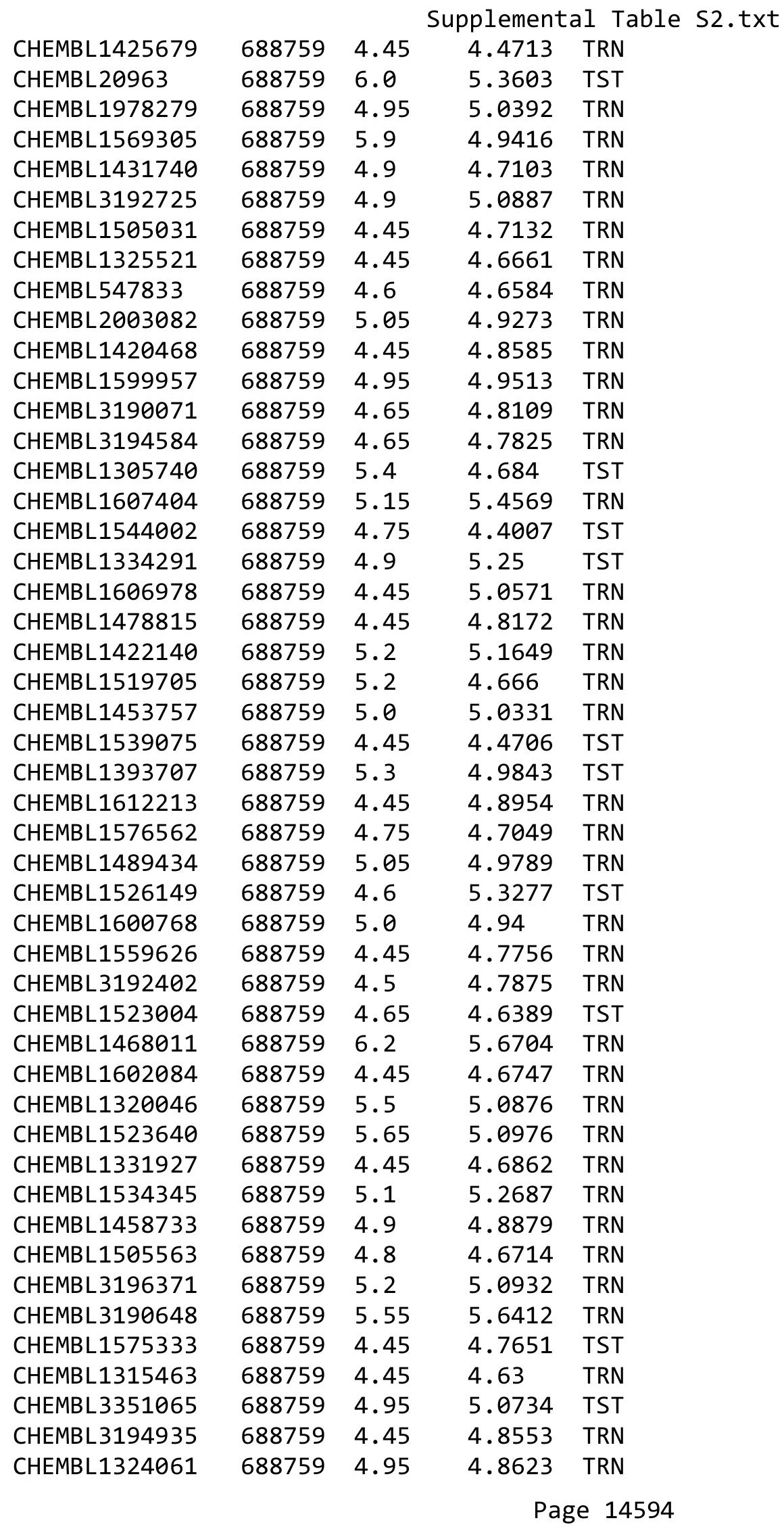




\begin{tabular}{|c|c|c|c|c|c|}
\hline \multicolumn{6}{|c|}{ Supplemental Table S2.txt } \\
\hline CHEMBL3196861 & 688759 & 5.2 & 5.1167 & TRN & \\
\hline CHEMBL1504109 & 688759 & 4.8 & 4.8572 & TRN & \\
\hline CHEMBL1332626 & 688759 & 5.0 & 5.0552 & TRN & \\
\hline CHEMBL1966691 & 688759 & 6.1 & 4.6583 & TRN & \\
\hline CHEMBL1556429 & 688759 & 4.45 & 4.9512 & TRN & \\
\hline CHEMBL1524324 & 688759 & 4.45 & 5.1128 & TRN & \\
\hline CHEMBL1319476 & 688759 & 4.7 & 4.6377 & TRN & \\
\hline CHEMBL1534484 & 688759 & 4.75 & 5.1526 & TRN & \\
\hline CHEMBL1377078 & 688759 & 4.45 & 4.6993 & TRN & \\
\hline CHEMBL321747 & 688759 & 5.25 & 5.3632 & TRN & \\
\hline CHEMBL1417620 & 688759 & 5.35 & 5.0682 & TRN & \\
\hline CHEMBL1442927 & 688759 & 6.05 & 5.0298 & TRN & \\
\hline CHEMBL596271 & 688759 & 4.45 & 4.9163 & TRN & \\
\hline CHEMBL1478451 & 688759 & 4.45 & 4.8094 & TST & \\
\hline CHEMBL1355669 & 688759 & 4.55 & 4.9465 & TST & \\
\hline CHEMBL1312554 & 688759 & 4.9 & 4.8722 & TRN & \\
\hline CHEMBL1521196 & 688759 & 6.15 & 4.8976 & TRN & \\
\hline CHEMBL1334272 & 688759 & 4.65 & 4.94300 & 00000000005 & TRN \\
\hline CHEMBL1350256 & 688759 & 4.65 & 4.7784 & TST & \\
\hline CHEMBL1444953 & 688759 & 4.9 & 5.0551 & TRN & \\
\hline CHEMBL3192272 & 688759 & 4.7 & 4.8054 & TRN & \\
\hline CHEMBL3190280 & 688759 & 5.6 & 5.4329 & TRN & \\
\hline CHEMBL1541490 & 688759 & 4.55 & 5.0576 & TST & \\
\hline CHEMBL1511962 & 688759 & 5.45 & 5.0099 & TRN & \\
\hline CHEMBL1453863 & 688759 & 4.45 & 4.9676 & TST & \\
\hline CHEMBL 3195180 & 688759 & 4.45 & 4.6368 & TRN & \\
\hline CHEMBL1305645 & 688759 & 4.55 & 4.6158 & TRN & \\
\hline CHEMBL1506670 & 688759 & 4.8 & 4.8652 & TRN & \\
\hline CHEMBL1527691 & 688759 & 5.25 & 5.3304 & TRN & \\
\hline CHEMBL1520479 & 688759 & 5.35 & 5.1755 & TRN & \\
\hline CHEMBL1333381 & 688759 & 4.9 & 4.7558 & TRN & \\
\hline CHEMBL1465487 & 688759 & 4.45 & 4.4919 & TRN & \\
\hline CHEMBL1409629 & 688759 & 4.45 & 4.8927 & TRN & \\
\hline CHEMBL1586425 & 688759 & 6.4 & 5.6415 & TRN & \\
\hline CHEMBL1432322 & 688759 & 4.45 & 4.8804 & TRN & \\
\hline CHEMBL1386550 & 688759 & 4.6 & 4.831 & TST & \\
\hline CHEMBL1499873 & 688759 & 4.45 & 4.5069 & TRN & \\
\hline CHEMBL1323309 & 688759 & 5.3 & 4.907 & TRN & \\
\hline CHEMBL1558868 & 688759 & 5.0 & 5.0 & TST & \\
\hline CHEMBL1339303 & 688759 & 4.85 & 4.7408 & TRN & \\
\hline CHEMBL1390177 & 688759 & 4.8 & 4.9075 & TRN & \\
\hline CHEMBL3197906 & 688759 & 5.0 & 4.9618 & TRN & \\
\hline CHEMBL1983220 & 688759 & 4.9 & 5.1885 & TST & \\
\hline CHEMBL1528869 & 688759 & 5.05 & 5.0065 & TRN & \\
\hline CHEMBL1352363 & 688759 & 4.45 & 4.8365 & TRN & \\
\hline CHEMBL1494080 & 688759 & 5.1 & 5.152 & TRN & \\
\hline CHEMBL1608348 & 688759 & 5.25 & 4.9865 & TRN & \\
\hline CHEMBL1544998 & 688759 & 5.3 & 4.8224 & TRN & \\
\hline
\end{tabular}




\begin{tabular}{|c|c|c|c|c|c|}
\hline \multicolumn{6}{|c|}{ Supplemental Table S2.txt } \\
\hline CHEMBL1494406 & 688759 & 4.75 & 4.9238 & TRN & \\
\hline CHEMBL1567778 & 688759 & 4.85 & 5.4 & TST & \\
\hline CHEMBL267548 & 688759 & 4.7 & 4.9059 & TST & \\
\hline CHEMBL1500510 & 688759 & 4.5 & 4.9029 & TRN & \\
\hline CHEMBL1609273 & 688759 & 4.65 & 4.8524 & TRN & \\
\hline CHEMBL1998967 & 688759 & 5.15 & 5.2138 & TRN & \\
\hline CHEMBL1430967 & 688759 & 4.45 & 4.9434 & TRN & \\
\hline CHEMBL1355466 & 688759 & 4.85 & 4.9648 & TST & \\
\hline CHEMBL1306783 & 688759 & 4.45 & 4.7461 & TRN & \\
\hline CHEMBL1460850 & 688759 & 4.45 & 4.8526 & TST & \\
\hline CHEMBL1398826 & 688759 & 5.15 & 5.2426 & TRN & \\
\hline CHEMBL1352067 & 688759 & 4.45 & 4.8988 & TRN & \\
\hline CHEMBL1510084 & 688759 & 4.5 & 4.6064 & TRN & \\
\hline CHEMBL3196492 & 688759 & 4.9 & 4.677 & TST & \\
\hline CHEMBL1987483 & 688759 & 4.45 & 4.5106 & TRN & \\
\hline CHEMBL1410460 & 688759 & 5.3 & 5.0528 & TRN & \\
\hline CHEMBL1078244 & 688759 & 4.9 & 5.0242 & TST & \\
\hline CHEMBL1999862 & 688759 & 4.45 & 4.8863 & TRN & \\
\hline CHEMBL1561412 & 688759 & 4.8 & 4.971 & TST & \\
\hline CHEMBL1304757 & 688759 & 4.75 & 4.5595 & TRN & \\
\hline CHEMBL1521106 & 688759 & 4.55 & 4.8139 & TRN & \\
\hline CHEMBL1602015 & 688759 & 4.6 & 4.7936 & TST & \\
\hline CHEMBL1340035 & 688759 & 4.45 & 4.9131 & TST & \\
\hline CHEMBL1479242 & 688759 & 4.95 & 4.8072 & TST & \\
\hline CHEMBL1452480 & 688759 & 5.35 & 5.1956 & TST & \\
\hline CHEMBL1303075 & 688759 & 4.75 & 4.6882 & TRN & \\
\hline CHEMBL1570688 & 688759 & 4.45 & 4.7418 & TST & \\
\hline CHEMBL1338518 & 688759 & 4.45 & 4.83899 & 99999999995 & TST \\
\hline CHEMBL1563508 & 688759 & 4.95 & 4.7835 & TRN & \\
\hline CHEMBL2002332 & 688759 & 4.95 & 5.2574 & TRN & \\
\hline CHEMBL1599870 & 688759 & 5.7 & 5.4134 & TRN & \\
\hline CHEMBL1898074 & 688759 & 5.9 & 5.4684 & TRN & \\
\hline CHEMBL3856095 & 688759 & 5.35 & 5.7248 & TRN & \\
\hline CHEMBL3191432 & 688759 & 5.0 & 5.0108 & TRN & \\
\hline CHEMBL1336688 & 688759 & 4.45 & 4.90300 & 00000000005 & TRN \\
\hline CHEMBL3190116 & 688759 & 4.65 & 4.7713 & TRN & \\
\hline CHEMBL1305103 & 688759 & 4.7 & 4.8392 & TST & \\
\hline CHEMBL1992154 & 688759 & 4.45 & 4.6642 & TRN & \\
\hline CHEMBL3195411 & 688759 & 5.0 & 5.0198 & TRN & \\
\hline CHEMBL1461040 & 688759 & 7.0 & 6.091 & TRN & \\
\hline CHEMBL1464153 & 688759 & 4.45 & 4.8285 & TRN & \\
\hline CHEMBL1577768 & 688759 & 5.25 & 4.8298 & TST & \\
\hline CHEMBL1539603 & 688759 & 4.65 & 4.5246 & TRN & \\
\hline CHEMBL1506021 & 688759 & 5.45 & 5.4129 & TST & \\
\hline CHEMBL1338544 & 688759 & 5.35 & 4.8098 & TST & \\
\hline CHEMBL1448929 & 688759 & 5.3 & 5.16700 & 0000000001 & TRN \\
\hline CHEMBL3211663 & 688759 & 4.65 & 4.6637 & TRN & \\
\hline CHEMBL1455231 & 688759 & 5.5 & 4.8772 & TRN & \\
\hline
\end{tabular}




\begin{tabular}{|c|c|c|c|c|}
\hline \multicolumn{5}{|c|}{ Supplemental Table S2.txt } \\
\hline CHEMBL1558878 & 688759 & 5.3 & 5.0239 & TRN \\
\hline CHEMBL1363034 & 688759 & 4.45 & 4.6597 & TRN \\
\hline CHEMBL550174 & 688759 & 4.7 & 4.7857 & TRN \\
\hline CHEMBL1338774 & 688759 & 4.45 & 4.8622 & TRN \\
\hline CHEMBL1549996 & 688759 & 5.45 & 4.8259 & TST \\
\hline CHEMBL1534618 & 688759 & 4.45 & 4.8542 & TRN \\
\hline CHEMBL1518500 & 688759 & 4.45 & 4.8352 & TST \\
\hline CHEMBL3212923 & 688759 & 5.1 & 5.0226 & TRN \\
\hline CHEMBL1328952 & 688759 & 5.15 & 5.1276 & TRN \\
\hline CHEMBL1337683 & 688759 & 4.5 & 4.7187 & TST \\
\hline CHEMBL1430678 & 688759 & 5.55 & 5.5889 & TRN \\
\hline CHEMBL1386513 & 688759 & 4.85 & 4.6279 & TST \\
\hline CHEMBL1425166 & 688759 & 4.55 & 4.7187 & TRN \\
\hline CHEMBL1901621 & 688759 & 4.45 & 4.769 & TRN \\
\hline CHEMBL1386897 & 688759 & 4.65 & 4.8564 & TRN \\
\hline CHEMBL3190713 & 688759 & 4.45 & 4.7922 & TRN \\
\hline CHEMBL1569542 & 688759 & 5.55 & 4.8683 & TRN \\
\hline CHEMBL3189272 & 688759 & 5.5 & 5.1611 & TST \\
\hline CHEMBL1479316 & 688759 & 6.0 & 5.5719 & TRN \\
\hline CHEMBL1404528 & 688759 & 4.9 & 4.8439 & TRN \\
\hline CHEMBL1992589 & 688759 & 6.35 & 5.675 & TRN \\
\hline CHEMBL1529864 & 688759 & 4.65 & 4.8647 & TST \\
\hline CHEMBL1312153 & 688759 & 4.9 & 4.665 & TRN \\
\hline CHEMBL1401669 & 688759 & 5.3 & 5.1183 & TRN \\
\hline CHEMBL1419959 & 688759 & 5.3 & 4.9299 & TRN \\
\hline CHEMBL3207849 & 688759 & 5.0 & 4.9003 & TRN \\
\hline CHEMBL1790039 & 688759 & 4.45 & 5.2607 & TRN \\
\hline CHEMBL1375321 & 688759 & 4.45 & 4.9646 & TST \\
\hline CHEMBL1341945 & 688759 & 4.9 & 5.0891 & TRN \\
\hline CHEMBL1465202 & 688759 & 4.9 & 5.0652 & TRN \\
\hline CHEMBL1332530 & 688759 & 6.0 & 4.6585 & TRN \\
\hline CHEMBL3199362 & 688759 & 5.95 & 5.2851 & TRN \\
\hline CHEMBL3199721 & 688759 & 5.4 & 4.6942 & TRN \\
\hline CHEMBL1321558 & 688759 & 5.0 & 4.7665 & TRN \\
\hline CHEMBL3193078 & 688759 & 4.65 & 4.8818 & TRN \\
\hline CHEMBL1386106 & 688759 & 4.7 & 4.843 & TST \\
\hline CHEMBL1698464 & 688759 & 5.25 & 4.80399 & 9999999999 \\
\hline CHEMBL1361230 & 688759 & 5.8 & 4.8597 & TRN \\
\hline CHEMBL1386134 & 688759 & 5.1 & 5.1476 & TRN \\
\hline CHEMBL3192262 & 688759 & 5.55 & 5.0779 & TST \\
\hline CHEMBL1521348 & 688759 & 4.5 & 4.7323 & TRN \\
\hline CHEMBL1438069 & 688759 & 4.7 & 4.6145 & TRN \\
\hline CHEMBL1376002 & 688759 & 6.6499 & 5.0767 & TRN \\
\hline CHEMBL1337384 & 688759 & 4.65 & 4.8275 & TRN \\
\hline CHEMBL1373969 & 688759 & 4.6 & 4.7271 & TRN \\
\hline CHEMBL1431573 & 688759 & 5.2 & 4.678 & TRN \\
\hline CHEMBL1441465 & 688759 & 4.45 & 5.0366 & TRN \\
\hline CHEMBL1489769 & 688759 & 6.0 & 5.5794 & TST \\
\hline
\end{tabular}




\begin{tabular}{|c|c|c|c|c|}
\hline \multicolumn{5}{|c|}{ Supplemental Table S2.txt } \\
\hline CHEMBL1549505 & 688759 & 6.0 & 5.8188 & TRN \\
\hline CHEMBL1487430 & 688759 & 5.2 & 5.1017 & TRN \\
\hline CHEMBL3194913 & 688759 & 5.45 & 4.9136 & TRN \\
\hline CHEMBL1351919 & 688759 & 4.45 & 4.4677 & TST \\
\hline CHEMBL1304596 & 688759 & 5.55 & 5.4714 & TRN \\
\hline CHEMBL1471088 & 688759 & 4.7 & 4.6614 & TRN \\
\hline CHEMBL3197102 & 688759 & 4.5 & 4.7928 & TRN \\
\hline CHEMBL3195025 & 688759 & 4.45 & 4.774 & TRN \\
\hline CHEMBL1479098 & 688759 & 6.9 & 4.8195 & TRN \\
\hline CHEMBL1570464 & 688759 & 6.5501 & 5.4813 & TRN \\
\hline CHEMBL1439166 & 688759 & 5.0 & 4.5399 & TRN \\
\hline CHEMBL1330459 & 688759 & 6.0 & 4.9367 & TST \\
\hline CHEMBL1534486 & 688759 & 4.45 & 4.8974 & TST \\
\hline CHEMBL1462918 & 688759 & 7.8508 & 4.9565 & TRN \\
\hline CHEMBL1562333 & 688759 & 4.65 & 4.8997 & TRN \\
\hline CHEMBL1588605 & 688759 & 5.35 & 5.2007 & TRN \\
\hline CHEMBL3193229 & 688759 & 4.95 & 4.9082 & TRN \\
\hline CHEMBL1369033 & 688759 & 4.9 & 5.2313 & TRN \\
\hline CHEMBL1409950 & 688759 & 4.45 & 4.927 & TRN \\
\hline CHEMBL1604090 & 688759 & 4.8 & 4.4736 & TST \\
\hline CHEMBL1540038 & 688759 & 4.65 & 4.7094 & TRN \\
\hline CHEMBL1529418 & 688759 & 4.95 & 4.9174 & TST \\
\hline CHEMBL1330308 & 688759 & 4.45 & 4.677 & TST \\
\hline CHEMBL1568796 & 688759 & 4.45 & 4.8114 & TRN \\
\hline CHEMBL1543196 & 688759 & 4.85 & 4.7068 & TRN \\
\hline CHEMBL3189607 & 688759 & 5.9 & 4.9803 & TRN \\
\hline CHEMBL1313901 & 688759 & 5.25 & 5.1104 & TRN \\
\hline CHEMBL1563351 & 688759 & 4.45 & 4.9755 & TST \\
\hline CHEMBL123 & 688759 & 6.0 & 5.0611 & TRN \\
\hline CHEMBL 2000750 & 688759 & 5.35 & 5.4438 & TRN \\
\hline CHEMBL1600858 & 688759 & 4.8 & 4.8667 & TST \\
\hline CHEMBL1323005 & 688759 & 5.15 & 5.0379 & TRN \\
\hline CHEMBL1581811 & 688759 & 4.45 & 4.6321 & TRN \\
\hline CHEMBL1517484 & 688759 & 4.45 & 4.8727 & TRN \\
\hline CHEMBL1987272 & 688759 & 4.45 & 4.6571 & TST \\
\hline CHEMBL1403320 & 688759 & 5.55 & 5.3812 & TRN \\
\hline CHEMBL1323575 & 688759 & 4.5 & 4.8768 & TST \\
\hline CHEMBL1313691 & 688759 & 4.45 & 4.9605 & TRN \\
\hline CHEMBL1407040 & 688759 & 4.8 & 4.6495 & TRN \\
\hline CHEMBL 3211420 & 688759 & 4.6 & 4.66 & TRN \\
\hline CHEMBL1490495 & 688759 & 6.15 & 5.1147 & TST \\
\hline CHEMBL3199635 & 688759 & 4.55 & 4.8718 & TRN \\
\hline CHEMBL345124 & 688759 & 5.6 & 5.4155 & TST \\
\hline CHEMBL1405962 & 688759 & 4.45 & 4.8651 & TRN \\
\hline CHEMBL1419256 & 688759 & 4.75 & 4.715 & TRN \\
\hline CHEMBL1595709 & 688759 & 6.15 & 4.9967 & TST \\
\hline CHEMBL3189796 & 688759 & 4.45 & 4.9605 & TRN \\
\hline CHEMBL1371704 & 688759 & 5.25 & 4.9575 & TRN \\
\hline
\end{tabular}




\begin{tabular}{|c|c|c|c|c|c|}
\hline \multicolumn{6}{|c|}{ Supplemental Table S2.txt } \\
\hline CHEMBL1484809 & 688759 & 4.75 & 4.5763 & TST & \\
\hline CHEMBL1479251 & 688759 & 4.6 & 4.8887 & TRN & \\
\hline CHEMBL1370100 & 688759 & 4.45 & 4.8403 & TRN & \\
\hline CHEMBL1541950 & 688759 & 4.45 & 4.8886 & TRN & \\
\hline CHEMBL1412091 & 688759 & 5.15 & 5.0095 & TRN & \\
\hline CHEMBL1362944 & 688759 & 4.6 & 4.9986 & TRN & \\
\hline CHEMBL1372170 & 688759 & 4.55 & 4.7106 & TRN & \\
\hline CHEMBL3199095 & 688759 & 4.5 & 5.1829 & TRN & \\
\hline CHEMBL1352633 & 688759 & 4.95 & 4.8935 & TRN & \\
\hline CHEMBL1333464 & 688759 & 4.75 & 4.8208 & TST & \\
\hline CHEMBL1377631 & 688759 & 5.25 & 4.955 & TST & \\
\hline CHEMBL1501390 & 688759 & 4.5 & 4.5784 & TRN & \\
\hline CHEMBL1583997 & 688759 & 4.45 & 4.9574 & TRN & \\
\hline CHEMBL3212246 & 688759 & 5.0 & 5.4888 & TRN & \\
\hline CHEMBL1428207 & 688759 & 4.45 & 4.6976 & TRN & \\
\hline CHEMBL1349034 & 688759 & 4.45 & 5.2975 & TRN & \\
\hline CHEMBL1542249 & 688759 & 4.6 & 4.825 & TRN & \\
\hline CHEMBL1466156 & 688759 & 4.45 & 5.42200 & 0000000001 & TRN \\
\hline CHEMBL1579114 & 688759 & 4.9 & 4.8162 & TRN & \\
\hline CHEMBL1385350 & 688759 & 4.45 & 4.828 & TST & \\
\hline CHEMBL1597238 & 688759 & 4.45 & 4.6412 & TRN & \\
\hline CHEMBL1603278 & 688759 & 4.8 & 4.9391 & TRN & \\
\hline CHEMBL1491800 & 688759 & 4.45 & 4.5868 & TRN & \\
\hline CHEMBL1503573 & 688759 & 4.45 & 4.6717 & TRN & \\
\hline CHEMBL1327203 & 688759 & 5.0 & 5.03600 & 00000000005 & TST \\
\hline CHEMBL1412583 & 688759 & 5.25 & 5.0327 & TST & \\
\hline CHEMBL1310721 & 688759 & 5.0 & 5.0865 & TRN & \\
\hline CHEMBL1986099 & 688759 & 4.45 & 4.7841 & TRN & \\
\hline CHEMBL1309607 & 688759 & 6.2 & 5.1208 & TRN & \\
\hline CHEMBL1509585 & 688759 & 4.65 & 4.7038 & TRN & \\
\hline CHEMBL1464174 & 688759 & 6.7501 & 4.8615 & TRN & \\
\hline CHEMBL1611556 & 688759 & 5.15 & 4.824 & TRN & \\
\hline CHEMBL3194955 & 688759 & 5.25 & 4.915 & TST & \\
\hline CHEMBL1536156 & 688759 & 4.45 & 4.9533 & TRN & \\
\hline CHEMBL1333360 & 688759 & 5.25 & 5.2842 & TRN & \\
\hline CHEMBL1499109 & 688759 & 4.6 & 4.7517 & TRN & \\
\hline CHEMBL1374490 & 688759 & 4.6 & 4.739 & TRN & \\
\hline CHEMBL3197099 & 688759 & 6.45 & 6.21700 & 00000000005 & TRN \\
\hline CHEMBL1411241 & 688759 & 4.7 & 5.0265 & TRN & \\
\hline CHEMBL1483657 & 688759 & 4.65 & 4.7773 & TRN & \\
\hline CHEMBL1506016 & 688759 & 4.85 & 4.7754 & TRN & \\
\hline CHEMBL1397706 & 688759 & 4.55 & 4.7958 & TST & \\
\hline CHEMBL1575809 & 688759 & 4.95 & 4.8358 & TST & \\
\hline CHEMBL1487707 & 688759 & 5.25 & 5.3416 & TRN & \\
\hline CHEMBL1313371 & 688759 & 4.45 & 4.7553 & TRN & \\
\hline CHEMBL1455894 & 688759 & 5.35 & 5.0359 & TRN & \\
\hline CHEMBL1557179 & 688759 & 4.85 & 5.0237 & TRN & \\
\hline CHEMBL1398669 & 688759 & 5.5 & 4.8213 & TRN & \\
\hline
\end{tabular}




\begin{tabular}{|c|c|c|c|c|c|}
\hline \multicolumn{6}{|c|}{ Supplemental Table S2.txt } \\
\hline CHEMBL3194932 & 688759 & 4.9 & 5.1122 & TRN & \\
\hline CHEMBL1504749 & 688759 & 4.45 & 4.6564 & TRN & \\
\hline CHEMBL1391191 & 688759 & 5.55 & 5.4859 & TRN & \\
\hline CHEMBL 2002995 & 688759 & 4.95 & 5.0039 & TRN & \\
\hline CHEMBL1588204 & 688759 & 4.65 & 4.771 & TRN & \\
\hline CHEMBL1416047 & 688759 & 4.45 & 4.6922 & TRN & \\
\hline CHEMBL1389379 & 688759 & 4.45 & 4.8822 & TST & \\
\hline CHEMBL1310319 & 688759 & 5.2 & 4.6846 & TST & \\
\hline CHEMBL1351979 & 688759 & 5.15 & 5.9558 & TRN & \\
\hline CHEMBL1352000 & 688759 & 4.45 & 4.9335 & TRN & \\
\hline CHEMBL1574485 & 688759 & 4.45 & 4.676 & TST & \\
\hline CHEMBL1517753 & 688759 & 5.9 & 5.6121 & TRN & \\
\hline CHEMBL1536665 & 688759 & 5.75 & 5.3723 & TRN & \\
\hline CHEMBL1449892 & 688759 & 4.95 & 5.3464 & TRN & \\
\hline CHEMBL1351567 & 688759 & 4.45 & 4.841 & TRN & \\
\hline CHEMBL1583195 & 688759 & 7.5003 & 6.53600 & 00000000005 & TRN \\
\hline CHEMBL3191799 & 688759 & 4.7 & 4.9851 & TST & \\
\hline CHEMBL1347449 & 688759 & 4.7 & 4.5333 & TRN & \\
\hline CHEMBL1346668 & 688759 & 4.45 & 4.9415 & TRN & \\
\hline CHEMBL1414813 & 688759 & 4.45 & 4.5795 & TRN & \\
\hline CHEMBL1327438 & 688759 & 4.9 & 4.8445 & TRN & \\
\hline CHEMBL1497197 & 688759 & 8.3468 & 5.1434 & TST & \\
\hline CHEMBL1466352 & 688759 & 5.45 & 5.0142 & TST & \\
\hline CHEMBL1345981 & 688759 & 4.7 & 4.5593 & TRN & \\
\hline CHEMBL1451642 & 688759 & 4.6 & 4.6386 & TST & \\
\hline CHEMBL1567861 & 688759 & 4.95 & 4.7014 & TRN & \\
\hline CHEMBL1307918 & 688759 & 4.45 & 4.9413 & TRN & \\
\hline CHEMBL1588285 & 688759 & 4.65 & 4.8347 & TRN & \\
\hline CHEMBL 1607857 & 688759 & 4.65 & 5.0805 & TST & \\
\hline CHEMBL1575749 & 688759 & 6.0 & 5.0092 & TRN & \\
\hline CHEMBL1457778 & 688759 & 4.45 & 4.7461 & TRN & \\
\hline CHEMBL1306457 & 688759 & 4.75 & 4.652 & TST & \\
\hline CHEMBL1367469 & 688759 & 4.65 & 4.9966 & TST & \\
\hline CHEMBL1438761 & 688759 & 4.45 & 4.454 & TRN & \\
\hline CHEMBL1449868 & 688759 & 4.75 & 4.9124 & TRN & \\
\hline CHEMBL1581537 & 688759 & 4.7 & 4.8611 & TST & \\
\hline CHEMBL1382587 & 688759 & 4.45 & 4.8081 & TRN & \\
\hline CHEMBL1387644 & 688759 & 5.15 & 4.8505 & TRN & \\
\hline CHEMBL1468127 & 688759 & 4.45 & 4.831 & TRN & \\
\hline CHEMBL1366178 & 688759 & 4.45 & 4.8782 & TRN & \\
\hline CHEMBL1579959 & 688759 & 4.45 & 4.6706 & TRN & \\
\hline CHEMBL1407812 & 688759 & 4.45 & 4.5329 & TRN & \\
\hline CHEMBL3199400 & 688759 & 4.45 & 4.8692 & TRN & \\
\hline CHEMBL1327817 & 688759 & 4.8 & 4.7233 & TRN & \\
\hline CHEMBL3193379 & 688759 & 4.6 & 4.6113 & TRN & \\
\hline CHEMBL1359820 & 688759 & 4.9 & 5.1597 & TRN & \\
\hline CHEMBL1471481 & 688759 & 4.45 & 4.8296 & TRN & \\
\hline CHEMBL1977678 & 688759 & 4.7 & 4.9727 & TRN & \\
\hline
\end{tabular}




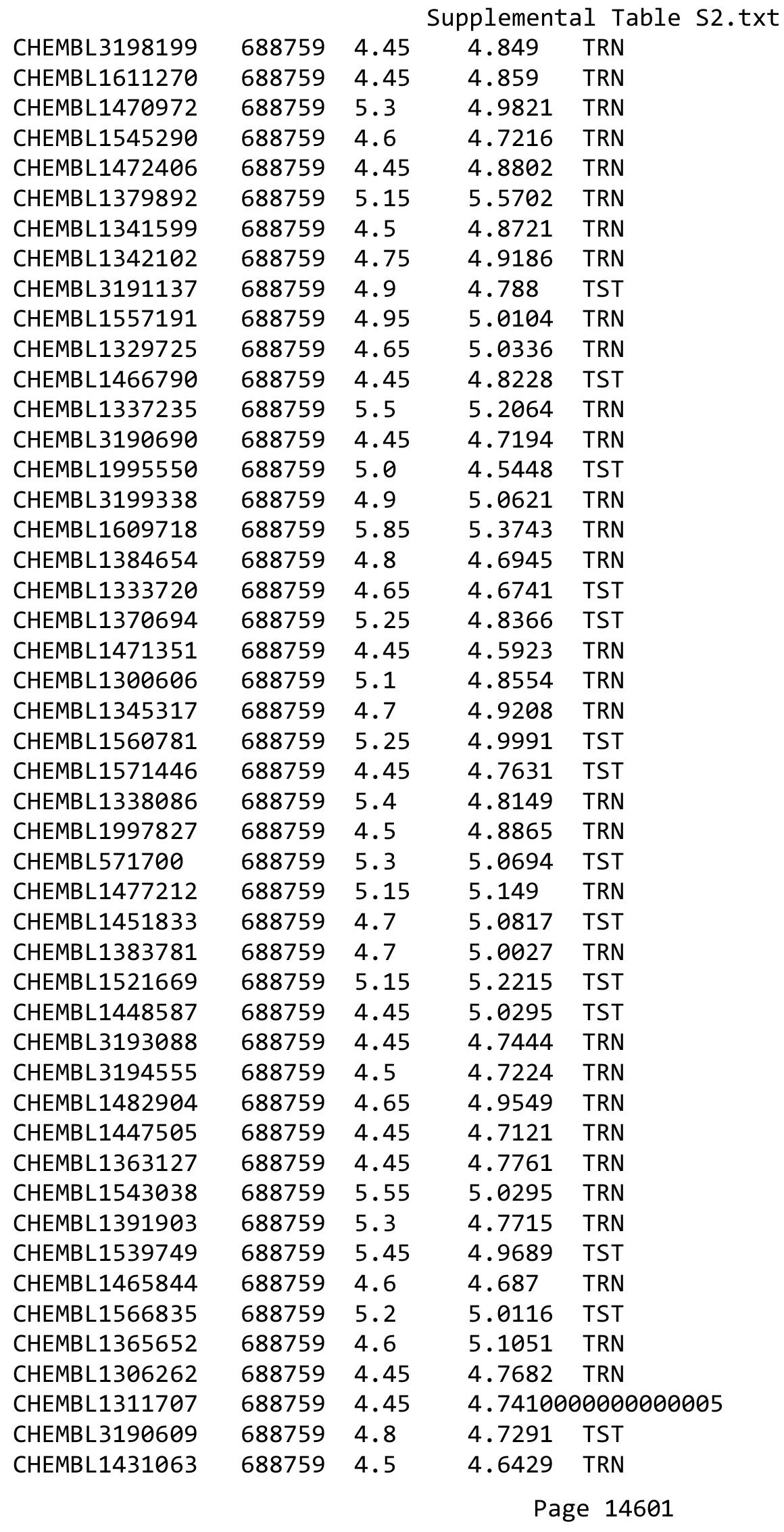




\begin{tabular}{|c|c|c|c|c|}
\hline \multicolumn{5}{|c|}{ Supplemental Table S2.txt } \\
\hline CHEMBL1593774 & 688759 & 4.7 & 4.7879 & TRN \\
\hline CHEMBL1350408 & 688759 & 4.6 & 4.9127 & TRN \\
\hline CHEMBL1466286 & 688759 & 4.75 & 4.8236 & TRN \\
\hline CHEMBL1457594 & 688759 & 4.9 & 4.5783 & TRN \\
\hline CHEMBL3199166 & 688759 & 4.45 & 4.7635 & TRN \\
\hline CHEMBL1348642 & 688759 & 4.45 & 4.9242 & TST \\
\hline CHEMBL1496095 & 688759 & 4.6 & 4.4743 & TRN \\
\hline CHEMBL1343883 & 688759 & 4.45 & 4.5546 & TRN \\
\hline CHEMBL1441008 & 688759 & 4.45 & 4.7665 & TRN \\
\hline CHEMBL1305058 & 688759 & 4.55 & 4.9235 & TRN \\
\hline CHEMBL1422035 & 688759 & 4.45 & 4.6624 & TST \\
\hline CHEMBL1994362 & 688759 & 4.45 & 4.8829 & TRN \\
\hline CHEMBL1578628 & 688759 & 4.45 & 4.7752 & TRN \\
\hline CHEMBL1340619 & 688759 & 4.9 & 4.5821 & TRN \\
\hline CHEMBL1538482 & 688759 & 4.65 & 4.7543 & TRN \\
\hline CHEMBL1582281 & 688759 & 4.65 & 4.5784 & TST \\
\hline CHEMBL3199253 & 688759 & 5.3 & 5.1994 & TST \\
\hline CHEMBL1376162 & 688759 & 4.55 & 4.7955 & TRN \\
\hline CHEMBL1545240 & 688759 & 6.25 & 5.1144 & TRN \\
\hline CHEMBL1312802 & 688759 & 4.9 & 4.9646 & TST \\
\hline CHEMBL585828 & 688759 & 4.9 & 4.987 & TRN \\
\hline CHEMBL3192867 & 688759 & 4.45 & 4.9629 & TRN \\
\hline CHEMBL1481651 & 688759 & 4.9 & 4.9975 & TRN \\
\hline CHEMBL1556473 & 688759 & 4.45 & 4.5809 & TST \\
\hline CHEMBL1418095 & 688759 & 4.65 & 4.93 & TRN \\
\hline CHEMBL1370035 & 688759 & 5.3 & 5.0354 & TRN \\
\hline CHEMBL1543238 & 688759 & 5.65 & 5.4551 & TRN \\
\hline CHEMBL1603555 & 688759 & 4.65 & 4.9757 & TRN \\
\hline CHEMBL1536844 & 688759 & 5.9 & 4.8631 & TST \\
\hline CHEMBL1480889 & 688759 & 4.45 & 5.0729 & TRN \\
\hline CHEMBL1583898 & 688759 & 4.75 & 4.8695 & TRN \\
\hline CHEMBL3195887 & 688759 & 4.45 & 4.9705 & TRN \\
\hline CHEMBL3192747 & 688759 & 4.75 & 4.9659 & TRN \\
\hline CHEMBL1344654 & 688759 & 5.05 & 4.5204 & TRN \\
\hline CHEMBL3191547 & 688759 & 5.25 & 4.8164 & TRN \\
\hline CHEMBL1982623 & 688759 & 5.25 & 5.1511 & TRN \\
\hline CHEMBL1523600 & 688759 & 4.65 & 4.8301 & TST \\
\hline CHEMBL1311732 & 688759 & 4.65 & 4.355 & TST \\
\hline CHEMBL3192089 & 688759 & 5.4 & 5.1749 & TST \\
\hline CHEMBL1393983 & 688759 & 4.8 & 5.6603 & TRN \\
\hline CHEMBL1583472 & 688759 & 4.6 & 5.121 & TRN \\
\hline CHEMBL1499083 & 688759 & 4.45 & 4.6466 & TRN \\
\hline CHEMBL1432156 & 688759 & 5.15 & 4.925 & TST \\
\hline CHEMBL1545104 & 688759 & 4.75 & 4.9898 & TRN \\
\hline CHEMBL2002169 & 688759 & 4.7 & 4.7947 & TRN \\
\hline CHEMBL1496142 & 688759 & 4.8 & 5.1983 & TRN \\
\hline CHEMBL1307190 & 688759 & 4.95 & 4.7872 & TRN \\
\hline CHEMBL1326034 & 688759 & 4.45 & 4.6954 & TRN \\
\hline
\end{tabular}




\begin{tabular}{|c|c|c|c|c|c|}
\hline & & \multicolumn{4}{|c|}{ Supplemental Table S2.txt } \\
\hline CHEMBL3213034 & 688759 & 5.15 & 5.1223 & TRN & \\
\hline CHEMBL1303364 & 688759 & 4.45 & 4.9045 & TST & \\
\hline CHEMBL1353581 & 688759 & 4.45 & 4.5409 & TRN & \\
\hline CHEMBL1589132 & 688759 & 5.15 & 4.5622 & TST & \\
\hline CHEMBL1549803 & 688759 & 4.75 & 4.8462 & TRN & \\
\hline CHEMBL1391066 & 688759 & 4.45 & 4.7161 & TRN & \\
\hline CHEMBL1531455 & 688759 & 4.9 & 5.138 & TRN & \\
\hline CHEMBL1541301 & 688759 & 5.5 & 4.8051 & TRN & \\
\hline CHEMBL1469692 & 688759 & 4.9 & 4.5757 & TRN & \\
\hline CHEMBL1394760 & 688759 & 4.45 & 4.7381 & TST & \\
\hline CHEMBL1309582 & 688759 & 5.0 & 4.8019 & TRN & \\
\hline CHEMBL602730 & 688759 & 5.9 & 5.6154 & TRN & \\
\hline CHEMBL1466340 & 688759 & 4.85 & 4.6361 & TST & \\
\hline CHEMBL1527840 & 688759 & 4.45 & 5.15799 & 99999999995 & TRN \\
\hline CHEMBL1598774 & 688759 & 4.7 & 4.6139 & TRN & \\
\hline CHEMBL1383424 & 688759 & 4.45 & 4.8891 & TST & \\
\hline CHEMBL1506351 & 688759 & 4.75 & 4.9677 & TRN & \\
\hline CHEMBL1307684 & 688759 & 4.75 & 4.9326 & TRN & \\
\hline CHEMBL3192275 & 688759 & 5.25 & 5.0664 & TST & \\
\hline CHEMBL 2002444 & 688759 & 5.7 & 5.657 & TRN & \\
\hline CHEMBL1300367 & 688759 & 4.7 & 4.808 & TST & \\
\hline CHEMBL1429198 & 688759 & 5.1 & 5.0299 & TST & \\
\hline CHEMBL1416484 & 688759 & 5.4 & 5.05 & TRN & \\
\hline CHEMBL1342485 & 688759 & 5.95 & 5.4732 & TST & \\
\hline CHEMBL1457013 & 688759 & 4.45 & 4.7835 & TST & \\
\hline CHEMBL1324034 & 688759 & 4.45 & 4.8501 & TRN & \\
\hline CHEMBL1607905 & 688759 & 4.9 & 4.8876 & TST & \\
\hline CHEMBL1329388 & 688759 & 6.25 & 4.7091 & TRN & \\
\hline CHEMBL1310489 & 688759 & 5.15 & 4.9936 & TRN & \\
\hline CHEMBL1539180 & 688759 & 4.5 & 4.6566 & TRN & \\
\hline CHEMBL1586979 & 688759 & 4.45 & 4.9289 & TST & \\
\hline CHEMBL1579770 & 688759 & 4.45 & 4.899 & TRN & \\
\hline CHEMBL1465049 & 688759 & 4.45 & 4.6453 & TRN & \\
\hline CHEMBL1517422 & 688759 & 4.95 & 4.809 & TST & \\
\hline CHEMBL1587190 & 688759 & 4.45 & 4.904 & TRN & \\
\hline CHEMBL1545054 & 688759 & 4.95 & 4.7587 & TRN & \\
\hline CHEMBL1598229 & 688759 & 4.6 & 4.717 & TRN & \\
\hline CHEMBL1393694 & 688759 & 4.45 & 4.6741 & TRN & \\
\hline CHEMBL1574798 & 688759 & 4.45 & 4.6707 & TRN & \\
\hline CHEMBL1575354 & 688759 & 4.8 & 4.9434 & TRN & \\
\hline CHEMBL1487065 & 688759 & 6.1 & 4.7976 & TST & \\
\hline CHEMBL1389360 & 688759 & 5.4 & 4.9205 & TRN & \\
\hline CHEMBL1416146 & 688759 & 4.45 & 4.6548 & TST & \\
\hline CHEMBL1341319 & 688759 & 5.1 & 4.8965 & TST & \\
\hline CHEMBL3210154 & 688759 & 5.9 & 5.4554 & TRN & \\
\hline CHEMBL1378626 & 688759 & 5.4 & 5.3306 & TRN & \\
\hline CHEMBL1595434 & 688759 & 5.5 & 4.8625 & TRN & \\
\hline CHEMBL1309733 & 688759 & 4.95 & 4.6739 & TRN & \\
\hline
\end{tabular}




\begin{tabular}{|c|c|c|c|c|c|}
\hline \multicolumn{6}{|c|}{ Supplemental Table S2.txt } \\
\hline CHEMBL1366175 & 688759 & 4.45 & 4.9292 & TRN & \\
\hline CHEMBL1538939 & 688759 & 4.6 & 4.7216 & TRN & \\
\hline CHEMBL1523684 & 688759 & 4.45 & 4.7952 & TST & \\
\hline CHEMBL1981923 & 688759 & 5.7 & 5.5111 & TRN & \\
\hline CHEMBL1422913 & 688759 & 4.8 & 4.8996 & TST & \\
\hline CHEMBL1504623 & 688759 & 5.2 & 5.1349 & TRN & \\
\hline CHEMBL1328538 & 688759 & 4.45 & 5.1195 & TRN & \\
\hline CHEMBL1557980 & 688759 & 4.65 & 4.7577 & TRN & \\
\hline CHEMBL 3190002 & 688759 & 4.7 & 4.8704 & TRN & \\
\hline CHEMBL1342653 & 688759 & 5.0 & 4.73300 & 00000000005 & TRN \\
\hline CHEMBL1583735 & 688759 & 4.65 & 4.6488 & TST & \\
\hline CHEMBL1402218 & 688759 & 4.65 & 4.6186 & TRN & \\
\hline CHEMBL1443335 & 688759 & 4.95 & 5.016 & TRN & \\
\hline CHEMBL1607846 & 688759 & 4.65 & 4.9112 & TST & \\
\hline CHEMBL 70902 & 688759 & 4.65 & 4.7996 & TST & \\
\hline CHEMBL1505940 & 688759 & 4.95 & 4.8811 & TRN & \\
\hline CHEMBL1432618 & 688759 & 4.45 & 4.9837 & TRN & \\
\hline CHEMBL1303361 & 688759 & 4.45 & 4.8066 & TRN & \\
\hline CHEMBL1379934 & 688759 & 4.45 & 4.6817 & TST & \\
\hline CHEMBL1322943 & 688759 & 5.2 & 4.9373 & TRN & \\
\hline CHEMBL1601945 & 688759 & 5.2 & 4.914 & TRN & \\
\hline CHEMBL1308061 & 688759 & 5.15 & 5.2113 & TRN & \\
\hline CHEMBL1338882 & 688759 & 4.65 & 4.4982 & TRN & \\
\hline CHEMBL104255 & 688759 & 4.85 & 4.648 & TRN & \\
\hline CHEMBL1541829 & 688759 & 4.45 & 4.5309 & TST & \\
\hline CHEMBL1345610 & 688759 & 4.45 & 4.6266 & TRN & \\
\hline CHEMBL1575552 & 688759 & 4.45 & 4.6162 & TRN & \\
\hline CHEMBL1561456 & 688759 & 5.4 & 4.7182 & TRN & \\
\hline CHEMBL447958 & 688759 & 5.65 & 5.0514 & TST & \\
\hline CHEMBL1546327 & 688759 & 5.2 & 5.4677 & TRN & \\
\hline CHEMBL1416776 & 688759 & 4.6 & 4.7909 & TST & \\
\hline CHEMBL1339815 & 688759 & 4.45 & 4.8452 & TRN & \\
\hline CHEMBL3195312 & 688759 & 4.75 & 4.8402 & TRN & \\
\hline CHEMBL1312712 & 688759 & 5.05 & 5.032 & TRN & \\
\hline CHEMBL1342619 & 688759 & 6.4 & 4.8446 & TST & \\
\hline CHEMBL1486832 & 688759 & 4.7 & 4.8627 & TRN & \\
\hline CHEMBL1402323 & 688759 & 4.85 & 4.923 & TRN & \\
\hline CHEMBL1496413 & 688759 & 5.25 & 5.1241 & TRN & \\
\hline CHEMBL1401953 & 688759 & 5.35 & 5.5357 & TRN & \\
\hline CHEMBL1536961 & 688759 & 4.55 & 5.0805 & TRN & \\
\hline CHEMBL1524649 & 688759 & 4.7 & 4.5671 & TRN & \\
\hline CHEMBL1301896 & 688759 & 4.45 & 4.7452 & TRN & \\
\hline CHEMBL1400406 & 688759 & 5.45 & 5.5172 & TRN & \\
\hline CHEMBL1555900 & 688759 & 4.8 & 4.7325 & TRN & \\
\hline CHEMBL1503961 & 688759 & 4.45 & 4.9262 & TST & \\
\hline CHEMBL1564713 & 688759 & 5.7 & 5.4635 & TRN & \\
\hline CHEMBL1712981 & 688759 & 4.45 & 4.816 & TST & \\
\hline CHEMBL1549846 & 688759 & 4.95 & 5.3353 & TRN & \\
\hline
\end{tabular}




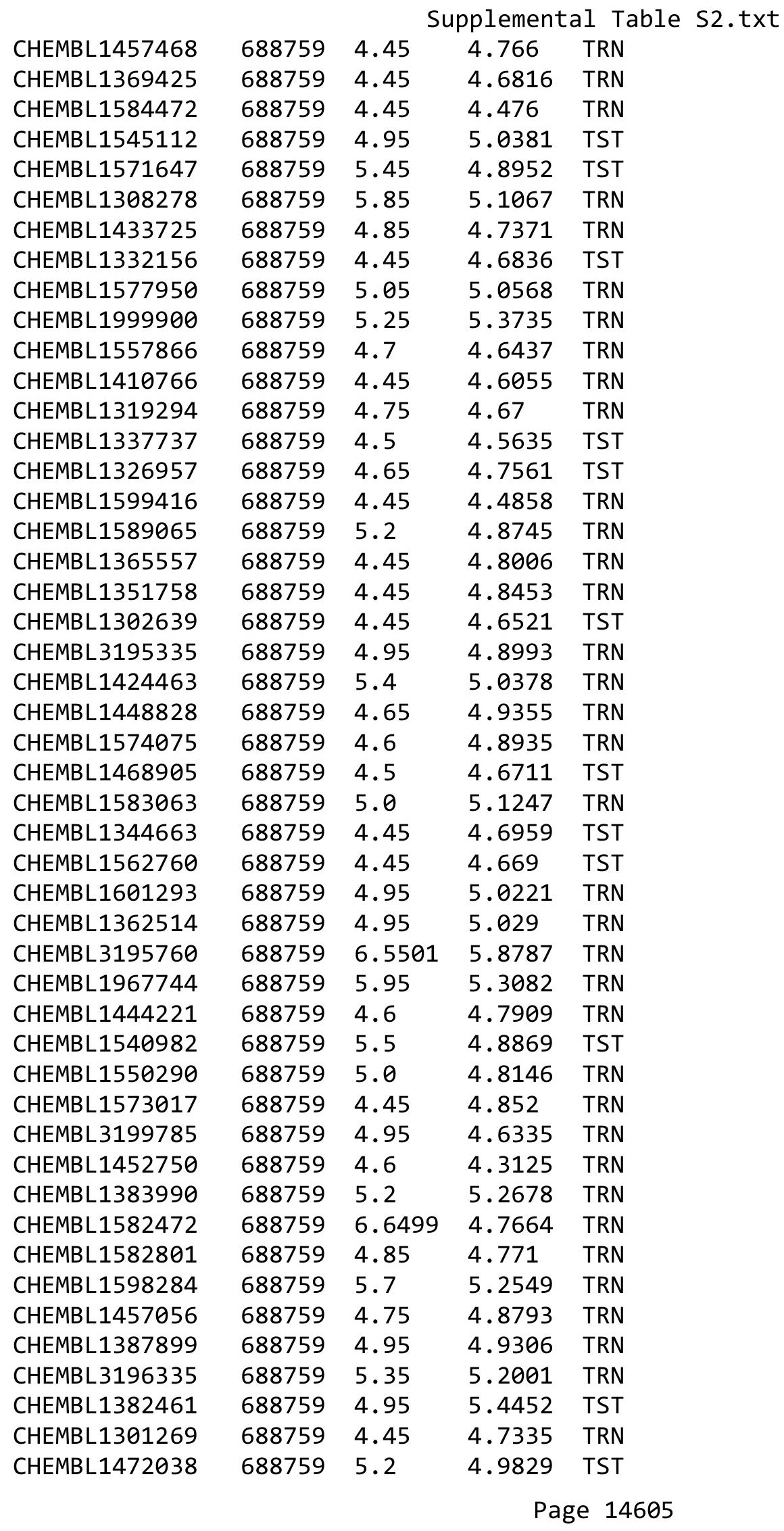




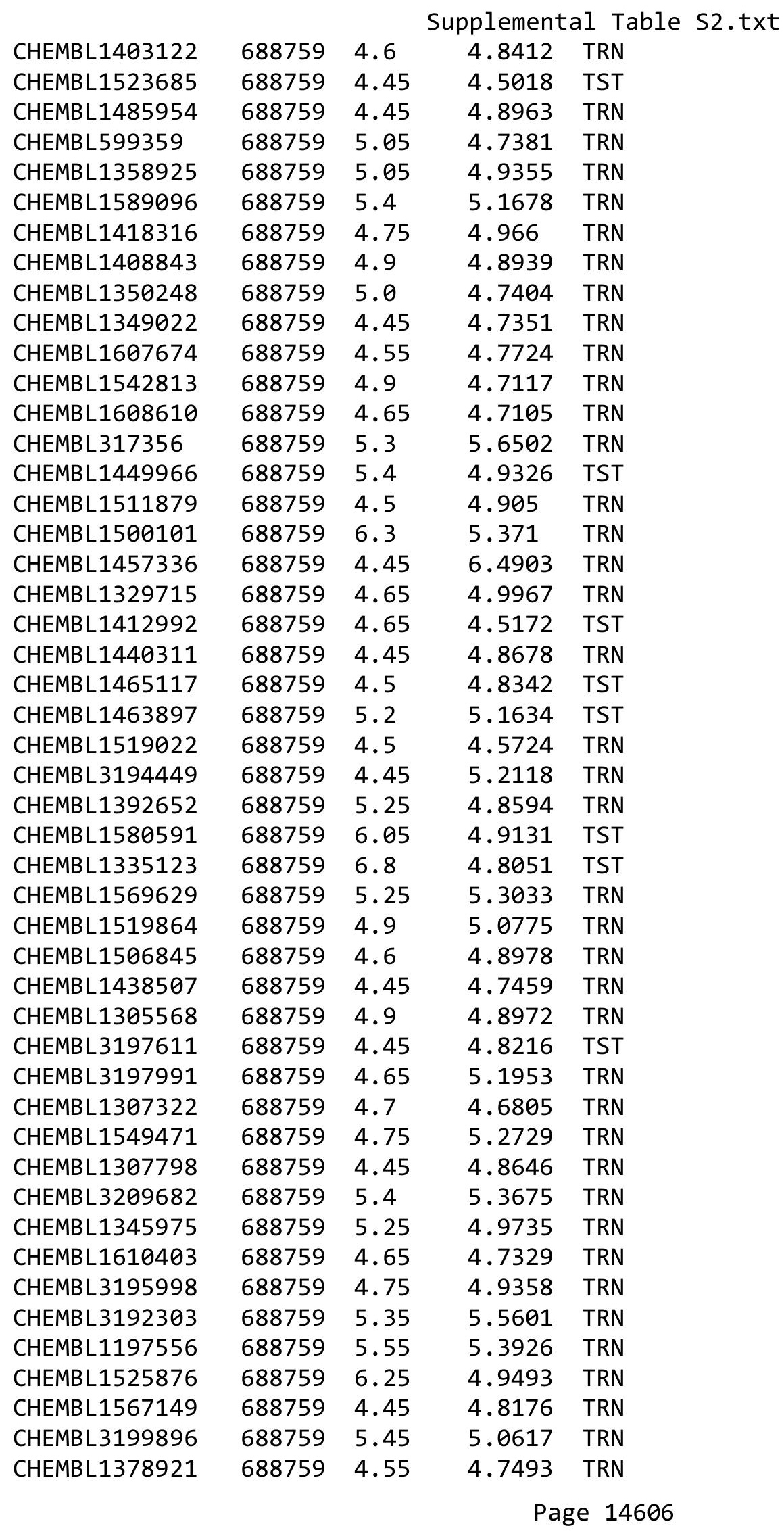




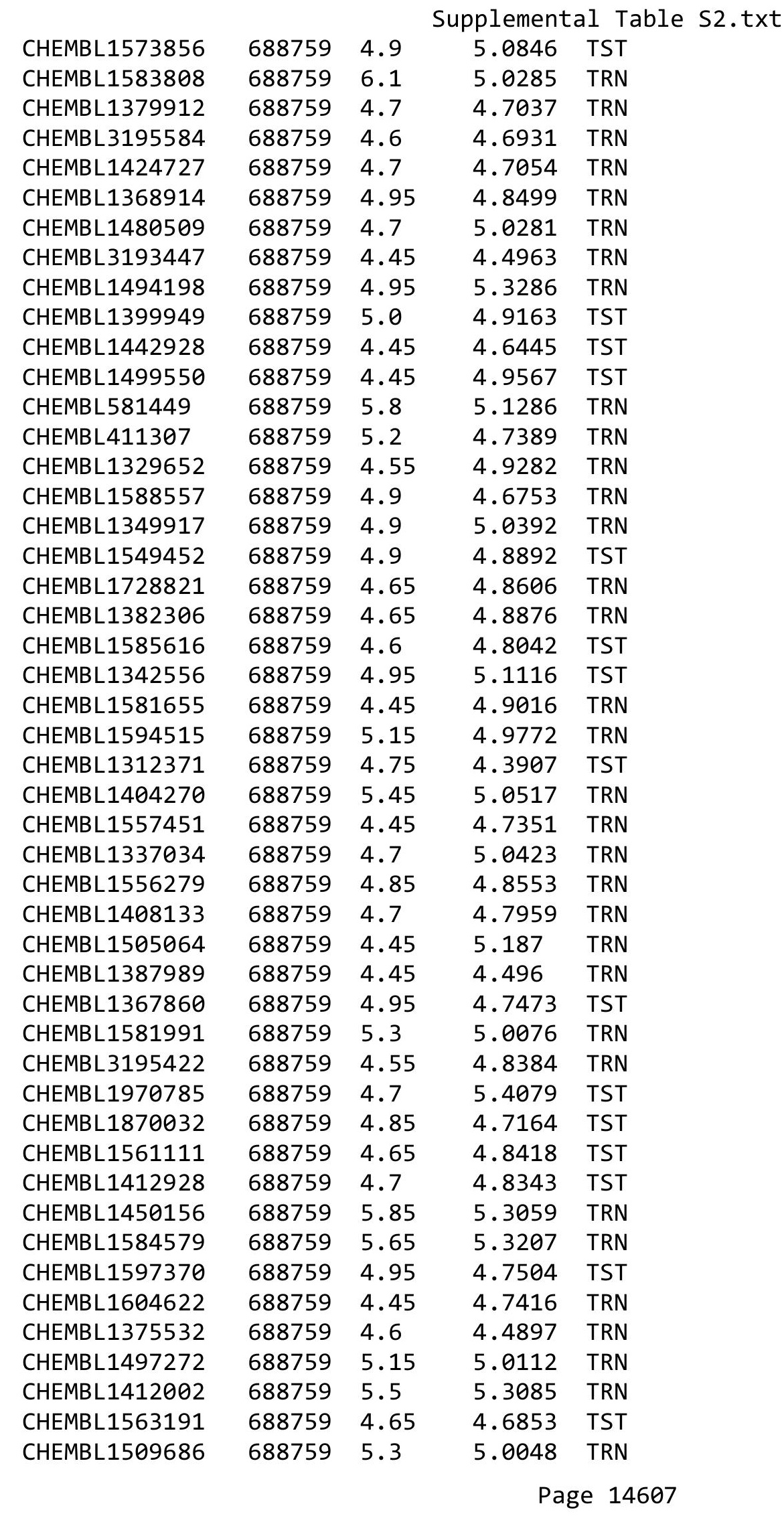




\begin{tabular}{|c|c|c|c|c|c|}
\hline \multicolumn{6}{|c|}{ Supplemental Table S2.txt } \\
\hline CHEMBL1561952 & 688759 & 5.0 & 5.0071 & TRN & \\
\hline CHEMBL1348699 & 688759 & 4.45 & 4.816 & TRN & \\
\hline CHEMBL1368797 & 688759 & 4.95 & 4.9637 & TRN & \\
\hline CHEMBL1374055 & 688759 & 7.1002 & 4.6807 & TST & \\
\hline CHEMBL1431762 & 688759 & 4.55 & 4.5687 & TRN & \\
\hline CHEMBL1549854 & 688759 & 5.0 & 4.7505 & TRN & \\
\hline CHEMBL1545810 & 688759 & 5.65 & 5.796 & TRN & \\
\hline CHEMBL1512797 & 688759 & 4.45 & 4.6767 & TST & \\
\hline CHEMBL1349472 & 688759 & 4.85 & 4.6713 & TRN & \\
\hline CHEMBL258317 & 688759 & 5.25 & 4.8137 & TRN & \\
\hline CHEMBL1539537 & 688759 & 4.45 & 4.6847 & TST & \\
\hline CHEMBL1390973 & 688759 & 4.6 & 4.591 & TRN & \\
\hline CHEMBL1410180 & 688759 & 4.8 & 4.9124 & TST & \\
\hline CHEMBL1306229 & 688759 & 5.85 & 5.4522 & TRN & \\
\hline CHEMBL3208842 & 688759 & 4.45 & 5.1725 & TRN & \\
\hline CHEMBL1506393 & 688759 & 4.45 & 4.7182 & TST & \\
\hline CHEMBL1498603 & 688759 & 4.65 & 4.8892 & TST & \\
\hline CHEMBL1485727 & 688759 & 4.95 & 4.99100 & 00000000005 & TST \\
\hline CHEMBL1609095 & 688759 & 4.45 & 4.9046 & TRN & \\
\hline CHEMBL1406528 & 688759 & 4.75 & 5.1488 & TRN & \\
\hline CHEMBL1408302 & 688759 & 4.45 & 4.8933 & TST & \\
\hline CHEMBL1385867 & 688759 & 4.7 & 4.6273 & TST & \\
\hline CHEMBL1305620 & 688759 & 5.3 & 4.8806 & TRN & \\
\hline CHEMBL1555433 & 688759 & 5.25 & 5.0394 & TRN & \\
\hline CHEMBL3197405 & 688759 & 4.7 & 4.8549 & TRN & \\
\hline CHEMBL153101 & 688759 & 4.65 & 4.8739 & TST & \\
\hline CHEMBL606532 & 688759 & 5.4 & 5.6445 & TRN & \\
\hline CHEMBL1342125 & 688759 & 4.45 & 4.6918 & TRN & \\
\hline CHEMBL1611956 & 688759 & 4.65 & 4.5553 & TRN & \\
\hline CHEMBL1992651 & 688759 & 4.65 & 4.9271 & TRN & \\
\hline CHEMBL3213956 & 688759 & 4.65 & 4.8748 & TRN & \\
\hline CHEMBL1409714 & 688759 & 4.45 & 4.9739 & TST & \\
\hline CHEMBL 2004056 & 688759 & 4.75 & 4.7588 & TRN & \\
\hline CHEMBL1346597 & 688759 & 4.6 & 4.9006 & TRN & \\
\hline CHEMBL1454419 & 688759 & 4.6 & 5.0061 & TRN & \\
\hline CHEMBL1533288 & 688759 & 4.8 & 4.9324 & TST & \\
\hline CHEMBL1304097 & 688759 & 4.95 & 4.8637 & TST & \\
\hline CHEMBL1400519 & 688759 & 4.95 & 4.7362 & TST & \\
\hline CHEMBL1347860 & 688759 & 4.45 & 4.8833 & TST & \\
\hline CHEMBL1517411 & 688759 & 4.65 & 4.748 & TST & \\
\hline CHEMBL1449101 & 688759 & 5.2 & 4.838 & TRN & \\
\hline CHEMBL1536960 & 688759 & 5.55 & 4.8952 & TRN & \\
\hline CHEMBL1567824 & 688759 & 4.45 & 4.7136 & TRN & \\
\hline CHEMBL1482655 & 688759 & 4.65 & 4.6645 & TRN & \\
\hline CHEMBL1479974 & 688759 & 6.5501 & 5.1531 & TRN & \\
\hline CHEMBL1971604 & 688759 & 5.5 & 4.7482 & TRN & \\
\hline CHEMBL1368549 & 688759 & 4.95 & 4.9179 & TST & \\
\hline CHEMBL1320721 & 688759 & 4.9 & 4.8723 & TRN & \\
\hline
\end{tabular}




\begin{tabular}{|c|c|c|c|c|c|}
\hline & & \multicolumn{4}{|c|}{ Supplemental Table S2.txt } \\
\hline CHEMBL1508902 & 688759 & 4.8 & 4.7104 & TRN & \\
\hline CHEMBL1449657 & 688759 & 4.45 & 4.745 & TRN & \\
\hline CHEMBL1329994 & 688759 & 4.6 & 5.019 & TST & \\
\hline CHEMBL1470253 & 688759 & 5.0 & 4.8409 & TRN & \\
\hline CHEMBL1610753 & 688759 & 4.9 & 4.7344 & TST & \\
\hline CHEMBL1306943 & 688759 & 4.95 & 4.8022 & TST & \\
\hline CHEMBL1567682 & 688759 & 4.45 & 4.8902 & TRN & \\
\hline CHEMBL1455735 & 688759 & 4.45 & 4.6281 & TRN & \\
\hline CHEMBL261681 & 688759 & 6.05 & \multicolumn{2}{|c|}{5.787000000000001} & TRN \\
\hline CHEMBL1327987 & 688759 & 5.15 & 4.5406 & TRN & \\
\hline CHEMBL1360977 & 688759 & 4.95 & 5.061 & TRN & \\
\hline CHEMBL1537902 & 688759 & 4.45 & 4.6065 & TRN & \\
\hline CHEMBL1392525 & 688759 & 4.85 & 4.6912 & TST & \\
\hline CHEMBL1568277 & 688759 & 5.55 & 5.5177 & TRN & \\
\hline CHEMBL1984190 & 688759 & 5.4 & 5.5868 & TRN & \\
\hline CHEMBL1565154 & 688759 & 4.45 & 4.7605 & TRN & \\
\hline CHEMBL1468546 & 688759 & 5.05 & 4.9164 & TRN & \\
\hline CHEMBL3193985 & 688759 & 4.45 & 4.8578 & TRN & \\
\hline CHEMBL1350449 & 688759 & 4.85 & 4.9373 & TRN & \\
\hline CHEMBL1569274 & 688759 & 4.75 & 4.5994 & TRN & \\
\hline CHEMBL1427674 & 688759 & 5.25 & 5.3037 & TRN & \\
\hline CHEMBL1419186 & 688759 & 4.45 & 4.9322 & TRN & \\
\hline CHEMBL1300000 & 688759 & 4.95 & 4.8673 & TRN & \\
\hline CHEMBL1486647 & 688759 & 4.6 & 4.8148 & TRN & \\
\hline CHEMBL1490664 & 688759 & 4.75 & 4.7405 & TST & \\
\hline CHEMBL1608775 & 688759 & 4.75 & 4.6462 & TST & \\
\hline CHEMBL1322557 & 688759 & 5.25 & 4.926 & TRN & \\
\hline CHEMBL1538574 & 688759 & 6.35 & 4.8695 & TST & \\
\hline CHEMBL1508884 & 688759 & 5.45 & 4.9363 & TRN & \\
\hline CHEMBL1608431 & 688759 & 4.95 & 5.0264 & TRN & \\
\hline CHEMBL1343919 & 688759 & 5.5 & 5.0569 & TST & \\
\hline CHEMBL1405347 & 688759 & 4.45 & 4.7506 & TRN & \\
\hline CHEMBL1970872 & 688759 & 4.95 & 5.3624 & TRN & \\
\hline CHEMBL399759 & 688759 & 4.8 & 4.7874 & TRN & \\
\hline CHEMBL1408767 & 688759 & 4.5 & 4.8841 & TRN & \\
\hline CHEMBL1333919 & 688759 & 4.9 & 4.5679 & TRN & \\
\hline CHEMBL1462643 & 688759 & 4.45 & 4.7107 & TRN & \\
\hline CHEMBL1577994 & 688759 & 4.45 & 4.5548 & TRN & \\
\hline CHEMBL1500981 & 688759 & 4.6 & 4.6224 & TST & \\
\hline CHEMBL1382215 & 688759 & 5.3 & 4.8609 & TRN & \\
\hline CHEMBL1303602 & 688759 & 4.45 & 4.8936 & TST & \\
\hline CHEMBL1601647 & 688759 & 5.35 & 5.3335 & TRN & \\
\hline CHEMBL1391908 & 688759 & 4.65 & 4.6726 & TRN & \\
\hline CHEMBL1585270 & 688759 & 5.55 & 4.7391 & TRN & \\
\hline CHEMBL1561548 & 688759 & 5.2 & 5.2009 & TRN & \\
\hline CHEMBL1546739 & 688759 & 6.05 & 5.6598 & TRN & \\
\hline CHEMBL1565372 & 688759 & 4.65 & 4.8115 & TST & \\
\hline CHEMBL1520801 & 688759 & 5.2 & 4.9588 & TRN & \\
\hline
\end{tabular}




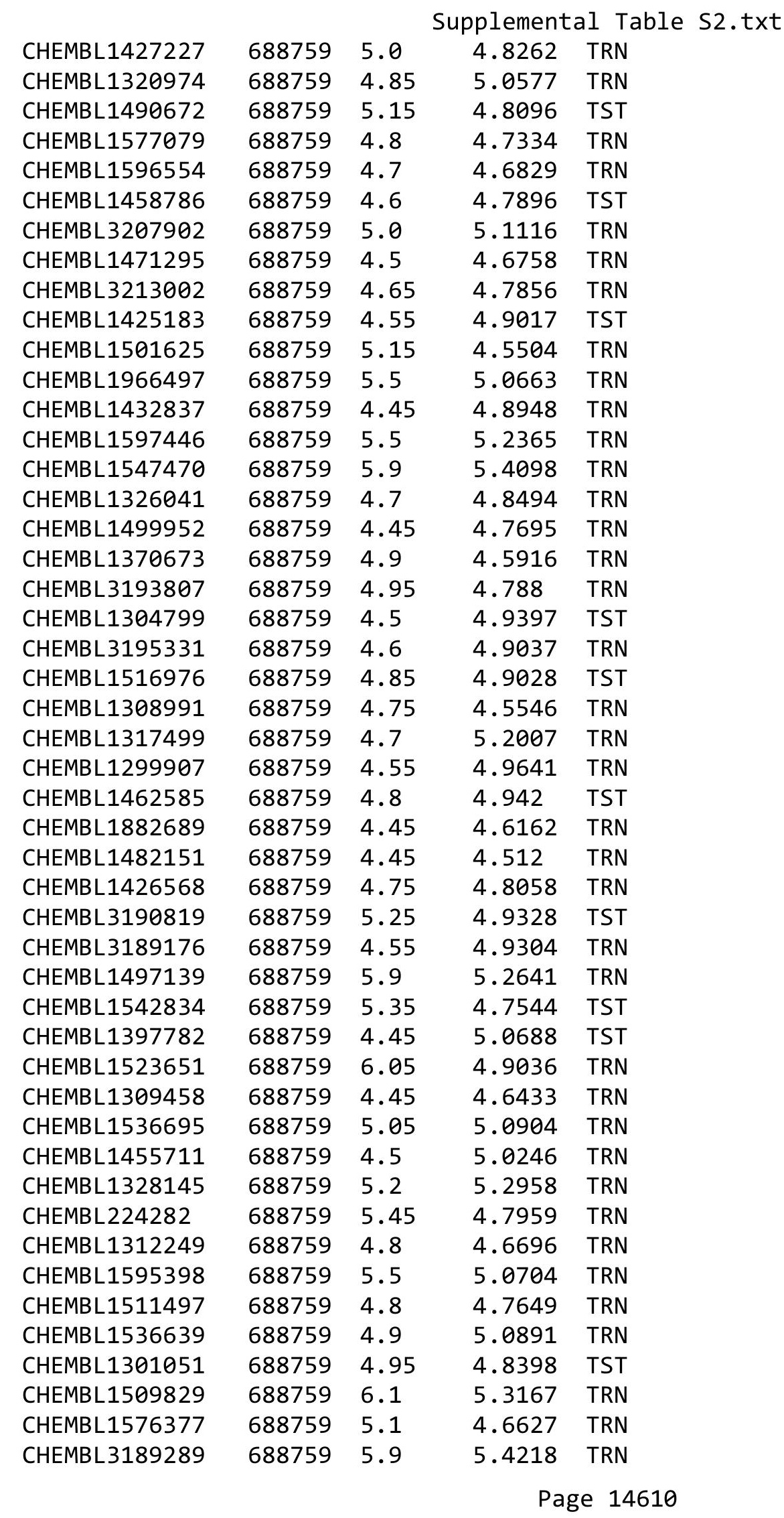




\begin{tabular}{|c|c|c|c|c|}
\hline \multirow[b]{2}{*}{ CHEMBL1461976 } & \multicolumn{4}{|c|}{ Supplemental Table S2.txt } \\
\hline & 688759 & 5.0 & 5.098 & TRN \\
\hline CHEMBL1534106 & 688759 & 5.2 & 4.9635 & TRN \\
\hline CHEMBL3209648 & 688759 & 4.65 & 4.6582 & TRN \\
\hline CHEMBL1559858 & 688759 & 5.75 & 5.5779 & TRN \\
\hline CHEMBL1492261 & 688759 & 5.05 & 4.6246 & TRN \\
\hline CHEMBL1576619 & 688759 & 4.65 & 5.0317 & TST \\
\hline CHEMBL1310497 & 688759 & 5.4 & 4.8726 & TRN \\
\hline CHEMBL1299463 & 688759 & 4.45 & 4.6629 & TRN \\
\hline CHEMBL1420485 & 688759 & 4.95 & 5.0194 & TRN \\
\hline CHEMBL1380946 & 688759 & 4.75 & 4.8796 & TRN \\
\hline CHEMBL1381842 & 688759 & 5.35 & 4.9178 & TRN \\
\hline CHEMBL1299713 & 688759 & 4.45 & 4.6379 & TRN \\
\hline CHEMBL1546607 & 688759 & 4.45 & 5.1138 & TRN \\
\hline CHEMBL1488269 & 688759 & 4.7 & 4.677 & TRN \\
\hline CHEMBL1406683 & 688759 & 5.4 & 4.9126 & TRN \\
\hline CHEMBL1510946 & 688759 & 4.9 & 4.8376 & TRN \\
\hline CHEMBL258767 & 688759 & 6.0 & 5.2726 & TRN \\
\hline CHEMBL1515369 & 688759 & 4.5 & 4.8016 & TRN \\
\hline CHEMBL1519450 & 688759 & 5.2 & 5.5059 & TRN \\
\hline CHEMBL1606390 & 688759 & 4.9 & 4.92 & TST \\
\hline CHEMBL1533919 & 688759 & 5.0 & 5.4121 & TRN \\
\hline CHEMBL1324371 & 688759 & 4.45 & 4.8579 & TRN \\
\hline CHEMBL1519211 & 688759 & 4.95 & 4.9736 & TST \\
\hline CHEMBL1498161 & 688759 & 5.15 & 4.8964 & TRN \\
\hline CHEMBL1321253 & 688759 & 8.3468 & 4.9768 & TRN \\
\hline CHEMBL1558694 & 688759 & 5.5 & 4.7174 & TST \\
\hline CHEMBL1607648 & 688759 & 4.95 & 4.7536 & TRN \\
\hline CHEMBL1421029 & 688759 & 5.25 & 4.5316 & TRN \\
\hline CHEMBL1303970 & 688759 & 4.45 & 4.8477 & TRN \\
\hline CHEMBL1303737 & 688759 & 4.6 & 4.8847 & TST \\
\hline CHEMBL1414655 & 688759 & 5.5 & 4.9363 & TST \\
\hline CHEMBL1446307 & 688759 & 5.5 & 4.8276 & TRN \\
\hline CHEMBL1370022 & 688759 & 5.25 & 5.0426 & TRN \\
\hline CHEMBL1968383 & 688759 & 5.4 & 5.4069 & TRN \\
\hline CHEMBL1566991 & 688759 & 4.45 & 4.7626 & TRN \\
\hline CHEMBL1343565 & 688759 & 4.9 & 4.5645 & TRN \\
\hline CHEMBL3197831 & 688759 & 5.3 & 5.0966 & TRN \\
\hline CHEMBL3207394 & 688759 & 4.75 & 5.2113 & TST \\
\hline CHEMBL1455938 & 688759 & 5.25 & 5.0863 & TRN \\
\hline CHEMBL1308557 & 688759 & 4.95 & 4.6959 & TRN \\
\hline CHEMBL1320665 & 688759 & 4.45 & 4.7938 & TST \\
\hline CHEMBL1367791 & 688759 & 5.35 & 5.2097 & TRN \\
\hline CHEMBL1579575 & 688759 & 4.65 & 4.8452 & TRN \\
\hline CHEMBL1349092 & 688759 & 4.65 & 4.6728 & TRN \\
\hline CHEMBL335265 & 688759 & 5.6 & 4.9564 & TST \\
\hline CHEMBL3198420 & 688759 & 4.65 & 4.6521 & TRN \\
\hline CHEMBL1341938 & 688759 & 4.7 & 4.9497 & TRN \\
\hline CHEMBL1486416 & 688759 & 5.3 & 4.6655 & TST \\
\hline
\end{tabular}




\begin{tabular}{|c|c|c|c|c|}
\hline \multicolumn{5}{|c|}{ Supplemental Table S2.txt } \\
\hline CHEMBL1456632 & 688759 & 5.65 & 5.4573 & TRN \\
\hline CHEMBL1526497 & 688759 & 4.45 & 4.8017 & TRN \\
\hline CHEMBL1418601 & 688759 & 4.45 & 4.8464 & TRN \\
\hline CHEMBL1464731 & 688759 & 5.4 & 5.5319 & TRN \\
\hline CHEMBL1509493 & 688759 & 5.9 & 4.9105 & TRN \\
\hline CHEMBL1405281 & 688759 & 4.65 & 4.5774 & TRN \\
\hline CHEMBL1978031 & 688759 & 4.85 & 4.9581 & TRN \\
\hline CHEMBL1967770 & 688759 & 4.45 & 4.6939 & TRN \\
\hline CHEMBL1594389 & 688759 & 4.45 & 4.7182 & TRN \\
\hline CHEMBL1336249 & 688759 & 4.6 & 4.7557 & TRN \\
\hline CHEMBL1428308 & 688759 & 4.5 & 4.873 & TRN \\
\hline CHEMBL3195406 & 688759 & 4.55 & 4.7262 & TRN \\
\hline CHEMBL 261870 & 688759 & 5.0 & 4.8078 & TRN \\
\hline CHEMBL1349306 & 688759 & 5.2 & 5.2325 & TRN \\
\hline CHEMBL1440160 & 688759 & 5.05 & 4.7287 & TRN \\
\hline CHEMBL1607604 & 688759 & 5.25 & 4.9204 & TRN \\
\hline CHEMBL1381218 & 688759 & 4.8 & 4.8862 & TST \\
\hline CHEMBL1448361 & 688759 & 5.25 & 4.783 & TRN \\
\hline CHEMBL1382961 & 688759 & 4.45 & 4.6982 & TST \\
\hline CHEMBL1587771 & 688759 & 4.8 & 5.3322 & TRN \\
\hline CHEMBL1545656 & 688759 & 5.45 & 4.96 & TRN \\
\hline CHEMBL1405952 & 688759 & 5.7 & 5.5259 & TRN \\
\hline CHEMBL1305458 & 688759 & 5.15 & 4.7825 & TRN \\
\hline CHEMBL1579943 & 688759 & 4.75 & 4.8529 & TRN \\
\hline CHEMBL1604282 & 688759 & 4.65 & 4.7013 & TRN \\
\hline CHEMBL1460833 & 688759 & 4.45 & 4.9509 & TRN \\
\hline CHEMBL1510200 & 688759 & 5.15 & 5.1386 & TRN \\
\hline CHEMBL1572405 & 688759 & 6.2 & 4.8978 & TRN \\
\hline CHEMBL1533249 & 688759 & 4.45 & 4.7314 & TRN \\
\hline CHEMBL1339800 & 688759 & 4.5 & 4.8037 & TRN \\
\hline CHEMBL1434111 & 688759 & 5.0 & 4.6249 & TST \\
\hline CHEMBL1563042 & 688759 & 4.75 & 4.9634 & TST \\
\hline CHEMBL1965132 & 688759 & 5.5 & 5.3554 & TRN \\
\hline CHEMBL1518799 & 688759 & 6.2 & 4.9612 & TRN \\
\hline CHEMBL210730 & 688759 & 5.1 & 5.1572 & TRN \\
\hline CHEMBL1484856 & 688759 & 5.7 & 5.1579 & TRN \\
\hline CHEMBL1605701 & 688759 & 4.7 & 5.0022 & TRN \\
\hline CHEMBL1342482 & 688759 & 4.75 & 4.8826 & TRN \\
\hline CHEMBL1492594 & 688759 & 4.45 & 4.8049 & TRN \\
\hline CHEMBL1547695 & 688759 & 4.9 & 5.2265 & TRN \\
\hline CHEMBL1305285 & 688759 & 5.25 & 5.0269 & TRN \\
\hline CHEMBL1519109 & 688759 & 4.45 & 4.7415 & TST \\
\hline CHEMBL1541697 & 688759 & 4.45 & 4.5664 & TST \\
\hline CHEMBL1459791 & 688759 & 4.85 & 4.8645 & TRN \\
\hline CHEMBL1547058 & 688759 & 5.3 & 4.9174 & TRN \\
\hline CHEMBL1320522 & 688759 & 4.45 & 5.2156 & TST \\
\hline CHEMBL472839 & 688759 & 4.45 & 4.7603 & TRN \\
\hline CHEMBL1472345 & 688759 & 4.45 & 4.7098 & TRN \\
\hline
\end{tabular}




\begin{tabular}{|c|c|c|c|c|}
\hline \multicolumn{5}{|c|}{ Supplemental Table S2.txt } \\
\hline CHEMBL1385689 & 688759 & 4.45 & 4.7421 & TRN \\
\hline CHEMBL1451636 & 688759 & 5.0 & 4.988 & TRN \\
\hline CHEMBL257286 & 688759 & 6.0 & 5.5551 & TRN \\
\hline CHEMBL1443775 & 688759 & 5.9 & 4.94 & TST \\
\hline CHEMBL1997635 & 688759 & 5.0 & 5.053 & TRN \\
\hline CHEMBL1539808 & 688759 & 4.45 & 4.5942 & TRN \\
\hline CHEMBL1576804 & 688759 & 4.65 & 4.5721 & TST \\
\hline CHEMBL1601788 & 688759 & 4.7 & 4.6748 & TRN \\
\hline CHEMBL1602315 & 688759 & 4.65 & 4.7916 & TRN \\
\hline CHEMBL1334230 & 688759 & 4.45 & 4.6816 & TST \\
\hline CHEMBL1448695 & 688759 & 4.45 & 4.8348 & TST \\
\hline CHEMBL1600498 & 688759 & 5.35 & 4.8846 & TST \\
\hline CHEMBL1421240 & 688759 & 4.45 & 4.9078 & TST \\
\hline CHEMBL 3190458 & 688759 & 5.9 & 5.3043 & TRN \\
\hline CHEMBL1415319 & 688759 & 4.65 & 4.8026 & TRN \\
\hline CHEMBL1351081 & 688759 & 5.5 & 5.1397 & TRN \\
\hline CHEMBL3208934 & 688759 & 4.6 & 4.6241 & TRN \\
\hline CHEMBL1303570 & 688759 & 4.55 & 4.9651 & TRN \\
\hline CHEMBL1422805 & 688759 & 4.65 & 4.8363 & TRN \\
\hline CHEMBL1461883 & 688759 & 6.25 & 5.4868 & TRN \\
\hline CHEMBL1459180 & 688759 & 5.3 & 5.0069 & TRN \\
\hline CHEMBL1460249 & 688759 & 4.65 & 4.6977 & TST \\
\hline CHEMBL1327682 & 688759 & 4.45 & 5.1069 & TRN \\
\hline CHEMBL1466463 & 688759 & 4.75 & 4.8263 & TRN \\
\hline CHEMBL1578619 & 688759 & 4.45 & 4.622 & TRN \\
\hline CHEMBL1405749 & 688759 & 4.45 & 4.8038 & TRN \\
\hline CHEMBL1534447 & 688759 & 5.05 & 4.8404 & TRN \\
\hline CHEMBL1378232 & 688759 & 6.2 & 5.8905 & TRN \\
\hline CHEMBL1488229 & 688759 & 5.85 & 5.7129 & TRN \\
\hline CHEMBL56731 & 688759 & 4.45 & 4.7936 & TRN \\
\hline CHEMBL1543792 & 688759 & 5.8 & 4.8862 & TRN \\
\hline CHEMBL1306893 & 688759 & 4.45 & 4.8644 & TRN \\
\hline CHEMBL1483080 & 688759 & 4.9 & 4.8142 & TST \\
\hline CHEMBL3198839 & 688759 & 4.6 & 4.5773 & TRN \\
\hline CHEMBL3199186 & 688759 & 5.45 & 5.3106 & TRN \\
\hline CHEMBL1421868 & 688759 & 4.65 & 4.7388 & TRN \\
\hline CHEMBL 1585578 & 688759 & 4.45 & 4.7582 & TRN \\
\hline CHEMBL1304009 & 688759 & 4.85 & 5.0113 & TRN \\
\hline CHEMBL1559070 & 688759 & 4.45 & 4.8725 & TRN \\
\hline CHEMBL1573068 & 688759 & 4.95 & 4.7741 & TRN \\
\hline CHEMBL1538100 & 688759 & 5.05 & 5.1307 & TRN \\
\hline CHEMBL1598950 & 688759 & 4.75 & 4.7892 & TRN \\
\hline CHEMBL1998030 & 688759 & 5.1 & 4.982 & TRN \\
\hline CHEMBL3192416 & 688759 & 4.45 & 4.7238 & TRN \\
\hline CHEMBL1332191 & 688759 & 4.9 & 4.7688 & TRN \\
\hline CHEMBL1504762 & 688759 & 5.9 & 6.145 & TRN \\
\hline CHEMBL1534964 & 688759 & 7.0501 & 4.8649 & TRN \\
\hline CHEMBL1420739 & 688759 & 4.95 & 4.8667 & TRN \\
\hline
\end{tabular}




\begin{tabular}{|c|c|c|c|c|}
\hline \multicolumn{5}{|c|}{ Supplemental Table S2.txt } \\
\hline CHEMBL1339672 & 688759 & 4.5 & 4.8473 & TRN \\
\hline CHEMBL1358722 & 688759 & 6.0 & 5.9796 & TST \\
\hline CHEMBL1490619 & 688759 & 5.25 & 4.9077 & TST \\
\hline CHEMBL1381295 & 688759 & 4.65 & 4.8517 & TRN \\
\hline CHEMBL3144985 & 688759 & 4.45 & 4.8495 & TRN \\
\hline CHEMBL1451524 & 688759 & 4.45 & 4.7715 & TRN \\
\hline CHEMBL1560476 & 688759 & 4.45 & 4.7624 & TRN \\
\hline CHEMBL1377550 & 688759 & 5.3 & 4.9732 & TST \\
\hline CHEMBL1531137 & 688759 & 7.1002 & 4.9337 & TST \\
\hline CHEMBL3195019 & 688759 & 4.45 & 4.7992 & TRN \\
\hline CHEMBL1543087 & 688759 & 5.8 & 5.519 & TRN \\
\hline CHEMBL3191466 & 688759 & 4.45 & 4.7654 & TRN \\
\hline CHEMBL1375126 & 688759 & 4.8 & 4.9593 & TRN \\
\hline CHEMBL1342361 & 688759 & 4.45 & 4.8347 & TRN \\
\hline CHEMBL1612633 & 688759 & 4.95 & 5.4671 & TRN \\
\hline CHEMBL1325302 & 688759 & 5.5 & 5.824 & TRN \\
\hline CHEMBL1967082 & 688759 & 4.65 & 4.6511 & TST \\
\hline CHEMBL1563746 & 688759 & 4.8 & 4.9641 & TST \\
\hline CHEMBL1422759 & 688759 & 4.45 & 4.7759 & TST \\
\hline CHEMBL1565408 & 688759 & 4.45 & 4.6678 & TRN \\
\hline CHEMBL1494650 & 688759 & 4.95 & 4.9616 & TRN \\
\hline CHEMBL1309291 & 688759 & 5.0 & 5.1799 & TRN \\
\hline CHEMBL1470520 & 688759 & 4.6 & 4.8309 & TRN \\
\hline CHEMBL 393417 & 688759 & 6.0 & 5.7198 & TRN \\
\hline CHEMBL1466554 & 688759 & 4.45 & 4.9942 & TST \\
\hline CHEMBL1523172 & 688759 & 4.75 & 5.3661 & TST \\
\hline CHEMBL3196894 & 688759 & 4.6 & 5.0015 & TRN \\
\hline CHEMBL1569136 & 688759 & 4.8 & 4.8629 & TRN \\
\hline CHEMBL 3191290 & 688759 & 4.45 & 4.9016 & TRN \\
\hline CHEMBL1563940 & 688759 & 4.9 & 4.6775 & TRN \\
\hline CHEMBL1353275 & 688759 & 4.7 & 4.66 & TRN \\
\hline CHEMBL1540772 & 688759 & 5.0 & 4.9057 & TRN \\
\hline CHEMBL1481781 & 688759 & 5.25 & 4.801 & TST \\
\hline CHEMBL1419082 & 688759 & 5.65 & 4.9673 & TRN \\
\hline CHEMBL1585425 & 688759 & 4.7 & 4.9586 & TRN \\
\hline CHEMBL1372889 & 688759 & 6.6 & 5.6476 & TRN \\
\hline CHEMBL3190270 & 688759 & 4.45 & 4.7549 & TST \\
\hline CHEMBL1367528 & 688759 & 4.75 & 4.8679 & TST \\
\hline CHEMBL3189969 & 688759 & 5.1 & 5.0586 & TRN \\
\hline CHEMBL1964702 & 688759 & 5.95 & 5.4463 & TRN \\
\hline CHEMBL1303170 & 688759 & 4.9 & 4.9693 & TRN \\
\hline CHEMBL1539867 & 688759 & 5.45 & 4.9574 & TRN \\
\hline CHEMBL465227 & 688759 & 4.7 & 4.8263 & TRN \\
\hline CHEMBL1445748 & 688759 & 5.3 & 5.5327 & TRN \\
\hline CHEMBL1403306 & 688759 & 5.15 & 4.6067 & TRN \\
\hline CHEMBL1453595 & 688759 & 5.4 & 4.8341 & TRN \\
\hline CHEMBL1400468 & 688759 & 6.0 & 4.7617 & TRN \\
\hline CHEMBL 3190740 & 688759 & 4.45 & 5.6112 & TRN \\
\hline
\end{tabular}




\begin{tabular}{|c|c|c|c|c|}
\hline \multicolumn{5}{|c|}{ Supplemental Table } \\
\hline CHEMBL3190657 & 688759 & 4.95 & 5.3431 & TRN \\
\hline CHEMBL 3197248 & 688759 & 4.45 & 4.5795 & TRN \\
\hline CHEMBL1439239 & 688759 & 4.45 & 4.8207 & TRN \\
\hline CHEMBL1381819 & 688759 & 4.85 & 4.854 & TST \\
\hline CHEMBL1556494 & 688759 & 4.9 & 5.2791 & TST \\
\hline CHEMBL1568335 & 688759 & 4.6 & 4.8059 & TRN \\
\hline CHEMBL3210290 & 688759 & 5.7 & 5.0594 & TRN \\
\hline CHEMBL1476862 & 688759 & 4.7 & 4.6411 & TRN \\
\hline CHEMBL1403781 & 688759 & 4.7 & 4.8267 & TRN \\
\hline CHEMBL1447614 & 688759 & 4.8 & 4.8123 & TRN \\
\hline CHEMBL1409314 & 688759 & 4.5 & 4.8452 & TRN \\
\hline CHEMBL1545761 & 688759 & 4.45 & 4.6605 & TRN \\
\hline CHEMBL 253202 & 688759 & 4.45 & 4.8108 & TRN \\
\hline CHEMBL1451389 & 688759 & 4.75 & 4.9516 & TRN \\
\hline CHEMBL1996714 & 688759 & 5.45 & 5.1736 & TRN \\
\hline CHEMBL1995314 & 688759 & 4.85 & 4.6624 & TST \\
\hline CHEMBL1519158 & 688759 & 4.45 & 4.867 & TRN \\
\hline CHEMBL 3190480 & 688759 & 4.6 & 4.4989 & TST \\
\hline CHEMBL 3392395 & 688759 & 6.5 & 6.0332 & TRN \\
\hline CHEMBL1346904 & 688759 & 4.45 & 4.4351 & TRN \\
\hline CHEMBL1982178 & 688759 & 4.7 & 4.8256 & TRN \\
\hline CHEMBL1313978 & 688759 & 4.55 & 4.6635 & TRN \\
\hline CHEMBL1539522 & 688759 & 5.3 & 4.9157 & TRN \\
\hline CHEMBL1559315 & 688759 & 4.45 & 4.7302 & TRN \\
\hline CHEMBL1594237 & 688759 & 4.45 & 5.1185 & TST \\
\hline CHEMBL1299914 & 688759 & 5.0 & 4.879 & TRN \\
\hline CHEMBL 2006730 & 688759 & 6.05 & 5.8334 & TRN \\
\hline CHEMBL1092115 & 688759 & 4.45 & 4.8626 & TST \\
\hline CHEMBL1302053 & 688759 & 5.55 & 5.3417 & TRN \\
\hline CHEMBL487958 & 688759 & 4.7 & 5.1578 & TRN \\
\hline CHEMBL1970636 & 688759 & 4.65 & 4.8286 & TRN \\
\hline CHEMBL1501554 & 688759 & 4.5 & 4.9452 & TRN \\
\hline CHEMBL1531280 & 688759 & 4.45 & 4.6773 & TRN \\
\hline CHEMBL583378 & 688759 & 6.1 & 4.9562 & TRN \\
\hline CHEMBL3199707 & 688759 & 5.55 & 5.5363 & TRN \\
\hline CHEMBL3196706 & 688759 & 4.55 & 4.5009 & TST \\
\hline CHEMBL1405919 & 688759 & 4.45 & 4.7373 & TST \\
\hline CHEMBL1527192 & 688759 & 5.05 & 5.1323 & TRN \\
\hline CHEMBL1478967 & 688759 & 4.45 & 4.7335 & TST \\
\hline CHEMBL 3208184 & 688759 & 4.75 & 5.0394 & TRN \\
\hline CHEMBL1466483 & 688759 & 4.65 & 4.9576 & TRN \\
\hline CHEMBL1435450 & 688759 & 5.0 & 4.7272 & TRN \\
\hline CHEMBL 3144881 & 688759 & 4.65 & 4.9587 & TRN \\
\hline CHEMBL 3212894 & 688759 & 6.05 & 5.2562 & TRN \\
\hline CHEMBL 3198723 & 688759 & 4.8 & 4.638 & TRN \\
\hline CHEMBL1311910 & 688759 & 4.45 & 4.4584 & TRN \\
\hline CHEMBL1520935 & 688759 & 4.95 & 5.1714 & TRN \\
\hline CHEMBL1481948 & 688759 & 4.45 & 5.3841 & TRN \\
\hline
\end{tabular}




\begin{tabular}{|c|c|c|c|c|}
\hline \multicolumn{5}{|c|}{ Supplemental Table S2.txt } \\
\hline CHEMBL1543742 & 688759 & 5.05 & 5.0808 & TRN \\
\hline CHEMBL1445010 & 688759 & 5.15 & 4.9084 & TRN \\
\hline CHEMBL1400397 & 688759 & 4.45 & 4.6439 & TRN \\
\hline CHEMBL1316236 & 688759 & 4.55 & 4.5885 & TRN \\
\hline CHEMBL1606850 & 688759 & 4.45 & 4.7124 & TRN \\
\hline CHEMBL1581798 & 688759 & 4.65 & 4.6532 & TRN \\
\hline CHEMBL1561191 & 688759 & 5.5 & 4.9615 & TST \\
\hline CHEMBL1469421 & 688759 & 4.8 & 4.8078 & TRN \\
\hline CHEMBL1431452 & 688759 & 4.6 & 4.5775 & TRN \\
\hline CHEMBL1600451 & 688759 & 4.7 & 4.5934 & TRN \\
\hline CHEMBL1351519 & 688759 & 5.25 & 5.0125 & TST \\
\hline CHEMBL1343458 & 688759 & 4.95 & 5.1615 & TRN \\
\hline CHEMBL1525575 & 688759 & 4.45 & 4.8403 & TRN \\
\hline CHEMBL1396572 & 688759 & 4.75 & 4.8793 & TRN \\
\hline CHEMBL1540231 & 688759 & 4.45 & 4.5777 & TST \\
\hline CHEMBL1463950 & 688759 & 5.25 & 4.8514 & TST \\
\hline CHEMBL1399985 & 688759 & 5.35 & 5.2958 & TRN \\
\hline CHEMBL1387474 & 688759 & 5.3 & 4.6406 & TRN \\
\hline CHEMBL1496587 & 688759 & 4.45 & 4.7588 & TRN \\
\hline CHEMBL3194303 & 688759 & 5.85 & 5.5708 & TRN \\
\hline CHEMBL1322689 & 688759 & 4.95 & 5.0315 & TRN \\
\hline CHEMBL1374956 & 688759 & 6.1 & 5.8638 & TRN \\
\hline CHEMBL1486131 & 688759 & 4.45 & 4.8067 & TST \\
\hline CHEMBL14284 & 688759 & 4.75 & 5.5299 & TRN \\
\hline CHEMBL1341913 & 688759 & 4.6 & 5.4209 & TRN \\
\hline CHEMBL1323542 & 688759 & 4.55 & 4.8087 & TST \\
\hline CHEMBL3193234 & 688759 & 4.95 & 5.0931 & TRN \\
\hline CHEMBL1399784 & 688759 & 4.45 & 5.1084 & TST \\
\hline CHEMBL1341522 & 688759 & 6.0 & 4.8439 & TRN \\
\hline CHEMBL1508414 & 688759 & 4.45 & 4.6289 & TST \\
\hline CHEMBL1410177 & 688759 & 5.05 & 5.2067 & TRN \\
\hline CHEMBL1311099 & 688759 & 4.65 & 5.0333 & TST \\
\hline CHEMBL3211069 & 688759 & 5.1 & 4.8395 & TRN \\
\hline CHEMBL1331257 & 688759 & 4.45 & 4.7545 & TRN \\
\hline CHEMBL1462447 & 688759 & 4.45 & 4.8385 & TRN \\
\hline CHEMBL1581013 & 688759 & 4.55 & 4.887 & TRN \\
\hline CHEMBL1503842 & 688759 & 4.45 & 4.9142 & TST \\
\hline CHEMBL1527690 & 688759 & 5.1 & 5.0826 & TRN \\
\hline CHEMBL1606355 & 688759 & 4.45 & 4.8505 & TST \\
\hline CHEMBL1384459 & 688759 & 5.05 & 4.8999 & TRN \\
\hline CHEMBL1383313 & 688759 & 7.3002 & 5.4366 & TST \\
\hline CHEMBL1411672 & 688759 & 4.9 & 4.9832 & TRN \\
\hline CHEMBL1609663 & 688759 & 5.25 & 5.2233 & TRN \\
\hline CHEMBL3194019 & 688759 & 4.45 & 4.6017 & TRN \\
\hline CHEMBL1587786 & 688759 & 5.4 & 5.0447 & TRN \\
\hline CHEMBL581251 & 688759 & 6.0 & 5.2059 & TST \\
\hline CHEMBL1598578 & 688759 & 4.75 & 4.7535 & TRN \\
\hline CHEMBL1387948 & 688759 & 4.45 & 4.8144 & TRN \\
\hline
\end{tabular}




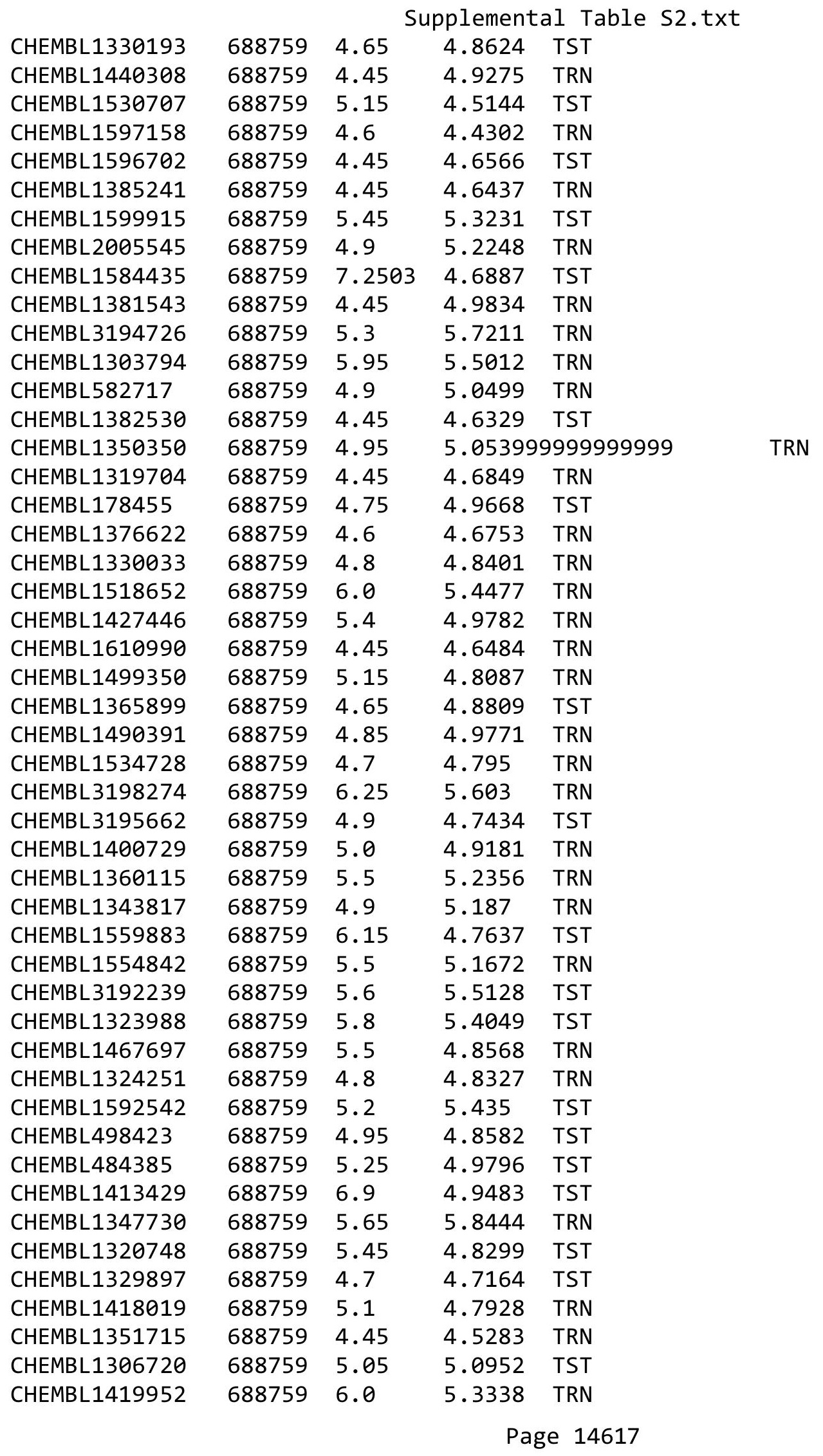




\begin{tabular}{|c|c|c|c|c|}
\hline \multicolumn{5}{|c|}{ Supplemental Table s2.txt } \\
\hline CHEMBL1440555 & 688759 & 4.45 & 4.6761 & TRN \\
\hline CHEMBL1574751 & 688759 & 4.8 & 4.965 & TRN \\
\hline CHEMBL3190622 & 688759 & 5.1 & 5.1656 & TRN \\
\hline CHEMBL1544377 & 688759 & 4.45 & 5.0894 & TRN \\
\hline CHEMBL1473922 & 688759 & 5.25 & 5.2929 & TRN \\
\hline CHEMBL1346705 & 688759 & 4.45 & 4.8848 & TRN \\
\hline CHEMBL1378636 & 688759 & 5.65 & 5.4008 & TRN \\
\hline CHEMBL3190201 & 688759 & 4.9 & 4.6504 & TST \\
\hline CHEMBL3210250 & 688759 & 6.15 & 5.8181 & TRN \\
\hline CHEMBL1405708 & 688759 & 4.45 & 4.8013 & TRN \\
\hline CHEMBL1379263 & 688759 & 4.9 & 4.9196 & TRN \\
\hline CHEMBL1567402 & 688759 & 4.65 & 4.454 & TST \\
\hline CHEMBL3189413 & 688759 & 4.45 & 4.728 & TRN \\
\hline CHEMBL1595480 & 688759 & 4.65 & 4.7576 & TST \\
\hline CHEMBL1461124 & 688759 & 4.75 & 4.9819 & TST \\
\hline CHEMBL1980308 & 688759 & 4.8 & 4.7956 & TRN \\
\hline CHEMBL1439751 & 688759 & 6.0 & 4.9456 & TRN \\
\hline CHEMBL3198909 & 688759 & 4.45 & 5.1022 & TST \\
\hline CHEMBL 259784 & 688759 & 6.7501 & 6.0951 & TRN \\
\hline CHEMBL1312418 & 688759 & 4.6 & 4.6996 & TRN \\
\hline CHEMBL1392608 & 688759 & 4.5 & 4.9103 & TST \\
\hline CHEMBL1503325 & 688759 & 5.05 & 5.5431 & TST \\
\hline CHEMBL1379048 & 688759 & 4.65 & 4.8019 & TST \\
\hline CHEMBL1466261 & 688759 & 4.45 & 4.8154 & TRN \\
\hline CHEMBL1510271 & 688759 & 4.7 & 4.4917 & TRN \\
\hline CHEMBL1498707 & 688759 & 4.45 & 4.6572 & TRN \\
\hline CHEMBL1425889 & 688759 & 5.15 & 5.3475 & TRN \\
\hline CHEMBL 3191242 & 688759 & 4.8 & 4.8909 & TRN \\
\hline CHEMBL1524495 & 688759 & 4.95 & 4.7907 & TRN \\
\hline CHEMBL1540761 & 688759 & 5.45 & 5.3733 & TST \\
\hline CHEMBL1530506 & 688759 & 4.45 & 4.9772 & TRN \\
\hline CHEMBL1332903 & 688759 & 4.45 & 4.9549 & TRN \\
\hline CHEMBL1539841 & 688759 & 5.05 & 5.0355 & TRN \\
\hline CHEMBL1499455 & 688759 & 4.6 & 4.7963 & TRN \\
\hline CHEMBL1373521 & 688759 & 4.5 & 4.5809 & TRN \\
\hline CHEMBL1429929 & 688759 & 4.8 & 5.0207 & TRN \\
\hline CHEMBL1449376 & 688759 & 5.15 & 5.1751 & TRN \\
\hline CHEMBL1383584 & 688759 & 4.75 & 4.7528 & TRN \\
\hline CHEMBL1609070 & 688759 & 4.45 & 4.8631 & TRN \\
\hline CHEMBL 1447537 & 688759 & 5.6 & 5.5199 & TRN \\
\hline CHEMBL1612872 & 688759 & 4.45 & 5.0884 & TRN \\
\hline CHEMBL1304638 & 688759 & 4.95 & 4.7094 & TRN \\
\hline CHEMBL1327205 & 688759 & 5.05 & 4.982 & TRN \\
\hline CHEMBL1441888 & 688759 & 5.35 & 4.9189 & TRN \\
\hline CHEMBL3214155 & 688759 & 4.45 & 4.7505 & TRN \\
\hline CHEMBL1557582 & 688759 & 5.4 & 5.79700 & 0000000001 \\
\hline CHEMBL1568105 & 688759 & 4.9 & 4.8793 & TRN \\
\hline CHEMBL1387470 & 688759 & 4.8 & 5.1118 & TST \\
\hline
\end{tabular}

TRN 


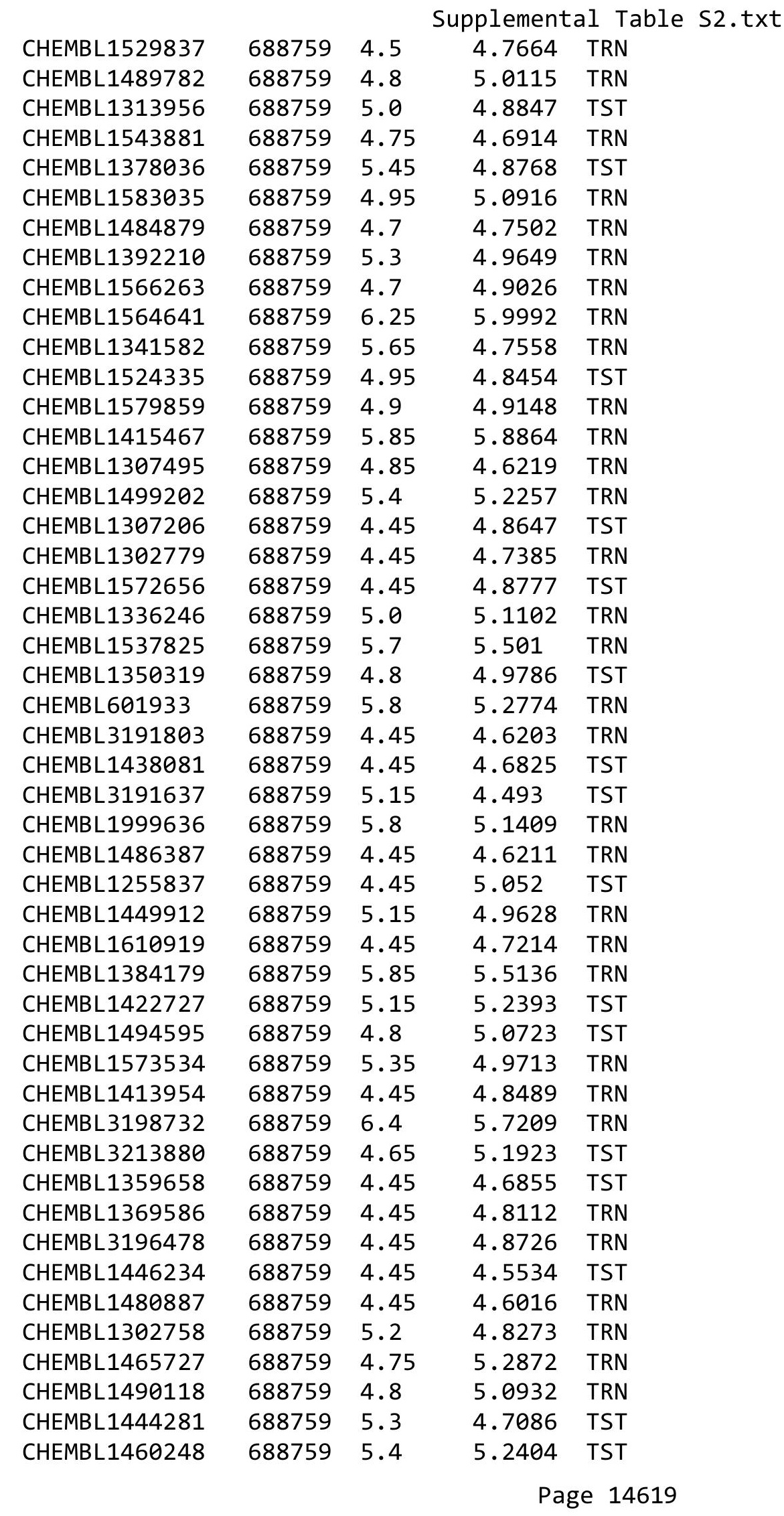




\begin{tabular}{|c|c|c|c|c|c|}
\hline \multirow[b]{2}{*}{ CHEMBL3191593 } & \multirow[b]{2}{*}{688759} & \multicolumn{4}{|c|}{ Supplemental Table S2.txt } \\
\hline & & 4.5 & 4.93199 & 99999999995 & TST \\
\hline CHEMBL3193377 & 688759 & 4.85 & 4.9738 & TRN & \\
\hline CHEMBL1324490 & 688759 & 5.55 & 5.80399 & 9999999999 & TRN \\
\hline CHEMBL1483208 & 688759 & 4.45 & 5.2134 & TRN & \\
\hline CHEMBL1431577 & 688759 & 5.0 & 5.1857 & TRN & \\
\hline CHEMBL1504736 & 688759 & 4.5 & 4.7477 & TST & \\
\hline CHEMBL1978819 & 688759 & 4.65 & 4.8422 & TRN & \\
\hline CHEMBL1346768 & 688759 & 4.75 & 4.931 & TRN & \\
\hline CHEMBL1393605 & 688759 & 4.7 & 4.8965 & TST & \\
\hline CHEMBL3195619 & 688759 & 5.4 & 5.2688 & TRN & \\
\hline CHEMBL1407169 & 688759 & 4.5 & 4.6909 & TST & \\
\hline CHEMBL1485335 & 688759 & 4.45 & 4.8264 & TST & \\
\hline CHEMBL1600771 & 688759 & 4.45 & 4.7591 & TRN & \\
\hline CHEMBL1350192 & 688759 & 4.45 & 5.0649 & TRN & \\
\hline CHEMBL530291 & 688759 & 4.95 & 5.1645 & TRN & \\
\hline CHEMBL1557234 & 688759 & 5.4 & 4.9583 & TST & \\
\hline CHEMBL1344611 & 688759 & 4.45 & 4.8947 & TRN & \\
\hline CHEMBL1510089 & 688759 & 4.45 & 4.705 & TRN & \\
\hline CHEMBL1550241 & 688759 & 4.45 & 4.5476 & TRN & \\
\hline CHEMBL3209859 & 688759 & 4.65 & 4.623 & TRN & \\
\hline CHEMBL1337148 & 688759 & 4.65 & 4.7488 & TST & \\
\hline CHEMBL1501466 & 688759 & 5.3 & 4.8329 & TRN & \\
\hline CHEMBL3207521 & 688759 & 5.0 & 5.0179 & TRN & \\
\hline CHEMBL1607098 & 688759 & 4.45 & 5.0353 & TST & \\
\hline CHEMBL1322624 & 688759 & 4.85 & 4.7824 & TRN & \\
\hline CHEMBL1391094 & 688759 & 5.1 & 5.0526 & TRN & \\
\hline CHEMBL1369194 & 688759 & 4.45 & 4.6212 & TRN & \\
\hline CHEMBL1350946 & 688759 & 4.9 & 4.8988 & TRN & \\
\hline CHEMBL1971634 & 688759 & 5.0 & 4.974 & TRN & \\
\hline CHEMBL1389496 & 688759 & 4.45 & 4.5693 & TST & \\
\hline CHEMBL1431448 & 688759 & 4.65 & 4.5433 & TST & \\
\hline CHEMBL1377707 & 688759 & 4.45 & 4.865 & TST & \\
\hline CHEMBL1324243 & 688759 & 4.75 & 4.8571 & TST & \\
\hline CHEMBL1484558 & 688759 & 4.45 & 4.723 & TST & \\
\hline CHEMBL1458858 & 688759 & 4.45 & 4.6903 & TRN & \\
\hline CHEMBL1446558 & 688759 & 4.45 & 4.8251 & TST & \\
\hline CHEMBL1477599 & 688759 & 4.65 & 4.4717 & TRN & \\
\hline CHEMBL1536767 & 688759 & 4.45 & 4.652 & TRN & \\
\hline CHEMBL1371231 & 688759 & 4.45 & 4.5844 & TRN & \\
\hline CHEMBL1509338 & 688759 & 5.75 & 4.8878 & TST & \\
\hline CHEMBL3192113 & 688759 & 4.9 & 4.9147 & TRN & \\
\hline CHEMBL1456538 & 688759 & 4.45 & 4.8453 & TST & \\
\hline CHEMBL1448387 & 688759 & 4.9 & 5.3744 & TST & \\
\hline CHEMBL 1587780 & 688759 & 6.1 & 5.1523 & TRN & \\
\hline CHEMBL1556628 & 688759 & 4.7 & 4.6501 & TRN & \\
\hline CHEMBL1369553 & 688759 & 5.25 & 4.8661 & TRN & \\
\hline CHEMBL1571572 & 688759 & 4.5 & 4.9274 & TRN & \\
\hline CHEMBL1352117 & 688759 & 4.45 & 4.5103 & TRN & \\
\hline
\end{tabular}




\begin{tabular}{|c|c|c|c|c|c|}
\hline \multicolumn{6}{|c|}{ Supplemental Table s2.txt } \\
\hline CHEMBL1969625 & 688759 & 6.45 & 5.0601 & TRN & \\
\hline CHEMBL 3209143 & 688759 & 4.45 & 4.9416 & TRN & \\
\hline CHEMBL1305563 & 688759 & 4.6 & 4.6123 & TRN & \\
\hline CHEMBL1326373 & 688759 & 4.65 & 4.7299 & TST & \\
\hline CHEMBL3199099 & 688759 & 5.1 & 4.9346 & TRN & \\
\hline CHEMBL1585663 & 688759 & 4.65 & 4.8359 & TST & \\
\hline CHEMBL1569554 & 688759 & 4.45 & 4.7497 & TRN & \\
\hline CHEMBL1454081 & 688759 & 4.55 & 4.7159 & TRN & \\
\hline CHEMBL1390421 & 688759 & 5.5 & 4.9582 & TRN & \\
\hline CHEMBL1596496 & 688759 & 5.0 & 4.6908 & TST & \\
\hline CHEMBL1606956 & 688759 & 4.55 & 4.9172 & TRN & \\
\hline CHEMBL1390775 & 688759 & 4.45 & 5.0007 & TRN & \\
\hline CHEMBL1525631 & 688759 & 5.7 & 4.6931 & TRN & \\
\hline CHEMBL 3198403 & 688759 & 4.95 & 5.0159 & TST & \\
\hline CHEMBL3192415 & 688759 & 5.7 & 5.0036 & TRN & \\
\hline CHEMBL1575684 & 688759 & 5.4 & 4.6669 & TRN & \\
\hline CHEMBL1489415 & 688759 & 4.45 & 4.8878 & TRN & \\
\hline CHEMBL1569257 & 688759 & 4.95 & 4.7066 & TRN & \\
\hline CHEMBL1472743 & 688759 & 4.6 & 4.8108 & TST & \\
\hline CHEMBL1458038 & 688759 & 4.45 & 4.8378 & TRN & \\
\hline CHEMBL1566487 & 688759 & 5.15 & 4.8295 & TRN & \\
\hline CHEMBL1375116 & 688759 & 4.45 & 4.8856 & TRN & \\
\hline CHEMBL3207446 & 688759 & 4.85 & 4.5862 & TRN & \\
\hline CHEMBL 3212190 & 688759 & 5.2 & 4.7686 & TRN & \\
\hline CHEMBL1598721 & 688759 & 4.65 & 4.8251 & TST & \\
\hline CHEMBL1447300 & 688759 & 4.45 & 4.6616 & TRN & \\
\hline CHEMBL1569724 & 688759 & 5.25 & 4.8147 & TRN & \\
\hline CHEMBL1388508 & 688759 & 6.5 & 5.1363 & TRN & \\
\hline CHEMBL1522067 & 688759 & 4.7 & 4.7585 & TRN & \\
\hline CHEMBL1529295 & 688759 & 4.45 & 4.899 & TRN & \\
\hline CHEMBL1490293 & 688759 & 7.1002 & 5.8325 & TRN & \\
\hline CHEMBL1376328 & 688759 & 4.45 & 4.7254 & TRN & \\
\hline CHEMBL1318989 & 688759 & 5.6 & 5.36600 & 00000000005 & TRN \\
\hline CHEMBL1450636 & 688759 & 5.45 & 5.08 & TRN & \\
\hline CHEMBL1531686 & 688759 & 5.15 & 4.9127 & TRN & \\
\hline CHEMBL1585661 & 688759 & 4.45 & 5.1211 & TRN & \\
\hline CHEMBL 2001105 & 688759 & 4.65 & 4.7731 & TRN & \\
\hline CHEMBL1339327 & 688759 & 4.5 & 4.8379 & TRN & \\
\hline CHEMBL1312170 & 688759 & 4.95 & 4.8679 & TST & \\
\hline CHEMBL1489824 & 688759 & 4.45 & 5.0972 & TRN & \\
\hline CHEMBL1350066 & 688759 & 4.45 & 4.6287 & TRN & \\
\hline CHEMBL1556214 & 688759 & 4.9 & 5.3813 & TRN & \\
\hline CHEMBL1468030 & 688759 & 4.45 & 4.8944 & TRN & \\
\hline CHEMBL1319643 & 688759 & 4.9 & 4.9422 & TST & \\
\hline CHEMBL1502639 & 688759 & 4.45 & 4.7716 & TRN & \\
\hline CHEMBL1539894 & 688759 & 4.45 & 4.9321 & TRN & \\
\hline CHEMBL1502199 & 688759 & 4.95 & 5.0758 & TRN & \\
\hline CHEMBL1379416 & 688759 & 5.15 & 5.3004 & TRN & \\
\hline
\end{tabular}




\begin{tabular}{|c|c|c|c|c|c|}
\hline \multicolumn{6}{|c|}{ Supplemental Table S2.txt } \\
\hline CHEMBL3194409 & 688759 & 5.25 & 4.7127 & TST & \\
\hline CHEMBL1439012 & 688759 & 5.25 & 4.855 & TRN & \\
\hline CHEMBL1986986 & 688759 & 5.3 & 5.2741 & TRN & \\
\hline CHEMBL 3192035 & 688759 & 6.0 & 5.0283 & TRN & \\
\hline CHEMBL1562360 & 688759 & 4.8 & 5.2692 & TRN & \\
\hline CHEMBL1451684 & 688759 & 6.0 & 5.6471 & TRN & \\
\hline CHEMBL1320386 & 688759 & 5.55 & 5.5412 & TRN & \\
\hline CHEMBL1456278 & 688759 & 4.45 & 4.9363 & TRN & \\
\hline CHEMBL1537522 & 688759 & 5.45 & 4.9939 & TRN & \\
\hline CHEMBL1605599 & 688759 & 4.6 & 4.7597 & TRN & \\
\hline CHEMBL1307120 & 688759 & 5.2 & 5.3249 & TRN & \\
\hline CHEMBL1462258 & 688759 & 4.55 & 4.8133 & TRN & \\
\hline CHEMBL1453722 & 688759 & 5.85 & 5.3136 & TRN & \\
\hline CHEMBL3195906 & 688759 & 5.75 & 5.3116 & TRN & \\
\hline CHEMBL1300553 & 688759 & 4.95 & 5.0647 & TRN & \\
\hline CHEMBL1389565 & 688759 & 4.45 & 4.7817 & TST & \\
\hline CHEMBL1510082 & 688759 & 4.45 & 4.5055 & TRN & \\
\hline CHEMBL1389757 & 688759 & 4.65 & 4.7007 & TRN & \\
\hline CHEMBL 3195837 & 688759 & 4.75 & 4.8759 & TRN & \\
\hline CHEMBL 3191788 & 688759 & 4.45 & 4.7459 & TRN & \\
\hline CHEMBL1342322 & 688759 & 4.9 & 4.747 & TRN & \\
\hline CHEMBL1345481 & 688759 & 5.35 & 4.5122 & TRN & \\
\hline CHEMBL1408752 & 688759 & 5.25 & 5.2284 & TRN & \\
\hline CHEMBL1531308 & 688759 & 5.5 & 5.1836 & TST & \\
\hline CHEMBL1308464 & 688759 & 4.45 & 4.6365 & TRN & \\
\hline CHEMBL1403638 & 688759 & 4.45 & 5.3026 & TRN & \\
\hline CHEMBL3210754 & 688759 & 5.05 & 4.8559 & TRN & \\
\hline CHEMBL1993662 & 688759 & 4.9 & 5.0998 & TRN & \\
\hline CHEMBL1574604 & 688759 & 4.45 & 5.3899 & TRN & \\
\hline CHEMBL1442876 & 688759 & 4.95 & 5.229 & TST & \\
\hline CHEMBL1580144 & 688759 & 6.15 & 5.6375 & TRN & \\
\hline CHEMBL1491174 & 688759 & 5.0 & 5.2204 & TRN & \\
\hline CHEMBL1486184 & 688759 & 4.8 & 4.5741 & TRN & \\
\hline CHEMBL1323985 & 688759 & 4.95 & 5.0738 & TRN & \\
\hline CHEMBL1527284 & 688759 & 6.15 & 4.7946 & TRN & \\
\hline CHEMBL1534129 & 688759 & 4.5 & 5.032 & TRN & \\
\hline CHEMBL1545854 & 688759 & 4.65 & 4.7631 & TRN & \\
\hline CHEMBL1371186 & 688759 & 4.45 & 4.7611 & TST & \\
\hline CHEMBL1440409 & 688759 & 5.75 & 4.7944 & TST & \\
\hline CHEMBL1378107 & 688759 & 5.25 & 4.9056 & TRN & \\
\hline CHEMBL 3210930 & 688759 & 5.3 & 5.13700 & 00000000005 & TRN \\
\hline CHEMBL3189299 & 688759 & 4.7 & 4.7537 & TRN & \\
\hline CHEMBL1310095 & 688759 & 4.65 & 4.9403 & TST & \\
\hline CHEMBL1497244 & 688759 & 5.4 & 4.9264 & TRN & \\
\hline CHEMBL1521425 & 688759 & 4.7 & 4.757 & TRN & \\
\hline CHEMBL1531572 & 688759 & 4.45 & 4.5061 & TRN & \\
\hline CHEMBL1495231 & 688759 & 4.45 & 4.7345 & TRN & \\
\hline CHEMBL1313375 & 688759 & 4.65 & 4.8127 & TRN & \\
\hline
\end{tabular}




\begin{tabular}{|c|c|c|c|c|c|}
\hline & & \multicolumn{4}{|c|}{ Supplemental Table S2.txt } \\
\hline CHEMBL1313038 & 688759 & 5.4 & 5.4204 & TRN & \\
\hline CHEMBL1596376 & 688759 & 4.45 & 4.5887 & TRN & \\
\hline CHEMBL1371528 & 688759 & 5.0 & 4.6452 & TRN & \\
\hline CHEMBL 3198701 & 688759 & 5.0 & 5.1923 & TRN & \\
\hline CHEMBL1429966 & 688759 & 5.45 & 5.401 & TRN & \\
\hline CHEMBL66854 & 688759 & 4.45 & 4.5288 & TST & \\
\hline CHEMBL1310306 & 688759 & 4.7 & 4.6856 & TST & \\
\hline CHEMBL1385645 & 688759 & 4.45 & 5.0351 & TRN & \\
\hline CHEMBL1598579 & 688759 & 5.0 & 5.2555 & TRN & \\
\hline CHEMBL368700 & 688759 & 4.6 & 4.9056 & TST & \\
\hline CHEMBL1613024 & 688759 & 4.95 & 5.1544 & TRN & \\
\hline CHEMBL1539502 & 688759 & 5.05 & 5.3653 & TRN & \\
\hline CHEMBL1387665 & 688759 & 4.45 & 4.7698 & TRN & \\
\hline CHEMBL1519457 & 688759 & 4.6 & 5.0175 & TRN & \\
\hline CHEMBL1457990 & 688759 & 4.75 & 4.8778 & TST & \\
\hline CHEMBL1338422 & 688759 & 4.55 & 4.8977 & TRN & \\
\hline CHEMBL1544460 & 688759 & 4.95 & 4.8567 & TRN & \\
\hline CHEMBL1480282 & 688759 & 4.45 & 4.952 & TRN & \\
\hline CHEMBL1321702 & 688759 & 5.15 & 4.8985 & TRN & \\
\hline CHEMBL1986444 & 688759 & 4.45 & 4.917 & TRN & \\
\hline CHEMBL1432276 & 688759 & 5.3 & 5.1754 & TST & \\
\hline CHEMBL1456621 & 688759 & 4.7 & 5.1066 & TRN & \\
\hline CHEMBL1388419 & 688759 & 5.0 & 4.9935 & TST & \\
\hline CHEMBL1544747 & 688759 & 4.65 & 4.7185 & TRN & \\
\hline CHEMBL1594162 & 688759 & 4.65 & 4.5963 & TRN & \\
\hline CHEMBL1401422 & 688759 & 4.75 & 4.7427 & TRN & \\
\hline CHEMBL1568589 & 688759 & 4.45 & 4.9758 & TST & \\
\hline CHEMBL1562851 & 688759 & 4.6 & 4.8478 & TRN & \\
\hline CHEMBL171620 & 688759 & 4.45 & 4.5505 & TST & \\
\hline CHEMBL1569156 & 688759 & 4.95 & 4.8889 & TRN & \\
\hline CHEMBL1445710 & 688759 & 4.85 & 4.8072 & TRN & \\
\hline CHEMBL1304750 & 688759 & 4.45 & 4.6135 & TRN & \\
\hline CHEMBL1425038 & 688759 & 5.1 & 4.8493 & TST & \\
\hline CHEMBL1371705 & 688759 & 4.45 & 4.5687 & TST & \\
\hline CHEMBL3213027 & 688759 & 4.45 & 4.7886 & TRN & \\
\hline CHEMBL589694 & 688759 & 4.8 & 4.7372 & TRN & \\
\hline CHEMBL3190418 & 688759 & 4.75 & 4.7597 & TRN & \\
\hline CHEMBL1388595 & 688759 & 4.7 & 4.6238 & TRN & \\
\hline CHEMBL1398887 & 688759 & 4.7 & 4.8237 & TRN & \\
\hline CHEMBL1549574 & 688759 & 5.05 & 4.8873 & TST & \\
\hline CHEMBL1402174 & 688759 & 5.3 & 5.07100 & 0000000001 & TRN \\
\hline CHEMBL1582376 & 688759 & 4.45 & 4.8861 & TST & \\
\hline CHEMBL1508850 & 688759 & 5.25 & 5.0034 & TRN & \\
\hline CHEMBL1432479 & 688759 & 5.45 & 4.8327 & TST & \\
\hline CHEMBL3192491 & 688759 & 4.45 & 4.7557 & TRN & \\
\hline CHEMBL3192850 & 688759 & 4.75 & 4.7571 & TRN & \\
\hline CHEMBL1437992 & 688759 & 5.25 & 4.8934 & TRN & \\
\hline CHEMBL1394008 & 688759 & 4.45 & 4.80399 & 9999999999 & TRN \\
\hline & & & & 14623 & \\
\hline
\end{tabular}




\begin{tabular}{|c|c|c|c|c|c|}
\hline \multicolumn{6}{|c|}{ Supplemental Table s2.txt } \\
\hline CHEMBL1540415 & 688759 & 5.05 & 5.0016 & TRN & \\
\hline CHEMBL1417886 & 688759 & 4.45 & 4.7938 & TRN & \\
\hline CHEMBL1549857 & 688759 & 4.65 & 4.8764 & TST & \\
\hline CHEMBL1541840 & 688759 & 5.1 & 4.794 & TRN & \\
\hline CHEMBL1438357 & 688759 & 4.8 & 4.9462 & TST & \\
\hline CHEMBL1330765 & 688759 & 4.45 & 4.7244 & TRN & \\
\hline CHEMBL1391556 & 688759 & 5.2 & 5.1158 & TRN & \\
\hline CHEMBL1556792 & 688759 & 4.5 & 4.7177 & TRN & \\
\hline CHEMBL1500291 & 688759 & 4.85 & 4.8659 & TST & \\
\hline CHEMBL1342798 & 688759 & 4.45 & 4.8262 & TRN & \\
\hline CHEMBL1409742 & 688759 & 5.9 & 4.9406 & TRN & \\
\hline CHEMBL1399408 & 688759 & 5.1 & 4.9667 & TST & \\
\hline CHEMBL1375158 & 688759 & 4.95 & 4.6517 & TRN & \\
\hline CHEMBL3195716 & 688759 & 6.5 & 6.0655 & TRN & \\
\hline CHEMBL1535261 & 688759 & 4.55 & 4.8279 & TST & \\
\hline CHEMBL1418911 & 688759 & 4.8 & 4.9399 & TRN & \\
\hline CHEMBL1563110 & 688759 & 6.3 & 4.9917 & TST & \\
\hline CHEMBL1506684 & 688759 & 4.85 & 4.6182 & TRN & \\
\hline CHEMBL1606462 & 688759 & 5.2 & 4.8089 & TRN & \\
\hline CHEMBL1324105 & 688759 & 4.7 & 4.6643 & TST & \\
\hline CHEMBL1423147 & 688759 & 4.65 & 4.9771 & TRN & \\
\hline CHEMBL1534248 & 688759 & 4.6 & 4.8506 & TST & \\
\hline CHEMBL1576545 & 688759 & 4.45 & 5.1995 & TRN & \\
\hline CHEMBL1502018 & 688759 & 5.05 & 5.0299 & TST & \\
\hline CHEMBL1468162 & 688759 & 4.95 & 4.9911 & TRN & \\
\hline CHEMBL1594465 & 688759 & 4.45 & 4.522 & TRN & \\
\hline CHEMBL1307181 & 688759 & 6.1 & 5.54299 & 9999999999 & TST \\
\hline CHEMBL3196750 & 688759 & 4.45 & 4.879 & TST & \\
\hline CHEMBL3392484 & 688759 & 6.2 & 5.335 & TRN & \\
\hline CHEMBL1540222 & 688759 & 5.45 & 4.9441 & TRN & \\
\hline CHEMBL1421328 & 688759 & 4.95 & 4.7991 & TST & \\
\hline CHEMBL1563861 & 688759 & 5.15 & 4.9863 & TRN & \\
\hline CHEMBL1313672 & 688759 & 4.8 & 4.7588 & TRN & \\
\hline CHEMBL1495517 & 688759 & 4.7 & 4.7384 & TRN & \\
\hline CHEMBL1439269 & 688759 & 4.45 & 4.65600 & 0000000001 & TST \\
\hline CHEMBL1579258 & 688759 & 5.2 & 5.4473 & TRN & \\
\hline CHEMBL1465753 & 688759 & 4.6 & 4.8428 & TRN & \\
\hline CHEMBL1610733 & 688759 & 4.45 & 4.7276 & TRN & \\
\hline CHEMBL1485549 & 688759 & 5.95 & 5.1395 & TRN & \\
\hline CHEMBL1520566 & 688759 & 6.05 & 4.9339 & TST & \\
\hline CHEMBL1995823 & 688759 & 6.1 & 5.6073 & TRN & \\
\hline CHEMBL1432162 & 688759 & 5.35 & 4.9022 & TST & \\
\hline CHEMBL1305639 & 688759 & 5.0 & 4.9024 & TST & \\
\hline CHEMBL1992582 & 688759 & 5.3 & 4.9484 & TRN & \\
\hline CHEMBL3190668 & 688759 & 4.45 & 5.2417 & TRN & \\
\hline CHEMBL1494985 & 688759 & 4.9 & 4.7735 & TRN & \\
\hline CHEMBL578929 & 688759 & 6.35 & 5.9046 & TST & \\
\hline CHEMBL1448771 & 688759 & 4.65 & 4.8956 & TST & \\
\hline
\end{tabular}




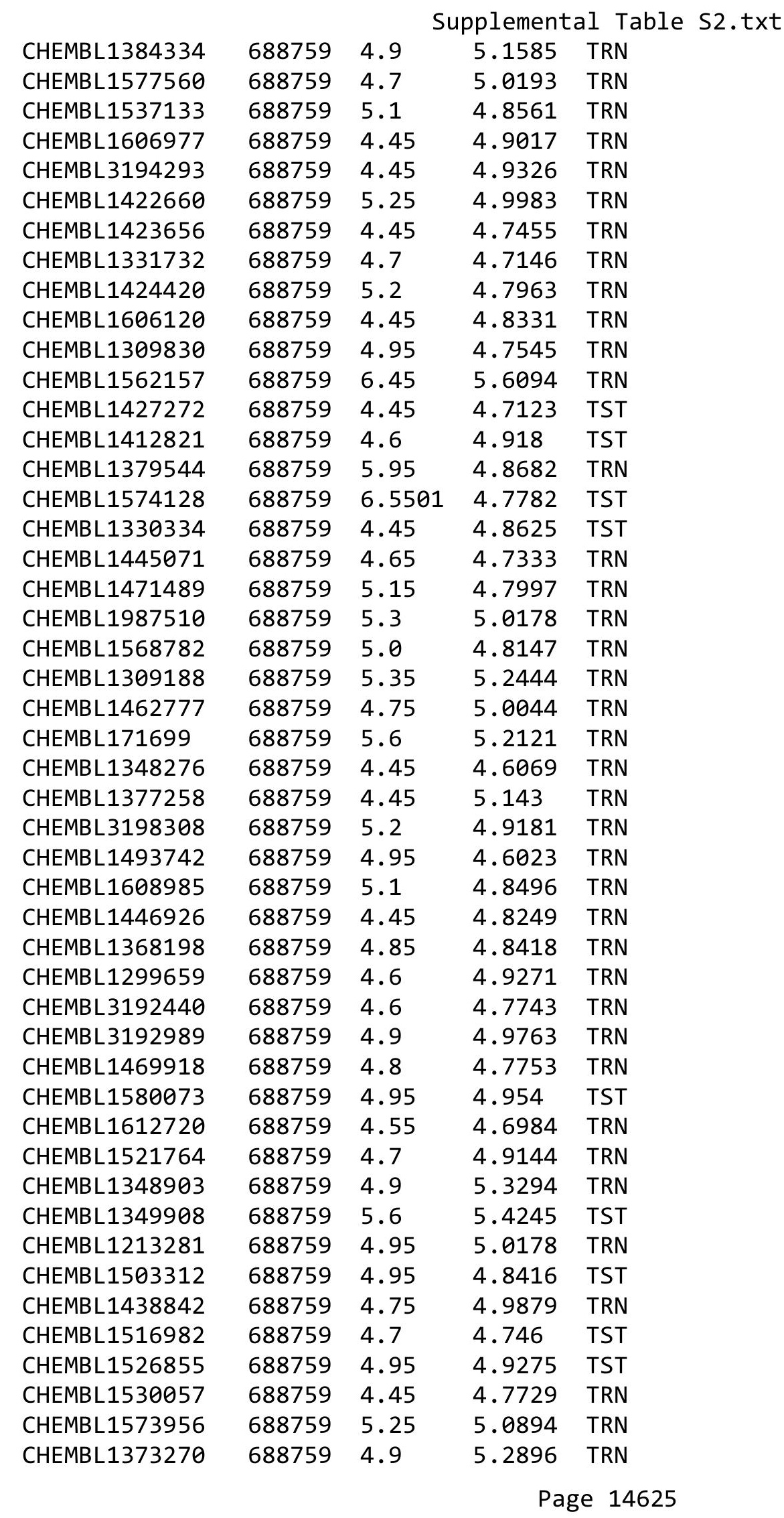




\begin{tabular}{|c|c|c|c|c|}
\hline \multicolumn{5}{|c|}{ Supplemental Table S2.txt } \\
\hline CHEMBL1424045 & 688759 & 5.55 & 4.7562 & TRN \\
\hline CHEMBL1309290 & 688759 & 4.45 & 4.8748 & TST \\
\hline CHEMBL3189682 & 688759 & 6.05 & 5.2798 & TRN \\
\hline CHEMBL3210917 & 688759 & 4.7 & 4.7861 & TRN \\
\hline CHEMBL501358 & 688759 & 4.85 & 4.9351 & TST \\
\hline CHEMBL483956 & 688759 & 4.65 & 5.1407 & TRN \\
\hline CHEMBL1410356 & 688759 & 5.4 & 5.3405 & TRN \\
\hline CHEMBL 3208035 & 688759 & 6.2 & 5.3739 & TRN \\
\hline CHEMBL3193632 & 688759 & 4.9 & 4.6741 & TRN \\
\hline CHEMBL1497617 & 688759 & 4.8 & 4.9068 & TRN \\
\hline CHEMBL1314144 & 688759 & 4.65 & 4.8201 & TST \\
\hline CHEMBL1461090 & 688759 & 4.45 & 4.6466 & TRN \\
\hline CHEMBL1311558 & 688759 & 4.55 & 4.675 & TRN \\
\hline CHEMBL1588495 & 688759 & 4.6 & 5.077 & TST \\
\hline CHEMBL1545971 & 688759 & 4.45 & 4.7611 & TRN \\
\hline CHEMBL1425065 & 688759 & 4.85 & 4.8372 & TRN \\
\hline CHEMBL1550861 & 688759 & 4.45 & 4.8078 & TRN \\
\hline CHEMBL1479432 & 688759 & 4.45 & 4.6253 & TRN \\
\hline CHEMBL1349898 & 688759 & 4.45 & 4.9177 & TST \\
\hline CHEMBL1385848 & 688759 & 4.45 & 4.5946 & TRN \\
\hline CHEMBL1493094 & 688759 & 5.4 & 5.325 & TRN \\
\hline CHEMBL1328768 & 688759 & 6.0 & 5.2481 & TST \\
\hline CHEMBL1388948 & 688759 & 4.75 & 4.784 & TRN \\
\hline CHEMBL1605698 & 688759 & 4.9 & 4.6281 & TRN \\
\hline CHEMBL1313174 & 688759 & 4.95 & 5.0458 & TRN \\
\hline CHEMBL1549315 & 688759 & 4.8 & 4.8313 & TRN \\
\hline CHEMBL1351473 & 688759 & 4.45 & 4.7447 & TST \\
\hline CHEMBL1389791 & 688759 & 4.9 & 4.6057 & TST \\
\hline CHEMBL1399587 & 688759 & 5.2 & 4.853 & TRN \\
\hline CHEMBL 3214588 & 688759 & 5.9 & 4.8516 & TRN \\
\hline CHEMBL1558551 & 688759 & 6.0 & 5.2621 & TRN \\
\hline CHEMBL1401489 & 688759 & 5.4 & 5.171 & TST \\
\hline CHEMBL1499384 & 688759 & 4.85 & 5.0881 & TRN \\
\hline CHEMBL1325571 & 688759 & 4.45 & 4.9452 & TRN \\
\hline CHEMBL1302894 & 688759 & 4.7 & 4.8156 & TST \\
\hline CHEMBL1308009 & 688759 & 5.15 & 5.0237 & TRN \\
\hline CHEMBL1977281 & 688759 & 4.45 & 4.7761 & TRN \\
\hline CHEMBL1491049 & 688759 & 4.45 & 4.7836 & TRN \\
\hline CHEMBL1311922 & 688759 & 4.85 & 4.7612 & TRN \\
\hline CHEMBL1498262 & 688759 & 4.45 & 4.6904 & TRN \\
\hline CHEMBL1374521 & 688759 & 5.75 & 4.8671 & TRN \\
\hline CHEMBL3192702 & 688759 & 5.3 & 4.6914 & TRN \\
\hline CHEMBL1506004 & 688759 & 5.0 & 5.1264 & TRN \\
\hline CHEMBL3195779 & 688759 & 6.6499 & 5.8488 & TRN \\
\hline CHEMBL1459385 & 688759 & 5.0 & 5.3352 & TRN \\
\hline CHEMBL1307361 & 688759 & 4.45 & 4.4553 & TRN \\
\hline CHEMBL1320940 & 688759 & 5.4 & 4.9572 & TRN \\
\hline CHEMBL1449416 & 688759 & 4.45 & 4.9557 & TRN \\
\hline
\end{tabular}




\begin{tabular}{|c|c|c|c|c|c|}
\hline \multirow{2}{*}{ CHEMBL1388308 } & \multirow{2}{*}{688759} & \\
\hline & & 5.0 & 4.9247 & TRN & \\
\hline CHEMBL1369302 & 688759 & 4.9 & 5.0856 & TST & \\
\hline CHEMBL1302442 & 688759 & 4.45 & 4.8253 & TRN & \\
\hline CHEMBL1597454 & 688759 & 4.45 & 4.9555 & TRN & \\
\hline CHEMBL1349638 & 688759 & 5.5 & 4.9763 & TST & \\
\hline CHEMBL1355709 & 688759 & 6.25 & 4.8636 & TST & \\
\hline CHEMBL1368330 & 688759 & 4.45 & 4.8544 & TRN & \\
\hline CHEMBL3197541 & 688759 & 5.0 & 4.7789 & TRN & \\
\hline CHEMBL1371912 & 688759 & 4.45 & 4.6724 & TRN & \\
\hline CHEMBL1571514 & 688759 & 4.75 & 4.9666 & TST & \\
\hline CHEMBL1488364 & 688759 & 6.25 & 5.7185 & TRN & \\
\hline CHEMBL1454609 & 688759 & 6.2 & 5.8421 & TRN & \\
\hline CHEMBL1392200 & 688759 & 5.6 & 5.6343 & TRN & \\
\hline CHEMBL1374155 & 688759 & 4.45 & 4.4959 & TRN & \\
\hline CHEMBL1362672 & 688759 & 4.45 & 4.59699 & 99999999995 & TRN \\
\hline CHEMBL1475669 & 688759 & 4.6 & 4.7241 & TRN & \\
\hline CHEMBL1497795 & 688759 & 5.45 & 4.8568 & TST & \\
\hline CHEMBL3199842 & 688759 & 4.65 & 4.9068 & TST & \\
\hline CHEMBL1600191 & 688759 & 4.6 & 4.7436 & TRN & \\
\hline CHEMBL1989315 & 688759 & 4.45 & 4.8953 & TRN & \\
\hline CHEMBL1301232 & 688759 & 4.75 & 4.9411 & TRN & \\
\hline CHEMBL1606641 & 688759 & 6.8499 & 4.6763 & TRN & \\
\hline CHEMBL3192371 & 688759 & 4.65 & 5.0934 & TRN & \\
\hline CHEMBL1501284 & 688759 & 4.45 & 4.6327 & TRN & \\
\hline CHEMBL1304575 & 688759 & 6.0 & 5.7717 & TRN & \\
\hline CHEMBL1348110 & 688759 & 4.45 & 4.7991 & TST & \\
\hline CHEMBL1427233 & 688759 & 4.65 & 4.8173 & TST & \\
\hline CHEMBL1326993 & 688759 & 5.05 & 5.1627 & TRN & \\
\hline CHEMBL 3211980 & 688759 & 5.95 & 5.33899 & 99999999995 & TRN \\
\hline CHEMBL1977480 & 688759 & 5.3 & 5.1618 & TRN & \\
\hline CHEMBL1547004 & 688759 & 4.8 & 5.038 & TRN & \\
\hline CHEMBL1465520 & 688759 & 4.95 & 4.8675 & TRN & \\
\hline CHEMBL1323075 & 688759 & 5.25 & 4.6857 & TRN & \\
\hline CHEMBL33242 & 688759 & 5.65 & 5.2273 & TRN & \\
\hline CHEMBL1384684 & 688759 & 5.5 & 5.1042 & TRN & \\
\hline CHEMBL1524838 & 688759 & 5.35 & 5.2512 & TRN & \\
\hline CHEMBL1424366 & 688759 & 5.0 & 4.9287 & TRN & \\
\hline CHEMBL1501064 & 688759 & 8.1487 & 5.1565 & TRN & \\
\hline CHEMBL1503797 & 688759 & 5.15 & 4.7709 & TST & \\
\hline CHEMBL1612145 & 688759 & 5.55 & 5.3547 & TST & \\
\hline CHEMBL1588142 & 688759 & 4.75 & 4.7787 & TST & \\
\hline CHEMBL1310278 & 688759 & 5.5 & 5.0481 & TRN & \\
\hline CHEMBL1431451 & 688759 & 4.8 & 5.06 & TRN & \\
\hline CHEMBL1449023 & 688759 & 5.3 & 5.3961 & TRN & \\
\hline CHEMBL1397125 & 688759 & 6.0 & 5.4071 & TRN & \\
\hline CHEMBL1365811 & 688759 & 4.45 & 4.8637 & TRN & \\
\hline CHEMBL1528189 & 688759 & 4.45 & 4.5862 & TRN & \\
\hline CHEMBL1975809 & 688759 & 6.25 & 5.7012 & TRN & \\
\hline
\end{tabular}




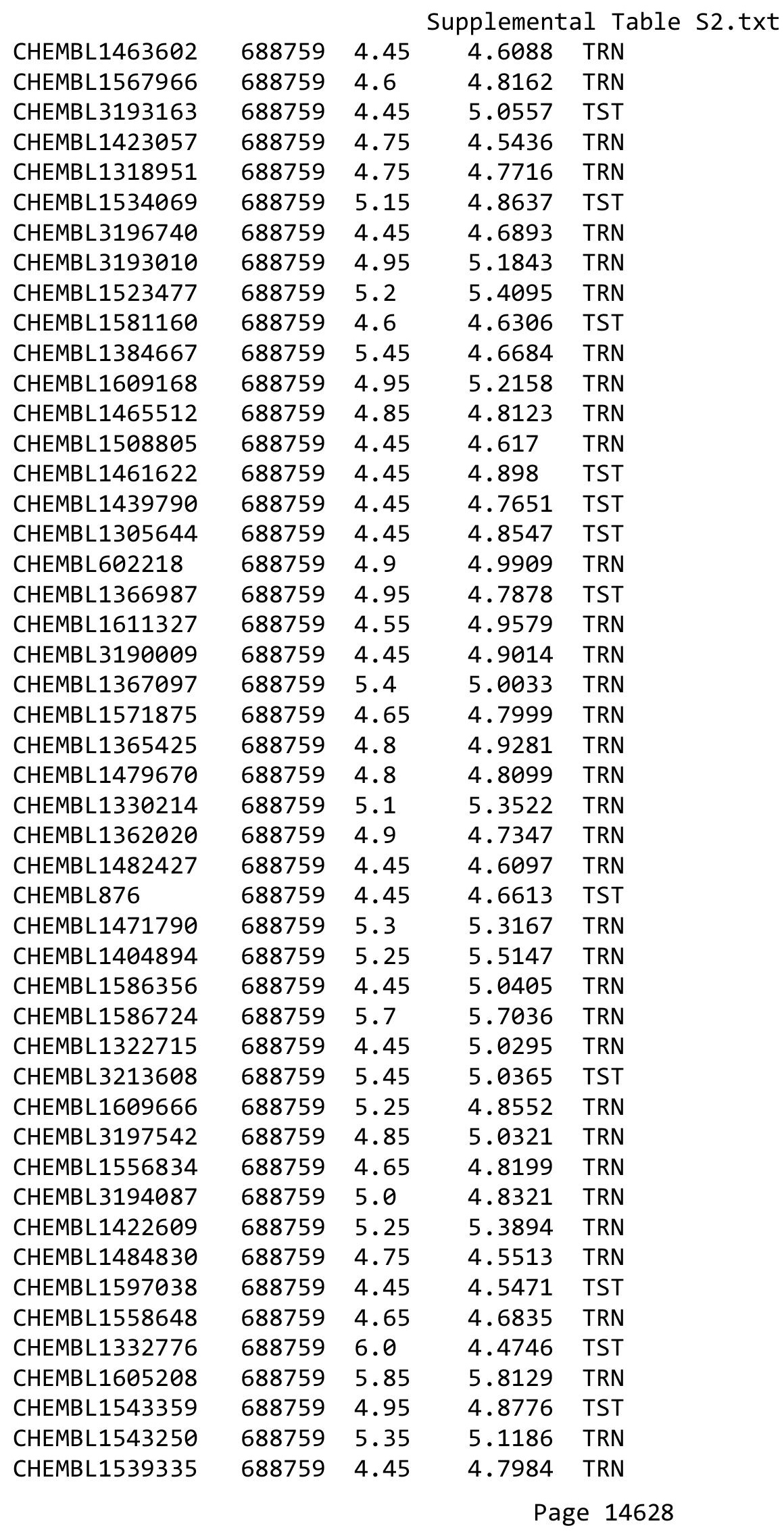




\begin{tabular}{|c|c|c|c|c|}
\hline \multicolumn{5}{|c|}{ Supplemental Table S2.txt } \\
\hline CHEMBL1471406 & 688759 & 5.15 & 5.3313 & TRN \\
\hline CHEMBL1601213 & 688759 & 4.45 & 4.655 & TRN \\
\hline CHEMBL1354079 & 688759 & 4.45 & 4.7591 & TRN \\
\hline CHEMBL1310857 & 688759 & 4.45 & 4.7308 & TST \\
\hline CHEMBL1569121 & 688759 & 5.6 & 5.4336 & TRN \\
\hline CHEMBL1612422 & 688759 & 4.9 & 4.9483 & TRN \\
\hline CHEMBL1319689 & 688759 & 4.95 & 4.908 & TRN \\
\hline CHEMBL1588790 & 688759 & 5.35 & 4.7102 & TRN \\
\hline CHEMBL1346136 & 688759 & 4.7 & 5.0639 & TRN \\
\hline CHEMBL1463165 & 688759 & 4.45 & 4.8422 & TST \\
\hline CHEMBL1415384 & 688759 & 5.25 & 4.712 & TRN \\
\hline CHEMBL1530004 & 688759 & 4.8 & 4.7832 & TRN \\
\hline CHEMBL1588002 & 688759 & 4.45 & 4.7673 & TRN \\
\hline CHEMBL1392899 & 688759 & 4.6 & 4.8505 & TRN \\
\hline CHEMBL1341384 & 688759 & 4.45 & 4.7353 & TRN \\
\hline CHEMBL1313595 & 688759 & 4.45 & 4.9744 & TST \\
\hline CHEMBL1412752 & 688759 & 4.6 & 5.182 & TRN \\
\hline CHEMBL1388186 & 688759 & 4.45 & 4.922 & TRN \\
\hline CHEMBL 399349 & 688759 & 4.75 & 4.8454 & TRN \\
\hline CHEMBL1467359 & 688759 & 4.85 & 5.1087 & TRN \\
\hline CHEMBL1558937 & 688759 & 4.75 & 4.6025 & TRN \\
\hline CHEMBL1606638 & 688759 & 4.45 & 4.5031 & TRN \\
\hline CHEMBL1376001 & 688759 & 4.45 & 5.0272 & TRN \\
\hline CHEMBL1377612 & 688759 & 4.8 & 4.6573 & TRN \\
\hline CHEMBL 3198757 & 688759 & 4.45 & 4.9831 & TRN \\
\hline CHEMBL1557136 & 688759 & 4.9 & 5.5221 & TRN \\
\hline CHEMBL1518714 & 688759 & 4.8 & 4.8668 & TRN \\
\hline CHEMBL1409963 & 688759 & 4.95 & 4.8947 & TRN \\
\hline CHEMBL1330896 & 688759 & 5.6 & 4.8662 & TST \\
\hline CHEMBL1424421 & 688759 & 4.75 & 4.6913 & TRN \\
\hline CHEMBL1310508 & 688759 & 5.2 & 5.0748 & TRN \\
\hline CHEMBL1310274 & 688759 & 4.5 & 4.7583 & TST \\
\hline CHEMBL1598294 & 688759 & 5.15 & 4.9857 & TRN \\
\hline CHEMBL1290361 & 688759 & 4.8 & 4.9107 & TST \\
\hline CHEMBL1414483 & 688759 & 4.75 & 4.7256 & TRN \\
\hline CHEMBL1592020 & 688759 & 4.6 & 4.8231 & TRN \\
\hline CHEMBL1412228 & 688759 & 4.45 & 4.9003 & TRN \\
\hline CHEMBL3208281 & 688759 & 4.7 & 4.9047 & TRN \\
\hline CHEMBL1422809 & 688759 & 4.45 & 5.086 & TRN \\
\hline CHEMBL1508040 & 688759 & 4.85 & 4.7411 & TRN \\
\hline CHEMBL1340519 & 688759 & 4.7 & 5.3727 & TRN \\
\hline CHEMBL1582507 & 688759 & 4.75 & 4.7509 & TRN \\
\hline CHEMBL1581813 & 688759 & 5.2 & 5.0759 & TRN \\
\hline CHEMBL 3195544 & 688759 & 4.45 & 4.9259 & TRN \\
\hline CHEMBL1411744 & 688759 & 4.9 & 4.8239 & TRN \\
\hline CHEMBL1588566 & 688759 & 5.15 & 5.2122 & TRN \\
\hline CHEMBL 2373677 & 688759 & 4.45 & 4.5546 & TST \\
\hline CHEMBL3192959 & 688759 & 5.3 & 5.0745 & TRN \\
\hline
\end{tabular}




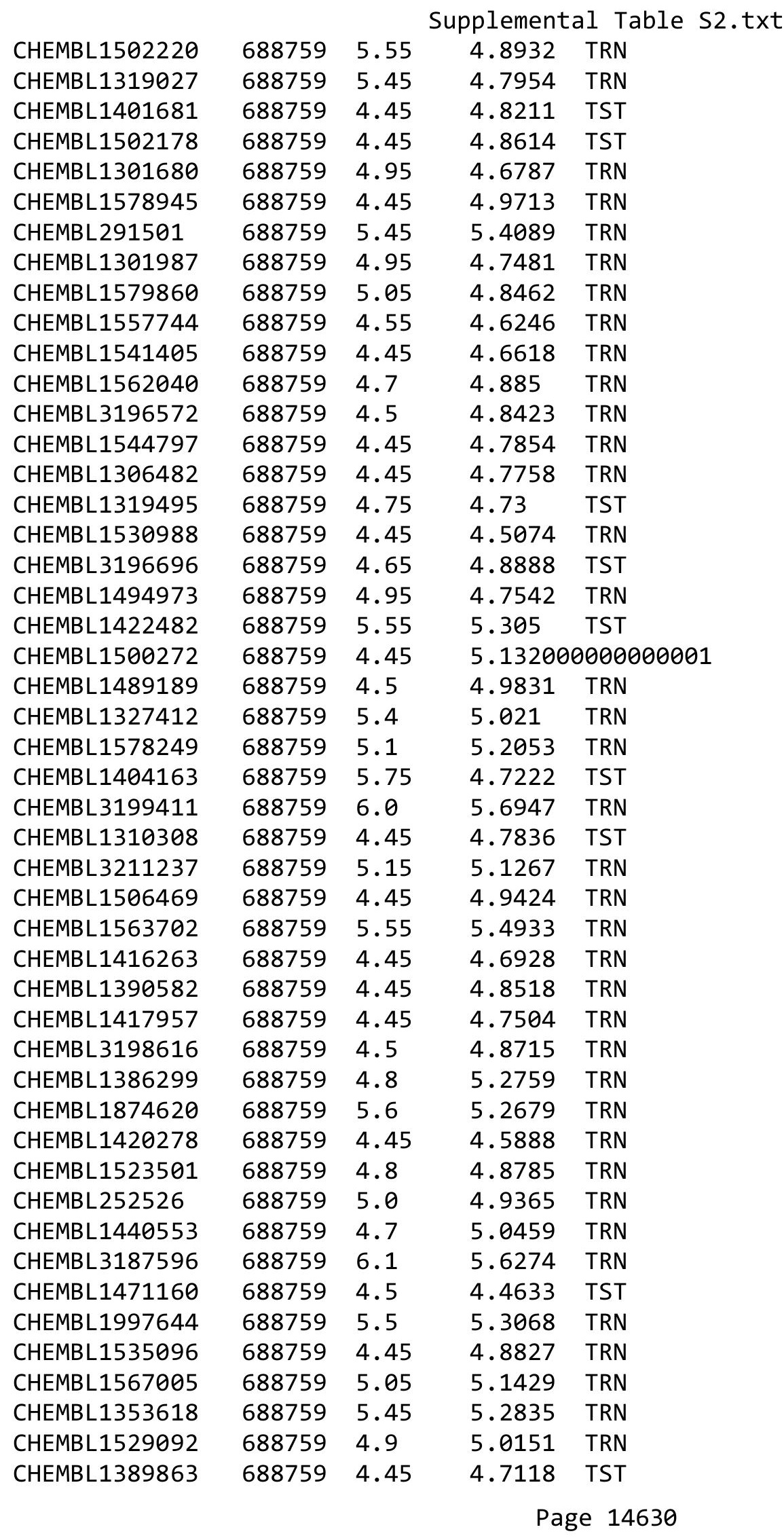




\begin{tabular}{|c|c|c|c|c|c|}
\hline & & \multicolumn{4}{|c|}{ Supplemental Table S2.txt } \\
\hline CHEMBL1453924 & 688759 & 4.45 & 5.016 & TST & \\
\hline CHEMBL1397748 & 688759 & 4.55 & 4.9162 & TST & \\
\hline CHEMBL1450058 & 688759 & 4.65 & 5.0834 & TRN & \\
\hline CHEMBL1577230 & 688759 & 4.7 & 5.1173 & TRN & \\
\hline CHEMBL3197663 & 688759 & 4.8 & 4.8731 & TRN & \\
\hline CHEMBL1423317 & 688759 & 6.0 & 5.9546 & TRN & \\
\hline CHEMBL1411330 & 688759 & 4.6 & 5.0179 & TRN & \\
\hline CHEMBL1577157 & 688759 & 5.45 & 5.37700 & 0000000001 & TRN \\
\hline CHEMBL1379602 & 688759 & 4.45 & 4.8434 & TRN & \\
\hline CHEMBL1605179 & 688759 & 4.8 & 5.2451 & TST & \\
\hline CHEMBL1479252 & 688759 & 4.5 & 5.0881 & TRN & \\
\hline CHEMBL1412298 & 688759 & 4.45 & 4.6142 & TST & \\
\hline CHEMBL3196939 & 688759 & 5.25 & 4.9695 & TRN & \\
\hline CHEMBL1306225 & 688759 & 5.45 & 4.768 & TST & \\
\hline CHEMBL1448343 & 688759 & 4.45 & 5.0273 & TST & \\
\hline CHEMBL1384396 & 688759 & 5.45 & 4.6615 & TRN & \\
\hline CHEMBL1538572 & 688759 & 4.45 & 4.7579 & TST & \\
\hline CHEMBL1324769 & 688759 & 4.75 & 4.8979 & TRN & \\
\hline CHEMBL1597693 & 688759 & 4.45 & 4.6596 & TRN & \\
\hline CHEMBL1401373 & 688759 & 5.35 & 4.9304 & TRN & \\
\hline CHEMBL494255 & 688759 & 5.0 & 5.1819 & TRN & \\
\hline CHEMBL3194837 & 688759 & 4.8 & 5.0432 & TRN & \\
\hline CHEMBL3194629 & 688759 & 4.45 & 4.7196 & TRN & \\
\hline CHEMBL1404786 & 688759 & 5.25 & 4.78 & TRN & \\
\hline CHEMBL1529322 & 688759 & 4.45 & 4.7861 & TRN & \\
\hline CHEMBL1316165 & 688759 & 5.3 & 4.8101 & TRN & \\
\hline CHEMBL1462315 & 688759 & 4.45 & 4.9057 & TRN & \\
\hline CHEMBL1550385 & 688759 & 5.0 & 4.9354 & TRN & \\
\hline CHEMBL1495025 & 688759 & 4.85 & 5.0548 & TST & \\
\hline CHEMBL1324005 & 688759 & 5.95 & 5.7329 & TRN & \\
\hline CHEMBL1321513 & 688759 & 4.9 & 4.6984 & TST & \\
\hline CHEMBL1511450 & 688759 & 4.45 & 4.5496 & TST & \\
\hline CHEMBL1334189 & 688759 & 5.0 & 4.8877 & TRN & \\
\hline CHEMBL1336963 & 688759 & 5.2 & 4.9654 & TST & \\
\hline CHEMBL1443881 & 688759 & 4.6 & 4.8441 & TRN & \\
\hline CHEMBL3194518 & 688759 & 5.0 & 5.4393 & TRN & \\
\hline CHEMBL1313265 & 688759 & 4.7 & 4.9828 & TST & \\
\hline CHEMBL1506103 & 688759 & 5.2 & 4.9696 & TST & \\
\hline CHEMBL1495860 & 688759 & 5.2 & 5.0402 & TRN & \\
\hline CHEMBL3197371 & 688759 & 4.8 & 4.7418 & TST & \\
\hline CHEMBL3211452 & 688759 & 4.85 & 5.0735 & TST & \\
\hline CHEMBL1436988 & 688759 & 4.45 & 4.6005 & TRN & \\
\hline CHEMBL1547600 & 688759 & 5.55 & 5.0249 & TRN & \\
\hline CHEMBL1350513 & 688759 & 4.45 & 5.0019 & TST & \\
\hline CHEMBL1608336 & 688759 & 4.75 & 4.7909 & TST & \\
\hline CHEMBL1572967 & 688759 & 5.2 & 4.6315 & TRN & \\
\hline CHEMBL1337288 & 688759 & 4.45 & 4.6408 & TRN & \\
\hline CHEMBL1368114 & 688759 & 4.45 & 4.7782 & TRN & \\
\hline
\end{tabular}




\begin{tabular}{|c|c|c|c|c|c|}
\hline \multicolumn{6}{|c|}{ Supplemental Table S2.txt } \\
\hline CHEMBL1322419 & 688759 & 4.45 & 4.5901 & TRN & \\
\hline CHEMBL1546012 & 688759 & 5.85 & 5.8328 & TRN & \\
\hline CHEMBL1520309 & 688759 & 5.55 & 4.8194 & TRN & \\
\hline CHEMBL1574206 & 688759 & 4.7 & 5.1166 & TST & \\
\hline CHEMBL 3196624 & 688759 & 5.55 & 5.6687 & TRN & \\
\hline CHEMBL1303916 & 688759 & 4.9 & 5.04 & TRN & \\
\hline CHEMBL1370087 & 688759 & 5.05 & 5.188 & TRN & \\
\hline CHEMBL1518543 & 688759 & 4.45 & 5.2212 & TST & \\
\hline CHEMBL1504064 & 688759 & 4.45 & 4.6256 & TRN & \\
\hline CHEMBL1423636 & 688759 & 4.85 & 4.5648 & TST & \\
\hline CHEMBL1557615 & 688759 & 5.25 & 5.4027 & TRN & \\
\hline CHEMBL1371045 & 688759 & 5.15 & 5.2859 & TRN & \\
\hline CHEMBL1427733 & 688759 & 4.65 & 4.7068 & TRN & \\
\hline CHEMBL 259849 & 688759 & 6.1 & 4.8648 & TRN & \\
\hline CHEMBL1410605 & 688759 & 5.5 & 5.1504 & TRN & \\
\hline CHEMBL1604473 & 688759 & 4.45 & 4.8549 & TRN & \\
\hline CHEMBL1448616 & 688759 & 4.45 & 4.7522 & TRN & \\
\hline CHEMBL1389275 & 688759 & 5.6 & 5.08899 & 99999999995 & TRN \\
\hline CHEMBL1569501 & 688759 & 4.45 & 4.9139 & TRN & \\
\hline CHEMBL1530133 & 688759 & 5.5 & 4.7818 & TRN & \\
\hline CHEMBL1457634 & 688759 & 4.85 & 5.004 & TRN & \\
\hline CHEMBL1982845 & 688759 & 5.35 & 5.4089 & TST & \\
\hline CHEMBL1318931 & 688759 & 4.6 & 4.8918 & TRN & \\
\hline CHEMBL1448409 & 688759 & 4.45 & 4.7851 & TST & \\
\hline CHEMBL1578233 & 688759 & 4.45 & 4.857 & TRN & \\
\hline CHEMBL297304 & 688759 & 5.45 & 5.5329 & TST & \\
\hline CHEMBL1341120 & 688759 & 4.45 & 4.6707 & TRN & \\
\hline CHEMBL1399072 & 688759 & 4.45 & 4.8506 & TRN & \\
\hline CHEMBL1399697 & 688759 & 4.45 & 4.7533 & TRN & \\
\hline CHEMBL3189529 & 688759 & 5.65 & 5.6665 & TRN & \\
\hline CHEMBL3196697 & 688759 & 5.55 & 5.1881 & TST & \\
\hline CHEMBL1422429 & 688759 & 7.8996 & 5.534 & TRN & \\
\hline CHEMBL3145289 & 688759 & 4.7 & 4.8111 & TST & \\
\hline CHEMBL1444739 & 688759 & 4.95 & 4.7247 & TRN & \\
\hline CHEMBL1341815 & 688759 & 6.25 & 4.8061 & TRN & \\
\hline CHEMBL1371920 & 688759 & 4.6 & 4.7811 & TRN & \\
\hline CHEMBL1390472 & 688759 & 4.65 & 5.0097 & TST & \\
\hline CHEMBL3211063 & 688759 & 5.0 & 5.1852 & TRN & \\
\hline CHEMBL1497817 & 688759 & 5.45 & 4.8583 & TRN & \\
\hline CHEMBL1338657 & 688759 & 4.7 & 4.7839 & TRN & \\
\hline CHEMBL1332842 & 688759 & 4.45 & 4.9254 & TRN & \\
\hline CHEMBL1556391 & 688759 & 5.25 & 4.8772 & TRN & \\
\hline CHEMBL1409132 & 688759 & 5.0 & 5.1145 & TRN & \\
\hline CHEMBL586135 & 688759 & 6.2 & 5.96399 & 99999999995 & TRN \\
\hline CHEMBL1385289 & 688759 & 4.95 & 4.7334 & TST & \\
\hline CHEMBL1601820 & 688759 & 4.45 & 4.7775 & TRN & \\
\hline CHEMBL1598614 & 688759 & 4.7 & 5.9062 & TRN & \\
\hline CHEMBL1417563 & 688759 & 4.75 & 4.9508 & TRN & \\
\hline
\end{tabular}




\begin{tabular}{|c|c|c|c|c|}
\hline \multicolumn{5}{|c|}{ Supplemental Table S2.txt } \\
\hline CHEMBL1416366 & 688759 & 5.6 & 5.1098 & TRN \\
\hline CHEMBL1557499 & 688759 & 4.7 & 5.1464 & TRN \\
\hline CHEMBL1340100 & 688759 & 5.25 & 4.7956 & TST \\
\hline CHEMBL1597234 & 688759 & 4.5 & 4.6862 & TRN \\
\hline CHEMBL1498940 & 688759 & 4.9 & 5.3918 & TRN \\
\hline CHEMBL1319328 & 688759 & 6.0 & 5.3211 & TST \\
\hline CHEMBL1466965 & 688759 & 4.45 & 4.776 & TRN \\
\hline CHEMBL1603591 & 688759 & 4.75 & 4.7321 & TST \\
\hline CHEMBL1426792 & 688759 & 5.45 & 5.2735 & TRN \\
\hline CHEMBL1469102 & 688759 & 5.4 & 4.7116 & TST \\
\hline CHEMBL1376440 & 688759 & 4.45 & 4.7344 & TST \\
\hline CHEMBL1462194 & 688759 & 4.65 & 4.7425 & TRN \\
\hline CHEMBL1997212 & 688759 & 5.2 & 4.8707 & TRN \\
\hline CHEMBL1308844 & 688759 & 5.45 & 4.6668 & TRN \\
\hline CHEMBL1586997 & 688759 & 4.45 & 4.7948 & TRN \\
\hline CHEMBL1419101 & 688759 & 4.45 & 4.8183 & TRN \\
\hline CHEMBL1569370 & 688759 & 4.6 & 4.6733 & TRN \\
\hline CHEMBL1332678 & 688759 & 4.45 & 4.564 & TST \\
\hline CHEMBL1302282 & 688759 & 4.45 & 4.8689 & TRN \\
\hline CHEMBL1552505 & 688759 & 4.45 & 4.8525 & TRN \\
\hline CHEMBL3198323 & 688759 & 5.15 & 5.0768 & TRN \\
\hline CHEMBL1327643 & 688759 & 4.6 & 4.7888 & TST \\
\hline CHEMBL1559425 & 688759 & 4.95 & 5.204 & TST \\
\hline CHEMBL1583105 & 688759 & 4.9 & 5.0419 & TST \\
\hline CHEMBL1577912 & 688759 & 4.85 & 5.0206 & TRN \\
\hline CHEMBL1598388 & 688759 & 4.8 & 4.8788 & TST \\
\hline CHEMBL1480172 & 688759 & 4.75 & 5.6721 & TRN \\
\hline CHEMBL1422453 & 688759 & 5.55 & 5.1042 & TRN \\
\hline CHEMBL 3195142 & 688759 & 4.95 & 5.0882 & TRN \\
\hline CHEMBL1595544 & 688759 & 5.15 & 5.3345 & TRN \\
\hline CHEMBL1364300 & 688759 & 5.2 & 4.6188 & TRN \\
\hline CHEMBL1560884 & 688759 & 5.2 & 5.2196 & TRN \\
\hline CHEMBL1301723 & 688759 & 5.75 & 5.1993 & TRN \\
\hline CHEMBL1336558 & 688759 & 4.95 & 4.4972 & TRN \\
\hline CHEMBL1484883 & 688759 & 4.45 & 4.7414 & TRN \\
\hline CHEMBL1565562 & 688759 & 5.0 & 5.0556 & TRN \\
\hline CHEMBL1335661 & 688759 & 4.9 & 4.7412 & TRN \\
\hline CHEMBL1424464 & 688759 & 7.4498 & 5.1557 & TRN \\
\hline CHEMBL1304619 & 688759 & 4.45 & 4.8332 & TRN \\
\hline CHEMBL1319703 & 688759 & 6.25 & 4.8941 & TRN \\
\hline CHEMBL3197091 & 688759 & 5.0 & 4.9668 & TRN \\
\hline CHEMBL1562720 & 688759 & 4.45 & 4.5997 & TRN \\
\hline CHEMBL1492161 & 688759 & 4.95 & 4.8886 & TRN \\
\hline CHEMBL1449188 & 688759 & 5.15 & 4.9378 & TRN \\
\hline CHEMBL1462426 & 688759 & 5.35 & 5.0523 & TRN \\
\hline CHEMBL1578324 & 688759 & 4.45 & 4.7096 & TRN \\
\hline CHEMBL1426034 & 688759 & 4.95 & 4.9319 & TST \\
\hline CHEMBL1423586 & 688759 & 4.45 & 4.6365 & TST \\
\hline
\end{tabular}




\begin{tabular}{|c|c|c|c|c|c|}
\hline \multicolumn{6}{|c|}{ Supplemental Table S2.txt } \\
\hline CHEMBL1314708 & 688759 & 4.45 & 5.0305 & TST & \\
\hline CHEMBL1300497 & 688759 & 5.3 & 5.4484 & TRN & \\
\hline CHEMBL1481412 & 688759 & 4.45 & 4.5055 & TST & \\
\hline CHEMBL1444315 & 688759 & 4.7 & 4.5234 & TST & \\
\hline CHEMBL1524482 & 688759 & 4.85 & 4.7975 & TRN & \\
\hline CHEMBL3193435 & 688759 & 4.45 & 4.6735 & TRN & \\
\hline CHEMBL1570626 & 688759 & 4.45 & 4.9023 & TST & \\
\hline CHEMBL1546290 & 688759 & 4.45 & 5.16799 & 9999999999 & TRN \\
\hline CHEMBL1505989 & 688759 & 4.95 & 5.0622 & TRN & \\
\hline CHEMBL607309 & 688759 & 4.45 & 4.6573 & TRN & \\
\hline CHEMBL1339050 & 688759 & 4.45 & 4.3969 & TRN & \\
\hline CHEMBL1432181 & 688759 & 4.45 & 4.7358 & TRN & \\
\hline CHEMBL3192154 & 688759 & 4.45 & 4.4729 & TRN & \\
\hline CHEMBL1500051 & 688759 & 4.85 & 4.9291 & TST & \\
\hline CHEMBL1507178 & 688759 & 4.75 & 4.6339 & TRN & \\
\hline CHEMBL1584333 & 688759 & 4.45 & 4.8883 & TST & \\
\hline CHEMBL3189620 & 688759 & 4.45 & 4.9059 & TRN & \\
\hline CHEMBL1334430 & 688759 & 4.5 & 4.9749 & TRN & \\
\hline CHEMBL1527752 & 688759 & 4.6 & 4.4656 & TRN & \\
\hline CHEMBL393883 & 688759 & 5.1 & 4.9192 & TRN & \\
\hline CHEMBL3212600 & 688759 & 4.75 & 5.1333 & TRN & \\
\hline CHEMBL1366606 & 688759 & 4.65 & 4.9326 & TRN & \\
\hline CHEMBL3193404 & 688759 & 5.15 & 5.3247 & TRN & \\
\hline CHEMBL1364440 & 688759 & 4.45 & 4.5774 & TRN & \\
\hline CHEMBL1969088 & 688759 & 4.45 & 4.8199 & TST & \\
\hline CHEMBL1532422 & 688759 & 4.9 & 6.5823 & TRN & \\
\hline CHEMBL1612551 & 688759 & 4.9 & 5.5388 & TST & \\
\hline CHEMBL1573551 & 688759 & 5.25 & 4.7004 & TRN & \\
\hline CHEMBL1535525 & 688759 & 5.35 & 5.46899 & 9999999999 & TRN \\
\hline CHEMBL1587905 & 688759 & 4.7 & 4.7261 & TRN & \\
\hline CHEMBL1489149 & 688759 & 5.6 & 5.32600 & 00000000005 & TRN \\
\hline CHEMBL 2001071 & 688759 & 5.5 & 5.2748 & TRN & \\
\hline CHEMBL1173673 & 688759 & 5.25 & 4.9939 & TRN & \\
\hline CHEMBL1381963 & 688759 & 5.2 & 5.4046 & TRN & \\
\hline CHEMBL1504565 & 688759 & 5.9 & 5.0636 & TRN & \\
\hline CHEMBL1528791 & 688759 & 4.9 & 5.0648 & TRN & \\
\hline CHEMBL1460066 & 688759 & 4.5 & 4.959 & TRN & \\
\hline CHEMBL1557928 & 688759 & 4.65 & 4.7933 & TST & \\
\hline CHEMBL1545064 & 688759 & 5.15 & 5.3956 & TRN & \\
\hline CHEMBL1503067 & 688759 & 5.0 & 4.9474 & TRN & \\
\hline CHEMBL1339993 & 688759 & 4.75 & 4.9903 & TST & \\
\hline CHEMBL1307681 & 688759 & 4.45 & 4.6366 & TRN & \\
\hline CHEMBL1526927 & 688759 & 4.45 & 5.0412 & TRN & \\
\hline CHEMBL1311932 & 688759 & 5.4 & 4.9742 & TRN & \\
\hline CHEMBL1403890 & 688759 & 4.45 & 4.6666 & TRN & \\
\hline CHEMBL1321604 & 688759 & 4.45 & 4.8584 & TRN & \\
\hline CHEMBL3191233 & 688759 & 4.95 & 5.1069 & TST & \\
\hline CHEMBL1505548 & 688759 & 4.45 & 4.9469 & TST & \\
\hline
\end{tabular}




\begin{tabular}{|c|c|c|c|c|c|}
\hline & & \multicolumn{4}{|c|}{ Supplemental Table s2.txt } \\
\hline CHEMBL1352138 & 688759 & 4.45 & 4.813 & TRN & \\
\hline CHEMBL1579950 & 688759 & 4.7 & 5.0452 & TRN & \\
\hline CHEMBL1471904 & 688759 & 4.75 & 4.9666 & TRN & \\
\hline CHEMBL1549748 & 688759 & 6.15 & 5.0481 & TRN & \\
\hline CHEMBL1534035 & 688759 & 6.25 & 5.8349 & TST & \\
\hline CHEMBL1356917 & 688759 & 4.45 & 4.7746 & TST & \\
\hline CHEMBL1307849 & 688759 & 4.8 & 4.8273 & TRN & \\
\hline CHEMBL1442884 & 688759 & 5.55 & 5.3992 & TST & \\
\hline CHEMBL1413099 & 688759 & 5.75 & 5.4803 & TRN & \\
\hline CHEMBL3208447 & 688759 & 5.75 & 5.63200 & 0000000001 & TRN \\
\hline CHEMBL1452385 & 688759 & 4.45 & 4.8816 & TST & \\
\hline CHEMBL444376 & 688759 & 4.95 & 5.1068 & TRN & \\
\hline CHEMBL1519156 & 688759 & 4.45 & 4.6845 & TRN & \\
\hline CHEMBL 3198622 & 688759 & 4.55 & 4.8869 & TRN & \\
\hline CHEMBL3190508 & 688759 & 4.9 & 4.9515 & TRN & \\
\hline CHEMBL3210131 & 688759 & 8.301 & 5.0693 & TST & \\
\hline CHEMBL3194790 & 688759 & 5.6 & 5.6637 & TRN & \\
\hline CHEMBL1608382 & 688759 & 5.65 & 5.3375 & TRN & \\
\hline CHEMBL1465007 & 688759 & 6.05 & 5.1402 & TRN & \\
\hline CHEMBL1410277 & 688759 & 5.2 & 4.8274 & TST & \\
\hline CHEMBL1445176 & 688759 & 5.75 & 5.5165 & TRN & \\
\hline CHEMBL1308017 & 688759 & 5.05 & 4.7594 & TRN & \\
\hline CHEMBL1303991 & 688759 & 4.95 & 5.2042 & TRN & \\
\hline CHEMBL1381459 & 688759 & 5.25 & 5.1114 & TRN & \\
\hline CHEMBL1343396 & 688759 & 4.95 & 5.1057 & TRN & \\
\hline CHEMBL1478271 & 688759 & 5.65 & 4.8148 & TST & \\
\hline CHEMBL1455873 & 688759 & 6.2 & 4.7259 & TRN & \\
\hline CHEMBL1583197 & 688759 & 4.6 & 4.8356 & TRN & \\
\hline CHEMBL1376741 & 688759 & 4.45 & 4.7751 & TST & \\
\hline CHEMBL1422726 & 688759 & 5.45 & 5.3812 & TRN & \\
\hline CHEMBL3190838 & 688759 & 5.25 & 5.0552 & TRN & \\
\hline CHEMBL1596567 & 688759 & 5.15 & 4.8593 & TST & \\
\hline CHEMBL3193085 & 688759 & 5.45 & 4.8067 & TST & \\
\hline CHEMBL1401657 & 688759 & 4.45 & 4.6465 & TST & \\
\hline CHEMBL1355307 & 688759 & 4.7 & 4.8367 & TRN & \\
\hline CHEMBL1523824 & 688759 & 4.95 & 5.0628 & TST & \\
\hline CHEMBL 3145314 & 688759 & 6.1 & 5.1786 & TST & \\
\hline CHEMBL1415803 & 688759 & 4.45 & 4.7818 & TRN & \\
\hline CHEMBL1391267 & 688759 & 4.7 & 4.7125 & TRN & \\
\hline CHEMBL1449836 & 688759 & 4.45 & 4.6247 & TRN & \\
\hline CHEMBL1576517 & 688759 & 6.0 & 5.3568 & TRN & \\
\hline CHEMBL1557023 & 688759 & 4.45 & 4.7959 & TRN & \\
\hline CHEMBL1361057 & 688759 & 4.45 & 4.8505 & TRN & \\
\hline CHEMBL1326467 & 688759 & 5.0 & 5.1159 & TST & \\
\hline CHEMBL1313084 & 688759 & 4.45 & 4.8686 & TRN & \\
\hline CHEMBL1514068 & 688759 & 5.35 & 4.6401 & TRN & \\
\hline CHEMBL1370456 & 688759 & 5.25 & 5.3882 & TST & \\
\hline CHEMBL1335020 & 688759 & 5.45 & 4.8961 & TRN & \\
\hline
\end{tabular}




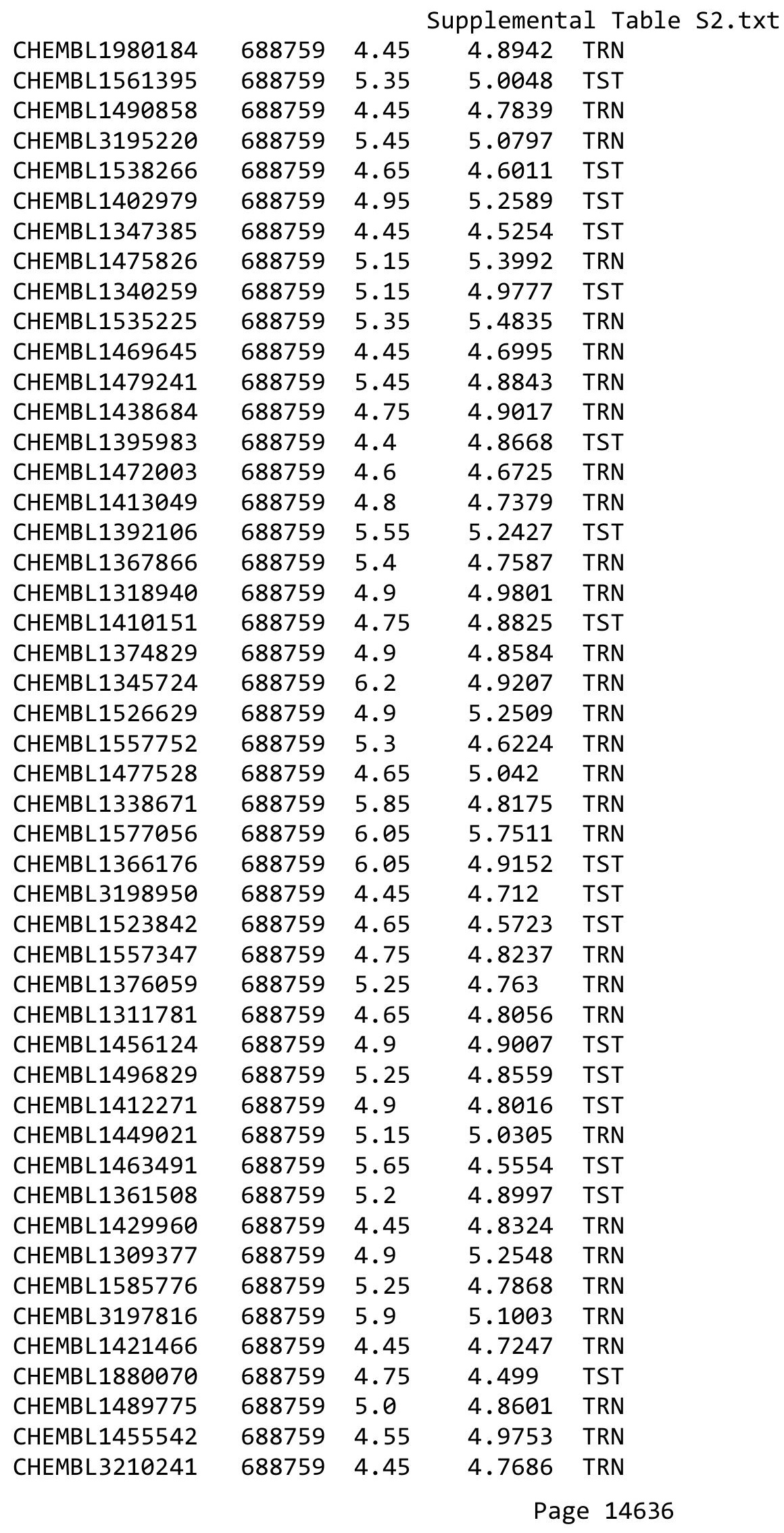




\begin{tabular}{|c|c|c|c|c|c|}
\hline \multicolumn{6}{|c|}{ Supplemental Table S2.txt } \\
\hline CHEMBL1384301 & 688759 & 5.05 & 5.6118 & TRN & \\
\hline CHEMBL1548062 & 688759 & 4.45 & 4.7711 & TRN & \\
\hline CHEMBL1307769 & 688759 & 4.85 & 4.9567 & TST & \\
\hline CHEMBL1301807 & 688759 & 4.45 & 4.7933 & TRN & \\
\hline CHEMBL1491843 & 688759 & 4.9 & 5.2486 & TRN & \\
\hline CHEMBL1537271 & 688759 & 4.8 & 4.8713 & TRN & \\
\hline CHEMBL1408873 & 688759 & 4.45 & 4.9857 & TRN & \\
\hline CHEMBL1602778 & 688759 & 4.7 & 5.0554 & TRN & \\
\hline CHEMBL1396798 & 688759 & 4.5 & 4.8275 & TRN & \\
\hline CHEMBL1352251 & 688759 & 5.3 & 5.2732 & TRN & \\
\hline CHEMBL30095 & 688759 & 4.5 & 4.8461 & TRN & \\
\hline CHEMBL1481186 & 688759 & 4.45 & 5.0077 & TST & \\
\hline CHEMBL3198044 & 688759 & 4.45 & 4.8227 & TRN & \\
\hline CHEMBL1600822 & 688759 & 4.45 & 4.7935 & TRN & \\
\hline CHEMBL1589282 & 688759 & 4.65 & 4.6078 & TST & \\
\hline CHEMBL1978331 & 688759 & 5.5 & 5.4104 & TRN & \\
\hline CHEMBL1453234 & 688759 & 4.45 & 4.7903 & TRN & \\
\hline CHEMBL1429998 & 688759 & 5.65 & 5.1677 & TRN & \\
\hline CHEMBL1510138 & 688759 & 4.45 & 4.8248 & TRN & \\
\hline CHEMBL1608091 & 688759 & 4.45 & 4.9164 & TRN & \\
\hline CHEMBL1587180 & 688759 & 4.6 & 4.96899 & 9999999999 & TRN \\
\hline CHEMBL1465353 & 688759 & 4.45 & 4.687 & TRN & \\
\hline CHEMBL1540318 & 688759 & 4.9 & 4.6127 & TRN & \\
\hline CHEMBL1581270 & 688759 & 5.3 & 5.5238 & TRN & \\
\hline CHEMBL1461887 & 688759 & 4.85 & 4.8153 & TRN & \\
\hline CHEMBL1423409 & 688759 & 4.75 & 5.3879 & TRN & \\
\hline CHEMBL1452449 & 688759 & 7.0501 & 6.4085 & TRN & \\
\hline CHEMBL1328661 & 688759 & 4.95 & 4.8546 & TRN & \\
\hline CHEMBL1362774 & 688759 & 4.9 & 4.79899 & 99999999995 & TRN \\
\hline CHEMBL1368609 & 688759 & 4.7 & 5.0945 & TST & \\
\hline CHEMBL584269 & 688759 & 4.45 & 4.5114 & TRN & \\
\hline CHEMBL1507569 & 688759 & 5.0 & 5.0548 & TRN & \\
\hline CHEMBL 2001895 & 688759 & 5.05 & 4.9119 & TST & \\
\hline CHEMBL3192684 & 688759 & 5.15 & 5.3046 & TRN & \\
\hline CHEMBL1413858 & 688759 & 5.15 & 4.7617 & TST & \\
\hline CHEMBL1519603 & 688759 & 5.4 & 4.8756 & TST & \\
\hline CHEMBL1466406 & 688759 & 5.25 & 5.3334 & TRN & \\
\hline CHEMBL1612754 & 688759 & 5.25 & 5.0266 & TRN & \\
\hline CHEMBL1579878 & 688759 & 5.05 & 4.9374 & TRN & \\
\hline CHEMBL1502724 & 688759 & 5.15 & 4.8803 & TRN & \\
\hline CHEMBL1565401 & 688759 & 5.1 & 5.7471 & TST & \\
\hline CHEMBL1425438 & 688759 & 5.0 & 4.69600 & 0000000001 & TRN \\
\hline CHEMBL1480902 & 688759 & 4.45 & 4.7669 & TST & \\
\hline CHEMBL1612111 & 688759 & 4.45 & 4.5826 & TST & \\
\hline CHEMBL1381322 & 688759 & 4.95 & 5.1172 & TRN & \\
\hline CHEMBL1572927 & 688759 & 4.95 & 4.8688 & TRN & \\
\hline CHEMBL1346034 & 688759 & 5.2 & 4.9934 & TST & \\
\hline CHEMBL1497504 & 688759 & 4.45 & 4.5559 & TRN & \\
\hline
\end{tabular}




\begin{tabular}{|c|c|c|c|c|c|}
\hline & & & & & \\
\hline CHEMBL1476099 & 688759 & 6.5 & 5.296 & TRN & \\
\hline CHEMBL3191910 & 688759 & 4.45 & 4.8867 & TRN & \\
\hline CHEMBL1462157 & 688759 & 4.95 & 5.2744 & TRN & \\
\hline CHEMBL1601589 & 688759 & 4.9 & 4.8303 & TRN & \\
\hline CHEMBL1577392 & 688759 & 4.45 & 4.8181 & TRN & \\
\hline CHEMBL1399928 & 688759 & 4.45 & 4.9782 & TRN & \\
\hline CHEMBL1310691 & 688759 & 4.75 & 4.5398 & TRN & \\
\hline CHEMBL1566570 & 688759 & 4.75 & 5.1629 & TRN & \\
\hline CHEMBL1603982 & 688759 & 5.05 & 5.1785 & TRN & \\
\hline CHEMBL1385302 & 688759 & 5.5 & 4.8514 & TST & \\
\hline CHEMBL1375966 & 688759 & 4.95 & 4.7356 & TRN & \\
\hline CHEMBL581880 & 688759 & 4.6 & 4.6661 & TRN & \\
\hline CHEMBL1301270 & 688759 & 4.45 & 4.84699 & 99999999995 & TRN \\
\hline CHEMBL1420839 & 688759 & 4.8 & 4.5441 & TRN & \\
\hline CHEMBL1402179 & 688759 & 4.45 & 4.9788 & TRN & \\
\hline CHEMBL1340316 & 688759 & 5.45 & 4.9114 & TRN & \\
\hline CHEMBL1499834 & 688759 & 6.15 & 4.9621 & TRN & \\
\hline CHEMBL1352146 & 688759 & 4.65 & 4.745 & TRN & \\
\hline CHEMBL1597107 & 688759 & 5.05 & 4.731 & TRN & \\
\hline CHEMBL1467872 & 688759 & 5.05 & 5.0358 & TRN & \\
\hline CHEMBL178334 & 688759 & 4.45 & 4.9758 & TST & \\
\hline CHEMBL1446210 & 688759 & 4.45 & 4.4528 & TRN & \\
\hline CHEMBL 1440090 & 688759 & 4.85 & 4.8429 & TRN & \\
\hline CHEMBL1520994 & 688759 & 4.45 & 4.7622 & TRN & \\
\hline CHEMBL1501840 & 688759 & 4.45 & 4.9065 & TRN & \\
\hline CHEMBL1471861 & 688759 & 4.65 & 4.7462 & TRN & \\
\hline CHEMBL1462675 & 688759 & 4.45 & 5.1637 & TRN & \\
\hline CHEMBL1371404 & 688759 & 4.65 & 4.5364 & TRN & \\
\hline CHEMBL1371237 & 688759 & 6.05 & 5.1111 & TRN & \\
\hline CHEMBL1364715 & 688759 & 5.15 & 4.8864 & TRN & \\
\hline CHEMBL1545093 & 688759 & 4.65 & 4.9124 & TRN & \\
\hline CHEMBL1361922 & 688759 & 6.05 & 6.1268 & TRN & \\
\hline CHEMBL1494390 & 688759 & 4.65 & 4.4948 & TRN & \\
\hline CHEMBL1389604 & 688759 & 4.9 & 4.8458 & TRN & \\
\hline CHEMBL584444 & 688759 & 4.45 & 4.46 & TRN & \\
\hline CHEMBL1462276 & 688759 & 4.6 & 4.871 & TST & \\
\hline CHEMBL1451245 & 688759 & 4.85 & 4.9857 & TRN & \\
\hline CHEMBL1307919 & 688759 & 5.55 & 5.3374 & TRN & \\
\hline CHEMBL1966570 & 688759 & 5.0 & 5.0328 & TRN & \\
\hline CHEMBL1508491 & 688759 & 4.45 & 4.7846 & TRN & \\
\hline CHEMBL1353905 & 688759 & 4.6 & 4.8635 & TRN & \\
\hline CHEMBL1447164 & 688759 & 5.9 & 5.6686 & TRN & \\
\hline CHEMBL1371456 & 688759 & 4.6 & 5.0403 & TST & \\
\hline CHEMBL1332916 & 688759 & 4.45 & 4.9514 & TRN & \\
\hline CHEMBL3194835 & 688759 & 4.95 & 4.82 & TRN & \\
\hline CHEMBL1594316 & 688759 & 4.9 & 5.1369 & TRN & \\
\hline CHEMBL3192413 & 688759 & 4.6 & 4.7947 & TRN & \\
\hline CHEMBL1468465 & 688759 & 4.65 & 4.8341 & TRN & \\
\hline
\end{tabular}




\begin{tabular}{|c|c|c|c|c|}
\hline \multicolumn{5}{|c|}{ Supplemental Table S2.txt } \\
\hline CHEMBL1970160 & 688759 & 4.9 & 5.5048 & TRN \\
\hline CHEMBL1545429 & 688759 & 6.0 & 5.2331 & TRN \\
\hline CHEMBL1536878 & 688759 & 4.85 & 4.7648 & TRN \\
\hline CHEMBL1320653 & 688759 & 5.05 & 4.8184 & TRN \\
\hline CHEMBL1384186 & 688759 & 6.0 & 5.9253 & TRN \\
\hline CHEMBL1428409 & 688759 & 4.6 & 4.6662 & TST \\
\hline CHEMBL 2001867 & 688759 & 4.5 & 4.7178 & TRN \\
\hline CHEMBL2369272 & 688759 & 4.45 & 4.959 & TRN \\
\hline CHEMBL1507550 & 688759 & 4.45 & 4.9287 & TST \\
\hline CHEMBL295344 & 688759 & 4.85 & 4.8611 & TRN \\
\hline CHEMBL3199124 & 688759 & 4.6 & 4.8166 & TRN \\
\hline CHEMBL1406726 & 688759 & 4.9 & 5.0133 & TRN \\
\hline CHEMBL3196182 & 688759 & 4.5 & 5.1804 & TST \\
\hline CHEMBL1318791 & 688759 & 4.45 & 4.74 & TRN \\
\hline CHEMBL1303276 & 688759 & 4.8 & 4.5844 & TRN \\
\hline CHEMBL1456042 & 688759 & 4.8 & 5.0082 & TRN \\
\hline CHEMBL 2003806 & 688759 & 5.5 & 5.2188 & TRN \\
\hline CHEMBL1408887 & 688759 & 4.9 & 4.9744 & TRN \\
\hline CHEMBL1346145 & 688759 & 5.2 & 4.9231 & TRN \\
\hline CHEMBL1587775 & 688759 & 4.6 & 5.0158 & TRN \\
\hline CHEMBL1371124 & 688759 & 4.75 & 4.7679 & TRN \\
\hline CHEMBL3199067 & 688759 & 4.55 & 4.7329 & TRN \\
\hline CHEMBL1573439 & 688759 & 4.7 & 4.5589 & TRN \\
\hline CHEMBL1536636 & 688759 & 5.0 & 5.0792 & TRN \\
\hline CHEMBL1464308 & 688759 & 4.6 & 4.8553 & TRN \\
\hline CHEMBL1585307 & 688759 & 4.6 & 4.9487 & TRN \\
\hline CHEMBL1372438 & 688759 & 5.45 & 5.2572 & TRN \\
\hline CHEMBL1431545 & 688759 & 4.45 & 5.0361 & TRN \\
\hline CHEMBL1578728 & 688759 & 4.6 & 4.4647 & TRN \\
\hline CHEMBL3197024 & 688759 & 4.45 & 4.9056 & TRN \\
\hline CHEMBL3199122 & 688759 & 4.95 & 4.7908 & TRN \\
\hline CHEMBL1363796 & 688759 & 5.7 & 5.2382 & TST \\
\hline CHEMBL1991736 & 688759 & 4.6 & 4.663 & TRN \\
\hline CHEMBL1371783 & 688759 & 4.75 & 4.9439 & TRN \\
\hline CHEMBL1498265 & 688759 & 4.65 & 4.8426 & TRN \\
\hline CHEMBL3190028 & 688759 & 5.75 & 5.3031 & TRN \\
\hline CHEMBL1370927 & 688759 & 4.65 & 4.8026 & TRN \\
\hline CHEMBL1981378 & 688759 & 5.3 & 5.4441 & TST \\
\hline CHEMBL1347122 & 688759 & 4.45 & 4.8976 & TST \\
\hline CHEMBL1373563 & 688759 & 6.0 & 5.4088 & TRN \\
\hline CHEMBL1308486 & 688759 & 4.45 & 4.8731 & TRN \\
\hline CHEMBL3199172 & 688759 & 5.65 & 5.3611 & TRN \\
\hline CHEMBL1481616 & 688759 & 5.8 & 5.5804 & TST \\
\hline CHEMBL1538739 & 688759 & 4.6 & 4.8106 & TRN \\
\hline CHEMBL1398775 & 688759 & 4.45 & 4.7786 & TST \\
\hline CHEMBL1460795 & 688759 & 4.45 & 4.7627 & TRN \\
\hline CHEMBL1540405 & 688759 & 6.0 & 5.3966 & TST \\
\hline CHEMBL1443506 & 688759 & 4.5 & 4.8087 & TST \\
\hline
\end{tabular}




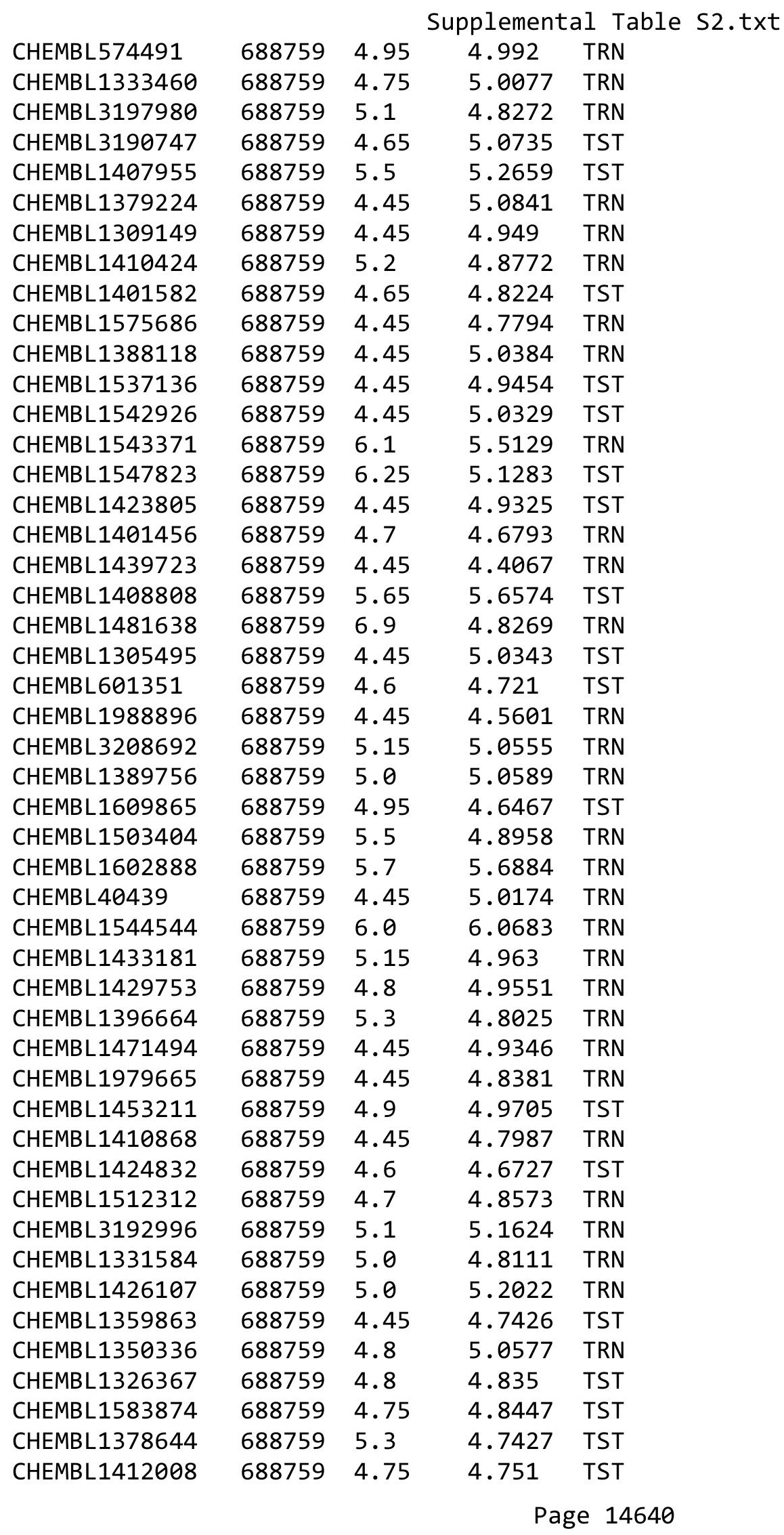




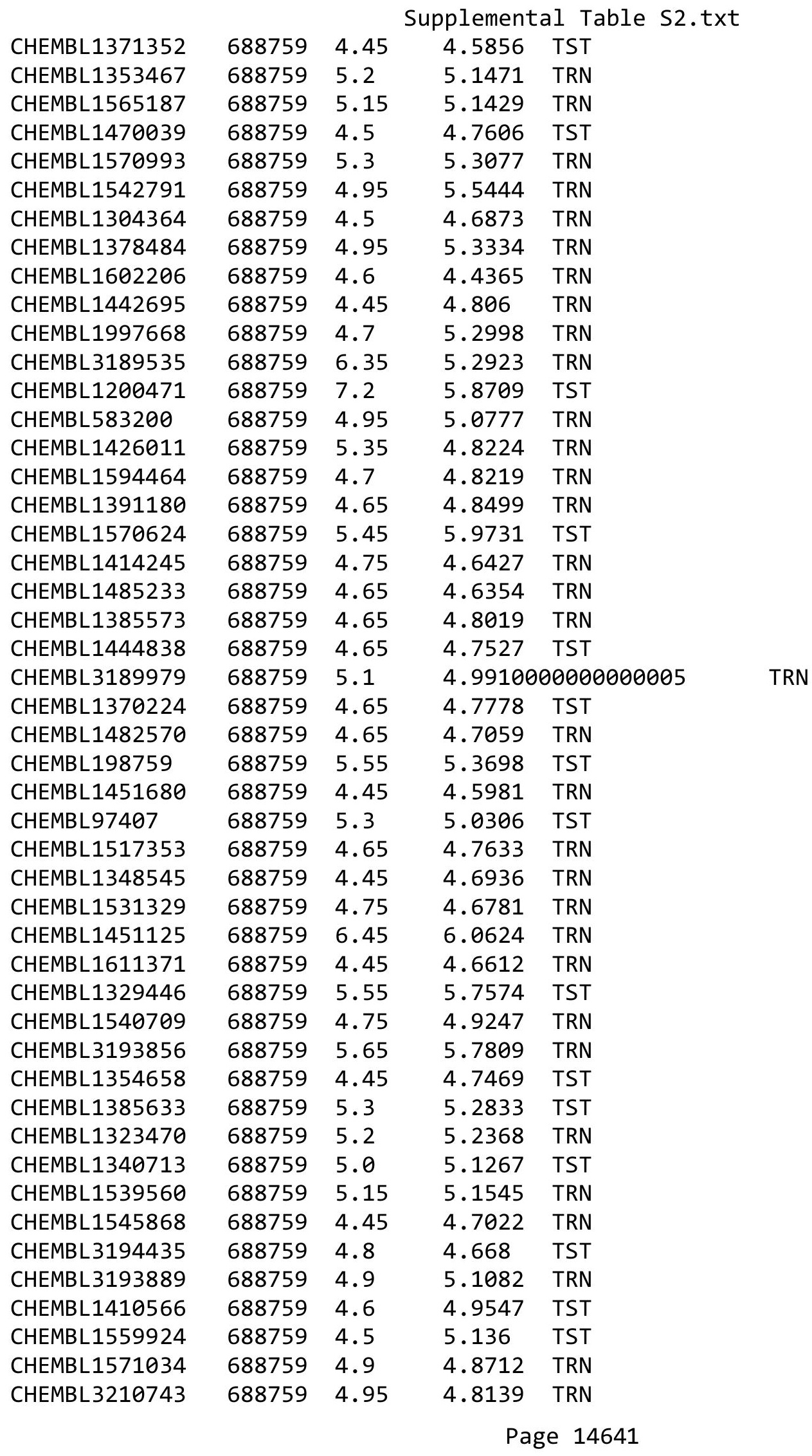




\begin{tabular}{|c|c|c|c|c|}
\hline & & & pplement & al $\mathrm{Ta}$ \\
\hline CHEMBL1307408 & 688759 & 6.9 & 4.9201 & TST \\
\hline CHEMBL3193841 & 688759 & 4.55 & 4.6469 & TRN \\
\hline CHEMBL1491714 & 688759 & 4.45 & 4.933 & TRN \\
\hline CHEMBL1426018 & 688759 & 6.2 & 5.8136 & TRN \\
\hline CHEMBL1555979 & 688759 & 6.35 & 5.1767 & TRN \\
\hline CHEMBL1478584 & 688759 & 6.35 & 4.7676 & TRN \\
\hline CHEMBL1400744 & 688759 & 5.2 & 4.5838 & TRN \\
\hline CHEMBL1485626 & 688759 & 4.45 & 4.6127 & TRN \\
\hline CHEMBL1401063 & 688759 & 4.45 & 4.8766 & TRN \\
\hline CHEMBL1529766 & 688759 & 4.45 & 4.7565 & TST \\
\hline CHEMBL1309985 & 688759 & 4.45 & 4.8343 & TST \\
\hline CHEMBL 3198706 & 688759 & 4.65 & 4.8494 & TST \\
\hline CHEMBL1606626 & 688759 & 4.55 & 4.8173 & TRN \\
\hline CHEMBL1408090 & 688759 & 5.0 & 5.2617 & TRN \\
\hline CHEMBL1537810 & 688759 & 6.25 & 5.4998 & TST \\
\hline CHEMBL1376759 & 688759 & 4.8 & 4.8904 & TRN \\
\hline CHEMBL1437888 & 688759 & 4.6 & 4.7563 & TRN \\
\hline CHEMBL1381628 & 688759 & 4.75 & 4.5543 & TRN \\
\hline CHEMBL1443523 & 688759 & 4.7 & 4.7147 & TRN \\
\hline CHEMBL1516632 & 688759 & 5.25 & 5.2428 & TRN \\
\hline CHEMBL3196076 & 688759 & 4.9 & 4.8879 & TRN \\
\hline CHEMBL1409917 & 688759 & 4.45 & 4.6429 & TRN \\
\hline CHEMBL1610489 & 688759 & 5.5 & 5.4306 & TST \\
\hline CHEMBL1411652 & 688759 & 5.85 & 4.9515 & TST \\
\hline CHEMBL1546432 & 688759 & 4.45 & 4.6948 & TST \\
\hline CHEMBL1488383 & 688759 & 4.45 & 4.7498 & TST \\
\hline CHEMBL1589259 & 688759 & 5.4 & 5.0056 & TRN \\
\hline CHEMBL1521793 & 688759 & 4.95 & 5.3011 & TRN \\
\hline CHEMBL1561338 & 688759 & 5.35 & 5.0118 & TRN \\
\hline CHEMBL3189594 & 688759 & 4.45 & 4.8369 & TRN \\
\hline CHEMBL1576055 & 688759 & 4.45 & 4.8485 & TRN \\
\hline CHEMBL598263 & 688759 & 6.0 & 5.8048 & TST \\
\hline CHEMBL3199726 & 688759 & 4.65 & 5.2573 & TST \\
\hline CHEMBL1564524 & 688759 & 6.5 & 4.9242 & TRN \\
\hline CHEMBL1328740 & 688759 & 6.4 & 5.8549 & TRN \\
\hline CHEMBL1420456 & 688759 & 5.0 & 4.8041 & TRN \\
\hline CHEMBL1301074 & 688759 & 6.5501 & 5.0289 & TRN \\
\hline CHEMBL1564523 & 688759 & 5.5 & 4.8027 & TRN \\
\hline CHEMBL1527563 & 688759 & 4.45 & 4.7987 & TST \\
\hline CHEMBL3207678 & 688759 & 5.15 & 5.2874 & TRN \\
\hline CHEMBL1413859 & 688759 & 5.25 & 5.348 & TRN \\
\hline CHEMBL1588395 & 688759 & 4.75 & 4.938 & TRN \\
\hline CHEMBL1347099 & 688759 & 5.05 & 4.9938 & TRN \\
\hline CHEMBL1452412 & 688759 & 4.85 & 5.1554 & TRN \\
\hline CHEMBL3196960 & 688759 & 5.35 & 5.29 & TRN \\
\hline CHEMBL1452892 & 688759 & 4.85 & 4.8785 & TRN \\
\hline CHEMBL1371399 & 688759 & 5.25 & 5.0115 & TST \\
\hline CHEMBL3209868 & 688759 & 4.85 & 4.9393 & TRN \\
\hline
\end{tabular}




\begin{tabular}{|c|c|c|c|c|}
\hline \multicolumn{5}{|c|}{ Supplemental Table S2.txt } \\
\hline CHEMBL1427633 & 688759 & 6.0 & 4.7314 & TRN \\
\hline CHEMBL1466104 & 688759 & 4.45 & 5.0161 & TRN \\
\hline CHEMBL3214517 & 688759 & 5.25 & 5.0166 & TST \\
\hline CHEMBL1998652 & 688759 & 5.35 & 5.1349 & TRN \\
\hline CHEMBL1544789 & 688759 & 4.95 & 5.0874 & TST \\
\hline CHEMBL1973669 & 688759 & 6.15 & 5.5868 & TRN \\
\hline CHEMBL1437138 & 688759 & 6.0 & 5.3748 & TST \\
\hline CHEMBL1506376 & 688759 & 4.75 & 4.8848 & TST \\
\hline CHEMBL1370497 & 688759 & 5.25 & 4.9233 & TRN \\
\hline CHEMBL1318751 & 688759 & 5.25 & 4.5994 & TST \\
\hline CHEMBL1336643 & 688759 & 4.65 & 5.0884 & TRN \\
\hline CHEMBL1493407 & 688759 & 5.25 & 4.7708 & TST \\
\hline CHEMBL3192865 & 688759 & 5.15 & 5.3138 & TRN \\
\hline CHEMBL1529450 & 688759 & 4.75 & 5.0821 & TRN \\
\hline CHEMBL1478751 & 688759 & 4.75 & 4.6469 & TRN \\
\hline CHEMBL1421976 & 688759 & 5.35 & 4.7482 & TRN \\
\hline CHEMBL3190816 & 688759 & 5.95 & 4.993 & TRN \\
\hline CHEMBL1408205 & 688759 & 5.25 & 4.8558 & TRN \\
\hline CHEMBL1482808 & 688759 & 5.0 & 4.7798 & TRN \\
\hline CHEMBL3199409 & 688759 & 4.9 & 5.0751 & TRN \\
\hline CHEMBL1499030 & 688759 & 5.55 & 5.082 & TST \\
\hline CHEMBL1492131 & 688759 & 4.45 & 4.949 & TRN \\
\hline CHEMBL3190426 & 688759 & 4.65 & 4.8012 & TST \\
\hline CHEMBL1485805 & 688759 & 4.45 & 4.6114 & TST \\
\hline CHEMBL201325 & 688759 & 5.65 & 5.0371 & TRN \\
\hline CHEMBL1519708 & 688759 & 6.5 & 5.7043 & TRN \\
\hline CHEMBL3207517 & 688759 & 5.2 & 4.9063 & TRN \\
\hline CHEMBL1501393 & 688759 & 4.65 & 4.6169 & TST \\
\hline CHEMBL1363803 & 688759 & 5.5 & 5.0111 & TRN \\
\hline CHEMBL1341927 & 688759 & 5.3 & 4.7293 & TRN \\
\hline CHEMBL1565706 & 688759 & 4.55 & 4.8844 & TST \\
\hline CHEMBL1310479 & 688759 & 4.6 & 5.1872 & TRN \\
\hline CHEMBL1472545 & 688759 & 4.75 & 4.8057 & TST \\
\hline CHEMBL1504766 & 688759 & 5.15 & 4.5655 & TRN \\
\hline CHEMBL1507111 & 688759 & 4.9 & 4.9598 & TRN \\
\hline CHEMBL1419973 & 688759 & 4.9 & 5.0183 & TRN \\
\hline CHEMBL1451023 & 688759 & 4.55 & 4.4508 & TRN \\
\hline CHEMBL3209942 & 688759 & 5.35 & 4.8127 & TRN \\
\hline CHEMBL1462775 & 688759 & 4.45 & 4.7078 & TRN \\
\hline CHEMBL1529214 & 688759 & 4.55 & 4.7732 & TRN \\
\hline CHEMBL1984295 & 688759 & 4.7 & 5.1809 & TRN \\
\hline CHEMBL1478733 & 688759 & 4.45 & 4.6716 & TRN \\
\hline CHEMBL3210172 & 688759 & 5.15 & 4.7294 & TRN \\
\hline CHEMBL 3209490 & 688759 & 4.65 & 4.9392 & TRN \\
\hline CHEMBL1975069 & 688759 & 4.45 & 4.7805 & TRN \\
\hline CHEMBL1489956 & 688759 & 4.7 & 4.8061 & TST \\
\hline CHEMBL1609509 & 688759 & 4.9 & 4.7022 & TST \\
\hline CHEMBL1419392 & 688759 & 4.75 & 4.8151 & TRN \\
\hline
\end{tabular}




\begin{tabular}{|c|c|c|c|c|}
\hline & & & pplement & al $\mathrm{Ta}$ \\
\hline CHEMBL1352328 & 688759 & 5.3 & 5.2349 & TRN \\
\hline CHEMBL1511423 & 688759 & 5.2 & 5.2505 & TRN \\
\hline CHEMBL1541376 & 688759 & 5.1 & 5.2973 & TRN \\
\hline CHEMBL1321669 & 688759 & 4.5 & 4.9843 & TRN \\
\hline CHEMBL1493720 & 688759 & 5.25 & 4.8637 & TST \\
\hline CHEMBL1328003 & 688759 & 4.45 & 4.6416 & TST \\
\hline CHEMBL1458031 & 688759 & 5.1 & 4.9971 & TST \\
\hline CHEMBL1424232 & 688759 & 4.55 & 4.6891 & TRN \\
\hline CHEMBL3195636 & 688759 & 4.45 & 4.8085 & TRN \\
\hline CHEMBL3198829 & 688759 & 5.25 & 5.0608 & TRN \\
\hline CHEMBL1407045 & 688759 & 4.7 & 5.0496 & TRN \\
\hline CHEMBL1544340 & 688759 & 5.5 & 4.9774 & TRN \\
\hline CHEMBL535315 & 688759 & 6.6 & 5.0426 & TRN \\
\hline CHEMBL3210836 & 688759 & 5.5 & 5.2312 & TRN \\
\hline CHEMBL1417282 & 688759 & 4.75 & 5.008 & TRN \\
\hline CHEMBL1524288 & 688759 & 4.8 & 4.6894 & TRN \\
\hline CHEMBL3209924 & 688759 & 4.6 & 4.671 & TST \\
\hline CHEMBL3191892 & 688759 & 4.6 & 4.8865 & TRN \\
\hline CHEMBL1584067 & 688759 & 5.15 & 4.7989 & TST \\
\hline CHEMBL1488198 & 688759 & 5.15 & 4.8933 & TRN \\
\hline CHEMBL1567345 & 688759 & 4.45 & 4.8958 & TRN \\
\hline CHEMBL1543735 & 688759 & 4.45 & 4.6899 & TRN \\
\hline CHEMBL1399757 & 688759 & 4.95 & 4.8928 & TST \\
\hline CHEMBL1423185 & 688759 & 4.9 & 4.7395 & TRN \\
\hline CHEMBL1453555 & 688759 & 4.55 & 4.6067 & TRN \\
\hline CHEMBL3208337 & 688759 & 4.85 & 4.7478 & TST \\
\hline CHEMBL1393443 & 688759 & 5.35 & 4.8755 & TRN \\
\hline CHEMBL1608149 & 688759 & 4.45 & 4.8302 & TRN \\
\hline CHEMBL3197094 & 688759 & 4.45 & 4.4747 & TRN \\
\hline CHEMBL3191958 & 688759 & 6.45 & 5.9407 & TRN \\
\hline CHEMBL501617 & 688759 & 5.2 & 5.5327 & TST \\
\hline CHEMBL1542121 & 688759 & 5.5 & 4.9331 & TST \\
\hline CHEMBL1388586 & 688759 & 4.45 & 4.7759 & TRN \\
\hline CHEMBL1347071 & 688759 & 5.6 & 5.1873 & TRN \\
\hline CHEMBL1609737 & 688759 & 4.9 & 4.9102 & TRN \\
\hline CHEMBL1533468 & 688759 & 4.45 & 4.7879 & TRN \\
\hline CHEMBL1364411 & 688759 & 4.45 & 4.4712 & TST \\
\hline CHEMBL1539807 & 688759 & 4.45 & 5.1687 & TRN \\
\hline CHEMBL1528476 & 688759 & 5.5 & 4.9128 & TRN \\
\hline CHEMBL1539405 & 688759 & 5.3 & 4.6901 & TRN \\
\hline CHEMBL1447796 & 688759 & 5.0 & 4.8206 & TST \\
\hline CHEMBL1502274 & 688759 & 5.25 & 4.9789 & TRN \\
\hline CHEMBL1308120 & 688759 & 6.2 & 4.9503 & TST \\
\hline CHEMBL1500256 & 688759 & 4.95 & 5.0591 & TRN \\
\hline CHEMBL1447313 & 688759 & 4.5 & 4.7708 & TRN \\
\hline CHEMBL1547818 & 688759 & 4.65 & 4.7446 & TST \\
\hline CHEMBL1457453 & 688759 & 5.25 & 5.0143 & TRN \\
\hline CHEMBL1462457 & 688759 & 5.1 & 4.768 & TRN \\
\hline
\end{tabular}




\begin{tabular}{|c|c|c|c|c|c|}
\hline \multicolumn{6}{|c|}{ Supplemental Table S2.txt } \\
\hline CHEMBL3209332 & 688759 & 5.3 & 4.9424 & TST & \\
\hline CHEMBL1310783 & 688759 & 4.45 & 4.7817 & TST & \\
\hline CHEMBL1576985 & 688759 & 4.7 & 4.7244 & TRN & \\
\hline CHEMBL1345143 & 688759 & 5.6 & 4.9568 & TST & \\
\hline CHEMBL1501148 & 688759 & 5.1 & 4.9061 & TRN & \\
\hline CHEMBL1337725 & 688759 & 4.5 & 4.7124 & TST & \\
\hline CHEMBL1573031 & 688759 & 4.45 & 4.8805 & TRN & \\
\hline CHEMBL1490554 & 688759 & 5.0 & 4.8588 & TRN & \\
\hline CHEMBL1368833 & 688759 & 5.15 & 4.9831 & TRN & \\
\hline CHEMBL1465867 & 688759 & 4.65 & 4.6745 & TRN & \\
\hline CHEMBL304858 & 688759 & 4.45 & 4.8967 & TST & \\
\hline CHEMBL1309134 & 688759 & 5.1 & 5.3618 & TST & \\
\hline CHEMBL1594251 & 688759 & 4.45 & 5.2114 & TRN & \\
\hline CHEMBL1454987 & 688759 & 4.75 & 4.743 & TRN & \\
\hline CHEMBL1483025 & 688759 & 4.7 & 4.7264 & TRN & \\
\hline CHEMBL1303164 & 688759 & 5.2 & 5.0098 & TST & \\
\hline CHEMBL1595759 & 688759 & 5.5 & 5.2154 & TRN & \\
\hline CHEMBL1305911 & 688759 & 4.75 & 4.6046 & TRN & \\
\hline CHEMBL3193537 & 688759 & 4.65 & 5.6023 & TRN & \\
\hline CHEMBL1596226 & 688759 & 4.65 & 4.5849 & TST & \\
\hline CHEMBL1558218 & 688759 & 4.45 & 4.7485 & TST & \\
\hline CHEMBL1976612 & 688759 & 4.95 & 4.8034 & TRN & \\
\hline CHEMBL1573161 & 688759 & 5.1 & 4.9082 & TST & \\
\hline CHEMBL1342894 & 688759 & 5.75 & 5.2249 & TST & \\
\hline CHEMBL1519060 & 688759 & 4.45 & 4.793 & TST & \\
\hline CHEMBL1511042 & 688759 & 4.85 & 4.7025 & TST & \\
\hline CHEMBL1403887 & 688759 & 4.65 & 4.7867 & TST & \\
\hline CHEMBL1497996 & 688759 & 4.7 & 4.7692 & TRN & \\
\hline CHEMBL1407401 & 688759 & 5.3 & 4.7812 & TST & \\
\hline CHEMBL1420249 & 688759 & 5.25 & 4.8769 & TRN & \\
\hline CHEMBL3189408 & 688759 & 4.45 & 4.7053 & TST & \\
\hline CHEMBL1456942 & 688759 & 5.1 & 5.296 & TRN & \\
\hline CHEMBL1468061 & 688759 & 4.5 & 5.05399 & 9999999999 & TRN \\
\hline CHEMBL1222385 & 688759 & 4.9 & 4.6315 & TRN & \\
\hline CHEMBL1429041 & 688759 & 4.85 & 4.7799 & TRN & \\
\hline CHEMBL3211483 & 688759 & 5.25 & 4.877 & TST & \\
\hline CHEMBL3198263 & 688759 & 4.8 & 4.6226 & TRN & \\
\hline CHEMBL1404493 & 688759 & 6.0 & 5.9765 & TRN & \\
\hline CHEMBL1380513 & 688759 & 5.7 & 5.6841 & TRN & \\
\hline CHEMBL1470886 & 688759 & 4.45 & $4.8260 e$ & 00000000005 & TRN \\
\hline CHEMBL198630 & 688759 & 6.1 & 5.5292 & TRN & \\
\hline CHEMBL1501782 & 688759 & 4.45 & 4.9097 & TRN & \\
\hline CHEMBL1461935 & 688759 & 4.8 & 4.8311 & TST & \\
\hline CHEMBL1550809 & 688759 & 4.75 & 4.9668 & TRN & \\
\hline CHEMBL1299705 & 688759 & 4.45 & 4.8325 & TST & \\
\hline CHEMBL1421920 & 688759 & 5.55 & 5.8459 & TRN & \\
\hline CHEMBL1559713 & 688759 & 4.95 & 5.0433 & TRN & \\
\hline CHEMBL1387298 & 688759 & 4.45 & 4.6499 & TRN & \\
\hline
\end{tabular}




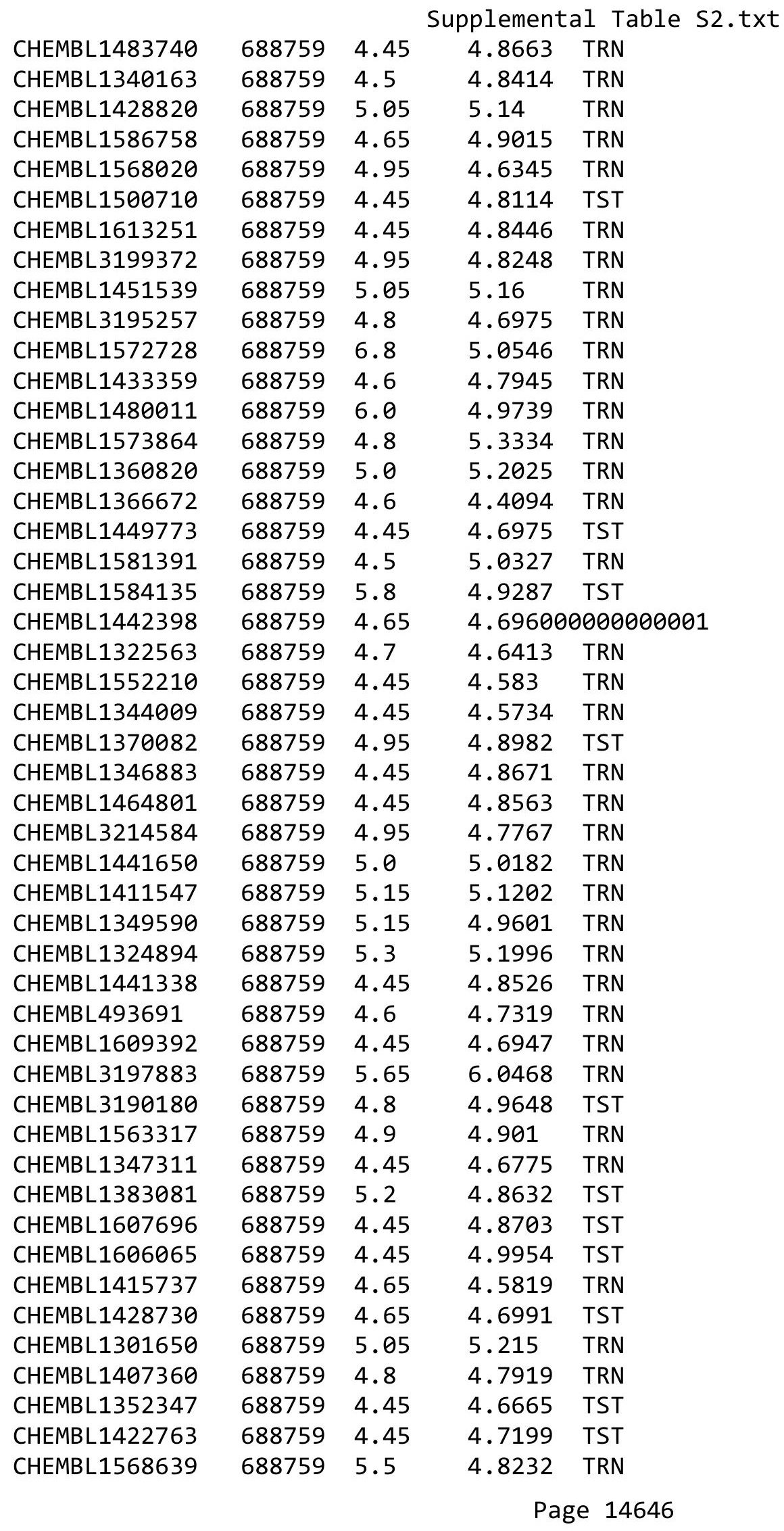

TRN 


\begin{tabular}{|c|c|c|c|c|}
\hline \multicolumn{5}{|c|}{ Supplemental Table S2.txt } \\
\hline CHEMBL 3196498 & 688759 & 4.5 & 4.8729 & TRN \\
\hline CHEMBL1367604 & 688759 & 5.25 & 5.0139 & TST \\
\hline CHEMBL1539375 & 688759 & 5.5 & 4.8225 & TRN \\
\hline CHEMBL1469035 & 688759 & 5.5 & 5.2561 & TRN \\
\hline CHEMBL1967566 & 688759 & 5.3 & 5.2331 & TRN \\
\hline CHEMBL1330304 & 688759 & 4.7 & 4.6245 & TST \\
\hline CHEMBL1545702 & 688759 & 6.15 & 5.4976 & TST \\
\hline CHEMBL1309620 & 688759 & 5.0 & 4.9906 & TRN \\
\hline CHEMBL1346128 & 688759 & 5.5 & 4.9428 & TRN \\
\hline CHEMBL1608645 & 688759 & 4.9 & 5.0364 & TST \\
\hline CHEMBL1351321 & 688759 & 4.6 & 4.8255 & TRN \\
\hline CHEMBL1321398 & 688759 & 4.75 & 5.073 & TST \\
\hline CHEMBL1446437 & 688759 & 5.8 & 5.5733 & TST \\
\hline CHEMBL388025 & 688759 & 4.7 & 5.2729 & TRN \\
\hline CHEMBL3188031 & 688759 & 4.45 & 4.5162 & TRN \\
\hline CHEMBL3209710 & 688759 & 4.45 & 4.7441 & TRN \\
\hline CHEMBL1307101 & 688759 & 4.7 & 5.0318 & TST \\
\hline CHEMBL1408762 & 688759 & 5.2 & 5.1395 & TRN \\
\hline CHEMBL1335097 & 688759 & 4.45 & 4.859 & TRN \\
\hline CHEMBL1484632 & 688759 & 4.9 & 4.7981 & TST \\
\hline CHEMBL1371541 & 688759 & 4.45 & 4.5203 & TST \\
\hline CHEMBL1337968 & 688759 & 5.5 & 5.4583 & TRN \\
\hline CHEMBL1442005 & 688759 & 4.95 & 4.9118 & TRN \\
\hline CHEMBL1456777 & 688759 & 4.45 & 4.9177 & TRN \\
\hline CHEMBL1596898 & 688759 & 4.45 & 4.8469 & TRN \\
\hline CHEMBL3199107 & 688759 & 5.35 & 4.967 & TRN \\
\hline CHEMBL1402207 & 688759 & 5.8 & 5.5849 & TRN \\
\hline CHEMBL1299775 & 688759 & 6.1 & 4.9593 & TST \\
\hline CHEMBL1453371 & 688759 & 4.65 & 4.9004 & TRN \\
\hline CHEMBL1370292 & 688759 & 5.0 & 4.8249 & TRN \\
\hline CHEMBL1996376 & 688759 & 5.0 & 4.7612 & TST \\
\hline CHEMBL1547000 & 688759 & 6.45 & 5.9876 & TRN \\
\hline CHEMBL1454039 & 688759 & 4.65 & 5.3194 & TRN \\
\hline CHEMBL1605348 & 688759 & 4.45 & 4.9245 & TRN \\
\hline CHEMBL1575467 & 688759 & 4.7 & 4.9559 & TST \\
\hline CHEMBL1419361 & 688759 & 4.9 & 4.7999 & TRN \\
\hline CHEMBL1509126 & 688759 & 4.45 & 5.0039 & TRN \\
\hline CHEMBL1408386 & 688759 & 4.45 & 4.5977 & TRN \\
\hline CHEMBL1596357 & 688759 & 4.65 & 4.7742 & TRN \\
\hline CHEMBL1436644 & 688759 & 4.75 & 4.6773 & TST \\
\hline CHEMBL1345525 & 688759 & 5.5 & 4.8276 & TRN \\
\hline CHEMBL 1558650 & 688759 & 4.45 & 4.8301 & TRN \\
\hline CHEMBL1506679 & 688759 & 4.65 & 4.9578 & TST \\
\hline CHEMBL3212159 & 688759 & 4.9 & 4.5876 & TRN \\
\hline CHEMBL1318412 & 688759 & 4.95 & 4.7948 & TST \\
\hline CHEMBL50207 & 688759 & 4.95 & 5.0361 & TST \\
\hline CHEMBL1483780 & 688759 & 5.15 & 4.9847 & TRN \\
\hline CHEMBL1587156 & 688759 & 5.7 & 5.1063 & TRN \\
\hline
\end{tabular}




\begin{tabular}{|c|c|c|c|c|}
\hline \multicolumn{5}{|c|}{ Supplemental Table S2.txt } \\
\hline CHEMBL1410190 & 688759 & 5.05 & 5.3009 & TRN \\
\hline CHEMBL1571765 & 688759 & 4.6 & 4.7821 & TRN \\
\hline CHEMBL1490684 & 688759 & 6.0 & 4.7701 & TRN \\
\hline CHEMBL3189499 & 688759 & 5.25 & 4.8736 & TRN \\
\hline CHEMBL1409088 & 688759 & 4.7 & 4.7986 & TRN \\
\hline CHEMBL492468 & 688759 & 4.65 & 4.9432 & TST \\
\hline CHEMBL1968569 & 688759 & 4.8 & 4.9144 & TRN \\
\hline CHEMBL1306839 & 688759 & 4.4 & 4.9878 & TRN \\
\hline CHEMBL1507982 & 688759 & 6.4 & 4.8834 & TRN \\
\hline CHEMBL1493071 & 688759 & 4.45 & 4.6498 & TRN \\
\hline CHEMBL1377210 & 688759 & 4.6 & 4.6293 & TRN \\
\hline CHEMBL1306416 & 688759 & 4.65 & 4.936 & TST \\
\hline CHEMBL1455861 & 688759 & 4.9 & 5.5098 & TRN \\
\hline CHEMBL1323553 & 688759 & 5.3 & 5.362 & TRN \\
\hline CHEMBL1501043 & 688759 & 4.45 & 4.7024 & TRN \\
\hline CHEMBL1596628 & 688759 & 6.2 & 5.7085 & TRN \\
\hline CHEMBL1330307 & 688759 & 5.65 & 5.5739 & TRN \\
\hline CHEMBL3208046 & 688759 & 4.65 & 4.7303 & TST \\
\hline CHEMBL 3195040 & 688759 & 4.45 & 4.6255 & TRN \\
\hline CHEMBL1465707 & 688759 & 4.4 & 4.3706 & TRN \\
\hline CHEMBL1992943 & 688759 & 5.3 & 4.9553 & TRN \\
\hline CHEMBL1422265 & 688759 & 4.45 & 4.9802 & TRN \\
\hline CHEMBL1384580 & 688759 & 4.9 & 4.8691 & TRN \\
\hline CHEMBL3194528 & 688759 & 5.0 & 5.0564 & TRN \\
\hline CHEMBL1448377 & 688759 & 4.8 & 4.8955 & TRN \\
\hline CHEMBL1539487 & 688759 & 4.8 & 4.7497 & TRN \\
\hline CHEMBL3198074 & 688759 & 4.45 & 4.7506 & TRN \\
\hline CHEMBL1964306 & 688759 & 4.65 & 5.0335 & TST \\
\hline CHEMBL1452409 & 688759 & 5.15 & 5.1911 & TRN \\
\hline CHEMBL1607801 & 688759 & 6.25 & 6.3184 & TRN \\
\hline CHEMBL1505008 & 688759 & 4.45 & 4.9355 & TST \\
\hline CHEMBL1305716 & 688759 & 4.45 & 4.8016 & TRN \\
\hline CHEMBL1441276 & 688759 & 4.45 & 4.7068 & TRN \\
\hline CHEMBL1469257 & 688759 & 4.9 & 4.9134 & TST \\
\hline CHEMBL1459324 & 688759 & 4.45 & 4.5194 & TRN \\
\hline CHEMBL 3209020 & 688759 & 4.65 & 4.7963 & TRN \\
\hline CHEMBL1557319 & 688759 & 4.95 & 4.9215 & TRN \\
\hline CHEMBL3197345 & 688759 & 4.45 & 5.1174 & TRN \\
\hline CHEMBL1502297 & 688759 & 4.8 & 4.8815 & TST \\
\hline CHEMBL1363917 & 688759 & 4.45 & 4.8677 & TRN \\
\hline CHEMBL1414273 & 688759 & 5.3 & 5.2144 & TRN \\
\hline CHEMBL479765 & 688759 & 5.5 & 5.3709 & TRN \\
\hline CHEMBL1978808 & 688759 & 4.85 & 5.0158 & TRN \\
\hline CHEMBL3212801 & 688759 & 4.65 & 4.7215 & TST \\
\hline CHEMBL1447382 & 688759 & 6.0 & 4.9085 & TRN \\
\hline CHEMBL1514861 & 688759 & 4.85 & 4.9578 & TRN \\
\hline CHEMBL3194325 & 688759 & 4.9 & 4.8811 & TRN \\
\hline CHEMBL3199256 & 688759 & 5.25 & 4.7144 & TRN \\
\hline
\end{tabular}




\begin{tabular}{|c|c|c|c|c|c|}
\hline \multicolumn{6}{|c|}{ Supplemental Table S2.txt } \\
\hline CHEMBL1541686 & 688759 & 4.65 & 4.5735 & TRN & \\
\hline CHEMBL1382191 & 688759 & 6.25 & 5.2757 & TST & \\
\hline CHEMBL1448496 & 688759 & 5.7 & 4.8588 & TRN & \\
\hline CHEMBL1511911 & 688759 & 4.55 & 4.7617 & TRN & \\
\hline CHEMBL1485005 & 688759 & 4.45 & 4.8717 & TRN & \\
\hline CHEMBL3190730 & 688759 & 4.55 & 4.6844 & TRN & \\
\hline CHEMBL1600116 & 688759 & 4.9 & 4.8059 & TRN & \\
\hline CHEMBL1425867 & 688759 & 5.15 & 4.9068 & TRN & \\
\hline CHEMBL1463094 & 688759 & 5.1 & 5.24200 & 0000000001 & TRN \\
\hline CHEMBL1442171 & 688759 & 5.3 & 5.1627 & TRN & \\
\hline CHEMBL1502279 & 688759 & 5.5 & 4.9329 & TRN & \\
\hline CHEMBL1478023 & 688759 & 4.45 & 4.6631 & TRN & \\
\hline CHEMBL3189611 & 688759 & 4.55 & 4.5133 & TST & \\
\hline CHEMBL1443425 & 688759 & 4.45 & 4.6838 & TRN & \\
\hline CHEMBL1561158 & 688759 & 4.5 & 4.953 & TRN & \\
\hline CHEMBL1605969 & 688759 & 5.15 & 4.7874 & TRN & \\
\hline CHEMBL1340777 & 688759 & 4.7 & 4.85 & TST & \\
\hline CHEMBL1419019 & 688759 & 5.2 & 5.0232 & TRN & \\
\hline CHEMBL1418998 & 688759 & 4.6 & 4.7773 & TRN & \\
\hline CHEMBL1412080 & 688759 & 5.15 & 4.9308 & TRN & \\
\hline CHEMBL1517486 & 688759 & 4.45 & 4.8728 & TST & \\
\hline CHEMBL1364584 & 688759 & 5.45 & 4.8961 & TRN & \\
\hline CHEMBL1506078 & 688759 & 5.45 & 5.2622 & TRN & \\
\hline CHEMBL3214309 & 688759 & 5.3 & 4.9324 & TST & \\
\hline CHEMBL1472013 & 688759 & 4.6 & 4.6542 & TRN & \\
\hline CHEMBL1497520 & 688759 & 4.8 & 4.7207 & TRN & \\
\hline CHEMBL1321614 & 688759 & 4.9 & 5.0032 & TRN & \\
\hline CHEMBL1971120 & 688759 & 4.7 & 4.5318 & TST & \\
\hline CHEMBL1452037 & 688759 & 5.15 & 5.0342 & TRN & \\
\hline CHEMBL1486109 & 688759 & 6.5 & 5.6164 & TRN & \\
\hline CHEMBL1343831 & 688759 & 5.45 & 4.9595 & TRN & \\
\hline CHEMBL1387726 & 688759 & 4.9 & 4.8903 & TST & \\
\hline CHEMBL1347551 & 688759 & 4.65 & 4.8741 & TST & \\
\hline CHEMBL1410260 & 688759 & 4.45 & 4.7541 & TST & \\
\hline CHEMBL1452115 & 688759 & 4.45 & 4.5191 & TRN & \\
\hline CHEMBL1451385 & 688759 & 4.45 & 4.88399 & 99999999995 & TRN \\
\hline CHEMBL1456036 & 688759 & 5.0 & 5.3784 & TRN & \\
\hline CHEMBL3197898 & 688759 & 4.65 & 4.7921 & TRN & \\
\hline CHEMBL1362990 & 688759 & 4.65 & 4.7124 & TST & \\
\hline CHEMBL1491185 & 688759 & 4.7 & 4.8748 & TRN & \\
\hline CHEMBL1329722 & 688759 & 5.0 & 4.6903 & TRN & \\
\hline CHEMBL1491117 & 688759 & 4.75 & 4.7973 & TRN & \\
\hline CHEMBL1342903 & 688759 & 4.45 & 4.9905 & TRN & \\
\hline CHEMBL1548211 & 688759 & 4.45 & 4.9606 & TRN & \\
\hline CHEMBL1549099 & 688759 & 5.1 & 5.0443 & TST & \\
\hline CHEMBL1385603 & 688759 & 4.95 & 5.0569 & TRN & \\
\hline CHEMBL1510118 & 688759 & 4.85 & 4.8752 & TRN & \\
\hline CHEMBL1464982 & 688759 & 4.95 & 4.785 & TRN & \\
\hline
\end{tabular}




\begin{tabular}{|c|c|c|c|c|c|}
\hline \\
\hline CHEMBL1509868 & 688759 & 4.9 & 4.7883 & TRN & \\
\hline CHEMBL1495621 & 688759 & 4.45 & 4.7319 & TRN & \\
\hline CHEMBL1386508 & 688759 & 4.45 & 4.8985 & TRN & \\
\hline CHEMBL1604453 & 688759 & 5.65 & 4.8695 & TST & \\
\hline CHEMBL1609320 & 688759 & 4.8 & 4.6461 & TST & \\
\hline CHEMBL1373473 & 688759 & 4.85 & 4.8644 & TST & \\
\hline CHEMBL1341577 & 688759 & 5.4 & 5.0015 & TRN & \\
\hline CHEMBL 2002248 & 688759 & 4.65 & 5.1441 & TRN & \\
\hline CHEMBL1608311 & 688759 & 4.7 & 4.6205 & TRN & \\
\hline CHEMBL1470840 & 688759 & 5.35 & 5.0181 & TRN & \\
\hline CHEMBL3196026 & 688759 & 6.2 & 5.61299 & 99999999995 & TRN \\
\hline CHEMBL1379656 & 688759 & 5.85 & 5.5417 & TRN & \\
\hline CHEMBL1363978 & 688759 & 4.6 & 4.8011 & TRN & \\
\hline CHEMBL1526865 & 688759 & 5.25 & 4.8734 & TST & \\
\hline CHEMBL1326299 & 688759 & 4.65 & 4.7649 & TRN & \\
\hline CHEMBL1419347 & 688759 & 4.65 & 4.9825 & TST & \\
\hline CHEMBL1529652 & 688759 & 4.65 & 4.6115 & TRN & \\
\hline CHEMBL1333894 & 688759 & 4.65 & 4.8247 & TST & \\
\hline CHEMBL1526090 & 688759 & 4.45 & 4.84 & TST & \\
\hline CHEMBL1458153 & 688759 & 4.55 & 4.7744 & TRN & \\
\hline CHEMBL1387034 & 688759 & 4.9 & 4.7394 & TRN & \\
\hline CHEMBL1587164 & 688759 & 4.9 & 4.9134 & TST & \\
\hline CHEMBL1503613 & 688759 & 4.5 & 4.9112 & TRN & \\
\hline CHEMBL1325370 & 688759 & 6.7501 & 4.8225 & TRN & \\
\hline CHEMBL1407587 & 688759 & 4.45 & 4.9814 & TRN & \\
\hline CHEMBL1470295 & 688759 & 4.8 & 4.8806 & TRN & \\
\hline CHEMBL3209965 & 688759 & 4.45 & 4.7966 & TRN & \\
\hline CHEMBL1426340 & 688759 & 5.45 & 5.6262 & TRN & \\
\hline CHEMBL1520019 & 688759 & 5.0 & 4.9487 & TRN & \\
\hline CHEMBL473106 & 688759 & 4.5 & 5.0933 & TST & \\
\hline CHEMBL3197209 & 688759 & 4.45 & 4.9654 & TST & \\
\hline CHEMBL1303210 & 688759 & 5.5 & 4.7302 & TRN & \\
\hline CHEMBL1580634 & 688759 & 4.45 & 4.9626 & TST & \\
\hline CHEMBL1379696 & 688759 & 4.95 & 4.8253 & TRN & \\
\hline CHEMBL3190674 & 688759 & 4.7 & 5.2537 & TRN & \\
\hline CHEMBL3199922 & 688759 & 4.55 & 4.5998 & TST & \\
\hline CHEMBL1467755 & 688759 & 4.45 & 4.7395 & TRN & \\
\hline CHEMBL1499346 & 688759 & 4.45 & 4.593 & TRN & \\
\hline CHEMBL1533086 & 688759 & 6.2 & 5.5947 & TRN & \\
\hline CHEMBL1410497 & 688759 & 4.45 & 4.9578 & TRN & \\
\hline CHEMBL1347607 & 688759 & 5.35 & 5.1259 & TRN & \\
\hline CHEMBL1401734 & 688759 & 4.45 & 4.559 & TRN & \\
\hline CHEMBL3190983 & 688759 & 5.15 & 5.2728 & TRN & \\
\hline CHEMBL1717301 & 688759 & 6.0 & 4.901 & TRN & \\
\hline CHEMBL1324332 & 688759 & 4.45 & 4.6398 & TRN & \\
\hline CHEMBL3194601 & 688759 & 4.45 & 4.7848 & TRN & \\
\hline CHEMBL1528635 & 688759 & 4.65 & 4.843 & TRN & \\
\hline CHEMBL3191182 & 688759 & 5.45 & 5.3964 & TRN & \\
\hline
\end{tabular}




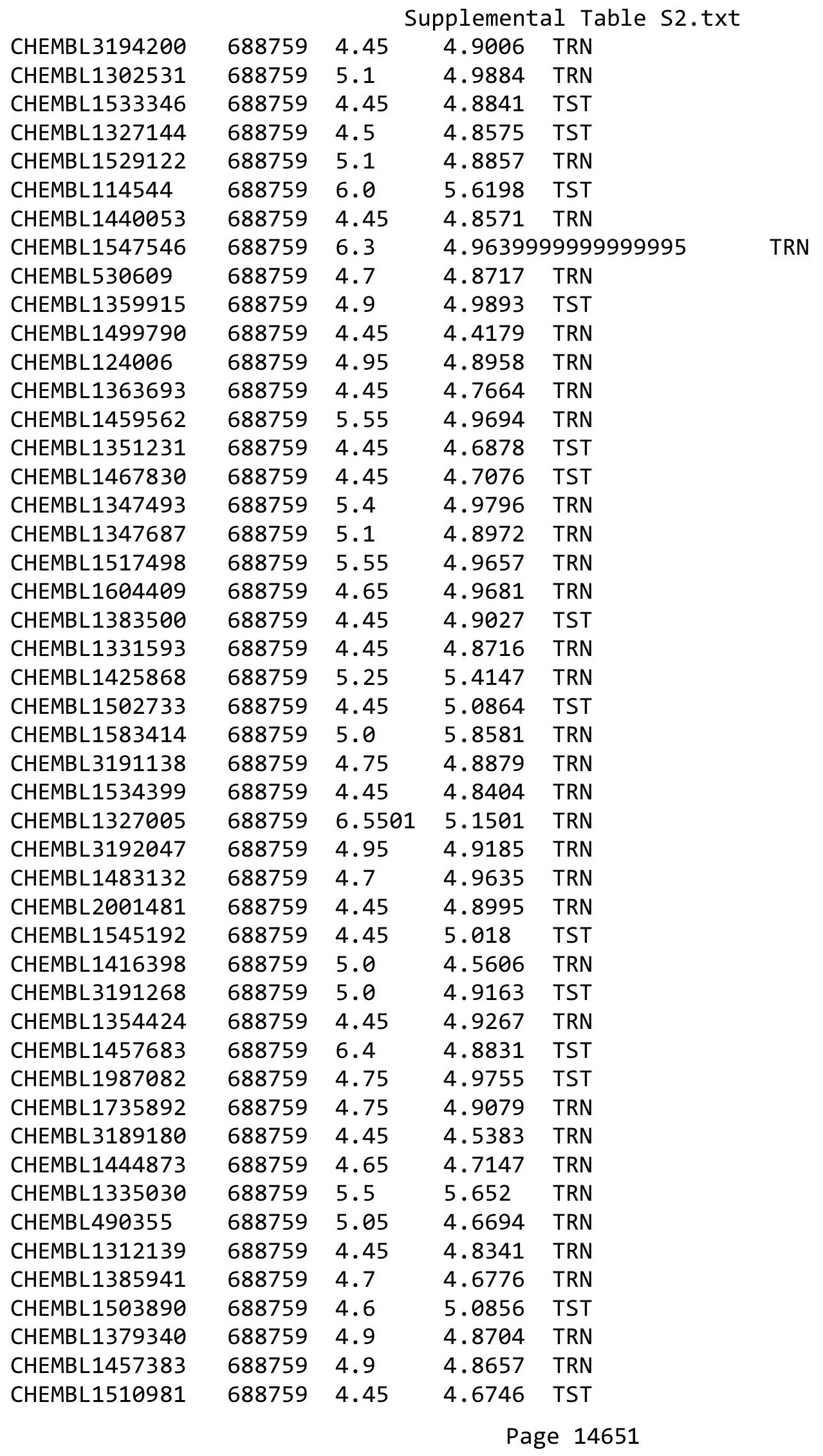




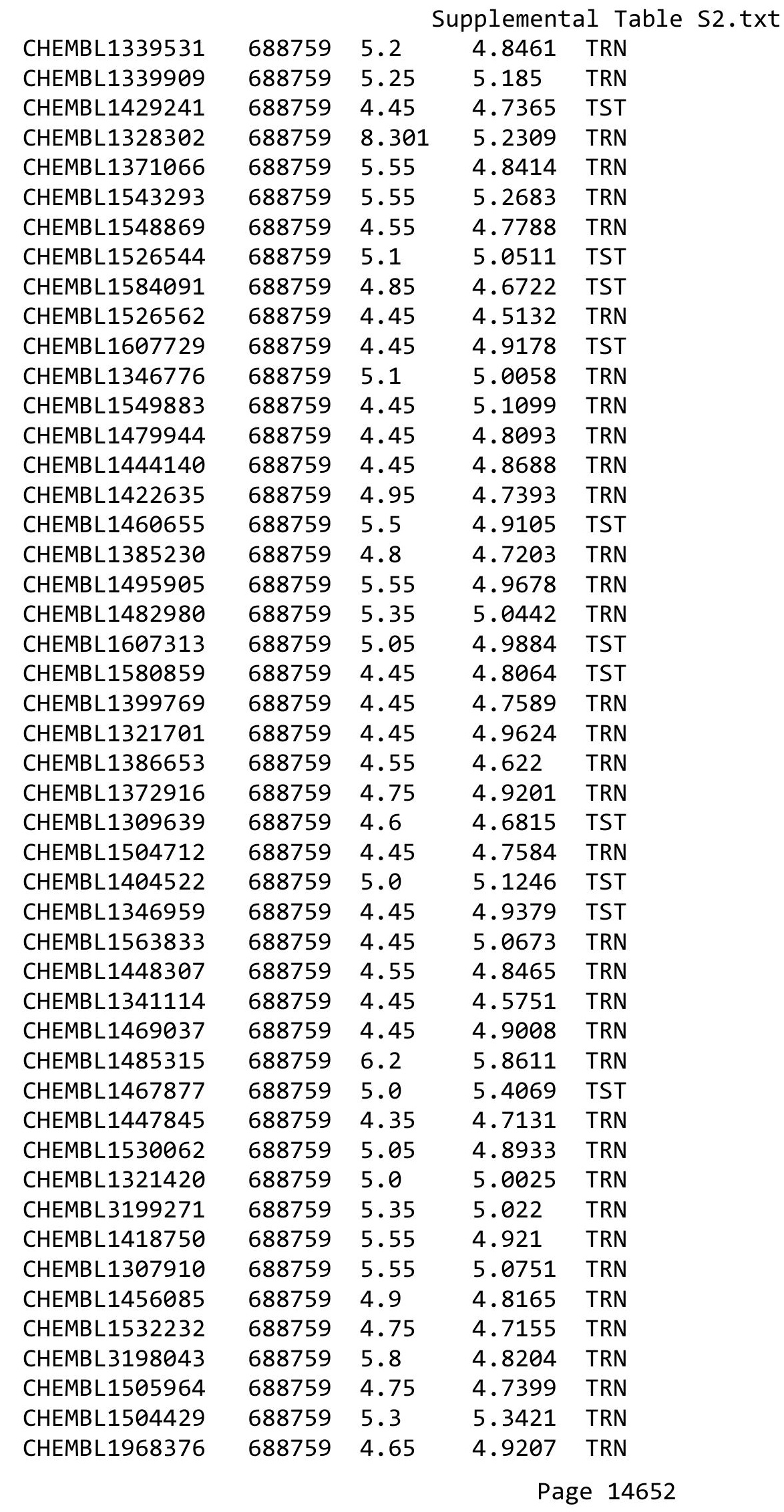




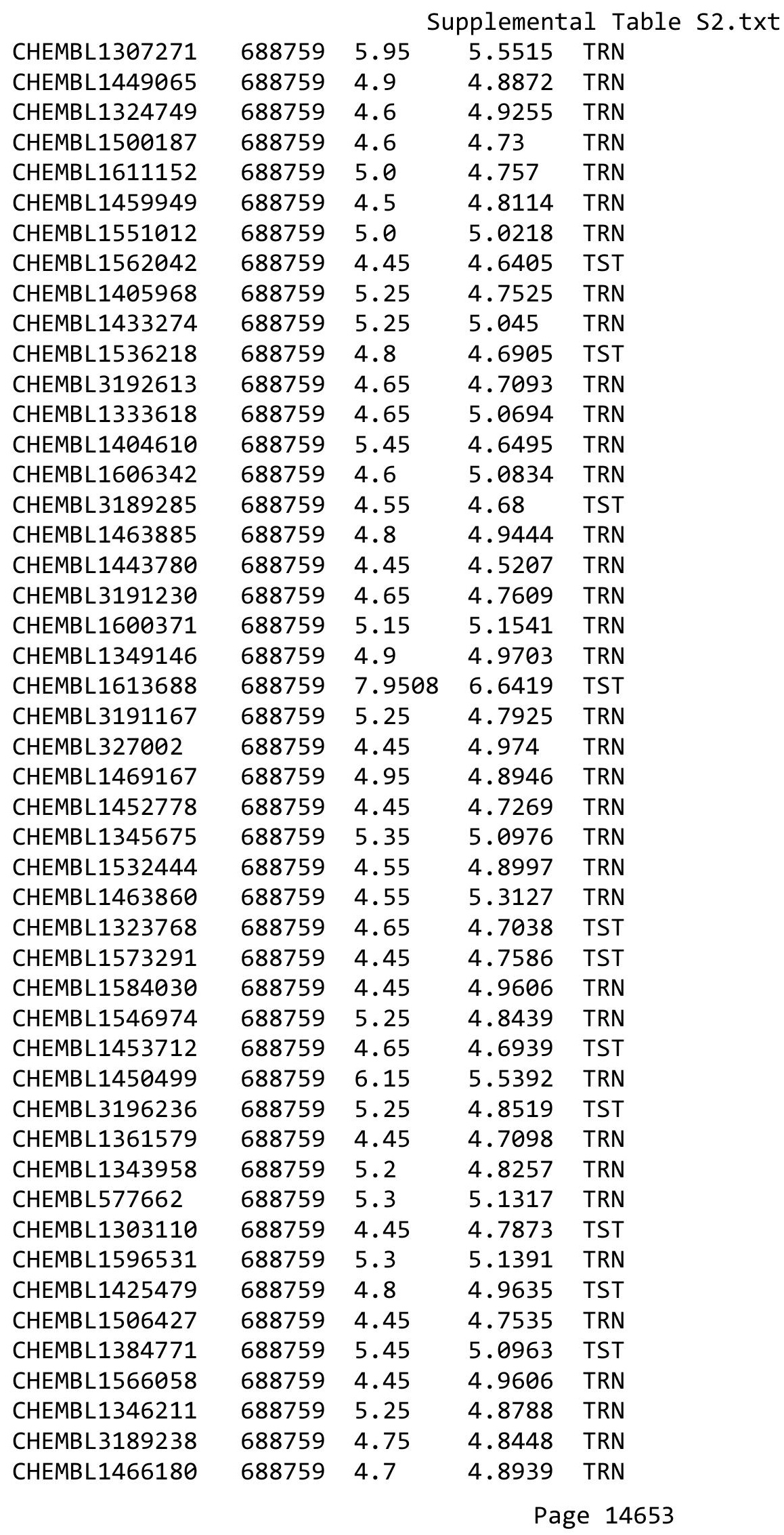




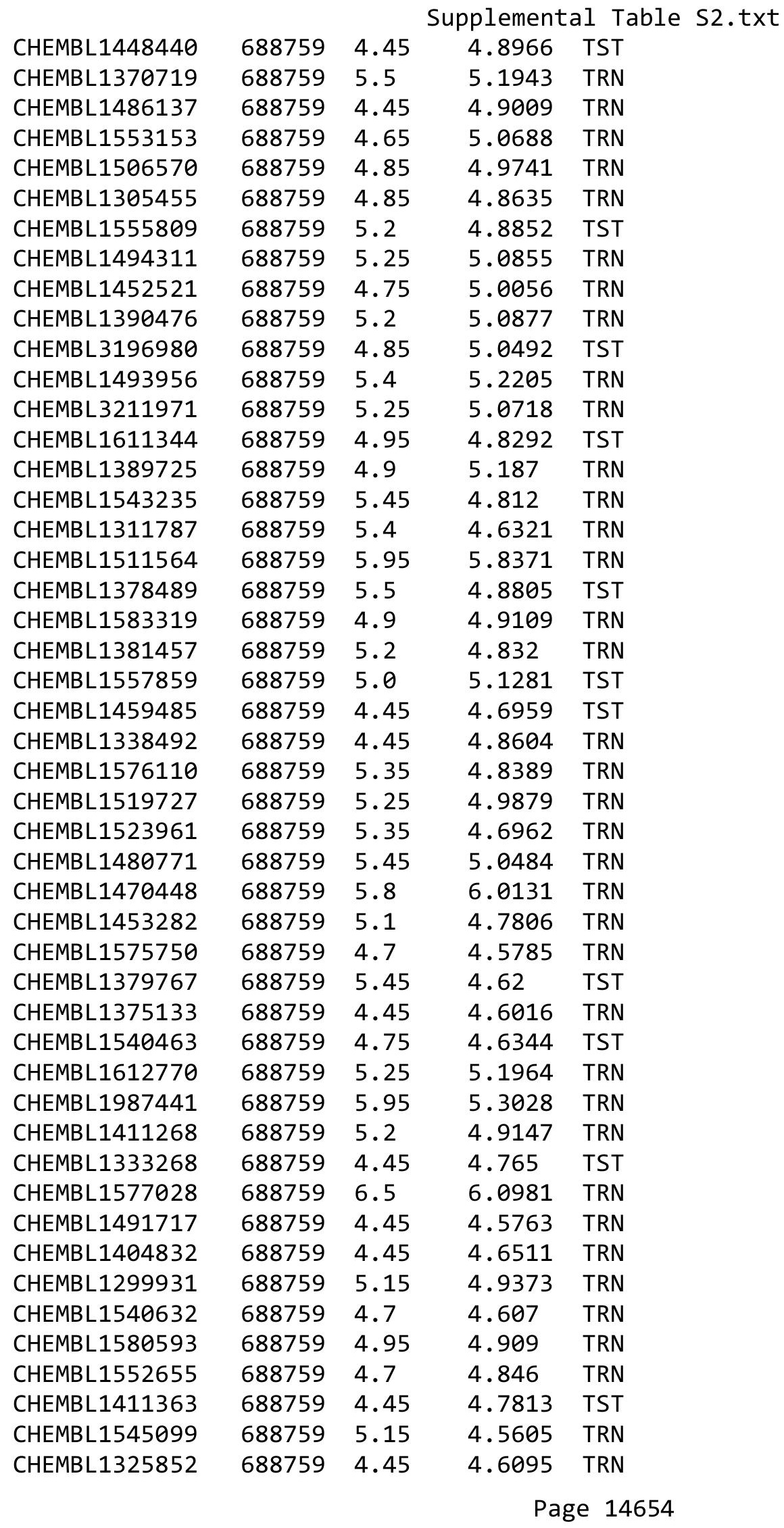




\begin{tabular}{|c|c|c|c|c|}
\hline \multicolumn{5}{|c|}{ Supplemental Table S2.txt } \\
\hline CHEMBL1557465 & 688759 & 4.45 & 4.7802 & TRN \\
\hline CHEMBL1501741 & 688759 & 4.45 & 4.5729 & TST \\
\hline CHEMBL3199323 & 688759 & 4.8 & 5.4481 & TRN \\
\hline CHEMBL1560165 & 688759 & 4.45 & 4.8299 & TRN \\
\hline CHEMBL1492677 & 688759 & 4.45 & 4.397 & TRN \\
\hline CHEMBL1613220 & 688759 & 6.0 & 5.3925 & TST \\
\hline CHEMBL1368361 & 688759 & 4.45 & 4.7378 & TST \\
\hline CHEMBL1429579 & 688759 & 4.45 & 4.718 & TRN \\
\hline CHEMBL1478602 & 688759 & 4.45 & 4.783 & TRN \\
\hline CHEMBL1489163 & 688759 & 4.45 & 4.95 & TRN \\
\hline CHEMBL1410093 & 688759 & 5.15 & 5.26 & TRN \\
\hline CHEMBL1469464 & 688759 & 4.45 & 4.6165 & TRN \\
\hline CHEMBL1506238 & 688759 & 4.65 & 4.7054 & TRN \\
\hline CHEMBL1516981 & 688759 & 5.1 & 5.0485 & TRN \\
\hline CHEMBL1324710 & 688759 & 4.85 & 4.9237 & TRN \\
\hline CHEMBL 200027 & 688759 & 4.45 & 4.593 & TST \\
\hline CHEMBL1570216 & 688759 & 5.95 & 5.0525 & TRN \\
\hline CHEMBL3192184 & 688759 & 5.4 & 5.0501 & TRN \\
\hline CHEMBL1381135 & 688759 & 4.85 & 4.8068 & TRN \\
\hline CHEMBL1594604 & 688759 & 4.9 & 4.6075 & TRN \\
\hline CHEMBL1443895 & 688759 & 4.85 & 4.9612 & TST \\
\hline CHEMBL1583254 & 688759 & 4.9 & 4.7595 & TRN \\
\hline CHEMBL1388430 & 688759 & 5.0 & 4.7691 & TRN \\
\hline CHEMBL1369496 & 688759 & 5.3 & 5.0299 & TRN \\
\hline CHEMBL1524484 & 688759 & 7.3497 & 5.482 & TRN \\
\hline CHEMBL1372428 & 688759 & 6.3 & 5.0033 & TRN \\
\hline CHEMBL1450728 & 688759 & 4.45 & 4.47 & TRN \\
\hline CHEMBL1580191 & 688759 & 5.3 & 4.9415 & TRN \\
\hline CHEMBL3195463 & 688759 & 5.5 & 4.7366 & TST \\
\hline CHEMBL1428758 & 688759 & 5.75 & 4.5911 & TRN \\
\hline CHEMBL1543776 & 688759 & 6.05 & 6.1019 & TRN \\
\hline CHEMBL1408814 & 688759 & 4.6 & 4.7175 & TRN \\
\hline CHEMBL1322385 & 688759 & 4.85 & 5.061 & TRN \\
\hline CHEMBL3145304 & 688759 & 5.95 & 5.479 & TRN \\
\hline CHEMBL1576272 & 688759 & 4.45 & 4.8622 & TST \\
\hline CHEMBL1507679 & 688759 & 5.15 & 4.8994 & TST \\
\hline CHEMBL1456099 & 688759 & 5.1 & 4.939 & TRN \\
\hline CHEMBL1376929 & 688759 & 4.45 & 4.96 & TST \\
\hline CHEMBL1518838 & 688759 & 4.45 & 4.697 & TST \\
\hline CHEMBL1562029 & 688759 & 5.2 & 4.9057 & TRN \\
\hline CHEMBL1604552 & 688759 & 4.6 & 4.8699 & TRN \\
\hline CHEMBL1608148 & 688759 & 5.3 & 4.8559 & TST \\
\hline CHEMBL583150 & 688759 & 5.65 & 5.2747 & TRN \\
\hline CHEMBL1413246 & 688759 & 4.8 & 4.7378 & TRN \\
\hline CHEMBL1441310 & 688759 & 4.95 & 4.8803 & TST \\
\hline CHEMBL1413639 & 688759 & 5.05 & 4.9251 & TRN \\
\hline CHEMBL1307240 & 688759 & 4.85 & 4.6896 & TST \\
\hline CHEMBL1408533 & 688759 & 4.45 & 4.6933 & TRN \\
\hline
\end{tabular}




\begin{tabular}{|c|c|c|c|c|}
\hline & & & upplemen & al $\mathrm{T}$ \\
\hline CHEMBL1360378 & 688759 & 4.9 & 4.8527 & TST \\
\hline CHEMBL1364036 & 688759 & 4.7 & 5.0017 & TRN \\
\hline CHEMBL1566853 & 688759 & 4.45 & 4.8765 & TRN \\
\hline CHEMBL1597389 & 688759 & 4.45 & 4.5511 & TRN \\
\hline CHEMBL1586771 & 688759 & 4.9 & 4.7776 & TST \\
\hline CHEMBL1536689 & 688759 & 5.2 & 5.3747 & TRN \\
\hline CHEMBL1312300 & 688759 & 4.9 & 4.895 & TRN \\
\hline CHEMBL1307362 & 688759 & 5.0 & 4.9001 & TST \\
\hline CHEMBL1496896 & 688759 & 4.45 & 4.875 & TRN \\
\hline CHEMBL120734 & 688759 & 5.55 & 5.2514 & TRN \\
\hline CHEMBL1360735 & 688759 & 4.7 & 4.5102 & TRN \\
\hline CHEMBL1576027 & 688759 & 4.45 & 4.43 & TRN \\
\hline CHEMBL1519544 & 688759 & 4.95 & 5.1666 & TRN \\
\hline CHEMBL 3144967 & 688759 & 4.8 & 4.7309 & TRN \\
\hline CHEMBL1557520 & 688759 & 4.75 & 4.7873 & TRN \\
\hline CHEMBL3190559 & 688759 & 4.45 & 4.7444 & TRN \\
\hline CHEMBL1313356 & 688759 & 4.8 & 4.7424 & TRN \\
\hline CHEMBL1461321 & 688759 & 4.95 & 4.7415 & TRN \\
\hline CHEMBL1328311 & 688759 & 4.65 & 4.8833 & TRN \\
\hline CHEMBL1517483 & 688759 & 4.45 & 4.5951 & TRN \\
\hline CHEMBL1442788 & 688759 & 5.55 & 5.2788 & TST \\
\hline CHEMBL1471587 & 688759 & 5.75 & 5.2356 & TRN \\
\hline CHEMBL1302681 & 688759 & 4.6 & 4.5814 & TRN \\
\hline CHEMBL1308558 & 688759 & 5.35 & 5.3027 & TRN \\
\hline CHEMBL1393594 & 688759 & 5.95 & 4.9185 & TST \\
\hline CHEMBL1530880 & 688759 & 4.45 & 4.8151 & TRN \\
\hline CHEMBL1400404 & 688759 & 4.7 & 4.7182 & TRN \\
\hline CHEMBL1521140 & 688759 & 4.65 & 4.4416 & TRN \\
\hline CHEMBL1320494 & 688759 & 4.45 & 4.6186 & TRN \\
\hline CHEMBL1566051 & 688759 & 4.6 & 4.8537 & TRN \\
\hline CHEMBL1979957 & 688759 & 4.6 & 4.8623 & TRN \\
\hline CHEMBL1413155 & 688759 & 4.45 & 4.8267 & TST \\
\hline CHEMBL1329733 & 688759 & 4.6 & 4.5997 & TRN \\
\hline CHEMBL1583295 & 688759 & 4.65 & 4.8566 & TRN \\
\hline CHEMBL1510714 & 688759 & 4.95 & 4.9069 & TRN \\
\hline CHEMBL1343711 & 688759 & 5.5 & 4.7931 & TRN \\
\hline CHEMBL1380082 & 688759 & 6.0 & 4.8059 & TST \\
\hline CHEMBL1319083 & 688759 & 4.45 & 4.5813 & TST \\
\hline CHEMBL1602964 & 688759 & 4.65 & 4.8455 & TST \\
\hline CHEMBL1422901 & 688759 & 5.05 & 4.7888 & TRN \\
\hline CHEMBL1588060 & 688759 & 4.7 & 4.8323 & TRN \\
\hline CHEMBL1581231 & 688759 & 4.95 & 5.2608 & TRN \\
\hline CHEMBL3145038 & 688759 & 4.45 & 4.8653 & TST \\
\hline CHEMBL1492540 & 688759 & 4.65 & 4.8173 & TST \\
\hline CHEMBL1302867 & 688759 & 5.55 & 4.7008 & TRN \\
\hline CHEMBL1427578 & 688759 & 4.85 & 4.9446 & TRN \\
\hline CHEMBL1522007 & 688759 & 5.65 & 5.2919 & TST \\
\hline CHEMBL1424815 & 688759 & 4.65 & 5.0651 & TRN \\
\hline
\end{tabular}




\begin{tabular}{|c|c|c|c|c|c|}
\hline \multicolumn{6}{|c|}{ Supplemental Table s2.txt } \\
\hline CHEMBL1308569 & 688759 & 6.0 & 4.865 & TRN & \\
\hline CHEMBL1387404 & 688759 & 4.55 & 4.5487 & TRN & \\
\hline CHEMBL1376423 & 688759 & 4.45 & 4.9362 & TRN & \\
\hline CHEMBL1438897 & 688759 & 5.25 & 4.7071 & TRN & \\
\hline CHEMBL1991710 & 688759 & 4.5 & 4.8488 & TRN & \\
\hline CHEMBL1310833 & 688759 & 5.35 & 4.9523 & TRN & \\
\hline CHEMBL1458024 & 688759 & 4.45 & \multicolumn{2}{|c|}{4.8180000000000005} & TRN \\
\hline CHEMBL1523905 & 688759 & 4.45 & 5.0179 & TRN & \\
\hline CHEMBL1312517 & 688759 & 6.1 & 4.8902 & TST & \\
\hline CHEMBL1609060 & 688759 & 4.65 & 4.6494 & TRN & \\
\hline CHEMBL1387232 & 688759 & 5.65 & 5.5134 & TRN & \\
\hline CHEMBL1442385 & 688759 & 5.2 & 5.0968 & TRN & \\
\hline CHEMBL3192555 & 688759 & 5.4 & 5.4782 & TRN & \\
\hline CHEMBL1611170 & 688759 & 4.45 & 4.7222 & TRN & \\
\hline CHEMBL1334936 & 688759 & 5.2 & 4.7912 & TRN & \\
\hline CHEMBL1415885 & 688759 & 5.0 & 4.7544 & TRN & \\
\hline CHEMBL429335 & 688759 & 5.15 & 4.8068 & TRN & \\
\hline CHEMBL1597726 & 688759 & 4.65 & 6.1921 & TRN & \\
\hline CHEMBL1439681 & 688759 & 4.45 & 4.7706 & TST & \\
\hline CHEMBL1304175 & 688759 & 5.25 & 4.8816 & TRN & \\
\hline CHEMBL1358468 & 688759 & 4.45 & 4.7069 & TST & \\
\hline CHEMBL1571574 & 688759 & 4.7 & 5.0791 & TST & \\
\hline CHEMBL1550564 & 688759 & 4.75 & 4.7211 & TST & \\
\hline CHEMBL1300645 & 688759 & 4.6 & 4.647 & TST & \\
\hline CHEMBL1500048 & 688759 & 4.45 & 4.7067 & TRN & \\
\hline CHEMBL1299720 & 688759 & 5.55 & 5.6584 & TRN & \\
\hline CHEMBL1391041 & 688759 & 5.75 & 4.79 & TST & \\
\hline CHEMBL3208210 & 688759 & 5.9 & 5.4986 & TRN & \\
\hline CHEMBL1605895 & 688759 & 4.9 & 4.7674 & TRN & \\
\hline CHEMBL1471788 & 688759 & 6.25 & 5.5771 & TRN & \\
\hline CHEMBL1407138 & 688759 & 6.05 & 5.148 & TRN & \\
\hline CHEMBL1375628 & 688759 & 4.85 & 5.0127 & TRN & \\
\hline CHEMBL1567335 & 688759 & 5.25 & 4.8169 & TRN & \\
\hline CHEMBL1303665 & 688759 & 5.2 & 4.7992 & TST & \\
\hline CHEMBL1610422 & 688759 & 4.65 & 4.6926 & TRN & \\
\hline CHEMBL3191364 & 688759 & 4.75 & 4.6095 & TRN & \\
\hline CHEMBL1441991 & 688759 & 5.55 & 5.2332 & TRN & \\
\hline CHEMBL1415337 & 688759 & 4.8 & 4.9727 & TRN & \\
\hline CHEMBL1498844 & 688759 & 4.6 & 5.2492 & TRN & \\
\hline CHEMBL1416603 & 688759 & 4.45 & 4.8859 & TRN & \\
\hline CHEMBL1336098 & 688759 & 4.6 & 5.5923 & TRN & \\
\hline CHEMBL1992800 & 688759 & 6.05 & 5.00899 & 99999999995 & TRN \\
\hline CHEMBL1605161 & 688759 & 4.65 & 5.0561 & TRN & \\
\hline CHEMBL1438431 & 688759 & 5.2 & 4.8344 & TST & \\
\hline CHEMBL1321224 & 688759 & 5.25 & 4.8909 & TRN & \\
\hline CHEMBL1326089 & 688759 & 4.6 & 4.8035 & TRN & \\
\hline CHEMBL1527779 & 688759 & 4.7 & 4.7035 & TST & \\
\hline CHEMBL1484515 & 688759 & 4.45 & 4.5838 & TRN & \\
\hline
\end{tabular}




\begin{tabular}{|c|c|c|c|c|c|}
\hline & & \multicolumn{4}{|c|}{ Supplemental Table S2.txt } \\
\hline CHEMBL1500545 & 688759 & 4.75 & 4.7355 & TRN & \\
\hline CHEMBL1442496 & 688759 & 4.5 & 4.7101 & TST & \\
\hline CHEMBL1467770 & 688759 & 4.65 & 4.762 & TST & \\
\hline CHEMBL1507781 & 688759 & 4.65 & 4.8184 & TRN & \\
\hline CHEMBL1566766 & 688759 & 4.45 & 4.9532 & TRN & \\
\hline CHEMBL1429677 & 688759 & 5.25 & 4.9528 & TRN & \\
\hline CHEMBL1576488 & 688759 & 5.1 & 5.027 & TST & \\
\hline CHEMBL1437997 & 688759 & 5.3 & 4.8278 & TST & \\
\hline CHEMBL1329587 & 688759 & 5.8 & 4.8302 & TRN & \\
\hline CHEMBL1535600 & 688759 & 4.45 & 4.819 & TST & \\
\hline CHEMBL1353723 & 688759 & 4.45 & 4.7193 & TRN & \\
\hline CHEMBL1465298 & 688759 & 4.65 & 4.927 & TRN & \\
\hline CHEMBL1300836 & 688759 & 4.85 & 4.8014 & TRN & \\
\hline CHEMBL1487485 & 688759 & 4.95 & 5.0299 & TRN & \\
\hline CHEMBL1378557 & 688759 & 5.15 & 5.2146 & TRN & \\
\hline CHEMBL1324417 & 688759 & 4.45 & 4.8 & TRN & \\
\hline CHEMBL1496706 & 688759 & 4.8 & 4.7634 & TRN & \\
\hline CHEMBL1323659 & 688759 & 4.45 & 4.7603 & TRN & \\
\hline CHEMBL1452165 & 688759 & 4.6 & 4.7141 & TRN & \\
\hline CHEMBL1515137 & 688759 & 4.45 & 4.6571 & TST & \\
\hline CHEMBL1989897 & 688759 & 5.55 & 5.2484 & TRN & \\
\hline CHEMBL1528089 & 688759 & 4.45 & 4.6209 & TST & \\
\hline CHEMBL1497482 & 688759 & 4.85 & 4.9403 & TST & \\
\hline CHEMBL1574887 & 688759 & 5.1 & 5.3011 & TRN & \\
\hline CHEMBL1306023 & 688759 & 5.0 & 4.8948 & TRN & \\
\hline CHEMBL1568018 & 688759 & 4.9 & 4.7575 & TRN & \\
\hline CHEMBL1367633 & 688759 & 4.7 & 4.6014 & TRN & \\
\hline CHEMBL498436 & 688759 & 4.5 & 4.6095 & TST & \\
\hline CHEMBL1373709 & 688759 & 6.0 & 5.0265 & TST & \\
\hline CHEMBL1462661 & 688759 & 4.65 & 4.8884 & TRN & \\
\hline CHEMBL1337414 & 688759 & 4.7 & 4.8329 & TST & \\
\hline CHEMBL1300430 & 688759 & 4.65 & 4.7343 & TRN & \\
\hline CHEMBL1360130 & 688759 & 4.45 & 4.8044 & TRN & \\
\hline CHEMBL3193473 & 688759 & 5.25 & 4.9036 & TRN & \\
\hline CHEMBL1345221 & 688759 & 5.35 & 4.9748 & TRN & \\
\hline CHEMBL1325494 & 688759 & 5.4 & 4.93199 & 99999999995 & TRN \\
\hline CHEMBL1448070 & 688759 & 4.45 & 4.5787 & TRN & \\
\hline CHEMBL1525775 & 688759 & 5.1 & 4.8378 & TRN & \\
\hline CHEMBL1372052 & 688759 & 5.2 & 5.1981 & TST & \\
\hline CHEMBL1390060 & 688759 & 4.8 & 4.8658 & TRN & \\
\hline CHEMBL1380398 & 688759 & 6.25 & 5.5738 & TRN & \\
\hline CHEMBL1410466 & 688759 & 4.45 & 5.0463 & TST & \\
\hline CHEMBL1425404 & 688759 & 4.85 & 4.8201 & TRN & \\
\hline CHEMBL3195447 & 688759 & 4.75 & 5.0081 & TRN & \\
\hline CHEMBL1305254 & 688759 & 5.5 & 4.9852 & TST & \\
\hline CHEMBL1530924 & 688759 & 6.05 & 5.0496 & TRN & \\
\hline CHEMBL1582584 & 688759 & 5.1 & 5.0568 & TRN & \\
\hline CHEMBL1350132 & 688759 & 4.95 & 4.9314 & TRN & \\
\hline
\end{tabular}




\begin{tabular}{|c|c|c|c|c|c|}
\hline & & \multicolumn{4}{|c|}{ Supplemental Table S2.txt } \\
\hline CHEMBL1482850 & 688759 & 4.45 & 4.939 & TST & \\
\hline CHEMBL1313119 & 688759 & 4.8 & 4.8989 & TRN & \\
\hline CHEMBL1411089 & 688759 & 4.8 & 4.8364 & TRN & \\
\hline CHEMBL1566617 & 688759 & 4.45 & 4.9098 & TST & \\
\hline CHEMBL1603123 & 688759 & 4.5 & 4.8316 & TRN & \\
\hline CHEMBL1588096 & 688759 & 5.2 & 4.5936 & TST & \\
\hline CHEMBL3194954 & 688759 & 4.65 & 5.0134 & TRN & \\
\hline CHEMBL1369337 & 688759 & 5.0 & 4.9969 & TST & \\
\hline CHEMBL1331312 & 688759 & 4.45 & \multicolumn{2}{|c|}{5.156000000000001} & TRN \\
\hline CHEMBL1427689 & 688759 & 4.7 & 4.6911 & TRN & \\
\hline CHEMBL1344501 & 688759 & 4.55 & 4.9455 & TRN & \\
\hline CHEMBL1533923 & 688759 & 4.45 & 5.2762 & TRN & \\
\hline CHEMBL3193818 & 688759 & 4.45 & 4.665 & TRN & \\
\hline CHEMBL1375414 & 688759 & 6.4 & 4.8395 & TST & \\
\hline CHEMBL1990527 & 688759 & 4.75 & 4.8751 & TRN & \\
\hline CHEMBL3192977 & 688759 & 6.9 & 5.1626 & TST & \\
\hline CHEMBL1382022 & 688759 & 4.55 & 4.6353 & TRN & \\
\hline CHEMBL1531787 & 688759 & 4.45 & 4.8194 & TST & \\
\hline CHEMBL1421286 & 688759 & 5.0 & 4.7661 & TRN & \\
\hline CHEMBL1601499 & 688759 & 4.75 & 5.1144 & TRN & \\
\hline CHEMBL1313643 & 688759 & 4.95 & 4.8343 & TRN & \\
\hline CHEMBL1415560 & 688759 & 4.8 & 4.9408 & TRN & \\
\hline CHEMBL1595152 & 688759 & 4.8 & 4.6538 & TST & \\
\hline CHEMBL3211170 & 688759 & 4.45 & 4.7031 & TRN & \\
\hline CHEMBL3210277 & 688759 & 4.6 & 4.6577 & TRN & \\
\hline CHEMBL1598800 & 688759 & 4.9 & 4.9341 & TST & \\
\hline CHEMBL3190162 & 688759 & 4.45 & 4.5573 & TRN & \\
\hline CHEMBL1497317 & 688759 & 4.65 & 4.5972 & TST & \\
\hline CHEMBL1323770 & 688759 & 4.65 & 5.1544 & TRN & \\
\hline CHEMBL1996749 & 688759 & 5.2 & 5.3184 & TRN & \\
\hline CHEMBL1466117 & 688759 & 4.95 & 4.7438 & TST & \\
\hline CHEMBL1536773 & 688759 & 4.45 & 4.9787 & TST & \\
\hline CHEMBL1352830 & 688759 & 4.45 & 4.7472 & TST & \\
\hline CHEMBL1589434 & 688759 & 5.25 & 4.8225 & TRN & \\
\hline CHEMBL512749 & 688759 & 5.15 & 5.25799 & 9999999999 & TRN \\
\hline CHEMBL1469303 & 688759 & 4.9 & 4.7637 & TRN & \\
\hline CHEMBL1513079 & 688759 & 5.15 & 5.1 & TRN & \\
\hline CHEMBL1459087 & 688759 & 4.65 & 4.7602 & TRN & \\
\hline CHEMBL 2002062 & 688759 & 4.7 & 4.8114 & TRN & \\
\hline CHEMBL 2003688 & 688759 & 5.9 & 5.5132 & TRN & \\
\hline CHEMBL1503313 & 688759 & 5.25 & 5.0154 & TRN & \\
\hline CHEMBL1428711 & 688759 & 4.45 & 4.7613 & TRN & \\
\hline CHEMBL1344930 & 688759 & 5.25 & 4.8212 & TRN & \\
\hline CHEMBL1369671 & 688759 & 4.9 & 4.6872 & TRN & \\
\hline CHEMBL1367235 & 688759 & 4.45 & 4.6024 & TRN & \\
\hline CHEMBL1508646 & 688759 & 4.7 & 4.6278 & TRN & \\
\hline CHEMBL1313548 & 688759 & 6.9 & 5.3068 & TRN & \\
\hline CHEMBL1301582 & 688759 & 5.3 & 5.2686 & TST & \\
\hline
\end{tabular}




\begin{tabular}{|c|c|c|c|c|}
\hline \multicolumn{5}{|c|}{ Supplemental Table S2.txt } \\
\hline CHEMBL1502819 & 688759 & 5.25 & 4.8945 & TRN \\
\hline CHEMBL1542862 & 688759 & 5.45 & 5.1683 & TRN \\
\hline CHEMBL1407228 & 688759 & 4.6 & 4.6884 & TST \\
\hline CHEMBL1602769 & 688759 & 4.6 & 4.8538 & TRN \\
\hline CHEMBL1342745 & 688759 & 4.45 & 4.9668 & TRN \\
\hline CHEMBL1966283 & 688759 & 5.3 & 5.5025 & TRN \\
\hline CHEMBL1439573 & 688759 & 4.9 & 5.1738 & TRN \\
\hline CHEMBL3196532 & 688759 & 4.85 & 4.8637 & TST \\
\hline CHEMBL1539787 & 688759 & 4.9 & 4.9146 & TRN \\
\hline CHEMBL1388113 & 688759 & 5.2 & 4.6891 & TST \\
\hline CHEMBL1514957 & 688759 & 5.55 & 4.9273 & TRN \\
\hline CHEMBL1549035 & 688759 & 5.0 & 4.7604 & TRN \\
\hline CHEMBL1370965 & 688759 & 4.45 & 4.835 & TRN \\
\hline CHEMBL3190585 & 688759 & 4.7 & 4.7785 & TRN \\
\hline CHEMBL1587027 & 688759 & 5.05 & 4.9045 & TST \\
\hline CHEMBL1342047 & 688759 & 4.45 & 4.6323 & TRN \\
\hline CHEMBL1978193 & 688759 & 5.2 & 4.7552 & TRN \\
\hline CHEMBL1398931 & 688759 & 4.6 & 4.9244 & TRN \\
\hline CHEMBL 2134991 & 688759 & 4.45 & 4.7791 & TST \\
\hline CHEMBL1379171 & 688759 & 6.0 & 5.2633 & TST \\
\hline CHEMBL1535529 & 688759 & 4.9 & 5.1565 & TRN \\
\hline CHEMBL1611364 & 688759 & 5.0 & 5.1221 & TRN \\
\hline CHEMBL1577071 & 688759 & 5.8 & 4.9671 & TRN \\
\hline CHEMBL1966905 & 688759 & 4.45 & 4.7905 & TRN \\
\hline CHEMBL1501328 & 688759 & 4.6 & 5.0354 & TRN \\
\hline CHEMBL1536572 & 688759 & 6.1 & 5.444 & TRN \\
\hline CHEMBL1323052 & 688759 & 5.55 & 5.0952 & TRN \\
\hline CHEMBL1302425 & 688759 & 4.45 & 5.004 & TST \\
\hline CHEMBL1539620 & 688759 & 4.45 & 4.6152 & TRN \\
\hline CHEMBL1558701 & 688759 & 4.6 & 4.4627 & TRN \\
\hline CHEMBL3199368 & 688759 & 4.85 & 4.8633 & TST \\
\hline CHEMBL1446067 & 688759 & 5.05 & 5.1826 & TRN \\
\hline CHEMBL1347491 & 688759 & 4.85 & 5.0806 & TRN \\
\hline CHEMBL1491635 & 688759 & 4.45 & 5.0027 & TRN \\
\hline CHEMBL1304405 & 688759 & 4.45 & 4.9247 & TRN \\
\hline CHEMBL1579015 & 688759 & 4.95 & 4.7665 & TRN \\
\hline CHEMBL1381397 & 688759 & 4.55 & 4.6175 & TST \\
\hline CHEMBL1980574 & 688759 & 4.8 & 4.6886 & TRN \\
\hline CHEMBL1366891 & 688759 & 4.9 & 5.4227 & TST \\
\hline CHEMBL1314172 & 688759 & 4.75 & 4.7367 & TRN \\
\hline CHEMBL1544679 & 688759 & 4.95 & 4.7978 & TRN \\
\hline CHEMBL1606520 & 688759 & 4.6 & 5.0091 & TRN \\
\hline CHEMBL1507854 & 688759 & 4.45 & 4.8815 & TRN \\
\hline CHEMBL1530409 & 688759 & 5.25 & 5.1066 & TRN \\
\hline CHEMBL1499122 & 688759 & 5.4 & 4.7767 & TRN \\
\hline CHEMBL1453731 & 688759 & 5.25 & 5.4116 & TRN \\
\hline CHEMBL1561379 & 688759 & 4.45 & 4.7985 & TRN \\
\hline CHEMBL1986805 & 688759 & 4.85 & 4.8804 & TRN \\
\hline
\end{tabular}




\begin{tabular}{|c|c|c|c|c|c|}
\hline \multicolumn{6}{|c|}{ Supplemental Table S2.txt } \\
\hline CHEMBL1612624 & 688759 & 4.45 & 5.022 & TST & \\
\hline CHEMBL1422270 & 688759 & 4.7 & 4.88 & TST & \\
\hline CHEMBL1547471 & 688759 & 4.7 & 4.8331 & TST & \\
\hline CHEMBL1550634 & 688759 & 4.8 & 4.9499 & TRN & \\
\hline CHEMBL1415826 & 688759 & 4.8 & 4.9827 & TRN & \\
\hline CHEMBL1341097 & 688759 & 4.45 & 4.7024 & TRN & \\
\hline CHEMBL3193332 & 688759 & 5.45 & 5.073 & TRN & \\
\hline CHEMBL1588853 & 688759 & 5.0 & 5.0398 & TRN & \\
\hline CHEMBL1386558 & 688759 & 5.2 & 4.9955 & TRN & \\
\hline CHEMBL3198259 & 688759 & 4.65 & 4.9195 & TRN & \\
\hline CHEMBL1322657 & 688759 & 4.7 & 4.9464 & TRN & \\
\hline CHEMBL 2004241 & 688759 & 4.7 & 4.7798 & TST & \\
\hline CHEMBL1988042 & 688759 & 5.3 & 5.2011 & TRN & \\
\hline CHEMBL1306377 & 688759 & 4.45 & 4.7678 & TRN & \\
\hline CHEMBL1402069 & 688759 & 4.45 & 5.229 & TST & \\
\hline CHEMBL1550202 & 688759 & 6.5501 & 4.9895 & TRN & \\
\hline CHEMBL1471716 & 688759 & 5.0 & 5.2064 & TRN & \\
\hline CHEMBL1382132 & 688759 & 4.95 & 4.7646 & TRN & \\
\hline CHEMBL1598139 & 688759 & 4.95 & 4.6945 & TRN & \\
\hline CHEMBL1349387 & 688759 & 5.5 & 5.3945 & TRN & \\
\hline CHEMBL1305766 & 688759 & 5.1 & 4.95100 & 00000000005 & TST \\
\hline CHEMBL1995645 & 688759 & 5.15 & 4.9172 & TRN & \\
\hline CHEMBL1606935 & 688759 & 4.8 & 4.7244 & TRN & \\
\hline CHEMBL1321826 & 688759 & 4.45 & 4.6949 & TST & \\
\hline CHEMBL1429406 & 688759 & 4.6 & 4.8408 & TRN & \\
\hline CHEMBL1490077 & 688759 & 5.0 & 4.8808 & TRN & \\
\hline CHEMBL1432524 & 688759 & 4.45 & 4.8801 & TRN & \\
\hline CHEMBL1337570 & 688759 & 4.6 & 4.5963 & TRN & \\
\hline CHEMBL1389332 & 688759 & 5.95 & 5.5814 & TRN & \\
\hline CHEMBL1366199 & 688759 & 4.45 & 4.8188 & TRN & \\
\hline CHEMBL1426912 & 688759 & 6.3 & 6.0455 & TRN & \\
\hline CHEMBL211969 & 688759 & 4.45 & 4.7578 & TST & \\
\hline CHEMBL1980204 & 688759 & 4.5 & 4.9351 & TRN & \\
\hline CHEMBL1404009 & 688759 & 5.6 & 4.7521 & TRN & \\
\hline CHEMBL1382175 & 688759 & 4.45 & 4.9053 & TRN & \\
\hline CHEMBL1443169 & 688759 & 4.65 & 5.0007 & TRN & \\
\hline CHEMBL1527217 & 688759 & 6.2 & 5.0223 & TRN & \\
\hline CHEMBL1505116 & 688759 & 4.45 & 5.2395 & TRN & \\
\hline CHEMBL1508175 & 688759 & 4.45 & 4.792 & TRN & \\
\hline CHEMBL1483794 & 688759 & 4.65 & 4.6899 & TRN & \\
\hline CHEMBL1588780 & 688759 & 5.95 & 5.7266 & TRN & \\
\hline CHEMBL1541199 & 688759 & 4.45 & 4.5362 & TRN & \\
\hline CHEMBL3208140 & 688759 & 4.85 & 4.9967 & TRN & \\
\hline CHEMBL1330152 & 688759 & 4.65 & 4.8071 & TRN & \\
\hline CHEMBL1517699 & 688759 & 4.65 & 4.7071 & TST & \\
\hline CHEMBL1577635 & 688759 & 4.45 & 4.7491 & TRN & \\
\hline CHEMBL1409627 & 688759 & 5.25 & 4.7993 & TRN & \\
\hline CHEMBL1564919 & 688759 & 5.4 & 4.958 & TRN & \\
\hline
\end{tabular}




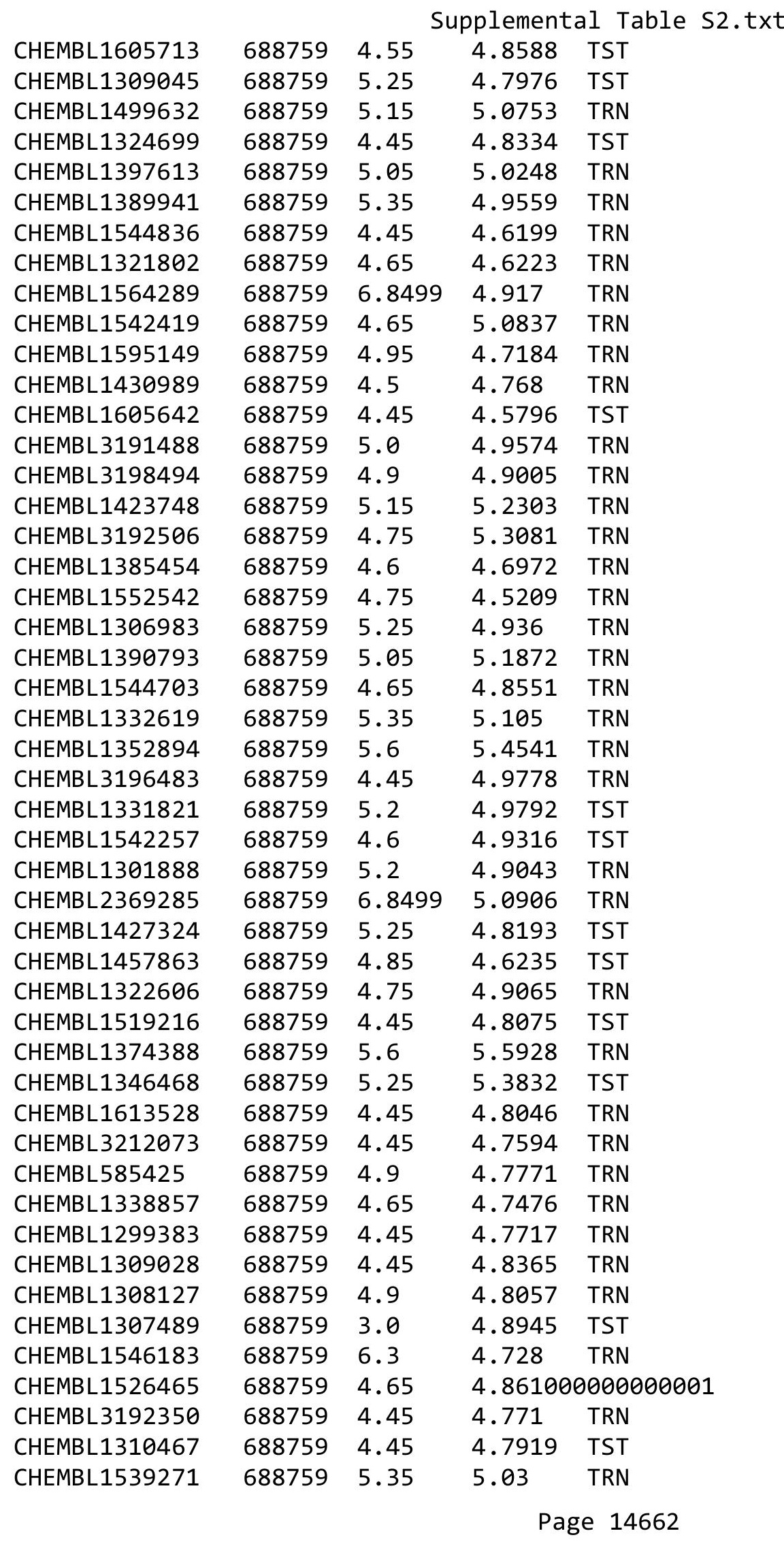




\begin{tabular}{|c|c|c|c|c|c|}
\hline \multicolumn{6}{|c|}{ Supplemental Table S2.txt } \\
\hline CHEMBL1598652 & 688759 & 5.1 & 4.7213 & TRN & \\
\hline CHEMBL3196652 & 688759 & 5.4 & 4.9807 & TRN & \\
\hline CHEMBL1370681 & 688759 & 5.25 & 4.949 & TRN & \\
\hline CHEMBL1560661 & 688759 & 4.7 & 5.25200 & 0000000001 & TRN \\
\hline CHEMBL 3195005 & 688759 & 4.5 & 4.484 & TRN & \\
\hline CHEMBL1469259 & 688759 & 4.85 & 4.5787 & TST & \\
\hline CHEMBL1501660 & 688759 & 5.65 & 5.0408 & TRN & \\
\hline CHEMBL2005079 & 688759 & 4.7 & 5.0944 & TST & \\
\hline CHEMBL1489984 & 688759 & 4.7 & 4.7663 & TRN & \\
\hline CHEMBL1482951 & 688759 & 5.35 & 5.1156 & TRN & \\
\hline CHEMBL1367543 & 688759 & 4.55 & 5.23600 & 0000000001 & TRN \\
\hline CHEMBL1420795 & 688759 & 4.65 & 4.8732 & TRN & \\
\hline CHEMBL1531358 & 688759 & 4.9 & 4.8429 & TRN & \\
\hline CHEMBL1335731 & 688759 & 4.65 & 4.5483 & TRN & \\
\hline CHEMBL1301790 & 688759 & 4.65 & 4.6634 & TRN & \\
\hline CHEMBL3189893 & 688759 & 4.45 & 4.8928 & TRN & \\
\hline CHEMBL1503794 & 688759 & 4.6 & 4.9801 & TST & \\
\hline CHEMBL1462733 & 688759 & 5.05 & 4.7346 & TST & \\
\hline CHEMBL 3392427 & 688759 & 5.45 & 5.1893 & TRN & \\
\hline CHEMBL1507160 & 688759 & 4.65 & 4.9054 & TRN & \\
\hline CHEMBL1969298 & 688759 & 4.95 & 4.8167 & TRN & \\
\hline CHEMBL1374244 & 688759 & 4.45 & 4.9893 & TRN & \\
\hline CHEMBL1452158 & 688759 & 4.6 & 4.9864 & TST & \\
\hline CHEMBL1413519 & 688759 & 4.45 & 4.8531 & TRN & \\
\hline CHEMBL 1477866 & 688759 & 5.25 & 4.7535 & TRN & \\
\hline CHEMBL3209478 & 688759 & 5.2 & 4.8581 & TRN & \\
\hline CHEMBL1383181 & 688759 & 4.45 & 5.1362 & TST & \\
\hline CHEMBL1585503 & 688759 & 4.65 & 4.7031 & TST & \\
\hline CHEMBL 3190273 & 688759 & 5.35 & 5.4222 & TRN & \\
\hline CHEMBL3199127 & 688759 & 5.1 & 4.9785 & TRN & \\
\hline CHEMBL1536556 & 688759 & 5.4 & 4.7566 & TST & \\
\hline CHEMBL 3192864 & 688759 & 4.7 & 4.5662 & TRN & \\
\hline CHEMBL 3189848 & 688759 & 5.4 & 5.0222 & TST & \\
\hline CHEMBL 3210860 & 688759 & 4.8 & 5.2273 & TRN & \\
\hline CHEMBL1578079 & 688759 & 5.0 & 4.8436 & TST & \\
\hline CHEMBL3194616 & 688759 & 5.35 & 4.789 & TST & \\
\hline CHEMBL1970032 & 688759 & 4.75 & 4.7544 & TRN & \\
\hline CHEMBL1388832 & 688759 & 4.45 & 4.9797 & TST & \\
\hline CHEMBL1604924 & 688759 & 4.65 & 4.8788 & TST & \\
\hline CHEMBL1466491 & 688759 & 5.3 & 4.9852 & TRN & \\
\hline CHEMBL1409488 & 688759 & 4.9 & 4.9511 & TRN & \\
\hline CHEMBL1509082 & 688759 & 4.6 & 4.9164 & TRN & \\
\hline CHEMBL1420354 & 688759 & 4.45 & 4.7742 & TRN & \\
\hline CHEMBL 3193493 & 688759 & 4.45 & 4.7114 & TRN & \\
\hline CHEMBL1611832 & 688759 & 4.5 & 4.6624 & TRN & \\
\hline CHEMBL1527899 & 688759 & 6.7501 & 5.1343 & TRN & \\
\hline CHEMBL1467769 & 688759 & 4.6 & 4.8454 & TRN & \\
\hline CHEMBL1375233 & 688759 & 5.05 & 5.0278 & TRN & \\
\hline
\end{tabular}




\begin{tabular}{|c|c|c|c|c|c|}
\hline \multirow[b]{2}{*}{ CHEMBL1497016 } & \multicolumn{5}{|c|}{ Supplemental Table S2.txt } \\
\hline & 688759 & 4.65 & 4.7721 & TRN & \\
\hline CHEMBL1328394 & 688759 & 7.6003 & 4.9283 & TRN & \\
\hline CHEMBL1343946 & 688759 & 4.45 & 4.8203 & TRN & \\
\hline CHEMBL1566511 & 688759 & 5.4 & 5.0067 & TRN & \\
\hline CHEMBL1332102 & 688759 & 4.45 & 4.7389 & TST & \\
\hline CHEMBL1556773 & 688759 & 4.7 & 4.7247 & TST & \\
\hline CHEMBL1364842 & 688759 & 4.45 & 4.8105 & TST & \\
\hline CHEMBL1454195 & 688759 & 4.75 & 4.4664 & TRN & \\
\hline CHEMBL1351716 & 688759 & 4.65 & 4.6341 & TST & \\
\hline CHEMBL1600726 & 688759 & 4.45 & 4.8244 & TST & \\
\hline CHEMBL1494713 & 688759 & 4.55 & 4.7054 & TST & \\
\hline CHEMBL1550476 & 688759 & 4.55 & 4.6906 & TRN & \\
\hline CHEMBL3193248 & 688759 & 4.65 & 4.8998 & TST & \\
\hline CHEMBL1440123 & 688759 & 4.65 & 4.8203 & TRN & \\
\hline CHEMBL1431296 & 688759 & 4.6 & 4.9711 & TRN & \\
\hline CHEMBL1415796 & 688759 & 6.0 & 5.032 & TRN & \\
\hline CHEMBL1477837 & 688759 & 4.45 & 4.9698 & TRN & \\
\hline CHEMBL1496347 & 688759 & 5.25 & 5.0265 & TRN & \\
\hline CHEMBL1427096 & 688759 & 5.2 & 4.8888 & TRN & \\
\hline CHEMBL1507132 & 688759 & 4.95 & 4.7956 & TRN & \\
\hline CHEMBL1583716 & 688759 & 4.45 & 4.7716 & TST & \\
\hline CHEMBL3191792 & 688759 & 4.45 & 4.6974 & TRN & \\
\hline CHEMBL85139 & 688759 & 4.9 & 4.8665 & TST & \\
\hline CHEMBL 1359447 & 688759 & 5.55 & 4.8438 & TST & \\
\hline CHEMBL1558840 & 688759 & 5.1 & 4.9426 & TRN & \\
\hline CHEMBL3198483 & 688759 & 4.45 & 4.7706 & TRN & \\
\hline CHEMBL3198227 & 688759 & 4.95 & 5.2984 & TRN & \\
\hline CHEMBL1385734 & 688759 & 4.45 & 4.902 & TRN & \\
\hline CHEMBL1332567 & 688759 & 5.05 & 4.9826 & TRN & \\
\hline CHEMBL210658 & 688759 & 6.1 & 5.54200 & 0000000001 & TRN \\
\hline CHEMBL1376392 & 688759 & 5.35 & 5.0599 & TST & \\
\hline CHEMBL1308619 & 688759 & 4.45 & 4.7654 & TRN & \\
\hline CHEMBL3209511 & 688759 & 5.3 & 4.9017 & TRN & \\
\hline CHEMBL1481132 & 688759 & 4.65 & 4.7241 & TRN & \\
\hline CHEMBL1505435 & 688759 & 4.8 & 5.0305 & TRN & \\
\hline CHEMBL1535387 & 688759 & 4.9 & 4.8392 & TRN & \\
\hline CHEMBL3191726 & 688759 & 4.8 & 5.0176 & TRN & \\
\hline CHEMBL1487709 & 688759 & 7.3497 & 4.8317 & TST & \\
\hline CHEMBL1514401 & 688759 & 5.35 & 4.9151 & TRN & \\
\hline CHEMBL1595841 & 688759 & 4.6 & 4.6919 & TRN & \\
\hline CHEMBL1471252 & 688759 & 4.45 & 4.7333 & TRN & \\
\hline CHEMBL1538398 & 688759 & 5.45 & 5.0482 & TST & \\
\hline CHEMBL1545727 & 688759 & 4.45 & 4.7558 & TRN & \\
\hline CHEMBL1479720 & 688759 & 5.55 & 4.7232 & TST & \\
\hline CHEMBL1979063 & 688759 & 4.45 & 4.7159 & TST & \\
\hline CHEMBL1999161 & 688759 & 5.0 & 5.2962 & TRN & \\
\hline CHEMBL1427479 & 688759 & 5.25 & 4.9505 & TRN & \\
\hline CHEMBL1440799 & 688759 & 4.65 & 4.8872 & TRN & \\
\hline
\end{tabular}




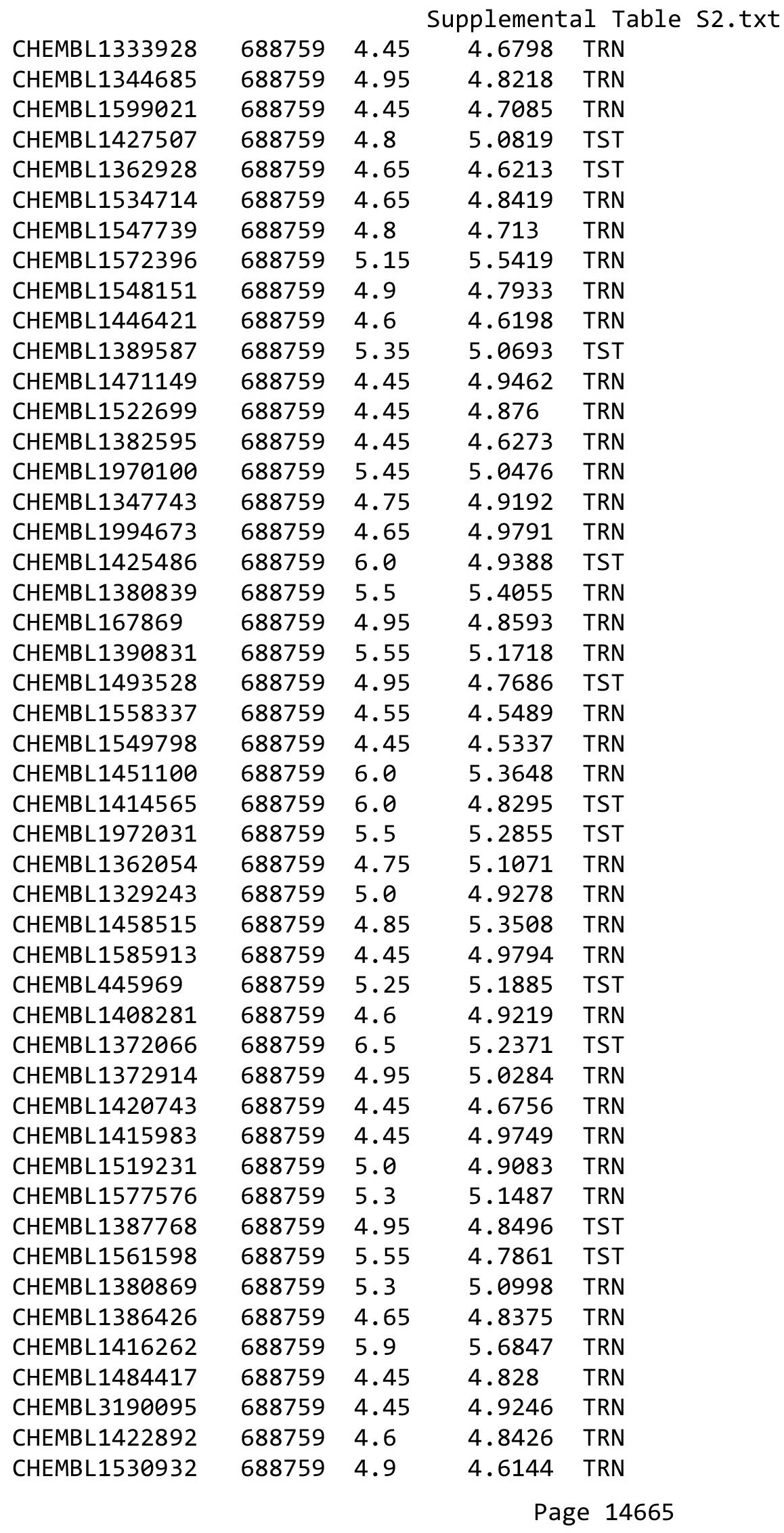




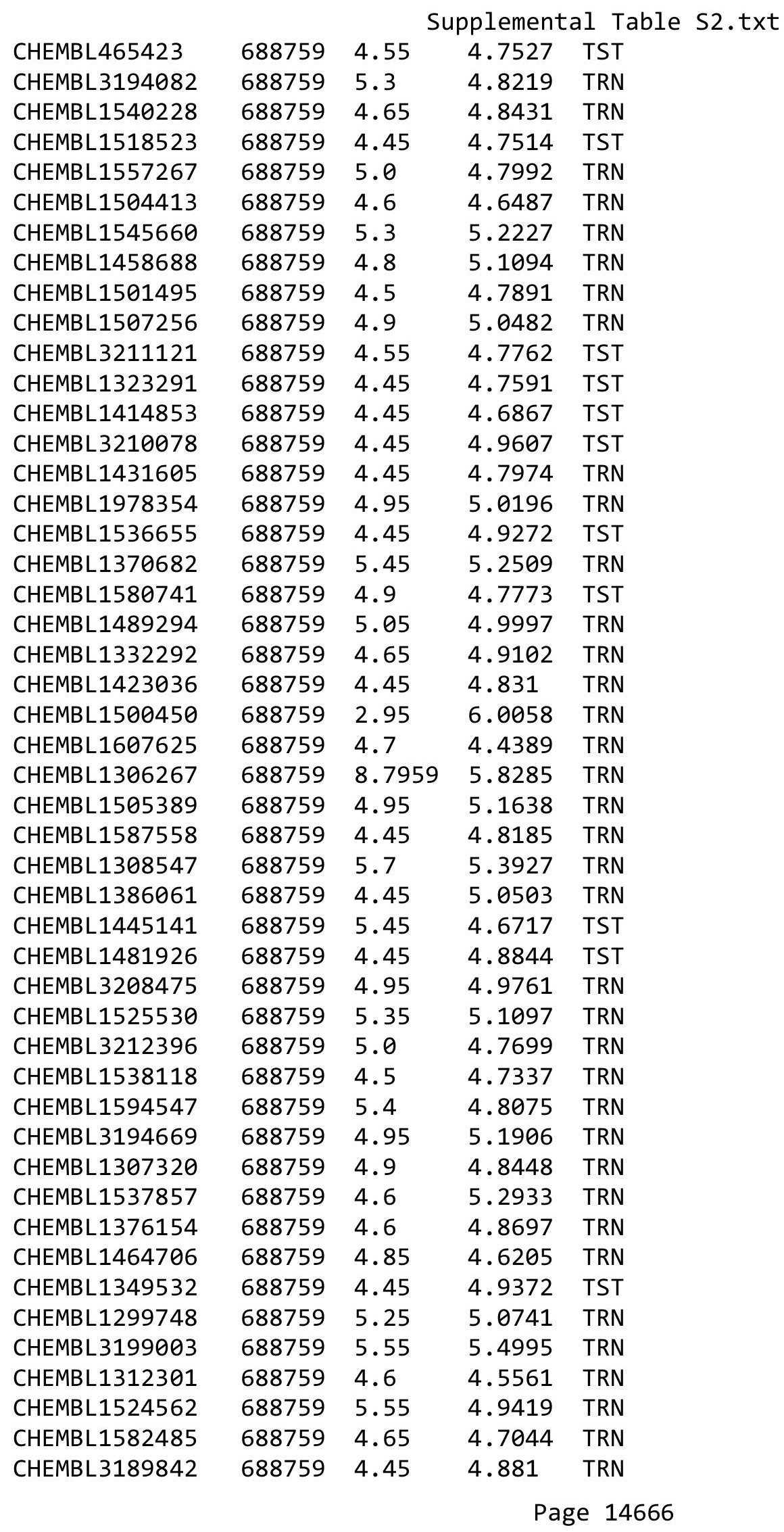




\begin{tabular}{|c|c|c|c|c|c|}
\hline \multicolumn{6}{|c|}{ Supplemental Table S2.txt } \\
\hline CHEMBL1509000 & 688759 & 5.35 & 5.2958 & TRN & \\
\hline CHEMBL1416756 & 688759 & 4.8 & 5.1775 & TRN & \\
\hline CHEMBL1417036 & 688759 & 5.2 & 4.6049 & TRN & \\
\hline CHEMBL1457690 & 688759 & 4.9 & 4.7359 & TRN & \\
\hline CHEMBL1301700 & 688759 & 4.8 & 4.868 & TRN & \\
\hline CHEMBL1463904 & 688759 & 5.25 & 4.8942 & TRN & \\
\hline CHEMBL1967105 & 688759 & 4.6 & 4.9991 & TRN & \\
\hline CHEMBL1419561 & 688759 & 4.75 & 4.948 & TST & \\
\hline CHEMBL1382750 & 688759 & 5.4 & 4.9201 & TST & \\
\hline CHEMBL1447358 & 688759 & 6.2 & 4.9334 & TRN & \\
\hline CHEMBL 2359467 & 688759 & 4.6 & 4.9069 & TST & \\
\hline CHEMBL1608143 & 688759 & 5.3 & 4.8938 & TST & \\
\hline CHEMBL1594890 & 688759 & 4.6 & 4.7972 & TRN & \\
\hline CHEMBL1508701 & 688759 & 4.45 & 4.9536 & TRN & \\
\hline CHEMBL1497426 & 688759 & 4.45 & 4.8642 & TRN & \\
\hline CHEMBL1599873 & 688759 & 4.9 & 5.0765 & TST & \\
\hline CHEMBL1302139 & 688759 & 5.3 & 5.0982 & TRN & \\
\hline CHEMBL3199762 & 688759 & 4.45 & 4.8809 & TRN & \\
\hline CHEMBL1415320 & 688759 & 5.25 & 4.9651 & TST & \\
\hline CHEMBL1559143 & 688759 & 4.45 & 4.5201 & TRN & \\
\hline CHEMBL3191021 & 688759 & 4.6 & 4.9386 & TRN & \\
\hline CHEMBL3208263 & 688759 & 4.45 & 4.8667 & TST & \\
\hline CHEMBL1593371 & 688759 & 4.45 & 4.7487 & TRN & \\
\hline CHEMBL1977747 & 688759 & 6.1 & 5.83799 & 7999999999 & TRN \\
\hline CHEMBL1556818 & 688759 & 5.15 & 4.8015 & TRN & \\
\hline CHEMBL3198886 & 688759 & 5.85 & 6.1014 & TRN & \\
\hline CHEMBL1550218 & 688759 & 4.45 & 4.8712 & TRN & \\
\hline CHEMBL1342950 & 688759 & 5.5 & 5.3741 & TRN & \\
\hline CHEMBL1582739 & 688759 & 5.25 & 4.9926 & TRN & \\
\hline CHEMBL1535696 & 688759 & 4.5 & 4.753 & TRN & \\
\hline CHEMBL1485256 & 688759 & 6.35 & 4.9482 & TST & \\
\hline CHEMBL1375765 & 688759 & 7.3497 & 5.0028 & TRN & \\
\hline CHEMBL567551 & 688759 & 4.6 & 4.855 & TRN & \\
\hline CHEMBL1608781 & 688759 & 4.45 & 4.8864 & TRN & \\
\hline CHEMBL1327494 & 688759 & 5.95 & 4.7374 & TRN & \\
\hline CHEMBL1346974 & 688759 & 4.55 & 4.6312 & TRN & \\
\hline CHEMBL1567314 & 688759 & 4.9 & 4.7152 & TRN & \\
\hline CHEMBL1339548 & 688759 & 5.45 & 5.1523 & TRN & \\
\hline CHEMBL1586066 & 688759 & 4.6 & 4.7358 & TST & \\
\hline CHEMBL572806 & 688759 & 4.45 & 4.8404 & TST & \\
\hline CHEMBL1589360 & 688759 & 4.75 & 4.963 & TRN & \\
\hline CHEMBL1301445 & 688759 & 4.7 & 4.9175 & TST & \\
\hline CHEMBL1347586 & 688759 & 4.45 & 5.2593 & TRN & \\
\hline CHEMBL1492160 & 688759 & 4.65 & 4.8285 & TRN & \\
\hline CHEMBL1461874 & 688759 & 4.45 & 4.8709 & TRN & \\
\hline CHEMBL1412723 & 688759 & 4.7 & 5.0086 & TRN & \\
\hline CHEMBL3209274 & 688759 & 4.45 & 4.667 & TRN & \\
\hline CHEMBL1605851 & 688759 & 4.8 & 4.8113 & TRN & \\
\hline
\end{tabular}




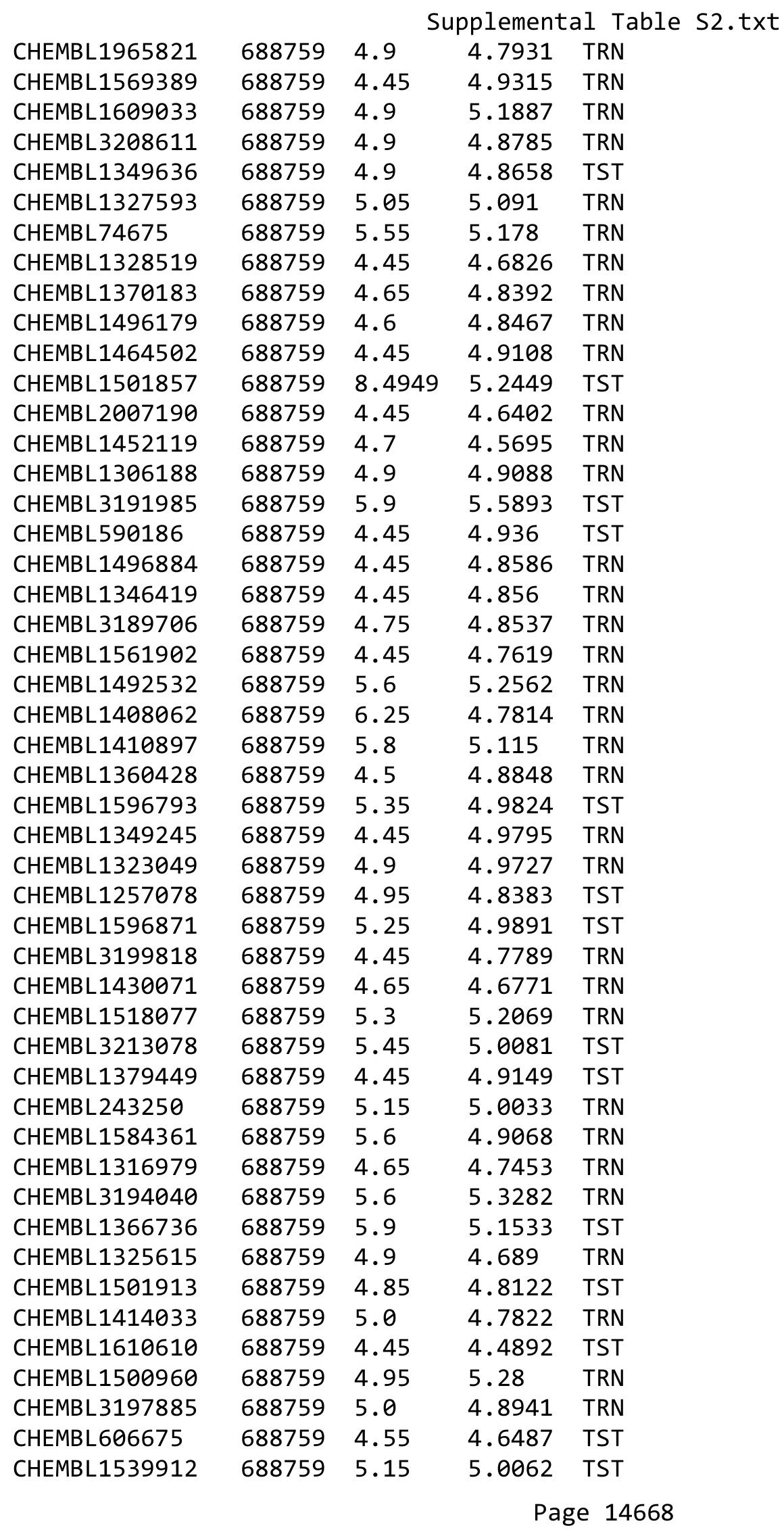




\begin{tabular}{|c|c|c|c|c|c|}
\hline & & \multicolumn{4}{|c|}{ Supplemental Table s2.txt } \\
\hline CHEMBL1343735 & 688759 & 4.95 & 4.7657 & TST & \\
\hline CHEMBL1389399 & 688759 & 4.95 & 5.0094 & TST & \\
\hline CHEMBL1613163 & 688759 & 4.45 & 4.7616 & TST & \\
\hline CHEMBL1425985 & 688759 & 4.45 & 4.6518 & TRN & \\
\hline CHEMBL1399908 & 688759 & 4.65 & 4.8568 & TRN & \\
\hline CHEMBL1382279 & 688759 & 4.65 & 4.6975 & TRN & \\
\hline CHEMBL1458403 & 688759 & 4.55 & 4.8151 & TST & \\
\hline CHEMBL1569268 & 688759 & 5.55 & 4.9813 & TST & \\
\hline CHEMBL3209703 & 688759 & 4.85 & 4.8639 & TRN & \\
\hline CHEMBL1548612 & 688759 & 4.45 & 5.061 & TST & \\
\hline CHEMBL1359966 & 688759 & 5.25 & 4.7525 & TST & \\
\hline CHEMBL1312591 & 688759 & 4.45 & 4.5869 & TST & \\
\hline CHEMBL1547542 & 688759 & 4.45 & 4.7626 & TRN & \\
\hline CHEMBL1441270 & 688759 & 4.65 & 4.7731 & TRN & \\
\hline CHEMBL1404146 & 688759 & 4.45 & 4.9738 & TRN & \\
\hline CHEMBL1486223 & 688759 & 4.45 & 4.9049 & TRN & \\
\hline CHEMBL1526637 & 688759 & 5.0 & 4.8929 & TRN & \\
\hline CHEMBL1388002 & 688759 & 4.65 & 4.9973 & TST & \\
\hline CHEMBL1310637 & 688759 & 6.5 & 5.2617 & TRN & \\
\hline CHEMBL1440968 & 688759 & 4.45 & 4.9909 & TRN & \\
\hline CHEMBL1582864 & 688759 & 4.9 & 4.96399 & 99999999995 & TST \\
\hline CHEMBL1376470 & 688759 & 5.2 & 4.8601 & TST & \\
\hline CHEMBL1326689 & 688759 & 4.65 & 4.8567 & TRN & \\
\hline CHEMBL1462185 & 688759 & 4.6 & 4.8379 & TRN & \\
\hline CHEMBL1464345 & 688759 & 4.85 & 5.2566 & TRN & \\
\hline CHEMBL1408652 & 688759 & 4.45 & 4.833 & TRN & \\
\hline CHEMBL3209153 & 688759 & 5.05 & 4.8049 & TRN & \\
\hline CHEMBL1313222 & 688759 & 4.65 & 4.7296 & TST & \\
\hline CHEMBL1608089 & 688759 & 4.45 & 4.8423 & TST & \\
\hline CHEMBL202752 & 688759 & 4.45 & 5.1435 & TRN & \\
\hline CHEMBL1367245 & 688759 & 5.45 & 5.1217 & TRN & \\
\hline CHEMBL3191236 & 688759 & 4.55 & 4.6713 & TRN & \\
\hline CHEMBL1363373 & 688759 & 4.65 & 4.6531 & TRN & \\
\hline CHEMBL3191795 & 688759 & 4.45 & 4.735 & TRN & \\
\hline CHEMBL1575751 & 688759 & 4.45 & 4.6082 & TST & \\
\hline CHEMBL1589180 & 688759 & 4.6 & 4.8022 & TRN & \\
\hline CHEMBL1570564 & 688759 & 4.55 & 5.1279 & TRN & \\
\hline CHEMBL1446857 & 688759 & 4.7 & 5.1657 & TRN & \\
\hline CHEMBL1597829 & 688759 & 4.45 & 4.8324 & TRN & \\
\hline CHEMBL1469913 & 688759 & 5.15 & 5.1195 & TRN & \\
\hline CHEMBL1481764 & 688759 & 5.1 & 4.7393 & TRN & \\
\hline CHEMBL1341851 & 688759 & 4.7 & 5.0651 & TRN & \\
\hline CHEMBL1534474 & 688759 & 4.95 & 4.9122 & TRN & \\
\hline CHEMBL3209779 & 688759 & 4.45 & 4.8663 & TST & \\
\hline CHEMBL1452612 & 688759 & 4.45 & 4.7886 & TRN & \\
\hline CHEMBL1513972 & 688759 & 4.45 & 4.6758 & TRN & \\
\hline CHEMBL1369725 & 688759 & 4.45 & 4.7188 & TST & \\
\hline CHEMBL1376672 & 688759 & 4.85 & 4.9769 & TRN & \\
\hline
\end{tabular}




\begin{tabular}{|c|c|c|c|c|}
\hline & & & upplement & $\mathrm{T}$ \\
\hline CHEMBL1612916 & 688759 & 4.45 & 4.6892 & TST \\
\hline CHEMBL1413351 & 688759 & 4.45 & 4.8572 & TST \\
\hline CHEMBL1361868 & 688759 & 5.6 & 5.528 & TRN \\
\hline CHEMBL1588946 & 688759 & 4.95 & 4.8796 & TRN \\
\hline CHEMBL1461025 & 688759 & 5.25 & 5.1851 & TRN \\
\hline CHEMBL1425131 & 688759 & 4.65 & 4.8498 & TRN \\
\hline CHEMBL1369357 & 688759 & 4.65 & 4.6977 & TRN \\
\hline CHEMBL1993291 & 688759 & 4.45 & 4.7616 & TRN \\
\hline CHEMBL1438898 & 688759 & 4.45 & 4.6206 & TST \\
\hline CHEMBL1431291 & 688759 & 6.0 & 4.7551 & TST \\
\hline CHEMBL1423414 & 688759 & 5.2 & 4.8584 & TST \\
\hline CHEMBL1361522 & 688759 & 4.7 & 5.1439 & TRN \\
\hline CHEMBL1455060 & 688759 & 5.5 & 5.4014 & TST \\
\hline CHEMBL1462568 & 688759 & 4.45 & 5.0601 & TST \\
\hline CHEMBL 226838 & 688759 & 5.15 & 5.3069 & TST \\
\hline CHEMBL1540711 & 688759 & 4.45 & 4.9173 & TST \\
\hline CHEMBL1509523 & 688759 & 5.5 & 5.4511 & TRN \\
\hline CHEMBL1593847 & 688759 & 4.8 & 4.6785 & TST \\
\hline CHEMBL1974901 & 688759 & 5.95 & 5.3422 & TRN \\
\hline CHEMBL1353565 & 688759 & 4.45 & 4.8737 & TST \\
\hline CHEMBL1428587 & 688759 & 4.5 & 5.1566 & TST \\
\hline CHEMBL1344136 & 688759 & 6.05 & 5.1 & TRN \\
\hline CHEMBL1546332 & 688759 & 4.8 & 5.015 & TST \\
\hline CHEMBL599098 & 688759 & 4.9 & 4.8714 & TRN \\
\hline CHEMBL1373205 & 688759 & 5.15 & 4.8704 & TST \\
\hline CHEMBL3196351 & 688759 & 5.45 & 5.1213 & TRN \\
\hline CHEMBL1503155 & 688759 & 4.5 & 4.7551 & TRN \\
\hline CHEMBL3190169 & 688759 & 5.15 & 5.1588 & TRN \\
\hline CHEMBL365739 & 688759 & 6.0 & 4.9165 & TST \\
\hline CHEMBL1308918 & 688759 & 4.45 & 4.6872 & TRN \\
\hline CHEMBL1394135 & 688759 & 4.5 & 4.7691 & TRN \\
\hline CHEMBL1524110 & 688759 & 4.45 & 4.7371 & TST \\
\hline CHEMBL1599994 & 688759 & 5.3 & 4.9149 & TRN \\
\hline CHEMBL1486209 & 688759 & 4.7 & 4.7331 & TRN \\
\hline CHEMBL1467676 & 688759 & 4.7 & 4.9391 & TRN \\
\hline CHEMBL1367572 & 688759 & 4.45 & 4.7424 & TRN \\
\hline CHEMBL 1353247 & 688759 & 5.65 & 4.8876 & TRN \\
\hline CHEMBL1309909 & 688759 & 5.75 & 4.7495 & TST \\
\hline CHEMBL1470809 & 688759 & 5.2 & 4.8324 & TST \\
\hline CHEMBL1505073 & 688759 & 5.2 & 5.2558 & TRN \\
\hline CHEMBL3197912 & 688759 & 6.45 & 5.9552 & TRN \\
\hline CHEMBL1547874 & 688759 & 4.45 & 4.7839 & TRN \\
\hline CHEMBL1542237 & 688759 & 4.7 & 4.6978 & TRN \\
\hline CHEMBL1494868 & 688759 & 4.45 & 4.8951 & TRN \\
\hline CHEMBL1516533 & 688759 & 4.45 & 4.8377 & TRN \\
\hline CHEMBL1339892 & 688759 & 4.85 & 4.7459 & TRN \\
\hline CHEMBL3198646 & 688759 & 4.45 & 4.5205 & TRN \\
\hline CHEMBL1351180 & 688759 & 4.55 & 5.0075 & TST \\
\hline
\end{tabular}




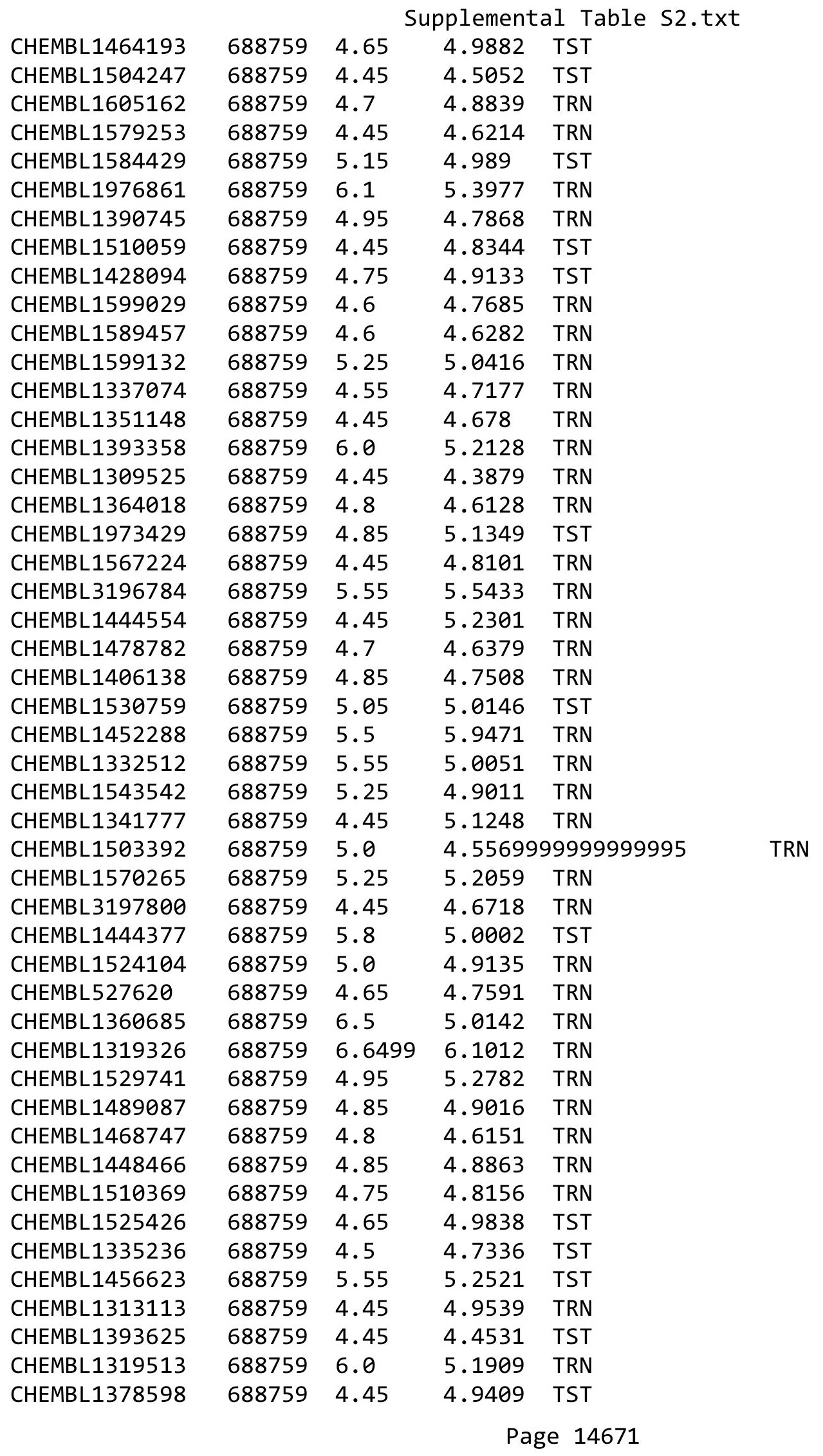




\begin{tabular}{|c|c|c|c|c|c|}
\hline & & \multicolumn{4}{|c|}{ Supplemental Table S2.txt } \\
\hline CHEMBL1374258 & 688759 & 5.0 & 4.9418 & TRN & \\
\hline CHEMBL1302890 & 688759 & 5.35 & 5.1913 & TRN & \\
\hline CHEMBL1534509 & 688759 & 4.7 & 5.0642 & TRN & \\
\hline CHEMBL1876078 & 688759 & 4.95 & 4.8347 & TRN & \\
\hline CHEMBL78010 & 688759 & 5.0 & 4.8799 & TRN & \\
\hline CHEMBL1429620 & 688759 & 5.15 & 4.7301 & TRN & \\
\hline CHEMBL1545264 & 688759 & 4.7 & 4.9014 & TST & \\
\hline CHEMBL1387058 & 688759 & 4.9 & 4.6735 & TRN & \\
\hline CHEMBL3192901 & 688759 & 5.15 & 5.1218 & TRN & \\
\hline CHEMBL1433330 & 688759 & 5.5 & 4.8398 & TST & \\
\hline CHEMBL1603001 & 688759 & 6.4 & 6.07700 & 0000000001 & TRN \\
\hline CHEMBL1597253 & 688759 & 4.45 & 4.9656 & TRN & \\
\hline CHEMBL1497370 & 688759 & 4.45 & 4.8841 & TRN & \\
\hline CHEMBL1455821 & 688759 & 4.95 & 4.9922 & TST & \\
\hline CHEMBL1546205 & 688759 & 4.5 & 4.5535 & TRN & \\
\hline CHEMBL1300780 & 688759 & 4.45 & 4.6421 & TRN & \\
\hline CHEMBL1370438 & 688759 & 4.45 & 4.805 & TRN & \\
\hline CHEMBL1458754 & 688759 & 4.75 & 4.6764 & TRN & \\
\hline CHEMBL1241671 & 688759 & 4.8 & 4.9385 & TST & \\
\hline CHEMBL1555697 & 688759 & 4.6 & 4.8833 & TST & \\
\hline CHEMBL1529991 & 688759 & 4.45 & 4.8251 & TRN & \\
\hline CHEMBL3192695 & 688759 & 4.45 & 4.8008 & TRN & \\
\hline CHEMBL1611777 & 688759 & 4.8 & 4.5271 & TRN & \\
\hline CHEMBL1448733 & 688759 & 4.8 & 4.5466 & TRN & \\
\hline CHEMBL1303653 & 688759 & 4.95 & 4.8849 & TRN & \\
\hline CHEMBL3195074 & 688759 & 4.7 & 4.7172 & TRN & \\
\hline CHEMBL1471547 & 688759 & 4.65 & 4.8621 & TRN & \\
\hline CHEMBL1325742 & 688759 & 5.85 & 4.7527 & TST & \\
\hline CHEMBL3191291 & 688759 & 5.4 & 4.7222 & TRN & \\
\hline CHEMBL1478629 & 688759 & 4.45 & 5.0472 & TRN & \\
\hline CHEMBL1480186 & 688759 & 4.45 & 4.9037 & TST & \\
\hline CHEMBL1444525 & 688759 & 4.65 & 4.9762 & TRN & \\
\hline CHEMBL1333657 & 688759 & 4.45 & 4.8243 & TRN & \\
\hline CHEMBL3208413 & 688759 & 4.45 & 4.8573 & TRN & \\
\hline CHEMBL1402670 & 688759 & 6.4 & 5.8968 & TRN & \\
\hline CHEMBL1520567 & 688759 & 4.45 & 4.7307 & TRN & \\
\hline CHEMBL1570846 & 688759 & 4.75 & 4.9896 & TRN & \\
\hline CHEMBL1328746 & 688759 & 5.25 & 5.0046 & TRN & \\
\hline CHEMBL1540416 & 688759 & 4.45 & 4.5733 & TST & \\
\hline CHEMBL1424913 & 688759 & 4.45 & 4.7975 & TRN & \\
\hline CHEMBL3145245 & 688759 & 6.25 & 5.4699 & TRN & \\
\hline CHEMBL1479506 & 688759 & 4.45 & 4.9202 & TRN & \\
\hline CHEMBL1393568 & 688759 & 5.0 & 4.9308 & TRN & \\
\hline CHEMBL1336722 & 688759 & 4.45 & 4.9812 & TRN & \\
\hline CHEMBL1529267 & 688759 & 5.55 & 5.0824 & TRN & \\
\hline CHEMBL1974506 & 688759 & 5.45 & 5.6218 & TRN & \\
\hline CHEMBL1313885 & 688759 & 4.45 & 4.6766 & TRN & \\
\hline CHEMBL3194627 & 688759 & 4.7 & 4.6912 & TST & \\
\hline
\end{tabular}




\begin{tabular}{|c|c|c|c|c|}
\hline \multicolumn{5}{|c|}{ Supplemental Table S2.txt } \\
\hline CHEMBL1327634 & 688759 & 4.75 & 5.0175 & TRN \\
\hline CHEMBL1424009 & 688759 & 5.25 & 4.8749 & TST \\
\hline CHEMBL1322297 & 688759 & 4.95 & 4.8705 & TRN \\
\hline CHEMBL1422689 & 688759 & 4.6 & 4.7436 & TRN \\
\hline CHEMBL1363615 & 688759 & 5.55 & 5.5164 & TRN \\
\hline CHEMBL1458166 & 688759 & 4.5 & 5.145 & TRN \\
\hline CHEMBL1469938 & 688759 & 5.35 & 5.1952 & TRN \\
\hline CHEMBL1308571 & 688759 & 5.25 & 4.9232 & TST \\
\hline CHEMBL1450526 & 688759 & 6.1 & 5.8427 & TRN \\
\hline CHEMBL1511274 & 688759 & 4.45 & 4.5391 & TRN \\
\hline CHEMBL1384349 & 688759 & 4.45 & 4.5391 & TRN \\
\hline CHEMBL 3193170 & 688759 & 5.25 & 4.7708 & TRN \\
\hline CHEMBL1520586 & 688759 & 5.15 & 5.0717 & TRN \\
\hline CHEMBL3196113 & 688759 & 4.45 & 4.7012 & TRN \\
\hline CHEMBL1488739 & 688759 & 4.5 & 4.7814 & TST \\
\hline CHEMBL1503254 & 688759 & 4.65 & 4.4183 & TRN \\
\hline CHEMBL1377518 & 688759 & 4.95 & 4.6298 & TRN \\
\hline CHEMBL1437118 & 688759 & 4.6 & 4.868 & TRN \\
\hline CHEMBL1373255 & 688759 & 5.05 & 4.7074 & TRN \\
\hline CHEMBL1530943 & 688759 & 6.2 & 5.5492 & TRN \\
\hline CHEMBL1980198 & 688759 & 4.65 & 4.6204 & TRN \\
\hline CHEMBL1302836 & 688759 & 5.5 & 5.2569 & TST \\
\hline CHEMBL533388 & 688759 & 4.45 & 4.9796 & TST \\
\hline CHEMBL1437667 & 688759 & 4.45 & 4.7237 & TST \\
\hline CHEMBL1520059 & 688759 & 4.95 & 4.8023 & TRN \\
\hline CHEMBL1540808 & 688759 & 4.65 & 4.8959 & TRN \\
\hline CHEMBL1422131 & 688759 & 4.65 & 4.9403 & TRN \\
\hline CHEMBL1328750 & 688759 & 4.7 & 4.8644 & TRN \\
\hline CHEMBL1509790 & 688759 & 4.7 & 5.0261 & TRN \\
\hline CHEMBL1518184 & 688759 & 4.95 & 4.9828 & TRN \\
\hline CHEMBL1966890 & 688759 & 5.2 & 5.1619 & TRN \\
\hline CHEMBL3214405 & 688759 & 4.75 & 4.8473 & TRN \\
\hline CHEMBL3199278 & 688759 & 4.5 & 4.5905 & TRN \\
\hline CHEMBL1564775 & 688759 & 6.8499 & 5.2668 & TRN \\
\hline CHEMBL1470512 & 688759 & 4.45 & 4.9471 & TRN \\
\hline CHEMBL1585050 & 688759 & 5.65 & 5.0498 & TRN \\
\hline CHEMBL1510599 & 688759 & 5.45 & 5.2319 & TRN \\
\hline CHEMBL1384037 & 688759 & 4.8 & 4.8556 & TST \\
\hline CHEMBL1600919 & 688759 & 5.3 & 5.2359 & TRN \\
\hline CHEMBL1369641 & 688759 & 5.85 & 5.6415 & TRN \\
\hline CHEMBL1609855 & 688759 & 4.9 & 4.8055 & TST \\
\hline CHEMBL1464776 & 688759 & 4.5 & 4.9667 & TRN \\
\hline CHEMBL1483652 & 688759 & 4.45 & 4.9205 & TST \\
\hline CHEMBL1565981 & 688759 & 4.45 & 5.0532 & TRN \\
\hline CHEMBL1495085 & 688759 & 7.0501 & 4.8163 & TST \\
\hline CHEMBL1311901 & 688759 & 4.8 & 5.0247 & TST \\
\hline CHEMBL1509590 & 688759 & 4.45 & 4.595 & TST \\
\hline CHEMBL1486358 & 688759 & 4.65 & 4.5204 & TST \\
\hline
\end{tabular}




\begin{tabular}{|c|c|c|c|c|c|}
\hline CHEMBL127757 & 688759 & 5.0 & $4.9910 e$ & 00000000005 & TRN \\
\hline CHEMBL1478628 & 688759 & 6.0 & 5.0602 & TRN & \\
\hline CHEMBL1423986 & 688759 & 5.45 & 4.8961 & TRN & \\
\hline CHEMBL1375052 & 688759 & 4.45 & 4.7027 & TRN & \\
\hline CHEMBL1599175 & 688759 & 5.0 & 5.075 & TRN & \\
\hline CHEMBL1976059 & 688759 & 4.95 & 5.5224 & TRN & \\
\hline CHEMBL1444625 & 688759 & 5.0 & 4.9741 & TST & \\
\hline CHEMBL1560672 & 688759 & 4.45 & 4.8468 & TRN & \\
\hline CHEMBL1390834 & 688759 & 4.9 & 4.6567 & TRN & \\
\hline CHEMBL1445257 & 688759 & 4.65 & 5.0337 & TRN & \\
\hline CHEMBL1564212 & 688759 & 5.0 & 5.1194 & TRN & \\
\hline CHEMBL1571462 & 688759 & 4.55 & 4.7323 & TRN & \\
\hline CHEMBL1608530 & 688759 & 4.45 & 4.8329 & TRN & \\
\hline CHEMBL1997928 & 688759 & 4.55 & 4.4522 & TRN & \\
\hline CHEMBL1348018 & 688759 & 4.45 & 4.8314 & TRN & \\
\hline CHEMBL403419 & 688759 & 5.9 & 5.4529 & TRN & \\
\hline CHEMBL1407520 & 688759 & 4.6 & 5.0374 & TRN & \\
\hline CHEMBL1582566 & 688759 & 5.15 & 4.7703 & TRN & \\
\hline CHEMBL1579583 & 688759 & 4.7 & 4.5725 & TRN & \\
\hline CHEMBL1439606 & 688759 & 4.95 & 4.7229 & TRN & \\
\hline CHEMBL1337145 & 688759 & 4.45 & 4.7938 & TST & \\
\hline CHEMBL1435715 & 688759 & 4.9 & 4.9172 & TST & \\
\hline CHEMBL1506252 & 688759 & 5.1 & 4.9834 & TRN & \\
\hline CHEMBL1334768 & 688759 & 5.0 & 4.7055 & TST & \\
\hline CHEMBL1599714 & 688759 & 4.45 & 4.6777 & TRN & \\
\hline CHEMBL1441833 & 688759 & 4.95 & 5.0191 & TRN & \\
\hline CHEMBL1358208 & 688759 & 4.4 & 4.8701 & TST & \\
\hline CHEMBL59030 & 688759 & 4.45 & 4.8418 & TST & \\
\hline CHEMBL 3211554 & 688759 & 4.95 & 5.6054 & TRN & \\
\hline CHEMBL1586531 & 688759 & 5.35 & 4.9704 & TST & \\
\hline CHEMBL1989354 & 688759 & 5.3 & 4.9757 & TRN & \\
\hline CHEMBL1547451 & 688759 & 4.45 & 4.8523 & TRN & \\
\hline CHEMBL1429052 & 688759 & 5.55 & 5.7586 & TRN & \\
\hline CHEMBL1595076 & 688759 & 4.9 & 5.0652 & TRN & \\
\hline CHEMBL1395226 & 688759 & 4.45 & 4.711 & TRN & \\
\hline CHEMBL1373057 & 688759 & 6.05 & 4.9486 & TRN & \\
\hline CHEMBL1527206 & 688759 & 4.95 & 4.957 & TRN & \\
\hline CHEMBL3197530 & 688759 & 5.55 & 5.1505 & TRN & \\
\hline CHEMBL1423567 & 688759 & 5.45 & 5.0396 & TRN & \\
\hline CHEMBL1477366 & 688759 & 5.75 & 5.9731 & TRN & \\
\hline CHEMBL1559953 & 688759 & 5.05 & 4.7857 & TRN & \\
\hline CHEMBL1400658 & 688759 & 4.9 & 4.9452 & TRN & \\
\hline CHEMBL3197288 & 688759 & 5.5 & 5.1736 & TRN & \\
\hline CHEMBL1466628 & 688759 & 6.1 & 5.9949 & TRN & \\
\hline CHEMBL1601664 & 688759 & 5.9 & 5.1044 & TRN & \\
\hline CHEMBL3192604 & 688759 & 4.5 & 4.8555 & TRN & \\
\hline CHEMBL1424415 & 688759 & 4.45 & 4.7332 & TRN & \\
\hline CHEMBL1904348 & 688759 & 5.15 & 5.5461 & TRN & \\
\hline
\end{tabular}




\begin{tabular}{|c|c|c|c|c|c|}
\hline \multicolumn{6}{|c|}{ 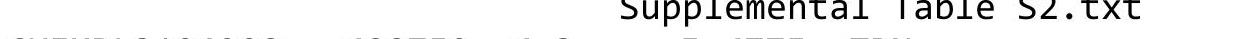 } \\
\hline CHEMBL3194298 & 688759 & 6.3 & 5.6775 & TRN & \\
\hline CHEMBL1712384 & 688759 & 4.95 & 4.4762 & TRN & \\
\hline CHEMBL1542525 & 688759 & 4.45 & 5.0123 & TRN & \\
\hline CHEMBL1469463 & 688759 & 4.45 & 4.8073 & TST & \\
\hline CHEMBL1432507 & 688759 & 4.65 & 4.6682 & TRN & \\
\hline CHEMBL 2000264 & 688759 & 4.8 & 5.0592 & TRN & \\
\hline CHEMBL3212879 & 688759 & 4.9 & 5.0916 & TRN & \\
\hline CHEMBL1462622 & 688759 & 4.7 & 4.5137 & TRN & \\
\hline CHEMBL1611468 & 688759 & 5.15 & 4.8731 & TRN & \\
\hline CHEMBL1311351 & 688759 & 4.75 & 4.976 & TST & \\
\hline CHEMBL1318954 & 688759 & 4.5 & 4.7508 & TST & \\
\hline CHEMBL1540189 & 688759 & 4.6 & 4.9424 & TRN & \\
\hline CHEMBL1400266 & 688759 & 4.45 & 4.6392 & TRN & \\
\hline CHEMBL1497918 & 688759 & 4.45 & 4.6856 & TRN & \\
\hline CHEMBL1409547 & 688759 & 4.75 & 5.3397 & TRN & \\
\hline CHEMBL1332294 & 688759 & 4.9 & 4.7537 & TST & \\
\hline CHEMBL1572681 & 688759 & 4.8 & 4.8917 & TST & \\
\hline CHEMBL3196962 & 688759 & 5.25 & 5.3759 & TST & \\
\hline CHEMBL1365508 & 688759 & 6.5 & 5.9403 & TRN & \\
\hline CHEMBL1348093 & 688759 & 5.0 & 5.0978 & TRN & \\
\hline CHEMBL1416329 & 688759 & 4.45 & 4.7329 & TRN & \\
\hline CHEMBL1462330 & 688759 & 6.95 & 4.9024 & TST & \\
\hline CHEMBL1556786 & 688759 & 5.4 & 5.407 & TRN & \\
\hline CHEMBL1359469 & 688759 & 5.65 & 5.4599 & TRN & \\
\hline CHEMBL1331905 & 688759 & 4.45 & 4.5248 & TST & \\
\hline CHEMBL1563592 & 688759 & 4.45 & 5.0544 & TST & \\
\hline CHEMBL1427834 & 688759 & 4.55 & 4.8462 & TST & \\
\hline CHEMBL1423501 & 688759 & 4.45 & 4.8168 & TST & \\
\hline CHEMBL1607458 & 688759 & 4.85 & 5.2818 & TRN & \\
\hline CHEMBL1328827 & 688759 & 4.45 & 4.7627 & TRN & \\
\hline CHEMBL3197958 & 688759 & 4.95 & 5.2757 & TRN & \\
\hline CHEMBL1302999 & 688759 & 4.55 & 4.9695 & TRN & \\
\hline CHEMBL1311282 & 688759 & 4.7 & 4.87 & TRN & \\
\hline CHEMBL1300752 & 688759 & 5.4 & 5.13899 & 9999999999 & TRN \\
\hline CHEMBL1392298 & 688759 & 4.45 & 4.8261 & TST & \\
\hline CHEMBL1567046 & 688759 & 6.0 & 5.7617 & TRN & \\
\hline CHEMBL1348149 & 688759 & 4.7 & 4.7817 & TRN & \\
\hline CHEMBL1547557 & 688759 & 5.3 & 4.9953 & TRN & \\
\hline CHEMBL1453475 & 688759 & 5.3 & 4.8175 & TRN & \\
\hline CHEMBL1415915 & 688759 & 5.25 & 5.2521 & TRN & \\
\hline CHEMBL1524599 & 688759 & 4.45 & 4.8409 & TST & \\
\hline CHEMBL1373533 & 688759 & 4.6 & 4.8967 & TRN & \\
\hline CHEMBL1588173 & 688759 & 5.15 & 4.8372 & TRN & \\
\hline CHEMBL584619 & 688759 & 5.0 & 4.6336 & TRN & \\
\hline CHEMBL1337615 & 688759 & 5.45 & 4.9132 & TRN & \\
\hline CHEMBL 3210962 & 688759 & 5.1 & 4.9957 & TRN & \\
\hline CHEMBL445153 & 688759 & 4.8 & 4.7546 & TRN & \\
\hline CHEMBL1572330 & 688759 & 5.7 & 5.4167 & TRN & \\
\hline
\end{tabular}




\begin{tabular}{|c|c|c|c|c|c|}
\hline \multicolumn{6}{|c|}{ Supplemental Table S2.txt } \\
\hline CHEMBL1480998 & 688759 & 4.55 & 4.8772 & TRN & \\
\hline CHEMBL1309208 & 688759 & 6.4 & 5.763 & TST & \\
\hline CHEMBL589238 & 688759 & 5.55 & 5.4225 & TST & \\
\hline CHEMBL1379454 & 688759 & 6.5501 & 4.8274 & TRN & \\
\hline CHEMBL1519376 & 688759 & 4.9 & 4.9107 & TST & \\
\hline CHEMBL1580548 & 688759 & 4.7 & 4.7717 & TRN & \\
\hline CHEMBL1365417 & 688759 & 4.95 & 4.7812 & TRN & \\
\hline CHEMBL1464941 & 688759 & 5.0 & 4.9967 & TRN & \\
\hline CHEMBL 3211206 & 688759 & 5.45 & 4.5851 & TRN & \\
\hline CHEMBL1407905 & 688759 & 4.45 & 4.6073 & TRN & \\
\hline CHEMBL1454247 & 688759 & 5.45 & 4.9296 & TRN & \\
\hline CHEMBL1526567 & 688759 & 5.35 & 5.0344 & TRN & \\
\hline CHEMBL1594182 & 688759 & 4.9 & 4.8807 & TRN & \\
\hline CHEMBL566933 & 688759 & 4.95 & 4.7566 & TRN & \\
\hline CHEMBL1422379 & 688759 & 5.3 & 4.9975 & TST & \\
\hline CHEMBL1568007 & 688759 & 5.25 & 4.7174 & TRN & \\
\hline CHEMBL1603234 & 688759 & 6.3 & 4.9746 & TST & \\
\hline CHEMBL1608805 & 688759 & 4.95 & 4.9908 & TRN & \\
\hline CHEMBL1423660 & 688759 & 6.2 & 5.7042 & TRN & \\
\hline CHEMBL3191012 & 688759 & 4.5 & 4.9582 & TRN & \\
\hline CHEMBL3197106 & 688759 & 4.5 & 4.7477 & TRN & \\
\hline CHEMBL1483355 & 688759 & 4.45 & 4.9349 & TRN & \\
\hline CHEMBL1583537 & 688759 & 4.45 & 4.8811 & TRN & \\
\hline CHEMBL1989294 & 688759 & 5.4 & 5.1215 & TRN & \\
\hline CHEMBL1462873 & 688759 & 4.65 & 4.882 & TRN & \\
\hline CHEMBL1458836 & 688759 & 5.35 & 4.6199 & TRN & \\
\hline CHEMBL1595696 & 688759 & 5.45 & 4.9722 & TRN & \\
\hline CHEMBL1311523 & 688759 & 5.0 & 5.0427 & TST & \\
\hline CHEMBL1598493 & 688759 & 4.45 & 4.9888 & TRN & \\
\hline CHEMBL1512807 & 688759 & 4.85 & 4.9002 & TRN & \\
\hline CHEMBL 3194960 & 688759 & 4.9 & 5.1532 & TRN & \\
\hline CHEMBL1449443 & 688759 & 4.45 & 4.71899 & 9999999999 & TRN \\
\hline CHEMBL1504437 & 688759 & 6.2 & 5.1363 & TRN & \\
\hline CHEMBL 3199651 & 688759 & 5.5 & 5.5078 & TRN & \\
\hline CHEMBL1299407 & 688759 & 4.45 & 4.7286 & TST & \\
\hline CHEMBL1393351 & 688759 & 6.0 & 5.3001 & TRN & \\
\hline CHEMBL1495594 & 688759 & 5.2 & 5.0595 & TRN & \\
\hline CHEMBL1569325 & 688759 & 5.45 & 4.8444 & TRN & \\
\hline CHEMBL1376261 & 688759 & 4.65 & 4.63 & TRN & \\
\hline CHEMBL1531352 & 688759 & 4.8 & 6.314 & TRN & \\
\hline CHEMBL1556928 & 688759 & 4.45 & 4.9719 & TST & \\
\hline CHEMBL1376141 & 688759 & 4.45 & 4.9625 & TST & \\
\hline CHEMBL1359366 & 688759 & 4.45 & 4.5324 & TRN & \\
\hline CHEMBL1445109 & 688759 & 4.45 & 4.8893 & TST & \\
\hline CHEMBL1526165 & 688759 & 4.45 & 4.5366 & TRN & \\
\hline CHEMBL1572095 & 688759 & 4.45 & 4.5828 & TST & \\
\hline CHEMBL 1508620 & 688759 & 4.45 & 4.9156 & TRN & \\
\hline CHEMBL3210129 & 688759 & 4.95 & 4.9997 & TRN & \\
\hline
\end{tabular}




\begin{tabular}{|c|c|c|c|c|}
\hline \multicolumn{5}{|c|}{ Supplemental Table S2.txt } \\
\hline CHEMBL1316803 & 688759 & 4.45 & 4.8162 & TST \\
\hline CHEMBL1409945 & 688759 & 4.45 & 4.756 & TRN \\
\hline CHEMBL1345789 & 688759 & 4.7 & 4.8603 & TST \\
\hline CHEMBL 3192125 & 688759 & 4.4 & 4.872 & TRN \\
\hline CHEMBL1479816 & 688759 & 4.45 & 4.9087 & TRN \\
\hline CHEMBL1446256 & 688759 & 4.95 & 4.9123 & TST \\
\hline CHEMBL1372368 & 688759 & 5.9 & 5.303 & TST \\
\hline CHEMBL1411912 & 688759 & 5.65 & 4.918 & TRN \\
\hline CHEMBL1379636 & 688759 & 4.45 & 4.7852 & TST \\
\hline CHEMBL1971185 & 688759 & 5.3 & 4.962 & TRN \\
\hline CHEMBL1603221 & 688759 & 4.45 & 4.632 & TST \\
\hline CHEMBL1354085 & 688759 & 4.9 & 5.138 & TRN \\
\hline CHEMBL1440298 & 688759 & 4.65 & 4.9147 & TRN \\
\hline CHEMBL1461491 & 688759 & 6.0 & 4.9215 & TST \\
\hline CHEMBL1342324 & 688759 & 4.85 & 4.8866 & TRN \\
\hline CHEMBL 3190274 & 688759 & 4.45 & 4.9253 & TRN \\
\hline CHEMBL1352189 & 688759 & 4.45 & 4.8312 & TST \\
\hline CHEMBL1347561 & 688759 & 4.55 & 4.7096 & TST \\
\hline CHEMBL1367356 & 688759 & 4.45 & 5.0116 & TST \\
\hline CHEMBL1601898 & 688759 & 4.6 & 4.8513 & TRN \\
\hline CHEMBL1308842 & 688759 & 5.45 & 4.993 & TST \\
\hline CHEMBL3199198 & 688759 & 5.2 & 4.7753 & TRN \\
\hline CHEMBL1461275 & 688759 & 4.8 & 5.1221 & TST \\
\hline CHEMBL1433275 & 688759 & 5.25 & 4.8779 & TRN \\
\hline CHEMBL1570972 & 688759 & 4.7 & 4.6877 & TRN \\
\hline CHEMBL1585936 & 688759 & 4.9 & 5.3008 & TRN \\
\hline CHEMBL1531935 & 688759 & 5.7 & 5.1815 & TRN \\
\hline CHEMBL1506071 & 688759 & 4.5 & 4.9975 & TRN \\
\hline CHEMBL1387279 & 688759 & 4.65 & 4.9578 & TRN \\
\hline CHEMBL1572197 & 688759 & 4.7 & 4.7338 & TRN \\
\hline CHEMBL1363376 & 688759 & 5.55 & 5.4795 & TRN \\
\hline CHEMBL3198962 & 688759 & 4.45 & 4.5143 & TRN \\
\hline CHEMBL1379674 & 688759 & 5.25 & 5.3093 & TRN \\
\hline CHEMBL1555855 & 688759 & 5.3 & 4.8954 & TST \\
\hline CHEMBL1480961 & 688759 & 4.45 & 4.8612 & TRN \\
\hline CHEMBL1465187 & 688759 & 4.9 & 5.0711 & TRN \\
\hline CHEMBL1492634 & 688759 & 5.05 & 4.9805 & TRN \\
\hline CHEMBL1533220 & 688759 & 4.55 & 4.6959 & TRN \\
\hline CHEMBL3192323 & 688759 & 5.1 & 5.0263 & TRN \\
\hline CHEMBL1584562 & 688759 & 4.45 & 4.7874 & TRN \\
\hline CHEMBL1428263 & 688759 & 4.75 & 4.7816 & TRN \\
\hline CHEMBL607979 & 688759 & 4.45 & 4.5975 & TST \\
\hline CHEMBL1563576 & 688759 & 4.45 & 4.9063 & TRN \\
\hline CHEMBL1479393 & 688759 & 4.45 & 4.7077 & TRN \\
\hline CHEMBL1430456 & 688759 & 4.45 & 4.7472 & TRN \\
\hline CHEMBL1542379 & 688759 & 4.8 & 4.854 & TRN \\
\hline CHEMBL1381105 & 688759 & 4.45 & 4.5578 & TRN \\
\hline CHEMBL1335699 & 688759 & 5.45 & 5.0866 & TRN \\
\hline
\end{tabular}




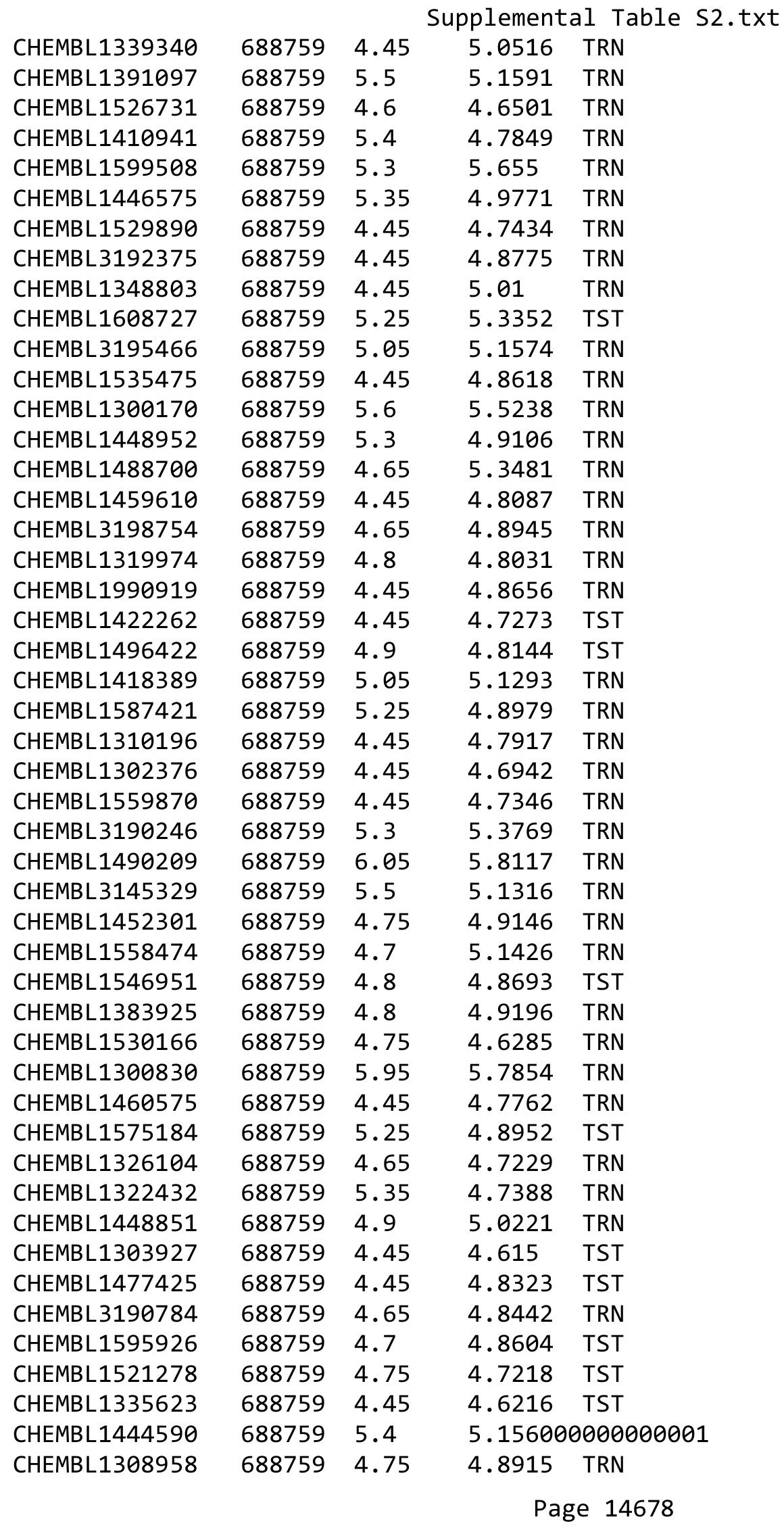

TRN 


\begin{tabular}{|c|c|c|c|c|c|}
\hline & & \multicolumn{4}{|c|}{ Supplemental Table S2.txt } \\
\hline CHEMBL1383582 & 688759 & 4.95 & 5.0814 & TRN & \\
\hline CHEMBL1430670 & 688759 & 4.5 & 4.7248 & TST & \\
\hline CHEMBL1974269 & 688759 & 4.45 & 4.7927 & TRN & \\
\hline CHEMBL1432406 & 688759 & 4.7 & 4.95100 & 00000000005 & TST \\
\hline CHEMBL1464689 & 688759 & 4.5 & 4.7888 & TRN & \\
\hline CHEMBL1418341 & 688759 & 4.45 & 4.7623 & TRN & \\
\hline CHEMBL1502401 & 688759 & 4.95 & 5.1884 & TRN & \\
\hline CHEMBL1380787 & 688759 & 5.9 & 4.8701 & TRN & \\
\hline CHEMBL435003 & 688759 & 4.75 & 5.0874 & TRN & \\
\hline CHEMBL3193344 & 688759 & 6.1 & 5.6429 & TRN & \\
\hline CHEMBL1418938 & 688759 & 4.45 & 4.9648 & TRN & \\
\hline CHEMBL3191680 & 688759 & 4.65 & 4.9191 & TRN & \\
\hline CHEMBL1398761 & 688759 & 4.65 & 4.7607 & TRN & \\
\hline CHEMBL1341224 & 688759 & 5.95 & 4.985 & TRN & \\
\hline CHEMBL1388714 & 688759 & 4.9 & 4.8559 & TST & \\
\hline CHEMBL1468678 & 688759 & 5.9 & 4.82100 & 0000000001 & TRN \\
\hline CHEMBL1334275 & 688759 & 4.9 & 4.7412 & TRN & \\
\hline CHEMBL1339206 & 688759 & 5.5 & 5.2628 & TST & \\
\hline CHEMBL1301153 & 688759 & 4.45 & 4.8363 & TST & \\
\hline CHEMBL1431995 & 688759 & 5.1 & 5.2477 & TRN & \\
\hline CHEMBL1429027 & 688759 & 4.95 & 4.8568 & TST & \\
\hline CHEMBL481854 & 688759 & 4.45 & 4.84699 & 99999999995 & TRN \\
\hline CHEMBL1376799 & 688759 & 4.45 & 4.5547 & TRN & \\
\hline CHEMBL1984098 & 688759 & 4.85 & 5.4677 & TST & \\
\hline CHEMBL3193886 & 688759 & 4.45 & 4.6847 & TST & \\
\hline CHEMBL3194356 & 688759 & 5.0 & 5.1948 & TRN & \\
\hline CHEMBL1399180 & 688759 & 4.8 & 4.8083 & TRN & \\
\hline CHEMBL1380507 & 688759 & 5.3 & 4.7536 & TRN & \\
\hline CHEMBL1347408 & 688759 & 4.45 & 4.8429 & TRN & \\
\hline CHEMBL1380849 & 688759 & 4.8 & 4.6362 & TRN & \\
\hline CHEMBL1359723 & 688759 & 5.05 & 4.9281 & TRN & \\
\hline CHEMBL1579673 & 688759 & 5.8 & 5.4751 & TRN & \\
\hline CHEMBL1562044 & 688759 & 5.6 & 5.3991 & TRN & \\
\hline CHEMBL3211940 & 688759 & 5.0 & 4.914 & TRN & \\
\hline CHEMBL1531859 & 688759 & 4.45 & 4.6354 & TST & \\
\hline CHEMBL1425414 & 688759 & 5.0 & 4.776 & TRN & \\
\hline CHEMBL1567006 & 688759 & 4.85 & 4.8994 & TST & \\
\hline CHEMBL1568611 & 688759 & 4.45 & 4.6434 & TRN & \\
\hline CHEMBL1389473 & 688759 & 4.45 & 4.9972 & TST & \\
\hline CHEMBL1318855 & 688759 & 4.45 & 4.9008 & TRN & \\
\hline CHEMBL1308348 & 688759 & 4.45 & 4.6291 & TRN & \\
\hline CHEMBL1396446 & 688759 & 5.8 & 4.8129 & TST & \\
\hline CHEMBL1557668 & 688759 & 4.5 & 4.6249 & TRN & \\
\hline CHEMBL1559061 & 688759 & 4.6 & 4.9705 & TRN & \\
\hline CHEMBL1437819 & 688759 & 4.5 & 4.7787 & TRN & \\
\hline CHEMBL1416658 & 688759 & 5.1 & 5.2667 & TRN & \\
\hline CHEMBL1324723 & 688759 & 4.95 & 4.6629 & TST & \\
\hline CHEMBL1472223 & 688759 & 5.5 & 4.8634 & TST & \\
\hline
\end{tabular}




\begin{tabular}{|c|c|c|c|c|c|}
\hline \multicolumn{6}{|c|}{ Supplemental Table S2.txt } \\
\hline CHEMBL1502681 & 688759 & 4.95 & 4.59 & TRN & \\
\hline CHEMBL1578294 & 688759 & 4.45 & 4.8051 & TRN & \\
\hline CHEMBL1498027 & 688759 & 4.8 & 4.8891 & TRN & \\
\hline CHEMBL1467265 & 688759 & 4.65 & 4.7943 & TST & \\
\hline CHEMBL1998304 & 688759 & 4.95 & 4.8071 & TRN & \\
\hline CHEMBL1362771 & 688759 & 6.5501 & 5.0849 & TRN & \\
\hline CHEMBL1342156 & 688759 & 4.45 & 4.9677 & TRN & \\
\hline CHEMBL1464195 & 688759 & 4.45 & 4.8979 & TRN & \\
\hline CHEMBL1520414 & 688759 & 4.45 & 4.7907 & TRN & \\
\hline CHEMBL1480782 & 688759 & 5.05 & 5.4795 & TRN & \\
\hline CHEMBL1353317 & 688759 & 4.8 & 4.9834 & TST & \\
\hline CHEMBL1464854 & 688759 & 5.05 & 5.4421 & TRN & \\
\hline CHEMBL1581808 & 688759 & 5.2 & 4.6419 & TST & \\
\hline CHEMBL1479218 & 688759 & 4.65 & 4.86100 & 0000000001 & TRN \\
\hline CHEMBL1402436 & 688759 & 5.4 & 5.2563 & TRN & \\
\hline CHEMBL3194022 & 688759 & 4.6 & 4.8332 & TRN & \\
\hline CHEMBL1494729 & 688759 & 5.35 & 4.7957 & TST & \\
\hline CHEMBL3198831 & 688759 & 4.45 & 4.9071 & TRN & \\
\hline CHEMBL1508739 & 688759 & 4.95 & 4.833 & TRN & \\
\hline CHEMBL1347227 & 688759 & 4.45 & 5.0751 & TRN & \\
\hline CHEMBL1342495 & 688759 & 4.55 & 4.7061 & TST & \\
\hline CHEMBL1378780 & 688759 & 6.25 & 5.3559 & TRN & \\
\hline CHEMBL1482069 & 688759 & 4.45 & 4.6093 & TST & \\
\hline CHEMBL1383269 & 688759 & 4.45 & 4.819 & TST & \\
\hline CHEMBL3193797 & 688759 & 5.8 & 4.7489 & TRN & \\
\hline CHEMBL1431668 & 688759 & 5.35 & 4.9557 & TRN & \\
\hline CHEMBL3194255 & 688759 & 4.85 & 4.6896 & TST & \\
\hline CHEMBL341904 & 688759 & 6.5501 & 5.7577 & TST & \\
\hline CHEMBL1389601 & 688759 & 4.45 & 4.5641 & TRN & \\
\hline CHEMBL1495759 & 688759 & 5.05 & 5.1822 & TRN & \\
\hline CHEMBL253220 & 688759 & 4.5 & 4.7879 & TRN & \\
\hline CHEMBL1328024 & 688759 & 7.0 & 5.0138 & TRN & \\
\hline CHEMBL1605635 & 688759 & 5.4 & 5.126 & TRN & \\
\hline CHEMBL1417098 & 688759 & 4.45 & 4.5696 & TRN & \\
\hline CHEMBL1988851 & 688759 & 4.8 & 4.8526 & TRN & \\
\hline CHEMBL1587145 & 688759 & 4.45 & 5.0266 & TRN & \\
\hline CHEMBL1510974 & 688759 & 5.55 & 5.10800 & 00000000005 & TRN \\
\hline CHEMBL1328321 & 688759 & 4.65 & 4.9729 & TRN & \\
\hline CHEMBL3197680 & 688759 & 6.1 & 5.7063 & TRN & \\
\hline CHEMBL1555853 & 688759 & 4.45 & 4.4915 & TRN & \\
\hline CHEMBL1365939 & 688759 & 5.25 & 4.6477 & TST & \\
\hline CHEMBL1301776 & 688759 & 4.45 & 5.3435 & TRN & \\
\hline CHEMBL1525484 & 688759 & 4.45 & 4.7842 & TRN & \\
\hline CHEMBL1429388 & 688759 & 4.9 & 4.9777 & TRN & \\
\hline CHEMBL1412870 & 688759 & 4.45 & 4.6204 & TRN & \\
\hline CHEMBL1453730 & 688759 & 4.45 & 4.7737 & TST & \\
\hline CHEMBL1443448 & 688759 & 6.0 & 4.6857 & TRN & \\
\hline CHEMBL1327531 & 688759 & 5.3 & 5.2062 & TRN & \\
\hline
\end{tabular}




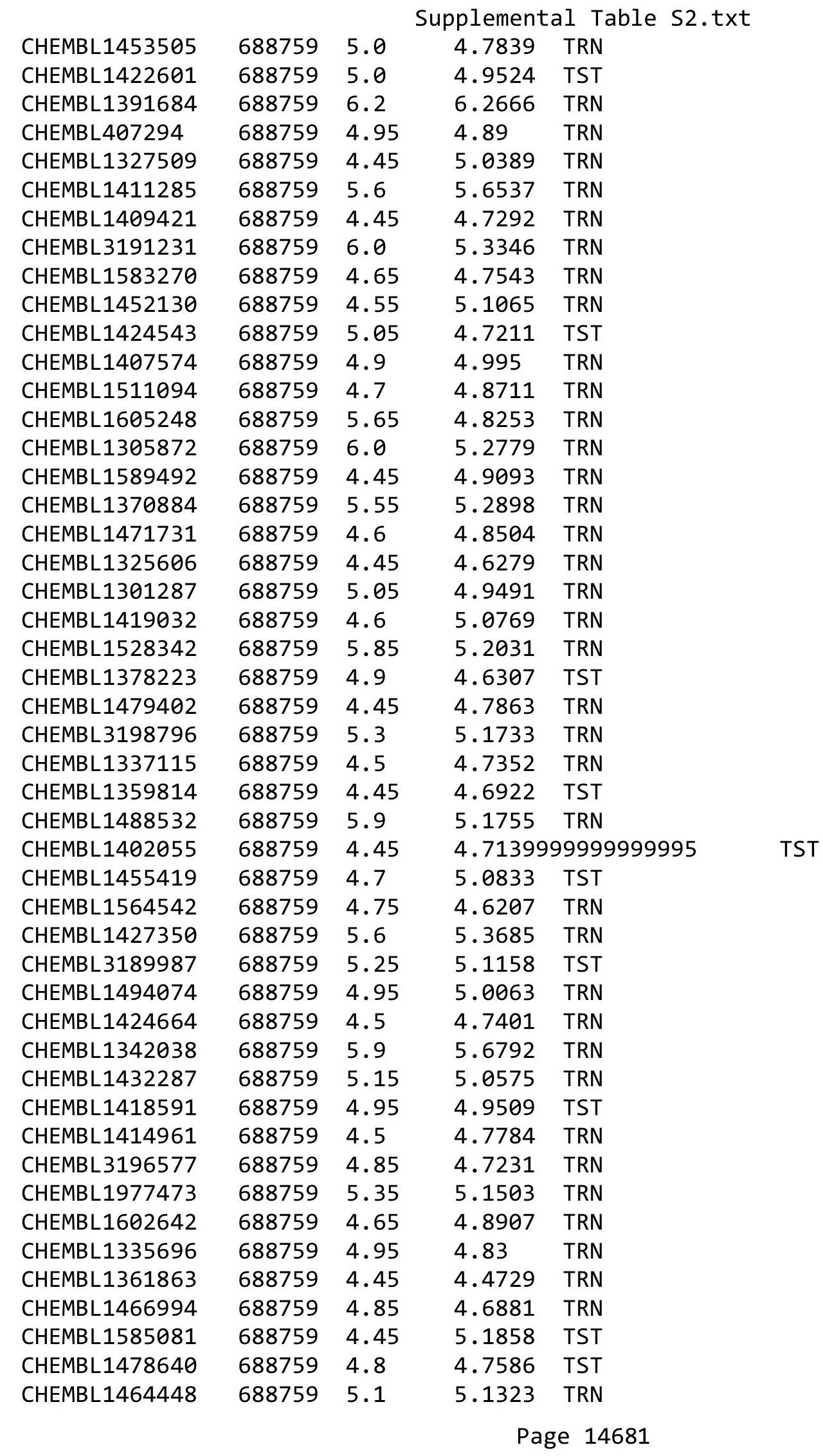




\begin{tabular}{|c|c|c|c|c|c|}
\hline \multicolumn{6}{|c|}{ Supplemental Table s2.txt } \\
\hline CHEMBL1469941 & 688759 & 4.45 & 4.6951 & TRN & \\
\hline CHEMBL1508467 & 688759 & 4.6 & 4.7065 & TRN & \\
\hline CHEMBL1502689 & 688759 & 4.45 & 4.941 & TRN & \\
\hline CHEMBL1601981 & 688759 & 5.05 & 5.0666 & TRN & \\
\hline CHEMBL1299791 & 688759 & 5.45 & 4.699 & TST & \\
\hline CHEMBL1501356 & 688759 & 5.0 & 4.8586 & TRN & \\
\hline CHEMBL1454734 & 688759 & 6.2 & 5.7901 & TRN & \\
\hline CHEMBL3191442 & 688759 & 5.25 & 5.0246 & TRN & \\
\hline CHEMBL1491352 & 688759 & 4.45 & 4.588 & TRN & \\
\hline CHEMBL1351661 & 688759 & 4.45 & 4.84 & TRN & \\
\hline CHEMBL1487256 & 688759 & 4.45 & 4.6745 & TRN & \\
\hline CHEMBL1324550 & 688759 & 4.55 & 4.8148 & TRN & \\
\hline CHEMBL1301885 & 688759 & 4.6 & 5.1612 & TRN & \\
\hline CHEMBL1402325 & 688759 & 4.45 & 4.6308 & TRN & \\
\hline CHEMBL1313803 & 688759 & 4.6 & 4.7486 & TRN & \\
\hline CHEMBL1235717 & 688759 & 5.5 & 4.9741 & TST & \\
\hline CHEMBL1522262 & 688759 & 6.35 & 5.9998 & TST & \\
\hline CHEMBL1408542 & 688759 & 6.5501 & 5.3677 & TRN & \\
\hline CHEMBL1341009 & 688759 & 4.45 & 4.6784 & TRN & \\
\hline CHEMBL1373194 & 688759 & 5.1 & 5.1233 & TRN & \\
\hline CHEMBL1594679 & 688759 & 4.9 & 4.9104 & TST & \\
\hline CHEMBL1991751 & 688759 & 4.95 & 4.6249 & TRN & \\
\hline CHEMBL 29097 & 688759 & 6.0 & 4.7257 & TST & \\
\hline CHEMBL1526446 & 688759 & 4.95 & 4.7751 & TST & \\
\hline CHEMBL1422733 & 688759 & 4.95 & 5.2988 & TST & \\
\hline CHEMBL3198209 & 688759 & 5.25 & 5.25200 & 0000000001 & TRN \\
\hline CHEMBL1352680 & 688759 & 4.7 & 4.8749 & TRN & \\
\hline CHEMBL1429833 & 688759 & 5.4 & 4.9124 & TRN & \\
\hline CHEMBL1383937 & 688759 & 4.45 & 4.6846 & TST & \\
\hline CHEMBL1301997 & 688759 & 4.45 & 4.9688 & TRN & \\
\hline CHEMBL1462544 & 688759 & 4.55 & 4.9529 & TRN & \\
\hline CHEMBL3209991 & 688759 & 5.0 & 4.7386 & TRN & \\
\hline CHEMBL1303498 & 688759 & 5.05 & 4.7968 & TRN & \\
\hline CHEMBL1426479 & 688759 & 4.45 & 4.7907 & TRN & \\
\hline CHEMBL1387790 & 688759 & 5.85 & 5.8343 & TRN & \\
\hline CHEMBL1336121 & 688759 & 5.3 & 4.9957 & TRN & \\
\hline CHEMBL1338596 & 688759 & 4.45 & 4.7796 & TST & \\
\hline CHEMBL1439149 & 688759 & 4.45 & 4.7559 & TRN & \\
\hline CHEMBL1969647 & 688759 & 5.5 & 5.4486 & TRN & \\
\hline CHEMBL1418735 & 688759 & 5.9 & 4.9511 & TST & \\
\hline CHEMBL1567172 & 688759 & 5.4 & 5.0886 & TRN & \\
\hline CHEMBL1977376 & 688759 & 5.2 & 4.9616 & TRN & \\
\hline CHEMBL1367897 & 688759 & 4.45 & 4.7256 & TRN & \\
\hline CHEMBL1452585 & 688759 & 4.95 & 4.9598 & TST & \\
\hline CHEMBL1382670 & 688759 & 4.45 & 5.039 & TST & \\
\hline CHEMBL1427981 & 688759 & 4.5 & 5.4149 & TRN & \\
\hline CHEMBL1594640 & 688759 & 4.7 & 4.973 & TRN & \\
\hline CHEMBL1393595 & 688759 & 5.15 & 4.9987 & TRN & \\
\hline
\end{tabular}




\begin{tabular}{|c|c|c|c|c|c|}
\hline \multicolumn{6}{|c|}{ Supplemental Table S2.txt } \\
\hline CHEMBL1417771 & 688759 & 4.5 & 4.7637 & TRN & \\
\hline CHEMBL1353424 & 688759 & 4.7 & 4.9149 & TRN & \\
\hline CHEMBL1372447 & 688759 & 5.25 & 5.0787 & TRN & \\
\hline CHEMBL1468899 & 688759 & 5.45 & 5.1589 & TRN & \\
\hline CHEMBL1542792 & 688759 & 5.2 & 5.1762 & TST & \\
\hline CHEMBL1505552 & 688759 & 5.25 & 5.0502 & TST & \\
\hline CHEMBL1459430 & 688759 & 4.95 & 5.1899 & TRN & \\
\hline CHEMBL3198070 & 688759 & 5.9 & 5.5403 & TRN & \\
\hline CHEMBL1990685 & 688759 & 5.45 & 4.7943 & TST & \\
\hline CHEMBL1404272 & 688759 & 5.25 & 4.8506 & TST & \\
\hline CHEMBL1977478 & 688759 & 5.0 & 5.0804 & TST & \\
\hline CHEMBL1538267 & 688759 & 4.9 & 4.5822 & TST & \\
\hline CHEMBL1306462 & 688759 & 4.45 & 5.0342 & TRN & \\
\hline CHEMBL1518550 & 688759 & 5.65 & 5.4035 & TRN & \\
\hline CHEMBL1608017 & 688759 & 5.65 & 5.0046 & TRN & \\
\hline CHEMBL1383868 & 688759 & 5.45 & 4.974 & TRN & \\
\hline CHEMBL1420168 & 688759 & 5.45 & 4.9999 & TRN & \\
\hline CHEMBL3197360 & 688759 & 4.55 & 4.7593 & TRN & \\
\hline CHEMBL1481805 & 688759 & 4.45 & 4.9534 & TST & \\
\hline CHEMBL1554412 & 688759 & 5.9 & 5.0549 & TRN & \\
\hline CHEMBL1539655 & 688759 & 4.45 & 4.9692 & TRN & \\
\hline CHEMBL402053 & 688759 & 5.9 & 5.2262 & TRN & \\
\hline CHEMBL1979383 & 688759 & 5.65 & $5.5020 e$ & 0000000001 & TRN \\
\hline CHEMBL3190830 & 688759 & 4.45 & 4.7158 & TST & \\
\hline CHEMBL299228 & 688759 & 4.6 & 4.7836 & TRN & \\
\hline CHEMBL1329293 & 688759 & 4.65 & 4.7677 & TST & \\
\hline CHEMBL15780 & 688759 & 4.45 & 4.8873 & TRN & \\
\hline CHEMBL1542748 & 688759 & 5.9 & 5.6556 & TRN & \\
\hline CHEMBL1310030 & 688759 & 4.45 & 4.6452 & TRN & \\
\hline CHEMBL1463207 & 688759 & 5.2 & 4.832 & TRN & \\
\hline CHEMBL3199234 & 688759 & 5.6 & 5.6327 & TRN & \\
\hline CHEMBL1462028 & 688759 & 6.3 & 5.6668 & TRN & \\
\hline CHEMBL236267 & 688759 & 5.5 & 5.1329 & TST & \\
\hline CHEMBL1570920 & 688759 & 4.9 & 4.7726 & TST & \\
\hline CHEMBL3194197 & 688759 & 5.3 & 5.2548 & TRN & \\
\hline CHEMBL1458346 & 688759 & 5.0 & 4.8807 & TST & \\
\hline CHEMBL1608045 & 688759 & 4.7 & 4.913 & TRN & \\
\hline CHEMBL1327737 & 688759 & 4.65 & 4.6306 & TRN & \\
\hline CHEMBL1586169 & 688759 & 4.6 & 4.8191 & TRN & \\
\hline CHEMBL1494725 & 688759 & 4.75 & 4.8021 & TST & \\
\hline CHEMBL3189687 & 688759 & 4.95 & 4.7482 & TST & \\
\hline CHEMBL1964389 & 688759 & 5.6 & 5.454 & TRN & \\
\hline CHEMBL3193680 & 688759 & 5.45 & 4.9081 & TRN & \\
\hline CHEMBL1447791 & 688759 & 4.45 & 4.8482 & TRN & \\
\hline CHEMBL1431118 & 688759 & 4.45 & 4.8958 & TRN & \\
\hline CHEMBL1466090 & 688759 & 5.05 & 4.8815 & TRN & \\
\hline CHEMBL1610989 & 688759 & 4.9 & 4.7368 & TRN & \\
\hline CHEMBL1470278 & 688759 & 4.45 & 4.6445 & TRN & \\
\hline
\end{tabular}




\begin{tabular}{|c|c|c|c|c|}
\hline \multicolumn{5}{|c|}{ Supplemental Table S2.txt } \\
\hline CHEMBL1328169 & 688759 & 5.25 & 4.989 & TRN \\
\hline CHEMBL1504716 & 688759 & 4.6 & 4.8031 & TRN \\
\hline CHEMBL1362215 & 688759 & 4.45 & 4.8113 & TRN \\
\hline CHEMBL3192651 & 688759 & 4.45 & 5.3608 & TRN \\
\hline CHEMBL1446061 & 688759 & 4.7 & 4.7721 & TST \\
\hline CHEMBL1454817 & 688759 & 4.95 & 5.0179 & TRN \\
\hline CHEMBL1418061 & 688759 & 5.05 & 5.1988 & TST \\
\hline CHEMBL1600203 & 688759 & 4.8 & 5.1279 & TRN \\
\hline CHEMBL1528614 & 688759 & 5.1 & 4.9513 & TRN \\
\hline CHEMBL1322597 & 688759 & 5.1 & 4.961 & TRN \\
\hline CHEMBL3199736 & 688759 & 4.7 & 4.7134 & TRN \\
\hline CHEMBL1999756 & 688759 & 4.45 & 4.784 & TRN \\
\hline CHEMBL428496 & 688759 & 6.0 & 5.2249 & TST \\
\hline CHEMBL1574553 & 688759 & 6.35 & 5.9145 & TST \\
\hline CHEMBL1550340 & 688759 & 5.15 & 5.0603 & TRN \\
\hline CHEMBL1427409 & 688759 & 4.45 & 4.7305 & TRN \\
\hline CHEMBL1308276 & 688759 & 4.45 & 4.938 & TST \\
\hline CHEMBL1442795 & 688759 & 4.65 & 4.8508 & TRN \\
\hline CHEMBL1502083 & 688759 & 4.45 & 4.583 & TRN \\
\hline CHEMBL1485656 & 688759 & 4.45 & 4.7069 & TRN \\
\hline CHEMBL1569483 & 688759 & 4.65 & 4.9162 & TRN \\
\hline CHEMBL1572195 & 688759 & 4.95 & 4.849 & TST \\
\hline CHEMBL1448050 & 688759 & 4.45 & 5.0462 & TST \\
\hline CHEMBL1443784 & 688759 & 6.9 & 5.9715 & TRN \\
\hline CHEMBL1470160 & 688759 & 4.45 & 4.9504 & TRN \\
\hline CHEMBL1307194 & 688759 & 5.6 & 4.76 & TRN \\
\hline CHEMBL3209206 & 688759 & 6.5 & 4.8859 & TRN \\
\hline CHEMBL1423399 & 688759 & 4.45 & 5.1074 & TRN \\
\hline CHEMBL1576565 & 688759 & 5.25 & 4.8913 & TRN \\
\hline CHEMBL1348667 & 688759 & 5.95 & 5.813 & TRN \\
\hline CHEMBL1565419 & 688759 & 5.25 & 5.1532 & TRN \\
\hline CHEMBL1607723 & 688759 & 4.45 & 5.0124 & TRN \\
\hline CHEMBL1462526 & 688759 & 4.45 & 4.7654 & TRN \\
\hline CHEMBL1984154 & 688759 & 4.45 & 4.8583 & TRN \\
\hline CHEMBL1373360 & 688759 & 4.8 & 4.978 & TRN \\
\hline CHEMBL1452120 & 688759 & 5.15 & 4.9381 & TRN \\
\hline CHEMBL1534981 & 688759 & 4.45 & 4.791 & TST \\
\hline CHEMBL1432064 & 688759 & 4.55 & 4.6277 & TST \\
\hline CHEMBL 3189722 & 688759 & 4.9 & 4.7601 & TRN \\
\hline CHEMBL1604024 & 688759 & 5.55 & 5.2725 & TRN \\
\hline CHEMBL1353062 & 688759 & 4.45 & 5.2312 & TRN \\
\hline CHEMBL1965612 & 688759 & 6.05 & 5.5484 & TRN \\
\hline CHEMBL1585781 & 688759 & 4.45 & 4.7293 & TRN \\
\hline CHEMBL1441930 & 688759 & 4.9 & 4.915 & TST \\
\hline CHEMBL1336346 & 688759 & 4.45 & 4.5029 & TRN \\
\hline CHEMBL3193254 & 688759 & 5.1 & 5.0878 & TRN \\
\hline CHEMBL1300001 & 688759 & 4.6 & 4.7337 & TRN \\
\hline CHEMBL1408935 & 688759 & 4.45 & 5.165 & TRN \\
\hline
\end{tabular}




\begin{tabular}{|c|c|c|c|c|c|}
\hline & & \multicolumn{4}{|c|}{ Supplemental Table S2.txt } \\
\hline CHEMBL1466549 & 688759 & 4.45 & 4.628 & TRN & \\
\hline CHEMBL3214330 & 688759 & 5.35 & 5.1517 & TRN & \\
\hline CHEMBL1302239 & 688759 & 4.75 & 4.9456 & TST & \\
\hline CHEMBL1381688 & 688759 & 4.65 & 4.6184 & TRN & \\
\hline CHEMBL1409318 & 688759 & 5.75 & 5.2766 & TRN & \\
\hline CHEMBL1509656 & 688759 & 4.95 & 5.1859 & TRN & \\
\hline CHEMBL421088 & 688759 & 4.95 & 5.188 & TRN & \\
\hline CHEMBL3194259 & 688759 & 4.45 & 5.0024 & TRN & \\
\hline CHEMBL1607013 & 688759 & 5.5 & 4.6278 & TST & \\
\hline CHEMBL1556088 & 688759 & 4.45 & 4.8113 & TRN & \\
\hline CHEMBL1391482 & 688759 & 4.45 & 4.7336 & TST & \\
\hline CHEMBL1416239 & 688759 & 4.65 & 4.9487 & TST & \\
\hline CHEMBL1595142 & 688759 & 5.55 & 5.1167 & TRN & \\
\hline CHEMBL1563369 & 688759 & 5.2 & 5.0162 & TST & \\
\hline CHEMBL1360997 & 688759 & 5.15 & 4.7034 & TRN & \\
\hline CHEMBL1329251 & 688759 & 5.3 & 5.4422 & TRN & \\
\hline CHEMBL1479226 & 688759 & 4.65 & 4.80699 & 99999999995 & TST \\
\hline CHEMBL1524014 & 688759 & 4.8 & 5.2849 & TRN & \\
\hline CHEMBL1302199 & 688759 & 5.65 & 4.9535 & TST & \\
\hline CHEMBL1424244 & 688759 & 6.6499 & 4.9432 & TRN & \\
\hline CHEMBL1562764 & 688759 & 4.85 & 4.9354 & TRN & \\
\hline CHEMBL3191871 & 688759 & 6.5 & 6.0147 & TRN & \\
\hline CHEMBL1301302 & 688759 & 4.45 & 4.9409 & TRN & \\
\hline CHEMBL1558347 & 688759 & 4.65 & 4.7216 & TRN & \\
\hline CHEMBL1495562 & 688759 & 4.45 & 4.8141 & TST & \\
\hline CHEMBL3195006 & 688759 & 4.6 & 4.7197 & TRN & \\
\hline CHEMBL1326890 & 688759 & 4.7 & 4.9752 & TRN & \\
\hline CHEMBL401504 & 688759 & 5.95 & 5.6464 & TRN & \\
\hline CHEMBL1530173 & 688759 & 4.9 & 4.5264 & TRN & \\
\hline CHEMBL1536751 & 688759 & 4.45 & 4.4656 & TRN & \\
\hline CHEMBL1309286 & 688759 & 5.3 & 4.9733 & TRN & \\
\hline CHEMBL1567586 & 688759 & 4.9 & 4.8747 & TRN & \\
\hline CHEMBL1450817 & 688759 & 4.5 & 4.9105 & TST & \\
\hline CHEMBL3190251 & 688759 & 4.65 & 5.0454 & TRN & \\
\hline CHEMBL1528493 & 688759 & 4.9 & 5.2869 & TRN & \\
\hline CHEMBL1538277 & 688759 & 4.45 & 4.8649 & TRN & \\
\hline CHEMBL3391990 & 688759 & 4.45 & 5.0448 & TST & \\
\hline CHEMBL3195778 & 688759 & 5.4 & 5.1663 & TST & \\
\hline CHEMBL1393666 & 688759 & 5.55 & 4.8456 & TRN & \\
\hline CHEMBL1588806 & 688759 & 4.45 & 4.8544 & TRN & \\
\hline CHEMBL1528821 & 688759 & 4.65 & 4.6893 & TRN & \\
\hline CHEMBL1333621 & 688759 & 4.7 & 5.0867 & TRN & \\
\hline CHEMBL1470421 & 688759 & 4.75 & 5.0256 & TRN & \\
\hline CHEMBL1968316 & 688759 & 4.65 & 4.7099 & TRN & \\
\hline CHEMBL1504086 & 688759 & 4.7 & 4.7629 & TRN & \\
\hline CHEMBL1540162 & 688759 & 5.3 & 4.9984 & TST & \\
\hline CHEMBL1557435 & 688759 & 5.7 & 5.1281 & TST & \\
\hline CHEMBL1369295 & 688759 & 5.0 & 5.0406 & TRN & \\
\hline
\end{tabular}




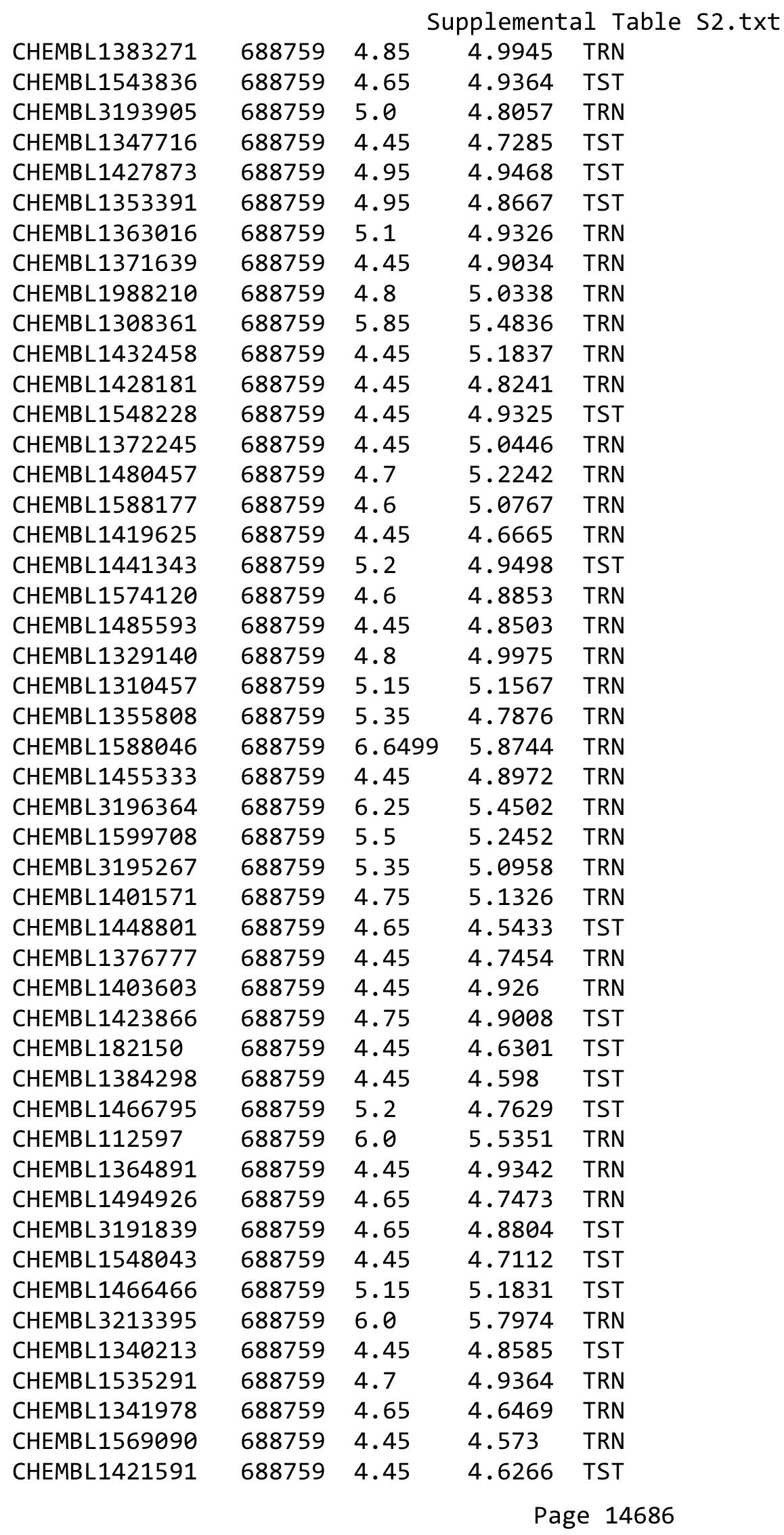




\begin{tabular}{|c|c|c|c|c|c|}
\hline & & \multicolumn{4}{|c|}{ Supplemental Table s2.txt } \\
\hline CHEMBL1422640 & 688759 & 4.45 & 4.6026 & TRN & \\
\hline CHEMBL1390930 & 688759 & 5.6 & 4.8339 & TRN & \\
\hline CHEMBL1596262 & 688759 & 4.75 & 4.7582 & TRN & \\
\hline CHEMBL3191227 & 688759 & 4.5 & 4.7998 & TRN & \\
\hline CHEMBL1344904 & 688759 & 4.85 & 4.7353 & TRN & \\
\hline CHEMBL507026 & 688759 & 6.6 & 5.6774 & TST & \\
\hline CHEMBL1529201 & 688759 & 4.65 & 4.8693 & TST & \\
\hline CHEMBL1472411 & 688759 & 4.85 & 5.1248 & TST & \\
\hline CHEMBL1429154 & 688759 & 5.8 & 5.2619 & TST & \\
\hline CHEMBL1581292 & 688759 & 4.85 & 5.0757 & TRN & \\
\hline CHEMBL1516649 & 688759 & 4.45 & 4.9347 & TRN & \\
\hline CHEMBL1559514 & 688759 & 5.65 & 4.7829 & TRN & \\
\hline CHEMBL1386577 & 688759 & 4.6 & 4.7923 & TRN & \\
\hline CHEMBL1299261 & 688759 & 4.85 & 4.7301 & TRN & \\
\hline CHEMBL1353015 & 688759 & 4.45 & 4.7326 & TRN & \\
\hline CHEMBL1329974 & 688759 & 4.6 & 4.6419 & TRN & \\
\hline CHEMBL1447840 & 688759 & 4.45 & 4.7545 & TRN & \\
\hline CHEMBL1594235 & 688759 & 4.95 & 4.8793 & TST & \\
\hline CHEMBL1352386 & 688759 & 4.45 & 4.957 & TRN & \\
\hline CHEMBL1431184 & 688759 & 4.45 & 4.6471 & TST & \\
\hline CHEMBL1419714 & 688759 & 4.7 & 4.5398 & TRN & \\
\hline CHEMBL1389417 & 688759 & 4.45 & 4.7819 & TRN & \\
\hline CHEMBL1318819 & 688759 & 4.85 & 4.7889 & TST & \\
\hline CHEMBL1540080 & 688759 & 4.45 & 4.6999 & TRN & \\
\hline CHEMBL1567802 & 688759 & 4.65 & 4.9137 & TRN & \\
\hline CHEMBL1383497 & 688759 & 4.45 & 4.6001 & TST & \\
\hline CHEMBL1413122 & 688759 & 4.9 & 4.9277 & TRN & \\
\hline CHEMBL1587154 & 688759 & 5.0 & 4.7103 & TRN & \\
\hline CHEMBL1432495 & 688759 & 5.25 & 5.1812 & TST & \\
\hline CHEMBL1412473 & 688759 & 4.7 & 4.7749 & TRN & \\
\hline CHEMBL1388526 & 688759 & 4.45 & 4.8261 & TRN & \\
\hline CHEMBL1370592 & 688759 & 5.2 & 5.1084 & TRN & \\
\hline CHEMBL1503359 & 688759 & 5.15 & 4.9581 & TST & \\
\hline CHEMBL1407542 & 688759 & 5.2 & 5.0559 & TRN & \\
\hline CHEMBL1367563 & 688759 & 4.75 & 4.6503 & TRN & \\
\hline CHEMBL1499302 & 688759 & 4.6 & 4.6794 & TRN & \\
\hline CHEMBL1613477 & 688759 & 4.45 & 5.1685 & TST & \\
\hline CHEMBL3195621 & 688759 & 4.45 & 4.6839 & TRN & \\
\hline CHEMBL 3189834 & 688759 & 4.6 & 4.7332 & TRN & \\
\hline CHEMBL1449259 & 688759 & 4.5 & 4.7242 & TRN & \\
\hline CHEMBL1609354 & 688759 & 4.85 & 4.7719 & TRN & \\
\hline CHEMBL1533523 & 688759 & 4.9 & 4.8205 & TRN & \\
\hline CHEMBL1586590 & 688759 & 6.05 & 6.0139 & 9999999999 & TRN \\
\hline CHEMBL1465195 & 688759 & 5.45 & 5.0811 & TST & \\
\hline CHEMBL1592647 & 688759 & 4.45 & 4.7662 & TRN & \\
\hline CHEMBL1458068 & 688759 & 5.25 & 4.8931 & TST & \\
\hline CHEMBL3194563 & 688759 & 6.5 & 5.7073 & TRN & \\
\hline CHEMBL1505788 & 688759 & 5.25 & 5.0033 & TRN & \\
\hline
\end{tabular}




\begin{tabular}{|c|c|c|c|c|}
\hline & & \multicolumn{3}{|c|}{ Supplemental Table S2.txt } \\
\hline CHEMBL3207641 & 688759 & 4.45 & 4.9258 & TST \\
\hline CHEMBL3196304 & 688759 & 5.1 & 5.4982 & TRN \\
\hline CHEMBL1712082 & 688759 & 6.05 & 5.1812 & TRN \\
\hline CHEMBL579967 & 688759 & 5.25 & 4.665 & TRN \\
\hline CHEMBL3208339 & 688759 & 4.65 & 4.7318 & TRN \\
\hline CHEMBL1510541 & 688759 & 4.95 & 5.1295 & TRN \\
\hline CHEMBL1302010 & 688759 & 4.45 & 4.8579 & TST \\
\hline CHEMBL1408146 & 688759 & 5.05 & 4.7542 & TRN \\
\hline CHEMBL1985479 & 688759 & 4.7 & 4.9698 & TRN \\
\hline CHEMBL3195239 & 688759 & 4.9 & 4.9097 & TRN \\
\hline CHEMBL1309816 & 688759 & 4.95 & 4.7216 & TST \\
\hline CHEMBL 3194320 & 688759 & 6.3 & 5.3715 & TRN \\
\hline CHEMBL3197808 & 688759 & 4.95 & 5.1625 & TRN \\
\hline CHEMBL1423564 & 688759 & 4.45 & 5.0818 & TRN \\
\hline CHEMBL1404560 & 688759 & 4.45 & 4.7348 & TRN \\
\hline CHEMBL1342826 & 688759 & 4.9 & 5.1597 & TRN \\
\hline CHEMBL1578386 & 688759 & 4.6 & 4.9627 & TRN \\
\hline CHEMBL1607997 & 688759 & 4.45 & 4.7455 & TRN \\
\hline CHEMBL 3197341 & 688759 & 4.65 & 4.7684 & TRN \\
\hline CHEMBL1509812 & 688759 & 4.65 & 4.731 & TRN \\
\hline CHEMBL1544385 & 688759 & 4.85 & 4.8603 & TRN \\
\hline CHEMBL1303912 & 688759 & 4.45 & 4.8063 & TRN \\
\hline CHEMBL1611860 & 688759 & 5.3 & 5.143 & TRN \\
\hline CHEMBL1504123 & 688759 & 5.35 & 4.8309 & TRN \\
\hline CHEMBL3191855 & 688759 & 5.25 & 4.9286 & TRN \\
\hline CHEMBL1493199 & 688759 & 4.45 & 5.0416 & TST \\
\hline CHEMBL3190220 & 688759 & 4.45 & 5.0141 & TRN \\
\hline CHEMBL1562549 & 688759 & 4.65 & 4.8176 & TRN \\
\hline CHEMBL3190676 & 688759 & 4.65 & 4.9907 & TRN \\
\hline CHEMBL1368820 & 688759 & 4.55 & 4.7625 & TRN \\
\hline CHEMBL1540422 & 688759 & 4.45 & 4.7028 & TRN \\
\hline CHEMBL1415277 & 688759 & 5.25 & 4.9088 & TRN \\
\hline CHEMBL1433286 & 688759 & 4.45 & 4.8595 & TST \\
\hline CHEMBL582444 & 688759 & 4.45 & 5.2313 & TST \\
\hline CHEMBL1323586 & 688759 & 4.75 & 4.7922 & TST \\
\hline CHEMBL1368075 & 688759 & 5.25 & 5.2177 & TRN \\
\hline CHEMBL1390266 & 688759 & 4.45 & 4.8233 & TRN \\
\hline CHEMBL1377010 & 688759 & 4.9 & 5.1294 & TST \\
\hline CHEMBL1425242 & 688759 & 4.95 & 4.7874 & TRN \\
\hline CHEMBL274070 & 688759 & 6.45 & 6.5075 & TRN \\
\hline CHEMBL1413175 & 688759 & 4.85 & 4.8323 & TRN \\
\hline CHEMBL1420187 & 688759 & 4.7 & 4.4676 & TRN \\
\hline CHEMBL1300027 & 688759 & 4.75 & 4.7168 & TRN \\
\hline CHEMBL1972506 & 688759 & 4.95 & 4.9934 & TRN \\
\hline CHEMBL18879 & 688759 & 4.8 & 5.1388 & TST \\
\hline CHEMBL 2007400 & 688759 & 4.9 & 4.6931 & TRN \\
\hline CHEMBL1425718 & 688759 & 4.45 & 4.77 & TRN \\
\hline CHEMBL609606 & 688759 & 5.3 & 5.1363 & TRN \\
\hline
\end{tabular}




\begin{tabular}{|c|c|c|c|c|}
\hline & & & pplement & al $\mathrm{T}$ \\
\hline CHEMBL1451449 & 688759 & 4.9 & 4.8823 & TRN \\
\hline CHEMBL1379675 & 688759 & 5.0 & 4.9936 & TRN \\
\hline CHEMBL1423318 & 688759 & 4.95 & 5.0746 & TRN \\
\hline CHEMBL1431389 & 688759 & 5.0 & 5.0376 & TRN \\
\hline CHEMBL244857 & 688759 & 5.6 & 4.8271 & TRN \\
\hline CHEMBL3193429 & 688759 & 5.55 & 5.2181 & TRN \\
\hline CHEMBL1468137 & 688759 & 4.55 & 5.3918 & TRN \\
\hline CHEMBL1519976 & 688759 & 5.0 & 4.8422 & TRN \\
\hline CHEMBL1430371 & 688759 & 4.45 & 5.0134 & TRN \\
\hline CHEMBL1455197 & 688759 & 4.45 & 4.7399 & TRN \\
\hline CHEMBL273103 & 688759 & 4.9 & 5.0318 & TRN \\
\hline CHEMBL1386519 & 688759 & 5.9 & 4.9947 & TRN \\
\hline CHEMBL1553726 & 688759 & 4.7 & 4.9401 & TST \\
\hline CHEMBL1549157 & 688759 & 4.7 & 4.8176 & TST \\
\hline CHEMBL1583833 & 688759 & 4.65 & 4.6475 & TRN \\
\hline CHEMBL1441085 & 688759 & 4.75 & 4.6335 & TST \\
\hline CHEMBL1451770 & 688759 & 4.45 & 4.7392 & TRN \\
\hline CHEMBL1569927 & 688759 & 4.95 & 4.7622 & TRN \\
\hline CHEMBL1335084 & 688759 & 4.45 & 4.8312 & TRN \\
\hline CHEMBL1549349 & 688759 & 4.45 & 5.1423 & TRN \\
\hline CHEMBL1968781 & 688759 & 4.45 & 4.6753 & TRN \\
\hline CHEMBL1347611 & 688759 & 4.95 & 5.1421 & TRN \\
\hline CHEMBL1431394 & 688759 & 5.2 & 5.131 & TRN \\
\hline CHEMBL1308491 & 688759 & 5.4 & 5.3693 & TST \\
\hline CHEMBL1326157 & 688759 & 5.2 & 5.3688 & TRN \\
\hline CHEMBL1484099 & 688759 & 4.65 & 4.6304 & TRN \\
\hline CHEMBL1343533 & 688759 & 8.2518 & 4.8563 & TRN \\
\hline CHEMBL1505618 & 688759 & 4.45 & 5.0798 & TRN \\
\hline CHEMBL1488131 & 688759 & 4.55 & 4.6814 & TST \\
\hline CHEMBL444236 & 688759 & 5.1 & 5.1275 & TST \\
\hline CHEMBL1345400 & 688759 & 4.45 & 4.7752 & TRN \\
\hline CHEMBL1427175 & 688759 & 4.65 & 4.5584 & TRN \\
\hline CHEMBL1457941 & 688759 & 5.0 & 4.9988 & TRN \\
\hline CHEMBL1365613 & 688759 & 5.25 & 4.9206 & TST \\
\hline CHEMBL1540834 & 688759 & 4.5 & 4.8928 & TST \\
\hline CHEMBL1987136 & 688759 & 4.65 & 4.9123 & TRN \\
\hline CHEMBL1471389 & 688759 & 4.45 & 4.9907 & TRN \\
\hline CHEMBL1534384 & 688759 & 4.9 & 4.7854 & TRN \\
\hline CHEMBL1532012 & 688759 & 4.8 & 5.1071 & TRN \\
\hline CHEMBL 1400185 & 688759 & 4.45 & 4.6967 & TRN \\
\hline CHEMBL1334130 & 688759 & 5.1 & 4.8798 & TST \\
\hline CHEMBL1455281 & 688759 & 5.35 & 4.9145 & TST \\
\hline CHEMBL1564731 & 688759 & 6.0 & 5.7947 & TRN \\
\hline CHEMBL1352169 & 688759 & 4.7 & 4.7174 & TST \\
\hline CHEMBL1437843 & 688759 & 4.45 & 4.8394 & TRN \\
\hline CHEMBL264702 & 688759 & 5.2 & 5.2078 & TRN \\
\hline CHEMBL1603615 & 688759 & 4.8 & 4.9747 & TST \\
\hline CHEMBL1554080 & 688759 & 4.6 & 4.7027 & TRN \\
\hline
\end{tabular}




\begin{tabular}{|c|c|c|c|c|c|}
\hline & & \multicolumn{4}{|c|}{ Supplemental Table S2.txt } \\
\hline CHEMBL1556035 & 688759 & 6.0 & 5.3756 & TRN & \\
\hline CHEMBL1333262 & 688759 & 4.95 & 4.745 & TRN & \\
\hline CHEMBL1575045 & 688759 & 4.45 & 4.8524 & TRN & \\
\hline CHEMBL1541000 & 688759 & 4.6 & 4.8417 & TRN & \\
\hline CHEMBL1587977 & 688759 & 4.65 & 4.5185 & TRN & \\
\hline CHEMBL1452652 & 688759 & 4.65 & 4.9661 & TRN & \\
\hline CHEMBL3194052 & 688759 & 4.9 & 4.9763 & TRN & \\
\hline CHEMBL1426546 & 688759 & 5.5 & 5.0314 & TRN & \\
\hline CHEMBL1564594 & 688759 & 6.25 & 5.8207 & TST & \\
\hline CHEMBL1411403 & 688759 & 4.95 & 5.1131 & TRN & \\
\hline CHEMBL1322923 & 688759 & 4.7 & 4.8162 & TRN & \\
\hline CHEMBL1582259 & 688759 & 5.25 & 5.0487 & TRN & \\
\hline CHEMBL1369647 & 688759 & 4.45 & 4.9129 & TST & \\
\hline CHEMBL1371111 & 688759 & 4.45 & 4.4478 & TRN & \\
\hline CHEMBL1385126 & 688759 & 5.4 & 5.5436 & TRN & \\
\hline CHEMBL3199937 & 688759 & 6.15 & 5.5409 & TRN & \\
\hline CHEMBL1482478 & 688759 & 5.25 & 5.0481 & TRN & \\
\hline CHEMBL3192627 & 688759 & 4.9 & 4.8041 & TRN & \\
\hline CHEMBL1378282 & 688759 & 5.5 & 5.0944 & TRN & \\
\hline CHEMBL3209149 & 688759 & 4.45 & 4.8287 & TRN & \\
\hline CHEMBL1368099 & 688759 & 4.45 & 4.8484 & TRN & \\
\hline CHEMBL1563440 & 688759 & 4.75 & 4.795 & TRN & \\
\hline CHEMBL1424069 & 688759 & 4.45 & 4.8256 & TRN & \\
\hline CHEMBL1531092 & 688759 & 4.65 & 4.541 & TRN & \\
\hline CHEMBL3190209 & 688759 & 6.1 & 5.8998 & TRN & \\
\hline CHEMBL1420182 & 688759 & 4.8 & 4.6802 & TRN & \\
\hline CHEMBL1505705 & 688759 & 4.9 & 4.8758 & TRN & \\
\hline CHEMBL1320524 & 688759 & 5.3 & 4.9746 & TRN & \\
\hline CHEMBL1976225 & 688759 & 4.75 & 4.9042 & TRN & \\
\hline CHEMBL1481836 & 688759 & 4.65 & 4.6546 & TST & \\
\hline CHEMBL1597015 & 688759 & 4.9 & 4.9136 & TRN & \\
\hline CHEMBL1539097 & 688759 & 4.45 & 4.6766 & TRN & \\
\hline CHEMBL1427897 & 688759 & 5.25 & 4.941 & TRN & \\
\hline CHEMBL1371387 & 688759 & 5.1 & 5.1213 & TST & \\
\hline CHEMBL1536250 & 688759 & 4.7 & 4.8246 & TRN & \\
\hline CHEMBL3189252 & 688759 & 4.45 & 4.6977 & TRN & \\
\hline CHEMBL1495474 & 688759 & 5.45 & 4.9338 & TRN & \\
\hline CHEMBL1443804 & 688759 & 4.95 & 4.584 & TRN & \\
\hline CHEMBL1338390 & 688759 & 5.15 & 4.9137 & TRN & \\
\hline CHEMBL1999548 & 688759 & 5.65 & 5.2895 & TRN & \\
\hline CHEMBL1373560 & 688759 & 4.55 & 4.811 & TRN & \\
\hline CHEMBL1401360 & 688759 & 4.6 & 4.8142 & TRN & \\
\hline CHEMBL1360416 & 688759 & 5.5 & 5.1789 & TRN & \\
\hline CHEMBL1560760 & 688759 & 5.0 & 5.4078 & TRN & \\
\hline CHEMBL1472593 & 688759 & 4.7 & 5.0528 & TRN & \\
\hline CHEMBL1432227 & 688759 & 5.1 & 5.0275 & TRN & \\
\hline CHEMBL1405854 & 688759 & 5.0 & 5.33299 & 9999999999 & TRN \\
\hline CHEMBL1347572 & 688759 & 4.45 & 4.6218 & TST & \\
\hline
\end{tabular}




\begin{tabular}{|c|c|c|c|c|}
\hline & & & upplement & al $\mathrm{T}$ \\
\hline CHEMBL1370953 & 688759 & 4.7 & 4.5052 & TST \\
\hline CHEMBL1504866 & 688759 & 5.3 & 4.9403 & TRN \\
\hline CHEMBL1497481 & 688759 & 4.95 & 4.8194 & TRN \\
\hline CHEMBL1421228 & 688759 & 4.85 & 4.9742 & TRN \\
\hline CHEMBL1345798 & 688759 & 4.85 & 4.7111 & TRN \\
\hline CHEMBL1609326 & 688759 & 5.25 & 4.9151 & TRN \\
\hline CHEMBL1411125 & 688759 & 4.45 & 4.6847 & TRN \\
\hline CHEMBL1431309 & 688759 & 5.45 & 4.7239 & TRN \\
\hline CHEMBL1408418 & 688759 & 4.45 & 4.9617 & TST \\
\hline CHEMBL1326523 & 688759 & 4.65 & 4.6344 & TRN \\
\hline CHEMBL1487152 & 688759 & 6.45 & 5.0348 & TRN \\
\hline CHEMBL1351242 & 688759 & 5.6 & 5.3177 & TST \\
\hline CHEMBL1497792 & 688759 & 5.0 & 4.9006 & TST \\
\hline CHEMBL3189433 & 688759 & 5.95 & 5.5143 & TRN \\
\hline CHEMBL1587516 & 688759 & 4.45 & 4.7366 & TRN \\
\hline CHEMBL1447884 & 688759 & 5.05 & 5.0216 & TRN \\
\hline CHEMBL1510926 & 688759 & 4.6 & 4.8218 & TRN \\
\hline CHEMBL1383789 & 688759 & 4.9 & 4.7841 & TST \\
\hline CHEMBL1340362 & 688759 & 5.25 & 5.2231 & TRN \\
\hline CHEMBL1789993 & 688759 & 4.6 & 5.4686 & TST \\
\hline CHEMBL1518142 & 688759 & 4.45 & 4.8561 & TRN \\
\hline CHEMBL3198975 & 688759 & 4.9 & 5.3628 & TRN \\
\hline CHEMBL1498328 & 688759 & 4.45 & 4.5954 & TST \\
\hline CHEMBL 257856 & 688759 & 4.65 & 4.6162 & TRN \\
\hline CHEMBL1485510 & 688759 & 4.45 & 4.7674 & TRN \\
\hline CHEMBL1303404 & 688759 & 5.7 & 5.4822 & TRN \\
\hline CHEMBL1464721 & 688759 & 4.55 & 4.8681 & TRN \\
\hline CHEMBL1350594 & 688759 & 5.2 & 5.5983 & TRN \\
\hline CHEMBL1570637 & 688759 & 4.6 & 4.8079 & TST \\
\hline CHEMBL1487272 & 688759 & 4.45 & 4.6765 & TST \\
\hline CHEMBL1612864 & 688759 & 4.65 & 4.8175 & TRN \\
\hline CHEMBL1353431 & 688759 & 4.6 & 4.7243 & TST \\
\hline CHEMBL3145361 & 688759 & 5.9 & 5.8669 & TRN \\
\hline CHEMBL3194157 & 688759 & 4.45 & 4.8118 & TST \\
\hline CHEMBL1401668 & 688759 & 4.45 & 4.4699 & TST \\
\hline CHEMBL1587453 & 688759 & 4.95 & 4.8466 & TRN \\
\hline CHEMBL1425574 & 688759 & 5.15 & 5.1113 & TST \\
\hline CHEMBL68096 & 688759 & 4.9 & 5.02 & TRN \\
\hline CHEMBL1478041 & 688759 & 6.2 & 6.0874 & TRN \\
\hline CHEMBL1425934 & 688759 & 5.9 & 4.9736 & TRN \\
\hline CHEMBL1519298 & 688759 & 5.15 & 4.9347 & TRN \\
\hline CHEMBL1527929 & 688759 & 5.15 & 5.0136 & TRN \\
\hline CHEMBL1422158 & 688759 & 5.9 & 5.376 & TRN \\
\hline CHEMBL1372573 & 688759 & 4.45 & 4.9302 & TRN \\
\hline CHEMBL3208036 & 688759 & 4.95 & 4.8044 & TRN \\
\hline CHEMBL1604217 & 688759 & 5.45 & 5.357 & TRN \\
\hline CHEMBL1414717 & 688759 & 5.25 & 4.9592 & TRN \\
\hline CHEMBL3211929 & 688759 & 4.45 & 4.5296 & TRN \\
\hline
\end{tabular}




\begin{tabular}{|c|c|c|c|c|c|}
\hline \multicolumn{6}{|c|}{ Supplemental Table S2.txt } \\
\hline CHEMBL1581406 & 688759 & 4.65 & 4.7343 & TRN & \\
\hline CHEMBL1384493 & 688759 & 6.2 & 5.0369 & TST & \\
\hline CHEMBL1558563 & 688759 & 4.8 & 4.5858 & TRN & \\
\hline CHEMBL1369873 & 688759 & 4.45 & 4.7309 & TRN & \\
\hline CHEMBL1379789 & 688759 & 4.7 & 4.5303 & TRN & \\
\hline CHEMBL3189832 & 688759 & 4.45 & 4.7764 & TRN & \\
\hline CHEMBL 3197201 & 688759 & 5.55 & 5.1278 & TRN & \\
\hline CHEMBL1557778 & 688759 & 5.55 & 4.7413 & TRN & \\
\hline CHEMBL1539204 & 688759 & 5.1 & 5.0794 & TRN & \\
\hline CHEMBL1508254 & 688759 & 4.7 & 4.9951 & TST & \\
\hline CHEMBL1461393 & 688759 & 6.0 & 4.6303 & TRN & \\
\hline CHEMBL1552306 & 688759 & 4.95 & 5.1386 & TRN & \\
\hline CHEMBL1413086 & 688759 & 4.45 & 4.8931 & TRN & \\
\hline CHEMBL1383679 & 688759 & 4.95 & 5.0284 & TST & \\
\hline CHEMBL1440964 & 688759 & 4.45 & 4.9168 & TRN & \\
\hline CHEMBL1503414 & 688759 & 5.4 & 5.5168 & TRN & \\
\hline CHEMBL1444191 & 688759 & 4.45 & 4.5376 & TST & \\
\hline CHEMBL1543700 & 688759 & 5.0 & 4.6861 & TRN & \\
\hline CHEMBL1584845 & 688759 & 5.4 & 4.7743 & TRN & \\
\hline CHEMBL1507923 & 688759 & 4.8 & 4.8035 & TST & \\
\hline CHEMBL591000 & 688759 & 4.45 & 5.0393 & TRN & \\
\hline CHEMBL459715 & 688759 & 4.45 & 4.8631 & TRN & \\
\hline CHEMBL1609686 & 688759 & 4.75 & 5.0913 & TRN & \\
\hline CHEMBL1459755 & 688759 & 4.45 & 4.5527 & TST & \\
\hline CHEMBL1427561 & 688759 & 4.45 & 4.6176 & TRN & \\
\hline CHEMBL1507587 & 688759 & 4.9 & 4.7792 & TRN & \\
\hline CHEMBL1386830 & 688759 & 4.75 & 4.8342 & TRN & \\
\hline CHEMBL 3193520 & 688759 & 5.3 & 5.0262 & TST & \\
\hline CHEMBL3213983 & 688759 & 4.45 & 4.566 & TST & \\
\hline CHEMBL1525074 & 688759 & 5.95 & 5.2539 & TRN & \\
\hline CHEMBL1388871 & 688759 & 4.95 & 4.9283 & TST & \\
\hline CHEMBL1335420 & 688759 & 4.45 & 4.8322 & TRN & \\
\hline CHEMBL1538945 & 688759 & 4.6 & 5.1628 & TRN & \\
\hline CHEMBL3207930 & 688759 & 4.45 & 4.8509 & TST & \\
\hline CHEMBL1519812 & 688759 & 4.95 & 4.7935 & TST & \\
\hline CHEMBL1579555 & 688759 & 5.8 & 5.433 & TRN & \\
\hline CHEMBL1438042 & 688759 & 4.45 & 4.8861 & TRN & \\
\hline CHEMBL1368818 & 688759 & 4.65 & 5.0616 & TRN & \\
\hline CHEMBL1419839 & 688759 & 5.9 & 4.9075 & TRN & \\
\hline CHEMBL1470949 & 688759 & 4.6 & 4.8473 & TRN & \\
\hline CHEMBL1521536 & 688759 & 4.45 & 4.8298 & TRN & \\
\hline CHEMBL1350768 & 688759 & 5.35 & 5.082 & TRN & \\
\hline CHEMBL1299934 & 688759 & 4.45 & 4.7479 & TRN & \\
\hline CHEMBL1390810 & 688759 & 4.45 & $5.1160 e$ & 00000000005 & TRN \\
\hline CHEMBL1571332 & 688759 & 4.45 & 4.8293 & TST & \\
\hline CHEMBL1399065 & 688759 & 5.85 & $4.8610 e$ & $\partial 000000001$ & TST \\
\hline CHEMBL1728993 & 688759 & 4.45 & 4.5954 & TRN & \\
\hline CHEMBL1408491 & 688759 & 4.45 & 4.9308 & TST & \\
\hline
\end{tabular}




\begin{tabular}{|c|c|c|c|c|c|}
\hline & & \multicolumn{4}{|c|}{ Supplemental Table s2.txt } \\
\hline CHEMBL1374633 & 688759 & 4.45 & 4.7209 & TST & \\
\hline CHEMBL1485028 & 688759 & 4.45 & 5.0055 & TST & \\
\hline CHEMBL1449626 & 688759 & 5.15 & 4.9094 & TRN & \\
\hline CHEMBL1419641 & 688759 & 4.45 & 4.8611 & TRN & \\
\hline CHEMBL1407457 & 688759 & 5.35 & 5.34200 & 00000000005 & TRN \\
\hline CHEMBL1531745 & 688759 & 4.45 & 4.8879 & TST & \\
\hline CHEMBL1406945 & 688759 & 4.7 & 4.8739 & TRN & \\
\hline CHEMBL1612177 & 688759 & 4.9 & 4.9194 & TRN & \\
\hline CHEMBL1504833 & 688759 & 4.45 & 4.2703 & TRN & \\
\hline CHEMBL1550760 & 688759 & 4.45 & 4.9209 & TRN & \\
\hline CHEMBL1516827 & 688759 & 5.6 & 4.8361 & TRN & \\
\hline CHEMBL 3213193 & 688759 & 4.45 & 4.9556 & TRN & \\
\hline CHEMBL1405259 & 688759 & 4.45 & 4.6034 & TRN & \\
\hline CHEMBL1509648 & 688759 & 4.45 & 4.9015 & TRN & \\
\hline CHEMBL1492696 & 688759 & 4.8 & 4.8509 & TRN & \\
\hline CHEMBL1351158 & 688759 & 4.75 & 4.4309 & TRN & \\
\hline CHEMBL1566362 & 688759 & 4.75 & 4.914 & TST & \\
\hline CHEMBL1509453 & 688759 & 4.75 & 4.8903 & TRN & \\
\hline CHEMBL1369980 & 688759 & 4.95 & 4.8544 & TST & \\
\hline CHEMBL1433107 & 688759 & 5.1 & 4.8895 & TRN & \\
\hline CHEMBL1465803 & 688759 & 4.55 & 4.8549 & TRN & \\
\hline CHEMBL1987427 & 688759 & 4.95 & 4.9392 & TRN & \\
\hline CHEMBL1538109 & 688759 & 4.95 & 5.8542 & TRN & \\
\hline CHEMBL1492825 & 688759 & 5.5 & 5.3586 & TRN & \\
\hline CHEMBL1456647 & 688759 & 4.45 & 4.747 & TRN & \\
\hline CHEMBL1468023 & 688759 & 4.85 & 4.926 & TRN & \\
\hline CHEMBL1567702 & 688759 & 4.75 & 4.9724 & TST & \\
\hline CHEMBL 3194360 & 688759 & 4.65 & 4.822 & TRN & \\
\hline CHEMBL1573661 & 688759 & 4.7 & 4.5444 & TRN & \\
\hline CHEMBL1502832 & 688759 & 4.45 & 4.6295 & TST & \\
\hline CHEMBL1605953 & 688759 & 4.45 & 4.82100 & 0000000001 & TRN \\
\hline CHEMBL1525017 & 688759 & 4.45 & 4.6687 & TRN & \\
\hline CHEMBL3194816 & 688759 & 5.05 & 5.2387 & TRN & \\
\hline CHEMBL577419 & 688759 & 4.6 & 5.105 & TRN & \\
\hline CHEMBL1491957 & 688759 & 4.45 & 4.9693 & TRN & \\
\hline CHEMBL1506279 & 688759 & 4.95 & 4.8793 & TRN & \\
\hline CHEMBL1479454 & 688759 & 5.2 & 4.9519 & TRN & \\
\hline CHEMBL1610706 & 688759 & 4.95 & 4.8914 & TRN & \\
\hline CHEMBL1544201 & 688759 & 4.5 & 4.6809 & TRN & \\
\hline CHEMBL1970867 & 688759 & 5.0 & 5.2483 & TRN & \\
\hline CHEMBL1401226 & 688759 & 4.45 & 4.7297 & TRN & \\
\hline CHEMBL1451647 & 688759 & 5.8 & 5.4063 & TRN & \\
\hline CHEMBL164989 & 688759 & 4.7 & 4.9313 & TST & \\
\hline CHEMBL1349925 & 688759 & 4.6 & 4.7789 & TST & \\
\hline CHEMBL1478696 & 688759 & 4.6 & 4.9312 & TRN & \\
\hline CHEMBL1440181 & 688759 & 4.5 & 4.6381 & TRN & \\
\hline CHEMBL1509409 & 688759 & 4.9 & 4.8932 & TRN & \\
\hline CHEMBL1423224 & 688759 & 5.05 & 5.0379 & TRN & \\
\hline
\end{tabular}




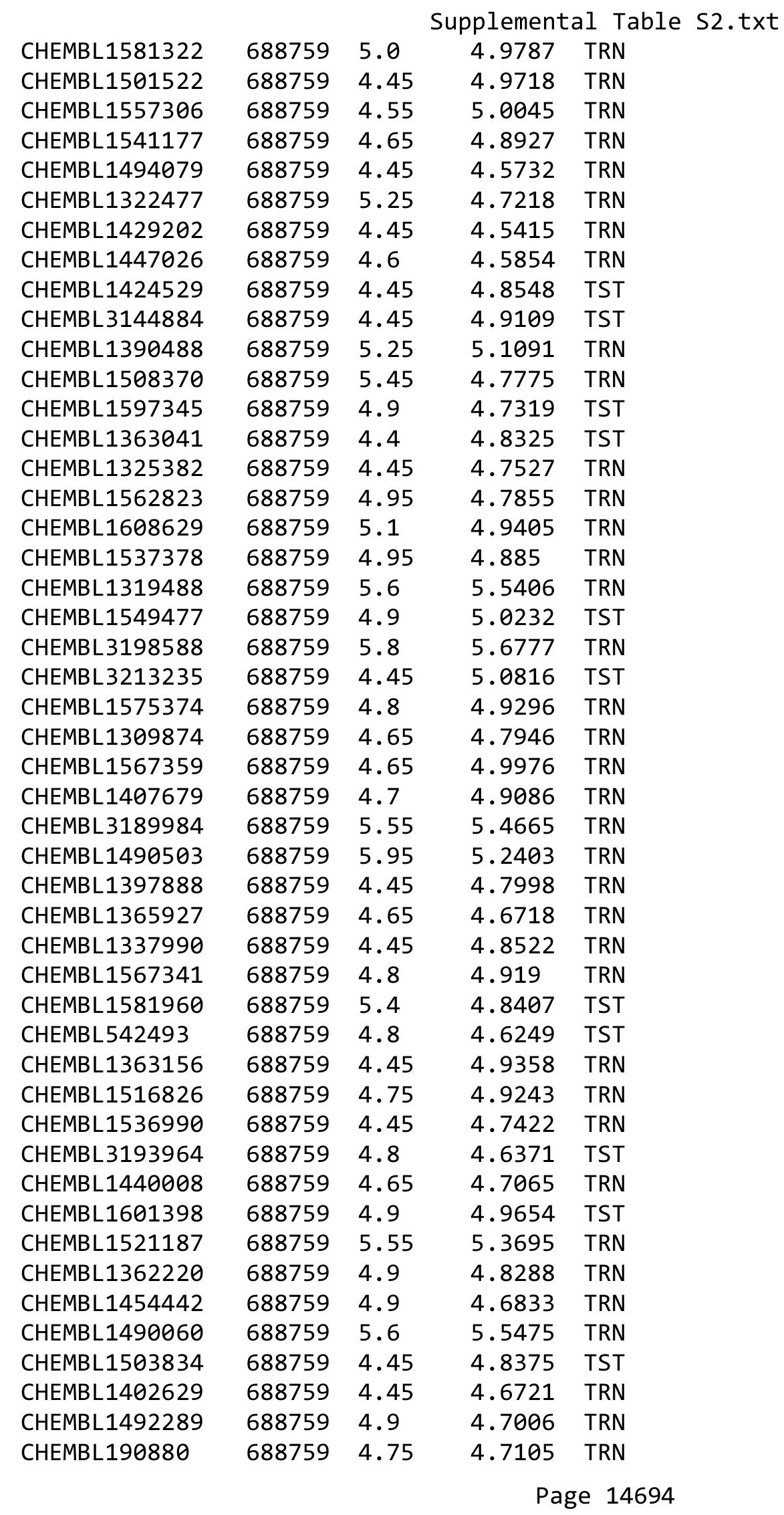




\begin{tabular}{|c|c|c|c|c|c|}
\hline \multicolumn{6}{|c|}{ Supplemental Table S2.txt } \\
\hline CHEMBL1361451 & 688759 & 5.85 & 4.8899 & TRN & \\
\hline CHEMBL1890899 & 688759 & 5.25 & 4.9945 & TRN & \\
\hline CHEMBL1601310 & 688759 & 4.95 & 4.7423 & TST & \\
\hline CHEMBL1466123 & 688759 & 4.45 & 4.8719 & TRN & \\
\hline CHEMBL1307317 & 688759 & 4.5 & 5.0226 & TST & \\
\hline CHEMBL1580377 & 688759 & 4.45 & 4.71 & TRN & \\
\hline CHEMBL337821 & 688759 & 5.7 & 5.4772 & TRN & \\
\hline CHEMBL 3213825 & 688759 & 4.45 & 4.8015 & TRN & \\
\hline CHEMBL1334120 & 688759 & 4.95 & 4.63899 & 9999999999 & TRN \\
\hline CHEMBL1574097 & 688759 & 4.55 & 4.7259 & TRN & \\
\hline CHEMBL1402110 & 688759 & 4.45 & 4.8422 & TRN & \\
\hline CHEMBL1377552 & 688759 & 4.45 & 4.8469 & TRN & \\
\hline CHEMBL1530548 & 688759 & 4.9 & 4.8279 & TRN & \\
\hline CHEMBL1504294 & 688759 & 4.45 & 4.7758 & TST & \\
\hline CHEMBL1420060 & 688759 & 4.5 & 4.6123 & TRN & \\
\hline CHEMBL1433332 & 688759 & 4.45 & 4.7269 & TRN & \\
\hline CHEMBL1424907 & 688759 & 4.95 & 4.8376 & TRN & \\
\hline CHEMBL1564908 & 688759 & 4.65 & 4.9678 & TST & \\
\hline CHEMBL1565949 & 688759 & 5.0 & 4.7942 & TRN & \\
\hline CHEMBL1389643 & 688759 & 5.2 & 5.084 & TST & \\
\hline CHEMBL3207351 & 688759 & 5.2 & 4.8581 & TRN & \\
\hline CHEMBL1455438 & 688759 & 4.6 & 5.0117 & TRN & \\
\hline CHEMBL1406554 & 688759 & 4.45 & 4.7061 & TST & \\
\hline CHEMBL1439324 & 688759 & 4.7 & 4.933 & TRN & \\
\hline CHEMBL3213463 & 688759 & 5.1 & 5.0762 & TRN & \\
\hline CHEMBL1555886 & 688759 & 4.9 & 4.8681 & TRN & \\
\hline CHEMBL1381179 & 688759 & 4.5 & 4.6439 & TRN & \\
\hline CHEMBL1323615 & 688759 & 4.75 & 4.8403 & TST & \\
\hline CHEMBL1546634 & 688759 & 4.45 & 4.9627 & TRN & \\
\hline CHEMBL1321366 & 688759 & 5.5 & 5.0338 & TRN & \\
\hline CHEMBL3197042 & 688759 & 4.45 & 4.7893 & TST & \\
\hline CHEMBL1365963 & 688759 & 5.25 & 4.7772 & TRN & \\
\hline CHEMBL1443374 & 688759 & 4.75 & 4.96399 & 99999999995 & TST \\
\hline CHEMBL1562522 & 688759 & 4.75 & 4.6872 & TRN & \\
\hline CHEMBL1509893 & 688759 & 6.5501 & 6.2796 & TST & \\
\hline CHEMBL1361131 & 688759 & 4.8 & 5.4774 & TRN & \\
\hline CHEMBL3191685 & 688759 & 4.45 & 4.5796 & TRN & \\
\hline CHEMBL1443722 & 688759 & 5.2 & 5.0532 & TRN & \\
\hline CHEMBL1594286 & 688759 & 4.95 & 4.9594 & TST & \\
\hline CHEMBL1572829 & 688759 & 4.45 & 4.8494 & TRN & \\
\hline CHEMBL1584516 & 688759 & 4.45 & 4.9466 & TRN & \\
\hline CHEMBL1562905 & 688759 & 4.85 & 4.6499 & TRN & \\
\hline CHEMBL1390880 & 688759 & 4.95 & 4.9592 & TRN & \\
\hline CHEMBL1492172 & 688759 & 4.45 & 4.8056 & TRN & \\
\hline CHEMBL1481637 & 688759 & 5.2 & 5.0665 & TRN & \\
\hline CHEMBL1491271 & 688759 & 4.6 & 4.8556 & TRN & \\
\hline CHEMBL1522766 & 688759 & 4.45 & 4.973 & TST & \\
\hline CHEMBL1427906 & 688759 & 5.1 & 5.0695 & TRN & \\
\hline
\end{tabular}




\begin{tabular}{|c|c|c|c|c|c|}
\hline \multicolumn{6}{|c|}{ Supplemental Table S2.txt } \\
\hline CHEMBL3210664 & 688759 & 5.05 & 4.6053 & TST & \\
\hline CHEMBL1493656 & 688759 & 4.45 & 4.8541 & TRN & \\
\hline CHEMBL1348057 & 688759 & 4.7 & 4.5277 & TRN & \\
\hline CHEMBL1414267 & 688759 & 5.15 & 4.6121 & TST & \\
\hline CHEMBL1587973 & 688759 & 4.45 & 4.6118 & TST & \\
\hline CHEMBL1483468 & 688759 & 4.65 & 4.8288 & TST & \\
\hline CHEMBL296641 & 688759 & 4.55 & 5.0795 & TST & \\
\hline CHEMBL1562170 & 688759 & 5.3 & 4.9091 & TST & \\
\hline CHEMBL1489831 & 688759 & 5.0 & 4.6612 & TRN & \\
\hline CHEMBL1313789 & 688759 & 4.65 & 5.0227 & TST & \\
\hline CHEMBL1475424 & 688759 & 4.65 & 5.0557 & TRN & \\
\hline CHEMBL1516217 & 688759 & 5.95 & 5.5349 & TRN & \\
\hline CHEMBL1562584 & 688759 & 4.75 & 4.71399 & 99999999995 & TRN \\
\hline CHEMBL1460786 & 688759 & 5.5 & 4.7402 & TRN & \\
\hline CHEMBL1563821 & 688759 & 6.8499 & 4.7568 & TST & \\
\hline CHEMBL1401378 & 688759 & 4.7 & 4.6962 & TST & \\
\hline CHEMBL1601128 & 688759 & 4.8 & 4.8255 & TRN & \\
\hline CHEMBL3211050 & 688759 & 5.45 & 5.4647 & TRN & \\
\hline CHEMBL1427661 & 688759 & 5.45 & 5.4057 & TRN & \\
\hline CHEMBL1371236 & 688759 & 5.05 & 4.8998 & TRN & \\
\hline CHEMBL1387595 & 688759 & 5.3 & 4.7981 & TRN & \\
\hline CHEMBL1481915 & 688759 & 4.45 & 4.8587 & TRN & \\
\hline CHEMBL1387961 & 688759 & 4.8 & 5.0757 & TRN & \\
\hline CHEMBL3208579 & 688759 & 5.85 & 5.6424 & TRN & \\
\hline CHEMBL1389237 & 688759 & 4.6 & 4.7423 & TST & \\
\hline CHEMBL1438848 & 688759 & 4.45 & 4.8534 & TST & \\
\hline CHEMBL1366224 & 688759 & 5.0 & 4.9439 & TST & \\
\hline CHEMBL1532165 & 688759 & 5.4 & 4.9016 & TST & \\
\hline CHEMBL1489104 & 688759 & 4.45 & 4.7033 & TRN & \\
\hline CHEMBL1408320 & 688759 & 4.45 & 4.6406 & TST & \\
\hline CHEMBL1428244 & 688759 & 6.0 & 5.7034 & TRN & \\
\hline CHEMBL1543320 & 688759 & 4.6 & 4.9162 & TST & \\
\hline CHEMBL1429884 & 688759 & 5.45 & 4.99106 & 00000000005 & TRN \\
\hline CHEMBL1349807 & 688759 & 4.45 & 4.6914 & TRN & \\
\hline CHEMBL1565800 & 688759 & 4.45 & 4.8192 & TST & \\
\hline CHEMBL1299600 & 688759 & 4.55 & 4.7725 & TST & \\
\hline CHEMBL587856 & 688759 & 4.45 & 5.1116 & TRN & \\
\hline CHEMBL1462421 & 688759 & 4.5 & 5.0253 & TRN & \\
\hline CHEMBL1427411 & 688759 & 4.45 & 4.8669 & TRN & \\
\hline CHEMBL1303211 & 688759 & 4.9 & 4.96899 & 9999999999 & TRN \\
\hline CHEMBL1438232 & 688759 & 4.45 & 4.6562 & TRN & \\
\hline CHEMBL3199590 & 688759 & 6.0 & 5.0503 & TRN & \\
\hline CHEMBL1403616 & 688759 & 4.9 & 4.6279 & TRN & \\
\hline CHEMBL1517935 & 688759 & 4.45 & 4.6024 & TRN & \\
\hline CHEMBL1366531 & 688759 & 4.6 & 4.5736 & TRN & \\
\hline CHEMBL1340684 & 688759 & 4.45 & 4.8205 & TST & \\
\hline CHEMBL1600573 & 688759 & 4.45 & 4.8502 & TRN & \\
\hline CHEMBL1521188 & 688759 & 5.95 & 5.6038 & TRN & \\
\hline
\end{tabular}




\begin{tabular}{|c|c|c|c|c|c|}
\hline & & \multicolumn{4}{|c|}{ Supplemental Table S2.txt } \\
\hline CHEMBL1349293 & 688759 & 4.45 & 4.8081 & TRN & \\
\hline CHEMBL1588704 & 688759 & 4.65 & 5.0614 & TST & \\
\hline CHEMBL1380541 & 688759 & 4.6 & 4.5834 & TRN & \\
\hline CHEMBL396994 & 688759 & 4.6 & 4.8266 & TRN & \\
\hline CHEMBL1384203 & 688759 & 4.45 & 4.803 & TRN & \\
\hline CHEMBL1502583 & 688759 & 4.8 & 5.0756 & TRN & \\
\hline CHEMBL1426134 & 688759 & 5.05 & 4.9214 & TRN & \\
\hline CHEMBL1299763 & 688759 & 5.45 & 5.3251 & TRN & \\
\hline CHEMBL3199327 & 688759 & 4.65 & 5.2839 & TRN & \\
\hline CHEMBL1304022 & 688759 & 4.45 & 4.7994 & TRN & \\
\hline CHEMBL1607194 & 688759 & 5.0 & 4.9649 & TRN & \\
\hline CHEMBL1501645 & 688759 & 5.15 & 4.6649 & TST & \\
\hline CHEMBL1451175 & 688759 & 6.6 & 5.8312 & TRN & \\
\hline CHEMBL1425614 & 688759 & 4.45 & 4.9328 & TRN & \\
\hline CHEMBL193888 & 688759 & 5.0 & 5.0051 & TRN & \\
\hline CHEMBL1489817 & 688759 & 6.35 & 4.809 & TRN & \\
\hline CHEMBL1466443 & 688759 & 4.45 & 5.1071 & TRN & \\
\hline CHEMBL1411897 & 688759 & 5.3 & 5.0515 & TST & \\
\hline CHEMBL1412884 & 688759 & 4.45 & 4.6848 & TRN & \\
\hline CHEMBL1386129 & 688759 & 6.05 & 5.7299 & TRN & \\
\hline CHEMBL1979843 & 688759 & 4.55 & 4.8873 & TRN & \\
\hline CHEMBL1599829 & 688759 & 4.45 & 4.6103 & TST & \\
\hline CHEMBL1559306 & 688759 & 5.4 & 5.2566 & TRN & \\
\hline CHEMBL1449401 & 688759 & 4.65 & 4.9535 & TRN & \\
\hline CHEMBL3195208 & 688759 & 4.7 & 4.5298 & TRN & \\
\hline CHEMBL1375659 & 688759 & 4.65 & 5.0433 & TRN & \\
\hline CHEMBL1456393 & 688759 & 5.25 & 5.54899 & 99999999995 & TRN \\
\hline CHEMBL1501752 & 688759 & 5.05 & 5.0534 & TRN & \\
\hline CHEMBL1419943 & 688759 & 4.45 & 4.9155 & TRN & \\
\hline CHEMBL1390063 & 688759 & 5.05 & 4.9101 & TST & \\
\hline CHEMBL3197310 & 688759 & 6.2 & 5.5591 & TRN & \\
\hline CHEMBL1302158 & 688759 & 5.45 & 5.3438 & TRN & \\
\hline CHEMBL 3145372 & 688759 & 5.9 & 5.7523 & TRN & \\
\hline CHEMBL1486757 & 688759 & 4.65 & 4.7011 & TRN & \\
\hline CHEMBL1407971 & 688759 & 4.7 & 4.8089 & TRN & \\
\hline CHEMBL1513705 & 688759 & 5.6 & 4.8696 & TST & \\
\hline CHEMBL1405286 & 688759 & 4.45 & 4.809 & TRN & \\
\hline CHEMBL1483627 & 688759 & 4.7 & 4.8314 & TRN & \\
\hline CHEMBL1605927 & 688759 & 5.4 & 5.3937 & TRN & \\
\hline CHEMBL1319698 & 688759 & 4.45 & 4.4968 & TRN & \\
\hline CHEMBL1418720 & 688759 & 4.85 & 4.9306 & TRN & \\
\hline CHEMBL1325068 & 688759 & 5.35 & 5.2035 & TRN & \\
\hline CHEMBL1583650 & 688759 & 6.05 & 5.0709 & TRN & \\
\hline CHEMBL1318878 & 688759 & 4.9 & 4.7408 & TRN & \\
\hline CHEMBL1601369 & 688759 & 4.95 & 5.0776 & TRN & \\
\hline CHEMBL3189791 & 688759 & 5.95 & 5.2341 & TRN & \\
\hline CHEMBL1241420 & 688759 & 4.45 & 4.5665 & TRN & \\
\hline CHEMBL1542911 & 688759 & 4.45 & 4.5293 & TRN & \\
\hline
\end{tabular}




\begin{tabular}{|c|c|c|c|c|}
\hline \multicolumn{5}{|c|}{ Supplemental Table S2.txt } \\
\hline CHEMBL1539124 & 688759 & 4.45 & 5.0068 & TST \\
\hline CHEMBL1453016 & 688759 & 4.45 & 5.0583 & TRN \\
\hline CHEMBL1313095 & 688759 & 4.8 & 4.6256 & TRN \\
\hline CHEMBL 2311178 & 688759 & 4.45 & 4.9517 & TST \\
\hline CHEMBL1483889 & 688759 & 4.95 & 4.6882 & TRN \\
\hline CHEMBL 3190275 & 688759 & 4.85 & 4.8675 & TST \\
\hline CHEMBL1382798 & 688759 & 4.95 & 5.087 & TRN \\
\hline CHEMBL1387479 & 688759 & 4.9 & 4.8347 & TRN \\
\hline CHEMBL1612805 & 688759 & 4.45 & 4.5527 & TRN \\
\hline CHEMBL1326833 & 688759 & 4.9 & 4.745 & TRN \\
\hline CHEMBL1340638 & 688759 & 4.65 & 4.692 & TST \\
\hline CHEMBL1383967 & 688759 & 5.1 & 5.0473 & TRN \\
\hline CHEMBL1337130 & 688759 & 4.9 & 4.7609 & TST \\
\hline CHEMBL 3189855 & 688759 & 5.25 & 5.2229 & TRN \\
\hline CHEMBL1600023 & 688759 & 4.45 & 5.078 & TRN \\
\hline CHEMBL1412216 & 688759 & 4.45 & 4.6557 & TRN \\
\hline CHEMBL1421287 & 688759 & 6.95 & 5.0578 & TRN \\
\hline CHEMBL1441418 & 688759 & 4.45 & 4.8798 & TRN \\
\hline CHEMBL1380112 & 688759 & 6.1 & 6.3974 & TRN \\
\hline CHEMBL469424 & 688759 & 5.15 & 4.9403 & TST \\
\hline CHEMBL1360730 & 688759 & 5.6 & 5.3316 & TRN \\
\hline CHEMBL3212049 & 688759 & 4.65 & 4.6004 & TRN \\
\hline CHEMBL1583224 & 688759 & 4.45 & 4.8769 & TRN \\
\hline CHEMBL1389657 & 688759 & 5.2 & 4.8178 & TRN \\
\hline CHEMBL1531272 & 688759 & 4.95 & 4.9319 & TRN \\
\hline CHEMBL1527438 & 688759 & 4.6 & 4.9723 & TRN \\
\hline CHEMBL1473402 & 688759 & 5.3 & 4.6447 & TRN \\
\hline CHEMBL1506174 & 688759 & 4.45 & 4.8498 & TRN \\
\hline CHEMBL1465372 & 688759 & 4.45 & 4.7909 & TRN \\
\hline CHEMBL1415624 & 688759 & 5.25 & 4.8292 & TRN \\
\hline CHEMBL1538784 & 688759 & 4.95 & 4.5856 & TRN \\
\hline CHEMBL1980684 & 688759 & 6.35 & 5.7796 & TRN \\
\hline CHEMBL1538039 & 688759 & 4.45 & 4.9554 & TRN \\
\hline CHEMBL1341919 & 688759 & 4.45 & 4.686 & TST \\
\hline CHEMBL1309878 & 688759 & 4.45 & 4.7676 & TST \\
\hline CHEMBL1486911 & 688759 & 4.95 & 5.0315 & TST \\
\hline CHEMBL1502626 & 688759 & 4.45 & 4.784 & TST \\
\hline CHEMBL1522542 & 688759 & 5.0 & 4.4291 & TRN \\
\hline CHEMBL3197167 & 688759 & 5.65 & 4.9813 & TRN \\
\hline CHEMBL1998715 & 688759 & 5.15 & 5.0815 & TRN \\
\hline CHEMBL1417726 & 688759 & 4.7 & 4.6001 & TRN \\
\hline CHEMBL1585460 & 688759 & 8.2518 & 4.8601 & TRN \\
\hline CHEMBL60718 & 688759 & 4.8 & 4.5937 & TST \\
\hline CHEMBL1498114 & 688759 & 4.45 & 4.7475 & TRN \\
\hline CHEMBL1444097 & 688759 & 5.05 & 4.9678 & TRN \\
\hline CHEMBL1497158 & 688759 & 4.85 & 5.1061 & TRN \\
\hline CHEMBL1322679 & 688759 & 5.8 & 5.004 & TRN \\
\hline CHEMBL1368371 & 688759 & 4.45 & 4.4486 & TRN \\
\hline
\end{tabular}




\begin{tabular}{|c|c|c|c|c|c|}
\hline \multicolumn{6}{|c|}{ Supplemental Table S2.txt } \\
\hline CHEMBL1582640 & 688759 & 4.6 & 4.9179 & TRN & \\
\hline CHEMBL1330201 & 688759 & 4.45 & 5.1239 & TRN & \\
\hline CHEMBL1998651 & 688759 & 4.7 & 4.4957 & TRN & \\
\hline CHEMBL1465472 & 688759 & 4.95 & 5.0747 & TRN & \\
\hline CHEMBL1609784 & 688759 & 4.45 & 4.9301 & TRN & \\
\hline CHEMBL1440340 & 688759 & 4.45 & 4.87 & TRN & \\
\hline CHEMBL1586945 & 688759 & 4.45 & 4.9342 & TST & \\
\hline CHEMBL3194508 & 688759 & 4.8 & 4.5465 & TST & \\
\hline CHEMBL1997837 & 688759 & 4.7 & 4.8359 & TRN & \\
\hline CHEMBL1311277 & 688759 & 4.45 & 4.76699 & 99999999995 & TRN \\
\hline CHEMBL1371780 & 688759 & 4.45 & 4.6867 & TRN & \\
\hline CHEMBL3194042 & 688759 & 4.9 & 4.8291 & TRN & \\
\hline CHEMBL1302552 & 688759 & 4.85 & 5.1472 & TRN & \\
\hline CHEMBL1964664 & 688759 & 5.8 & 4.8687 & TRN & \\
\hline CHEMBL1346580 & 688759 & 4.65 & 4.7503 & TRN & \\
\hline CHEMBL1480994 & 688759 & 4.8 & 4.8699 & TRN & \\
\hline CHEMBL1480827 & 688759 & 6.0 & 5.7781 & TRN & \\
\hline CHEMBL1304002 & 688759 & 4.95 & 4.7833 & TRN & \\
\hline CHEMBL1432420 & 688759 & 4.45 & 4.8285 & TRN & \\
\hline CHEMBL1483904 & 688759 & 5.95 & 5.7892 & TRN & \\
\hline CHEMBL1502718 & 688759 & 4.45 & 4.5651 & TRN & \\
\hline CHEMBL1300154 & 688759 & 5.75 & 5.2763 & TRN & \\
\hline CHEMBL1526067 & 688759 & 5.55 & 5.1426 & TRN & \\
\hline CHEMBL1445772 & 688759 & 4.45 & 4.8097 & TRN & \\
\hline CHEMBL1526751 & 688759 & 5.15 & 4.9511 & TRN & \\
\hline CHEMBL1471262 & 688759 & 5.25 & 4.9359 & TRN & \\
\hline CHEMBL1546139 & 688759 & 4.6 & 4.4612 & TST & \\
\hline CHEMBL1538399 & 688759 & 4.45 & 4.9774 & TST & \\
\hline CHEMBL1377485 & 688759 & 4.5 & 4.9854 & TRN & \\
\hline CHEMBL3190291 & 688759 & 4.45 & 5.0452 & TRN & \\
\hline CHEMBL1594263 & 688759 & 5.1 & 4.996 & TRN & \\
\hline CHEMBL3197782 & 688759 & 4.65 & 4.7432 & TRN & \\
\hline CHEMBL600490 & 688759 & 5.55 & 4.7264 & TRN & \\
\hline CHEMBL1508353 & 688759 & 5.15 & 5.1813 & TRN & \\
\hline CHEMBL3213945 & 688759 & 4.45 & 4.9642 & TRN & \\
\hline CHEMBL1535989 & 688759 & 4.45 & 4.7826 & TST & \\
\hline CHEMBL1361913 & 688759 & 5.15 & 4.9117 & TST & \\
\hline CHEMBL1550033 & 688759 & 5.1 & 4.809 & TRN & \\
\hline CHEMBL1573240 & 688759 & 4.45 & 4.6251 & TRN & \\
\hline CHEMBL1529557 & 688759 & 4.65 & 4.9554 & TST & \\
\hline CHEMBL1352873 & 688759 & 4.45 & 4.8071 & TRN & \\
\hline CHEMBL1411878 & 688759 & 4.95 & 4.8025 & TRN & \\
\hline CHEMBL1431002 & 688759 & 4.45 & 4.6663 & TST & \\
\hline CHEMBL3195806 & 688759 & 4.45 & 4.8881 & TRN & \\
\hline CHEMBL1437850 & 688759 & 5.15 & 5.1138 & TRN & \\
\hline CHEMBL1606394 & 688759 & 4.9 & 4.8426 & TRN & \\
\hline CHEMBL3197599 & 688759 & 4.6 & 4.5537 & TRN & \\
\hline CHEMBL1344813 & 688759 & 5.1 & 5.1736 & TRN & \\
\hline
\end{tabular}




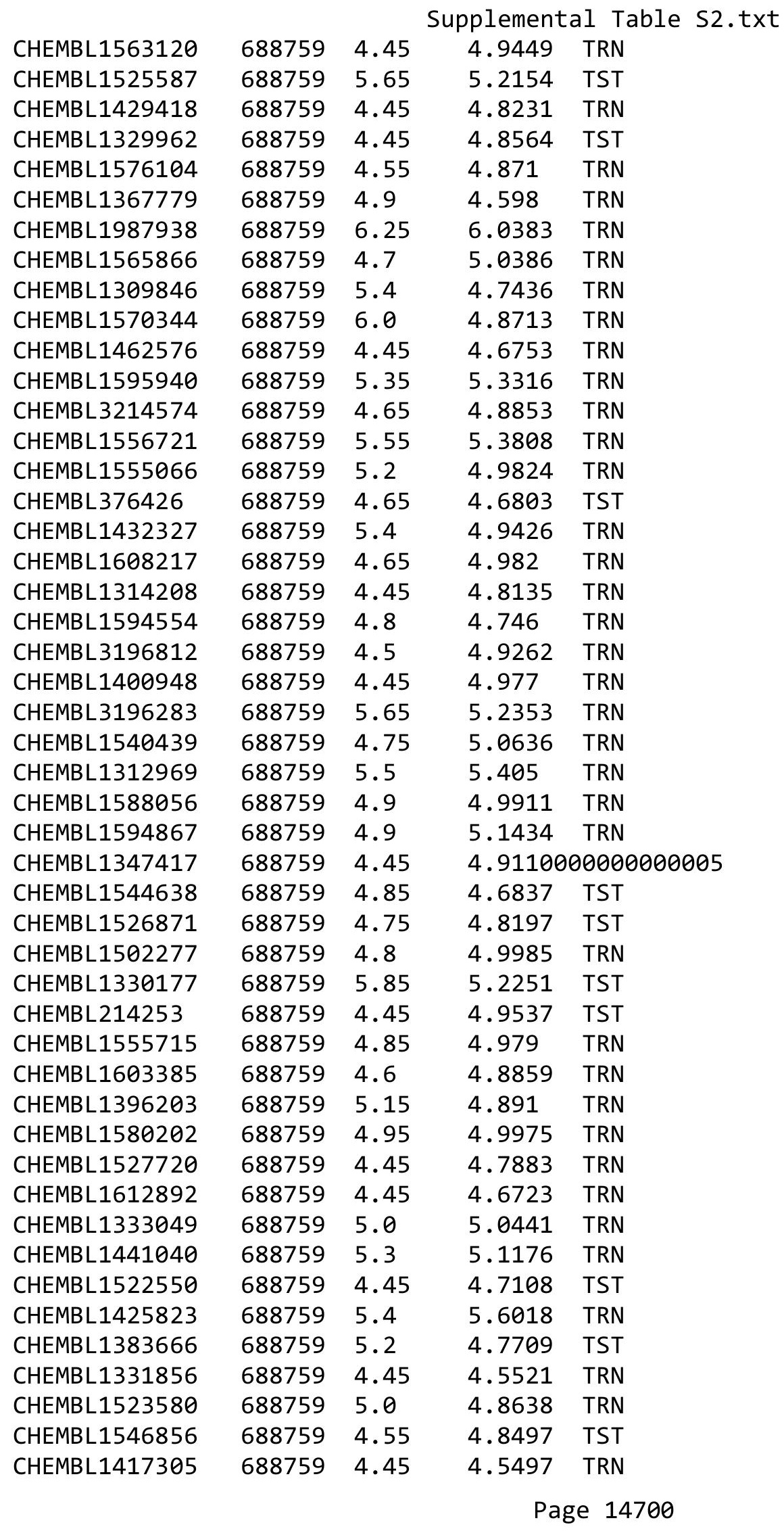




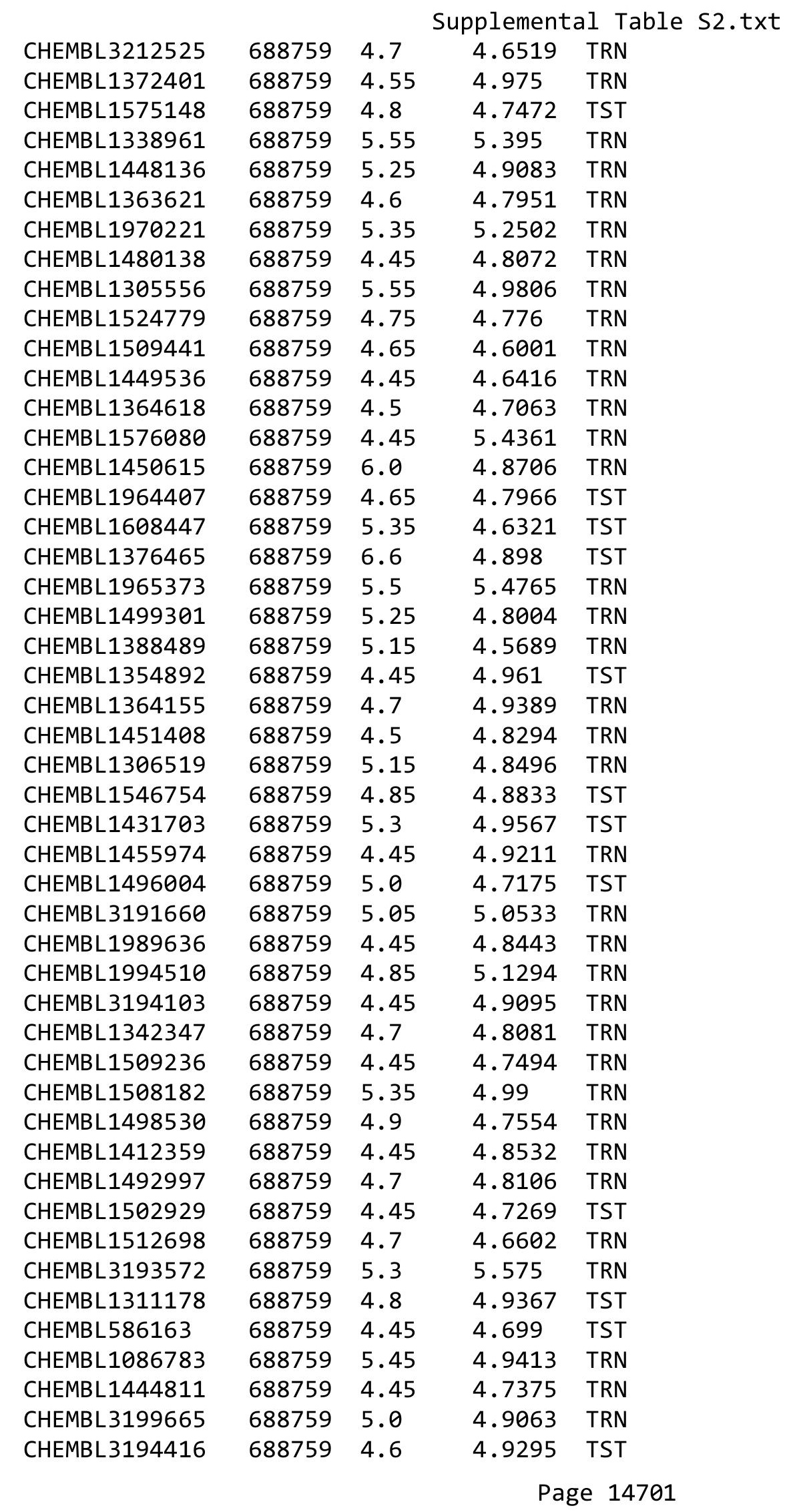




\begin{tabular}{|c|c|c|c|c|c|}
\hline \multicolumn{6}{|c|}{ Supplemental Table s2.txt } \\
\hline CHEMBL1589039 & 688759 & 4.6 & 4.4455 & TRN & \\
\hline CHEMBL 3214100 & 688759 & 5.35 & 5.0963 & TRN & \\
\hline CHEMBL1371618 & 688759 & 5.25 & 4.8882 & TRN & \\
\hline CHEMBL1363875 & 688759 & 5.45 & 5.0318 & TRN & \\
\hline CHEMBL1606858 & 688759 & 4.5 & 4.8812 & TRN & \\
\hline CHEMBL1547324 & 688759 & 4.45 & 4.5191 & TRN & \\
\hline CHEMBL1550274 & 688759 & 5.7 & 5.2327 & TRN & \\
\hline CHEMBL1462036 & 688759 & 5.0 & 4.8688 & TRN & \\
\hline CHEMBL3193331 & 688759 & 5.25 & 4.8264 & TST & \\
\hline CHEMBL1302419 & 688759 & 4.45 & 4.6318 & TRN & \\
\hline CHEMBL1612606 & 688759 & 4.9 & 6.096 & TRN & \\
\hline CHEMBL1967050 & 688759 & 4.9 & 5.0131 & TRN & \\
\hline CHEMBL1968824 & 688759 & 4.55 & 4.7134 & TRN & \\
\hline CHEMBL1547095 & 688759 & 5.8 & 5.3617 & TRN & \\
\hline CHEMBL1401904 & 688759 & 5.55 & 4.6678 & TRN & \\
\hline CHEMBL1433386 & 688759 & 4.45 & 4.819 & TST & \\
\hline CHEMBL1363249 & 688759 & 5.3 & 5.3141 & TRN & \\
\hline CHEMBL3197607 & 688759 & 4.65 & 4.8078 & TST & \\
\hline CHEMBL259421 & 688759 & 4.45 & 4.9365 & TRN & \\
\hline CHEMBL1523011 & 688759 & 4.65 & 5.2425 & TRN & \\
\hline CHEMBL1563213 & 688759 & 4.6 & 4.6968 & TST & \\
\hline CHEMBL1427115 & 688759 & 5.25 & 5.0009 & TRN & \\
\hline CHEMBL1457289 & 688759 & 4.75 & 4.6365 & TRN & \\
\hline CHEMBL1340511 & 688759 & 4.75 & 4.8488 & TRN & \\
\hline CHEMBL1346529 & 688759 & 5.55 & 4.8564 & TRN & \\
\hline CHEMBL1350415 & 688759 & 4.45 & 4.7091 & TRN & \\
\hline CHEMBL1388373 & 688759 & 4.65 & 5.0798 & TST & \\
\hline CHEMBL1482585 & 688759 & 4.95 & 5.0766 & TST & \\
\hline CHEMBL1441078 & 688759 & 4.6 & 4.8316 & TST & \\
\hline CHEMBL1386785 & 688759 & 5.0 & 4.6956 & TRN & \\
\hline CHEMBL1487134 & 688759 & 5.25 & $5.3210 e$ & 0000000001 & TRN \\
\hline CHEMBL1532412 & 688759 & 4.45 & 5.2222 & TST & \\
\hline CHEMBL1380166 & 688759 & 4.7 & 5.2517 & TST & \\
\hline CHEMBL1971875 & 688759 & 5.4 & 5.3585 & TRN & \\
\hline CHEMBL1327568 & 688759 & 4.9 & 4.8233 & TRN & \\
\hline CHEMBL1603456 & 688759 & 4.75 & 4.7517 & TRN & \\
\hline CHEMBL1525559 & 688759 & 4.9 & 4.5842 & TST & \\
\hline CHEMBL1504444 & 688759 & 4.45 & 4.8759 & TRN & \\
\hline CHEMBL1524329 & 688759 & 4.75 & 4.8572 & TST & \\
\hline CHEMBL3214114 & 688759 & 4.8 & 4.8468 & TRN & \\
\hline CHEMBL3195417 & 688759 & 5.05 & 4.5651 & TRN & \\
\hline CHEMBL1556555 & 688759 & 6.15 & 4.7143 & TRN & \\
\hline CHEMBL1974085 & 688759 & 5.2 & 4.8049 & TST & \\
\hline CHEMBL1579487 & 688759 & 5.2 & 4.7473 & TST & \\
\hline CHEMBL1308129 & 688759 & 4.45 & 4.8259 & TRN & \\
\hline CHEMBL1508563 & 688759 & 5.2 & 5.2328 & TST & \\
\hline CHEMBL1505859 & 688759 & 4.95 & 4.6558 & TRN & \\
\hline CHEMBL1303809 & 688759 & 4.95 & 4.7474 & TRN & \\
\hline
\end{tabular}




\begin{tabular}{|c|c|c|c|c|c|}
\hline \multirow{3}{*}{$\begin{array}{l}\text { CHEMBL } 3199092 \\
\text { CHEMBL } 3212708\end{array}$} & & \multicolumn{4}{|c|}{ Supplemental Table s2.txt } \\
\hline & 688759 & 4.7 & \multicolumn{2}{|c|}{4.5089999999999995} & TRN \\
\hline & 688759 & 4.45 & 4.9014 & TRN & \\
\hline CHEMBL295960 & 688759 & 4.45 & 4.8325 & TST & \\
\hline CHEMBL1561190 & 688759 & 5.0 & 4.9644 & TRN & \\
\hline CHEMBL1566205 & 688759 & 5.95 & 5.5866 & TST & \\
\hline CHEMBL1577072 & 688759 & 5.8 & 5.8509 & TRN & \\
\hline CHEMBL1599063 & 688759 & 4.45 & 5.2088 & TRN & \\
\hline CHEMBL1975447 & 688759 & 4.7 & 5.3442 & TRN & \\
\hline CHEMBL1439225 & 688759 & 8.3468 & 4.8961 & TRN & \\
\hline CHEMBL1970621 & 688759 & 4.6 & 4.6808 & TRN & \\
\hline CHEMBL1537926 & 688759 & 4.45 & 4.7513 & TRN & \\
\hline CHEMBL1371804 & 688759 & 4.9 & 4.9779 & TRN & \\
\hline CHEMBL3196164 & 688759 & 4.8 & 5.1107 & TRN & \\
\hline CHEMBL1310080 & 688759 & 6.0 & \multicolumn{2}{|c|}{5.367000000000001} & TRN \\
\hline CHEMBL1419990 & 688759 & 4.45 & 5.055 & TRN & \\
\hline CHEMBL3199022 & 688759 & 5.9 & 5.5244 & TRN & \\
\hline CHEMBL1535798 & 688759 & 4.65 & 4.7462 & TRN & \\
\hline CHEMBL1606022 & 688759 & 4.45 & 5.3215 & TRN & \\
\hline CHEMBL525889 & 688759 & 4.45 & 4.7409 & TST & \\
\hline CHEMBL1500642 & 688759 & 4.8 & 4.9123 & TRN & \\
\hline CHEMBL1384359 & 688759 & 5.3 & 4.859 & TST & \\
\hline CHEMBL1440021 & 688759 & 5.45 & 4.8412 & TRN & \\
\hline CHEMBL1529978 & 688759 & 4.45 & 4.6332 & TRN & \\
\hline CHEMBL1544147 & 688759 & 5.0 & 4.9901 & TST & \\
\hline CHEMBL1383333 & 688759 & 5.1 & 5.2776 & TRN & \\
\hline CHEMBL1388966 & 688759 & 4.45 & 4.7352 & TRN & \\
\hline CHEMBL1430258 & 688759 & 4.45 & 4.5898 & TRN & \\
\hline CHEMBL1457079 & 688759 & 5.15 & 4.8899 & TRN & \\
\hline CHEMBL1609015 & 688759 & 5.15 & 6.5166 & TST & \\
\hline CHEMBL1482117 & 688759 & 4.45 & 4.5972 & TST & \\
\hline CHEMBL1497933 & 688759 & 4.45 & 4.9073 & TST & \\
\hline CHEMBL1533860 & 688759 & 4.45 & 4.9627 & TRN & \\
\hline CHEMBL1506144 & 688759 & 4.45 & 4.7968 & TRN & \\
\hline CHEMBL1996150 & 688759 & 4.45 & 4.6064 & TRN & \\
\hline CHEMBL1411456 & 688759 & 4.9 & 4.84399 & 9999999999 & TRN \\
\hline CHEMBL1585920 & 688759 & 4.8 & 4.5903 & TRN & \\
\hline CHEMBL1302519 & 688759 & 5.0 & 5.356 & TRN & \\
\hline CHEMBL1370304 & 688759 & 4.75 & 4.868 & TST & \\
\hline CHEMBL1408779 & 688759 & 5.0 & 5.0738 & TRN & \\
\hline CHEMBL1562592 & 688759 & 5.0 & 4.8524 & TST & \\
\hline CHEMBL1414291 & 688759 & 4.9 & 4.7639 & TST & \\
\hline CHEMBL1321204 & 688759 & 4.45 & 4.8716 & TST & \\
\hline CHEMBL1502586 & 688759 & 4.65 & 5.0842 & TST & \\
\hline CHEMBL1372781 & 688759 & 4.45 & 4.8454 & TRN & \\
\hline CHEMBL1372283 & 688759 & 4.45 & 4.5735 & TST & \\
\hline CHEMBL1602458 & 688759 & 4.45 & 4.8236 & TRN & \\
\hline CHEMBL1460479 & 688759 & 5.35 & 5.51 & TRN & \\
\hline CHEMBL1406094 & 688759 & 4.45 & 4.9919 & TRN & \\
\hline
\end{tabular}




\begin{tabular}{|c|c|c|c|c|c|}
\hline & & \multicolumn{4}{|c|}{ Supplemental Table S2.txt } \\
\hline CHEMBL1381456 & 688759 & 4.6 & 4.8031 & TRN & \\
\hline CHEMBL1323184 & 688759 & 5.9 & 4.8107 & TRN & \\
\hline CHEMBL1537642 & 688759 & 4.45 & 4.9186 & TRN & \\
\hline CHEMBL1390995 & 688759 & 4.7 & 5.1669 & TRN & \\
\hline CHEMBL1377868 & 688759 & 4.45 & 4.7739 & TRN & \\
\hline CHEMBL1580973 & 688759 & 4.85 & 5.0544 & TRN & \\
\hline CHEMBL563306 & 688759 & 4.6 & 4.9184 & TST & \\
\hline CHEMBL1308461 & 688759 & 4.75 & 4.6581 & TRN & \\
\hline CHEMBL1423977 & 688759 & 4.7 & 5.2293 & TRN & \\
\hline CHEMBL1494120 & 688759 & 5.55 & 5.808 & TRN & \\
\hline CHEMBL1526162 & 688759 & 4.65 & 4.6915 & TRN & \\
\hline CHEMBL1980667 & 688759 & 4.9 & 5.2479 & TRN & \\
\hline CHEMBL1408854 & 688759 & 4.45 & $4.8260 e$ & 00000000005 & TRN \\
\hline CHEMBL1448901 & 688759 & 4.45 & 5.1038 & TRN & \\
\hline CHEMBL1466752 & 688759 & 4.75 & 4.7968 & TRN & \\
\hline CHEMBL1536293 & 688759 & 4.65 & 4.5172 & TRN & \\
\hline CHEMBL1386372 & 688759 & 4.45 & 4.7806 & TRN & \\
\hline CHEMBL1400130 & 688759 & 4.65 & 4.4988 & TST & \\
\hline CHEMBL1336644 & 688759 & 4.55 & 4.7315 & TRN & \\
\hline CHEMBL1441180 & 688759 & 4.45 & 4.5101 & TST & \\
\hline CHEMBL1439547 & 688759 & 4.45 & 4.6925 & TRN & \\
\hline CHEMBL1420683 & 688759 & 4.75 & 4.7936 & TST & \\
\hline CHEMBL1324158 & 688759 & 4.45 & 4.8545 & TRN & \\
\hline CHEMBL1453408 & 688759 & 4.45 & 4.6116 & TRN & \\
\hline CHEMBL1348336 & 688759 & 4.45 & 4.6677 & TRN & \\
\hline CHEMBL3208808 & 688759 & 4.85 & 4.7464 & TRN & \\
\hline CHEMBL3211272 & 688759 & 4.45 & 4.8321 & TRN & \\
\hline CHEMBL1484627 & 688759 & 4.9 & 4.785 & TRN & \\
\hline CHEMBL1569185 & 688759 & 4.45 & 4.7585 & TST & \\
\hline CHEMBL1589656 & 688759 & 4.45 & 4.9596 & TST & \\
\hline CHEMBL3195911 & 688759 & 4.45 & 4.6982 & TRN & \\
\hline CHEMBL 3198800 & 688759 & 4.85 & 5.04 & TRN & \\
\hline CHEMBL1414859 & 688759 & 4.45 & 4.7969 & TRN & \\
\hline CHEMBL1549549 & 688759 & 4.85 & 4.8075 & TRN & \\
\hline CHEMBL1505848 & 688759 & 4.45 & 4.7568 & TRN & \\
\hline CHEMBL1541520 & 688759 & 4.65 & 4.8961 & TST & \\
\hline CHEMBL1459904 & 688759 & 4.55 & 4.8777 & TST & \\
\hline CHEMBL591519 & 688759 & 4.45 & 4.9022 & TST & \\
\hline CHEMBL1404139 & 688759 & 4.65 & 4.5077 & TRN & \\
\hline CHEMBL1985598 & 688759 & 4.45 & 4.829 & TRN & \\
\hline CHEMBL1337227 & 688759 & 4.6 & 4.5427 & TRN & \\
\hline CHEMBL1402138 & 688759 & 4.7 & 4.8449 & TRN & \\
\hline CHEMBL1500771 & 688759 & 4.45 & 5.0196 & TST & \\
\hline CHEMBL1452426 & 688759 & 5.1 & 5.1188 & TRN & \\
\hline CHEMBL 3189284 & 688759 & 4.95 & 4.8488 & TRN & \\
\hline CHEMBL1368212 & 688759 & 5.9 & 5.5852 & TRN & \\
\hline CHEMBL473721 & 688759 & 5.05 & 5.2778 & TST & \\
\hline CHEMBL1526539 & 688759 & 5.15 & 4.5968 & TRN & \\
\hline
\end{tabular}




\begin{tabular}{|c|c|c|c|c|}
\hline \multicolumn{5}{|c|}{ Supplemental Table S2.txt } \\
\hline CHEMBL1342784 & 688759 & 4.45 & 4.8255 & TRN \\
\hline CHEMBL1381755 & 688759 & 5.25 & 5.0044 & TRN \\
\hline CHEMBL 3208181 & 688759 & 5.9 & 5.3788 & TRN \\
\hline CHEMBL1501456 & 688759 & 4.45 & 4.7221 & TRN \\
\hline CHEMBL1382325 & 688759 & 4.45 & 4.6564 & TRN \\
\hline CHEMBL1379059 & 688759 & 4.95 & 4.7641 & TRN \\
\hline CHEMBL1305341 & 688759 & 4.65 & 4.9622 & TRN \\
\hline CHEMBL1458178 & 688759 & 5.25 & 5.3271 & TST \\
\hline CHEMBL1496962 & 688759 & 4.9 & 4.7105 & TST \\
\hline CHEMBL1409985 & 688759 & 4.45 & 4.5971 & TST \\
\hline CHEMBL1455904 & 688759 & 6.2 & 5.8792 & TRN \\
\hline CHEMBL1509371 & 688759 & 5.2 & 4.8548 & TST \\
\hline CHEMBL1549476 & 688759 & 4.45 & 4.6767 & TRN \\
\hline CHEMBL1608500 & 688759 & 5.8 & 4.8736 & TRN \\
\hline CHEMBL1975888 & 688759 & 4.45 & 4.7966 & TST \\
\hline CHEMBL1329752 & 688759 & 4.75 & 4.9046 & TST \\
\hline CHEMBL1340811 & 688759 & 4.9 & 5.1977 & TRN \\
\hline CHEMBL1464144 & 688759 & 6.1 & 5.1401 & TRN \\
\hline CHEMBL1388270 & 688759 & 4.8 & 5.0169 & TST \\
\hline CHEMBL567175 & 688759 & 4.45 & 4.4121 & TST \\
\hline CHEMBL1409738 & 688759 & 4.5 & 5.1716 & TRN \\
\hline CHEMBL1564529 & 688759 & 4.45 & 4.7219 & TRN \\
\hline CHEMBL1459767 & 688759 & 5.05 & 4.9477 & TRN \\
\hline CHEMBL1581043 & 688759 & 4.45 & 4.7942 & TRN \\
\hline CHEMBL1494091 & 688759 & 4.45 & 4.9928 & TST \\
\hline CHEMBL1393833 & 688759 & 4.45 & 4.704 & TRN \\
\hline CHEMBL1360343 & 688759 & 4.45 & 4.4755 & TRN \\
\hline CHEMBL1311574 & 688759 & 5.45 & 5.2862 & TRN \\
\hline CHEMBL1301323 & 688759 & 4.9 & 4.5207 & TRN \\
\hline CHEMBL1455662 & 688759 & 4.65 & 4.7194 & TST \\
\hline CHEMBL1504809 & 688759 & 5.25 & 4.8771 & TRN \\
\hline CHEMBL3207660 & 688759 & 5.85 & 5.3404 & TRN \\
\hline CHEMBL1318261 & 688759 & 4.95 & 4.9517 & TRN \\
\hline CHEMBL1529348 & 688759 & 4.45 & 4.7792 & TRN \\
\hline CHEMBL1610429 & 688759 & 5.85 & 5.3934 & TRN \\
\hline CHEMBL1417492 & 688759 & 4.65 & 4.7366 & TRN \\
\hline CHEMBL1452398 & 688759 & 4.6 & 4.7851 & TRN \\
\hline CHEMBL1418079 & 688759 & 5.1 & 4.8802 & TST \\
\hline CHEMBL1582609 & 688759 & 4.85 & 4.794 & TRN \\
\hline CHEMBL1400196 & 688759 & 5.0 & 5.3847 & TST \\
\hline CHEMBL1443328 & 688759 & 4.65 & 4.8083 & TRN \\
\hline CHEMBL 1482571 & 688759 & 5.5 & 5.0197 & TRN \\
\hline CHEMBL1520867 & 688759 & 4.45 & 4.6671 & TRN \\
\hline CHEMBL1496169 & 688759 & 4.45 & 4.8506 & TST \\
\hline CHEMBL1588104 & 688759 & 4.45 & 4.6803 & TST \\
\hline CHEMBL1406702 & 688759 & 6.2 & 6.1994 & TRN \\
\hline CHEMBL3197737 & 688759 & 5.55 & 4.8577 & TRN \\
\hline CHEMBL1569573 & 688759 & 5.25 & 4.851 & TRN \\
\hline
\end{tabular}




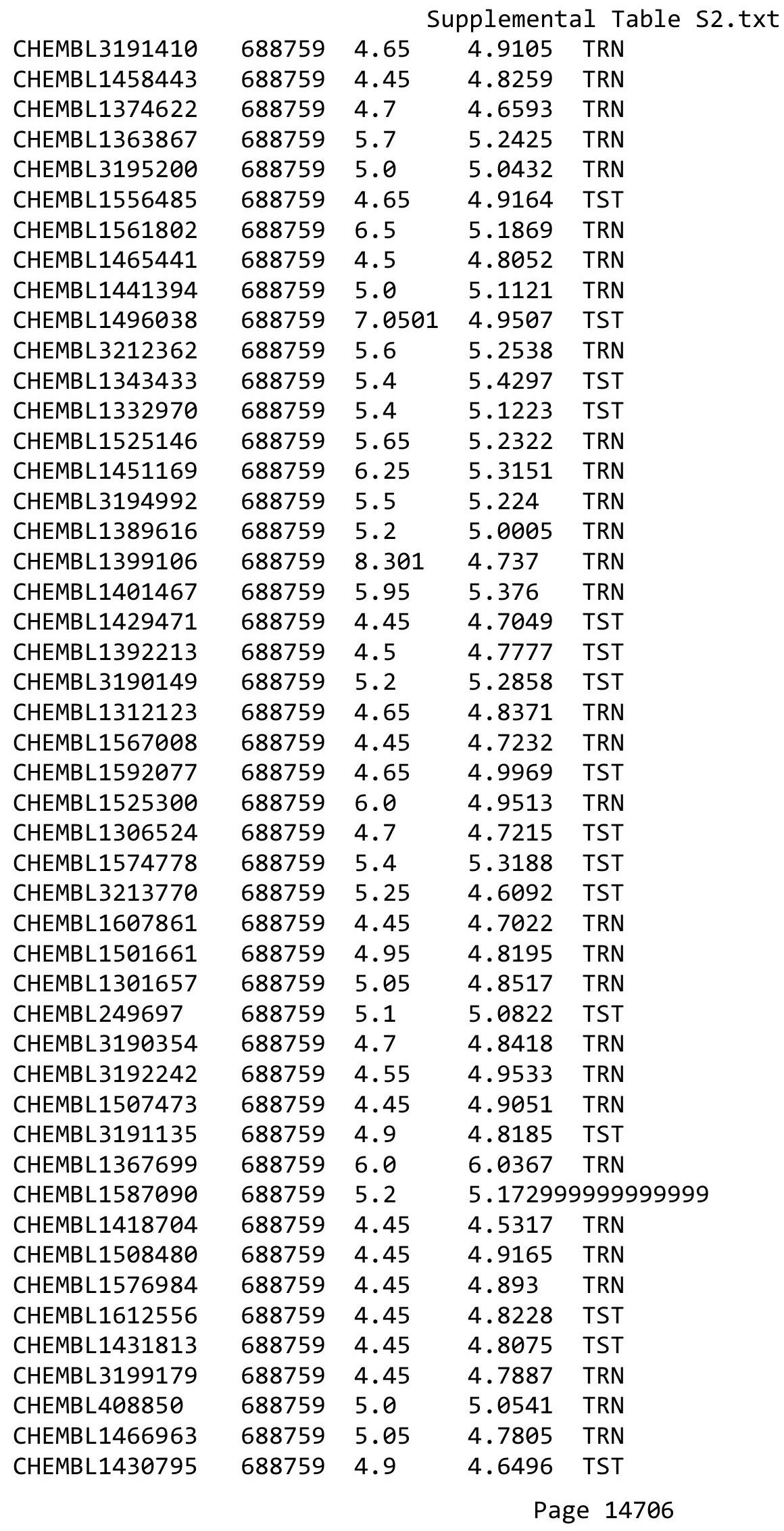




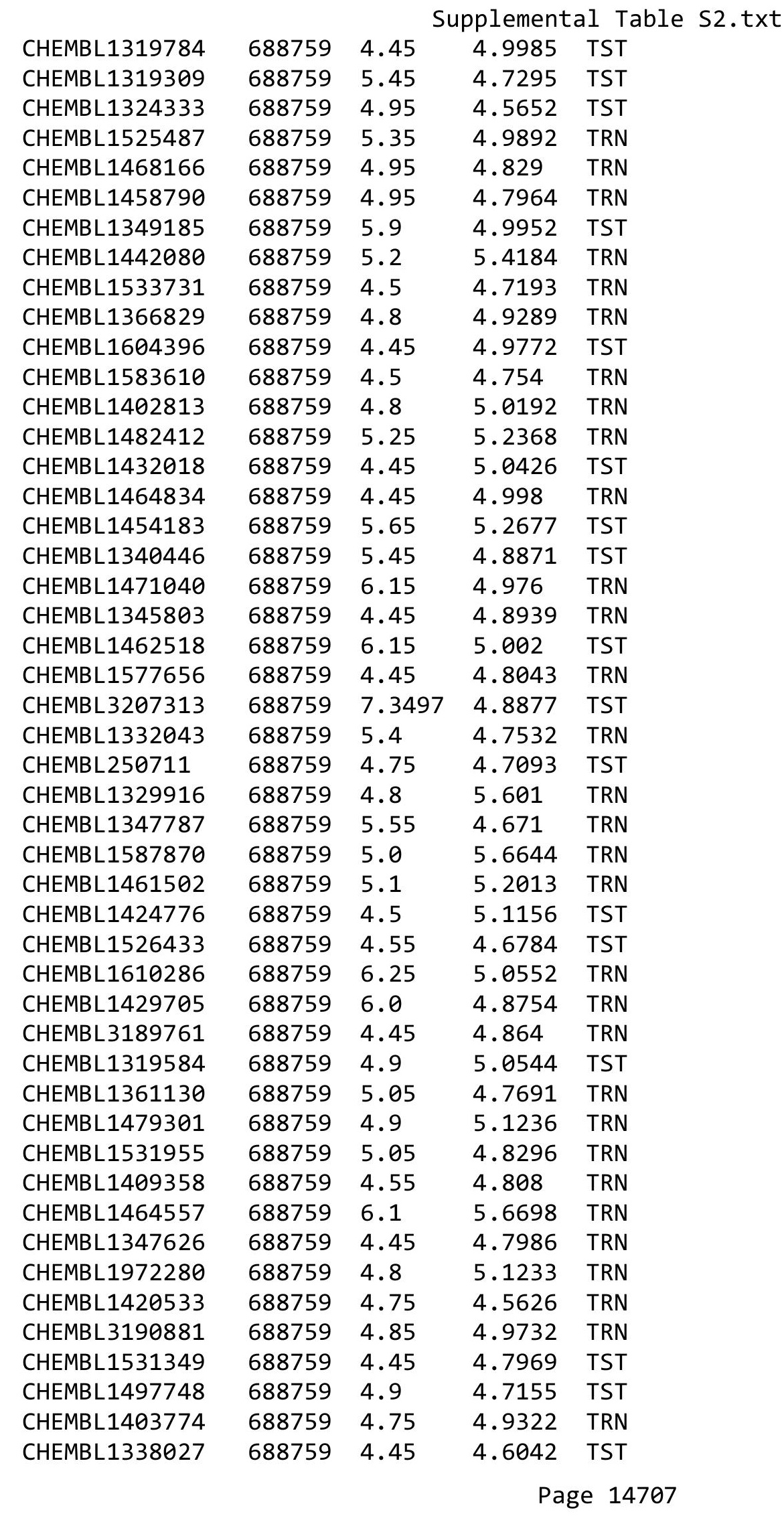




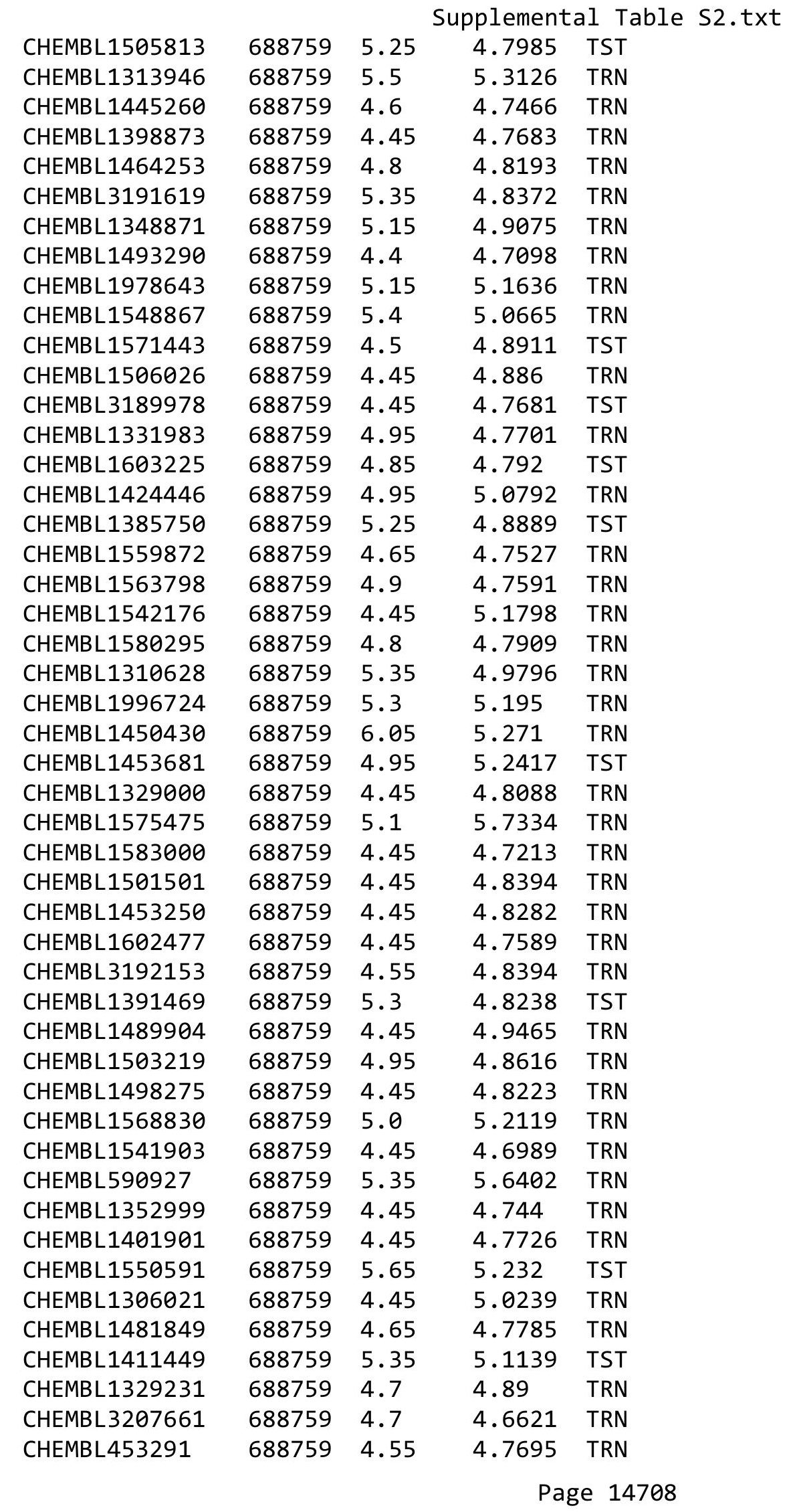




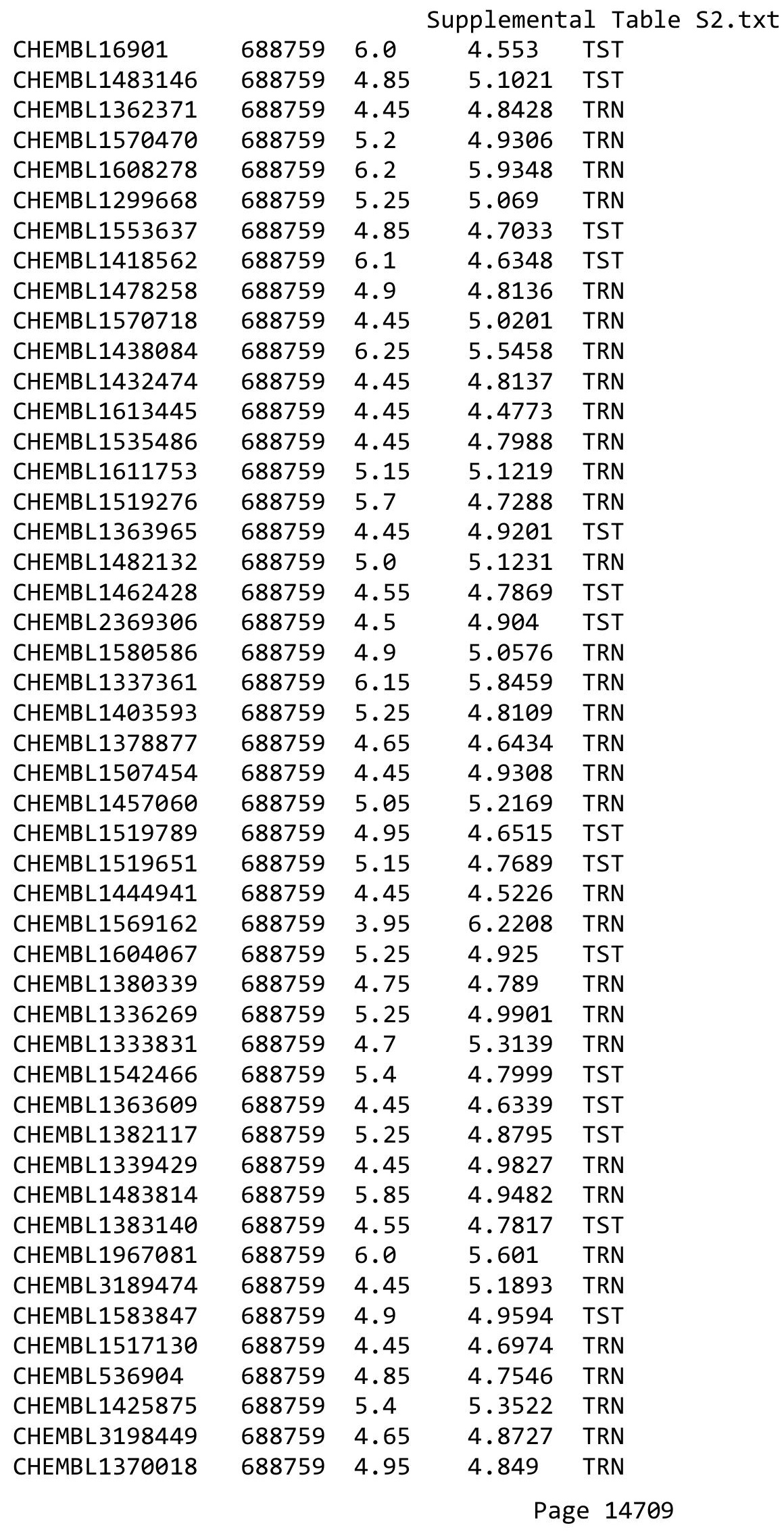




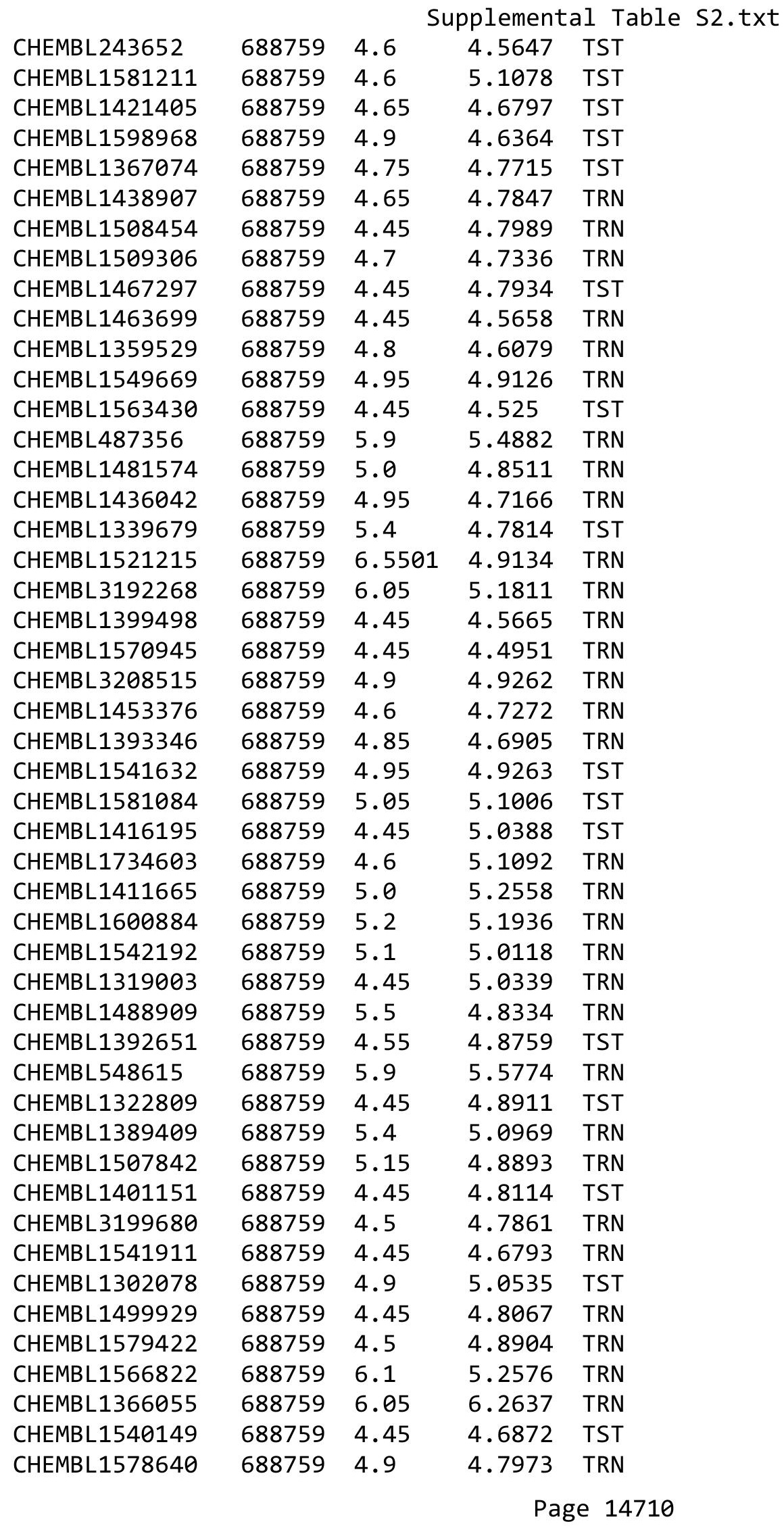




\begin{tabular}{|c|c|c|c|c|}
\hline & & & pplement & al $\mathrm{Ta}$ \\
\hline CHEMBL1505879 & 688759 & 6.0 & 5.3754 & TRN \\
\hline CHEMBL1378480 & 688759 & 5.3 & 5.2728 & TRN \\
\hline CHEMBL2369241 & 688759 & 5.85 & 5.6629 & TRN \\
\hline CHEMBL1566477 & 688759 & 4.45 & 4.874 & TST \\
\hline CHEMBL1525057 & 688759 & 5.55 & 4.8284 & TRN \\
\hline CHEMBL1338713 & 688759 & 5.35 & 4.7347 & TRN \\
\hline CHEMBL603522 & 688759 & 4.95 & 5.3195 & TRN \\
\hline CHEMBL3192451 & 688759 & 4.45 & 5.0031 & TRN \\
\hline CHEMBL3190179 & 688759 & 4.7 & 4.7492 & TRN \\
\hline CHEMBL1495254 & 688759 & 6.25 & 5.9052 & TRN \\
\hline CHEMBL3196654 & 688759 & 5.1 & 5.3064 & TRN \\
\hline CHEMBL1503543 & 688759 & 4.9 & 4.9974 & TRN \\
\hline CHEMBL1392977 & 688759 & 4.95 & 4.9771 & TST \\
\hline CHEMBL1540663 & 688759 & 4.45 & 4.8671 & TRN \\
\hline CHEMBL1310609 & 688759 & 4.45 & 4.4276 & TRN \\
\hline CHEMBL1335043 & 688759 & 4.65 & 4.8319 & TRN \\
\hline CHEMBL3194721 & 688759 & 4.75 & 5.09 & TRN \\
\hline CHEMBL1483187 & 688759 & 5.5 & 4.5679 & TRN \\
\hline CHEMBL1541388 & 688759 & 5.35 & 5.1143 & TRN \\
\hline CHEMBL1416015 & 688759 & 4.45 & 4.8225 & TRN \\
\hline CHEMBL3191867 & 688759 & 4.65 & 4.8079 & TRN \\
\hline CHEMBL1484117 & 688759 & 5.25 & 4.8266 & TST \\
\hline CHEMBL1386739 & 688759 & 5.25 & 4.8303 & TST \\
\hline CHEMBL2369230 & 688759 & 5.7 & 5.4936 & TRN \\
\hline CHEMBL1492112 & 688759 & 4.45 & 5.2318 & TST \\
\hline CHEMBL1330524 & 688759 & 4.55 & 4.6832 & TRN \\
\hline CHEMBL1601244 & 688759 & 4.45 & 4.789 & TST \\
\hline CHEMBL3207817 & 688759 & 5.2 & 5.0421 & TRN \\
\hline CHEMBL1510205 & 688759 & 4.45 & 4.918 & TST \\
\hline CHEMBL1366555 & 688759 & 5.1 & 5.2855 & TRN \\
\hline CHEMBL2369277 & 688759 & 5.15 & 4.4636 & TRN \\
\hline CHEMBL1496240 & 688759 & 4.65 & 4.6352 & TRN \\
\hline CHEMBL1309876 & 688759 & 5.3 & 4.959 & TRN \\
\hline CHEMBL1430979 & 688759 & 4.45 & 4.57 & TST \\
\hline CHEMBL1377825 & 688759 & 5.45 & 5.1851 & TRN \\
\hline CHEMBL1429408 & 688759 & 4.45 & 4.9418 & TRN \\
\hline CHEMBL1402882 & 688759 & 6.45 & 4.8998 & TRN \\
\hline CHEMBL1556907 & 688759 & 4.9 & 4.7466 & TRN \\
\hline CHEMBL1392343 & 688759 & 5.55 & 4.8411 & TST \\
\hline CHEMBL1392292 & 688759 & 4.95 & 4.8886 & TRN \\
\hline CHEMBL 1443830 & 688759 & 4.65 & 4.8386 & TRN \\
\hline CHEMBL1421060 & 688759 & 5.2 & 4.8914 & TRN \\
\hline CHEMBL1322650 & 688759 & 4.6 & 4.8748 & TRN \\
\hline CHEMBL1402539 & 688759 & 4.95 & 4.8105 & TST \\
\hline CHEMBL1416268 & 688759 & 6.2 & 5.3786 & TST \\
\hline CHEMBL1475080 & 688759 & 5.0 & 5.0484 & TST \\
\hline CHEMBL1329192 & 688759 & 5.2 & 4.9628 & TST \\
\hline CHEMBL1310341 & 688759 & 5.6 & 5.0251 & TRN \\
\hline
\end{tabular}




\begin{tabular}{|c|c|c|c|c|c|}
\hline & & \multicolumn{4}{|c|}{ Supplemental Table s2.txt } \\
\hline CHEMBL1573851 & 688759 & 5.05 & 4.8243 & TRN & \\
\hline CHEMBL1421320 & 688759 & 5.0 & 4.8804 & TRN & \\
\hline CHEMBL3194824 & 688759 & 4.85 & 4.8709 & TRN & \\
\hline CHEMBL1542074 & 688759 & 5.6 & 5.4875 & TRN & \\
\hline CHEMBL1347878 & 688759 & 4.45 & 4.9086 & TST & \\
\hline CHEMBL528694 & 688759 & 4.15 & 6.1858 & TRN & \\
\hline CHEMBL1352127 & 688759 & 5.0 & 5.2213 & TRN & \\
\hline CHEMBL1378096 & 688759 & 4.45 & 4.518 & TRN & \\
\hline CHEMBL 3191640 & 688759 & 4.45 & 4.9971 & TRN & \\
\hline CHEMBL1465628 & 688759 & 5.1 & 4.918 & TST & \\
\hline CHEMBL1450607 & 688759 & 5.55 & 5.1662 & TST & \\
\hline CHEMBL1410183 & 688759 & 4.45 & 4.9758 & TRN & \\
\hline CHEMBL1490530 & 688759 & 4.65 & 4.7825 & TST & \\
\hline CHEMBL1973192 & 688759 & 5.15 & 5.083 & TRN & \\
\hline CHEMBL1413153 & 688759 & 4.7 & 4.9716 & TRN & \\
\hline CHEMBL1559722 & 688759 & 4.7 & 4.7518 & TRN & \\
\hline CHEMBL1350656 & 688759 & 5.3 & 5.3425 & TRN & \\
\hline CHEMBL3196849 & 688759 & 4.55 & 4.8865 & TST & \\
\hline CHEMBL1509467 & 688759 & 4.9 & 4.6676 & TRN & \\
\hline CHEMBL1609234 & 688759 & 4.45 & 4.8253 & TRN & \\
\hline CHEMBL1543478 & 688759 & 4.85 & 4.739 & TRN & \\
\hline CHEMBL3212532 & 688759 & 4.75 & 4.8016 & TRN & \\
\hline CHEMBL1439140 & 688759 & 4.9 & 4.8152 & TRN & \\
\hline CHEMBL492418 & 688759 & 4.55 & 5.271 & TST & \\
\hline CHEMBL1586460 & 688759 & 4.7 & 5.147 & TRN & \\
\hline CHEMBL1369297 & 688759 & 4.9 & 4.6374 & TRN & \\
\hline CHEMBL1304169 & 688759 & 5.25 & 5.2748 & TRN & \\
\hline CHEMBL1489147 & 688759 & 4.95 & 4.8628 & TRN & \\
\hline CHEMBL1409445 & 688759 & 5.3 & 4.8084 & TST & \\
\hline CHEMBL1984604 & 688759 & 5.3 & 5.1744 & TRN & \\
\hline CHEMBL1547664 & 688759 & 4.45 & 4.8907 & TST & \\
\hline CHEMBL1490691 & 688759 & 4.5 & 5.2224 & TRN & \\
\hline CHEMBL1607703 & 688759 & 4.95 & 4.49100 & 00000000005 & TRN \\
\hline CHEMBL1306932 & 688759 & 5.0 & 4.9795 & TRN & \\
\hline CHEMBL1383720 & 688759 & 4.45 & 4.887 & TST & \\
\hline CHEMBL1554835 & 688759 & 4.8 & 4.7694 & TST & \\
\hline CHEMBL1973921 & 688759 & 6.5 & 5.7083 & TRN & \\
\hline CHEMBL1611989 & 688759 & 4.45 & 5.5798 & TRN & \\
\hline CHEMBL1470284 & 688759 & 4.65 & 5.0242 & TRN & \\
\hline CHEMBL1432842 & 688759 & 4.55 & 4.7517 & TST & \\
\hline CHEMBL3208449 & 688759 & 4.45 & 4.6873 & TRN & \\
\hline CHEMBL3192078 & 688759 & 5.2 & 5.1685 & TRN & \\
\hline CHEMBL3213738 & 688759 & 5.0 & 5.1927 & TRN & \\
\hline CHEMBL1448248 & 688759 & 4.6 & 4.8835 & TST & \\
\hline CHEMBL1557704 & 688759 & 4.7 & 4.4851 & TRN & \\
\hline CHEMBL1302121 & 688759 & 4.8 & 4.845 & TST & \\
\hline CHEMBL1541480 & 688759 & 5.5 & 4.6041 & TRN & \\
\hline CHEMBL1469789 & 688759 & 4.55 & 5.0125 & TRN & \\
\hline
\end{tabular}




\begin{tabular}{|c|c|c|c|c|}
\hline & & & upplement & \\
\hline CHEMBL1401057 & 688759 & 6.3 & 5.9542 & TRN \\
\hline CHEMBL1445118 & 688759 & 4.45 & 4.5285 & TST \\
\hline CHEMBL3191263 & 688759 & 4.45 & 4.7304 & TRN \\
\hline CHEMBL1300713 & 688759 & 4.95 & 4.6512 & TRN \\
\hline CHEMBL1568474 & 688759 & 4.6 & 4.6744 & TST \\
\hline CHEMBL1372817 & 688759 & 4.45 & 4.6693 & TRN \\
\hline CHEMBL1366447 & 688759 & 4.5 & 4.9036 & TST \\
\hline CHEMBL1520830 & 688759 & 4.9 & 4.8089 & TRN \\
\hline CHEMBL 281980 & 688759 & 6.0 & 4.8768 & TRN \\
\hline CHEMBL2140526 & 688759 & 4.95 & 5.0816 & TRN \\
\hline CHEMBL1990210 & 688759 & 4.75 & 4.8714 & TRN \\
\hline CHEMBL1346015 & 688759 & 5.25 & 4.6008 & TRN \\
\hline CHEMBL1363773 & 688759 & 5.2 & 5.1143 & TRN \\
\hline CHEMBL1545922 & 688759 & 4.45 & 4.6596 & TRN \\
\hline CHEMBL1432403 & 688759 & 4.45 & 5.0263 & TST \\
\hline CHEMBL1608515 & 688759 & 5.25 & 4.8333 & TRN \\
\hline CHEMBL1300097 & 688759 & 4.45 & 4.8039 & TRN \\
\hline CHEMBL3196400 & 688759 & 4.45 & 4.776 & TRN \\
\hline CHEMBL1518470 & 688759 & 4.45 & 4.6894 & TST \\
\hline CHEMBL1329287 & 688759 & 4.95 & 4.8473 & TRN \\
\hline CHEMBL1310713 & 688759 & 4.95 & 4.9794 & TRN \\
\hline CHEMBL1480178 & 688759 & 5.35 & 5.1773 & TRN \\
\hline CHEMBL1519201 & 688759 & 4.45 & 4.8569 & TST \\
\hline CHEMBL1487277 & 688759 & 5.7 & 5.4572 & TRN \\
\hline CHEMBL3197842 & 688759 & 5.7 & 5.5522 & TST \\
\hline CHEMBL3209776 & 688759 & 4.45 & 4.644 & TRN \\
\hline CHEMBL1348298 & 688759 & 4.45 & 4.8567 & TST \\
\hline CHEMBL1368300 & 688759 & 4.9 & 4.8242 & TRN \\
\hline CHEMBL1585374 & 688759 & 4.8 & 4.8613 & TST \\
\hline CHEMBL1420932 & 688759 & 4.75 & 4.6923 & TST \\
\hline CHEMBL1455178 & 688759 & 5.4 & 4.7637 & TRN \\
\hline CHEMBL1991516 & 688759 & 5.5 & 5.4661 & TRN \\
\hline CHEMBL1571615 & 688759 & 5.1 & 4.9824 & TRN \\
\hline CHEMBL1588234 & 688759 & 5.3 & 5.5425 & TRN \\
\hline CHEMBL1523563 & 688759 & 4.45 & 4.8998 & TST \\
\hline CHEMBL1400211 & 688759 & 4.9 & 4.7225 & TRN \\
\hline CHEMBL1311053 & 688759 & 4.9 & 4.8839 & TST \\
\hline CHEMBL1302903 & 688759 & 4.9 & 4.7852 & TST \\
\hline CHEMBL1599050 & 688759 & 5.4 & 4.7212 & TST \\
\hline CHEMBL1363221 & 688759 & 4.9 & 4.4257 & TRN \\
\hline CHEMBL1305166 & 688759 & 5.15 & 5.1452 & TRN \\
\hline CHEMBL1412289 & 688759 & 5.55 & 5.9078 & TRN \\
\hline CHEMBL1343143 & 688759 & 4.5 & 4.626 & TRN \\
\hline CHEMBL1469340 & 688759 & 4.65 & 4.8845 & TST \\
\hline CHEMBL1574950 & 688759 & 5.3 & 4.8086 & TST \\
\hline CHEMBL1580757 & 688759 & 4.45 & 4.6214 & TRN \\
\hline CHEMBL1613594 & 688759 & 4.65 & 4.8389 & TRN \\
\hline CHEMBL259327 & 688759 & 4.65 & 4.7968 & TST \\
\hline
\end{tabular}




\begin{tabular}{|c|c|c|c|c|}
\hline \multicolumn{5}{|c|}{ pplemental T } \\
\hline CHEMBL1373387 & 688759 & 4.9 & 4.9191 & TRN \\
\hline CHEMBL3193878 & 688759 & 4.9 & 4.664 & TRN \\
\hline CHEMBL1323906 & 688759 & 4.85 & 4.9776 & TRN \\
\hline CHEMBL1379214 & 688759 & 4.55 & 4.7297 & TRN \\
\hline CHEMBL1554002 & 688759 & 5.4 & 5.2202 & TRN \\
\hline CHEMBL567130 & 688759 & 4.6 & 4.8752 & TRN \\
\hline CHEMBL1539536 & 688759 & 4.8 & 4.7805 & TRN \\
\hline CHEMBL1344459 & 688759 & 4.45 & 4.6024 & TRN \\
\hline CHEMBL1986557 & 688759 & 4.45 & 4.727 & TRN \\
\hline CHEMBL1583364 & 688759 & 4.45 & 4.7181 & TRN \\
\hline CHEMBL3199050 & 688759 & 5.95 & 5.3265 & TRN \\
\hline CHEMBL1466518 & 688759 & 4.95 & 4.8874 & TRN \\
\hline CHEMBL1385992 & 688759 & 4.9 & 5.1057 & TST \\
\hline CHEMBL1421500 & 688759 & 5.15 & 5.0181 & TRN \\
\hline CHEMBL1386959 & 688759 & 4.75 & 4.7337 & TRN \\
\hline CHEMBL1585777 & 688759 & 4.65 & 4.5296 & TRN \\
\hline CHEMBL1585099 & 688759 & 4.45 & 4.7068 & TRN \\
\hline CHEMBL1543284 & 688759 & 4.45 & 4.6196 & TRN \\
\hline CHEMBL3198084 & 688759 & 4.65 & 4.9087 & TRN \\
\hline CHEMBL1383137 & 688759 & 4.7 & 4.7659 & TST \\
\hline CHEMBL3198619 & 688759 & 4.45 & 4.5246 & TST \\
\hline CHEMBL1516412 & 688759 & 5.2 & 5.1267 & TRN \\
\hline CHEMBL1545361 & 688759 & 4.85 & 4.8775 & TRN \\
\hline CHEMBL1980657 & 688759 & 6.25 & 5.6459 & TRN \\
\hline CHEMBL1434044 & 688759 & 6.0 & 5.1595 & TST \\
\hline CHEMBL1578304 & 688759 & 4.6 & 4.9788 & TRN \\
\hline CHEMBL1383049 & 688759 & 4.9 & 4.9223 & TRN \\
\hline CHEMBL1312321 & 688759 & 5.95 & 5.0187 & TST \\
\hline CHEMBL1330874 & 688759 & 5.15 & 5.2706 & TRN \\
\hline CHEMBL1578958 & 688759 & 5.25 & 4.9882 & TRN \\
\hline CHEMBL1422747 & 688759 & 5.2 & 5.6796 & TRN \\
\hline CHEMBL1461602 & 688759 & 4.45 & 4.9502 & TRN \\
\hline CHEMBL1374822 & 688759 & 4.7 & 4.7862 & TRN \\
\hline CHEMBL1305787 & 688759 & 5.1 & 5.1183 & TST \\
\hline CHEMBL1558635 & 688759 & 5.55 & 5.0116 & TRN \\
\hline CHEMBL1440924 & 688759 & 4.45 & 4.8141 & TRN \\
\hline CHEMBL1332001 & 688759 & 4.45 & 5.0733 & TST \\
\hline CHEMBL1587496 & 688759 & 4.45 & 4.677 & TRN \\
\hline CHEMBL1321025 & 688759 & 5.35 & 5.4872 & TRN \\
\hline CHEMBL1320525 & 688759 & 4.65 & 4.6753 & TRN \\
\hline CHEMBL1332010 & 688759 & 4.45 & 4.9788 & TRN \\
\hline CHEMBL1493395 & 688759 & 4.45 & 4.7533 & TST \\
\hline CHEMBL1307285 & 688759 & 5.35 & 5.0795 & TRN \\
\hline CHEMBL388676 & 688759 & 6.0 & 5.294 & TST \\
\hline CHEMBL1430927 & 688759 & 4.45 & 4.648 & TRN \\
\hline CHEMBL1439219 & 688759 & 4.65 & 4.8671 & TRN \\
\hline CHEMBL1541763 & 688759 & 5.2 & 4.7751 & TRN \\
\hline CHEMBL1301104 & 688759 & 5.2 & 4.9676 & TST \\
\hline
\end{tabular}




\begin{tabular}{|c|c|c|c|c|}
\hline \multicolumn{5}{|c|}{ Supplemental Tabl } \\
\hline CHEMBL1427136 & 688759 & 4.45 & 4.8378 & TST \\
\hline CHEMBL1353608 & 688759 & 5.5 & 5.1516 & TRN \\
\hline CHEMBL3199064 & 688759 & 5.6 & 5.296 & TRN \\
\hline CHEMBL1605369 & 688759 & 4.7 & 5.0209 & TST \\
\hline CHEMBL1510804 & 688759 & 5.7 & 5.3661 & TRN \\
\hline CHEMBL1379600 & 688759 & 4.5 & 4.5061 & TRN \\
\hline CHEMBL1487546 & 688759 & 4.45 & 4.6389 & TRN \\
\hline CHEMBL1600144 & 688759 & 4.45 & 4.8006 & TRN \\
\hline CHEMBL3212390 & 688759 & 5.65 & 5.3392 & TST \\
\hline CHEMBL3189513 & 688759 & 4.95 & 4.9714 & TRN \\
\hline CHEMBL3191350 & 688759 & 5.1 & 4.8812 & TST \\
\hline CHEMBL1572752 & 688759 & 5.0 & 5.0425 & TRN \\
\hline CHEMBL1344902 & 688759 & 4.75 & 4.8554 & TRN \\
\hline CHEMBL1339536 & 688759 & 4.55 & 4.916 & TRN \\
\hline CHEMBL1451658 & 688759 & 6.2 & 4.9083 & TST \\
\hline CHEMBL586465 & 688759 & 5.1 & 5.2147 & TRN \\
\hline CHEMBL3199470 & 688759 & 5.9 & 5.5667 & TRN \\
\hline CHEMBL1503729 & 688759 & 5.25 & 5.3984 & TRN \\
\hline CHEMBL1472135 & 688759 & 4.6 & 4.6871 & TRN \\
\hline CHEMBL1431679 & 688759 & 4.95 & 4.8898 & TST \\
\hline CHEMBL1579151 & 688759 & 4.65 & 4.7414 & TRN \\
\hline CHEMBL1495002 & 688759 & 4.75 & 4.8583 & TRN \\
\hline CHEMBL1332989 & 688759 & 4.65 & 4.9278 & TRN \\
\hline CHEMBL3209052 & 688759 & 4.7 & 4.9646 & TST \\
\hline CHEMBL1964464 & 688759 & 5.6 & 5.8745 & TRN \\
\hline CHEMBL1443553 & 688759 & 4.85 & 4.8772 & TST \\
\hline CHEMBL1442245 & 688759 & 4.65 & 4.9891 & TRN \\
\hline CHEMBL1555444 & 688759 & 4.45 & 4.7053 & TRN \\
\hline CHEMBL1487877 & 688759 & 4.45 & 4.7337 & TST \\
\hline CHEMBL 3190420 & 688759 & 4.9 & 4.7698 & TST \\
\hline CHEMBL1509630 & 688759 & 4.45 & 4.6204 & TRN \\
\hline CHEMBL1568658 & 688759 & 4.8 & 4.7674 & TST \\
\hline CHEMBL1504204 & 688759 & 4.45 & 5.0599 & TRN \\
\hline CHEMBL118595 & 688759 & 4.45 & 5.2691 & TRN \\
\hline CHEMBL1993029 & 688759 & 4.45 & 4.7439 & TRN \\
\hline CHEMBL11709 & 688759 & 5.2 & 4.704 & TST \\
\hline CHEMBL1370804 & 688759 & 4.8 & 5.0001 & TRN \\
\hline CHEMBL3189991 & 688759 & 4.7 & 5.033 & TRN \\
\hline CHEMBL1362352 & 688759 & 4.8 & 4.776 & TRN \\
\hline CHEMBL1369603 & 688759 & 4.45 & 4.9297 & TST \\
\hline CHEMBL1411310 & 688759 & 4.45 & 4.9616 & TST \\
\hline CHEMBL1459105 & 688759 & 4.65 & 4.5568 & TRN \\
\hline CHEMBL1300340 & 688759 & 5.25 & 4.9454 & TST \\
\hline CHEMBL1599510 & 688759 & 5.45 & 5.0055 & TST \\
\hline CHEMBL1432342 & 688759 & 5.0 & 4.4383 & TRN \\
\hline CHEMBL1966872 & 688759 & 4.8 & 4.5259 & TRN \\
\hline CHEMBL1456421 & 688759 & 4.45 & 4.8244 & TRN \\
\hline CHEMBL1478725 & 688759 & 4.9 & 4.3224 & TST \\
\hline
\end{tabular}




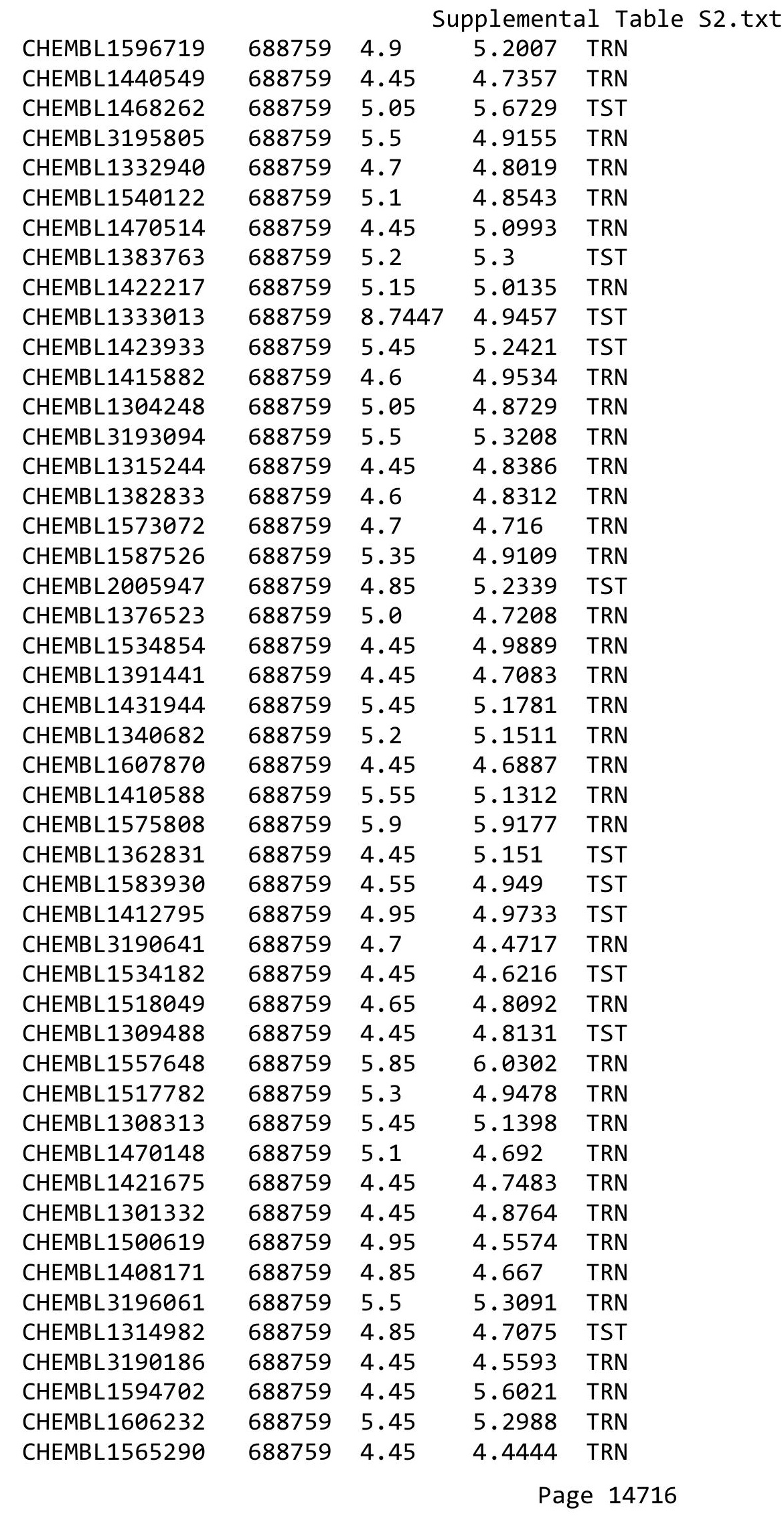




\begin{tabular}{|c|c|c|c|c|c|}
\hline \\
\hline CHEMBL1376389 & 688759 & 5.1 & 4.6496 & TST & \\
\hline CHEMBL1311218 & 688759 & 4.65 & 4.8513 & TRN & \\
\hline CHEMBL1536133 & 688759 & 4.45 & 4.5632 & TRN & \\
\hline CHEMBL1502945 & 688759 & 5.25 & 4.8375 & TRN & \\
\hline CHEMBL1501373 & 688759 & 4.45 & 4.7342 & TRN & \\
\hline CHEMBL3212373 & 688759 & 5.3 & 4.9634 & TRN & \\
\hline CHEMBL1974091 & 688759 & 4.65 & 5.0617 & TRN & \\
\hline CHEMBL1504946 & 688759 & 4.8 & 4.8133 & TST & \\
\hline CHEMBL1413152 & 688759 & 4.6 & 4.7297 & TRN & \\
\hline CHEMBL1577121 & 688759 & 4.7 & 4.8133 & TST & \\
\hline CHEMBL1565243 & 688759 & 4.95 & 5.2045 & TRN & \\
\hline CHEMBL1412419 & 688759 & 5.0 & 5.01 & TRN & \\
\hline CHEMBL1605021 & 688759 & 5.9 & 5.6107 & TST & \\
\hline CHEMBL1578287 & 688759 & 4.5 & 5.1392 & TRN & \\
\hline CHEMBL1427629 & 688759 & 5.2 & 5.0434 & TRN & \\
\hline CHEMBL1599630 & 688759 & 4.95 & 4.6011 & TRN & \\
\hline CHEMBL1424186 & 688759 & 4.45 & 4.9689 & TRN & \\
\hline CHEMBL1407080 & 688759 & 4.6 & 4.8889 & TST & \\
\hline CHEMBL1509391 & 688759 & 4.45 & 4.6419 & TST & \\
\hline CHEMBL1299834 & 688759 & 5.5 & 4.8125 & TRN & \\
\hline CHEMBL1390748 & 688759 & 4.7 & 4.8106 & TRN & \\
\hline CHEMBL1382993 & 688759 & 5.55 & 5.8554 & TRN & \\
\hline CHEMBL1488618 & 688759 & 4.45 & 4.8947 & TRN & \\
\hline CHEMBL1972405 & 688759 & 5.25 & 4.7962 & TRN & \\
\hline CHEMBL1994048 & 688759 & 4.45 & 4.6708 & TRN & \\
\hline CHEMBL1328939 & 688759 & 4.45 & 4.6793 & TRN & \\
\hline CHEMBL1577446 & 688759 & 4.45 & 4.5315 & TST & \\
\hline CHEMBL1409900 & 688759 & 6.0 & 5.8618 & TRN & \\
\hline CHEMBL1415229 & 688759 & 4.45 & 4.8546 & TRN & \\
\hline CHEMBL1580157 & 688759 & 5.4 & 5.0105 & TRN & \\
\hline CHEMBL1382917 & 688759 & 8.5528 & 5.8117 & TRN & \\
\hline CHEMBL1344470 & 688759 & 4.45 & 4.9088 & TST & \\
\hline CHEMBL1577077 & 688759 & 4.45 & 4.7009 & TST & \\
\hline CHEMBL1337243 & 688759 & 4.45 & 4.88899 & 9999999999 & TRN \\
\hline CHEMBL1475999 & 688759 & 4.45 & 5.2023 & TRN & \\
\hline CHEMBL1527134 & 688759 & 4.7 & 4.8212 & TRN & \\
\hline CHEMBL1517696 & 688759 & 4.45 & 4.6045 & TST & \\
\hline CHEMBL1556666 & 688759 & 4.65 & 4.5858 & TST & \\
\hline CHEMBL1308955 & 688759 & 4.45 & 4.9466 & TST & \\
\hline CHEMBL1500650 & 688759 & 4.7 & 4.9161 & TST & \\
\hline CHEMBL1547465 & 688759 & 4.45 & 4.6313 & TRN & \\
\hline CHEMBL3196633 & 688759 & 5.05 & 5.3164 & TRN & \\
\hline CHEMBL1575670 & 688759 & 4.6 & 4.907 & TRN & \\
\hline CHEMBL1570322 & 688759 & 5.0 & 4.8428 & TRN & \\
\hline CHEMBL1572549 & 688759 & 4.5 & 4.6874 & TRN & \\
\hline CHEMBL1405722 & 688759 & 6.0 & 5.1236 & TRN & \\
\hline CHEMBL3209403 & 688759 & 4.45 & 4.5118 & TST & \\
\hline CHEMBL1597435 & 688759 & 6.2 & 6.0319 & TRN & \\
\hline & & & & 471 & \\
\hline
\end{tabular}




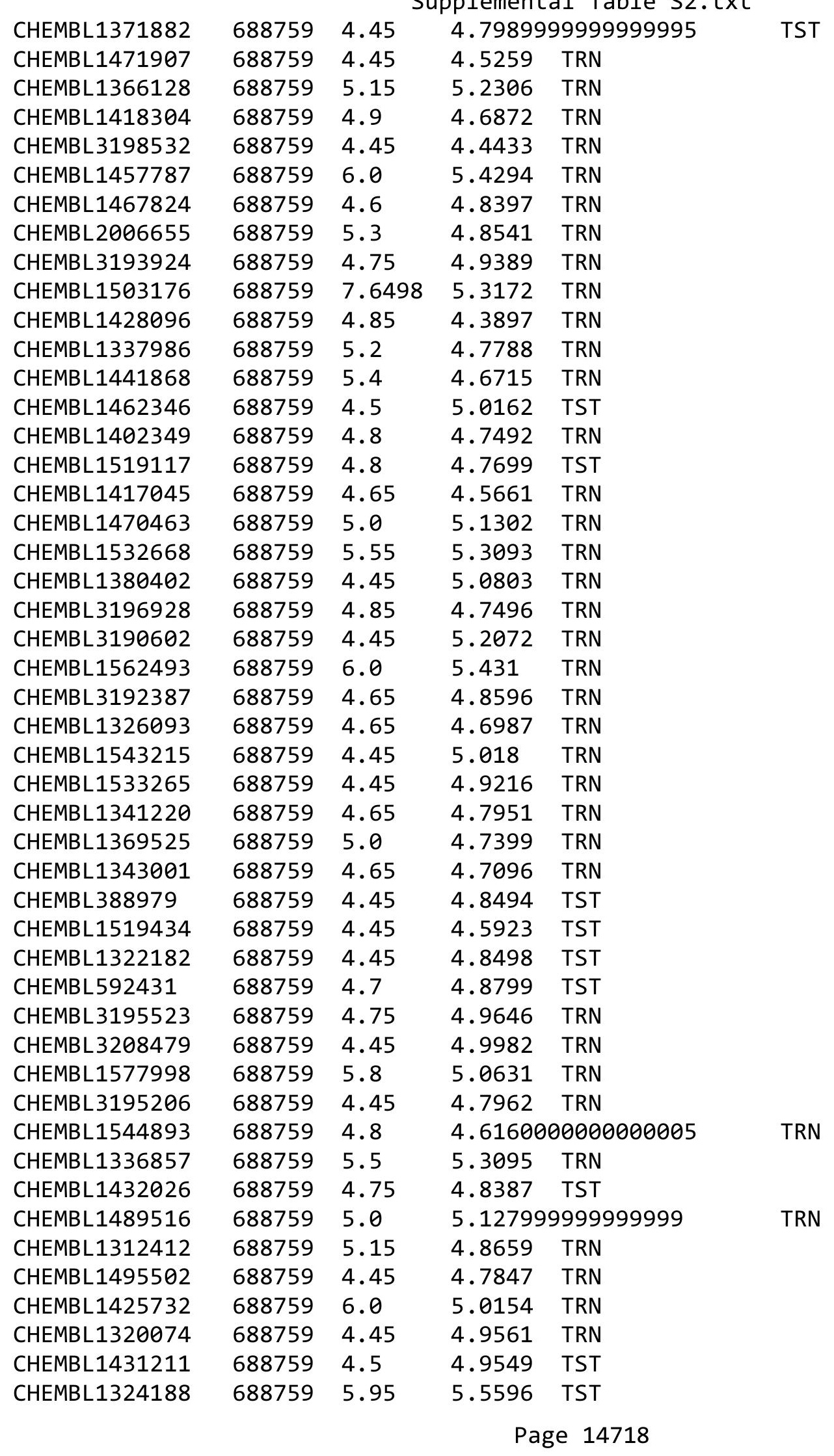




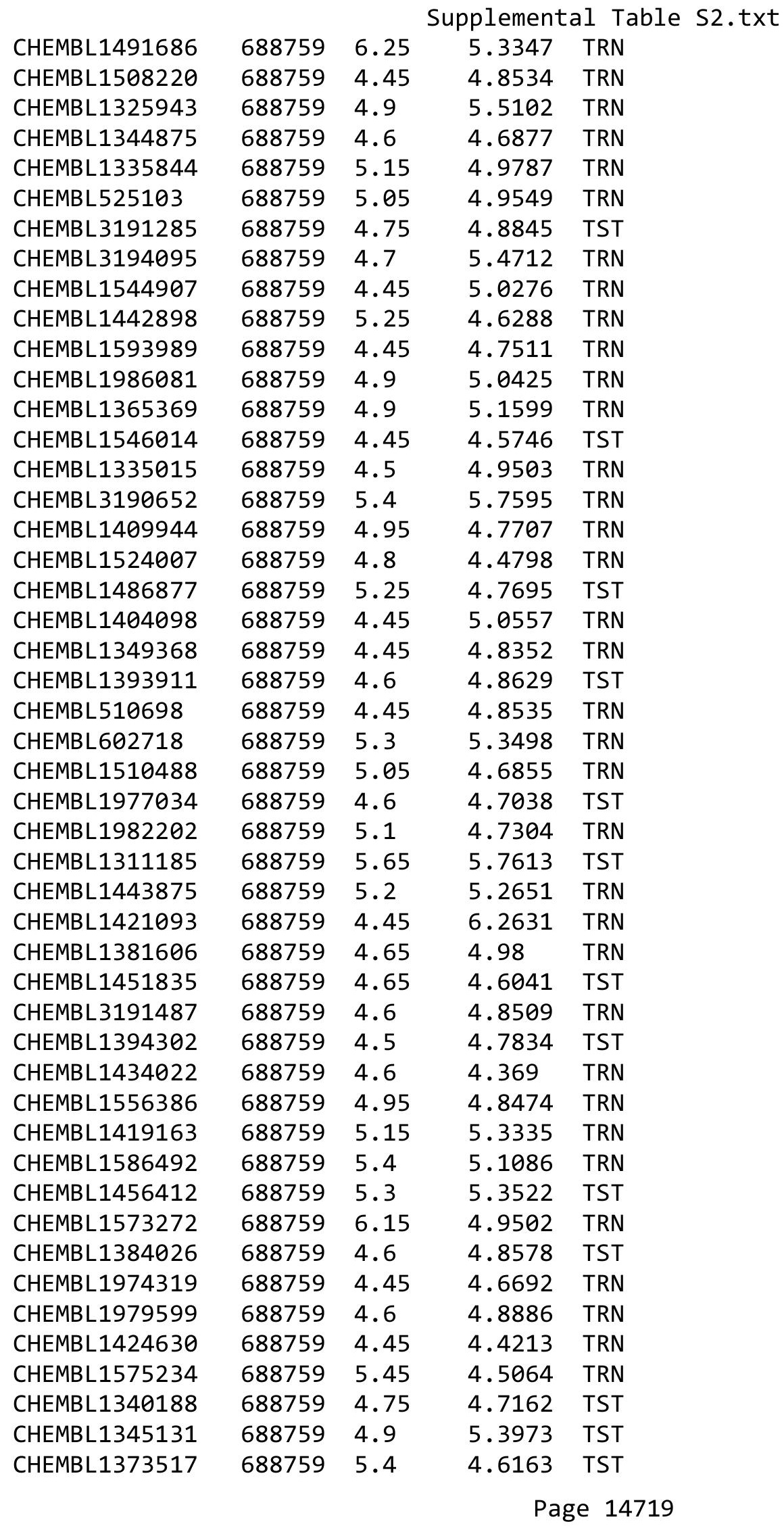




\begin{tabular}{|c|c|c|c|c|c|}
\hline & & & & & \\
\hline CHEMBL3190683 & 688759 & 4.9 & 4.7082 & TRN & \\
\hline CHEMBL1538370 & 688759 & 4.7 & 4.8224 & TRN & \\
\hline CHEMBL1445160 & 688759 & 4.65 & 4.7569 & TRN & \\
\hline CHEMBL1469429 & 688759 & 4.95 & 4.8364 & TRN & \\
\hline CHEMBL3211515 & 688759 & 5.35 & 4.7937 & TRN & \\
\hline CHEMBL1484561 & 688759 & 4.45 & 5.0357 & TST & \\
\hline CHEMBL3194213 & 688759 & 5.2 & 5.2789 & TRN & \\
\hline CHEMBL1343515 & 688759 & 5.05 & 4.9084 & TRN & \\
\hline CHEMBL1418727 & 688759 & 4.95 & 4.9776 & TRN & \\
\hline CHEMBL1429373 & 688759 & 5.6 & 5.36799 & 9999999999 & TRN \\
\hline CHEMBL1529000 & 688759 & 4.75 & 4.6191 & TRN & \\
\hline CHEMBL1555566 & 688759 & 4.65 & 4.8872 & TRN & \\
\hline CHEMBL1494880 & 688759 & 4.9 & 5.1747 & TRN & \\
\hline CHEMBL3189742 & 688759 & 4.5 & 5.3339 & TST & \\
\hline CHEMBL1389400 & 688759 & 5.35 & 4.7499 & TRN & \\
\hline CHEMBL1508017 & 688759 & 4.6 & 4.6814 & TST & \\
\hline CHEMBL1561574 & 688759 & 4.45 & 4.8176 & TRN & \\
\hline CHEMBL1419795 & 688759 & 5.35 & 4.6223 & TST & \\
\hline CHEMBL1595098 & 688759 & 5.35 & 5.5854 & TRN & \\
\hline CHEMBL1507820 & 688759 & 5.15 & 4.86600 & 00000000005 & TRN \\
\hline CHEMBL1565819 & 688759 & 4.5 & 4.8498 & TRN & \\
\hline CHEMBL456678 & 688759 & 4.55 & 4.7757 & TRN & \\
\hline CHEMBL1351748 & 688759 & 5.25 & 4.9102 & TST & \\
\hline CHEMBL1338533 & 688759 & 5.15 & 4.897 & TRN & \\
\hline CHEMBL1613332 & 688759 & 4.75 & 4.9215 & TRN & \\
\hline CHEMBL3197327 & 688759 & 4.45 & 4.8476 & TRN & \\
\hline CHEMBL1352969 & 688759 & 5.45 & 5.5877 & TRN & \\
\hline CHEMBL1386918 & 688759 & 4.45 & 4.7956 & TRN & \\
\hline CHEMBL1377336 & 688759 & 4.75 & 4.82100 & 0000000001 & TRN \\
\hline CHEMBL1328493 & 688759 & 6.5501 & 6.1914 & TRN & \\
\hline CHEMBL3194844 & 688759 & 5.1 & 5.2805 & TRN & \\
\hline CHEMBL1410134 & 688759 & 5.15 & 5.1433 & TST & \\
\hline CHEMBL1313622 & 688759 & 5.1 & 4.9299 & TST & \\
\hline CHEMBL3196921 & 688759 & 5.3 & 5.2215 & TRN & \\
\hline CHEMBL1611922 & 688759 & 4.75 & 4.686 & TRN & \\
\hline CHEMBL1445229 & 688759 & 4.45 & 5.0553 & TRN & \\
\hline CHEMBL1486729 & 688759 & 5.35 & 4.944 & TRN & \\
\hline CHEMBL1348888 & 688759 & 5.05 & 5.0189 & TRN & \\
\hline CHEMBL1489660 & 688759 & 5.3 & 5.0016 & TRN & \\
\hline CHEMBL1368315 & 688759 & 4.45 & 4.9433 & TRN & \\
\hline CHEMBL1570875 & 688759 & 4.45 & 4.6026 & TRN & \\
\hline CHEMBL1424512 & 688759 & 5.2 & 4.9763 & TRN & \\
\hline CHEMBL1420470 & 688759 & 5.15 & 4.9169 & TST & \\
\hline CHEMBL1430679 & 688759 & 4.65 & 4.6996 & TRN & \\
\hline CHEMBL2000122 & 688759 & 4.75 & 4.921 & TRN & \\
\hline CHEMBL1359992 & 688759 & 4.8 & 4.7999 & TST & \\
\hline CHEMBL1304801 & 688759 & 5.4 & 4.4766 & TRN & \\
\hline CHEMBL1566136 & 688759 & 4.45 & 4.7176 & TST & \\
\hline & & & & 472 & \\
\hline
\end{tabular}




\begin{tabular}{|c|c|c|c|c|}
\hline \multicolumn{5}{|c|}{ Supplemental Table S2.txt } \\
\hline CHEMBL1972774 & 688759 & 5.5 & 4.9254 & TRN \\
\hline CHEMBL1572898 & 688759 & 5.5 & 4.8526 & TRN \\
\hline CHEMBL1442432 & 688759 & 4.65 & 4.7225 & TRN \\
\hline CHEMBL1343808 & 688759 & 4.45 & 4.8894 & TRN \\
\hline CHEMBL1299831 & 688759 & 4.45 & 4.7805 & TRN \\
\hline CHEMBL1467018 & 688759 & 4.45 & 5.1188 & TRN \\
\hline CHEMBL3198201 & 688759 & 4.75 & 4.7947 & TRN \\
\hline CHEMBL1979988 & 688759 & 4.75 & 5.1222 & TRN \\
\hline CHEMBL1453995 & 688759 & 4.9 & 4.7738 & TRN \\
\hline CHEMBL1479344 & 688759 & 4.75 & 4.8514 & TRN \\
\hline CHEMBL1965280 & 688759 & 4.45 & 5.0004 & TRN \\
\hline CHEMBL1545697 & 688759 & 6.0 & 5.9668 & TRN \\
\hline CHEMBL1473891 & 688759 & 4.45 & 4.8121 & TRN \\
\hline CHEMBL1377322 & 688759 & 4.45 & 4.817 & TRN \\
\hline CHEMBL1449821 & 688759 & 5.05 & 4.9583 & TST \\
\hline CHEMBL1366092 & 688759 & 4.65 & 4.5931 & TRN \\
\hline CHEMBL1308538 & 688759 & 4.75 & 4.5442 & TRN \\
\hline CHEMBL1526167 & 688759 & 5.05 & 4.9286 & TRN \\
\hline CHEMBL1308004 & 688759 & 5.05 & 4.543 & TRN \\
\hline CHEMBL1412273 & 688759 & 4.45 & 4.9163 & TRN \\
\hline CHEMBL1346539 & 688759 & 4.6 & 5.2494 & TST \\
\hline CHEMBL1595302 & 688759 & 4.85 & 4.923 & TST \\
\hline CHEMBL1339563 & 688759 & 5.5 & 5.0759 & TRN \\
\hline CHEMBL1976839 & 688759 & 4.45 & 4.6818 & TRN \\
\hline CHEMBL1543752 & 688759 & 4.65 & 4.4248 & TST \\
\hline CHEMBL1435409 & 688759 & 4.9 & 4.7424 & TRN \\
\hline CHEMBL1995385 & 688759 & 4.45 & 4.7175 & TRN \\
\hline CHEMBL1499111 & 688759 & 4.45 & 5.4186 & TRN \\
\hline CHEMBL1498695 & 688759 & 5.85 & 5.6576 & TRN \\
\hline CHEMBL1597288 & 688759 & 4.45 & 4.8775 & TRN \\
\hline CHEMBL3191866 & 688759 & 4.45 & 5.2463 & TRN \\
\hline CHEMBL1412406 & 688759 & 6.45 & 5.6017 & TRN \\
\hline CHEMBL1527186 & 688759 & 5.05 & 5.1811 & TRN \\
\hline CHEMBL1457782 & 688759 & 4.45 & 4.5991 & TRN \\
\hline CHEMBL 2001582 & 688759 & 4.45 & 4.5403 & TRN \\
\hline CHEMBL1581782 & 688759 & 4.45 & 4.7453 & TRN \\
\hline CHEMBL3191794 & 688759 & 4.45 & 4.9145 & TRN \\
\hline CHEMBL1379943 & 688759 & 5.0 & 5.4292 & TRN \\
\hline CHEMBL1341096 & 688759 & 4.45 & 4.7117 & TRN \\
\hline CHEMBL1346550 & 688759 & 4.45 & 4.5616 & TST \\
\hline CHEMBL3145107 & 688759 & 4.45 & 5.0455 & TST \\
\hline CHEMBL1528814 & 688759 & 5.25 & 5.1041 & TST \\
\hline CHEMBL1559385 & 688759 & 5.0 & 4.9239 & TRN \\
\hline CHEMBL582694 & 688759 & 4.5 & 4.6671 & TRN \\
\hline CHEMBL1597544 & 688759 & 6.0 & 4.5528 & TRN \\
\hline CHEMBL1389669 & 688759 & 5.2 & 5.2433 & TRN \\
\hline CHEMBL1510543 & 688759 & 4.7 & 4.6286 & TST \\
\hline CHEMBL1382069 & 688759 & 5.2 & 5.0867 & TST \\
\hline
\end{tabular}




\begin{tabular}{|c|c|c|c|c|c|}
\hline \multicolumn{6}{|c|}{ Supplemental Table S2.txt } \\
\hline CHEMBL1422457 & 688759 & 5.35 & 5.1321 & TRN & \\
\hline CHEMBL1332376 & 688759 & 5.25 & 5.2818 & TRN & \\
\hline CHEMBL1300410 & 688759 & 5.35 & 5.1885 & TRN & \\
\hline CHEMBL1603637 & 688759 & 4.9 & 4.8547 & TST & \\
\hline CHEMBL1400308 & 688759 & 5.5 & 4.848 & TRN & \\
\hline CHEMBL1463156 & 688759 & 4.6 & 4.6461 & TRN & \\
\hline CHEMBL1582137 & 688759 & 5.15 & 5.7056 & TRN & \\
\hline CHEMBL1182777 & 688759 & 5.15 & 4.8843 & TST & \\
\hline CHEMBL1533377 & 688759 & 4.9 & 4.6568 & TST & \\
\hline CHEMBL1533549 & 688759 & 5.3 & 4.9246 & TRN & \\
\hline CHEMBL1302491 & 688759 & 4.45 & 5.3707 & TRN & \\
\hline CHEMBL1480332 & 688759 & 5.25 & 4.6991 & TRN & \\
\hline CHEMBL1601731 & 688759 & 5.25 & 4.9931 & TRN & \\
\hline CHEMBL1467982 & 688759 & 4.8 & 4.8255 & TST & \\
\hline CHEMBL1360252 & 688759 & 5.45 & 5.1551 & TRN & \\
\hline CHEMBL1982991 & 688759 & 5.45 & 5.5089 & TRN & \\
\hline CHEMBL1468261 & 688759 & 4.85 & 5.1149 & TRN & \\
\hline CHEMBL1465660 & 688759 & 5.45 & 5.0087 & TRN & \\
\hline CHEMBL1366037 & 688759 & 4.55 & 5.0183 & TRN & \\
\hline CHEMBL1563898 & 688759 & 5.0 & 4.8962 & TRN & \\
\hline CHEMBL1587433 & 688759 & 4.45 & 5.0005 & TRN & \\
\hline CHEMBL1405817 & 688759 & 5.4 & 5.5156 & TRN & \\
\hline CHEMBL1385132 & 688759 & 5.65 & 4.8396 & TRN & \\
\hline CHEMBL1612855 & 688759 & 5.55 & 4.9167 & TST & \\
\hline CHEMBL1378385 & 688759 & 5.0 & 4.7724 & TRN & \\
\hline CHEMBL1462820 & 688759 & 5.2 & 5.2281 & TRN & \\
\hline CHEMBL1373664 & 688759 & 5.05 & 5.1507 & TRN & \\
\hline CHEMBL1360319 & 688759 & 5.4 & 4.7155 & TRN & \\
\hline CHEMBL1387664 & 688759 & 5.2 & 4.876 & TST & \\
\hline CHEMBL1526856 & 688759 & 4.85 & 4.80399 & 9999999999 & TRN \\
\hline CHEMBL1390036 & 688759 & 5.0 & 4.7454 & TRN & \\
\hline CHEMBL1451827 & 688759 & 4.95 & 4.5809 & TST & \\
\hline CHEMBL1602833 & 688759 & 4.45 & 4.7358 & TRN & \\
\hline CHEMBL1450215 & 688759 & 4.55 & 4.8539 & TRN & \\
\hline CHEMBL1324556 & 688759 & 4.85 & 4.8378 & TRN & \\
\hline CHEMBL1328051 & 688759 & 4.95 & 4.8021 & TRN & \\
\hline CHEMBL1430138 & 688759 & 4.45 & 4.76399 & 9999999999 & TST \\
\hline CHEMBL393136 & 688759 & 4.65 & 4.4822 & TST & \\
\hline CHEMBL3190003 & 688759 & 5.4 & 4.6215 & TRN & \\
\hline CHEMBL3190314 & 688759 & 5.15 & 4.9444 & TRN & \\
\hline CHEMBL1466482 & 688759 & 4.45 & 4.7431 & TRN & \\
\hline CHEMBL1400691 & 688759 & 4.45 & 4.6874 & TRN & \\
\hline CHEMBL1359141 & 688759 & 4.45 & 4.8165 & TRN & \\
\hline CHEMBL1540181 & 688759 & 4.45 & 4.8211 & TRN & \\
\hline CHEMBL1329235 & 688759 & 8.0506 & 5.98600 & 0000000001 & TRN \\
\hline CHEMBL1424424 & 688759 & 4.45 & 4.6581 & TRN & \\
\hline CHEMBL1547891 & 688759 & 4.45 & 4.8812 & TRN & \\
\hline CHEMBL1428445 & 688759 & 6.0 & 5.9205 & TRN & \\
\hline
\end{tabular}




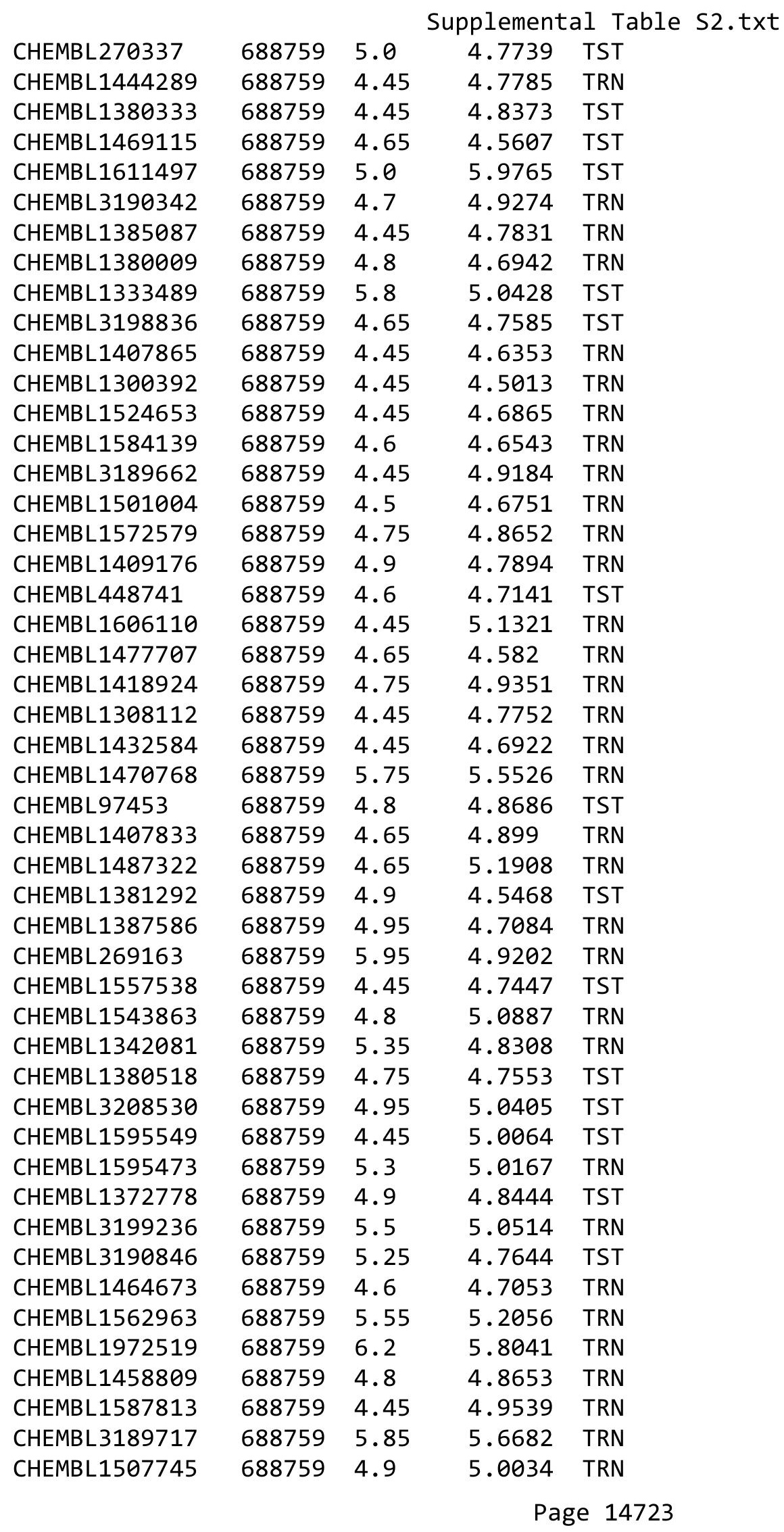




\begin{tabular}{|c|c|c|c|c|c|}
\hline & & \multicolumn{4}{|c|}{ Supplemental Table S2.txt } \\
\hline CHEMBL1467956 & 688759 & 4.45 & 4.7176 & TRN & \\
\hline CHEMBL1560005 & 688759 & 5.4 & 4.7063 & TST & \\
\hline CHEMBL1982539 & 688759 & 5.65 & 5.36799 & 7999999999 & TRN \\
\hline CHEMBL1563079 & 688759 & 4.45 & 4.6224 & TRN & \\
\hline CHEMBL1345015 & 688759 & 6.05 & 4.9027 & TRN & \\
\hline CHEMBL1968327 & 688759 & 4.45 & 4.7582 & TRN & \\
\hline CHEMBL1333059 & 688759 & 5.4 & 4.6221 & TRN & \\
\hline CHEMBL1369847 & 688759 & 5.1 & 4.782 & TRN & \\
\hline CHEMBL1471899 & 688759 & 5.25 & 5.3059 & TST & \\
\hline CHEMBL1458783 & 688759 & 4.6 & 4.8809 & TRN & \\
\hline CHEMBL1304144 & 688759 & 4.65 & 4.6971 & TST & \\
\hline CHEMBL1519418 & 688759 & 8.301 & 4.9925 & TST & \\
\hline CHEMBL1481154 & 688759 & 4.45 & 4.7318 & TRN & \\
\hline CHEMBL1300843 & 688759 & 4.45 & 4.8729 & TRN & \\
\hline CHEMBL1465553 & 688759 & 4.55 & 4.9221 & TRN & \\
\hline CHEMBL1334443 & 688759 & 4.6 & 4.7627 & TST & \\
\hline CHEMBL1352172 & 688759 & 4.45 & 4.7837 & TST & \\
\hline CHEMBL1468537 & 688759 & 5.25 & 4.8347 & TRN & \\
\hline CHEMBL3190261 & 688759 & 5.35 & 4.9757 & TRN & \\
\hline CHEMBL1588052 & 688759 & 4.85 & 5.0184 & TRN & \\
\hline CHEMBL1385375 & 688759 & 4.45 & 4.4935 & TST & \\
\hline CHEMBL1420135 & 688759 & 4.75 & 4.6851 & TST & \\
\hline CHEMBL1468974 & 688759 & 4.65 & 4.6558 & TRN & \\
\hline CHEMBL1407914 & 688759 & 4.85 & 4.7039 & TRN & \\
\hline CHEMBL1598625 & 688759 & 5.25 & 4.9767 & TST & \\
\hline CHEMBL1460310 & 688759 & 5.3 & 5.0671 & TRN & \\
\hline CHEMBL1467043 & 688759 & 4.9 & 4.6919 & TST & \\
\hline CHEMBL1371789 & 688759 & 4.6 & 4.7581 & TRN & \\
\hline CHEMBL 3211803 & 688759 & 4.45 & 4.9297 & TRN & \\
\hline CHEMBL1372513 & 688759 & 4.45 & 4.7439 & TRN & \\
\hline CHEMBL1482663 & 688759 & 5.0 & 5.0129 & TST & \\
\hline CHEMBL3198511 & 688759 & 6.45 & 5.7457 & TRN & \\
\hline CHEMBL 1447350 & 688759 & 5.5 & 5.0993 & TRN & \\
\hline CHEMBL1537753 & 688759 & 4.45 & 4.6607 & TRN & \\
\hline CHEMBL1326259 & 688759 & 4.75 & 4.9664 & TRN & \\
\hline CHEMBL1330318 & 688759 & 6.05 & 5.409 & TRN & \\
\hline CHEMBL1472218 & 688759 & 5.2 & 5.23 & TST & \\
\hline CHEMBL1536318 & 688759 & 4.45 & 4.8881 & TRN & \\
\hline CHEMBL538430 & 688759 & 5.05 & 5.2883 & TRN & \\
\hline CHEMBL3190052 & 688759 & 4.65 & 4.7747 & TRN & \\
\hline CHEMBL1367821 & 688759 & 4.45 & 4.5142 & TRN & \\
\hline CHEMBL1555832 & 688759 & 4.8 & 4.8248 & TST & \\
\hline CHEMBL1584590 & 688759 & 5.2 & 4.8387 & TRN & \\
\hline CHEMBL1447343 & 688759 & 4.65 & 4.8381 & TRN & \\
\hline CHEMBL3212028 & 688759 & 4.45 & 4.729 & TRN & \\
\hline CHEMBL1306418 & 688759 & 4.45 & 4.9042 & TRN & \\
\hline CHEMBL3210873 & 688759 & 4.45 & 4.9327 & TRN & \\
\hline CHEMBL1412533 & 688759 & 4.45 & 4.8538 & TST & \\
\hline
\end{tabular}




\begin{tabular}{|c|c|c|c|c|}
\hline & & \multicolumn{3}{|c|}{ Supplemental Table S2.txt } \\
\hline CHEMBL3209842 & 688759 & 4.45 & 4.8149 & TST \\
\hline CHEMBL 3213590 & 688759 & 5.45 & 4.9862 & TST \\
\hline CHEMBL1361507 & 688759 & 4.75 & 4.6208 & TRN \\
\hline CHEMBL1383742 & 688759 & 4.45 & 4.9411 & TRN \\
\hline CHEMBL1517732 & 688759 & 4.45 & 4.6143 & TRN \\
\hline CHEMBL1410652 & 688759 & 4.45 & 4.8995 & TST \\
\hline CHEMBL1385159 & 688759 & 4.65 & 4.8128 & TRN \\
\hline CHEMBL1303257 & 688759 & 4.45 & 4.6802 & TRN \\
\hline CHEMBL343732 & 688759 & 4.45 & 4.43 & TRN \\
\hline CHEMBL1999571 & 688759 & 5.6 & 5.4302 & TRN \\
\hline CHEMBL1471051 & 688759 & 4.65 & 4.9941 & TST \\
\hline CHEMBL1420537 & 688759 & 4.45 & 4.6311 & TST \\
\hline CHEMBL1992486 & 688759 & 4.95 & 5.1587 & TST \\
\hline CHEMBL1596966 & 688759 & 5.7 & 4.6542 & TRN \\
\hline CHEMBL 3213428 & 688759 & 5.25 & 5.1081 & TRN \\
\hline CHEMBL1523603 & 688759 & 4.45 & 4.7828 & TST \\
\hline CHEMBL1986619 & 688759 & 4.7 & 4.9456 & TST \\
\hline CHEMBL1423009 & 688759 & 4.45 & 4.6369 & TRN \\
\hline CHEMBL1477786 & 688759 & 5.0 & 4.9149 & TRN \\
\hline CHEMBL 3197372 & 688759 & 5.0 & 5.1523 & TRN \\
\hline CHEMBL1427447 & 688759 & 4.45 & 4.7687 & TRN \\
\hline CHEMBL1353696 & 688759 & 4.45 & 4.9267 & TRN \\
\hline CHEMBL582070 & 688759 & 4.95 & 4.6197 & TST \\
\hline CHEMBL1569119 & 688759 & 6.4 & 5.2865 & TST \\
\hline CHEMBL1608237 & 688759 & 4.45 & 4.74 & TRN \\
\hline CHEMBL1384843 & 688759 & 4.5 & 4.8882 & TST \\
\hline CHEMBL1608171 & 688759 & 4.6 & 4.724 & TRN \\
\hline CHEMBL1466985 & 688759 & 4.45 & 4.9118 & TST \\
\hline CHEMBL1424360 & 688759 & 4.8 & 5.0104 & TRN \\
\hline CHEMBL1542070 & 688759 & 5.15 & 4.6918 & TRN \\
\hline CHEMBL1338489 & 688759 & 4.5 & 4.8304 & TRN \\
\hline CHEMBL1343026 & 688759 & 4.9 & 4.8248 & TST \\
\hline CHEMBL1570465 & 688759 & 4.8 & 4.5623 & TRN \\
\hline CHEMBL1378240 & 688759 & 6.25 & 5.3839 & TRN \\
\hline CHEMBL1543164 & 688759 & 4.45 & 4.9762 & TRN \\
\hline CHEMBL1372327 & 688759 & 5.1 & 5.1987 & TRN \\
\hline CHEMBL1521276 & 688759 & 4.9 & 4.7787 & TRN \\
\hline CHEMBL1539607 & 688759 & 4.45 & 4.7853 & TRN \\
\hline CHEMBL1564773 & 688759 & 4.9 & 4.5612 & TRN \\
\hline CHEMBL1488675 & 688759 & 4.45 & 4.8181 & TST \\
\hline CHEMBL1431705 & 688759 & 5.35 & 5.087 & TRN \\
\hline CHEMBL1585223 & 688759 & 5.05 & 4.8132 & TST \\
\hline CHEMBL1539579 & 688759 & 4.6 & 4.9529 & TST \\
\hline CHEMBL1978989 & 688759 & 4.45 & 4.4911 & TRN \\
\hline CHEMBL1462306 & 688759 & 4.45 & 4.7967 & TST \\
\hline CHEMBL1488923 & 688759 & 6.5 & 5.9112 & TRN \\
\hline CHEMBL1506947 & 688759 & 4.95 & 4.8625 & TST \\
\hline CHEMBL1588575 & 688759 & 4.95 & 4.9239 & TRN \\
\hline
\end{tabular}




\begin{tabular}{|c|c|c|c|c|c|}
\hline \multicolumn{6}{|c|}{ Supplemental Table s2.txt } \\
\hline CHEMBL1969851 & 688759 & 4.45 & 5.1609 & TRN & \\
\hline CHEMBL1332244 & 688759 & 4.45 & 4.863 & TRN & \\
\hline CHEMBL1418931 & 688759 & 4.7 & 4.8228 & TRN & \\
\hline CHEMBL1597004 & 688759 & 4.55 & 4.6818 & TRN & \\
\hline CHEMBL1556428 & 688759 & 5.15 & 4.8672 & TRN & \\
\hline CHEMBL1369926 & 688759 & 5.5 & 5.0204 & TRN & \\
\hline CHEMBL1440404 & 688759 & 5.3 & 4.8203 & TRN & \\
\hline CHEMBL1399608 & 688759 & 5.25 & 5.0391 & TRN & \\
\hline CHEMBL1595412 & 688759 & 4.5 & \multicolumn{2}{|c|}{5.138999999999999} & TRN \\
\hline CHEMBL1347736 & 688759 & 4.9 & 4.7218 & TRN & \\
\hline CHEMBL1329164 & 688759 & 4.45 & 4.5918 & TRN & \\
\hline CHEMBL2369168 & 688759 & 4.45 & 4.5263 & TRN & \\
\hline CHEMBL1566871 & 688759 & 4.75 & 4.9494 & TST & \\
\hline CHEMBL1481570 & 688759 & 5.65 & 5.6931 & TRN & \\
\hline CHEMBL1375781 & 688759 & 4.65 & 4.9447 & TST & \\
\hline CHEMBL1360674 & 688759 & 5.05 & 5.1305 & TRN & \\
\hline CHEMBL1462848 & 688759 & 5.4 & 5.2458 & TRN & \\
\hline CHEMBL1473975 & 688759 & 4.45 & 4.819 & TST & \\
\hline CHEMBL1467758 & 688759 & 4.65 & 4.6918 & TRN & \\
\hline CHEMBL1539228 & 688759 & 4.65 & 4.8068 & TRN & \\
\hline CHEMBL1482041 & 688759 & 4.45 & 5.5128 & TRN & \\
\hline CHEMBL1359277 & 688759 & 4.45 & 5.051 & TRN & \\
\hline CHEMBL1387810 & 688759 & 4.45 & 4.9029 & TRN & \\
\hline CHEMBL1382198 & 688759 & 4.45 & 4.6631 & TST & \\
\hline CHEMBL1458626 & 688759 & 4.45 & 4.4493 & TRN & \\
\hline CHEMBL1995193 & 688759 & 4.45 & 4.9989 & TRN & \\
\hline CHEMBL1341999 & 688759 & 4.5 & 4.4542 & TRN & \\
\hline CHEMBL408653 & 688759 & 5.05 & 5.2158 & TRN & \\
\hline CHEMBL1354529 & 688759 & 4.45 & 5.3579 & TST & \\
\hline CHEMBL1301129 & 688759 & 4.45 & 4.4805 & TST & \\
\hline CHEMBL1449322 & 688759 & 4.45 & 4.5228 & TRN & \\
\hline CHEMBL1315848 & 688759 & 4.6 & 4.9061 & TRN & \\
\hline CHEMBL3195302 & 688759 & 4.9 & 4.757 & TRN & \\
\hline CHEMBL1451436 & 688759 & 4.5 & 4.8436 & TST & \\
\hline CHEMBL1342073 & 688759 & 4.45 & 4.7818 & TST & \\
\hline CHEMBL1469481 & 688759 & 4.8 & 4.6808 & TST & \\
\hline CHEMBL1410008 & 688759 & 5.0 & 5.0145 & TRN & \\
\hline CHEMBL1461308 & 688759 & 5.0 & 4.9448 & TRN & \\
\hline CHEMBL1488347 & 688759 & 4.45 & 4.9208 & TRN & \\
\hline CHEMBL1504779 & 688759 & 4.6 & 4.8424 & TRN & \\
\hline CHEMBL1366461 & 688759 & 5.35 & 5.7963 & TRN & \\
\hline CHEMBL1410610 & 688759 & 5.95 & 4.7801 & TRN & \\
\hline CHEMBL1328595 & 688759 & 5.35 & 4.8683 & TRN & \\
\hline CHEMBL3198402 & 688759 & 4.95 & 4.8108 & TRN & \\
\hline CHEMBL1328501 & 688759 & 5.3 & 5.1861 & TRN & \\
\hline CHEMBL1318736 & 688759 & 5.9 & 5.2243 & TST & \\
\hline CHEMBL1402502 & 688759 & 4.9 & 4.6017 & TRN & \\
\hline \multirow[t]{2}{*}{ CHEMBL1413134 } & 688759 & 6.1 & 5.84399 & 9999999999 & TRN \\
\hline & & \multicolumn{4}{|c|}{ Page 14726} \\
\hline
\end{tabular}




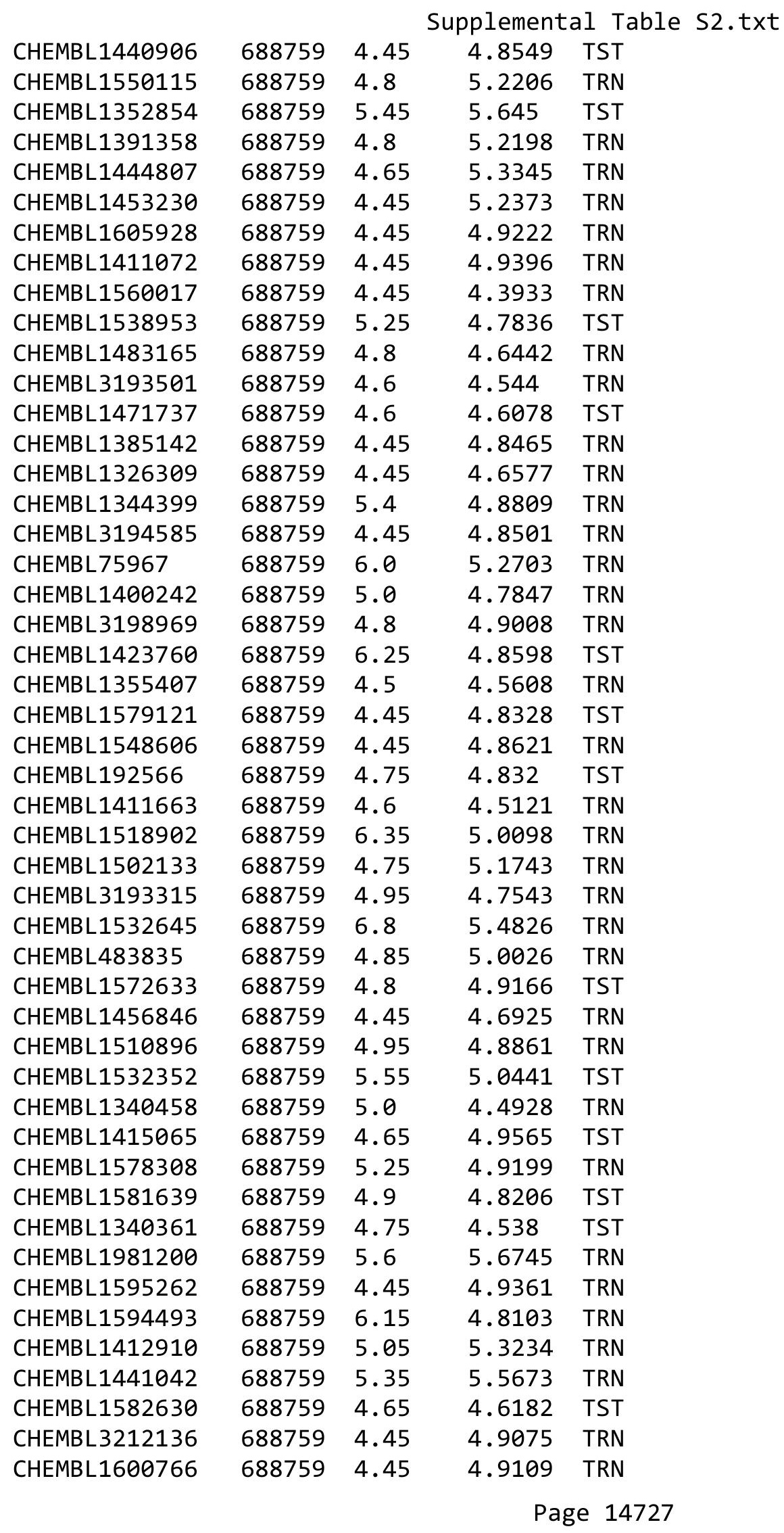




\begin{tabular}{|c|c|c|c|c|c|}
\hline \multicolumn{6}{|c|}{ Supplemental Table S2.txt } \\
\hline CHEMBL1357005 & 688759 & 5.0 & 5.0716 & TRN & \\
\hline CHEMBL1491896 & 688759 & 5.75 & 4.963 & TST & \\
\hline CHEMBL1375548 & 688759 & 4.45 & 5.2216 & TRN & \\
\hline CHEMBL1347767 & 688759 & 4.95 & 5.0918 & TRN & \\
\hline CHEMBL1430858 & 688759 & 4.45 & 4.8317 & TST & \\
\hline CHEMBL1352623 & 688759 & 4.95 & 4.9075 & TRN & \\
\hline CHEMBL1545565 & 688759 & 5.25 & 5.0776 & TRN & \\
\hline CHEMBL1422311 & 688759 & 4.45 & 4.5677 & TRN & \\
\hline CHEMBL1540473 & 688759 & 5.5 & 4.9692 & TRN & \\
\hline CHEMBL1611486 & 688759 & 4.45 & 5.0933 & TRN & \\
\hline CHEMBL1407961 & 688759 & 5.4 & 5.2357 & TRN & \\
\hline CHEMBL1377993 & 688759 & 4.6 & 4.5661 & TRN & \\
\hline CHEMBL1990184 & 688759 & 4.45 & 4.9095 & TRN & \\
\hline CHEMBL3213842 & 688759 & 4.7 & 4.6939 & TRN & \\
\hline CHEMBL1440884 & 688759 & 4.45 & 4.7052 & TST & \\
\hline CHEMBL1971760 & 688759 & 6.2 & 6.1567 & TST & \\
\hline CHEMBL1537873 & 688759 & 4.95 & 4.8289 & TRN & \\
\hline CHEMBL1496171 & 688759 & 6.05 & 4.6939 & TST & \\
\hline CHEMBL1550445 & 688759 & 4.65 & 4.4852 & TRN & \\
\hline CHEMBL1432466 & 688759 & 5.05 & 5.112 & TRN & \\
\hline CHEMBL1557088 & 688759 & 5.3 & 4.9584 & TRN & \\
\hline CHEMBL3195509 & 688759 & 5.25 & 4.86100 & 0000000001 & TST \\
\hline CHEMBL1543765 & 688759 & 4.45 & 4.8039 & TRN & \\
\hline CHEMBL1313206 & 688759 & 4.45 & 4.8977 & TRN & \\
\hline CHEMBL1327489 & 688759 & 4.45 & 4.8286 & TRN & \\
\hline CHEMBL455984 & 688759 & 4.45 & 4.8151 & TRN & \\
\hline CHEMBL3199143 & 688759 & 4.45 & 4.8567 & TRN & \\
\hline CHEMBL1314388 & 688759 & 4.45 & 4.8019 & TRN & \\
\hline CHEMBL1412623 & 688759 & 4.45 & 4.945 & TRN & \\
\hline CHEMBL1346839 & 688759 & 4.75 & 4.7692 & TRN & \\
\hline CHEMBL1521092 & 688759 & 4.9 & 4.9866 & TST & \\
\hline CHEMBL1392019 & 688759 & 4.5 & 4.9017 & TST & \\
\hline CHEMBL1391866 & 688759 & 5.2 & 5.2899 & TRN & \\
\hline CHEMBL1375555 & 688759 & 4.45 & 4.7437 & TRN & \\
\hline CHEMBL 3194446 & 688759 & 5.5 & 5.07600 & 00000000005 & TRN \\
\hline CHEMBL1389685 & 688759 & 4.7 & 4.9291 & TST & \\
\hline CHEMBL1478346 & 688759 & 5.0 & 4.7463 & TRN & \\
\hline CHEMBL3145365 & 688759 & 5.55 & 5.8041 & TRN & \\
\hline CHEMBL1554960 & 688759 & 5.0 & 4.954 & TRN & \\
\hline CHEMBL1487803 & 688759 & 4.45 & 4.8704 & TST & \\
\hline CHEMBL1388963 & 688759 & 4.55 & 4.7331 & TRN & \\
\hline CHEMBL1366683 & 688759 & 4.65 & 4.7526 & TRN & \\
\hline CHEMBL1454748 & 688759 & 4.65 & 5.4566 & TRN & \\
\hline CHEMBL1508465 & 688759 & 4.45 & 4.7213 & TRN & \\
\hline CHEMBL1601718 & 688759 & 5.0 & 5.096 & TRN & \\
\hline CHEMBL 2002875 & 688759 & 4.45 & 4.7173 & TRN & \\
\hline CHEMBL1301359 & 688759 & 4.7 & 4.7488 & TRN & \\
\hline CHEMBL1459353 & 688759 & 5.15 & 5.1624 & TST & \\
\hline
\end{tabular}




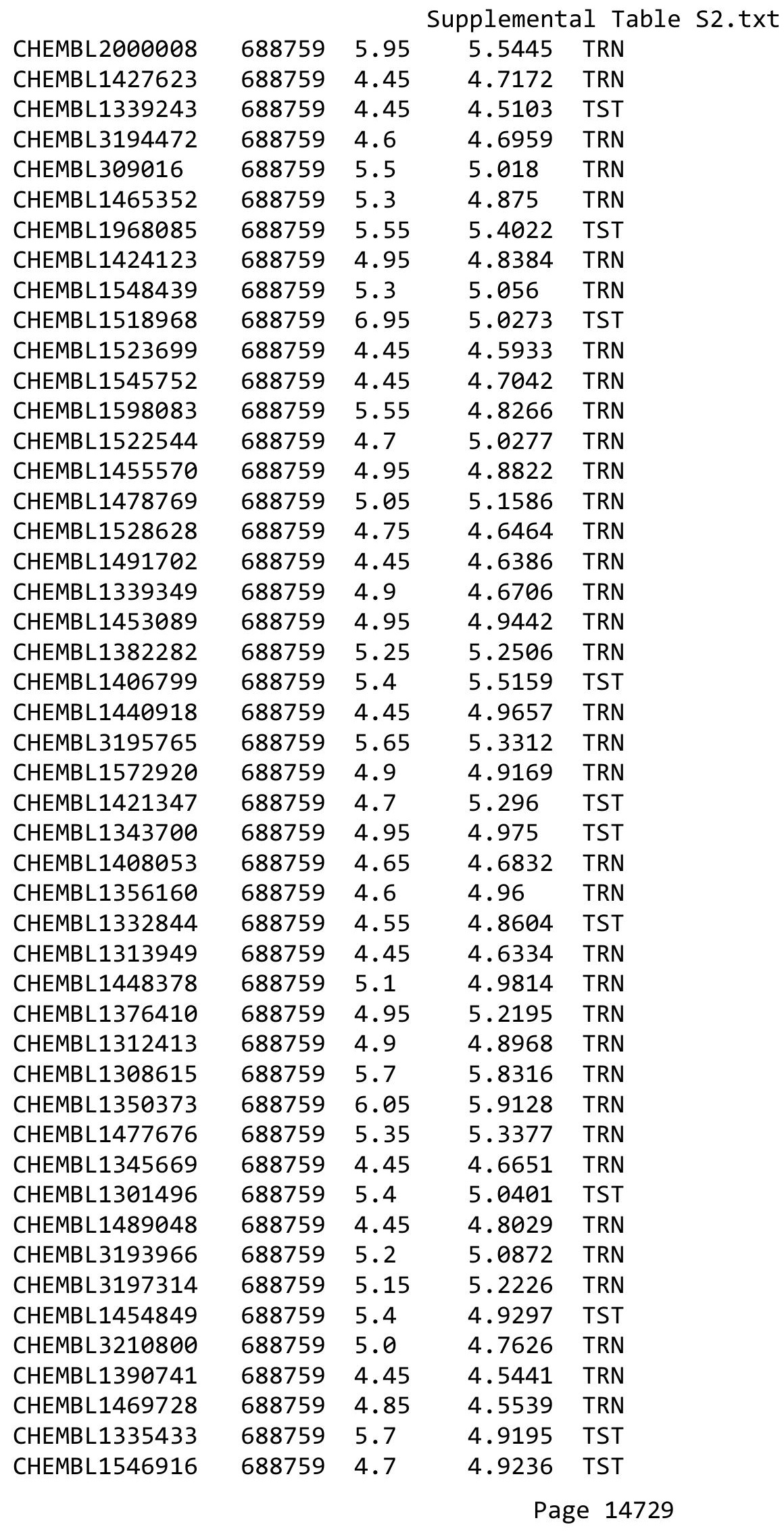




\begin{tabular}{|c|c|c|c|c|c|}
\hline \multirow{3}{*}{$\begin{array}{l}\text { CHEMBL1418016 } \\
\text { CHEMBL1412855 }\end{array}$} & \multirow{3}{*}{$\begin{array}{l}688759 \\
688759\end{array}$} & \multicolumn{4}{|c|}{ Supplemental Table S2.txt } \\
\hline & & 4.95 & \multicolumn{2}{|c|}{5.013999999999999} & \multirow{2}{*}{ TRN } \\
\hline & & 5.2 & 5.0807 & TRN & \\
\hline CHEMBL1989917 & 688759 & 4.45 & 5.0461 & TRN & \\
\hline CHEMBL1550794 & 688759 & 4.45 & 5.0072 & TRN & \\
\hline CHEMBL1404915 & 688759 & 4.55 & 4.5634 & TST & \\
\hline CHEMBL1328747 & 688759 & 5.45 & 4.8183 & TST & \\
\hline CHEMBL1539206 & 688759 & 4.65 & 4.7189 & TRN & \\
\hline CHEMBL1313954 & 688759 & 4.45 & \multicolumn{2}{|c|}{4.8919999999999995} & TST \\
\hline CHEMBL1557559 & 688759 & 5.35 & 5.3233 & TRN & \\
\hline CHEMBL1574761 & 688759 & 4.45 & 4.6528 & TRN & \\
\hline CHEMBL1348675 & 688759 & 4.6 & 5.0441 & TRN & \\
\hline CHEMBL1430820 & 688759 & 4.45 & 5.0759 & TRN & \\
\hline CHEMBL1414330 & 688759 & 4.85 & 4.6787 & TRN & \\
\hline CHEMBL1430666 & 688759 & 5.25 & 4.9532 & TST & \\
\hline CHEMBL1526101 & 688759 & 5.2 & 4.9933 & TST & \\
\hline CHEMBL1349498 & 688759 & 5.0 & 5.0245 & TST & \\
\hline CHEMBL1501197 & 688759 & 4.65 & 4.9038 & TRN & \\
\hline CHEMBL1483857 & 688759 & 4.85 & 4.9822 & TRN & \\
\hline CHEMBL1469551 & 688759 & 4.45 & 4.837 & TRN & \\
\hline CHEMBL1439411 & 688759 & 4.45 & 4.7276 & TST & \\
\hline CHEMBL1427972 & 688759 & 4.95 & 5.5102 & TRN & \\
\hline CHEMBL1460529 & 688759 & 5.2 & 4.8395 & TST & \\
\hline CHEMBL1431684 & 688759 & 4.5 & 4.817 & TRN & \\
\hline CHEMBL1542319 & 688759 & 6.5501 & 5.9784 & TRN & \\
\hline CHEMBL1515739 & 688759 & 5.1 & 5.239 & TRN & \\
\hline CHEMBL375966 & 688759 & 6.0 & 5.0644 & TST & \\
\hline CHEMBL524664 & 688759 & 6.0 & 5.2828 & TST & \\
\hline CHEMBL1505384 & 688759 & 4.45 & 4.9221 & TRN & \\
\hline CHEMBL1342109 & 688759 & 4.95 & 4.8757 & TST & \\
\hline CHEMBL1565150 & 688759 & 4.5 & 4.819 & TRN & \\
\hline CHEMBL1429962 & 688759 & 4.7 & 4.8595 & TRN & \\
\hline CHEMBL1440149 & 688759 & 4.95 & 4.7927 & TRN & \\
\hline CHEMBL1483746 & 688759 & 5.5 & 5.5869 & TRN & \\
\hline CHEMBL1443778 & 688759 & 5.3 & 4.8896 & TST & \\
\hline CHEMBL3198824 & 688759 & 4.75 & 4.9165 & TRN & \\
\hline CHEMBL1332624 & 688759 & 4.45 & 4.8193 & TRN & \\
\hline CHEMBL1337382 & 688759 & 4.9 & 4.9529 & TRN & \\
\hline CHEMBL1386699 & 688759 & 4.6 & 4.7772 & TRN & \\
\hline CHEMBL1450748 & 688759 & 5.95 & 5.4976 & TRN & \\
\hline CHEMBL1455619 & 688759 & 4.65 & 4.9488 & TRN & \\
\hline CHEMBL1311989 & 688759 & 4.45 & 4.9034 & TST & \\
\hline CHEMBL104468 & 688759 & 4.45 & 4.9287 & TST & \\
\hline CHEMBL1577004 & 688759 & 4.45 & 4.649 & TST & \\
\hline CHEMBL1371706 & 688759 & 5.45 & 5.0139 & TRN & \\
\hline CHEMBL1500229 & 688759 & 4.45 & 4.63899 & 9999999999 & TST \\
\hline CHEMBL1468260 & 688759 & 5.0 & 4.7143 & TRN & \\
\hline CHEMBL1403632 & 688759 & 4.65 & 4.8733 & TRN & \\
\hline CHEMBL1334568 & 688759 & 4.95 & 4.8582 & TRN & \\
\hline
\end{tabular}




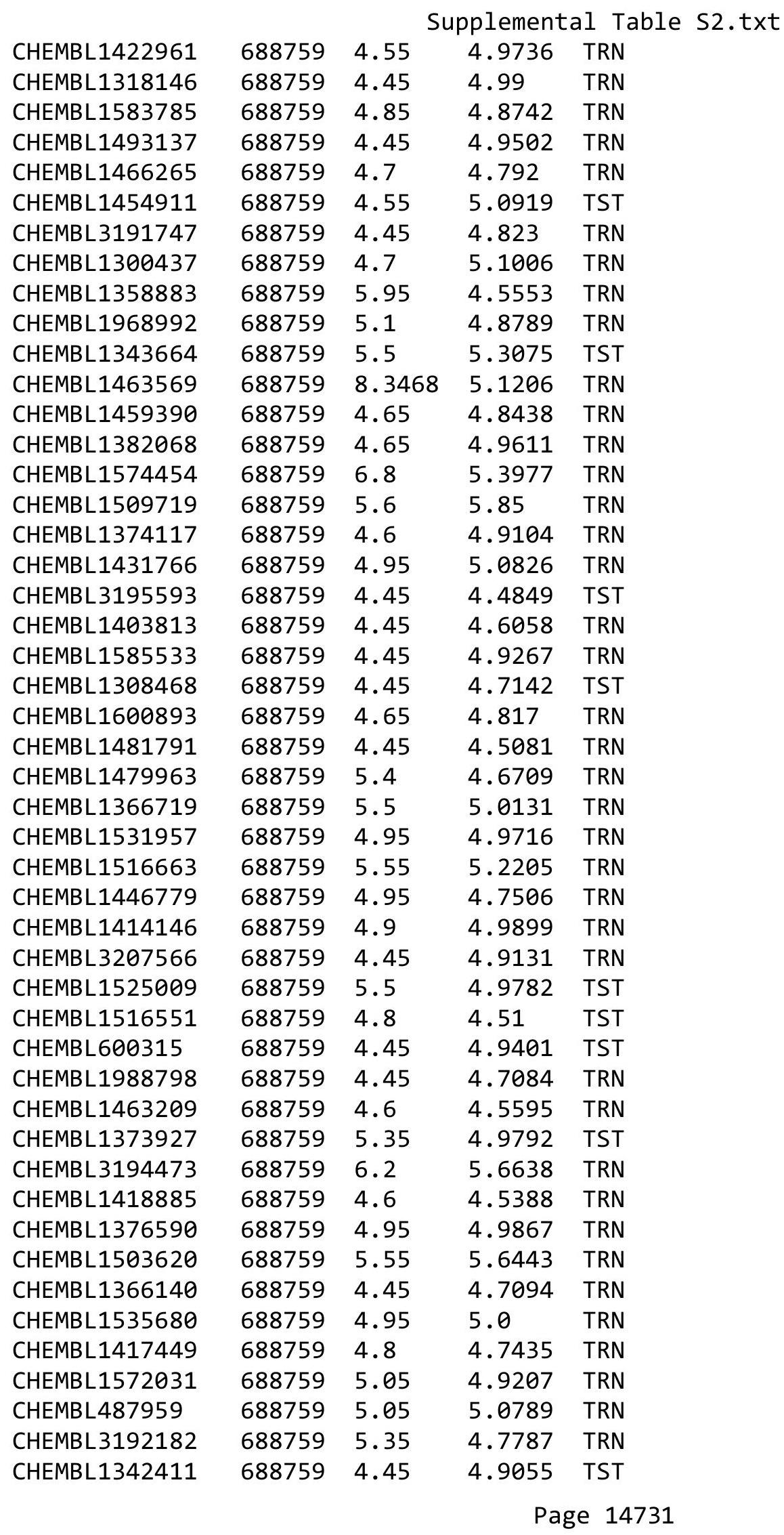




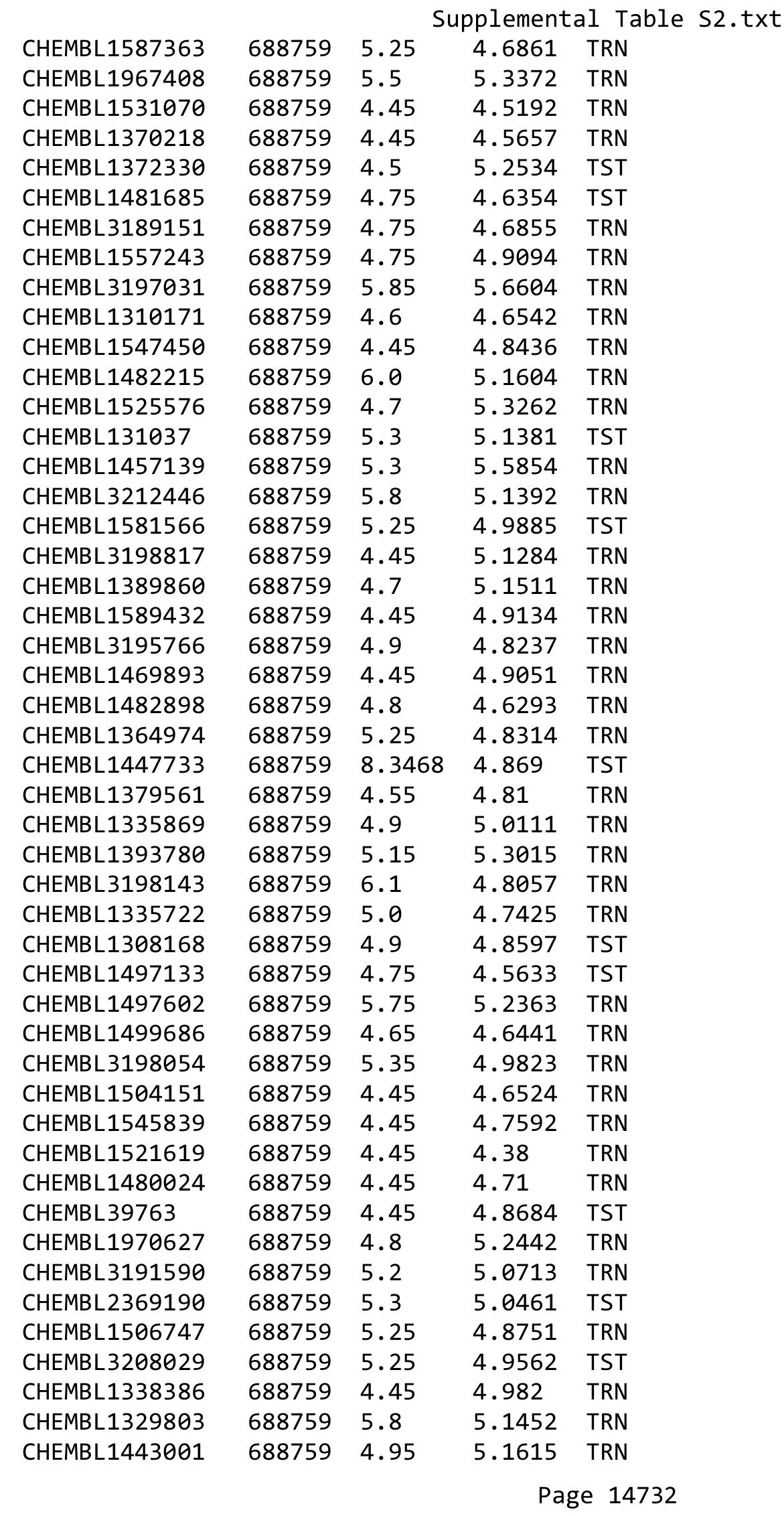




\begin{tabular}{|c|c|c|c|c|c|}
\hline \multirow{3}{*}{$\begin{array}{l}\text { CHEMBL1412660 } \\
\text { CHEMBL } 1445496\end{array}$} & \multirow{3}{*}{$\begin{array}{l}688759 \\
688759\end{array}$} & \multicolumn{4}{|c|}{ Supplemental Table S2.txt } \\
\hline & & 5.85 & 4.9289 & 9999999999 & TRN \\
\hline & & 4.65 & 4.9529 & TRN & \\
\hline CHEMBL1491094 & 688759 & 6.25 & 5.9499 & TRN & \\
\hline CHEMBL1517609 & 688759 & 4.45 & 4.9316 & TST & \\
\hline CHEMBL1306242 & 688759 & 7.699 & 5.0737 & TRN & \\
\hline CHEMBL1452330 & 688759 & 5.25 & 4.978 & TRN & \\
\hline CHEMBL3198156 & 688759 & 6.0 & 5.5094 & TRN & \\
\hline CHEMBL1984479 & 688759 & 4.7 & 4.8963 & TRN & \\
\hline CHEMBL1400205 & 688759 & 5.2 & 5.0127 & TST & \\
\hline CHEMBL1213608 & 688759 & 4.65 & 4.9387 & TRN & \\
\hline CHEMBL1369253 & 688759 & 5.05 & 5.28 & TRN & \\
\hline CHEMBL1306573 & 688759 & 5.35 & 4.9889 & TRN & \\
\hline CHEMBL1570079 & 688759 & 4.6 & 5.0975 & TRN & \\
\hline CHEMBL1530089 & 688759 & 5.55 & 5.24 & TRN & \\
\hline CHEMBL1391459 & 688759 & 4.7 & 4.5813 & TRN & \\
\hline CHEMBL1409219 & 688759 & 5.8 & 5.4428 & TRN & \\
\hline CHEMBL1583174 & 688759 & 4.45 & 4.8103 & TST & \\
\hline CHEMBL1578300 & 688759 & 6.05 & 5.8972 & TRN & \\
\hline CHEMBL1511627 & 688759 & 4.45 & 4.6797 & TRN & \\
\hline CHEMBL1447882 & 688759 & 5.35 & 4.9661 & TRN & \\
\hline CHEMBL1467896 & 688759 & 4.9 & 5.1015 & TRN & \\
\hline CHEMBL1351876 & 688759 & 4.8 & 5.0292 & TRN & \\
\hline CHEMBL1460877 & 688759 & 4.75 & 4.6767 & TRN & \\
\hline CHEMBL1333411 & 688759 & 4.45 & 4.9422 & TRN & \\
\hline CHEMBL1493661 & 688759 & 4.6 & 4.6614 & TST & \\
\hline CHEMBL1347688 & 688759 & 4.95 & 4.6435 & TST & \\
\hline CHEMBL1312037 & 688759 & 4.45 & 4.9079 & TST & \\
\hline CHEMBL1459454 & 688759 & 4.45 & 4.908 & TRN & \\
\hline CHEMBL1546037 & 688759 & 6.25 & 4.9202 & TRN & \\
\hline CHEMBL1578467 & 688759 & 4.45 & 5.012 & TST & \\
\hline CHEMBL1350245 & 688759 & 4.45 & 4.8392 & TRN & \\
\hline CHEMBL 1487212 & 688759 & 4.45 & 4.8674 & TST & \\
\hline CHEMBL366814 & 688759 & 5.2 & 4.9012 & TRN & \\
\hline CHEMBL1503598 & 688759 & 6.05 & 4.941 & TST & \\
\hline CHEMBL1610219 & 688759 & 5.65 & 5.5358 & TST & \\
\hline CHEMBL1393319 & 688759 & 6.25 & 5.9272 & TRN & \\
\hline CHEMBL3192873 & 688759 & 5.4 & 5.5215 & TRN & \\
\hline CHEMBL1320646 & 688759 & 4.65 & 5.1444 & TRN & \\
\hline CHEMBL1427146 & 688759 & 6.0 & 4.9954 & TST & \\
\hline CHEMBL1403894 & 688759 & 8.301 & 5.1696 & TST & \\
\hline CHEMBL1412104 & 688759 & 4.55 & 4.6195 & TRN & \\
\hline CHEMBL1303463 & 688759 & 5.1 & 4.6043 & TRN & \\
\hline CHEMBL1362785 & 688759 & 4.5 & 4.7238 & TST & \\
\hline CHEMBL1388619 & 688759 & 4.95 & 4.9408 & TRN & \\
\hline CHEMBL1306666 & 688759 & 6.9 & 6.6645 & TRN & \\
\hline CHEMBL1487182 & 688759 & 4.65 & 5.0672 & TRN & \\
\hline CHEMBL1421654 & 688759 & 4.6 & 4.6757 & TST & \\
\hline CHEMBL1507613 & 688759 & 4.6 & 5.0376 & TRN & \\
\hline
\end{tabular}




\begin{tabular}{|c|c|c|c|c|}
\hline \multicolumn{5}{|c|}{ Supplemental Table S2.txt } \\
\hline CHEMBL3193485 & 688759 & 5.0 & 4.586 & TRN \\
\hline CHEMBL580955 & 688759 & 5.55 & 5.614 & TRN \\
\hline CHEMBL1585660 & 688759 & 4.9 & 5.0841 & TST \\
\hline CHEMBL1423419 & 688759 & 4.45 & 4.7523 & TST \\
\hline CHEMBL1308492 & 688759 & 4.65 & 4.6786 & TST \\
\hline CHEMBL1584130 & 688759 & 5.5 & 5.3058 & TRN \\
\hline CHEMBL1450947 & 688759 & 6.0 & 4.7931 & TRN \\
\hline CHEMBL1564959 & 688759 & 4.65 & 4.7065 & TRN \\
\hline CHEMBL1570247 & 688759 & 4.45 & 4.7846 & TRN \\
\hline CHEMBL1560643 & 688759 & 4.7 & 4.7652 & TST \\
\hline CHEMBL1560446 & 688759 & 5.35 & 5.763 & TRN \\
\hline CHEMBL1547690 & 688759 & 4.45 & 4.5402 & TRN \\
\hline CHEMBL1353314 & 688759 & 4.95 & 4.8649 & TRN \\
\hline CHEMBL1457623 & 688759 & 4.95 & 4.7386 & TST \\
\hline CHEMBL3197941 & 688759 & 5.5 & 5.0726 & TRN \\
\hline CHEMBL1449916 & 688759 & 5.7 & 5.5805 & TRN \\
\hline CHEMBL1606010 & 688759 & 4.75 & 4.9607 & TST \\
\hline CHEMBL1502208 & 688759 & 4.45 & 4.9371 & TRN \\
\hline CHEMBL1387666 & 688759 & 4.65 & 4.4423 & TRN \\
\hline CHEMBL1974563 & 688759 & 5.9 & 5.8473 & TRN \\
\hline CHEMBL1501206 & 688759 & 4.45 & 4.8227 & TRN \\
\hline CHEMBL1323364 & 688759 & 4.45 & 4.7349 & TST \\
\hline CHEMBL1415950 & 688759 & 4.75 & 4.8347 & TRN \\
\hline CHEMBL1601865 & 688759 & 4.65 & 4.6609 & TST \\
\hline CHEMBL1422720 & 688759 & 5.35 & 4.9404 & TRN \\
\hline CHEMBL530499 & 688759 & 6.3 & 5.9057 & TRN \\
\hline CHEMBL1302988 & 688759 & 4.55 & 4.5802 & TST \\
\hline CHEMBL1508153 & 688759 & 4.95 & 4.7773 & TRN \\
\hline CHEMBL1558181 & 688759 & 5.75 & 5.5155 & TRN \\
\hline CHEMBL1557403 & 688759 & 5.35 & 4.8453 & TST \\
\hline CHEMBL1568243 & 688759 & 5.05 & 4.8013 & TRN \\
\hline CHEMBL1526409 & 688759 & 4.45 & 4.6596 & TRN \\
\hline CHEMBL1371134 & 688759 & 5.7 & 4.8481 & TST \\
\hline CHEMBL1464848 & 688759 & 4.9 & 4.8482 & TRN \\
\hline CHEMBL1979243 & 688759 & 4.8 & 5.266 & TRN \\
\hline CHEMBL1517469 & 688759 & 5.65 & 4.8599 & TRN \\
\hline CHEMBL1339659 & 688759 & 4.45 & 4.8142 & TRN \\
\hline CHEMBL1607384 & 688759 & 4.45 & 4.8405 & TRN \\
\hline CHEMBL3210871 & 688759 & 4.45 & 4.9956 & TRN \\
\hline CHEMBL1581957 & 688759 & 4.45 & 4.9562 & TRN \\
\hline CHEMBL1309248 & 688759 & 6.25 & 6.1631 & TRN \\
\hline CHEMBL1309107 & 688759 & 4.45 & 4.6613 & TST \\
\hline CHEMBL1472246 & 688759 & 6.15 & 4.9673 & TRN \\
\hline CHEMBL1415997 & 688759 & 4.6 & 4.6034 & TRN \\
\hline CHEMBL1458579 & 688759 & 4.65 & 4.8068 & TRN \\
\hline CHEMBL1534710 & 688759 & 4.45 & 4.6263 & TRN \\
\hline CHEMBL1606246 & 688759 & 4.85 & 4.8885 & TRN \\
\hline CHEMBL1312031 & 688759 & 5.15 & 5.0041 & TRN \\
\hline
\end{tabular}




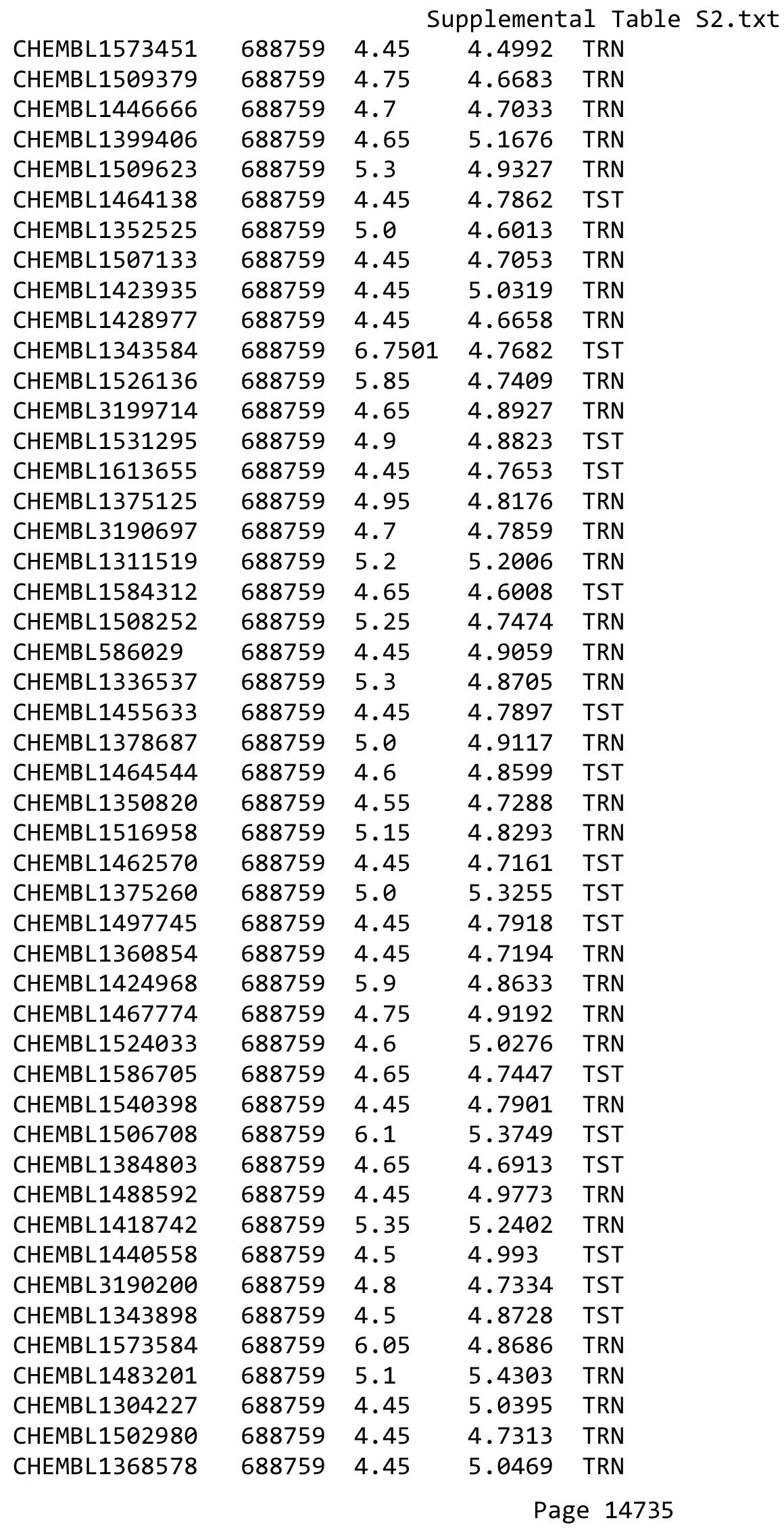




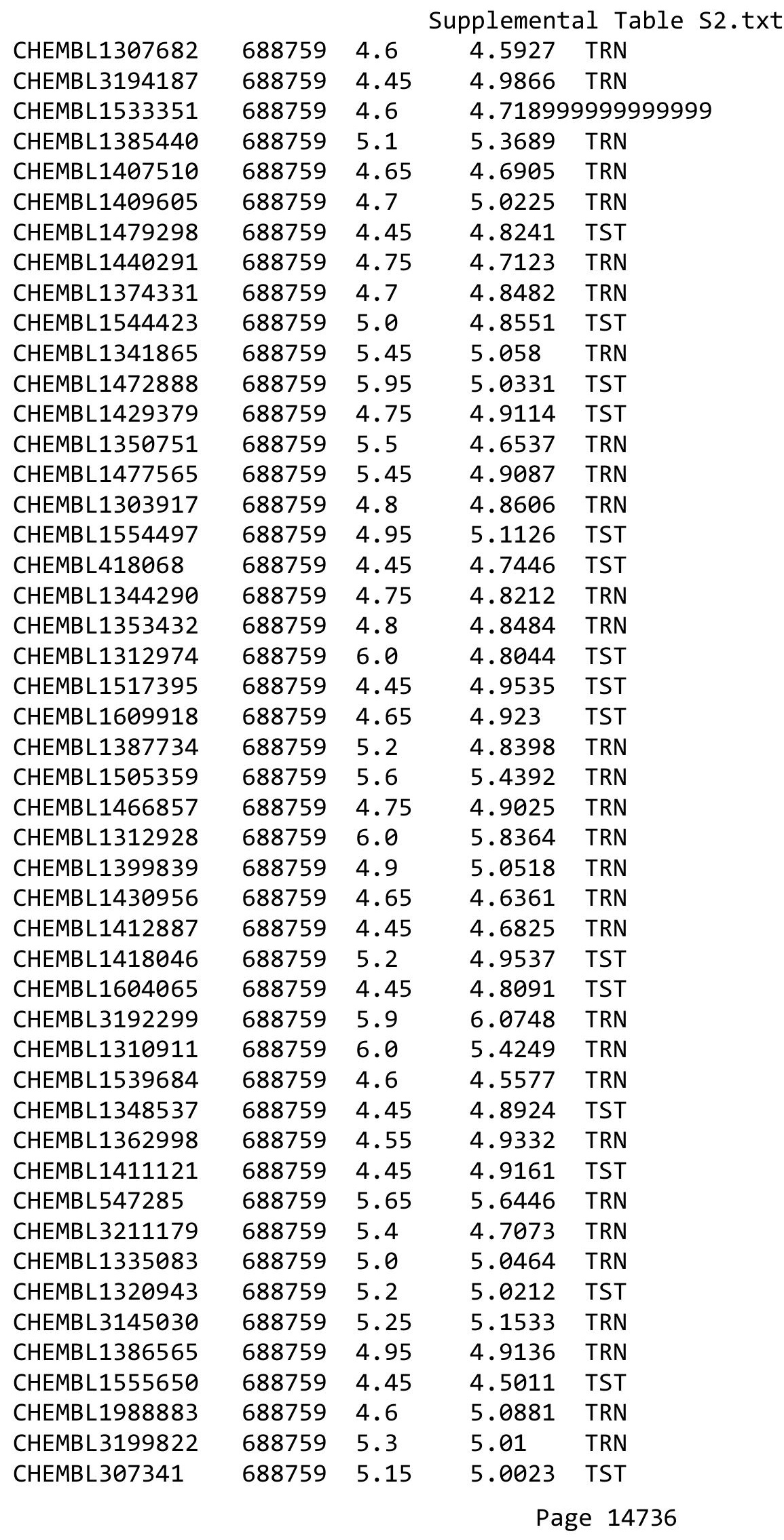




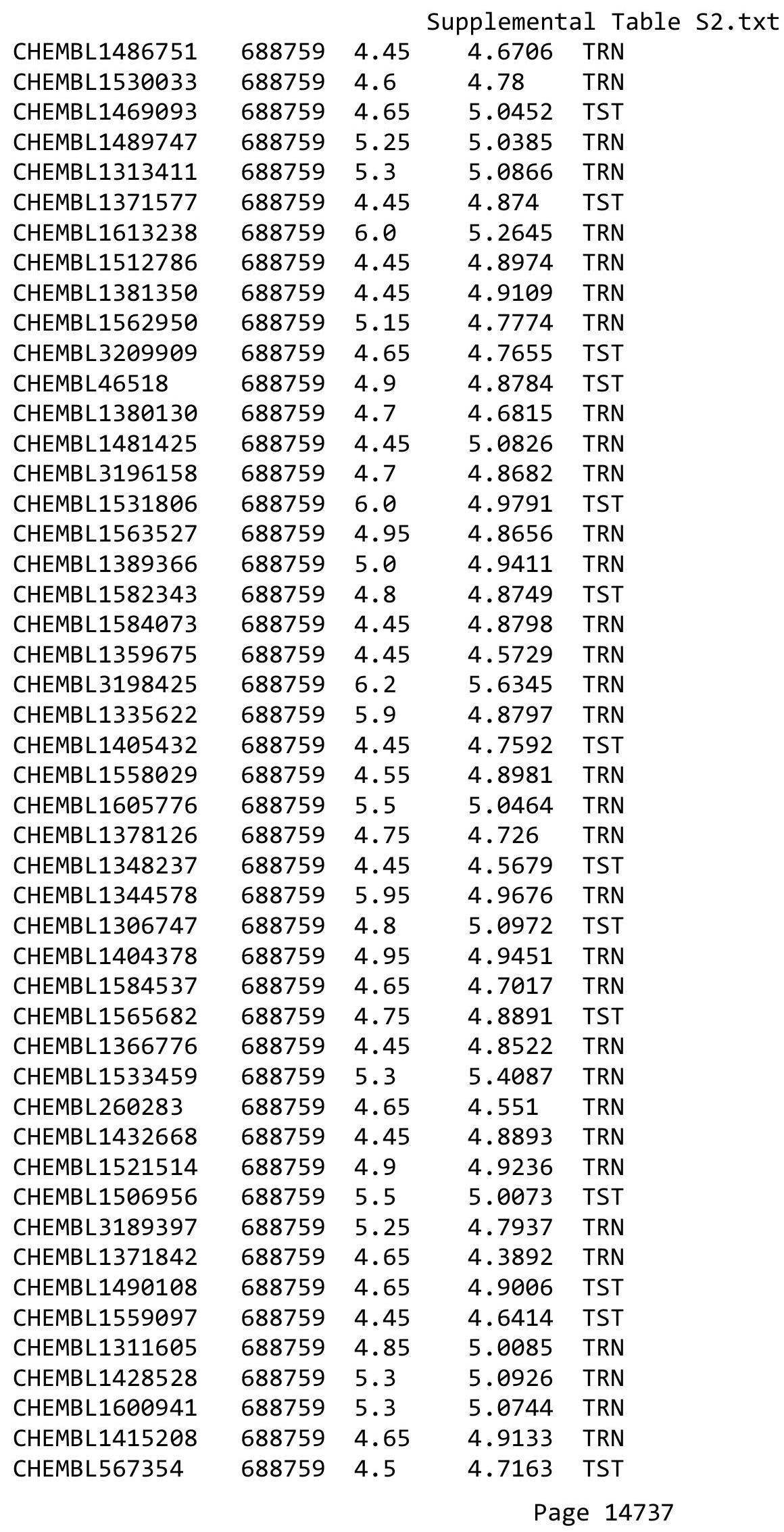




\begin{tabular}{|c|c|c|c|c|c|}
\hline \multicolumn{6}{|c|}{ Supplemental Table S2.txt } \\
\hline CHEMBL3199295 & 688759 & 5.85 & 5.2753 & TST & \\
\hline CHEMBL1544202 & 688759 & 4.95 & 4.86600 & 00000000005 & TRN \\
\hline CHEMBL1312057 & 688759 & 4.45 & 4.7978 & TRN & \\
\hline CHEMBL1388255 & 688759 & 5.1 & 5.0446 & TRN & \\
\hline CHEMBL1350824 & 688759 & 4.65 & 4.6006 & TRN & \\
\hline CHEMBL1583082 & 688759 & 4.95 & 5.1421 & TRN & \\
\hline CHEMBL1399311 & 688759 & 4.55 & 4.9272 & TST & \\
\hline CHEMBL1594807 & 688759 & 4.8 & 5.0659 & TRN & \\
\hline CHEMBL1564808 & 688759 & 5.45 & 4.9421 & TRN & \\
\hline CHEMBL1453773 & 688759 & 4.45 & 4.7581 & TRN & \\
\hline CHEMBL1566145 & 688759 & 5.55 & 5.2322 & TRN & \\
\hline CHEMBL1374945 & 688759 & 4.8 & 4.6757 & TST & \\
\hline CHEMBL1480700 & 688759 & 5.55 & 5.1162 & TST & \\
\hline CHEMBL1420176 & 688759 & 4.65 & 4.7533 & TST & \\
\hline CHEMBL1487420 & 688759 & 4.95 & 4.9343 & TST & \\
\hline CHEMBL1527612 & 688759 & 4.95 & 4.9792 & TRN & \\
\hline CHEMBL1346575 & 688759 & 4.8 & 5.17899 & 9999999999 & TRN \\
\hline CHEMBL1548624 & 688759 & 4.7 & 4.806 & TRN & \\
\hline CHEMBL3198683 & 688759 & 5.35 & 5.1543 & TRN & \\
\hline CHEMBL1544472 & 688759 & 5.0 & 4.6933 & TRN & \\
\hline CHEMBL1414151 & 688759 & 4.65 & 4.5261 & TRN & \\
\hline CHEMBL3198941 & 688759 & 4.6 & 4.7721 & TRN & \\
\hline CHEMBL1507815 & 688759 & 4.45 & 4.7461 & TRN & \\
\hline CHEMBL1486111 & 688759 & 5.0 & 5.2358 & TRN & \\
\hline CHEMBL1370817 & 688759 & 4.85 & 4.7807 & TST & \\
\hline CHEMBL1530735 & 688759 & 5.1 & 4.8353 & TRN & \\
\hline CHEMBL1531180 & 688759 & 4.45 & 4.5727 & TRN & \\
\hline CHEMBL1348654 & 688759 & 4.45 & 4.8592 & TRN & \\
\hline CHEMBL603156 & 688759 & 6.0 & 5.3613 & TST & \\
\hline CHEMBL1311391 & 688759 & 5.0 & 5.0526 & TRN & \\
\hline CHEMBL3192284 & 688759 & 5.45 & 5.2229 & TRN & \\
\hline CHEMBL1340513 & 688759 & 4.45 & 4.5902 & TRN & \\
\hline CHEMBL1565496 & 688759 & 4.75 & 4.5659 & TST & \\
\hline CHEMBL1534610 & 688759 & 5.1 & 4.9907 & TST & \\
\hline CHEMBL1537373 & 688759 & 5.25 & 4.8166 & TST & \\
\hline CHEMBL1462940 & 688759 & 5.15 & 4.9838 & TST & \\
\hline CHEMBL1609325 & 688759 & 5.6 & 5.0926 & TST & \\
\hline CHEMBL1353886 & 688759 & 4.6 & 4.7515 & TRN & \\
\hline CHEMBL106525 & 688759 & 5.0 & 4.8093 & TRN & \\
\hline CHEMBL1987078 & 688759 & 4.45 & 4.7726 & TRN & \\
\hline CHEMBL1450071 & 688759 & 5.0 & 4.8571 & TRN & \\
\hline CHEMBL1413252 & 688759 & 4.6 & 4.7935 & TST & \\
\hline CHEMBL1549240 & 688759 & 4.9 & 4.6636 & TST & \\
\hline CHEMBL3213317 & 688759 & 4.9 & 4.8904 & TRN & \\
\hline CHEMBL269477 & 688759 & 5.4 & 4.9671 & TRN & \\
\hline CHEMBL3198953 & 688759 & 4.95 & 4.9479 & TRN & \\
\hline CHEMBL1528547 & 688759 & 4.55 & 4.5762 & TRN & \\
\hline CHEMBL1601905 & 688759 & 5.4 & 4.8646 & TST & \\
\hline
\end{tabular}




\begin{tabular}{|c|c|c|c|c|c|}
\hline \multicolumn{6}{|c|}{ Supplemental Table S2.txt } \\
\hline CHEMBL1567660 & 688759 & 5.25 & 5.1704 & TST & \\
\hline CHEMBL1518824 & 688759 & 4.45 & 4.71 & TRN & \\
\hline CHEMBL1344242 & 688759 & 4.45 & 4.83899 & 99999999995 & TRN \\
\hline CHEMBL1487493 & 688759 & 5.15 & 4.8525 & TST & \\
\hline CHEMBL1989467 & 688759 & 4.45 & 4.7276 & TRN & \\
\hline CHEMBL1519931 & 688759 & 5.0 & 4.8207 & TST & \\
\hline CHEMBL1366812 & 688759 & 5.35 & 5.45 & TRN & \\
\hline CHEMBL1405895 & 688759 & 5.05 & 4.8471 & TST & \\
\hline CHEMBL1334169 & 688759 & 4.5 & 4.7995 & TRN & \\
\hline CHEMBL1497854 & 688759 & 4.6 & 4.7336 & TRN & \\
\hline CHEMBL1299667 & 688759 & 5.05 & 4.7634 & TRN & \\
\hline CHEMBL1305747 & 688759 & 4.45 & 4.7324 & TRN & \\
\hline CHEMBL1606370 & 688759 & 5.6 & 4.7374 & TRN & \\
\hline CHEMBL1599257 & 688759 & 4.7 & 4.8735 & TST & \\
\hline CHEMBL 2006511 & 688759 & 4.45 & 4.9527 & TST & \\
\hline CHEMBL1575766 & 688759 & 4.95 & 4.7502 & TRN & \\
\hline CHEMBL1458286 & 688759 & 4.45 & 4.586 & TST & \\
\hline CHEMBL1440084 & 688759 & 4.45 & 4.6422 & TRN & \\
\hline CHEMBL1438566 & 688759 & 5.05 & 5.3499 & TRN & \\
\hline CHEMBL1409101 & 688759 & 4.45 & 4.9926 & TRN & \\
\hline CHEMBL1705518 & 688759 & 4.65 & 4.7683 & TRN & \\
\hline CHEMBL1455896 & 688759 & 5.1 & 5.0156 & TST & \\
\hline CHEMBL1970965 & 688759 & 4.45 & 4.6905 & TRN & \\
\hline CHEMBL1566744 & 688759 & 4.65 & 4.7604 & TRN & \\
\hline CHEMBL1426119 & 688759 & 4.9 & 4.5776 & TST & \\
\hline CHEMBL1522566 & 688759 & 5.05 & 5.0661 & TRN & \\
\hline CHEMBL1494433 & 688759 & 5.05 & 5.0928 & TRN & \\
\hline CHEMBL1500889 & 688759 & 4.9 & 5.0292 & TRN & \\
\hline CHEMBL1459539 & 688759 & 4.45 & 4.7483 & TRN & \\
\hline CHEMBL1612230 & 688759 & 4.45 & 4.7401 & TRN & \\
\hline CHEMBL1341870 & 688759 & 4.95 & 5.0292 & TRN & \\
\hline CHEMBL 3195216 & 688759 & 4.5 & 4.8471 & TST & \\
\hline CHEMBL1449995 & 688759 & 4.45 & 4.7111 & TRN & \\
\hline CHEMBL3208054 & 688759 & 6.05 & 4.94600 & 0000000001 & TRN \\
\hline CHEMBL581870 & 688759 & 4.9 & 4.3771 & TST & \\
\hline CHEMBL3209594 & 688759 & 4.45 & 4.5876 & TRN & \\
\hline CHEMBL1511589 & 688759 & 4.6 & 5.0432 & TRN & \\
\hline CHEMBL563503 & 688759 & 4.45 & 5.0158 & TST & \\
\hline CHEMBL1522915 & 688759 & 4.45 & 4.8356 & TST & \\
\hline CHEMBL 3190868 & 688759 & 5.25 & 5.1506 & TRN & \\
\hline CHEMBL1308604 & 688759 & 4.45 & 4.9693 & TRN & \\
\hline CHEMBL1553700 & 688759 & 5.2 & 4.8781 & TST & \\
\hline CHEMBL1546440 & 688759 & 6.25 & 5.9595 & TRN & \\
\hline CHEMBL1557619 & 688759 & 5.2 & 5.1655 & TRN & \\
\hline CHEMBL1486739 & 688759 & 5.45 & 5.3108 & TRN & \\
\hline CHEMBL3198492 & 688759 & 5.15 & 5.1714 & TST & \\
\hline CHEMBL1492392 & 688759 & 5.2 & 4.9622 & TRN & \\
\hline CHEMBL1461593 & 688759 & 5.95 & 5.4268 & TRN & \\
\hline
\end{tabular}




\begin{tabular}{|c|c|c|c|c|}
\hline \multicolumn{5}{|c|}{ Supplemental Table } \\
\hline CHEMBL1383646 & 688759 & 5.35 & 5.3991 & TRN \\
\hline CHEMBL1528581 & 688759 & 5.25 & 4.7952 & TRN \\
\hline CHEMBL1474989 & 688759 & 4.45 & 4.765 & TRN \\
\hline CHEMBL1380762 & 688759 & 4.45 & 4.7889 & TRN \\
\hline CHEMBL1481794 & 688759 & 5.2 & 4.9015 & TRN \\
\hline CHEMBL1567899 & 688759 & 4.9 & 5.2373 & TRN \\
\hline CHEMBL485690 & 688759 & 6.1 & 4.8856 & TRN \\
\hline CHEMBL1360331 & 688759 & 4.45 & 4.5722 & TRN \\
\hline CHEMBL1531172 & 688759 & 4.45 & 4.9211 & TRN \\
\hline CHEMBL1541693 & 688759 & 4.55 & 4.5888 & TRN \\
\hline CHEMBL1446385 & 688759 & 5.25 & 4.8086 & TST \\
\hline CHEMBL1364270 & 688759 & 5.6 & 4.8547 & TRN \\
\hline CHEMBL1438256 & 688759 & 5.25 & 5.0258 & TRN \\
\hline CHEMBL1348765 & 688759 & 5.45 & 5.0496 & TST \\
\hline CHEMBL1580322 & 688759 & 4.6 & 4.7881 & TRN \\
\hline CHEMBL1407580 & 688759 & 4.45 & 4.8441 & TRN \\
\hline CHEMBL1475029 & 688759 & 5.8 & 5.0593 & TST \\
\hline CHEMBL1579568 & 688759 & 4.75 & 4.9913 & TST \\
\hline CHEMBL1412213 & 688759 & 5.0 & 4.6037 & TST \\
\hline CHEMBL3196840 & 688759 & 4.45 & 4.8371 & TRN \\
\hline CHEMBL1300211 & 688759 & 5.95 & 5.3591 & TRN \\
\hline CHEMBL1329658 & 688759 & 4.45 & 4.6566 & TRN \\
\hline CHEMBL1462381 & 688759 & 5.0 & 5.0296 & TRN \\
\hline CHEMBL1300587 & 688759 & 5.25 & 4.8912 & TST \\
\hline CHEMBL1424822 & 688759 & 5.15 & 4.8747 & TST \\
\hline CHEMBL1364933 & 688759 & 4.45 & 4.8762 & TRN \\
\hline CHEMBL1313487 & 688759 & 4.45 & 4.5595 & TST \\
\hline CHEMBL1486653 & 688759 & 4.45 & 4.6798 & TRN \\
\hline CHEMBL1562986 & 688759 & 6.0 & 5.8506 & TRN \\
\hline CHEMBL1472067 & 688759 & 4.95 & 5.0106 & TST \\
\hline CHEMBL1336823 & 688759 & 5.2 & 5.1393 & TST \\
\hline CHEMBL1388947 & 688759 & 4.85 & 4.8996 & TRN \\
\hline CHEMBL1527043 & 688759 & 5.4 & 4.9549 & TRN \\
\hline CHEMBL1556606 & 688759 & 4.45 & 4.7197 & TRN \\
\hline CHEMBL1411316 & 688759 & 4.45 & 4.7725 & TRN \\
\hline CHEMBL3193922 & 688759 & 5.3 & 4.9694 & TRN \\
\hline CHEMBL 1425446 & 688759 & 5.55 & 5.2829 & TST \\
\hline CHEMBL1459202 & 688759 & 5.9 & 5.5305 & TRN \\
\hline CHEMBL1581005 & 688759 & 5.15 & 5.1987 & TRN \\
\hline CHEMBL1313520 & 688759 & 5.2 & 6.1803 & TRN \\
\hline CHEMBL1302941 & 688759 & 5.0 & 4.8073 & TRN \\
\hline CHEMBL1491340 & 688759 & 6.0 & 5.4798 & TRN \\
\hline CHEMBL1540170 & 688759 & 5.0 & 4.8908 & TRN \\
\hline CHEMBL3191526 & 688759 & 5.5 & 4.9287 & TST \\
\hline CHEMBL1440790 & 688759 & 5.95 & 5.3545 & TRN \\
\hline CHEMBL1308062 & 688759 & 5.1 & 5.1791 & TRN \\
\hline CHEMBL1383585 & 688759 & 5.75 & 5.2771 & TRN \\
\hline CHEMBL1589454 & 688759 & 4.65 & 4.8187 & TRN \\
\hline
\end{tabular}




\begin{tabular}{|c|c|c|c|c|c|}
\hline \multicolumn{6}{|c|}{ Supplemental Table S2.txt } \\
\hline CHEMBL 38832 & 688759 & 4.45 & 4.5959 & TST & \\
\hline CHEMBL 3190045 & 688759 & 4.5 & 4.8318 & TST & \\
\hline CHEMBL1364216 & 688759 & 5.35 & 5.0799 & TST & \\
\hline CHEMBL1503520 & 688759 & 4.6 & 4.426 & TRN & \\
\hline CHEMBL1455767 & 688759 & 4.45 & 5.042 & TRN & \\
\hline CHEMBL1321246 & 688759 & 4.45 & 4.6613 & TRN & \\
\hline CHEMBL1520494 & 688759 & 4.45 & 4.6012 & TRN & \\
\hline CHEMBL1524583 & 688759 & 4.65 & 4.8628 & TST & \\
\hline CHEMBL1498825 & 688759 & 4.45 & 4.891 & TRN & \\
\hline CHEMBL1481987 & 688759 & 5.45 & 4.8378 & TST & \\
\hline CHEMBL1563223 & 688759 & 4.95 & 5.1017 & TRN & \\
\hline CHEMBL1408583 & 688759 & 6.15 & 5.1068 & TST & \\
\hline CHEMBL1346885 & 688759 & 4.45 & 4.7717 & TRN & \\
\hline CHEMBL 2000992 & 688759 & 5.0 & 4.8697 & TST & \\
\hline CHEMBL1449500 & 688759 & 4.9 & 5.2985 & TRN & \\
\hline CHEMBL3199889 & 688759 & 4.45 & 4.7984 & TRN & \\
\hline CHEMBL1562112 & 688759 & 4.85 & 4.8187 & TRN & \\
\hline CHEMBL1704074 & 688759 & 5.7 & 5.6273 & TRN & \\
\hline CHEMBL1529377 & 688759 & 4.45 & 4.5342 & TST & \\
\hline CHEMBL1312723 & 688759 & 4.45 & 4.7252 & TRN & \\
\hline CHEMBL1401819 & 688759 & 4.4 & 4.7896 & TST & \\
\hline CHEMBL1588024 & 688759 & 5.2 & 4.865 & TRN & \\
\hline CHEMBL1488320 & 688759 & 4.45 & 4.4472 & TRN & \\
\hline CHEMBL1361099 & 688759 & 4.45 & 4.8021 & TRN & \\
\hline CHEMBL1400514 & 688759 & 4.45 & 4.9691 & TRN & \\
\hline CHEMBL 3195082 & 688759 & 4.7 & 4.8406 & TRN & \\
\hline CHEMBL1383612 & 688759 & 6.0 & 5.5693 & TRN & \\
\hline CHEMBL1982025 & 688759 & 4.7 & 4.8831 & TST & \\
\hline CHEMBL1338860 & 688759 & 4.85 & 5.0775 & TST & \\
\hline CHEMBL1505809 & 688759 & 4.9 & 5.0525 & TST & \\
\hline CHEMBL1600448 & 688759 & 4.9 & 4.8335 & TRN & \\
\hline CHEMBL1361686 & 688759 & 4.6 & 4.5071 & TRN & \\
\hline CHEMBL1542642 & 688759 & 4.65 & 4.7914 & TRN & \\
\hline CHEMBL1556891 & 688759 & 4.5 & 4.9423 & TRN & \\
\hline CHEMBL1431496 & 688759 & 5.15 & 4.9547 & TRN & \\
\hline CHEMBL1426729 & 688759 & 4.45 & 4.6912 & TRN & \\
\hline CHEMBL1314582 & 688759 & 4.95 & 6.6149 & TST & \\
\hline CHEMBL1391118 & 688759 & 4.8 & 4.8315 & TST & \\
\hline CHEMBL1428009 & 688759 & 4.45 & 4.6041 & TRN & \\
\hline CHEMBL1562654 & 688759 & 4.45 & 4.7255 & TRN & \\
\hline CHEMBL1583103 & 688759 & 4.6 & 5.12200 & 0000000001 & TRN \\
\hline CHEMBL 2000380 & 688759 & 6.8 & 5.0937 & TRN & \\
\hline CHEMBL1465990 & 688759 & 5.05 & 4.7879 & TRN & \\
\hline CHEMBL1303963 & 688759 & 4.7 & 5.0206 & TRN & \\
\hline CHEMBL3211137 & 688759 & 5.9 & 4.8014 & TRN & \\
\hline CHEMBL1584810 & 688759 & 5.85 & 5.895 & TRN & \\
\hline CHEMBL1379723 & 688759 & 4.45 & 4.9406 & TRN & \\
\hline CHEMBL1537413 & 688759 & 6.8499 & 4.8439 & TST & \\
\hline
\end{tabular}




\begin{tabular}{|c|c|c|c|c|}
\hline & & & upplement & al Table S \\
\hline CHEMBL1507490 & 688759 & 5.2 & 5.0464 & TRN \\
\hline CHEMBL1382035 & 688759 & 4.5 & 4.80399 & 9999999999 \\
\hline CHEMBL1407552 & 688759 & 4.45 & 4.7168 & TST \\
\hline CHEMBL1327047 & 688759 & 4.45 & 4.8294 & TRN \\
\hline CHEMBL1342350 & 688759 & 5.35 & 4.7075 & TRN \\
\hline CHEMBL1525669 & 688759 & 4.65 & 4.606 & TRN \\
\hline CHEMBL1471369 & 688759 & 5.35 & 4.5985 & TRN \\
\hline CHEMBL1428521 & 688759 & 4.6 & 4.6765 & TRN \\
\hline CHEMBL1598715 & 688759 & 5.0 & 4.7648 & TRN \\
\hline CHEMBL1451172 & 688759 & 4.6 & 4.8453 & TRN \\
\hline CHEMBL 1470332 & 688759 & 4.8 & 4.602 & TST \\
\hline CHEMBL198918 & 688759 & 4.75 & 4.6585 & TRN \\
\hline CHEMBL3191481 & 688759 & 5.5 & 5.2513 & TRN \\
\hline CHEMBL1381509 & 688759 & 4.95 & 5.063 & TRN \\
\hline CHEMBL 1403742 & 688759 & 4.45 & 4.6468 & TRN \\
\hline CHEMBL1531268 & 688759 & 5.4 & 4.7885 & TRN \\
\hline CHEMBL1593484 & 688759 & 4.45 & 4.4946 & TRN \\
\hline CHEMBL1526080 & 688759 & 4.95 & 4.8177 & TRN \\
\hline CHEMBL1351221 & 688759 & 4.45 & 4.8611 & TRN \\
\hline CHEMBL1457608 & 688759 & 4.45 & 4.7278 & TST \\
\hline CHEMBL1557948 & 688759 & 6.1 & 4.9384 & TRN \\
\hline CHEMBL1350585 & 688759 & 5.35 & 5.3 & TRN \\
\hline CHEMBL1344416 & 688759 & 4.45 & 4.7703 & TRN \\
\hline CHEMBL1978120 & 688759 & 4.95 & 4.7728 & TRN \\
\hline CHEMBL1976810 & 688759 & 5.35 & 4.8871 & TRN \\
\hline CHEMBL1499797 & 688759 & 4.55 & 4.6043 & TRN \\
\hline CHEMBL1362856 & 688759 & 4.45 & 4.8526 & TRN \\
\hline CHEMBL1079664 & 688759 & 5.0 & 5.0401 & TRN \\
\hline CHEMBL1417778 & 688759 & 4.45 & 4.9211 & TRN \\
\hline CHEMBL1443354 & 688759 & 4.45 & 6.3811 & TST \\
\hline CHEMBL1518455 & 688759 & 4.45 & 4.7977 & TST \\
\hline CHEMBL1546832 & 688759 & 4.45 & 4.7185 & TRN \\
\hline CHEMBL1347924 & 688759 & 5.55 & 5.5931 & TRN \\
\hline CHEMBL1479139 & 688759 & 4.45 & 4.8453 & TRN \\
\hline CHEMBL1483733 & 688759 & 4.8 & 4.8022 & TST \\
\hline CHEMBL1438758 & 688759 & 4.9 & 4.7929 & TRN \\
\hline CHEMBL1576073 & 688759 & 5.0 & 4.9491 & TRN \\
\hline CHEMBL1445899 & 688759 & 4.45 & 4.9184 & TST \\
\hline CHEMBL1601129 & 688759 & 4.5 & 4.8223 & TRN \\
\hline CHEMBL1376451 & 688759 & 5.25 & 4.956 & TST \\
\hline CHEMBL1308194 & 688759 & 4.45 & 4.7727 & TRN \\
\hline CHEMBL1985429 & 688759 & 5.2 & 4.8495 & TRN \\
\hline CHEMBL1457127 & 688759 & 5.9 & 4.8928 & TST \\
\hline CHEMBL3197092 & 688759 & 5.5 & 5.0588 & TST \\
\hline CHEMBL1585831 & 688759 & 4.45 & 4.9429 & TRN \\
\hline CHEMBL1323301 & 688759 & 4.8 & 4.9385 & TRN \\
\hline CHEMBL1382494 & 688759 & 4.45 & 4.8152 & TST \\
\hline CHEMBL1382649 & 688759 & 6.1 & 5.0155 & TST \\
\hline
\end{tabular}

TRN 


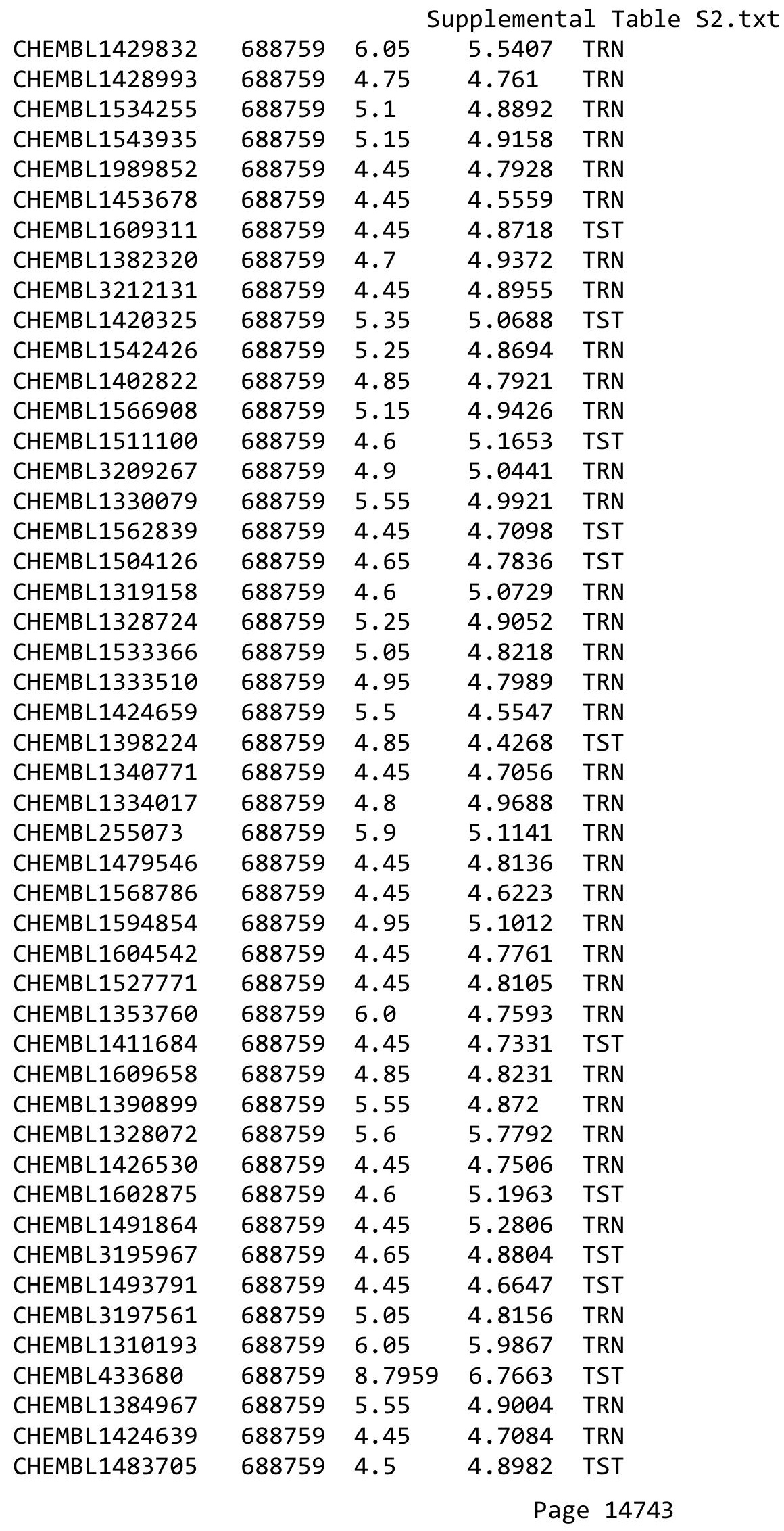




\begin{tabular}{|c|c|c|c|c|c|}
\hline \multicolumn{6}{|c|}{ Supplemental Table S2.txt } \\
\hline CHEMBL1509485 & 688759 & 4.45 & 4.7397 & TRN & \\
\hline CHEMBL1330885 & 688759 & 5.15 & 4.7381 & TST & \\
\hline CHEMBL 2006386 & 688759 & 4.9 & 4.6133 & TRN & \\
\hline CHEMBL1326813 & 688759 & 4.45 & 4.9968 & TRN & \\
\hline CHEMBL1609214 & 688759 & 3.9 & 4.433 & TRN & \\
\hline CHEMBL3197902 & 688759 & 5.25 & 5.4288 & TRN & \\
\hline CHEMBL1304868 & 688759 & 4.9 & 5.0811 & TRN & \\
\hline CHEMBL1527502 & 688759 & 4.95 & 4.9811 & TRN & \\
\hline CHEMBL3208621 & 688759 & 5.05 & 4.916 & TRN & \\
\hline CHEMBL1443347 & 688759 & 4.95 & 4.9421 & TST & \\
\hline CHEMBL1470047 & 688759 & 4.5 & 4.8465 & TRN & \\
\hline CHEMBL3198080 & 688759 & 5.25 & 5.2086 & TRN & \\
\hline CHEMBL1546905 & 688759 & 5.0 & 5.0752 & TRN & \\
\hline CHEMBL1392791 & 688759 & 4.45 & 5.3258 & TRN & \\
\hline CHEMBL528506 & 688759 & 4.7 & 4.7693 & TRN & \\
\hline CHEMBL1366670 & 688759 & 4.65 & 4.9701 & TRN & \\
\hline CHEMBL1497287 & 688759 & 4.45 & 5.4128 & TRN & \\
\hline CHEMBL1459502 & 688759 & 5.15 & 4.9485 & TRN & \\
\hline CHEMBL1373090 & 688759 & 5.5 & 4.9083 & TRN & \\
\hline CHEMBL1383793 & 688759 & 6.0 & 4.751 & TRN & \\
\hline CHEMBL1340385 & 688759 & 5.35 & 5.4552 & TRN & \\
\hline CHEMBL1477663 & 688759 & 5.55 & 5.7412 & TRN & \\
\hline CHEMBL472437 & 688759 & 5.25 & 5.3162 & TST & \\
\hline CHEMBL1538330 & 688759 & 4.45 & 4.51399 & э999999999 & TRN \\
\hline CHEMBL1425572 & 688759 & 5.0 & 4.9839 & TST & \\
\hline CHEMBL1312318 & 688759 & 5.35 & 5.4093 & TRN & \\
\hline CHEMBL1524904 & 688759 & 5.0 & 4.9149 & TRN & \\
\hline CHEMBL1504422 & 688759 & 4.75 & 4.8047 & TRN & \\
\hline CHEMBL1526190 & 688759 & 4.45 & 4.5413 & TRN & \\
\hline CHEMBL1486643 & 688759 & 4.9 & 4.7552 & TRN & \\
\hline CHEMBL1301707 & 688759 & 5.15 & 4.9342 & TST & \\
\hline CHEMBL1470314 & 688759 & 4.85 & 4.7438 & TRN & \\
\hline CHEMBL1597279 & 688759 & 4.65 & 4.7609 & TRN & \\
\hline CHEMBL1887153 & 688759 & 5.6 & 5.5808 & TRN & \\
\hline CHEMBL1509720 & 688759 & 5.0 & 4.7749 & TST & \\
\hline CHEMBL1375461 & 688759 & 5.2 & 5.0265 & TST & \\
\hline CHEMBL1586104 & 688759 & 4.6 & 4.5526 & TRN & \\
\hline CHEMBL1365988 & 688759 & 5.3 & 5.2399 & TRN & \\
\hline CHEMBL1569493 & 688759 & 5.25 & 5.0457 & TRN & \\
\hline CHEMBL1352235 & 688759 & 4.6 & 4.5495 & TST & \\
\hline CHEMBL1363125 & 688759 & 5.5 & 4.8837 & TRN & \\
\hline CHEMBL1414933 & 688759 & 4.9 & 5.0391 & TRN & \\
\hline CHEMBL1990959 & 688759 & 5.5 & 5.7181 & TRN & \\
\hline CHEMBL3197411 & 688759 & 6.05 & 5.3993 & TRN & \\
\hline CHEMBL1540477 & 688759 & 4.6 & 4.851 & TRN & \\
\hline CHEMBL1585733 & 688759 & 5.1 & 5.1513 & TRN & \\
\hline CHEMBL1520656 & 688759 & 6.95 & 4.7507 & TRN & \\
\hline CHEMBL1399492 & 688759 & 5.35 & 5.1256 & TRN & \\
\hline
\end{tabular}




\begin{tabular}{|c|c|c|c|c|}
\hline \multicolumn{5}{|c|}{ Supplemental Table S2.txt } \\
\hline CHEMBL1379286 & 688759 & 5.2 & 4.9707 & TRN \\
\hline CHEMBL1428861 & 688759 & 5.25 & 4.6965 & TRN \\
\hline CHEMBL3199129 & 688759 & 4.5 & 4.8604 & TST \\
\hline CHEMBL1610224 & 688759 & 4.9 & 4.869 & TRN \\
\hline CHEMBL3190597 & 688759 & 5.05 & 4.984 & TRN \\
\hline CHEMBL1455905 & 688759 & 4.8 & 4.8002 & TRN \\
\hline CHEMBL1328442 & 688759 & 4.7 & 4.7868 & TRN \\
\hline CHEMBL1377809 & 688759 & 4.45 & 4.8979 & TRN \\
\hline CHEMBL1562637 & 688759 & 4.8 & 4.8615 & TRN \\
\hline CHEMBL1363219 & 688759 & 5.3 & 5.191 & TRN \\
\hline CHEMBL1510453 & 688759 & 4.5 & 4.7831 & TST \\
\hline CHEMBL1359806 & 688759 & 4.6 & 5.0472 & TST \\
\hline CHEMBL1463707 & 688759 & 4.45 & 4.9699 & TST \\
\hline CHEMBL600895 & 688759 & 4.45 & 4.886 & TRN \\
\hline CHEMBL3145316 & 688759 & 4.9 & 4.9957 & TRN \\
\hline CHEMBL1307744 & 688759 & 4.45 & 4.8211 & TST \\
\hline CHEMBL1485571 & 688759 & 4.6 & 4.8011 & TRN \\
\hline CHEMBL1352981 & 688759 & 4.55 & 4.7365 & TRN \\
\hline CHEMBL1351581 & 688759 & 4.9 & 4.6231 & TST \\
\hline CHEMBL1511184 & 688759 & 4.8 & 4.9152 & TST \\
\hline CHEMBL1558571 & 688759 & 4.45 & 4.8202 & TST \\
\hline CHEMBL1574187 & 688759 & 4.45 & 4.973 & TST \\
\hline CHEMBL1541438 & 688759 & 4.65 & 5.006 & TRN \\
\hline CHEMBL1595033 & 688759 & 4.5 & 4.8165 & TRN \\
\hline CHEMBL3209430 & 688759 & 4.45 & 4.5686 & TRN \\
\hline CHEMBL1305654 & 688759 & 4.45 & 4.5702 & TRN \\
\hline CHEMBL1547271 & 688759 & 5.5 & 5.0465 & TRN \\
\hline CHEMBL1328707 & 688759 & 5.3 & 5.5154 & TRN \\
\hline CHEMBL1383549 & 688759 & 4.45 & 4.638 & TRN \\
\hline CHEMBL1331465 & 688759 & 4.45 & 4.8109 & TRN \\
\hline CHEMBL1965713 & 688759 & 5.3 & 4.8679 & TST \\
\hline CHEMBL1597245 & 688759 & 5.25 & 5.1767 & TRN \\
\hline CHEMBL1351871 & 688759 & 4.65 & 4.8008 & TRN \\
\hline CHEMBL1300729 & 688759 & 6.6499 & 6.1491 & TRN \\
\hline CHEMBL1462913 & 688759 & 4.45 & 4.8033 & TST \\
\hline CHEMBL1470089 & 688759 & 4.75 & 4.6258 & TST \\
\hline CHEMBL1420051 & 688759 & 5.95 & 5.7726 & TRN \\
\hline CHEMBL3197435 & 688759 & 4.75 & 5.1721 & TRN \\
\hline CHEMBL1340021 & 688759 & 4.9 & 4.8683 & TST \\
\hline CHEMBL3193897 & 688759 & 4.45 & 4.6406 & TRN \\
\hline CHEMBL1359982 & 688759 & 4.7 & 4.9534 & TRN \\
\hline CHEMBL1426042 & 688759 & 4.8 & 4.9299 & TRN \\
\hline CHEMBL1504370 & 688759 & 5.2 & 5.2177 & TRN \\
\hline CHEMBL1300355 & 688759 & 4.45 & 4.9641 & TRN \\
\hline CHEMBL1328771 & 688759 & 4.45 & 4.8179 & TRN \\
\hline CHEMBL1412093 & 688759 & 5.4 & 5.1275 & TRN \\
\hline CHEMBL1551065 & 688759 & 5.0 & 4.8583 & TST \\
\hline CHEMBL448620 & 688759 & 4.45 & 4.5895 & TST \\
\hline
\end{tabular}




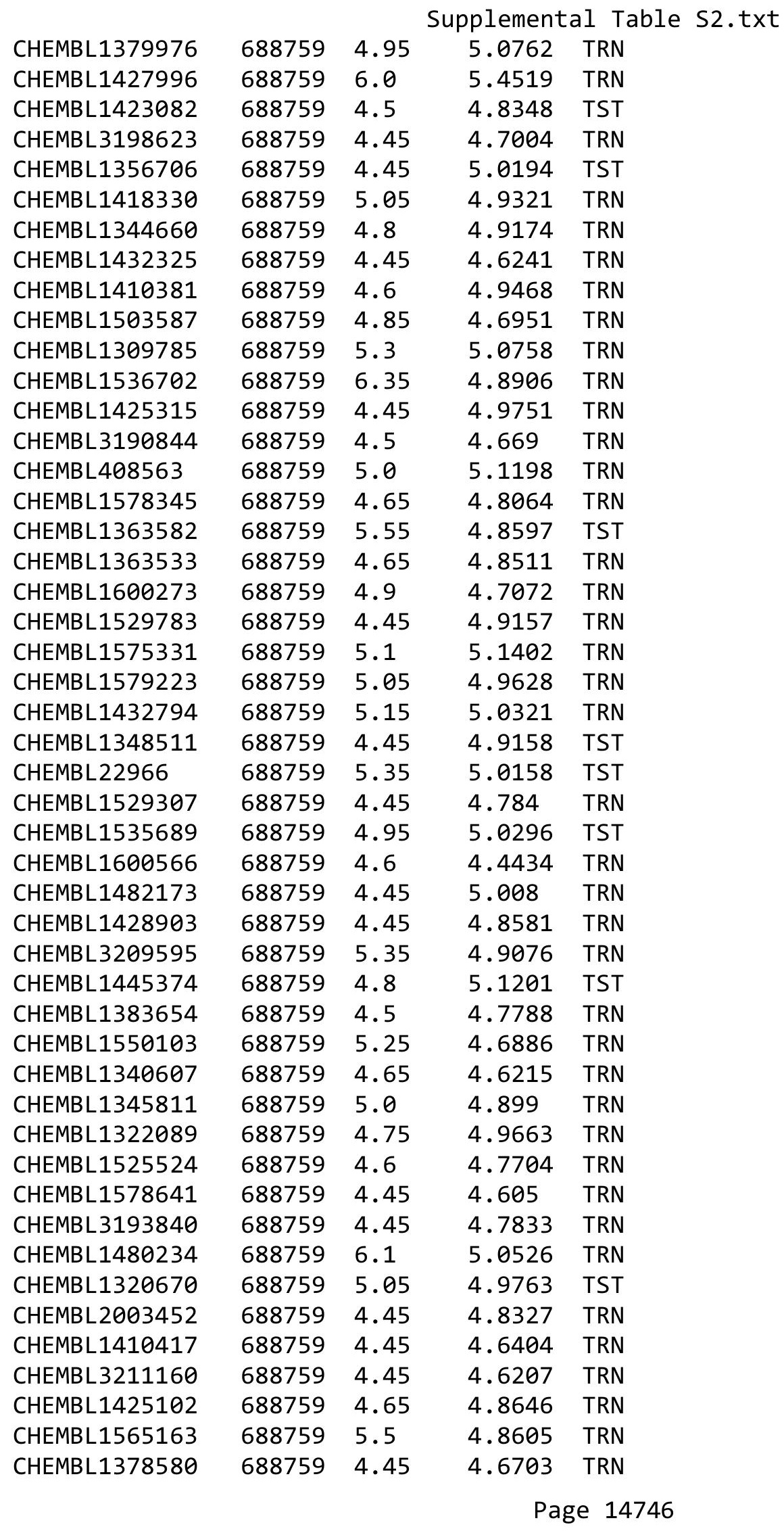




\begin{tabular}{|c|c|c|c|c|}
\hline \multicolumn{5}{|c|}{ Supplemental Table S2.txt } \\
\hline CHEMBL1609696 & 688759 & 4.65 & 4.402 & TRN \\
\hline CHEMBL1340894 & 688759 & 5.3 & 4.8936 & TST \\
\hline CHEMBL1569923 & 688759 & 4.7 & 5.2696 & TRN \\
\hline CHEMBL1403484 & 688759 & 6.25 & 5.0882 & TST \\
\hline CHEMBL1311023 & 688759 & 4.45 & 4.9812 & TST \\
\hline CHEMBL1430358 & 688759 & 4.45 & 4.8477 & TST \\
\hline CHEMBL1407002 & 688759 & 4.45 & 4.6681 & TST \\
\hline CHEMBL 3214230 & 688759 & 4.45 & 4.8782 & TRN \\
\hline CHEMBL1581030 & 688759 & 4.45 & 4.891 & TRN \\
\hline CHEMBL1503386 & 688759 & 5.4 & 5.415 & TRN \\
\hline CHEMBL1558102 & 688759 & 4.45 & 4.8771 & TRN \\
\hline CHEMBL1386689 & 688759 & 5.0 & 5.2199 & TRN \\
\hline CHEMBL1587613 & 688759 & 5.25 & 4.8431 & TRN \\
\hline CHEMBL1423377 & 688759 & 5.05 & 5.2006 & TRN \\
\hline CHEMBL1469391 & 688759 & 5.3 & 4.7555 & TST \\
\hline CHEMBL1510709 & 688759 & 4.45 & 5.2907 & TRN \\
\hline CHEMBL1354208 & 688759 & 4.9 & 4.5983 & TRN \\
\hline CHEMBL 3193080 & 688759 & 4.9 & 4.9026 & TRN \\
\hline CHEMBL1406051 & 688759 & 6.95 & 5.9941 & TRN \\
\hline CHEMBL1468720 & 688759 & 6.35 & 5.0158 & TRN \\
\hline CHEMBL1562359 & 688759 & 4.45 & 4.9915 & TRN \\
\hline CHEMBL1464927 & 688759 & 4.95 & 4.8223 & TRN \\
\hline CHEMBL1560607 & 688759 & 4.85 & 4.8561 & TRN \\
\hline CHEMBL 3199628 & 688759 & 4.95 & 5.039 & TRN \\
\hline CHEMBL1387092 & 688759 & 8.301 & 5.1233 & TRN \\
\hline CHEMBL3213007 & 688759 & 4.45 & 4.721 & TRN \\
\hline CHEMBL1341741 & 688759 & 4.9 & 4.6602 & TRN \\
\hline CHEMBL1607429 & 688759 & 4.85 & 5.1318 & TRN \\
\hline CHEMBL1448670 & 688759 & 5.6 & 5.0263 & TST \\
\hline CHEMBL564979 & 688759 & 4.45 & 4.6702 & TRN \\
\hline CHEMBL1490287 & 688759 & 5.2 & 5.0064 & TRN \\
\hline CHEMBL1370989 & 688759 & 4.45 & 4.8963 & TST \\
\hline CHEMBL1495592 & 688759 & 6.0 & 4.7991 & TST \\
\hline CHEMBL1540682 & 688759 & 6.1 & 5.3823 & TRN \\
\hline CHEMBL1324273 & 688759 & 4.65 & 4.8717 & TRN \\
\hline CHEMBL 2003602 & 688759 & 5.3 & 5.0106 & TRN \\
\hline CHEMBL1974032 & 688759 & 4.45 & 4.862 & TST \\
\hline CHEMBL1537920 & 688759 & 4.45 & 4.5084 & TRN \\
\hline CHEMBL1379804 & 688759 & 4.45 & 4.7517 & TRN \\
\hline CHEMBL1345241 & 688759 & 4.45 & 4.7887 & TST \\
\hline CHEMBL1484182 & 688759 & 4.8 & 5.2035 & TRN \\
\hline CHEMBL1388928 & 688759 & 5.0 & 5.0573 & TRN \\
\hline CHEMBL1459417 & 688759 & 4.95 & 5.0265 & TST \\
\hline CHEMBL581886 & 688759 & 8.0 & 6.1382 & TRN \\
\hline CHEMBL1602831 & 688759 & 4.95 & 4.7284 & TRN \\
\hline CHEMBL1538225 & 688759 & 4.45 & 4.8346 & TRN \\
\hline CHEMBL1448965 & 688759 & 5.4 & 5.0681 & TRN \\
\hline CHEMBL1509691 & 688759 & 5.95 & 5.9337 & TRN \\
\hline
\end{tabular}




\begin{tabular}{|c|c|c|c|c|c|}
\hline & & \multicolumn{4}{|c|}{ Supplemental Table S2.txt } \\
\hline CHEMBL1522119 & 688759 & 5.05 & 4.9326 & TST & \\
\hline CHEMBL1550291 & 688759 & 4.45 & 4.8199 & TRN & \\
\hline CHEMBL1302170 & 688759 & 4.65 & 4.641 & TST & \\
\hline CHEMBL1333144 & 688759 & 4.95 & 4.5825 & TRN & \\
\hline CHEMBL1310951 & 688759 & 4.45 & 4.7613 & TRN & \\
\hline CHEMBL1375943 & 688759 & 4.45 & 4.8369 & TRN & \\
\hline CHEMBL1559988 & 688759 & 4.45 & 5.0654 & TRN & \\
\hline CHEMBL1447930 & 688759 & 5.55 & 4.9588 & TRN & \\
\hline CHEMBL1335610 & 688759 & 5.05 & 4.9694 & TRN & \\
\hline CHEMBL1591647 & 688759 & 5.7 & 5.4735 & TRN & \\
\hline CHEMBL1613518 & 688759 & 4.45 & 4.8691 & TST & \\
\hline CHEMBL1501718 & 688759 & 4.45 & 4.6427 & TRN & \\
\hline CHEMBL1569725 & 688759 & 4.45 & 4.8592 & TST & \\
\hline CHEMBL1368088 & 688759 & 5.15 & 5.0184 & TRN & \\
\hline CHEMBL3210600 & 688759 & 4.45 & 4.7042 & TRN & \\
\hline CHEMBL145897 & 688759 & 5.9 & 5.3335 & TRN & \\
\hline CHEMBL1382036 & 688759 & 4.6 & 4.5871 & TRN & \\
\hline CHEMBL3191307 & 688759 & 5.1 & 5.0858 & TRN & \\
\hline CHEMBL1533632 & 688759 & 4.45 & 4.784 & TRN & \\
\hline CHEMBL1502512 & 688759 & 4.45 & 4.8237 & TST & \\
\hline CHEMBL 2005411 & 688759 & 4.45 & 5.181 & TRN & \\
\hline CHEMBL3199008 & 688759 & 4.9 & 5.13200 & 0000000001 & TRN \\
\hline CHEMBL1369604 & 688759 & 5.35 & 4.8797 & TST & \\
\hline CHEMBL1508551 & 688759 & 4.45 & 4.9981 & TST & \\
\hline CHEMBL1445757 & 688759 & 4.65 & 4.9576 & TST & \\
\hline CHEMBL1380493 & 688759 & 4.6 & 4.4368 & TRN & \\
\hline CHEMBL1428882 & 688759 & 4.45 & 4.9462 & TRN & \\
\hline CHEMBL1380670 & 688759 & 4.95 & 4.8203 & TRN & \\
\hline CHEMBL1964868 & 688759 & 4.9 & 4.9661 & TST & \\
\hline CHEMBL 3194336 & 688759 & 5.25 & 5.2533 & TST & \\
\hline CHEMBL 3207461 & 688759 & 4.45 & 4.8463 & TST & \\
\hline CHEMBL1429300 & 688759 & 6.0 & 4.7695 & TRN & \\
\hline CHEMBL1327351 & 688759 & 4.65 & 4.6064 & TRN & \\
\hline CHEMBL 3195232 & 688759 & 5.05 & 4.4712 & TRN & \\
\hline CHEMBL 3195273 & 688759 & 5.55 & 5.3053 & TRN & \\
\hline CHEMBL1456984 & 688759 & 6.15 & 5.0748 & TRN & \\
\hline CHEMBL1508930 & 688759 & 4.6 & 5.0633 & TST & \\
\hline CHEMBL1978327 & 688759 & 4.95 & 4.9976 & TRN & \\
\hline CHEMBL1452321 & 688759 & 4.7 & 4.7798 & TST & \\
\hline CHEMBL1565635 & 688759 & 4.45 & 4.8322 & TRN & \\
\hline CHEMBL3191765 & 688759 & 4.95 & 4.8117 & TST & \\
\hline CHEMBL3196241 & 688759 & 5.65 & 5.7618 & TRN & \\
\hline CHEMBL1332801 & 688759 & 4.65 & 4.7631 & TRN & \\
\hline CHEMBL1545516 & 688759 & 4.45 & 4.7952 & TST & \\
\hline CHEMBL1610129 & 688759 & 4.45 & 5.1583 & TST & \\
\hline CHEMBL1542861 & 688759 & 5.45 & 5.0216 & TRN & \\
\hline CHEMBL1332550 & 688759 & 4.65 & 5.0024 & TST & \\
\hline CHEMBL1418530 & 688759 & 4.85 & 4.8951 & TRN & \\
\hline
\end{tabular}




\begin{tabular}{|c|c|c|c|c|c|}
\hline \multicolumn{6}{|c|}{ Supplemental Table s2.txt } \\
\hline CHEMBL3190203 & 688759 & 5.4 & 5.4454 & TRN & \\
\hline CHEMBL3199599 & 688759 & 4.8 & 4.9702 & TRN & \\
\hline CHEMBL1518396 & 688759 & 4.95 & 5.2475 & TRN & \\
\hline CHEMBL 3212848 & 688759 & 4.7 & 4.9773 & TST & \\
\hline CHEMBL1385763 & 688759 & 4.45 & 4.9614 & TRN & \\
\hline CHEMBL1610344 & 688759 & 4.45 & 4.8718 & TRN & \\
\hline CHEMBL1382232 & 688759 & 4.75 & 4.9835 & TRN & \\
\hline CHEMBL1463112 & 688759 & 6.7001 & 4.8351 & TRN & \\
\hline CHEMBL1561469 & 688759 & 4.7 & 4.4404 & TRN & \\
\hline CHEMBL1608526 & 688759 & 4.45 & 4.8595 & TRN & \\
\hline CHEMBL1562664 & 688759 & 5.85 & 5.2774 & TRN & \\
\hline CHEMBL1320060 & 688759 & 4.65 & 4.9668 & TRN & \\
\hline CHEMBL1444294 & 688759 & 4.45 & 4.57600 & 00000000005 & TRN \\
\hline CHEMBL1325381 & 688759 & 5.0 & 5.1213 & TRN & \\
\hline CHEMBL1456015 & 688759 & 4.8 & 4.8424 & TRN & \\
\hline CHEMBL1390252 & 688759 & 4.55 & 4.7298 & TRN & \\
\hline CHEMBL1602997 & 688759 & 4.45 & 4.7338 & TRN & \\
\hline CHEMBL187349 & 688759 & 4.6 & 4.9461 & TRN & \\
\hline CHEMBL1432884 & 688759 & 4.45 & 4.7326 & TRN & \\
\hline CHEMBL1544629 & 688759 & 5.05 & 5.1098 & TRN & \\
\hline CHEMBL1473934 & 688759 & 4.55 & 4.8912 & TRN & \\
\hline CHEMBL1374744 & 688759 & 5.65 & 4.833 & TRN & \\
\hline CHEMBL3189997 & 688759 & 4.6 & 5.1793 & TST & \\
\hline CHEMBL1306281 & 688759 & 4.45 & 4.7429 & TRN & \\
\hline CHEMBL1478589 & 688759 & 4.6 & 4.7002 & TST & \\
\hline CHEMBL1331076 & 688759 & 5.7 & 5.2864 & TRN & \\
\hline CHEMBL1366821 & 688759 & 4.45 & 4.942 & TST & \\
\hline CHEMBL1335042 & 688759 & 5.3 & 4.8032 & TRN & \\
\hline CHEMBL1422136 & 688759 & 5.0 & 4.978 & TRN & \\
\hline CHEMBL1337641 & 688759 & 6.45 & 4.9522 & TST & \\
\hline CHEMBL3189804 & 688759 & 4.45 & 4.7473 & TRN & \\
\hline CHEMBL3193095 & 688759 & 4.7 & 4.5659 & TRN & \\
\hline CHEMBL3195399 & 688759 & 4.45 & 4.8584 & TRN & \\
\hline CHEMBL3190678 & 688759 & 4.95 & 5.0971 & TRN & \\
\hline CHEMBL3199536 & 688759 & 5.2 & 5.2775 & TRN & \\
\hline CHEMBL1604286 & 688759 & 4.95 & 5.0523 & TST & \\
\hline CHEMBL1552181 & 688759 & 4.45 & 5.0736 & TRN & \\
\hline CHEMBL1305174 & 688759 & 6.0 & 5.8024 & TRN & \\
\hline CHEMBL1535022 & 688759 & 4.45 & 4.5358 & TRN & \\
\hline CHEMBL1535921 & 688759 & 4.8 & 5.2322 & TRN & \\
\hline CHEMBL1313592 & 688759 & 5.1 & 4.7387 & TRN & \\
\hline CHEMBL1427357 & 688759 & 5.5 & 5.09399 & 9999999999 & TRN \\
\hline CHEMBL1535521 & 688759 & 4.95 & 4.7487 & TRN & \\
\hline CHEMBL1408101 & 688759 & 4.45 & 4.7211 & TRN & \\
\hline CHEMBL1441788 & 688759 & 4.8 & 4.6661 & TST & \\
\hline CHEMBL1995020 & 688759 & 5.25 & 5.1244 & TRN & \\
\hline CHEMBL1463211 & 688759 & 6.1 & 5.8114 & TRN & \\
\hline CHEMBL1350727 & 688759 & 4.45 & 4.6644 & TRN & \\
\hline
\end{tabular}




\begin{tabular}{|c|c|c|c|c|c|}
\hline \multicolumn{6}{|c|}{ Supplemental Table S2.txt } \\
\hline CHEMBL608673 & 688759 & 4.45 & 4.6882 & TRN & \\
\hline CHEMBL1464274 & 688759 & 5.15 & 4.95100 & 00000000005 & TRN \\
\hline CHEMBL1458196 & 688759 & 4.95 & 4.9781 & TRN & \\
\hline CHEMBL1585064 & 688759 & 5.3 & 4.7886 & TRN & \\
\hline CHEMBL3392364 & 688759 & 6.05 & 5.795 & TRN & \\
\hline CHEMBL1328161 & 688759 & 4.65 & 4.7831 & TRN & \\
\hline CHEMBL3194588 & 688759 & 4.45 & 4.7579 & TST & \\
\hline CHEMBL1492060 & 688759 & 4.45 & 4.6408 & TRN & \\
\hline CHEMBL1540680 & 688759 & 4.65 & 5.0178 & TST & \\
\hline CHEMBL1383859 & 688759 & 5.35 & 5.2037 & TRN & \\
\hline CHEMBL3209207 & 688759 & 4.9 & 4.7339 & TST & \\
\hline CHEMBL1443595 & 688759 & 4.45 & 4.9627 & TRN & \\
\hline CHEMBL1549937 & 688759 & 4.45 & 4.6801 & TRN & \\
\hline CHEMBL1492878 & 688759 & 4.6 & 4.859 & TST & \\
\hline CHEMBL1573368 & 688759 & 5.35 & 5.1316 & TRN & \\
\hline CHEMBL1559244 & 688759 & 5.5 & 4.8095 & TRN & \\
\hline CHEMBL1307496 & 688759 & 4.9 & 4.9598 & TRN & \\
\hline CHEMBL1999595 & 688759 & 4.95 & 5.0073 & TRN & \\
\hline CHEMBL1545480 & 688759 & 4.45 & 5.0988 & TRN & \\
\hline CHEMBL1472492 & 688759 & 5.15 & 4.9934 & TRN & \\
\hline CHEMBL1309174 & 688759 & 4.95 & 4.7953 & TST & \\
\hline CHEMBL1505538 & 688759 & 4.65 & 4.917 & TRN & \\
\hline CHEMBL1392808 & 688759 & 5.9 & 5.2242 & TRN & \\
\hline CHEMBL1509884 & 688759 & 5.0 & 4.9612 & TRN & \\
\hline CHEMBL1539721 & 688759 & 6.6499 & 4.9054 & TRN & \\
\hline CHEMBL512048 & 688759 & 4.95 & 5.039 & TRN & \\
\hline CHEMBL1403422 & 688759 & 4.8 & 4.90300 & 00000000005 & TRN \\
\hline CHEMBL1504253 & 688759 & 5.45 & 5.5116 & TRN & \\
\hline CHEMBL1445097 & 688759 & 4.85 & 4.8925 & TRN & \\
\hline CHEMBL1524431 & 688759 & 5.25 & 5.0334 & TRN & \\
\hline CHEMBL1466299 & 688759 & 5.0 & 5.0048 & TRN & \\
\hline CHEMBL3198748 & 688759 & 6.0 & 4.676 & TRN & \\
\hline CHEMBL1375741 & 688759 & 4.45 & 4.4757 & TRN & \\
\hline CHEMBL1603879 & 688759 & 4.55 & 4.7832 & TRN & \\
\hline CHEMBL3191757 & 688759 & 5.0 & 5.1424 & TRN & \\
\hline CHEMBL1346263 & 688759 & 4.45 & 5.2494 & TRN & \\
\hline CHEMBL1349500 & 688759 & 4.75 & 5.0939 & TRN & \\
\hline CHEMBL1613003 & 688759 & 4.9 & 4.8817 & TST & \\
\hline CHEMBL1343389 & 688759 & 4.95 & 5.1657 & TRN & \\
\hline CHEMBL1376312 & 688759 & 4.45 & 4.859 & TRN & \\
\hline CHEMBL1478236 & 688759 & 4.45 & 4.7481 & TST & \\
\hline CHEMBL1464555 & 688759 & 5.0 & 5.0574 & TRN & \\
\hline CHEMBL1407572 & 688759 & 4.75 & 4.7915 & TRN & \\
\hline CHEMBL1446691 & 688759 & 4.45 & 4.9566 & TRN & \\
\hline CHEMBL 3189578 & 688759 & 5.0 & 4.9911 & TRN & \\
\hline CHEMBL1538764 & 688759 & 5.0 & 5.1914 & TRN & \\
\hline CHEMBL1600937 & 688759 & 4.65 & 4.7804 & TRN & \\
\hline CHEMBL 264931 & 688759 & 5.7 & 5.3333 & TST & \\
\hline
\end{tabular}




\begin{tabular}{|c|c|c|c|c|c|}
\hline \multirow[b]{2}{*}{ CHEMBL1466500 } & \multirow[b]{2}{*}{688759} & \multicolumn{4}{|c|}{ Supplemental Table s2.txt } \\
\hline & & 4.45 & 4.6453 & TRN & \\
\hline CHEMBL1380201 & 688759 & 6.05 & 5.4278 & TRN & \\
\hline CHEMBL3195954 & 688759 & 4.8 & 4.8997 & TRN & \\
\hline CHEMBL1538763 & 688759 & 4.65 & 4.71 & TST & \\
\hline CHEMBL1526463 & 688759 & 5.0 & 5.1587 & TRN & \\
\hline CHEMBL1607001 & 688759 & 4.75 & 4.7147 & TRN & \\
\hline CHEMBL1548803 & 688759 & 5.25 & 5.1068 & TRN & \\
\hline CHEMBL1331656 & 688759 & 5.45 & 4.9253 & TRN & \\
\hline CHEMBL528791 & 688759 & 4.45 & 4.8453 & TRN & \\
\hline CHEMBL1350929 & 688759 & 5.35 & \multicolumn{2}{|c|}{5.327000000000001} & TRN \\
\hline CHEMBL1338805 & 688759 & 4.8 & 4.8414 & TRN & \\
\hline CHEMBL1382463 & 688759 & 5.5 & 4.6875 & TRN & \\
\hline CHEMBL1344000 & 688759 & 5.4 & 5.1902 & TRN & \\
\hline CHEMBL1453239 & 688759 & 4.45 & 4.9697 & TST & \\
\hline CHEMBL1353964 & 688759 & 5.4 & 4.8771 & TRN & \\
\hline CHEMBL1409579 & 688759 & 5.05 & 4.9874 & TRN & \\
\hline CHEMBL1351525 & 688759 & 4.8 & 4.7123 & TRN & \\
\hline CHEMBL1320956 & 688759 & 4.45 & 4.7372 & TRN & \\
\hline CHEMBL1550551 & 688759 & 4.45 & 4.931 & TRN & \\
\hline CHEMBL1556657 & 688759 & 4.95 & 4.9364 & TRN & \\
\hline CHEMBL1445590 & 688759 & 6.3 & 6.1479 & TRN & \\
\hline CHEMBL1305642 & 688759 & 4.55 & 4.559 & TST & \\
\hline CHEMBL3208862 & 688759 & 4.45 & 4.5975 & TRN & \\
\hline CHEMBL1491315 & 688759 & 4.45 & 4.9691 & TRN & \\
\hline CHEMBL1510144 & 688759 & 5.2 & 5.2727 & TRN & \\
\hline CHEMBL1534321 & 688759 & 4.45 & 4.8741 & TRN & \\
\hline CHEMBL1392092 & 688759 & 4.95 & 4.9046 & TRN & \\
\hline CHEMBL1534183 & 688759 & 4.45 & 4.8391 & TRN & \\
\hline CHEMBL1522056 & 688759 & 4.6 & \multicolumn{2}{|c|}{4.763999999999999} & TST \\
\hline CHEMBL1438908 & 688759 & 4.75 & 4.9321 & TRN & \\
\hline CHEMBL1504462 & 688759 & 4.8 & 4.8862 & TRN & \\
\hline CHEMBL1983587 & 688759 & 4.9 & 4.9025 & TRN & \\
\hline CHEMBL3392455 & 688759 & 4.95 & 5.3961 & TRN & \\
\hline CHEMBL1595277 & 688759 & 4.45 & 4.6763 & TRN & \\
\hline CHEMBL1419492 & 688759 & 5.05 & 4.6333 & TST & \\
\hline CHEMBL1370840 & 688759 & 4.65 & 5.0581 & TRN & \\
\hline CHEMBL3210330 & 688759 & 4.95 & 4.7596 & TRN & \\
\hline CHEMBL1492357 & 688759 & 4.65 & 4.9177 & TRN & \\
\hline CHEMBL1602755 & 688759 & 4.85 & 4.9966 & TST & \\
\hline CHEMBL1505756 & 688759 & 5.0 & 5.092 & TRN & \\
\hline CHEMBL1343420 & 688759 & 4.45 & 4.6683 & TRN & \\
\hline CHEMBL1379227 & 688759 & 4.45 & 4.8079 & TRN & \\
\hline CHEMBL1497102 & 688759 & 4.45 & 5.2315 & TST & \\
\hline CHEMBL1468657 & 688759 & 4.45 & \multicolumn{2}{|c|}{4.696000000000001} & TRN \\
\hline CHEMBL1417479 & 688759 & 4.85 & 4.7547 & TRN & \\
\hline CHEMBL1421311 & 688759 & 4.6 & 4.6414 & TST & \\
\hline CHEMBL1409959 & 688759 & 4.7 & 4.8118 & TRN & \\
\hline \multirow[t]{2}{*}{ CHEMBL1560237 } & 688759 & 6.0 & 5.7741 & TRN & \\
\hline & & \multicolumn{4}{|c|}{ Page 14751} \\
\hline
\end{tabular}




\begin{tabular}{|c|c|c|c|c|c|}
\hline \multicolumn{6}{|c|}{ Supplemental Table S2.txt } \\
\hline CHEMBL1569944 & 688759 & 5.05 & 5.0056 & TRN & \\
\hline CHEMBL3190337 & 688759 & 5.6 & 5.18 & TRN & \\
\hline CHEMBL1358963 & 688759 & 4.45 & 4.8958 & TST & \\
\hline CHEMBL 3210375 & 688759 & 4.6 & 4.5203 & TRN & \\
\hline CHEMBL1516211 & 688759 & 4.45 & 5.2111 & TRN & \\
\hline CHEMBL1422505 & 688759 & 4.45 & 4.7098 & TRN & \\
\hline CHEMBL1236103 & 688759 & 5.85 & 5.224 & TST & \\
\hline CHEMBL1526505 & 688759 & 4.45 & 4.8232 & TRN & \\
\hline CHEMBL1327697 & 688759 & 5.0 & 4.6502 & TRN & \\
\hline CHEMBL1364282 & 688759 & 5.65 & 5.343 & TRN & \\
\hline CHEMBL1420840 & 688759 & 5.45 & 5.0033 & TST & \\
\hline CHEMBL1438681 & 688759 & 4.45 & 4.8987 & TRN & \\
\hline CHEMBL1469730 & 688759 & 4.45 & 4.9689 & TRN & \\
\hline CHEMBL1454519 & 688759 & 4.95 & 4.893 & TRN & \\
\hline CHEMBL3196936 & 688759 & 6.25 & 5.7857 & TRN & \\
\hline CHEMBL1583256 & 688759 & 4.9 & 5.1143 & TRN & \\
\hline CHEMBL1343562 & 688759 & 4.7 & 4.8539 & TRN & \\
\hline CHEMBL507264 & 688759 & 4.9 & 4.5113 & TRN & \\
\hline CHEMBL1509850 & 688759 & 4.45 & 4.8187 & TST & \\
\hline CHEMBL1994910 & 688759 & 5.45 & 5.4489 & TRN & \\
\hline CHEMBL1605045 & 688759 & 5.25 & 5.2154 & TRN & \\
\hline CHEMBL1403854 & 688759 & 4.45 & 4.518 & TRN & \\
\hline CHEMBL1500431 & 688759 & 4.95 & 4.9691 & TRN & \\
\hline CHEMBL1368793 & 688759 & 5.0 & 4.8955 & TST & \\
\hline CHEMBL1386323 & 688759 & 4.55 & 4.9942 & TRN & \\
\hline CHEMBL1332933 & 688759 & 5.2 & 4.9809 & TRN & \\
\hline CHEMBL1361167 & 688759 & 4.85 & 4.5845 & TST & \\
\hline CHEMBL1532881 & 688759 & 4.65 & 4.6646 & TRN & \\
\hline CHEMBL3191688 & 688759 & 4.5 & 4.71399 & 99999999995 & TST \\
\hline CHEMBL1332369 & 688759 & 5.3 & 4.8104 & TST & \\
\hline CHEMBL1487967 & 688759 & 5.35 & 5.1882 & TRN & \\
\hline CHEMBL1451307 & 688759 & 5.0 & 5.1199 & TRN & \\
\hline CHEMBL1401841 & 688759 & 4.65 & 4.7569 & TST & \\
\hline CHEMBL1479249 & 688759 & 5.4 & 5.2404 & TRN & \\
\hline CHEMBL1562684 & 688759 & 4.85 & 5.0861 & TRN & \\
\hline CHEMBL1385169 & 688759 & 5.7 & 4.7594 & TRN & \\
\hline CHEMBL1467288 & 688759 & 4.5 & 4.8663 & TRN & \\
\hline CHEMBL1589131 & 688759 & 4.45 & 4.8719 & TRN & \\
\hline CHEMBL1380158 & 688759 & 4.55 & 4.8488 & TRN & \\
\hline CHEMBL1321387 & 688759 & 4.45 & 4.7184 & TRN & \\
\hline CHEMBL1417112 & 688759 & 4.9 & 5.1277 & TRN & \\
\hline CHEMBL1363124 & 688759 & 4.45 & 4.5695 & TRN & \\
\hline CHEMBL1439337 & 688759 & 5.4 & 4.8709 & TRN & \\
\hline CHEMBL1361072 & 688759 & 5.0 & 4.6121 & TRN & \\
\hline CHEMBL1351549 & 688759 & 4.45 & 4.6719 & TRN & \\
\hline CHEMBL1427770 & 688759 & 4.75 & 4.9993 & TRN & \\
\hline CHEMBL1424601 & 688759 & 4.45 & 4.6809 & TRN & \\
\hline CHEMBL1343489 & 688759 & 4.45 & 4.6461 & TRN & \\
\hline
\end{tabular}




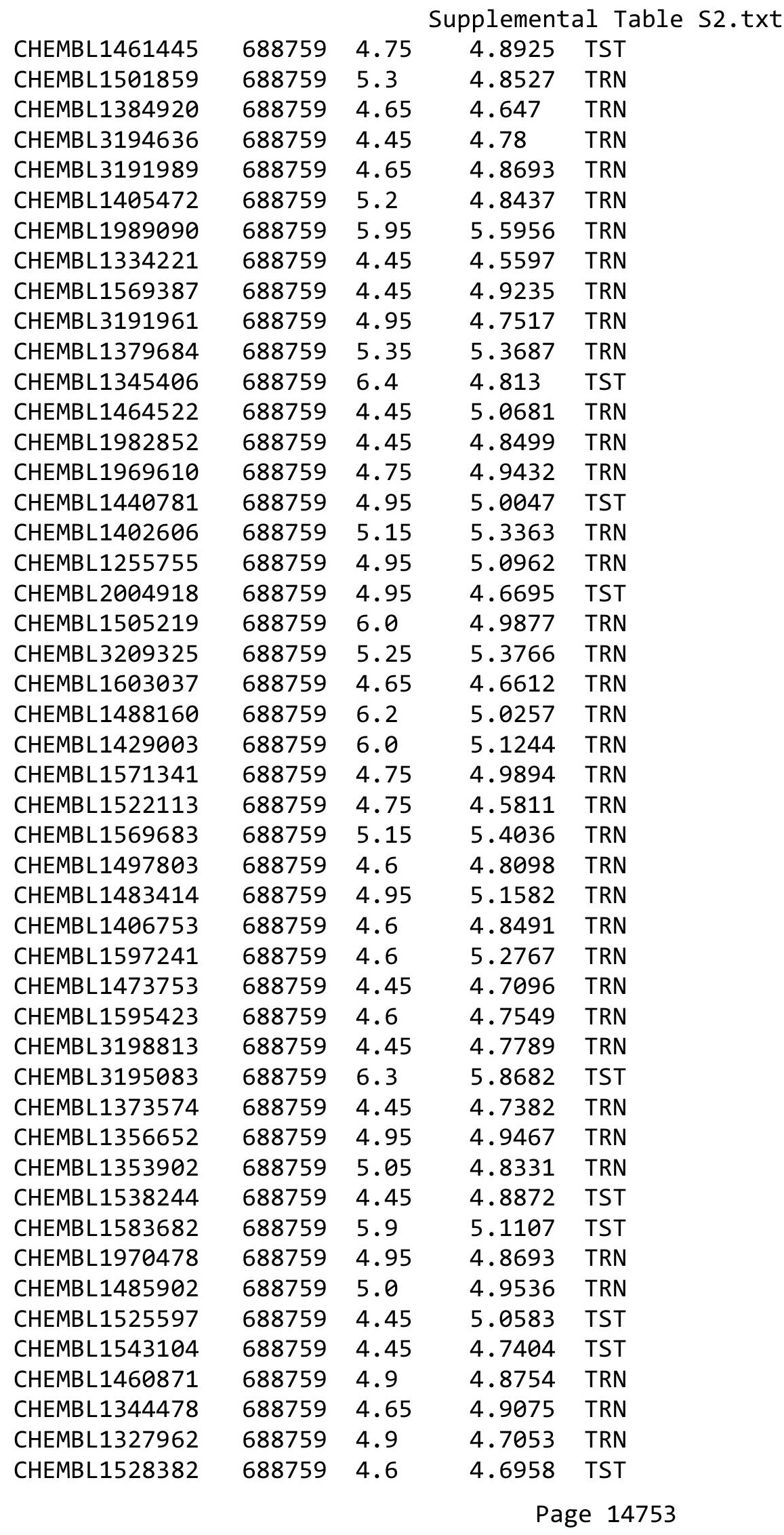




\begin{tabular}{|c|c|c|c|c|c|}
\hline \\
\hline CHEMBL1469882 & 688759 & 5.1 & 4.8877 & TRN & \\
\hline CHEMBL1484714 & 688759 & 6.4 & 4.8142 & TRN & \\
\hline CHEMBL1303619 & 688759 & 4.45 & 5.1295 & TRN & \\
\hline CHEMBL1309526 & 688759 & 5.25 & 4.819 & TST & \\
\hline CHEMBL3197681 & 688759 & 4.7 & 5.2109 & TRN & \\
\hline CHEMBL1504271 & 688759 & 4.8 & 4.8716 & TST & \\
\hline CHEMBL1597291 & 688759 & 5.4 & 4.8083 & TRN & \\
\hline CHEMBL1582067 & 688759 & 5.0 & 4.8235 & TRN & \\
\hline CHEMBL1319865 & 688759 & 5.0 & 5.0898 & TRN & \\
\hline CHEMBL1968538 & 688759 & 5.5 & 4.6718 & TST & \\
\hline CHEMBL1340792 & 688759 & 4.45 & 4.6294 & TST & \\
\hline CHEMBL1457260 & 688759 & 4.65 & 4.8642 & TST & \\
\hline CHEMBL1347706 & 688759 & 6.0 & 4.8776 & TST & \\
\hline CHEMBL1562397 & 688759 & 4.45 & 4.7826 & TRN & \\
\hline CHEMBL1518468 & 688759 & 4.45 & 4.8086 & TRN & \\
\hline CHEMBL1342811 & 688759 & 4.45 & 5.0258 & TRN & \\
\hline CHEMBL1360792 & 688759 & 5.65 & 5.0346 & TST & \\
\hline CHEMBL1570774 & 688759 & 4.8 & 4.9079 & TRN & \\
\hline CHEMBL1349967 & 688759 & 4.65 & 4.7304 & TRN & \\
\hline CHEMBL1570469 & 688759 & 5.45 & 5.1628 & TST & \\
\hline CHEMBL1344692 & 688759 & 4.45 & 4.94 & TRN & \\
\hline CHEMBL1601509 & 688759 & 5.3 & 4.9422 & TRN & \\
\hline CHEMBL1506216 & 688759 & 5.85 & 4.8987 & TRN & \\
\hline CHEMBL1511709 & 688759 & 4.45 & 4.84399 & 9999999999 & TRN \\
\hline CHEMBL1525712 & 688759 & 5.35 & 4.8829 & TRN & \\
\hline CHEMBL1418505 & 688759 & 5.4 & 5.1424 & TRN & \\
\hline CHEMBL1467025 & 688759 & 5.95 & 5.0761 & TRN & \\
\hline CHEMBL1422706 & 688759 & 5.0 & 5.2352 & TRN & \\
\hline CHEMBL3189738 & 688759 & 5.3 & 5.5884 & TRN & \\
\hline CHEMBL1566760 & 688759 & 5.15 & 4.8775 & TRN & \\
\hline CHEMBL1541260 & 688759 & 4.9 & 4.7321 & TRN & \\
\hline CHEMBL1499817 & 688759 & 5.6 & 4.835 & TST & \\
\hline CHEMBL3199756 & 688759 & 5.85 & 4.9223 & TRN & \\
\hline CHEMBL1391911 & 688759 & 4.45 & 4.5942 & TRN & \\
\hline CHEMBL1970152 & 688759 & 4.45 & 4.8982 & TRN & \\
\hline CHEMBL1559942 & 688759 & 4.55 & 4.8148 & TRN & \\
\hline CHEMBL1489433 & 688759 & 4.45 & 5.0076 & TRN & \\
\hline CHEMBL1527248 & 688759 & 4.95 & 4.8585 & TRN & \\
\hline CHEMBL1451398 & 688759 & 4.55 & 4.849 & TRN & \\
\hline CHEMBL1540377 & 688759 & 4.95 & 4.7212 & TRN & \\
\hline CHEMBL1467672 & 688759 & 5.55 & 6.0439 & TST & \\
\hline CHEMBL1464523 & 688759 & 5.7 & 4.8502 & TST & \\
\hline CHEMBL1580197 & 688759 & 5.5 & 5.4462 & TRN & \\
\hline CHEMBL1462375 & 688759 & 4.95 & 4.7616 & TRN & \\
\hline CHEMBL1573608 & 688759 & 4.95 & 4.9184 & TRN & \\
\hline CHEMBL1460676 & 688759 & 4.9 & 4.6935 & TRN & \\
\hline CHEMBL1998853 & 688759 & 4.7 & 5.3804 & TRN & \\
\hline CHEMBL1537827 & 688759 & 4.95 & 4.6025 & TRN & \\
\hline & & & & 14754 & \\
\hline
\end{tabular}




\begin{tabular}{|c|c|c|c|c|c|}
\hline \multicolumn{6}{|c|}{ Supplemental Table S2.txt } \\
\hline CHEMBL1588246 & 688759 & 4.45 & 4.7524 & TST & \\
\hline CHEMBL1301811 & 688759 & 5.05 & 4.8457 & TRN & \\
\hline CHEMBL1495271 & 688759 & 4.5 & 4.9137 & TRN & \\
\hline CHEMBL 3210407 & 688759 & 4.45 & 4.904 & TRN & \\
\hline CHEMBL1991888 & 688759 & 4.7 & 5.0842 & TRN & \\
\hline CHEMBL1987106 & 688759 & 4.95 & 4.7308 & TRN & \\
\hline CHEMBL1311406 & 688759 & 6.2 & 4.6893 & TRN & \\
\hline CHEMBL1579977 & 688759 & 4.95 & 5.1405 & TRN & \\
\hline CHEMBL1533315 & 688759 & 4.65 & 4.7285 & TRN & \\
\hline CHEMBL194594 & 688759 & 5.0 & 5.04 & TRN & \\
\hline CHEMBL1337734 & 688759 & 4.6 & 4.831 & TST & \\
\hline CHEMBL1359319 & 688759 & 4.9 & 4.9662 & TRN & \\
\hline CHEMBL1432700 & 688759 & 6.2 & 5.9833 & TRN & \\
\hline CHEMBL1339613 & 688759 & 4.45 & 4.6019 & TRN & \\
\hline CHEMBL1560769 & 688759 & 4.65 & 4.913 & TST & \\
\hline CHEMBL1378919 & 688759 & 4.45 & 4.734 & TRN & \\
\hline CHEMBL504977 & 688759 & 6.6499 & 6.40799 & 99999999995 & TRN \\
\hline CHEMBL1528149 & 688759 & 4.45 & 5.0911 & TST & \\
\hline CHEMBL1303079 & 688759 & 5.3 & 5.1575 & TST & \\
\hline CHEMBL3199006 & 688759 & 4.85 & 4.7573 & TST & \\
\hline CHEMBL1601612 & 688759 & 4.45 & 4.5866 & TRN & \\
\hline CHEMBL1494925 & 688759 & 4.45 & 4.6985 & TRN & \\
\hline CHEMBL1598781 & 688759 & 4.55 & 4.627 & TST & \\
\hline CHEMBL1483999 & 688759 & 4.6 & 4.8953 & TRN & \\
\hline CHEMBL 213896 & 688759 & 4.45 & 4.8136 & TRN & \\
\hline CHEMBL1359198 & 688759 & 5.4 & 4.8117 & TRN & \\
\hline CHEMBL228078 & 688759 & 6.0 & 5.4779 & TRN & \\
\hline CHEMBL3191780 & 688759 & 5.15 & 5.2034 & TRN & \\
\hline CHEMBL3199498 & 688759 & 4.45 & 4.896 & TST & \\
\hline CHEMBL 3208258 & 688759 & 4.45 & 4.6688 & TRN & \\
\hline CHEMBL1405447 & 688759 & 4.55 & 4.7674 & TST & \\
\hline CHEMBL1607503 & 688759 & 4.8 & 4.9861 & TST & \\
\hline CHEMBL1572555 & 688759 & 5.4 & 4.9353 & TST & \\
\hline CHEMBL1470511 & 688759 & 4.75 & 4.6837 & TRN & \\
\hline CHEMBL1601913 & 688759 & 4.7 & 4.8296 & TRN & \\
\hline CHEMBL1419114 & 688759 & 7.0 & 4.6266 & TRN & \\
\hline CHEMBL1386117 & 688759 & 4.6 & 4.7685 & TRN & \\
\hline CHEMBL3191982 & 688759 & 4.9 & 4.8873 & TST & \\
\hline CHEMBL1607304 & 688759 & 4.8 & 4.8967 & TRN & \\
\hline CHEMBL1458848 & 688759 & 6.35 & 4.9702 & TRN & \\
\hline CHEMBL1534857 & 688759 & 6.15 & 4.675 & TST & \\
\hline CHEMBL3195315 & 688759 & 4.45 & 4.7441 & TRN & \\
\hline CHEMBL1342926 & 688759 & 4.8 & 4.8223 & TST & \\
\hline CHEMBL1425552 & 688759 & 5.5 & 5.3473 & TRN & \\
\hline CHEMBL1599743 & 688759 & 5.3 & 4.651 & TRN & \\
\hline CHEMBL3194346 & 688759 & 4.45 & 4.9063 & TRN & \\
\hline CHEMBL1447770 & 688759 & 6.2 & 4.8508 & TRN & \\
\hline CHEMBL1381149 & 688759 & 4.45 & 4.6352 & TRN & \\
\hline
\end{tabular}




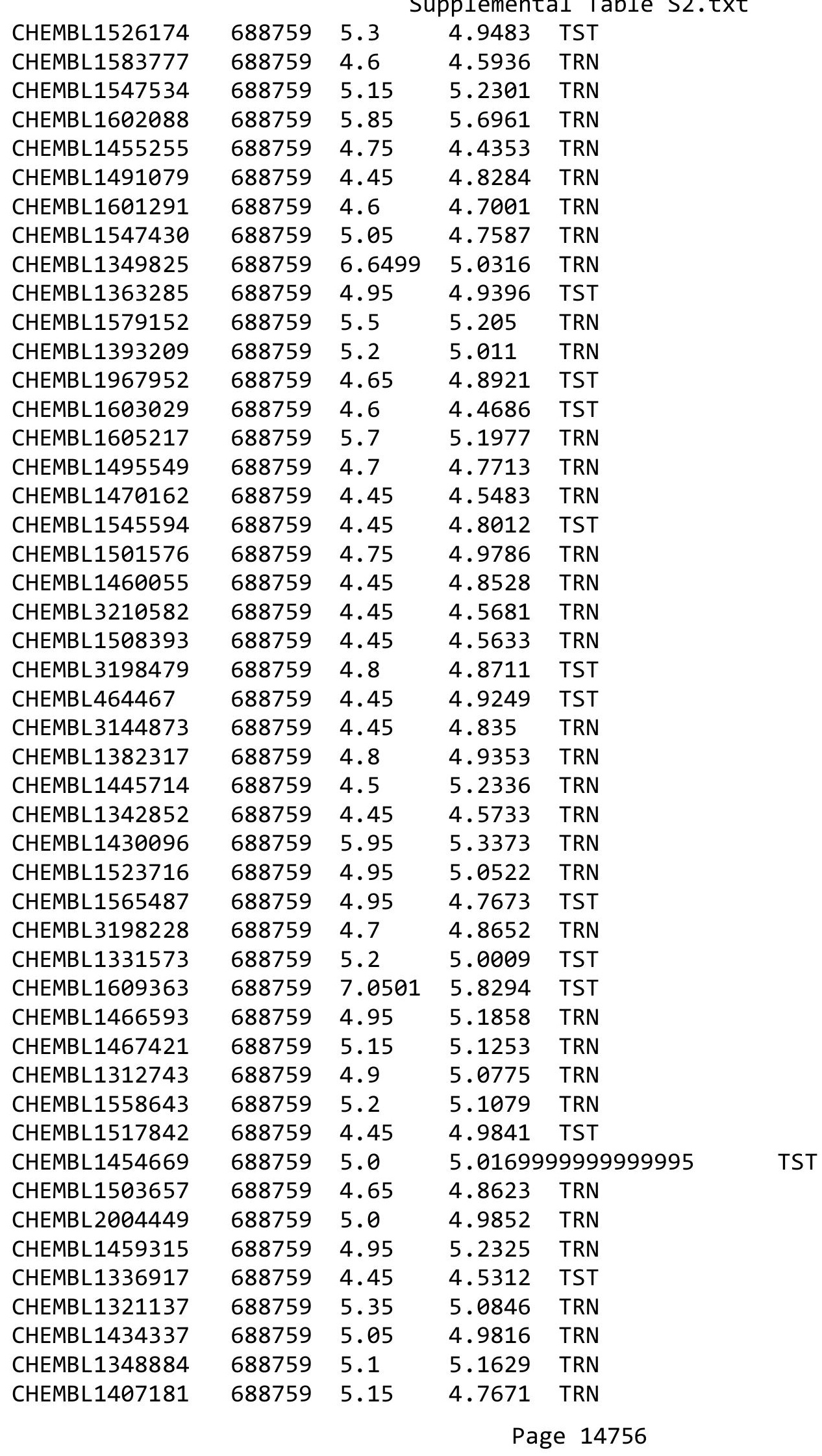




\begin{tabular}{|c|c|c|c|c|c|}
\hline \multicolumn{6}{|c|}{ Supplemental Table S2.txt } \\
\hline CHEMBL1522279 & 688759 & 4.45 & 4.9037 & TRN & \\
\hline CHEMBL1325023 & 688759 & 4.75 & 4.6921 & TRN & \\
\hline CHEMBL 2003521 & 688759 & 5.15 & 5.3561 & TRN & \\
\hline CHEMBL1345374 & 688759 & 5.35 & 5.4373 & TRN & \\
\hline CHEMBL1610719 & 688759 & 4.45 & 5.0649 & TRN & \\
\hline CHEMBL3198697 & 688759 & 4.45 & 4.8246 & TRN & \\
\hline CHEMBL1506369 & 688759 & 4.75 & 4.9525 & TRN & \\
\hline CHEMBL1352168 & 688759 & 5.15 & 4.8012 & TRN & \\
\hline CHEMBL1329279 & 688759 & 4.45 & 4.55699 & 99999999995 & TRN \\
\hline CHEMBL1449992 & 688759 & 4.45 & 4.76399 & 9999999999 & TRN \\
\hline CHEMBL1597322 & 688759 & 5.7 & 5.1829 & TST & \\
\hline CHEMBL1597459 & 688759 & 4.95 & 4.9692 & TST & \\
\hline CHEMBL1968540 & 688759 & 5.25 & 5.272 & TRN & \\
\hline CHEMBL1610300 & 688759 & 5.6 & 4.882 & TRN & \\
\hline CHEMBL1468055 & 688759 & 4.95 & 4.8412 & TRN & \\
\hline CHEMBL1486065 & 688759 & 5.6 & 4.9081 & TST & \\
\hline CHEMBL1470732 & 688759 & 5.5 & 5.0268 & TST & \\
\hline CHEMBL3192842 & 688759 & 4.45 & 4.9 & TST & \\
\hline CHEMBL1370403 & 688759 & 4.45 & 5.0605 & TRN & \\
\hline CHEMBL1389769 & 688759 & 4.75 & 4.6631 & TRN & \\
\hline CHEMBL1348813 & 688759 & 4.45 & 4.7085 & TST & \\
\hline CHEMBL1969992 & 688759 & 5.35 & 5.3656 & TRN & \\
\hline CHEMBL1334074 & 688759 & 5.3 & 5.3028 & TRN & \\
\hline CHEMBL576607 & 688759 & 4.65 & 5.4203 & TRN & \\
\hline CHEMBL 2000321 & 688759 & 5.1 & 4.9068 & TRN & \\
\hline CHEMBL1441032 & 688759 & 5.3 & 5.1746 & TRN & \\
\hline CHEMBL1606227 & 688759 & 4.65 & 4.8388 & TRN & \\
\hline CHEMBL1538093 & 688759 & 4.7 & 4.6608 & TRN & \\
\hline CHEMBL1445279 & 688759 & 5.35 & 4.7992 & TST & \\
\hline CHEMBL1496651 & 688759 & 5.0 & 4.8905 & TRN & \\
\hline CHEMBL1490989 & 688759 & 4.95 & 4.8553 & TRN & \\
\hline CHEMBL1454222 & 688759 & 5.65 & 5.0852 & TRN & \\
\hline CHEMBL3192138 & 688759 & 5.45 & 5.1258 & TRN & \\
\hline CHEMBL1328929 & 688759 & 5.0 & 4.5122 & TST & \\
\hline CHEMBL1516463 & 688759 & 4.9 & 4.8364 & TST & \\
\hline CHEMBL1496986 & 688759 & 4.7 & 4.8723 & TRN & \\
\hline CHEMBL1489223 & 688759 & 5.65 & 4.7611 & TRN & \\
\hline CHEMBL1505997 & 688759 & 5.25 & 4.7831 & TRN & \\
\hline CHEMBL1458016 & 688759 & 4.45 & 4.7886 & TRN & \\
\hline CHEMBL1463088 & 688759 & 5.5 & 5.5206 & TRN & \\
\hline CHEMBL1569904 & 688759 & 4.65 & 5.0837 & TRN & \\
\hline CHEMBL428784 & 688759 & 5.9 & 5.6217 & TST & \\
\hline CHEMBL1420725 & 688759 & 5.3 & 5.0201 & TRN & \\
\hline CHEMBL3213616 & 688759 & 4.7 & 5.0304 & TST & \\
\hline CHEMBL1603493 & 688759 & 4.65 & 4.8025 & TST & \\
\hline CHEMBL3190952 & 688759 & 5.4 & 5.0152 & TRN & \\
\hline CHEMBL1550172 & 688759 & 4.8 & 4.7962 & TRN & \\
\hline CHEMBL1472979 & 688759 & 4.65 & 5.048 & TRN & \\
\hline
\end{tabular}




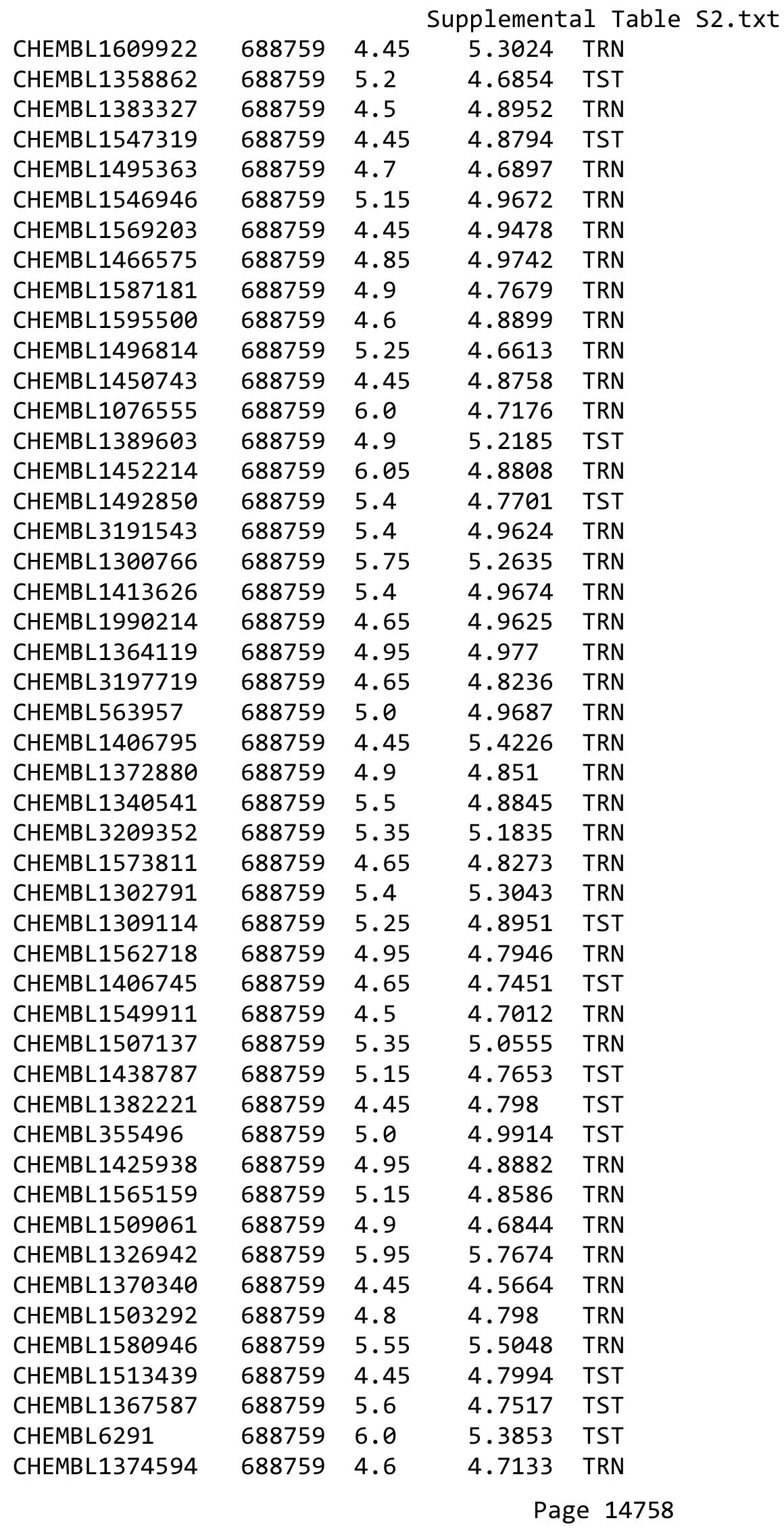




\begin{tabular}{|c|c|c|c|c|c|}
\hline & & \multicolumn{4}{|c|}{ Supplemental Table s2.txt } \\
\hline CHEMBL1573690 & 688759 & 5.25 & 4.7639 & TST & \\
\hline CHEMBL1389509 & 688759 & 4.7 & 4.6455 & TRN & \\
\hline CHEMBL1392090 & 688759 & 5.25 & 4.8187 & TRN & \\
\hline CHEMBL1425487 & 688759 & 4.95 & 4.8775 & TRN & \\
\hline CHEMBL1967256 & 688759 & 5.35 & 5.2515 & TST & \\
\hline CHEMBL1449243 & 688759 & 4.65 & 4.8903 & TRN & \\
\hline CHEMBL1374840 & 688759 & 6.15 & 5.4111 & TRN & \\
\hline CHEMBL1420271 & 688759 & 4.8 & 4.8747 & TRN & \\
\hline CHEMBL1517166 & 688759 & 4.75 & 5.0156 & TRN & \\
\hline CHEMBL1433127 & 688759 & 4.9 & 4.795 & TST & \\
\hline CHEMBL1609063 & 688759 & 5.4 & 4.9433 & TRN & \\
\hline CHEMBL1502479 & 688759 & 4.65 & 4.7553 & TST & \\
\hline CHEMBL1382277 & 688759 & 4.9 & 4.8256 & TRN & \\
\hline CHEMBL1537101 & 688759 & 5.0 & 4.8454 & TST & \\
\hline CHEMBL1608584 & 688759 & 4.95 & 4.6602 & TRN & \\
\hline CHEMBL1531383 & 688759 & 4.65 & 4.8196 & TRN & \\
\hline CHEMBL1546668 & 688759 & 4.55 & 4.9078 & TRN & \\
\hline CHEMBL1525961 & 688759 & 4.8 & 5.0996 & TRN & \\
\hline CHEMBL1487978 & 688759 & 4.75 & 4.5616 & TST & \\
\hline CHEMBL3193873 & 688759 & 5.7 & 5.3039 & TRN & \\
\hline CHEMBL3192245 & 688759 & 4.45 & 4.6963 & TRN & \\
\hline CHEMBL1316449 & 688759 & 5.35 & 5.534 & TRN & \\
\hline CHEMBL1416075 & 688759 & 4.4 & 4.9442 & TST & \\
\hline CHEMBL1373503 & 688759 & 4.95 & 4.6366 & TRN & \\
\hline CHEMBL1542669 & 688759 & 4.65 & 4.6967 & TRN & \\
\hline CHEMBL1527312 & 688759 & 5.45 & 5.21399 & 99999999995 & TRN \\
\hline CHEMBL1470382 & 688759 & 4.75 & 5.7438 & TRN & \\
\hline CHEMBL587449 & 688759 & 5.45 & 4.7921 & TST & \\
\hline CHEMBL1366698 & 688759 & 4.6 & 4.8837 & TRN & \\
\hline CHEMBL1373096 & 688759 & 5.8 & 5.50799 & 9999999999 & TRN \\
\hline CHEMBL1474079 & 688759 & 5.4 & 4.9252 & TST & \\
\hline CHEMBL3199549 & 688759 & 4.9 & 4.6907 & TRN & \\
\hline CHEMBL405686 & 688759 & 4.45 & 4.8085 & TRN & \\
\hline CHEMBL3198246 & 688759 & 5.6 & 5.5001 & TRN & \\
\hline CHEMBL1352370 & 688759 & 4.65 & 4.9453 & TST & \\
\hline CHEMBL3208042 & 688759 & 4.9 & 4.5495 & TRN & \\
\hline CHEMBL1516899 & 688759 & 5.35 & 4.6467 & TST & \\
\hline CHEMBL1517141 & 688759 & 5.7 & 4.979 & TRN & \\
\hline CHEMBL3196563 & 688759 & 6.8 & 5.0211 & TRN & \\
\hline CHEMBL1495785 & 688759 & 5.25 & 5.0967 & TRN & \\
\hline CHEMBL1336373 & 688759 & 4.8 & 4.8539 & TRN & \\
\hline CHEMBL1499840 & 688759 & 4.45 & 4.7277 & TRN & \\
\hline CHEMBL1323491 & 688759 & 4.95 & 5.1842 & TRN & \\
\hline CHEMBL1347842 & 688759 & 5.15 & 5.176 & TRN & \\
\hline CHEMBL1430334 & 688759 & 5.25 & 4.8876 & TRN & \\
\hline CHEMBL1420175 & 688759 & 4.65 & 4.7063 & TRN & \\
\hline CHEMBL1446527 & 688759 & 5.0 & 4.7333 & TRN & \\
\hline CHEMBL1370701 & 688759 & 5.55 & 5.3668 & TRN & \\
\hline
\end{tabular}




\begin{tabular}{|c|c|c|c|c|}
\hline \multicolumn{5}{|c|}{ Supplemental Table S2.txt } \\
\hline CHEMBL1418843 & 688759 & 5.2 & 4.5321 & TRN \\
\hline CHEMBL1376656 & 688759 & 4.7 & 4.8244 & TRN \\
\hline CHEMBL1427929 & 688759 & 5.1 & 4.845 & TRN \\
\hline CHEMBL3194061 & 688759 & 5.35 & 5.4791 & TRN \\
\hline CHEMBL1590048 & 688759 & 4.65 & 5.2887 & TST \\
\hline CHEMBL1610772 & 688759 & 4.45 & 4.8041 & TST \\
\hline CHEMBL1387434 & 688759 & 4.45 & 4.6725 & TRN \\
\hline CHEMBL1417809 & 688759 & 4.65 & 4.9991 & TRN \\
\hline CHEMBL1379058 & 688759 & 4.65 & 4.8721 & TRN \\
\hline CHEMBL1869875 & 688759 & 6.5 & 6.2371 & TRN \\
\hline CHEMBL1573605 & 688759 & 4.45 & 4.7608 & TRN \\
\hline CHEMBL1320587 & 688759 & 4.6 & 4.5885 & TRN \\
\hline CHEMBL3191834 & 688759 & 5.2 & 5.6367 & TRN \\
\hline CHEMBL3208518 & 688759 & 4.45 & 4.8738 & TRN \\
\hline CHEMBL1481304 & 688759 & 5.4 & 4.5173 & TRN \\
\hline CHEMBL1563401 & 688759 & 4.75 & 5.0002 & TRN \\
\hline CHEMBL1542091 & 688759 & 4.9 & 5.0919 & TRN \\
\hline CHEMBL1084625 & 688759 & 4.6 & 4.9071 & TST \\
\hline CHEMBL1554760 & 688759 & 4.7 & 4.8458 & TST \\
\hline CHEMBL1448972 & 688759 & 4.65 & 4.803 & TRN \\
\hline CHEMBL1426300 & 688759 & 4.45 & 5.0456 & TRN \\
\hline CHEMBL1348925 & 688759 & 5.0 & 4.8696 & TRN \\
\hline CHEMBL1502987 & 688759 & 4.65 & 5.0739 & TRN \\
\hline CHEMBL1387605 & 688759 & 5.85 & 5.9039 & TRN \\
\hline CHEMBL1548295 & 688759 & 4.45 & 4.6908 & TRN \\
\hline CHEMBL1559027 & 688759 & 5.1 & 4.9967 & TRN \\
\hline CHEMBL1967837 & 688759 & 4.65 & 4.7221 & TRN \\
\hline CHEMBL1472304 & 688759 & 5.55 & 5.0544 & TRN \\
\hline CHEMBL1542173 & 688759 & 4.45 & 5.0471 & TRN \\
\hline CHEMBL1595976 & 688759 & 5.25 & 4.9225 & TRN \\
\hline CHEMBL1489731 & 688759 & 4.45 & 5.0626 & TRN \\
\hline CHEMBL3199269 & 688759 & 5.35 & 4.8724 & TRN \\
\hline CHEMBL1446764 & 688759 & 5.0 & 5.0323 & TST \\
\hline CHEMBL1305221 & 688759 & 4.95 & 5.0065 & TRN \\
\hline CHEMBL1587553 & 688759 & 4.5 & 4.8404 & TRN \\
\hline CHEMBL1489510 & 688759 & 4.6 & 4.7513 & TRN \\
\hline CHEMBL1311913 & 688759 & 5.65 & 5.0346 & TRN \\
\hline CHEMBL1330101 & 688759 & 4.9 & 4.6951 & TST \\
\hline CHEMBL1506397 & 688759 & 4.95 & 4.9973 & TRN \\
\hline CHEMBL1314007 & 688759 & 4.85 & 4.7982 & TST \\
\hline CHEMBL1403489 & 688759 & 5.45 & 5.0269 & TRN \\
\hline CHEMBL1521947 & 688759 & 5.45 & 4.7789 & TRN \\
\hline CHEMBL1436162 & 688759 & 4.45 & 4.835 & TST \\
\hline CHEMBL1505293 & 688759 & 4.5 & 4.9936 & TST \\
\hline CHEMBL1568835 & 688759 & 5.0 & 5.3144 & TRN \\
\hline CHEMBL1585209 & 688759 & 4.7 & 4.9947 & TRN \\
\hline CHEMBL1348179 & 688759 & 5.65 & 5.5876 & TRN \\
\hline CHEMBL1449794 & 688759 & 5.5 & 4.9647 & TRN \\
\hline
\end{tabular}




\begin{tabular}{|c|c|c|c|c|c|}
\hline & & \multicolumn{4}{|c|}{ Supplemental Table s2.txt } \\
\hline CHEMBL1579693 & 688759 & 5.45 & 5.1185 & TRN & \\
\hline CHEMBL1496641 & 688759 & 4.45 & 4.9006 & TST & \\
\hline CHEMBL1543150 & 688759 & 5.2 & 4.9994 & TRN & \\
\hline CHEMBL1326124 & 688759 & 6.0 & 5.3948 & TRN & \\
\hline CHEMBL1478966 & 688759 & 5.25 & 4.851 & TRN & \\
\hline CHEMBL1526545 & 688759 & 5.35 & 4.7808 & TRN & \\
\hline CHEMBL1389042 & 688759 & 4.45 & 4.503 & TRN & \\
\hline CHEMBL1530147 & 688759 & 4.45 & 4.4583 & TRN & \\
\hline CHEMBL1469557 & 688759 & 4.45 & 4.5195 & TRN & \\
\hline CHEMBL1385620 & 688759 & 4.85 & 4.8483 & TST & \\
\hline CHEMBL1572576 & 688759 & 5.3 & 4.8746 & TRN & \\
\hline CHEMBL1478520 & 688759 & 4.45 & 4.7114 & TRN & \\
\hline CHEMBL1599666 & 688759 & 4.65 & 4.652 & TST & \\
\hline CHEMBL3190634 & 688759 & 4.45 & 4.66100 & 00000000005 & TRN \\
\hline CHEMBL1465906 & 688759 & 4.45 & 4.773 & TST & \\
\hline CHEMBL1420563 & 688759 & 4.45 & 4.802 & TRN & \\
\hline CHEMBL1376065 & 688759 & 4.45 & 4.8041 & TRN & \\
\hline CHEMBL1563714 & 688759 & 5.35 & 5.2347 & TRN & \\
\hline CHEMBL1389446 & 688759 & 4.95 & 4.8892 & TRN & \\
\hline CHEMBL1461283 & 688759 & 4.8 & 4.4927 & TRN & \\
\hline CHEMBL1303914 & 688759 & 4.95 & 4.945 & TRN & \\
\hline CHEMBL1578922 & 688759 & 4.6 & 4.8371 & TST & \\
\hline CHEMBL1502964 & 688759 & 4.5 & 4.8567 & TRN & \\
\hline CHEMBL1352105 & 688759 & 4.7 & 5.0272 & TRN & \\
\hline CHEMBL1386407 & 688759 & 4.6 & 4.7544 & TST & \\
\hline CHEMBL1508670 & 688759 & 4.95 & 4.6214 & TRN & \\
\hline CHEMBL1429205 & 688759 & 5.1 & 5.0587 & TRN & \\
\hline CHEMBL1498509 & 688759 & 5.45 & 5.4171 & TRN & \\
\hline CHEMBL1430619 & 688759 & 4.75 & 4.7854 & TRN & \\
\hline CHEMBL1511525 & 688759 & 4.45 & 4.7611 & TRN & \\
\hline CHEMBL1442458 & 688759 & 4.45 & 4.8508 & TST & \\
\hline CHEMBL2373626 & 688759 & 4.5 & 5.0768 & TST & \\
\hline CHEMBL1538014 & 688759 & 4.5 & 4.6368 & TRN & \\
\hline CHEMBL1575557 & 688759 & 4.45 & 4.9451 & TRN & \\
\hline CHEMBL1557263 & 688759 & 4.55 & 4.6669 & TST & \\
\hline CHEMBL1499328 & 688759 & 4.55 & 4.8216 & TRN & \\
\hline CHEMBL1431985 & 688759 & 4.7 & 4.9141 & TRN & \\
\hline CHEMBL1509181 & 688759 & 5.0 & 4.7153 & TRN & \\
\hline CHEMBL1361743 & 688759 & 5.0 & 4.902 & TRN & \\
\hline CHEMBL1413364 & 688759 & 4.5 & 4.9265 & TRN & \\
\hline CHEMBL1272069 & 688759 & 5.55 & 4.7226 & TST & \\
\hline CHEMBL1299997 & 688759 & 4.65 & 4.9019 & TST & \\
\hline CHEMBL1469839 & 688759 & 4.9 & 4.5406 & TST & \\
\hline CHEMBL1493336 & 688759 & 4.45 & 5.0083 & TRN & \\
\hline CHEMBL1427736 & 688759 & 5.15 & 5.1216 & TRN & \\
\hline CHEMBL1406235 & 688759 & 4.45 & 4.6664 & TRN & \\
\hline CHEMBL1569988 & 688759 & 5.2 & 5.3956 & TRN & \\
\hline CHEMBL3196665 & 688759 & 4.45 & 5.0246 & TRN & \\
\hline
\end{tabular}




\begin{tabular}{|c|c|c|c|c|}
\hline \multicolumn{5}{|c|}{ Supplemental Table S2.txt } \\
\hline CHEMBL1599604 & 688759 & 4.5 & 4.8314 & TRN \\
\hline CHEMBL1339684 & 688759 & 4.45 & 4.5086 & TST \\
\hline CHEMBL1524542 & 688759 & 4.45 & 5.2432 & TRN \\
\hline CHEMBL3193711 & 688759 & 4.95 & 5.2713 & TST \\
\hline CHEMBL1374745 & 688759 & 4.65 & 4.8783 & TRN \\
\hline CHEMBL1985660 & 688759 & 4.65 & 4.6174 & TST \\
\hline CHEMBL1462948 & 688759 & 4.8 & 4.6539 & TRN \\
\hline CHEMBL1501376 & 688759 & 4.45 & 4.3533 & TRN \\
\hline CHEMBL1430758 & 688759 & 4.45 & 4.7424 & TRN \\
\hline CHEMBL1392611 & 688759 & 5.95 & 5.4545 & TST \\
\hline CHEMBL1584778 & 688759 & 4.45 & 4.648 & TST \\
\hline CHEMBL1452116 & 688759 & 5.6 & 5.3941 & TST \\
\hline CHEMBL1604971 & 688759 & 5.5 & 5.1362 & TST \\
\hline CHEMBL1574842 & 688759 & 4.95 & 4.904 & TST \\
\hline CHEMBL1429067 & 688759 & 4.45 & 4.9683 & TST \\
\hline CHEMBL1484482 & 688759 & 5.45 & 4.828 & TST \\
\hline CHEMBL1432280 & 688759 & 5.25 & 4.9422 & TRN \\
\hline CHEMBL1523661 & 688759 & 5.25 & 4.9921 & TST \\
\hline CHEMBL1429303 & 688759 & 5.5 & 4.5861 & TRN \\
\hline CHEMBL1586785 & 688759 & 4.85 & 4.9158 & TST \\
\hline CHEMBL1979937 & 688759 & 4.45 & 4.5267 & TRN \\
\hline CHEMBL1443976 & 688759 & 4.65 & 4.7884 & TRN \\
\hline CHEMBL1391613 & 688759 & 4.65 & 4.9736 & TST \\
\hline CHEMBL1461800 & 688759 & 4.45 & 4.9598 & TRN \\
\hline CHEMBL1708334 & 688759 & 4.45 & 4.6283 & TRN \\
\hline CHEMBL1418096 & 688759 & 4.95 & 4.7404 & TRN \\
\hline CHEMBL1391114 & 688759 & 4.45 & 4.936 & TRN \\
\hline CHEMBL1570956 & 688759 & 5.35 & 5.1973 & TRN \\
\hline CHEMBL1568334 & 688759 & 4.95 & 5.2062 & TRN \\
\hline CHEMBL1977773 & 688759 & 4.9 & 4.7887 & TRN \\
\hline CHEMBL1530086 & 688759 & 5.45 & 5.3742 & TRN \\
\hline CHEMBL1608074 & 688759 & 4.45 & 4.7752 & TRN \\
\hline CHEMBL1478020 & 688759 & 4.5 & 4.6494 & TST \\
\hline CHEMBL1978997 & 688759 & 5.95 & 5.6593 & TRN \\
\hline CHEMBL1364239 & 688759 & 4.45 & 4.8839 & TST \\
\hline CHEMBL1254288 & 688759 & 4.75 & 4.9254 & TST \\
\hline CHEMBL1521511 & 688759 & 4.45 & 4.9415 & TRN \\
\hline CHEMBL1301374 & 688759 & 4.9 & 5.2349 & TRN \\
\hline CHEMBL1321179 & 688759 & 4.7 & 4.98 & TRN \\
\hline CHEMBL1503238 & 688759 & 4.95 & 5.0197 & TRN \\
\hline CHEMBL1367292 & 688759 & 4.9 & 4.5565 & TRN \\
\hline CHEMBL1366269 & 688759 & 5.55 & 4.9688 & TRN \\
\hline CHEMBL578257 & 688759 & 5.45 & 5.3111 & TRN \\
\hline CHEMBL1377648 & 688759 & 4.65 & 4.8541 & TRN \\
\hline CHEMBL1401717 & 688759 & 5.65 & 4.8673 & TST \\
\hline CHEMBL1591263 & 688759 & 4.8 & 4.6027 & TRN \\
\hline CHEMBL1376243 & 688759 & 4.45 & 4.6749 & TRN \\
\hline CHEMBL1988546 & 688759 & 5.55 & 5.1894 & TRN \\
\hline
\end{tabular}




\begin{tabular}{|c|c|c|c|c|}
\hline \multicolumn{5}{|c|}{ Supplemental Table S2.txt } \\
\hline CHEMBL1489461 & 688759 & 4.8 & 4.6706 & TRN \\
\hline CHEMBL1327939 & 688759 & 4.9 & 4.7691 & TRN \\
\hline CHEMBL1599372 & 688759 & 5.95 & 5.6893 & TRN \\
\hline CHEMBL1430436 & 688759 & 4.45 & 4.8591 & TRN \\
\hline CHEMBL1431850 & 688759 & 4.8 & 4.9019 & TST \\
\hline CHEMBL1524994 & 688759 & 4.95 & 4.9384 & TRN \\
\hline CHEMBL1311415 & 688759 & 4.7 & 4.9864 & TST \\
\hline CHEMBL1333503 & 688759 & 4.9 & 4.8642 & TRN \\
\hline CHEMBL1367966 & 688759 & 5.25 & 5.0715 & TRN \\
\hline CHEMBL260342 & 688759 & 4.95 & 4.8185 & TRN \\
\hline CHEMBL1421401 & 688759 & 5.9 & 5.0632 & TRN \\
\hline CHEMBL1999960 & 688759 & 4.55 & 4.9676 & TRN \\
\hline CHEMBL1478120 & 688759 & 6.0 & 5.3466 & TRN \\
\hline CHEMBL1451220 & 688759 & 5.3 & 4.9662 & TRN \\
\hline CHEMBL1536815 & 688759 & 4.7 & 4.7156 & TRN \\
\hline CHEMBL1369359 & 688759 & 4.9 & 4.7984 & TST \\
\hline CHEMBL1607285 & 688759 & 4.8 & 4.7262 & TST \\
\hline CHEMBL1303281 & 688759 & 5.55 & 5.2546 & TRN \\
\hline CHEMBL3190346 & 688759 & 4.65 & 4.6598 & TRN \\
\hline CHEMBL1407037 & 688759 & 4.7 & 4.7633 & TRN \\
\hline CHEMBL1335594 & 688759 & 4.45 & 5.0407 & TRN \\
\hline CHEMBL3189938 & 688759 & 5.0 & 4.9566 & TRN \\
\hline CHEMBL1353967 & 688759 & 4.45 & 4.8766 & TST \\
\hline CHEMBL3199912 & 688759 & 4.8 & 4.8215 & TST \\
\hline CHEMBL1972450 & 688759 & 5.35 & 5.3507 & TRN \\
\hline CHEMBL1323000 & 688759 & 4.45 & 4.3602 & TRN \\
\hline CHEMBL3191579 & 688759 & 4.7 & 4.809 & TRN \\
\hline CHEMBL1875040 & 688759 & 4.45 & 4.926 & TST \\
\hline CHEMBL1469567 & 688759 & 4.5 & 4.7024 & TRN \\
\hline CHEMBL3194704 & 688759 & 5.15 & 5.3694 & TRN \\
\hline CHEMBL1508251 & 688759 & 4.55 & 4.9826 & TRN \\
\hline CHEMBL1504135 & 688759 & 5.35 & 5.1775 & TRN \\
\hline CHEMBL1376367 & 688759 & 4.45 & 4.7855 & TST \\
\hline CHEMBL1498894 & 688759 & 4.95 & 5.008 & TRN \\
\hline CHEMBL1390508 & 688759 & 4.9 & 5.1019 & TST \\
\hline CHEMBL1345933 & 688759 & 5.5 & 4.9625 & TRN \\
\hline CHEMBL1408871 & 688759 & 4.6 & 4.8864 & TRN \\
\hline CHEMBL1316562 & 688759 & 4.75 & 4.8237 & TRN \\
\hline CHEMBL3196162 & 688759 & 4.9 & 5.0722 & TRN \\
\hline CHEMBL1341735 & 688759 & 5.15 & 4.9563 & TRN \\
\hline CHEMBL1350846 & 688759 & 4.45 & 4.7925 & TRN \\
\hline CHEMBL3199725 & 688759 & 5.65 & 5.687 & TRN \\
\hline CHEMBL1500175 & 688759 & 4.45 & 4.7766 & TST \\
\hline CHEMBL1540172 & 688759 & 4.7 & 4.965 & TST \\
\hline CHEMBL1429822 & 688759 & 4.7 & 4.6588 & TRN \\
\hline CHEMBL1364030 & 688759 & 4.6 & 4.7408 & TRN \\
\hline CHEMBL1585234 & 688759 & 4.45 & 4.7407 & TRN \\
\hline CHEMBL3192796 & 688759 & 4.9 & 4.5896 & TRN \\
\hline
\end{tabular}




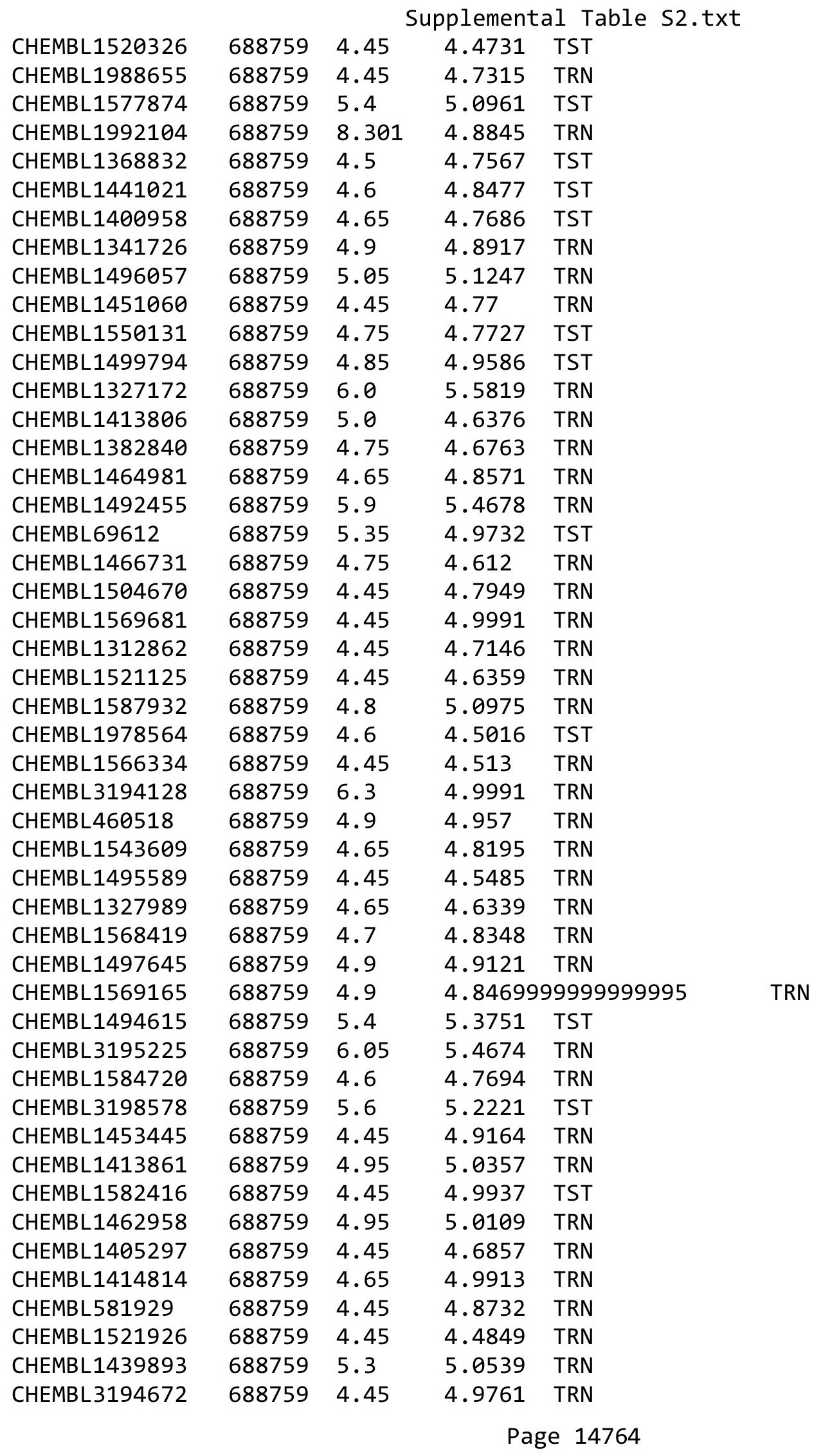




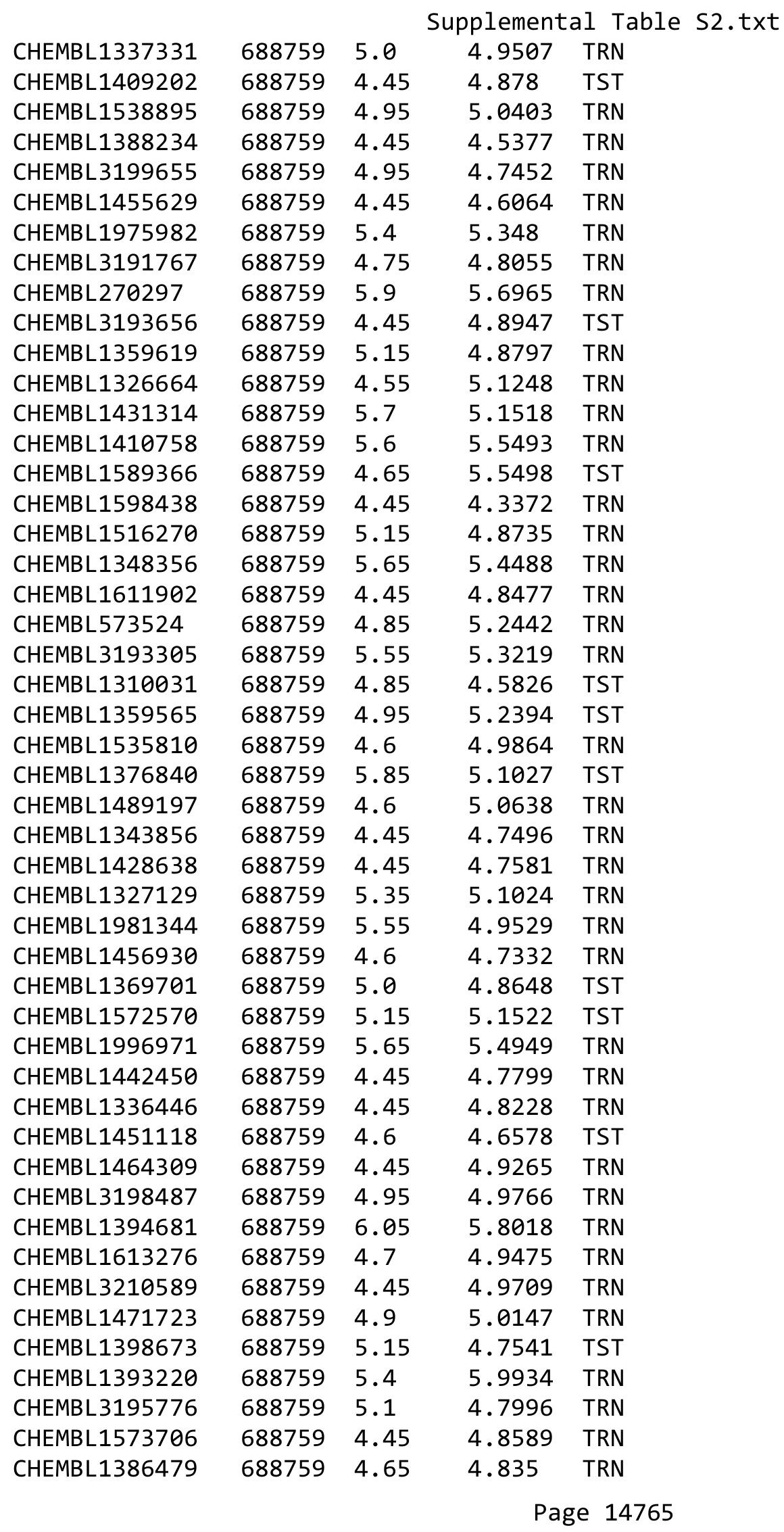




\begin{tabular}{|c|c|c|c|c|c|}
\hline \multicolumn{6}{|c|}{ Supplemental Table S2.txt } \\
\hline CHEMBL1368792 & 688759 & 5.0 & 4.8296 & TRN & \\
\hline CHEMBL1401390 & 688759 & 4.65 & 4.857 & TRN & \\
\hline CHEMBL1594282 & 688759 & 5.55 & 5.1464 & TRN & \\
\hline CHEMBL1378668 & 688759 & 4.8 & 4.6651 & TRN & \\
\hline CHEMBL1490931 & 688759 & 5.1 & 4.77800 & 00000000005 & TST \\
\hline CHEMBL1570200 & 688759 & 4.45 & 4.7729 & TRN & \\
\hline CHEMBL1599458 & 688759 & 5.7 & 5.7421 & TRN & \\
\hline CHEMBL1517811 & 688759 & 4.75 & 4.8922 & TRN & \\
\hline CHEMBL589313 & 688759 & 4.45 & 4.7609 & TRN & \\
\hline CHEMBL1326171 & 688759 & 4.45 & 4.73 & TRN & \\
\hline CHEMBL1393695 & 688759 & 4.5 & 4.5583 & TRN & \\
\hline CHEMBL1325873 & 688759 & 5.25 & 4.7229 & TRN & \\
\hline CHEMBL1312137 & 688759 & 4.5 & 4.7938 & TST & \\
\hline CHEMBL1304368 & 688759 & 5.05 & 4.9438 & TRN & \\
\hline CHEMBL1517608 & 688759 & 5.0 & 4.9628 & TRN & \\
\hline CHEMBL1572726 & 688759 & 4.5 & 4.8136 & TRN & \\
\hline CHEMBL3197442 & 688759 & 4.8 & 4.936 & TRN & \\
\hline CHEMBL3198573 & 688759 & 6.05 & 5.29899 & 99999999995 & TRN \\
\hline CHEMBL1491019 & 688759 & 5.4 & 5.1139 & TST & \\
\hline CHEMBL1541125 & 688759 & 5.2 & 4.9004 & TRN & \\
\hline CHEMBL1537141 & 688759 & 4.85 & 4.8868 & TST & \\
\hline CHEMBL1443787 & 688759 & 4.45 & 4.7102 & TRN & \\
\hline CHEMBL1542401 & 688759 & 4.8 & 4.7247 & TRN & \\
\hline CHEMBL1319277 & 688759 & 4.7 & 5.6735 & TRN & \\
\hline CHEMBL1608332 & 688759 & 5.05 & 4.9334 & TST & \\
\hline CHEMBL1309594 & 688759 & 5.2 & 5.1693 & TRN & \\
\hline CHEMBL1337784 & 688759 & 5.5 & 5.0063 & TRN & \\
\hline CHEMBL1483308 & 688759 & 4.45 & 4.6276 & TST & \\
\hline CHEMBL1526841 & 688759 & 5.45 & 5.449 & TRN & \\
\hline CHEMBL3190805 & 688759 & 5.25 & 5.37 & TRN & \\
\hline CHEMBL1506318 & 688759 & 4.55 & 4.7692 & TRN & \\
\hline CHEMBL3196327 & 688759 & 5.35 & 4.9317 & TST & \\
\hline CHEMBL1375390 & 688759 & 4.8 & 4.7893 & TST & \\
\hline CHEMBL1449743 & 688759 & 4.45 & 5.0416 & TRN & \\
\hline CHEMBL1537509 & 688759 & 4.75 & 5.3681 & TST & \\
\hline CHEMBL1453798 & 688759 & 5.25 & 4.8426 & TST & \\
\hline CHEMBL1339676 & 688759 & 4.45 & 4.7749 & TST & \\
\hline CHEMBL1582423 & 688759 & 4.45 & 5.0611 & TRN & \\
\hline CHEMBL1362552 & 688759 & 5.0 & 5.0389 & TRN & \\
\hline CHEMBL1369237 & 688759 & 4.7 & 4.9501 & TRN & \\
\hline CHEMBL1341781 & 688759 & 4.45 & 4.7229 & TRN & \\
\hline CHEMBL1495832 & 688759 & 4.5 & 5.2187 & TRN & \\
\hline CHEMBL1419735 & 688759 & 4.45 & 4.9049 & TRN & \\
\hline CHEMBL1363488 & 688759 & 4.45 & 5.1024 & TST & \\
\hline CHEMBL1374135 & 688759 & 4.95 & 4.8039 & TRN & \\
\hline CHEMBL1483432 & 688759 & 6.3 & 5.1571 & TRN & \\
\hline CHEMBL1378625 & 688759 & 4.45 & 4.6377 & TST & \\
\hline CHEMBL1431878 & 688759 & 4.55 & 4.8649 & TST & \\
\hline
\end{tabular}




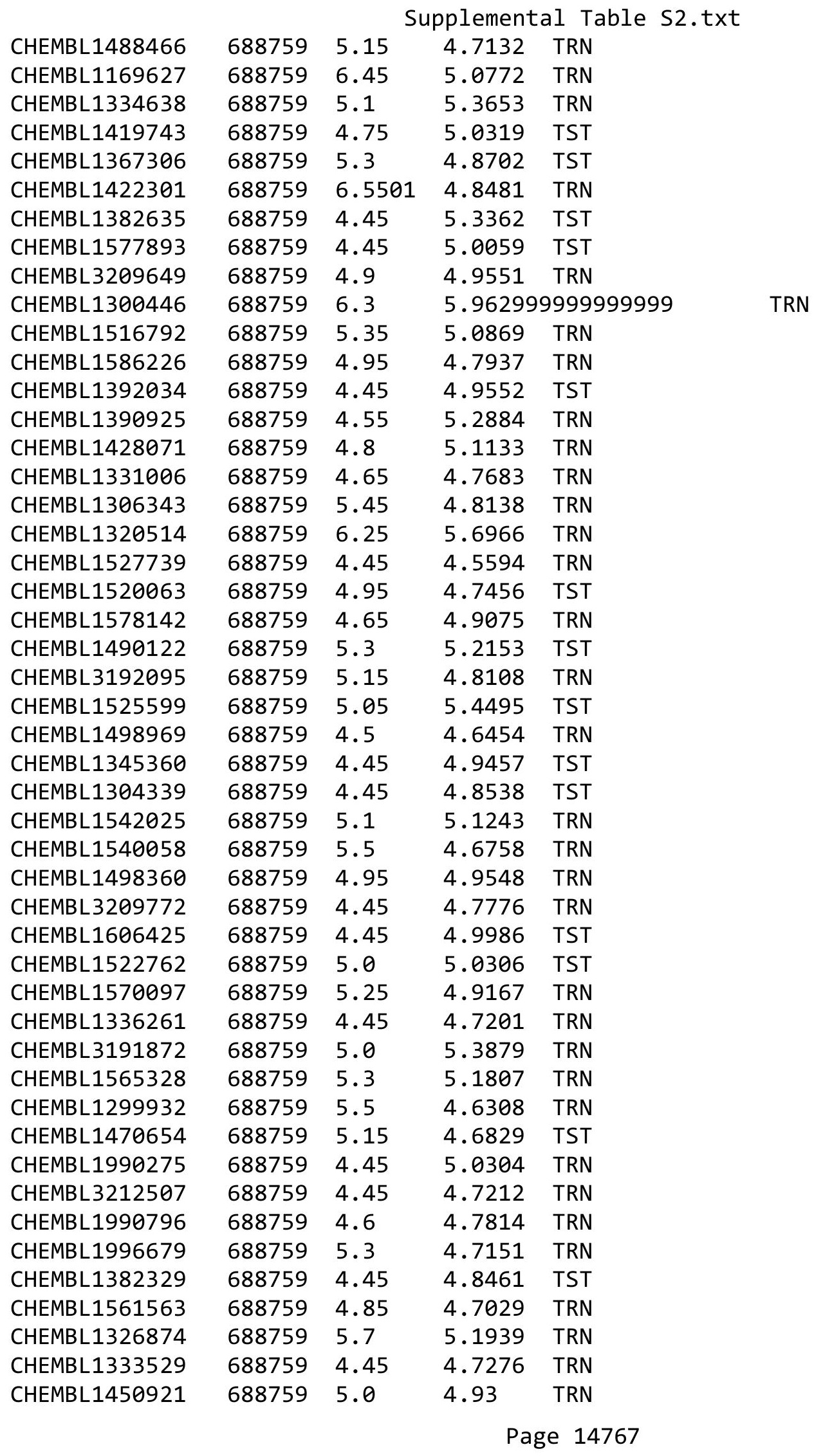




\begin{tabular}{|c|c|c|c|c|c|}
\hline \\
\hline CHEMBL1582409 & 688759 & 6.3 & 4.8372 & TRN & \\
\hline CHEMBL1430566 & 688759 & 4.65 & 4.8465 & TST & \\
\hline CHEMBL1516879 & 688759 & 5.05 & 5.2386 & TRN & \\
\hline CHEMBL1547409 & 688759 & 4.45 & 4.7636 & TRN & \\
\hline CHEMBL1547207 & 688759 & 4.45 & 4.7046 & TST & \\
\hline CHEMBL1581528 & 688759 & 5.2 & 5.2798 & TRN & \\
\hline CHEMBL1546298 & 688759 & 4.45 & 4.8952 & TST & \\
\hline CHEMBL1483850 & 688759 & 4.75 & 4.93199 & 99999999995 & TRN \\
\hline CHEMBL1375707 & 688759 & 6.15 & 4.8142 & TST & \\
\hline CHEMBL3196380 & 688759 & 5.1 & 4.8209 & TRN & \\
\hline CHEMBL 3194985 & 688759 & 4.45 & 4.8542 & TST & \\
\hline CHEMBL1603368 & 688759 & 5.4 & 4.9893 & TRN & \\
\hline CHEMBL1462631 & 688759 & 4.8 & 4.4659 & TRN & \\
\hline CHEMBL1523656 & 688759 & 4.9 & 4.7359 & TST & \\
\hline CHEMBL1346324 & 688759 & 4.75 & 5.0092 & TRN & \\
\hline CHEMBL1349840 & 688759 & 4.45 & 4.6957 & TST & \\
\hline CHEMBL3209295 & 688759 & 4.5 & 4.6084 & TRN & \\
\hline CHEMBL1380666 & 688759 & 4.45 & 4.9213 & TRN & \\
\hline CHEMBL1342702 & 688759 & 4.45 & 4.8888 & TRN & \\
\hline CHEMBL1310888 & 688759 & 4.9 & 4.5943 & TRN & \\
\hline CHEMBL1492648 & 688759 & 5.8 & 5.5782 & TRN & \\
\hline CHEMBL1991215 & 688759 & 4.7 & 4.5978 & TRN & \\
\hline CHEMBL1497759 & 688759 & 4.9 & 4.9634 & TST & \\
\hline CHEMBL1547474 & 688759 & 4.45 & 4.7515 & TRN & \\
\hline CHEMBL1598249 & 688759 & 4.9 & 5.0874 & TRN & \\
\hline CHEMBL1528130 & 688759 & 4.95 & 4.7073 & TRN & \\
\hline CHEMBL1474468 & 688759 & 4.85 & 4.5658 & TRN & \\
\hline CHEMBL1424827 & 688759 & 5.0 & 4.7148 & TRN & \\
\hline CHEMBL1571596 & 688759 & 4.6 & 4.7394 & TRN & \\
\hline CHEMBL1429133 & 688759 & 4.45 & 4.7206 & TRN & \\
\hline CHEMBL1487952 & 688759 & 5.35 & 5.1815 & TRN & \\
\hline CHEMBL1444429 & 688759 & 4.6 & 4.8965 & TST & \\
\hline CHEMBL1339058 & 688759 & 5.3 & 5.0317 & TST & \\
\hline CHEMBL1449562 & 688759 & 5.35 & 5.2684 & TRN & \\
\hline CHEMBL1372600 & 688759 & 4.75 & 4.9916 & TRN & \\
\hline CHEMBL1567058 & 688759 & 4.45 & 4.6682 & TRN & \\
\hline CHEMBL1417302 & 688759 & 4.6 & 4.6281 & TRN & \\
\hline CHEMBL1318808 & 688759 & 4.75 & 4.8686 & TST & \\
\hline CHEMBL1525944 & 688759 & 4.95 & 4.8791 & TST & \\
\hline CHEMBL1542161 & 688759 & 4.45 & 5.2577 & TRN & \\
\hline CHEMBL1300633 & 688759 & 4.45 & 4.8561 & TST & \\
\hline CHEMBL1592493 & 688759 & 5.65 & 5.1602 & TST & \\
\hline CHEMBL1420969 & 688759 & 4.45 & 4.8444 & TRN & \\
\hline CHEMBL1353186 & 688759 & 4.45 & 4.7386 & TRN & \\
\hline CHEMBL1378436 & 688759 & 4.45 & 4.633 & TRN & \\
\hline CHEMBL1478221 & 688759 & 4.9 & 4.4002 & TST & \\
\hline CHEMBL1489787 & 688759 & 4.45 & 4.7459 & TST & \\
\hline CHEMBL1349405 & 688759 & 4.45 & 4.6996 & TRN & \\
\hline
\end{tabular}




\begin{tabular}{|c|c|c|c|c|c|}
\hline \multicolumn{6}{|c|}{ Supplemental Table S2.txt } \\
\hline CHEMBL1375365 & 688759 & 4.45 & 4.601 & TRN & \\
\hline CHEMBL3208053 & 688759 & 4.45 & 4.7032 & TRN & \\
\hline CHEMBL1592571 & 688759 & 5.45 & 4.7766 & TST & \\
\hline CHEMBL399530 & 688759 & 4.45 & 4.7374 & TRN & \\
\hline CHEMBL3214323 & 688759 & 5.05 & 4.5922 & TRN & \\
\hline CHEMBL1489113 & 688759 & 5.15 & 5.4853 & TRN & \\
\hline CHEMBL1419303 & 688759 & 4.9 & 4.63899 & 9999999999 & TST \\
\hline CHEMBL1326568 & 688759 & 5.25 & 4.9481 & TRN & \\
\hline CHEMBL1427686 & 688759 & 4.75 & 4.7868 & TST & \\
\hline CHEMBL1985649 & 688759 & 4.75 & 4.798 & TST & \\
\hline CHEMBL1373239 & 688759 & 4.95 & 5.0526 & TRN & \\
\hline CHEMBL1505938 & 688759 & 4.45 & 4.8156 & TRN & \\
\hline CHEMBL1404744 & 688759 & 4.45 & 4.6789 & TRN & \\
\hline CHEMBL3195811 & 688759 & 5.5 & 5.0738 & TRN & \\
\hline CHEMBL1418271 & 688759 & 5.65 & 4.9337 & TRN & \\
\hline CHEMBL1423818 & 688759 & 4.6 & 4.9224 & TRN & \\
\hline CHEMBL1597933 & 688759 & 6.5501 & 5.1247 & TST & \\
\hline CHEMBL1398137 & 688759 & 4.45 & 4.7647 & TRN & \\
\hline CHEMBL1499320 & 688759 & 6.0 & 5.3185 & TRN & \\
\hline CHEMBL1457742 & 688759 & 5.45 & 4.7206 & TRN & \\
\hline CHEMBL1606097 & 688759 & 6.25 & 5.4266 & TRN & \\
\hline CHEMBL1413268 & 688759 & 5.1 & 5.0096 & TRN & \\
\hline CHEMBL1448363 & 688759 & 4.95 & 4.9994 & TRN & \\
\hline CHEMBL1442786 & 688759 & 4.45 & 4.5442 & TRN & \\
\hline CHEMBL3195981 & 688759 & 5.1 & 4.743 & TST & \\
\hline CHEMBL1599631 & 688759 & 4.7 & 5.4404 & TST & \\
\hline CHEMBL1452689 & 688759 & 4.45 & 4.9677 & TRN & \\
\hline CHEMBL1471779 & 688759 & 5.45 & 4.7186 & TRN & \\
\hline CHEMBL1583705 & 688759 & 4.8 & 4.757 & TST & \\
\hline CHEMBL1301278 & 688759 & 4.9 & 4.6622 & TST & \\
\hline CHEMBL1341936 & 688759 & 4.95 & 4.82 & TRN & \\
\hline CHEMBL3212193 & 688759 & 4.85 & 4.9105 & TST & \\
\hline CHEMBL1560356 & 688759 & 4.8 & 4.8882 & TRN & \\
\hline CHEMBL1522373 & 688759 & 5.95 & 5.5368 & TRN & \\
\hline CHEMBL1396030 & 688759 & 4.7 & 4.9146 & TRN & \\
\hline CHEMBL1469661 & 688759 & 5.1 & 4.9237 & TRN & \\
\hline CHEMBL1331822 & 688759 & 4.8 & 4.6237 & TST & \\
\hline CHEMBL1390605 & 688759 & 4.9 & 5.0338 & TST & \\
\hline CHEMBL1454087 & 688759 & 4.45 & 4.774 & TRN & \\
\hline CHEMBL1464553 & 688759 & 5.5 & 5.12200 & 0000000001 & TRN \\
\hline CHEMBL1390369 & 688759 & 4.8 & 4.9686 & TRN & \\
\hline CHEMBL1300373 & 688759 & 5.5 & 4.7877 & TST & \\
\hline CHEMBL1425049 & 688759 & 4.45 & 4.831 & TRN & \\
\hline CHEMBL1463671 & 688759 & 5.35 & 4.9118 & TRN & \\
\hline CHEMBL3195997 & 688759 & 5.2 & 5.4843 & TRN & \\
\hline CHEMBL1543666 & 688759 & 4.65 & 4.6544 & TRN & \\
\hline CHEMBL1414115 & 688759 & 4.45 & 4.6991 & TST & \\
\hline CHEMBL1558440 & 688759 & 5.1 & 4.8304 & TRN & \\
\hline
\end{tabular}




\begin{tabular}{|c|c|c|c|c|c|}
\hline & & \multicolumn{4}{|c|}{ Supplemental Table S2.txt } \\
\hline CHEMBL1338263 & 688759 & 7.2 & 5.277 & TST & \\
\hline CHEMBL1607077 & 688759 & 4.85 & 4.7986 & TRN & \\
\hline CHEMBL3199333 & 688759 & 5.3 & 4.8052 & TRN & \\
\hline CHEMBL1607115 & 688759 & 5.85 & 5.2701 & TRN & \\
\hline CHEMBL1582777 & 688759 & 5.7 & 5.6831 & TST & \\
\hline CHEMBL1308665 & 688759 & 4.45 & 4.9805 & TST & \\
\hline CHEMBL1498505 & 688759 & 5.25 & 4.8264 & TST & \\
\hline CHEMBL1332753 & 688759 & 4.45 & 4.8984 & TST & \\
\hline CHEMBL1365471 & 688759 & 4.8 & $5.3210 e$ & 2000000001 & TST \\
\hline CHEMBL1504715 & 688759 & 4.45 & 4.7107 & TST & \\
\hline CHEMBL1410515 & 688759 & 4.45 & 4.8828 & TST & \\
\hline CHEMBL1449018 & 688759 & 4.45 & 4.5637 & TRN & \\
\hline CHEMBL1462636 & 688759 & 5.45 & 5.235 & TST & \\
\hline CHEMBL1587904 & 688759 & 4.65 & 4.9011 & TRN & \\
\hline CHEMBL1580362 & 688759 & 4.45 & 4.933 & TRN & \\
\hline CHEMBL1321591 & 688759 & 4.95 & 5.0314 & TRN & \\
\hline CHEMBL1305589 & 688759 & 5.6 & 5.4539 & TRN & \\
\hline CHEMBL1330986 & 688759 & 5.0 & 4.6997 & TST & \\
\hline CHEMBL1409469 & 688759 & 4.6 & 4.6972 & TST & \\
\hline CHEMBL1393874 & 688759 & 5.0 & 5.2094 & TRN & \\
\hline CHEMBL1460627 & 688759 & 5.5 & 4.8613 & TRN & \\
\hline CHEMBL193627 & 688759 & 5.0 & 5.8708 & TRN & \\
\hline CHEMBL1517120 & 688759 & 4.9 & 5.2716 & TRN & \\
\hline CHEMBL1581396 & 688759 & 4.45 & 4.5678 & TRN & \\
\hline CHEMBL1322699 & 688759 & 5.45 & 5.0082 & TRN & \\
\hline CHEMBL1328822 & 688759 & 4.45 & 4.6999 & TRN & \\
\hline CHEMBL1361279 & 688759 & 4.45 & 5.1547 & TRN & \\
\hline CHEMBL1369804 & 688759 & 5.15 & 4.9699 & TRN & \\
\hline CHEMBL1495762 & 688759 & 4.6 & 4.8004 & TRN & \\
\hline CHEMBL1408817 & 688759 & 4.45 & 4.7538 & TRN & \\
\hline CHEMBL3191084 & 688759 & 4.45 & 4.5145 & TRN & \\
\hline CHEMBL1603720 & 688759 & 4.45 & 4.5044 & TRN & \\
\hline CHEMBL3198469 & 688759 & 5.2 & 5.1378 & TRN & \\
\hline CHEMBL1555936 & 688759 & 4.8 & 4.9715 & TST & \\
\hline CHEMBL1405262 & 688759 & 5.1 & $5.2970 e$ & 0000000001 & TRN \\
\hline CHEMBL1589147 & 688759 & 5.4 & 5.5544 & TRN & \\
\hline CHEMBL1385057 & 688759 & 5.85 & 5.3842 & TRN & \\
\hline CHEMBL1458396 & 688759 & 4.95 & 4.5873 & TRN & \\
\hline CHEMBL1422269 & 688759 & 4.65 & 4.7877 & TRN & \\
\hline CHEMBL1536321 & 688759 & 4.45 & 4.835 & TRN & \\
\hline CHEMBL1328987 & 688759 & 5.85 & 5.4153 & TST & \\
\hline CHEMBL1426069 & 688759 & 4.6 & 4.76 & TRN & \\
\hline CHEMBL1459329 & 688759 & 4.45 & 5.0701 & TRN & \\
\hline CHEMBL1558163 & 688759 & 6.05 & 5.0222 & TRN & \\
\hline CHEMBL1443992 & 688759 & 4.45 & 5.0004 & TRN & \\
\hline CHEMBL1969046 & 688759 & 4.75 & 4.8283 & TRN & \\
\hline CHEMBL3196053 & 688759 & 4.45 & 4.8466 & TRN & \\
\hline CHEMBL1332746 & 688759 & 4.65 & 4.7383 & TST & \\
\hline
\end{tabular}




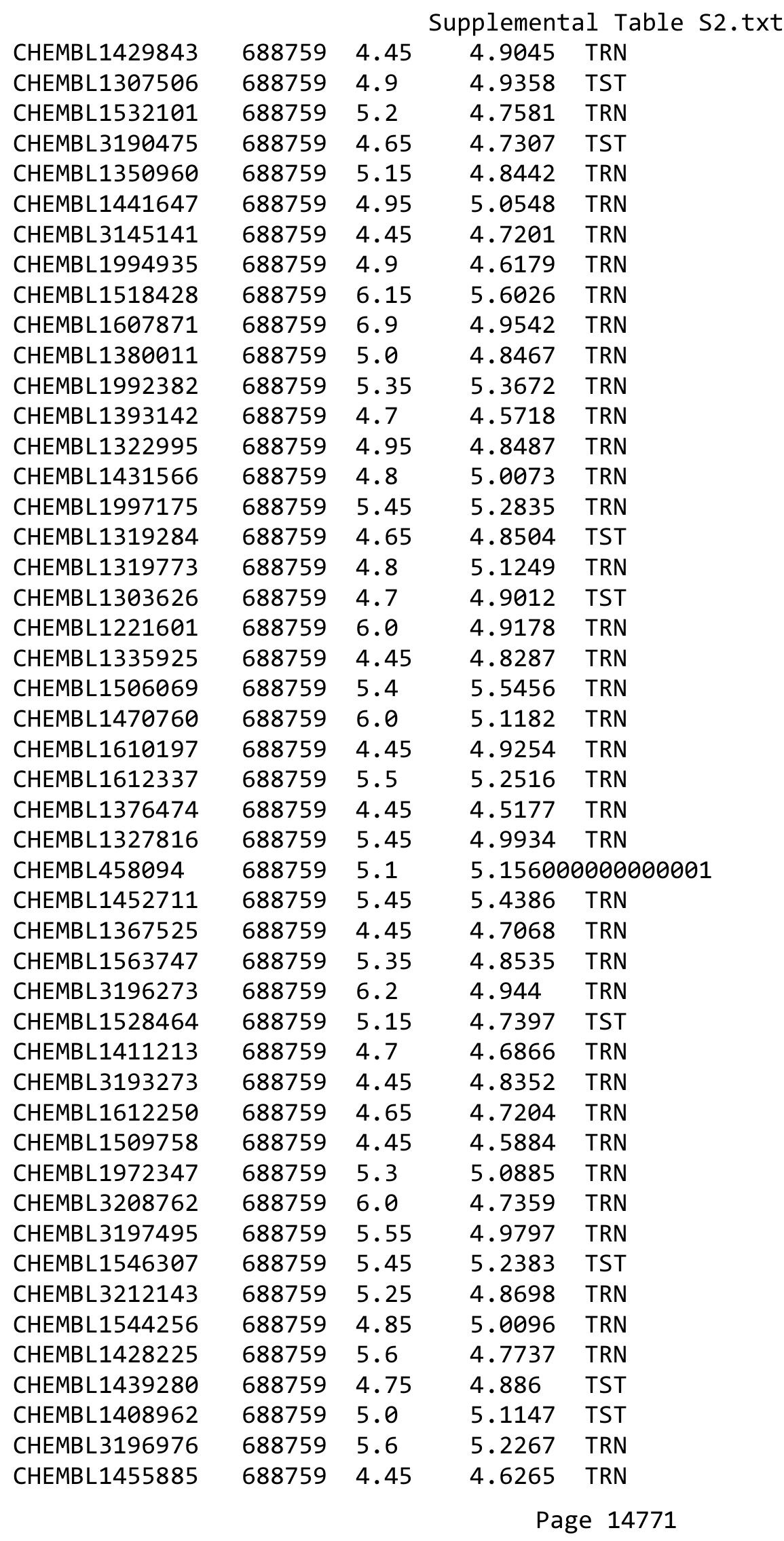




\begin{tabular}{|c|c|c|c|c|}
\hline \multicolumn{5}{|c|}{ Supplemental Table } \\
\hline CHEMBL1303835 & 688759 & 5.45 & 5.034 & TRN \\
\hline CHEMBL1319274 & 688759 & 4.9 & 4.9452 & TRN \\
\hline CHEMBL3193457 & 688759 & 4.65 & 4.7212 & TRN \\
\hline CHEMBL1320969 & 688759 & 4.65 & 4.8111 & TRN \\
\hline CHEMBL1459658 & 688759 & 2.85 & 6.4482 & TRN \\
\hline CHEMBL1558833 & 688759 & 4.7 & 4.9524 & TRN \\
\hline CHEMBL1517686 & 688759 & 5.25 & 5.0936 & TRN \\
\hline CHEMBL1539905 & 688759 & 4.75 & 4.8132 & TST \\
\hline CHEMBL1501104 & 688759 & 5.1 & 4.8873 & TRN \\
\hline CHEMBL1445732 & 688759 & 5.15 & 5.1551 & TRN \\
\hline CHEMBL1480831 & 688759 & 4.45 & 4.6836 & TRN \\
\hline CHEMBL3208722 & 688759 & 4.45 & 4.8053 & TST \\
\hline CHEMBL1458639 & 688759 & 5.25 & 4.8712 & TRN \\
\hline CHEMBL1402845 & 688759 & 5.35 & 5.1467 & TST \\
\hline CHEMBL1415468 & 688759 & 4.85 & 4.8202 & TRN \\
\hline CHEMBL1353110 & 688759 & 5.2 & 4.7007 & TRN \\
\hline CHEMBL3189570 & 688759 & 5.25 & 4.9069 & TRN \\
\hline CHEMBL1387938 & 688759 & 4.45 & 4.6797 & TRN \\
\hline CHEMBL1557782 & 688759 & 4.65 & 4.6614 & TRN \\
\hline CHEMBL1539706 & 688759 & 5.4 & 4.512 & TST \\
\hline CHEMBL1527393 & 688759 & 4.55 & 4.5116 & TRN \\
\hline CHEMBL1351389 & 688759 & 4.45 & 4.8435 & TST \\
\hline CHEMBL 3213480 & 688759 & 4.6 & 4.7034 & TRN \\
\hline CHEMBL1613684 & 688759 & 4.8 & 5.0307 & TST \\
\hline CHEMBL1519133 & 688759 & 4.45 & 4.8769 & TST \\
\hline CHEMBL1363679 & 688759 & 5.05 & 4.8416 & TRN \\
\hline CHEMBL3212679 & 688759 & 5.2 & 4.7845 & TST \\
\hline CHEMBL3196315 & 688759 & 5.2 & 5.4815 & TRN \\
\hline CHEMBL1403311 & 688759 & 4.8 & 4.8565 & TST \\
\hline CHEMBL580819 & 688759 & 4.45 & 4.6305 & TST \\
\hline CHEMBL1484484 & 688759 & 5.45 & 5.0197 & TST \\
\hline CHEMBL1393215 & 688759 & 4.75 & 4.9329 & TST \\
\hline CHEMBL1540901 & 688759 & 5.05 & 5.1677 & TRN \\
\hline CHEMBL1390855 & 688759 & 4.6 & 4.8695 & TST \\
\hline CHEMBL406557 & 688759 & 5.0 & 4.7633 & TRN \\
\hline CHEMBL1596094 & 688759 & 4.45 & 4.7807 & TST \\
\hline CHEMBL1417753 & 688759 & 6.3 & 5.0385 & TST \\
\hline CHEMBL533082 & 688759 & 4.9 & 4.8178 & TRN \\
\hline CHEMBL1412159 & 688759 & 5.3 & 5.154 & TRN \\
\hline CHEMBL1965461 & 688759 & 4.65 & 4.7712 & TST \\
\hline CHEMBL1371482 & 688759 & 4.45 & 4.6937 & TRN \\
\hline CHEMBL1549022 & 688759 & 5.35 & 4.8888 & TRN \\
\hline CHEMBL3194350 & 688759 & 4.45 & 4.9705 & TRN \\
\hline CHEMBL1999630 & 688759 & 5.3 & 4.8908 & TRN \\
\hline CHEMBL1412284 & 688759 & 4.85 & 4.7883 & TST \\
\hline CHEMBL1324052 & 688759 & 4.95 & 5.0368 & TRN \\
\hline CHEMBL1366463 & 688759 & 4.5 & 4.5331 & TRN \\
\hline CHEMBL1332805 & 688759 & 4.45 & 4.6389 & TRN \\
\hline
\end{tabular}




\begin{tabular}{|c|c|c|c|c|}
\hline \multirow[b]{2}{*}{ CHEMBL1547884 } & \multicolumn{4}{|c|}{ Supplemental Table S2.tx } \\
\hline & 688759 & 5.2 & 4.9297 & TRN \\
\hline CHEMBL1491777 & 688759 & 4.95 & 4.9286 & TRN \\
\hline CHEMBL447620 & 688759 & 5.3 & 5.0509 & TRN \\
\hline CHEMBL3193275 & 688759 & 4.45 & 4.7271 & TRN \\
\hline CHEMBL1422155 & 688759 & 5.3 & 4.6652 & TRN \\
\hline CHEMBL1490887 & 688759 & 4.5 & 5.0393 & TST \\
\hline CHEMBL1542737 & 688759 & 5.0 & 4.6146 & TRN \\
\hline CHEMBL 3195277 & 688759 & 4.8 & 4.887 & TST \\
\hline CHEMBL1382470 & 688759 & 4.95 & 5.2214 & TST \\
\hline CHEMBL1426610 & 688759 & 4.95 & 4.9995 & TRN \\
\hline CHEMBL1422261 & 688759 & 4.45 & 4.8414 & TRN \\
\hline CHEMBL1323968 & 688759 & 5.0 & 5.1568 & TRN \\
\hline CHEMBL1382062 & 688759 & 4.45 & 4.6928 & TRN \\
\hline CHEMBL1458746 & 688759 & 5.0 & 4.824 & TRN \\
\hline CHEMBL1539000 & 688759 & 4.6 & 4.7823 & TST \\
\hline CHEMBL1579464 & 688759 & 5.15 & 4.9885 & TRN \\
\hline CHEMBL1461079 & 688759 & 4.45 & 4.4058 & TRN \\
\hline CHEMBL1489459 & 688759 & 5.5 & 5.0908 & TRN \\
\hline CHEMBL 3210312 & 688759 & 5.0 & 4.6747 & TRN \\
\hline CHEMBL1342746 & 688759 & 5.15 & 4.5317 & TRN \\
\hline CHEMBL1342174 & 688759 & 4.95 & 4.7145 & TST \\
\hline CHEMBL1401923 & 688759 & 5.4 & 5.0478 & TRN \\
\hline CHEMBL1425820 & 688759 & 5.3 & 4.9193 & TRN \\
\hline CHEMBL1998946 & 688759 & 4.9 & 4.7664 & TRN \\
\hline CHEMBL1423192 & 688759 & 6.0 & 5.6187 & TRN \\
\hline CHEMBL1968089 & 688759 & 4.9 & 4.913 & TRN \\
\hline CHEMBL1477047 & 688759 & 5.5 & 4.7388 & TST \\
\hline CHEMBL1483419 & 688759 & 5.5 & 4.8193 & TRN \\
\hline CHEMBL1586274 & 688759 & 4.65 & 4.8548 & TRN \\
\hline CHEMBL1534999 & 688759 & 5.0 & 4.8471 & TRN \\
\hline CHEMBL1485892 & 688759 & 5.35 & 5.6208 & TRN \\
\hline CHEMBL3199346 & 688759 & 4.45 & 4.703 & TRN \\
\hline CHEMBL1490834 & 688759 & 4.45 & 4.7319 & TST \\
\hline CHEMBL1413026 & 688759 & 4.95 & 4.8199 & TRN \\
\hline CHEMBL1369483 & 688759 & 5.7 & 4.8999 & TRN \\
\hline CHEMBL1541017 & 688759 & 5.55 & 5.3501 & TST \\
\hline CHEMBL1470309 & 688759 & 5.95 & 5.6048 & TRN \\
\hline CHEMBL1997098 & 688759 & 5.35 & 5.1894 & TRN \\
\hline CHEMBL1502192 & 688759 & 5.1 & 5.3952 & TRN \\
\hline CHEMBL1426048 & 688759 & 4.7 & 4.8175 & TRN \\
\hline CHEMBL1401534 & 688759 & 4.65 & 4.4913 & TRN \\
\hline CHEMBL1508694 & 688759 & 4.9 & 5.0982 & TRN \\
\hline CHEMBL1575251 & 688759 & 4.65 & 4.86 & TST \\
\hline CHEMBL1576480 & 688759 & 4.9 & 4.9288 & TRN \\
\hline CHEMBL1560307 & 688759 & 5.4 & 4.7122 & TST \\
\hline CHEMBL1548453 & 688759 & 4.85 & 4.7558 & TST \\
\hline CHEMBL1549208 & 688759 & 6.8 & 5.1625 & TRN \\
\hline CHEMBL1483326 & 688759 & 5.5 & 5.4424 & TRN \\
\hline
\end{tabular}




\begin{tabular}{|c|c|c|c|c|c|}
\hline \multicolumn{6}{|c|}{ Supplemental Table s2.txt } \\
\hline CHEMBL1986541 & 688759 & 5.1 & 5.2474 & TRN & \\
\hline CHEMBL1457798 & 688759 & 5.85 & 4.9306 & TST & \\
\hline CHEMBL1493481 & 688759 & 5.6 & 5.6011 & TRN & \\
\hline CHEMBL1579034 & 688759 & 4.45 & 4.8826 & TST & \\
\hline CHEMBL588038 & 688759 & 4.65 & 4.849 & TST & \\
\hline CHEMBL1608375 & 688759 & 4.45 & 4.6882 & TST & \\
\hline CHEMBL1340648 & 688759 & 4.45 & 4.4255 & TRN & \\
\hline CHEMBL2000259 & 688759 & 4.45 & 4.6072 & TST & \\
\hline CHEMBL1360110 & 688759 & 4.85 & 4.8708 & TRN & \\
\hline CHEMBL1300173 & 688759 & 4.65 & 5.0309 & TRN & \\
\hline CHEMBL1581924 & 688759 & 5.4 & 5.2277 & TST & \\
\hline CHEMBL1308319 & 688759 & 5.95 & 5.7594 & TRN & \\
\hline CHEMBL1591374 & 688759 & 4.45 & 4.5722 & TRN & \\
\hline CHEMBL1379999 & 688759 & 4.55 & 4.6198 & TRN & \\
\hline CHEMBL1337826 & 688759 & 5.15 & 5.0944 & TST & \\
\hline CHEMBL1465527 & 688759 & 5.35 & 5.13299 & 9999999999 & TST \\
\hline CHEMBL1327986 & 688759 & 4.45 & 4.9974 & TRN & \\
\hline CHEMBL1325794 & 688759 & 5.45 & 4.5028 & TST & \\
\hline CHEMBL1425542 & 688759 & 6.05 & 4.9984 & TST & \\
\hline CHEMBL1390557 & 688759 & 4.95 & 4.87 & TRN & \\
\hline CHEMBL1605419 & 688759 & 4.65 & 4.7396 & TRN & \\
\hline CHEMBL1604884 & 688759 & 5.9 & 5.8653 & TRN & \\
\hline CHEMBL1598327 & 688759 & 4.9 & 4.8743 & TRN & \\
\hline CHEMBL1464159 & 688759 & 4.45 & 4.6027 & TRN & \\
\hline CHEMBL1479550 & 688759 & 4.45 & 4.9298 & TRN & \\
\hline CHEMBL1496702 & 688759 & 4.45 & 4.8312 & TRN & \\
\hline CHEMBL1438948 & 688759 & 4.55 & 4.8633 & TRN & \\
\hline CHEMBL1472126 & 688759 & 4.45 & 4.8222 & TRN & \\
\hline CHEMBL3191677 & 688759 & 5.15 & 5.0783 & TRN & \\
\hline CHEMBL3191435 & 688759 & 4.45 & 4.7241 & TRN & \\
\hline CHEMBL3208922 & 688759 & 4.45 & 4.8003 & TRN & \\
\hline CHEMBL1493792 & 688759 & 5.6 & 4.9895 & TRN & \\
\hline CHEMBL1332827 & 688759 & 5.2 & 5.0716 & TRN & \\
\hline CHEMBL1369594 & 688759 & 5.0 & 5.2067 & TRN & \\
\hline CHEMBL1404788 & 688759 & 5.6 & 5.5483 & TRN & \\
\hline CHEMBL1540358 & 688759 & 4.45 & 4.7541 & TST & \\
\hline CHEMBL1341271 & 688759 & 5.25 & 4.7369 & TST & \\
\hline CHEMBL1352280 & 688759 & 4.65 & 4.8447 & TRN & \\
\hline CHEMBL1439282 & 688759 & 6.0 & 4.6179 & TRN & \\
\hline CHEMBL1339149 & 688759 & 4.7 & 4.6701 & TRN & \\
\hline CHEMBL1543813 & 688759 & 5.2 & 5.1931 & TRN & \\
\hline CHEMBL1403345 & 688759 & 4.9 & 4.7809 & TST & \\
\hline CHEMBL1369655 & 688759 & 5.5 & 5.2259 & TRN & \\
\hline CHEMBL1426380 & 688759 & 5.3 & 5.1762 & TRN & \\
\hline CHEMBL1401744 & 688759 & 6.0 & 5.2034 & TRN & \\
\hline CHEMBL1403442 & 688759 & 4.8 & 4.988 & TRN & \\
\hline CHEMBL1558863 & 688759 & 5.35 & 4.8781 & TST & \\
\hline CHEMBL1407672 & 688759 & 5.0 & 5.2455 & TST & \\
\hline
\end{tabular}




\begin{tabular}{|c|c|c|c|c|}
\hline \multicolumn{5}{|c|}{ Supplemental Table S2.txt } \\
\hline CHEMBL1498087 & 688759 & 5.4 & 5.2955 & TRN \\
\hline CHEMBL1453148 & 688759 & 5.4 & 5.0765 & TRN \\
\hline CHEMBL1459689 & 688759 & 4.45 & 4.7134 & TRN \\
\hline CHEMBL1419137 & 688759 & 4.45 & 4.8448 & TRN \\
\hline CHEMBL1470904 & 688759 & 5.0 & 5.164 & TRN \\
\hline CHEMBL1463258 & 688759 & 5.4 & 4.985 & TRN \\
\hline CHEMBL3192348 & 688759 & 5.15 & 5.1541 & TRN \\
\hline CHEMBL1304154 & 688759 & 5.35 & 5.0038 & TRN \\
\hline CHEMBL1468471 & 688759 & 4.65 & 4.7414 & TRN \\
\hline CHEMBL1314077 & 688759 & 4.55 & 4.8707 & TRN \\
\hline CHEMBL1561673 & 688759 & 4.6 & 4.8188 & TST \\
\hline CHEMBL3190812 & 688759 & 5.9 & 5.0213 & TRN \\
\hline CHEMBL1448998 & 688759 & 5.05 & 4.7945 & TRN \\
\hline CHEMBL1565164 & 688759 & 4.75 & 4.882 & TST \\
\hline CHEMBL1544553 & 688759 & 5.9 & 5.5625 & TST \\
\hline CHEMBL1365260 & 688759 & 4.45 & 4.75 & TRN \\
\hline CHEMBL1417626 & 688759 & 4.65 & 5.1577 & TRN \\
\hline CHEMBL1312534 & 688759 & 4.55 & 4.6664 & TRN \\
\hline CHEMBL1307191 & 688759 & 4.55 & 4.6103 & TRN \\
\hline CHEMBL1529355 & 688759 & 4.95 & 4.9436 & TRN \\
\hline CHEMBL1391828 & 688759 & 4.45 & 5.0648 & TRN \\
\hline CHEMBL1527817 & 688759 & 4.65 & 4.6446 & TST \\
\hline CHEMBL 2004361 & 688759 & 5.3 & 5.4593 & TRN \\
\hline CHEMBL1457476 & 688759 & 5.3 & 4.6666 & TST \\
\hline CHEMBL1361220 & 688759 & 6.25 & 5.0252 & TRN \\
\hline CHEMBL600090 & 688759 & 4.5 & 4.8916 & TST \\
\hline CHEMBL1502684 & 688759 & 4.75 & 4.9759 & TST \\
\hline CHEMBL 2003587 & 688759 & 5.75 & 5.1763 & TRN \\
\hline CHEMBL1498043 & 688759 & 4.45 & 4.9255 & TRN \\
\hline CHEMBL1427844 & 688759 & 4.45 & 4.9575 & TST \\
\hline CHEMBL1321739 & 688759 & 4.45 & 4.6733 & TRN \\
\hline CHEMBL1353481 & 688759 & 4.85 & 4.9663 & TST \\
\hline CHEMBL3196542 & 688759 & 4.45 & 4.7045 & TRN \\
\hline CHEMBL1420629 & 688759 & 5.85 & 5.3706 & TRN \\
\hline CHEMBL1579444 & 688759 & 4.45 & 4.7844 & TRN \\
\hline CHEMBL1310819 & 688759 & 4.45 & 4.5636 & TRN \\
\hline CHEMBL1486737 & 688759 & 4.9 & 4.8214 & TRN \\
\hline CHEMBL1595000 & 688759 & 4.45 & 4.7576 & TRN \\
\hline CHEMBL1347413 & 688759 & 4.45 & 4.7946 & TST \\
\hline CHEMBL1530629 & 688759 & 4.9 & 4.9205 & TRN \\
\hline CHEMBL1583647 & 688759 & 4.7 & 5.0834 & TRN \\
\hline CHEMBL3209458 & 688759 & 5.25 & 4.8641 & TRN \\
\hline CHEMBL1564958 & 688759 & 5.55 & 5.579 & TRN \\
\hline CHEMBL1465741 & 688759 & 4.45 & 4.828 & TRN \\
\hline CHEMBL1559111 & 688759 & 4.8 & 4.979 & TRN \\
\hline CHEMBL1562819 & 688759 & 4.65 & 4.6603 & TRN \\
\hline CHEMBL1423138 & 688759 & 4.65 & 4.6982 & TST \\
\hline CHEMBL1543736 & 688759 & 4.45 & 4.6112 & TRN \\
\hline
\end{tabular}




\begin{tabular}{|c|c|c|c|c|c|}
\hline \multicolumn{6}{|c|}{ Supplemental Table S2.txt } \\
\hline CHEMBL1558527 & 688759 & 4.95 & 4.8291 & TST & \\
\hline CHEMBL601119 & 688759 & 5.5 & $5.2920 €$ & 0000000001 & TRN \\
\hline CHEMBL1366500 & 688759 & 5.55 & 5.191 & TRN & \\
\hline CHEMBL1419500 & 688759 & 6.5 & 4.8314 & TRN & \\
\hline CHEMBL 2373662 & 688759 & 4.45 & 4.9899 & TST & \\
\hline CHEMBL1353392 & 688759 & 5.0 & 4.9791 & TRN & \\
\hline CHEMBL3193106 & 688759 & 4.45 & 4.8504 & TRN & \\
\hline CHEMBL1498192 & 688759 & 4.6 & 4.9128 & TRN & \\
\hline CHEMBL1380221 & 688759 & 4.7 & $4.6819 \subseteq$ & 99999999995 & TRN \\
\hline CHEMBL1486249 & 688759 & 4.9 & 4.8136 & TRN & \\
\hline CHEMBL1339723 & 688759 & 4.7 & 4.5838 & TRN & \\
\hline CHEMBL1372535 & 688759 & 4.75 & 5.0555 & TST & \\
\hline CHEMBL1462189 & 688759 & 5.45 & 5.2435 & TRN & \\
\hline CHEMBL61133 & 688759 & 4.45 & 4.9528 & TST & \\
\hline CHEMBL1366169 & 688759 & 4.6 & 4.8961 & TST & \\
\hline CHEMBL1491825 & 688759 & 5.35 & 4.8505 & TST & \\
\hline CHEMBL3198670 & 688759 & 4.95 & 5.0442 & TRN & \\
\hline CHEMBL1460959 & 688759 & 6.35 & 5.1914 & TRN & \\
\hline CHEMBL1256869 & 688759 & 4.5 & 4.5918 & TST & \\
\hline CHEMBL1448893 & 688759 & 4.45 & 4.7301 & TRN & \\
\hline CHEMBL1502141 & 688759 & 5.0 & 4.8981 & TRN & \\
\hline CHEMBL1547026 & 688759 & 5.2 & 4.8536 & TRN & \\
\hline CHEMBL1521274 & 688759 & 4.45 & 4.9956 & TST & \\
\hline CHEMBL1373673 & 688759 & 4.6 & 4.7413 & TST & \\
\hline CHEMBL1380643 & 688759 & 4.45 & 5.048 & TRN & \\
\hline CHEMBL1361699 & 688759 & 4.45 & 4.6528 & TRN & \\
\hline CHEMBL3192108 & 688759 & 4.75 & 6.7013 & TRN & \\
\hline CHEMBL1324528 & 688759 & 4.45 & 4.7477 & TRN & \\
\hline CHEMBL1256656 & 688759 & 4.5 & 4.8785 & TST & \\
\hline CHEMBL1385094 & 688759 & 4.95 & 4.5397 & TRN & \\
\hline CHEMBL3193378 & 688759 & 7.0501 & 5.5694 & TRN & \\
\hline CHEMBL1521213 & 688759 & 4.45 & 4.9459 & TRN & \\
\hline CHEMBL1392046 & 688759 & 4.95 & 4.7746 & TRN & \\
\hline CHEMBL1499671 & 688759 & 5.75 & 5.6239 & TRN & \\
\hline CHEMBL1403519 & 688759 & 4.85 & 4.8175 & TRN & \\
\hline CHEMBL1418582 & 688759 & 4.95 & 4.5614 & TRN & \\
\hline CHEMBL1539967 & 688759 & 5.1 & 4.9756 & TRN & \\
\hline CHEMBL1611091 & 688759 & 4.45 & 4.6801 & TRN & \\
\hline CHEMBL1520803 & 688759 & 5.55 & 5.4996 & TRN & \\
\hline CHEMBL1599291 & 688759 & 5.5 & 5.0111 & TRN & \\
\hline CHEMBL1499012 & 688759 & 4.9 & 4.9073 & TRN & \\
\hline CHEMBL1545180 & 688759 & 5.5 & 4.6994 & TRN & \\
\hline CHEMBL1504937 & 688759 & 6.15 & 5.9423 & TRN & \\
\hline CHEMBL3209674 & 688759 & 4.45 & 4.8176 & TST & \\
\hline CHEMBL1371536 & 688759 & 4.65 & 4.7524 & TRN & \\
\hline CHEMBL1385701 & 688759 & 4.7 & 4.5264 & TRN & \\
\hline CHEMBL1326930 & 688759 & 4.65 & 5.1785 & TRN & \\
\hline CHEMBL1423548 & 688759 & 4.45 & 4.8052 & TST & \\
\hline
\end{tabular}




\begin{tabular}{|c|c|c|c|c|}
\hline \multicolumn{5}{|c|}{ Supplemental Table S2.txt } \\
\hline CHEMBL 3145171 & 688759 & 5.85 & 5.1394 & TRN \\
\hline CHEMBL3196933 & 688759 & 5.15 & 4.8205 & TRN \\
\hline CHEMBL1362650 & 688759 & 6.2 & 4.6653 & TRN \\
\hline CHEMBL1544108 & 688759 & 4.45 & 4.7778 & TRN \\
\hline CHEMBL1420943 & 688759 & 4.9 & 4.498 & TST \\
\hline CHEMBL1468130 & 688759 & 5.25 & 5.4139 & TST \\
\hline CHEMBL1305348 & 688759 & 4.45 & 4.7675 & TRN \\
\hline CHEMBL1339455 & 688759 & 5.3 & 4.8429 & TRN \\
\hline CHEMBL453974 & 688759 & 6.0 & 5.5202 & TST \\
\hline CHEMBL1506414 & 688759 & 5.25 & 4.8745 & TRN \\
\hline CHEMBL3194815 & 688759 & 4.45 & 4.7304 & TRN \\
\hline CHEMBL3193414 & 688759 & 5.9 & 5.5131 & TRN \\
\hline CHEMBL1376248 & 688759 & 4.65 & 4.8901 & TRN \\
\hline CHEMBL1371805 & 688759 & 4.45 & 4.6277 & TST \\
\hline CHEMBL1388896 & 688759 & 4.85 & 5.1388 & TRN \\
\hline CHEMBL1323431 & 688759 & 6.5501 & 5.1669 & TRN \\
\hline CHEMBL1377376 & 688759 & 5.5 & 5.9713 & TRN \\
\hline CHEMBL1490791 & 688759 & 4.45 & 4.5814 & TST \\
\hline CHEMBL1367500 & 688759 & 4.45 & 4.7406 & TRN \\
\hline CHEMBL1495372 & 688759 & 5.4 & 4.92 & TRN \\
\hline CHEMBL1345095 & 688759 & 5.6 & 4.8104 & TRN \\
\hline CHEMBL1610831 & 688759 & 4.45 & 4.6697 & TST \\
\hline CHEMBL1608333 & 688759 & 5.35 & 5.0385 & TRN \\
\hline CHEMBL1580532 & 688759 & 4.45 & 4.6676 & TRN \\
\hline CHEMBL1312783 & 688759 & 5.15 & 4.9315 & TRN \\
\hline CHEMBL1548517 & 688759 & 4.45 & 4.7439 & TST \\
\hline CHEMBL1419798 & 688759 & 5.3 & 5.1504 & TRN \\
\hline CHEMBL1574064 & 688759 & 4.6 & 4.7582 & TRN \\
\hline CHEMBL1393633 & 688759 & 5.45 & 5.6214 & TRN \\
\hline CHEMBL1600314 & 688759 & 5.3 & 5.0294 & TRN \\
\hline CHEMBL1300605 & 688759 & 4.5 & 4.8345 & TRN \\
\hline CHEMBL1339696 & 688759 & 4.45 & 4.5144 & TRN \\
\hline CHEMBL1534505 & 688759 & 4.45 & 4.6087 & TRN \\
\hline CHEMBL1412205 & 688759 & 4.9 & 4.7718 & TRN \\
\hline CHEMBL1526940 & 688759 & 4.85 & 4.6375 & TRN \\
\hline CHEMBL1986128 & 688759 & 4.45 & 4.4157 & TRN \\
\hline CHEMBL1300959 & 688759 & 4.65 & 5.0881 & TST \\
\hline CHEMBL1389210 & 688759 & 4.7 & 4.6777 & TRN \\
\hline CHEMBL1407075 & 688759 & 4.7 & 4.8394 & TST \\
\hline CHEMBL1611026 & 688759 & 4.45 & 4.5638 & TST \\
\hline CHEMBL1508044 & 688759 & 4.6 & 4.8226 & TST \\
\hline CHEMBL1498133 & 688759 & 5.2 & 5.118 & TST \\
\hline CHEMBL1362246 & 688759 & 4.7 & 4.8257 & TST \\
\hline CHEMBL1381354 & 688759 & 6.1 & 5.1073 & TRN \\
\hline CHEMBL1368203 & 688759 & 4.8 & 4.7582 & TST \\
\hline CHEMBL1310036 & 688759 & 4.65 & 4.7088 & TRN \\
\hline CHEMBL3211998 & 688759 & 5.4 & 5.1166 & TRN \\
\hline CHEMBL3196367 & 688759 & 5.1 & 5.2586 & TST \\
\hline
\end{tabular}




\begin{tabular}{|c|c|c|c|c|}
\hline \multicolumn{5}{|c|}{ Supplemental Table s2.txt } \\
\hline CHEMBL1362068 & 688759 & 4.9 & 4.8337 & TRN \\
\hline CHEMBL1557678 & 688759 & 5.5 & 6.1665 & TRN \\
\hline CHEMBL1429713 & 688759 & 6.15 & 5.7724 & TRN \\
\hline CHEMBL1480751 & 688759 & 4.45 & 4.8454 & TST \\
\hline CHEMBL31782 & 688759 & 6.2 & 5.3559 & TRN \\
\hline CHEMBL1575258 & 688759 & 4.45 & 4.7243 & TRN \\
\hline CHEMBL 3212844 & 688759 & 6.3 & 4.8093 & TST \\
\hline CHEMBL 2005317 & 688759 & 5.3 & 5.0034 & TRN \\
\hline CHEMBL1613550 & 688759 & 4.45 & 4.7028 & TST \\
\hline CHEMBL1480625 & 688759 & 4.45 & 5.3514 & TST \\
\hline CHEMBL1369865 & 688759 & 5.0 & 5.2287 & TRN \\
\hline CHEMBL1557288 & 688759 & 7.4001 & 5.5852 & TRN \\
\hline CHEMBL1539698 & 688759 & 4.45 & 4.8957 & TST \\
\hline CHEMBL1413673 & 688759 & 4.45 & 4.5182 & TRN \\
\hline CHEMBL3196983 & 688759 & 5.45 & 4.6625 & TRN \\
\hline CHEMBL1486161 & 688759 & 5.0 & 5.1143 & TRN \\
\hline CHEMBL1464037 & 688759 & 4.45 & 4.9431 & TRN \\
\hline CHEMBL1428399 & 688759 & 4.65 & 4.7902 & TRN \\
\hline CHEMBL1504026 & 688759 & 4.75 & 5.0662 & TRN \\
\hline CHEMBL1544782 & 688759 & 4.95 & 4.9945 & TRN \\
\hline CHEMBL1441903 & 688759 & 4.7 & 4.8508 & TRN \\
\hline CHEMBL1404718 & 688759 & 4.45 & 4.6211 & TRN \\
\hline CHEMBL3193205 & 688759 & 4.85 & 4.7194 & TST \\
\hline CHEMBL1610180 & 688759 & 4.45 & 4.7216 & TRN \\
\hline CHEMBL1341131 & 688759 & 4.45 & 4.9821 & TST \\
\hline CHEMBL1603212 & 688759 & 4.5 & 4.9463 & TRN \\
\hline CHEMBL1345661 & 688759 & 4.45 & 4.8556 & TRN \\
\hline CHEMBL1577704 & 688759 & 5.5 & 4.9048 & TST \\
\hline CHEMBL3198832 & 688759 & 5.8 & 4.9245 & TRN \\
\hline CHEMBL1308759 & 688759 & 4.45 & 4.8537 & TST \\
\hline CHEMBL1548033 & 688759 & 4.6 & 4.6577 & TRN \\
\hline CHEMBL1309976 & 688759 & 4.7 & 4.9682 & TST \\
\hline CHEMBL1449393 & 688759 & 5.2 & 4.9951 & TRN \\
\hline CHEMBL1462473 & 688759 & 4.65 & 4.855 & TRN \\
\hline CHEMBL1981939 & 688759 & 4.45 & 4.836 & TRN \\
\hline CHEMBL3212135 & 688759 & 6.1 & 5.1343 & TRN \\
\hline CHEMBL1539588 & 688759 & 5.55 & 5.3268 & TRN \\
\hline CHEMBL1525880 & 688759 & 4.45 & 4.7659 & TST \\
\hline CHEMBL1377852 & 688759 & 4.45 & 4.5128 & TRN \\
\hline CHEMBL1312716 & 688759 & 5.55 & 5.2010 & 00000000005 \\
\hline CHEMBL1316828 & 688759 & 4.9 & 4.814 & TST \\
\hline CHEMBL1346003 & 688759 & 4.45 & 4.7584 & TRN \\
\hline CHEMBL1504815 & 688759 & 4.6 & 4.6429 & TRN \\
\hline CHEMBL1519655 & 688759 & 5.05 & 4.708 & TRN \\
\hline CHEMBL1603505 & 688759 & 5.4 & 4.8249 & TRN \\
\hline CHEMBL1546082 & 688759 & 5.3 & 4.7553 & TRN \\
\hline CHEMBL 2001996 & 688759 & 4.45 & 4.7307 & TRN \\
\hline CHEMBL1612636 & 688759 & 5.7 & 5.4388 & TST \\
\hline
\end{tabular}




\begin{tabular}{|c|c|c|c|c|c|}
\hline \\
\hline CHEMBL1540399 & 688759 & 4.7 & 5.0729 & TRN & \\
\hline CHEMBL1459294 & 688759 & 4.55 & 4.8859 & TST & \\
\hline CHEMBL1562596 & 688759 & 4.8 & 4.6634 & TST & \\
\hline CHEMBL1442391 & 688759 & 4.45 & 5.0474 & TRN & \\
\hline CHEMBL3196010 & 688759 & 4.45 & 4.7513 & TRN & \\
\hline CHEMBL1510525 & 688759 & 5.35 & 5.1674 & TRN & \\
\hline CHEMBL3195258 & 688759 & 5.25 & 5.0035 & TRN & \\
\hline CHEMBL1533802 & 688759 & 4.65 & 4.9165 & TRN & \\
\hline CHEMBL1403577 & 688759 & 4.45 & 4.9231 & TRN & \\
\hline CHEMBL1465947 & 688759 & 4.8 & 4.6142 & TRN & \\
\hline CHEMBL1600062 & 688759 & 5.65 & 5.1138 & TRN & \\
\hline CHEMBL1587722 & 688759 & 4.95 & 4.7909 & TRN & \\
\hline CHEMBL1323432 & 688759 & 4.9 & 5.21399 & 99999999995 & TRN \\
\hline CHEMBL1605872 & 688759 & 4.45 & 4.86600 & 00000000005 & TRN \\
\hline CHEMBL1579256 & 688759 & 4.55 & 4.85800 & 00000000005 & TRN \\
\hline CHEMBL1388327 & 688759 & 5.05 & 5.0443 & TRN & \\
\hline CHEMBL1523058 & 688759 & 4.8 & 4.9963 & TST & \\
\hline CHEMBL1506256 & 688759 & 5.5 & 5.0817 & TRN & \\
\hline CHEMBL1406434 & 688759 & 5.65 & 5.3716 & TRN & \\
\hline CHEMBL1575294 & 688759 & 5.15 & 5.1779 & TRN & \\
\hline CHEMBL1448550 & 688759 & 4.45 & 4.8374 & TRN & \\
\hline CHEMBL3195389 & 688759 & 6.5 & 5.6692 & TRN & \\
\hline CHEMBL1984114 & 688759 & 4.45 & 4.7962 & TRN & \\
\hline CHEMBL1572329 & 688759 & 5.25 & 4.7437 & TRN & \\
\hline CHEMBL1370406 & 688759 & 4.45 & 4.7999 & TST & \\
\hline CHEMBL1470074 & 688759 & 6.0 & 4.8057 & TRN & \\
\hline CHEMBL1546029 & 688759 & 5.1 & 4.6735 & TST & \\
\hline CHEMBL1322058 & 688759 & 5.25 & 4.7254 & TRN & \\
\hline CHEMBL1343453 & 688759 & 4.45 & 4.9424 & TRN & \\
\hline CHEMBL3191859 & 688759 & 4.65 & 4.9409 & TST & \\
\hline CHEMBL1606973 & 688759 & 4.45 & 4.8822 & TRN & \\
\hline CHEMBL1459877 & 688759 & 5.65 & 4.5635 & TST & \\
\hline CHEMBL1448984 & 688759 & 5.25 & 5.2744 & TRN & \\
\hline CHEMBL1340123 & 688759 & 4.7 & 4.7585 & TRN & \\
\hline CHEMBL1994007 & 688759 & 4.6 & 4.8141 & TRN & \\
\hline CHEMBL1331520 & 688759 & 5.4 & 5.191 & TRN & \\
\hline CHEMBL1343274 & 688759 & 5.45 & 4.7221 & TRN & \\
\hline CHEMBL1333050 & 688759 & 5.15 & 5.3553 & TRN & \\
\hline CHEMBL1998944 & 688759 & 4.95 & 4.5652 & TRN & \\
\hline CHEMBL1505136 & 688759 & 4.9 & 5.0437 & TRN & \\
\hline CHEMBL1313451 & 688759 & 4.45 & 4.7384 & TRN & \\
\hline CHEMBL1528765 & 688759 & 4.45 & 4.948 & TST & \\
\hline CHEMBL1341776 & 688759 & 5.15 & 4.8412 & TRN & \\
\hline CHEMBL1999437 & 688759 & 5.35 & 5.0888 & TRN & \\
\hline CHEMBL1415374 & 688759 & 4.45 & 4.6233 & TRN & \\
\hline CHEMBL1444886 & 688759 & 4.9 & 4.8443 & TST & \\
\hline CHEMBL1503912 & 688759 & 4.9 & 5.2178 & TRN & \\
\hline CHEMBL1317657 & 688759 & 6.0 & 5.6186 & TRN & \\
\hline
\end{tabular}




\begin{tabular}{|c|c|c|c|c|c|}
\hline \multicolumn{6}{|c|}{ Supplemental Table S2.txt } \\
\hline CHEMBL1350384 & 688759 & 5.85 & 5.1905 & TST & \\
\hline CHEMBL1366322 & 688759 & 7.2 & 5.3832 & TST & \\
\hline CHEMBL1407081 & 688759 & 4.95 & 5.1444 & TST & \\
\hline CHEMBL1421206 & 688759 & 5.7 & 5.2754 & TST & \\
\hline CHEMBL1511289 & 688759 & 4.9 & 4.7969 & TRN & \\
\hline CHEMBL3192439 & 688759 & 5.15 & 4.94600 & 0000000001 & TRN \\
\hline CHEMBL1523746 & 688759 & 4.45 & 5.0556 & TRN & \\
\hline CHEMBL1568934 & 688759 & 4.45 & 4.7037 & TRN & \\
\hline CHEMBL1532771 & 688759 & 4.8 & 4.8971 & TRN & \\
\hline CHEMBL3194761 & 688759 & 5.7 & 5.0506 & TRN & \\
\hline CHEMBL1557232 & 688759 & 4.65 & 5.0583 & TRN & \\
\hline CHEMBL1421857 & 688759 & 4.95 & 4.9903 & TST & \\
\hline CHEMBL445420 & 688759 & 4.45 & 5.042 & TST & \\
\hline CHEMBL1976414 & 688759 & 4.9 & 4.9406 & TRN & \\
\hline CHEMBL1311219 & 688759 & 4.6 & 4.8565 & TRN & \\
\hline CHEMBL1353228 & 688759 & 5.05 & 4.98600 & 0000000001 & TRN \\
\hline CHEMBL1301024 & 688759 & 4.65 & 4.7273 & TRN & \\
\hline CHEMBL1345547 & 688759 & 4.45 & 4.9596 & TST & \\
\hline CHEMBL1424321 & 688759 & 4.45 & 5.0082 & TRN & \\
\hline CHEMBL1536831 & 688759 & 4.85 & 5.3717 & TRN & \\
\hline CHEMBL1451017 & 688759 & 4.45 & 4.6709 & TRN & \\
\hline CHEMBL1349879 & 688759 & 5.1 & 5.244 & TRN & \\
\hline CHEMBL1604678 & 688759 & 4.45 & 4.7817 & TRN & \\
\hline CHEMBL1376213 & 688759 & 4.9 & 4.9666 & TRN & \\
\hline CHEMBL1359318 & 688759 & 4.8 & 4.4242 & TRN & \\
\hline CHEMBL1433375 & 688759 & 4.45 & 5.0343 & TST & \\
\hline CHEMBL3192833 & 688759 & 5.2 & 4.7607 & TRN & \\
\hline CHEMBL1467785 & 688759 & 4.45 & 4.7955 & TST & \\
\hline CHEMBL1490500 & 688759 & 5.5 & 5.567 & TRN & \\
\hline CHEMBL1340698 & 688759 & 6.15 & 5.5487 & TRN & \\
\hline CHEMBL1310906 & 688759 & 3.2 & 4.8423 & TST & \\
\hline CHEMBL1436933 & 688759 & 5.25 & 5.0352 & TRN & \\
\hline CHEMBL1492912 & 688759 & 4.75 & 4.8848 & TRN & \\
\hline CHEMBL3213088 & 688759 & 4.45 & 4.5656 & TRN & \\
\hline CHEMBL1329008 & 688759 & 4.65 & 4.8646 & TRN & \\
\hline CHEMBL3196823 & 688759 & 5.35 & 4.9648 & TRN & \\
\hline CHEMBL1351433 & 688759 & 6.0 & 5.07600 & 00000000005 & TRN \\
\hline CHEMBL1578699 & 688759 & 5.0 & 4.7299 & TRN & \\
\hline CHEMBL1527735 & 688759 & 5.05 & 4.747 & TST & \\
\hline CHEMBL1417287 & 688759 & 5.55 & 5.1467 & TRN & \\
\hline CHEMBL1548741 & 688759 & 4.45 & 4.8776 & TST & \\
\hline CHEMBL1393450 & 688759 & 4.45 & 4.9024 & TST & \\
\hline CHEMBL1313719 & 688759 & 5.45 & 4.8294 & TST & \\
\hline CHEMBL1347405 & 688759 & 4.45 & 4.6697 & TST & \\
\hline CHEMBL1478324 & 688759 & 4.8 & 4.8157 & TST & \\
\hline CHEMBL1400370 & 688759 & 5.55 & 5.4859 & TRN & \\
\hline CHEMBL1526068 & 688759 & 4.45 & 4.629 & TRN & \\
\hline CHEMBL1590615 & 688759 & 4.6 & 4.5673 & TRN & \\
\hline
\end{tabular}




\begin{tabular}{|c|c|c|c|c|c|}
\hline \multicolumn{6}{|c|}{ Supplemental Table S2.txt } \\
\hline CHEMBL1602059 & 688759 & 5.25 & 4.7325 & TRN & \\
\hline CHEMBL1432784 & 688759 & 6.15 & 6.019 & TRN & \\
\hline CHEMBL1544639 & 688759 & 4.45 & 4.6451 & TRN & \\
\hline CHEMBL1488036 & 688759 & 4.45 & 4.5485 & TST & \\
\hline CHEMBL1524930 & 688759 & 4.95 & 5.1302 & TRN & \\
\hline CHEMBL1390492 & 688759 & 4.8 & 5.2381 & TRN & \\
\hline CHEMBL1968928 & 688759 & 4.65 & 4.724 & TRN & \\
\hline CHEMBL1328140 & 688759 & 4.45 & 4.8289 & TRN & \\
\hline CHEMBL1504227 & 688759 & 4.85 & 4.8048 & TRN & \\
\hline CHEMBL1557122 & 688759 & 4.65 & 4.6694 & TRN & \\
\hline CHEMBL1587459 & 688759 & 4.45 & 4.7724 & TST & \\
\hline CHEMBL1302984 & 688759 & 4.45 & 4.7577 & TRN & \\
\hline CHEMBL1432964 & 688759 & 5.45 & 5.3143 & TRN & \\
\hline CHEMBL1336006 & 688759 & 4.8 & 4.711 & TRN & \\
\hline CHEMBL1612344 & 688759 & 5.25 & 4.8008 & TRN & \\
\hline CHEMBL1319647 & 688759 & 6.5501 & 4.8448 & TST & \\
\hline CHEMBL3194521 & 688759 & 5.15 & 5.0469 & TRN & \\
\hline CHEMBL1549415 & 688759 & 5.05 & 4.8547 & TRN & \\
\hline CHEMBL1359949 & 688759 & 4.45 & 4.6668 & TRN & \\
\hline CHEMBL1573242 & 688759 & 4.65 & 4.5301 & TST & \\
\hline CHEMBL1330740 & 688759 & 4.45 & 4.9181 & TRN & \\
\hline CHEMBL1352290 & 688759 & 5.55 & 5.0586 & TRN & \\
\hline CHEMBL1326919 & 688759 & 4.55 & 5.0596 & TRN & \\
\hline CHEMBL1308975 & 688759 & 4.45 & 4.5709 & TST & \\
\hline CHEMBL1469748 & 688759 & 4.95 & 4.8962 & TRN & \\
\hline CHEMBL1540116 & 688759 & 6.05 & 5.4829 & TRN & \\
\hline CHEMBL1596406 & 688759 & 6.1 & 5.3381 & TRN & \\
\hline CHEMBL1520845 & 688759 & 4.5 & 4.978 & TST & \\
\hline CHEMBL1597934 & 688759 & 4.45 & 4.5888 & TRN & \\
\hline CHEMBL1477335 & 688759 & 4.6 & 4.8966 & TST & \\
\hline CHEMBL1562605 & 688759 & 4.45 & 4.63899 & 9999999999 & TRN \\
\hline CHEMBL1413629 & 688759 & 5.25 & 5.4211 & TRN & \\
\hline CHEMBL1426247 & 688759 & 4.45 & 4.7728 & TRN & \\
\hline CHEMBL1504087 & 688759 & 4.45 & 5.1458 & TRN & \\
\hline CHEMBL1404676 & 688759 & 4.45 & 4.8566 & TRN & \\
\hline CHEMBL1306402 & 688759 & 4.65 & 4.8692 & TST & \\
\hline CHEMBL3207617 & 688759 & 5.65 & 5.2501 & TRN & \\
\hline CHEMBL1399096 & 688759 & 5.0 & 4.9691 & TRN & \\
\hline CHEMBL1534330 & 688759 & 5.3 & 5.0792 & TRN & \\
\hline CHEMBL1368599 & 688759 & 5.4 & 5.1248 & TRN & \\
\hline CHEMBL1430872 & 688759 & 4.45 & 4.7107 & TRN & \\
\hline CHEMBL1400613 & 688759 & 4.65 & 5.1432 & TRN & \\
\hline CHEMBL3189421 & 688759 & 5.05 & 4.9332 & TRN & \\
\hline CHEMBL1551610 & 688759 & 5.9 & 5.0404 & TST & \\
\hline CHEMBL1324954 & 688759 & 4.45 & 4.824 & TRN & \\
\hline CHEMBL1969470 & 688759 & 5.4 & 5.4475 & TRN & \\
\hline CHEMBL1319473 & 688759 & 4.45 & 4.8163 & TRN & \\
\hline CHEMBL1978651 & 688759 & 5.6 & 5.4445 & TRN & \\
\hline
\end{tabular}




\begin{tabular}{|c|c|c|c|c|}
\hline \multicolumn{5}{|c|}{ Supplemental Table S2.txt } \\
\hline CHEMBL1542320 & 688759 & 4.65 & 4.9663 & TRN \\
\hline CHEMBL1445134 & 688759 & 4.65 & 5.1897 & TRN \\
\hline CHEMBL1438617 & 688759 & 4.45 & 4.7533 & TRN \\
\hline CHEMBL1479491 & 688759 & 4.75 & 4.8808 & TST \\
\hline CHEMBL3196726 & 688759 & 5.45 & 5.6296 & TRN \\
\hline CHEMBL1530968 & 688759 & 4.9 & 4.6595 & TRN \\
\hline CHEMBL1493757 & 688759 & 4.9 & 4.9693 & TRN \\
\hline CHEMBL1610970 & 688759 & 5.05 & 4.9445 & TST \\
\hline CHEMBL1584846 & 688759 & 4.65 & 5.0047 & TRN \\
\hline CHEMBL586830 & 688759 & 5.5 & 4.6731 & TRN \\
\hline CHEMBL259840 & 688759 & 6.0 & 4.8269 & TST \\
\hline CHEMBL1351654 & 688759 & 4.8 & 4.6469 & TRN \\
\hline CHEMBL3199102 & 688759 & 4.45 & 4.9679 & TRN \\
\hline CHEMBL12998 & 688759 & 4.45 & 4.7901 & TST \\
\hline CHEMBL1979721 & 688759 & 5.15 & 5.2653 & TRN \\
\hline CHEMBL1448221 & 688759 & 5.4 & 5.2582 & TST \\
\hline CHEMBL1454006 & 688759 & 4.45 & 4.713 & TRN \\
\hline CHEMBL3196754 & 688759 & 4.9 & 5.4592 & TRN \\
\hline CHEMBL1335250 & 688759 & 5.25 & 5.2049 & TRN \\
\hline CHEMBL1300577 & 688759 & 4.85 & 4.738 & TRN \\
\hline CHEMBL341910 & 688759 & 5.5 & 4.8586 & TST \\
\hline CHEMBL1495377 & 688759 & 5.2 & 4.7973 & TRN \\
\hline CHEMBL1367915 & 688759 & 4.45 & 5.0785 & TRN \\
\hline CHEMBL1401907 & 688759 & 5.45 & 4.9491 & TRN \\
\hline CHEMBL1307156 & 688759 & 4.45 & 4.7352 & TRN \\
\hline CHEMBL3198792 & 688759 & 4.65 & 4.7214 & TRN \\
\hline CHEMBL1342840 & 688759 & 4.45 & 4.6218 & TRN \\
\hline CHEMBL1535977 & 688759 & 4.95 & 4.8535 & TST \\
\hline CHEMBL1322828 & 688759 & 4.8 & 5.0539 & TRN \\
\hline CHEMBL3208691 & 688759 & 4.85 & 5.0904 & TRN \\
\hline CHEMBL 2000025 & 688759 & 5.25 & 5.3523 & TRN \\
\hline CHEMBL1562725 & 688759 & 4.65 & 4.8403 & TRN \\
\hline CHEMBL1331836 & 688759 & 4.85 & 4.8277 & TRN \\
\hline CHEMBL1572333 & 688759 & 5.05 & 4.7657 & TRN \\
\hline CHEMBL1568922 & 688759 & 4.8 & 4.5783 & TRN \\
\hline CHEMBL1461352 & 688759 & 6.25 & 5.5646 & TRN \\
\hline CHEMBL1445607 & 688759 & 6.2 & 4.9358 & TRN \\
\hline CHEMBL140979 & 688759 & 4.65 & 4.973 & TST \\
\hline CHEMBL1488827 & 688759 & 4.95 & 4.8856 & TRN \\
\hline CHEMBL1421212 & 688759 & 4.6 & 4.7031 & TST \\
\hline CHEMBL3189193 & 688759 & 6.1 & 5.3195 & TRN \\
\hline CHEMBL1486002 & 688759 & 4.65 & 5.0383 & TRN \\
\hline CHEMBL1477069 & 688759 & 4.5 & 4.4486 & TST \\
\hline CHEMBL 258881 & 688759 & 4.95 & 4.8673 & TRN \\
\hline CHEMBL3190381 & 688759 & 4.9 & 4.8172 & TST \\
\hline CHEMBL1416890 & 688759 & 4.6 & 4.7799 & TRN \\
\hline CHEMBL1609946 & 688759 & 6.5501 & 6.353 & TRN \\
\hline CHEMBL1172021 & 688759 & 4.45 & 4.7577 & TST \\
\hline
\end{tabular}




\begin{tabular}{|c|c|c|c|c|c|}
\hline & & \multicolumn{4}{|c|}{ Supplemental Table s2.txt } \\
\hline CHEMBL1392564 & 688759 & 4.45 & 5.1295 & TRN & \\
\hline CHEMBL1607263 & 688759 & 4.45 & 4.7486 & TRN & \\
\hline CHEMBL1337675 & 688759 & 4.65 & 4.582 & TRN & \\
\hline CHEMBL1581250 & 688759 & 4.45 & 4.5605 & TRN & \\
\hline CHEMBL66654 & 688759 & 4.45 & 5.0726 & TST & \\
\hline CHEMBL1609685 & 688759 & 4.6 & 4.6746 & TRN & \\
\hline CHEMBL1448431 & 688759 & 6.05 & 5.2787 & TRN & \\
\hline CHEMBL600906 & 688759 & 4.5 & 4.74100 & 00000000005 & TRN \\
\hline CHEMBL1323550 & 688759 & 4.45 & 4.7119 & TRN & \\
\hline CHEMBL1419188 & 688759 & 5.15 & 5.0603 & TST & \\
\hline CHEMBL1518765 & 688759 & 4.45 & 4.6706 & TRN & \\
\hline CHEMBL1487422 & 688759 & 4.55 & 4.7766 & TRN & \\
\hline CHEMBL1449478 & 688759 & 4.95 & 5.0626 & TRN & \\
\hline CHEMBL1332013 & 688759 & 6.0 & 5.4166 & TRN & \\
\hline CHEMBL1510628 & 688759 & 4.45 & 4.8652 & TST & \\
\hline CHEMBL1477416 & 688759 & 4.45 & 4.7726 & TRN & \\
\hline CHEMBL1584597 & 688759 & 4.65 & 4.5666 & TRN & \\
\hline CHEMBL1583925 & 688759 & 4.45 & 5.0977 & TRN & \\
\hline CHEMBL406835 & 688759 & 5.15 & 4.9307 & TST & \\
\hline CHEMBL1408097 & 688759 & 4.6 & 4.9157 & TRN & \\
\hline CHEMBL 2028186 & 688759 & 4.95 & 4.8233 & TST & \\
\hline CHEMBL1352171 & 688759 & 4.45 & 4.6114 & TRN & \\
\hline CHEMBL1459600 & 688759 & 4.45 & 4.7866 & TST & \\
\hline CHEMBL1310873 & 688759 & 5.15 & 4.7641 & TST & \\
\hline CHEMBL1596647 & 688759 & 4.75 & 4.7441 & TRN & \\
\hline CHEMBL1531169 & 688759 & 4.65 & 4.6862 & TST & \\
\hline CHEMBL1559204 & 688759 & 4.9 & 4.6156 & TRN & \\
\hline CHEMBL1578242 & 688759 & 5.25 & 5.0442 & TRN & \\
\hline CHEMBL1496555 & 688759 & 4.75 & 4.8499 & TRN & \\
\hline CHEMBL1407976 & 688759 & 4.45 & 4.6913 & TST & \\
\hline CHEMBL1344374 & 688759 & 4.45 & 4.698 & TRN & \\
\hline CHEMBL1576854 & 688759 & 4.55 & 4.8413 & TRN & \\
\hline CHEMBL1359358 & 688759 & 6.05 & 4.936 & TRN & \\
\hline CHEMBL1469778 & 688759 & 4.45 & 4.9726 & TST & \\
\hline CHEMBL1410423 & 688759 & 4.7 & 4.6949 & TRN & \\
\hline CHEMBL1428763 & 688759 & 4.45 & 4.694 & TRN & \\
\hline CHEMBL3194438 & 688759 & 4.45 & 4.8369 & TRN & \\
\hline CHEMBL1588656 & 688759 & 5.35 & 5.0289 & TRN & \\
\hline CHEMBL1352023 & 688759 & 4.75 & 5.1797 & TRN & \\
\hline CHEMBL1434819 & 688759 & 4.7 & 4.712 & TRN & \\
\hline CHEMBL1467940 & 688759 & 5.1 & 4.9671 & TST & \\
\hline CHEMBL3198212 & 688759 & 4.8 & 4.797 & TRN & \\
\hline CHEMBL1350185 & 688759 & 4.45 & 4.9176 & TST & \\
\hline CHEMBL3198917 & 688759 & 6.1 & 4.9182 & TST & \\
\hline CHEMBL1486934 & 688759 & 5.35 & 5.1336 & TRN & \\
\hline CHEMBL1458745 & 688759 & 5.35 & 4.8544 & TRN & \\
\hline CHEMBL1428659 & 688759 & 4.7 & 5.0459 & TRN & \\
\hline CHEMBL1325416 & 688759 & 4.8 & 4.7888 & TRN & \\
\hline
\end{tabular}




\begin{tabular}{|c|c|c|c|c|}
\hline \multicolumn{5}{|c|}{ Supplemental Table S2.txt } \\
\hline CHEMBL1421575 & 688759 & 4.45 & 5.0239 & TRN \\
\hline CHEMBL1547041 & 688759 & 5.4 & 5.0157 & TST \\
\hline CHEMBL1486197 & 688759 & 5.1 & 4.5204 & TRN \\
\hline CHEMBL1354150 & 688759 & 4.45 & 4.5298 & TRN \\
\hline CHEMBL3192655 & 688759 & 5.1 & 5.1472 & TRN \\
\hline CHEMBL1412529 & 688759 & 5.3 & 4.8742 & TRN \\
\hline CHEMBL1389470 & 688759 & 5.25 & 4.9142 & TST \\
\hline CHEMBL1312443 & 688759 & 5.25 & 5.277 & TRN \\
\hline CHEMBL1550619 & 688759 & 4.45 & 4.7207 & TRN \\
\hline CHEMBL1407336 & 688759 & 4.8 & 4.7026 & TRN \\
\hline CHEMBL3189236 & 688759 & 4.45 & 4.7202 & TST \\
\hline CHEMBL1402749 & 688759 & 5.2 & 5.041 & TRN \\
\hline CHEMBL1482713 & 688759 & 4.85 & 5.0278 & TRN \\
\hline CHEMBL1505476 & 688759 & 8.2007 & 5.1161 & TRN \\
\hline CHEMBL1326053 & 688759 & 4.45 & 4.8995 & TST \\
\hline CHEMBL1341915 & 688759 & 5.3 & 4.6964 & TST \\
\hline CHEMBL1326873 & 688759 & 4.65 & 4.6526 & TRN \\
\hline CHEMBL1328427 & 688759 & 4.95 & 5.0127 & TST \\
\hline CHEMBL1535913 & 688759 & 5.35 & 5.5566 & TRN \\
\hline CHEMBL1322961 & 688759 & 4.65 & 4.7418 & TRN \\
\hline CHEMBL1611296 & 688759 & 5.2 & 5.1176 & TRN \\
\hline CHEMBL1335008 & 688759 & 4.45 & 4.8158 & TRN \\
\hline CHEMBL1586047 & 688759 & 5.4 & 5.2327 & TRN \\
\hline CHEMBL579390 & 688759 & 4.95 & $5.1620 e$ & 0000000001 \\
\hline CHEMBL1413671 & 688759 & 5.05 & 5.0668 & TRN \\
\hline CHEMBL1384373 & 688759 & 4.75 & 4.8316 & TRN \\
\hline CHEMBL1380743 & 688759 & 4.45 & 4.9443 & TRN \\
\hline CHEMBL1477849 & 688759 & 4.45 & 4.7111 & TRN \\
\hline CHEMBL1323868 & 688759 & 4.45 & 4.921 & TRN \\
\hline CHEMBL1569211 & 688759 & 5.55 & 5.0198 & TRN \\
\hline CHEMBL1406759 & 688759 & 4.45 & 4.7154 & TRN \\
\hline CHEMBL1319026 & 688759 & 4.45 & 4.7963 & TRN \\
\hline CHEMBL1520156 & 688759 & 4.45 & 4.887 & TST \\
\hline CHEMBL1442190 & 688759 & 5.1 & 5.0099 & TRN \\
\hline CHEMBL1439531 & 688759 & 5.15 & 4.9481 & TRN \\
\hline CHEMBL1569210 & 688759 & 5.45 & 5.0362 & TRN \\
\hline CHEMBL1611800 & 688759 & 6.0 & 4.9329 & TRN \\
\hline CHEMBL1603788 & 688759 & 4.9 & 4.7537 & TRN \\
\hline CHEMBL1546973 & 688759 & 4.45 & 4.532 & TST \\
\hline CHEMBL175266 & 688759 & 5.0 & 4.7849 & TRN \\
\hline CHEMBL3191585 & 688759 & 4.65 & 4.8622 & TST \\
\hline CHEMBL1309432 & 688759 & 4.9 & 4.9601 & TRN \\
\hline CHEMBL1501587 & 688759 & 4.5 & 5.1422 & TRN \\
\hline CHEMBL1579232 & 688759 & 5.2 & 4.7667 & TST \\
\hline CHEMBL1546393 & 688759 & 8.301 & 4.7939 & TRN \\
\hline CHEMBL1359883 & 688759 & 4.45 & 5.0899 & TRN \\
\hline CHEMBL1327153 & 688759 & 4.45 & 4.9451 & TRN \\
\hline CHEMBL1545998 & 688759 & 4.45 & 4.7495 & TRN \\
\hline
\end{tabular}




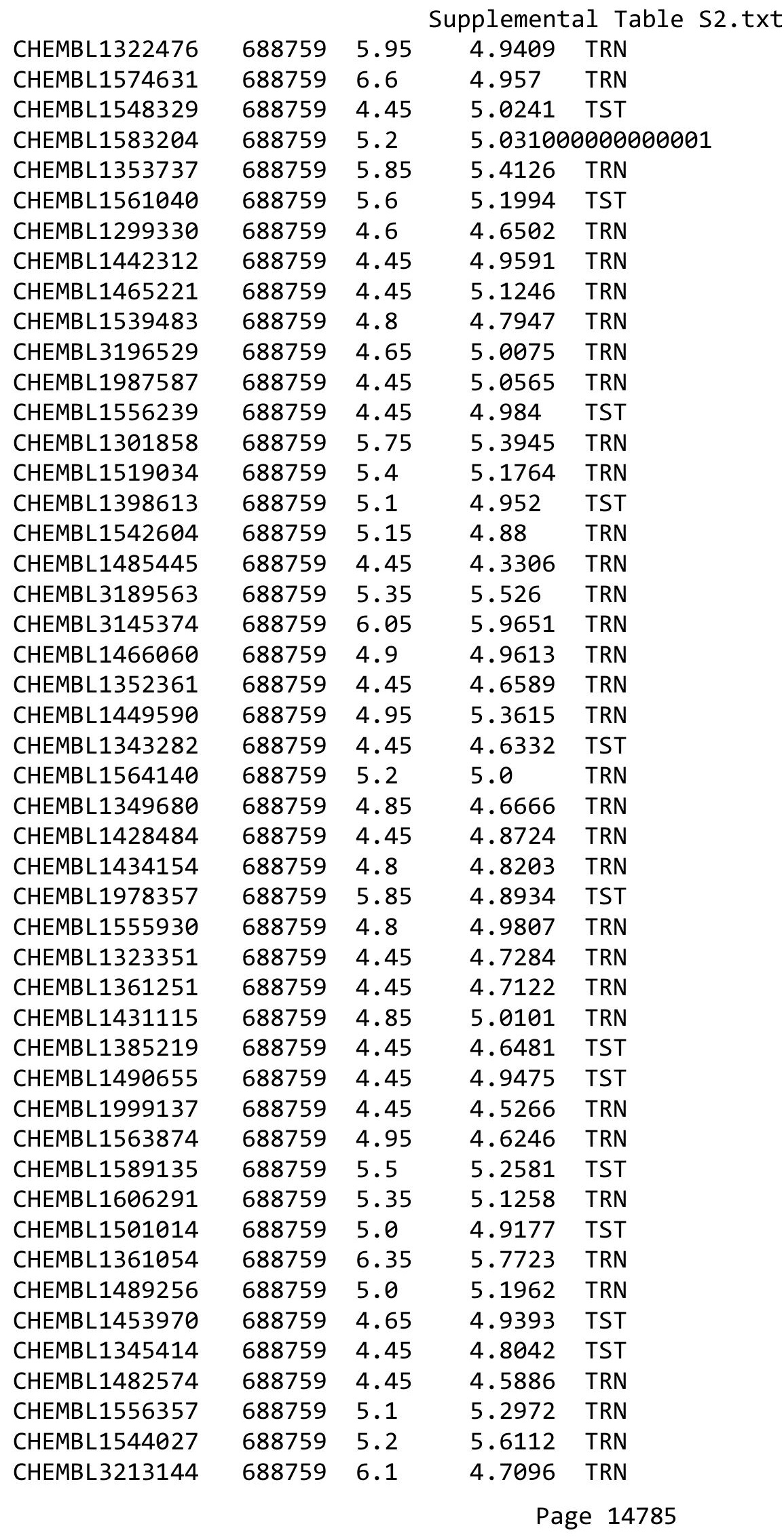

TRN 


\begin{tabular}{|c|c|c|c|c|c|}
\hline & & \multicolumn{4}{|c|}{ Supplemental Table s2.txt } \\
\hline CHEMBL1388744 & 688759 & 4.45 & 4.7585 & TRN & \\
\hline CHEMBL1392099 & 688759 & 4.45 & 4.5895 & TST & \\
\hline CHEMBL1539281 & 688759 & 4.8 & 4.8098 & TRN & \\
\hline CHEMBL1550806 & 688759 & 5.5 & 5.0762 & TRN & \\
\hline CHEMBL436589 & 688759 & 4.7 & 5.0317 & TRN & \\
\hline CHEMBL1419772 & 688759 & 4.65 & 4.9834 & TST & \\
\hline CHEMBL1967019 & 688759 & 5.15 & 5.4199 & TRN & \\
\hline CHEMBL1342701 & 688759 & 4.6 & 4.7044 & TRN & \\
\hline CHEMBL1508412 & 688759 & 4.5 & 4.7246 & TRN & \\
\hline CHEMBL1393193 & 688759 & 4.45 & 4.6266 & TRN & \\
\hline CHEMBL1305881 & 688759 & 4.55 & 5.1485 & TRN & \\
\hline CHEMBL3193622 & 688759 & 4.75 & 5.1656 & TRN & \\
\hline CHEMBL 2000420 & 688759 & 6.6 & 5.806 & TRN & \\
\hline CHEMBL1602510 & 688759 & 4.45 & 4.8688 & TRN & \\
\hline CHEMBL1568289 & 688759 & 5.15 & 5.0733 & TRN & \\
\hline CHEMBL1308101 & 688759 & 4.45 & 4.6278 & TST & \\
\hline CHEMBL3197879 & 688759 & 4.85 & 4.9266 & TRN & \\
\hline CHEMBL1502311 & 688759 & 4.95 & 5.2876 & TRN & \\
\hline CHEMBL1982308 & 688759 & 4.45 & 4.8795 & TRN & \\
\hline CHEMBL1425986 & 688759 & 4.65 & 4.7067 & TRN & \\
\hline CHEMBL1470298 & 688759 & 4.6 & 4.77800 & 00000000005 & TRN \\
\hline CHEMBL3191017 & 688759 & 4.45 & 4.8333 & TRN & \\
\hline CHEMBL1520122 & 688759 & 4.95 & 4.6775 & TRN & \\
\hline CHEMBL1351261 & 688759 & 4.75 & 4.7444 & TRN & \\
\hline CHEMBL3191485 & 688759 & 4.9 & 4.8277 & TRN & \\
\hline CHEMBL1548695 & 688759 & 5.6 & 5.1089 & TRN & \\
\hline CHEMBL1547533 & 688759 & 4.5 & 4.6674 & TST & \\
\hline CHEMBL1309539 & 688759 & 4.45 & 4.7016 & TRN & \\
\hline CHEMBL1984298 & 688759 & 4.45 & 4.6483 & TRN & \\
\hline CHEMBL1520407 & 688759 & 4.45 & 4.7438 & TRN & \\
\hline CHEMBL1541834 & 688759 & 5.95 & 5.8139 & TRN & \\
\hline CHEMBL3197136 & 688759 & 4.6 & 4.9165 & TRN & \\
\hline CHEMBL1391745 & 688759 & 4.45 & 4.9141 & TRN & \\
\hline CHEMBL1309234 & 688759 & 5.75 & 5.3829 & TRN & \\
\hline CHEMBL1378414 & 688759 & 5.9 & 4.7598 & TST & \\
\hline CHEMBL1366992 & 688759 & 5.95 & 5.29200 & 0000000001 & TRN \\
\hline CHEMBL3194029 & 688759 & 5.15 & 4.8893 & TRN & \\
\hline CHEMBL3197219 & 688759 & 5.55 & 4.9619 & TRN & \\
\hline CHEMBL3209333 & 688759 & 4.5 & 5.1069 & TRN & \\
\hline CHEMBL1441938 & 688759 & 4.5 & 4.9957 & TST & \\
\hline CHEMBL1423899 & 688759 & 4.45 & 4.7229 & TRN & \\
\hline CHEMBL1389734 & 688759 & 4.45 & 5.0373 & TRN & \\
\hline CHEMBL1321640 & 688759 & 5.75 & 4.7623 & TRN & \\
\hline CHEMBL1409400 & 688759 & 5.45 & 5.2096 & TRN & \\
\hline CHEMBL1337193 & 688759 & 4.75 & 4.9891 & TST & \\
\hline CHEMBL1531623 & 688759 & 5.35 & 4.87 & TST & \\
\hline CHEMBL1505511 & 688759 & 4.9 & 4.7206 & TST & \\
\hline CHEMBL1427499 & 688759 & 4.45 & 4.8993 & TRN & \\
\hline
\end{tabular}




\begin{tabular}{|c|c|c|c|c|c|}
\hline \multirow{3}{*}{$\begin{array}{l}\text { CHEMBL3197633 } \\
\text { CHEMBL1404122 }\end{array}$} & \multirow{3}{*}{$\begin{array}{l}688759 \\
688759\end{array}$} & \multicolumn{4}{|c|}{ Supplemental Table S2.txt } \\
\hline & & 5.85 & \multicolumn{2}{|c|}{4.7780000000000005} & TRN \\
\hline & & 4.95 & 4.7072 & TRN & \\
\hline CHEMBL1410650 & 688759 & 6.0 & 5.63 & TRN & \\
\hline CHEMBL1493322 & 688759 & 4.75 & 4.588 & TRN & \\
\hline CHEMBL1419342 & 688759 & 4.45 & 4.8072 & TRN & \\
\hline CHEMBL3189643 & 688759 & 6.2 & 5.4687 & TRN & \\
\hline CHEMBL1302640 & 688759 & 4.8 & 5.0503 & TRN & \\
\hline CHEMBL1458874 & 688759 & 5.85 & 4.7847 & TRN & \\
\hline CHEMBL1311819 & 688759 & 4.9 & 4.6572 & TRN & \\
\hline CHEMBL1501031 & 688759 & 5.25 & 4.7307 & TRN & \\
\hline CHEMBL1492541 & 688759 & 4.45 & 4.6685 & TRN & \\
\hline CHEMBL1520318 & 688759 & 4.5 & 5.5221 & TST & \\
\hline CHEMBL1352223 & 688759 & 4.6 & 4.4449 & TRN & \\
\hline CHEMBL3210636 & 688759 & 4.95 & 4.8842 & TST & \\
\hline CHEMBL1536020 & 688759 & 6.25 & 4.8955 & TRN & \\
\hline CHEMBL1425050 & 688759 & 4.6 & 4.8261 & TRN & \\
\hline CHEMBL3197277 & 688759 & 4.9 & 4.628 & TRN & \\
\hline CHEMBL1501957 & 688759 & 6.1 & 4.9433 & TST & \\
\hline CHEMBL1572294 & 688759 & 4.45 & 4.8126 & TRN & \\
\hline CHEMBL1368535 & 688759 & 6.0 & 5.401 & TST & \\
\hline CHEMBL1300243 & 688759 & 4.65 & 4.8363 & TRN & \\
\hline CHEMBL3195056 & 688759 & 4.45 & 5.36299 & 99999999995 & TRN \\
\hline CHEMBL1472327 & 688759 & 4.45 & 4.7378 & TST & \\
\hline CHEMBL1446863 & 688759 & 4.6 & 4.756 & TST & \\
\hline CHEMBL1445375 & 688759 & 4.6 & 4.7786 & TRN & \\
\hline CHEMBL1366820 & 688759 & 4.9 & 4.8347 & TRN & \\
\hline CHEMBL1468192 & 688759 & 6.0 & 5.1005 & TRN & \\
\hline CHEMBL1593867 & 688759 & 6.0 & 4.9237 & TRN & \\
\hline CHEMBL1502091 & 688759 & 4.65 & 5.3237 & TST & \\
\hline CHEMBL1324032 & 688759 & 5.25 & 4.8598 & TST & \\
\hline CHEMBL1478054 & 688759 & 4.45 & 4.55699 & 99999999995 & TRN \\
\hline CHEMBL1531250 & 688759 & 4.5 & 4.7901 & TST & \\
\hline CHEMBL1428562 & 688759 & 4.95 & 4.9163 & TRN & \\
\hline CHEMBL1402496 & 688759 & 5.5 & 5.3052 & TST & \\
\hline CHEMBL1407507 & 688759 & 5.25 & 5.0649 & TRN & \\
\hline CHEMBL1345931 & 688759 & 4.45 & 4.7588 & TRN & \\
\hline CHEMBL1376872 & 688759 & 4.8 & 4.9078 & TRN & \\
\hline CHEMBL1997716 & 688759 & 5.35 & 5.7002 & TRN & \\
\hline CHEMBL1608757 & 688759 & 4.55 & 4.4493 & TST & \\
\hline CHEMBL1584742 & 688759 & 4.7 & 4.5762 & TRN & \\
\hline CHEMBL1450999 & 688759 & 4.7 & 4.726 & TRN & \\
\hline CHEMBL1424472 & 688759 & 4.95 & 4.9695 & TRN & \\
\hline CHEMBL1530553 & 688759 & 4.45 & 4.8531 & TST & \\
\hline CHEMBL1444501 & 688759 & 4.55 & 4.559 & TRN & \\
\hline CHEMBL1409750 & 688759 & 4.45 & 4.6409 & TST & \\
\hline CHEMBL1348850 & 688759 & 4.45 & 5.0805 & TRN & \\
\hline CHEMBL1372738 & 688759 & 4.45 & 4.5335 & TRN & \\
\hline CHEMBL1454602 & 688759 & 4.9 & 5.4745 & TRN & \\
\hline
\end{tabular}




\begin{tabular}{|c|c|c|c|c|}
\hline \multicolumn{5}{|c|}{ Supplemental Table S2.txt } \\
\hline CHEMBL1468778 & 688759 & 5.25 & 5.0147 & TRN \\
\hline CHEMBL1505015 & 688759 & 5.3 & 4.8007 & TRN \\
\hline CHEMBL1403808 & 688759 & 5.3 & 4.842 & TRN \\
\hline CHEMBL1448267 & 688759 & 5.15 & 4.8624 & TRN \\
\hline CHEMBL1523697 & 688759 & 4.9 & 4.9859 & TRN \\
\hline CHEMBL1604837 & 688759 & 4.8 & 4.7156 & TRN \\
\hline CHEMBL3208408 & 688759 & 5.05 & 4.6728 & TST \\
\hline CHEMBL 3208237 & 688759 & 6.1 & 5.5179 & TRN \\
\hline CHEMBL3195746 & 688759 & 5.1 & 5.0019 & TRN \\
\hline CHEMBL1425401 & 688759 & 4.65 & 4.6323 & TRN \\
\hline CHEMBL1489853 & 688759 & 4.45 & 4.746 & TRN \\
\hline CHEMBL1370667 & 688759 & 4.45 & 4.9924 & TRN \\
\hline CHEMBL1486606 & 688759 & 4.45 & 4.7714 & TRN \\
\hline CHEMBL1493000 & 688759 & 4.45 & 4.5554 & TRN \\
\hline CHEMBL1379991 & 688759 & 4.6 & 4.6646 & TST \\
\hline CHEMBL1608362 & 688759 & 4.65 & 4.5111 & TRN \\
\hline CHEMBL1506264 & 688759 & 4.45 & 4.5112 & TRN \\
\hline CHEMBL1391607 & 688759 & 4.5 & 4.7655 & TRN \\
\hline CHEMBL1323978 & 688759 & 4.9 & 5.2187 & TRN \\
\hline CHEMBL1361040 & 688759 & 4.45 & 4.6834 & TRN \\
\hline CHEMBL1607486 & 688759 & 4.45 & 4.6786 & TRN \\
\hline CHEMBL1442271 & 688759 & 4.45 & 5.1767 & TRN \\
\hline CHEMBL1333594 & 688759 & 4.6 & 4.6752 & TRN \\
\hline CHEMBL1540446 & 688759 & 4.6 & 4.707 & TRN \\
\hline CHEMBL1457407 & 688759 & 4.65 & 5.1021 & TST \\
\hline CHEMBL1585181 & 688759 & 5.15 & 4.8726 & TRN \\
\hline CHEMBL585656 & 688759 & 4.7 & 5.003 & TST \\
\hline CHEMBL1374665 & 688759 & 5.6 & 4.8622 & TRN \\
\hline CHEMBL1544371 & 688759 & 4.6 & 5.6961 & TRN \\
\hline CHEMBL1269809 & 688759 & 4.7 & 4.926 & TRN \\
\hline CHEMBL1557054 & 688759 & 4.45 & 4.9019 & TST \\
\hline CHEMBL1536291 & 688759 & 7.0 & 4.8067 & TST \\
\hline CHEMBL1594827 & 688759 & 5.0 & 4.6165 & TST \\
\hline CHEMBL3211341 & 688759 & 4.65 & 4.7502 & TRN \\
\hline CHEMBL1377938 & 688759 & 4.45 & 4.7759 & TRN \\
\hline CHEMBL1407281 & 688759 & 4.6 & 4.8762 & TRN \\
\hline CHEMBL1500252 & 688759 & 5.4 & 4.898 & TST \\
\hline CHEMBL1991055 & 688759 & 5.45 & 5.4044 & TRN \\
\hline CHEMBL1452315 & 688759 & 4.45 & 4.8533 & TST \\
\hline CHEMBL1391045 & 688759 & 5.0 & 4.8742 & TRN \\
\hline CHEMBL1337795 & 688759 & 4.65 & 4.9028 & TST \\
\hline CHEMBL1313191 & 688759 & 4.45 & 4.7899 & TST \\
\hline CHEMBL1303151 & 688759 & 5.35 & 4.9529 & TRN \\
\hline CHEMBL1509727 & 688759 & 5.2 & 4.8432 & TRN \\
\hline CHEMBL1329291 & 688759 & 4.45 & 4.7028 & TST \\
\hline CHEMBL1449499 & 688759 & 4.45 & 4.7062 & TRN \\
\hline CHEMBL1462009 & 688759 & 5.4 & 4.8929 & TRN \\
\hline CHEMBL1470624 & 688759 & 4.65 & 4.7378 & TST \\
\hline
\end{tabular}




\begin{tabular}{|c|c|c|c|c|}
\hline \multirow[b]{2}{*}{ CHEMBL1540558 } & \multicolumn{4}{|c|}{ Supplemental Table S2.txt } \\
\hline & 688759 & 6.0 & 4.9455 & TST \\
\hline CHEMBL1559001 & 688759 & 4.45 & 4.7004 & TRN \\
\hline CHEMBL1370591 & 688759 & 4.6 & 4.8702 & TRN \\
\hline CHEMBL1501996 & 688759 & 4.45 & 5.0704 & TST \\
\hline CHEMBL1502216 & 688759 & 4.8 & 4.7515 & TRN \\
\hline CHEMBL1345707 & 688759 & 5.4 & 4.8888 & TST \\
\hline CHEMBL1299270 & 688759 & 5.1 & 5.1819 & TRN \\
\hline CHEMBL1375149 & 688759 & 4.45 & 4.5967 & TST \\
\hline CHEMBL1438779 & 688759 & 4.75 & 4.8081 & TST \\
\hline CHEMBL1428486 & 688759 & 4.95 & 4.8451 & TRN \\
\hline CHEMBL1545838 & 688759 & 4.55 & 4.9367 & TST \\
\hline CHEMBL1441940 & 688759 & 5.25 & 4.9827 & TST \\
\hline CHEMBL3189326 & 688759 & 4.45 & 4.8822 & TRN \\
\hline CHEMBL1366794 & 688759 & 5.25 & 4.7814 & TST \\
\hline CHEMBL1544103 & 688759 & 4.9 & 4.8917 & TRN \\
\hline CHEMBL1392228 & 688759 & 5.65 & 5.4251 & TRN \\
\hline CHEMBL1353825 & 688759 & 4.55 & 4.8342 & TRN \\
\hline CHEMBL1463172 & 688759 & 4.45 & 4.5905 & TST \\
\hline CHEMBL1332895 & 688759 & 4.75 & 4.6824 & TRN \\
\hline CHEMBL1304770 & 688759 & 4.9 & 5.1432 & TRN \\
\hline CHEMBL1587981 & 688759 & 4.9 & 4.8264 & TRN \\
\hline CHEMBL1254918 & 688759 & 5.05 & 4.8271 & TRN \\
\hline CHEMBL1445725 & 688759 & 5.3 & 5.6402 & TRN \\
\hline CHEMBL579105 & 688759 & 4.45 & 4.7882 & TRN \\
\hline CHEMBL1371275 & 688759 & 6.5 & 4.8029 & TRN \\
\hline CHEMBL1486090 & 688759 & 5.3 & 4.8688 & TST \\
\hline CHEMBL1457830 & 688759 & 5.65 & 5.4544 & TRN \\
\hline CHEMBL1544141 & 688759 & 5.35 & 5.5018 & TRN \\
\hline CHEMBL1369691 & 688759 & 4.5 & 4.788 & TRN \\
\hline CHEMBL1343309 & 688759 & 4.95 & 5.0056 & TRN \\
\hline CHEMBL3195530 & 688759 & 5.35 & 5.2941 & TRN \\
\hline CHEMBL1455446 & 688759 & 6.05 & 5.9625 & TRN \\
\hline CHEMBL3195943 & 688759 & 4.45 & 4.5794 & TRN \\
\hline CHEMBL3195387 & 688759 & 5.25 & 4.9423 & TRN \\
\hline CHEMBL1307808 & 688759 & 4.45 & 4.6886 & TST \\
\hline CHEMBL1361271 & 688759 & 5.25 & 4.7866 & TST \\
\hline CHEMBL1428059 & 688759 & 5.1 & 5.4395 & TST \\
\hline CHEMBL1432589 & 688759 & 4.5 & 4.5701 & TRN \\
\hline CHEMBL1340265 & 688759 & 4.55 & 4.5254 & TRN \\
\hline CHEMBL1311820 & 688759 & 4.45 & 4.7797 & TST \\
\hline CHEMBL1570277 & 688759 & 4.5 & 4.7209 & TRN \\
\hline CHEMBL1360609 & 688759 & 4.75 & 4.6854 & TRN \\
\hline CHEMBL1450412 & 688759 & 5.15 & 4.6178 & TRN \\
\hline CHEMBL1399495 & 688759 & 4.7 & 4.9009 & TRN \\
\hline CHEMBL1561288 & 688759 & 4.45 & 4.9626 & TST \\
\hline CHEMBL3199694 & 688759 & 4.45 & 5.0444 & TRN \\
\hline CHEMBL1300049 & 688759 & 4.85 & 4.5983 & TRN \\
\hline CHEMBL1605446 & 688759 & 4.7 & 4.9641 & TRN \\
\hline
\end{tabular}




\begin{tabular}{|c|c|c|c|c|c|}
\hline & & \multicolumn{4}{|c|}{ Supplemental Table s2.txt } \\
\hline CHEMBL1989426 & 688759 & 5.95 & 5.1566 & TRN & \\
\hline CHEMBL1564490 & 688759 & 4.45 & 4.8275 & TRN & \\
\hline CHEMBL1310930 & 688759 & 4.45 & 4.6782 & TRN & \\
\hline CHEMBL1487895 & 688759 & 4.45 & 4.73300 & 00000000005 & TRN \\
\hline CHEMBL3192773 & 688759 & 4.45 & 4.6582 & TRN & \\
\hline CHEMBL1347204 & 688759 & 5.35 & 5.5211 & TRN & \\
\hline CHEMBL1537250 & 688759 & 4.85 & 5.0289 & TST & \\
\hline CHEMBL1416690 & 688759 & 4.7 & 4.8884 & TRN & \\
\hline CHEMBL1500035 & 688759 & 4.9 & 4.9579 & TRN & \\
\hline CHEMBL1349823 & 688759 & 4.8 & 5.0231 & TRN & \\
\hline CHEMBL3192567 & 688759 & 5.3 & 4.9221 & TRN & \\
\hline CHEMBL1302089 & 688759 & 5.4 & 4.9276 & TRN & \\
\hline CHEMBL1904956 & 688759 & 4.75 & 4.7724 & TRN & \\
\hline CHEMBL1437560 & 688759 & 4.45 & 4.5116 & TST & \\
\hline CHEMBL1373280 & 688759 & 4.45 & 5.0275 & TRN & \\
\hline CHEMBL1508232 & 688759 & 4.45 & 4.756 & TST & \\
\hline CHEMBL1966848 & 688759 & 4.45 & 5.1111 & TRN & \\
\hline CHEMBL1300653 & 688759 & 4.75 & 5.006 & TST & \\
\hline CHEMBL1587205 & 688759 & 4.85 & 4.7038 & TST & \\
\hline CHEMBL1459316 & 688759 & 4.45 & 4.9367 & TRN & \\
\hline CHEMBL1482683 & 688759 & 6.05 & 4.9659 & TRN & \\
\hline CHEMBL1587837 & 688759 & 4.65 & 4.6786 & TST & \\
\hline CHEMBL1300735 & 688759 & 5.0 & 5.2965 & TRN & \\
\hline CHEMBL1332378 & 688759 & 4.8 & 4.9451 & TST & \\
\hline CHEMBL1383873 & 688759 & 4.6 & 4.5843 & TST & \\
\hline CHEMBL1408207 & 688759 & 4.95 & 4.9589 & TST & \\
\hline CHEMBL312487 & 688759 & 5.35 & 5.1895 & TRN & \\
\hline CHEMBL1606367 & 688759 & 6.0 & 5.2843 & TRN & \\
\hline CHEMBL1533645 & 688759 & 4.55 & 4.6042 & TST & \\
\hline CHEMBL1582611 & 688759 & 4.65 & 4.7299 & TRN & \\
\hline CHEMBL1562517 & 688759 & 4.45 & 4.7972 & TRN & \\
\hline CHEMBL1351862 & 688759 & 5.0 & 4.9889 & TST & \\
\hline CHEMBL1585524 & 688759 & 4.45 & 4.6458 & TRN & \\
\hline CHEMBL1586270 & 688759 & 4.45 & 4.626 & TRN & \\
\hline CHEMBL1341020 & 688759 & 4.75 & 5.0586 & TRN & \\
\hline CHEMBL1468473 & 688759 & 4.9 & 4.6674 & TRN & \\
\hline CHEMBL1607290 & 688759 & 4.45 & 4.7651 & TRN & \\
\hline CHEMBL1408846 & 688759 & 4.45 & 4.6503 & TRN & \\
\hline CHEMBL1412262 & 688759 & 4.55 & 4.7191 & TRN & \\
\hline CHEMBL1471795 & 688759 & 4.45 & 4.8628 & TRN & \\
\hline CHEMBL1517072 & 688759 & 5.0 & 5.0423 & TRN & \\
\hline CHEMBL1460653 & 688759 & 4.65 & 4.8666 & TRN & \\
\hline CHEMBL1393113 & 688759 & 4.45 & 4.9424 & TRN & \\
\hline CHEMBL1544695 & 688759 & 5.3 & 4.9814 & TRN & \\
\hline CHEMBL579322 & 688759 & 5.3 & 4.8908 & TRN & \\
\hline CHEMBL491953 & 688759 & 4.6 & 4.6021 & TRN & \\
\hline CHEMBL1352996 & 688759 & 4.45 & 4.525 & TRN & \\
\hline CHEMBL1214525 & 688759 & 4.95 & 4.7636 & TRN & \\
\hline
\end{tabular}




\begin{tabular}{|c|c|c|c|c|c|}
\hline & & \multicolumn{4}{|c|}{ Supplemental Table s2.txt } \\
\hline CHEMBL1427397 & 688759 & 4.45 & 4.7009 & TST & \\
\hline CHEMBL1586817 & 688759 & 4.45 & 4.6837 & TRN & \\
\hline CHEMBL1405925 & 688759 & 4.6 & 4.8383 & TST & \\
\hline CHEMBL1996299 & 688759 & 5.0 & 5.0477 & TRN & \\
\hline CHEMBL 3197576 & 688759 & 4.95 & 5.0621 & TST & \\
\hline CHEMBL1460947 & 688759 & 5.0 & 4.9355 & TRN & \\
\hline CHEMBL 3211285 & 688759 & 4.45 & 5.1207 & TST & \\
\hline CHEMBL1432196 & 688759 & 5.1 & 4.6779 & TRN & \\
\hline CHEMBL1381265 & 688759 & 6.15 & 5.8957 & TRN & \\
\hline CHEMBL3193462 & 688759 & 4.45 & 4.8092 & TRN & \\
\hline CHEMBL1383011 & 688759 & 5.9 & 5.1245 & TST & \\
\hline CHEMBL1497594 & 688759 & 4.45 & 4.6801 & TRN & \\
\hline CHEMBL1427868 & 688759 & 4.45 & 4.9813 & TST & \\
\hline CHEMBL1527433 & 688759 & 5.2 & 5.3322 & TRN & \\
\hline CHEMBL3207822 & 688759 & 6.2 & 4.8665 & TRN & \\
\hline CHEMBL1371614 & 688759 & 4.45 & 4.6045 & TRN & \\
\hline CHEMBL1458572 & 688759 & 4.45 & 4.9183 & TRN & \\
\hline CHEMBL1500686 & 688759 & 4.65 & 4.7456 & TRN & \\
\hline CHEMBL1577632 & 688759 & 4.95 & 4.9166 & TRN & \\
\hline CHEMBL1570382 & 688759 & 4.7 & 4.8954 & TRN & \\
\hline CHEMBL1603813 & 688759 & 4.9 & 4.6505 & TRN & \\
\hline CHEMBL1576577 & 688759 & 4.65 & 4.7796 & TST & \\
\hline CHEMBL1375373 & 688759 & 6.3 & 6.2927 & TRN & \\
\hline CHEMBL1584840 & 688759 & 4.6 & 4.6014 & TRN & \\
\hline CHEMBL111654 & 688759 & 6.0 & 5.2143 & TRN & \\
\hline CHEMBL 3190583 & 688759 & 4.65 & 4.9089 & TST & \\
\hline CHEMBL1497713 & 688759 & 5.25 & 5.1029 & TRN & \\
\hline CHEMBL1500112 & 688759 & 5.05 & 5.1372 & TRN & \\
\hline CHEMBL1406312 & 688759 & 4.75 & 4.9323 & TRN & \\
\hline CHEMBL3191030 & 688759 & 5.5 & 5.2104 & TRN & \\
\hline CHEMBL1526240 & 688759 & 5.65 & 5.3314 & TRN & \\
\hline CHEMBL1530108 & 688759 & 5.25 & 5.1584 & TRN & \\
\hline CHEMBL1433195 & 688759 & 4.7 & 4.8464 & TRN & \\
\hline CHEMBL1497115 & 688759 & 4.7 & 4.9042 & TRN & \\
\hline CHEMBL1544054 & 688759 & 6.0 & 4.9759 & TRN & \\
\hline CHEMBL1490222 & 688759 & 6.2 & 5.7441 & TRN & \\
\hline CHEMBL1516729 & 688759 & 4.9 & 4.7247 & TRN & \\
\hline CHEMBL1303090 & 688759 & 4.45 & 4.92399 & 99999999995 & TRN \\
\hline CHEMBL1388379 & 688759 & 4.45 & 4.5918 & TRN & \\
\hline CHEMBL1501015 & 688759 & 4.5 & 4.908 & TST & \\
\hline CHEMBL1419965 & 688759 & 4.75 & 5.1263 & TRN & \\
\hline CHEMBL437571 & 688759 & 5.55 & 4.8669 & TRN & \\
\hline CHEMBL1582029 & 688759 & 5.95 & 4.9495 & TST & \\
\hline CHEMBL1486635 & 688759 & 4.9 & 4.8089 & TRN & \\
\hline CHEMBL1451694 & 688759 & 5.2 & 5.1188 & TRN & \\
\hline CHEMBL1410837 & 688759 & 5.25 & 4.7652 & TRN & \\
\hline CHEMBL1602479 & 688759 & 5.15 & 5.0963 & TRN & \\
\hline CHEMBL1346370 & 688759 & 4.45 & 4.796 & TRN & \\
\hline
\end{tabular}




\begin{tabular}{|c|c|c|c|c|c|}
\hline \multicolumn{6}{|c|}{ Supplemental Table S2.txt } \\
\hline CHEMBL1506828 & 688759 & 4.45 & 4.7413 & TRN & \\
\hline CHEMBL1308789 & 688759 & 4.45 & 4.6544 & TRN & \\
\hline CHEMBL3197910 & 688759 & 4.45 & 4.7604 & TRN & \\
\hline CHEMBL1464137 & 688759 & 5.25 & 5.1197 & TRN & \\
\hline CHEMBL1452610 & 688759 & 4.9 & 4.629 & TRN & \\
\hline CHEMBL1577981 & 688759 & 5.15 & 4.758 & TRN & \\
\hline CHEMBL1506218 & 688759 & 4.45 & 5.0973 & TRN & \\
\hline CHEMBL1502397 & 688759 & 5.5 & 4.9985 & TRN & \\
\hline CHEMBL3190048 & 688759 & 5.0 & 4.8733 & TST & \\
\hline CHEMBL1510905 & 688759 & 6.2 & 6.08200 & 0000000001 & TRN \\
\hline CHEMBL1526319 & 688759 & 4.7 & 4.8202 & TST & \\
\hline CHEMBL1599815 & 688759 & 5.7 & 5.606 & TRN & \\
\hline CHEMBL1613463 & 688759 & 4.45 & 4.7935 & TST & \\
\hline CHEMBL1322180 & 688759 & 4.6 & 4.7468 & TST & \\
\hline CHEMBL1488922 & 688759 & 4.85 & 5.0222 & TRN & \\
\hline CHEMBL1536326 & 688759 & 4.65 & 4.9139 & TRN & \\
\hline CHEMBL3195641 & 688759 & 5.5 & 5.2973 & TRN & \\
\hline CHEMBL1973532 & 688759 & 6.05 & 5.5322 & TRN & \\
\hline CHEMBL1419442 & 688759 & 4.65 & 4.8806 & TRN & \\
\hline CHEMBL1406953 & 688759 & 4.45 & 5.0844 & TRN & \\
\hline CHEMBL1555952 & 688759 & 4.75 & 4.6337 & TRN & \\
\hline CHEMBL1536394 & 688759 & 4.6 & 5.2475 & TRN & \\
\hline CHEMBL1318220 & 688759 & 4.95 & 4.6551 & TRN & \\
\hline CHEMBL1328069 & 688759 & 4.85 & 4.6757 & TRN & \\
\hline CHEMBL1424327 & 688759 & 5.0 & 4.7754 & TRN & \\
\hline CHEMBL1589652 & 688759 & 4.8 & 4.7913 & TST & \\
\hline CHEMBL1445915 & 688759 & 4.45 & 4.8173 & TRN & \\
\hline CHEMBL1534479 & 688759 & 5.25 & 4.9051 & TRN & \\
\hline CHEMBL1461524 & 688759 & 5.45 & 4.7901 & TRN & \\
\hline CHEMBL1530600 & 688759 & 4.7 & 4.8796 & TRN & \\
\hline CHEMBL1324324 & 688759 & 5.0 & 5.118 & TRN & \\
\hline CHEMBL1471399 & 688759 & 4.65 & 4.9668 & TRN & \\
\hline CHEMBL1459740 & 688759 & 4.45 & 4.978 & TRN & \\
\hline CHEMBL1331030 & 688759 & 4.45 & 4.9437 & TRN & \\
\hline CHEMBL1604527 & 688759 & 4.95 & 4.7809 & TRN & \\
\hline CHEMBL1610372 & 688759 & 4.45 & 4.8054 & TRN & \\
\hline CHEMBL1580495 & 688759 & 4.5 & 4.9015 & TRN & \\
\hline CHEMBL1492909 & 688759 & 4.45 & 4.8572 & TRN & \\
\hline CHEMBL1546039 & 688759 & 5.2 & 4.9188 & TRN & \\
\hline CHEMBL1325961 & 688759 & 4.45 & 4.8193 & TST & \\
\hline CHEMBL1367985 & 688759 & 5.95 & 5.6487 & TRN & \\
\hline CHEMBL1461664 & 688759 & 4.45 & 4.7384 & TRN & \\
\hline CHEMBL1372597 & 688759 & 4.45 & 4.8187 & TRN & \\
\hline CHEMBL1494139 & 688759 & 4.55 & 4.5817 & TST & \\
\hline CHEMBL1317897 & 688759 & 4.45 & 4.9007 & TRN & \\
\hline CHEMBL1570567 & 688759 & 5.15 & 5.4444 & TRN & \\
\hline CHEMBL1467739 & 688759 & 4.45 & 4.8055 & TRN & \\
\hline CHEMBL1365210 & 688759 & 4.45 & 4.5423 & TRN & \\
\hline
\end{tabular}




\begin{tabular}{|c|c|c|c|c|c|}
\hline \multicolumn{6}{|c|}{ Supplemental Table s2.txt } \\
\hline CHEMBL1604325 & 688759 & 4.9 & 4.8967 & TRN & \\
\hline CHEMBL3189917 & 688759 & 5.7 & 5.3267 & TRN & \\
\hline CHEMBL1531997 & 688759 & 4.45 & 4.7519 & TRN & \\
\hline CHEMBL1966684 & 688759 & 5.45 & 5.1857 & TRN & \\
\hline CHEMBL1501785 & 688759 & 4.5 & 4.6264 & TRN & \\
\hline CHEMBL1727447 & 688759 & 4.9 & 4.8278 & TRN & \\
\hline CHEMBL1538036 & 688759 & 4.45 & 5.0793 & TST & \\
\hline CHEMBL1520601 & 688759 & 4.65 & 4.8884 & TRN & \\
\hline CHEMBL1473160 & 688759 & 4.45 & 4.7159 & TRN & \\
\hline CHEMBL1421179 & 688759 & 4.45 & 4.7746 & TRN & \\
\hline CHEMBL3198307 & 688759 & 4.45 & 5.0363 & TRN & \\
\hline CHEMBL1488667 & 688759 & 6.35 & 5.0223 & TRN & \\
\hline CHEMBL3191354 & 688759 & 4.45 & 4.7084 & TRN & \\
\hline CHEMBL1548454 & 688759 & 4.9 & 4.9942 & TRN & \\
\hline CHEMBL1345652 & 688759 & 5.45 & 4.8302 & TRN & \\
\hline CHEMBL1390840 & 688759 & 4.75 & 4.6985 & TST & \\
\hline CHEMBL1437963 & 688759 & 5.4 & 4.9796 & TST & \\
\hline CHEMBL1568716 & 688759 & 4.95 & 5.3387 & TRN & \\
\hline CHEMBL1492652 & 688759 & 4.45 & 4.8004 & TST & \\
\hline CHEMBL1503041 & 688759 & 5.1 & 4.9735 & TRN & \\
\hline CHEMBL1364561 & 688759 & 4.65 & 4.9493 & TRN & \\
\hline CHEMBL1613147 & 688759 & 5.3 & 5.2575 & TRN & \\
\hline CHEMBL1372805 & 688759 & 4.6 & 4.6567 & TRN & \\
\hline CHEMBL1415438 & 688759 & 4.7 & 4.739 & TST & \\
\hline CHEMBL1469734 & 688759 & 4.6 & 5.1588 & TRN & \\
\hline CHEMBL3191000 & 688759 & 5.95 & 4.7567 & TRN & \\
\hline CHEMBL1403276 & 688759 & 5.9 & 5.6781 & TRN & \\
\hline CHEMBL3196095 & 688759 & 4.45 & 4.9507 & TRN & \\
\hline CHEMBL1585907 & 688759 & 4.9 & 5.0196 & TRN & \\
\hline CHEMBL1363092 & 688759 & 7.5003 & 4.7976 & TST & \\
\hline CHEMBL462576 & 688759 & 6.0 & 4.994 & TST & \\
\hline CHEMBL1540862 & 688759 & 4.95 & 4.7867 & TRN & \\
\hline CHEMBL1995879 & 688759 & 5.55 & 5.1948 & TRN & \\
\hline CHEMBL1609818 & 688759 & 4.65 & 4.7282 & TST & \\
\hline CHEMBL1455631 & 688759 & 4.5 & 4.66 & TRN & \\
\hline CHEMBL3196340 & 688759 & 5.3 & 5.1247 & TRN & \\
\hline CHEMBL1518057 & 688759 & 4.9 & 4.8518 & TRN & \\
\hline CHEMBL1530011 & 688759 & 4.95 & 4.9475 & TRN & \\
\hline CHEMBL1606732 & 688759 & 5.25 & 4.8022 & TST & \\
\hline CHEMBL1601109 & 688759 & 4.45 & 5.21700 & 00000000005 & TRN \\
\hline CHEMBL1369853 & 688759 & 4.45 & 4.9862 & TST & \\
\hline CHEMBL3193239 & 688759 & 4.45 & 4.8919 & TST & \\
\hline CHEMBL1497201 & 688759 & 4.95 & 5.3825 & TRN & \\
\hline CHEMBL1340431 & 688759 & 4.45 & 4.6207 & TST & \\
\hline CHEMBL1431419 & 688759 & 4.6 & 4.4964 & TRN & \\
\hline CHEMBL1302906 & 688759 & 4.8 & 4.6698 & TST & \\
\hline CHEMBL1312943 & 688759 & 4.45 & 5.2781 & TRN & \\
\hline CHEMBL1481444 & 688759 & 5.3 & 5.044 & TST & \\
\hline
\end{tabular}




\begin{tabular}{|c|c|c|c|c|c|}
\hline \multicolumn{6}{|c|}{ pplemental lable S2.t } \\
\hline CHEMBL1480604 & 688759 & 6.0 & 5.8414 & TRN & \\
\hline CHEMBL1454614 & 688759 & 5.5 & 5.032 & TRN & \\
\hline CHEMBL3189357 & 688759 & 5.45 & 4.9641 & TRN & \\
\hline CHEMBL3213960 & 688759 & 5.0 & 5.1419 & TST & \\
\hline CHEMBL1454827 & 688759 & 5.25 & 5.0462 & TRN & \\
\hline CHEMBL1333798 & 688759 & 4.45 & 4.8748 & TRN & \\
\hline CHEMBL1519955 & 688759 & 6.2 & 5.1309 & TRN & \\
\hline CHEMBL1489219 & 688759 & 6.1 & 4.5114 & TRN & \\
\hline CHEMBL1606431 & 688759 & 4.95 & 5.0918 & TRN & \\
\hline CHEMBL1557373 & 688759 & 4.45 & 4.6985 & TST & \\
\hline CHEMBL1372865 & 688759 & 4.45 & 4.9354 & TRN & \\
\hline CHEMBL1080213 & 688759 & 4.5 & 4.7242 & TRN & \\
\hline CHEMBL1572111 & 688759 & 4.9 & 4.9826 & TRN & \\
\hline CHEMBL1381281 & 688759 & 4.45 & 4.5411 & TRN & \\
\hline CHEMBL1612019 & 688759 & 5.4 & 5.0761 & TST & \\
\hline CHEMBL1991791 & 688759 & 4.45 & 4.5083 & TRN & \\
\hline CHEMBL1341720 & 688759 & 4.45 & 4.4602 & TRN & \\
\hline CHEMBL1547077 & 688759 & 4.45 & 4.6093 & TRN & \\
\hline CHEMBL1602046 & 688759 & 4.45 & 4.8497 & TST & \\
\hline CHEMBL1570224 & 688759 & 5.2 & 5.2266 & TRN & \\
\hline CHEMBL1557816 & 688759 & 4.6 & 4.96899 & 9999999999 & TST \\
\hline CHEMBL1333461 & 688759 & 6.0 & 5.7023 & TRN & \\
\hline CHEMBL1479434 & 688759 & 4.65 & 4.9685 & TRN & \\
\hline CHEMBL1584630 & 688759 & 6.0 & 4.8842 & TRN & \\
\hline CHEMBL1500106 & 688759 & 4.45 & 4.9786 & TRN & \\
\hline CHEMBL1580037 & 688759 & 4.45 & 4.6433 & TRN & \\
\hline CHEMBL1436865 & 688759 & 4.45 & 4.4654 & TRN & \\
\hline CHEMBL1303227 & 688759 & 4.45 & 5.3832 & TRN & \\
\hline CHEMBL1347453 & 688759 & 5.7 & 5.0696 & TRN & \\
\hline CHEMBL1540929 & 688759 & 5.15 & 5.0865 & TRN & \\
\hline CHEMBL1450605 & 688759 & 5.3 & 5.1695 & TRN & \\
\hline CHEMBL1613274 & 688759 & 5.1 & 4.9606 & TRN & \\
\hline CHEMBL1459852 & 688759 & 4.65 & 4.9079 & TST & \\
\hline CHEMBL1469344 & 688759 & 4.95 & 4.8786 & TRN & \\
\hline CHEMBL 3210057 & 688759 & 4.45 & 5.1397 & TRN & \\
\hline CHEMBL1464620 & 688759 & 4.9 & 5.6428 & TRN & \\
\hline CHEMBL1562821 & 688759 & 5.7 & 4.7752 & TRN & \\
\hline CHEMBL1535555 & 688759 & 5.4 & 4.8804 & TRN & \\
\hline CHEMBL1547580 & 688759 & 4.45 & 4.8301 & TRN & \\
\hline CHEMBL3144932 & 688759 & 4.45 & 4.6812 & TRN & \\
\hline CHEMBL1613198 & 688759 & 6.0 & 5.0592 & TRN & \\
\hline CHEMBL133576 & 688759 & 5.0 & 4.9514 & TST & \\
\hline CHEMBL1607584 & 688759 & 4.7 & 4.5896 & TRN & \\
\hline CHEMBL 210868 & 688759 & 4.5 & 4.6882 & TST & \\
\hline CHEMBL1361567 & 688759 & 4.45 & 4.7951 & TST & \\
\hline CHEMBL1403180 & 688759 & 4.9 & 5.0409 & TRN & \\
\hline CHEMBL1531233 & 688759 & 4.65 & 5.26200 & 20000000005 & TRN \\
\hline CHEMBL3208233 & 688759 & 5.2 & 4.8899 & TRN & \\
\hline & & & & 14794 & \\
\hline
\end{tabular}




\begin{tabular}{|c|c|c|c|c|c|}
\hline \\
\hline CHEMBL1336953 & 688759 & 4.6 & 4.9268 & TRN & \\
\hline CHEMBL484744 & 688759 & 5.0 & 4.9838 & TRN & \\
\hline CHEMBL1449275 & 688759 & 4.9 & 4.7698 & TST & \\
\hline CHEMBL1517973 & 688759 & 4.8 & 4.6899 & TRN & \\
\hline CHEMBL1601469 & 688759 & 5.5 & 5.6369 & TRN & \\
\hline CHEMBL1493429 & 688759 & 5.5 & 5.4035 & TRN & \\
\hline CHEMBL1530369 & 688759 & 4.5 & 4.8402 & TRN & \\
\hline CHEMBL1596490 & 688759 & 4.55 & 4.8077 & TRN & \\
\hline CHEMBL1354548 & 688759 & 5.0 & 5.00899 & 99999999995 & TRN \\
\hline CHEMBL1580668 & 688759 & 4.45 & 4.9061 & TST & \\
\hline CHEMBL1431511 & 688759 & 4.7 & 4.9248 & TST & \\
\hline CHEMBL1580565 & 688759 & 4.8 & 5.0032 & TRN & \\
\hline CHEMBL1527982 & 688759 & 4.45 & 4.9302 & TRN & \\
\hline CHEMBL1355405 & 688759 & 4.45 & 4.7049 & TRN & \\
\hline CHEMBL1405318 & 688759 & 4.7 & 4.6581 & TRN & \\
\hline CHEMBL 3195372 & 688759 & 4.9 & 4.9083 & TRN & \\
\hline CHEMBL1545370 & 688759 & 4.45 & 4.9058 & TST & \\
\hline CHEMBL3207969 & 688759 & 4.45 & 4.7037 & TST & \\
\hline CHEMBL3207775 & 688759 & 6.05 & 5.4324 & TRN & \\
\hline CHEMBL1494202 & 688759 & 4.45 & 4.7221 & TST & \\
\hline CHEMBL 2136569 & 688759 & 4.95 & 5.0142 & TRN & \\
\hline CHEMBL1471011 & 688759 & 4.45 & 4.756 & TRN & \\
\hline CHEMBL1491847 & 688759 & 4.6 & 4.8621 & TST & \\
\hline CHEMBL3196548 & 688759 & 5.5 & 5.2174 & TRN & \\
\hline CHEMBL1485078 & 688759 & 6.4 & 6.267 & TRN & \\
\hline CHEMBL1982391 & 688759 & 6.0 & 5.7142 & TRN & \\
\hline CHEMBL1321795 & 688759 & 4.95 & 4.9212 & TRN & \\
\hline CHEMBL 7973 & 688759 & 5.15 & 5.2305 & TRN & \\
\hline CHEMBL1503259 & 688759 & 4.6 & 4.8442 & TST & \\
\hline CHEMBL1341560 & 688759 & 5.15 & 5.0444 & TST & \\
\hline CHEMBL1364639 & 688759 & 4.85 & 4.7757 & TRN & \\
\hline CHEMBL1344391 & 688759 & 4.45 & 4.9335 & TRN & \\
\hline CHEMBL1347378 & 688759 & 6.2 & 6.0226 & TRN & \\
\hline CHEMBL 3392440 & 688759 & 4.5 & 4.6507 & TST & \\
\hline CHEMBL1503068 & 688759 & 4.95 & 4.9885 & TRN & \\
\hline CHEMBL1328836 & 688759 & 5.95 & 5.5158 & TRN & \\
\hline CHEMBL1380523 & 688759 & 5.75 & 5.649 & TRN & \\
\hline CHEMBL1487693 & 688759 & 4.65 & 4.6404 & TRN & \\
\hline CHEMBL1569241 & 688759 & 4.6 & 4.7549 & TRN & \\
\hline CHEMBL1608279 & 688759 & 5.4 & 5.1749 & TRN & \\
\hline CHEMBL1392031 & 688759 & 5.9 & 5.8178 & TRN & \\
\hline CHEMBL236554 & 688759 & 4.45 & 4.8377 & TRN & \\
\hline CHEMBL1346337 & 688759 & 5.2 & 5.0472 & TST & \\
\hline CHEMBL1324386 & 688759 & 4.75 & 4.8249 & TRN & \\
\hline CHEMBL3196391 & 688759 & 5.2 & 5.0854 & TRN & \\
\hline CHEMBL1369821 & 688759 & 4.65 & 5.121 & TRN & \\
\hline CHEMBL1323315 & 688759 & 5.1 & 4.6157 & TRN & \\
\hline CHEMBL1302254 & 688759 & 4.45 & 4.868 & TST & \\
\hline
\end{tabular}




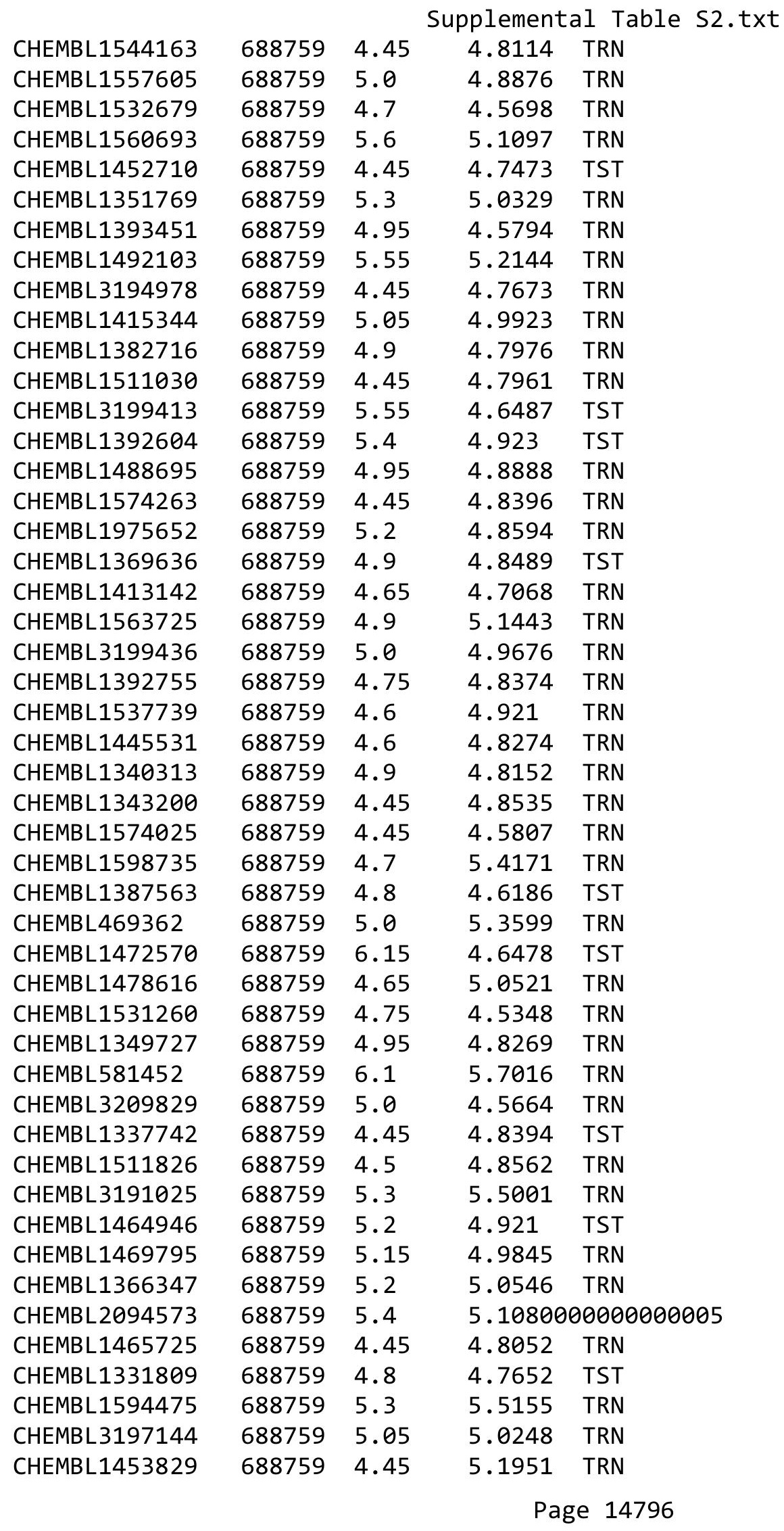

TRN 


\begin{tabular}{|c|c|c|c|c|}
\hline \multicolumn{5}{|c|}{ Supplemental Table S2.txt } \\
\hline CHEMBL1536362 & 688759 & 4.8 & 4.7743 & TRN \\
\hline CHEMBL1370161 & 688759 & 6.5 & 5.1106 & TRN \\
\hline CHEMBL1538892 & 688759 & 6.6 & 5.7688 & TRN \\
\hline CHEMBL1553072 & 688759 & 5.0 & 5.0157 & TST \\
\hline CHEMBL1491308 & 688759 & 4.65 & 4.756 & TRN \\
\hline CHEMBL1393212 & 688759 & 4.9 & 4.8942 & TRN \\
\hline CHEMBL3196031 & 688759 & 5.5 & 5.1171 & TRN \\
\hline CHEMBL1544727 & 688759 & 4.5 & 4.9351 & TRN \\
\hline CHEMBL1539401 & 688759 & 4.45 & 4.5068 & TRN \\
\hline CHEMBL1389707 & 688759 & 4.75 & 4.7771 & TRN \\
\hline CHEMBL1457241 & 688759 & 4.45 & 4.8132 & TRN \\
\hline CHEMBL3192152 & 688759 & 4.55 & 5.0682 & TRN \\
\hline CHEMBL3195761 & 688759 & 5.4 & 5.4102 & TRN \\
\hline CHEMBL1343121 & 688759 & 5.1 & 4.8211 & TST \\
\hline CHEMBL3212998 & 688759 & 4.45 & 4.9131 & TRN \\
\hline CHEMBL3197012 & 688759 & 4.95 & 5.0481 & TRN \\
\hline CHEMBL1566275 & 688759 & 5.0 & 4.8859 & TRN \\
\hline CHEMBL1306027 & 688759 & 5.5 & 4.9911 & TST \\
\hline CHEMBL3192814 & 688759 & 4.45 & 4.6159 & TRN \\
\hline CHEMBL1310236 & 688759 & 4.8 & 5.0868 & TRN \\
\hline CHEMBL1352661 & 688759 & 4.6 & 4.6596 & TRN \\
\hline CHEMBL1423547 & 688759 & 4.75 & 4.8258 & TRN \\
\hline CHEMBL1385296 & 688759 & 4.45 & 4.8788 & TRN \\
\hline CHEMBL 3197570 & 688759 & 4.6 & 5.2442 & TST \\
\hline CHEMBL1520694 & 688759 & 4.65 & 4.9199 & TRN \\
\hline CHEMBL1580139 & 688759 & 4.45 & 5.0344 & TRN \\
\hline CHEMBL1414529 & 688759 & 5.95 & 4.8849 & TST \\
\hline CHEMBL1300007 & 688759 & 4.45 & 4.6984 & TRN \\
\hline CHEMBL1598878 & 688759 & 5.15 & 4.8296 & TST \\
\hline CHEMBL1310758 & 688759 & 4.95 & 4.5727 & TST \\
\hline CHEMBL1559496 & 688759 & 4.45 & 4.9087 & TRN \\
\hline CHEMBL3198286 & 688759 & 5.6 & 5.0228 & TRN \\
\hline CHEMBL1408676 & 688759 & 4.45 & 4.6024 & TRN \\
\hline CHEMBL1519202 & 688759 & 5.15 & 4.8037 & TRN \\
\hline CHEMBL3212689 & 688759 & 5.85 & 4.8402 & TRN \\
\hline CHEMBL199194 & 688759 & 5.2 & 5.1495 & TRN \\
\hline CHEMBL1309281 & 688759 & 5.85 & 5.5465 & TRN \\
\hline CHEMBL1575828 & 688759 & 4.45 & 4.4588 & TRN \\
\hline CHEMBL1360308 & 688759 & 4.7 & 5.081 & TST \\
\hline CHEMBL1491893 & 688759 & 4.8 & 4.8346 & TRN \\
\hline CHEMBL1563528 & 688759 & 6.3 & 4.8508 & TRN \\
\hline CHEMBL1492564 & 688759 & 4.45 & 4.7332 & TST \\
\hline CHEMBL1461991 & 688759 & 4.65 & 5.0439 & TRN \\
\hline CHEMBL1448114 & 688759 & 4.95 & 4.9332 & TRN \\
\hline CHEMBL1334716 & 688759 & 4.6 & 4.822 & TRN \\
\hline CHEMBL1508245 & 688759 & 5.25 & 4.8911 & TRN \\
\hline CHEMBL3189239 & 688759 & 4.9 & 4.8403 & TRN \\
\hline CHEMBL1546532 & 688759 & 4.45 & 4.8996 & TST \\
\hline
\end{tabular}




\begin{tabular}{|c|c|c|c|c|}
\hline \multicolumn{5}{|c|}{ Supplemental Table S2.txt } \\
\hline CHEMBL1562496 & 688759 & 4.85 & 5.0519 & TRN \\
\hline CHEMBL105310 & 688759 & 4.45 & 5.1881 & TRN \\
\hline CHEMBL1329764 & 688759 & 4.45 & 4.8681 & TRN \\
\hline CHEMBL1409423 & 688759 & 5.1 & 5.1302 & TRN \\
\hline CHEMBL1361128 & 688759 & 5.2 & 4.8795 & TRN \\
\hline CHEMBL1521990 & 688759 & 7.0 & 5.5977 & TRN \\
\hline CHEMBL1457159 & 688759 & 4.75 & 5.1579 & TST \\
\hline CHEMBL16687 & 688759 & 6.0 & 4.8439 & TST \\
\hline CHEMBL1608925 & 688759 & 5.35 & 5.0461 & TRN \\
\hline CHEMBL1533748 & 688759 & 5.55 & 5.4073 & TRN \\
\hline CHEMBL1451742 & 688759 & 5.45 & 5.2467 & TRN \\
\hline CHEMBL1329358 & 688759 & 5.3 & 4.9048 & TRN \\
\hline CHEMBL1437741 & 688759 & 4.45 & 4.7704 & TST \\
\hline CHEMBL1419925 & 688759 & 4.45 & 4.6113 & TST \\
\hline CHEMBL3189770 & 688759 & 4.45 & 4.7297 & TST \\
\hline CHEMBL1509569 & 688759 & 5.1 & 5.1714 & TST \\
\hline CHEMBL1333256 & 688759 & 4.6 & 4.7105 & TRN \\
\hline CHEMBL1411726 & 688759 & 5.45 & 4.6896 & TRN \\
\hline CHEMBL1501953 & 688759 & 4.45 & 4.6639 & TST \\
\hline CHEMBL1445924 & 688759 & 5.05 & 4.8879 & TST \\
\hline CHEMBL1450294 & 688759 & 6.0 & 5.5883 & TRN \\
\hline CHEMBL1084478 & 688759 & 4.95 & 4.916 & TRN \\
\hline CHEMBL1486651 & 688759 & 5.7 & 5.6041 & TRN \\
\hline CHEMBL1466669 & 688759 & 4.45 & 4.8235 & TRN \\
\hline CHEMBL1482246 & 688759 & 4.7 & 5.066 & TST \\
\hline CHEMBL1386510 & 688759 & 4.55 & 4.7357 & TST \\
\hline CHEMBL1305250 & 688759 & 4.55 & 4.8805 & TRN \\
\hline CHEMBL1359299 & 688759 & 4.8 & 4.7825 & TRN \\
\hline CHEMBL1518407 & 688759 & 4.65 & 4.9199 & TRN \\
\hline CHEMBL3191048 & 688759 & 5.1 & 5.8399 & TRN \\
\hline CHEMBL1356775 & 688759 & 4.45 & 4.6833 & TRN \\
\hline CHEMBL 1467878 & 688759 & 5.9 & 5.891 & TRN \\
\hline CHEMBL1545501 & 688759 & 4.65 & 4.8114 & TRN \\
\hline CHEMBL1430411 & 688759 & 4.7 & 4.9957 & TRN \\
\hline CHEMBL1350780 & 688759 & 6.05 & 5.8738 & TRN \\
\hline CHEMBL1453121 & 688759 & 4.45 & 4.86 & TRN \\
\hline CHEMBL1416413 & 688759 & 4.9 & 4.8957 & TRN \\
\hline CHEMBL3199322 & 688759 & 5.6 & 5.6479 & TRN \\
\hline CHEMBL1569967 & 688759 & 7.2503 & 5.3193 & TRN \\
\hline CHEMBL1467583 & 688759 & 4.45 & 4.9184 & TRN \\
\hline CHEMBL1323673 & 688759 & 5.65 & 5.487 & TRN \\
\hline CHEMBL1520399 & 688759 & 4.9 & 4.6317 & TRN \\
\hline CHEMBL1575079 & 688759 & 5.45 & 4.8627 & TRN \\
\hline CHEMBL1307894 & 688759 & 5.1 & 5.1122 & TRN \\
\hline CHEMBL1345405 & 688759 & 4.9 & 4.5873 & TRN \\
\hline CHEMBL1571245 & 688759 & 4.65 & 4.6146 & TRN \\
\hline CHEMBL1438134 & 688759 & 4.7 & 4.8015 & TST \\
\hline CHEMBL1509500 & 688759 & 4.45 & 4.7076 & TST \\
\hline
\end{tabular}




\begin{tabular}{|c|c|c|c|c|}
\hline \multicolumn{5}{|c|}{ Supplemental Table S2.txt } \\
\hline CHEMBL1328706 & 688759 & 4.8 & 4.7969 & TST \\
\hline CHEMBL1535533 & 688759 & 4.9 & 4.7091 & TST \\
\hline CHEMBL1564931 & 688759 & 4.95 & 4.9207 & TRN \\
\hline CHEMBL1504829 & 688759 & 4.6 & 4.7678 & TRN \\
\hline CHEMBL1243269 & 688759 & 5.2 & 4.5553 & TST \\
\hline CHEMBL1499788 & 688759 & 4.9 & 4.8975 & TRN \\
\hline CHEMBL1384368 & 688759 & 6.1 & 6.1732 & TRN \\
\hline CHEMBL1358777 & 688759 & 5.6 & 4.7043 & TRN \\
\hline CHEMBL1412481 & 688759 & 4.8 & 4.9512 & TRN \\
\hline CHEMBL1306030 & 688759 & 4.6 & 4.8063 & TST \\
\hline CHEMBL1544400 & 688759 & 4.75 & 5.0258 & TRN \\
\hline CHEMBL1382040 & 688759 & 4.9 & 5.0835 & TST \\
\hline CHEMBL1465559 & 688759 & 4.9 & 4.8319 & TRN \\
\hline CHEMBL1580951 & 688759 & 4.45 & 4.6642 & TRN \\
\hline CHEMBL1472369 & 688759 & 5.0 & 4.8187 & TST \\
\hline CHEMBL3210267 & 688759 & 5.65 & 5.2968 & TRN \\
\hline CHEMBL1536840 & 688759 & 4.45 & 4.7448 & TRN \\
\hline CHEMBL1545470 & 688759 & 4.7 & 4.8512 & TRN \\
\hline CHEMBL1507579 & 688759 & 4.45 & 5.0732 & TRN \\
\hline CHEMBL1488386 & 688759 & 5.1 & 6.0065 & TRN \\
\hline CHEMBL3199546 & 688759 & 4.8 & 4.7583 & TRN \\
\hline CHEMBL1497812 & 688759 & 4.45 & 4.7915 & TRN \\
\hline CHEMBL 2004950 & 688759 & 4.8 & 5.0899 & TRN \\
\hline CHEMBL1380039 & 688759 & 5.0 & 4.9918 & TRN \\
\hline CHEMBL1368409 & 688759 & 4.95 & 5.2156 & TRN \\
\hline CHEMBL1402547 & 688759 & 4.8 & 5.0373 & TRN \\
\hline CHEMBL1365344 & 688759 & 4.75 & 4.8569 & TRN \\
\hline CHEMBL1304903 & 688759 & 6.5 & 4.7959 & TST \\
\hline CHEMBL3197977 & 688759 & 5.3 & 5.5289 & TRN \\
\hline CHEMBL1441827 & 688759 & 4.65 & 4.5492 & TRN \\
\hline CHEMBL1310430 & 688759 & 4.45 & 4.8066 & TRN \\
\hline CHEMBL1405577 & 688759 & 5.15 & 4.9555 & TST \\
\hline CHEMBL1388359 & 688759 & 4.9 & 4.6887 & TRN \\
\hline CHEMBL1369307 & 688759 & 4.45 & 4.5721 & TRN \\
\hline CHEMBL1449731 & 688759 & 4.45 & 4.5867 & TST \\
\hline CHEMBL1309420 & 688759 & 4.85 & 4.7601 & TRN \\
\hline CHEMBL1420531 & 688759 & 4.8 & 4.908 & TST \\
\hline CHEMBL1467442 & 688759 & 4.45 & 4.9047 & TST \\
\hline CHEMBL1516495 & 688759 & 4.6 & 4.8034 & TRN \\
\hline CHEMBL1504609 & 688759 & 4.45 & 4.9346 & TRN \\
\hline CHEMBL3193482 & 688759 & 4.45 & 4.7181 & TRN \\
\hline CHEMBL1413192 & 688759 & 4.45 & 4.6569 & TST \\
\hline CHEMBL1392420 & 688759 & 4.45 & 4.9396 & TST \\
\hline CHEMBL3194491 & 688759 & 4.5 & 5.1259 & TRN \\
\hline CHEMBL3212590 & 688759 & 4.45 & 4.9904 & TST \\
\hline CHEMBL1311340 & 688759 & 4.6 & 5.0315 & TRN \\
\hline CHEMBL1353508 & 688759 & 4.45 & 4.9325 & TST \\
\hline CHEMBL1313081 & 688759 & 4.75 & 4.6815 & TRN \\
\hline
\end{tabular}




\begin{tabular}{|c|c|c|c|c|c|}
\hline \\
\hline CHEMBL1464433 & 688759 & 5.3 & 4.7853 & TRN & \\
\hline CHEMBL1374268 & 688759 & 4.45 & 4.6884 & TST & \\
\hline CHEMBL1477355 & 688759 & 5.25 & 5.0984 & TRN & \\
\hline CHEMBL1343537 & 688759 & 4.8 & 4.9081 & TST & \\
\hline CHEMBL1581441 & 688759 & 5.0 & 4.9512 & TRN & \\
\hline CHEMBL1481525 & 688759 & 4.95 & 4.5743 & TRN & \\
\hline CHEMBL1362595 & 688759 & 4.6 & 5.1635 & TST & \\
\hline CHEMBL1312784 & 688759 & 4.6 & 4.8953 & TRN & \\
\hline CHEMBL1500457 & 688759 & 4.75 & 4.9715 & TST & \\
\hline CHEMBL1546970 & 688759 & 6.05 & 5.8785 & TRN & \\
\hline CHEMBL1353666 & 688759 & 4.45 & 4.6216 & TST & \\
\hline CHEMBL1323899 & 688759 & 4.85 & 4.9491 & TST & \\
\hline CHEMBL1504390 & 688759 & 4.75 & 5.0843 & TRN & \\
\hline CHEMBL1507645 & 688759 & 5.15 & 5.0266 & TRN & \\
\hline CHEMBL3211947 & 688759 & 4.65 & 4.8939 & TST & \\
\hline CHEMBL1332756 & 688759 & 5.7 & $5.6720 e$ & 0000000001 & TRN \\
\hline CHEMBL1511339 & 688759 & 4.45 & 4.6704 & TRN & \\
\hline CHEMBL1328462 & 688759 & 4.95 & 4.9852 & TRN & \\
\hline CHEMBL1310139 & 688759 & 5.3 & 5.2463 & TST & \\
\hline CHEMBL1536084 & 688759 & 5.45 & 5.3217 & TRN & \\
\hline CHEMBL3198996 & 688759 & 5.5 & 5.1536 & TRN & \\
\hline CHEMBL1364949 & 688759 & 5.5 & 5.1543 & TRN & \\
\hline CHEMBL1471918 & 688759 & 4.45 & 5.2461 & TRN & \\
\hline CHEMBL1428256 & 688759 & 4.6 & 4.5848 & TST & \\
\hline CHEMBL1574283 & 688759 & 5.35 & 5.9071 & TRN & \\
\hline CHEMBL1602142 & 688759 & 4.95 & 5.0078 & TST & \\
\hline CHEMBL3190949 & 688759 & 5.45 & 5.5728 & TRN & \\
\hline CHEMBL1326705 & 688759 & 4.8 & 4.9058 & TST & \\
\hline CHEMBL1539409 & 688759 & 5.85 & 5.516 & TRN & \\
\hline CHEMBL1433015 & 688759 & 6.5 & 5.1997 & TST & \\
\hline CHEMBL1528108 & 688759 & 4.45 & 4.7222 & TRN & \\
\hline CHEMBL1610755 & 688759 & 5.25 & 4.8431 & TRN & \\
\hline CHEMBL1526527 & 688759 & 4.55 & 4.9084 & TRN & \\
\hline CHEMBL1400501 & 688759 & 6.15 & 4.9681 & TRN & \\
\hline CHEMBL1508674 & 688759 & 4.9 & 4.5338 & TRN & \\
\hline CHEMBL1369040 & 688759 & 4.45 & 4.5294 & TST & \\
\hline CHEMBL1160028 & 688759 & 4.75 & 5.0423 & TST & \\
\hline CHEMBL1428443 & 688759 & 5.6 & 5.30399 & 9999999999 & TST \\
\hline CHEMBL1449745 & 688759 & 4.65 & 4.797 & TRN & \\
\hline CHEMBL1973188 & 688759 & 4.65 & 4.9563 & TRN & \\
\hline CHEMBL1574921 & 688759 & 4.45 & 4.914 & TST & \\
\hline CHEMBL3190423 & 688759 & 4.45 & 4.6837 & TST & \\
\hline CHEMBL1509085 & 688759 & 5.45 & 4.7054 & TRN & \\
\hline CHEMBL1378215 & 688759 & 4.95 & 4.737 & TRN & \\
\hline CHEMBL1442141 & 688759 & 4.45 & 4.4409 & TRN & \\
\hline CHEMBL1378258 & 688759 & 4.45 & 4.5539 & TRN & \\
\hline CHEMBL 222334 & 688759 & 6.0 & 5.4414 & TST & \\
\hline CHEMBL1585327 & 688759 & 4.45 & 4.7803 & TST & \\
\hline
\end{tabular}




\begin{tabular}{|c|c|c|c|c|c|}
\hline & & \multicolumn{4}{|c|}{ Supplemental Table S2.txt } \\
\hline CHEMBL1602506 & 688759 & 5.25 & 4.9949 & TRN & \\
\hline CHEMBL3210791 & 688759 & 4.75 & 5.0505 & TRN & \\
\hline CHEMBL1493120 & 688759 & 4.45 & 5.0698 & TRN & \\
\hline CHEMBL1365796 & 688759 & 4.8 & 4.7653 & TRN & \\
\hline CHEMBL1310444 & 688759 & 4.65 & 4.8354 & TRN & \\
\hline CHEMBL1462854 & 688759 & 4.55 & 4.5938 & TRN & \\
\hline CHEMBL1438567 & 688759 & 4.45 & 4.8054 & TST & \\
\hline CHEMBL3196361 & 688759 & 5.8 & 5.5842 & TRN & \\
\hline CHEMBL1316664 & 688759 & 4.45 & 4.7739 & TRN & \\
\hline CHEMBL1484944 & 688759 & 4.95 & 4.7805 & TRN & \\
\hline CHEMBL1479338 & 688759 & 4.65 & 5.1292 & TST & \\
\hline CHEMBL1518827 & 688759 & 4.65 & 4.91 & TST & \\
\hline CHEMBL1398919 & 688759 & 4.7 & 4.6475 & TRN & \\
\hline CHEMBL600976 & 688759 & 4.65 & 4.9358 & TRN & \\
\hline CHEMBL1599895 & 688759 & 4.7 & 5.4377 & TRN & \\
\hline CHEMBL1605412 & 688759 & 4.7 & 4.5232 & TRN & \\
\hline CHEMBL1320430 & 688759 & 5.45 & 5.2331 & TST & \\
\hline CHEMBL1340782 & 688759 & 4.45 & 4.9981 & TRN & \\
\hline CHEMBL1587596 & 688759 & 5.45 & 5.269 & TRN & \\
\hline CHEMBL1307453 & 688759 & 5.35 & 5.2184 & TRN & \\
\hline CHEMBL3191805 & 688759 & 4.75 & 4.8511 & TRN & \\
\hline CHEMBL3198419 & 688759 & 5.6 & 5.59399 & 9999999999 & TRN \\
\hline CHEMBL1345642 & 688759 & 4.65 & 4.6662 & TRN & \\
\hline CHEMBL1373913 & 688759 & 4.75 & 5.0868 & TRN & \\
\hline CHEMBL1458004 & 688759 & 4.45 & 4.8726 & TRN & \\
\hline CHEMBL419564 & 688759 & 4.7 & 5.2218 & TRN & \\
\hline CHEMBL1496545 & 688759 & 4.85 & 4.9002 & TST & \\
\hline CHEMBL1369003 & 688759 & 4.45 & 4.978 & TRN & \\
\hline CHEMBL1321271 & 688759 & 4.45 & 4.9176 & TST & \\
\hline CHEMBL1308118 & 688759 & 4.9 & 4.827 & TST & \\
\hline CHEMBL1504607 & 688759 & 4.45 & 4.8055 & TRN & \\
\hline CHEMBL1375957 & 688759 & 4.45 & 4.8528 & TRN & \\
\hline CHEMBL1547422 & 688759 & 4.9 & 4.9649 & TST & \\
\hline CHEMBL1978355 & 688759 & 5.35 & 5.4952 & TRN & \\
\hline CHEMBL3189459 & 688759 & 6.4 & 5.2778 & TRN & \\
\hline CHEMBL1510100 & 688759 & 4.45 & 4.7844 & TRN & \\
\hline CHEMBL1548832 & 688759 & 4.45 & 4.7137 & TRN & \\
\hline CHEMBL1323687 & 688759 & 5.2 & 5.0479 & TRN & \\
\hline CHEMBL1585506 & 688759 & 5.1 & 4.9187 & TST & \\
\hline CHEMBL1491389 & 688759 & 5.9 & 5.2942 & TRN & \\
\hline CHEMBL1351076 & 688759 & 5.25 & 4.7531 & TRN & \\
\hline CHEMBL3193912 & 688759 & 4.65 & 4.6747 & TRN & \\
\hline CHEMBL1336059 & 688759 & 4.45 & 4.9237 & TST & \\
\hline CHEMBL1480330 & 688759 & 4.65 & 4.8344 & TRN & \\
\hline CHEMBL1451691 & 688759 & 4.95 & 5.267 & TRN & \\
\hline CHEMBL1585773 & 688759 & 5.0 & 5.38 & TRN & \\
\hline CHEMBL1465144 & 688759 & 4.45 & 4.846 & TRN & \\
\hline CHEMBL3191329 & 688759 & 4.75 & 4.7934 & TST & \\
\hline
\end{tabular}




\begin{tabular}{|c|c|c|c|c|}
\hline & & & pplement & al $\mathrm{Ta}$ \\
\hline CHEMBL1570381 & 688759 & 4.9 & 4.9439 & TST \\
\hline CHEMBL1971282 & 688759 & 5.45 & 4.862 & TRN \\
\hline CHEMBL 3191174 & 688759 & 4.45 & 4.6188 & TRN \\
\hline CHEMBL1599290 & 688759 & 5.3 & 5.6653 & TRN \\
\hline CHEMBL1575937 & 688759 & 6.5 & 6.0446 & TRN \\
\hline CHEMBL1504424 & 688759 & 4.9 & 4.8922 & TRN \\
\hline CHEMBL1538941 & 688759 & 4.75 & 4.8011 & TRN \\
\hline CHEMBL1984804 & 688759 & 4.9 & 4.8259 & TST \\
\hline CHEMBL1477072 & 688759 & 4.45 & 4.8489 & TRN \\
\hline CHEMBL1365214 & 688759 & 4.75 & 5.0173 & TRN \\
\hline CHEMBL1580662 & 688759 & 4.95 & 5.0582 & TRN \\
\hline CHEMBL1537070 & 688759 & 4.45 & 4.9644 & TST \\
\hline CHEMBL475198 & 688759 & 4.85 & 4.7887 & TRN \\
\hline CHEMBL1578226 & 688759 & 4.6 & 4.9868 & TRN \\
\hline CHEMBL1427687 & 688759 & 5.25 & 5.0251 & TRN \\
\hline CHEMBL3199540 & 688759 & 4.95 & 4.982 & TRN \\
\hline CHEMBL1414262 & 688759 & 4.45 & 4.8144 & TRN \\
\hline CHEMBL1366720 & 688759 & 6.5 & 4.852 & TRN \\
\hline CHEMBL1576774 & 688759 & 5.75 & 5.1627 & TRN \\
\hline CHEMBL 3210072 & 688759 & 5.65 & 5.5973 & TST \\
\hline CHEMBL1527175 & 688759 & 4.45 & 4.9097 & TRN \\
\hline CHEMBL1451905 & 688759 & 4.65 & 4.7983 & TRN \\
\hline CHEMBL1402587 & 688759 & 5.05 & 4.897 & TST \\
\hline CHEMBL593433 & 688759 & 4.7 & 4.7375 & TRN \\
\hline CHEMBL1587518 & 688759 & 4.45 & 4.6816 & TST \\
\hline CHEMBL1419633 & 688759 & 4.9 & 4.7672 & TRN \\
\hline CHEMBL1397395 & 688759 & 6.0 & 5.3595 & TRN \\
\hline CHEMBL1477741 & 688759 & 4.45 & 4.6513 & TRN \\
\hline CHEMBL1510979 & 688759 & 4.45 & 4.6193 & TRN \\
\hline CHEMBL1412448 & 688759 & 5.3 & 4.762 & TRN \\
\hline CHEMBL1319787 & 688759 & 5.7 & 5.4908 & TRN \\
\hline CHEMBL1528258 & 688759 & 5.0 & 4.9131 & TRN \\
\hline CHEMBL1414269 & 688759 & 4.6 & 4.6926 & TRN \\
\hline CHEMBL 3214603 & 688759 & 5.1 & 5.0144 & TRN \\
\hline CHEMBL1569547 & 688759 & 5.4 & 5.1261 & TRN \\
\hline CHEMBL1420521 & 688759 & 4.95 & 4.6705 & TRN \\
\hline CHEMBL1501994 & 688759 & 4.95 & 4.8667 & TST \\
\hline CHEMBL1422329 & 688759 & 6.35 & 5.0409 & TRN \\
\hline CHEMBL 3191763 & 688759 & 2.7 & 6.2099 & TRN \\
\hline CHEMBL 3427349 & 688759 & 4.45 & 4.7708 & TRN \\
\hline CHEMBL1507172 & 688759 & 4.7 & 4.7576 & TRN \\
\hline CHEMBL1345313 & 688759 & 4.95 & 4.8307 & TRN \\
\hline CHEMBL1529150 & 688759 & 4.45 & 5.2728 & TRN \\
\hline CHEMBL1457395 & 688759 & 4.5 & 4.6884 & TRN \\
\hline CHEMBL 3193604 & 688759 & 4.95 & 4.8064 & TRN \\
\hline CHEMBL1452227 & 688759 & 5.0 & 4.9617 & TRN \\
\hline CHEMBL1501101 & 688759 & 4.9 & 5.0171 & TRN \\
\hline CHEMBL1325767 & 688759 & 4.7 & 5.0701 & TRN \\
\hline
\end{tabular}




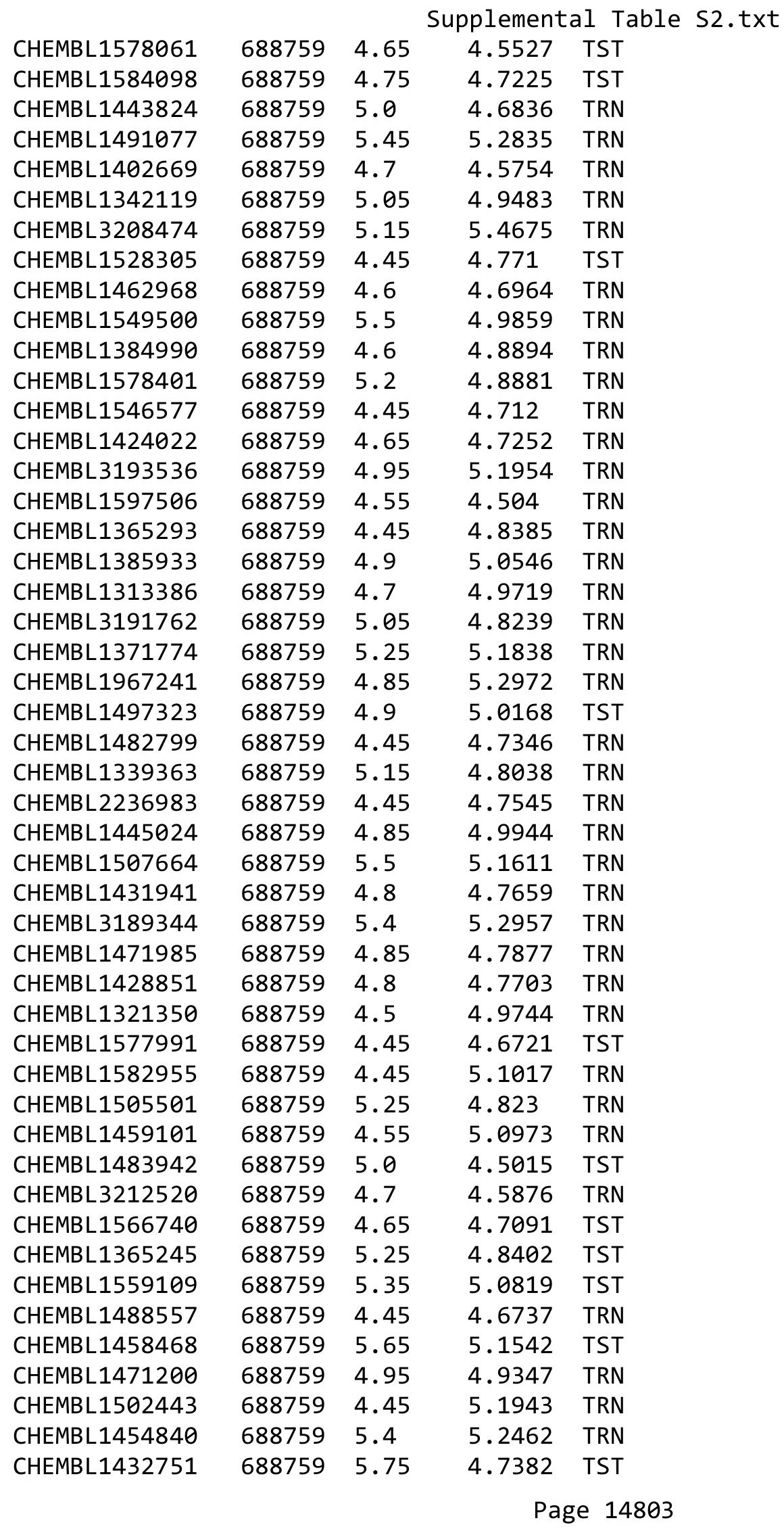




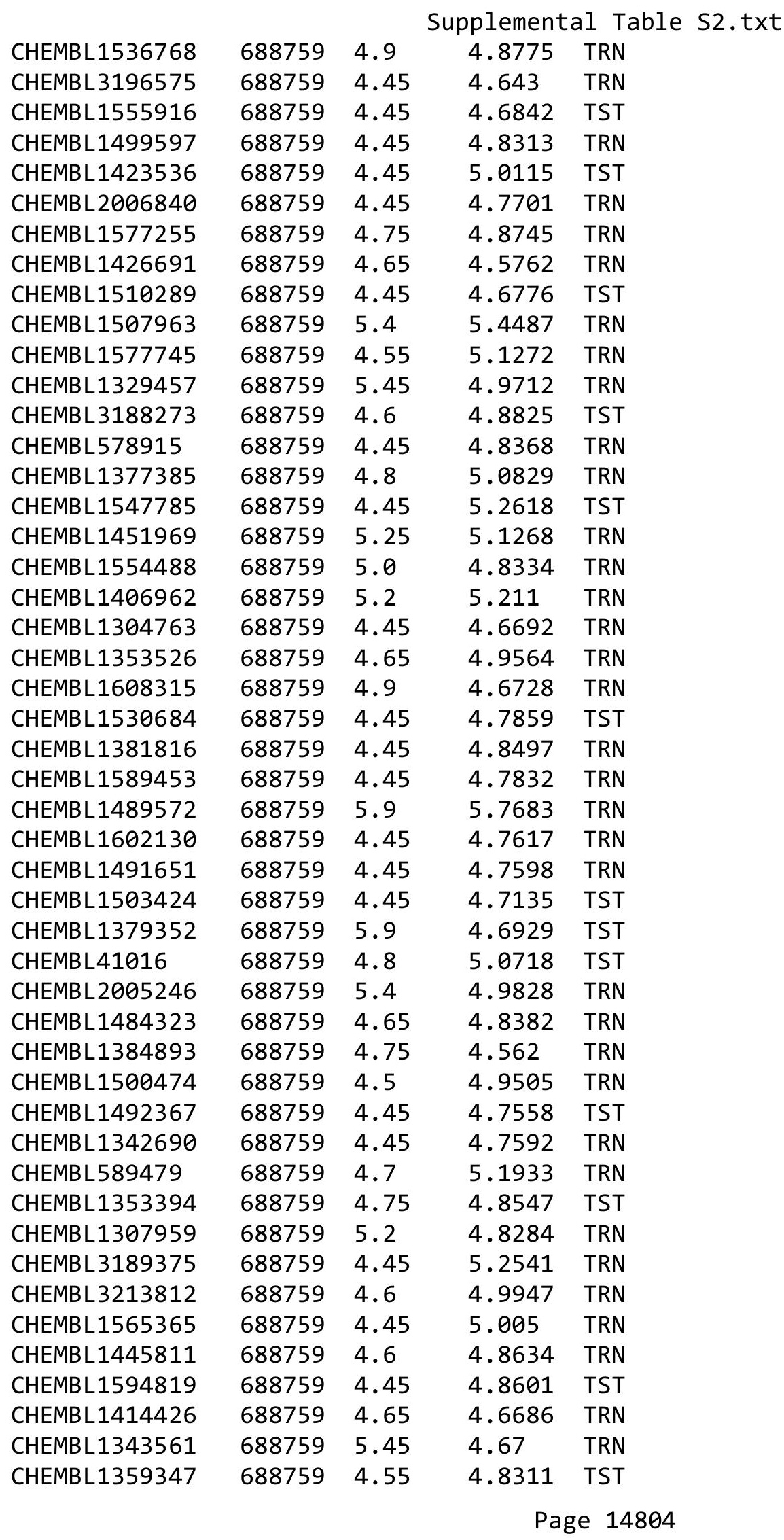




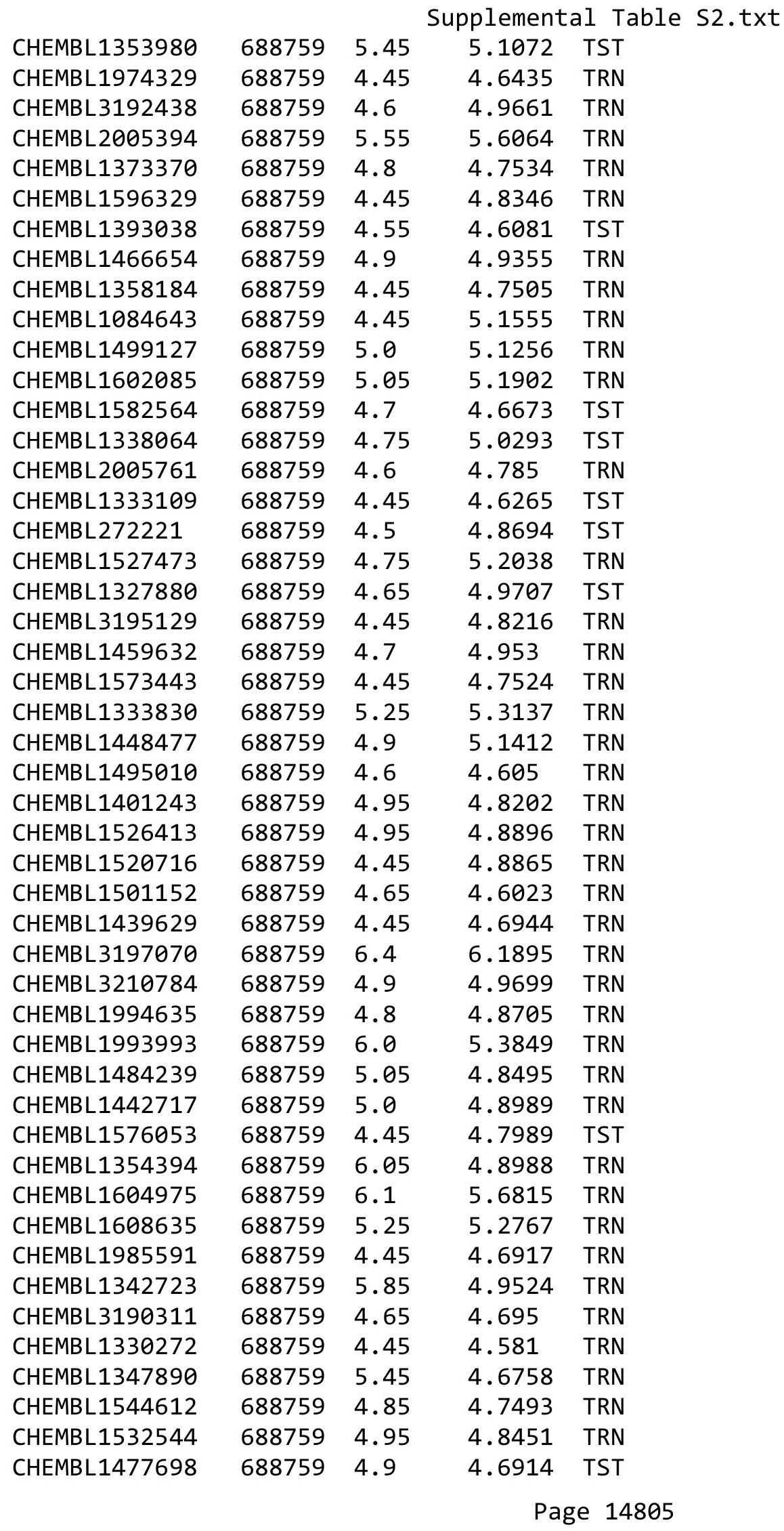




\begin{tabular}{|c|c|c|c|c|c|}
\hline \multicolumn{6}{|c|}{ Supplemental Table S2.txt } \\
\hline CHEMBL1473676 & 688759 & 6.0 & 5.6782 & TRN & \\
\hline CHEMBL3193530 & 688759 & 7.3497 & 6.4667 & TRN & \\
\hline CHEMBL1340525 & 688759 & 4.45 & 4.7098 & TRN & \\
\hline CHEMBL1575272 & 688759 & 5.45 & 5.4637 & TRN & \\
\hline CHEMBL1390639 & 688759 & 5.05 & 4.94 & TRN & \\
\hline CHEMBL1438160 & 688759 & 4.95 & 4.9507 & TST & \\
\hline CHEMBL1363713 & 688759 & 5.65 & 5.2243 & TST & \\
\hline CHEMBL1367691 & 688759 & 4.95 & 4.7669 & TRN & \\
\hline CHEMBL1563019 & 688759 & 5.0 & 4.9914 & TRN & \\
\hline CHEMBL1345723 & 688759 & 6.1 & 4.9389 & TRN & \\
\hline CHEMBL1388529 & 688759 & 5.0 & 4.8975 & TRN & \\
\hline CHEMBL1389174 & 688759 & 4.45 & 4.6659 & TRN & \\
\hline CHEMBL3195436 & 688759 & 4.9 & 5.0683 & TRN & \\
\hline CHEMBL1333156 & 688759 & 4.45 & 4.8159 & TRN & \\
\hline CHEMBL1984315 & 688759 & 4.6 & 4.6517 & TRN & \\
\hline CHEMBL3214342 & 688759 & 4.65 & 4.8335 & TRN & \\
\hline CHEMBL1330311 & 688759 & 4.45 & 4.7952 & TST & \\
\hline CHEMBL1424589 & 688759 & 4.95 & 4.669 & TRN & \\
\hline CHEMBL1491934 & 688759 & 5.2 & 5.14 & TRN & \\
\hline CHEMBL1439902 & 688759 & 4.45 & 4.7637 & TST & \\
\hline CHEMBL1501793 & 688759 & 4.45 & 4.6389 & TST & \\
\hline CHEMBL1469980 & 688759 & 6.15 & 5.693 & TRN & \\
\hline CHEMBL1339678 & 688759 & 5.7 & 5.4679 & TRN & \\
\hline CHEMBL1349720 & 688759 & 4.55 & 4.7641 & TRN & \\
\hline CHEMBL1968986 & 688759 & 4.65 & 4.8342 & TST & \\
\hline CHEMBL1425753 & 688759 & 5.65 & 5.2479 & TST & \\
\hline CHEMBL1323536 & 688759 & 4.65 & 4.4801 & TRN & \\
\hline CHEMBL1543627 & 688759 & 4.85 & 4.47199 & 99999999995 & TRN \\
\hline CHEMBL1472318 & 688759 & 4.65 & 4.8527 & TRN & \\
\hline CHEMBL1575198 & 688759 & 6.0 & 4.9825 & TRN & \\
\hline CHEMBL1547301 & 688759 & 5.3 & 5.0399 & TRN & \\
\hline CHEMBL1416887 & 688759 & 4.45 & 4.824 & TRN & \\
\hline CHEMBL1461501 & 688759 & 4.45 & 5.0521 & TRN & \\
\hline CHEMBL1352498 & 688759 & 4.95 & 5.0735 & TRN & \\
\hline CHEMBL1496110 & 688759 & 4.9 & 4.7723 & TRN & \\
\hline CHEMBL3198840 & 688759 & 4.65 & 5.0307 & TRN & \\
\hline CHEMBL 1416713 & 688759 & 5.0 & 4.7002 & TST & \\
\hline CHEMBL1565979 & 688759 & 5.5 & 5.2774 & TRN & \\
\hline CHEMBL1376883 & 688759 & 5.15 & 5.266 & TRN & \\
\hline CHEMBL1510146 & 688759 & 4.95 & 5.0968 & TRN & \\
\hline CHEMBL1557627 & 688759 & 4.7 & 4.8457 & TRN & \\
\hline CHEMBL1543712 & 688759 & 4.7 & 5.1791 & TRN & \\
\hline CHEMBL1466934 & 688759 & 4.75 & 4.8546 & TST & \\
\hline CHEMBL1391533 & 688759 & 5.8 & 5.2063 & TRN & \\
\hline CHEMBL1574939 & 688759 & 5.2 & 4.9207 & TRN & \\
\hline CHEMBL3213155 & 688759 & 4.45 & 4.9465 & TRN & \\
\hline CHEMBL 220845 & 688759 & 4.9 & 4.7485 & TST & \\
\hline CHEMBL97688 & 688759 & 4.75 & 4.8836 & TST & \\
\hline
\end{tabular}




\begin{tabular}{|c|c|c|c|c|c|}
\hline \multicolumn{6}{|c|}{ Supplemental Table S2.txt } \\
\hline CHEMBL3191770 & 688759 & 4.55 & 5.0409 & TRN & \\
\hline CHEMBL1337463 & 688759 & 4.8 & 4.7865 & TRN & \\
\hline CHEMBL1597833 & 688759 & 5.15 & 5.063 & TRN & \\
\hline CHEMBL1492752 & 688759 & 6.05 & 4.9538 & TRN & \\
\hline CHEMBL1395977 & 688759 & 5.2 & 4.9763 & TST & \\
\hline CHEMBL1339487 & 688759 & 5.5 & 5.4269 & TRN & \\
\hline CHEMBL1527622 & 688759 & 4.45 & 4.8085 & TST & \\
\hline CHEMBL3210272 & 688759 & 4.55 & 4.8703 & TRN & \\
\hline CHEMBL1420581 & 688759 & 4.45 & 4.7372 & TRN & \\
\hline CHEMBL1534947 & 688759 & 4.6 & 4.7643 & TRN & \\
\hline CHEMBL1571030 & 688759 & 4.65 & 5.0155 & TRN & \\
\hline CHEMBL1451282 & 688759 & 4.45 & 4.6973 & TRN & \\
\hline CHEMBL1532595 & 688759 & 4.45 & 4.7263 & TRN & \\
\hline CHEMBL1424168 & 688759 & 4.85 & 4.96899 & 9999999999 & TST \\
\hline CHEMBL1335175 & 688759 & 4.45 & 5.0806 & TRN & \\
\hline CHEMBL1525186 & 688759 & 4.75 & 4.7734 & TRN & \\
\hline CHEMBL1524861 & 688759 & 4.45 & 4.9331 & TRN & \\
\hline CHEMBL1429718 & 688759 & 6.0 & 5.4228 & TRN & \\
\hline CHEMBL1361457 & 688759 & 4.7 & 4.7492 & TRN & \\
\hline CHEMBL1425194 & 688759 & 4.45 & 5.0634 & TRN & \\
\hline CHEMBL1376721 & 688759 & 4.45 & 4.8627 & TST & \\
\hline CHEMBL1448533 & 688759 & 4.45 & 4.836 & TRN & \\
\hline CHEMBL1442026 & 688759 & 4.65 & 4.7238 & TRN & \\
\hline CHEMBL1608944 & 688759 & 4.95 & 4.8691 & TRN & \\
\hline CHEMBL1412727 & 688759 & 4.75 & 4.6363 & TRN & \\
\hline CHEMBL1313737 & 688759 & 4.6 & 4.8766 & TRN & \\
\hline CHEMBL1390586 & 688759 & 5.15 & 4.8425 & TRN & \\
\hline CHEMBL 2002166 & 688759 & 4.45 & 4.8352 & TRN & \\
\hline CHEMBL1325162 & 688759 & 5.4 & 5.3119 & TRN & \\
\hline CHEMBL1309738 & 688759 & 5.0 & 5.1322 & TRN & \\
\hline CHEMBL1406933 & 688759 & 5.25 & 4.852 & TST & \\
\hline CHEMBL1300063 & 688759 & 4.45 & 4.6629 & TRN & \\
\hline CHEMBL1550294 & 688759 & 4.85 & 4.6463 & TRN & \\
\hline CHEMBL1275655 & 688759 & 4.45 & 4.7254 & TRN & \\
\hline CHEMBL1368234 & 688759 & 4.45 & 5.222 & TRN & \\
\hline CHEMBL1456071 & 688759 & 4.95 & 4.7699 & TRN & \\
\hline CHEMBL3192014 & 688759 & 4.45 & 4.9089 & TRN & \\
\hline CHEMBL1382220 & 688759 & 4.95 & 4.7788 & TRN & \\
\hline CHEMBL1485883 & 688759 & 4.45 & 4.84399 & 9999999999 & TRN \\
\hline CHEMBL1393194 & 688759 & 4.45 & 4.6198 & TRN & \\
\hline CHEMBL1414723 & 688759 & 4.95 & 5.3413 & TST & \\
\hline CHEMBL1373979 & 688759 & 4.9 & 4.8128 & TST & \\
\hline CHEMBL3189514 & 688759 & 5.2 & 5.0498 & TRN & \\
\hline CHEMBL1427370 & 688759 & 5.15 & 5.3112 & TRN & \\
\hline CHEMBL3197860 & 688759 & 4.95 & 5.0885 & TST & \\
\hline CHEMBL1464237 & 688759 & 5.85 & 4.88899 & 9999999999 & TST \\
\hline CHEMBL1337334 & 688759 & 4.7 & 4.8283 & TRN & \\
\hline CHEMBL1602756 & 688759 & 4.45 & 4.6034 & TRN & \\
\hline
\end{tabular}




\begin{tabular}{|c|c|c|c|c|}
\hline \multicolumn{5}{|c|}{ Supplemental Table S2.txt } \\
\hline CHEMBL1430300 & 688759 & 4.75 & 4.5864 & TRN \\
\hline CHEMBL592600 & 688759 & 5.55 & 5.5542 & TRN \\
\hline CHEMBL1584182 & 688759 & 4.65 & 4.8629 & TST \\
\hline CHEMBL3194846 & 688759 & 6.35 & 5.6723 & TRN \\
\hline CHEMBL1445101 & 688759 & 5.15 & 5.0147 & TST \\
\hline CHEMBL1998606 & 688759 & 5.5 & 5.5079 & TRN \\
\hline CHEMBL1441265 & 688759 & 4.6 & 4.9932 & TRN \\
\hline CHEMBL1362285 & 688759 & 4.6 & 4.6327 & TRN \\
\hline CHEMBL1404222 & 688759 & 4.45 & 4.8753 & TRN \\
\hline CHEMBL1584669 & 688759 & 4.45 & 4.6425 & TRN \\
\hline CHEMBL1352612 & 688759 & 5.0 & 4.7653 & TRN \\
\hline CHEMBL1466539 & 688759 & 4.9 & 4.8993 & TST \\
\hline CHEMBL1495687 & 688759 & 4.95 & 4.8021 & TST \\
\hline CHEMBL1543306 & 688759 & 4.45 & 4.6846 & TRN \\
\hline CHEMBL1517587 & 688759 & 5.6 & 4.9788 & TRN \\
\hline CHEMBL1401731 & 688759 & 4.45 & 5.0329 & TST \\
\hline CHEMBL3193819 & 688759 & 5.0 & 5.3846 & TST \\
\hline CHEMBL1562304 & 688759 & 4.55 & 4.6157 & TST \\
\hline CHEMBL3191293 & 688759 & 5.1 & 5.3871 & TRN \\
\hline CHEMBL1393056 & 688759 & 7.15 & 4.9817 & TST \\
\hline CHEMBL1468661 & 688759 & 4.6 & 4.8279 & TRN \\
\hline CHEMBL1480375 & 688759 & 4.45 & 4.7669 & TRN \\
\hline CHEMBL1363280 & 688759 & 4.45 & 4.8218 & TRN \\
\hline CHEMBL1337301 & 688759 & 5.15 & 4.8564 & TRN \\
\hline CHEMBL1606326 & 688759 & 4.7 & 4.803 & TRN \\
\hline CHEMBL1559981 & 688759 & 4.45 & 4.6844 & TST \\
\hline CHEMBL1524024 & 688759 & 5.0 & 5.0958 & TRN \\
\hline CHEMBL1564254 & 688759 & 4.45 & 4.6175 & TRN \\
\hline CHEMBL1344292 & 688759 & 4.95 & 4.9817 & TRN \\
\hline CHEMBL1427553 & 688759 & 6.15 & 5.8213 & TRN \\
\hline CHEMBL1449640 & 688759 & 5.25 & 5.1561 & TRN \\
\hline CHEMBL1371873 & 688759 & 4.65 & 4.4365 & TST \\
\hline CHEMBL3211326 & 688759 & 5.35 & 5.1866 & TRN \\
\hline CHEMBL1359902 & 688759 & 5.5 & 5.0119 & TRN \\
\hline CHEMBL3191188 & 688759 & 5.5 & 5.1607 & TRN \\
\hline CHEMBL1442427 & 688759 & 5.55 & 5.1154 & TRN \\
\hline CHEMBL 1308848 & 688759 & 5.8 & 5.5418 & TRN \\
\hline CHEMBL1328088 & 688759 & 4.45 & 4.7748 & TST \\
\hline CHEMBL1392852 & 688759 & 4.65 & 4.8497 & TRN \\
\hline CHEMBL1341399 & 688759 & 4.45 & 4.8312 & TRN \\
\hline CHEMBL1305637 & 688759 & 4.5 & 4.9126 & TRN \\
\hline CHEMBL1532656 & 688759 & 4.9 & 4.7943 & TRN \\
\hline CHEMBL1353868 & 688759 & 4.6 & 5.0148 & TRN \\
\hline CHEMBL1443192 & 688759 & 4.45 & 4.8449 & TST \\
\hline CHEMBL1539650 & 688759 & 4.8 & 4.9198 & TST \\
\hline CHEMBL1407094 & 688759 & 5.3 & 5.078 & TRN \\
\hline CHEMBL1489033 & 688759 & 4.6 & 4.7986 & TST \\
\hline CHEMBL1401555 & 688759 & 5.15 & 4.8852 & TRN \\
\hline
\end{tabular}




\begin{tabular}{|c|c|c|c|c|}
\hline \multicolumn{5}{|c|}{ Supplemental Table S2.txt } \\
\hline CHEMBL119769 & 688759 & 5.0 & 4.9398 & TRN \\
\hline CHEMBL3190119 & 688759 & 5.4 & 5.2428 & TRN \\
\hline CHEMBL1367149 & 688759 & 4.45 & 4.9156 & TRN \\
\hline CHEMBL1595274 & 688759 & 6.5501 & 5.1212 & TRN \\
\hline CHEMBL1507242 & 688759 & 4.45 & 4.994 & TRN \\
\hline CHEMBL1420276 & 688759 & 5.05 & 4.883 & TRN \\
\hline CHEMBL1549610 & 688759 & 6.8499 & 4.8904 & TST \\
\hline CHEMBL3145369 & 688759 & 7.8996 & 6.1236 & TRN \\
\hline CHEMBL1516593 & 688759 & 4.45 & 4.7539 & TRN \\
\hline CHEMBL1095276 & 688759 & 5.9 & 5.2047 & TRN \\
\hline CHEMBL1502423 & 688759 & 4.8 & 4.5471 & TRN \\
\hline CHEMBL1568147 & 688759 & 5.1 & 4.9761 & TRN \\
\hline CHEMBL1549036 & 688759 & 4.45 & 4.918 & TST \\
\hline CHEMBL3190965 & 688759 & 5.05 & 5.2547 & TRN \\
\hline CHEMBL1430405 & 688759 & 4.55 & 4.6398 & TRN \\
\hline CHEMBL602776 & 688759 & 4.5 & 4.7262 & TRN \\
\hline CHEMBL1555769 & 688759 & 4.75 & 4.7538 & TRN \\
\hline CHEMBL1487478 & 688759 & 6.3 & 4.7909 & TRN \\
\hline CHEMBL1427149 & 688759 & 7.6498 & 4.9671 & TST \\
\hline CHEMBL1430105 & 688759 & 4.95 & 4.7184 & TST \\
\hline CHEMBL1326110 & 688759 & 5.15 & 4.9234 & TST \\
\hline CHEMBL1452303 & 688759 & 6.6499 & 5.1392 & TST \\
\hline CHEMBL1306981 & 688759 & 4.9 & 4.852 & TRN \\
\hline CHEMBL1352341 & 688759 & 5.1 & 4.9273 & TRN \\
\hline CHEMBL1424818 & 688759 & 5.45 & 5.1566 & TRN \\
\hline CHEMBL1531249 & 688759 & 5.15 & 4.9797 & TRN \\
\hline CHEMBL1379872 & 688759 & 6.5 & 4.8783 & TST \\
\hline CHEMBL1993431 & 688759 & 6.5 & 5.461 & TRN \\
\hline CHEMBL1377406 & 688759 & 4.65 & 4.7326 & TRN \\
\hline CHEMBL1520621 & 688759 & 4.45 & 4.8164 & TRN \\
\hline CHEMBL1460179 & 688759 & 4.75 & 4.9946 & TRN \\
\hline CHEMBL1491327 & 688759 & 5.75 & 5.336 & TRN \\
\hline CHEMBL1503039 & 688759 & 4.75 & 4.5345 & TRN \\
\hline CHEMBL1327583 & 688759 & 4.45 & 4.5759 & TRN \\
\hline CHEMBL1459707 & 688759 & 4.8 & 4.8788 & TST \\
\hline CHEMBL1330322 & 688759 & 4.95 & 4.9983 & TRN \\
\hline CHEMBL1479829 & 688759 & 4.95 & 4.7617 & TRN \\
\hline CHEMBL1390717 & 688759 & 4.95 & 4.8531 & TST \\
\hline CHEMBL1604844 & 688759 & 4.45 & 4.5353 & TRN \\
\hline CHEMBL1412297 & 688759 & 5.5 & 4.9008 & TST \\
\hline CHEMBL1545191 & 688759 & 4.9 & 4.9698 & TRN \\
\hline CHEMBL1482541 & 688759 & 5.7 & 5.2586 & TRN \\
\hline CHEMBL1424945 & 688759 & 4.9 & 4.7762 & TRN \\
\hline CHEMBL1307326 & 688759 & 5.15 & 5.4011 & TRN \\
\hline CHEMBL1565673 & 688759 & 4.6 & 4.7829 & TRN \\
\hline CHEMBL1444901 & 688759 & 4.45 & 4.8347 & TRN \\
\hline CHEMBL1548799 & 688759 & 5.1 & 5.0932 & TRN \\
\hline CHEMBL1208858 & 688759 & 4.95 & 5.0639 & TST \\
\hline
\end{tabular}




\begin{tabular}{|c|c|c|c|c|}
\hline & & & upplement & $\mathrm{T}$ \\
\hline CHEMBL1339707 & 688759 & 4.45 & 4.8136 & TRN \\
\hline CHEMBL1300204 & 688759 & 4.7 & 4.9336 & TST \\
\hline CHEMBL1543948 & 688759 & 4.95 & 5.4397 & TRN \\
\hline CHEMBL1994179 & 688759 & 5.25 & 5.2019 & TRN \\
\hline CHEMBL1390698 & 688759 & 5.4 & 5.4735 & TRN \\
\hline CHEMBL1370932 & 688759 & 4.5 & 4.8515 & TRN \\
\hline CHEMBL1459807 & 688759 & 5.05 & 4.8365 & TST \\
\hline CHEMBL1588256 & 688759 & 4.6 & 4.8001 & TRN \\
\hline CHEMBL1407802 & 688759 & 4.95 & 5.0396 & TST \\
\hline CHEMBL1556968 & 688759 & 5.25 & 4.6951 & TST \\
\hline CHEMBL1381331 & 688759 & 4.75 & 4.7184 & TRN \\
\hline CHEMBL1425202 & 688759 & 5.4 & 4.9568 & TRN \\
\hline CHEMBL1089006 & 688759 & 5.0 & 5.0219 & TRN \\
\hline CHEMBL400478 & 688759 & 4.65 & 5.2066 & TST \\
\hline CHEMBL137648 & 688759 & 4.45 & 4.7774 & TST \\
\hline CHEMBL3193671 & 688759 & 5.45 & 5.2967 & TRN \\
\hline CHEMBL1535944 & 688759 & 5.55 & 5.1074 & TRN \\
\hline CHEMBL1352181 & 688759 & 4.65 & 4.8728 & TRN \\
\hline CHEMBL1539727 & 688759 & 4.7 & 5.0028 & TRN \\
\hline CHEMBL1573487 & 688759 & 4.45 & 4.9775 & TRN \\
\hline CHEMBL1489081 & 688759 & 5.2 & 5.2002 & TRN \\
\hline CHEMBL1567225 & 688759 & 4.45 & 4.6369 & TST \\
\hline CHEMBL1540864 & 688759 & 4.55 & 4.6771 & TST \\
\hline CHEMBL1532474 & 688759 & 4.5 & 4.8564 & TRN \\
\hline CHEMBL3190091 & 688759 & 6.2 & 5.0695 & TRN \\
\hline CHEMBL1303750 & 688759 & 4.7 & 4.846 & TST \\
\hline CHEMBL1085065 & 688759 & 4.45 & 4.6677 & TRN \\
\hline CHEMBL1602567 & 688759 & 5.0 & 5.1821 & TRN \\
\hline CHEMBL1585332 & 688759 & 4.45 & 4.6821 & TRN \\
\hline CHEMBL 3194847 & 688759 & 5.05 & 5.0936 & TRN \\
\hline CHEMBL1536910 & 688759 & 5.25 & 4.8861 & TRN \\
\hline CHEMBL1602425 & 688759 & 4.75 & 4.5816 & TST \\
\hline CHEMBL1349814 & 688759 & 5.0 & 5.3784 & TRN \\
\hline CHEMBL1363028 & 688759 & 4.7 & 4.8051 & TRN \\
\hline CHEMBL1401928 & 688759 & 6.05 & 5.1688 & TRN \\
\hline CHEMBL1600680 & 688759 & 4.7 & 4.667 & TST \\
\hline CHEMBL1390678 & 688759 & 4.45 & 4.8953 & TRN \\
\hline CHEMBL3197110 & 688759 & 5.0 & 4.8339 & TST \\
\hline CHEMBL 3196777 & 688759 & 5.3 & 5.3468 & TRN \\
\hline CHEMBL1484381 & 688759 & 4.5 & 4.8877 & TST \\
\hline CHEMBL1419771 & 688759 & 4.65 & 4.7742 & TRN \\
\hline CHEMBL 289277 & 688759 & 4.45 & 5.0237 & TST \\
\hline CHEMBL1340133 & 688759 & 5.0 & 4.8963 & TRN \\
\hline CHEMBL1360580 & 688759 & 4.45 & 5.2133 & TST \\
\hline CHEMBL1518376 & 688759 & 4.45 & 4.9289 & TST \\
\hline CHEMBL1471288 & 688759 & 4.45 & 4.5842 & TRN \\
\hline CHEMBL1496330 & 688759 & 4.45 & 5.0409 & TST \\
\hline CHEMBL1559170 & 688759 & 4.65 & 5.093 & TST \\
\hline
\end{tabular}




\begin{tabular}{|c|c|c|c|c|c|}
\hline \multicolumn{6}{|c|}{ opıemental } \\
\hline CHEMBL1387950 & 688759 & 6.1 & 5.7011 & TRN & \\
\hline CHEMBL405358 & 688759 & 5.55 & 5.3055 & TST & \\
\hline CHEMBL2094665 & 688759 & 5.1 & 4.948 & TRN & \\
\hline CHEMBL1441934 & 688759 & 5.45 & 5.2257 & TRN & \\
\hline CHEMBL1328855 & 688759 & 4.6 & 4.8842 & TRN & \\
\hline CHEMBL1594553 & 688759 & 5.4 & 5.5813 & TRN & \\
\hline CHEMBL1405220 & 688759 & 4.9 & 5.0059 & TRN & \\
\hline CHEMBL1400420 & 688759 & 4.55 & 5.0478 & TRN & \\
\hline CHEMBL3199558 & 688759 & 4.45 & 4.7929 & TRN & \\
\hline CHEMBL1542790 & 688759 & 4.75 & 4.9756 & TRN & \\
\hline CHEMBL1426991 & 688759 & 4.9 & 4.7862 & TRN & \\
\hline CHEMBL1308931 & 688759 & 5.0 & 4.9126 & TRN & \\
\hline CHEMBL 249987 & 688759 & 4.85 & 5.2044 & TRN & \\
\hline CHEMBL1505090 & 688759 & 5.5 & 4.9234 & TRN & \\
\hline CHEMBL1595865 & 688759 & 4.95 & 5.0079 & TST & \\
\hline CHEMBL1348874 & 688759 & 5.25 & 4.9699 & TRN & \\
\hline CHEMBL1382683 & 688759 & 4.7 & 5.1216 & TRN & \\
\hline CHEMBL1307449 & 688759 & 6.0 & 5.0026 & TST & \\
\hline CHEMBL1523087 & 688759 & 4.8 & 4.65 & TRN & \\
\hline CHEMBL1456921 & 688759 & 4.45 & 4.7865 & TRN & \\
\hline CHEMBL1346530 & 688759 & 5.25 & 4.7558 & TRN & \\
\hline CHEMBL1993401 & 688759 & 5.45 & 4.8979 & TRN & \\
\hline CHEMBL1370145 & 688759 & 5.7 & 4.9668 & TRN & \\
\hline CHEMBL1461987 & 688759 & 4.45 & 4.7074 & TRN & \\
\hline CHEMBL1464670 & 688759 & 4.45 & 4.7623 & TRN & \\
\hline CHEMBL1418007 & 688759 & 4.45 & 4.7021 & TRN & \\
\hline CHEMBL1519160 & 688759 & 4.85 & 4.7666 & TRN & \\
\hline CHEMBL1602849 & 688759 & 4.45 & 4.5506 & TRN & \\
\hline CHEMBL1565929 & 688759 & 6.2 & 4.8091 & TST & \\
\hline CHEMBL3196813 & 688759 & 5.5 & 5.1062 & TST & \\
\hline CHEMBL1368174 & 688759 & 5.15 & 5.0407 & TST & \\
\hline CHEMBL1443873 & 688759 & 5.35 & 5.7098 & TRN & \\
\hline CHEMBL1505510 & 688759 & 6.1 & 5.6564 & TRN & \\
\hline CHEMBL3191734 & 688759 & 4.45 & $4.9830 e$ & 00000000005 & TRN \\
\hline CHEMBL1485910 & 688759 & 5.05 & 4.8714 & TRN & \\
\hline CHEMBL1339385 & 688759 & 4.45 & 5.0322 & TRN & \\
\hline CHEMBL1437782 & 688759 & 4.45 & 4.7752 & TST & \\
\hline CHEMBL1545357 & 688759 & 4.45 & 4.4082 & TRN & \\
\hline CHEMBL1504569 & 688759 & 5.8 & 5.5146 & TRN & \\
\hline CHEMBL1467980 & 688759 & 4.45 & 4.8973 & TRN & \\
\hline CHEMBL1511526 & 688759 & 4.6 & 4.7443 & TRN & \\
\hline CHEMBL1463826 & 688759 & 4.65 & 4.936 & TRN & \\
\hline CHEMBL1337611 & 688759 & 4.95 & 4.7568 & TRN & \\
\hline CHEMBL1329553 & 688759 & 4.85 & 4.9508 & TST & \\
\hline CHEMBL1496223 & 688759 & 4.65 & 5.0364 & TRN & \\
\hline CHEMBL1501238 & 688759 & 5.0 & 4.8281 & TRN & \\
\hline CHEMBL1466481 & 688759 & 5.15 & 4.9765 & TRN & \\
\hline CHEMBL3197758 & 688759 & 4.45 & 4.8796 & TRN & \\
\hline
\end{tabular}




\begin{tabular}{|c|c|c|c|c|c|}
\hline \multirow{3}{*}{$\begin{array}{l}\text { CHEMBL1531328 } \\
\text { CHEMBL1327844 }\end{array}$} & \multirow{3}{*}{$\begin{array}{l}688759 \\
688759\end{array}$} & \multicolumn{4}{|c|}{ Supplemental Table S2.txt } \\
\hline & & 5.85 & \multicolumn{2}{|c|}{5.0760000000000005} & TRN \\
\hline & & 5.4 & 4.9366 & TRN & \\
\hline CHEMBL1577657 & 688759 & 4.8 & 4.6745 & TRN & \\
\hline CHEMBL1537258 & 688759 & 4.75 & 4.7164 & TRN & \\
\hline CHEMBL1370733 & 688759 & 4.85 & 4.8027 & TRN & \\
\hline CHEMBL1585485 & 688759 & 4.45 & 4.8958 & TRN & \\
\hline CHEMBL1426193 & 688759 & 4.65 & 4.8888 & TRN & \\
\hline CHEMBL3145381 & 688759 & 5.6 & \multicolumn{2}{|c|}{5.6770000000000005} & TRN \\
\hline CHEMBL1399900 & 688759 & 4.85 & 4.7955 & TRN & \\
\hline CHEMBL1478149 & 688759 & 4.45 & 4.7796 & TRN & \\
\hline CHEMBL1993788 & 688759 & 5.5 & 5.4587 & TRN & \\
\hline CHEMBL1460375 & 688759 & 5.25 & 4.9534 & TST & \\
\hline CHEMBL1542313 & 688759 & 4.45 & 4.6623 & TRN & \\
\hline CHEMBL1330920 & 688759 & 4.65 & 4.8674 & TRN & \\
\hline CHEMBL1370454 & 688759 & 5.0 & 5.1695 & TRN & \\
\hline CHEMBL1321578 & 688759 & 4.95 & 4.7547 & TRN & \\
\hline CHEMBL1565526 & 688759 & 5.4 & 5.0928 & TRN & \\
\hline CHEMBL1585848 & 688759 & 5.0 & 4.7429 & TRN & \\
\hline CHEMBL3210966 & 688759 & 5.3 & 5.0153 & TRN & \\
\hline CHEMBL1986073 & 688759 & 4.65 & 4.7217 & TRN & \\
\hline CHEMBL1480100 & 688759 & 4.9 & 4.7209 & TST & \\
\hline CHEMBL1420275 & 688759 & 9.301 & 5.0687 & TST & \\
\hline CHEMBL1348131 & 688759 & 5.0 & 4.6098 & TRN & \\
\hline CHEMBL1336028 & 688759 & 4.45 & 4.6684 & TRN & \\
\hline CHEMBL3210497 & 688759 & 5.1 & 4.7757 & TRN & \\
\hline CHEMBL1479457 & 688759 & 4.45 & 4.9249 & TRN & \\
\hline CHEMBL1988782 & 688759 & 5.55 & 5.6187 & TRN & \\
\hline CHEMBL1460167 & 688759 & 4.9 & 4.7523 & TRN & \\
\hline CHEMBL3192537 & 688759 & 4.5 & 4.7223 & TRN & \\
\hline CHEMBL3197716 & 688759 & 4.55 & 5.1039 & TST & \\
\hline CHEMBL1468321 & 688759 & 4.9 & 4.9935 & TRN & \\
\hline CHEMBL 2007461 & 688759 & 4.6 & 5.0496 & TRN & \\
\hline CHEMBL1600334 & 688759 & 4.65 & 4.8265 & TRN & \\
\hline CHEMBL1361295 & 688759 & 4.45 & 4.8145 & TST & \\
\hline CHEMBL1421903 & 688759 & 5.15 & 5.0681 & TRN & \\
\hline CHEMBL1602058 & 688759 & 4.5 & 4.7443 & TRN & \\
\hline CHEMBL1575221 & 688759 & 4.65 & 5.0273 & TRN & \\
\hline CHEMBL1402627 & 688759 & 4.9 & 5.1697 & TRN & \\
\hline CHEMBL66620 & 688759 & 6.0 & 5.0943 & TRN & \\
\hline CHEMBL1558536 & 688759 & 4.45 & 4.7965 & TRN & \\
\hline CHEMBL1402872 & 688759 & 4.75 & 4.746 & TRN & \\
\hline CHEMBL1311943 & 688759 & 4.6 & 5.0929 & TST & \\
\hline CHEMBL1604932 & 688759 & 5.15 & 4.875 & TRN & \\
\hline CHEMBL1361244 & 688759 & 5.05 & 4.8666 & TRN & \\
\hline CHEMBL1349593 & 688759 & 5.4 & 4.8629 & TRN & \\
\hline CHEMBL1350251 & 688759 & 6.1 & 5.1012 & TST & \\
\hline CHEMBL1528420 & 688759 & 5.45 & 5.5265 & TRN & \\
\hline CHEMBL1328408 & 688759 & 4.65 & 5.1536 & TRN & \\
\hline
\end{tabular}




\begin{tabular}{|c|c|c|c|c|}
\hline \multicolumn{5}{|c|}{ Supplemental Table S2.txt } \\
\hline CHEMBL1489855 & 688759 & 5.25 & 5.2114 & TRN \\
\hline CHEMBL1605163 & 688759 & 4.85 & 4.9258 & TRN \\
\hline CHEMBL1569226 & 688759 & 4.65 & 4.8378 & TRN \\
\hline CHEMBL 2002046 & 688759 & 4.65 & 4.8632 & TRN \\
\hline CHEMBL1528633 & 688759 & 4.95 & 4.5058 & TRN \\
\hline CHEMBL1431343 & 688759 & 4.65 & 4.7067 & TRN \\
\hline CHEMBL1351176 & 688759 & 4.45 & 4.6558 & TRN \\
\hline CHEMBL1311206 & 688759 & 4.65 & 4.9993 & TRN \\
\hline CHEMBL1457193 & 688759 & 5.55 & 5.4465 & TST \\
\hline CHEMBL1389917 & 688759 & 7.0 & 4.9 & TST \\
\hline CHEMBL1967901 & 688759 & 6.4 & 5.645 & TRN \\
\hline CHEMBL1607586 & 688759 & 4.55 & 4.5793 & TST \\
\hline CHEMBL1346096 & 688759 & 6.05 & 5.7971 & TST \\
\hline CHEMBL1362985 & 688759 & 4.45 & 4.5911 & TRN \\
\hline CHEMBL3192789 & 688759 & 5.15 & 5.0417 & TRN \\
\hline CHEMBL1607108 & 688759 & 4.45 & 4.8345 & TST \\
\hline CHEMBL1312191 & 688759 & 5.05 & 5.4511 & TRN \\
\hline CHEMBL1382989 & 688759 & 5.15 & 5.0497 & TRN \\
\hline CHEMBL3199309 & 688759 & 5.2 & 5.0808 & TRN \\
\hline CHEMBL1503698 & 688759 & 4.45 & 4.6913 & TRN \\
\hline CHEMBL1443690 & 688759 & 5.0 & 4.5346 & TST \\
\hline CHEMBL1486366 & 688759 & 4.65 & 4.8375 & TRN \\
\hline CHEMBL1501717 & 688759 & 6.2 & 4.8148 & TRN \\
\hline CHEMBL1348102 & 688759 & 4.6 & 4.5386 & TRN \\
\hline CHEMBL1543054 & 688759 & 4.45 & 5.1732 & TRN \\
\hline CHEMBL3213828 & 688759 & 5.55 & 4.6558 & TRN \\
\hline CHEMBL1331851 & 688759 & 5.5 & 6.1042 & TRN \\
\hline CHEMBL1313979 & 688759 & 5.5 & 5.3791 & TRN \\
\hline CHEMBL3191471 & 688759 & 5.2 & 5.1911 & TRN \\
\hline CHEMBL1345700 & 688759 & 5.05 & 4.976 & TRN \\
\hline CHEMBL3193349 & 688759 & 6.0 & 5.0537 & TRN \\
\hline CHEMBL3196832 & 688759 & 4.9 & 5.013 & TRN \\
\hline CHEMBL1426267 & 688759 & 4.45 & 4.5528 & TRN \\
\hline CHEMBL1561717 & 688759 & 4.5 & 4.5401 & TRN \\
\hline CHEMBL1550406 & 688759 & 4.7 & 4.9063 & TRN \\
\hline CHEMBL1332533 & 688759 & 5.85 & 5.2483 & TRN \\
\hline CHEMBL1575038 & 688759 & 5.5 & 5.4612 & TRN \\
\hline CHEMBL1470650 & 688759 & 5.1 & 5.0336 & TRN \\
\hline CHEMBL1360295 & 688759 & 5.05 & 5.1707 & TRN \\
\hline CHEMBL1604486 & 688759 & 5.0 & 4.9251 & TRN \\
\hline CHEMBL3213630 & 688759 & 5.7 & 5.1394 & TRN \\
\hline CHEMBL1399365 & 688759 & 4.45 & 4.8579 & TST \\
\hline CHEMBL1353538 & 688759 & 4.65 & 4.8865 & TRN \\
\hline CHEMBL1394850 & 688759 & 4.55 & 4.7336 & TRN \\
\hline CHEMBL1413610 & 688759 & 5.5 & 5.026 & TRN \\
\hline CHEMBL1573380 & 688759 & 5.0 & 5.329 & TRN \\
\hline CHEMBL1459702 & 688759 & 5.4 & 4.603 & TRN \\
\hline CHEMBL1302215 & 688759 & 4.9 & 4.996 & TST \\
\hline
\end{tabular}




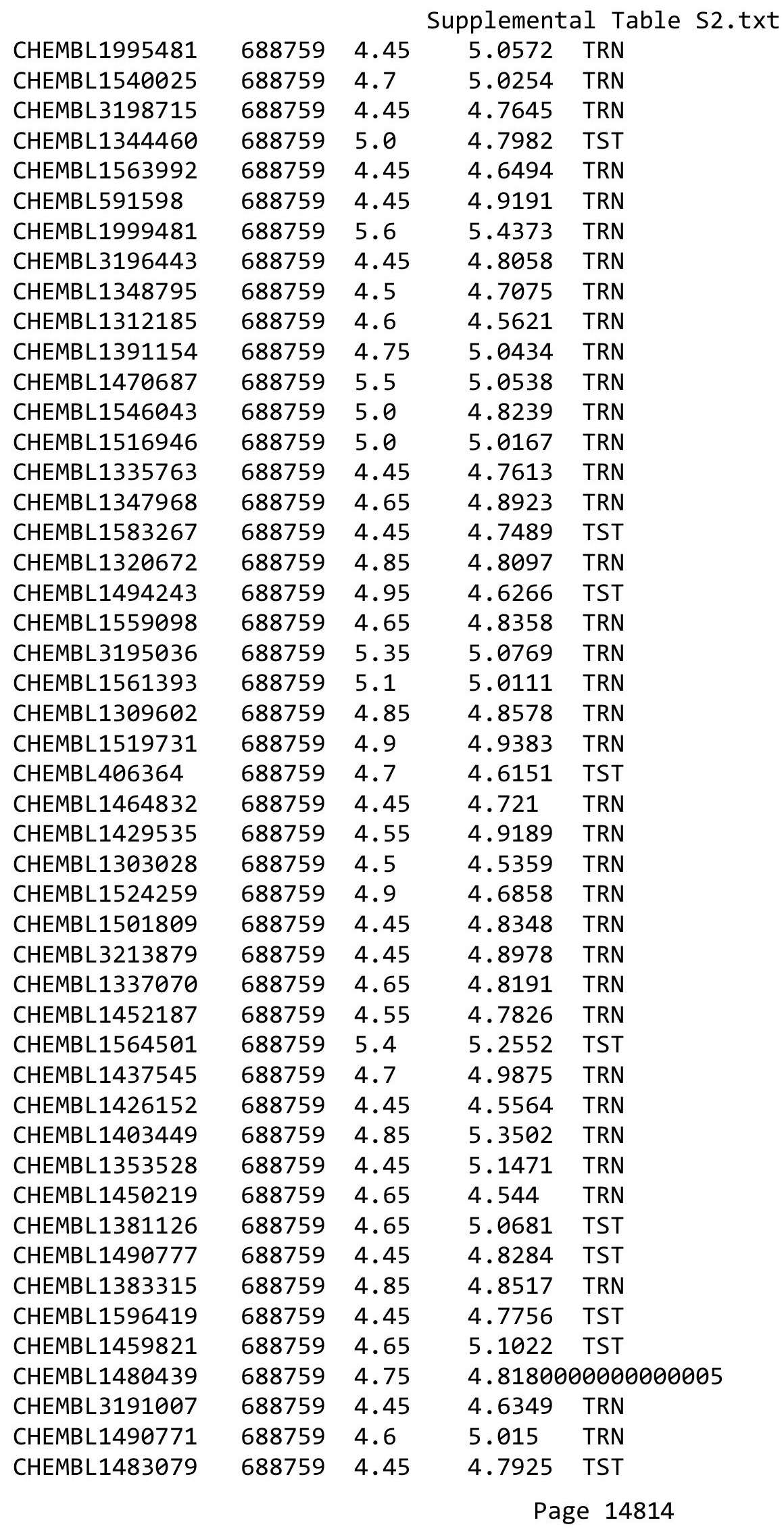




\begin{tabular}{|c|c|c|c|c|}
\hline \multicolumn{5}{|c|}{ Supplemental Table S2.txt } \\
\hline CHEMBL1505356 & 688759 & 4.8 & 4.7049 & TRN \\
\hline CHEMBL1426440 & 688759 & 5.0 & 4.8392 & TRN \\
\hline CHEMBL1451615 & 688759 & 4.65 & 4.8475 & TRN \\
\hline CHEMBL1322812 & 688759 & 4.45 & 4.9028 & TRN \\
\hline CHEMBL1301889 & 688759 & 4.85 & 4.9117 & TRN \\
\hline CHEMBL1457925 & 688759 & 4.55 & 4.4515 & TRN \\
\hline CHEMBL1313598 & 688759 & 5.15 & 5.1285 & TRN \\
\hline CHEMBL1467116 & 688759 & 4.45 & 4.877 & TST \\
\hline CHEMBL 2000529 & 688759 & 4.5 & 4.96899 & 9999999999 \\
\hline CHEMBL1991936 & 688759 & 4.45 & 4.8445 & TST \\
\hline CHEMBL1575415 & 688759 & 4.6 & 5.0182 & TRN \\
\hline CHEMBL1546843 & 688759 & 5.3 & 5.0297 & TST \\
\hline CHEMBL1561933 & 688759 & 4.95 & 4.4833 & TST \\
\hline CHEMBL1600506 & 688759 & 5.25 & 5.3728 & TRN \\
\hline CHEMBL1301406 & 688759 & 4.65 & 4.5698 & TRN \\
\hline CHEMBL1454473 & 688759 & 4.45 & 4.5968 & TRN \\
\hline CHEMBL1584359 & 688759 & 4.45 & 4.8555 & TST \\
\hline CHEMBL1578584 & 688759 & 4.6 & 5.2981 & TRN \\
\hline CHEMBL1447122 & 688759 & 4.65 & 4.7289 & TRN \\
\hline CHEMBL1397601 & 688759 & 4.45 & 5.1434 & TRN \\
\hline CHEMBL1520193 & 688759 & 4.7 & 4.9122 & TST \\
\hline CHEMBL1483902 & 688759 & 4.7 & 4.671 & TST \\
\hline CHEMBL1335804 & 688759 & 4.65 & 4.7296 & TRN \\
\hline CHEMBL1390460 & 688759 & 5.0 & 4.8802 & TRN \\
\hline CHEMBL1609909 & 688759 & 5.25 & 4.84 & TST \\
\hline CHEMBL1455549 & 688759 & 4.45 & 4.6313 & TST \\
\hline CHEMBL116438 & 688759 & 6.0 & 5.3255 & TRN \\
\hline CHEMBL1413408 & 688759 & 4.95 & 5.0329 & TRN \\
\hline CHEMBL1588762 & 688759 & 6.3 & 4.8492 & TRN \\
\hline CHEMBL1541549 & 688759 & 4.9 & 5.1969 & TST \\
\hline CHEMBL1464647 & 688759 & 5.45 & 5.3581 & TRN \\
\hline CHEMBL1981538 & 688759 & 4.65 & 5.2252 & TRN \\
\hline CHEMBL1333428 & 688759 & 4.65 & 5.1477 & TRN \\
\hline CHEMBL1542809 & 688759 & 5.6 & 5.0786 & TRN \\
\hline CHEMBL1549101 & 688759 & 5.3 & 5.0515 & TRN \\
\hline CHEMBL1446626 & 688759 & 4.45 & 4.9436 & TRN \\
\hline CHEMBL3214536 & 688759 & 4.9 & 4.8867 & TRN \\
\hline CHEMBL1990598 & 688759 & 5.6 & 5.2236 & TRN \\
\hline CHEMBL1546528 & 688759 & 4.45 & 4.849 & TRN \\
\hline CHEMBL1362105 & 688759 & 4.45 & 4.6772 & TRN \\
\hline CHEMBL1569170 & 688759 & 5.8 & 5.1531 & TRN \\
\hline CHEMBL1598643 & 688759 & 4.45 & 4.8512 & TRN \\
\hline CHEMBL3208732 & 688759 & 5.1 & 5.3748 & TRN \\
\hline CHEMBL1545737 & 688759 & 4.45 & 4.9708 & TRN \\
\hline CHEMBL1499215 & 688759 & 4.45 & 4.6602 & TRN \\
\hline CHEMBL1606206 & 688759 & 4.45 & 4.7386 & TRN \\
\hline CHEMBL1388019 & 688759 & 4.45 & 4.8318 & TRN \\
\hline CHEMBL1452881 & 688759 & 4.5 & 5.0587 & TST \\
\hline
\end{tabular}




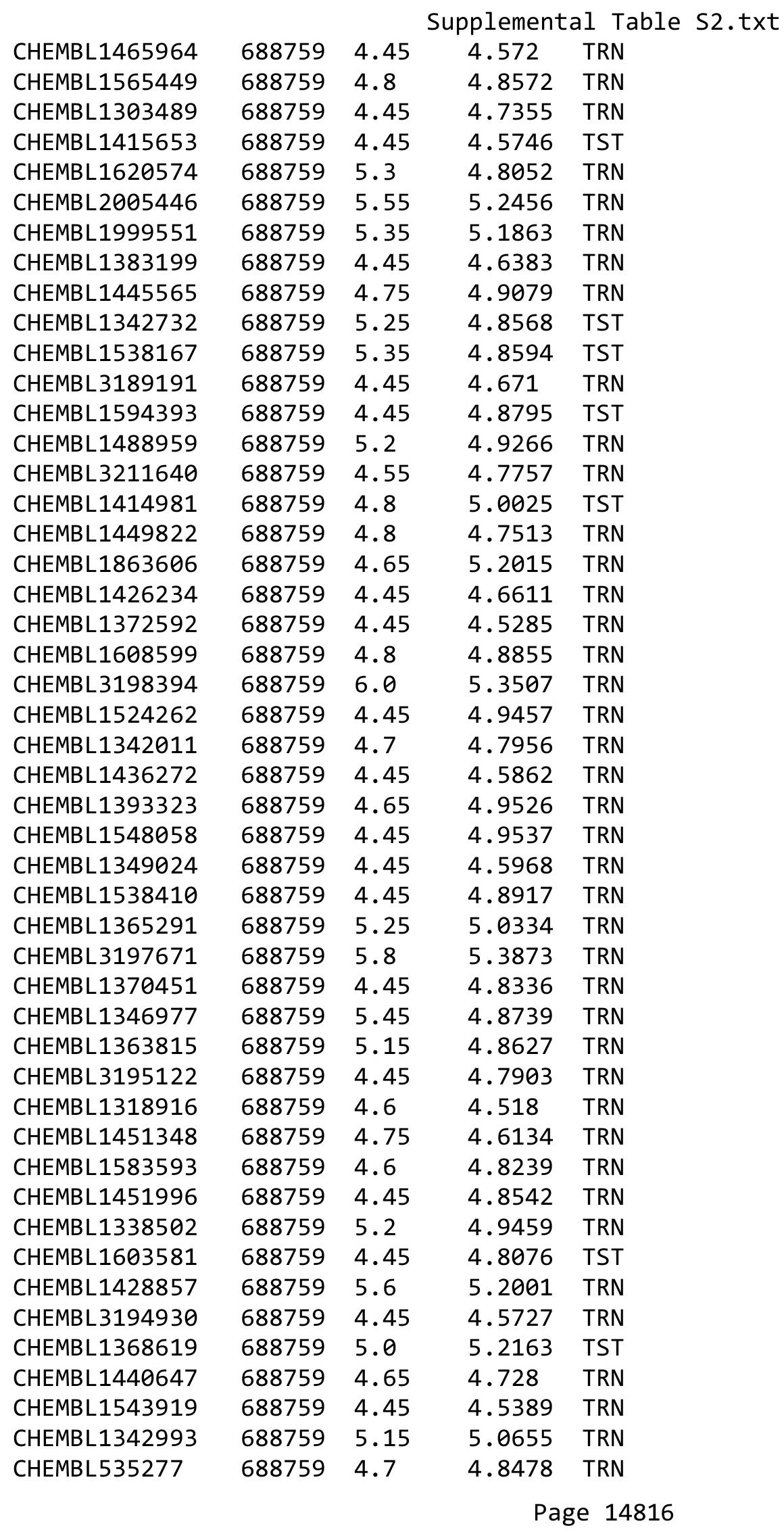




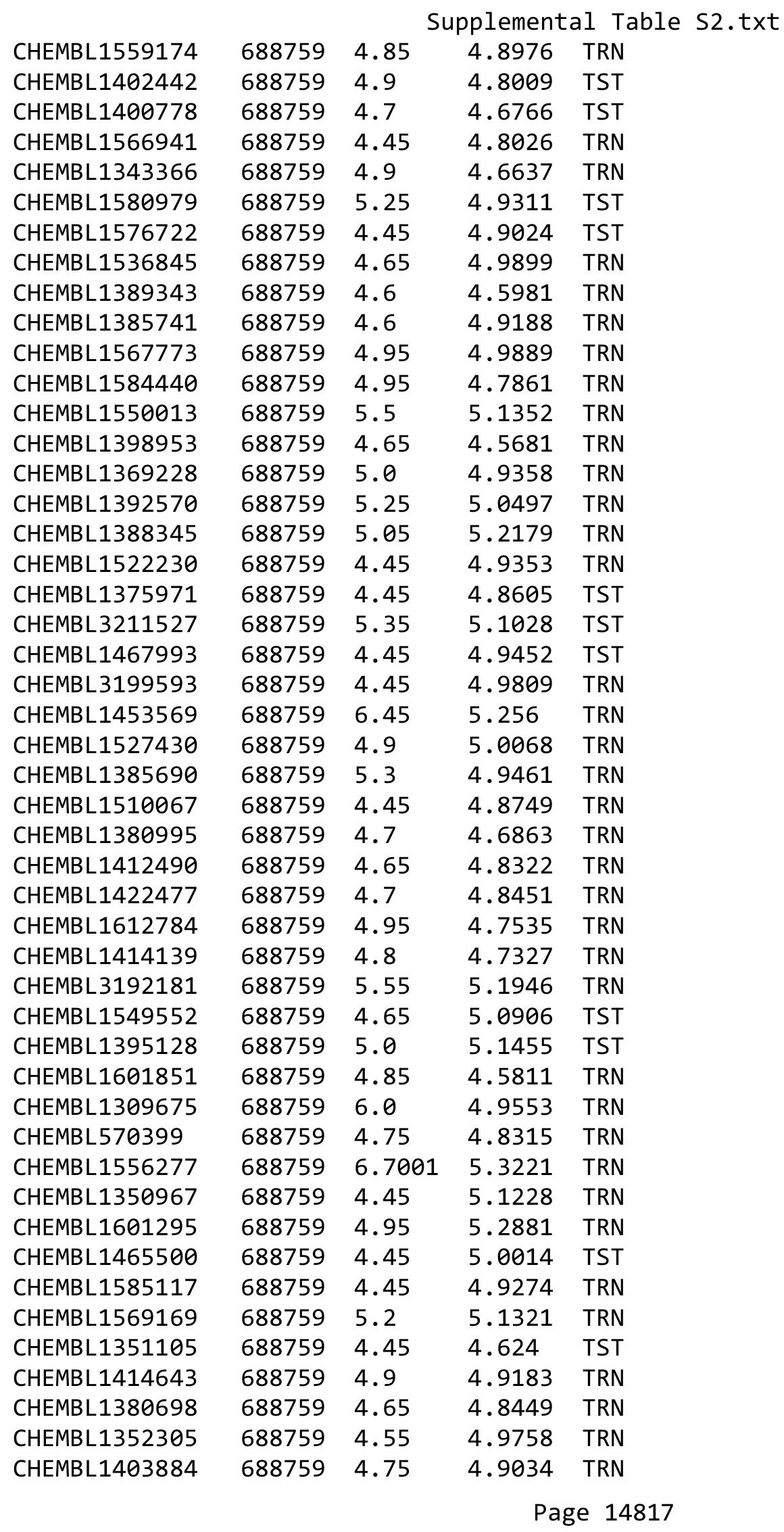




\begin{tabular}{|c|c|c|c|c|c|}
\hline \multicolumn{6}{|c|}{ Supplemental Table s2.txt } \\
\hline CHEMBL1969590 & 688759 & 5.55 & 5.3288 & TRN & \\
\hline CHEMBL1517971 & 688759 & 4.9 & 5.1471 & TRN & \\
\hline CHEMBL1300745 & 688759 & 5.4 & 5.2278 & TRN & \\
\hline CHEMBL1606735 & 688759 & 5.85 & 5.6476 & TST & \\
\hline CHEMBL1558079 & 688759 & 5.25 & 4.599 & TRN & \\
\hline CHEMBL3195881 & 688759 & 4.6 & 4.8903 & TST & \\
\hline CHEMBL1482661 & 688759 & 4.45 & 5.115 & TRN & \\
\hline CHEMBL3208147 & 688759 & 5.35 & 4.9175 & TST & \\
\hline CHEMBL1363461 & 688759 & 5.25 & 4.9929 & TRN & \\
\hline CHEMBL1431028 & 688759 & 5.3 & 4.9247 & TST & \\
\hline CHEMBL3207466 & 688759 & 5.45 & 4.9603 & TST & \\
\hline CHEMBL1446759 & 688759 & 6.05 & 4.8301 & TRN & \\
\hline CHEMBL1432468 & 688759 & 5.55 & 4.9048 & TST & \\
\hline CHEMBL1550135 & 688759 & 5.15 & 5.4303 & TRN & \\
\hline CHEMBL1417489 & 688759 & 4.85 & 4.836 & TRN & \\
\hline CHEMBL1302367 & 688759 & 4.7 & 4.6611 & TRN & \\
\hline CHEMBL1492537 & 688759 & 4.45 & 4.8526 & TRN & \\
\hline CHEMBL3193456 & 688759 & 4.7 & 4.6945 & TRN & \\
\hline CHEMBL1428950 & 688759 & 5.1 & 4.7203 & TRN & \\
\hline CHEMBL1560072 & 688759 & 6.0 & 5.3939 & TRN & \\
\hline CHEMBL1566191 & 688759 & 5.2 & 5.0131 & TRN & \\
\hline CHEMBL1599268 & 688759 & 4.8 & 4.6375 & TRN & \\
\hline CHEMBL 2002818 & 688759 & 5.0 & 4.8417 & TST & \\
\hline CHEMBL1465705 & 688759 & 4.45 & 5.0022 & TST & \\
\hline CHEMBL1501778 & 688759 & 5.25 & 5.0672 & TRN & \\
\hline CHEMBL3210469 & 688759 & 4.9 & 5.0624 & TRN & \\
\hline CHEMBL1392209 & 688759 & 4.45 & 4.7898 & TRN & \\
\hline CHEMBL1323984 & 688759 & 4.45 & 4.692 & TST & \\
\hline CHEMBL3192554 & 688759 & 4.75 & 4.5157 & TRN & \\
\hline CHEMBL1469012 & 688759 & 4.95 & 4.8155 & TRN & \\
\hline CHEMBL1465659 & 688759 & 5.15 & 4.89 & TST & \\
\hline CHEMBL1303722 & 688759 & 4.45 & 4.7459 & TRN & \\
\hline CHEMBL1457665 & 688759 & 4.6 & 4.8163 & TRN & \\
\hline CHEMBL1547641 & 688759 & 4.6 & 4.7056 & TRN & \\
\hline CHEMBL1544925 & 688759 & 4.45 & 4.7975 & TRN & \\
\hline CHEMBL1487013 & 688759 & 4.45 & 4.5222 & TRN & \\
\hline CHEMBL1584745 & 688759 & 5.4 & 4.8531 & TRN & \\
\hline CHEMBL1996445 & 688759 & 4.6 & 4.7843 & TRN & \\
\hline CHEMBL1411257 & 688759 & 5.65 & 5.5645 & TRN & \\
\hline CHEMBL1483138 & 688759 & 4.45 & 4.4927 & TRN & \\
\hline CHEMBL1327276 & 688759 & 5.2 & 4.569 & TRN & \\
\hline CHEMBL1352061 & 688759 & 5.95 & 4.7766 & TST & \\
\hline CHEMBL1450266 & 688759 & 4.65 & 4.8572 & TRN & \\
\hline CHEMBL1568027 & 688759 & 5.2 & 5.129 & TRN & \\
\hline CHEMBL1488674 & 688759 & 5.3 & 4.9494 & TRN & \\
\hline CHEMBL1327451 & 688759 & 4.45 & 4.7309 & TST & \\
\hline CHEMBL1306266 & 688759 & 5.35 & 5.343 & TST & \\
\hline CHEMBL1536982 & 688759 & 4.95 & 5.17200 & 0000000001 & TRN \\
\hline & & & & 14818 & \\
\hline
\end{tabular}




\begin{tabular}{|c|c|c|c|c|}
\hline & & \multicolumn{3}{|c|}{ Supplemental Table s2.txt } \\
\hline CHEMBL1390384 & 688759 & 4.45 & 4.6528 & TRN \\
\hline CHEMBL1508142 & 688759 & 4.7 & 4.66 & TRN \\
\hline CHEMBL1425652 & 688759 & 5.5 & 5.1893 & TRN \\
\hline CHEMBL476513 & 688759 & 5.05 & 5.2062 & TRN \\
\hline CHEMBL1459259 & 688759 & 4.45 & 4.8765 & TST \\
\hline CHEMBL1388997 & 688759 & 5.35 & 5.2492 & TRN \\
\hline CHEMBL1992397 & 688759 & 5.15 & 5.1589 & TRN \\
\hline CHEMBL239276 & 688759 & 5.1 & 5.0949 & TRN \\
\hline CHEMBL1413018 & 688759 & 4.45 & 4.7209 & TRN \\
\hline CHEMBL1489442 & 688759 & 4.45 & 4.9385 & TRN \\
\hline CHEMBL1452840 & 688759 & 6.05 & 5.1625 & TRN \\
\hline CHEMBL1497717 & 688759 & 4.8 & 4.8945 & TST \\
\hline CHEMBL1372808 & 688759 & 5.4 & 5.4237 & TRN \\
\hline CHEMBL1454143 & 688759 & 4.9 & 4.9143 & TST \\
\hline CHEMBL1536682 & 688759 & 4.7 & 4.9107 & TST \\
\hline CHEMBL1457192 & 688759 & 5.25 & 4.9772 & TST \\
\hline CHEMBL1417478 & 688759 & 7.0 & 4.9554 & TRN \\
\hline CHEMBL1392674 & 688759 & 5.75 & 5.025 & TRN \\
\hline CHEMBL1341356 & 688759 & 5.0 & 5.2145 & TRN \\
\hline CHEMBL1399558 & 688759 & 4.45 & 4.8293 & TST \\
\hline CHEMBL1493711 & 688759 & 4.45 & 4.6713 & TRN \\
\hline CHEMBL1608860 & 688759 & 4.6 & 5.0477 & TST \\
\hline CHEMBL1404673 & 688759 & 4.65 & 5.0267 & TRN \\
\hline CHEMBL3210517 & 688759 & 5.35 & 5.066 & TRN \\
\hline CHEMBL1416992 & 688759 & 4.45 & 4.956 & TST \\
\hline CHEMBL1348125 & 688759 & 4.45 & 4.659 & TRN \\
\hline CHEMBL1388030 & 688759 & 5.25 & 4.8493 & TRN \\
\hline CHEMBL485636 & 688759 & 4.8 & 5.3554 & TRN \\
\hline CHEMBL1446971 & 688759 & 5.75 & 5.4274 & TRN \\
\hline CHEMBL1426669 & 688759 & 4.7 & 4.8298 & TRN \\
\hline CHEMBL3195324 & 688759 & 5.45 & 5.0 & TRN \\
\hline CHEMBL1511683 & 688759 & 5.15 & 5.2273 & TRN \\
\hline CHEMBL3199036 & 688759 & 4.45 & 4.6368 & TRN \\
\hline CHEMBL509531 & 688759 & 4.95 & 4.936 & TST \\
\hline CHEMBL1374924 & 688759 & 4.45 & 4.9701 & TRN \\
\hline CHEMBL1533343 & 688759 & 4.85 & 4.8382 & TRN \\
\hline CHEMBL1603033 & 688759 & 4.65 & 4.9107 & TRN \\
\hline CHEMBL1446531 & 688759 & 4.5 & 4.9556 & TST \\
\hline CHEMBL1378812 & 688759 & 5.85 & 5.0518 & TST \\
\hline CHEMBL1350019 & 688759 & 4.45 & 5.003 & TRN \\
\hline CHEMBL1572387 & 688759 & 4.45 & 4.8336 & TRN \\
\hline CHEMBL1350352 & 688759 & 4.75 & 4.8688 & TRN \\
\hline CHEMBL1380154 & 688759 & 4.45 & 4.7438 & TRN \\
\hline CHEMBL1343397 & 688759 & 6.0 & 6.0074 & TRN \\
\hline CHEMBL1500725 & 688759 & 4.45 & 4.7964 & TRN \\
\hline CHEMBL1478344 & 688759 & 4.45 & 4.5494 & TRN \\
\hline CHEMBL1988138 & 688759 & 5.7 & 5.4474 & TRN \\
\hline CHEMBL1399653 & 688759 & 5.15 & 5.0536 & TRN \\
\hline
\end{tabular}




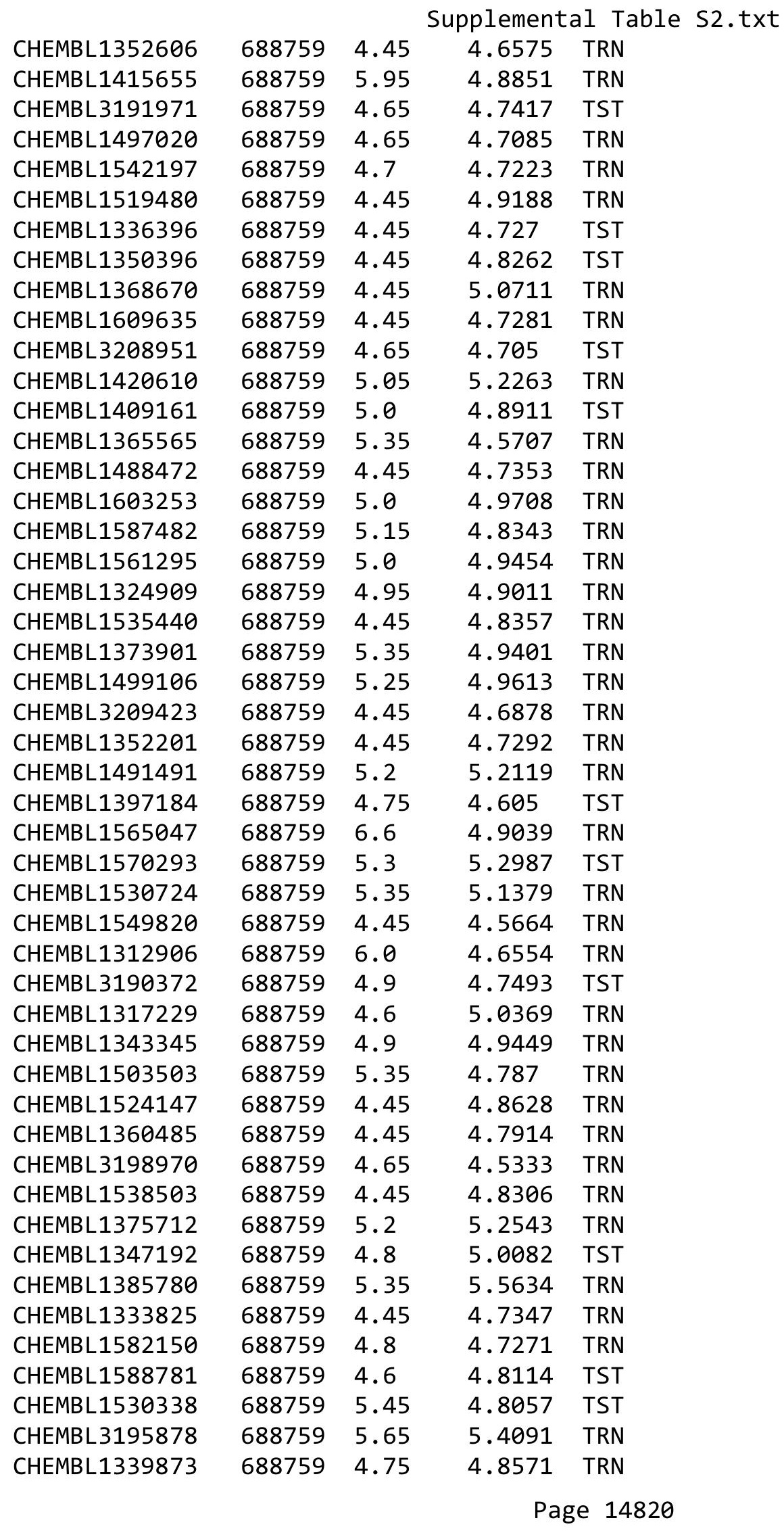




\begin{tabular}{|c|c|c|c|c|c|}
\hline & & \multicolumn{4}{|c|}{ Supplemental Table S2.txt } \\
\hline CHEMBL1368138 & 688759 & 5.85 & 4.7509 & TRN & \\
\hline CHEMBL1350264 & 688759 & 4.95 & 4.9726 & TRN & \\
\hline CHEMBL3196534 & 688759 & 4.5 & 4.5741 & TRN & \\
\hline CHEMBL1371270 & 688759 & 4.6 & 5.0049 & TRN & \\
\hline CHEMBL1351991 & 688759 & 5.25 & 5.5002 & TRN & \\
\hline CHEMBL1508959 & 688759 & 4.45 & 4.8728 & TST & \\
\hline CHEMBL1498502 & 688759 & 4.45 & 4.7329 & TRN & \\
\hline CHEMBL475376 & 688759 & 4.65 & 4.6643 & TRN & \\
\hline CHEMBL1335401 & 688759 & 4.75 & 4.7941 & TRN & \\
\hline CHEMBL1581682 & 688759 & 4.6 & 4.9363 & TRN & \\
\hline CHEMBL1306978 & 688759 & 4.8 & 4.9058 & TRN & \\
\hline CHEMBL1419374 & 688759 & 4.95 & 4.7779 & TRN & \\
\hline CHEMBL1466304 & 688759 & 4.7 & 4.7421 & TST & \\
\hline CHEMBL1605613 & 688759 & 6.1 & 5.0851 & TRN & \\
\hline CHEMBL1308295 & 688759 & 4.45 & 4.6794 & TRN & \\
\hline CHEMBL1301861 & 688759 & 4.65 & 4.9068 & TRN & \\
\hline CHEMBL3189249 & 688759 & 4.7 & 4.7761 & TRN & \\
\hline CHEMBL1609332 & 688759 & 6.05 & 4.7769 & TRN & \\
\hline CHEMBL 3194078 & 688759 & 4.7 & 4.7081 & TST & \\
\hline CHEMBL1470905 & 688759 & 5.35 & 4.9585 & TRN & \\
\hline CHEMBL1495227 & 688759 & 4.85 & 5.0777 & TRN & \\
\hline CHEMBL1445416 & 688759 & 5.5 & 5.1124 & TST & \\
\hline CHEMBL1465114 & 688759 & 5.0 & 4.5565 & TRN & \\
\hline CHEMBL1566520 & 688759 & 4.65 & 4.8994 & TST & \\
\hline CHEMBL1529960 & 688759 & 7.0 & 6.1584 & TRN & \\
\hline CHEMBL1213834 & 688759 & 6.2 & 5.0372 & TRN & \\
\hline CHEMBL1538919 & 688759 & 4.55 & 4.6345 & TRN & \\
\hline CHEMBL1561222 & 688759 & 5.35 & 4.9843 & TRN & \\
\hline CHEMBL1369945 & 688759 & 4.45 & 4.76399 & & TRN \\
\hline CHEMBL1533953 & 688759 & 6.0 & 4.9167 & TST & \\
\hline CHEMBL3198090 & 688759 & 4.55 & 4.8214 & TRN & \\
\hline CHEMBL1334405 & 688759 & 4.65 & 4.6484 & TST & \\
\hline CHEMBL1452827 & 688759 & 4.45 & 4.8575 & TRN & \\
\hline CHEMBL1418145 & 688759 & 6.45 & 4.7993 & TRN & \\
\hline CHEMBL1459198 & 688759 & 4.45 & 4.6931 & TRN & \\
\hline CHEMBL1504952 & 688759 & 4.55 & 4.8392 & TRN & \\
\hline CHEMBL1511315 & 688759 & 4.45 & 4.8001 & TST & \\
\hline CHEMBL1517889 & 688759 & 4.45 & 5.066 & TRN & \\
\hline CHEMBL1312885 & 688759 & 4.65 & 4.5337 & TRN & \\
\hline CHEMBL1381936 & 688759 & 5.15 & 5.0958 & TRN & \\
\hline CHEMBL1605328 & 688759 & 4.5 & 4.8765 & TRN & \\
\hline CHEMBL1404337 & 688759 & 5.2 & 5.2757 & TRN & \\
\hline CHEMBL1329080 & 688759 & 5.2 & 5.0998 & TRN & \\
\hline CHEMBL1505055 & 688759 & 5.4 & 4.9911 & TRN & \\
\hline CHEMBL1399316 & 688759 & 5.15 & 5.1878 & TRN & \\
\hline CHEMBL1416856 & 688759 & 5.3 & 4.6681 & TST & \\
\hline CHEMBL1546407 & 688759 & 5.8 & 5.8511 & TST & \\
\hline CHEMBL1531291 & 688759 & 5.3 & 5.0676 & TRN & \\
\hline
\end{tabular}




\begin{tabular}{|c|c|c|c|c|c|}
\hline \multicolumn{6}{|c|}{ Supplemental Table S2.txt } \\
\hline CHEMBL1558285 & 688759 & 4.95 & 5.0848 & TST & \\
\hline CHEMBL1607071 & 688759 & 4.45 & 4.6909 & TRN & \\
\hline CHEMBL1466102 & 688759 & 5.1 & 5.1607 & TRN & \\
\hline CHEMBL1588733 & 688759 & 4.45 & 4.8002 & TST & \\
\hline CHEMBL1547262 & 688759 & 5.35 & 5.3489 & TST & \\
\hline CHEMBL1490169 & 688759 & 4.7 & 4.9499 & TRN & \\
\hline CHEMBL1440093 & 688759 & 5.9 & 4.8316 & TRN & \\
\hline CHEMBL1541596 & 688759 & 4.85 & 4.7886 & TRN & \\
\hline CHEMBL1309568 & 688759 & 4.45 & 4.8968 & TST & \\
\hline CHEMBL1489407 & 688759 & 5.55 & 5.3402 & TRN & \\
\hline CHEMBL1398602 & 688759 & 5.0 & 4.9226 & TRN & \\
\hline CHEMBL1316265 & 688759 & 6.0 & 4.8292 & TST & \\
\hline CHEMBL1496237 & 688759 & 5.4 & 5.07 & TRN & \\
\hline CHEMBL3199538 & 688759 & 5.5 & 5.0609 & TRN & \\
\hline CHEMBL3189449 & 688759 & 5.3 & 4.813 & TRN & \\
\hline CHEMBL1563221 & 688759 & 5.15 & 4.9432 & TRN & \\
\hline CHEMBL1332454 & 688759 & 5.55 & 5.2163 & TRN & \\
\hline CHEMBL1508375 & 688759 & 6.0 & 5.7684 & TRN & \\
\hline CHEMBL1362999 & 688759 & 4.45 & 4.504 & TST & \\
\hline CHEMBL1569716 & 688759 & 4.45 & 4.6091 & TRN & \\
\hline CHEMBL1450447 & 688759 & 4.45 & 4.4421 & TRN & \\
\hline CHEMBL1472426 & 688759 & 4.45 & 4.9154 & TST & \\
\hline CHEMBL1304625 & 688759 & 4.6 & 4.6454 & TST & \\
\hline CHEMBL1328837 & 688759 & 5.2 & 4.9888 & TRN & \\
\hline CHEMBL1383597 & 688759 & 5.4 & 5.3623 & TRN & \\
\hline CHEMBL1551915 & 688759 & 4.6 & 4.7411 & TST & \\
\hline CHEMBL1558789 & 688759 & 5.45 & 4.8616 & TRN & \\
\hline CHEMBL1494716 & 688759 & 5.1 & 5.1506 & TRN & \\
\hline CHEMBL1327131 & 688759 & 4.65 & 5.3561 & TRN & \\
\hline CHEMBL1351964 & 688759 & 4.45 & 4.63899 & 9999999999 & TRN \\
\hline CHEMBL1446404 & 688759 & 6.1 & 4.8331 & TRN & \\
\hline CHEMBL1562738 & 688759 & 4.45 & 4.9281 & TRN & \\
\hline CHEMBL1391778 & 688759 & 4.45 & 4.8217 & TRN & \\
\hline CHEMBL312163 & 688759 & 4.65 & 5.1206 & TRN & \\
\hline CHEMBL3198663 & 688759 & 4.65 & 4.7822 & TRN & \\
\hline CHEMBL1352106 & 688759 & 4.45 & 5.2956 & TRN & \\
\hline CHEMBL1572332 & 688759 & 5.5 & 5.0138 & TRN & \\
\hline CHEMBL1326336 & 688759 & 4.45 & 4.7885 & TST & \\
\hline CHEMBL 3212376 & 688759 & 5.55 & 4.99100 & 20000000005 & TRN \\
\hline CHEMBL1550545 & 688759 & 4.45 & 4.5752 & TST & \\
\hline CHEMBL1441056 & 688759 & 4.45 & 4.8825 & TST & \\
\hline CHEMBL1431042 & 688759 & 4.65 & 4.7809 & TST & \\
\hline CHEMBL1390868 & 688759 & 4.45 & 5.1184 & TST & \\
\hline CHEMBL1390836 & 688759 & 5.0 & 4.8071 & TRN & \\
\hline CHEMBL1333635 & 688759 & 4.55 & 4.7889 & TRN & \\
\hline CHEMBL1472638 & 688759 & 4.6 & 4.7568 & TRN & \\
\hline CHEMBL1575716 & 688759 & 5.3 & 5.1646 & TRN & \\
\hline CHEMBL1447890 & 688759 & 4.65 & 4.808 & TRN & \\
\hline
\end{tabular}




\begin{tabular}{|c|c|c|c|c|c|}
\hline \multicolumn{6}{|c|}{ Supplemental Table S2.txt } \\
\hline CHEMBL1350861 & 688759 & 4.45 & 5.1401 & TRN & \\
\hline CHEMBL566691 & 688759 & 4.6 & 4.7375 & TRN & \\
\hline CHEMBL1518459 & 688759 & 4.65 & 4.7796 & TRN & \\
\hline CHEMBL1457530 & 688759 & 4.45 & 4.7814 & TRN & \\
\hline CHEMBL1309218 & 688759 & 5.25 & 5.1631 & TRN & \\
\hline CHEMBL1449204 & 688759 & 5.3 & 5.101 & TRN & \\
\hline CHEMBL1308897 & 688759 & 4.55 & 4.7293 & TRN & \\
\hline CHEMBL1609978 & 688759 & 4.75 & 4.8176 & TRN & \\
\hline CHEMBL1415691 & 688759 & 4.8 & 4.8089 & TST & \\
\hline CHEMBL1481622 & 688759 & 5.75 & 5.9436 & TRN & \\
\hline CHEMBL1340370 & 688759 & 4.95 & 4.9747 & TRN & \\
\hline CHEMBL1410552 & 688759 & 5.4 & 4.8569 & TRN & \\
\hline CHEMBL1510165 & 688759 & 4.65 & 4.9035 & TST & \\
\hline CHEMBL1366035 & 688759 & 4.9 & 5.0987 & TRN & \\
\hline CHEMBL1362969 & 688759 & 4.45 & 4.88899 & 9999999999 & TRN \\
\hline CHEMBL1541339 & 688759 & 5.5 & 5.1363 & TRN & \\
\hline CHEMBL1468889 & 688759 & 4.45 & 4.6776 & TST & \\
\hline CHEMBL1446329 & 688759 & 5.9 & 5.1475 & TRN & \\
\hline CHEMBL1966298 & 688759 & 5.65 & 5.4155 & TST & \\
\hline CHEMBL398765 & 688759 & 5.3 & 5.5395 & TRN & \\
\hline CHEMBL1605857 & 688759 & 5.55 & 5.3201 & TRN & \\
\hline CHEMBL1508582 & 688759 & 5.0 & 5.0491 & TST & \\
\hline CHEMBL1347279 & 688759 & 4.8 & 4.6337 & TRN & \\
\hline CHEMBL1586557 & 688759 & 4.65 & 4.7639 & TRN & \\
\hline CHEMBL1354012 & 688759 & 4.7 & 4.5908 & TRN & \\
\hline CHEMBL1368363 & 688759 & 4.6 & 4.7898 & TRN & \\
\hline CHEMBL1417894 & 688759 & 4.6 & 4.9564 & TST & \\
\hline CHEMBL1438700 & 688759 & 4.85 & 4.7412 & TRN & \\
\hline CHEMBL1996742 & 688759 & 4.9 & 5.1414 & TRN & \\
\hline CHEMBL1509635 & 688759 & 4.7 & 4.8629 & TRN & \\
\hline CHEMBL1471729 & 688759 & 4.45 & 4.9279 & TST & \\
\hline CHEMBL1490683 & 688759 & 4.85 & 4.6634 & TRN & \\
\hline CHEMBL1410644 & 688759 & 5.35 & 4.8791 & TRN & \\
\hline CHEMBL1605733 & 688759 & 5.25 & 5.1012 & TRN & \\
\hline CHEMBL1611360 & 688759 & 4.45 & 4.9823 & TRN & \\
\hline CHEMBL1539755 & 688759 & 4.7 & 4.8508 & TST & \\
\hline CHEMBL 1413336 & 688759 & 4.45 & 4.6065 & TRN & \\
\hline CHEMBL1389702 & 688759 & 5.15 & 4.937 & TRN & \\
\hline CHEMBL1504505 & 688759 & 6.2 & 5.0814 & TRN & \\
\hline CHEMBL1464140 & 688759 & 4.45 & 4.6663 & TRN & \\
\hline CHEMBL1487641 & 688759 & 5.25 & 5.375 & TRN & \\
\hline CHEMBL1598785 & 688759 & 5.5 & 5.6663 & TRN & \\
\hline CHEMBL1564712 & 688759 & 5.15 & 5.2613 & TRN & \\
\hline CHEMBL1349748 & 688759 & 5.25 & 5.1685 & TRN & \\
\hline CHEMBL1608142 & 688759 & 4.45 & 4.9537 & TRN & \\
\hline CHEMBL1966865 & 688759 & 4.95 & 5.2218 & TRN & \\
\hline CHEMBL1409429 & 688759 & 5.15 & 4.7387 & TRN & \\
\hline CHEMBL1578762 & 688759 & 4.95 & 4.8116 & TRN & \\
\hline
\end{tabular}




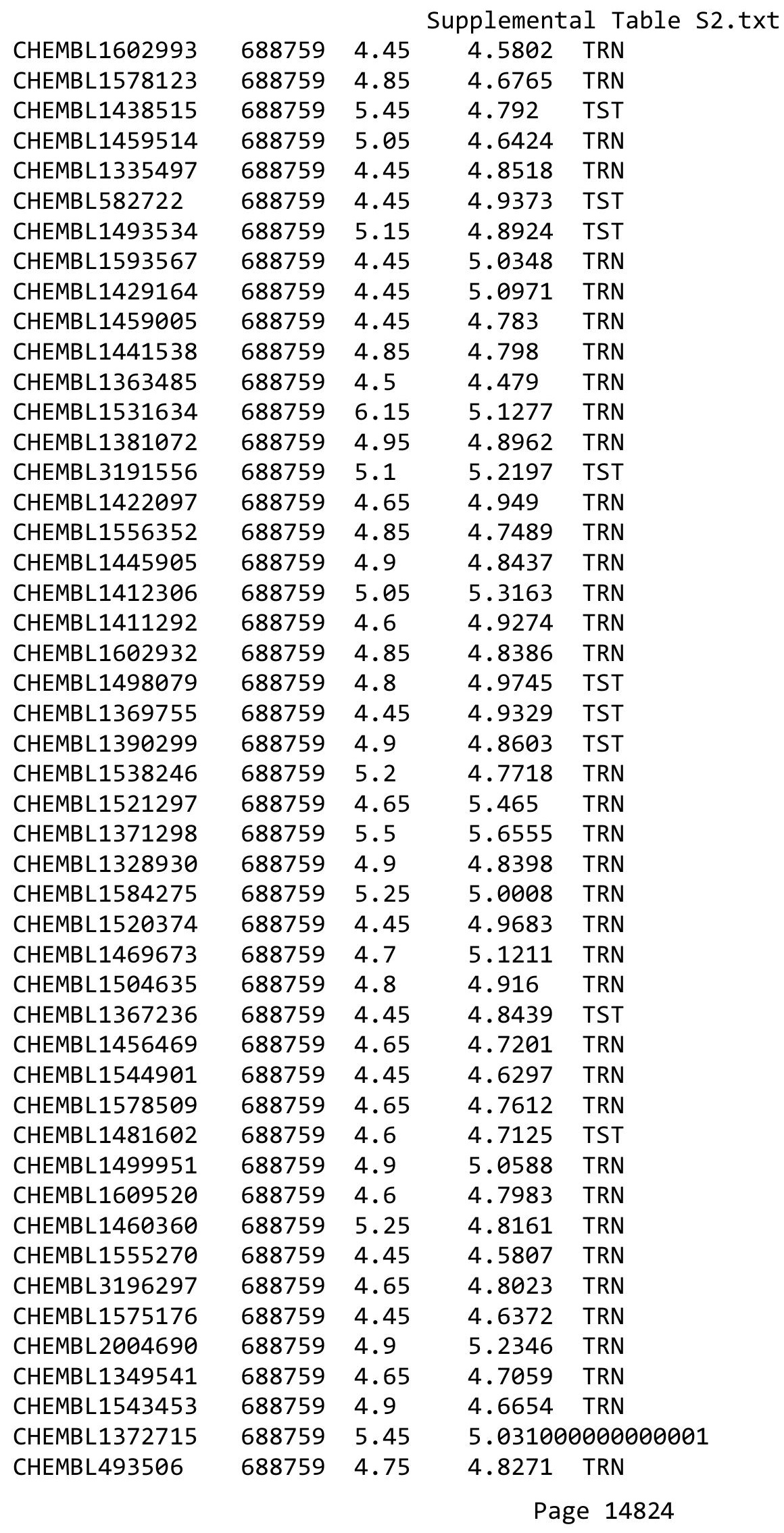

TRN 


\begin{tabular}{|c|c|c|c|c|c|}
\hline \multicolumn{6}{|c|}{ Supplemental Table S2.txt } \\
\hline CHEMBL1360665 & 688759 & 4.8 & 4.8479 & TRN & \\
\hline CHEMBL1435938 & 688759 & 7.0 & 4.9789 & TST & \\
\hline CHEMBL601146 & 688759 & 6.0 & 5.0489 & TRN & \\
\hline CHEMBL1320055 & 688759 & 4.45 & 4.8073 & TRN & \\
\hline CHEMBL1442056 & 688759 & 4.45 & 4.9833 & TRN & \\
\hline CHEMBL1546161 & 688759 & 4.65 & 4.7163 & TRN & \\
\hline CHEMBL1416795 & 688759 & 5.2 & 4.6975 & TRN & \\
\hline CHEMBL1501333 & 688759 & 4.45 & 4.7191 & TRN & \\
\hline CHEMBL1412539 & 688759 & 4.65 & 4.7743 & TRN & \\
\hline CHEMBL1421086 & 688759 & 4.8 & 4.8803 & TRN & \\
\hline CHEMBL1558611 & 688759 & 5.15 & 5.0238 & TST & \\
\hline CHEMBL1580335 & 688759 & 4.5 & 4.849 & TRN & \\
\hline CHEMBL1403152 & 688759 & 4.85 & 4.7675 & TRN & \\
\hline CHEMBL1372434 & 688759 & 4.45 & 4.9038 & TRN & \\
\hline CHEMBL1562371 & 688759 & 5.0 & 4.8539 & TRN & \\
\hline CHEMBL1383036 & 688759 & 5.5 & 5.1366 & TRN & \\
\hline CHEMBL1300136 & 688759 & 5.15 & 4.6883 & TST & \\
\hline CHEMBL1542650 & 688759 & 4.45 & 4.8674 & TRN & \\
\hline CHEMBL1422502 & 688759 & 5.2 & 5.4584 & TRN & \\
\hline CHEMBL1528183 & 688759 & 5.1 & 5.2131 & TST & \\
\hline CHEMBL1329841 & 688759 & 4.45 & 4.7277 & TRN & \\
\hline CHEMBL1570065 & 688759 & 4.45 & 4.7446 & TRN & \\
\hline CHEMBL1585275 & 688759 & 4.65 & 4.7815 & TRN & \\
\hline CHEMBL1327303 & 688759 & 5.05 & 4.7518 & TRN & \\
\hline CHEMBL1392696 & 688759 & 4.8 & 4.9151 & TST & \\
\hline CHEMBL3193616 & 688759 & 4.7 & 4.8625 & TRN & \\
\hline CHEMBL1344288 & 688759 & 4.8 & 4.5887 & TST & \\
\hline CHEMBL1598287 & 688759 & 4.95 & 4.8714 & TRN & \\
\hline CHEMBL1301769 & 688759 & 4.45 & 4.698 & TST & \\
\hline CHEMBL1314116 & 688759 & 4.45 & 4.934 & TST & \\
\hline CHEMBL1986355 & 688759 & 5.5 & 5.5564 & TRN & \\
\hline CHEMBL1377188 & 688759 & 5.3 & 5.2139 & TST & \\
\hline CHEMBL3212312 & 688759 & 5.15 & 4.8922 & TRN & \\
\hline CHEMBL1490677 & 688759 & 4.9 & 4.9776 & TST & \\
\hline CHEMBL1337630 & 688759 & 4.95 & 4.8014 & TRN & \\
\hline CHEMBL1510627 & 688759 & 4.85 & 4.8732 & TRN & \\
\hline CHEMBL1529891 & 688759 & 4.55 & 4.7487 & TRN & \\
\hline CHEMBL1459271 & 688759 & 4.6 & 4.8078 & TRN & \\
\hline CHEMBL1309690 & 688759 & 4.7 & 4.97199 & 99999999995 & TST \\
\hline CHEMBL1468451 & 688759 & 4.65 & 4.5601 & TRN & \\
\hline CHEMBL1442968 & 688759 & 4.45 & 5.0848 & TST & \\
\hline CHEMBL1584506 & 688759 & 5.35 & 5.269 & TRN & \\
\hline CHEMBL1612007 & 688759 & 4.45 & $4.9110 e$ & 00000000005 & TRN \\
\hline CHEMBL1594910 & 688759 & 4.45 & 5.0556 & TRN & \\
\hline CHEMBL504791 & 688759 & 4.75 & 4.8206 & TRN & \\
\hline CHEMBL1602798 & 688759 & 5.1 & 4.6463 & TRN & \\
\hline CHEMBL1611725 & 688759 & 4.45 & 4.8167 & TRN & \\
\hline CHEMBL1326881 & 688759 & 5.0 & 4.8069 & TRN & \\
\hline
\end{tabular}




\begin{tabular}{|c|c|c|c|c|c|}
\hline & & \multicolumn{4}{|c|}{ Supplemental Table S2.txt } \\
\hline CHEMBL1457058 & 688759 & 4.55 & 5.399 & TRN & \\
\hline CHEMBL1534136 & 688759 & 4.65 & 5.4249 & TRN & \\
\hline CHEMBL1353257 & 688759 & 5.35 & 5.0745 & TRN & \\
\hline CHEMBL1322711 & 688759 & 4.95 & 4.8903 & TRN & \\
\hline CHEMBL1610149 & 688759 & 4.45 & 4.3954 & TRN & \\
\hline CHEMBL1977082 & 688759 & 4.45 & 4.3343 & TRN & \\
\hline CHEMBL600060 & 688759 & 6.05 & 5.87700 & 0000000001 & TRN \\
\hline CHEMBL1507012 & 688759 & 4.6 & 4.6863 & TRN & \\
\hline CHEMBL1330285 & 688759 & 4.45 & 4.9969 & TRN & \\
\hline CHEMBL1543936 & 688759 & 4.85 & 4.587 & TRN & \\
\hline CHEMBL3210669 & 688759 & 4.8 & 4.945 & TRN & \\
\hline CHEMBL1499612 & 688759 & 4.45 & 4.9098 & TRN & \\
\hline CHEMBL1329054 & 688759 & 4.45 & 5.1288 & TRN & \\
\hline CHEMBL1608347 & 688759 & 5.0 & 4.9717 & TST & \\
\hline CHEMBL1498217 & 688759 & 4.7 & 4.8127 & TRN & \\
\hline CHEMBL1388193 & 688759 & 5.25 & 4.8416 & TRN & \\
\hline CHEMBL1575704 & 688759 & 4.45 & 4.8108 & TRN & \\
\hline CHEMBL1351178 & 688759 & 5.2 & 4.7011 & TST & \\
\hline CHEMBL 227726 & 688759 & 5.9 & 5.3066 & TRN & \\
\hline CHEMBL1544762 & 688759 & 5.5 & 5.1865 & TRN & \\
\hline CHEMBL1426004 & 688759 & 4.45 & 4.6447 & TST & \\
\hline CHEMBL1565276 & 688759 & 4.7 & 4.6978 & TRN & \\
\hline CHEMBL1460595 & 688759 & 4.9 & 5.1104 & TRN & \\
\hline CHEMBL3191405 & 688759 & 4.65 & 5.1708 & TRN & \\
\hline CHEMBL1525672 & 688759 & 5.55 & 4.8484 & TRN & \\
\hline CHEMBL1300736 & 688759 & 4.45 & 4.6464 & TST & \\
\hline CHEMBL1560679 & 688759 & 4.95 & 4.9841 & TST & \\
\hline CHEMBL412010 & 688759 & 4.85 & 5.3774 & TRN & \\
\hline CHEMBL1562104 & 688759 & 6.2 & 5.4276 & TST & \\
\hline CHEMBL3191773 & 688759 & 5.05 & 5.1624 & TST & \\
\hline CHEMBL3199913 & 688759 & 4.65 & 4.8591 & TRN & \\
\hline CHEMBL1424226 & 688759 & 4.45 & 4.7976 & TST & \\
\hline CHEMBL3193652 & 688759 & 5.9 & 5.3154 & TST & \\
\hline CHEMBL1326400 & 688759 & 4.45 & 4.627 & TRN & \\
\hline CHEMBL1370083 & 688759 & 4.45 & 5.05399 & 9999999999 & TRN \\
\hline CHEMBL29898 & 688759 & 4.45 & 5.7397 & TST & \\
\hline CHEMBL1307905 & 688759 & 4.45 & 4.9087 & TRN & \\
\hline CHEMBL1522058 & 688759 & 4.65 & 4.7552 & TRN & \\
\hline CHEMBL1343296 & 688759 & 4.7 & 4.977 & TRN & \\
\hline CHEMBL1307950 & 688759 & 5.0 & 4.9905 & TRN & \\
\hline CHEMBL1310645 & 688759 & 4.65 & 4.6684 & TRN & \\
\hline CHEMBL1344455 & 688759 & 4.75 & 4.8807 & TRN & \\
\hline CHEMBL1347725 & 688759 & 5.05 & 4.9558 & TRN & \\
\hline CHEMBL1468147 & 688759 & 4.8 & 4.9735 & TRN & \\
\hline CHEMBL1363218 & 688759 & 4.45 & 4.7831 & TRN & \\
\hline CHEMBL3197588 & 688759 & 4.6 & 4.4881 & TRN & \\
\hline CHEMBL1534267 & 688759 & 4.9 & 4.8805 & TST & \\
\hline CHEMBL1464462 & 688759 & 5.0 & 4.8981 & TRN & \\
\hline
\end{tabular}




\begin{tabular}{|c|c|c|c|c|c|}
\hline \multirow[b]{2}{*}{ CHEMBL1393940 } & \\
\hline & 688759 & 4.5 & 4.9917 & TRN & \\
\hline CHEMBL1995910 & 688759 & 5.3 & 5.5084 & TRN & \\
\hline CHEMBL1481671 & 688759 & 4.85 & 4.64199 & 99999999995 & TRN \\
\hline CHEMBL1393349 & 688759 & 4.6 & 4.9216 & TST & \\
\hline CHEMBL1581855 & 688759 & 4.65 & 4.80699 & 99999999995 & TRN \\
\hline CHEMBL1604633 & 688759 & 4.95 & 4.9945 & TRN & \\
\hline CHEMBL1368206 & 688759 & 4.6 & 4.9186 & TST & \\
\hline CHEMBL1313991 & 688759 & 5.1 & 4.8246 & TRN & \\
\hline CHEMBL1326892 & 688759 & 4.45 & 4.8649 & TST & \\
\hline CHEMBL1560061 & 688759 & 5.5 & 4.7563 & TRN & \\
\hline CHEMBL242080 & 688759 & 6.0 & 5.2501 & TRN & \\
\hline CHEMBL1389300 & 688759 & 4.45 & 4.7942 & TST & \\
\hline CHEMBL1581818 & 688759 & 4.45 & 4.6053 & TST & \\
\hline CHEMBL1372421 & 688759 & 5.15 & 5.3036 & TRN & \\
\hline CHEMBL1319606 & 688759 & 4.75 & 4.9648 & TST & \\
\hline CHEMBL3198003 & 688759 & 5.5 & 5.3172 & TRN & \\
\hline CHEMBL1500023 & 688759 & 5.9 & 5.4734 & TRN & \\
\hline CHEMBL1582771 & 688759 & 8.301 & 4.8187 & TST & \\
\hline CHEMBL1595942 & 688759 & 4.95 & 5.09399 & 9999999999 & TST \\
\hline CHEMBL1339398 & 688759 & 4.95 & 4.6683 & TST & \\
\hline CHEMBL1964690 & 688759 & 4.45 & 5.2591 & TRN & \\
\hline CHEMBL1598843 & 688759 & 4.45 & 4.5576 & TRN & \\
\hline CHEMBL1415660 & 688759 & 4.45 & 4.5193 & TST & \\
\hline CHEMBL1362309 & 688759 & 4.7 & 4.76699 & 99999999995 & TRN \\
\hline CHEMBL1471264 & 688759 & 4.95 & 4.9311 & TRN & \\
\hline CHEMBL1599540 & 688759 & 4.45 & 4.8559 & TRN & \\
\hline CHEMBL1409173 & 688759 & 4.45 & 4.9336 & TRN & \\
\hline CHEMBL3198413 & 688759 & 5.6 & 5.4059 & TRN & \\
\hline CHEMBL1384581 & 688759 & 5.15 & 4.843 & TRN & \\
\hline CHEMBL1566658 & 688759 & 4.45 & 4.8209 & TRN & \\
\hline CHEMBL1305662 & 688759 & 4.9 & 4.8382 & TRN & \\
\hline CHEMBL1494111 & 688759 & 4.45 & 4.7847 & TST & \\
\hline CHEMBL1414766 & 688759 & 4.6 & 5.1254 & TRN & \\
\hline CHEMBL1990599 & 688759 & 4.45 & 5.6747 & TRN & \\
\hline CHEMBL3195177 & 688759 & 5.0 & 4.9339 & TRN & \\
\hline CHEMBL3195409 & 688759 & 5.25 & 4.9816 & TRN & \\
\hline CHEMBL1362838 & 688759 & 4.95 & 4.881 & TRN & \\
\hline CHEMBL1482064 & 688759 & 4.75 & 4.9824 & TRN & \\
\hline CHEMBL1510796 & 688759 & 4.95 & 5.0862 & TRN & \\
\hline CHEMBL1544251 & 688759 & 4.45 & 5.1201 & TRN & \\
\hline CHEMBL1526189 & 688759 & 4.45 & 4.8509 & TRN & \\
\hline CHEMBL1347196 & 688759 & 4.45 & 4.9148 & TST & \\
\hline CHEMBL1605816 & 688759 & 4.45 & 4.7446 & TRN & \\
\hline CHEMBL1975120 & 688759 & 4.45 & 4.7049 & TRN & \\
\hline CHEMBL1548848 & 688759 & 4.45 & 4.7383 & TRN & \\
\hline CHEMBL1358873 & 688759 & 4.45 & 4.7708 & TRN & \\
\hline CHEMBL1321507 & 688759 & 4.95 & 5.0644 & TRN & \\
\hline CHEMBL1467821 & 688759 & 4.65 & 4.8279 & TRN & \\
\hline & & & & 14827 & \\
\hline
\end{tabular}




\begin{tabular}{|c|c|c|c|c|c|}
\hline \multirow[b]{2}{*}{ CHEMBL1565379 } & \multicolumn{5}{|c|}{ Supplemental Table S2.txt } \\
\hline & 688759 & 4.45 & 4.5828 & TST & \\
\hline CHEMBL1396537 & 688759 & 4.65 & 4.74100 & 00000000005 & TST \\
\hline CHEMBL1525969 & 688759 & 4.95 & 5.3283 & TRN & \\
\hline CHEMBL1370293 & 688759 & 4.7 & 5.0317 & TRN & \\
\hline CHEMBL1569124 & 688759 & 4.5 & 4.7724 & TRN & \\
\hline CHEMBL1536625 & 688759 & 4.45 & 4.6182 & TRN & \\
\hline CHEMBL1565304 & 688759 & 5.0 & 4.7185 & TST & \\
\hline CHEMBL1438591 & 688759 & 4.45 & 4.8416 & TST & \\
\hline CHEMBL3196686 & 688759 & 4.45 & 4.9061 & TRN & \\
\hline CHEMBL1544712 & 688759 & 4.8 & 4.7175 & TRN & \\
\hline CHEMBL1424411 & 688759 & 5.0 & 5.0866 & TRN & \\
\hline CHEMBL1518159 & 688759 & 4.95 & 4.65600 & 0000000001 & TST \\
\hline CHEMBL1371877 & 688759 & 4.9 & 4.8648 & TRN & \\
\hline CHEMBL1598695 & 688759 & 4.45 & 5.0734 & TRN & \\
\hline CHEMBL1471276 & 688759 & 4.75 & 4.5888 & TRN & \\
\hline CHEMBL1382298 & 688759 & 5.25 & 5.7814 & TRN & \\
\hline CHEMBL1375577 & 688759 & 4.65 & 4.6775 & TRN & \\
\hline CHEMBL1596508 & 688759 & 5.2 & 4.8234 & TRN & \\
\hline CHEMBL1516992 & 688759 & 4.8 & 5.0737 & TRN & \\
\hline CHEMBL1420984 & 688759 & 4.45 & 4.9612 & TRN & \\
\hline CHEMBL1510040 & 688759 & 4.75 & 4.6968 & TRN & \\
\hline CHEMBL1540485 & 688759 & 4.55 & 4.9443 & TRN & \\
\hline CHEMBL1440762 & 688759 & 5.35 & 5.0955 & TRN & \\
\hline CHEMBL1501923 & 688759 & 6.5501 & 4.9155 & TRN & \\
\hline CHEMBL1303449 & 688759 & 4.45 & 4.7554 & TRN & \\
\hline CHEMBL532412 & 688759 & 4.8 & 4.6113 & TST & \\
\hline CHEMBL1404633 & 688759 & 4.65 & 4.8678 & TRN & \\
\hline CHEMBL1401469 & 688759 & 4.8 & 4.8794 & TST & \\
\hline CHEMBL1597487 & 688759 & 4.45 & 4.8506 & TST & \\
\hline CHEMBL1541314 & 688759 & 4.5 & 4.8568 & TRN & \\
\hline CHEMBL1598562 & 688759 & 5.0 & 4.9211 & TRN & \\
\hline CHEMBL1368921 & 688759 & 4.6 & 4.7939 & TST & \\
\hline CHEMBL1981464 & 688759 & 4.5 & 4.7834 & TRN & \\
\hline CHEMBL1586899 & 688759 & 5.3 & 5.2488 & TST & \\
\hline CHEMBL1578718 & 688759 & 5.15 & 5.0482 & TRN & \\
\hline CHEMBL1478578 & 688759 & 4.75 & 4.7843 & TRN & \\
\hline CHEMBL1334238 & 688759 & 4.75 & 5.1193 & TRN & \\
\hline CHEMBL1431769 & 688759 & 5.5 & 5.2735 & TRN & \\
\hline CHEMBL1467749 & 688759 & 4.45 & 4.7932 & TRN & \\
\hline CHEMBL1366774 & 688759 & 4.9 & 4.9241 & TST & \\
\hline CHEMBL1382928 & 688759 & 4.65 & 4.4838 & TRN & \\
\hline CHEMBL1468783 & 688759 & 4.65 & 5.0295 & TRN & \\
\hline CHEMBL1580059 & 688759 & 4.45 & 5.0224 & TRN & \\
\hline CHEMBL1577487 & 688759 & 4.8 & 5.1008 & TRN & \\
\hline CHEMBL1378872 & 688759 & 6.15 & 4.9222 & TST & \\
\hline CHEMBL1445370 & 688759 & 4.45 & 4.5778 & TRN & \\
\hline CHEMBL179583 & 688759 & 4.6 & 5.0108 & TST & \\
\hline CHEMBL1411344 & 688759 & 5.05 & 4.9505 & TRN & \\
\hline
\end{tabular}




\begin{tabular}{|c|c|c|c|c|c|}
\hline \multirow[b]{2}{*}{ CHEMBL1421199 } & \multicolumn{5}{|c|}{ Supplemental Table S2.txt } \\
\hline & 688759 & 4.65 & 4.966 & TST & \\
\hline CHEMBL1612057 & 688759 & 4.45 & 4.88899 & 9999999999 & TST \\
\hline CHEMBL1341465 & 688759 & 5.0 & 4.6773 & TRN & \\
\hline CHEMBL1405979 & 688759 & 5.2 & 4.6566 & TRN & \\
\hline CHEMBL3209789 & 688759 & 4.6 & 4.7735 & TRN & \\
\hline CHEMBL1539040 & 688759 & 4.9 & 4.9111 & TRN & \\
\hline CHEMBL1463966 & 688759 & 5.0 & 5.1268 & TRN & \\
\hline CHEMBL1309890 & 688759 & 5.4 & 5.4644 & TRN & \\
\hline CHEMBL 2000525 & 688759 & 4.6 & 5.052 & TST & \\
\hline CHEMBL1388767 & 688759 & 4.45 & 4.605 & TST & \\
\hline CHEMBL3208425 & 688759 & 4.45 & 4.8764 & TST & \\
\hline CHEMBL3212675 & 688759 & 6.0 & 5.0248 & TRN & \\
\hline CHEMBL1592834 & 688759 & 5.35 & 4.9551 & TRN & \\
\hline CHEMBL1414108 & 688759 & 4.45 & 4.7138 & TRN & \\
\hline CHEMBL1392982 & 688759 & 4.45 & 4.7728 & TRN & \\
\hline CHEMBL1477622 & 688759 & 4.7 & 4.8577 & TRN & \\
\hline CHEMBL1363026 & 688759 & 4.8 & 5.1215 & TRN & \\
\hline CHEMBL3209034 & 688759 & 5.0 & 4.6963 & TRN & \\
\hline CHEMBL1385031 & 688759 & 4.7 & 4.8078 & TRN & \\
\hline CHEMBL1352059 & 688759 & 4.65 & 4.6032 & TRN & \\
\hline CHEMBL1311991 & 688759 & 4.9 & 5.0207 & TRN & \\
\hline CHEMBL1390555 & 688759 & 4.45 & 5.2767 & TST & \\
\hline CHEMBL1400410 & 688759 & 4.45 & 4.8134 & TST & \\
\hline CHEMBL1546822 & 688759 & 4.95 & 4.7526 & TRN & \\
\hline CHEMBL1490933 & 688759 & 4.45 & 4.7668 & TRN & \\
\hline CHEMBL1496395 & 688759 & 5.25 & 4.8223 & TST & \\
\hline CHEMBL1974521 & 688759 & 6.0 & 5.47 & TRN & \\
\hline CHEMBL1352175 & 688759 & 4.45 & 4.6648 & TRN & \\
\hline CHEMBL1412746 & 688759 & 4.65 & 4.783 & TST & \\
\hline CHEMBL1459350 & 688759 & 5.65 & 5.49200 & 0000000001 & TRN \\
\hline CHEMBL1566546 & 688759 & 4.45 & 4.8543 & TRN & \\
\hline CHEMBL1467601 & 688759 & 4.45 & 5.0063 & TRN & \\
\hline CHEMBL1965804 & 688759 & 4.45 & 4.7815 & TRN & \\
\hline CHEMBL1421112 & 688759 & 4.95 & 5.1376 & TRN & \\
\hline CHEMBL1429336 & 688759 & 5.35 & 4.749 & TRN & \\
\hline CHEMBL3197478 & 688759 & 5.75 & 5.3638 & TRN & \\
\hline CHEMBL1461714 & 688759 & 4.45 & 4.8511 & TRN & \\
\hline CHEMBL1323859 & 688759 & 4.8 & 4.8822 & TST & \\
\hline CHEMBL1977424 & 688759 & 5.4 & 5.7066 & TRN & \\
\hline CHEMBL3197508 & 688759 & 4.45 & 4.3887 & TRN & \\
\hline CHEMBL1463416 & 688759 & 4.55 & 4.7986 & TRN & \\
\hline CHEMBL1326010 & 688759 & 4.45 & 4.7701 & TST & \\
\hline CHEMBL1422413 & 688759 & 4.7 & 4.8487 & TST & \\
\hline CHEMBL1426666 & 688759 & 4.5 & 4.8338 & TST & \\
\hline CHEMBL1409802 & 688759 & 5.05 & 5.4013 & TST & \\
\hline CHEMBL1301418 & 688759 & 5.0 & 4.6956 & TRN & \\
\hline CHEMBL1441123 & 688759 & 4.95 & 4.8839 & TST & \\
\hline CHEMBL3192051 & 688759 & 4.9 & 5.0007 & TRN & \\
\hline
\end{tabular}




\begin{tabular}{|c|c|c|c|c|c|}
\hline \multicolumn{6}{|c|}{ Supplemental Table S2.txt } \\
\hline CHEMBL1482160 & 688759 & 5.15 & 5.0892 & TRN & \\
\hline CHEMBL1322750 & 688759 & 5.0 & 5.0146 & TRN & \\
\hline CHEMBL1476404 & 688759 & 4.6 & 4.6754 & TST & \\
\hline CHEMBL52884 & 688759 & 5.4 & 5.0206 & TST & \\
\hline CHEMBL260533 & 688759 & 4.8 & 4.8862 & TST & \\
\hline CHEMBL1311636 & 688759 & 4.45 & 4.8309 & TRN & \\
\hline CHEMBL1399761 & 688759 & 4.45 & 4.6981 & TRN & \\
\hline CHEMBL3193865 & 688759 & 4.45 & 5.129 & TST & \\
\hline CHEMBL1322645 & 688759 & 4.45 & 5.2044 & TRN & \\
\hline CHEMBL1458027 & 688759 & 5.35 & 4.9125 & TST & \\
\hline CHEMBL1559923 & 688759 & 5.2 & 5.2044 & TRN & \\
\hline CHEMBL1437123 & 688759 & 4.6 & 4.8368 & TRN & \\
\hline CHEMBL1379902 & 688759 & 4.45 & 4.8794 & TRN & \\
\hline CHEMBL462430 & 688759 & 4.45 & 4.7774 & TRN & \\
\hline CHEMBL1549004 & 688759 & 4.65 & 4.7885 & TRN & \\
\hline CHEMBL1569380 & 688759 & 5.35 & 5.0529 & TST & \\
\hline CHEMBL1523876 & 688759 & 4.65 & 4.9948 & TRN & \\
\hline CHEMBL1440188 & 688759 & 5.0 & 5.0911 & TRN & \\
\hline CHEMBL1587897 & 688759 & 4.8 & 4.9959 & TRN & \\
\hline CHEMBL3199288 & 688759 & 5.3 & 4.942 & TRN & \\
\hline CHEMBL1377231 & 688759 & 4.8 & 4.9145 & TRN & \\
\hline CHEMBL1401565 & 688759 & 5.85 & 5.3685 & TRN & \\
\hline CHEMBL1498207 & 688759 & 4.45 & 4.7838 & TRN & \\
\hline CHEMBL3199945 & 688759 & 4.9 & 5.3539 & TRN & \\
\hline CHEMBL1400782 & 688759 & 5.05 & 4.9178 & TST & \\
\hline CHEMBL1348532 & 688759 & 4.45 & 4.7547 & TRN & \\
\hline CHEMBL1463847 & 688759 & 4.9 & 4.739 & TRN & \\
\hline CHEMBL1541037 & 688759 & 4.45 & 4.6163 & TRN & \\
\hline CHEMBL1489819 & 688759 & 5.15 & 4.7586 & TRN & \\
\hline CHEMBL1349832 & 688759 & 6.0 & 4.7579 & TRN & \\
\hline CHEMBL1404102 & 688759 & 4.45 & 4.8704 & TRN & \\
\hline CHEMBL1378545 & 688759 & 4.45 & 4.8583 & TRN & \\
\hline CHEMBL1583434 & 688759 & 4.65 & 4.7559 & TRN & \\
\hline CHEMBL1426818 & 688759 & 4.45 & 4.633 & TST & \\
\hline CHEMBL3195611 & 688759 & 5.4 & 5.4545 & TRN & \\
\hline CHEMBL1485047 & 688759 & 4.95 & 4.7943 & TRN & \\
\hline CHEMBL1365154 & 688759 & 4.9 & 4.8201 & TRN & \\
\hline CHEMBL3190025 & 688759 & 4.45 & 4.8228 & TRN & \\
\hline CHEMBL1420170 & 688759 & 4.45 & 4.5167 & TST & \\
\hline CHEMBL1323955 & 688759 & 5.25 & 4.9526 & TRN & \\
\hline CHEMBL1581195 & 688759 & 4.45 & 4.7168 & TRN & \\
\hline CHEMBL3199352 & 688759 & 4.85 & 4.7099 & TRN & \\
\hline CHEMBL3214354 & 688759 & 4.45 & 4.93199 & 99999999995 & TRN \\
\hline CHEMBL1422974 & 688759 & 4.45 & 4.6988 & TRN & \\
\hline CHEMBL1307145 & 688759 & 5.2 & 4.9203 & TRN & \\
\hline CHEMBL1603096 & 688759 & 4.55 & 4.6676 & TRN & \\
\hline CHEMBL1408102 & 688759 & 5.25 & 5.0322 & TRN & \\
\hline CHEMBL1306017 & 688759 & 4.95 & 4.6705 & TST & \\
\hline
\end{tabular}




\begin{tabular}{|c|c|c|c|c|c|}
\hline & & \multicolumn{4}{|c|}{ Supplemental Table S2.txt } \\
\hline CHEMBL1439675 & 688759 & 5.05 & 4.8153 & TRN & \\
\hline CHEMBL1734063 & 688759 & 4.8 & 4.8254 & TRN & \\
\hline CHEMBL1978504 & 688759 & 6.05 & 6.0006 & TRN & \\
\hline CHEMBL1528847 & 688759 & 5.7 & 5.9641 & TRN & \\
\hline CHEMBL1486097 & 688759 & 4.45 & 5.0123 & TST & \\
\hline CHEMBL1550209 & 688759 & 5.4 & 5.1803 & TRN & \\
\hline CHEMBL3199298 & 688759 & 5.7 & 5.0401 & TRN & \\
\hline CHEMBL1485243 & 688759 & 4.6 & 4.8319 & TRN & \\
\hline CHEMBL1547504 & 688759 & 5.45 & 5.0272 & TRN & \\
\hline CHEMBL1471900 & 688759 & 4.45 & 4.7673 & TRN & \\
\hline CHEMBL1336035 & 688759 & 4.45 & 4.8584 & TRN & \\
\hline CHEMBL1364092 & 688759 & 4.45 & 4.7169 & TRN & \\
\hline CHEMBL1333549 & 688759 & 4.45 & 4.6494 & TST & \\
\hline CHEMBL1976375 & 688759 & 6.0 & 5.2814 & TRN & \\
\hline CHEMBL1981408 & 688759 & 5.35 & 5.2066 & TRN & \\
\hline CHEMBL1386527 & 688759 & 5.2 & 4.9043 & TST & \\
\hline CHEMBL3210315 & 688759 & 6.2 & 4.8159 & TRN & \\
\hline CHEMBL1582898 & 688759 & 4.65 & 4.8935 & TST & \\
\hline CHEMBL1479794 & 688759 & 6.15 & 4.9427 & TST & \\
\hline CHEMBL296586 & 688759 & 4.6 & 4.8655 & TST & \\
\hline CHEMBL1321003 & 688759 & 4.45 & 4.9065 & TRN & \\
\hline CHEMBL3194542 & 688759 & 4.5 & 4.5553 & TST & \\
\hline CHEMBL1343605 & 688759 & 5.85 & 4.9093 & TST & \\
\hline CHEMBL1309674 & 688759 & 4.45 & 4.6593 & TRN & \\
\hline CHEMBL1535361 & 688759 & 5.25 & $5.3610 e$ & 0000000001 & TRN \\
\hline CHEMBL1301555 & 688759 & 4.65 & 4.7798 & TST & \\
\hline CHEMBL3190745 & 688759 & 5.4 & 5.3169 & TRN & \\
\hline CHEMBL1463898 & 688759 & 4.75 & 4.596 & TRN & \\
\hline CHEMBL3195437 & 688759 & 6.1 & 5.4805 & TRN & \\
\hline CHEMBL1319227 & 688759 & 5.65 & 4.9276 & TST & \\
\hline CHEMBL1468853 & 688759 & 4.7 & 4.6489 & TRN & \\
\hline CHEMBL1453057 & 688759 & 5.45 & 4.8156 & TRN & \\
\hline CHEMBL1987145 & 688759 & 5.3 & 5.0969 & TRN & \\
\hline CHEMBL1550197 & 688759 & 5.35 & 4.6941 & TST & \\
\hline CHEMBL1598226 & 688759 & 5.15 & 4.857 & TRN & \\
\hline CHEMBL1968402 & 688759 & 5.1 & 5.2274 & TRN & \\
\hline CHEMBL1409016 & 688759 & 4.45 & 4.867 & TRN & \\
\hline CHEMBL1507676 & 688759 & 5.0 & 4.8323 & TST & \\
\hline CHEMBL1429415 & 688759 & 4.9 & 4.7182 & TRN & \\
\hline CHEMBL1549893 & 688759 & 6.0 & 4.7562 & TRN & \\
\hline CHEMBL1481678 & 688759 & 4.65 & 4.7592 & TRN & \\
\hline CHEMBL1411225 & 688759 & 4.45 & 5.043 & TST & \\
\hline CHEMBL1484582 & 688759 & 5.35 & 4.9507 & TRN & \\
\hline CHEMBL1403048 & 688759 & 4.9 & 5.525 & TST & \\
\hline CHEMBL475541 & 688759 & 4.65 & 5.16 & TST & \\
\hline CHEMBL1594322 & 688759 & 5.25 & 5.4471 & TRN & \\
\hline CHEMBL1413633 & 688759 & 4.45 & 4.8589 & TRN & \\
\hline CHEMBL3208143 & 688759 & 4.45 & 4.7101 & TRN & \\
\hline
\end{tabular}




\begin{tabular}{|c|c|c|c|c|c|}
\hline \multicolumn{6}{|c|}{ Supplemental Table s2.txt } \\
\hline CHEMBL1389740 & 688759 & 6.0 & 5.2138 & TRN & \\
\hline CHEMBL1600630 & 688759 & 4.45 & 4.9652 & TRN & \\
\hline CHEMBL1379480 & 688759 & 4.65 & 4.9024 & TRN & \\
\hline CHEMBL1586809 & 688759 & 5.5 & 4.7529 & TRN & \\
\hline CHEMBL1526490 & 688759 & 4.45 & 4.5018 & TRN & \\
\hline CHEMBL1481361 & 688759 & 4.75 & 4.89199 & 99999999995 & TRN \\
\hline CHEMBL1453890 & 688759 & 4.9 & 4.7986 & TRN & \\
\hline CHEMBL1598524 & 688759 & 6.95 & 5.0705 & TST & \\
\hline CHEMBL571087 & 688759 & 4.45 & 4.669 & TRN & \\
\hline CHEMBL1382807 & 688759 & 4.45 & 4.6076 & TRN & \\
\hline CHEMBL1498909 & 688759 & 4.6 & 4.7298 & TRN & \\
\hline CHEMBL1400090 & 688759 & 5.55 & 5.6437 & TRN & \\
\hline CHEMBL1545215 & 688759 & 4.5 & 4.9126 & TRN & \\
\hline CHEMBL1571696 & 688759 & 4.9 & 4.6741 & TRN & \\
\hline CHEMBL1446973 & 688759 & 5.0 & 4.9647 & TRN & \\
\hline CHEMBL1422079 & 688759 & 4.55 & 4.5848 & TRN & \\
\hline CHEMBL1349539 & 688759 & 4.6 & 4.6362 & TRN & \\
\hline CHEMBL1323248 & 688759 & 4.45 & 4.7371 & TRN & \\
\hline CHEMBL1601779 & 688759 & 5.65 & 5.066 & TST & \\
\hline CHEMBL1557356 & 688759 & 4.65 & 4.8863 & TRN & \\
\hline CHEMBL1376821 & 688759 & 4.45 & 4.7344 & TST & \\
\hline CHEMBL1610478 & 688759 & 5.45 & 5.4374 & TRN & \\
\hline CHEMBL1399270 & 688759 & 4.8 & 4.8468 & TRN & \\
\hline CHEMBL1605088 & 688759 & 4.7 & 4.9551 & TST & \\
\hline CHEMBL1447341 & 688759 & 5.15 & 4.6157 & TRN & \\
\hline CHEMBL1708510 & 688759 & 4.6 & 5.2115 & TRN & \\
\hline CHEMBL1449825 & 688759 & 4.6 & 4.9484 & TST & \\
\hline CHEMBL3213916 & 688759 & 5.4 & 4.8652 & TRN & \\
\hline CHEMBL1378304 & 688759 & 4.45 & 4.6968 & TRN & \\
\hline CHEMBL3392045 & 688759 & 4.45 & 5.0735 & TST & \\
\hline CHEMBL1463488 & 688759 & 4.9 & 4.9063 & TRN & \\
\hline CHEMBL1405373 & 688759 & 5.15 & 4.8849 & TRN & \\
\hline CHEMBL1446194 & 688759 & 4.45 & 4.5457 & TRN & \\
\hline CHEMBL1555576 & 688759 & 4.9 & 5.3303 & TRN & \\
\hline CHEMBL1381567 & 688759 & 4.7 & 4.5908 & TRN & \\
\hline CHEMBL1461721 & 688759 & 5.5 & 4.7791 & TRN & \\
\hline CHEMBL1392281 & 688759 & 4.45 & 4.8627 & TRN & \\
\hline CHEMBL1427457 & 688759 & 4.45 & 5.1311 & TRN & \\
\hline CHEMBL2002849 & 688759 & 4.75 & 5.3439 & TRN & \\
\hline CHEMBL1452026 & 688759 & 4.45 & 4.7847 & TRN & \\
\hline CHEMBL1487705 & 688759 & 4.45 & 4.6195 & TRN & \\
\hline CHEMBL1489599 & 688759 & 4.95 & 4.7849 & TST & \\
\hline CHEMBL1381362 & 688759 & 4.7 & 5.0301 & TRN & \\
\hline CHEMBL1454711 & 688759 & 4.45 & 4.8248 & TST & \\
\hline CHEMBL1537169 & 688759 & 4.95 & 4.6983 & TRN & \\
\hline CHEMBL1458003 & 688759 & 5.05 & 4.8455 & TRN & \\
\hline CHEMBL1359019 & 688759 & 5.15 & 5.442 & TRN & \\
\hline CHEMBL1334187 & 688759 & 6.05 & 4.9293 & TRN & \\
\hline
\end{tabular}




\begin{tabular}{|c|c|c|c|c|}
\hline \multicolumn{5}{|c|}{ Supplemental Table S2.txt } \\
\hline CHEMBL3192432 & 688759 & 2.95 & 6.5465 & TRN \\
\hline CHEMBL1550302 & 688759 & 4.65 & 4.6757 & TRN \\
\hline CHEMBL1458645 & 688759 & 4.45 & 4.7325 & TRN \\
\hline CHEMBL1390333 & 688759 & 4.7 & 5.1005 & TRN \\
\hline CHEMBL1481705 & 688759 & 4.75 & 4.8525 & TRN \\
\hline CHEMBL1478935 & 688759 & 4.45 & 4.9272 & TST \\
\hline CHEMBL1454332 & 688759 & 4.75 & 4.9851 & TRN \\
\hline CHEMBL1396109 & 688759 & 4.65 & 4.8289 & TRN \\
\hline CHEMBL1571407 & 688759 & 4.6 & 5.0113 & TST \\
\hline CHEMBL3190909 & 688759 & 5.85 & 5.1326 & TRN \\
\hline CHEMBL3199428 & 688759 & 5.15 & 5.1823 & TRN \\
\hline CHEMBL1323909 & 688759 & 5.55 & 5.2986 & TRN \\
\hline CHEMBL3189809 & 688759 & 4.7 & 5.2451 & TRN \\
\hline CHEMBL1388539 & 688759 & 4.65 & 5.0554 & TST \\
\hline CHEMBL1507915 & 688759 & 5.3 & 4.9278 & TRN \\
\hline CHEMBL1511480 & 688759 & 4.65 & 4.9262 & TRN \\
\hline CHEMBL1499999 & 688759 & 4.65 & 4.8578 & TRN \\
\hline CHEMBL1495046 & 688759 & 4.45 & 4.8674 & TST \\
\hline CHEMBL1588446 & 688759 & 4.45 & 4.7447 & TRN \\
\hline CHEMBL1510228 & 688759 & 5.45 & 5.3363 & TST \\
\hline CHEMBL1592626 & 688759 & 4.45 & 5.002 & TRN \\
\hline CHEMBL1409242 & 688759 & 5.25 & 4.7533 & TRN \\
\hline CHEMBL1458837 & 688759 & 4.45 & 4.5989 & TRN \\
\hline CHEMBL1401274 & 688759 & 6.1 & 5.7693 & TRN \\
\hline CHEMBL1409207 & 688759 & 5.0 & 5.0849 & TRN \\
\hline CHEMBL1549929 & 688759 & 4.85 & 4.5932 & TST \\
\hline CHEMBL1333929 & 688759 & 6.0 & 4.7942 & TRN \\
\hline CHEMBL601970 & 688759 & 4.45 & 4.652 & TST \\
\hline CHEMBL1393851 & 688759 & 4.75 & 4.6957 & TST \\
\hline CHEMBL1431414 & 688759 & 4.45 & 4.6583 & TRN \\
\hline CHEMBL26320 & 688759 & 4.45 & 4.5814 & TST \\
\hline CHEMBL1560159 & 688759 & 4.45 & 4.7851 & TST \\
\hline CHEMBL1308223 & 688759 & 5.1 & 5.2061 & TRN \\
\hline CHEMBL1452955 & 688759 & 4.45 & 4.6706 & TRN \\
\hline CHEMBL1550791 & 688759 & 4.95 & 4.6252 & TRN \\
\hline CHEMBL1385457 & 688759 & 4.45 & 4.7563 & TRN \\
\hline CHEMBL1440515 & 688759 & 4.6 & 4.4986 & TRN \\
\hline CHEMBL1575888 & 688759 & 4.45 & 4.9317 & TRN \\
\hline CHEMBL1986785 & 688759 & 5.1 & 4.9847 & TRN \\
\hline CHEMBL1556748 & 688759 & 5.4 & 5.1807 & TST \\
\hline CHEMBL1340950 & 688759 & 4.45 & 4.6225 & TST \\
\hline CHEMBL1341833 & 688759 & 4.45 & 4.6945 & TST \\
\hline CHEMBL1307765 & 688759 & 4.85 & 5.4037 & TRN \\
\hline CHEMBL 233347 & 688759 & 4.6 & 4.7373 & TRN \\
\hline CHEMBL3194677 & 688759 & 4.75 & 4.9643 & TRN \\
\hline CHEMBL1547784 & 688759 & 5.15 & 4.8382 & TRN \\
\hline CHEMBL1325124 & 688759 & 4.65 & 4.9019 & TST \\
\hline CHEMBL1582802 & 688759 & 5.25 & 4.6732 & TST \\
\hline
\end{tabular}




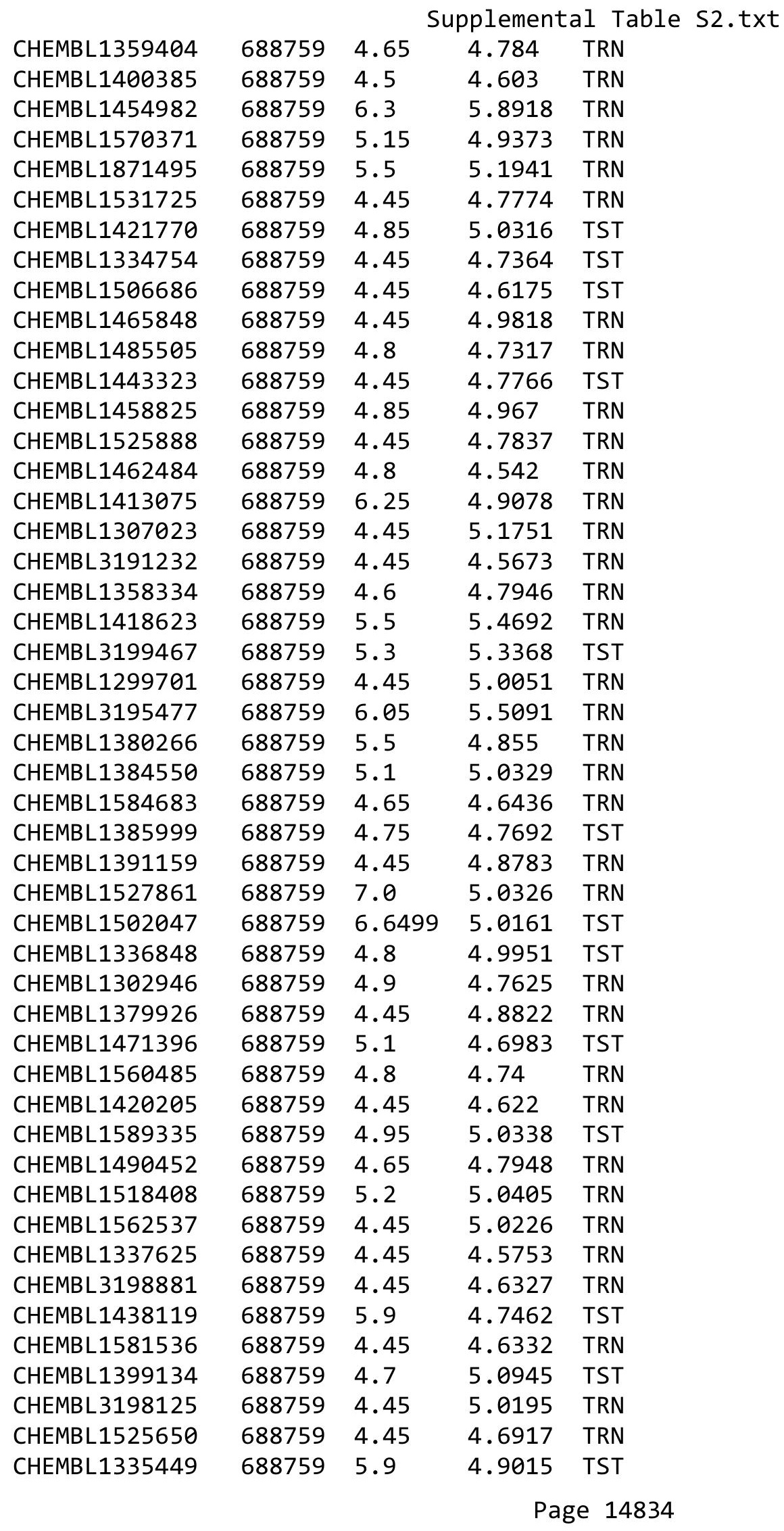




\begin{tabular}{|c|c|c|c|c|}
\hline & & & upplement & al \\
\hline CHEMBL1559240 & 688759 & 4.45 & 4.9146 & TST \\
\hline CHEMBL1443980 & 688759 & 5.5 & 5.0144 & TRN \\
\hline CHEMBL1479189 & 688759 & 4.45 & 4.6064 & TRN \\
\hline CHEMBL 3196794 & 688759 & 4.7 & 4.8496 & TRN \\
\hline CHEMBL1368478 & 688759 & 4.5 & 5.0441 & TRN \\
\hline CHEMBL1981840 & 688759 & 4.75 & 4.963 & TRN \\
\hline CHEMBL1302115 & 688759 & 4.65 & 4.735 & TRN \\
\hline CHEMBL1303878 & 688759 & 4.45 & 4.8695 & TST \\
\hline CHEMBL1493912 & 688759 & 4.45 & 4.8347 & TST \\
\hline CHEMBL1548825 & 688759 & 4.45 & 5.0753 & TRN \\
\hline CHEMBL3196900 & 688759 & 5.3 & 5.2459 & TRN \\
\hline CHEMBL1424777 & 688759 & 4.6 & 5.0752 & TRN \\
\hline CHEMBL1526909 & 688759 & 5.2 & 4.8366 & TRN \\
\hline CHEMBL1364999 & 688759 & 5.45 & 5.2284 & TST \\
\hline CHEMBL1583756 & 688759 & 4.85 & 4.717 & TRN \\
\hline CHEMBL1235568 & 688759 & 5.1 & 5.2248 & TRN \\
\hline CHEMBL1403329 & 688759 & 4.95 & 5.355 & TRN \\
\hline CHEMBL3193012 & 688759 & 5.25 & 5.0584 & TRN \\
\hline CHEMBL1448611 & 688759 & 6.25 & 5.0838 & TST \\
\hline CHEMBL1320798 & 688759 & 4.9 & 4.8747 & TRN \\
\hline CHEMBL1360575 & 688759 & 5.15 & 4.8994 & TST \\
\hline CHEMBL1303116 & 688759 & 5.2 & 4.798 & TRN \\
\hline CHEMBL1460577 & 688759 & 4.45 & 4.4818 & TRN \\
\hline CHEMBL1482179 & 688759 & 4.65 & 4.9978 & TRN \\
\hline CHEMBL1443649 & 688759 & 4.45 & 4.6512 & TRN \\
\hline CHEMBL1256749 & 688759 & 4.45 & 4.4812 & TST \\
\hline CHEMBL3192214 & 688759 & 6.2 & 5.9198 & TST \\
\hline CHEMBL1570378 & 688759 & 4.45 & 4.4817 & TRN \\
\hline CHEMBL1574857 & 688759 & 4.75 & 5.3429 & TRN \\
\hline CHEMBL1573366 & 688759 & 5.15 & 5.4598 & TRN \\
\hline CHEMBL1525742 & 688759 & 4.45 & 4.6546 & TRN \\
\hline CHEMBL1498431 & 688759 & 4.45 & 4.8642 & TRN \\
\hline CHEMBL1578113 & 688759 & 5.15 & 4.8257 & TRN \\
\hline CHEMBL1382136 & 688759 & 4.9 & 4.836 & TRN \\
\hline CHEMBL1464307 & 688759 & 4.8 & 4.9446 & TST \\
\hline CHEMBL1485168 & 688759 & 6.25 & 5.6508 & TST \\
\hline CHEMBL3191069 & 688759 & 4.6 & 4.9669 & TRN \\
\hline CHEMBL1419015 & 688759 & 4.45 & 4.6251 & TRN \\
\hline CHEMBL1468020 & 688759 & 4.45 & 4.8343 & TRN \\
\hline CHEMBL1390438 & 688759 & 5.6 & 5.0217 & TST \\
\hline CHEMBL1430941 & 688759 & 4.8 & 5.0557 & TRN \\
\hline CHEMBL1508463 & 688759 & 5.0 & 4.593 & TRN \\
\hline CHEMBL1575402 & 688759 & 6.15 & 5.5978 & TRN \\
\hline CHEMBL1510454 & 688759 & 4.8 & 4.7891 & TRN \\
\hline CHEMBL1586515 & 688759 & 4.75 & 4.9743 & TRN \\
\hline CHEMBL1991112 & 688759 & 5.75 & 5.8001 & TST \\
\hline CHEMBL1523000 & 688759 & 4.9 & 5.1256 & TRN \\
\hline CHEMBL1359417 & 688759 & 5.15 & 5.0687 & TRN \\
\hline
\end{tabular}




\begin{tabular}{|c|c|c|c|c|c|}
\hline & & \multicolumn{4}{|c|}{ Supplemental Table s2.txt } \\
\hline CHEMBL1992346 & 688759 & 4.75 & 5.7712 & TRN & \\
\hline CHEMBL1330184 & 688759 & 4.9 & 5.0734 & TRN & \\
\hline CHEMBL3196521 & 688759 & 5.25 & 4.9388 & TRN & \\
\hline CHEMBL1327977 & 688759 & 4.7 & 4.9451 & TST & \\
\hline CHEMBL1368715 & 688759 & 4.45 & 5.0687 & TST & \\
\hline CHEMBL1545824 & 688759 & 4.9 & 5.215 & TRN & \\
\hline CHEMBL1577340 & 688759 & 4.65 & 4.8777 & TST & \\
\hline CHEMBL1325063 & 688759 & 4.45 & 5.3708 & TRN & \\
\hline CHEMBL1431731 & 688759 & 5.0 & 4.9708 & TRN & \\
\hline CHEMBL3199751 & 688759 & 4.6 & 4.6235 & TST & \\
\hline CHEMBL1391644 & 688759 & 5.0 & 4.8617 & TRN & \\
\hline CHEMBL1597880 & 688759 & 5.1 & 4.6914 & TRN & \\
\hline CHEMBL1516988 & 688759 & 4.45 & 4.9836 & TST & \\
\hline CHEMBL1545425 & 688759 & 5.85 & 5.4885 & TRN & \\
\hline CHEMBL1490339 & 688759 & 5.95 & 5.7582 & TRN & \\
\hline CHEMBL1430911 & 688759 & 4.45 & 5.1583 & TST & \\
\hline CHEMBL1610883 & 688759 & 5.35 & 4.5326 & TRN & \\
\hline CHEMBL3195104 & 688759 & 4.45 & 4.5267 & TRN & \\
\hline CHEMBL1523064 & 688759 & 4.7 & 4.55699 & 99999999995 & TST \\
\hline CHEMBL3189392 & 688759 & 4.6 & 4.6579 & TRN & \\
\hline CHEMBL1453038 & 688759 & 5.3 & 4.9041 & TRN & \\
\hline CHEMBL1362011 & 688759 & 4.6 & 5.1787 & TRN & \\
\hline CHEMBL1609564 & 688759 & 4.9 & 4.644 & TST & \\
\hline CHEMBL1505057 & 688759 & 5.4 & 5.3763 & TRN & \\
\hline CHEMBL1990194 & 688759 & 4.7 & 4.8005 & TRN & \\
\hline CHEMBL1468728 & 688759 & 4.45 & 4.6735 & TRN & \\
\hline CHEMBL1574481 & 688759 & 5.3 & 4.9455 & TRN & \\
\hline CHEMBL1522356 & 688759 & 4.45 & 4.8512 & TST & \\
\hline CHEMBL1497301 & 688759 & 5.15 & 4.7469 & TRN & \\
\hline CHEMBL1400785 & 688759 & 4.45 & 4.8382 & TST & \\
\hline CHEMBL1541329 & 688759 & 4.45 & 4.7316 & TRN & \\
\hline CHEMBL1561507 & 688759 & 5.85 & 5.5151 & TRN & \\
\hline CHEMBL1548794 & 688759 & 4.65 & 5.4437 & TRN & \\
\hline CHEMBL1568614 & 688759 & 4.8 & 4.5607 & TST & \\
\hline CHEMBL1601624 & 688759 & 4.55 & 4.6312 & TRN & \\
\hline CHEMBL1588436 & 688759 & 4.45 & 4.6735 & TRN & \\
\hline CHEMBL1353541 & 688759 & 4.95 & 5.1401 & TRN & \\
\hline CHEMBL1521052 & 688759 & 4.45 & 4.6263 & TRN & \\
\hline CHEMBL48449 & 688759 & 6.0 & 5.4085 & TST & \\
\hline CHEMBL1989210 & 688759 & 5.45 & 5.2922 & TRN & \\
\hline CHEMBL1605711 & 688759 & 5.25 & 4.8781 & TRN & \\
\hline CHEMBL1312789 & 688759 & 5.7 & 4.9712 & TRN & \\
\hline CHEMBL1424264 & 688759 & 5.3 & 5.1959 & TST & \\
\hline CHEMBL1507539 & 688759 & 4.5 & 4.9928 & TST & \\
\hline CHEMBL1308385 & 688759 & 5.4 & 5.3662 & TST & \\
\hline CHEMBL1387704 & 688759 & 5.45 & 4.9463 & TRN & \\
\hline CHEMBL1351260 & 688759 & 4.65 & 4.9288 & TST & \\
\hline CHEMBL1445964 & 688759 & 5.0 & 4.9093 & TST & \\
\hline
\end{tabular}




\begin{tabular}{|c|c|c|c|c|c|}
\hline \multicolumn{6}{|c|}{ Supplemental Table S2.txt } \\
\hline CHEMBL1534924 & 688759 & 5.25 & 5.2433 & TST & \\
\hline CHEMBL1409740 & 688759 & 4.9 & 4.8586 & TRN & \\
\hline CHEMBL1335068 & 688759 & 4.8 & 4.6361 & TRN & \\
\hline CHEMBL1299985 & 688759 & 4.45 & 4.7282 & TRN & \\
\hline CHEMBL1487334 & 688759 & 5.45 & 5.0953 & TST & \\
\hline CHEMBL1300584 & 688759 & 4.45 & 4.7784 & TST & \\
\hline CHEMBL1299796 & 688759 & 4.9 & 4.9818 & TRN & \\
\hline CHEMBL1321390 & 688759 & 5.45 & 5.2393 & TRN & \\
\hline CHEMBL3189304 & 688759 & 4.45 & 4.6356 & TRN & \\
\hline CHEMBL3189416 & 688759 & 5.25 & 5.4141 & TRN & \\
\hline CHEMBL1318970 & 688759 & 4.75 & 4.9406 & TRN & \\
\hline CHEMBL1460155 & 688759 & 4.95 & 5.082 & TRN & \\
\hline CHEMBL1312648 & 688759 & 5.0 & 4.98300 & 00000000005 & TRN \\
\hline CHEMBL1425309 & 688759 & 5.0 & 5.0481 & TRN & \\
\hline CHEMBL3193014 & 688759 & 5.15 & 5.0146 & TRN & \\
\hline CHEMBL3213352 & 688759 & 4.75 & 5.0768 & TRN & \\
\hline CHEMBL1422092 & 688759 & 4.45 & 4.79899 & 99999999995 & TRN \\
\hline CHEMBL1401926 & 688759 & 4.8 & 5.4214 & TRN & \\
\hline CHEMBL1517718 & 688759 & 4.8 & 4.984 & TRN & \\
\hline CHEMBL1382956 & 688759 & 4.65 & 4.7679 & TST & \\
\hline CHEMBL1601031 & 688759 & 4.45 & 4.9333 & TST & \\
\hline CHEMBL1327034 & 688759 & 4.75 & 4.6587 & TST & \\
\hline CHEMBL1579389 & 688759 & 7.15 & 5.1284 & TRN & \\
\hline CHEMBL1464947 & 688759 & 4.45 & 4.8797 & TRN & \\
\hline CHEMBL1996730 & 688759 & 4.95 & 5.1496 & TRN & \\
\hline CHEMBL1500832 & 688759 & 5.2 & 4.918 & TRN & \\
\hline CHEMBL1346307 & 688759 & 4.65 & 4.8503 & TRN & \\
\hline CHEMBL1504890 & 688759 & 4.95 & 4.7486 & TST & \\
\hline CHEMBL1549975 & 688759 & 6.0 & 5.3591 & TRN & \\
\hline CHEMBL1489209 & 688759 & 5.65 & 4.9787 & TRN & \\
\hline CHEMBL1567774 & 688759 & 4.55 & 4.8573 & TST & \\
\hline CHEMBL1510693 & 688759 & 4.45 & 4.9383 & TST & \\
\hline CHEMBL1577637 & 688759 & 5.45 & 4.954 & TST & \\
\hline CHEMBL1564480 & 688759 & 5.8 & 5.2713 & TRN & \\
\hline CHEMBL1966328 & 688759 & 4.75 & 4.8907 & TRN & \\
\hline CHEMBL1969987 & 688759 & 4.45 & 4.8769 & TST & \\
\hline CHEMBL3197587 & 688759 & 5.4 & 5.2947 & TST & \\
\hline CHEMBL1351686 & 688759 & 5.55 & 4.837 & TST & \\
\hline CHEMBL1595375 & 688759 & 4.65 & 5.1517 & TRN & \\
\hline CHEMBL3211356 & 688759 & 5.25 & 5.2363 & TRN & \\
\hline CHEMBL1985696 & 688759 & 5.05 & 4.8045 & TRN & \\
\hline CHEMBL1309542 & 688759 & 4.45 & 4.8104 & TRN & \\
\hline CHEMBL1572595 & 688759 & 4.45 & 4.8048 & TST & \\
\hline CHEMBL1497797 & 688759 & 4.8 & 4.8059 & TST & \\
\hline CHEMBL1590682 & 688759 & 4.9 & 5.0705 & TST & \\
\hline CHEMBL1307185 & 688759 & 4.95 & 4.7795 & TRN & \\
\hline CHEMBL1604350 & 688759 & 5.15 & 4.8829 & TRN & \\
\hline CHEMBL1599070 & 688759 & 4.7 & 4.6512 & TST & \\
\hline
\end{tabular}




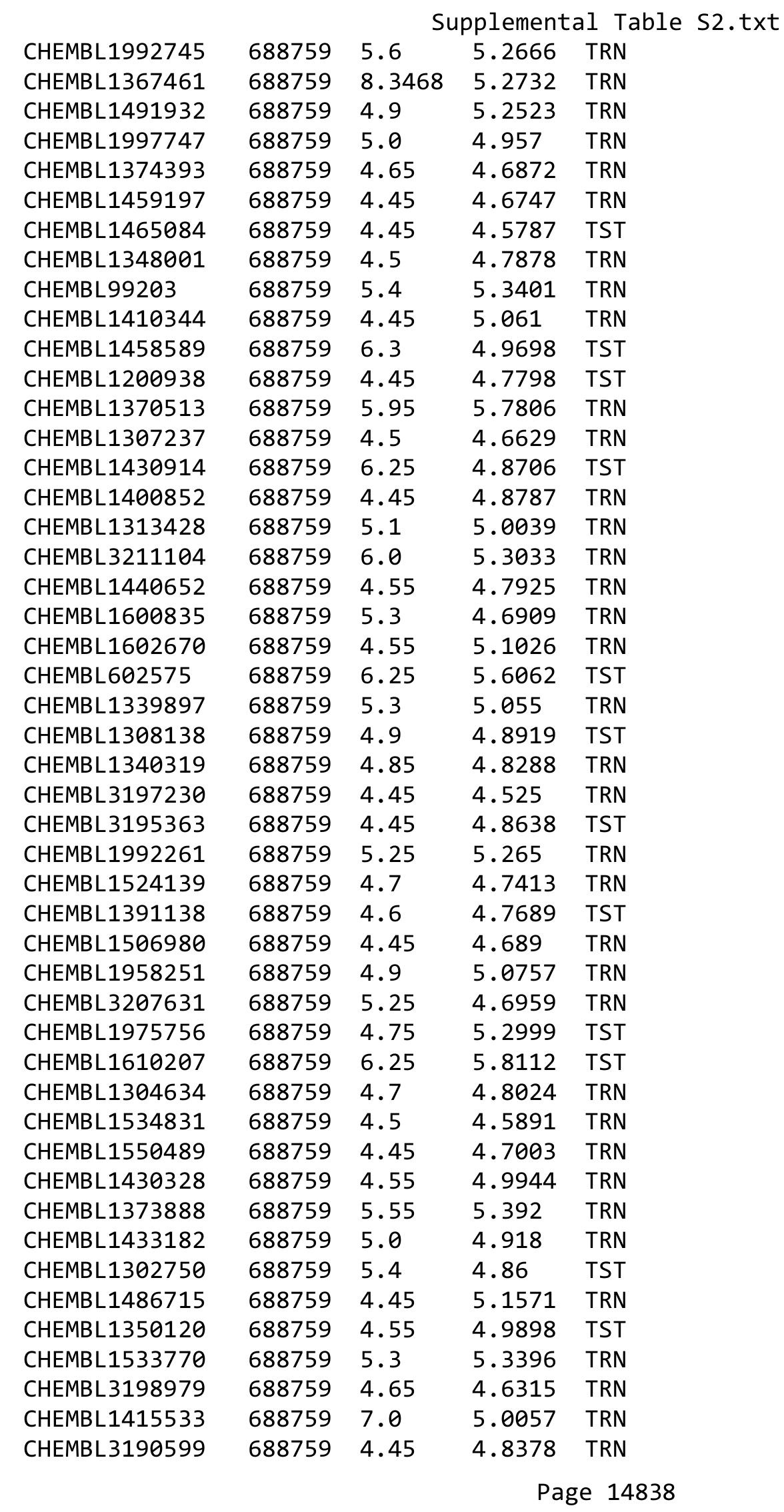




\begin{tabular}{|c|c|c|c|c|c|}
\hline \multirow[b]{2}{*}{ CHEMBL1522228 } & \multirow[b]{2}{*}{688759} & \multicolumn{4}{|c|}{ Supplemental Table S2.txt } \\
\hline & & 4.45 & 4.8374 & TRN & \\
\hline CHEMBL1607187 & 688759 & 5.35 & 4.7712 & TRN & \\
\hline CHEMBL 3190020 & 688759 & 4.95 & 5.016 & TRN & \\
\hline CHEMBL 3193298 & 688759 & 4.85 & 5.1426 & TRN & \\
\hline CHEMBL1341012 & 688759 & 4.45 & 4.398 & TRN & \\
\hline CHEMBL1539595 & 688759 & 4.8 & \multicolumn{2}{|c|}{4.763999999999999} & TRN \\
\hline CHEMBL1486913 & 688759 & 4.45 & 4.6802 & TST & \\
\hline CHEMBL1421625 & 688759 & 5.15 & 4.9178 & TRN & \\
\hline CHEMBL1393638 & 688759 & 5.25 & 4.817 & TST & \\
\hline CHEMBL1339036 & 688759 & 5.15 & 4.8218 & TST & \\
\hline CHEMBL188734 & 688759 & 4.55 & 4.7365 & TRN & \\
\hline CHEMBL1389226 & 688759 & 4.75 & 5.1157 & TST & \\
\hline CHEMBL1489280 & 688759 & 4.7 & 4.7118 & TRN & \\
\hline CHEMBL1486457 & 688759 & 4.45 & 4.7082 & TRN & \\
\hline CHEMBL1505749 & 688759 & 4.45 & 4.8318 & TRN & \\
\hline CHEMBL1452229 & 688759 & 5.3 & 4.6984 & TRN & \\
\hline CHEMBL1527501 & 688759 & 5.3 & 4.8933 & TRN & \\
\hline CHEMBL1536919 & 688759 & 4.45 & 4.6962 & TST & \\
\hline CHEMBL1534490 & 688759 & 5.15 & 4.9617 & TST & \\
\hline CHEMBL1524792 & 688759 & 4.45 & 4.6709 & TRN & \\
\hline CHEMBL1529395 & 688759 & 4.65 & 5.2254 & TRN & \\
\hline CHEMBL1607636 & 688759 & 4.45 & 4.5996 & TRN & \\
\hline CHEMBL1377522 & 688759 & 4.45 & 4.7685 & TRN & \\
\hline CHEMBL1412904 & 688759 & 6.0 & 4.6352 & TRN & \\
\hline CHEMBL1501354 & 688759 & 4.45 & 4.7987 & TRN & \\
\hline CHEMBL1332705 & 688759 & 4.95 & 4.9067 & TST & \\
\hline CHEMBL1538540 & 688759 & 4.7 & 4.831 & TST & \\
\hline CHEMBL1299188 & 688759 & 5.25 & 4.8375 & TRN & \\
\hline CHEMBL1346791 & 688759 & 5.2 & 5.0114 & TRN & \\
\hline CHEMBL1566358 & 688759 & 4.45 & 4.6576 & TST & \\
\hline CHEMBL1546699 & 688759 & 4.45 & 4.8117 & TST & \\
\hline CHEMBL428064 & 688759 & 5.6 & 5.4711 & TST & \\
\hline CHEMBL 2369244 & 688759 & 5.95 & 5.6407 & TRN & \\
\hline CHEMBL3190122 & 688759 & 5.25 & 4.5661 & TRN & \\
\hline CHEMBL3196661 & 688759 & 5.1 & 5.0318 & TRN & \\
\hline CHEMBL3192020 & 688759 & 4.9 & 4.6402 & TRN & \\
\hline CHEMBL1388315 & 688759 & 4.55 & 4.7143 & TRN & \\
\hline CHEMBL1392558 & 688759 & 4.75 & 5.0669 & TRN & \\
\hline CHEMBL1319574 & 688759 & 4.7 & 4.72199 & 99999999995 & TST \\
\hline CHEMBL3197858 & 688759 & 6.0 & 5.4892 & TRN & \\
\hline CHEMBL1319669 & 688759 & 4.45 & 4.7858 & TST & \\
\hline CHEMBL504598 & 688759 & 4.5 & 5.0773 & TRN & \\
\hline CHEMBL1462786 & 688759 & 4.45 & 4.6869 & TST & \\
\hline CHEMBL1330531 & 688759 & 4.45 & 4.8083 & TST & \\
\hline CHEMBL1599256 & 688759 & 5.45 & 5.4855 & TRN & \\
\hline CHEMBL1450414 & 688759 & 4.8 & 5.0154 & TRN & \\
\hline CHEMBL1447267 & 688759 & 4.95 & 4.8202 & TRN & \\
\hline CHEMBL1901606 & 688759 & 4.6 & 4.7086 & TRN & \\
\hline & & & & 14839 & \\
\hline
\end{tabular}




\begin{tabular}{|c|c|c|c|c|c|}
\hline \multicolumn{6}{|c|}{ Supplemental Table S2.txt } \\
\hline CHEMBL1547855 & 688759 & 4.45 & 5.0455 & TRN & \\
\hline CHEMBL1406251 & 688759 & 4.45 & 4.868 & TRN & \\
\hline CHEMBL1576815 & 688759 & 4.45 & 4.9344 & TST & \\
\hline CHEMBL1485521 & 688759 & 4.45 & 4.8371 & TST & \\
\hline CHEMBL1609264 & 688759 & 6.05 & 6.3365 & TRN & \\
\hline CHEMBL1302891 & 688759 & 5.4 & 5.1779 & TST & \\
\hline CHEMBL354676 & 688759 & 5.45 & 4.9277 & TRN & \\
\hline CHEMBL3194505 & 688759 & 4.45 & 4.8224 & TRN & \\
\hline CHEMBL1996068 & 688759 & 5.9 & 5.5104 & TST & \\
\hline CHEMBL1392895 & 688759 & 4.9 & 4.9121 & TRN & \\
\hline CHEMBL1573693 & 688759 & 4.45 & 5.1056 & TST & \\
\hline CHEMBL1338487 & 688759 & 4.8 & 4.7639 & TRN & \\
\hline CHEMBL1605104 & 688759 & 5.45 & 4.6428 & TRN & \\
\hline CHEMBL1452706 & 688759 & 4.55 & 5.0722 & TST & \\
\hline CHEMBL1393761 & 688759 & 4.6 & 4.725 & TST & \\
\hline CHEMBL1400709 & 688759 & 4.45 & 4.7493 & TRN & \\
\hline CHEMBL1569435 & 688759 & 4.9 & 4.8335 & TRN & \\
\hline CHEMBL1534147 & 688759 & 4.65 & 4.7895 & TST & \\
\hline CHEMBL1443820 & 688759 & 4.45 & 4.7862 & TST & \\
\hline CHEMBL1610066 & 688759 & 4.9 & 5.0654 & TRN & \\
\hline CHEMBL1438618 & 688759 & 5.0 & 5.1824 & TRN & \\
\hline CHEMBL1483389 & 688759 & 5.45 & 5.09699 & 99999999995 & TRN \\
\hline CHEMBL1306243 & 688759 & 5.45 & 5.2777 & TRN & \\
\hline CHEMBL1454217 & 688759 & 4.45 & 4.7302 & TST & \\
\hline CHEMBL1446705 & 688759 & 5.25 & 4.9843 & TRN & \\
\hline CHEMBL1573523 & 688759 & 4.65 & 5.0427 & TRN & \\
\hline CHEMBL3208957 & 688759 & 4.9 & 4.522 & TRN & \\
\hline CHEMBL1527133 & 688759 & 4.45 & 4.7756 & TRN & \\
\hline CHEMBL1323014 & 688759 & 4.45 & 5.2169 & TRN & \\
\hline CHEMBL3211136 & 688759 & 4.45 & 4.8885 & TRN & \\
\hline CHEMBL1481358 & 688759 & 4.95 & 4.7986 & TRN & \\
\hline CHEMBL1441319 & 688759 & 5.0 & 4.8054 & TRN & \\
\hline CHEMBL1547860 & 688759 & 5.5 & 5.1494 & TRN & \\
\hline CHEMBL1490334 & 688759 & 4.7 & 4.8445 & TRN & \\
\hline CHEMBL1502601 & 688759 & 4.45 & 4.7953 & TRN & \\
\hline CHEMBL1307953 & 688759 & 4.9 & 4.8176 & TRN & \\
\hline CHEMBL1492918 & 688759 & 4.55 & 4.89199 & 99999999995 & TRN \\
\hline CHEMBL3192019 & 688759 & 5.4 & 5.0733 & TRN & \\
\hline CHEMBL1608079 & 688759 & 4.45 & 4.7562 & TST & \\
\hline CHEMBL1479089 & 688759 & 5.0 & 4.7946 & TST & \\
\hline CHEMBL1987232 & 688759 & 4.45 & 4.9095 & TRN & \\
\hline CHEMBL1339856 & 688759 & 4.9 & 4.8651 & TRN & \\
\hline CHEMBL1563446 & 688759 & 4.8 & 4.9377 & TRN & \\
\hline CHEMBL 3212503 & 688759 & 4.45 & 4.4464 & TRN & \\
\hline CHEMBL1482365 & 688759 & 4.5 & 4.7489 & TRN & \\
\hline CHEMBL1550657 & 688759 & 4.85 & 4.8558 & TRN & \\
\hline CHEMBL1571307 & 688759 & 5.4 & 5.09 & TRN & \\
\hline CHEMBL1546992 & 688759 & 6.1 & 4.6824 & TRN & \\
\hline
\end{tabular}




\begin{tabular}{|c|c|c|c|c|c|}
\hline \multicolumn{6}{|c|}{ oplemental Table S } \\
\hline CHEMBL1504840 & 688759 & 5.1 & 4.9976 & TRN & \\
\hline CHEMBL1390450 & 688759 & 4.45 & 4.8976 & TRN & \\
\hline CHEMBL3197931 & 688759 & 5.45 & 5.2065 & TRN & \\
\hline CHEMBL1369620 & 688759 & 4.45 & 4.9039 & TRN & \\
\hline CHEMBL1420908 & 688759 & 5.3 & 5.482 & TRN & \\
\hline CHEMBL1582307 & 688759 & 4.45 & 4.5899 & TRN & \\
\hline CHEMBL3192204 & 688759 & 4.7 & 5.4282 & TRN & \\
\hline CHEMBL1449253 & 688759 & 6.0 & 5.0445 & TRN & \\
\hline CHEMBL1300859 & 688759 & 4.45 & 5.1597 & TRN & \\
\hline CHEMBL3191353 & 688759 & 4.6 & 4.7763 & TST & \\
\hline CHEMBL1506505 & 688759 & 4.45 & 4.7706 & TST & \\
\hline CHEMBL 2001739 & 688759 & 6.45 & 5.8469 & TRN & \\
\hline CHEMBL1604371 & 688759 & 4.7 & 4.8435 & TRN & \\
\hline CHEMBL1603294 & 688759 & 5.25 & 5.1581 & TRN & \\
\hline CHEMBL1526773 & 688759 & 5.2 & 4.9057 & TRN & \\
\hline CHEMBL1539520 & 688759 & 5.3 & 4.9738 & TRN & \\
\hline CHEMBL1384341 & 688759 & 4.65 & 4.8191 & TST & \\
\hline CHEMBL1352337 & 688759 & 6.0 & 4.7897 & TRN & \\
\hline CHEMBL1464812 & 688759 & 4.65 & 4.8244 & TRN & \\
\hline CHEMBL1431591 & 688759 & 4.55 & 4.758 & TRN & \\
\hline CHEMBL1441109 & 688759 & 4.7 & 4.9045 & TRN & \\
\hline CHEMBL1595632 & 688759 & 5.8 & 5.6384 & TRN & \\
\hline CHEMBL1438703 & 688759 & 4.45 & 4.73300 & 00000000005 & TST \\
\hline CHEMBL1993522 & 688759 & 4.95 & 5.0597 & TRN & \\
\hline CHEMBL3195713 & 688759 & 5.95 & 5.4373 & TRN & \\
\hline CHEMBL 3145371 & 688759 & 6.0 & 5.9411 & TRN & \\
\hline CHEMBL1477816 & 688759 & 5.5 & 5.2032 & TRN & \\
\hline CHEMBL1370019 & 688759 & 4.5 & 4.4796 & TRN & \\
\hline CHEMBL1582294 & 688759 & 5.25 & 5.1644 & TRN & \\
\hline CHEMBL1577962 & 688759 & 5.3 & 5.239 & TRN & \\
\hline CHEMBL1455331 & 688759 & 4.45 & 4.8672 & TST & \\
\hline CHEMBL1441257 & 688759 & 4.45 & 4.6135 & TRN & \\
\hline CHEMBL 1407426 & 688759 & 4.45 & 4.7705 & TRN & \\
\hline CHEMBL1459414 & 688759 & 4.7 & 5.0639 & TRN & \\
\hline CHEMBL1469326 & 688759 & 4.45 & 4.8919 & TRN & \\
\hline CHEMBL1374526 & 688759 & 4.45 & 4.7359 & TRN & \\
\hline CHEMBL1579435 & 688759 & 4.5 & 4.8968 & TRN & \\
\hline CHEMBL393018 & 688759 & 5.35 & 5.1207 & TRN & \\
\hline CHEMBL3191265 & 688759 & 4.7 & 5.2874 & TRN & \\
\hline CHEMBL1502419 & 688759 & 4.55 & 4.7307 & TRN & \\
\hline CHEMBL1518327 & 688759 & 5.4 & 4.8941 & TST & \\
\hline CHEMBL 3190734 & 688759 & 4.95 & 4.8495 & TRN & \\
\hline CHEMBL1571085 & 688759 & 4.6 & 4.7098 & TRN & \\
\hline CHEMBL1464642 & 688759 & 4.65 & 4.8052 & TRN & \\
\hline CHEMBL1347858 & 688759 & 5.0 & 4.5346 & TRN & \\
\hline CHEMBL1558038 & 688759 & 5.1 & 5.222 & TRN & \\
\hline CHEMBL1584768 & 688759 & 4.45 & 4.8769 & TRN & \\
\hline CHEMBL1574212 & 688759 & 5.0 & 5.0047 & TST & \\
\hline
\end{tabular}




\begin{tabular}{|c|c|c|c|c|c|}
\hline & & \multicolumn{4}{|c|}{ Supplemental Table S2.txt } \\
\hline CHEMBL1502342 & 688759 & 5.15 & 4.7742 & TRN & \\
\hline CHEMBL1364807 & 688759 & 4.6 & 4.5573 & TRN & \\
\hline CHEMBL1525579 & 688759 & 5.25 & 4.9512 & TRN & \\
\hline CHEMBL1541007 & 688759 & 4.45 & 4.7788 & TST & \\
\hline CHEMBL1389346 & 688759 & 4.65 & 4.7213 & TST & \\
\hline CHEMBL1597777 & 688759 & 5.35 & 5.2633 & TRN & \\
\hline CHEMBL1580710 & 688759 & 4.45 & 4.7355 & TRN & \\
\hline CHEMBL1453723 & 688759 & 5.4 & 5.3844 & TRN & \\
\hline CHEMBL1521985 & 688759 & 4.45 & 5.0027 & TRN & \\
\hline CHEMBL3193400 & 688759 & 4.65 & 4.958 & TRN & \\
\hline CHEMBL1574508 & 688759 & 4.65 & 4.7475 & TST & \\
\hline CHEMBL1548927 & 688759 & 4.5 & 5.0364 & TST & \\
\hline CHEMBL1349747 & 688759 & 4.75 & 4.8882 & TRN & \\
\hline CHEMBL1383884 & 688759 & 4.65 & 4.934 & TST & \\
\hline CHEMBL1402000 & 688759 & 4.95 & 4.795 & TST & \\
\hline CHEMBL1328215 & 688759 & 4.9 & 4.9957 & TRN & \\
\hline CHEMBL3210037 & 688759 & 4.5 & 4.7374 & TRN & \\
\hline CHEMBL1564403 & 688759 & 5.3 & 5.1332 & TRN & \\
\hline CHEMBL1431328 & 688759 & 4.45 & 4.8082 & TST & \\
\hline CHEMBL1588536 & 688759 & 5.95 & 5.4209 & TRN & \\
\hline CHEMBL1368979 & 688759 & 4.6 & 4.6828 & TRN & \\
\hline CHEMBL1406350 & 688759 & 5.3 & 4.7657 & TRN & \\
\hline CHEMBL1528883 & 688759 & 4.8 & 4.8592 & TRN & \\
\hline CHEMBL1489723 & 688759 & 4.45 & 4.5963 & TRN & \\
\hline CHEMBL1994838 & 688759 & 5.35 & 5.24200 & 0000000001 & TRN \\
\hline CHEMBL1466798 & 688759 & 4.65 & 4.6346 & TRN & \\
\hline CHEMBL1485126 & 688759 & 5.0 & 5.0121 & TRN & \\
\hline CHEMBL1497960 & 688759 & 5.0 & 5.2543 & TRN & \\
\hline CHEMBL1516914 & 688759 & 4.7 & 4.8156 & TST & \\
\hline CHEMBL1463695 & 688759 & 4.45 & 4.9997 & TST & \\
\hline CHEMBL1571123 & 688759 & 5.65 & 5.1122 & TRN & \\
\hline CHEMBL1359792 & 688759 & 4.45 & 4.6933 & TST & \\
\hline CHEMBL3196757 & 688759 & 5.5 & 5.3101 & TRN & \\
\hline CHEMBL1401850 & 688759 & 4.45 & 4.7385 & TRN & \\
\hline CHEMBL1571483 & 688759 & 5.5 & 5.4396 & TRN & \\
\hline CHEMBL3208002 & 688759 & 5.0 & 4.7596 & TRN & \\
\hline CHEMBL1337448 & 688759 & 5.2 & 5.1636 & TST & \\
\hline CHEMBL1532713 & 688759 & 4.45 & 4.5122 & TRN & \\
\hline CHEMBL1348385 & 688759 & 5.15 & 5.1464 & TRN & \\
\hline CHEMBL1994837 & 688759 & 4.6 & 4.9436 & TRN & \\
\hline CHEMBL1447162 & 688759 & 4.45 & 4.7682 & TST & \\
\hline CHEMBL1200567 & 688759 & 5.35 & 5.2169 & TRN & \\
\hline CHEMBL1564687 & 688759 & 4.8 & 5.1393 & TRN & \\
\hline CHEMBL1414095 & 688759 & 4.7 & 4.5923 & TST & \\
\hline CHEMBL1310449 & 688759 & 5.5 & 5.2974 & TRN & \\
\hline CHEMBL1450964 & 688759 & 4.65 & 5.1155 & TRN & \\
\hline CHEMBL1533469 & 688759 & 5.1 & 5.2182 & TRN & \\
\hline CHEMBL1361709 & 688759 & 4.75 & 4.7657 & TST & \\
\hline
\end{tabular}




\begin{tabular}{|c|c|c|c|c|c|}
\hline \multicolumn{6}{|c|}{ Supplemental Table S2.txt } \\
\hline CHEMBL1585685 & 688759 & 4.45 & 4.9339 & TRN & \\
\hline CHEMBL1467128 & 688759 & 4.6 & 4.4776 & TRN & \\
\hline CHEMBL1532330 & 688759 & 4.85 & 4.9182 & TST & \\
\hline CHEMBL1386076 & 688759 & 5.1 & 4.8706 & TRN & \\
\hline CHEMBL1425167 & 688759 & 5.2 & 4.8803 & TST & \\
\hline CHEMBL1584880 & 688759 & 5.0 & 4.9452 & TRN & \\
\hline CHEMBL1504573 & 688759 & 4.5 & 4.5405 & TRN & \\
\hline CHEMBL1299707 & 688759 & 5.25 & 5.0343 & TRN & \\
\hline CHEMBL1320446 & 688759 & 5.5 & 5.1584 & TRN & \\
\hline CHEMBL3190824 & 688759 & 5.3 & 5.0444 & TRN & \\
\hline CHEMBL1999667 & 688759 & 5.15 & 5.48 & TRN & \\
\hline CHEMBL1385993 & 688759 & 4.55 & 4.9706 & TST & \\
\hline CHEMBL1547501 & 688759 & 4.9 & 4.9093 & TRN & \\
\hline CHEMBL1378837 & 688759 & 4.45 & 4.6624 & TRN & \\
\hline CHEMBL1599201 & 688759 & 4.95 & 5.0209 & TRN & \\
\hline CHEMBL1343875 & 688759 & 4.45 & 4.5504 & TRN & \\
\hline CHEMBL1595326 & 688759 & 5.3 & 5.0778 & TRN & \\
\hline CHEMBL1429201 & 688759 & 4.65 & 4.7484 & TRN & \\
\hline CHEMBL1446989 & 688759 & 5.0 & 4.82100 & 0000000001 & TRN \\
\hline CHEMBL1519463 & 688759 & 4.6 & 4.4968 & TST & \\
\hline CHEMBL1544987 & 688759 & 5.2 & 5.0254 & TRN & \\
\hline CHEMBL1580695 & 688759 & 4.75 & 5.0012 & TST & \\
\hline CHEMBL1468365 & 688759 & 4.9 & 4.9607 & TRN & \\
\hline CHEMBL1570587 & 688759 & 5.0 & 5.0428 & TRN & \\
\hline CHEMBL1385532 & 688759 & 6.1 & 5.3512 & TRN & \\
\hline CHEMBL1330963 & 688759 & 4.45 & 4.6827 & TRN & \\
\hline CHEMBL1343203 & 688759 & 4.75 & 4.9295 & TRN & \\
\hline CHEMBL1610003 & 688759 & 4.45 & 4.7687 & TRN & \\
\hline CHEMBL1581470 & 688759 & 4.65 & 4.9255 & TST & \\
\hline CHEMBL1383991 & 688759 & 5.3 & 5.2478 & TRN & \\
\hline CHEMBL 1487750 & 688759 & 4.5 & 4.8338 & TRN & \\
\hline CHEMBL1563187 & 688759 & 6.1 & 4.9637 & TRN & \\
\hline CHEMBL1555120 & 688759 & 5.1 & 4.754 & TST & \\
\hline CHEMBL1564386 & 688759 & 4.65 & 4.9817 & TRN & \\
\hline CHEMBL1540751 & 688759 & 6.8 & 4.8689 & TST & \\
\hline CHEMBL1302741 & 688759 & 4.95 & 4.7564 & TRN & \\
\hline CHEMBL3195531 & 688759 & 5.4 & 4.956 & TRN & \\
\hline CHEMBL1446907 & 688759 & 4.5 & 4.8116 & TRN & \\
\hline CHEMBL1313763 & 688759 & 4.95 & 4.863 & TST & \\
\hline CHEMBL1417940 & 688759 & 4.65 & 4.7375 & TST & \\
\hline CHEMBL1464228 & 688759 & 5.15 & 5.2155 & TRN & \\
\hline CHEMBL1449746 & 688759 & 4.9 & 4.6452 & TRN & \\
\hline CHEMBL1391551 & 688759 & 4.45 & 4.7703 & TST & \\
\hline CHEMBL1313961 & 688759 & 4.45 & 4.8985 & TST & \\
\hline CHEMBL1365033 & 688759 & 5.5 & 5.0945 & TRN & \\
\hline CHEMBL1400339 & 688759 & 4.45 & 5.1564 & TRN & \\
\hline CHEMBL1449503 & 688759 & 5.5 & 5.266 & TST & \\
\hline CHEMBL1366456 & 688759 & 4.65 & 4.8093 & TRN & \\
\hline
\end{tabular}




\begin{tabular}{|c|c|c|c|c|}
\hline \multicolumn{5}{|c|}{ Supplemental Table } \\
\hline CHEMBL1539813 & 688759 & 4.8 & 5.0128 & TST \\
\hline CHEMBL1383505 & 688759 & 4.45 & 4.5671 & TRN \\
\hline CHEMBL1578473 & 688759 & 5.5 & 5.1464 & TST \\
\hline CHEMBL1387010 & 688759 & 4.45 & 4.6984 & TRN \\
\hline CHEMBL1980588 & 688759 & 5.35 & 4.7759 & TRN \\
\hline CHEMBL1597146 & 688759 & 4.45 & 4.515 & TST \\
\hline CHEMBL1332154 & 688759 & 4.45 & 4.8284 & TRN \\
\hline CHEMBL1347818 & 688759 & 4.45 & 4.6072 & TST \\
\hline CHEMBL1348176 & 688759 & 4.75 & 4.9447 & TRN \\
\hline CHEMBL1465424 & 688759 & 4.45 & 5.0595 & TST \\
\hline CHEMBL1613160 & 688759 & 5.15 & 5.3659 & TRN \\
\hline CHEMBL1387462 & 688759 & 4.45 & 4.6513 & TRN \\
\hline CHEMBL1352604 & 688759 & 4.45 & 4.8173 & TRN \\
\hline CHEMBL1426500 & 688759 & 4.95 & 4.7647 & TST \\
\hline CHEMBL3145375 & 688759 & 5.7 & 5.9467 & TRN \\
\hline CHEMBL1508579 & 688759 & 4.45 & 4.4561 & TST \\
\hline CHEMBL2369157 & 688759 & 5.6 & 5.6722 & TRN \\
\hline CHEMBL1392479 & 688759 & 5.4 & 4.5113 & TRN \\
\hline CHEMBL451748 & 688759 & 5.1 & 4.8123 & TRN \\
\hline CHEMBL1572263 & 688759 & 5.0 & 4.8578 & TRN \\
\hline CHEMBL1439833 & 688759 & 5.9 & 5.6393 & TRN \\
\hline CHEMBL1579968 & 688759 & 4.8 & 4.5293 & TRN \\
\hline CHEMBL1509214 & 688759 & 5.35 & 5.0867 & TRN \\
\hline CHEMBL1543470 & 688759 & 5.35 & 5.0169 & TRN \\
\hline CHEMBL3199170 & 688759 & 5.45 & 5.585 & TRN \\
\hline CHEMBL1467372 & 688759 & 4.45 & 4.8453 & TST \\
\hline CHEMBL3198597 & 688759 & 4.5 & 4.981 & TST \\
\hline CHEMBL1510832 & 688759 & 4.6 & 4.9328 & TRN \\
\hline CHEMBL1574282 & 688759 & 4.65 & 4.9154 & TRN \\
\hline CHEMBL1466926 & 688759 & 5.05 & 4.8462 & TRN \\
\hline CHEMBL1460492 & 688759 & 4.65 & 4.7122 & TRN \\
\hline CHEMBL3190512 & 688759 & 4.45 & 4.8497 & TRN \\
\hline CHEMBL3197023 & 688759 & 4.7 & 4.5185 & TRN \\
\hline CHEMBL1448854 & 688759 & 4.95 & 4.8332 & TST \\
\hline CHEMBL1555494 & 688759 & 4.45 & 4.5387 & TRN \\
\hline CHEMBL1331498 & 688759 & 5.0 & 4.708 & TRN \\
\hline CHEMBL3190115 & 688759 & 5.45 & 5.0594 & TRN \\
\hline CHEMBL1979580 & 688759 & 4.7 & 5.0188 & TRN \\
\hline CHEMBL1342526 & 688759 & 5.0 & 5.3974 & TRN \\
\hline CHEMBL1539260 & 688759 & 4.65 & 4.8944 & TRN \\
\hline CHEMBL1408438 & 688759 & 5.1 & 5.064 & TRN \\
\hline CHEMBL1491015 & 688759 & 4.95 & 4.989 & TRN \\
\hline CHEMBL1451899 & 688759 & 5.15 & 5.0079 & TRN \\
\hline CHEMBL1508072 & 688759 & 5.65 & 5.7083 & TST \\
\hline CHEMBL1499034 & 688759 & 4.45 & 4.6467 & TRN \\
\hline CHEMBL582073 & 688759 & 6.0 & 5.206 & TRN \\
\hline CHEMBL 278081 & 688759 & 4.45 & 4.8208 & TST \\
\hline CHEMBL1556270 & 688759 & 4.95 & 5.083 & TRN \\
\hline
\end{tabular}




\begin{tabular}{|c|c|c|c|c|}
\hline \multicolumn{5}{|c|}{ Supplemental Table S2.txt } \\
\hline CHEMBL1541475 & 688759 & 4.95 & 4.8834 & TRN \\
\hline CHEMBL1413072 & 688759 & 5.5 & 5.1378 & TRN \\
\hline CHEMBL3209204 & 688759 & 4.75 & 4.5034 & TRN \\
\hline CHEMBL3190447 & 688759 & 6.05 & 5.3255 & TRN \\
\hline CHEMBL1503808 & 688759 & 4.45 & 4.8562 & TRN \\
\hline CHEMBL3197098 & 688759 & 5.45 & 5.2157 & TRN \\
\hline CHEMBL1392623 & 688759 & 7.0 & 4.7546 & TRN \\
\hline CHEMBL1563127 & 688759 & 5.55 & 4.7468 & TRN \\
\hline CHEMBL1537002 & 688759 & 4.45 & 4.7503 & TRN \\
\hline CHEMBL1990174 & 688759 & 6.9 & 6.0174 & TRN \\
\hline CHEMBL1353548 & 688759 & 4.6 & 4.7947 & TRN \\
\hline CHEMBL1304065 & 688759 & 6.1 & 4.8387 & TRN \\
\hline CHEMBL1496854 & 688759 & 5.7 & 5.6083 & TST \\
\hline CHEMBL 3197870 & 688759 & 4.5 & 4.5766 & TRN \\
\hline CHEMBL1494979 & 688759 & 4.9 & 4.8475 & TST \\
\hline CHEMBL3192653 & 688759 & 4.75 & 4.6267 & TRN \\
\hline CHEMBL1456276 & 688759 & 4.65 & 4.9392 & TST \\
\hline CHEMBL1456521 & 688759 & 4.9 & 4.9836 & TRN \\
\hline CHEMBL1490860 & 688759 & 4.45 & 4.8452 & TST \\
\hline CHEMBL1549555 & 688759 & 6.0 & 4.8594 & TRN \\
\hline CHEMBL1411494 & 688759 & 4.7 & 5.0393 & TRN \\
\hline CHEMBL1570139 & 688759 & 4.7 & 4.7859 & TRN \\
\hline CHEMBL1999149 & 688759 & 4.65 & 4.7156 & TST \\
\hline CHEMBL323936 & 688759 & 5.8 & 4.739 & TRN \\
\hline CHEMBL1509526 & 688759 & 4.45 & 4.9571 & TST \\
\hline CHEMBL1556149 & 688759 & 4.95 & 5.0115 & TRN \\
\hline CHEMBL1543102 & 688759 & 5.0 & 4.7525 & TST \\
\hline CHEMBL1403909 & 688759 & 4.45 & 4.6151 & TRN \\
\hline CHEMBL1543897 & 688759 & 6.15 & 4.8143 & TRN \\
\hline CHEMBL1597484 & 688759 & 4.45 & 4.6111 & TST \\
\hline CHEMBL1557105 & 688759 & 4.45 & 4.5087 & TRN \\
\hline CHEMBL1351554 & 688759 & 4.45 & 4.7671 & TRN \\
\hline CHEMBL1313550 & 688759 & 4.95 & 4.6688 & TRN \\
\hline CHEMBL1566846 & 688759 & 5.5 & 5.1293 & TRN \\
\hline CHEMBL1352655 & 688759 & 4.45 & 4.4629 & TST \\
\hline CHEMBL1476170 & 688759 & 6.0 & 5.2547 & TST \\
\hline CHEMBL1460733 & 688759 & 4.55 & 4.8377 & TRN \\
\hline CHEMBL1425234 & 688759 & 4.45 & 4.7272 & TST \\
\hline CHEMBL1484119 & 688759 & 4.9 & 4.838 & TST \\
\hline CHEMBL1338577 & 688759 & 4.45 & $4.8580 e$ & 00000000005 \\
\hline CHEMBL3194371 & 688759 & 5.5 & 5.3137 & TRN \\
\hline CHEMBL1488893 & 688759 & 5.15 & 5.4217 & TRN \\
\hline CHEMBL1350524 & 688759 & 4.45 & 5.5878 & TST \\
\hline CHEMBL1965298 & 688759 & 6.05 & 5.6441 & TRN \\
\hline CHEMBL1350777 & 688759 & 4.45 & 4.8893 & TRN \\
\hline CHEMBL1585055 & 688759 & 5.1 & 5.8085 & TRN \\
\hline CHEMBL1525618 & 688759 & 4.45 & 4.5909 & TST \\
\hline CHEMBL1365249 & 688759 & 4.45 & 4.6849 & TST \\
\hline
\end{tabular}




\begin{tabular}{|c|c|c|c|c|c|}
\hline \multicolumn{6}{|c|}{ Supplemental Table S2.txt } \\
\hline CHEMBL404214 & 688759 & 6.6 & 5.1171 & TRN & \\
\hline CHEMBL1574374 & 688759 & 5.25 & 5.2375 & TST & \\
\hline CHEMBL1325077 & 688759 & 6.1 & 4.9107 & TRN & \\
\hline CHEMBL1483321 & 688759 & 4.45 & 4.8378 & TST & \\
\hline CHEMBL1372891 & 688759 & 4.45 & 4.6418 & TRN & \\
\hline CHEMBL1313509 & 688759 & 4.45 & 4.8537 & TRN & \\
\hline CHEMBL1336445 & 688759 & 4.9 & 5.0041 & TST & \\
\hline CHEMBL 3212111 & 688759 & 5.15 & 5.0752 & TRN & \\
\hline CHEMBL1487597 & 688759 & 4.5 & 5.005 & TRN & \\
\hline CHEMBL1531253 & 688759 & 5.15 & 5.0131 & TST & \\
\hline CHEMBL1350749 & 688759 & 4.65 & 4.6657 & TRN & \\
\hline CHEMBL1429715 & 688759 & 4.6 & 4.8172 & TRN & \\
\hline CHEMBL1506434 & 688759 & 4.7 & 4.5618 & TRN & \\
\hline CHEMBL1554976 & 688759 & 4.45 & 4.5967 & TRN & \\
\hline CHEMBL1369171 & 688759 & 4.45 & 4.8271 & TST & \\
\hline CHEMBL1497198 & 688759 & 4.45 & 4.8968 & TRN & \\
\hline CHEMBL1492443 & 688759 & 4.45 & 4.7794 & TRN & \\
\hline CHEMBL1425491 & 688759 & 4.45 & 4.797 & TRN & \\
\hline CHEMBL1574507 & 688759 & 5.2 & 5.1685 & TST & \\
\hline CHEMBL3195657 & 688759 & 6.6 & 6.4412 & TRN & \\
\hline CHEMBL1509559 & 688759 & 5.25 & 4.8265 & TST & \\
\hline CHEMBL1442264 & 688759 & 4.45 & 4.904 & TRN & \\
\hline CHEMBL1469709 & 688759 & 4.65 & 4.3684 & TRN & \\
\hline CHEMBL592869 & 688759 & 4.9 & 4.6449 & TRN & \\
\hline CHEMBL1428196 & 688759 & 4.95 & 5.0428 & TST & \\
\hline CHEMBL1364745 & 688759 & 4.65 & 4.6698 & TST & \\
\hline CHEMBL1348593 & 688759 & 4.8 & 4.7438 & TRN & \\
\hline CHEMBL1471293 & 688759 & 4.65 & 4.7176 & TST & \\
\hline CHEMBL1446651 & 688759 & 5.15 & 4.9204 & TRN & \\
\hline CHEMBL1533711 & 688759 & 4.95 & 5.1155 & TRN & \\
\hline CHEMBL1506585 & 688759 & 4.85 & 4.7071 & TRN & \\
\hline CHEMBL1372053 & 688759 & 4.65 & 4.85800 & 00000000005 & TST \\
\hline CHEMBL1374663 & 688759 & 5.2 & 4.9028 & TRN & \\
\hline CHEMBL1530652 & 688759 & 4.5 & 4.9987 & TRN & \\
\hline CHEMBL1410633 & 688759 & 4.45 & 4.9922 & TRN & \\
\hline CHEMBL1582495 & 688759 & 5.55 & 4.8933 & TRN & \\
\hline CHEMBL1319353 & 688759 & 4.7 & 4.688 & TRN & \\
\hline CHEMBL1352801 & 688759 & 5.25 & 5.4232 & TST & \\
\hline CHEMBL1448179 & 688759 & 4.9 & 5.1689 & TRN & \\
\hline CHEMBL1503755 & 688759 & 5.2 & 4.9301 & TRN & \\
\hline CHEMBL3191542 & 688759 & 5.45 & 5.0097 & TRN & \\
\hline CHEMBL1353318 & 688759 & 4.95 & 4.8545 & TST & \\
\hline CHEMBL1558313 & 688759 & 4.8 & 5.1885 & TST & \\
\hline CHEMBL188343 & 688759 & 4.65 & 4.8249 & TST & \\
\hline CHEMBL1458371 & 688759 & 4.45 & 4.806 & TRN & \\
\hline CHEMBL63426 & 688759 & 4.5 & 4.7209 & TST & \\
\hline CHEMBL1579716 & 688759 & 4.5 & 4.813 & TST & \\
\hline CHEMBL1454792 & 688759 & 4.6 & 4.7479 & TRN & \\
\hline
\end{tabular}




\begin{tabular}{|c|c|c|c|c|}
\hline \multicolumn{5}{|c|}{ Supplemental Table S2.txt } \\
\hline CHEMBL1416660 & 688759 & 5.1 & 5.1146 & TRN \\
\hline CHEMBL1401083 & 688759 & 4.9 & 4.6027 & TRN \\
\hline CHEMBL1414628 & 688759 & 4.45 & 4.6916 & TRN \\
\hline CHEMBL1370343 & 688759 & 4.45 & 4.8873 & TST \\
\hline CHEMBL 1477680 & 688759 & 6.5 & 4.7715 & TRN \\
\hline CHEMBL1467006 & 688759 & 5.25 & 5.3611 & TST \\
\hline CHEMBL1534503 & 688759 & 4.8 & 4.745 & TRN \\
\hline CHEMBL1587301 & 688759 & 4.65 & 4.8287 & TRN \\
\hline CHEMBL1497141 & 688759 & 5.5 & 5.2548 & TRN \\
\hline CHEMBL1536834 & 688759 & 4.65 & 4.8385 & TRN \\
\hline CHEMBL1580621 & 688759 & 4.95 & 4.8832 & TST \\
\hline CHEMBL1505039 & 688759 & 4.45 & 4.9286 & TST \\
\hline CHEMBL1521818 & 688759 & 5.6 & 4.3006 & TRN \\
\hline CHEMBL1482526 & 688759 & 4.45 & 4.8995 & TST \\
\hline CHEMBL1320072 & 688759 & 5.25 & 4.9016 & TRN \\
\hline CHEMBL1346301 & 688759 & 4.5 & 4.7825 & TRN \\
\hline CHEMBL1309295 & 688759 & 4.45 & 4.6757 & TRN \\
\hline CHEMBL1574975 & 688759 & 4.45 & 4.902 & TRN \\
\hline CHEMBL1496202 & 688759 & 5.4 & 5.2496 & TRN \\
\hline CHEMBL1343966 & 688759 & 5.15 & 4.9494 & TRN \\
\hline CHEMBL1303434 & 688759 & 4.45 & 5.3111 & TRN \\
\hline CHEMBL1365163 & 688759 & 4.7 & 4.871 & TRN \\
\hline CHEMBL3192448 & 688759 & 4.6 & 4.8643 & TRN \\
\hline CHEMBL1320260 & 688759 & 4.65 & 4.5892 & TRN \\
\hline CHEMBL1511442 & 688759 & 4.65 & 4.8931 & TRN \\
\hline CHEMBL1535546 & 688759 & 5.25 & 5.1311 & TRN \\
\hline CHEMBL1580339 & 688759 & 4.45 & 4.9832 & TST \\
\hline CHEMBL1481281 & 688759 & 4.45 & 4.7695 & TRN \\
\hline CHEMBL1387391 & 688759 & 4.9 & 4.9175 & TRN \\
\hline CHEMBL1518594 & 688759 & 4.8 & 4.5674 & TRN \\
\hline CHEMBL1365480 & 688759 & 5.0 & 5.1195 & TRN \\
\hline CHEMBL1301260 & 688759 & 4.45 & 4.8144 & TRN \\
\hline CHEMBL1574211 & 688759 & 4.45 & 4.7145 & TRN \\
\hline CHEMBL1587121 & 688759 & 4.6 & 5.1404 & TST \\
\hline CHEMBL1609459 & 688759 & 4.95 & 5.0004 & TST \\
\hline CHEMBL1516871 & 688759 & 5.0 & 5.4364 & TRN \\
\hline CHEMBL1526537 & 688759 & 4.45 & 4.8469 & TRN \\
\hline CHEMBL1398575 & 688759 & 4.45 & 4.962 & TRN \\
\hline CHEMBL1383637 & 688759 & 5.25 & 4.6478 & TRN \\
\hline CHEMBL1488730 & 688759 & 5.35 & 5.3278 & TRN \\
\hline CHEMBL1380684 & 688759 & 6.0 & 5.3557 & TST \\
\hline CHEMBL1494520 & 688759 & 5.0 & 5.0444 & TRN \\
\hline CHEMBL1534767 & 688759 & 4.8 & 4.8404 & TST \\
\hline CHEMBL2003651 & 688759 & 4.45 & 4.7707 & TRN \\
\hline CHEMBL1473980 & 688759 & 6.25 & 4.8499 & TST \\
\hline CHEMBL1580187 & 688759 & 5.5 & 4.5932 & TST \\
\hline CHEMBL1412702 & 688759 & 4.7 & 4.9601 & TRN \\
\hline CHEMBL1307125 & 688759 & 4.65 & 4.9331 & TST \\
\hline
\end{tabular}




\begin{tabular}{|c|c|c|c|c|}
\hline & & & pplement & al $\mathrm{Ta}$ \\
\hline CHEMBL1562420 & 688759 & 6.0 & 5.5239 & TST \\
\hline CHEMBL1373636 & 688759 & 5.0 & 5.0488 & TRN \\
\hline CHEMBL1492412 & 688759 & 5.55 & 5.3486 & TRN \\
\hline CHEMBL1381571 & 688759 & 4.45 & 4.6864 & TRN \\
\hline CHEMBL1393245 & 688759 & 4.95 & 5.0109 & TRN \\
\hline CHEMBL1391770 & 688759 & 4.55 & 4.7897 & TRN \\
\hline CHEMBL3211298 & 688759 & 4.8 & 4.8826 & TRN \\
\hline CHEMBL1484833 & 688759 & 5.25 & 4.9855 & TST \\
\hline CHEMBL1490016 & 688759 & 5.2 & 5.2429 & TRN \\
\hline CHEMBL1584469 & 688759 & 4.45 & 4.7547 & TRN \\
\hline CHEMBL3193020 & 688759 & 4.45 & 4.6607 & TRN \\
\hline CHEMBL 3194544 & 688759 & 4.65 & 4.6744 & TRN \\
\hline CHEMBL1606353 & 688759 & 4.7 & 4.9726 & TRN \\
\hline CHEMBL1388790 & 688759 & 4.6 & 4.6125 & TRN \\
\hline CHEMBL1442332 & 688759 & 4.45 & 4.8102 & TRN \\
\hline CHEMBL1426711 & 688759 & 4.5 & 4.6312 & TRN \\
\hline CHEMBL1452779 & 688759 & 4.7 & 4.9598 & TST \\
\hline CHEMBL1303524 & 688759 & 5.0 & 5.3645 & TRN \\
\hline CHEMBL140425 & 688759 & 5.9 & 5.5828 & TRN \\
\hline CHEMBL1350077 & 688759 & 4.95 & 5.3299 & TST \\
\hline CHEMBL1542654 & 688759 & 5.9 & 5.7907 & TRN \\
\hline CHEMBL1507002 & 688759 & 4.6 & 4.794 & TST \\
\hline CHEMBL1339225 & 688759 & 5.0 & 5.3163 & TRN \\
\hline CHEMBL1317066 & 688759 & 4.45 & 4.7582 & TRN \\
\hline CHEMBL1530792 & 688759 & 4.45 & 4.8178 & TRN \\
\hline CHEMBL1452171 & 688759 & 4.45 & 4.8765 & TRN \\
\hline CHEMBL1545637 & 688759 & 4.7 & 4.6526 & TRN \\
\hline CHEMBL1976317 & 688759 & 5.3 & 5.2179 & TRN \\
\hline CHEMBL3191635 & 688759 & 4.7 & 4.8009 & TST \\
\hline CHEMBL1360970 & 688759 & 5.25 & 4.9432 & TRN \\
\hline CHEMBL1334983 & 688759 & 4.65 & 5.0185 & TRN \\
\hline CHEMBL3198859 & 688759 & 4.6 & 4.9292 & TRN \\
\hline CHEMBL2369261 & 688759 & 6.0 & 5.0829 & TST \\
\hline CHEMBL1469042 & 688759 & 5.15 & 4.6775 & TST \\
\hline CHEMBL1584350 & 688759 & 6.7001 & 5.2008 & TRN \\
\hline CHEMBL1343301 & 688759 & 4.45 & 4.947 & TRN \\
\hline CHEMBL1353775 & 688759 & 4.65 & 5.062 & TRN \\
\hline CHEMBL1468265 & 688759 & 4.6 & 4.5754 & TST \\
\hline CHEMBL1444328 & 688759 & 4.45 & 4.9379 & TST \\
\hline CHEMBL1543295 & 688759 & 4.65 & 4.7329 & TRN \\
\hline CHEMBL1483036 & 688759 & 4.65 & 4.7663 & TRN \\
\hline CHEMBL1573667 & 688759 & 4.6 & 4.9298 & TRN \\
\hline CHEMBL1503999 & 688759 & 5.15 & 5.1459 & TST \\
\hline CHEMBL1504651 & 688759 & 4.45 & 4.5868 & TST \\
\hline CHEMBL1539804 & 688759 & 6.15 & 5.1626 & TST \\
\hline CHEMBL1587395 & 688759 & 5.0 & 4.8045 & TST \\
\hline CHEMBL1455463 & 688759 & 5.25 & 4.7099 & TRN \\
\hline CHEMBL1443036 & 688759 & 4.45 & 4.8221 & TRN \\
\hline
\end{tabular}




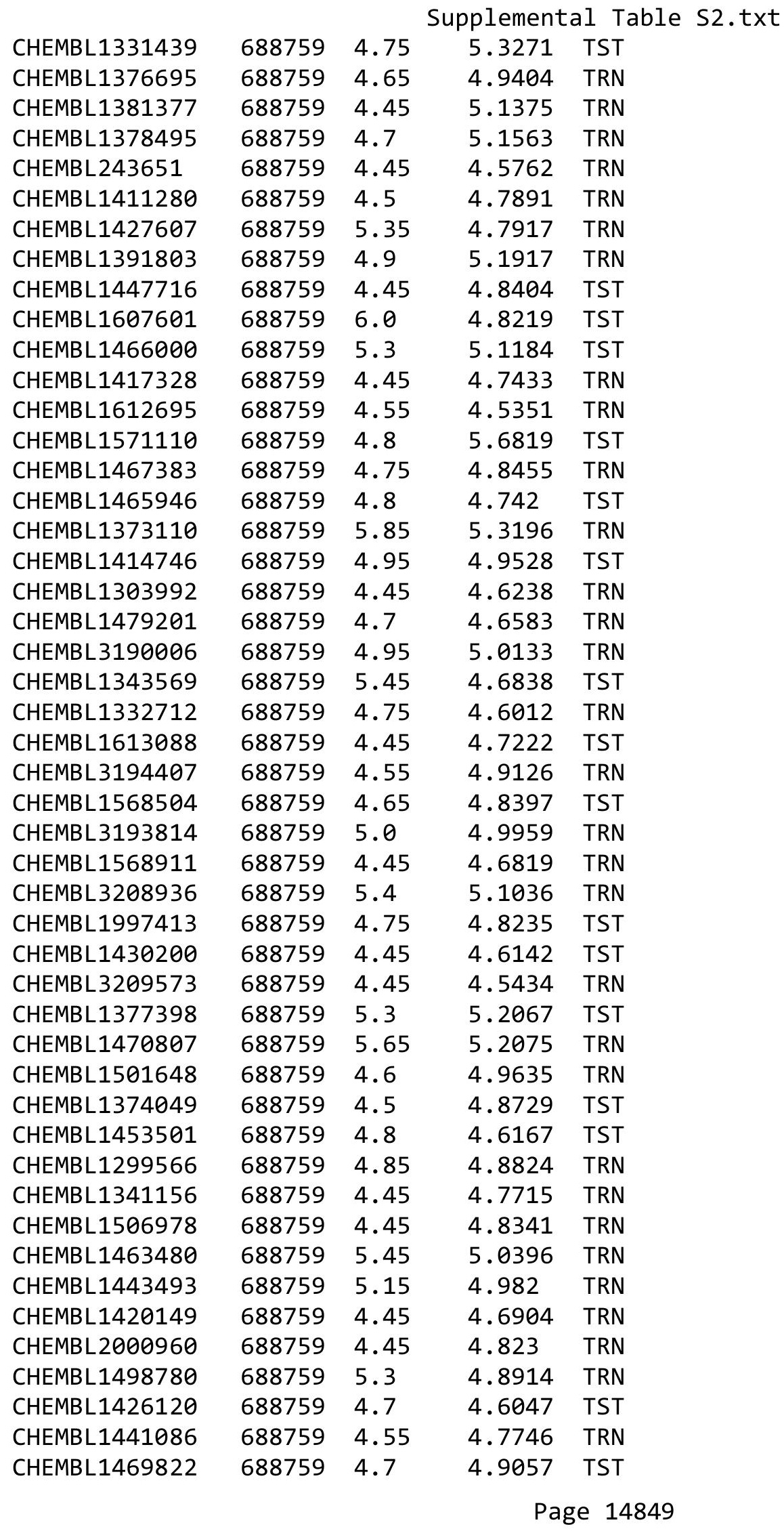




\begin{tabular}{|c|c|c|c|c|c|}
\hline \multicolumn{6}{|c|}{ Supplemental Table S2.txt } \\
\hline CHEMBL1446519 & 688759 & 4.45 & 4.7781 & TST & \\
\hline CHEMBL1450105 & 688759 & 4.75 & 4.6631 & TRN & \\
\hline CHEMBL1540841 & 688759 & 5.55 & 5.0305 & TRN & \\
\hline CHEMBL1387307 & 688759 & 4.45 & 4.6256 & TRN & \\
\hline CHEMBL1362187 & 688759 & 5.45 & 5.2254 & TRN & \\
\hline CHEMBL1519626 & 688759 & 5.25 & 4.8531 & TST & \\
\hline CHEMBL3193990 & 688759 & 4.65 & 5.0425 & TRN & \\
\hline CHEMBL1452858 & 688759 & 5.25 & 5.2965 & TRN & \\
\hline CHEMBL3198561 & 688759 & 4.45 & 4.5565 & TRN & \\
\hline CHEMBL584074 & 688759 & 5.15 & 4.9645 & TRN & \\
\hline CHEMBL1302822 & 688759 & 4.9 & 4.8892 & TRN & \\
\hline CHEMBL1524554 & 688759 & 4.5 & 4.6765 & TRN & \\
\hline CHEMBL1500786 & 688759 & 5.4 & 4.873 & TST & \\
\hline CHEMBL1408913 & 688759 & 4.8 & 4.8157 & TRN & \\
\hline CHEMBL1516375 & 688759 & 4.75 & 4.8782 & TST & \\
\hline CHEMBL1412144 & 688759 & 4.45 & 4.7009 & TRN & \\
\hline CHEMBL1417656 & 688759 & 4.5 & 4.7361 & TRN & \\
\hline CHEMBL1399080 & 688759 & 5.1 & 5.2365 & TRN & \\
\hline CHEMBL1388709 & 688759 & 6.05 & 4.7314 & TRN & \\
\hline CHEMBL1372183 & 688759 & 4.75 & 4.8998 & TST & \\
\hline CHEMBL1430741 & 688759 & 4.45 & 4.8193 & TRN & \\
\hline CHEMBL1549744 & 688759 & 4.45 & 4.7406 & TRN & \\
\hline CHEMBL1302293 & 688759 & 4.45 & 4.6139 & TRN & \\
\hline CHEMBL1970918 & 688759 & 5.35 & 5.2893 & TRN & \\
\hline CHEMBL1384487 & 688759 & 5.45 & 5.4869 & TRN & \\
\hline CHEMBL3211316 & 688759 & 4.45 & 4.859 & TST & \\
\hline CHEMBL1545455 & 688759 & 4.6 & 4.7485 & TST & \\
\hline CHEMBL1516772 & 688759 & 4.55 & 4.8204 & TRN & \\
\hline CHEMBL1464497 & 688759 & 4.6 & 4.7957 & TRN & \\
\hline CHEMBL1391535 & 688759 & 4.6 & 4.6726 & TST & \\
\hline CHEMBL1313141 & 688759 & 4.7 & 4.3967 & TRN & \\
\hline CHEMBL1576333 & 688759 & 8.1024 & 6.0827 & TST & \\
\hline CHEMBL1588498 & 688759 & 5.0 & 4.8149 & TRN & \\
\hline CHEMBL1459596 & 688759 & 4.8 & 4.8054 & TRN & \\
\hline CHEMBL1404805 & 688759 & 4.45 & 4.7196 & TRN & \\
\hline CHEMBL1426435 & 688759 & 5.25 & 4.9755 & TRN & \\
\hline CHEMBL1602851 & 688759 & 4.45 & 4.8611 & TST & \\
\hline CHEMBL1521269 & 688759 & 4.75 & 5.1664 & TRN & \\
\hline CHEMBL2006503 & 688759 & 5.3 & 5.2954 & TRN & \\
\hline CHEMBL1609163 & 688759 & 4.45 & 5.1181 & TRN & \\
\hline CHEMBL1579743 & 688759 & 4.75 & 4.9575 & TRN & \\
\hline CHEMBL1457794 & 688759 & 4.65 & 5.051 & TRN & \\
\hline CHEMBL3190063 & 688759 & 5.7 & 5.4368 & TRN & \\
\hline CHEMBL1608346 & 688759 & 5.5 & 5.0115 & TST & \\
\hline CHEMBL1381882 & 688759 & 4.8 & 5.0031 & TRN & \\
\hline CHEMBL1570760 & 688759 & 4.95 & 5.2532 & TRN & \\
\hline CHEMBL1374384 & 688759 & 5.3 & 5.0403 & TST & \\
\hline CHEMBL1969912 & 688759 & 5.6 & 5.41299 & 9999999999 & TRN \\
\hline & & & & 14850 & \\
\hline
\end{tabular}




\begin{tabular}{|c|c|c|c|c|c|}
\hline \multicolumn{6}{|c|}{ Supplemental Table S2.txt } \\
\hline CHEMBL1579499 & 688759 & 4.8 & 4.6812 & TRN & \\
\hline CHEMBL1522012 & 688759 & 4.45 & 4.9953 & TRN & \\
\hline CHEMBL1424443 & 688759 & 4.6 & 4.6304 & TST & \\
\hline CHEMBL1506738 & 688759 & 4.5 & 4.7204 & TRN & \\
\hline CHEMBL1564660 & 688759 & 4.65 & 4.6248 & TST & \\
\hline CHEMBL1415960 & 688759 & 5.1 & 5.0556 & TRN & \\
\hline CHEMBL1484825 & 688759 & 4.8 & 4.8414 & TRN & \\
\hline CHEMBL1584976 & 688759 & 4.85 & 4.7353 & TST & \\
\hline CHEMBL1359648 & 688759 & 5.2 & 5.3373 & TRN & \\
\hline CHEMBL1351676 & 688759 & 6.1 & 5.6644 & TRN & \\
\hline CHEMBL1438796 & 688759 & 4.45 & 5.1363 & TRN & \\
\hline CHEMBL1341556 & 688759 & 4.55 & 4.9952 & TRN & \\
\hline CHEMBL1988657 & 688759 & 5.15 & 5.1038 & TRN & \\
\hline CHEMBL1585849 & 688759 & 4.65 & 4.8748 & TRN & \\
\hline CHEMBL1979295 & 688759 & 4.7 & 5.043 & TRN & \\
\hline CHEMBL1309091 & 688759 & 5.4 & 5.0779 & TRN & \\
\hline CHEMBL1426961 & 688759 & 5.3 & 4.7587 & TST & \\
\hline CHEMBL1481374 & 688759 & 5.2 & 5.113 & TRN & \\
\hline CHEMBL1976719 & 688759 & 5.2 & 4.8819 & TRN & \\
\hline CHEMBL3192086 & 688759 & 4.5 & 4.9445 & TRN & \\
\hline CHEMBL1564136 & 688759 & 6.6499 & 5.7608 & TST & \\
\hline CHEMBL1441122 & 688759 & 4.45 & 4.966 & TST & \\
\hline CHEMBL1576560 & 688759 & 4.45 & 4.8793 & TRN & \\
\hline CHEMBL3189776 & 688759 & 4.45 & 5.0268 & TRN & \\
\hline CHEMBL1416089 & 688759 & 5.55 & 5.4263 & TRN & \\
\hline CHEMBL1580910 & 688759 & 4.65 & 4.6257 & TST & \\
\hline CHEMBL1509538 & 688759 & 5.3 & 4.8058 & TRN & \\
\hline CHEMBL3191694 & 688759 & 4.75 & 4.7986 & TRN & \\
\hline CHEMBL1967857 & 688759 & 5.05 & 5.1464 & TRN & \\
\hline CHEMBL3191444 & 688759 & 5.0 & 5.2497 & TRN & \\
\hline CHEMBL1337087 & 688759 & 4.9 & 4.8538 & TRN & \\
\hline CHEMBL1419938 & 688759 & 4.95 & 5.0275 & TRN & \\
\hline CHEMBL1336748 & 688759 & 4.95 & 4.7811 & TRN & \\
\hline CHEMBL1403085 & 688759 & 5.25 & 5.1587 & TRN & \\
\hline CHEMBL3189568 & 688759 & 4.45 & 4.939 & TRN & \\
\hline CHEMBL1340397 & 688759 & 4.8 & 4.8192 & TRN & \\
\hline CHEMBL1368293 & 688759 & 5.5 & 4.7928 & TST & \\
\hline CHEMBL1969672 & 688759 & 4.5 & 5.0137 & TST & \\
\hline CHEMBL1388085 & 688759 & 5.25 & 4.88 & TST & \\
\hline CHEMBL1568897 & 688759 & 4.45 & 6.227 & TRN & \\
\hline CHEMBL1589588 & 688759 & 4.45 & 4.5341 & TST & \\
\hline CHEMBL3209049 & 688759 & 4.95 & 4.7202 & TRN & \\
\hline CHEMBL1518393 & 688759 & 4.65 & 5.01699 & 99999999995 & TRN \\
\hline CHEMBL1335148 & 688759 & 5.45 & 5.1175 & TRN & \\
\hline CHEMBL1402699 & 688759 & 4.6 & 4.7982 & TST & \\
\hline CHEMBL1368029 & 688759 & 4.45 & 5.0338 & TRN & \\
\hline CHEMBL1415157 & 688759 & 4.45 & 4.7738 & TRN & \\
\hline CHEMBL1569514 & 688759 & 4.45 & 4.7528 & TRN & \\
\hline
\end{tabular}




\begin{tabular}{|c|c|c|c|c|c|}
\hline \multicolumn{6}{|c|}{ Supplemental Table S2.txt } \\
\hline CHEMBL444309 & 688759 & 4.45 & 4.6975 & TST & \\
\hline CHEMBL1599234 & 688759 & 4.5 & 4.6002 & TRN & \\
\hline CHEMBL1485854 & 688759 & 4.7 & 4.7389 & TRN & \\
\hline CHEMBL1522386 & 688759 & 5.35 & 4.6618 & TRN & \\
\hline CHEMBL1387241 & 688759 & 4.85 & 4.9375 & TRN & \\
\hline CHEMBL1524050 & 688759 & 4.65 & 4.9164 & TRN & \\
\hline CHEMBL1567685 & 688759 & 4.45 & 4.9743 & TRN & \\
\hline CHEMBL355159 & 688759 & 4.65 & 4.9174 & TRN & \\
\hline CHEMBL3196800 & 688759 & 6.7001 & 5.4092 & TRN & \\
\hline CHEMBL1445900 & 688759 & 5.0 & 4.995 & TST & \\
\hline CHEMBL1380331 & 688759 & 6.9 & 5.2573 & TRN & \\
\hline CHEMBL1548603 & 688759 & 5.05 & 4.7693 & TST & \\
\hline CHEMBL1454770 & 688759 & 4.45 & 4.6403 & TST & \\
\hline CHEMBL1495154 & 688759 & 5.0 & 5.1676 & TRN & \\
\hline CHEMBL3207486 & 688759 & 5.5 & 5.351 & TRN & \\
\hline CHEMBL1330568 & 688759 & 4.9 & 4.7174 & TST & \\
\hline CHEMBL1607684 & 688759 & 4.45 & 4.7586 & TST & \\
\hline CHEMBL1451344 & 688759 & 4.45 & 4.816 & TRN & \\
\hline CHEMBL1436003 & 688759 & 4.65 & 4.816 & TRN & \\
\hline CHEMBL1326897 & 688759 & 4.45 & 4.7854 & TRN & \\
\hline CHEMBL1544980 & 688759 & 4.45 & 4.6919 & TRN & \\
\hline CHEMBL1507682 & 688759 & 4.45 & 4.7109 & TST & \\
\hline CHEMBL1509508 & 688759 & 5.55 & 5.5905 & TRN & \\
\hline CHEMBL1377860 & 688759 & 4.45 & 4.7943 & TRN & \\
\hline CHEMBL3195841 & 688759 & 5.15 & 5.36100 & 0000000001 & TRN \\
\hline CHEMBL1571907 & 688759 & 5.1 & 4.6318 & TRN & \\
\hline CHEMBL17201 & 688759 & 4.45 & 4.7996 & TRN & \\
\hline CHEMBL1551561 & 688759 & 5.15 & 4.8781 & TRN & \\
\hline CHEMBL1491705 & 688759 & 5.5 & 5.4226 & TST & \\
\hline CHEMBL1580472 & 688759 & 4.95 & 4.9913 & TRN & \\
\hline CHEMBL1386452 & 688759 & 4.8 & 4.8598 & TRN & \\
\hline CHEMBL1323490 & 688759 & 4.95 & 5.0471 & TRN & \\
\hline CHEMBL3196275 & 688759 & 4.9 & 4.6437 & TST & \\
\hline CHEMBL1342830 & 688759 & 4.45 & 4.8948 & TRN & \\
\hline CHEMBL1430510 & 688759 & 5.5 & 5.2042 & TRN & \\
\hline CHEMBL1316398 & 688759 & 4.65 & 4.8504 & TRN & \\
\hline CHEMBL1532249 & 688759 & 4.8 & 4.8572 & TRN & \\
\hline CHEMBL1365318 & 688759 & 4.45 & 4.8309 & TST & \\
\hline CHEMBL1376635 & 688759 & 4.55 & 4.6025 & TRN & \\
\hline CHEMBL1464342 & 688759 & 4.9 & 4.981 & TRN & \\
\hline CHEMBL1585377 & 688759 & 5.0 & 4.9667 & TST & \\
\hline CHEMBL1364657 & 688759 & 4.55 & 4.8036 & TRN & \\
\hline CHEMBL1381439 & 688759 & 5.3 & 4.7592 & TST & \\
\hline CHEMBL1605286 & 688759 & 5.6 & 5.1572 & TST & \\
\hline CHEMBL1532506 & 688759 & 4.45 & 4.9132 & TRN & \\
\hline CHEMBL1382628 & 688759 & 5.6 & 5.4096 & TRN & \\
\hline CHEMBL1484586 & 688759 & 4.75 & 4.6486 & TRN & \\
\hline CHEMBL3195764 & 688759 & 5.4 & 5.6224 & TRN & \\
\hline
\end{tabular}




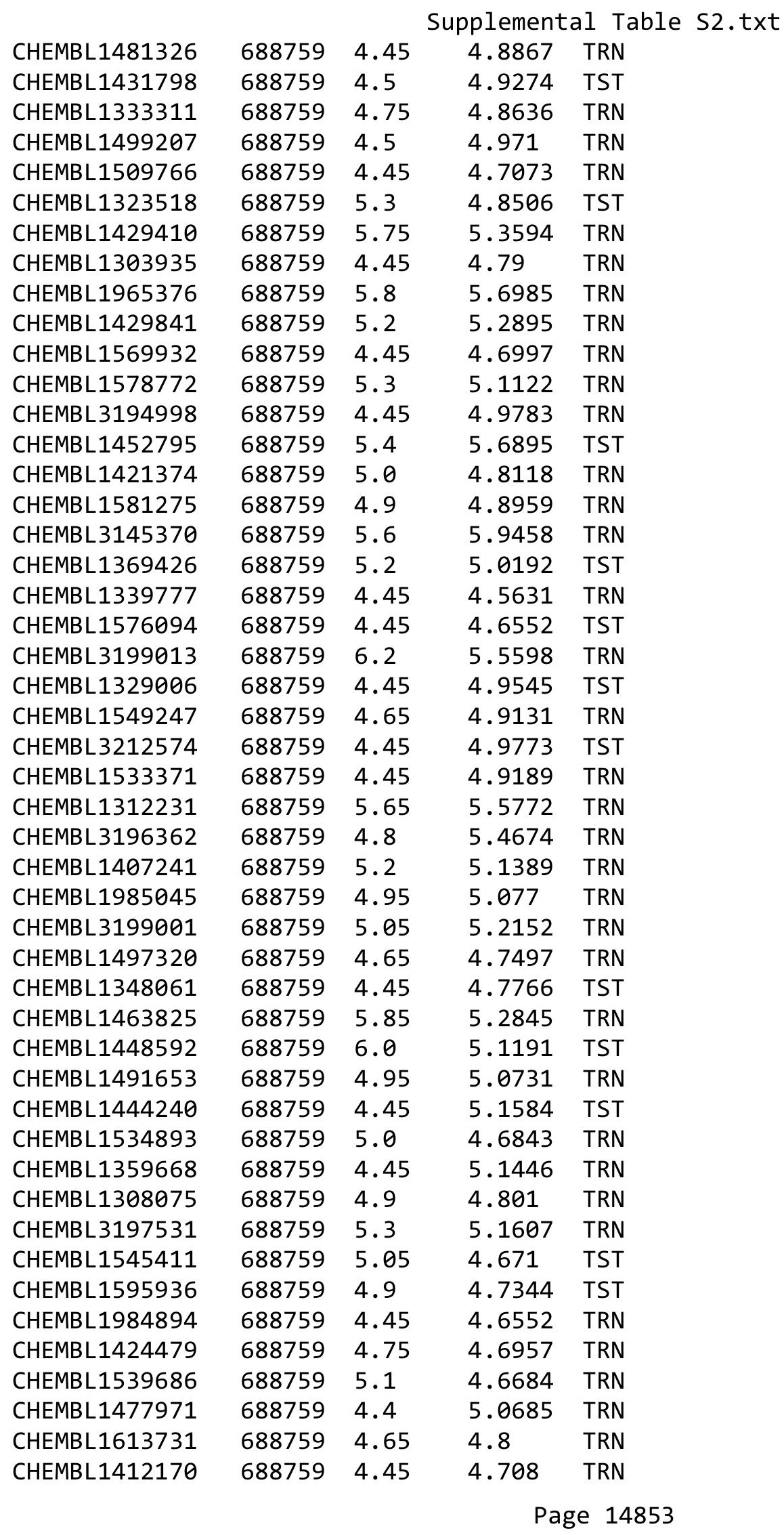




\begin{tabular}{|c|c|c|c|c|c|}
\hline \multirow{3}{*}{$\begin{array}{l}\text { CHEMBL1567378 } \\
\text { CHEMBL602969 }\end{array}$} & \multirow{3}{*}{$\begin{array}{l}688759 \\
688759\end{array}$} & \multicolumn{4}{|c|}{ Supplemental Table S2.txt } \\
\hline & & 5.2 & 4.63899 & 9999999999 & TST \\
\hline & & 4.45 & 4.9052 & TST & \\
\hline CHEMBL1608929 & 688759 & 5.25 & 5.0963 & TRN & \\
\hline CHEMBL1543549 & 688759 & 4.8 & 4.9795 & TST & \\
\hline CHEMBL1378950 & 688759 & 4.45 & 4.9156 & TRN & \\
\hline CHEMBL1410218 & 688759 & 5.3 & 4.8126 & TRN & \\
\hline CHEMBL1503683 & 688759 & 4.8 & 4.8576 & TST & \\
\hline CHEMBL1557666 & 688759 & 4.45 & 4.8507 & TRN & \\
\hline CHEMBL1408715 & 688759 & 4.75 & 4.7267 & TRN & \\
\hline CHEMBL1391741 & 688759 & 5.25 & 4.9966 & TST & \\
\hline CHEMBL1381526 & 688759 & 5.2 & 5.0561 & TST & \\
\hline CHEMBL3191949 & 688759 & 4.85 & 4.8702 & TRN & \\
\hline CHEMBL1320383 & 688759 & 4.6 & 4.7356 & TST & \\
\hline CHEMBL1449222 & 688759 & 4.45 & 4.8506 & TRN & \\
\hline CHEMBL1360928 & 688759 & 5.4 & 5.2426 & TRN & \\
\hline CHEMBL1548784 & 688759 & 4.45 & 4.8941 & TRN & \\
\hline CHEMBL3193388 & 688759 & 4.45 & 4.7884 & TRN & \\
\hline CHEMBL1501312 & 688759 & 5.8 & 4.8562 & TST & \\
\hline CHEMBL1974713 & 688759 & 4.7 & 4.7894 & TRN & \\
\hline CHEMBL3207792 & 688759 & 5.6 & 4.8702 & TRN & \\
\hline CHEMBL1573850 & 688759 & 4.45 & 4.7031 & TRN & \\
\hline CHEMBL1457262 & 688759 & 4.45 & 4.6815 & TRN & \\
\hline CHEMBL1497419 & 688759 & 4.45 & 4.6833 & TRN & \\
\hline CHEMBL1571355 & 688759 & 4.45 & 4.7204 & TRN & \\
\hline CHEMBL1345564 & 688759 & 4.9 & 4.8347 & TST & \\
\hline CHEMBL1497537 & 688759 & 4.75 & 5.0692 & TRN & \\
\hline CHEMBL1463249 & 688759 & 4.9 & 4.8106 & TST & \\
\hline CHEMBL1303119 & 688759 & 6.7001 & 4.9593 & TRN & \\
\hline CHEMBL 3211265 & 688759 & 4.45 & 4.7455 & TRN & \\
\hline CHEMBL1560775 & 688759 & 5.25 & 4.9086 & TRN & \\
\hline CHEMBL1349751 & 688759 & 4.95 & 4.7076 & TST & \\
\hline CHEMBL3192282 & 688759 & 4.65 & 5.0193 & TST & \\
\hline CHEMBL451260 & 688759 & 5.65 & 5.4223 & TRN & \\
\hline CHEMBL1442202 & 688759 & 4.65 & 4.7075 & TRN & \\
\hline CHEMBL1413424 & 688759 & 5.4 & 5.2257 & TRN & \\
\hline CHEMBL3207649 & 688759 & 5.0 & 4.79 & TRN & \\
\hline CHEMBL3211944 & 688759 & 7.2503 & 4.9258 & TRN & \\
\hline CHEMBL1497265 & 688759 & 4.55 & 4.7046 & TRN & \\
\hline CHEMBL1558070 & 688759 & 5.55 & 5.9964 & TRN & \\
\hline CHEMBL1456933 & 688759 & 4.45 & 4.6923 & TRN & \\
\hline CHEMBL1965172 & 688759 & 4.45 & 4.6049 & TRN & \\
\hline CHEMBL1555354 & 688759 & 5.8 & 5.4134 & TST & \\
\hline CHEMBL1299582 & 688759 & 6.0 & 5.6356 & TRN & \\
\hline CHEMBL1522285 & 688759 & 4.45 & 4.729 & TRN & \\
\hline CHEMBL1378111 & 688759 & 4.55 & 4.8408 & TRN & \\
\hline CHEMBL1499890 & 688759 & 4.9 & 4.6028 & TRN & \\
\hline CHEMBL1420639 & 688759 & 4.8 & 5.0039 & TRN & \\
\hline CHEMBL1324471 & 688759 & 5.25 & 4.9798 & TRN & \\
\hline
\end{tabular}




\begin{tabular}{|c|c|c|c|c|c|}
\hline \multirow[b]{2}{*}{ CHEMBL1976866 } & \multicolumn{5}{|c|}{ Supplemental Table S2.txt } \\
\hline & 688759 & 4.95 & 5.3999 & TRN & \\
\hline CHEMBL3193642 & 688759 & 5.5 & 5.13200 & 0000000001 & TRN \\
\hline CHEMBL3212023 & 688759 & 5.35 & 4.78100 & 3000000001 & TRN \\
\hline CHEMBL1500227 & 688759 & 4.45 & 4.7868 & TRN & \\
\hline CHEMBL1501295 & 688759 & 4.45 & 4.537 & TRN & \\
\hline CHEMBL1568084 & 688759 & 4.45 & 4.6964 & TRN & \\
\hline CHEMBL1976692 & 688759 & 4.45 & 4.8074 & TRN & \\
\hline CHEMBL1370636 & 688759 & 4.65 & 4.9022 & TRN & \\
\hline CHEMBL1421583 & 688759 & 5.0 & 4.8096 & TRN & \\
\hline CHEMBL1519411 & 688759 & 4.65 & 4.6672 & TST & \\
\hline CHEMBL1335916 & 688759 & 4.45 & 4.8254 & TST & \\
\hline CHEMBL3191716 & 688759 & 4.9 & 4.833 & TST & \\
\hline CHEMBL1334327 & 688759 & 4.5 & 4.9236 & TRN & \\
\hline CHEMBL1451345 & 688759 & 5.0 & 4.8289 & TST & \\
\hline CHEMBL1487221 & 688759 & 4.45 & 4.8419 & TRN & \\
\hline CHEMBL1348169 & 688759 & 5.6 & 4.9994 & TST & \\
\hline CHEMBL1398645 & 688759 & 5.3 & 5.3993 & TST & \\
\hline CHEMBL1484786 & 688759 & 4.7 & 4.8226 & TST & \\
\hline CHEMBL1320464 & 688759 & 4.45 & 4.7423 & TRN & \\
\hline CHEMBL1586612 & 688759 & 4.45 & 4.603 & TST & \\
\hline CHEMBL 394242 & 688759 & 6.1 & 5.7204 & TRN & \\
\hline CHEMBL1480403 & 688759 & 4.8 & 4.9129 & TRN & \\
\hline CHEMBL1351315 & 688759 & 4.45 & 4.7253 & TST & \\
\hline CHEMBL1556431 & 688759 & 4.45 & 4.4673 & TRN & \\
\hline CHEMBL1401158 & 688759 & 5.0 & 4.9081 & TST & \\
\hline CHEMBL1323741 & 688759 & 6.0 & 5.4813 & TRN & \\
\hline CHEMBL1440061 & 688759 & 6.5501 & 4.9487 & TST & \\
\hline CHEMBL1478961 & 688759 & 4.55 & 4.6195 & TRN & \\
\hline CHEMBL1457902 & 688759 & 5.0 & 4.927 & TRN & \\
\hline CHEMBL1342351 & 688759 & 4.7 & 4.8911 & TST & \\
\hline CHEMBL1373171 & 688759 & 4.85 & 4.9252 & TST & \\
\hline CHEMBL3213491 & 688759 & 5.15 & 5.0738 & TRN & \\
\hline CHEMBL1302266 & 688759 & 5.25 & 5.3544 & TST & \\
\hline CHEMBL3197640 & 688759 & 5.15 & 5.4757 & TRN & \\
\hline CHEMBL1545467 & 688759 & 5.85 & 6.396 & TST & \\
\hline CHEMBL1988133 & 688759 & 5.2 & 4.7144 & TRN & \\
\hline CHEMBL3212753 & 688759 & 5.25 & 4.8804 & TST & \\
\hline CHEMBL1608294 & 688759 & 4.9 & 4.8191 & TST & \\
\hline CHEMBL1486352 & 688759 & 5.3 & 5.0679 & TRN & \\
\hline CHEMBL1536683 & 688759 & 4.9 & 4.8579 & TST & \\
\hline CHEMBL1497953 & 688759 & 5.3 & 4.5828 & TST & \\
\hline CHEMBL1312320 & 688759 & 4.45 & 4.7719 & TRN & \\
\hline CHEMBL1465652 & 688759 & 4.45 & 4.6255 & TST & \\
\hline CHEMBL1398923 & 688759 & 4.45 & 4.8593 & TST & \\
\hline CHEMBL1468969 & 688759 & 4.45 & 4.7151 & TST & \\
\hline CHEMBL1985073 & 688759 & 5.35 & 5.3533 & TRN & \\
\hline CHEMBL1556966 & 688759 & 5.6 & 6.3194 & TST & \\
\hline CHEMBL1484261 & 688759 & 4.45 & 4.6755 & TRN & \\
\hline
\end{tabular}




\begin{tabular}{|c|c|c|c|c|c|}
\hline & & \multicolumn{4}{|c|}{ Supplemental Table S2.txt } \\
\hline CHEMBL1458458 & 688759 & 4.45 & 4.6949 & TST & \\
\hline CHEMBL1340334 & 688759 & 4.9 & 4.8126 & TST & \\
\hline CHEMBL1532659 & 688759 & 4.7 & 4.9589 & TRN & \\
\hline CHEMBL1384911 & 688759 & 4.8 & 4.8124 & TRN & \\
\hline CHEMBL1323821 & 688759 & 5.6 & 5.0907 & TST & \\
\hline CHEMBL1417269 & 688759 & 4.9 & 4.8546 & TRN & \\
\hline CHEMBL1299445 & 688759 & 4.7 & 5.008 & TST & \\
\hline CHEMBL1311858 & 688759 & 4.8 & 4.7284 & TRN & \\
\hline CHEMBL1549084 & 688759 & 4.55 & 4.9059 & TRN & \\
\hline CHEMBL3211502 & 688759 & 6.15 & 5.1857 & TRN & \\
\hline CHEMBL1563800 & 688759 & 4.65 & 4.8428 & TRN & \\
\hline CHEMBL1459918 & 688759 & 5.45 & 5.5589 & TRN & \\
\hline CHEMBL1528135 & 688759 & 4.7 & 4.9756 & TRN & \\
\hline CHEMBL1305233 & 688759 & 4.45 & 5.0231 & TRN & \\
\hline CHEMBL1462765 & 688759 & 4.75 & 5.2937 & TRN & \\
\hline CHEMBL1418913 & 688759 & 6.1 & 6.3834 & TST & \\
\hline CHEMBL1457010 & 688759 & 5.3 & 4.9392 & TRN & \\
\hline CHEMBL1362952 & 688759 & 4.95 & 4.8754 & TST & \\
\hline CHEMBL 3194190 & 688759 & 4.6 & 4.8629 & TRN & \\
\hline CHEMBL1319607 & 688759 & 4.6 & 5.0031 & TST & \\
\hline CHEMBL1519770 & 688759 & 4.45 & 5.0012 & TST & \\
\hline CHEMBL1374795 & 688759 & 4.8 & 4.6859 & TRN & \\
\hline CHEMBL1502635 & 688759 & 6.5 & 4.9544 & TRN & \\
\hline CHEMBL1424293 & 688759 & 4.65 & 4.8801 & TRN & \\
\hline CHEMBL1442242 & 688759 & 5.05 & 4.8091 & TRN & \\
\hline CHEMBL1575708 & 688759 & 5.15 & 5.2248 & TRN & \\
\hline CHEMBL1542043 & 688759 & 4.75 & 5.3903 & TRN & \\
\hline CHEMBL604321 & 688759 & 4.65 & 4.9734 & TRN & \\
\hline CHEMBL1518851 & 688759 & 5.6 & 5.3354 & TRN & \\
\hline CHEMBL1510103 & 688759 & 4.8 & 5.0993 & TRN & \\
\hline CHEMBL1560360 & 688759 & 4.45 & 4.7771 & TRN & \\
\hline CHEMBL1565595 & 688759 & 4.6 & 4.74100 & 00000000005 & TRN \\
\hline CHEMBL147514 & 688759 & 4.95 & 4.7364 & TST & \\
\hline CHEMBL 3189512 & 688759 & 4.45 & 5.0778 & TRN & \\
\hline CHEMBL1520325 & 688759 & 5.0 & 5.1061 & TST & \\
\hline CHEMBL1566633 & 688759 & 4.7 & 5.0191 & TRN & \\
\hline CHEMBL3198849 & 688759 & 4.45 & 5.1378 & TST & \\
\hline CHEMBL3210216 & 688759 & 4.45 & 4.9819 & TST & \\
\hline CHEMBL1577648 & 688759 & 5.35 & 4.8439 & TRN & \\
\hline CHEMBL1429437 & 688759 & 4.9 & 4.5748 & TST & \\
\hline CHEMBL1525839 & 688759 & 5.95 & 5.5901 & TRN & \\
\hline CHEMBL 3213240 & 688759 & 4.45 & 4.6792 & TRN & \\
\hline CHEMBL1587777 & 688759 & 4.7 & 4.6403 & TRN & \\
\hline CHEMBL1464104 & 688759 & 5.0 & 4.8357 & TRN & \\
\hline CHEMBL1387312 & 688759 & 4.8 & 5.022 & TRN & \\
\hline CHEMBL1546652 & 688759 & 5.0 & 4.9326 & TST & \\
\hline CHEMBL3190798 & 688759 & 4.85 & 4.8877 & TRN & \\
\hline CHEMBL3197520 & 688759 & 4.8 & 4.7824 & TST & \\
\hline
\end{tabular}




\begin{tabular}{|c|c|c|c|c|c|}
\hline & & \multicolumn{4}{|c|}{ Supplemental Table S2.txt } \\
\hline CHEMBL1438499 & 688759 & 4.7 & 4.841 & TST & \\
\hline CHEMBL 275311 & 688759 & 4.9 & 5.084 & TST & \\
\hline CHEMBL1428575 & 688759 & 6.0 & 5.4462 & TRN & \\
\hline CHEMBL1335805 & 688759 & 4.9 & 4.692 & TST & \\
\hline CHEMBL1345859 & 688759 & 4.45 & 4.731 & TRN & \\
\hline CHEMBL1393620 & 688759 & 5.2 & 4.792 & TRN & \\
\hline CHEMBL1374923 & 688759 & 4.5 & 4.7145 & TRN & \\
\hline CHEMBL1451630 & 688759 & 4.65 & 4.8805 & TRN & \\
\hline CHEMBL576038 & 688759 & 4.75 & 4.8236 & TRN & \\
\hline CHEMBL3197122 & 688759 & 5.55 & 5.1914 & TRN & \\
\hline CHEMBL1368413 & 688759 & 6.15 & 5.2044 & TRN & \\
\hline CHEMBL1460748 & 688759 & 4.45 & 4.6358 & TRN & \\
\hline CHEMBL1519781 & 688759 & 4.8 & 4.6395 & TST & \\
\hline CHEMBL1314946 & 688759 & 5.6 & 5.1017 & TRN & \\
\hline CHEMBL1511323 & 688759 & 4.45 & 5.0697 & TRN & \\
\hline CHEMBL3197761 & 688759 & 5.6 & 5.38299 & 9999999999 & TRN \\
\hline CHEMBL1438683 & 688759 & 4.45 & 4.7514 & TST & \\
\hline CHEMBL 2007057 & 688759 & 4.6 & 4.7069 & TRN & \\
\hline CHEMBL1405976 & 688759 & 4.8 & 4.8699 & TRN & \\
\hline CHEMBL1583461 & 688759 & 4.45 & 4.8238 & TRN & \\
\hline CHEMBL1470495 & 688759 & 4.65 & 5.081 & TRN & \\
\hline CHEMBL3199019 & 688759 & 5.35 & 4.6604 & TST & \\
\hline CHEMBL1414848 & 688759 & 5.45 & 4.9537 & TRN & \\
\hline CHEMBL292785 & 688759 & 5.8 & 4.9954 & TRN & \\
\hline CHEMBL1581970 & 688759 & 5.0 & 4.8808 & TRN & \\
\hline CHEMBL1483246 & 688759 & 5.45 & 4.7603 & TRN & \\
\hline CHEMBL3210325 & 688759 & 4.45 & 4.7035 & TRN & \\
\hline CHEMBL3193064 & 688759 & 4.7 & 4.7115 & TST & \\
\hline CHEMBL1353918 & 688759 & 4.45 & 4.7176 & TRN & \\
\hline CHEMBL3211919 & 688759 & 4.45 & 4.8524 & TRN & \\
\hline CHEMBL1458446 & 688759 & 5.55 & 5.2375 & TRN & \\
\hline CHEMBL1582713 & 688759 & 5.2 & 5.4177 & TRN & \\
\hline CHEMBL530361 & 688759 & 5.15 & 5.3035 & TRN & \\
\hline CHEMBL1973050 & 688759 & 5.0 & 4.784 & TRN & \\
\hline CHEMBL1403917 & 688759 & 6.05 & 5.8018 & TRN & \\
\hline CHEMBL1472063 & 688759 & 5.25 & 4.7119 & TST & \\
\hline CHEMBL1457655 & 688759 & 5.5 & 4.8982 & TST & \\
\hline CHEMBL1459140 & 688759 & 6.0 & 5.5961 & TST & \\
\hline CHEMBL1497403 & 688759 & 5.0 & 4.9125 & TRN & \\
\hline CHEMBL592111 & 688759 & 4.65 & 4.6038 & TRN & \\
\hline CHEMBL1493490 & 688759 & 5.3 & 5.2088 & TRN & \\
\hline CHEMBL1500830 & 688759 & 5.4 & 4.5203 & TRN & \\
\hline CHEMBL1578769 & 688759 & 4.95 & 5.1189 & TRN & \\
\hline CHEMBL1602361 & 688759 & 4.45 & 4.8884 & TST & \\
\hline CHEMBL3196210 & 688759 & 4.45 & 4.8143 & TRN & \\
\hline CHEMBL3189155 & 688759 & 4.65 & 4.7177 & TRN & \\
\hline CHEMBL1513736 & 688759 & 4.95 & 5.0096 & TST & \\
\hline CHEMBL1596909 & 688759 & 5.3 & 5.188 & TRN & \\
\hline
\end{tabular}




\begin{tabular}{|c|c|c|c|c|c|}
\hline \multicolumn{6}{|c|}{ Supplemental Table S2.txt } \\
\hline CHEMBL 3199178 & 688759 & 5.05 & 5.4289 & TRN & \\
\hline CHEMBL1530521 & 688759 & 4.8 & 4.6805 & TRN & \\
\hline CHEMBL1607758 & 688759 & 4.6 & 4.8022 & TRN & \\
\hline CHEMBL1543379 & 688759 & 4.7 & 4.8829 & TRN & \\
\hline CHEMBL1546799 & 688759 & 4.55 & 4.6471 & TRN & \\
\hline CHEMBL 256202 & 688759 & 4.85 & 4.7379 & TST & \\
\hline CHEMBL1612277 & 688759 & 4.55 & 4.9876 & TRN & \\
\hline CHEMBL1420074 & 688759 & 5.25 & 4.8135 & TST & \\
\hline CHEMBL1324077 & 688759 & 5.35 & 5.3461 & TRN & \\
\hline CHEMBL1574726 & 688759 & 4.45 & 4.7098 & TRN & \\
\hline CHEMBL1348445 & 688759 & 4.45 & 4.8349 & TRN & \\
\hline CHEMBL1410536 & 688759 & 4.85 & 5.2351 & TRN & \\
\hline CHEMBL1320934 & 688759 & 4.7 & 4.9697 & TRN & \\
\hline CHEMBL1378813 & 688759 & 5.25 & 5.1298 & TRN & \\
\hline CHEMBL1352590 & 688759 & 6.15 & 5.1142 & TST & \\
\hline CHEMBL1446412 & 688759 & 5.15 & 5.1668 & TST & \\
\hline CHEMBL1365755 & 688759 & 4.85 & 4.8802 & TST & \\
\hline CHEMBL1600994 & 688759 & 4.85 & 4.5771 & TRN & \\
\hline CHEMBL1989853 & 688759 & 4.45 & 5.0586 & TST & \\
\hline CHEMBL1438698 & 688759 & 4.8 & 4.7881 & TRN & \\
\hline CHEMBL1496665 & 688759 & 4.6 & 4.9034 & TRN & \\
\hline CHEMBL1376944 & 688759 & 4.5 & 4.8781 & TRN & \\
\hline CHEMBL1304120 & 688759 & 4.65 & 4.8544 & TRN & \\
\hline CHEMBL1978063 & 688759 & 5.0 & 5.2282 & TRN & \\
\hline CHEMBL1569771 & 688759 & 5.15 & 5.0131 & TRN & \\
\hline CHEMBL1535831 & 688759 & 5.15 & 4.9653 & TRN & \\
\hline CHEMBL1564268 & 688759 & 4.45 & 5.1426 & TRN & \\
\hline CHEMBL1500408 & 688759 & 4.65 & 4.8258 & TRN & \\
\hline CHEMBL1305070 & 688759 & 4.65 & 4.8891 & TST & \\
\hline CHEMBL1366735 & 688759 & 5.45 & 5.2391 & TRN & \\
\hline CHEMBL1401090 & 688759 & 5.75 & 5.3103 & TRN & \\
\hline CHEMBL1463349 & 688759 & 6.15 & 5.57100 & 0000000001 & TRN \\
\hline CHEMBL1966952 & 688759 & 5.35 & 4.9948 & TST & \\
\hline CHEMBL1542492 & 688759 & 5.6 & 5.0807 & TRN & \\
\hline CHEMBL1482029 & 688759 & 4.5 & 4.7183 & TST & \\
\hline CHEMBL 3199710 & 688759 & 4.8 & 5.0359 & TRN & \\
\hline CHEMBL1449007 & 688759 & 5.55 & 4.9383 & TST & \\
\hline CHEMBL1377608 & 688759 & 4.45 & 4.6402 & TRN & \\
\hline CHEMBL1333847 & 688759 & 6.0 & 5.3862 & TRN & \\
\hline CHEMBL1498273 & 688759 & 5.95 & 5.8852 & TRN & \\
\hline CHEMBL1433263 & 688759 & 4.8 & 4.8147 & TRN & \\
\hline CHEMBL1508793 & 688759 & 4.45 & 4.8788 & TRN & \\
\hline CHEMBL596674 & 688759 & 5.6 & 5.0679 & TST & \\
\hline CHEMBL1404157 & 688759 & 5.3 & 5.1932 & TRN & \\
\hline CHEMBL1305893 & 688759 & 4.45 & 4.7668 & TRN & \\
\hline CHEMBL 3195443 & 688759 & 4.65 & 4.9099 & TRN & \\
\hline CHEMBL1349059 & 688759 & 4.9 & 4.5686 & TRN & \\
\hline CHEMBL3196390 & 688759 & 5.0 & 4.9548 & TRN & \\
\hline
\end{tabular}




\begin{tabular}{|c|c|c|c|c|c|}
\hline & & \multicolumn{4}{|c|}{ Supplemental Table S2.txt } \\
\hline CHEMBL1301126 & 688759 & 4.45 & 4.6336 & TST & \\
\hline CHEMBL 305695 & 688759 & 4.45 & 5.2943 & TRN & \\
\hline CHEMBL1320183 & 688759 & 4.5 & 4.8954 & TST & \\
\hline CHEMBL1509078 & 688759 & 4.45 & 4.6989 & TRN & \\
\hline CHEMBL1321953 & 688759 & 4.45 & 4.9952 & TST & \\
\hline CHEMBL1458475 & 688759 & 4.6 & 5.0172 & TRN & \\
\hline CHEMBL1303712 & 688759 & 4.45 & 5.2089 & TST & \\
\hline CHEMBL1312827 & 688759 & 4.45 & 4.6992 & TRN & \\
\hline CHEMBL1448119 & 688759 & 5.5 & 5.5003 & TRN & \\
\hline CHEMBL1565847 & 688759 & 4.6 & 4.677 & TST & \\
\hline CHEMBL1519257 & 688759 & 4.45 & 4.6054 & TRN & \\
\hline CHEMBL1365829 & 688759 & 4.75 & 4.7336 & TRN & \\
\hline CHEMBL1567007 & 688759 & 4.65 & 4.7754 & TRN & \\
\hline CHEMBL1580858 & 688759 & 4.45 & 4.8368 & TRN & \\
\hline CHEMBL1337775 & 688759 & 4.6 & 4.8639 & TST & \\
\hline CHEMBL3196694 & 688759 & 5.5 & 5.4401 & TRN & \\
\hline CHEMBL1333065 & 688759 & 4.55 & 4.8065 & TRN & \\
\hline CHEMBL3199303 & 688759 & 4.45 & 4.5671 & TRN & \\
\hline CHEMBL1320504 & 688759 & 4.9 & 5.0232 & TRN & \\
\hline CHEMBL1541511 & 688759 & 5.0 & 4.9196 & TST & \\
\hline CHEMBL1371380 & 688759 & 4.8 & 4.6107 & TRN & \\
\hline CHEMBL1395807 & 688759 & 4.65 & 5.1427 & TST & \\
\hline CHEMBL1446154 & 688759 & 4.45 & 4.8465 & TST & \\
\hline CHEMBL1424779 & 688759 & 4.45 & 4.5788 & TST & \\
\hline CHEMBL1593824 & 688759 & 4.6 & 4.9646 & TRN & \\
\hline CHEMBL1527429 & 688759 & 4.45 & 4.7433 & TRN & \\
\hline CHEMBL1305558 & 688759 & 4.45 & 4.7124 & TRN & \\
\hline CHEMBL1468188 & 688759 & 4.45 & 4.5329 & TRN & \\
\hline CHEMBL1497557 & 688759 & 4.9 & 4.8704 & TRN & \\
\hline CHEMBL1493293 & 688759 & 4.45 & 4.7078 & TRN & \\
\hline CHEMBL3190256 & 688759 & 6.0 & 5.41799 & 9999999999 & TRN \\
\hline CHEMBL1599106 & 688759 & 4.9 & 5.3481 & TRN & \\
\hline CHEMBL1460507 & 688759 & 4.6 & 4.8372 & TRN & \\
\hline CHEMBL1531529 & 688759 & 4.7 & 4.8367 & TRN & \\
\hline CHEMBL1467140 & 688759 & 4.5 & 4.9309 & TRN & \\
\hline CHEMBL1445650 & 688759 & 6.0 & 5.7433 & TRN & \\
\hline CHEMBL1456687 & 688759 & 5.1 & 4.9835 & TST & \\
\hline CHEMBL1331727 & 688759 & 4.75 & 4.7095 & TRN & \\
\hline CHEMBL1324647 & 688759 & 4.45 & 4.8919 & TRN & \\
\hline CHEMBL1337447 & 688759 & 6.4 & 4.7958 & TRN & \\
\hline CHEMBL1366474 & 688759 & 5.35 & 5.1926 & TRN & \\
\hline CHEMBL1509327 & 688759 & 5.2 & 4.7583 & TRN & \\
\hline CHEMBL1549777 & 688759 & 5.25 & 4.7612 & TRN & \\
\hline CHEMBL1341748 & 688759 & 5.25 & 5.3304 & TRN & \\
\hline CHEMBL1445894 & 688759 & 5.35 & 4.8351 & TRN & \\
\hline CHEMBL1539889 & 688759 & 5.25 & 5.1797 & TRN & \\
\hline CHEMBL1556373 & 688759 & 5.2 & 5.4302 & TRN & \\
\hline CHEMBL1522422 & 688759 & 4.5 & 4.9732 & TST & \\
\hline
\end{tabular}




\begin{tabular}{|c|c|c|c|c|c|}
\hline & & \multicolumn{4}{|c|}{ Supplemental Table s2.txt } \\
\hline CHEMBL1313631 & 688759 & 4.45 & 4.9748 & TRN & \\
\hline CHEMBL3197908 & 688759 & 5.3 & 5.0862 & TRN & \\
\hline CHEMBL1340733 & 688759 & 4.55 & 5.1473 & TST & \\
\hline CHEMBL1581066 & 688759 & 5.45 & 5.4523 & TRN & \\
\hline CHEMBL1506317 & 688759 & 4.95 & 4.9653 & TRN & \\
\hline CHEMBL1412402 & 688759 & 5.0 & 4.9253 & TST & \\
\hline CHEMBL1575744 & 688759 & 5.5 & 5.5555 & TRN & \\
\hline CHEMBL3194920 & 688759 & 4.65 & 4.7117 & TRN & \\
\hline CHEMBL1540200 & 688759 & 5.55 & 4.6363 & TRN & \\
\hline CHEMBL1376012 & 688759 & 4.8 & 4.9431 & TRN & \\
\hline CHEMBL1328598 & 688759 & 6.2 & 4.975 & TRN & \\
\hline CHEMBL1983234 & 688759 & 5.8 & 5.4965 & TRN & \\
\hline CHEMBL1389449 & 688759 & 4.45 & 4.7385 & TRN & \\
\hline CHEMBL1572157 & 688759 & 4.7 & 4.7631 & TRN & \\
\hline CHEMBL1597968 & 688759 & 4.45 & 4.6839 & TRN & \\
\hline CHEMBL1452297 & 688759 & 5.2 & 5.05699 & 99999999995 & TRN \\
\hline CHEMBL1596594 & 688759 & 4.75 & 4.6858 & TRN & \\
\hline CHEMBL1565111 & 688759 & 5.0 & 4.9863 & TRN & \\
\hline CHEMBL1322853 & 688759 & 5.85 & 4.815 & TST & \\
\hline CHEMBL1350949 & 688759 & 4.45 & 4.6407 & TRN & \\
\hline CHEMBL1406371 & 688759 & 4.75 & 4.9544 & TRN & \\
\hline CHEMBL1593582 & 688759 & 5.55 & 4.7783 & TRN & \\
\hline CHEMBL1379262 & 688759 & 4.45 & 4.5443 & TRN & \\
\hline CHEMBL1307153 & 688759 & 5.35 & 4.9414 & TST & \\
\hline CHEMBL1302272 & 688759 & 4.85 & 4.8461 & TST & \\
\hline CHEMBL1520671 & 688759 & 4.8 & 5.1773 & TRN & \\
\hline CHEMBL1425004 & 688759 & 4.45 & 4.5716 & TRN & \\
\hline CHEMBL1477586 & 688759 & 4.45 & 4.5631 & TRN & \\
\hline CHEMBL3191271 & 688759 & 5.8 & 4.9741 & TRN & \\
\hline CHEMBL1529772 & 688759 & 6.0 & 4.7739 & TRN & \\
\hline CHEMBL1383700 & 688759 & 4.75 & 4.8679 & TRN & \\
\hline CHEMBL1441948 & 688759 & 4.45 & 4.71 & TRN & \\
\hline CHEMBL3199812 & 688759 & 4.45 & 4.5391 & TRN & \\
\hline CHEMBL3198424 & 688759 & 5.25 & 5.2 & TRN & \\
\hline CHEMBL1587286 & 688759 & 4.75 & 4.5604 & TST & \\
\hline CHEMBL1371065 & 688759 & 4.55 & 4.8464 & TRN & \\
\hline CHEMBL1480188 & 688759 & 4.45 & 5.0751 & TRN & \\
\hline CHEMBL1528383 & 688759 & 4.65 & 4.8257 & TRN & \\
\hline CHEMBL490577 & 688759 & 4.5 & 4.7612 & TRN & \\
\hline CHEMBL3193392 & 688759 & 4.85 & 4.914 & TRN & \\
\hline CHEMBL1411205 & 688759 & 4.6 & 4.9089 & TRN & \\
\hline CHEMBL1606550 & 688759 & 4.65 & 4.6705 & TRN & \\
\hline CHEMBL1542725 & 688759 & 4.45 & 4.6605 & TST & \\
\hline CHEMBL259139 & 688759 & 4.65 & 4.7875 & TST & \\
\hline CHEMBL3194794 & 688759 & 4.45 & 4.6819 & TST & \\
\hline CHEMBL1535257 & 688759 & 4.45 & 4.6102 & TRN & \\
\hline CHEMBL1529007 & 688759 & 4.65 & 5.0384 & TST & \\
\hline CHEMBL1359985 & 688759 & 5.3 & 5.3725 & TRN & \\
\hline
\end{tabular}




\begin{tabular}{|c|c|c|c|c|c|}
\hline & & \multicolumn{4}{|c|}{ Supplemental Table s2.txt } \\
\hline CHEMBL1375362 & 688759 & 4.95 & 5.1775 & TRN & \\
\hline CHEMBL1340543 & 688759 & 4.45 & 4.7287 & TRN & \\
\hline CHEMBL1560595 & 688759 & 4.45 & 4.9274 & TRN & \\
\hline CHEMBL1471601 & 688759 & 5.75 & 4.8859 & TRN & \\
\hline CHEMBL1422337 & 688759 & 4.45 & 4.7227 & TRN & \\
\hline CHEMBL1333579 & 688759 & 5.15 & 5.19799 & 99999999995 & TRN \\
\hline CHEMBL1518098 & 688759 & 5.2 & 4.9519 & TST & \\
\hline CHEMBL 3192625 & 688759 & 5.3 & 5.3051 & TRN & \\
\hline CHEMBL1581627 & 688759 & 5.3 & 4.8431 & TRN & \\
\hline CHEMBL1540877 & 688759 & 4.9 & 4.9403 & TRN & \\
\hline CHEMBL1497475 & 688759 & 4.45 & 4.8277 & TRN & \\
\hline CHEMBL1595234 & 688759 & 4.45 & 4.6506 & TRN & \\
\hline CHEMBL1389421 & 688759 & 5.1 & 4.877 & TRN & \\
\hline CHEMBL1609965 & 688759 & 5.55 & 4.8307 & TST & \\
\hline CHEMBL1402726 & 688759 & 4.45 & 5.0133 & TST & \\
\hline CHEMBL1427522 & 688759 & 4.45 & 5.025 & TST & \\
\hline CHEMBL1466789 & 688759 & 4.45 & 4.8268 & TST & \\
\hline CHEMBL1428930 & 688759 & 5.3 & 5.0627 & TRN & \\
\hline CHEMBL1410115 & 688759 & 4.45 & 4.7237 & TST & \\
\hline CHEMBL1355396 & 688759 & 5.6 & 5.0117 & TRN & \\
\hline CHEMBL1563117 & 688759 & 4.45 & 4.5166 & TST & \\
\hline CHEMBL1474515 & 688759 & 4.45 & 4.9316 & TRN & \\
\hline CHEMBL1994856 & 688759 & 5.3 & 5.5613 & TRN & \\
\hline CHEMBL1332003 & 688759 & 5.7 & 5.6582 & TRN & \\
\hline CHEMBL1454256 & 688759 & 4.45 & 4.7596 & TRN & \\
\hline CHEMBL1353274 & 688759 & 5.0 & 5.185 & TRN & \\
\hline CHEMBL1581738 & 688759 & 5.5 & 4.8887 & TRN & \\
\hline CHEMBL1401853 & 688759 & 4.65 & 4.7258 & TST & \\
\hline CHEMBL1487473 & 688759 & 4.9 & 4.8082 & TRN & \\
\hline CHEMBL1363198 & 688759 & 4.45 & 4.7275 & TRN & \\
\hline CHEMBL1411932 & 688759 & 4.45 & 4.8525 & TRN & \\
\hline CHEMBL1428063 & 688759 & 4.45 & 4.9704 & TST & \\
\hline CHEMBL1503771 & 688759 & 5.05 & 4.9548 & TRN & \\
\hline CHEMBL1978186 & 688759 & 4.9 & 4.9556 & TRN & \\
\hline CHEMBL1415541 & 688759 & 5.0 & 5.0097 & TRN & \\
\hline CHEMBL1471121 & 688759 & 4.45 & 4.855 & TRN & \\
\hline CHEMBL1465356 & 688759 & 4.65 & 4.8194 & TRN & \\
\hline CHEMBL1522563 & 688759 & 4.75 & 5.0696 & TST & \\
\hline CHEMBL1564737 & 688759 & 4.45 & 4.8688 & TRN & \\
\hline CHEMBL1545668 & 688759 & 4.65 & 4.9843 & TRN & \\
\hline CHEMBL1299655 & 688759 & 5.45 & 5.2906 & TRN & \\
\hline CHEMBL3195386 & 688759 & 4.65 & 4.6858 & TRN & \\
\hline CHEMBL1536401 & 688759 & 5.2 & 4.99 & TRN & \\
\hline CHEMBL1985797 & 688759 & 5.1 & 4.977 & TRN & \\
\hline CHEMBL1410147 & 688759 & 5.1 & 5.0178 & TST & \\
\hline CHEMBL1529391 & 688759 & 4.85 & 4.8045 & TST & \\
\hline CHEMBL1607205 & 688759 & 4.45 & 4.8201 & TRN & \\
\hline CHEMBL580727 & 688759 & 5.55 & 5.6204 & TRN & \\
\hline
\end{tabular}




\begin{tabular}{|c|c|c|c|c|}
\hline \multirow[b]{2}{*}{ CHEMBL1471685 } & & & pplement & al $\mathrm{T}$ \\
\hline & 688759 & 4.9 & 4.922 & TST \\
\hline CHEMBL1412950 & 688759 & 6.0 & 4.8994 & TST \\
\hline CHEMBL1599228 & 688759 & 4.9 & 5.0074 & TRN \\
\hline CHEMBL1300171 & 688759 & 4.65 & 4.7368 & TRN \\
\hline CHEMBL1563905 & 688759 & 5.6 & 4.7306 & TST \\
\hline CHEMBL1576523 & 688759 & 4.5 & 4.676 & TRN \\
\hline CHEMBL1556955 & 688759 & 4.5 & 4.8187 & TRN \\
\hline CHEMBL1477915 & 688759 & 4.7 & 4.6596 & TRN \\
\hline CHEMBL1498868 & 688759 & 4.65 & 5.0912 & TRN \\
\hline CHEMBL1302587 & 688759 & 4.7 & 4.902 & TRN \\
\hline CHEMBL1372386 & 688759 & 5.75 & 4.8946 & TRN \\
\hline CHEMBL1452349 & 688759 & 4.95 & 5.0356 & TRN \\
\hline CHEMBL1562608 & 688759 & 5.55 & 5.7782 & TRN \\
\hline CHEMBL1441920 & 688759 & 4.45 & 5.4345 & TST \\
\hline CHEMBL3195924 & 688759 & 4.45 & 4.7403 & TST \\
\hline CHEMBL1493448 & 688759 & 5.15 & 5.2305 & TRN \\
\hline CHEMBL1325188 & 688759 & 4.65 & 5.1482 & TST \\
\hline CHEMBL1576260 & 688759 & 5.25 & 4.9421 & TST \\
\hline CHEMBL1513226 & 688759 & 4.65 & 4.8277 & TRN \\
\hline CHEMBL1478358 & 688759 & 5.25 & 4.8426 & TRN \\
\hline CHEMBL1557569 & 688759 & 5.25 & 5.0642 & TRN \\
\hline CHEMBL3213672 & 688759 & 4.9 & 4.7904 & TST \\
\hline CHEMBL1442305 & 688759 & 4.8 & 4.7029 & TST \\
\hline CHEMBL1362995 & 688759 & 4.85 & 4.6067 & TRN \\
\hline CHEMBL1417818 & 688759 & 4.75 & 4.5488 & TRN \\
\hline CHEMBL1315183 & 688759 & 4.4 & 4.8559 & TRN \\
\hline CHEMBL1440502 & 688759 & 5.45 & 5.4171 & TRN \\
\hline CHEMBL1579281 & 688759 & 4.45 & 5.0245 & TRN \\
\hline CHEMBL1479350 & 688759 & 6.15 & 4.7249 & TST \\
\hline CHEMBL1427606 & 688759 & 4.45 & 4.995 & TRN \\
\hline CHEMBL1533651 & 688759 & 4.95 & 4.6539 & TST \\
\hline CHEMBL1407513 & 688759 & 5.0 & 5.2077 & TRN \\
\hline CHEMBL1332026 & 688759 & 4.45 & 4.9681 & TRN \\
\hline CHEMBL1585333 & 688759 & 4.45 & 4.4194 & TRN \\
\hline CHEMBL1455128 & 688759 & 4.65 & 4.7603 & TST \\
\hline CHEMBL1505832 & 688759 & 4.45 & 4.9745 & TRN \\
\hline CHEMBL1344702 & 688759 & 4.45 & 4.7788 & TRN \\
\hline CHEMBL 201986 & 688759 & 4.5 & 4.8469 & TRN \\
\hline CHEMBL1545216 & 688759 & 5.4 & 5.1839 & TRN \\
\hline CHEMBL1454169 & 688759 & 5.2 & 5.2147 & TRN \\
\hline CHEMBL1306986 & 688759 & 7.8508 & 5.2882 & TRN \\
\hline CHEMBL1322941 & 688759 & 5.05 & 5.2531 & TRN \\
\hline CHEMBL1578528 & 688759 & 4.55 & 5.0173 & TRN \\
\hline CHEMBL3199673 & 688759 & 6.95 & 6.2975 & TRN \\
\hline CHEMBL 3213442 & 688759 & 5.8 & 4.8975 & TRN \\
\hline CHEMBL1460004 & 688759 & 4.45 & 4.8235 & TRN \\
\hline CHEMBL 1347250 & 688759 & 4.45 & 4.9635 & TRN \\
\hline CHEMBL3213855 & 688759 & 5.9 & 5.574 & TRN \\
\hline
\end{tabular}




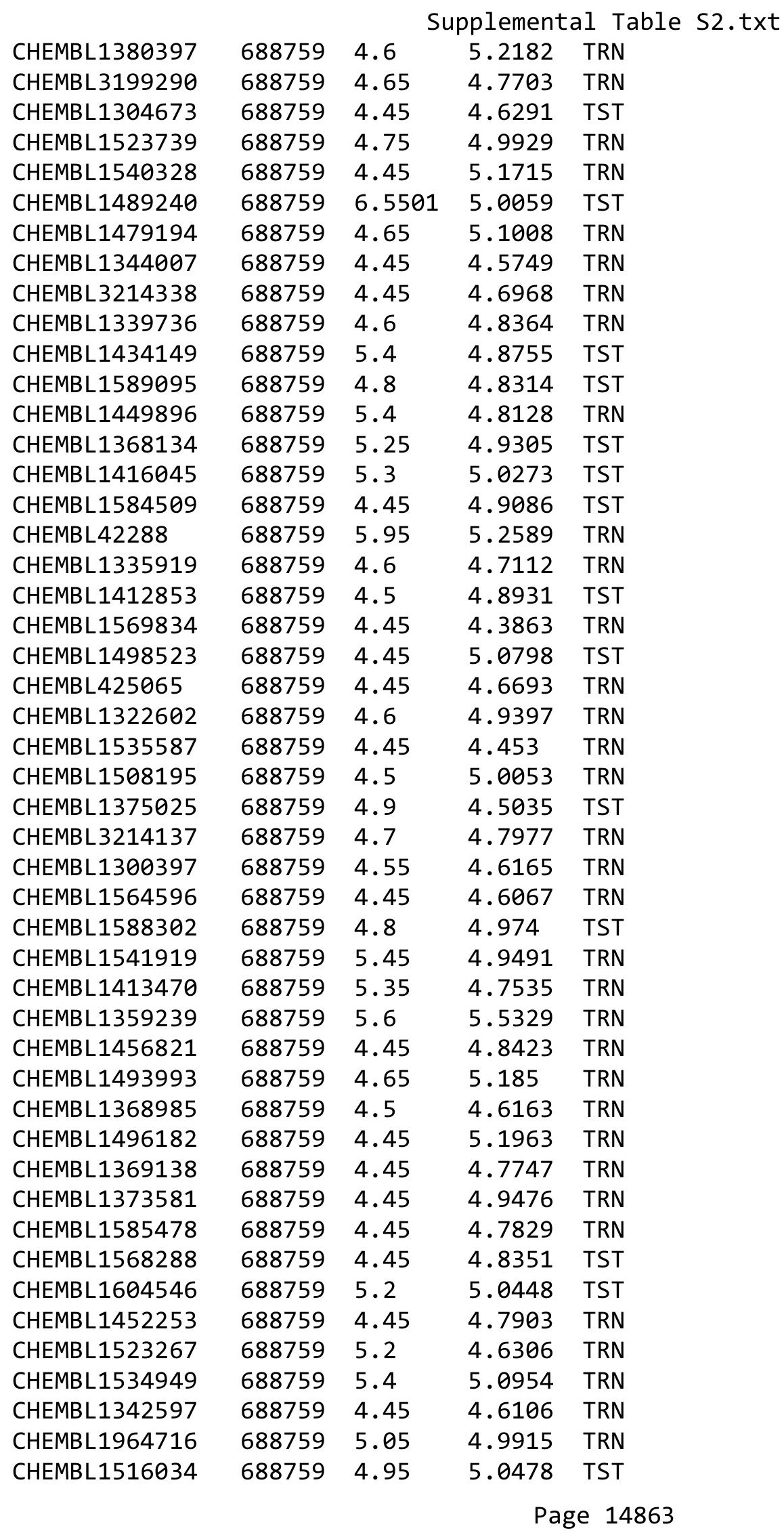




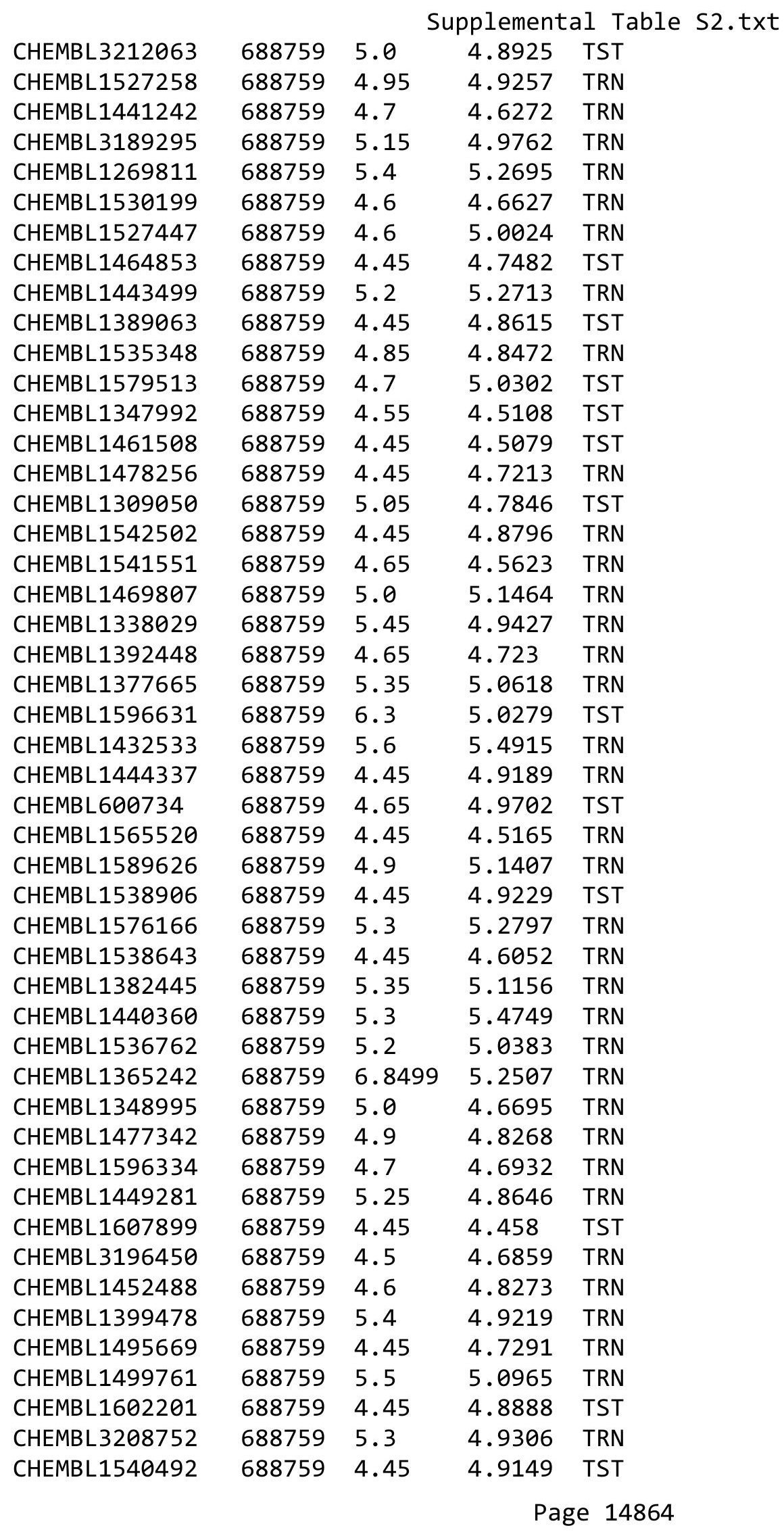




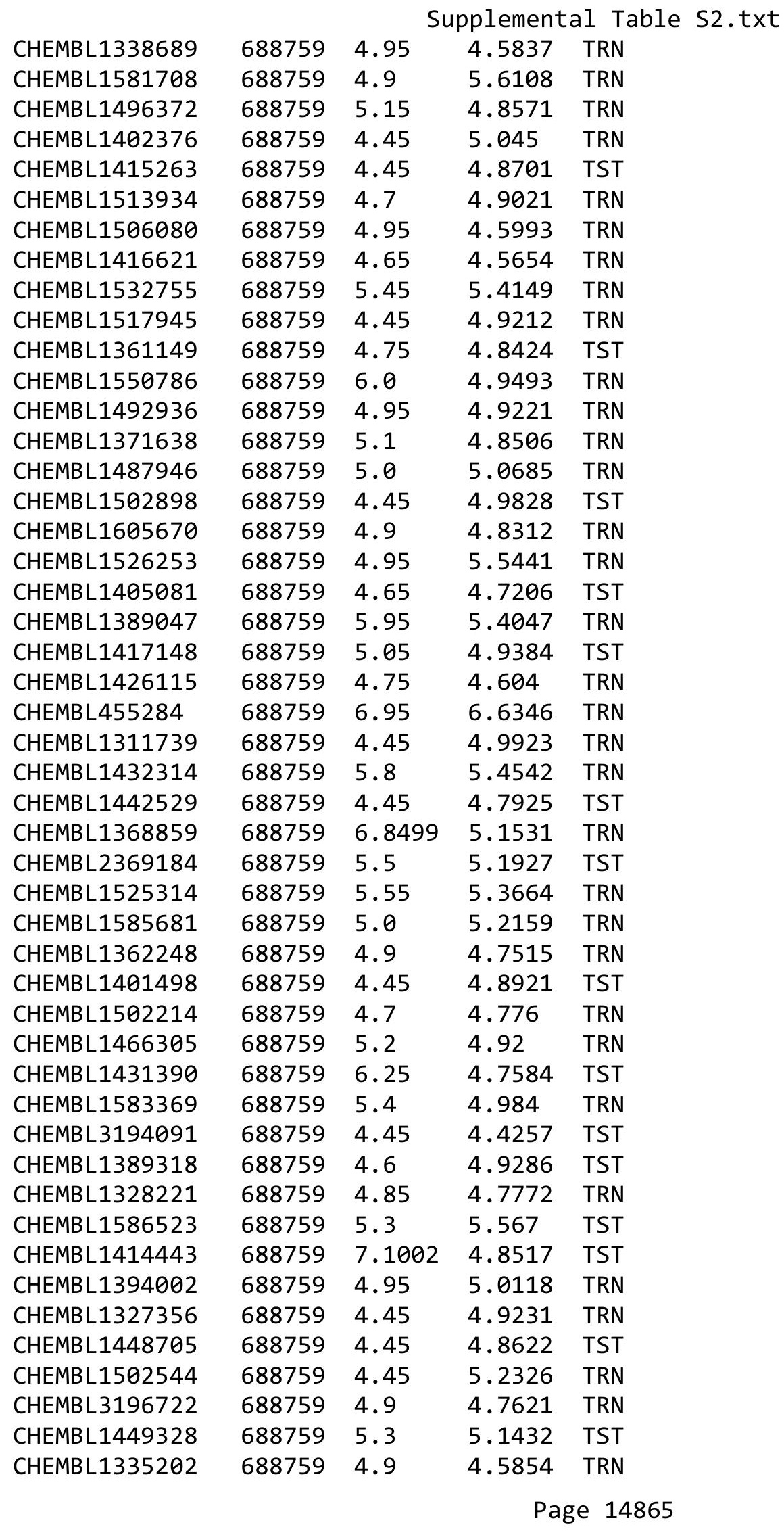




\begin{tabular}{|c|c|c|c|c|}
\hline & & & upplement & al Table s2. \\
\hline CHEMBL3192010 & 688759 & 5.55 & 5.3915 & TRN \\
\hline CHEMBL1533659 & 688759 & 5.5 & 5.0456 & TRN \\
\hline CHEMBL1364988 & 688759 & 5.8 & 4.9169 & TRN \\
\hline CHEMBL1571838 & 688759 & 4.7 & 4.749 & TRN \\
\hline CHEMBL1507917 & 688759 & 4.5 & 4.8145 & TRN \\
\hline CHEMBL1594556 & 688759 & 4.7 & 5.0273 & TRN \\
\hline CHEMBL1427407 & 688759 & 4.55 & 4.8184 & TRN \\
\hline CHEMBL1515132 & 688759 & 4.45 & 5.1674 & TST \\
\hline CHEMBL1598101 & 688759 & 5.5 & 5.0242 & TRN \\
\hline CHEMBL1430435 & 688759 & 5.0 & 5.0326 & TRN \\
\hline CHEMBL1410063 & 688759 & 4.45 & 4.8682 & TST \\
\hline CHEMBL1496863 & 688759 & 4.45 & 4.8318 & TRN \\
\hline CHEMBL1489546 & 688759 & 4.95 & 4.615 & TRN \\
\hline CHEMBL1581201 & 688759 & 5.3 & 5.2339 & TST \\
\hline CHEMBL1532997 & 688759 & 5.55 & 5.2472 & TST \\
\hline CHEMBL1463476 & 688759 & 4.8 & 4.9279 & TST \\
\hline CHEMBL1488060 & 688759 & 4.95 & 4.7232 & TRN \\
\hline CHEMBL1359377 & 688759 & 5.35 & 5.5827 & TST \\
\hline CHEMBL3190958 & 688759 & 5.15 & 5.1908 & TRN \\
\hline CHEMBL1489024 & 688759 & 5.1 & 5.3589 & TRN \\
\hline CHEMBL1478797 & 688759 & 4.45 & 4.7667 & TRN \\
\hline CHEMBL1584960 & 688759 & 5.0 & 4.9121 & TST \\
\hline CHEMBL1352208 & 688759 & 4.7 & 4.8368 & TRN \\
\hline CHEMBL1371679 & 688759 & 4.45 & 5.0134 & TRN \\
\hline CHEMBL3212919 & 688759 & 6.0 & 4.8629 & TST \\
\hline CHEMBL1344918 & 688759 & 4.45 & 4.8613 & TST \\
\hline CHEMBL1489650 & 688759 & 5.1 & 5.1827 & TRN \\
\hline CHEMBL3190715 & 688759 & 4.65 & 4.8994 & TRN \\
\hline CHEMBL1424992 & 688759 & 4.85 & 4.5698 & TST \\
\hline CHEMBL1603053 & 688759 & 5.0 & 4.8882 & TRN \\
\hline CHEMBL1998200 & 688759 & 4.95 & 4.9427 & TRN \\
\hline CHEMBL3198081 & 688759 & 4.6 & 4.8577 & TRN \\
\hline CHEMBL1556157 & 688759 & 4.45 & 4.6637 & TRN \\
\hline CHEMBL1597669 & 688759 & 5.85 & 5.2749 & TRN \\
\hline CHEMBL1449446 & 688759 & 4.95 & 4.6277 & TRN \\
\hline CHEMBL1609319 & 688759 & 4.45 & 4.5956 & TRN \\
\hline CHEMBL1500265 & 688759 & 5.2 & 5.3982 & TRN \\
\hline CHEMBL1581463 & 688759 & 6.05 & 4.9574 & TST \\
\hline CHEMBL1427042 & 688759 & 4.45 & 4.7152 & TST \\
\hline CHEMBL1518866 & 688759 & 6.95 & 4.885 & TRN \\
\hline CHEMBL3193612 & 688759 & 4.45 & 4.7341 & TRN \\
\hline CHEMBL3211985 & 688759 & 4.75 & 4.7892 & TRN \\
\hline CHEMBL1311052 & 688759 & 4.65 & 4.57 & TRN \\
\hline CHEMBL1494871 & 688759 & 6.0 & 4.739 & TRN \\
\hline CHEMBL1582176 & 688759 & 4.5 & 4.9366 & TRN \\
\hline CHEMBL1336856 & 688759 & 4.75 & 4.7415 & TST \\
\hline CHEMBL1605131 & 688759 & 4.85 & 4.72199 & 99999999995 \\
\hline CHEMBL1581773 & 688759 & 4.45 & 5.0012 & TST \\
\hline
\end{tabular}

TRN 


\begin{tabular}{|c|c|c|c|c|}
\hline \multicolumn{5}{|c|}{ Supplemental Table } \\
\hline CHEMBL1528987 & 688759 & 4.45 & 4.953 & TRN \\
\hline CHEMBL1497282 & 688759 & 5.9 & 5.2476 & TRN \\
\hline CHEMBL1572169 & 688759 & 4.55 & 4.85 & TRN \\
\hline CHEMBL1403397 & 688759 & 4.45 & 5.0193 & TST \\
\hline CHEMBL3198987 & 688759 & 4.65 & 4.7672 & TST \\
\hline CHEMBL1986725 & 688759 & 5.8 & 5.4962 & TRN \\
\hline CHEMBL1337009 & 688759 & 4.45 & 4.8382 & TRN \\
\hline CHEMBL1538775 & 688759 & 5.1 & 4.979 & TRN \\
\hline CHEMBL1579136 & 688759 & 5.1 & 5.0425 & TRN \\
\hline CHEMBL1384240 & 688759 & 4.45 & 4.6509 & TST \\
\hline CHEMBL1305023 & 688759 & 5.0 & 4.9928 & TST \\
\hline CHEMBL1574908 & 688759 & 5.3 & 5.1263 & TST \\
\hline CHEMBL1505641 & 688759 & 4.8 & 4.971 & TRN \\
\hline CHEMBL1586380 & 688759 & 4.45 & 4.7979 & TRN \\
\hline CHEMBL1542879 & 688759 & 4.45 & 4.6148 & TST \\
\hline CHEMBL1497479 & 688759 & 5.25 & 5.0451 & TRN \\
\hline CHEMBL1402401 & 688759 & 5.25 & 5.0062 & TST \\
\hline CHEMBL442925 & 688759 & 5.5 & 5.3754 & TRN \\
\hline CHEMBL1588531 & 688759 & 4.95 & 4.6713 & TST \\
\hline CHEMBL1349475 & 688759 & 4.45 & 4.7313 & TST \\
\hline CHEMBL3925157 & 688759 & 4.45 & 5.1366 & TRN \\
\hline CHEMBL1391897 & 688759 & 4.7 & 4.6174 & TRN \\
\hline CHEMBL1487609 & 688759 & 5.0 & 4.6835 & TRN \\
\hline CHEMBL1587266 & 688759 & 5.05 & 5.0346 & TRN \\
\hline CHEMBL 262627 & 688759 & 5.15 & 4.595 & TRN \\
\hline CHEMBL1479315 & 688759 & 4.95 & 4.854 & TRN \\
\hline CHEMBL1412432 & 688759 & 4.45 & 5.0402 & TRN \\
\hline CHEMBL3196499 & 688759 & 4.95 & 5.1478 & TRN \\
\hline CHEMBL1309336 & 688759 & 4.6 & 4.7738 & TST \\
\hline CHEMBL1604027 & 688759 & 4.65 & 4.5813 & TRN \\
\hline CHEMBL1613004 & 688759 & 4.8 & 4.8558 & TST \\
\hline CHEMBL1449219 & 688759 & 4.75 & 4.8381 & TRN \\
\hline CHEMBL1589244 & 688759 & 4.45 & 4.8169 & TRN \\
\hline CHEMBL1371379 & 688759 & 4.9 & 5.048 & TST \\
\hline CHEMBL1495902 & 688759 & 4.6 & 4.8491 & TST \\
\hline CHEMBL1300895 & 688759 & 4.9 & 5.1996 & TRN \\
\hline CHEMBL1585511 & 688759 & 5.4 & 4.7927 & TRN \\
\hline CHEMBL 2006740 & 688759 & 5.35 & 5.2354 & TRN \\
\hline CHEMBL1482824 & 688759 & 5.25 & 4.8769 & TRN \\
\hline CHEMBL1429178 & 688759 & 4.65 & 4.8483 & TRN \\
\hline CHEMBL1401580 & 688759 & 4.65 & 4.8116 & TRN \\
\hline CHEMBL1557333 & 688759 & 5.8 & 5.291 & TRN \\
\hline CHEMBL1462865 & 688759 & 4.9 & 4.6406 & TRN \\
\hline CHEMBL1371974 & 688759 & 4.95 & 5.0877 & TRN \\
\hline CHEMBL1336598 & 688759 & 4.65 & 4.9571 & TST \\
\hline CHEMBL1486371 & 688759 & 4.45 & 4.8496 & TRN \\
\hline CHEMBL1457165 & 688759 & 4.55 & 5.1169 & TRN \\
\hline CHEMBL1309678 & 688759 & 4.95 & 5.5335 & TST \\
\hline
\end{tabular}




\begin{tabular}{|c|c|c|c|c|c|}
\hline \multicolumn{6}{|c|}{ Supplemental Table s2.txt } \\
\hline CHEMBL1447975 & 688759 & 4.95 & 4.6515 & TRN & \\
\hline CHEMBL1993301 & 688759 & 4.8 & 4.7644 & TRN & \\
\hline CHEMBL1548259 & 688759 & 4.45 & 5.0169 & TRN & \\
\hline CHEMBL1384700 & 688759 & 4.65 & 4.9321 & TRN & \\
\hline CHEMBL1600589 & 688759 & 5.55 & 4.8798 & TRN & \\
\hline CHEMBL1528165 & 688759 & 4.45 & 4.5425 & TRN & \\
\hline CHEMBL1574121 & 688759 & 6.95 & 6.2701 & TRN & \\
\hline CHEMBL1443706 & 688759 & 4.45 & 5.1472 & TST & \\
\hline CHEMBL1502019 & 688759 & 5.15 & 5.0984 & TRN & \\
\hline CHEMBL1582803 & 688759 & 4.6 & 4.9355 & TRN & \\
\hline CHEMBL1598592 & 688759 & 6.5 & 4.8661 & TST & \\
\hline CHEMBL1426880 & 688759 & 5.9 & 5.4333 & TRN & \\
\hline CHEMBL1534763 & 688759 & 4.55 & 4.9465 & TRN & \\
\hline CHEMBL1533027 & 688759 & 5.0 & 5.1235 & TRN & \\
\hline CHEMBL1325533 & 688759 & 5.5 & 4.7357 & TRN & \\
\hline CHEMBL1328504 & 688759 & 5.55 & 5.24299 & 9999999999 & TRN \\
\hline CHEMBL1492868 & 688759 & 4.45 & 4.7903 & TRN & \\
\hline CHEMBL1510156 & 688759 & 4.45 & 4.7337 & TRN & \\
\hline CHEMBL1595790 & 688759 & 6.35 & 5.928 & TRN & \\
\hline CHEMBL1457961 & 688759 & 4.45 & 5.0177 & TRN & \\
\hline CHEMBL1541324 & 688759 & 4.45 & 5.1417 & TRN & \\
\hline CHEMBL1449960 & 688759 & 4.45 & 4.9356 & TRN & \\
\hline CHEMBL3145305 & 688759 & 4.6 & 4.867 & TST & \\
\hline CHEMBL1510125 & 688759 & 5.2 & 5.0024 & TRN & \\
\hline CHEMBL1580040 & 688759 & 5.0 & 5.1984 & TRN & \\
\hline CHEMBL1523867 & 688759 & 5.45 & 4.6191 & TRN & \\
\hline CHEMBL1306269 & 688759 & 4.45 & 4.8762 & TST & \\
\hline CHEMBL1470716 & 688759 & 4.45 & 4.7888 & TRN & \\
\hline CHEMBL1350400 & 688759 & 4.45 & 4.4851 & TRN & \\
\hline CHEMBL1537964 & 688759 & 5.2 & 5.001 & TRN & \\
\hline CHEMBL1319113 & 688759 & 4.9 & 4.816 & TST & \\
\hline CHEMBL1608323 & 688759 & 6.6499 & 5.1023 & TRN & \\
\hline CHEMBL1348191 & 688759 & 4.65 & 4.4315 & TRN & \\
\hline CHEMBL1362739 & 688759 & 4.45 & 4.939 & TRN & \\
\hline CHEMBL3194218 & 688759 & 4.45 & 4.7742 & TST & \\
\hline CHEMBL1610499 & 688759 & 4.45 & 4.5241 & TRN & \\
\hline CHEMBL1341186 & 688759 & 4.9 & 4.8721 & TST & \\
\hline CHEMBL1376731 & 688759 & 5.6 & 4.8431 & TRN & \\
\hline CHEMBL1382888 & 688759 & 4.45 & 4.7806 & TRN & \\
\hline CHEMBL1325777 & 688759 & 4.45 & 4.8489 & TST & \\
\hline CHEMBL1527964 & 688759 & 4.45 & 4.6592 & TRN & \\
\hline CHEMBL1577787 & 688759 & 5.5 & 4.9356 & TRN & \\
\hline CHEMBL1378333 & 688759 & 5.15 & 5.0986 & TRN & \\
\hline CHEMBL1557623 & 688759 & 4.95 & 4.7759 & TRN & \\
\hline CHEMBL1501864 & 688759 & 4.65 & 4.6798 & TRN & \\
\hline CHEMBL1504590 & 688759 & 5.0 & 5.2554 & TRN & \\
\hline CHEMBL3214479 & 688759 & 5.25 & 5.02800 & 00000000005 & TST \\
\hline CHEMBL1453873 & 688759 & 5.45 & 4.8653 & TRN & \\
\hline
\end{tabular}




\begin{tabular}{|c|c|c|c|c|c|}
\hline \multicolumn{6}{|c|}{ Supplemental Table S2.txt } \\
\hline CHEMBL1405314 & 688759 & 4.8 & 4.7238 & TRN & \\
\hline CHEMBL1443044 & 688759 & 5.0 & 5.1733 & TRN & \\
\hline CHEMBL3194441 & 688759 & 6.05 & 5.612 & TRN & \\
\hline CHEMBL1612138 & 688759 & 5.0 & 5.117 & TST & \\
\hline CHEMBL1387362 & 688759 & 4.95 & 4.833 & TST & \\
\hline CHEMBL1348839 & 688759 & 4.45 & 4.9421 & TST & \\
\hline CHEMBL1583479 & 688759 & 4.65 & 4.9577 & TRN & \\
\hline CHEMBL1604186 & 688759 & 4.45 & 4.7743 & TRN & \\
\hline CHEMBL1384544 & 688759 & 4.65 & 4.8612 & TRN & \\
\hline CHEMBL1558012 & 688759 & 5.1 & 4.5648 & TRN & \\
\hline CHEMBL3194227 & 688759 & 4.45 & 4.6094 & TRN & \\
\hline CHEMBL1383312 & 688759 & 5.9 & 5.7647 & TRN & \\
\hline CHEMBL3199550 & 688759 & 5.2 & 5.2996 & TRN & \\
\hline CHEMBL1562110 & 688759 & 6.0 & 4.5974 & TRN & \\
\hline CHEMBL1575559 & 688759 & 4.6 & 4.59399 & 7999999999 & TRN \\
\hline CHEMBL1392537 & 688759 & 5.15 & 5.0191 & TRN & \\
\hline CHEMBL1555014 & 688759 & 4.45 & 4.8046 & TRN & \\
\hline CHEMBL1469446 & 688759 & 6.0 & 4.8754 & TRN & \\
\hline CHEMBL3195022 & 688759 & 4.9 & 5.0711 & TRN & \\
\hline CHEMBL1504928 & 688759 & 4.45 & 4.9696 & TST & \\
\hline CHEMBL1504492 & 688759 & 4.55 & 4.9228 & TRN & \\
\hline CHEMBL1303581 & 688759 & 5.5 & 4.9874 & TRN & \\
\hline CHEMBL1526471 & 688759 & 4.45 & 5.0285 & TRN & \\
\hline CHEMBL3193899 & 688759 & 4.9 & 4.9457 & TRN & \\
\hline CHEMBL1569507 & 688759 & 4.65 & 4.5794 & TRN & \\
\hline CHEMBL581044 & 688759 & 4.45 & 4.7133 & TRN & \\
\hline CHEMBL1396374 & 688759 & 4.45 & 4.62 & TRN & \\
\hline CHEMBL1567196 & 688759 & 5.0 & 5.2475 & TRN & \\
\hline CHEMBL1585247 & 688759 & 4.65 & 5.4107 & TST & \\
\hline CHEMBL1416946 & 688759 & 4.45 & 4.8589 & TRN & \\
\hline CHEMBL1421170 & 688759 & 4.95 & 5.0611 & TRN & \\
\hline CHEMBL3191127 & 688759 & 4.85 & 5.1435 & TRN & \\
\hline CHEMBL3193884 & 688759 & 4.45 & 4.712 & TRN & \\
\hline CHEMBL1343996 & 688759 & 4.45 & 4.6119 & TRN & \\
\hline CHEMBL1360283 & 688759 & 4.45 & 4.8234 & TST & \\
\hline CHEMBL3210499 & 688759 & 5.2 & 4.9572 & TRN & \\
\hline CHEMBL1434411 & 688759 & 5.0 & 4.7059 & TRN & \\
\hline CHEMBL1566077 & 688759 & 5.55 & 5.0759 & TRN & \\
\hline CHEMBL1351823 & 688759 & 4.7 & 4.8948 & TRN & \\
\hline CHEMBL1581280 & 688759 & 4.55 & 5.5397 & TST & \\
\hline CHEMBL1302596 & 688759 & 6.05 & 6.1272 & TRN & \\
\hline CHEMBL1299900 & 688759 & 5.2 & 5.0441 & TRN & \\
\hline CHEMBL1503246 & 688759 & 5.1 & 5.0641 & TRN & \\
\hline CHEMBL1487466 & 688759 & 5.0 & 4.9748 & TRN & \\
\hline CHEMBL1310737 & 688759 & 4.45 & 4.648 & TRN & \\
\hline CHEMBL1523974 & 688759 & 4.6 & 4.7362 & TRN & \\
\hline CHEMBL1321314 & 688759 & 4.75 & 5.2385 & TRN & \\
\hline CHEMBL3189307 & 688759 & 5.8 & 5.4812 & TST & \\
\hline
\end{tabular}




\begin{tabular}{|c|c|c|c|c|c|}
\hline & & \multicolumn{4}{|c|}{ Supplemental Table S2.txt } \\
\hline CHEMBL1456813 & 688759 & 5.05 & 4.907 & TRN & \\
\hline CHEMBL1565644 & 688759 & 4.9 & 4.7382 & TST & \\
\hline CHEMBL1492697 & 688759 & 5.2 & 5.1872 & TST & \\
\hline CHEMBL1422048 & 688759 & 5.25 & 4.9639 & TRN & \\
\hline CHEMBL1541055 & 688759 & 4.85 & 4.7652 & TRN & \\
\hline CHEMBL3194718 & 688759 & 4.45 & 4.4592 & TST & \\
\hline CHEMBL1604863 & 688759 & 4.45 & 4.8626 & TRN & \\
\hline CHEMBL1519347 & 688759 & 4.65 & 5.1594 & TRN & \\
\hline CHEMBL1453565 & 688759 & 5.15 & 5.94600 & 2000000001 & TRN \\
\hline CHEMBL1577064 & 688759 & 5.35 & 5.0435 & TST & \\
\hline CHEMBL1407677 & 688759 & 4.45 & 4.5758 & TRN & \\
\hline CHEMBL1381599 & 688759 & 5.3 & 5.01 & TRN & \\
\hline CHEMBL1349206 & 688759 & 4.7 & 5.0438 & TST & \\
\hline CHEMBL1591487 & 688759 & 5.2 & 5.3358 & TRN & \\
\hline CHEMBL1392353 & 688759 & 4.45 & 4.787 & TRN & \\
\hline CHEMBL1384697 & 688759 & 4.55 & 4.6624 & TRN & \\
\hline CHEMBL1378710 & 688759 & 4.65 & 4.9457 & TST & \\
\hline CHEMBL1393579 & 688759 & 4.65 & 4.9579 & TRN & \\
\hline CHEMBL1337422 & 688759 & 4.45 & 4.546 & TRN & \\
\hline CHEMBL1374866 & 688759 & 5.0 & 4.5294 & TST & \\
\hline CHEMBL1417312 & 688759 & 4.45 & 5.072 & TRN & \\
\hline CHEMBL1334090 & 688759 & 4.7 & 5.0868 & TRN & \\
\hline CHEMBL3194912 & 688759 & 5.25 & 4.7895 & TRN & \\
\hline CHEMBL1492096 & 688759 & 4.8 & 4.6705 & TRN & \\
\hline CHEMBL1977683 & 688759 & 4.45 & 4.9889 & TST & \\
\hline CHEMBL1548704 & 688759 & 4.45 & 5.1114 & TST & \\
\hline CHEMBL1450107 & 688759 & 5.1 & 5.1378 & TRN & \\
\hline CHEMBL1360227 & 688759 & 4.45 & 4.73 & TST & \\
\hline CHEMBL 3194477 & 688759 & 5.8 & 5.2115 & TRN & \\
\hline CHEMBL1595336 & 688759 & 4.45 & 4.7797 & TRN & \\
\hline CHEMBL1523809 & 688759 & 4.7 & 5.0503 & TRN & \\
\hline CHEMBL1415992 & 688759 & 4.95 & 4.8781 & TRN & \\
\hline CHEMBL1538469 & 688759 & 4.95 & 5.1336 & TRN & \\
\hline CHEMBL1539046 & 688759 & 5.35 & 5.1551 & TRN & \\
\hline CHEMBL1546964 & 688759 & 4.55 & 4.7205 & TRN & \\
\hline CHEMBL405857 & 688759 & 4.65 & 4.587 & TRN & \\
\hline CHEMBL 1447523 & 688759 & 4.9 & 6.1404 & TRN & \\
\hline CHEMBL1449869 & 688759 & 4.65 & 4.7102 & TRN & \\
\hline CHEMBL1320429 & 688759 & 5.0 & 5.0849 & TRN & \\
\hline CHEMBL1430772 & 688759 & 4.6 & 4.6679 & TRN & \\
\hline CHEMBL1457044 & 688759 & 6.3 & 4.8667 & TST & \\
\hline CHEMBL1385295 & 688759 & 5.1 & 5.0217 & TST & \\
\hline CHEMBL1386090 & 688759 & 5.05 & 5.2818 & TST & \\
\hline CHEMBL1489573 & 688759 & 4.8 & 4.9002 & TST & \\
\hline CHEMBL1511495 & 688759 & 4.45 & 4.7852 & TRN & \\
\hline CHEMBL1401381 & 688759 & 4.65 & 4.8108 & TRN & \\
\hline CHEMBL1431194 & 688759 & 4.45 & 4.928 & TST & \\
\hline CHEMBL1353297 & 688759 & 5.4 & 5.2302 & TRN & \\
\hline
\end{tabular}




\begin{tabular}{|c|c|c|c|c|c|}
\hline \multicolumn{6}{|c|}{ Supplemental Table S2.txt } \\
\hline CHEMBL1456772 & 688759 & 5.0 & 4.8493 & TST & \\
\hline CHEMBL3191831 & 688759 & 4.95 & 4.9908 & TRN & \\
\hline CHEMBL1456696 & 688759 & 5.9 & 5.50799 & 9999999999 & TRN \\
\hline CHEMBL1307370 & 688759 & 4.85 & 4.8376 & TRN & \\
\hline CHEMBL1311505 & 688759 & 4.6 & 4.7962 & TRN & \\
\hline CHEMBL1319984 & 688759 & 5.0 & 5.1154 & TRN & \\
\hline CHEMBL1370909 & 688759 & 5.3 & 5.4723 & TRN & \\
\hline CHEMBL1536942 & 688759 & 4.45 & 4.5878 & TRN & \\
\hline CHEMBL1327783 & 688759 & 5.45 & 5.3926 & TRN & \\
\hline CHEMBL1426012 & 688759 & 4.7 & 4.5796 & TRN & \\
\hline CHEMBL3209322 & 688759 & 4.45 & 4.8929 & TRN & \\
\hline CHEMBL1353892 & 688759 & 4.45 & 4.9483 & TST & \\
\hline CHEMBL1378952 & 688759 & 5.85 & 5.5541 & TRN & \\
\hline CHEMBL1480238 & 688759 & 5.95 & 5.7411 & TRN & \\
\hline CHEMBL1300020 & 688759 & 7.1002 & 4.8538 & TST & \\
\hline CHEMBL3145170 & 688759 & 5.0 & 5.0317 & TRN & \\
\hline CHEMBL1505211 & 688759 & 4.9 & 5.035 & TRN & \\
\hline CHEMBL1484499 & 688759 & 4.45 & 4.715 & TRN & \\
\hline CHEMBL1486562 & 688759 & 5.25 & 4.7641 & TRN & \\
\hline CHEMBL3196978 & 688759 & 4.6 & 4.9459 & TRN & \\
\hline CHEMBL1328831 & 688759 & 4.6 & 4.831 & TRN & \\
\hline CHEMBL1524932 & 688759 & 5.15 & 5.0447 & TRN & \\
\hline CHEMBL 3189154 & 688759 & 4.7 & 4.834 & TST & \\
\hline CHEMBL1430845 & 688759 & 4.75 & 4.518 & TRN & \\
\hline CHEMBL1445125 & 688759 & 5.0 & 5.1404 & TRN & \\
\hline CHEMBL3193310 & 688759 & 4.95 & 5.2053 & TRN & \\
\hline CHEMBL3212614 & 688759 & 4.45 & 4.6251 & TST & \\
\hline CHEMBL1505469 & 688759 & 5.95 & 4.8591 & TRN & \\
\hline CHEMBL1544409 & 688759 & 4.85 & 5.2981 & TRN & \\
\hline CHEMBL1418699 & 688759 & 5.45 & 4.8324 & TRN & \\
\hline CHEMBL1343733 & 688759 & 4.9 & 5.148 & TST & \\
\hline CHEMBL1467989 & 688759 & 4.45 & 5.0506 & TRN & \\
\hline CHEMBL1300555 & 688759 & 4.45 & 4.8014 & TRN & \\
\hline CHEMBL1345029 & 688759 & 4.8 & 4.6603 & TST & \\
\hline CHEMBL1979338 & 688759 & 5.4 & 4.9228 & TRN & \\
\hline CHEMBL1391330 & 688759 & 4.95 & 4.9215 & TRN & \\
\hline CHEMBL1484097 & 688759 & 4.45 & 4.8615 & TRN & \\
\hline CHEMBL1506503 & 688759 & 5.65 & 5.6476 & TRN & \\
\hline CHEMBL1599744 & 688759 & 4.8 & 4.5256 & TRN & \\
\hline CHEMBL1608245 & 688759 & 4.75 & 4.6269 & TRN & \\
\hline CHEMBL1570497 & 688759 & 4.6 & 4.935 & TRN & \\
\hline CHEMBL1426638 & 688759 & 4.65 & 4.4799 & TRN & \\
\hline CHEMBL1581194 & 688759 & 5.4 & 5.0908 & TST & \\
\hline CHEMBL1544662 & 688759 & 4.5 & 4.6745 & TST & \\
\hline CHEMBL 2236631 & 688759 & 4.45 & 4.5449 & TRN & \\
\hline CHEMBL1442373 & 688759 & 4.65 & 4.5031 & TRN & \\
\hline CHEMBL1563673 & 688759 & 5.5 & 4.808 & TRN & \\
\hline CHEMBL1595687 & 688759 & 4.75 & 4.7283 & TST & \\
\hline
\end{tabular}




\begin{tabular}{|c|c|c|c|c|c|}
\hline \multicolumn{6}{|c|}{ Supplemental Table S2.txt } \\
\hline CHEMBL 3198502 & 688759 & 4.95 & 4.7862 & TRN & \\
\hline CHEMBL1372152 & 688759 & 4.9 & 4.8081 & TRN & \\
\hline CHEMBL1537147 & 688759 & 5.2 & 5.4347 & TRN & \\
\hline CHEMBL1428607 & 688759 & 4.7 & 4.8219 & TRN & \\
\hline CHEMBL1380931 & 688759 & 4.5 & 4.7647 & TRN & \\
\hline CHEMBL3198085 & 688759 & 4.45 & 4.9522 & TST & \\
\hline CHEMBL1383298 & 688759 & 4.95 & 4.9981 & TRN & \\
\hline CHEMBL1433128 & 688759 & 5.0 & 4.774 & TRN & \\
\hline CHEMBL1481910 & 688759 & 4.9 & 4.9767 & TRN & \\
\hline CHEMBL1305691 & 688759 & 4.9 & 4.9336 & TRN & \\
\hline CHEMBL1405454 & 688759 & 4.45 & 4.8409 & TRN & \\
\hline CHEMBL1446929 & 688759 & 5.15 & 5.1546 & TST & \\
\hline CHEMBL1479706 & 688759 & 5.2 & 5.2148 & TRN & \\
\hline CHEMBL1535997 & 688759 & 4.45 & 4.6728 & TRN & \\
\hline CHEMBL1302050 & 688759 & 4.45 & 4.6158 & TRN & \\
\hline CHEMBL1492689 & 688759 & 4.8 & 4.9784 & TRN & \\
\hline CHEMBL1414263 & 688759 & 4.45 & 4.6587 & TRN & \\
\hline CHEMBL1487849 & 688759 & 5.65 & 5.53799 & 9999999999 & TRN \\
\hline CHEMBL1413056 & 688759 & 4.85 & 4.9981 & TRN & \\
\hline CHEMBL1370285 & 688759 & 4.45 & 4.9664 & TRN & \\
\hline CHEMBL1446169 & 688759 & 4.95 & 5.0199 & TRN & \\
\hline CHEMBL547161 & 688759 & 4.45 & 4.5965 & TST & \\
\hline CHEMBL1586732 & 688759 & 4.95 & 5.0919 & TRN & \\
\hline CHEMBL1431459 & 688759 & 4.45 & 4.83899 & 99999999995 & TRN \\
\hline CHEMBL3199656 & 688759 & 4.9 & 4.8712 & TRN & \\
\hline CHEMBL1428292 & 688759 & 4.6 & 4.5959 & TRN & \\
\hline CHEMBL1965808 & 688759 & 4.9 & 5.0124 & TST & \\
\hline CHEMBL1571845 & 688759 & 4.45 & 4.8965 & TST & \\
\hline CHEMBL1981150 & 688759 & 5.95 & 5.5225 & TRN & \\
\hline CHEMBL1456420 & 688759 & 4.8 & $4.6160 e$ & 00000000005 & TRN \\
\hline CHEMBL1497078 & 688759 & 4.75 & 4.6115 & TRN & \\
\hline CHEMBL 3207360 & 688759 & 4.45 & 4.9665 & TRN & \\
\hline CHEMBL1360754 & 688759 & 4.45 & 4.8994 & TRN & \\
\hline CHEMBL1999965 & 688759 & 4.65 & 4.9445 & TRN & \\
\hline CHEMBL3191517 & 688759 & 4.45 & 5.1868 & TRN & \\
\hline CHEMBL1479709 & 688759 & 4.45 & 5.0244 & TST & \\
\hline CHEMBL118109 & 688759 & 4.85 & 5.0858 & TRN & \\
\hline CHEMBL1395454 & 688759 & 4.5 & 4.7264 & TRN & \\
\hline CHEMBL1555827 & 688759 & 4.8 & 4.8542 & TRN & \\
\hline CHEMBL 83527 & 688759 & 5.4 & 5.1046 & TRN & \\
\hline CHEMBL1971234 & 688759 & 4.9 & 4.8543 & TST & \\
\hline CHEMBL1469277 & 688759 & 4.85 & 5.0043 & TRN & \\
\hline CHEMBL1319986 & 688759 & 4.45 & 4.8486 & TRN & \\
\hline CHEMBL1489151 & 688759 & 4.8 & 4.63899 & 9999999999 & TRN \\
\hline CHEMBL1477595 & 688759 & 5.15 & 5.2448 & TRN & \\
\hline CHEMBL1479522 & 688759 & 4.45 & 4.77 & TRN & \\
\hline CHEMBL1581100 & 688759 & 4.45 & 4.6545 & TST & \\
\hline CHEMBL1982028 & 688759 & 4.9 & 4.7788 & TRN & \\
\hline
\end{tabular}




\begin{tabular}{|c|c|c|c|c|}
\hline \multicolumn{5}{|c|}{ Supplemental Table S2.txt } \\
\hline CHEMBL1359029 & 688759 & 4.7 & 5.0584 & TRN \\
\hline CHEMBL1471075 & 688759 & 4.45 & 5.1225 & TRN \\
\hline CHEMBL1518205 & 688759 & 4.7 & 4.8754 & TRN \\
\hline CHEMBL1310348 & 688759 & 5.85 & 5.5303 & TST \\
\hline CHEMBL3199348 & 688759 & 6.2 & 5.0282 & TRN \\
\hline CHEMBL1507070 & 688759 & 5.5 & 4.8396 & TST \\
\hline CHEMBL1425682 & 688759 & 4.95 & 4.9195 & TRN \\
\hline CHEMBL1568896 & 688759 & 4.85 & 5.2029 & TST \\
\hline CHEMBL3199608 & 688759 & 5.05 & 4.5727 & TRN \\
\hline CHEMBL1527900 & 688759 & 4.45 & 4.6709 & TRN \\
\hline CHEMBL1378664 & 688759 & 5.45 & 4.6914 & TRN \\
\hline CHEMBL1328166 & 688759 & 5.45 & 5.3668 & TST \\
\hline CHEMBL1313842 & 688759 & 4.45 & 4.7444 & TRN \\
\hline CHEMBL1413804 & 688759 & 4.45 & 4.8494 & TRN \\
\hline CHEMBL1368516 & 688759 & 4.45 & 4.762 & TRN \\
\hline CHEMBL1610388 & 688759 & 4.75 & 5.0614 & TRN \\
\hline CHEMBL3196084 & 688759 & 5.05 & 5.0348 & TRN \\
\hline CHEMBL1336649 & 688759 & 4.55 & 4.7226 & TRN \\
\hline CHEMBL3212393 & 688759 & 6.2 & 4.8725 & TST \\
\hline CHEMBL1310717 & 688759 & 4.45 & 5.4876 & TRN \\
\hline CHEMBL1424842 & 688759 & 5.05 & 4.8877 & TST \\
\hline CHEMBL1372585 & 688759 & 4.9 & 4.7939 & TRN \\
\hline CHEMBL1471973 & 688759 & 4.45 & 4.9582 & TRN \\
\hline CHEMBL3197642 & 688759 & 6.7501 & 5.8247 & TRN \\
\hline CHEMBL1611370 & 688759 & 5.6 & 4.5884 & TST \\
\hline CHEMBL1470543 & 688759 & 4.45 & 5.2847 & TRN \\
\hline CHEMBL1558822 & 688759 & 6.25 & 6.0515 & TRN \\
\hline CHEMBL3191193 & 688759 & 5.05 & 5.0884 & TRN \\
\hline CHEMBL3208391 & 688759 & 4.65 & 4.7274 & TRN \\
\hline CHEMBL1608459 & 688759 & 4.45 & 4.739 & TRN \\
\hline CHEMBL1500844 & 688759 & 5.25 & 4.9247 & TRN \\
\hline CHEMBL1311392 & 688759 & 5.75 & 5.1761 & TRN \\
\hline CHEMBL1518148 & 688759 & 4.9 & 4.7975 & TST \\
\hline CHEMBL1359467 & 688759 & 4.65 & 4.9113 & TRN \\
\hline CHEMBL1571839 & 688759 & 5.1 & 5.0211 & TRN \\
\hline CHEMBL1495977 & 688759 & 5.45 & 5.9466 & TRN \\
\hline CHEMBL1537969 & 688759 & 5.25 & 4.8332 & TST \\
\hline CHEMBL1457924 & 688759 & 4.7 & 4.8385 & TRN \\
\hline CHEMBL1525989 & 688759 & 4.9 & 4.6202 & TST \\
\hline CHEMBL1495205 & 688759 & 4.45 & 4.8061 & TRN \\
\hline CHEMBL1322588 & 688759 & 4.8 & 6.1444 & TRN \\
\hline CHEMBL1531776 & 688759 & 5.0 & 4.7311 & TRN \\
\hline CHEMBL319244 & 688759 & 6.0 & 4.9062 & TST \\
\hline CHEMBL1422190 & 688759 & 4.45 & 4.8895 & TRN \\
\hline CHEMBL1327719 & 688759 & 4.45 & 5.0219 & TRN \\
\hline CHEMBL1340957 & 688759 & 4.65 & 5.0526 & TRN \\
\hline CHEMBL1608608 & 688759 & 5.15 & 5.0573 & TRN \\
\hline CHEMBL1570871 & 688759 & 4.65 & 4.4227 & TRN \\
\hline
\end{tabular}




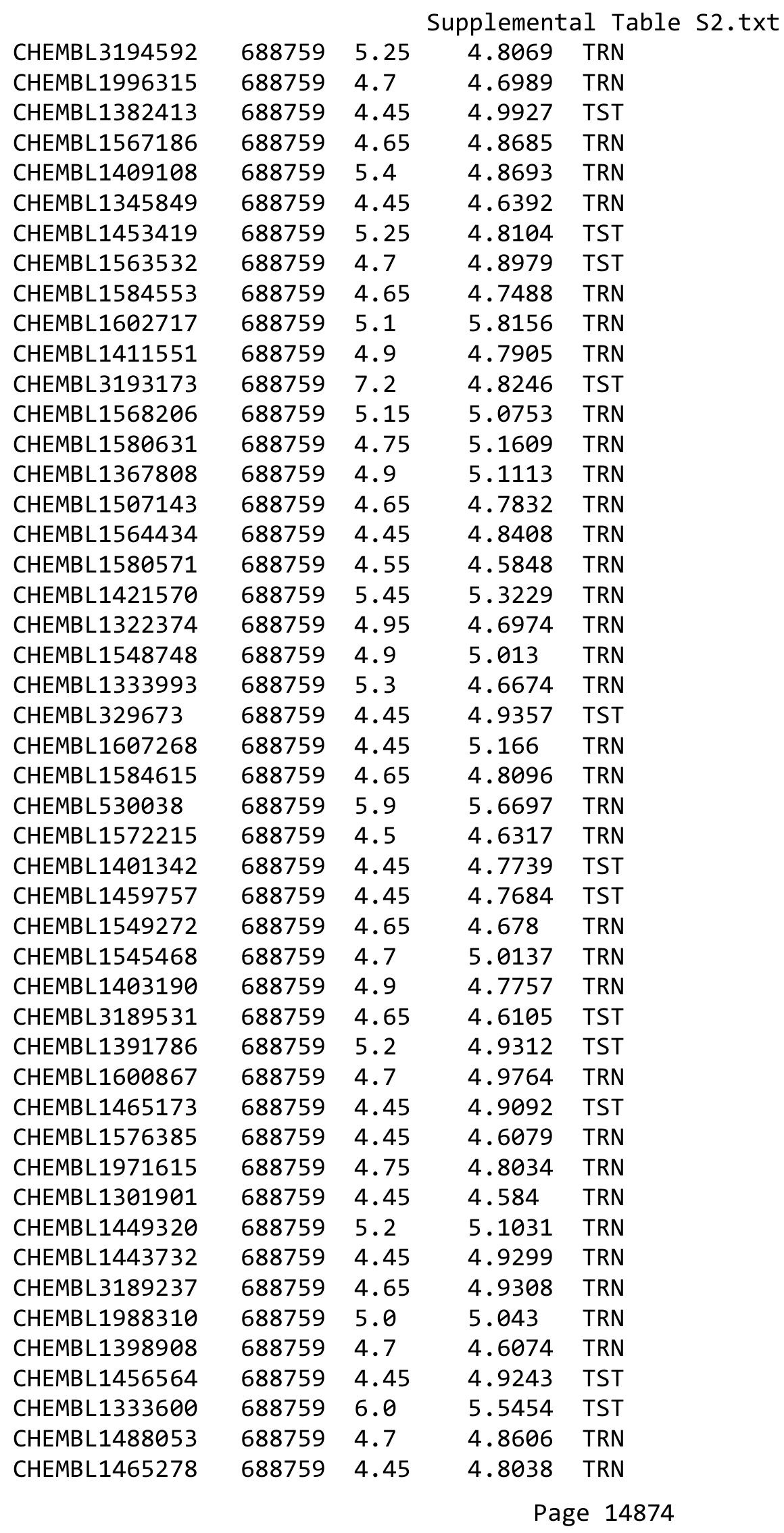




\begin{tabular}{|c|c|c|c|c|}
\hline \multirow[b]{2}{*}{ CHEMBL1575150 } & \multicolumn{4}{|c|}{ Supplemental Table S2.txt } \\
\hline & 688759 & 4.5 & 4.6911 & TRN \\
\hline CHEMBL1533375 & 688759 & 5.25 & 4.9753 & TST \\
\hline CHEMBL1351434 & 688759 & 4.45 & 5.0178 & TST \\
\hline CHEMBL1580407 & 688759 & 4.45 & 4.9764 & TRN \\
\hline CHEMBL1605904 & 688759 & 4.8 & 4.9742 & TRN \\
\hline CHEMBL1482310 & 688759 & 4.6 & 5.2864 & TST \\
\hline CHEMBL 3199926 & 688759 & 5.0 & 5.197 & TRN \\
\hline CHEMBL1350869 & 688759 & 5.55 & 4.5316 & TRN \\
\hline CHEMBL1445318 & 688759 & 4.45 & 4.8802 & TRN \\
\hline CHEMBL1508706 & 688759 & 4.45 & 4.7416 & TRN \\
\hline CHEMBL1393664 & 688759 & 4.6 & 4.6671 & TST \\
\hline CHEMBL1518472 & 688759 & 4.45 & 4.6226 & TRN \\
\hline CHEMBL1381896 & 688759 & 4.45 & 4.6466 & TRN \\
\hline CHEMBL1353805 & 688759 & 4.9 & 4.8026 & TRN \\
\hline CHEMBL3195749 & 688759 & 5.5 & 4.9897 & TRN \\
\hline CHEMBL1344207 & 688759 & 5.55 & 4.7835 & TST \\
\hline CHEMBL3190421 & 688759 & 5.2 & 5.3847 & TRN \\
\hline CHEMBL1352266 & 688759 & 4.45 & 4.927 & TST \\
\hline CHEMBL1347351 & 688759 & 5.9 & 5.1976 & TRN \\
\hline CHEMBL1590745 & 688759 & 6.15 & 4.7614 & TRN \\
\hline CHEMBL1988501 & 688759 & 4.45 & 4.8216 & TRN \\
\hline CHEMBL1442317 & 688759 & 4.9 & 4.8295 & TRN \\
\hline CHEMBL1363985 & 688759 & 5.9 & 5.0215 & TST \\
\hline CHEMBL1410792 & 688759 & 4.85 & 5.1488 & TRN \\
\hline CHEMBL1378567 & 688759 & 4.45 & 4.8445 & TRN \\
\hline CHEMBL1317298 & 688759 & 4.45 & 4.7725 & TRN \\
\hline CHEMBL3195559 & 688759 & 4.95 & 4.6972 & TRN \\
\hline CHEMBL1351197 & 688759 & 4.45 & 4.8572 & TST \\
\hline CHEMBL1310132 & 688759 & 5.55 & 4.827 & TRN \\
\hline CHEMBL1485924 & 688759 & 5.9 & 4.9523 & TRN \\
\hline CHEMBL1369200 & 688759 & 5.25 & 4.6456 & TRN \\
\hline CHEMBL1303592 & 688759 & 5.35 & 4.9683 & TRN \\
\hline CHEMBL1565809 & 688759 & 5.2 & 4.9266 & TST \\
\hline CHEMBL1364100 & 688759 & 4.9 & 4.8397 & TST \\
\hline CHEMBL1598555 & 688759 & 4.55 & 4.8445 & TRN \\
\hline CHEMBL1508916 & 688759 & 5.3 & 4.7211 & TRN \\
\hline CHEMBL3194300 & 688759 & 5.3 & 4.9003 & TRN \\
\hline CHEMBL1524995 & 688759 & 5.3 & 5.2695 & TRN \\
\hline CHEMBL1532466 & 688759 & 4.65 & 4.705 & TRN \\
\hline CHEMBL1545991 & 688759 & 4.75 & 5.3828 & TRN \\
\hline CHEMBL1602596 & 688759 & 5.15 & 4.9536 & TRN \\
\hline CHEMBL1420688 & 688759 & 4.5 & 4.6662 & TST \\
\hline CHEMBL1596791 & 688759 & 4.8 & 4.7276 & TST \\
\hline CHEMBL1320262 & 688759 & 4.55 & 4.6742 & TRN \\
\hline CHEMBL1306900 & 688759 & 4.5 & 4.7628 & TRN \\
\hline CHEMBL1318943 & 688759 & 4.9 & 4.7439 & TST \\
\hline CHEMBL1588869 & 688759 & 4.65 & 4.7386 & TRN \\
\hline CHEMBL1581944 & 688759 & 5.9 & 4.8563 & TST \\
\hline
\end{tabular}




\begin{tabular}{|c|c|c|c|c|c|}
\hline & & \multicolumn{4}{|c|}{ Supplemental Table S2.txt } \\
\hline CHEMBL1430861 & 688759 & 4.45 & 4.6971 & TRN & \\
\hline CHEMBL1601316 & 688759 & 4.45 & 4.6246 & TRN & \\
\hline CHEMBL1327703 & 688759 & 4.85 & 4.88899 & 7999999999 & TRN \\
\hline CHEMBL1539504 & 688759 & 4.95 & 4.8224 & TRN & \\
\hline CHEMBL1382865 & 688759 & 5.3 & 5.7342 & TRN & \\
\hline CHEMBL1333565 & 688759 & 5.6 & 5.4899 & TRN & \\
\hline CHEMBL1369666 & 688759 & 4.45 & 4.788 & TST & \\
\hline CHEMBL1424725 & 688759 & 4.45 & 4.6115 & TRN & \\
\hline CHEMBL1583914 & 688759 & 5.45 & 4.7824 & TRN & \\
\hline CHEMBL3145320 & 688759 & 6.0 & 5.693 & TRN & \\
\hline CHEMBL 2005042 & 688759 & 5.1 & 4.8313 & TRN & \\
\hline CHEMBL1583504 & 688759 & 4.45 & 4.5519 & TRN & \\
\hline CHEMBL1594719 & 688759 & 4.75 & 4.9412 & TRN & \\
\hline CHEMBL233896 & 688759 & 4.7 & 4.8553 & TST & \\
\hline CHEMBL1364651 & 688759 & 4.45 & 4.8507 & TRN & \\
\hline CHEMBL1371969 & 688759 & 4.8 & 4.8346 & TST & \\
\hline CHEMBL1392364 & 688759 & 5.4 & 5.2195 & TRN & \\
\hline CHEMBL1405593 & 688759 & 5.4 & 5.3537 & TRN & \\
\hline CHEMBL1318944 & 688759 & 4.45 & 5.0146 & TST & \\
\hline CHEMBL1517045 & 688759 & 5.4 & 4.9788 & TRN & \\
\hline CHEMBL1390743 & 688759 & 4.45 & 4.882 & TST & \\
\hline CHEMBL1425260 & 688759 & 4.45 & 4.8705 & TST & \\
\hline CHEMBL1385727 & 688759 & 5.3 & 5.1545 & TRN & \\
\hline CHEMBL1453417 & 688759 & 5.35 & 4.9397 & TRN & \\
\hline CHEMBL1320108 & 688759 & 5.1 & 5.0521 & TRN & \\
\hline CHEMBL1463840 & 688759 & 4.5 & 4.6989 & TST & \\
\hline CHEMBL1608392 & 688759 & 4.45 & 4.688 & TRN & \\
\hline CHEMBL3208993 & 688759 & 5.35 & 4.6417 & TRN & \\
\hline CHEMBL1484329 & 688759 & 4.45 & 4.8705 & TST & \\
\hline CHEMBL1442252 & 688759 & 4.7 & 4.7322 & TRN & \\
\hline CHEMBL1492120 & 688759 & 4.65 & 5.3 & TRN & \\
\hline CHEMBL3197927 & 688759 & 4.45 & 4.5712 & TST & \\
\hline CHEMBL1375884 & 688759 & 5.5 & 5.1753 & TRN & \\
\hline CHEMBL1322748 & 688759 & 4.45 & 5.1088 & TST & \\
\hline CHEMBL1430227 & 688759 & 4.85 & 4.6321 & TRN & \\
\hline CHEMBL73451 & 688759 & 4.5 & 4.8487 & TST & \\
\hline CHEMBL1582688 & 688759 & 4.9 & 4.893 & TRN & \\
\hline CHEMBL1992764 & 688759 & 4.95 & 4.9537 & TRN & \\
\hline CHEMBL1555679 & 688759 & 4.75 & 5.1496 & TRN & \\
\hline CHEMBL1549336 & 688759 & 4.9 & 4.8035 & TST & \\
\hline CHEMBL1503854 & 688759 & 5.2 & 4.909 & TST & \\
\hline CHEMBL1465554 & 688759 & 4.65 & 5.0551 & TRN & \\
\hline CHEMBL1349559 & 688759 & 4.8 & 4.9409 & TRN & \\
\hline CHEMBL1477662 & 688759 & 5.45 & 4.954 & TST & \\
\hline CHEMBL1338698 & 688759 & 5.05 & 5.3041 & TRN & \\
\hline CHEMBL1364424 & 688759 & 4.85 & 5.0167 & TRN & \\
\hline CHEMBL1388921 & 688759 & 5.0 & 5.0656 & TRN & \\
\hline CHEMBL1382834 & 688759 & 4.45 & 4.6025 & TST & \\
\hline
\end{tabular}




\begin{tabular}{|c|c|c|c|c|c|}
\hline \multicolumn{6}{|c|}{ pplemental labıe S2.txt } \\
\hline CHEMBL1406980 & 688759 & 5.1 & 4.8247 & TRN & \\
\hline CHEMBL3199445 & 688759 & 5.4 & 5.1532 & TRN & \\
\hline CHEMBL3194596 & 688759 & 5.15 & 5.0664 & TRN & \\
\hline CHEMBL1504972 & 688759 & 4.45 & 4.6675 & TRN & \\
\hline CHEMBL1500868 & 688759 & 4.85 & 5.0421 & TRN & \\
\hline CHEMBL1533662 & 688759 & 4.5 & 4.9289 & TRN & \\
\hline CHEMBL1421708 & 688759 & 5.4 & 5.1333 & TRN & \\
\hline CHEMBL1390947 & 688759 & 4.45 & 4.5837 & TRN & \\
\hline CHEMBL259389 & 688759 & 4.55 & 5.2408 & TST & \\
\hline CHEMBL1546315 & 688759 & 5.5 & 4.8232 & TRN & \\
\hline CHEMBL1426831 & 688759 & 4.95 & 4.97 & TST & \\
\hline CHEMBL1508068 & 688759 & 4.45 & 4.8045 & TRN & \\
\hline CHEMBL363419 & 688759 & 4.65 & 4.7171 & TST & \\
\hline CHEMBL1427763 & 688759 & 4.7 & 4.7599 & TST & \\
\hline CHEMBL1561817 & 688759 & 4.5 & 4.9125 & TRN & \\
\hline CHEMBL1607005 & 688759 & 4.65 & 4.7892 & TRN & \\
\hline CHEMBL1559624 & 688759 & 4.7 & 5.041 & TRN & \\
\hline CHEMBL1502931 & 688759 & 4.95 & 4.812 & TST & \\
\hline CHEMBL1335515 & 688759 & 5.15 & 5.4189 & TRN & \\
\hline CHEMBL582005 & 688759 & 4.45 & 4.627 & TST & \\
\hline CHEMBL1332015 & 688759 & 4.45 & 4.8343 & TRN & \\
\hline CHEMBL1457966 & 688759 & 4.9 & 4.7848 & TST & \\
\hline CHEMBL1524775 & 688759 & 4.85 & 4.7363 & TRN & \\
\hline CHEMBL1387697 & 688759 & 4.45 & 4.8731 & TRN & \\
\hline CHEMBL 3213612 & 688759 & 4.45 & 4.8983 & TST & \\
\hline CHEMBL1504637 & 688759 & 4.45 & 4.5767 & TRN & \\
\hline CHEMBL1300192 & 688759 & 4.45 & 4.7742 & TRN & \\
\hline CHEMBL1600007 & 688759 & 5.0 & 5.0621 & TRN & \\
\hline CHEMBL1336295 & 688759 & 6.0 & 4.8606 & TRN & \\
\hline CHEMBL3189853 & 688759 & 4.45 & 4.8583 & TRN & \\
\hline CHEMBL1522485 & 688759 & 4.45 & 4.6958 & TST & \\
\hline CHEMBL1576787 & 688759 & 4.45 & 4.9599 & TRN & \\
\hline CHEMBL1410592 & 688759 & 4.8 & 4.5325 & TST & \\
\hline CHEMBL1331961 & 688759 & 5.45 & 5.0577 & TRN & \\
\hline CHEMBL1442505 & 688759 & 5.0 & 4.98600 & 0000000001 & TST \\
\hline CHEMBL1338990 & 688759 & 4.65 & 4.6645 & TST & \\
\hline CHEMBL1323884 & 688759 & 4.45 & 4.9619 & TRN & \\
\hline CHEMBL1329048 & 688759 & 4.5 & 4.8572 & TST & \\
\hline CHEMBL1309514 & 688759 & 5.0 & 4.9518 & TRN & \\
\hline CHEMBL1480718 & 688759 & 4.45 & 4.5494 & TST & \\
\hline CHEMBL1386012 & 688759 & 4.65 & 4.8597 & TRN & \\
\hline CHEMBL483582 & 688759 & 5.15 & 4.9278 & TRN & \\
\hline CHEMBL1391366 & 688759 & 4.45 & 4.7898 & TRN & \\
\hline CHEMBL1991578 & 688759 & 4.7 & 4.7184 & TRN & \\
\hline CHEMBL1605514 & 688759 & 5.7 & 5.3519 & TST & \\
\hline CHEMBL1458624 & 688759 & 6.95 & 4.7979 & TST & \\
\hline CHEMBL1428415 & 688759 & 5.5 & 5.1752 & TRN & \\
\hline CHEMBL1340427 & 688759 & 4.95 & 4.8767 & TST & \\
\hline
\end{tabular}




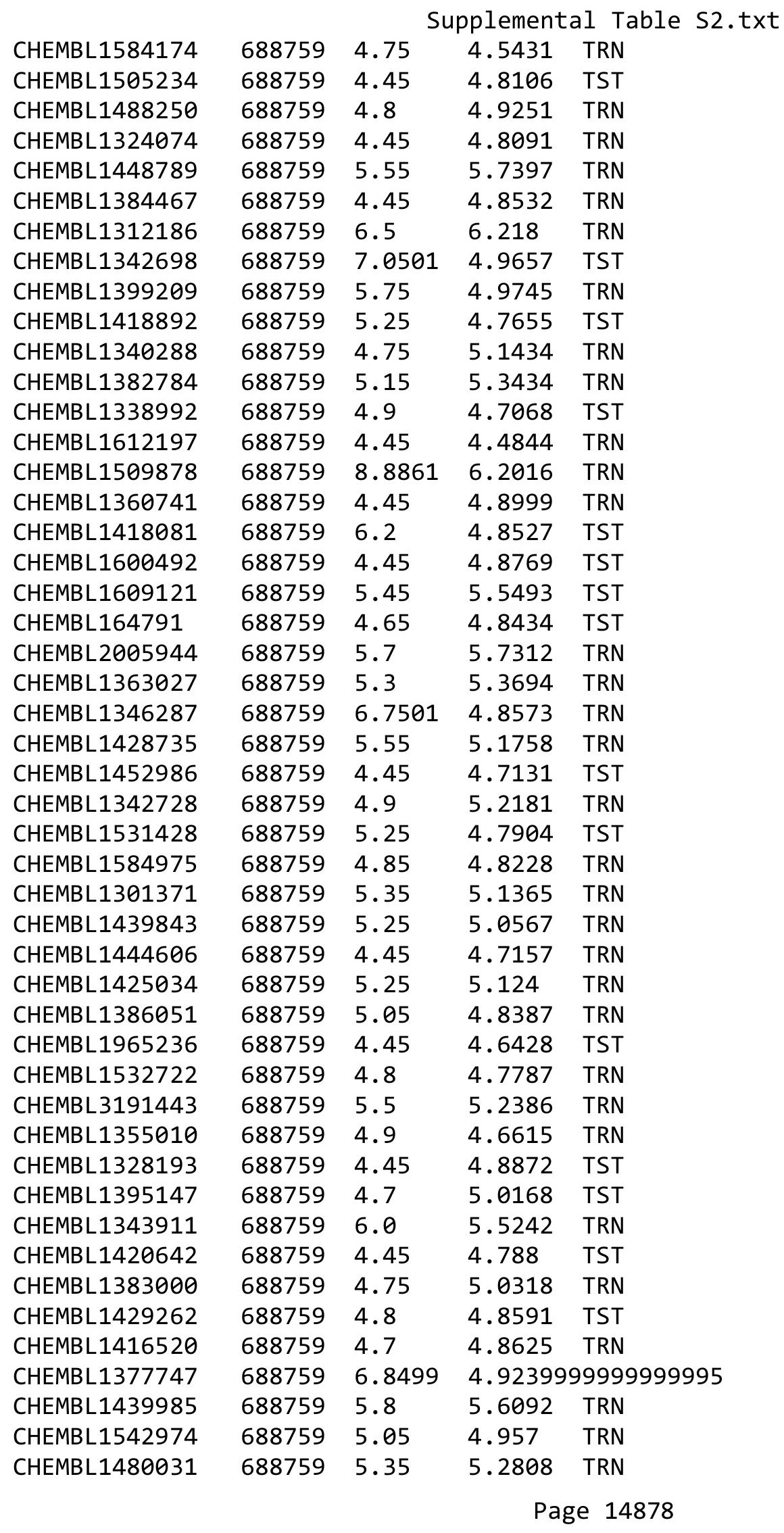




\begin{tabular}{|c|c|c|c|c|c|}
\hline \multicolumn{6}{|c|}{ Supplemental Table s2.txt } \\
\hline CHEMBL1995726 & 688759 & 4.45 & 5.0111 & TRN & \\
\hline CHEMBL1965316 & 688759 & 4.75 & 4.6977 & TRN & \\
\hline CHEMBL1399950 & 688759 & 4.75 & 4.9731 & TST & \\
\hline CHEMBL1468042 & 688759 & 4.65 & 4.9038 & TST & \\
\hline CHEMBL1438543 & 688759 & 4.65 & 4.9116 & TRN & \\
\hline CHEMBL1481192 & 688759 & 4.65 & 5.026 & TRN & \\
\hline CHEMBL1456081 & 688759 & 4.45 & 4.936 & TRN & \\
\hline CHEMBL1580162 & 688759 & 4.45 & 4.8799 & TST & \\
\hline CHEMBL1333931 & 688759 & 4.45 & 4.93199 & 99999999995 & TST \\
\hline CHEMBL1432239 & 688759 & 5.15 & 5.0248 & TRN & \\
\hline CHEMBL1348774 & 688759 & 5.25 & 5.0179 & TRN & \\
\hline CHEMBL1351844 & 688759 & 4.75 & 5.4544 & TRN & \\
\hline CHEMBL1964878 & 688759 & 4.45 & 4.8774 & TST & \\
\hline CHEMBL1390003 & 688759 & 4.45 & 4.8818 & TST & \\
\hline CHEMBL1528668 & 688759 & 4.8 & 5.1903 & TRN & \\
\hline CHEMBL1502364 & 688759 & 5.0 & 5.10800 & 00000000005 & TST \\
\hline CHEMBL1561089 & 688759 & 5.45 & 5.1454 & TST & \\
\hline CHEMBL3198694 & 688759 & 4.55 & 4.7066 & TST & \\
\hline CHEMBL3208293 & 688759 & 5.55 & 4.6547 & TRN & \\
\hline CHEMBL1422161 & 688759 & 4.8 & 4.8014 & TRN & \\
\hline CHEMBL1309456 & 688759 & 5.35 & 5.3363 & TRN & \\
\hline CHEMBL1403315 & 688759 & 4.45 & 4.8737 & TST & \\
\hline CHEMBL1562003 & 688759 & 4.8 & 5.0162 & TST & \\
\hline CHEMBL 3209257 & 688759 & 4.45 & 4.9878 & TRN & \\
\hline CHEMBL1507048 & 688759 & 5.5 & 4.7518 & TRN & \\
\hline CHEMBL1444529 & 688759 & 4.45 & 4.9439 & TST & \\
\hline CHEMBL1444905 & 688759 & 4.55 & 4.9943 & TRN & \\
\hline CHEMBL1331638 & 688759 & 5.85 & 5.0214 & TRN & \\
\hline CHEMBL 303958 & 688759 & 4.45 & 5.3579 & TST & \\
\hline CHEMBL1461546 & 688759 & 4.65 & 4.5535 & TRN & \\
\hline CHEMBL1453338 & 688759 & 4.55 & 4.8562 & TST & \\
\hline CHEMBL1539657 & 688759 & 4.8 & 4.9259 & TRN & \\
\hline CHEMBL1308048 & 688759 & 4.75 & 5.0653 & TRN & \\
\hline CHEMBL1371995 & 688759 & 4.45 & 4.7327 & TRN & \\
\hline CHEMBL1404485 & 688759 & 4.45 & 4.9394 & TRN & \\
\hline CHEMBL1345573 & 688759 & 5.95 & 4.7881 & TRN & \\
\hline CHEMBL1423809 & 688759 & 5.0 & 4.9452 & TRN & \\
\hline CHEMBL1561320 & 688759 & 6.45 & 5.0554 & TRN & \\
\hline CHEMBL1584194 & 688759 & 4.45 & 4.5817 & TST & \\
\hline CHEMBL1366942 & 688759 & 4.05 & 5.6065 & TRN & \\
\hline CHEMBL3197247 & 688759 & 4.65 & 4.8346 & TST & \\
\hline CHEMBL1386344 & 688759 & 4.65 & 4.5054 & TRN & \\
\hline CHEMBL1379181 & 688759 & 5.25 & 5.0833 & TST & \\
\hline CHEMBL1339313 & 688759 & 5.0 & 4.8716 & TRN & \\
\hline CHEMBL1391167 & 688759 & 4.6 & 4.6405 & TRN & \\
\hline CHEMBL1505747 & 688759 & 4.55 & 4.8692 & TRN & \\
\hline CHEMBL3192672 & 688759 & 5.3 & 5.0797 & TRN & \\
\hline CHEMBL1424419 & 688759 & 4.65 & 4.6383 & TRN & \\
\hline
\end{tabular}




\begin{tabular}{|c|c|c|c|c|c|}
\hline \multirow[b]{2}{*}{ CHEMBL1494296 } & \multirow[b]{2}{*}{688759} & \multicolumn{4}{|c|}{ Supplemental Table S2.txt } \\
\hline & & 4.95 & 4.9039 & TRN & \\
\hline CHEMBL3213682 & 688759 & 5.95 & 5.74299 & 9999999999 & TRN \\
\hline CHEMBL1318830 & 688759 & 4.65 & 4.7921 & TRN & \\
\hline CHEMBL1508987 & 688759 & 5.4 & 5.1379 & TST & \\
\hline CHEMBL1533321 & 688759 & 5.45 & 4.895 & TRN & \\
\hline CHEMBL1993070 & 688759 & 4.7 & 5.0196 & TRN & \\
\hline CHEMBL1985744 & 688759 & 4.45 & 5.0004 & TRN & \\
\hline CHEMBL1410070 & 688759 & 6.4 & 4.8096 & TRN & \\
\hline CHEMBL1422696 & 688759 & 4.9 & 4.9175 & TRN & \\
\hline CHEMBL1308108 & 688759 & 5.2 & 4.8035 & TRN & \\
\hline CHEMBL1347702 & 688759 & 5.3 & 4.9211 & TST & \\
\hline CHEMBL1412825 & 688759 & 4.45 & 4.9225 & TST & \\
\hline CHEMBL1429351 & 688759 & 4.65 & 4.8695 & TRN & \\
\hline CHEMBL1604264 & 688759 & 4.55 & 5.0065 & TRN & \\
\hline CHEMBL1309567 & 688759 & 4.45 & 4.7234 & TRN & \\
\hline CHEMBL1344367 & 688759 & 4.8 & 4.7945 & TST & \\
\hline CHEMBL1594362 & 688759 & 5.25 & 4.9539 & TST & \\
\hline CHEMBL488140 & 688759 & 4.95 & 5.2935 & TRN & \\
\hline CHEMBL1387800 & 688759 & 4.45 & 4.7274 & TST & \\
\hline CHEMBL1499792 & 688759 & 5.15 & 4.8247 & TRN & \\
\hline CHEMBL1597570 & 688759 & 4.65 & 4.8451 & TST & \\
\hline CHEMBL1485364 & 688759 & 5.15 & 4.6265 & TRN & \\
\hline CHEMBL1482546 & 688759 & 5.0 & 4.8026 & TRN & \\
\hline CHEMBL1328084 & 688759 & 4.95 & 5.0851 & TRN & \\
\hline CHEMBL1494455 & 688759 & 4.95 & 4.8074 & TST & \\
\hline CHEMBL3198747 & 688759 & 5.5 & 5.0819 & TST & \\
\hline CHEMBL1595244 & 688759 & 5.55 & 5.2321 & TRN & \\
\hline CHEMBL1541769 & 688759 & 4.45 & 4.7332 & TRN & \\
\hline CHEMBL1612574 & 688759 & 4.45 & 4.9484 & TRN & \\
\hline CHEMBL1548109 & 688759 & 4.45 & 4.7659 & TRN & \\
\hline CHEMBL1498342 & 688759 & 4.85 & 4.8649 & TRN & \\
\hline CHEMBL179033 & 688759 & 4.8 & 4.9657 & TST & \\
\hline CHEMBL1542903 & 688759 & 4.6 & 4.76699 & 99999999995 & TST \\
\hline CHEMBL1368993 & 688759 & 7.2 & 4.995 & TRN & \\
\hline CHEMBL1332336 & 688759 & 4.8 & 5.0496 & TRN & \\
\hline CHEMBL1604256 & 688759 & 4.95 & 4.8417 & TRN & \\
\hline CHEMBL1526238 & 688759 & 4.45 & 4.838 & TST & \\
\hline CHEMBL1402309 & 688759 & 4.45 & 4.6812 & TST & \\
\hline CHEMBL1361939 & 688759 & 4.45 & 4.7522 & TRN & \\
\hline CHEMBL1466243 & 688759 & 5.25 & 4.7748 & TRN & \\
\hline CHEMBL1613717 & 688759 & 5.35 & 5.2408 & TRN & \\
\hline CHEMBL1423325 & 688759 & 4.85 & 4.5639 & TRN & \\
\hline CHEMBL1973626 & 688759 & 5.7 & 5.7265 & TRN & \\
\hline CHEMBL1351539 & 688759 & 5.25 & 5.5386 & TST & \\
\hline CHEMBL1468802 & 688759 & 4.75 & 4.6056 & TRN & \\
\hline CHEMBL1502410 & 688759 & 5.2 & 4.9231 & TRN & \\
\hline CHEMBL1606077 & 688759 & 4.8 & 4.5017 & TRN & \\
\hline CHEMBL1459406 & 688759 & 5.8 & 4.938 & TRN & \\
\hline
\end{tabular}




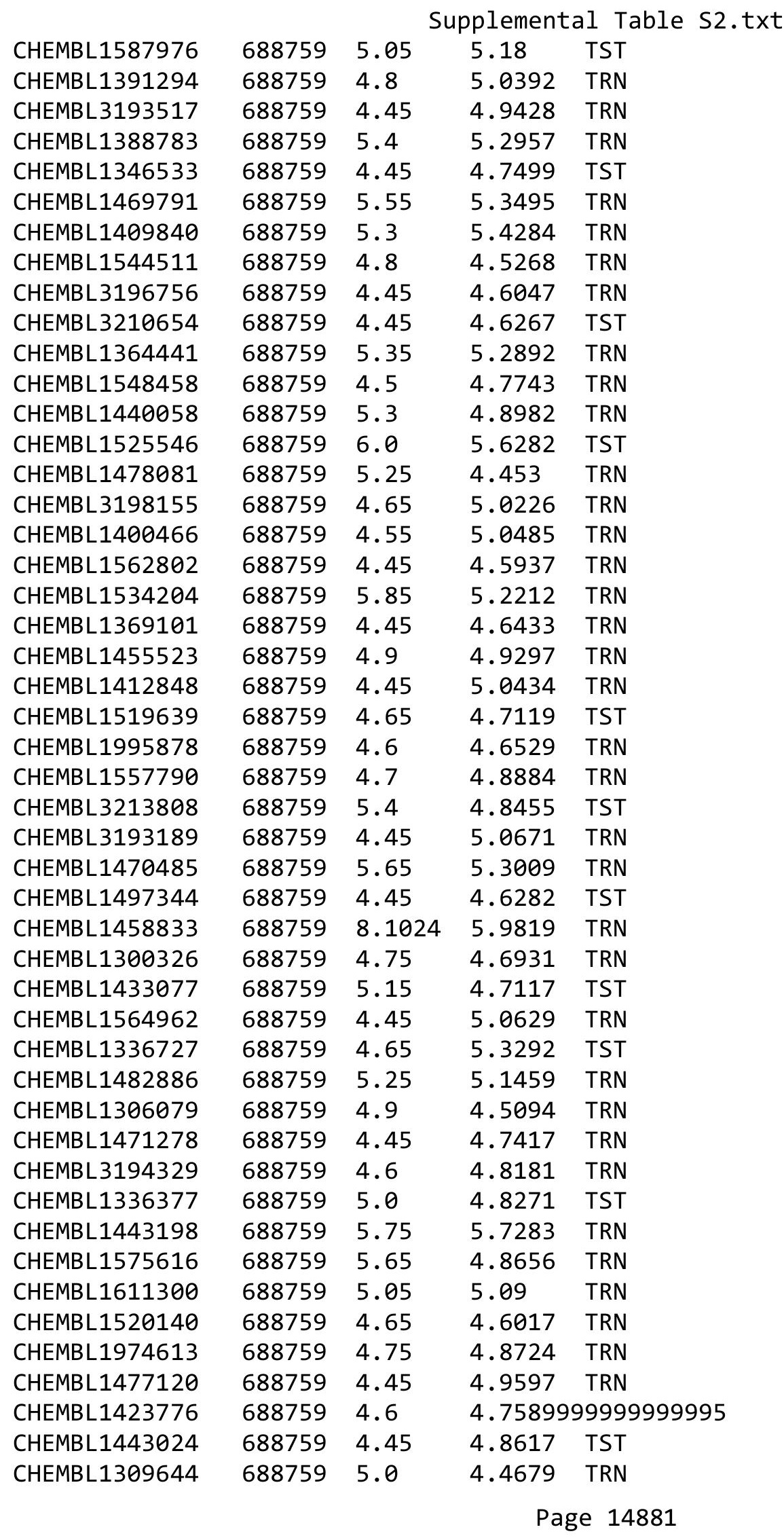




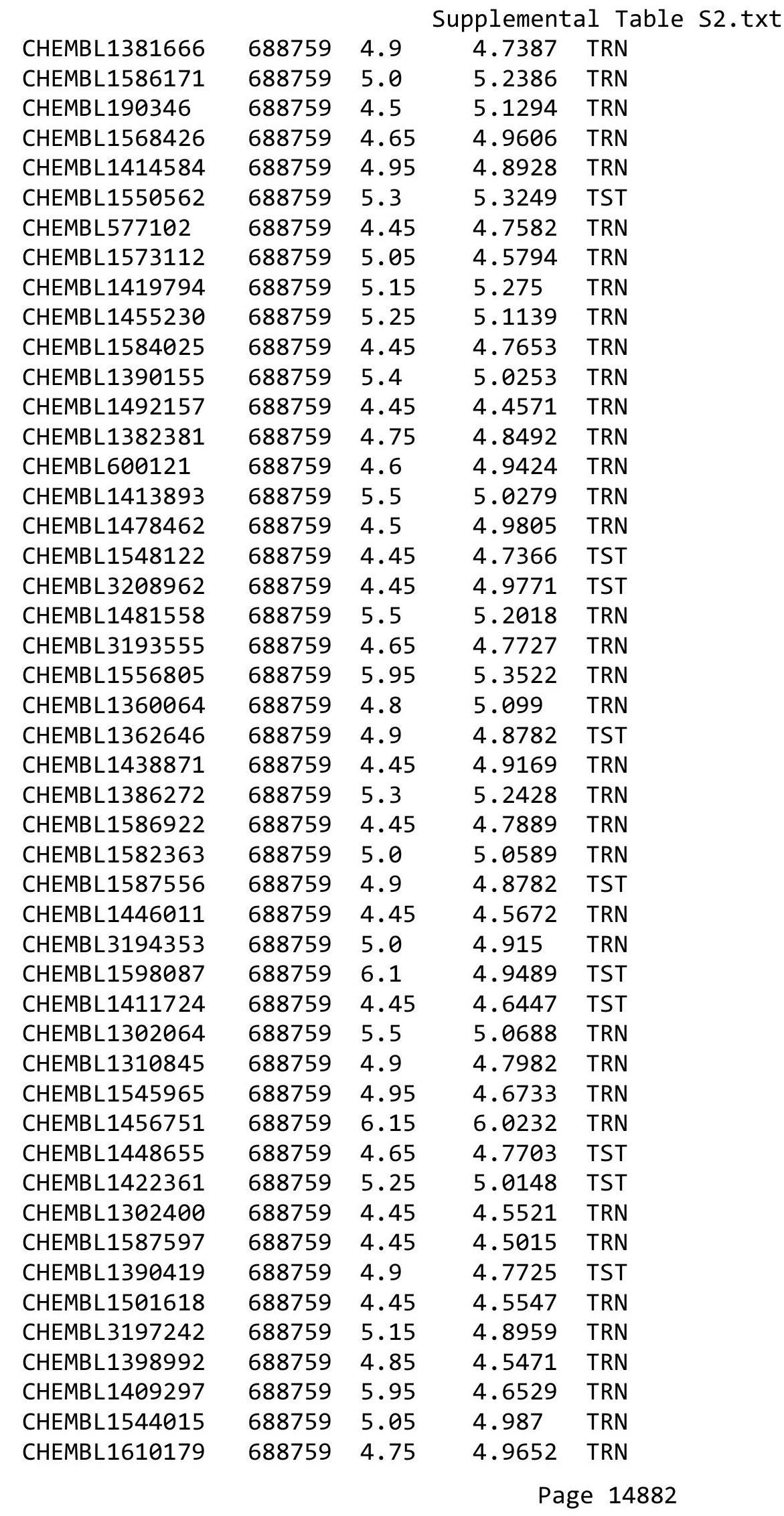




\begin{tabular}{|c|c|c|c|c|c|}
\hline & & \multicolumn{4}{|c|}{ Supplemental Table s2.txt } \\
\hline CHEMBL1482389 & 688759 & 4.95 & 4.9116 & TST & \\
\hline CHEMBL1457353 & 688759 & 4.65 & 4.7948 & TST & \\
\hline CHEMBL3208617 & 688759 & 5.55 & 4.8281 & TRN & \\
\hline CHEMBL1976388 & 688759 & 5.05 & 4.7317 & TRN & \\
\hline CHEMBL1420685 & 688759 & 4.9 & 4.7859 & TRN & \\
\hline CHEMBL1363753 & 688759 & 4.7 & 4.547 & TRN & \\
\hline CHEMBL1363050 & 688759 & 4.7 & 4.9913 & TST & \\
\hline CHEMBL1597150 & 688759 & 4.45 & 5.0491 & TRN & \\
\hline CHEMBL1412980 & 688759 & 4.75 & 5.1615 & TST & \\
\hline CHEMBL578504 & 688759 & 5.55 & 5.0678 & TRN & \\
\hline CHEMBL1978150 & 688759 & 4.65 & 4.6573 & TRN & \\
\hline CHEMBL1511250 & 688759 & 4.85 & 4.6142 & TRN & \\
\hline CHEMBL1440207 & 688759 & 5.25 & 5.2213 & TRN & \\
\hline CHEMBL1533029 & 688759 & 4.45 & 4.7432 & TRN & \\
\hline CHEMBL1431130 & 688759 & 4.45 & 4.8747 & TRN & \\
\hline CHEMBL1503104 & 688759 & 4.55 & 4.6399 & TRN & \\
\hline CHEMBL1383426 & 688759 & 5.0 & 5.0846 & TRN & \\
\hline CHEMBL1505601 & 688759 & 4.45 & 5.28 & TRN & \\
\hline CHEMBL239275 & 688759 & 5.3 & 5.5906 & TRN & \\
\hline CHEMBL1341349 & 688759 & 5.1 & 5.0098 & TRN & \\
\hline CHEMBL1561653 & 688759 & 4.65 & 4.8065 & TRN & \\
\hline CHEMBL1386978 & 688759 & 4.9 & 4.8901 & TRN & \\
\hline CHEMBL1456701 & 688759 & 5.5 & 5.684 & TRN & \\
\hline CHEMBL1508644 & 688759 & 4.75 & 4.8386 & TRN & \\
\hline CHEMBL1468601 & 688759 & 4.45 & 4.9688 & TST & \\
\hline CHEMBL1490336 & 688759 & 5.55 & 5.6372 & TRN & \\
\hline CHEMBL3351063 & 688759 & 5.05 & 4.9431 & TRN & \\
\hline CHEMBL1390303 & 688759 & 4.75 & 4.6037 & TST & \\
\hline CHEMBL1558277 & 688759 & 4.45 & 4.7506 & TRN & \\
\hline CHEMBL1306816 & 688759 & 4.65 & 4.4323 & TST & \\
\hline CHEMBL1468684 & 688759 & 4.6 & 4.8795 & TRN & \\
\hline CHEMBL3197863 & 688759 & 4.75 & 4.9093 & TRN & \\
\hline CHEMBL1533577 & 688759 & 5.3 & 4.8781 & TST & \\
\hline CHEMBL1377705 & 688759 & 4.45 & 5.064 & TRN & \\
\hline CHEMBL1486667 & 688759 & 5.85 & 5.0217 & TRN & \\
\hline CHEMBL1402123 & 688759 & 4.45 & 4.8192 & TST & \\
\hline CHEMBL1402750 & 688759 & 5.2 & 4.7164 & TST & \\
\hline CHEMBL595700 & 688759 & 4.95 & 4.9376 & TRN & \\
\hline CHEMBL3194151 & 688759 & 5.4 & 4.6553 & TRN & \\
\hline CHEMBL1444820 & 688759 & 5.05 & 5.0912 & TRN & \\
\hline CHEMBL460517 & 688759 & 4.8 & 5.0451 & TRN & \\
\hline CHEMBL1389650 & 688759 & 5.0 & 5.0401 & TRN & \\
\hline CHEMBL1380938 & 688759 & 4.75 & 4.8884 & TRN & \\
\hline CHEMBL1444703 & 688759 & 5.4 & 4.9768 & TRN & \\
\hline CHEMBL1472926 & 688759 & 6.6 & 4.9478 & TRN & \\
\hline CHEMBL1432115 & 688759 & 5.55 & 5.50899 & 99999999995 & TRN \\
\hline CHEMBL1457120 & 688759 & 5.55 & 4.9643 & TRN & \\
\hline CHEMBL1568247 & 688759 & 4.85 & 4.6614 & TRN & \\
\hline
\end{tabular}




\begin{tabular}{|c|c|c|c|c|c|}
\hline \multicolumn{6}{|c|}{ Supplemental Table s2.txt } \\
\hline CHEMBL1465630 & 688759 & 5.4 & 4.9661 & TRN & \\
\hline CHEMBL1502604 & 688759 & 4.45 & 4.5909 & TRN & \\
\hline CHEMBL1583180 & 688759 & 4.45 & 4.6279 & TRN & \\
\hline CHEMBL1456271 & 688759 & 4.45 & 5.0845 & TRN & \\
\hline CHEMBL1599423 & 688759 & 4.9 & 5.0939 & TRN & \\
\hline CHEMBL1976198 & 688759 & 4.5 & 4.6574 & TRN & \\
\hline CHEMBL1579963 & 688759 & 4.65 & 4.592 & TRN & \\
\hline CHEMBL1438771 & 688759 & 4.45 & 4.8064 & TRN & \\
\hline CHEMBL1403046 & 688759 & 5.35 & 4.7931 & TRN & \\
\hline CHEMBL1384249 & 688759 & 4.7 & 4.8191 & TRN & \\
\hline CHEMBL1481136 & 688759 & 6.1 & 4.8171 & TST & \\
\hline CHEMBL1356748 & 688759 & 5.35 & 5.2793 & TST & \\
\hline CHEMBL1533653 & 688759 & 4.45 & 4.9212 & TRN & \\
\hline CHEMBL1603386 & 688759 & 4.45 & 4.8244 & TRN & \\
\hline CHEMBL1418726 & 688759 & 4.45 & 4.8517 & TRN & \\
\hline CHEMBL1441408 & 688759 & 4.45 & 4.9768 & TST & \\
\hline CHEMBL1417243 & 688759 & 4.75 & 4.6632 & TRN & \\
\hline CHEMBL1976499 & 688759 & 4.45 & 4.8372 & TRN & \\
\hline CHEMBL1382820 & 688759 & 5.5 & 5.1728 & TST & \\
\hline CHEMBL1308147 & 688759 & 4.45 & 4.742 & TST & \\
\hline CHEMBL1612383 & 688759 & 5.2 & 5.307 & TRN & \\
\hline CHEMBL1530090 & 688759 & 4.7 & 5.4503 & TRN & \\
\hline CHEMBL1407295 & 688759 & 4.45 & 6.3297 & TST & \\
\hline CHEMBL1517521 & 688759 & 5.55 & 4.8874 & TRN & \\
\hline CHEMBL1544847 & 688759 & 5.55 & 5.0382 & TRN & \\
\hline CHEMBL1331485 & 688759 & 6.3 & 5.9275 & TRN & \\
\hline CHEMBL1329554 & 688759 & 5.25 & $5.4110 e$ & 00000000005 & TRN \\
\hline CHEMBL1361393 & 688759 & 4.8 & 4.8162 & TRN & \\
\hline CHEMBL1607550 & 688759 & 4.65 & 4.7307 & TST & \\
\hline CHEMBL 1479462 & 688759 & 4.9 & 5.1838 & TRN & \\
\hline CHEMBL1545542 & 688759 & 4.9 & 4.9596 & TRN & \\
\hline CHEMBL1484597 & 688759 & 4.85 & 4.6506 & TRN & \\
\hline CHEMBL1378755 & 688759 & 4.45 & 4.4577 & TST & \\
\hline CHEMBL1483475 & 688759 & 4.45 & 4.6282 & TRN & \\
\hline CHEMBL1543354 & 688759 & 6.0 & 5.5952 & TRN & \\
\hline CHEMBL1421149 & 688759 & 5.4 & 5.0914 & TRN & \\
\hline CHEMBL1342248 & 688759 & 4.45 & 4.8562 & TRN & \\
\hline CHEMBL1363471 & 688759 & 4.75 & 5.081 & TRN & \\
\hline CHEMBL1489273 & 688759 & 4.9 & 4.9801 & TST & \\
\hline CHEMBL1425456 & 688759 & 4.45 & 5.0833 & TRN & \\
\hline CHEMBL3190216 & 688759 & 4.85 & 4.725 & TRN & \\
\hline CHEMBL1534128 & 688759 & 4.65 & 4.7159 & TST & \\
\hline CHEMBL1421117 & 688759 & 4.85 & 4.9723 & TRN & \\
\hline CHEMBL461579 & 688759 & 6.0 & 5.7736 & TRN & \\
\hline CHEMBL1347933 & 688759 & 4.65 & 5.4862 & TRN & \\
\hline CHEMBL1547696 & 688759 & 4.45 & 4.7246 & TRN & \\
\hline CHEMBL1569063 & 688759 & 4.7 & 4.8943 & TRN & \\
\hline CHEMBL3198204 & 688759 & 4.45 & 4.6727 & TRN & \\
\hline
\end{tabular}




\begin{tabular}{|c|c|c|c|c|c|}
\hline & & \multicolumn{4}{|c|}{ Supplemental Table S2.txt } \\
\hline CHEMBL1380826 & 688759 & 5.15 & 5.1655 & TRN & \\
\hline CHEMBL1560550 & 688759 & 4.5 & 5.2803 & TRN & \\
\hline CHEMBL1430601 & 688759 & 4.45 & 4.6535 & TST & \\
\hline CHEMBL1441415 & 688759 & 4.8 & 4.57100 & 0000000001 & TRN \\
\hline CHEMBL1965415 & 688759 & 5.4 & 5.3531 & TRN & \\
\hline CHEMBL1600720 & 688759 & 6.2 & 4.9574 & TRN & \\
\hline CHEMBL1335855 & 688759 & 4.95 & 5.0854 & TRN & \\
\hline CHEMBL1344775 & 688759 & 4.45 & 4.9962 & TRN & \\
\hline CHEMBL3193038 & 688759 & 4.45 & 4.8421 & TRN & \\
\hline CHEMBL 1487608 & 688759 & 4.45 & 4.6932 & TRN & \\
\hline CHEMBL1322795 & 688759 & 4.5 & 4.7128 & TST & \\
\hline CHEMBL1438346 & 688759 & 5.0 & 4.9425 & TRN & \\
\hline CHEMBL1576310 & 688759 & 6.95 & 4.7994 & TST & \\
\hline CHEMBL1384253 & 688759 & 5.55 & 5.3235 & TST & \\
\hline CHEMBL1358939 & 688759 & 5.0 & 5.1701 & TRN & \\
\hline CHEMBL1595509 & 688759 & 4.45 & 5.1586 & TRN & \\
\hline CHEMBL1607585 & 688759 & 4.55 & 4.6115 & TST & \\
\hline CHEMBL1443692 & 688759 & 4.45 & 4.80399 & 9999999999 & TRN \\
\hline CHEMBL1554531 & 688759 & 4.45 & 4.8632 & TST & \\
\hline CHEMBL1474479 & 688759 & 5.95 & 5.5227 & TRN & \\
\hline CHEMBL 2369166 & 688759 & 4.8 & 4.7732 & TST & \\
\hline CHEMBL1568078 & 688759 & 5.7 & 5.1095 & TRN & \\
\hline CHEMBL1537086 & 688759 & 5.5 & 5.5728 & TRN & \\
\hline CHEMBL1308972 & 688759 & 4.65 & 4.9679 & TRN & \\
\hline CHEMBL3193139 & 688759 & 6.0 & 5.5148 & TRN & \\
\hline CHEMBL1549221 & 688759 & 5.6 & 5.6357 & TRN & \\
\hline CHEMBL1547064 & 688759 & 5.25 & 4.9241 & TRN & \\
\hline CHEMBL1376586 & 688759 & 4.75 & 5.1663 & TRN & \\
\hline CHEMBL1507251 & 688759 & 6.2 & 5.6144 & TRN & \\
\hline CHEMBL1546956 & 688759 & 5.5 & 4.6959 & TRN & \\
\hline CHEMBL1574277 & 688759 & 5.15 & 4.699 & TRN & \\
\hline CHEMBL1310816 & 688759 & 5.9 & 5.6373 & TRN & \\
\hline CHEMBL1475990 & 688759 & 5.0 & 4.8411 & TRN & \\
\hline CHEMBL1407612 & 688759 & 5.0 & 4.6949 & TST & \\
\hline CHEMBL1497989 & 688759 & 4.5 & 4.8674 & TRN & \\
\hline CHEMBL1544740 & 688759 & 4.7 & 4.9684 & TRN & \\
\hline CHEMBL1318817 & 688759 & 4.6 & 4.6387 & TRN & \\
\hline CHEMBL1466396 & 688759 & 4.45 & 4.6248 & TRN & \\
\hline CHEMBL1427169 & 688759 & 4.5 & 4.6514 & TST & \\
\hline CHEMBL1450386 & 688759 & 4.95 & 5.1367 & TRN & \\
\hline CHEMBL1328174 & 688759 & 4.8 & 4.9252 & TRN & \\
\hline CHEMBL1600759 & 688759 & 4.45 & 4.8574 & TRN & \\
\hline CHEMBL1360461 & 688759 & 4.45 & 4.7832 & TRN & \\
\hline CHEMBL1997425 & 688759 & 5.35 & 4.9273 & TRN & \\
\hline CHEMBL1402650 & 688759 & 4.45 & 4.6051 & TRN & \\
\hline CHEMBL1312676 & 688759 & 5.45 & 5.2176 & TRN & \\
\hline CHEMBL 1349010 & 688759 & 4.45 & 4.5741 & TST & \\
\hline CHEMBL1455638 & 688759 & 4.85 & 4.7646 & TRN & \\
\hline
\end{tabular}




\begin{tabular}{|c|c|c|c|c|}
\hline \multicolumn{5}{|c|}{ Supplemental Table S2.txt } \\
\hline CHEMBL3194857 & 688759 & 4.75 & 4.6588 & TRN \\
\hline CHEMBL1374616 & 688759 & 5.5 & 5.2315 & TRN \\
\hline CHEMBL1384796 & 688759 & 5.3 & 5.1784 & TRN \\
\hline CHEMBL 3189743 & 688759 & 5.5 & 5.8015 & TRN \\
\hline CHEMBL1382041 & 688759 & 7.0501 & 5.0753 & TRN \\
\hline CHEMBL1578962 & 688759 & 4.75 & 4.9022 & TRN \\
\hline CHEMBL1578064 & 688759 & 4.45 & 4.5424 & TRN \\
\hline CHEMBL1373211 & 688759 & 4.85 & 5.0474 & TRN \\
\hline CHEMBL1328285 & 688759 & 5.5 & 5.0794 & TRN \\
\hline CHEMBL1400437 & 688759 & 4.55 & 4.8329 & TST \\
\hline CHEMBL1592975 & 688759 & 4.8 & 4.921 & TST \\
\hline CHEMBL1604002 & 688759 & 4.65 & 4.7641 & TST \\
\hline CHEMBL1579916 & 688759 & 4.55 & 4.7052 & TST \\
\hline CHEMBL3198639 & 688759 & 4.85 & 4.7505 & TST \\
\hline CHEMBL1405419 & 688759 & 4.85 & 4.7586 & TRN \\
\hline CHEMBL1543386 & 688759 & 5.2 & 5.2417 & TRN \\
\hline CHEMBL1456116 & 688759 & 4.65 & 4.8381 & TST \\
\hline CHEMBL1556884 & 688759 & 4.45 & 4.9211 & TRN \\
\hline CHEMBL1466756 & 688759 & 4.8 & 4.6513 & TST \\
\hline CHEMBL1557320 & 688759 & 4.9 & 5.0745 & TST \\
\hline CHEMBL3195172 & 688759 & 4.65 & 4.5603 & TRN \\
\hline CHEMBL1471636 & 688759 & 4.6 & 4.7786 & TRN \\
\hline CHEMBL1483287 & 688759 & 6.2 & 5.5846 & TRN \\
\hline CHEMBL1422861 & 688759 & 5.75 & 4.9539 & TRN \\
\hline CHEMBL1461730 & 688759 & 6.25 & 5.7303 & TRN \\
\hline CHEMBL1310577 & 688759 & 4.85 & 4.8212 & TRN \\
\hline CHEMBL1578163 & 688759 & 5.25 & 5.3088 & TRN \\
\hline CHEMBL1499359 & 688759 & 5.2 & 5.2169 & TRN \\
\hline CHEMBL1379419 & 688759 & 4.45 & 4.7756 & TST \\
\hline CHEMBL3212766 & 688759 & 4.95 & 5.0248 & TRN \\
\hline CHEMBL 2003195 & 688759 & 5.5 & 5.2163 & TST \\
\hline CHEMBL1565252 & 688759 & 4.6 & 4.5821 & TRN \\
\hline CHEMBL1320643 & 688759 & 4.6 & 5.1337 & TRN \\
\hline CHEMBL1532364 & 688759 & 5.4 & 4.9426 & TRN \\
\hline CHEMBL1339003 & 688759 & 5.5 & 4.7853 & TRN \\
\hline CHEMBL1599481 & 688759 & 4.45 & 4.5476 & TST \\
\hline CHEMBL 251603 & 688759 & 4.8 & 4.9827 & TRN \\
\hline CHEMBL600255 & 688759 & 4.45 & 4.4172 & TRN \\
\hline CHEMBL1432873 & 688759 & 5.25 & 4.8004 & TRN \\
\hline CHEMBL1392533 & 688759 & 5.35 & 4.8001 & TRN \\
\hline CHEMBL1574944 & 688759 & 4.45 & 4.6673 & TST \\
\hline CHEMBL1537171 & 688759 & 6.9 & 4.2917 & TST \\
\hline CHEMBL3190632 & 688759 & 5.0 & 4.8622 & TRN \\
\hline CHEMBL1468929 & 688759 & 5.7 & 5.5581 & TST \\
\hline CHEMBL1581173 & 688759 & 4.95 & 4.9918 & TRN \\
\hline CHEMBL1360965 & 688759 & 4.45 & 5.0134 & TST \\
\hline CHEMBL1326787 & 688759 & 4.85 & 5.3391 & TST \\
\hline CHEMBL1969548 & 688759 & 4.75 & 4.7215 & TRN \\
\hline
\end{tabular}




\begin{tabular}{|c|c|c|c|c|}
\hline \multicolumn{5}{|c|}{ Supplemental Table S2.txt } \\
\hline CHEMBL1537063 & 688759 & 4.75 & 4.9802 & TRN \\
\hline CHEMBL1309957 & 688759 & 5.6 & 5.8102 & TRN \\
\hline CHEMBL1409486 & 688759 & 4.95 & 4.7047 & TST \\
\hline CHEMBL598885 & 688759 & 4.9 & 5.3334 & TRN \\
\hline CHEMBL 3197844 & 688759 & 5.4 & 4.9726 & TRN \\
\hline CHEMBL1402435 & 688759 & 5.05 & 5.0292 & TST \\
\hline CHEMBL1423814 & 688759 & 5.25 & 4.9401 & TRN \\
\hline CHEMBL1556254 & 688759 & 5.45 & 5.074 & TRN \\
\hline CHEMBL3213935 & 688759 & 4.45 & 4.7328 & TRN \\
\hline CHEMBL1555363 & 688759 & 5.35 & 4.76 & TRN \\
\hline CHEMBL1599901 & 688759 & 4.45 & 4.8123 & TRN \\
\hline CHEMBL1516937 & 688759 & 4.85 & 4.633 & TRN \\
\hline CHEMBL1411470 & 688759 & 4.5 & 4.9936 & TRN \\
\hline CHEMBL1388646 & 688759 & 5.65 & 5.0308 & TRN \\
\hline CHEMBL1443052 & 688759 & 4.45 & 4.5437 & TRN \\
\hline CHEMBL1509103 & 688759 & 4.8 & 4.7581 & TST \\
\hline CHEMBL1578482 & 688759 & 5.35 & 5.1194 & TRN \\
\hline CHEMBL1313502 & 688759 & 4.45 & 4.8223 & TST \\
\hline CHEMBL1322267 & 688759 & 5.2 & 4.8612 & TST \\
\hline CHEMBL3194618 & 688759 & 5.9 & 5.61 & TRN \\
\hline CHEMBL1347499 & 688759 & 4.45 & 4.6475 & TRN \\
\hline CHEMBL88272 & 688759 & 4.8 & 4.7316 & TST \\
\hline CHEMBL1566928 & 688759 & 5.4 & 4.6168 & TST \\
\hline CHEMBL1595476 & 688759 & 4.75 & 4.874 & TRN \\
\hline CHEMBL1478435 & 688759 & 4.95 & 4.9142 & TST \\
\hline CHEMBL1456496 & 688759 & 5.65 & 5.0226 & TRN \\
\hline CHEMBL1490845 & 688759 & 4.45 & 4.6712 & TRN \\
\hline CHEMBL1420331 & 688759 & 4.45 & 4.8183 & TRN \\
\hline CHEMBL1494629 & 688759 & 4.45 & 4.5117 & TRN \\
\hline CHEMBL1384998 & 688759 & 4.45 & 4.9823 & TRN \\
\hline CHEMBL1163763 & 688759 & 4.95 & 4.8923 & TST \\
\hline CHEMBL1417295 & 688759 & 5.55 & 4.9668 & TRN \\
\hline CHEMBL1502997 & 688759 & 5.5 & 5.1079 & TRN \\
\hline CHEMBL1391765 & 688759 & 4.45 & 4.6482 & TRN \\
\hline CHEMBL1380058 & 688759 & 4.45 & 4.6722 & TST \\
\hline CHEMBL1494058 & 688759 & 6.0 & 5.0087 & TRN \\
\hline CHEMBL1567271 & 688759 & 5.4 & 5.0169 & TRN \\
\hline CHEMBL1398680 & 688759 & 4.95 & 4.8218 & TRN \\
\hline CHEMBL1335453 & 688759 & 4.6 & 4.8359 & TST \\
\hline CHEMBL1324054 & 688759 & 4.6 & 4.7136 & TRN \\
\hline CHEMBL1540389 & 688759 & 5.3 & 5.1975 & TRN \\
\hline CHEMBL1467294 & 688759 & 4.45 & 4.8521 & TST \\
\hline CHEMBL1469193 & 688759 & 4.45 & 4.9227 & TRN \\
\hline CHEMBL1412386 & 688759 & 4.45 & 4.7416 & TRN \\
\hline CHEMBL1570012 & 688759 & 4.45 & 4.7775 & TST \\
\hline CHEMBL1425497 & 688759 & 4.55 & 4.5904 & TRN \\
\hline CHEMBL1466460 & 688759 & 5.0 & 4.8573 & TRN \\
\hline CHEMBL1575781 & 688759 & 4.45 & 5.0971 & TRN \\
\hline
\end{tabular}




\begin{tabular}{|c|c|c|c|c|}
\hline \multicolumn{5}{|c|}{ Supplemental Table S2.txt } \\
\hline CHEMBL1302028 & 688759 & 4.6 & 4.6989 & TRN \\
\hline CHEMBL1446978 & 688759 & 5.7 & 4.8965 & TST \\
\hline CHEMBL1431231 & 688759 & 4.9 & 4.9771 & TRN \\
\hline CHEMBL1371107 & 688759 & 4.8 & 4.6085 & TRN \\
\hline CHEMBL1566964 & 688759 & 4.45 & 4.7209 & TST \\
\hline CHEMBL1565349 & 688759 & 5.5 & 4.8587 & TRN \\
\hline CHEMBL1486569 & 688759 & 5.3 & 5.0875 & TRN \\
\hline CHEMBL 3190041 & 688759 & 4.7 & 4.9048 & TST \\
\hline CHEMBL1600846 & 688759 & 5.25 & 5.0459 & TST \\
\hline CHEMBL1491145 & 688759 & 4.45 & 4.8086 & TRN \\
\hline CHEMBL1374947 & 688759 & 5.0 & 4.9845 & TRN \\
\hline CHEMBL1529701 & 688759 & 4.75 & 4.7197 & TRN \\
\hline CHEMBL3193439 & 688759 & 4.45 & 4.4919 & TRN \\
\hline CHEMBL1732228 & 688759 & 4.45 & 4.706 & TRN \\
\hline CHEMBL1331753 & 688759 & 5.4 & 5.6759 & TRN \\
\hline CHEMBL3144885 & 688759 & 5.25 & 4.9984 & TRN \\
\hline CHEMBL1601735 & 688759 & 4.55 & 4.7405 & TRN \\
\hline CHEMBL 2001474 & 688759 & 4.8 & 4.8864 & TRN \\
\hline CHEMBL1323693 & 688759 & 4.45 & 4.9205 & TST \\
\hline CHEMBL1537850 & 688759 & 4.95 & 4.846 & TRN \\
\hline CHEMBL1300140 & 688759 & 4.45 & 4.6386 & TRN \\
\hline CHEMBL1337897 & 688759 & 4.45 & 4.9365 & TRN \\
\hline CHEMBL1369506 & 688759 & 5.0 & 4.9078 & TRN \\
\hline CHEMBL1455854 & 688759 & 5.4 & 4.856 & TRN \\
\hline CHEMBL1576307 & 688759 & 4.9 & 5.0392 & TRN \\
\hline CHEMBL1423439 & 688759 & 4.65 & 4.7482 & TRN \\
\hline CHEMBL1535189 & 688759 & 4.75 & 4.8665 & TST \\
\hline CHEMBL3194161 & 688759 & 5.3 & 4.8804 & TRN \\
\hline CHEMBL1311628 & 688759 & 5.1 & 4.6476 & TRN \\
\hline CHEMBL1518454 & 688759 & 4.75 & 4.7719 & TRN \\
\hline CHEMBL1443952 & 688759 & 4.45 & 5.5144 & TST \\
\hline CHEMBL1502235 & 688759 & 4.45 & 4.8315 & TRN \\
\hline CHEMBL311070 & 688759 & 5.25 & 5.0811 & TRN \\
\hline CHEMBL1565221 & 688759 & 6.05 & 4.8891 & TRN \\
\hline CHEMBL1423518 & 688759 & 4.6 & 4.659 & TRN \\
\hline CHEMBL1491946 & 688759 & 6.05 & 4.5562 & TRN \\
\hline CHEMBL1596810 & 688759 & 5.15 & 4.7231 & TRN \\
\hline CHEMBL1443237 & 688759 & 4.45 & 4.7959 & TRN \\
\hline CHEMBL1502227 & 688759 & 4.45 & 4.6547 & TRN \\
\hline CHEMBL1533233 & 688759 & 4.45 & 4.6914 & TRN \\
\hline CHEMBL1331369 & 688759 & 4.75 & 4.8075 & TRN \\
\hline CHEMBL1573351 & 688759 & 4.95 & 4.9335 & TRN \\
\hline CHEMBL1470605 & 688759 & 4.8 & 4.7512 & TRN \\
\hline CHEMBL1550246 & 688759 & 4.45 & 4.8253 & TRN \\
\hline CHEMBL 2005486 & 688759 & 4.7 & 4.7529 & TRN \\
\hline CHEMBL1464300 & 688759 & 4.45 & 4.7479 & TST \\
\hline CHEMBL1330860 & 688759 & 5.45 & 5.376 & TRN \\
\hline CHEMBL1408450 & 688759 & 5.3 & 5.1583 & TRN \\
\hline
\end{tabular}




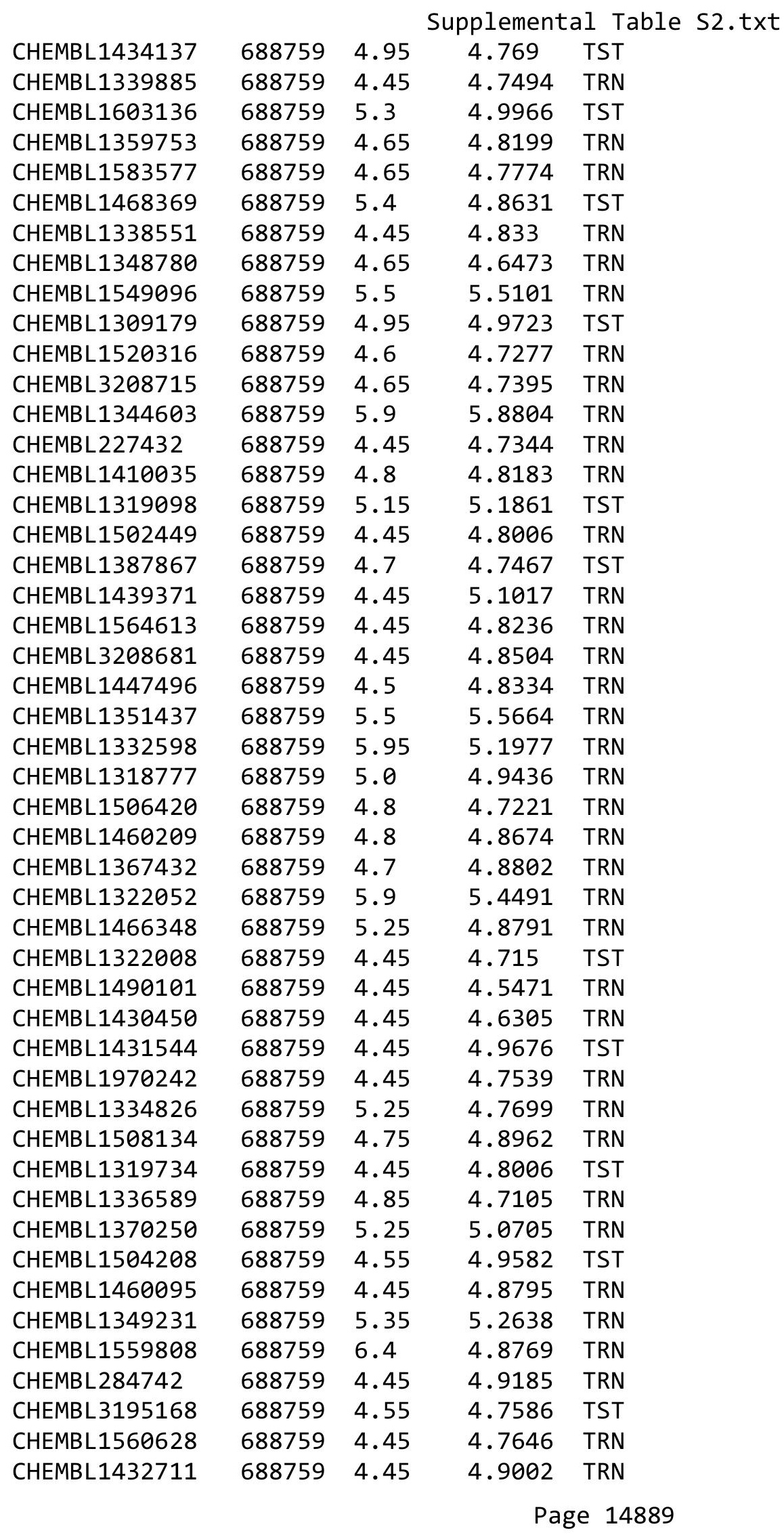




\begin{tabular}{|c|c|c|c|c|}
\hline \multicolumn{5}{|c|}{ Supplemental Table s2.txt } \\
\hline CHEMBL1496375 & 688759 & 5.4 & 5.1196 & TRN \\
\hline CHEMBL1409902 & 688759 & 5.25 & 4.7496 & TRN \\
\hline CHEMBL1524790 & 688759 & 4.45 & 4.6318 & TRN \\
\hline CHEMBL1586019 & 688759 & 5.5 & 4.8414 & TRN \\
\hline CHEMBL601184 & 688759 & 4.45 & 4.8748 & TRN \\
\hline CHEMBL1497433 & 688759 & 5.55 & 4.8792 & TRN \\
\hline CHEMBL1421736 & 688759 & 4.7 & 4.8468 & TRN \\
\hline CHEMBL1439909 & 688759 & 5.15 & 5.4032 & TRN \\
\hline CHEMBL1599360 & 688759 & 4.95 & 5.4466 & TRN \\
\hline CHEMBL1388944 & 688759 & 4.45 & 4.6373 & TRN \\
\hline CHEMBL65 & 688759 & 6.0 & 6.0391 & TRN \\
\hline CHEMBL 3198618 & 688759 & 4.95 & 5.2998 & TRN \\
\hline CHEMBL1610681 & 688759 & 4.65 & 4.762 & TRN \\
\hline CHEMBL1378788 & 688759 & 4.5 & 4.8881 & TRN \\
\hline CHEMBL1351044 & 688759 & 5.45 & 5.0837 & TST \\
\hline CHEMBL1550934 & 688759 & 4.65 & 5.0163 & TST \\
\hline CHEMBL1481942 & 688759 & 6.45 & 5.1309 & TRN \\
\hline CHEMBL3211692 & 688759 & 4.75 & 4.7556 & TST \\
\hline CHEMBL1361486 & 688759 & 4.6 & 4.8868 & TRN \\
\hline CHEMBL1508782 & 688759 & 4.55 & 4.8785 & TRN \\
\hline CHEMBL1573208 & 688759 & 4.9 & 4.6417 & TST \\
\hline CHEMBL1503778 & 688759 & 4.6 & 4.6221 & TST \\
\hline CHEMBL1307735 & 688759 & 5.05 & 5.16 & TRN \\
\hline CHEMBL3208415 & 688759 & 5.75 & 5.4433 & TRN \\
\hline CHEMBL1460561 & 688759 & 4.6 & 4.6046 & TRN \\
\hline CHEMBL1380594 & 688759 & 4.45 & 4.8698 & TRN \\
\hline CHEMBL3196408 & 688759 & 5.0 & 5.1739 & TRN \\
\hline CHEMBL1300774 & 688759 & 5.25 & 4.8156 & TRN \\
\hline CHEMBL1534899 & 688759 & 5.05 & 4.6148 & TRN \\
\hline CHEMBL1549026 & 688759 & 4.95 & 4.8016 & TRN \\
\hline CHEMBL1379160 & 688759 & 4.7 & 4.7955 & TRN \\
\hline CHEMBL1462919 & 688759 & 4.95 & 4.9308 & TST \\
\hline CHEMBL1084720 & 688759 & 4.45 & 4.8569 & TST \\
\hline CHEMBL1495112 & 688759 & 4.75 & 4.9109 & TRN \\
\hline CHEMBL1495991 & 688759 & 4.95 & 5.102 & TST \\
\hline CHEMBL1509813 & 688759 & 6.25 & 4.7563 & TST \\
\hline CHEMBL1463540 & 688759 & 4.7 & 4.5521 & TST \\
\hline CHEMBL1319418 & 688759 & 4.45 & 4.7575 & TRN \\
\hline CHEMBL1585020 & 688759 & 4.65 & 4.7835 & TRN \\
\hline CHEMBL1361127 & 688759 & 5.2 & 4.9393 & TST \\
\hline CHEMBL1299470 & 688759 & 5.45 & 4.5031 & TRN \\
\hline CHEMBL1349525 & 688759 & 5.25 & 4.8652 & TST \\
\hline CHEMBL1353991 & 688759 & 5.65 & 4.8349 & TRN \\
\hline CHEMBL1610203 & 688759 & 6.2 & $5.7020 e$ & 3000000001 \\
\hline CHEMBL1382999 & 688759 & 5.5 & 4.883 & TST \\
\hline CHEMBL1584869 & 688759 & 4.65 & 4.9013 & TST \\
\hline CHEMBL3196703 & 688759 & 4.8 & 4.9271 & TRN \\
\hline CHEMBL1369747 & 688759 & 5.35 & 5.4381 & TRN \\
\hline
\end{tabular}

TRN 


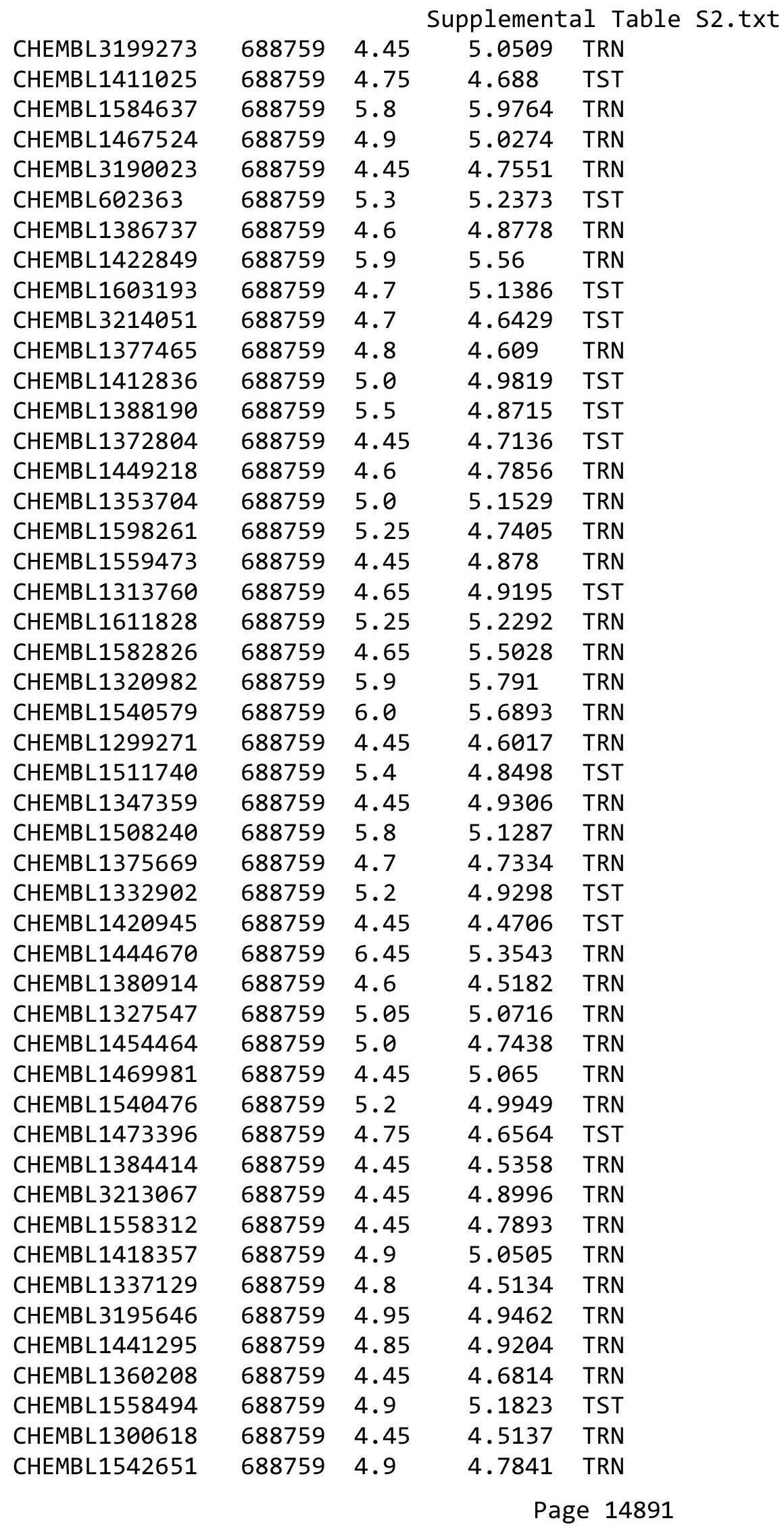




\begin{tabular}{|c|c|c|c|c|}
\hline \multicolumn{5}{|c|}{ Supplemental Table S2.txt } \\
\hline CHEMBL1337347 & 688759 & 5.15 & 5.4962 & TRN \\
\hline CHEMBL1375473 & 688759 & 4.5 & 5.2393 & TRN \\
\hline CHEMBL1433108 & 688759 & 4.45 & 4.874 & TRN \\
\hline CHEMBL1461981 & 688759 & 6.45 & 5.796 & TRN \\
\hline CHEMBL1370394 & 688759 & 4.65 & 4.7851 & TRN \\
\hline CHEMBL1524353 & 688759 & 4.45 & 4.6349 & TST \\
\hline CHEMBL1362026 & 688759 & 4.65 & 4.8655 & TST \\
\hline CHEMBL1608386 & 688759 & 4.6 & 4.7399 & TRN \\
\hline CHEMBL1332984 & 688759 & 4.65 & 4.5265 & TRN \\
\hline CHEMBL1455814 & 688759 & 5.05 & 5.1068 & TRN \\
\hline CHEMBL589703 & 688759 & 4.45 & 4.6335 & TRN \\
\hline CHEMBL1392367 & 688759 & 4.75 & 4.7599 & TRN \\
\hline CHEMBL3192897 & 688759 & 4.65 & 4.8437 & TST \\
\hline CHEMBL 3194541 & 688759 & 5.25 & 4.9621 & TST \\
\hline CHEMBL146525 & 688759 & 5.0 & 4.8418 & TST \\
\hline CHEMBL1334616 & 688759 & 5.2 & 5.0627 & TRN \\
\hline CHEMBL1300144 & 688759 & 4.45 & 4.7786 & TST \\
\hline CHEMBL3189829 & 688759 & 4.5 & 4.6289 & TRN \\
\hline CHEMBL 3190877 & 688759 & 4.45 & 4.5125 & TRN \\
\hline CHEMBL1331206 & 688759 & 4.45 & 4.7105 & TRN \\
\hline CHEMBL1362297 & 688759 & 4.45 & 4.9315 & TRN \\
\hline CHEMBL1353522 & 688759 & 5.3 & 5.0032 & TST \\
\hline CHEMBL1416298 & 688759 & 4.45 & 4.7885 & TST \\
\hline CHEMBL1561240 & 688759 & 4.6 & 4.3323 & TRN \\
\hline CHEMBL1427709 & 688759 & 4.45 & 5.0862 & TRN \\
\hline CHEMBL1386857 & 688759 & 4.45 & 4.7308 & TST \\
\hline CHEMBL1528930 & 688759 & 5.3 & 5.16 & TRN \\
\hline CHEMBL3194527 & 688759 & 4.45 & 5.0538 & TST \\
\hline CHEMBL1390938 & 688759 & 4.65 & 4.9674 & TRN \\
\hline CHEMBL1559947 & 688759 & 4.45 & 4.856 & TRN \\
\hline CHEMBL1321343 & 688759 & 4.65 & 4.6282 & TRN \\
\hline CHEMBL1301586 & 688759 & 5.4 & 4.9401 & TRN \\
\hline CHEMBL1305523 & 688759 & 4.45 & 4.5392 & TRN \\
\hline CHEMBL1333553 & 688759 & 4.45 & 4.8238 & TRN \\
\hline CHEMBL1431204 & 688759 & 4.95 & 4.8196 & TRN \\
\hline CHEMBL1352270 & 688759 & 5.5 & 5.1021 & TRN \\
\hline CHEMBL1442273 & 688759 & 8.301 & 4.9241 & TRN \\
\hline CHEMBL1546383 & 688759 & 4.45 & 4.9721 & TRN \\
\hline CHEMBL1407661 & 688759 & 4.75 & 4.7738 & TST \\
\hline CHEMBL1549849 & 688759 & 4.95 & 5.2706 & TRN \\
\hline CHEMBL1423263 & 688759 & 4.85 & 4.7574 & TST \\
\hline CHEMBL1333842 & 688759 & 4.75 & 4.6118 & TRN \\
\hline CHEMBL1546489 & 688759 & 8.4949 & 4.9982 & TST \\
\hline CHEMBL1606780 & 688759 & 4.45 & 4.9481 & TRN \\
\hline CHEMBL1348119 & 688759 & 6.0 & 5.5098 & TRN \\
\hline CHEMBL1392225 & 688759 & 4.6 & 4.829 & TRN \\
\hline CHEMBL 2007000 & 688759 & 4.45 & 5.2531 & TRN \\
\hline CHEMBL3207619 & 688759 & 6.2 & 5.2637 & TRN \\
\hline
\end{tabular}




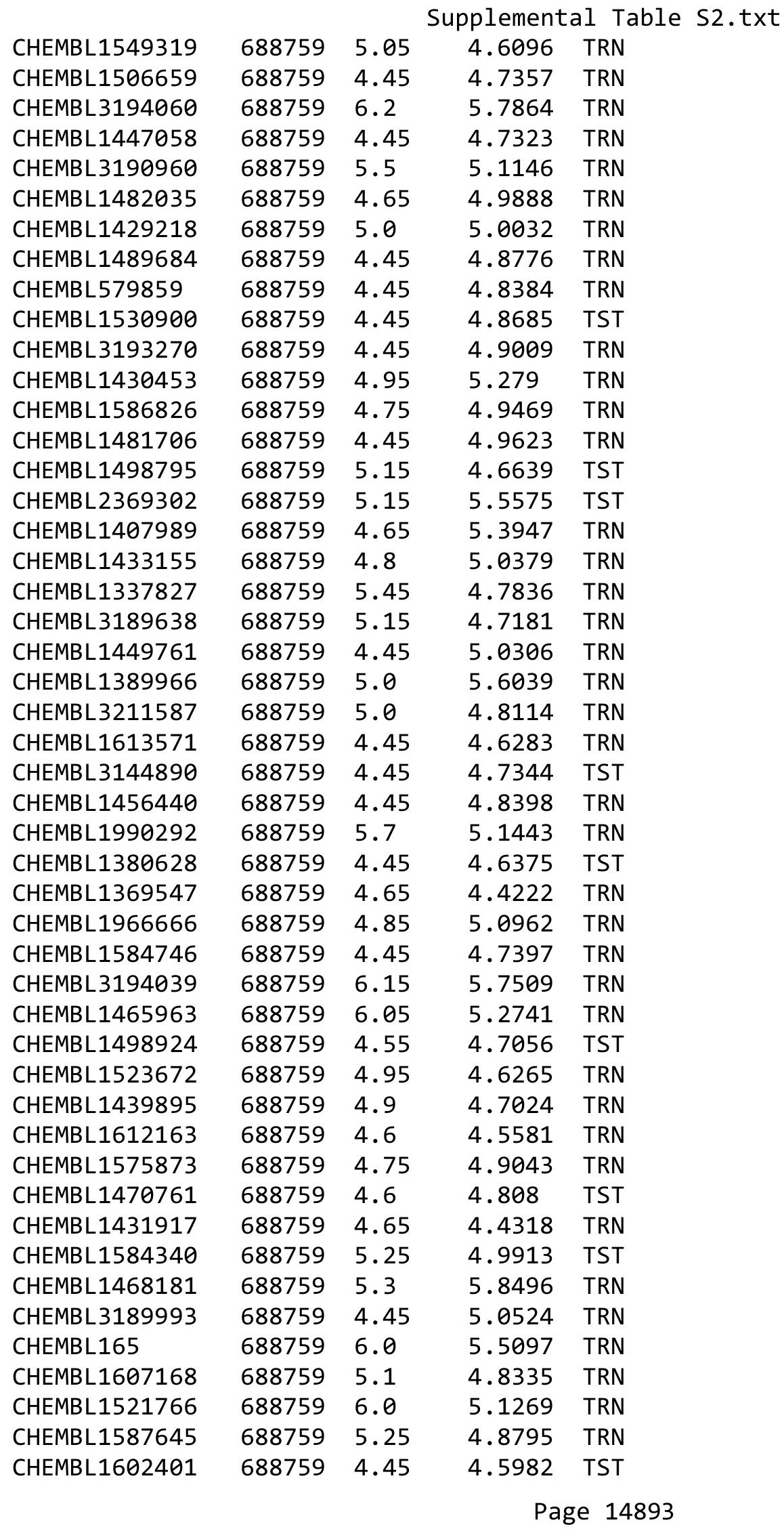




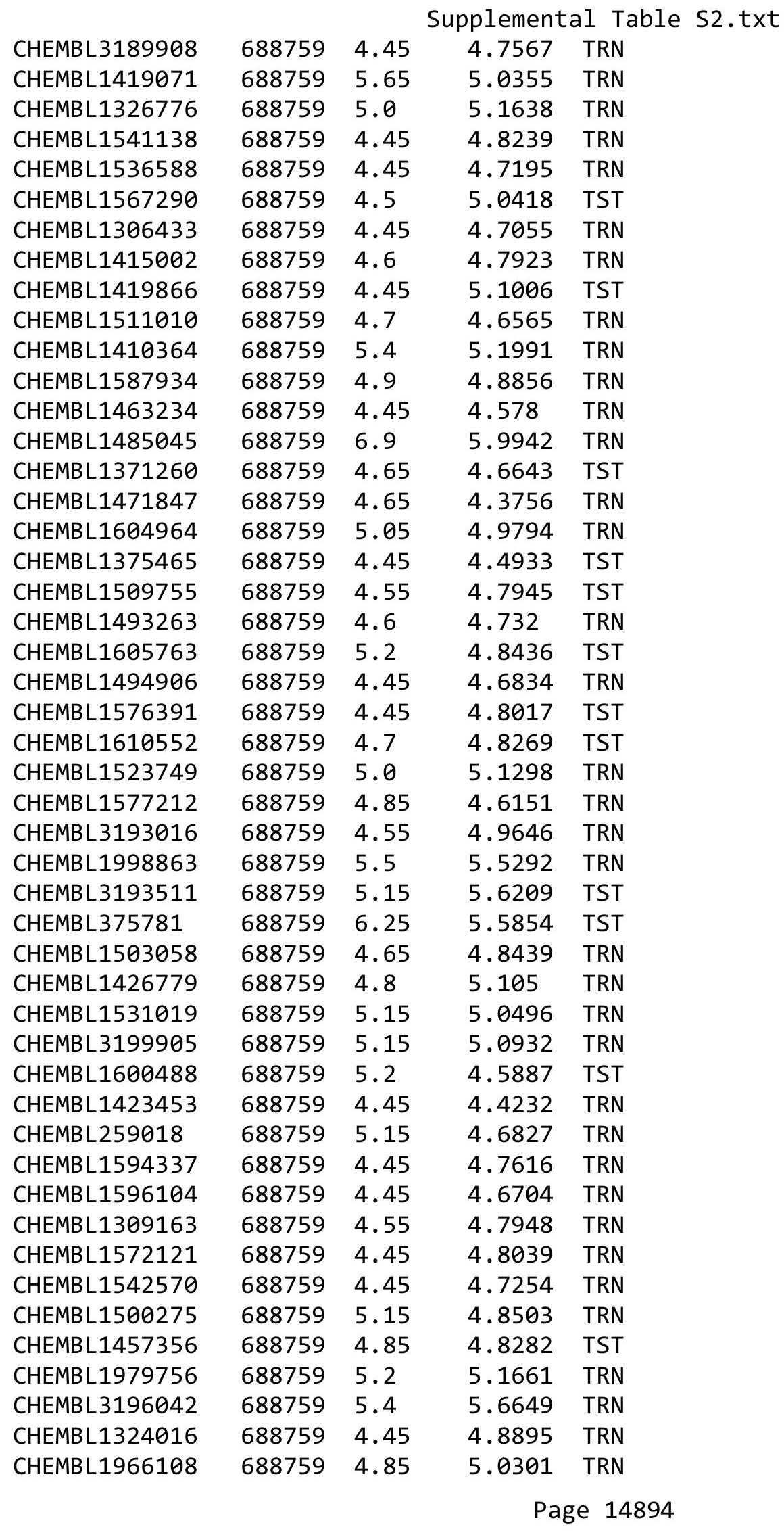




\begin{tabular}{|c|c|c|c|c|c|}
\hline & & \multicolumn{4}{|c|}{ Supplemental Table s2.txt } \\
\hline CHEMBL1442773 & 688759 & 4.75 & 5.0451 & TST & \\
\hline CHEMBL 2005572 & 688759 & 4.8 & 4.8426 & TRN & \\
\hline CHEMBL1516070 & 688759 & 4.8 & 4.9516 & TRN & \\
\hline CHEMBL 3214463 & 688759 & 5.25 & 4.8404 & TST & \\
\hline CHEMBL1524592 & 688759 & 4.65 & 5.2188 & TRN & \\
\hline CHEMBL1517564 & 688759 & 5.45 & 5.2095 & TRN & \\
\hline CHEMBL 3145048 & 688759 & 5.55 & 5.563 & TRN & \\
\hline CHEMBL1501426 & 688759 & 5.0 & 4.958 & TRN & \\
\hline CHEMBL1565344 & 688759 & 5.5 & 5.0813 & TRN & \\
\hline CHEMBL1612106 & 688759 & 4.9 & 5.2353 & TRN & \\
\hline CHEMBL 3192217 & 688759 & 4.75 & 4.9189 & TRN & \\
\hline CHEMBL3208451 & 688759 & 6.05 & 5.3748 & TRN & \\
\hline CHEMBL3208836 & 688759 & 4.8 & 5.0117 & TRN & \\
\hline CHEMBL1469317 & 688759 & 5.8 & 5.5038 & TRN & \\
\hline CHEMBL1393197 & 688759 & 5.25 & 4.7036 & TRN & \\
\hline CHEMBL 29542 & 688759 & 4.95 & 5.0702 & TRN & \\
\hline CHEMBL1586715 & 688759 & 5.0 & 5.1205 & TRN & \\
\hline CHEMBL1519564 & 688759 & 4.45 & 5.0344 & TRN & \\
\hline CHEMBL1431340 & 688759 & 5.0 & 5.7426 & TRN & \\
\hline CHEMBL1508228 & 688759 & 4.95 & 4.6381 & TRN & \\
\hline CHEMBL1329935 & 688759 & 4.8 & 4.654 & TRN & \\
\hline CHEMBL1607858 & 688759 & 4.85 & 4.7952 & TRN & \\
\hline CHEMBL1482845 & 688759 & 5.35 & 5.36600 & 00000000005 & TRN \\
\hline CHEMBL1559139 & 688759 & 4.45 & 4.6824 & TST & \\
\hline CHEMBL1577720 & 688759 & 4.95 & 5.0573 & TST & \\
\hline CHEMBL1325898 & 688759 & 4.45 & 4.6625 & TRN & \\
\hline CHEMBL1540984 & 688759 & 4.45 & 4.8455 & TRN & \\
\hline CHEMBL1546239 & 688759 & 4.45 & 4.784 & TST & \\
\hline CHEMBL1396907 & 688759 & 4.45 & 4.6542 & TST & \\
\hline CHEMBL1412303 & 688759 & 5.05 & 5.1186 & TRN & \\
\hline CHEMBL1534675 & 688759 & 4.5 & 4.9258 & TRN & \\
\hline CHEMBL1499622 & 688759 & 4.45 & 4.8862 & TST & \\
\hline CHEMBL1489954 & 688759 & 5.25 & 4.9639 & TST & \\
\hline CHEMBL1547314 & 688759 & 5.2 & 5.0419 & TRN & \\
\hline CHEMBL1472513 & 688759 & 5.25 & 4.962 & TRN & \\
\hline CHEMBL1527364 & 688759 & 4.65 & 4.9038 & TRN & \\
\hline CHEMBL1441551 & 688759 & 4.45 & 4.8532 & TRN & \\
\hline CHEMBL1518672 & 688759 & 5.85 & 5.4796 & TRN & \\
\hline CHEMBL1536441 & 688759 & 4.45 & 4.6799 & TRN & \\
\hline CHEMBL1441918 & 688759 & 4.95 & 4.8045 & TST & \\
\hline CHEMBL1393312 & 688759 & 4.45 & 4.5275 & TRN & \\
\hline CHEMBL1448849 & 688759 & 4.45 & 4.7792 & TRN & \\
\hline CHEMBL1330975 & 688759 & 5.25 & 4.9392 & TRN & \\
\hline CHEMBL 3212728 & 688759 & 4.45 & 4.5927 & TRN & \\
\hline CHEMBL1402549 & 688759 & 5.3 & 5.102 & TRN & \\
\hline CHEMBL1541804 & 688759 & 4.45 & 4.8174 & TST & \\
\hline CHEMBL1524805 & 688759 & 4.95 & 4.8684 & TST & \\
\hline CHEMBL1986678 & 688759 & 5.4 & 5.4039 & TRN & \\
\hline
\end{tabular}




\begin{tabular}{|c|c|c|c|c|c|}
\hline \multicolumn{6}{|c|}{ Supplemental Table s2.txt } \\
\hline CHEMBL1523429 & 688759 & 4.8 & 4.8656 & TRN & \\
\hline CHEMBL1504104 & 688759 & 4.45 & 4.8245 & TRN & \\
\hline CHEMBL1577312 & 688759 & 4.9 & 4.5708 & TRN & \\
\hline CHEMBL1310988 & 688759 & 5.3 & 4.8037 & TRN & \\
\hline CHEMBL1490227 & 688759 & 4.95 & 4.8364 & TST & \\
\hline CHEMBL1978701 & 688759 & 5.3 & 5.2233 & TRN & \\
\hline CHEMBL1489506 & 688759 & 4.45 & 4.8383 & TST & \\
\hline CHEMBL1438737 & 688759 & 4.45 & 4.5328 & TST & \\
\hline CHEMBL1412369 & 688759 & 4.95 & 4.6353 & TRN & \\
\hline CHEMBL1601331 & 688759 & 4.45 & 4.4834 & TRN & \\
\hline CHEMBL1309960 & 688759 & 5.15 & 5.1213 & TST & \\
\hline CHEMBL 3198868 & 688759 & 5.35 & 5.2255 & TRN & \\
\hline CHEMBL1508402 & 688759 & 4.55 & 4.67899 & & TRN \\
\hline CHEMBL1544754 & 688759 & 5.1 & 5.4355 & TRN & \\
\hline CHEMBL1548976 & 688759 & 4.8 & 4.6542 & TRN & \\
\hline CHEMBL1600040 & 688759 & 4.5 & 4.8287 & TST & \\
\hline CHEMBL3192954 & 688759 & 5.0 & 5.0428 & TST & \\
\hline CHEMBL3195608 & 688759 & 5.3 & 5.3982 & TRN & \\
\hline CHEMBL1522953 & 688759 & 5.25 & 4.815 & TRN & \\
\hline CHEMBL1564143 & 688759 & 4.45 & 4.5447 & TST & \\
\hline CHEMBL1391818 & 688759 & 4.45 & 4.7313 & TRN & \\
\hline CHEMBL1527600 & 688759 & 5.05 & 5.0233 & TRN & \\
\hline CHEMBL1508351 & 688759 & 5.5 & 5.2822 & TRN & \\
\hline CHEMBL1581429 & 688759 & 4.65 & 4.7025 & TRN & \\
\hline CHEMBL1996281 & 688759 & 5.8 & 5.4281 & TRN & \\
\hline CHEMBL1370874 & 688759 & 4.45 & 4.6723 & TST & \\
\hline CHEMBL3191088 & 688759 & 4.65 & 4.9814 & TST & \\
\hline CHEMBL1338136 & 688759 & 4.1 & 4.8811 & TST & \\
\hline CHEMBL1321120 & 688759 & 4.45 & 5.1963 & TST & \\
\hline CHEMBL493153 & 688759 & 5.2 & 4.8871 & TST & \\
\hline CHEMBL1329925 & 688759 & 4.9 & 4.9008 & TRN & \\
\hline CHEMBL1338187 & 688759 & 4.45 & 4.6898 & TST & \\
\hline CHEMBL1612126 & 688759 & 4.45 & 4.9982 & TRN & \\
\hline CHEMBL1307535 & 688759 & 4.95 & 5.0421 & TST & \\
\hline CHEMBL1364721 & 688759 & 4.45 & 4.9341 & TRN & \\
\hline CHEMBL1494967 & 688759 & 4.45 & 4.6025 & TRN & \\
\hline CHEMBL1349809 & 688759 & 5.0 & 5.0169 & TST & \\
\hline CHEMBL1481343 & 688759 & 5.2 & 5.1756 & TRN & \\
\hline CHEMBL1446198 & 688759 & 6.2 & 5.0798 & TRN & \\
\hline CHEMBL1517374 & 688759 & 4.45 & 4.5359 & TST & \\
\hline CHEMBL3213387 & 688759 & 5.0 & 5.0163 & TRN & \\
\hline CHEMBL1567503 & 688759 & 4.9 & 4.806 & TRN & \\
\hline CHEMBL1568855 & 688759 & 4.95 & 5.0168 & TRN & \\
\hline CHEMBL1582193 & 688759 & 4.65 & 4.9561 & TRN & \\
\hline CHEMBL1506340 & 688759 & 5.1 & 4.8257 & TST & \\
\hline CHEMBL3199766 & 688759 & 5.5 & 4.6377 & TRN & \\
\hline CHEMBL1415921 & 688759 & 5.25 & 4.9244 & TRN & \\
\hline CHEMBL339304 & 688759 & 4.95 & 5.0767 & TRN & \\
\hline
\end{tabular}




\begin{tabular}{|c|c|c|c|c|c|}
\hline \multicolumn{6}{|c|}{ Supplemental Table S2.txt } \\
\hline CHEMBL1300347 & 688759 & 5.0 & 4.8358 & TRN & \\
\hline CHEMBL1371370 & 688759 & 5.05 & 5.1009 & TRN & \\
\hline CHEMBL1598851 & 688759 & 4.9 & 4.9551 & TST & \\
\hline CHEMBL1322462 & 688759 & 4.55 & 4.8903 & TRN & \\
\hline CHEMBL1493701 & 688759 & 4.45 & 4.6986 & TRN & \\
\hline CHEMBL1569910 & 688759 & 5.5 & 5.0092 & TRN & \\
\hline CHEMBL1372557 & 688759 & 4.6 & 4.4444 & TRN & \\
\hline CHEMBL1974056 & 688759 & 5.5 & 5.6073 & TRN & \\
\hline CHEMBL1407866 & 688759 & 5.45 & 4.8377 & TRN & \\
\hline CHEMBL1424113 & 688759 & 4.6 & 4.9131 & TRN & \\
\hline CHEMBL1327596 & 688759 & 4.45 & 4.8293 & TRN & \\
\hline CHEMBL1311547 & 688759 & 4.9 & 4.6353 & TRN & \\
\hline CHEMBL1351688 & 688759 & 4.45 & 4.7077 & TST & \\
\hline CHEMBL1377439 & 688759 & 5.4 & 5.2261 & TRN & \\
\hline CHEMBL1341696 & 688759 & 5.15 & 4.5745 & TRN & \\
\hline CHEMBL1994148 & 688759 & 4.45 & 4.6847 & TRN & \\
\hline CHEMBL540848 & 688759 & 4.6 & 4.5944 & TST & \\
\hline CHEMBL1566615 & 688759 & 4.45 & 4.8168 & TRN & \\
\hline CHEMBL1379178 & 688759 & 5.5 & 5.1663 & TRN & \\
\hline CHEMBL1597131 & 688759 & 4.45 & 4.6571 & TRN & \\
\hline CHEMBL1990772 & 688759 & 4.75 & 5.1166 & TRN & \\
\hline CHEMBL1527891 & 688759 & 4.95 & 4.641 & TRN & \\
\hline CHEMBL1346258 & 688759 & 5.85 & 4.1164 & TRN & \\
\hline CHEMBL1393926 & 688759 & 4.45 & 4.737 & TRN & \\
\hline CHEMBL1429284 & 688759 & 5.25 & 4.9204 & TRN & \\
\hline CHEMBL1550803 & 688759 & 4.45 & 4.6252 & TRN & \\
\hline CHEMBL1361396 & 688759 & 4.65 & 4.7702 & TRN & \\
\hline CHEMBL1467483 & 688759 & 4.75 & 5.0694 & TRN & \\
\hline CHEMBL1378396 & 688759 & 4.85 & 4.5838 & TRN & \\
\hline CHEMBL1375286 & 688759 & 4.9 & 5.1467 & TST & \\
\hline CHEMBL 3191362 & 688759 & 5.25 & 5.1914 & TRN & \\
\hline CHEMBL1566043 & 688759 & 4.7 & 4.63399 & 99999999995 & TRN \\
\hline CHEMBL1327839 & 688759 & 4.8 & 4.6738 & TRN & \\
\hline CHEMBL1418555 & 688759 & 4.9 & 4.737 & TRN & \\
\hline CHEMBL1585456 & 688759 & 5.2 & 5.0846 & TRN & \\
\hline CHEMBL1345290 & 688759 & 5.1 & 4.8593 & TRN & \\
\hline CHEMBL1459948 & 688759 & 4.65 & 4.8318 & TRN & \\
\hline CHEMBL1475198 & 688759 & 4.8 & 4.8227 & TRN & \\
\hline CHEMBL1449470 & 688759 & 5.15 & 5.1805 & TRN & \\
\hline CHEMBL1598190 & 688759 & 4.45 & 4.955 & TRN & \\
\hline CHEMBL1967586 & 688759 & 4.95 & 5.0923 & TST & \\
\hline CHEMBL1556971 & 688759 & 4.45 & 4.7146 & TRN & \\
\hline CHEMBL1363109 & 688759 & 5.2 & 4.8 & TST & \\
\hline CHEMBL1576000 & 688759 & 4.75 & 4.9347 & TRN & \\
\hline CHEMBL1354156 & 688759 & 4.45 & 4.7678 & TRN & \\
\hline CHEMBL572994 & 688759 & 5.35 & 5.1582 & TST & \\
\hline CHEMBL3197150 & 688759 & 4.75 & 5.0197 & TRN & \\
\hline CHEMBL1548037 & 688759 & 7.8013 & 4.838 & TRN & \\
\hline
\end{tabular}




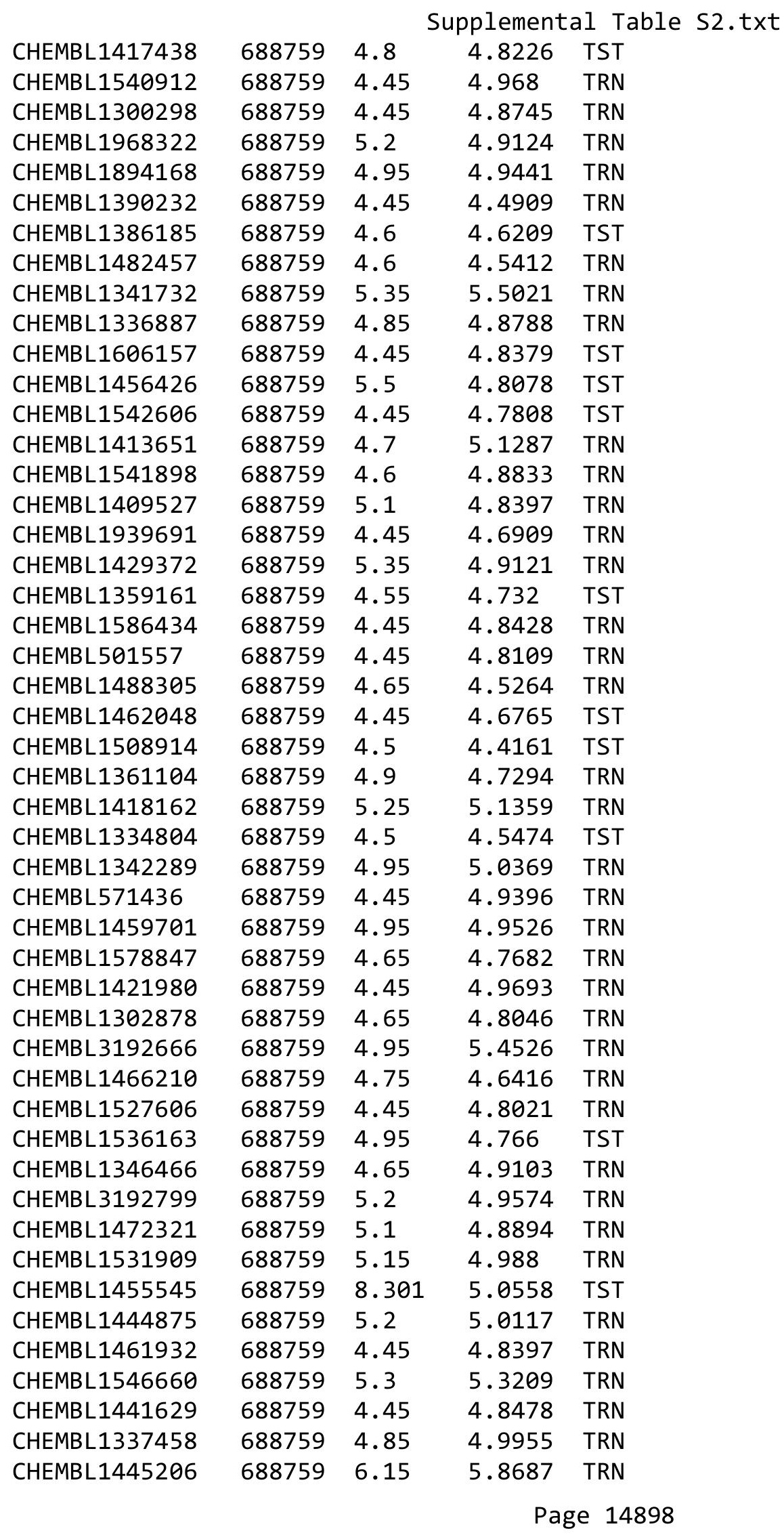




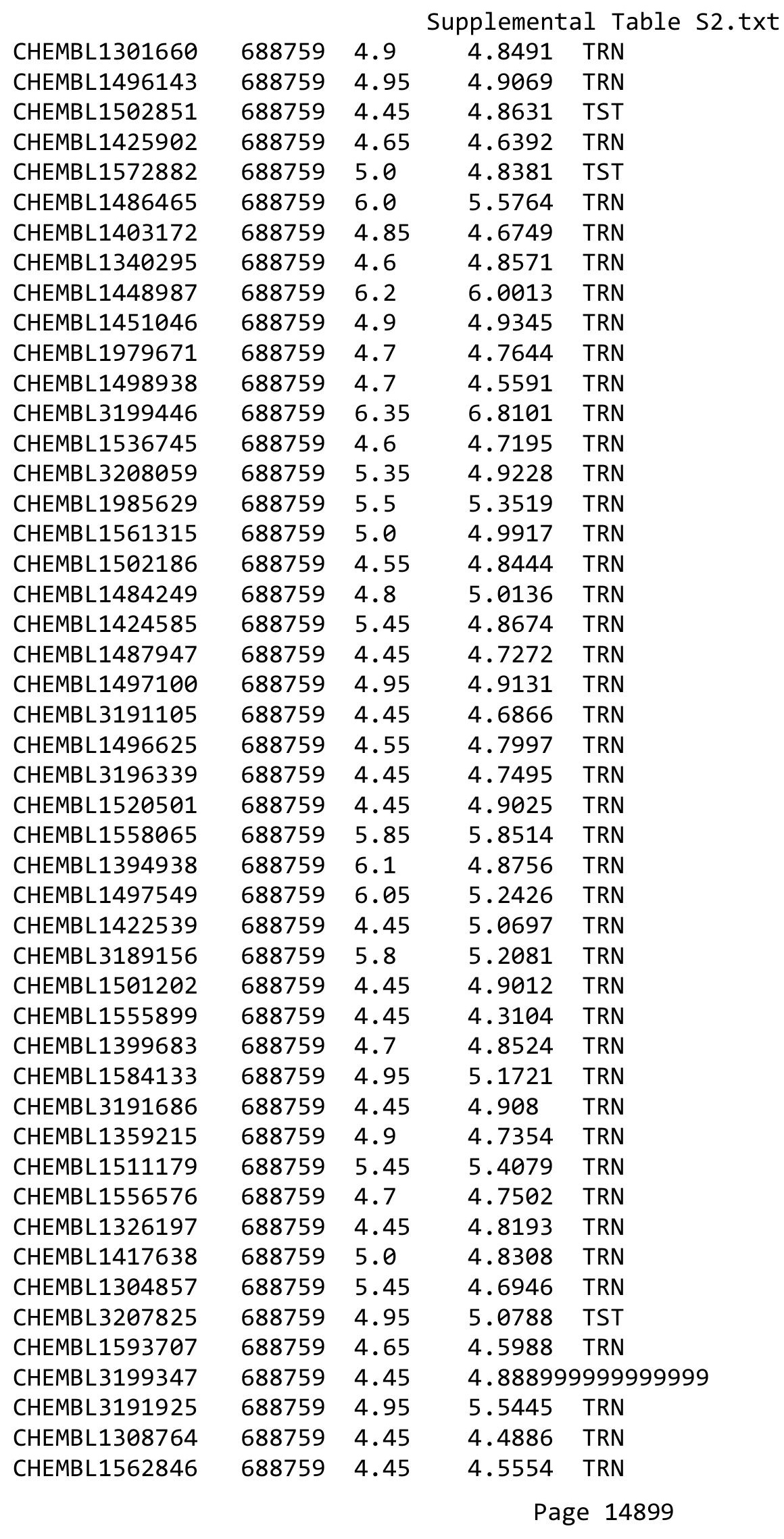

TRN 


\begin{tabular}{|c|c|c|c|c|}
\hline \multicolumn{5}{|c|}{ Supplemental Table S2.txt } \\
\hline CHEMBL 3212332 & 688759 & 4.55 & 4.7993 & TST \\
\hline CHEMBL1574199 & 688759 & 4.8 & 5.0944 & TRN \\
\hline CHEMBL1510852 & 688759 & 6.0 & 5.695 & TRN \\
\hline CHEMBL 3197270 & 688759 & 6.05 & 5.2597 & TRN \\
\hline CHEMBL 3195572 & 688759 & 4.45 & 4.8096 & TRN \\
\hline CHEMBL1409175 & 688759 & 4.45 & 4.7758 & TRN \\
\hline CHEMBL1307433 & 688759 & 4.45 & 4.6471 & TRN \\
\hline CHEMBL1348091 & 688759 & 4.45 & 4.8663 & TRN \\
\hline CHEMBL1387156 & 688759 & 4.5 & 4.7944 & TST \\
\hline CHEMBL1479010 & 688759 & 4.85 & 4.9231 & TST \\
\hline CHEMBL1404006 & 688759 & 4.55 & 4.8048 & TRN \\
\hline CHEMBL1403294 & 688759 & 4.9 & 4.6486 & TRN \\
\hline CHEMBL1549705 & 688759 & 4.45 & 4.9366 & TRN \\
\hline CHEMBL1598690 & 688759 & 4.45 & 4.8564 & TRN \\
\hline CHEMBL1460304 & 688759 & 4.45 & 4.7952 & TRN \\
\hline CHEMBL1566931 & 688759 & 5.8 & 5.1017 & TRN \\
\hline CHEMBL1324975 & 688759 & 5.25 & 4.9406 & TST \\
\hline CHEMBL1378004 & 688759 & 4.6 & 4.8531 & TRN \\
\hline CHEMBL1491924 & 688759 & 4.5 & 5.0554 & TST \\
\hline CHEMBL1561582 & 688759 & 4.75 & 4.8465 & TRN \\
\hline CHEMBL1399776 & 688759 & 4.45 & 4.7013 & TRN \\
\hline CHEMBL1969593 & 688759 & 4.45 & 4.5462 & TRN \\
\hline CHEMBL3207465 & 688759 & 4.45 & 4.8525 & TRN \\
\hline CHEMBL1423432 & 688759 & 4.45 & 4.7191 & TRN \\
\hline CHEMBL1365699 & 688759 & 4.65 & 4.8719 & TRN \\
\hline CHEMBL1370467 & 688759 & 4.5 & 5.1563 & TST \\
\hline CHEMBL1414078 & 688759 & 4.45 & 4.4689 & TRN \\
\hline CHEMBL1392626 & 688759 & 4.7 & 4.5751 & TRN \\
\hline CHEMBL1453386 & 688759 & 6.15 & 5.5198 & TRN \\
\hline CHEMBL1464450 & 688759 & 4.45 & 4.8066 & TRN \\
\hline CHEMBL491771 & 688759 & 5.45 & 4.9478 & TRN \\
\hline CHEMBL1605015 & 688759 & 5.5 & 5.2519 & TRN \\
\hline CHEMBL1545421 & 688759 & 4.45 & 4.882 & TRN \\
\hline CHEMBL1345063 & 688759 & 4.45 & 4.7712 & TRN \\
\hline CHEMBL1469532 & 688759 & 4.6 & 4.6719 & TST \\
\hline CHEMBL3208161 & 688759 & 5.25 & 4.8988 & TST \\
\hline CHEMBL1368337 & 688759 & 4.7 & 4.8052 & TRN \\
\hline CHEMBL1446811 & 688759 & 7.0501 & 4.7346 & TST \\
\hline CHEMBL1398964 & 688759 & 4.8 & 4.8879 & TST \\
\hline CHEMBL1372929 & 688759 & 5.1 & 4.9914 & TRN \\
\hline CHEMBL1360190 & 688759 & 4.9 & 4.8531 & TRN \\
\hline CHEMBL1377250 & 688759 & 5.0 & 5.0146 & TST \\
\hline CHEMBL 603020 & 688759 & 4.45 & 4.5679 & TRN \\
\hline CHEMBL1407257 & 688759 & 4.85 & 4.7458 & TRN \\
\hline CHEMBL1417355 & 688759 & 4.9 & 4.7076 & TRN \\
\hline CHEMBL3192433 & 688759 & 4.45 & 5.0325 & TRN \\
\hline CHEMBL1550866 & 688759 & 4.7 & 4.9252 & TST \\
\hline CHEMBL1486842 & 688759 & 4.7 & 4.9578 & TRN \\
\hline
\end{tabular}




\begin{tabular}{|c|c|c|c|c|c|}
\hline \multicolumn{6}{|c|}{ Supplemental Table s2.txt } \\
\hline CHEMBL1390349 & 688759 & 4.5 & 4.6555 & TST & \\
\hline CHEMBL1327638 & 688759 & 4.85 & 4.7773 & TRN & \\
\hline CHEMBL1367759 & 688759 & 5.55 & 5.3825 & TST & \\
\hline CHEMBL70783 & 688759 & 4.9 & 5.0081 & TST & \\
\hline CHEMBL1400829 & 688759 & 5.15 & 5.1662 & TRN & \\
\hline CHEMBL1210920 & 688759 & 4.8 & 4.9301 & TRN & \\
\hline CHEMBL1496398 & 688759 & 4.6 & 4.8157 & TST & \\
\hline CHEMBL1334247 & 688759 & 4.45 & 4.9156 & TST & \\
\hline CHEMBL1485358 & 688759 & 4.75 & 4.9555 & TST & \\
\hline CHEMBL1467984 & 688759 & 5.4 & 4.9398 & TRN & \\
\hline CHEMBL1343144 & 688759 & 4.45 & 4.7622 & TRN & \\
\hline CHEMBL1334770 & 688759 & 4.95 & 4.9594 & TRN & \\
\hline CHEMBL1579380 & 688759 & 5.65 & 5.0575 & TRN & \\
\hline CHEMBL1344370 & 688759 & 5.1 & 4.9138 & TRN & \\
\hline CHEMBL3191962 & 688759 & 5.45 & 5.6816 & TRN & \\
\hline CHEMBL1510184 & 688759 & 5.25 & 4.8773 & TRN & \\
\hline CHEMBL1480151 & 688759 & 4.7 & 4.672 & TST & \\
\hline CHEMBL1548641 & 688759 & 4.9 & 4.8189 & TRN & \\
\hline CHEMBL1986086 & 688759 & 4.7 & 4.90300 & 00000000005 & TRN \\
\hline CHEMBL1329817 & 688759 & 5.1 & 4.7852 & TST & \\
\hline CHEMBL1494575 & 688759 & 6.05 & 4.817 & TRN & \\
\hline CHEMBL 2004226 & 688759 & 5.3 & 5.1454 & TRN & \\
\hline CHEMBL1460585 & 688759 & 4.65 & 4.6847 & TST & \\
\hline CHEMBL1507704 & 688759 & 4.8 & 4.7865 & TRN & \\
\hline CHEMBL1453825 & 688759 & 4.75 & 4.9129 & TRN & \\
\hline CHEMBL1445538 & 688759 & 4.9 & 4.8127 & TRN & \\
\hline CHEMBL1503106 & 688759 & 4.45 & 4.8165 & TRN & \\
\hline CHEMBL1383537 & 688759 & 4.45 & 5.3084 & TRN & \\
\hline CHEMBL1509229 & 688759 & 4.65 & 4.4337 & TRN & \\
\hline CHEMBL1407735 & 688759 & 5.5 & 5.7473 & TRN & \\
\hline CHEMBL1506207 & 688759 & 4.8 & 4.9154 & TRN & \\
\hline CHEMBL1558117 & 688759 & 4.45 & 4.8642 & TRN & \\
\hline CHEMBL1460176 & 688759 & 4.45 & 4.5776 & TRN & \\
\hline CHEMBL1313089 & 688759 & 5.35 & 5.0851 & TRN & \\
\hline CHEMBL1368936 & 688759 & 4.9 & 4.5427 & TST & \\
\hline CHEMBL1568877 & 688759 & 5.55 & 5.0358 & TRN & \\
\hline CHEMBL1409289 & 688759 & 5.45 & 4.793 & TRN & \\
\hline CHEMBL1362793 & 688759 & 4.7 & 4.49100 & 00000000005 & TST \\
\hline CHEMBL1504283 & 688759 & 4.45 & 4.6696 & TST & \\
\hline CHEMBL3207957 & 688759 & 4.45 & 4.8974 & TRN & \\
\hline CHEMBL1546122 & 688759 & 5.2 & 4.5903 & TRN & \\
\hline CHEMBL1368553 & 688759 & 4.45 & 4.6579 & TST & \\
\hline CHEMBL1333245 & 688759 & 5.1 & 5.0095 & TRN & \\
\hline CHEMBL1477316 & 688759 & 4.45 & 4.623 & TRN & \\
\hline CHEMBL1508519 & 688759 & 5.2 & 4.8092 & TRN & \\
\hline CHEMBL505670 & 688759 & 6.0 & 5.4098 & TST & \\
\hline CHEMBL1582269 & 688759 & 4.45 & 4.8287 & TRN & \\
\hline CHEMBL1496916 & 688759 & 4.45 & 4.7681 & TRN & \\
\hline
\end{tabular}




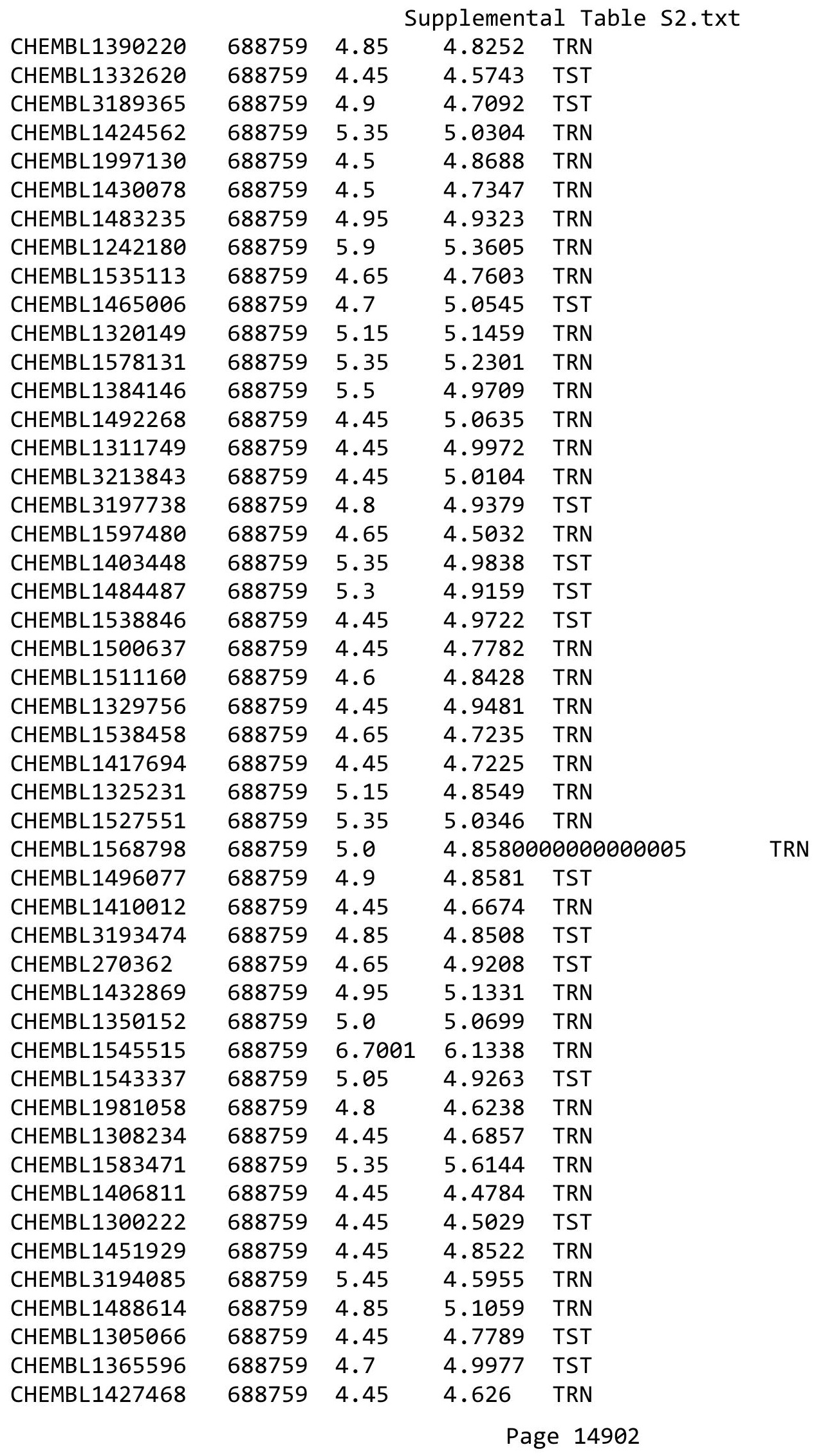




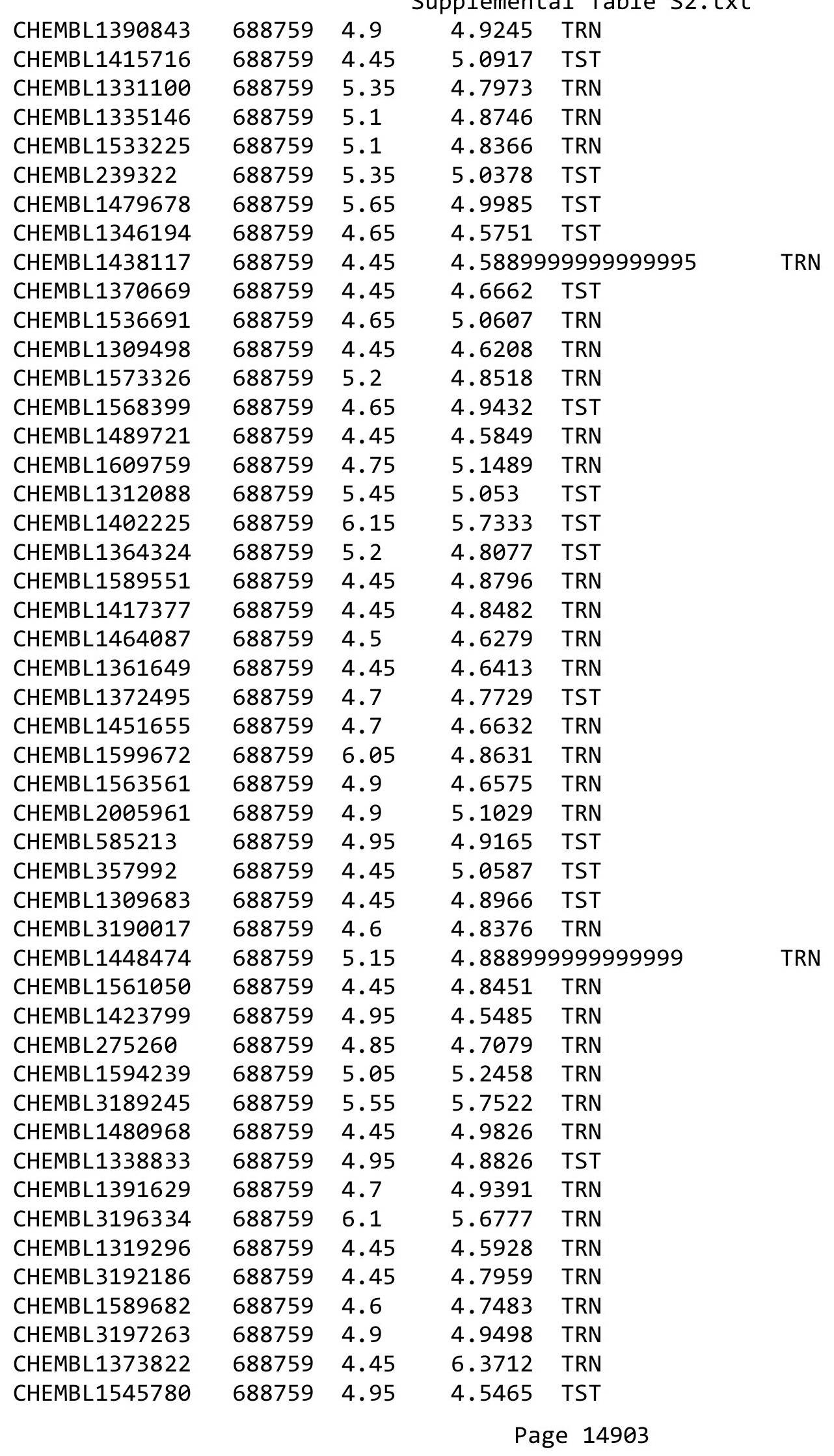




\begin{tabular}{|c|c|c|c|c|}
\hline & & & upplement & al $\mathrm{T}$ \\
\hline CHEMBL1312208 & 688759 & 5.25 & 4.9397 & TST \\
\hline CHEMBL1582804 & 688759 & 4.45 & 4.6007 & TRN \\
\hline CHEMBL1525271 & 688759 & 5.2 & 5.2471 & TRN \\
\hline CHEMBL1431123 & 688759 & 4.45 & 4.5726 & TRN \\
\hline CHEMBL1558926 & 688759 & 4.45 & 5.1932 & TRN \\
\hline CHEMBL3191922 & 688759 & 5.0 & 5.0709 & TRN \\
\hline CHEMBL1563575 & 688759 & 5.0 & 4.5613 & TRN \\
\hline CHEMBL1424355 & 688759 & 4.45 & 5.0029 & TRN \\
\hline CHEMBL1530878 & 688759 & 4.65 & 4.6193 & TRN \\
\hline CHEMBL1964450 & 688759 & 5.05 & 5.354 & TST \\
\hline CHEMBL1446181 & 688759 & 4.65 & 4.5381 & TRN \\
\hline CHEMBL1330109 & 688759 & 4.45 & 4.6464 & TRN \\
\hline CHEMBL1453086 & 688759 & 4.5 & 4.9989 & TRN \\
\hline CHEMBL1417863 & 688759 & 4.95 & 4.8358 & TRN \\
\hline CHEMBL494668 & 688759 & 4.9 & 5.0704 & TST \\
\hline CHEMBL162808 & 688759 & 4.45 & 4.7158 & TRN \\
\hline CHEMBL1497807 & 688759 & 5.3 & 5.4706 & TRN \\
\hline CHEMBL1608041 & 688759 & 5.1 & 4.6017 & TRN \\
\hline CHEMBL1330980 & 688759 & 5.15 & 5.0639 & TRN \\
\hline CHEMBL1519577 & 688759 & 4.45 & 4.8042 & TRN \\
\hline CHEMBL1553211 & 688759 & 4.45 & 4.7037 & TRN \\
\hline CHEMBL1467250 & 688759 & 4.75 & 4.667 & TRN \\
\hline CHEMBL1505857 & 688759 & 6.25 & 5.7352 & TRN \\
\hline CHEMBL1457149 & 688759 & 5.0 & 4.7415 & TRN \\
\hline CHEMBL1436143 & 688759 & 4.55 & 5.2429 & TRN \\
\hline CHEMBL1414188 & 688759 & 4.45 & 4.8832 & TRN \\
\hline CHEMBL1484363 & 688759 & 6.35 & 5.1197 & TRN \\
\hline CHEMBL1601080 & 688759 & 4.9 & 4.8381 & TRN \\
\hline CHEMBL1563283 & 688759 & 5.25 & 5.2203 & TRN \\
\hline CHEMBL1613695 & 688759 & 5.5 & 4.7639 & TRN \\
\hline CHEMBL1568135 & 688759 & 4.45 & 4.6315 & TRN \\
\hline CHEMBL1559846 & 688759 & 5.25 & 4.6217 & TRN \\
\hline CHEMBL1586089 & 688759 & 5.05 & 4.7326 & TRN \\
\hline CHEMBL1966612 & 688759 & 4.45 & 5.0226 & TST \\
\hline CHEMBL1415306 & 688759 & 4.55 & 4.4581 & TRN \\
\hline CHEMBL1603921 & 688759 & 4.9 & 4.6256 & TRN \\
\hline CHEMBL1411327 & 688759 & 5.75 & 5.0617 & TRN \\
\hline CHEMBL239478 & 688759 & 5.9 & 5.6186 & TRN \\
\hline CHEMBL1492209 & 688759 & 4.95 & 4.9527 & TRN \\
\hline CHEMBL1416417 & 688759 & 4.65 & 4.726 & TST \\
\hline CHEMBL1577452 & 688759 & 4.45 & 4.7464 & TRN \\
\hline CHEMBL1392918 & 688759 & 4.6 & 4.6925 & TRN \\
\hline CHEMBL1586224 & 688759 & 4.45 & 4.8673 & TRN \\
\hline CHEMBL1343311 & 688759 & 5.25 & 5.5029 & TRN \\
\hline CHEMBL1560352 & 688759 & 5.15 & 4.9719 & TRN \\
\hline CHEMBL1993555 & 688759 & 4.6 & 4.7088 & TRN \\
\hline CHEMBL1391362 & 688759 & 4.75 & 4.8258 & TRN \\
\hline CHEMBL1338045 & 688759 & 5.2 & 5.0866 & TRN \\
\hline
\end{tabular}




\begin{tabular}{|c|c|c|c|c|c|}
\hline & & \multicolumn{4}{|c|}{ Supplemental Table S2.txt } \\
\hline CHEMBL1426686 & 688759 & 4.75 & 4.7512 & TRN & \\
\hline CHEMBL3189325 & 688759 & 5.95 & 5.7126 & TRN & \\
\hline CHEMBL3198110 & 688759 & 4.8 & 4.7968 & TRN & \\
\hline CHEMBL1495198 & 688759 & 5.25 & 5.0577 & TRN & \\
\hline CHEMBL1351599 & 688759 & 5.2 & 5.1719 & TRN & \\
\hline CHEMBL1611369 & 688759 & 5.85 & 5.0418 & TRN & \\
\hline CHEMBL1595887 & 688759 & 4.45 & 4.6282 & TRN & \\
\hline CHEMBL1608144 & 688759 & 4.45 & 4.8831 & TRN & \\
\hline CHEMBL1400505 & 688759 & 4.95 & 5.0471 & TRN & \\
\hline CHEMBL1423626 & 688759 & 5.4 & 5.129 & TST & \\
\hline CHEMBL1300969 & 688759 & 7.15 & 5.03600 & 00000000005 & TRN \\
\hline CHEMBL1547123 & 688759 & 4.85 & 5.1918 & TRN & \\
\hline CHEMBL3196086 & 688759 & 4.75 & 4.5999 & TST & \\
\hline CHEMBL1388951 & 688759 & 4.55 & 4.6704 & TST & \\
\hline CHEMBL1380801 & 688759 & 5.05 & 4.9847 & TRN & \\
\hline CHEMBL1424786 & 688759 & 4.45 & 4.7474 & TRN & \\
\hline CHEMBL1360449 & 688759 & 5.75 & 4.7183 & TRN & \\
\hline CHEMBL1580885 & 688759 & 4.45 & 4.5281 & TRN & \\
\hline CHEMBL1423421 & 688759 & 4.45 & 4.9637 & TST & \\
\hline CHEMBL1489969 & 688759 & 5.2 & 5.0179 & TRN & \\
\hline CHEMBL1487415 & 688759 & 4.75 & 5.2024 & TRN & \\
\hline CHEMBL1585233 & 688759 & 4.5 & 4.6652 & TRN & \\
\hline CHEMBL1596969 & 688759 & 4.45 & 4.6999 & TST & \\
\hline CHEMBL1576355 & 688759 & 5.0 & 5.0024 & TST & \\
\hline CHEMBL1997508 & 688759 & 4.9 & 4.7993 & TRN & \\
\hline CHEMBL1477813 & 688759 & 4.45 & 4.7099 & TRN & \\
\hline CHEMBL1541678 & 688759 & 4.65 & 4.9217 & TRN & \\
\hline CHEMBL 242112 & 688759 & 5.2 & 5.1717 & TRN & \\
\hline CHEMBL3199908 & 688759 & 4.7 & 4.94300 & 00000000005 & TST \\
\hline CHEMBL1311398 & 688759 & 4.95 & 4.9942 & TRN & \\
\hline CHEMBL1596589 & 688759 & 4.65 & 4.6217 & TRN & \\
\hline CHEMBL1451470 & 688759 & 5.25 & 4.8382 & TRN & \\
\hline CHEMBL1321254 & 688759 & 4.45 & 4.7861 & TST & \\
\hline CHEMBL1386738 & 688759 & 4.45 & 5.081 & TST & \\
\hline CHEMBL3192817 & 688759 & 5.6 & 5.3937 & TRN & \\
\hline CHEMBL1319652 & 688759 & 4.45 & 4.7634 & TST & \\
\hline CHEMBL1545553 & 688759 & 5.1 & 5.1126 & TRN & \\
\hline CHEMBL1409470 & 688759 & 5.45 & 4.8492 & TRN & \\
\hline CHEMBL1584002 & 688759 & 5.15 & 5.2161 & TRN & \\
\hline CHEMBL1358189 & 688759 & 4.45 & 4.8448 & TST & \\
\hline CHEMBL1344696 & 688759 & 5.55 & 5.5208 & TRN & \\
\hline CHEMBL1537317 & 688759 & 5.45 & 4.865 & TRN & \\
\hline CHEMBL1599947 & 688759 & 4.65 & 4.8227 & TRN & \\
\hline CHEMBL1462802 & 688759 & 4.95 & 4.6691 & TRN & \\
\hline CHEMBL3190777 & 688759 & 4.95 & 4.9285 & TRN & \\
\hline CHEMBL1431444 & 688759 & 5.9 & 5.029 & TRN & \\
\hline CHEMBL3193925 & 688759 & 4.9 & 4.8255 & TRN & \\
\hline CHEMBL1310240 & 688759 & 5.45 & 5.228 & TRN & \\
\hline
\end{tabular}




\begin{tabular}{|c|c|c|c|c|}
\hline \multicolumn{5}{|c|}{ Supplemental Table S2.txt } \\
\hline CHEMBL1447324 & 688759 & 4.75 & 4.7711 & TRN \\
\hline CHEMBL3191678 & 688759 & 4.45 & 4.9215 & TRN \\
\hline CHEMBL1391819 & 688759 & 4.45 & 5.1073 & TST \\
\hline CHEMBL1364139 & 688759 & 4.95 & 4.8361 & TRN \\
\hline CHEMBL3195249 & 688759 & 5.0 & 5.0981 & TRN \\
\hline CHEMBL1484089 & 688759 & 4.65 & 4.8524 & TRN \\
\hline CHEMBL1300081 & 688759 & 6.15 & 4.7515 & TST \\
\hline CHEMBL1524828 & 688759 & 5.8 & 5.2304 & TRN \\
\hline CHEMBL1464128 & 688759 & 4.9 & 5.0343 & TST \\
\hline CHEMBL3195170 & 688759 & 4.45 & 4.768 & TRN \\
\hline CHEMBL1491461 & 688759 & 4.45 & 4.9823 & TST \\
\hline CHEMBL1600405 & 688759 & 5.25 & 4.8358 & TRN \\
\hline CHEMBL1399702 & 688759 & 5.5 & 5.1194 & TRN \\
\hline CHEMBL1360135 & 688759 & 5.1 & 4.9329 & TST \\
\hline CHEMBL1352344 & 688759 & 5.7 & 5.4482 & TRN \\
\hline CHEMBL1375007 & 688759 & 4.6 & 4.7304 & TRN \\
\hline CHEMBL53898 & 688759 & 6.0 & 4.7299 & TRN \\
\hline CHEMBL1470923 & 688759 & 6.2 & 5.1664 & TST \\
\hline CHEMBL1968859 & 688759 & 6.3 & 5.8251 & TRN \\
\hline CHEMBL1348483 & 688759 & 4.8 & 4.8823 & TRN \\
\hline CHEMBL1517362 & 688759 & 4.9 & 5.0027 & TRN \\
\hline CHEMBL1537884 & 688759 & 5.25 & 5.4724 & TRN \\
\hline CHEMBL1568223 & 688759 & 4.95 & 5.1677 & TRN \\
\hline CHEMBL3211109 & 688759 & 5.3 & 4.7935 & TRN \\
\hline CHEMBL1605158 & 688759 & 5.2 & 4.9723 & TRN \\
\hline CHEMBL3194760 & 688759 & 5.2 & 4.9681 & TRN \\
\hline CHEMBL261123 & 688759 & 5.15 & 5.3772 & TRN \\
\hline CHEMBL1613580 & 688759 & 4.45 & 4.817 & TRN \\
\hline CHEMBL1415651 & 688759 & 4.75 & 4.7874 & TST \\
\hline CHEMBL1408190 & 688759 & 5.25 & 4.9498 & TST \\
\hline CHEMBL1409196 & 688759 & 4.45 & 5.1368 & TRN \\
\hline CHEMBL1407508 & 688759 & 4.9 & 4.8312 & TRN \\
\hline CHEMBL1408535 & 688759 & 4.45 & 4.8145 & TRN \\
\hline CHEMBL1536374 & 688759 & 5.25 & 5.3358 & TRN \\
\hline CHEMBL1584144 & 688759 & 5.25 & 4.9276 & TRN \\
\hline CHEMBL1372698 & 688759 & 5.3 & 5.2087 & TST \\
\hline CHEMBL1410197 & 688759 & 4.5 & 5.2646 & TRN \\
\hline CHEMBL1435298 & 688759 & 4.6 & 4.9407 & TRN \\
\hline CHEMBL1339706 & 688759 & 4.65 & 4.7053 & TRN \\
\hline CHEMBL1301230 & 688759 & 4.55 & 4.9538 & TRN \\
\hline CHEMBL3190539 & 688759 & 4.75 & 4.9915 & TRN \\
\hline CHEMBL1493273 & 688759 & 5.25 & 5.1628 & TRN \\
\hline CHEMBL398233 & 688759 & 4.65 & 4.6999 & TST \\
\hline CHEMBL1585003 & 688759 & 4.65 & 4.6849 & TST \\
\hline CHEMBL1482681 & 688759 & 4.9 & 4.7442 & TST \\
\hline CHEMBL1541656 & 688759 & 4.65 & 4.6199 & TRN \\
\hline CHEMBL1375600 & 688759 & 4.45 & 4.67 & TRN \\
\hline CHEMBL1994685 & 688759 & 5.3 & 5.1294 & TST \\
\hline
\end{tabular}




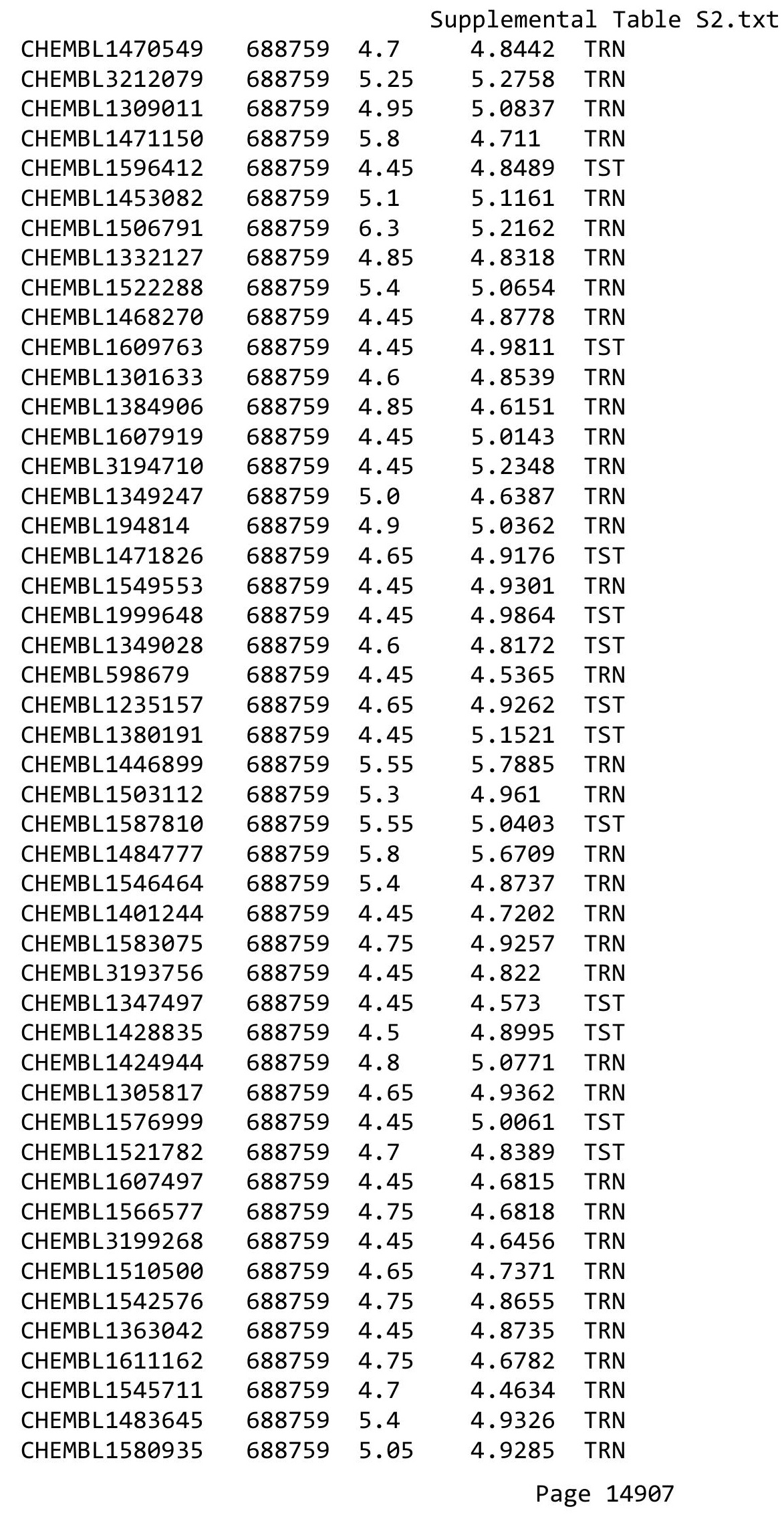




\begin{tabular}{|c|c|c|c|c|c|}
\hline \multirow[b]{2}{*}{ CHEMBL1453351 } & \multicolumn{5}{|c|}{ Supplemental Table S2.txt } \\
\hline & 688759 & 4.45 & 4.6649 & TRN & \\
\hline CHEMBL1307660 & 688759 & 4.45 & 4.90306 & 00000000005 & TRN \\
\hline CHEMBL1443900 & 688759 & 5.8 & 4.8382 & TRN & \\
\hline CHEMBL1447940 & 688759 & 4.75 & 4.5697 & TRN & \\
\hline CHEMBL 1334426 & 688759 & 4.65 & 4.7589 & TRN & \\
\hline CHEMBL1591674 & 688759 & 4.55 & 4.5697 & TRN & \\
\hline CHEMBL1484580 & 688759 & 5.3 & 4.8065 & TRN & \\
\hline CHEMBL3192355 & 688759 & 5.35 & 5.4295 & TRN & \\
\hline CHEMBL1503609 & 688759 & 4.45 & 4.9186 & TRN & \\
\hline CHEMBL3191609 & 688759 & 4.5 & 4.8111 & TRN & \\
\hline CHEMBL1584049 & 688759 & 6.3 & 4.9136 & TRN & \\
\hline CHEMBL1344303 & 688759 & 5.5 & 5.249 & TRN & \\
\hline CHEMBL3210236 & 688759 & 5.4 & 4.8667 & TST & \\
\hline CHEMBL3191874 & 688759 & 4.45 & 5.3339 & TRN & \\
\hline CHEMBL3211517 & 688759 & 6.3 & 4.9748 & TRN & \\
\hline CHEMBL1300338 & 688759 & 6.5 & 5.5479 & TRN & \\
\hline CHEMBL1485632 & 688759 & 4.45 & 4.7124 & TRN & \\
\hline CHEMBL1377035 & 688759 & 4.45 & 4.8469 & TRN & \\
\hline CHEMBL1391475 & 688759 & 4.65 & 4.635 & TST & \\
\hline CHEMBL1409100 & 688759 & 5.15 & 4.8066 & TRN & \\
\hline CHEMBL1362279 & 688759 & 4.65 & 4.5565 & TRN & \\
\hline CHEMBL1379515 & 688759 & 4.9 & 4.7146 & TRN & \\
\hline CHEMBL1330948 & 688759 & 4.55 & 4.9333 & TST & \\
\hline CHEMBL1609065 & 688759 & 5.3 & 4.8205 & TRN & \\
\hline CHEMBL1405855 & 688759 & 4.45 & 4.7575 & TRN & \\
\hline CHEMBL1370720 & 688759 & 4.85 & 4.8112 & TRN & \\
\hline CHEMBL1365299 & 688759 & 4.7 & 4.8933 & TRN & \\
\hline CHEMBL1583505 & 688759 & 5.0 & 5.0717 & TRN & \\
\hline CHEMBL1345913 & 688759 & 4.6 & 4.8843 & TST & \\
\hline CHEMBL1365954 & 688759 & 6.0 & 5.3273 & TRN & \\
\hline CHEMBL1530789 & 688759 & 5.6 & 5.062 & TRN & \\
\hline CHEMBL3189891 & 688759 & 4.55 & 4.9993 & TRN & \\
\hline CHEMBL3195848 & 688759 & 4.45 & 4.795 & TRN & \\
\hline CHEMBL1355835 & 688759 & 5.5 & 4.7629 & TRN & \\
\hline CHEMBL3195094 & 688759 & 4.9 & 4.7536 & TST & \\
\hline CHEMBL1571926 & 688759 & 7.0501 & 4.8198 & TST & \\
\hline CHEMBL1587261 & 688759 & 6.15 & 5.4994 & TRN & \\
\hline CHEMBL1377154 & 688759 & 5.2 & 5.1702 & TRN & \\
\hline CHEMBL3196952 & 688759 & 4.45 & 5.1056 & TRN & \\
\hline CHEMBL1505259 & 688759 & 4.65 & 4.7776 & TRN & \\
\hline CHEMBL1527341 & 688759 & 5.35 & 4.9861 & TRN & \\
\hline CHEMBL1608588 & 688759 & 4.65 & 4.7507 & TRN & \\
\hline CHEMBL1433269 & 688759 & 4.85 & 4.7736 & TST & \\
\hline CHEMBL1454920 & 688759 & 4.8 & 4.6927 & TRN & \\
\hline CHEMBL1602774 & 688759 & 4.95 & 4.8545 & TST & \\
\hline CHEMBL1448718 & 688759 & 4.9 & 4.7669 & TRN & \\
\hline CHEMBL1494427 & 688759 & 4.45 & 4.788 & TST & \\
\hline CHEMBL1388041 & 688759 & 4.85 & 4.9445 & TRN & \\
\hline
\end{tabular}




\begin{tabular}{|c|c|c|c|c|c|}
\hline & & \multicolumn{4}{|c|}{ Supplemental Table S2.txt } \\
\hline CHEMBL1529298 & 688759 & 6.6499 & 5.043 & TRN & \\
\hline CHEMBL1582675 & 688759 & 4.5 & 4.6626 & TRN & \\
\hline CHEMBL1361434 & 688759 & 4.45 & 4.8048 & TRN & \\
\hline CHEMBL1576677 & 688759 & 4.9 & 4.9903 & TRN & \\
\hline CHEMBL1502996 & 688759 & 4.45 & 4.7853 & TST & \\
\hline CHEMBL1403817 & 688759 & 4.45 & 4.6637 & TST & \\
\hline CHEMBL1381975 & 688759 & 4.45 & 4.4056 & TRN & \\
\hline CHEMBL1600260 & 688759 & 5.15 & 4.9515 & TRN & \\
\hline CHEMBL1522171 & 688759 & 5.6 & 5.3097 & TRN & \\
\hline CHEMBL1309598 & 688759 & 4.85 & 5.0638 & TRN & \\
\hline CHEMBL527336 & 688759 & 4.45 & 4.7823 & TRN & \\
\hline CHEMBL 3194483 & 688759 & 4.7 & 4.8093 & TRN & \\
\hline CHEMBL1347339 & 688759 & 4.6 & 4.6337 & TST & \\
\hline CHEMBL3194842 & 688759 & 4.95 & 4.5547 & TRN & \\
\hline CHEMBL1550877 & 688759 & 4.45 & 4.8469 & TST & \\
\hline CHEMBL1450621 & 688759 & 4.5 & 4.6614 & TRN & \\
\hline CHEMBL1568849 & 688759 & 4.55 & 4.9509 & TRN & \\
\hline CHEMBL1972996 & 688759 & 5.35 & 5.4572 & TRN & \\
\hline CHEMBL1578523 & 688759 & 4.8 & 4.7944 & TST & \\
\hline CHEMBL1381808 & 688759 & 4.45 & 4.5109 & TRN & \\
\hline CHEMBL1433040 & 688759 & 5.9 & 5.131 & TRN & \\
\hline CHEMBL1384173 & 688759 & 5.25 & 4.7651 & TRN & \\
\hline CHEMBL1488955 & 688759 & 4.65 & 5.1312 & TST & \\
\hline CHEMBL1305465 & 688759 & 5.25 & 5.048 & TRN & \\
\hline CHEMBL1523756 & 688759 & 4.7 & 5.1119 & TRN & \\
\hline CHEMBL3191618 & 688759 & 4.65 & 4.6271 & TRN & \\
\hline CHEMBL1609493 & 688759 & 4.95 & 4.9813 & TST & \\
\hline CHEMBL1604216 & 688759 & 4.45 & 4.8103 & TRN & \\
\hline CHEMBL1588103 & 688759 & 4.95 & 4.977 & TRN & \\
\hline CHEMBL1414388 & 688759 & 4.6 & 4.6059 & TST & \\
\hline CHEMBL1409634 & 688759 & 4.65 & 4.7137 & TST & \\
\hline CHEMBL1557323 & 688759 & 4.45 & 4.9356 & TRN & \\
\hline CHEMBL3213330 & 688759 & 5.9 & 5.5744 & TRN & \\
\hline CHEMBL1311534 & 688759 & 4.9 & 5.0073 & TST & \\
\hline CHEMBL1345447 & 688759 & 5.25 & 4.6623 & TST & \\
\hline CHEMBL1608430 & 688759 & 5.15 & 4.9441 & TRN & \\
\hline CHEMBL1326624 & 688759 & 4.65 & 4.6271 & TRN & \\
\hline CHEMBL1339184 & 688759 & 4.95 & 4.9941 & TRN & \\
\hline CHEMBL1430341 & 688759 & 4.7 & 4.7291 & TRN & \\
\hline CHEMBL1302807 & 688759 & 4.45 & 4.8117 & TRN & \\
\hline CHEMBL1493283 & 688759 & 4.5 & 4.7002 & TST & \\
\hline CHEMBL1436128 & 688759 & 5.15 & 5.0637 & TRN & \\
\hline CHEMBL1407756 & 688759 & 4.9 & 4.855 & TST & \\
\hline CHEMBL1429798 & 688759 & 5.25 & 4.9167 & TRN & \\
\hline CHEMBL1449505 & 688759 & 4.75 & 5.0963 & TST & \\
\hline CHEMBL1453960 & 688759 & 4.9 & 4.6852 & TRN & \\
\hline CHEMBL1402390 & 688759 & 4.45 & 5.17700 & 00000000005 & TRN \\
\hline CHEMBL1414496 & 688759 & 4.65 & 4.9969 & TRN & \\
\hline
\end{tabular}




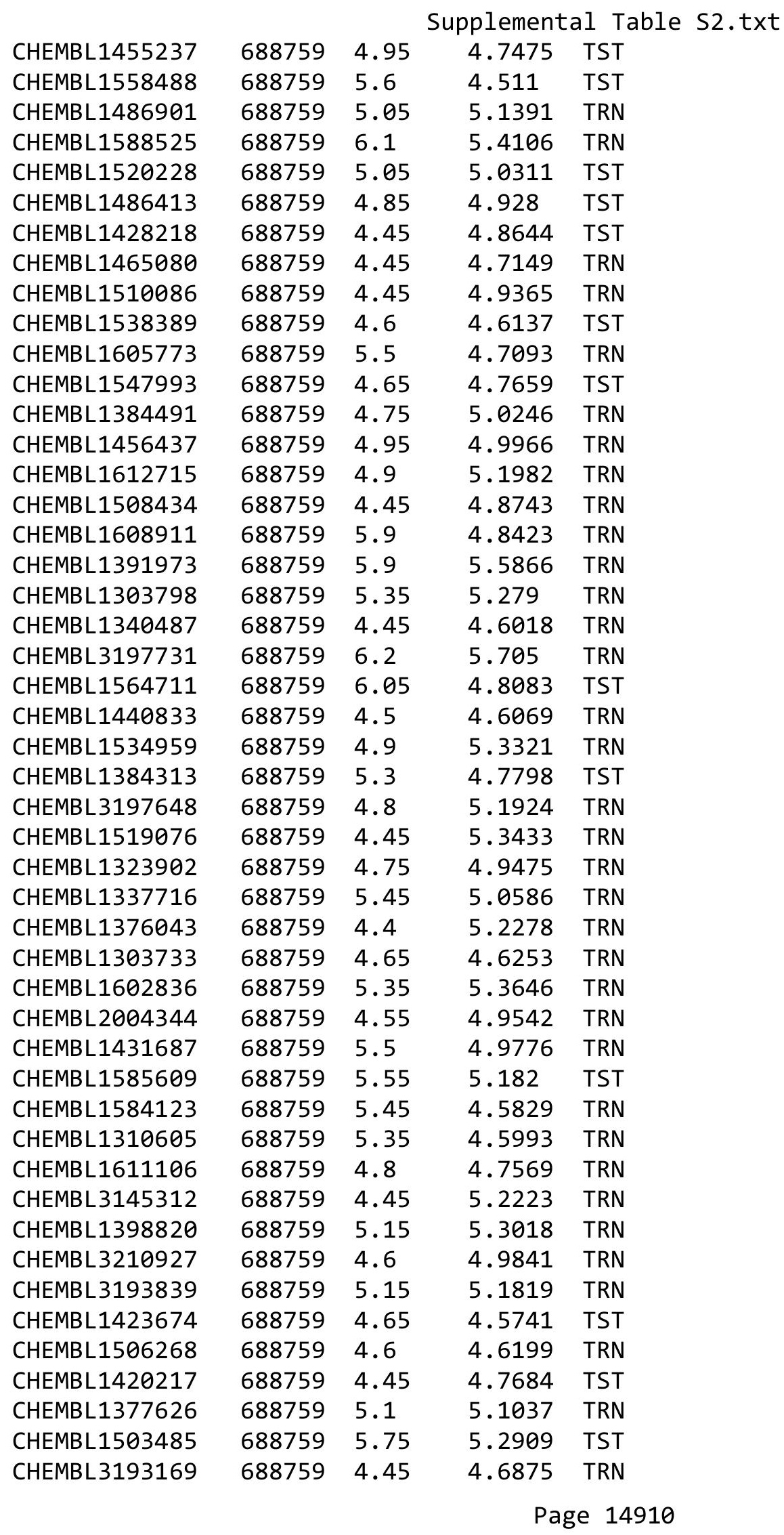




\begin{tabular}{|c|c|c|c|c|}
\hline \multicolumn{5}{|c|}{ Supplemental Tabl } \\
\hline CHEMBL1521747 & 688759 & 4.45 & 4.5792 & TRN \\
\hline CHEMBL1307050 & 688759 & 5.5 & 5.7934 & TRN \\
\hline CHEMBL1424694 & 688759 & 4.5 & 4.8944 & TST \\
\hline CHEMBL1411039 & 688759 & 5.35 & 4.8207 & TRN \\
\hline CHEMBL1968983 & 688759 & 6.15 & 5.7277 & TRN \\
\hline CHEMBL1333118 & 688759 & 4.45 & 4.9854 & TST \\
\hline CHEMBL1341756 & 688759 & 4.45 & 4.7833 & TRN \\
\hline CHEMBL3193942 & 688759 & 5.6 & 5.4927 & TRN \\
\hline CHEMBL83170 & 688759 & 5.15 & 4.7959 & TST \\
\hline CHEMBL1603696 & 688759 & 4.5 & 4.8946 & TRN \\
\hline CHEMBL1528290 & 688759 & 5.85 & 5.3795 & TRN \\
\hline CHEMBL1337528 & 688759 & 4.9 & 5.8551 & TRN \\
\hline CHEMBL1588471 & 688759 & 5.5 & 5.5277 & TRN \\
\hline CHEMBL3189797 & 688759 & 5.5 & 4.7168 & TST \\
\hline CHEMBL1452783 & 688759 & 4.8 & 4.6639 & TRN \\
\hline CHEMBL1606017 & 688759 & 4.45 & 4.6296 & TRN \\
\hline CHEMBL1576130 & 688759 & 5.0 & 4.7826 & TST \\
\hline CHEMBL1468063 & 688759 & 5.05 & 4.5892 & TRN \\
\hline CHEMBL1332409 & 688759 & 4.65 & 5.0237 & TST \\
\hline CHEMBL1310463 & 688759 & 4.65 & 4.9053 & TRN \\
\hline CHEMBL1594466 & 688759 & 4.65 & 4.7806 & TRN \\
\hline CHEMBL1374491 & 688759 & 4.7 & 4.5513 & TRN \\
\hline CHEMBL1563660 & 688759 & 4.45 & 4.978 & TST \\
\hline CHEMBL1431036 & 688759 & 4.45 & 4.8253 & TST \\
\hline CHEMBL1580641 & 688759 & 4.45 & 5.3542 & TRN \\
\hline CHEMBL1371188 & 688759 & 4.45 & 4.792 & TRN \\
\hline CHEMBL3192753 & 688759 & 4.6 & 4.7491 & TRN \\
\hline CHEMBL1604007 & 688759 & 5.35 & 5.2935 & TST \\
\hline CHEMBL1526721 & 688759 & 4.45 & 4.7657 & TST \\
\hline CHEMBL1537370 & 688759 & 5.1 & 4.9106 & TRN \\
\hline CHEMBL1321788 & 688759 & 5.2 & 4.9643 & TST \\
\hline CHEMBL1504324 & 688759 & 5.15 & 5.0051 & TRN \\
\hline CHEMBL1547822 & 688759 & 4.85 & 5.1436 & TRN \\
\hline CHEMBL1530074 & 688759 & 4.45 & 4.7485 & TRN \\
\hline CHEMBL1408463 & 688759 & 4.45 & 4.6155 & TST \\
\hline CHEMBL1540577 & 688759 & 4.75 & 4.8339 & TRN \\
\hline CHEMBL1560074 & 688759 & 4.65 & 4.9141 & TST \\
\hline CHEMBL1544502 & 688759 & 5.2 & 4.97 & TST \\
\hline CHEMBL1415348 & 688759 & 4.45 & 4.8384 & TRN \\
\hline CHEMBL235928 & 688759 & 4.45 & 4.8535 & TRN \\
\hline CHEMBL1460698 & 688759 & 4.45 & 4.9951 & TRN \\
\hline CHEMBL1983839 & 688759 & 5.9 & 5.1783 & TRN \\
\hline CHEMBL1586245 & 688759 & 4.45 & 4.5727 & TRN \\
\hline CHEMBL1306503 & 688759 & 4.45 & 4.6829 & TRN \\
\hline CHEMBL1594896 & 688759 & 4.65 & 4.8453 & TRN \\
\hline CHEMBL1419867 & 688759 & 4.85 & 4.6688 & TST \\
\hline CHEMBL1366160 & 688759 & 5.4 & 4.815 & TRN \\
\hline CHEMBL1393037 & 688759 & 4.85 & 5.0912 & TRN \\
\hline
\end{tabular}




\begin{tabular}{|c|c|c|c|c|c|}
\hline & & \multicolumn{4}{|c|}{ Supplemental Table S2.txt } \\
\hline CHEMBL3196682 & 688759 & 4.85 & 4.8082 & TST & \\
\hline CHEMBL1411884 & 688759 & 7.0 & 5.8843 & TST & \\
\hline CHEMBL 2002392 & 688759 & 4.45 & 4.7786 & TRN & \\
\hline CHEMBL1494293 & 688759 & 5.5 & 5.1167 & TRN & \\
\hline CHEMBL1370891 & 688759 & 6.0 & 4.8374 & TRN & \\
\hline CHEMBL1584250 & 688759 & 5.95 & 5.3127 & TRN & \\
\hline CHEMBL3209196 & 688759 & 4.45 & 4.7255 & TRN & \\
\hline CHEMBL1581626 & 688759 & 5.0 & 5.3331 & TRN & \\
\hline CHEMBL 3194523 & 688759 & 5.65 & 5.6304 & TST & \\
\hline CHEMBL1384836 & 688759 & 4.95 & 4.9559 & TST & \\
\hline CHEMBL1402899 & 688759 & 5.45 & 4.854 & TRN & \\
\hline CHEMBL1435687 & 688759 & 4.6 & 4.8229 & TRN & \\
\hline CHEMBL1342874 & 688759 & 4.45 & 4.6898 & TRN & \\
\hline CHEMBL1381328 & 688759 & 5.35 & 5.5257 & TRN & \\
\hline CHEMBL1406634 & 688759 & 4.6 & 4.7377 & TST & \\
\hline CHEMBL1349075 & 688759 & 5.0 & 4.9757 & TRN & \\
\hline CHEMBL1565302 & 688759 & 4.85 & 4.6165 & TRN & \\
\hline CHEMBL1967031 & 688759 & 5.25 & 5.2628 & TRN & \\
\hline CHEMBL 3190547 & 688759 & 5.35 & 4.8097 & TRN & \\
\hline CHEMBL1416041 & 688759 & 4.6 & 4.5086 & TST & \\
\hline CHEMBL1581018 & 688759 & 4.9 & 4.849 & TST & \\
\hline CHEMBL1345067 & 688759 & 5.8 & 5.1366 & TRN & \\
\hline CHEMBL1566949 & 688759 & 5.25 & 5.0881 & TRN & \\
\hline CHEMBL1583835 & 688759 & 5.35 & 4.8402 & TST & \\
\hline CHEMBL1608059 & 688759 & 4.9 & 5.0012 & TST & \\
\hline CHEMBL1972491 & 688759 & 4.95 & 4.9523 & TST & \\
\hline CHEMBL1508166 & 688759 & 5.4 & 4.9323 & TRN & \\
\hline CHEMBL1308441 & 688759 & 4.45 & 4.4536 & TRN & \\
\hline CHEMBL1561880 & 688759 & 4.6 & 4.9245 & TRN & \\
\hline CHEMBL1390373 & 688759 & 4.45 & 4.7993 & TRN & \\
\hline CHEMBL1519840 & 688759 & 4.45 & 4.9413 & TRN & \\
\hline CHEMBL3189714 & 688759 & 5.25 & 5.3997 & TRN & \\
\hline CHEMBL1451592 & 688759 & 4.95 & 4.9672 & TRN & \\
\hline CHEMBL1464071 & 688759 & 5.4 & 4.9441 & TRN & \\
\hline CHEMBL1301125 & 688759 & 5.5 & 5.178 & TRN & \\
\hline CHEMBL1388334 & 688759 & 4.6 & 5.2634 & TST & \\
\hline CHEMBL1579037 & 688759 & 5.55 & 5.358 & TRN & \\
\hline CHEMBL1500708 & 688759 & 4.95 & 4.7647 & TRN & \\
\hline CHEMBL1309569 & 688759 & 4.45 & 4.8164 & TRN & \\
\hline CHEMBL1365239 & 688759 & 4.8 & 4.9158 & TRN & \\
\hline CHEMBL1979747 & 688759 & 4.65 & 4.963 & TRN & \\
\hline CHEMBL1448424 & 688759 & 5.8 & 4.9296 & TRN & \\
\hline CHEMBL1381612 & 688759 & 4.55 & 5.1149 & TST & \\
\hline CHEMBL3212074 & 688759 & 5.45 & 4.9125 & TST & \\
\hline CHEMBL1497859 & 688759 & 5.05 & 4.802 & TRN & \\
\hline CHEMBL1508440 & 688759 & 5.2 & 5.21700 & 00000000005 & TRN \\
\hline CHEMBL1413923 & 688759 & 4.45 & 4.8697 & TRN & \\
\hline CHEMBL1354850 & 688759 & 4.45 & 4.4781 & TRN & \\
\hline
\end{tabular}




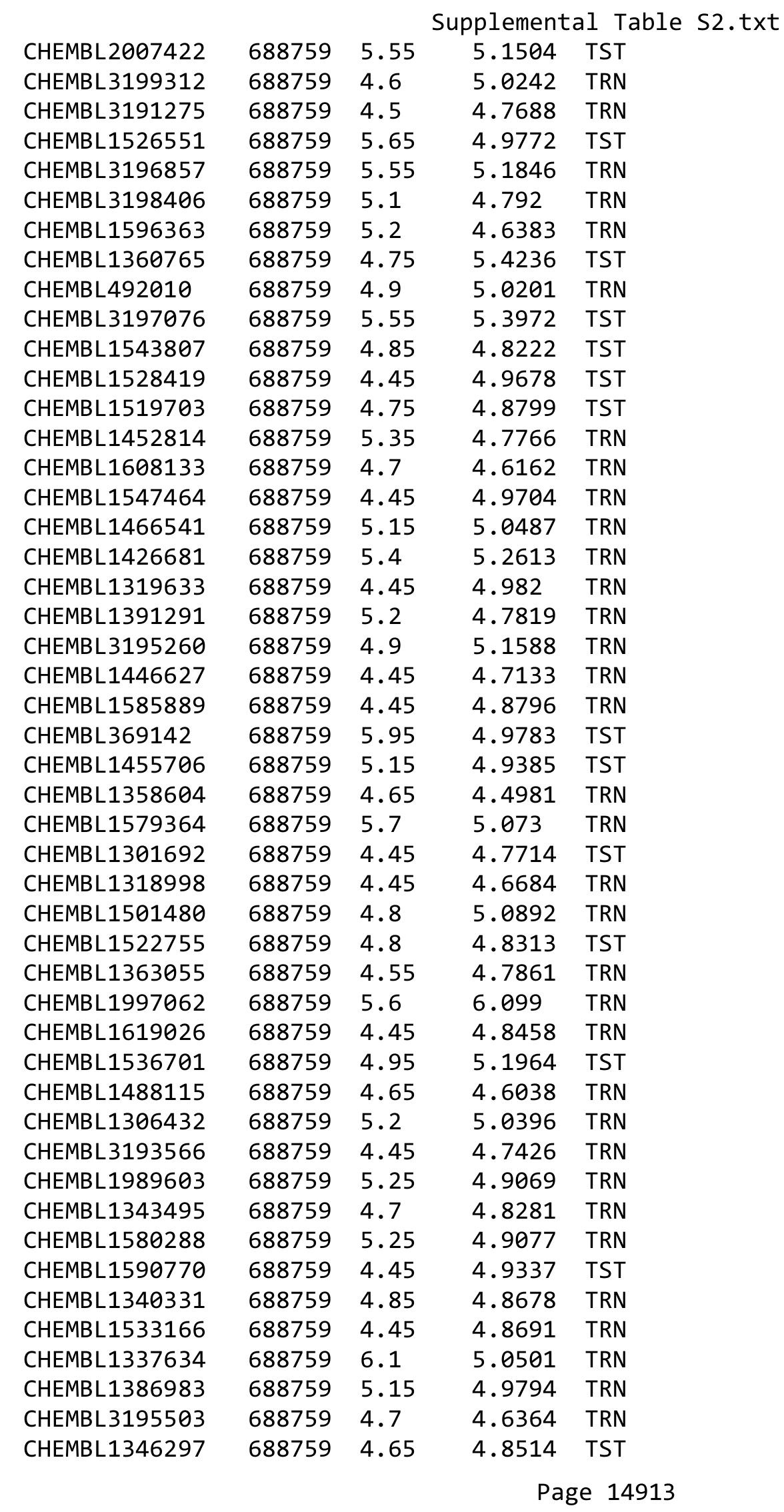




\begin{tabular}{|c|c|c|c|c|c|}
\hline & & \multicolumn{4}{|c|}{ Supplemental Table s2.txt } \\
\hline CHEMBL1351323 & 688759 & 4.75 & 4.591 & TRN & \\
\hline CHEMBL1450860 & 688759 & 4.45 & 4.6409 & TRN & \\
\hline CHEMBL1444730 & 688759 & 4.8 & 4.8399 & TRN & \\
\hline CHEMBL466930 & 688759 & 4.45 & 4.791 & TRN & \\
\hline CHEMBL1320352 & 688759 & 4.95 & 5.1253 & TRN & \\
\hline CHEMBL1535542 & 688759 & 4.95 & 4.9398 & TRN & \\
\hline CHEMBL 3197637 & 688759 & 4.7 & 4.6191 & TRN & \\
\hline CHEMBL1333334 & 688759 & 4.75 & 4.7555 & TRN & \\
\hline CHEMBL1300116 & 688759 & 4.75 & 5.1134 & TST & \\
\hline CHEMBL1434553 & 688759 & 4.45 & 5.0913 & TRN & \\
\hline CHEMBL1548711 & 688759 & 4.45 & 4.9335 & TRN & \\
\hline CHEMBL 3208570 & 688759 & 6.4 & 4.9423 & TRN & \\
\hline CHEMBL1499911 & 688759 & 4.7 & 4.8127 & TST & \\
\hline CHEMBL1456311 & 688759 & 4.45 & 4.8848 & TRN & \\
\hline CHEMBL3196226 & 688759 & 4.45 & 4.9051 & TRN & \\
\hline CHEMBL3189916 & 688759 & 5.45 & 5.1333 & TRN & \\
\hline CHEMBL1350361 & 688759 & 5.85 & 4.8192 & TRN & \\
\hline CHEMBL1368468 & 688759 & 4.6 & 4.5065 & TST & \\
\hline CHEMBL1327840 & 688759 & 5.0 & 4.8424 & TST & \\
\hline CHEMBL1338852 & 688759 & 4.95 & 5.3041 & TST & \\
\hline CHEMBL1563757 & 688759 & 4.65 & 4.7685 & TRN & \\
\hline CHEMBL1468271 & 688759 & 4.45 & 4.7633 & TRN & \\
\hline CHEMBL1362676 & 688759 & 5.55 & 4.9525 & TRN & \\
\hline CHEMBL1996363 & 688759 & 4.45 & 4.5418 & TST & \\
\hline CHEMBL1530766 & 688759 & 4.9 & 4.8855 & TRN & \\
\hline CHEMBL1308052 & 688759 & 4.7 & 5.0254 & TRN & \\
\hline CHEMBL1447887 & 688759 & 4.45 & 4.8578 & TST & \\
\hline CHEMBL1415111 & 688759 & 5.0 & 4.6196 & TRN & \\
\hline CHEMBL 3198194 & 688759 & 4.45 & 4.8749 & TRN & \\
\hline CHEMBL1431867 & 688759 & 4.5 & 4.8279 & TRN & \\
\hline CHEMBL1335863 & 688759 & 4.8 & 4.8455 & TRN & \\
\hline CHEMBL1362956 & 688759 & 5.1 & 4.9705 & TRN & \\
\hline CHEMBL1611198 & 688759 & 5.35 & 4.8242 & TRN & \\
\hline CHEMBL1541625 & 688759 & 4.45 & 4.9548 & TRN & \\
\hline CHEMBL1597627 & 688759 & 5.95 & 5.8296 & TRN & \\
\hline CHEMBL1351933 & 688759 & 4.8 & 4.8341 & TST & \\
\hline CHEMBL518430 & 688759 & 4.8 & 5.0135 & TRN & \\
\hline CHEMBL 180920 & 688759 & 6.0 & 4.66 & TST & \\
\hline CHEMBL1495409 & 688759 & 5.05 & 5.15799 & 99999999995 & TRN \\
\hline CHEMBL1534571 & 688759 & 4.9 & 4.9638 & TST & \\
\hline CHEMBL1379485 & 688759 & 4.8 & 4.9583 & TRN & \\
\hline CHEMBL1378868 & 688759 & 4.45 & 4.8324 & TRN & \\
\hline CHEMBL1536467 & 688759 & 4.45 & 4.667 & TRN & \\
\hline CHEMBL1320050 & 688759 & 4.45 & 4.6964 & TST & \\
\hline CHEMBL1501360 & 688759 & 4.65 & 4.7461 & TST & \\
\hline CHEMBL1586579 & 688759 & 4.8 & 4.9518 & TRN & \\
\hline CHEMBL1502296 & 688759 & 5.45 & 5.0015 & TST & \\
\hline CHEMBL1506934 & 688759 & 4.7 & 4.6974 & TRN & \\
\hline
\end{tabular}




\begin{tabular}{|c|c|c|c|c|c|}
\hline \multicolumn{6}{|c|}{ Supplemental Table S2.txt } \\
\hline CHEMBL3192947 & 688759 & 5.0 & 4.9423 & TRN & \\
\hline CHEMBL 1445854 & 688759 & 4.45 & 5.0375 & TRN & \\
\hline CHEMBL1417829 & 688759 & 4.65 & 4.873 & TRN & \\
\hline CHEMBL1334025 & 688759 & 4.7 & 4.6793 & TRN & \\
\hline CHEMBL1551453 & 688759 & 4.6 & 4.6749 & TST & \\
\hline CHEMBL1398781 & 688759 & 5.55 & 4.773 & TRN & \\
\hline CHEMBL3189636 & 688759 & 4.8 & 5.1897 & TRN & \\
\hline CHEMBL1530420 & 688759 & 5.3 & 5.1077 & TRN & \\
\hline CHEMBL3211016 & 688759 & 4.95 & 4.663 & TRN & \\
\hline CHEMBL1320718 & 688759 & 5.1 & 4.5938 & TRN & \\
\hline CHEMBL 3190182 & 688759 & 5.2 & 5.1917 & TRN & \\
\hline CHEMBL1328527 & 688759 & 5.0 & 5.20700 & 2000000001 & TRN \\
\hline CHEMBL1504125 & 688759 & 5.95 & 5.7611 & TRN & \\
\hline CHEMBL1391592 & 688759 & 4.65 & 4.76 & TRN & \\
\hline CHEMBL3189256 & 688759 & 4.45 & 4.8033 & TRN & \\
\hline CHEMBL1378976 & 688759 & 5.0 & 5.2453 & TRN & \\
\hline CHEMBL1482692 & 688759 & 4.45 & 4.8296 & TRN & \\
\hline CHEMBL1405253 & 688759 & 4.45 & 4.7938 & TRN & \\
\hline CHEMBL1340517 & 688759 & 4.45 & 4.9536 & TST & \\
\hline CHEMBL1422652 & 688759 & 4.45 & 4.7925 & TRN & \\
\hline CHEMBL1470515 & 688759 & 5.85 & 5.0119 & TRN & \\
\hline CHEMBL3197524 & 688759 & 4.45 & 4.9062 & TST & \\
\hline CHEMBL1538368 & 688759 & 4.45 & 4.6291 & TST & \\
\hline CHEMBL1606306 & 688759 & 4.45 & 5.113 & TRN & \\
\hline CHEMBL1438022 & 688759 & 4.75 & 4.7785 & TRN & \\
\hline CHEMBL1970812 & 688759 & 6.25 & 4.8742 & TST & \\
\hline CHEMBL1542375 & 688759 & 4.65 & 5.2429 & TRN & \\
\hline CHEMBL1415513 & 688759 & 4.95 & 4.5932 & TST & \\
\hline CHEMBL1578607 & 688759 & 5.85 & 5.9747 & TRN & \\
\hline CHEMBL1479186 & 688759 & 4.65 & 4.6398 & TRN & \\
\hline CHEMBL1495376 & 688759 & 4.8 & 4.9822 & TRN & \\
\hline CHEMBL1340499 & 688759 & 5.8 & 5.2139 & TRN & \\
\hline CHEMBL3392397 & 688759 & 5.25 & 5.1876 & TRN & \\
\hline CHEMBL373481 & 688759 & 4.45 & 4.6985 & TST & \\
\hline CHEMBL1544106 & 688759 & 4.55 & 4.8815 & TST & \\
\hline CHEMBL1589267 & 688759 & 5.3 & 5.7191 & TRN & \\
\hline CHEMBL1507780 & 688759 & 4.65 & 5.1742 & TRN & \\
\hline CHEMBL1607724 & 688759 & 4.45 & 4.8095 & TRN & \\
\hline CHEMBL1580001 & 688759 & 4.9 & 4.8723 & TRN & \\
\hline CHEMBL1428326 & 688759 & 5.55 & 5.1682 & TRN & \\
\hline CHEMBL1611394 & 688759 & 4.95 & 5.0286 & TRN & \\
\hline CHEMBL1357872 & 688759 & 4.45 & 5.1789 & TRN & \\
\hline CHEMBL1601730 & 688759 & 4.95 & 5.0518 & TST & \\
\hline CHEMBL1524267 & 688759 & 4.5 & 4.8924 & TRN & \\
\hline CHEMBL1336785 & 688759 & 4.45 & 4.8373 & TST & \\
\hline CHEMBL1608582 & 688759 & 5.25 & 5.1846 & TRN & \\
\hline CHEMBL1339491 & 688759 & 5.5 & 4.9684 & TST & \\
\hline CHEMBL1478844 & 688759 & 4.55 & 4.7381 & TRN & \\
\hline
\end{tabular}




\begin{tabular}{|c|c|c|c|c|c|}
\hline & & \multicolumn{4}{|c|}{ Supplemental Table s2.txt } \\
\hline CHEMBL1378047 & 688759 & 6.35 & 4.8323 & TRN & \\
\hline CHEMBL1313310 & 688759 & 4.95 & 4.8794 & TRN & \\
\hline CHEMBL1366948 & 688759 & 5.5 & 5.2635 & TST & \\
\hline CHEMBL1545132 & 688759 & 4.7 & 4.8322 & TST & \\
\hline CHEMBL1558301 & 688759 & 5.6 & 4.8511 & TRN & \\
\hline CHEMBL1607824 & 688759 & 4.7 & 4.8264 & TST & \\
\hline CHEMBL1523301 & 688759 & 5.65 & 5.051 & TST & \\
\hline CHEMBL1587352 & 688759 & 4.95 & 4.9177 & TRN & \\
\hline CHEMBL1311425 & 688759 & 5.95 & 4.9895 & TRN & \\
\hline CHEMBL3211169 & 688759 & 5.1 & 4.7774 & TRN & \\
\hline CHEMBL131921 & 688759 & 4.9 & 4.6259 & TRN & \\
\hline CHEMBL1365290 & 688759 & 5.15 & 4.9667 & TRN & \\
\hline CHEMBL1346232 & 688759 & 4.45 & 4.5289 & TRN & \\
\hline CHEMBL1383511 & 688759 & 5.3 & 5.4523 & TRN & \\
\hline CHEMBL1323267 & 688759 & 5.05 & 5.2656 & TRN & \\
\hline CHEMBL1385055 & 688759 & 4.95 & 4.74 & TST & \\
\hline CHEMBL1600232 & 688759 & 6.0 & 5.2973 & TST & \\
\hline CHEMBL1331268 & 688759 & 5.55 & 5.1964 & TST & \\
\hline CHEMBL1321935 & 688759 & 4.75 & 4.8002 & TST & \\
\hline CHEMBL1404497 & 688759 & 6.05 & 5.475 & TRN & \\
\hline CHEMBL1350332 & 688759 & 5.35 & 5.3302 & TRN & \\
\hline CHEMBL1396639 & 688759 & 5.0 & 4.7279 & TRN & \\
\hline CHEMBL1481434 & 688759 & 5.25 & 4.8273 & TST & \\
\hline CHEMBL1403115 & 688759 & 4.5 & 4.9846 & TRN & \\
\hline CHEMBL533226 & 688759 & 4.8 & 5.1043 & TST & \\
\hline CHEMBL1450690 & 688759 & 4.95 & 4.737 & TRN & \\
\hline CHEMBL1532037 & 688759 & 4.95 & 5.2163 & TRN & \\
\hline CHEMBL1537419 & 688759 & 4.45 & 4.8852 & TRN & \\
\hline CHEMBL3193651 & 688759 & 4.7 & 4.8402 & TRN & \\
\hline CHEMBL3189207 & 688759 & 4.9 & 5.0818 & TST & \\
\hline CHEMBL1328473 & 688759 & 4.95 & 5.0214 & TRN & \\
\hline CHEMBL1349113 & 688759 & 5.0 & 4.9891 & TST & \\
\hline CHEMBL1460118 & 688759 & 4.45 & 5.0577 & TRN & \\
\hline CHEMBL1527187 & 688759 & 4.5 & 4.84699 & 99999999995 & TRN \\
\hline CHEMBL3196332 & 688759 & 4.65 & 4.8718 & TRN & \\
\hline CHEMBL1338349 & 688759 & 4.9 & 4.9194 & TST & \\
\hline CHEMBL1383170 & 688759 & 4.8 & 4.9444 & TRN & \\
\hline CHEMBL1487865 & 688759 & 4.45 & 4.8029 & TRN & \\
\hline CHEMBL1351709 & 688759 & 4.45 & 5.03100 & 3000000001 & TST \\
\hline CHEMBL3190869 & 688759 & 5.2 & 4.9851 & TRN & \\
\hline CHEMBL1507043 & 688759 & 5.7 & 5.3762 & TRN & \\
\hline CHEMBL1997463 & 688759 & 4.6 & 5.0675 & TRN & \\
\hline CHEMBL1502351 & 688759 & 4.95 & 5.3369 & TRN & \\
\hline CHEMBL1389914 & 688759 & 4.95 & 5.1745 & TRN & \\
\hline CHEMBL1608456 & 688759 & 4.85 & 4.6546 & TRN & \\
\hline CHEMBL1307415 & 688759 & 4.75 & 4.7119 & TRN & \\
\hline CHEMBL1584138 & 688759 & 5.4 & 4.9495 & TRN & \\
\hline CHEMBL1383223 & 688759 & 4.65 & 5.1576 & TST & \\
\hline
\end{tabular}




\begin{tabular}{|c|c|c|c|c|c|}
\hline \multicolumn{6}{|c|}{ Supplemental Table S2.txt } \\
\hline CHEMBL1971613 & 688759 & 4.7 & 4.8885 & TST & \\
\hline CHEMBL1539499 & 688759 & 6.2 & 4.9637 & TST & \\
\hline CHEMBL1391544 & 688759 & 4.45 & 4.771 & TST & \\
\hline CHEMBL1313927 & 688759 & 5.0 & 4.9354 & TRN & \\
\hline CHEMBL1331045 & 688759 & 4.6 & 5.1492 & TST & \\
\hline CHEMBL1349646 & 688759 & 4.95 & 5.115 & TST & \\
\hline CHEMBL1348070 & 688759 & 4.6 & 4.8668 & TRN & \\
\hline CHEMBL1413958 & 688759 & 5.25 & 4.9289 & TST & \\
\hline CHEMBL197131 & 688759 & 4.7 & 4.6904 & TRN & \\
\hline CHEMBL1611169 & 688759 & 5.25 & 4.7475 & TRN & \\
\hline CHEMBL1579839 & 688759 & 5.95 & 5.9742 & TRN & \\
\hline CHEMBL1501141 & 688759 & 4.65 & 4.7088 & TRN & \\
\hline CHEMBL 3212687 & 688759 & 4.95 & 4.8543 & TRN & \\
\hline CHEMBL1448231 & 688759 & 4.6 & 4.8335 & TRN & \\
\hline CHEMBL1372932 & 688759 & 5.05 & 5.2998 & TRN & \\
\hline CHEMBL1344732 & 688759 & 4.45 & 4.7394 & TRN & \\
\hline CHEMBL1589921 & 688759 & 5.5 & 5.4846 & TST & \\
\hline CHEMBL1455788 & 688759 & 4.45 & 4.7094 & TRN & \\
\hline CHEMBL1391279 & 688759 & 4.75 & 5.0208 & TST & \\
\hline CHEMBL495778 & 688759 & 6.0 & 5.3772 & TST & \\
\hline CHEMBL1386546 & 688759 & 4.45 & 4.4565 & TRN & \\
\hline CHEMBL1415454 & 688759 & 4.45 & 4.7178 & TST & \\
\hline CHEMBL1513856 & 688759 & 4.45 & 4.9019 & TST & \\
\hline CHEMBL1322572 & 688759 & 4.6 & 4.8236 & TST & \\
\hline CHEMBL1458729 & 688759 & 5.35 & 4.9794 & TRN & \\
\hline CHEMBL1488964 & 688759 & 4.45 & 4.7395 & TRN & \\
\hline CHEMBL1453822 & 688759 & 4.5 & 4.7281 & TRN & \\
\hline CHEMBL1452421 & 688759 & 5.35 & 5.23799 & 99999999995 & TRN \\
\hline CHEMBL1402936 & 688759 & 4.65 & $5.2620 e$ & 00000000005 & TRN \\
\hline CHEMBL1365561 & 688759 & 4.5 & 4.8137 & TRN & \\
\hline CHEMBL1504340 & 688759 & 5.2 & 4.9109 & TRN & \\
\hline CHEMBL1332956 & 688759 & 4.45 & 4.6408 & TST & \\
\hline CHEMBL1584885 & 688759 & 4.85 & 4.9192 & TRN & \\
\hline CHEMBL1531828 & 688759 & 4.45 & 4.5771 & TRN & \\
\hline CHEMBL1451743 & 688759 & 5.4 & 4.7453 & TRN & \\
\hline CHEMBL1323246 & 688759 & 4.7 & 4.7821 & TRN & \\
\hline CHEMBL1521846 & 688759 & 4.75 & 5.1432 & TRN & \\
\hline CHEMBL3189179 & 688759 & 6.0 & 5.4369 & TRN & \\
\hline CHEMBL 3210985 & 688759 & 4.45 & 5.0754 & TRN & \\
\hline CHEMBL1489100 & 688759 & 4.85 & 4.7562 & TST & \\
\hline CHEMBL1310416 & 688759 & 4.75 & 4.6067 & TRN & \\
\hline CHEMBL1343422 & 688759 & 4.45 & 4.819 & TRN & \\
\hline CHEMBL1374874 & 688759 & 4.7 & 4.8798 & TST & \\
\hline CHEMBL1469111 & 688759 & 6.05 & 6.0455 & TRN & \\
\hline CHEMBL1543930 & 688759 & 4.9 & 5.052 & TRN & \\
\hline CHEMBL1345124 & 688759 & 4.45 & 4.5983 & TRN & \\
\hline CHEMBL1346930 & 688759 & 5.4 & 4.8675 & TRN & \\
\hline CHEMBL1538328 & 688759 & 6.1 & 4.8502 & TST & \\
\hline
\end{tabular}




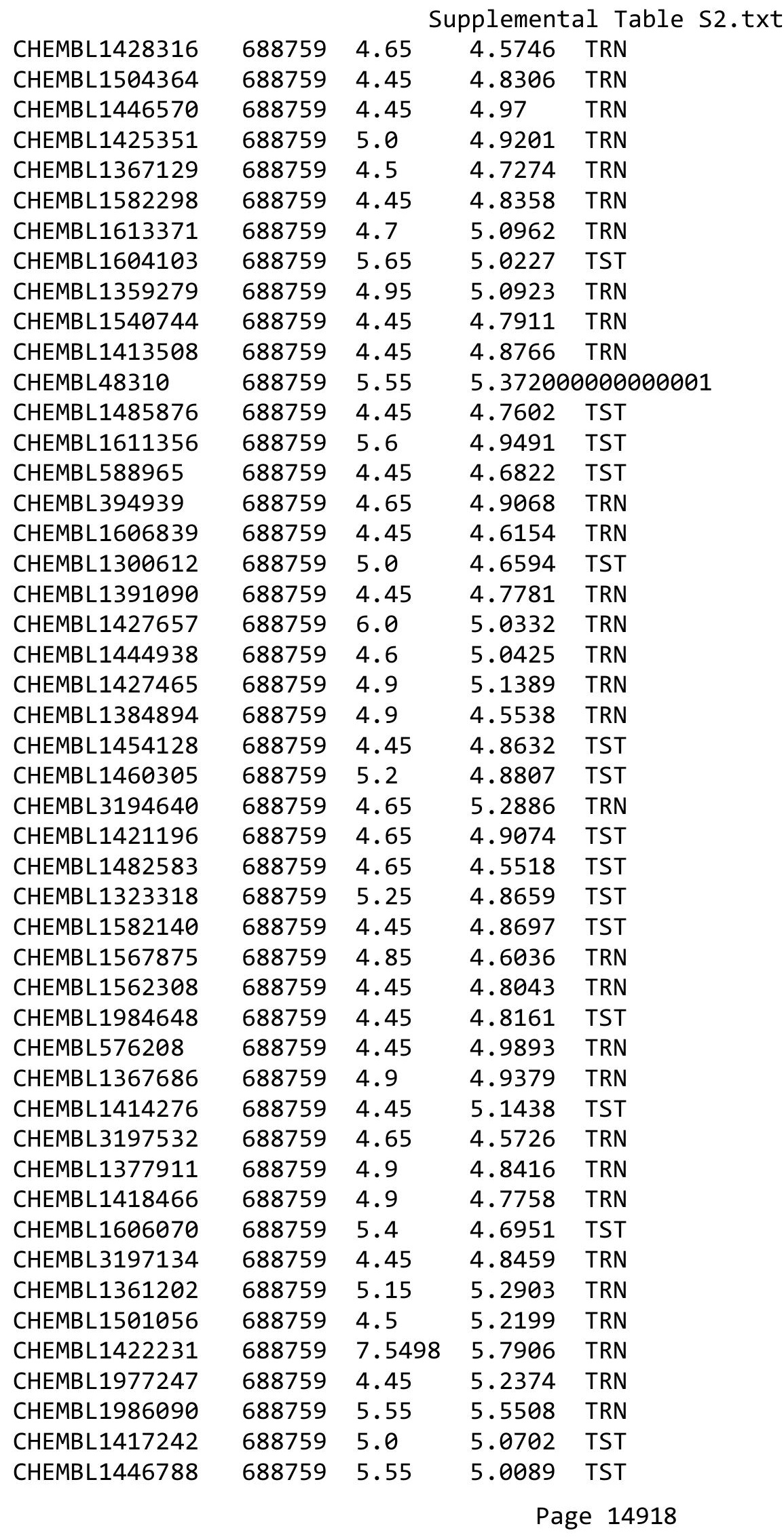




\begin{tabular}{|c|c|c|c|c|c|}
\hline \multicolumn{6}{|c|}{ Supplemental Table S2.txt } \\
\hline CHEMBL1468437 & 688759 & 4.65 & 4.8006 & TRN & \\
\hline CHEMBL1505760 & 688759 & 6.05 & 5.689 & TRN & \\
\hline CHEMBL1422053 & 688759 & 5.95 & 5.4287 & TRN & \\
\hline CHEMBL1394024 & 688759 & 4.45 & 4.8334 & TRN & \\
\hline CHEMBL 3193650 & 688759 & 5.15 & 5.2065 & TRN & \\
\hline CHEMBL3196698 & 688759 & 4.75 & 4.7684 & TST & \\
\hline CHEMBL1445606 & 688759 & 4.45 & 4.9138 & TST & \\
\hline CHEMBL1349322 & 688759 & 6.0 & 5.8269 & TRN & \\
\hline CHEMBL 3196470 & 688759 & 4.7 & 4.7568 & TRN & \\
\hline CHEMBL1310986 & 688759 & 5.25 & 4.7315 & TST & \\
\hline CHEMBL609438 & 688759 & 5.1 & 5.0434 & TRN & \\
\hline CHEMBL1335283 & 688759 & 5.0 & 4.6512 & TRN & \\
\hline CHEMBL1483015 & 688759 & 4.8 & 4.7417 & TST & \\
\hline CHEMBL1556273 & 688759 & 4.95 & 4.7833 & TST & \\
\hline CHEMBL1522027 & 688759 & 4.45 & 4.6402 & TRN & \\
\hline CHEMBL1320561 & 688759 & 4.65 & 5.1379 & TRN & \\
\hline CHEMBL3197688 & 688759 & 5.5 & 4.713 & TRN & \\
\hline CHEMBL1595410 & 688759 & 4.95 & 4.9279 & TRN & \\
\hline CHEMBL1462730 & 688759 & 5.5 & 4.8115 & TST & \\
\hline CHEMBL1337226 & 688759 & 4.45 & 4.7408 & TRN & \\
\hline CHEMBL1563163 & 688759 & 4.75 & 4.9922 & TRN & \\
\hline CHEMBL1443015 & 688759 & 5.45 & 4.779 & TRN & \\
\hline CHEMBL 2093214 & 688759 & 5.05 & 4.8946 & TRN & \\
\hline CHEMBL 3189543 & 688759 & 5.0 & 4.6758 & TRN & \\
\hline CHEMBL1471194 & 688759 & 4.95 & 5.0514 & TST & \\
\hline CHEMBL 3189645 & 688759 & 4.45 & 4.8979 & TRN & \\
\hline CHEMBL1381358 & 688759 & 5.85 & 5.0471 & TRN & \\
\hline CHEMBL1535665 & 688759 & 5.55 & 5.0893 & TST & \\
\hline CHEMBL1422039 & 688759 & 5.35 & 5.046 & TRN & \\
\hline CHEMBL1583715 & 688759 & 4.45 & 5.0241 & TST & \\
\hline CHEMBL1368048 & 688759 & 4.85 & 4.7919 & TST & \\
\hline CHEMBL1328856 & 688759 & 4.55 & 4.9965 & TST & \\
\hline CHEMBL1569271 & 688759 & 4.75 & 4.7128 & TRN & \\
\hline CHEMBL1336100 & 688759 & 4.55 & 4.7468 & TRN & \\
\hline CHEMBL1372933 & 688759 & 4.9 & 4.65600 & 0000000001 & TST \\
\hline CHEMBL1412480 & 688759 & 4.9 & 4.8825 & TST & \\
\hline CHEMBL1378959 & 688759 & 4.5 & 4.7584 & TST & \\
\hline CHEMBL 2006750 & 688759 & 4.9 & 4.9426 & TRN & \\
\hline CHEMBL1326475 & 688759 & 5.05 & 5.0847 & TRN & \\
\hline CHEMBL1497837 & 688759 & 5.3 & 5.1339 & TST & \\
\hline CHEMBL1526321 & 688759 & 5.35 & 4.9367 & TRN & \\
\hline CHEMBL1385998 & 688759 & 5.55 & 4.9393 & TST & \\
\hline CHEMBL1506387 & 688759 & 5.0 & 5.3962 & TRN & \\
\hline CHEMBL1474649 & 688759 & 4.8 & 4.9357 & TRN & \\
\hline CHEMBL 3199233 & 688759 & 4.45 & 4.7726 & TRN & \\
\hline CHEMBL3213501 & 688759 & 5.9 & 5.6832 & TRN & \\
\hline CHEMBL1498886 & 688759 & 4.9 & 4.8558 & TST & \\
\hline CHEMBL1468953 & 688759 & 4.65 & 4.6479 & TRN & \\
\hline
\end{tabular}




\begin{tabular}{|c|c|c|c|c|c|}
\hline \multicolumn{6}{|c|}{ Supplemental Table S2.txt } \\
\hline CHEMBL1419680 & 688759 & 5.25 & 4.9136 & TST & \\
\hline CHEMBL1301655 & 688759 & 7.0501 & 5.8887 & TRN & \\
\hline CHEMBL3191652 & 688759 & 5.6 & 4.6865 & TRN & \\
\hline CHEMBL3208851 & 688759 & 5.5 & 5.8754 & TRN & \\
\hline CHEMBL1324834 & 688759 & 4.45 & 4.6622 & TRN & \\
\hline CHEMBL1483408 & 688759 & 4.6 & 4.7796 & TRN & \\
\hline CHEMBL1477754 & 688759 & 4.75 & 4.9241 & TST & \\
\hline CHEMBL1452622 & 688759 & 5.2 & 4.9949 & TST & \\
\hline CHEMBL1582705 & 688759 & 4.7 & 4.648 & TRN & \\
\hline CHEMBL1439992 & 688759 & 5.0 & 4.6844 & TST & \\
\hline CHEMBL1343954 & 688759 & 5.85 & 5.0155 & TRN & \\
\hline CHEMBL1324374 & 688759 & 4.45 & 4.9019 & TST & \\
\hline CHEMBL1509135 & 688759 & 4.8 & 4.9867 & TRN & \\
\hline CHEMBL1495055 & 688759 & 5.0 & 4.6939 & TRN & \\
\hline CHEMBL1370479 & 688759 & 5.0 & 4.8901 & TRN & \\
\hline CHEMBL1595586 & 688759 & 4.9 & 4.4799 & TST & \\
\hline CHEMBL1319860 & 688759 & 4.9 & 4.9714 & TRN & \\
\hline CHEMBL1549401 & 688759 & 4.45 & 4.8992 & TRN & \\
\hline CHEMBL1363513 & 688759 & 5.55 & 4.8534 & TST & \\
\hline CHEMBL1570106 & 688759 & 6.1 & 4.8592 & TST & \\
\hline CHEMBL1382231 & 688759 & 4.45 & 4.8543 & TST & \\
\hline CHEMBL1572228 & 688759 & 4.45 & 4.8239 & TRN & \\
\hline CHEMBL1509962 & 688759 & 4.75 & 4.9654 & TRN & \\
\hline CHEMBL3199029 & 688759 & 5.0 & 4.9262 & TRN & \\
\hline CHEMBL1349863 & 688759 & 5.35 & 5.2495 & TRN & \\
\hline CHEMBL1537449 & 688759 & 5.15 & 5.0685 & TRN & \\
\hline CHEMBL1537363 & 688759 & 5.45 & 5.0134 & TRN & \\
\hline CHEMBL1392366 & 688759 & 5.5 & 4.6927 & TRN & \\
\hline CHEMBL1505313 & 688759 & 4.45 & 4.6395 & TST & \\
\hline CHEMBL1496874 & 688759 & 4.8 & 4.7179 & TRN & \\
\hline CHEMBL1496299 & 688759 & 4.8 & 4.7858 & TST & \\
\hline CHEMBL1441642 & 688759 & 5.1 & 4.9431 & TRN & \\
\hline CHEMBL1516561 & 688759 & 4.45 & 4.69306 & 00000000005 & TRN \\
\hline CHEMBL1389153 & 688759 & 5.0 & 4.893 & TRN & \\
\hline CHEMBL1585596 & 688759 & 4.45 & 4.7932 & TRN & \\
\hline CHEMBL1320243 & 688759 & 5.35 & 4.6985 & TRN & \\
\hline CHEMBL493863 & 688759 & 4.9 & 4.5059 & TST & \\
\hline CHEMBL1372085 & 688759 & 5.4 & 4.7751 & TST & \\
\hline CHEMBL3194605 & 688759 & 4.8 & 4.4973 & TST & \\
\hline CHEMBL1587460 & 688759 & 4.45 & 5.003 & TST & \\
\hline CHEMBL1505177 & 688759 & 4.45 & 5.0609 & TRN & \\
\hline CHEMBL1415308 & 688759 & 4.45 & 5.0649 & TRN & \\
\hline CHEMBL1309190 & 688759 & 5.55 & 5.4534 & TRN & \\
\hline CHEMBL1501375 & 688759 & 5.3 & 5.3995 & TRN & \\
\hline CHEMBL1610266 & 688759 & 4.85 & 4.9179 & TRN & \\
\hline CHEMBL3190551 & 688759 & 4.85 & 4.6223 & TST & \\
\hline CHEMBL1595294 & 688759 & 5.0 & 4.8323 & TRN & \\
\hline CHEMBL122360 & 688759 & 4.45 & 4.7152 & TST & \\
\hline
\end{tabular}




\begin{tabular}{|c|c|c|c|c|c|}
\hline \multicolumn{6}{|c|}{ Supplemental Table S2.txt } \\
\hline CHEMBL1404205 & 688759 & 5.2 & 4.9641 & TRN & \\
\hline CHEMBL 3188020 & 688759 & 4.85 & 4.5977 & TRN & \\
\hline CHEMBL1352375 & 688759 & 4.45 & 4.5749 & TRN & \\
\hline CHEMBL1482924 & 688759 & 4.45 & 4.9245 & TRN & \\
\hline CHEMBL1526678 & 688759 & 6.5 & 4.902 & TRN & \\
\hline CHEMBL3192871 & 688759 & 4.45 & 4.7933 & TRN & \\
\hline CHEMBL1538232 & 688759 & 4.45 & 4.925 & TST & \\
\hline CHEMBL1525602 & 688759 & 4.5 & 4.5409 & TRN & \\
\hline CHEMBL1389113 & 688759 & 6.1 & 4.7843 & TRN & \\
\hline CHEMBL1586895 & 688759 & 5.2 & 4.8569 & TRN & \\
\hline CHEMBL1495847 & 688759 & 6.8 & 6.25700 & 0000000001 & TRN \\
\hline CHEMBL1539083 & 688759 & 5.65 & 5.5477 & TRN & \\
\hline CHEMBL1372071 & 688759 & 6.0 & 5.7894 & TST & \\
\hline CHEMBL3208696 & 688759 & 4.65 & 5.1563 & TRN & \\
\hline CHEMBL3190635 & 688759 & 5.0 & 5.0294 & TRN & \\
\hline CHEMBL1389748 & 688759 & 4.95 & 4.8791 & TRN & \\
\hline CHEMBL3209203 & 688759 & 4.7 & 4.7867 & TRN & \\
\hline CHEMBL1326208 & 688759 & 4.45 & 5.0497 & TRN & \\
\hline CHEMBL1530020 & 688759 & 4.55 & 5.1409 & TRN & \\
\hline CHEMBL1541859 & 688759 & 4.65 & 4.9608 & TRN & \\
\hline CHEMBL1505780 & 688759 & 5.2 & 4.9345 & TRN & \\
\hline CHEMBL1478826 & 688759 & 5.4 & 5.4391 & TRN & \\
\hline CHEMBL1445458 & 688759 & 4.45 & 4.8177 & TRN & \\
\hline CHEMBL1416038 & 688759 & 4.6 & 4.651 & TRN & \\
\hline CHEMBL1570863 & 688759 & 4.6 & 4.7309 & TRN & \\
\hline CHEMBL1503129 & 688759 & 4.45 & 4.8815 & TRN & \\
\hline CHEMBL1483229 & 688759 & 4.45 & 4.8663 & TRN & \\
\hline CHEMBL1511358 & 688759 & 4.7 & 4.8059 & TRN & \\
\hline CHEMBL1585826 & 688759 & 4.45 & 4.7766 & TST & \\
\hline CHEMBL1609242 & 688759 & 4.45 & 4.6595 & TST & \\
\hline CHEMBL1577346 & 688759 & 4.45 & 4.9405 & TST & \\
\hline CHEMBL1545233 & 688759 & 5.2 & 5.0217 & TRN & \\
\hline CHEMBL1301983 & 688759 & 4.45 & 4.8244 & TRN & \\
\hline CHEMBL1501964 & 688759 & 4.65 & 4.5262 & TRN & \\
\hline CHEMBL1335966 & 688759 & 4.65 & 4.7571 & TRN & \\
\hline CHEMBL1381488 & 688759 & 4.9 & 4.6965 & TST & \\
\hline CHEMBL3194398 & 688759 & 4.95 & 4.8418 & TRN & \\
\hline CHEMBL1967497 & 688759 & 4.95 & 4.8223 & TRN & \\
\hline CHEMBL3195095 & 688759 & 5.55 & 4.7274 & TRN & \\
\hline CHEMBL1584750 & 688759 & 5.3 & 5.1144 & TST & \\
\hline CHEMBL1543168 & 688759 & 4.45 & 4.7958 & TRN & \\
\hline CHEMBL1373933 & 688759 & 4.45 & 4.8437 & TRN & \\
\hline CHEMBL1567184 & 688759 & 4.75 & 4.9776 & TRN & \\
\hline CHEMBL1520166 & 688759 & 4.5 & 4.8348 & TRN & \\
\hline CHEMBL1345966 & 688759 & 4.95 & 4.8626 & TRN & \\
\hline CHEMBL1567212 & 688759 & 4.9 & 4.7614 & TST & \\
\hline CHEMBL3191649 & 688759 & 4.55 & 4.8122 & TST & \\
\hline CHEMBL1550652 & 688759 & 4.45 & 4.9107 & TRN & \\
\hline
\end{tabular}




\begin{tabular}{|c|c|c|c|c|c|}
\hline & & \multicolumn{4}{|c|}{ Supplemental Table s2.txt } \\
\hline CHEMBL3195352 & 688759 & 4.7 & 4.6588 & TRN & \\
\hline CHEMBL1403009 & 688759 & 4.5 & 5.0133 & TRN & \\
\hline CHEMBL1359376 & 688759 & 4.7 & 4.7863 & TST & \\
\hline CHEMBL1410076 & 688759 & 4.45 & 4.6488 & TRN & \\
\hline CHEMBL1082422 & 688759 & 4.45 & 4.9628 & TRN & \\
\hline CHEMBL1359525 & 688759 & 5.15 & 4.8102 & TRN & \\
\hline CHEMBL1300912 & 688759 & 4.95 & 4.96899 & 9999999999 & TRN \\
\hline CHEMBL1310934 & 688759 & 5.35 & 4.8759 & TST & \\
\hline CHEMBL1501558 & 688759 & 5.35 & 5.296 & TRN & \\
\hline CHEMBL1379254 & 688759 & 4.95 & 5.0502 & TRN & \\
\hline CHEMBL3192749 & 688759 & 4.45 & 4.6035 & TST & \\
\hline CHEMBL1310064 & 688759 & 4.55 & 4.9871 & TRN & \\
\hline CHEMBL1422233 & 688759 & 4.65 & 4.8494 & TST & \\
\hline CHEMBL1419690 & 688759 & 4.45 & 4.8357 & TST & \\
\hline CHEMBL1588205 & 688759 & 4.45 & 4.9738 & TRN & \\
\hline CHEMBL1417737 & 688759 & 4.5 & 4.8575 & TRN & \\
\hline CHEMBL3190807 & 688759 & 5.4 & 5.1636 & TRN & \\
\hline CHEMBL1609126 & 688759 & 5.25 & 4.8784 & TST & \\
\hline CHEMBL1446839 & 688759 & 4.9 & 5.6907 & TRN & \\
\hline CHEMBL1312363 & 688759 & 4.45 & 5.2518 & TST & \\
\hline CHEMBL1521770 & 688759 & 5.25 & 4.8771 & TRN & \\
\hline CHEMBL1482046 & 688759 & 4.7 & 4.8617 & TRN & \\
\hline CHEMBL1610857 & 688759 & 4.6 & 5.2502 & TRN & \\
\hline CHEMBL1497946 & 688759 & 5.1 & 4.9521 & TRN & \\
\hline CHEMBL 2001904 & 688759 & 6.0 & 5.4241 & TST & \\
\hline CHEMBL1393171 & 688759 & 4.45 & 4.8665 & TRN & \\
\hline CHEMBL1367712 & 688759 & 5.3 & 5.4287 & TRN & \\
\hline CHEMBL1369767 & 688759 & 5.2 & 5.2555 & TST & \\
\hline CHEMBL1367325 & 688759 & 5.1 & 5.1408 & TRN & \\
\hline CHEMBL1572533 & 688759 & 4.65 & 4.7525 & TRN & \\
\hline CHEMBL1432917 & 688759 & 5.25 & 4.9417 & TRN & \\
\hline CHEMBL1335688 & 688759 & 4.75 & 4.8541 & TRN & \\
\hline CHEMBL1571202 & 688759 & 4.6 & 4.8025 & TRN & \\
\hline CHEMBL1464424 & 688759 & 5.55 & 5.4064 & TRN & \\
\hline CHEMBL294018 & 688759 & 6.05 & 5.4042 & TST & \\
\hline CHEMBL1335273 & 688759 & 4.45 & 4.5414 & TRN & \\
\hline CHEMBL1566699 & 688759 & 5.3 & 5.0085 & TRN & \\
\hline CHEMBL1417354 & 688759 & 5.5 & 5.0079 & TRN & \\
\hline CHEMBL1505130 & 688759 & 4.45 & 4.6767 & TRN & \\
\hline CHEMBL1496362 & 688759 & 4.45 & 4.8557 & TST & \\
\hline CHEMBL1547376 & 688759 & 4.45 & 4.9384 & TST & \\
\hline CHEMBL3194401 & 688759 & 4.45 & 4.881 & TRN & \\
\hline CHEMBL1462106 & 688759 & 5.9 & 4.809 & TRN & \\
\hline CHEMBL1413984 & 688759 & 4.65 & 4.9901 & TRN & \\
\hline CHEMBL1374282 & 688759 & 4.45 & 4.768 & TRN & \\
\hline CHEMBL1305388 & 688759 & 4.8 & 4.9364 & TRN & \\
\hline CHEMBL3196429 & 688759 & 4.45 & 4.8055 & TRN & \\
\hline CHEMBL1494414 & 688759 & 4.95 & 4.9704 & TST & \\
\hline
\end{tabular}




\begin{tabular}{|c|c|c|c|c|}
\hline & & & pplement & \\
\hline CHEMBL590665 & 688759 & 5.5 & 5.2916 & TRN \\
\hline CHEMBL1548372 & 688759 & 5.35 & 4.9749 & TRN \\
\hline CHEMBL1425523 & 688759 & 4.55 & 4.6528 & TST \\
\hline CHEMBL1380514 & 688759 & 4.5 & 4.8502 & TRN \\
\hline CHEMBL1968789 & 688759 & 5.0 & 5.0945 & TRN \\
\hline CHEMBL1470135 & 688759 & 5.5 & 5.1848 & TRN \\
\hline CHEMBL1304016 & 688759 & 4.45 & 4.6319 & TST \\
\hline CHEMBL1542693 & 688759 & 5.15 & 4.8052 & TRN \\
\hline CHEMBL1367396 & 688759 & 4.6 & 4.751 & TRN \\
\hline CHEMBL1486861 & 688759 & 4.65 & 5.1723 & TRN \\
\hline CHEMBL1613531 & 688759 & 5.45 & 4.6679 & TRN \\
\hline CHEMBL1426788 & 688759 & 4.45 & 4.7412 & TST \\
\hline CHEMBL1565083 & 688759 & 4.55 & 5.4224 & TRN \\
\hline CHEMBL 230156 & 688759 & 4.45 & 4.9343 & TRN \\
\hline CHEMBL1559478 & 688759 & 4.65 & 4.7255 & TST \\
\hline CHEMBL1326349 & 688759 & 5.6 & 5.3254 & TRN \\
\hline CHEMBL1566957 & 688759 & 4.75 & 4.9992 & TST \\
\hline CHEMBL1376704 & 688759 & 5.2 & 5.0472 & TRN \\
\hline CHEMBL1520725 & 688759 & 5.4 & 5.0729 & TRN \\
\hline CHEMBL1343895 & 688759 & 4.8 & 5.007 & TRN \\
\hline CHEMBL1490692 & 688759 & 5.55 & 4.9586 & TST \\
\hline CHEMBL3192160 & 688759 & 5.2 & 5.4581 & TRN \\
\hline CHEMBL1429396 & 688759 & 5.05 & 4.8951 & TRN \\
\hline CHEMBL1583674 & 688759 & 4.45 & 4.7504 & TRN \\
\hline CHEMBL1979367 & 688759 & 4.45 & 4.6814 & TRN \\
\hline CHEMBL1485372 & 688759 & 5.35 & 4.9239 & TRN \\
\hline CHEMBL1498340 & 688759 & 4.6 & 4.9916 & TRN \\
\hline CHEMBL1577759 & 688759 & 4.75 & 4.6798 & TRN \\
\hline CHEMBL1501275 & 688759 & 4.75 & 4.8288 & TRN \\
\hline CHEMBL1368766 & 688759 & 4.65 & 4.676 & TST \\
\hline CHEMBL1604214 & 688759 & 5.85 & 5.2894 & TRN \\
\hline CHEMBL580918 & 688759 & 5.6 & 5.5214 & TRN \\
\hline CHEMBL1387641 & 688759 & 4.95 & 5.0699 & TRN \\
\hline CHEMBL1371457 & 688759 & 5.5 & 5.1358 & TRN \\
\hline CHEMBL602828 & 688759 & 4.8 & 5.4015 & TRN \\
\hline CHEMBL3198162 & 688759 & 4.45 & 5.0722 & TRN \\
\hline CHEMBL 1488705 & 688759 & 5.25 & 4.9231 & TRN \\
\hline CHEMBL1370387 & 688759 & 4.45 & 5.0058 & TRN \\
\hline CHEMBL3191957 & 688759 & 5.2 & 5.1133 & TRN \\
\hline CHEMBL3193979 & 688759 & 4.45 & 4.8014 & TRN \\
\hline CHEMBL1350744 & 688759 & 5.0 & 5.0634 & TRN \\
\hline CHEMBL1589352 & 688759 & 4.45 & 4.7796 & TRN \\
\hline CHEMBL1406348 & 688759 & 4.85 & 5.3539 & TRN \\
\hline CHEMBL1602151 & 688759 & 4.5 & 4.9921 & TRN \\
\hline CHEMBL1578184 & 688759 & 4.6 & 4.7519 & TST \\
\hline CHEMBL1313588 & 688759 & 5.5 & 5.3693 & TRN \\
\hline CHEMBL1608488 & 688759 & 4.45 & 4.6293 & TRN \\
\hline CHEMBL1554942 & 688759 & 4.45 & 5.0009 & TRN \\
\hline
\end{tabular}




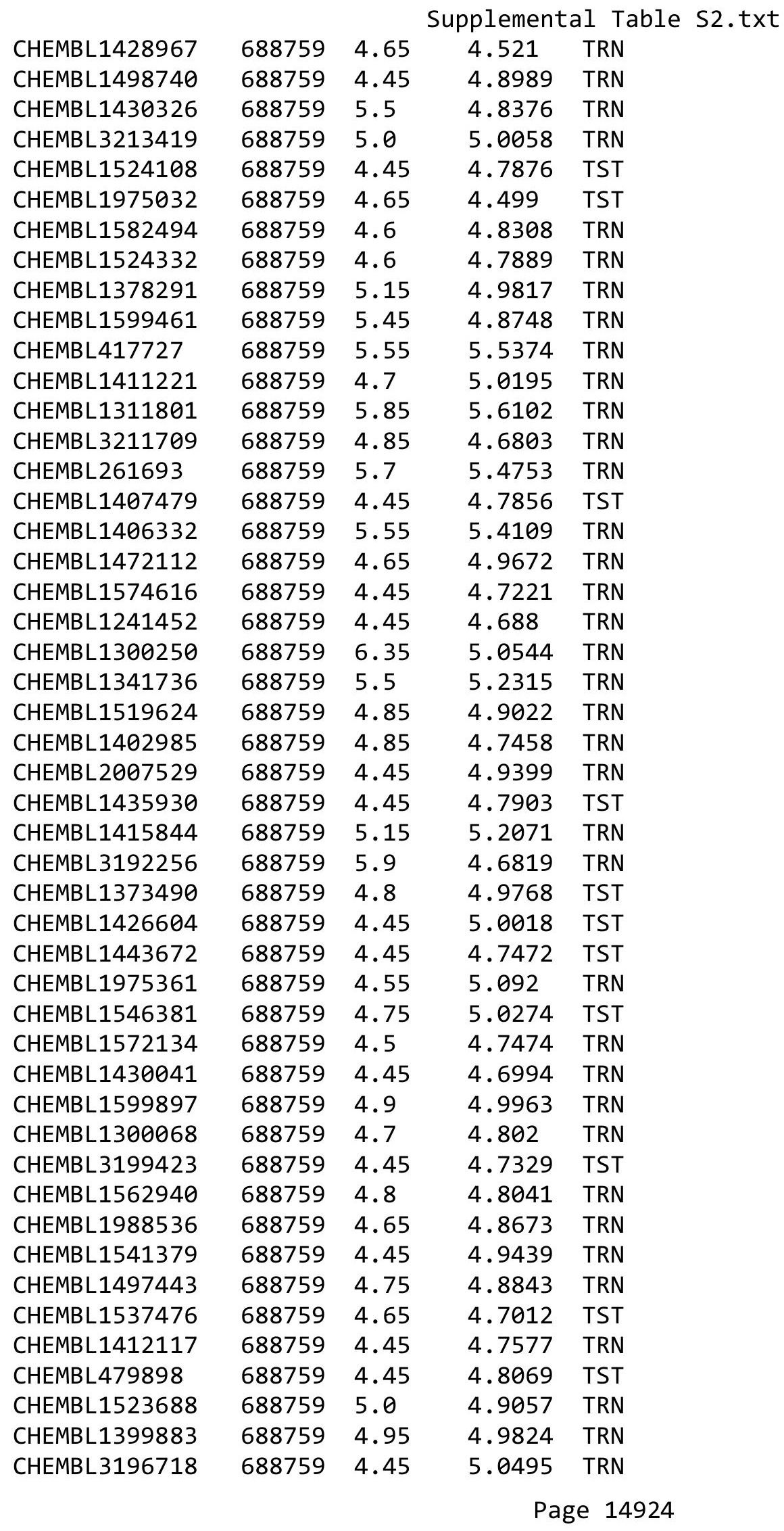




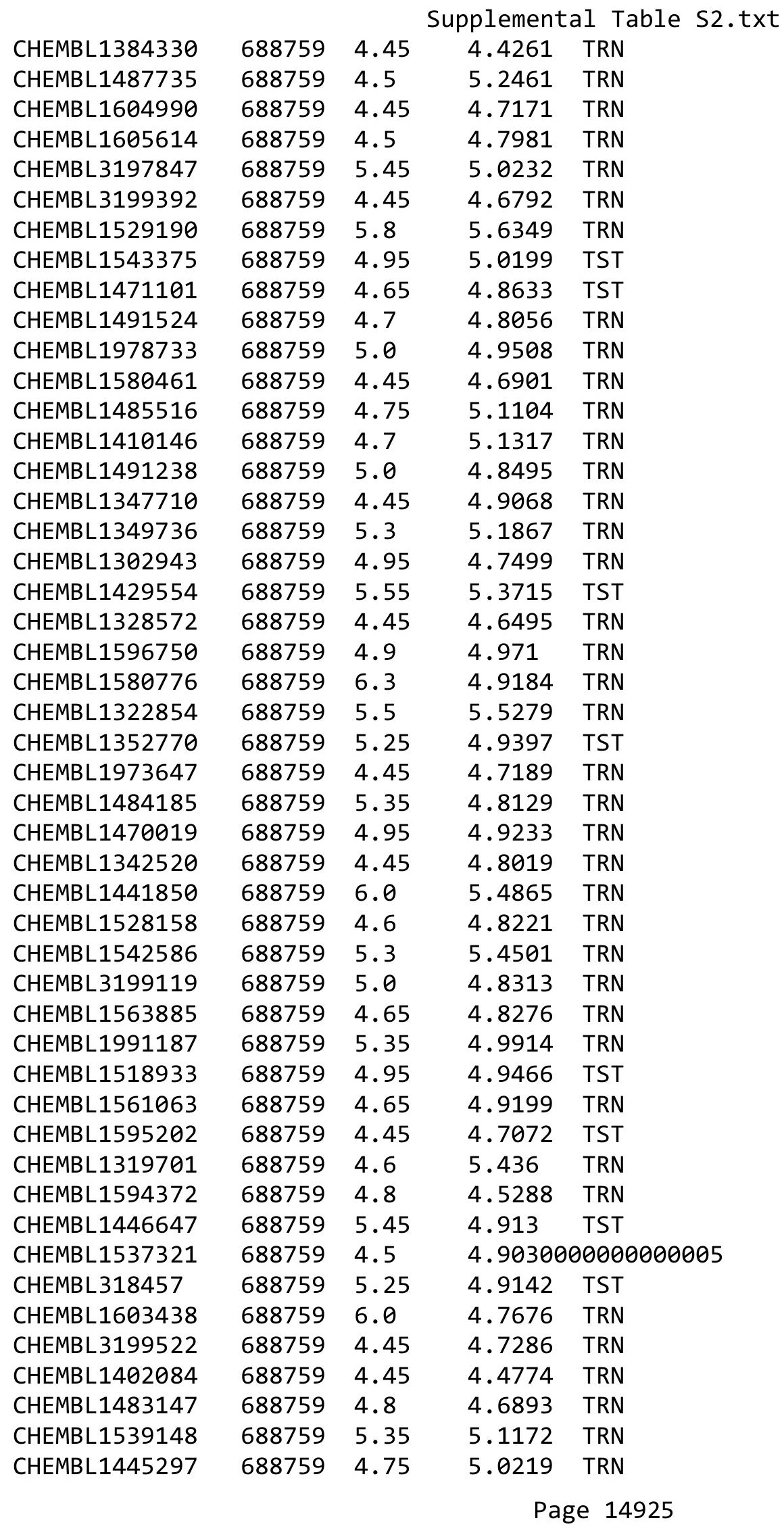




\begin{tabular}{|c|c|c|c|c|c|}
\hline \multicolumn{6}{|c|}{ Supplemental Table s2.txt } \\
\hline CHEMBL1582238 & 688759 & 5.0 & 4.8165 & TRN & \\
\hline CHEMBL 3194264 & 688759 & 4.45 & 4.6463 & TRN & \\
\hline CHEMBL1450365 & 688759 & 5.25 & 4.7822 & TRN & \\
\hline CHEMBL1433926 & 688759 & 5.15 & \multicolumn{2}{|c|}{5.242999999999999} & TRN \\
\hline CHEMBL1462884 & 688759 & 5.2 & 4.9221 & TRN & \\
\hline CHEMBL1535436 & 688759 & 4.8 & 4.9575 & TRN & \\
\hline CHEMBL1334890 & 688759 & 4.7 & 5.0843 & TRN & \\
\hline CHEMBL1573942 & 688759 & 5.05 & 5.1009 & TRN & \\
\hline CHEMBL1465511 & 688759 & 5.2 & 4.7116 & TRN & \\
\hline CHEMBL1463974 & 688759 & 4.45 & 4.8902 & TRN & \\
\hline CHEMBL 3208083 & 688759 & 5.2 & 5.3552 & TRN & \\
\hline CHEMBL1346130 & 688759 & 4.45 & 4.6512 & TRN & \\
\hline CHEMBL1387181 & 688759 & 5.5 & 4.9386 & TRN & \\
\hline CHEMBL1537079 & 688759 & 4.9 & 4.7881 & TRN & \\
\hline CHEMBL3196566 & 688759 & 6.05 & 5.0717 & TST & \\
\hline CHEMBL1446498 & 688759 & 4.65 & 4.748 & TRN & \\
\hline CHEMBL1966316 & 688759 & 4.7 & 4.9064 & TRN & \\
\hline CHEMBL1579535 & 688759 & 4.9 & 4.942 & TRN & \\
\hline CHEMBL270605 & 688759 & 6.0 & 5.6305 & TRN & \\
\hline CHEMBL1322280 & 688759 & 5.0 & 4.9051 & TRN & \\
\hline CHEMBL1965069 & 688759 & 4.55 & 5.2483 & TRN & \\
\hline CHEMBL1341771 & 688759 & 4.8 & 4.8457 & TRN & \\
\hline CHEMBL1574971 & 688759 & 4.45 & 4.7975 & TRN & \\
\hline CHEMBL1334044 & 688759 & 4.9 & 4.7546 & TRN & \\
\hline CHEMBL1315275 & 688759 & 4.95 & 4.8718 & TRN & \\
\hline CHEMBL1440303 & 688759 & 5.3 & 5.4467 & TRN & \\
\hline CHEMBL1300297 & 688759 & 5.4 & 4.7487 & TRN & \\
\hline CHEMBL1462267 & 688759 & 4.75 & \multicolumn{2}{|c|}{4.8260000000000005} & TST \\
\hline CHEMBL1340150 & 688759 & 4.9 & 4.8102 & TST & \\
\hline CHEMBL3198687 & 688759 & 4.45 & 4.8203 & TRN & \\
\hline CHEMBL1420484 & 688759 & 4.45 & 4.7489 & TST & \\
\hline CHEMBL3196614 & 688759 & 4.45 & 4.8498 & TRN & \\
\hline CHEMBL1565251 & 688759 & 4.75 & 4.4327 & TRN & \\
\hline CHEMBL1307340 & 688759 & 4.9 & 4.7585 & TRN & \\
\hline CHEMBL1400839 & 688759 & 4.95 & \multicolumn{2}{|c|}{ 4.8919999999999995 } & TST \\
\hline CHEMBL1572644 & 688759 & 4.85 & 5.0406 & TST & \\
\hline CHEMBL1534716 & 688759 & 5.6 & 5.5062 & TRN & \\
\hline CHEMBL1465525 & 688759 & 5.85 & 4.8751 & TST & \\
\hline CHEMBL1311474 & 688759 & 4.7 & 4.9756 & TRN & \\
\hline CHEMBL3196123 & 688759 & 5.6 & \multicolumn{2}{|c|}{5.742000000000001} & TST \\
\hline CHEMBL1581190 & 688759 & 5.1 & 4.9061 & TRN & \\
\hline CHEMBL1379221 & 688759 & 4.5 & 4.7994 & TST & \\
\hline CHEMBL1390929 & 688759 & 4.45 & 4.7387 & TRN & \\
\hline CHEMBL1990081 & 688759 & 4.75 & 4.4622 & TST & \\
\hline CHEMBL400912 & 688759 & 5.5 & 5.0232 & TRN & \\
\hline CHEMBL1319907 & 688759 & 4.45 & 4.8234 & TRN & \\
\hline CHEMBL1460408 & 688759 & 4.45 & 4.9126 & TRN & \\
\hline CHEMBL1563943 & 688759 & 6.45 & 5.2884 & TRN & \\
\hline
\end{tabular}




\begin{tabular}{|c|c|c|c|c|c|}
\hline \\
\hline CHEMBL3197792 & 688759 & 4.7 & 5.074 & TRN & \\
\hline CHEMBL1301310 & 688759 & 4.9 & 4.9291 & TRN & \\
\hline CHEMBL1403819 & 688759 & 4.65 & 4.9601 & TST & \\
\hline CHEMBL1479741 & 688759 & 4.8 & 4.8487 & TRN & \\
\hline CHEMBL1456092 & 688759 & 4.75 & 4.5807 & TRN & \\
\hline CHEMBL1977369 & 688759 & 5.2 & 5.1119 & TRN & \\
\hline CHEMBL1529656 & 688759 & 4.45 & 4.9617 & TRN & \\
\hline CHEMBL1380020 & 688759 & 4.45 & 4.6039 & TST & \\
\hline CHEMBL460601 & 688759 & 4.45 & 4.9707 & TST & \\
\hline CHEMBL3198460 & 688759 & 4.95 & 5.0771 & TRN & \\
\hline CHEMBL1577938 & 688759 & 6.45 & 5.6357 & TRN & \\
\hline CHEMBL1464390 & 688759 & 5.25 & 4.9624 & TRN & \\
\hline CHEMBL1341752 & 688759 & 4.55 & 4.7822 & TST & \\
\hline CHEMBL1519333 & 688759 & 5.35 & 5.1623 & TST & \\
\hline CHEMBL1312504 & 688759 & 5.3 & 5.0188 & TRN & \\
\hline CHEMBL578878 & 688759 & 4.6 & 4.937 & TRN & \\
\hline CHEMBL1560186 & 688759 & 4.95 & 5.0011 & TRN & \\
\hline CHEMBL1612190 & 688759 & 5.55 & 4.7513 & TRN & \\
\hline CHEMBL1518129 & 688759 & 4.65 & 4.7842 & TST & \\
\hline CHEMBL463574 & 688759 & 4.7 & 5.1396 & TST & \\
\hline CHEMBL1472138 & 688759 & 6.2 & 4.8571 & TST & \\
\hline CHEMBL1427072 & 688759 & 5.45 & 5.3036 & TRN & \\
\hline CHEMBL1502390 & 688759 & 4.65 & 4.7383 & TST & \\
\hline CHEMBL1577162 & 688759 & 4.65 & 4.8133 & TRN & \\
\hline CHEMBL1602150 & 688759 & 4.65 & 4.9685 & TRN & \\
\hline CHEMBL1404077 & 688759 & 5.35 & 5.1282 & TST & \\
\hline CHEMBL 2004182 & 688759 & 5.35 & 4.5793 & TRN & \\
\hline CHEMBL1583901 & 688759 & 4.65 & 4.6675 & TRN & \\
\hline CHEMBL1983843 & 688759 & 4.65 & 4.7172 & TRN & \\
\hline CHEMBL1385570 & 688759 & 4.45 & 4.9009 & TRN & \\
\hline CHEMBL1338475 & 688759 & 6.05 & 5.1262 & TRN & \\
\hline CHEMBL1605437 & 688759 & 4.45 & 5.0299 & TRN & \\
\hline CHEMBL1351770 & 688759 & 4.45 & 4.7999 & TST & \\
\hline CHEMBL1373577 & 688759 & 4.8 & 5.0519 & TRN & \\
\hline CHEMBL3208941 & 688759 & 5.8 & 4.8995 & TRN & \\
\hline CHEMBL1545633 & 688759 & 5.2 & 4.9451 & TRN & \\
\hline CHEMBL1361042 & 688759 & 5.2 & 5.0237 & TRN & \\
\hline CHEMBL1451528 & 688759 & 4.65 & 4.6652 & TRN & \\
\hline CHEMBL3212192 & 688759 & 5.35 & 5.09399 & 9999999999 & TRN \\
\hline CHEMBL1592031 & 688759 & 4.45 & 4.7032 & TRN & \\
\hline CHEMBL380979 & 688759 & 5.2 & 5.4346 & TRN & \\
\hline CHEMBL1343952 & 688759 & 4.45 & 4.5455 & TRN & \\
\hline CHEMBL1499768 & 688759 & 4.45 & 4.7864 & TST & \\
\hline CHEMBL1446889 & 688759 & 5.5 & 4.7903 & TRN & \\
\hline CHEMBL1528414 & 688759 & 4.85 & 5.0301 & TRN & \\
\hline CHEMBL1492640 & 688759 & 5.2 & 4.7433 & TRN & \\
\hline CHEMBL1391621 & 688759 & 4.8 & 4.6545 & TRN & \\
\hline CHEMBL1536981 & 688759 & 4.45 & 4.9035 & TRN & \\
\hline & & & & 14927 & \\
\hline
\end{tabular}




\begin{tabular}{|c|c|c|c|c|c|}
\hline \multicolumn{6}{|c|}{ Supplemental Table S2.txt } \\
\hline CHEMBL1332456 & 688759 & 4.85 & 4.6346 & TST & \\
\hline CHEMBL1547880 & 688759 & 4.95 & 4.8571 & TRN & \\
\hline CHEMBL1341763 & 688759 & 4.8 & 5.0013 & TRN & \\
\hline CHEMBL1613396 & 688759 & 5.45 & 4.7635 & TRN & \\
\hline CHEMBL1477696 & 688759 & 5.4 & 5.5383 & TRN & \\
\hline CHEMBL3210740 & 688759 & 4.45 & 4.8662 & TST & \\
\hline CHEMBL1402713 & 688759 & 5.15 & 5.0107 & TRN & \\
\hline CHEMBL1481098 & 688759 & 5.1 & 4.9863 & TRN & \\
\hline CHEMBL1582590 & 688759 & 5.0 & 4.8941 & TST & \\
\hline CHEMBL1422851 & 688759 & 5.25 & 5.0179 & TRN & \\
\hline CHEMBL1501508 & 688759 & 5.4 & 4.8814 & TRN & \\
\hline CHEMBL1499697 & 688759 & 4.95 & 5.4203 & TRN & \\
\hline CHEMBL1580096 & 688759 & 5.15 & 5.3111 & TRN & \\
\hline CHEMBL 2369298 & 688759 & 5.7 & 5.5513 & TRN & \\
\hline CHEMBL1483685 & 688759 & 4.65 & 4.6945 & TRN & \\
\hline CHEMBL1362945 & 688759 & 7.2503 & 5.0678 & TRN & \\
\hline CHEMBL1446625 & 688759 & 5.0 & 5.0203 & TRN & \\
\hline CHEMBL1523468 & 688759 & 6.95 & 5.0808 & TRN & \\
\hline CHEMBL3198630 & 688759 & 4.9 & 4.8786 & TRN & \\
\hline CHEMBL1518608 & 688759 & 4.75 & 4.9282 & TRN & \\
\hline CHEMBL1528854 & 688759 & 4.5 & 4.63399 & 99999999995 & TRN \\
\hline CHEMBL1574261 & 688759 & 4.7 & 4.7346 & TRN & \\
\hline CHEMBL1495208 & 688759 & 4.45 & 4.803 & TRN & \\
\hline CHEMBL1445768 & 688759 & 5.55 & 5.3788 & TRN & \\
\hline CHEMBL1253586 & 688759 & 5.25 & 4.8509 & TST & \\
\hline CHEMBL1334530 & 688759 & 4.45 & 4.6087 & TRN & \\
\hline CHEMBL1337464 & 688759 & 4.9 & 4.8461 & TRN & \\
\hline CHEMBL3191908 & 688759 & 5.05 & 4.902 & TRN & \\
\hline CHEMBL1989657 & 688759 & 4.65 & 4.9115 & TRN & \\
\hline CHEMBL1449739 & 688759 & 4.7 & 5.0343 & TRN & \\
\hline CHEMBL1339039 & 688759 & 4.8 & 4.99100 & 00000000005 & TRN \\
\hline CHEMBL1324652 & 688759 & 5.9 & 5.6937 & TST & \\
\hline CHEMBL1969343 & 688759 & 4.95 & 4.9112 & TRN & \\
\hline CHEMBL1308684 & 688759 & 4.7 & 4.8162 & TRN & \\
\hline CHEMBL1400056 & 688759 & 4.45 & 4.6186 & TRN & \\
\hline CHEMBL1410500 & 688759 & 4.45 & 4.7134 & TST & \\
\hline CHEMBL1483507 & 688759 & 4.45 & 5.1022 & TRN & \\
\hline CHEMBL1377479 & 688759 & 4.45 & 4.5797 & TRN & \\
\hline CHEMBL1487489 & 688759 & 5.0 & 5.0839 & TRN & \\
\hline CHEMBL1350326 & 688759 & 4.45 & 4.9313 & TRN & \\
\hline CHEMBL1343155 & 688759 & 4.45 & 5.0087 & TRN & \\
\hline CHEMBL1380186 & 688759 & 5.05 & 4.74100 & 00000000005 & TRN \\
\hline CHEMBL1367246 & 688759 & 6.2 & 5.2512 & TRN & \\
\hline CHEMBL1518080 & 688759 & 4.6 & 4.8696 & TST & \\
\hline CHEMBL1314122 & 688759 & 5.45 & 4.8983 & TRN & \\
\hline CHEMBL1441584 & 688759 & 5.4 & 4.6227 & TRN & \\
\hline CHEMBL1427663 & 688759 & 5.3 & 5.0664 & TRN & \\
\hline CHEMBL1567166 & 688759 & 5.05 & 4.9217 & TRN & \\
\hline
\end{tabular}




\begin{tabular}{|c|c|c|c|c|}
\hline & & & ipplement & $a_{\perp}$ \\
\hline CHEMBL1452597 & 688759 & 4.7 & 4.7932 & TST \\
\hline CHEMBL1085765 & 688759 & 4.6 & 4.8157 & TST \\
\hline CHEMBL1378314 & 688759 & 4.95 & 4.8468 & TRN \\
\hline CHEMBL3195680 & 688759 & 4.85 & 4.7767 & TRN \\
\hline CHEMBL1548261 & 688759 & 4.45 & 4.7725 & TST \\
\hline CHEMBL1345220 & 688759 & 4.65 & 4.9383 & TRN \\
\hline CHEMBL1542076 & 688759 & 4.6 & 5.0312 & TST \\
\hline CHEMBL1506234 & 688759 & 5.25 & 4.7298 & TRN \\
\hline CHEMBL1432059 & 688759 & 5.5 & 5.5091 & TRN \\
\hline CHEMBL1309348 & 688759 & 4.85 & 4.6619 & TRN \\
\hline CHEMBL1366850 & 688759 & 4.5 & 4.6207 & TST \\
\hline CHEMBL1350755 & 688759 & 4.45 & 4.9953 & TST \\
\hline CHEMBL1502830 & 688759 & 4.45 & 4.7176 & TRN \\
\hline CHEMBL1371669 & 688759 & 4.55 & 4.5775 & TRN \\
\hline CHEMBL1502358 & 688759 & 5.15 & 5.0276 & TST \\
\hline CHEMBL1311453 & 688759 & 4.45 & 4.8196 & TST \\
\hline CHEMBL1571002 & 688759 & 4.45 & 4.7857 & TRN \\
\hline CHEMBL1505028 & 688759 & 5.65 & 5.586 & TRN \\
\hline CHEMBL 3198674 & 688759 & 4.65 & 5.2819 & TRN \\
\hline CHEMBL1529953 & 688759 & 4.9 & 5.0341 & TRN \\
\hline CHEMBL3196193 & 688759 & 4.45 & 4.8078 & TRN \\
\hline CHEMBL1534553 & 688759 & 5.45 & 4.9018 & TST \\
\hline CHEMBL1376784 & 688759 & 4.7 & 4.6721 & TRN \\
\hline CHEMBL1541052 & 688759 & 4.45 & 4.8371 & TST \\
\hline CHEMBL1508576 & 688759 & 4.9 & 4.9707 & TRN \\
\hline CHEMBL1493256 & 688759 & 4.85 & 4.802 & TST \\
\hline CHEMBL1305472 & 688759 & 4.95 & 4.9567 & TRN \\
\hline CHEMBL1422439 & 688759 & 4.95 & 4.9238 & TST \\
\hline CHEMBL1572904 & 688759 & 4.9 & 4.9463 & TRN \\
\hline CHEMBL 2003172 & 688759 & 4.95 & 5.0198 & TST \\
\hline CHEMBL1542172 & 688759 & 4.65 & 4.5119 & TRN \\
\hline CHEMBL1499401 & 688759 & 5.05 & 5.1563 & TRN \\
\hline CHEMBL1569152 & 688759 & 5.25 & 4.9199 & TRN \\
\hline CHEMBL1518934 & 688759 & 5.15 & 4.6999 & TRN \\
\hline CHEMBL1606733 & 688759 & 6.0 & 5.3837 & TRN \\
\hline CHEMBL1607029 & 688759 & 4.9 & 5.1148 & TRN \\
\hline CHEMBL1335915 & 688759 & 5.2 & 4.8337 & TRN \\
\hline CHEMBL1441485 & 688759 & 4.45 & 4.8772 & TRN \\
\hline CHEMBL1484278 & 688759 & 4.45 & 5.0219 & TRN \\
\hline CHEMBL1442136 & 688759 & 4.45 & 4.6223 & TST \\
\hline CHEMBL1580581 & 688759 & 4.45 & 4.6415 & TRN \\
\hline CHEMBL1393685 & 688759 & 4.45 & 4.7381 & TRN \\
\hline CHEMBL1348586 & 688759 & 4.45 & 5.0925 & TRN \\
\hline CHEMBL1504280 & 688759 & 4.75 & 4.6333 & TRN \\
\hline CHEMBL1464684 & 688759 & 4.85 & 4.915 & TRN \\
\hline CHEMBL1334643 & 688759 & 5.4 & 4.6025 & TRN \\
\hline CHEMBL 1344322 & 688759 & 4.45 & 4.8591 & TRN \\
\hline CHEMBL1487320 & 688759 & 5.25 & 4.9628 & TST \\
\hline
\end{tabular}




\begin{tabular}{|c|c|c|c|c|c|}
\hline & & \multicolumn{4}{|c|}{ Supplemental Table S2.txt } \\
\hline CHEMBL1398780 & 688759 & 4.7 & 4.6145 & TRN & \\
\hline CHEMBL1363060 & 688759 & 4.45 & 4.7171 & TRN & \\
\hline CHEMBL1488591 & 688759 & 5.15 & 5.1356 & TRN & \\
\hline CHEMBL1404979 & 688759 & 4.85 & 4.973 & TRN & \\
\hline CHEMBL1457319 & 688759 & 5.85 & 4.8679 & TRN & \\
\hline CHEMBL3196290 & 688759 & 5.25 & 4.7432 & TST & \\
\hline CHEMBL1350141 & 688759 & 4.45 & 4.7728 & TRN & \\
\hline CHEMBL1374312 & 688759 & 5.1 & 5.0397 & TRN & \\
\hline CHEMBL 3207480 & 688759 & 4.55 & 4.8446 & TRN & \\
\hline CHEMBL1332431 & 688759 & 4.45 & 4.6735 & TRN & \\
\hline CHEMBL1424387 & 688759 & 4.45 & 4.621 & TRN & \\
\hline CHEMBL1507938 & 688759 & 4.55 & 5.2645 & TRN & \\
\hline CHEMBL1440641 & 688759 & 4.45 & 4.539 & TRN & \\
\hline CHEMBL1520210 & 688759 & 5.0 & 4.8436 & TST & \\
\hline CHEMBL1582976 & 688759 & 4.6 & 4.6353 & TRN & \\
\hline CHEMBL1532716 & 688759 & 5.25 & 5.1842 & TRN & \\
\hline CHEMBL1300666 & 688759 & 4.45 & 4.7935 & TRN & \\
\hline CHEMBL3191812 & 688759 & 6.25 & 5.4951 & TRN & \\
\hline CHEMBL1565498 & 688759 & 4.9 & 4.5469 & TRN & \\
\hline CHEMBL1309236 & 688759 & 4.45 & 4.6455 & TST & \\
\hline CHEMBL1511487 & 688759 & 5.45 & 4.9372 & TRN & \\
\hline CHEMBL117108 & 688759 & 4.55 & 4.709 & TRN & \\
\hline CHEMBL592363 & 688759 & 4.45 & 4.7735 & TST & \\
\hline CHEMBL1418738 & 688759 & 4.65 & 4.8219 & TRN & \\
\hline CHEMBL1499053 & 688759 & 5.45 & 5.28299 & 99999999995 & TRN \\
\hline CHEMBL1333645 & 688759 & 4.45 & 4.7983 & TRN & \\
\hline CHEMBL1338495 & 688759 & 4.75 & 4.8449 & TRN & \\
\hline CHEMBL1488342 & 688759 & 4.75 & 4.7292 & TST & \\
\hline CHEMBL1452507 & 688759 & 4.45 & 4.7483 & TRN & \\
\hline CHEMBL3196795 & 688759 & 5.0 & 5.117 & TRN & \\
\hline CHEMBL1492621 & 688759 & 5.2 & 4.9656 & TST & \\
\hline CHEMBL1610676 & 688759 & 4.8 & 4.8594 & TRN & \\
\hline CHEMBL1556138 & 688759 & 4.45 & 4.6784 & TRN & \\
\hline CHEMBL1391630 & 688759 & 4.95 & 5.0271 & TRN & \\
\hline CHEMBL1578041 & 688759 & 4.6 & 4.8886 & TST & \\
\hline CHEMBL1378255 & 688759 & 4.45 & 4.6258 & TRN & \\
\hline CHEMBL1970265 & 688759 & 4.8 & 4.487 & TRN & \\
\hline CHEMBL1423682 & 688759 & 4.45 & 4.7465 & TRN & \\
\hline CHEMBL1531656 & 688759 & 4.55 & 5.0171 & TRN & \\
\hline CHEMBL3198341 & 688759 & 5.8 & 4.9784 & TRN & \\
\hline CHEMBL1328498 & 688759 & 4.45 & 4.3861 & TRN & \\
\hline CHEMBL1377849 & 688759 & 4.8 & 4.69300 & 00000000005 & TRN \\
\hline CHEMBL1526599 & 688759 & 4.8 & 5.251 & TRN & \\
\hline CHEMBL1332758 & 688759 & 4.45 & 4.6775 & TST & \\
\hline CHEMBL74913 & 688759 & 5.1 & 5.0389 & TRN & \\
\hline CHEMBL1455739 & 688759 & 4.45 & 4.7269 & TRN & \\
\hline CHEMBL1504121 & 688759 & 4.45 & 5.0737 & TRN & \\
\hline CHEMBL1491066 & 688759 & 4.6 & 4.4836 & TRN & \\
\hline
\end{tabular}




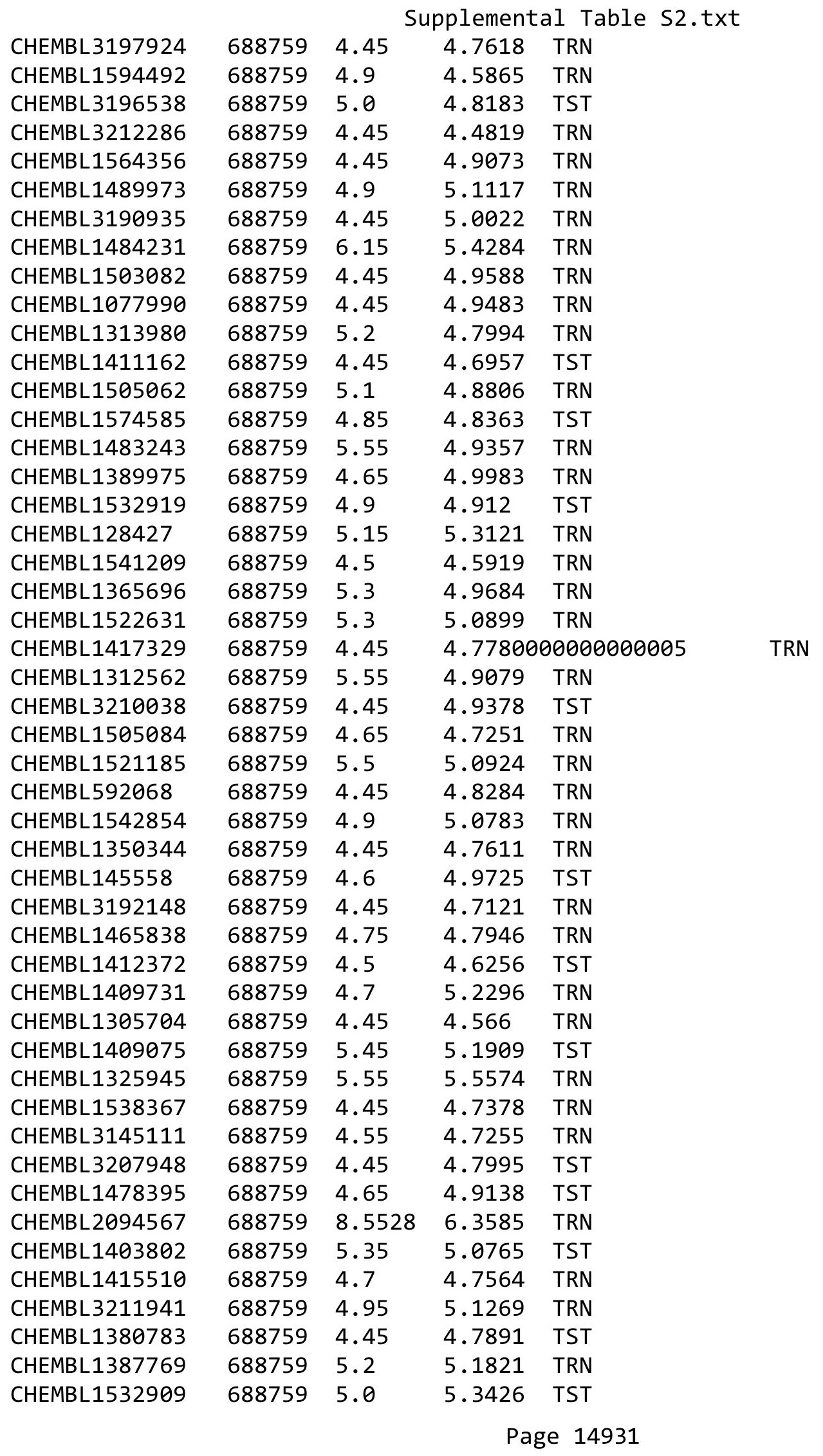




\begin{tabular}{|c|c|c|c|c|}
\hline \multicolumn{5}{|c|}{ Supplemental Table S2.txt } \\
\hline CHEMBL 3210471 & 688759 & 5.1 & 4.9088 & TRN \\
\hline CHEMBL1581716 & 688759 & 5.2 & 4.859 & TRN \\
\hline CHEMBL1481347 & 688759 & 5.5 & 5.1645 & TRN \\
\hline CHEMBL1968739 & 688759 & 5.25 & 5.0077 & TRN \\
\hline CHEMBL3209211 & 688759 & 5.15 & 4.8472 & TRN \\
\hline CHEMBL1529866 & 688759 & 4.45 & 4.7584 & TRN \\
\hline CHEMBL3212030 & 688759 & 4.45 & 4.7869 & TRN \\
\hline CHEMBL1373958 & 688759 & 4.85 & 4.8477 & TRN \\
\hline CHEMBL1588339 & 688759 & 4.45 & 4.7651 & TRN \\
\hline CHEMBL1333542 & 688759 & 4.6 & 5.1937 & TRN \\
\hline CHEMBL1487402 & 688759 & 4.45 & 4.6783 & TRN \\
\hline CHEMBL1311112 & 688759 & 4.45 & 4.9401 & TST \\
\hline CHEMBL534535 & 688759 & 4.45 & 4.3518 & TST \\
\hline CHEMBL1571019 & 688759 & 6.0 & 5.7686 & TRN \\
\hline CHEMBL1332636 & 688759 & 4.45 & 4.6215 & TST \\
\hline CHEMBL1327470 & 688759 & 4.9 & 4.8407 & TST \\
\hline CHEMBL1348619 & 688759 & 4.9 & 4.8833 & TST \\
\hline CHEMBL1373033 & 688759 & 5.2 & 4.7446 & TRN \\
\hline CHEMBL1441071 & 688759 & 5.95 & 5.6872 & TRN \\
\hline CHEMBL1333047 & 688759 & 4.95 & 4.8363 & TRN \\
\hline CHEMBL1373166 & 688759 & 4.6 & 4.704 & TRN \\
\hline CHEMBL1451663 & 688759 & 4.9 & 4.7938 & TST \\
\hline CHEMBL1375044 & 688759 & 4.75 & 4.7631 & TRN \\
\hline CHEMBL1527772 & 688759 & 5.6 & 4.7003 & TRN \\
\hline CHEMBL1461029 & 688759 & 4.7 & 4.9159 & TST \\
\hline CHEMBL1482448 & 688759 & 5.5 & 4.9865 & TRN \\
\hline CHEMBL1458581 & 688759 & 5.1 & 4.7633 & TST \\
\hline CHEMBL3193166 & 688759 & 5.5 & 4.7905 & TRN \\
\hline CHEMBL1406681 & 688759 & 4.45 & 4.7361 & TRN \\
\hline CHEMBL1351868 & 688759 & 6.35 & 4.8116 & TRN \\
\hline CHEMBL3199314 & 688759 & 4.45 & 4.8098 & TST \\
\hline CHEMBL1351305 & 688759 & 5.2 & 5.0804 & TST \\
\hline CHEMBL1570734 & 688759 & 4.95 & 5.0295 & TRN \\
\hline CHEMBL1469690 & 688759 & 4.55 & 4.677 & TRN \\
\hline CHEMBL1375153 & 688759 & 4.45 & 4.5724 & TST \\
\hline CHEMBL1477639 & 688759 & 5.15 & 4.94 & TRN \\
\hline CHEMBL1421288 & 688759 & 4.95 & 4.8345 & TST \\
\hline CHEMBL606460 & 688759 & 4.6 & 4.596 & TRN \\
\hline CHEMBL1466191 & 688759 & 8.2518 & 5.4558 & TRN \\
\hline CHEMBL1602850 & 688759 & 4.8 & 5.5272 & TRN \\
\hline CHEMBL1413039 & 688759 & 4.65 & 4.6667 & TRN \\
\hline CHEMBL1565121 & 688759 & 4.9 & 4.8267 & TRN \\
\hline CHEMBL1613089 & 688759 & 4.45 & 4.748 & TRN \\
\hline CHEMBL1375780 & 688759 & 4.75 & 4.6213 & TST \\
\hline CHEMBL1422647 & 688759 & 6.7501 & 5.1439 & TST \\
\hline CHEMBL1451134 & 688759 & 5.15 & 5.0397 & TRN \\
\hline CHEMBL3190293 & 688759 & 5.55 & 5.5591 & TRN \\
\hline CHEMBL1363614 & 688759 & 5.05 & 4.6669 & TRN \\
\hline
\end{tabular}




\begin{tabular}{|c|c|c|c|c|c|}
\hline \multicolumn{6}{|c|}{ Supplemental Table S2.txt } \\
\hline CHEMBL1544991 & 688759 & 5.4 & 4.7879 & TST & \\
\hline CHEMBL 1456383 & 688759 & 4.45 & 4.7652 & TRN & \\
\hline CHEMBL3193960 & 688759 & 4.45 & 4.7324 & TRN & \\
\hline CHEMBL1349856 & 688759 & 4.45 & 4.8269 & TRN & \\
\hline CHEMBL1580341 & 688759 & 5.3 & 4.9878 & TRN & \\
\hline CHEMBL 238188 & 688759 & 6.0 & 4.5884 & TST & \\
\hline CHEMBL1563733 & 688759 & 4.45 & 4.8666 & TRN & \\
\hline CHEMBL1329798 & 688759 & 5.3 & 5.3873 & TST & \\
\hline CHEMBL1322116 & 688759 & 4.45 & 4.649 & TRN & \\
\hline CHEMBL221612 & 688759 & 4.7 & 4.9417 & TST & \\
\hline CHEMBL1420556 & 688759 & 4.45 & 4.6051 & TST & \\
\hline CHEMBL1338825 & 688759 & 4.7 & 4.4399 & TRN & \\
\hline CHEMBL1495537 & 688759 & 5.0 & 4.9988 & TRN & \\
\hline CHEMBL1327414 & 688759 & 4.9 & 4.6272 & TRN & \\
\hline CHEMBL1384335 & 688759 & 4.45 & 4.9585 & TST & \\
\hline CHEMBL1607666 & 688759 & 4.55 & 4.6677 & TRN & \\
\hline CHEMBL1498237 & 688759 & 4.95 & 4.7613 & TRN & \\
\hline CHEMBL3190610 & 688759 & 5.15 & 5.3668 & TRN & \\
\hline CHEMBL1353013 & 688759 & 5.35 & 5.1811 & TRN & \\
\hline CHEMBL1451897 & 688759 & 4.5 & 4.5368 & TRN & \\
\hline CHEMBL1472423 & 688759 & 4.95 & 4.9549 & TST & \\
\hline CHEMBL3213589 & 688759 & 4.65 & 4.6363 & TRN & \\
\hline CHEMBL1594882 & 688759 & 4.45 & 4.7697 & TST & \\
\hline CHEMBL1610878 & 688759 & 5.05 & 5.0126 & TST & \\
\hline CHEMBL1383447 & 688759 & 4.45 & 5.1742 & TST & \\
\hline CHEMBL1353335 & 688759 & 4.45 & 4.6959 & TST & \\
\hline CHEMBL1427275 & 688759 & 5.45 & 4.6843 & TRN & \\
\hline CHEMBL1500475 & 688759 & 5.0 & 4.6748 & TST & \\
\hline CHEMBL1453801 & 688759 & 4.45 & 4.9282 & TST & \\
\hline CHEMBL1445004 & 688759 & 4.6 & 4.6696 & TRN & \\
\hline CHEMBL1383283 & 688759 & 4.55 & 4.5901 & TRN & \\
\hline CHEMBL1416695 & 688759 & 8.3468 & 4.6227 & TRN & \\
\hline CHEMBL244645 & 688759 & 4.45 & 4.78100 & 0000000001 & TRN \\
\hline CHEMBL1382777 & 688759 & 4.45 & 4.7834 & TRN & \\
\hline CHEMBL1494847 & 688759 & 4.7 & 4.8811 & TRN & \\
\hline CHEMBL1424153 & 688759 & 5.6 & 4.5452 & TRN & \\
\hline CHEMBL3191528 & 688759 & 4.9 & 4.7166 & TRN & \\
\hline CHEMBL1600849 & 688759 & 6.0 & 5.739 & TRN & \\
\hline CHEMBL1321756 & 688759 & 4.8 & 5.1396 & TRN & \\
\hline CHEMBL1439954 & 688759 & 6.0 & 4.897 & TRN & \\
\hline CHEMBL1391839 & 688759 & 6.4 & 4.6392 & TRN & \\
\hline CHEMBL1383012 & 688759 & 6.25 & 5.9949 & TRN & \\
\hline CHEMBL1995333 & 688759 & 4.45 & 5.0138 & TRN & \\
\hline CHEMBL1340447 & 688759 & 4.75 & 4.702 & TRN & \\
\hline CHEMBL1546016 & 688759 & 5.4 & 5.2663 & TRN & \\
\hline CHEMBL1348742 & 688759 & 4.45 & 4.7696 & TRN & \\
\hline CHEMBL1530294 & 688759 & 5.5 & 5.0144 & TRN & \\
\hline CHEMBL1401951 & 688759 & 4.7 & 4.7995 & TST & \\
\hline
\end{tabular}




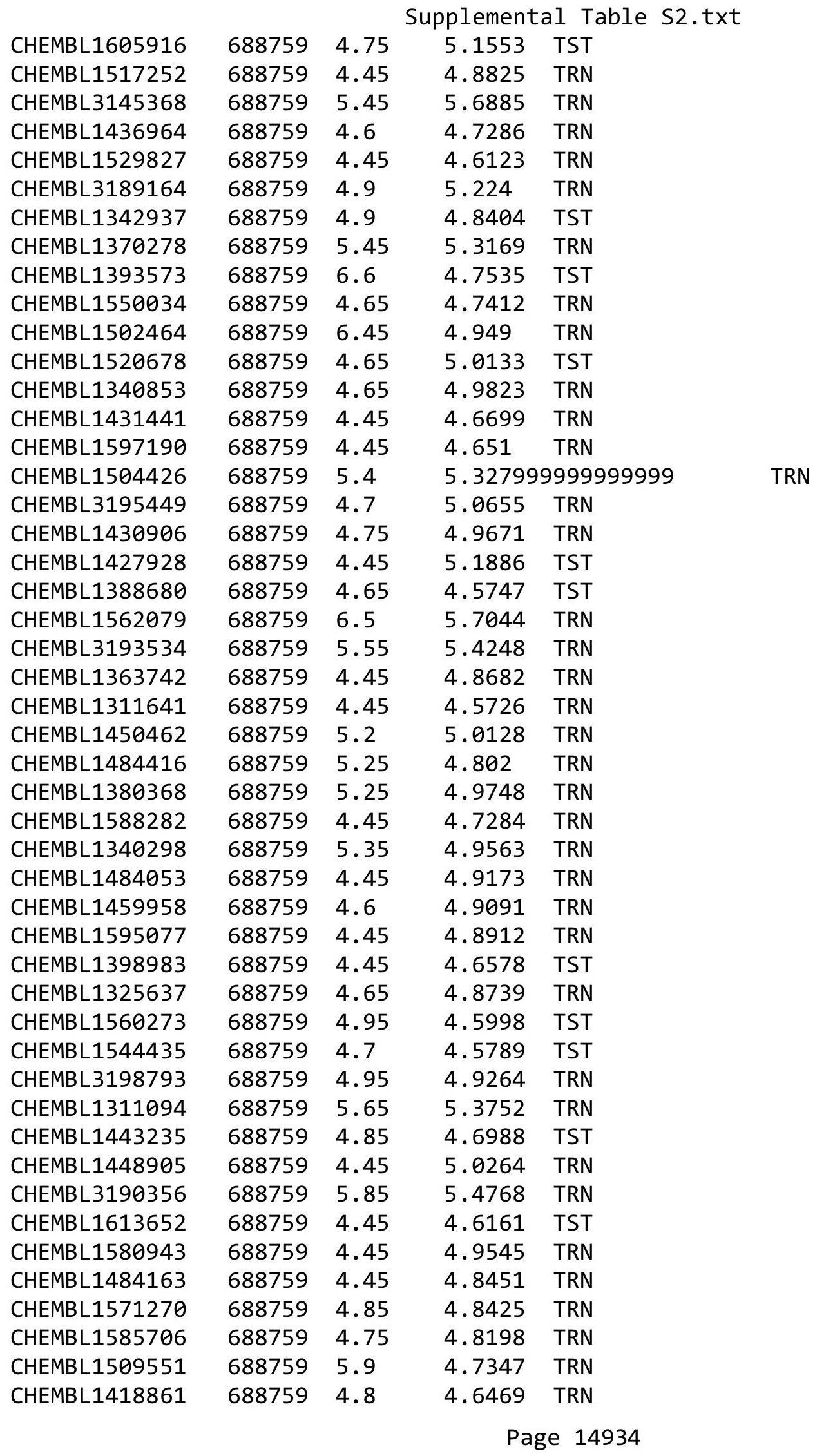




\begin{tabular}{|c|c|c|c|c|c|}
\hline \multicolumn{6}{|c|}{ Supplemental Table S2.txt } \\
\hline CHEMBL1336245 & 688759 & 4.8 & 4.5737 & TRN & \\
\hline CHEMBL1512593 & 688759 & 4.45 & 4.7287 & TRN & \\
\hline CHEMBL1372112 & 688759 & 4.7 & 4.7281 & TRN & \\
\hline CHEMBL1312152 & 688759 & 4.45 & 4.7015 & TRN & \\
\hline CHEMBL1479809 & 688759 & 6.35 & 4.8679 & TRN & \\
\hline CHEMBL 3194305 & 688759 & 4.7 & 5.04899 & 99999999995 & TRN \\
\hline CHEMBL 3210043 & 688759 & 4.9 & 4.658 & TRN & \\
\hline CHEMBL1594805 & 688759 & 6.0 & 4.8542 & TRN & \\
\hline CHEMBL1572058 & 688759 & 6.1 & 5.1603 & TST & \\
\hline CHEMBL3198844 & 688759 & 4.55 & 4.4933 & TRN & \\
\hline CHEMBL1517796 & 688759 & 4.6 & 4.8889 & TRN & \\
\hline CHEMBL1611789 & 688759 & 4.45 & 4.7882 & TRN & \\
\hline CHEMBL1494587 & 688759 & 5.15 & 5.1575 & TRN & \\
\hline CHEMBL1466574 & 688759 & 4.8 & 4.7328 & TRN & \\
\hline CHEMBL1384509 & 688759 & 4.85 & 4.4772 & TST & \\
\hline CHEMBL1966944 & 688759 & 5.7 & 5.2576 & TRN & \\
\hline CHEMBL1540384 & 688759 & 4.65 & 4.8344 & TRN & \\
\hline CHEMBL1376514 & 688759 & 4.8 & 4.7109 & TST & \\
\hline CHEMBL1576631 & 688759 & 5.1 & 4.9298 & TRN & \\
\hline CHEMBL1595494 & 688759 & 6.0 & 5.9955 & TST & \\
\hline CHEMBL1549638 & 688759 & 4.45 & 4.7757 & TRN & \\
\hline CHEMBL1431021 & 688759 & 4.45 & 4.78600 & 00000000005 & TRN \\
\hline CHEMBL3195609 & 688759 & 4.65 & 5.0715 & TRN & \\
\hline CHEMBL1419031 & 688759 & 5.45 & 5.0668 & TRN & \\
\hline CHEMBL1588411 & 688759 & 5.2 & 5.2276 & TRN & \\
\hline CHEMBL1453826 & 688759 & 4.7 & 4.4336 & TST & \\
\hline CHEMBL584854 & 688759 & 4.5 & 4.7792 & TRN & \\
\hline CHEMBL1528067 & 688759 & 4.7 & 5.193 & TRN & \\
\hline CHEMBL3194654 & 688759 & 4.45 & 4.834 & TRN & \\
\hline CHEMBL3197342 & 688759 & 4.45 & 4.9182 & TRN & \\
\hline CHEMBL1348503 & 688759 & 4.95 & 4.882 & TRN & \\
\hline CHEMBL1368433 & 688759 & 4.45 & 4.5195 & TRN & \\
\hline CHEMBL1376582 & 688759 & 5.15 & 4.8428 & TRN & \\
\hline CHEMBL1404745 & 688759 & 5.35 & 5.0708 & TST & \\
\hline CHEMBL1305470 & 688759 & 5.35 & 4.834 & TRN & \\
\hline CHEMBL1503780 & 688759 & 6.95 & 5.0317 & TRN & \\
\hline CHEMBL1349108 & 688759 & 5.45 & 5.244 & TRN & \\
\hline CHEMBL1552313 & 688759 & 8.301 & 4.7395 & TST & \\
\hline CHEMBL1352043 & 688759 & 4.55 & 4.6022 & TRN & \\
\hline CHEMBL1404301 & 688759 & 4.65 & 4.9054 & TRN & \\
\hline CHEMBL1330352 & 688759 & 4.45 & 5.7777 & TRN & \\
\hline CHEMBL1506840 & 688759 & 4.6 & 5.4921 & TRN & \\
\hline CHEMBL3197127 & 688759 & 5.2 & 5.2627 & TRN & \\
\hline CHEMBL3195622 & 688759 & 4.75 & 4.6062 & TRN & \\
\hline CHEMBL1577285 & 688759 & 4.45 & 5.0415 & TRN & \\
\hline CHEMBL1401756 & 688759 & 4.65 & 5.2555 & TRN & \\
\hline CHEMBL3195889 & 688759 & 5.25 & 5.5623 & TRN & \\
\hline CHEMBL1592925 & 688759 & 4.4 & 4.76 & TRN & \\
\hline
\end{tabular}




\begin{tabular}{|c|c|c|c|c|c|}
\hline & & \multicolumn{4}{|c|}{ Supplemental Table S2.txt } \\
\hline CHEMBL1311314 & 688759 & 4.45 & 4.7414 & TRN & \\
\hline CHEMBL1408650 & 688759 & 4.8 & 4.6831 & TRN & \\
\hline CHEMBL1450485 & 688759 & 4.45 & 4.7742 & TST & \\
\hline CHEMBL1392427 & 688759 & 5.85 & 5.5267 & TRN & \\
\hline CHEMBL1391602 & 688759 & 4.9 & 4.90600 & 0000000001 & TST \\
\hline CHEMBL1345628 & 688759 & 5.0 & 5.4636 & TRN & \\
\hline CHEMBL3190843 & 688759 & 4.45 & 4.7392 & TRN & \\
\hline CHEMBL1347781 & 688759 & 4.45 & 4.7136 & TST & \\
\hline CHEMBL1471206 & 688759 & 4.8 & 5.0049 & TRN & \\
\hline CHEMBL1489184 & 688759 & 4.45 & 5.0362 & TRN & \\
\hline CHEMBL1472560 & 688759 & 4.65 & 4.7042 & TST & \\
\hline CHEMBL1424707 & 688759 & 4.95 & 4.8976 & TRN & \\
\hline CHEMBL1456197 & 688759 & 5.4 & 5.3097 & TST & \\
\hline CHEMBL1527377 & 688759 & 5.3 & 5.2987 & TRN & \\
\hline CHEMBL1389307 & 688759 & 4.75 & 5.155 & TRN & \\
\hline CHEMBL1381287 & 688759 & 6.05 & 5.5943 & TRN & \\
\hline CHEMBL1345959 & 688759 & 4.45 & 4.8442 & TST & \\
\hline CHEMBL 2369301 & 688759 & 5.75 & 5.4719 & TRN & \\
\hline CHEMBL1214345 & 688759 & 4.95 & 4.96899 & 9999999999 & TRN \\
\hline CHEMBL3212207 & 688759 & 4.45 & 4.8915 & TST & \\
\hline CHEMBL1527035 & 688759 & 4.75 & 4.7899 & TRN & \\
\hline CHEMBL1599520 & 688759 & 5.35 & 5.2249 & TST & \\
\hline CHEMBL1438801 & 688759 & 4.75 & 4.6914 & TRN & \\
\hline CHEMBL1547278 & 688759 & 4.45 & 4.7226 & TRN & \\
\hline CHEMBL1598920 & 688759 & 4.65 & 4.8565 & TRN & \\
\hline CHEMBL1605239 & 688759 & 4.45 & 4.8669 & TST & \\
\hline CHEMBL1567448 & 688759 & 5.8 & 4.6754 & TRN & \\
\hline CHEMBL1376258 & 688759 & 4.75 & 5.0486 & TRN & \\
\hline CHEMBL1401900 & 688759 & 4.45 & 4.7968 & TRN & \\
\hline CHEMBL1310865 & 688759 & 4.45 & 4.7684 & TRN & \\
\hline CHEMBL1335252 & 688759 & 4.45 & 4.7468 & TRN & \\
\hline CHEMBL1361487 & 688759 & 4.45 & 4.7487 & TRN & \\
\hline CHEMBL1573823 & 688759 & 5.5 & 4.86 & TRN & \\
\hline CHEMBL1381795 & 688759 & 4.55 & 4.7848 & TRN & \\
\hline CHEMBL1992356 & 688759 & 4.6 & 4.8197 & TRN & \\
\hline CHEMBL1322350 & 688759 & 4.75 & 4.3733 & TRN & \\
\hline CHEMBL1349609 & 688759 & 4.65 & 4.6127 & TRN & \\
\hline CHEMBL1975473 & 688759 & 5.05 & 5.0704 & TRN & \\
\hline CHEMBL1348183 & 688759 & 5.15 & 4.9428 & TST & \\
\hline CHEMBL3213830 & 688759 & 5.2 & 4.9692 & TST & \\
\hline CHEMBL1494784 & 688759 & 4.45 & 4.5819 & TST & \\
\hline CHEMBL1398976 & 688759 & 6.0 & 6.0532 & TRN & \\
\hline CHEMBL3191520 & 688759 & 5.2 & 5.0912 & TRN & \\
\hline CHEMBL1376120 & 688759 & 4.45 & 4.8362 & TRN & \\
\hline CHEMBL3210640 & 688759 & 4.45 & 5.0256 & TRN & \\
\hline CHEMBL1427854 & 688759 & 4.45 & 4.5721 & TRN & \\
\hline CHEMBL1455053 & 688759 & 5.2 & 4.9192 & TRN & \\
\hline CHEMBL1583490 & 688759 & 4.95 & 4.6356 & TRN & \\
\hline
\end{tabular}




\begin{tabular}{|c|c|c|c|c|}
\hline \multicolumn{5}{|c|}{ Supplemental Table S2.txt } \\
\hline CHEMBL1412811 & 688759 & 4.45 & 4.8546 & TRN \\
\hline CHEMBL3191125 & 688759 & 4.45 & 4.8969 & TRN \\
\hline CHEMBL1299187 & 688759 & 5.25 & 4.8056 & TRN \\
\hline CHEMBL1342468 & 688759 & 4.45 & 4.8827 & TRN \\
\hline CHEMBL561114 & 688759 & 4.65 & 4.8496 & TRN \\
\hline CHEMBL1610937 & 688759 & 4.75 & 5.275 & TRN \\
\hline CHEMBL1601456 & 688759 & 5.05 & 5.0793 & TRN \\
\hline CHEMBL1544768 & 688759 & 5.15 & 4.7989 & TRN \\
\hline CHEMBL1567764 & 688759 & 4.75 & 4.8155 & TST \\
\hline CHEMBL1385421 & 688759 & 5.75 & 5.1372 & TRN \\
\hline CHEMBL1323548 & 688759 & 5.55 & 4.6524 & TRN \\
\hline CHEMBL261641 & 688759 & 4.7 & 4.6085 & TST \\
\hline CHEMBL1336271 & 688759 & 4.45 & 5.1447 & TRN \\
\hline CHEMBL3192557 & 688759 & 5.7 & 5.4071 & TRN \\
\hline CHEMBL1580300 & 688759 & 5.5 & 4.6502 & TRN \\
\hline CHEMBL1421023 & 688759 & 4.45 & 4.725 & TRN \\
\hline CHEMBL1597024 & 688759 & 4.75 & 4.9299 & TRN \\
\hline CHEMBL1606916 & 688759 & 5.0 & 4.9106 & TRN \\
\hline CHEMBL1392145 & 688759 & 5.3 & 5.1179 & TRN \\
\hline CHEMBL1326933 & 688759 & 4.85 & 4.9507 & TRN \\
\hline CHEMBL1507949 & 688759 & 5.55 & 5.0656 & TRN \\
\hline CHEMBL1342256 & 688759 & 5.1 & 4.9068 & TRN \\
\hline CHEMBL1427654 & 688759 & 5.2 & 4.9041 & TST \\
\hline CHEMBL3195456 & 688759 & 4.45 & 4.8908 & TST \\
\hline CHEMBL1544099 & 688759 & 4.95 & 4.9281 & TRN \\
\hline CHEMBL1613230 & 688759 & 4.45 & 4.9347 & TRN \\
\hline CHEMBL1599098 & 688759 & 4.65 & 5.0161 & TRN \\
\hline CHEMBL3209876 & 688759 & 4.45 & 4.5903 & TRN \\
\hline CHEMBL1529631 & 688759 & 6.2 & 5.7576 & TRN \\
\hline CHEMBL1450720 & 688759 & 4.5 & 4.9794 & TRN \\
\hline CHEMBL3190920 & 688759 & 4.45 & 4.7754 & TRN \\
\hline CHEMBL1441098 & 688759 & 4.85 & 4.7108 & TRN \\
\hline CHEMBL1303426 & 688759 & 5.4 & 5.2321 & TRN \\
\hline CHEMBL1577183 & 688759 & 5.0 & 5.0755 & TRN \\
\hline CHEMBL1550268 & 688759 & 6.1 & 5.0595 & TST \\
\hline CHEMBL1419587 & 688759 & 4.45 & 4.6488 & TRN \\
\hline CHEMBL1524190 & 688759 & 4.5 & 4.7077 & TST \\
\hline CHEMBL1572014 & 688759 & 4.65 & 4.7606 & TRN \\
\hline CHEMBL1456922 & 688759 & 4.95 & 4.6859 & TRN \\
\hline CHEMBL 3145282 & 688759 & 5.25 & 5.0165 & TRN \\
\hline CHEMBL1597299 & 688759 & 4.75 & 4.8578 & TRN \\
\hline CHEMBL1313225 & 688759 & 4.45 & 4.8062 & TRN \\
\hline CHEMBL3194239 & 688759 & 4.9 & 5.0274 & TRN \\
\hline CHEMBL1569786 & 688759 & 4.95 & 4.7055 & TRN \\
\hline CHEMBL1312429 & 688759 & 5.3 & 4.7706 & TRN \\
\hline CHEMBL1539988 & 688759 & 5.35 & 4.8451 & TST \\
\hline CHEMBL3196884 & 688759 & 4.45 & 4.9761 & TRN \\
\hline CHEMBL1421098 & 688759 & 4.7 & 4.7458 & TST \\
\hline
\end{tabular}




\begin{tabular}{|c|c|c|c|c|c|}
\hline & & \multicolumn{4}{|c|}{ Supplemental Table S2.txt } \\
\hline CHEMBL1451721 & 688759 & 4.65 & 4.6368 & TST & \\
\hline CHEMBL1449921 & 688759 & 5.2 & 4.896 & TRN & \\
\hline CHEMBL526468 & 688759 & 4.85 & 4.7385 & TRN & \\
\hline CHEMBL1333583 & 688759 & 4.45 & 4.74100 & 00000000005 & TST \\
\hline CHEMBL1511182 & 688759 & 4.75 & 5.0154 & TST & \\
\hline CHEMBL1603844 & 688759 & 4.45 & 4.6966 & TST & \\
\hline CHEMBL 3190068 & 688759 & 4.85 & 5.0138 & TRN & \\
\hline CHEMBL1540341 & 688759 & 4.45 & 4.5479 & TRN & \\
\hline CHEMBL3198992 & 688759 & 4.7 & 4.95 & TST & \\
\hline CHEMBL602526 & 688759 & 4.95 & 4.7791 & TRN & \\
\hline CHEMBL1386044 & 688759 & 4.65 & 4.3529 & TRN & \\
\hline CHEMBL1409076 & 688759 & 4.5 & 4.702 & TRN & \\
\hline CHEMBL1497862 & 688759 & 4.45 & 4.8391 & TRN & \\
\hline CHEMBL1466791 & 688759 & 4.6 & 4.8832 & TRN & \\
\hline CHEMBL1459681 & 688759 & 5.4 & 5.126 & TST & \\
\hline CHEMBL427692 & 688759 & 4.7 & 4.7939 & TRN & \\
\hline CHEMBL1299190 & 688759 & 4.45 & 4.7709 & TST & \\
\hline CHEMBL1527552 & 688759 & 4.6 & 4.8819 & TST & \\
\hline CHEMBL1544270 & 688759 & 4.7 & 4.8015 & TRN & \\
\hline CHEMBL1322258 & 688759 & 4.7 & 4.9041 & TRN & \\
\hline CHEMBL1379434 & 688759 & 4.45 & 4.534 & TST & \\
\hline CHEMBL1310248 & 688759 & 4.65 & 4.684 & TRN & \\
\hline CHEMBL1329996 & 688759 & 4.65 & 4.9622 & TST & \\
\hline CHEMBL1309272 & 688759 & 5.5 & 4.8739 & TST & \\
\hline CHEMBL1451336 & 688759 & 5.2 & 4.9227 & TST & \\
\hline CHEMBL1504592 & 688759 & 4.95 & 5.0433 & TST & \\
\hline CHEMBL1337866 & 688759 & 4.45 & 4.7844 & TRN & \\
\hline CHEMBL1460445 & 688759 & 5.25 & 4.8782 & TRN & \\
\hline CHEMBL1359961 & 688759 & 4.95 & 5.2748 & TRN & \\
\hline CHEMBL1440355 & 688759 & 4.45 & 4.7497 & TRN & \\
\hline CHEMBL1299674 & 688759 & 5.4 & 5.0733 & TRN & \\
\hline CHEMBL 3196289 & 688759 & 4.65 & 4.8862 & TRN & \\
\hline CHEMBL1323757 & 688759 & 4.9 & 4.8769 & TST & \\
\hline CHEMBL1471269 & 688759 & 4.8 & 4.7467 & TST & \\
\hline CHEMBL1427801 & 688759 & 5.55 & 5.0631 & TRN & \\
\hline CHEMBL513436 & 688759 & 5.15 & 5.1828 & TRN & \\
\hline CHEMBL1309252 & 688759 & 4.45 & 4.6046 & TRN & \\
\hline CHEMBL1517966 & 688759 & 6.5501 & 5.0264 & TRN & \\
\hline CHEMBL3190865 & 688759 & 4.75 & 4.7529 & TRN & \\
\hline CHEMBL1337367 & 688759 & 5.4 & 5.0646 & TRN & \\
\hline CHEMBL3199919 & 688759 & 4.6 & 4.672 & TRN & \\
\hline CHEMBL3196463 & 688759 & 4.45 & 4.8118 & TRN & \\
\hline CHEMBL1607561 & 688759 & 5.2 & 5.0378 & TRN & \\
\hline CHEMBL1548577 & 688759 & 4.45 & 4.6256 & TRN & \\
\hline CHEMBL1573038 & 688759 & 4.75 & 4.8585 & TRN & \\
\hline CHEMBL1333275 & 688759 & 4.5 & 4.5408 & TRN & \\
\hline CHEMBL1449009 & 688759 & 4.45 & 4.9021 & TRN & \\
\hline CHEMBL1310534 & 688759 & 4.95 & 4.959 & TST & \\
\hline
\end{tabular}




\begin{tabular}{|c|c|c|c|c|}
\hline \multicolumn{5}{|c|}{ Supplemental Table S2.txt } \\
\hline CHEMBL 3213411 & 688759 & 5.25 & 4.8725 & TST \\
\hline CHEMBL1603760 & 688759 & 4.45 & 4.8032 & TRN \\
\hline CHEMBL1404356 & 688759 & 5.15 & 5.4137 & TRN \\
\hline CHEMBL1399221 & 688759 & 6.0 & 5.2588 & TRN \\
\hline CHEMBL1503411 & 688759 & 5.25 & 4.7903 & TST \\
\hline CHEMBL1463865 & 688759 & 4.45 & 4.7545 & TRN \\
\hline CHEMBL1349482 & 688759 & 4.95 & 4.9367 & TST \\
\hline CHEMBL1558051 & 688759 & 6.0 & 4.7945 & TRN \\
\hline CHEMBL1602160 & 688759 & 6.0 & 5.5061 & TST \\
\hline CHEMBL1430088 & 688759 & 4.45 & 4.871 & TST \\
\hline CHEMBL1528861 & 688759 & 4.65 & 5.1552 & TRN \\
\hline CHEMBL1496640 & 688759 & 4.45 & 4.7795 & TRN \\
\hline CHEMBL1594735 & 688759 & 4.45 & 4.9238 & TRN \\
\hline CHEMBL1550704 & 688759 & 4.95 & 5.024 & TRN \\
\hline CHEMBL1565744 & 688759 & 5.4 & 4.9924 & TST \\
\hline CHEMBL1419533 & 688759 & 7.6003 & 5.0153 & TRN \\
\hline CHEMBL1589208 & 688759 & 5.4 & 4.9257 & TST \\
\hline CHEMBL1459215 & 688759 & 4.45 & 4.8316 & TRN \\
\hline CHEMBL1304324 & 688759 & 4.65 & 4.8163 & TRN \\
\hline CHEMBL1406192 & 688759 & 5.4 & 4.8395 & TST \\
\hline CHEMBL1352113 & 688759 & 5.4 & 4.9528 & TST \\
\hline CHEMBL1449250 & 688759 & 4.45 & 4.6485 & TRN \\
\hline CHEMBL1419166 & 688759 & 8.8539 & 5.0265 & TRN \\
\hline CHEMBL1492980 & 688759 & 5.25 & 5.0254 & TRN \\
\hline CHEMBL1482542 & 688759 & 4.95 & 5.2529 & TRN \\
\hline CHEMBL1605123 & 688759 & 4.7 & 4.5863 & TST \\
\hline CHEMBL1551649 & 688759 & 4.45 & 4.817 & TRN \\
\hline CHEMBL1599168 & 688759 & 6.0 & 5.2802 & TRN \\
\hline CHEMBL1386659 & 688759 & 5.95 & 5.065 & TRN \\
\hline CHEMBL1320542 & 688759 & 6.1 & 5.9009 & TRN \\
\hline CHEMBL1411550 & 688759 & 4.6 & 5.1381 & TRN \\
\hline CHEMBL1571276 & 688759 & 6.45 & 4.9079 & TST \\
\hline CHEMBL1448958 & 688759 & 5.25 & 5.2109 & TRN \\
\hline CHEMBL1451772 & 688759 & 4.5 & 4.8265 & TRN \\
\hline CHEMBL1608942 & 688759 & 4.75 & 4.7703 & TRN \\
\hline CHEMBL1460367 & 688759 & 4.45 & 4.5653 & TRN \\
\hline CHEMBL1305695 & 688759 & 4.8 & 4.7886 & TST \\
\hline CHEMBL1334594 & 688759 & 5.5 & 5.3714 & TRN \\
\hline CHEMBL1977978 & 688759 & 5.35 & 5.4115 & TRN \\
\hline CHEMBL1331106 & 688759 & 4.8 & 5.1792 & TRN \\
\hline CHEMBL1467026 & 688759 & 5.25 & 5.2104 & TRN \\
\hline CHEMBL1347975 & 688759 & 4.45 & 4.4206 & TRN \\
\hline CHEMBL1498783 & 688759 & 4.65 & 4.7964 & TST \\
\hline CHEMBL1439231 & 688759 & 4.8 & 4.8278 & TRN \\
\hline CHEMBL1506662 & 688759 & 4.45 & 4.5169 & TRN \\
\hline CHEMBL1457585 & 688759 & 5.15 & 4.9412 & TRN \\
\hline CHEMBL1596156 & 688759 & 4.45 & 4.6753 & TRN \\
\hline CHEMBL1567154 & 688759 & 4.65 & 5.0217 & TRN \\
\hline
\end{tabular}




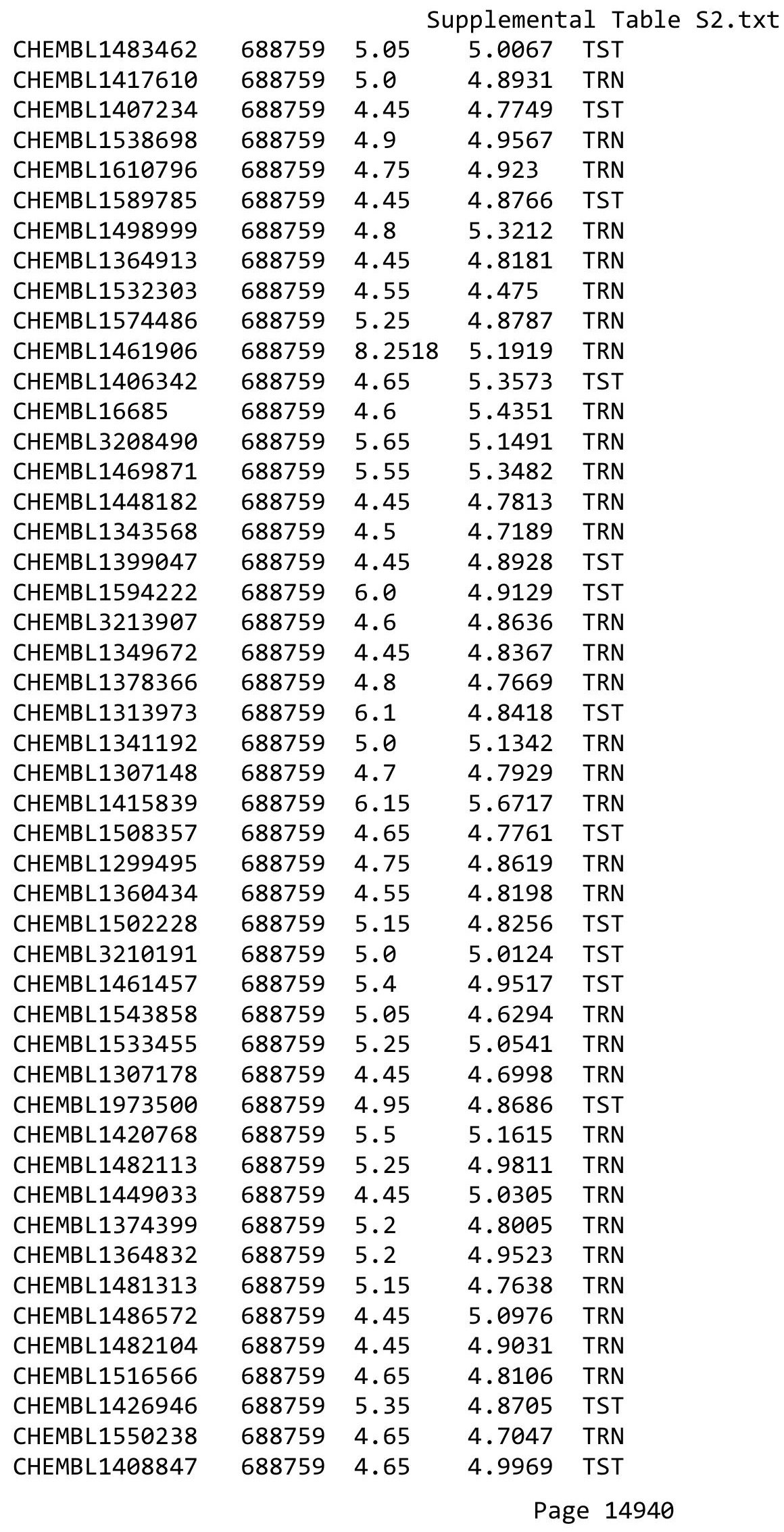




\begin{tabular}{|c|c|c|c|c|c|}
\hline & & \multicolumn{4}{|c|}{ Supplemental Table S2.txt } \\
\hline CHEMBL1539324 & 688759 & 4.9 & 4.8178 & TST & \\
\hline CHEMBL1438722 & 688759 & 4.45 & 5.8125 & TRN & \\
\hline CHEMBL3197876 & 688759 & 5.55 & 5.4891 & TRN & \\
\hline CHEMBL1377067 & 688759 & 5.2 & 5.117 & TRN & \\
\hline CHEMBL1393481 & 688759 & 4.5 & 4.7072 & TRN & \\
\hline CHEMBL1451047 & 688759 & 5.8 & 4.9362 & TRN & \\
\hline CHEMBL1549459 & 688759 & 4.55 & 5.3849 & TST & \\
\hline CHEMBL1509550 & 688759 & 4.45 & 4.6019 & TRN & \\
\hline CHEMBL1449828 & 688759 & 5.5 & 5.2443 & TRN & \\
\hline CHEMBL1353285 & 688759 & 4.45 & 4.7993 & TST & \\
\hline CHEMBL1542776 & 688759 & 4.6 & 4.5817 & TRN & \\
\hline CHEMBL1518163 & 688759 & 5.0 & 4.6364 & TRN & \\
\hline CHEMBL1410739 & 688759 & 4.45 & 4.8166 & TRN & \\
\hline CHEMBL1494263 & 688759 & 5.4 & 5.0293 & TRN & \\
\hline CHEMBL1576796 & 688759 & 4.45 & 4.9015 & TRN & \\
\hline CHEMBL1535828 & 688759 & 6.1 & 4.9699 & TRN & \\
\hline CHEMBL3199091 & 688759 & 4.7 & 4.9117 & TRN & \\
\hline CHEMBL1535652 & 688759 & 4.45 & 4.898 & TRN & \\
\hline CHEMBL1380251 & 688759 & 10.9 & 6.5214 & TRN & \\
\hline CHEMBL1568014 & 688759 & 4.7 & 4.8339 & TRN & \\
\hline CHEMBL1372810 & 688759 & 6.3 & 4.6415 & TRN & \\
\hline CHEMBL1479240 & 688759 & 4.95 & 4.8504 & TRN & \\
\hline CHEMBL1322124 & 688759 & 4.45 & 4.683 & TRN & \\
\hline CHEMBL3207475 & 688759 & 4.65 & 4.7607 & TST & \\
\hline CHEMBL1460718 & 688759 & 5.35 & 4.7745 & TST & \\
\hline CHEMBL1425408 & 688759 & 4.45 & 4.7573 & TST & \\
\hline CHEMBL1577186 & 688759 & 5.1 & 4.8833 & TRN & \\
\hline CHEMBL1350340 & 688759 & 4.65 & 4.7394 & TRN & \\
\hline CHEMBL1320118 & 688759 & 4.65 & 4.8607 & TRN & \\
\hline CHEMBL1389219 & 688759 & 4.9 & 4.5829 & TST & \\
\hline CHEMBL1443825 & 688759 & 4.6 & 4.7371 & TRN & \\
\hline CHEMBL1514181 & 688759 & 4.55 & 4.6965 & TST & \\
\hline CHEMBL1460913 & 688759 & 5.25 & 4.7989 & TST & \\
\hline CHEMBL1338482 & 688759 & 5.2 & 4.8586 & TRN & \\
\hline CHEMBL1478705 & 688759 & 5.2 & 5.13899 & 9999999999 & TRN \\
\hline CHEMBL1409532 & 688759 & 4.45 & 4.5227 & TRN & \\
\hline CHEMBL1565005 & 688759 & 5.1 & 5.3244 & TST & \\
\hline CHEMBL1482777 & 688759 & 5.5 & 5.1798 & TRN & \\
\hline CHEMBL1579888 & 688759 & 5.15 & 5.09 & TST & \\
\hline CHEMBL1489018 & 688759 & 5.9 & 5.347 & TRN & \\
\hline CHEMBL1530061 & 688759 & 5.55 & 5.3992 & TRN & \\
\hline CHEMBL1420568 & 688759 & 4.6 & 4.7293 & TST & \\
\hline CHEMBL1373307 & 688759 & 5.2 & 5.0446 & TRN & \\
\hline CHEMBL1416410 & 688759 & 4.95 & 4.7463 & TRN & \\
\hline CHEMBL1562502 & 688759 & 4.8 & 5.2499 & TRN & \\
\hline CHEMBL1312989 & 688759 & 4.55 & 4.7156 & TST & \\
\hline CHEMBL1380962 & 688759 & 4.45 & 5.4502 & TRN & \\
\hline CHEMBL1522239 & 688759 & 5.4 & 4.9002 & TRN & \\
\hline
\end{tabular}




\begin{tabular}{|c|c|c|c|c|c|}
\hline \multicolumn{6}{|c|}{ Supplemental Table S2.txt } \\
\hline CHEMBL1494038 & 688759 & 4.6 & 4.7209 & TST & \\
\hline CHEMBL1997220 & 688759 & 5.5 & 5.5516 & TRN & \\
\hline CHEMBL1506110 & 688759 & 4.5 & 4.7584 & TRN & \\
\hline CHEMBL1580603 & 688759 & 4.5 & 4.9462 & TRN & \\
\hline CHEMBL1501755 & 688759 & 4.6 & 4.8265 & TRN & \\
\hline CHEMBL1456705 & 688759 & 4.65 & 4.5829 & TRN & \\
\hline CHEMBL1328325 & 688759 & 4.9 & 4.3832 & TRN & \\
\hline CHEMBL1608551 & 688759 & 5.9 & 5.7005 & TRN & \\
\hline CHEMBL1354100 & 688759 & 5.65 & 4.8908 & TRN & \\
\hline CHEMBL1348848 & 688759 & 5.25 & 4.5583 & TST & \\
\hline CHEMBL1563864 & 688759 & 5.2 & 5.1981 & TRN & \\
\hline CHEMBL1423407 & 688759 & 4.45 & 4.8109 & TRN & \\
\hline CHEMBL1390860 & 688759 & 4.45 & 4.9443 & TRN & \\
\hline CHEMBL226876 & 688759 & 4.7 & 4.6647 & TRN & \\
\hline CHEMBL1544276 & 688759 & 5.0 & 5.1035 & TRN & \\
\hline CHEMBL1548809 & 688759 & 4.65 & 4.6672 & TRN & \\
\hline CHEMBL1338645 & 688759 & 4.45 & 4.8498 & TST & \\
\hline CHEMBL1416710 & 688759 & 4.5 & 4.6728 & TRN & \\
\hline CHEMBL1366304 & 688759 & 4.45 & 4.8986 & TST & \\
\hline CHEMBL1375338 & 688759 & 5.35 & 5.26399 & 9999999999 & TRN \\
\hline CHEMBL1405744 & 688759 & 4.45 & 4.8623 & TST & \\
\hline CHEMBL1428629 & 688759 & 4.45 & 5.2146 & TRN & \\
\hline CHEMBL1562195 & 688759 & 5.6 & 5.7209 & TRN & \\
\hline CHEMBL1472925 & 688759 & 4.85 & 5.7477 & TRN & \\
\hline CHEMBL 3197272 & 688759 & 5.6 & 5.4888 & TRN & \\
\hline CHEMBL1328261 & 688759 & 5.35 & 5.3829 & TRN & \\
\hline CHEMBL1973864 & 688759 & 5.6 & 5.3566 & TRN & \\
\hline CHEMBL1605213 & 688759 & 4.9 & 4.8533 & TRN & \\
\hline CHEMBL1995280 & 688759 & 5.75 & 5.4861 & TRN & \\
\hline CHEMBL3194013 & 688759 & 4.95 & 5.0416 & TRN & \\
\hline CHEMBL1312115 & 688759 & 4.5 & 4.744 & TST & \\
\hline CHEMBL401402 & 688759 & 4.45 & 4.7519 & TRN & \\
\hline CHEMBL270299 & 688759 & 6.1 & 5.6243 & TST & \\
\hline CHEMBL1416440 & 688759 & 4.45 & 4.8336 & TRN & \\
\hline CHEMBL1602808 & 688759 & 4.7 & 4.782 & TRN & \\
\hline CHEMBL1376658 & 688759 & 4.6 & 5.0445 & TRN & \\
\hline CHEMBL1482869 & 688759 & 5.6 & 5.1656 & TRN & \\
\hline CHEMBL3190936 & 688759 & 4.45 & 4.6474 & TRN & \\
\hline CHEMBL 3193161 & 688759 & 5.2 & 5.0361 & TRN & \\
\hline CHEMBL1337614 & 688759 & 5.45 & 5.5112 & TRN & \\
\hline CHEMBL1454633 & 688759 & 4.45 & 4.6896 & TRN & \\
\hline CHEMBL1453835 & 688759 & 4.45 & 4.8934 & TRN & \\
\hline CHEMBL1463067 & 688759 & 5.35 & 4.94 & TST & \\
\hline CHEMBL2369239 & 688759 & 4.45 & 4.6105 & TST & \\
\hline CHEMBL 3212466 & 688759 & 4.95 & 5.2672 & TRN & \\
\hline CHEMBL1534790 & 688759 & 5.0 & 5.3825 & TRN & \\
\hline CHEMBL1332802 & 688759 & 4.45 & 4.569 & TRN & \\
\hline CHEMBL1966192 & 688759 & 4.6 & 4.6014 & TRN & \\
\hline
\end{tabular}




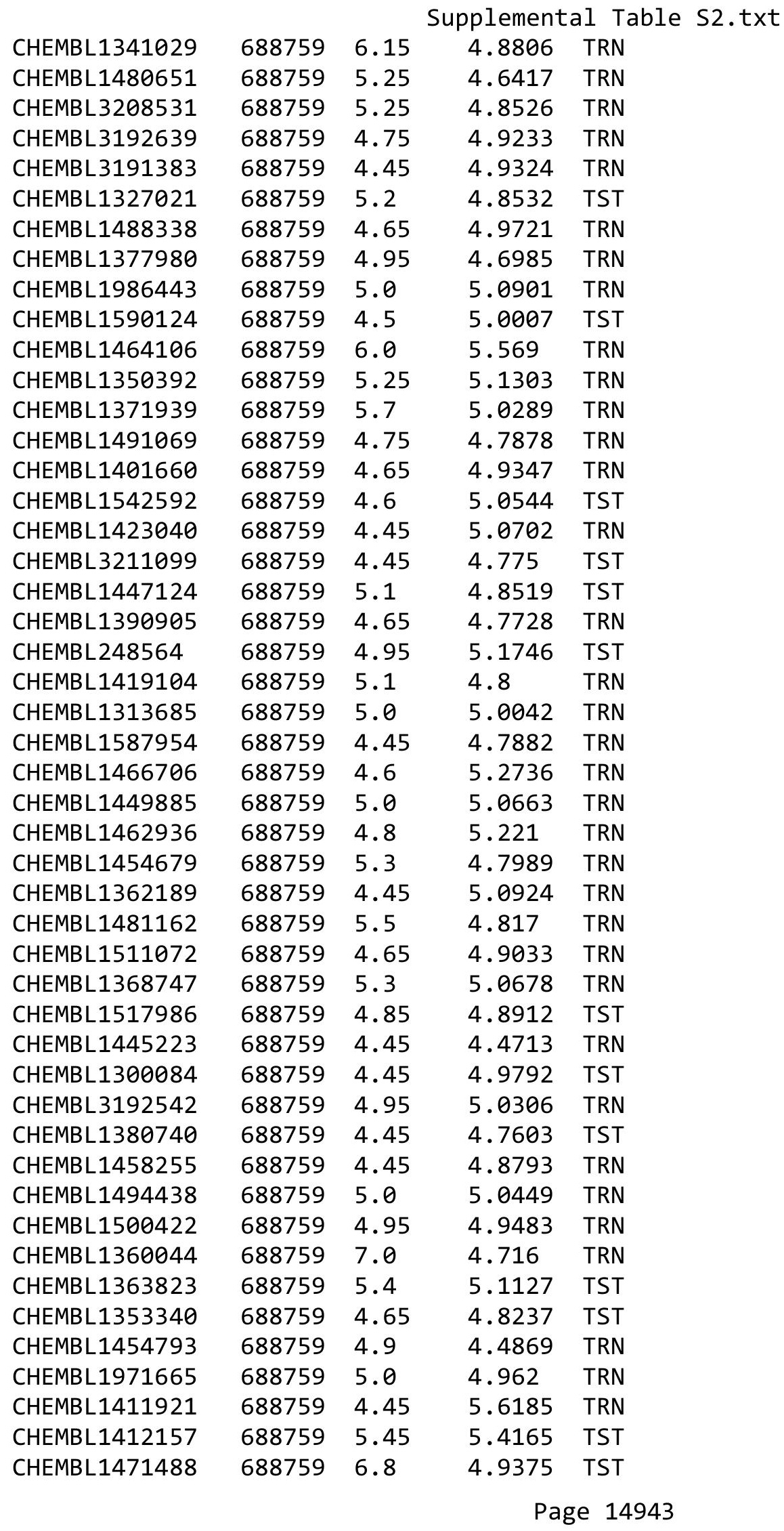




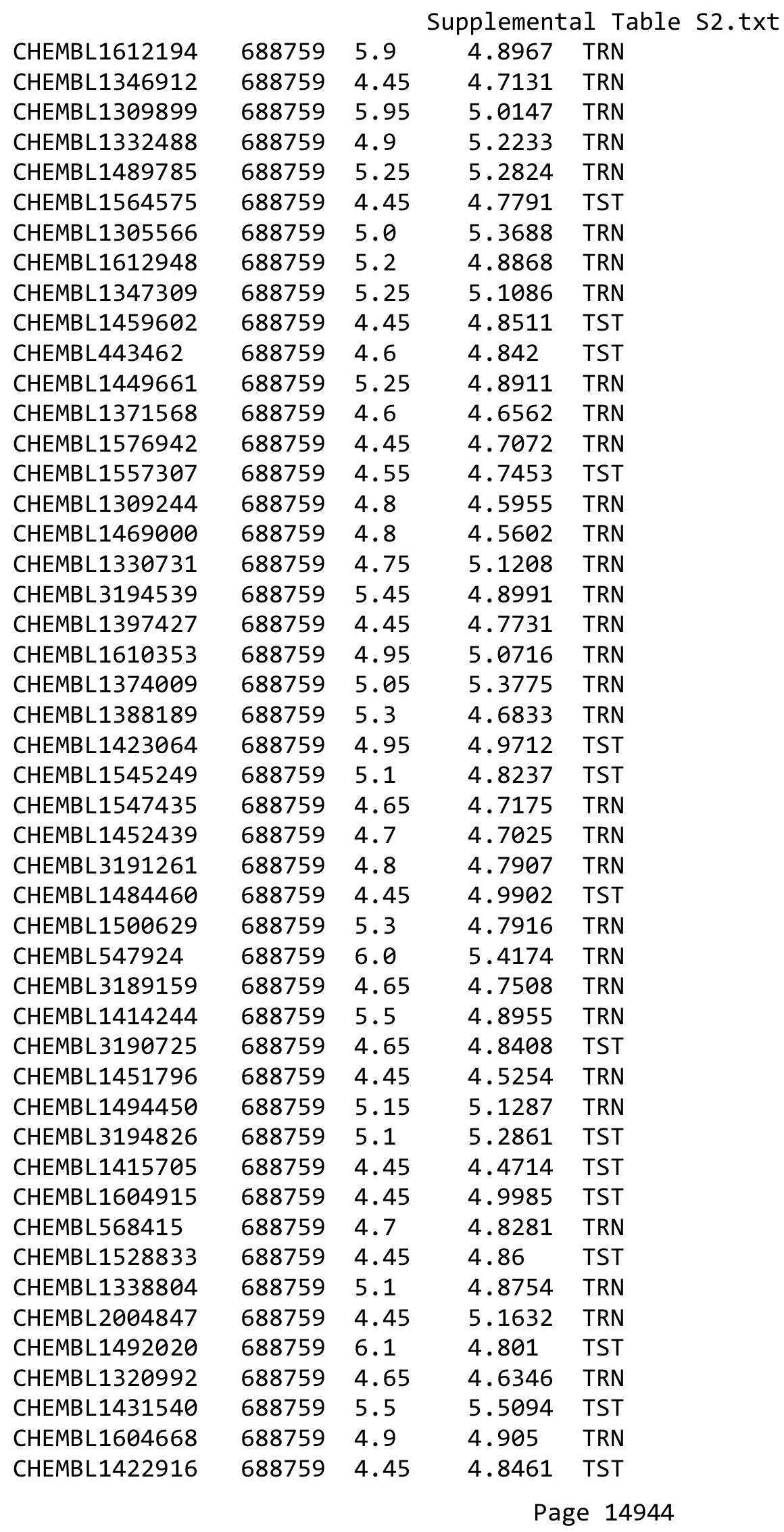




\begin{tabular}{|c|c|c|c|c|}
\hline \multicolumn{5}{|c|}{ Supplemental Table S2.txt } \\
\hline CHEMBL1369196 & 688759 & 5.0 & 4.9722 & TRN \\
\hline CHEMBL1335391 & 688759 & 4.45 & 4.8008 & TST \\
\hline CHEMBL1496534 & 688759 & 5.35 & 5.1097 & TST \\
\hline CHEMBL1455424 & 688759 & 4.8 & 5.215 & TRN \\
\hline CHEMBL1451525 & 688759 & 5.2 & 4.8504 & TRN \\
\hline CHEMBL1605431 & 688759 & 4.6 & 5.1602 & TRN \\
\hline CHEMBL3144933 & 688759 & 5.35 & 5.1163 & TST \\
\hline CHEMBL1558101 & 688759 & 4.7 & 4.8853 & TRN \\
\hline CHEMBL1465015 & 688759 & 4.5 & 4.8358 & TST \\
\hline CHEMBL1451278 & 688759 & 4.45 & 5.1296 & TRN \\
\hline CHEMBL1571069 & 688759 & 4.45 & 4.6746 & TRN \\
\hline CHEMBL1386083 & 688759 & 4.6 & 4.8828 & TST \\
\hline CHEMBL1505370 & 688759 & 4.7 & 5.0544 & TST \\
\hline CHEMBL1467410 & 688759 & 5.3 & 5.2527 & TRN \\
\hline CHEMBL1508696 & 688759 & 4.45 & 4.6604 & TRN \\
\hline CHEMBL1575275 & 688759 & 5.65 & 5.5503 & TRN \\
\hline CHEMBL1583946 & 688759 & 4.45 & 4.4717 & TRN \\
\hline CHEMBL3145112 & 688759 & 4.45 & 4.9402 & TRN \\
\hline CHEMBL1343467 & 688759 & 4.9 & 4.833 & TRN \\
\hline CHEMBL1445645 & 688759 & 5.25 & 4.9094 & TRN \\
\hline CHEMBL1418869 & 688759 & 5.4 & 4.8793 & TRN \\
\hline CHEMBL1432867 & 688759 & 5.3 & 4.9695 & TRN \\
\hline CHEMBL1471114 & 688759 & 5.2 & 5.0777 & TRN \\
\hline CHEMBL1450990 & 688759 & 5.55 & 5.4145 & TRN \\
\hline CHEMBL1343364 & 688759 & 4.45 & 4.6329 & TRN \\
\hline CHEMBL1352554 & 688759 & 6.0 & 6.0247 & TRN \\
\hline CHEMBL1344166 & 688759 & 4.8 & 4.8388 & TRN \\
\hline CHEMBL10206 & 688759 & 6.45 & 5.4013 & TRN \\
\hline CHEMBL1504345 & 688759 & 4.45 & 4.8364 & TRN \\
\hline CHEMBL1500315 & 688759 & 4.75 & 4.6579 & TRN \\
\hline CHEMBL1323360 & 688759 & 5.9 & 4.7769 & TST \\
\hline CHEMBL1429784 & 688759 & 6.45 & 5.2046 & TST \\
\hline CHEMBL1332804 & 688759 & 4.85 & 5.0309 & TRN \\
\hline CHEMBL1568946 & 688759 & 5.35 & 5.4776 & TRN \\
\hline CHEMBL1547021 & 688759 & 5.25 & 5.0059 & TRN \\
\hline CHEMBL1535532 & 688759 & 5.35 & 5.409 & TRN \\
\hline CHEMBL 1475255 & 688759 & 4.45 & 4.8277 & TRN \\
\hline CHEMBL1363146 & 688759 & 5.45 & 4.6947 & TST \\
\hline CHEMBL1558954 & 688759 & 4.65 & 4.5303 & TRN \\
\hline CHEMBL1505112 & 688759 & 4.85 & 4.8969 & TRN \\
\hline CHEMBL1353706 & 688759 & 4.45 & 4.8047 & TRN \\
\hline CHEMBL1369629 & 688759 & 4.65 & 4.5754 & TST \\
\hline CHEMBL1452794 & 688759 & 4.45 & 4.7308 & TRN \\
\hline CHEMBL300389 & 688759 & 6.0 & 5.6179 & TST \\
\hline CHEMBL3207423 & 688759 & 4.45 & 4.8594 & TRN \\
\hline CHEMBL1506644 & 688759 & 4.75 & 4.8701 & TRN \\
\hline CHEMBL3213820 & 688759 & 4.45 & 4.9363 & TRN \\
\hline CHEMBL1487935 & 688759 & 4.45 & 4.9607 & TRN \\
\hline
\end{tabular}




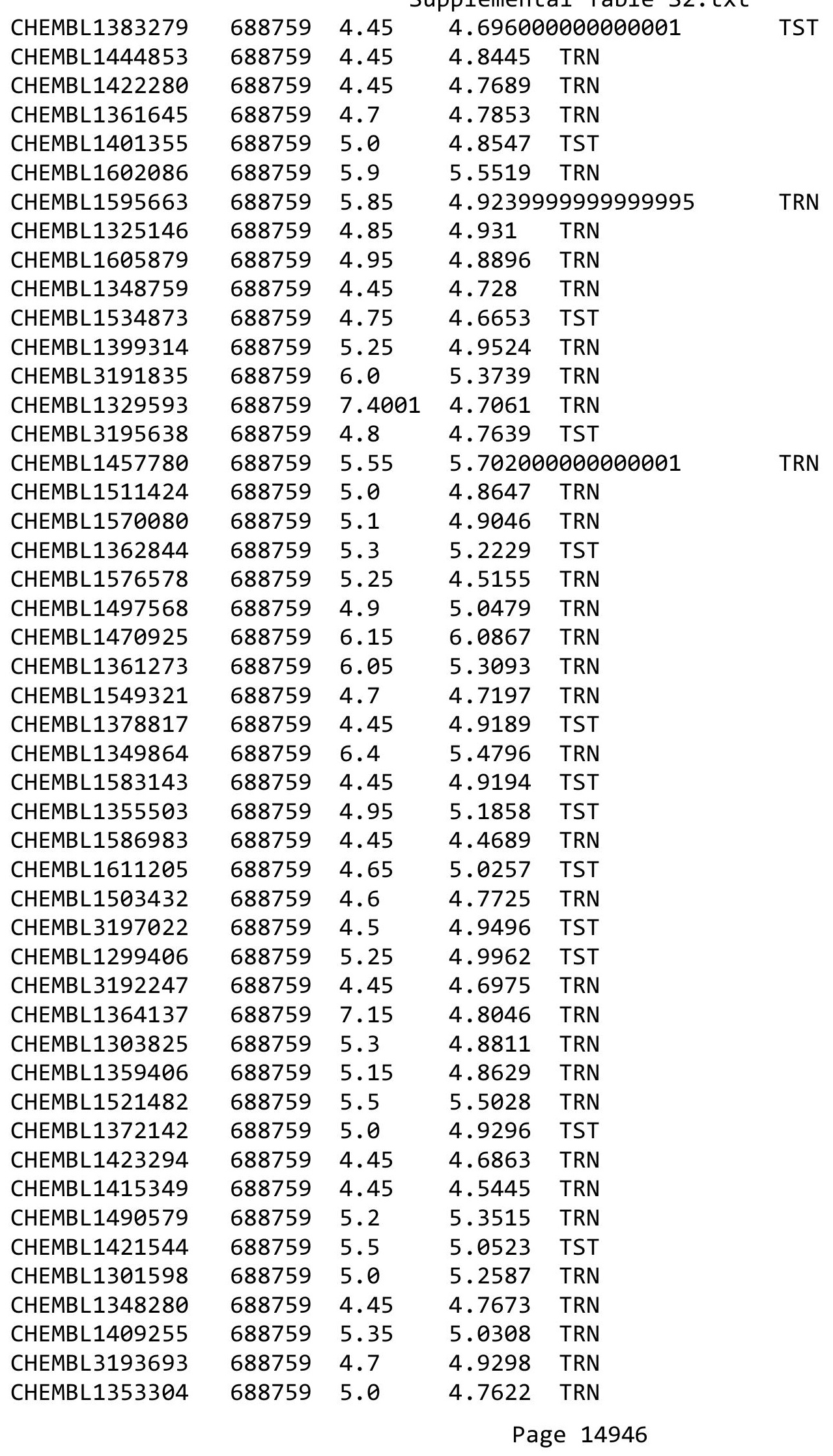




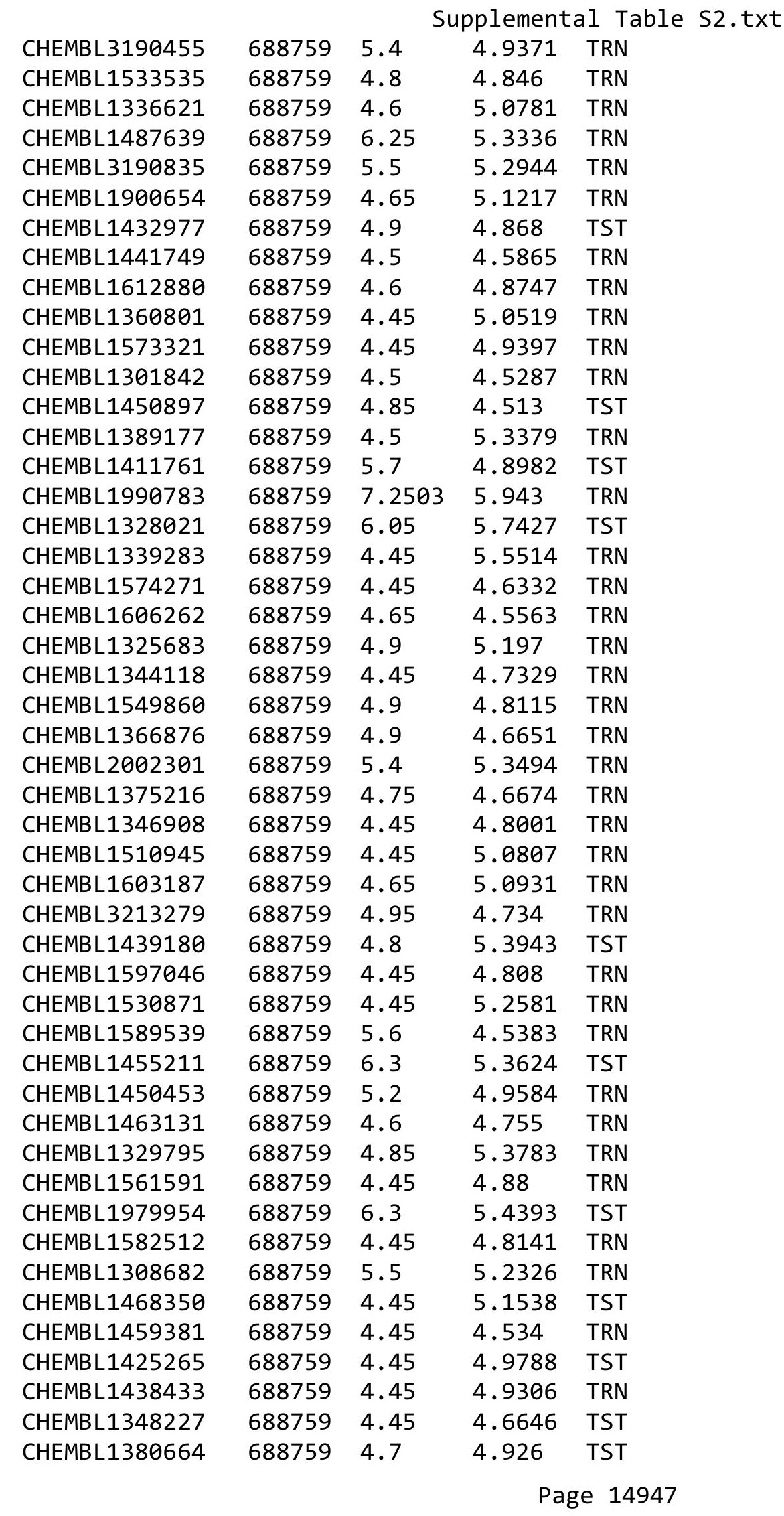




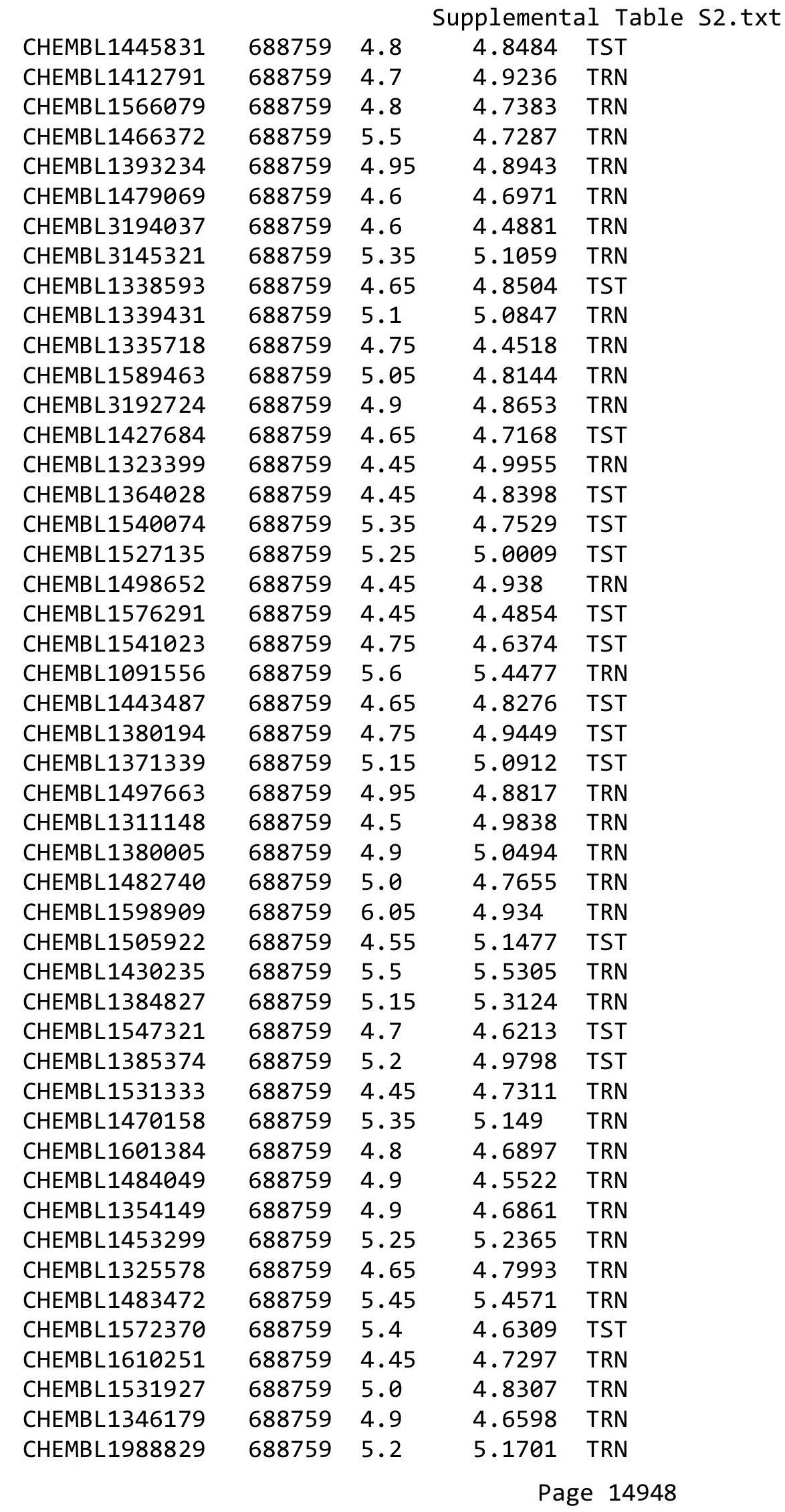




\begin{tabular}{|c|c|c|c|c|}
\hline \multicolumn{5}{|c|}{ Supplemental Table S2.txt } \\
\hline CHEMBL1477969 & 688759 & 4.8 & 5.0004 & TST \\
\hline CHEMBL1444371 & 688759 & 5.5 & 5.24 & TRN \\
\hline CHEMBL1410697 & 688759 & 8.301 & 4.8809 & TST \\
\hline CHEMBL1548430 & 688759 & 4.45 & 5.0264 & TST \\
\hline CHEMBL1992105 & 688759 & 4.6 & 4.6193 & TRN \\
\hline CHEMBL 3197921 & 688759 & 4.45 & 4.6749 & TRN \\
\hline CHEMBL1503651 & 688759 & 5.55 & 4.6879 & TRN \\
\hline CHEMBL1330991 & 688759 & 4.85 & 5.1359 & TST \\
\hline CHEMBL1352758 & 688759 & 4.75 & 5.506 & TRN \\
\hline CHEMBL1468438 & 688759 & 4.45 & 4.482 & TRN \\
\hline CHEMBL 3211430 & 688759 & 4.45 & 4.7484 & TST \\
\hline CHEMBL1311709 & 688759 & 6.7001 & 4.9191 & TRN \\
\hline CHEMBL1417631 & 688759 & 4.7 & 4.7034 & TRN \\
\hline CHEMBL1406607 & 688759 & 6.0 & 5.0759 & TST \\
\hline CHEMBL1458131 & 688759 & 4.95 & 5.1615 & TRN \\
\hline CHEMBL1442120 & 688759 & 4.45 & 4.8417 & TRN \\
\hline CHEMBL465843 & 688759 & 6.0 & 5.3861 & TRN \\
\hline CHEMBL1349331 & 688759 & 5.0 & 4.9762 & TRN \\
\hline CHEMBL1300159 & 688759 & 4.45 & 4.7761 & TRN \\
\hline CHEMBL1336378 & 688759 & 4.7 & 4.8656 & TRN \\
\hline CHEMBL1550962 & 688759 & 4.45 & 4.8403 & TST \\
\hline CHEMBL1307736 & 688759 & 5.4 & 4.979 & TRN \\
\hline CHEMBL1572585 & 688759 & 4.7 & 4.8546 & TRN \\
\hline CHEMBL1584524 & 688759 & 4.95 & 4.7923 & TRN \\
\hline CHEMBL 260799 & 688759 & 4.45 & 4.5065 & TRN \\
\hline CHEMBL1391048 & 688759 & 5.6 & 5.3979 & TST \\
\hline CHEMBL1484898 & 688759 & 4.65 & 4.9788 & TRN \\
\hline CHEMBL1309975 & 688759 & 5.4 & 4.9623 & TST \\
\hline CHEMBL1452576 & 688759 & 4.9 & 4.9505 & TRN \\
\hline CHEMBL1588732 & 688759 & 4.65 & 4.7858 & TRN \\
\hline CHEMBL1994163 & 688759 & 4.75 & 4.6567 & TST \\
\hline CHEMBL582980 & 688759 & 4.45 & 5.0761 & TRN \\
\hline CHEMBL3195968 & 688759 & 4.9 & 4.9194 & TRN \\
\hline CHEMBL1525374 & 688759 & 4.45 & 4.5901 & TST \\
\hline CHEMBL1479322 & 688759 & 6.15 & 4.605 & TRN \\
\hline CHEMBL1613510 & 688759 & 4.75 & 4.4541 & TRN \\
\hline CHEMBL1568091 & 688759 & 4.45 & 4.8379 & TRN \\
\hline CHEMBL1530379 & 688759 & 5.0 & 5.0811 & TRN \\
\hline CHEMBL 328834 & 688759 & 5.9 & 5.0858 & TRN \\
\hline CHEMBL1382429 & 688759 & 4.8 & 4.7595 & TRN \\
\hline CHEMBL1560635 & 688759 & 4.6 & 4.7837 & TST \\
\hline CHEMBL3189593 & 688759 & 4.45 & 4.8263 & TST \\
\hline CHEMBL1580327 & 688759 & 4.45 & 4.8619 & TRN \\
\hline CHEMBL1448413 & 688759 & 4.95 & 4.9603 & TRN \\
\hline CHEMBL1463331 & 688759 & 4.45 & 4.6809 & TRN \\
\hline CHEMBL3190592 & 688759 & 5.5 & 5.1577 & TRN \\
\hline CHEMBL1613707 & 688759 & 4.45 & 4.8261 & TRN \\
\hline CHEMBL1489200 & 688759 & 5.35 & 5.2722 & TRN \\
\hline
\end{tabular}




\begin{tabular}{|c|c|c|c|c|}
\hline \multicolumn{5}{|c|}{ Supplemental Table } \\
\hline CHEMBL1609633 & 688759 & 4.45 & 4.8757 & TST \\
\hline CHEMBL1366622 & 688759 & 5.05 & 4.7323 & TRN \\
\hline CHEMBL1488081 & 688759 & 4.5 & 4.9902 & TRN \\
\hline CHEMBL1329982 & 688759 & 5.25 & 4.7511 & TRN \\
\hline CHEMBL1574603 & 688759 & 4.7 & 4.6413 & TRN \\
\hline CHEMBL1511689 & 688759 & 4.45 & 4.9464 & TRN \\
\hline CHEMBL1447748 & 688759 & 4.55 & 4.499 & TST \\
\hline CHEMBL1409055 & 688759 & 5.35 & 5.1292 & TST \\
\hline CHEMBL1523417 & 688759 & 4.6 & 4.9217 & TRN \\
\hline CHEMBL1333395 & 688759 & 4.75 & 4.8187 & TRN \\
\hline CHEMBL1500258 & 688759 & 4.9 & 5.0744 & TRN \\
\hline CHEMBL1532879 & 688759 & 5.45 & 4.7361 & TST \\
\hline CHEMBL3191815 & 688759 & 4.45 & 4.9808 & TST \\
\hline CHEMBL1556383 & 688759 & 4.45 & 4.6414 & TST \\
\hline CHEMBL1463247 & 688759 & 5.2 & 5.0775 & TRN \\
\hline CHEMBL514988 & 688759 & 4.8 & 4.7777 & TRN \\
\hline CHEMBL1471880 & 688759 & 4.45 & 5.3501 & TRN \\
\hline CHEMBL1377889 & 688759 & 4.65 & 4.9341 & TST \\
\hline CHEMBL1459641 & 688759 & 5.25 & 5.1879 & TRN \\
\hline CHEMBL1478806 & 688759 & 5.25 & 5.0178 & TRN \\
\hline CHEMBL3191034 & 688759 & 5.2 & 5.0775 & TST \\
\hline CHEMBL1478490 & 688759 & 4.9 & 4.8963 & TST \\
\hline CHEMBL 2374090 & 688759 & 5.5 & 5.1406 & TST \\
\hline CHEMBL1503559 & 688759 & 5.45 & 5.0408 & TST \\
\hline CHEMBL1387610 & 688759 & 5.5 & 5.2508 & TRN \\
\hline CHEMBL1600539 & 688759 & 5.05 & 4.9752 & TRN \\
\hline CHEMBL1344539 & 688759 & 5.35 & 4.9859 & TRN \\
\hline CHEMBL1600986 & 688759 & 4.45 & 4.8899 & TRN \\
\hline CHEMBL1415726 & 688759 & 4.6 & 4.5685 & TRN \\
\hline CHEMBL2359911 & 688759 & 5.35 & 5.1229 & TRN \\
\hline CHEMBL1383149 & 688759 & 4.65 & 4.9729 & TST \\
\hline CHEMBL1498773 & 688759 & 6.5501 & 5.0984 & TRN \\
\hline CHEMBL1417967 & 688759 & 6.2 & 4.9194 & TRN \\
\hline CHEMBL1458 & 688759 & 6.2 & 5.0654 & TST \\
\hline CHEMBL3197639 & 688759 & 5.7 & 4.94 & TST \\
\hline CHEMBL1412789 & 688759 & 4.65 & 4.8545 & TST \\
\hline CHEMBL1503995 & 688759 & 4.45 & 4.7304 & TST \\
\hline CHEMBL1971051 & 688759 & 5.05 & 5.0091 & TRN \\
\hline CHEMBL1410241 & 688759 & 5.4 & 4.7687 & TST \\
\hline CHEMBL3190606 & 688759 & 4.7 & 4.5967 & TRN \\
\hline CHEMBL3198450 & 688759 & 6.0 & 5.1325 & TRN \\
\hline CHEMBL1393852 & 688759 & 5.35 & 4.8801 & TRN \\
\hline CHEMBL1596449 & 688759 & 4.45 & 5.0432 & TST \\
\hline CHEMBL1421079 & 688759 & 6.05 & 5.5525 & TRN \\
\hline CHEMBL1417365 & 688759 & 5.25 & 4.8187 & TST \\
\hline CHEMBL1351929 & 688759 & 4.5 & 5.1283 & TRN \\
\hline CHEMBL1308836 & 688759 & 5.2 & 5.1469 & TRN \\
\hline CHEMBL1507368 & 688759 & 5.3 & 5.0467 & TRN \\
\hline
\end{tabular}




\begin{tabular}{|c|c|c|c|c|c|}
\hline & & \multicolumn{4}{|c|}{ Supplemental Table S2.txt } \\
\hline CHEMBL1460461 & 688759 & 4.6 & 4.6314 & TST & \\
\hline CHEMBL1308791 & 688759 & 4.8 & 4.9578 & TRN & \\
\hline CHEMBL1364895 & 688759 & 5.0 & 4.995 & TRN & \\
\hline CHEMBL1543657 & 688759 & 4.95 & 4.788 & TRN & \\
\hline CHEMBL1611580 & 688759 & 5.3 & 5.0712 & TRN & \\
\hline CHEMBL1354151 & 688759 & 4.45 & 4.7654 & TRN & \\
\hline CHEMBL1489384 & 688759 & 5.55 & 4.9146 & TST & \\
\hline CHEMBL1463624 & 688759 & 4.95 & 5.1859 & TRN & \\
\hline CHEMBL1446450 & 688759 & 5.0 & 5.5064 & TST & \\
\hline CHEMBL1569696 & 688759 & 4.6 & 4.9902 & TST & \\
\hline CHEMBL1506459 & 688759 & 4.65 & 4.8681 & TST & \\
\hline CHEMBL1420295 & 688759 & 4.45 & 4.9044 & TST & \\
\hline CHEMBL1425278 & 688759 & 4.8 & 4.5398 & TRN & \\
\hline CHEMBL1459410 & 688759 & 5.45 & 5.58799 & 9999999999 & TRN \\
\hline CHEMBL1453438 & 688759 & 4.55 & 4.7067 & TRN & \\
\hline CHEMBL1588200 & 688759 & 5.25 & 4.819 & TRN & \\
\hline CHEMBL1309052 & 688759 & 4.95 & 4.829 & TRN & \\
\hline CHEMBL1467382 & 688759 & 5.45 & 5.5667 & TRN & \\
\hline CHEMBL3212366 & 688759 & 5.65 & 5.1699 & TRN & \\
\hline CHEMBL3194400 & 688759 & 5.2 & 5.3697 & TRN & \\
\hline CHEMBL3195189 & 688759 & 5.2 & 5.2533 & TRN & \\
\hline CHEMBL47986 & 688759 & 4.8 & 4.8531 & TST & \\
\hline CHEMBL1419968 & 688759 & 5.4 & 4.9315 & TRN & \\
\hline CHEMBL3198327 & 688759 & 5.2 & 5.1632 & TRN & \\
\hline CHEMBL1459084 & 688759 & 4.45 & 4.9124 & TRN & \\
\hline CHEMBL1558052 & 688759 & 4.65 & 4.9989 & TRN & \\
\hline CHEMBL3197323 & 688759 & 5.3 & 5.5508 & TRN & \\
\hline CHEMBL1300370 & 688759 & 4.75 & 4.819 & TST & \\
\hline CHEMBL1501835 & 688759 & 4.45 & 4.8149 & TST & \\
\hline CHEMBL1508735 & 688759 & 5.25 & 5.1038 & TRN & \\
\hline CHEMBL1302213 & 688759 & 5.45 & 4.8795 & TST & \\
\hline CHEMBL3192891 & 688759 & 5.4 & 5.0562 & TRN & \\
\hline CHEMBL1306525 & 688759 & 4.45 & 4.7729 & TRN & \\
\hline CHEMBL1383947 & 688759 & 4.9 & 5.2592 & TRN & \\
\hline CHEMBL1455985 & 688759 & 4.45 & 4.8346 & TRN & \\
\hline CHEMBL1341879 & 688759 & 5.7 & 4.8832 & TRN & \\
\hline CHEMBL3190277 & 688759 & 5.05 & 5.2963 & TST & \\
\hline CHEMBL1425648 & 688759 & 4.65 & 4.7105 & TRN & \\
\hline CHEMBL1308001 & 688759 & 5.6 & 5.1365 & TRN & \\
\hline CHEMBL1969475 & 688759 & 5.4 & 5.2608 & TRN & \\
\hline CHEMBL1389262 & 688759 & 4.5 & 4.6479 & TRN & \\
\hline CHEMBL1478280 & 688759 & 5.4 & 5.8681 & TRN & \\
\hline CHEMBL578061 & 688759 & 4.5 & 4.902 & TRN & \\
\hline CHEMBL1383683 & 688759 & 4.45 & 4.6084 & TRN & \\
\hline CHEMBL1483562 & 688759 & 4.7 & 4.8931 & TST & \\
\hline CHEMBL1537008 & 688759 & 5.45 & 5.0617 & TST & \\
\hline CHEMBL1571433 & 688759 & 4.8 & 4.761 & TRN & \\
\hline CHEMBL1452489 & 688759 & 4.6 & 4.9552 & TRN & \\
\hline
\end{tabular}




\begin{tabular}{|c|c|c|c|c|c|}
\hline \multicolumn{6}{|c|}{ Supplemental Table s2.txt } \\
\hline CHEMBL3198951 & 688759 & 5.6 & 5.1452 & TRN & \\
\hline CHEMBL1398617 & 688759 & 5.3 & 5.0036 & TST & \\
\hline CHEMBL3212518 & 688759 & 4.45 & 4.978 & TST & \\
\hline CHEMBL1368261 & 688759 & 4.85 & 4.9663 & TST & \\
\hline CHEMBL1420938 & 688759 & 5.0 & 4.691 & TRN & \\
\hline CHEMBL1461972 & 688759 & 4.6 & 5.3557 & TRN & \\
\hline CHEMBL1582419 & 688759 & 5.35 & \multicolumn{2}{|c|}{5.162000000000001} & TRN \\
\hline CHEMBL1360102 & 688759 & 4.45 & 4.6486 & TRN & \\
\hline CHEMBL1313348 & 688759 & 5.0 & 4.7615 & TRN & \\
\hline CHEMBL1552283 & 688759 & 4.85 & 4.8599 & TST & \\
\hline CHEMBL1576318 & 688759 & 4.65 & 4.7811 & TRN & \\
\hline CHEMBL1548189 & 688759 & 5.25 & 5.0778 & TST & \\
\hline CHEMBL1500341 & 688759 & 4.95 & 4.8365 & TST & \\
\hline CHEMBL1580311 & 688759 & 4.65 & 4.8548 & TRN & \\
\hline CHEMBL1585098 & 688759 & 4.65 & 4.7929 & TST & \\
\hline CHEMBL1453214 & 688759 & 4.45 & 4.6298 & TRN & \\
\hline CHEMBL1577218 & 688759 & 4.7 & 4.8577 & TRN & \\
\hline CHEMBL1495160 & 688759 & 4.65 & 4.8152 & TRN & \\
\hline CHEMBL1588516 & 688759 & 5.4 & 4.9612 & TRN & \\
\hline CHEMBL1305973 & 688759 & 5.6 & 5.5387 & TRN & \\
\hline CHEMBL1401652 & 688759 & 5.25 & 5.7046 & TRN & \\
\hline CHEMBL3198963 & 688759 & 5.55 & 5.3914 & TRN & \\
\hline CHEMBL1535446 & 688759 & 4.6 & 4.7625 & TRN & \\
\hline CHEMBL1347202 & 688759 & 4.45 & 4.5015 & TRN & \\
\hline CHEMBL1471435 & 688759 & 4.9 & 4.6472 & TRN & \\
\hline CHEMBL1305429 & 688759 & 4.95 & 4.5952 & TRN & \\
\hline CHEMBL1507759 & 688759 & 4.45 & 4.5598 & TST & \\
\hline CHEMBL1361921 & 688759 & 4.75 & 4.7819 & TRN & \\
\hline CHEMBL1424853 & 688759 & 5.0 & 5.1053 & TRN & \\
\hline CHEMBL1339266 & 688759 & 4.45 & 4.9119 & TRN & \\
\hline CHEMBL1605356 & 688759 & 4.6 & 4.5085 & TRN & \\
\hline CHEMBL1463714 & 688759 & 4.55 & 4.7426 & TRN & \\
\hline CHEMBL1606066 & 688759 & 5.25 & 4.9679 & TRN & \\
\hline CHEMBL1577640 & 688759 & 5.35 & 4.9612 & TRN & \\
\hline CHEMBL1586685 & 688759 & 4.45 & 4.6567 & TST & \\
\hline CHEMBL1385479 & 688759 & 4.5 & 4.7163 & TRN & \\
\hline CHEMBL1521066 & 688759 & 6.15 & 4.5186 & TST & \\
\hline CHEMBL469664 & 688759 & 5.1 & 4.7996 & TRN & \\
\hline CHEMBL 3144970 & 688759 & 4.6 & 4.8803 & TRN & \\
\hline CHEMBL3195185 & 688759 & 5.5 & 5.6874 & TRN & \\
\hline CHEMBL1403981 & 688759 & 4.8 & 4.8333 & TST & \\
\hline CHEMBL86104 & 688759 & 5.0 & 5.0518 & TRN & \\
\hline CHEMBL1444774 & 688759 & 4.45 & 4.7976 & TST & \\
\hline CHEMBL1332969 & 688759 & 4.45 & 4.5198 & TRN & \\
\hline CHEMBL1419733 & 688759 & 6.0 & 5.5645 & TRN & \\
\hline CHEMBL1481697 & 688759 & 5.25 & 4.8917 & TRN & \\
\hline CHEMBL1984721 & 688759 & 5.4 & 5.24799 & 9999999999 & TRN \\
\hline CHEMBL1365177 & 688759 & 5.25 & 5.2783 & TRN & \\
\hline
\end{tabular}




\begin{tabular}{|c|c|c|c|c|c|}
\hline & & \multicolumn{4}{|c|}{ Supplemental Table s2.txt } \\
\hline CHEMBL1534881 & 688759 & 4.45 & 4.7963 & TST & \\
\hline CHEMBL1343358 & 688759 & 4.6 & 4.6623 & TRN & \\
\hline CHEMBL1587043 & 688759 & 5.5 & 5.0459 & TRN & \\
\hline CHEMBL 3197199 & 688759 & 4.5 & 4.8151 & TST & \\
\hline CHEMBL1312730 & 688759 & 4.6 & 5.1619 & TST & \\
\hline CHEMBL1535846 & 688759 & 5.55 & 5.1826 & TRN & \\
\hline CHEMBL1346421 & 688759 & 4.5 & 4.6567 & TST & \\
\hline CHEMBL1336019 & 688759 & 5.95 & 5.51 & TRN & \\
\hline CHEMBL1542241 & 688759 & 4.5 & 4.6985 & TRN & \\
\hline CHEMBL1508147 & 688759 & 4.65 & 4.7307 & TRN & \\
\hline CHEMBL1995862 & 688759 & 4.7 & 4.5975 & TRN & \\
\hline CHEMBL182653 & 688759 & 6.45 & 6.0941 & TRN & \\
\hline CHEMBL1449424 & 688759 & 4.55 & 4.8484 & TRN & \\
\hline CHEMBL1542109 & 688759 & 4.6 & 4.7177 & TST & \\
\hline CHEMBL1378561 & 688759 & 4.65 & 4.8788 & TRN & \\
\hline CHEMBL1571985 & 688759 & 4.45 & 4.64 & TRN & \\
\hline CHEMBL3199494 & 688759 & 4.45 & 4.7242 & TRN & \\
\hline CHEMBL1450527 & 688759 & 5.7 & 4.9676 & TRN & \\
\hline CHEMBL1995377 & 688759 & 5.25 & 5.1699 & TRN & \\
\hline CHEMBL1600061 & 688759 & 4.75 & 4.7299 & TRN & \\
\hline CHEMBL1447563 & 688759 & 5.35 & 5.0749 & TST & \\
\hline CHEMBL1458599 & 688759 & 5.2 & 4.98300 & 00000000005 & TRN \\
\hline CHEMBL 3210228 & 688759 & 5.2 & 5.3641 & TRN & \\
\hline CHEMBL1611675 & 688759 & 4.95 & 5.3592 & TRN & \\
\hline CHEMBL3209382 & 688759 & 5.45 & 6.3631 & TRN & \\
\hline CHEMBL3199555 & 688759 & 4.45 & 4.8465 & TRN & \\
\hline CHEMBL1313945 & 688759 & 4.45 & 5.3301 & TST & \\
\hline CHEMBL1359238 & 688759 & 4.45 & 4.7548 & TRN & \\
\hline CHEMBL1346889 & 688759 & 5.0 & 4.9491 & TST & \\
\hline CHEMBL1437883 & 688759 & 4.45 & 4.4927 & TRN & \\
\hline CHEMBL1300984 & 688759 & 4.45 & 4.7164 & TST & \\
\hline CHEMBL1328466 & 688759 & 4.6 & 5.0346 & TRN & \\
\hline CHEMBL1383247 & 688759 & 4.9 & 4.9935 & TST & \\
\hline CHEMBL1409554 & 688759 & 5.45 & 5.0443 & TRN & \\
\hline CHEMBL1532862 & 688759 & 5.5 & 5.3498 & TRN & \\
\hline CHEMBL1589634 & 688759 & 5.4 & 5.006 & TST & \\
\hline CHEMBL3193168 & 688759 & 4.45 & 4.6963 & TST & \\
\hline CHEMBL1522275 & 688759 & 4.85 & 5.0154 & TST & \\
\hline CHEMBL1411847 & 688759 & 5.0 & 4.9503 & TRN & \\
\hline CHEMBL1424382 & 688759 & 5.9 & 5.5175 & TRN & \\
\hline CHEMBL1571150 & 688759 & 5.1 & 4.8186 & TRN & \\
\hline CHEMBL1538157 & 688759 & 5.5 & 5.1268 & TRN & \\
\hline CHEMBL98245 & 688759 & 5.95 & 4.9972 & TST & \\
\hline CHEMBL1459618 & 688759 & 4.45 & 4.5463 & TRN & \\
\hline CHEMBL1521086 & 688759 & 4.6 & 4.8292 & TST & \\
\hline CHEMBL1344491 & 688759 & 4.45 & 4.6775 & TRN & \\
\hline CHEMBL3196046 & 688759 & 4.45 & 4.7054 & TRN & \\
\hline CHEMBL515670 & 688759 & 4.45 & 4.8838 & TRN & \\
\hline
\end{tabular}




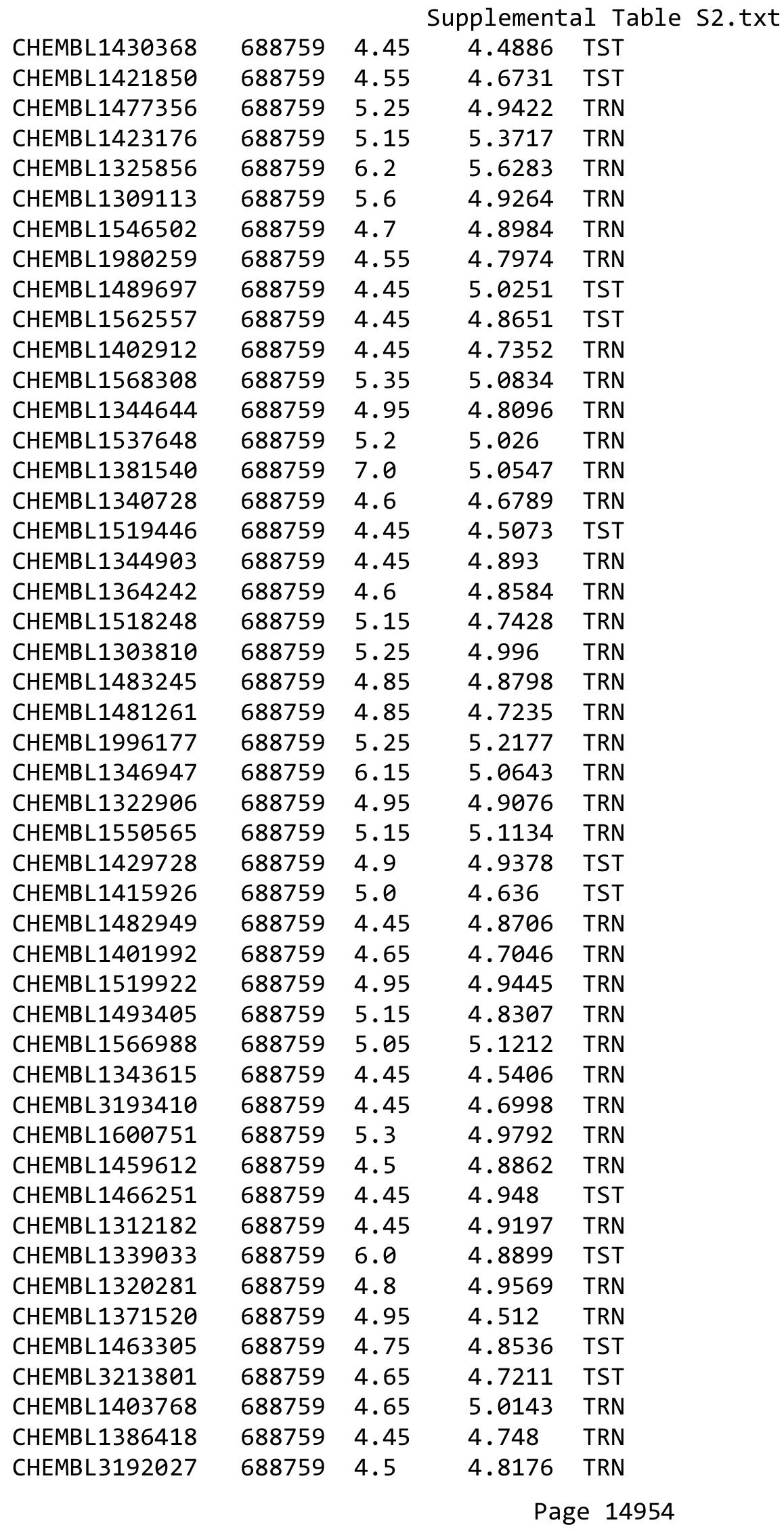




\begin{tabular}{|c|c|c|c|c|}
\hline \multicolumn{5}{|c|}{ Supplemental Table S2.txt } \\
\hline CHEMBL1304919 & 688759 & 4.45 & 4.7485 & TRN \\
\hline CHEMBL1343110 & 688759 & 4.45 & 4.8014 & TRN \\
\hline CHEMBL1585062 & 688759 & 4.45 & 4.8213 & TRN \\
\hline CHEMBL1366980 & 688759 & 4.8 & 4.9881 & TST \\
\hline CHEMBL1311088 & 688759 & 4.45 & 4.8238 & TRN \\
\hline CHEMBL1611892 & 688759 & 5.2 & 4.9107 & TRN \\
\hline CHEMBL1430499 & 688759 & 4.7 & 5.3859 & TST \\
\hline CHEMBL1351241 & 688759 & 4.45 & 4.7483 & TRN \\
\hline CHEMBL1543779 & 688759 & 4.95 & 4.8821 & TRN \\
\hline CHEMBL1541942 & 688759 & 6.25 & 5.4872 & TRN \\
\hline CHEMBL1304723 & 688759 & 4.65 & 4.4729 & TRN \\
\hline CHEMBL1599555 & 688759 & 6.0 & 4.6906 & TRN \\
\hline CHEMBL1532936 & 688759 & 5.6 & 4.9409 & TRN \\
\hline CHEMBL1432663 & 688759 & 4.45 & 4.9554 & TST \\
\hline CHEMBL1335052 & 688759 & 5.45 & 5.4786 & TRN \\
\hline CHEMBL1376387 & 688759 & 4.6 & 4.9781 & TST \\
\hline CHEMBL1313175 & 688759 & 4.9 & 4.9126 & TRN \\
\hline CHEMBL1995364 & 688759 & 5.2 & 5.3527 & TRN \\
\hline CHEMBL1603779 & 688759 & 4.95 & 4.8614 & TRN \\
\hline CHEMBL1402803 & 688759 & 4.6 & 4.7636 & TRN \\
\hline CHEMBL93353 & 688759 & 6.0 & 5.0642 & TST \\
\hline CHEMBL1565500 & 688759 & 5.0 & 4.8357 & TRN \\
\hline CHEMBL1368402 & 688759 & 4.9 & 4.6573 & TRN \\
\hline CHEMBL1511142 & 688759 & 5.3 & 5.2891 & TRN \\
\hline CHEMBL1388482 & 688759 & 5.5 & 4.7416 & TST \\
\hline CHEMBL1481951 & 688759 & 4.6 & 5.1009 & TRN \\
\hline CHEMBL1599120 & 688759 & 5.0 & 4.5418 & TST \\
\hline CHEMBL1420009 & 688759 & 4.6 & 4.6198 & TST \\
\hline CHEMBL1602923 & 688759 & 4.9 & 4.93 & TRN \\
\hline CHEMBL1373189 & 688759 & 4.45 & 4.8583 & TRN \\
\hline CHEMBL1382739 & 688759 & 4.6 & 4.9189 & TRN \\
\hline CHEMBL1518715 & 688759 & 4.45 & 4.6648 & TRN \\
\hline CHEMBL3196245 & 688759 & 4.95 & 5.0967 & TRN \\
\hline CHEMBL3209472 & 688759 & 4.65 & 4.4933 & TRN \\
\hline CHEMBL1431604 & 688759 & 4.45 & 4.9011 & TST \\
\hline CHEMBL1428175 & 688759 & 4.55 & 5.0573 & TRN \\
\hline CHEMBL1330583 & 688759 & 5.05 & 5.2566 & TRN \\
\hline CHEMBL1346241 & 688759 & 4.45 & 4.6063 & TRN \\
\hline CHEMBL1456722 & 688759 & 5.75 & 5.0459 & TRN \\
\hline CHEMBL1418831 & 688759 & 6.2 & 5.8925 & TST \\
\hline CHEMBL1561133 & 688759 & 4.65 & 4.6765 & TRN \\
\hline CHEMBL1608276 & 688759 & 4.75 & 4.9866 & TST \\
\hline CHEMBL1584555 & 688759 & 4.85 & 4.8036 & TST \\
\hline CHEMBL1483347 & 688759 & 4.9 & 4.5603 & TRN \\
\hline CHEMBL1384521 & 688759 & 4.45 & 4.9872 & TRN \\
\hline CHEMBL1419873 & 688759 & 4.95 & 4.9928 & TRN \\
\hline CHEMBL1362878 & 688759 & 4.75 & 4.9395 & TRN \\
\hline CHEMBL1319342 & 688759 & 4.45 & 5.0282 & TRN \\
\hline
\end{tabular}




\begin{tabular}{|c|c|c|c|c|c|}
\hline \multicolumn{6}{|c|}{ Supplemental Table s2.txt } \\
\hline CHEMBL1302695 & 688759 & 5.2 & 5.2815 & TRN & \\
\hline CHEMBL1540855 & 688759 & 6.0 & 5.6247 & TRN & \\
\hline CHEMBL1445578 & 688759 & 4.85 & 4.6315 & TRN & \\
\hline CHEMBL1603192 & 688759 & 4.75 & 4.8355 & TRN & \\
\hline CHEMBL1428581 & 688759 & 4.5 & 4.8116 & TRN & \\
\hline CHEMBL1570636 & 688759 & 4.65 & 5.0239 & TST & \\
\hline CHEMBL1495383 & 688759 & 6.1 & 4.9122 & TST & \\
\hline CHEMBL3199220 & 688759 & 4.45 & 4.7829 & TST & \\
\hline CHEMBL1432421 & 688759 & 4.8 & 4.8524 & TRN & \\
\hline CHEMBL1481929 & 688759 & 4.45 & 5.0103 & TRN & \\
\hline CHEMBL1429924 & 688759 & 4.9 & 4.7226 & TRN & \\
\hline CHEMBL1400593 & 688759 & 5.0 & 4.9329 & TST & \\
\hline CHEMBL1346336 & 688759 & 4.45 & 4.6215 & TST & \\
\hline CHEMBL1528087 & 688759 & 4.7 & 5.09699 & 99999999995 & TST \\
\hline CHEMBL1345332 & 688759 & 4.5 & 4.7157 & TST & \\
\hline CHEMBL1519755 & 688759 & 4.9 & 4.9889 & TRN & \\
\hline CHEMBL1309640 & 688759 & 5.25 & 4.7764 & TRN & \\
\hline CHEMBL1533640 & 688759 & 5.5 & 5.1705 & TRN & \\
\hline CHEMBL1402869 & 688759 & 4.75 & 4.555 & TRN & \\
\hline CHEMBL1446012 & 688759 & 6.3 & 5.0507 & TRN & \\
\hline CHEMBL1486922 & 688759 & 4.85 & 4.8416 & TRN & \\
\hline CHEMBL1378944 & 688759 & 5.35 & 5.2869 & TRN & \\
\hline CHEMBL1550708 & 688759 & 5.45 & 4.8694 & TRN & \\
\hline CHEMBL1462768 & 688759 & 5.5 & 4.9787 & TRN & \\
\hline CHEMBL1557157 & 688759 & 4.9 & 4.6847 & TRN & \\
\hline CHEMBL1360178 & 688759 & 4.65 & 4.843 & TRN & \\
\hline CHEMBL1372705 & 688759 & 4.9 & 4.7507 & TST & \\
\hline CHEMBL1603623 & 688759 & 4.65 & 4.8863 & TRN & \\
\hline CHEMBL1533408 & 688759 & 4.45 & 4.8245 & TRN & \\
\hline CHEMBL1351959 & 688759 & 4.9 & 4.6708 & TRN & \\
\hline CHEMBL1586103 & 688759 & 4.9 & 5.0706 & TRN & \\
\hline CHEMBL1602141 & 688759 & 4.7 & 4.9372 & TRN & \\
\hline CHEMBL1450136 & 688759 & 4.8 & 4.9692 & TRN & \\
\hline CHEMBL1383443 & 688759 & 4.45 & 4.5089 & TRN & \\
\hline CHEMBL1567934 & 688759 & 5.25 & 4.8784 & TST & \\
\hline CHEMBL1372398 & 688759 & 4.45 & 4.5428 & TRN & \\
\hline CHEMBL1525436 & 688759 & 4.6 & 4.6166 & TRN & \\
\hline CHEMBL47875 & 688759 & 4.45 & 5.0767 & TRN & \\
\hline CHEMBL1527190 & 688759 & 4.75 & 4.7125 & TRN & \\
\hline CHEMBL1542122 & 688759 & 4.45 & 4.5159 & TST & \\
\hline CHEMBL1585171 & 688759 & 5.45 & 5.0354 & TST & \\
\hline CHEMBL1321333 & 688759 & 5.15 & 5.1113 & TRN & \\
\hline CHEMBL1399925 & 688759 & 4.65 & 4.7585 & TRN & \\
\hline CHEMBL1334477 & 688759 & 4.9 & 4.7865 & TRN & \\
\hline CHEMBL1412659 & 688759 & 5.4 & 4.9173 & TRN & \\
\hline CHEMBL1340428 & 688759 & 5.9 & 5.0335 & TRN & \\
\hline CHEMBL1480925 & 688759 & 5.25 & 4.9041 & TRN & \\
\hline CHEMBL1386200 & 688759 & 4.65 & 4.8684 & TST & \\
\hline
\end{tabular}




\begin{tabular}{|c|c|c|c|c|}
\hline \multicolumn{5}{|c|}{ Supplemental Table S2.txt } \\
\hline CHEMBL1572700 & 688759 & 5.5 & 4.6077 & TST \\
\hline CHEMBL1365055 & 688759 & 6.1 & 4.959 & TRN \\
\hline CHEMBL1565189 & 688759 & 4.95 & 5.0438 & TST \\
\hline CHEMBL1420826 & 688759 & 4.45 & 4.5652 & TRN \\
\hline CHEMBL1610953 & 688759 & 4.45 & 5.0549 & TST \\
\hline CHEMBL1388759 & 688759 & 5.0 & 5.2228 & TST \\
\hline CHEMBL1454512 & 688759 & 5.25 & 5.2415 & TST \\
\hline CHEMBL1377927 & 688759 & 6.0 & 5.353 & TST \\
\hline CHEMBL1444106 & 688759 & 5.9 & 5.4675 & TRN \\
\hline CHEMBL599890 & 688759 & 4.65 & 4.3629 & TRN \\
\hline CHEMBL1303657 & 688759 & 4.45 & 4.6735 & TRN \\
\hline CHEMBL1585480 & 688759 & 4.6 & 4.8195 & TST \\
\hline CHEMBL2004304 & 688759 & 4.95 & 4.7888 & TST \\
\hline CHEMBL1412597 & 688759 & 4.9 & 5.1141 & TRN \\
\hline CHEMBL1461949 & 688759 & 5.0 & 4.6856 & TRN \\
\hline CHEMBL1325786 & 688759 & 5.05 & 4.9063 & TRN \\
\hline CHEMBL1586805 & 688759 & 4.65 & 4.8755 & TST \\
\hline CHEMBL1381892 & 688759 & 4.45 & 4.7534 & TRN \\
\hline CHEMBL1577070 & 688759 & 5.3 & 6.1866 & TRN \\
\hline CHEMBL1569074 & 688759 & 5.8 & 5.1538 & TRN \\
\hline CHEMBL 2004417 & 688759 & 5.5 & 5.1413 & TRN \\
\hline CHEMBL1414689 & 688759 & 4.45 & 4.7932 & TRN \\
\hline CHEMBL1408689 & 688759 & 4.45 & 5.1385 & TRN \\
\hline CHEMBL1313488 & 688759 & 4.85 & 5.0876 & TRN \\
\hline CHEMBL303516 & 688759 & 4.85 & 5.3891 & TST \\
\hline CHEMBL1602077 & 688759 & 4.45 & 4.5295 & TRN \\
\hline CHEMBL1306992 & 688759 & 6.1 & 4.4873 & TRN \\
\hline CHEMBL1509668 & 688759 & 4.45 & 4.578 & TRN \\
\hline CHEMBL1556272 & 688759 & 4.65 & 4.8495 & TRN \\
\hline CHEMBL1306578 & 688759 & 4.45 & 5.2559 & TRN \\
\hline CHEMBL1389605 & 688759 & 4.45 & 4.8085 & TRN \\
\hline CHEMBL1308364 & 688759 & 4.95 & 4.7928 & TRN \\
\hline CHEMBL1550219 & 688759 & 4.7 & 4.855 & TRN \\
\hline CHEMBL1398913 & 688759 & 5.3 & 5.1338 & TRN \\
\hline CHEMBL1343971 & 688759 & 5.25 & 5.0998 & TRN \\
\hline CHEMBL1346902 & 688759 & 6.05 & 4.6393 & TST \\
\hline CHEMBL1372203 & 688759 & 7.0 & 5.1799 & TRN \\
\hline CHEMBL1376365 & 688759 & 4.6 & 4.6416 & TST \\
\hline CHEMBL1399893 & 688759 & 5.0 & 4.8098 & TRN \\
\hline CHEMBL3190669 & 688759 & 6.15 & 5.8085 & TRN \\
\hline CHEMBL3208443 & 688759 & 6.2 & 5.6218 & TRN \\
\hline CHEMBL1441350 & 688759 & 5.0 & 4.9767 & TRN \\
\hline CHEMBL1544664 & 688759 & 4.45 & 4.8344 & TRN \\
\hline CHEMBL1422986 & 688759 & 5.1 & 5.3202 & TRN \\
\hline CHEMBL3198745 & 688759 & 4.5 & 4.4797 & TRN \\
\hline CHEMBL1329046 & 688759 & 5.2 & 5.1454 & TRN \\
\hline CHEMBL1453420 & 688759 & 4.45 & 4.7242 & TRN \\
\hline CHEMBL3192786 & 688759 & 4.45 & 4.9165 & TRN \\
\hline
\end{tabular}




\begin{tabular}{|c|c|c|c|c|c|}
\hline \multicolumn{6}{|c|}{ Supplemental Table S2.txt } \\
\hline CHEMBL1499711 & 688759 & 5.55 & 5.3815 & TRN & \\
\hline CHEMBL1455159 & 688759 & 5.3 & 5.1154 & TRN & \\
\hline CHEMBL1402525 & 688759 & 4.45 & 4.8259 & TRN & \\
\hline CHEMBL1497532 & 688759 & 5.1 & 5.4733 & TST & \\
\hline CHEMBL1448029 & 688759 & 4.95 & 5.1687 & TRN & \\
\hline CHEMBL1470339 & 688759 & 6.8499 & 4.8357 & TRN & \\
\hline CHEMBL1343726 & 688759 & 4.45 & 4.6732 & TRN & \\
\hline CHEMBL1972249 & 688759 & 4.45 & 4.8865 & TST & \\
\hline CHEMBL1348389 & 688759 & 4.55 & 4.6792 & TST & \\
\hline CHEMBL3194788 & 688759 & 4.6 & 4.4639 & TRN & \\
\hline CHEMBL1306807 & 688759 & 4.65 & 4.7568 & TRN & \\
\hline CHEMBL1970286 & 688759 & 4.95 & 4.9446 & TRN & \\
\hline CHEMBL1429902 & 688759 & 4.45 & 4.6842 & TRN & \\
\hline CHEMBL1966867 & 688759 & 4.9 & 5.1279 & TST & \\
\hline CHEMBL1353204 & 688759 & 4.45 & 4.6057 & TRN & \\
\hline CHEMBL1080648 & 688759 & 4.65 & 4.9545 & TST & \\
\hline CHEMBL1340296 & 688759 & 5.25 & 4.7999 & TRN & \\
\hline CHEMBL1442177 & 688759 & 5.5 & 4.8958 & TRN & \\
\hline CHEMBL1573138 & 688759 & 5.15 & 5.285 & TRN & \\
\hline CHEMBL1422461 & 688759 & 5.25 & 5.4267 & TRN & \\
\hline CHEMBL1310776 & 688759 & 5.5 & 4.8888 & TRN & \\
\hline CHEMBL1509919 & 688759 & 4.45 & 4.9697 & TST & \\
\hline CHEMBL1486323 & 688759 & 5.15 & 5.1291 & TRN & \\
\hline CHEMBL1488023 & 688759 & 5.75 & 5.4731 & TRN & \\
\hline CHEMBL1468229 & 688759 & 4.45 & 6.1192 & TRN & \\
\hline CHEMBL474589 & 688759 & 4.45 & 4.8651 & TRN & \\
\hline CHEMBL 2436539 & 688759 & 4.95 & 4.5664 & TRN & \\
\hline CHEMBL1512190 & 688759 & 4.95 & 4.7478 & TRN & \\
\hline CHEMBL1427012 & 688759 & 4.75 & 4.5429 & TRN & \\
\hline CHEMBL1494231 & 688759 & 5.75 & 4.9203 & TST & \\
\hline CHEMBL1581949 & 688759 & 5.4 & 4.9711 & TRN & \\
\hline CHEMBL1085358 & 688759 & 4.9 & 5.0366 & TST & \\
\hline CHEMBL3195430 & 688759 & 5.5 & 5.58700 & 3000000001 & TRN \\
\hline CHEMBL1488453 & 688759 & 6.95 & 4.7832 & TST & \\
\hline CHEMBL1556698 & 688759 & 5.4 & 5.189 & TRN & \\
\hline CHEMBL1560989 & 688759 & 4.85 & 5.0389 & TRN & \\
\hline CHEMBL1407741 & 688759 & 4.45 & 5.0261 & TRN & \\
\hline CHEMBL3189520 & 688759 & 4.45 & 5.5224 & TRN & \\
\hline CHEMBL1987949 & 688759 & 5.0 & 4.8858 & TRN & \\
\hline CHEMBL1556055 & 688759 & 4.9 & 4.8231 & TRN & \\
\hline CHEMBL3198017 & 688759 & 4.55 & 5.062 & TST & \\
\hline CHEMBL1500997 & 688759 & 5.15 & 4.6633 & TRN & \\
\hline CHEMBL1460502 & 688759 & 4.6 & 4.6159 & TRN & \\
\hline CHEMBL1438236 & 688759 & 5.95 & 4.8242 & TRN & \\
\hline CHEMBL1308750 & 688759 & 6.05 & 4.8199 & TST & \\
\hline CHEMBL1351293 & 688759 & 4.6 & 4.8127 & TRN & \\
\hline CHEMBL 2005434 & 688759 & 6.25 & 5.1255 & TRN & \\
\hline CHEMBL1331541 & 688759 & 5.55 & 5.0574 & TRN & \\
\hline
\end{tabular}




\begin{tabular}{|c|c|c|c|c|c|}
\hline \multicolumn{6}{|c|}{ Supplemental Table S2.txt } \\
\hline CHEMBL1578100 & 688759 & 4.45 & 4.7949 & TRN & \\
\hline CHEMBL1462803 & 688759 & 6.0 & 5.0413 & TRN & \\
\hline CHEMBL1456330 & 688759 & 4.5 & 4.758 & TST & \\
\hline CHEMBL1971674 & 688759 & 4.45 & 4.9245 & TRN & \\
\hline CHEMBL1416282 & 688759 & 5.25 & 5.206 & TST & \\
\hline CHEMBL1365262 & 688759 & 4.45 & 5.0761 & TRN & \\
\hline CHEMBL1341180 & 688759 & 5.9 & 4.909 & TST & \\
\hline CHEMBL1611549 & 688759 & 4.45 & 4.7552 & TRN & \\
\hline CHEMBL1577579 & 688759 & 5.45 & 4.7993 & TST & \\
\hline CHEMBL1455737 & 688759 & 4.95 & 4.9433 & TRN & \\
\hline CHEMBL1994902 & 688759 & 5.55 & 5.3302 & TRN & \\
\hline CHEMBL1497597 & 688759 & 4.65 & 4.6152 & TRN & \\
\hline CHEMBL1544514 & 688759 & 4.45 & 4.828 & TST & \\
\hline CHEMBL1576615 & 688759 & 4.7 & 4.7104 & TRN & \\
\hline CHEMBL1483387 & 688759 & 4.9 & 4.7713 & TRN & \\
\hline CHEMBL1352867 & 688759 & 5.75 & 5.6413 & TRN & \\
\hline CHEMBL1548216 & 688759 & 4.7 & 4.904 & TRN & \\
\hline CHEMBL1333766 & 688759 & 4.65 & 4.8977 & TRN & \\
\hline CHEMBL1613520 & 688759 & 4.95 & 4.9337 & TRN & \\
\hline CHEMBL1492396 & 688759 & 4.45 & 4.7102 & TRN & \\
\hline CHEMBL1603873 & 688759 & 5.05 & 4.8968 & TRN & \\
\hline CHEMBL1500855 & 688759 & 5.4 & 4.9084 & TRN & \\
\hline CHEMBL1445693 & 688759 & 5.45 & 4.8452 & TRN & \\
\hline CHEMBL1571258 & 688759 & 4.65 & 4.6468 & TST & \\
\hline CHEMBL1565315 & 688759 & 4.45 & 4.8576 & TRN & \\
\hline CHEMBL 2004884 & 688759 & 4.45 & 5.0651 & TRN & \\
\hline CHEMBL1349719 & 688759 & 5.1 & 5.1077 & TRN & \\
\hline CHEMBL3197807 & 688759 & 4.45 & 4.7364 & TST & \\
\hline CHEMBL3196860 & 688759 & 4.45 & 4.8305 & TRN & \\
\hline CHEMBL1310527 & 688759 & 5.15 & 4.565 & TST & \\
\hline CHEMBL1439266 & 688759 & 4.45 & 4.6947 & TRN & \\
\hline CHEMBL1432229 & 688759 & 5.0 & 4.8668 & TRN & \\
\hline CHEMBL1364340 & 688759 & 4.9 & 4.7891 & TRN & \\
\hline CHEMBL1426173 & 688759 & 4.45 & 4.8531 & TRN & \\
\hline CHEMBL1451181 & 688759 & 4.45 & 4.8331 & TRN & \\
\hline CHEMBL1384533 & 688759 & 4.8 & 4.9628 & TRN & \\
\hline CHEMBL1529695 & 688759 & 5.55 & 5.4138 & TST & \\
\hline CHEMBL1588586 & 688759 & 4.45 & 4.7559 & TST & \\
\hline CHEMBL1530066 & 688759 & 5.2 & 5.21899 & 9999999999 & TRN \\
\hline CHEMBL1575372 & 688759 & 4.55 & 4.4927 & TRN & \\
\hline CHEMBL1507187 & 688759 & 4.45 & 4.36600 & 00000000005 & TRN \\
\hline CHEMBL3198462 & 688759 & 6.1 & 4.7548 & TRN & \\
\hline CHEMBL3194643 & 688759 & 5.35 & 5.2268 & TRN & \\
\hline CHEMBL1402274 & 688759 & 4.85 & 4.6763 & TRN & \\
\hline CHEMBL1577929 & 688759 & 4.9 & 5.1534 & TRN & \\
\hline CHEMBL260451 & 688759 & 5.0 & 5.9704 & TRN & \\
\hline CHEMBL1542554 & 688759 & 6.15 & 5.5627 & TRN & \\
\hline CHEMBL1440440 & 688759 & 4.7 & 5.0183 & TST & \\
\hline
\end{tabular}




\begin{tabular}{|c|c|c|c|c|c|}
\hline \multicolumn{6}{|c|}{ 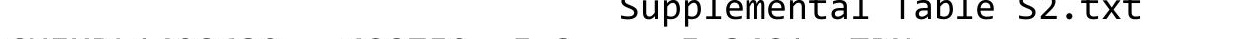 } \\
\hline CHEMBL1498639 & 688759 & 5.3 & 5.3481 & TRN & \\
\hline CHEMBL1417059 & 688759 & 5.45 & 5.0335 & TRN & \\
\hline CHEMBL1978668 & 688759 & 4.7 & 4.8535 & TST & \\
\hline CHEMBL1409389 & 688759 & 5.95 & 5.4459 & TST & \\
\hline CHEMBL3196071 & 688759 & 4.45 & 4.8443 & TST & \\
\hline CHEMBL1565837 & 688759 & 4.9 & 4.9868 & TRN & \\
\hline CHEMBL1470698 & 688759 & 4.7 & 4.5573 & TST & \\
\hline CHEMBL1334550 & 688759 & 5.5 & 5.3286 & TRN & \\
\hline CHEMBL1370557 & 688759 & 5.6 & 5.1072 & TST & \\
\hline CHEMBL1409621 & 688759 & 4.6 & 4.5464 & TRN & \\
\hline CHEMBL1607000 & 688759 & 4.9 & 5.2738 & TRN & \\
\hline CHEMBL1595831 & 688759 & 4.55 & 5.0544 & TST & \\
\hline CHEMBL1404553 & 688759 & 4.75 & 4.8071 & TRN & \\
\hline CHEMBL1361948 & 688759 & 5.35 & 5.0781 & TRN & \\
\hline CHEMBL1311961 & 688759 & 4.85 & 4.7589 & TST & \\
\hline CHEMBL1300797 & 688759 & 4.75 & 4.8125 & TRN & \\
\hline CHEMBL1299925 & 688759 & 4.95 & 4.7884 & TRN & \\
\hline CHEMBL1610009 & 688759 & 4.65 & 5.0888 & TST & \\
\hline CHEMBL1358035 & 688759 & 4.45 & 4.84 & TRN & \\
\hline CHEMBL3195729 & 688759 & 6.25 & 5.4859 & TRN & \\
\hline CHEMBL1387091 & 688759 & 4.45 & 4.5798 & TRN & \\
\hline CHEMBL1383496 & 688759 & 4.45 & 4.55699 & 99999999995 & TRN \\
\hline CHEMBL1599322 & 688759 & 4.45 & 4.9269 & TRN & \\
\hline CHEMBL1497466 & 688759 & 4.65 & 4.7785 & TRN & \\
\hline CHEMBL1428363 & 688759 & 4.6 & 4.9166 & TRN & \\
\hline CHEMBL1545441 & 688759 & 4.45 & 4.5854 & TRN & \\
\hline CHEMBL1414651 & 688759 & 4.7 & 4.8307 & TST & \\
\hline CHEMBL1604098 & 688759 & 4.9 & 4.5921 & TRN & \\
\hline CHEMBL1483062 & 688759 & 6.35 & 5.1125 & TRN & \\
\hline CHEMBL1548069 & 688759 & 5.05 & 5.1961 & TRN & \\
\hline CHEMBL1504982 & 688759 & 5.55 & 5.2019 & TRN & \\
\hline CHEMBL1508135 & 688759 & 4.9 & 5.0164 & TRN & \\
\hline CHEMBL1518620 & 688759 & 4.6 & 4.8354 & TST & \\
\hline CHEMBL3207920 & 688759 & 4.6 & 4.7753 & TST & \\
\hline CHEMBL1378513 & 688759 & 4.45 & 4.90600 & $\partial 000000001$ & TRN \\
\hline CHEMBL1366620 & 688759 & 4.65 & 4.7127 & TRN & \\
\hline CHEMBL1420411 & 688759 & 4.5 & 4.7067 & TRN & \\
\hline CHEMBL1401599 & 688759 & 4.65 & 4.9414 & TRN & \\
\hline CHEMBL1412798 & 688759 & 4.55 & 4.7979 & TRN & \\
\hline CHEMBL1582329 & 688759 & 4.45 & 4.7711 & TRN & \\
\hline CHEMBL1492681 & 688759 & 4.85 & 4.7309 & TRN & \\
\hline CHEMBL1341505 & 688759 & 5.15 & 4.9295 & TST & \\
\hline CHEMBL1420179 & 688759 & 5.25 & 4.8766 & TST & \\
\hline CHEMBL1343334 & 688759 & 4.45 & 4.9 & TRN & \\
\hline CHEMBL509283 & 688759 & 4.75 & 4.8171 & TST & \\
\hline CHEMBL1581920 & 688759 & 4.7 & 5.4326 & TRN & \\
\hline CHEMBL1599085 & 688759 & 4.85 & 4.8276 & TRN & \\
\hline CHEMBL 2007056 & 688759 & 5.25 & 4.6656 & TST & \\
\hline
\end{tabular}




\begin{tabular}{|c|c|c|c|c|}
\hline & & & oplement & al Table S \\
\hline CHEMBL1600978 & 688759 & 4.5 & 4.8329 & TST \\
\hline CHEMBL1501092 & 688759 & 4.75 & 4.9055 & TRN \\
\hline CHEMBL1448894 & 688759 & 4.45 & 5.0064 & TRN \\
\hline CHEMBL1336111 & 688759 & 6.3 & 4.8412 & TRN \\
\hline CHEMBL1611689 & 688759 & 4.45 & 4.7775 & TRN \\
\hline CHEMBL1415810 & 688759 & 4.65 & 5.182 & TRN \\
\hline CHEMBL1368428 & 688759 & 4.9 & 4.9247 & TRN \\
\hline CHEMBL1468575 & 688759 & 5.75 & 5.5585 & TRN \\
\hline CHEMBL1443766 & 688759 & 6.05 & 5.8191 & TRN \\
\hline CHEMBL1583663 & 688759 & 4.9 & 4.5702 & TST \\
\hline CHEMBL1365626 & 688759 & 4.45 & 4.7335 & TRN \\
\hline CHEMBL1494608 & 688759 & 4.45 & 4.8265 & TRN \\
\hline CHEMBL1567087 & 688759 & 4.45 & 4.9378 & TST \\
\hline CHEMBL1386457 & 688759 & 6.25 & 5.0285 & TRN \\
\hline CHEMBL1393562 & 688759 & 4.45 & 4.7123 & TRN \\
\hline CHEMBL1448945 & 688759 & 4.9 & 4.5945 & TRN \\
\hline CHEMBL 3207730 & 688759 & 4.95 & 4.8517 & TRN \\
\hline CHEMBL259103 & 688759 & 4.6 & 5.3318 & TRN \\
\hline CHEMBL3190988 & 688759 & 5.0 & 5.0762 & TRN \\
\hline CHEMBL1382783 & 688759 & 4.95 & 4.8927 & TRN \\
\hline CHEMBL569020 & 688759 & 4.65 & 4.744 & TRN \\
\hline CHEMBL1447263 & 688759 & 5.25 & 4.8606 & TRN \\
\hline CHEMBL1597682 & 688759 & 4.75 & 4.9778 & TRN \\
\hline CHEMBL1456192 & 688759 & 4.7 & 4.5071 & TRN \\
\hline CHEMBL1547694 & 688759 & 5.0 & 4.7828 & TRN \\
\hline CHEMBL1506728 & 688759 & 6.2 & 5.6699 & TRN \\
\hline CHEMBL1509065 & 688759 & 5.4 & 5.3511 & TRN \\
\hline CHEMBL1334307 & 688759 & 6.7501 & 4.9446 & TST \\
\hline CHEMBL486541 & 688759 & 4.45 & 4.7846 & TRN \\
\hline CHEMBL1544739 & 688759 & 4.75 & 4.6324 & TST \\
\hline CHEMBL1374413 & 688759 & 4.45 & 4.5799 & TRN \\
\hline CHEMBL1410999 & 688759 & 4.5 & 4.8102 & TRN \\
\hline CHEMBL1309734 & 688759 & 4.45 & 4.8665 & TRN \\
\hline CHEMBL1325226 & 688759 & 5.2 & 4.7352 & TRN \\
\hline CHEMBL1529740 & 688759 & 4.45 & 4.7345 & TRN \\
\hline CHEMBL1537740 & 688759 & 4.95 & 4.9712 & TRN \\
\hline CHEMBL1533767 & 688759 & 5.0 & 4.9075 & TRN \\
\hline CHEMBL258893 & 688759 & 5.05 & 5.3808 & TST \\
\hline CHEMBL3199311 & 688759 & 5.15 & 5.1201 & TRN \\
\hline CHEMBL1525780 & 688759 & 5.45 & 5.34399 & 9999999999 \\
\hline CHEMBL1991388 & 688759 & 5.05 & 4.9822 & TRN \\
\hline CHEMBL3198019 & 688759 & 4.45 & 5.1029 & TRN \\
\hline CHEMBL1445795 & 688759 & 5.0 & 4.8938 & TRN \\
\hline CHEMBL1428935 & 688759 & 5.95 & 5.2416 & TRN \\
\hline CHEMBL1417204 & 688759 & 5.5 & 5.2183 & TRN \\
\hline CHEMBL1383154 & 688759 & 4.55 & 4.7798 & TRN \\
\hline CHEMBL1540317 & 688759 & 4.55 & 4.949 & TRN \\
\hline CHEMBL3211107 & 688759 & 4.95 & 4.7055 & TRN \\
\hline
\end{tabular}




\begin{tabular}{|c|c|c|c|c|c|}
\hline & & \multicolumn{4}{|c|}{ Supplemental Table S2.txt } \\
\hline CHEMBL1536673 & 688759 & 4.45 & 4.9302 & TRN & \\
\hline CHEMBL3194608 & 688759 & 4.75 & 5.2831 & TRN & \\
\hline CHEMBL1523175 & 688759 & 4.9 & 4.7849 & TRN & \\
\hline CHEMBL 3213275 & 688759 & 4.6 & 4.7335 & TRN & \\
\hline CHEMBL3195674 & 688759 & 4.65 & 5.07600 & 00000000005 & TRN \\
\hline CHEMBL1391614 & 688759 & 4.8 & 4.8928 & TST & \\
\hline CHEMBL1580028 & 688759 & 4.55 & 4.67399 & 99999999995 & TST \\
\hline CHEMBL3191886 & 688759 & 4.7 & 4.4971 & TST & \\
\hline CHEMBL1457910 & 688759 & 4.45 & 4.9492 & TRN & \\
\hline CHEMBL1555488 & 688759 & 4.65 & 4.6989 & TRN & \\
\hline CHEMBL1558198 & 688759 & 4.45 & 4.7711 & TRN & \\
\hline CHEMBL1574203 & 688759 & 5.25 & 4.8929 & TRN & \\
\hline CHEMBL1517768 & 688759 & 5.35 & 4.7664 & TST & \\
\hline CHEMBL1540134 & 688759 & 5.25 & 4.8512 & TST & \\
\hline CHEMBL1477851 & 688759 & 4.75 & 4.5415 & TST & \\
\hline CHEMBL1582971 & 688759 & 5.0 & 5.0286 & TRN & \\
\hline CHEMBL1374464 & 688759 & 4.8 & 4.94600 & 0000000001 & TRN \\
\hline CHEMBL1407475 & 688759 & 5.45 & 5.0954 & TRN & \\
\hline CHEMBL1545984 & 688759 & 4.7 & 5.1917 & TRN & \\
\hline CHEMBL3197073 & 688759 & 4.65 & 5.0568 & TRN & \\
\hline CHEMBL1561874 & 688759 & 4.65 & 5.0329 & TRN & \\
\hline CHEMBL1446544 & 688759 & 4.45 & 4.7222 & TST & \\
\hline CHEMBL1572542 & 688759 & 4.8 & 5.1924 & TST & \\
\hline CHEMBL1577277 & 688759 & 4.65 & 4.8536 & TRN & \\
\hline CHEMBL1596758 & 688759 & 4.45 & 4.6146 & TRN & \\
\hline CHEMBL1083103 & 688759 & 4.9 & 4.6887 & TRN & \\
\hline CHEMBL524222 & 688759 & 4.65 & 4.8336 & TRN & \\
\hline CHEMBL1330496 & 688759 & 4.45 & 4.9073 & TRN & \\
\hline CHEMBL1412497 & 688759 & 4.6 & 4.9908 & TST & \\
\hline CHEMBL1544997 & 688759 & 5.1 & 4.8017 & TST & \\
\hline CHEMBL1432377 & 688759 & 5.1 & 4.9346 & TRN & \\
\hline CHEMBL1367811 & 688759 & 4.5 & 4.7091 & TRN & \\
\hline CHEMBL1375651 & 688759 & 5.4 & 5.6159 & TRN & \\
\hline CHEMBL1487500 & 688759 & 4.85 & 4.9343 & TRN & \\
\hline CHEMBL1371940 & 688759 & 4.45 & 4.8839 & TST & \\
\hline CHEMBL1432804 & 688759 & 4.45 & 5.0081 & TST & \\
\hline CHEMBL3197720 & 688759 & 4.65 & 5.1502 & TRN & \\
\hline CHEMBL1517429 & 688759 & 4.45 & 4.7568 & TRN & \\
\hline CHEMBL1583281 & 688759 & 4.45 & 4.8308 & TST & \\
\hline CHEMBL1611944 & 688759 & 4.45 & 4.9762 & TRN & \\
\hline CHEMBL1559671 & 688759 & 4.85 & 5.0132 & TRN & \\
\hline CHEMBL1516103 & 688759 & 4.8 & 4.5965 & TRN & \\
\hline CHEMBL3197444 & 688759 & 4.45 & 4.6657 & TRN & \\
\hline CHEMBL1466186 & 688759 & 6.0 & 5.4472 & TRN & \\
\hline CHEMBL1540266 & 688759 & 4.65 & 4.8883 & TRN & \\
\hline CHEMBL1609181 & 688759 & 4.7 & 4.9222 & TRN & \\
\hline CHEMBL1330510 & 688759 & 5.7 & 5.3066 & TRN & \\
\hline CHEMBL1528535 & 688759 & 4.5 & 4.8452 & TRN & \\
\hline
\end{tabular}




\begin{tabular}{|c|c|c|c|c|c|}
\hline \multicolumn{6}{|c|}{ Supplemental Table s2.txt } \\
\hline CHEMBL1362731 & 688759 & 4.6 & 4.8412 & TST & \\
\hline CHEMBL1455608 & 688759 & 4.45 & 4.7953 & TRN & \\
\hline CHEMBL1324093 & 688759 & 4.45 & 4.6411 & TRN & \\
\hline CHEMBL1324299 & 688759 & 4.85 & 4.8614 & TRN & \\
\hline CHEMBL1426693 & 688759 & 4.7 & 4.9443 & TST & \\
\hline CHEMBL1306564 & 688759 & 4.65 & 4.6372 & TRN & \\
\hline CHEMBL1448753 & 688759 & 4.8 & 4.7321 & TRN & \\
\hline CHEMBL1411595 & 688759 & 4.5 & 4.90600 & 0000000001 & TRN \\
\hline CHEMBL1471131 & 688759 & 5.7 & 4.7822 & TST & \\
\hline CHEMBL1507474 & 688759 & 4.6 & 5.3175 & TRN & \\
\hline CHEMBL1459031 & 688759 & 4.45 & 4.832 & TST & \\
\hline CHEMBL1417237 & 688759 & 5.25 & 5.1743 & TRN & \\
\hline CHEMBL1308887 & 688759 & 5.45 & 4.9204 & TRN & \\
\hline CHEMBL1575588 & 688759 & 5.15 & 4.603 & TST & \\
\hline CHEMBL1500011 & 688759 & 4.9 & 4.7054 & TST & \\
\hline CHEMBL1364284 & 688759 & 5.3 & 4.9987 & TST & \\
\hline CHEMBL1307549 & 688759 & 4.45 & 5.106 & TRN & \\
\hline CHEMBL1540959 & 688759 & 4.8 & 4.9575 & TRN & \\
\hline CHEMBL1417344 & 688759 & 4.65 & 4.8168 & TRN & \\
\hline CHEMBL1537293 & 688759 & 5.15 & 5.2236 & TRN & \\
\hline CHEMBL3189932 & 688759 & 4.8 & 4.7709 & TRN & \\
\hline CHEMBL 3189574 & 688759 & 6.25 & 5.5347 & TRN & \\
\hline CHEMBL1586981 & 688759 & 4.8 & 4.8392 & TRN & \\
\hline CHEMBL3195226 & 688759 & 6.05 & 6.2645 & TRN & \\
\hline CHEMBL1424881 & 688759 & 4.8 & 4.7817 & TRN & \\
\hline CHEMBL1359128 & 688759 & 5.5 & 5.1647 & TRN & \\
\hline CHEMBL1565592 & 688759 & 4.45 & 4.6878 & TRN & \\
\hline CHEMBL1408891 & 688759 & 6.5 & 5.0905 & TST & \\
\hline CHEMBL1416960 & 688759 & 4.45 & 5.0116 & TRN & \\
\hline CHEMBL1502874 & 688759 & 4.45 & 4.9628 & TRN & \\
\hline CHEMBL1431735 & 688759 & 4.5 & 4.4298 & TRN & \\
\hline CHEMBL1524076 & 688759 & 4.45 & 4.5029 & TRN & \\
\hline CHEMBL1366727 & 688759 & 6.15 & 4.80399 & 9999999999 & TRN \\
\hline CHEMBL1334957 & 688759 & 4.45 & 4.7016 & TRN & \\
\hline CHEMBL3196270 & 688759 & 5.7 & 5.2677 & TRN & \\
\hline CHEMBL3194522 & 688759 & 4.95 & 4.5652 & TRN & \\
\hline CHEMBL1348468 & 688759 & 4.45 & 4.7739 & TRN & \\
\hline CHEMBL3211624 & 688759 & 5.8 & 5.4829 & TRN & \\
\hline CHEMBL3197827 & 688759 & 6.0 & 5.5635 & TRN & \\
\hline CHEMBL1269508 & 688759 & 4.45 & 4.6712 & TRN & \\
\hline CHEMBL1341112 & 688759 & 4.95 & 4.7653 & TRN & \\
\hline CHEMBL1299194 & 688759 & 4.65 & 4.8005 & TRN & \\
\hline CHEMBL1369728 & 688759 & 6.0 & 4.9282 & TST & \\
\hline CHEMBL1518369 & 688759 & 4.45 & 4.8176 & TST & \\
\hline CHEMBL1347053 & 688759 & 5.65 & 4.9928 & TRN & \\
\hline CHEMBL1389933 & 688759 & 5.3 & 5.2685 & TRN & \\
\hline CHEMBL1576337 & 688759 & 4.65 & 4.9925 & TRN & \\
\hline CHEMBL1587773 & 688759 & 5.35 & 4.8781 & TRN & \\
\hline
\end{tabular}




\begin{tabular}{|c|c|c|c|c|c|}
\hline \multicolumn{6}{|c|}{ Supplemental Table S2.txt } \\
\hline CHEMBL1405916 & 688759 & 5.3 & 5.2434 & TRN & \\
\hline CHEMBL1582302 & 688759 & 4.45 & 4.9408 & TRN & \\
\hline CHEMBL3191845 & 688759 & 4.45 & 4.7523 & TST & \\
\hline CHEMBL1415024 & 688759 & 5.1 & 5.1451 & TRN & \\
\hline CHEMBL209793 & 688759 & 4.95 & 4.5926 & TRN & \\
\hline CHEMBL1441675 & 688759 & 4.65 & 4.9672 & TRN & \\
\hline CHEMBL3189872 & 688759 & 4.45 & 4.8955 & TRN & \\
\hline CHEMBL1430582 & 688759 & 4.95 & 4.8233 & TST & \\
\hline CHEMBL1503747 & 688759 & 4.9 & 4.7575 & TST & \\
\hline CHEMBL1302146 & 688759 & 5.3 & 5.2213 & TRN & \\
\hline CHEMBL1341585 & 688759 & 4.95 & 5.0732 & TST & \\
\hline CHEMBL3194971 & 688759 & 4.55 & 4.8107 & TRN & \\
\hline CHEMBL508779 & 688759 & 5.25 & 5.2502 & TST & \\
\hline CHEMBL1586196 & 688759 & 4.65 & 4.9845 & TST & \\
\hline CHEMBL1996163 & 688759 & 4.55 & 4.7478 & TRN & \\
\hline CHEMBL1985827 & 688759 & 4.45 & 4.8718 & TST & \\
\hline CHEMBL1588641 & 688759 & 4.7 & 4.8417 & TRN & \\
\hline CHEMBL1498428 & 688759 & 5.5 & 5.1509 & TRN & \\
\hline CHEMBL1597716 & 688759 & 4.7 & 4.5716 & TRN & \\
\hline CHEMBL1597103 & 688759 & 4.45 & 4.5789 & TRN & \\
\hline CHEMBL1561893 & 688759 & 4.45 & 4.8329 & TST & \\
\hline CHEMBL1390261 & 688759 & 4.45 & 4.7831 & TRN & \\
\hline CHEMBL1371851 & 688759 & 4.6 & 4.8994 & TRN & \\
\hline CHEMBL1531311 & 688759 & 4.55 & 5.3181 & TRN & \\
\hline CHEMBL1400912 & 688759 & 4.65 & 4.6825 & TRN & \\
\hline CHEMBL1504973 & 688759 & 5.0 & 5.2115 & TRN & \\
\hline CHEMBL1345016 & 688759 & 4.7 & 4.8027 & TST & \\
\hline CHEMBL1573071 & 688759 & 4.95 & 5.0435 & TST & \\
\hline CHEMBL1486734 & 688759 & 4.8 & 4.7322 & TRN & \\
\hline CHEMBL1478837 & 688759 & 4.45 & 4.6565 & TRN & \\
\hline CHEMBL1382203 & 688759 & 4.45 & 4.8654 & TRN & \\
\hline CHEMBL1570389 & 688759 & 4.85 & 5.20299 & 9999999999 & TRN \\
\hline CHEMBL1573887 & 688759 & 4.65 & 4.7895 & TST & \\
\hline CHEMBL3193575 & 688759 & 4.65 & 4.6091 & TRN & \\
\hline CHEMBL1397552 & 688759 & 4.45 & 4.776 & TRN & \\
\hline CHEMBL1567655 & 688759 & 5.2 & 4.9204 & TRN & \\
\hline CHEMBL1397323 & 688759 & 5.0 & 4.7504 & TRN & \\
\hline CHEMBL1392630 & 688759 & 4.45 & 4.5686 & TRN & \\
\hline CHEMBL1301428 & 688759 & 3.65 & 5.0094 & TRN & \\
\hline CHEMBL1583161 & 688759 & 4.55 & 4.7977 & TRN & \\
\hline CHEMBL1400512 & 688759 & 4.75 & 4.7811 & TST & \\
\hline CHEMBL1428066 & 688759 & 4.6 & 4.8274 & TST & \\
\hline CHEMBL1606613 & 688759 & 5.15 & 5.1199 & TRN & \\
\hline CHEMBL1507425 & 688759 & 4.45 & 4.5095 & TST & \\
\hline CHEMBL186366 & 688759 & 4.45 & 5.0675 & TRN & \\
\hline CHEMBL3210081 & 688759 & 4.85 & 4.9795 & TST & \\
\hline CHEMBL1456709 & 688759 & 4.9 & 5.1077 & TRN & \\
\hline CHEMBL1431698 & 688759 & 4.45 & 4.8455 & TRN & \\
\hline
\end{tabular}




\begin{tabular}{|c|c|c|c|c|c|}
\hline & & \multicolumn{4}{|c|}{ Supplemental Table S2.txt } \\
\hline CHEMBL1534112 & 688759 & 4.7 & 4.7727 & TRN & \\
\hline CHEMBL3212346 & 688759 & 4.45 & 4.8974 & TRN & \\
\hline CHEMBL1487657 & 688759 & 4.45 & 4.8624 & TRN & \\
\hline CHEMBL1349374 & 688759 & 4.95 & 5.0207 & TRN & \\
\hline CHEMBL1504295 & 688759 & 4.45 & 4.8893 & TRN & \\
\hline CHEMBL1482449 & 688759 & 5.55 & 5.2385 & TST & \\
\hline CHEMBL1538342 & 688759 & 4.7 & 4.5699 & TRN & \\
\hline CHEMBL1543517 & 688759 & 5.35 & 5.0584 & TRN & \\
\hline CHEMBL1479978 & 688759 & 5.55 & 4.8739 & TRN & \\
\hline CHEMBL1311588 & 688759 & 4.55 & 5.1404 & TST & \\
\hline CHEMBL3195193 & 688759 & 4.95 & 4.7045 & TRN & \\
\hline CHEMBL1385122 & 688759 & 5.15 & 4.9023 & TRN & \\
\hline CHEMBL1525066 & 688759 & 4.85 & 4.9767 & TRN & \\
\hline CHEMBL1526148 & 688759 & 4.45 & 4.6913 & TRN & \\
\hline CHEMBL3192531 & 688759 & 4.75 & 4.9312 & TRN & \\
\hline CHEMBL1445277 & 688759 & 4.55 & 4.7806 & TRN & \\
\hline CHEMBL1495264 & 688759 & 4.45 & 4.7937 & TST & \\
\hline CHEMBL1323660 & 688759 & 4.8 & 4.96899 & 9999999999 & TST \\
\hline CHEMBL1377193 & 688759 & 5.15 & 5.0987 & TRN & \\
\hline CHEMBL1406345 & 688759 & 4.45 & 4.5008 & TRN & \\
\hline CHEMBL1404573 & 688759 & 5.75 & 5.2233 & TST & \\
\hline CHEMBL1346788 & 688759 & 6.25 & 5.2628 & TRN & \\
\hline CHEMBL1346981 & 688759 & 4.45 & 4.5899 & TST & \\
\hline CHEMBL3192061 & 688759 & 5.5 & 4.7817 & TRN & \\
\hline CHEMBL1429682 & 688759 & 6.3 & 5.5959 & TRN & \\
\hline CHEMBL1326627 & 688759 & 4.9 & 4.7647 & TRN & \\
\hline CHEMBL1596996 & 688759 & 4.65 & 4.692 & TRN & \\
\hline CHEMBL1322473 & 688759 & 4.55 & 4.7306 & TRN & \\
\hline CHEMBL3190022 & 688759 & 5.3 & 4.7671 & TST & \\
\hline CHEMBL1347236 & 688759 & 4.75 & 4.9691 & TRN & \\
\hline CHEMBL1344130 & 688759 & 4.8 & 4.793 & TST & \\
\hline CHEMBL1480793 & 688759 & 5.0 & 5.2782 & TRN & \\
\hline CHEMBL1513765 & 688759 & 4.45 & 4.7286 & TRN & \\
\hline CHEMBL1558849 & 688759 & 4.65 & 5.0786 & TRN & \\
\hline CHEMBL1402830 & 688759 & 5.95 & 4.8723 & TST & \\
\hline CHEMBL1464773 & 688759 & 4.45 & 4.5133 & TRN & \\
\hline CHEMBL395653 & 688759 & 5.5 & 4.829 & TST & \\
\hline CHEMBL602158 & 688759 & 5.25 & 4.8432 & TRN & \\
\hline CHEMBL1529289 & 688759 & 4.45 & 4.9126 & TRN & \\
\hline CHEMBL1362695 & 688759 & 5.8 & 5.1173 & TRN & \\
\hline CHEMBL486569 & 688759 & 5.55 & 4.9962 & TRN & \\
\hline CHEMBL1579287 & 688759 & 5.5 & 4.775 & TRN & \\
\hline CHEMBL1462683 & 688759 & 4.65 & 4.7163 & TRN & \\
\hline CHEMBL1336081 & 688759 & 4.6 & 4.9003 & TRN & \\
\hline CHEMBL1540843 & 688759 & 5.4 & 5.0573 & TRN & \\
\hline CHEMBL1375375 & 688759 & 4.95 & 4.7854 & TRN & \\
\hline CHEMBL1509694 & 688759 & 4.75 & 4.6196 & TRN & \\
\hline CHEMBL3194405 & 688759 & 4.65 & 4.5056 & TRN & \\
\hline
\end{tabular}




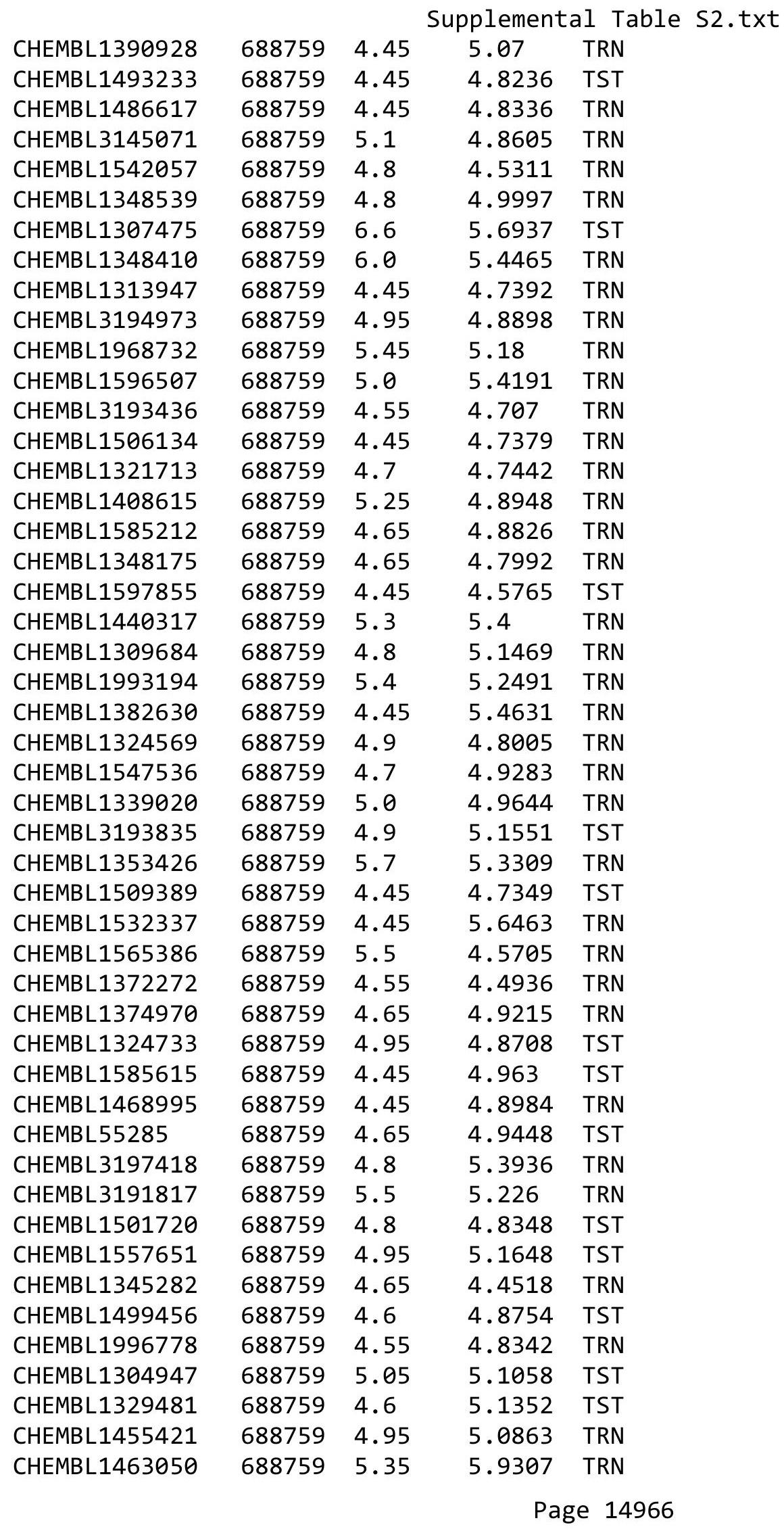




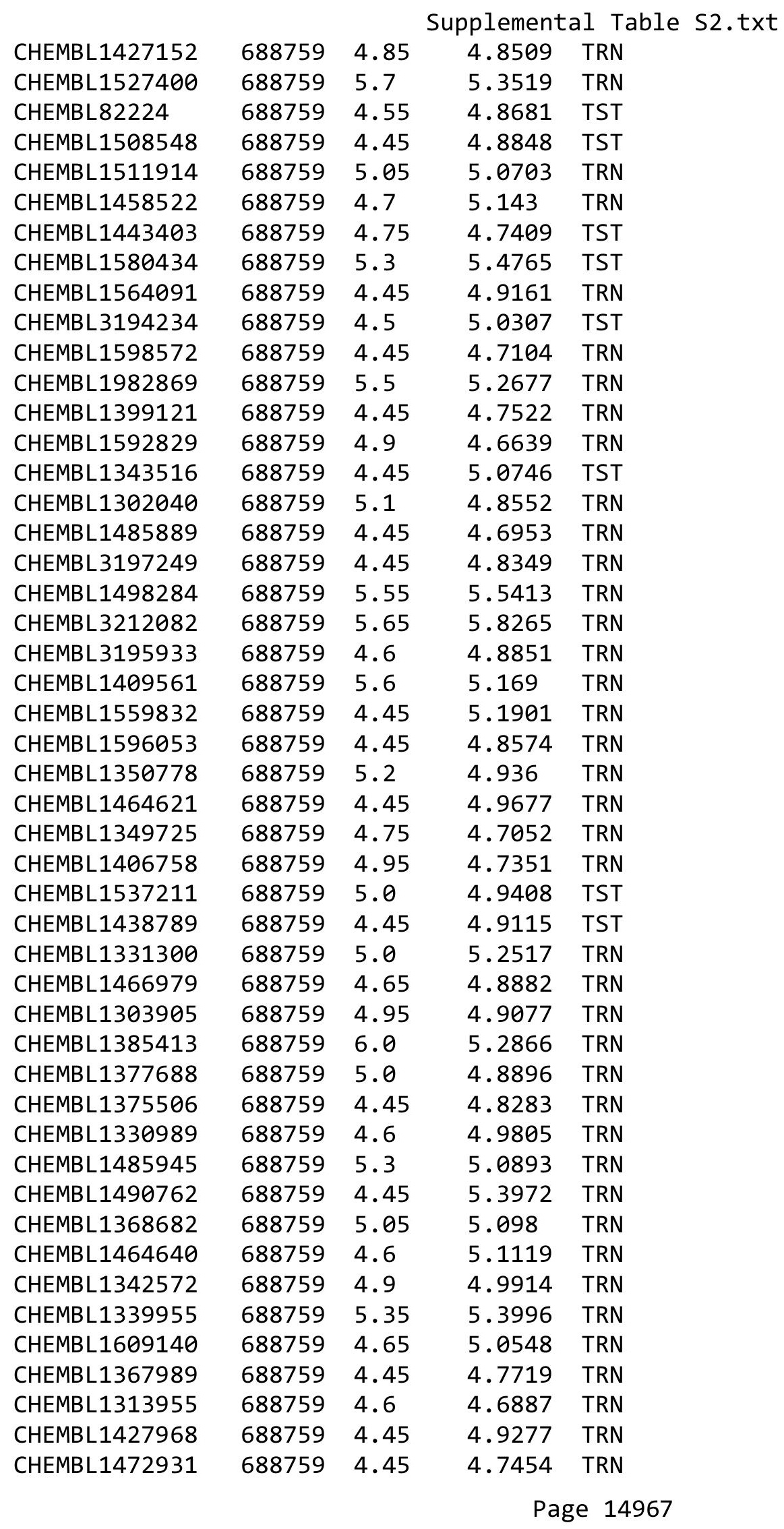




\begin{tabular}{|c|c|c|c|c|}
\hline \multicolumn{5}{|c|}{ Supplemental Table S2.txt } \\
\hline CHEMBL1510230 & 688759 & 5.1 & 5.0103 & TRN \\
\hline CHEMBL1535469 & 688759 & 4.45 & 4.5457 & TRN \\
\hline CHEMBL1452939 & 688759 & 4.45 & 4.5645 & TST \\
\hline CHEMBL1401188 & 688759 & 6.2 & 5.8536 & TRN \\
\hline CHEMBL3191091 & 688759 & 5.8 & 5.4699 & TRN \\
\hline CHEMBL1464276 & 688759 & 4.65 & 4.8006 & TRN \\
\hline CHEMBL1558328 & 688759 & 4.45 & 4.9182 & TST \\
\hline CHEMBL1447011 & 688759 & 4.8 & 4.5305 & TRN \\
\hline CHEMBL1309171 & 688759 & 4.7 & 4.8186 & TRN \\
\hline CHEMBL1403955 & 688759 & 5.35 & 5.5804 & TRN \\
\hline CHEMBL1603776 & 688759 & 6.0 & 5.3829 & TST \\
\hline CHEMBL1462019 & 688759 & 4.6 & 4.705 & TST \\
\hline CHEMBL1328716 & 688759 & 5.0 & 5.0857 & TRN \\
\hline CHEMBL1461631 & 688759 & 5.6 & 4.8363 & TRN \\
\hline CHEMBL1389030 & 688759 & 4.75 & 4.9222 & TST \\
\hline CHEMBL1506257 & 688759 & 4.45 & 4.8099 & TST \\
\hline CHEMBL1307739 & 688759 & 4.45 & 4.7417 & TRN \\
\hline CHEMBL3198173 & 688759 & 4.95 & 4.7884 & TRN \\
\hline CHEMBL365161 & 688759 & 4.9 & 5.059 & TST \\
\hline CHEMBL1411259 & 688759 & 4.6 & 4.7172 & TST \\
\hline CHEMBL1350224 & 688759 & 5.15 & 5.0153 & TRN \\
\hline CHEMBL3192605 & 688759 & 4.45 & 4.8535 & TST \\
\hline CHEMBL1364073 & 688759 & 5.25 & 5.1912 & TRN \\
\hline CHEMBL1601701 & 688759 & 5.5 & 5.2369 & TST \\
\hline CHEMBL1307450 & 688759 & 4.45 & 5.0506 & TST \\
\hline CHEMBL1611481 & 688759 & 4.85 & 4.8372 & TRN \\
\hline CHEMBL1424353 & 688759 & 4.6 & 4.8946 & TRN \\
\hline CHEMBL1372606 & 688759 & 5.2 & 5.0447 & TRN \\
\hline CHEMBL1492285 & 688759 & 4.45 & 4.7945 & TRN \\
\hline CHEMBL1538932 & 688759 & 4.75 & 4.7563 & TRN \\
\hline CHEMBL1545848 & 688759 & 4.75 & 4.9707 & TRN \\
\hline CHEMBL1602676 & 688759 & 4.45 & 5.472 & TST \\
\hline CHEMBL1499196 & 688759 & 5.3 & 4.9546 & TRN \\
\hline CHEMBL3199475 & 688759 & 5.0 & 5.3091 & TRN \\
\hline CHEMBL3195828 & 688759 & 4.7 & 4.6978 & TRN \\
\hline CHEMBL1602981 & 688759 & 4.85 & 4.772 & TST \\
\hline CHEMBL1545701 & 688759 & 4.45 & 4.8331 & TST \\
\hline CHEMBL1459387 & 688759 & 5.05 & 4.9333 & TRN \\
\hline CHEMBL3195763 & 688759 & 5.05 & 5.7725 & TRN \\
\hline CHEMBL1370103 & 688759 & 4.8 & 4.8695 & TST \\
\hline CHEMBL1303320 & 688759 & 4.45 & 5.1092 & TRN \\
\hline CHEMBL1466204 & 688759 & 5.5 & 5.3006 & TRN \\
\hline CHEMBL1349639 & 688759 & 5.0 & 4.8175 & TRN \\
\hline CHEMBL3392034 & 688759 & 4.45 & 4.7262 & TST \\
\hline CHEMBL1424373 & 688759 & 5.55 & 4.7936 & TRN \\
\hline CHEMBL1492208 & 688759 & 6.05 & 5.1329 & TRN \\
\hline CHEMBL1409414 & 688759 & 5.5 & 4.9565 & TRN \\
\hline CHEMBL1984666 & 688759 & 5.15 & 5.2341 & TRN \\
\hline
\end{tabular}




\begin{tabular}{|c|c|c|c|c|c|}
\hline \multicolumn{6}{|c|}{ Supplemental Table S2.txt } \\
\hline CHEMBL1424345 & 688759 & 4.9 & 4.8345 & TRN & \\
\hline CHEMBL1545588 & 688759 & 4.45 & 4.8703 & TRN & \\
\hline CHEMBL1568055 & 688759 & 4.45 & 4.6655 & TST & \\
\hline CHEMBL1556269 & 688759 & 4.95 & 4.7041 & TRN & \\
\hline CHEMBL3209113 & 688759 & 4.55 & 4.5089 & TRN & \\
\hline CHEMBL1969712 & 688759 & 6.0 & 5.246 & TRN & \\
\hline CHEMBL1474036 & 688759 & 4.8 & 4.8054 & TRN & \\
\hline CHEMBL1455227 & 688759 & 5.4 & 5.1366 & TRN & \\
\hline CHEMBL1480641 & 688759 & 4.6 & 4.8985 & TRN & \\
\hline CHEMBL3191915 & 688759 & 4.95 & 4.9814 & TRN & \\
\hline CHEMBL1405119 & 688759 & 4.45 & 4.5932 & TRN & \\
\hline CHEMBL1542804 & 688759 & 5.2 & 4.8347 & TRN & \\
\hline CHEMBL581471 & 688759 & 5.35 & 4.9676 & TST & \\
\hline CHEMBL1390085 & 688759 & 5.3 & 4.8266 & TRN & \\
\hline CHEMBL1547042 & 688759 & 4.45 & 4.9791 & TRN & \\
\hline CHEMBL1583257 & 688759 & 4.45 & 4.8285 & TRN & \\
\hline CHEMBL3207601 & 688759 & 4.7 & 4.6759 & TST & \\
\hline CHEMBL1332485 & 688759 & 4.45 & 4.5124 & TRN & \\
\hline CHEMBL1583357 & 688759 & 4.65 & 4.7145 & TRN & \\
\hline CHEMBL1994078 & 688759 & 4.9 & 4.9401 & TRN & \\
\hline CHEMBL1531419 & 688759 & 4.55 & 4.5885 & TRN & \\
\hline CHEMBL1337445 & 688759 & 4.45 & 4.65300 & 00000000005 & TST \\
\hline CHEMBL1579765 & 688759 & 5.25 & 5.2508 & TRN & \\
\hline CHEMBL1340287 & 688759 & 4.5 & 4.9521 & TRN & \\
\hline CHEMBL1321240 & 688759 & 5.35 & 4.8473 & TRN & \\
\hline CHEMBL1565341 & 688759 & 4.65 & 4.9956 & TST & \\
\hline CHEMBL1368489 & 688759 & 4.45 & 4.647 & TRN & \\
\hline CHEMBL1608208 & 688759 & 4.65 & 5.0598 & TRN & \\
\hline CHEMBL1506105 & 688759 & 4.9 & 4.9451 & TRN & \\
\hline CHEMBL3189533 & 688759 & 5.0 & 5.2857 & TRN & \\
\hline CHEMBL3211859 & 688759 & 4.8 & 5.5191 & TRN & \\
\hline CHEMBL2354668 & 688759 & 4.45 & 4.6456 & TST & \\
\hline CHEMBL1447872 & 688759 & 4.45 & 4.602 & TRN & \\
\hline CHEMBL1319374 & 688759 & 4.95 & 4.6383 & TST & \\
\hline CHEMBL3190917 & 688759 & 5.6 & 5.5645 & TRN & \\
\hline CHEMBL1423596 & 688759 & 4.5 & 4.6412 & TRN & \\
\hline CHEMBL1450448 & 688759 & 4.8 & 5.0277 & TRN & \\
\hline CHEMBL1299575 & 688759 & 5.15 & 5.0506 & TRN & \\
\hline CHEMBL1452467 & 688759 & 5.5 & 5.3029 & TRN & \\
\hline CHEMBL1964556 & 688759 & 4.8 & 4.7822 & TRN & \\
\hline CHEMBL1566864 & 688759 & 4.45 & 5.016 & TRN & \\
\hline CHEMBL1336882 & 688759 & 7.0501 & 4.8436 & TST & \\
\hline CHEMBL1383353 & 688759 & 4.65 & 4.485 & TRN & \\
\hline CHEMBL1578118 & 688759 & 5.3 & 4.7621 & TST & \\
\hline CHEMBL1347469 & 688759 & 5.5 & 4.6194 & TRN & \\
\hline CHEMBL1321503 & 688759 & 4.75 & 4.8082 & TST & \\
\hline CHEMBL3192079 & 688759 & 5.9 & 5.6181 & TRN & \\
\hline CHEMBL1548182 & 688759 & 4.45 & 4.5272 & TST & \\
\hline
\end{tabular}




\begin{tabular}{|c|c|c|c|c|}
\hline & & & pplement & al Tá \\
\hline CHEMBL1535988 & 688759 & 4.7 & 5.0416 & TRN \\
\hline CHEMBL1309032 & 688759 & 5.55 & 4.8214 & TRN \\
\hline CHEMBL1314913 & 688759 & 4.65 & 4.6518 & TST \\
\hline CHEMBL3195101 & 688759 & 5.55 & 5.4851 & TRN \\
\hline CHEMBL593254 & 688759 & 4.8 & 4.5827 & TST \\
\hline CHEMBL1462999 & 688759 & 5.45 & 5.029 & TRN \\
\hline CHEMBL1433860 & 688759 & 5.05 & 5.2763 & TRN \\
\hline CHEMBL1419341 & 688759 & 5.2 & 4.7536 & TST \\
\hline CHEMBL1419721 & 688759 & 4.9 & 4.5618 & TRN \\
\hline CHEMBL1313001 & 688759 & 5.2 & 4.6694 & TRN \\
\hline CHEMBL1345298 & 688759 & 4.8 & 4.5608 & TST \\
\hline CHEMBL1431189 & 688759 & 5.3 & 4.9661 & TRN \\
\hline CHEMBL1382372 & 688759 & 4.85 & 4.7947 & TST \\
\hline CHEMBL1460001 & 688759 & 4.45 & 5.0603 & TRN \\
\hline CHEMBL1390226 & 688759 & 4.6 & 5.0455 & TRN \\
\hline CHEMBL1306590 & 688759 & 5.0 & 5.0404 & TRN \\
\hline CHEMBL1596753 & 688759 & 4.8 & 4.8542 & TST \\
\hline CHEMBL261055 & 688759 & 5.15 & 4.8398 & TRN \\
\hline CHEMBL1507537 & 688759 & 4.45 & 5.2432 & TRN \\
\hline CHEMBL1431894 & 688759 & 4.95 & 5.1172 & TRN \\
\hline CHEMBL1560494 & 688759 & 4.7 & 4.6041 & TRN \\
\hline CHEMBL1572325 & 688759 & 4.95 & 4.8782 & TST \\
\hline CHEMBL1447219 & 688759 & 6.0 & 5.8197 & TRN \\
\hline CHEMBL1549681 & 688759 & 5.25 & 5.0024 & TRN \\
\hline CHEMBL3190849 & 688759 & 4.8 & 5.0674 & TRN \\
\hline CHEMBL 1407770 & 688759 & 5.25 & 4.9782 & TRN \\
\hline CHEMBL1409624 & 688759 & 4.45 & 5.0605 & TRN \\
\hline CHEMBL1343097 & 688759 & 4.75 & 4.9269 & TRN \\
\hline CHEMBL1321228 & 688759 & 4.6 & 4.7428 & TRN \\
\hline CHEMBL1533190 & 688759 & 5.25 & 4.9663 & TST \\
\hline CHEMBL1404671 & 688759 & 4.75 & 4.5636 & TST \\
\hline CHEMBL1535314 & 688759 & 4.85 & 4.7793 & TRN \\
\hline CHEMBL1881714 & 688759 & 5.4 & 5.2312 & TRN \\
\hline CHEMBL1337753 & 688759 & 5.25 & 4.694 & TRN \\
\hline CHEMBL1342268 & 688759 & 5.2 & 5.5885 & TRN \\
\hline CHEMBL1572500 & 688759 & 5.4 & 5.0439 & TRN \\
\hline CHEMBL1310367 & 688759 & 4.45 & 4.7674 & TRN \\
\hline CHEMBL1449336 & 688759 & 4.9 & 4.8984 & TST \\
\hline CHEMBL1397089 & 688759 & 6.0 & 6.1006 & TST \\
\hline CHEMBL1466082 & 688759 & 5.2 & 5.1632 & TRN \\
\hline CHEMBL1524800 & 688759 & 5.6 & 5.0007 & TST \\
\hline CHEMBL1464842 & 688759 & 4.95 & 4.8445 & TRN \\
\hline CHEMBL1341816 & 688759 & 4.75 & 5.0812 & TRN \\
\hline CHEMBL1418884 & 688759 & 4.45 & 4.5596 & TST \\
\hline CHEMBL1584415 & 688759 & 4.95 & 4.8224 & TRN \\
\hline CHEMBL1427053 & 688759 & 4.45 & 4.6944 & TRN \\
\hline CHEMBL1539146 & 688759 & 4.65 & 4.8255 & TRN \\
\hline CHEMBL 3199765 & 688759 & 5.45 & 5.0837 & TRN \\
\hline
\end{tabular}




\begin{tabular}{|c|c|c|c|c|}
\hline \multicolumn{5}{|c|}{ Supplemental Table S2.tx } \\
\hline CHEMBL1420215 & 688759 & 6.8499 & 5.0268 & TRN \\
\hline CHEMBL1470473 & 688759 & 4.45 & 4.8316 & TST \\
\hline CHEMBL1339546 & 688759 & 4.65 & 4.7739 & TRN \\
\hline CHEMBL1350975 & 688759 & 4.45 & 4.5931 & TST \\
\hline CHEMBL1337075 & 688759 & 4.65 & 4.9047 & TRN \\
\hline CHEMBL1310745 & 688759 & 4.85 & 4.8694 & TRN \\
\hline CHEMBL1579210 & 688759 & 4.55 & 4.7437 & TST \\
\hline CHEMBL1325460 & 688759 & 4.45 & 4.6929 & TST \\
\hline CHEMBL1342221 & 688759 & 5.3 & 5.13 & TRN \\
\hline CHEMBL1379951 & 688759 & 4.75 & 4.8741 & TRN \\
\hline CHEMBL1579235 & 688759 & 5.15 & 5.3363 & TRN \\
\hline CHEMBL1370261 & 688759 & 4.8 & 4.9028 & TST \\
\hline CHEMBL1509051 & 688759 & 5.45 & 5.7437 & TST \\
\hline CHEMBL1371847 & 688759 & 4.45 & 5.0481 & TRN \\
\hline CHEMBL1367073 & 688759 & 4.6 & 4.7899 & TRN \\
\hline CHEMBL1364379 & 688759 & 4.45 & 4.9616 & TST \\
\hline CHEMBL1335522 & 688759 & 4.65 & 4.7851 & TST \\
\hline CHEMBL1460423 & 688759 & 4.45 & 4.7705 & TRN \\
\hline CHEMBL1511121 & 688759 & 4.8 & 4.6342 & TRN \\
\hline CHEMBL1425788 & 688759 & 4.6 & 5.0623 & TRN \\
\hline CHEMBL1594507 & 688759 & 5.4 & 4.9013 & TRN \\
\hline CHEMBL1477576 & 688759 & 4.55 & 4.7245 & TRN \\
\hline CHEMBL1501402 & 688759 & 4.45 & 4.8641 & TRN \\
\hline CHEMBL3392448 & 688759 & 6.2 & 5.5594 & TRN \\
\hline CHEMBL1986151 & 688759 & 5.7 & 5.38899 & 9999999999 \\
\hline CHEMBL 2003808 & 688759 & 5.4 & 5.2762 & TRN \\
\hline CHEMBL1503976 & 688759 & 5.1 & 4.9377 & TST \\
\hline CHEMBL1575869 & 688759 & 4.65 & 4.5016 & TRN \\
\hline CHEMBL1505819 & 688759 & 4.75 & 4.8248 & TST \\
\hline CHEMBL1978764 & 688759 & 6.0 & 5.7965 & TRN \\
\hline CHEMBL1566046 & 688759 & 4.7 & 4.8351 & TRN \\
\hline CHEMBL1388566 & 688759 & 5.25 & 4.9712 & TRN \\
\hline CHEMBL1307180 & 688759 & 4.9 & 4.7872 & TRN \\
\hline CHEMBL3197400 & 688759 & 4.55 & 4.9164 & TRN \\
\hline CHEMBL 3196414 & 688759 & 4.45 & 4.8499 & TRN \\
\hline CHEMBL569708 & 688759 & 4.45 & 4.6765 & TRN \\
\hline CHEMBL1450487 & 688759 & 4.45 & 5.0434 & TST \\
\hline CHEMBL1325219 & 688759 & 5.9 & 4.8777 & TST \\
\hline CHEMBL1424588 & 688759 & 5.25 & 5.1623 & TRN \\
\hline CHEMBL1429943 & 688759 & 4.8 & 5.1007 & TRN \\
\hline CHEMBL1550430 & 688759 & 6.05 & 6.3986 & TRN \\
\hline CHEMBL1508374 & 688759 & 4.65 & 4.6657 & TST \\
\hline CHEMBL1325239 & 688759 & 4.9 & 4.7518 & TRN \\
\hline CHEMBL1300339 & 688759 & 4.45 & 4.7437 & TRN \\
\hline CHEMBL1464976 & 688759 & 4.55 & 4.8909 & TRN \\
\hline CHEMBL1467073 & 688759 & 5.5 & 5.7517 & TRN \\
\hline CHEMBL1372459 & 688759 & 5.25 & 4.8774 & TRN \\
\hline CHEMBL3195514 & 688759 & 5.0 & 4.8303 & TRN \\
\hline
\end{tabular}




\begin{tabular}{|c|c|c|c|c|}
\hline \multicolumn{5}{|c|}{ Supplemental Table S2.txt } \\
\hline CHEMBL1506888 & 688759 & 5.25 & 4.9379 & TRN \\
\hline CHEMBL1492670 & 688759 & 4.9 & 4.7338 & TRN \\
\hline CHEMBL3214241 & 688759 & 4.45 & 4.8962 & TRN \\
\hline CHEMBL1311237 & 688759 & 4.95 & 5.1558 & TST \\
\hline CHEMBL1321898 & 688759 & 4.45 & 4.8857 & TRN \\
\hline CHEMBL1605314 & 688759 & 5.25 & 4.9833 & TST \\
\hline CHEMBL1482820 & 688759 & 4.65 & 4.89 & TST \\
\hline CHEMBL1313697 & 688759 & 4.45 & 4.8583 & TST \\
\hline CHEMBL1587432 & 688759 & 4.7 & 4.7643 & TST \\
\hline CHEMBL1420837 & 688759 & 5.0 & 4.7992 & TRN \\
\hline CHEMBL1334040 & 688759 & 4.45 & 4.7781 & TST \\
\hline CHEMBL1385406 & 688759 & 4.8 & 4.8282 & TRN \\
\hline CHEMBL1459487 & 688759 & 4.85 & 5.9575 & TRN \\
\hline CHEMBL1433075 & 688759 & 4.45 & 4.8933 & TRN \\
\hline CHEMBL1522586 & 688759 & 4.65 & 4.6328 & TRN \\
\hline CHEMBL3209987 & 688759 & 4.6 & 4.7942 & TRN \\
\hline CHEMBL1439984 & 688759 & 4.65 & 4.8662 & TRN \\
\hline CHEMBL1611222 & 688759 & 4.65 & 4.9071 & TRN \\
\hline CHEMBL1544985 & 688759 & 5.6 & 5.0798 & TRN \\
\hline CHEMBL1394409 & 688759 & 5.0 & 4.9277 & TST \\
\hline CHEMBL1483908 & 688759 & 5.7 & 4.5844 & TRN \\
\hline CHEMBL1526099 & 688759 & 4.45 & 4.6219 & TRN \\
\hline CHEMBL1411911 & 688759 & 4.7 & 4.707 & TRN \\
\hline CHEMBL1375894 & 688759 & 4.65 & 4.5564 & TRN \\
\hline CHEMBL1610633 & 688759 & 5.0 & 5.1109 & TRN \\
\hline CHEMBL1310877 & 688759 & 5.7 & 4.9737 & TRN \\
\hline CHEMBL3194582 & 688759 & 4.45 & 4.7679 & TRN \\
\hline CHEMBL1309871 & 688759 & 4.45 & 4.7102 & TRN \\
\hline CHEMBL1394738 & 688759 & 4.7 & 4.7199 & TRN \\
\hline CHEMBL1445361 & 688759 & 4.85 & 4.8644 & TST \\
\hline CHEMBL1421102 & 688759 & 4.5 & 4.8661 & TRN \\
\hline CHEMBL1458934 & 688759 & 5.4 & 5.0287 & TST \\
\hline CHEMBL1549233 & 688759 & 4.8 & 4.9224 & TRN \\
\hline CHEMBL1581345 & 688759 & 4.75 & 4.7621 & TRN \\
\hline CHEMBL1384363 & 688759 & 4.45 & 4.7225 & TRN \\
\hline CHEMBL1489709 & 688759 & 5.3 & 5.035 & TRN \\
\hline CHEMBL1569860 & 688759 & 6.1 & 5.0866 & TRN \\
\hline CHEMBL1308081 & 688759 & 4.5 & 4.8111 & TRN \\
\hline CHEMBL1392799 & 688759 & 4.7 & 5.0747 & TRN \\
\hline CHEMBL1529050 & 688759 & 4.95 & 4.7607 & TRN \\
\hline CHEMBL1440503 & 688759 & 4.7 & 4.8278 & TST \\
\hline CHEMBL1508058 & 688759 & 5.25 & 5.3289 & TRN \\
\hline CHEMBL1557428 & 688759 & 4.45 & 4.7725 & TRN \\
\hline CHEMBL1458957 & 688759 & 4.75 & 4.6673 & TST \\
\hline CHEMBL1504858 & 688759 & 5.9 & 5.7584 & TRN \\
\hline CHEMBL1549881 & 688759 & 4.45 & 4.5914 & TRN \\
\hline CHEMBL1481061 & 688759 & 5.5 & 5.3106 & TST \\
\hline CHEMBL3197873 & 688759 & 5.3 & 5.0513 & TRN \\
\hline
\end{tabular}




\begin{tabular}{|c|c|c|c|c|c|}
\hline \multicolumn{6}{|c|}{ Supplemental Table S2.txt } \\
\hline CHEMBL1363569 & 688759 & 5.5 & 5.3058 & TRN & \\
\hline CHEMBL1450119 & 688759 & 5.0 & 5.2326 & TRN & \\
\hline CHEMBL1498122 & 688759 & 4.6 & 4.8859 & TRN & \\
\hline CHEMBL 3213184 & 688759 & 4.7 & 4.6334 & TRN & \\
\hline CHEMBL1477770 & 688759 & 4.65 & 4.8333 & TST & \\
\hline CHEMBL1516933 & 688759 & 4.45 & 4.9707 & TST & \\
\hline CHEMBL1494176 & 688759 & 4.75 & 5.0537 & TRN & \\
\hline CHEMBL1550286 & 688759 & 5.15 & 4.9192 & TRN & \\
\hline CHEMBL1544745 & 688759 & 5.3 & 5.7506 & TRN & \\
\hline CHEMBL1545751 & 688759 & 4.75 & 4.9459 & TST & \\
\hline CHEMBL1587218 & 688759 & 4.45 & 4.9208 & TST & \\
\hline CHEMBL1408997 & 688759 & 5.2 & 4.9228 & TRN & \\
\hline CHEMBL1489239 & 688759 & 5.1 & 4.61100 & 3000000001 & TRN \\
\hline CHEMBL1360748 & 688759 & 4.45 & 4.8413 & TST & \\
\hline CHEMBL1338304 & 688759 & 5.35 & 5.3279 & TRN & \\
\hline CHEMBL1608591 & 688759 & 5.25 & 4.6444 & TST & \\
\hline CHEMBL1468835 & 688759 & 4.45 & 4.8251 & TRN & \\
\hline CHEMBL1353131 & 688759 & 4.45 & 5.0057 & TST & \\
\hline CHEMBL1417475 & 688759 & 5.25 & 5.1147 & TRN & \\
\hline CHEMBL1313162 & 688759 & 4.55 & 4.552 & TRN & \\
\hline CHEMBL1606823 & 688759 & 4.45 & 4.6784 & TRN & \\
\hline CHEMBL1496162 & 688759 & 4.6 & 4.8761 & TST & \\
\hline CHEMBL1376605 & 688759 & 4.55 & 4.8457 & TRN & \\
\hline CHEMBL1502254 & 688759 & 4.45 & 4.6739 & TRN & \\
\hline CHEMBL1582985 & 688759 & 4.45 & 4.9135 & TST & \\
\hline CHEMBL1547217 & 688759 & 4.85 & 5.0694 & TRN & \\
\hline CHEMBL1971267 & 688759 & 4.9 & 5.0217 & TRN & \\
\hline CHEMBL1398171 & 688759 & 5.2 & 4.9773 & TRN & \\
\hline CHEMBL1388295 & 688759 & 4.75 & 4.8896 & TRN & \\
\hline CHEMBL1462776 & 688759 & 5.8 & 5.5134 & TRN & \\
\hline CHEMBL1363577 & 688759 & 4.75 & 4.8204 & TST & \\
\hline CHEMBL1464030 & 688759 & 4.45 & 4.6652 & TRN & \\
\hline CHEMBL1574059 & 688759 & 4.95 & 4.9374 & TRN & \\
\hline CHEMBL1413033 & 688759 & 5.9 & 5.2103 & TRN & \\
\hline CHEMBL1331944 & 688759 & 5.25 & 4.8486 & TRN & \\
\hline CHEMBL3190827 & 688759 & 5.85 & 5.3459 & TRN & \\
\hline CHEMBL1530611 & 688759 & 5.05 & 4.8385 & TRN & \\
\hline CHEMBL1343037 & 688759 & 5.15 & 5.2474 & TRN & \\
\hline CHEMBL1518326 & 688759 & 5.15 & 4.9193 & TST & \\
\hline CHEMBL3213492 & 688759 & 4.7 & 4.5665 & TRN & \\
\hline CHEMBL1463077 & 688759 & 5.85 & 5.4819 & TRN & \\
\hline CHEMBL1613554 & 688759 & 6.5501 & 5.0347 & TRN & \\
\hline CHEMBL3211327 & 688759 & 4.6 & 4.6681 & TRN & \\
\hline CHEMBL1570958 & 688759 & 5.4 & 5.0911 & TRN & \\
\hline CHEMBL1483596 & 688759 & 4.45 & 4.6775 & TST & \\
\hline CHEMBL1448094 & 688759 & 4.65 & 4.6421 & TRN & \\
\hline CHEMBL1971629 & 688759 & 4.45 & 4.668 & TRN & \\
\hline CHEMBL1329311 & 688759 & 4.6 & 4.8443 & TRN & \\
\hline
\end{tabular}




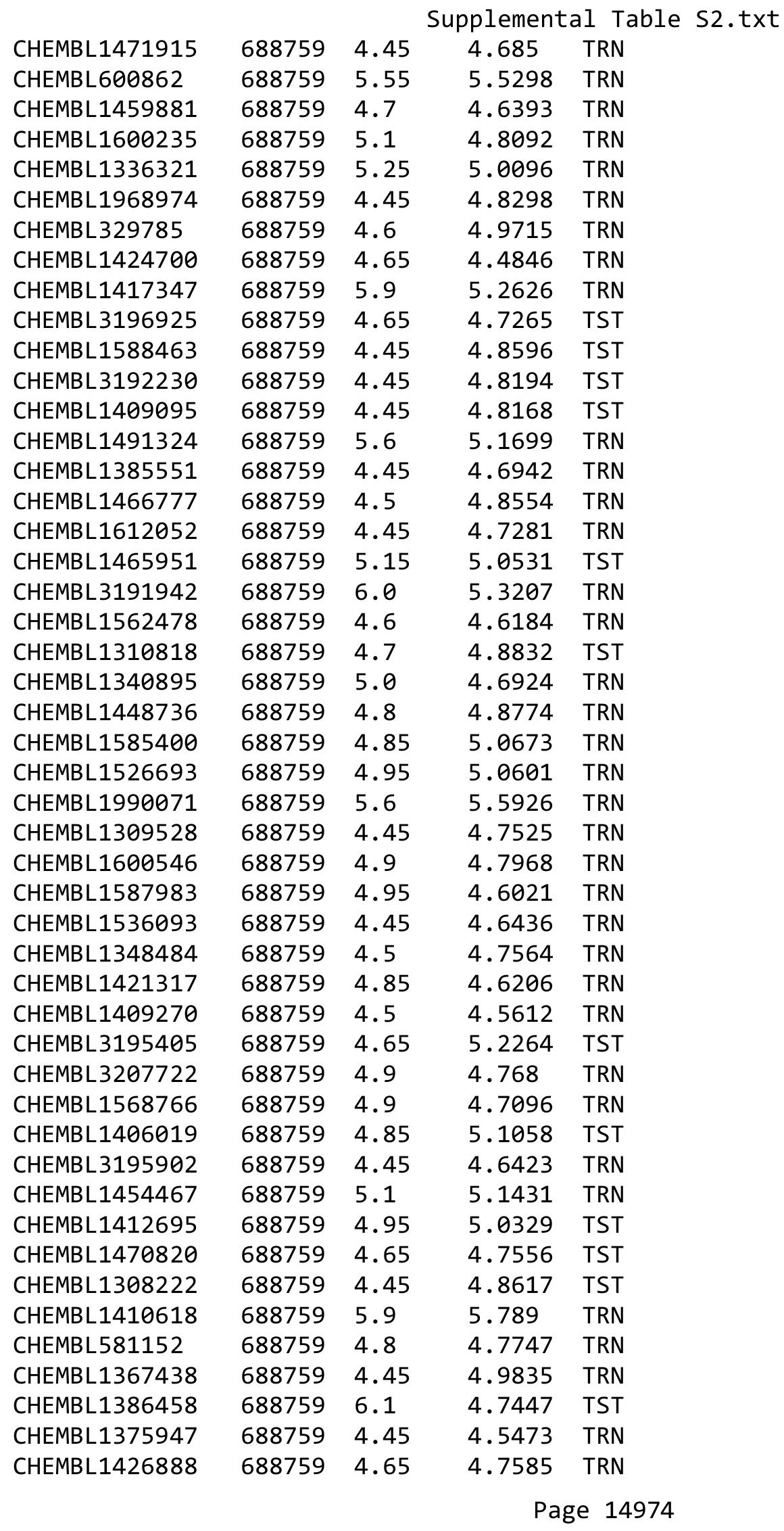




\begin{tabular}{|c|c|c|c|c|c|}
\hline \multicolumn{6}{|c|}{ Supplemental Table S2.txt } \\
\hline CHEMBL3196326 & 688759 & 5.7 & 5.5626 & TRN & \\
\hline CHEMBL1421261 & 688759 & 4.7 & 4.5594 & TRN & \\
\hline CHEMBL140 & 688759 & 6.0 & 5.33 & TRN & \\
\hline CHEMBL1339090 & 688759 & 4.85 & 4.6255 & TRN & \\
\hline CHEMBL1366888 & 688759 & 4.45 & 4.7324 & TRN & \\
\hline CHEMBL600100 & 688759 & 4.95 & 5.0701 & TRN & \\
\hline CHEMBL1347173 & 688759 & 4.45 & 4.9792 & TRN & \\
\hline CHEMBL1409781 & 688759 & 4.45 & 4.7246 & TST & \\
\hline CHEMBL1482004 & 688759 & 4.45 & 4.8751 & TST & \\
\hline CHEMBL1516385 & 688759 & 5.05 & 5.0055 & TRN & \\
\hline CHEMBL1539789 & 688759 & 5.05 & 5.1901 & TRN & \\
\hline CHEMBL3194043 & 688759 & 4.5 & 4.8061 & TRN & \\
\hline CHEMBL1606235 & 688759 & 4.95 & 4.6571 & TST & \\
\hline CHEMBL1565124 & 688759 & 5.2 & 4.7655 & TRN & \\
\hline CHEMBL 3190841 & 688759 & 4.9 & 4.7775 & TRN & \\
\hline CHEMBL1393701 & 688759 & 4.65 & 4.8443 & TRN & \\
\hline CHEMBL1453996 & 688759 & 5.9 & 5.9943 & TRN & \\
\hline CHEMBL 3197573 & 688759 & 4.55 & 4.7811 & TRN & \\
\hline CHEMBL1407441 & 688759 & 6.45 & 4.8521 & TST & \\
\hline CHEMBL1477259 & 688759 & 5.05 & 5.0594 & TRN & \\
\hline CHEMBL1362462 & 688759 & 4.45 & 4.5238 & TRN & \\
\hline CHEMBL1528427 & 688759 & 4.9 & 4.7513 & TST & \\
\hline CHEMBL 3212907 & 688759 & 5.7 & 5.6179 & TRN & \\
\hline CHEMBL1575299 & 688759 & 4.45 & 4.7887 & TST & \\
\hline CHEMBL610198 & 688759 & 4.95 & 4.9251 & TRN & \\
\hline CHEMBL1605206 & 688759 & 4.45 & 4.7634 & TRN & \\
\hline CHEMBL1471353 & 688759 & 4.65 & 4.6929 & TRN & \\
\hline CHEMBL1304089 & 688759 & 5.35 & 5.0251 & TST & \\
\hline CHEMBL1538183 & 688759 & 4.8 & 4.7605 & TST & \\
\hline CHEMBL1563288 & 688759 & 5.25 & 5.2518 & TRN & \\
\hline CHEMBL1587497 & 688759 & 4.45 & 5.0912 & TRN & \\
\hline CHEMBL1456244 & 688759 & 4.65 & 4.994 & TST & \\
\hline CHEMBL1330586 & 688759 & 5.4 & 4.8232 & TST & \\
\hline CHEMBL1307805 & 688759 & 4.45 & 4.8045 & TRN & \\
\hline CHEMBL1415393 & 688759 & 4.45 & 4.8287 & TST & \\
\hline CHEMBL1322160 & 688759 & 4.8 & 4.66100 & 00000000005 & TRN \\
\hline CHEMBL1377023 & 688759 & 4.45 & 4.8032 & TRN & \\
\hline CHEMBL1361740 & 688759 & 5.35 & 5.2757 & TST & \\
\hline CHEMBL1458457 & 688759 & 4.6 & 4.7277 & TRN & \\
\hline CHEMBL1345937 & 688759 & 4.45 & 4.848 & TRN & \\
\hline CHEMBL1313354 & 688759 & 4.45 & 4.8899 & TST & \\
\hline CHEMBL3199662 & 688759 & 4.65 & 5.165 & TRN & \\
\hline CHEMBL1505962 & 688759 & 4.9 & 5.3345 & TRN & \\
\hline CHEMBL1571982 & 688759 & 4.6 & 5.1943 & TRN & \\
\hline CHEMBL1386707 & 688759 & 4.8 & 4.7714 & TRN & \\
\hline CHEMBL1402537 & 688759 & 4.4 & 4.885 & TST & \\
\hline CHEMBL1551979 & 688759 & 4.65 & 4.8042 & TRN & \\
\hline CHEMBL3193212 & 688759 & 4.45 & 4.8915 & TRN & \\
\hline
\end{tabular}




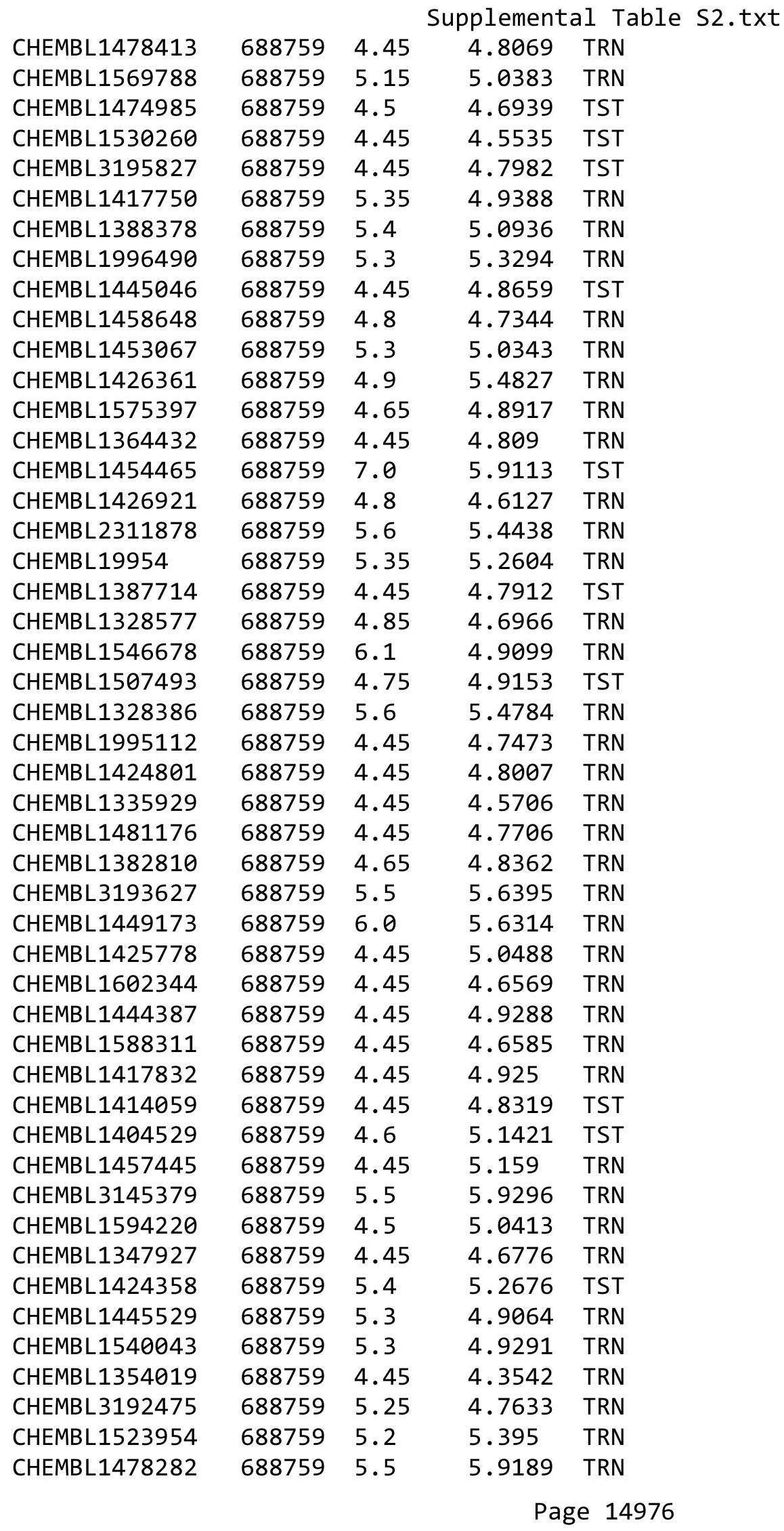




\begin{tabular}{|c|c|c|c|c|c|}
\hline \\
\hline CHEMBL1561472 & 688759 & 4.5 & 4.725 & TST & \\
\hline CHEMBL1420129 & 688759 & 4.45 & 4.7471 & TST & \\
\hline CHEMBL1601941 & 688759 & 4.45 & 4.9272 & TRN & \\
\hline CHEMBL1578392 & 688759 & 5.3 & 5.2499 & TRN & \\
\hline CHEMBL1567619 & 688759 & 4.9 & 4.8732 & TRN & \\
\hline CHEMBL1405107 & 688759 & 4.7 & 4.8672 & TRN & \\
\hline CHEMBL1529378 & 688759 & 5.85 & 4.6978 & TRN & \\
\hline CHEMBL1384442 & 688759 & 5.05 & 4.8974 & TRN & \\
\hline CHEMBL1567223 & 688759 & 5.45 & 5.1622 & TRN & \\
\hline CHEMBL1372353 & 688759 & 4.85 & 4.9597 & TRN & \\
\hline CHEMBL1423463 & 688759 & 4.75 & 4.6497 & TRN & \\
\hline CHEMBL1410096 & 688759 & 4.45 & 4.7348 & TRN & \\
\hline CHEMBL1359321 & 688759 & 5.65 & 5.3518 & TRN & \\
\hline CHEMBL1424091 & 688759 & 4.8 & 4.4768 & TST & \\
\hline CHEMBL1544361 & 688759 & 6.0 & 4.8324 & TRN & \\
\hline CHEMBL1359801 & 688759 & 5.6 & 5.0634 & TST & \\
\hline CHEMBL1539339 & 688759 & 5.5 & 5.4291 & TRN & \\
\hline CHEMBL1524449 & 688759 & 4.55 & 4.8845 & TRN & \\
\hline CHEMBL1328522 & 688759 & 4.45 & 4.8877 & TRN & \\
\hline CHEMBL1554179 & 688759 & 4.45 & 4.9993 & TST & \\
\hline CHEMBL1549279 & 688759 & 4.65 & 5.0473 & TRN & \\
\hline CHEMBL1460823 & 688759 & 4.45 & 5.0099 & TRN & \\
\hline CHEMBL3144896 & 688759 & 4.65 & 4.7435 & TRN & \\
\hline CHEMBL3190809 & 688759 & 5.7 & 5.3837 & TRN & \\
\hline CHEMBL1596784 & 688759 & 4.45 & 4.8983 & TST & \\
\hline CHEMBL1485417 & 688759 & 4.95 & 5.16299 & 9999999999 & TRN \\
\hline CHEMBL1411870 & 688759 & 4.45 & 4.8144 & TST & \\
\hline CHEMBL1500404 & 688759 & 5.15 & 4.6906 & TRN & \\
\hline CHEMBL3192976 & 688759 & 4.45 & 4.9121 & TRN & \\
\hline CHEMBL1563192 & 688759 & 4.6 & 5.0196 & TRN & \\
\hline CHEMBL1538197 & 688759 & 5.2 & 5.5891 & TRN & \\
\hline CHEMBL1415077 & 688759 & 4.95 & 4.7317 & TST & \\
\hline CHEMBL1510594 & 688759 & 4.45 & 4.6694 & TRN & \\
\hline CHEMBL 3199448 & 688759 & 5.25 & 5.1051 & TRN & \\
\hline CHEMBL3199832 & 688759 & 5.0 & 5.1288 & TRN & \\
\hline CHEMBL1996451 & 688759 & 5.0 & 4.9128 & TRN & \\
\hline CHEMBL53753 & 688759 & 4.9 & 4.7576 & TST & \\
\hline CHEMBL1328803 & 688759 & 4.5 & 4.8982 & TST & \\
\hline CHEMBL1432841 & 688759 & 4.45 & 4.8676 & TRN & \\
\hline CHEMBL1458722 & 688759 & 4.65 & 5.1808 & TST & \\
\hline CHEMBL1325019 & 688759 & 5.1 & 4.7651 & TRN & \\
\hline CHEMBL1419429 & 688759 & 4.75 & 4.7385 & TRN & \\
\hline CHEMBL1502458 & 688759 & 4.8 & 4.7783 & TST & \\
\hline CHEMBL1308170 & 688759 & 4.8 & 5.0779 & TST & \\
\hline CHEMBL1352760 & 688759 & 5.3 & 5.0951 & TRN & \\
\hline CHEMBL1498476 & 688759 & 5.0 & 4.7524 & TRN & \\
\hline CHEMBL1561862 & 688759 & 4.65 & 4.8165 & TRN & \\
\hline CHEMBL1523955 & 688759 & 5.1 & 5.2602 & TRN & \\
\hline & & & & 14977 & \\
\hline
\end{tabular}




\begin{tabular}{|c|c|c|c|c|c|}
\hline \\
\hline CHEMBL1480836 & 688759 & 4.8 & 4.6497 & TRN & \\
\hline CHEMBL1581065 & 688759 & 5.95 & 5.1038 & TST & \\
\hline CHEMBL1971441 & 688759 & 4.95 & 4.7872 & TRN & \\
\hline CHEMBL1400768 & 688759 & 4.45 & 4.9407 & TRN & \\
\hline CHEMBL1343357 & 688759 & 4.95 & 4.9793 & TRN & \\
\hline CHEMBL1304553 & 688759 & 5.2 & 4.954 & TST & \\
\hline CHEMBL1381893 & 688759 & 4.5 & 4.7525 & TRN & \\
\hline CHEMBL1567553 & 688759 & 4.45 & 5.0061 & TRN & \\
\hline CHEMBL1571491 & 688759 & 4.45 & 4.6752 & TRN & \\
\hline CHEMBL1321577 & 688759 & 4.45 & 4.8155 & TRN & \\
\hline CHEMBL1406540 & 688759 & 4.7 & 4.8869 & TRN & \\
\hline CHEMBL1910223 & 688759 & 4.45 & 5.0593 & TRN & \\
\hline CHEMBL1488564 & 688759 & 4.5 & 4.6886 & TRN & \\
\hline CHEMBL1606586 & 688759 & 4.6 & 4.6501 & TRN & \\
\hline CHEMBL1393490 & 688759 & 4.9 & 4.8938 & TRN & \\
\hline CHEMBL1610497 & 688759 & 5.4 & 5.1012 & TRN & \\
\hline CHEMBL1464534 & 688759 & 4.85 & 5.0572 & TST & \\
\hline CHEMBL1299227 & 688759 & 4.65 & 4.8403 & TRN & \\
\hline CHEMBL1303391 & 688759 & 4.85 & 5.0813 & TRN & \\
\hline CHEMBL1505623 & 688759 & 5.05 & 5.05699 & 99999999995 & TRN \\
\hline CHEMBL1420527 & 688759 & 4.55 & 4.8062 & TRN & \\
\hline CHEMBL1586423 & 688759 & 4.6 & 4.9378 & TRN & \\
\hline CHEMBL1534185 & 688759 & 6.0 & 4.9921 & TST & \\
\hline CHEMBL1387512 & 688759 & 4.55 & 5.4208 & TST & \\
\hline CHEMBL1378852 & 688759 & 5.15 & 4.9897 & TRN & \\
\hline CHEMBL1466923 & 688759 & 4.45 & 5.0627 & TRN & \\
\hline CHEMBL1583760 & 688759 & 4.45 & 4.7428 & TRN & \\
\hline CHEMBL1351128 & 688759 & 5.3 & 5.1385 & TST & \\
\hline CHEMBL1330478 & 688759 & 4.9 & 4.9536 & TRN & \\
\hline CHEMBL1373869 & 688759 & 4.65 & 4.617 & TRN & \\
\hline CHEMBL1374707 & 688759 & 5.65 & 4.9861 & TRN & \\
\hline CHEMBL 2369309 & 688759 & 4.7 & 4.8098 & TRN & \\
\hline CHEMBL3199526 & 688759 & 5.45 & 4.9418 & TRN & \\
\hline CHEMBL1349223 & 688759 & 5.0 & 4.8696 & TRN & \\
\hline CHEMBL1535636 & 688759 & 4.65 & 4.417 & TRN & \\
\hline CHEMBL1404362 & 688759 & 5.35 & 4.6642 & TRN & \\
\hline CHEMBL1413843 & 688759 & 4.6 & 4.875 & TRN & \\
\hline CHEMBL1604121 & 688759 & 4.75 & 4.7281 & TRN & \\
\hline CHEMBL1446966 & 688759 & 5.0 & 5.1769 & TRN & \\
\hline CHEMBL1382702 & 688759 & 4.45 & 4.6332 & TST & \\
\hline CHEMBL1350665 & 688759 & 4.45 & 4.6374 & TST & \\
\hline CHEMBL1487764 & 688759 & 5.2 & 4.8909 & TRN & \\
\hline CHEMBL1306008 & 688759 & 4.95 & 4.8782 & TRN & \\
\hline CHEMBL1964873 & 688759 & 5.5 & 5.136 & TRN & \\
\hline CHEMBL1551022 & 688759 & 4.65 & 4.963 & TRN & \\
\hline CHEMBL1375496 & 688759 & 5.6 & 4.8029 & TRN & \\
\hline CHEMBL1979854 & 688759 & 6.15 & 5.7909 & TRN & \\
\hline CHEMBL1364016 & 688759 & 4.7 & 4.8796 & TST & \\
\hline
\end{tabular}




\begin{tabular}{|c|c|c|c|c|c|}
\hline \multicolumn{6}{|c|}{ Supplemental Table S2.txt } \\
\hline CHEMBL1503659 & 688759 & 5.55 & 5.0345 & TRN & \\
\hline CHEMBL1580856 & 688759 & 4.95 & 4.9847 & TRN & \\
\hline CHEMBL1579926 & 688759 & 4.95 & 4.8986 & TRN & \\
\hline CHEMBL 3192731 & 688759 & 4.45 & 4.8438 & TST & \\
\hline CHEMBL1390565 & 688759 & 6.05 & 5.7632 & TRN & \\
\hline CHEMBL1542064 & 688759 & 4.95 & 4.9317 & TST & \\
\hline CHEMBL1402730 & 688759 & 4.65 & 5.2148 & TST & \\
\hline CHEMBL1301788 & 688759 & 4.45 & 4.572 & TRN & \\
\hline CHEMBL 3196961 & 688759 & 6.2 & 5.5406 & TRN & \\
\hline CHEMBL1524972 & 688759 & 4.45 & 4.8254 & TRN & \\
\hline CHEMBL1332879 & 688759 & 4.75 & 4.7456 & TRN & \\
\hline CHEMBL1385598 & 688759 & 4.45 & 4.6565 & TRN & \\
\hline CHEMBL3211687 & 688759 & 4.85 & 5.3336 & TRN & \\
\hline CHEMBL1410022 & 688759 & 4.65 & 4.4645 & TRN & \\
\hline CHEMBL1585417 & 688759 & 4.9 & 4.7991 & TRN & \\
\hline CHEMBL3193486 & 688759 & 6.15 & 5.6379 & TRN & \\
\hline CHEMBL3197896 & 688759 & 4.65 & 4.7389 & TRN & \\
\hline CHEMBL1558411 & 688759 & 4.9 & 4.669 & TRN & \\
\hline CHEMBL1604524 & 688759 & 4.75 & 4.9797 & TST & \\
\hline CHEMBL1978069 & 688759 & 4.45 & 4.6704 & TRN & \\
\hline CHEMBL1509308 & 688759 & 4.55 & 4.729 & TRN & \\
\hline CHEMBL3196711 & 688759 & 5.2 & 5.4548 & TRN & \\
\hline CHEMBL1549875 & 688759 & 6.0 & 4.7841 & TST & \\
\hline CHEMBL1455056 & 688759 & 4.65 & 4.7749 & TRN & \\
\hline CHEMBL 2001381 & 688759 & 5.5 & 5.32600 & 00000000005 & TRN \\
\hline CHEMBL1441088 & 688759 & 5.4 & 5.2055 & TRN & \\
\hline CHEMBL1487125 & 688759 & 5.05 & 4.8449 & TRN & \\
\hline CHEMBL1502232 & 688759 & 5.25 & 4.9026 & TRN & \\
\hline CHEMBL 3198944 & 688759 & 4.7 & 4.7834 & TRN & \\
\hline CHEMBL1539656 & 688759 & 4.7 & 4.7424 & TRN & \\
\hline CHEMBL1310859 & 688759 & 4.45 & 4.6686 & TRN & \\
\hline CHEMBL 3145069 & 688759 & 4.65 & 4.9988 & TRN & \\
\hline CHEMBL1497219 & 688759 & 4.45 & 4.5161 & TRN & \\
\hline CHEMBL1421603 & 688759 & 5.6 & 5.3965 & TST & \\
\hline CHEMBL1346587 & 688759 & 5.15 & 4.6302 & TRN & \\
\hline CHEMBL1516774 & 688759 & 4.45 & 4.7346 & TRN & \\
\hline CHEMBL1445171 & 688759 & 4.45 & 5.0964 & TST & \\
\hline CHEMBL1407546 & 688759 & 4.45 & 4.6549 & TRN & \\
\hline CHEMBL1352829 & 688759 & 4.75 & 4.7168 & TRN & \\
\hline CHEMBL1532917 & 688759 & 5.0 & 4.9587 & TRN & \\
\hline CHEMBL1469047 & 688759 & 5.05 & 5.1877 & TRN & \\
\hline CHEMBL1508505 & 688759 & 4.45 & 4.6607 & TRN & \\
\hline CHEMBL1974810 & 688759 & 5.25 & 5.0052 & TRN & \\
\hline CHEMBL1480424 & 688759 & 5.2 & 4.9664 & TRN & \\
\hline CHEMBL1520564 & 688759 & 5.25 & 4.8137 & TRN & \\
\hline CHEMBL1457128 & 688759 & 4.9 & 5.0208 & TRN & \\
\hline CHEMBL3199920 & 688759 & 4.45 & 4.8873 & TRN & \\
\hline CHEMBL1467273 & 688759 & 4.45 & 4.7208 & TRN & \\
\hline
\end{tabular}




\begin{tabular}{|c|c|c|c|c|c|}
\hline \multirow[b]{2}{*}{ CHEMBL1490987 } & \multirow[b]{2}{*}{688759} & \multicolumn{4}{|c|}{ Supplemental Table S2.txt } \\
\hline & & 4.65 & 4.604 & TRN & \\
\hline CHEMBL1403169 & 688759 & 4.95 & 4.8426 & TRN & \\
\hline CHEMBL1358812 & 688759 & 5.6 & 4.9408 & TRN & \\
\hline CHEMBL 3208420 & 688759 & 4.65 & 4.60800 & 00000000005 & TRN \\
\hline CHEMBL1365827 & 688759 & 6.4 & 5.6575 & TST & \\
\hline CHEMBL1311742 & 688759 & 4.45 & 4.6153 & TRN & \\
\hline CHEMBL1458689 & 688759 & 5.35 & 4.9032 & TRN & \\
\hline CHEMBL1540009 & 688759 & 5.5 & 4.587 & TRN & \\
\hline CHEMBL3195620 & 688759 & 4.45 & 4.9658 & TST & \\
\hline CHEMBL3210190 & 688759 & 4.5 & 5.013 & TST & \\
\hline CHEMBL 74474 & 688759 & 4.45 & 5.0551 & TST & \\
\hline CHEMBL1534118 & 688759 & 4.45 & 4.8514 & TRN & \\
\hline CHEMBL3197208 & 688759 & 5.05 & 5.2201 & TRN & \\
\hline CHEMBL1541706 & 688759 & 4.75 & 4.8963 & TRN & \\
\hline CHEMBL1464339 & 688759 & 4.5 & 6.4356 & TRN & \\
\hline CHEMBL1502056 & 688759 & 5.3 & 5.0437 & TRN & \\
\hline CHEMBL1393399 & 688759 & 4.55 & 4.8592 & TRN & \\
\hline CHEMBL1481543 & 688759 & 5.2 & 5.2273 & TRN & \\
\hline CHEMBL1342357 & 688759 & 4.45 & 4.6703 & TST & \\
\hline CHEMBL1537081 & 688759 & 4.7 & 4.6171 & TRN & \\
\hline CHEMBL1385192 & 688759 & 5.0 & 4.8089 & TRN & \\
\hline CHEMBL1537137 & 688759 & 4.45 & 4.9262 & TRN & \\
\hline CHEMBL1547232 & 688759 & 4.65 & 5.0547 & TRN & \\
\hline CHEMBL1518284 & 688759 & 4.5 & 4.7732 & TST & \\
\hline CHEMBL1565713 & 688759 & 4.6 & 4.7788 & TST & \\
\hline CHEMBL1326290 & 688759 & 4.7 & 4.6859 & TRN & \\
\hline CHEMBL1383454 & 688759 & 5.9 & 5.0368 & TRN & \\
\hline CHEMBL1411044 & 688759 & 4.7 & 5.0457 & TST & \\
\hline CHEMBL1542542 & 688759 & 4.85 & 4.7909 & TRN & \\
\hline CHEMBL1598264 & 688759 & 5.15 & 5.0301 & TRN & \\
\hline CHEMBL1425624 & 688759 & 5.65 & 5.6282 & TRN & \\
\hline CHEMBL1462828 & 688759 & 4.9 & 4.8867 & TRN & \\
\hline CHEMBL1306132 & 688759 & 5.7 & 5.4296 & TST & \\
\hline CHEMBL1582023 & 688759 & 4.45 & 4.5199 & TST & \\
\hline CHEMBL1412987 & 688759 & 6.5 & 4.927 & TRN & \\
\hline CHEMBL1487987 & 688759 & 4.95 & 4.4993 & TRN & \\
\hline CHEMBL1549839 & 688759 & 5.25 & 4.8147 & TRN & \\
\hline CHEMBL1423060 & 688759 & 5.05 & 5.0619 & TRN & \\
\hline CHEMBL1165197 & 688759 & 4.45 & 4.7481 & TRN & \\
\hline CHEMBL1380943 & 688759 & 4.65 & 4.6992 & TRN & \\
\hline CHEMBL1465465 & 688759 & 5.95 & 4.8663 & TRN & \\
\hline CHEMBL1426620 & 688759 & 4.45 & 4.6898 & TRN & \\
\hline CHEMBL1427508 & 688759 & 4.45 & 4.7294 & TRN & \\
\hline CHEMBL1508230 & 688759 & 4.65 & 4.7919 & TST & \\
\hline CHEMBL1363068 & 688759 & 5.65 & 4.7622 & TRN & \\
\hline CHEMBL1609148 & 688759 & 4.45 & 4.5685 & TST & \\
\hline CHEMBL1581503 & 688759 & 4.45 & 4.7276 & TRN & \\
\hline CHEMBL1567859 & 688759 & 4.85 & 4.8825 & TRN & \\
\hline
\end{tabular}




\begin{tabular}{|c|c|c|c|c|c|}
\hline & & \multicolumn{4}{|c|}{ Supplemental Table s2.txt } \\
\hline CHEMBL1576706 & 688759 & 4.65 & 4.5408 & TRN & \\
\hline CHEMBL3197605 & 688759 & 4.45 & 4.7907 & TRN & \\
\hline CHEMBL1569849 & 688759 & 4.9 & 4.7365 & TRN & \\
\hline CHEMBL 3197130 & 688759 & 4.95 & 4.9966 & TRN & \\
\hline CHEMBL1598744 & 688759 & 4.45 & 5.0141 & TST & \\
\hline CHEMBL1581929 & 688759 & 4.95 & 4.9107 & TST & \\
\hline CHEMBL1531825 & 688759 & 4.45 & 4.7056 & TRN & \\
\hline CHEMBL1405735 & 688759 & 4.95 & 4.7573 & TST & \\
\hline CHEMBL1318742 & 688759 & 4.45 & 4.8 & TST & \\
\hline CHEMBL1541012 & 688759 & 5.05 & 5.0343 & TRN & \\
\hline CHEMBL1542664 & 688759 & 4.95 & 4.6206 & TRN & \\
\hline CHEMBL1502004 & 688759 & 5.1 & 5.0504 & TRN & \\
\hline CHEMBL1386582 & 688759 & 4.85 & 4.7798 & TST & \\
\hline CHEMBL 3208742 & 688759 & 4.45 & 5.0152 & TRN & \\
\hline CHEMBL1523608 & 688759 & 4.45 & 4.7858 & TST & \\
\hline CHEMBL601952 & 688759 & 4.45 & 4.6892 & TST & \\
\hline CHEMBL1523486 & 688759 & 4.65 & 4.8484 & TRN & \\
\hline CHEMBL1612656 & 688759 & 5.25 & 4.8728 & TST & \\
\hline CHEMBL3213086 & 688759 & 5.25 & 4.9256 & TRN & \\
\hline CHEMBL1586660 & 688759 & 5.0 & 4.6154 & TRN & \\
\hline CHEMBL3213058 & 688759 & 4.45 & 4.7304 & TRN & \\
\hline CHEMBL31156 & 688759 & 4.45 & 4.8359 & TST & \\
\hline CHEMBL1302109 & 688759 & 5.05 & 4.8753 & TRN & \\
\hline CHEMBL1575912 & 688759 & 5.9 & 4.6175 & TRN & \\
\hline CHEMBL1604846 & 688759 & 4.55 & 4.8325 & TST & \\
\hline CHEMBL1525081 & 688759 & 5.05 & 4.8168 & TST & \\
\hline CHEMBL1561686 & 688759 & 4.45 & 4.5096 & TRN & \\
\hline CHEMBL1340716 & 688759 & 4.8 & 4.9867 & TRN & \\
\hline CHEMBL1497551 & 688759 & 4.45 & 4.9619 & TST & \\
\hline CHEMBL1580727 & 688759 & 4.75 & 4.791 & TST & \\
\hline CHEMBL1498966 & 688759 & 4.9 & 4.8925 & TRN & \\
\hline CHEMBL3194782 & 688759 & 5.55 & 5.6326 & TRN & \\
\hline CHEMBL1973156 & 688759 & 5.0 & 4.7105 & TRN & \\
\hline CHEMBL1378421 & 688759 & 4.8 & 4.8532 & TST & \\
\hline CHEMBL1339274 & 688759 & 4.45 & 4.8401 & TST & \\
\hline CHEMBL1375245 & 688759 & 6.1 & 5.5331 & TRN & \\
\hline CHEMBL3198827 & 688759 & 4.8 & 4.9323 & TRN & \\
\hline CHEMBL1600287 & 688759 & 5.15 & 5.17299 & 9999999999 & TRN \\
\hline CHEMBL1439498 & 688759 & 4.45 & 4.6724 & TST & \\
\hline CHEMBL1591209 & 688759 & 4.55 & 4.5886 & TST & \\
\hline CHEMBL3189746 & 688759 & 5.25 & 5.21700 & 00000000005 & TRN \\
\hline CHEMBL1596174 & 688759 & 5.2 & 4.9129 & TRN & \\
\hline CHEMBL1417654 & 688759 & 4.7 & 5.1538 & TST & \\
\hline CHEMBL1458111 & 688759 & 5.5 & 5.29899 & 99999999995 & TST \\
\hline CHEMBL1319952 & 688759 & 4.45 & 4.5048 & TRN & \\
\hline CHEMBL1440661 & 688759 & 5.4 & 5.2609 & TRN & \\
\hline CHEMBL3194753 & 688759 & 4.45 & 4.7369 & TST & \\
\hline CHEMBL1567920 & 688759 & 4.45 & 4.8166 & TRN & \\
\hline
\end{tabular}




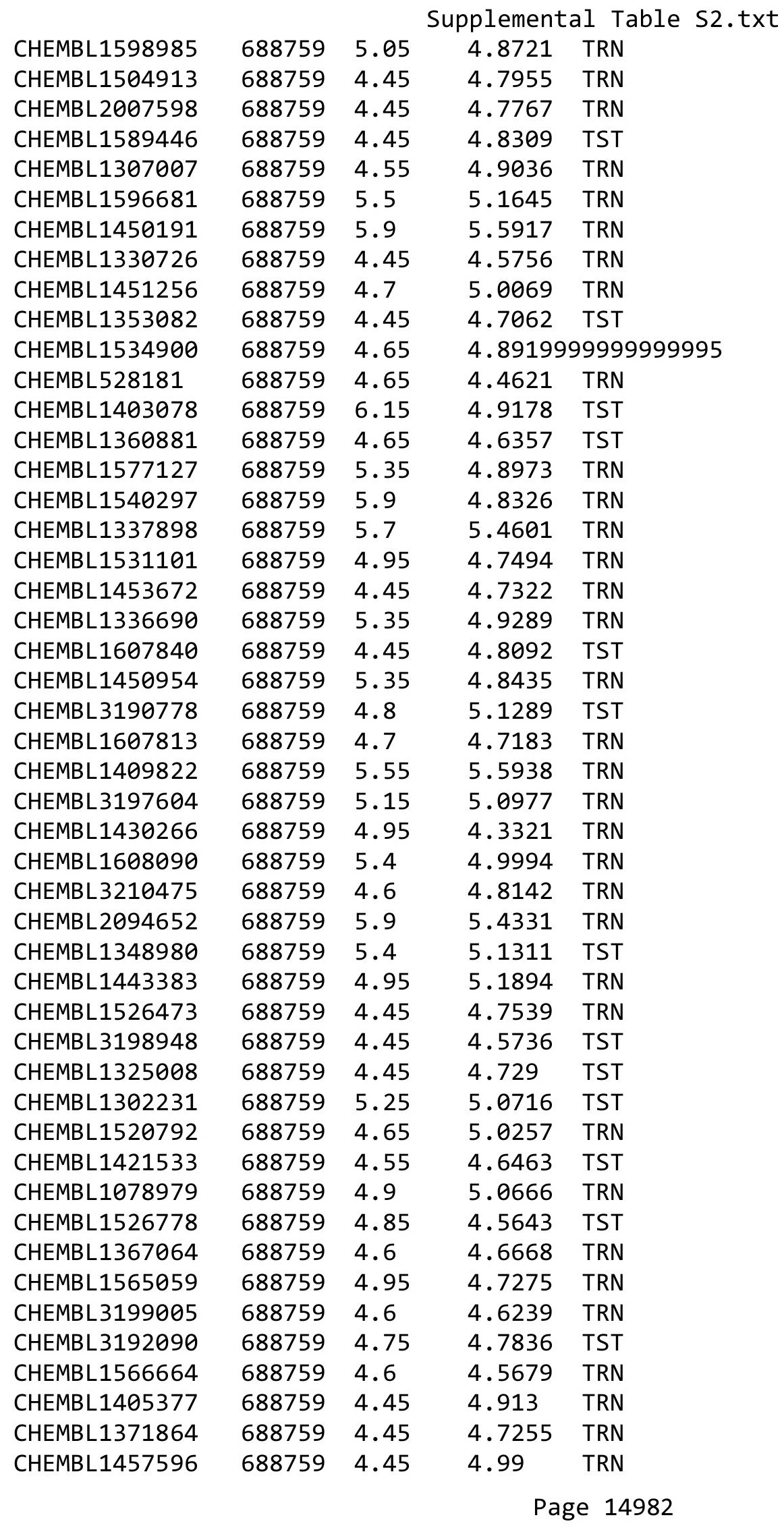




\begin{tabular}{|c|c|c|c|c|}
\hline \\
\hline CHEMBL1305677 & 688759 & 4.8 & 4.835 & TRN \\
\hline CHEMBL1391965 & 688759 & 5.4 & \multicolumn{2}{|c|}{5.367999999999999} \\
\hline CHEMBL1557418 & 688759 & 4.5 & 4.8381 & TST \\
\hline CHEMBL1338507 & 688759 & 4.45 & 4.9051 & TRN \\
\hline CHEMBL1223587 & 688759 & 4.45 & 5.1557 & TRN \\
\hline CHEMBL1587272 & 688759 & 4.45 & 4.8796 & TST \\
\hline CHEMBL1545927 & 688759 & 5.15 & 4.8593 & TRN \\
\hline CHEMBL1440995 & 688759 & 4.45 & 5.4556 & TRN \\
\hline CHEMBL1482119 & 688759 & 4.45 & 4.8107 & TST \\
\hline CHEMBL1374685 & 688759 & 4.45 & 4.6882 & TRN \\
\hline CHEMBL1587745 & 688759 & 4.65 & 4.9558 & TRN \\
\hline CHEMBL3189709 & 688759 & 4.7 & 4.9414 & TRN \\
\hline CHEMBL 2086964 & 688759 & 4.45 & 4.5285 & TRN \\
\hline CHEMBL1462116 & 688759 & 5.35 & 5.5901 & TRN \\
\hline CHEMBL 3212447 & 688759 & 4.6 & 4.7124 & TRN \\
\hline CHEMBL1968290 & 688759 & 4.65 & 4.8725 & TST \\
\hline CHEMBL1486574 & 688759 & 4.45 & 4.6791 & TST \\
\hline CHEMBL1597143 & 688759 & 4.85 & 4.7967 & TRN \\
\hline CHEMBL1429650 & 688759 & 4.45 & 5.1638 & TRN \\
\hline CHEMBL591126 & 688759 & 6.0 & 5.3936 & TRN \\
\hline CHEMBL3192863 & 688759 & 4.9 & 5.1995 & TRN \\
\hline CHEMBL1520827 & 688759 & 4.6 & 4.803 & TST \\
\hline CHEMBL 3194340 & 688759 & 4.45 & 4.7357 & TRN \\
\hline CHEMBL3196827 & 688759 & 4.95 & 4.896 & TRN \\
\hline CHEMBL1509034 & 688759 & 4.6 & 4.8407 & TRN \\
\hline CHEMBL1463322 & 688759 & 5.2 & 5.02 & TRN \\
\hline CHEMBL1496958 & 688759 & 4.5 & 4.9167 & TRN \\
\hline CHEMBL1398762 & 688759 & 5.0 & 5.0983 & TRN \\
\hline CHEMBL1416853 & 688759 & 6.95 & 5.1524 & TRN \\
\hline CHEMBL1324590 & 688759 & 4.65 & 4.8223 & TRN \\
\hline CHEMBL1501896 & 688759 & 5.6 & 5.7298 & TRN \\
\hline CHEMBL1519844 & 688759 & 6.0 & 5.3726 & TRN \\
\hline CHEMBL1329228 & 688759 & 4.75 & 4.9176 & TRN \\
\hline CHEMBL1507387 & 688759 & 4.75 & 4.8699 & TRN \\
\hline CHEMBL1518151 & 688759 & 4.7 & 4.9558 & TST \\
\hline CHEMBL1321561 & 688759 & 5.25 & 4.6357 & TST \\
\hline CHEMBL1447463 & 688759 & 4.45 & 4.7708 & TRN \\
\hline CHEMBL1391248 & 688759 & 4.45 & 4.8662 & TRN \\
\hline CHEMBL1446455 & 688759 & 4.45 & 4.6789 & TST \\
\hline CHEMBL1383971 & 688759 & 4.8 & 4.8111 & TRN \\
\hline CHEMBL1511688 & 688759 & 4.7 & 4.8363 & TST \\
\hline CHEMBL 2001139 & 688759 & 5.5 & 5.556 & TRN \\
\hline CHEMBL1453619 & 688759 & 6.0 & 5.9531 & TRN \\
\hline CHEMBL1525292 & 688759 & 4.6 & 4.9472 & TST \\
\hline CHEMBL1967273 & 688759 & 4.45 & 4.8733 & TRN \\
\hline CHEMBL3209159 & 688759 & 5.9 & 5.4607 & TRN \\
\hline CHEMBL1383772 & 688759 & 5.15 & 5.0247 & TRN \\
\hline CHEMBL1310172 & 688759 & 4.45 & 4.8422 & TRN \\
\hline
\end{tabular}

TRN 


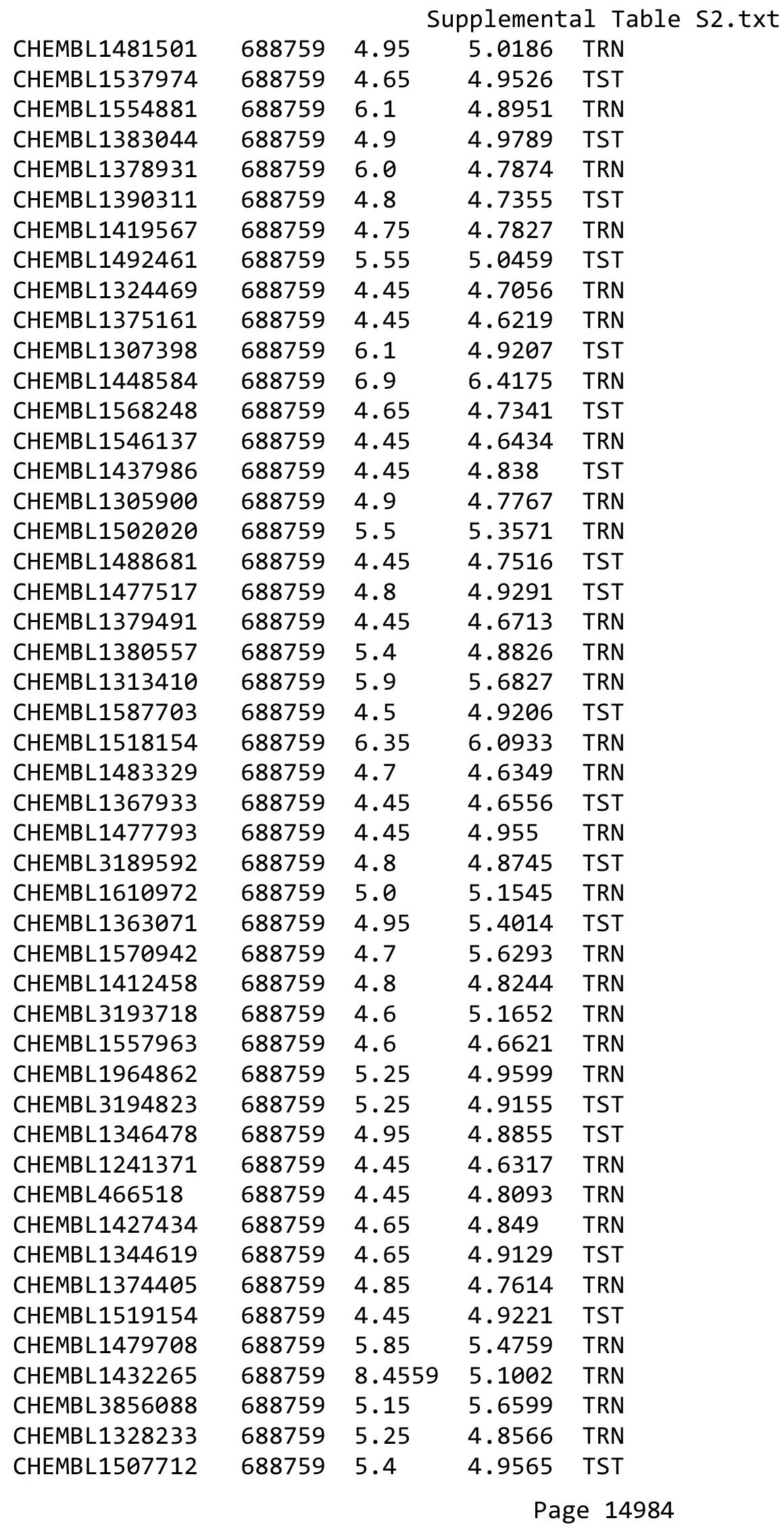




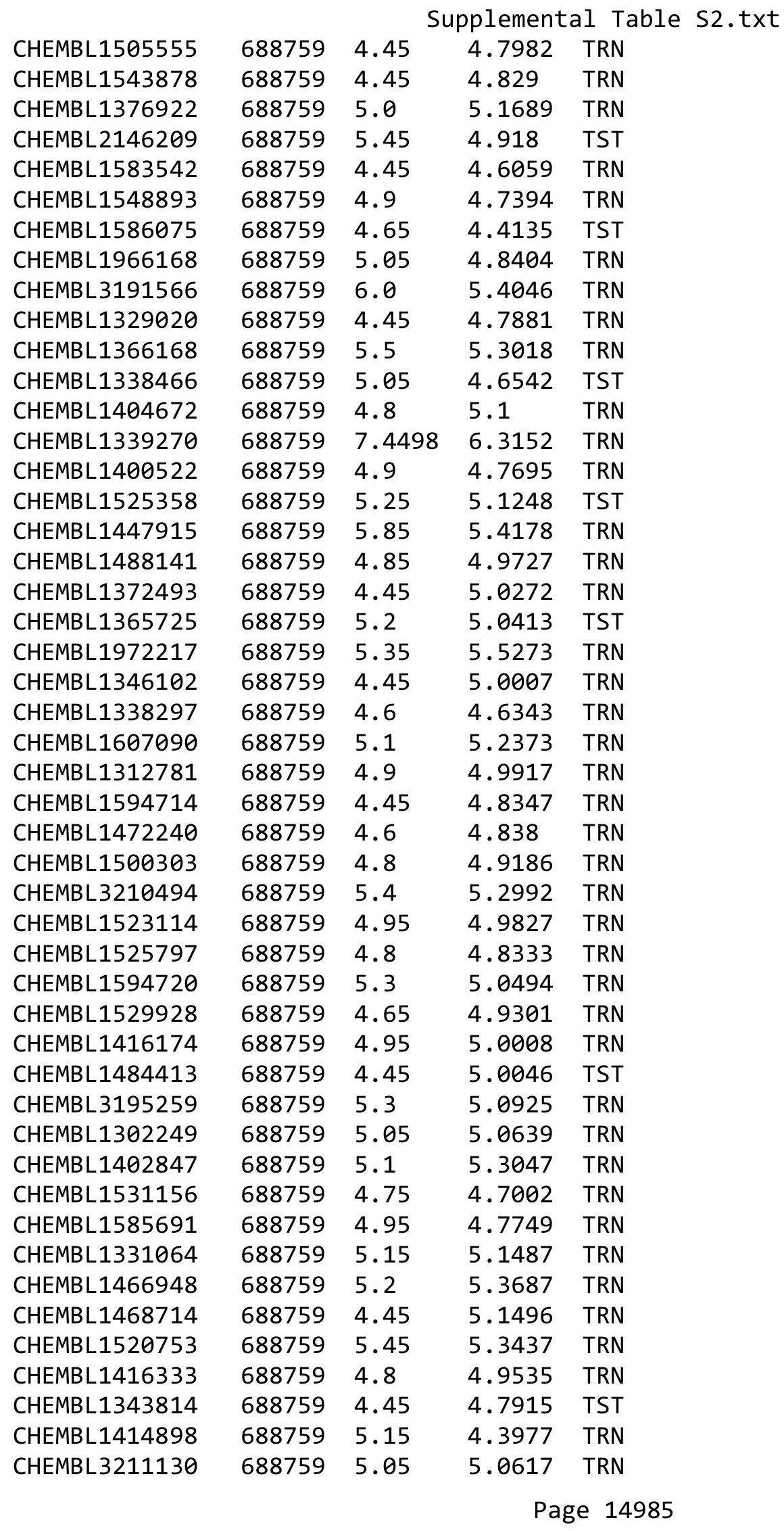




\begin{tabular}{|c|c|c|c|c|c|}
\hline \multicolumn{6}{|c|}{ Supplemental Table S2.txt } \\
\hline CHEMBL1492655 & 688759 & 4.65 & 4.9072 & TST & \\
\hline CHEMBL3190131 & 688759 & 5.45 & 5.1642 & TRN & \\
\hline CHEMBL1609237 & 688759 & 5.15 & 5.4055 & TRN & \\
\hline CHEMBL1341061 & 688759 & 4.45 & 4.9761 & TRN & \\
\hline CHEMBL1576343 & 688759 & 5.65 & 5.4514 & TRN & \\
\hline CHEMBL1485101 & 688759 & 5.0 & 4.9203 & TRN & \\
\hline CHEMBL1508196 & 688759 & 5.2 & 5.1852 & TRN & \\
\hline CHEMBL1465800 & 688759 & 4.8 & 4.8251 & TRN & \\
\hline CHEMBL1470953 & 688759 & 4.45 & 4.6819 & TRN & \\
\hline CHEMBL1407396 & 688759 & 6.15 & 4.6901 & TST & \\
\hline CHEMBL1433559 & 688759 & 4.75 & 4.9687 & TRN & \\
\hline CHEMBL202721 & 688759 & 4.8 & 4.7478 & TST & \\
\hline CHEMBL1328426 & 688759 & 6.05 & 5.1313 & TRN & \\
\hline CHEMBL 3145032 & 688759 & 6.1 & 5.7002 & TRN & \\
\hline CHEMBL1597334 & 688759 & 5.5 & 4.9464 & TRN & \\
\hline CHEMBL1430609 & 688759 & 5.9 & 4.9819 & TRN & \\
\hline CHEMBL1387808 & 688759 & 6.5 & 4.8987 & TST & \\
\hline CHEMBL1611402 & 688759 & 4.6 & 4.7347 & TRN & \\
\hline CHEMBL1604967 & 688759 & 4.45 & 4.6107 & TRN & \\
\hline CHEMBL1348866 & 688759 & 4.45 & 4.7346 & TRN & \\
\hline CHEMBL1312629 & 688759 & 4.95 & 4.8109 & TRN & \\
\hline CHEMBL3198373 & 688759 & 4.95 & 5.5451 & TRN & \\
\hline CHEMBL1360714 & 688759 & 5.55 & 5.6809 & TRN & \\
\hline CHEMBL584888 & 688759 & 5.3 & 4.9441 & TRN & \\
\hline CHEMBL1380452 & 688759 & 5.25 & 4.8486 & TRN & \\
\hline CHEMBL1988666 & 688759 & 5.75 & 5.4609 & TRN & \\
\hline CHEMBL505209 & 688759 & 5.4 & 5.3931 & TRN & \\
\hline CHEMBL1398520 & 688759 & 4.9 & 5.0973 & TRN & \\
\hline CHEMBL1575745 & 688759 & 4.65 & 4.5389 & TRN & \\
\hline CHEMBL1498241 & 688759 & 4.45 & 4.8837 & TRN & \\
\hline CHEMBL1502503 & 688759 & 5.25 & 5.136 & TRN & \\
\hline CHEMBL1605956 & 688759 & 5.0 & 4.7154 & TRN & \\
\hline CHEMBL1532766 & 688759 & 4.45 & 4.8909 & TST & \\
\hline CHEMBL1360870 & 688759 & 4.45 & 4.9082 & TST & \\
\hline CHEMBL582030 & 688759 & 4.45 & 5.0222 & TRN & \\
\hline CHEMBL1403112 & 688759 & 5.15 & 5.0611 & TRN & \\
\hline CHEMBL1385348 & 688759 & 6.45 & 4.9613 & TST & \\
\hline CHEMBL1428543 & 688759 & 4.65 & 4.8722 & TRN & \\
\hline CHEMBL1379549 & 688759 & 4.45 & 5.0092 & TRN & \\
\hline CHEMBL1536864 & 688759 & 5.6 & 5.4781 & TRN & \\
\hline CHEMBL1345352 & 688759 & 5.25 & 4.9831 & TST & \\
\hline CHEMBL1490225 & 688759 & 5.35 & 4.8587 & TRN & \\
\hline CHEMBL1493037 & 688759 & 4.5 & 4.537 & TST & \\
\hline CHEMBL1414284 & 688759 & 4.45 & 4.8591 & TRN & \\
\hline CHEMBL1303527 & 688759 & 4.65 & 4.5162 & TRN & \\
\hline CHEMBL1522183 & 688759 & 4.45 & 4.7707 & TRN & \\
\hline CHEMBL1439346 & 688759 & 5.25 & 4.7276 & TRN & \\
\hline CHEMBL1564646 & 688759 & 4.95 & 4.60800 & 00000000 & TRN \\
\hline
\end{tabular}




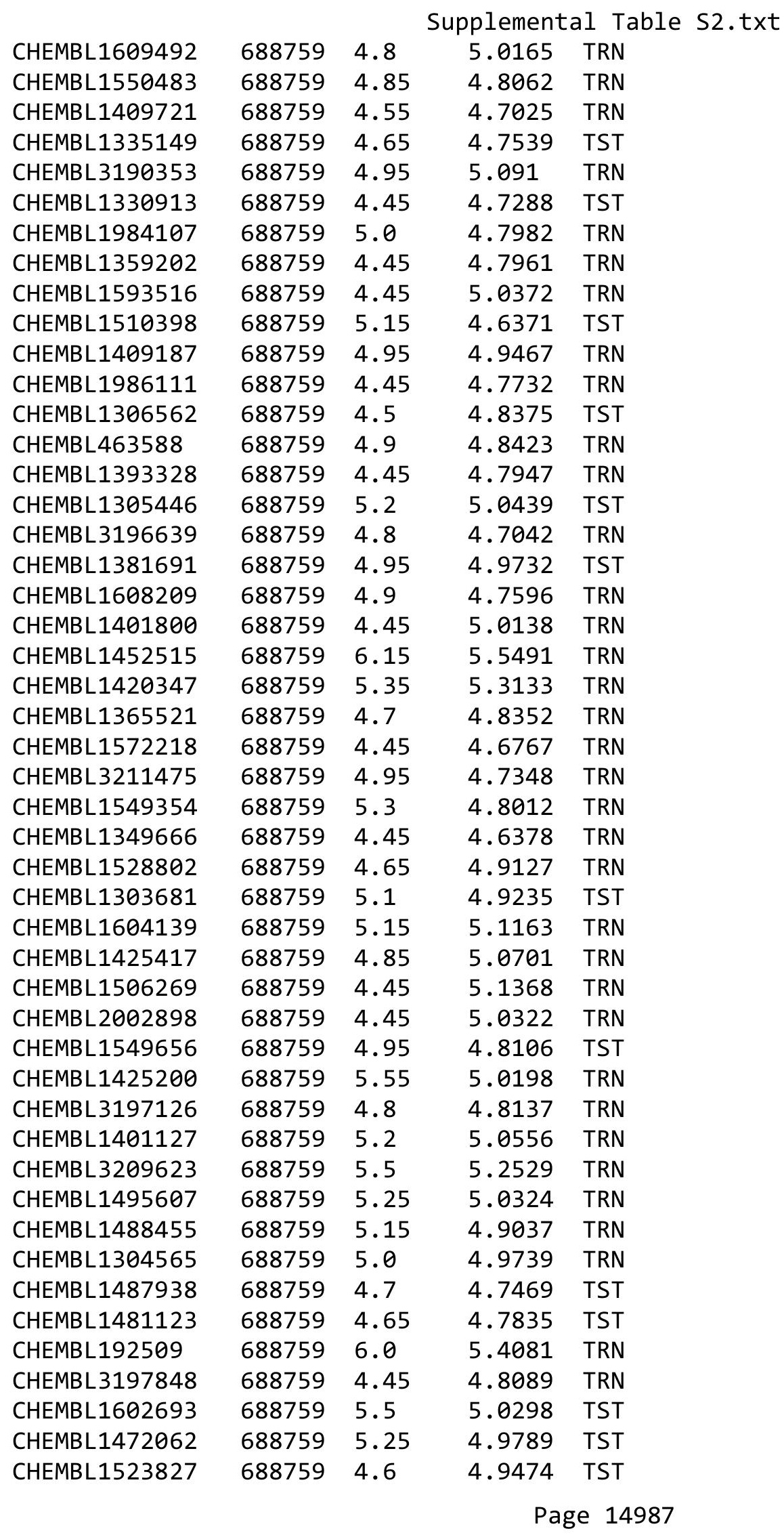




\begin{tabular}{|c|c|c|c|c|c|}
\hline & & \multicolumn{4}{|c|}{ Supplemental Table S2.txt } \\
\hline CHEMBL1371666 & 688759 & 4.45 & 4.4443 & TRN & \\
\hline CHEMBL1471128 & 688759 & 4.7 & 5.2153 & TRN & \\
\hline CHEMBL1578551 & 688759 & 5.8 & 4.7225 & TST & \\
\hline CHEMBL 3198142 & 688759 & 4.55 & 4.749 & TRN & \\
\hline CHEMBL1986274 & 688759 & 4.75 & 4.8106 & TRN & \\
\hline CHEMBL 3193285 & 688759 & 4.55 & 4.9796 & TRN & \\
\hline CHEMBL1409212 & 688759 & 4.85 & 4.8713 & TST & \\
\hline CHEMBL3195592 & 688759 & 5.3 & 5.3138 & TRN & \\
\hline CHEMBL1543323 & 688759 & 5.2 & 5.0005 & TRN & \\
\hline CHEMBL1350195 & 688759 & 5.2 & 4.8936 & TRN & \\
\hline CHEMBL1393007 & 688759 & 4.8 & 4.6587 & TRN & \\
\hline CHEMBL 3197382 & 688759 & 5.2 & 5.4095 & TRN & \\
\hline CHEMBL1567603 & 688759 & 5.0 & 5.1536 & TRN & \\
\hline CHEMBL1444409 & 688759 & 5.5 & 5.2545 & TST & \\
\hline CHEMBL3191926 & 688759 & 4.7 & 4.6673 & TRN & \\
\hline CHEMBL3199808 & 688759 & 5.35 & 5.1694 & TRN & \\
\hline CHEMBL1342766 & 688759 & 5.45 & 5.5275 & TST & \\
\hline CHEMBL1532401 & 688759 & 5.0 & 4.9223 & TST & \\
\hline CHEMBL1447973 & 688759 & 6.05 & 4.751 & TST & \\
\hline CHEMBL1328832 & 688759 & 5.3 & 4.7205 & TRN & \\
\hline CHEMBL1478270 & 688759 & 4.9 & 4.7315 & TRN & \\
\hline CHEMBL1493506 & 688759 & 5.25 & 5.1320 & 0000000001 & TRN \\
\hline CHEMBL1501632 & 688759 & 5.25 & 4.8913 & TRN & \\
\hline CHEMBL1545489 & 688759 & 4.45 & 4.7466 & TST & \\
\hline CHEMBL1305357 & 688759 & 5.6 & 5.1616 & TST & \\
\hline CHEMBL1451293 & 688759 & 5.6 & 5.2810 & 0000000001 & TRN \\
\hline CHEMBL1331891 & 688759 & 4.65 & 4.9614 & TST & \\
\hline CHEMBL1382652 & 688759 & 5.15 & 4.9247 & TRN & \\
\hline CHEMBL1393095 & 688759 & 5.3 & 5.4315 & TRN & \\
\hline CHEMBL1603928 & 688759 & 4.75 & 5.0433 & TST & \\
\hline CHEMBL1609081 & 688759 & 4.45 & 4.8693 & TRN & \\
\hline CHEMBL1347585 & 688759 & 4.45 & 4.8411 & TRN & \\
\hline CHEMBL3193359 & 688759 & 5.2 & 4.9423 & TRN & \\
\hline CHEMBL1482686 & 688759 & 5.2 & 4.8453 & TST & \\
\hline CHEMBL1312654 & 688759 & 4.45 & 4.823 & TRN & \\
\hline CHEMBL1603388 & 688759 & 4.45 & 4.5933 & TRN & \\
\hline CHEMBL1578223 & 688759 & 4.5 & 4.9974 & TRN & \\
\hline CHEMBL1426149 & 688759 & 4.8 & 4.497 & TST & \\
\hline CHEMBL1451376 & 688759 & 4.45 & 4.453 & TST & \\
\hline CHEMBL1582872 & 688759 & 4.55 & 4.6548 & TRN & \\
\hline CHEMBL1387015 & 688759 & 4.45 & 4.7545 & TRN & \\
\hline CHEMBL1485525 & 688759 & 4.45 & 4.5069 & TRN & \\
\hline CHEMBL1406316 & 688759 & 4.45 & 4.8766 & TST & \\
\hline CHEMBL1565906 & 688759 & 5.7 & 4.9644 & TRN & \\
\hline CHEMBL1322435 & 688759 & 4.95 & 4.647 & TST & \\
\hline CHEMBL1373924 & 688759 & 4.85 & 4.9679 & TRN & \\
\hline CHEMBL1533964 & 688759 & 4.55 & 5.3617 & TRN & \\
\hline CHEMBL1407794 & 688759 & 5.9 & 5.1486 & TRN & \\
\hline
\end{tabular}




\begin{tabular}{|c|c|c|c|c|c|}
\hline \multicolumn{6}{|c|}{ Supplemental Table S2.txt } \\
\hline CHEMBL1441281 & 688759 & 4.6 & 4.664 & TRN & \\
\hline CHEMBL1597252 & 688759 & 4.65 & 4.8299 & TST & \\
\hline CHEMBL1346269 & 688759 & 5.55 & 4.8701 & TRN & \\
\hline CHEMBL1342423 & 688759 & 5.55 & 5.2738 & TRN & \\
\hline CHEMBL1508982 & 688759 & 5.5 & 5.4235 & TRN & \\
\hline CHEMBL 3192248 & 688759 & 5.1 & 5.1286 & TRN & \\
\hline CHEMBL3196067 & 688759 & 4.9 & 4.7413 & TRN & \\
\hline CHEMBL3193967 & 688759 & 4.45 & 4.8628 & TRN & \\
\hline CHEMBL1998824 & 688759 & 4.65 & 4.8378 & TRN & \\
\hline CHEMBL1509216 & 688759 & 6.6 & 4.6574 & TRN & \\
\hline CHEMBL1570606 & 688759 & 5.25 & 4.8568 & TST & \\
\hline CHEMBL1461142 & 688759 & 4.9 & 4.8543 & TST & \\
\hline CHEMBL3211916 & 688759 & 6.0 & 4.9306 & TRN & \\
\hline CHEMBL1378334 & 688759 & 4.95 & 4.8749 & TST & \\
\hline CHEMBL1491556 & 688759 & 6.9 & 5.42899 & 9999999999 & TRN \\
\hline CHEMBL1541257 & 688759 & 4.65 & 4.6365 & TRN & \\
\hline CHEMBL1557521 & 688759 & 5.25 & 5.0216 & TST & \\
\hline CHEMBL1363305 & 688759 & 4.75 & 4.7901 & TRN & \\
\hline CHEMBL1309142 & 688759 & 4.6 & 5.0534 & TRN & \\
\hline CHEMBL376503 & 688759 & 4.45 & 5.0612 & TST & \\
\hline CHEMBL1470390 & 688759 & 4.55 & 4.9149 & TRN & \\
\hline CHEMBL3190911 & 688759 & 4.85 & 4.816 & TRN & \\
\hline CHEMBL1409039 & 688759 & 4.65 & 4.8337 & TRN & \\
\hline CHEMBL1578756 & 688759 & 4.95 & 5.0583 & TRN & \\
\hline CHEMBL3190786 & 688759 & 6.05 & 5.4321 & TRN & \\
\hline CHEMBL1418209 & 688759 & 5.1 & 4.6968 & TRN & \\
\hline CHEMBL1373549 & 688759 & 4.6 & 5.2783 & TRN & \\
\hline CHEMBL1586325 & 688759 & 4.45 & 4.8237 & TRN & \\
\hline CHEMBL1360793 & 688759 & 5.45 & 4.8733 & TRN & \\
\hline CHEMBL1469837 & 688759 & 5.15 & 4.8414 & TRN & \\
\hline CHEMBL1413680 & 688759 & 5.5 & 5.2509 & TST & \\
\hline CHEMBL1465116 & 688759 & 4.7 & 4.8813 & TRN & \\
\hline CHEMBL478960 & 688759 & 4.45 & 5.0242 & TST & \\
\hline CHEMBL1437922 & 688759 & 5.0 & 4.7837 & TRN & \\
\hline CHEMBL1526910 & 688759 & 5.6 & 5.1697 & TST & \\
\hline CHEMBL1332448 & 688759 & 5.0 & 4.9138 & TRN & \\
\hline CHEMBL 1425522 & 688759 & 6.5 & 5.1395 & TRN & \\
\hline CHEMBL1387529 & 688759 & 4.55 & 5.2339 & TRN & \\
\hline CHEMBL1611585 & 688759 & 5.45 & 5.1835 & TRN & \\
\hline CHEMBL1401302 & 688759 & 4.45 & 4.9669 & TRN & \\
\hline CHEMBL1311528 & 688759 & 5.25 & 5.3414 & TRN & \\
\hline CHEMBL1492876 & 688759 & 4.6 & 4.842 & TST & \\
\hline CHEMBL1593888 & 688759 & 5.3 & 5.3182 & TRN & \\
\hline CHEMBL1564332 & 688759 & 6.3 & 4.5829 & TST & \\
\hline CHEMBL1391617 & 688759 & 4.45 & 5.2512 & TRN & \\
\hline CHEMBL1496286 & 688759 & 4.95 & 4.6233 & TRN & \\
\hline CHEMBL1566280 & 688759 & 6.0 & 4.8806 & TST & \\
\hline CHEMBL1454174 & 688759 & 4.45 & 4.5964 & TRN & \\
\hline
\end{tabular}




\begin{tabular}{|c|c|c|c|c|}
\hline \multicolumn{5}{|c|}{ Supplemental Table S2.txt } \\
\hline CHEMBL1416136 & 688759 & 6.05 & 4.8356 & TRN \\
\hline CHEMBL1594260 & 688759 & 4.55 & 4.7188 & TRN \\
\hline CHEMBL1302101 & 688759 & 4.6 & 4.6644 & TRN \\
\hline CHEMBL 3210594 & 688759 & 4.55 & 4.825 & TST \\
\hline CHEMBL1598827 & 688759 & 5.1 & 4.8461 & TRN \\
\hline CHEMBL1557211 & 688759 & 5.25 & 4.7299 & TRN \\
\hline CHEMBL1516456 & 688759 & 4.45 & 4.7704 & TRN \\
\hline CHEMBL1422176 & 688759 & 4.45 & 4.925 & TRN \\
\hline CHEMBL1527082 & 688759 & 5.4 & 5.1752 & TRN \\
\hline CHEMBL3197197 & 688759 & 4.9 & 4.5849 & TRN \\
\hline CHEMBL1978315 & 688759 & 4.6 & 5.1446 & TRN \\
\hline CHEMBL1443205 & 688759 & 5.6 & 5.5633 & TRN \\
\hline CHEMBL1387649 & 688759 & 4.65 & 4.9512 & TRN \\
\hline CHEMBL1493814 & 688759 & 4.45 & 5.0346 & TRN \\
\hline CHEMBL1582900 & 688759 & 6.7501 & 5.7188 & TST \\
\hline CHEMBL1465135 & 688759 & 4.65 & 4.6217 & TRN \\
\hline CHEMBL1987820 & 688759 & 5.65 & 5.652 & TRN \\
\hline CHEMBL1597510 & 688759 & 4.45 & 4.5732 & TRN \\
\hline CHEMBL1540071 & 688759 & 5.15 & 4.9329 & TRN \\
\hline CHEMBL1406161 & 688759 & 4.45 & 4.8921 & TRN \\
\hline CHEMBL1511234 & 688759 & 4.45 & 4.9698 & TRN \\
\hline CHEMBL1463025 & 688759 & 5.6 & 4.8914 & TRN \\
\hline CHEMBL3197446 & 688759 & 5.65 & 5.5146 & TRN \\
\hline CHEMBL261131 & 688759 & 4.45 & 4.8861 & TRN \\
\hline CHEMBL1568558 & 688759 & 4.95 & 4.9995 & TRN \\
\hline CHEMBL1427726 & 688759 & 4.45 & 4.9997 & TRN \\
\hline CHEMBL1431625 & 688759 & 4.7 & 4.7858 & TRN \\
\hline CHEMBL3195308 & 688759 & 4.8 & 4.7628 & TRN \\
\hline CHEMBL3198812 & 688759 & 4.75 & 5.0351 & TRN \\
\hline CHEMBL3191458 & 688759 & 5.25 & 5.1308 & TRN \\
\hline CHEMBL1510513 & 688759 & 4.45 & 4.6671 & TST \\
\hline CHEMBL3196050 & 688759 & 4.45 & 4.8942 & TRN \\
\hline CHEMBL1323686 & 688759 & 4.45 & 4.503 & TRN \\
\hline CHEMBL1378287 & 688759 & 4.45 & 4.4465 & TRN \\
\hline CHEMBL1528279 & 688759 & 4.75 & 4.9975 & TRN \\
\hline CHEMBL1299765 & 688759 & 4.8 & 4.609 & TRN \\
\hline CHEMBL1584037 & 688759 & 4.45 & 4.7272 & TST \\
\hline CHEMBL1534558 & 688759 & 4.85 & 4.7085 & TRN \\
\hline CHEMBL1468736 & 688759 & 4.45 & 4.7313 & TRN \\
\hline CHEMBL3189497 & 688759 & 4.45 & 4.5895 & TRN \\
\hline CHEMBL1572867 & 688759 & 4.45 & 5.2025 & TRN \\
\hline CHEMBL1328283 & 688759 & 4.7 & 4.9021 & TST \\
\hline CHEMBL3198581 & 688759 & 5.95 & 5.4549 & TRN \\
\hline CHEMBL1358967 & 688759 & 5.25 & 4.8727 & TRN \\
\hline CHEMBL1570616 & 688759 & 5.2 & 5.1484 & TRN \\
\hline CHEMBL1310004 & 688759 & 4.8 & 4.9902 & TRN \\
\hline CHEMBL1988496 & 688759 & 4.8 & 4.7648 & TST \\
\hline CHEMBL1325612 & 688759 & 5.2 & 4.8606 & TRN \\
\hline
\end{tabular}




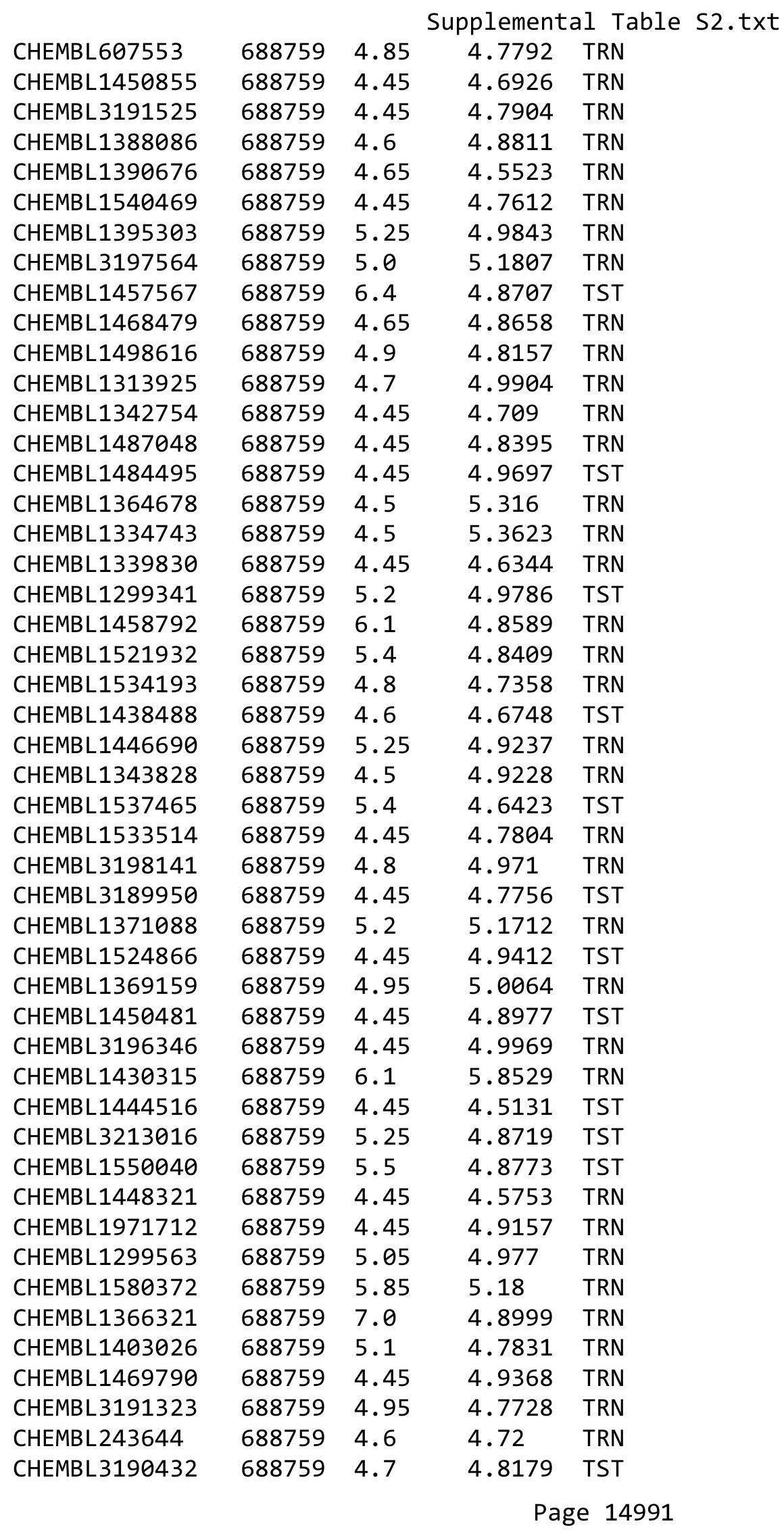




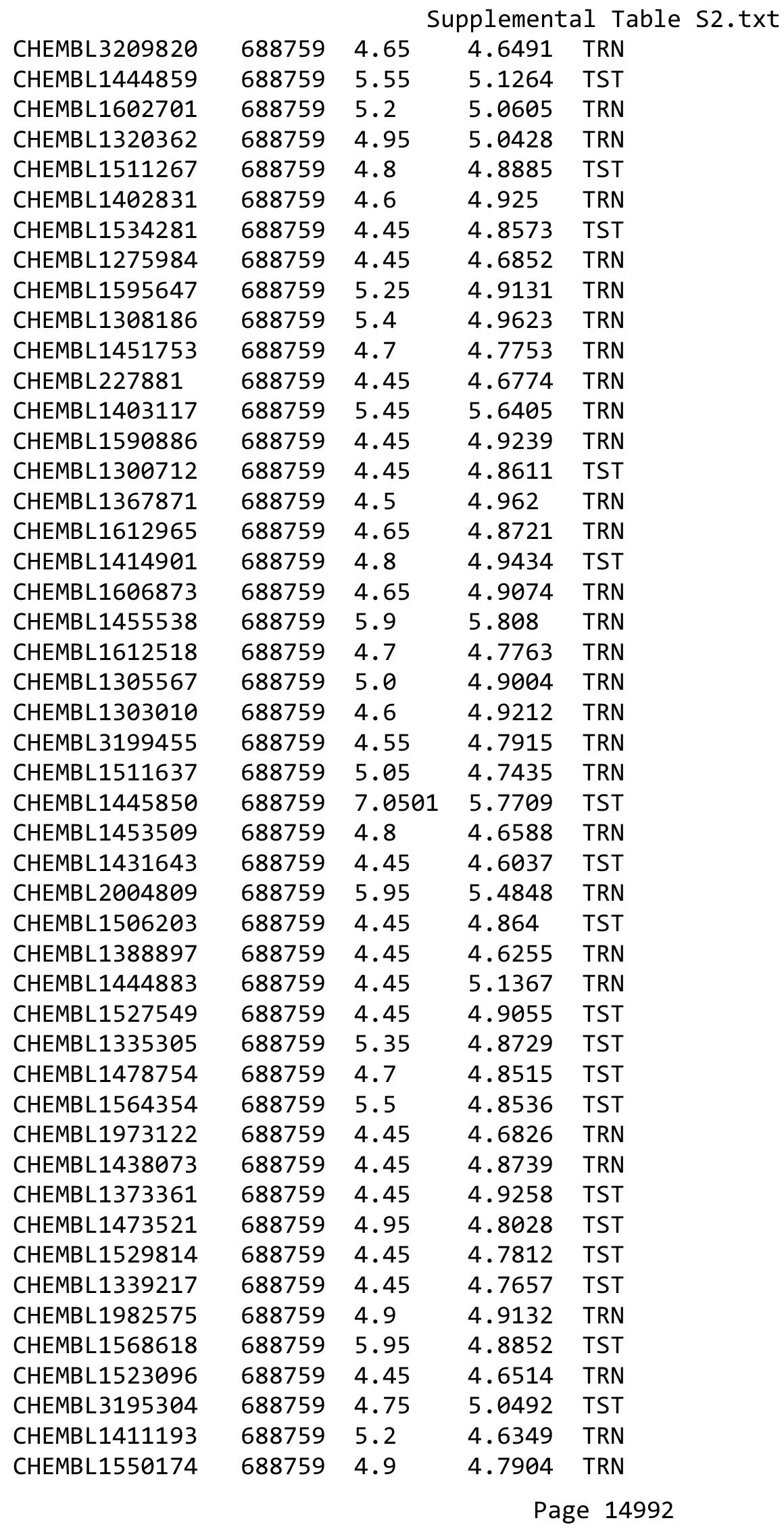




\begin{tabular}{|c|c|c|c|c|c|}
\hline & & \multicolumn{4}{|c|}{ Supplemental Table S2.txt } \\
\hline CHEMBL1364553 & 688759 & 5.55 & 4.734 & TRN & \\
\hline CHEMBL1493724 & 688759 & 4.95 & 5.4022 & TST & \\
\hline CHEMBL498373 & 688759 & 4.6 & 4.7235 & TRN & \\
\hline CHEMBL1602303 & 688759 & 5.95 & 4.8209 & TRN & \\
\hline CHEMBL3196186 & 688759 & 6.2 & 5.5521 & TRN & \\
\hline CHEMBL1599925 & 688759 & 4.45 & 5.0092 & TST & \\
\hline CHEMBL1432857 & 688759 & 5.25 & 5.0982 & TRN & \\
\hline CHEMBL1991009 & 688759 & 4.6 & 5.0238 & TRN & \\
\hline CHEMBL1417080 & 688759 & 4.45 & 4.8438 & TRN & \\
\hline CHEMBL1327389 & 688759 & 4.45 & 5.0891 & TST & \\
\hline CHEMBL460515 & 688759 & 4.75 & 4.9729 & TST & \\
\hline CHEMBL 3210347 & 688759 & 5.2 & 5.3032 & TRN & \\
\hline CHEMBL1406698 & 688759 & 4.8 & 4.92899 & 9999999999 & TST \\
\hline CHEMBL1332882 & 688759 & 4.95 & 4.8574 & TRN & \\
\hline CHEMBL3145364 & 688759 & 4.9 & 5.6809 & TST & \\
\hline CHEMBL1381433 & 688759 & 4.45 & 4.7924 & TRN & \\
\hline CHEMBL1545605 & 688759 & 6.25 & 4.9104 & TST & \\
\hline CHEMBL1539236 & 688759 & 4.85 & 4.9414 & TRN & \\
\hline CHEMBL3199221 & 688759 & 4.45 & 4.9017 & TST & \\
\hline CHEMBL1441100 & 688759 & 5.25 & 4.9043 & TST & \\
\hline CHEMBL1507630 & 688759 & 4.45 & 4.7267 & TRN & \\
\hline CHEMBL1438598 & 688759 & 4.85 & 4.8705 & TRN & \\
\hline CHEMBL1301243 & 688759 & 4.95 & 4.7151 & TST & \\
\hline CHEMBL1376201 & 688759 & 5.9 & 5.8053 & TRN & \\
\hline CHEMBL1532956 & 688759 & 4.5 & 4.5645 & TST & \\
\hline CHEMBL3197923 & 688759 & 5.4 & 4.845 & TST & \\
\hline CHEMBL1448295 & 688759 & 4.7 & 4.8755 & TST & \\
\hline CHEMBL1379137 & 688759 & 4.45 & 4.9203 & TST & \\
\hline CHEMBL1531245 & 688759 & 5.1 & 4.6935 & TST & \\
\hline CHEMBL1500354 & 688759 & 4.85 & 4.7339 & TRN & \\
\hline CHEMBL1381922 & 688759 & 5.1 & 4.8868 & TRN & \\
\hline CHEMBL1430319 & 688759 & 5.5 & 4.9779 & TRN & \\
\hline CHEMBL3214357 & 688759 & 5.1 & 4.9473 & TRN & \\
\hline CHEMBL3209462 & 688759 & 4.95 & 4.7959 & TRN & \\
\hline CHEMBL1602908 & 688759 & 4.45 & 4.6566 & TRN & \\
\hline CHEMBL1346192 & 688759 & 4.45 & 5.0152 & TRN & \\
\hline CHEMBL1450916 & 688759 & 4.85 & 4.7521 & TRN & \\
\hline CHEMBL1438159 & 688759 & 4.9 & 4.64199 & 99999999995 & TRN \\
\hline CHEMBL1550646 & 688759 & 4.85 & 4.8903 & TRN & \\
\hline CHEMBL3193467 & 688759 & 4.45 & 4.879 & TRN & \\
\hline CHEMBL1511459 & 688759 & 5.1 & 4.8461 & TRN & \\
\hline CHEMBL1344711 & 688759 & 4.45 & 4.6885 & TRN & \\
\hline CHEMBL1340570 & 688759 & 4.55 & 4.8063 & TRN & \\
\hline CHEMBL1540976 & 688759 & 5.55 & 5.7378 & TRN & \\
\hline CHEMBL1468497 & 688759 & 5.4 & 5.0865 & TRN & \\
\hline CHEMBL1372333 & 688759 & 4.8 & 5.0054 & TRN & \\
\hline CHEMBL1496707 & 688759 & 4.65 & 5.4898 & TST & \\
\hline CHEMBL1583572 & 688759 & 4.6 & 4.6974 & TRN & \\
\hline
\end{tabular}




\begin{tabular}{|c|c|c|c|c|c|}
\hline \multicolumn{6}{|c|}{ Supplemental Table S2.txt } \\
\hline CHEMBL233531 & 688759 & 6.35 & 5.178 & TRN & \\
\hline CHEMBL1344115 & 688759 & 4.75 & 4.7332 & TRN & \\
\hline CHEMBL443510 & 688759 & 5.4 & 5.3489 & TST & \\
\hline CHEMBL1338156 & 688759 & 4.95 & 4.5921 & TST & \\
\hline CHEMBL 1426228 & 688759 & 4.65 & 4.9128 & TST & \\
\hline CHEMBL1580518 & 688759 & 4.8 & 4.8946 & TRN & \\
\hline CHEMBL1380138 & 688759 & 4.75 & 4.5286 & TRN & \\
\hline CHEMBL3189409 & 688759 & 4.65 & 4.467 & TRN & \\
\hline CHEMBL1604138 & 688759 & 4.45 & 4.8648 & TST & \\
\hline CHEMBL1395687 & 688759 & 4.95 & 5.0693 & TST & \\
\hline CHEMBL1601181 & 688759 & 7.4001 & 5.32299 & 99999999995 & TRN \\
\hline CHEMBL1563490 & 688759 & 4.5 & 5.2181 & TRN & \\
\hline CHEMBL1324364 & 688759 & 4.6 & 4.8495 & TRN & \\
\hline CHEMBL1465339 & 688759 & 4.45 & 4.6897 & TRN & \\
\hline CHEMBL1487236 & 688759 & 4.65 & 4.8673 & TRN & \\
\hline CHEMBL1531463 & 688759 & 5.55 & 5.1309 & TRN & \\
\hline CHEMBL 293776 & 688759 & 4.45 & 4.7065 & TRN & \\
\hline CHEMBL1350660 & 688759 & 4.45 & 4.8148 & TRN & \\
\hline CHEMBL1333224 & 688759 & 4.75 & 5.0388 & TRN & \\
\hline CHEMBL1497238 & 688759 & 4.45 & 4.8367 & TST & \\
\hline CHEMBL1388472 & 688759 & 4.45 & 4.7797 & TRN & \\
\hline CHEMBL1372613 & 688759 & 6.0 & 5.3299 & TRN & \\
\hline CHEMBL1341853 & 688759 & 5.3 & 5.2808 & TST & \\
\hline CHEMBL1343400 & 688759 & 4.45 & 4.8106 & TRN & \\
\hline CHEMBL1481381 & 688759 & 4.45 & 4.6645 & TST & \\
\hline CHEMBL1348092 & 688759 & 4.45 & 4.81 & TRN & \\
\hline CHEMBL1608707 & 688759 & 4.95 & 5.331 & TRN & \\
\hline CHEMBL1611421 & 688759 & 5.4 & 4.8142 & TST & \\
\hline CHEMBL1542378 & 688759 & 5.3 & 5.3568 & TRN & \\
\hline CHEMBL1588702 & 688759 & 6.2 & 5.6998 & TRN & \\
\hline CHEMBL1301813 & 688759 & 5.2 & 5.0706 & TRN & \\
\hline CHEMBL 2003351 & 688759 & 4.45 & 4.7945 & TST & \\
\hline CHEMBL1412086 & 688759 & 4.7 & 5.0618 & TST & \\
\hline CHEMBL1454342 & 688759 & 5.25 & 4.9135 & TRN & \\
\hline CHEMBL1403383 & 688759 & 5.25 & 4.8918 & TST & \\
\hline CHEMBL1533768 & 688759 & 5.2 & 5.0133 & TRN & \\
\hline CHEMBL1324616 & 688759 & 4.95 & 4.5866 & TRN & \\
\hline CHEMBL1608476 & 688759 & 4.95 & 5.1314 & TRN & \\
\hline CHEMBL1372444 & 688759 & 5.25 & 4.857 & TRN & \\
\hline CHEMBL1449185 & 688759 & 4.7 & 5.0179 & TRN & \\
\hline CHEMBL1995156 & 688759 & 5.0 & 5.8312 & TRN & \\
\hline CHEMBL1991935 & 688759 & 4.45 & 4.8024 & TRN & \\
\hline CHEMBL1445515 & 688759 & 4.65 & 4.4601 & TRN & \\
\hline CHEMBL3195580 & 688759 & 6.15 & 5.2369 & TRN & \\
\hline CHEMBL1568257 & 688759 & 4.45 & 4.8207 & TRN & \\
\hline CHEMBL3199851 & 688759 & 5.35 & 5.0981 & TRN & \\
\hline CHEMBL1509067 & 688759 & 4.9 & 4.8968 & TRN & \\
\hline CHEMBL1509659 & 688759 & 4.55 & 4.53 & TRN & \\
\hline
\end{tabular}




\begin{tabular}{|c|c|c|c|c|}
\hline \multicolumn{5}{|c|}{ Supplemental Table } \\
\hline CHEMBL1380317 & 688759 & 4.45 & 4.7921 & TRN \\
\hline CHEMBL1310728 & 688759 & 4.95 & 4.8039 & TRN \\
\hline CHEMBL1438995 & 688759 & 5.25 & 4.9041 & TRN \\
\hline CHEMBL1583677 & 688759 & 5.15 & 4.9743 & TRN \\
\hline CHEMBL1531003 & 688759 & 5.15 & 4.9683 & TST \\
\hline CHEMBL1564153 & 688759 & 4.45 & 4.8337 & TST \\
\hline CHEMBL1391192 & 688759 & 4.7 & 5.4584 & TRN \\
\hline CHEMBL3196469 & 688759 & 6.5501 & 4.9628 & TRN \\
\hline CHEMBL1459746 & 688759 & 4.65 & 4.9971 & TRN \\
\hline CHEMBL1378376 & 688759 & 4.45 & 4.4632 & TRN \\
\hline CHEMBL1348256 & 688759 & 4.75 & 4.7675 & TRN \\
\hline CHEMBL1342644 & 688759 & 4.9 & 5.0956 & TRN \\
\hline CHEMBL1549287 & 688759 & 4.95 & 4.7695 & TST \\
\hline CHEMBL1438210 & 688759 & 4.7 & 4.4929 & TRN \\
\hline CHEMBL1606790 & 688759 & 4.55 & 4.9861 & TRN \\
\hline CHEMBL1609797 & 688759 & 5.5 & 4.9484 & TRN \\
\hline CHEMBL1410374 & 688759 & 4.45 & 4.8197 & TRN \\
\hline CHEMBL1594864 & 688759 & 4.45 & 4.8342 & TST \\
\hline CHEMBL1558995 & 688759 & 4.95 & 5.0605 & TRN \\
\hline CHEMBL1557632 & 688759 & 4.45 & 4.7541 & TST \\
\hline CHEMBL1340097 & 688759 & 6.0 & 5.021 & TRN \\
\hline CHEMBL1401945 & 688759 & 4.45 & 4.9104 & TRN \\
\hline CHEMBL1509929 & 688759 & 5.45 & 5.0116 & TRN \\
\hline CHEMBL1390516 & 688759 & 4.7 & 4.7875 & TRN \\
\hline CHEMBL3195989 & 688759 & 5.0 & 4.9503 & TRN \\
\hline CHEMBL3194593 & 688759 & 5.25 & 5.1081 & TRN \\
\hline CHEMBL1569425 & 688759 & 4.9 & 4.9962 & TRN \\
\hline CHEMBL1350763 & 688759 & 5.2 & 4.8857 & TST \\
\hline CHEMBL1565980 & 688759 & 4.65 & 4.7911 & TRN \\
\hline CHEMBL1427517 & 688759 & 4.8 & 4.8824 & TST \\
\hline CHEMBL1467411 & 688759 & 5.95 & 5.0176 & TST \\
\hline CHEMBL1425286 & 688759 & 4.45 & 4.7168 & TRN \\
\hline CHEMBL1471033 & 688759 & 4.45 & 4.6978 & TRN \\
\hline CHEMBL1342053 & 688759 & 5.05 & 5.0412 & TST \\
\hline CHEMBL1408872 & 688759 & 4.5 & 4.6947 & TRN \\
\hline CHEMBL3191999 & 688759 & 4.95 & 4.7639 & TRN \\
\hline CHEMBL 1347237 & 688759 & 5.2 & 4.8639 & TRN \\
\hline CHEMBL1494178 & 688759 & 4.45 & 5.1247 & TRN \\
\hline CHEMBL1374046 & 688759 & 4.45 & 4.9004 & TRN \\
\hline CHEMBL1450020 & 688759 & 4.45 & 4.7925 & TST \\
\hline CHEMBL1547468 & 688759 & 4.6 & 4.7092 & TST \\
\hline CHEMBL1520360 & 688759 & 5.45 & 4.7515 & TRN \\
\hline CHEMBL1556415 & 688759 & 5.4 & 5.725 & TST \\
\hline CHEMBL3193732 & 688759 & 4.6 & 4.9585 & TRN \\
\hline CHEMBL1454999 & 688759 & 4.9 & 5.0306 & TRN \\
\hline CHEMBL1408241 & 688759 & 4.45 & 5.0736 & TRN \\
\hline CHEMBL1572136 & 688759 & 5.05 & 4.784 & TRN \\
\hline CHEMBL1339851 & 688759 & 4.85 & 5.0245 & TRN \\
\hline
\end{tabular}




\begin{tabular}{|c|c|c|c|c|}
\hline \multicolumn{5}{|c|}{ Supplemental Table S2.txt } \\
\hline CHEMBL1467088 & 688759 & 5.3 & 5.1365 & TRN \\
\hline CHEMBL3198734 & 688759 & 4.8 & 5.2492 & TRN \\
\hline CHEMBL3194100 & 688759 & 4.45 & 4.8185 & TRN \\
\hline CHEMBL1531791 & 688759 & 4.75 & 5.0485 & TRN \\
\hline CHEMBL1532649 & 688759 & 4.7 & 4.8276 & TRN \\
\hline CHEMBL1585563 & 688759 & 4.65 & 4.8446 & TRN \\
\hline CHEMBL1531073 & 688759 & 5.6 & 5.1374 & TRN \\
\hline CHEMBL1983791 & 688759 & 4.45 & 4.8405 & TST \\
\hline CHEMBL1452168 & 688759 & 4.9 & 4.9233 & TRN \\
\hline CHEMBL1543191 & 688759 & 4.45 & 4.8451 & TST \\
\hline CHEMBL1528484 & 688759 & 4.45 & 4.7015 & TRN \\
\hline CHEMBL1429999 & 688759 & 4.45 & 5.0943 & TRN \\
\hline CHEMBL1327658 & 688759 & 4.45 & 4.6942 & TRN \\
\hline CHEMBL1340194 & 688759 & 4.6 & 4.6834 & TRN \\
\hline CHEMBL1368556 & 688759 & 5.25 & 4.9061 & TRN \\
\hline CHEMBL3195162 & 688759 & 5.15 & 5.0886 & TRN \\
\hline CHEMBL1347191 & 688759 & 4.65 & 4.6204 & TRN \\
\hline CHEMBL1338747 & 688759 & 5.5 & 4.9758 & TST \\
\hline CHEMBL1307889 & 688759 & 5.0 & 5.6068 & TRN \\
\hline CHEMBL1309391 & 688759 & 5.15 & 5.0173 & TRN \\
\hline CHEMBL1537619 & 688759 & 4.45 & 4.8863 & TST \\
\hline CHEMBL1303831 & 688759 & 4.95 & 4.6982 & TST \\
\hline CHEMBL1524454 & 688759 & 4.45 & 4.7798 & TRN \\
\hline CHEMBL1588286 & 688759 & 4.5 & 4.5992 & TRN \\
\hline CHEMBL1478376 & 688759 & 4.45 & 4.9612 & TST \\
\hline CHEMBL1517873 & 688759 & 4.6 & 4.5425 & TRN \\
\hline CHEMBL3199316 & 688759 & 5.35 & 5.1251 & TRN \\
\hline CHEMBL1414967 & 688759 & 5.4 & 4.8302 & TST \\
\hline CHEMBL1324425 & 688759 & 4.45 & 4.9498 & TRN \\
\hline CHEMBL1568012 & 688759 & 4.5 & 5.2022 & TRN \\
\hline CHEMBL1596487 & 688759 & 4.45 & 4.8992 & TRN \\
\hline CHEMBL3191490 & 688759 & 5.1 & 4.8413 & TRN \\
\hline CHEMBL1980967 & 688759 & 5.0 & 4.8608 & TRN \\
\hline CHEMBL1352742 & 688759 & 4.95 & 4.9492 & TRN \\
\hline CHEMBL1469660 & 688759 & 5.05 & 5.0682 & TRN \\
\hline CHEMBL1341173 & 688759 & 4.65 & 4.9157 & TRN \\
\hline CHEMBL1504476 & 688759 & 4.95 & 4.7901 & TRN \\
\hline CHEMBL1308993 & 688759 & 4.45 & 4.5305 & TST \\
\hline CHEMBL1529676 & 688759 & 4.65 & 4.7289 & TRN \\
\hline CHEMBL1373326 & 688759 & 4.9 & 4.8257 & TRN \\
\hline CHEMBL1372769 & 688759 & 4.7 & 4.5588 & TRN \\
\hline CHEMBL1983075 & 688759 & 4.6 & 5.1113 & TRN \\
\hline CHEMBL1613512 & 688759 & 5.5 & 5.7166 & TRN \\
\hline CHEMBL1534674 & 688759 & 5.25 & 5.1058 & TRN \\
\hline CHEMBL 3209878 & 688759 & 4.45 & 4.8048 & TST \\
\hline CHEMBL1486615 & 688759 & 4.95 & 4.6777 & TRN \\
\hline CHEMBL1354014 & 688759 & 4.9 & 5.1971 & TRN \\
\hline CHEMBL1609585 & 688759 & 4.8 & 5.0254 & TRN \\
\hline
\end{tabular}




\begin{tabular}{|c|c|c|c|c|}
\hline \multicolumn{5}{|c|}{ Supplemental Table S2.txt } \\
\hline CHEMBL1300817 & 688759 & 4.8 & 4.9122 & TST \\
\hline CHEMBL 3189185 & 688759 & 5.25 & 4.9704 & TST \\
\hline CHEMBL252418 & 688759 & 5.1 & 4.8017 & TRN \\
\hline CHEMBL1431785 & 688759 & 5.45 & 4.8856 & TRN \\
\hline CHEMBL495068 & 688759 & 4.45 & 4.9234 & TRN \\
\hline CHEMBL1381161 & 688759 & 4.8 & 4.9046 & TRN \\
\hline CHEMBL2369161 & 688759 & 4.6 & 5.1348 & TST \\
\hline CHEMBL1491189 & 688759 & 5.35 & 4.8598 & TRN \\
\hline CHEMBL1527588 & 688759 & 5.35 & 5.1388 & TST \\
\hline CHEMBL1709970 & 688759 & 4.45 & 5.4312 & TRN \\
\hline CHEMBL2003819 & 688759 & 4.45 & 4.9166 & TRN \\
\hline CHEMBL1365184 & 688759 & 4.95 & 4.7788 & TST \\
\hline CHEMBL1573221 & 688759 & 4.45 & 5.3859 & TRN \\
\hline CHEMBL3192133 & 688759 & 5.35 & 4.9061 & TRN \\
\hline CHEMBL531990 & 688759 & 5.6 & 5.5822 & TST \\
\hline CHEMBL1601288 & 688759 & 4.9 & 4.7882 & TST \\
\hline CHEMBL1438446 & 688759 & 5.2 & 4.8389 & TST \\
\hline CHEMBL1325445 & 688759 & 4.6 & 4.9158 & TRN \\
\hline CHEMBL1364310 & 688759 & 5.3 & 4.8207 & TRN \\
\hline CHEMBL1384895 & 688759 & 4.45 & 5.5102 & TST \\
\hline CHEMBL1570511 & 688759 & 5.3 & 4.8548 & TRN \\
\hline CHEMBL1491120 & 688759 & 5.3 & 5.2991 & TRN \\
\hline CHEMBL1350005 & 688759 & 4.65 & 4.7599 & TRN \\
\hline CHEMBL1484480 & 688759 & 4.45 & 4.5119 & TRN \\
\hline CHEMBL1379603 & 688759 & 4.45 & 4.8382 & TST \\
\hline CHEMBL1450872 & 688759 & 5.2 & 4.8713 & TST \\
\hline CHEMBL1326693 & 688759 & 4.55 & 4.9332 & TRN \\
\hline CHEMBL1422386 & 688759 & 5.95 & 5.7489 & TRN \\
\hline CHEMBL1524664 & 688759 & 4.65 & 4.9039 & TRN \\
\hline CHEMBL1573933 & 688759 & 4.9 & 4.7997 & TRN \\
\hline CHEMBL1449398 & 688759 & 5.1 & 5.183 & TRN \\
\hline CHEMBL1608472 & 688759 & 4.45 & 4.5947 & TRN \\
\hline CHEMBL1531848 & 688759 & 4.45 & 4.8255 & TST \\
\hline CHEMBL1477603 & 688759 & 4.5 & 4.6218 & TRN \\
\hline CHEMBL1469057 & 688759 & 5.25 & 4.7312 & TRN \\
\hline CHEMBL1392953 & 688759 & 5.3 & 5.0258 & TRN \\
\hline CHEMBL1481584 & 688759 & 4.45 & 5.098 & TRN \\
\hline CHEMBL1406457 & 688759 & 5.3 & 5.1705 & TRN \\
\hline CHEMBL3191704 & 688759 & 4.55 & 4.776 & TRN \\
\hline CHEMBL1458167 & 688759 & 5.45 & 4.949 & TRN \\
\hline CHEMBL1447430 & 688759 & 4.45 & 4.6708 & TRN \\
\hline CHEMBL1542180 & 688759 & 4.75 & 4.6518 & TRN \\
\hline CHEMBL3195235 & 688759 & 5.4 & 5.3152 & TRN \\
\hline CHEMBL1470137 & 688759 & 4.95 & 4.8176 & TRN \\
\hline CHEMBL1409277 & 688759 & 5.25 & 4.979 & TST \\
\hline CHEMBL1453809 & 688759 & 5.3 & 5.048 & TST \\
\hline CHEMBL3144902 & 688759 & 6.1 & 4.6081 & TRN \\
\hline CHEMBL1488793 & 688759 & 5.0 & 4.9629 & TRN \\
\hline
\end{tabular}




\begin{tabular}{|c|c|c|c|c|c|}
\hline \\
\hline CHEMBL1545105 & 688759 & 6.1 & 6.0062 & TRN & \\
\hline CHEMBL1523538 & 688759 & 5.5 & 4.9029 & TRN & \\
\hline CHEMBL3195207 & 688759 & 4.85 & 4.7808 & TRN & \\
\hline CHEMBL1986343 & 688759 & 5.65 & 5.4743 & TRN & \\
\hline CHEMBL1525725 & 688759 & 4.45 & 4.5823 & TRN & \\
\hline CHEMBL1507515 & 688759 & 4.95 & 4.9504 & TRN & \\
\hline CHEMBL3189301 & 688759 & 5.6 & 5.5833 & TRN & \\
\hline CHEMBL1484350 & 688759 & 4.65 & 4.617 & TRN & \\
\hline CHEMBL3196116 & 688759 & 5.2 & 5.0291 & TRN & \\
\hline CHEMBL1367314 & 688759 & 4.45 & 4.8386 & TRN & \\
\hline CHEMBL1306077 & 688759 & 5.25 & 5.2312 & TRN & \\
\hline CHEMBL1544190 & 688759 & 5.55 & 4.9519 & TRN & \\
\hline CHEMBL1421905 & 688759 & 4.7 & 4.7812 & TRN & \\
\hline CHEMBL1421427 & 688759 & 5.35 & 5.4738 & TRN & \\
\hline CHEMBL1455198 & 688759 & 4.65 & 4.6661 & TRN & \\
\hline CHEMBL1544344 & 688759 & 5.25 & 5.25200 & $\partial 000000001$ & TRN \\
\hline CHEMBL1587562 & 688759 & 4.45 & 4.7274 & TST & \\
\hline CHEMBL1580977 & 688759 & 4.45 & 4.6468 & TST & \\
\hline CHEMBL1372293 & 688759 & 4.45 & 4.4681 & TRN & \\
\hline CHEMBL3197836 & 688759 & 4.5 & 4.9149 & TRN & \\
\hline CHEMBL1574610 & 688759 & 5.25 & 4.795 & TRN & \\
\hline CHEMBL1493769 & 688759 & 4.45 & 5.1898 & TRN & \\
\hline CHEMBL1345120 & 688759 & 4.75 & 4.8103 & TRN & \\
\hline CHEMBL1453140 & 688759 & 4.45 & 4.436 & TRN & \\
\hline CHEMBL1335288 & 688759 & 4.9 & 5.2312 & TRN & \\
\hline CHEMBL1449514 & 688759 & 4.45 & 4.75899 & 99999999995 & TRN \\
\hline CHEMBL1525098 & 688759 & 5.1 & 5.4868 & TRN & \\
\hline CHEMBL1481778 & 688759 & 4.45 & 4.92399 & 99999999995 & TRN \\
\hline CHEMBL3211775 & 688759 & 5.3 & 4.9082 & TRN & \\
\hline CHEMBL1309395 & 688759 & 4.5 & 5.1071 & TRN & \\
\hline CHEMBL1411323 & 688759 & 5.35 & 4.7965 & TRN & \\
\hline CHEMBL1427609 & 688759 & 4.45 & 4.9227 & TRN & \\
\hline CHEMBL1493478 & 688759 & 4.7 & 4.8533 & TRN & \\
\hline CHEMBL1451774 & 688759 & 4.45 & 4.6289 & TRN & \\
\hline CHEMBL1342147 & 688759 & 5.05 & 5.2973 & TRN & \\
\hline CHEMBL1403250 & 688759 & 4.95 & 5.084 & TRN & \\
\hline CHEMBL1546631 & 688759 & 5.15 & 5.0788 & TRN & \\
\hline CHEMBL1371623 & 688759 & 4.95 & 4.7666 & TRN & \\
\hline CHEMBL1329001 & 688759 & 4.45 & 4.6836 & TRN & \\
\hline CHEMBL1557961 & 688759 & 4.55 & 4.8749 & TST & \\
\hline CHEMBL1584319 & 688759 & 7.3497 & 4.9129 & TST & \\
\hline CHEMBL1606829 & 688759 & 4.95 & 4.6745 & TRN & \\
\hline CHEMBL1415929 & 688759 & 4.7 & 5.2674 & TRN & \\
\hline CHEMBL1309521 & 688759 & 4.75 & 4.7359 & TST & \\
\hline CHEMBL3193491 & 688759 & 4.65 & 4.7004 & TST & \\
\hline CHEMBL259358 & 688759 & 4.45 & 4.8388 & TRN & \\
\hline CHEMBL1534781 & 688759 & 4.95 & 5.0899 & TRN & \\
\hline CHEMBL1328941 & 688759 & 6.15 & 5.0376 & TST & \\
\hline
\end{tabular}




\begin{tabular}{|c|c|c|c|c|c|}
\hline \multicolumn{6}{|c|}{ Supplemental Table S2.txt } \\
\hline CHEMBL1536327 & 688759 & 4.45 & 4.7321 & TRN & \\
\hline CHEMBL1597655 & 688759 & 5.0 & 5.6004 & TRN & \\
\hline CHEMBL1165723 & 688759 & 4.65 & 4.9042 & TRN & \\
\hline CHEMBL1424398 & 688759 & 5.35 & 4.8901 & TRN & \\
\hline CHEMBL1350258 & 688759 & 4.7 & 5.5379 & TRN & \\
\hline CHEMBL3198496 & 688759 & 5.85 & 5.2874 & TRN & \\
\hline CHEMBL1600480 & 688759 & 5.95 & 5.5413 & TRN & \\
\hline CHEMBL1326851 & 688759 & 4.45 & 4.6841 & TRN & \\
\hline CHEMBL1335464 & 688759 & 5.1 & 5.16299 & 9999999999 & TRN \\
\hline CHEMBL483190 & 688759 & 4.45 & 4.5983 & TRN & \\
\hline CHEMBL1348278 & 688759 & 4.45 & 4.8254 & TRN & \\
\hline CHEMBL 3189442 & 688759 & 4.45 & 5.2021 & TRN & \\
\hline CHEMBL1575447 & 688759 & 4.45 & 4.5759 & TRN & \\
\hline CHEMBL1467094 & 688759 & 4.7 & 4.8188 & TRN & \\
\hline CHEMBL1578019 & 688759 & 4.45 & 4.7023 & TRN & \\
\hline CHEMBL1387872 & 688759 & 4.45 & 4.7002 & TRN & \\
\hline CHEMBL1427212 & 688759 & 4.95 & 5.2169 & TRN & \\
\hline CHEMBL1580285 & 688759 & 4.7 & 4.9003 & TRN & \\
\hline CHEMBL1301998 & 688759 & 5.0 & 4.9699 & TST & \\
\hline CHEMBL1427051 & 688759 & 5.2 & 4.9331 & TRN & \\
\hline CHEMBL1541594 & 688759 & 5.9 & 5.4852 & TST & \\
\hline CHEMBL1350168 & 688759 & 4.9 & 4.6648 & TRN & \\
\hline CHEMBL1415033 & 688759 & 5.4 & 4.9245 & TRN & \\
\hline CHEMBL578928 & 688759 & 4.8 & 5.0928 & TRN & \\
\hline CHEMBL3211020 & 688759 & 4.45 & 4.8622 & TST & \\
\hline CHEMBL1458036 & 688759 & 4.45 & 4.7658 & TRN & \\
\hline CHEMBL3145192 & 688759 & 4.9 & 4.9399 & TRN & \\
\hline CHEMBL 2005998 & 688759 & 6.05 & 5.4183 & TST & \\
\hline CHEMBL1511432 & 688759 & 4.9 & 4.4668 & TRN & \\
\hline CHEMBL1529845 & 688759 & 4.75 & 4.7055 & TRN & \\
\hline CHEMBL1538950 & 688759 & 5.0 & 5.0244 & TRN & \\
\hline CHEMBL1544818 & 688759 & 6.5 & 6.1953 & TRN & \\
\hline CHEMBL1600462 & 688759 & 4.45 & 4.8309 & TRN & \\
\hline CHEMBL1392592 & 688759 & 4.7 & 4.6616 & TRN & \\
\hline CHEMBL3189963 & 688759 & 4.45 & 5.3504 & TST & \\
\hline CHEMBL1487871 & 688759 & 5.4 & 5.084 & TRN & \\
\hline CHEMBL1493812 & 688759 & 4.65 & 4.7774 & TRN & \\
\hline CHEMBL1587580 & 688759 & 5.0 & 4.8559 & TRN & \\
\hline CHEMBL1372017 & 688759 & 5.2 & 4.8849 & TRN & \\
\hline CHEMBL1566583 & 688759 & 4.8 & 5.1604 & TRN & \\
\hline CHEMBL1595998 & 688759 & 4.45 & 4.6927 & TRN & \\
\hline CHEMBL1494117 & 688759 & 5.45 & 4.9734 & TRN & \\
\hline CHEMBL1399803 & 688759 & 5.25 & 5.2113 & TRN & \\
\hline CHEMBL1366261 & 688759 & 4.3 & 4.9181 & TRN & \\
\hline CHEMBL1579153 & 688759 & 4.6 & 5.2168 & TST & \\
\hline CHEMBL3191203 & 688759 & 4.45 & 4.684 & TRN & \\
\hline CHEMBL1560581 & 688759 & 5.85 & 4.9541 & TRN & \\
\hline CHEMBL1588140 & 688759 & 5.45 & 5.1758 & TRN & \\
\hline
\end{tabular}




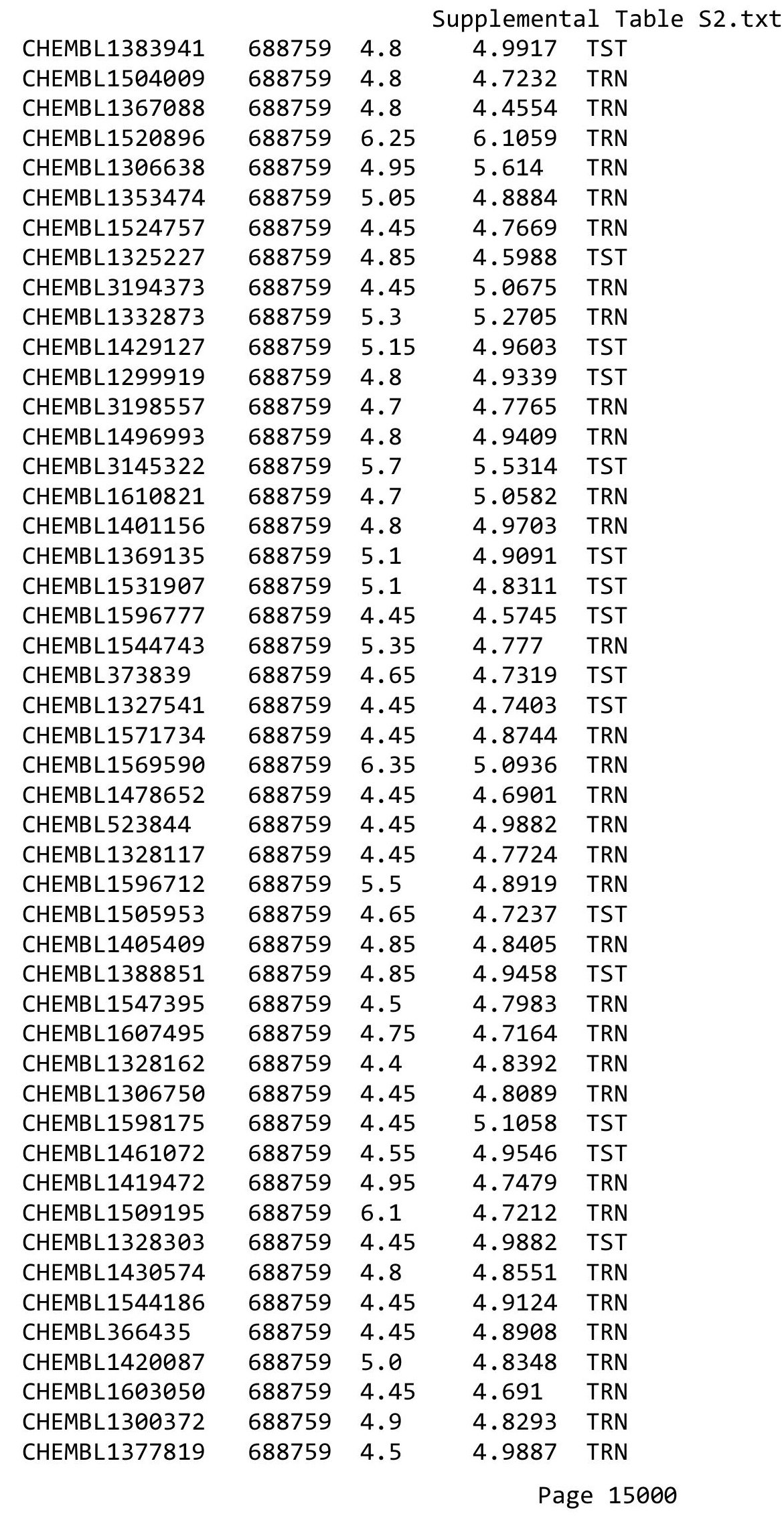




\begin{tabular}{|c|c|c|c|c|}
\hline \multicolumn{5}{|c|}{ Supplemental Table S2.txt } \\
\hline CHEMBL1353711 & 688759 & 4.5 & 5.0028 & TRN \\
\hline CHEMBL1576899 & 688759 & 4.45 & 4.7376 & TRN \\
\hline CHEMBL1405588 & 688759 & 5.15 & 4.9053 & TRN \\
\hline CHEMBL1572433 & 688759 & 5.3 & 5.0184 & TRN \\
\hline CHEMBL1511490 & 688759 & 5.0 & 4.4926 & TRN \\
\hline CHEMBL1582659 & 688759 & 4.45 & 4.9275 & TST \\
\hline CHEMBL1427061 & 688759 & 5.85 & 4.9876 & TST \\
\hline CHEMBL1302321 & 688759 & 4.7 & 4.6767 & TRN \\
\hline CHEMBL1335155 & 688759 & 4.65 & 4.8375 & TRN \\
\hline CHEMBL1496769 & 688759 & 5.1 & 4.8637 & TST \\
\hline CHEMBL1579275 & 688759 & 4.5 & 4.9221 & TRN \\
\hline CHEMBL1540795 & 688759 & 4.45 & 4.6854 & TRN \\
\hline CHEMBL1382332 & 688759 & 4.7 & 4.7909 & TRN \\
\hline CHEMBL2003939 & 688759 & 5.6 & 5.2956 & TST \\
\hline CHEMBL1608078 & 688759 & 5.45 & 5.0647 & TRN \\
\hline CHEMBL1352348 & 688759 & 4.55 & 4.769 & TRN \\
\hline CHEMBL 2007021 & 688759 & 4.6 & 5.0348 & TRN \\
\hline CHEMBL1459784 & 688759 & 4.45 & 4.8771 & TST \\
\hline CHEMBL1347512 & 688759 & 5.85 & 5.5492 & TRN \\
\hline CHEMBL1342983 & 688759 & 4.85 & 4.4629 & TRN \\
\hline CHEMBL3199399 & 688759 & 4.95 & 4.9042 & TRN \\
\hline CHEMBL1352840 & 688759 & 5.25 & 5.2824 & TRN \\
\hline CHEMBL1508682 & 688759 & 4.65 & 5.0149 & TST \\
\hline CHEMBL1458399 & 688759 & 4.95 & 5.1156 & TRN \\
\hline CHEMBL1521938 & 688759 & 4.75 & 4.8645 & TRN \\
\hline CHEMBL1416010 & 688759 & 5.4 & 5.0002 & TRN \\
\hline CHEMBL3196295 & 688759 & 5.95 & 5.6644 & TRN \\
\hline CHEMBL1438627 & 688759 & 5.1 & 5.0642 & TRN \\
\hline CHEMBL1978755 & 688759 & 4.65 & 4.5476 & TRN \\
\hline CHEMBL3198035 & 688759 & 5.0 & 5.0741 & TRN \\
\hline CHEMBL1508474 & 688759 & 6.25 & 6.0939 & TRN \\
\hline CHEMBL1460097 & 688759 & 4.45 & 4.6599 & TRN \\
\hline CHEMBL1598405 & 688759 & 4.95 & 5.0903 & TRN \\
\hline CHEMBL1486929 & 688759 & 4.85 & 5.0073 & TST \\
\hline CHEMBL1369165 & 688759 & 5.05 & 5.1613 & TRN \\
\hline CHEMBL1477128 & 688759 & 4.65 & 5.0495 & TRN \\
\hline CHEMBL3193022 & 688759 & 4.75 & 5.197 & TRN \\
\hline CHEMBL1414611 & 688759 & 4.85 & 4.8895 & TRN \\
\hline CHEMBL1367931 & 688759 & 4.7 & 4.6991 & TRN \\
\hline CHEMBL1433343 & 688759 & 4.75 & 4.9962 & TRN \\
\hline CHEMBL1501551 & 688759 & 4.55 & 4.9292 & TRN \\
\hline CHEMBL1326216 & 688759 & 5.45 & 5.3838 & TRN \\
\hline CHEMBL1346995 & 688759 & 4.75 & 4.9938 & TRN \\
\hline CHEMBL3189597 & 688759 & 4.7 & 4.5814 & TST \\
\hline CHEMBL1327493 & 688759 & 4.45 & 5.1423 & TRN \\
\hline CHEMBL1565831 & 688759 & 4.65 & 4.5932 & TRN \\
\hline CHEMBL1528025 & 688759 & 5.65 & 5.853 & TRN \\
\hline CHEMBL1362918 & 688759 & 4.45 & 4.8915 & TST \\
\hline
\end{tabular}




\begin{tabular}{|c|c|c|c|c|c|}
\hline \multicolumn{6}{|c|}{ Supplemental Table s2.txt } \\
\hline CHEMBL1348114 & 688759 & 5.25 & 5.0482 & TRN & \\
\hline CHEMBL1368841 & 688759 & 4.95 & 4.938 & TST & \\
\hline CHEMBL1529939 & 688759 & 4.45 & 4.7647 & TRN & \\
\hline CHEMBL1445566 & 688759 & 4.9 & 4.9701 & TRN & \\
\hline CHEMBL3195767 & 688759 & 4.45 & 5.013 & TRN & \\
\hline CHEMBL1313924 & 688759 & 5.25 & 5.0207 & TRN & \\
\hline CHEMBL3191438 & 688759 & 4.45 & 4.8387 & TRN & \\
\hline CHEMBL3196366 & 688759 & 6.5 & 5.191 & TRN & \\
\hline CHEMBL1546614 & 688759 & 4.45 & 4.4924 & TST & \\
\hline CHEMBL1339682 & 688759 & 5.55 & 5.6936 & TRN & \\
\hline CHEMBL1603040 & 688759 & 5.15 & 4.7165 & TST & \\
\hline CHEMBL1445687 & 688759 & 4.55 & 4.4849 & TRN & \\
\hline CHEMBL1520319 & 688759 & 6.3 & 4.9988 & TRN & \\
\hline CHEMBL1336753 & 688759 & 5.05 & 4.7053 & TRN & \\
\hline CHEMBL1525619 & 688759 & 6.25 & 6.0346 & TRN & \\
\hline CHEMBL1463212 & 688759 & 4.5 & 4.9528 & TRN & \\
\hline CHEMBL1430584 & 688759 & 4.7 & 4.7301 & TRN & \\
\hline CHEMBL1521680 & 688759 & 5.55 & 5.0168 & TST & \\
\hline CHEMBL603031 & 688759 & 4.45 & 4.5319 & TST & \\
\hline CHEMBL1999160 & 688759 & 5.2 & 5.1838 & TRN & \\
\hline CHEMBL1346869 & 688759 & 4.45 & 4.7632 & TRN & \\
\hline CHEMBL1510087 & 688759 & 4.65 & 4.63399 & 99999999995 & TRN \\
\hline CHEMBL1528552 & 688759 & 4.6 & 5.0226 & TRN & \\
\hline CHEMBL1582683 & 688759 & 4.9 & 5.1846 & TRN & \\
\hline CHEMBL1568497 & 688759 & 4.55 & 4.9388 & TRN & \\
\hline CHEMBL1450152 & 688759 & 4.45 & 5.0305 & TST & \\
\hline CHEMBL316796 & 688759 & 5.5 & 5.3057 & TRN & \\
\hline CHEMBL1576769 & 688759 & 4.45 & 4.4651 & TRN & \\
\hline CHEMBL1399220 & 688759 & 4.9 & 5.0223 & TRN & \\
\hline CHEMBL1466997 & 688759 & 5.0 & 5.0391 & TRN & \\
\hline CHEMBL1305960 & 688759 & 4.6 & 4.7888 & TRN & \\
\hline CHEMBL1364596 & 688759 & 4.45 & 5.098 & TRN & \\
\hline CHEMBL1503743 & 688759 & 4.65 & 4.883 & TRN & \\
\hline CHEMBL1313851 & 688759 & 5.25 & 4.8026 & TST & \\
\hline CHEMBL1475077 & 688759 & 4.45 & 4.4439 & TST & \\
\hline CHEMBL1539870 & 688759 & 4.95 & 4.4784 & TRN & \\
\hline CHEMBL1387238 & 688759 & 4.6 & 4.8101 & TRN & \\
\hline CHEMBL1301294 & 688759 & 5.05 & 4.7893 & TRN & \\
\hline CHEMBL3197968 & 688759 & 5.35 & 4.9828 & TRN & \\
\hline CHEMBL1431779 & 688759 & 4.45 & 4.9873 & TRN & \\
\hline CHEMBL1349905 & 688759 & 5.65 & 5.6718 & TRN & \\
\hline CHEMBL3210487 & 688759 & 5.0 & 5.0919 & TRN & \\
\hline CHEMBL1589168 & 688759 & 4.9 & 4.7562 & TST & \\
\hline CHEMBL 1375740 & 688759 & 5.75 & 5.5439 & TRN & \\
\hline CHEMBL1419255 & 688759 & 5.35 & 5.5229 & TRN & \\
\hline CHEMBL1448605 & 688759 & 4.45 & 4.9769 & TST & \\
\hline CHEMBL1506972 & 688759 & 4.45 & 4.6788 & TRN & \\
\hline CHEMBL1452644 & 688759 & 4.45 & 4.6583 & TRN & \\
\hline
\end{tabular}




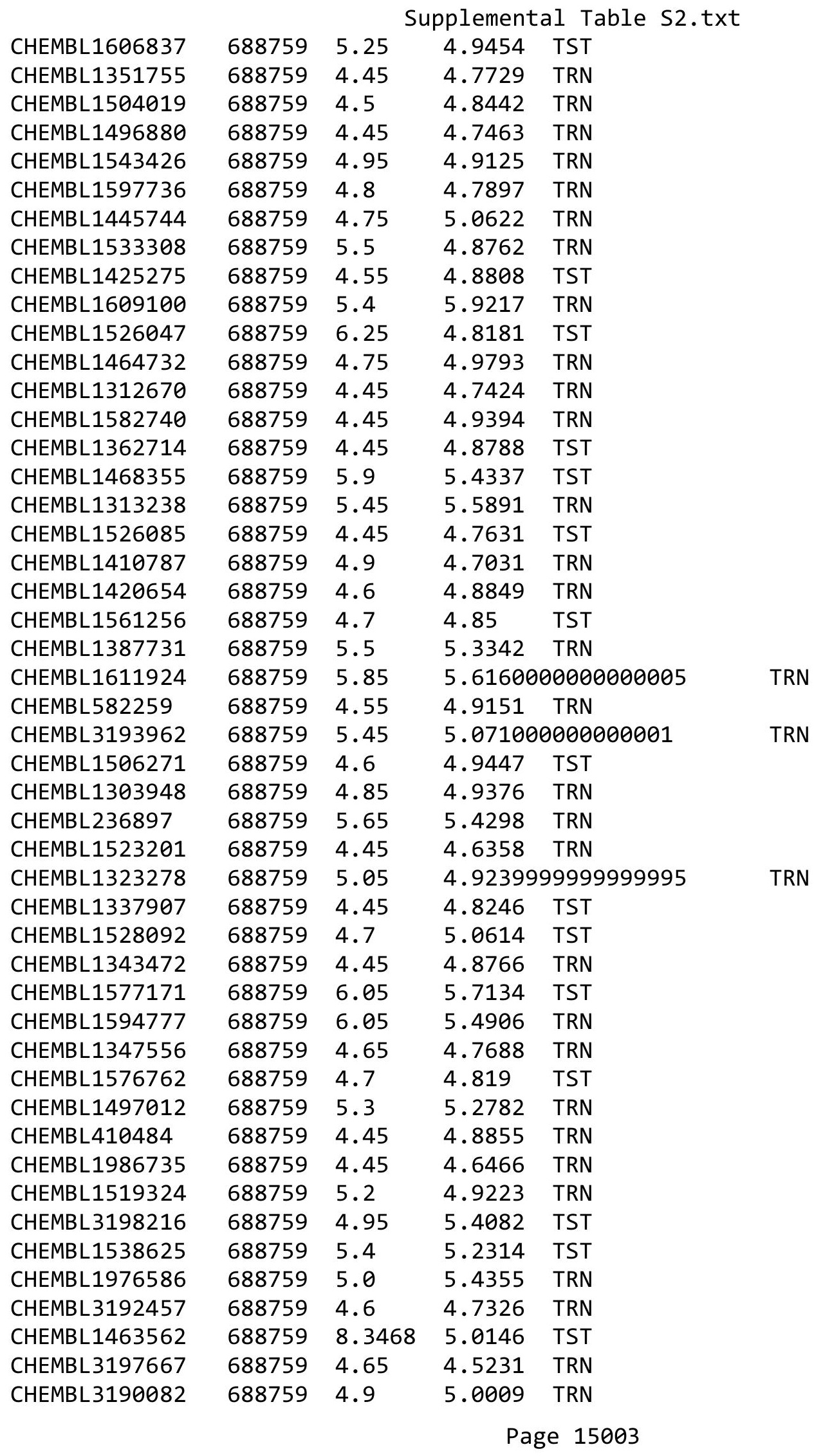




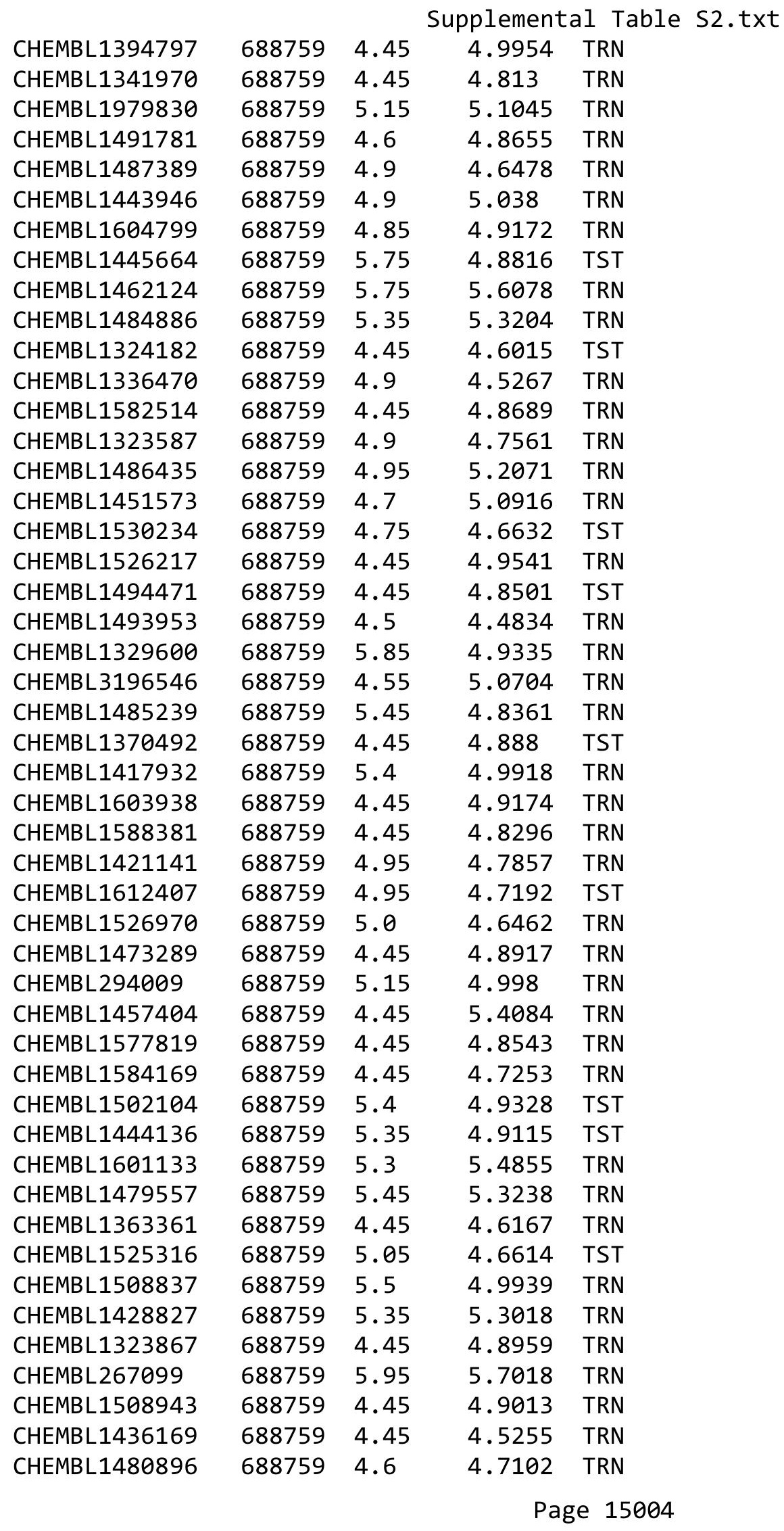




\begin{tabular}{|c|c|c|c|c|}
\hline \multicolumn{5}{|c|}{ plemental } \\
\hline CHEMBL1558250 & 688759 & 5.0 & 4.9911 & TRN \\
\hline CHEMBL3195161 & 688759 & 6.1 & 5.8534 & TRN \\
\hline CHEMBL1599509 & 688759 & 4.65 & 4.79899 & 99999999995 \\
\hline CHEMBL1572856 & 688759 & 6.9 & 4.8737 & TST \\
\hline CHEMBL1465857 & 688759 & 4.65 & 4.5832 & TRN \\
\hline CHEMBL3199692 & 688759 & 4.45 & 4.5734 & TRN \\
\hline CHEMBL1372796 & 688759 & 4.65 & 4.6989 & TRN \\
\hline CHEMBL1313740 & 688759 & 5.15 & 4.641 & TRN \\
\hline CHEMBL1201304 & 688759 & 4.45 & 5.107 & TST \\
\hline CHEMBL1345026 & 688759 & 5.0 & 5.0604 & TST \\
\hline CHEMBL3189434 & 688759 & 4.45 & 4.7055 & TRN \\
\hline CHEMBL1510953 & 688759 & 4.9 & 4.5381 & TRN \\
\hline CHEMBL1508180 & 688759 & 4.85 & 4.7166 & TRN \\
\hline CHEMBL1497867 & 688759 & 4.6 & 4.734 & TRN \\
\hline CHEMBL 3189740 & 688759 & 6.0 & 5.3222 & TRN \\
\hline CHEMBL1366957 & 688759 & 4.8 & 4.7127 & TRN \\
\hline CHEMBL1603088 & 688759 & 5.3 & 4.8191 & TST \\
\hline CHEMBL1735171 & 688759 & 4.45 & 4.8304 & TST \\
\hline CHEMBL1494025 & 688759 & 4.45 & 4.7756 & TST \\
\hline CHEMBL1315381 & 688759 & 4.45 & 4.5643 & TRN \\
\hline CHEMBL1464757 & 688759 & 4.45 & 4.8346 & TST \\
\hline CHEMBL1436049 & 688759 & 4.65 & 4.9069 & TRN \\
\hline CHEMBL1602852 & 688759 & 4.65 & 4.7518 & TST \\
\hline CHEMBL1575332 & 688759 & 5.05 & 4.8328 & TRN \\
\hline CHEMBL1424253 & 688759 & 4.9 & 4.6278 & TRN \\
\hline CHEMBL1326403 & 688759 & 4.45 & 4.6289 & TRN \\
\hline CHEMBL1578521 & 688759 & 4.65 & 4.525 & TRN \\
\hline CHEMBL1450760 & 688759 & 4.45 & 5.0038 & TST \\
\hline CHEMBL1379322 & 688759 & 4.55 & 4.9371 & TRN \\
\hline CHEMBL1345006 & 688759 & 4.7 & 4.7124 & TST \\
\hline CHEMBL1486467 & 688759 & 5.4 & 4.8978 & TRN \\
\hline CHEMBL1498623 & 688759 & 6.1 & 5.7176 & TRN \\
\hline CHEMBL1404770 & 688759 & 5.25 & 4.7689 & TST \\
\hline CHEMBL1484172 & 688759 & 4.45 & 4.8692 & TRN \\
\hline CHEMBL1353602 & 688759 & 4.45 & 4.8829 & TST \\
\hline CHEMBL1417719 & 688759 & 4.65 & 5.0206 & TRN \\
\hline CHEMBL1392878 & 688759 & 5.05 & 5.0438 & TST \\
\hline CHEMBL1462695 & 688759 & 4.45 & 4.7968 & TST \\
\hline CHEMBL1384233 & 688759 & 4.45 & 4.7892 & TST \\
\hline CHEMBL1527656 & 688759 & 4.85 & 4.8738 & TRN \\
\hline CHEMBL1401211 & 688759 & 4.65 & 4.9542 & TRN \\
\hline CHEMBL1310546 & 688759 & 4.45 & 4.7887 & TRN \\
\hline CHEMBL1495725 & 688759 & 5.4 & 4.9125 & TRN \\
\hline CHEMBL1338750 & 688759 & 6.2 & 4.873 & TST \\
\hline CHEMBL1562575 & 688759 & 6.15 & 6.1074 & TRN \\
\hline CHEMBL1966948 & 688759 & 4.7 & 4.6217 & TRN \\
\hline CHEMBL 1483734 & 688759 & 5.5 & 5.2324 & TRN \\
\hline CHEMBL1363342 & 688759 & 4.75 & 4.5938 & TRN \\
\hline
\end{tabular}

TRN 


\begin{tabular}{|c|c|c|c|c|c|}
\hline \multicolumn{6}{|c|}{ Supplemental Table S2.txt } \\
\hline CHEMBL1498099 & 688759 & 5.45 & 4.8384 & TST & \\
\hline CHEMBL1496023 & 688759 & 4.45 & 4.769 & TST & \\
\hline CHEMBL3191113 & 688759 & 4.95 & 5.0766 & TRN & \\
\hline CHEMBL3208363 & 688759 & 5.15 & 5.2284 & TRN & \\
\hline CHEMBL1412661 & 688759 & 5.1 & 5.0337 & TRN & \\
\hline CHEMBL1304887 & 688759 & 4.7 & 4.9745 & TRN & \\
\hline CHEMBL1377529 & 688759 & 5.9 & 4.5704 & TRN & \\
\hline CHEMBL1577231 & 688759 & 5.3 & 4.9933 & TRN & \\
\hline CHEMBL1352698 & 688759 & 6.05 & 5.9031 & TRN & \\
\hline CHEMBL1335220 & 688759 & 4.45 & 4.7915 & TRN & \\
\hline CHEMBL1386409 & 688759 & 4.45 & 4.7667 & TRN & \\
\hline CHEMBL1329420 & 688759 & 4.95 & 4.6952 & TRN & \\
\hline CHEMBL1611077 & 688759 & 4.8 & 4.8906 & TRN & \\
\hline CHEMBL1301796 & 688759 & 4.8 & 4.7451 & TRN & \\
\hline CHEMBL1444925 & 688759 & 4.6 & 4.6117 & TRN & \\
\hline CHEMBL3392389 & 688759 & 7.6498 & 4.9862 & TST & \\
\hline CHEMBL1409525 & 688759 & 6.5 & 6.2242 & TRN & \\
\hline CHEMBL1383810 & 688759 & 4.45 & 4.6527 & TRN & \\
\hline CHEMBL1400983 & 688759 & 5.0 & 4.7305 & TRN & \\
\hline CHEMBL268559 & 688759 & 5.15 & 5.4772 & TRN & \\
\hline CHEMBL1405741 & 688759 & 4.6 & 4.7477 & TRN & \\
\hline CHEMBL1463984 & 688759 & 4.6 & 4.6275 & TRN & \\
\hline CHEMBL 3144856 & 688759 & 4.45 & 4.8734 & TRN & \\
\hline CHEMBL1499966 & 688759 & 6.0 & 5.5849 & TST & \\
\hline CHEMBL1393200 & 688759 & 5.6 & 4.7722 & TST & \\
\hline CHEMBL1468845 & 688759 & 4.75 & 4.8362 & TST & \\
\hline CHEMBL1521681 & 688759 & 5.0 & 5.1276 & TST & \\
\hline CHEMBL1359004 & 688759 & 4.85 & 4.8166 & TRN & \\
\hline CHEMBL1585974 & 688759 & 4.5 & 4.90600 & $\partial 000000001$ & TRN \\
\hline CHEMBL1584645 & 688759 & 4.45 & 5.0159 & TRN & \\
\hline CHEMBL 3207478 & 688759 & 5.5 & 5.7143 & TRN & \\
\hline CHEMBL1510359 & 688759 & 4.55 & 4.8207 & TST & \\
\hline CHEMBL1413715 & 688759 & 4.45 & 4.6731 & TST & \\
\hline CHEMBL1413332 & 688759 & 4.65 & 4.8192 & TST & \\
\hline CHEMBL1378873 & 688759 & 4.45 & 4.7842 & TRN & \\
\hline CHEMBL2269362 & 688759 & 5.2 & 4.9483 & TST & \\
\hline CHEMBL1326021 & 688759 & 5.45 & 4.8333 & TST & \\
\hline CHEMBL3196265 & 688759 & 5.5 & 4.7557 & TST & \\
\hline CHEMBL1376629 & 688759 & 4.45 & 4.776 & TRN & \\
\hline CHEMBL3196619 & 688759 & 5.95 & 5.4084 & TRN & \\
\hline CHEMBL1325810 & 688759 & 5.25 & 4.9508 & TST & \\
\hline CHEMBL1550240 & 688759 & 4.95 & 5.28700 & 0000000001 & TRN \\
\hline CHEMBL1584571 & 688759 & 4.45 & 4.7989 & TRN & \\
\hline CHEMBL1598130 & 688759 & 5.0 & 4.8732 & TRN & \\
\hline CHEMBL1529687 & 688759 & 6.1 & 5.4127 & TRN & \\
\hline CHEMBL 3197368 & 688759 & 4.7 & 5.0181 & TRN & \\
\hline CHEMBL1517171 & 688759 & 4.55 & 4.84399 & 9999999999 & TST \\
\hline CHEMBL1584740 & 688759 & 4.95 & 4.9124 & TRN & \\
\hline
\end{tabular}




\begin{tabular}{|c|c|c|c|c|c|}
\hline \\
\hline CHEMBL1201088 & 688759 & 5.6 & 5.0543 & TRN & \\
\hline CHEMBL1471734 & 688759 & 5.6 & 5.5956 & TRN & \\
\hline CHEMBL1391325 & 688759 & 4.9 & 4.9847 & TRN & \\
\hline CHEMBL1384630 & 688759 & 4.75 & 4.8372 & TST & \\
\hline CHEMBL1474684 & 688759 & 5.0 & 4.5693 & TST & \\
\hline CHEMBL1374750 & 688759 & 5.55 & 5.3239 & TRN & \\
\hline CHEMBL1438614 & 688759 & 5.6 & 5.1004 & TST & \\
\hline CHEMBL1453479 & 688759 & 4.8 & 4.9473 & TRN & \\
\hline CHEMBL1557966 & 688759 & 5.2 & 5.3797 & TST & \\
\hline CHEMBL1550690 & 688759 & 4.6 & 4.7863 & TRN & \\
\hline CHEMBL3195289 & 688759 & 5.3 & 5.1108 & TRN & \\
\hline CHEMBL 1450887 & 688759 & 5.35 & 5.0794 & TRN & \\
\hline CHEMBL1542594 & 688759 & 4.55 & 5.0453 & TRN & \\
\hline CHEMBL1394121 & 688759 & 4.6 & 4.5738 & TST & \\
\hline CHEMBL1529254 & 688759 & 4.75 & 4.9364 & TRN & \\
\hline CHEMBL3193838 & 688759 & 4.45 & 4.5723 & TRN & \\
\hline CHEMBL1302460 & 688759 & 4.45 & 4.97199 & 99999999995 & TST \\
\hline CHEMBL1449129 & 688759 & 4.45 & 4.8561 & TRN & \\
\hline CHEMBL567529 & 688759 & 5.35 & 5.113 & TRN & \\
\hline CHEMBL1376040 & 688759 & 5.35 & 5.0303 & TRN & \\
\hline CHEMBL3192658 & 688759 & 4.7 & 4.8122 & TRN & \\
\hline CHEMBL1400145 & 688759 & 5.25 & 4.7969 & TRN & \\
\hline CHEMBL1379386 & 688759 & 4.95 & 4.8395 & TRN & \\
\hline CHEMBL304291 & 688759 & 4.7 & 5.7665 & TRN & \\
\hline CHEMBL1402708 & 688759 & 4.9 & 4.6792 & TRN & \\
\hline CHEMBL1500243 & 688759 & 5.0 & 4.8708 & TRN & \\
\hline CHEMBL1613404 & 688759 & 4.95 & 5.0191 & TRN & \\
\hline CHEMBL1455660 & 688759 & 4.45 & 4.6936 & TST & \\
\hline CHEMBL1445414 & 688759 & 5.4 & 5.1175 & TRN & \\
\hline CHEMBL1527163 & 688759 & 4.45 & 4.6848 & TRN & \\
\hline CHEMBL1310394 & 688759 & 5.05 & 4.9901 & TRN & \\
\hline CHEMBL1329360 & 688759 & 4.95 & 4.7892 & TRN & \\
\hline CHEMBL1540430 & 688759 & 4.45 & 4.7099 & TST & \\
\hline CHEMBL1587943 & 688759 & 4.45 & 4.8106 & TRN & \\
\hline CHEMBL1399203 & 688759 & 5.3 & 4.7049 & TRN & \\
\hline CHEMBL1365006 & 688759 & 4.45 & 4.6549 & TRN & \\
\hline CHEMBL1523496 & 688759 & 4.45 & 4.7087 & TRN & \\
\hline CHEMBL1568900 & 688759 & 4.95 & 4.9268 & TST & \\
\hline CHEMBL1467813 & 688759 & 4.45 & 4.7775 & TST & \\
\hline CHEMBL3195808 & 688759 & 5.65 & 5.6717 & TRN & \\
\hline CHEMBL1544756 & 688759 & 4.45 & 4.6487 & TST & \\
\hline CHEMBL1502720 & 688759 & 4.75 & 4.5783 & TST & \\
\hline CHEMBL1597878 & 688759 & 5.4 & 4.8123 & TRN & \\
\hline CHEMBL1319301 & 688759 & 4.6 & 4.9856 & TRN & \\
\hline CHEMBL 1455906 & 688759 & 5.55 & 5.553 & TST & \\
\hline CHEMBL 2000807 & 688759 & 4.95 & 5.1734 & TRN & \\
\hline CHEMBL1605885 & 688759 & 5.65 & 4.9854 & TRN & \\
\hline CHEMBL3191340 & 688759 & 5.35 & 4.9356 & TST & \\
\hline
\end{tabular}




\begin{tabular}{|c|c|c|c|c|}
\hline & & & upplement & al $\mathrm{T}$ \\
\hline CHEMBL1359169 & 688759 & 4.45 & 4.9949 & TST \\
\hline CHEMBL1467199 & 688759 & 5.05 & 4.6068 & TST \\
\hline CHEMBL1491784 & 688759 & 5.5 & 5.4364 & TRN \\
\hline CHEMBL 3191540 & 688759 & 5.55 & 5.0613 & TRN \\
\hline CHEMBL1399190 & 688759 & 4.65 & 4.7284 & TRN \\
\hline CHEMBL3208559 & 688759 & 4.8 & 4.9755 & TST \\
\hline CHEMBL1425713 & 688759 & 4.45 & 4.9659 & TST \\
\hline CHEMBL3191821 & 688759 & 4.9 & 4.6952 & TRN \\
\hline CHEMBL1451087 & 688759 & 4.5 & 4.5858 & TST \\
\hline CHEMBL1462901 & 688759 & 4.45 & 4.9006 & TST \\
\hline CHEMBL1548937 & 688759 & 4.95 & 4.8456 & TRN \\
\hline CHEMBL1568284 & 688759 & 5.2 & 4.5317 & TST \\
\hline CHEMBL1585538 & 688759 & 5.2 & 4.8708 & TRN \\
\hline CHEMBL1535938 & 688759 & 5.0 & 4.9595 & TRN \\
\hline CHEMBL1472145 & 688759 & 5.2 & 4.8936 & TST \\
\hline CHEMBL1336992 & 688759 & 4.75 & 4.7721 & TRN \\
\hline CHEMBL1526621 & 688759 & 4.5 & 4.8663 & TRN \\
\hline CHEMBL1549236 & 688759 & 4.45 & 4.8876 & TST \\
\hline CHEMBL3192112 & 688759 & 4.7 & 4.8537 & TST \\
\hline CHEMBL1517758 & 688759 & 4.8 & 4.6084 & TRN \\
\hline CHEMBL1544597 & 688759 & 4.45 & 4.899 & TRN \\
\hline CHEMBL1359343 & 688759 & 6.0 & 5.1217 & TRN \\
\hline CHEMBL3213686 & 688759 & 4.65 & 4.7371 & TST \\
\hline CHEMBL1442479 & 688759 & 5.05 & 4.5467 & TRN \\
\hline CHEMBL1568043 & 688759 & 4.55 & 4.7493 & TST \\
\hline CHEMBL1504452 & 688759 & 4.6 & 4.7694 & TRN \\
\hline CHEMBL1512909 & 688759 & 5.25 & 5.0348 & TST \\
\hline CHEMBL1439136 & 688759 & 4.45 & 4.909 & TST \\
\hline CHEMBL90124 & 688759 & 6.0 & 5.8578 & TRN \\
\hline CHEMBL1381025 & 688759 & 4.95 & 4.9506 & TRN \\
\hline CHEMBL1486726 & 688759 & 4.85 & 5.3011 & TRN \\
\hline CHEMBL1338110 & 688759 & 5.9 & 5.4908 & TST \\
\hline CHEMBL1605430 & 688759 & 4.45 & 4.8405 & TST \\
\hline CHEMBL473735 & 688759 & 5.35 & 5.3378 & TRN \\
\hline CHEMBL3189150 & 688759 & 4.45 & 4.8287 & TRN \\
\hline CHEMBL1348454 & 688759 & 5.2 & 4.9376 & TRN \\
\hline CHEMBL3209420 & 688759 & 4.65 & 4.7723 & TST \\
\hline CHEMBL1380094 & 688759 & 4.65 & 4.8733 & TST \\
\hline CHEMBL1527843 & 688759 & 4.65 & 4.9782 & TST \\
\hline CHEMBL1864040 & 688759 & 5.35 & 5.1294 & TRN \\
\hline CHEMBL3192335 & 688759 & 6.1 & 5.5704 & TRN \\
\hline CHEMBL1582088 & 688759 & 4.6 & 4.712 & TRN \\
\hline CHEMBL1469620 & 688759 & 4.55 & 4.7235 & TRN \\
\hline CHEMBL1516975 & 688759 & 4.45 & 4.7537 & TST \\
\hline CHEMBL1993020 & 688759 & 5.15 & 4.979 & TRN \\
\hline CHEMBL1424158 & 688759 & 5.0 & 4.8427 & TRN \\
\hline CHEMBL1502956 & 688759 & 4.95 & 4.9865 & TRN \\
\hline CHEMBL1561015 & 688759 & 5.85 & 4.9531 & TRN \\
\hline
\end{tabular}




\begin{tabular}{|c|c|c|c|c|c|}
\hline \multicolumn{6}{|c|}{ Supplemental Table S2.txt } \\
\hline CHEMBL1579509 & 688759 & 4.45 & 5.0226 & TST & \\
\hline CHEMBL1572281 & 688759 & 4.75 & 4.8199 & TRN & \\
\hline CHEMBL1407543 & 688759 & 5.4 & 5.311 & TRN & \\
\hline CHEMBL1563318 & 688759 & 4.45 & 4.6647 & TRN & \\
\hline CHEMBL1365241 & 688759 & 4.55 & 4.8209 & TST & \\
\hline CHEMBL1447704 & 688759 & 4.45 & 4.995 & TST & \\
\hline CHEMBL1359256 & 688759 & 4.45 & 4.8098 & TRN & \\
\hline CHEMBL1409680 & 688759 & 4.45 & 4.7566 & TRN & \\
\hline CHEMBL1505963 & 688759 & 4.45 & 4.8272 & TRN & \\
\hline CHEMBL1467157 & 688759 & 4.45 & 5.0173 & TRN & \\
\hline CHEMBL1512122 & 688759 & 5.2 & 5.0797 & TRN & \\
\hline CHEMBL1451521 & 688759 & 5.45 & 4.7592 & TRN & \\
\hline CHEMBL1467843 & 688759 & 5.35 & 5.0027 & TRN & \\
\hline CHEMBL1468996 & 688759 & 4.45 & 4.8596 & TRN & \\
\hline CHEMBL3198904 & 688759 & 6.05 & 5.0179 & TRN & \\
\hline CHEMBL1582123 & 688759 & 4.45 & 4.7716 & TST & \\
\hline CHEMBL1407008 & 688759 & 4.45 & 4.7584 & TRN & \\
\hline CHEMBL1426455 & 688759 & 4.65 & 5.0132 & TRN & \\
\hline CHEMBL1443791 & 688759 & 5.0 & 4.6612 & TRN & \\
\hline CHEMBL328710 & 688759 & 4.45 & 4.8693 & TRN & \\
\hline CHEMBL1417249 & 688759 & 4.45 & 4.9044 & TST & \\
\hline CHEMBL1406910 & 688759 & 4.45 & 4.8872 & TST & \\
\hline CHEMBL1610025 & 688759 & 5.35 & 5.2087 & TRN & \\
\hline CHEMBL1986418 & 688759 & 6.6 & 5.8572 & TRN & \\
\hline CHEMBL1478574 & 688759 & 4.45 & 4.75899 & 99999999995 & TST \\
\hline CHEMBL1608316 & 688759 & 4.8 & 5.0683 & TRN & \\
\hline CHEMBL1324508 & 688759 & 4.8 & 4.8296 & TST & \\
\hline CHEMBL1434438 & 688759 & 4.45 & 5.1842 & TRN & \\
\hline CHEMBL1439124 & 688759 & 4.95 & 4.805 & TRN & \\
\hline CHEMBL3208946 & 688759 & 4.45 & 4.6551 & TST & \\
\hline CHEMBL1568213 & 688759 & 5.0 & 5.0776 & TRN & \\
\hline CHEMBL1579526 & 688759 & 4.6 & 4.9188 & TST & \\
\hline CHEMBL3192597 & 688759 & 4.8 & 4.8457 & TRN & \\
\hline CHEMBL1538196 & 688759 & 5.45 & 5.7041 & TST & \\
\hline CHEMBL1570005 & 688759 & 4.7 & 4.9002 & TRN & \\
\hline CHEMBL1439360 & 688759 & 4.5 & 4.78600 & 00000000005 & TRN \\
\hline CHEMBL1599200 & 688759 & 4.45 & 4.9118 & TRN & \\
\hline CHEMBL3193181 & 688759 & 5.55 & 5.3929 & TST & \\
\hline CHEMBL116919 & 688759 & 5.15 & 5.2303 & TRN & \\
\hline CHEMBL1418091 & 688759 & 5.1 & 5.1506 & TRN & \\
\hline CHEMBL1581706 & 688759 & 4.45 & 4.8701 & TRN & \\
\hline CHEMBL1607568 & 688759 & 5.45 & 5.1496 & TST & \\
\hline CHEMBL1480464 & 688759 & 5.15 & 4.8999 & TRN & \\
\hline CHEMBL1481917 & 688759 & 4.45 & 4.8803 & TRN & \\
\hline CHEMBL559612 & 688759 & 4.5 & 4.4136 & TST & \\
\hline CHEMBL1523565 & 688759 & 5.75 & 5.1057 & TST & \\
\hline CHEMBL1375217 & 688759 & 4.7 & 4.7729 & TRN & \\
\hline CHEMBL1302036 & 688759 & 5.5 & 4.7323 & TRN & \\
\hline
\end{tabular}




\begin{tabular}{|c|c|c|c|c|c|}
\hline \multicolumn{6}{|c|}{ Supplemental Table S2.txt } \\
\hline CHEMBL1350990 & 688759 & 4.45 & 4.9245 & TST & \\
\hline CHEMBL1483515 & 688759 & 4.6 & 4.6137 & TRN & \\
\hline CHEMBL1398633 & 688759 & 4.45 & 5.0359 & TRN & \\
\hline CHEMBL1550076 & 688759 & 4.85 & 4.6568 & TRN & \\
\hline CHEMBL1560795 & 688759 & 4.45 & 4.6907 & TRN & \\
\hline CHEMBL1382405 & 688759 & 5.1 & 5.0696 & TRN & \\
\hline CHEMBL1492639 & 688759 & 4.85 & 4.7257 & TRN & \\
\hline CHEMBL1563149 & 688759 & 5.1 & 5.2203 & TST & \\
\hline CHEMBL1327627 & 688759 & 4.45 & 4.8649 & TRN & \\
\hline CHEMBL3210851 & 688759 & 4.65 & 4.792 & TST & \\
\hline CHEMBL3195594 & 688759 & 4.6 & 4.5403 & TRN & \\
\hline CHEMBL1411869 & 688759 & 4.45 & 5.0754 & TRN & \\
\hline CHEMBL1428453 & 688759 & 5.3 & 4.7307 & TST & \\
\hline CHEMBL1605404 & 688759 & 4.45 & 4.763 & TRN & \\
\hline CHEMBL1337833 & 688759 & 4.7 & 4.9824 & TRN & \\
\hline CHEMBL1407598 & 688759 & 5.9 & 5.7614 & TRN & \\
\hline CHEMBL1540891 & 688759 & 5.55 & 4.6108 & TRN & \\
\hline CHEMBL1972736 & 688759 & 5.4 & 5.454 & TST & \\
\hline CHEMBL1607457 & 688759 & 5.1 & 5.1145 & TRN & \\
\hline CHEMBL1350270 & 688759 & 4.95 & 4.6197 & TRN & \\
\hline CHEMBL1547033 & 688759 & 4.45 & 4.6011 & TRN & \\
\hline CHEMBL1471998 & 688759 & 4.45 & 4.5878 & TRN & \\
\hline CHEMBL1400617 & 688759 & 4.9 & 4.7848 & TRN & \\
\hline CHEMBL1536914 & 688759 & 5.75 & 5.1884 & TRN & \\
\hline CHEMBL1405071 & 688759 & 4.9 & 4.6148 & TRN & \\
\hline CHEMBL3209886 & 688759 & 5.85 & 5.0942 & TST & \\
\hline CHEMBL1971410 & 688759 & 5.25 & 4.9749 & TRN & \\
\hline CHEMBL1573657 & 688759 & 5.35 & 4.7765 & TRN & \\
\hline CHEMBL1454677 & 688759 & 4.4 & 4.7348 & TST & \\
\hline CHEMBL1978608 & 688759 & 5.1 & 4.8167 & TRN & \\
\hline CHEMBL1483032 & 688759 & 5.65 & 4.8835 & TST & \\
\hline CHEMBL1535631 & 688759 & 5.95 & 5.4145 & TRN & \\
\hline CHEMBL1606460 & 688759 & 8.3468 & 5.0364 & TRN & \\
\hline CHEMBL1419493 & 688759 & 5.2 & 4.9248 & TST & \\
\hline CHEMBL1370305 & 688759 & 4.45 & 4.7404 & TRN & \\
\hline CHEMBL1387744 & 688759 & 4.45 & 4.8409 & TRN & \\
\hline CHEMBL1540429 & 688759 & 4.45 & 4.4351 & TRN & \\
\hline CHEMBL1600990 & 688759 & 4.45 & 4.7399 & TRN & \\
\hline CHEMBL1370704 & 688759 & 4.9 & 4.7951 & TRN & \\
\hline CHEMBL1343788 & 688759 & 4.9 & 4.7921 & TRN & \\
\hline CHEMBL3195067 & 688759 & 5.0 & 4.92899 & 9999999999 & TRN \\
\hline CHEMBL1575647 & 688759 & 5.15 & 5.1462 & TRN & \\
\hline CHEMBL3189595 & 688759 & 4.95 & 5.2412 & TRN & \\
\hline CHEMBL1377964 & 688759 & 5.4 & 4.88399 & 99999999995 & TRN \\
\hline CHEMBL1568179 & 688759 & 4.65 & 4.6544 & TST & \\
\hline CHEMBL1347063 & 688759 & 4.45 & 4.7736 & TRN & \\
\hline CHEMBL1438145 & 688759 & 6.15 & 4.77 & TST & \\
\hline CHEMBL1366417 & 688759 & 5.5 & 5.4974 & TRN & \\
\hline
\end{tabular}




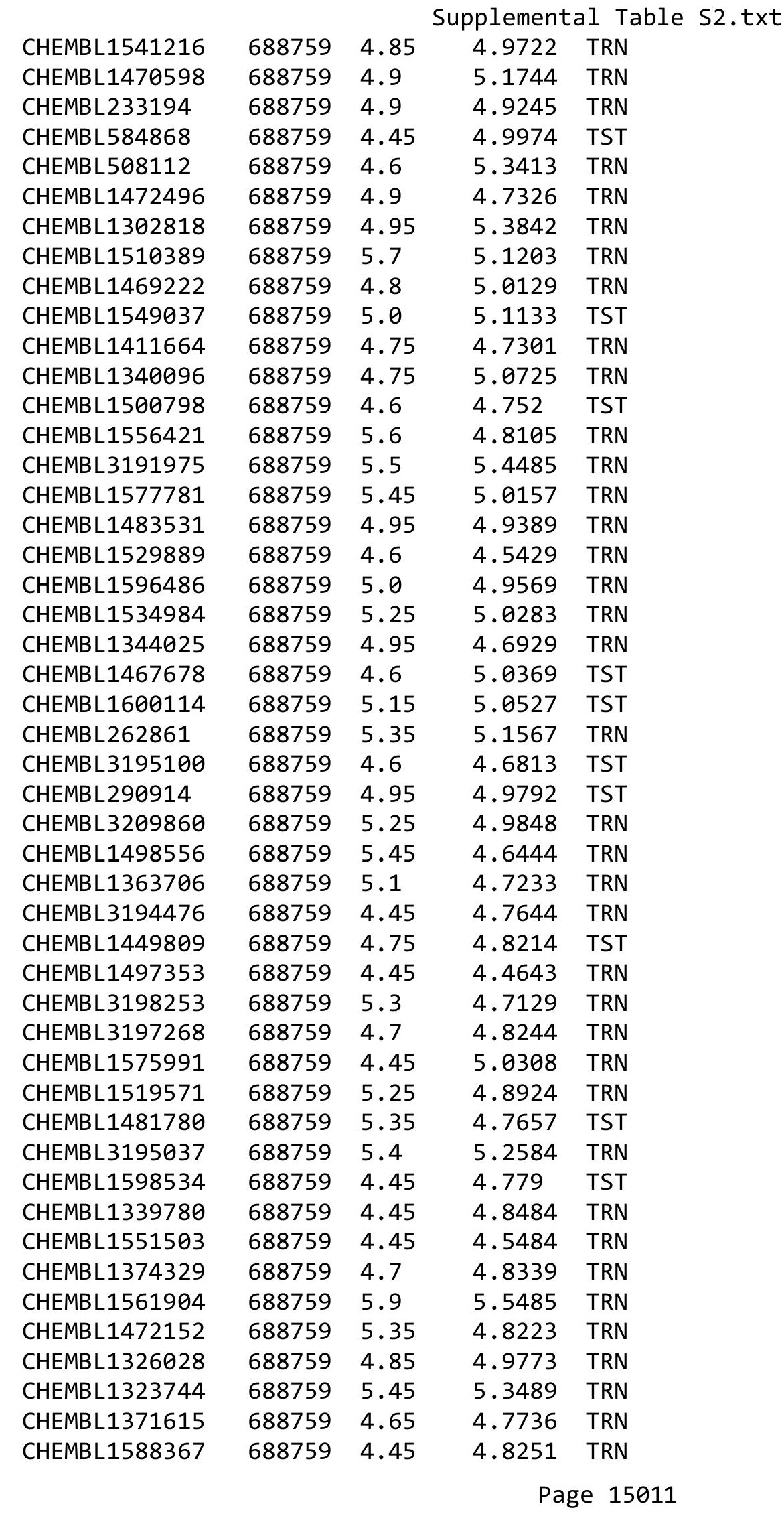




\begin{tabular}{|c|c|c|c|c|c|}
\hline & & \\
\hline CHEMBL1506848 & 688759 & 5.2 & 4.9723 & TRN & \\
\hline CHEMBL1367711 & 688759 & 5.25 & 4.6563 & TRN & \\
\hline CHEMBL1556047 & 688759 & 4.45 & 5.1111 & TRN & \\
\hline CHEMBL3190693 & 688759 & 4.75 & 4.7428 & TRN & \\
\hline CHEMBL1341707 & 688759 & 4.45 & 4.8336 & TRN & \\
\hline CHEMBL1996233 & 688759 & 4.45 & 4.8274 & TST & \\
\hline CHEMBL1473760 & 688759 & 4.75 & 4.7058 & TRN & \\
\hline CHEMBL1417414 & 688759 & 4.45 & 4.8131 & TRN & \\
\hline CHEMBL1519302 & 688759 & 5.5 & 5.5133 & TRN & \\
\hline CHEMBL1548886 & 688759 & 4.95 & 4.9719 & TRN & \\
\hline CHEMBL1522807 & 688759 & 5.55 & 5.58899 & 99999999995 & TRN \\
\hline CHEMBL1468263 & 688759 & 4.45 & 4.834 & TST & \\
\hline CHEMBL1466078 & 688759 & 4.45 & 4.5604 & TRN & \\
\hline CHEMBL1399980 & 688759 & 5.0 & 4.8113 & TRN & \\
\hline CHEMBL1489567 & 688759 & 4.75 & 5.143 & TRN & \\
\hline CHEMBL1329980 & 688759 & 4.55 & 4.8223 & TRN & \\
\hline CHEMBL1516500 & 688759 & 5.2 & 5.2517 & TRN & \\
\hline CHEMBL1331376 & 688759 & 4.6 & 4.6435 & TST & \\
\hline CHEMBL1606412 & 688759 & 5.95 & 5.3758 & TRN & \\
\hline CHEMBL1589563 & 688759 & 5.8 & 5.5838 & TST & \\
\hline CHEMBL1546681 & 688759 & 4.7 & 4.5377 & TRN & \\
\hline CHEMBL1309573 & 688759 & 5.8 & 5.7692 & TRN & \\
\hline CHEMBL1486397 & 688759 & 4.45 & 4.6064 & TRN & \\
\hline CHEMBL1307133 & 688759 & 5.9 & 5.1958 & TRN & \\
\hline CHEMBL1313702 & 688759 & 4.95 & 4.5846 & TRN & \\
\hline CHEMBL1391921 & 688759 & 5.2 & 4.8499 & TRN & \\
\hline CHEMBL1510582 & 688759 & 4.55 & 4.5244 & TRN & \\
\hline CHEMBL1564569 & 688759 & 4.45 & 4.9578 & TRN & \\
\hline CHEMBL1490750 & 688759 & 5.3 & 5.3715 & TRN & \\
\hline CHEMBL1406665 & 688759 & 5.05 & 5.0379 & TRN & \\
\hline CHEMBL1422255 & 688759 & 5.15 & 5.07600 & 00000000005 & TRN \\
\hline CHEMBL1464547 & 688759 & 5.45 & 5.0099 & TRN & \\
\hline CHEMBL1533437 & 688759 & 5.4 & 4.8914 & TRN & \\
\hline CHEMBL1588738 & 688759 & 5.25 & 4.7109 & TRN & \\
\hline CHEMBL1573280 & 688759 & 4.45 & 4.5673 & TST & \\
\hline CHEMBL1542701 & 688759 & 4.45 & 4.7723 & TST & \\
\hline CHEMBL1388490 & 688759 & 4.75 & 5.1181 & TRN & \\
\hline CHEMBL1581772 & 688759 & 4.9 & 4.8126 & TRN & \\
\hline CHEMBL3192960 & 688759 & 4.5 & 4.89 & TRN & \\
\hline CHEMBL1562926 & 688759 & 6.7501 & 6.3868 & TRN & \\
\hline CHEMBL1313134 & 688759 & 4.45 & 4.9323 & TST & \\
\hline CHEMBL1493903 & 688759 & 6.0 & 4.6931 & TRN & \\
\hline CHEMBL1476311 & 688759 & 4.85 & 5.1764 & TRN & \\
\hline CHEMBL1608830 & 688759 & 5.45 & 5.0212 & TST & \\
\hline CHEMBL1374569 & 688759 & 4.95 & 4.88 & TRN & \\
\hline CHEMBL1571063 & 688759 & 4.45 & 4.6746 & TRN & \\
\hline CHEMBL1390782 & 688759 & 4.45 & 4.8161 & TRN & \\
\hline CHEMBL1428541 & 688759 & 4.65 & 4.7449 & TST & \\
\hline & & & & 15012 & \\
\hline
\end{tabular}




\begin{tabular}{|c|c|c|c|c|c|}
\hline \multicolumn{6}{|c|}{ Supplemental Table S2.txt } \\
\hline CHEMBL1506034 & 688759 & 5.2 & 4.9275 & TST & \\
\hline CHEMBL1451851 & 688759 & 6.25 & 4.8557 & TRN & \\
\hline CHEMBL1575577 & 688759 & 4.85 & 4.6489 & TRN & \\
\hline CHEMBL1440471 & 688759 & 4.45 & 5.1226 & TRN & \\
\hline CHEMBL1351271 & 688759 & 5.4 & 5.0371 & TRN & \\
\hline CHEMBL1605854 & 688759 & 4.6 & 4.8075 & TRN & \\
\hline CHEMBL3208834 & 688759 & 4.45 & 4.7495 & TRN & \\
\hline CHEMBL 2000091 & 688759 & 4.8 & 4.5577 & TST & \\
\hline CHEMBL1567025 & 688759 & 4.7 & 4.7284 & TST & \\
\hline CHEMBL3198006 & 688759 & 4.45 & 5.1416 & TRN & \\
\hline CHEMBL1387100 & 688759 & 4.65 & 4.6132 & TRN & \\
\hline CHEMBL1580116 & 688759 & 4.8 & 4.5802 & TRN & \\
\hline CHEMBL1370589 & 688759 & 4.45 & 4.6424 & TRN & \\
\hline CHEMBL1431254 & 688759 & 4.45 & 4.75899 & 99999999995 & TRN \\
\hline CHEMBL1417239 & 688759 & 4.75 & 4.8625 & TRN & \\
\hline CHEMBL3192874 & 688759 & 5.0 & 4.8907 & TRN & \\
\hline CHEMBL1464286 & 688759 & 4.45 & 4.4966 & TRN & \\
\hline CHEMBL1393612 & 688759 & 6.8499 & 4.9414 & TST & \\
\hline CHEMBL1503400 & 688759 & 4.45 & 4.8704 & TRN & \\
\hline CHEMBL1419822 & 688759 & 5.25 & 5.1311 & TRN & \\
\hline CHEMBL534047 & 688759 & 5.05 & 5.4343 & TST & \\
\hline CHEMBL1579026 & 688759 & 4.95 & 4.8326 & TRN & \\
\hline CHEMBL1594846 & 688759 & 4.9 & 4.7145 & TRN & \\
\hline CHEMBL1344529 & 688759 & 5.05 & 5.1667 & TRN & \\
\hline CHEMBL1477384 & 688759 & 5.05 & 4.817 & TRN & \\
\hline CHEMBL1502771 & 688759 & 4.45 & 4.9077 & TRN & \\
\hline CHEMBL1472168 & 688759 & 4.9 & 4.8064 & TRN & \\
\hline CHEMBL1382447 & 688759 & 4.9 & 4.6807 & TRN & \\
\hline CHEMBL3197849 & 688759 & 4.45 & 4.8436 & TRN & \\
\hline CHEMBL1485648 & 688759 & 4.7 & 4.8435 & TST & \\
\hline CHEMBL1613127 & 688759 & 4.9 & 4.8976 & TRN & \\
\hline CHEMBL418353 & 688759 & 4.45 & 4.6331 & TRN & \\
\hline CHEMBL1384554 & 688759 & 4.45 & 4.8644 & TST & \\
\hline CHEMBL1369493 & 688759 & 4.45 & 4.9173 & TST & \\
\hline CHEMBL1570503 & 688759 & 4.65 & 4.761 & TRN & \\
\hline CHEMBL1349063 & 688759 & 5.5 & 5.2841 & TST & \\
\hline CHEMBL3194516 & 688759 & 4.5 & 5.2715 & TRN & \\
\hline CHEMBL1303580 & 688759 & 4.9 & 4.6943 & TRN & \\
\hline CHEMBL1351048 & 688759 & 4.9 & 5.1068 & TRN & \\
\hline CHEMBL1558405 & 688759 & 4.9 & 4.8408 & TRN & \\
\hline CHEMBL1446161 & 688759 & 7.3497 & 5.0833 & TST & \\
\hline CHEMBL3190468 & 688759 & 5.5 & 5.4027 & TRN & \\
\hline CHEMBL1410647 & 688759 & 5.0 & 5.0861 & TRN & \\
\hline CHEMBL1558086 & 688759 & 4.65 & 4.8984 & TRN & \\
\hline CHEMBL1361325 & 688759 & 4.6 & 4.9918 & TRN & \\
\hline CHEMBL1412114 & 688759 & 4.45 & 4.7222 & TST & \\
\hline CHEMBL 2094789 & 688759 & 5.65 & 5.6111 & TST & \\
\hline CHEMBL1303920 & 688759 & 4.45 & 4.8012 & TRN & \\
\hline
\end{tabular}




\begin{tabular}{|c|c|c|c|c|c|}
\hline & & \multicolumn{4}{|c|}{ Supplemental Table S2.txt } \\
\hline CHEMBL1573773 & 688759 & 4.65 & 4.9748 & TRN & \\
\hline CHEMBL1332589 & 688759 & 4.6 & 5.0804 & TRN & \\
\hline CHEMBL1990093 & 688759 & 6.05 & 5.4063 & TRN & \\
\hline CHEMBL1324930 & 688759 & 4.45 & 4.591 & TRN & \\
\hline CHEMBL3189847 & 688759 & 5.35 & 4.9187 & TRN & \\
\hline CHEMBL1429789 & 688759 & 5.45 & 5.2479 & TRN & \\
\hline CHEMBL1426462 & 688759 & 5.25 & 4.8695 & TRN & \\
\hline CHEMBL1527002 & 688759 & 4.85 & 4.8741 & TRN & \\
\hline CHEMBL1456659 & 688759 & 4.5 & 4.7217 & TST & \\
\hline CHEMBL1567150 & 688759 & 4.65 & 4.8919 & TST & \\
\hline CHEMBL1390139 & 688759 & 4.45 & 4.5714 & TRN & \\
\hline CHEMBL1530030 & 688759 & 4.8 & 4.7366 & TST & \\
\hline CHEMBL1484425 & 688759 & 4.45 & 4.6651 & TST & \\
\hline CHEMBL1345417 & 688759 & 4.55 & 4.9197 & TST & \\
\hline CHEMBL3192285 & 688759 & 4.9 & 4.8707 & TRN & \\
\hline CHEMBL3192121 & 688759 & 4.85 & 4.9947 & TST & \\
\hline CHEMBL1362470 & 688759 & 4.95 & 4.6555 & TST & \\
\hline CHEMBL 3190272 & 688759 & 5.15 & 4.9152 & TRN & \\
\hline CHEMBL1542021 & 688759 & 4.45 & 4.6662 & TRN & \\
\hline CHEMBL3195792 & 688759 & 4.45 & 4.6261 & TRN & \\
\hline CHEMBL 2003964 & 688759 & 6.15 & 5.9598 & TRN & \\
\hline CHEMBL1467022 & 688759 & 4.7 & 4.621 & TRN & \\
\hline CHEMBL1348100 & 688759 & 4.6 & 4.955 & TST & \\
\hline CHEMBL1349968 & 688759 & 5.3 & 4.9972 & TRN & \\
\hline CHEMBL1573676 & 688759 & 4.45 & 4.7714 & TRN & \\
\hline CHEMBL1372908 & 688759 & 4.45 & 4.6181 & TST & \\
\hline CHEMBL1529115 & 688759 & 5.3 & 5.7804 & TRN & \\
\hline CHEMBL1490789 & 688759 & 4.45 & 4.9184 & TRN & \\
\hline CHEMBL3196809 & 688759 & 4.8 & 5.1946 & TRN & \\
\hline CHEMBL1438100 & 688759 & 4.55 & 5.58899 & 99999999995 & TRN \\
\hline CHEMBL3190429 & 688759 & 5.7 & 5.4298 & TRN & \\
\hline CHEMBL1373267 & 688759 & 5.05 & 4.7766 & TST & \\
\hline CHEMBL1538845 & 688759 & 4.45 & 4.643 & TRN & \\
\hline CHEMBL1409180 & 688759 & 5.0 & 4.9829 & TRN & \\
\hline CHEMBL1448766 & 688759 & 4.45 & 4.5622 & TRN & \\
\hline CHEMBL1429779 & 688759 & 4.45 & 4.6932 & TRN & \\
\hline CHEMBL1608676 & 688759 & 4.9 & 4.9692 & TST & \\
\hline CHEMBL1511429 & 688759 & 5.25 & 5.0123 & TRN & \\
\hline CHEMBL1502352 & 688759 & 4.8 & 4.6706 & TRN & \\
\hline CHEMBL1308879 & 688759 & 4.45 & 4.5346 & TRN & \\
\hline CHEMBL1308733 & 688759 & 4.45 & 4.9319 & TST & \\
\hline CHEMBL1299525 & 688759 & 4.45 & 4.8672 & TRN & \\
\hline CHEMBL1457114 & 688759 & 4.45 & 4.8127 & TST & \\
\hline CHEMBL3213900 & 688759 & 4.75 & 4.9696 & TRN & \\
\hline CHEMBL1588417 & 688759 & 4.5 & 5.0084 & TRN & \\
\hline CHEMBL1452213 & 688759 & 4.45 & 4.8872 & TRN & \\
\hline CHEMBL1409789 & 688759 & 5.5 & 5.4734 & TRN & \\
\hline CHEMBL1387668 & 688759 & 4.85 & 4.9467 & TRN & \\
\hline
\end{tabular}




\begin{tabular}{|c|c|c|c|c|}
\hline \multicolumn{5}{|c|}{ Supplemental Table S2.txt } \\
\hline CHEMBL1467832 & 688759 & 4.8 & 4.9171 & TRN \\
\hline CHEMBL1372558 & 688759 & 4.75 & 4.829 & TRN \\
\hline CHEMBL1492399 & 688759 & 5.9 & 5.5751 & TRN \\
\hline CHEMBL1587831 & 688759 & 5.6 & 4.8062 & TST \\
\hline CHEMBL1589403 & 688759 & 4.55 & 4.7862 & TRN \\
\hline CHEMBL 2000196 & 688759 & 5.25 & 5.2593 & TRN \\
\hline CHEMBL1557703 & 688759 & 5.15 & 4.8811 & TST \\
\hline CHEMBL3192635 & 688759 & 4.45 & 4.8089 & TRN \\
\hline CHEMBL1342473 & 688759 & 4.45 & 4.9099 & TRN \\
\hline CHEMBL1529276 & 688759 & 4.65 & 4.8632 & TRN \\
\hline CHEMBL1421774 & 688759 & 4.45 & 5.3962 & TRN \\
\hline CHEMBL1583535 & 688759 & 4.45 & 4.8015 & TRN \\
\hline CHEMBL3192393 & 688759 & 4.45 & 4.5756 & TRN \\
\hline CHEMBL1984523 & 688759 & 4.45 & 4.7344 & TST \\
\hline CHEMBL1613389 & 688759 & 4.8 & 4.7899 & TRN \\
\hline CHEMBL1304631 & 688759 & 5.0 & 4.9003 & TRN \\
\hline CHEMBL1532065 & 688759 & 4.45 & 4.71 & TST \\
\hline CHEMBL1374957 & 688759 & 4.45 & 4.6725 & TRN \\
\hline CHEMBL1568022 & 688759 & 6.05 & 4.904 & TRN \\
\hline CHEMBL1485577 & 688759 & 4.95 & 4.9189 & TRN \\
\hline CHEMBL1360352 & 688759 & 5.3 & 5.0084 & TRN \\
\hline CHEMBL1377653 & 688759 & 4.65 & 4.7329 & TRN \\
\hline CHEMBL1599757 & 688759 & 4.45 & 4.8971 & TRN \\
\hline CHEMBL1471750 & 688759 & 4.6 & 4.5885 & TRN \\
\hline CHEMBL1386604 & 688759 & 4.5 & 4.8397 & TRN \\
\hline CHEMBL1451037 & 688759 & 4.45 & 4.9445 & TRN \\
\hline CHEMBL3209340 & 688759 & 5.2 & 5.1554 & TRN \\
\hline CHEMBL1610275 & 688759 & 4.75 & 4.8235 & TRN \\
\hline CHEMBL1537722 & 688759 & 4.45 & 4.8374 & TRN \\
\hline CHEMBL1601797 & 688759 & 5.35 & 4.9222 & TRN \\
\hline CHEMBL3196451 & 688759 & 5.2 & 5.1995 & TRN \\
\hline CHEMBL1509382 & 688759 & 5.55 & 5.4113 & TRN \\
\hline CHEMBL1441361 & 688759 & 4.75 & 5.1703 & TST \\
\hline CHEMBL1585963 & 688759 & 5.25 & 4.9179 & TRN \\
\hline CHEMBL1487078 & 688759 & 5.0 & 5.2556 & TST \\
\hline CHEMBL1574831 & 688759 & 6.2 & 5.4898 & TRN \\
\hline CHEMBL1375882 & 688759 & 5.4 & 4.6193 & TRN \\
\hline CHEMBL1457369 & 688759 & 5.15 & 4.8685 & TRN \\
\hline CHEMBL1361193 & 688759 & 4.45 & 4.9143 & TST \\
\hline CHEMBL1414624 & 688759 & 4.85 & 5.0355 & TRN \\
\hline CHEMBL515998 & 688759 & 4.45 & 4.6932 & TRN \\
\hline CHEMBL3198175 & 688759 & 4.55 & 4.8047 & TRN \\
\hline CHEMBL1371100 & 688759 & 5.0 & 4.6885 & TRN \\
\hline CHEMBL1472481 & 688759 & 4.45 & 5.1515 & TRN \\
\hline CHEMBL1345003 & 688759 & 4.65 & 5.018 & TRN \\
\hline CHEMBL1369795 & 688759 & 4.45 & 5.0428 & TRN \\
\hline CHEMBL 2095095 & 688759 & 5.3 & 5.2815 & TRN \\
\hline CHEMBL1584334 & 688759 & 4.9 & 4.9184 & TRN \\
\hline
\end{tabular}




\begin{tabular}{|c|c|c|c|c|}
\hline & & & upplement & al $\mathrm{T}$ \\
\hline CHEMBL3199677 & 688759 & 5.25 & 4.6419 & TST \\
\hline CHEMBL1470302 & 688759 & 4.8 & 4.8594 & TRN \\
\hline CHEMBL1480056 & 688759 & 5.9 & 5.2925 & TRN \\
\hline CHEMBL1347635 & 688759 & 4.95 & 5.169 & TRN \\
\hline CHEMBL1361341 & 688759 & 6.3 & 6.0285 & TRN \\
\hline CHEMBL1451682 & 688759 & 4.65 & 4.9885 & TRN \\
\hline CHEMBL 3190324 & 688759 & 4.85 & 4.5262 & TRN \\
\hline CHEMBL1333412 & 688759 & 4.55 & 4.865 & TRN \\
\hline CHEMBL1379443 & 688759 & 4.65 & 4.8653 & TRN \\
\hline CHEMBL3198864 & 688759 & 5.1 & 5.5723 & TRN \\
\hline CHEMBL1565394 & 688759 & 5.25 & 5.3613 & TRN \\
\hline CHEMBL1501129 & 688759 & 4.45 & 4.7209 & TST \\
\hline CHEMBL1411048 & 688759 & 4.45 & 4.9711 & TRN \\
\hline CHEMBL3193907 & 688759 & 7.0 & 6.0923 & TRN \\
\hline CHEMBL1430381 & 688759 & 4.7 & 4.8655 & TRN \\
\hline CHEMBL1430650 & 688759 & 5.6 & 4.9165 & TRN \\
\hline CHEMBL1461623 & 688759 & 4.9 & 4.6286 & TRN \\
\hline CHEMBL1503208 & 688759 & 5.2 & 4.8341 & TRN \\
\hline CHEMBL1462938 & 688759 & 4.65 & 4.7862 & TST \\
\hline CHEMBL1332308 & 688759 & 4.45 & 4.8732 & TRN \\
\hline CHEMBL1518710 & 688759 & 4.9 & 4.8296 & TRN \\
\hline CHEMBL1365357 & 688759 & 4.75 & 4.878 & TRN \\
\hline CHEMBL1311207 & 688759 & 6.25 & 4.7607 & TST \\
\hline CHEMBL1484622 & 688759 & 5.75 & 5.1104 & TST \\
\hline CHEMBL1300175 & 688759 & 4.45 & 4.9275 & TST \\
\hline CHEMBL1583722 & 688759 & 4.7 & 5.0107 & TRN \\
\hline CHEMBL1362088 & 688759 & 4.45 & 4.7731 & TRN \\
\hline CHEMBL1505674 & 688759 & 4.6 & 5.0874 & TRN \\
\hline CHEMBL1305658 & 688759 & 4.45 & 4.6857 & TRN \\
\hline CHEMBL1529261 & 688759 & 6.0 & 6.2962 & TRN \\
\hline CHEMBL1381466 & 688759 & 4.45 & 4.7637 & TRN \\
\hline CHEMBL1312083 & 688759 & 4.65 & 4.8463 & TRN \\
\hline CHEMBL1580165 & 688759 & 5.15 & 4.7346 & TST \\
\hline CHEMBL1561910 & 688759 & 5.15 & 5.1205 & TRN \\
\hline CHEMBL1569751 & 688759 & 4.85 & 4.8883 & TRN \\
\hline CHEMBL1991021 & 688759 & 4.45 & 4.6816 & TRN \\
\hline CHEMBL3198134 & 688759 & 5.55 & 5.2782 & TRN \\
\hline CHEMBL3191459 & 688759 & 4.65 & 5.2585 & TRN \\
\hline CHEMBL1570510 & 688759 & 4.45 & 4.6305 & TRN \\
\hline CHEMBL1353363 & 688759 & 4.6 & 4.6979 & TST \\
\hline CHEMBL3214253 & 688759 & 4.75 & 4.6688 & TST \\
\hline CHEMBL1430366 & 688759 & 5.3 & 5.1184 & TST \\
\hline CHEMBL1588079 & 688759 & 5.15 & 4.9907 & TRN \\
\hline CHEMBL1448275 & 688759 & 6.2 & 5.6015 & TRN \\
\hline CHEMBL1470470 & 688759 & 5.4 & 4.8551 & TRN \\
\hline CHEMBL1997177 & 688759 & 4.45 & 4.7533 & TRN \\
\hline CHEMBL1544649 & 688759 & 5.0 & 4.7998 & TST \\
\hline CHEMBL1368838 & 688759 & 4.65 & 4.7219 & TRN \\
\hline
\end{tabular}




\begin{tabular}{|c|c|c|c|c|c|}
\hline \\
\hline CHEMBL1530520 & 688759 & 6.0 & 5.0513 & TRN & \\
\hline CHEMBL3209244 & 688759 & 4.8 & 4.9456 & TRN & \\
\hline CHEMBL1539631 & 688759 & 4.6 & 4.9969 & TRN & \\
\hline CHEMBL1445583 & 688759 & 6.0 & 5.2859 & TRN & \\
\hline CHEMBL1542759 & 688759 & 4.45 & 5.1584 & TRN & \\
\hline CHEMBL1512725 & 688759 & 4.9 & 4.6922 & TST & \\
\hline CHEMBL1571803 & 688759 & 5.3 & 4.758 & TST & \\
\hline CHEMBL1351347 & 688759 & 4.45 & 4.918 & TRN & \\
\hline CHEMBL1360808 & 688759 & 4.45 & 4.4361 & TRN & \\
\hline CHEMBL1416166 & 688759 & 4.95 & 4.9505 & TRN & \\
\hline CHEMBL1485312 & 688759 & 5.6 & 5.371 & TRN & \\
\hline CHEMBL1390121 & 688759 & 5.5 & 5.4911 & TST & \\
\hline CHEMBL2006545 & 688759 & 5.9 & 5.5677 & TRN & \\
\hline CHEMBL1490785 & 688759 & 5.2 & 4.7126 & TRN & \\
\hline CHEMBL1517229 & 688759 & 5.55 & 4.8537 & TRN & \\
\hline CHEMBL339561 & 688759 & 5.05 & 5.0105 & TRN & \\
\hline CHEMBL1587767 & 688759 & 5.7 & 5.6414 & TRN & \\
\hline CHEMBL1510734 & 688759 & 4.45 & 4.7395 & TRN & \\
\hline CHEMBL1359081 & 688759 & 4.7 & 4.7509 & TST & \\
\hline CHEMBL1474734 & 688759 & 4.75 & 4.5521 & TRN & \\
\hline CHEMBL1485151 & 688759 & 5.25 & 4.8392 & TRN & \\
\hline CHEMBL1543722 & 688759 & 5.3 & 5.0416 & TST & \\
\hline CHEMBL 2000670 & 688759 & 4.75 & 4.7922 & TRN & \\
\hline CHEMBL3194456 & 688759 & 4.65 & 4.7539 & TRN & \\
\hline CHEMBL1419049 & 688759 & 4.6 & 5.0538 & TRN & \\
\hline CHEMBL1571054 & 688759 & 5.2 & 4.9797 & TRN & \\
\hline CHEMBL1311412 & 688759 & 4.55 & 4.7267 & TRN & \\
\hline CHEMBL1610037 & 688759 & 4.6 & 4.5826 & TRN & \\
\hline CHEMBL3193526 & 688759 & 4.65 & 4.9378 & TRN & \\
\hline CHEMBL1388095 & 688759 & 5.0 & 4.7913 & TRN & \\
\hline CHEMBL1368430 & 688759 & 4.6 & 4.7702 & TST & \\
\hline CHEMBL1502755 & 688759 & 4.45 & 5.0276 & TRN & \\
\hline CHEMBL1985664 & 688759 & 4.6 & 5.069 & TRN & \\
\hline CHEMBL3195475 & 688759 & 5.55 & 5.1603 & TRN & \\
\hline CHEMBL1426938 & 688759 & 6.95 & 5.0638 & TRN & \\
\hline CHEMBL1401450 & 688759 & 5.2 & 4.65300 & 00000000005 & TST \\
\hline CHEMBL1566556 & 688759 & 4.5 & 4.916 & TST & \\
\hline CHEMBL580421 & 688759 & 6.0 & 5.4146 & TST & \\
\hline CHEMBL1607687 & 688759 & 5.1 & 4.8441 & TRN & \\
\hline CHEMBL3194778 & 688759 & 6.5501 & 5.4275 & TST & \\
\hline CHEMBL1299353 & 688759 & 5.05 & 4.9393 & TRN & \\
\hline CHEMBL1393381 & 688759 & 5.15 & 5.4687 & TRN & \\
\hline CHEMBL1398324 & 688759 & 4.45 & 4.8297 & TRN & \\
\hline CHEMBL1449875 & 688759 & 5.55 & 5.32600 & 00000000005 & TRN \\
\hline CHEMBL1430905 & 688759 & 4.75 & 4.6656 & TRN & \\
\hline CHEMBL1986827 & 688759 & 5.25 & 4.8528 & TST & \\
\hline CHEMBL1312582 & 688759 & 4.7 & 4.8348 & TRN & \\
\hline CHEMBL1303553 & 688759 & 4.65 & 4.752 & TRN & \\
\hline
\end{tabular}




\begin{tabular}{|c|c|c|c|c|c|}
\hline & & \multicolumn{4}{|c|}{ Supplemental Table S2.txt } \\
\hline CHEMBL1346822 & 688759 & 4.6 & 4.8385 & TRN & \\
\hline CHEMBL1532060 & 688759 & 5.35 & 5.0064 & TRN & \\
\hline CHEMBL1367163 & 688759 & 5.4 & 4.673 & TRN & \\
\hline CHEMBL1527266 & 688759 & 4.45 & 4.8093 & TST & \\
\hline CHEMBL1413615 & 688759 & 4.85 & 5.2194 & TRN & \\
\hline CHEMBL1587583 & 688759 & 4.7 & 4.7643 & TRN & \\
\hline CHEMBL1430882 & 688759 & 4.6 & 4.8538 & TST & \\
\hline CHEMBL1577695 & 688759 & 4.9 & 5.0838 & TRN & \\
\hline CHEMBL1600998 & 688759 & 4.45 & 4.7611 & TRN & \\
\hline CHEMBL3195280 & 688759 & 5.0 & 4.9507 & TRN & \\
\hline CHEMBL1534923 & 688759 & 4.95 & 4.9002 & TRN & \\
\hline CHEMBL1599034 & 688759 & 6.0 & 5.3913 & TRN & \\
\hline CHEMBL1417929 & 688759 & 4.8 & 4.8632 & TRN & \\
\hline CHEMBL3190495 & 688759 & 4.45 & 4.619 & TST & \\
\hline CHEMBL1398933 & 688759 & 4.75 & 4.7123 & TRN & \\
\hline CHEMBL1996179 & 688759 & 5.1 & 5.3937 & TRN & \\
\hline CHEMBL1575353 & 688759 & 4.45 & 5.4376 & TRN & \\
\hline CHEMBL 3194241 & 688759 & 4.45 & 4.5218 & TRN & \\
\hline CHEMBL1969721 & 688759 & 4.7 & 5.13200 & 2000000001 & TST \\
\hline CHEMBL1503075 & 688759 & 4.85 & 4.5043 & TRN & \\
\hline CHEMBL1441683 & 688759 & 6.15 & 4.9559 & TRN & \\
\hline CHEMBL1576589 & 688759 & 5.2 & 5.0114 & TRN & \\
\hline CHEMBL1215100 & 688759 & 4.5 & 4.8222 & TRN & \\
\hline CHEMBL3196064 & 688759 & 4.45 & 4.592 & TRN & \\
\hline CHEMBL1505153 & 688759 & 5.45 & 4.9719 & TRN & \\
\hline CHEMBL1310410 & 688759 & 4.6 & 4.6924 & TRN & \\
\hline CHEMBL1429249 & 688759 & 4.45 & 4.9131 & TST & \\
\hline CHEMBL601547 & 688759 & 4.45 & 4.6363 & TRN & \\
\hline CHEMBL3208338 & 688759 & 5.25 & 4.6925 & TRN & \\
\hline CHEMBL1613033 & 688759 & 5.55 & 4.9255 & TST & \\
\hline CHEMBL1464606 & 688759 & 4.45 & 5.0294 & TRN & \\
\hline CHEMBL1326060 & 688759 & 6.25 & 6.0128 & TRN & \\
\hline CHEMBL 227423 & 688759 & 4.45 & 4.7212 & TRN & \\
\hline CHEMBL1464504 & 688759 & 5.35 & 5.0297 & TRN & \\
\hline CHEMBL1471217 & 688759 & 4.45 & 4.584 & TRN & \\
\hline CHEMBL1333728 & 688759 & 4.45 & 4.7758 & TRN & \\
\hline CHEMBL1359489 & 688759 & 4.75 & 4.8224 & TRN & \\
\hline CHEMBL1606712 & 688759 & 4.45 & 4.7523 & TRN & \\
\hline CHEMBL1589925 & 688759 & 4.45 & 4.7522 & TRN & \\
\hline CHEMBL1505636 & 688759 & 5.1 & 4.9497 & TRN & \\
\hline CHEMBL1503441 & 688759 & 5.25 & 4.7715 & TST & \\
\hline CHEMBL1520559 & 688759 & 5.3 & 5.4231 & TRN & \\
\hline CHEMBL1578174 & 688759 & 4.45 & 4.771 & TRN & \\
\hline CHEMBL1427975 & 688759 & 4.45 & 4.809 & TRN & \\
\hline CHEMBL1540221 & 688759 & 4.45 & 4.6772 & TRN & \\
\hline CHEMBL1581425 & 688759 & 4.45 & 4.6893 & TRN & \\
\hline CHEMBL1581163 & 688759 & 4.65 & 4.6695 & TRN & \\
\hline CHEMBL1540015 & 688759 & 4.5 & 5.0654 & TRN & \\
\hline
\end{tabular}




\begin{tabular}{|c|c|c|c|c|c|}
\hline \multicolumn{6}{|c|}{ Supplemental Table S2.txt } \\
\hline CHEMBL1500958 & 688759 & 4.45 & 4.5801 & TST & \\
\hline CHEMBL1538563 & 688759 & 4.65 & 5.1856 & TRN & \\
\hline CHEMBL3195327 & 688759 & 4.8 & 4.5309 & TRN & \\
\hline CHEMBL1350435 & 688759 & 4.45 & 5.2725 & TRN & \\
\hline CHEMBL1389500 & 688759 & 4.55 & 4.8863 & TST & \\
\hline CHEMBL1442672 & 688759 & 4.9 & 5.1019 & TRN & \\
\hline CHEMBL1605426 & 688759 & 4.45 & 4.971 & TST & \\
\hline CHEMBL1341924 & 688759 & 5.05 & 4.7587 & TRN & \\
\hline CHEMBL1484972 & 688759 & 4.65 & 4.9204 & TRN & \\
\hline CHEMBL1462804 & 688759 & 4.45 & 4.5529 & TRN & \\
\hline CHEMBL1594311 & 688759 & 4.6 & 5.0013 & TRN & \\
\hline CHEMBL1467726 & 688759 & 4.45 & 4.8612 & TRN & \\
\hline CHEMBL3199135 & 688759 & 5.05 & 5.3393 & TRN & \\
\hline CHEMBL3190880 & 688759 & 4.45 & 4.7827 & TRN & \\
\hline CHEMBL1340130 & 688759 & 4.75 & 4.8471 & TST & \\
\hline CHEMBL1423712 & 688759 & 4.6 & 4.7721 & TRN & \\
\hline CHEMBL1554137 & 688759 & 4.5 & 4.8114 & TRN & \\
\hline CHEMBL1536400 & 688759 & 4.8 & 4.8323 & TRN & \\
\hline CHEMBL3189485 & 688759 & 4.7 & 4.78600 & 00000000005 & TRN \\
\hline CHEMBL1492807 & 688759 & 5.5 & 5.176 & TRN & \\
\hline CHEMBL1451553 & 688759 & 4.8 & 5.0501 & TRN & \\
\hline CHEMBL1459131 & 688759 & 5.0 & 4.6085 & TRN & \\
\hline CHEMBL1336126 & 688759 & 8.3468 & 4.8892 & TRN & \\
\hline CHEMBL3207824 & 688759 & 4.8 & 4.8092 & TRN & \\
\hline CHEMBL1332881 & 688759 & 5.25 & 4.7476 & TRN & \\
\hline CHEMBL1502840 & 688759 & 6.0 & 5.3048 & TRN & \\
\hline CHEMBL1481938 & 688759 & 5.05 & 4.7851 & TST & \\
\hline CHEMBL1556134 & 688759 & 4.55 & 4.6539 & TRN & \\
\hline CHEMBL1311436 & 688759 & 4.45 & 4.7904 & TRN & \\
\hline CHEMBL1404229 & 688759 & 5.5 & 4.9165 & TRN & \\
\hline CHEMBL1482007 & 688759 & 4.45 & 4.5569 & TRN & \\
\hline CHEMBL1598585 & 688759 & 4.95 & 4.97 & TRN & \\
\hline CHEMBL1504346 & 688759 & 4.45 & 4.6741 & TRN & \\
\hline CHEMBL1472307 & 688759 & 4.45 & 5.3843 & TRN & \\
\hline CHEMBL1478089 & 688759 & 5.9 & 4.9813 & TRN & \\
\hline CHEMBL1454619 & 688759 & 5.25 & 4.8634 & TST & \\
\hline CHEMBL1545042 & 688759 & 4.45 & 4.814 & TRN & \\
\hline CHEMBL1509920 & 688759 & 6.45 & 4.9051 & TRN & \\
\hline CHEMBL1585906 & 688759 & 5.7 & 5.2611 & TRN & \\
\hline CHEMBL1539934 & 688759 & 6.1 & 4.9194 & TRN & \\
\hline CHEMBL1610679 & 688759 & 6.0 & 5.1671 & TRN & \\
\hline CHEMBL1490208 & 688759 & 4.8 & 4.9155 & TRN & \\
\hline CHEMBL3190453 & 688759 & 5.0 & 4.9755 & TRN & \\
\hline CHEMBL1333826 & 688759 & 4.45 & 4.8339 & TST & \\
\hline CHEMBL 3145000 & 688759 & 4.45 & 4.7551 & TRN & \\
\hline CHEMBL 2007612 & 688759 & 5.5 & 5.4335 & TRN & \\
\hline CHEMBL3194611 & 688759 & 5.45 & 4.9841 & TRN & \\
\hline CHEMBL1561718 & 688759 & 5.15 & 5.5745 & TST & \\
\hline
\end{tabular}




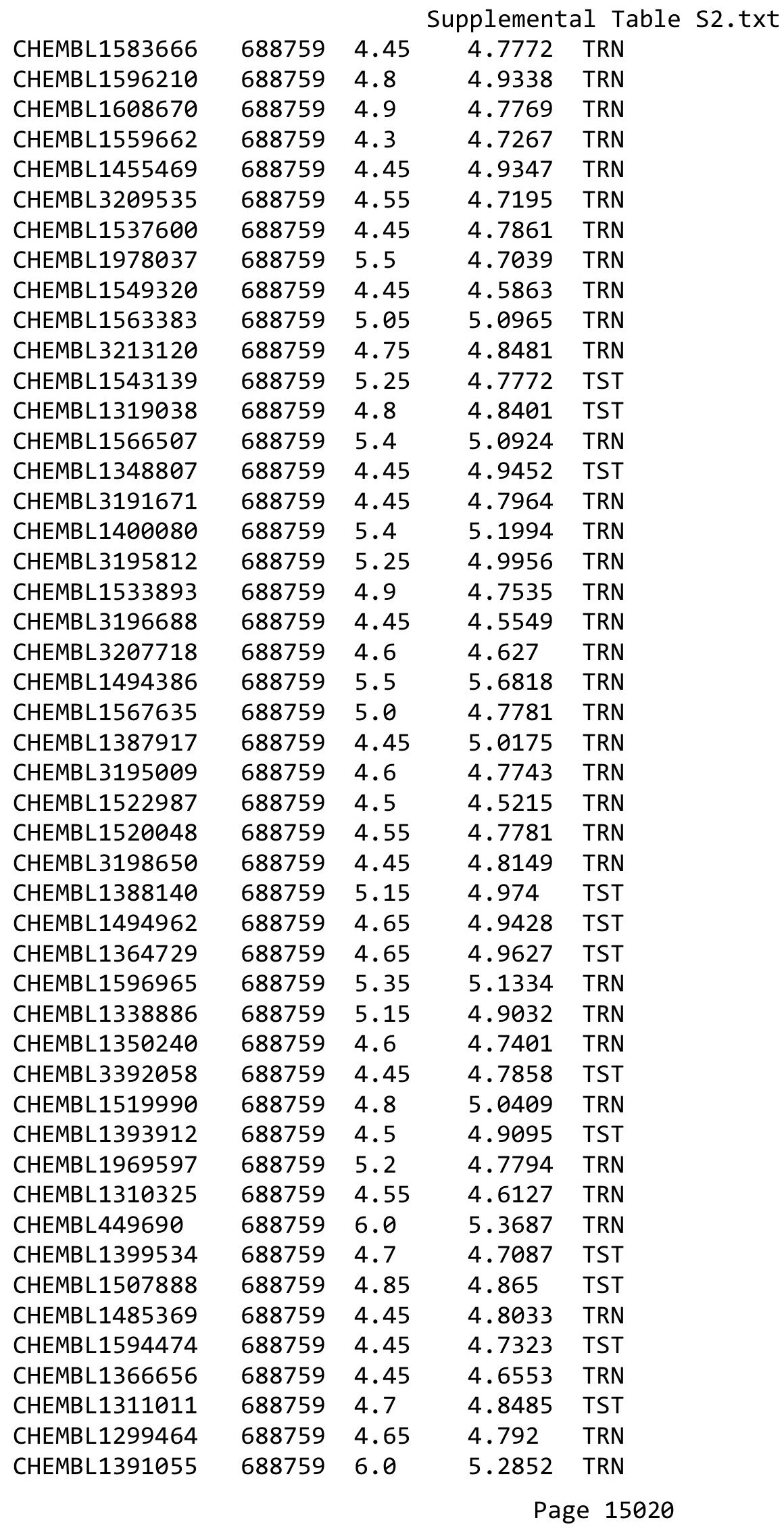




\begin{tabular}{|c|c|c|c|c|}
\hline & & & & \\
\hline CHEMBL1425054 & 688759 & 6.3 & 5.5669 & TRN \\
\hline CHEMBL1572968 & 688759 & 4.8 & 5.1597 & TRN \\
\hline CHEMBL1521960 & 688759 & 5.45 & 5.4258 & TRN \\
\hline CHEMBL1441176 & 688759 & 4.45 & 4.8517 & TRN \\
\hline CHEMBL1448282 & 688759 & 5.55 & 5.6128 & TRN \\
\hline CHEMBL1541563 & 688759 & 5.5 & 5.2261 & TST \\
\hline CHEMBL1304194 & 688759 & 5.15 & 5.0591 & TRN \\
\hline CHEMBL1495237 & 688759 & 4.7 & 4.71899 & 9999999999 \\
\hline CHEMBL1323854 & 688759 & 5.15 & 4.9704 & TRN \\
\hline CHEMBL1516369 & 688759 & 6.5501 & 5.1448 & TRN \\
\hline CHEMBL1570140 & 688759 & 5.1 & 5.0697 & TRN \\
\hline CHEMBL1414932 & 688759 & 4.65 & 4.88 & TRN \\
\hline CHEMBL1513485 & 688759 & 4.45 & 4.9237 & TRN \\
\hline CHEMBL1343922 & 688759 & 4.45 & 4.9972 & TRN \\
\hline CHEMBL1421559 & 688759 & 5.2 & 5.1174 & TRN \\
\hline CHEMBL1583944 & 688759 & 4.5 & 4.5842 & TRN \\
\hline CHEMBL1578835 & 688759 & 4.9 & 5.0233 & TRN \\
\hline CHEMBL1363915 & 688759 & 4.45 & 4.4664 & TRN \\
\hline CHEMBL1563809 & 688759 & 4.45 & 4.8156 & TRN \\
\hline CHEMBL1986681 & 688759 & 4.45 & 4.5846 & TRN \\
\hline CHEMBL1401122 & 688759 & 5.85 & 5.4194 & TRN \\
\hline CHEMBL375126 & 688759 & 4.45 & 4.65600 & 0000000001 \\
\hline CHEMBL1412285 & 688759 & 5.4 & 4.9468 & TST \\
\hline CHEMBL1439138 & 688759 & 5.1 & 4.8183 & TRN \\
\hline CHEMBL1401346 & 688759 & 5.25 & 5.4209 & TRN \\
\hline CHEMBL1604790 & 688759 & 6.2 & 4.9254 & TST \\
\hline CHEMBL1481232 & 688759 & 4.45 & 4.6501 & TRN \\
\hline CHEMBL1446317 & 688759 & 5.5 & 4.8085 & TST \\
\hline CHEMBL1313346 & 688759 & 4.9 & 4.5732 & TST \\
\hline CHEMBL1335738 & 688759 & 4.65 & 4.7764 & TRN \\
\hline CHEMBL1541111 & 688759 & 4.8 & 4.9298 & TRN \\
\hline CHEMBL1420601 & 688759 & 5.15 & 4.8532 & TRN \\
\hline CHEMBL1368827 & 688759 & 4.5 & 4.8467 & TRN \\
\hline CHEMBL1405820 & 688759 & 4.75 & 4.8721 & TRN \\
\hline CHEMBL1609391 & 688759 & 4.55 & 4.8336 & TRN \\
\hline CHEMBL1401344 & 688759 & 7.3002 & 5.6966 & TRN \\
\hline CHEMBL1604245 & 688759 & 5.2 & 5.3519 & TRN \\
\hline CHEMBL3199216 & 688759 & 5.95 & 5.9697 & TRN \\
\hline CHEMBL1367466 & 688759 & 4.45 & 4.7684 & TRN \\
\hline CHEMBL1569013 & 688759 & 4.7 & 4.6804 & TRN \\
\hline CHEMBL1328720 & 688759 & 4.65 & 4.7744 & TRN \\
\hline CHEMBL1425608 & 688759 & 4.5 & 4.8168 & TRN \\
\hline CHEMBL1345820 & 688759 & 5.3 & 5.5428 & TRN \\
\hline CHEMBL1538015 & 688759 & 4.45 & 4.5927 & TRN \\
\hline CHEMBL1315948 & 688759 & 4.65 & 4.7935 & TRN \\
\hline CHEMBL1524333 & 688759 & 5.2 & 4.9894 & TRN \\
\hline CHEMBL1498843 & 688759 & 4.7 & 4.8609 & TRN \\
\hline CHEMBL1595075 & 688759 & 4.45 & 4.9743 & TST \\
\hline
\end{tabular}




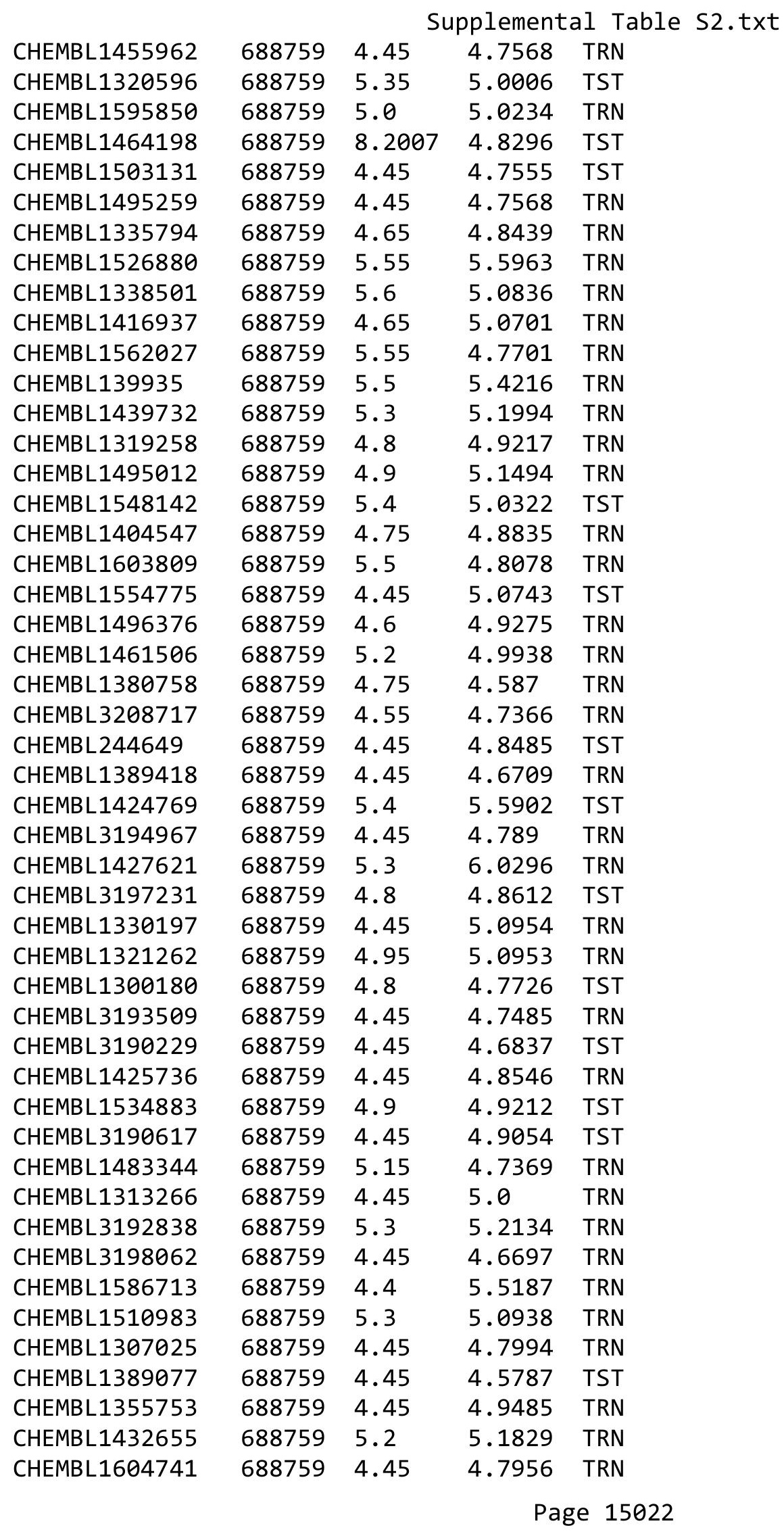




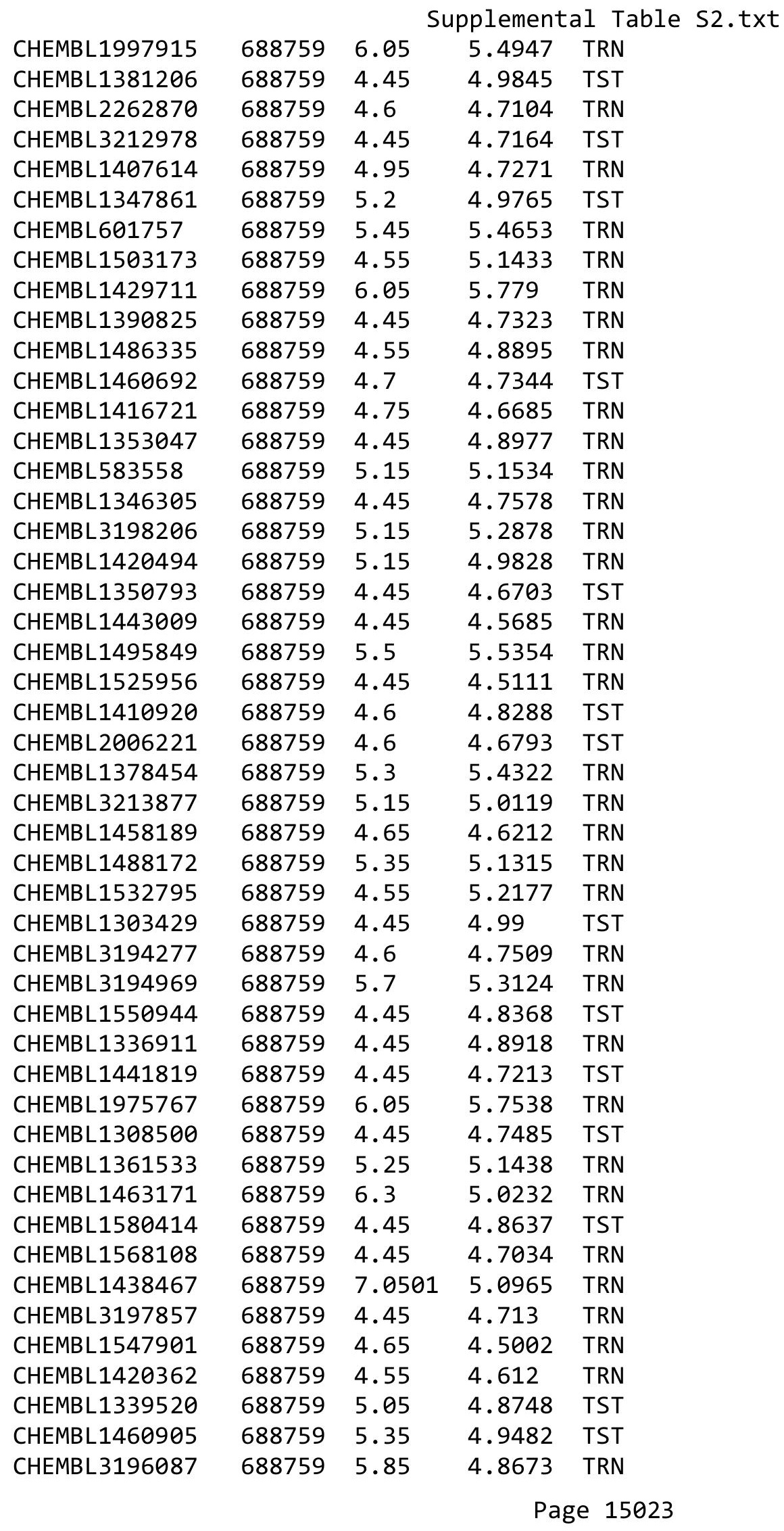




\begin{tabular}{|c|c|c|c|c|c|}
\hline \multicolumn{6}{|c|}{ Supplemental Table S2.txt } \\
\hline CHEMBL1428228 & 688759 & 5.15 & 5.0099 & TRN & \\
\hline CHEMBL1353184 & 688759 & 5.9 & 5.0331 & TRN & \\
\hline CHEMBL1976308 & 688759 & 4.85 & 5.6173 & TRN & \\
\hline CHEMBL1575720 & 688759 & 5.8 & 5.1349 & TRN & \\
\hline CHEMBL1530662 & 688759 & 5.55 & 4.9573 & TST & \\
\hline CHEMBL1213045 & 688759 & 5.15 & 4.9485 & TRN & \\
\hline CHEMBL1472294 & 688759 & 4.65 & 4.6884 & TRN & \\
\hline CHEMBL1565851 & 688759 & 5.15 & 5.1415 & TRN & \\
\hline CHEMBL1498243 & 688759 & 4.45 & 4.8077 & TRN & \\
\hline CHEMBL1379110 & 688759 & 4.95 & 5.1918 & TRN & \\
\hline CHEMBL1462192 & 688759 & 5.95 & 4.9183 & TST & \\
\hline CHEMBL1559596 & 688759 & 4.45 & 4.648 & TST & \\
\hline CHEMBL1972216 & 688759 & 5.95 & 5.5935 & TRN & \\
\hline CHEMBL1420615 & 688759 & 4.9 & 4.8969 & TST & \\
\hline CHEMBL1598289 & 688759 & 4.45 & 4.5988 & TRN & \\
\hline CHEMBL1578993 & 688759 & 4.95 & 4.8763 & TRN & \\
\hline CHEMBL3190916 & 688759 & 4.7 & 4.8239 & TST & \\
\hline CHEMBL1599126 & 688759 & 6.0 & 4.8004 & TRN & \\
\hline CHEMBL1454245 & 688759 & 5.3 & 5.1066 & TRN & \\
\hline CHEMBL1583559 & 688759 & 4.45 & 5.0659 & TRN & \\
\hline CHEMBL1517847 & 688759 & 5.65 & 4.8814 & TRN & \\
\hline CHEMBL1495195 & 688759 & 5.55 & 5.1147 & TRN & \\
\hline CHEMBL1349243 & 688759 & 5.2 & 5.0406 & TRN & \\
\hline CHEMBL1386464 & 688759 & 5.05 & 4.8838 & TRN & \\
\hline CHEMBL1486520 & 688759 & 4.45 & 5.0939 & TRN & \\
\hline CHEMBL1441984 & 688759 & 5.45 & 4.9911 & TRN & \\
\hline CHEMBL1364703 & 688759 & 5.0 & 4.88399 & 99999999995 & TRN \\
\hline CHEMBL1972090 & 688759 & 5.45 & 4.9757 & TRN & \\
\hline CHEMBL1300504 & 688759 & 4.6 & 4.8327 & TRN & \\
\hline CHEMBL1462671 & 688759 & 8.301 & 4.7266 & TRN & \\
\hline CHEMBL1349032 & 688759 & 4.45 & 4.6346 & TRN & \\
\hline CHEMBL1453410 & 688759 & 4.6 & 4.9376 & TRN & \\
\hline CHEMBL1520005 & 688759 & 4.8 & 4.7303 & TRN & \\
\hline CHEMBL1408238 & 688759 & 4.8 & 5.1244 & TRN & \\
\hline CHEMBL1345890 & 688759 & 4.45 & 5.141 & TRN & \\
\hline CHEMBL1483809 & 688759 & 4.7 & 4.8868 & TRN & \\
\hline CHEMBL3193187 & 688759 & 4.45 & 4.8539 & TRN & \\
\hline CHEMBL1464730 & 688759 & 4.45 & 5.0448 & TST & \\
\hline CHEMBL 3195371 & 688759 & 5.65 & 5.5378 & TRN & \\
\hline CHEMBL1601842 & 688759 & 5.5 & 5.555 & TRN & \\
\hline CHEMBL1373412 & 688759 & 5.0 & 5.0255 & TRN & \\
\hline CHEMBL1385147 & 688759 & 4.8 & 4.8379 & TST & \\
\hline CHEMBL1569208 & 688759 & 6.0 & 5.3331 & TRN & \\
\hline CHEMBL1382304 & 688759 & 4.55 & 4.9796 & TRN & \\
\hline CHEMBL1528051 & 688759 & 5.05 & 4.9343 & TRN & \\
\hline CHEMBL1388398 & 688759 & 4.75 & 4.9992 & TST & \\
\hline CHEMBL1338441 & 688759 & 4.95 & 4.869 & TRN & \\
\hline CHEMBL 3189582 & 688759 & 5.7 & 5.6802 & TRN & \\
\hline
\end{tabular}




\begin{tabular}{|c|c|c|c|c|}
\hline \multicolumn{5}{|c|}{ Supplemental Table S2.txt } \\
\hline CHEMBL1555061 & 688759 & 4.65 & 4.8056 & TRN \\
\hline CHEMBL 3208849 & 688759 & 4.85 & 4.8957 & TRN \\
\hline CHEMBL1331509 & 688759 & 6.95 & 5.5641 & TRN \\
\hline CHEMBL 3145130 & 688759 & 4.6 & 4.8799 & TRN \\
\hline CHEMBL1496478 & 688759 & 5.15 & 5.4145 & TRN \\
\hline CHEMBL1430531 & 688759 & 5.1 & 5.0392 & TRN \\
\hline CHEMBL1442416 & 688759 & 4.65 & 4.9696 & TRN \\
\hline CHEMBL1501135 & 688759 & 4.9 & 4.6457 & TST \\
\hline CHEMBL3209935 & 688759 & 5.05 & 5.1287 & TRN \\
\hline CHEMBL3191398 & 688759 & 5.35 & 5.2964 & TRN \\
\hline CHEMBL1486503 & 688759 & 5.3 & 4.8752 & TRN \\
\hline CHEMBL1441315 & 688759 & 4.9 & 4.7653 & TRN \\
\hline CHEMBL1449485 & 688759 & 4.45 & 4.8063 & TST \\
\hline CHEMBL1319420 & 688759 & 5.45 & 4.8209 & TST \\
\hline CHEMBL1449172 & 688759 & 4.95 & 4.9825 & TRN \\
\hline CHEMBL1384433 & 688759 & 4.6 & 4.8152 & TST \\
\hline CHEMBL1353770 & 688759 & 6.2 & 5.3813 & TST \\
\hline CHEMBL1534650 & 688759 & 4.85 & 4.8065 & TRN \\
\hline CHEMBL1502481 & 688759 & 4.75 & 4.9865 & TRN \\
\hline CHEMBL1568310 & 688759 & 6.0 & 5.9453 & TRN \\
\hline CHEMBL1438200 & 688759 & 5.1 & 4.6348 & TRN \\
\hline CHEMBL172997 & 688759 & 4.7 & 5.1235 & TST \\
\hline CHEMBL 3194327 & 688759 & 5.5 & 5.5517 & TRN \\
\hline CHEMBL1539586 & 688759 & 4.45 & 4.9257 & TST \\
\hline CHEMBL1605193 & 688759 & 8.1024 & 4.9473 & TST \\
\hline CHEMBL1425003 & 688759 & 4.45 & 4.6906 & TST \\
\hline CHEMBL1326517 & 688759 & 5.2 & 5.0865 & TST \\
\hline CHEMBL1407230 & 688759 & 4.65 & 4.6014 & TRN \\
\hline CHEMBL458504 & 688759 & 4.65 & 4.7701 & TRN \\
\hline CHEMBL1377971 & 688759 & 4.5 & 4.8782 & TRN \\
\hline CHEMBL1546228 & 688759 & 5.45 & 5.0787 & TST \\
\hline CHEMBL1604104 & 688759 & 6.15 & 4.8872 & TST \\
\hline CHEMBL1509244 & 688759 & 4.7 & 4.7844 & TRN \\
\hline CHEMBL1256667 & 688759 & 5.4 & 5.0185 & TST \\
\hline CHEMBL1488012 & 688759 & 5.1 & 4.9188 & TRN \\
\hline CHEMBL1540133 & 688759 & 4.95 & 4.7823 & TRN \\
\hline CHEMBL1522947 & 688759 & 4.55 & 4.8578 & TRN \\
\hline CHEMBL1500083 & 688759 & 6.25 & 5.3561 & TRN \\
\hline CHEMBL1497991 & 688759 & 5.2 & 4.6979 & TRN \\
\hline CHEMBL1332630 & 688759 & 4.65 & 4.6787 & TRN \\
\hline CHEMBL1370471 & 688759 & 4.8 & 4.7359 & TRN \\
\hline CHEMBL3196666 & 688759 & 4.55 & 4.647 & TRN \\
\hline CHEMBL1409837 & 688759 & 4.5 & 4.8809 & TRN \\
\hline CHEMBL1326386 & 688759 & 4.45 & 4.6847 & TST \\
\hline CHEMBL1403308 & 688759 & 4.45 & 4.5042 & TRN \\
\hline CHEMBL1445886 & 688759 & 5.15 & 5.171 & TRN \\
\hline CHEMBL1540436 & 688759 & 5.15 & 5.2634 & TRN \\
\hline CHEMBL1461055 & 688759 & 5.15 & 4.9566 & TRN \\
\hline
\end{tabular}




\begin{tabular}{|c|c|c|c|c|c|}
\hline & & \multicolumn{4}{|c|}{ Supplemental Table S2.txt } \\
\hline CHEMBL1501975 & 688759 & 4.45 & 4.8239 & TRN & \\
\hline CHEMBL1490020 & 688759 & 4.55 & 4.4831 & TRN & \\
\hline CHEMBL1509207 & 688759 & 5.2 & 5.0015 & TRN & \\
\hline CHEMBL206483 & 688759 & 4.9 & 4.7619 & TRN & \\
\hline CHEMBL1093246 & 688759 & 5.0 & 4.7357 & TRN & \\
\hline CHEMBL1466487 & 688759 & 5.25 & 5.1862 & TRN & \\
\hline CHEMBL1547706 & 688759 & 5.2 & 4.9375 & TST & \\
\hline CHEMBL1319510 & 688759 & 4.75 & 4.448 & TRN & \\
\hline CHEMBL1523268 & 688759 & 4.85 & 5.0828 & TRN & \\
\hline CHEMBL1454951 & 688759 & 4.9 & 4.8864 & TST & \\
\hline CHEMBL1510704 & 688759 & 4.45 & 4.7279 & TRN & \\
\hline CHEMBL1416805 & 688759 & 4.9 & 4.8113 & TRN & \\
\hline CHEMBL1422691 & 688759 & 4.45 & 4.9163 & TST & \\
\hline CHEMBL 3194422 & 688759 & 5.2 & 5.0458 & TST & \\
\hline CHEMBL1301484 & 688759 & 4.45 & 4.5554 & TRN & \\
\hline CHEMBL1345511 & 688759 & 5.5 & 4.8077 & TRN & \\
\hline CHEMBL1339426 & 688759 & 4.8 & 4.6071 & TRN & \\
\hline CHEMBL1540112 & 688759 & 5.35 & 5.5395 & TRN & \\
\hline CHEMBL1388137 & 688759 & 4.6 & 4.8017 & TRN & \\
\hline CHEMBL1565623 & 688759 & 4.65 & 4.82100 & 0000000001 & TRN \\
\hline CHEMBL1447893 & 688759 & 4.45 & 4.8345 & TRN & \\
\hline CHEMBL 3192486 & 688759 & 4.45 & 4.9086 & TRN & \\
\hline CHEMBL1334622 & 688759 & 4.9 & 4.9047 & TRN & \\
\hline CHEMBL1387251 & 688759 & 4.45 & 4.8825 & TRN & \\
\hline CHEMBL1432065 & 688759 & 5.5 & 5.3529 & TST & \\
\hline CHEMBL1329471 & 688759 & 5.0 & 5.0773 & TRN & \\
\hline CHEMBL1542471 & 688759 & 4.75 & 4.8732 & TRN & \\
\hline CHEMBL1549422 & 688759 & 4.45 & 5.0462 & TRN & \\
\hline CHEMBL1527610 & 688759 & 4.45 & 4.8273 & TST & \\
\hline CHEMBL1393831 & 688759 & 5.25 & 4.8612 & TRN & \\
\hline CHEMBL1411712 & 688759 & 5.5 & 5.6085 & TRN & \\
\hline CHEMBL1494428 & 688759 & 4.7 & 4.9157 & TRN & \\
\hline CHEMBL1509587 & 688759 & 4.75 & 4.8467 & TST & \\
\hline CHEMBL 3194900 & 688759 & 4.75 & 5.0168 & TRN & \\
\hline CHEMBL1299489 & 688759 & 4.8 & 5.2481 & TRN & \\
\hline CHEMBL1464645 & 688759 & 5.55 & 5.3303 & TRN & \\
\hline CHEMBL1353130 & 688759 & 4.85 & 4.8396 & TRN & \\
\hline CHEMBL1567315 & 688759 & 5.2 & 5.2847 & TRN & \\
\hline CHEMBL1407309 & 688759 & 4.65 & 4.4914 & TRN & \\
\hline CHEMBL1436028 & 688759 & 5.2 & 4.8725 & TST & \\
\hline CHEMBL1426754 & 688759 & 5.4 & 4.9081 & TRN & \\
\hline CHEMBL1439408 & 688759 & 4.45 & 4.8881 & TST & \\
\hline CHEMBL1422199 & 688759 & 5.2 & 4.9346 & TRN & \\
\hline CHEMBL 3198485 & 688759 & 5.5 & 5.6483 & TRN & \\
\hline CHEMBL3213318 & 688759 & 4.45 & 4.8074 & TRN & \\
\hline CHEMBL1510951 & 688759 & 4.95 & 5.1621 & TRN & \\
\hline CHEMBL1541975 & 688759 & 4.45 & 4.6338 & TRN & \\
\hline CHEMBL1441323 & 688759 & 4.45 & 4.9544 & TST & \\
\hline
\end{tabular}




\begin{tabular}{|c|c|c|c|c|c|}
\hline & & \multicolumn{4}{|c|}{ Supplemental Table s2.txt } \\
\hline CHEMBL1535028 & 688759 & 4.65 & 5.0361 & TST & \\
\hline CHEMBL1506259 & 688759 & 4.6 & 4.8918 & TRN & \\
\hline CHEMBL365063 & 688759 & 4.45 & 4.8986 & TST & \\
\hline CHEMBL1334524 & 688759 & 4.45 & 4.6908 & TRN & \\
\hline CHEMBL1407286 & 688759 & 4.95 & 4.7869 & TRN & \\
\hline CHEMBL1449971 & 688759 & 4.95 & 4.7921 & TRN & \\
\hline CHEMBL1431909 & 688759 & 4.6 & 4.9674 & TRN & \\
\hline CHEMBL1421473 & 688759 & 5.3 & 4.9748 & TRN & \\
\hline CHEMBL1585888 & 688759 & 4.6 & 4.8579 & TRN & \\
\hline CHEMBL1331440 & 688759 & 4.65 & 4.6797 & TST & \\
\hline CHEMBL3191503 & 688759 & 5.65 & 5.3758 & TRN & \\
\hline CHEMBL3191938 & 688759 & 5.05 & 4.9179 & TRN & \\
\hline CHEMBL3193056 & 688759 & 4.6 & 4.8348 & TRN & \\
\hline CHEMBL1494966 & 688759 & 5.2 & 5.08899 & 99999999995 & TRN \\
\hline CHEMBL1501171 & 688759 & 5.35 & 4.9647 & TRN & \\
\hline CHEMBL1335825 & 688759 & 4.85 & 4.9271 & TST & \\
\hline CHEMBL1596960 & 688759 & 4.95 & 4.8079 & TST & \\
\hline CHEMBL548619 & 688759 & 5.15 & 5.2774 & TRN & \\
\hline CHEMBL1375468 & 688759 & 4.45 & 4.9201 & TRN & \\
\hline CHEMBL1579833 & 688759 & 4.45 & 4.676 & TST & \\
\hline CHEMBL457504 & 688759 & 6.0 & 5.2602 & TRN & \\
\hline CHEMBL1531757 & 688759 & 5.0 & 5.1384 & TST & \\
\hline CHEMBL3193017 & 688759 & 4.65 & 4.6842 & TRN & \\
\hline CHEMBL1425463 & 688759 & 4.45 & 5.0413 & TST & \\
\hline CHEMBL1382044 & 688759 & 4.45 & 5.012 & TST & \\
\hline CHEMBL1576548 & 688759 & 4.7 & 5.0757 & TRN & \\
\hline CHEMBL1300869 & 688759 & 4.45 & 5.0578 & TST & \\
\hline CHEMBL1539616 & 688759 & 5.0 & 5.0208 & TST & \\
\hline CHEMBL1530391 & 688759 & 5.8 & 4.8182 & TRN & \\
\hline CHEMBL3197704 & 688759 & 4.6 & 4.8961 & TRN & \\
\hline CHEMBL1574504 & 688759 & 5.65 & 4.6909 & TST & \\
\hline CHEMBL1334887 & 688759 & 4.65 & 4.5702 & TST & \\
\hline CHEMBL1560212 & 688759 & 5.55 & 5.0033 & TRN & \\
\hline CHEMBL1423702 & 688759 & 4.45 & 4.9975 & TRN & \\
\hline CHEMBL1491143 & 688759 & 5.45 & 5.0396 & TST & \\
\hline CHEMBL1595855 & 688759 & 4.7 & 4.7722 & TRN & \\
\hline CHEMBL1367596 & 688759 & 6.05 & 5.4645 & TRN & \\
\hline CHEMBL1391791 & 688759 & 4.55 & 4.9176 & TRN & \\
\hline CHEMBL1476712 & 688759 & 5.6 & 4.8314 & TRN & \\
\hline CHEMBL242384 & 688759 & 5.0 & 4.9868 & TRN & \\
\hline CHEMBL1575634 & 688759 & 4.45 & 4.783 & TRN & \\
\hline CHEMBL1430219 & 688759 & 4.95 & 4.7241 & TRN & \\
\hline CHEMBL1484106 & 688759 & 4.45 & 4.7101 & TST & \\
\hline CHEMBL3213314 & 688759 & 5.9 & 5.0681 & TRN & \\
\hline CHEMBL1449201 & 688759 & 4.45 & 4.9071 & TRN & \\
\hline CHEMBL1425983 & 688759 & 4.65 & 4.7724 & TRN & \\
\hline CHEMBL1452852 & 688759 & 5.55 & 4.8585 & TRN & \\
\hline CHEMBL225951 & 688759 & 5.15 & 4.996 & TRN & \\
\hline
\end{tabular}




\begin{tabular}{|c|c|c|c|c|}
\hline \multicolumn{5}{|c|}{ Supplemental Table S2.txt } \\
\hline CHEMBL1455809 & 688759 & 6.05 & 5.7132 & TRN \\
\hline CHEMBL3191004 & 688759 & 5.15 & 5.0634 & TRN \\
\hline CHEMBL1557721 & 688759 & 5.35 & 4.5794 & TRN \\
\hline CHEMBL1543865 & 688759 & 5.05 & 4.664 & TST \\
\hline CHEMBL1417672 & 688759 & 4.45 & 4.9798 & TRN \\
\hline CHEMBL1571234 & 688759 & 4.7 & 4.7239 & TRN \\
\hline CHEMBL1470568 & 688759 & 5.55 & 5.5081 & TRN \\
\hline CHEMBL3193893 & 688759 & 5.55 & 4.8692 & TST \\
\hline CHEMBL1352339 & 688759 & 5.2 & 4.9814 & TST \\
\hline CHEMBL1818878 & 688759 & 8.301 & 5.4823 & TRN \\
\hline CHEMBL1331080 & 688759 & 6.5501 & 4.9267 & TST \\
\hline CHEMBL1456690 & 688759 & 4.45 & 4.9336 & TRN \\
\hline CHEMBL1382898 & 688759 & 4.95 & 5.1227 & TRN \\
\hline CHEMBL1460513 & 688759 & 4.85 & 4.6807 & TRN \\
\hline CHEMBL1550672 & 688759 & 4.75 & 4.8025 & TRN \\
\hline CHEMBL1424732 & 688759 & 4.6 & 4.8153 & TST \\
\hline CHEMBL1465043 & 688759 & 5.0 & 5.0641 & TST \\
\hline CHEMBL 3213017 & 688759 & 4.8 & 5.0628 & TST \\
\hline CHEMBL 2000560 & 688759 & 4.45 & 4.5497 & TRN \\
\hline CHEMBL1518994 & 688759 & 5.5 & 5.4534 & TRN \\
\hline CHEMBL3198376 & 688759 & 5.3 & 4.9749 & TRN \\
\hline CHEMBL1565963 & 688759 & 4.45 & 4.8061 & TRN \\
\hline CHEMBL1325289 & 688759 & 4.5 & 4.7232 & TRN \\
\hline CHEMBL1342518 & 688759 & 5.45 & 5.4176 & TST \\
\hline CHEMBL1413479 & 688759 & 5.35 & 5.2772 & TRN \\
\hline CHEMBL1387248 & 688759 & 5.35 & 5.0729 & TST \\
\hline CHEMBL1363829 & 688759 & 6.1 & 4.8943 & TRN \\
\hline CHEMBL1611105 & 688759 & 4.6 & 4.5262 & TRN \\
\hline CHEMBL1547792 & 688759 & 5.9 & 5.7788 & TRN \\
\hline CHEMBL1610391 & 688759 & 5.0 & 4.9391 & TRN \\
\hline CHEMBL1433240 & 688759 & 4.65 & 4.6312 & TRN \\
\hline CHEMBL1342021 & 688759 & 4.65 & 4.4374 & TRN \\
\hline CHEMBL3214397 & 688759 & 4.65 & 4.8895 & TST \\
\hline CHEMBL3191881 & 688759 & 4.65 & 4.7372 & TRN \\
\hline CHEMBL1371455 & 688759 & 4.45 & 4.7885 & TRN \\
\hline CHEMBL1977555 & 688759 & 4.45 & 4.6246 & TRN \\
\hline CHEMBL1465709 & 688759 & 4.6 & 4.8318 & TST \\
\hline CHEMBL1562060 & 688759 & 4.6 & 4.7739 & TRN \\
\hline CHEMBL1548590 & 688759 & 5.5 & 5.1093 & TRN \\
\hline CHEMBL1502187 & 688759 & 4.75 & 4.8897 & TST \\
\hline CHEMBL1580839 & 688759 & 5.65 & 4.914 & TRN \\
\hline CHEMBL1519910 & 688759 & 4.8 & 5.0451 & TRN \\
\hline CHEMBL1516549 & 688759 & 4.45 & 4.7392 & TRN \\
\hline CHEMBL3189479 & 688759 & 6.05 & 5.7787 & TRN \\
\hline CHEMBL1566354 & 688759 & 4.5 & 4.6927 & TRN \\
\hline CHEMBL1609372 & 688759 & 4.45 & 4.8082 & TRN \\
\hline CHEMBL1305398 & 688759 & 5.05 & 4.9568 & TRN \\
\hline CHEMBL1978383 & 688759 & 5.3 & 5.347 & TST \\
\hline
\end{tabular}




\begin{tabular}{|c|c|c|c|c|c|}
\hline & & \multicolumn{4}{|c|}{ Supplemental Table S2.txt } \\
\hline CHEMBL1439432 & 688759 & 4.75 & 4.6207 & TRN & \\
\hline CHEMBL1535952 & 688759 & 5.0 & 5.0589 & TRN & \\
\hline CHEMBL1362364 & 688759 & 4.7 & 4.8684 & TST & \\
\hline CHEMBL 3198094 & 688759 & 4.9 & 5.0354 & TRN & \\
\hline CHEMBL1985327 & 688759 & 5.4 & 5.0476 & TRN & \\
\hline CHEMBL1487751 & 688759 & 4.6 & 4.9906 & TRN & \\
\hline CHEMBL448515 & 688759 & 5.35 & 5.2323 & TST & \\
\hline CHEMBL1460352 & 688759 & 6.05 & 5.2244 & TRN & \\
\hline CHEMBL1501505 & 688759 & 4.45 & 4.7818 & TRN & \\
\hline CHEMBL1606572 & 688759 & 4.75 & 4.9366 & TRN & \\
\hline CHEMBL 3192143 & 688759 & 5.75 & 5.1653 & TRN & \\
\hline CHEMBL1319867 & 688759 & 5.55 & 5.0697 & TRN & \\
\hline CHEMBL1370515 & 688759 & 4.5 & 4.7095 & TRN & \\
\hline CHEMBL1301497 & 688759 & 5.15 & 4.9823 & TRN & \\
\hline CHEMBL 2369200 & 688759 & 5.3 & 5.2141 & TRN & \\
\hline CHEMBL1579296 & 688759 & 6.1 & 4.9948 & TRN & \\
\hline CHEMBL 1330400 & 688759 & 4.45 & 4.859 & TRN & \\
\hline CHEMBL1336959 & 688759 & 5.8 & 5.1406 & TRN & \\
\hline CHEMBL1422381 & 688759 & 5.15 & 4.5739 & TST & \\
\hline CHEMBL3193628 & 688759 & 4.8 & 4.8735 & TRN & \\
\hline CHEMBL1595769 & 688759 & 4.75 & 4.7124 & TRN & \\
\hline CHEMBL 1351776 & 688759 & 5.25 & 4.8351 & TST & \\
\hline CHEMBL1411270 & 688759 & 4.65 & 4.8665 & TST & \\
\hline CHEMBL1428073 & 688759 & 4.65 & \multicolumn{2}{|c|}{4.6930000000000005} & TRN \\
\hline CHEMBL1420285 & 688759 & 4.75 & 4.6228 & TRN & \\
\hline CHEMBL1576423 & 688759 & 4.75 & 4.8799 & TRN & \\
\hline CHEMBL1417134 & 688759 & 5.45 & 4.935 & TRN & \\
\hline CHEMBL1410157 & 688759 & 5.5 & 5.0933 & TRN & \\
\hline CHEMBL1420229 & 688759 & 4.45 & 4.6229 & TRN & \\
\hline CHEMBL1518350 & 688759 & 4.45 & 4.6534 & TST & \\
\hline CHEMBL1478310 & 688759 & 4.95 & 5.0553 & TST & \\
\hline CHEMBL1411398 & 688759 & 4.95 & 4.9115 & TRN & \\
\hline CHEMBL1478819 & 688759 & 4.45 & 4.7363 & TRN & \\
\hline CHEMBL1532562 & 688759 & 4.65 & 4.8428 & TRN & \\
\hline CHEMBL391997 & 688759 & 4.55 & 4.8251 & TST & \\
\hline CHEMBL1568482 & 688759 & 4.7 & 4.8306 & TRN & \\
\hline CHEMBL 1602860 & 688759 & 4.9 & 4.6414 & TRN & \\
\hline CHEMBL1449575 & 688759 & 4.45 & 4.879 & TST & \\
\hline CHEMBL1373146 & 688759 & 4.95 & 4.9971 & TRN & \\
\hline CHEMBL1426734 & 688759 & 6.15 & 5.8122 & TST & \\
\hline CHEMBL1500288 & 688759 & 4.9 & 4.9831 & TST & \\
\hline CHEMBL1605705 & 688759 & 4.95 & 4.9143 & TRN & \\
\hline CHEMBL1407724 & 688759 & 5.3 & \multicolumn{2}{|c|}{5.2620000000000005} & TST \\
\hline CHEMBL3211817 & 688759 & 5.25 & 4.7474 & TST & \\
\hline CHEMBL1462076 & 688759 & 5.1 & 5.1841 & TRN & \\
\hline CHEMBL1525334 & 688759 & 5.0 & 4.9776 & TRN & \\
\hline CHEMBL1367717 & 688759 & 5.3 & 4.8054 & TRN & \\
\hline CHEMBL1336535 & 688759 & 9.1549 & 6.3367 & TRN & \\
\hline
\end{tabular}




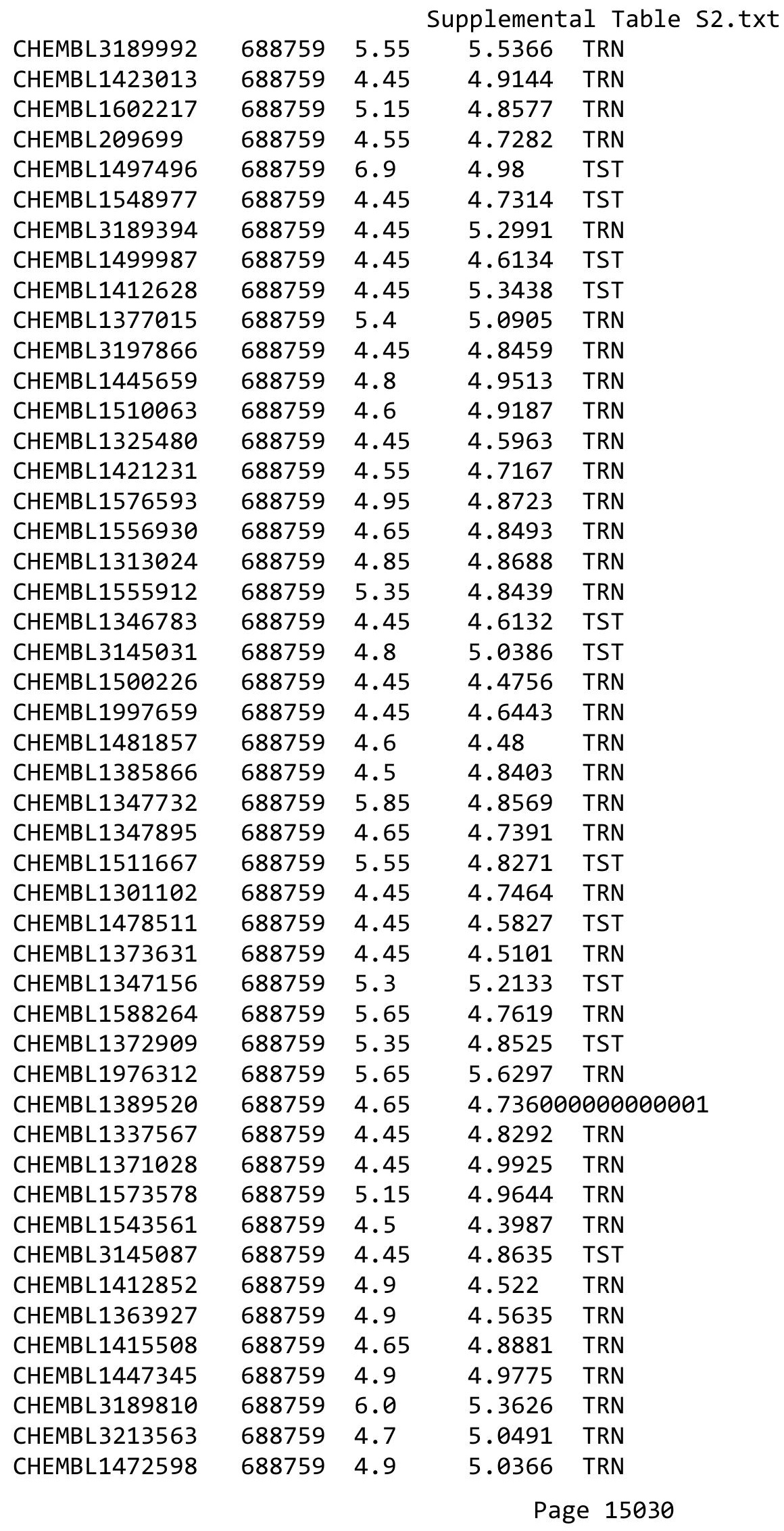




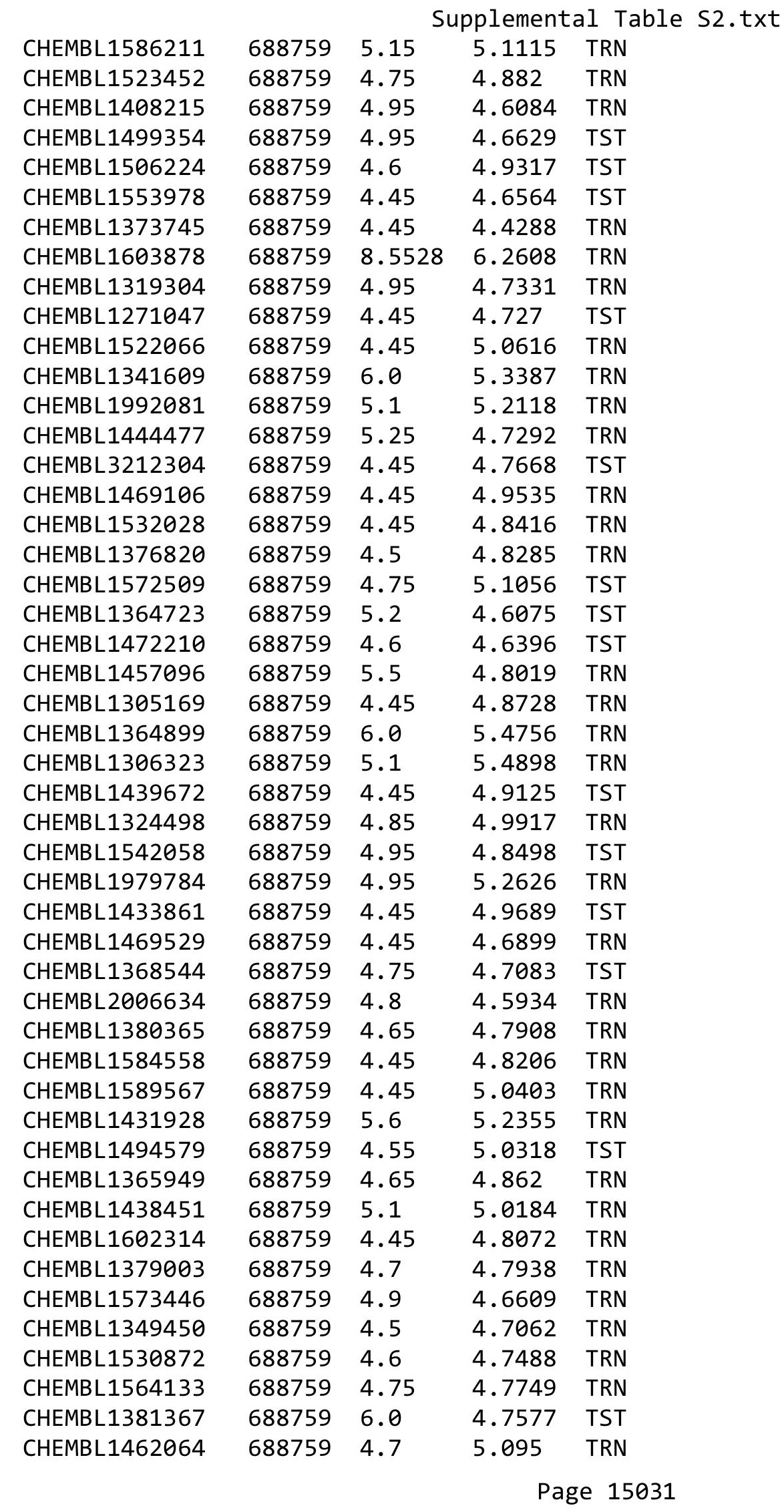




\begin{tabular}{|c|c|c|c|c|c|}
\hline \multirow[b]{2}{*}{ CHEMBL1470373 } & \multirow[b]{2}{*}{688759} & \multicolumn{4}{|c|}{ Supplemental Table s2.txt } \\
\hline & & 4.45 & 4.6481 & TST & \\
\hline CHEMBL1572552 & 688759 & 4.6 & 4.9711 & TRN & \\
\hline CHEMBL 3190654 & 688759 & 4.45 & 4.8354 & TST & \\
\hline CHEMBL1433339 & 688759 & 6.15 & 4.6903 & TRN & \\
\hline CHEMBL3199217 & 688759 & 4.65 & 4.7543 & TST & \\
\hline CHEMBL1308246 & 688759 & 4.95 & 4.82100 & 0000000001 & TRN \\
\hline CHEMBL 3209844 & 688759 & 4.45 & 4.8569 & TST & \\
\hline CHEMBL1335050 & 688759 & 4.45 & 5.001 & TRN & \\
\hline CHEMBL1519649 & 688759 & 5.05 & 4.6506 & TRN & \\
\hline CHEMBL7939 & 688759 & 4.6 & 4.7698 & TST & \\
\hline CHEMBL1348581 & 688759 & 5.5 & 4.9968 & TRN & \\
\hline CHEMBL1338838 & 688759 & 4.75 & 4.8132 & TRN & \\
\hline CHEMBL1481145 & 688759 & 4.7 & 4.544 & TRN & \\
\hline CHEMBL454211 & 688759 & 6.8 & 5.0009 & TRN & \\
\hline CHEMBL1505918 & 688759 & 5.2 & 4.8851 & TRN & \\
\hline CHEMBL1543124 & 688759 & 4.75 & 4.8071 & TST & \\
\hline CHEMBL1303139 & 688759 & 4.9 & 4.7302 & TST & \\
\hline CHEMBL1583603 & 688759 & 4.85 & 4.9293 & TRN & \\
\hline CHEMBL1610522 & 688759 & 4.9 & 4.9325 & TST & \\
\hline CHEMBL1585432 & 688759 & 4.95 & 4.9371 & TRN & \\
\hline CHEMBL1429108 & 688759 & 4.7 & 4.8803 & TRN & \\
\hline CHEMBL3195238 & 688759 & 5.65 & 5.9491 & TRN & \\
\hline CHEMBL1521141 & 688759 & 4.45 & 4.8789 & TRN & \\
\hline CHEMBL1443240 & 688759 & 4.45 & 4.8481 & TST & \\
\hline CHEMBL1336197 & 688759 & 5.15 & 5.0857 & TRN & \\
\hline CHEMBL355612 & 688759 & 5.15 & 4.6749 & TRN & \\
\hline CHEMBL1468723 & 688759 & 4.65 & 4.8811 & TRN & \\
\hline CHEMBL1312514 & 688759 & 5.1 & 4.8955 & TRN & \\
\hline CHEMBL1353771 & 688759 & 4.45 & 4.6548 & TRN & \\
\hline CHEMBL1529346 & 688759 & 5.2 & 4.9794 & TRN & \\
\hline CHEMBL1592649 & 688759 & 4.45 & 5.0372 & TST & \\
\hline CHEMBL1550748 & 688759 & 5.1 & 4.9346 & TST & \\
\hline CHEMBL 3145293 & 688759 & 5.25 & 4.9811 & TRN & \\
\hline CHEMBL1345273 & 688759 & 6.1 & 4.8693 & TRN & \\
\hline CHEMBL1310620 & 688759 & 4.5 & 4.8805 & TRN & \\
\hline CHEMBL1470049 & 688759 & 4.65 & 4.7594 & TRN & \\
\hline CHEMBL1439295 & 688759 & 5.95 & 5.5291 & TRN & \\
\hline CHEMBL1320353 & 688759 & 5.15 & 5.3865 & TRN & \\
\hline CHEMBL1596041 & 688759 & 5.95 & 5.7519 & TRN & \\
\hline CHEMBL1329497 & 688759 & 4.65 & 4.5815 & TRN & \\
\hline CHEMBL1495273 & 688759 & 4.75 & 4.649 & TRN & \\
\hline CHEMBL1450898 & 688759 & 4.8 & 4.5512 & TRN & \\
\hline CHEMBL1306817 & 688759 & 4.7 & 4.7419 & TRN & \\
\hline CHEMBL1549664 & 688759 & 5.6 & 4.9875 & TRN & \\
\hline CHEMBL1561273 & 688759 & 4.45 & 4.6316 & TRN & \\
\hline CHEMBL1607989 & 688759 & 4.55 & 4.9034 & TST & \\
\hline CHEMBL3198124 & 688759 & 4.45 & 4.5869 & TRN & \\
\hline CHEMBL1528965 & 688759 & 4.85 & 4.8584 & TST & \\
\hline
\end{tabular}




\begin{tabular}{|c|c|c|c|c|c|}
\hline \multicolumn{6}{|c|}{ Supplemental Table S2.txt } \\
\hline CHEMBL1570845 & 688759 & 5.35 & 4.9692 & TRN & \\
\hline CHEMBL1507795 & 688759 & 4.45 & 4.9511 & TST & \\
\hline CHEMBL1422037 & 688759 & 4.45 & 5.1658 & TRN & \\
\hline CHEMBL1573766 & 688759 & 5.45 & 5.3903 & TRN & \\
\hline CHEMBL1384263 & 688759 & 4.7 & \multicolumn{2}{|c|}{5.0360000000000005} & TRN \\
\hline CHEMBL1341327 & 688759 & 5.25 & 4.9001 & TRN & \\
\hline CHEMBL1375590 & 688759 & 5.0 & 4.7479 & TRN & \\
\hline CHEMBL1471592 & 688759 & 4.6 & 4.9443 & TRN & \\
\hline CHEMBL1444644 & 688759 & 4.45 & 4.6265 & TRN & \\
\hline CHEMBL1595904 & 688759 & 4.8 & 4.7248 & TRN & \\
\hline CHEMBL1499932 & 688759 & 4.65 & 4.8134 & TST & \\
\hline CHEMBL1341586 & 688759 & 6.0 & 5.1838 & TRN & \\
\hline CHEMBL1455268 & 688759 & 4.45 & 4.7101 & TRN & \\
\hline CHEMBL1340037 & 688759 & 4.45 & 4.7883 & TRN & \\
\hline CHEMBL1299502 & 688759 & 4.95 & 4.7847 & TST & \\
\hline CHEMBL1527139 & 688759 & 4.65 & 4.7484 & TRN & \\
\hline CHEMBL1335678 & 688759 & 4.5 & 4.8685 & TRN & \\
\hline CHEMBL1502522 & 688759 & 5.5 & 5.2608 & TRN & \\
\hline CHEMBL1377420 & 688759 & 5.0 & 4.9992 & TRN & \\
\hline CHEMBL1491862 & 688759 & 4.6 & 4.9733 & TRN & \\
\hline CHEMBL1352016 & 688759 & 4.45 & \multicolumn{2}{|c|}{4.7410000000000005} & TRN \\
\hline CHEMBL1973042 & 688759 & 4.75 & 4.6133 & TRN & \\
\hline CHEMBL3197287 & 688759 & 5.55 & 5.4351 & TRN & \\
\hline CHEMBL1301308 & 688759 & 4.7 & 4.8022 & TST & \\
\hline CHEMBL 2001887 & 688759 & 4.45 & 4.9391 & TRN & \\
\hline CHEMBL1579451 & 688759 & 5.45 & 5.6068 & TRN & \\
\hline CHEMBL1408581 & 688759 & 4.9 & 4.9412 & TRN & \\
\hline CHEMBL1562983 & 688759 & 4.45 & 4.703 & TRN & \\
\hline CHEMBL1550538 & 688759 & 5.55 & 4.8178 & TRN & \\
\hline CHEMBL1470619 & 688759 & 4.85 & 4.8586 & TRN & \\
\hline CHEMBL1485708 & 688759 & 6.95 & 5.7993 & TST & \\
\hline CHEMBL1450031 & 688759 & 4.65 & 5.2698 & TRN & \\
\hline CHEMBL1499365 & 688759 & 4.9 & 4.8124 & TRN & \\
\hline CHEMBL1406920 & 688759 & 6.0 & 5.9068 & TRN & \\
\hline CHEMBL1531811 & 688759 & 4.65 & 4.9481 & TST & \\
\hline CHEMBL1535580 & 688759 & 4.9 & 4.9272 & TRN & \\
\hline CHEMBL1541933 & 688759 & 4.8 & 5.2454 & TRN & \\
\hline CHEMBL1571440 & 688759 & 4.8 & 4.9927 & TRN & \\
\hline CHEMBL1353194 & 688759 & 5.05 & 5.0432 & TRN & \\
\hline CHEMBL1368299 & 688759 & 4.8 & 4.9365 & TRN & \\
\hline CHEMBL1501731 & 688759 & 4.45 & 4.9194 & TRN & \\
\hline CHEMBL1470450 & 688759 & 5.0 & 4.7424 & TRN & \\
\hline CHEMBL3213113 & 688759 & 5.2 & 4.7577 & TRN & \\
\hline CHEMBL1403635 & 688759 & 4.95 & 5.0261 & TRN & \\
\hline CHEMBL3195652 & 688759 & 5.15 & 4.9074 & TRN & \\
\hline CHEMBL1992286 & 688759 & 4.5 & 4.6163 & TRN & \\
\hline CHEMBL1344206 & 688759 & 5.3 & 4.8544 & TRN & \\
\hline CHEMBL1971968 & 688759 & 4.45 & 4.8259 & TRN & \\
\hline
\end{tabular}




\begin{tabular}{|c|c|c|c|c|c|}
\hline \multicolumn{6}{|c|}{ Supplemental Table S2.txt } \\
\hline CHEMBL1426039 & 688759 & 5.1 & 4.955 & TRN & \\
\hline CHEMBL1425600 & 688759 & 4.55 & 4.4589 & TRN & \\
\hline CHEMBL 2003605 & 688759 & 5.0 & 4.9416 & TRN & \\
\hline CHEMBL1384909 & 688759 & 5.4 & 5.0962 & TRN & \\
\hline CHEMBL1324123 & 688759 & 4.75 & 5.088 & TRN & \\
\hline CHEMBL1573581 & 688759 & 4.55 & 5.7281 & TRN & \\
\hline CHEMBL1421436 & 688759 & 4.45 & 4.8303 & TST & \\
\hline CHEMBL1468351 & 688759 & 4.75 & 4.7871 & TRN & \\
\hline CHEMBL1541147 & 688759 & 5.2 & 5.0297 & TST & \\
\hline CHEMBL1382097 & 688759 & 5.4 & 4.8416 & TRN & \\
\hline CHEMBL1402668 & 688759 & 4.7 & 4.5733 & TRN & \\
\hline CHEMBL1452154 & 688759 & 5.35 & 4.7146 & TRN & \\
\hline CHEMBL1300765 & 688759 & 6.7001 & 4.9453 & TRN & \\
\hline CHEMBL1540365 & 688759 & 4.75 & 4.9182 & TRN & \\
\hline CHEMBL1509020 & 688759 & 4.45 & 4.7439 & TRN & \\
\hline CHEMBL2001100 & 688759 & 6.35 & 5.7629 & TRN & \\
\hline CHEMBL1390116 & 688759 & 4.45 & 5.1223 & TRN & \\
\hline CHEMBL1434816 & 688759 & 5.2 & 4.9761 & TST & \\
\hline CHEMBL1469402 & 688759 & 4.7 & 4.7766 & TRN & \\
\hline CHEMBL1534223 & 688759 & 5.15 & 4.68199 & 99999999995 & TRN \\
\hline CHEMBL1327251 & 688759 & 4.45 & 4.7402 & TRN & \\
\hline CHEMBL1538258 & 688759 & 5.3 & 5.2093 & TRN & \\
\hline CHEMBL1383061 & 688759 & 5.25 & 4.7703 & TRN & \\
\hline CHEMBL1488994 & 688759 & 4.65 & 4.9266 & TRN & \\
\hline CHEMBL1364417 & 688759 & 4.45 & 5.1362 & TRN & \\
\hline CHEMBL3197361 & 688759 & 5.2 & 5.2283 & TST & \\
\hline CHEMBL1428192 & 688759 & 4.45 & 4.8296 & TRN & \\
\hline CHEMBL1347084 & 688759 & 5.3 & 4.8178 & TRN & \\
\hline CHEMBL1432712 & 688759 & 4.7 & 4.706 & TRN & \\
\hline CHEMBL1441707 & 688759 & 4.45 & 4.7129 & TRN & \\
\hline CHEMBL1446027 & 688759 & 4.5 & 4.5065 & TRN & \\
\hline CHEMBL1583765 & 688759 & 4.45 & 4.6468 & TRN & \\
\hline CHEMBL1503795 & 688759 & 5.0 & 5.0386 & TRN & \\
\hline CHEMBL1489293 & 688759 & 4.45 & 5.0493 & TST & \\
\hline CHEMBL1467751 & 688759 & 4.65 & 5.0976 & TRN & \\
\hline CHEMBL1507778 & 688759 & 5.2 & 5.2444 & TRN & \\
\hline CHEMBL 3193144 & 688759 & 5.5 & 4.8097 & TST & \\
\hline CHEMBL1573563 & 688759 & 5.85 & 5.5823 & TRN & \\
\hline CHEMBL1391233 & 688759 & 4.55 & 4.7734 & TST & \\
\hline CHEMBL1606532 & 688759 & 4.45 & 4.7485 & TRN & \\
\hline CHEMBL3192856 & 688759 & 5.4 & 5.4163 & TRN & \\
\hline CHEMBL1579046 & 688759 & 5.45 & 4.9893 & TRN & \\
\hline CHEMBL1468165 & 688759 & 4.45 & 4.7058 & TRN & \\
\hline CHEMBL1349225 & 688759 & 6.0 & 4.6632 & TRN & \\
\hline CHEMBL1582517 & 688759 & 4.45 & 4.8617 & TST & \\
\hline CHEMBL1426485 & 688759 & 4.45 & 4.7426 & TST & \\
\hline CHEMBL1602449 & 688759 & 4.9 & 5.2087 & TRN & \\
\hline CHEMBL1545990 & 688759 & 4.45 & 5.1289 & TST & \\
\hline
\end{tabular}




\begin{tabular}{|c|c|c|c|c|c|}
\hline & & \multicolumn{4}{|c|}{ Supplemental Table S2.txt } \\
\hline CHEMBL1319259 & 688759 & 4.95 & 5.0252 & TST & \\
\hline CHEMBL1573118 & 688759 & 5.9 & 4.7495 & TRN & \\
\hline CHEMBL1441814 & 688759 & 4.5 & 4.8855 & TST & \\
\hline CHEMBL1402439 & 688759 & 4.95 & 5.2341 & TRN & \\
\hline CHEMBL225354 & 688759 & 4.85 & 4.9112 & TRN & \\
\hline CHEMBL1360491 & 688759 & 4.65 & 4.8702 & TST & \\
\hline CHEMBL478825 & 688759 & 5.2 & 5.1002 & TRN & \\
\hline CHEMBL1482466 & 688759 & 4.45 & 4.6345 & TRN & \\
\hline CHEMBL1572028 & 688759 & 4.8 & 5.7565 & TRN & \\
\hline CHEMBL1583953 & 688759 & 5.25 & 5.2594 & TST & \\
\hline CHEMBL1340535 & 688759 & 4.45 & 4.8268 & TRN & \\
\hline CHEMBL1414734 & 688759 & 6.2 & 5.358 & TRN & \\
\hline CHEMBL3192018 & 688759 & 4.8 & 5.1636 & TRN & \\
\hline CHEMBL1403859 & 688759 & 5.5 & \multicolumn{2}{|c|}{5.167000000000001} & TRN \\
\hline CHEMBL1442229 & 688759 & 4.45 & 4.7064 & TRN & \\
\hline CHEMBL1449490 & 688759 & 5.5 & 4.8237 & TST & \\
\hline CHEMBL1456766 & 688759 & 4.45 & 4.7035 & TRN & \\
\hline CHEMBL1351118 & 688759 & 5.0 & 4.9865 & TRN & \\
\hline CHEMBL1567939 & 688759 & 4.9 & 4.8685 & TST & \\
\hline CHEMBL 240333 & 688759 & 4.95 & 4.8381 & TRN & \\
\hline CHEMBL1374511 & 688759 & 4.65 & 4.7566 & TRN & \\
\hline CHEMBL1330029 & 688759 & 5.55 & 4.7385 & TRN & \\
\hline CHEMBL1466678 & 688759 & 4.65 & 4.704 & TRN & \\
\hline CHEMBL1399930 & 688759 & 5.25 & 5.4465 & TRN & \\
\hline CHEMBL1561372 & 688759 & 4.45 & 4.8654 & TST & \\
\hline CHEMBL1482717 & 688759 & 4.9 & 5.3225 & TRN & \\
\hline CHEMBL1484486 & 688759 & 4.45 & 4.8212 & TRN & \\
\hline CHEMBL1421166 & 688759 & 4.45 & 4.8196 & TRN & \\
\hline CHEMBL1428632 & 688759 & 5.1 & 4.9796 & TRN & \\
\hline CHEMBL1532266 & 688759 & 4.45 & 4.6794 & TRN & \\
\hline CHEMBL1329383 & 688759 & 4.8 & 5.1337 & TRN & \\
\hline CHEMBL1413556 & 688759 & 5.2 & 5.1753 & TST & \\
\hline CHEMBL1322110 & 688759 & 4.45 & 4.4046 & TRN & \\
\hline CHEMBL1577282 & 688759 & 4.9 & 4.7806 & TST & \\
\hline CHEMBL1453108 & 688759 & 6.0 & 5.4181 & TRN & \\
\hline CHEMBL1441685 & 688759 & 5.3 & 5.3921 & TRN & \\
\hline CHEMBL1347662 & 688759 & 4.45 & 4.8308 & TRN & \\
\hline CHEMBL1546709 & 688759 & 4.95 & 4.9788 & TRN & \\
\hline CHEMBL1568127 & 688759 & 5.25 & 5.0422 & TST & \\
\hline CHEMBL1497081 & 688759 & 4.8 & 4.7061 & TST & \\
\hline CHEMBL1519067 & 688759 & 7.4498 & 5.5117 & TRN & \\
\hline CHEMBL1345002 & 688759 & 4.65 & 4.814 & TRN & \\
\hline CHEMBL1348232 & 688759 & 5.5 & 5.3122 & TRN & \\
\hline CHEMBL1479679 & 688759 & 5.45 & 5.2084 & TRN & \\
\hline CHEMBL1455191 & 688759 & 4.75 & 4.8894 & TST & \\
\hline CHEMBL3196904 & 688759 & 4.65 & 4.6044 & TRN & \\
\hline CHEMBL1539318 & 688759 & 4.85 & 4.8187 & TRN & \\
\hline CHEMBL1605542 & 688759 & 4.45 & 4.7805 & TRN & \\
\hline
\end{tabular}




\begin{tabular}{|c|c|c|c|c|c|}
\hline \multicolumn{6}{|c|}{ Supplemental Table S2.txt } \\
\hline CHEMBL1393098 & 688759 & 5.15 & 5.0627 & TRN & \\
\hline CHEMBL1524617 & 688759 & 6.35 & 5.3986 & TST & \\
\hline CHEMBL1477826 & 688759 & 4.5 & 4.6088 & TRN & \\
\hline CHEMBL1487461 & 688759 & 6.0 & 4.9463 & TRN & \\
\hline CHEMBL1497024 & 688759 & 4.7 & 4.9977 & TRN & \\
\hline CHEMBL1521115 & 688759 & 5.0 & 5.4047 & TRN & \\
\hline CHEMBL1511328 & 688759 & 5.0 & 4.9058 & TRN & \\
\hline CHEMBL1467414 & 688759 & 4.95 & 4.9266 & TST & \\
\hline CHEMBL1325564 & 688759 & 4.75 & 4.9978 & TST & \\
\hline CHEMBL1454995 & 688759 & 5.0 & 4.9769 & TRN & \\
\hline CHEMBL1359561 & 688759 & 4.7 & 5.0722 & TST & \\
\hline CHEMBL1526269 & 688759 & 4.8 & 5.0173 & TST & \\
\hline CHEMBL1353155 & 688759 & 6.0 & 5.6653 & TRN & \\
\hline CHEMBL1430125 & 688759 & 4.45 & 4.9458 & TRN & \\
\hline CHEMBL93109 & 688759 & 5.0 & 5.2425 & TRN & \\
\hline CHEMBL1417710 & 688759 & 5.3 & 4.9036 & TRN & \\
\hline CHEMBL72683 & 688759 & 5.2 & 5.2588 & TRN & \\
\hline CHEMBL1386256 & 688759 & 4.45 & 4.6072 & TRN & \\
\hline CHEMBL1425871 & 688759 & 4.45 & 4.675 & TRN & \\
\hline CHEMBL3193111 & 688759 & 5.1 & 5.1333 & TRN & \\
\hline CHEMBL1561927 & 688759 & 4.45 & 4.8096 & TRN & \\
\hline CHEMBL1448305 & 688759 & 4.45 & 4.6865 & TRN & \\
\hline CHEMBL3189973 & 688759 & 4.9 & 4.907 & TRN & \\
\hline CHEMBL1325788 & 688759 & 4.45 & 4.8449 & TRN & \\
\hline CHEMBL1416301 & 688759 & 5.5 & 5.0383 & TST & \\
\hline CHEMBL1533616 & 688759 & 4.45 & 4.885 & TRN & \\
\hline CHEMBL1584829 & 688759 & 5.45 & 4.8751 & TRN & \\
\hline CHEMBL1375310 & 688759 & 7.0501 & 4.8628 & TST & \\
\hline CHEMBL1426199 & 688759 & 5.55 & 5.3213 & TRN & \\
\hline CHEMBL1451735 & 688759 & 4.9 & 5.2131 & TST & \\
\hline CHEMBL1578437 & 688759 & 5.35 & 5.34200 & $\partial 0000000005$ & TRN \\
\hline CHEMBL1306073 & 688759 & 4.45 & 4.7709 & TRN & \\
\hline CHEMBL1443660 & 688759 & 4.7 & 4.8026 & TRN & \\
\hline CHEMBL1487782 & 688759 & 4.45 & 5.0009 & TST & \\
\hline CHEMBL1494478 & 688759 & 5.25 & 4.7685 & TRN & \\
\hline CHEMBL1968326 & 688759 & 5.4 & 4.8909 & TRN & \\
\hline CHEMBL1336630 & 688759 & 4.95 & 4.55699 & 99999999995 & TRN \\
\hline CHEMBL1534646 & 688759 & 5.0 & 4.9921 & TRN & \\
\hline CHEMBL338474 & 688759 & 5.5 & 5.4749 & TRN & \\
\hline CHEMBL1500993 & 688759 & 4.7 & 5.077 & TST & \\
\hline CHEMBL1386049 & 688759 & 6.3 & 5.6842 & TRN & \\
\hline CHEMBL1585859 & 688759 & 5.55 & 5.3625 & TRN & \\
\hline CHEMBL1584080 & 688759 & 4.45 & 4.5697 & TST & \\
\hline CHEMBL1505991 & 688759 & 5.05 & 4.8906 & TRN & \\
\hline CHEMBL3195213 & 688759 & 4.45 & 4.7399 & TRN & \\
\hline CHEMBL1488833 & 688759 & 4.65 & 4.5867 & TST & \\
\hline CHEMBL3197900 & 688759 & 4.45 & 4.739 & TRN & \\
\hline CHEMBL1971154 & 688759 & 5.45 & 5.4568 & TST & \\
\hline
\end{tabular}




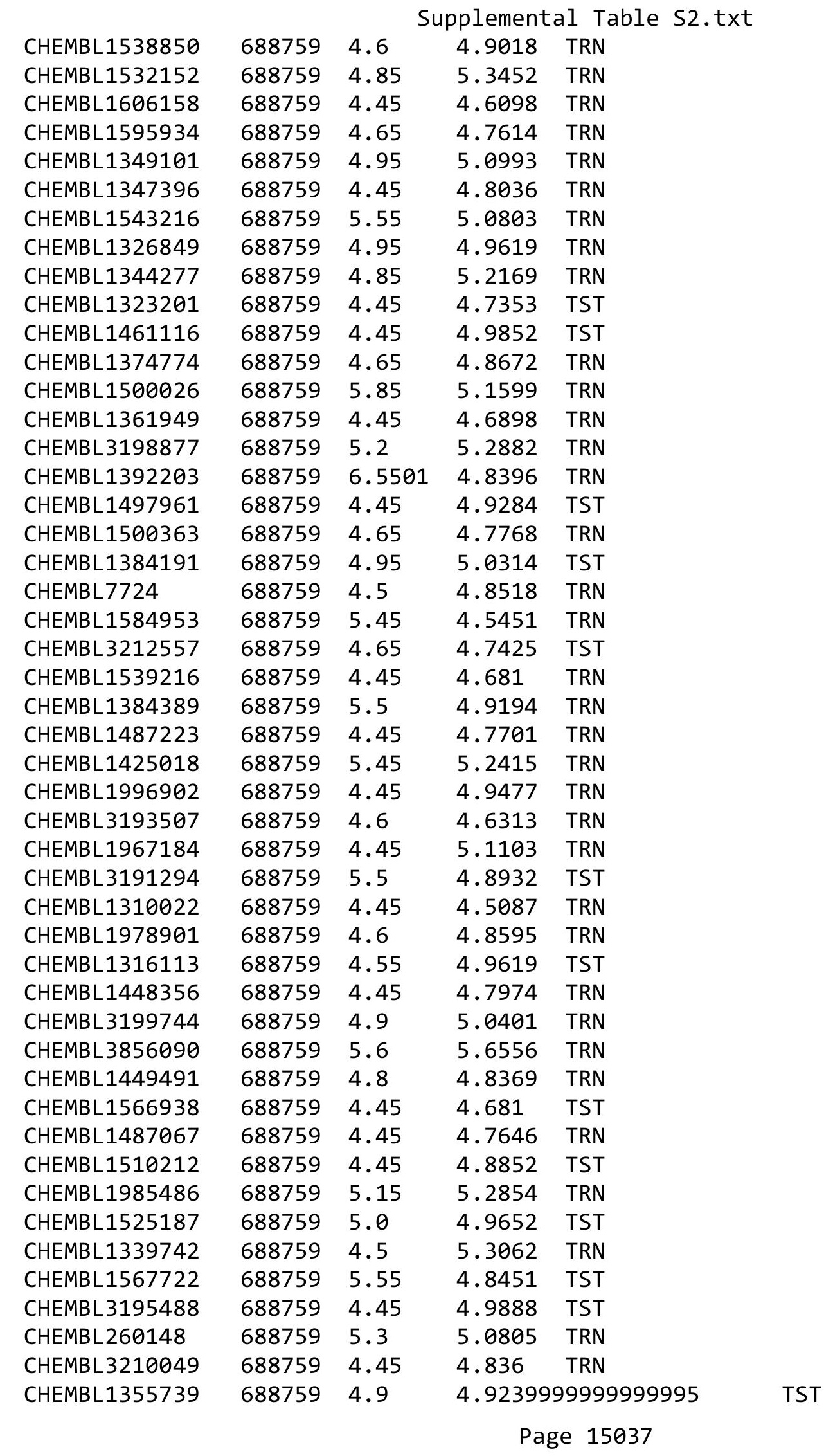




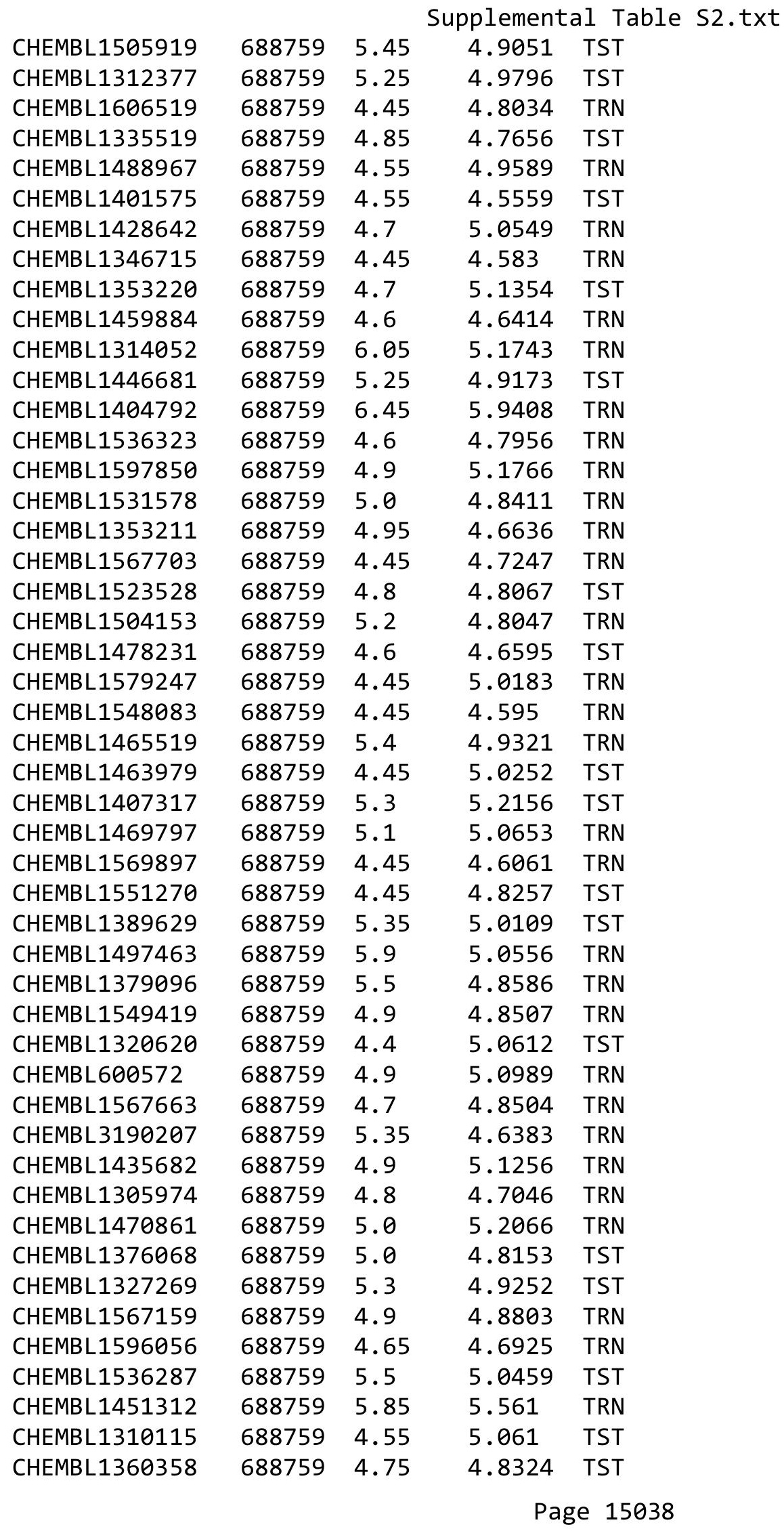




\begin{tabular}{|c|c|c|c|c|}
\hline \multicolumn{5}{|c|}{ Supplemental Table S2.txt } \\
\hline CHEMBL1309232 & 688759 & 5.5 & 5.1749 & TRN \\
\hline CHEMBL1330333 & 688759 & 4.6 & 4.7381 & TRN \\
\hline CHEMBL1607948 & 688759 & 4.45 & 4.7692 & TRN \\
\hline CHEMBL1427627 & 688759 & 4.65 & 4.7259 & TST \\
\hline CHEMBL 3194287 & 688759 & 4.95 & 4.8717 & TST \\
\hline CHEMBL1537269 & 688759 & 5.25 & 4.6439 & TST \\
\hline CHEMBL3198711 & 688759 & 4.9 & 4.8064 & TST \\
\hline CHEMBL1429992 & 688759 & 5.15 & 5.0584 & TRN \\
\hline CHEMBL1490352 & 688759 & 4.9 & 4.8201 & TRN \\
\hline CHEMBL1422312 & 688759 & 5.05 & 4.9793 & TRN \\
\hline CHEMBL1540101 & 688759 & 5.35 & 4.9024 & TST \\
\hline CHEMBL1441437 & 688759 & 4.65 & 4.7111 & TRN \\
\hline CHEMBL1474362 & 688759 & 5.0 & 4.8371 & TST \\
\hline CHEMBL1347328 & 688759 & 4.9 & 4.8598 & TRN \\
\hline CHEMBL1363844 & 688759 & 4.45 & 4.6857 & TST \\
\hline CHEMBL1425773 & 688759 & 5.8 & 5.006 & TRN \\
\hline CHEMBL3199222 & 688759 & 4.45 & 4.5755 & TST \\
\hline CHEMBL1508528 & 688759 & 4.85 & 4.5547 & TRN \\
\hline CHEMBL1456096 & 688759 & 4.95 & 5.1743 & TRN \\
\hline CHEMBL3193197 & 688759 & 4.45 & 4.8014 & TST \\
\hline CHEMBL1579082 & 688759 & 4.8 & 4.8525 & TRN \\
\hline CHEMBL1305090 & 688759 & 4.9 & 4.5704 & TST \\
\hline CHEMBL1557834 & 688759 & 5.35 & 5.3281 & TRN \\
\hline CHEMBL1374555 & 688759 & 6.6 & 6.0311 & TRN \\
\hline CHEMBL1311666 & 688759 & 5.7 & 5.2299 & TRN \\
\hline CHEMBL1479639 & 688759 & 4.45 & 4.6674 & TRN \\
\hline CHEMBL1505295 & 688759 & 4.8 & 5.0192 & TRN \\
\hline CHEMBL573111 & 688759 & 4.95 & 4.7241 & TRN \\
\hline CHEMBL195008 & 688759 & 5.55 & 5.1568 & TST \\
\hline CHEMBL2086626 & 688759 & 4.45 & 4.7518 & TRN \\
\hline CHEMBL1612042 & 688759 & 5.35 & 5.3585 & TRN \\
\hline CHEMBL1450645 & 688759 & 4.8 & 4.8095 & TST \\
\hline CHEMBL1596856 & 688759 & 4.45 & 4.7932 & TRN \\
\hline CHEMBL1466844 & 688759 & 5.75 & 5.5397 & TRN \\
\hline CHEMBL1594622 & 688759 & 4.85 & 4.7061 & TRN \\
\hline CHEMBL1602517 & 688759 & 4.75 & 5.0033 & TST \\
\hline CHEMBL1452734 & 688759 & 4.9 & 4.7671 & TST \\
\hline CHEMBL1570486 & 688759 & 4.95 & 5.0074 & TST \\
\hline CHEMBL1428865 & 688759 & 5.25 & 4.8782 & TRN \\
\hline CHEMBL3212048 & 688759 & 4.45 & 4.585 & TRN \\
\hline CHEMBL1330578 & 688759 & 4.8 & 4.7758 & TRN \\
\hline CHEMBL3194319 & 688759 & 4.65 & 4.61 & TRN \\
\hline CHEMBL1587495 & 688759 & 4.95 & 4.9092 & TRN \\
\hline CHEMBL3195999 & 688759 & 4.65 & 4.9161 & TRN \\
\hline CHEMBL1492955 & 688759 & 5.95 & 4.902 & TST \\
\hline CHEMBL1518819 & 688759 & 4.45 & 4.7674 & TST \\
\hline CHEMBL1344662 & 688759 & 5.65 & 5.0294 & TRN \\
\hline CHEMBL1439890 & 688759 & 4.65 & 4.7841 & TRN \\
\hline
\end{tabular}




\begin{tabular}{|c|c|c|c|c|}
\hline \multicolumn{5}{|c|}{ Supplemental Table S2.txt } \\
\hline CHEMBL1489816 & 688759 & 4.95 & 4.7912 & TRN \\
\hline CHEMBL1343068 & 688759 & 4.45 & 4.6061 & TRN \\
\hline CHEMBL1549167 & 688759 & 5.0 & 4.8392 & TRN \\
\hline CHEMBL3211263 & 688759 & 4.75 & 4.7567 & TRN \\
\hline CHEMBL 1585488 & 688759 & 4.65 & 4.6881 & TRN \\
\hline CHEMBL1333821 & 688759 & 4.65 & 4.9823 & TRN \\
\hline CHEMBL1604471 & 688759 & 4.65 & 4.7132 & TRN \\
\hline CHEMBL1478722 & 688759 & 4.75 & 4.9366 & TRN \\
\hline CHEMBL1368189 & 688759 & 5.4 & 4.8478 & TRN \\
\hline CHEMBL1430804 & 688759 & 4.45 & 5.1858 & TRN \\
\hline CHEMBL1343329 & 688759 & 4.45 & 4.747 & TST \\
\hline CHEMBL1546343 & 688759 & 4.45 & 4.855 & TRN \\
\hline CHEMBL3194372 & 688759 & 4.9 & 4.6675 & TRN \\
\hline CHEMBL1541814 & 688759 & 4.45 & 4.8124 & TRN \\
\hline CHEMBL1428961 & 688759 & 4.95 & 4.961 & TRN \\
\hline CHEMBL1472083 & 688759 & 4.6 & 4.9582 & TRN \\
\hline CHEMBL1347185 & 688759 & 4.45 & 4.7319 & TRN \\
\hline CHEMBL1566611 & 688759 & 5.3 & 4.8324 & TRN \\
\hline CHEMBL1433095 & 688759 & 4.5 & 4.5669 & TST \\
\hline CHEMBL1421785 & 688759 & 4.8 & 4.9856 & TST \\
\hline CHEMBL1320570 & 688759 & 5.6 & 4.8799 & TRN \\
\hline CHEMBL1545664 & 688759 & 6.1 & 5.3728 & TRN \\
\hline CHEMBL1584016 & 688759 & 4.45 & 4.6869 & TRN \\
\hline CHEMBL77098 & 688759 & 4.45 & 4.9676 & TRN \\
\hline CHEMBL3209351 & 688759 & 4.45 & 4.8158 & TST \\
\hline CHEMBL1609077 & 688759 & 4.5 & 4.7826 & TRN \\
\hline CHEMBL1327417 & 688759 & 5.1 & 4.994 & TRN \\
\hline CHEMBL1425172 & 688759 & 5.0 & 4.9819 & TST \\
\hline CHEMBL1300092 & 688759 & 4.45 & 5.0139 & TST \\
\hline CHEMBL3195772 & 688759 & 5.2 & 4.5604 & TST \\
\hline CHEMBL1373094 & 688759 & 4.7 & 4.6754 & TRN \\
\hline CHEMBL1560046 & 688759 & 5.55 & 4.8743 & TRN \\
\hline CHEMBL1387220 & 688759 & 4.55 & 4.9303 & TRN \\
\hline CHEMBL1598442 & 688759 & 4.85 & 4.8595 & TRN \\
\hline CHEMBL446313 & 688759 & 4.45 & 4.8324 & TRN \\
\hline CHEMBL3199258 & 688759 & 5.55 & 4.7799 & TRN \\
\hline CHEMBL 1486140 & 688759 & 4.45 & 4.7484 & TRN \\
\hline CHEMBL1536901 & 688759 & 4.45 & 4.7894 & TRN \\
\hline CHEMBL1539056 & 688759 & 5.9 & 5.3772 & TST \\
\hline CHEMBL1495682 & 688759 & 4.45 & 4.909 & TRN \\
\hline CHEMBL1559622 & 688759 & 4.95 & 4.7989 & TRN \\
\hline CHEMBL1476858 & 688759 & 4.75 & 4.7667 & TST \\
\hline CHEMBL1389995 & 688759 & 4.45 & 4.6759 & TRN \\
\hline CHEMBL1546415 & 688759 & 5.0 & 5.1985 & TRN \\
\hline CHEMBL1393071 & 688759 & 5.05 & 4.9571 & TRN \\
\hline CHEMBL1969867 & 688759 & 5.3 & 5.244 & TRN \\
\hline CHEMBL368036 & 688759 & 4.45 & 4.8394 & TRN \\
\hline CHEMBL3199054 & 688759 & 4.75 & 4.6498 & TST \\
\hline
\end{tabular}




\begin{tabular}{|c|c|c|c|c|c|}
\hline \multicolumn{6}{|c|}{ Supplemental Table S2.txt } \\
\hline CHEMBL1431473 & 688759 & 4.9 & 4.4342 & TRN & \\
\hline CHEMBL3193227 & 688759 & 4.95 & 4.8117 & TST & \\
\hline CHEMBL1443648 & 688759 & 4.65 & 4.7595 & TST & \\
\hline CHEMBL1429434 & 688759 & 4.45 & 5.2778 & TRN & \\
\hline CHEMBL1369014 & 688759 & 4.9 & 4.8818 & TRN & \\
\hline CHEMBL1417307 & 688759 & 4.5 & 4.698 & TRN & \\
\hline CHEMBL3198823 & 688759 & 4.95 & 4.9914 & TRN & \\
\hline CHEMBL1312401 & 688759 & 4.85 & 4.9425 & TRN & \\
\hline CHEMBL 3213254 & 688759 & 4.45 & 4.8047 & TRN & \\
\hline CHEMBL1984884 & 688759 & 4.65 & 4.8201 & TRN & \\
\hline CHEMBL1443196 & 688759 & 4.45 & 5.0223 & TRN & \\
\hline CHEMBL1431792 & 688759 & 4.5 & 4.9194 & TST & \\
\hline CHEMBL1544781 & 688759 & 4.9 & 4.9467 & TRN & \\
\hline CHEMBL1456749 & 688759 & 4.75 & 6.5207 & TRN & \\
\hline CHEMBL1346111 & 688759 & 4.95 & 4.8865 & TRN & \\
\hline CHEMBL1539910 & 688759 & 5.25 & 4.7576 & TRN & \\
\hline CHEMBL1530097 & 688759 & 5.55 & 5.5298 & TRN & \\
\hline CHEMBL1371310 & 688759 & 4.7 & 5.272 & TRN & \\
\hline CHEMBL1302618 & 688759 & 4.65 & 4.63399 & 99999999995 & TST \\
\hline CHEMBL1351290 & 688759 & 5.15 & 5.0531 & TST & \\
\hline CHEMBL1463414 & 688759 & 4.8 & 4.9854 & TST & \\
\hline CHEMBL3193077 & 688759 & 5.25 & 4.7316 & TRN & \\
\hline CHEMBL1388976 & 688759 & 4.85 & 4.8786 & TST & \\
\hline CHEMBL1502313 & 688759 & 6.0 & 4.695 & TST & \\
\hline CHEMBL1376595 & 688759 & 4.95 & 5.0765 & TRN & \\
\hline CHEMBL3193015 & 688759 & 5.45 & 5.3193 & TST & \\
\hline CHEMBL1324224 & 688759 & 4.95 & 4.9496 & TRN & \\
\hline CHEMBL1517623 & 688759 & 4.7 & 4.8707 & TRN & \\
\hline CHEMBL1341407 & 688759 & 4.45 & 4.9796 & TST & \\
\hline CHEMBL1585362 & 688759 & 5.2 & 4.7979 & TRN & \\
\hline CHEMBL 3197628 & 688759 & 5.15 & 5.0079 & TRN & \\
\hline CHEMBL1562033 & 688759 & 5.55 & 5.1845 & TRN & \\
\hline CHEMBL195506 & 688759 & 4.65 & 5.1059 & TRN & \\
\hline CHEMBL45349 & 688759 & 4.6 & 4.6164 & TST & \\
\hline CHEMBL1345046 & 688759 & 5.0 & 5.1003 & TRN & \\
\hline CHEMBL1350097 & 688759 & 4.45 & 5.0728 & TRN & \\
\hline CHEMBL1464041 & 688759 & 5.2 & 4.7642 & TST & \\
\hline CHEMBL1332025 & 688759 & 2.35 & 6.1687 & TST & \\
\hline CHEMBL1393722 & 688759 & 4.45 & 4.7731 & TRN & \\
\hline CHEMBL1414376 & 688759 & 4.45 & 4.7157 & TRN & \\
\hline CHEMBL1318620 & 688759 & 4.45 & 4.643 & TST & \\
\hline CHEMBL1466302 & 688759 & 4.6 & 4.5763 & TRN & \\
\hline CHEMBL1329551 & 688759 & 4.5 & 4.8212 & TRN & \\
\hline CHEMBL1300188 & 688759 & 4.95 & 4.8899 & TRN & \\
\hline CHEMBL3194306 & 688759 & 4.45 & 4.8447 & TRN & \\
\hline CHEMBL1448774 & 688759 & 4.45 & 4.9378 & TRN & \\
\hline CHEMBL1392673 & 688759 & 4.9 & 5.0355 & TRN & \\
\hline CHEMBL1337805 & 688759 & 4.9 & 4.6205 & TRN & \\
\hline
\end{tabular}




\begin{tabular}{|c|c|c|c|c|}
\hline \multicolumn{5}{|c|}{ Supplemental Table s2.txt } \\
\hline CHEMBL1548492 & 688759 & 5.55 & 5.5007 & TRN \\
\hline CHEMBL1482786 & 688759 & 4.9 & 4.9088 & TRN \\
\hline CHEMBL1973482 & 688759 & 4.75 & 5.1321 & TRN \\
\hline CHEMBL1385247 & 688759 & 4.85 & 4.9067 & TRN \\
\hline CHEMBL1899958 & 688759 & 4.45 & 5.1088 & TRN \\
\hline CHEMBL1566829 & 688759 & 4.45 & 4.544 & TRN \\
\hline CHEMBL1562798 & 688759 & 4.45 & 4.8429 & TST \\
\hline CHEMBL1455095 & 688759 & 4.45 & 4.9751 & TRN \\
\hline CHEMBL1469158 & 688759 & 5.1 & 4.9034 & TST \\
\hline CHEMBL1601639 & 688759 & 5.0 & 5.1216 & TRN \\
\hline CHEMBL1544968 & 688759 & 4.45 & 4.9257 & TRN \\
\hline CHEMBL1320975 & 688759 & 5.4 & 4.9332 & TST \\
\hline CHEMBL1542002 & 688759 & 4.45 & 4.4573 & TRN \\
\hline CHEMBL1339053 & 688759 & 5.05 & 4.9038 & TRN \\
\hline CHEMBL1548862 & 688759 & 5.2 & 5.2594 & TRN \\
\hline CHEMBL1404959 & 688759 & 4.6 & 4.9118 & TRN \\
\hline CHEMBL1472260 & 688759 & 4.7 & 4.9627 & TST \\
\hline CHEMBL3190853 & 688759 & 5.3 & 5.1251 & TRN \\
\hline CHEMBL1525055 & 688759 & 4.8 & 4.9048 & TRN \\
\hline CHEMBL3193997 & 688759 & 4.55 & 4.8139 & TRN \\
\hline CHEMBL1423723 & 688759 & 4.45 & 5.1174 & TST \\
\hline CHEMBL1331218 & 688759 & 4.45 & 4.9785 & TRN \\
\hline CHEMBL3192745 & 688759 & 4.6 & 4.7808 & TRN \\
\hline CHEMBL1613360 & 688759 & 4.95 & 4.763 & TRN \\
\hline CHEMBL1542932 & 688759 & 4.9 & 5.0123 & TRN \\
\hline CHEMBL1368021 & 688759 & 4.95 & 4.893 & TST \\
\hline CHEMBL1320808 & 688759 & 4.45 & 4.7856 & TRN \\
\hline CHEMBL1379971 & 688759 & 5.0 & 5.1765 & TRN \\
\hline CHEMBL1589210 & 688759 & 4.45 & 4.6663 & TRN \\
\hline CHEMBL2006175 & 688759 & 5.8 & 4.6441 & TRN \\
\hline CHEMBL1457385 & 688759 & 4.45 & 4.8469 & TRN \\
\hline CHEMBL1531501 & 688759 & 4.45 & 4.9507 & TRN \\
\hline CHEMBL1532756 & 688759 & 4.85 & 4.8899 & TST \\
\hline CHEMBL3211904 & 688759 & 6.0 & 4.9276 & TRN \\
\hline CHEMBL1603910 & 688759 & 4.45 & 4.4954 & TRN \\
\hline CHEMBL3196054 & 688759 & 5.1 & 4.8872 & TRN \\
\hline CHEMBL1373950 & 688759 & 4.45 & 4.9439 & TST \\
\hline CHEMBL3198517 & 688759 & 4.7 & 4.8395 & TST \\
\hline CHEMBL1546051 & 688759 & 4.45 & 4.9635 & TST \\
\hline CHEMBL1511013 & 688759 & 4.7 & 5.1179 & TRN \\
\hline CHEMBL1485396 & 688759 & 5.4 & 4.8114 & TRN \\
\hline CHEMBL1544548 & 688759 & 6.0 & 5.2254 & TST \\
\hline CHEMBL1329136 & 688759 & 4.7 & 4.7959 & TST \\
\hline CHEMBL1503584 & 688759 & 6.15 & 5.1754 & TRN \\
\hline CHEMBL1299629 & 688759 & 5.4 & 5.0654 & TST \\
\hline CHEMBL1417970 & 688759 & 5.3 & 4.9528 & TRN \\
\hline CHEMBL3210060 & 688759 & 4.45 & 4.6042 & TRN \\
\hline CHEMBL1589781 & 688759 & 5.45 & 4.8644 & TRN \\
\hline
\end{tabular}




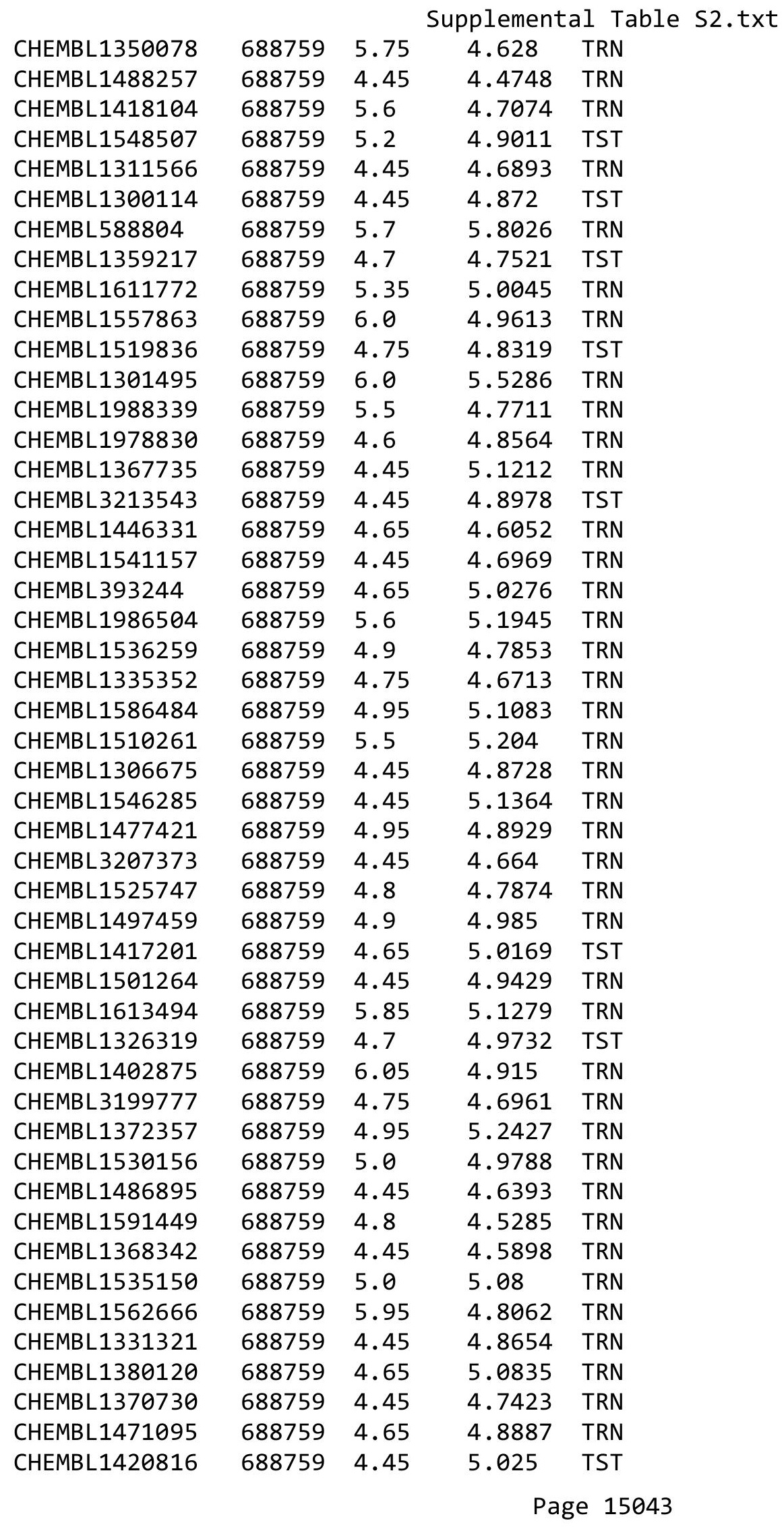




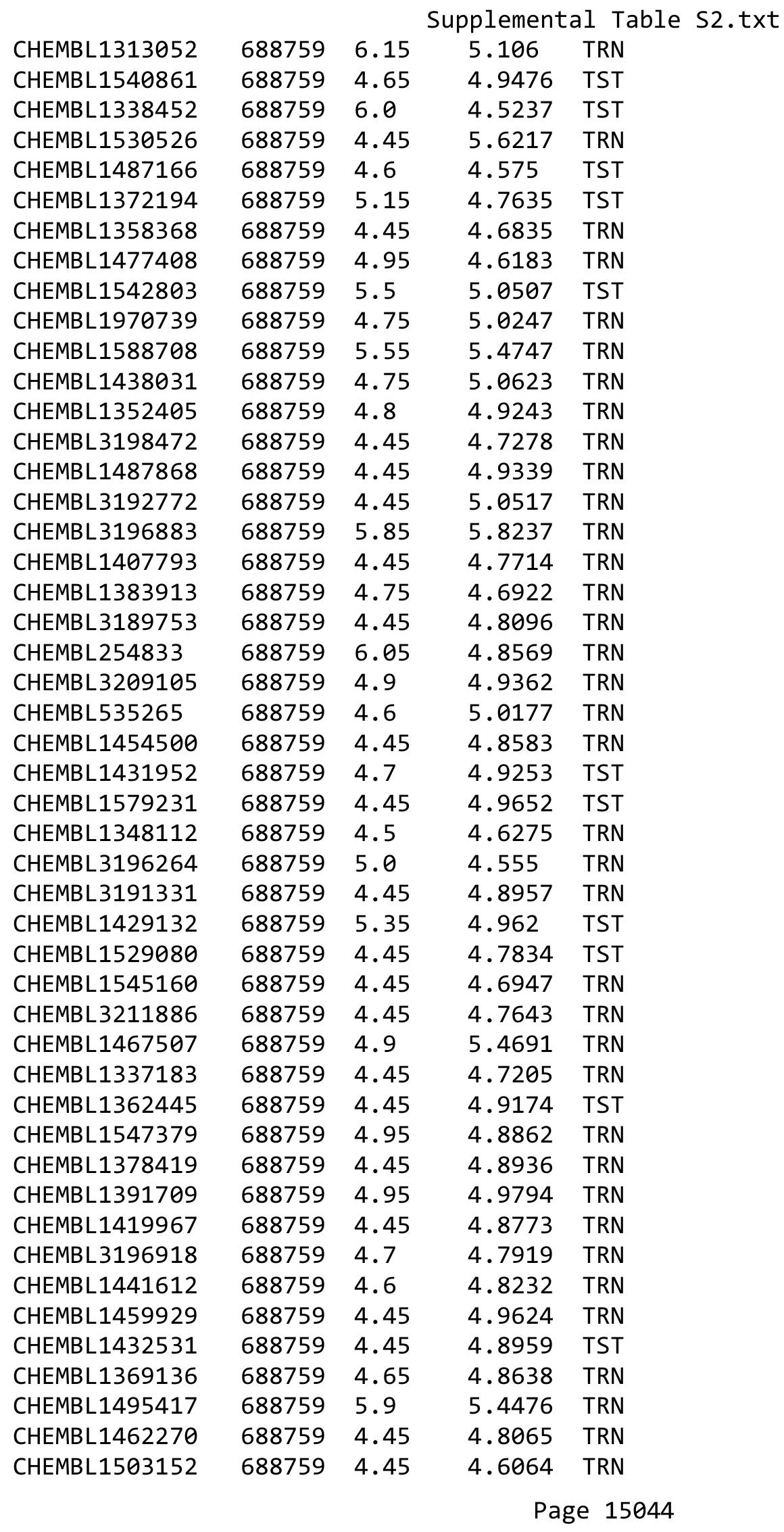




\begin{tabular}{|c|c|c|c|c|c|}
\hline \multicolumn{6}{|c|}{ Supplemental Table S2.txt } \\
\hline CHEMBL1413873 & 688759 & 4.45 & 4.8765 & TRN & \\
\hline CHEMBL1535086 & 688759 & 4.95 & 4.9576 & TRN & \\
\hline CHEMBL1508547 & 688759 & 4.6 & 4.8595 & TRN & \\
\hline CHEMBL1469916 & 688759 & 5.9 & 5.0923 & TRN & \\
\hline CHEMBL1994401 & 688759 & 5.65 & 5.4872 & TRN & \\
\hline CHEMBL 3198224 & 688759 & 4.45 & 5.0783 & TRN & \\
\hline CHEMBL1487686 & 688759 & 4.45 & 4.9722 & TRN & \\
\hline CHEMBL1406828 & 688759 & 4.45 & 4.9472 & TST & \\
\hline CHEMBL1467763 & 688759 & 4.45 & 4.6979 & TRN & \\
\hline CHEMBL1608787 & 688759 & 4.45 & 4.9098 & TRN & \\
\hline CHEMBL1526277 & 688759 & 4.45 & 4.8535 & TRN & \\
\hline CHEMBL1329081 & 688759 & 5.3 & 4.8841 & TRN & \\
\hline CHEMBL1302868 & 688759 & 4.6 & 4.8791 & TRN & \\
\hline CHEMBL1516695 & 688759 & 5.45 & 4.7361 & TRN & \\
\hline CHEMBL1440868 & 688759 & 4.45 & 4.6145 & TST & \\
\hline CHEMBL1328393 & 688759 & 4.45 & 4.9263 & TRN & \\
\hline CHEMBL1409312 & 688759 & 4.45 & 4.7365 & TST & \\
\hline CHEMBL1368155 & 688759 & 4.45 & 4.901 & TRN & \\
\hline CHEMBL1888628 & 688759 & 4.7 & 4.8884 & TRN & \\
\hline CHEMBL1377446 & 688759 & 4.55 & 4.64199 & 99999999995 & TRN \\
\hline CHEMBL1604501 & 688759 & 4.9 & 4.7967 & TRN & \\
\hline CHEMBL1337319 & 688759 & 4.45 & 4.8973 & TRN & \\
\hline CHEMBL1490097 & 688759 & 4.45 & 4.7655 & TST & \\
\hline CHEMBL1978855 & 688759 & 4.7 & 4.8703 & TST & \\
\hline CHEMBL1530846 & 688759 & 5.55 & 4.7259 & TRN & \\
\hline CHEMBL1305035 & 688759 & 5.3 & 5.2205 & TRN & \\
\hline CHEMBL1483261 & 688759 & 4.9 & 4.7832 & TRN & \\
\hline CHEMBL1317554 & 688759 & 5.55 & 4.702 & TST & \\
\hline CHEMBL1567800 & 688759 & 4.45 & 4.9353 & TST & \\
\hline CHEMBL1458145 & 688759 & 4.45 & 4.791 & TRN & \\
\hline CHEMBL 3213761 & 688759 & 4.6 & 4.8237 & TRN & \\
\hline CHEMBL1467905 & 688759 & 4.55 & 4.6217 & TRN & \\
\hline CHEMBL570400 & 688759 & 5.15 & 4.7982 & TST & \\
\hline CHEMBL1595173 & 688759 & 5.1 & 5.0045 & TRN & \\
\hline CHEMBL1386636 & 688759 & 4.45 & 5.1373 & TRN & \\
\hline CHEMBL1405092 & 688759 & 6.0 & 5.4886 & TRN & \\
\hline CHEMBL1363870 & 688759 & 4.9 & 4.8934 & TST & \\
\hline CHEMBL1400996 & 688759 & 5.8 & 5.8582 & TRN & \\
\hline CHEMBL1343794 & 688759 & 4.45 & 5.2827 & TRN & \\
\hline CHEMBL3191980 & 688759 & 5.65 & 5.3785 & TRN & \\
\hline CHEMBL1984639 & 688759 & 5.7 & 5.0275 & TRN & \\
\hline CHEMBL1413488 & 688759 & 4.75 & 4.6835 & TST & \\
\hline CHEMBL3195898 & 688759 & 5.95 & 5.5661 & TRN & \\
\hline CHEMBL 3209588 & 688759 & 4.45 & 4.5549 & TRN & \\
\hline CHEMBL3198205 & 688759 & 5.4 & 5.0272 & TRN & \\
\hline CHEMBL1472108 & 688759 & 4.45 & 4.9347 & TRN & \\
\hline CHEMBL 1455087 & 688759 & 4.7 & 4.9304 & TRN & \\
\hline CHEMBL1365406 & 688759 & 4.6 & 4.7932 & TRN & \\
\hline
\end{tabular}




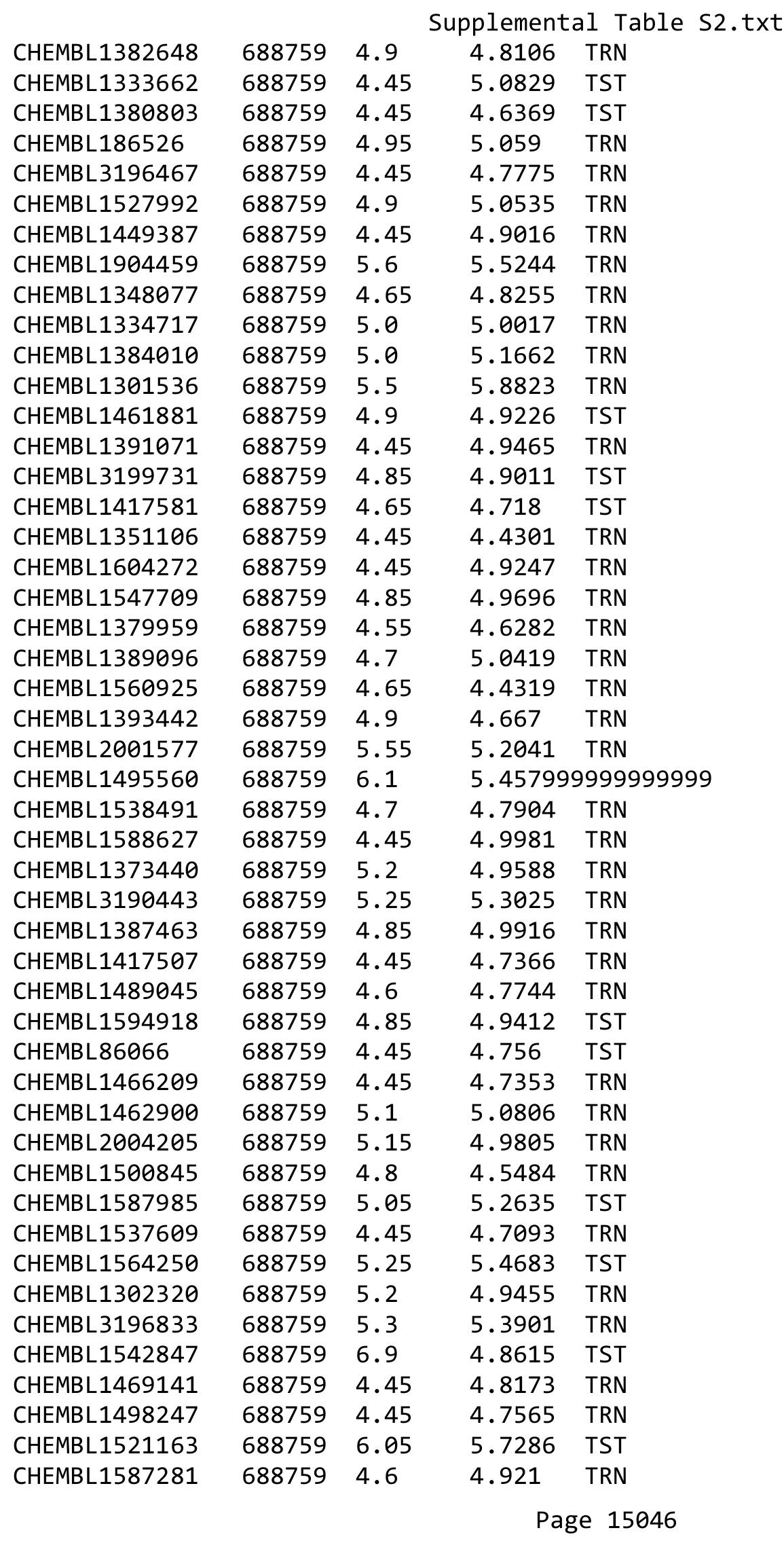




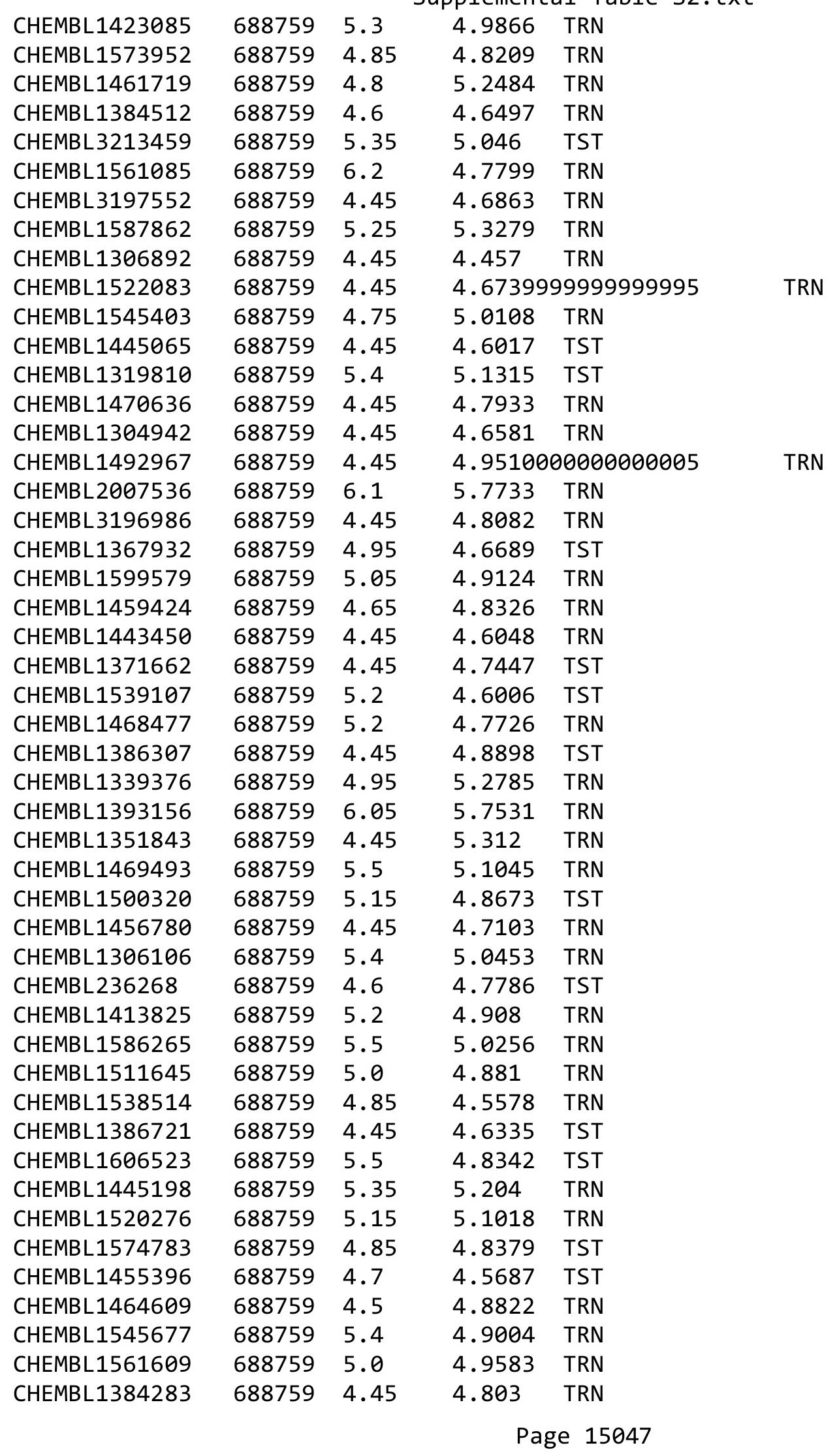




\begin{tabular}{|c|c|c|c|c|}
\hline & & & upplement & $\mathrm{T}$ \\
\hline CHEMBL1504045 & 688759 & 5.65 & 4.8774 & TST \\
\hline CHEMBL 2359072 & 688759 & 4.95 & 4.9104 & TRN \\
\hline CHEMBL3348955 & 688759 & 5.9 & 5.5609 & TST \\
\hline CHEMBL3189905 & 688759 & 5.25 & 5.0362 & TRN \\
\hline CHEMBL1503006 & 688759 & 6.6 & 6.4896 & TRN \\
\hline CHEMBL1544641 & 688759 & 6.0 & 5.7298 & TRN \\
\hline CHEMBL1453596 & 688759 & 4.95 & 5.019 & TRN \\
\hline CHEMBL1543177 & 688759 & 4.45 & 4.823 & TRN \\
\hline CHEMBL1438641 & 688759 & 4.9 & 4.9596 & TRN \\
\hline CHEMBL1998281 & 688759 & 5.2 & 5.1085 & TRN \\
\hline CHEMBL1300625 & 688759 & 4.45 & 4.9392 & TRN \\
\hline CHEMBL1334479 & 688759 & 4.95 & 5.5059 & TRN \\
\hline CHEMBL1991908 & 688759 & 4.45 & 4.6249 & TRN \\
\hline CHEMBL1480798 & 688759 & 5.2 & 4.7107 & TRN \\
\hline CHEMBL1309401 & 688759 & 4.9 & 4.5794 & TRN \\
\hline CHEMBL1510148 & 688759 & 4.85 & 4.82 & TRN \\
\hline CHEMBL1336277 & 688759 & 5.1 & 5.1455 & TST \\
\hline CHEMBL1409866 & 688759 & 4.45 & 4.8507 & TRN \\
\hline CHEMBL1455041 & 688759 & 5.9 & 5.1099 & TRN \\
\hline CHEMBL1414166 & 688759 & 4.95 & 5.275 & TST \\
\hline CHEMBL1972651 & 688759 & 4.7 & 5.2946 & TRN \\
\hline CHEMBL1563370 & 688759 & 4.95 & 4.8921 & TST \\
\hline CHEMBL1602157 & 688759 & 5.0 & 5.1926 & TRN \\
\hline CHEMBL1443860 & 688759 & 4.45 & 4.7541 & TRN \\
\hline CHEMBL490268 & 688759 & 4.6 & 4.8428 & TRN \\
\hline CHEMBL1329016 & 688759 & 4.45 & 4.6403 & TRN \\
\hline CHEMBL1305287 & 688759 & 5.15 & 5.1048 & TRN \\
\hline CHEMBL1584697 & 688759 & 4.8 & 5.1729 & TRN \\
\hline CHEMBL1528363 & 688759 & 5.5 & 4.9714 & TST \\
\hline CHEMBL1466712 & 688759 & 5.55 & 5.3711 & TRN \\
\hline CHEMBL1524034 & 688759 & 5.9 & 4.9189 & TRN \\
\hline CHEMBL1561102 & 688759 & 4.45 & 4.7449 & TST \\
\hline CHEMBL1569546 & 688759 & 5.55 & 4.8345 & TST \\
\hline CHEMBL1290347 & 688759 & 4.45 & 4.6594 & TRN \\
\hline CHEMBL336280 & 688759 & 5.55 & 4.7395 & TRN \\
\hline CHEMBL3189329 & 688759 & 4.45 & 4.5338 & TRN \\
\hline CHEMBL1538177 & 688759 & 4.45 & 4.6238 & TST \\
\hline CHEMBL1582928 & 688759 & 4.45 & 4.7815 & TRN \\
\hline CHEMBL1613433 & 688759 & 4.6 & 4.7907 & TRN \\
\hline CHEMBL1546363 & 688759 & 4.65 & 4.7634 & TST \\
\hline CHEMBL1518359 & 688759 & 4.85 & 4.7807 & TST \\
\hline CHEMBL1525699 & 688759 & 4.95 & 5.1855 & TRN \\
\hline CHEMBL1429591 & 688759 & 4.45 & 4.9863 & TRN \\
\hline CHEMBL1500654 & 688759 & 5.2 & 4.8108 & TRN \\
\hline CHEMBL1998741 & 688759 & 5.5 & 5.3875 & TST \\
\hline CHEMBL1325496 & 688759 & 4.6 & 4.874 & TRN \\
\hline CHEMBL1529936 & 688759 & 5.0 & 5.6019 & TRN \\
\hline CHEMBL1588956 & 688759 & 4.45 & 4.5589 & TRN \\
\hline
\end{tabular}




\begin{tabular}{|c|c|c|c|c|c|}
\hline & & \multicolumn{4}{|c|}{ Supplemental Table s2.txt } \\
\hline CHEMBL1588743 & 688759 & 4.45 & 4.8587 & TRN & \\
\hline CHEMBL1466571 & 688759 & 4.65 & 4.9067 & TST & \\
\hline CHEMBL3197369 & 688759 & 5.3 & 5.2423 & TRN & \\
\hline CHEMBL1497473 & 688759 & 4.45 & 4.899 & TRN & \\
\hline CHEMBL1497363 & 688759 & 5.55 & 5.13700 & 00000000005 & TRN \\
\hline CHEMBL3392494 & 688759 & 5.7 & 5.7957 & TRN & \\
\hline CHEMBL1335490 & 688759 & 4.45 & 4.9186 & TRN & \\
\hline CHEMBL1517393 & 688759 & 4.45 & 5.0812 & TRN & \\
\hline CHEMBL1483000 & 688759 & 4.45 & 4.7788 & TRN & \\
\hline CHEMBL1588275 & 688759 & 4.45 & 4.765 & TRN & \\
\hline CHEMBL1321046 & 688759 & 5.4 & 5.0102 & TRN & \\
\hline CHEMBL1447277 & 688759 & 5.5 & 4.7423 & TRN & \\
\hline CHEMBL1304170 & 688759 & 4.45 & 4.6814 & TST & \\
\hline CHEMBL1608197 & 688759 & 4.7 & 5.0376 & TRN & \\
\hline CHEMBL3193890 & 688759 & 5.0 & 4.7754 & TRN & \\
\hline CHEMBL1406305 & 688759 & 4.45 & 5.1851 & TRN & \\
\hline CHEMBL1576360 & 688759 & 4.45 & 4.8053 & TRN & \\
\hline CHEMBL1606007 & 688759 & 5.0 & 5.0157 & TST & \\
\hline CHEMBL1399370 & 688759 & 5.4 & 5.0312 & TRN & \\
\hline CHEMBL3214169 & 688759 & 5.55 & 4.9825 & TRN & \\
\hline CHEMBL1393396 & 688759 & 4.45 & 5.0405 & TRN & \\
\hline CHEMBL1451809 & 688759 & 4.55 & 4.8811 & TRN & \\
\hline CHEMBL1975892 & 688759 & 4.45 & 4.7044 & TRN & \\
\hline CHEMBL 3208540 & 688759 & 4.95 & 4.968 & TST & \\
\hline CHEMBL1599370 & 688759 & 4.6 & 4.988 & TRN & \\
\hline CHEMBL1517441 & 688759 & 5.05 & 4.8883 & TRN & \\
\hline CHEMBL1555127 & 688759 & 4.45 & 4.9407 & TRN & \\
\hline CHEMBL1488037 & 688759 & 4.75 & 4.7407 & TST & \\
\hline CHEMBL1520557 & 688759 & 5.25 & 4.9581 & TST & \\
\hline CHEMBL602620 & 688759 & 4.45 & 4.8751 & TRN & \\
\hline CHEMBL1443309 & 688759 & 4.65 & 4.5554 & TRN & \\
\hline CHEMBL1350071 & 688759 & 4.95 & 5.3008 & TRN & \\
\hline CHEMBL1529063 & 688759 & 4.7 & 4.6652 & TST & \\
\hline CHEMBL1412113 & 688759 & 4.45 & 4.9319 & TRN & \\
\hline CHEMBL1353968 & 688759 & 4.65 & 4.5318 & TRN & \\
\hline CHEMBL1555729 & 688759 & 4.95 & 4.7653 & TRN & \\
\hline CHEMBL1383057 & 688759 & 6.3 & 5.4097 & TRN & \\
\hline CHEMBL1340300 & 688759 & 4.45 & 4.6733 & TRN & \\
\hline CHEMBL1566610 & 688759 & 6.2 & 5.801 & TRN & \\
\hline CHEMBL1597568 & 688759 & 5.45 & 4.9512 & TST & \\
\hline CHEMBL1507186 & 688759 & 4.65 & 5.0962 & TST & \\
\hline CHEMBL1531312 & 688759 & 5.2 & 5.1971 & TRN & \\
\hline CHEMBL3192046 & 688759 & 4.45 & 5.1622 & TRN & \\
\hline CHEMBL1577681 & 688759 & 4.45 & 4.6561 & TRN & \\
\hline CHEMBL1502101 & 688759 & 5.4 & 4.8901 & TRN & \\
\hline CHEMBL1306094 & 688759 & 5.25 & 4.8668 & TRN & \\
\hline CHEMBL1366342 & 688759 & 4.9 & 4.6209 & TRN & \\
\hline CHEMBL1418643 & 688759 & 5.3 & 5.2098 & TRN & \\
\hline
\end{tabular}




\begin{tabular}{|c|c|c|c|c|}
\hline \multicolumn{5}{|c|}{ Supplemental Table S2.txt } \\
\hline CHEMBL1362510 & 688759 & 5.2 & 4.9451 & TRN \\
\hline CHEMBL1308002 & 688759 & 4.95 & 4.9565 & TRN \\
\hline CHEMBL1342665 & 688759 & 4.45 & 4.8479 & TRN \\
\hline CHEMBL1459910 & 688759 & 4.9 & 4.9548 & TRN \\
\hline CHEMBL1364404 & 688759 & 5.6 & 5.1313 & TST \\
\hline CHEMBL1587167 & 688759 & 4.9 & 4.9712 & TRN \\
\hline CHEMBL234378 & 688759 & 5.15 & 4.9515 & TRN \\
\hline CHEMBL1334587 & 688759 & 4.75 & 4.8673 & TRN \\
\hline CHEMBL1316462 & 688759 & 5.25 & 4.9847 & TRN \\
\hline CHEMBL3192161 & 688759 & 5.7 & 5.6679 & TRN \\
\hline CHEMBL1586728 & 688759 & 4.95 & 4.8968 & TST \\
\hline CHEMBL1496635 & 688759 & 4.65 & 5.0336 & TST \\
\hline CHEMBL1492420 & 688759 & 4.95 & 5.1088 & TRN \\
\hline CHEMBL1595866 & 688759 & 4.45 & 4.871 & TST \\
\hline CHEMBL3195410 & 688759 & 4.85 & 4.7972 & TRN \\
\hline CHEMBL1987622 & 688759 & 5.4 & 5.2208 & TST \\
\hline CHEMBL1577871 & 688759 & 4.85 & 4.9481 & TRN \\
\hline CHEMBL1379724 & 688759 & 4.55 & 4.8679 & TRN \\
\hline CHEMBL 3212185 & 688759 & 4.7 & 4.671 & TRN \\
\hline CHEMBL1446346 & 688759 & 6.7501 & 4.918 & TRN \\
\hline CHEMBL1384974 & 688759 & 4.45 & 4.8323 & TST \\
\hline CHEMBL1364157 & 688759 & 4.65 & 5.0445 & TRN \\
\hline CHEMBL1385655 & 688759 & 4.45 & 4.8713 & TRN \\
\hline CHEMBL1312160 & 688759 & 4.45 & 4.7951 & TRN \\
\hline CHEMBL1433006 & 688759 & 4.45 & 4.595 & TST \\
\hline CHEMBL1546725 & 688759 & 4.45 & 5.0284 & TRN \\
\hline CHEMBL1530839 & 688759 & 5.3 & 4.8832 & TST \\
\hline CHEMBL1348523 & 688759 & 4.9 & 4.8857 & TRN \\
\hline CHEMBL1461059 & 688759 & 5.25 & 5.1126 & TRN \\
\hline CHEMBL1332450 & 688759 & 6.05 & 5.8879 & TRN \\
\hline CHEMBL1602240 & 688759 & 5.5 & 5.1444 & TRN \\
\hline CHEMBL1505655 & 688759 & 4.9 & 4.9708 & TRN \\
\hline CHEMBL1322009 & 688759 & 4.6 & 4.6694 & TRN \\
\hline CHEMBL1991441 & 688759 & 5.45 & 5.2985 & TRN \\
\hline CHEMBL1412866 & 688759 & 4.95 & 5.0365 & TRN \\
\hline CHEMBL1970958 & 688759 & 5.95 & 5.7037 & TRN \\
\hline CHEMBL1321076 & 688759 & 5.2 & 5.1284 & TRN \\
\hline CHEMBL1541391 & 688759 & 5.55 & 5.1445 & TRN \\
\hline CHEMBL1423474 & 688759 & 4.45 & 4.7897 & TRN \\
\hline CHEMBL1590283 & 688759 & 4.45 & 4.723 & TRN \\
\hline CHEMBL1558941 & 688759 & 4.45 & 4.4721 & TRN \\
\hline CHEMBL3189149 & 688759 & 4.45 & 5.07 & TST \\
\hline CHEMBL1558561 & 688759 & 5.3 & 5.2055 & TRN \\
\hline CHEMBL1402915 & 688759 & 5.15 & 4.9873 & TST \\
\hline CHEMBL1438047 & 688759 & 4.7 & 4.9371 & TRN \\
\hline CHEMBL1335174 & 688759 & 4.85 & 4.9543 & TRN \\
\hline CHEMBL579075 & 688759 & 4.95 & 4.5059 & TRN \\
\hline CHEMBL1303703 & 688759 & 5.3 & 4.9308 & TRN \\
\hline
\end{tabular}




\begin{tabular}{|c|c|c|c|c|c|}
\hline \multicolumn{6}{|c|}{ Supplemental Table S2.txt } \\
\hline CHEMBL1419479 & 688759 & 4.95 & 5.001 & TRN & \\
\hline CHEMBL1594633 & 688759 & 4.5 & 4.7141 & TST & \\
\hline CHEMBL1457747 & 688759 & 4.95 & 4.7468 & TRN & \\
\hline CHEMBL3193556 & 688759 & 5.0 & 4.9616 & TRN & \\
\hline CHEMBL1970368 & 688759 & 5.35 & 5.1375 & TRN & \\
\hline CHEMBL1348595 & 688759 & 4.95 & 4.8264 & TRN & \\
\hline CHEMBL1610385 & 688759 & 4.45 & 5.0739 & TST & \\
\hline CHEMBL1572589 & 688759 & 4.9 & 5.13399 & 99999999995 & TRN \\
\hline CHEMBL1451548 & 688759 & 5.35 & 4.8041 & TRN & \\
\hline CHEMBL1565081 & 688759 & 6.9 & 4.6575 & TRN & \\
\hline CHEMBL1384287 & 688759 & 6.2 & 5.4877 & TST & \\
\hline CHEMBL1610835 & 688759 & 4.45 & 4.9864 & TRN & \\
\hline CHEMBL3198170 & 688759 & 4.45 & 4.7425 & TRN & \\
\hline CHEMBL1337817 & 688759 & 5.05 & 5.1128 & TRN & \\
\hline CHEMBL3199077 & 688759 & 4.45 & 4.7029 & TRN & \\
\hline CHEMBL1508055 & 688759 & 5.3 & 5.0861 & TRN & \\
\hline CHEMBL3199528 & 688759 & 5.3 & 4.8982 & TRN & \\
\hline CHEMBL1396786 & 688759 & 5.25 & 4.6184 & TRN & \\
\hline CHEMBL1484335 & 688759 & 4.8 & 4.716 & TRN & \\
\hline CHEMBL1594655 & 688759 & 5.35 & 4.8408 & TRN & \\
\hline CHEMBL1340055 & 688759 & 4.6 & 5.1489 & TRN & \\
\hline CHEMBL1492738 & 688759 & 4.9 & 4.9593 & TRN & \\
\hline CHEMBL1580904 & 688759 & 4.85 & 4.7647 & TST & \\
\hline CHEMBL1599075 & 688759 & 4.45 & 4.9816 & TRN & \\
\hline CHEMBL1334517 & 688759 & 5.3 & 5.0882 & TRN & \\
\hline CHEMBL1422933 & 688759 & 5.5 & 5.1547 & TRN & \\
\hline CHEMBL 2004657 & 688759 & 5.45 & 5.1504 & TRN & \\
\hline CHEMBL591412 & 688759 & 5.65 & 5.34399 & 9999999999 & TRN \\
\hline CHEMBL1995109 & 688759 & 4.75 & 5.0252 & TRN & \\
\hline CHEMBL1350897 & 688759 & 5.4 & 4.9033 & TST & \\
\hline CHEMBL1299634 & 688759 & 5.15 & 4.9943 & TRN & \\
\hline CHEMBL1472578 & 688759 & 4.45 & 4.822 & TST & \\
\hline CHEMBL1470676 & 688759 & 5.7 & 5.3354 & TRN & \\
\hline CHEMBL1576078 & 688759 & 4.6 & 5.0176 & TST & \\
\hline CHEMBL1337242 & 688759 & 4.65 & 4.9296 & TRN & \\
\hline CHEMBL1410003 & 688759 & 4.45 & 4.8599 & TRN & \\
\hline CHEMBL1306448 & 688759 & 4.55 & 4.832 & TRN & \\
\hline CHEMBL1967821 & 688759 & 5.5 & 5.2765 & TRN & \\
\hline CHEMBL1333661 & 688759 & 5.25 & 4.8672 & TRN & \\
\hline CHEMBL1444616 & 688759 & 5.45 & 4.657 & TRN & \\
\hline CHEMBL3196880 & 688759 & 4.95 & 4.9762 & TRN & \\
\hline CHEMBL1606697 & 688759 & 4.45 & 5.609 & TRN & \\
\hline CHEMBL1377607 & 688759 & 5.3 & 5.0699 & TST & \\
\hline CHEMBL1407304 & 688759 & 4.45 & 4.9474 & TRN & \\
\hline CHEMBL1529460 & 688759 & 5.35 & 4.9014 & TST & \\
\hline CHEMBL1428739 & 688759 & 5.65 & 5.7391 & TRN & \\
\hline CHEMBL1548071 & 688759 & 5.15 & 4.883 & TRN & \\
\hline CHEMBL1389371 & 688759 & 4.45 & 4.595 & TRN & \\
\hline
\end{tabular}




\begin{tabular}{|c|c|c|c|c|}
\hline \multicolumn{5}{|c|}{ Supplemental Table } \\
\hline CHEMBL1420895 & 688759 & 4.45 & 4.8512 & TRN \\
\hline CHEMBL3212029 & 688759 & 6.3 & 5.8617 & TRN \\
\hline CHEMBL1445324 & 688759 & 4.45 & 5.2564 & TRN \\
\hline CHEMBL 3196278 & 688759 & 4.45 & 4.7568 & TRN \\
\hline CHEMBL1586401 & 688759 & 4.7 & 5.2313 & TRN \\
\hline CHEMBL 2001024 & 688759 & 4.75 & 4.9519 & TRN \\
\hline CHEMBL1309207 & 688759 & 8.2518 & 5.7162 & TRN \\
\hline CHEMBL1460682 & 688759 & 5.7 & 4.9073 & TRN \\
\hline CHEMBL1374505 & 688759 & 5.05 & 4.9149 & TRN \\
\hline CHEMBL1409713 & 688759 & 4.8 & 4.7004 & TST \\
\hline CHEMBL1605873 & 688759 & 5.05 & 4.6929 & TST \\
\hline CHEMBL1572001 & 688759 & 5.15 & 4.8511 & TST \\
\hline CHEMBL1469435 & 688759 & 4.45 & 4.73 & TRN \\
\hline CHEMBL1450911 & 688759 & 4.65 & 5.0153 & TRN \\
\hline CHEMBL1460719 & 688759 & 4.65 & 4.9049 & TRN \\
\hline CHEMBL1446439 & 688759 & 4.45 & 4.7296 & TST \\
\hline CHEMBL1523663 & 688759 & 5.15 & 4.8977 & TRN \\
\hline CHEMBL3189194 & 688759 & 4.85 & 5.0571 & TRN \\
\hline CHEMBL1372745 & 688759 & 4.85 & 5.002 & TRN \\
\hline CHEMBL3211695 & 688759 & 4.45 & 4.7884 & TRN \\
\hline CHEMBL1302824 & 688759 & 4.6 & 4.7738 & TRN \\
\hline CHEMBL1423219 & 688759 & 5.35 & 4.8585 & TRN \\
\hline CHEMBL1404780 & 688759 & 6.25 & 4.8552 & TRN \\
\hline CHEMBL1347980 & 688759 & 5.4 & 4.9782 & TST \\
\hline CHEMBL1532460 & 688759 & 4.45 & 4.7718 & TRN \\
\hline CHEMBL1531203 & 688759 & 4.7 & 4.7584 & TST \\
\hline CHEMBL1993929 & 688759 & 5.15 & 5.4476 & TST \\
\hline CHEMBL1525212 & 688759 & 4.7 & 4.8185 & TRN \\
\hline CHEMBL1363130 & 688759 & 4.75 & 4.5799 & TRN \\
\hline CHEMBL1535162 & 688759 & 5.6 & 5.2677 & TST \\
\hline CHEMBL1460315 & 688759 & 4.55 & 5.0634 & TRN \\
\hline CHEMBL1366886 & 688759 & 4.45 & 4.5136 & TST \\
\hline CHEMBL1438149 & 688759 & 5.0 & 5.147 & TRN \\
\hline CHEMBL1536886 & 688759 & 8.1487 & 5.2532 & TRN \\
\hline CHEMBL1381704 & 688759 & 5.5 & 5.2536 & TRN \\
\hline CHEMBL1451423 & 688759 & 5.35 & 4.9213 & TRN \\
\hline CHEMBL1569924 & 688759 & 4.45 & 4.8115 & TRN \\
\hline CHEMBL1328153 & 688759 & 4.45 & 4.6982 & TRN \\
\hline CHEMBL1547204 & 688759 & 5.35 & 5.2979 & TST \\
\hline CHEMBL1533710 & 688759 & 4.9 & 4.9675 & TRN \\
\hline CHEMBL1312765 & 688759 & 4.55 & 4.6696 & TRN \\
\hline CHEMBL591178 & 688759 & 5.3 & 5.1619 & TRN \\
\hline CHEMBL1499689 & 688759 & 4.55 & 4.6468 & TRN \\
\hline CHEMBL1359263 & 688759 & 4.7 & 4.9046 & TST \\
\hline CHEMBL1427060 & 688759 & 4.45 & 4.9465 & TST \\
\hline CHEMBL1472942 & 688759 & 4.45 & 4.9423 & TST \\
\hline CHEMBL 2005198 & 688759 & 5.2 & 4.7772 & TRN \\
\hline CHEMBL1439835 & 688759 & 4.6 & 4.755 & TRN \\
\hline
\end{tabular}




\begin{tabular}{|c|c|c|c|c|c|}
\hline \multicolumn{6}{|c|}{ Supplemental Table S2.txt } \\
\hline CHEMBL1347448 & 688759 & 4.45 & 4.9079 & TST & \\
\hline CHEMBL1331203 & 688759 & 4.6 & 4.8522 & TRN & \\
\hline CHEMBL1422690 & 688759 & 4.8 & 4.7867 & TST & \\
\hline CHEMBL1488030 & 688759 & 4.85 & 5.6228 & TRN & \\
\hline CHEMBL1459814 & 688759 & 4.9 & 4.908 & TST & \\
\hline CHEMBL3194910 & 688759 & 4.45 & 4.8817 & TRN & \\
\hline CHEMBL1537460 & 688759 & 5.25 & 4.8675 & TRN & \\
\hline CHEMBL1312328 & 688759 & 4.45 & 4.6368 & TRN & \\
\hline CHEMBL346516 & 688759 & 5.0 & 4.8855 & TST & \\
\hline CHEMBL1500423 & 688759 & 4.8 & 4.7303 & TST & \\
\hline CHEMBL1520849 & 688759 & 4.85 & 5.0004 & TRN & \\
\hline CHEMBL1393867 & 688759 & 5.25 & 5.4325 & TRN & \\
\hline CHEMBL1508917 & 688759 & 4.85 & 4.8913 & TRN & \\
\hline CHEMBL1492277 & 688759 & 4.65 & 4.7507 & TRN & \\
\hline CHEMBL 2003564 & 688759 & 4.5 & 5.0708 & TRN & \\
\hline CHEMBL1532732 & 688759 & 5.95 & 5.62299 & 9999999999 & TRN \\
\hline CHEMBL1577395 & 688759 & 4.45 & 4.69300 & 00000000005 & TST \\
\hline CHEMBL1476766 & 688759 & 5.0 & 4.9285 & TST & \\
\hline CHEMBL1422806 & 688759 & 4.45 & 5.1304 & TST & \\
\hline CHEMBL1445360 & 688759 & 4.45 & 4.8137 & TRN & \\
\hline CHEMBL1320741 & 688759 & 5.4 & 5.2318 & TRN & \\
\hline CHEMBL3191250 & 688759 & 5.25 & 4.9068 & TST & \\
\hline CHEMBL1303891 & 688759 & 5.25 & 4.8993 & TRN & \\
\hline CHEMBL1971117 & 688759 & 4.55 & 5.1089 & TRN & \\
\hline CHEMBL1373091 & 688759 & 4.5 & 4.9551 & TRN & \\
\hline CHEMBL 2234807 & 688759 & 4.45 & 4.5898 & TRN & \\
\hline CHEMBL1531435 & 688759 & 4.5 & 4.9673 & TRN & \\
\hline CHEMBL3193994 & 688759 & 4.85 & 4.7183 & TRN & \\
\hline CHEMBL1442500 & 688759 & 4.7 & 5.6118 & TRN & \\
\hline CHEMBL1310302 & 688759 & 4.45 & 4.6284 & TRN & \\
\hline CHEMBL186422 & 688759 & 4.9 & 5.0895 & TST & \\
\hline CHEMBL1436228 & 688759 & 4.45 & 4.7275 & TRN & \\
\hline CHEMBL1383915 & 688759 & 5.5 & 5.9183 & TRN & \\
\hline CHEMBL1458873 & 688759 & 4.45 & 4.7139 & TST & \\
\hline CHEMBL1391800 & 688759 & 5.2 & 5.1638 & TRN & \\
\hline CHEMBL1411334 & 688759 & 4.45 & 4.8024 & TRN & \\
\hline CHEMBL1580731 & 688759 & 4.8 & 5.0125 & TRN & \\
\hline CHEMBL1536992 & 688759 & 4.45 & 4.7276 & TST & \\
\hline CHEMBL1603974 & 688759 & 4.45 & 4.6052 & TRN & \\
\hline CHEMBL1977301 & 688759 & 5.3 & 5.192 & TRN & \\
\hline CHEMBL1448566 & 688759 & 4.45 & 4.563 & TST & \\
\hline CHEMBL1533857 & 688759 & 7.0501 & 4.6825 & TST & \\
\hline CHEMBL497186 & 688759 & 7.6498 & 4.8006 & TST & \\
\hline CHEMBL1334489 & 688759 & 4.45 & 4.7417 & TRN & \\
\hline CHEMBL1450091 & 688759 & 4.45 & 5.0386 & TRN & \\
\hline CHEMBL1310358 & 688759 & 5.9 & 4.8133 & TST & \\
\hline CHEMBL 1608722 & 688759 & 4.55 & 4.92 & TST & \\
\hline CHEMBL3197431 & 688759 & 4.85 & 5.1491 & TRN & \\
\hline
\end{tabular}




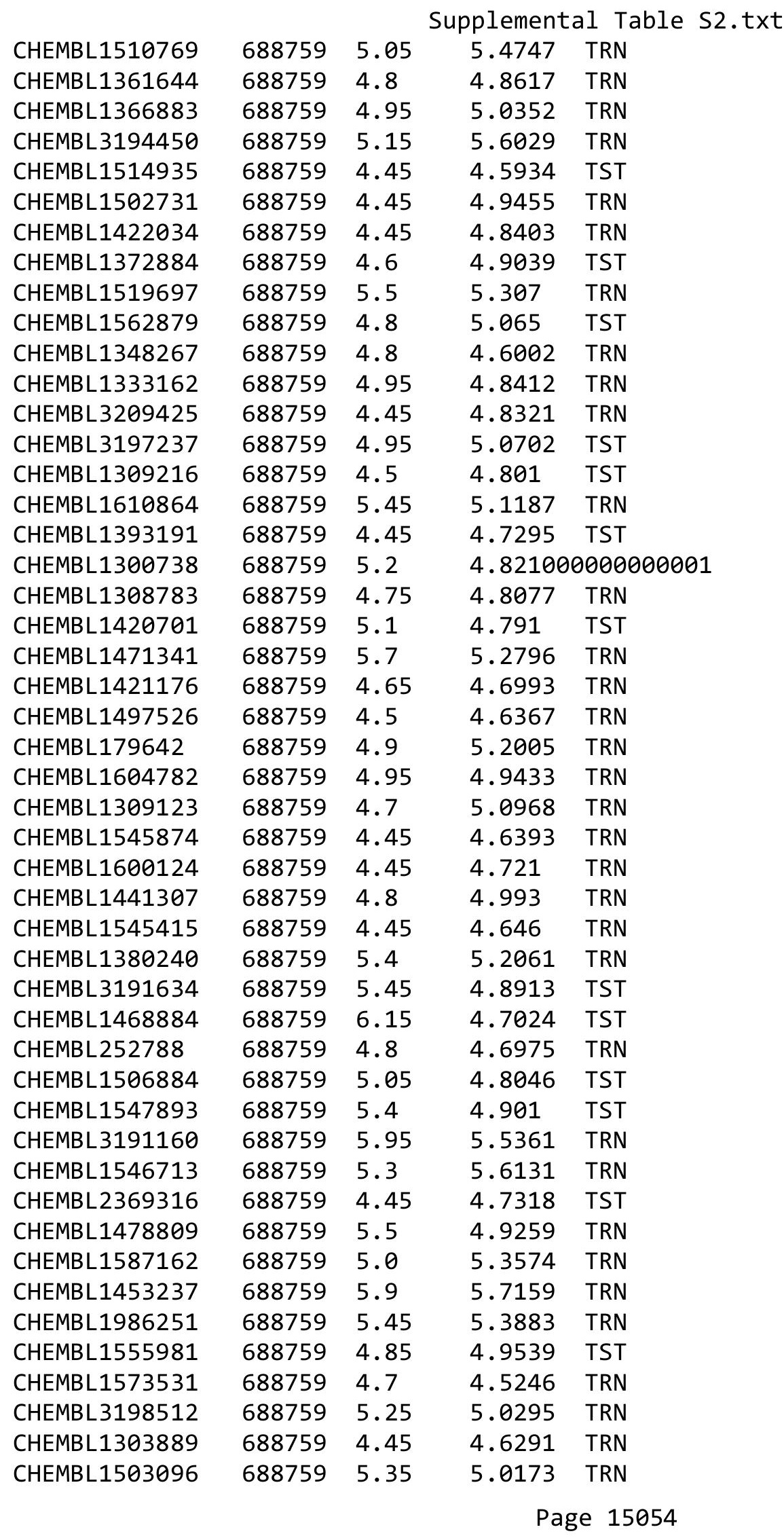




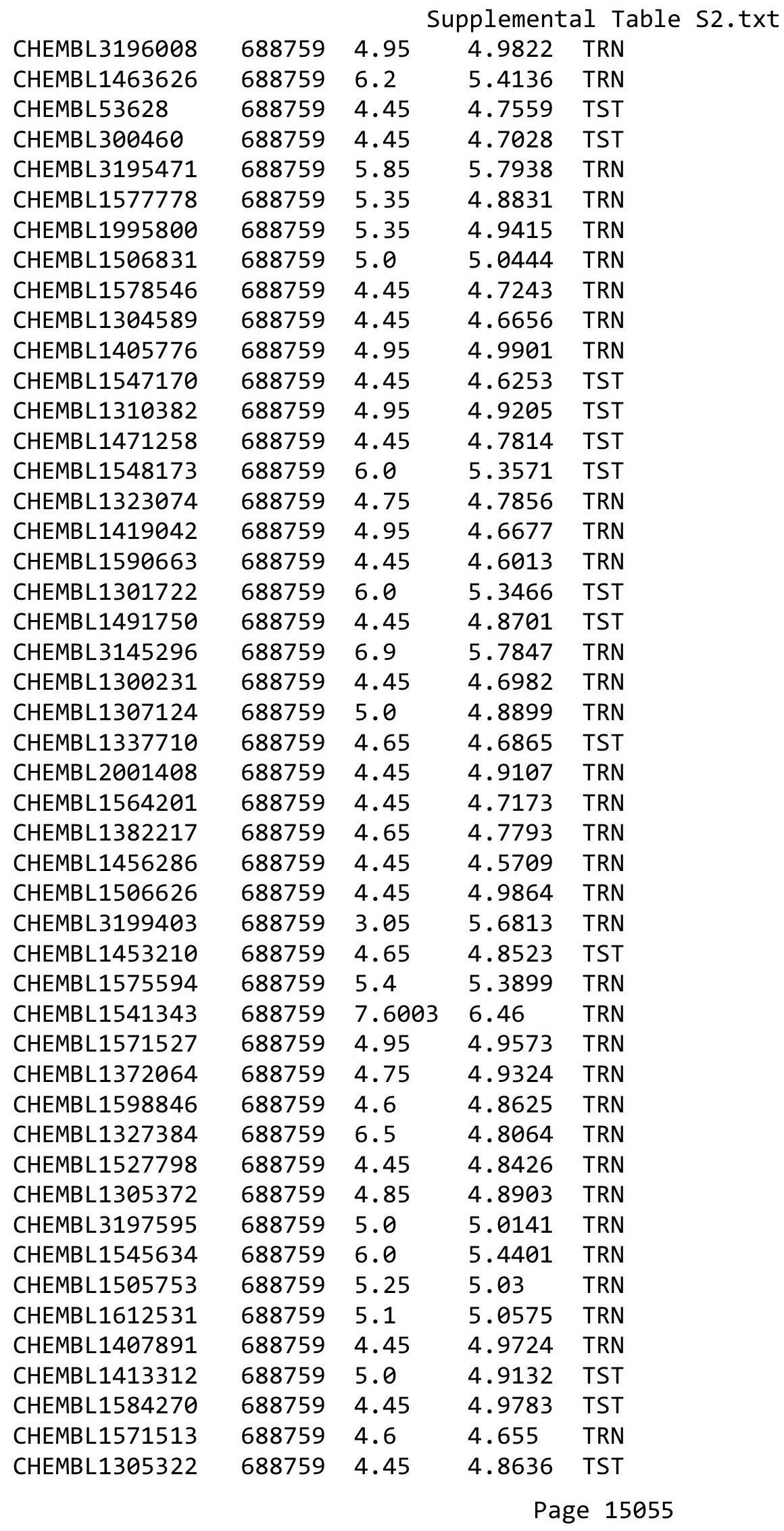




\begin{tabular}{|c|c|c|c|c|c|}
\hline \multicolumn{6}{|c|}{ Supplemental Table S2.txt } \\
\hline CHEMBL602807 & 688759 & 4.45 & 4.7667 & TRN & \\
\hline CHEMBL1603275 & 688759 & 4.45 & 4.683 & TRN & \\
\hline CHEMBL1299346 & 688759 & 4.65 & 4.9334 & TST & \\
\hline CHEMBL3198805 & 688759 & 4.95 & 5.2733 & TRN & \\
\hline CHEMBL3192781 & 688759 & 4.95 & 5.0922 & TRN & \\
\hline CHEMBL1328712 & 688759 & 4.85 & 4.5766 & TST & \\
\hline CHEMBL1406314 & 688759 & 5.4 & 4.9204 & TRN & \\
\hline CHEMBL1521882 & 688759 & 5.2 & 4.6825 & TST & \\
\hline CHEMBL1363032 & 688759 & 5.7 & 5.7792 & TRN & \\
\hline CHEMBL1425381 & 688759 & 4.45 & 4.6291 & TRN & \\
\hline CHEMBL1407910 & 688759 & 4.65 & 4.5695 & TRN & \\
\hline CHEMBL1413554 & 688759 & 4.45 & 4.9474 & TST & \\
\hline CHEMBL3190723 & 688759 & 4.8 & 4.6261 & TRN & \\
\hline CHEMBL1578137 & 688759 & 4.45 & 4.6931 & TRN & \\
\hline CHEMBL3197290 & 688759 & 5.05 & 5.0363 & TRN & \\
\hline CHEMBL1540646 & 688759 & 4.7 & 4.4074 & TRN & \\
\hline CHEMBL1550518 & 688759 & 6.45 & 6.2615 & TRN & \\
\hline CHEMBL1563140 & 688759 & 4.45 & 4.6188 & TST & \\
\hline CHEMBL1505806 & 688759 & 5.0 & 4.949 & TRN & \\
\hline CHEMBL1973307 & 688759 & 4.6 & 4.6908 & TRN & \\
\hline CHEMBL1558746 & 688759 & 4.45 & 5.0467 & TRN & \\
\hline CHEMBL1453923 & 688759 & 4.9 & 5.1916 & TRN & \\
\hline CHEMBL1430902 & 688759 & 5.2 & 5.3194 & TRN & \\
\hline CHEMBL1523387 & 688759 & 5.25 & 4.8977 & TST & \\
\hline CHEMBL1498537 & 688759 & 4.7 & 4.8133 & TRN & \\
\hline CHEMBL1535451 & 688759 & 5.4 & 5.47 & TRN & \\
\hline CHEMBL1598694 & 688759 & 4.65 & 4.5007 & TST & \\
\hline CHEMBL1329037 & 688759 & 5.1 & 5.2559 & TST & \\
\hline CHEMBL1423779 & 688759 & 4.6 & 4.8346 & TRN & \\
\hline CHEMBL1353506 & 688759 & 4.55 & 4.9262 & TRN & \\
\hline CHEMBL1538774 & 688759 & 4.45 & 4.4479 & TRN & \\
\hline CHEMBL1384261 & 688759 & 4.7 & 4.735 & TST & \\
\hline CHEMBL3196240 & 688759 & 7.4001 & 5.96399 & 99999999995 & TRN \\
\hline CHEMBL1425241 & 688759 & 4.45 & 4.7461 & TRN & \\
\hline CHEMBL1459314 & 688759 & 5.35 & 4.8086 & TRN & \\
\hline CHEMBL1458824 & 688759 & 5.85 & 5.0945 & TRN & \\
\hline CHEMBL1339492 & 688759 & 5.5 & 5.1348 & TRN & \\
\hline CHEMBL1544793 & 688759 & 4.45 & 4.8072 & TRN & \\
\hline CHEMBL1549205 & 688759 & 5.05 & 5.0917 & TRN & \\
\hline CHEMBL1482355 & 688759 & 4.65 & 4.6854 & TRN & \\
\hline CHEMBL1449621 & 688759 & 4.95 & 4.8342 & TRN & \\
\hline CHEMBL1534101 & 688759 & 5.15 & 5.0708 & TRN & \\
\hline CHEMBL1600035 & 688759 & 5.05 & 5.0415 & TRN & \\
\hline CHEMBL1577055 & 688759 & 4.45 & 4.6332 & TRN & \\
\hline CHEMBL1408890 & 688759 & 4.6 & 4.7074 & TRN & \\
\hline CHEMBL3197790 & 688759 & 4.9 & 5.3781 & TRN & \\
\hline CHEMBL1387787 & 688759 & 4.45 & 4.837 & TRN & \\
\hline CHEMBL1549179 & 688759 & 4.45 & 4.9985 & TST & \\
\hline
\end{tabular}




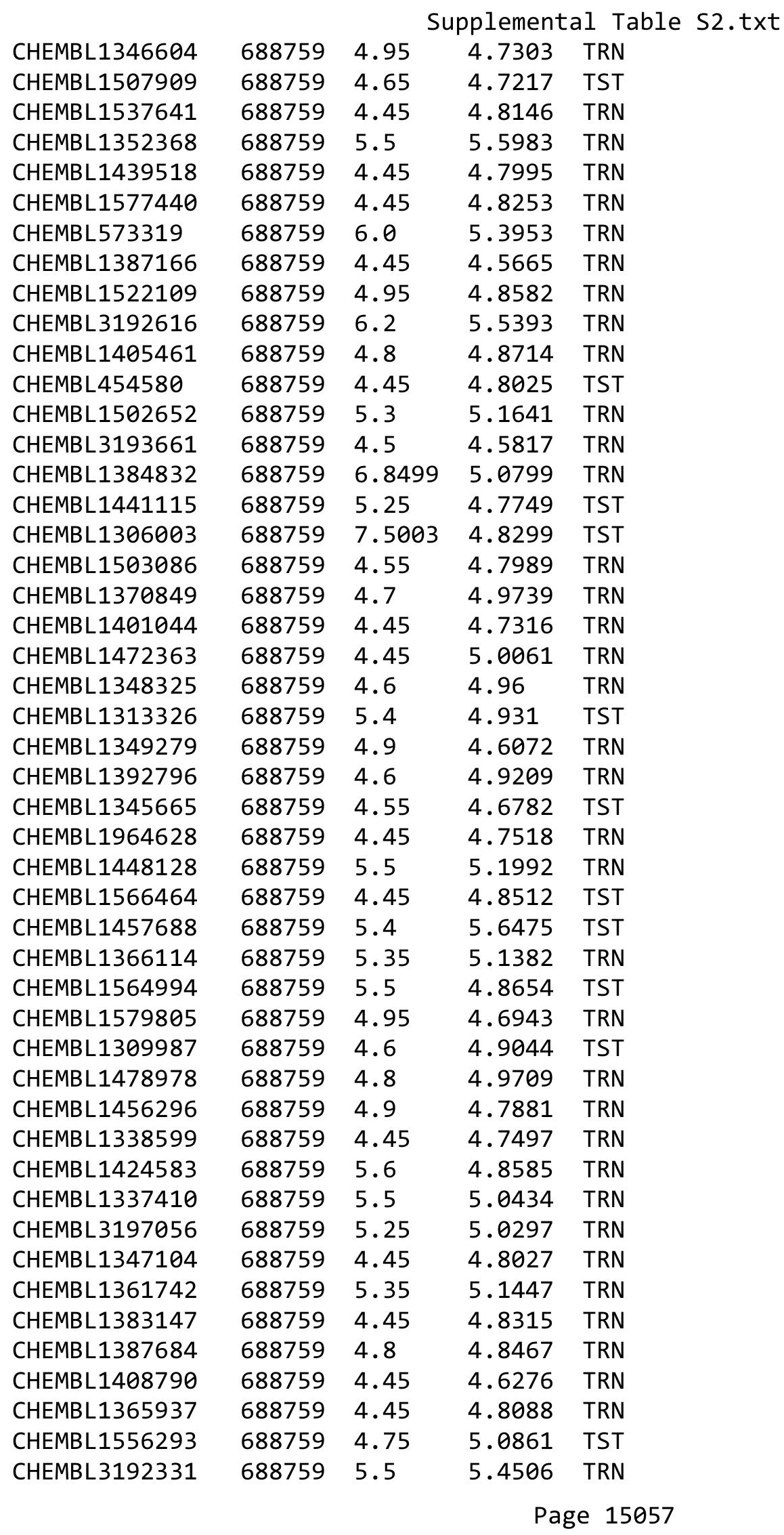




\begin{tabular}{|c|c|c|c|c|c|}
\hline & & \multicolumn{4}{|c|}{ Supplemental Table s2.txt } \\
\hline CHEMBL1469733 & 688759 & 5.75 & 5.6524 & TRN & \\
\hline CHEMBL1381651 & 688759 & 4.45 & 4.6202 & TRN & \\
\hline CHEMBL1359157 & 688759 & 4.45 & 4.6265 & TST & \\
\hline CHEMBL1561002 & 688759 & 5.4 & 4.9279 & TRN & \\
\hline CHEMBL1309398 & 688759 & 4.85 & 5.1485 & TRN & \\
\hline CHEMBL1442874 & 688759 & 5.45 & 5.7951 & TRN & \\
\hline CHEMBL164968 & 688759 & 5.5 & 5.2466 & TRN & \\
\hline CHEMBL1388940 & 688759 & 4.45 & 4.7029 & TRN & \\
\hline CHEMBL3193093 & 688759 & 5.5 & 5.3578 & TRN & \\
\hline CHEMBL1382564 & 688759 & 6.15 & 5.0602 & TRN & \\
\hline CHEMBL 2369162 & 688759 & 5.6 & 5.2801 & TRN & \\
\hline CHEMBL337173 & 688759 & 6.0 & 5.3562 & TRN & \\
\hline CHEMBL1407362 & 688759 & 4.65 & 5.0525 & TRN & \\
\hline CHEMBL1521991 & 688759 & 4.5 & 4.6581 & TST & \\
\hline CHEMBL1456111 & 688759 & 4.45 & 4.8819 & TRN & \\
\hline CHEMBL1511933 & 688759 & 4.6 & 4.61600 & 00000000005 & TRN \\
\hline CHEMBL1576282 & 688759 & 5.5 & 5.0325 & TRN & \\
\hline CHEMBL1377216 & 688759 & 4.65 & 5.0095 & TST & \\
\hline CHEMBL1300360 & 688759 & 4.65 & 4.8446 & TST & \\
\hline CHEMBL1451337 & 688759 & 4.45 & 4.569 & TRN & \\
\hline CHEMBL1465485 & 688759 & 5.4 & 4.8949 & TRN & \\
\hline CHEMBL1595665 & 688759 & 4.45 & 5.1092 & TRN & \\
\hline CHEMBL597251 & 688759 & 4.45 & 4.4862 & TRN & \\
\hline CHEMBL3189694 & 688759 & 4.45 & 4.6679 & TRN & \\
\hline CHEMBL1361365 & 688759 & 5.2 & 4.9188 & TRN & \\
\hline CHEMBL1418451 & 688759 & 5.55 & 4.8302 & TRN & \\
\hline CHEMBL1423466 & 688759 & 4.75 & 5.0484 & TRN & \\
\hline CHEMBL1477488 & 688759 & 4.5 & 4.8682 & TRN & \\
\hline CHEMBL1598230 & 688759 & 4.45 & 4.9089 & TRN & \\
\hline CHEMBL1403284 & 688759 & 4.45 & 5.0187 & TRN & \\
\hline CHEMBL3194623 & 688759 & 6.05 & 5.4596 & TRN & \\
\hline CHEMBL1550237 & 688759 & 4.85 & 4.8935 & TRN & \\
\hline CHEMBL1548383 & 688759 & 5.1 & 5.3404 & TRN & \\
\hline CHEMBL1582664 & 688759 & 4.9 & 4.8401 & TRN & \\
\hline CHEMBL3193338 & 688759 & 4.45 & 4.7041 & TRN & \\
\hline CHEMBL1607938 & 688759 & 4.6 & 4.4007 & TRN & \\
\hline CHEMBL1429863 & 688759 & 5.15 & 5.1868 & TRN & \\
\hline CHEMBL1301325 & 688759 & 4.95 & 5.2097 & TRN & \\
\hline CHEMBL1429872 & 688759 & 4.5 & 4.7163 & TST & \\
\hline CHEMBL1507740 & 688759 & 4.95 & 5.1333 & TRN & \\
\hline CHEMBL1334996 & 688759 & 4.45 & 5.0484 & TRN & \\
\hline CHEMBL1530911 & 688759 & 5.3 & 4.7252 & TRN & \\
\hline CHEMBL1607862 & 688759 & 4.45 & 4.7719 & TST & \\
\hline CHEMBL1460460 & 688759 & 4.45 & 5.0475 & TRN & \\
\hline CHEMBL3194167 & 688759 & 6.0 & 5.5365 & TRN & \\
\hline CHEMBL1535794 & 688759 & 4.45 & 4.923 & TRN & \\
\hline CHEMBL1387172 & 688759 & 4.45 & 4.8477 & TRN & \\
\hline CHEMBL1483460 & 688759 & 4.45 & 4.793 & TST & \\
\hline
\end{tabular}




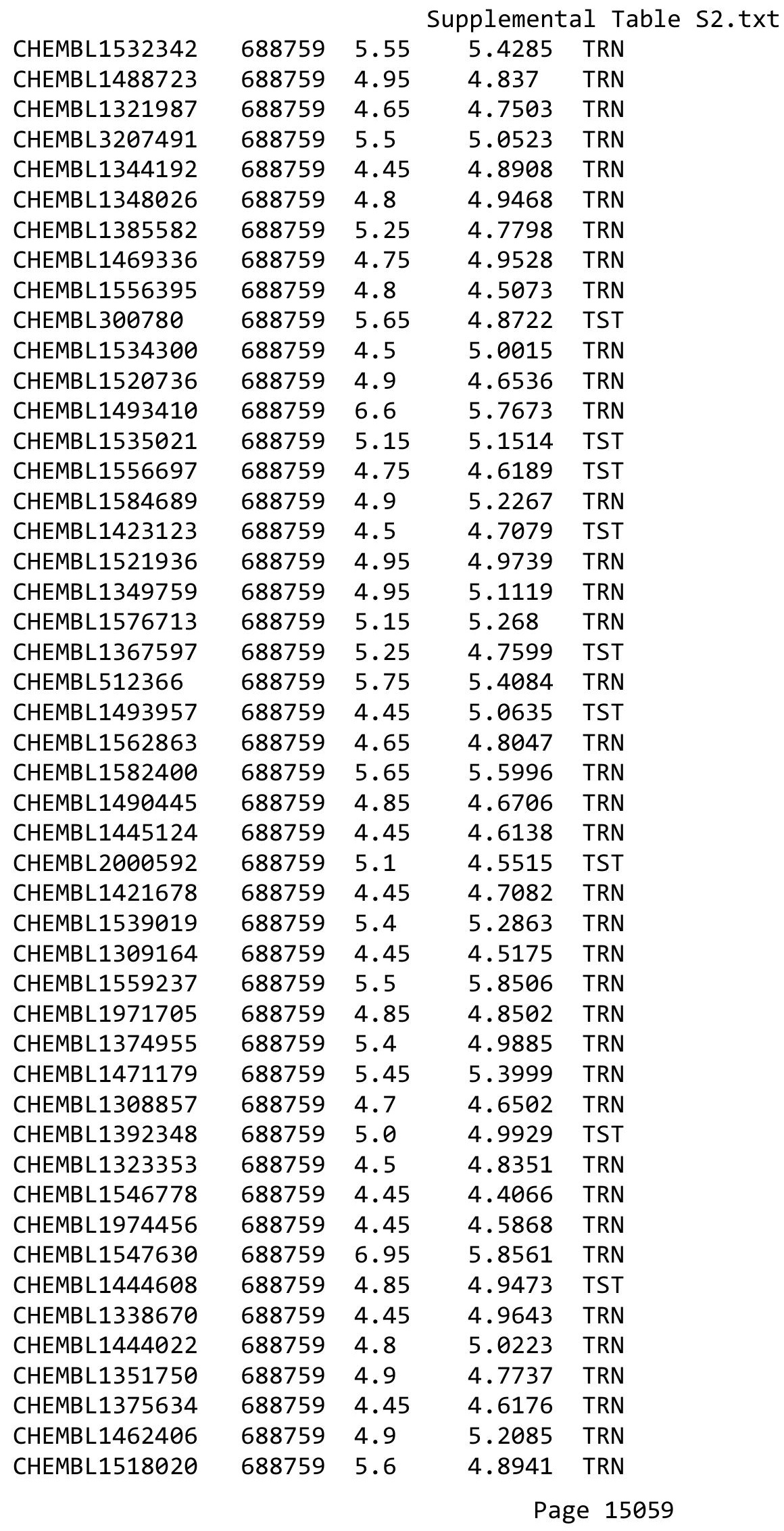




\begin{tabular}{|c|c|c|c|c|}
\hline & & & ipplement & al Table \\
\hline CHEMBL1534782 & 688759 & 4.7 & 4.5552 & TRN \\
\hline CHEMBL1319012 & 688759 & 4.75 & 4.7444 & TRN \\
\hline CHEMBL1439933 & 688759 & 4.65 & 4.5627 & TRN \\
\hline CHEMBL3208365 & 688759 & 4.65 & 4.876 & TRN \\
\hline CHEMBL 2006757 & 688759 & 5.35 & 5.4093 & TRN \\
\hline CHEMBL1608798 & 688759 & 4.45 & 5.3909 & TRN \\
\hline CHEMBL1595646 & 688759 & 5.4 & 4.7165 & TRN \\
\hline CHEMBL1387773 & 688759 & 4.45 & 4.8683 & TST \\
\hline CHEMBL1334510 & 688759 & 4.85 & 5.206 & TRN \\
\hline CHEMBL3214518 & 688759 & 4.95 & 4.8174 & TRN \\
\hline CHEMBL353759 & 688759 & 4.9 & 5.3365 & TST \\
\hline CHEMBL1450299 & 688759 & 5.2 & 4.8471 & TRN \\
\hline CHEMBL1466843 & 688759 & 5.25 & 4.7174 & TRN \\
\hline CHEMBL1565984 & 688759 & 4.7 & 4.8594 & TRN \\
\hline CHEMBL1483768 & 688759 & 4.6 & 4.5708 & TRN \\
\hline CHEMBL1316317 & 688759 & 4.45 & 4.7672 & TST \\
\hline CHEMBL1449103 & 688759 & 5.25 & 4.5263 & TRN \\
\hline CHEMBL1327663 & 688759 & 5.3 & 4.6339 & TRN \\
\hline CHEMBL1548872 & 688759 & 4.9 & 4.8357 & TST \\
\hline CHEMBL1459866 & 688759 & 6.4 & 5.0179 & TRN \\
\hline CHEMBL1441617 & 688759 & 5.0 & 4.9304 & TRN \\
\hline CHEMBL1353816 & 688759 & 4.65 & 4.6836 & TRN \\
\hline CHEMBL1469310 & 688759 & 5.5 & 5.3202 & TRN \\
\hline CHEMBL1305448 & 688759 & 4.45 & 4.6244 & TST \\
\hline CHEMBL1505663 & 688759 & 4.45 & 4.5511 & TRN \\
\hline CHEMBL1994221 & 688759 & 5.3 & 5.3443 & TRN \\
\hline CHEMBL3192235 & 688759 & 5.35 & 5.1592 & TRN \\
\hline CHEMBL1413377 & 688759 & 5.45 & 5.6512 & TRN \\
\hline CHEMBL1332975 & 688759 & 4.85 & 4.9117 & TRN \\
\hline CHEMBL1608084 & 688759 & 4.45 & 4.9306 & TRN \\
\hline CHEMBL1540020 & 688759 & 4.5 & 4.9281 & TRN \\
\hline CHEMBL3193142 & 688759 & 5.55 & 5.2449 & TRN \\
\hline CHEMBL3192583 & 688759 & 4.95 & 4.7812 & TST \\
\hline CHEMBL3197825 & 688759 & 4.75 & 4.8799 & TRN \\
\hline CHEMBL1598326 & 688759 & 4.75 & 4.5921 & TRN \\
\hline CHEMBL1472773 & 688759 & 4.9 & 5.0264 & TST \\
\hline CHEMBL1458707 & 688759 & 4.65 & 4.9542 & TRN \\
\hline CHEMBL1446321 & 688759 & 4.5 & 4.7276 & TRN \\
\hline CHEMBL1348979 & 688759 & 4.45 & 5.0063 & TRN \\
\hline CHEMBL1304485 & 688759 & 4.8 & 4.8517 & TST \\
\hline CHEMBL1385616 & 688759 & 4.65 & 4.7536 & TST \\
\hline CHEMBL1999906 & 688759 & 4.45 & 4.4466 & TRN \\
\hline CHEMBL3194758 & 688759 & 4.45 & 4.6758 & TRN \\
\hline CHEMBL1510609 & 688759 & 4.7 & 5.0442 & TST \\
\hline CHEMBL1443122 & 688759 & 4.9 & 4.9322 & TRN \\
\hline CHEMBL1586902 & 688759 & 4.5 & 4.7486 & TRN \\
\hline CHEMBL1503066 & 688759 & 5.15 & 5.1103 & TRN \\
\hline CHEMBL1448153 & 688759 & 4.95 & 5.0268 & TRN \\
\hline
\end{tabular}




\begin{tabular}{|c|c|c|c|c|c|}
\hline & & \multicolumn{4}{|c|}{ Supplemental Table S2.txt } \\
\hline CHEMBL1973360 & 688759 & 5.35 & 5.34200 & 00000000005 & TRN \\
\hline CHEMBL3194214 & 688759 & 6.15 & 5.6412 & TRN & \\
\hline CHEMBL1478679 & 688759 & 4.45 & 4.8854 & TST & \\
\hline CHEMBL1584754 & 688759 & 5.0 & 5.0544 & TST & \\
\hline CHEMBL1453054 & 688759 & 4.45 & 4.8466 & TRN & \\
\hline CHEMBL1416834 & 688759 & 4.95 & 4.94300 & 00000000005 & TST \\
\hline CHEMBL1551645 & 688759 & 5.0 & 5.3547 & TRN & \\
\hline CHEMBL1303862 & 688759 & 6.1 & 4.9453 & TST & \\
\hline CHEMBL1383534 & 688759 & 5.35 & 5.1504 & TRN & \\
\hline CHEMBL1420386 & 688759 & 4.55 & 4.4591 & TRN & \\
\hline CHEMBL1433402 & 688759 & 4.45 & 4.6119 & TRN & \\
\hline CHEMBL3392353 & 688759 & 4.45 & 4.9955 & TST & \\
\hline CHEMBL1305111 & 688759 & 4.45 & 4.8253 & TST & \\
\hline CHEMBL1348337 & 688759 & 5.0 & 4.7728 & TST & \\
\hline CHEMBL1439052 & 688759 & 5.1 & 4.8114 & TRN & \\
\hline CHEMBL1331590 & 688759 & 4.45 & 5.2098 & TRN & \\
\hline CHEMBL3190638 & 688759 & 4.45 & 4.6102 & TRN & \\
\hline CHEMBL1319618 & 688759 & 4.55 & 4.9581 & TRN & \\
\hline CHEMBL1504286 & 688759 & 5.5 & 4.9774 & TRN & \\
\hline CHEMBL1603797 & 688759 & 5.0 & 5.1385 & TRN & \\
\hline CHEMBL1426898 & 688759 & 4.7 & 4.8164 & TRN & \\
\hline CHEMBL1466004 & 688759 & 4.45 & 4.545 & TST & \\
\hline CHEMBL1332139 & 688759 & 5.4 & 5.2345 & TRN & \\
\hline CHEMBL1605788 & 688759 & 4.7 & 4.96 & TST & \\
\hline CHEMBL1413255 & 688759 & 4.45 & 5.0343 & TRN & \\
\hline CHEMBL1390567 & 688759 & 4.45 & 4.9705 & TST & \\
\hline CHEMBL1365170 & 688759 & 4.9 & 4.68199 & 99999999995 & TST \\
\hline CHEMBL1545527 & 688759 & 4.95 & 4.7977 & TRN & \\
\hline CHEMBL1448495 & 688759 & 4.95 & 4.9893 & TRN & \\
\hline CHEMBL1487458 & 688759 & 4.9 & 4.8605 & TST & \\
\hline CHEMBL1319615 & 688759 & 4.95 & 4.8589 & TRN & \\
\hline CHEMBL1390641 & 688759 & 4.75 & 4.9839 & TRN & \\
\hline CHEMBL1427282 & 688759 & 4.95 & 4.8012 & TRN & \\
\hline CHEMBL507237 & 688759 & 4.45 & 4.8839 & TST & \\
\hline CHEMBL1493504 & 688759 & 4.9 & 4.629 & TRN & \\
\hline CHEMBL1517787 & 688759 & 4.6 & 4.6046 & TRN & \\
\hline CHEMBL1402267 & 688759 & 4.45 & 4.9084 & TRN & \\
\hline CHEMBL1414925 & 688759 & 4.65 & 4.8659 & TRN & \\
\hline CHEMBL1322695 & 688759 & 5.45 & 5.2926 & TRN & \\
\hline CHEMBL490592 & 688759 & 5.0 & 5.1516 & TRN & \\
\hline CHEMBL1309381 & 688759 & 5.1 & 5.2142 & TST & \\
\hline CHEMBL1408016 & 688759 & 4.95 & 4.8398 & TRN & \\
\hline CHEMBL1472200 & 688759 & 4.45 & 4.7264 & TRN & \\
\hline CHEMBL1520232 & 688759 & 4.7 & 4.8397 & TRN & \\
\hline CHEMBL1460974 & 688759 & 4.45 & 4.9379 & TRN & \\
\hline CHEMBL1440622 & 688759 & 4.45 & 4.9984 & TST & \\
\hline CHEMBL1546374 & 688759 & 5.85 & 5.2087 & TST & \\
\hline CHEMBL1605229 & 688759 & 5.15 & 5.2176 & TRN & \\
\hline
\end{tabular}




\begin{tabular}{|c|c|c|c|c|c|}
\hline \multicolumn{6}{|c|}{ Supplemental Table S2.txt } \\
\hline CHEMBL1519587 & 688759 & 4.45 & 4.8558 & TRN & \\
\hline CHEMBL1485494 & 688759 & 4.6 & 5.0218 & TST & \\
\hline CHEMBL1405007 & 688759 & 5.4 & 4.9602 & TRN & \\
\hline CHEMBL1520320 & 688759 & 4.75 & 5.16200 & 0000000001 & TRN \\
\hline CHEMBL1321328 & 688759 & 5.15 & 4.6632 & TST & \\
\hline CHEMBL1999060 & 688759 & 4.45 & 4.8053 & TST & \\
\hline CHEMBL1483430 & 688759 & 6.15 & 4.8554 & TRN & \\
\hline CHEMBL1425240 & 688759 & 4.8 & 4.7551 & TRN & \\
\hline CHEMBL3191300 & 688759 & 4.65 & 4.7616 & TRN & \\
\hline CHEMBL1421652 & 688759 & 5.65 & 4.9019 & TRN & \\
\hline CHEMBL1522479 & 688759 & 4.75 & 4.8174 & TRN & \\
\hline CHEMBL3190487 & 688759 & 5.45 & 5.4865 & TRN & \\
\hline CHEMBL357389 & 688759 & 4.6 & 4.6755 & TST & \\
\hline CHEMBL1568423 & 688759 & 4.7 & 4.519 & TRN & \\
\hline CHEMBL1402974 & 688759 & 4.45 & 4.5958 & TST & \\
\hline CHEMBL1386304 & 688759 & 5.2 & 5.1298 & TRN & \\
\hline CHEMBL3199724 & 688759 & 5.25 & 5.2997 & TRN & \\
\hline CHEMBL1490308 & 688759 & 4.6 & 4.758 & TST & \\
\hline CHEMBL1403468 & 688759 & 4.45 & 4.64199 & 99999999995 & TRN \\
\hline CHEMBL1362775 & 688759 & 4.45 & 4.5115 & TRN & \\
\hline CHEMBL1300411 & 688759 & 4.75 & 4.9875 & TRN & \\
\hline CHEMBL1556661 & 688759 & 5.3 & 4.9093 & TST & \\
\hline CHEMBL1459323 & 688759 & 4.45 & 4.9647 & TRN & \\
\hline CHEMBL1466616 & 688759 & 5.25 & 5.3629 & TRN & \\
\hline CHEMBL1321942 & 688759 & 6.25 & 4.9702 & TRN & \\
\hline CHEMBL1603150 & 688759 & 4.6 & 4.6422 & TRN & \\
\hline CHEMBL1299529 & 688759 & 4.6 & 4.7655 & TST & \\
\hline CHEMBL1412818 & 688759 & 5.2 & 4.9671 & TST & \\
\hline CHEMBL1484818 & 688759 & 4.95 & 5.3168 & TRN & \\
\hline CHEMBL1460435 & 688759 & 4.95 & 5.1821 & TRN & \\
\hline CHEMBL1437007 & 688759 & 4.65 & 4.6384 & TRN & \\
\hline CHEMBL1307912 & 688759 & 5.05 & 5.2605 & TRN & \\
\hline CHEMBL1353947 & 688759 & 4.45 & 4.7848 & TRN & \\
\hline CHEMBL1363415 & 688759 & 4.9 & 4.8519 & TRN & \\
\hline CHEMBL3191541 & 688759 & 5.2 & 5.4672 & TRN & \\
\hline CHEMBL1465096 & 688759 & 5.0 & 4.5657 & TRN & \\
\hline CHEMBL3189610 & 688759 & 5.6 & 5.0251 & TRN & \\
\hline CHEMBL1479133 & 688759 & 4.75 & 4.9576 & TRN & \\
\hline CHEMBL1441782 & 688759 & 5.6 & 5.6032 & TRN & \\
\hline CHEMBL1347686 & 688759 & 4.9 & 4.883 & TRN & \\
\hline CHEMBL1370929 & 688759 & 5.2 & 5.3769 & TRN & \\
\hline CHEMBL3209278 & 688759 & 4.65 & 4.7343 & TRN & \\
\hline CHEMBL1340626 & 688759 & 8.0506 & 4.9305 & TRN & \\
\hline CHEMBL1480203 & 688759 & 5.45 & 5.2912 & TRN & \\
\hline CHEMBL1335489 & 688759 & 4.7 & 4.9746 & TRN & \\
\hline CHEMBL1409835 & 688759 & 4.45 & 4.6781 & TST & \\
\hline CHEMBL1405558 & 688759 & 4.7 & 4.9031 & TRN & \\
\hline CHEMBL1375574 & 688759 & 4.45 & 4.8728 & TRN & \\
\hline
\end{tabular}




\begin{tabular}{|c|c|c|c|c|}
\hline \multicolumn{5}{|c|}{ Supplemental Table s2.txt } \\
\hline CHEMBL1306451 & 688759 & 5.3 & 5.1227 & TRN \\
\hline CHEMBL3192890 & 688759 & 5.55 & 5.4431 & TRN \\
\hline CHEMBL1560177 & 688759 & 5.6 & 4.8165 & TRN \\
\hline CHEMBL1596694 & 688759 & 4.8 & 4.8958 & TRN \\
\hline CHEMBL598695 & 688759 & 4.45 & 4.9989 & TST \\
\hline CHEMBL1383995 & 688759 & 4.45 & 4.7472 & TST \\
\hline CHEMBL1496488 & 688759 & 5.45 & 5.2787 & TST \\
\hline CHEMBL3190377 & 688759 & 4.6 & 4.7482 & TRN \\
\hline CHEMBL1566137 & 688759 & 5.2 & 4.9543 & TRN \\
\hline CHEMBL1498281 & 688759 & 4.5 & 5.02 & TRN \\
\hline CHEMBL1431124 & 688759 & 5.0 & 4.8247 & TRN \\
\hline CHEMBL1588749 & 688759 & 4.5 & 5.0284 & TST \\
\hline CHEMBL3196550 & 688759 & 4.45 & 4.9548 & TRN \\
\hline CHEMBL1302039 & 688759 & 4.5 & 4.5787 & TRN \\
\hline CHEMBL1411972 & 688759 & 4.8 & 4.9103 & TRN \\
\hline CHEMBL3192915 & 688759 & 4.45 & 4.8611 & TRN \\
\hline CHEMBL1606466 & 688759 & 4.8 & 4.9189 & TST \\
\hline CHEMBL1477916 & 688759 & 5.45 & 4.922 & TRN \\
\hline CHEMBL3193872 & 688759 & 4.6 & 4.7985 & TRN \\
\hline CHEMBL1572900 & 688759 & 4.45 & 4.9321 & TST \\
\hline CHEMBL1444339 & 688759 & 4.55 & 4.9649 & TRN \\
\hline CHEMBL1579578 & 688759 & 5.15 & 4.8334 & TRN \\
\hline CHEMBL1469921 & 688759 & 4.75 & 5.1166 & TRN \\
\hline CHEMBL149322 & 688759 & 5.0 & 5.0339 & TRN \\
\hline CHEMBL1409997 & 688759 & 4.9 & 4.8162 & TST \\
\hline CHEMBL1555491 & 688759 & 4.45 & 4.4878 & TRN \\
\hline CHEMBL1442316 & 688759 & 5.7 & 5.0314 & TRN \\
\hline CHEMBL1337483 & 688759 & 5.4 & 4.846 & TST \\
\hline CHEMBL1375563 & 688759 & 4.45 & 4.7273 & TRN \\
\hline CHEMBL1307406 & 688759 & 5.2 & 4.6197 & TRN \\
\hline CHEMBL1521259 & 688759 & 4.65 & 4.5944 & TRN \\
\hline CHEMBL1510253 & 688759 & 4.45 & 4.8608 & TRN \\
\hline CHEMBL1306725 & 688759 & 4.45 & 4.5344 & TRN \\
\hline CHEMBL1973328 & 688759 & 4.45 & 4.6431 & TRN \\
\hline CHEMBL1503406 & 688759 & 4.45 & 4.9533 & TRN \\
\hline CHEMBL1572827 & 688759 & 5.5 & 5.1781 & TRN \\
\hline CHEMBL 272005 & 688759 & 5.1 & 5.0034 & TRN \\
\hline CHEMBL1599453 & 688759 & 4.45 & 4.8451 & TRN \\
\hline CHEMBL1377160 & 688759 & 4.75 & 4.4829 & TST \\
\hline CHEMBL1373120 & 688759 & 5.2 & 5.5956 & TRN \\
\hline CHEMBL1362490 & 688759 & 5.05 & 4.9466 & TRN \\
\hline CHEMBL1982152 & 688759 & 5.5 & 5.1638 & TRN \\
\hline CHEMBL596631 & 688759 & 4.45 & 4.7091 & TST \\
\hline CHEMBL1423597 & 688759 & 4.9 & 4.8639 & TST \\
\hline CHEMBL1550547 & 688759 & 4.45 & 4.6184 & TRN \\
\hline CHEMBL1537604 & 688759 & 4.45 & 4.7243 & TRN \\
\hline CHEMBL1526173 & 688759 & 5.25 & 5.2799 & TST \\
\hline CHEMBL1320392 & 688759 & 5.2 & 4.9253 & TRN \\
\hline
\end{tabular}




\begin{tabular}{|c|c|c|c|c|c|}
\hline \multicolumn{6}{|c|}{ Supplemental Table s2.txt } \\
\hline CHEMBL1504701 & 688759 & 5.55 & 5.3093 & TRN & \\
\hline CHEMBL1557212 & 688759 & 5.45 & 5.2139 & TRN & \\
\hline CHEMBL3196847 & 688759 & 4.45 & 5.0096 & TST & \\
\hline CHEMBL3194869 & 688759 & 5.0 & 4.6916 & TRN & \\
\hline CHEMBL1580953 & 688759 & 4.65 & \multicolumn{2}{|c|}{5.1370000000000005} & TST \\
\hline CHEMBL1602759 & 688759 & 5.5 & 5.3755 & TRN & \\
\hline CHEMBL1320102 & 688759 & 4.45 & 4.6744 & TST & \\
\hline CHEMBL2094532 & 688759 & 5.5 & 5.4749 & TRN & \\
\hline CHEMBL1514639 & 688759 & 4.45 & 4.7551 & TST & \\
\hline CHEMBL3197567 & 688759 & 4.85 & 4.936 & TRN & \\
\hline CHEMBL607299 & 688759 & 4.65 & 4.994 & TST & \\
\hline CHEMBL1341421 & 688759 & 4.9 & 4.7795 & TST & \\
\hline CHEMBL1320319 & 688759 & 5.1 & 4.9784 & TST & \\
\hline CHEMBL1492896 & 688759 & 4.6 & 4.8456 & TRN & \\
\hline CHEMBL1352200 & 688759 & 4.45 & 4.9301 & TRN & \\
\hline CHEMBL492091 & 688759 & 5.3 & 4.8992 & TRN & \\
\hline CHEMBL1975006 & 688759 & 6.5 & 5.8214 & TRN & \\
\hline CHEMBL1487678 & 688759 & 5.35 & 4.8883 & TRN & \\
\hline CHEMBL1508466 & 688759 & 5.1 & 5.0512 & TRN & \\
\hline CHEMBL1572685 & 688759 & 5.5 & 4.7192 & TRN & \\
\hline CHEMBL1498581 & 688759 & 4.95 & 4.9342 & TRN & \\
\hline CHEMBL1497184 & 688759 & 6.3 & 4.8818 & TRN & \\
\hline CHEMBL3198169 & 688759 & 5.25 & 4.8233 & TST & \\
\hline CHEMBL3190016 & 688759 & 5.35 & 5.0807 & TST & \\
\hline CHEMBL1362564 & 688759 & 5.05 & 4.8812 & TRN & \\
\hline CHEMBL1345999 & 688759 & 4.75 & 4.6554 & TST & \\
\hline CHEMBL1457175 & 688759 & 5.2 & 4.8425 & TST & \\
\hline CHEMBL1308056 & 688759 & 4.45 & 4.8654 & TRN & \\
\hline CHEMBL3199752 & 688759 & 4.45 & 5.2323 & TRN & \\
\hline CHEMBL1418940 & 688759 & 5.0 & 5.0408 & TRN & \\
\hline CHEMBL1588509 & 688759 & 4.75 & 4.9265 & TST & \\
\hline CHEMBL1583838 & 688759 & 4.9 & 4.9409 & TST & \\
\hline CHEMBL1421441 & 688759 & 4.75 & 4.9228 & TRN & \\
\hline CHEMBL1576051 & 688759 & 4.75 & 4.5854 & TRN & \\
\hline CHEMBL1466544 & 688759 & 4.45 & 4.8867 & TRN & \\
\hline CHEMBL1493952 & 688759 & 4.5 & 4.6761 & TST & \\
\hline CHEMBL1600347 & 688759 & 4.45 & 4.7927 & TST & \\
\hline CHEMBL3190605 & 688759 & 4.6 & 4.6906 & TRN & \\
\hline CHEMBL1344675 & 688759 & 4.45 & 4.3682 & TRN & \\
\hline CHEMBL1427004 & 688759 & 5.55 & 4.9364 & TRN & \\
\hline CHEMBL1453145 & 688759 & 6.4 & 4.8044 & TST & \\
\hline CHEMBL1567765 & 688759 & 4.45 & 4.8458 & TST & \\
\hline CHEMBL1538990 & 688759 & 4.65 & 4.7258 & TST & \\
\hline CHEMBL1299290 & 688759 & 4.45 & 5.022 & TRN & \\
\hline CHEMBL1389155 & 688759 & 4.45 & 4.7404 & TRN & \\
\hline CHEMBL1538435 & 688759 & 6.9 & 5.1758 & TRN & \\
\hline CHEMBL1331898 & 688759 & 4.65 & 4.7803 & TRN & \\
\hline CHEMBL3208373 & 688759 & 5.75 & 5.12700 & $\partial 000000001$ & TRN \\
\hline & & & & 15064 & \\
\hline
\end{tabular}




\begin{tabular}{|c|c|c|c|c|}
\hline \multicolumn{5}{|c|}{ Supplemental Table s2.txt } \\
\hline CHEMBL1359684 & 688759 & 4.45 & 4.7879 & TRN \\
\hline CHEMBL1427538 & 688759 & 4.75 & 4.8507 & TRN \\
\hline CHEMBL1319591 & 688759 & 5.2 & 5.034 & TRN \\
\hline CHEMBL1560778 & 688759 & 5.3 & 4.9571 & TRN \\
\hline CHEMBL1457085 & 688759 & 5.0 & 5.2141 & TRN \\
\hline CHEMBL1484934 & 688759 & 5.0 & 4.748 & TST \\
\hline CHEMBL3211931 & 688759 & 4.6 & 4.8489 & TST \\
\hline CHEMBL1382939 & 688759 & 5.25 & 4.8555 & TST \\
\hline CHEMBL 3189322 & 688759 & 5.6 & 5.393 & TRN \\
\hline CHEMBL1563507 & 688759 & 5.0 & 4.822 & TRN \\
\hline CHEMBL1312122 & 688759 & 4.45 & 4.614 & TRN \\
\hline CHEMBL1577728 & 688759 & 5.25 & 4.857 & TRN \\
\hline CHEMBL1497651 & 688759 & 5.05 & 4.8397 & TST \\
\hline CHEMBL1582404 & 688759 & 4.45 & 5.0587 & TST \\
\hline CHEMBL1358100 & 688759 & 5.25 & 4.7569 & TST \\
\hline CHEMBL1480760 & 688759 & 4.45 & 5.0165 & TRN \\
\hline CHEMBL1313883 & 688759 & 5.25 & 5.1137 & TRN \\
\hline CHEMBL1470446 & 688759 & 4.45 & 4.5271 & TST \\
\hline CHEMBL1358562 & 688759 & 4.8 & 4.774 & TRN \\
\hline CHEMBL1529850 & 688759 & 4.45 & 4.8821 & TRN \\
\hline CHEMBL1306184 & 688759 & 6.2 & 5.818 & TRN \\
\hline CHEMBL1535377 & 688759 & 5.35 & 4.8232 & TST \\
\hline CHEMBL1467136 & 688759 & 4.8 & 4.827 & TST \\
\hline CHEMBL1581364 & 688759 & 5.25 & 4.9751 & TRN \\
\hline CHEMBL1370276 & 688759 & 4.7 & 4.8717 & TRN \\
\hline CHEMBL590184 & 688759 & 5.5 & 5.2042 & TRN \\
\hline CHEMBL1361204 & 688759 & 4.45 & 4.7247 & TRN \\
\hline CHEMBL1974450 & 688759 & 4.5 & 4.7807 & TRN \\
\hline CHEMBL1461621 & 688759 & 4.45 & 4.8395 & TRN \\
\hline CHEMBL1430881 & 688759 & 5.2 & 5.0496 & TRN \\
\hline CHEMBL1335114 & 688759 & 4.7 & 4.6436 & TRN \\
\hline CHEMBL1574879 & 688759 & 5.95 & 5.7437 & TRN \\
\hline CHEMBL1486501 & 688759 & 4.45 & 4.8439 & TRN \\
\hline CHEMBL1334877 & 688759 & 4.6 & 4.6456 & TRN \\
\hline CHEMBL1426390 & 688759 & 4.45 & 4.8057 & TRN \\
\hline CHEMBL1566153 & 688759 & 5.15 & 5.1714 & TRN \\
\hline CHEMBL1516812 & 688759 & 4.45 & 4.7058 & TRN \\
\hline CHEMBL3211191 & 688759 & 6.1 & 4.9811 & TST \\
\hline CHEMBL1560671 & 688759 & 4.45 & 4.9812 & TST \\
\hline CHEMBL1589526 & 688759 & 5.5 & 5.1146 & TRN \\
\hline CHEMBL261454 & 688759 & 5.5 & 5.2063 & TST \\
\hline CHEMBL1550642 & 688759 & 4.45 & 4.7879 & TST \\
\hline CHEMBL1542028 & 688759 & 4.75 & 5.2484 & TRN \\
\hline CHEMBL1302495 & 688759 & 4.65 & 4.7792 & TST \\
\hline CHEMBL1305912 & 688759 & 4.95 & 4.6991 & TRN \\
\hline CHEMBL1977596 & 688759 & 4.95 & 4.9395 & TRN \\
\hline CHEMBL1994068 & 688759 & 5.15 & 5.2746 & TRN \\
\hline CHEMBL1389618 & 688759 & 4.6 & 4.783 & TRN \\
\hline
\end{tabular}




\begin{tabular}{|c|c|c|c|c|}
\hline \multicolumn{5}{|c|}{ Supplemental Table S2.txt } \\
\hline CHEMBL1458623 & 688759 & 4.6 & 4.9768 & TRN \\
\hline CHEMBL1507520 & 688759 & 6.2 & 5.5579 & TRN \\
\hline CHEMBL1558612 & 688759 & 4.45 & 4.9117 & TRN \\
\hline CHEMBL1497721 & 688759 & 4.45 & 4.7358 & TRN \\
\hline CHEMBL1480646 & 688759 & 4.65 & 4.9709 & TRN \\
\hline CHEMBL1540493 & 688759 & 5.3 & 5.1829 & TRN \\
\hline CHEMBL1418830 & 688759 & 5.35 & 5.1505 & TRN \\
\hline CHEMBL1506928 & 688759 & 4.65 & 5.0708 & TRN \\
\hline CHEMBL1467543 & 688759 & 4.85 & 4.9887 & TRN \\
\hline CHEMBL1440005 & 688759 & 4.65 & 5.0443 & TST \\
\hline CHEMBL1500498 & 688759 & 4.95 & 4.8686 & TRN \\
\hline CHEMBL1385480 & 688759 & 5.55 & 5.0066 & TRN \\
\hline CHEMBL1438860 & 688759 & 5.45 & 5.5526 & TRN \\
\hline CHEMBL1336374 & 688759 & 4.45 & 4.6589 & TRN \\
\hline CHEMBL1420636 & 688759 & 4.45 & 4.9109 & TRN \\
\hline CHEMBL1448333 & 688759 & 4.85 & 4.8102 & TST \\
\hline CHEMBL1385920 & 688759 & 4.45 & 4.8975 & TST \\
\hline CHEMBL1563441 & 688759 & 6.9 & 4.8214 & TST \\
\hline CHEMBL1480290 & 688759 & 4.55 & 4.7943 & TRN \\
\hline CHEMBL1528400 & 688759 & 4.65 & 4.931 & TRN \\
\hline CHEMBL1439091 & 688759 & 4.45 & 5.1077 & TRN \\
\hline CHEMBL1604952 & 688759 & 4.45 & 4.6545 & TRN \\
\hline CHEMBL1439755 & 688759 & 5.2 & 5.559 & TRN \\
\hline CHEMBL590706 & 688759 & 5.5 & 5.2774 & TRN \\
\hline CHEMBL1445967 & 688759 & 5.2 & 5.0639 & TRN \\
\hline CHEMBL1568641 & 688759 & 4.45 & 4.6851 & TST \\
\hline CHEMBL1457108 & 688759 & 4.7 & 4.7661 & TRN \\
\hline CHEMBL1582489 & 688759 & 6.3 & 5.0 & TRN \\
\hline CHEMBL1582866 & 688759 & 4.45 & 4.5593 & TRN \\
\hline CHEMBL1525343 & 688759 & 5.05 & 4.8633 & TRN \\
\hline CHEMBL1557638 & 688759 & 4.85 & 4.8811 & TRN \\
\hline CHEMBL1379860 & 688759 & 4.45 & 4.4554 & TRN \\
\hline CHEMBL1549163 & 688759 & 4.8 & 4.9886 & TRN \\
\hline CHEMBL1336009 & 688759 & 4.9 & 4.9323 & TST \\
\hline CHEMBL1454327 & 688759 & 4.45 & 5.2472 & TRN \\
\hline CHEMBL1526797 & 688759 & 4.45 & 4.8954 & TRN \\
\hline CHEMBL601140 & 688759 & 4.65 & 4.6783 & TRN \\
\hline CHEMBL1532309 & 688759 & 4.55 & 4.7987 & TST \\
\hline CHEMBL1582580 & 688759 & 5.45 & 4.941 & TRN \\
\hline CHEMBL1609134 & 688759 & 4.7 & 4.9899 & TRN \\
\hline CHEMBL1313320 & 688759 & 4.95 & 5.023 & TRN \\
\hline CHEMBL1540898 & 688759 & 4.75 & 4.8463 & TST \\
\hline CHEMBL1457753 & 688759 & 4.9 & 4.9143 & TRN \\
\hline CHEMBL3211569 & 688759 & 5.6 & 4.9761 & TRN \\
\hline CHEMBL1349184 & 688759 & 5.45 & 4.6798 & TRN \\
\hline CHEMBL1327195 & 688759 & 5.25 & 4.9229 & TST \\
\hline CHEMBL1374415 & 688759 & 8.301 & 4.8442 & TST \\
\hline CHEMBL1308871 & 688759 & 4.7 & 4.8023 & TRN \\
\hline
\end{tabular}




\begin{tabular}{|c|c|c|c|c|c|}
\hline \multirow{3}{*}{$\begin{array}{l}\text { CHEMBL } 1352586 \\
\text { CHFMBI } 1432253\end{array}$} & \multirow{3}{*}{$\begin{array}{l}688759 \\
688759\end{array}$} & \multicolumn{4}{|c|}{ Supplemental Table S2.txt } \\
\hline & & 5.5 & \multicolumn{2}{|c|}{5.1160000000000005} & TST \\
\hline & & 4.45 & 5.0303 & TRN & \\
\hline CHEMBL1413169 & 688759 & 6.0 & 4.9826 & TRN & \\
\hline CHEMBL1510565 & 688759 & 4.5 & \multicolumn{2}{|c|}{4.7780000000000005} & TRN \\
\hline CHEMBL1545909 & 688759 & 4.95 & 5.1268 & TST & \\
\hline CHEMBL1311440 & 688759 & 4.75 & 4.835 & TRN & \\
\hline CHEMBL1486258 & 688759 & 4.45 & 4.8321 & TRN & \\
\hline CHEMBL1309461 & 688759 & 4.45 & 4.9304 & TRN & \\
\hline CHEMBL1419932 & 688759 & 4.9 & 4.8922 & TST & \\
\hline CHEMBL1606843 & 688759 & 4.45 & 5.0779 & TRN & \\
\hline CHEMBL1341008 & 688759 & 5.35 & 4.9504 & TST & \\
\hline CHEMBL1523236 & 688759 & 5.9 & 5.8062 & TRN & \\
\hline CHEMBL1309596 & 688759 & 4.45 & 4.8476 & TRN & \\
\hline CHEMBL1474567 & 688759 & 4.85 & 5.0917 & TST & \\
\hline CHEMBL1460697 & 688759 & 4.85 & 4.6511 & TRN & \\
\hline CHEMBL1480010 & 688759 & 4.65 & 4.7044 & TST & \\
\hline CHEMBL1567830 & 688759 & 5.5 & 5.016 & TST & \\
\hline CHEMBL1468543 & 688759 & 5.15 & 4.9211 & TRN & \\
\hline CHEMBL1341087 & 688759 & 4.75 & 4.6155 & TST & \\
\hline CHEMBL1448711 & 688759 & 4.5 & 4.7047 & TRN & \\
\hline CHEMBL1605586 & 688759 & 4.65 & 4.9794 & TRN & \\
\hline CHEMBL3195642 & 688759 & 4.65 & 4.8088 & TRN & \\
\hline CHEMBL1527154 & 688759 & 4.45 & 4.8731 & TRN & \\
\hline CHEMBL1502828 & 688759 & 4.5 & 4.8104 & TST & \\
\hline CHEMBL1605460 & 688759 & 4.5 & 4.5999 & TRN & \\
\hline CHEMBL1571121 & 688759 & 4.45 & 4.7042 & TST & \\
\hline CHEMBL1522723 & 688759 & 4.6 & 4.6414 & TRN & \\
\hline CHEMBL1479740 & 688759 & 4.55 & 4.8797 & TRN & \\
\hline CHEMBL1452077 & 688759 & 4.45 & 4.8447 & TST & \\
\hline CHEMBL1558503 & 688759 & 4.65 & 4.7258 & TRN & \\
\hline CHEMBL1319848 & 688759 & 4.45 & 4.8766 & TRN & \\
\hline CHEMBL1467705 & 688759 & 4.5 & 4.7884 & TRN & \\
\hline CHEMBL1417167 & 688759 & 5.35 & 5.3317 & TRN & \\
\hline CHEMBL3192779 & 688759 & 5.15 & 5.4581 & TRN & \\
\hline CHEMBL3191888 & 688759 & 5.5 & 4.9666 & TRN & \\
\hline CHEMBL3191118 & 688759 & 4.7 & 4.8197 & TRN & \\
\hline CHEMBL1458127 & 688759 & 4.75 & 4.6473 & TRN & \\
\hline CHEMBL1347724 & 688759 & 4.45 & 4.8727 & TRN & \\
\hline CHEMBL1983243 & 688759 & 6.5 & 5.6224 & TRN & \\
\hline CHEMBL1557137 & 688759 & 4.45 & 4.7566 & TRN & \\
\hline CHEMBL1342287 & 688759 & 4.95 & 5.1575 & TRN & \\
\hline CHEMBL1366088 & 688759 & 4.85 & 5.3095 & TRN & \\
\hline CHEMBL3197145 & 688759 & 6.4 & 4.9888 & TRN & \\
\hline CHEMBL1349081 & 688759 & 4.45 & 4.9225 & TRN & \\
\hline CHEMBL1480367 & 688759 & 5.0 & 4.8514 & TRN & \\
\hline CHEMBL405317 & 688759 & 5.85 & 5.3928 & TRN & \\
\hline CHEMBL1609591 & 688759 & 4.65 & 4.9922 & TST & \\
\hline CHEMBL1518893 & 688759 & 5.35 & 5.117 & TRN & \\
\hline
\end{tabular}




\begin{tabular}{|c|c|c|c|c|}
\hline \multicolumn{5}{|c|}{ Supplemental Table S2.txt } \\
\hline CHEMBL379179 & 688759 & 5.05 & 5.0923 & TRN \\
\hline CHEMBL1323073 & 688759 & 4.85 & 4.9369 & TRN \\
\hline CHEMBL1439851 & 688759 & 5.25 & 5.0208 & TRN \\
\hline CHEMBL1423731 & 688759 & 4.7 & 4.7958 & TRN \\
\hline CHEMBL1402368 & 688759 & 4.45 & 4.9389 & TRN \\
\hline CHEMBL1377924 & 688759 & 5.55 & 5.6215 & TRN \\
\hline CHEMBL1498292 & 688759 & 4.75 & 5.0222 & TRN \\
\hline CHEMBL1304085 & 688759 & 4.45 & 4.9345 & TRN \\
\hline CHEMBL1471684 & 688759 & 5.3 & 4.8748 & TRN \\
\hline CHEMBL1323861 & 688759 & 4.8 & 4.7152 & TRN \\
\hline CHEMBL1400202 & 688759 & 5.5 & 4.9959 & TRN \\
\hline CHEMBL1543473 & 688759 & 4.7 & 4.577 & TRN \\
\hline CHEMBL1381941 & 688759 & 5.2 & 5.2654 & TRN \\
\hline CHEMBL 3198788 & 688759 & 5.4 & 4.8604 & TRN \\
\hline CHEMBL1996271 & 688759 & 4.6 & 4.7314 & TRN \\
\hline CHEMBL1380360 & 688759 & 4.8 & 4.7228 & TRN \\
\hline CHEMBL1411508 & 688759 & 4.45 & 4.9045 & TRN \\
\hline CHEMBL3194829 & 688759 & 4.55 & 4.6831 & TRN \\
\hline CHEMBL1598507 & 688759 & 5.55 & 5.5876 & TRN \\
\hline CHEMBL1499152 & 688759 & 5.05 & 5.4877 & TRN \\
\hline CHEMBL1560539 & 688759 & 4.45 & 4.9316 & TST \\
\hline CHEMBL1312788 & 688759 & 6.0 & 5.0389 & TRN \\
\hline CHEMBL 3214537 & 688759 & 4.75 & 4.8551 & TRN \\
\hline CHEMBL3197152 & 688759 & 4.55 & 4.751 & TRN \\
\hline CHEMBL1341358 & 688759 & 6.3 & 5.518 & TST \\
\hline CHEMBL1497036 & 688759 & 4.7 & 4.6062 & TRN \\
\hline CHEMBL600778 & 688759 & 5.75 & 5.5201 & TRN \\
\hline CHEMBL 375530 & 688759 & 6.0 & 5.4062 & TRN \\
\hline CHEMBL1422163 & 688759 & 4.6 & 5.5763 & TRN \\
\hline CHEMBL1518954 & 688759 & 4.45 & 4.9149 & TST \\
\hline CHEMBL1492762 & 688759 & 4.45 & 4.8394 & TST \\
\hline CHEMBL1376683 & 688759 & 4.45 & 4.7985 & TRN \\
\hline CHEMBL1482685 & 688759 & 4.9 & 4.9485 & TST \\
\hline CHEMBL1458261 & 688759 & 5.3 & 5.1747 & TRN \\
\hline CHEMBL1454930 & 688759 & 4.55 & 4.9578 & TRN \\
\hline CHEMBL1555954 & 688759 & 4.65 & 4.8462 & TST \\
\hline CHEMBL1319659 & 688759 & 4.65 & 4.8592 & TRN \\
\hline CHEMBL1445486 & 688759 & 4.95 & 4.9585 & TRN \\
\hline CHEMBL1499458 & 688759 & 4.85 & 4.9955 & TST \\
\hline CHEMBL1533676 & 688759 & 4.45 & 4.9539 & TRN \\
\hline CHEMBL3197741 & 688759 & 4.45 & 4.9664 & TST \\
\hline CHEMBL1585138 & 688759 & 4.45 & 4.6344 & TRN \\
\hline CHEMBL1401767 & 688759 & 4.45 & 4.4822 & TST \\
\hline CHEMBL1461945 & 688759 & 5.45 & 5.0397 & TRN \\
\hline CHEMBL3194195 & 688759 & 4.65 & 4.6266 & TRN \\
\hline CHEMBL1325207 & 688759 & 5.4 & 4.6076 & TRN \\
\hline CHEMBL3209150 & 688759 & 4.45 & 4.7721 & TRN \\
\hline CHEMBL1975504 & 688759 & 4.8 & 5.1744 & TRN \\
\hline
\end{tabular}




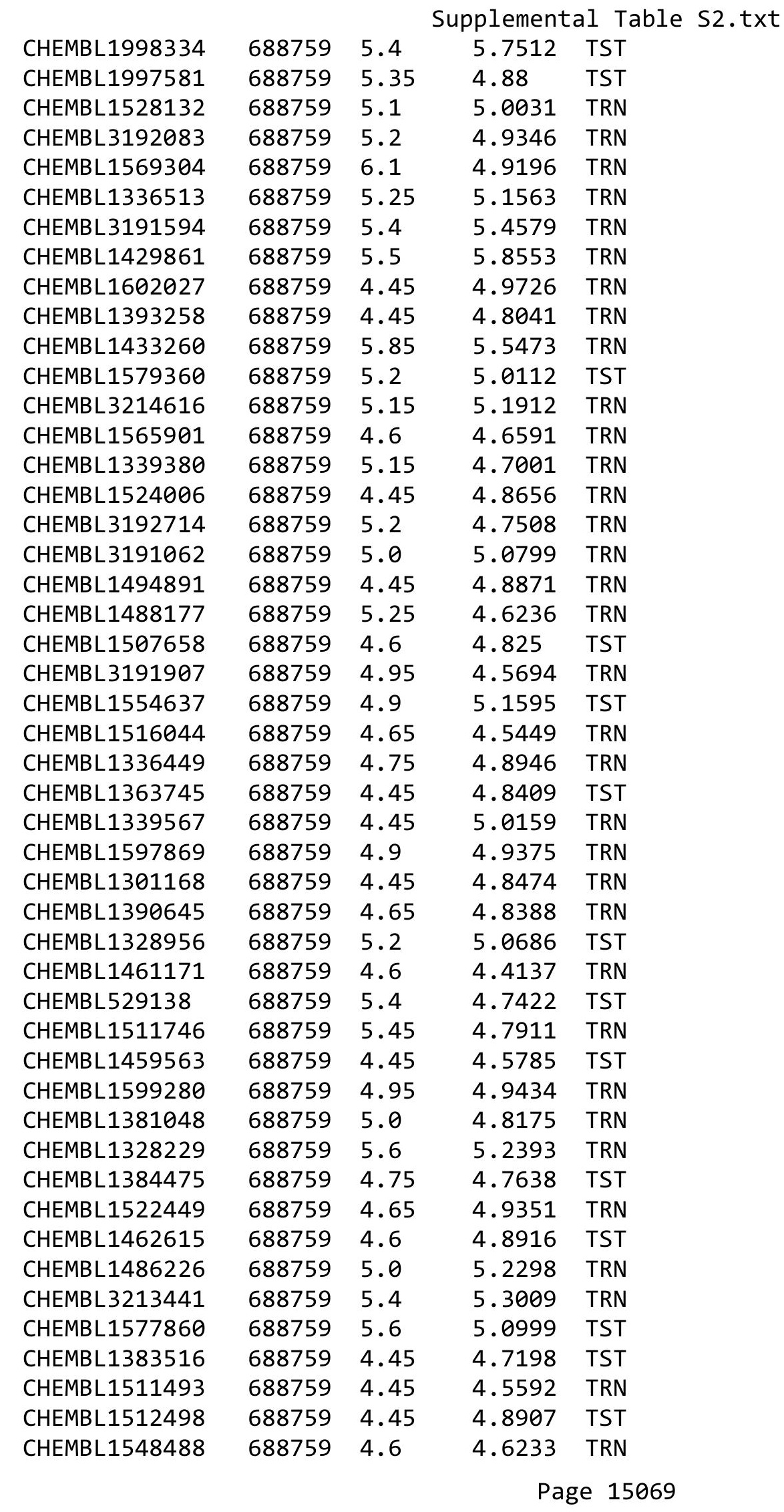




\begin{tabular}{|c|c|c|c|c|c|}
\hline \multicolumn{6}{|c|}{ Supplemental Table S2.txt } \\
\hline CHEMBL1544803 & 688759 & 4.45 & 4.707 & TRN & \\
\hline CHEMBL1366809 & 688759 & 4.65 & 4.9595 & TRN & \\
\hline CHEMBL1375791 & 688759 & 4.7 & 4.9007 & TST & \\
\hline CHEMBL1608268 & 688759 & 4.45 & 4.5962 & TRN & \\
\hline CHEMBL1377568 & 688759 & 4.45 & 4.8549 & TST & \\
\hline CHEMBL1364603 & 688759 & 5.45 & 5.4019 & TRN & \\
\hline CHEMBL1369129 & 688759 & 6.4 & 4.9646 & TST & \\
\hline CHEMBL1990786 & 688759 & 5.35 & 5.2159 & TRN & \\
\hline CHEMBL1412057 & 688759 & 4.45 & 4.8299 & TRN & \\
\hline CHEMBL1520041 & 688759 & 4.45 & 4.8399 & TRN & \\
\hline CHEMBL1539398 & 688759 & 5.0 & 5.1295 & TRN & \\
\hline CHEMBL1377903 & 688759 & 5.35 & 5.0211 & TST & \\
\hline CHEMBL1470441 & 688759 & 4.45 & 4.5217 & TRN & \\
\hline CHEMBL1541861 & 688759 & 4.75 & 5.1868 & TRN & \\
\hline CHEMBL1496766 & 688759 & 4.45 & 4.853 & TRN & \\
\hline CHEMBL1602145 & 688759 & 5.95 & 5.5229 & TRN & \\
\hline CHEMBL1571186 & 688759 & 5.1 & 4.7753 & TRN & \\
\hline CHEMBL1336068 & 688759 & 4.45 & 4.7452 & TRN & \\
\hline CHEMBL1563297 & 688759 & 4.6 & 4.65300 & 00000000005 & TRN \\
\hline CHEMBL1510848 & 688759 & 4.45 & 5.0061 & TST & \\
\hline CHEMBL1504020 & 688759 & 5.45 & 4.8787 & TRN & \\
\hline CHEMBL1423897 & 688759 & 4.45 & 5.0161 & TST & \\
\hline CHEMBL243813 & 688759 & 5.5 & 4.9184 & TRN & \\
\hline CHEMBL3191582 & 688759 & 5.25 & 4.9028 & TRN & \\
\hline CHEMBL3195723 & 688759 & 4.9 & 4.7269 & TST & \\
\hline CHEMBL1558402 & 688759 & 4.45 & 4.6618 & TRN & \\
\hline CHEMBL1299365 & 688759 & 4.45 & 4.5326 & TRN & \\
\hline CHEMBL1468099 & 688759 & 4.55 & 4.7207 & TST & \\
\hline CHEMBL1352240 & 688759 & 5.65 & 4.6685 & TST & \\
\hline CHEMBL1602753 & 688759 & 4.5 & 4.5819 & TRN & \\
\hline CHEMBL1432670 & 688759 & 4.45 & 4.4135 & TRN & \\
\hline CHEMBL1419445 & 688759 & 4.5 & 4.9554 & TRN & \\
\hline CHEMBL1340639 & 688759 & 5.9 & 4.9623 & TST & \\
\hline CHEMBL1438864 & 688759 & 6.0 & 4.7909 & TRN & \\
\hline CHEMBL1543042 & 688759 & 4.75 & 4.5048 & TRN & \\
\hline CHEMBL1507494 & 688759 & 4.75 & 4.7836 & TRN & \\
\hline CHEMBL1371385 & 688759 & 6.05 & 5.9026 & TRN & \\
\hline CHEMBL3193765 & 688759 & 5.2 & 5.29799 & 9999999999 & TRN \\
\hline CHEMBL3190482 & 688759 & 4.55 & 4.7273 & TST & \\
\hline CHEMBL1610521 & 688759 & 6.05 & 4.9967 & TST & \\
\hline CHEMBL1596598 & 688759 & 7.0 & 4.8636 & TST & \\
\hline CHEMBL3208869 & 688759 & 5.0 & 4.7944 & TST & \\
\hline CHEMBL1538322 & 688759 & 4.45 & 4.8509 & TST & \\
\hline CHEMBL1467047 & 688759 & 5.5 & 5.0895 & TRN & \\
\hline CHEMBL3190986 & 688759 & 6.0 & 5.4258 & TRN & \\
\hline CHEMBL1508169 & 688759 & 4.9 & 4.8905 & TST & \\
\hline CHEMBL1498604 & 688759 & 4.7 & 4.7497 & TRN & \\
\hline CHEMBL1351129 & 688759 & 4.7 & 4.6007 & TST & \\
\hline
\end{tabular}




\begin{tabular}{|c|c|c|c|c|}
\hline \multicolumn{5}{|c|}{ Supplemental Table S2.txt } \\
\hline CHEMBL1321717 & 688759 & 4.45 & 5.2246 & TST \\
\hline CHEMBL1977563 & 688759 & 4.45 & 4.6972 & TRN \\
\hline CHEMBL1466165 & 688759 & 4.9 & 4.6796 & TST \\
\hline CHEMBL 3198285 & 688759 & 6.0 & 5.8236 & TRN \\
\hline CHEMBL1382438 & 688759 & 5.35 & 5.6979 & TRN \\
\hline CHEMBL1441999 & 688759 & 4.95 & 5.1422 & TRN \\
\hline CHEMBL1366257 & 688759 & 7.6003 & 4.774 & TST \\
\hline CHEMBL3189704 & 688759 & 5.2 & 5.2582 & TRN \\
\hline CHEMBL1587473 & 688759 & 5.1 & 4.9163 & TRN \\
\hline CHEMBL1575100 & 688759 & 4.7 & 5.0639 & TRN \\
\hline CHEMBL1556453 & 688759 & 4.45 & 4.8221 & TST \\
\hline CHEMBL1334157 & 688759 & 4.65 & 4.9682 & TRN \\
\hline CHEMBL3192022 & 688759 & 5.25 & 5.0528 & TRN \\
\hline CHEMBL1582652 & 688759 & 4.45 & 4.99 & TRN \\
\hline CHEMBL3196460 & 688759 & 4.45 & 4.8843 & TRN \\
\hline CHEMBL1447359 & 688759 & 6.2 & 5.1117 & TRN \\
\hline CHEMBL1497780 & 688759 & 4.45 & 4.7775 & TRN \\
\hline CHEMBL1509816 & 688759 & 4.45 & 5.0265 & TST \\
\hline CHEMBL1563347 & 688759 & 4.75 & 5.008 & TRN \\
\hline CHEMBL1571490 & 688759 & 4.75 & 4.7721 & TST \\
\hline CHEMBL1386788 & 688759 & 5.5 & 5.5001 & TRN \\
\hline CHEMBL1501205 & 688759 & 4.45 & 4.9404 & TST \\
\hline CHEMBL3211676 & 688759 & 4.45 & 4.8694 & TRN \\
\hline CHEMBL1607663 & 688759 & 4.45 & 4.8677 & TRN \\
\hline CHEMBL1517911 & 688759 & 4.55 & 4.843 & TST \\
\hline CHEMBL1406195 & 688759 & 4.45 & 4.7052 & TRN \\
\hline CHEMBL1403377 & 688759 & 4.45 & 4.7547 & TRN \\
\hline CHEMBL1608376 & 688759 & 5.05 & 4.9655 & TST \\
\hline CHEMBL1535134 & 688759 & 6.1 & 4.9366 & TRN \\
\hline CHEMBL1336039 & 688759 & 6.0 & 5.1837 & TRN \\
\hline CHEMBL1595172 & 688759 & 4.7 & 4.7075 & TRN \\
\hline CHEMBL1479427 & 688759 & 4.75 & 4.7729 & TRN \\
\hline CHEMBL3194004 & 688759 & 5.4 & 4.5863 & TRN \\
\hline CHEMBL1401293 & 688759 & 4.6 & 4.8148 & TST \\
\hline CHEMBL590691 & 688759 & 4.95 & 4.7898 & TRN \\
\hline CHEMBL1470679 & 688759 & 4.9 & 4.6016 & TRN \\
\hline CHEMBL3199914 & 688759 & 4.5 & 4.7736 & TRN \\
\hline CHEMBL1518085 & 688759 & 5.35 & 5.7042 & TRN \\
\hline CHEMBL1423762 & 688759 & 5.8 & 4.865 & TST \\
\hline CHEMBL3198105 & 688759 & 4.85 & 5.3359 & TRN \\
\hline CHEMBL1528898 & 688759 & 5.05 & 5.0939 & TRN \\
\hline CHEMBL1353885 & 688759 & 5.75 & 5.4759 & TRN \\
\hline CHEMBL1332718 & 688759 & 4.45 & 4.9412 & TRN \\
\hline CHEMBL1534944 & 688759 & 4.45 & 4.6215 & TST \\
\hline CHEMBL1587323 & 688759 & 4.65 & 5.0547 & TRN \\
\hline CHEMBL1350933 & 688759 & 4.75 & 4.7315 & TRN \\
\hline CHEMBL1362224 & 688759 & 5.15 & 4.8059 & TRN \\
\hline CHEMBL1409883 & 688759 & 5.4 & 5.4676 & TRN \\
\hline
\end{tabular}




\begin{tabular}{|c|c|c|c|c|c|}
\hline & & \multicolumn{4}{|c|}{ Supplemental Table s2.txt } \\
\hline CHEMBL1361355 & 688759 & 4.45 & 4.6554 & TRN & \\
\hline CHEMBL1452628 & 688759 & 5.9 & 4.6988 & TRN & \\
\hline CHEMBL1405717 & 688759 & 4.65 & 5.1048 & TRN & \\
\hline CHEMBL1997585 & 688759 & 4.65 & 4.5613 & TST & \\
\hline CHEMBL3208533 & 688759 & 4.45 & 4.7095 & TRN & \\
\hline CHEMBL1538426 & 688759 & 5.95 & 5.0124 & TRN & \\
\hline CHEMBL1530525 & 688759 & 5.4 & 5.1851 & TRN & \\
\hline CHEMBL1517902 & 688759 & 4.75 & 4.8613 & TRN & \\
\hline CHEMBL1360457 & 688759 & 4.45 & 4.564 & TST & \\
\hline CHEMBL1346397 & 688759 & 4.65 & 4.7472 & TRN & \\
\hline CHEMBL1324941 & 688759 & 5.25 & 4.8836 & TST & \\
\hline CHEMBL1346114 & 688759 & 4.95 & 5.0589 & TST & \\
\hline CHEMBL1989760 & 688759 & 5.35 & 5.3028 & TRN & \\
\hline CHEMBL1305816 & 688759 & 5.25 & 4.9495 & TST & \\
\hline CHEMBL1462373 & 688759 & 5.0 & 4.9504 & TRN & \\
\hline CHEMBL1608954 & 688759 & 5.8 & 4.6863 & TRN & \\
\hline CHEMBL1380545 & 688759 & 4.65 & 4.74100 & 00000000005 & TRN \\
\hline CHEMBL1575124 & 688759 & 5.2 & 5.3503 & TRN & \\
\hline CHEMBL1582999 & 688759 & 5.05 & 4.9129 & TRN & \\
\hline CHEMBL1340573 & 688759 & 4.9 & 4.7497 & TST & \\
\hline CHEMBL1570857 & 688759 & 4.45 & 4.6133 & TRN & \\
\hline CHEMBL1965860 & 688759 & 5.2 & 5.2895 & TRN & \\
\hline CHEMBL1418371 & 688759 & 4.45 & 4.6203 & TRN & \\
\hline CHEMBL1498599 & 688759 & 5.3 & 5.012 & TRN & \\
\hline CHEMBL1374246 & 688759 & 5.4 & 5.2931 & TRN & \\
\hline CHEMBL1485643 & 688759 & 4.45 & 4.7531 & TST & \\
\hline CHEMBL1487563 & 688759 & 4.45 & 4.60800 & 00000000005 & TRN \\
\hline CHEMBL1324082 & 688759 & 4.65 & 4.9892 & TST & \\
\hline CHEMBL1405344 & 688759 & 4.7 & 4.7129 & TST & \\
\hline CHEMBL1432382 & 688759 & 4.95 & 4.7958 & TST & \\
\hline CHEMBL 3212868 & 688759 & 5.4 & 5.0924 & TRN & \\
\hline CHEMBL1568646 & 688759 & 5.1 & 4.8893 & TRN & \\
\hline CHEMBL1462553 & 688759 & 4.95 & 5.0072 & TST & \\
\hline CHEMBL3189541 & 688759 & 6.05 & 5.1983 & TRN & \\
\hline CHEMBL1313167 & 688759 & 4.6 & 4.9009 & TRN & \\
\hline CHEMBL1493766 & 688759 & 5.15 & 4.7219 & TST & \\
\hline CHEMBL1416844 & 688759 & 4.65 & 4.7991 & TRN & \\
\hline CHEMBL1524740 & 688759 & 4.45 & 4.7252 & TST & \\
\hline CHEMBL1443295 & 688759 & 4.8 & 4.8621 & TST & \\
\hline CHEMBL1578082 & 688759 & 6.0 & 4.995 & TRN & \\
\hline CHEMBL1443262 & 688759 & 6.2 & 5.7382 & TRN & \\
\hline CHEMBL3195128 & 688759 & 5.35 & 5.4591 & TRN & \\
\hline CHEMBL1339737 & 688759 & 5.15 & 5.2774 & TRN & \\
\hline CHEMBL1576076 & 688759 & 5.0 & 4.8263 & TRN & \\
\hline CHEMBL1418980 & 688759 & 4.65 & 4.687 & TRN & \\
\hline CHEMBL1445275 & 688759 & 4.9 & 5.09 & TST & \\
\hline CHEMBL1560954 & 688759 & 5.05 & 5.0587 & TRN & \\
\hline CHEMBL1329659 & 688759 & 4.45 & 4.6408 & TRN & \\
\hline
\end{tabular}




\begin{tabular}{|c|c|c|c|c|c|}
\hline \multicolumn{6}{|c|}{ Supplemental Table S2.txt } \\
\hline CHEMBL1308000 & 688759 & 4.45 & 4.5928 & TRN & \\
\hline CHEMBL1576759 & 688759 & 4.45 & 4.5705 & TRN & \\
\hline CHEMBL1986514 & 688759 & 5.35 & 5.5586 & TRN & \\
\hline CHEMBL1424823 & 688759 & 4.45 & 4.8232 & TRN & \\
\hline CHEMBL1337224 & 688759 & 4.45 & 4.9957 & TRN & \\
\hline CHEMBL1609545 & 688759 & 5.5 & 4.8859 & TRN & \\
\hline CHEMBL1388060 & 688759 & 5.45 & 4.9224 & TRN & \\
\hline CHEMBL1319005 & 688759 & 4.45 & 4.6974 & TRN & \\
\hline CHEMBL1498907 & 688759 & 5.25 & 4.7936 & TST & \\
\hline CHEMBL1427773 & 688759 & 4.45 & 4.7301 & TRN & \\
\hline CHEMBL1610727 & 688759 & 4.45 & 5.1217 & TST & \\
\hline CHEMBL1308721 & 688759 & 5.1 & 4.6299 & TRN & \\
\hline CHEMBL1485485 & 688759 & 4.45 & 4.9995 & TST & \\
\hline CHEMBL1504102 & 688759 & 4.45 & 4.8636 & TRN & \\
\hline CHEMBL1477201 & 688759 & 5.6 & 5.0556 & TRN & \\
\hline CHEMBL1469798 & 688759 & 5.25 & 4.7161 & TST & \\
\hline CHEMBL1407633 & 688759 & 4.75 & 4.7883 & TRN & \\
\hline CHEMBL1456900 & 688759 & 4.45 & 4.8829 & TST & \\
\hline CHEMBL1429444 & 688759 & 4.6 & 4.7343 & TRN & \\
\hline CHEMBL1570176 & 688759 & 4.45 & 5.015 & TST & \\
\hline CHEMBL3197517 & 688759 & 4.45 & 4.71 & TST & \\
\hline CHEMBL1342858 & 688759 & 4.45 & 4.9839 & TRN & \\
\hline CHEMBL1447108 & 688759 & 4.85 & 4.8093 & TST & \\
\hline CHEMBL 3207377 & 688759 & 4.45 & 4.8285 & TST & \\
\hline CHEMBL1376601 & 688759 & 5.6 & 4.6488 & TRN & \\
\hline CHEMBL1354434 & 688759 & 4.45 & 4.6584 & TRN & \\
\hline CHEMBL1538160 & 688759 & 4.45 & 5.29299 & 9999999999 & TRN \\
\hline CHEMBL1390724 & 688759 & 4.6 & 4.927 & TST & \\
\hline CHEMBL1307209 & 688759 & 4.9 & 4.8215 & TRN & \\
\hline CHEMBL1525875 & 688759 & 5.25 & 4.9439 & TRN & \\
\hline CHEMBL1387455 & 688759 & 4.45 & 4.935 & TST & \\
\hline CHEMBL1497387 & 688759 & 4.75 & 5.1354 & TRN & \\
\hline CHEMBL1584684 & 688759 & 5.2 & 5.2448 & TRN & \\
\hline CHEMBL1440051 & 688759 & 5.0 & 4.8393 & TRN & \\
\hline CHEMBL1610272 & 688759 & 4.6 & 4.7694 & TST & \\
\hline CHEMBL3195133 & 688759 & 6.1 & 4.91 & TRN & \\
\hline CHEMBL1613616 & 688759 & 4.65 & 4.5388 & TRN & \\
\hline CHEMBL1351908 & 688759 & 5.7 & 6.0715 & TRN & \\
\hline CHEMBL3195197 & 688759 & 5.05 & 5.1466 & TRN & \\
\hline CHEMBL1992793 & 688759 & 6.25 & 5.50200 & 0000000001 & TRN \\
\hline CHEMBL1460981 & 688759 & 5.4 & 5.2629 & TRN & \\
\hline CHEMBL1379136 & 688759 & 4.9 & 5.2554 & TRN & \\
\hline CHEMBL1308181 & 688759 & 4.85 & 5.0017 & TST & \\
\hline CHEMBL1487635 & 688759 & 6.0 & 5.5521 & TRN & \\
\hline CHEMBL1544833 & 688759 & 4.85 & 5.0457 & TRN & \\
\hline CHEMBL1392403 & 688759 & 5.05 & 4.9114 & TRN & \\
\hline CHEMBL1517794 & 688759 & 4.45 & 4.8504 & TST & \\
\hline CHEMBL1526419 & 688759 & 5.15 & 5.318 & TRN & \\
\hline
\end{tabular}




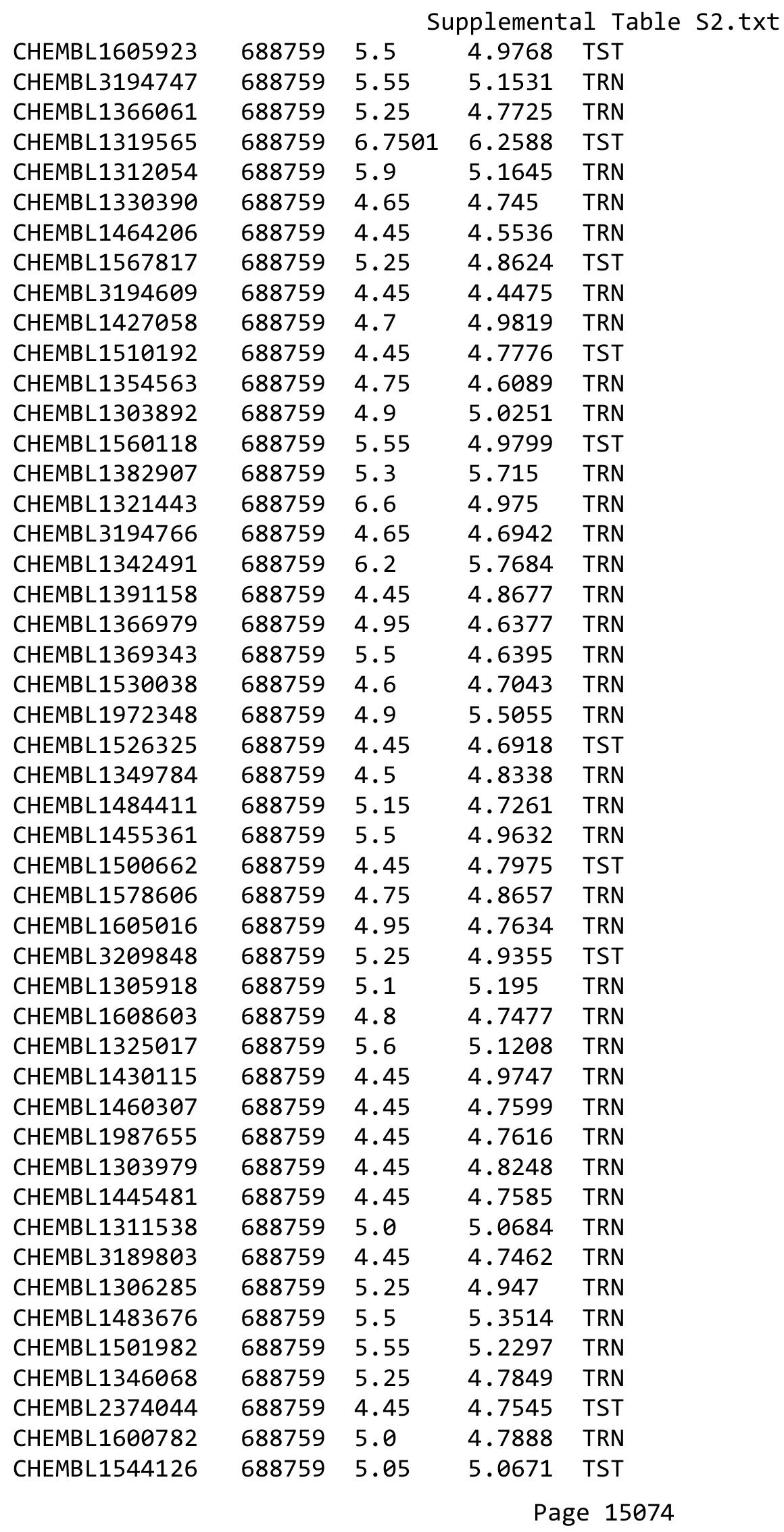




\begin{tabular}{|c|c|c|c|c|c|}
\hline & & \multicolumn{4}{|c|}{ Supplemental Table S2.txt } \\
\hline CHEMBL 3199580 & 688759 & 5.45 & 5.4365 & TRN & \\
\hline CHEMBL1482317 & 688759 & 4.7 & 4.9289 & TRN & \\
\hline CHEMBL1524986 & 688759 & 4.65 & 5.0517 & TRN & \\
\hline CHEMBL1510652 & 688759 & 4.45 & 4.8091 & TST & \\
\hline CHEMBL3194326 & 688759 & 4.85 & 4.809 & TRN & \\
\hline CHEMBL1477101 & 688759 & 5.25 & 4.67399 & 99999999995 & TRN \\
\hline CHEMBL3198275 & 688759 & 5.3 & 4.7817 & TRN & \\
\hline CHEMBL1344372 & 688759 & 5.3 & 5.1316 & TRN & \\
\hline CHEMBL1467235 & 688759 & 4.45 & 4.9727 & TST & \\
\hline CHEMBL1529081 & 688759 & 5.2 & 4.8935 & TST & \\
\hline CHEMBL 3193259 & 688759 & 6.5 & 5.6628 & TRN & \\
\hline CHEMBL1607355 & 688759 & 5.5 & 5.3782 & TRN & \\
\hline CHEMBL1342870 & 688759 & 4.55 & 4.6432 & TRN & \\
\hline CHEMBL1393356 & 688759 & 4.75 & 5.0544 & TRN & \\
\hline CHEMBL1366823 & 688759 & 4.9 & 4.9491 & TRN & \\
\hline CHEMBL1535339 & 688759 & 5.35 & 5.3412 & TRN & \\
\hline CHEMBL1523232 & 688759 & 5.5 & 5.4011 & TRN & \\
\hline CHEMBL1547236 & 688759 & 4.5 & 5.0635 & TST & \\
\hline CHEMBL1367899 & 688759 & 4.45 & 4.266 & TRN & \\
\hline CHEMBL1491609 & 688759 & 4.8 & 4.7878 & TRN & \\
\hline CHEMBL1381837 & 688759 & 5.3 & 5.1136 & TRN & \\
\hline CHEMBL1420432 & 688759 & 5.4 & 4.6311 & TRN & \\
\hline CHEMBL1460376 & 688759 & 4.9 & 4.7822 & TRN & \\
\hline CHEMBL1481094 & 688759 & 4.6 & 4.6764 & TRN & \\
\hline CHEMBL1506512 & 688759 & 5.05 & 4.7413 & TRN & \\
\hline CHEMBL1534053 & 688759 & 4.9 & 4.8809 & TRN & \\
\hline CHEMBL1392767 & 688759 & 4.75 & 4.8361 & TST & \\
\hline CHEMBL3193701 & 688759 & 5.0 & 5.1474 & TRN & \\
\hline CHEMBL1563390 & 688759 & 4.95 & 4.8073 & TRN & \\
\hline CHEMBL3207823 & 688759 & 6.4 & 4.9154 & TRN & \\
\hline CHEMBL1414311 & 688759 & 4.95 & 4.8248 & TST & \\
\hline CHEMBL1359209 & 688759 & 4.6 & 4.7355 & TRN & \\
\hline CHEMBL1435292 & 688759 & 4.45 & 5.0297 & TRN & \\
\hline CHEMBL1884996 & 688759 & 6.6 & 6.1424 & TRN & \\
\hline CHEMBL1483660 & 688759 & 4.45 & 4.5793 & TRN & \\
\hline CHEMBL1520417 & 688759 & 4.45 & 4.8857 & TRN & \\
\hline CHEMBL3195883 & 688759 & 4.75 & 4.9538 & TRN & \\
\hline CHEMBL1379740 & 688759 & 4.45 & 4.9491 & TST & \\
\hline CHEMBL1502942 & 688759 & 4.75 & 4.6591 & TRN & \\
\hline CHEMBL1600073 & 688759 & 4.9 & 4.8743 & TRN & \\
\hline CHEMBL1588805 & 688759 & 4.45 & 4.7169 & TRN & \\
\hline CHEMBL1416344 & 688759 & 4.7 & 4.8936 & TRN & \\
\hline CHEMBL1521937 & 688759 & 4.45 & 4.7231 & TST & \\
\hline CHEMBL1359195 & 688759 & 4.65 & 4.8497 & TRN & \\
\hline CHEMBL1309162 & 688759 & 5.25 & 5.2717 & TRN & \\
\hline CHEMBL192984 & 688759 & 4.9 & 5.0372 & TRN & \\
\hline CHEMBL1404888 & 688759 & 4.6 & 5.039 & TRN & \\
\hline CHEMBL1381059 & 688759 & 4.8 & 4.8572 & TRN & \\
\hline
\end{tabular}




\begin{tabular}{|c|c|c|c|c|c|}
\hline & & \multicolumn{4}{|c|}{ Supplemental Table s2.txt } \\
\hline CHEMBL1545122 & 688759 & 4.65 & 4.878 & TST & \\
\hline CHEMBL1348219 & 688759 & 4.45 & 4.7188 & TST & \\
\hline CHEMBL1975834 & 688759 & 4.8 & 5.153 & TRN & \\
\hline CHEMBL1456643 & 688759 & 4.65 & 4.7536 & TST & \\
\hline CHEMBL1482241 & 688759 & 4.5 & 4.8746 & TRN & \\
\hline CHEMBL1317059 & 688759 & 4.85 & 5.0328 & TST & \\
\hline CHEMBL1455170 & 688759 & 4.65 & 4.8614 & TST & \\
\hline CHEMBL1425453 & 688759 & 4.65 & 5.0387 & TST & \\
\hline CHEMBL1596325 & 688759 & 5.1 & 4.8867 & TRN & \\
\hline CHEMBL1556901 & 688759 & 5.35 & 5.269 & TRN & \\
\hline CHEMBL1338548 & 688759 & 4.45 & 5.03600 & 00000000005 & TST \\
\hline CHEMBL1513114 & 688759 & 4.9 & 4.8725 & TRN & \\
\hline CHEMBL1523537 & 688759 & 4.5 & 4.7768 & TRN & \\
\hline CHEMBL1413333 & 688759 & 4.65 & 4.8134 & TRN & \\
\hline CHEMBL1557342 & 688759 & 4.6 & 4.8325 & TRN & \\
\hline CHEMBL1609827 & 688759 & 5.35 & 5.1854 & TRN & \\
\hline CHEMBL1301743 & 688759 & 4.35 & 4.8471 & TRN & \\
\hline CHEMBL1579020 & 688759 & 4.45 & 4.7931 & TST & \\
\hline CHEMBL1336407 & 688759 & 5.25 & 4.9502 & TST & \\
\hline CHEMBL1600749 & 688759 & 4.6 & 4.9085 & TRN & \\
\hline CHEMBL1534738 & 688759 & 4.9 & 4.9393 & TST & \\
\hline CHEMBL1365469 & 688759 & 4.6 & 5.1307 & TST & \\
\hline CHEMBL1303674 & 688759 & 5.15 & 5.2316 & TST & \\
\hline CHEMBL1608637 & 688759 & 4.45 & 4.7866 & TRN & \\
\hline CHEMBL1426877 & 688759 & 5.25 & 5.0704 & TRN & \\
\hline CHEMBL1463252 & 688759 & 4.5 & 4.8295 & TRN & \\
\hline CHEMBL1334796 & 688759 & 5.1 & 4.5769 & TRN & \\
\hline CHEMBL1323459 & 688759 & 4.65 & 4.3874 & TRN & \\
\hline CHEMBL1405602 & 688759 & 4.8 & 4.9417 & TRN & \\
\hline CHEMBL1458930 & 688759 & 5.45 & 4.9716 & TRN & \\
\hline CHEMBL1986380 & 688759 & 4.45 & 4.6671 & TRN & \\
\hline CHEMBL1420766 & 688759 & 4.85 & 5.0116 & TST & \\
\hline CHEMBL1444290 & 688759 & 4.7 & 4.7044 & TST & \\
\hline CHEMBL1524529 & 688759 & 4.7 & 4.6556 & TRN & \\
\hline CHEMBL1522108 & 688759 & 6.0 & 4.9691 & TRN & \\
\hline CHEMBL1464631 & 688759 & 5.25 & 4.908 & TRN & \\
\hline CHEMBL1455912 & 688759 & 5.25 & 4.8289 & TST & \\
\hline CHEMBL1461574 & 688759 & 4.95 & 4.773 & TST & \\
\hline CHEMBL1332358 & 688759 & 5.0 & 4.5419 & TRN & \\
\hline CHEMBL1313043 & 688759 & 4.95 & 5.0393 & TRN & \\
\hline CHEMBL1424864 & 688759 & 4.55 & 4.9187 & TRN & \\
\hline CHEMBL1320209 & 688759 & 4.75 & 4.8657 & TST & \\
\hline CHEMBL1482840 & 688759 & 4.45 & 4.6632 & TRN & \\
\hline CHEMBL1465899 & 688759 & 4.45 & 5.0767 & TRN & \\
\hline CHEMBL1467753 & 688759 & 4.9 & 4.9105 & TST & \\
\hline CHEMBL1349726 & 688759 & 4.5 & 5.0105 & TRN & \\
\hline CHEMBL1497776 & 688759 & 5.0 & 4.8032 & TRN & \\
\hline CHEMBL1522504 & 688759 & 5.25 & 4.7324 & TRN & \\
\hline
\end{tabular}




\begin{tabular}{|c|c|c|c|c|c|}
\hline & & \multicolumn{4}{|c|}{ Supplemental Table S2.txt } \\
\hline CHEMBL1407846 & 688759 & 4.45 & 4.9544 & TST & \\
\hline CHEMBL1407483 & 688759 & 4.45 & 4.7858 & TST & \\
\hline CHEMBL1457349 & 688759 & 4.65 & 4.6828 & TRN & \\
\hline CHEMBL1530216 & 688759 & 4.75 & 4.8444 & TRN & \\
\hline CHEMBL1603704 & 688759 & 5.8 & 5.2609 & TRN & \\
\hline CHEMBL1509461 & 688759 & 4.45 & 4.7601 & TRN & \\
\hline CHEMBL 1453880 & 688759 & 4.55 & 4.8676 & TRN & \\
\hline CHEMBL1596675 & 688759 & 4.8 & 5.0014 & TST & \\
\hline CHEMBL 2007297 & 688759 & 5.6 & 5.4166 & TRN & \\
\hline CHEMBL1477794 & 688759 & 4.7 & 4.90300 & 00000000005 & TRN \\
\hline CHEMBL1459376 & 688759 & 4.6 & 4.5323 & TRN & \\
\hline CHEMBL1346284 & 688759 & 4.65 & 4.6761 & TRN & \\
\hline CHEMBL1469505 & 688759 & 4.45 & 4.53100 & 0000000001 & TRN \\
\hline CHEMBL1569018 & 688759 & 4.45 & 5.27 & TST & \\
\hline CHEMBL1605565 & 688759 & 5.45 & 5.0038 & TRN & \\
\hline CHEMBL1386122 & 688759 & 5.25 & 4.7779 & TST & \\
\hline CHEMBL1388614 & 688759 & 4.9 & 4.9173 & TRN & \\
\hline CHEMBL1458758 & 688759 & 5.25 & 4.8757 & TST & \\
\hline CHEMBL1413724 & 688759 & 4.5 & 4.9878 & TST & \\
\hline CHEMBL1502902 & 688759 & 4.45 & 4.8933 & TRN & \\
\hline CHEMBL3198912 & 688759 & 4.7 & 4.9076 & TRN & \\
\hline CHEMBL1987472 & 688759 & 4.95 & 5.1789 & TST & \\
\hline CHEMBL1481559 & 688759 & 4.45 & 4.7808 & TST & \\
\hline CHEMBL1427003 & 688759 & 4.85 & 4.8947 & TST & \\
\hline CHEMBL1383321 & 688759 & 5.3 & 4.8839 & TRN & \\
\hline CHEMBL191015 & 688759 & 4.45 & 5.0714 & TRN & \\
\hline CHEMBL1578036 & 688759 & 4.45 & 4.7073 & TRN & \\
\hline CHEMBL1389306 & 688759 & 4.55 & 4.7306 & TRN & \\
\hline CHEMBL1340878 & 688759 & 4.5 & 4.7943 & TST & \\
\hline CHEMBL1460935 & 688759 & 5.1 & 4.9203 & TRN & \\
\hline CHEMBL1400260 & 688759 & 4.45 & 4.5949 & TRN & \\
\hline CHEMBL3192563 & 688759 & 4.75 & 4.9388 & TST & \\
\hline CHEMBL1342090 & 688759 & 5.5 & 4.8925 & TST & \\
\hline CHEMBL1969707 & 688759 & 4.45 & 4.9102 & TRN & \\
\hline CHEMBL3207963 & 688759 & 4.65 & 4.7225 & TRN & \\
\hline CHEMBL1424926 & 688759 & 4.6 & 4.6435 & TST & \\
\hline CHEMBL1368219 & 688759 & 5.0 & 4.9807 & TRN & \\
\hline CHEMBL1442384 & 688759 & 4.45 & 4.8636 & TRN & \\
\hline CHEMBL1300414 & 688759 & 5.65 & 4.7915 & TRN & \\
\hline CHEMBL1548542 & 688759 & 4.85 & 4.4135 & TRN & \\
\hline CHEMBL1571977 & 688759 & 4.95 & 5.1412 & TRN & \\
\hline CHEMBL1342803 & 688759 & 5.25 & 4.8712 & TRN & \\
\hline CHEMBL1306320 & 688759 & 4.45 & 4.9902 & TRN & \\
\hline CHEMBL1460956 & 688759 & 5.4 & 5.0329 & TRN & \\
\hline CHEMBL1570020 & 688759 & 4.9 & 5.0651 & TRN & \\
\hline CHEMBL1388380 & 688759 & 4.8 & 4.592 & TST & \\
\hline CHEMBL1442155 & 688759 & 4.95 & 5.2706 & TST & \\
\hline CHEMBL1568695 & 688759 & 4.65 & 4.6608 & TRN & \\
\hline
\end{tabular}




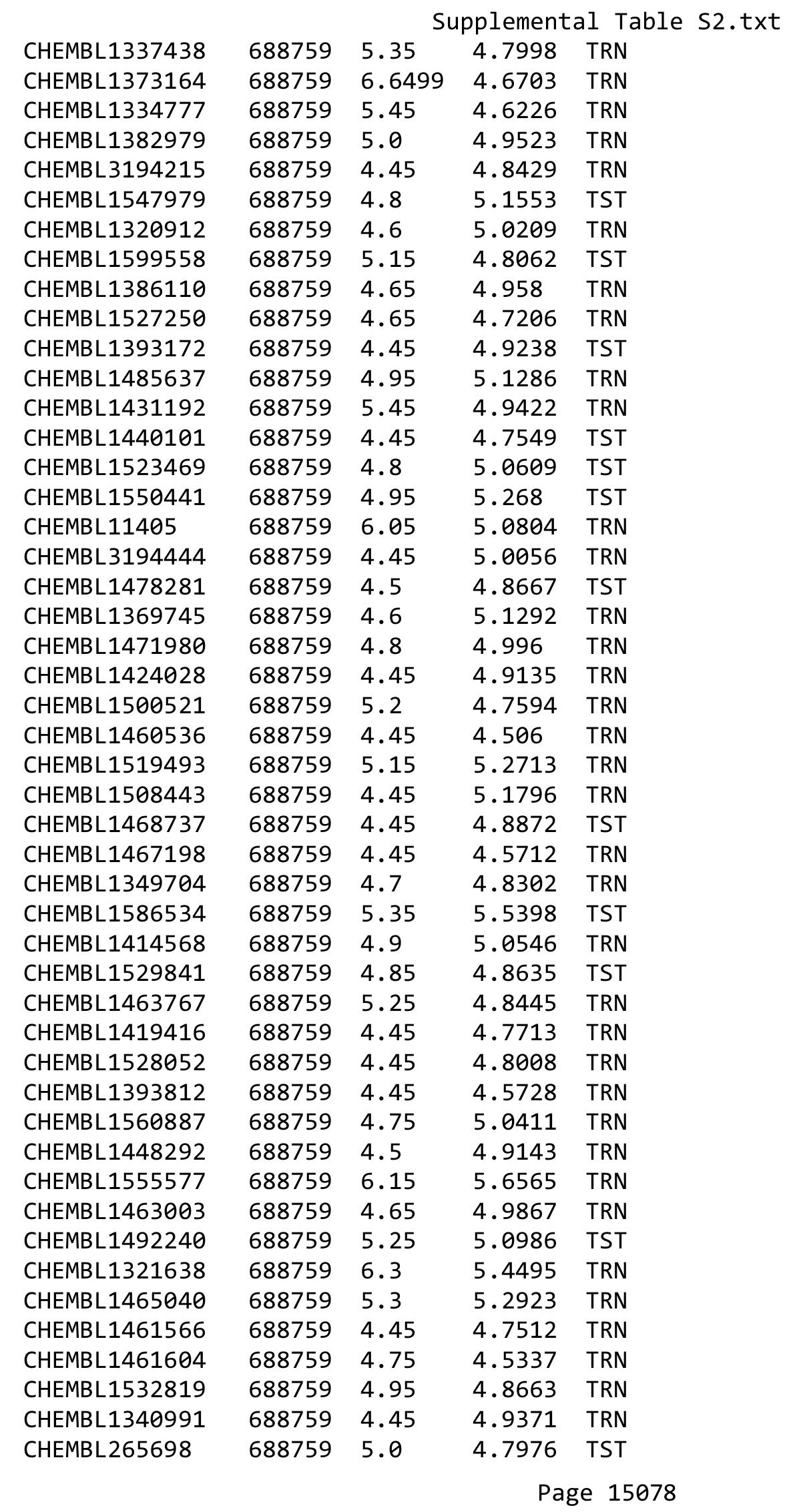




\begin{tabular}{|c|c|c|c|c|}
\hline \multicolumn{5}{|c|}{ Supplemental Table S2.txt } \\
\hline CHEMBL1341023 & 688759 & 4.6 & 4.5495 & TST \\
\hline CHEMBL1609102 & 688759 & 4.45 & 4.9548 & TRN \\
\hline CHEMBL3193531 & 688759 & 4.45 & 4.6835 & TRN \\
\hline CHEMBL1503034 & 688759 & 5.25 & 5.1912 & TRN \\
\hline CHEMBL1593722 & 688759 & 4.65 & 5.0075 & TRN \\
\hline CHEMBL1467966 & 688759 & 5.45 & 4.9744 & TRN \\
\hline CHEMBL3190460 & 688759 & 4.45 & 4.7983 & TRN \\
\hline CHEMBL1327715 & 688759 & 4.9 & 5.1723 & TRN \\
\hline CHEMBL 3198466 & 688759 & 4.7 & 4.9431 & TRN \\
\hline CHEMBL1463659 & 688759 & 6.25 & 5.6614 & TRN \\
\hline CHEMBL3194506 & 688759 & 4.45 & 4.8596 & TRN \\
\hline CHEMBL1345947 & 688759 & 4.45 & 4.5947 & TST \\
\hline CHEMBL1376674 & 688759 & 5.85 & 5.8096 & TRN \\
\hline CHEMBL1324553 & 688759 & 4.7 & 4.6076 & TST \\
\hline CHEMBL530636 & 688759 & 5.1 & 5.105 & TRN \\
\hline CHEMBL1306176 & 688759 & 4.65 & 4.8711 & TRN \\
\hline CHEMBL1326788 & 688759 & 4.45 & 4.9014 & TST \\
\hline CHEMBL1390396 & 688759 & 4.55 & 4.7902 & TST \\
\hline CHEMBL1516918 & 688759 & 4.45 & 5.2106 & TRN \\
\hline CHEMBL585827 & 688759 & 5.6 & 5.5692 & TRN \\
\hline CHEMBL1421414 & 688759 & 4.65 & 4.8167 & TST \\
\hline CHEMBL1464703 & 688759 & 6.15 & 5.0186 & TST \\
\hline CHEMBL1462403 & 688759 & 4.45 & 4.8951 & TRN \\
\hline CHEMBL1449747 & 688759 & 5.25 & 5.2559 & TRN \\
\hline CHEMBL3196927 & 688759 & 4.9 & 4.6883 & TRN \\
\hline CHEMBL1467727 & 688759 & 4.6 & 4.9405 & TRN \\
\hline CHEMBL 2004428 & 688759 & 5.95 & 5.6014 & TRN \\
\hline CHEMBL1506321 & 688759 & 4.7 & 4.6744 & TST \\
\hline CHEMBL1308005 & 688759 & 4.8 & 4.6531 & TST \\
\hline CHEMBL1342613 & 688759 & 4.6 & 4.7421 & TRN \\
\hline CHEMBL3195574 & 688759 & 4.7 & 4.6948 & TST \\
\hline CHEMBL1337160 & 688759 & 5.25 & 4.8458 & TRN \\
\hline CHEMBL1343689 & 688759 & 5.3 & 5.5807 & TRN \\
\hline CHEMBL1361754 & 688759 & 4.45 & 4.6755 & TRN \\
\hline CHEMBL1302154 & 688759 & 5.15 & 4.9266 & TRN \\
\hline CHEMBL1496891 & 688759 & 5.15 & 5.7323 & TRN \\
\hline CHEMBL1432389 & 688759 & 4.45 & 5.0054 & TST \\
\hline CHEMBL1299635 & 688759 & 4.45 & 5.0744 & TRN \\
\hline CHEMBL3199917 & 688759 & 5.0 & 5.4096 & TRN \\
\hline CHEMBL1399595 & 688759 & 4.6 & 4.8136 & TRN \\
\hline CHEMBL1387355 & 688759 & 4.45 & 4.8764 & TRN \\
\hline CHEMBL1387889 & 688759 & 4.75 & 4.8747 & TRN \\
\hline CHEMBL1589316 & 688759 & 4.5 & 4.4187 & TST \\
\hline CHEMBL1403438 & 688759 & 5.3 & 5.1151 & TRN \\
\hline CHEMBL1607286 & 688759 & 4.8 & 4.7088 & TST \\
\hline CHEMBL1518216 & 688759 & 6.4 & 5.045 & TRN \\
\hline CHEMBL1537905 & 688759 & 4.45 & 5.8128 & TST \\
\hline CHEMBL1378793 & 688759 & 6.45 & 4.9962 & TRN \\
\hline
\end{tabular}




\begin{tabular}{|c|c|c|c|c|c|}
\hline \multicolumn{6}{|c|}{ Supplemental Table S2.txt } \\
\hline CHEMBL1492539 & 688759 & 4.45 & 4.7829 & TRN & \\
\hline CHEMBL1342711 & 688759 & 5.15 & 5.4534 & TRN & \\
\hline CHEMBL1520647 & 688759 & 4.9 & 4.8533 & TRN & \\
\hline CHEMBL3195221 & 688759 & 4.45 & 4.8887 & TRN & \\
\hline CHEMBL 3210696 & 688759 & 4.45 & 4.8106 & TRN & \\
\hline CHEMBL1492742 & 688759 & 4.5 & 4.9208 & TST & \\
\hline CHEMBL1325723 & 688759 & 4.45 & 4.744 & TRN & \\
\hline CHEMBL1343490 & 688759 & 5.1 & 5.0171 & TRN & \\
\hline CHEMBL1413838 & 688759 & 5.35 & 5.0242 & TST & \\
\hline CHEMBL1416886 & 688759 & 5.05 & 4.9345 & TRN & \\
\hline CHEMBL1415756 & 688759 & 4.45 & 5.1932 & TRN & \\
\hline CHEMBL1571722 & 688759 & 4.45 & 4.8353 & TRN & \\
\hline CHEMBL3198008 & 688759 & 5.3 & 5.2815 & TRN & \\
\hline CHEMBL1421445 & 688759 & 4.75 & 5.0203 & TRN & \\
\hline CHEMBL1456926 & 688759 & 4.9 & 5.0238 & TRN & \\
\hline CHEMBL1566383 & 688759 & 4.45 & 4.8331 & TRN & \\
\hline CHEMBL1413485 & 688759 & 5.35 & 5.0651 & TRN & \\
\hline CHEMBL1318851 & 688759 & 4.45 & 5.00899 & 99999999995 & TST \\
\hline CHEMBL1322885 & 688759 & 4.75 & 4.9804 & TST & \\
\hline CHEMBL1458104 & 688759 & 4.5 & 4.6513 & TRN & \\
\hline CHEMBL1994445 & 688759 & 5.9 & 5.0273 & TRN & \\
\hline CHEMBL1504758 & 688759 & 4.9 & 4.8598 & TRN & \\
\hline CHEMBL1376349 & 688759 & 6.95 & 4.6726 & TST & \\
\hline CHEMBL1570278 & 688759 & 4.6 & 4.8123 & TRN & \\
\hline CHEMBL1415473 & 688759 & 5.3 & 4.9652 & TST & \\
\hline CHEMBL1428652 & 688759 & 4.45 & 4.792 & TRN & \\
\hline CHEMBL3191969 & 688759 & 6.0 & 5.2302 & TRN & \\
\hline CHEMBL1570765 & 688759 & 4.45 & 5.2006 & TST & \\
\hline CHEMBL3191626 & 688759 & 4.9 & 4.625 & TRN & \\
\hline CHEMBL1391622 & 688759 & 4.5 & 5.1303 & TRN & \\
\hline CHEMBL1348078 & 688759 & 4.45 & 4.6733 & TRN & \\
\hline CHEMBL1454988 & 688759 & 5.2 & 4.8807 & TRN & \\
\hline CHEMBL1478896 & 688759 & 4.7 & 4.9417 & TRN & \\
\hline CHEMBL1345175 & 688759 & 4.9 & 4.9268 & TST & \\
\hline CHEMBL1389312 & 688759 & 4.5 & 4.6074 & TRN & \\
\hline CHEMBL1396345 & 688759 & 4.95 & 4.6305 & TRN & \\
\hline CHEMBL1373064 & 688759 & 5.45 & 4.9475 & TRN & \\
\hline CHEMBL1588827 & 688759 & 4.7 & 4.9372 & TRN & \\
\hline CHEMBL1429318 & 688759 & 4.45 & 5.5224 & TST & \\
\hline CHEMBL1308346 & 688759 & 4.45 & 4.6363 & TRN & \\
\hline CHEMBL1461224 & 688759 & 5.1 & 4.7167 & TRN & \\
\hline CHEMBL1526223 & 688759 & 5.25 & 4.9611 & TST & \\
\hline CHEMBL1410852 & 688759 & 4.45 & 4.7139 & TRN & \\
\hline CHEMBL1584486 & 688759 & 5.25 & 5.4941 & TRN & \\
\hline CHEMBL1593375 & 688759 & 5.45 & 4.9473 & TRN & \\
\hline CHEMBL1522529 & 688759 & 4.45 & 4.85 & TST & \\
\hline CHEMBL1440501 & 688759 & 5.25 & 4.9884 & TRN & \\
\hline CHEMBL1477154 & 688759 & 4.95 & 4.7752 & TRN & \\
\hline
\end{tabular}




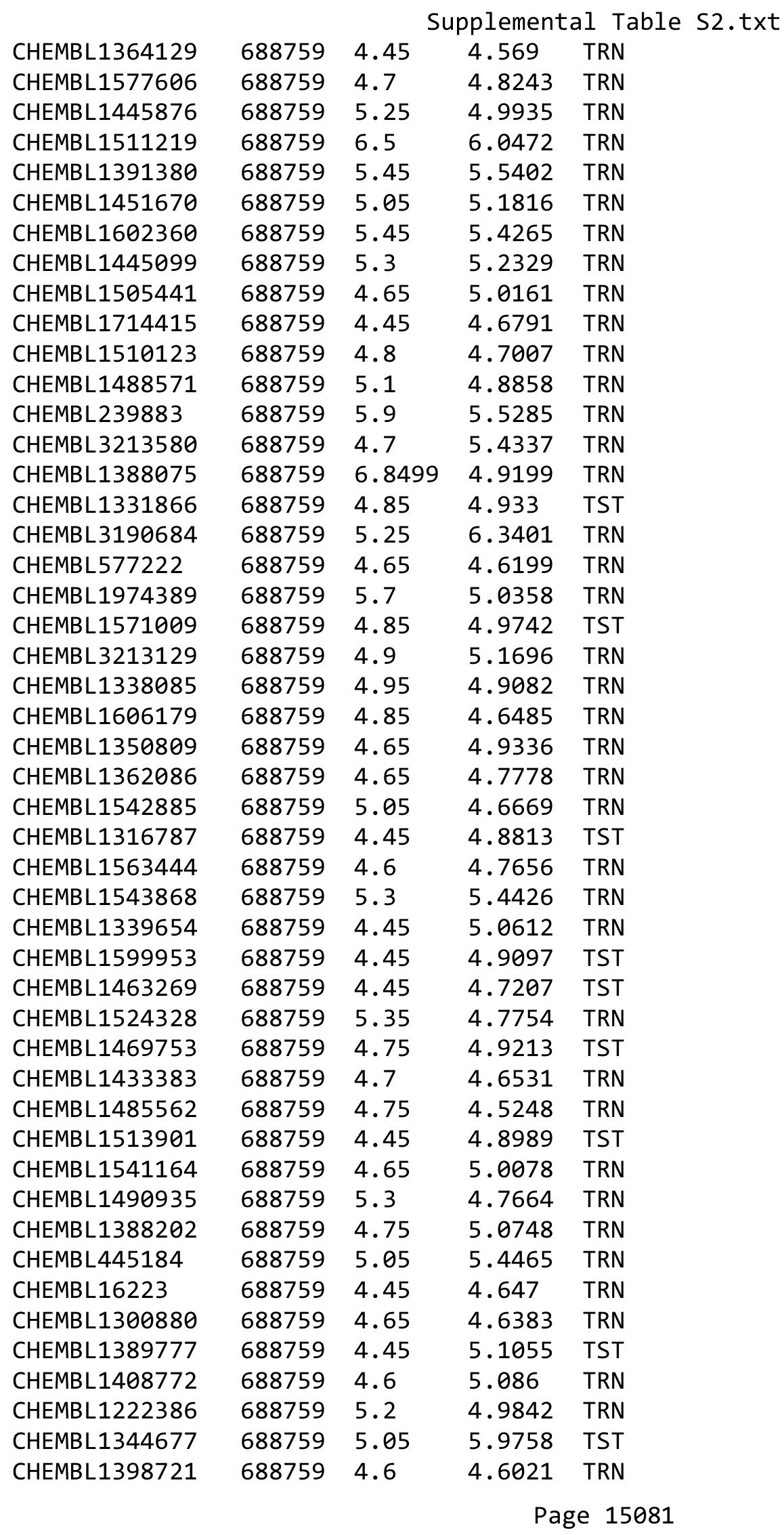




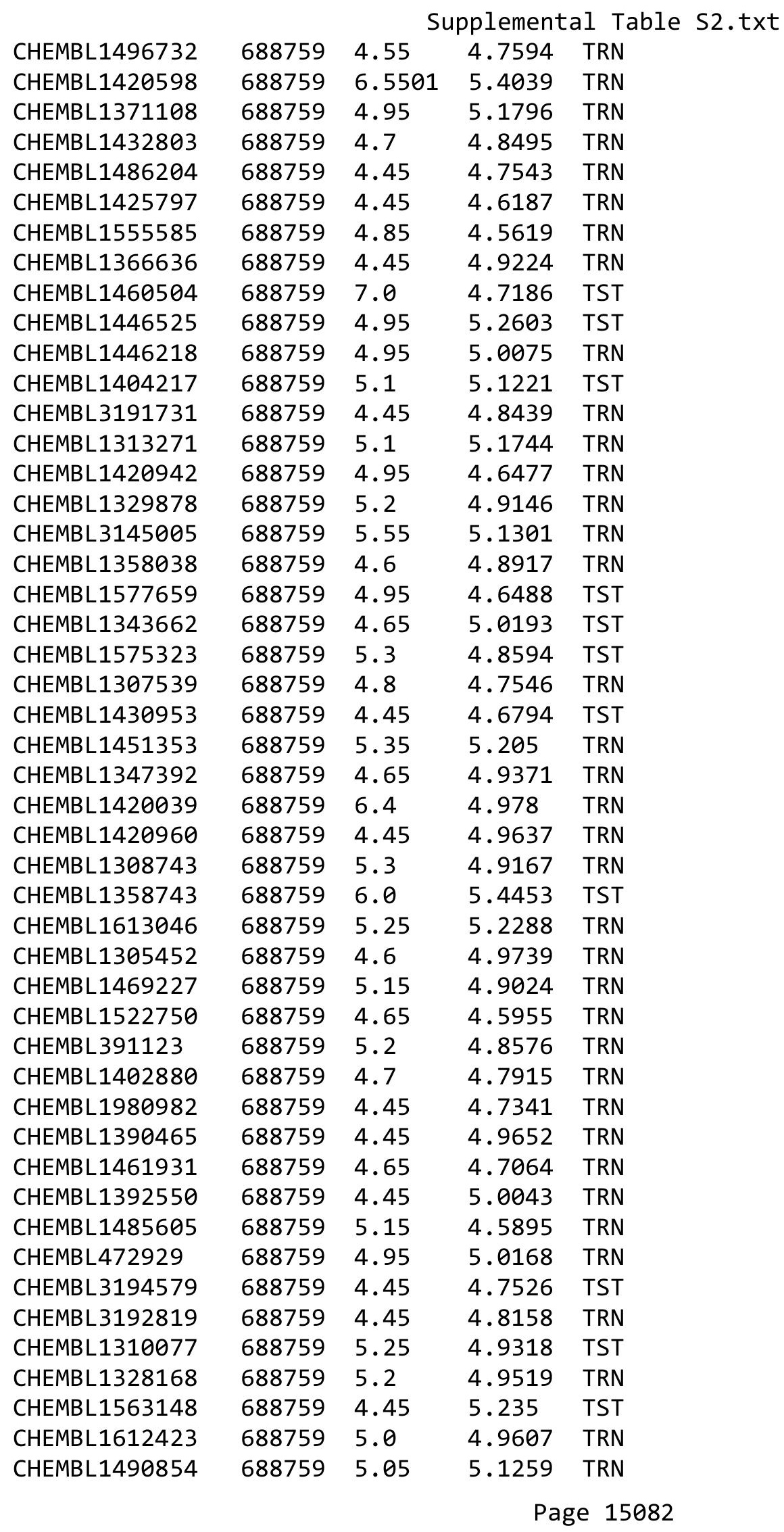




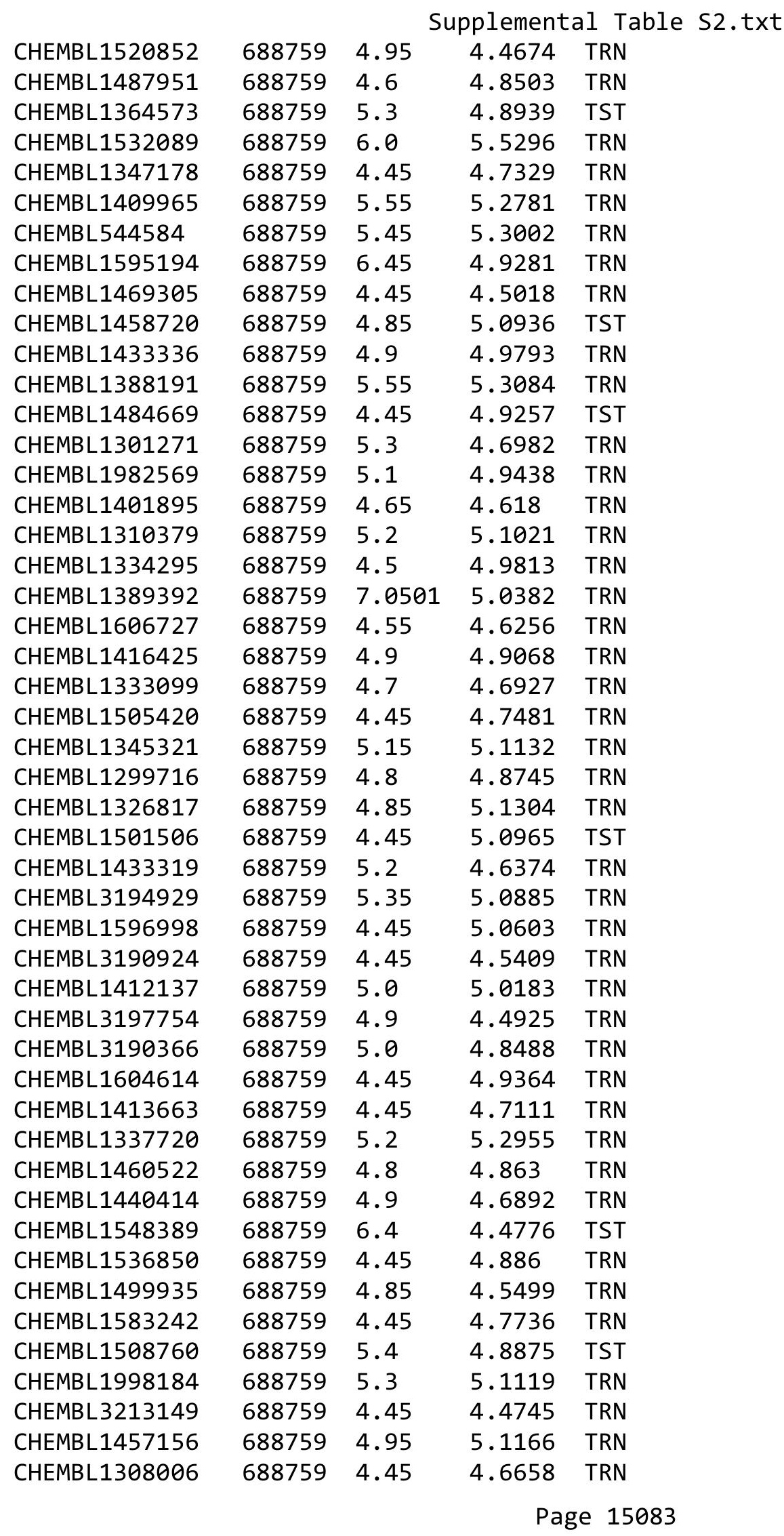




\begin{tabular}{|c|c|c|c|c|c|}
\hline \multicolumn{6}{|c|}{ oplemental Table S2 } \\
\hline CHEMBL1384068 & 688759 & 4.9 & 4.7239 & TRN & \\
\hline CHEMBL1496868 & 688759 & 6.0 & 5.2498 & TRN & \\
\hline CHEMBL1301368 & 688759 & 5.3 & 4.8345 & TRN & \\
\hline CHEMBL1346860 & 688759 & 4.45 & 4.8192 & TST & \\
\hline CHEMBL1395485 & 688759 & 4.45 & 4.6669 & TRN & \\
\hline CHEMBL1411862 & 688759 & 5.25 & 4.9587 & TRN & \\
\hline CHEMBL1439709 & 688759 & 4.45 & 4.9258 & TRN & \\
\hline CHEMBL1503667 & 688759 & 4.95 & 5.2692 & TST & \\
\hline CHEMBL1590627 & 688759 & 4.7 & 4.7926 & TRN & \\
\hline CHEMBL1562452 & 688759 & 5.0 & 4.7523 & TRN & \\
\hline CHEMBL1343823 & 688759 & 5.5 & 5.3219 & TST & \\
\hline CHEMBL1464042 & 688759 & 4.85 & 4.8848 & TRN & \\
\hline CHEMBL3198107 & 688759 & 4.6 & 4.9142 & TRN & \\
\hline CHEMBL1988918 & 688759 & 4.7 & 4.4508 & TRN & \\
\hline CHEMBL1533489 & 688759 & 5.6 & 5.5226 & TRN & \\
\hline CHEMBL1386050 & 688759 & 4.45 & 5.0446 & TRN & \\
\hline CHEMBL1544093 & 688759 & 5.3 & 4.9647 & TRN & \\
\hline CHEMBL1335330 & 688759 & 4.45 & 4.5382 & TST & \\
\hline CHEMBL1310617 & 688759 & 5.4 & 5.3442 & TST & \\
\hline CHEMBL1323722 & 688759 & 4.9 & 4.791 & TRN & \\
\hline CHEMBL1412330 & 688759 & 4.95 & 5.0967 & TRN & \\
\hline CHEMBL1300359 & 688759 & 4.6 & 5.2118 & TRN & \\
\hline CHEMBL1390650 & 688759 & 4.9 & 5.1591 & TRN & \\
\hline CHEMBL1545280 & 688759 & 4.45 & 4.65606 & 0000000001 & TST \\
\hline CHEMBL1521935 & 688759 & 5.65 & 5.49206 & 0000000001 & TRN \\
\hline CHEMBL1303719 & 688759 & 5.0 & 4.6362 & TST & \\
\hline CHEMBL1523878 & 688759 & 4.65 & 4.8317 & TST & \\
\hline CHEMBL252403 & 688759 & 5.4 & 5.2613 & TRN & \\
\hline CHEMBL1577430 & 688759 & 5.5 & 4.9286 & TRN & \\
\hline CHEMBL3193504 & 688759 & 4.45 & 4.876 & TRN & \\
\hline CHEMBL1390716 & 688759 & 6.1 & 5.775 & TRN & \\
\hline CHEMBL1303801 & 688759 & 4.45 & 4.7842 & TRN & \\
\hline CHEMBL1325313 & 688759 & 4.45 & 4.8951 & TRN & \\
\hline CHEMBL1483867 & 688759 & 5.25 & 4.8865 & TST & \\
\hline CHEMBL1342049 & 688759 & 4.8 & 4.6393 & TRN & \\
\hline CHEMBL 259805 & 688759 & 5.25 & 5.2524 & TRN & \\
\hline CHEMBL1403292 & 688759 & 5.0 & 4.8558 & TRN & \\
\hline CHEMBL1581369 & 688759 & 6.05 & 5.0889 & 99999999995 & TST \\
\hline CHEMBL1574173 & 688759 & 4.45 & 4.7362 & TST & \\
\hline CHEMBL1363154 & 688759 & 4.45 & 5.1727 & TST & \\
\hline CHEMBL1584860 & 688759 & 5.0 & 4.9407 & TRN & \\
\hline CHEMBL1311681 & 688759 & 5.25 & 4.9238 & TRN & \\
\hline CHEMBL1540286 & 688759 & 4.7 & 4.848 & TRN & \\
\hline CHEMBL3194235 & 688759 & 6.0 & 5.4202 & TRN & \\
\hline CHEMBL3191906 & 688759 & 5.2 & 5.3363 & TRN & \\
\hline CHEMBL1595516 & 688759 & 4.45 & 4.7775 & TRN & \\
\hline CHEMBL1460032 & 688759 & 4.45 & 4.7898 & TST & \\
\hline CHEMBL1584391 & 688759 & 4.65 & 4.6853 & TRN & \\
\hline
\end{tabular}




\begin{tabular}{|c|c|c|c|c|}
\hline \multicolumn{5}{|c|}{ Supplemental Table } \\
\hline CHEMBL1521312 & 688759 & 5.15 & 4.9729 & TRN \\
\hline CHEMBL1346662 & 688759 & 4.75 & 4.8533 & TRN \\
\hline CHEMBL3191689 & 688759 & 4.45 & 4.5793 & TRN \\
\hline CHEMBL1308676 & 688759 & 4.45 & 4.7146 & TRN \\
\hline CHEMBL1531971 & 688759 & 4.45 & 4.8923 & TRN \\
\hline CHEMBL1569543 & 688759 & 5.6 & 5.5125 & TRN \\
\hline CHEMBL1362818 & 688759 & 4.75 & 4.7491 & TRN \\
\hline CHEMBL1454369 & 688759 & 4.85 & 5.5363 & TRN \\
\hline CHEMBL 3212743 & 688759 & 4.45 & 4.6678 & TRN \\
\hline CHEMBL1604664 & 688759 & 4.6 & 4.7698 & TRN \\
\hline CHEMBL1334601 & 688759 & 4.8 & 4.4689 & TRN \\
\hline CHEMBL1332551 & 688759 & 4.45 & 4.9055 & TST \\
\hline CHEMBL1471197 & 688759 & 5.1 & 4.8191 & TRN \\
\hline CHEMBL1426358 & 688759 & 5.1 & 5.1689 & TST \\
\hline CHEMBL1349365 & 688759 & 4.95 & 4.6752 & TRN \\
\hline CHEMBL1327969 & 688759 & 4.95 & 4.7641 & TRN \\
\hline CHEMBL1508896 & 688759 & 5.3 & 5.0338 & TRN \\
\hline CHEMBL3197662 & 688759 & 4.45 & 4.6828 & TRN \\
\hline CHEMBL1532073 & 688759 & 4.6 & 4.5299 & TRN \\
\hline CHEMBL1309592 & 688759 & 5.55 & 5.2125 & TRN \\
\hline CHEMBL1486848 & 688759 & 4.65 & 4.7627 & TRN \\
\hline CHEMBL1361260 & 688759 & 4.65 & 4.7868 & TRN \\
\hline CHEMBL1426586 & 688759 & 4.85 & 4.8035 & TRN \\
\hline CHEMBL1440038 & 688759 & 4.45 & 4.5764 & TRN \\
\hline CHEMBL1576520 & 688759 & 4.7 & 4.8574 & TRN \\
\hline CHEMBL1458926 & 688759 & 4.45 & 4.7055 & TST \\
\hline CHEMBL1378551 & 688759 & 5.95 & 4.9249 & TRN \\
\hline CHEMBL1508508 & 688759 & 4.95 & 4.9707 & TRN \\
\hline CHEMBL1565737 & 688759 & 4.45 & 4.672 & TRN \\
\hline CHEMBL1597250 & 688759 & 5.2 & 4.9875 & TRN \\
\hline CHEMBL1414227 & 688759 & 4.95 & 4.9358 & TRN \\
\hline CHEMBL1344838 & 688759 & 4.6 & 4.5202 & TST \\
\hline CHEMBL1519220 & 688759 & 4.65 & 4.8524 & TRN \\
\hline CHEMBL1097074 & 688759 & 4.45 & 4.8203 & TRN \\
\hline CHEMBL1583337 & 688759 & 4.45 & 4.7949 & TST \\
\hline CHEMBL1351223 & 688759 & 4.45 & 4.881 & TST \\
\hline CHEMBL 1460523 & 688759 & 4.45 & 4.8431 & TST \\
\hline CHEMBL1541038 & 688759 & 4.95 & 4.7292 & TRN \\
\hline CHEMBL1992631 & 688759 & 4.45 & 4.9903 & TRN \\
\hline CHEMBL1472027 & 688759 & 5.0 & 4.9321 & TST \\
\hline CHEMBL1506815 & 688759 & 5.65 & 5.0999 & TRN \\
\hline CHEMBL86931 & 688759 & 4.6 & 4.6127 & TST \\
\hline CHEMBL1420649 & 688759 & 5.2 & 5.0572 & TRN \\
\hline CHEMBL1326587 & 688759 & 4.95 & 4.7047 & TRN \\
\hline CHEMBL1419309 & 688759 & 5.2 & 5.3191 & TRN \\
\hline CHEMBL1524607 & 688759 & 4.45 & 4.8207 & TRN \\
\hline CHEMBL1383381 & 688759 & 4.95 & 4.9958 & TRN \\
\hline CHEMBL1420251 & 688759 & 5.1 & 5.2093 & TRN \\
\hline
\end{tabular}




\begin{tabular}{|c|c|c|c|c|c|}
\hline \\
\hline CHEMBL1510888 & 688759 & 4.6 & 4.8771 & TRN & \\
\hline CHEMBL1570869 & 688759 & 4.95 & 4.822 & TST & \\
\hline CHEMBL1330058 & 688759 & 5.2 & 5.4893 & TRN & \\
\hline CHEMBL1426370 & 688759 & 4.45 & 4.6258 & TRN & \\
\hline CHEMBL1529203 & 688759 & 4.8 & 5.2256 & TRN & \\
\hline CHEMBL3212938 & 688759 & 4.45 & 4.6899 & TRN & \\
\hline CHEMBL1307776 & 688759 & 4.85 & 4.8703 & TRN & \\
\hline CHEMBL1341017 & 688759 & 4.9 & 4.9074 & TRN & \\
\hline CHEMBL1405230 & 688759 & 4.85 & 5.0536 & TST & \\
\hline CHEMBL1377316 & 688759 & 5.45 & 5.3306 & TRN & \\
\hline CHEMBL1391552 & 688759 & 4.45 & 4.9659 & TRN & \\
\hline CHEMBL1605071 & 688759 & 5.7 & 5.13399 & 99999999995 & TRN \\
\hline CHEMBL1601781 & 688759 & 4.7 & 4.707 & TRN & \\
\hline CHEMBL3191687 & 688759 & 5.55 & 5.4398 & TRN & \\
\hline CHEMBL1321849 & 688759 & 4.9 & 5.0312 & TST & \\
\hline CHEMBL1384725 & 688759 & 4.45 & 4.7588 & TST & \\
\hline CHEMBL1376386 & 688759 & 4.45 & 4.8248 & TST & \\
\hline CHEMBL3197433 & 688759 & 5.6 & 5.5589 & TRN & \\
\hline CHEMBL3195432 & 688759 & 6.1 & 5.0637 & TST & \\
\hline CHEMBL1539609 & 688759 & 5.15 & 4.9385 & TRN & \\
\hline CHEMBL1494130 & 688759 & 4.9 & 4.833 & TRN & \\
\hline CHEMBL1580758 & 688759 & 5.0 & 4.8181 & TST & \\
\hline CHEMBL1318033 & 688759 & 4.9 & 4.4261 & TRN & \\
\hline CHEMBL3196069 & 688759 & 4.45 & 4.668 & TRN & \\
\hline CHEMBL1397653 & 688759 & 5.0 & 4.8649 & TRN & \\
\hline CHEMBL1510681 & 688759 & 4.65 & 4.88 & TRN & \\
\hline CHEMBL1405922 & 688759 & 4.45 & 4.7556 & TST & \\
\hline CHEMBL1427564 & 688759 & 4.6 & 4.9053 & TRN & \\
\hline CHEMBL1419519 & 688759 & 4.95 & 4.7965 & TST & \\
\hline CHEMBL1451778 & 688759 & 4.45 & 5.0398 & TRN & \\
\hline CHEMBL1990866 & 688759 & 4.45 & 4.8186 & TST & \\
\hline CHEMBL1457209 & 688759 & 4.45 & 5.0983 & TRN & \\
\hline CHEMBL 2369290 & 688759 & 5.0 & 4.645 & TRN & \\
\hline CHEMBL1383863 & 688759 & 4.45 & 4.9673 & TRN & \\
\hline CHEMBL1445262 & 688759 & 4.45 & 4.9655 & TRN & \\
\hline CHEMBL1311795 & 688759 & 5.2 & 4.8527 & TST & \\
\hline CHEMBL1492214 & 688759 & 4.45 & 4.6988 & TST & \\
\hline CHEMBL1376239 & 688759 & 5.2 & 5.1447 & TRN & \\
\hline CHEMBL1342270 & 688759 & 5.4 & 5.1482 & TRN & \\
\hline CHEMBL1539670 & 688759 & 5.05 & 4.9705 & TRN & \\
\hline CHEMBL1523597 & 688759 & 4.45 & 4.793 & TRN & \\
\hline CHEMBL1515929 & 688759 & 4.75 & 4.8305 & TRN & \\
\hline CHEMBL1502607 & 688759 & 4.95 & 4.8578 & TRN & \\
\hline CHEMBL1457791 & 688759 & 4.45 & 4.9106 & TRN & \\
\hline CHEMBL1337938 & 688759 & 5.0 & 4.6969 & TST & \\
\hline CHEMBL1383818 & 688759 & 4.75 & 5.1169 & TRN & \\
\hline CHEMBL1388225 & 688759 & 4.7 & 4.8403 & TRN & \\
\hline CHEMBL1549835 & 688759 & 4.75 & 4.9441 & TRN & \\
\hline
\end{tabular}




\begin{tabular}{|c|c|c|c|c|c|}
\hline \multicolumn{6}{|c|}{ Supplemental Table S2.txt } \\
\hline CHEMBL1483975 & 688759 & 5.6 & 5.6381 & TRN & \\
\hline CHEMBL197014 & 688759 & 4.45 & 4.5974 & TRN & \\
\hline CHEMBL1585109 & 688759 & 4.45 & 4.7824 & TRN & \\
\hline CHEMBL 3213752 & 688759 & 4.5 & 4.5937 & TRN & \\
\hline CHEMBL3209719 & 688759 & 4.65 & 5.5084 & TRN & \\
\hline CHEMBL1456654 & 688759 & 5.35 & 5.5141 & TRN & \\
\hline CHEMBL3196770 & 688759 & 5.4 & 5.2853 & TRN & \\
\hline CHEMBL1603330 & 688759 & 5.45 & 5.5221 & TRN & \\
\hline CHEMBL1489297 & 688759 & 4.6 & 4.9044 & TRN & \\
\hline CHEMBL1389370 & 688759 & 4.9 & 4.5376 & TRN & \\
\hline CHEMBL1452089 & 688759 & 5.25 & 5.0987 & TRN & \\
\hline CHEMBL1382747 & 688759 & 4.45 & 4.441 & TRN & \\
\hline CHEMBL1490539 & 688759 & 4.45 & 4.7973 & TRN & \\
\hline CHEMBL1529878 & 688759 & 4.65 & 4.8067 & TRN & \\
\hline CHEMBL 3208388 & 688759 & 5.05 & 5.1647 & TRN & \\
\hline CHEMBL1321096 & 688759 & 4.45 & 4.6325 & TRN & \\
\hline CHEMBL1709028 & 688759 & 5.45 & 5.53299 & 99999999995 & TRN \\
\hline CHEMBL1477547 & 688759 & 4.45 & 4.7937 & TST & \\
\hline CHEMBL1338076 & 688759 & 4.45 & 4.5651 & TRN & \\
\hline CHEMBL1568643 & 688759 & 5.25 & 4.9707 & TST & \\
\hline CHEMBL1527629 & 688759 & 4.45 & 4.792 & TRN & \\
\hline CHEMBL1323203 & 688759 & 8.5528 & 4.8175 & TRN & \\
\hline CHEMBL1362346 & 688759 & 4.45 & 4.9128 & TRN & \\
\hline CHEMBL1400667 & 688759 & 4.95 & 4.879 & TST & \\
\hline CHEMBL1400606 & 688759 & 4.45 & 4.5783 & TST & \\
\hline CHEMBL 2000011 & 688759 & 5.25 & 4.7796 & TRN & \\
\hline CHEMBL1517741 & 688759 & 4.75 & 5.1742 & TRN & \\
\hline CHEMBL1965811 & 688759 & 5.2 & 5.4695 & TRN & \\
\hline CHEMBL1323433 & 688759 & 4.7 & 4.9439 & TRN & \\
\hline CHEMBL1352881 & 688759 & 4.45 & 4.6863 & TST & \\
\hline CHEMBL1513711 & 688759 & 4.65 & 4.8252 & TRN & \\
\hline CHEMBL1511291 & 688759 & 5.15 & 5.2838 & TRN & \\
\hline CHEMBL 2007091 & 688759 & 4.45 & 4.8083 & TRN & \\
\hline CHEMBL3199418 & 688759 & 7.0 & 4.9929 & TRN & \\
\hline CHEMBL1325258 & 688759 & 4.45 & 4.8236 & TRN & \\
\hline CHEMBL1585390 & 688759 & 5.45 & 5.4222 & TRN & \\
\hline CHEMBL1413254 & 688759 & 5.3 & 5.2538 & TRN & \\
\hline CHEMBL1500091 & 688759 & 4.65 & 4.6928 & TRN & \\
\hline CHEMBL3197711 & 688759 & 6.1 & 4.8293 & TST & \\
\hline CHEMBL1519443 & 688759 & 4.9 & 4.6194 & TST & \\
\hline CHEMBL1436984 & 688759 & 4.85 & 4.6627 & TRN & \\
\hline CHEMBL1320454 & 688759 & 4.9 & 4.5222 & TRN & \\
\hline CHEMBL1600415 & 688759 & 5.25 & 5.2287 & TRN & \\
\hline CHEMBL1531595 & 688759 & 4.95 & 4.8493 & TRN & \\
\hline CHEMBL1303501 & 688759 & 6.5501 & 5.5085 & TRN & \\
\hline CHEMBL1320268 & 688759 & 4.45 & 4.8903 & TST & \\
\hline CHEMBL1535618 & 688759 & 6.5 & 5.0209 & TRN & \\
\hline CHEMBL1555743 & 688759 & 5.7 & 5.6185 & TRN & \\
\hline
\end{tabular}




\begin{tabular}{|c|c|c|c|c|c|}
\hline & & \multicolumn{4}{|c|}{ Supplemental Table S2.txt } \\
\hline CHEMBL1565563 & 688759 & 4.55 & 4.8165 & TRN & \\
\hline CHEMBL1334164 & 688759 & 4.65 & 4.5729 & TST & \\
\hline CHEMBL 3190540 & 688759 & 4.45 & 5.0112 & TRN & \\
\hline CHEMBL1452634 & 688759 & 5.5 & 5.1677 & TRN & \\
\hline CHEMBL3210117 & 688759 & 4.45 & 4.8562 & TRN & \\
\hline CHEMBL1501445 & 688759 & 4.55 & 4.7946 & TRN & \\
\hline CHEMBL1613410 & 688759 & 4.65 & 4.7183 & TRN & \\
\hline CHEMBL1417165 & 688759 & 5.4 & 5.2396 & TRN & \\
\hline CHEMBL1423858 & 688759 & 4.65 & 4.9 & TRN & \\
\hline CHEMBL1365627 & 688759 & 4.45 & 4.6128 & TST & \\
\hline CHEMBL1351542 & 688759 & 6.05 & 5.8851 & TRN & \\
\hline CHEMBL1320438 & 688759 & 4.85 & 4.6392 & TRN & \\
\hline CHEMBL1359384 & 688759 & 4.45 & 4.6886 & TRN & \\
\hline CHEMBL1557027 & 688759 & 4.45 & 4.8033 & TST & \\
\hline CHEMBL1524777 & 688759 & 4.55 & 4.7711 & TST & \\
\hline CHEMBL1359472 & 688759 & 5.25 & 4.9396 & TST & \\
\hline CHEMBL1386367 & 688759 & 4.45 & 4.56800 & 00000000005 & TRN \\
\hline CHEMBL1306480 & 688759 & 5.0 & 5.3387 & TRN & \\
\hline CHEMBL1304952 & 688759 & 4.6 & 4.7747 & TRN & \\
\hline CHEMBL1506025 & 688759 & 4.45 & 4.8822 & TRN & \\
\hline CHEMBL1529142 & 688759 & 4.7 & 4.6512 & TST & \\
\hline CHEMBL565657 & 688759 & 5.4 & 5.8138 & TRN & \\
\hline CHEMBL1493385 & 688759 & 4.45 & 5.4379 & TRN & \\
\hline CHEMBL1466183 & 688759 & 4.8 & 4.8613 & TRN & \\
\hline CHEMBL1582011 & 688759 & 4.45 & 4.51699 & э9999999995 & TRN \\
\hline CHEMBL1458376 & 688759 & 4.8 & 4.7741 & TRN & \\
\hline CHEMBL1378186 & 688759 & 5.3 & 5.0636 & TRN & \\
\hline CHEMBL1500735 & 688759 & 4.9 & 4.5936 & TRN & \\
\hline CHEMBL1356838 & 688759 & 4.9 & 4.9293 & TRN & \\
\hline CHEMBL1609233 & 688759 & 4.8 & 4.9374 & TRN & \\
\hline CHEMBL1445548 & 688759 & 4.9 & 5.0223 & TRN & \\
\hline CHEMBL1465749 & 688759 & 4.45 & 4.606 & TST & \\
\hline CHEMBL1557622 & 688759 & 4.55 & 5.1797 & TRN & \\
\hline CHEMBL124706 & 688759 & 4.45 & 4.7389 & TST & \\
\hline CHEMBL1445784 & 688759 & 4.45 & 4.66 & TRN & \\
\hline CHEMBL1445490 & 688759 & 4.65 & 4.8315 & TRN & \\
\hline CHEMBL1304454 & 688759 & 4.45 & 4.6204 & TRN & \\
\hline CHEMBL1375773 & 688759 & 4.6 & 5.24100 & 00000000005 & TRN \\
\hline CHEMBL1482193 & 688759 & 4.5 & 4.7301 & TRN & \\
\hline CHEMBL1490867 & 688759 & 4.6 & 4.7448 & TRN & \\
\hline CHEMBL1520481 & 688759 & 5.15 & 5.0424 & TRN & \\
\hline CHEMBL1380126 & 688759 & 4.45 & 4.7016 & TST & \\
\hline CHEMBL1446036 & 688759 & 4.45 & 4.6019 & TRN & \\
\hline CHEMBL1441604 & 688759 & 5.55 & 5.0404 & TRN & \\
\hline CHEMBL3214255 & 688759 & 4.8 & 4.9159 & TST & \\
\hline CHEMBL1363089 & 688759 & 5.2 & 5.0258 & TRN & \\
\hline CHEMBL1400896 & 688759 & 5.25 & 4.9673 & TRN & \\
\hline CHEMBL1489456 & 688759 & 4.8 & 4.7372 & TRN & \\
\hline
\end{tabular}




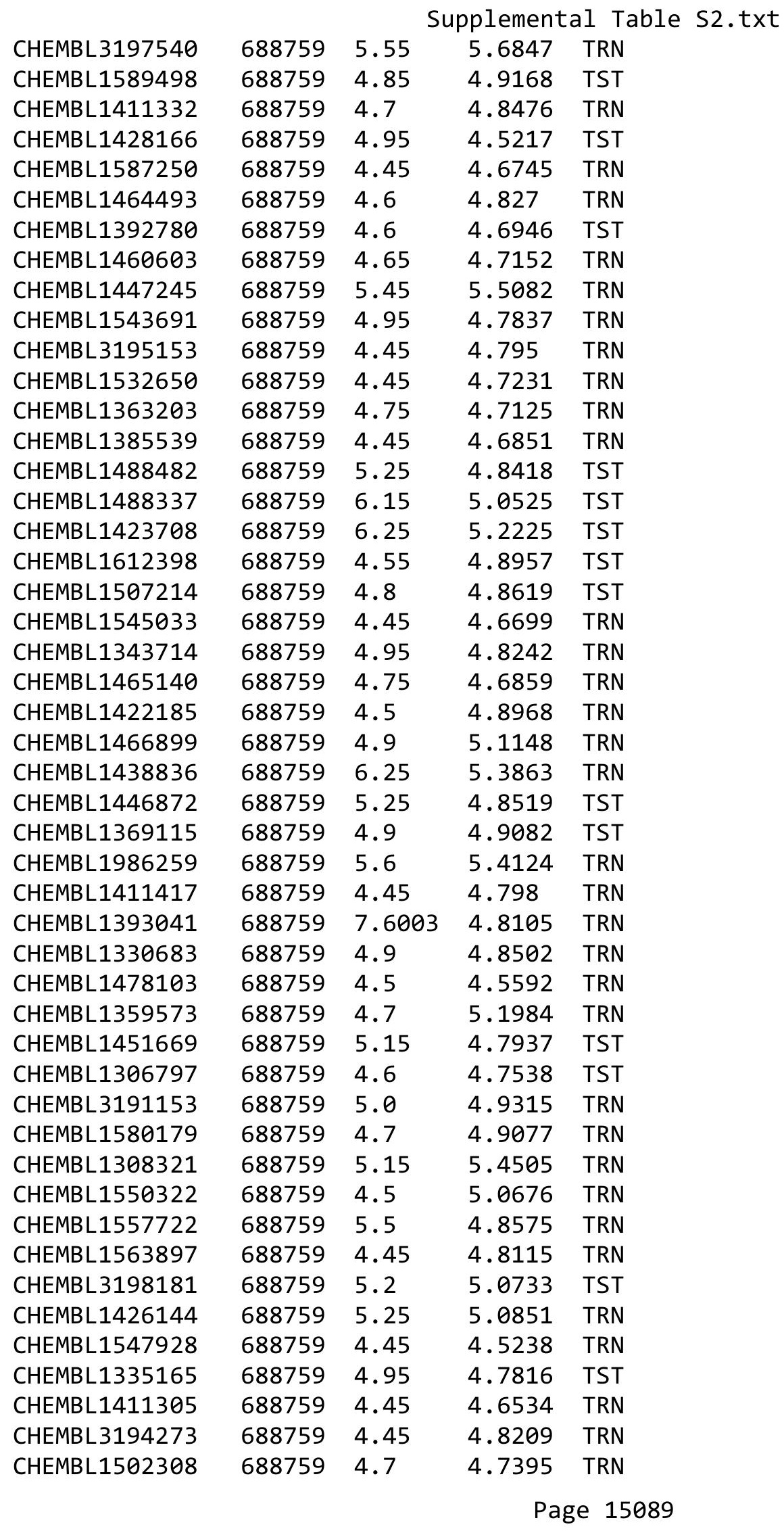




\begin{tabular}{|c|c|c|c|c|}
\hline & & & pplement & al Table S2 \\
\hline CHEMBL1528781 & 688759 & 4.45 & 4.8891 & TRN \\
\hline CHEMBL1549210 & 688759 & 5.0 & 4.9399 & TRN \\
\hline CHEMBL1568451 & 688759 & 4.75 & 4.9037 & TRN \\
\hline CHEMBL1569753 & 688759 & 5.05 & 5.2452 & TRN \\
\hline CHEMBL1326864 & 688759 & 4.45 & 4.8335 & TRN \\
\hline CHEMBL1414458 & 688759 & 4.75 & 4.7359 & TRN \\
\hline CHEMBL1479172 & 688759 & 5.2 & 5.2103 & TRN \\
\hline CHEMBL1556007 & 688759 & 5.4 & 4.9077 & TRN \\
\hline CHEMBL1333647 & 688759 & 6.1 & 5.0134 & TST \\
\hline CHEMBL1345090 & 688759 & 4.5 & 4.765 & TST \\
\hline CHEMBL1312486 & 688759 & 5.25 & 4.9281 & TRN \\
\hline CHEMBL 3212625 & 688759 & 4.75 & 4.9021 & TRN \\
\hline CHEMBL1472433 & 688759 & 4.65 & 4.6724 & TRN \\
\hline CHEMBL1574955 & 688759 & 4.75 & 4.9566 & TRN \\
\hline CHEMBL3214238 & 688759 & 4.7 & 4.5962 & TRN \\
\hline CHEMBL1380633 & 688759 & 4.45 & 4.5784 & TST \\
\hline CHEMBL1334210 & 688759 & 5.0 & 4.9079 & TST \\
\hline CHEMBL1417363 & 688759 & 4.5 & 4.7457 & TRN \\
\hline CHEMBL3196606 & 688759 & 4.9 & 4.9716 & TRN \\
\hline CHEMBL1440942 & 688759 & 5.0 & 5.3333 & TRN \\
\hline CHEMBL1582996 & 688759 & 4.95 & 4.8199 & TST \\
\hline CHEMBL578716 & 688759 & 4.7 & 5.3654 & TST \\
\hline CHEMBL1486039 & 688759 & 6.05 & 4.8597 & TST \\
\hline CHEMBL1463939 & 688759 & 4.9 & 4.7431 & TRN \\
\hline CHEMBL1531351 & 688759 & 4.45 & 5.1031 & TRN \\
\hline CHEMBL1338764 & 688759 & 4.45 & 4.5149 & TRN \\
\hline CHEMBL1569117 & 688759 & 4.9 & 4.9577 & TST \\
\hline CHEMBL1612311 & 688759 & 4.6 & 4.7989 & TRN \\
\hline CHEMBL1511796 & 688759 & 4.95 & 5.1977 & TRN \\
\hline CHEMBL1565285 & 688759 & 5.3 & 4.7635 & TRN \\
\hline CHEMBL1423271 & 688759 & 4.45 & 4.8151 & TRN \\
\hline CHEMBL1373918 & 688759 & 4.45 & 4.9535 & TST \\
\hline CHEMBL1595553 & 688759 & 4.45 & 4.7216 & TST \\
\hline CHEMBL3190729 & 688759 & 4.45 & 4.7133 & TRN \\
\hline CHEMBL1974937 & 688759 & 4.7 & 4.8965 & TRN \\
\hline CHEMBL3190594 & 688759 & 6.25 & 6.2341 & TRN \\
\hline CHEMBL583849 & 688759 & 7.0 & 5.4943 & TST \\
\hline CHEMBL1308230 & 688759 & 4.95 & 5.269 & TRN \\
\hline CHEMBL1352406 & 688759 & 4.45 & 4.8132 & TRN \\
\hline CHEMBL1540024 & 688759 & 4.95 & 4.9475 & TRN \\
\hline CHEMBL1304319 & 688759 & 5.25 & $5.3420 e$ & 00000000005 \\
\hline CHEMBL1581644 & 688759 & 4.55 & 4.7097 & TST \\
\hline CHEMBL1351847 & 688759 & 5.3 & 4.6999 & TST \\
\hline CHEMBL1415612 & 688759 & 4.75 & 4.9359 & TRN \\
\hline CHEMBL1347230 & 688759 & 4.8 & 4.7609 & TRN \\
\hline CHEMBL1559452 & 688759 & 4.45 & 4.802 & TRN \\
\hline CHEMBL1484000 & 688759 & 5.9 & 4.9447 & TST \\
\hline CHEMBL1584502 & 688759 & 5.15 & 4.7798 & TST \\
\hline
\end{tabular}




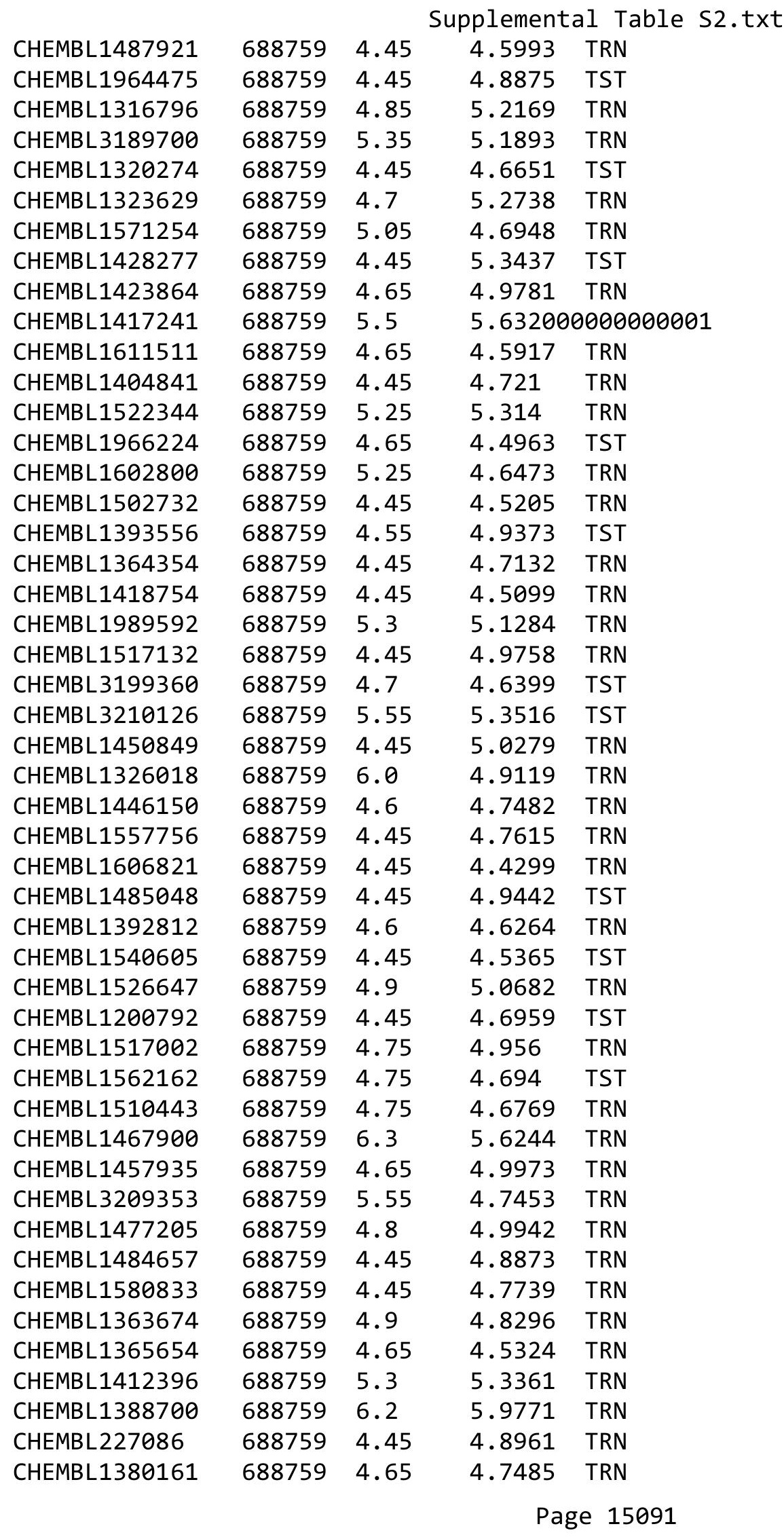




\begin{tabular}{|c|c|c|c|c|}
\hline \multirow[b]{2}{*}{ CHEMBL1573804 } & \multicolumn{4}{|c|}{ Supplemental Table S2.txt } \\
\hline & 688759 & 5.2 & 4.8059 & TRN \\
\hline CHEMBL1545715 & 688759 & 5.55 & 5.2885 & TRN \\
\hline CHEMBL1481947 & 688759 & 4.75 & 4.7994 & TST \\
\hline CHEMBL1333399 & 688759 & 5.25 & 4.7794 & TRN \\
\hline CHEMBL1392913 & 688759 & 4.6 & 4.6303 & TRN \\
\hline CHEMBL1345989 & 688759 & 4.45 & 4.7481 & TST \\
\hline CHEMBL1528996 & 688759 & 4.45 & 4.9402 & TRN \\
\hline CHEMBL 75267 & 688759 & 4.45 & 4.8679 & TST \\
\hline CHEMBL1391919 & 688759 & 4.45 & 4.9636 & TRN \\
\hline CHEMBL1585373 & 688759 & 4.95 & 4.5088 & TRN \\
\hline CHEMBL1323954 & 688759 & 4.45 & 4.7797 & TRN \\
\hline CHEMBL1566671 & 688759 & 4.65 & 4.8032 & TRN \\
\hline CHEMBL1607821 & 688759 & 5.55 & 4.8144 & TRN \\
\hline CHEMBL1602614 & 688759 & 5.1 & 4.9733 & TRN \\
\hline CHEMBL1432154 & 688759 & 5.35 & 4.7563 & TRN \\
\hline CHEMBL591404 & 688759 & 4.7 & 4.4806 & TRN \\
\hline CHEMBL1404883 & 688759 & 4.7 & 4.7935 & TRN \\
\hline CHEMBL1431083 & 688759 & 5.6 & 5.0663 & TST \\
\hline CHEMBL1420406 & 688759 & 6.2 & 4.6626 & TST \\
\hline CHEMBL1512260 & 688759 & 4.9 & 4.6214 & TRN \\
\hline CHEMBL1422969 & 688759 & 5.05 & 4.7957 & TRN \\
\hline CHEMBL1438832 & 688759 & 5.45 & 5.021 & TST \\
\hline CHEMBL1309140 & 688759 & 4.65 & 5.0139 & TRN \\
\hline CHEMBL1412731 & 688759 & 4.6 & 4.7878 & TRN \\
\hline CHEMBL1401291 & 688759 & 4.6 & 4.7519 & TRN \\
\hline CHEMBL1410843 & 688759 & 5.05 & 5.0228 & TRN \\
\hline CHEMBL1485602 & 688759 & 4.95 & 4.5589 & TST \\
\hline CHEMBL1480572 & 688759 & 4.75 & 4.739 & TRN \\
\hline CHEMBL1473672 & 688759 & 5.25 & 5.0104 & TRN \\
\hline CHEMBL1381340 & 688759 & 4.45 & 4.8293 & TRN \\
\hline CHEMBL1319467 & 688759 & 6.4 & 5.0625 & TST \\
\hline CHEMBL1510459 & 688759 & 4.45 & 4.5561 & TRN \\
\hline CHEMBL1383406 & 688759 & 4.45 & 4.7466 & TRN \\
\hline CHEMBL1323212 & 688759 & 5.7 & 4.8206 & TRN \\
\hline CHEMBL1466538 & 688759 & 4.7 & 4.5926 & TST \\
\hline CHEMBL1486041 & 688759 & 4.45 & 4.6153 & TRN \\
\hline CHEMBL1578927 & 688759 & 4.95 & 5.2263 & TRN \\
\hline CHEMBL1502286 & 688759 & 4.6 & 4.9184 & TST \\
\hline CHEMBL1576405 & 688759 & 5.7 & 5.5068 & TRN \\
\hline CHEMBL1488126 & 688759 & 4.45 & 4.5012 & TRN \\
\hline CHEMBL1470141 & 688759 & 4.75 & 4.8799 & TRN \\
\hline CHEMBL1399183 & 688759 & 4.9 & 4.666 & TRN \\
\hline CHEMBL1439384 & 688759 & 4.45 & 4.77 & TRN \\
\hline CHEMBL1419526 & 688759 & 4.85 & 4.525 & TRN \\
\hline CHEMBL1364289 & 688759 & 4.9 & 4.9572 & TRN \\
\hline CHEMBL1403488 & 688759 & 5.05 & 4.6888 & TRN \\
\hline CHEMBL1345376 & 688759 & 4.5 & 5.1423 & TRN \\
\hline CHEMBL2369206 & 688759 & 5.25 & 4.8916 & TST \\
\hline
\end{tabular}




\begin{tabular}{|c|c|c|c|c|c|}
\hline \multicolumn{6}{|c|}{ Supplemental Table S2.txt } \\
\hline CHEMBL 3199630 & 688759 & 5.55 & 4.8919 & TST & \\
\hline CHEMBL1392258 & 688759 & 4.9 & 4.8079 & TRN & \\
\hline CHEMBL3209373 & 688759 & 4.95 & 4.7701 & TRN & \\
\hline CHEMBL1429539 & 688759 & 4.65 & 4.7784 & TRN & \\
\hline CHEMBL1561889 & 688759 & 4.65 & 4.6678 & TST & \\
\hline CHEMBL1432578 & 688759 & 4.45 & 4.5839 & TST & \\
\hline CHEMBL1502010 & 688759 & 4.45 & 4.6812 & TST & \\
\hline CHEMBL3193702 & 688759 & 5.45 & 5.2002 & TRN & \\
\hline CHEMBL1508325 & 688759 & 5.2 & 5.0838 & TRN & \\
\hline CHEMBL3193863 & 688759 & 4.5 & 4.9814 & TRN & \\
\hline CHEMBL1612858 & 688759 & 4.5 & 4.8602 & TST & \\
\hline CHEMBL1392560 & 688759 & 4.75 & 4.8695 & TRN & \\
\hline CHEMBL1308511 & 688759 & 4.65 & 4.8533 & TST & \\
\hline CHEMBL1408235 & 688759 & 5.0 & 4.9546 & TRN & \\
\hline CHEMBL1494034 & 688759 & 4.45 & 4.8843 & TRN & \\
\hline CHEMBL1402510 & 688759 & 8.3468 & 5.5582 & TRN & \\
\hline CHEMBL1585742 & 688759 & 4.65 & 5.2835 & TRN & \\
\hline CHEMBL1603691 & 688759 & 4.75 & 4.9383 & TST & \\
\hline CHEMBL1453625 & 688759 & 5.15 & 5.1757 & TRN & \\
\hline CHEMBL1338018 & 688759 & 4.45 & 4.6801 & TRN & \\
\hline CHEMBL1416576 & 688759 & 4.75 & 4.848 & TRN & \\
\hline CHEMBL3195603 & 688759 & 4.45 & 4.8891 & TRN & \\
\hline CHEMBL3199286 & 688759 & 5.3 & 5.12700 & 0000000001 & TRN \\
\hline CHEMBL1458363 & 688759 & 4.45 & 4.6248 & TRN & \\
\hline CHEMBL1570667 & 688759 & 4.45 & 4.854 & TRN & \\
\hline CHEMBL1442771 & 688759 & 4.95 & 4.8839 & TRN & \\
\hline CHEMBL1486585 & 688759 & 6.1 & 5.3621 & TRN & \\
\hline CHEMBL1311362 & 688759 & 4.95 & 4.7683 & TST & \\
\hline CHEMBL1541901 & 688759 & 4.8 & 5.3139 & TRN & \\
\hline CHEMBL1517677 & 688759 & 4.55 & 4.83899 & 99999999995 & TRN \\
\hline CHEMBL1478213 & 688759 & 4.6 & 4.7746 & TRN & \\
\hline CHEMBL1423270 & 688759 & 4.7 & 4.8538 & TRN & \\
\hline CHEMBL3189551 & 688759 & 5.45 & 4.8278 & TRN & \\
\hline CHEMBL 3191037 & 688759 & 4.45 & 4.9309 & TRN & \\
\hline CHEMBL3191598 & 688759 & 4.95 & 5.0551 & TRN & \\
\hline CHEMBL1534146 & 688759 & 5.45 & 4.81 & TST & \\
\hline CHEMBL1470744 & 688759 & 4.65 & 4.5502 & TRN & \\
\hline CHEMBL3199932 & 688759 & 4.45 & 4.9208 & TRN & \\
\hline CHEMBL1393533 & 688759 & 4.95 & 5.4536 & TRN & \\
\hline CHEMBL1421605 & 688759 & 4.45 & 4.7719 & TRN & \\
\hline CHEMBL1469772 & 688759 & 5.55 & 5.5236 & TRN & \\
\hline CHEMBL1343481 & 688759 & 4.45 & 5.0105 & TRN & \\
\hline CHEMBL1564590 & 688759 & 4.9 & 4.7162 & TRN & \\
\hline CHEMBL3189698 & 688759 & 5.15 & 5.0713 & TRN & \\
\hline CHEMBL1426852 & 688759 & 4.75 & 4.9614 & TRN & \\
\hline CHEMBL3213958 & 688759 & 4.45 & 4.6107 & TRN & \\
\hline CHEMBL1469975 & 688759 & 4.45 & 4.704 & TRN & \\
\hline CHEMBL1337919 & 688759 & 4.75 & 4.7689 & TRN & \\
\hline
\end{tabular}




\begin{tabular}{|c|c|c|c|c|}
\hline & & & ıpplement & al $\mathrm{T}$ \\
\hline CHEMBL1362370 & 688759 & 5.1 & 5.1039 & TRN \\
\hline CHEMBL1497019 & 688759 & 5.7 & 5.4306 & TRN \\
\hline CHEMBL1324805 & 688759 & 5.3 & 5.1802 & TRN \\
\hline CHEMBL1430053 & 688759 & 4.45 & 4.9608 & TST \\
\hline CHEMBL1418494 & 688759 & 4.45 & 4.5195 & TST \\
\hline CHEMBL1313614 & 688759 & 4.45 & 4.8823 & TRN \\
\hline CHEMBL1215474 & 688759 & 4.45 & 4.8733 & TRN \\
\hline CHEMBL1341553 & 688759 & 5.1 & 5.6397 & TRN \\
\hline CHEMBL1408659 & 688759 & 4.45 & 4.9824 & TST \\
\hline CHEMBL1560825 & 688759 & 4.5 & 4.8259 & TRN \\
\hline CHEMBL1365959 & 688759 & 4.75 & 4.5313 & TST \\
\hline CHEMBL1461960 & 688759 & 5.55 & 5.5952 & TRN \\
\hline CHEMBL1401844 & 688759 & 4.65 & 4.9315 & TRN \\
\hline CHEMBL1492585 & 688759 & 5.95 & 5.3994 & TRN \\
\hline CHEMBL 256042 & 688759 & 6.0 & 5.7019 & TRN \\
\hline CHEMBL1577595 & 688759 & 5.45 & 5.6448 & TRN \\
\hline CHEMBL1553635 & 688759 & 3.0 & 6.4472 & TST \\
\hline CHEMBL1318959 & 688759 & 5.0 & 5.2568 & TRN \\
\hline CHEMBL 3213220 & 688759 & 5.2 & 5.2206 & TRN \\
\hline CHEMBL1342842 & 688759 & 4.65 & 4.7119 & TRN \\
\hline CHEMBL1409034 & 688759 & 4.5 & 4.851 & TRN \\
\hline CHEMBL1344709 & 688759 & 4.6 & 4.4631 & TST \\
\hline CHEMBL 3197191 & 688759 & 4.45 & 4.7657 & TST \\
\hline CHEMBL1451622 & 688759 & 4.5 & 4.8158 & TRN \\
\hline CHEMBL3196681 & 688759 & 4.8 & 5.0923 & TST \\
\hline CHEMBL1581227 & 688759 & 4.7 & 5.4597 & TRN \\
\hline CHEMBL600336 & 688759 & 4.65 & 5.0456 & TRN \\
\hline CHEMBL1587863 & 688759 & 5.5 & 5.3026 & TRN \\
\hline CHEMBL1572908 & 688759 & 6.35 & 4.7764 & TRN \\
\hline CHEMBL3208342 & 688759 & 4.45 & 4.6992 & TRN \\
\hline CHEMBL1414798 & 688759 & 4.65 & 5.015 & TRN \\
\hline CHEMBL1454301 & 688759 & 5.55 & 4.8433 & TST \\
\hline CHEMBL1486248 & 688759 & 4.45 & 4.6707 & TST \\
\hline CHEMBL1432352 & 688759 & 4.45 & 5.048 & TRN \\
\hline CHEMBL1482495 & 688759 & 4.75 & 4.8989 & TRN \\
\hline CHEMBL1406279 & 688759 & 4.45 & 5.0672 & TRN \\
\hline CHEMBL1996024 & 688759 & 4.45 & 4.7901 & TRN \\
\hline CHEMBL1331561 & 688759 & 4.45 & 4.7194 & TRN \\
\hline CHEMBL1564325 & 688759 & 4.65 & 4.8482 & TRN \\
\hline CHEMBL1392009 & 688759 & 5.35 & 5.4971 & TRN \\
\hline CHEMBL1350628 & 688759 & 5.4 & 4.7521 & TST \\
\hline CHEMBL1421135 & 688759 & 4.45 & 4.7258 & TRN \\
\hline CHEMBL3209142 & 688759 & 5.65 & 5.2627 & TRN \\
\hline CHEMBL1408223 & 688759 & 4.9 & 4.7697 & TRN \\
\hline CHEMBL1486325 & 688759 & 5.1 & 5.0696 & TRN \\
\hline CHEMBL3199384 & 688759 & 4.65 & 4.7829 & TST \\
\hline CHEMBL3189850 & 688759 & 5.0 & 5.1093 & TRN \\
\hline CHEMBL1612006 & 688759 & 4.45 & 4.9581 & TST \\
\hline
\end{tabular}




\begin{tabular}{|c|c|c|c|c|}
\hline \multicolumn{5}{|c|}{ Supplemental Table S2.txt } \\
\hline CHEMBL3195977 & 688759 & 4.65 & 4.7868 & TST \\
\hline CHEMBL1556831 & 688759 & 4.45 & 4.9747 & TST \\
\hline CHEMBL1599598 & 688759 & 4.5 & 4.737 & TRN \\
\hline CHEMBL1993889 & 688759 & 4.8 & 4.9302 & TRN \\
\hline CHEMBL1518167 & 688759 & 4.8 & 4.7596 & TRN \\
\hline CHEMBL1510913 & 688759 & 6.1 & 4.9445 & TRN \\
\hline CHEMBL1562216 & 688759 & 4.45 & 4.7884 & TRN \\
\hline CHEMBL3209796 & 688759 & 7.3002 & 5.3218 & TST \\
\hline CHEMBL1540268 & 688759 & 4.75 & 4.6724 & TRN \\
\hline CHEMBL1559704 & 688759 & 4.45 & 4.7761 & TST \\
\hline CHEMBL3196551 & 688759 & 5.35 & 5.2491 & TST \\
\hline CHEMBL1497472 & 688759 & 4.95 & 4.8539 & TRN \\
\hline CHEMBL1503950 & 688759 & 6.0 & 4.6256 & TRN \\
\hline CHEMBL1444627 & 688759 & 4.45 & 4.9965 & TRN \\
\hline CHEMBL1333625 & 688759 & 5.05 & 4.9605 & TST \\
\hline CHEMBL1346801 & 688759 & 4.45 & 4.9722 & TST \\
\hline CHEMBL1541900 & 688759 & 4.7 & 4.6924 & TST \\
\hline CHEMBL3209467 & 688759 & 4.45 & 4.6552 & TST \\
\hline CHEMBL1524515 & 688759 & 4.85 & 5.2011 & TRN \\
\hline CHEMBL1310217 & 688759 & 4.45 & 4.8311 & TRN \\
\hline CHEMBL1526462 & 688759 & 5.0 & 5.2712 & TRN \\
\hline CHEMBL1467332 & 688759 & 4.85 & 4.8186 & TRN \\
\hline CHEMBL1411288 & 688759 & 4.7 & 4.7413 & TRN \\
\hline CHEMBL1451434 & 688759 & 5.35 & 5.0347 & TRN \\
\hline CHEMBL1425768 & 688759 & 4.7 & 4.7615 & TST \\
\hline CHEMBL1430506 & 688759 & 4.45 & 4.6811 & TRN \\
\hline CHEMBL1564471 & 688759 & 4.9 & 5.3037 & TRN \\
\hline CHEMBL1469860 & 688759 & 4.45 & 4.8266 & TRN \\
\hline CHEMBL1558076 & 688759 & 4.8 & 4.7532 & TST \\
\hline CHEMBL1374550 & 688759 & 4.45 & 4.8217 & TRN \\
\hline CHEMBL1482199 & 688759 & 5.55 & 5.1232 & TRN \\
\hline CHEMBL1384675 & 688759 & 5.15 & 5.2981 & TRN \\
\hline CHEMBL3189453 & 688759 & 5.15 & 5.4665 & TRN \\
\hline CHEMBL1606962 & 688759 & 5.25 & 5.0673 & TRN \\
\hline CHEMBL1453257 & 688759 & 4.45 & 4.7527 & TST \\
\hline CHEMBL1406664 & 688759 & 4.65 & 4.5972 & TRN \\
\hline CHEMBL1501432 & 688759 & 4.95 & 4.83 & TRN \\
\hline CHEMBL1456677 & 688759 & 4.75 & 4.8531 & TST \\
\hline CHEMBL3192549 & 688759 & 4.45 & 5.04 & TRN \\
\hline CHEMBL1519338 & 688759 & 5.1 & 4.9892 & TRN \\
\hline CHEMBL1328255 & 688759 & 5.35 & 5.0417 & TRN \\
\hline CHEMBL1424127 & 688759 & 4.75 & 4.7668 & TRN \\
\hline CHEMBL1584557 & 688759 & 6.25 & 5.6962 & TRN \\
\hline CHEMBL1459175 & 688759 & 4.75 & 4.4827 & TST \\
\hline CHEMBL3196333 & 688759 & 4.55 & 4.8662 & TRN \\
\hline CHEMBL1404342 & 688759 & 4.9 & 4.7729 & TRN \\
\hline CHEMBL1439066 & 688759 & 4.7 & 4.8492 & TRN \\
\hline CHEMBL1522232 & 688759 & 5.25 & 4.8654 & TRN \\
\hline
\end{tabular}




\begin{tabular}{|c|c|c|c|c|c|}
\hline \multicolumn{6}{|c|}{ Supplemental Table S2.txt } \\
\hline CHEMBL1580622 & 688759 & 4.45 & 4.9709 & TRN & \\
\hline CHEMBL1439782 & 688759 & 5.9 & 5.0341 & TRN & \\
\hline CHEMBL1319024 & 688759 & 4.45 & 4.6512 & TRN & \\
\hline CHEMBL1542329 & 688759 & 5.45 & 4.8424 & TST & \\
\hline CHEMBL1425829 & 688759 & 4.45 & 4.9089 & TST & \\
\hline CHEMBL1462049 & 688759 & 4.9 & 4.7174 & TRN & \\
\hline CHEMBL1300080 & 688759 & 6.45 & 6.2849 & TRN & \\
\hline CHEMBL3194762 & 688759 & 4.7 & 4.5171 & TST & \\
\hline CHEMBL1563250 & 688759 & 4.55 & 4.6896 & TST & \\
\hline CHEMBL1383068 & 688759 & 4.6 & 4.8704 & TRN & \\
\hline CHEMBL1577294 & 688759 & 4.45 & 5.1392 & TRN & \\
\hline CHEMBL1467016 & 688759 & 5.25 & 5.1413 & TRN & \\
\hline CHEMBL1326200 & 688759 & 4.95 & 4.979 & TRN & \\
\hline CHEMBL1379604 & 688759 & 4.55 & 4.5694 & TRN & \\
\hline CHEMBL1537098 & 688759 & 6.1 & 5.7216 & TRN & \\
\hline CHEMBL1490584 & 688759 & 4.75 & 4.8487 & TRN & \\
\hline CHEMBL1420706 & 688759 & 4.7 & 4.7819 & TRN & \\
\hline CHEMBL1471698 & 688759 & 6.3 & 5.1274 & TST & \\
\hline CHEMBL1466435 & 688759 & 4.45 & 4.9343 & TST & \\
\hline CHEMBL1388157 & 688759 & 4.9 & 4.7142 & TRN & \\
\hline CHEMBL1412703 & 688759 & 4.9 & 5.0269 & TRN & \\
\hline CHEMBL 3190793 & 688759 & 5.15 & 5.0675 & TRN & \\
\hline CHEMBL1537011 & 688759 & 4.45 & 4.8529 & TRN & \\
\hline CHEMBL1444031 & 688759 & 8.1024 & 6.2322 & TRN & \\
\hline CHEMBL1378118 & 688759 & 4.6 & 4.7744 & TRN & \\
\hline CHEMBL1994402 & 688759 & 5.4 & 5.4526 & TRN & \\
\hline CHEMBL1302386 & 688759 & 4.8 & 4.57600 & 00000000005 & TRN \\
\hline CHEMBL1459310 & 688759 & 4.45 & 5.1713 & TRN & \\
\hline CHEMBL1428546 & 688759 & 4.45 & 4.9525 & TRN & \\
\hline CHEMBL1504895 & 688759 & 5.0 & 4.7875 & TRN & \\
\hline CHEMBL3196970 & 688759 & 5.25 & 5.5367 & TRN & \\
\hline CHEMBL1567738 & 688759 & 5.85 & 5.7678 & TRN & \\
\hline CHEMBL3210628 & 688759 & 4.45 & 4.8889 & TST & \\
\hline CHEMBL1343125 & 688759 & 4.45 & 4.9331 & TST & \\
\hline CHEMBL1384915 & 688759 & 4.7 & 4.7223 & TRN & \\
\hline CHEMBL1580074 & 688759 & 4.5 & 5.1848 & TST & \\
\hline CHEMBL1432936 & 688759 & 4.65 & 5.0132 & TST & \\
\hline CHEMBL1431662 & 688759 & 4.45 & 4.8164 & TST & \\
\hline CHEMBL1416171 & 688759 & 4.95 & 4.7134 & TST & \\
\hline CHEMBL1310778 & 688759 & 4.45 & 4.8192 & TRN & \\
\hline CHEMBL1492188 & 688759 & 4.45 & 4.8853 & TRN & \\
\hline CHEMBL1351624 & 688759 & 4.55 & 4.8694 & TRN & \\
\hline CHEMBL1540265 & 688759 & 4.8 & 4.8462 & TRN & \\
\hline CHEMBL1431645 & 688759 & 4.45 & 4.7335 & TRN & \\
\hline CHEMBL1508121 & 688759 & 5.3 & 5.2178 & TRN & \\
\hline CHEMBL1568030 & 688759 & 4.45 & 5.0222 & TRN & \\
\hline CHEMBL1606098 & 688759 & 4.5 & 4.8832 & TRN & \\
\hline CHEMBL1588664 & 688759 & 4.95 & 5.0766 & TRN & \\
\hline
\end{tabular}




\begin{tabular}{|c|c|c|c|c|c|}
\hline \multicolumn{6}{|c|}{ Supplemental Table S2.txt } \\
\hline CHEMBL3207361 & 688759 & 5.3 & 5.1433 & TRN & \\
\hline CHEMBL1419812 & 688759 & 4.95 & 4.915 & TRN & \\
\hline CHEMBL1584212 & 688759 & 4.45 & 4.9072 & TST & \\
\hline CHEMBL1568208 & 688759 & 4.85 & 4.7335 & TRN & \\
\hline CHEMBL1349663 & 688759 & 5.5 & 5.2669 & TRN & \\
\hline CHEMBL1362008 & 688759 & 4.8 & 4.8826 & TST & \\
\hline CHEMBL1359587 & 688759 & 5.45 & 5.04899 & 99999999995 & TRN \\
\hline CHEMBL1538749 & 688759 & 5.15 & 5.2171 & TRN & \\
\hline CHEMBL1370409 & 688759 & 5.8 & 4.7242 & TRN & \\
\hline CHEMBL1428157 & 688759 & 5.3 & 4.9228 & TRN & \\
\hline CHEMBL1325754 & 688759 & 5.1 & 5.268 & TST & \\
\hline CHEMBL591613 & 688759 & 4.7 & 4.8515 & TST & \\
\hline CHEMBL1412734 & 688759 & 4.5 & 4.8332 & TST & \\
\hline CHEMBL1538726 & 688759 & 5.5 & 4.9691 & TRN & \\
\hline CHEMBL1489999 & 688759 & 4.75 & 4.7907 & TST & \\
\hline CHEMBL1541904 & 688759 & 5.3 & 5.192 & TRN & \\
\hline CHEMBL1360615 & 688759 & 4.45 & 4.9139 & TRN & \\
\hline CHEMBL1331601 & 688759 & 4.8 & 4.7233 & TRN & \\
\hline CHEMBL1399193 & 688759 & 5.35 & 5.5052 & TRN & \\
\hline CHEMBL1559868 & 688759 & 4.65 & 4.668 & TRN & \\
\hline CHEMBL1348733 & 688759 & 6.05 & 5.5999 & TRN & \\
\hline CHEMBL1479386 & 688759 & 4.45 & 4.8284 & TRN & \\
\hline CHEMBL1463312 & 688759 & 4.5 & 4.8693 & TRN & \\
\hline CHEMBL1586263 & 688759 & 4.45 & 4.6978 & TRN & \\
\hline CHEMBL1319601 & 688759 & 5.1 & 4.7513 & TST & \\
\hline CHEMBL533772 & 688759 & 5.15 & 5.0873 & TST & \\
\hline CHEMBL1346461 & 688759 & 4.45 & 4.6894 & TRN & \\
\hline CHEMBL1493464 & 688759 & 4.45 & 4.9823 & TRN & \\
\hline CHEMBL1382389 & 688759 & 4.45 & 4.8757 & TRN & \\
\hline CHEMBL1441501 & 688759 & 4.65 & 5.1649 & TRN & \\
\hline CHEMBL1612532 & 688759 & 4.45 & 5.1834 & TST & \\
\hline CHEMBL3209647 & 688759 & 4.7 & 4.8314 & TST & \\
\hline CHEMBL1431725 & 688759 & 5.15 & 4.852 & TRN & \\
\hline CHEMBL1446480 & 688759 & 4.8 & 4.5951 & TRN & \\
\hline CHEMBL302004 & 688759 & 5.6 & 4.6126 & TRN & \\
\hline CHEMBL1602599 & 688759 & 4.95 & 4.8741 & TRN & \\
\hline CHEMBL1493052 & 688759 & 5.05 & 4.8938 & TRN & \\
\hline CHEMBL1436882 & 688759 & 4.75 & 5.1641 & TRN & \\
\hline CHEMBL1998940 & 688759 & 5.3 & 4.9886 & TRN & \\
\hline CHEMBL1451935 & 688759 & 4.45 & 4.6791 & TRN & \\
\hline CHEMBL1535326 & 688759 & 4.9 & 4.6909 & TRN & \\
\hline CHEMBL1347477 & 688759 & 5.25 & 5.3438 & TRN & \\
\hline CHEMBL1373084 & 688759 & 4.6 & 4.6305 & TRN & \\
\hline CHEMBL1523539 & 688759 & 4.85 & 4.9666 & TRN & \\
\hline CHEMBL1493497 & 688759 & 4.65 & 5.0584 & TRN & \\
\hline CHEMBL1339956 & 688759 & 4.45 & 4.7108 & TST & \\
\hline CHEMBL1375784 & 688759 & 4.8 & 4.7982 & TST & \\
\hline CHEMBL3191212 & 688759 & 4.8 & 4.8374 & TRN & \\
\hline
\end{tabular}




\begin{tabular}{|c|c|c|c|c|c|}
\hline & & \multicolumn{4}{|c|}{ Supplemental Table s2.txt } \\
\hline CHEMBL1373197 & 688759 & 4.75 & 4.922 & TRN & \\
\hline CHEMBL1482299 & 688759 & 5.3 & 5.2773 & TRN & \\
\hline CHEMBL1495939 & 688759 & 4.45 & 4.5383 & TST & \\
\hline CHEMBL1576069 & 688759 & 5.1 & 5.0327 & TRN & \\
\hline CHEMBL1979536 & 688759 & 4.45 & 4.6167 & TRN & \\
\hline CHEMBL3191564 & 688759 & 4.95 & 5.0516 & TST & \\
\hline CHEMBL1586630 & 688759 & 4.45 & 5.159 & TST & \\
\hline CHEMBL1446678 & 688759 & 4.55 & 4.8553 & TRN & \\
\hline CHEMBL1332877 & 688759 & 5.25 & 4.9675 & TST & \\
\hline CHEMBL1523938 & 688759 & 5.15 & 5.0103 & TST & \\
\hline CHEMBL1587807 & 688759 & 6.1 & 4.8714 & TRN & \\
\hline CHEMBL1355200 & 688759 & 5.95 & 5.1985 & TRN & \\
\hline CHEMBL1348245 & 688759 & 6.4 & 5.1748 & TST & \\
\hline CHEMBL1393179 & 688759 & 4.45 & 4.9556 & TRN & \\
\hline CHEMBL1505864 & 688759 & 4.55 & 4.9141 & TRN & \\
\hline CHEMBL1328350 & 688759 & 5.0 & 4.7966 & TRN & \\
\hline CHEMBL1380300 & 688759 & 4.45 & 5.1496 & TRN & \\
\hline CHEMBL1519374 & 688759 & 4.65 & 5.0216 & TRN & \\
\hline CHEMBL3192213 & 688759 & 4.45 & 4.9283 & TST & \\
\hline CHEMBL3194496 & 688759 & 4.45 & 4.8313 & TRN & \\
\hline CHEMBL3212906 & 688759 & 4.45 & 4.688 & TST & \\
\hline CHEMBL1499736 & 688759 & 4.5 & 4.6741 & TRN & \\
\hline CHEMBL1471113 & 688759 & 4.7 & 4.7064 & TRN & \\
\hline CHEMBL1572778 & 688759 & 4.95 & 4.8754 & TST & \\
\hline CHEMBL1584244 & 688759 & 5.0 & 5.0654 & TRN & \\
\hline CHEMBL1341377 & 688759 & 4.45 & 4.6322 & TRN & \\
\hline CHEMBL1429150 & 688759 & 4.65 & 4.5667 & TST & \\
\hline CHEMBL1529161 & 688759 & 5.3 & 4.8902 & TRN & \\
\hline CHEMBL1323133 & 688759 & 5.5 & 5.2378 & TRN & \\
\hline CHEMBL1540690 & 688759 & 4.6 & 4.8011 & TST & \\
\hline CHEMBL3213942 & 688759 & 4.5 & 4.6931 & TRN & \\
\hline CHEMBL1460262 & 688759 & 5.25 & 5.0835 & TRN & \\
\hline CHEMBL3189838 & 688759 & 4.45 & 4.8191 & TRN & \\
\hline CHEMBL1611070 & 688759 & 4.9 & 4.4773 & TST & \\
\hline CHEMBL1573592 & 688759 & 4.85 & 5.6047 & TRN & \\
\hline CHEMBL1611186 & 688759 & 4.45 & 4.874 & TRN & \\
\hline CHEMBL1457519 & 688759 & 4.45 & 5.4052 & TRN & \\
\hline CHEMBL1483628 & 688759 & 5.0 & 4.8746 & TRN & \\
\hline CHEMBL1577139 & 688759 & 5.15 & 5.4512 & TST & \\
\hline CHEMBL1351353 & 688759 & 4.45 & 5.0974 & TST & \\
\hline CHEMBL443343 & 688759 & 4.45 & 4.9791 & TST & \\
\hline CHEMBL1970925 & 688759 & 4.85 & 5.3260 & 00000000005 & TRN \\
\hline CHEMBL1328199 & 688759 & 4.9 & 4.9351 & TRN & \\
\hline CHEMBL1452415 & 688759 & 5.45 & 5.0933 & TST & \\
\hline CHEMBL1385433 & 688759 & 4.45 & 4.5177 & TST & \\
\hline CHEMBL1566108 & 688759 & 4.45 & 5.0008 & TRN & \\
\hline CHEMBL1339669 & 688759 & 4.8 & 4.864 & TRN & \\
\hline CHEMBL1491616 & 688759 & 4.95 & 4.9124 & TRN & \\
\hline
\end{tabular}




\begin{tabular}{|c|c|c|c|c|c|}
\hline \multicolumn{6}{|c|}{ Supplemental Table S2.txt } \\
\hline CHEMBL1304775 & 688759 & 4.45 & 4.7776 & TRN & \\
\hline CHEMBL1364725 & 688759 & 5.05 & 5.1132 & TST & \\
\hline CHEMBL1585763 & 688759 & 4.75 & 4.8525 & TRN & \\
\hline CHEMBL1299774 & 688759 & 4.45 & 4.8001 & TRN & \\
\hline CHEMBL3208852 & 688759 & 4.8 & 4.6126 & TRN & \\
\hline CHEMBL1431608 & 688759 & 5.45 & 5.2626 & TST & \\
\hline CHEMBL1511104 & 688759 & 4.45 & 4.8799 & TST & \\
\hline CHEMBL3191679 & 688759 & 4.45 & 4.8546 & TRN & \\
\hline CHEMBL1559106 & 688759 & 4.6 & 4.7903 & TST & \\
\hline CHEMBL1330015 & 688759 & 4.45 & 4.7478 & TST & \\
\hline CHEMBL1346450 & 688759 & 4.7 & 4.9347 & TST & \\
\hline CHEMBL1436498 & 688759 & 4.65 & 4.8324 & TRN & \\
\hline CHEMBL1413949 & 688759 & 4.45 & 4.7207 & TRN & \\
\hline CHEMBL1464997 & 688759 & 4.85 & 4.8007 & TRN & \\
\hline CHEMBL1311109 & 688759 & 5.2 & 5.2181 & TRN & \\
\hline CHEMBL1602385 & 688759 & 4.65 & 4.9245 & TST & \\
\hline CHEMBL1393137 & 688759 & 5.0 & 4.832 & TST & \\
\hline CHEMBL1575742 & 688759 & 4.45 & 5.0604 & TST & \\
\hline CHEMBL1490289 & 688759 & 5.25 & 4.9949 & TST & \\
\hline CHEMBL3199820 & 688759 & 5.4 & 5.2652 & TRN & \\
\hline CHEMBL1484227 & 688759 & 4.85 & 4.9413 & TST & \\
\hline CHEMBL1521044 & 688759 & 4.7 & 4.8832 & TST & \\
\hline CHEMBL1397674 & 688759 & 4.8 & 4.8252 & TRN & \\
\hline CHEMBL1490882 & 688759 & 6.2 & 4.8929 & TRN & \\
\hline CHEMBL1510038 & 688759 & 4.45 & 4.8428 & TRN & \\
\hline CHEMBL1481801 & 688759 & 4.65 & 4.8433 & TRN & \\
\hline CHEMBL1537844 & 688759 & 4.9 & 5.2831 & TRN & \\
\hline CHEMBL1537106 & 688759 & 4.65 & 4.9566 & TRN & \\
\hline CHEMBL1363558 & 688759 & 5.45 & 4.7956 & TRN & \\
\hline CHEMBL1399490 & 688759 & 4.65 & 4.8212 & TRN & \\
\hline CHEMBL1371874 & 688759 & 4.8 & 4.5502 & TRN & \\
\hline CHEMBL1523942 & 688759 & 4.95 & 4.81800 & 00000000005 & TST \\
\hline CHEMBL1521696 & 688759 & 4.45 & 4.8772 & TST & \\
\hline CHEMBL1434433 & 688759 & 5.2 & 4.9712 & TST & \\
\hline CHEMBL1323602 & 688759 & 4.65 & 4.744 & TRN & \\
\hline CHEMBL1985499 & 688759 & 5.2 & 5.0895 & TRN & \\
\hline CHEMBL1412317 & 688759 & 4.65 & 4.9203 & TRN & \\
\hline CHEMBL1367001 & 688759 & 4.7 & 4.8188 & TRN & \\
\hline CHEMBL1306570 & 688759 & 5.35 & 5.4989 & TST & \\
\hline CHEMBL1401323 & 688759 & 5.9 & 4.6355 & TRN & \\
\hline CHEMBL1351680 & 688759 & 4.45 & 4.9046 & TRN & \\
\hline CHEMBL1360139 & 688759 & 4.45 & 4.9257 & TRN & \\
\hline CHEMBL1327338 & 688759 & 7.3497 & 6.1222 & TRN & \\
\hline CHEMBL1597701 & 688759 & 4.45 & 4.7247 & TST & \\
\hline CHEMBL1965348 & 688759 & 4.5 & 4.8845 & TRN & \\
\hline CHEMBL1584207 & 688759 & 4.9 & 4.9031 & TRN & \\
\hline CHEMBL1539539 & 688759 & 4.45 & 4.857 & TRN & \\
\hline CHEMBL3189233 & 688759 & 4.45 & 4.9326 & TRN & \\
\hline
\end{tabular}




\begin{tabular}{|c|c|c|c|c|}
\hline \multicolumn{5}{|c|}{ Supplemental Table S2.txt } \\
\hline CHEMBL1531320 & 688759 & 5.0 & 5.1193 & TRN \\
\hline CHEMBL1557566 & 688759 & 4.75 & 4.8938 & TST \\
\hline CHEMBL1373152 & 688759 & 4.5 & 4.7611 & TRN \\
\hline CHEMBL1371353 & 688759 & 4.45 & 4.6376 & TRN \\
\hline CHEMBL1997052 & 688759 & 4.95 & 4.7861 & TRN \\
\hline CHEMBL1589156 & 688759 & 4.75 & 4.8771 & TRN \\
\hline CHEMBL1572356 & 688759 & 6.7001 & 5.7708 & TRN \\
\hline CHEMBL1337035 & 688759 & 5.9 & 4.9008 & TST \\
\hline CHEMBL1404460 & 688759 & 4.9 & 4.9011 & TST \\
\hline CHEMBL1499099 & 688759 & 5.0 & 4.9847 & TST \\
\hline CHEMBL3193664 & 688759 & 4.6 & 4.4468 & TRN \\
\hline CHEMBL1357114 & 688759 & 4.5 & 4.6224 & TST \\
\hline CHEMBL1462691 & 688759 & 5.0 & 4.957 & TRN \\
\hline CHEMBL 3193444 & 688759 & 5.2 & 4.8822 & TRN \\
\hline CHEMBL3193425 & 688759 & 5.75 & 5.599 & TRN \\
\hline CHEMBL1398664 & 688759 & 6.2 & 5.8111 & TRN \\
\hline CHEMBL199925 & 688759 & 4.45 & 4.9463 & TRN \\
\hline CHEMBL3189790 & 688759 & 4.95 & 4.8728 & TRN \\
\hline CHEMBL3196262 & 688759 & 5.45 & 5.6159 & TRN \\
\hline CHEMBL600034 & 688759 & 4.8 & 5.2501 & TRN \\
\hline CHEMBL1479699 & 688759 & 4.45 & 4.7473 & TRN \\
\hline CHEMBL1585868 & 688759 & 5.25 & 4.5767 & TRN \\
\hline CHEMBL1517746 & 688759 & 4.75 & 4.7292 & TST \\
\hline CHEMBL1433033 & 688759 & 4.7 & 5.0553 & TRN \\
\hline CHEMBL1407561 & 688759 & 4.7 & 4.7813 & TRN \\
\hline CHEMBL 2003508 & 688759 & 5.0 & 5.2962 & TRN \\
\hline CHEMBL1361987 & 688759 & 4.65 & 4.6201 & TRN \\
\hline CHEMBL3199305 & 688759 & 5.25 & 5.0486 & TRN \\
\hline CHEMBL536151 & 688759 & 6.0 & 5.2979 & TST \\
\hline CHEMBL1448590 & 688759 & 4.65 & 4.8369 & TST \\
\hline CHEMBL1610049 & 688759 & 5.15 & 5.1346 & TRN \\
\hline CHEMBL1987108 & 688759 & 4.55 & 4.8654 & TRN \\
\hline CHEMBL1571971 & 688759 & 4.9 & 4.828 & TRN \\
\hline CHEMBL1343485 & 688759 & 5.3 & 5.3336 & TRN \\
\hline CHEMBL1490582 & 688759 & 4.45 & 4.6049 & TRN \\
\hline CHEMBL1502130 & 688759 & 5.25 & 4.752 & TRN \\
\hline CHEMBL3196263 & 688759 & 5.15 & 5.638 & TRN \\
\hline CHEMBL3193102 & 688759 & 5.0 & 4.7165 & TRN \\
\hline CHEMBL1485259 & 688759 & 4.45 & 4.7062 & TRN \\
\hline CHEMBL1373731 & 688759 & 5.15 & 4.8741 & TRN \\
\hline CHEMBL1331419 & 688759 & 4.5 & 4.6857 & TRN \\
\hline CHEMBL1557018 & 688759 & 4.45 & 5.1369 & TRN \\
\hline CHEMBL3213421 & 688759 & 4.9 & 4.6019 & TRN \\
\hline CHEMBL1589042 & 688759 & 4.45 & 4.809 & TRN \\
\hline CHEMBL1362683 & 688759 & 4.9 & 4.8021 & TRN \\
\hline CHEMBL3189493 & 688759 & 5.5 & 5.088 & TRN \\
\hline CHEMBL1299577 & 688759 & 4.65 & 4.9666 & TRN \\
\hline CHEMBL1301393 & 688759 & 4.65 & 4.5974 & TRN \\
\hline
\end{tabular}




\begin{tabular}{|c|c|c|c|c|}
\hline \multicolumn{5}{|c|}{ Supplemental Table S2.txt } \\
\hline CHEMBL1562166 & 688759 & 4.45 & 4.7448 & TST \\
\hline CHEMBL1466855 & 688759 & 5.25 & 5.1012 & TRN \\
\hline CHEMBL3192190 & 688759 & 4.75 & 4.8075 & TRN \\
\hline CHEMBL1523068 & 688759 & 4.45 & 4.4338 & TRN \\
\hline CHEMBL3208560 & 688759 & 5.6 & 5.9343 & TRN \\
\hline CHEMBL1431422 & 688759 & 4.45 & 5.046 & TRN \\
\hline CHEMBL1996589 & 688759 & 5.2 & 5.414 & TST \\
\hline CHEMBL3208030 & 688759 & 5.35 & 4.9542 & TST \\
\hline CHEMBL1583964 & 688759 & 4.8 & 4.8936 & TST \\
\hline CHEMBL1486661 & 688759 & 4.8 & 4.9797 & TST \\
\hline CHEMBL1464446 & 688759 & 5.5 & 5.0987 & TRN \\
\hline CHEMBL1299281 & 688759 & 4.85 & 4.5486 & TRN \\
\hline CHEMBL3207519 & 688759 & 4.45 & 4.7191 & TRN \\
\hline CHEMBL1585801 & 688759 & 4.6 & 4.8745 & TRN \\
\hline CHEMBL1409654 & 688759 & 5.25 & 4.9096 & TRN \\
\hline CHEMBL1373283 & 688759 & 4.45 & 4.5067 & TRN \\
\hline CHEMBL1457019 & 688759 & 4.55 & 4.6463 & TRN \\
\hline CHEMBL1353773 & 688759 & 4.45 & 4.927 & TST \\
\hline CHEMBL1334906 & 688759 & 4.45 & 4.5648 & TST \\
\hline CHEMBL1973139 & 688759 & 4.65 & 5.6336 & TRN \\
\hline CHEMBL1382868 & 688759 & 4.7 & 4.9582 & TRN \\
\hline CHEMBL1459819 & 688759 & 4.95 & 4.5286 & TRN \\
\hline CHEMBL1595975 & 688759 & 4.45 & 4.8697 & TST \\
\hline CHEMBL3195941 & 688759 & 5.5 & 4.8483 & TRN \\
\hline CHEMBL1345620 & 688759 & 6.1 & 5.3716 & TRN \\
\hline CHEMBL1536341 & 688759 & 5.1 & 5.0782 & TRN \\
\hline CHEMBL1421612 & 688759 & 4.45 & 4.7057 & TRN \\
\hline CHEMBL1434806 & 688759 & 4.5 & 4.783 & TRN \\
\hline CHEMBL 2006997 & 688759 & 5.8 & 5.6805 & TRN \\
\hline CHEMBL1332670 & 688759 & 5.5 & 4.8771 & TST \\
\hline CHEMBL3196126 & 688759 & 4.45 & 4.8224 & TRN \\
\hline CHEMBL3192469 & 688759 & 4.95 & 4.5486 & TRN \\
\hline CHEMBL1561232 & 688759 & 4.65 & 4.6986 & TST \\
\hline CHEMBL1495100 & 688759 & 4.55 & 5.2941 & TRN \\
\hline CHEMBL1334026 & 688759 & 4.8 & 4.8147 & TRN \\
\hline CHEMBL1510332 & 688759 & 5.45 & 5.1762 & TRN \\
\hline CHEMBL1508437 & 688759 & 4.8 & 4.4874 & TRN \\
\hline CHEMBL579219 & 688759 & 4.45 & 4.798 & TRN \\
\hline CHEMBL1403707 & 688759 & 4.95 & 4.6984 & TST \\
\hline CHEMBL1533117 & 688759 & 4.75 & 4.8848 & TRN \\
\hline CHEMBL1560117 & 688759 & 5.3 & 4.64 & TRN \\
\hline CHEMBL1424109 & 688759 & 4.95 & 5.218 & TRN \\
\hline CHEMBL1555719 & 688759 & 5.0 & 4.9511 & TRN \\
\hline CHEMBL1441851 & 688759 & 5.0 & 5.105 & TST \\
\hline CHEMBL1485694 & 688759 & 5.0 & 4.9594 & TRN \\
\hline CHEMBL3196621 & 688759 & 5.5 & 5.4935 & TRN \\
\hline CHEMBL 1478788 & 688759 & 4.8 & 4.4967 & TRN \\
\hline CHEMBL1346615 & 688759 & 5.15 & 4.7433 & TST \\
\hline
\end{tabular}




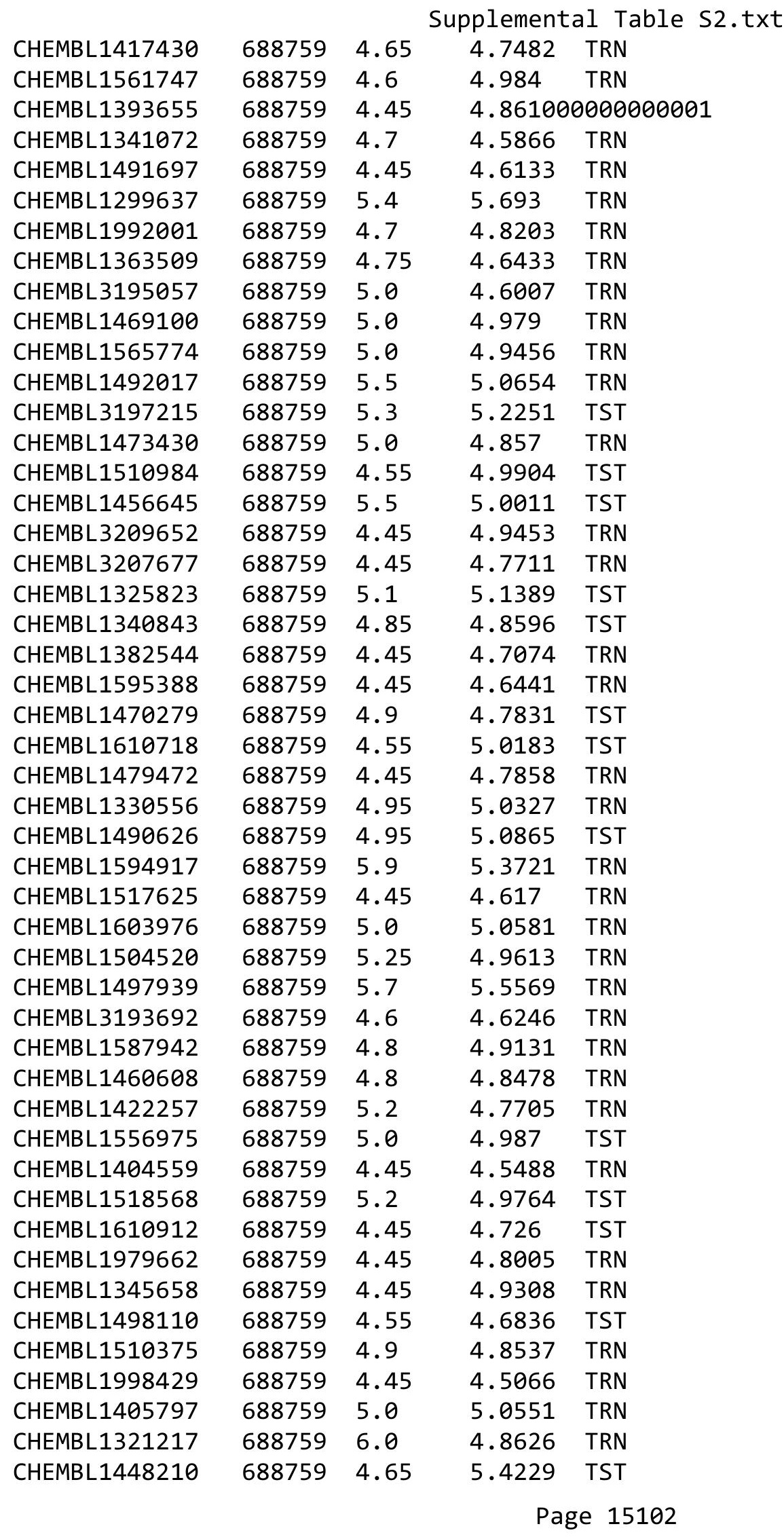

TRN 


\begin{tabular}{|c|c|c|c|c|c|}
\hline \multicolumn{6}{|c|}{ Supplemental Table S2.txt } \\
\hline CHEMBL1537520 & 688759 & 4.45 & 4.8293 & TST & \\
\hline CHEMBL1439056 & 688759 & 4.9 & 4.7766 & TST & \\
\hline CHEMBL1407566 & 688759 & 4.45 & 4.7982 & TRN & \\
\hline CHEMBL 3197978 & 688759 & 5.5 & 5.3201 & TRN & \\
\hline CHEMBL3191015 & 688759 & 5.0 & 4.6308 & TRN & \\
\hline CHEMBL3189217 & 688759 & 6.1 & 5.2541 & TRN & \\
\hline CHEMBL1352534 & 688759 & 4.45 & 4.9653 & TRN & \\
\hline CHEMBL1341443 & 688759 & 4.95 & 4.5785 & TRN & \\
\hline CHEMBL 2006390 & 688759 & 5.6 & \multicolumn{2}{|c|}{5.4639999999999995} & TRN \\
\hline CHEMBL1607927 & 688759 & 4.45 & 4.596 & TRN & \\
\hline CHEMBL3196965 & 688759 & 4.45 & 4.6697 & TRN & \\
\hline CHEMBL1510824 & 688759 & 4.45 & 4.9081 & TRN & \\
\hline CHEMBL1440304 & 688759 & 5.0 & 4.8206 & TRN & \\
\hline CHEMBL1580601 & 688759 & 4.95 & \multicolumn{2}{|c|}{ 4.5169999999999995 } & TRN \\
\hline CHEMBL1322196 & 688759 & 4.45 & 4.4538 & TRN & \\
\hline CHEMBL1310992 & 688759 & 4.95 & 4.9255 & TRN & \\
\hline CHEMBL1397381 & 688759 & 4.85 & 4.9935 & TRN & \\
\hline CHEMBL1419383 & 688759 & 4.9 & 4.9935 & TRN & \\
\hline CHEMBL1308686 & 688759 & 4.45 & 4.8875 & TST & \\
\hline CHEMBL1480448 & 688759 & 5.5 & \multicolumn{2}{|c|}{4.736000000000001} & TRN \\
\hline CHEMBL1604032 & 688759 & 5.15 & 5.1215 & TRN & \\
\hline CHEMBL1405350 & 688759 & 4.45 & 4.8665 & TRN & \\
\hline CHEMBL1523673 & 688759 & 5.25 & 4.9398 & TRN & \\
\hline CHEMBL1554577 & 688759 & 4.45 & 4.7628 & TRN & \\
\hline CHEMBL3189856 & 688759 & 4.75 & 5.0594 & TRN & \\
\hline CHEMBL1982195 & 688759 & 5.8 & 5.4477 & TRN & \\
\hline CHEMBL1540641 & 688759 & 5.25 & 4.912 & TRN & \\
\hline CHEMBL1445776 & 688759 & 5.25 & 4.9721 & TST & \\
\hline CHEMBL1410316 & 688759 & 4.45 & 4.7361 & TRN & \\
\hline CHEMBL3189882 & 688759 & 5.3 & 4.6863 & TRN & \\
\hline CHEMBL1180 & 688759 & 4.45 & 5.0152 & TST & \\
\hline CHEMBL1367562 & 688759 & 5.35 & 5.0733 & TRN & \\
\hline CHEMBL1419335 & 688759 & 5.05 & 4.7384 & TRN & \\
\hline CHEMBL1477785 & 688759 & 4.7 & 5.0906 & TST & \\
\hline CHEMBL1428108 & 688759 & 4.65 & 5.013 & TRN & \\
\hline CHEMBL1480530 & 688759 & 4.6 & 4.9339 & TST & \\
\hline CHEMBL3190979 & 688759 & 4.45 & 5.2437 & TRN & \\
\hline CHEMBL1998868 & 688759 & 4.6 & 4.8883 & TRN & \\
\hline CHEMBL1486963 & 688759 & 5.35 & 5.0948 & TRN & \\
\hline CHEMBL1545556 & 688759 & 5.55 & 4.9965 & TRN & \\
\hline CHEMBL3191399 & 688759 & 4.85 & 4.7415 & TRN & \\
\hline CHEMBL1584229 & 688759 & 4.6 & 5.021 & TRN & \\
\hline CHEMBL1481025 & 688759 & 4.6 & 4.9622 & TRN & \\
\hline CHEMBL1594176 & 688759 & 7.3002 & 4.9637 & TRN & \\
\hline CHEMBL1404709 & 688759 & 5.5 & 4.9117 & TRN & \\
\hline CHEMBL1492119 & 688759 & 6.3 & 5.1436 & TRN & \\
\hline CHEMBL1427959 & 688759 & 4.9 & 5.0066 & TRN & \\
\hline CHEMBL1438075 & 688759 & 5.45 & 4.9578 & TST & \\
\hline
\end{tabular}




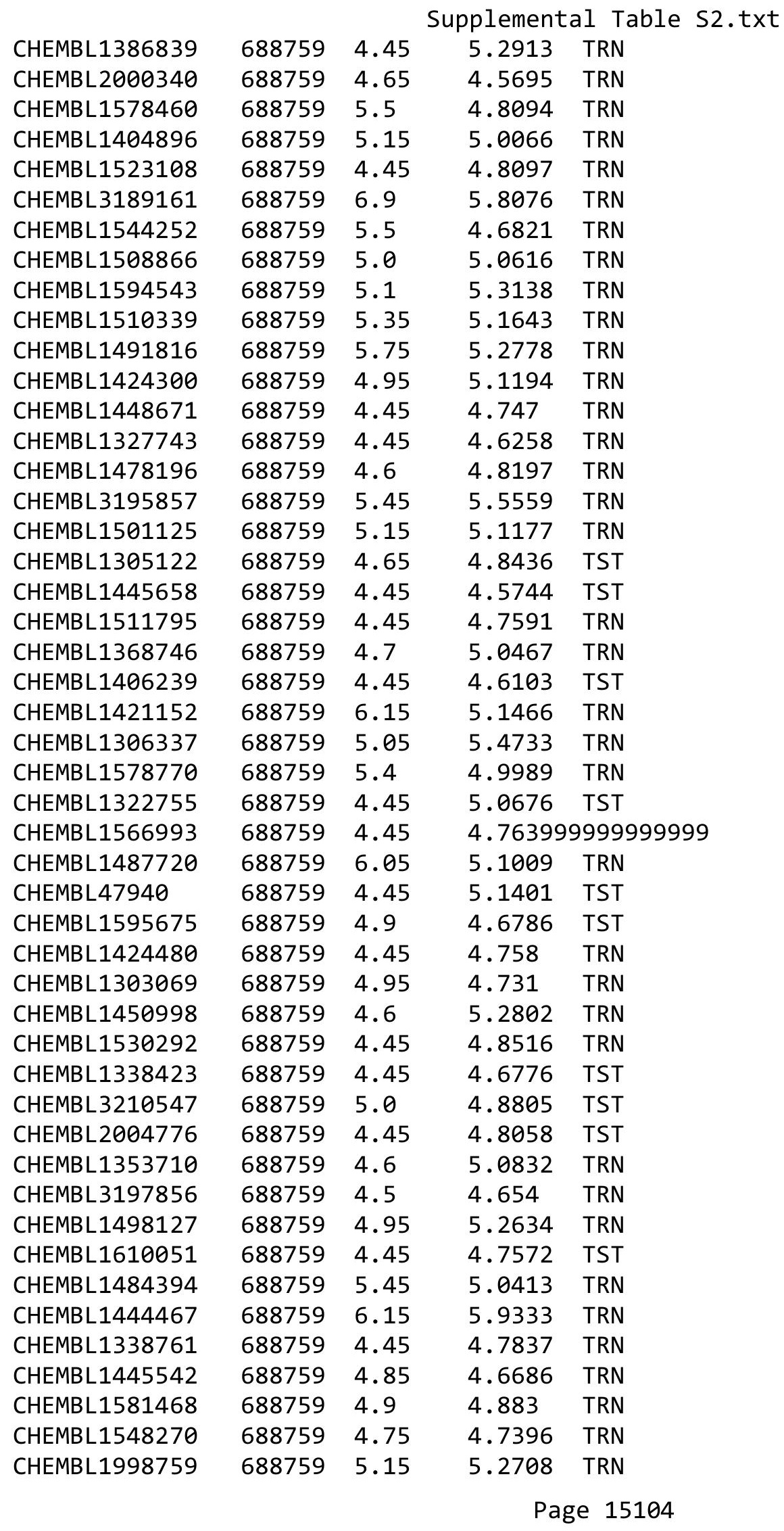

TRN 


\begin{tabular}{|c|c|c|c|c|c|}
\hline \multicolumn{6}{|c|}{ Supplemental Table S2.txt } \\
\hline CHEMBL3210528 & 688759 & 4.45 & 4.5766 & TRN & \\
\hline CHEMBL1563063 & 688759 & 4.55 & 4.9795 & TST & \\
\hline CHEMBL1604476 & 688759 & 4.8 & 4.7826 & TST & \\
\hline CHEMBL1389794 & 688759 & 4.65 & 4.6954 & TRN & \\
\hline CHEMBL1964967 & 688759 & 5.2 & 5.0687 & TRN & \\
\hline CHEMBL1342313 & 688759 & 4.7 & 4.7216 & TRN & \\
\hline CHEMBL1598445 & 688759 & 6.5501 & 5.0733 & TRN & \\
\hline CHEMBL3198050 & 688759 & 4.85 & 5.3025 & TRN & \\
\hline CHEMBL1589240 & 688759 & 5.0 & 4.8281 & TRN & \\
\hline CHEMBL1555618 & 688759 & 4.45 & 4.6881 & TRN & \\
\hline CHEMBL1420195 & 688759 & 4.45 & 4.6945 & TRN & \\
\hline CHEMBL1343730 & 688759 & 4.95 & 4.9664 & TRN & \\
\hline CHEMBL105712 & 688759 & 4.8 & 4.8603 & TRN & \\
\hline CHEMBL1481675 & 688759 & 5.95 & 4.8916 & TRN & \\
\hline CHEMBL3208261 & 688759 & 6.6499 & 5.04899 & 99999999995 & TRN \\
\hline CHEMBL1538559 & 688759 & 4.95 & 4.6934 & TRN & \\
\hline CHEMBL1412518 & 688759 & 4.9 & 4.7952 & TRN & \\
\hline CHEMBL3192320 & 688759 & 5.45 & 5.2907 & TRN & \\
\hline CHEMBL3193543 & 688759 & 6.15 & 4.6167 & TRN & \\
\hline CHEMBL1523998 & 688759 & 4.45 & 4.9876 & TST & \\
\hline CHEMBL1345258 & 688759 & 4.55 & 4.8712 & TRN & \\
\hline CHEMBL1539127 & 688759 & 4.5 & 5.0359 & TRN & \\
\hline CHEMBL1491972 & 688759 & 4.65 & 4.7242 & TRN & \\
\hline CHEMBL1327806 & 688759 & 4.8 & 4.8117 & TRN & \\
\hline CHEMBL1405111 & 688759 & 4.6 & 4.5281 & TRN & \\
\hline CHEMBL3192045 & 688759 & 4.95 & 4.9641 & TRN & \\
\hline CHEMBL59507 & 688759 & 4.55 & 4.7923 & TST & \\
\hline CHEMBL1304247 & 688759 & 6.05 & 4.9345 & TST & \\
\hline CHEMBL1571934 & 688759 & 4.65 & 4.5384 & TRN & \\
\hline CHEMBL1500469 & 688759 & 5.3 & 5.2179 & TRN & \\
\hline CHEMBL1523492 & 688759 & 4.45 & 4.7509 & TRN & \\
\hline CHEMBL1418189 & 688759 & 4.85 & 4.5675 & TST & \\
\hline CHEMBL3197171 & 688759 & 5.25 & 5.25 & TRN & \\
\hline CHEMBL1574191 & 688759 & 4.45 & 5.266 & TST & \\
\hline CHEMBL3192785 & 688759 & 5.5 & 5.3062 & TRN & \\
\hline CHEMBL1603038 & 688759 & 5.6 & 4.8592 & TRN & \\
\hline CHEMBL1562232 & 688759 & 4.6 & 4.8577 & TRN & \\
\hline CHEMBL1369502 & 688759 & 4.45 & 4.7592 & TRN & \\
\hline CHEMBL3198582 & 688759 & 6.1 & 4.9887 & TRN & \\
\hline CHEMBL1334083 & 688759 & 4.6 & 4.9475 & TRN & \\
\hline CHEMBL1507967 & 688759 & 4.8 & 4.9179 & TRN & \\
\hline CHEMBL1453624 & 688759 & 5.2 & 4.75899 & 99999999995 & TRN \\
\hline CHEMBL1303587 & 688759 & 4.45 & 4.7776 & TRN & \\
\hline CHEMBL1381584 & 688759 & 5.2 & 5.1661 & TRN & \\
\hline CHEMBL1525565 & 688759 & 4.5 & 5.0033 & TST & \\
\hline CHEMBL1555752 & 688759 & 5.15 & 4.8957 & TST & \\
\hline CHEMBL1337947 & 688759 & 6.0 & 5.4875 & TRN & \\
\hline CHEMBL1307951 & 688759 & 6.45 & 4.9486 & TRN & \\
\hline
\end{tabular}




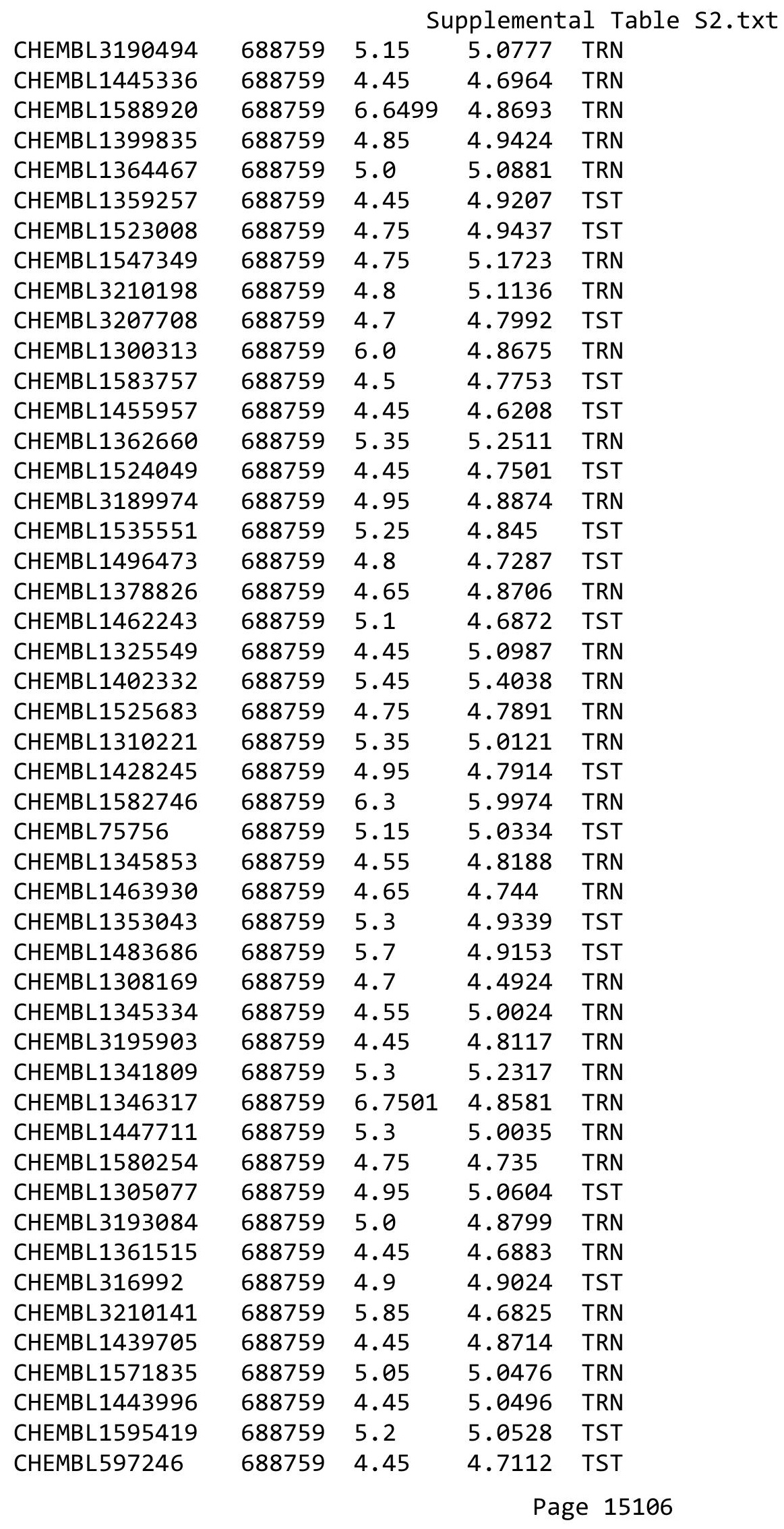




\begin{tabular}{|c|c|c|c|c|c|}
\hline \multicolumn{6}{|c|}{ Supplemental Table S2.txt } \\
\hline CHEMBL1423633 & 688759 & 5.8 & 5.642 & TRN & \\
\hline CHEMBL1401740 & 688759 & 4.6 & 4.7812 & TRN & \\
\hline CHEMBL1574571 & 688759 & 5.5 & 5.4001 & TRN & \\
\hline CHEMBL1441348 & 688759 & 4.45 & 4.7468 & TST & \\
\hline CHEMBL83294 & 688759 & 5.85 & 5.0143 & TRN & \\
\hline CHEMBL1494338 & 688759 & 5.05 & 5.1362 & TRN & \\
\hline CHEMBL1568298 & 688759 & 4.45 & 4.7486 & TRN & \\
\hline CHEMBL1366482 & 688759 & 5.25 & 4.9889 & TST & \\
\hline CHEMBL1464319 & 688759 & 4.75 & 4.7339 & TST & \\
\hline CHEMBL 2000633 & 688759 & 4.5 & 4.6295 & TRN & \\
\hline CHEMBL3190348 & 688759 & 5.0 & 5.421 & TRN & \\
\hline CHEMBL3191401 & 688759 & 4.45 & 4.6757 & TRN & \\
\hline CHEMBL1548410 & 688759 & 5.0 & 4.9038 & TRN & \\
\hline CHEMBL1595779 & 688759 & 4.65 & 4.8889 & TRN & \\
\hline CHEMBL1970272 & 688759 & 5.5 & 4.9685 & TST & \\
\hline CHEMBL1372492 & 688759 & 6.0 & 5.724 & TRN & \\
\hline CHEMBL1399398 & 688759 & 4.9 & 4.9199 & TRN & \\
\hline CHEMBL1573037 & 688759 & 5.45 & 4.8045 & TST & \\
\hline CHEMBL1456487 & 688759 & 4.45 & 4.985 & TRN & \\
\hline CHEMBL1547782 & 688759 & 5.35 & 5.3006 & TRN & \\
\hline CHEMBL1371943 & 688759 & 6.2 & 4.8434 & TST & \\
\hline CHEMBL1410498 & 688759 & 4.55 & 4.6264 & TST & \\
\hline CHEMBL 2004144 & 688759 & 4.6 & 4.8317 & TRN & \\
\hline CHEMBL1329484 & 688759 & 4.8 & 4.466 & TRN & \\
\hline CHEMBL1556527 & 688759 & 5.25 & 5.0983 & TRN & \\
\hline CHEMBL1558672 & 688759 & 5.4 & 5.13299 & 9999999999 & TRN \\
\hline CHEMBL1527484 & 688759 & 5.4 & 4.9967 & TST & \\
\hline CHEMBL1406800 & 688759 & 4.45 & 4.8604 & TRN & \\
\hline CHEMBL1302418 & 688759 & 4.45 & 4.8314 & TRN & \\
\hline CHEMBL1536188 & 688759 & 6.05 & 5.1249 & TRN & \\
\hline CHEMBL3199492 & 688759 & 4.45 & 4.7727 & TRN & \\
\hline CHEMBL1414397 & 688759 & 4.45 & 5.2402 & TRN & \\
\hline CHEMBL1420838 & 688759 & 4.45 & 5.0444 & TRN & \\
\hline CHEMBL1431815 & 688759 & 4.7 & 4.996 & TST & \\
\hline CHEMBL1991565 & 688759 & 5.45 & 5.1523 & TRN & \\
\hline CHEMBL1572931 & 688759 & 4.6 & 5.1866 & TRN & \\
\hline CHEMBL1341788 & 688759 & 4.45 & 4.7991 & TRN & \\
\hline CHEMBL1307394 & 688759 & 5.45 & 5.1156 & TRN & \\
\hline CHEMBL3211718 & 688759 & 4.45 & 4.8002 & TRN & \\
\hline CHEMBL1560637 & 688759 & 5.3 & 5.1323 & TRN & \\
\hline CHEMBL1359756 & 688759 & 5.25 & 4.8617 & TRN & \\
\hline CHEMBL1342291 & 688759 & 4.65 & 4.7234 & TST & \\
\hline CHEMBL1607116 & 688759 & 4.45 & 4.7719 & TRN & \\
\hline CHEMBL1427352 & 688759 & 5.5 & 5.3435 & TRN & \\
\hline CHEMBL1441491 & 688759 & 5.65 & 5.5806 & TST & \\
\hline CHEMBL1334365 & 688759 & 4.45 & 5.0037 & TRN & \\
\hline CHEMBL1567379 & 688759 & 4.75 & 4.3304 & TRN & \\
\hline CHEMBL1550554 & 688759 & 4.45 & 4.5339 & TRN & \\
\hline
\end{tabular}




\begin{tabular}{|c|c|c|c|c|}
\hline \multicolumn{5}{|c|}{ Supplemental Table S2.txt } \\
\hline CHEMBL1498517 & 688759 & 5.3 & 5.2167 & TRN \\
\hline CHEMBL1333429 & 688759 & 4.45 & 4.8262 & TRN \\
\hline CHEMBL1413244 & 688759 & 4.45 & 4.6929 & TRN \\
\hline CHEMBL1560646 & 688759 & 4.55 & 4.7683 & TRN \\
\hline CHEMBL1544790 & 688759 & 5.2 & 4.9599 & TST \\
\hline CHEMBL1576212 & 688759 & 4.45 & 4.9 & TRN \\
\hline CHEMBL1341981 & 688759 & 5.35 & 4.8571 & TRN \\
\hline CHEMBL 3195054 & 688759 & 4.45 & 4.9328 & TRN \\
\hline CHEMBL373937 & 688759 & 4.6 & 4.9073 & TST \\
\hline CHEMBL1350773 & 688759 & 4.95 & 4.8134 & TST \\
\hline CHEMBL3210642 & 688759 & 5.3 & 5.4065 & TST \\
\hline CHEMBL1457198 & 688759 & 5.45 & 4.8255 & TRN \\
\hline CHEMBL1500489 & 688759 & 4.45 & 4.6078 & TST \\
\hline CHEMBL1370412 & 688759 & 5.9 & 5.5828 & TRN \\
\hline CHEMBL1333757 & 688759 & 4.45 & 4.8544 & TST \\
\hline CHEMBL1337056 & 688759 & 4.6 & 4.9555 & TRN \\
\hline CHEMBL 261237 & 688759 & 4.45 & 4.7557 & TST \\
\hline CHEMBL1517284 & 688759 & 5.6 & 5.3981 & TRN \\
\hline CHEMBL1605192 & 688759 & 4.45 & 5.0922 & TST \\
\hline CHEMBL1482184 & 688759 & 4.65 & 4.8438 & TST \\
\hline CHEMBL1345695 & 688759 & 4.45 & 4.757 & TRN \\
\hline CHEMBL1997970 & 688759 & 5.5 & 5.0636 & TRN \\
\hline CHEMBL1458079 & 688759 & 4.65 & 4.9627 & TRN \\
\hline CHEMBL1604180 & 688759 & 4.45 & 4.9131 & TRN \\
\hline CHEMBL1549611 & 688759 & 4.7 & 4.7322 & TRN \\
\hline CHEMBL1381448 & 688759 & 6.15 & 5.2625 & TRN \\
\hline CHEMBL1580917 & 688759 & 4.45 & 4.6136 & TRN \\
\hline CHEMBL1313427 & 688759 & 4.55 & 4.6473 & TRN \\
\hline CHEMBL1446248 & 688759 & 5.75 & 5.3847 & TRN \\
\hline CHEMBL1498477 & 688759 & 5.0 & 4.8692 & TRN \\
\hline CHEMBL1398961 & 688759 & 5.05 & 4.7968 & TRN \\
\hline CHEMBL3145049 & 688759 & 4.45 & 4.8136 & TRN \\
\hline CHEMBL1388197 & 688759 & 4.45 & 4.6449 & TRN \\
\hline CHEMBL1414384 & 688759 & 4.45 & 4.9323 & TRN \\
\hline CHEMBL1339113 & 688759 & 4.9 & 4.726 & TRN \\
\hline CHEMBL1430337 & 688759 & 4.45 & 4.6511 & TRN \\
\hline CHEMBL1349739 & 688759 & 4.65 & 4.8922 & TRN \\
\hline CHEMBL1467418 & 688759 & 5.0 & 4.817 & TRN \\
\hline CHEMBL1992492 & 688759 & 5.15 & 4.8025 & TRN \\
\hline CHEMBL1401026 & 688759 & 4.65 & 4.8098 & TST \\
\hline CHEMBL1978373 & 688759 & 5.0 & 5.2367 & TRN \\
\hline CHEMBL1385886 & 688759 & 4.8 & 4.6207 & TRN \\
\hline CHEMBL1993711 & 688759 & 4.5 & 4.6437 & TRN \\
\hline CHEMBL1340706 & 688759 & 4.65 & 5.072 & TRN \\
\hline CHEMBL1565407 & 688759 & 4.55 & 4.8295 & TRN \\
\hline CHEMBL1343034 & 688759 & 5.55 & 4.7211 & TST \\
\hline CHEMBL1980665 & 688759 & 5.35 & 5.3121 & TST \\
\hline CHEMBL1323644 & 688759 & 4.45 & 4.715 & TRN \\
\hline
\end{tabular}




\begin{tabular}{|c|c|c|c|c|c|}
\hline & & \multicolumn{4}{|c|}{ Supplemental Table s2.txt } \\
\hline CHEMBL1306502 & 688759 & 4.45 & 4.8462 & TST & \\
\hline CHEMBL1519562 & 688759 & 4.7 & 4.8285 & TRN & \\
\hline CHEMBL3198058 & 688759 & 4.45 & 4.9207 & TRN & \\
\hline CHEMBL1413416 & 688759 & 5.8 & 5.4915 & TST & \\
\hline CHEMBL1320036 & 688759 & 5.95 & 4.7053 & TRN & \\
\hline CHEMBL 2006154 & 688759 & 4.45 & 4.9189 & TRN & \\
\hline CHEMBL3190436 & 688759 & 4.45 & 4.6972 & TRN & \\
\hline CHEMBL1483370 & 688759 & 5.15 & 5.4018 & TST & \\
\hline CHEMBL3198499 & 688759 & 4.85 & 5.3357 & TRN & \\
\hline CHEMBL1539368 & 688759 & 4.9 & 4.9742 & TST & \\
\hline CHEMBL3198569 & 688759 & 4.6 & 4.8192 & TRN & \\
\hline CHEMBL1547563 & 688759 & 4.9 & 4.7788 & TST & \\
\hline CHEMBL1224755 & 688759 & 5.3 & 5.0568 & TRN & \\
\hline CHEMBL1471740 & 688759 & 4.45 & 4.8165 & TRN & \\
\hline CHEMBL1523034 & 688759 & 4.45 & 4.7314 & TRN & \\
\hline CHEMBL1303788 & 688759 & 4.7 & 4.7601 & TRN & \\
\hline CHEMBL3191104 & 688759 & 4.65 & 4.7865 & TRN & \\
\hline CHEMBL1492943 & 688759 & 4.65 & 4.9143 & TRN & \\
\hline CHEMBL1527565 & 688759 & 4.8 & 4.8307 & TST & \\
\hline CHEMBL1571298 & 688759 & 4.45 & 4.9283 & TRN & \\
\hline CHEMBL1492871 & 688759 & 4.45 & 4.831 & TRN & \\
\hline CHEMBL1583978 & 688759 & 4.95 & 4.7069 & TRN & \\
\hline CHEMBL1442569 & 688759 & 5.5 & 5.0543 & TST & \\
\hline CHEMBL1468169 & 688759 & 4.45 & 4.6177 & TRN & \\
\hline CHEMBL1488661 & 688759 & 4.45 & 4.8719 & TRN & \\
\hline CHEMBL1965814 & 688759 & 4.55 & 4.7984 & TRN & \\
\hline CHEMBL3196576 & 688759 & 4.65 & 4.8281 & TRN & \\
\hline CHEMBL1447321 & 688759 & 4.95 & 4.9384 & TST & \\
\hline CHEMBL1580006 & 688759 & 5.75 & 5.4109 & TRN & \\
\hline CHEMBL1567585 & 688759 & 5.25 & 4.9755 & TST & \\
\hline CHEMBL1540594 & 688759 & 4.75 & 4.8349 & TST & \\
\hline CHEMBL3193419 & 688759 & 5.35 & 5.1292 & TRN & \\
\hline CHEMBL1972500 & 688759 & 5.05 & 5.0879 & TRN & \\
\hline CHEMBL259507 & 688759 & 4.8 & 4.8619 & TST & \\
\hline CHEMBL1477236 & 688759 & 4.6 & 4.9287 & TST & \\
\hline CHEMBL1429980 & 688759 & 5.75 & 5.37799 & 9999999999 & TRN \\
\hline CHEMBL 2095128 & 688759 & 5.55 & 5.3189 & TRN & \\
\hline CHEMBL1549745 & 688759 & 5.15 & 5.2936 & TRN & \\
\hline CHEMBL1972235 & 688759 & 4.45 & 4.7019 & TRN & \\
\hline CHEMBL1324863 & 688759 & 4.8 & 5.039 & TST & \\
\hline CHEMBL1392324 & 688759 & 4.9 & 4.7503 & TST & \\
\hline CHEMBL1584449 & 688759 & 4.7 & 4.8533 & TRN & \\
\hline CHEMBL1548044 & 688759 & 4.55 & 4.8917 & TRN & \\
\hline CHEMBL3192986 & 688759 & 5.05 & 4.74100 & 00000000005 & TRN \\
\hline CHEMBL1574195 & 688759 & 4.45 & 4.8953 & TRN & \\
\hline CHEMBL1412519 & 688759 & 4.9 & 5.1258 & TST & \\
\hline CHEMBL3196901 & 688759 & 4.75 & 4.5698 & TRN & \\
\hline CHEMBL1579873 & 688759 & 5.45 & 4.8527 & TRN & \\
\hline
\end{tabular}




\begin{tabular}{|c|c|c|c|c|c|}
\hline & & \multicolumn{4}{|c|}{ Supplemental Table s2.txt } \\
\hline CHEMBL1985826 & 688759 & 5.25 & 4.9635 & TST & \\
\hline CHEMBL1603869 & 688759 & 4.45 & 5.269 & TRN & \\
\hline CHEMBL1380929 & 688759 & 5.5 & 5.222 & TRN & \\
\hline CHEMBL1440011 & 688759 & 4.45 & 4.6769 & TRN & \\
\hline CHEMBL1380817 & 688759 & 4.45 & 4.8875 & TRN & \\
\hline CHEMBL1464666 & 688759 & 4.45 & 4.7685 & TST & \\
\hline CHEMBL1333294 & 688759 & 4.45 & 4.8625 & TRN & \\
\hline CHEMBL1481689 & 688759 & 5.2 & 4.8396 & TRN & \\
\hline CHEMBL1329113 & 688759 & 4.65 & 4.7645 & TRN & \\
\hline CHEMBL1388286 & 688759 & 4.45 & 4.9086 & TRN & \\
\hline CHEMBL1446425 & 688759 & 4.45 & 4.7582 & TST & \\
\hline CHEMBL1452645 & 688759 & 4.65 & 4.897 & TRN & \\
\hline CHEMBL1599344 & 688759 & 5.0 & 4.9901 & TRN & \\
\hline CHEMBL 3193568 & 688759 & 4.95 & 4.758 & TRN & \\
\hline CHEMBL1421739 & 688759 & 4.45 & 4.7045 & TST & \\
\hline CHEMBL1312636 & 688759 & 4.5 & 4.9052 & TRN & \\
\hline CHEMBL1421255 & 688759 & 5.55 & 5.4466 & TRN & \\
\hline CHEMBL1559227 & 688759 & 5.05 & 5.1209 & TRN & \\
\hline CHEMBL3196873 & 688759 & 4.45 & 4.9352 & TRN & \\
\hline CHEMBL1546793 & 688759 & 4.45 & 4.607 & TRN & \\
\hline CHEMBL1370700 & 688759 & 5.5 & 4.9774 & TRN & \\
\hline CHEMBL3196761 & 688759 & 4.45 & 4.7714 & TRN & \\
\hline CHEMBL1407223 & 688759 & 4.5 & 5.0488 & TRN & \\
\hline CHEMBL1422962 & 688759 & 6.05 & 4.9437 & TRN & \\
\hline CHEMBL1349390 & 688759 & 5.05 & 5.1087 & TRN & \\
\hline CHEMBL1310332 & 688759 & 4.65 & 4.5874 & TRN & \\
\hline CHEMBL3195149 & 688759 & 4.45 & 4.6877 & TRN & \\
\hline CHEMBL1453581 & 688759 & 5.0 & 4.9169 & TST & \\
\hline CHEMBL1384148 & 688759 & 4.45 & 4.6523 & TRN & \\
\hline CHEMBL1553049 & 688759 & 5.6 & 5.1317 & TST & \\
\hline CHEMBL1420379 & 688759 & 4.8 & 4.9572 & TST & \\
\hline CHEMBL1999014 & 688759 & 4.9 & 4.7699 & TST & \\
\hline CHEMBL1516865 & 688759 & 4.45 & 4.66100 & 00000000005 & TRN \\
\hline CHEMBL1509254 & 688759 & 4.45 & 5.1526 & TRN & \\
\hline CHEMBL1571554 & 688759 & 4.6 & 4.4243 & TRN & \\
\hline CHEMBL1507250 & 688759 & 6.95 & 6.3611 & TRN & \\
\hline CHEMBL1310437 & 688759 & 4.8 & 4.7517 & TST & \\
\hline CHEMBL1571885 & 688759 & 4.45 & 4.8736 & TRN & \\
\hline CHEMBL1433227 & 688759 & 4.8 & 4.8894 & TRN & \\
\hline CHEMBL1392500 & 688759 & 5.4 & 5.3834 & TRN & \\
\hline CHEMBL1306053 & 688759 & 4.45 & 4.8498 & TRN & \\
\hline CHEMBL1548234 & 688759 & 4.55 & 4.5154 & TRN & \\
\hline CHEMBL1432518 & 688759 & 4.65 & 5.2723 & TRN & \\
\hline CHEMBL1368225 & 688759 & 4.85 & 5.102 & TRN & \\
\hline CHEMBL1303302 & 688759 & 4.8 & 4.5521 & TST & \\
\hline CHEMBL3189712 & 688759 & 4.8 & 5.1962 & TRN & \\
\hline CHEMBL1607620 & 688759 & 4.55 & 4.9395 & TRN & \\
\hline CHEMBL3191932 & 688759 & 4.45 & 4.6588 & TRN & \\
\hline
\end{tabular}




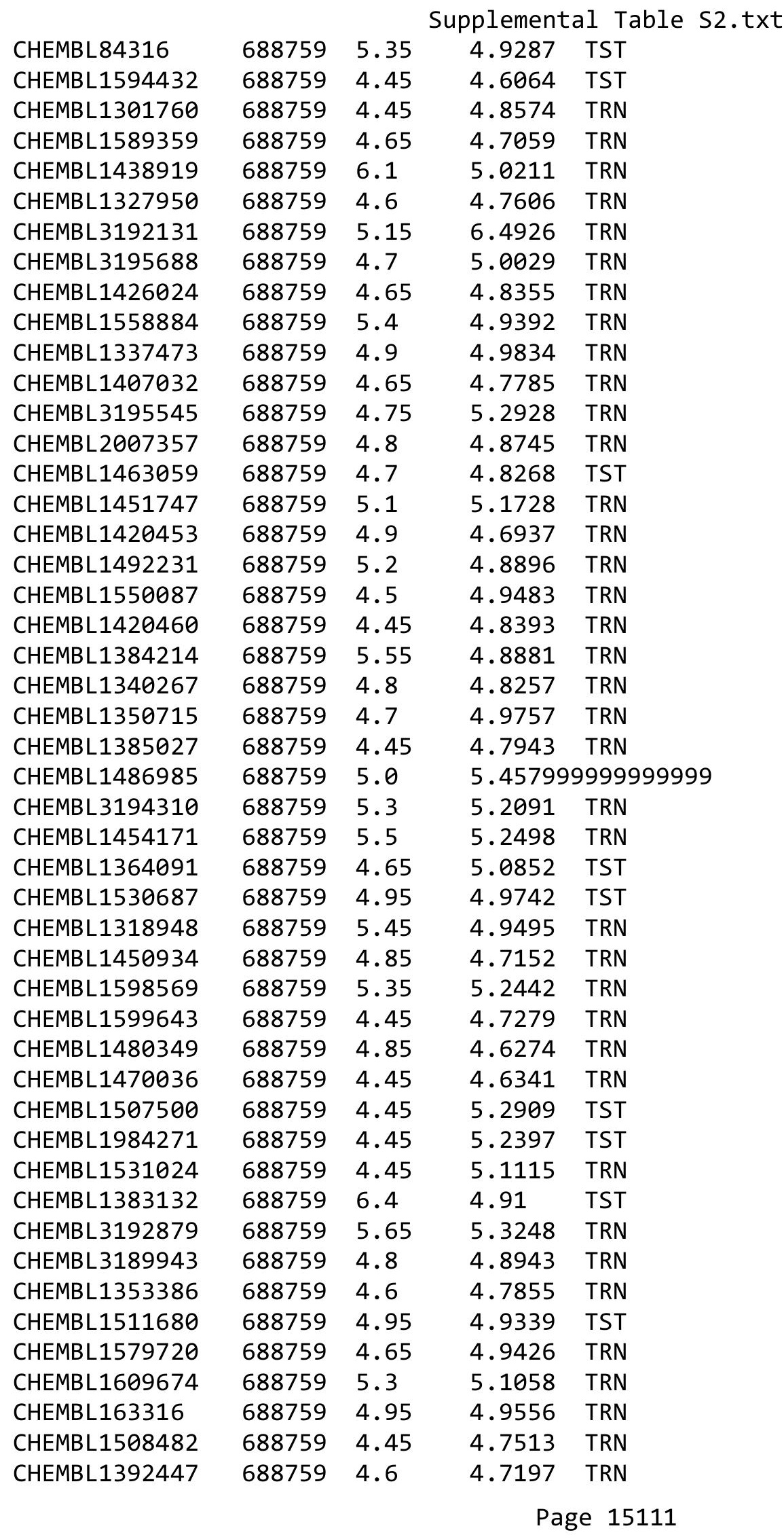




\begin{tabular}{|c|c|c|c|c|c|}
\hline \multicolumn{6}{|c|}{ able S2. } \\
\hline CHEMBL1529180 & 688759 & 4.8 & 4.6837 & TRN & \\
\hline CHEMBL1404029 & 688759 & 4.65 & 4.6443 & TRN & \\
\hline CHEMBL1610650 & 688759 & 4.65 & 4.8978 & TRN & \\
\hline CHEMBL1562581 & 688759 & 5.0 & 4.6927 & TST & \\
\hline CHEMBL1608218 & 688759 & 4.45 & 4.7434 & TRN & \\
\hline CHEMBL1528049 & 688759 & 4.9 & 4.7579 & TRN & \\
\hline CHEMBL1496094 & 688759 & 4.8 & 4.6629 & TST & \\
\hline CHEMBL1503847 & 688759 & 4.45 & 4.6807 & TRN & \\
\hline CHEMBL3392043 & 688759 & 5.0 & 4.988 & TRN & \\
\hline CHEMBL3196701 & 688759 & 4.55 & 5.1931 & TRN & \\
\hline CHEMBL1363310 & 688759 & 5.2 & 4.9759 & TST & \\
\hline CHEMBL1528206 & 688759 & 5.2 & 5.0406 & TRN & \\
\hline CHEMBL1351301 & 688759 & 4.45 & 5.0417 & TST & \\
\hline CHEMBL3213611 & 688759 & 4.95 & 4.4849 & TRN & \\
\hline CHEMBL1486062 & 688759 & 4.6 & 4.7085 & TRN & \\
\hline CHEMBL3208807 & 688759 & 4.45 & 4.6032 & TRN & \\
\hline CHEMBL1299253 & 688759 & 4.45 & 4.8614 & TRN & \\
\hline CHEMBL1529389 & 688759 & 4.65 & 4.8702 & TST & \\
\hline CHEMBL1583865 & 688759 & 4.45 & 4.6885 & TST & \\
\hline CHEMBL1605247 & 688759 & 4.65 & 4.7112 & TST & \\
\hline CHEMBL1457907 & 688759 & 4.95 & 5.0439 & TST & \\
\hline CHEMBL1319426 & 688759 & 4.45 & 4.8215 & TRN & \\
\hline CHEMBL1454956 & 688759 & 4.5 & 4.5807 & TRN & \\
\hline CHEMBL2003973 & 688759 & 4.7 & 4.81800 & 00000000005 & TST \\
\hline CHEMBL1333995 & 688759 & 5.15 & 5.1135 & TRN & \\
\hline CHEMBL3198038 & 688759 & 5.45 & 5.012 & TST & \\
\hline CHEMBL1595689 & 688759 & 4.65 & 4.7723 & TRN & \\
\hline CHEMBL1528399 & 688759 & 5.2 & 4.6583 & TRN & \\
\hline CHEMBL1300716 & 688759 & 5.5 & 5.1566 & TRN & \\
\hline CHEMBL1325319 & 688759 & 5.95 & 4.9371 & TST & \\
\hline CHEMBL1443454 & 688759 & 5.35 & 4.848 & TRN & \\
\hline CHEMBL1388845 & 688759 & 5.2 & 5.5793 & TRN & \\
\hline CHEMBL1484357 & 688759 & 4.45 & 4.6546 & TRN & \\
\hline CHEMBL1336405 & 688759 & 4.45 & 4.7861 & TRN & \\
\hline CHEMBL3194739 & 688759 & 5.0 & 5.0634 & TRN & \\
\hline CHEMBL1611776 & 688759 & 4.6 & 4.8634 & TRN & \\
\hline CHEMBL1382443 & 688759 & 4.9 & 4.6462 & TST & \\
\hline CHEMBL1549213 & 688759 & 4.45 & 5.07100 & 0000000001 & TRN \\
\hline CHEMBL3211378 & 688759 & 4.85 & 4.9521 & TRN & \\
\hline CHEMBL1388278 & 688759 & 5.75 & 5.0776 & TRN & \\
\hline CHEMBL1343306 & 688759 & 5.0 & 5.1336 & TRN & \\
\hline CHEMBL1308625 & 688759 & 4.45 & 4.891 & TRN & \\
\hline CHEMBL1580463 & 688759 & 4.9 & 4.7767 & TRN & \\
\hline CHEMBL3199613 & 688759 & 5.0 & 4.7419 & TRN & \\
\hline CHEMBL1576173 & 688759 & 4.85 & 5.0211 & TRN & \\
\hline CHEMBL 3196798 & 688759 & 4.95 & 4.9204 & TRN & \\
\hline CHEMBL3191087 & 688759 & 5.55 & 5.4815 & TRN & \\
\hline CHEMBL3196620 & 688759 & 6.8499 & 5.1768 & TRN & \\
\hline
\end{tabular}




\begin{tabular}{|c|c|c|c|c|c|}
\hline \multicolumn{6}{|c|}{ Supplemental Table S2.txt } \\
\hline CHEMBL1417400 & 688759 & 4.45 & 4.9818 & TRN & \\
\hline CHEMBL1596869 & 688759 & 4.9 & 4.8933 & TRN & \\
\hline CHEMBL3191970 & 688759 & 5.2 & 4.9566 & TRN & \\
\hline CHEMBL566293 & 688759 & 4.9 & 5.0974 & TRN & \\
\hline CHEMBL1442958 & 688759 & 4.55 & 4.8496 & TST & \\
\hline CHEMBL1479214 & 688759 & 5.6 & 5.1243 & TST & \\
\hline CHEMBL1451422 & 688759 & 5.4 & 5.1406 & TRN & \\
\hline CHEMBL1998521 & 688759 & 6.1 & 5.965 & TRN & \\
\hline CHEMBL1383041 & 688759 & 4.45 & 4.6301 & TRN & \\
\hline CHEMBL1371961 & 688759 & 4.8 & 4.756 & TRN & \\
\hline CHEMBL1359298 & 688759 & 4.6 & 4.7251 & TRN & \\
\hline CHEMBL1438798 & 688759 & 4.45 & 4.9317 & TRN & \\
\hline CHEMBL117804 & 688759 & 6.25 & 5.55206 & 00000000005 & TRN \\
\hline CHEMBL1365183 & 688759 & 4.45 & 4.8085 & TST & \\
\hline CHEMBL1401074 & 688759 & 6.05 & 5.814 & TRN & \\
\hline CHEMBL3189547 & 688759 & 5.15 & 5.1825 & TRN & \\
\hline CHEMBL1302523 & 688759 & 4.45 & 4.8076 & TRN & \\
\hline CHEMBL1373334 & 688759 & 4.5 & 4.8101 & TRN & \\
\hline CHEMBL1439031 & 688759 & 4.75 & 4.9844 & TRN & \\
\hline CHEMBL1499662 & 688759 & 4.45 & 4.8692 & TST & \\
\hline CHEMBL1509380 & 688759 & 4.45 & 5.1389 & 9999999999 & TRN \\
\hline CHEMBL1352052 & 688759 & 5.0 & 5.1498 & TRN & \\
\hline CHEMBL1323127 & 688759 & 6.8499 & 5.8605 & TRN & \\
\hline CHEMBL3199891 & 688759 & 4.45 & 5.0189 & TRN & \\
\hline CHEMBL1347212 & 688759 & 5.4 & 4.8597 & TST & \\
\hline CHEMBL1603297 & 688759 & 4.5 & 4.5714 & TRN & \\
\hline CHEMBL1468577 & 688759 & 4.45 & 5.1493 & TRN & \\
\hline CHEMBL1500926 & 688759 & 5.55 & 4.8345 & TRN & \\
\hline CHEMBL1348981 & 688759 & 6.45 & 4.8926 & TST & \\
\hline CHEMBL1608578 & 688759 & 4.45 & 4.7421 & TRN & \\
\hline CHEMBL50175 & 688759 & 4.55 & 4.8474 & TRN & \\
\hline CHEMBL1509271 & 688759 & 5.25 & 4.8901 & TST & \\
\hline CHEMBL1323098 & 688759 & 4.45 & 4.6688 & TRN & \\
\hline CHEMBL1300502 & 688759 & 4.55 & 4.7841 & TST & \\
\hline CHEMBL1428862 & 688759 & 4.75 & 4.5997 & TRN & \\
\hline CHEMBL1595923 & 688759 & 4.95 & 5.2099 & TRN & \\
\hline CHEMBL1587880 & 688759 & 4.45 & 4.5258 & TRN & \\
\hline CHEMBL1549699 & 688759 & 4.8 & 4.5582 & TST & \\
\hline CHEMBL1467069 & 688759 & 5.85 & 4.8398 & TRN & \\
\hline CHEMBL1324804 & 688759 & 4.5 & 4.9219 & TRN & \\
\hline CHEMBL1558406 & 688759 & 5.0 & 5.0307 & TST & \\
\hline CHEMBL1332829 & 688759 & 4.65 & 4.8316 & TRN & \\
\hline CHEMBL1488408 & 688759 & 4.45 & 4.6288 & TST & \\
\hline CHEMBL1544010 & 688759 & 5.05 & 4.8753 & TST & \\
\hline CHEMBL1480398 & 688759 & 4.45 & 4.7567 & TST & \\
\hline CHEMBL1606479 & 688759 & 4.45 & 4.9845 & TRN & \\
\hline CHEMBL1467631 & 688759 & 5.4 & 5.1892 & TRN & \\
\hline CHEMBL1506390 & 688759 & 4.95 & 4.9787 & TST & \\
\hline
\end{tabular}




\begin{tabular}{|c|c|c|c|c|}
\hline \multicolumn{5}{|c|}{ Supplemental Table S2.txt } \\
\hline CHEMBL1415356 & 688759 & 4.9 & 5.4926 & TRN \\
\hline CHEMBL1341869 & 688759 & 4.9 & 4.6315 & TRN \\
\hline CHEMBL1383949 & 688759 & 4.6 & 4.9759 & TRN \\
\hline CHEMBL1598791 & 688759 & 4.6 & 4.6278 & TST \\
\hline CHEMBL1320354 & 688759 & 4.45 & 4.5748 & TRN \\
\hline CHEMBL1317504 & 688759 & 4.9 & 4.7567 & TRN \\
\hline CHEMBL1588685 & 688759 & 4.85 & 4.9014 & TST \\
\hline CHEMBL1411317 & 688759 & 5.5 & 5.5073 & TRN \\
\hline CHEMBL1516818 & 688759 & 4.45 & 4.8519 & TRN \\
\hline CHEMBL1416934 & 688759 & 5.2 & 4.8397 & TRN \\
\hline CHEMBL1510220 & 688759 & 6.95 & 4.7953 & TST \\
\hline CHEMBL1496007 & 688759 & 5.5 & 5.4853 & TRN \\
\hline CHEMBL1442340 & 688759 & 4.85 & 4.8794 & TRN \\
\hline CHEMBL 3211801 & 688759 & 4.9 & 4.6487 & TRN \\
\hline CHEMBL1316409 & 688759 & 4.95 & 4.9409 & TRN \\
\hline CHEMBL1407588 & 688759 & 4.8 & 4.8114 & TRN \\
\hline CHEMBL1526729 & 688759 & 4.45 & 4.9598 & TRN \\
\hline CHEMBL1520721 & 688759 & 4.9 & 5.1153 & TRN \\
\hline CHEMBL1404702 & 688759 & 4.45 & 4.8347 & TST \\
\hline CHEMBL1573775 & 688759 & 4.8 & 4.8676 & TST \\
\hline CHEMBL1611499 & 688759 & 4.45 & 4.7583 & TST \\
\hline CHEMBL1567944 & 688759 & 6.0 & 6.0672 & TST \\
\hline CHEMBL1422230 & 688759 & 4.45 & 4.9334 & TRN \\
\hline CHEMBL1979221 & 688759 & 5.6 & 5.2662 & TST \\
\hline CHEMBL1393347 & 688759 & 4.65 & 4.6318 & TRN \\
\hline CHEMBL1418203 & 688759 & 5.55 & 5.2062 & TRN \\
\hline CHEMBL1333250 & 688759 & 5.0 & 4.9572 & TRN \\
\hline CHEMBL1303193 & 688759 & 5.2 & 4.9098 & TRN \\
\hline CHEMBL1516647 & 688759 & 4.65 & 5.4841 & TRN \\
\hline CHEMBL1546853 & 688759 & 4.45 & 4.6641 & TRN \\
\hline CHEMBL1603146 & 688759 & 4.45 & 4.5185 & TST \\
\hline CHEMBL 2004244 & 688759 & 5.2 & 5.0701 & TRN \\
\hline CHEMBL1579622 & 688759 & 4.45 & 4.7526 & TST \\
\hline CHEMBL1484011 & 688759 & 4.55 & 5.0354 & TRN \\
\hline CHEMBL1410974 & 688759 & 4.7 & 4.8656 & TST \\
\hline CHEMBL1304552 & 688759 & 4.45 & 4.9166 & TST \\
\hline CHEMBL3196660 & 688759 & 5.75 & 5.4752 & TRN \\
\hline CHEMBL1350285 & 688759 & 5.45 & 4.8679 & TRN \\
\hline CHEMBL1569975 & 688759 & 5.5 & 5.5608 & TRN \\
\hline CHEMBL1579992 & 688759 & 4.45 & 4.6919 & TRN \\
\hline CHEMBL 2001337 & 688759 & 4.45 & 4.7821 & TRN \\
\hline CHEMBL1985343 & 688759 & 4.45 & 4.6202 & TST \\
\hline CHEMBL1500966 & 688759 & 4.95 & 4.8205 & TRN \\
\hline CHEMBL3194813 & 688759 & 4.5 & 4.6417 & TRN \\
\hline CHEMBL 2369282 & 688759 & 5.6 & 5.2572 & TRN \\
\hline CHEMBL1608965 & 688759 & 4.65 & 4.7894 & TRN \\
\hline CHEMBL1348546 & 688759 & 5.0 & 4.7908 & TRN \\
\hline CHEMBL1599249 & 688759 & 4.45 & 4.6915 & TRN \\
\hline
\end{tabular}




\begin{tabular}{|c|c|c|c|c|c|}
\hline \multicolumn{6}{|c|}{ Supplemental Table S2.txt } \\
\hline CHEMBL1549202 & 688759 & 5.5 & 5.1065 & TRN & \\
\hline CHEMBL3196049 & 688759 & 4.7 & 4.5028 & TRN & \\
\hline CHEMBL1582785 & 688759 & 6.2 & 5.144 & TRN & \\
\hline CHEMBL3197095 & 688759 & 4.65 & 4.8685 & TST & \\
\hline CHEMBL1553168 & 688759 & 4.75 & 4.8496 & TST & \\
\hline CHEMBL1388120 & 688759 & 4.45 & 4.7653 & TRN & \\
\hline CHEMBL1413309 & 688759 & 4.9 & 5.2001 & TST & \\
\hline CHEMBL1468811 & 688759 & 4.9 & 5.0243 & TRN & \\
\hline CHEMBL1415099 & 688759 & 4.65 & 4.7014 & TST & \\
\hline CHEMBL1510168 & 688759 & 5.2 & 4.73600 & $\partial 000000001$ & TST \\
\hline CHEMBL1460296 & 688759 & 4.65 & 4.97 & TRN & \\
\hline CHEMBL1336158 & 688759 & 5.0 & 4.7702 & TRN & \\
\hline CHEMBL1504011 & 688759 & 4.45 & 4.756 & TRN & \\
\hline CHEMBL42178 & 688759 & 4.9 & 5.1295 & TRN & \\
\hline CHEMBL1384061 & 688759 & 4.45 & 4.7482 & TRN & \\
\hline CHEMBL1485037 & 688759 & 4.45 & 5.0905 & TRN & \\
\hline CHEMBL1494456 & 688759 & 4.45 & 5.101 & TRN & \\
\hline CHEMBL1612474 & 688759 & 5.1 & 4.7836 & TST & \\
\hline CHEMBL1352754 & 688759 & 5.15 & 5.106 & TRN & \\
\hline CHEMBL1361534 & 688759 & 5.15 & 5.0492 & TRN & \\
\hline CHEMBL1608876 & 688759 & 4.45 & 4.6354 & TST & \\
\hline CHEMBL1382452 & 688759 & 8.2007 & 4.6811 & TST & \\
\hline CHEMBL1384524 & 688759 & 6.5 & 6.2826 & TRN & \\
\hline CHEMBL1446676 & 688759 & 5.35 & 5.1248 & TRN & \\
\hline CHEMBL1596326 & 688759 & 4.45 & 4.7954 & TRN & \\
\hline CHEMBL1337333 & 688759 & 4.7 & 4.8742 & TST & \\
\hline CHEMBL1588125 & 688759 & 4.7 & 4.6974 & TST & \\
\hline CHEMBL1319365 & 688759 & 5.15 & 5.1163 & TRN & \\
\hline CHEMBL3192706 & 688759 & 5.25 & 5.2438 & TRN & \\
\hline CHEMBL1378378 & 688759 & 5.5 & 4.8896 & TST & \\
\hline CHEMBL1420864 & 688759 & 4.95 & 4.8838 & TRN & \\
\hline CHEMBL1341878 & 688759 & 4.75 & 4.7572 & TRN & \\
\hline CHEMBL1544559 & 688759 & 4.45 & 4.8316 & TRN & \\
\hline CHEMBL1490080 & 688759 & 4.65 & 4.7832 & TRN & \\
\hline CHEMBL1353597 & 688759 & 4.45 & 4.8217 & TRN & \\
\hline CHEMBL1501824 & 688759 & 4.45 & 4.9236 & TRN & \\
\hline CHEMBL1481621 & 688759 & 4.45 & 4.9188 & TRN & \\
\hline CHEMBL1575194 & 688759 & 4.8 & 4.8075 & TRN & \\
\hline CHEMBL1455379 & 688759 & 4.65 & 4.4941 & TST & \\
\hline CHEMBL1988416 & 688759 & 4.65 & 5.0895 & TST & \\
\hline CHEMBL1459373 & 688759 & 4.8 & 4.8177 & TRN & \\
\hline CHEMBL1480548 & 688759 & 5.5 & 5.0937 & TRN & \\
\hline CHEMBL3198276 & 688759 & 5.95 & 5.1207 & TRN & \\
\hline CHEMBL1369149 & 688759 & 4.45 & 4.593 & TRN & \\
\hline CHEMBL1407548 & 688759 & 4.7 & 4.7961 & TRN & \\
\hline CHEMBL1469351 & 688759 & 4.85 & 4.90600 & 0000000001 & TRN \\
\hline CHEMBL3213869 & 688759 & 4.45 & 4.9271 & TRN & \\
\hline CHEMBL1467648 & 688759 & 4.45 & 4.7906 & TST & \\
\hline
\end{tabular}




\begin{tabular}{|c|c|c|c|c|c|}
\hline & & \multicolumn{4}{|c|}{ Supplemental Table s2.txt } \\
\hline CHEMBL1509792 & 688759 & 4.45 & 5.185 & TRN & \\
\hline CHEMBL1308936 & 688759 & 4.7 & 4.7537 & TRN & \\
\hline CHEMBL1452139 & 688759 & 4.65 & 4.9168 & TRN & \\
\hline CHEMBL1504357 & 688759 & 4.95 & 4.7919 & TRN & \\
\hline CHEMBL467987 & 688759 & 4.9 & 4.8232 & TRN & \\
\hline CHEMBL1419888 & 688759 & 5.15 & 5.1373 & TST & \\
\hline CHEMBL1340977 & 688759 & 4.45 & 4.6745 & TRN & \\
\hline CHEMBL1429893 & 688759 & 4.95 & 5.0169 & TRN & \\
\hline CHEMBL1500086 & 688759 & 5.2 & 5.073 & TRN & \\
\hline CHEMBL1367313 & 688759 & 5.0 & 4.9374 & TRN & \\
\hline CHEMBL1458398 & 688759 & 4.45 & 5.0478 & TRN & \\
\hline CHEMBL1557128 & 688759 & 4.7 & 4.6796 & TST & \\
\hline CHEMBL3208271 & 688759 & 4.85 & 4.7604 & TST & \\
\hline CHEMBL1404086 & 688759 & 5.3 & 5.2108 & TRN & \\
\hline CHEMBL1372890 & 688759 & 4.45 & 5.1192 & TRN & \\
\hline CHEMBL1546177 & 688759 & 4.9 & 4.8576 & TRN & \\
\hline CHEMBL1539245 & 688759 & 4.45 & 4.8118 & TRN & \\
\hline CHEMBL1365705 & 688759 & 7.0 & 5.8354 & TRN & \\
\hline CHEMBL1385628 & 688759 & 4.45 & 4.705 & TRN & \\
\hline CHEMBL1501692 & 688759 & 4.9 & 4.8345 & TRN & \\
\hline CHEMBL1543548 & 688759 & 4.65 & 4.6016 & TRN & \\
\hline CHEMBL1528951 & 688759 & 4.65 & 5.0666 & TRN & \\
\hline CHEMBL1442881 & 688759 & 5.0 & 5.3366 & TRN & \\
\hline CHEMBL1313607 & 688759 & 4.75 & 4.9552 & TST & \\
\hline CHEMBL1528479 & 688759 & 4.45 & 4.4798 & TRN & \\
\hline CHEMBL1521959 & 688759 & 4.45 & 4.7044 & TRN & \\
\hline CHEMBL3191185 & 688759 & 5.05 & 5.261 & TRN & \\
\hline CHEMBL1382562 & 688759 & 4.45 & 4.828 & TST & \\
\hline CHEMBL1503007 & 688759 & 4.45 & 4.8391 & TST & \\
\hline CHEMBL1455950 & 688759 & 4.45 & 4.624 & TRN & \\
\hline CHEMBL1522322 & 688759 & 4.8 & 5.0161 & TRN & \\
\hline CHEMBL1524249 & 688759 & 5.4 & 5.022 & TRN & \\
\hline CHEMBL1409166 & 688759 & 6.95 & 5.129 & TRN & \\
\hline CHEMBL1613479 & 688759 & 4.45 & 5.3848 & TRN & \\
\hline CHEMBL1324947 & 688759 & 5.45 & 5.1342 & TRN & \\
\hline CHEMBL1308689 & 688759 & 4.45 & 4.59699 & 99999999995 & TRN \\
\hline CHEMBL1372137 & 688759 & 6.25 & 4.9175 & TRN & \\
\hline CHEMBL1564558 & 688759 & 4.65 & 4.9298 & TST & \\
\hline CHEMBL 3145380 & 688759 & 5.0 & 5.3822 & TRN & \\
\hline CHEMBL1368559 & 688759 & 4.45 & 4.8935 & TRN & \\
\hline CHEMBL1560014 & 688759 & 4.85 & 4.9483 & TST & \\
\hline CHEMBL1370453 & 688759 & 4.45 & 5.1681 & TRN & \\
\hline CHEMBL1310861 & 688759 & 4.7 & 4.7341 & TST & \\
\hline CHEMBL1431565 & 688759 & 5.35 & 5.5502 & TRN & \\
\hline CHEMBL1320084 & 688759 & 5.2 & 4.8772 & TRN & \\
\hline CHEMBL 3197453 & 688759 & 4.7 & 5.0406 & TRN & \\
\hline CHEMBL1512222 & 688759 & 4.7 & 4.6336 & TRN & \\
\hline CHEMBL1581769 & 688759 & 5.2 & 5.3498 & TRN & \\
\hline
\end{tabular}




\begin{tabular}{|c|c|c|c|c|c|}
\hline & & & & & \\
\hline CHEMBL1472154 & 688759 & 4.5 & 4.7892 & TRN & \\
\hline CHEMBL1489271 & 688759 & 5.2 & 4.9497 & TRN & \\
\hline CHEMBL1404447 & 688759 & 4.5 & 4.4475 & TRN & \\
\hline CHEMBL1989723 & 688759 & 4.75 & 4.6418 & TRN & \\
\hline CHEMBL1344582 & 688759 & 5.6 & 5.54299 & 9999999999 & TRN \\
\hline CHEMBL1560181 & 688759 & 5.35 & 5.0524 & TRN & \\
\hline CHEMBL1537624 & 688759 & 4.65 & 4.8585 & TRN & \\
\hline CHEMBL1333266 & 688759 & 4.85 & 4.9961 & TRN & \\
\hline CHEMBL1460624 & 688759 & 4.45 & 4.8586 & TST & \\
\hline CHEMBL 2373646 & 688759 & 5.2 & 4.9726 & TRN & \\
\hline CHEMBL1310318 & 688759 & 5.55 & 5.1336 & TST & \\
\hline CHEMBL1548873 & 688759 & 4.45 & 4.4848 & TRN & \\
\hline CHEMBL1421182 & 688759 & 4.55 & 4.8203 & TRN & \\
\hline CHEMBL1534592 & 688759 & 5.0 & 5.0738 & TRN & \\
\hline CHEMBL1373338 & 688759 & 6.5501 & 4.9689 & TRN & \\
\hline CHEMBL3190012 & 688759 & 5.55 & 5.4704 & TRN & \\
\hline CHEMBL1349757 & 688759 & 4.9 & 5.1408 & TRN & \\
\hline CHEMBL502774 & 688759 & 4.45 & 5.6144 & TRN & \\
\hline CHEMBL1552476 & 688759 & 4.65 & 4.6865 & TST & \\
\hline CHEMBL1490899 & 688759 & 4.55 & 4.8486 & TRN & \\
\hline CHEMBL1353124 & 688759 & 4.45 & 4.8905 & TRN & \\
\hline CHEMBL1301812 & 688759 & 4.95 & 5.1155 & TRN & \\
\hline CHEMBL 1442517 & 688759 & 5.4 & 6.1621 & TST & \\
\hline CHEMBL1328579 & 688759 & 4.9 & 4.8739 & TRN & \\
\hline CHEMBL1516784 & 688759 & 6.15 & 4.9372 & TRN & \\
\hline CHEMBL1382323 & 688759 & 4.9 & 4.8239 & TRN & \\
\hline CHEMBL1483623 & 688759 & 5.05 & 4.6092 & TRN & \\
\hline CHEMBL3196139 & 688759 & 6.8499 & 6.0918 & TRN & \\
\hline CHEMBL1493028 & 688759 & 5.55 & 5.1585 & TRN & \\
\hline CHEMBL1522486 & 688759 & 4.55 & 5.4704 & TRN & \\
\hline CHEMBL 2001950 & 688759 & 4.45 & 4.8367 & TRN & \\
\hline CHEMBL1576979 & 688759 & 5.1 & 4.7384 & TRN & \\
\hline CHEMBL3196872 & 688759 & 4.6 & 4.7577 & TRN & \\
\hline CHEMBL1987343 & 688759 & 4.95 & 5.2711 & TRN & \\
\hline CHEMBL1467762 & 688759 & 5.2 & 5.0162 & TST & \\
\hline CHEMBL1568373 & 688759 & 4.45 & 6.1182 & TRN & \\
\hline CHEMBL1526414 & 688759 & 4.45 & 4.6742 & TRN & \\
\hline CHEMBL3197004 & 688759 & 4.8 & 4.8867 & TRN & \\
\hline CHEMBL3210819 & 688759 & 5.0 & 4.8929 & TRN & \\
\hline CHEMBL 1367422 & 688759 & 4.45 & 4.9098 & TST & \\
\hline CHEMBL1443336 & 688759 & 4.45 & 4.6718 & TRN & \\
\hline CHEMBL1421305 & 688759 & 5.35 & 4.8796 & TST & \\
\hline CHEMBL1369602 & 688759 & 5.0 & 5.4187 & TRN & \\
\hline CHEMBL3144954 & 688759 & 4.85 & 4.9735 & TST & \\
\hline CHEMBL1410621 & 688759 & 4.75 & 4.5335 & TRN & \\
\hline CHEMBL1430919 & 688759 & 4.45 & 4.6835 & TRN & \\
\hline CHEMBL1521242 & 688759 & 5.3 & 5.0276 & TST & \\
\hline CHEMBL1541649 & 688759 & 5.15 & 5.0466 & TRN & \\
\hline & & & & 15117 & \\
\hline
\end{tabular}




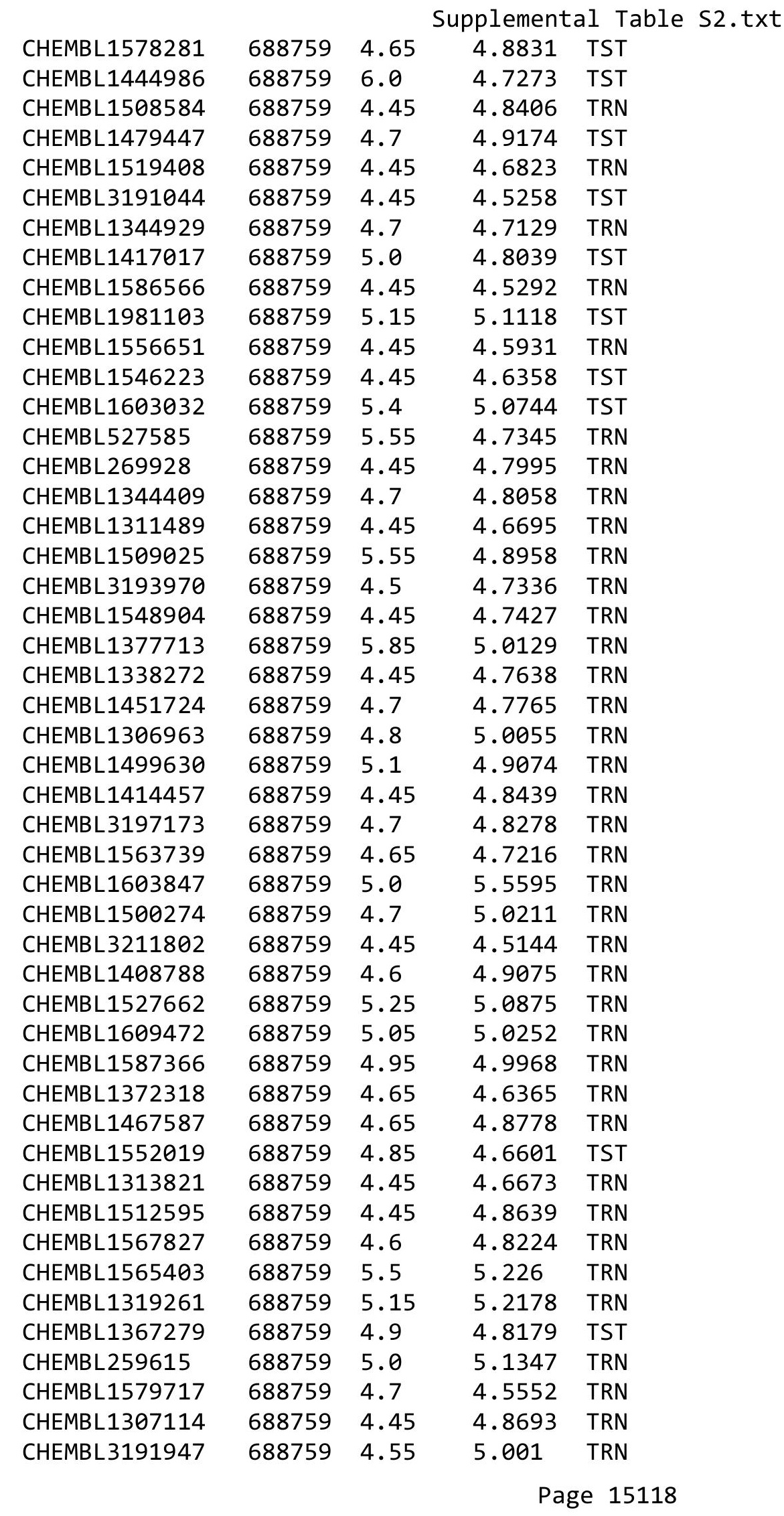




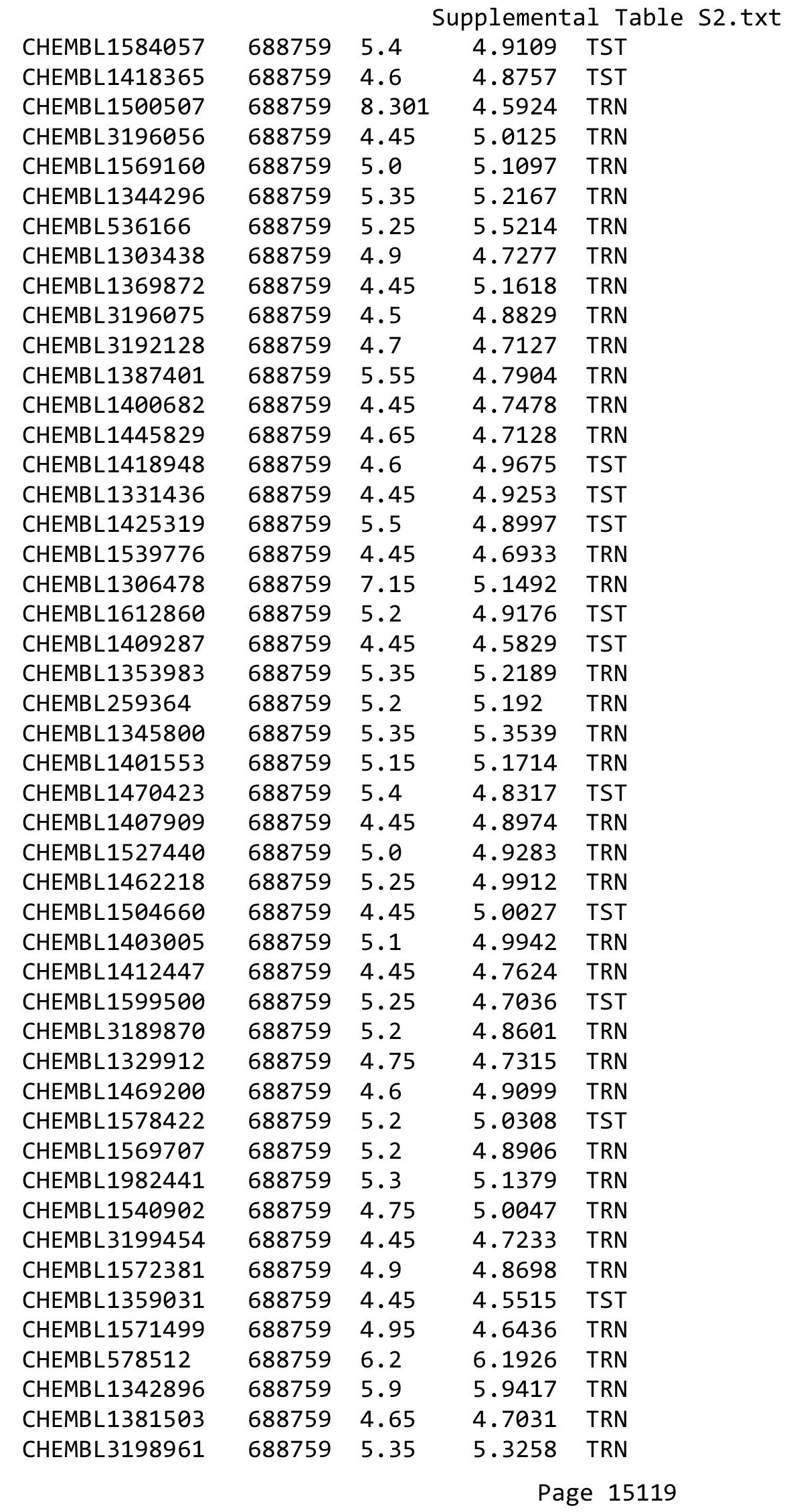




\begin{tabular}{|c|c|c|c|c|}
\hline & & & upplement & al $\mathrm{T}$ \\
\hline CHEMBL1354181 & 688759 & 4.65 & 4.6409 & TST \\
\hline CHEMBL1569760 & 688759 & 5.15 & 5.3494 & TST \\
\hline CHEMBL1988500 & 688759 & 5.9 & 5.5585 & TRN \\
\hline CHEMBL1326533 & 688759 & 5.8 & 4.849 & TRN \\
\hline CHEMBL1422487 & 688759 & 4.45 & 4.9773 & TRN \\
\hline CHEMBL1427189 & 688759 & 4.95 & 4.7505 & TST \\
\hline CHEMBL1609841 & 688759 & 4.45 & 4.6614 & TRN \\
\hline CHEMBL1343879 & 688759 & 5.9 & 5.6738 & TRN \\
\hline CHEMBL1378880 & 688759 & 4.95 & 4.6609 & TRN \\
\hline CHEMBL1360066 & 688759 & 4.55 & 4.522 & TRN \\
\hline CHEMBL1361904 & 688759 & 4.6 & 4.5898 & TST \\
\hline CHEMBL1568551 & 688759 & 4.5 & 4.6002 & TST \\
\hline CHEMBL1420282 & 688759 & 4.6 & 4.9135 & TRN \\
\hline CHEMBL1985606 & 688759 & 5.4 & 5.3937 & TRN \\
\hline CHEMBL1611030 & 688759 & 4.6 & 4.8122 & TRN \\
\hline CHEMBL1399857 & 688759 & 4.8 & 4.6351 & TST \\
\hline CHEMBL1372007 & 688759 & 5.15 & 5.7931 & TRN \\
\hline CHEMBL1502457 & 688759 & 4.8 & 4.7472 & TRN \\
\hline CHEMBL1543395 & 688759 & 5.0 & 4.7523 & TRN \\
\hline CHEMBL1495244 & 688759 & 4.75 & 4.6893 & TRN \\
\hline CHEMBL1529472 & 688759 & 4.95 & 4.9111 & TST \\
\hline CHEMBL1562777 & 688759 & 4.45 & 5.4861 & TRN \\
\hline CHEMBL1376126 & 688759 & 4.6 & 5.0432 & TRN \\
\hline CHEMBL3207664 & 688759 & 4.85 & 4.8052 & TST \\
\hline CHEMBL1413901 & 688759 & 5.1 & 5.3631 & TRN \\
\hline CHEMBL1424653 & 688759 & 4.95 & 4.617 & TRN \\
\hline CHEMBL1575985 & 688759 & 4.45 & 4.6124 & TRN \\
\hline CHEMBL1504299 & 688759 & 4.45 & 4.3826 & TRN \\
\hline CHEMBL1601853 & 688759 & 4.95 & 4.8275 & TRN \\
\hline CHEMBL1412324 & 688759 & 4.45 & 4.9513 & TRN \\
\hline CHEMBL1419983 & 688759 & 4.45 & 4.562 & TRN \\
\hline CHEMBL1981797 & 688759 & 5.7 & 5.2989 & TRN \\
\hline CHEMBL1505221 & 688759 & 4.45 & 4.6048 & TST \\
\hline CHEMBL1321639 & 688759 & 5.0 & 4.8727 & TRN \\
\hline CHEMBL1579305 & 688759 & 4.45 & 4.8391 & TRN \\
\hline CHEMBL1404654 & 688759 & 4.65 & 4.6985 & TST \\
\hline CHEMBL1518452 & 688759 & 4.9 & 4.7505 & TRN \\
\hline CHEMBL1428785 & 688759 & 4.65 & 4.5055 & TST \\
\hline CHEMBL1495590 & 688759 & 4.8 & 4.7978 & TRN \\
\hline CHEMBL3192766 & 688759 & 4.95 & 5.2232 & TRN \\
\hline CHEMBL3193209 & 688759 & 4.45 & 4.7615 & TRN \\
\hline CHEMBL1346653 & 688759 & 4.5 & 4.8331 & TRN \\
\hline CHEMBL1299822 & 688759 & 4.45 & 4.7302 & TRN \\
\hline CHEMBL1347467 & 688759 & 4.45 & 4.7978 & TST \\
\hline CHEMBL1982658 & 688759 & 4.45 & 4.7146 & TRN \\
\hline CHEMBL1385608 & 688759 & 5.4 & 4.758 & TST \\
\hline CHEMBL1351455 & 688759 & 4.45 & 4.777 & TST \\
\hline CHEMBL1526831 & 688759 & 4.45 & 4.6421 & TRN \\
\hline
\end{tabular}




\begin{tabular}{|c|c|c|c|c|}
\hline \multicolumn{5}{|c|}{ Supplemental Table S2.txt } \\
\hline CHEMBL3196305 & 688759 & 5.2 & 5.6724 & TRN \\
\hline CHEMBL1484292 & 688759 & 4.7 & 4.8305 & TRN \\
\hline CHEMBL1459008 & 688759 & 5.25 & 5.0522 & TRN \\
\hline CHEMBL1585349 & 688759 & 5.15 & 5.6208 & TRN \\
\hline CHEMBL1330231 & 688759 & 4.85 & 4.9231 & TRN \\
\hline CHEMBL1423783 & 688759 & 5.0 & 5.0078 & TRN \\
\hline CHEMBL1442105 & 688759 & 5.25 & 4.9648 & TRN \\
\hline CHEMBL3196817 & 688759 & 4.9 & 4.9759 & TST \\
\hline CHEMBL1412177 & 688759 & 5.35 & 5.1199 & TRN \\
\hline CHEMBL3199120 & 688759 & 6.05 & 5.6678 & TRN \\
\hline CHEMBL1548564 & 688759 & 4.9 & 4.5217 & TRN \\
\hline CHEMBL1603658 & 688759 & 4.6 & 4.9062 & TRN \\
\hline CHEMBL119556 & 688759 & 4.75 & 5.5499 & TRN \\
\hline CHEMBL1459266 & 688759 & 4.9 & 5.0785 & TRN \\
\hline CHEMBL3194855 & 688759 & 4.85 & 5.1361 & TRN \\
\hline CHEMBL1544159 & 688759 & 4.85 & 4.9567 & TRN \\
\hline CHEMBL1487681 & 688759 & 5.3 & 4.962 & TRN \\
\hline CHEMBL3196743 & 688759 & 5.0 & 5.2097 & TST \\
\hline CHEMBL1381742 & 688759 & 5.35 & 4.7158 & TST \\
\hline CHEMBL1610860 & 688759 & 4.45 & 4.8848 & TRN \\
\hline CHEMBL1304187 & 688759 & 5.5 & 4.9762 & TRN \\
\hline CHEMBL1345869 & 688759 & 4.8 & 4.7837 & TRN \\
\hline CHEMBL1577692 & 688759 & 4.9 & 4.8596 & TRN \\
\hline CHEMBL1410809 & 688759 & 4.6 & 4.6662 & TRN \\
\hline CHEMBL1572219 & 688759 & 4.45 & 4.7483 & TRN \\
\hline CHEMBL1608383 & 688759 & 5.6 & 5.2285 & TRN \\
\hline CHEMBL1448743 & 688759 & 5.95 & 5.4403 & TRN \\
\hline CHEMBL3189401 & 688759 & 4.45 & 4.6576 & TRN \\
\hline CHEMBL1456911 & 688759 & 4.45 & 4.8061 & TRN \\
\hline CHEMBL3197038 & 688759 & 3.75 & 4.4985 & TST \\
\hline CHEMBL1386161 & 688759 & 4.45 & 4.9427 & TRN \\
\hline CHEMBL1447072 & 688759 & 4.9 & 4.7664 & TRN \\
\hline CHEMBL1577342 & 688759 & 4.75 & 4.6143 & TRN \\
\hline CHEMBL1444231 & 688759 & 4.45 & 4.914 & TST \\
\hline CHEMBL1533899 & 688759 & 5.65 & 4.6571 & TRN \\
\hline CHEMBL1398592 & 688759 & 4.45 & 4.5712 & TRN \\
\hline CHEMBL1498227 & 688759 & 4.8 & 4.6552 & TRN \\
\hline CHEMBL1539429 & 688759 & 4.45 & 4.8318 & TRN \\
\hline CHEMBL 3208020 & 688759 & 4.8 & 4.8437 & TRN \\
\hline CHEMBL1591194 & 688759 & 4.45 & 4.9956 & TRN \\
\hline CHEMBL1413363 & 688759 & 4.45 & 4.784 & TRN \\
\hline CHEMBL 1373840 & 688759 & 4.65 & 4.9105 & TRN \\
\hline CHEMBL1351311 & 688759 & 4.45 & 4.9611 & TRN \\
\hline CHEMBL1606593 & 688759 & 4.45 & 4.4836 & TRN \\
\hline CHEMBL3195032 & 688759 & 5.3 & 5.0115 & TRN \\
\hline CHEMBL1485579 & 688759 & 4.45 & 4.5885 & TRN \\
\hline CHEMBL1426407 & 688759 & 5.5 & 4.8812 & TRN \\
\hline CHEMBL1405320 & 688759 & 6.5 & 6.0035 & TRN \\
\hline
\end{tabular}




\begin{tabular}{|c|c|c|c|c|c|}
\hline \\
\hline CHEMBL1377737 & 688759 & 5.4 & 5.7007 & TRN & \\
\hline CHEMBL1344836 & 688759 & 4.45 & 4.7889 & TRN & \\
\hline CHEMBL1429565 & 688759 & 4.65 & 4.9799 & TRN & \\
\hline CHEMBL1398922 & 688759 & 4.5 & 4.7799 & TRN & \\
\hline CHEMBL1543172 & 688759 & 4.45 & 4.57600 & 00000000005 & TST \\
\hline CHEMBL1448400 & 688759 & 4.7 & 4.8641 & TRN & \\
\hline CHEMBL1463284 & 688759 & 4.6 & 4.7455 & TST & \\
\hline CHEMBL1548223 & 688759 & 4.7 & 4.6622 & TRN & \\
\hline CHEMBL1421390 & 688759 & 4.8 & 4.8925 & TRN & \\
\hline CHEMBL1445909 & 688759 & 5.0 & 5.3417 & TRN & \\
\hline CHEMBL1605478 & 688759 & 6.25 & 5.0218 & TRN & \\
\hline CHEMBL1334055 & 688759 & 5.45 & 4.918 & TST & \\
\hline CHEMBL1420007 & 688759 & 5.1 & 4.5564 & TRN & \\
\hline CHEMBL1539074 & 688759 & 5.6 & 5.4418 & TRN & \\
\hline CHEMBL1558637 & 688759 & 4.9 & 4.9698 & TST & \\
\hline CHEMBL1458320 & 688759 & 6.1 & 5.5199 & TRN & \\
\hline CHEMBL1576144 & 688759 & 4.95 & 4.8699 & TRN & \\
\hline CHEMBL1432860 & 688759 & 5.2 & 4.8664 & TRN & \\
\hline CHEMBL1447081 & 688759 & 4.45 & 4.6248 & TRN & \\
\hline CHEMBL1486691 & 688759 & 4.45 & 4.8547 & TST & \\
\hline CHEMBL1373217 & 688759 & 4.45 & 4.5825 & TRN & \\
\hline CHEMBL1532925 & 688759 & 4.55 & 5.0583 & TST & \\
\hline CHEMBL1491451 & 688759 & 5.6 & 4.7969 & TST & \\
\hline CHEMBL1457955 & 688759 & 4.45 & 4.8126 & TRN & \\
\hline CHEMBL1565122 & 688759 & 5.2 & 4.853 & TRN & \\
\hline CHEMBL1302130 & 688759 & 5.85 & 5.57299 & 99999999995 & TST \\
\hline CHEMBL1604502 & 688759 & 5.25 & 4.8333 & TRN & \\
\hline CHEMBL1373486 & 688759 & 4.45 & 4.5709 & TST & \\
\hline CHEMBL1373253 & 688759 & 4.6 & 4.7472 & TST & \\
\hline CHEMBL455399 & 688759 & 4.45 & 4.8188 & TRN & \\
\hline CHEMBL1442111 & 688759 & 4.45 & 4.8537 & TRN & \\
\hline CHEMBL1351963 & 688759 & 5.35 & 5.1325 & TRN & \\
\hline CHEMBL1601897 & 688759 & 4.45 & 4.8487 & TST & \\
\hline CHEMBL1323732 & 688759 & 4.65 & 4.6943 & TRN & \\
\hline CHEMBL1393877 & 688759 & 4.75 & 5.0501 & TRN & \\
\hline CHEMBL1504595 & 688759 & 4.45 & 5.0088 & TST & \\
\hline CHEMBL1452189 & 688759 & 5.2 & 4.69600 & 3000000001 & TRN \\
\hline CHEMBL1454811 & 688759 & 4.45 & 4.5741 & TRN & \\
\hline CHEMBL1452313 & 688759 & 4.45 & 4.7815 & TST & \\
\hline CHEMBL1388440 & 688759 & 4.95 & 4.9353 & TRN & \\
\hline CHEMBL1311768 & 688759 & 4.65 & 4.9172 & TST & \\
\hline CHEMBL1450896 & 688759 & 4.45 & 4.9473 & TRN & \\
\hline CHEMBL1579217 & 688759 & 5.15 & 5.1114 & TRN & \\
\hline CHEMBL1399452 & 688759 & 4.75 & 4.8299 & TRN & \\
\hline CHEMBL1573891 & 688759 & 5.3 & 5.0102 & TRN & \\
\hline CHEMBL1431538 & 688759 & 4.45 & 4.7957 & TRN & \\
\hline CHEMBL1518456 & 688759 & 4.45 & 5.51 & TRN & \\
\hline CHEMBL1459781 & 688759 & 4.7 & 4.7333 & TRN & \\
\hline
\end{tabular}




\begin{tabular}{|c|c|c|c|c|c|}
\hline & & \multicolumn{4}{|c|}{ Supplemental Table S2.txt } \\
\hline CHEMBL1521758 & 688759 & 4.45 & 4.7973 & TST & \\
\hline CHEMBL1451931 & 688759 & 4.45 & 4.8726 & TRN & \\
\hline CHEMBL1329138 & 688759 & 6.25 & 5.4063 & TRN & \\
\hline CHEMBL1429647 & 688759 & 6.25 & 4.9854 & TST & \\
\hline CHEMBL 3213807 & 688759 & 5.45 & 4.6259 & TRN & \\
\hline CHEMBL1460750 & 688759 & 5.3 & 5.36700 & 0000000001 & TRN \\
\hline CHEMBL3209255 & 688759 & 5.15 & 4.784 & TRN & \\
\hline CHEMBL1489007 & 688759 & 4.6 & 4.9625 & TST & \\
\hline CHEMBL3194335 & 688759 & 4.75 & 4.8511 & TRN & \\
\hline CHEMBL1599165 & 688759 & 4.95 & 5.0712 & TRN & \\
\hline CHEMBL1454070 & 688759 & 4.75 & 4.9092 & TRN & \\
\hline CHEMBL3210192 & 688759 & 4.45 & 4.8072 & TRN & \\
\hline CHEMBL1492272 & 688759 & 4.55 & 4.9094 & TRN & \\
\hline CHEMBL1535379 & 688759 & 5.35 & 5.2125 & TRN & \\
\hline CHEMBL1528131 & 688759 & 4.6 & 4.7936 & TRN & \\
\hline CHEMBL1340363 & 688759 & 4.45 & 5.019 & TST & \\
\hline CHEMBL1325331 & 688759 & 4.65 & 4.7279 & TRN & \\
\hline CHEMBL1302175 & 688759 & 4.45 & 5.0654 & TRN & \\
\hline CHEMBL1307766 & 688759 & 4.7 & 4.9221 & TRN & \\
\hline CHEMBL1572087 & 688759 & 4.65 & 4.9024 & TST & \\
\hline CHEMBL1453212 & 688759 & 4.8 & 4.8569 & TST & \\
\hline CHEMBL1501204 & 688759 & 4.95 & 4.8355 & TST & \\
\hline CHEMBL1332955 & 688759 & 4.85 & 4.7817 & TRN & \\
\hline CHEMBL1404052 & 688759 & 4.8 & 4.9566 & TRN & \\
\hline CHEMBL1461853 & 688759 & 4.45 & 4.7896 & TRN & \\
\hline CHEMBL1409513 & 688759 & 4.8 & 5.2983 & TRN & \\
\hline CHEMBL1304402 & 688759 & 5.3 & 5.5503 & TRN & \\
\hline CHEMBL1561420 & 688759 & 4.5 & 4.9413 & TRN & \\
\hline CHEMBL 3214605 & 688759 & 4.95 & 4.7665 & TRN & \\
\hline CHEMBL1562495 & 688759 & 4.7 & 4.7585 & TRN & \\
\hline CHEMBL3198896 & 688759 & 4.45 & 4.8571 & TST & \\
\hline CHEMBL1303620 & 688759 & 5.35 & 5.2216 & TRN & \\
\hline CHEMBL1370623 & 688759 & 4.95 & 5.8051 & TRN & \\
\hline CHEMBL1349903 & 688759 & 4.7 & 5.0691 & TST & \\
\hline CHEMBL1531753 & 688759 & 4.75 & 4.7987 & TRN & \\
\hline CHEMBL1507266 & 688759 & 4.7 & 5.0598 & TRN & \\
\hline CHEMBL3198122 & 688759 & 5.2 & 4.9295 & TST & \\
\hline CHEMBL1606685 & 688759 & 6.0 & 5.7669 & TRN & \\
\hline CHEMBL1403969 & 688759 & 4.65 & 4.8393 & TST & \\
\hline CHEMBL1535539 & 688759 & 4.45 & 5.1604 & TST & \\
\hline CHEMBL1410405 & 688759 & 4.45 & 4.7641 & TST & \\
\hline CHEMBL1432336 & 688759 & 4.45 & 4.8746 & TRN & \\
\hline CHEMBL565893 & 688759 & 4.75 & 4.8277 & TRN & \\
\hline CHEMBL1312050 & 688759 & 4.75 & 4.7206 & TST & \\
\hline CHEMBL1301364 & 688759 & 4.75 & 4.378 & TRN & \\
\hline CHEMBL1530692 & 688759 & 4.9 & 4.9086 & TST & \\
\hline CHEMBL1424688 & 688759 & 5.25 & 5.0289 & TRN & \\
\hline CHEMBL1364853 & 688759 & 4.95 & 5.3007 & TRN & \\
\hline
\end{tabular}




\begin{tabular}{|c|c|c|c|c|c|}
\hline \multicolumn{6}{|c|}{ Supplemental Table S2.txt } \\
\hline CHEMBL3192858 & 688759 & 5.4 & 5.777 & TRN & \\
\hline CHEMBL3199735 & 688759 & 4.85 & 5.077 & TRN & \\
\hline CHEMBL1564487 & 688759 & 5.2 & 5.2507 & TRN & \\
\hline CHEMBL1368700 & 688759 & 4.8 & 5.0015 & TST & \\
\hline CHEMBL1497196 & 688759 & 4.45 & 4.8981 & TRN & \\
\hline CHEMBL1346753 & 688759 & 5.25 & 5.027 & TRN & \\
\hline CHEMBL1329126 & 688759 & 4.45 & 4.7698 & TRN & \\
\hline CHEMBL1470537 & 688759 & 5.4 & 4.7295 & TST & \\
\hline CHEMBL1353845 & 688759 & 5.35 & 5.2246 & TRN & \\
\hline CHEMBL1459903 & 688759 & 4.85 & 4.9517 & TRN & \\
\hline CHEMBL1456801 & 688759 & 4.65 & 4.6584 & TST & \\
\hline CHEMBL3194489 & 688759 & 4.75 & 4.9306 & TRN & \\
\hline CHEMBL1348555 & 688759 & 4.45 & 5.05399 & 9999999999 & TRN \\
\hline CHEMBL1989179 & 688759 & 4.45 & 4.7522 & TRN & \\
\hline CHEMBL1561887 & 688759 & 4.6 & 5.2879 & TST & \\
\hline CHEMBL3212910 & 688759 & 4.45 & 4.8173 & TRN & \\
\hline CHEMBL1443258 & 688759 & 4.75 & 4.9145 & TRN & \\
\hline CHEMBL1487813 & 688759 & 4.9 & 4.6502 & TST & \\
\hline CHEMBL1536460 & 688759 & 5.25 & 5.0613 & TRN & \\
\hline CHEMBL1408585 & 688759 & 5.95 & 5.6345 & TRN & \\
\hline CHEMBL1501774 & 688759 & 5.9 & 4.891 & TRN & \\
\hline CHEMBL1339208 & 688759 & 4.45 & 4.7206 & TRN & \\
\hline CHEMBL1375889 & 688759 & 4.9 & 4.7072 & TST & \\
\hline CHEMBL1325260 & 688759 & 5.3 & 5.0939 & TRN & \\
\hline CHEMBL1555208 & 688759 & 4.45 & 4.6677 & TST & \\
\hline CHEMBL1377693 & 688759 & 5.0 & 4.8243 & TRN & \\
\hline CHEMBL1299492 & 688759 & 4.6 & 4.9102 & TST & \\
\hline CHEMBL1363178 & 688759 & 5.05 & 5.1441 & TRN & \\
\hline CHEMBL1352538 & 688759 & 6.2 & 4.8423 & TRN & \\
\hline CHEMBL1494812 & 688759 & 4.9 & 5.3957 & TST & \\
\hline CHEMBL1341308 & 688759 & 4.45 & 4.6957 & TST & \\
\hline CHEMBL1311520 & 688759 & 4.45 & 4.9498 & TRN & \\
\hline CHEMBL1312126 & 688759 & 4.45 & 4.8316 & TRN & \\
\hline CHEMBL3193542 & 688759 & 5.1 & 4.9725 & TRN & \\
\hline CHEMBL1418214 & 688759 & 5.3 & 4.9726 & TST & \\
\hline CHEMBL1460085 & 688759 & 5.95 & 5.5492 & TRN & \\
\hline CHEMBL1992801 & 688759 & 4.8 & 5.0463 & TRN & \\
\hline CHEMBL1607138 & 688759 & 4.95 & 4.5949 & TRN & \\
\hline CHEMBL1404906 & 688759 & 5.0 & 4.8874 & TRN & \\
\hline CHEMBL1382236 & 688759 & 4.45 & 4.7898 & TRN & \\
\hline CHEMBL1979558 & 688759 & 4.45 & 5.3595 & TST & \\
\hline CHEMBL1379451 & 688759 & 4.6 & 4.8949 & TRN & \\
\hline CHEMBL1527885 & 688759 & 4.7 & 4.5973 & TST & \\
\hline CHEMBL1363123 & 688759 & 4.55 & 4.7726 & TRN & \\
\hline CHEMBL1577336 & 688759 & 4.45 & 4.8953 & TRN & \\
\hline CHEMBL1343298 & 688759 & 4.45 & 4.4921 & TST & \\
\hline CHEMBL1391518 & 688759 & 4.95 & 5.0194 & TRN & \\
\hline CHEMBL1571642 & 688759 & 4.6 & 4.8702 & TRN & \\
\hline
\end{tabular}




\begin{tabular}{|c|c|c|c|c|}
\hline \multicolumn{5}{|c|}{ Supplemental Table S2.txt } \\
\hline CHEMBL1563743 & 688759 & 4.8 & 4.8008 & TRN \\
\hline CHEMBL1540919 & 688759 & 4.6 & 4.8442 & TST \\
\hline CHEMBL1300278 & 688759 & 5.35 & 4.4953 & TRN \\
\hline CHEMBL1331231 & 688759 & 4.45 & 4.5408 & TRN \\
\hline CHEMBL1449997 & 688759 & 5.15 & 5.0548 & TRN \\
\hline CHEMBL494083 & 688759 & 4.45 & 5.0594 & TST \\
\hline CHEMBL 3212000 & 688759 & 4.85 & 4.7423 & TRN \\
\hline CHEMBL1430718 & 688759 & 4.45 & 4.768 & TRN \\
\hline CHEMBL1307972 & 688759 & 5.15 & 5.3533 & TRN \\
\hline CHEMBL1595941 & 688759 & 4.65 & 4.7504 & TRN \\
\hline CHEMBL1424951 & 688759 & 4.9 & 4.6134 & TRN \\
\hline CHEMBL1341513 & 688759 & 4.45 & 4.6803 & TST \\
\hline CHEMBL1484306 & 688759 & 4.45 & 4.74 & TRN \\
\hline CHEMBL1519734 & 688759 & 4.6 & 4.7361 & TRN \\
\hline CHEMBL1534507 & 688759 & 4.65 & 4.5828 & TRN \\
\hline CHEMBL1531990 & 688759 & 4.9 & 4.9603 & TRN \\
\hline CHEMBL1391810 & 688759 & 4.55 & 5.7191 & TRN \\
\hline CHEMBL1567097 & 688759 & 4.45 & 5.1239 & TST \\
\hline CHEMBL1390293 & 688759 & 5.4 & 4.6736 & TRN \\
\hline CHEMBL1339179 & 688759 & 4.55 & 4.69 & TRN \\
\hline CHEMBL1539529 & 688759 & 5.1 & 5.0646 & TRN \\
\hline CHEMBL1558160 & 688759 & 5.1 & 4.9201 & TRN \\
\hline CHEMBL1563340 & 688759 & 5.25 & 5.0015 & TRN \\
\hline CHEMBL1392838 & 688759 & 6.0 & 4.6844 & TRN \\
\hline CHEMBL1483577 & 688759 & 5.5 & 5.3372 & TRN \\
\hline CHEMBL1319037 & 688759 & 5.0 & 4.9746 & TRN \\
\hline CHEMBL3196684 & 688759 & 4.95 & 4.7334 & TRN \\
\hline CHEMBL1431075 & 688759 & 4.45 & 4.954 & TRN \\
\hline CHEMBL1337409 & 688759 & 5.2 & 5.3709 & TRN \\
\hline CHEMBL1530261 & 688759 & 4.45 & 4.8359 & TRN \\
\hline CHEMBL1405435 & 688759 & 5.15 & 4.8415 & TRN \\
\hline CHEMBL1360654 & 688759 & 4.65 & 4.9485 & TRN \\
\hline CHEMBL1485614 & 688759 & 5.1 & 5.0845 & TRN \\
\hline CHEMBL587919 & 688759 & 4.5 & 4.8473 & TRN \\
\hline CHEMBL1603730 & 688759 & 4.7 & 4.7025 & TRN \\
\hline CHEMBL1589431 & 688759 & 4.9 & 4.6118 & TRN \\
\hline CHEMBL1411596 & 688759 & 5.2 & 4.8991 & TRN \\
\hline CHEMBL1388895 & 688759 & 5.8 & 5.6276 & TRN \\
\hline CHEMBL 3189212 & 688759 & 4.6 & 4.9836 & TST \\
\hline CHEMBL1173693 & 688759 & 4.65 & 4.8025 & TST \\
\hline CHEMBL1977568 & 688759 & 4.5 & 5.1192 & TRN \\
\hline CHEMBL1576836 & 688759 & 4.65 & 4.8052 & TRN \\
\hline CHEMBL3197029 & 688759 & 4.45 & 4.8766 & TRN \\
\hline CHEMBL1427706 & 688759 & 4.9 & 4.998 & TST \\
\hline CHEMBL1580075 & 688759 & 4.55 & 5.0376 & TRN \\
\hline CHEMBL1420139 & 688759 & 4.9 & 5.1991 & TRN \\
\hline CHEMBL1449195 & 688759 & 5.15 & 5.2217 & TRN \\
\hline CHEMBL1524254 & 688759 & 5.4 & 4.7224 & TRN \\
\hline
\end{tabular}




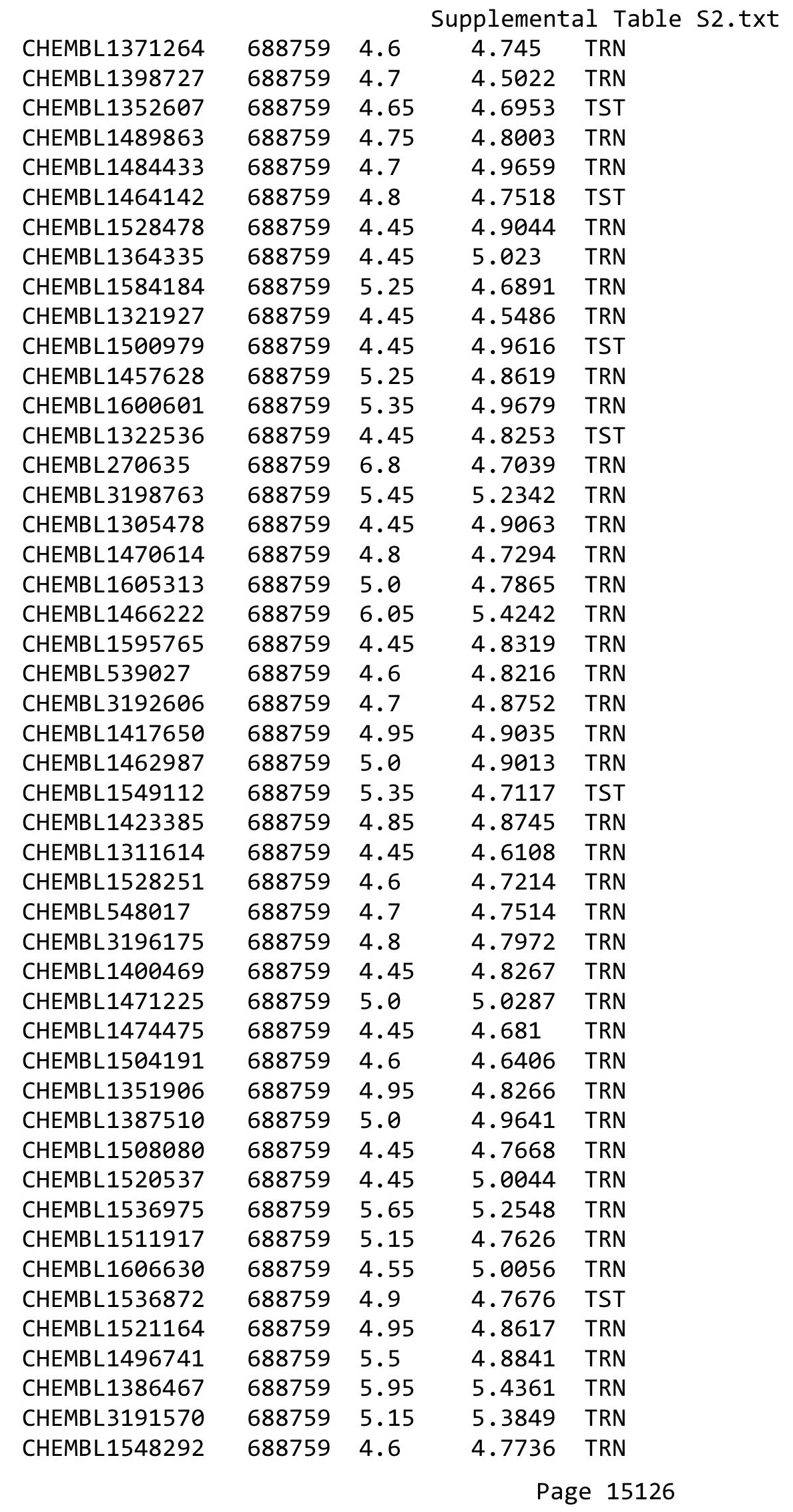




\begin{tabular}{|c|c|c|c|c|c|}
\hline \\
\hline CHEMBL1499996 & 688759 & 5.3 & 5.0666 & TRN & \\
\hline CHEMBL1340284 & 688759 & 4.9 & 4.843 & TST & \\
\hline CHEMBL3191103 & 688759 & 4.8 & 4.9179 & TRN & \\
\hline CHEMBL1523020 & 688759 & 4.45 & 4.90300 & 00000000005 & TRN \\
\hline CHEMBL1423551 & 688759 & 5.15 & 5.2052 & TRN & \\
\hline CHEMBL1499080 & 688759 & 5.15 & 4.7637 & TRN & \\
\hline CHEMBL1510023 & 688759 & 4.9 & 5.1992 & TRN & \\
\hline CHEMBL1569012 & 688759 & 5.35 & 4.8186 & TRN & \\
\hline CHEMBL1566434 & 688759 & 4.95 & 5.2954 & TRN & \\
\hline CHEMBL1481546 & 688759 & 4.9 & 4.9311 & TRN & \\
\hline CHEMBL1391073 & 688759 & 4.5 & 4.5783 & TRN & \\
\hline CHEMBL1543133 & 688759 & 4.5 & 4.8593 & TRN & \\
\hline CHEMBL1303872 & 688759 & 4.45 & 4.7749 & TRN & \\
\hline CHEMBL1384649 & 688759 & 6.05 & 5.6551 & TRN & \\
\hline CHEMBL19231 & 688759 & 4.45 & 4.7876 & TST & \\
\hline CHEMBL1533104 & 688759 & 4.9 & 4.6289 & TRN & \\
\hline CHEMBL1542458 & 688759 & 5.25 & 4.896 & TST & \\
\hline CHEMBL1606023 & 688759 & 4.7 & 5.0333 & TST & \\
\hline CHEMBL3198456 & 688759 & 4.65 & 4.6726 & TRN & \\
\hline CHEMBL1573692 & 688759 & 4.45 & 4.5137 & TRN & \\
\hline CHEMBL1541331 & 688759 & 4.45 & 4.9804 & TST & \\
\hline CHEMBL1384673 & 688759 & 5.0 & 5.1151 & TRN & \\
\hline CHEMBL1443478 & 688759 & 5.3 & 4.9717 & TRN & \\
\hline CHEMBL1305633 & 688759 & 5.3 & 5.2462 & TRN & \\
\hline CHEMBL3213107 & 688759 & 5.4 & 5.4485 & TRN & \\
\hline CHEMBL1474988 & 688759 & 4.65 & 4.5063 & TST & \\
\hline CHEMBL1336422 & 688759 & 4.45 & 4.8111 & TRN & \\
\hline CHEMBL1463115 & 688759 & 4.65 & 4.7712 & TRN & \\
\hline CHEMBL1381031 & 688759 & 5.3 & 4.835 & TRN & \\
\hline CHEMBL1386486 & 688759 & 5.25 & 4.9546 & TST & \\
\hline CHEMBL1496605 & 688759 & 4.45 & 4.7157 & TRN & \\
\hline CHEMBL1364763 & 688759 & 4.9 & 4.9583 & TRN & \\
\hline CHEMBL2374086 & 688759 & 5.2 & 5.1487 & TRN & \\
\hline CHEMBL1524688 & 688759 & 5.55 & 5.2801 & TRN & \\
\hline CHEMBL1458451 & 688759 & 4.65 & 4.7421 & TRN & \\
\hline CHEMBL1311573 & 688759 & 5.4 & 5.0661 & TRN & \\
\hline CHEMBL1587892 & 688759 & 5.45 & 4.6482 & TRN & \\
\hline CHEMBL1429228 & 688759 & 4.95 & 4.6881 & TRN & \\
\hline CHEMBL1494284 & 688759 & 5.9 & 5.6651 & TRN & \\
\hline CHEMBL1533853 & 688759 & 4.45 & 4.6574 & TRN & \\
\hline CHEMBL1508699 & 688759 & 5.35 & 4.5735 & TRN & \\
\hline CHEMBL3193107 & 688759 & 4.45 & 4.9398 & TRN & \\
\hline CHEMBL1480185 & 688759 & 4.45 & 4.8603 & TRN & \\
\hline CHEMBL572339 & 688759 & 5.4 & 4.7958 & TRN & \\
\hline CHEMBL1877896 & 688759 & 4.9 & 5.1229 & TRN & \\
\hline CHEMBL1526966 & 688759 & 4.85 & 4.7833 & TST & \\
\hline CHEMBL 2006620 & 688759 & 4.65 & 4.8873 & TRN & \\
\hline CHEMBL1304326 & 688759 & 5.0 & 4.7982 & TRN & \\
\hline
\end{tabular}




\begin{tabular}{|c|c|c|c|c|}
\hline \multicolumn{5}{|c|}{ Supplemental Table } \\
\hline CHEMBL1346846 & 688759 & 4.75 & 4.8834 & TRN \\
\hline CHEMBL1494214 & 688759 & 5.4 & 5.0176 & TRN \\
\hline CHEMBL1467104 & 688759 & 5.35 & 4.775 & TRN \\
\hline CHEMBL1312763 & 688759 & 5.2 & 4.9977 & TRN \\
\hline CHEMBL1337592 & 688759 & 6.1 & 4.7372 & TRN \\
\hline CHEMBL1378642 & 688759 & 4.6 & 4.7765 & TRN \\
\hline CHEMBL1367689 & 688759 & 4.65 & 5.0002 & TRN \\
\hline CHEMBL3192328 & 688759 & 5.9 & 5.7862 & TRN \\
\hline CHEMBL1349452 & 688759 & 4.45 & 4.6587 & TRN \\
\hline CHEMBL1425519 & 688759 & 4.45 & 4.6612 & TRN \\
\hline CHEMBL1477065 & 688759 & 4.95 & 4.6276 & TRN \\
\hline CHEMBL1554220 & 688759 & 4.65 & 4.8194 & TRN \\
\hline CHEMBL3196796 & 688759 & 5.0 & 4.9826 & TRN \\
\hline CHEMBL1403958 & 688759 & 5.6 & 4.7069 & TRN \\
\hline CHEMBL1465370 & 688759 & 5.1 & 4.9993 & TRN \\
\hline CHEMBL1564543 & 688759 & 4.45 & 4.8875 & TRN \\
\hline CHEMBL51931 & 688759 & 5.5 & 5.4227 & TRN \\
\hline CHEMBL3195672 & 688759 & 4.45 & 4.9848 & TRN \\
\hline CHEMBL1383777 & 688759 & 4.75 & 4.914 & TST \\
\hline CHEMBL1308386 & 688759 & 4.7 & 4.8039 & TRN \\
\hline CHEMBL1403116 & 688759 & 6.25 & 4.7552 & TRN \\
\hline CHEMBL1606127 & 688759 & 6.8 & 5.2568 & TRN \\
\hline CHEMBL1464711 & 688759 & 5.25 & 5.1451 & TST \\
\hline CHEMBL3192417 & 688759 & 4.45 & 4.9563 & TRN \\
\hline CHEMBL3190132 & 688759 & 5.4 & 5.2059 & TRN \\
\hline CHEMBL1309888 & 688759 & 4.9 & 4.9022 & TST \\
\hline CHEMBL1971144 & 688759 & 6.15 & 5.3379 & TRN \\
\hline CHEMBL1345825 & 688759 & 5.2 & 4.8333 & TRN \\
\hline CHEMBL1423566 & 688759 & 4.45 & 4.8007 & TRN \\
\hline CHEMBL1433218 & 688759 & 4.45 & 4.567 & TST \\
\hline CHEMBL1588191 & 688759 & 5.15 & 4.9153 & TRN \\
\hline CHEMBL1550752 & 688759 & 5.0 & 5.4481 & TRN \\
\hline CHEMBL1423337 & 688759 & 4.45 & 4.6126 & TST \\
\hline CHEMBL1545205 & 688759 & 4.45 & 4.7527 & TRN \\
\hline CHEMBL3191273 & 688759 & 4.45 & 5.0695 & TRN \\
\hline CHEMBL1576288 & 688759 & 5.25 & 5.06 & TRN \\
\hline CHEMBL1611575 & 688759 & 4.45 & 4.883 & TRN \\
\hline CHEMBL1551302 & 688759 & 4.95 & 4.9508 & TRN \\
\hline CHEMBL1482065 & 688759 & 4.8 & 5.0137 & TRN \\
\hline CHEMBL1600459 & 688759 & 5.0 & 5.1859 & TRN \\
\hline CHEMBL1374907 & 688759 & 5.5 & 5.3743 & TRN \\
\hline CHEMBL1407077 & 688759 & 6.1 & 5.0226 & TRN \\
\hline CHEMBL1979727 & 688759 & 6.0 & 5.5589 & TRN \\
\hline CHEMBL1348332 & 688759 & 5.4 & 4.805 & TST \\
\hline CHEMBL1520718 & 688759 & 4.45 & 4.4543 & TRN \\
\hline CHEMBL3190974 & 688759 & 4.65 & 5.14 & TRN \\
\hline CHEMBL1522809 & 688759 & 5.3 & 5.1377 & TRN \\
\hline CHEMBL1306537 & 688759 & 5.75 & 5.8525 & TRN \\
\hline
\end{tabular}




\begin{tabular}{|c|c|c|c|c|}
\hline \multicolumn{5}{|c|}{ Supplemental Table S2.txt } \\
\hline CHEMBL1574834 & 688759 & 4.45 & 4.6454 & TRN \\
\hline CHEMBL1382773 & 688759 & 4.75 & 4.8366 & TST \\
\hline CHEMBL1544094 & 688759 & 5.55 & 5.1919 & TRN \\
\hline CHEMBL1460223 & 688759 & 5.15 & 5.2576 & TRN \\
\hline CHEMBL1432273 & 688759 & 4.55 & 4.6359 & TRN \\
\hline CHEMBL1400508 & 688759 & 5.5 & 4.8239 & TRN \\
\hline CHEMBL1513325 & 688759 & 4.65 & 4.9705 & TRN \\
\hline CHEMBL3189671 & 688759 & 5.3 & 4.9227 & TST \\
\hline CHEMBL1419321 & 688759 & 4.8 & 4.9199 & TRN \\
\hline CHEMBL1478814 & 688759 & 5.8 & 5.3949 & TRN \\
\hline CHEMBL1399016 & 688759 & 4.45 & 4.6251 & TRN \\
\hline CHEMBL 3211110 & 688759 & 6.0 & 5.0318 & TRN \\
\hline CHEMBL1500447 & 688759 & 4.5 & 4.9875 & TST \\
\hline CHEMBL1966289 & 688759 & 5.5 & 4.657 & TRN \\
\hline CHEMBL1457174 & 688759 & 4.65 & 4.5165 & TRN \\
\hline CHEMBL1300237 & 688759 & 5.35 & 4.9765 & TRN \\
\hline CHEMBL1456424 & 688759 & 5.05 & 4.9885 & TRN \\
\hline CHEMBL1459166 & 688759 & 4.5 & 4.6128 & TRN \\
\hline CHEMBL1455024 & 688759 & 4.45 & 4.7829 & TRN \\
\hline CHEMBL1462205 & 688759 & 4.6 & 4.434 & TRN \\
\hline CHEMBL1486568 & 688759 & 5.1 & 5.0373 & TRN \\
\hline CHEMBL1402378 & 688759 & 6.1 & 4.8778 & TRN \\
\hline CHEMBL1542307 & 688759 & 4.65 & 4.9932 & TST \\
\hline CHEMBL1498470 & 688759 & 4.95 & 4.9084 & TRN \\
\hline CHEMBL1505491 & 688759 & 4.6 & 5.0146 & TST \\
\hline CHEMBL1322078 & 688759 & 4.6 & 4.999 & TRN \\
\hline CHEMBL1567309 & 688759 & 4.7 & 4.7985 & TRN \\
\hline CHEMBL1360184 & 688759 & 4.75 & 4.9739 & TST \\
\hline CHEMBL1454278 & 688759 & 5.45 & 5.0237 & TRN \\
\hline CHEMBL1503117 & 688759 & 4.45 & 4.7431 & TRN \\
\hline CHEMBL1429982 & 688759 & 5.25 & 5.0218 & TRN \\
\hline CHEMBL1537417 & 688759 & 5.3 & 5.0807 & TST \\
\hline CHEMBL1458012 & 688759 & 4.45 & 4.8086 & TRN \\
\hline CHEMBL3209643 & 688759 & 4.65 & 4.82 & TRN \\
\hline CHEMBL1595562 & 688759 & 4.9 & 5.1594 & TRN \\
\hline CHEMBL592124 & 688759 & 5.2 & 4.9114 & TRN \\
\hline CHEMBL1460908 & 688759 & 8.0506 & 4.9731 & TST \\
\hline CHEMBL1582665 & 688759 & 5.5 & 5.4683 & TRN \\
\hline CHEMBL1425943 & 688759 & 4.45 & 5.2197 & TRN \\
\hline CHEMBL3195773 & 688759 & 4.45 & 4.8561 & TRN \\
\hline CHEMBL1450561 & 688759 & 4.45 & 4.6765 & TRN \\
\hline CHEMBL1577760 & 688759 & 4.45 & 4.976 & TST \\
\hline CHEMBL1520039 & 688759 & 4.45 & 4.7676 & TRN \\
\hline CHEMBL1423327 & 688759 & 4.7 & 4.9406 & TRN \\
\hline CHEMBL3190103 & 688759 & 5.45 & 5.218 & TST \\
\hline CHEMBL1512708 & 688759 & 4.95 & 4.7654 & TRN \\
\hline CHEMBL1448642 & 688759 & 4.5 & 4.645 & TRN \\
\hline CHEMBL1454775 & 688759 & 4.9 & 4.9528 & TST \\
\hline
\end{tabular}




\begin{tabular}{|c|c|c|c|c|c|}
\hline \multicolumn{6}{|c|}{ Supplemental Table s2.txt } \\
\hline CHEMBL1366958 & 688759 & 4.9 & 4.7662 & TRN & \\
\hline CHEMBL1379982 & 688759 & 4.5 & 5.0526 & TST & \\
\hline CHEMBL1499858 & 688759 & 4.45 & 4.6668 & TRN & \\
\hline CHEMBL1516839 & 688759 & 4.9 & 4.7082 & TRN & \\
\hline CHEMBL1600320 & 688759 & 4.45 & 4.7973 & TRN & \\
\hline CHEMBL1499369 & 688759 & 4.45 & 4.882 & TRN & \\
\hline CHEMBL1530557 & 688759 & 4.8 & 4.3972 & TRN & \\
\hline CHEMBL3190892 & 688759 & 4.45 & 4.8623 & TRN & \\
\hline CHEMBL1360080 & 688759 & 4.5 & 4.7637 & TRN & \\
\hline CHEMBL1507205 & 688759 & 5.0 & 5.8709 & TST & \\
\hline CHEMBL1441793 & 688759 & 4.6 & 4.8689 & TST & \\
\hline CHEMBL1496644 & 688759 & 6.1 & 5.5818 & TST & \\
\hline CHEMBL1502267 & 688759 & 5.2 & 5.114 & TRN & \\
\hline CHEMBL1313693 & 688759 & 4.95 & 4.6445 & TST & \\
\hline CHEMBL1376678 & 688759 & 4.95 & 4.8979 & TRN & \\
\hline CHEMBL498677 & 688759 & 5.1 & 4.942 & TRN & \\
\hline CHEMBL134291 & 688759 & 4.45 & 4.9319 & TRN & \\
\hline CHEMBL1485354 & 688759 & 4.45 & 5.1282 & TRN & \\
\hline CHEMBL1494997 & 688759 & 4.8 & 4.9568 & TST & \\
\hline CHEMBL3196997 & 688759 & 4.85 & 5.019 & TRN & \\
\hline CHEMBL1588852 & 688759 & 4.8 & 4.9416 & TRN & \\
\hline CHEMBL1613109 & 688759 & 4.65 & 4.8247 & TRN & \\
\hline CHEMBL1478575 & 688759 & 4.45 & 4.7592 & TRN & \\
\hline CHEMBL1407885 & 688759 & 4.45 & 4.72199 & 99999999995 & TS \\
\hline CHEMBL1543294 & 688759 & 4.7 & 4.9721 & TRN & \\
\hline CHEMBL1423914 & 688759 & 5.5 & 5.1282 & TRN & \\
\hline CHEMBL1559181 & 688759 & 4.45 & 4.9779 & TRN & \\
\hline CHEMBL1559640 & 688759 & 4.75 & 4.5523 & TRN & \\
\hline CHEMBL1451542 & 688759 & 5.05 & 5.117 & TST & \\
\hline CHEMBL3213146 & 688759 & 4.45 & 4.8069 & TRN & \\
\hline CHEMBL1402312 & 688759 & 4.65 & 4.829 & TRN & \\
\hline CHEMBL1318728 & 688759 & 4.8 & 5.0069 & TRN & \\
\hline CHEMBL1455756 & 688759 & 5.05 & 5.2833 & TRN & \\
\hline CHEMBL1331091 & 688759 & 4.45 & 4.6278 & TRN & \\
\hline CHEMBL1382459 & 688759 & 6.15 & 4.7702 & TRN & \\
\hline CHEMBL1562012 & 688759 & 4.8 & 4.9961 & TRN & \\
\hline CHEMBL1492505 & 688759 & 4.95 & 4.9844 & TRN & \\
\hline CHEMBL1372833 & 688759 & 4.65 & 4.7633 & TRN & \\
\hline CHEMBL1524035 & 688759 & 4.65 & 5.0302 & TRN & \\
\hline CHEMBL1317820 & 688759 & 4.45 & 4.8757 & TRN & \\
\hline CHEMBL1347056 & 688759 & 4.45 & 5.0745 & TST & \\
\hline CHEMBL1373294 & 688759 & 4.85 & 5.1049 & TRN & \\
\hline CHEMBL1489794 & 688759 & 5.25 & 4.8471 & TRN & \\
\hline CHEMBL1427516 & 688759 & 4.8 & 4.7108 & TST & \\
\hline CHEMBL1362653 & 688759 & 4.45 & 4.7147 & TRN & \\
\hline CHEMBL1474333 & 688759 & 4.95 & 4.8661 & TST & \\
\hline CHEMBL1560412 & 688759 & 4.45 & 4.5502 & TRN & \\
\hline CHEMBL1430680 & 688759 & 4.65 & 4.9019 & TST & \\
\hline
\end{tabular}




\begin{tabular}{|c|c|c|c|c|c|}
\hline \multirow[b]{2}{*}{ CHEMBL1417064 } & \multicolumn{5}{|c|}{ Supplemental Table s2.txt } \\
\hline & 688759 & 5.25 & 6.4281 & TRN & \\
\hline CHEMBL1400801 & 688759 & 4.7 & 4.92399 & 99999999995 & TRN \\
\hline CHEMBL1603074 & 688759 & 4.45 & 4.9674 & TRN & \\
\hline CHEMBL1433204 & 688759 & 4.6 & 4.8845 & TRN & \\
\hline CHEMBL1337553 & 688759 & 5.0 & 5.0847 & TRN & \\
\hline CHEMBL1360672 & 688759 & 4.65 & 4.9425 & TRN & \\
\hline CHEMBL1500878 & 688759 & 5.25 & 4.7106 & TST & \\
\hline CHEMBL1419410 & 688759 & 4.6 & 4.7644 & TRN & \\
\hline CHEMBL1487406 & 688759 & 4.65 & 4.8263 & TST & \\
\hline CHEMBL3193323 & 688759 & 5.05 & 5.1337 & TRN & \\
\hline CHEMBL1586427 & 688759 & 5.5 & 4.8771 & TST & \\
\hline CHEMBL1415903 & 688759 & 5.55 & 5.0772 & TST & \\
\hline CHEMBL1508624 & 688759 & 4.45 & 4.6625 & TST & \\
\hline CHEMBL1302598 & 688759 & 4.95 & 5.2079 & TRN & \\
\hline CHEMBL1309228 & 688759 & 4.9 & 4.8244 & TRN & \\
\hline CHEMBL1364992 & 688759 & 5.55 & 4.8277 & TST & \\
\hline CHEMBL1509841 & 688759 & 4.9 & 4.888 & TRN & \\
\hline CHEMBL1458806 & 688759 & 4.45 & 5.01 & TST & \\
\hline CHEMBL1514750 & 688759 & 4.6 & 4.6505 & TST & \\
\hline CHEMBL1349964 & 688759 & 4.45 & 4.8786 & TRN & \\
\hline CHEMBL1575094 & 688759 & 5.35 & 5.2857 & TST & \\
\hline CHEMBL1539902 & 688759 & 5.0 & 4.881 & TRN & \\
\hline CHEMBL1465119 & 688759 & 5.8 & 5.71700 & 00000000005 & TRN \\
\hline CHEMBL3189565 & 688759 & 5.3 & 5.2496 & TRN & \\
\hline CHEMBL443127 & 688759 & 4.45 & 4.9167 & TST & \\
\hline CHEMBL1420577 & 688759 & 6.4 & 5.0123 & TST & \\
\hline CHEMBL1407113 & 688759 & 4.7 & 4.7744 & TST & \\
\hline CHEMBL1547124 & 688759 & 5.4 & 5.0874 & TRN & \\
\hline CHEMBL1426565 & 688759 & 4.45 & 4.5409 & TRN & \\
\hline CHEMBL1323326 & 688759 & 5.4 & 4.9212 & TST & \\
\hline CHEMBL1333235 & 688759 & 4.55 & 4.7391 & TST & \\
\hline CHEMBL3207385 & 688759 & 4.55 & 4.8288 & TRN & \\
\hline CHEMBL 263116 & 688759 & 4.9 & 4.8774 & TRN & \\
\hline CHEMBL1575830 & 688759 & 5.0 & 4.9181 & TRN & \\
\hline CHEMBL1353660 & 688759 & 4.6 & 4.8913 & TRN & \\
\hline CHEMBL1459508 & 688759 & 4.8 & 4.8263 & TST & \\
\hline CHEMBL3191811 & 688759 & 4.45 & 4.687 & TST & \\
\hline CHEMBL175858 & 688759 & 5.5 & 5.5392 & TST & \\
\hline CHEMBL1500090 & 688759 & 4.45 & 4.8241 & TRN & \\
\hline CHEMBL1408075 & 688759 & 4.75 & 4.9224 & TST & \\
\hline CHEMBL3211115 & 688759 & 5.5 & 5.4891 & TRN & \\
\hline CHEMBL1339189 & 688759 & 4.45 & 4.8251 & TRN & \\
\hline CHEMBL 2016644 & 688759 & 5.55 & 5.2497 & TRN & \\
\hline CHEMBL1420747 & 688759 & 4.95 & 4.7361 & TRN & \\
\hline CHEMBL3197192 & 688759 & 5.25 & 5.3693 & TST & \\
\hline CHEMBL1421108 & 688759 & 4.5 & 5.2133 & TRN & \\
\hline CHEMBL369842 & 688759 & 6.6499 & 5.8296 & TST & \\
\hline CHEMBL1387229 & 688759 & 5.05 & 4.948 & TRN & \\
\hline
\end{tabular}




\begin{tabular}{|c|c|c|c|c|}
\hline & & & upplement & al $\mathrm{T}$ \\
\hline CHEMBL1518040 & 688759 & 4.7 & 4.9016 & TST \\
\hline CHEMBL1493705 & 688759 & 5.75 & 5.1625 & TST \\
\hline CHEMBL1504659 & 688759 & 4.7 & 4.7623 & TRN \\
\hline CHEMBL1366480 & 688759 & 5.4 & 5.2099 & TRN \\
\hline CHEMBL1501078 & 688759 & 4.65 & 4.7417 & TRN \\
\hline CHEMBL1531592 & 688759 & 5.6 & 4.9564 & TRN \\
\hline CHEMBL430266 & 688759 & 6.0 & 5.6176 & TST \\
\hline CHEMBL1345306 & 688759 & 5.5 & 4.6096 & TRN \\
\hline CHEMBL1528175 & 688759 & 6.05 & 5.8811 & TRN \\
\hline CHEMBL1338594 & 688759 & 4.45 & 4.7514 & TRN \\
\hline CHEMBL1495174 & 688759 & 5.3 & 5.0608 & TRN \\
\hline CHEMBL1409541 & 688759 & 5.35 & 4.8926 & TRN \\
\hline CHEMBL1433353 & 688759 & 4.7 & 4.7901 & TRN \\
\hline CHEMBL1306160 & 688759 & 4.45 & 4.586 & TRN \\
\hline CHEMBL1494201 & 688759 & 5.45 & 4.9228 & TST \\
\hline CHEMBL1524357 & 688759 & 5.2 & 5.0384 & TRN \\
\hline CHEMBL1344388 & 688759 & 4.75 & 5.2454 & TRN \\
\hline CHEMBL1547812 & 688759 & 4.65 & 4.8622 & TST \\
\hline CHEMBL1369885 & 688759 & 4.95 & 4.7391 & TRN \\
\hline CHEMBL1483171 & 688759 & 5.1 & 4.5732 & TST \\
\hline CHEMBL1428456 & 688759 & 4.45 & 5.0062 & TRN \\
\hline CHEMBL1582569 & 688759 & 4.85 & 4.6169 & TRN \\
\hline CHEMBL1505695 & 688759 & 4.5 & 5.0389 & TST \\
\hline CHEMBL1538692 & 688759 & 5.5 & 4.8485 & TRN \\
\hline CHEMBL1360333 & 688759 & 4.45 & 4.8704 & TRN \\
\hline CHEMBL1610173 & 688759 & 5.4 & 5.1283 & TRN \\
\hline CHEMBL 3145204 & 688759 & 4.55 & 5.1845 & TRN \\
\hline CHEMBL1402664 & 688759 & 6.0 & 5.6816 & TRN \\
\hline CHEMBL1534804 & 688759 & 5.3 & 4.8486 & TRN \\
\hline CHEMBL1474674 & 688759 & 5.2 & 5.2705 & TRN \\
\hline CHEMBL1522208 & 688759 & 4.75 & 4.7393 & TRN \\
\hline CHEMBL 241858 & 688759 & 4.45 & 4.6452 & TRN \\
\hline CHEMBL1374818 & 688759 & 5.1 & 5.2149 & TRN \\
\hline CHEMBL1335692 & 688759 & 4.45 & 4.8188 & TST \\
\hline CHEMBL1424036 & 688759 & 4.75 & 4.5548 & TRN \\
\hline CHEMBL1864716 & 688759 & 4.6 & 5.3247 & TRN \\
\hline CHEMBL3213319 & 688759 & 4.45 & 4.8241 & TST \\
\hline CHEMBL1319149 & 688759 & 4.55 & 4.7747 & TRN \\
\hline CHEMBL1376851 & 688759 & 4.75 & 4.5802 & TST \\
\hline CHEMBL1351724 & 688759 & 4.7 & 4.4597 & TRN \\
\hline CHEMBL1458479 & 688759 & 5.05 & 5.2003 & TRN \\
\hline CHEMBL1326255 & 688759 & 4.45 & 4.6803 & TRN \\
\hline CHEMBL1364012 & 688759 & 5.2 & 4.7981 & TRN \\
\hline CHEMBL3189259 & 688759 & 4.7 & 4.4811 & TRN \\
\hline CHEMBL1305395 & 688759 & 4.45 & 4.7125 & TRN \\
\hline CHEMBL1534683 & 688759 & 4.85 & 5.0513 & TRN \\
\hline CHEMBL1334407 & 688759 & 5.0 & 4.7986 & TRN \\
\hline CHEMBL1454726 & 688759 & 4.45 & 4.8261 & TST \\
\hline
\end{tabular}




\begin{tabular}{|c|c|c|c|c|c|}
\hline \multirow[b]{2}{*}{ CHEMBL1550085 } & \multicolumn{5}{|c|}{ Supplemental Table S2.txt } \\
\hline & 688759 & 4.45 & 4.7233 & TRN & \\
\hline CHEMBL1990057 & 688759 & 4.45 & 4.72199 & 99999999995 & TRN \\
\hline CHEMBL1532221 & 688759 & 4.9 & 5.2618 & TRN & \\
\hline CHEMBL1975487 & 688759 & 4.75 & 4.9286 & TST & \\
\hline CHEMBL1458922 & 688759 & 5.15 & 5.3516 & TRN & \\
\hline CHEMBL3198533 & 688759 & 4.45 & 4.7912 & TST & \\
\hline CHEMBL1510489 & 688759 & 4.45 & 4.9338 & TST & \\
\hline CHEMBL1362222 & 688759 & 4.45 & 4.848 & TRN & \\
\hline CHEMBL1477637 & 688759 & 6.0 & 5.7584 & TRN & \\
\hline CHEMBL1308212 & 688759 & 5.3 & 4.8953 & TRN & \\
\hline CHEMBL1587557 & 688759 & 4.9 & 4.9487 & TST & \\
\hline CHEMBL1348635 & 688759 & 5.15 & 5.0323 & TRN & \\
\hline CHEMBL1533864 & 688759 & 4.45 & 4.8575 & TRN & \\
\hline CHEMBL1490191 & 688759 & 5.55 & 5.2095 & TRN & \\
\hline CHEMBL1380651 & 688759 & 6.3 & 4.9512 & TRN & \\
\hline CHEMBL1409104 & 688759 & 5.05 & 4.7802 & TST & \\
\hline CHEMBL1383086 & 688759 & 4.45 & 4.687 & TRN & \\
\hline CHEMBL1457509 & 688759 & 4.45 & 4.7562 & TRN & \\
\hline CHEMBL1332994 & 688759 & 5.85 & 4.8964 & TRN & \\
\hline CHEMBL1557386 & 688759 & 4.85 & 5.0561 & TRN & \\
\hline CHEMBL1329450 & 688759 & 4.45 & 4.5657 & TRN & \\
\hline CHEMBL3190310 & 688759 & 5.4 & 5.0151 & TRN & \\
\hline CHEMBL1585980 & 688759 & 4.6 & 5.0954 & TRN & \\
\hline CHEMBL1581409 & 688759 & 4.45 & 4.8286 & TRN & \\
\hline CHEMBL334255 & 688759 & 6.0 & 5.5216 & TST & \\
\hline CHEMBL1501881 & 688759 & 4.6 & 4.8247 & TRN & \\
\hline CHEMBL3189719 & 688759 & 4.45 & 4.7546 & TRN & \\
\hline CHEMBL1550895 & 688759 & 5.0 & 5.0006 & TRN & \\
\hline CHEMBL3198016 & 688759 & 4.45 & 4.6583 & TST & \\
\hline CHEMBL1454017 & 688759 & 4.45 & 4.7892 & TRN & \\
\hline CHEMBL1480271 & 688759 & 5.2 & 5.3813 & TRN & \\
\hline CHEMBL15192 & 688759 & 5.25 & 5.2533 & TST & \\
\hline CHEMBL1605568 & 688759 & 5.1 & 4.7369 & TRN & \\
\hline CHEMBL1344907 & 688759 & 6.7501 & 5.0434 & TST & \\
\hline CHEMBL1528742 & 688759 & 4.45 & 4.7407 & TRN & \\
\hline CHEMBL1500970 & 688759 & 5.4 & 4.865 & TRN & \\
\hline CHEMBL1346970 & 688759 & 5.0 & 4.9113 & TRN & \\
\hline CHEMBL3214173 & 688759 & 4.45 & 4.4444 & TRN & \\
\hline CHEMBL1342453 & 688759 & 5.15 & 4.8983 & TRN & \\
\hline CHEMBL1424484 & 688759 & 4.45 & 4.8003 & TRN & \\
\hline CHEMBL3190873 & 688759 & 4.65 & 4.5555 & TRN & \\
\hline CHEMBL1500586 & 688759 & 4.7 & 4.7695 & TRN & \\
\hline CHEMBL1504915 & 688759 & 4.75 & 4.7138 & TRN & \\
\hline CHEMBL1495714 & 688759 & 5.3 & 5.1908 & TRN & \\
\hline CHEMBL1336541 & 688759 & 5.5 & 5.5645 & TRN & \\
\hline CHEMBL1518663 & 688759 & 5.2 & 4.9447 & TRN & \\
\hline CHEMBL1571568 & 688759 & 4.65 & 6.3398 & TRN & \\
\hline CHEMBL496727 & 688759 & 5.05 & 4.9738 & TRN & \\
\hline
\end{tabular}




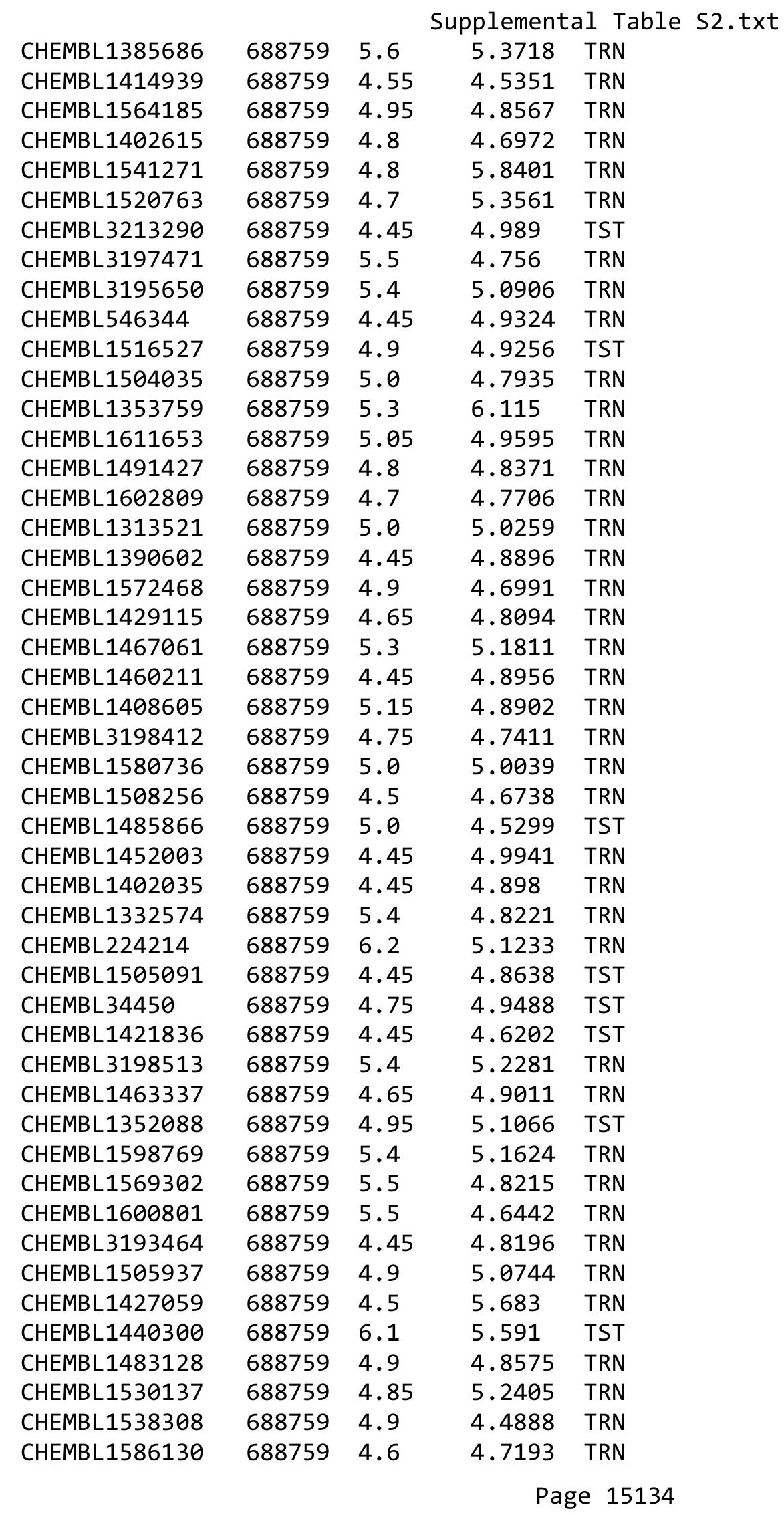




\begin{tabular}{|c|c|c|c|c|}
\hline & & & upplement & al $\mathrm{T}$ \\
\hline CHEMBL1439699 & 688759 & 4.8 & 5.0933 & TRN \\
\hline CHEMBL1600447 & 688759 & 4.7 & 4.8662 & TST \\
\hline CHEMBL1362824 & 688759 & 4.75 & 4.7231 & TRN \\
\hline CHEMBL 271958 & 688759 & 4.45 & 4.9747 & TST \\
\hline CHEMBL3189792 & 688759 & 4.55 & 4.7203 & TRN \\
\hline CHEMBL 3192825 & 688759 & 5.9 & 5.3073 & TST \\
\hline CHEMBL1992109 & 688759 & 5.5 & 5.4024 & TRN \\
\hline CHEMBL1538598 & 688759 & 4.65 & 4.8316 & TST \\
\hline CHEMBL1977078 & 688759 & 5.05 & 5.2774 & TRN \\
\hline CHEMBL1359398 & 688759 & 4.65 & 4.6586 & TRN \\
\hline CHEMBL1353400 & 688759 & 6.15 & 4.8706 & TRN \\
\hline CHEMBL1536795 & 688759 & 4.45 & 4.6424 & TRN \\
\hline CHEMBL1518508 & 688759 & 4.5 & 5.0427 & TRN \\
\hline CHEMBL 3190562 & 688759 & 4.85 & 5.1199 & TRN \\
\hline CHEMBL1470321 & 688759 & 4.95 & 4.8949 & TRN \\
\hline CHEMBL1521317 & 688759 & 4.45 & 4.717 & TRN \\
\hline CHEMBL1529847 & 688759 & 4.45 & 4.7413 & TRN \\
\hline CHEMBL1363379 & 688759 & 4.8 & 5.0136 & TST \\
\hline CHEMBL1462213 & 688759 & 4.6 & 4.6779 & TRN \\
\hline CHEMBL1486156 & 688759 & 5.45 & 4.6806 & TRN \\
\hline CHEMBL1572139 & 688759 & 6.05 & 6.1025 & TRN \\
\hline CHEMBL1409160 & 688759 & 4.45 & 4.8369 & TRN \\
\hline CHEMBL1368398 & 688759 & 4.65 & 4.9715 & TST \\
\hline CHEMBL1414519 & 688759 & 5.55 & 5.6515 & TRN \\
\hline CHEMBL1583500 & 688759 & 5.25 & 4.8774 & TST \\
\hline CHEMBL1374973 & 688759 & 4.8 & 4.6741 & TRN \\
\hline CHEMBL1334367 & 688759 & 5.0 & 4.7754 & TRN \\
\hline CHEMBL1521955 & 688759 & 5.4 & 4.8349 & TST \\
\hline CHEMBL1374075 & 688759 & 5.65 & 4.8125 & TRN \\
\hline CHEMBL 3193688 & 688759 & 5.05 & 4.5764 & TRN \\
\hline CHEMBL1433138 & 688759 & 5.05 & 4.6463 & TST \\
\hline CHEMBL1430931 & 688759 & 4.95 & 4.6655 & TST \\
\hline CHEMBL1345831 & 688759 & 4.65 & 4.8017 & TST \\
\hline CHEMBL1536233 & 688759 & 4.45 & 4.6398 & TST \\
\hline CHEMBL1383176 & 688759 & 4.65 & 4.8231 & TST \\
\hline CHEMBL1429775 & 688759 & 5.35 & 5.0268 & TRN \\
\hline CHEMBL1541995 & 688759 & 4.5 & 4.704 & TRN \\
\hline CHEMBL3199169 & 688759 & 5.0 & 5.1443 & TRN \\
\hline CHEMBL1491944 & 688759 & 4.9 & 4.8663 & TRN \\
\hline CHEMBL 3214022 & 688759 & 5.55 & 5.228 & TRN \\
\hline CHEMBL1522964 & 688759 & 5.45 & 5.1589 & TRN \\
\hline CHEMBL1976197 & 688759 & 5.1 & 5.2045 & TRN \\
\hline CHEMBL1323610 & 688759 & 4.85 & 4.6688 & TRN \\
\hline CHEMBL414890 & 688759 & 5.55 & 5.118 & TRN \\
\hline CHEMBL1469565 & 688759 & 5.1 & 4.9385 & TRN \\
\hline CHEMBL1594527 & 688759 & 4.65 & 4.5201 & TRN \\
\hline CHEMBL1413648 & 688759 & 4.8 & 4.9015 & TRN \\
\hline CHEMBL1430064 & 688759 & 4.65 & 5.1072 & TRN \\
\hline
\end{tabular}




\begin{tabular}{|c|c|c|c|c|c|}
\hline & & \multicolumn{4}{|c|}{ Supplemental Table S2.txt } \\
\hline CHEMBL1564934 & 688759 & 4.75 & 4.7517 & TRN & \\
\hline CHEMBL3191810 & 688759 & 4.95 & 4.9294 & TRN & \\
\hline CHEMBL1404312 & 688759 & 4.8 & 5.3092 & TRN & \\
\hline CHEMBL1526681 & 688759 & 4.45 & 4.6515 & TRN & \\
\hline CHEMBL1429266 & 688759 & 4.45 & 4.9138 & TRN & \\
\hline CHEMBL1305022 & 688759 & 4.45 & 4.7695 & TRN & \\
\hline CHEMBL1359713 & 688759 & 6.0 & 4.6948 & TST & \\
\hline CHEMBL1576905 & 688759 & 4.95 & 4.8284 & TST & \\
\hline CHEMBL1426842 & 688759 & 4.9 & 5.0188 & TST & \\
\hline CHEMBL1467736 & 688759 & 5.4 & 4.9801 & TST & \\
\hline CHEMBL1304189 & 688759 & 4.45 & 4.8569 & TRN & \\
\hline CHEMBL1369927 & 688759 & 5.45 & 5.0414 & TRN & \\
\hline CHEMBL1406639 & 688759 & 5.0 & 4.8036 & TST & \\
\hline CHEMBL1509504 & 688759 & 5.55 & 5.62700 & 0000000001 & TRN \\
\hline CHEMBL1607594 & 688759 & 4.75 & 4.8092 & TRN & \\
\hline CHEMBL3190328 & 688759 & 4.45 & 4.648 & TRN & \\
\hline CHEMBL1587606 & 688759 & 4.6 & 4.6903 & TST & \\
\hline CHEMBL1576791 & 688759 & 5.55 & 5.545 & TRN & \\
\hline CHEMBL597035 & 688759 & 4.45 & 4.945 & TRN & \\
\hline CHEMBL1486372 & 688759 & 4.95 & 4.8075 & TST & \\
\hline CHEMBL1440974 & 688759 & 5.0 & 5.0662 & TRN & \\
\hline CHEMBL1464985 & 688759 & 4.45 & 4.8415 & TRN & \\
\hline CHEMBL1431146 & 688759 & 4.45 & 4.6647 & TRN & \\
\hline CHEMBL1520312 & 688759 & 4.8 & 5.3216 & TRN & \\
\hline CHEMBL3192950 & 688759 & 5.25 & 4.9207 & TST & \\
\hline CHEMBL1612493 & 688759 & 5.4 & 5.5539 & TRN & \\
\hline CHEMBL3196930 & 688759 & 4.8 & 4.7598 & TST & \\
\hline CHEMBL1346826 & 688759 & 4.7 & 4.7397 & TST & \\
\hline CHEMBL1547169 & 688759 & 4.9 & 4.8685 & TRN & \\
\hline CHEMBL1380683 & 688759 & 4.45 & 5.0338 & TRN & \\
\hline CHEMBL1391217 & 688759 & 4.9 & 4.9446 & TST & \\
\hline CHEMBL1546688 & 688759 & 5.05 & 4.7799 & TRN & \\
\hline CHEMBL1391742 & 688759 & 4.95 & 5.0522 & TRN & \\
\hline CHEMBL1505089 & 688759 & 4.9 & 4.6521 & TRN & \\
\hline CHEMBL592106 & 688759 & 4.9 & 4.5901 & TST & \\
\hline CHEMBL570345 & 688759 & 4.95 & 4.8832 & TRN & \\
\hline CHEMBL1433109 & 688759 & 4.45 & 4.6945 & TST & \\
\hline CHEMBL1564553 & 688759 & 4.45 & 4.9743 & TST & \\
\hline CHEMBL1426159 & 688759 & 5.4 & 5.3074 & TRN & \\
\hline CHEMBL1318884 & 688759 & 5.3 & 4.8492 & TST & \\
\hline CHEMBL1361600 & 688759 & 4.45 & 4.4466 & TRN & \\
\hline CHEMBL1413625 & 688759 & 5.85 & 5.4963 & TRN & \\
\hline CHEMBL1418103 & 688759 & 4.6 & 5.0843 & TRN & \\
\hline CHEMBL305686 & 688759 & 6.0 & 5.5428 & TST & \\
\hline CHEMBL1509483 & 688759 & 5.35 & 4.8476 & TRN & \\
\hline CHEMBL1458840 & 688759 & 4.75 & 4.8514 & TRN & \\
\hline CHEMBL1504270 & 688759 & 4.65 & 4.9338 & TST & \\
\hline CHEMBL1409210 & 688759 & 4.8 & 4.7058 & TRN & \\
\hline
\end{tabular}




\begin{tabular}{|c|c|c|c|c|c|}
\hline \multicolumn{6}{|c|}{ Supplemental Table S2.txt } \\
\hline CHEMBL1331694 & 688759 & 6.0 & 5.4704 & TRN & \\
\hline CHEMBL1599610 & 688759 & 4.75 & 5.001 & TRN & \\
\hline CHEMBL3195487 & 688759 & 4.7 & 4.6363 & TRN & \\
\hline CHEMBL1546438 & 688759 & 4.65 & 4.4929 & TRN & \\
\hline CHEMBL1528827 & 688759 & 5.3 & 5.4148 & TRN & \\
\hline CHEMBL1393596 & 688759 & 4.45 & 4.7135 & TST & \\
\hline CHEMBL1605875 & 688759 & 4.95 & 5.0271 & TRN & \\
\hline CHEMBL 3213496 & 688759 & 4.45 & 4.8943 & TRN & \\
\hline CHEMBL1428237 & 688759 & 4.8 & 4.6798 & TRN & \\
\hline CHEMBL3194994 & 688759 & 4.45 & 4.7345 & TRN & \\
\hline CHEMBL1519327 & 688759 & 6.0 & 5.5339 & TST & \\
\hline CHEMBL 2002573 & 688759 & 5.35 & 5.2244 & TRN & \\
\hline CHEMBL1370300 & 688759 & 5.5 & 4.7928 & TRN & \\
\hline CHEMBL1346310 & 688759 & 5.3 & 4.7227 & TST & \\
\hline CHEMBL1430107 & 688759 & 6.3 & 6.0465 & TRN & \\
\hline CHEMBL3190532 & 688759 & 4.8 & 4.7438 & TST & \\
\hline CHEMBL1542538 & 688759 & 4.45 & 4.6254 & TRN & \\
\hline CHEMBL1573641 & 688759 & 4.45 & 4.8583 & TRN & \\
\hline CHEMBL1370611 & 688759 & 4.65 & 4.9675 & TST & \\
\hline CHEMBL1319249 & 688759 & 4.45 & 4.5242 & TRN & \\
\hline CHEMBL1373821 & 688759 & 4.7 & 5.2493 & TRN & \\
\hline CHEMBL1565626 & 688759 & 4.95 & 4.9406 & TRN & \\
\hline CHEMBL1367285 & 688759 & 5.0 & 5.1038 & TRN & \\
\hline CHEMBL3192120 & 688759 & 5.35 & 5.2289 & TRN & \\
\hline CHEMBL1536629 & 688759 & 4.45 & 4.7653 & TRN & \\
\hline CHEMBL1998531 & 688759 & 4.95 & 4.7906 & TRN & \\
\hline CHEMBL1333203 & 688759 & 4.45 & 4.8406 & TRN & \\
\hline CHEMBL1466525 & 688759 & 5.05 & 5.1208 & TRN & \\
\hline CHEMBL1994709 & 688759 & 5.4 & 5.2205 & TRN & \\
\hline CHEMBL 1602573 & 688759 & 4.45 & 4.6848 & TRN & \\
\hline CHEMBL609027 & 688759 & 5.25 & 5.0688 & TST & \\
\hline CHEMBL1430757 & 688759 & 5.15 & 4.7636 & TRN & \\
\hline CHEMBL1581881 & 688759 & 5.5 & 4.8199 & TRN & \\
\hline CHEMBL1310255 & 688759 & 4.95 & 5.0544 & TST & \\
\hline CHEMBL1582488 & 688759 & 6.35 & 4.8826 & TRN & \\
\hline CHEMBL1612634 & 688759 & 5.0 & 4.7873 & TST & \\
\hline CHEMBL1967103 & 688759 & 5.5 & 5.20299 & 9999999999 & TST \\
\hline CHEMBL1969300 & 688759 & 5.85 & 5.5605 & TRN & \\
\hline CHEMBL1501265 & 688759 & 4.45 & 4.8543 & TRN & \\
\hline CHEMBL1501567 & 688759 & 5.45 & 4.874 & TST & \\
\hline CHEMBL1493221 & 688759 & 4.65 & 4.8942 & TRN & \\
\hline CHEMBL1419766 & 688759 & 5.15 & $4.9910 €$ & 00000000005 & TST \\
\hline CHEMBL1550664 & 688759 & 5.0 & 5.0415 & TRN & \\
\hline CHEMBL1522033 & 688759 & 4.45 & 5.0092 & TRN & \\
\hline CHEMBL1490944 & 688759 & 4.45 & 4.6307 & TRN & \\
\hline CHEMBL1307654 & 688759 & 4.5 & 5.0173 & TRN & \\
\hline CHEMBL1982304 & 688759 & 5.9 & 5.4914 & TRN & \\
\hline CHEMBL3198554 & 688759 & 6.0 & 5.7658 & TST & \\
\hline
\end{tabular}




\begin{tabular}{|c|c|c|c|c|c|}
\hline \multirow[b]{2}{*}{ CHEMBL1469710 } & \multirow{2}{*}{688759} & \\
\hline & & 4.6 & 4.6732 & TRN & \multirow[b]{2}{*}{ TRN } \\
\hline CHEMBL1375192 & 688759 & 4.8 & \multicolumn{2}{|c|}{5.236000000000001} & \\
\hline CHEMBL1493782 & 688759 & 4.85 & 4.9942 & TRN & \\
\hline CHEMBL1485053 & 688759 & 6.35 & 5.9497 & TRN & \\
\hline CHEMBL1423715 & 688759 & 4.45 & 5.234 & TST & \\
\hline CHEMBL1511284 & 688759 & 4.85 & 4.8828 & TRN & \\
\hline CHEMBL1508525 & 688759 & 4.65 & 4.831 & TRN & \\
\hline CHEMBL1419536 & 688759 & 4.95 & 5.2882 & TRN & \\
\hline CHEMBL1484215 & 688759 & 4.85 & 4.6859 & TST & \\
\hline CHEMBL1389052 & 688759 & 4.45 & 4.8862 & TRN & \\
\hline CHEMBL1593691 & 688759 & 4.45 & 4.9044 & TRN & \\
\hline CHEMBL1346645 & 688759 & 5.5 & 5.0295 & TRN & \\
\hline CHEMBL3192251 & 688759 & 4.9 & 5.0496 & TRN & \\
\hline CHEMBL1353992 & 688759 & 5.0 & 5.4645 & TRN & \\
\hline CHEMBL1213640 & 688759 & 5.3 & 5.2142 & TRN & \\
\hline CHEMBL1585346 & 688759 & 5.3 & 4.8829 & TST & \\
\hline CHEMBL1342349 & 688759 & 5.0 & 5.0431 & TRN & \\
\hline CHEMBL1426767 & 688759 & 4.7 & 4.6032 & TRN & \\
\hline CHEMBL3208651 & 688759 & 5.4 & 5.1246 & TRN & \\
\hline CHEMBL1299184 & 688759 & 5.3 & 4.7468 & TRN & \\
\hline CHEMBL1985061 & 688759 & 4.65 & 5.0891 & TRN & \\
\hline CHEMBL3191393 & 688759 & 4.9 & 4.7611 & TRN & \\
\hline CHEMBL1576622 & 688759 & 5.25 & 4.9291 & TST & \\
\hline CHEMBL1375199 & 688759 & 4.8 & 4.9078 & TRN & \\
\hline CHEMBL3190507 & 688759 & 5.5 & 5.4686 & TRN & \\
\hline CHEMBL 2000686 & 688759 & 4.7 & 4.766 & TRN & \\
\hline CHEMBL1560204 & 688759 & 4.45 & 4.7961 & TRN & \\
\hline CHEMBL454173 & 688759 & 6.0 & 4.97 & TRN & \\
\hline CHEMBL1381656 & 688759 & 4.9 & 4.9605 & TRN & \\
\hline CHEMBL1501412 & 688759 & 4.45 & 4.5926 & TRN & \\
\hline CHEMBL1454279 & 688759 & 4.5 & 4.6379 & TRN & \\
\hline CHEMBL1606177 & 688759 & 4.45 & 4.8881 & TST & \\
\hline CHEMBL1524967 & 688759 & 4.95 & 4.7719 & TRN & \\
\hline CHEMBL1479772 & 688759 & 4.95 & 5.09 & TRN & \\
\hline CHEMBL1538219 & 688759 & 5.25 & 4.9657 & TST & \\
\hline CHEMBL1338478 & 688759 & 4.45 & 4.8458 & TRN & \\
\hline CHEMBL1340717 & 688759 & 5.4 & 5.0723 & TRN & \\
\hline CHEMBL3199325 & 688759 & 5.9 & 5.6702 & TST & \\
\hline CHEMBL1569293 & 688759 & 4.45 & 4.7206 & TST & \\
\hline CHEMBL3197953 & 688759 & 4.8 & 4.8713 & TRN & \\
\hline CHEMBL1312329 & 688759 & 4.55 & 4.8667 & TST & \\
\hline CHEMBL1370194 & 688759 & 4.45 & 5.2214 & TRN & \\
\hline CHEMBL1556571 & 688759 & 5.2 & 4.8507 & TRN & \\
\hline CHEMBL1565668 & 688759 & 5.2 & $5.0680 e$ & 00000000005 & TRN \\
\hline CHEMBL532641 & 688759 & 4.6 & 4.6418 & TRN & \\
\hline CHEMBL1531670 & 688759 & 4.6 & 4.9027 & TRN & \\
\hline CHEMBL1304389 & 688759 & 6.8 & 5.0225 & TRN & \\
\hline CHEMBL1537130 & 688759 & 4.9 & 4.8914 & TST & \\
\hline & & & & 15138 & \\
\hline
\end{tabular}




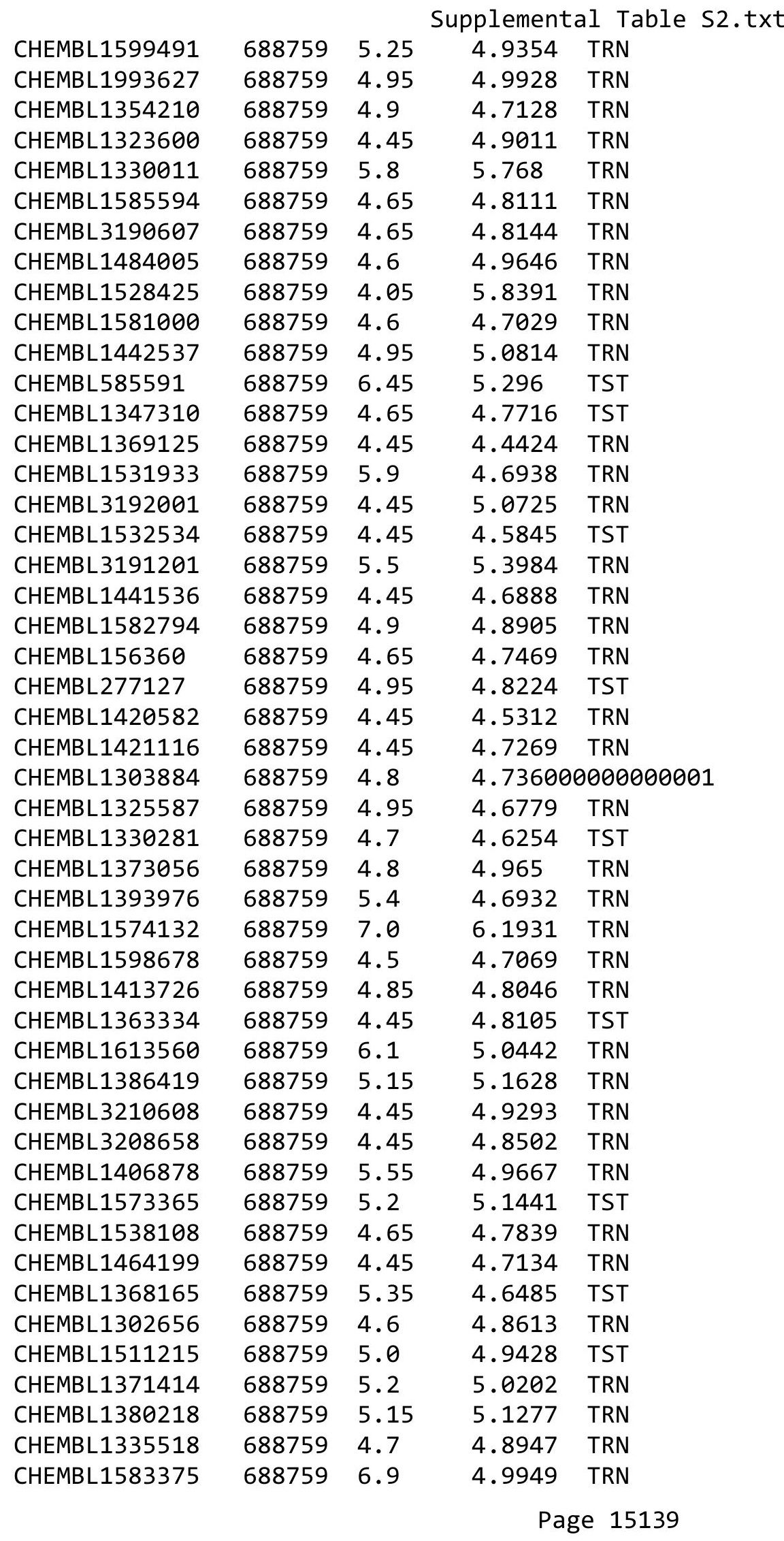




\begin{tabular}{|c|c|c|c|c|c|}
\hline CHEMBL1548647 & 688759 & 4.5 & \multicolumn{2}{|c|}{5.0680000000000005} & TST \\
\hline CHEMBL1586867 & 688759 & 4.45 & 4.7056 & TRN & \\
\hline CHEMBL1439808 & 688759 & 6.05 & 4.8579 & TRN & \\
\hline CHEMBL1612521 & 688759 & 4.45 & 4.8467 & TRN & \\
\hline CHEMBL1480872 & 688759 & 5.55 & 5.2453 & TRN & \\
\hline CHEMBL1552017 & 688759 & 4.8 & 4.7145 & TRN & \\
\hline CHEMBL1325967 & 688759 & 6.1 & 5.0473 & TRN & \\
\hline CHEMBL1428120 & 688759 & 5.25 & 4.9301 & TRN & \\
\hline CHEMBL1586518 & 688759 & 4.85 & 4.7611 & TRN & \\
\hline CHEMBL1315083 & 688759 & 4.7 & 4.9209 & TRN & \\
\hline CHEMBL1490152 & 688759 & 5.7 & 5.4258 & TRN & \\
\hline CHEMBL3213886 & 688759 & 4.45 & 4.8457 & TRN & \\
\hline CHEMBL1337527 & 688759 & 5.25 & 5.0975 & TRN & \\
\hline CHEMBL1526236 & 688759 & 4.45 & 4.6422 & TST & \\
\hline CHEMBL1405247 & 688759 & 5.25 & 4.7785 & TRN & \\
\hline CHEMBL1408586 & 688759 & 4.6 & 4.7302 & TRN & \\
\hline CHEMBL1587756 & 688759 & 5.05 & 5.0143 & TRN & \\
\hline CHEMBL1305651 & 688759 & 4.7 & 4.8145 & TRN & \\
\hline CHEMBL1458977 & 688759 & 5.35 & 5.3027 & TRN & \\
\hline CHEMBL1333496 & 688759 & 4.45 & 4.9681 & TRN & \\
\hline CHEMBL1468110 & 688759 & 5.1 & 4.9779 & TRN & \\
\hline CHEMBL1570763 & 688759 & 4.8 & 4.5458 & TRN & \\
\hline CHEMBL1566417 & 688759 & 4.45 & 4.5958 & TRN & \\
\hline CHEMBL1491402 & 688759 & 5.35 & 5.4321 & TST & \\
\hline CHEMBL1533891 & 688759 & 4.45 & 4.7159 & TRN & \\
\hline CHEMBL3196040 & 688759 & 4.45 & 4.523 & TST & \\
\hline CHEMBL1385137 & 688759 & 5.2 & 4.8388 & TRN & \\
\hline CHEMBL1979106 & 688759 & 4.45 & 4.8466 & TRN & \\
\hline CHEMBL1542694 & 688759 & 6.25 & 5.9248 & TRN & \\
\hline CHEMBL1505969 & 688759 & 4.65 & 4.7795 & TRN & \\
\hline CHEMBL3145382 & 688759 & 5.4 & 5.8054 & TRN & \\
\hline CHEMBL1410089 & 688759 & 4.8 & 4.5602 & TRN & \\
\hline CHEMBL1516427 & 688759 & 5.25 & 4.8198 & TRN & \\
\hline CHEMBL1605277 & 688759 & 4.7 & 4.9931 & TRN & \\
\hline CHEMBL1373336 & 688759 & 4.8 & 5.2835 & TRN & \\
\hline CHEMBL1302439 & 688759 & 6.0 & 5.3838 & TRN & \\
\hline CHEMBL1610677 & 688759 & 4.95 & 4.9635 & TRN & \\
\hline CHEMBL1508433 & 688759 & 6.0 & 5.5011 & TST & \\
\hline CHEMBL1375254 & 688759 & 5.55 & 4.7941 & TRN & \\
\hline CHEMBL1378639 & 688759 & 5.2 & 5.1558 & TRN & \\
\hline CHEMBL1612974 & 688759 & 4.7 & 4.8079 & TRN & \\
\hline CHEMBL1492194 & 688759 & 4.45 & 4.7699 & TRN & \\
\hline CHEMBL3195756 & 688759 & 5.9 & 5.0982 & TRN & \\
\hline CHEMBL1352748 & 688759 & 4.45 & 4.7393 & TRN & \\
\hline CHEMBL1493646 & 688759 & 5.0 & 5.0371 & TST & \\
\hline CHEMBL1488473 & 688759 & 4.65 & 5.3941 & TRN & \\
\hline CHEMBL2369297 & 688759 & 5.85 & 5.0762 & TRN & \\
\hline CHEMBL1396117 & 688759 & 4.4 & 4.9393 & TRN & \\
\hline
\end{tabular}




\begin{tabular}{|c|c|c|c|c|c|}
\hline \multicolumn{6}{|c|}{ Supplemental Table S2.txt } \\
\hline CHEMBL1386906 & 688759 & 5.0 & 5.0534 & TST & \\
\hline CHEMBL1541243 & 688759 & 4.45 & 4.6736 & TRN & \\
\hline CHEMBL1349687 & 688759 & 4.75 & 4.6855 & TRN & \\
\hline CHEMBL1322014 & 688759 & 4.65 & 4.8319 & TRN & \\
\hline CHEMBL1453489 & 688759 & 4.65 & 4.7083 & TRN & \\
\hline CHEMBL 3197594 & 688759 & 5.65 & 5.57600 & 00000000005 & TRN \\
\hline CHEMBL1536685 & 688759 & 4.7 & 4.8441 & TST & \\
\hline CHEMBL1533680 & 688759 & 4.65 & 4.6742 & TRN & \\
\hline CHEMBL1509149 & 688759 & 5.2 & 4.8445 & TST & \\
\hline CHEMBL1545086 & 688759 & 4.45 & 4.655 & TST & \\
\hline CHEMBL1566197 & 688759 & 4.45 & 4.738 & TRN & \\
\hline CHEMBL1342433 & 688759 & 5.45 & 5.0174 & TRN & \\
\hline CHEMBL1369893 & 688759 & 5.3 & 5.4082 & TRN & \\
\hline CHEMBL1336054 & 688759 & 4.65 & 5.0986 & TRN & \\
\hline CHEMBL1448931 & 688759 & 4.65 & 5.0614 & TRN & \\
\hline CHEMBL1419205 & 688759 & 5.2 & 5.0276 & TRN & \\
\hline CHEMBL1900850 & 688759 & 6.5501 & 6.0456 & TRN & \\
\hline CHEMBL1393102 & 688759 & 4.7 & 4.6049 & TRN & \\
\hline CHEMBL1343572 & 688759 & 4.65 & 4.5876 & TRN & \\
\hline CHEMBL1330351 & 688759 & 5.15 & 5.3384 & TRN & \\
\hline CHEMBL1561181 & 688759 & 5.7 & 4.6145 & TRN & \\
\hline CHEMBL 1448630 & 688759 & 4.45 & 4.8113 & TRN & \\
\hline CHEMBL3196052 & 688759 & 4.95 & 5.0129 & TRN & \\
\hline CHEMBL1528871 & 688759 & 4.5 & 4.7611 & TRN & \\
\hline CHEMBL1494420 & 688759 & 4.9 & 5.0788 & TRN & \\
\hline CHEMBL1336910 & 688759 & 5.5 & 5.1642 & TRN & \\
\hline CHEMBL1491526 & 688759 & 5.25 & 5.1976 & TRN & \\
\hline CHEMBL1332687 & 688759 & 4.75 & 4.9308 & TRN & \\
\hline CHEMBL 2001476 & 688759 & 4.9 & 4.7541 & TRN & \\
\hline CHEMBL1563875 & 688759 & 4.45 & 4.8209 & TST & \\
\hline CHEMBL 3194457 & 688759 & 5.25 & 4.8791 & TRN & \\
\hline CHEMBL1481542 & 688759 & 4.95 & 4.6856 & TRN & \\
\hline CHEMBL3191730 & 688759 & 5.9 & 5.5247 & TRN & \\
\hline CHEMBL1444050 & 688759 & 4.45 & 4.9811 & TRN & \\
\hline CHEMBL1310458 & 688759 & 5.5 & 4.9236 & TST & \\
\hline CHEMBL1570797 & 688759 & 4.45 & 4.6202 & TRN & \\
\hline CHEMBL1721226 & 688759 & 5.05 & 6.1704 & TRN & \\
\hline CHEMBL1588235 & 688759 & 5.85 & 5.6731 & TRN & \\
\hline CHEMBL3198356 & 688759 & 4.45 & 4.5232 & TRN & \\
\hline CHEMBL3209840 & 688759 & 4.55 & 4.6894 & TRN & \\
\hline CHEMBL1383253 & 688759 & 5.25 & 5.0334 & TRN & \\
\hline CHEMBL1415702 & 688759 & 4.45 & 4.6983 & TRN & \\
\hline CHEMBL1565212 & 688759 & 4.45 & 4.7453 & TRN & \\
\hline CHEMBL1305291 & 688759 & 4.9 & 5.0195 & TRN & \\
\hline CHEMBL162783 & 688759 & 5.15 & 5.0441 & TST & \\
\hline CHEMBL1417418 & 688759 & 5.0 & 5.2521 & TRN & \\
\hline CHEMBL1423607 & 688759 & 5.3 & 5.0112 & TRN & \\
\hline CHEMBL1399228 & 688759 & 5.05 & 5.1231 & TRN & \\
\hline
\end{tabular}




\begin{tabular}{|c|c|c|c|c|}
\hline \multicolumn{5}{|c|}{ Supplemental Table S2.txt } \\
\hline CHEMBL1392602 & 688759 & 4.7 & 5.2116 & TST \\
\hline CHEMBL1534901 & 688759 & 5.0 & 4.9714 & TRN \\
\hline CHEMBL1432494 & 688759 & 4.65 & 4.8433 & TST \\
\hline CHEMBL1534263 & 688759 & 4.85 & 4.7986 & TST \\
\hline CHEMBL3214455 & 688759 & 5.65 & 5.278 & TRN \\
\hline CHEMBL1431053 & 688759 & 5.3 & 5.0633 & TST \\
\hline CHEMBL3209626 & 688759 & 4.45 & 4.6706 & TRN \\
\hline CHEMBL3210193 & 688759 & 5.25 & 5.0822 & TRN \\
\hline CHEMBL1375064 & 688759 & 5.65 & 5.4701 & TRN \\
\hline CHEMBL1611728 & 688759 & 4.8 & 4.9758 & TRN \\
\hline CHEMBL1558407 & 688759 & 4.45 & 4.9899 & TRN \\
\hline CHEMBL1364707 & 688759 & 5.25 & 4.6033 & TRN \\
\hline CHEMBL1987784 & 688759 & 5.5 & 4.7697 & TST \\
\hline CHEMBL1445249 & 688759 & 4.8 & 4.8564 & TRN \\
\hline CHEMBL3210115 & 688759 & 4.45 & 4.664 & TRN \\
\hline CHEMBL1506175 & 688759 & 4.7 & 5.0754 & TST \\
\hline CHEMBL1319980 & 688759 & 4.45 & 5.0583 & TRN \\
\hline CHEMBL1569989 & 688759 & 7.0501 & 5.8876 & TRN \\
\hline CHEMBL1432740 & 688759 & 4.85 & 4.9595 & TST \\
\hline CHEMBL1371792 & 688759 & 5.45 & 4.9395 & TST \\
\hline CHEMBL1307201 & 688759 & 4.75 & 4.7859 & TRN \\
\hline CHEMBL1504469 & 688759 & 4.45 & 4.627 & TRN \\
\hline CHEMBL1403024 & 688759 & 4.9 & 5.0666 & TRN \\
\hline CHEMBL 3207627 & 688759 & 5.25 & 5.3256 & TST \\
\hline CHEMBL1499710 & 688759 & 4.45 & 4.5665 & TST \\
\hline CHEMBL3214498 & 688759 & 4.9 & 4.9816 & TST \\
\hline CHEMBL1388271 & 688759 & 4.45 & 4.919 & TRN \\
\hline CHEMBL1467702 & 688759 & 5.25 & 4.9409 & TST \\
\hline CHEMBL1340678 & 688759 & 6.0 & 5.4484 & TRN \\
\hline CHEMBL1978730 & 688759 & 5.65 & 4.9832 & TRN \\
\hline CHEMBL1928491 & 688759 & 4.8 & 4.5498 & TRN \\
\hline CHEMBL1479211 & 688759 & 4.45 & 4.9868 & TRN \\
\hline CHEMBL3195285 & 688759 & 4.85 & 4.5727 & TRN \\
\hline CHEMBL1300295 & 688759 & 4.9 & 4.6567 & TST \\
\hline CHEMBL1610334 & 688759 & 4.55 & 4.8736 & TRN \\
\hline CHEMBL1364445 & 688759 & 4.5 & 4.8814 & TST \\
\hline CHEMBL1529086 & 688759 & 4.6 & 5.2696 & TRN \\
\hline CHEMBL1589616 & 688759 & 4.65 & 4.7662 & TRN \\
\hline CHEMBL1362729 & 688759 & 4.45 & 4.7517 & TST \\
\hline CHEMBL1384658 & 688759 & 5.0 & 5.7338 & TRN \\
\hline CHEMBL 2007163 & 688759 & 4.45 & 4.6798 & TST \\
\hline CHEMBL1383632 & 688759 & 5.05 & 4.8676 & TRN \\
\hline CHEMBL1569238 & 688759 & 4.6 & 4.8668 & TST \\
\hline CHEMBL1380876 & 688759 & 4.8 & 4.6571 & TRN \\
\hline CHEMBL3193478 & 688759 & 5.0 & 4.8223 & TRN \\
\hline CHEMBL3195742 & 688759 & 5.95 & 5.8184 & TRN \\
\hline CHEMBL1537550 & 688759 & 4.45 & 4.595 & TRN \\
\hline CHEMBL1335616 & 688759 & 4.45 & 5.0281 & TRN \\
\hline
\end{tabular}




\begin{tabular}{|c|c|c|c|c|c|}
\hline \multicolumn{6}{|c|}{ Supplemental Table s2.txt } \\
\hline CHEMBL1445381 & 688759 & 4.45 & 4.7986 & TRN & \\
\hline CHEMBL1369587 & 688759 & 4.45 & 4.7823 & TRN & \\
\hline CHEMBL1426204 & 688759 & 4.5 & 5.563 & TRN & \\
\hline CHEMBL1439025 & 688759 & 5.6 & 5.0982 & TRN & \\
\hline CHEMBL1400237 & 688759 & 5.85 & 5.6736 & TRN & \\
\hline CHEMBL1360916 & 688759 & 5.25 & 5.1819 & TRN & \\
\hline CHEMBL1501437 & 688759 & 4.45 & 4.6226 & TRN & \\
\hline CHEMBL1527176 & 688759 & 5.0 & 4.994 & TRN & \\
\hline CHEMBL1468761 & 688759 & 4.45 & 5.0014 & TST & \\
\hline CHEMBL3212305 & 688759 & 5.15 & 5.28299 & 99999999995 & TRN \\
\hline CHEMBL1547647 & 688759 & 4.95 & 4.7541 & TRN & \\
\hline CHEMBL1330781 & 688759 & 4.45 & 5.06 & TRN & \\
\hline CHEMBL1599223 & 688759 & 5.3 & 4.6926 & TST & \\
\hline CHEMBL1578360 & 688759 & 5.35 & 5.518 & TRN & \\
\hline CHEMBL1460740 & 688759 & 4.65 & 4.6612 & TRN & \\
\hline CHEMBL1357663 & 688759 & 4.65 & 4.8651 & TST & \\
\hline CHEMBL1343599 & 688759 & 5.6 & 5.4484 & TRN & \\
\hline CHEMBL1450466 & 688759 & 5.2 & 5.2431 & TST & \\
\hline CHEMBL1591965 & 688759 & 5.45 & 4.9123 & TRN & \\
\hline CHEMBL1401066 & 688759 & 6.0 & 4.9097 & TRN & \\
\hline CHEMBL1346184 & 688759 & 5.0 & 4.6881 & TRN & \\
\hline CHEMBL1977602 & 688759 & 4.45 & 4.7386 & TRN & \\
\hline CHEMBL1579080 & 688759 & 4.45 & 4.7843 & TRN & \\
\hline CHEMBL1519764 & 688759 & 5.45 & 4.7239 & TST & \\
\hline CHEMBL1496464 & 688759 & 4.45 & 4.8201 & TST & \\
\hline CHEMBL3209655 & 688759 & 4.45 & 4.9088 & TST & \\
\hline CHEMBL1579552 & 688759 & 4.9 & 4.7847 & TRN & \\
\hline CHEMBL1372094 & 688759 & 5.25 & 5.2691 & TRN & \\
\hline CHEMBL1324698 & 688759 & 4.45 & 4.7772 & TST & \\
\hline CHEMBL3199419 & 688759 & 5.15 & 5.0449 & TRN & \\
\hline CHEMBL1351516 & 688759 & 4.5 & 4.8216 & TRN & \\
\hline CHEMBL1516808 & 688759 & 4.45 & 4.7068 & TST & \\
\hline CHEMBL1322290 & 688759 & 4.7 & 4.9974 & TST & \\
\hline CHEMBL1575549 & 688759 & 5.25 & 4.6461 & TRN & \\
\hline CHEMBL1550571 & 688759 & 5.55 & 4.9301 & TRN & \\
\hline CHEMBL1468642 & 688759 & 5.1 & 4.7387 & TRN & \\
\hline CHEMBL1405604 & 688759 & 4.95 & 5.1154 & TRN & \\
\hline CHEMBL1331945 & 688759 & 4.8 & 4.6943 & TRN & \\
\hline CHEMBL3211833 & 688759 & 4.7 & 4.4856 & TRN & \\
\hline CHEMBL599304 & 688759 & 4.45 & 4.6149 & TRN & \\
\hline CHEMBL1478496 & 688759 & 4.45 & 4.7201 & TRN & \\
\hline CHEMBL3194285 & 688759 & 4.6 & 4.8462 & TRN & \\
\hline CHEMBL1582283 & 688759 & 8.301 & 4.94300 & 00000000005 & TST \\
\hline CHEMBL1567480 & 688759 & 4.7 & 4.7368 & TRN & \\
\hline CHEMBL1570553 & 688759 & 4.45 & 4.7232 & TRN & \\
\hline CHEMBL3189599 & 688759 & 4.65 & 4.9831 & TST & \\
\hline CHEMBL1489961 & 688759 & 4.45 & 4.725 & TRN & \\
\hline CHEMBL1418598 & 688759 & 4.45 & 4.6035 & TRN & \\
\hline
\end{tabular}




\begin{tabular}{|c|c|c|c|c|}
\hline \multicolumn{5}{|c|}{ Supplemental Table S2.txt } \\
\hline CHEMBL3198167 & 688759 & 6.2 & 5.6435 & TRN \\
\hline CHEMBL399491 & 688759 & 6.5 & 5.5862 & TST \\
\hline CHEMBL1432583 & 688759 & 5.05 & 5.6853 & TRN \\
\hline CHEMBL1320708 & 688759 & 4.6 & 4.9853 & TRN \\
\hline CHEMBL3197334 & 688759 & 4.95 & 5.1235 & TST \\
\hline CHEMBL1466446 & 688759 & 5.25 & 4.9722 & TRN \\
\hline CHEMBL3197078 & 688759 & 4.45 & 4.6009 & TRN \\
\hline CHEMBL1407917 & 688759 & 4.45 & 4.6848 & TST \\
\hline CHEMBL1477979 & 688759 & 4.95 & 4.9948 & TST \\
\hline CHEMBL1561596 & 688759 & 5.05 & 4.9404 & TRN \\
\hline CHEMBL1373809 & 688759 & 4.65 & 4.6917 & TRN \\
\hline CHEMBL1411646 & 688759 & 4.45 & 4.7162 & TRN \\
\hline CHEMBL1309266 & 688759 & 4.45 & 4.8172 & TRN \\
\hline CHEMBL1486180 & 688759 & 4.85 & 5.0099 & TRN \\
\hline CHEMBL1607320 & 688759 & 4.45 & 4.6559 & TRN \\
\hline CHEMBL3196527 & 688759 & 4.95 & 4.9049 & TRN \\
\hline CHEMBL1440203 & 688759 & 5.0 & 4.797 & TRN \\
\hline CHEMBL1567594 & 688759 & 4.45 & 4.7068 & TRN \\
\hline CHEMBL1477081 & 688759 & 5.3 & 5.3012 & TRN \\
\hline CHEMBL1358948 & 688759 & 4.65 & 4.8231 & TST \\
\hline CHEMBL1463492 & 688759 & 4.65 & 4.8367 & TST \\
\hline CHEMBL1560815 & 688759 & 4.65 & 4.8881 & TRN \\
\hline CHEMBL3209173 & 688759 & 4.45 & 4.5994 & TST \\
\hline CHEMBL3209428 & 688759 & 5.75 & 5.0071 & TST \\
\hline CHEMBL1573636 & 688759 & 4.45 & 4.9653 & TRN \\
\hline CHEMBL1405970 & 688759 & 5.7 & 4.7407 & TST \\
\hline CHEMBL3198185 & 688759 & 5.75 & 5.4294 & TRN \\
\hline CHEMBL1495475 & 688759 & 4.85 & 4.8047 & TST \\
\hline CHEMBL491940 & 688759 & 4.45 & 4.6823 & TRN \\
\hline CHEMBL1299459 & 688759 & 4.8 & 4.9969 & TRN \\
\hline CHEMBL1468403 & 688759 & 4.45 & 4.7177 & TRN \\
\hline CHEMBL3211055 & 688759 & 4.45 & 4.9425 & TRN \\
\hline CHEMBL1597356 & 688759 & 5.25 & 4.8773 & TRN \\
\hline CHEMBL1431676 & 688759 & 5.55 & 5.5023 & TRN \\
\hline CHEMBL3196347 & 688759 & 5.15 & 5.106 & TRN \\
\hline CHEMBL1573407 & 688759 & 4.45 & 4.7378 & TRN \\
\hline CHEMBL1325645 & 688759 & 4.45 & 4.8988 & TRN \\
\hline CHEMBL1601421 & 688759 & 4.45 & 4.7949 & TRN \\
\hline CHEMBL1607638 & 688759 & 4.6 & 4.7007 & TRN \\
\hline CHEMBL3191453 & 688759 & 5.15 & 4.9785 & TRN \\
\hline CHEMBL1549188 & 688759 & 5.55 & 4.9365 & TRN \\
\hline CHEMBL1461108 & 688759 & 4.45 & 4.863 & TST \\
\hline CHEMBL1974063 & 688759 & 4.45 & 5.3731 & TRN \\
\hline CHEMBL1431692 & 688759 & 5.1 & 4.8987 & TRN \\
\hline CHEMBL1966367 & 688759 & 4.45 & 4.4867 & TRN \\
\hline CHEMBL568739 & 688759 & 4.45 & 4.7807 & TST \\
\hline CHEMBL3192707 & 688759 & 4.75 & 4.4836 & TRN \\
\hline CHEMBL3193631 & 688759 & 5.05 & 4.9204 & TRN \\
\hline
\end{tabular}




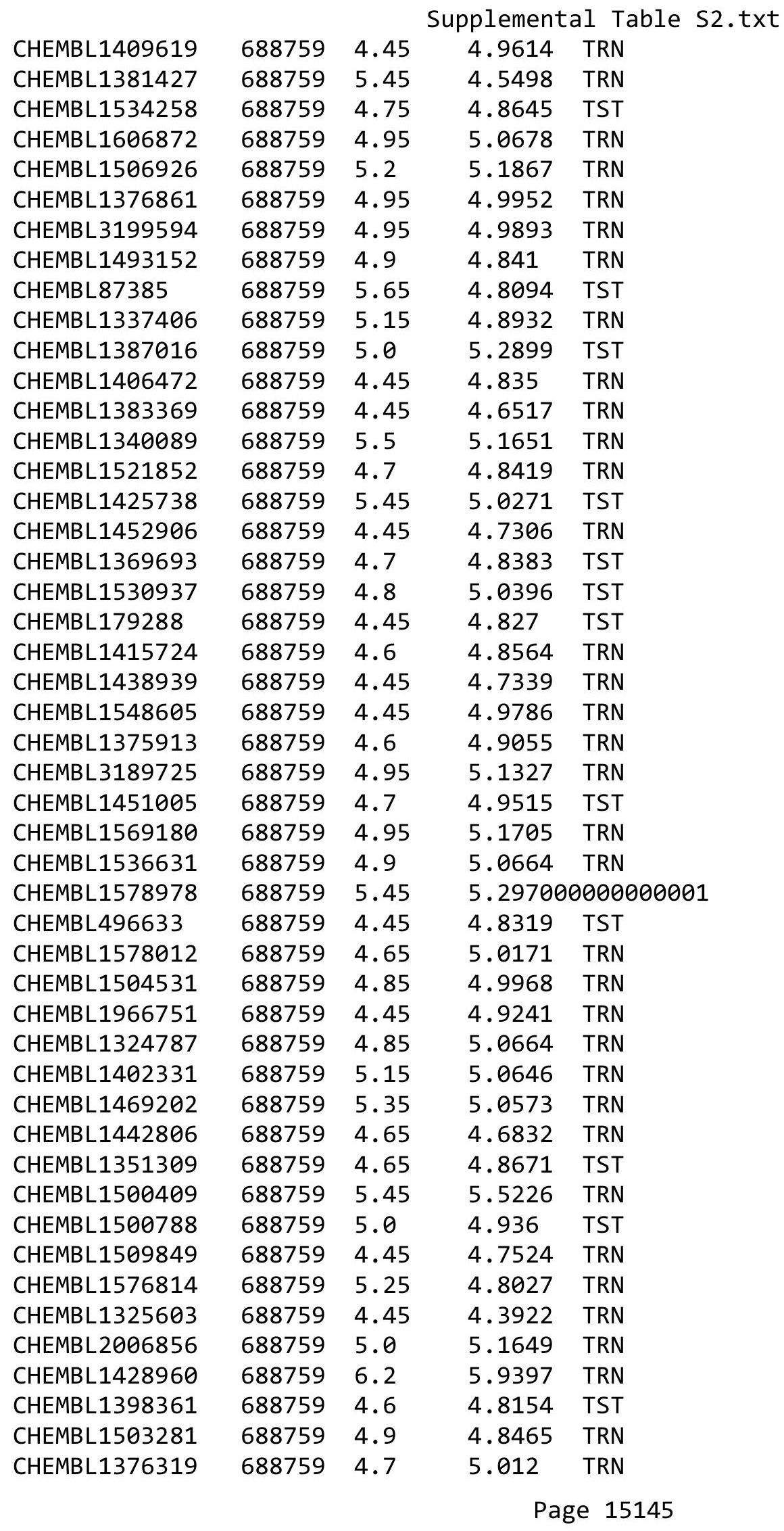




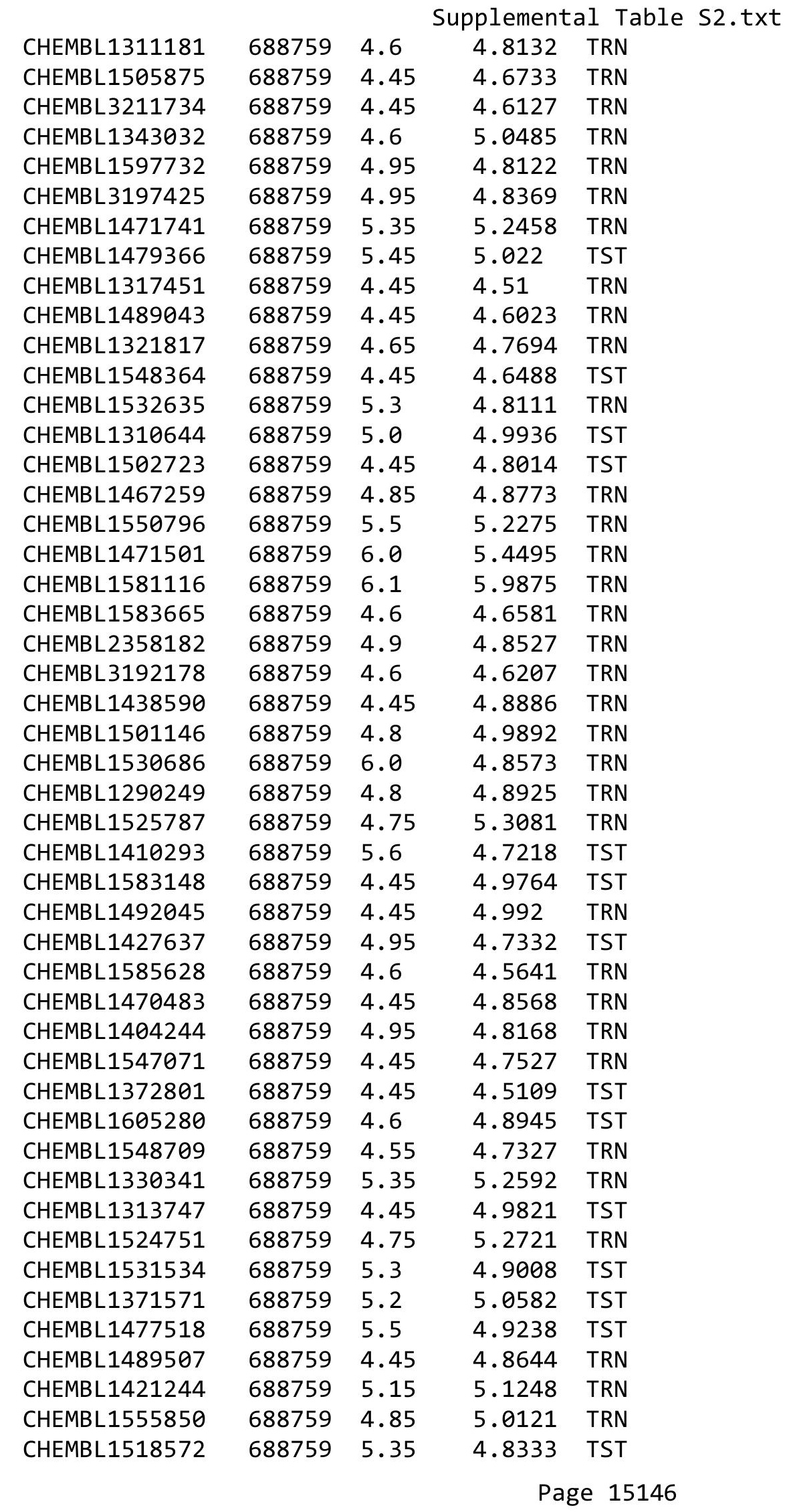




\begin{tabular}{|c|c|c|c|c|}
\hline \multicolumn{5}{|c|}{ Supplemental Table S2.txt } \\
\hline CHEMBL1337147 & 688759 & 4.7 & 5.1549 & TRN \\
\hline CHEMBL1344536 & 688759 & 4.65 & 4.4562 & TRN \\
\hline CHEMBL1386681 & 688759 & 4.95 & 5.0971 & TRN \\
\hline CHEMBL1421530 & 688759 & 4.5 & 4.9182 & TRN \\
\hline CHEMBL1378034 & 688759 & 4.5 & 4.955 & TRN \\
\hline CHEMBL1505240 & 688759 & 4.45 & 5.0295 & TRN \\
\hline CHEMBL1364057 & 688759 & 4.45 & 4.9887 & TRN \\
\hline CHEMBL1589386 & 688759 & 4.8 & 4.445 & TRN \\
\hline CHEMBL1996199 & 688759 & 4.85 & 5.0401 & TRN \\
\hline CHEMBL1453776 & 688759 & 4.45 & 4.7553 & TRN \\
\hline CHEMBL1445728 & 688759 & 4.45 & 5.0797 & TRN \\
\hline CHEMBL1511718 & 688759 & 4.65 & 4.8383 & TRN \\
\hline CHEMBL1322187 & 688759 & 5.2 & 4.8432 & TRN \\
\hline CHEMBL1342984 & 688759 & 4.85 & 4.9381 & TRN \\
\hline CHEMBL1472098 & 688759 & 4.5 & 4.8063 & TRN \\
\hline CHEMBL1391134 & 688759 & 4.5 & 5.026 & TST \\
\hline CHEMBL1457559 & 688759 & 4.45 & 4.7193 & TRN \\
\hline CHEMBL3144976 & 688759 & 5.35 & 5.3833 & TRN \\
\hline CHEMBL1971515 & 688759 & 5.3 & 5.0449 & TRN \\
\hline CHEMBL1350497 & 688759 & 4.95 & 4.7439 & TRN \\
\hline CHEMBL1310855 & 688759 & 5.5 & 4.9495 & TRN \\
\hline CHEMBL1483689 & 688759 & 5.35 & 4.7324 & TRN \\
\hline CHEMBL1430579 & 688759 & 4.45 & 5.3045 & TRN \\
\hline CHEMBL1353662 & 688759 & 4.45 & 4.7077 & TST \\
\hline CHEMBL1465829 & 688759 & 4.6 & 4.7832 & TST \\
\hline CHEMBL1539624 & 688759 & 6.4 & 5.9907 & TRN \\
\hline CHEMBL1354119 & 688759 & 4.8 & 4.5169 & TRN \\
\hline CHEMBL3195099 & 688759 & 4.55 & 4.77 & TST \\
\hline CHEMBL566899 & 688759 & 4.45 & 4.6219 & TRN \\
\hline CHEMBL1387633 & 688759 & 5.0 & 5.0908 & TST \\
\hline CHEMBL1466196 & 688759 & 4.45 & 4.9063 & TRN \\
\hline CHEMBL1431945 & 688759 & 4.85 & 4.6438 & TRN \\
\hline CHEMBL1480227 & 688759 & 4.45 & 4.5291 & TRN \\
\hline CHEMBL3192075 & 688759 & 4.75 & 4.7146 & TRN \\
\hline CHEMBL1461353 & 688759 & 4.45 & 4.9887 & TRN \\
\hline CHEMBL3196151 & 688759 & 4.9 & 4.7646 & TRN \\
\hline CHEMBL1571312 & 688759 & 5.7 & 4.8986 & TRN \\
\hline CHEMBL1319828 & 688759 & 4.65 & 4.7504 & TRN \\
\hline CHEMBL1327970 & 688759 & 4.65 & 4.7707 & TRN \\
\hline CHEMBL252966 & 688759 & 6.9 & 5.3695 & TRN \\
\hline CHEMBL1341424 & 688759 & 4.45 & 4.593 & TRN \\
\hline CHEMBL3192880 & 688759 & 5.35 & 5.1895 & TRN \\
\hline CHEMBL1385326 & 688759 & 6.0 & 4.9572 & TRN \\
\hline CHEMBL1442507 & 688759 & 4.45 & 5.1532 & TRN \\
\hline CHEMBL1565776 & 688759 & 5.7 & 5.3468 & TRN \\
\hline CHEMBL1348198 & 688759 & 4.6 & 4.6342 & TST \\
\hline CHEMBL1526933 & 688759 & 4.65 & 5.2927 & TRN \\
\hline CHEMBL1447922 & 688759 & 5.05 & 4.5739 & TRN \\
\hline
\end{tabular}




\begin{tabular}{|c|c|c|c|c|}
\hline \multicolumn{5}{|c|}{ Supplemental Table S2.txt } \\
\hline CHEMBL1964909 & 688759 & 5.1 & 5.6071 & TRN \\
\hline CHEMBL1482343 & 688759 & 4.45 & 4.6223 & TRN \\
\hline CHEMBL3196648 & 688759 & 5.0 & 5.1038 & TRN \\
\hline CHEMBL1370977 & 688759 & 4.95 & 4.8807 & TST \\
\hline CHEMBL1421876 & 688759 & 4.45 & 4.7733 & TRN \\
\hline CHEMBL1462350 & 688759 & 6.0 & 4.6245 & TRN \\
\hline CHEMBL3192710 & 688759 & 4.9 & 4.9637 & TRN \\
\hline CHEMBL1465214 & 688759 & 4.45 & 4.7406 & TRN \\
\hline CHEMBL1382740 & 688759 & 4.45 & 4.8499 & TRN \\
\hline CHEMBL1361693 & 688759 & 4.45 & 4.942 & TRN \\
\hline CHEMBL1500614 & 688759 & 4.65 & 4.5612 & TRN \\
\hline CHEMBL1334943 & 688759 & 4.55 & 4.702 & TST \\
\hline CHEMBL1335185 & 688759 & 4.65 & 4.7249 & TST \\
\hline CHEMBL1382483 & 688759 & 4.45 & 4.5113 & TRN \\
\hline CHEMBL1528348 & 688759 & 4.45 & 4.8239 & TRN \\
\hline CHEMBL1485411 & 688759 & 5.05 & 5.065 & TST \\
\hline CHEMBL1378778 & 688759 & 4.8 & 4.7868 & TRN \\
\hline CHEMBL1413737 & 688759 & 5.2 & 5.2719 & TRN \\
\hline CHEMBL1302746 & 688759 & 6.2 & 4.9175 & TST \\
\hline CHEMBL1308924 & 688759 & 4.95 & 5.0001 & TRN \\
\hline CHEMBL1456106 & 688759 & 4.6 & 4.8481 & TRN \\
\hline CHEMBL1564015 & 688759 & 5.55 & 4.9292 & TRN \\
\hline CHEMBL1469223 & 688759 & 5.2 & 5.3226 & TRN \\
\hline CHEMBL1530813 & 688759 & 4.45 & 4.7917 & TRN \\
\hline CHEMBL1609247 & 688759 & 4.65 & 5.0551 & TST \\
\hline CHEMBL1350330 & 688759 & 4.45 & 4.8095 & TRN \\
\hline CHEMBL1399966 & 688759 & 4.65 & 4.6835 & TRN \\
\hline CHEMBL1332761 & 688759 & 4.45 & 4.5904 & TRN \\
\hline CHEMBL1315410 & 688759 & 4.45 & 4.8874 & TRN \\
\hline CHEMBL 3197344 & 688759 & 5.55 & 5.5769 & TRN \\
\hline CHEMBL1465529 & 688759 & 4.7 & 4.7831 & TRN \\
\hline CHEMBL1426108 & 688759 & 5.0 & 4.9434 & TRN \\
\hline CHEMBL1420727 & 688759 & 4.45 & 4.9119 & TRN \\
\hline CHEMBL1559022 & 688759 & 4.8 & 5.0164 & TST \\
\hline CHEMBL 276473 & 688759 & 4.45 & 4.8172 & TRN \\
\hline CHEMBL1465342 & 688759 & 4.45 & 4.6303 & TRN \\
\hline CHEMBL1379343 & 688759 & 4.65 & 4.7569 & TST \\
\hline CHEMBL1335957 & 688759 & 5.0 & 4.9495 & TRN \\
\hline CHEMBL1302178 & 688759 & 6.2 & 6.1299 & TRN \\
\hline CHEMBL1964615 & 688759 & 4.45 & 4.6957 & TRN \\
\hline CHEMBL1584954 & 688759 & 4.45 & 5.0673 & TRN \\
\hline CHEMBL1347649 & 688759 & 4.45 & 4.7053 & TRN \\
\hline CHEMBL1504554 & 688759 & 5.45 & 5.1365 & TRN \\
\hline CHEMBL1550592 & 688759 & 5.65 & 4.7532 & TRN \\
\hline CHEMBL1448101 & 688759 & 4.45 & 4.9772 & TRN \\
\hline CHEMBL1369789 & 688759 & 4.85 & 4.7659 & TRN \\
\hline CHEMBL1544486 & 688759 & 4.45 & 5.1208 & TST \\
\hline CHEMBL1333829 & 688759 & 6.2 & 4.665 & TST \\
\hline
\end{tabular}




\begin{tabular}{|c|c|c|c|c|c|}
\hline & & \multicolumn{4}{|c|}{ Supplemental Table S2.txt } \\
\hline CHEMBL 2000655 & 688759 & 5.15 & 4.8867 & TST & \\
\hline CHEMBL1330401 & 688759 & 6.0 & 5.5799 & TRN & \\
\hline CHEMBL1613092 & 688759 & 6.4 & 5.6455 & TRN & \\
\hline CHEMBL 3209870 & 688759 & 4.45 & 4.7176 & TRN & \\
\hline CHEMBL1579186 & 688759 & 6.05 & 5.4126 & TRN & \\
\hline CHEMBL1359240 & 688759 & 5.4 & 4.9944 & TST & \\
\hline CHEMBL1503493 & 688759 & 5.05 & \multicolumn{2}{|c|}{4.7330000000000005} & TRN \\
\hline CHEMBL1975660 & 688759 & 4.85 & 4.9365 & TST & \\
\hline CHEMBL1539110 & 688759 & 4.45 & 4.912 & TRN & \\
\hline CHEMBL1427185 & 688759 & 5.2 & 5.0144 & TRN & \\
\hline CHEMBL1421048 & 688759 & 4.45 & 4.5449 & TRN & \\
\hline CHEMBL1601617 & 688759 & 4.45 & 4.7464 & TRN & \\
\hline CHEMBL1580134 & 688759 & 4.45 & 4.7584 & TRN & \\
\hline CHEMBL 2003214 & 688759 & 4.45 & 4.6614 & TRN & \\
\hline CHEMBL1334260 & 688759 & 4.5 & 4.7464 & TRN & \\
\hline CHEMBL1404231 & 688759 & 4.45 & 4.6856 & TRN & \\
\hline CHEMBL3211227 & 688759 & 5.45 & 4.7626 & TRN & \\
\hline CHEMBL 3214390 & 688759 & 4.45 & 4.8199 & TRN & \\
\hline CHEMBL1328585 & 688759 & 4.45 & 5.0021 & TRN & \\
\hline CHEMBL1549830 & 688759 & 5.15 & 5.0856 & TRN & \\
\hline CHEMBL1425524 & 688759 & 4.75 & 5.0771 & TRN & \\
\hline CHEMBL1385557 & 688759 & 5.9 & 5.0783 & TRN & \\
\hline CHEMBL1581016 & 688759 & 5.5 & 4.7925 & TRN & \\
\hline CHEMBL1488597 & 688759 & 5.45 & 5.2893 & TST & \\
\hline CHEMBL1482540 & 688759 & 5.95 & 5.6183 & TRN & \\
\hline CHEMBL1408218 & 688759 & 5.0 & 4.8352 & TRN & \\
\hline CHEMBL3199283 & 688759 & 4.45 & 4.8969 & TRN & \\
\hline CHEMBL3194048 & 688759 & 4.45 & 5.2988 & TRN & \\
\hline CHEMBL1517493 & 688759 & 4.65 & 4.6945 & TRN & \\
\hline CHEMBL1350754 & 688759 & 5.55 & 5.5325 & TRN & \\
\hline CHEMBL310310 & 688759 & 6.0 & 5.2498 & TST & \\
\hline CHEMBL1505170 & 688759 & 5.2 & 5.37299 & 9999999999 & TST \\
\hline CHEMBL1608785 & 688759 & 5.05 & 4.8853 & TRN & \\
\hline CHEMBL1393813 & 688759 & 5.45 & 5.4486 & TRN & \\
\hline CHEMBL1309979 & 688759 & 4.8 & 4.7949 & TRN & \\
\hline CHEMBL1447501 & 688759 & 4.65 & 4.7398 & TRN & \\
\hline CHEMBL1606948 & 688759 & 4.45 & 4.6317 & TRN & \\
\hline CHEMBL1327291 & 688759 & 6.2 & 5.6982 & TRN & \\
\hline CHEMBL3209451 & 688759 & 6.05 & 5.6545 & TRN & \\
\hline CHEMBL1170485 & 688759 & 4.9 & 5.7875 & TST & \\
\hline CHEMBL1427219 & 688759 & 4.55 & 4.4984 & TRN & \\
\hline CHEMBL1546431 & 688759 & 4.45 & 4.6423 & TST & \\
\hline CHEMBL1984876 & 688759 & 7.5498 & 6.2504 & TRN & \\
\hline CHEMBL1424867 & 688759 & 5.35 & 4.9001 & TRN & \\
\hline CHEMBL1360419 & 688759 & 5.3 & 5.0164 & TST & \\
\hline CHEMBL3191218 & 688759 & 6.5 & 5.98 & TRN & \\
\hline CHEMBL1494012 & 688759 & 4.6 & 4.8933 & TST & \\
\hline CHEMBL1479292 & 688759 & 4.55 & 4.5502 & TST & \\
\hline
\end{tabular}




\begin{tabular}{|c|c|c|c|c|}
\hline \multicolumn{5}{|c|}{ Supplemental Table s2.txt } \\
\hline CHEMBL1393034 & 688759 & 4.7 & 4.814 & TRN \\
\hline CHEMBL1378654 & 688759 & 4.45 & 5.0166 & TRN \\
\hline CHEMBL2141886 & 688759 & 4.45 & 4.9546 & TST \\
\hline CHEMBL1478962 & 688759 & 5.25 & 5.1814 & TRN \\
\hline CHEMBL1576532 & 688759 & 5.0 & 5.0489 & TRN \\
\hline CHEMBL1488150 & 688759 & 4.45 & 4.3601 & TRN \\
\hline CHEMBL1567331 & 688759 & 5.6 & 5.0372 & TRN \\
\hline CHEMBL3211930 & 688759 & 5.25 & 5.095 & TRN \\
\hline CHEMBL3191320 & 688759 & 4.95 & 5.0786 & TRN \\
\hline CHEMBL1536547 & 688759 & 6.0 & 5.0454 & TRN \\
\hline CHEMBL1406729 & 688759 & 4.45 & 4.9225 & TRN \\
\hline CHEMBL1451701 & 688759 & 4.45 & 4.8807 & TST \\
\hline CHEMBL1587422 & 688759 & 4.95 & 5.033 & TRN \\
\hline CHEMBL1499770 & 688759 & 4.9 & 5.1399 & TRN \\
\hline CHEMBL1579024 & 688759 & 5.2 & 4.7489 & TST \\
\hline CHEMBL1512990 & 688759 & 4.45 & 4.4273 & TRN \\
\hline CHEMBL1429636 & 688759 & 4.45 & 4.8769 & TRN \\
\hline CHEMBL1460075 & 688759 & 4.65 & 4.8149 & TRN \\
\hline CHEMBL1360591 & 688759 & 4.45 & 4.7762 & TRN \\
\hline CHEMBL3190102 & 688759 & 4.95 & 4.8562 & TRN \\
\hline CHEMBL1380970 & 688759 & 4.45 & 4.7252 & TRN \\
\hline CHEMBL1466432 & 688759 & 4.45 & 4.8638 & TST \\
\hline CHEMBL1458408 & 688759 & 4.7 & 4.7023 & TRN \\
\hline CHEMBL1585709 & 688759 & 5.0 & 4.9326 & TRN \\
\hline CHEMBL1469922 & 688759 & 7.0501 & 4.8377 & TRN \\
\hline CHEMBL1488712 & 688759 & 5.05 & 5.0081 & TRN \\
\hline CHEMBL1408091 & 688759 & 4.65 & 4.6929 & TRN \\
\hline CHEMBL1556158 & 688759 & 4.45 & 4.792 & TRN \\
\hline CHEMBL1441524 & 688759 & 4.65 & 4.8362 & TST \\
\hline CHEMBL601616 & 688759 & 4.5 & 4.4651 & TRN \\
\hline CHEMBL1462111 & 688759 & 5.2 & 5.0347 & TRN \\
\hline CHEMBL1482468 & 688759 & 4.75 & 4.9647 & TST \\
\hline CHEMBL1483252 & 688759 & 6.15 & 5.6319 & TRN \\
\hline CHEMBL1500221 & 688759 & 5.05 & 5.3531 & TRN \\
\hline CHEMBL1461318 & 688759 & 5.25 & 4.8754 & TST \\
\hline CHEMBL1523703 & 688759 & 6.6499 & 4.7409 & TRN \\
\hline CHEMBL1609296 & 688759 & 4.65 & 4.8042 & TRN \\
\hline CHEMBL3195079 & 688759 & 4.65 & 4.8107 & TST \\
\hline CHEMBL1608890 & 688759 & 4.5 & 4.4721 & TRN \\
\hline CHEMBL1530694 & 688759 & 5.0 & 4.8354 & TRN \\
\hline CHEMBL1530414 & 688759 & 4.45 & 4.7616 & TRN \\
\hline CHEMBL1455707 & 688759 & 4.65 & 4.605 & TRN \\
\hline CHEMBL3195922 & 688759 & 4.45 & 4.9685 & TRN \\
\hline CHEMBL1421679 & 688759 & 4.45 & 4.9281 & TRN \\
\hline CHEMBL1455730 & 688759 & 4.6 & 4.7844 & TST \\
\hline CHEMBL1463470 & 688759 & 5.3 & 5.245 & TRN \\
\hline CHEMBL1577394 & 688759 & 4.55 & 4.9972 & TRN \\
\hline CHEMBL1306155 & 688759 & 5.45 & 4.8344 & TRN \\
\hline
\end{tabular}




\begin{tabular}{|c|c|c|c|c|}
\hline \multicolumn{5}{|c|}{ Supplemental Table S2.txt } \\
\hline CHEMBL1449911 & 688759 & 4.45 & 4.9835 & TRN \\
\hline CHEMBL1547595 & 688759 & 4.75 & 4.8069 & TRN \\
\hline CHEMBL1422335 & 688759 & 7.1002 & 5.545 & TRN \\
\hline CHEMBL1611354 & 688759 & 5.6 & 5.5427 & TRN \\
\hline CHEMBL1411432 & 688759 & 4.45 & 4.8336 & TRN \\
\hline CHEMBL1540635 & 688759 & 5.5 & 5.0679 & TST \\
\hline CHEMBL1973332 & 688759 & 5.9 & 5.1337 & TRN \\
\hline CHEMBL1409001 & 688759 & 5.25 & 4.7713 & TST \\
\hline CHEMBL1384194 & 688759 & 4.45 & 4.6134 & TRN \\
\hline CHEMBL1359782 & 688759 & 4.45 & 4.7467 & TRN \\
\hline CHEMBL1333987 & 688759 & 5.45 & 5.4168 & TRN \\
\hline CHEMBL3191495 & 688759 & 5.35 & 4.7694 & TRN \\
\hline CHEMBL1457884 & 688759 & 4.65 & 4.6162 & TRN \\
\hline CHEMBL1506093 & 688759 & 4.45 & 4.6306 & TST \\
\hline CHEMBL1313499 & 688759 & 5.25 & 5.4101 & TST \\
\hline CHEMBL1323290 & 688759 & 5.3 & 5.2449 & TRN \\
\hline CHEMBL1478478 & 688759 & 5.45 & 4.9153 & TRN \\
\hline CHEMBL1340715 & 688759 & 5.4 & 5.5785 & TRN \\
\hline CHEMBL3208212 & 688759 & 5.2 & 4.7814 & TRN \\
\hline CHEMBL1536014 & 688759 & 4.95 & 5.1321 & TRN \\
\hline CHEMBL1448982 & 688759 & 5.45 & 5.4783 & TRN \\
\hline CHEMBL1423649 & 688759 & 5.25 & 5.2017 & TRN \\
\hline CHEMBL1580379 & 688759 & 4.7 & 4.7012 & TRN \\
\hline CHEMBL1522147 & 688759 & 4.5 & 4.9516 & TRN \\
\hline CHEMBL3214090 & 688759 & 6.2 & 5.6227 & TRN \\
\hline CHEMBL1427740 & 688759 & 5.45 & 4.9215 & TST \\
\hline CHEMBL1329513 & 688759 & 4.45 & 4.7119 & TRN \\
\hline CHEMBL1371126 & 688759 & 4.75 & 4.9224 & TST \\
\hline CHEMBL1602608 & 688759 & 5.05 & 4.7317 & TST \\
\hline CHEMBL1455113 & 688759 & 4.95 & 4.6698 & TST \\
\hline CHEMBL1552663 & 688759 & 4.4 & 4.7896 & TRN \\
\hline CHEMBL3194469 & 688759 & 6.2 & 5.5942 & TRN \\
\hline CHEMBL1586301 & 688759 & 4.45 & 4.8732 & TRN \\
\hline CHEMBL1585528 & 688759 & 5.25 & 5.2577 & TRN \\
\hline CHEMBL1188078 & 688759 & 4.6 & 4.6861 & TRN \\
\hline CHEMBL1442300 & 688759 & 4.8 & 4.9326 & TST \\
\hline CHEMBL3212409 & 688759 & 4.45 & 5.061 & TRN \\
\hline CHEMBL3208881 & 688759 & 6.1 & 4.765 & TRN \\
\hline CHEMBL1431811 & 688759 & 4.45 & 5.086 & TST \\
\hline CHEMBL1449566 & 688759 & 4.45 & 6.29700 & 0000000001 \\
\hline CHEMBL1485551 & 688759 & 4.8 & 4.5648 & TRN \\
\hline CHEMBL1303807 & 688759 & 4.95 & 4.9728 & TRN \\
\hline CHEMBL1518840 & 688759 & 4.75 & 4.7151 & TRN \\
\hline CHEMBL1302189 & 688759 & 5.15 & 5.0337 & TRN \\
\hline CHEMBL1502374 & 688759 & 4.55 & 4.9225 & TRN \\
\hline CHEMBL 213580 & 688759 & 5.3 & 5.1533 & TRN \\
\hline CHEMBL3197306 & 688759 & 4.6 & 4.5331 & TRN \\
\hline CHEMBL1384722 & 688759 & 4.85 & 4.6321 & TRN \\
\hline
\end{tabular}




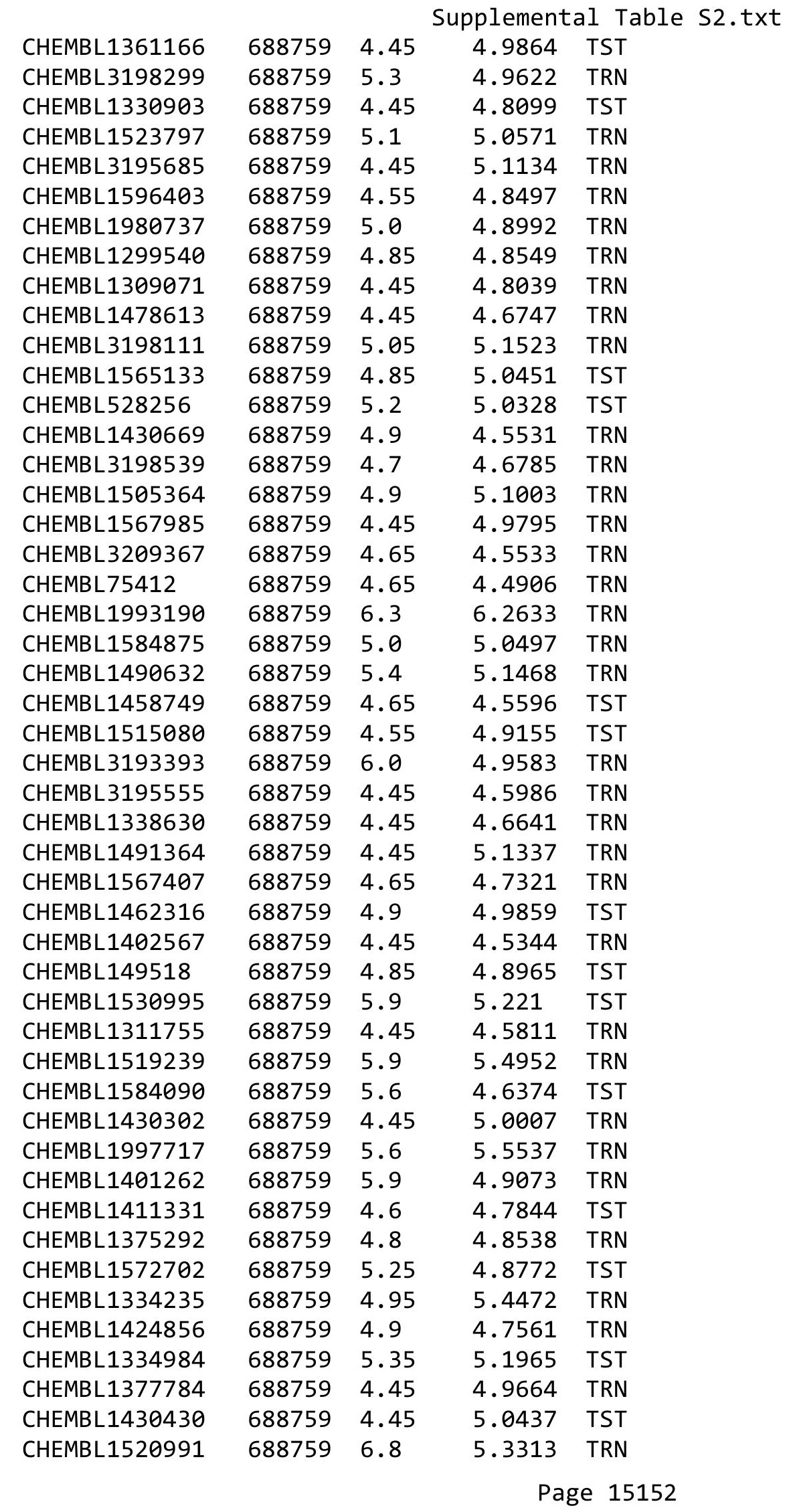




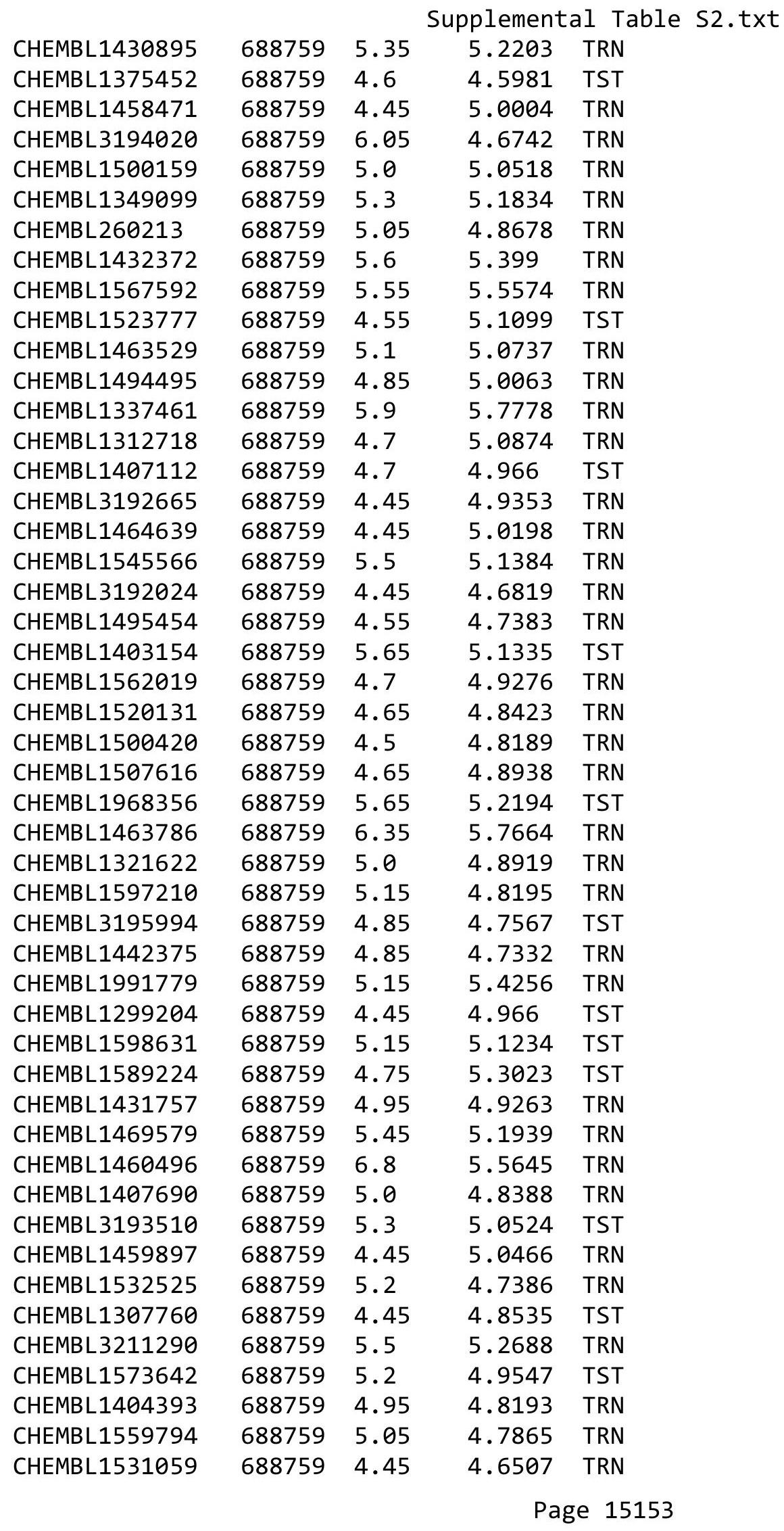




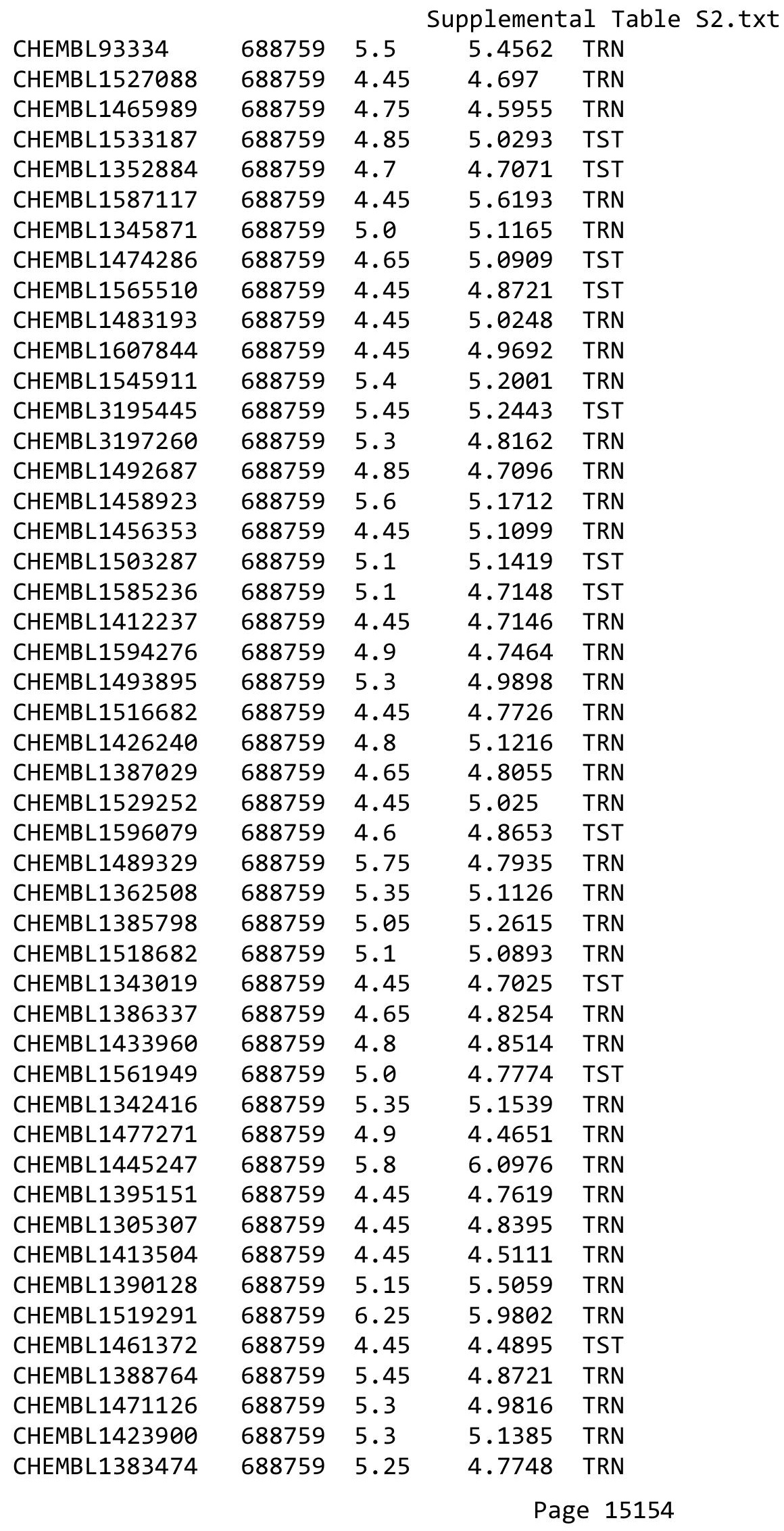




\begin{tabular}{|c|c|c|c|c|}
\hline \multicolumn{5}{|c|}{ Supplemental Table S2.txt } \\
\hline CHEMBL1388603 & 688759 & 4.7 & 4.746 & TRN \\
\hline CHEMBL1519585 & 688759 & 4.45 & 4.9113 & TRN \\
\hline CHEMBL1469727 & 688759 & 4.55 & 5.1676 & TRN \\
\hline CHEMBL1405321 & 688759 & 5.4 & 4.5274 & TST \\
\hline CHEMBL1482964 & 688759 & 4.45 & 5.131 & TRN \\
\hline CHEMBL1313406 & 688759 & 5.15 & 4.9917 & TRN \\
\hline CHEMBL1426461 & 688759 & 4.65 & 4.8007 & TRN \\
\hline CHEMBL1583510 & 688759 & 4.45 & 4.7435 & TRN \\
\hline CHEMBL1485134 & 688759 & 4.75 & 4.4952 & TRN \\
\hline CHEMBL1390038 & 688759 & 4.45 & 4.7975 & TRN \\
\hline CHEMBL1464975 & 688759 & 4.55 & 4.8509 & TRN \\
\hline CHEMBL1360480 & 688759 & 5.3 & 4.6942 & TRN \\
\hline CHEMBL1351978 & 688759 & 4.45 & 5.0043 & TST \\
\hline CHEMBL1504867 & 688759 & 4.45 & 5.0688 & TRN \\
\hline CHEMBL1345985 & 688759 & 4.45 & 4.777 & TRN \\
\hline CHEMBL1447294 & 688759 & 4.95 & 4.6883 & TRN \\
\hline CHEMBL1335952 & 688759 & 4.45 & 5.0408 & TRN \\
\hline CHEMBL1307827 & 688759 & 4.45 & 4.8311 & TST \\
\hline CHEMBL1428095 & 688759 & 6.45 & 5.3964 & TRN \\
\hline CHEMBL1390033 & 688759 & 4.5 & 4.8147 & TRN \\
\hline CHEMBL1416115 & 688759 & 5.2 & 4.8985 & TRN \\
\hline CHEMBL1531705 & 688759 & 4.7 & 5.0083 & TRN \\
\hline CHEMBL1580448 & 688759 & 4.55 & 4.7619 & TRN \\
\hline CHEMBL1370653 & 688759 & 6.9 & 6.0079 & TRN \\
\hline CHEMBL1582148 & 688759 & 4.45 & 4.9611 & TRN \\
\hline CHEMBL1456001 & 688759 & 4.7 & 5.0143 & TRN \\
\hline CHEMBL3196029 & 688759 & 4.65 & 4.6966 & TRN \\
\hline CHEMBL1328589 & 688759 & 5.45 & 5.0858 & TRN \\
\hline CHEMBL1324638 & 688759 & 5.3 & 4.7285 & TRN \\
\hline CHEMBL1536708 & 688759 & 6.9 & 4.9939 & TRN \\
\hline CHEMBL1469415 & 688759 & 4.45 & 4.9166 & TST \\
\hline CHEMBL 3208585 & 688759 & 4.45 & 5.0615 & TRN \\
\hline CHEMBL1988121 & 688759 & 5.45 & 5.436 & TRN \\
\hline CHEMBL1450467 & 688759 & 4.55 & 4.8493 & TRN \\
\hline CHEMBL 2003559 & 688759 & 4.45 & 4.9813 & TST \\
\hline CHEMBL1477889 & 688759 & 5.5 & 4.9436 & TRN \\
\hline CHEMBL1339863 & 688759 & 4.45 & 4.8273 & TRN \\
\hline CHEMBL1364510 & 688759 & 5.5 & 5.5237 & TRN \\
\hline CHEMBL1605977 & 688759 & 5.5 & 6.1458 & TRN \\
\hline CHEMBL1566706 & 688759 & 4.6 & 4.7594 & TRN \\
\hline CHEMBL1315766 & 688759 & 4.45 & 4.8033 & TRN \\
\hline CHEMBL1332862 & 688759 & 5.15 & 5.0353 & TRN \\
\hline CHEMBL1440193 & 688759 & 4.8 & 4.9492 & TRN \\
\hline CHEMBL1352941 & 688759 & 5.3 & 4.9581 & TRN \\
\hline CHEMBL1345362 & 688759 & 4.65 & 4.851 & TST \\
\hline CHEMBL1384677 & 688759 & 4.95 & 4.7061 & TST \\
\hline CHEMBL1447076 & 688759 & 4.45 & 4.4745 & TRN \\
\hline CHEMBL3198368 & 688759 & 5.55 & 5.5567 & TRN \\
\hline
\end{tabular}




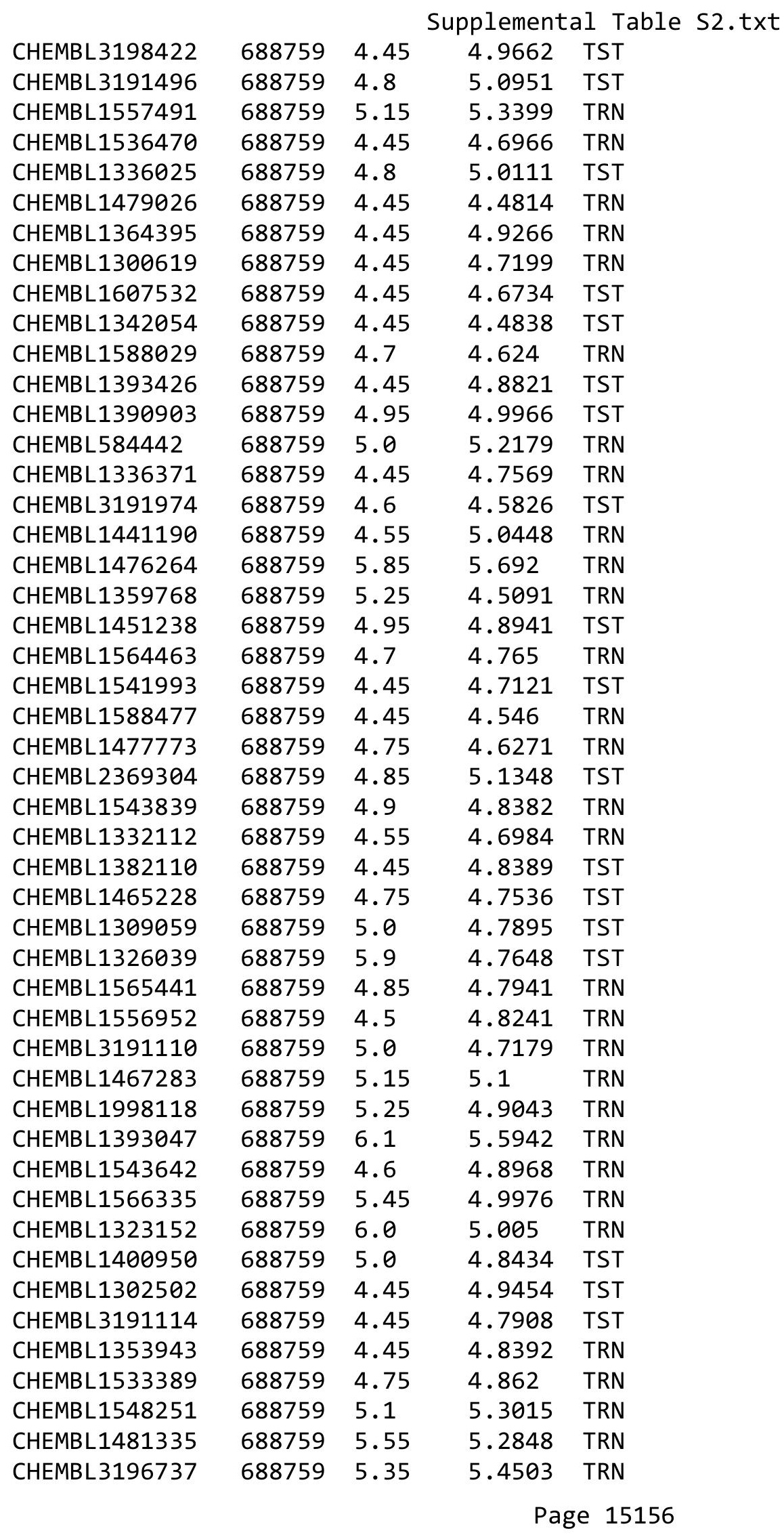




\begin{tabular}{|c|c|c|c|c|c|}
\hline & & \multicolumn{4}{|c|}{ Supplemental Table S2.txt } \\
\hline CHEMBL1573418 & 688759 & 4.75 & 5.4425 & TRN & \\
\hline CHEMBL1464303 & 688759 & 4.5 & 4.9432 & TRN & \\
\hline CHEMBL1519843 & 688759 & 6.0 & 4.6432 & TRN & \\
\hline CHEMBL 3212802 & 688759 & 5.25 & 4.9258 & TST & \\
\hline CHEMBL1338166 & 688759 & 5.0 & 5.0384 & TRN & \\
\hline CHEMBL1540920 & 688759 & 4.9 & 4.9726 & TRN & \\
\hline CHEMBL1389279 & 688759 & 4.8 & 4.8423 & TRN & \\
\hline CHEMBL1414053 & 688759 & 5.2 & 4.7501 & TRN & \\
\hline CHEMBL1535462 & 688759 & 5.25 & 4.8279 & TRN & \\
\hline CHEMBL1313479 & 688759 & 4.9 & 4.8544 & TRN & \\
\hline CHEMBL1440827 & 688759 & 5.15 & 5.1445 & TRN & \\
\hline CHEMBL1503605 & 688759 & 4.45 & 4.7759 & TRN & \\
\hline CHEMBL1428850 & 688759 & 5.1 & 5.01 & TRN & \\
\hline CHEMBL1388866 & 688759 & 4.95 & 4.8432 & TRN & \\
\hline CHEMBL1358680 & 688759 & 4.75 & 5.468 & TRN & \\
\hline CHEMBL1331721 & 688759 & 4.9 & 4.6842 & TST & \\
\hline CHEMBL1596423 & 688759 & 4.45 & 4.9866 & TRN & \\
\hline CHEMBL3197065 & 688759 & 4.95 & 5.4572 & TRN & \\
\hline CHEMBL1413585 & 688759 & 4.45 & 4.6184 & TST & \\
\hline CHEMBL1310837 & 688759 & 4.45 & 4.7554 & TST & \\
\hline CHEMBL392680 & 688759 & 5.95 & 5.40600 & 0000000001 & TRN \\
\hline CHEMBL1299515 & 688759 & 4.95 & 5.1951 & TRN & \\
\hline CHEMBL1580474 & 688759 & 4.7 & 4.9233 & TRN & \\
\hline CHEMBL1350948 & 688759 & 4.45 & 4.6927 & TRN & \\
\hline CHEMBL1401661 & 688759 & 6.0 & 4.614 & TRN & \\
\hline CHEMBL1426524 & 688759 & 4.6 & 4.687 & TRN & \\
\hline CHEMBL3194737 & 688759 & 4.75 & 4.5975 & TRN & \\
\hline CHEMBL1360868 & 688759 & 5.2 & 4.9842 & TRN & \\
\hline CHEMBL1413798 & 688759 & 4.45 & 4.6548 & TRN & \\
\hline CHEMBL1522655 & 688759 & 4.45 & 4.7216 & TRN & \\
\hline CHEMBL1456019 & 688759 & 4.45 & 4.7558 & TRN & \\
\hline CHEMBL1540343 & 688759 & 7.0 & 4.8723 & TST & \\
\hline CHEMBL3198651 & 688759 & 5.5 & 5.3034 & TRN & \\
\hline CHEMBL3209038 & 688759 & 4.45 & 4.8561 & TST & \\
\hline CHEMBL1485612 & 688759 & 5.5 & 5.0548 & TRN & \\
\hline CHEMBL1420849 & 688759 & 4.95 & 4.8894 & TST & \\
\hline CHEMBL1976567 & 688759 & 4.7 & 4.8613 & TRN & \\
\hline CHEMBL1425932 & 688759 & 6.35 & 4.9647 & TST & \\
\hline CHEMBL1553643 & 688759 & 4.7 & 4.8029 & TRN & \\
\hline CHEMBL1348390 & 688759 & 4.9 & 4.9856 & TRN & \\
\hline CHEMBL1370158 & 688759 & 4.85 & 4.846 & TRN & \\
\hline CHEMBL1453905 & 688759 & 5.55 & 4.9515 & TRN & \\
\hline CHEMBL1589329 & 688759 & 4.45 & 4.5064 & TRN & \\
\hline CHEMBL1404448 & 688759 & 4.45 & 4.9814 & TRN & \\
\hline CHEMBL1562960 & 688759 & 5.5 & 4.9962 & TST & \\
\hline CHEMBL1458915 & 688759 & 4.95 & 4.7232 & TRN & \\
\hline CHEMBL1347665 & 688759 & 4.45 & 4.9992 & TST & \\
\hline CHEMBL599255 & 688759 & 5.35 & 5.2952 & TRN & \\
\hline
\end{tabular}




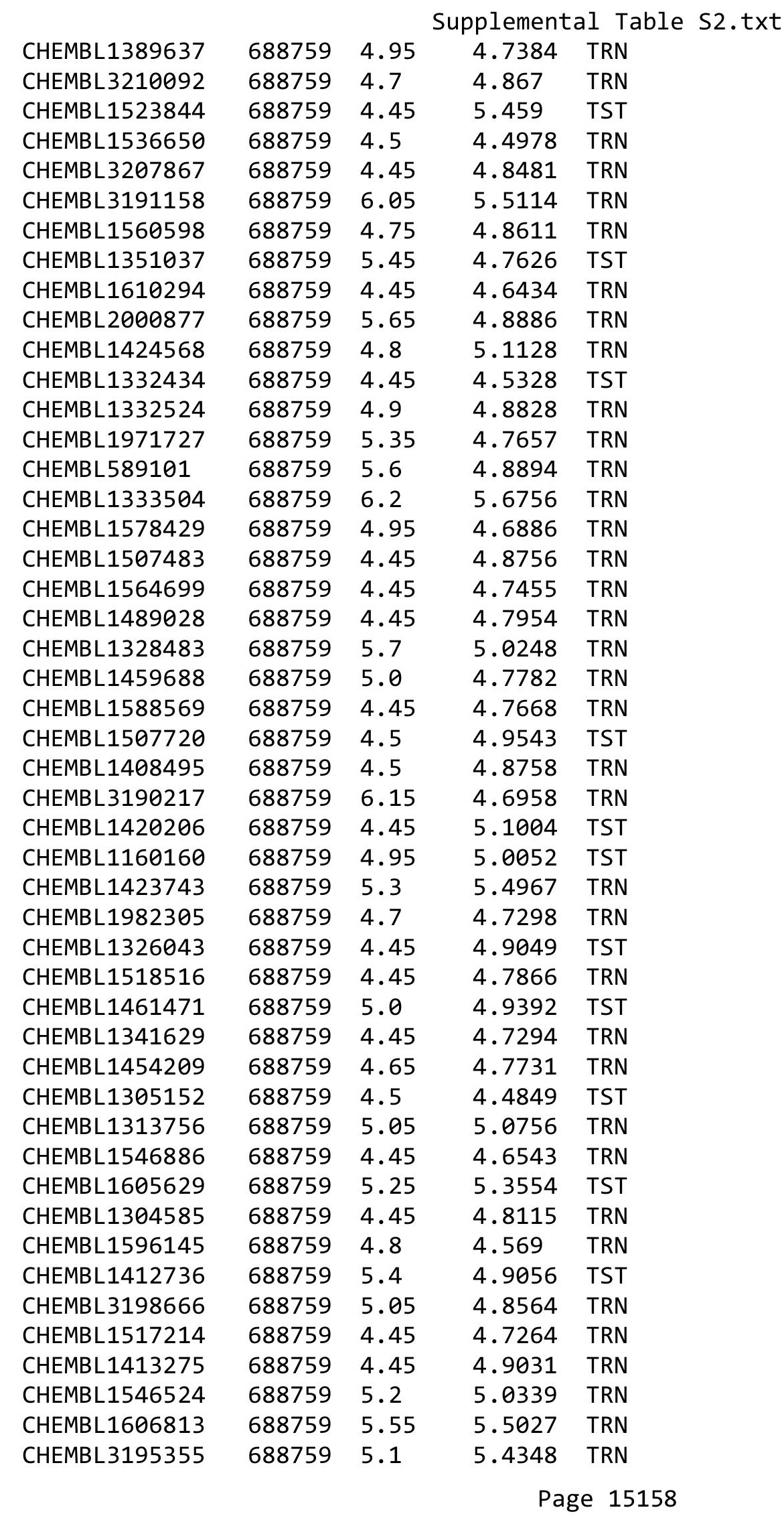




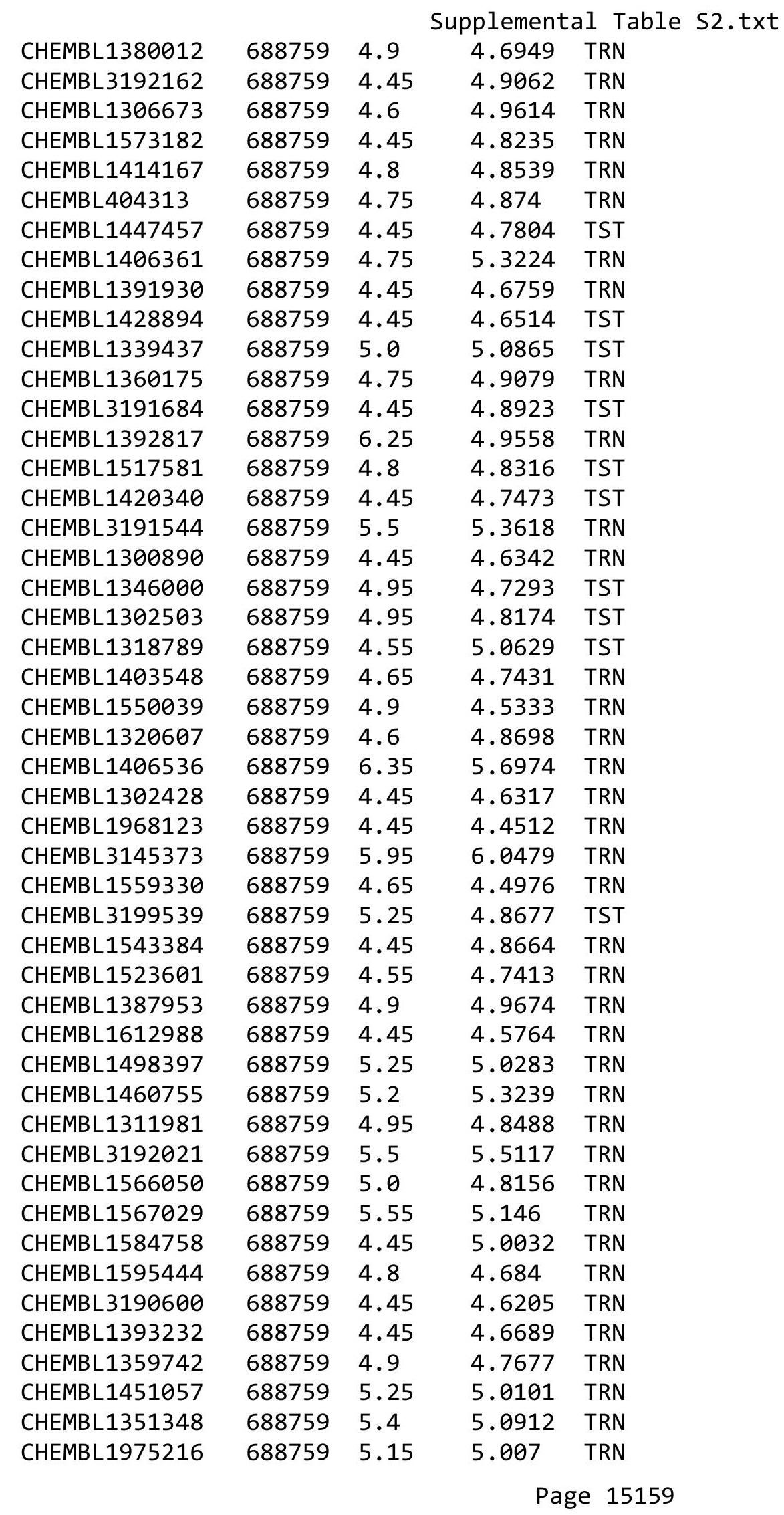




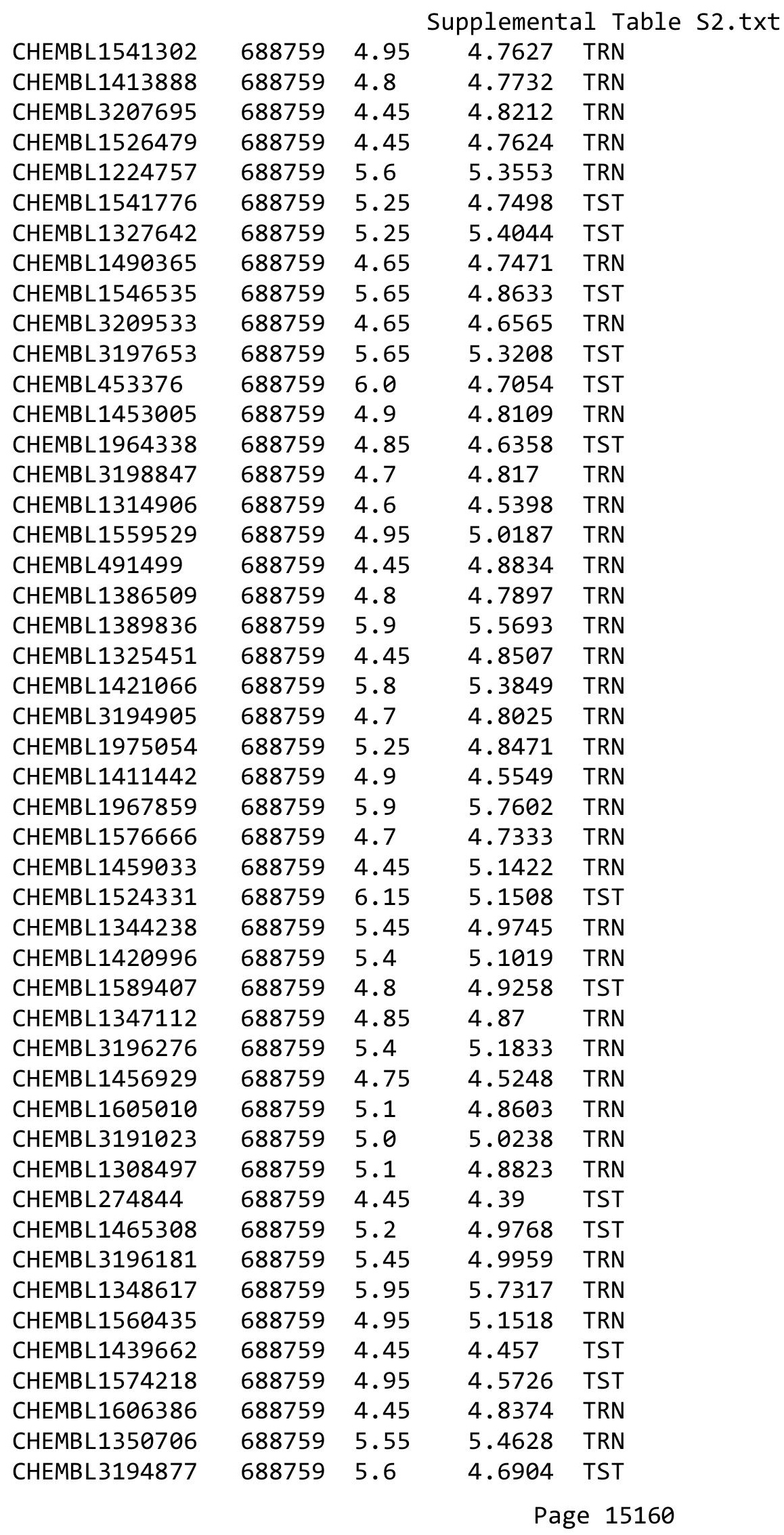




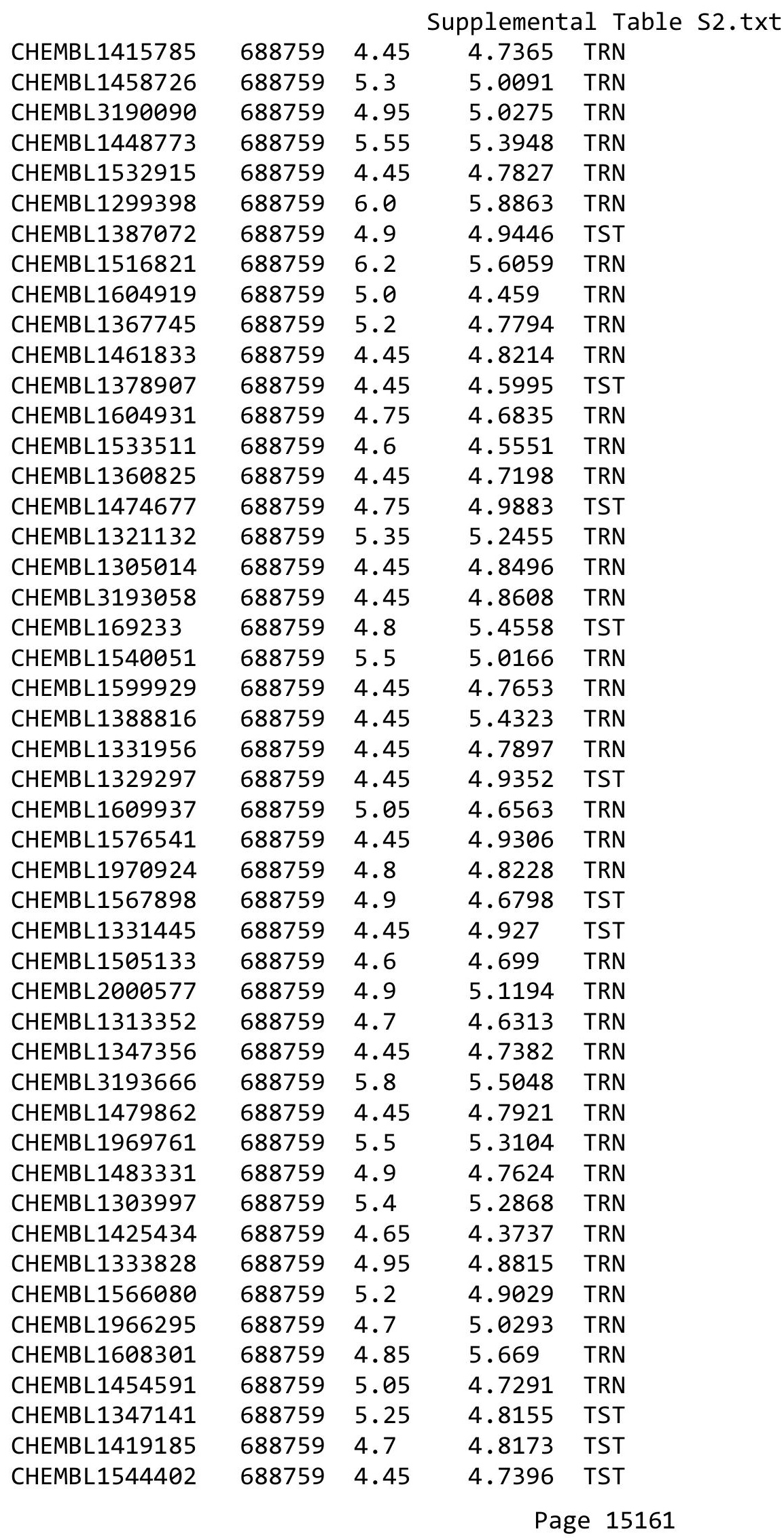




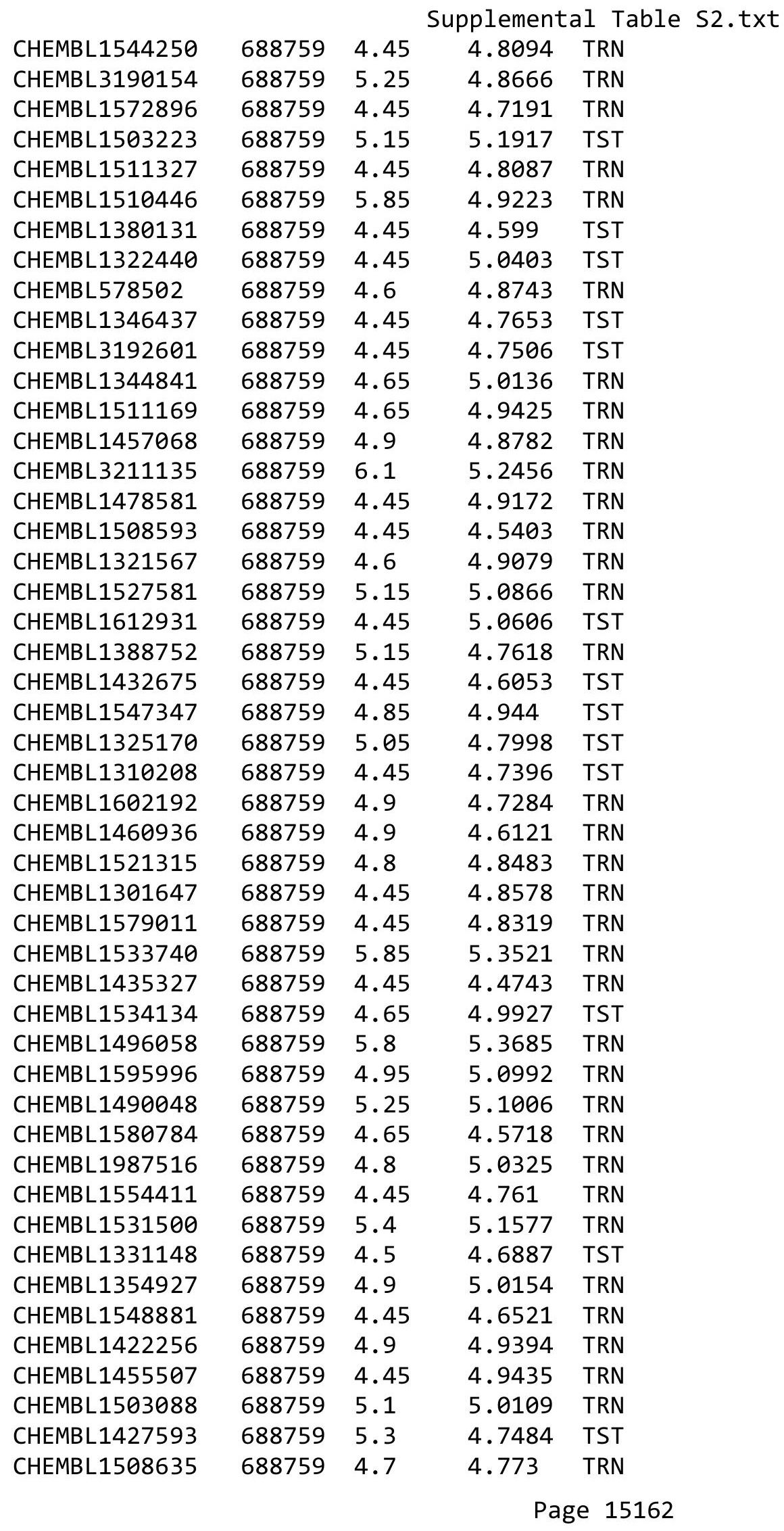




\begin{tabular}{|c|c|c|c|c|c|}
\hline \multicolumn{6}{|c|}{ Supplemental Table S2.txt } \\
\hline CHEMBL1487284 & 688759 & 4.7 & 5.11 & TST & \\
\hline CHEMBL1416854 & 688759 & 4.45 & 4.8894 & TST & \\
\hline CHEMBL 3198232 & 688759 & 5.5 & 4.8087 & TRN & \\
\hline CHEMBL 3207562 & 688759 & 4.1 & 4.9402 & TST & \\
\hline CHEMBL1383664 & 688759 & 5.0 & 4.9866 & TST & \\
\hline CHEMBL1864436 & 688759 & 4.95 & 4.8618 & TST & \\
\hline CHEMBL429095 & 688759 & 6.0 & 5.4508 & TST & \\
\hline CHEMBL1583056 & 688759 & 4.65 & 4.8766 & TRN & \\
\hline CHEMBL1517325 & 688759 & 4.8 & 5.0953 & TRN & \\
\hline CHEMBL1488898 & 688759 & 4.75 & 4.7832 & TRN & \\
\hline CHEMBL1344571 & 688759 & 4.65 & 4.8203 & TRN & \\
\hline CHEMBL 3192726 & 688759 & 4.5 & 5.0707 & TRN & \\
\hline CHEMBL1463600 & 688759 & 4.45 & 4.9239 & TRN & \\
\hline CHEMBL1345173 & 688759 & 4.55 & 4.6583 & TST & \\
\hline CHEMBL1443210 & 688759 & 4.45 & 4.7326 & TRN & \\
\hline CHEMBL1565854 & 688759 & 4.95 & 4.8759 & TRN & \\
\hline CHEMBL1586097 & 688759 & 4.5 & 4.7513 & TRN & \\
\hline CHEMBL1567823 & 688759 & 4.45 & 4.5325 & TST & \\
\hline CHEMBL3189614 & 688759 & 5.2 & 5.4357 & TRN & \\
\hline CHEMBL1533657 & 688759 & 4.55 & 4.8602 & TRN & \\
\hline CHEMBL1443798 & 688759 & 4.45 & 4.5978 & TST & \\
\hline CHEMBL1524101 & 688759 & 4.8 & 5.2422 & TRN & \\
\hline CHEMBL1521233 & 688759 & 4.65 & 4.8209 & TRN & \\
\hline CHEMBL1607301 & 688759 & 4.5 & 5.002 & TRN & \\
\hline CHEMBL1384564 & 688759 & 5.15 & 5.1553 & TRN & \\
\hline CHEMBL1343728 & 688759 & 4.55 & 4.9661 & TRN & \\
\hline CHEMBL1546375 & 688759 & 4.65 & 4.9121 & TRN & \\
\hline CHEMBL1576528 & 688759 & 4.9 & 4.8464 & TST & \\
\hline CHEMBL3191006 & 688759 & 4.45 & 4.6399 & TST & \\
\hline CHEMBL1333978 & 688759 & 4.45 & 4.5397 & TRN & \\
\hline CHEMBL1592917 & 688759 & 4.6 & 4.7272 & TST & \\
\hline CHEMBL 3190397 & 688759 & 4.7 & 5.143 & TST & \\
\hline CHEMBL1556319 & 688759 & 4.45 & 4.6402 & TRN & \\
\hline CHEMBL1490498 & 688759 & 4.9 & 5.341 & TST & \\
\hline CHEMBL1369837 & 688759 & 4.45 & 4.5679 & TRN & \\
\hline CHEMBL1602132 & 688759 & 4.65 & 4.8485 & TRN & \\
\hline CHEMBL1322504 & 688759 & 4.45 & 4.7671 & TRN & \\
\hline CHEMBL1503010 & 688759 & 5.0 & 5.0298 & TST & \\
\hline CHEMBL1360998 & 688759 & 4.45 & 4.9464 & TST & \\
\hline CHEMBL1337500 & 688759 & 5.5 & 5.1922 & TST & \\
\hline CHEMBL1557655 & 688759 & 4.7 & 4.57100 & 0000000001 & TRN \\
\hline CHEMBL1575649 & 688759 & 4.7 & 4.6752 & TRN & \\
\hline CHEMBL1604958 & 688759 & 5.15 & 5.284 & TRN & \\
\hline CHEMBL1374640 & 688759 & 5.4 & 4.8513 & TRN & \\
\hline CHEMBL1508503 & 688759 & 4.45 & 4.6715 & TRN & \\
\hline CHEMBL1544918 & 688759 & 5.2 & 5.032 & TRN & \\
\hline CHEMBL1976677 & 688759 & 5.15 & 5.3411 & TRN & \\
\hline CHEMBL3197546 & 688759 & 4.45 & 4.7816 & TST & \\
\hline
\end{tabular}




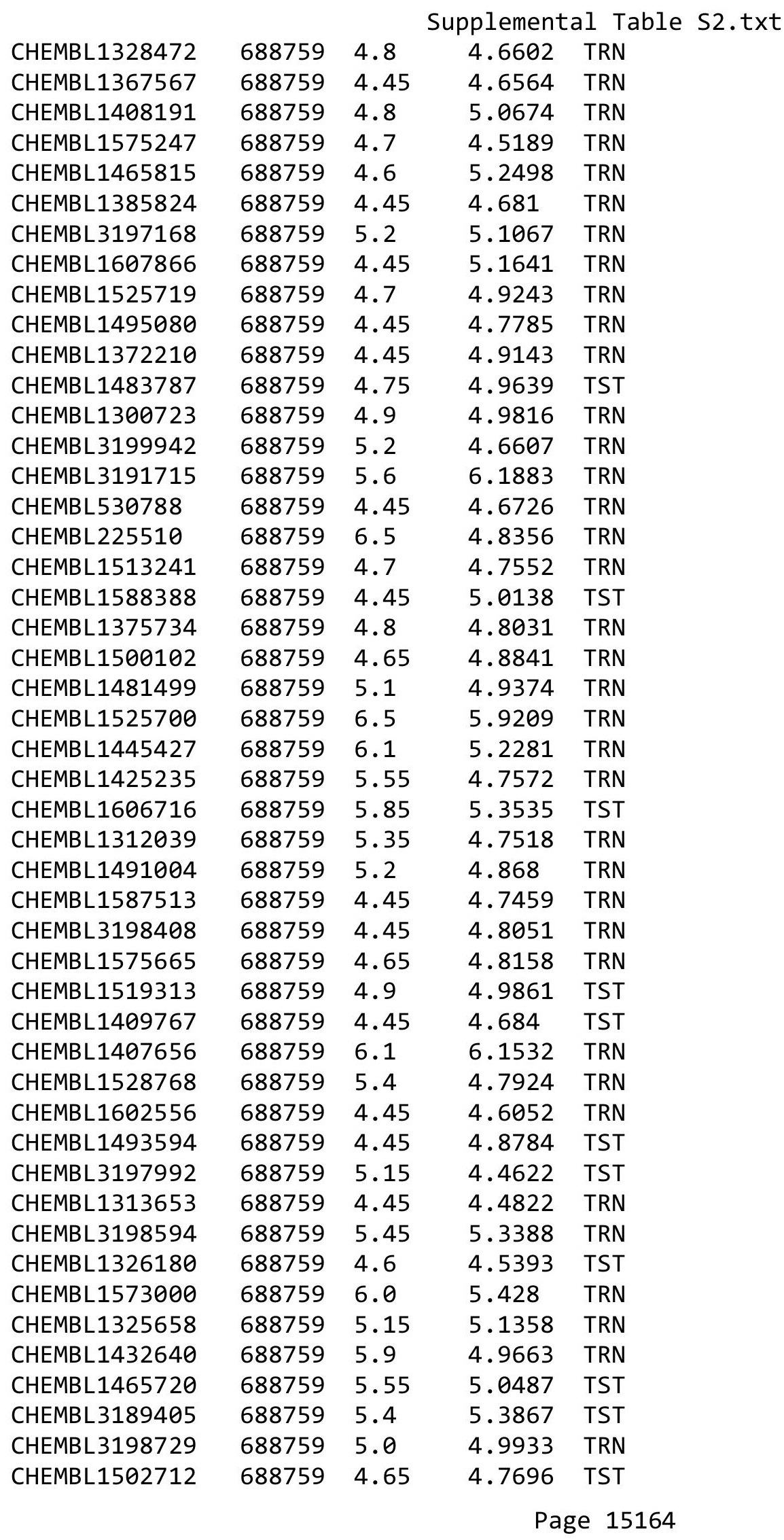




\begin{tabular}{|c|c|c|c|c|c|}
\hline \multicolumn{6}{|c|}{ S } \\
\hline CHEMBL1558040 & 688759 & 4.45 & 4.4768 & TST & \\
\hline CHEMBL1556669 & 688759 & 4.65 & 4.6175 & TRN & \\
\hline CHEMBL1461392 & 688759 & 4.6 & 4.8676 & TRN & \\
\hline CHEMBL1582710 & 688759 & 5.35 & 4.9413 & TRN & \\
\hline CHEMBL1384292 & 688759 & 6.1 & 5.6947 & TRN & \\
\hline CHEMBL1510400 & 688759 & 4.45 & 4.6845 & TST & \\
\hline CHEMBL1409111 & 688759 & 6.8 & 5.0039 & TRN & \\
\hline CHEMBL1572810 & 688759 & 4.45 & 4.8648 & TRN & \\
\hline CHEMBL1369231 & 688759 & 5.9 & 5.5546 & TST & \\
\hline CHEMBL3209857 & 688759 & 5.2 & 4.9615 & TRN & \\
\hline CHEMBL1366632 & 688759 & 4.45 & 4.7431 & TRN & \\
\hline CHEMBL1532159 & 688759 & 4.65 & 4.6384 & TRN & \\
\hline CHEMBL1532867 & 688759 & 4.45 & 4.6244 & TRN & \\
\hline CHEMBL1497963 & 688759 & 4.75 & 4.90300 & 00000000005 & TRN \\
\hline CHEMBL1453291 & 688759 & 5.05 & 5.033 & TST & \\
\hline CHEMBL1451961 & 688759 & 4.85 & 4.6719 & TRN & \\
\hline CHEMBL1497000 & 688759 & 4.45 & 4.7874 & TST & \\
\hline CHEMBL328430 & 688759 & 5.3 & 5.4605 & TST & \\
\hline CHEMBL1532305 & 688759 & 5.5 & 5.035 & TST & \\
\hline CHEMBL1444064 & 688759 & 4.45 & 4.6337 & TRN & \\
\hline CHEMBL1440122 & 688759 & 5.5 & 5.1612 & TRN & \\
\hline CHEMBL1455606 & 688759 & 5.45 & 4.7689 & TST & \\
\hline CHEMBL1883149 & 688759 & 5.0 & 4.7575 & TRN & \\
\hline CHEMBL1306086 & 688759 & 4.95 & 5.5539 & TST & \\
\hline CHEMBL1408807 & 688759 & 5.25 & 4.9847 & TRN & \\
\hline CHEMBL 2369281 & 688759 & 5.5 & 4.9292 & TST & \\
\hline CHEMBL585685 & 688759 & 4.45 & 4.646 & TRN & \\
\hline CHEMBL3192648 & 688759 & 5.0 & 5.3456 & TRN & \\
\hline CHEMBL 1607338 & 688759 & 4.8 & 4.7016 & TRN & \\
\hline CHEMBL 3212488 & 688759 & 4.45 & 4.752 & TST & \\
\hline CHEMBL1367139 & 688759 & 4.65 & 4.9257 & TRN & \\
\hline CHEMBL1407258 & 688759 & 5.4 & 5.1211 & TRN & \\
\hline CHEMBL1307220 & 688759 & 4.45 & 4.7463 & TST & \\
\hline CHEMBL1389335 & 688759 & 4.5 & 5.2003 & TRN & \\
\hline CHEMBL1362310 & 688759 & 5.0 & 5.1271 & TRN & \\
\hline CHEMBL1536907 & 688759 & 4.6 & 4.5256 & TRN & \\
\hline CHEMBL1305302 & 688759 & 5.5 & 5.4632 & TST & \\
\hline CHEMBL3195546 & 688759 & 4.45 & 4.7159 & TRN & \\
\hline CHEMBL1412646 & 688759 & 4.65 & 4.4639 & TRN & \\
\hline CHEMBL3190118 & 688759 & 5.05 & 5.2223 & TRN & \\
\hline CHEMBL1304549 & 688759 & 4.7 & 4.9411 & TRN & \\
\hline CHEMBL1469735 & 688759 & 4.8 & 4.7215 & TRN & \\
\hline CHEMBL1559175 & 688759 & 4.75 & 4.6799 & TRN & \\
\hline CHEMBL1461522 & 688759 & 4.45 & 4.8444 & TRN & \\
\hline CHEMBL1446697 & 688759 & 4.45 & 5.0038 & TRN & \\
\hline CHEMBL1422794 & 688759 & 5.2 & 5.086 & TRN & \\
\hline CHEMBL1583706 & 688759 & 4.45 & 4.5086 & TRN & \\
\hline CHEMBL1585269 & 688759 & 5.2 & 5.0225 & TRN & \\
\hline
\end{tabular}




\begin{tabular}{|c|c|c|c|c|}
\hline \multicolumn{5}{|c|}{ Supplemental Table S2.txt } \\
\hline CHEMBL1533823 & 688759 & 6.0 & 5.5309 & TST \\
\hline CHEMBL1349286 & 688759 & 4.45 & 4.6685 & TRN \\
\hline CHEMBL3196525 & 688759 & 4.95 & 4.6074 & TRN \\
\hline CHEMBL 3192578 & 688759 & 5.15 & 5.0861 & TRN \\
\hline CHEMBL1542993 & 688759 & 7.2503 & 4.8441 & TST \\
\hline CHEMBL1520199 & 688759 & 4.65 & 4.8931 & TRN \\
\hline CHEMBL3209043 & 688759 & 5.2 & 5.0963 & TRN \\
\hline CHEMBL1543123 & 688759 & 4.6 & 4.8655 & TST \\
\hline CHEMBL1477597 & 688759 & 5.15 & 5.32799 & 9999999999 \\
\hline CHEMBL1504575 & 688759 & 5.75 & 5.1218 & TRN \\
\hline CHEMBL1372136 & 688759 & 4.45 & 4.648 & TRN \\
\hline CHEMBL1405067 & 688759 & 4.45 & 4.8795 & TRN \\
\hline CHEMBL1477846 & 688759 & 4.95 & 5.1159 & TRN \\
\hline CHEMBL3194196 & 688759 & 4.85 & 4.7204 & TRN \\
\hline CHEMBL1577799 & 688759 & 4.75 & 5.138 & TRN \\
\hline CHEMBL1365353 & 688759 & 4.75 & 4.6734 & TRN \\
\hline CHEMBL3213606 & 688759 & 5.35 & 5.3747 & TRN \\
\hline CHEMBL1503699 & 688759 & 4.45 & 4.8563 & TRN \\
\hline CHEMBL313339 & 688759 & 4.95 & 5.0687 & TRN \\
\hline CHEMBL156383 & 688759 & 4.45 & 4.8609 & TRN \\
\hline CHEMBL3212279 & 688759 & 4.45 & 4.8912 & TST \\
\hline CHEMBL1364769 & 688759 & 4.45 & 4.7833 & TRN \\
\hline CHEMBL1317220 & 688759 & 4.9 & 5.4732 & TRN \\
\hline CHEMBL1538737 & 688759 & 5.05 & 4.7139 & TST \\
\hline CHEMBL574583 & 688759 & 4.45 & 4.8972 & TRN \\
\hline CHEMBL1420365 & 688759 & 5.25 & 5.688 & TRN \\
\hline CHEMBL1503163 & 688759 & 4.45 & 4.7068 & TST \\
\hline CHEMBL1375302 & 688759 & 4.65 & 4.7579 & TST \\
\hline CHEMBL1521826 & 688759 & 5.25 & 4.9099 & TRN \\
\hline CHEMBL1423448 & 688759 & 4.45 & 4.8354 & TST \\
\hline CHEMBL1368400 & 688759 & 4.6 & 4.864 & TRN \\
\hline CHEMBL1380640 & 688759 & 4.75 & 4.9898 & TST \\
\hline CHEMBL1609270 & 688759 & 4.6 & 4.6307 & TRN \\
\hline CHEMBL1468389 & 688759 & 4.45 & 4.9543 & TRN \\
\hline CHEMBL1365205 & 688759 & 5.0 & 4.9765 & TRN \\
\hline CHEMBL3199509 & 688759 & 4.6 & 4.9836 & TRN \\
\hline CHEMBL1613578 & 688759 & 5.3 & 5.1514 & TST \\
\hline CHEMBL1465013 & 688759 & 5.05 & 5.3207 & TRN \\
\hline CHEMBL1301056 & 688759 & 4.45 & 4.6106 & TST \\
\hline CHEMBL1544170 & 688759 & 4.65 & 4.8031 & TRN \\
\hline CHEMBL1493171 & 688759 & 4.9 & 4.9293 & TRN \\
\hline CHEMBL1464127 & 688759 & 4.6 & 4.9882 & TRN \\
\hline CHEMBL1376212 & 688759 & 4.6 & 4.9392 & TRN \\
\hline CHEMBL1269379 & 688759 & 4.45 & 4.6217 & TST \\
\hline CHEMBL1991440 & 688759 & 4.45 & 4.6007 & TRN \\
\hline CHEMBL3197815 & 688759 & 5.4 & 5.2953 & TRN \\
\hline CHEMBL1450497 & 688759 & 8.0506 & 6.8207 & TST \\
\hline CHEMBL1575790 & 688759 & 4.45 & 4.7231 & TRN \\
\hline
\end{tabular}




\begin{tabular}{|c|c|c|c|c|}
\hline \multicolumn{5}{|c|}{ Supplemental Table S2.txt } \\
\hline CHEMBL1371584 & 688759 & 4.45 & 4.9273 & TRN \\
\hline CHEMBL 3189448 & 688759 & 5.0 & 5.2714 & TRN \\
\hline CHEMBL187866 & 688759 & 5.7 & 4.8018 & TRN \\
\hline CHEMBL1382028 & 688759 & 4.8 & 5.0618 & TRN \\
\hline CHEMBL1374601 & 688759 & 5.55 & 5.6987 & TRN \\
\hline CHEMBL532160 & 688759 & 5.85 & 4.9777 & TRN \\
\hline CHEMBL 3197982 & 688759 & 4.95 & 5.0218 & TRN \\
\hline CHEMBL 207714 & 688759 & 4.7 & 4.8651 & TST \\
\hline CHEMBL1308380 & 688759 & 4.45 & 4.6107 & TST \\
\hline CHEMBL1463649 & 688759 & 4.6 & 4.8028 & TRN \\
\hline CHEMBL1487135 & 688759 & 5.15 & 4.8336 & TRN \\
\hline CHEMBL1558957 & 688759 & 4.9 & 4.8765 & TRN \\
\hline CHEMBL1506543 & 688759 & 5.3 & 5.1863 & TST \\
\hline CHEMBL1564063 & 688759 & 4.55 & 4.8589 & TST \\
\hline CHEMBL1515194 & 688759 & 4.7 & 4.4585 & TRN \\
\hline CHEMBL1542001 & 688759 & 4.8 & 5.1382 & TST \\
\hline CHEMBL1483028 & 688759 & 5.35 & 5.0884 & TST \\
\hline CHEMBL1581519 & 688759 & 4.45 & 4.8147 & TRN \\
\hline CHEMBL1340868 & 688759 & 4.9 & 4.8236 & TRN \\
\hline CHEMBL1461917 & 688759 & 4.45 & 4.6431 & TRN \\
\hline CHEMBL1323619 & 688759 & 4.9 & 4.9099 & TST \\
\hline CHEMBL1304854 & 688759 & 5.3 & 5.3882 & TRN \\
\hline CHEMBL1613209 & 688759 & 4.8 & 4.7604 & TST \\
\hline CHEMBL1572461 & 688759 & 5.45 & 5.3514 & TST \\
\hline CHEMBL1368368 & 688759 & 4.7 & 4.6073 & TRN \\
\hline CHEMBL3196384 & 688759 & 5.95 & 5.6643 & TST \\
\hline CHEMBL1365150 & 688759 & 4.5 & 4.6083 & TRN \\
\hline CHEMBL1403877 & 688759 & 6.25 & 5.2856 & TRN \\
\hline CHEMBL 3194774 & 688759 & 4.65 & 4.9304 & TST \\
\hline CHEMBL1416487 & 688759 & 4.45 & 4.7756 & TRN \\
\hline CHEMBL1334968 & 688759 & 4.65 & 4.7524 & TRN \\
\hline CHEMBL1567593 & 688759 & 5.55 & 5.4116 & TRN \\
\hline CHEMBL1547350 & 688759 & 5.45 & 5.3498 & TRN \\
\hline CHEMBL1322823 & 688759 & 4.6 & 4.7656 & TST \\
\hline CHEMBL1390300 & 688759 & 5.75 & 5.3809 & TRN \\
\hline CHEMBL1498096 & 688759 & 4.65 & 4.8346 & TRN \\
\hline CHEMBL1537044 & 688759 & 5.2 & 4.8907 & TRN \\
\hline CHEMBL1347395 & 688759 & 4.45 & 4.4765 & TRN \\
\hline CHEMBL1398939 & 688759 & 4.95 & 4.8727 & TRN \\
\hline CHEMBL1613320 & 688759 & 4.45 & 4.9716 & TRN \\
\hline CHEMBL1541713 & 688759 & 5.2 & 5.2288 & TST \\
\hline CHEMBL437061 & 688759 & 4.45 & 4.8431 & TRN \\
\hline CHEMBL1613478 & 688759 & 4.7 & 4.7538 & TRN \\
\hline CHEMBL3211444 & 688759 & 4.45 & 4.8084 & TRN \\
\hline CHEMBL1390575 & 688759 & 5.55 & 5.17 & TRN \\
\hline CHEMBL1465644 & 688759 & 5.75 & 5.3655 & TRN \\
\hline CHEMBL3194088 & 688759 & 6.45 & 4.9256 & TST \\
\hline CHEMBL3197664 & 688759 & 5.25 & 5.5804 & TRN \\
\hline
\end{tabular}




\begin{tabular}{|c|c|c|c|c|}
\hline \multicolumn{5}{|c|}{ Supplemental Table S2.txt } \\
\hline CHEMBL1378665 & 688759 & 4.45 & 4.87 & TRN \\
\hline CHEMBL1472248 & 688759 & 4.7 & 5.1155 & TRN \\
\hline CHEMBL1600000 & 688759 & 4.75 & 5.1072 & TRN \\
\hline CHEMBL 3213140 & 688759 & 6.05 & 5.5566 & TRN \\
\hline CHEMBL1578469 & 688759 & 4.65 & 4.6427 & TRN \\
\hline CHEMBL1382570 & 688759 & 4.45 & 5.2613 & TRN \\
\hline CHEMBL1305831 & 688759 & 4.45 & 4.9466 & TRN \\
\hline CHEMBL1478848 & 688759 & 4.9 & 5.1752 & TRN \\
\hline CHEMBL1471730 & 688759 & 4.5 & 4.8978 & TST \\
\hline CHEMBL1411883 & 688759 & 6.1 & 5.0631 & TST \\
\hline CHEMBL1339553 & 688759 & 4.45 & 4.67 & TST \\
\hline CHEMBL1501452 & 688759 & 4.9 & 4.801 & TST \\
\hline CHEMBL3197018 & 688759 & 4.45 & 4.6077 & TST \\
\hline CHEMBL1443802 & 688759 & 4.45 & 4.63 & TRN \\
\hline CHEMBL3196622 & 688759 & 6.5 & 4.9622 & TRN \\
\hline CHEMBL1372119 & 688759 & 4.7 & 4.7655 & TRN \\
\hline CHEMBL1485023 & 688759 & 4.45 & 4.8596 & TRN \\
\hline CHEMBL1603997 & 688759 & 4.45 & 5.0397 & TST \\
\hline CHEMBL1523566 & 688759 & 5.7 & 5.5027 & TRN \\
\hline CHEMBL1505180 & 688759 & 4.45 & 4.7847 & TST \\
\hline CHEMBL1376504 & 688759 & 4.6 & 4.6961 & TRN \\
\hline CHEMBL1442711 & 688759 & 5.65 & 4.8946 & TRN \\
\hline CHEMBL1352555 & 688759 & 4.5 & 5.5237 & TRN \\
\hline CHEMBL3191549 & 688759 & 5.35 & 5.3957 & TRN \\
\hline CHEMBL1501061 & 688759 & 5.95 & 5.8526 & TRN \\
\hline CHEMBL1486519 & 688759 & 4.45 & 4.7791 & TRN \\
\hline CHEMBL1566045 & 688759 & 5.75 & 5.4007 & TST \\
\hline CHEMBL1328226 & 688759 & 4.45 & 4.8383 & TRN \\
\hline CHEMBL1594828 & 688759 & 4.45 & 4.7727 & TRN \\
\hline CHEMBL1308284 & 688759 & 4.6 & 4.602 & TST \\
\hline CHEMBL1503930 & 688759 & 4.95 & 5.0184 & TRN \\
\hline CHEMBL3210051 & 688759 & 4.45 & 4.7336 & TRN \\
\hline CHEMBL1559122 & 688759 & 4.45 & 4.6072 & TRN \\
\hline CHEMBL1575118 & 688759 & 4.45 & 4.592 & TRN \\
\hline CHEMBL465909 & 688759 & 4.55 & 4.6169 & TRN \\
\hline CHEMBL3192278 & 688759 & 4.65 & 5.3169 & TRN \\
\hline CHEMBL3191497 & 688759 & 4.45 & 4.7069 & TRN \\
\hline CHEMBL 234583 & 688759 & 4.85 & 4.9846 & TRN \\
\hline CHEMBL1319715 & 688759 & 4.45 & 4.6208 & TRN \\
\hline CHEMBL1968458 & 688759 & 5.15 & 4.9852 & TRN \\
\hline CHEMBL1462840 & 688759 & 4.95 & 5.05 & TRN \\
\hline CHEMBL1432362 & 688759 & 5.5 & 5.0037 & TRN \\
\hline CHEMBL1525306 & 688759 & 5.1 & 4.8471 & TRN \\
\hline CHEMBL1546288 & 688759 & 5.15 & 4.7065 & TST \\
\hline CHEMBL1338114 & 688759 & 4.45 & 5.1155 & TRN \\
\hline CHEMBL1470131 & 688759 & 4.9 & 4.8719 & TRN \\
\hline CHEMBL1531919 & 688759 & 4.45 & 4.57 & TRN \\
\hline CHEMBL1486354 & 688759 & 5.35 & 5.0216 & TRN \\
\hline
\end{tabular}




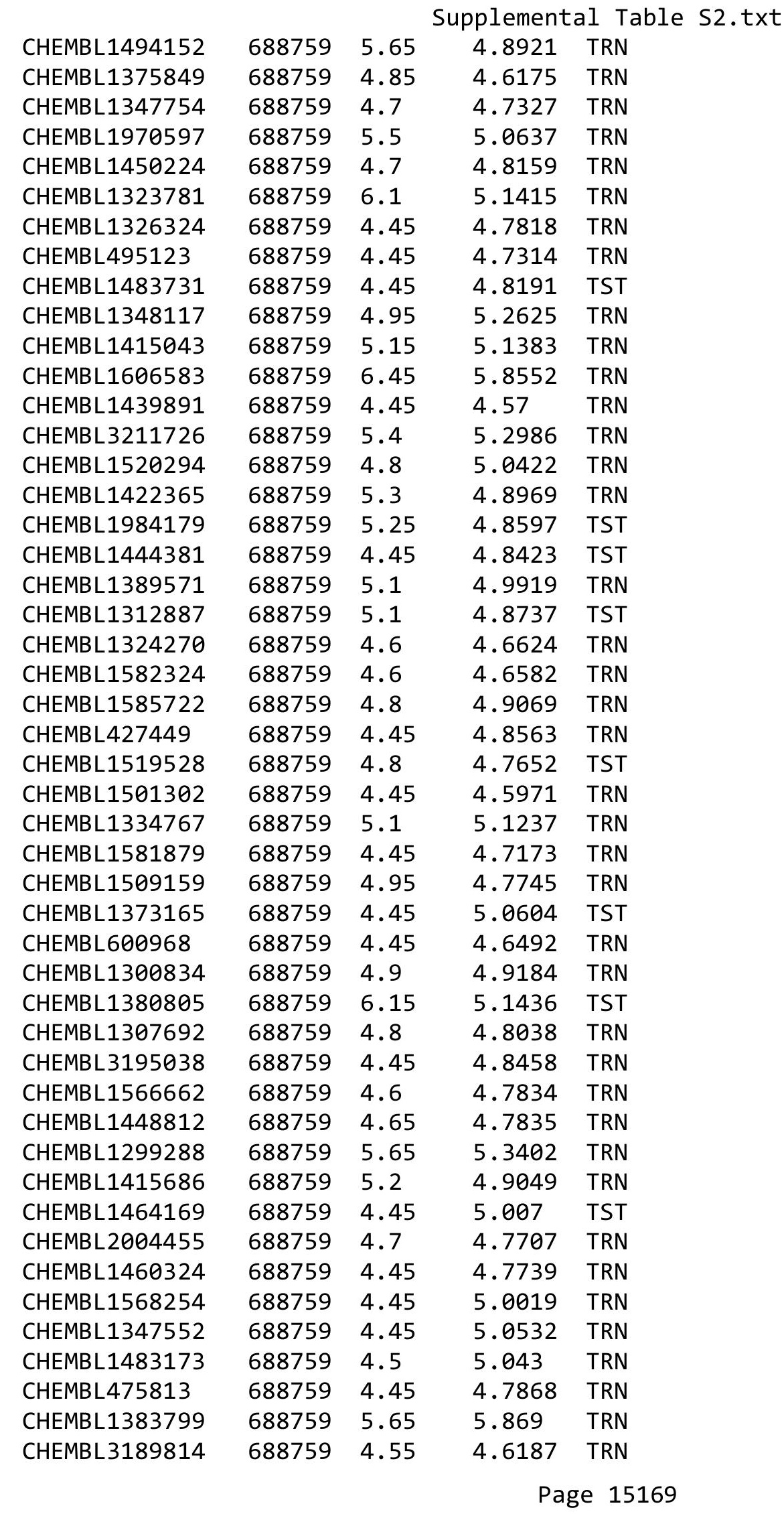




\begin{tabular}{|c|c|c|c|c|c|}
\hline \multicolumn{6}{|c|}{ Supplemental Table S2.txt } \\
\hline CHEMBL1372660 & 688759 & 4.7 & 4.9306 & TRN & \\
\hline CHEMBL1353715 & 688759 & 4.9 & 5.4155 & TRN & \\
\hline CHEMBL1604152 & 688759 & 4.75 & 4.9598 & TST & \\
\hline CHEMBL1334348 & 688759 & 4.7 & 4.6586 & TRN & \\
\hline CHEMBL1337705 & 688759 & 5.25 & 5.1386 & TRN & \\
\hline CHEMBL1571597 & 688759 & 5.25 & 4.9726 & TRN & \\
\hline CHEMBL1449624 & 688759 & 4.85 & 4.9427 & TST & \\
\hline CHEMBL1585299 & 688759 & 4.75 & 4.7506 & TRN & \\
\hline CHEMBL1361889 & 688759 & 4.45 & 4.6978 & TRN & \\
\hline CHEMBL2369258 & 688759 & 5.35 & 5.3421 & TRN & \\
\hline CHEMBL3191208 & 688759 & 4.45 & 4.9323 & TST & \\
\hline CHEMBL1449742 & 688759 & 5.2 & 4.9383 & TRN & \\
\hline CHEMBL1562869 & 688759 & 4.45 & 4.6454 & TRN & \\
\hline CHEMBL1538234 & 688759 & 4.75 & 4.6676 & TRN & \\
\hline CHEMBL1386804 & 688759 & 6.95 & 5.9725 & TRN & \\
\hline CHEMBL1553604 & 688759 & 5.15 & 5.2802 & TRN & \\
\hline CHEMBL3209041 & 688759 & 4.65 & 4.5795 & TRN & \\
\hline CHEMBL1574539 & 688759 & 4.85 & 5.7727 & TRN & \\
\hline CHEMBL1499074 & 688759 & 5.35 & 5.0142 & TRN & \\
\hline CHEMBL1530807 & 688759 & 4.45 & 4.7431 & TRN & \\
\hline CHEMBL1353529 & 688759 & 5.2 & 4.8658 & TRN & \\
\hline CHEMBL1471495 & 688759 & 4.45 & 4.9515 & TRN & \\
\hline CHEMBL1504407 & 688759 & 5.15 & 4.9049 & TST & \\
\hline CHEMBL1351131 & 688759 & 5.35 & 4.8308 & TRN & \\
\hline CHEMBL1410997 & 688759 & 4.45 & 4.6805 & TST & \\
\hline CHEMBL1387587 & 688759 & 4.65 & 5.0107 & TRN & \\
\hline CHEMBL1446199 & 688759 & 6.35 & 5.1792 & TRN & \\
\hline CHEMBL1304848 & 688759 & 5.15 & 4.6771 & TRN & \\
\hline CHEMBL1465434 & 688759 & 4.45 & 5.2033 & TRN & \\
\hline CHEMBL3191266 & 688759 & 4.9 & 4.782 & TRN & \\
\hline CHEMBL1533447 & 688759 & 5.3 & 5.0206 & TST & \\
\hline CHEMBL1361821 & 688759 & 5.45 & 4.8049 & TRN & \\
\hline CHEMBL1964793 & 688759 & 4.95 & 5.1366 & TRN & \\
\hline CHEMBL1591258 & 688759 & 6.0 & 5.4884 & TST & \\
\hline CHEMBL1345881 & 688759 & 5.25 & 5.0673 & TRN & \\
\hline CHEMBL1524921 & 688759 & 4.9 & 5.5075 & TRN & \\
\hline CHEMBL1335934 & 688759 & 4.45 & 5.0198 & TRN & \\
\hline CHEMBL1416276 & 688759 & 4.45 & 4.5776 & TRN & \\
\hline CHEMBL1420939 & 688759 & 5.65 & 5.1053 & TST & \\
\hline CHEMBL1420519 & 688759 & 4.45 & 4.6855 & TRN & \\
\hline CHEMBL1966921 & 688759 & 6.6 & 5.4927 & TRN & \\
\hline CHEMBL1369796 & 688759 & 4.85 & 4.81800 & 00000000005 & TRN \\
\hline CHEMBL1487723 & 688759 & 4.45 & 4.8925 & TRN & \\
\hline CHEMBL1418667 & 688759 & 4.45 & 4.9891 & TRN & \\
\hline CHEMBL3194599 & 688759 & 4.6 & 5.1268 & TST & \\
\hline CHEMBL1483312 & 688759 & 4.45 & 4.6744 & TST & \\
\hline CHEMBL1533139 & 688759 & 4.9 & 4.8556 & TRN & \\
\hline CHEMBL3199899 & 688759 & 4.8 & 4.6742 & TRN & \\
\hline
\end{tabular}




\begin{tabular}{|c|c|c|c|c|}
\hline \multicolumn{5}{|c|}{ Supplemental Table s2.txt } \\
\hline CHEMBL3199876 & 688759 & 4.9 & 4.8523 & TRN \\
\hline CHEMBL3191122 & 688759 & 4.95 & 5.0367 & TRN \\
\hline CHEMBL1382905 & 688759 & 4.65 & 4.7335 & TRN \\
\hline CHEMBL1334840 & 688759 & 5.2 & 4.8788 & TST \\
\hline CHEMBL1602111 & 688759 & 6.0 & 4.961 & TRN \\
\hline CHEMBL1509479 & 688759 & 4.75 & 4.9447 & TRN \\
\hline CHEMBL1485651 & 688759 & 5.95 & 4.9972 & TST \\
\hline CHEMBL1995152 & 688759 & 4.65 & 4.6878 & TST \\
\hline CHEMBL1425715 & 688759 & 6.0 & 5.7501 & TRN \\
\hline CHEMBL570844 & 688759 & 4.65 & 4.8388 & TRN \\
\hline CHEMBL1312953 & 688759 & 4.8 & 5.2579 & TRN \\
\hline CHEMBL1390211 & 688759 & 4.45 & 5.0045 & TRN \\
\hline CHEMBL1432243 & 688759 & 5.15 & 4.5841 & TRN \\
\hline CHEMBL1386630 & 688759 & 5.9 & 5.6421 & TRN \\
\hline CHEMBL1453942 & 688759 & 5.25 & 4.5862 & TST \\
\hline CHEMBL1602561 & 688759 & 4.45 & 5.0101 & TRN \\
\hline CHEMBL1304540 & 688759 & 5.05 & 5.1281 & TRN \\
\hline CHEMBL1519638 & 688759 & 5.25 & 4.8659 & TRN \\
\hline CHEMBL1470466 & 688759 & 4.45 & 5.0255 & TST \\
\hline CHEMBL1308088 & 688759 & 6.0 & 4.9002 & TRN \\
\hline CHEMBL1363732 & 688759 & 6.5 & 4.7907 & TST \\
\hline CHEMBL1471635 & 688759 & 4.95 & 4.9459 & TST \\
\hline CHEMBL 1583579 & 688759 & 4.6 & 4.8553 & TST \\
\hline CHEMBL1600860 & 688759 & 4.85 & 4.7852 & TRN \\
\hline CHEMBL1412747 & 688759 & 5.9 & 5.0166 & TRN \\
\hline CHEMBL1457897 & 688759 & 5.2 & 4.9512 & TRN \\
\hline CHEMBL1380353 & 688759 & 4.8 & 4.9876 & TST \\
\hline CHEMBL1342907 & 688759 & 4.9 & 5.0111 & TST \\
\hline CHEMBL1304694 & 688759 & 4.45 & 4.782 & TRN \\
\hline CHEMBL1321192 & 688759 & 5.05 & 5.0359 & TRN \\
\hline CHEMBL1964583 & 688759 & 4.65 & 4.887 & TRN \\
\hline CHEMBL1584397 & 688759 & 5.35 & 4.6114 & TRN \\
\hline CHEMBL1318387 & 688759 & 4.5 & 4.8454 & TRN \\
\hline CHEMBL1591969 & 688759 & 4.5 & 4.7925 & TST \\
\hline CHEMBL1520132 & 688759 & 5.25 & 4.9638 & TST \\
\hline CHEMBL199405 & 688759 & 5.55 & 4.9943 & TRN \\
\hline CHEMBL1608330 & 688759 & 5.4 & 4.881 & TRN \\
\hline CHEMBL1448881 & 688759 & 4.45 & 4.4773 & TRN \\
\hline CHEMBL1443757 & 688759 & 4.45 & 4.7607 & TRN \\
\hline CHEMBL1974180 & 688759 & 4.65 & 5.0293 & TRN \\
\hline CHEMBL1581730 & 688759 & 5.25 & 5.29799 & 9999999999 \\
\hline CHEMBL1347369 & 688759 & 4.45 & 4.8645 & TRN \\
\hline CHEMBL1546134 & 688759 & 5.35 & 5.1342 & TRN \\
\hline CHEMBL 3194076 & 688759 & 5.45 & 5.0037 & TRN \\
\hline CHEMBL 2369172 & 688759 & 4.45 & 4.5831 & TRN \\
\hline CHEMBL1505519 & 688759 & 5.6 & 5.3399 & TRN \\
\hline CHEMBL1336838 & 688759 & 4.45 & 4.6298 & TRN \\
\hline CHEMBL3197447 & 688759 & 5.8 & 4.9517 & TRN \\
\hline
\end{tabular}




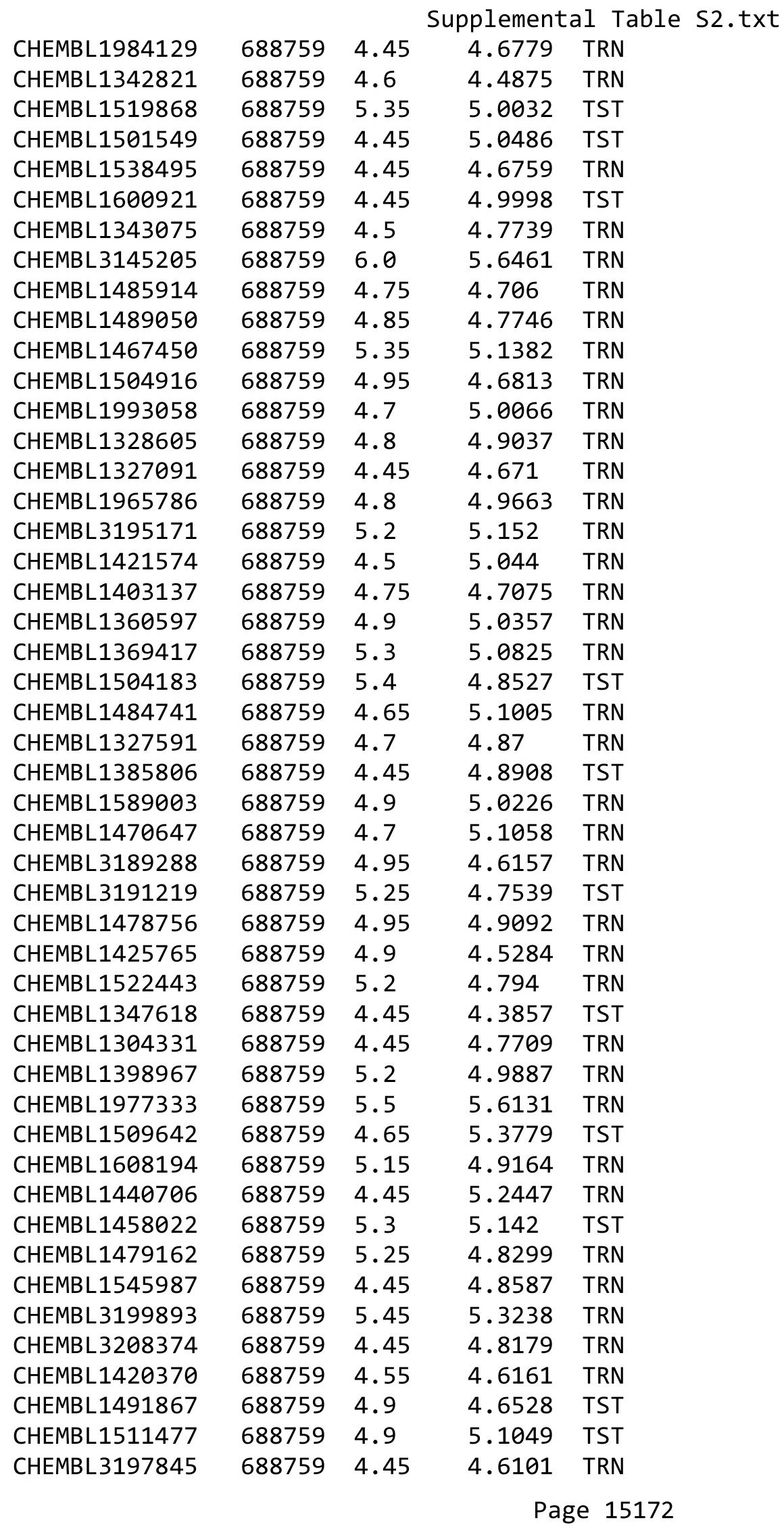




\begin{tabular}{|c|c|c|c|c|}
\hline \multicolumn{5}{|c|}{ Supplemental Table S2.txt } \\
\hline CHEMBL 3210852 & 688759 & 4.95 & 5.1843 & TST \\
\hline CHEMBL1550446 & 688759 & 5.55 & 5.2858 & TRN \\
\hline CHEMBL1446040 & 688759 & 5.4 & 5.3161 & TRN \\
\hline CHEMBL1523289 & 688759 & 5.25 & 4.8715 & TRN \\
\hline CHEMBL1307605 & 688759 & 5.3 & 4.8495 & TST \\
\hline CHEMBL1529236 & 688759 & 4.45 & 4.6793 & TRN \\
\hline CHEMBL20562 & 688759 & 4.5 & 4.8756 & TST \\
\hline CHEMBL1301367 & 688759 & 4.45 & 5.0207 & TST \\
\hline CHEMBL1537781 & 688759 & 4.7 & 5.1046 & TRN \\
\hline CHEMBL1480814 & 688759 & 4.85 & 5.0052 & TRN \\
\hline CHEMBL1503002 & 688759 & 6.45 & 5.6454 & TRN \\
\hline CHEMBL1455547 & 688759 & 4.95 & 4.8256 & TRN \\
\hline CHEMBL1444975 & 688759 & 5.8 & 4.885 & TST \\
\hline CHEMBL1445152 & 688759 & 4.45 & 4.7249 & TRN \\
\hline CHEMBL1418971 & 688759 & 5.85 & 5.8748 & TST \\
\hline CHEMBL1462613 & 688759 & 4.9 & 4.8282 & TRN \\
\hline CHEMBL1440674 & 688759 & 5.15 & 5.2405 & TRN \\
\hline CHEMBL 24510 & 688759 & 6.0 & 5.4625 & TRN \\
\hline CHEMBL1543047 & 688759 & 5.5 & 4.8624 & TRN \\
\hline CHEMBL1561828 & 688759 & 4.45 & 4.9938 & TRN \\
\hline CHEMBL1604497 & 688759 & 4.45 & 4.732 & TRN \\
\hline CHEMBL1339082 & 688759 & 4.45 & 4.4204 & TRN \\
\hline CHEMBL567132 & 688759 & 4.45 & 5.2445 & TRN \\
\hline CHEMBL1368713 & 688759 & 4.55 & 4.8036 & TRN \\
\hline CHEMBL399760 & 688759 & 4.6 & 5.2561 & TRN \\
\hline CHEMBL1322279 & 688759 & 4.95 & 4.8433 & TRN \\
\hline CHEMBL1557346 & 688759 & 4.5 & 4.7972 & TRN \\
\hline CHEMBL1451690 & 688759 & 5.85 & 5.3465 & TRN \\
\hline CHEMBL1551025 & 688759 & 4.45 & 4.7485 & TST \\
\hline CHEMBL1392681 & 688759 & 4.6 & 4.5011 & TRN \\
\hline CHEMBL1605577 & 688759 & 4.6 & 4.8547 & TRN \\
\hline CHEMBL1463048 & 688759 & 4.45 & 4.8274 & TRN \\
\hline CHEMBL1399109 & 688759 & 4.45 & 4.9234 & TRN \\
\hline CHEMBL1507939 & 688759 & 5.55 & 5.1743 & TRN \\
\hline CHEMBL2016645 & 688759 & 5.35 & 5.0877 & TRN \\
\hline CHEMBL1584295 & 688759 & 5.25 & 5.3915 & TRN \\
\hline CHEMBL1446277 & 688759 & 4.45 & 4.8793 & TRN \\
\hline CHEMBL1434938 & 688759 & 4.45 & 4.8563 & TST \\
\hline CHEMBL1370844 & 688759 & 4.8 & 4.7932 & TST \\
\hline CHEMBL1368251 & 688759 & 4.85 & 5.1441 & TRN \\
\hline CHEMBL1369296 & 688759 & 4.45 & 4.6442 & TRN \\
\hline CHEMBL1479116 & 688759 & 4.45 & 4.7433 & TRN \\
\hline CHEMBL1351838 & 688759 & 5.05 & 4.8491 & TST \\
\hline CHEMBL1522548 & 688759 & 4.8 & 4.8865 & TRN \\
\hline CHEMBL3198736 & 688759 & 6.0 & 5.2278 & TST \\
\hline CHEMBL1418866 & 688759 & 4.65 & 4.6901 & TST \\
\hline CHEMBL1464039 & 688759 & 4.45 & 4.752 & TRN \\
\hline CHEMBL1430695 & 688759 & 6.05 & 5.1274 & TST \\
\hline
\end{tabular}




\begin{tabular}{|c|c|c|c|c|c|}
\hline \multicolumn{6}{|c|}{ Supplemental Table S2.txt } \\
\hline CHEMBL1559258 & 688759 & 5.95 & 5.8439 & TRN & \\
\hline CHEMBL 2007448 & 688759 & 4.45 & 4.7915 & TRN & \\
\hline CHEMBL1375559 & 688759 & 5.75 & 5.6895 & TRN & \\
\hline CHEMBL1459286 & 688759 & 4.7 & 4.689 & TRN & \\
\hline CHEMBL 3191897 & 688759 & 5.3 & 5.2521 & TRN & \\
\hline CHEMBL1518234 & 688759 & 5.45 & 4.9827 & TRN & \\
\hline CHEMBL1511486 & 688759 & 4.45 & 5.0175 & TRN & \\
\hline CHEMBL1445819 & 688759 & 5.15 & 4.4941 & TRN & \\
\hline CHEMBL299853 & 688759 & 4.8 & 5.0368 & TRN & \\
\hline CHEMBL1379997 & 688759 & 4.6 & 4.7833 & TRN & \\
\hline CHEMBL 3197019 & 688759 & 5.15 & 5.2059 & TRN & \\
\hline CHEMBL 3213214 & 688759 & 4.95 & 4.8162 & TRN & \\
\hline CHEMBL1536075 & 688759 & 5.5 & 4.7263 & TRN & \\
\hline CHEMBL1585542 & 688759 & 4.45 & 4.8508 & TRN & \\
\hline CHEMBL1610255 & 688759 & 5.95 & 4.8911 & TRN & \\
\hline CHEMBL1430762 & 688759 & 5.2 & 4.9649 & TST & \\
\hline CHEMBL1349175 & 688759 & 4.8 & 4.6843 & TRN & \\
\hline CHEMBL1530075 & 688759 & 4.95 & 4.9184 & TRN & \\
\hline CHEMBL1481367 & 688759 & 4.85 & 4.9525 & TRN & \\
\hline CHEMBL1421833 & 688759 & 4.9 & 4.9826 & TST & \\
\hline CHEMBL1566639 & 688759 & 6.15 & 5.1429 & TRN & \\
\hline CHEMBL 3199687 & 688759 & 4.45 & 4.9014 & TRN & \\
\hline CHEMBL1379714 & 688759 & 4.65 & 4.9164 & TRN & \\
\hline CHEMBL 3198375 & 688759 & 4.7 & 4.9653 & TRN & \\
\hline CHEMBL1982484 & 688759 & 4.55 & 4.84 & TRN & \\
\hline CHEMBL1994683 & 688759 & 6.0 & 5.3029 & TRN & \\
\hline CHEMBL1499663 & 688759 & 5.2 & 4.8888 & TST & \\
\hline CHEMBL1508790 & 688759 & 5.1 & 4.7057 & TST & \\
\hline CHEMBL1451209 & 688759 & 4.45 & 4.7491 & TST & \\
\hline CHEMBL1421259 & 688759 & 4.65 & 4.6343 & TRN & \\
\hline CHEMBL1567422 & 688759 & 4.8 & 4.9874 & TRN & \\
\hline CHEMBL1343532 & 688759 & 5.85 & 5.32299 & 99999999995 & TRN \\
\hline CHEMBL1510973 & 688759 & 4.75 & 4.7599 & TRN & \\
\hline CHEMBL1399833 & 688759 & 5.25 & 4.907 & TST & \\
\hline CHEMBL601110 & 688759 & 4.45 & 4.6195 & TRN & \\
\hline CHEMBL1339810 & 688759 & 4.45 & 4.6527 & TRN & \\
\hline CHEMBL1584598 & 688759 & 5.0 & 5.2472 & TRN & \\
\hline CHEMBL1489566 & 688759 & 4.95 & 4.7691 & TRN & \\
\hline CHEMBL1595582 & 688759 & 5.2 & 5.2129 & TRN & \\
\hline CHEMBL1524322 & 688759 & 4.7 & 4.8395 & TST & \\
\hline CHEMBL1555583 & 688759 & 4.45 & 4.6847 & TST & \\
\hline CHEMBL 1422010 & 688759 & 5.1 & 5.2872 & TRN & \\
\hline CHEMBL1430724 & 688759 & 5.2 & 5.0344 & TRN & \\
\hline CHEMBL1375678 & 688759 & 4.8 & 4.8415 & TRN & \\
\hline CHEMBL1528669 & 688759 & 4.9 & 4.8398 & TRN & \\
\hline CHEMBL1350491 & 688759 & 4.65 & 4.5014 & TRN & \\
\hline CHEMBL1423464 & 688759 & 4.95 & 4.8727 & TST & \\
\hline CHEMBL1487136 & 688759 & 8.1024 & 5.2916 & TRN & \\
\hline
\end{tabular}




\begin{tabular}{|c|c|c|c|c|}
\hline \multicolumn{5}{|c|}{ Supplemental Table S2.txt } \\
\hline CHEMBL 3197697 & 688759 & 5.3 & 4.7642 & TRN \\
\hline CHEMBL1516806 & 688759 & 4.75 & 5.0577 & TRN \\
\hline CHEMBL1549310 & 688759 & 5.45 & 5.4373 & TRN \\
\hline CHEMBL1305504 & 688759 & 5.45 & 4.7514 & TRN \\
\hline CHEMBL1578407 & 688759 & 4.45 & 4.9658 & TST \\
\hline CHEMBL1586344 & 688759 & 4.45 & 4.6633 & TST \\
\hline CHEMBL 3194964 & 688759 & 5.5 & 5.5157 & TRN \\
\hline CHEMBL1328528 & 688759 & 5.35 & 4.9931 & TST \\
\hline CHEMBL1384110 & 688759 & 4.8 & 4.8682 & TRN \\
\hline CHEMBL1477131 & 688759 & 4.45 & 4.6452 & TRN \\
\hline CHEMBL1572324 & 688759 & 6.45 & 4.9038 & TRN \\
\hline CHEMBL1420315 & 688759 & 4.45 & 4.7096 & TRN \\
\hline CHEMBL1977653 & 688759 & 5.7 & 5.6689 & TRN \\
\hline CHEMBL1524503 & 688759 & 4.45 & 4.6684 & TRN \\
\hline CHEMBL1404060 & 688759 & 4.6 & 4.7534 & TRN \\
\hline CHEMBL1563059 & 688759 & 5.85 & 4.6136 & TRN \\
\hline CHEMBL1338432 & 688759 & 4.9 & 4.9232 & TRN \\
\hline CHEMBL1328510 & 688759 & 6.0 & 5.4245 & TRN \\
\hline CHEMBL1488586 & 688759 & 5.2 & 5.27 & TRN \\
\hline CHEMBL1577772 & 688759 & 5.25 & 4.8753 & TRN \\
\hline CHEMBL3193028 & 688759 & 4.8 & 4.9936 & TST \\
\hline CHEMBL1426584 & 688759 & 4.45 & 4.5447 & TRN \\
\hline CHEMBL3195347 & 688759 & 5.0 & 4.7709 & TRN \\
\hline CHEMBL1418939 & 688759 & 4.8 & 5.0297 & TRN \\
\hline CHEMBL 75913 & 688759 & 4.8 & 4.4736 & TRN \\
\hline CHEMBL1573966 & 688759 & 5.0 & 4.8176 & TRN \\
\hline CHEMBL1424559 & 688759 & 4.45 & 4.9117 & TRN \\
\hline CHEMBL1430052 & 688759 & 5.45 & 5.0485 & TRN \\
\hline CHEMBL1490422 & 688759 & 4.6 & 4.8658 & TRN \\
\hline CHEMBL1304869 & 688759 & 4.45 & 4.8366 & TRN \\
\hline CHEMBL3190146 & 688759 & 5.2 & 5.3028 & TRN \\
\hline CHEMBL1503616 & 688759 & 4.65 & 4.7052 & TST \\
\hline CHEMBL1317867 & 688759 & 4.45 & 4.7337 & TRN \\
\hline CHEMBL1405694 & 688759 & 5.2 & 5.0743 & TST \\
\hline CHEMBL1403108 & 688759 & 4.55 & 4.9 & TRN \\
\hline CHEMBL1417172 & 688759 & 4.45 & 5.0518 & TRN \\
\hline CHEMBL1438863 & 688759 & 4.45 & 4.7817 & TST \\
\hline CHEMBL1448312 & 688759 & 4.45 & 4.7868 & TST \\
\hline CHEMBL1547478 & 688759 & 4.95 & 5.0553 & TRN \\
\hline CHEMBL1378070 & 688759 & 5.65 & 5.0507 & TRN \\
\hline CHEMBL1996360 & 688759 & 4.8 & 4.6536 & TRN \\
\hline CHEMBL1507181 & 688759 & 5.3 & 5.0821 & TRN \\
\hline CHEMBL1308027 & 688759 & 5.6 & 5.5521 & TRN \\
\hline CHEMBL1487700 & 688759 & 4.75 & 4.7172 & TST \\
\hline CHEMBL 2003794 & 688759 & 5.95 & 4.9198 & TRN \\
\hline CHEMBL1603614 & 688759 & 4.45 & 4.6646 & TST \\
\hline CHEMBL1497217 & 688759 & 5.2 & 5.1051 & TRN \\
\hline CHEMBL1488248 & 688759 & 4.9 & 4.8 & TRN \\
\hline
\end{tabular}




\begin{tabular}{|c|c|c|c|c|}
\hline \multicolumn{5}{|c|}{ Supplemental Table S2.txt } \\
\hline CHEMBL1364037 & 688759 & 4.95 & 4.8963 & TRN \\
\hline CHEMBL1348461 & 688759 & 4.75 & 4.8064 & TRN \\
\hline CHEMBL 3189348 & 688759 & 4.45 & 4.7362 & TST \\
\hline CHEMBL1319582 & 688759 & 4.45 & 4.6319 & TRN \\
\hline CHEMBL1560903 & 688759 & 5.3 & 4.9677 & TRN \\
\hline CHEMBL3192626 & 688759 & 4.7 & 4.8825 & TRN \\
\hline CHEMBL1585446 & 688759 & 4.8 & 4.8809 & TST \\
\hline CHEMBL3191920 & 688759 & 4.45 & 4.8111 & TRN \\
\hline CHEMBL1459959 & 688759 & 4.6 & 4.7366 & TST \\
\hline CHEMBL 1404578 & 688759 & 5.4 & 5.3212 & TRN \\
\hline CHEMBL1360927 & 688759 & 4.95 & 4.5326 & TRN \\
\hline CHEMBL1541518 & 688759 & 5.3 & 5.0006 & TST \\
\hline CHEMBL1389212 & 688759 & 4.45 & 4.7425 & TRN \\
\hline CHEMBL1410677 & 688759 & 4.45 & 4.8319 & TRN \\
\hline CHEMBL1984554 & 688759 & 4.95 & 5.1186 & TRN \\
\hline CHEMBL1599549 & 688759 & 4.6 & 4.7412 & TRN \\
\hline CHEMBL1534655 & 688759 & 5.45 & 5.6543 & TRN \\
\hline CHEMBL1488377 & 688759 & 5.3 & 5.0976 & TRN \\
\hline CHEMBL1566730 & 688759 & 5.0 & 4.9788 & TRN \\
\hline CHEMBL1511924 & 688759 & 5.2 & 4.9433 & TRN \\
\hline CHEMBL1534748 & 688759 & 5.35 & 4.9824 & TST \\
\hline CHEMBL1087863 & 688759 & 4.7 & 5.1757 & TRN \\
\hline CHEMBL1576660 & 688759 & 5.0 & 5.7098 & TRN \\
\hline CHEMBL1304177 & 688759 & 4.9 & 4.7432 & TST \\
\hline CHEMBL1387650 & 688759 & 4.75 & 4.7623 & TST \\
\hline CHEMBL1422346 & 688759 & 4.9 & 4.7964 & TRN \\
\hline CHEMBL1582632 & 688759 & 4.75 & 4.7536 & TRN \\
\hline CHEMBL1999700 & 688759 & 4.65 & 5.1703 & TRN \\
\hline CHEMBL1573962 & 688759 & 5.2 & 5.0425 & TRN \\
\hline CHEMBL1547811 & 688759 & 4.55 & 4.8241 & TST \\
\hline CHEMBL3194953 & 688759 & 4.75 & 4.5525 & TST \\
\hline CHEMBL1490991 & 688759 & 5.0 & 5.0308 & TRN \\
\hline CHEMBL1495950 & 688759 & 5.3 & 4.8872 & TST \\
\hline CHEMBL1381054 & 688759 & 6.0 & 5.0351 & TRN \\
\hline CHEMBL1467945 & 688759 & 4.75 & 4.8086 & TRN \\
\hline CHEMBL1496396 & 688759 & 4.45 & 4.5801 & TRN \\
\hline CHEMBL1508278 & 688759 & 5.0 & 4.6536 & TRN \\
\hline CHEMBL1565879 & 688759 & 5.25 & 4.9523 & TRN \\
\hline CHEMBL1540319 & 688759 & 4.65 & 4.6952 & TRN \\
\hline CHEMBL1472428 & 688759 & 5.2 & 5.4004 & TRN \\
\hline CHEMBL1429958 & 688759 & 5.4 & 4.9667 & TRN \\
\hline CHEMBL1402601 & 688759 & 5.3 & 5.0427 & TST \\
\hline CHEMBL1418431 & 688759 & 8.3468 & 4.8856 & TRN \\
\hline CHEMBL1979987 & 688759 & 5.25 & 5.2841 & TRN \\
\hline CHEMBL1451141 & 688759 & 4.45 & 4.7823 & TRN \\
\hline CHEMBL1705092 & 688759 & 5.2 & 5.2475 & TST \\
\hline CHEMBL3196457 & 688759 & 4.45 & 4.8377 & TRN \\
\hline CHEMBL1335944 & 688759 & 5.1 & 4.6885 & TRN \\
\hline
\end{tabular}




\begin{tabular}{|c|c|c|c|c|c|}
\hline \multicolumn{6}{|c|}{ Supplemental Table S2.txt } \\
\hline CHEMBL1602624 & 688759 & 4.45 & 5.191 & TRN & \\
\hline CHEMBL1452264 & 688759 & 5.75 & 5.1233 & TRN & \\
\hline CHEMBL3196365 & 688759 & 5.15 & 5.3746 & TRN & \\
\hline CHEMBL1405335 & 688759 & 4.9 & 5.1018 & TRN & \\
\hline CHEMBL1380037 & 688759 & 4.65 & 4.5883 & TRN & \\
\hline CHEMBL1585185 & 688759 & 4.45 & 4.6696 & TRN & \\
\hline CHEMBL1347829 & 688759 & 4.45 & 4.8074 & TST & \\
\hline CHEMBL153535 & 688759 & 6.8499 & 4.9698 & TRN & \\
\hline CHEMBL1611778 & 688759 & 5.1 & 5.0325 & TRN & \\
\hline CHEMBL1446095 & 688759 & 4.45 & 4.7887 & TST & \\
\hline CHEMBL1476339 & 688759 & 4.45 & 4.7002 & TST & \\
\hline CHEMBL1581674 & 688759 & 4.95 & 4.6135 & TRN & \\
\hline CHEMBL1528265 & 688759 & 4.45 & 4.8327 & TRN & \\
\hline CHEMBL1374950 & 688759 & 5.9 & 5.0856 & TRN & \\
\hline CHEMBL1970453 & 688759 & 5.45 & 5.1815 & TRN & \\
\hline CHEMBL1334413 & 688759 & 4.45 & 4.7334 & TRN & \\
\hline CHEMBL3191239 & 688759 & 5.0 & 5.1005 & TRN & \\
\hline CHEMBL1999390 & 688759 & 5.2 & 5.2023 & TRN & \\
\hline CHEMBL1464896 & 688759 & 5.65 & 4.7597 & TRN & \\
\hline CHEMBL1382658 & 688759 & 5.1 & 5.1496 & TRN & \\
\hline CHEMBL1558673 & 688759 & 4.45 & 4.7368 & TST & \\
\hline CHEMBL1392187 & 688759 & 4.45 & 4.52 & TRN & \\
\hline CHEMBL3209997 & 688759 & 4.45 & 4.604 & TRN & \\
\hline CHEMBL1359181 & 688759 & 6.0 & 5.3105 & TST & \\
\hline CHEMBL1390570 & 688759 & 5.3 & 5.438 & TRN & \\
\hline CHEMBL1369226 & 688759 & 5.55 & 5.1705 & TST & \\
\hline CHEMBL1553235 & 688759 & 4.7 & 4.8786 & TRN & \\
\hline CHEMBL3195951 & 688759 & 5.25 & 4.9843 & TRN & \\
\hline CHEMBL1477100 & 688759 & 5.0 & 5.0054 & TRN & \\
\hline CHEMBL1439489 & 688759 & 4.95 & 4.9618 & TST & \\
\hline CHEMBL1574078 & 688759 & 4.55 & 5.0006 & TRN & \\
\hline CHEMBL 3189386 & 688759 & 5.2 & 5.2664 & TRN & \\
\hline CHEMBL1563594 & 688759 & 4.55 & 4.9894 & TRN & \\
\hline CHEMBL1588987 & 688759 & 5.1 & 5.0386 & TST & \\
\hline CHEMBL1412171 & 688759 & 4.45 & 4.9012 & TRN & \\
\hline CHEMBL1480976 & 688759 & 4.7 & 4.7639 & TRN & \\
\hline CHEMBL1359410 & 688759 & 4.95 & 4.9116 & TRN & \\
\hline CHEMBL1460547 & 688759 & 4.8 & 4.7996 & TRN & \\
\hline CHEMBL1383955 & 688759 & 4.8 & 4.82100 & 0000000001 & TRN \\
\hline CHEMBL585426 & 688759 & 4.9 & 4.6073 & TST & \\
\hline CHEMBL1351058 & 688759 & 4.75 & 4.5031 & TRN & \\
\hline CHEMBL1602489 & 688759 & 4.45 & 4.7548 & TRN & \\
\hline CHEMBL1351371 & 688759 & 5.5 & 4.8552 & TRN & \\
\hline CHEMBL1522859 & 688759 & 6.4 & 4.8247 & TRN & \\
\hline CHEMBL525098 & 688759 & 4.65 & 5.0256 & TRN & \\
\hline CHEMBL1364577 & 688759 & 5.3 & 6.0524 & TRN & \\
\hline CHEMBL1981242 & 688759 & 5.0 & 4.908 & TRN & \\
\hline CHEMBL1403985 & 688759 & 5.55 & 4.8436 & TRN & \\
\hline
\end{tabular}




\begin{tabular}{|c|c|c|c|c|c|}
\hline \multicolumn{6}{|c|}{ Supplemental Table S2.txt } \\
\hline CHEMBL1496823 & 688759 & 5.0 & 5.0359 & TRN & \\
\hline CHEMBL1391917 & 688759 & 4.9 & 4.7694 & TRN & \\
\hline CHEMBL1455115 & 688759 & 4.45 & 4.9088 & TRN & \\
\hline CHEMBL1988708 & 688759 & 6.15 & 5.5752 & TRN & \\
\hline CHEMBL1385214 & 688759 & 4.45 & 4.7189 & TST & \\
\hline CHEMBL1452547 & 688759 & 4.95 & 4.6521 & TST & \\
\hline CHEMBL1444094 & 688759 & 4.45 & 4.9335 & TRN & \\
\hline CHEMBL1506689 & 688759 & 4.6 & 4.882 & TRN & \\
\hline CHEMBL1431979 & 688759 & 4.45 & 6.3484 & TST & \\
\hline CHEMBL1437995 & 688759 & 4.8 & 4.8986 & TRN & \\
\hline CHEMBL3199300 & 688759 & 4.95 & \multicolumn{2}{|c|}{5.207999999999999} & TRN \\
\hline CHEMBL3209231 & 688759 & 4.9 & 5.1184 & TRN & \\
\hline CHEMBL3208917 & 688759 & 4.65 & 4.5343 & TRN & \\
\hline CHEMBL1335002 & 688759 & 5.5 & \multicolumn{2}{|c|}{5.138999999999999} & TRN \\
\hline CHEMBL1523970 & 688759 & 4.75 & 4.6799 & TRN & \\
\hline CHEMBL1327964 & 688759 & 4.45 & 4.6916 & TRN & \\
\hline CHEMBL1563836 & 688759 & 4.55 & 4.9397 & TRN & \\
\hline CHEMBL1310824 & 688759 & 6.15 & 4.8404 & TRN & \\
\hline CHEMBL3194594 & 688759 & 4.9 & 4.744 & TRN & \\
\hline CHEMBL1503463 & 688759 & 4.65 & 4.8202 & TST & \\
\hline CHEMBL1439899 & 688759 & 5.4 & 4.7355 & TRN & \\
\hline CHEMBL1381063 & 688759 & 4.45 & 4.6907 & TST & \\
\hline CHEMBL3194635 & 688759 & 4.9 & 4.9462 & TRN & \\
\hline CHEMBL1428407 & 688759 & 4.45 & 4.718 & TRN & \\
\hline CHEMBL3194667 & 688759 & 6.4 & 5.9676 & TRN & \\
\hline CHEMBL1321689 & 688759 & 4.65 & 5.2366 & TRN & \\
\hline CHEMBL1336187 & 688759 & 4.75 & 4.9783 & TST & \\
\hline CHEMBL1525545 & 688759 & 5.6 & 5.3256 & TST & \\
\hline CHEMBL1451901 & 688759 & 5.4 & 5.3902 & TRN & \\
\hline CHEMBL3192905 & 688759 & 5.25 & 4.9279 & TRN & \\
\hline CHEMBL1544131 & 688759 & 5.55 & 5.1882 & TRN & \\
\hline CHEMBL1410437 & 688759 & 4.45 & 4.9187 & TRN & \\
\hline CHEMBL1341674 & 688759 & 5.35 & 4.7774 & TST & \\
\hline CHEMBL1483056 & 688759 & 4.95 & 4.9674 & TRN & \\
\hline CHEMBL1312568 & 688759 & 5.4 & 5.2162 & TRN & \\
\hline CHEMBL548540 & 688759 & 5.45 & 5.5977 & TRN & \\
\hline CHEMBL1339860 & 688759 & 4.55 & 4.7974 & TRN & \\
\hline CHEMBL1336588 & 688759 & 5.45 & 5.1165 & TRN & \\
\hline CHEMBL3195298 & 688759 & 4.45 & 4.9716 & TST & \\
\hline CHEMBL1438890 & 688759 & 4.75 & 4.6503 & TRN & \\
\hline CHEMBL1546442 & 688759 & 5.0 & 4.83899 & 99999999995 & TRN \\
\hline CHEMBL1570490 & 688759 & 5.55 & 5.1404 & TRN & \\
\hline CHEMBL1516388 & 688759 & 6.0 & 5.4638 & TST & \\
\hline CHEMBL1368143 & 688759 & 4.45 & 4.9761 & TRN & \\
\hline CHEMBL1306897 & 688759 & 4.55 & 4.9859 & TRN & \\
\hline CHEMBL1583970 & 688759 & 5.5 & 4.7215 & TRN & \\
\hline CHEMBL1442895 & 688759 & 4.5 & 4.6373 & TRN & \\
\hline CHEMBL1976542 & 688759 & 5.25 & 4.7936 & TRN & \\
\hline
\end{tabular}




\begin{tabular}{|c|c|c|c|c|c|}
\hline \multicolumn{6}{|c|}{ Supplemental Table S2.txt } \\
\hline CHEMBL1572929 & 688759 & 5.45 & 4.9641 & TRN & \\
\hline CHEMBL3199382 & 688759 & 4.65 & 4.7747 & TRN & \\
\hline CHEMBL1444180 & 688759 & 5.25 & 4.7284 & TRN & \\
\hline CHEMBL1570963 & 688759 & 4.45 & 4.7665 & TRN & \\
\hline CHEMBL1516990 & 688759 & 4.45 & 4.6771 & TRN & \\
\hline CHEMBL1314094 & 688759 & 4.8 & $4.8580 €$ & 00000000005 & TRN \\
\hline CHEMBL1979800 & 688759 & 4.75 & 5.5771 & TST & \\
\hline CHEMBL1495891 & 688759 & 4.75 & 4.8619 & TRN & \\
\hline CHEMBL1452029 & 688759 & 4.95 & 4.91 & TST & \\
\hline CHEMBL3193515 & 688759 & 6.1 & $5.5310 €$ & 0000000001 & TRN \\
\hline CHEMBL1439366 & 688759 & 4.9 & 4.7846 & TRN & \\
\hline CHEMBL1495505 & 688759 & 4.75 & 4.9654 & TRN & \\
\hline CHEMBL1419421 & 688759 & 4.9 & 4.6989 & TRN & \\
\hline CHEMBL1431253 & 688759 & 6.05 & 4.9463 & TRN & \\
\hline CHEMBL1542936 & 688759 & 5.5 & 4.8915 & TRN & \\
\hline CHEMBL1570548 & 688759 & 4.45 & 4.7417 & TRN & \\
\hline CHEMBL1500853 & 688759 & 5.25 & 4.84399 & 9999999999 & TRN \\
\hline CHEMBL1524500 & 688759 & 5.35 & 5.2953 & TRN & \\
\hline CHEMBL3194186 & 688759 & 5.55 & 5.6142 & TST & \\
\hline CHEMBL1502883 & 688759 & 6.35 & 5.8626 & TRN & \\
\hline CHEMBL1526507 & 688759 & 4.45 & 5.0618 & TRN & \\
\hline CHEMBL1444518 & 688759 & 6.4 & 5.5737 & TRN & \\
\hline CHEMBL1344361 & 688759 & 4.8 & 4.8964 & TRN & \\
\hline CHEMBL1527838 & 688759 & 4.45 & 4.6861 & TRN & \\
\hline CHEMBL1350851 & 688759 & 4.45 & 4.6628 & TST & \\
\hline CHEMBL1408276 & 688759 & 5.2 & 4.9507 & TRN & \\
\hline CHEMBL1536608 & 688759 & 5.6 & 5.3778 & TRN & \\
\hline CHEMBL1443305 & 688759 & 4.45 & 5.0273 & TRN & \\
\hline CHEMBL1542566 & 688759 & 4.45 & 4.9595 & TRN & \\
\hline CHEMBL 2001455 & 688759 & 5.25 & 5.2047 & TRN & \\
\hline CHEMBL1603343 & 688759 & 4.45 & 4.606 & TST & \\
\hline CHEMBL1587290 & 688759 & 5.45 & 4.8048 & TST & \\
\hline CHEMBL1413931 & 688759 & 5.6 & 5.1851 & TRN & \\
\hline CHEMBL3196200 & 688759 & 5.2 & 5.0604 & TRN & \\
\hline CHEMBL1310167 & 688759 & 7.3497 & 4.9742 & TST & \\
\hline CHEMBL1390223 & 688759 & 4.45 & 4.6019 & TRN & \\
\hline CHEMBL1506358 & 688759 & 4.85 & 5.0699 & TRN & \\
\hline CHEMBL603024 & 688759 & 4.65 & 4.9071 & TST & \\
\hline CHEMBL1352056 & 688759 & 5.5 & 4.9667 & TRN & \\
\hline CHEMBL1538883 & 688759 & 4.45 & 4.5562 & TST & \\
\hline CHEMBL1500202 & 688759 & 4.45 & 5.0162 & TRN & \\
\hline CHEMBL1991885 & 688759 & 5.15 & 5.1435 & TRN & \\
\hline CHEMBL1977877 & 688759 & 6.05 & 5.8181 & TRN & \\
\hline CHEMBL1299342 & 688759 & 4.65 & 4.8222 & TRN & \\
\hline CHEMBL1419696 & 688759 & 4.9 & 4.7748 & TST & \\
\hline CHEMBL1357090 & 688759 & 4.9 & 4.9571 & TST & \\
\hline CHEMBL1550862 & 688759 & 4.9 & 4.713 & TRN & \\
\hline CHEMBL1302262 & 688759 & 4.9 & 4.9577 & TRN & \\
\hline
\end{tabular}




\begin{tabular}{|c|c|c|c|c|}
\hline & & & ıpplement & al $\mathrm{T}$ \\
\hline CHEMBL1490467 & 688759 & 5.4 & 5.0229 & TRN \\
\hline CHEMBL1549128 & 688759 & 5.35 & 5.0176 & TST \\
\hline CHEMBL1613483 & 688759 & 6.1 & 4.9446 & TRN \\
\hline CHEMBL1421478 & 688759 & 4.45 & 4.994 & TRN \\
\hline CHEMBL1575506 & 688759 & 4.45 & 4.8982 & TRN \\
\hline CHEMBL1463988 & 688759 & 5.9 & 5.5726 & TRN \\
\hline CHEMBL3211001 & 688759 & 6.1 & 5.0363 & TRN \\
\hline CHEMBL1534463 & 688759 & 4.6 & 4.7345 & TST \\
\hline CHEMBL1462445 & 688759 & 4.45 & 4.9034 & TRN \\
\hline CHEMBL1523189 & 688759 & 5.0 & 5.0359 & TRN \\
\hline CHEMBL 3210071 & 688759 & 5.25 & 4.8552 & TST \\
\hline CHEMBL1581915 & 688759 & 4.45 & 5.1498 & TRN \\
\hline CHEMBL1504790 & 688759 & 5.0 & 4.8209 & TST \\
\hline CHEMBL1425549 & 688759 & 6.3 & 4.8678 & TST \\
\hline CHEMBL3193913 & 688759 & 4.45 & 4.9977 & TRN \\
\hline CHEMBL1327059 & 688759 & 4.45 & 4.4639 & TRN \\
\hline CHEMBL1311374 & 688759 & 4.95 & 5.0747 & TST \\
\hline CHEMBL1382763 & 688759 & 4.6 & 4.9971 & TST \\
\hline CHEMBL1450168 & 688759 & 5.0 & 4.9715 & TRN \\
\hline CHEMBL1393303 & 688759 & 4.95 & 4.7551 & TRN \\
\hline CHEMBL3189702 & 688759 & 5.2 & 4.9007 & TRN \\
\hline CHEMBL1487779 & 688759 & 4.45 & 4.8401 & TRN \\
\hline CHEMBL1528733 & 688759 & 5.25 & 4.9313 & TST \\
\hline CHEMBL1474804 & 688759 & 4.45 & 4.5559 & TST \\
\hline CHEMBL1478673 & 688759 & 4.45 & 4.7428 & TRN \\
\hline CHEMBL1541948 & 688759 & 4.7 & 5.0104 & TST \\
\hline CHEMBL1477129 & 688759 & 4.45 & 4.539 & TST \\
\hline CHEMBL1525147 & 688759 & 4.45 & 4.7245 & TRN \\
\hline CHEMBL1582775 & 688759 & 4.8 & 4.853 & TST \\
\hline CHEMBL1384199 & 688759 & 4.6 & 4.3899 & TST \\
\hline CHEMBL1571208 & 688759 & 4.65 & 4.6501 & TRN \\
\hline CHEMBL1533063 & 688759 & 5.4 & 5.6424 & TRN \\
\hline CHEMBL1526339 & 688759 & 5.2 & 4.8374 & TST \\
\hline CHEMBL1606209 & 688759 & 4.45 & 4.9944 & TRN \\
\hline CHEMBL1335835 & 688759 & 4.45 & 4.9276 & TRN \\
\hline CHEMBL567422 & 688759 & 6.05 & 5.2379 & TST \\
\hline CHEMBL1326665 & 688759 & 4.85 & 5.1455 & TST \\
\hline CHEMBL1324956 & 688759 & 4.95 & 4.7668 & TRN \\
\hline CHEMBL1348126 & 688759 & 4.45 & 4.7311 & TRN \\
\hline CHEMBL1502407 & 688759 & 4.8 & 5.0169 & TST \\
\hline CHEMBL1498146 & 688759 & 6.0 & 4.7158 & TRN \\
\hline CHEMBL 3210233 & 688759 & 5.55 & 5.2333 & TRN \\
\hline CHEMBL1423969 & 688759 & 4.45 & 4.6377 & TRN \\
\hline CHEMBL3213230 & 688759 & 4.75 & 4.898 & TRN \\
\hline CHEMBL546649 & 688759 & 4.65 & 5.0451 & TRN \\
\hline CHEMBL1333653 & 688759 & 4.9 & 5.0008 & TST \\
\hline CHEMBL1319658 & 688759 & 5.95 & 4.7562 & TRN \\
\hline CHEMBL1431353 & 688759 & 4.75 & 4.7489 & TRN \\
\hline
\end{tabular}




\begin{tabular}{|c|c|c|c|c|c|}
\hline & & \multicolumn{4}{|c|}{ Supplemental Table S2.txt } \\
\hline CHEMBL1451744 & 688759 & 4.85 & 4.8436 & TST & \\
\hline CHEMBL1438330 & 688759 & 7.0 & 4.7777 & TST & \\
\hline CHEMBL1484167 & 688759 & 5.15 & 5.4096 & TST & \\
\hline CHEMBL1405839 & 688759 & 4.45 & 4.6982 & TST & \\
\hline CHEMBL1547643 & 688759 & 4.6 & 4.8037 & TST & \\
\hline CHEMBL1417819 & 688759 & 4.95 & 4.9142 & TRN & \\
\hline CHEMBL3208219 & 688759 & 4.5 & 4.9574 & TRN & \\
\hline CHEMBL17976 & 688759 & 4.7 & 5.0838 & TST & \\
\hline CHEMBL1309183 & 688759 & 4.8 & 4.46899 & 9999999999 & TRN \\
\hline CHEMBL1588716 & 688759 & 4.5 & 4.8063 & TST & \\
\hline CHEMBL1565919 & 688759 & 4.6 & 5.1572 & TRN & \\
\hline CHEMBL1505060 & 688759 & 5.3 & 5.2929 & TRN & \\
\hline CHEMBL1500938 & 688759 & 6.95 & 4.9132 & TRN & \\
\hline CHEMBL1597970 & 688759 & 4.45 & 4.6135 & TRN & \\
\hline CHEMBL1561872 & 688759 & 4.55 & 4.7435 & TST & \\
\hline CHEMBL1405288 & 688759 & 5.4 & 5.2775 & TRN & \\
\hline CHEMBL1507560 & 688759 & 5.0 & 5.1362 & TRN & \\
\hline CHEMBL1556049 & 688759 & 4.45 & 4.7644 & TRN & \\
\hline CHEMBL1366577 & 688759 & 4.95 & 4.8817 & TRN & \\
\hline CHEMBL234180 & 688759 & 4.45 & 4.6259 & TRN & \\
\hline CHEMBL1401140 & 688759 & 4.5 & 4.9937 & TST & \\
\hline CHEMBL1448265 & 688759 & 4.45 & 4.9732 & TRN & \\
\hline CHEMBL1598883 & 688759 & 5.25 & 5.3479 & TRN & \\
\hline CHEMBL1523355 & 688759 & 5.0 & 5.2845 & TRN & \\
\hline CHEMBL3196230 & 688759 & 4.45 & 5.0801 & TST & \\
\hline CHEMBL 242946 & 688759 & 4.45 & 4.7632 & TRN & \\
\hline CHEMBL1311191 & 688759 & 4.45 & 4.907 & TRN & \\
\hline CHEMBL1440561 & 688759 & 4.45 & 5.6971 & TRN & \\
\hline CHEMBL1481630 & 688759 & 4.65 & 4.6912 & TRN & \\
\hline CHEMBL 3190993 & 688759 & 6.0 & 5.3827 & TRN & \\
\hline CHEMBL1480156 & 688759 & 4.45 & 4.7731 & TRN & \\
\hline CHEMBL1419954 & 688759 & 4.7 & 4.7591 & TST & \\
\hline CHEMBL1345972 & 688759 & 4.5 & 4.6008 & TRN & \\
\hline CHEMBL1563220 & 688759 & 5.95 & 4.7689 & TST & \\
\hline CHEMBL1419481 & 688759 & 5.15 & 4.9308 & TRN & \\
\hline CHEMBL551004 & 688759 & 5.3 & 4.8112 & TRN & \\
\hline CHEMBL1385328 & 688759 & 4.5 & 5.0268 & TRN & \\
\hline CHEMBL1582997 & 688759 & 4.95 & 5.2103 & TST & \\
\hline CHEMBL 3208123 & 688759 & 4.45 & 4.7174 & TST & \\
\hline CHEMBL1965045 & 688759 & 4.8 & 5.112 & TRN & \\
\hline CHEMBL1325440 & 688759 & 4.45 & 4.9036 & TST & \\
\hline CHEMBL1345219 & 688759 & 4.6 & 4.7367 & TRN & \\
\hline CHEMBL1528448 & 688759 & 5.5 & 5.3909 & TRN & \\
\hline CHEMBL1386941 & 688759 & 4.45 & 4.9328 & TRN & \\
\hline CHEMBL1332174 & 688759 & 4.95 & 5.1716 & TRN & \\
\hline CHEMBL1451448 & 688759 & 5.5 & 5.1734 & TRN & \\
\hline CHEMBL1299319 & 688759 & 4.45 & 4.8658 & TRN & \\
\hline CHEMBL1491742 & 688759 & 4.45 & 4.649 & TRN & \\
\hline
\end{tabular}




\begin{tabular}{|c|c|c|c|c|c|}
\hline & & \multicolumn{4}{|c|}{ Supplemental Table s2.txt } \\
\hline CHEMBL1404067 & 688759 & 4.55 & 4.7584 & TST & \\
\hline CHEMBL1510524 & 688759 & 4.45 & 4.9967 & TRN & \\
\hline CHEMBL1412647 & 688759 & 6.05 & 5.5993 & TRN & \\
\hline CHEMBL1381043 & 688759 & 4.45 & 4.5324 & TST & \\
\hline CHEMBL1532140 & 688759 & 6.0 & 4.7375 & TST & \\
\hline CHEMBL1312276 & 688759 & 5.1 & 5.3045 & TRN & \\
\hline CHEMBL1557974 & 688759 & 5.15 & 5.0109 & TRN & \\
\hline CHEMBL1530743 & 688759 & 5.85 & 5.4923 & TRN & \\
\hline CHEMBL1464521 & 688759 & 4.95 & 4.995 & TRN & \\
\hline CHEMBL546170 & 688759 & 3.45 & 6.0874 & TRN & \\
\hline CHEMBL1567324 & 688759 & 5.35 & 4.948 & TRN & \\
\hline CHEMBL1549175 & 688759 & 5.35 & 4.9878 & TRN & \\
\hline CHEMBL1533317 & 688759 & 4.45 & 4.8533 & TRN & \\
\hline CHEMBL1307051 & 688759 & 5.55 & 4.9453 & TRN & \\
\hline CHEMBL1306739 & 688759 & 5.2 & 4.8006 & TRN & \\
\hline CHEMBL1305860 & 688759 & 4.45 & 4.5747 & TRN & \\
\hline CHEMBL1573025 & 688759 & 4.45 & 5.2217 & TRN & \\
\hline CHEMBL1325354 & 688759 & 4.6 & 4.7696 & TRN & \\
\hline CHEMBL1604207 & 688759 & 5.25 & 5.04 & TST & \\
\hline CHEMBL1399767 & 688759 & 5.95 & 4.9114 & TRN & \\
\hline CHEMBL1385111 & 688759 & 4.7 & 5.1193 & TST & \\
\hline CHEMBL1306856 & 688759 & 4.85 & 5.0843 & TRN & \\
\hline CHEMBL1491179 & 688759 & 4.5 & 4.81800 & 00000000005 & TST \\
\hline CHEMBL1566253 & 688759 & 5.2 & 5.2428 & TST & \\
\hline CHEMBL1392911 & 688759 & 5.25 & 4.7309 & TRN & \\
\hline CHEMBL1522005 & 688759 & 4.45 & 4.8944 & TST & \\
\hline CHEMBL1584190 & 688759 & 4.65 & 5.0409 & TRN & \\
\hline CHEMBL1385516 & 688759 & 6.1 & 5.0339 & TRN & \\
\hline CHEMBL1521565 & 688759 & 4.45 & 4.7369 & TRN & \\
\hline CHEMBL1455883 & 688759 & 4.45 & 4.6594 & TRN & \\
\hline CHEMBL1495125 & 688759 & 4.6 & 4.6866 & TRN & \\
\hline CHEMBL1351775 & 688759 & 5.95 & 4.5988 & TRN & \\
\hline CHEMBL1460519 & 688759 & 4.85 & 4.8365 & TST & \\
\hline CHEMBL1361413 & 688759 & 5.1 & 5.1621 & TRN & \\
\hline CHEMBL1452736 & 688759 & 4.75 & 4.9548 & TRN & \\
\hline CHEMBL1357724 & 688759 & 4.45 & 4.6676 & TRN & \\
\hline CHEMBL1596917 & 688759 & 4.45 & 4.7731 & TST & \\
\hline CHEMBL1382305 & 688759 & 4.45 & 5.099 & TRN & \\
\hline CHEMBL1556151 & 688759 & 4.95 & 4.7547 & TST & \\
\hline CHEMBL1459370 & 688759 & 4.55 & 4.5496 & TST & \\
\hline CHEMBL1446827 & 688759 & 5.65 & 5.1275 & TRN & \\
\hline CHEMBL1451252 & 688759 & 4.85 & 4.8533 & TRN & \\
\hline CHEMBL1606530 & 688759 & 4.7 & 4.7715 & TRN & \\
\hline CHEMBL1533488 & 688759 & 5.4 & 5.0253 & TRN & \\
\hline CHEMBL1421200 & 688759 & 4.8 & 4.8376 & TRN & \\
\hline CHEMBL1447755 & 688759 & 4.75 & 4.6983 & TRN & \\
\hline CHEMBL1490574 & 688759 & 5.55 & 5.7338 & TRN & \\
\hline CHEMBL1493868 & 688759 & 5.55 & 5.6374 & TRN & \\
\hline
\end{tabular}




\begin{tabular}{|c|c|c|c|c|c|}
\hline & & \multicolumn{4}{|c|}{ Supplemental Table S2.txt } \\
\hline CHEMBL1403127 & 688759 & 5.4 & 5.2368 & TRN & \\
\hline CHEMBL1391454 & 688759 & 4.45 & 4.4989 & TST & \\
\hline CHEMBL1342614 & 688759 & 5.15 & 4.9681 & TRN & \\
\hline CHEMBL1599113 & 688759 & 4.5 & 4.6917 & TRN & \\
\hline CHEMBL1569544 & 688759 & 5.05 & 4.7316 & TRN & \\
\hline CHEMBL1542825 & 688759 & 5.25 & 4.9151 & TRN & \\
\hline CHEMBL1407635 & 688759 & 4.45 & 4.6403 & TRN & \\
\hline CHEMBL1575550 & 688759 & 6.05 & 4.9841 & TST & \\
\hline CHEMBL3197634 & 688759 & 4.6 & 4.7586 & TRN & \\
\hline CHEMBL1370120 & 688759 & 4.45 & 4.8843 & TST & \\
\hline CHEMBL1350791 & 688759 & 4.8 & 4.9761 & TST & \\
\hline CHEMBL1392045 & 688759 & 4.8 & 4.9962 & TRN & \\
\hline CHEMBL1538753 & 688759 & 4.9 & 4.6017 & TRN & \\
\hline CHEMBL1599607 & 688759 & 4.45 & 4.8972 & TST & \\
\hline CHEMBL1385617 & 688759 & 4.95 & 5.9168 & TRN & \\
\hline CHEMBL1348954 & 688759 & 5.15 & 4.724 & TRN & \\
\hline CHEMBL1491599 & 688759 & 4.45 & 4.8501 & TRN & \\
\hline CHEMBL1440909 & 688759 & 4.9 & 4.8224 & TRN & \\
\hline CHEMBL1306692 & 688759 & 5.25 & 4.3424 & TRN & \\
\hline CHEMBL1358310 & 688759 & 4.75 & 5.4631 & TRN & \\
\hline CHEMBL1462444 & 688759 & 5.5 & 5.3914 & TRN & \\
\hline CHEMBL1490481 & 688759 & 4.7 & 4.756 & TRN & \\
\hline CHEMBL1995252 & 688759 & 4.9 & 5.336 & TRN & \\
\hline CHEMBL1546347 & 688759 & 6.0 & 5.4477 & TST & \\
\hline CHEMBL1596995 & 688759 & 6.15 & 5.2049 & TRN & \\
\hline CHEMBL1528603 & 688759 & 4.65 & 4.7658 & TRN & \\
\hline CHEMBL1556072 & 688759 & 4.95 & 4.8001 & TST & \\
\hline CHEMBL172064 & 688759 & 5.2 & 4.9204 & TRN & \\
\hline CHEMBL3191225 & 688759 & 4.45 & 4.854 & TST & \\
\hline CHEMBL1361747 & 688759 & 4.75 & 4.8592 & TRN & \\
\hline CHEMBL1586235 & 688759 & 4.7 & 4.976 & TST & \\
\hline CHEMBL 3198874 & 688759 & 4.75 & 4.6445 & TRN & \\
\hline CHEMBL1488876 & 688759 & 4.45 & 4.8209 & TRN & \\
\hline CHEMBL1393740 & 688759 & 4.55 & 4.9103 & TRN & \\
\hline CHEMBL1372937 & 688759 & 4.7 & 4.5679 & TRN & \\
\hline CHEMBL3196690 & 688759 & 4.45 & 4.8878 & TRN & \\
\hline CHEMBL1505665 & 688759 & 4.45 & 4.9445 & TRN & \\
\hline CHEMBL162598 & 688759 & 5.65 & 5.0179 & TST & \\
\hline CHEMBL1566940 & 688759 & 5.0 & 4.7039 & TRN & \\
\hline CHEMBL1508679 & 688759 & 5.85 & 4.7811 & TRN & \\
\hline CHEMBL1583053 & 688759 & 4.95 & 4.5234 & TRN & \\
\hline CHEMBL1430139 & 688759 & 4.45 & 4.7281 & TRN & \\
\hline CHEMBL1367476 & 688759 & 5.25 & 4.9724 & TST & \\
\hline CHEMBL1419516 & 688759 & 4.75 & 4.8273 & TST & \\
\hline CHEMBL3194519 & 688759 & 4.65 & $4.8180 €$ & 00000000005 & TRN \\
\hline CHEMBL1974538 & 688759 & 5.55 & 5.5301 & TRN & \\
\hline CHEMBL1351068 & 688759 & 4.65 & 4.7412 & TST & \\
\hline CHEMBL1575729 & 688759 & 5.45 & 4.7676 & TRN & \\
\hline & & & & 15183 & \\
\hline
\end{tabular}




\begin{tabular}{|c|c|c|c|c|}
\hline \multicolumn{5}{|c|}{ Supplemental Table S2.txt } \\
\hline CHEMBL243185 & 688759 & 4.7 & 4.8951 & TRN \\
\hline CHEMBL1972143 & 688759 & 5.3 & 5.1304 & TRN \\
\hline CHEMBL65374 & 688759 & 5.35 & 5.0891 & TRN \\
\hline CHEMBL1424783 & 688759 & 5.25 & 4.7517 & TRN \\
\hline CHEMBL600686 & 688759 & 4.45 & 4.7186 & TRN \\
\hline CHEMBL478754 & 688759 & 4.9 & 4.6375 & TST \\
\hline CHEMBL1474890 & 688759 & 4.9 & 4.6686 & TRN \\
\hline CHEMBL1597561 & 688759 & 5.05 & 4.9805 & TRN \\
\hline CHEMBL1498444 & 688759 & 4.7 & 4.7938 & TRN \\
\hline CHEMBL590285 & 688759 & 5.6 & 4.8816 & TRN \\
\hline CHEMBL1321952 & 688759 & 4.65 & 4.5223 & TRN \\
\hline CHEMBL1561979 & 688759 & 4.45 & 4.82 & TRN \\
\hline CHEMBL3212469 & 688759 & 4.6 & 4.7601 & TRN \\
\hline CHEMBL1419466 & 688759 & 4.5 & 4.8708 & TRN \\
\hline CHEMBL1334945 & 688759 & 4.45 & 5.0331 & TRN \\
\hline CHEMBL1444691 & 688759 & 6.0 & 4.7092 & TRN \\
\hline CHEMBL1381783 & 688759 & 4.45 & 4.8528 & TST \\
\hline CHEMBL1345893 & 688759 & 4.9 & 4.9432 & TRN \\
\hline CHEMBL1555793 & 688759 & 4.45 & 4.8669 & TRN \\
\hline CHEMBL1569394 & 688759 & 5.5 & 4.8178 & TRN \\
\hline CHEMBL1305380 & 688759 & 4.7 & 4.9512 & TRN \\
\hline CHEMBL1497488 & 688759 & 6.25 & 5.2712 & TRN \\
\hline CHEMBL1548184 & 688759 & 4.75 & 4.7417 & TST \\
\hline CHEMBL1558024 & 688759 & 4.95 & 4.9568 & TRN \\
\hline CHEMBL1459578 & 688759 & 5.15 & 4.999 & TST \\
\hline CHEMBL3191858 & 688759 & 4.75 & 4.7813 & TRN \\
\hline CHEMBL3199161 & 688759 & 5.25 & 4.957 & TRN \\
\hline CHEMBL3198269 & 688759 & 5.0 & 4.8848 & TRN \\
\hline CHEMBL 3392047 & 688759 & 4.45 & 4.9213 & TST \\
\hline CHEMBL1381178 & 688759 & 4.65 & 5.0269 & TRN \\
\hline CHEMBL3199367 & 688759 & 4.45 & 4.7725 & TRN \\
\hline CHEMBL1446609 & 688759 & 4.9 & 4.9033 & TRN \\
\hline CHEMBL1352986 & 688759 & 5.25 & 4.9067 & TRN \\
\hline CHEMBL1453708 & 688759 & 4.55 & 4.6882 & TST \\
\hline CHEMBL1432097 & 688759 & 4.6 & 4.7979 & TRN \\
\hline CHEMBL1381832 & 688759 & 5.2 & 5.1532 & TRN \\
\hline CHEMBL 251815 & 688759 & 4.65 & 4.8609 & TRN \\
\hline CHEMBL1499789 & 688759 & 5.95 & 5.4912 & TRN \\
\hline CHEMBL1578299 & 688759 & 4.45 & 4.6557 & TRN \\
\hline CHEMBL1385217 & 688759 & 6.05 & 5.4254 & TST \\
\hline CHEMBL1546670 & 688759 & 5.35 & 4.8772 & TST \\
\hline CHEMBL1442260 & 688759 & 4.45 & 4.9621 & TRN \\
\hline CHEMBL1463755 & 688759 & 5.25 & 5.2126 & TRN \\
\hline CHEMBL1433308 & 688759 & 4.65 & 4.7187 & TRN \\
\hline CHEMBL1411641 & 688759 & 4.45 & 5.1196 & TRN \\
\hline CHEMBL1541292 & 688759 & 5.05 & 4.8965 & TRN \\
\hline CHEMBL1335411 & 688759 & 4.6 & 4.8571 & TRN \\
\hline CHEMBL1371600 & 688759 & 5.1 & 5.2829 & TRN \\
\hline
\end{tabular}




\begin{tabular}{|c|c|c|c|c|c|}
\hline \multicolumn{6}{|c|}{ Supplemental Table S2.txt } \\
\hline CHEMBL1993643 & 688759 & 5.5 & 4.5706 & TRN & \\
\hline CHEMBL1439768 & 688759 & 6.7501 & 4.9759 & TRN & \\
\hline CHEMBL1451332 & 688759 & 4.45 & 4.9328 & TST & \\
\hline CHEMBL1987685 & 688759 & 4.65 & 4.8802 & TRN & \\
\hline CHEMBL1505687 & 688759 & 5.15 & 4.6418 & TRN & \\
\hline CHEMBL1324559 & 688759 & 7.6003 & 4.9918 & TST & \\
\hline CHEMBL1372746 & 688759 & 5.85 & 5.2573 & TRN & \\
\hline CHEMBL1400434 & 688759 & 4.55 & 4.6221 & TRN & \\
\hline CHEMBL1576047 & 688759 & 4.8 & 4.7421 & TRN & \\
\hline CHEMBL1341241 & 688759 & 4.75 & 4.5609 & TRN & \\
\hline CHEMBL 3208645 & 688759 & 4.7 & 4.9484 & TRN & \\
\hline CHEMBL3208493 & 688759 & 5.45 & 4.8705 & TRN & \\
\hline CHEMBL188423 & 688759 & 4.85 & 4.6351 & TRN & \\
\hline CHEMBL 1400280 & 688759 & 4.45 & 4.8501 & TST & \\
\hline CHEMBL1466002 & 688759 & 4.5 & 4.8163 & TRN & \\
\hline CHEMBL3198339 & 688759 & 4.45 & 4.8185 & TRN & \\
\hline CHEMBL1465029 & 688759 & 4.45 & 4.6451 & TST & \\
\hline CHEMBL1320882 & 688759 & 5.15 & 4.8632 & TRN & \\
\hline CHEMBL 222759 & 688759 & 4.45 & 5.0556 & TRN & \\
\hline CHEMBL 28 & 688759 & 6.25 & 5.4644 & TRN & \\
\hline CHEMBL1329511 & 688759 & 4.7 & 5.1933 & TRN & \\
\hline CHEMBL1539141 & 688759 & 4.45 & 4.8183 & TRN & \\
\hline CHEMBL1339927 & 688759 & 5.35 & 4.8944 & TRN & \\
\hline CHEMBL1490043 & 688759 & 5.2 & 5.0097 & TRN & \\
\hline CHEMBL1532749 & 688759 & 5.5 & 5.0643 & TST & \\
\hline CHEMBL1458228 & 688759 & 4.45 & 4.8719 & TST & \\
\hline CHEMBL3192493 & 688759 & 4.45 & 4.5877 & TST & \\
\hline CHEMBL1531587 & 688759 & 4.45 & 5.1428 & TRN & \\
\hline CHEMBL1340572 & 688759 & 5.2 & 4.9731 & TRN & \\
\hline CHEMBL1598160 & 688759 & 5.0 & 5.0633 & TST & \\
\hline CHEMBL1471603 & 688759 & 6.8499 & 5.042 & TRN & \\
\hline CHEMBL1484041 & 688759 & 4.45 & 4.4786 & TRN & \\
\hline CHEMBL3199868 & 688759 & 5.4 & 5.38899 & 9999999999 & TRN \\
\hline CHEMBL1382105 & 688759 & 5.15 & 5.1819 & TRN & \\
\hline CHEMBL1402428 & 688759 & 5.05 & 5.1335 & TRN & \\
\hline CHEMBL1365395 & 688759 & 5.0 & 4.6791 & TRN & \\
\hline CHEMBL1336419 & 688759 & 4.6 & 4.7562 & TRN & \\
\hline CHEMBL1478314 & 688759 & 4.45 & 4.966 & TRN & \\
\hline CHEMBL1597182 & 688759 & 4.85 & 5.1169 & TRN & \\
\hline CHEMBL1440589 & 688759 & 4.75 & 4.6213 & TST & \\
\hline CHEMBL3191808 & 688759 & 5.15 & 5.1221 & TRN & \\
\hline CHEMBL3211497 & 688759 & 4.6 & 4.8398 & TRN & \\
\hline CHEMBL1309768 & 688759 & 5.25 & 5.2331 & TRN & \\
\hline CHEMBL1353709 & 688759 & 4.45 & 4.6855 & TRN & \\
\hline CHEMBL1369356 & 688759 & 5.0 & 4.853 & TRN & \\
\hline CHEMBL1368932 & 688759 & 5.45 & 5.1628 & TRN & \\
\hline CHEMBL1353079 & 688759 & 5.1 & 5.0246 & TRN & \\
\hline CHEMBL1458174 & 688759 & 4.45 & 4.9285 & TRN & \\
\hline
\end{tabular}




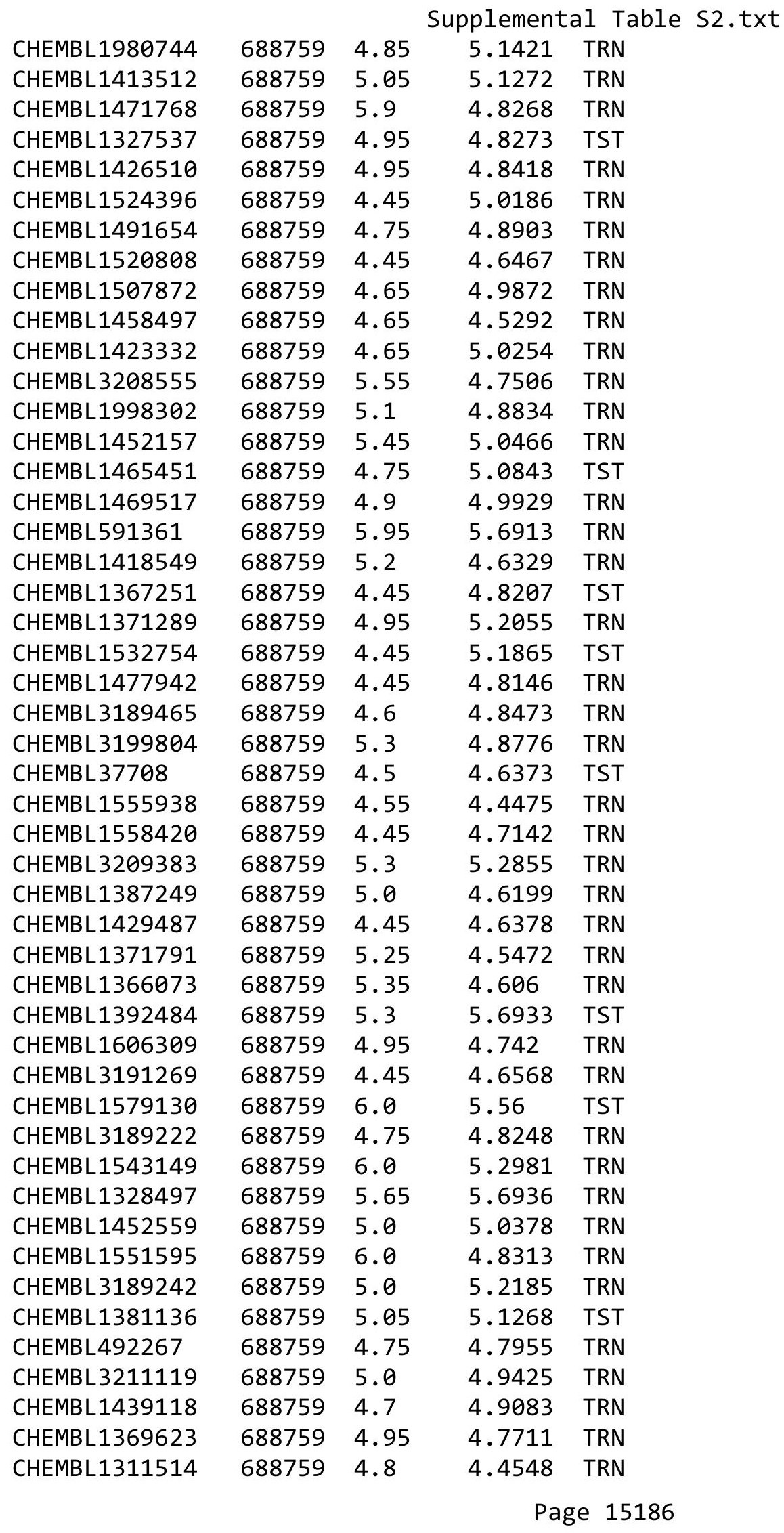




\begin{tabular}{|c|c|c|c|c|c|}
\hline \multicolumn{6}{|c|}{ Supplemental Table S2.txt } \\
\hline CHEMBL602646 & 688759 & 5.15 & 5.1057 & TST & \\
\hline CHEMBL1542962 & 688759 & 4.45 & 4.7556 & TST & \\
\hline CHEMBL1341544 & 688759 & 5.55 & 5.6812 & TRN & \\
\hline CHEMBL1444721 & 688759 & 4.75 & 4.7304 & TRN & \\
\hline CHEMBL1444481 & 688759 & 4.65 & 4.7022 & TRN & \\
\hline CHEMBL1534519 & 688759 & 5.8 & 5.6355 & TRN & \\
\hline CHEMBL1388491 & 688759 & 6.3 & 5.0864 & TRN & \\
\hline CHEMBL1318259 & 688759 & 5.0 & 4.7877 & TST & \\
\hline CHEMBL1402255 & 688759 & 4.85 & 4.7049 & TST & \\
\hline CHEMBL3212943 & 688759 & 5.3 & 4.9948 & TRN & \\
\hline CHEMBL1595607 & 688759 & 5.0 & 4.7155 & TRN & \\
\hline CHEMBL1502843 & 688759 & 4.95 & 4.6711 & TRN & \\
\hline CHEMBL1374351 & 688759 & 4.9 & 4.8543 & TRN & \\
\hline CHEMBL1448336 & 688759 & 4.85 & 5.2631 & TRN & \\
\hline CHEMBL1522618 & 688759 & 6.25 & 4.9245 & TRN & \\
\hline CHEMBL1557850 & 688759 & 4.65 & 4.9156 & TST & \\
\hline CHEMBL1393721 & 688759 & 4.6 & 4.891 & TRN & \\
\hline CHEMBL1606959 & 688759 & 4.9 & 5.0457 & TRN & \\
\hline CHEMBL1372039 & 688759 & 4.85 & 4.7555 & TRN & \\
\hline CHEMBL1430673 & 688759 & 4.75 & 4.6241 & TRN & \\
\hline CHEMBL1487117 & 688759 & 5.15 & 5.1492 & TRN & \\
\hline CHEMBL1539876 & 688759 & 4.85 & 4.9079 & TRN & \\
\hline CHEMBL1303089 & 688759 & 4.45 & 4.6652 & TST & \\
\hline CHEMBL1511029 & 688759 & 5.1 & 5.0641 & TRN & \\
\hline CHEMBL3193761 & 688759 & 4.95 & 4.7916 & TRN & \\
\hline CHEMBL1964614 & 688759 & 6.1 & 5.6799 & TRN & \\
\hline CHEMBL1457146 & 688759 & 4.45 & 5.0577 & TRN & \\
\hline CHEMBL1567551 & 688759 & 4.95 & 5.1169 & TRN & \\
\hline CHEMBL1310422 & 688759 & 4.8 & 5.3094 & TRN & \\
\hline CHEMBL1385437 & 688759 & 4.6 & 4.6947 & TRN & \\
\hline CHEMBL1431315 & 688759 & 4.6 & 4.8094 & TRN & \\
\hline CHEMBL1541961 & 688759 & 4.7 & 4.7483 & TRN & \\
\hline CHEMBL1438615 & 688759 & 4.65 & 4.9743 & TRN & \\
\hline CHEMBL1432997 & 688759 & 4.6 & 4.8979 & TST & \\
\hline CHEMBL1324328 & 688759 & 4.6 & 4.9259 & TRN & \\
\hline CHEMBL3144830 & 688759 & 5.25 & 5.1623 & TST & \\
\hline CHEMBL1337397 & 688759 & 4.45 & 4.8319 & TRN & \\
\hline CHEMBL1377728 & 688759 & 4.8 & 5.1249 & TST & \\
\hline CHEMBL1992977 & 688759 & 5.2 & 4.977 & TRN & \\
\hline CHEMBL3189452 & 688759 & 4.45 & 5.0496 & TST & \\
\hline CHEMBL88961 & 688759 & 4.45 & 4.5954 & TST & \\
\hline CHEMBL1411760 & 688759 & 5.35 & 5.3775 & TRN & \\
\hline CHEMBL1986741 & 688759 & 4.45 & $4.5760 e$ & 00000000005 & TRN \\
\hline CHEMBL1405401 & 688759 & 6.7501 & 5.6135 & TRN & \\
\hline CHEMBL1591005 & 688759 & 4.65 & 4.7806 & TRN & \\
\hline CHEMBL1518697 & 688759 & 4.45 & 4.9253 & TST & \\
\hline CHEMBL3197568 & 688759 & 4.55 & 5.0231 & TST & \\
\hline CHEMBL1989586 & 688759 & 5.4 & 5.2792 & TRN & \\
\hline
\end{tabular}




\begin{tabular}{|c|c|c|c|c|c|}
\hline \multicolumn{6}{|c|}{ Supplemental Table S2.txt } \\
\hline CHEMBL1448349 & 688759 & 5.5 & 5.3167 & TRN & \\
\hline CHEMBL3208669 & 688759 & 4.75 & 5.0351 & TRN & \\
\hline CHEMBL1511523 & 688759 & 4.95 & 4.6714 & TST & \\
\hline CHEMBL1422008 & 688759 & 4.9 & 4.9151 & TRN & \\
\hline CHEMBL1528823 & 688759 & 4.9 & 4.7241 & TST & \\
\hline CHEMBL1583824 & 688759 & 4.5 & 4.6127 & TRN & \\
\hline CHEMBL339587 & 688759 & 4.6 & 4.6541 & TRN & \\
\hline CHEMBL3199878 & 688759 & 4.45 & 4.9758 & TRN & \\
\hline CHEMBL1559818 & 688759 & 4.45 & 4.5393 & TRN & \\
\hline CHEMBL1479436 & 688759 & 4.6 & 4.9624 & TST & \\
\hline CHEMBL1456105 & 688759 & 4.8 & 4.8872 & TRN & \\
\hline CHEMBL1303315 & 688759 & 4.95 & 5.1771 & TRN & \\
\hline CHEMBL334707 & 688759 & 5.4 & 5.3688 & TRN & \\
\hline CHEMBL1501515 & 688759 & 4.45 & 4.9145 & TRN & \\
\hline CHEMBL1586542 & 688759 & 5.0 & 4.8659 & TRN & \\
\hline CHEMBL1504139 & 688759 & 4.45 & 4.6818 & TST & \\
\hline CHEMBL1548970 & 688759 & 4.7 & 4.9448 & TRN & \\
\hline CHEMBL1345127 & 688759 & 4.65 & 5.0835 & TRN & \\
\hline CHEMBL1561956 & 688759 & 4.9 & 5.195 & TRN & \\
\hline CHEMBL1565793 & 688759 & 4.9 & 4.6044 & TRN & \\
\hline CHEMBL1306121 & 688759 & 4.45 & 4.9253 & TRN & \\
\hline CHEMBL3193422 & 688759 & 5.8 & 5.7256 & TRN & \\
\hline CHEMBL1587527 & 688759 & 4.9 & 4.6636 & TRN & \\
\hline CHEMBL1590598 & 688759 & 4.45 & 4.6884 & TRN & \\
\hline CHEMBL3194562 & 688759 & 5.1 & 5.2368 & TRN & \\
\hline CHEMBL3195892 & 688759 & 5.35 & 4.8886 & TRN & \\
\hline CHEMBL3192212 & 688759 & 4.75 & 4.6094 & TRN & \\
\hline CHEMBL1534478 & 688759 & 5.3 & 5.1335 & TRN & \\
\hline CHEMBL1431154 & 688759 & 4.45 & 4.5482 & TST & \\
\hline CHEMBL1580272 & 688759 & 3.7 & 5.8684 & TRN & \\
\hline CHEMBL1407417 & 688759 & 5.35 & 5.1285 & TST & \\
\hline CHEMBL1335210 & 688759 & 4.45 & 4.6377 & TRN & \\
\hline CHEMBL1613430 & 688759 & 4.85 & 4.5947 & TRN & \\
\hline CHEMBL1508092 & 688759 & 4.8 & 4.6063 & TRN & \\
\hline CHEMBL1455124 & 688759 & 5.65 & 4.8074 & TRN & \\
\hline CHEMBL1521885 & 688759 & 4.8 & 5.025 & TRN & \\
\hline CHEMBL3190262 & 688759 & 6.3 & 4.6446 & TST & \\
\hline CHEMBL1535055 & 688759 & 4.65 & 4.7946 & TRN & \\
\hline CHEMBL3191894 & 688759 & 4.5 & 4.7818 & TRN & \\
\hline CHEMBL1534477 & 688759 & 4.6 & 4.8983 & TRN & \\
\hline CHEMBL1332117 & 688759 & 4.45 & 4.8893 & TRN & \\
\hline CHEMBL1718568 & 688759 & 5.85 & 5.57600 & 00000000005 & TRN \\
\hline CHEMBL1353515 & 688759 & 4.8 & 4.7615 & TST & \\
\hline CHEMBL1331816 & 688759 & 5.5 & 5.5293 & TRN & \\
\hline CHEMBL1459735 & 688759 & 4.45 & 4.738 & TRN & \\
\hline CHEMBL1573352 & 688759 & 4.7 & 4.9081 & TRN & \\
\hline CHEMBL1345952 & 688759 & 4.65 & 5.0679 & TST & \\
\hline CHEMBL1555983 & 688759 & 4.5 & 4.7124 & TST & \\
\hline
\end{tabular}




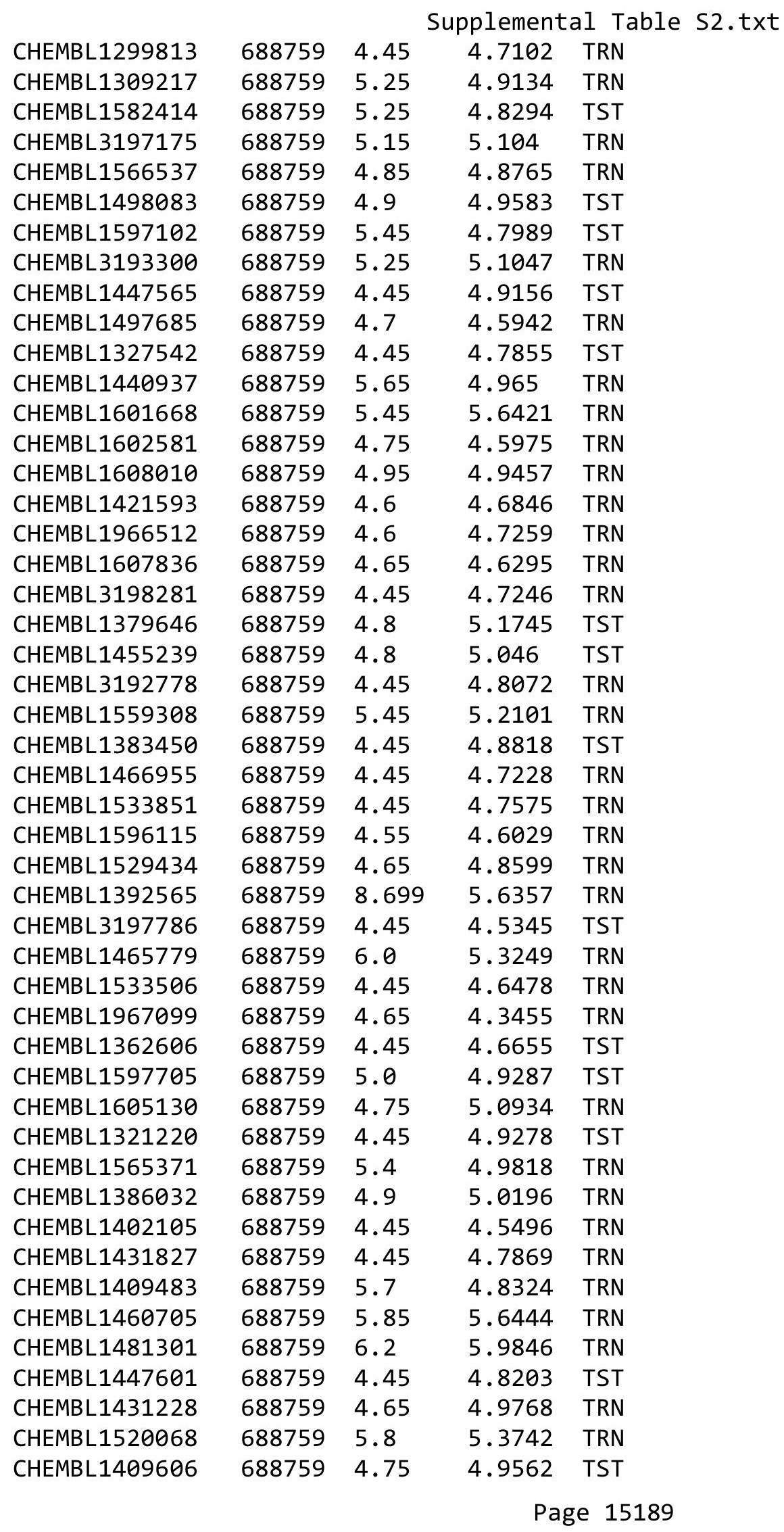




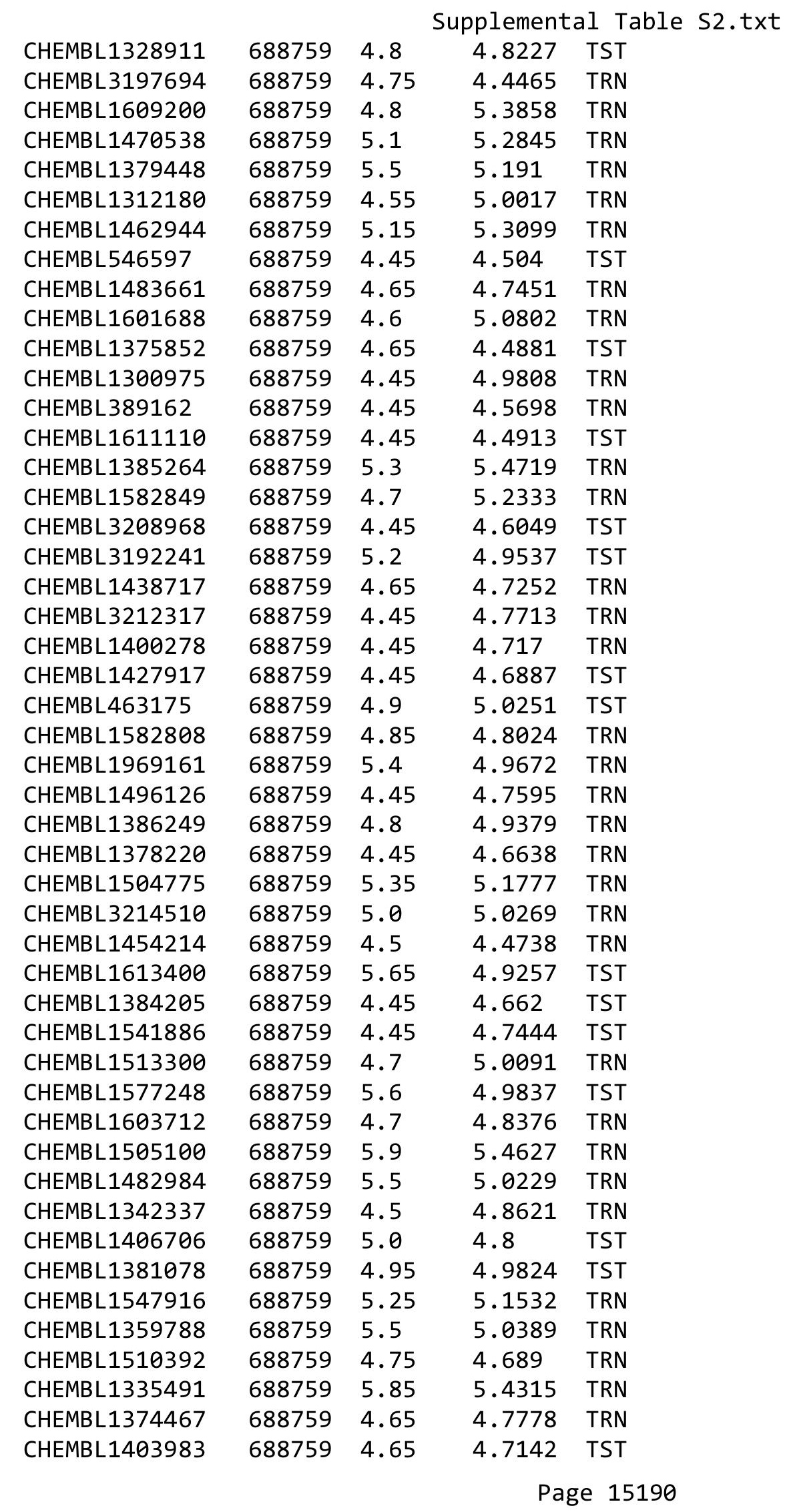




\begin{tabular}{|c|c|c|c|c|c|}
\hline \multicolumn{6}{|c|}{ Supplemental Table S2.txt } \\
\hline CHEMBL1993826 & 688759 & 4.7 & 4.5847 & TRN & \\
\hline CHEMBL530682 & 688759 & 5.15 & 4.885 & TRN & \\
\hline CHEMBL1444277 & 688759 & 4.85 & 5.0443 & TST & \\
\hline CHEMBL1338803 & 688759 & 4.45 & 4.6749 & TST & \\
\hline CHEMBL1423790 & 688759 & 5.0 & 5.047 & TRN & \\
\hline CHEMBL1481776 & 688759 & 5.0 & 4.7031 & TRN & \\
\hline CHEMBL1353341 & 688759 & 5.4 & 4.9136 & TRN & \\
\hline CHEMBL1980050 & 688759 & 5.35 & 5.315 & TRN & \\
\hline CHEMBL1519012 & 688759 & 6.15 & 5.1291 & TRN & \\
\hline CHEMBL1565342 & 688759 & 4.7 & 4.7524 & TST & \\
\hline CHEMBL1577093 & 688759 & 5.5 & 5.4012 & TST & \\
\hline CHEMBL 2002945 & 688759 & 4.45 & 4.7242 & TST & \\
\hline CHEMBL1300348 & 688759 & 4.65 & 4.8898 & TRN & \\
\hline CHEMBL1339387 & 688759 & 5.35 & 4.8382 & TRN & \\
\hline CHEMBL1588513 & 688759 & 5.25 & 5.5353 & TST & \\
\hline CHEMBL1462318 & 688759 & 5.1 & 4.7467 & TRN & \\
\hline CHEMBL1507355 & 688759 & 4.95 & 5.0492 & TRN & \\
\hline CHEMBL1604201 & 688759 & 4.5 & 4.668 & TRN & \\
\hline CHEMBL1572145 & 688759 & 4.65 & 5.0343 & TRN & \\
\hline CHEMBL1353664 & 688759 & 4.45 & 4.458 & TRN & \\
\hline CHEMBL1533593 & 688759 & 4.8 & 4.6115 & TRN & \\
\hline CHEMBL1379241 & 688759 & 4.45 & 4.8461 & TST & \\
\hline CHEMBL3193156 & 688759 & 4.45 & 4.7542 & TRN & \\
\hline CHEMBL1306051 & 688759 & 4.45 & 4.8827 & TRN & \\
\hline CHEMBL3191890 & 688759 & 4.85 & 5.0304 & TRN & \\
\hline CHEMBL1980813 & 688759 & 6.5 & 5.697 & TST & \\
\hline CHEMBL1463268 & 688759 & 5.35 & 5.0786 & TRN & \\
\hline CHEMBL1541883 & 688759 & 5.85 & 5.4555 & TRN & \\
\hline CHEMBL1532308 & 688759 & 5.0 & 4.7337 & TST & \\
\hline CHEMBL1451515 & 688759 & 5.4 & 4.8347 & TRN & \\
\hline CHEMBL1385676 & 688759 & 6.0 & 5.4154 & TRN & \\
\hline CHEMBL1426309 & 688759 & 5.8 & 4.7306 & TRN & \\
\hline CHEMBL1423047 & 688759 & 7.699 & 4.8891 & TRN & \\
\hline CHEMBL1575537 & 688759 & 4.45 & 4.5629 & TRN & \\
\hline CHEMBL1479640 & 688759 & 5.35 & 4.9707 & TRN & \\
\hline CHEMBL1416355 & 688759 & 5.4 & 5.1627 & TRN & \\
\hline CHEMBL1387117 & 688759 & 4.45 & 4.5521 & TRN & \\
\hline CHEMBL1492256 & 688759 & 6.25 & 4.7709 & TRN & \\
\hline CHEMBL1405948 & 688759 & 4.5 & 4.9803 & TRN & \\
\hline CHEMBL1321851 & 688759 & 5.2 & $4.9110 e$ & 00000000005 & TRN \\
\hline CHEMBL1570491 & 688759 & 4.45 & 5.0391 & TST & \\
\hline CHEMBL3197867 & 688759 & 6.1 & 4.7998 & TRN & \\
\hline CHEMBL1338243 & 688759 & 4.45 & 4.8831 & TST & \\
\hline CHEMBL1301746 & 688759 & 5.25 & 5.3759 & TRN & \\
\hline CHEMBL1469628 & 688759 & 4.45 & 4.8949 & TRN & \\
\hline CHEMBL1982454 & 688759 & 5.1 & 5.1176 & TRN & \\
\hline CHEMBL1500941 & 688759 & 5.2 & 4.9609 & TST & \\
\hline CHEMBL1998692 & 688759 & 4.55 & 4.6662 & TRN & \\
\hline
\end{tabular}




\begin{tabular}{|c|c|c|c|c|c|}
\hline & & \multicolumn{4}{|c|}{ Supplemental Table s2.txt } \\
\hline CHEMBL1585134 & 688759 & 4.45 & 4.8241 & TRN & \\
\hline CHEMBL1541367 & 688759 & 5.3 & 4.9094 & TRN & \\
\hline CHEMBL3210181 & 688759 & 4.9 & 5.0174 & TST & \\
\hline CHEMBL1486183 & 688759 & 5.2 & 4.9898 & TST & \\
\hline CHEMBL1565008 & 688759 & 5.05 & 4.8498 & TRN & \\
\hline CHEMBL1364010 & 688759 & 5.4 & 5.709 & TRN & \\
\hline CHEMBL3208223 & 688759 & 5.25 & 4.9556 & TST & \\
\hline CHEMBL3192459 & 688759 & 4.45 & 4.8609 & TRN & \\
\hline CHEMBL 211481 & 688759 & 4.95 & 4.7595 & TRN & \\
\hline CHEMBL1544272 & 688759 & 4.7 & 4.9227 & TST & \\
\hline CHEMBL1566725 & 688759 & 6.0 & 5.7712 & TRN & \\
\hline CHEMBL1349451 & 688759 & 4.9 & 5.2258 & TRN & \\
\hline CHEMBL3194662 & 688759 & 5.05 & 5.1842 & TRN & \\
\hline CHEMBL1708832 & 688759 & 4.6 & 4.7263 & TRN & \\
\hline CHEMBL1301066 & 688759 & 5.85 & 5.002 & TRN & \\
\hline CHEMBL1442635 & 688759 & 4.45 & 5.1086 & TRN & \\
\hline CHEMBL1546299 & 688759 & 5.9 & 5.7956 & TRN & \\
\hline CHEMBL1367591 & 688759 & 4.9 & 4.8693 & TRN & \\
\hline CHEMBL1304356 & 688759 & 5.7 & 5.096 & TST & \\
\hline CHEMBL1454149 & 688759 & 6.15 & 5.1174 & TRN & \\
\hline CHEMBL1994596 & 688759 & 4.55 & 4.5643 & TST & \\
\hline CHEMBL1563558 & 688759 & 5.3 & 4.8129 & TRN & \\
\hline CHEMBL1426282 & 688759 & 4.9 & 4.7035 & TRN & \\
\hline CHEMBL1583600 & 688759 & 4.45 & 5.185 & TRN & \\
\hline CHEMBL1327018 & 688759 & 4.65 & 4.5735 & TRN & \\
\hline CHEMBL1343423 & 688759 & 4.6 & 5.15799 & 99999999995 & TRN \\
\hline CHEMBL1332602 & 688759 & 5.55 & 5.2782 & TRN & \\
\hline CHEMBL1448425 & 688759 & 5.65 & 5.3806 & TRN & \\
\hline CHEMBL1375996 & 688759 & 4.8 & 4.9692 & TRN & \\
\hline CHEMBL1369762 & 688759 & 6.05 & 6.0035 & TRN & \\
\hline CHEMBL1365720 & 688759 & 4.45 & 4.8622 & TRN & \\
\hline CHEMBL1606715 & 688759 & 4.45 & 4.9069 & TRN & \\
\hline CHEMBL1470712 & 688759 & 4.75 & 4.8616 & TRN & \\
\hline CHEMBL1441178 & 688759 & 4.65 & 4.663 & TST & \\
\hline CHEMBL1352313 & 688759 & 5.25 & 4.9462 & TST & \\
\hline CHEMBL1303690 & 688759 & 4.75 & 4.7287 & TST & \\
\hline CHEMBL1553738 & 688759 & 4.6 & 4.7739 & TRN & \\
\hline CHEMBL1364809 & 688759 & 5.45 & 4.8552 & TRN & \\
\hline CHEMBL1391098 & 688759 & 4.45 & 4.7211 & TRN & \\
\hline CHEMBL1505297 & 688759 & 4.45 & 4.9829 & TRN & \\
\hline CHEMBL1486484 & 688759 & 5.65 & 5.2818 & TRN & \\
\hline CHEMBL1349166 & 688759 & 5.65 & 4.9043 & TRN & \\
\hline CHEMBL1602290 & 688759 & 4.45 & 4.6109 & TRN & \\
\hline CHEMBL1321104 & 688759 & 5.55 & 4.8869 & TRN & \\
\hline CHEMBL1445078 & 688759 & 4.45 & 4.7507 & TST & \\
\hline CHEMBL1579680 & 688759 & 4.45 & 4.7615 & TRN & \\
\hline CHEMBL1499138 & 688759 & 4.9 & 4.7788 & TRN & \\
\hline CHEMBL1364837 & 688759 & 5.25 & 4.7954 & TST & \\
\hline
\end{tabular}




\begin{tabular}{|c|c|c|c|c|}
\hline \multicolumn{5}{|c|}{ Supplemental Table S2.txt } \\
\hline CHEMBL1482400 & 688759 & 5.3 & 4.8292 & TRN \\
\hline CHEMBL1333905 & 688759 & 5.25 & 4.8729 & TRN \\
\hline CHEMBL1448391 & 688759 & 4.8 & 4.8904 & TRN \\
\hline CHEMBL1385060 & 688759 & 4.45 & 5.6552 & TRN \\
\hline CHEMBL1566337 & 688759 & 4.75 & 4.9338 & TRN \\
\hline CHEMBL1610999 & 688759 & 5.4 & 5.2921 & TST \\
\hline CHEMBL1341488 & 688759 & 4.45 & 4.561 & TRN \\
\hline CHEMBL1549939 & 688759 & 4.85 & 4.9878 & TRN \\
\hline CHEMBL1540355 & 688759 & 5.2 & 5.002 & TRN \\
\hline CHEMBL1982808 & 688759 & 5.85 & 5.6582 & TST \\
\hline CHEMBL1342062 & 688759 & 4.45 & 4.6561 & TRN \\
\hline CHEMBL1456466 & 688759 & 4.45 & 4.6242 & TRN \\
\hline CHEMBL1501968 & 688759 & 4.45 & 4.6309 & TST \\
\hline CHEMBL1347584 & 688759 & 5.25 & 4.8434 & TRN \\
\hline CHEMBL1428400 & 688759 & 5.85 & 5.6722 & TRN \\
\hline CHEMBL3192837 & 688759 & 4.8 & 4.6359 & TRN \\
\hline CHEMBL1468292 & 688759 & 4.45 & 4.8203 & TRN \\
\hline CHEMBL1432577 & 688759 & 5.9 & 6.0994 & TRN \\
\hline CHEMBL1605276 & 688759 & 4.45 & 5.06 & TRN \\
\hline CHEMBL1405130 & 688759 & 5.5 & 5.2872 & TRN \\
\hline CHEMBL3195732 & 688759 & 4.9 & 4.8559 & TRN \\
\hline CHEMBL1426365 & 688759 & 4.55 & 4.7001 & TRN \\
\hline CHEMBL1522950 & 688759 & 4.45 & 5.0015 & TRN \\
\hline CHEMBL1605892 & 688759 & 4.45 & 5.0288 & TRN \\
\hline CHEMBL1419621 & 688759 & 4.45 & 5.0389 & TRN \\
\hline CHEMBL1339107 & 688759 & 4.9 & 4.9161 & TRN \\
\hline CHEMBL1971965 & 688759 & 4.45 & 4.4604 & TRN \\
\hline CHEMBL189584 & 688759 & 4.45 & 5.2013 & TST \\
\hline CHEMBL3207616 & 688759 & 4.85 & 4.8698 & TRN \\
\hline CHEMBL1610689 & 688759 & 4.45 & 4.6513 & TRN \\
\hline CHEMBL3195091 & 688759 & 4.9 & 5.3552 & TST \\
\hline CHEMBL1387096 & 688759 & 4.45 & 4.8823 & TRN \\
\hline CHEMBL1325970 & 688759 & 4.45 & 4.5757 & TST \\
\hline CHEMBL1429440 & 688759 & 5.25 & 4.9769 & TST \\
\hline CHEMBL1383658 & 688759 & 4.6 & 5.0668 & TRN \\
\hline CHEMBL1382262 & 688759 & 4.45 & 4.8282 & TST \\
\hline CHEMBL3190811 & 688759 & 4.7 & 5.2389 & TRN \\
\hline CHEMBL76904 & 688759 & 4.85 & 5.2114 & TRN \\
\hline CHEMBL1352765 & 688759 & 6.1 & 4.8212 & TST \\
\hline CHEMBL1366027 & 688759 & 6.95 & 5.7254 & TRN \\
\hline CHEMBL1444302 & 688759 & 5.0 & 5.2309 & TRN \\
\hline CHEMBL3193098 & 688759 & 4.9 & 5.6136 & TRN \\
\hline CHEMBL1970734 & 688759 & 4.65 & 4.9169 & TST \\
\hline CHEMBL1430249 & 688759 & 4.65 & 4.895 & TST \\
\hline CHEMBL1527584 & 688759 & 4.85 & 5.334 & TRN \\
\hline CHEMBL1369262 & 688759 & 5.35 & 4.9209 & TRN \\
\hline CHEMBL1563978 & 688759 & 4.45 & 5.0031 & TST \\
\hline CHEMBL1519256 & 688759 & 5.45 & 4.9704 & TRN \\
\hline
\end{tabular}




\begin{tabular}{|c|c|c|c|c|c|}
\hline \multicolumn{6}{|c|}{ Supplemental Table S2.txt } \\
\hline CHEMBL1300172 & 688759 & 5.15 & 4.9725 & TRN & \\
\hline CHEMBL 3210045 & 688759 & 5.35 & 4.7669 & TRN & \\
\hline CHEMBL1470124 & 688759 & 4.45 & 4.7547 & TST & \\
\hline CHEMBL1534308 & 688759 & 4.45 & 4.8859 & TST & \\
\hline CHEMBL84010 & 688759 & 7.15 & 5.0409 & TRN & \\
\hline CHEMBL1547145 & 688759 & 5.8 & 5.1831 & TRN & \\
\hline CHEMBL 3212746 & 688759 & 4.65 & 4.814 & TRN & \\
\hline CHEMBL1349182 & 688759 & 4.75 & 4.9741 & TST & \\
\hline CHEMBL 578487 & 688759 & 5.25 & 4.9952 & TRN & \\
\hline CHEMBL1412182 & 688759 & 4.85 & 4.8986 & TRN & \\
\hline CHEMBL1578022 & 688759 & 4.5 & 4.7297 & TRN & \\
\hline CHEMBL1465606 & 688759 & 5.8 & 5.01399 & 9999999999 & TST \\
\hline CHEMBL3199175 & 688759 & 5.3 & 4.8168 & TRN & \\
\hline CHEMBL1542099 & 688759 & 4.45 & 4.9108 & TRN & \\
\hline CHEMBL1310029 & 688759 & 4.45 & 4.9399 & TRN & \\
\hline CHEMBL1498249 & 688759 & 4.6 & 4.678 & TRN & \\
\hline CHEMBL1597739 & 688759 & 4.95 & 5.1285 & TRN & \\
\hline CHEMBL1574669 & 688759 & 5.05 & 4.5678 & TRN & \\
\hline CHEMBL 290904 & 688759 & 5.6 & 5.2464 & TRN & \\
\hline CHEMBL1580257 & 688759 & 4.9 & 4.8566 & TRN & \\
\hline CHEMBL1340852 & 688759 & 5.05 & 5.1252 & TST & \\
\hline CHEMBL1538965 & 688759 & 4.45 & 4.6754 & TRN & \\
\hline CHEMBL1548676 & 688759 & 4.95 & 5.4585 & TRN & \\
\hline CHEMBL1325097 & 688759 & 4.75 & 4.9765 & TRN & \\
\hline CHEMBL1366712 & 688759 & 5.85 & 5.71899 & 9999999999 & TRN \\
\hline CHEMBL1413497 & 688759 & 4.45 & 4.7152 & TRN & \\
\hline CHEMBL1418191 & 688759 & 4.45 & 4.8979 & TRN & \\
\hline CHEMBL1585257 & 688759 & 5.0 & 4.8527 & TST & \\
\hline CHEMBL1391281 & 688759 & 4.5 & 4.535 & TST & \\
\hline CHEMBL1368180 & 688759 & 4.65 & 4.8773 & TRN & \\
\hline CHEMBL1353869 & 688759 & 4.95 & 4.9343 & TST & \\
\hline CHEMBL1594883 & 688759 & 4.45 & 4.7679 & TRN & \\
\hline CHEMBL3197803 & 688759 & 5.9 & 5.4898 & TRN & \\
\hline CHEMBL1505482 & 688759 & 5.35 & 5.081 & TRN & \\
\hline CHEMBL1990258 & 688759 & 5.1 & 5.2017 & TRN & \\
\hline CHEMBL1545616 & 688759 & 4.8 & 4.9151 & TRN & \\
\hline CHEMBL 2001029 & 688759 & 4.8 & 4.9409 & TRN & \\
\hline CHEMBL1563863 & 688759 & 4.45 & 4.4154 & TRN & \\
\hline CHEMBL1408451 & 688759 & 4.45 & 4.8966 & TRN & \\
\hline CHEMBL1337802 & 688759 & 4.6 & 4.81 & TRN & \\
\hline CHEMBL1588579 & 688759 & 4.65 & 4.9076 & TRN & \\
\hline CHEMBL1468306 & 688759 & 5.3 & 5.3942 & TRN & \\
\hline CHEMBL1613632 & 688759 & 4.7 & 4.9243 & TRN & \\
\hline CHEMBL1346796 & 688759 & 4.95 & 4.9409 & TST & \\
\hline CHEMBL3196605 & 688759 & 5.2 & 4.919 & TRN & \\
\hline CHEMBL1525949 & 688759 & 5.25 & 4.636 & TRN & \\
\hline CHEMBL1333387 & 688759 & 4.45 & 4.7315 & TRN & \\
\hline CHEMBL1425350 & 688759 & 4.45 & 4.413 & TST & \\
\hline
\end{tabular}




\begin{tabular}{|c|c|c|c|c|}
\hline \multicolumn{5}{|c|}{ Supplemental Table S2.txt } \\
\hline CHEMBL451574 & 688759 & 5.5 & 5.5291 & TST \\
\hline CHEMBL1609111 & 688759 & 6.2 & 5.0806 & TRN \\
\hline CHEMBL1564836 & 688759 & 7.0501 & 4.9243 & TRN \\
\hline CHEMBL1428003 & 688759 & 4.45 & 4.6258 & TRN \\
\hline CHEMBL1351164 & 688759 & 4.95 & 4.481 & TRN \\
\hline CHEMBL1511583 & 688759 & 5.85 & 5.5706 & TST \\
\hline CHEMBL1470134 & 688759 & 5.0 & 4.7374 & TRN \\
\hline CHEMBL1491222 & 688759 & 5.35 & 5.9827 & TRN \\
\hline CHEMBL1415977 & 688759 & 4.75 & 4.6347 & TST \\
\hline CHEMBL1379071 & 688759 & 4.8 & 4.8379 & TRN \\
\hline CHEMBL1440565 & 688759 & 5.0 & 4.8064 & TRN \\
\hline CHEMBL592552 & 688759 & 4.45 & 4.6235 & TRN \\
\hline CHEMBL1343656 & 688759 & 4.45 & 4.8743 & TRN \\
\hline CHEMBL1600947 & 688759 & 4.6 & 5.9622 & TRN \\
\hline CHEMBL1310127 & 688759 & 4.45 & 4.5258 & TST \\
\hline CHEMBL1345253 & 688759 & 5.25 & 5.136 & TRN \\
\hline CHEMBL1539359 & 688759 & 5.45 & 5.5053 & TRN \\
\hline CHEMBL1544056 & 688759 & 5.35 & 5.2445 & TRN \\
\hline CHEMBL1393028 & 688759 & 4.45 & 4.9315 & TRN \\
\hline CHEMBL1433360 & 688759 & 5.2 & 5.055 & TST \\
\hline CHEMBL1596302 & 688759 & 5.2 & 5.125 & TRN \\
\hline CHEMBL1413019 & 688759 & 4.85 & 4.9242 & TST \\
\hline CHEMBL1349928 & 688759 & 5.4 & 4.8468 & TRN \\
\hline CHEMBL1431737 & 688759 & 4.95 & 4.7599 & TRN \\
\hline CHEMBL1455663 & 688759 & 5.4 & 4.8941 & TRN \\
\hline CHEMBL1551004 & 688759 & 4.65 & 4.9048 & TRN \\
\hline CHEMBL3212619 & 688759 & 5.5 & 5.2389 & TST \\
\hline CHEMBL1565693 & 688759 & 4.75 & 5.0871 & TRN \\
\hline CHEMBL1439373 & 688759 & 4.65 & 4.7636 & TRN \\
\hline CHEMBL1581456 & 688759 & 4.75 & 4.5168 & TRN \\
\hline CHEMBL1481353 & 688759 & 5.45 & 5.0962 & TRN \\
\hline CHEMBL1518735 & 688759 & 5.5 & 5.0034 & TRN \\
\hline CHEMBL1541562 & 688759 & 5.8 & 4.7559 & TST \\
\hline CHEMBL1457898 & 688759 & 4.8 & 5.1075 & TRN \\
\hline CHEMBL1518026 & 688759 & 5.25 & 4.7887 & TRN \\
\hline CHEMBL1343063 & 688759 & 4.45 & 4.6938 & TST \\
\hline CHEMBL1415233 & 688759 & 4.55 & 4.5696 & TRN \\
\hline CHEMBL199868 & 688759 & 5.5 & 5.5967 & TRN \\
\hline CHEMBL1305004 & 688759 & 5.4 & 5.2569 & TRN \\
\hline CHEMBL1559853 & 688759 & 6.1 & 5.6334 & TST \\
\hline CHEMBL1402545 & 688759 & 4.45 & 4.867 & TRN \\
\hline CHEMBL1535759 & 688759 & 5.75 & 5.2589 & TRN \\
\hline CHEMBL1304384 & 688759 & 4.55 & 4.7436 & TRN \\
\hline CHEMBL1343023 & 688759 & 5.1 & 4.7762 & TRN \\
\hline CHEMBL1483697 & 688759 & 5.15 & 4.8471 & TRN \\
\hline CHEMBL1567701 & 688759 & 4.45 & 4.6244 & TRN \\
\hline CHEMBL 236899 & 688759 & 4.65 & 5.055 & TRN \\
\hline CHEMBL 3191827 & 688759 & 4.5 & 4.7241 & TRN \\
\hline
\end{tabular}




\begin{tabular}{|c|c|c|c|c|}
\hline \multicolumn{5}{|c|}{ Supplemental Table S2.txt } \\
\hline CHEMBL1368016 & 688759 & 5.4 & 4.8896 & TRN \\
\hline CHEMBL1418469 & 688759 & 5.3 & 5.0855 & TRN \\
\hline CHEMBL1494836 & 688759 & 4.45 & 4.7812 & TRN \\
\hline CHEMBL1405475 & 688759 & 5.55 & 5.7779 & TRN \\
\hline CHEMBL1574431 & 688759 & 4.75 & 5.1669 & TST \\
\hline CHEMBL1565900 & 688759 & 4.65 & 4.8632 & TRN \\
\hline CHEMBL1547829 & 688759 & 5.3 & 4.8643 & TRN \\
\hline CHEMBL3199695 & 688759 & 4.45 & 4.8298 & TRN \\
\hline CHEMBL1497618 & 688759 & 4.75 & 4.93 & TST \\
\hline CHEMBL1558165 & 688759 & 4.45 & 4.7219 & TST \\
\hline CHEMBL518292 & 688759 & 5.95 & 5.3489 & TST \\
\hline CHEMBL1437053 & 688759 & 4.65 & 4.9488 & TRN \\
\hline CHEMBL1343131 & 688759 & 4.5 & 4.8978 & TRN \\
\hline CHEMBL3145299 & 688759 & 5.4 & 4.9706 & TST \\
\hline CHEMBL1361994 & 688759 & 4.45 & 4.7866 & TST \\
\hline CHEMBL1498612 & 688759 & 5.35 & 5.0605 & TRN \\
\hline CHEMBL1601387 & 688759 & 4.45 & 4.7595 & TRN \\
\hline CHEMBL3192208 & 688759 & 4.5 & 4.7804 & TRN \\
\hline CHEMBL1608514 & 688759 & 4.45 & 4.6066 & TRN \\
\hline CHEMBL1425148 & 688759 & 4.45 & 4.8306 & TRN \\
\hline CHEMBL1360146 & 688759 & 4.45 & 4.5526 & TRN \\
\hline CHEMBL1565697 & 688759 & 5.25 & 4.8858 & TRN \\
\hline CHEMBL1551399 & 688759 & 4.45 & 4.6621 & TRN \\
\hline CHEMBL1493059 & 688759 & 4.5 & 4.8424 & TRN \\
\hline CHEMBL1988303 & 688759 & 4.7 & 4.8998 & TRN \\
\hline CHEMBL1461504 & 688759 & 4.45 & 4.7191 & TRN \\
\hline CHEMBL1980581 & 688759 & 5.05 & 5.5339 & TRN \\
\hline CHEMBL3194500 & 688759 & 4.45 & 4.9885 & TRN \\
\hline CHEMBL1343687 & 688759 & 5.6 & 4.6501 & TRN \\
\hline CHEMBL3185655 & 688759 & 5.25 & 6.2445 & TRN \\
\hline CHEMBL1498754 & 688759 & 5.05 & 5.0759 & TRN \\
\hline CHEMBL1333172 & 688759 & 4.45 & 4.7245 & TRN \\
\hline CHEMBL1458062 & 688759 & 4.95 & 4.6484 & TRN \\
\hline CHEMBL1432938 & 688759 & 4.75 & 4.8334 & TRN \\
\hline CHEMBL1379390 & 688759 & 5.0 & 4.9861 & TRN \\
\hline CHEMBL1425623 & 688759 & 4.6 & 4.5329 & TRN \\
\hline CHEMBL1594268 & 688759 & 4.45 & 4.8581 & TRN \\
\hline CHEMBL1545296 & 688759 & 4.45 & 4.7901 & TRN \\
\hline CHEMBL1344157 & 688759 & 4.45 & 4.7039 & TST \\
\hline CHEMBL1472004 & 688759 & 4.45 & 4.9071 & TRN \\
\hline CHEMBL1520058 & 688759 & 4.45 & 4.684 & TRN \\
\hline CHEMBL3199915 & 688759 & 5.15 & 4.9974 & TRN \\
\hline CHEMBL1308328 & 688759 & 4.85 & 5.0488 & TRN \\
\hline CHEMBL1440262 & 688759 & 4.95 & 4.9686 & TRN \\
\hline CHEMBL1536272 & 688759 & 4.65 & 4.7299 & TRN \\
\hline CHEMBL1460061 & 688759 & 4.65 & 5.0611 & TRN \\
\hline CHEMBL1532472 & 688759 & 5.4 & 5.1781 & TRN \\
\hline CHEMBL1600399 & 688759 & 4.85 & 5.2413 & TST \\
\hline
\end{tabular}




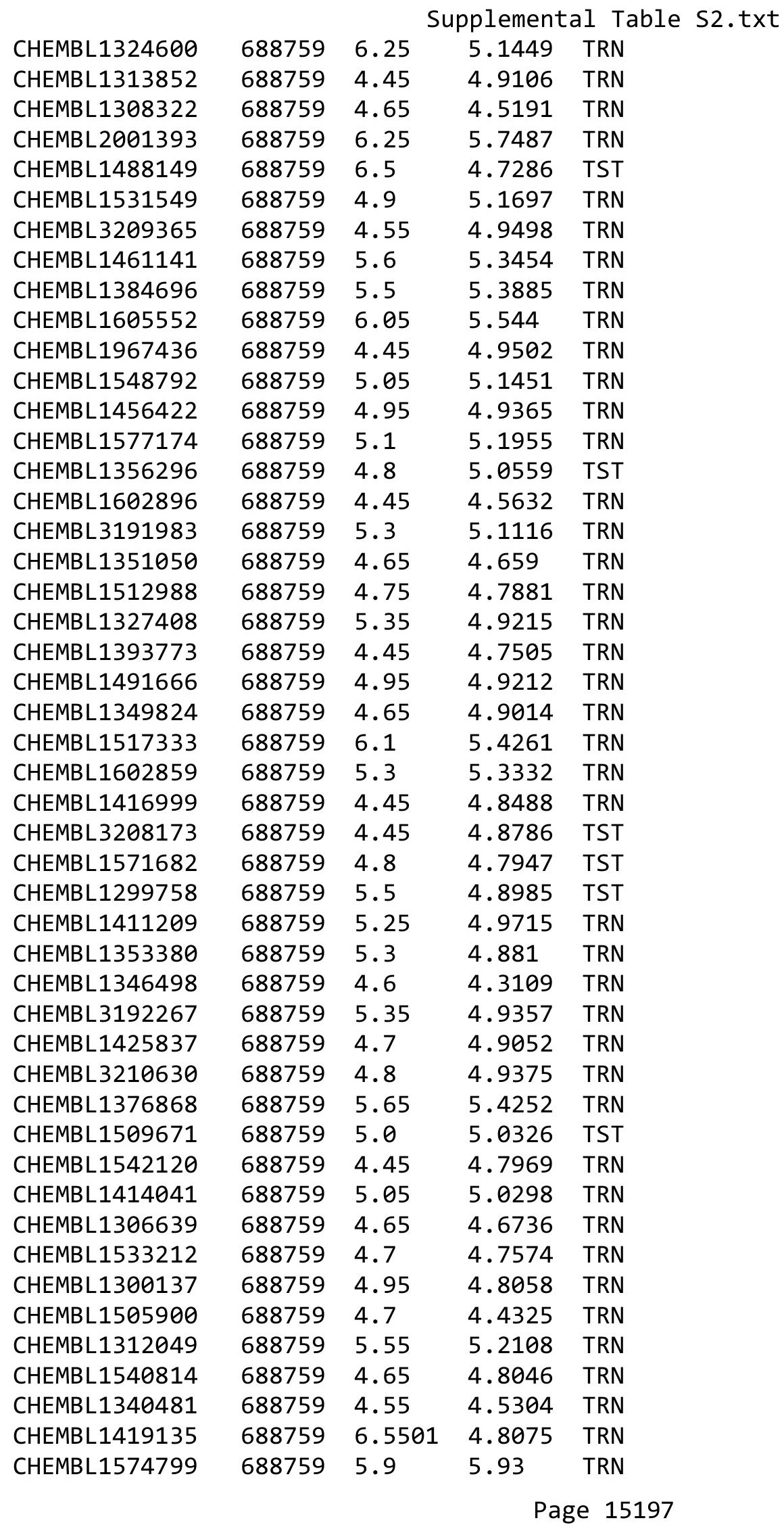




\begin{tabular}{|c|c|c|c|c|c|}
\hline & & \multicolumn{4}{|c|}{ Supplemental Table S2.txt } \\
\hline CHEMBL1498882 & 688759 & 5.25 & 5.0007 & TRN & \\
\hline CHEMBL1565327 & 688759 & 4.45 & 4.8027 & TST & \\
\hline CHEMBL1519311 & 688759 & 4.45 & 5.05699 & 99999999995 & TST \\
\hline CHEMBL1418021 & 688759 & 5.65 & 4.7069 & TRN & \\
\hline CHEMBL1530145 & 688759 & 5.25 & 5.2265 & TRN & \\
\hline CHEMBL1470060 & 688759 & 4.6 & 4.9801 & TRN & \\
\hline CHEMBL1457427 & 688759 & 4.45 & 5.0415 & TRN & \\
\hline CHEMBL1324142 & 688759 & 4.65 & 5.0 & TST & \\
\hline CHEMBL1400159 & 688759 & 5.3 & 5.1737 & TRN & \\
\hline CHEMBL1382542 & 688759 & 4.45 & 4.9561 & TRN & \\
\hline CHEMBL 2016647 & 688759 & 5.0 & 5.3147 & TRN & \\
\hline CHEMBL1496893 & 688759 & 5.25 & 4.8969 & TST & \\
\hline CHEMBL1393538 & 688759 & 5.05 & 4.7326 & TRN & \\
\hline CHEMBL3199018 & 688759 & 5.3 & 5.0643 & TRN & \\
\hline CHEMBL1403609 & 688759 & 5.45 & 4.8456 & TST & \\
\hline CHEMBL1382518 & 688759 & 6.0 & 4.8027 & TRN & \\
\hline CHEMBL3207993 & 688759 & 4.65 & 4.7155 & TRN & \\
\hline CHEMBL1299363 & 688759 & 5.45 & 4.944 & TST & \\
\hline CHEMBL1608762 & 688759 & 4.8 & 4.8656 & TRN & \\
\hline CHEMBL1340329 & 688759 & 4.45 & 5.0257 & TRN & \\
\hline CHEMBL1380123 & 688759 & 4.45 & 4.6624 & TRN & \\
\hline CHEMBL1419791 & 688759 & 4.45 & 4.8732 & TST & \\
\hline CHEMBL1522352 & 688759 & 4.7 & 4.7984 & TRN & \\
\hline CHEMBL1366836 & 688759 & 4.45 & 4.7144 & TST & \\
\hline CHEMBL1520525 & 688759 & 4.9 & 5.2949 & TRN & \\
\hline CHEMBL1457442 & 688759 & 4.45 & 4.9022 & TST & \\
\hline CHEMBL586602 & 688759 & 5.2 & 5.5214 & TRN & \\
\hline CHEMBL1458990 & 688759 & 4.7 & 4.7985 & TRN & \\
\hline CHEMBL1390548 & 688759 & 4.8 & 5.0265 & TST & \\
\hline CHEMBL3197224 & 688759 & 4.95 & 4.8257 & TST & \\
\hline CHEMBL1442115 & 688759 & 4.45 & 5.1443 & TRN & \\
\hline CHEMBL1420184 & 688759 & 5.05 & 5.1055 & TRN & \\
\hline CHEMBL1580587 & 688759 & 4.55 & 5.025 & TST & \\
\hline CHEMBL1526304 & 688759 & 4.45 & 4.7081 & TST & \\
\hline CHEMBL1379881 & 688759 & 5.55 & 5.2757 & TST & \\
\hline CHEMBL1524587 & 688759 & 5.0 & 5.2839 & TRN & \\
\hline CHEMBL1508647 & 688759 & 4.75 & 4.8275 & TRN & \\
\hline CHEMBL1387416 & 688759 & 4.6 & 4.9929 & TRN & \\
\hline CHEMBL1499828 & 688759 & 4.75 & 4.868 & TRN & \\
\hline CHEMBL1313581 & 688759 & 6.5 & 6.1965 & TRN & \\
\hline CHEMBL1426651 & 688759 & 4.65 & 4.7202 & TRN & \\
\hline CHEMBL1382842 & 688759 & 4.7 & 4.8755 & TRN & \\
\hline CHEMBL151 & 688759 & 6.0 & 5.4028 & TRN & \\
\hline CHEMBL1579923 & 688759 & 5.0 & 4.9529 & TRN & \\
\hline CHEMBL1385905 & 688759 & 5.2 & 4.6272 & TRN & \\
\hline CHEMBL1383113 & 688759 & 5.0 & 4.88399 & 99999999995 & TST \\
\hline CHEMBL1333992 & 688759 & 5.1 & 5.11 & TRN & \\
\hline CHEMBL1381242 & 688759 & 6.1 & 5.6157 & TRN & \\
\hline
\end{tabular}




\begin{tabular}{|c|c|c|c|c|c|}
\hline & & & & & \\
\hline CHEMBL1477280 & 688759 & 5.5 & 4.9706 & TRN & \\
\hline CHEMBL1313483 & 688759 & 4.85 & 4.8062 & TST & \\
\hline CHEMBL1606575 & 688759 & 4.45 & 4.4406 & TRN & \\
\hline CHEMBL1427365 & 688759 & 5.9 & 5.3743 & TRN & \\
\hline CHEMBL1560399 & 688759 & 4.45 & 4.7065 & TRN & \\
\hline CHEMBL1471350 & 688759 & 4.95 & 4.732 & TST & \\
\hline CHEMBL1426259 & 688759 & 5.45 & 4.90300 & 00000000005 & TRN \\
\hline CHEMBL3196561 & 688759 & 5.25 & 4.7111 & TRN & \\
\hline CHEMBL1563128 & 688759 & 5.3 & 4.6171 & TRN & \\
\hline CHEMBL1497259 & 688759 & 4.6 & 4.6508 & TRN & \\
\hline CHEMBL1337416 & 688759 & 5.2 & 5.1873 & TRN & \\
\hline CHEMBL1452177 & 688759 & 4.95 & 4.7136 & TST & \\
\hline CHEMBL1461706 & 688759 & 4.65 & 4.9332 & TRN & \\
\hline CHEMBL1452235 & 688759 & 4.9 & 4.7101 & TRN & \\
\hline CHEMBL1409782 & 688759 & 4.55 & 4.9049 & TST & \\
\hline CHEMBL1352342 & 688759 & 4.65 & 4.5649 & TRN & \\
\hline CHEMBL1379736 & 688759 & 6.8499 & 4.9535 & TST & \\
\hline CHEMBL1324773 & 688759 & 4.75 & 4.6671 & TRN & \\
\hline CHEMBL1982652 & 688759 & 4.9 & 4.6507 & TRN & \\
\hline CHEMBL3194026 & 688759 & 4.95 & 4.9892 & TRN & \\
\hline CHEMBL35482 & 688759 & 4.5 & 5.1012 & TRN & \\
\hline CHEMBL1425620 & 688759 & 5.25 & 4.9341 & TRN & \\
\hline CHEMBL3194211 & 688759 & 5.3 & 5.2968 & TRN & \\
\hline CHEMBL1462497 & 688759 & 4.45 & 4.9658 & TRN & \\
\hline CHEMBL1980018 & 688759 & 4.55 & 4.7439 & TRN & \\
\hline CHEMBL1525965 & 688759 & 4.7 & 4.9577 & TRN & \\
\hline CHEMBL1451366 & 688759 & 5.05 & 4.7846 & TRN & \\
\hline CHEMBL1469670 & 688759 & 6.2 & 5.4769 & TRN & \\
\hline CHEMBL1487438 & 688759 & 4.45 & 5.0718 & TST & \\
\hline CHEMBL1589234 & 688759 & 4.45 & 4.7893 & TST & \\
\hline CHEMBL1583435 & 688759 & 4.45 & 6.20200 & 0000000001 & TST \\
\hline CHEMBL1404842 & 688759 & 5.6 & 4.8674 & TRN & \\
\hline CHEMBL1419659 & 688759 & 4.9 & 4.8685 & TRN & \\
\hline CHEMBL1342700 & 688759 & 4.45 & 4.5798 & TRN & \\
\hline CHEMBL1526406 & 688759 & 4.65 & 4.9495 & TRN & \\
\hline CHEMBL1579773 & 688759 & 4.45 & 5.2585 & TRN & \\
\hline CHEMBL1506697 & 688759 & 4.65 & 5.0081 & TRN & \\
\hline CHEMBL1507226 & 688759 & 4.45 & 4.9457 & TRN & \\
\hline CHEMBL3193153 & 688759 & 4.65 & 4.8142 & TRN & \\
\hline CHEMBL1483157 & 688759 & 4.65 & 4.585 & TRN & \\
\hline CHEMBL3208744 & 688759 & 4.75 & 4.8749 & TRN & \\
\hline CHEMBL 1460758 & 688759 & 4.75 & 4.8668 & TRN & \\
\hline CHEMBL3193759 & 688759 & 4.45 & 4.6955 & TRN & \\
\hline CHEMBL1326967 & 688759 & 5.0 & 5.2842 & TRN & \\
\hline CHEMBL1328894 & 688759 & 4.5 & 5.035 & TRN & \\
\hline CHEMBL1517446 & 688759 & 5.15 & 5.17299 & 9999999999 & TRN \\
\hline CHEMBL1501518 & 688759 & 4.95 & 4.9578 & TRN & \\
\hline CHEMBL3194914 & 688759 & 4.95 & 4.6308 & TST & \\
\hline & & & & 15199 & \\
\hline
\end{tabular}




\begin{tabular}{|c|c|c|c|c|c|}
\hline & & \multicolumn{4}{|c|}{ Supplemental Table s2.txt } \\
\hline CHEMBL1365067 & 688759 & 4.95 & 4.6774 & TRN & \\
\hline CHEMBL1512116 & 688759 & 4.45 & 4.9031 & TST & \\
\hline CHEMBL1198307 & 688759 & 4.45 & 4.8201 & TRN & \\
\hline CHEMBL1462209 & 688759 & 4.95 & 5.0412 & TRN & \\
\hline CHEMBL1330282 & 688759 & 4.9 & 4.7782 & TRN & \\
\hline CHEMBL1335131 & 688759 & 4.45 & 4.7621 & TRN & \\
\hline CHEMBL1540894 & 688759 & 5.2 & 5.2421 & TRN & \\
\hline CHEMBL1563623 & 688759 & 5.35 & 5.1273 & TRN & \\
\hline CHEMBL1518566 & 688759 & 4.45 & 4.7416 & TST & \\
\hline CHEMBL1309743 & 688759 & 4.45 & 4.8174 & TST & \\
\hline CHEMBL1363096 & 688759 & 4.6 & 4.6886 & TST & \\
\hline CHEMBL1375778 & 688759 & 4.6 & 5.192 & TRN & \\
\hline CHEMBL1546603 & 688759 & 4.45 & 4.82600 & 00000000005 & TRN \\
\hline CHEMBL1310385 & 688759 & 4.45 & 4.8085 & TRN & \\
\hline CHEMBL1333733 & 688759 & 4.8 & 4.6719 & TRN & \\
\hline CHEMBL1454611 & 688759 & 5.4 & 5.2898 & TRN & \\
\hline CHEMBL1548769 & 688759 & 4.5 & 4.7205 & TRN & \\
\hline CHEMBL1456490 & 688759 & 5.2 & 4.8445 & TRN & \\
\hline CHEMBL 3210824 & 688759 & 4.75 & 4.8056 & TRN & \\
\hline CHEMBL3199094 & 688759 & 4.65 & 4.6529 & TRN & \\
\hline CHEMBL3211385 & 688759 & 4.45 & 4.7454 & TRN & \\
\hline CHEMBL1352787 & 688759 & 5.25 & 4.8856 & TST & \\
\hline CHEMBL1343658 & 688759 & 4.45 & 4.7275 & TRN & \\
\hline CHEMBL1482965 & 688759 & 4.95 & 4.4883 & TST & \\
\hline CHEMBL1403138 & 688759 & 4.6 & 4.5477 & TRN & \\
\hline CHEMBL1548455 & 688759 & 4.5 & 4.8552 & TRN & \\
\hline CHEMBL1992432 & 688759 & 5.2 & 4.9016 & TRN & \\
\hline CHEMBL1465797 & 688759 & 4.45 & 4.706 & TRN & \\
\hline CHEMBL1424816 & 688759 & 4.45 & 4.7087 & TRN & \\
\hline CHEMBL1306426 & 688759 & 4.55 & 4.8957 & TRN & \\
\hline CHEMBL1526922 & 688759 & 4.65 & 4.9061 & TRN & \\
\hline CHEMBL3193242 & 688759 & 4.8 & 4.5749 & TRN & \\
\hline CHEMBL1460225 & 688759 & 4.45 & 4.6869 & TST & \\
\hline CHEMBL1304256 & 688759 & 5.55 & 5.0136 & TRN & \\
\hline CHEMBL1531932 & 688759 & 5.15 & 5.2499 & TRN & \\
\hline CHEMBL1457065 & 688759 & 5.2 & 5.0968 & TRN & \\
\hline CHEMBL3192165 & 688759 & 5.85 & 5.3945 & TRN & \\
\hline CHEMBL1526520 & 688759 & 5.35 & 4.984 & TRN & \\
\hline CHEMBL1324944 & 688759 & 5.5 & 5.1845 & TRN & \\
\hline CHEMBL1471827 & 688759 & 4.9 & 4.7722 & TST & \\
\hline CHEMBL3192820 & 688759 & 4.5 & 4.7579 & TRN & \\
\hline CHEMBL1468917 & 688759 & 5.9 & 5.3198 & TRN & \\
\hline CHEMBL1388469 & 688759 & 4.45 & 4.7916 & TRN & \\
\hline CHEMBL3194024 & 688759 & 4.65 & 5.1089 & TRN & \\
\hline CHEMBL1486076 & 688759 & 4.45 & 4.643 & TRN & \\
\hline CHEMBL1420893 & 688759 & 4.45 & 4.6863 & TRN & \\
\hline CHEMBL1536566 & 688759 & 4.65 & 5.0371 & TRN & \\
\hline CHEMBL429023 & 688759 & 6.0 & 5.847 & TRN & \\
\hline
\end{tabular}




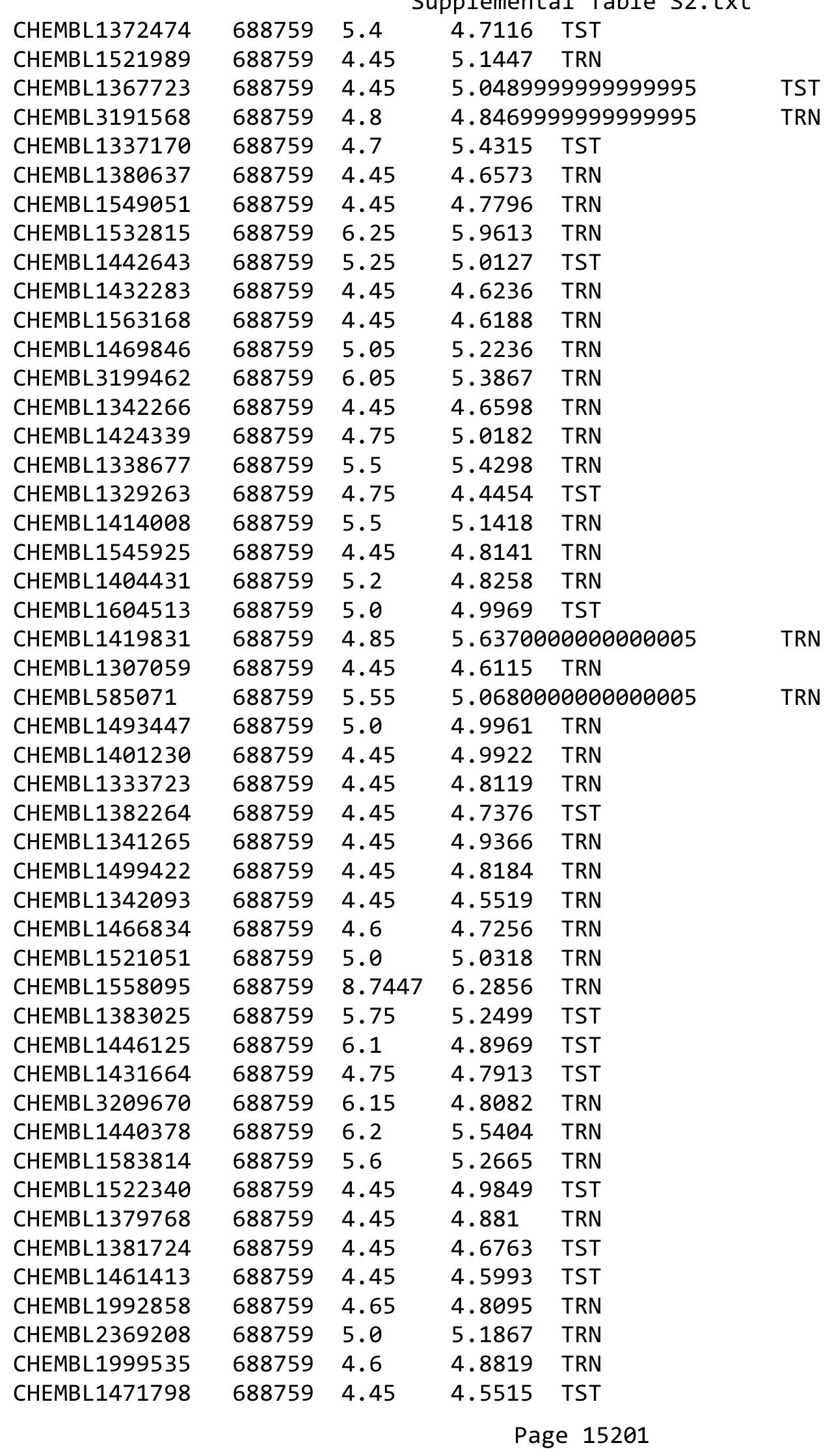




\begin{tabular}{|c|c|c|c|c|}
\hline \multicolumn{5}{|c|}{ Supplemental Table S2.txt } \\
\hline CHEMBL1427458 & 688759 & 4.65 & 4.8008 & TRN \\
\hline CHEMBL3192945 & 688759 & 5.0 & 4.7801 & TST \\
\hline CHEMBL1528992 & 688759 & 4.65 & 4.8055 & TRN \\
\hline CHEMBL1521877 & 688759 & 4.95 & 4.9422 & TRN \\
\hline CHEMBL1393858 & 688759 & 4.75 & 4.7024 & TRN \\
\hline CHEMBL1439210 & 688759 & 5.2 & 5.0098 & TRN \\
\hline CHEMBL1412039 & 688759 & 4.95 & 4.617 & TRN \\
\hline CHEMBL1580960 & 688759 & 4.45 & 4.499 & TRN \\
\hline CHEMBL1404507 & 688759 & 4.5 & \multicolumn{2}{|c|}{4.638999999999999} \\
\hline CHEMBL1391718 & 688759 & 4.8 & 4.8675 & TRN \\
\hline CHEMBL1390028 & 688759 & 4.9 & 5.3114 & TRN \\
\hline CHEMBL3195143 & 688759 & 5.2 & 4.6996 & TST \\
\hline CHEMBL1504927 & 688759 & 4.45 & 4.9828 & TRN \\
\hline CHEMBL 3191222 & 688759 & 4.45 & 4.7195 & TRN \\
\hline CHEMBL494326 & 688759 & 4.75 & 4.7875 & TRN \\
\hline CHEMBL1482919 & 688759 & 5.4 & 5.4153 & TRN \\
\hline CHEMBL2000339 & 688759 & 5.0 & 4.8073 & TRN \\
\hline CHEMBL1345292 & 688759 & 4.45 & 4.7716 & TRN \\
\hline CHEMBL1490670 & 688759 & 5.3 & 5.1404 & TRN \\
\hline CHEMBL1983581 & 688759 & 4.45 & 4.8157 & TRN \\
\hline CHEMBL1370221 & 688759 & 4.75 & 4.8077 & TRN \\
\hline CHEMBL1602788 & 688759 & 6.35 & 6.2351 & TRN \\
\hline CHEMBL1377992 & 688759 & 5.3 & 4.9511 & TST \\
\hline CHEMBL1546297 & 688759 & 4.45 & 4.9427 & TST \\
\hline CHEMBL1519536 & 688759 & 4.95 & 4.8935 & TRN \\
\hline CHEMBL535331 & 688759 & 5.0 & 5.0646 & TRN \\
\hline CHEMBL1586113 & 688759 & 5.3 & 4.8763 & TRN \\
\hline CHEMBL1564127 & 688759 & 4.45 & 4.9101 & TST \\
\hline CHEMBL1388372 & 688759 & 7.0 & 5.8749 & TST \\
\hline CHEMBL1464768 & 688759 & 5.4 & 4.7133 & TST \\
\hline CHEMBL1610923 & 688759 & 4.45 & 4.7201 & TRN \\
\hline CHEMBL1436075 & 688759 & 5.2 & 5.0138 & TRN \\
\hline CHEMBL1422074 & 688759 & 4.8 & 4.9644 & TRN \\
\hline CHEMBL3195939 & 688759 & 4.6 & 4.879 & TRN \\
\hline CHEMBL1330666 & 688759 & 4.45 & 4.8096 & TRN \\
\hline CHEMBL1523209 & 688759 & 7.15 & 5.4986 & TRN \\
\hline CHEMBL1572510 & 688759 & 4.8 & 5.05 & TRN \\
\hline CHEMBL155563 & 688759 & 4.9 & 4.9119 & TRN \\
\hline CHEMBL1583585 & 688759 & 6.1 & 5.3966 & TRN \\
\hline CHEMBL1536425 & 688759 & 4.45 & 5.0632 & TST \\
\hline CHEMBL1447503 & 688759 & 4.45 & 4.6064 & TST \\
\hline CHEMBL1367872 & 688759 & 4.45 & 4.8711 & TST \\
\hline CHEMBL1414298 & 688759 & 5.45 & 4.9805 & TRN \\
\hline CHEMBL1489353 & 688759 & 4.45 & 5.4248 & TST \\
\hline CHEMBL3392458 & 688759 & 5.2 & 5.1418 & TST \\
\hline CHEMBL1375648 & 688759 & 4.45 & 4.9632 & TRN \\
\hline CHEMBL1385857 & 688759 & 4.45 & 4.7164 & TST \\
\hline CHEMBL1365774 & 688759 & 4.45 & 4.7945 & TST \\
\hline
\end{tabular}




\begin{tabular}{|c|c|c|c|c|c|}
\hline & & \multicolumn{4}{|c|}{ Supplemental Table s2.txt } \\
\hline CHEMBL1429297 & 688759 & 4.75 & 4.5693 & TST & \\
\hline CHEMBL1487451 & 688759 & 5.25 & 4.7861 & TRN & \\
\hline CHEMBL1511290 & 688759 & 4.45 & 4.6894 & TRN & \\
\hline CHEMBL1330113 & 688759 & 4.9 & 4.9816 & TST & \\
\hline CHEMBL1420812 & 688759 & 5.25 & 4.8365 & TRN & \\
\hline CHEMBL1439350 & 688759 & 4.45 & 4.7179 & TRN & \\
\hline CHEMBL1301644 & 688759 & 4.6 & 4.5912 & TRN & \\
\hline CHEMBL1500467 & 688759 & 5.45 & 4.7721 & TST & \\
\hline CHEMBL1426910 & 688759 & 6.15 & 4.9811 & TRN & \\
\hline CHEMBL1463032 & 688759 & 5.4 & 4.802 & TRN & \\
\hline CHEMBL1487418 & 688759 & 5.5 & 5.7621 & TST & \\
\hline CHEMBL1366074 & 688759 & 5.2 & 5.2912 & TRN & \\
\hline CHEMBL1429443 & 688759 & 4.95 & 5.0277 & TST & \\
\hline CHEMBL1447198 & 688759 & 4.45 & 4.7881 & TRN & \\
\hline CHEMBL1596319 & 688759 & 5.35 & 5.5767 & TRN & \\
\hline CHEMBL1342524 & 688759 & 4.45 & 4.9369 & TRN & \\
\hline CHEMBL1556967 & 688759 & 5.2 & 4.8487 & TRN & \\
\hline CHEMBL1491987 & 688759 & 4.6 & 5.0029 & TST & \\
\hline CHEMBL1303707 & 688759 & 4.65 & 4.9313 & TST & \\
\hline CHEMBL1467431 & 688759 & 4.8 & 4.98 & TRN & \\
\hline CHEMBL1564408 & 688759 & 4.45 & 4.8809 & TRN & \\
\hline CHEMBL1376495 & 688759 & 4.45 & 4.9958 & TRN & \\
\hline CHEMBL1367385 & 688759 & 5.3 & 5.0489 & TST & \\
\hline CHEMBL3194269 & 688759 & 5.45 & 5.8245 & TRN & \\
\hline CHEMBL1456070 & 688759 & 4.45 & 5.1088 & TRN & \\
\hline CHEMBL1368485 & 688759 & 5.35 & 4.9978 & TST & \\
\hline CHEMBL1389194 & 688759 & 5.5 & 4.9505 & TST & \\
\hline CHEMBL1543947 & 688759 & 4.65 & 4.8533 & TRN & \\
\hline CHEMBL1579214 & 688759 & 4.6 & 4.7207 & TRN & \\
\hline CHEMBL1535159 & 688759 & 5.1 & 4.9029 & TRN & \\
\hline CHEMBL1547201 & 688759 & 4.65 & 4.7391 & TRN & \\
\hline CHEMBL3191991 & 688759 & 5.15 & 5.4278 & TRN & \\
\hline CHEMBL1556086 & 688759 & 4.85 & 5.0098 & TRN & \\
\hline CHEMBL1336833 & 688759 & 5.15 & 5.0312 & TST & \\
\hline CHEMBL1372863 & 688759 & 4.85 & 5.1203 & TRN & \\
\hline CHEMBL1517172 & 688759 & 4.8 & 4.8267 & TRN & \\
\hline CHEMBL1482690 & 688759 & 4.9 & 4.6716 & TRN & \\
\hline CHEMBL1610646 & 688759 & 5.0 & 4.7098 & TRN & \\
\hline CHEMBL1355340 & 688759 & 5.85 & 5.1531 & TRN & \\
\hline CHEMBL1409760 & 688759 & 5.6 & 5.1943 & TST & \\
\hline CHEMBL1448403 & 688759 & 4.65 & 5.2461 & TRN & \\
\hline CHEMBL1387775 & 688759 & 5.15 & 5.183 & TRN & \\
\hline CHEMBL1506850 & 688759 & 4.45 & 4.8938 & TRN & \\
\hline CHEMBL1612026 & 688759 & 4.45 & 4.83899 & 99999999995 & TRN \\
\hline CHEMBL1390549 & 688759 & 5.0 & 4.8343 & TST & \\
\hline CHEMBL1572474 & 688759 & 5.45 & 5.4564 & TRN & \\
\hline CHEMBL1517143 & 688759 & 5.1 & 4.985 & TRN & \\
\hline CHEMBL1324457 & 688759 & 4.45 & 4.7369 & TRN & \\
\hline
\end{tabular}




\begin{tabular}{|c|c|c|c|c|c|}
\hline \multicolumn{6}{|c|}{ Supplemental Table S2.txt } \\
\hline CHEMBL 2000440 & 688759 & 5.25 & 5.3253 & TRN & \\
\hline CHEMBL1457861 & 688759 & 4.45 & 4.6486 & TRN & \\
\hline CHEMBL1407918 & 688759 & 4.9 & 4.7917 & TRN & \\
\hline CHEMBL1440535 & 688759 & 4.75 & 4.5164 & TST & \\
\hline CHEMBL 388978 & 688759 & 5.2 & 6.8456 & TST & \\
\hline CHEMBL1451512 & 688759 & 5.0 & 4.9658 & TRN & \\
\hline CHEMBL1496313 & 688759 & 4.85 & 4.8927 & TST & \\
\hline CHEMBL1449792 & 688759 & 4.45 & 4.8833 & TRN & \\
\hline CHEMBL1524509 & 688759 & 4.85 & 4.7359 & TRN & \\
\hline CHEMBL1979316 & 688759 & 5.55 & 5.7805 & TRN & \\
\hline CHEMBL1447085 & 688759 & 4.8 & 4.8959 & TST & \\
\hline CHEMBL1403995 & 688759 & 4.45 & 4.4806 & TST & \\
\hline CHEMBL1340602 & 688759 & 4.6 & 5.0116 & TRN & \\
\hline CHEMBL1379011 & 688759 & 6.0 & 4.9616 & TRN & \\
\hline CHEMBL1428072 & 688759 & 4.85 & 4.984 & TRN & \\
\hline CHEMBL3196689 & 688759 & 4.45 & 4.5349 & TRN & \\
\hline CHEMBL1431406 & 688759 & 5.45 & 5.1916 & TRN & \\
\hline CHEMBL1585641 & 688759 & 4.45 & 4.7592 & TRN & \\
\hline CHEMBL1469171 & 688759 & 4.45 & 4.5382 & TRN & \\
\hline CHEMBL1497149 & 688759 & 4.85 & 4.8996 & TRN & \\
\hline CHEMBL1361285 & 688759 & 5.2 & 5.1728 & TST & \\
\hline CHEMBL1589350 & 688759 & 5.45 & 4.6184 & TRN & \\
\hline CHEMBL1301315 & 688759 & 4.45 & 4.7569 & TRN & \\
\hline CHEMBL1320794 & 688759 & 5.35 & 5.324 & TRN & \\
\hline CHEMBL1304164 & 688759 & 5.0 & 4.9695 & TRN & \\
\hline CHEMBL1400761 & 688759 & 5.05 & 4.8231 & TRN & \\
\hline CHEMBL1337963 & 688759 & 4.45 & 4.7048 & TRN & \\
\hline CHEMBL1611688 & 688759 & 5.25 & 5.1419 & TST & \\
\hline CHEMBL1447284 & 688759 & 6.8499 & 6.2746 & TRN & \\
\hline CHEMBL1608066 & 688759 & 4.95 & 4.9389 & TRN & \\
\hline CHEMBL1498306 & 688759 & 4.45 & 5.0031 & TST & \\
\hline CHEMBL1477555 & 688759 & 4.5 & 4.8481 & TST & \\
\hline CHEMBL3197504 & 688759 & 4.45 & 5.072 & TRN & \\
\hline CHEMBL1461819 & 688759 & 5.2 & 5.24100 & 00000000005 & TRN \\
\hline CHEMBL1408020 & 688759 & 5.0 & 5.1564 & TRN & \\
\hline CHEMBL1521520 & 688759 & 4.45 & 4.6154 & TRN & \\
\hline CHEMBL1362649 & 688759 & 6.25 & 4.8299 & TRN & \\
\hline CHEMBL1339740 & 688759 & 4.65 & 4.7008 & TRN & \\
\hline CHEMBL 3196746 & 688759 & 6.2 & 4.8046 & TRN & \\
\hline CHEMBL1331563 & 688759 & 4.45 & 4.6577 & TRN & \\
\hline CHEMBL1471405 & 688759 & 4.75 & 4.6552 & TST & \\
\hline CHEMBL1433246 & 688759 & 4.45 & 4.6874 & TRN & \\
\hline CHEMBL1485231 & 688759 & 4.45 & 4.7283 & TRN & \\
\hline CHEMBL1377634 & 688759 & 4.45 & 4.8193 & TRN & \\
\hline CHEMBL1338935 & 688759 & 4.65 & 4.6176 & TRN & \\
\hline CHEMBL1555516 & 688759 & 5.0 & 5.2537 & TST & \\
\hline CHEMBL3196212 & 688759 & 4.85 & 4.7828 & TRN & \\
\hline CHEMBL1328436 & 688759 & 4.45 & 4.9282 & TST & \\
\hline
\end{tabular}




\begin{tabular}{|c|c|c|c|c|c|}
\hline \multicolumn{6}{|c|}{ Supplemental Table S2.txt } \\
\hline CHEMBL1334310 & 688759 & 4.45 & 4.7486 & TRN & \\
\hline CHEMBL1328249 & 688759 & 4.7 & 4.7772 & TRN & \\
\hline CHEMBL602975 & 688759 & 4.45 & 4.6387 & TRN & \\
\hline CHEMBL1417770 & 688759 & 4.45 & 4.7405 & TRN & \\
\hline CHEMBL1401459 & 688759 & 4.45 & 4.7098 & TRN & \\
\hline CHEMBL1510509 & 688759 & 4.45 & 4.8706 & TRN & \\
\hline CHEMBL1499501 & 688759 & 5.2 & 4.9211 & TRN & \\
\hline CHEMBL1374587 & 688759 & 4.8 & 4.8701 & TRN & \\
\hline CHEMBL1582205 & 688759 & 5.05 & 4.9261 & TRN & \\
\hline CHEMBL1456699 & 688759 & 4.65 & 4.8844 & TRN & \\
\hline CHEMBL1611014 & 688759 & 8.2518 & 4.8173 & TST & \\
\hline CHEMBL1597037 & 688759 & 4.65 & 4.8108 & TRN & \\
\hline CHEMBL1362679 & 688759 & 5.3 & 4.6566 & TRN & \\
\hline CHEMBL1353157 & 688759 & 5.2 & 4.8655 & TRN & \\
\hline CHEMBL1403641 & 688759 & 5.15 & 4.9311 & TST & \\
\hline CHEMBL1379186 & 688759 & 4.6 & 5.118 & TST & \\
\hline CHEMBL1338167 & 688759 & 5.3 & 5.3645 & TRN & \\
\hline CHEMBL1426189 & 688759 & 5.3 & 4.8708 & TST & \\
\hline CHEMBL1582032 & 688759 & 5.25 & 4.8035 & TST & \\
\hline CHEMBL1329556 & 688759 & 5.2 & 4.8916 & TST & \\
\hline CHEMBL3208182 & 688759 & 5.0 & 5.1867 & TRN & \\
\hline CHEMBL1595298 & 688759 & 5.2 & 5.1091 & TST & \\
\hline CHEMBL1378357 & 688759 & 4.65 & 4.7882 & TRN & \\
\hline CHEMBL1348029 & 688759 & 4.45 & 4.8544 & TRN & \\
\hline CHEMBL3191324 & 688759 & 5.8 & 5.4915 & TRN & \\
\hline CHEMBL1519902 & 688759 & 6.4 & 6.0644 & TRN & \\
\hline CHEMBL1994540 & 688759 & 5.3 & 5.0692 & TRN & \\
\hline CHEMBL1353619 & 688759 & 4.65 & 4.7366 & TRN & \\
\hline CHEMBL395590 & 688759 & 5.95 & 4.9235 & TRN & \\
\hline CHEMBL1346640 & 688759 & 4.45 & 4.6377 & TRN & \\
\hline CHEMBL1363975 & 688759 & 4.45 & 5.0977 & TRN & \\
\hline CHEMBL240332 & 688759 & 5.35 & 5.20100 & 00000000005 & TRN \\
\hline CHEMBL1329491 & 688759 & 4.85 & 4.7827 & TRN & \\
\hline CHEMBL1474312 & 688759 & 4.45 & 4.5935 & TST & \\
\hline CHEMBL1407514 & 688759 & 4.45 & 5.1754 & TST & \\
\hline CHEMBL1449150 & 688759 & 4.45 & 4.7036 & TRN & \\
\hline CHEMBL1595175 & 688759 & 4.45 & 4.7113 & TRN & \\
\hline CHEMBL1500353 & 688759 & 5.45 & 5.2738 & TRN & \\
\hline CHEMBL1522163 & 688759 & 4.7 & 4.8573 & TRN & \\
\hline CHEMBL1310254 & 688759 & 4.65 & 4.8717 & TST & \\
\hline CHEMBL1478774 & 688759 & 4.45 & 4.6549 & TRN & \\
\hline CHEMBL600070 & 688759 & 5.4 & 4.8921 & TRN & \\
\hline CHEMBL1451791 & 688759 & 4.9 & 5.0766 & TRN & \\
\hline CHEMBL1300033 & 688759 & 5.15 & 4.9236 & TRN & \\
\hline CHEMBL1365436 & 688759 & 4.45 & 4.9895 & TST & \\
\hline CHEMBL1371766 & 688759 & 5.6 & 5.1401 & TRN & \\
\hline CHEMBL1570257 & 688759 & 4.95 & 4.8095 & TRN & \\
\hline CHEMBL3199046 & 688759 & 5.25 & 4.8359 & TST & \\
\hline
\end{tabular}




\begin{tabular}{|c|c|c|c|c|c|}
\hline \multicolumn{6}{|c|}{ Supplemental Table S2.txt } \\
\hline CHEMBL1458173 & 688759 & 5.2 & 4.8935 & TRN & \\
\hline CHEMBL1458441 & 688759 & 4.45 & 4.7857 & TST & \\
\hline CHEMBL1310684 & 688759 & 4.45 & 4.8952 & TST & \\
\hline CHEMBL1413969 & 688759 & 5.45 & 5.3586 & TRN & \\
\hline CHEMBL1310111 & 688759 & 5.0 & 5.4838 & TST & \\
\hline CHEMBL1539863 & 688759 & 6.15 & 4.8595 & TST & \\
\hline CHEMBL606167 & 688759 & 5.0 & 4.871 & TST & \\
\hline CHEMBL1335224 & 688759 & 4.45 & 4.6776 & TST & \\
\hline CHEMBL1508136 & 688759 & 5.2 & 4.7098 & TRN & \\
\hline CHEMBL1334907 & 688759 & 4.7 & 5.1368 & TRN & \\
\hline CHEMBL1569374 & 688759 & 5.25 & 5.12700 & 0000000001 & TRN \\
\hline CHEMBL1587910 & 688759 & 4.75 & 4.8401 & TRN & \\
\hline CHEMBL1322308 & 688759 & 4.9 & 5.1765 & TRN & \\
\hline CHEMBL1483479 & 688759 & 5.1 & 4.8049 & TRN & \\
\hline CHEMBL1379329 & 688759 & 5.25 & 5.1137 & TRN & \\
\hline CHEMBL1546568 & 688759 & 5.1 & 5.2629 & TRN & \\
\hline CHEMBL1482387 & 688759 & 6.5 & 6.1646 & TRN & \\
\hline CHEMBL1455557 & 688759 & 4.7 & 4.8578 & TRN & \\
\hline CHEMBL1896831 & 688759 & 4.7 & 5.2087 & TRN & \\
\hline CHEMBL1613227 & 688759 & 4.65 & 4.9227 & TRN & \\
\hline CHEMBL3214461 & 688759 & 4.45 & 4.8795 & TRN & \\
\hline CHEMBL3213432 & 688759 & 5.5 & 5.4581 & TRN & \\
\hline CHEMBL1431977 & 688759 & 4.9 & 4.7823 & TRN & \\
\hline CHEMBL1302188 & 688759 & 4.45 & 5.0124 & TRN & \\
\hline CHEMBL1379799 & 688759 & 4.45 & 4.6144 & TRN & \\
\hline CHEMBL 2002140 & 688759 & 4.9 & 4.9229 & TRN & \\
\hline CHEMBL1328544 & 688759 & 4.45 & 5.086 & TRN & \\
\hline CHEMBL1342574 & 688759 & 5.3 & 5.1942 & TRN & \\
\hline CHEMBL45152 & 688759 & 5.55 & 5.1714 & TRN & \\
\hline CHEMBL1539591 & 688759 & 4.65 & 4.6054 & TRN & \\
\hline CHEMBL1514790 & 688759 & 4.7 & 4.7807 & TRN & \\
\hline CHEMBL1367679 & 688759 & 4.9 & 4.6995 & TRN & \\
\hline CHEMBL1365689 & 688759 & 5.3 & 5.0967 & TRN & \\
\hline CHEMBL1334926 & 688759 & 4.95 & 4.6668 & TST & \\
\hline CHEMBL1389505 & 688759 & 5.9 & 5.1241 & TRN & \\
\hline CHEMBL1979195 & 688759 & 5.5 & 5.2664 & TRN & \\
\hline CHEMBL1494965 & 688759 & 5.2 & 5.2297 & TRN & \\
\hline CHEMBL1312681 & 688759 & 5.55 & 5.8987 & TST & \\
\hline CHEMBL1581596 & 688759 & 4.95 & 4.7134 & TRN & \\
\hline CHEMBL1559369 & 688759 & 4.45 & 4.6198 & TST & \\
\hline CHEMBL1556041 & 688759 & 4.75 & 4.578 & TRN & \\
\hline CHEMBL1406699 & 688759 & 4.6 & 4.742 & TRN & \\
\hline CHEMBL3145330 & 688759 & 6.0 & 5.4504 & TRN & \\
\hline CHEMBL 3145377 & 688759 & 5.15 & 5.8419 & TRN & \\
\hline CHEMBL1418541 & 688759 & 4.45 & 4.9114 & TST & \\
\hline CHEMBL1494489 & 688759 & 4.45 & 4.7326 & TRN & \\
\hline CHEMBL1375569 & 688759 & 5.25 & 4.9212 & TRN & \\
\hline CHEMBL1303266 & 688759 & 4.75 & 5.3502 & TST & \\
\hline
\end{tabular}




\begin{tabular}{|c|c|c|c|c|}
\hline \multicolumn{5}{|c|}{ Supplemental Table S2.txt } \\
\hline CHEMBL1391165 & 688759 & 4.65 & 4.8023 & TRN \\
\hline CHEMBL1499752 & 688759 & 4.6 & 4.8915 & TST \\
\hline CHEMBL1563862 & 688759 & 4.45 & 4.4069 & TRN \\
\hline CHEMBL1487730 & 688759 & 4.95 & 5.0968 & TRN \\
\hline CHEMBL 3213780 & 688759 & 4.9 & 4.8235 & TRN \\
\hline CHEMBL14435 & 688759 & 6.5501 & 4.763 & TST \\
\hline CHEMBL1432548 & 688759 & 4.45 & 4.7968 & TRN \\
\hline CHEMBL1439347 & 688759 & 5.55 & 4.6571 & TRN \\
\hline CHEMBL1489311 & 688759 & 5.4 & 4.8729 & TRN \\
\hline CHEMBL1371778 & 688759 & 4.6 & 4.6451 & TRN \\
\hline CHEMBL1365535 & 688759 & 6.1 & 5.5511 & TRN \\
\hline CHEMBL1368525 & 688759 & 5.4 & 4.8369 & TRN \\
\hline CHEMBL1584417 & 688759 & 4.45 & 4.6078 & TRN \\
\hline CHEMBL1327674 & 688759 & 4.45 & 5.2765 & TRN \\
\hline CHEMBL1341270 & 688759 & 5.5 & 5.0908 & TRN \\
\hline CHEMBL1426642 & 688759 & 4.65 & 4.6615 & TRN \\
\hline CHEMBL1542681 & 688759 & 4.65 & 4.979 & TST \\
\hline CHEMBL1426480 & 688759 & 4.5 & 4.8395 & TST \\
\hline CHEMBL1716494 & 688759 & 4.8 & 4.4568 & TST \\
\hline CHEMBL1996013 & 688759 & 5.3 & 5.5243 & TRN \\
\hline CHEMBL1588258 & 688759 & 4.45 & 4.7313 & TST \\
\hline CHEMBL3193771 & 688759 & 4.55 & 4.6986 & TRN \\
\hline CHEMBL418562 & 688759 & 4.45 & 5.2458 & TRN \\
\hline CHEMBL521653 & 688759 & 4.45 & 5.1552 & TRN \\
\hline CHEMBL3193820 & 688759 & 5.35 & 5.1479 & TST \\
\hline CHEMBL3211008 & 688759 & 5.5 & 4.9076 & TRN \\
\hline CHEMBL1511181 & 688759 & 4.55 & 4.7662 & TRN \\
\hline CHEMBL1343176 & 688759 & 4.9 & 5.0679 & TRN \\
\hline CHEMBL1610357 & 688759 & 4.75 & 4.6064 & TRN \\
\hline CHEMBL3199262 & 688759 & 5.15 & 5.3421 & TST \\
\hline CHEMBL3210850 & 688759 & 5.15 & 5.2694 & TRN \\
\hline CHEMBL1581410 & 688759 & 5.1 & 4.8704 & TRN \\
\hline CHEMBL 256062 & 688759 & 6.0 & 5.568 & TRN \\
\hline CHEMBL1441512 & 688759 & 5.25 & 4.8247 & TST \\
\hline CHEMBL1419484 & 688759 & 4.65 & 5.0966 & TRN \\
\hline CHEMBL1456981 & 688759 & 4.65 & 4.6028 & TRN \\
\hline CHEMBL1542536 & 688759 & 5.9 & 4.7437 & TRN \\
\hline CHEMBL1400298 & 688759 & 5.5 & 5.7084 & TRN \\
\hline CHEMBL1544911 & 688759 & 4.95 & 4.9713 & TRN \\
\hline CHEMBL1303830 & 688759 & 4.7 & 4.7091 & TRN \\
\hline CHEMBL1427334 & 688759 & 4.95 & 4.7486 & TST \\
\hline CHEMBL3197869 & 688759 & 4.9 & 5.1192 & TRN \\
\hline CHEMBL1559461 & 688759 & 5.2 & 5.1356 & TRN \\
\hline CHEMBL1303373 & 688759 & 4.75 & 4.8666 & TRN \\
\hline CHEMBL1420466 & 688759 & 5.0 & 5.1076 & TRN \\
\hline CHEMBL1492729 & 688759 & 6.0 & 5.1062 & TST \\
\hline CHEMBL 2373651 & 688759 & 5.05 & 5.20299 & 9999999999 \\
\hline CHEMBL1347315 & 688759 & 4.75 & 4.8348 & TRN \\
\hline
\end{tabular}




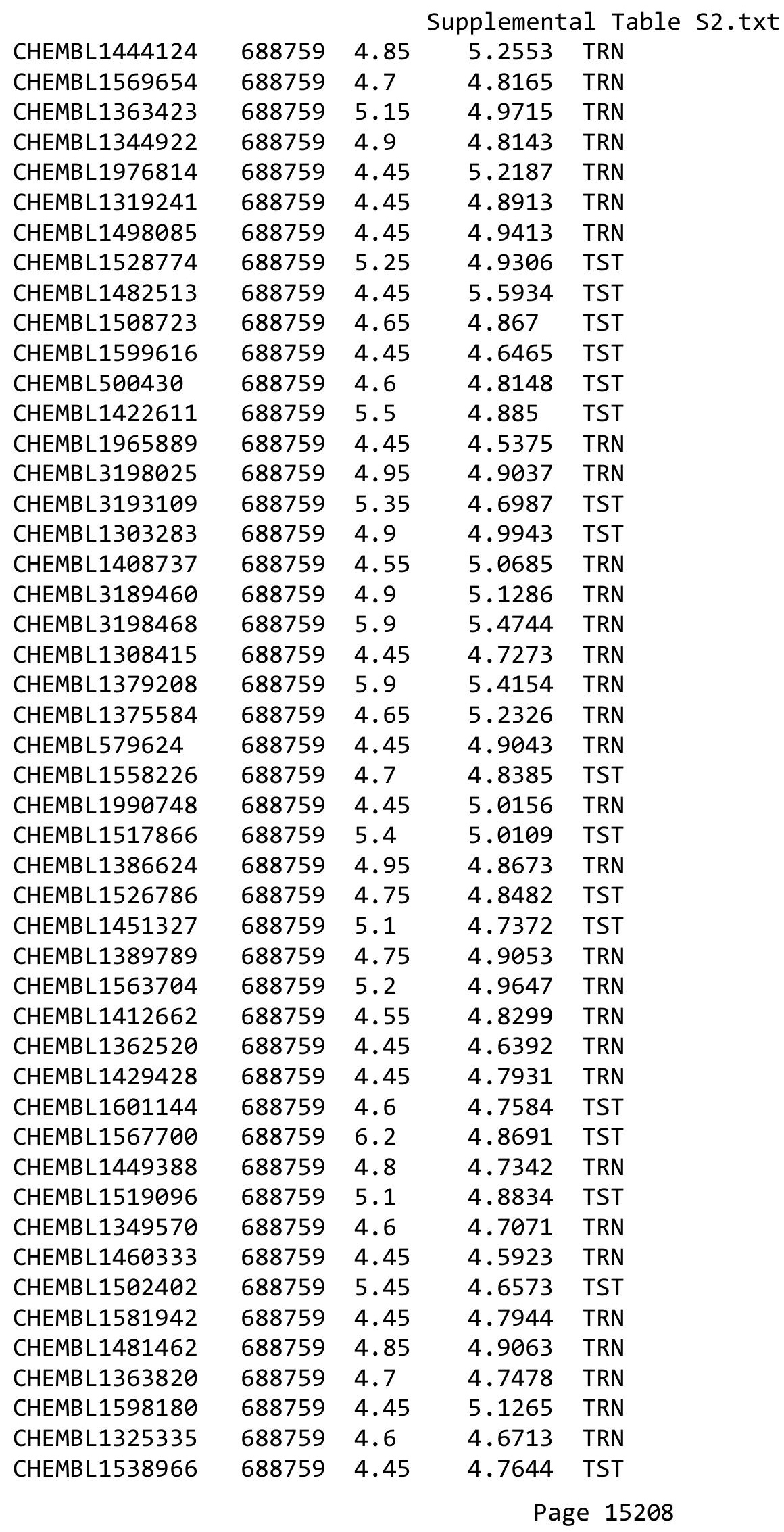




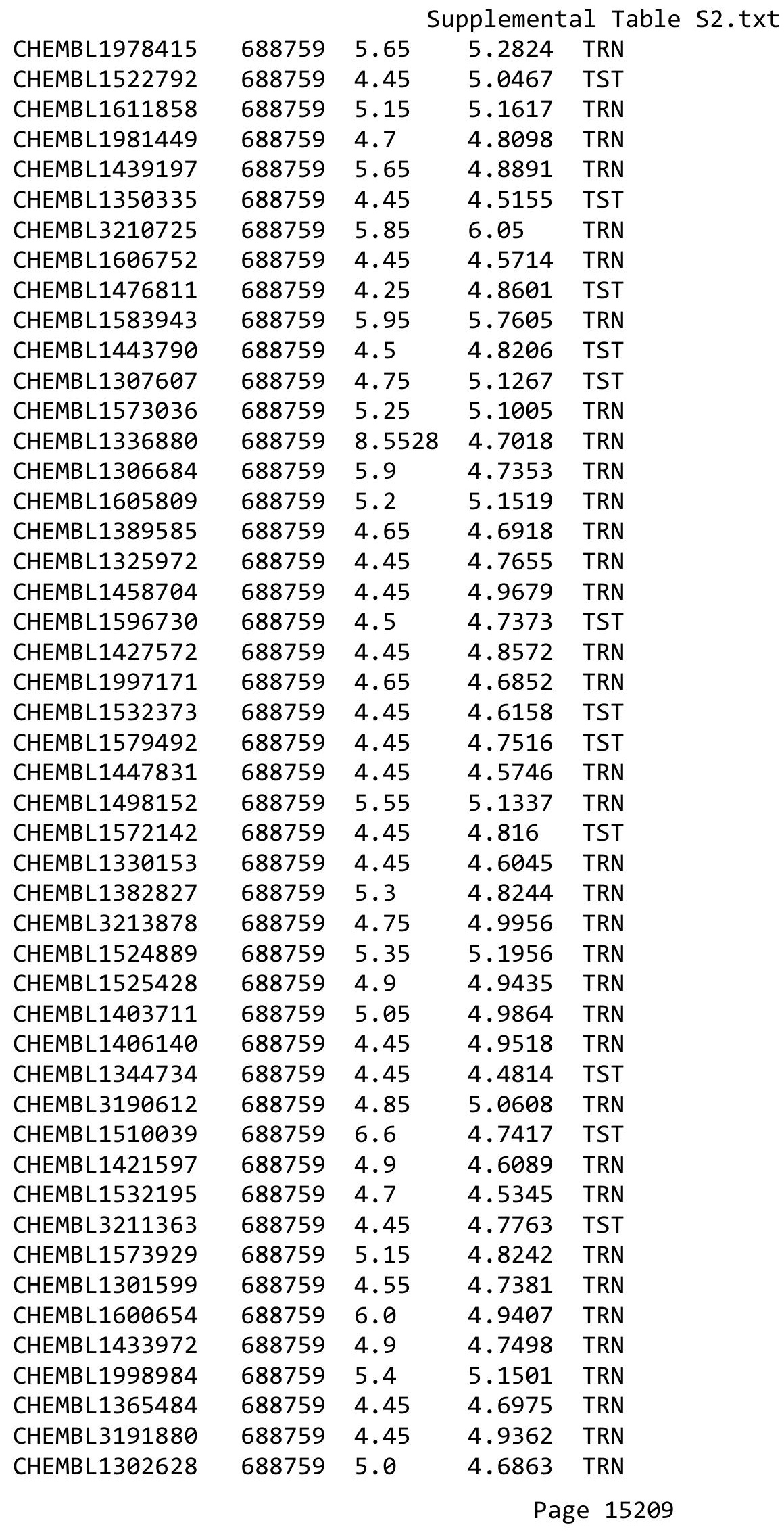




\begin{tabular}{|c|c|c|c|c|c|}
\hline & & \multicolumn{4}{|c|}{ Supplemental Table s2.txt } \\
\hline CHEMBL1492417 & 688759 & 4.45 & 4.8028 & TRN & \\
\hline CHEMBL1411636 & 688759 & 4.9 & 4.8494 & TRN & \\
\hline CHEMBL1307635 & 688759 & 4.9 & 5.2246 & TRN & \\
\hline CHEMBL3195536 & 688759 & 5.5 & 5.0665 & TRN & \\
\hline CHEMBL1885024 & 688759 & 4.95 & 4.7084 & TRN & \\
\hline CHEMBL1469414 & 688759 & 4.7 & 4.8454 & TST & \\
\hline CHEMBL1529281 & 688759 & 5.05 & 4.8445 & TRN & \\
\hline CHEMBL1385558 & 688759 & 4.45 & 4.7967 & TRN & \\
\hline CHEMBL1308899 & 688759 & 4.65 & 4.5971 & TRN & \\
\hline CHEMBL3193584 & 688759 & 4.7 & 4.7231 & TST & \\
\hline CHEMBL1524184 & 688759 & 4.95 & 4.6915 & TRN & \\
\hline CHEMBL1306838 & 688759 & 4.55 & 4.9391 & TRN & \\
\hline CHEMBL1454267 & 688759 & 4.45 & 4.8276 & TST & \\
\hline CHEMBL1973722 & 688759 & 4.95 & 4.6624 & TRN & \\
\hline CHEMBL1469602 & 688759 & 4.65 & 4.8665 & TRN & \\
\hline CHEMBL3197396 & 688759 & 4.9 & 5.2651 & TRN & \\
\hline CHEMBL1403911 & 688759 & 4.7 & 4.725 & TRN & \\
\hline CHEMBL1494014 & 688759 & 4.45 & 4.6981 & TRN & \\
\hline CHEMBL3193805 & 688759 & 5.95 & 5.6238 & TST & \\
\hline CHEMBL1485153 & 688759 & 4.45 & 4.995 & TST & \\
\hline CHEMBL1497089 & 688759 & 4.9 & 4.9095 & TRN & \\
\hline CHEMBL1302851 & 688759 & 4.75 & 4.8197 & TST & \\
\hline CHEMBL1605435 & 688759 & 4.85 & 4.6823 & TRN & \\
\hline CHEMBL1408901 & 688759 & 5.6 & 4.8203 & TST & \\
\hline CHEMBL1457776 & 688759 & 5.0 & 4.9924 & TRN & \\
\hline CHEMBL1528353 & 688759 & 4.65 & 4.5843 & TRN & \\
\hline CHEMBL1503948 & 688759 & 4.5 & 4.7411 & TRN & \\
\hline CHEMBL1348251 & 688759 & 4.6 & 4.795 & TRN & \\
\hline CHEMBL1604770 & 688759 & 4.45 & 4.5008 & TRN & \\
\hline CHEMBL1561649 & 688759 & 6.45 & 4.9475 & TST & \\
\hline CHEMBL1511259 & 688759 & 4.95 & 5.08899 & 99999999995 & TRN \\
\hline CHEMBL1596906 & 688759 & 4.45 & 4.7182 & TRN & \\
\hline CHEMBL1602636 & 688759 & 4.7 & 4.9566 & TRN & \\
\hline CHEMBL1543269 & 688759 & 4.45 & 4.4773 & TRN & \\
\hline CHEMBL1424231 & 688759 & 4.6 & 4.8973 & TST & \\
\hline CHEMBL1510710 & 688759 & 4.45 & 5.0636 & TRN & \\
\hline CHEMBL1442513 & 688759 & 4.7 & 4.8979 & TRN & \\
\hline CHEMBL3196495 & 688759 & 4.45 & 4.8111 & TRN & \\
\hline CHEMBL1547406 & 688759 & 5.2 & 4.8706 & TST & \\
\hline CHEMBL1538515 & 688759 & 5.0 & 5.0234 & TRN & \\
\hline CHEMBL1569755 & 688759 & 6.8 & 6.0171 & TRN & \\
\hline CHEMBL1971033 & 688759 & 5.35 & 5.4702 & TRN & \\
\hline CHEMBL1510587 & 688759 & 5.5 & 5.1341 & TRN & \\
\hline CHEMBL1541426 & 688759 & 5.5 & 5.3446 & TRN & \\
\hline CHEMBL1308154 & 688759 & 4.45 & 4.4652 & TRN & \\
\hline CHEMBL1532450 & 688759 & 4.45 & 4.78600 & 00000000005 & TRN \\
\hline CHEMBL1428913 & 688759 & 4.45 & 4.7456 & TRN & \\
\hline CHEMBL1352019 & 688759 & 4.9 & 4.4356 & TRN & \\
\hline
\end{tabular}




\begin{tabular}{|c|c|c|c|c|}
\hline \multicolumn{5}{|c|}{ Supplemental Table S2.txt } \\
\hline CHEMBL1968522 & 688759 & 4.45 & 4.8447 & TRN \\
\hline CHEMBL1596438 & 688759 & 5.3 & 4.9701 & TRN \\
\hline CHEMBL3195093 & 688759 & 4.45 & 4.9937 & TRN \\
\hline CHEMBL 3197151 & 688759 & 4.7 & 4.7072 & TST \\
\hline CHEMBL3197739 & 688759 & 4.9 & 4.933 & TST \\
\hline CHEMBL1450780 & 688759 & 4.85 & 4.908 & TRN \\
\hline CHEMBL1408314 & 688759 & 4.45 & 4.7685 & TRN \\
\hline CHEMBL1508874 & 688759 & 4.65 & 4.7788 & TRN \\
\hline CHEMBL482116 & 688759 & 5.9 & 5.6031 & TRN \\
\hline CHEMBL3213784 & 688759 & 5.5 & 4.9819 & TST \\
\hline CHEMBL1581789 & 688759 & 4.6 & 4.6756 & TST \\
\hline CHEMBL1980103 & 688759 & 7.0 & 6.1255 & TRN \\
\hline CHEMBL3197129 & 688759 & 4.45 & 5.0054 & TST \\
\hline CHEMBL1450648 & 688759 & 5.05 & 4.8127 & TST \\
\hline CHEMBL1985345 & 688759 & 5.35 & 5.0013 & TRN \\
\hline CHEMBL1412523 & 688759 & 4.95 & 4.5764 & TRN \\
\hline CHEMBL1432597 & 688759 & 4.45 & 4.9761 & TRN \\
\hline CHEMBL1546056 & 688759 & 4.5 & 4.7274 & TRN \\
\hline CHEMBL1500088 & 688759 & 5.35 & 5.0628 & TRN \\
\hline CHEMBL1406782 & 688759 & 5.2 & 4.9024 & TRN \\
\hline CHEMBL3348820 & 688759 & 4.45 & 4.724 & TST \\
\hline CHEMBL1603469 & 688759 & 4.95 & 4.5263 & TST \\
\hline CHEMBL1307716 & 688759 & 4.95 & 4.9072 & TST \\
\hline CHEMBL122355 & 688759 & 4.45 & 4.7138 & TST \\
\hline CHEMBL1496348 & 688759 & 4.6 & 4.5748 & TRN \\
\hline CHEMBL1346150 & 688759 & 5.2 & 4.7454 & TRN \\
\hline CHEMBL1322193 & 688759 & 6.25 & 4.8851 & TRN \\
\hline CHEMBL1410474 & 688759 & 6.2 & 5.9302 & TRN \\
\hline CHEMBL1364131 & 688759 & 5.25 & 4.9038 & TRN \\
\hline CHEMBL1607362 & 688759 & 4.45 & 5.0653 & TRN \\
\hline CHEMBL1599128 & 688759 & 5.45 & 5.5331 & TRN \\
\hline CHEMBL1451617 & 688759 & 5.1 & 5.0754 & TRN \\
\hline CHEMBL1438512 & 688759 & 5.15 & 5.064 & TRN \\
\hline CHEMBL3192953 & 688759 & 4.95 & 4.7767 & TRN \\
\hline CHEMBL1338004 & 688759 & 4.65 & 5.0325 & TRN \\
\hline CHEMBL1531512 & 688759 & 5.2 & 4.9168 & TRN \\
\hline CHEMBL1573847 & 688759 & 4.65 & 4.8485 & TRN \\
\hline CHEMBL1510792 & 688759 & 4.85 & 5.0514 & TRN \\
\hline CHEMBL1392873 & 688759 & 6.0 & 4.9 & TRN \\
\hline CHEMBL3195733 & 688759 & 4.45 & 4.8456 & TST \\
\hline CHEMBL1416689 & 688759 & 4.6 & 4.6398 & TRN \\
\hline CHEMBL1332390 & 688759 & 4.5 & 4.6132 & TST \\
\hline CHEMBL1373256 & 688759 & 5.2 & 5.1275 & TRN \\
\hline CHEMBL1439734 & 688759 & 4.45 & 4.5196 & TRN \\
\hline CHEMBL1338179 & 688759 & 5.35 & 4.9858 & TST \\
\hline CHEMBL3209388 & 688759 & 5.0 & 4.9448 & TRN \\
\hline CHEMBL3190135 & 688759 & 4.55 & 4.7532 & TRN \\
\hline CHEMBL1500704 & 688759 & 5.85 & 5.5275 & TRN \\
\hline
\end{tabular}




\begin{tabular}{|c|c|c|c|c|}
\hline \multicolumn{5}{|c|}{ Supplemental Table S2.txt } \\
\hline CHEMBL1545244 & 688759 & 5.15 & 4.9458 & TRN \\
\hline CHEMBL3195715 & 688759 & 4.8 & 4.8387 & TRN \\
\hline CHEMBL1578344 & 688759 & 4.45 & 4.9136 & TRN \\
\hline CHEMBL1445168 & 688759 & 5.3 & 5.3452 & TRN \\
\hline CHEMBL1471373 & 688759 & 4.85 & 4.8007 & TRN \\
\hline CHEMBL1464344 & 688759 & 5.2 & 4.7301 & TRN \\
\hline CHEMBL3198426 & 688759 & 4.9 & 4.7063 & TRN \\
\hline CHEMBL1360162 & 688759 & 4.85 & 4.9398 & TRN \\
\hline CHEMBL1550620 & 688759 & 4.65 & 4.8897 & TRN \\
\hline CHEMBL1461236 & 688759 & 4.65 & 4.3866 & TST \\
\hline CHEMBL1981541 & 688759 & 4.45 & 4.9752 & TST \\
\hline CHEMBL1429941 & 688759 & 4.45 & 4.5972 & TRN \\
\hline CHEMBL1421146 & 688759 & 4.65 & 4.7852 & TRN \\
\hline CHEMBL1386475 & 688759 & 4.9 & 4.8103 & TRN \\
\hline CHEMBL1504989 & 688759 & 4.45 & 4.9815 & TRN \\
\hline CHEMBL1604558 & 688759 & 4.95 & 5.0071 & TRN \\
\hline CHEMBL1421039 & 688759 & 4.45 & 4.5761 & TRN \\
\hline CHEMBL 2006338 & 688759 & 5.1 & 4.7818 & TRN \\
\hline CHEMBL1529809 & 688759 & 4.6 & 4.6072 & TRN \\
\hline CHEMBL1352666 & 688759 & 4.6 & 4.6584 & TRN \\
\hline CHEMBL1466774 & 688759 & 4.45 & 4.9023 & TRN \\
\hline CHEMBL2369315 & 688759 & 4.65 & 5.1855 & TST \\
\hline CHEMBL1542189 & 688759 & 4.75 & 4.9823 & TRN \\
\hline CHEMBL1534042 & 688759 & 5.75 & 4.8512 & TST \\
\hline CHEMBL1557049 & 688759 & 4.45 & 4.9964 & TST \\
\hline CHEMBL1549879 & 688759 & 4.45 & 4.5663 & TRN \\
\hline CHEMBL1324988 & 688759 & 4.95 & 5.0009 & TRN \\
\hline CHEMBL1611067 & 688759 & 4.95 & 4.8051 & TST \\
\hline CHEMBL1579339 & 688759 & 5.0 & 4.9907 & TRN \\
\hline CHEMBL1350432 & 688759 & 4.45 & 4.567 & TST \\
\hline CHEMBL1504497 & 688759 & 4.95 & 4.7989 & TST \\
\hline CHEMBL1305890 & 688759 & 4.45 & 4.8384 & TRN \\
\hline CHEMBL1368665 & 688759 & 5.05 & 4.7628 & TST \\
\hline CHEMBL3192277 & 688759 & 4.7 & 4.898 & TRN \\
\hline CHEMBL1442973 & 688759 & 4.8 & 4.8059 & TRN \\
\hline CHEMBL1583778 & 688759 & 4.45 & 4.9225 & TST \\
\hline CHEMBL3190753 & 688759 & 4.95 & 4.6554 & TRN \\
\hline CHEMBL1585637 & 688759 & 4.95 & 4.9509 & TRN \\
\hline CHEMBL1531906 & 688759 & 5.05 & 5.0706 & TRN \\
\hline CHEMBL1447697 & 688759 & 5.5 & 5.0724 & TST \\
\hline CHEMBL3194751 & 688759 & 4.9 & 4.7743 & TRN \\
\hline CHEMBL1335660 & 688759 & 4.7 & 4.9038 & TRN \\
\hline CHEMBL1610614 & 688759 & 6.0 & 4.919 & TRN \\
\hline CHEMBL1350390 & 688759 & 5.35 & 5.1556 & TRN \\
\hline CHEMBL1389572 & 688759 & 4.45 & 4.9617 & TRN \\
\hline CHEMBL3196157 & 688759 & 4.7 & 4.84399 & 9999999999 \\
\hline CHEMBL1352510 & 688759 & 5.0 & 4.7776 & TRN \\
\hline CHEMBL1432080 & 688759 & 5.15 & 5.1124 & TRN \\
\hline
\end{tabular}

TRN 


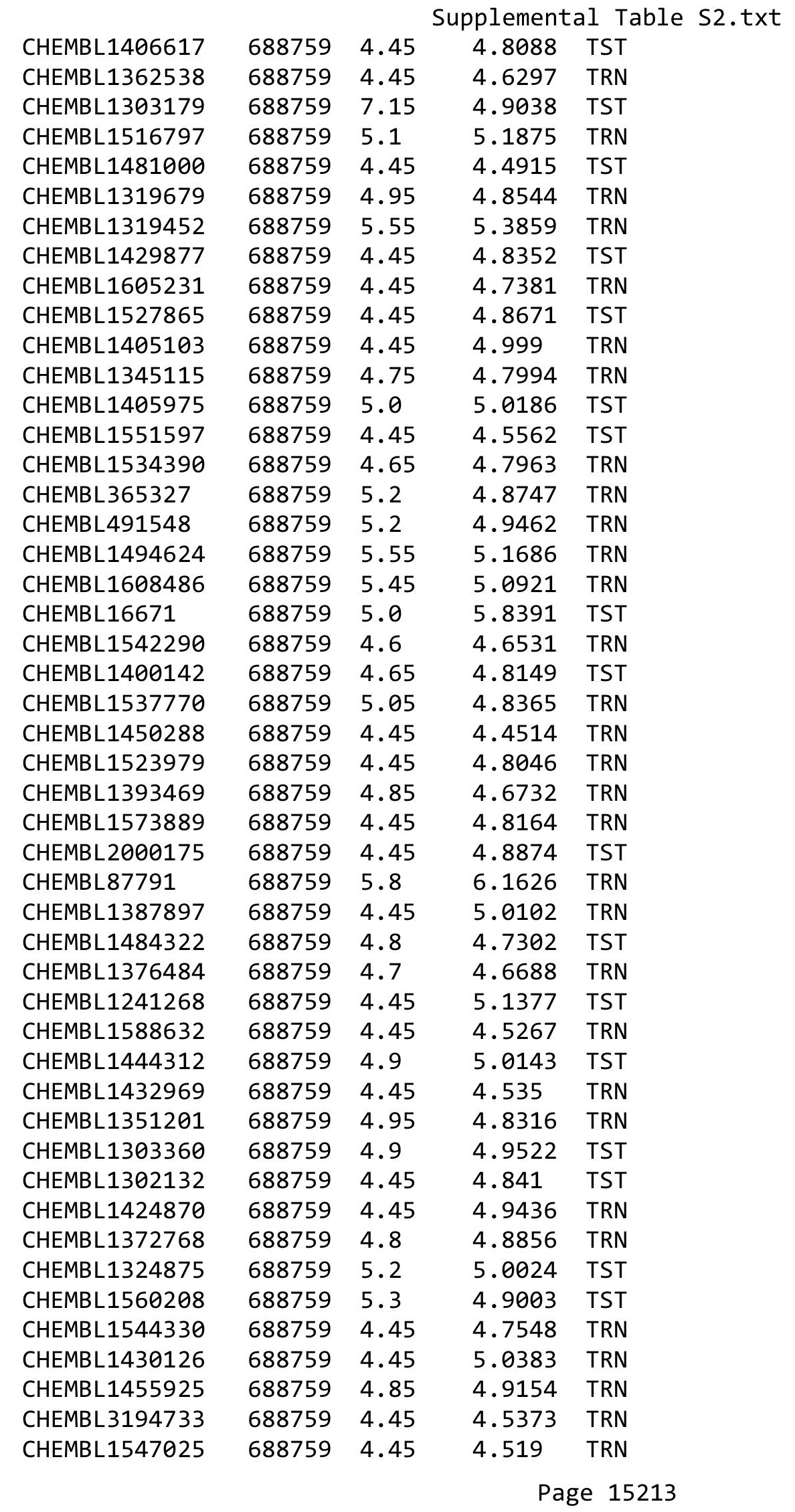




\begin{tabular}{|c|c|c|c|c|}
\hline \multicolumn{5}{|c|}{ Supplemental Table S2.txt } \\
\hline CHEMBL1533538 & 688759 & 5.15 & 5.37 & TRN \\
\hline CHEMBL1553527 & 688759 & 4.85 & 5.1346 & TRN \\
\hline CHEMBL1348808 & 688759 & 4.85 & 5.0467 & TRN \\
\hline CHEMBL1362588 & 688759 & 4.95 & 4.7711 & TRN \\
\hline CHEMBL1541725 & 688759 & 5.3 & 5.1446 & TRN \\
\hline CHEMBL1522803 & 688759 & 4.9 & 4.8028 & TST \\
\hline CHEMBL1431288 & 688759 & 4.65 & 4.8203 & TST \\
\hline CHEMBL1542165 & 688759 & 4.8 & 4.9106 & TRN \\
\hline CHEMBL1324585 & 688759 & 4.8 & 5.1127 & TRN \\
\hline CHEMBL3211667 & 688759 & 4.6 & 4.9611 & TST \\
\hline CHEMBL1995707 & 688759 & 4.9 & 5.1688 & TRN \\
\hline CHEMBL1426245 & 688759 & 4.45 & 4.8042 & TRN \\
\hline CHEMBL1464108 & 688759 & 7.0501 & 4.8296 & TRN \\
\hline CHEMBL1548943 & 688759 & 4.8 & 4.7854 & TRN \\
\hline CHEMBL1544223 & 688759 & 4.45 & 4.752 & TRN \\
\hline CHEMBL1453857 & 688759 & 6.05 & 5.6848 & TRN \\
\hline CHEMBL1467239 & 688759 & 4.7 & 4.831 & TRN \\
\hline CHEMBL1509545 & 688759 & 4.8 & 4.521 & TRN \\
\hline CHEMBL1566348 & 688759 & 5.0 & 4.9222 & TRN \\
\hline CHEMBL1548574 & 688759 & 4.45 & 4.7698 & TRN \\
\hline CHEMBL1359297 & 688759 & 5.35 & 5.027 & TST \\
\hline CHEMBL1535050 & 688759 & 4.95 & 5.4641 & TRN \\
\hline CHEMBL1409430 & 688759 & 8.2518 & 4.7147 & TRN \\
\hline CHEMBL1555884 & 688759 & 4.3 & 7.2698 & TST \\
\hline CHEMBL1595820 & 688759 & 6.3 & 6.2422 & TRN \\
\hline CHEMBL1442421 & 688759 & 4.65 & 4.6936 & TST \\
\hline CHEMBL1447028 & 688759 & 4.7 & 4.9224 & TRN \\
\hline CHEMBL1537623 & 688759 & 6.0 & 4.8556 & TRN \\
\hline CHEMBL3190891 & 688759 & 6.7001 & 5.4323 & TRN \\
\hline CHEMBL1395972 & 688759 & 6.0 & 4.8913 & TST \\
\hline CHEMBL1425890 & 688759 & 5.3 & 4.6204 & TRN \\
\hline CHEMBL1303280 & 688759 & 5.55 & 5.4961 & TRN \\
\hline CHEMBL1565369 & 688759 & 6.15 & 6.0425 & TRN \\
\hline CHEMBL3197506 & 688759 & 5.2 & 5.3341 & TRN \\
\hline CHEMBL1506066 & 688759 & 4.45 & 4.724 & TRN \\
\hline CHEMBL1383631 & 688759 & 5.65 & 5.3027 & TRN \\
\hline CHEMBL1407015 & 688759 & 7.15 & 4.8139 & TRN \\
\hline CHEMBL1326543 & 688759 & 5.05 & 4.9483 & TRN \\
\hline CHEMBL1611896 & 688759 & 6.7001 & 5.1563 & TRN \\
\hline CHEMBL1359449 & 688759 & 6.8 & 5.035 & TST \\
\hline CHEMBL1308855 & 688759 & 5.0 & 4.9705 & TRN \\
\hline CHEMBL1350543 & 688759 & 5.05 & 5.0344 & TRN \\
\hline CHEMBL1557101 & 688759 & 4.65 & 4.6069 & TRN \\
\hline CHEMBL1467363 & 688759 & 5.15 & 5.9632 & TRN \\
\hline CHEMBL1428625 & 688759 & 5.4 & 5.4378 & TRN \\
\hline CHEMBL1458448 & 688759 & 7.0 & 4.8601 & TST \\
\hline CHEMBL1418748 & 688759 & 5.05 & 4.8759 & TRN \\
\hline CHEMBL1341298 & 688759 & 4.45 & 5.1185 & TRN \\
\hline
\end{tabular}




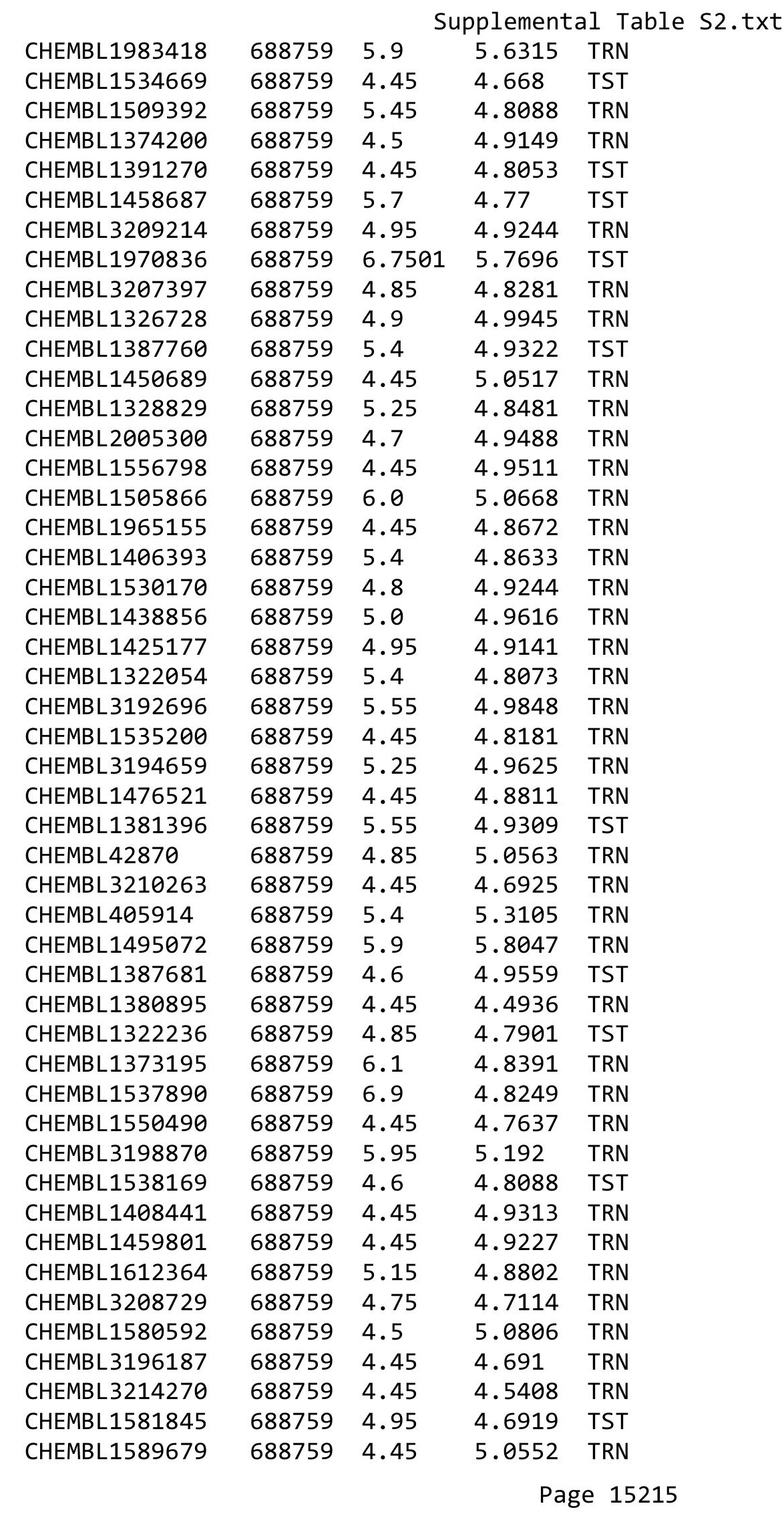




\begin{tabular}{|c|c|c|c|c|c|}
\hline & & \multicolumn{4}{|c|}{ Supplemental Table S2.txt } \\
\hline CHEMBL1556861 & 688759 & 6.2 & 4.9181 & TRN & \\
\hline CHEMBL1549689 & 688759 & 4.45 & 4.7864 & TST & \\
\hline CHEMBL1612355 & 688759 & 4.95 & 4.8495 & TST & \\
\hline CHEMBL 3190047 & 688759 & 4.8 & 4.7973 & TRN & \\
\hline CHEMBL1714669 & 688759 & 6.05 & 5.4283 & TST & \\
\hline CHEMBL1526443 & 688759 & 4.45 & 4.8638 & TRN & \\
\hline CHEMBL1327933 & 688759 & 4.7 & 4.7211 & TST & \\
\hline CHEMBL1454433 & 688759 & 5.0 & 4.6308 & TST & \\
\hline CHEMBL1530313 & 688759 & 5.3 & 4.997 & TRN & \\
\hline CHEMBL1430892 & 688759 & 4.65 & 4.82600 & 00000000005 & TRN \\
\hline CHEMBL1300405 & 688759 & 5.3 & 4.8367 & TRN & \\
\hline CHEMBL1448882 & 688759 & 4.45 & 4.5842 & TRN & \\
\hline CHEMBL3190719 & 688759 & 5.25 & 5.3642 & TRN & \\
\hline CHEMBL1519320 & 688759 & 5.25 & 4.9204 & TST & \\
\hline CHEMBL1623897 & 688759 & 4.45 & 4.8609 & TRN & \\
\hline CHEMBL1568465 & 688759 & 4.6 & 5.1235 & TRN & \\
\hline CHEMBL1604653 & 688759 & 4.95 & 4.7708 & TRN & \\
\hline CHEMBL1396779 & 688759 & 4.45 & 4.6735 & TRN & \\
\hline CHEMBL295316 & 688759 & 6.0 & 5.3069 & TST & \\
\hline CHEMBL3193654 & 688759 & 4.65 & 4.7702 & TRN & \\
\hline CHEMBL1316831 & 688759 & 5.35 & 5.3924 & TRN & \\
\hline CHEMBL1521913 & 688759 & 5.2 & 5.0315 & TRN & \\
\hline CHEMBL1419941 & 688759 & 6.1 & 5.3062 & TRN & \\
\hline CHEMBL1587881 & 688759 & 5.0 & 5.1257 & TRN & \\
\hline CHEMBL3193113 & 688759 & 5.35 & 5.2097 & TRN & \\
\hline CHEMBL1543962 & 688759 & 6.0 & 5.4021 & TST & \\
\hline CHEMBL1379833 & 688759 & 4.6 & 4.7844 & TRN & \\
\hline CHEMBL1462283 & 688759 & 5.35 & 5.1999 & TRN & \\
\hline CHEMBL1546005 & 688759 & 6.0 & 5.3711 & TRN & \\
\hline CHEMBL602366 & 688759 & 4.45 & 4.635 & TST & \\
\hline CHEMBL1466455 & 688759 & 4.45 & 4.6313 & TRN & \\
\hline CHEMBL1385158 & 688759 & 4.8 & 4.8983 & TRN & \\
\hline CHEMBL1535564 & 688759 & 4.45 & 4.6597 & TRN & \\
\hline CHEMBL1300358 & 688759 & 4.8 & 4.7722 & TRN & \\
\hline CHEMBL1392351 & 688759 & 4.95 & 4.8662 & TRN & \\
\hline CHEMBL1511593 & 688759 & 4.85 & 4.6708 & TRN & \\
\hline CHEMBL1428141 & 688759 & 4.65 & 4.8641 & TST & \\
\hline CHEMBL1479804 & 688759 & 5.15 & 5.723 & TRN & \\
\hline CHEMBL1520457 & 688759 & 4.45 & 4.9241 & TRN & \\
\hline CHEMBL1454061 & 688759 & 4.95 & 5.0037 & TRN & \\
\hline CHEMBL1502014 & 688759 & 5.0 & 4.8194 & TST & \\
\hline CHEMBL1325000 & 688759 & 5.05 & 4.651 & TST & \\
\hline CHEMBL1313313 & 688759 & 7.6498 & 4.9742 & TRN & \\
\hline CHEMBL1461181 & 688759 & 4.5 & 4.6762 & TRN & \\
\hline CHEMBL3193579 & 688759 & 4.45 & 4.8489 & TRN & \\
\hline CHEMBL1321238 & 688759 & 4.45 & 4.8201 & TST & \\
\hline CHEMBL1364180 & 688759 & 4.45 & 4.8723 & TRN & \\
\hline CHEMBL1421125 & 688759 & 4.85 & 4.9485 & TRN & \\
\hline
\end{tabular}




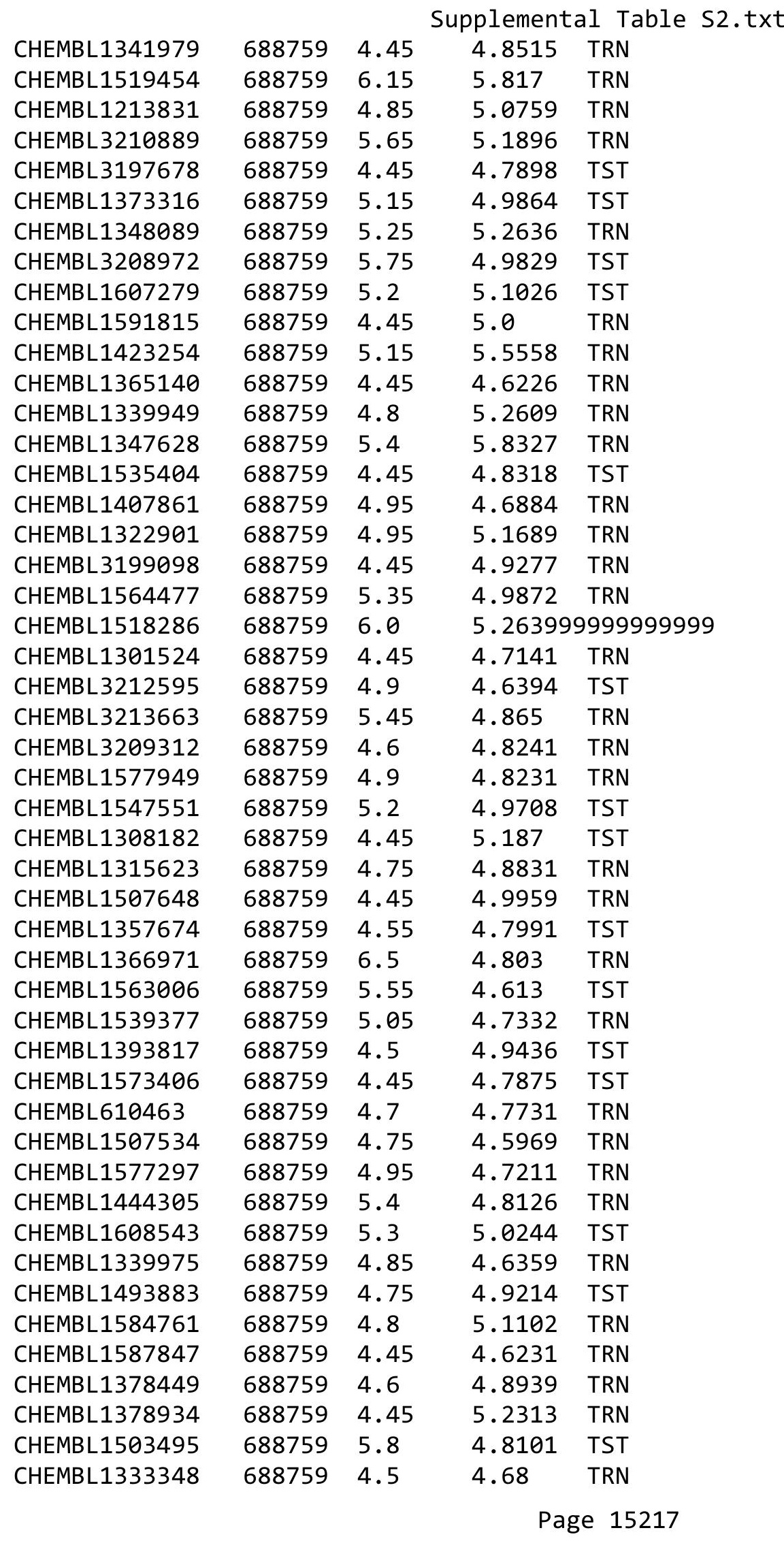




\begin{tabular}{|c|c|c|c|c|c|}
\hline \multicolumn{6}{|c|}{ Supplemental Table s2.txt } \\
\hline CHEMBL1463750 & 688759 & 5.55 & 5.3177 & TRN & \\
\hline CHEMBL1434237 & 688759 & 5.05 & 4.7482 & TST & \\
\hline CHEMBL3192197 & 688759 & 6.0 & 5.4326 & TRN & \\
\hline CHEMBL1379983 & 688759 & 4.6 & 4.8801 & TRN & \\
\hline CHEMBL1504171 & 688759 & 4.45 & 4.8459 & TRN & \\
\hline CHEMBL1377790 & 688759 & 4.45 & 4.6261 & TRN & \\
\hline CHEMBL1470181 & 688759 & 4.9 & 4.9388 & TST & \\
\hline CHEMBL1507350 & 688759 & 5.8 & 4.6313 & TRN & \\
\hline CHEMBL1440902 & 688759 & 4.45 & 4.3999 & TRN & \\
\hline CHEMBL1483365 & 688759 & 6.5501 & 4.966 & TST & \\
\hline CHEMBL1478032 & 688759 & 4.8 & 4.9542 & TST & \\
\hline CHEMBL1359554 & 688759 & 4.9 & 4.9164 & TRN & \\
\hline CHEMBL1425740 & 688759 & 4.95 & 5.154 & TRN & \\
\hline CHEMBL1483105 & 688759 & 5.0 & 4.7982 & TRN & \\
\hline CHEMBL1278182 & 688759 & 4.45 & 4.7392 & TRN & \\
\hline CHEMBL1889837 & 688759 & 5.45 & 4.9104 & TRN & \\
\hline CHEMBL1611484 & 688759 & 4.9 & 5.0241 & TRN & \\
\hline CHEMBL1503477 & 688759 & 5.65 & 4.8535 & TRN & \\
\hline CHEMBL1454295 & 688759 & 5.0 & 4.9647 & TRN & \\
\hline CHEMBL1498608 & 688759 & 4.45 & 5.3347 & TRN & \\
\hline CHEMBL1453819 & 688759 & 5.05 & 4.811 & TRN & \\
\hline CHEMBL1300311 & 688759 & 4.45 & 4.6505 & TRN & \\
\hline CHEMBL1322948 & 688759 & 4.45 & 4.6958 & TRN & \\
\hline CHEMBL1408412 & 688759 & 4.45 & 4.6747 & TRN & \\
\hline CHEMBL1546405 & 688759 & 5.0 & 4.9462 & TRN & \\
\hline CHEMBL1456836 & 688759 & 4.8 & 4.8353 & TST & \\
\hline CHEMBL1584901 & 688759 & 4.9 & 4.7361 & TRN & \\
\hline CHEMBL1409443 & 688759 & 4.45 & 4.9139 & TRN & \\
\hline CHEMBL1321882 & 688759 & 4.9 & 4.771 & TRN & \\
\hline CHEMBL1968355 & 688759 & 4.45 & 4.6253 & TRN & \\
\hline CHEMBL1370419 & 688759 & 5.65 & 5.1854 & TRN & \\
\hline CHEMBL1478604 & 688759 & 4.45 & 4.8416 & TRN & \\
\hline CHEMBL1359641 & 688759 & 5.1 & 4.7277 & TST & \\
\hline CHEMBL 3195358 & 688759 & 4.45 & 4.8739 & TRN & \\
\hline CHEMBL1535074 & 688759 & 5.7 & 4.8711 & TRN & \\
\hline CHEMBL1376732 & 688759 & 4.9 & 4.91100 & 00000000005 & TRN \\
\hline CHEMBL1306181 & 688759 & 4.6 & 4.5802 & TRN & \\
\hline CHEMBL1442369 & 688759 & 4.65 & 4.6256 & TRN & \\
\hline CHEMBL1416124 & 688759 & 5.9 & 5.1139 & TST & \\
\hline CHEMBL1418827 & 688759 & 4.45 & 4.7148 & TST & \\
\hline CHEMBL1990675 & 688759 & 6.15 & 5.4008 & TRN & \\
\hline CHEMBL3211658 & 688759 & 5.55 & 4.7865 & TST & \\
\hline CHEMBL1559327 & 688759 & 4.45 & 4.7249 & TRN & \\
\hline CHEMBL1366252 & 688759 & 5.5 & 4.902 & TRN & \\
\hline CHEMBL1493103 & 688759 & 5.55 & 4.9144 & TST & \\
\hline CHEMBL1508417 & 688759 & 4.75 & 4.9659 & TRN & \\
\hline CHEMBL3195570 & 688759 & 5.15 & 5.3488 & TRN & \\
\hline CHEMBL1351522 & 688759 & 5.45 & 5.0787 & TRN & \\
\hline
\end{tabular}




\begin{tabular}{|c|c|c|c|c|}
\hline \multicolumn{5}{|c|}{ Supplemental Table S2.txt } \\
\hline CHEMBL1308259 & 688759 & 4.75 & 4.7817 & TRN \\
\hline CHEMBL1536934 & 688759 & 5.3 & 4.8241 & TRN \\
\hline CHEMBL1467316 & 688759 & 4.45 & 4.7873 & TRN \\
\hline CHEMBL1355075 & 688759 & 4.45 & 4.7459 & TRN \\
\hline CHEMBL1360828 & 688759 & 5.4 & 4.8669 & TST \\
\hline CHEMBL1313440 & 688759 & 4.45 & 4.8674 & TRN \\
\hline CHEMBL1305854 & 688759 & 5.15 & 5.2921 & TRN \\
\hline CHEMBL1472331 & 688759 & 5.9 & 5.245 & TRN \\
\hline CHEMBL1488874 & 688759 & 4.95 & 4.7379 & TRN \\
\hline CHEMBL1418442 & 688759 & 4.7 & 4.5804 & TRN \\
\hline CHEMBL1451268 & 688759 & 4.45 & 4.9052 & TRN \\
\hline CHEMBL1406300 & 688759 & 4.45 & 4.9922 & TRN \\
\hline CHEMBL1369243 & 688759 & 4.45 & 4.8157 & TRN \\
\hline CHEMBL1320236 & 688759 & 4.45 & 4.6997 & TRN \\
\hline CHEMBL1605241 & 688759 & 4.95 & 4.6096 & TRN \\
\hline CHEMBL1543255 & 688759 & 4.6 & 4.7234 & TRN \\
\hline CHEMBL1503941 & 688759 & 5.1 & 4.8264 & TRN \\
\hline CHEMBL1305365 & 688759 & 4.65 & 4.5864 & TRN \\
\hline CHEMBL1411843 & 688759 & 5.6 & 5.2102 & TRN \\
\hline CHEMBL1462280 & 688759 & 5.8 & 5.0494 & TRN \\
\hline CHEMBL1480062 & 688759 & 4.7 & 4.877 & TST \\
\hline CHEMBL1346316 & 688759 & 4.9 & 4.7522 & TRN \\
\hline CHEMBL1422567 & 688759 & 4.6 & 4.9407 & TRN \\
\hline CHEMBL1302281 & 688759 & 4.75 & 4.8962 & TRN \\
\hline CHEMBL1556350 & 688759 & 5.9 & 5.3786 & TRN \\
\hline CHEMBL3195899 & 688759 & 4.45 & 4.604 & TRN \\
\hline CHEMBL1484787 & 688759 & 4.6 & 5.0277 & TRN \\
\hline CHEMBL1584343 & 688759 & 4.8 & 4.7849 & TST \\
\hline CHEMBL1391287 & 688759 & 5.8 & 5.858 & TRN \\
\hline CHEMBL3392064 & 688759 & 4.45 & 4.7474 & TST \\
\hline CHEMBL1440683 & 688759 & 5.5 & 4.586 & TRN \\
\hline CHEMBL1603129 & 688759 & 4.45 & 4.9154 & TRN \\
\hline CHEMBL454843 & 688759 & 4.45 & 5.0701 & TRN \\
\hline CHEMBL1549657 & 688759 & 4.45 & 4.8326 & TRN \\
\hline CHEMBL1496705 & 688759 & 5.25 & 4.9466 & TRN \\
\hline CHEMBL3145218 & 688759 & 4.45 & 4.9208 & TRN \\
\hline CHEMBL1562036 & 688759 & 4.55 & 4.6938 & TRN \\
\hline CHEMBL1580127 & 688759 & 4.45 & 4.7861 & TRN \\
\hline CHEMBL1542902 & 688759 & 4.45 & 4.6332 & TRN \\
\hline CHEMBL1349248 & 688759 & 4.9 & 4.6985 & TRN \\
\hline CHEMBL1389850 & 688759 & 5.0 & 5.3101 & TRN \\
\hline CHEMBL3208127 & 688759 & 4.45 & 4.7099 & TST \\
\hline CHEMBL1578875 & 688759 & 4.5 & 4.9059 & TRN \\
\hline CHEMBL601137 & 688759 & 5.0 & 5.1213 & TRN \\
\hline CHEMBL1502900 & 688759 & 4.65 & 5.0002 & TRN \\
\hline CHEMBL1536873 & 688759 & 4.45 & 4.7991 & TRN \\
\hline CHEMBL1506102 & 688759 & 4.85 & 4.92899 & 9999999999 \\
\hline CHEMBL1588263 & 688759 & 5.0 & 4.8146 & TST \\
\hline
\end{tabular}




\begin{tabular}{|c|c|c|c|c|}
\hline \multicolumn{5}{|c|}{ Supplemental Table S2.txt } \\
\hline CHEMBL1531579 & 688759 & 4.45 & 4.5838 & TST \\
\hline CHEMBL1558960 & 688759 & 5.65 & 4.9631 & TST \\
\hline CHEMBL1500641 & 688759 & 6.05 & 5.2421 & TRN \\
\hline CHEMBL1491068 & 688759 & 4.45 & 4.9847 & TRN \\
\hline CHEMBL1490747 & 688759 & 4.45 & 4.9347 & TRN \\
\hline CHEMBL1399612 & 688759 & 4.85 & 4.5041 & TRN \\
\hline CHEMBL1437961 & 688759 & 5.2 & 4.8558 & TRN \\
\hline CHEMBL1342868 & 688759 & 4.65 & 4.7774 & TRN \\
\hline CHEMBL1345903 & 688759 & 5.6 & 5.047 & TST \\
\hline CHEMBL1545642 & 688759 & 5.1 & 4.8441 & TST \\
\hline CHEMBL1600668 & 688759 & 4.95 & 5.0816 & TRN \\
\hline CHEMBL3199697 & 688759 & 4.6 & 4.9664 & TRN \\
\hline CHEMBL1523410 & 688759 & 4.45 & 4.4819 & TRN \\
\hline CHEMBL1424933 & 688759 & 4.45 & 4.8135 & TRN \\
\hline CHEMBL3197021 & 688759 & 6.1 & 5.6342 & TRN \\
\hline CHEMBL1303446 & 688759 & 4.5 & 4.9244 & TST \\
\hline CHEMBL1333554 & 688759 & 5.8 & 5.5391 & TRN \\
\hline CHEMBL2005302 & 688759 & 5.25 & 4.8803 & TRN \\
\hline CHEMBL468167 & 688759 & 5.75 & 5.0843 & TST \\
\hline CHEMBL1574914 & 688759 & 5.25 & 5.3731 & TRN \\
\hline CHEMBL1461201 & 688759 & 4.45 & 4.845 & TST \\
\hline CHEMBL1360458 & 688759 & 4.75 & 4.728 & TRN \\
\hline CHEMBL1527645 & 688759 & 4.75 & 4.6348 & TRN \\
\hline CHEMBL1505396 & 688759 & 4.45 & 4.8339 & TRN \\
\hline CHEMBL1302392 & 688759 & 4.45 & 4.8391 & TRN \\
\hline CHEMBL1464293 & 688759 & 5.2 & 4.8649 & TRN \\
\hline CHEMBL1567103 & 688759 & 4.8 & 5.0249 & TST \\
\hline CHEMBL1332887 & 688759 & 4.45 & 4.8874 & TRN \\
\hline CHEMBL1311527 & 688759 & 4.65 & 4.6912 & TRN \\
\hline CHEMBL1495859 & 688759 & 4.45 & 4.8673 & TRN \\
\hline CHEMBL1307663 & 688759 & 5.25 & 5.0215 & TST \\
\hline CHEMBL1310867 & 688759 & 4.75 & 4.9493 & TRN \\
\hline CHEMBL1382814 & 688759 & 5.1 & 4.8491 & TST \\
\hline CHEMBL1603103 & 688759 & 4.9 & 5.1534 & TRN \\
\hline CHEMBL1598583 & 688759 & 4.45 & 4.8932 & TRN \\
\hline CHEMBL1546092 & 688759 & 4.65 & 4.7422 & TRN \\
\hline CHEMBL1566410 & 688759 & 5.0 & 4.916 & TST \\
\hline CHEMBL1589608 & 688759 & 4.65 & 4.7613 & TRN \\
\hline CHEMBL1347198 & 688759 & 5.1 & 4.9695 & TRN \\
\hline CHEMBL1387817 & 688759 & 5.35 & 5.2176 & TST \\
\hline CHEMBL1492308 & 688759 & 5.45 & 5.1587 & TRN \\
\hline CHEMBL1467405 & 688759 & 5.55 & 5.2149 & TRN \\
\hline CHEMBL1388972 & 688759 & 4.95 & 4.6227 & TRN \\
\hline CHEMBL1596066 & 688759 & 4.9 & 4.8768 & TRN \\
\hline CHEMBL1493500 & 688759 & 4.45 & 4.9833 & TRN \\
\hline CHEMBL1603796 & 688759 & 4.85 & 4.8176 & TST \\
\hline CHEMBL1576537 & 688759 & 6.25 & 5.0657 & TRN \\
\hline CHEMBL1305364 & 688759 & 4.8 & 4.8682 & TRN \\
\hline
\end{tabular}




\begin{tabular}{|c|c|c|c|c|c|}
\hline & & \multicolumn{4}{|c|}{ Supplemental Table s2.txt } \\
\hline CHEMBL1526662 & 688759 & 4.65 & 4.8153 & TST & \\
\hline CHEMBL1583188 & 688759 & 4.65 & 4.6962 & TRN & \\
\hline CHEMBL1501117 & 688759 & 4.75 & 5.2493 & TRN & \\
\hline CHEMBL1303631 & 688759 & 4.95 & 4.961 & TRN & \\
\hline CHEMBL1447106 & 688759 & 4.55 & 4.7241 & TRN & \\
\hline CHEMBL1559578 & 688759 & 5.05 & 5.6079 & TST & \\
\hline CHEMBL1477643 & 688759 & 4.7 & 4.8836 & TRN & \\
\hline CHEMBL1347654 & 688759 & 4.65 & 4.8677 & TRN & \\
\hline CHEMBL1452952 & 688759 & 4.45 & 5.0549 & TST & \\
\hline CHEMBL1471841 & 688759 & 4.6 & 4.65300 & 00000000005 & TRN \\
\hline CHEMBL1327926 & 688759 & 5.0 & 5.0503 & TRN & \\
\hline CHEMBL1390882 & 688759 & 4.45 & 4.6965 & TRN & \\
\hline CHEMBL3198523 & 688759 & 4.95 & 4.9175 & TRN & \\
\hline CHEMBL1589879 & 688759 & 4.45 & 4.5754 & TST & \\
\hline CHEMBL1476347 & 688759 & 4.45 & 4.9016 & TRN & \\
\hline CHEMBL1609054 & 688759 & 4.45 & 4.9313 & TST & \\
\hline CHEMBL3190967 & 688759 & 6.2 & 5.9206 & TRN & \\
\hline CHEMBL1612234 & 688759 & 5.55 & 5.4403 & TRN & \\
\hline CHEMBL1470242 & 688759 & 5.0 & 5.0864 & TRN & \\
\hline CHEMBL1602772 & 688759 & 5.05 & 4.6869 & TST & \\
\hline CHEMBL1299978 & 688759 & 5.05 & 4.9733 & TRN & \\
\hline CHEMBL1386149 & 688759 & 5.1 & 5.1413 & TST & \\
\hline CHEMBL1364002 & 688759 & 4.85 & 5.155 & TRN & \\
\hline CHEMBL1351173 & 688759 & 4.95 & 5.0153 & TST & \\
\hline CHEMBL1588844 & 688759 & 4.85 & 4.6455 & TRN & \\
\hline CHEMBL1422880 & 688759 & 4.85 & 4.5695 & TRN & \\
\hline CHEMBL1594197 & 688759 & 4.45 & 4.5956 & TRN & \\
\hline CHEMBL1450797 & 688759 & 5.0 & 5.1345 & TRN & \\
\hline CHEMBL1345104 & 688759 & 4.45 & 4.6536 & TST & \\
\hline CHEMBL1412259 & 688759 & 4.65 & 4.7384 & TRN & \\
\hline CHEMBL1457803 & 688759 & 5.4 & 4.7676 & TRN & \\
\hline CHEMBL1561918 & 688759 & 5.0 & 5.0538 & TRN & \\
\hline CHEMBL1344740 & 688759 & 4.45 & 4.6179 & TRN & \\
\hline CHEMBL1557911 & 688759 & 4.45 & 4.835 & TRN & \\
\hline CHEMBL1494743 & 688759 & 5.2 & 4.6816 & TRN & \\
\hline CHEMBL1588449 & 688759 & 4.95 & 4.8291 & TRN & \\
\hline CHEMBL1341334 & 688759 & 4.45 & 4.7876 & TRN & \\
\hline CHEMBL1583107 & 688759 & 4.45 & 4.835 & TRN & \\
\hline CHEMBL36296 & 688759 & 4.85 & 4.6451 & TST & \\
\hline CHEMBL3195339 & 688759 & 4.45 & 4.7278 & TRN & \\
\hline CHEMBL1587031 & 688759 & 4.9 & 4.4768 & TST & \\
\hline CHEMBL1300277 & 688759 & 4.45 & 4.5624 & TRN & \\
\hline CHEMBL1610364 & 688759 & 5.35 & 5.1935 & TRN & \\
\hline CHEMBL1400485 & 688759 & 4.75 & 5.8057 & TRN & \\
\hline CHEMBL1507463 & 688759 & 5.15 & 4.9126 & TRN & \\
\hline CHEMBL1440967 & 688759 & 4.45 & 4.8236 & TST & \\
\hline CHEMBL1372595 & 688759 & 4.9 & 4.7701 & TRN & \\
\hline CHEMBL1375571 & 688759 & 5.2 & 5.3768 & TRN & \\
\hline
\end{tabular}




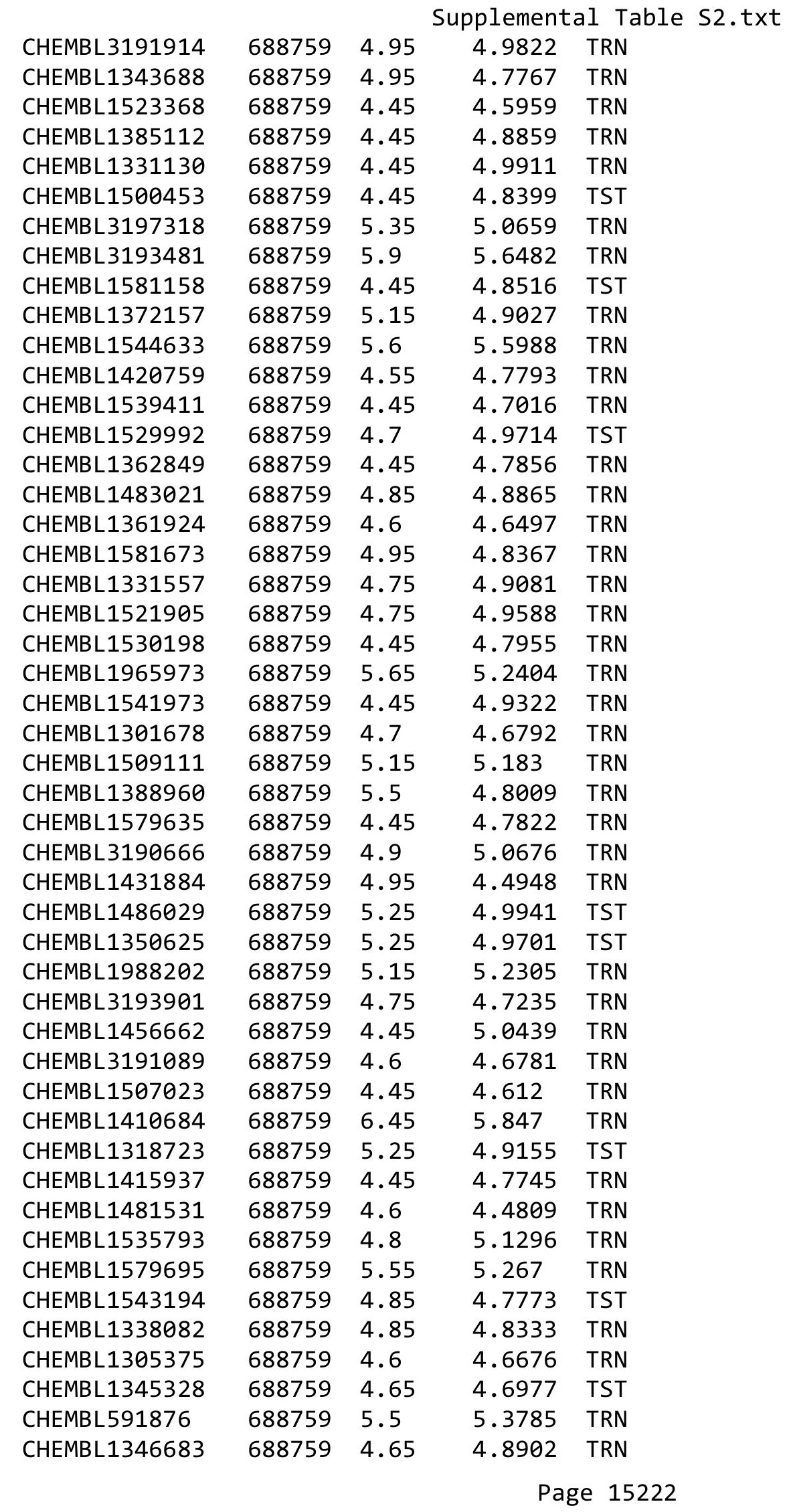




\begin{tabular}{|c|c|c|c|c|c|}
\hline & & \multicolumn{4}{|c|}{ Supplemental Table s2.txt } \\
\hline CHEMBL1480522 & 688759 & 5.65 & 5.4133 & TRN & \\
\hline CHEMBL1510825 & 688759 & 4.45 & 4.7615 & TRN & \\
\hline CHEMBL3197603 & 688759 & 6.15 & 5.5521 & TRN & \\
\hline CHEMBL1585988 & 688759 & 4.45 & 4.6959 & TST & \\
\hline CHEMBL 3190410 & 688759 & 4.45 & 4.8134 & TRN & \\
\hline CHEMBL1450163 & 688759 & 5.2 & 5.1058 & TRN & \\
\hline CHEMBL1451003 & 688759 & 4.45 & 4.9511 & TRN & \\
\hline CHEMBL1514227 & 688759 & 4.45 & 4.735 & TST & \\
\hline CHEMBL1337195 & 688759 & 4.65 & 4.7231 & TRN & \\
\hline CHEMBL510515 & 688759 & 4.6 & 4.8132 & TRN & \\
\hline CHEMBL1377462 & 688759 & 4.45 & 4.7219 & TST & \\
\hline CHEMBL1324790 & 688759 & 4.9 & 4.7977 & TRN & \\
\hline CHEMBL1599069 & 688759 & 4.45 & 4.8349 & TRN & \\
\hline CHEMBL1302934 & 688759 & 5.2 & 4.9035 & TRN & \\
\hline CHEMBL1555866 & 688759 & 4.7 & 4.6718 & TRN & \\
\hline CHEMBL1716874 & 688759 & 4.65 & 4.9807 & TRN & \\
\hline CHEMBL1302930 & 688759 & 4.75 & 4.8599 & TRN & \\
\hline CHEMBL1353266 & 688759 & 4.45 & 4.9369 & TRN & \\
\hline CHEMBL1471710 & 688759 & 6.8 & \multicolumn{2}{|c|}{5.0360000000000005} & TST \\
\hline CHEMBL1583850 & 688759 & 4.45 & 5.291 & TRN & \\
\hline CHEMBL1561150 & 688759 & 4.45 & 4.574 & TRN & \\
\hline CHEMBL1351406 & 688759 & 4.65 & 4.7993 & TRN & \\
\hline CHEMBL1463433 & 688759 & 4.45 & 4.8134 & TRN & \\
\hline CHEMBL1583538 & 688759 & 4.45 & 4.8419 & TST & \\
\hline CHEMBL1506580 & 688759 & 5.65 & 5.5004 & TRN & \\
\hline CHEMBL 8260 & 688759 & 4.45 & 5.3182 & TRN & \\
\hline CHEMBL1563896 & 688759 & 5.2 & 4.7475 & TRN & \\
\hline CHEMBL1426744 & 688759 & 4.45 & 4.7052 & TST & \\
\hline CHEMBL 236357 & 688759 & 4.6 & 4.7914 & TST & \\
\hline CHEMBL3193299 & 688759 & 4.8 & 4.8115 & TST & \\
\hline CHEMBL1540036 & 688759 & 4.45 & 4.8819 & TST & \\
\hline CHEMBL1543826 & 688759 & 4.9 & 4.7493 & TST & \\
\hline CHEMBL1349417 & 688759 & 4.5 & \multicolumn{2}{|c|}{4.6930000000000005} & TRN \\
\hline CHEMBL1352955 & 688759 & 4.85 & 4.7831 & TRN & \\
\hline CHEMBL1458822 & 688759 & 5.1 & 4.9846 & TRN & \\
\hline CHEMBL1332730 & 688759 & 5.3 & 5.1957 & TRN & \\
\hline CHEMBL1334132 & 688759 & 4.9 & 4.8997 & TRN & \\
\hline CHEMBL1504690 & 688759 & 4.45 & 4.8267 & TST & \\
\hline CHEMBL1600521 & 688759 & 5.45 & 4.9903 & TST & \\
\hline CHEMBL1418531 & 688759 & 5.2 & 4.6088 & TRN & \\
\hline CHEMBL1392442 & 688759 & 4.5 & 5.1792 & TRN & \\
\hline CHEMBL1326779 & 688759 & 5.1 & 5.1149 & TRN & \\
\hline CHEMBL1613279 & 688759 & 6.0 & 5.2627 & TRN & \\
\hline CHEMBL1556520 & 688759 & 4.7 & 4.814 & TRN & \\
\hline CHEMBL1331422 & 688759 & 5.85 & 5.0978 & TRN & \\
\hline CHEMBL1469615 & 688759 & 4.45 & 4.8845 & TST & \\
\hline CHEMBL1535767 & 688759 & 5.45 & 4.9688 & TRN & \\
\hline CHEMBL1304480 & 688759 & 5.25 & 4.8251 & TST & \\
\hline
\end{tabular}




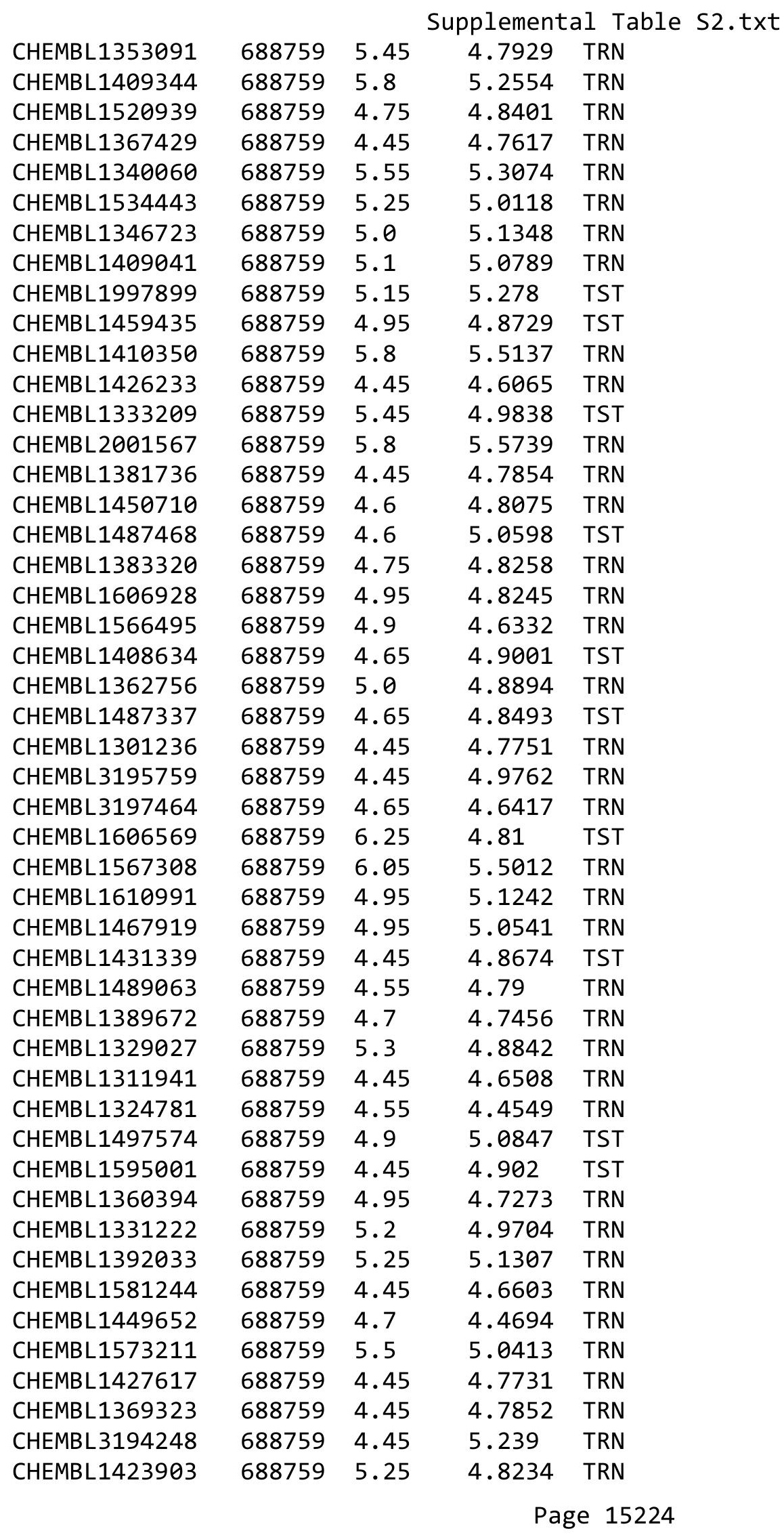




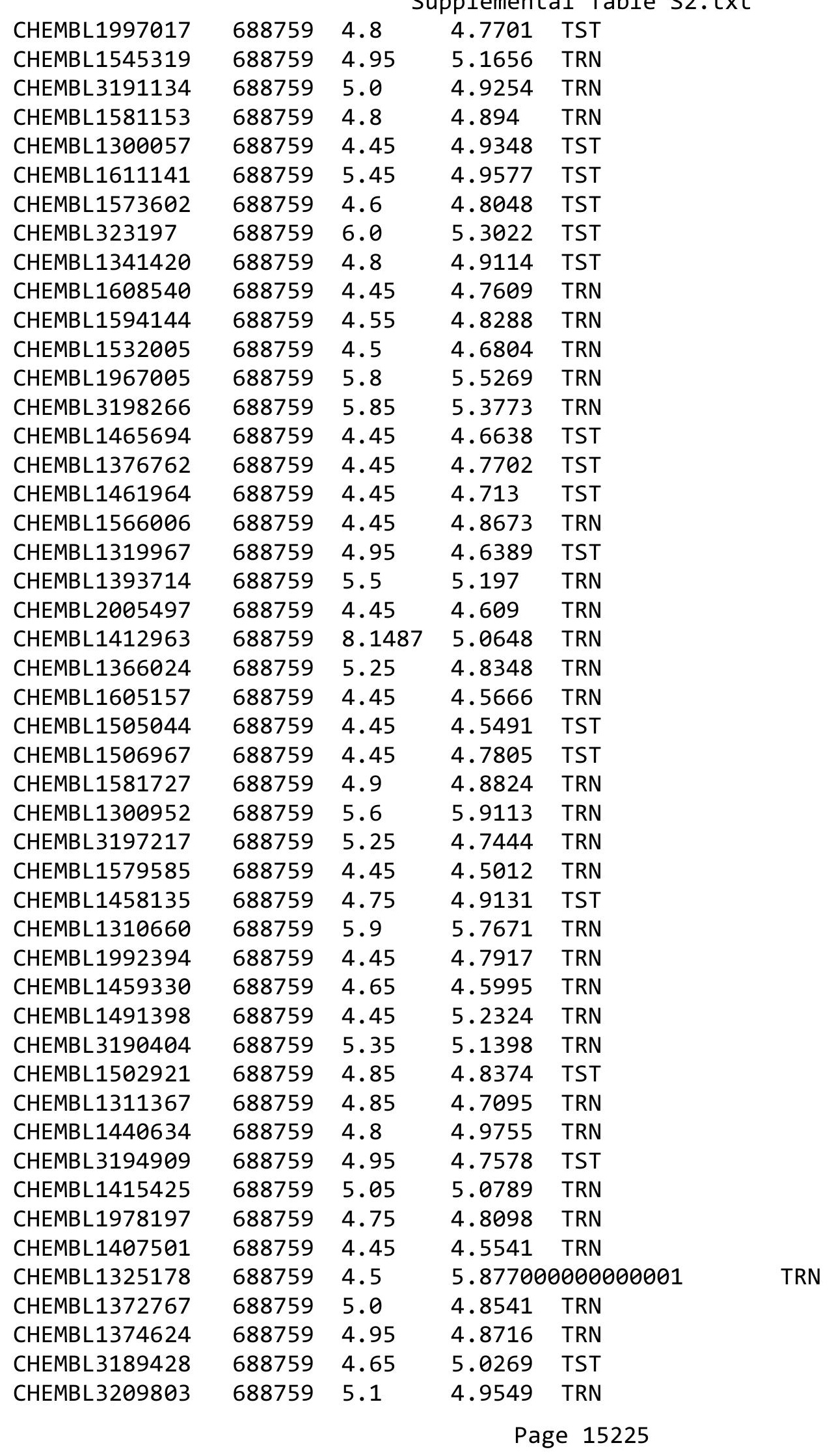




\begin{tabular}{|c|c|c|c|c|c|}
\hline & & \multicolumn{4}{|c|}{ Supplemental Table S2.txt } \\
\hline CHEMBL1580279 & 688759 & 4.85 & 4.8409 & TRN & \\
\hline CHEMBL1360948 & 688759 & 4.45 & 4.7401 & TRN & \\
\hline CHEMBL1370498 & 688759 & 4.7 & 4.7883 & TRN & \\
\hline CHEMBL276139 & 688759 & 5.0 & 5.0308 & TST & \\
\hline CHEMBL1388239 & 688759 & 4.75 & 5.6461 & TRN & \\
\hline CHEMBL1461873 & 688759 & 5.25 & 5.3119 & TRN & \\
\hline CHEMBL3191610 & 688759 & 5.0 & 4.9354 & TRN & \\
\hline CHEMBL1574752 & 688759 & 4.45 & 5.1863 & TST & \\
\hline CHEMBL1325877 & 688759 & 4.65 & 4.544 & TRN & \\
\hline CHEMBL1583292 & 688759 & 5.8 & 5.7123 & TRN & \\
\hline CHEMBL1543856 & 688759 & 4.45 & 4.8534 & TRN & \\
\hline CHEMBL1550070 & 688759 & 4.45 & 4.5859 & TRN & \\
\hline CHEMBL1447641 & 688759 & 5.25 & 4.435 & TRN & \\
\hline CHEMBL1573994 & 688759 & 6.0 & 5.4488 & TRN & \\
\hline CHEMBL1332415 & 688759 & 5.85 & 4.9281 & TRN & \\
\hline CHEMBL1304997 & 688759 & 4.6 & 4.8086 & TST & \\
\hline CHEMBL1516035 & 688759 & 5.2 & 5.1296 & TRN & \\
\hline CHEMBL1585477 & 688759 & 4.7 & 5.2188 & TRN & \\
\hline CHEMBL1322337 & 688759 & 4.95 & 4.6987 & TRN & \\
\hline CHEMBL1425460 & 688759 & 5.2 & 4.8834 & TST & \\
\hline CHEMBL1464578 & 688759 & 5.3 & 4.8786 & TST & \\
\hline CHEMBL1556634 & 688759 & 4.45 & 4.5605 & TRN & \\
\hline CHEMBL1393793 & 688759 & 5.0 & 4.9081 & TRN & \\
\hline CHEMBL1310003 & 688759 & 4.75 & 4.8654 & TRN & \\
\hline CHEMBL1589030 & 688759 & 4.9 & 4.8697 & TRN & \\
\hline CHEMBL1549758 & 688759 & 4.45 & 4.8828 & TRN & \\
\hline CHEMBL1463351 & 688759 & 4.7 & 5.0445 & TRN & \\
\hline CHEMBL1543483 & 688759 & 4.45 & 5.2281 & TST & \\
\hline CHEMBL1450612 & 688759 & 4.75 & 4.69300 & 00000000005 & TRN \\
\hline CHEMBL1969934 & 688759 & 5.1 & 4.8597 & TRN & \\
\hline CHEMBL1300385 & 688759 & 4.5 & 4.9292 & TRN & \\
\hline CHEMBL1322375 & 688759 & 4.85 & 4.8276 & TRN & \\
\hline CHEMBL1338462 & 688759 & 4.45 & 4.805 & TST & \\
\hline CHEMBL1429537 & 688759 & 4.65 & 4.7961 & TST & \\
\hline CHEMBL 2094833 & 688759 & 5.9 & 5.4988 & TRN & \\
\hline CHEMBL1378128 & 688759 & 4.65 & 4.8553 & TRN & \\
\hline CHEMBL1549933 & 688759 & 4.45 & 4.8353 & TRN & \\
\hline CHEMBL1573977 & 688759 & 4.45 & 4.7592 & TRN & \\
\hline CHEMBL1594647 & 688759 & 4.45 & 4.8693 & TRN & \\
\hline CHEMBL1479092 & 688759 & 4.45 & 4.7439 & TRN & \\
\hline CHEMBL394108 & 688759 & 5.25 & 5.0154 & TST & \\
\hline CHEMBL1446055 & 688759 & 4.85 & 4.6327 & TST & \\
\hline CHEMBL1991311 & 688759 & 5.35 & 4.7996 & TST & \\
\hline CHEMBL1599375 & 688759 & 5.2 & 4.9157 & TRN & \\
\hline CHEMBL1465666 & 688759 & 4.45 & 4.9219 & TRN & \\
\hline CHEMBL1586062 & 688759 & 4.5 & 4.7609 & TRN & \\
\hline CHEMBL1337664 & 688759 & 5.25 & 4.7243 & TST & \\
\hline CHEMBL1486522 & 688759 & 5.0 & 4.9357 & TRN & \\
\hline
\end{tabular}




\begin{tabular}{|c|c|c|c|c|c|}
\hline \multicolumn{6}{|c|}{ Supplemental Table S2.txt } \\
\hline CHEMBL1588660 & 688759 & 4.45 & 4.6707 & TRN & \\
\hline CHEMBL1399797 & 688759 & 4.45 & 4.7047 & TRN & \\
\hline CHEMBL1574379 & 688759 & 5.0 & 4.8959 & TRN & \\
\hline CHEMBL1411730 & 688759 & 4.95 & 5.0216 & TRN & \\
\hline CHEMBL1380852 & 688759 & 4.95 & 4.3863 & TRN & \\
\hline CHEMBL1405059 & 688759 & 5.5 & 5.3479 & TRN & \\
\hline CHEMBL1403420 & 688759 & 4.6 & 4.7052 & TRN & \\
\hline CHEMBL1414682 & 688759 & 4.65 & 4.6503 & TST & \\
\hline CHEMBL1336520 & 688759 & 4.95 & 5.0164 & TST & \\
\hline CHEMBL1587354 & 688759 & 4.55 & 4.8047 & TRN & \\
\hline CHEMBL1373808 & 688759 & 4.7 & 5.1971 & TRN & \\
\hline CHEMBL3211463 & 688759 & 4.45 & 4.8709 & TRN & \\
\hline CHEMBL3198620 & 688759 & 6.35 & 4.8018 & TST & \\
\hline CHEMBL1545502 & 688759 & 5.15 & 4.9643 & TRN & \\
\hline CHEMBL3199829 & 688759 & 4.75 & 4.8585 & TRN & \\
\hline CHEMBL1352025 & 688759 & 4.45 & 4.9705 & TST & \\
\hline CHEMBL1403534 & 688759 & 4.95 & 4.872 & TRN & \\
\hline CHEMBL1567317 & 688759 & 4.95 & 5.1865 & TRN & \\
\hline CHEMBL1579419 & 688759 & 4.65 & 5.5207 & TRN & \\
\hline CHEMBL1353637 & 688759 & 4.55 & 4.976 & TRN & \\
\hline CHEMBL1589110 & 688759 & 4.45 & 5.1082 & TST & \\
\hline CHEMBL1441993 & 688759 & 5.3 & 4.6904 & TRN & \\
\hline CHEMBL1321994 & 688759 & 4.45 & 4.7729 & TRN & \\
\hline CHEMBL1301732 & 688759 & 6.1 & 5.1896 & TRN & \\
\hline CHEMBL1456899 & 688759 & 4.45 & 4.6999 & TRN & \\
\hline CHEMBL1522331 & 688759 & 4.85 & 4.8476 & TRN & \\
\hline CHEMBL1336005 & 688759 & 4.75 & 4.7073 & TRN & \\
\hline CHEMBL1500316 & 688759 & 5.4 & 5.1059 & TST & \\
\hline CHEMBL1579737 & 688759 & 4.45 & 4.7394 & TRN & \\
\hline CHEMBL1335130 & 688759 & 4.65 & 4.6344 & TRN & \\
\hline CHEMBL3198388 & 688759 & 4.45 & 4.6512 & TRN & \\
\hline CHEMBL1494942 & 688759 & 4.95 & 4.7175 & TRN & \\
\hline CHEMBL1525071 & 688759 & 6.15 & 5.6075 & TRN & \\
\hline CHEMBL1467492 & 688759 & 4.7 & 4.9208 & TRN & \\
\hline CHEMBL 3211380 & 688759 & 5.25 & 5.36700 & 2000000001 & TRN \\
\hline CHEMBL1993708 & 688759 & 4.45 & 4.5224 & TRN & \\
\hline CHEMBL1596655 & 688759 & 4.45 & 4.8696 & TST & \\
\hline CHEMBL577546 & 688759 & 4.65 & 4.8011 & TRN & \\
\hline CHEMBL1336970 & 688759 & 4.6 & 5.024 & TRN & \\
\hline CHEMBL1494929 & 688759 & 4.45 & 4.6937 & TRN & \\
\hline CHEMBL3199489 & 688759 & 5.7 & 5.4276 & TRN & \\
\hline CHEMBL1976507 & 688759 & 6.5 & 5.9555 & TRN & \\
\hline CHEMBL1987173 & 688759 & 4.5 & 4.6981 & TRN & \\
\hline CHEMBL1443113 & 688759 & 6.5 & 4.8362 & TRN & \\
\hline CHEMBL3198613 & 688759 & 4.45 & 4.7996 & TRN & \\
\hline CHEMBL1370523 & 688759 & 4.45 & 4.7879 & TRN & \\
\hline CHEMBL1366268 & 688759 & 4.45 & 4.5584 & TST & \\
\hline CHEMBL1452854 & 688759 & 4.9 & 4.8055 & TRN & \\
\hline
\end{tabular}




\begin{tabular}{|c|c|c|c|c|}
\hline & & & pplement & al $\mathrm{Ta}$ \\
\hline CHEMBL1548890 & 688759 & 4.9 & 4.7122 & TRN \\
\hline CHEMBL1409915 & 688759 & 4.85 & 4.6724 & TST \\
\hline CHEMBL1573569 & 688759 & 4.75 & 5.0803 & TRN \\
\hline CHEMBL1378153 & 688759 & 4.5 & 4.7075 & TRN \\
\hline CHEMBL 3199044 & 688759 & 5.1 & 5.1979 & TRN \\
\hline CHEMBL3198692 & 688759 & 5.0 & 4.8751 & TRN \\
\hline CHEMBL1420219 & 688759 & 4.8 & 4.6019 & TRN \\
\hline CHEMBL1300622 & 688759 & 4.7 & 4.7512 & TST \\
\hline CHEMBL1531688 & 688759 & 4.85 & 4.9095 & TRN \\
\hline CHEMBL1579634 & 688759 & 4.75 & 6.1186 & TRN \\
\hline CHEMBL1454738 & 688759 & 4.65 & 5.0409 & TRN \\
\hline CHEMBL1454678 & 688759 & 5.0 & 5.1713 & TRN \\
\hline CHEMBL1394710 & 688759 & 4.45 & 4.6755 & TST \\
\hline CHEMBL1503057 & 688759 & 4.45 & 4.551 & TRN \\
\hline CHEMBL1513511 & 688759 & 4.75 & 4.5111 & TRN \\
\hline CHEMBL1588657 & 688759 & 4.45 & 4.7726 & TRN \\
\hline CHEMBL1388600 & 688759 & 4.45 & 4.9028 & TST \\
\hline CHEMBL186872 & 688759 & 6.0 & 5.2365 & TST \\
\hline CHEMBL1987419 & 688759 & 5.65 & 5.4828 & TRN \\
\hline CHEMBL1458548 & 688759 & 5.5 & 5.4757 & TRN \\
\hline CHEMBL1566083 & 688759 & 4.45 & 4.7539 & TRN \\
\hline CHEMBL1596126 & 688759 & 5.0 & 5.0626 & TRN \\
\hline CHEMBL1519335 & 688759 & 4.45 & 4.7361 & TRN \\
\hline CHEMBL 1442502 & 688759 & 4.6 & 5.0375 & TRN \\
\hline CHEMBL1463385 & 688759 & 4.45 & 4.8745 & TST \\
\hline CHEMBL1522846 & 688759 & 5.1 & 5.0364 & TST \\
\hline CHEMBL1498359 & 688759 & 4.45 & 4.9672 & TRN \\
\hline CHEMBL3191706 & 688759 & 4.8 & 4.6399 & TRN \\
\hline CHEMBL1495313 & 688759 & 4.9 & 5.3636 & TRN \\
\hline CHEMBL1458664 & 688759 & 4.6 & 5.1361 & TRN \\
\hline CHEMBL1450153 & 688759 & 4.45 & 4.8423 & TRN \\
\hline CHEMBL1484108 & 688759 & 6.15 & 5.0038 & TRN \\
\hline CHEMBL1360199 & 688759 & 4.55 & 5.0018 & TRN \\
\hline CHEMBL1991242 & 688759 & 5.55 & 5.1723 & TRN \\
\hline CHEMBL1324125 & 688759 & 5.1 & 5.1281 & TST \\
\hline CHEMBL 2004291 & 688759 & 4.85 & 4.5027 & TRN \\
\hline CHEMBL1510664 & 688759 & 5.3 & 4.6866 & TST \\
\hline CHEMBL1390866 & 688759 & 4.45 & 5.2021 & TRN \\
\hline CHEMBL1466178 & 688759 & 6.3 & 5.5364 & TRN \\
\hline CHEMBL531079 & 688759 & 4.95 & 5.1033 & TST \\
\hline CHEMBL1447424 & 688759 & 5.9 & 4.9645 & TST \\
\hline CHEMBL1561767 & 688759 & 5.65 & 5.0398 & TRN \\
\hline CHEMBL1599847 & 688759 & 4.45 & 4.651 & TRN \\
\hline CHEMBL1505450 & 688759 & 4.8 & 5.1647 & TRN \\
\hline CHEMBL1377632 & 688759 & 5.45 & 5.2893 & TRN \\
\hline CHEMBL1572605 & 688759 & 4.9 & 5.0239 & TST \\
\hline CHEMBL1450631 & 688759 & 4.45 & 4.829 & TRN \\
\hline CHEMBL1468713 & 688759 & 4.5 & 5.2465 & TRN \\
\hline
\end{tabular}




\begin{tabular}{|c|c|c|c|c|c|}
\hline \multicolumn{6}{|c|}{ Supplemental Table S2.txt } \\
\hline CHEMBL1587178 & 688759 & 5.0 & 4.8805 & TRN & \\
\hline CHEMBL1549151 & 688759 & 4.6 & 4.6865 & TST & \\
\hline CHEMBL1386664 & 688759 & 5.15 & 5.0374 & TRN & \\
\hline CHEMBL1472348 & 688759 & 4.65 & 4.9071 & TRN & \\
\hline CHEMBL1380796 & 688759 & 6.0 & 4.8625 & TST & \\
\hline CHEMBL1520970 & 688759 & 4.45 & 4.7422 & TRN & \\
\hline CHEMBL1582099 & 688759 & 4.45 & 4.8172 & TST & \\
\hline CHEMBL1610314 & 688759 & 4.45 & 4.7454 & TRN & \\
\hline CHEMBL1450665 & 688759 & 5.6 & 5.3605 & TRN & \\
\hline CHEMBL3196165 & 688759 & 4.65 & 4.6829 & TRN & \\
\hline CHEMBL1351669 & 688759 & 4.8 & 4.8306 & TRN & \\
\hline CHEMBL1602934 & 688759 & 4.9 & 5.1528 & TST & \\
\hline CHEMBL1426498 & 688759 & 4.6 & 4.6593 & TRN & \\
\hline CHEMBL1577977 & 688759 & 4.9 & 4.9334 & TRN & \\
\hline CHEMBL1467422 & 688759 & 4.45 & 5.0236 & TRN & \\
\hline CHEMBL1425536 & 688759 & 4.45 & 5.2899 & TRN & \\
\hline CHEMBL1420123 & 688759 & 6.0 & 5.8439 & TRN & \\
\hline CHEMBL599503 & 688759 & 4.45 & 4.6146 & TST & \\
\hline CHEMBL1304506 & 688759 & 4.45 & 4.7158 & TRN & \\
\hline CHEMBL1367414 & 688759 & 4.65 & 4.7424 & TRN & \\
\hline CHEMBL1568747 & 688759 & 5.0 & 5.3825 & TRN & \\
\hline CHEMBL1491154 & 688759 & 4.45 & 4.78600 & 00000000005 & TRN \\
\hline CHEMBL1360933 & 688759 & 4.45 & 4.8314 & TRN & \\
\hline CHEMBL1564414 & 688759 & 4.45 & 4.7266 & TRN & \\
\hline CHEMBL1450384 & 688759 & 4.65 & 5.1929 & TRN & \\
\hline CHEMBL1506120 & 688759 & 4.45 & 5.0576 & TRN & \\
\hline CHEMBL1478382 & 688759 & 4.45 & 4.8497 & TST & \\
\hline CHEMBL1487833 & 688759 & 4.7 & 5.1105 & TRN & \\
\hline CHEMBL1540371 & 688759 & 4.45 & 4.8021 & TST & \\
\hline CHEMBL1302011 & 688759 & 4.7 & 4.7797 & TRN & \\
\hline CHEMBL1523658 & 688759 & 4.25 & 4.9974 & TST & \\
\hline CHEMBL1576243 & 688759 & 5.45 & 4.8402 & TRN & \\
\hline CHEMBL1399756 & 688759 & 4.45 & 4.7319 & TRN & \\
\hline CHEMBL1581527 & 688759 & 4.9 & 4.6809 & TST & \\
\hline CHEMBL1373529 & 688759 & 4.6 & 4.507 & TRN & \\
\hline CHEMBL1532242 & 688759 & 5.2 & 5.0376 & TRN & \\
\hline CHEMBL 225903 & 688759 & 5.5 & 5.2508 & TRN & \\
\hline CHEMBL1455009 & 688759 & 4.8 & 4.9636 & TST & \\
\hline CHEMBL1573586 & 688759 & 4.85 & 4.8364 & TST & \\
\hline CHEMBL1338736 & 688759 & 5.55 & 5.01 & TRN & \\
\hline CHEMBL1445962 & 688759 & 4.45 & 4.5139 & TST & \\
\hline CHEMBL1579650 & 688759 & 5.0 & 5.1991 & TRN & \\
\hline CHEMBL1583419 & 688759 & 4.65 & 4.4592 & TRN & \\
\hline CHEMBL3210386 & 688759 & 5.25 & 4.9632 & TRN & \\
\hline CHEMBL3192231 & 688759 & 5.3 & 5.3329 & TRN & \\
\hline CHEMBL1494526 & 688759 & 4.45 & 4.4977 & TST & \\
\hline CHEMBL1420257 & 688759 & 4.5 & 4.8139 & TRN & \\
\hline CHEMBL1538518 & 688759 & 4.45 & 4.8923 & TRN & \\
\hline
\end{tabular}




\begin{tabular}{|c|c|c|c|c|c|}
\hline & & \multicolumn{4}{|c|}{ Supplemental Table S2.txt } \\
\hline CHEMBL1480730 & 688759 & 5.45 & 4.7659 & TST & \\
\hline CHEMBL1453673 & 688759 & 4.55 & 4.931 & TRN & \\
\hline CHEMBL1435080 & 688759 & 4.9 & 4.8212 & TRN & \\
\hline CHEMBL1410288 & 688759 & 4.5 & 4.7068 & TRN & \\
\hline CHEMBL1339001 & 688759 & 4.45 & 4.7632 & TRN & \\
\hline CHEMBL1324104 & 688759 & 5.3 & 5.7626 & TRN & \\
\hline CHEMBL1378322 & 688759 & 4.45 & 4.8429 & TRN & \\
\hline CHEMBL1340223 & 688759 & 5.5 & 4.9818 & TRN & \\
\hline CHEMBL1393988 & 688759 & 5.6 & 4.6327 & TRN & \\
\hline CHEMBL1407100 & 688759 & 4.45 & 4.7782 & TST & \\
\hline CHEMBL3212202 & 688759 & 5.25 & 5.2755 & TRN & \\
\hline CHEMBL3191151 & 688759 & 4.95 & 5.0311 & TRN & \\
\hline CHEMBL1322111 & 688759 & 4.45 & 4.7674 & TST & \\
\hline CHEMBL1612044 & 688759 & 5.95 & 5.6795 & TRN & \\
\hline CHEMBL1331798 & 688759 & 4.65 & 4.542 & TRN & \\
\hline CHEMBL1582184 & 688759 & 4.45 & 5.0078 & TST & \\
\hline CHEMBL1417195 & 688759 & 6.1 & 5.4396 & TRN & \\
\hline CHEMBL1460273 & 688759 & 4.65 & 4.5837 & TRN & \\
\hline CHEMBL1430289 & 688759 & 4.8 & 5.1434 & TST & \\
\hline CHEMBL1549787 & 688759 & 4.65 & 4.988 & TST & \\
\hline CHEMBL1469950 & 688759 & 5.15 & 4.98300 & 00000000005 & TRN \\
\hline CHEMBL1460661 & 688759 & 5.15 & 4.8689 & TRN & \\
\hline CHEMBL1602173 & 688759 & 5.0 & 5.0766 & TRN & \\
\hline CHEMBL1334474 & 688759 & 4.8 & 4.7301 & TRN & \\
\hline CHEMBL1516556 & 688759 & 4.45 & 4.7832 & TRN & \\
\hline CHEMBL1301544 & 688759 & 4.5 & 4.7026 & TRN & \\
\hline CHEMBL1543187 & 688759 & 4.65 & 4.598 & TRN & \\
\hline CHEMBL1504438 & 688759 & 4.45 & 5.2312 & TRN & \\
\hline CHEMBL1416848 & 688759 & 5.3 & 5.3622 & TST & \\
\hline CHEMBL1477337 & 688759 & 5.0 & 4.8082 & TRN & \\
\hline CHEMBL1441738 & 688759 & 4.7 & 4.6551 & TST & \\
\hline CHEMBL1523734 & 688759 & 4.45 & 4.8096 & TST & \\
\hline CHEMBL1458653 & 688759 & 5.0 & 4.6989 & TRN & \\
\hline CHEMBL1605038 & 688759 & 5.1 & 4.7988 & TRN & \\
\hline CHEMBL243596 & 688759 & 4.45 & 4.6387 & TST & \\
\hline CHEMBL1337176 & 688759 & 4.7 & 4.6395 & TST & \\
\hline CHEMBL3191083 & 688759 & 4.45 & 4.9539 & TRN & \\
\hline CHEMBL1430068 & 688759 & 4.45 & 4.7853 & TRN & \\
\hline CHEMBL1538366 & 688759 & 5.25 & 4.9403 & TRN & \\
\hline CHEMBL1332764 & 688759 & 5.0 & 5.2094 & TRN & \\
\hline CHEMBL1343308 & 688759 & 4.45 & 4.6072 & TRN & \\
\hline CHEMBL1335528 & 688759 & 4.65 & 4.6799 & TST & \\
\hline CHEMBL1362119 & 688759 & 4.45 & 4.8222 & TRN & \\
\hline CHEMBL3212089 & 688759 & 5.05 & 5.2451 & TRN & \\
\hline CHEMBL1559609 & 688759 & 5.35 & 5.1199 & TRN & \\
\hline CHEMBL1314376 & 688759 & 4.45 & 4.6727 & TST & \\
\hline CHEMBL1600587 & 688759 & 5.0 & 5.0773 & TRN & \\
\hline CHEMBL3210119 & 688759 & 4.75 & 4.7248 & TRN & \\
\hline
\end{tabular}




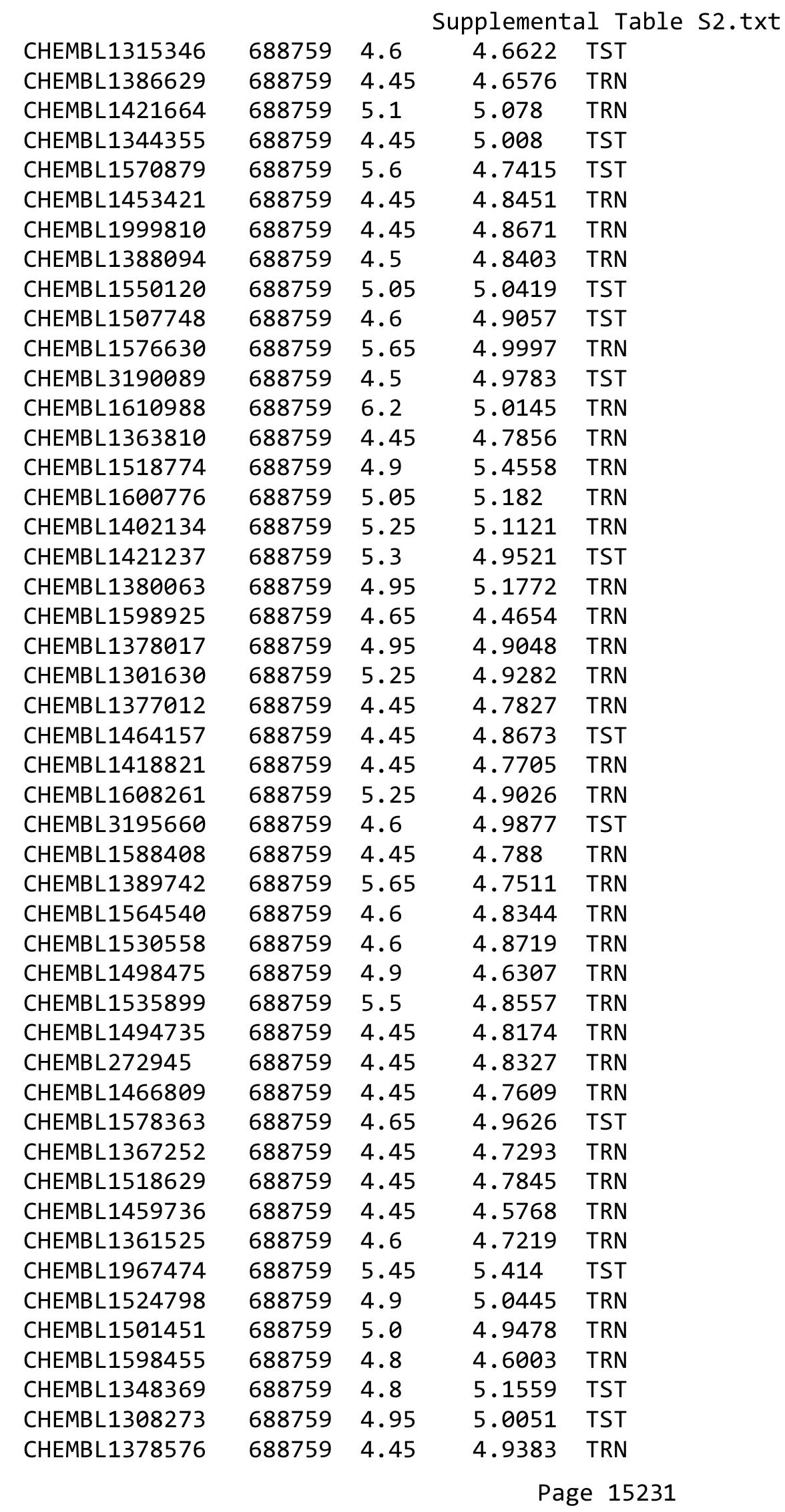




\begin{tabular}{|c|c|c|c|c|}
\hline \multicolumn{5}{|c|}{ Supplemental Table S2.txt } \\
\hline CHEMBL1561610 & 688759 & 4.45 & 4.8136 & TRN \\
\hline CHEMBL1965453 & 688759 & 4.75 & 4.765 & TRN \\
\hline CHEMBL1578341 & 688759 & 5.2 & 4.8405 & TRN \\
\hline CHEMBL1572909 & 688759 & 4.85 & 4.7877 & TRN \\
\hline CHEMBL1303225 & 688759 & 5.85 & 5.443 & TRN \\
\hline CHEMBL1489449 & 688759 & 4.45 & 4.8317 & TRN \\
\hline CHEMBL1365476 & 688759 & 4.95 & 4.874 & TRN \\
\hline CHEMBL1483501 & 688759 & 4.85 & 5.189 & TRN \\
\hline CHEMBL1403645 & 688759 & 5.1 & 5.067 & TST \\
\hline CHEMBL3210339 & 688759 & 4.55 & 4.8006 & TRN \\
\hline CHEMBL1334814 & 688759 & 4.85 & 4.6208 & TRN \\
\hline CHEMBL1597593 & 688759 & 4.45 & 4.8765 & TST \\
\hline CHEMBL1309842 & 688759 & 4.7 & 4.5487 & TRN \\
\hline CHEMBL1532554 & 688759 & 5.2 & 5.12 & TST \\
\hline CHEMBL1392237 & 688759 & 4.45 & 4.9868 & TRN \\
\hline CHEMBL1308370 & 688759 & 4.65 & 5.1381 & TST \\
\hline CHEMBL1495194 & 688759 & 5.05 & 5.4138 & TRN \\
\hline CHEMBL3192049 & 688759 & 4.95 & 5.3746 & TRN \\
\hline CHEMBL1491952 & 688759 & 4.45 & 4.9215 & TRN \\
\hline CHEMBL1370490 & 688759 & 5.55 & 5.2809 & TST \\
\hline CHEMBL3197612 & 688759 & 4.5 & 4.7771 & TRN \\
\hline CHEMBL1350852 & 688759 & 4.45 & 4.907 & TRN \\
\hline CHEMBL1520841 & 688759 & 5.55 & 4.8782 & TRN \\
\hline CHEMBL1419462 & 688759 & 4.8 & 5.0177 & TRN \\
\hline CHEMBL1336400 & 688759 & 5.05 & 4.875 & TST \\
\hline CHEMBL1487114 & 688759 & 4.85 & 4.9149 & TST \\
\hline CHEMBL1732967 & 688759 & 5.5 & 5.6027 & TRN \\
\hline CHEMBL1326723 & 688759 & 4.8 & 4.7487 & TRN \\
\hline CHEMBL1462967 & 688759 & 5.0 & 5.0763 & TRN \\
\hline CHEMBL1353221 & 688759 & 4.45 & 4.7047 & TST \\
\hline CHEMBL1606486 & 688759 & 6.2 & 5.3314 & TRN \\
\hline CHEMBL1332083 & 688759 & 4.8 & 4.6412 & TRN \\
\hline CHEMBL1409011 & 688759 & 4.45 & 4.7536 & TRN \\
\hline CHEMBL1577665 & 688759 & 4.6 & 4.938 & TST \\
\hline CHEMBL1555935 & 688759 & 6.15 & 5.4 & TRN \\
\hline CHEMBL1590450 & 688759 & 4.85 & 4.8821 & TRN \\
\hline CHEMBL1541239 & 688759 & 4.9 & 4.9583 & TST \\
\hline CHEMBL1612745 & 688759 & 4.65 & 4.7454 & TST \\
\hline CHEMBL1400481 & 688759 & 5.15 & 5.058 & TST \\
\hline CHEMBL1539016 & 688759 & 4.45 & 4.9131 & TRN \\
\hline CHEMBL1374672 & 688759 & 4.45 & 4.4695 & TRN \\
\hline CHEMBL1376037 & 688759 & 4.45 & 4.6837 & TRN \\
\hline CHEMBL1531117 & 688759 & 4.95 & 4.7693 & TRN \\
\hline CHEMBL1314100 & 688759 & 5.45 & 5.0947 & TRN \\
\hline CHEMBL1999237 & 688759 & 4.45 & 4.7034 & TST \\
\hline CHEMBL1441746 & 688759 & 4.8 & 4.8502 & TRN \\
\hline CHEMBL1488549 & 688759 & 4.7 & 5.1136 & TRN \\
\hline CHEMBL3194222 & 688759 & 4.45 & 4.7968 & TST \\
\hline
\end{tabular}




\begin{tabular}{|c|c|c|c|c|}
\hline & & & pplemen & al $\mathrm{T}$ \\
\hline CHEMBL3213705 & 688759 & 5.3 & 5.0571 & TRN \\
\hline CHEMBL1256876 & 688759 & 4.7 & 4.655 & TST \\
\hline CHEMBL1307864 & 688759 & 5.0 & 5.1967 & TRN \\
\hline CHEMBL1563855 & 688759 & 4.95 & 5.0349 & TRN \\
\hline CHEMBL1968044 & 688759 & 5.55 & 5.1822 & TRN \\
\hline CHEMBL1500199 & 688759 & 4.6 & 4.4127 & TRN \\
\hline CHEMBL1337727 & 688759 & 4.95 & 5.1037 & TRN \\
\hline CHEMBL1605583 & 688759 & 5.6 & 4.6509 & TRN \\
\hline CHEMBL1380763 & 688759 & 4.45 & 4.8561 & TRN \\
\hline CHEMBL1342795 & 688759 & 4.7 & 4.5059 & TRN \\
\hline CHEMBL3195460 & 688759 & 5.35 & 5.2347 & TRN \\
\hline CHEMBL1358278 & 688759 & 4.45 & 4.9048 & TRN \\
\hline CHEMBL1462360 & 688759 & 5.4 & 5.1903 & TRN \\
\hline CHEMBL1530087 & 688759 & 5.55 & 5.2334 & TRN \\
\hline CHEMBL1359871 & 688759 & 5.9 & 5.6025 & TRN \\
\hline CHEMBL1492459 & 688759 & 5.0 & 5.3345 & TRN \\
\hline CHEMBL1374860 & 688759 & 4.75 & 4.8707 & TRN \\
\hline CHEMBL1319933 & 688759 & 4.6 & 5.0187 & TRN \\
\hline CHEMBL1424806 & 688759 & 4.65 & 4.4545 & TRN \\
\hline CHEMBL1586082 & 688759 & 4.45 & 4.7117 & TST \\
\hline CHEMBL1576955 & 688759 & 4.45 & 4.9338 & TRN \\
\hline CHEMBL3145053 & 688759 & 6.15 & 5.1695 & TRN \\
\hline CHEMBL1419293 & 688759 & 5.45 & 5.1623 & TRN \\
\hline CHEMBL1558796 & 688759 & 5.25 & 4.6539 & TST \\
\hline CHEMBL1521379 & 688759 & 4.7 & 5.0766 & TRN \\
\hline CHEMBL1410454 & 688759 & 5.55 & 5.4119 & TRN \\
\hline CHEMBL1421270 & 688759 & 4.45 & 5.0471 & TST \\
\hline CHEMBL1981570 & 688759 & 6.3 & 6.011 & TRN \\
\hline CHEMBL1342293 & 688759 & 6.0 & 5.8621 & TRN \\
\hline CHEMBL1600372 & 688759 & 5.05 & 4.9408 & TST \\
\hline CHEMBL1301571 & 688759 & 4.45 & 4.7564 & TRN \\
\hline CHEMBL1422844 & 688759 & 5.45 & 4.9215 & TRN \\
\hline CHEMBL1486363 & 688759 & 4.75 & 4.6417 & TRN \\
\hline CHEMBL1498545 & 688759 & 4.45 & 4.723 & TRN \\
\hline CHEMBL1349459 & 688759 & 4.45 & 4.4566 & TST \\
\hline CHEMBL1471896 & 688759 & 4.9 & 4.7577 & TST \\
\hline CHEMBL 3190384 & 688759 & 5.25 & 4.7703 & TRN \\
\hline CHEMBL1313660 & 688759 & 5.45 & 4.9213 & TRN \\
\hline CHEMBL1379370 & 688759 & 6.0 & 5.7296 & TRN \\
\hline CHEMBL1976304 & 688759 & 4.65 & 4.8163 & TST \\
\hline CHEMBL1416617 & 688759 & 5.9 & 5.0238 & TRN \\
\hline CHEMBL1308687 & 688759 & 4.75 & 5.0027 & TRN \\
\hline CHEMBL1422068 & 688759 & 4.9 & 4.7582 & TRN \\
\hline CHEMBL1581629 & 688759 & 4.7 & 4.8048 & TST \\
\hline CHEMBL1303400 & 688759 & 5.5 & 5.3212 & TRN \\
\hline CHEMBL1547865 & 688759 & 4.45 & 4.5298 & TST \\
\hline CHEMBL1356949 & 688759 & 4.4 & 4.7351 & TRN \\
\hline CHEMBL1993488 & 688759 & 4.45 & 4.5898 & TRN \\
\hline
\end{tabular}




\begin{tabular}{|c|c|c|c|c|c|}
\hline & & \multicolumn{4}{|c|}{ Supplemental Table s2.txt } \\
\hline CHEMBL1564473 & 688759 & 4.45 & 4.4734 & TRN & \\
\hline CHEMBL3199440 & 688759 & 4.6 & 5.0128 & TRN & \\
\hline CHEMBL1408744 & 688759 & 4.8 & 4.9124 & TRN & \\
\hline CHEMBL1344617 & 688759 & 4.8 & 4.7648 & TRN & \\
\hline CHEMBL1425896 & 688759 & 4.5 & 4.9474 & TRN & \\
\hline CHEMBL3190400 & 688759 & 4.45 & 5.035 & TRN & \\
\hline CHEMBL1487063 & 688759 & 4.45 & 4.9871 & TRN & \\
\hline CHEMBL597744 & 688759 & 4.9 & 5.1242 & TRN & \\
\hline CHEMBL1559877 & 688759 & 4.45 & 4.928 & TRN & \\
\hline CHEMBL1333867 & 688759 & 6.0 & 5.3877 & TST & \\
\hline CHEMBL1340442 & 688759 & 5.05 & 4.6265 & TRN & \\
\hline CHEMBL3192783 & 688759 & 4.95 & 5.0194 & TRN & \\
\hline CHEMBL1444103 & 688759 & 5.5 & 5.0613 & TRN & \\
\hline CHEMBL1410575 & 688759 & 4.45 & 4.6283 & TST & \\
\hline CHEMBL1518282 & 688759 & 4.65 & 4.9268 & TRN & \\
\hline CHEMBL3196640 & 688759 & 5.0 & 5.0553 & TRN & \\
\hline CHEMBL1576059 & 688759 & 4.45 & 4.7875 & TST & \\
\hline CHEMBL1464457 & 688759 & 5.45 & 5.5651 & TRN & \\
\hline CHEMBL1399917 & 688759 & 5.25 & 5.7798 & TRN & \\
\hline CHEMBL1491099 & 688759 & 4.7 & 4.5942 & TST & \\
\hline CHEMBL3199277 & 688759 & 4.95 & 4.9861 & TRN & \\
\hline CHEMBL1407095 & 688759 & 6.2 & 4.9014 & TRN & \\
\hline CHEMBL1559423 & 688759 & 4.6 & 4.9037 & TRN & \\
\hline CHEMBL1327502 & 688759 & 5.1 & 5.1917 & TRN & \\
\hline CHEMBL1352186 & 688759 & 4.45 & 4.7201 & TRN & \\
\hline CHEMBL1373849 & 688759 & 4.6 & 4.7485 & TRN & \\
\hline CHEMBL1374814 & 688759 & 5.1 & 4.953 & TRN & \\
\hline CHEMBL1312361 & 688759 & 5.0 & 5.2255 & TRN & \\
\hline CHEMBL1498242 & 688759 & 4.45 & 5.9171 & TST & \\
\hline CHEMBL1477624 & 688759 & 4.6 & 5.0879 & TST & \\
\hline CHEMBL1407173 & 688759 & 4.45 & 5.0987 & TST & \\
\hline CHEMBL1352371 & 688759 & 4.6 & 4.8735 & TRN & \\
\hline CHEMBL1577550 & 688759 & 4.85 & 5.0633 & TRN & \\
\hline CHEMBL1466644 & 688759 & 6.0 & 6.04299 & & TRN \\
\hline CHEMBL1301945 & 688759 & 5.3 & 4.7467 & TRN & \\
\hline CHEMBL1350032 & 688759 & 5.05 & 5.1058 & TRN & \\
\hline CHEMBL1602311 & 688759 & 5.25 & 4.7249 & TST & \\
\hline CHEMBL1332688 & 688759 & 5.0 & 5.1726 & TRN & \\
\hline CHEMBL1506239 & 688759 & 4.65 & 4.6798 & TRN & \\
\hline CHEMBL1421954 & 688759 & 4.45 & 4.7689 & TRN & \\
\hline CHEMBL1424478 & 688759 & 5.4 & 4.6381 & TRN & \\
\hline CHEMBL1379139 & 688759 & 5.25 & 5.0983 & TRN & \\
\hline CHEMBL1421256 & 688759 & 5.5 & 5.2301 & TRN & \\
\hline CHEMBL1310356 & 688759 & 4.9 & 4.6503 & TRN & \\
\hline CHEMBL1523568 & 688759 & 4.95 & 4.8093 & TRN & \\
\hline CHEMBL1426861 & 688759 & 5.2 & 5.2226 & TRN & \\
\hline CHEMBL1588832 & 688759 & 5.4 & 5.2634 & TRN & \\
\hline CHEMBL3209659 & 688759 & 5.5 & 5.0621 & TRN & \\
\hline
\end{tabular}




\begin{tabular}{|c|c|c|c|c|c|}
\hline \multicolumn{6}{|c|}{ Supplemental Table S2.txt } \\
\hline CHEMBL1965873 & 688759 & 4.45 & 4.6702 & TRN & \\
\hline CHEMBL1409347 & 688759 & 4.8 & 5.0585 & TRN & \\
\hline CHEMBL1402010 & 688759 & 5.65 & 5.1528 & TRN & \\
\hline CHEMBL1451074 & 688759 & 4.5 & 4.8436 & TRN & \\
\hline CHEMBL3193369 & 688759 & 5.3 & 5.2232 & TRN & \\
\hline CHEMBL1319430 & 688759 & 4.85 & 5.1038 & TST & \\
\hline CHEMBL1471170 & 688759 & 4.5 & 5.2814 & TRN & \\
\hline CHEMBL1370437 & 688759 & 5.2 & 5.0558 & TRN & \\
\hline CHEMBL1172912 & 688759 & 4.45 & 4.8351 & TRN & \\
\hline CHEMBL3210546 & 688759 & 4.65 & 4.8126 & TRN & \\
\hline CHEMBL1390351 & 688759 & 4.6 & 4.4853 & TRN & \\
\hline CHEMBL1390082 & 688759 & 5.85 & 5.0014 & TST & \\
\hline CHEMBL3190334 & 688759 & 5.0 & 5.4846 & TRN & \\
\hline CHEMBL1373914 & 688759 & 6.95 & 5.0056 & TRN & \\
\hline CHEMBL3191484 & 688759 & 4.6 & 4.8435 & TRN & \\
\hline CHEMBL1353757 & 688759 & 4.45 & 4.7588 & TRN & \\
\hline CHEMBL1558306 & 688759 & 5.45 & 5.5849 & TRN & \\
\hline CHEMBL1374649 & 688759 & 4.95 & 5.0515 & TST & \\
\hline CHEMBL3144917 & 688759 & 4.6 & 4.6408 & TRN & \\
\hline CHEMBL1502858 & 688759 & 4.45 & 4.9284 & TRN & \\
\hline CHEMBL1538339 & 688759 & 4.45 & 4.4547 & TRN & \\
\hline CHEMBL1580664 & 688759 & 4.9 & 4.9142 & TST & \\
\hline CHEMBL1313811 & 688759 & 6.7501 & 5.4937 & TRN & \\
\hline CHEMBL1489130 & 688759 & 4.6 & 4.829 & TRN & \\
\hline CHEMBL1613447 & 688759 & 5.95 & 5.0627 & TST & \\
\hline CHEMBL1603644 & 688759 & 4.6 & 4.9135 & TRN & \\
\hline CHEMBL1606356 & 688759 & 4.45 & 4.7836 & TRN & \\
\hline CHEMBL1539518 & 688759 & 5.0 & 5.1828 & TST & \\
\hline CHEMBL1333323 & 688759 & 5.2 & 4.8066 & TST & \\
\hline CHEMBL1538198 & 688759 & 4.6 & 4.8826 & TST & \\
\hline CHEMBL1588968 & 688759 & 4.9 & 4.8516 & TRN & \\
\hline CHEMBL 82134 & 688759 & 4.85 & 5.1117 & TRN & \\
\hline CHEMBL1464798 & 688759 & 5.5 & $5.1679 \mathrm{c}$ & 9999999999 & TRN \\
\hline CHEMBL1987891 & 688759 & 4.6 & 4.8324 & TST & \\
\hline CHEMBL1597128 & 688759 & 4.45 & 4.5998 & TRN & \\
\hline CHEMBL3216363 & 688759 & 5.15 & 5.0952 & TRN & \\
\hline CHEMBL555689 & 688759 & 5.9 & 5.5902 & TRN & \\
\hline CHEMBL1596224 & 688759 & 4.45 & 4.8318 & TRN & \\
\hline CHEMBL3190295 & 688759 & 4.65 & 4.7539 & TRN & \\
\hline CHEMBL1407969 & 688759 & 4.5 & 4.5795 & TRN & \\
\hline CHEMBL3196490 & 688759 & 4.85 & 4.7481 & TRN & \\
\hline CHEMBL3391864 & 688759 & 5.4 & 5.0034 & TRN & \\
\hline CHEMBL1529946 & 688759 & 5.4 & 4.8207 & TST & \\
\hline CHEMBL1463884 & 688759 & 4.75 & 4.5696 & TST & \\
\hline CHEMBL1480734 & 688759 & 5.15 & 4.9805 & TRN & \\
\hline CHEMBL1582990 & 688759 & 4.85 & 5.0799 & TRN & \\
\hline CHEMBL3198714 & 688759 & 4.45 & 4.4954 & TRN & \\
\hline CHEMBL3199041 & 688759 & 4.75 & 4.9547 & TRN & \\
\hline
\end{tabular}




\begin{tabular}{|c|c|c|c|c|}
\hline \multicolumn{5}{|c|}{ Supplemental Table } \\
\hline CHEMBL1418347 & 688759 & 4.95 & 5.0145 & TRN \\
\hline CHEMBL1584128 & 688759 & 5.2 & 5.0005 & TRN \\
\hline CHEMBL1572910 & 688759 & 5.4 & 5.0416 & TRN \\
\hline CHEMBL1568919 & 688759 & 4.65 & 4.5759 & TRN \\
\hline CHEMBL3198417 & 688759 & 6.25 & 5.2939 & TRN \\
\hline CHEMBL1445424 & 688759 & 4.45 & 4.7515 & TRN \\
\hline CHEMBL584759 & 688759 & 6.0 & 5.6846 & TRN \\
\hline CHEMBL3197486 & 688759 & 4.45 & 4.9617 & TRN \\
\hline CHEMBL1308199 & 688759 & 5.15 & 4.7981 & TRN \\
\hline CHEMBL1585127 & 688759 & 6.8 & 5.4826 & TRN \\
\hline CHEMBL1440952 & 688759 & 6.0 & 5.6801 & TRN \\
\hline CHEMBL590947 & 688759 & 4.45 & 4.9867 & TRN \\
\hline CHEMBL1381722 & 688759 & 4.65 & 4.7954 & TRN \\
\hline CHEMBL1492739 & 688759 & 4.45 & 4.8962 & TRN \\
\hline CHEMBL1535318 & 688759 & 5.9 & 5.6819 & TRN \\
\hline CHEMBL1341961 & 688759 & 4.45 & 4.871 & TRN \\
\hline CHEMBL1371904 & 688759 & 4.6 & 4.6525 & TST \\
\hline CHEMBL3212972 & 688759 & 5.3 & 4.9995 & TRN \\
\hline CHEMBL1549794 & 688759 & 4.45 & 4.756 & TST \\
\hline CHEMBL1084441 & 688759 & 4.8 & 4.7922 & TRN \\
\hline CHEMBL34704 & 688759 & 4.45 & 4.6406 & TST \\
\hline CHEMBL1565483 & 688759 & 4.45 & 4.7272 & TRN \\
\hline CHEMBL1549418 & 688759 & 4.65 & 4.9341 & TST \\
\hline CHEMBL1588296 & 688759 & 4.45 & 4.794 & TRN \\
\hline CHEMBL1537461 & 688759 & 4.9 & 4.8433 & TRN \\
\hline CHEMBL1419914 & 688759 & 5.25 & 4.9738 & TST \\
\hline CHEMBL1486033 & 688759 & 4.85 & 4.7692 & TST \\
\hline CHEMBL1320404 & 688759 & 4.45 & 5.0127 & TRN \\
\hline CHEMBL1980226 & 688759 & 5.55 & 5.4416 & TRN \\
\hline CHEMBL1347093 & 688759 & 5.8 & 5.5544 & TST \\
\hline CHEMBL1422442 & 688759 & 4.95 & 4.918 & TRN \\
\hline CHEMBL1489071 & 688759 & 5.9 & 5.572 & TRN \\
\hline CHEMBL1983939 & 688759 & 5.55 & 5.1602 & TRN \\
\hline CHEMBL1448213 & 688759 & 4.9 & 5.0876 & TRN \\
\hline CHEMBL1421017 & 688759 & 4.85 & 4.7547 & TRN \\
\hline CHEMBL1589010 & 688759 & 4.6 & 4.9152 & TST \\
\hline CHEMBL1414265 & 688759 & 5.4 & 5.0101 & TST \\
\hline CHEMBL1607142 & 688759 & 5.1 & 4.9792 & TST \\
\hline CHEMBL1585758 & 688759 & 5.9 & 5.3613 & TRN \\
\hline CHEMBL1553265 & 688759 & 5.0 & 5.0865 & TRN \\
\hline CHEMBL1486939 & 688759 & 4.95 & 5.1561 & TRN \\
\hline CHEMBL1421604 & 688759 & 4.45 & 4.7757 & TST \\
\hline CHEMBL1369220 & 688759 & 4.85 & 4.7865 & TRN \\
\hline CHEMBL3191314 & 688759 & 4.9 & 4.9626 & TST \\
\hline CHEMBL1558090 & 688759 & 5.15 & 5.0422 & TRN \\
\hline CHEMBL1566486 & 688759 & 4.9 & 5.2734 & TRN \\
\hline CHEMBL1984454 & 688759 & 4.6 & 5.2981 & TST \\
\hline CHEMBL3189477 & 688759 & 4.95 & 5.0618 & TRN \\
\hline
\end{tabular}




\begin{tabular}{|c|c|c|c|c|c|}
\hline \multicolumn{6}{|c|}{ Supplemental Table s2.txt } \\
\hline CHEMBL1405914 & 688759 & 5.0 & 5.0266 & TRN & \\
\hline CHEMBL1389495 & 688759 & 5.65 & 5.7012 & TRN & \\
\hline CHEMBL1412794 & 688759 & 6.25 & 4.9037 & TST & \\
\hline CHEMBL1342145 & 688759 & 4.65 & 5.0333 & TST & \\
\hline CHEMBL1450753 & 688759 & 5.15 & 5.2532 & TRN & \\
\hline CHEMBL1523620 & 688759 & 4.45 & 4.8811 & TRN & \\
\hline CHEMBL1410577 & 688759 & 4.75 & 5.1726 & TRN & \\
\hline CHEMBL1598685 & 688759 & 6.1 & 5.3081 & TRN & \\
\hline CHEMBL1448137 & 688759 & 4.45 & 4.8066 & TRN & \\
\hline CHEMBL1343932 & 688759 & 4.45 & 4.7416 & TRN & \\
\hline CHEMBL1421614 & 688759 & 5.0 & 5.2758 & TRN & \\
\hline CHEMBL3199855 & 688759 & 6.0 & 5.4533 & TRN & \\
\hline CHEMBL1421987 & 688759 & 5.2 & 4.8497 & TST & \\
\hline CHEMBL1454593 & 688759 & 4.7 & 4.8592 & TRN & \\
\hline CHEMBL1570037 & 688759 & 4.95 & 4.9713 & TRN & \\
\hline CHEMBL1497295 & 688759 & 5.0 & 5.0082 & TRN & \\
\hline CHEMBL3189162 & 688759 & 4.45 & 4.7668 & TRN & \\
\hline CHEMBL1523293 & 688759 & 4.45 & 4.8638 & TRN & \\
\hline CHEMBL1346824 & 688759 & 4.45 & 4.574 & TST & \\
\hline CHEMBL3212099 & 688759 & 5.15 & 4.9213 & TRN & \\
\hline CHEMBL3191308 & 688759 & 6.0 & 5.9514 & TRN & \\
\hline CHEMBL3189632 & 688759 & 5.1 & 5.3671 & TRN & \\
\hline CHEMBL1453900 & 688759 & 5.95 & 5.8836 & TRN & \\
\hline CHEMBL1566023 & 688759 & 5.45 & 5.4326 & TRN & \\
\hline CHEMBL611207 & 688759 & 4.45 & 4.9869 & TST & \\
\hline CHEMBL3198642 & 688759 & 4.45 & 4.7133 & TRN & \\
\hline CHEMBL1571290 & 688759 & 6.0 & 5.2636 & TRN & \\
\hline CHEMBL1392102 & 688759 & 5.75 & 5.3335 & TRN & \\
\hline CHEMBL1533422 & 688759 & 6.1 & 5.6948 & TRN & \\
\hline CHEMBL1515004 & 688759 & 5.2 & 4.72199 & 99999999995 & TRN \\
\hline CHEMBL1367421 & 688759 & 4.9 & 5.0292 & TRN & \\
\hline CHEMBL3213690 & 688759 & 4.7 & 5.0794 & TRN & \\
\hline CHEMBL1385841 & 688759 & 4.7 & 4.8427 & TST & \\
\hline CHEMBL1374367 & 688759 & 5.25 & 5.1288 & TST & \\
\hline CHEMBL1427265 & 688759 & 4.95 & 4.9746 & TRN & \\
\hline CHEMBL3211092 & 688759 & 4.75 & 5.3893 & TRN & \\
\hline CHEMBL1526370 & 688759 & 6.1 & 5.6735 & TRN & \\
\hline CHEMBL1994034 & 688759 & 4.9 & 5.19799 & 99999999995 & TRN \\
\hline CHEMBL1305741 & 688759 & 4.6 & 4.8528 & TRN & \\
\hline CHEMBL1553256 & 688759 & 4.6 & 4.834 & TST & \\
\hline CHEMBL3196535 & 688759 & 4.85 & 5.0791 & TRN & \\
\hline CHEMBL1421754 & 688759 & 4.45 & 4.9313 & TRN & \\
\hline CHEMBL1442742 & 688759 & 4.9 & 4.5131 & TST & \\
\hline CHEMBL1348618 & 688759 & 4.45 & 5.2398 & TST & \\
\hline CHEMBL1503124 & 688759 & 5.6 & 6.1578 & TRN & \\
\hline CHEMBL1439119 & 688759 & 5.0 & 4.8597 & TRN & \\
\hline CHEMBL1388358 & 688759 & 4.9 & 4.7538 & TRN & \\
\hline CHEMBL1401755 & 688759 & 5.15 & 5.0844 & TRN & \\
\hline
\end{tabular}




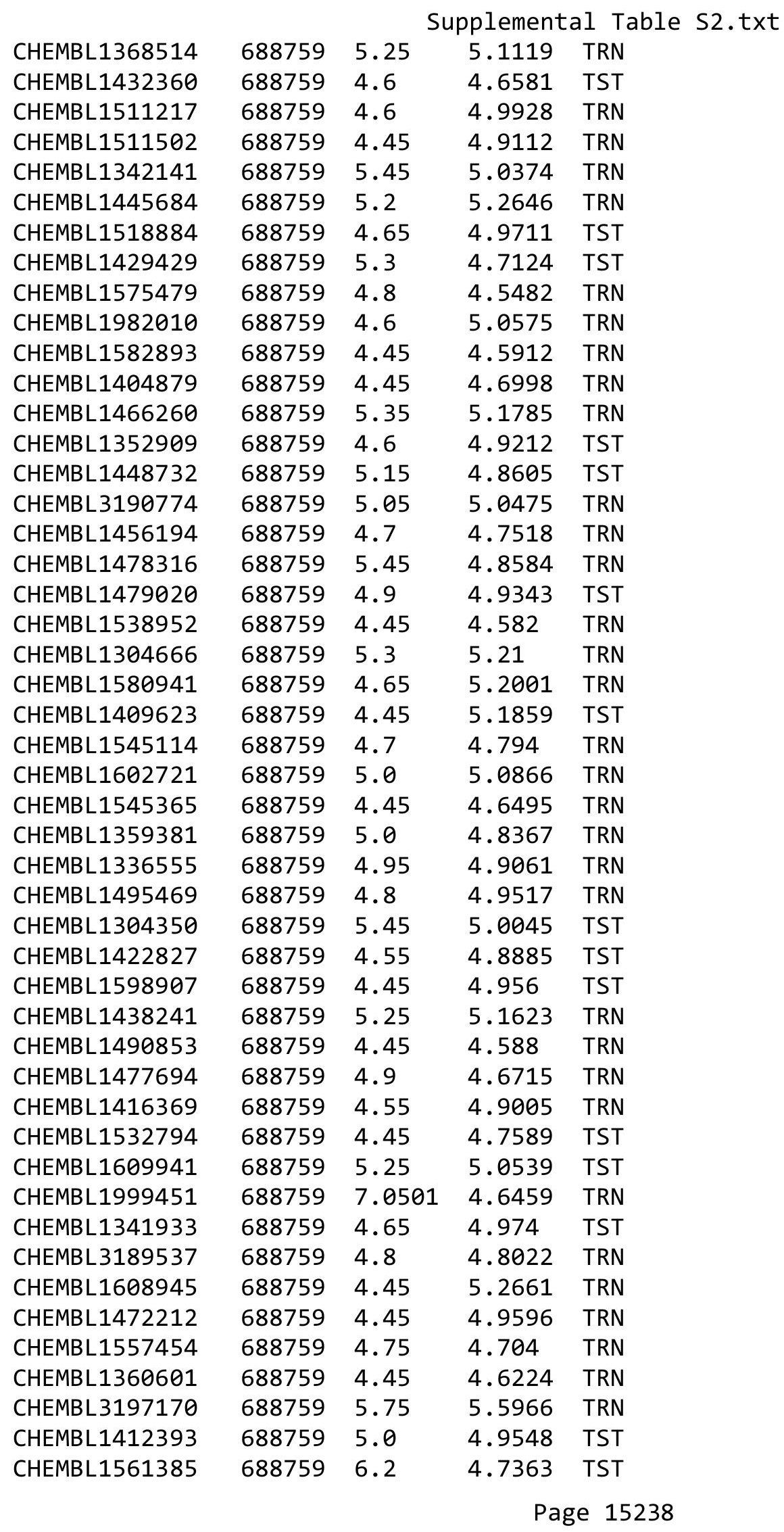




\begin{tabular}{|c|c|c|c|c|c|}
\hline \multicolumn{6}{|c|}{ Supplemental Table S2.txt } \\
\hline CHEMBL1454186 & 688759 & 5.85 & 5.9351 & TRN & \\
\hline CHEMBL1429338 & 688759 & 4.45 & 4.9178 & TST & \\
\hline CHEMBL1492712 & 688759 & 7.5003 & 4.8844 & TRN & \\
\hline CHEMBL1530581 & 688759 & 6.0 & 5.444 & TRN & \\
\hline CHEMBL1351052 & 688759 & 5.1 & 4.9918 & TST & \\
\hline CHEMBL1568827 & 688759 & 5.0 & 4.9993 & TST & \\
\hline CHEMBL1304988 & 688759 & 4.6 & 4.8495 & TRN & \\
\hline CHEMBL1336312 & 688759 & 4.95 & 5.0163 & TRN & \\
\hline CHEMBL1388639 & 688759 & 6.0 & 5.0895 & TRN & \\
\hline CHEMBL1537930 & 688759 & 4.65 & 4.8244 & TRN & \\
\hline CHEMBL1299411 & 688759 & 4.45 & 4.4989 & TRN & \\
\hline CHEMBL1509824 & 688759 & 5.35 & 5.1575 & TRN & \\
\hline CHEMBL1547164 & 688759 & 4.45 & 4.529 & TRN & \\
\hline CHEMBL1343804 & 688759 & 4.45 & 4.5415 & TRN & \\
\hline CHEMBL1408512 & 688759 & 5.5 & 5.1212 & TRN & \\
\hline CHEMBL1331018 & 688759 & 4.45 & 4.8053 & TRN & \\
\hline CHEMBL1969232 & 688759 & 4.45 & 5.2891 & TRN & \\
\hline CHEMBL 2369236 & 688759 & 4.45 & 4.9372 & TRN & \\
\hline CHEMBL1366559 & 688759 & 5.95 & 4.8538 & TRN & \\
\hline CHEMBL3194202 & 688759 & 5.45 & 5.20200 & 0000000001 & TRN \\
\hline CHEMBL1491378 & 688759 & 5.3 & 5.2574 & TRN & \\
\hline CHEMBL3197044 & 688759 & 5.2 & 4.7237 & TRN & \\
\hline CHEMBL1299217 & 688759 & 4.45 & 4.6121 & TRN & \\
\hline CHEMBL1582831 & 688759 & 5.3 & 5.6135 & TRN & \\
\hline CHEMBL1546693 & 688759 & 5.9 & 5.3235 & TRN & \\
\hline CHEMBL1507372 & 688759 & 4.45 & 4.9158 & TRN & \\
\hline CHEMBL1583947 & 688759 & 5.15 & 4.8755 & TRN & \\
\hline CHEMBL1353497 & 688759 & 5.7 & 5.2579 & TRN & \\
\hline CHEMBL1420572 & 688759 & 8.3468 & 4.9978 & TST & \\
\hline CHEMBL1994257 & 688759 & 5.25 & 4.9837 & TRN & \\
\hline CHEMBL411085 & 688759 & 4.7 & 4.5481 & TRN & \\
\hline CHEMBL3197336 & 688759 & 5.3 & 5.5786 & TRN & \\
\hline CHEMBL1511175 & 688759 & 4.95 & 5.0317 & TRN & \\
\hline CHEMBL1442201 & 688759 & 5.35 & 4.9883 & TRN & \\
\hline CHEMBL1537656 & 688759 & 4.45 & 4.84699 & 99999999995 & TST \\
\hline CHEMBL1482438 & 688759 & 4.6 & 5.1153 & TRN & \\
\hline CHEMBL1597815 & 688759 & 4.95 & 4.9553 & TRN & \\
\hline CHEMBL1310744 & 688759 & 4.45 & 4.8111 & TRN & \\
\hline CHEMBL1462874 & 688759 & 6.8 & 4.8778 & TRN & \\
\hline CHEMBL407491 & 688759 & 6.3 & 5.8965 & TRN & \\
\hline CHEMBL 2297588 & 688759 & 4.8 & 5.0085 & TST & \\
\hline CHEMBL1581795 & 688759 & 4.65 & 4.5282 & TRN & \\
\hline CHEMBL1332107 & 688759 & 5.05 & 4.8456 & TRN & \\
\hline CHEMBL1597343 & 688759 & 4.9 & 4.8625 & TRN & \\
\hline CHEMBL1334792 & 688759 & 4.75 & 4.9976 & TRN & \\
\hline CHEMBL1310338 & 688759 & 4.95 & 5.0865 & TRN & \\
\hline CHEMBL1600326 & 688759 & 4.45 & 4.9275 & TST & \\
\hline CHEMBL3193769 & 688759 & 4.75 & 4.703 & TRN & \\
\hline
\end{tabular}




\begin{tabular}{|c|c|c|c|c|c|}
\hline \multicolumn{6}{|c|}{ Supplemental Table S2.txt } \\
\hline CHEMBL1332088 & 688759 & 4.9 & 4.7661 & TRN & \\
\hline CHEMBL1511922 & 688759 & 4.85 & 5.1895 & TRN & \\
\hline CHEMBL1320591 & 688759 & 5.15 & 4.9392 & TRN & \\
\hline CHEMBL1573859 & 688759 & 6.0 & 4.8898 & TST & \\
\hline CHEMBL1465276 & 688759 & 6.2 & 5.7138 & TST & \\
\hline CHEMBL1372635 & 688759 & 6.2 & 4.8473 & TRN & \\
\hline CHEMBL1563827 & 688759 & 4.7 & 4.6949 & TST & \\
\hline CHEMBL1350223 & 688759 & 4.85 & 4.6542 & TRN & \\
\hline CHEMBL1531298 & 688759 & 4.65 & 4.7435 & TST & \\
\hline CHEMBL1365700 & 688759 & 5.4 & 4.9044 & TST & \\
\hline CHEMBL1574550 & 688759 & 8.3468 & 4.9472 & TST & \\
\hline CHEMBL1330039 & 688759 & 4.45 & 5.0479 & TST & \\
\hline CHEMBL1409229 & 688759 & 4.8 & 5.1457 & TRN & \\
\hline CHEMBL3198061 & 688759 & 4.45 & $4.5280 €$ & 00000000005 & TST \\
\hline CHEMBL1510044 & 688759 & 5.6 & 5.2082 & TRN & \\
\hline CHEMBL1540815 & 688759 & 4.45 & 5.0305 & TRN & \\
\hline CHEMBL1392821 & 688759 & 5.9 & 5.7679 & TRN & \\
\hline CHEMBL1403980 & 688759 & 4.6 & 5.0072 & TRN & \\
\hline CHEMBL 1350757 & 688759 & 4.5 & 4.6812 & TRN & \\
\hline CHEMBL1572132 & 688759 & 4.45 & 4.9532 & TST & \\
\hline CHEMBL612129 & 688759 & 5.5 & 5.347 & TST & \\
\hline CHEMBL1538779 & 688759 & 4.45 & $5.0710 €$ & 0000000001 & TRN \\
\hline CHEMBL 3145363 & 688759 & 5.8 & 5.8756 & TRN & \\
\hline CHEMBL1406807 & 688759 & 4.45 & 4.8782 & TRN & \\
\hline CHEMBL1510598 & 688759 & 5.55 & 5.3569 & TRN & \\
\hline CHEMBL1497286 & 688759 & 4.95 & 4.7981 & TRN & \\
\hline CHEMBL1406560 & 688759 & 4.45 & 4.925 & TST & \\
\hline CHEMBL1390636 & 688759 & 4.55 & 4.5738 & TRN & \\
\hline CHEMBL 1458812 & 688759 & 4.45 & 4.7499 & TST & \\
\hline CHEMBL1476869 & 688759 & 4.5 & 4.8963 & TST & \\
\hline CHEMBL1470745 & 688759 & 5.15 & 4.8282 & TST & \\
\hline CHEMBL1379970 & 688759 & 6.5 & 5.3076 & TRN & \\
\hline CHEMBL1349431 & 688759 & 4.45 & 4.9067 & TST & \\
\hline CHEMBL1486883 & 688759 & 4.85 & 4.7238 & TST & \\
\hline CHEMBL1584505 & 688759 & 4.65 & 4.4851 & TRN & \\
\hline CHEMBL1504587 & 688759 & 6.25 & 4.9129 & TST & \\
\hline CHEMBL1471658 & 688759 & 5.0 & 4.9154 & TRN & \\
\hline CHEMBL3192164 & 688759 & 4.45 & 5.0034 & TRN & \\
\hline CHEMBL1377633 & 688759 & 6.5 & 6.2418 & TRN & \\
\hline CHEMBL1588873 & 688759 & 5.75 & 5.8487 & TRN & \\
\hline CHEMBL1441811 & 688759 & 4.45 & 5.0324 & TRN & \\
\hline CHEMBL1501682 & 688759 & 5.2 & 5.1081 & TRN & \\
\hline CHEMBL1563176 & 688759 & 4.45 & 4.5965 & TRN & \\
\hline CHEMBL1324043 & 688759 & 5.35 & 5.0661 & TRN & \\
\hline CHEMBL1460715 & 688759 & 5.3 & 4.8366 & TRN & \\
\hline CHEMBL1522758 & 688759 & 4.95 & 4.6811 & TRN & \\
\hline CHEMBL1303357 & 688759 & 4.8 & 4.6075 & TRN & \\
\hline CHEMBL1509665 & 688759 & 4.6 & 4.7778 & TRN & \\
\hline
\end{tabular}




\begin{tabular}{|c|c|c|c|c|}
\hline \multicolumn{5}{|c|}{ Supplemental Table S2.txt } \\
\hline CHEMBL1519607 & 688759 & 4.45 & 5.4422 & TRN \\
\hline CHEMBL1544212 & 688759 & 4.65 & 4.9492 & TRN \\
\hline CHEMBL1997112 & 688759 & 4.65 & 4.8191 & TST \\
\hline CHEMBL1427279 & 688759 & 5.55 & 5.2688 & TRN \\
\hline CHEMBL1377415 & 688759 & 4.8 & 5.0862 & TRN \\
\hline CHEMBL1449028 & 688759 & 4.7 & 4.9664 & TST \\
\hline CHEMBL1414009 & 688759 & 4.45 & 4.6589 & TRN \\
\hline CHEMBL1372514 & 688759 & 4.8 & 4.9489 & TRN \\
\hline CHEMBL1439288 & 688759 & 4.45 & 5.0319 & TST \\
\hline CHEMBL1427821 & 688759 & 4.45 & 4.8012 & TRN \\
\hline CHEMBL1448969 & 688759 & 4.45 & 5.0209 & TST \\
\hline CHEMBL1489411 & 688759 & 4.75 & 4.7017 & TST \\
\hline CHEMBL1544389 & 688759 & 4.6 & 4.8247 & TST \\
\hline CHEMBL1505577 & 688759 & 4.45 & 4.7813 & TRN \\
\hline CHEMBL1576070 & 688759 & 4.45 & 4.8622 & TST \\
\hline CHEMBL1309540 & 688759 & 4.7 & 4.8704 & TRN \\
\hline CHEMBL1363275 & 688759 & 4.45 & 4.5504 & TRN \\
\hline CHEMBL1328148 & 688759 & 5.55 & 4.8565 & TST \\
\hline CHEMBL1538493 & 688759 & 4.9 & 5.0209 & TRN \\
\hline CHEMBL1343229 & 688759 & 4.45 & 4.7356 & TST \\
\hline CHEMBL1608776 & 688759 & 5.1 & 4.919 & TST \\
\hline CHEMBL1345991 & 688759 & 5.6 & 5.8464 & TRN \\
\hline CHEMBL1482357 & 688759 & 6.25 & 4.9376 & TRN \\
\hline CHEMBL1437421 & 688759 & 5.2 & 5.0899 & TRN \\
\hline CHEMBL1601973 & 688759 & 5.2 & 5.0986 & TRN \\
\hline CHEMBL 3197120 & 688759 & 5.35 & 5.0494 & TRN \\
\hline CHEMBL1503333 & 688759 & 5.25 & 5.2071 & TRN \\
\hline CHEMBL1494637 & 688759 & 4.45 & 4.7357 & TRN \\
\hline CHEMBL1430309 & 688759 & 4.45 & 4.7496 & TST \\
\hline CHEMBL1340220 & 688759 & 6.0 & 4.8735 & TRN \\
\hline CHEMBL1570064 & 688759 & 4.9 & 4.7586 & TST \\
\hline CHEMBL1305853 & 688759 & 5.2 & 4.8628 & TRN \\
\hline CHEMBL1557890 & 688759 & 4.75 & 4.8443 & TST \\
\hline CHEMBL 3195814 & 688759 & 4.9 & 4.7472 & TST \\
\hline CHEMBL1989234 & 688759 & 4.8 & 4.8788 & TST \\
\hline CHEMBL1520311 & 688759 & 5.4 & 5.5778 & TRN \\
\hline CHEMBL1444133 & 688759 & 5.1 & 4.7919 & TRN \\
\hline CHEMBL1508616 & 688759 & 6.25 & 6.1373 & TRN \\
\hline CHEMBL1991234 & 688759 & 4.8 & 5.3734 & TST \\
\hline CHEMBL1403436 & 688759 & 4.9 & 4.8014 & TST \\
\hline CHEMBL1388059 & 688759 & 6.1 & 4.7495 & TST \\
\hline CHEMBL 1539400 & 688759 & 5.2 & 5.4287 & TRN \\
\hline CHEMBL1416026 & 688759 & 4.6 & 4.7188 & TRN \\
\hline CHEMBL1599252 & 688759 & 4.65 & 4.7376 & TRN \\
\hline CHEMBL1338885 & 688759 & 4.7 & 4.7303 & TRN \\
\hline CHEMBL546493 & 688759 & 5.1 & 4.6957 & TRN \\
\hline CHEMBL1497656 & 688759 & 4.6 & 4.8701 & TRN \\
\hline CHEMBL601135 & 688759 & 4.65 & 4.6382 & TRN \\
\hline
\end{tabular}




\begin{tabular}{|c|c|c|c|c|c|}
\hline & & \multicolumn{4}{|c|}{ Supplemental Table S2.txt } \\
\hline CHEMBL1460929 & 688759 & 4.75 & 4.6543 & TST & \\
\hline CHEMBL1598292 & 688759 & 6.2 & 4.8512 & TST & \\
\hline CHEMBL1341103 & 688759 & 5.0 & 4.985 & TRN & \\
\hline CHEMBL1327789 & 688759 & 4.65 & 4.8136 & TRN & \\
\hline CHEMBL1570495 & 688759 & 5.15 & 5.1783 & TRN & \\
\hline CHEMBL1447404 & 688759 & 4.45 & 4.7187 & TRN & \\
\hline CHEMBL1555271 & 688759 & 5.35 & 5.4706 & TRN & \\
\hline CHEMBL1552997 & 688759 & 4.45 & 4.599 & TST & \\
\hline CHEMBL1533279 & 688759 & 5.4 & 5.0879 & TRN & \\
\hline CHEMBL1578466 & 688759 & 4.75 & 4.5682 & TRN & \\
\hline CHEMBL117 & 688759 & 6.0 & 5.4793 & TRN & \\
\hline CHEMBL1305841 & 688759 & 5.15 & 4.7866 & TRN & \\
\hline CHEMBL1534492 & 688759 & 4.95 & 5.0139 & TRN & \\
\hline CHEMBL1378143 & 688759 & 4.45 & 4.7997 & TRN & \\
\hline CHEMBL1511784 & 688759 & 5.2 & 4.8958 & TRN & \\
\hline CHEMBL1330435 & 688759 & 4.65 & 4.6006 & TST & \\
\hline CHEMBL1412664 & 688759 & 4.5 & 4.4756 & TRN & \\
\hline CHEMBL1326083 & 688759 & 6.1 & 5.5477 & TRN & \\
\hline CHEMBL1351213 & 688759 & 6.15 & 5.0512 & TRN & \\
\hline CHEMBL1320263 & 688759 & 4.45 & 4.88899 & 9999999999 & TRN \\
\hline CHEMBL90290 & 688759 & 4.6 & 4.5438 & TRN & \\
\hline CHEMBL1517513 & 688759 & 5.5 & 4.8981 & TST & \\
\hline CHEMBL1429567 & 688759 & 4.6 & 4.8563 & TRN & \\
\hline CHEMBL3191198 & 688759 & 5.15 & 4.8833 & TRN & \\
\hline CHEMBL1547516 & 688759 & 4.9 & 4.6516 & TRN & \\
\hline CHEMBL1403323 & 688759 & 5.0 & 5.4292 & TRN & \\
\hline CHEMBL1506510 & 688759 & 4.45 & 4.8631 & TRN & \\
\hline CHEMBL1469224 & 688759 & 4.65 & 4.824 & TST & \\
\hline CHEMBL1492859 & 688759 & 4.45 & 4.7958 & TST & \\
\hline CHEMBL1375888 & 688759 & 4.5 & 4.4844 & TRN & \\
\hline CHEMBL1378510 & 688759 & 4.65 & 4.9618 & TST & \\
\hline CHEMBL1978671 & 688759 & 4.45 & 4.762 & TRN & \\
\hline CHEMBL1520413 & 688759 & 4.85 & 4.9983 & TST & \\
\hline CHEMBL1420020 & 688759 & 4.45 & 4.627 & TST & \\
\hline CHEMBL1892270 & 688759 & 5.2 & 5.0982 & TRN & \\
\hline CHEMBL1343424 & 688759 & 4.45 & 4.8687 & TRN & \\
\hline CHEMBL1459626 & 688759 & 4.45 & 4.827 & TRN & \\
\hline CHEMBL1549093 & 688759 & 4.45 & 4.8178 & TRN & \\
\hline CHEMBL3191675 & 688759 & 4.75 & 4.7618 & TST & \\
\hline CHEMBL3192122 & 688759 & 5.1 & 4.6787 & TST & \\
\hline CHEMBL1375975 & 688759 & 4.65 & 4.7213 & TRN & \\
\hline CHEMBL1608865 & 688759 & 4.45 & 4.7361 & TRN & \\
\hline CHEMBL1996757 & 688759 & 5.5 & 5.4776 & TRN & \\
\hline CHEMBL3196218 & 688759 & 5.1 & 4.9394 & TRN & \\
\hline CHEMBL1377468 & 688759 & 5.0 & 4.8756 & TST & \\
\hline CHEMBL1475791 & 688759 & 4.65 & 4.612 & TST & \\
\hline CHEMBL1335383 & 688759 & 5.4 & 5.393 & TST & \\
\hline CHEMBL3198350 & 688759 & 4.65 & 5.0862 & TRN & \\
\hline
\end{tabular}




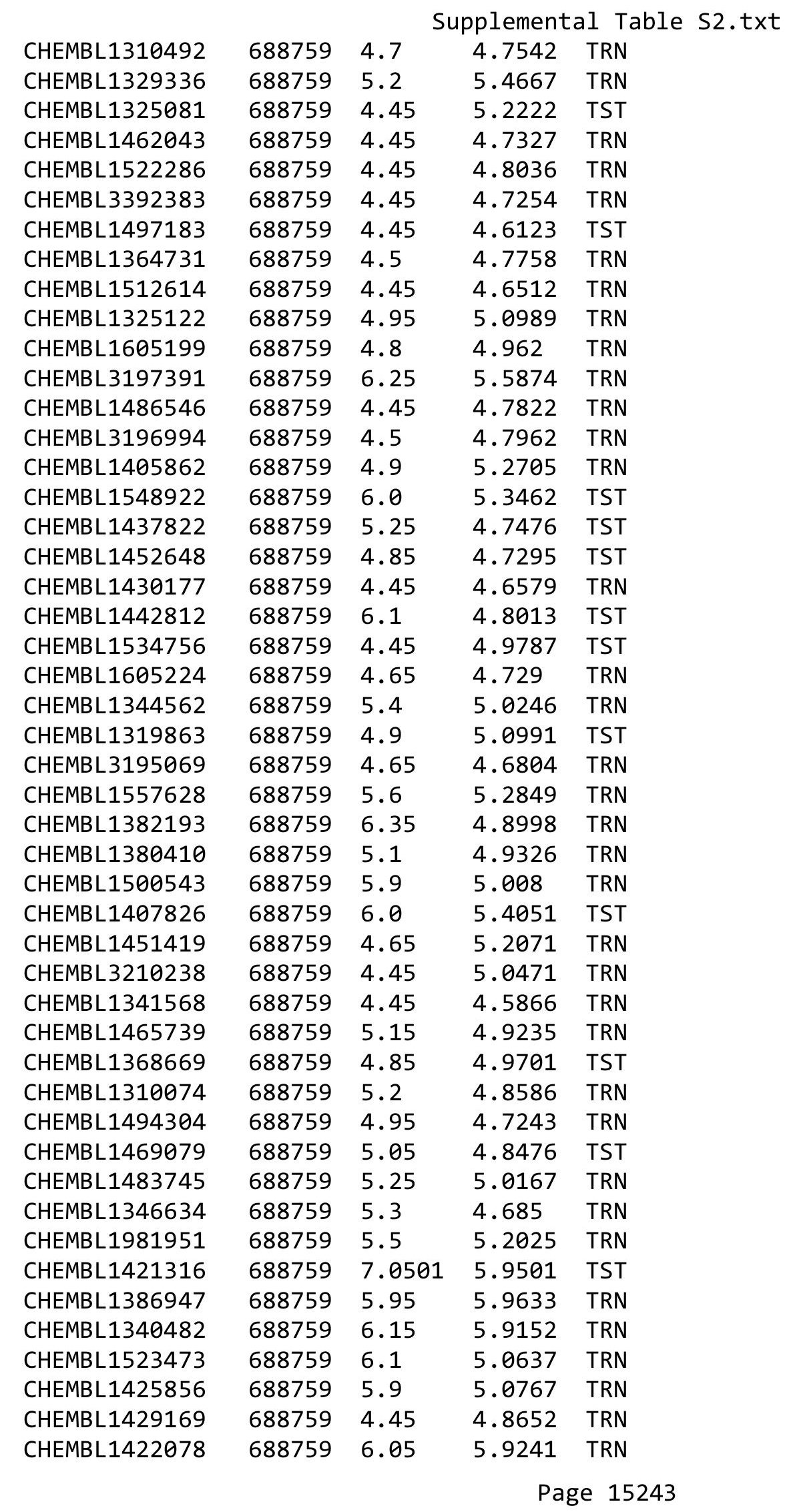




\begin{tabular}{|c|c|c|c|c|}
\hline \multicolumn{5}{|c|}{ Supplemental Table S2.txt } \\
\hline CHEMBL1966753 & 688759 & 4.95 & 4.7399 & TRN \\
\hline CHEMBL1418620 & 688759 & 4.45 & 4.6872 & TRN \\
\hline CHEMBL1365670 & 688759 & 5.05 & 5.1827 & TRN \\
\hline CHEMBL1389886 & 688759 & 4.65 & 4.5319 & TRN \\
\hline CHEMBL1453439 & 688759 & 4.95 & 4.8544 & TST \\
\hline CHEMBL3194133 & 688759 & 4.45 & 4.5259 & TRN \\
\hline CHEMBL1377048 & 688759 & 4.9 & 4.7751 & TRN \\
\hline CHEMBL1499856 & 688759 & 6.25 & 5.0569 & TRN \\
\hline CHEMBL469036 & 688759 & 4.65 & 4.7965 & TST \\
\hline CHEMBL1526057 & 688759 & 5.55 & 4.7958 & TRN \\
\hline CHEMBL1563650 & 688759 & 5.5 & 4.4383 & TRN \\
\hline CHEMBL1467455 & 688759 & 4.45 & 4.7103 & TRN \\
\hline CHEMBL1581788 & 688759 & 4.45 & 4.9201 & TST \\
\hline CHEMBL1357562 & 688759 & 4.95 & 5.1477 & TRN \\
\hline CHEMBL1818881 & 688759 & 4.65 & 4.7781 & TRN \\
\hline CHEMBL1312574 & 688759 & 5.2 & 5.2086 & TRN \\
\hline CHEMBL3198540 & 688759 & 6.8 & 5.4487 & TRN \\
\hline CHEMBL1418299 & 688759 & 4.55 & 4.8396 & TST \\
\hline CHEMBL1598676 & 688759 & 4.6 & 4.792 & TRN \\
\hline CHEMBL1449349 & 688759 & 5.3 & 5.0107 & TRN \\
\hline CHEMBL1558210 & 688759 & 5.4 & 5.1066 & TST \\
\hline CHEMBL1382565 & 688759 & 4.65 & 4.8752 & TST \\
\hline CHEMBL1415500 & 688759 & 4.65 & 4.8752 & TRN \\
\hline CHEMBL1334314 & 688759 & 5.25 & 4.8766 & TST \\
\hline CHEMBL1407196 & 688759 & 4.45 & 4.6786 & TRN \\
\hline CHEMBL1330342 & 688759 & 5.2 & 4.9127 & TRN \\
\hline CHEMBL1549399 & 688759 & 6.0 & 5.693 & TRN \\
\hline CHEMBL1457301 & 688759 & 4.8 & 5.2314 & TRN \\
\hline CHEMBL1301123 & 688759 & 4.45 & 4.9681 & TST \\
\hline CHEMBL1482670 & 688759 & 4.9 & 4.8802 & TRN \\
\hline CHEMBL1421507 & 688759 & 5.3 & 4.7858 & TRN \\
\hline CHEMBL3189539 & 688759 & 4.45 & 4.6525 & TRN \\
\hline CHEMBL1542491 & 688759 & 4.65 & 4.8608 & TST \\
\hline CHEMBL1561096 & 688759 & 5.3 & 4.9858 & TRN \\
\hline CHEMBL1567962 & 688759 & 5.55 & 4.8541 & TST \\
\hline CHEMBL1428050 & 688759 & 4.65 & 5.0748 & TRN \\
\hline CHEMBL1499747 & 688759 & 4.9 & 5.0566 & TRN \\
\hline CHEMBL1459069 & 688759 & 4.7 & 4.4896 & TRN \\
\hline CHEMBL1598371 & 688759 & 4.45 & 4.5738 & TRN \\
\hline CHEMBL1417496 & 688759 & 4.45 & 4.6152 & TRN \\
\hline CHEMBL1526799 & 688759 & 5.3 & 5.245 & TRN \\
\hline CHEMBL1451817 & 688759 & 5.4 & 5.1147 & TRN \\
\hline CHEMBL1548533 & 688759 & 4.45 & 4.6884 & TRN \\
\hline CHEMBL3214434 & 688759 & 5.35 & 4.9668 & TST \\
\hline CHEMBL1353516 & 688759 & 4.45 & 4.7569 & TRN \\
\hline CHEMBL1492553 & 688759 & 4.45 & 4.8331 & TRN \\
\hline CHEMBL1418957 & 688759 & 4.7 & 4.8142 & TST \\
\hline CHEMBL1415497 & 688759 & 4.45 & 4.6536 & TRN \\
\hline
\end{tabular}




\begin{tabular}{|c|c|c|c|c|c|}
\hline \multicolumn{6}{|c|}{ Supplemental Table s2.txt } \\
\hline CHEMBL 2004157 & 688759 & 4.45 & 4.8088 & TRN & \\
\hline CHEMBL1597967 & 688759 & 4.45 & 4.6102 & TRN & \\
\hline CHEMBL1425826 & 688759 & 5.0 & 5.0545 & TRN & \\
\hline CHEMBL1380087 & 688759 & 5.35 & 4.8491 & TST & \\
\hline CHEMBL1375731 & 688759 & 4.45 & 4.7685 & TRN & \\
\hline CHEMBL1560290 & 688759 & 4.7 & 4.6943 & TRN & \\
\hline CHEMBL1467170 & 688759 & 4.45 & 4.6823 & TRN & \\
\hline CHEMBL1300592 & 688759 & 4.65 & 4.6256 & TST & \\
\hline CHEMBL1596277 & 688759 & 5.05 & 4.8654 & TRN & \\
\hline CHEMBL1479749 & 688759 & 4.9 & 4.9851 & TST & \\
\hline CHEMBL1509473 & 688759 & 5.0 & 5.2546 & TRN & \\
\hline CHEMBL1383892 & 688759 & 4.9 & 4.9713 & TRN & \\
\hline CHEMBL1549676 & 688759 & 5.8 & 4.805 & TRN & \\
\hline CHEMBL 3196257 & 688759 & 6.05 & 5.5692 & TRN & \\
\hline CHEMBL1427291 & 688759 & 5.15 & 5.0132 & TRN & \\
\hline CHEMBL1589283 & 688759 & 4.8 & 4.7951 & TRN & \\
\hline CHEMBL1554982 & 688759 & 4.45 & 4.8872 & TST & \\
\hline CHEMBL3213980 & 688759 & 5.2 & 4.8074 & TST & \\
\hline CHEMBL1371603 & 688759 & 4.7 & 4.5176 & TST & \\
\hline CHEMBL1481850 & 688759 & 5.25 & 4.6364 & TST & \\
\hline CHEMBL1985575 & 688759 & 6.6499 & 4.9392 & TRN & \\
\hline CHEMBL 2374050 & 688759 & 6.0 & 5.3532 & TST & \\
\hline CHEMBL1470016 & 688759 & 5.95 & 5.7171 & TRN & \\
\hline CHEMBL1504022 & 688759 & 5.4 & 5.1717 & TRN & \\
\hline CHEMBL1301322 & 688759 & 5.95 & 5.0073 & TRN & \\
\hline CHEMBL1335355 & 688759 & 4.45 & 4.6761 & TRN & \\
\hline CHEMBL1589796 & 688759 & 5.4 & 5.0315 & TRN & \\
\hline CHEMBL1304507 & 688759 & 7.0501 & 5.0443 & TRN & \\
\hline CHEMBL1529820 & 688759 & 4.45 & 4.7755 & TRN & \\
\hline CHEMBL1438892 & 688759 & 5.2 & 4.9948 & TST & \\
\hline CHEMBL1312876 & 688759 & 5.55 & 5.2148 & TRN & \\
\hline CHEMBL1464966 & 688759 & 6.1 & 4.9453 & TST & \\
\hline CHEMBL1344449 & 688759 & 5.0 & 4.9789 & TRN & \\
\hline CHEMBL1391764 & 688759 & 4.65 & 4.9637 & TRN & \\
\hline CHEMBL1984115 & 688759 & 5.6 & 4.77800 & 00000000005 & TRN \\
\hline CHEMBL 2002565 & 688759 & 4.45 & 4.7892 & TRN & \\
\hline CHEMBL1300242 & 688759 & 5.3 & 4.8117 & TRN & \\
\hline CHEMBL1577986 & 688759 & 4.45 & 4.8113 & TST & \\
\hline CHEMBL1466824 & 688759 & 4.45 & 4.801 & TST & \\
\hline CHEMBL3198998 & 688759 & 5.15 & 5.2708 & TST & \\
\hline CHEMBL1358938 & 688759 & 5.55 & 5.6114 & TRN & \\
\hline CHEMBL3189622 & 688759 & 4.45 & 4.8539 & TST & \\
\hline CHEMBL1530295 & 688759 & 6.0 & 5.3474 & TRN & \\
\hline CHEMBL1489936 & 688759 & 4.45 & 4.9183 & TRN & \\
\hline CHEMBL1348936 & 688759 & 4.65 & 4.9838 & TRN & \\
\hline CHEMBL1450229 & 688759 & 5.1 & 4.9842 & TST & \\
\hline CHEMBL1349002 & 688759 & 5.25 & 4.9317 & TST & \\
\hline CHEMBL1326420 & 688759 & 4.65 & 5.2485 & TRN & \\
\hline
\end{tabular}




\begin{tabular}{|c|c|c|c|c|c|}
\hline \multicolumn{6}{|c|}{ Supplemental Table S2.txt } \\
\hline CHEMBL1457472 & 688759 & 4.95 & 4.8544 & TST & \\
\hline CHEMBL1409800 & 688759 & 4.45 & 4.749 & TRN & \\
\hline CHEMBL1595295 & 688759 & 4.75 & 4.8615 & TRN & \\
\hline CHEMBL1328036 & 688759 & 4.5 & 4.9322 & TRN & \\
\hline CHEMBL1369236 & 688759 & 4.45 & 4.6865 & TST & \\
\hline CHEMBL1533547 & 688759 & 4.45 & 4.9066 & TRN & \\
\hline CHEMBL3199578 & 688759 & 4.45 & 5.2669 & TRN & \\
\hline CHEMBL1431286 & 688759 & 4.45 & 4.7521 & TST & \\
\hline CHEMBL1510646 & 688759 & 5.55 & $5.6320 e$ & 0000000001 & TRN \\
\hline CHEMBL3197979 & 688759 & 5.15 & 5.1035 & TRN & \\
\hline CHEMBL1579396 & 688759 & 5.0 & 5.0466 & TRN & \\
\hline CHEMBL1493516 & 688759 & 4.45 & 4.6869 & TST & \\
\hline CHEMBL1483153 & 688759 & 5.0 & 5.2668 & TRN & \\
\hline CHEMBL1453837 & 688759 & 5.55 & 4.922 & TRN & \\
\hline CHEMBL1402697 & 688759 & 4.45 & 4.8544 & TRN & \\
\hline CHEMBL1565558 & 688759 & 4.75 & 4.7313 & TRN & \\
\hline CHEMBL1504728 & 688759 & 5.55 & 5.1804 & TRN & \\
\hline CHEMBL1453461 & 688759 & 4.45 & 4.6247 & TRN & \\
\hline CHEMBL1426085 & 688759 & 4.6 & 4.6311 & TRN & \\
\hline CHEMBL1562934 & 688759 & 5.25 & 5.1636 & TRN & \\
\hline CHEMBL1482750 & 688759 & 4.7 & 4.9424 & TST & \\
\hline CHEMBL1469467 & 688759 & 4.45 & 4.9357 & TRN & \\
\hline CHEMBL1604933 & 688759 & 5.5 & 4.7519 & TST & \\
\hline CHEMBL1450068 & 688759 & 4.5 & 4.9432 & TRN & \\
\hline CHEMBL1351915 & 688759 & 5.45 & 4.9914 & TRN & \\
\hline CHEMBL3196057 & 688759 & 4.45 & 4.9315 & TRN & \\
\hline CHEMBL1509674 & 688759 & 4.45 & 4.864 & TRN & \\
\hline CHEMBL3192073 & 688759 & 4.45 & 4.9738 & TRN & \\
\hline CHEMBL1576308 & 688759 & 4.45 & 4.856 & TRN & \\
\hline CHEMBL1481686 & 688759 & 4.8 & 5.33899 & 99999999995 & TST \\
\hline CHEMBL1339776 & 688759 & 4.45 & 4.9939 & TST & \\
\hline CHEMBL1442326 & 688759 & 5.1 & 4.988 & TRN & \\
\hline CHEMBL1443793 & 688759 & 4.75 & 5.2436 & TRN & \\
\hline CHEMBL1322589 & 688759 & 4.65 & 4.7375 & TST & \\
\hline CHEMBL1366838 & 688759 & 5.0 & 4.7837 & TST & \\
\hline CHEMBL1393424 & 688759 & 4.45 & 4.7562 & TRN & \\
\hline CHEMBL1444147 & 688759 & 4.45 & 4.7323 & TRN & \\
\hline CHEMBL1559375 & 688759 & 4.95 & 4.9393 & TRN & \\
\hline CHEMBL 3211808 & 688759 & 5.3 & 5.2686 & TRN & \\
\hline CHEMBL1301932 & 688759 & 5.1 & 4.7387 & TRN & \\
\hline CHEMBL1339141 & 688759 & 4.65 & 5.13299 & 9999999999 & TST \\
\hline CHEMBL1486695 & 688759 & 4.4 & 4.6763 & TRN & \\
\hline CHEMBL1413904 & 688759 & 4.45 & 4.8823 & TRN & \\
\hline CHEMBL1336675 & 688759 & 5.6 & 4.8982 & TRN & \\
\hline CHEMBL1464103 & 688759 & 4.6 & 5.0377 & TST & \\
\hline CHEMBL1557083 & 688759 & 5.0 & 4.9595 & TRN & \\
\hline CHEMBL1991487 & 688759 & 6.0 & 5.5382 & TRN & \\
\hline CHEMBL1339997 & 688759 & 5.3 & 5.0185 & TRN & \\
\hline
\end{tabular}




\begin{tabular}{|c|c|c|c|c|}
\hline \multicolumn{5}{|c|}{ Supplemental Table S2.txt } \\
\hline CHEMBL1401689 & 688759 & 4.45 & 4.8254 & TRN \\
\hline CHEMBL1492376 & 688759 & 5.8 & 5.4955 & TRN \\
\hline CHEMBL1479629 & 688759 & 4.45 & 4.8184 & TRN \\
\hline CHEMBL1573243 & 688759 & 4.45 & 4.8034 & TRN \\
\hline CHEMBL3212205 & 688759 & 5.35 & 4.7269 & TRN \\
\hline CHEMBL1407338 & 688759 & 5.45 & 5.1023 & TRN \\
\hline CHEMBL1350329 & 688759 & 4.45 & 4.6905 & TRN \\
\hline CHEMBL1494075 & 688759 & 6.5 & 4.8197 & TST \\
\hline CHEMBL1360823 & 688759 & 4.9 & 4.4929 & TRN \\
\hline CHEMBL1305755 & 688759 & 4.45 & 4.8798 & TRN \\
\hline CHEMBL1566838 & 688759 & 4.85 & 4.9604 & TRN \\
\hline CHEMBL1534986 & 688759 & 5.2 & 4.9856 & TRN \\
\hline CHEMBL1582442 & 688759 & 4.6 & 4.5499 & TRN \\
\hline CHEMBL1477452 & 688759 & 4.45 & 4.8609 & TRN \\
\hline CHEMBL1360644 & 688759 & 5.3 & 5.3245 & TST \\
\hline CHEMBL3195017 & 688759 & 5.4 & 5.5289 & TRN \\
\hline CHEMBL1442633 & 688759 & 6.0 & 5.1333 & TRN \\
\hline CHEMBL1365388 & 688759 & 4.7 & 4.6219 & TRN \\
\hline CHEMBL1509927 & 688759 & 4.9 & 4.829 & TRN \\
\hline CHEMBL1429655 & 688759 & 5.25 & 5.3066 & TRN \\
\hline CHEMBL1346493 & 688759 & 5.3 & 5.0854 & TST \\
\hline CHEMBL1469379 & 688759 & 5.05 & 4.575 & TRN \\
\hline CHEMBL1507823 & 688759 & 5.5 & 5.1699 & TRN \\
\hline CHEMBL1568357 & 688759 & 4.95 & 4.6565 & TRN \\
\hline CHEMBL3198627 & 688759 & 5.75 & 5.5865 & TRN \\
\hline CHEMBL1542622 & 688759 & 5.1 & 4.9022 & TRN \\
\hline CHEMBL1472282 & 688759 & 4.9 & 4.9683 & TST \\
\hline CHEMBL1489778 & 688759 & 4.95 & 5.046 & TRN \\
\hline CHEMBL1432925 & 688759 & 4.55 & 4.8981 & TST \\
\hline CHEMBL3190379 & 688759 & 5.05 & 5.4276 & TRN \\
\hline CHEMBL1481433 & 688759 & 5.45 & 5.0093 & TRN \\
\hline CHEMBL1347657 & 688759 & 4.8 & 4.9125 & TRN \\
\hline CHEMBL1393123 & 688759 & 4.6 & 4.7174 & TRN \\
\hline CHEMBL1517912 & 688759 & 4.65 & 4.8776 & TRN \\
\hline CHEMBL1303693 & 688759 & 4.9 & 5.022 & TRN \\
\hline CHEMBL1527596 & 688759 & 4.45 & 4.7734 & TRN \\
\hline CHEMBL1330361 & 688759 & 4.45 & 4.8219 & TST \\
\hline CHEMBL1391353 & 688759 & 4.8 & 5.024 & TRN \\
\hline CHEMBL1368469 & 688759 & 4.75 & 4.8427 & TRN \\
\hline CHEMBL1364654 & 688759 & 4.45 & 5.1254 & TRN \\
\hline CHEMBL1583708 & 688759 & 4.45 & 4.9496 & TRN \\
\hline CHEMBL1328429 & 688759 & 4.45 & 4.7387 & TRN \\
\hline CHEMBL1330890 & 688759 & 5.4 & 5.0959 & TRN \\
\hline CHEMBL1589443 & 688759 & 4.9 & 5.0068 & TRN \\
\hline CHEMBL1456624 & 688759 & 4.45 & 4.9608 & TRN \\
\hline CHEMBL1447634 & 688759 & 4.45 & 4.8923 & TRN \\
\hline CHEMBL3190913 & 688759 & 4.65 & 4.9523 & TRN \\
\hline CHEMBL1335766 & 688759 & 5.05 & 5.1617 & TRN \\
\hline
\end{tabular}




\begin{tabular}{|c|c|c|c|c|c|}
\hline \multirow[b]{2}{*}{ CHEMBL1412381 } & & \multicolumn{4}{|c|}{ Supplemental Table s2.txt } \\
\hline & 688759 & 4.65 & 4.8065 & TST & \\
\hline CHEMBL1532278 & 688759 & 4.45 & 5.0194 & TRN & \\
\hline CHEMBL1613030 & 688759 & 4.45 & 4.8695 & TST & \\
\hline CHEMBL1517676 & 688759 & 4.45 & 4.4943 & TRN & \\
\hline CHEMBL1509595 & 688759 & 4.6 & 4.6889 & TRN & \\
\hline CHEMBL1466506 & 688759 & 4.7 & 4.4923 & TRN & \\
\hline CHEMBL3191946 & 688759 & 6.5 & 6.2527 & TRN & \\
\hline CHEMBL1461540 & 688759 & 5.25 & 4.627 & TRN & \\
\hline CHEMBL1323824 & 688759 & 4.6 & 4.9022 & TRN & \\
\hline CHEMBL3197304 & 688759 & 5.1 & 4.9571 & TRN & \\
\hline CHEMBL1964943 & 688759 & 5.15 & 5.0957 & TRN & \\
\hline CHEMBL1986025 & 688759 & 6.25 & 5.7392 & TRN & \\
\hline CHEMBL1405021 & 688759 & 4.45 & 4.8627 & TRN & \\
\hline CHEMBL1379161 & 688759 & 5.3 & 5.2268 & TRN & \\
\hline CHEMBL1414465 & 688759 & 4.45 & 4.6761 & TST & \\
\hline CHEMBL1986690 & 688759 & 4.9 & 4.823 & TRN & \\
\hline CHEMBL1487155 & 688759 & 5.65 & 4.8263 & TST & \\
\hline CHEMBL1394070 & 688759 & 5.45 & 5.5182 & TRN & \\
\hline CHEMBL1363165 & 688759 & 4.95 & 5.255 & TRN & \\
\hline CHEMBL1366760 & 688759 & 4.9 & 4.8244 & TRN & \\
\hline CHEMBL3214013 & 688759 & 5.3 & 4.9186 & TRN & \\
\hline CHEMBL1312087 & 688759 & 5.5 & 5.2435 & TRN & \\
\hline CHEMBL1344317 & 688759 & 4.8 & 5.0258 & TRN & \\
\hline CHEMBL1386466 & 688759 & 5.0 & 5.2334 & TRN & \\
\hline CHEMBL1521023 & 688759 & 5.0 & 5.5379 & TRN & \\
\hline CHEMBL1606450 & 688759 & 4.75 & 4.6316 & TRN & \\
\hline CHEMBL1498963 & 688759 & 5.3 & 4.8203 & TRN & \\
\hline CHEMBL1518921 & 688759 & 5.25 & 5.0055 & TST & \\
\hline CHEMBL1573411 & 688759 & 4.45 & 4.768 & TST & \\
\hline CHEMBL1462809 & 688759 & 4.45 & 4.7887 & TST & \\
\hline CHEMBL1345824 & 688759 & 4.9 & 4.7854 & TRN & \\
\hline CHEMBL1547657 & 688759 & 4.45 & 4.9142 & TRN & \\
\hline CHEMBL1999019 & 688759 & 6.05 & 5.4012 & TRN & \\
\hline CHEMBL1345843 & 688759 & 4.45 & 4.7384 & TRN & \\
\hline CHEMBL1374157 & 688759 & 4.45 & 4.98600 & 0000000001 & TRN \\
\hline CHEMBL1478620 & 688759 & 4.9 & 5.0523 & TST & \\
\hline CHEMBL1522786 & 688759 & 5.0 & 4.9436 & TRN & \\
\hline CHEMBL1384548 & 688759 & 4.5 & 4.7889 & TRN & \\
\hline CHEMBL1432007 & 688759 & 6.15 & 5.1828 & TRN & \\
\hline CHEMBL1377167 & 688759 & 4.9 & 5.5656 & TRN & \\
\hline CHEMBL1464354 & 688759 & 4.95 & 4.76699 & 99999999995 & TST \\
\hline CHEMBL1550841 & 688759 & 4.95 & 5.0834 & TRN & \\
\hline CHEMBL1554856 & 688759 & 4.6 & 4.8148 & TRN & \\
\hline CHEMBL1495602 & 688759 & 4.45 & 4.7023 & TST & \\
\hline CHEMBL1605312 & 688759 & 4.6 & 4.7551 & TRN & \\
\hline CHEMBL1586067 & 688759 & 4.55 & 4.7977 & TST & \\
\hline CHEMBL1427734 & 688759 & 4.95 & 4.8067 & TRN & \\
\hline CHEMBL1455992 & 688759 & 4.75 & 5.1132 & TST & \\
\hline
\end{tabular}




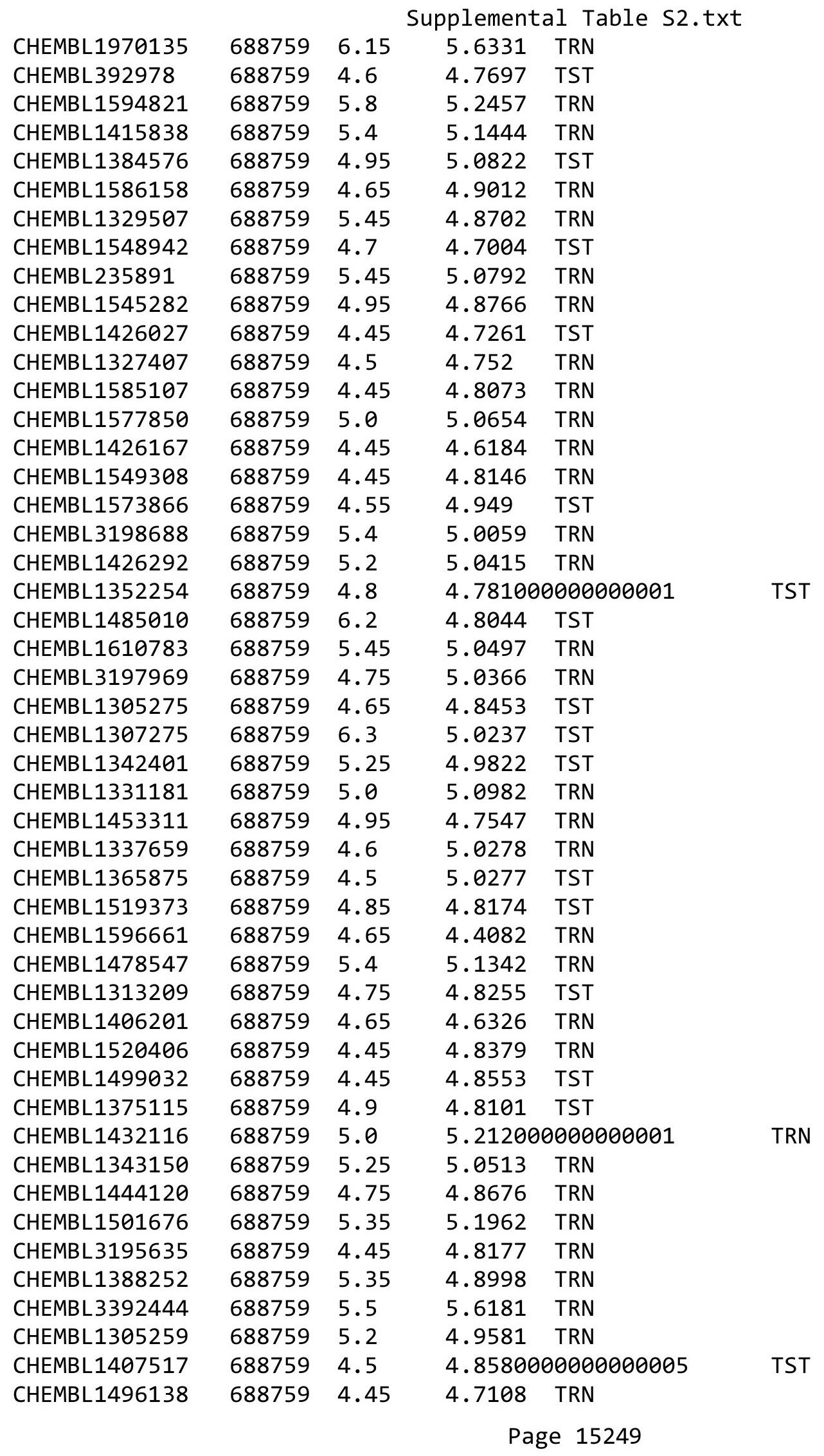




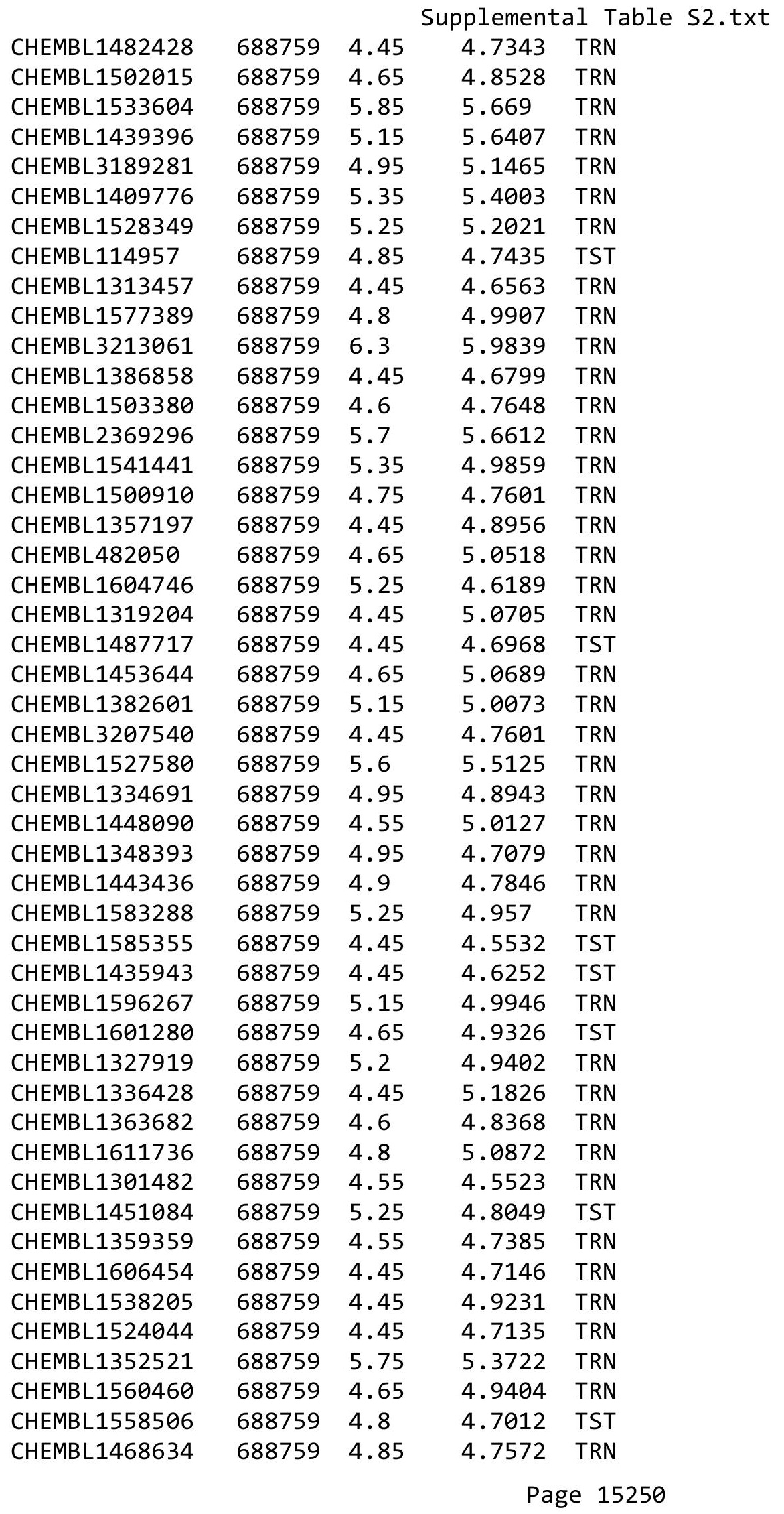




\begin{tabular}{|c|c|c|c|c|c|}
\hline \multicolumn{6}{|c|}{ Supplemental Table S2.txt } \\
\hline CHEMBL1603362 & 688759 & 4.45 & 4.8774 & TRN & \\
\hline CHEMBL1534595 & 688759 & 4.75 & 4.9446 & TST & \\
\hline CHEMBL1581337 & 688759 & 4.6 & 4.4433 & TRN & \\
\hline CHEMBL1446283 & 688759 & 4.45 & 4.5931 & TST & \\
\hline CHEMBL1498555 & 688759 & 4.45 & 4.5816 & TRN & \\
\hline CHEMBL1528893 & 688759 & 6.6499 & 4.6163 & TRN & \\
\hline CHEMBL15594 & 688759 & 4.45 & 5.3027 & TRN & \\
\hline CHEMBL1377205 & 688759 & 5.15 & 5.0818 & TRN & \\
\hline CHEMBL 2006168 & 688759 & 5.65 & 5.7435 & TST & \\
\hline CHEMBL1453335 & 688759 & 4.65 & 4.5849 & TRN & \\
\hline CHEMBL1299247 & 688759 & 4.95 & 5.0616 & TRN & \\
\hline CHEMBL1519501 & 688759 & 5.25 & 4.694 & TRN & \\
\hline CHEMBL1379987 & 688759 & 4.5 & 4.6061 & TRN & \\
\hline CHEMBL1323160 & 688759 & 4.7 & 4.8175 & TST & \\
\hline CHEMBL1422160 & 688759 & 4.85 & 5.0068 & TRN & \\
\hline CHEMBL1976754 & 688759 & 5.55 & 5.37799 & 9999999999 & TRN \\
\hline CHEMBL3212856 & 688759 & 4.6 & 4.743 & TRN & \\
\hline CHEMBL1430472 & 688759 & 5.35 & 4.808 & TRN & \\
\hline CHEMBL1470617 & 688759 & 5.1 & 4.9417 & TRN & \\
\hline CHEMBL1425409 & 688759 & 4.7 & 4.8531 & TST & \\
\hline CHEMBL1497761 & 688759 & 5.45 & 4.7749 & TRN & \\
\hline CHEMBL1476114 & 688759 & 5.15 & 4.9722 & TRN & \\
\hline CHEMBL1311740 & 688759 & 4.9 & 4.9156 & TRN & \\
\hline CHEMBL1505127 & 688759 & 4.65 & 4.581 & TRN & \\
\hline CHEMBL1354400 & 688759 & 4.6 & 4.8477 & TST & \\
\hline CHEMBL 2311901 & 688759 & 4.6 & 4.7235 & TRN & \\
\hline CHEMBL1311637 & 688759 & 4.6 & 4.8845 & TRN & \\
\hline CHEMBL1467860 & 688759 & 4.75 & 4.4428 & TRN & \\
\hline CHEMBL1582945 & 688759 & 5.15 & 5.2698 & TRN & \\
\hline CHEMBL1505604 & 688759 & 5.7 & 5.8747 & TRN & \\
\hline CHEMBL1423346 & 688759 & 5.7 & 5.8953 & TRN & \\
\hline CHEMBL1416565 & 688759 & 6.9 & 5.0195 & TST & \\
\hline CHEMBL1411785 & 688759 & 4.5 & 4.5868 & TRN & \\
\hline CHEMBL1468829 & 688759 & 4.45 & 4.7498 & TRN & \\
\hline CHEMBL1425525 & 688759 & 4.5 & 4.9513 & TRN & \\
\hline CHEMBL1454658 & 688759 & 4.75 & 5.2125 & TST & \\
\hline CHEMBL1478123 & 688759 & 5.35 & 5.1569 & TST & \\
\hline CHEMBL584015 & 688759 & 4.9 & 4.6302 & TST & \\
\hline CHEMBL1506272 & 688759 & 5.25 & 5.0849 & TRN & \\
\hline CHEMBL1433291 & 688759 & 5.45 & 5.2004 & TRN & \\
\hline CHEMBL3196358 & 688759 & 4.45 & 4.7376 & TRN & \\
\hline CHEMBL3196515 & 688759 & 4.45 & 4.6113 & TST & \\
\hline CHEMBL1479888 & 688759 & 4.45 & 4.8758 & TST & \\
\hline CHEMBL1587103 & 688759 & 4.65 & 4.5251 & TRN & \\
\hline CHEMBL3192378 & 688759 & 4.45 & 4.8479 & TRN & \\
\hline CHEMBL3190321 & 688759 & 5.3 & 4.9405 & TRN & \\
\hline CHEMBL1374288 & 688759 & 4.9 & 5.5447 & TST & \\
\hline CHEMBL1307792 & 688759 & 5.15 & 5.1163 & TST & \\
\hline
\end{tabular}




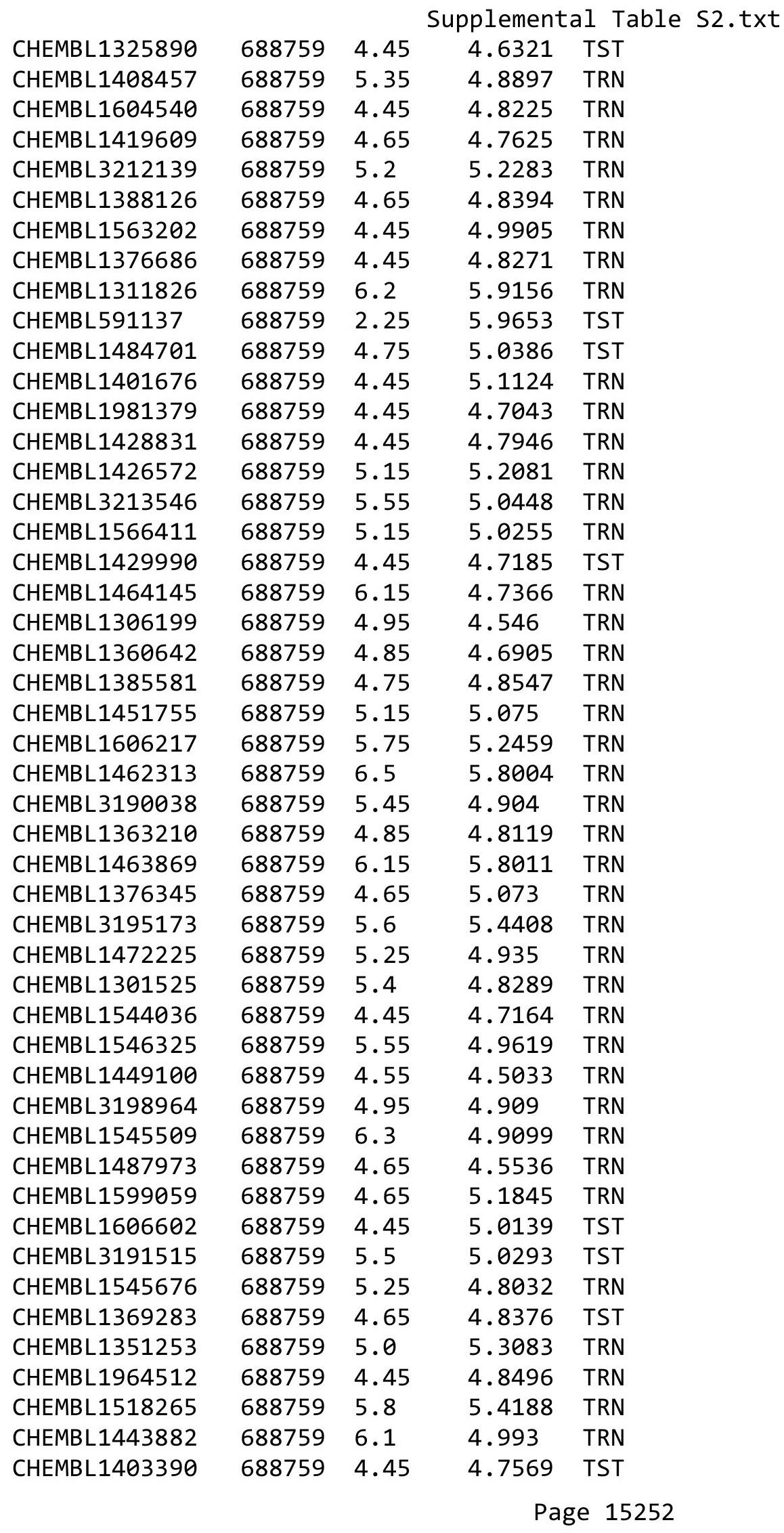




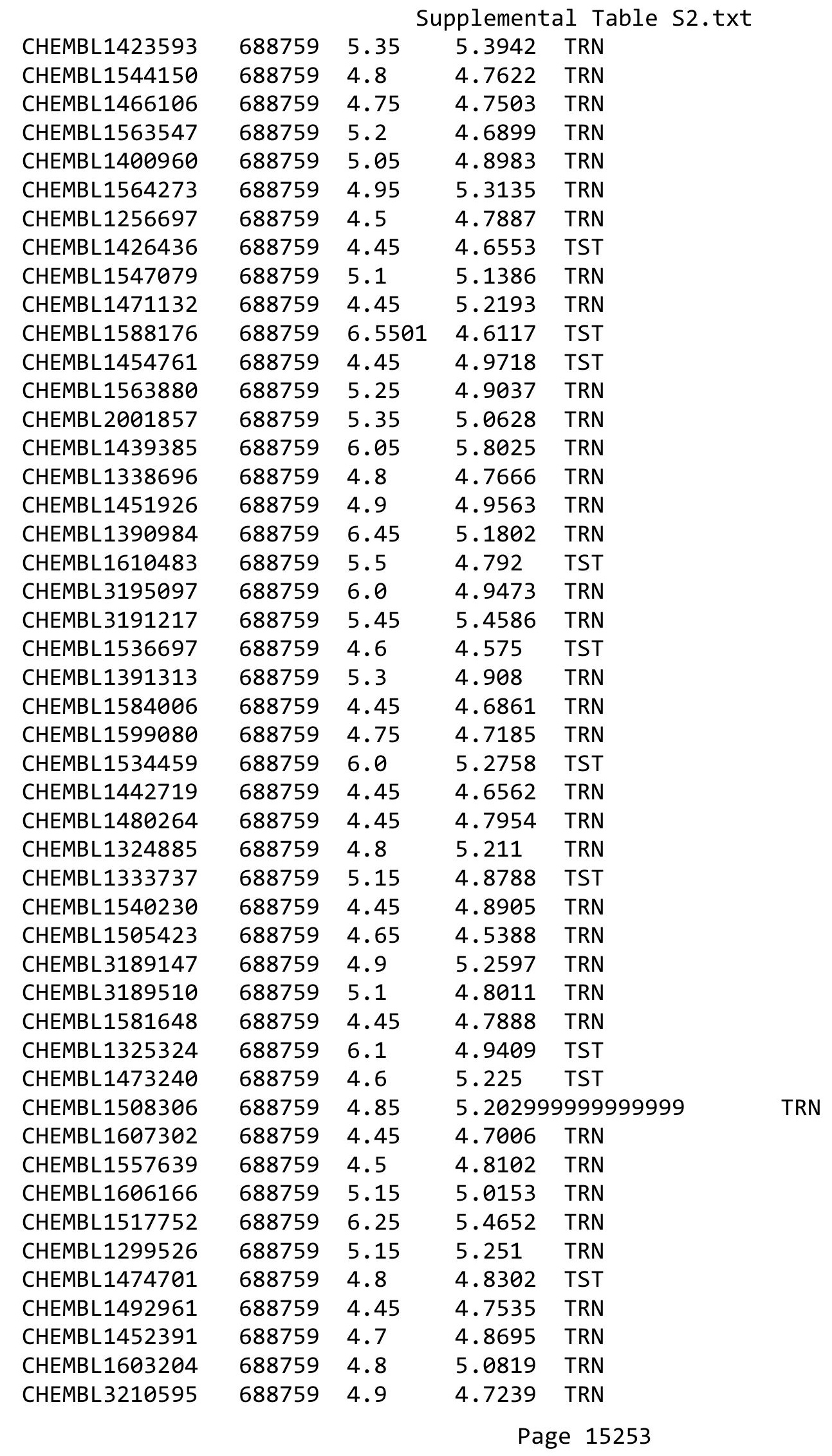




\begin{tabular}{|c|c|c|c|c|c|}
\hline & & \multicolumn{4}{|c|}{ Supplemental Table S2.txt } \\
\hline CHEMBL3212940 & 688759 & 5.55 & 5.244 & TRN & \\
\hline CHEMBL1347888 & 688759 & 5.0 & 4.9604 & TRN & \\
\hline CHEMBL3199854 & 688759 & 6.95 & 4.5836 & TST & \\
\hline CHEMBL3197913 & 688759 & 4.45 & 4.8683 & TRN & \\
\hline CHEMBL1354694 & 688759 & 5.9 & 4.898 & TRN & \\
\hline CHEMBL1421263 & 688759 & 6.05 & 5.9122 & TRN & \\
\hline CHEMBL1537047 & 688759 & 4.45 & 4.80399 & 9999999999 & TRN \\
\hline CHEMBL1584663 & 688759 & 4.9 & 5.0077 & TRN & \\
\hline CHEMBL3192106 & 688759 & 4.85 & 4.8519 & TST & \\
\hline CHEMBL1409694 & 688759 & 4.8 & 5.0353 & TRN & \\
\hline CHEMBL1545498 & 688759 & 5.8 & 4.9423 & TRN & \\
\hline CHEMBL1531992 & 688759 & 4.5 & 4.9197 & TRN & \\
\hline CHEMBL529349 & 688759 & 6.0 & 5.4411 & TST & \\
\hline CHEMBL1353904 & 688759 & 5.25 & 4.8112 & TRN & \\
\hline CHEMBL1557484 & 688759 & 4.9 & 4.8073 & TRN & \\
\hline CHEMBL1481523 & 688759 & 5.0 & 4.7712 & TRN & \\
\hline CHEMBL1458566 & 688759 & 4.45 & 4.7853 & TRN & \\
\hline CHEMBL3192913 & 688759 & 4.45 & 5.3125 & TRN & \\
\hline CHEMBL1599005 & 688759 & 4.75 & 4.8881 & TRN & \\
\hline CHEMBL1477718 & 688759 & 4.95 & 4.7753 & TST & \\
\hline CHEMBL1391972 & 688759 & 5.05 & 5.1151 & TRN & \\
\hline CHEMBL1478795 & 688759 & 5.9 & 4.8415 & TST & \\
\hline CHEMBL1406155 & 688759 & 4.7 & 4.6651 & TRN & \\
\hline CHEMBL1528375 & 688759 & 5.9 & 4.7682 & TRN & \\
\hline CHEMBL1534566 & 688759 & 4.45 & 4.84 & TRN & \\
\hline CHEMBL1493869 & 688759 & 5.25 & 5.2513 & TRN & \\
\hline CHEMBL544348 & 688759 & 4.45 & 4.6281 & TRN & \\
\hline CHEMBL1503742 & 688759 & 4.65 & 4.7418 & TST & \\
\hline CHEMBL3199180 & 688759 & 5.8 & 5.5767 & TRN & \\
\hline CHEMBL1416480 & 688759 & 4.45 & 4.7918 & TST & \\
\hline CHEMBL1466762 & 688759 & 4.45 & 5.3334 & TRN & \\
\hline CHEMBL1548105 & 688759 & 4.45 & 5.0029 & TRN & \\
\hline CHEMBL1429837 & 688759 & 4.85 & 4.6119 & TRN & \\
\hline CHEMBL579621 & 688759 & 4.5 & 4.9534 & TST & \\
\hline CHEMBL1399453 & 688759 & 4.45 & 4.78600 & 00000000005 & TRN \\
\hline CHEMBL1372464 & 688759 & 5.2 & 5.1222 & TRN & \\
\hline CHEMBL1319880 & 688759 & 4.45 & 4.5922 & TRN & \\
\hline CHEMBL1567220 & 688759 & 4.7 & 4.8387 & TRN & \\
\hline CHEMBL1545580 & 688759 & 7.0 & 4.9335 & TRN & \\
\hline CHEMBL1532567 & 688759 & 4.4 & 4.953 & TRN & \\
\hline CHEMBL3190459 & 688759 & 5.6 & 5.3906 & TRN & \\
\hline CHEMBL1486330 & 688759 & 4.8 & 4.71 & TRN & \\
\hline CHEMBL3211091 & 688759 & 4.85 & 4.8693 & TRN & \\
\hline CHEMBL1498216 & 688759 & 5.5 & 4.8325 & TRN & \\
\hline CHEMBL1311025 & 688759 & 4.45 & 4.8894 & TRN & \\
\hline CHEMBL1489306 & 688759 & 4.45 & 4.8829 & TRN & \\
\hline CHEMBL3192307 & 688759 & 5.55 & 5.7979 & TRN & \\
\hline CHEMBL1460520 & 688759 & 7.0 & 5.0727 & TST & \\
\hline
\end{tabular}




\begin{tabular}{|c|c|c|c|c|c|}
\hline \multicolumn{6}{|c|}{ Supplemental Table s2.txt } \\
\hline CHEMBL1429485 & 688759 & 4.45 & 4.5621 & TRN & \\
\hline CHEMBL1349546 & 688759 & 4.9 & 4.7273 & TRN & \\
\hline CHEMBL1595355 & 688759 & 4.85 & 5.3238 & TRN & \\
\hline CHEMBL1321349 & 688759 & 6.0 & 4.8841 & TRN & \\
\hline CHEMBL1577928 & 688759 & 4.5 & 4.7634 & TST & \\
\hline CHEMBL1500472 & 688759 & 5.35 & 4.8005 & TRN & \\
\hline CHEMBL1420146 & 688759 & 4.85 & 5.1917 & TRN & \\
\hline CHEMBL1482344 & 688759 & 4.5 & 4.6992 & TRN & \\
\hline CHEMBL1501983 & 688759 & 5.3 & 5.8386 & TRN & \\
\hline CHEMBL1381495 & 688759 & 4.9 & 4.8113 & TST & \\
\hline CHEMBL1562114 & 688759 & 4.45 & 4.779 & TST & \\
\hline CHEMBL1538767 & 688759 & 5.25 & 4.8667 & TST & \\
\hline CHEMBL58033 & 688759 & 5.25 & 4.7846 & TST & \\
\hline CHEMBL184074 & 688759 & 4.7 & 4.7541 & TST & \\
\hline CHEMBL1459930 & 688759 & 4.65 & 4.6517 & TST & \\
\hline CHEMBL3198659 & 688759 & 4.45 & 4.7842 & TRN & \\
\hline CHEMBL1537440 & 688759 & 4.45 & 5.0856 & TST & \\
\hline CHEMBL1360662 & 688759 & 4.5 & 4.8772 & TRN & \\
\hline CHEMBL3191446 & 688759 & 4.45 & 4.7451 & TRN & \\
\hline CHEMBL1882125 & 688759 & 4.95 & 4.9944 & TRN & \\
\hline CHEMBL1381845 & 688759 & 5.55 & 4.8568 & TRN & \\
\hline CHEMBL1443188 & 688759 & 4.65 & 4.8719 & TRN & \\
\hline CHEMBL1510371 & 688759 & 4.45 & 4.5126 & TRN & \\
\hline CHEMBL1389542 & 688759 & 6.25 & 6.193 & TRN & \\
\hline CHEMBL1988857 & 688759 & 4.45 & 4.8954 & TRN & \\
\hline CHEMBL1359887 & 688759 & 5.4 & 5.0579 & TRN & \\
\hline CHEMBL1485865 & 688759 & 4.75 & 4.8276 & TST & \\
\hline CHEMBL1432530 & 688759 & 4.45 & 4.8329 & TRN & \\
\hline CHEMBL1533609 & 688759 & 4.9 & 5.0993 & TST & \\
\hline CHEMBL1421600 & 688759 & 4.95 & 4.8312 & TST & \\
\hline CHEMBL1368794 & 688759 & 6.2 & 5.8269 & TRN & \\
\hline CHEMBL2369189 & 688759 & 5.5 & 5.0516 & TST & \\
\hline CHEMBL1523272 & 688759 & 4.45 & 4.6934 & TRN & \\
\hline CHEMBL1610053 & 688759 & 4.45 & 4.4984 & TRN & \\
\hline CHEMBL1301611 & 688759 & 6.3 & 5.0097 & TRN & \\
\hline CHEMBL1334115 & 688759 & 5.25 & 5.0937 & TRN & \\
\hline CHEMBL1585966 & 688759 & 5.2 & 4.8032 & TRN & \\
\hline CHEMBL1534203 & 688759 & 4.45 & 4.9352 & TRN & \\
\hline CHEMBL1420254 & 688759 & 5.0 & 4.9516 & TRN & \\
\hline CHEMBL1583127 & 688759 & 5.45 & 4.7339 & TRN & \\
\hline CHEMBL1347447 & 688759 & 4.45 & 4.8998 & TST & \\
\hline CHEMBL1982381 & 688759 & 5.6 & 5.12799 & 9999999999 & TRN \\
\hline CHEMBL1468558 & 688759 & 4.45 & 4.748 & TRN & \\
\hline CHEMBL1438142 & 688759 & 5.2 & 5.0255 & TRN & \\
\hline CHEMBL3199821 & 688759 & 4.95 & 4.9633 & TRN & \\
\hline CHEMBL1537864 & 688759 & 4.8 & 5.4794 & TRN & \\
\hline CHEMBL1373833 & 688759 & 4.45 & 4.6039 & TRN & \\
\hline CHEMBL3209877 & 688759 & 5.5 & $5.8320 e$ & 2000000001 & TRN \\
\hline & & & & 15255 & \\
\hline
\end{tabular}




\begin{tabular}{|c|c|c|c|c|c|}
\hline \multicolumn{6}{|c|}{ Supplemental Table S2.txt } \\
\hline CHEMBL3197483 & 688759 & 4.75 & 4.8308 & TRN & \\
\hline CHEMBL1533132 & 688759 & 4.9 & 4.9484 & TRN & \\
\hline CHEMBL1277546 & 688759 & 5.95 & 5.2002 & TST & \\
\hline CHEMBL1529138 & 688759 & 5.15 & 5.4534 & TRN & \\
\hline CHEMBL1455409 & 688759 & 6.0 & 5.6884 & TRN & \\
\hline CHEMBL1377589 & 688759 & 6.6 & 4.8159 & TRN & \\
\hline CHEMBL1335988 & 688759 & 5.8 & 4.8743 & TRN & \\
\hline CHEMBL1565709 & 688759 & 5.0 & 4.6753 & TRN & \\
\hline CHEMBL3193915 & 688759 & 4.65 & 4.5812 & TRN & \\
\hline CHEMBL1319778 & 688759 & 4.45 & 4.5744 & TRN & \\
\hline CHEMBL1416808 & 688759 & 4.65 & 4.6552 & TRN & \\
\hline CHEMBL3193795 & 688759 & 7.4001 & 5.5851 & TRN & \\
\hline CHEMBL1414090 & 688759 & 5.25 & 5.1427 & TST & \\
\hline CHEMBL1582829 & 688759 & 4.5 & 4.8711 & TRN & \\
\hline CHEMBL1372096 & 688759 & 4.45 & 4.8401 & TRN & \\
\hline CHEMBL1574813 & 688759 & 4.7 & 4.6589 & TRN & \\
\hline CHEMBL3192463 & 688759 & 6.3 & 5.8083 & TRN & \\
\hline CHEMBL3199397 & 688759 & 4.55 & 4.8156 & TRN & \\
\hline CHEMBL 1416950 & 688759 & 4.55 & 4.6054 & TRN & \\
\hline CHEMBL1577902 & 688759 & 4.95 & 5.3622 & TRN & \\
\hline CHEMBL1418671 & 688759 & 4.45 & 4.9152 & TRN & \\
\hline CHEMBL1405834 & 688759 & 5.4 & 4.8386 & TST & \\
\hline CHEMBL1416486 & 688759 & 4.45 & 4.9848 & TST & \\
\hline CHEMBL1519965 & 688759 & 5.9 & 5.5446 & TRN & \\
\hline CHEMBL1306784 & 688759 & 4.9 & 4.8187 & TST & \\
\hline CHEMBL285480 & 688759 & 4.45 & 5.008 & TRN & \\
\hline CHEMBL1445372 & 688759 & 5.3 & 4.8565 & TRN & \\
\hline CHEMBL1459809 & 688759 & 5.1 & 5.54899 & 99999999995 & TRN \\
\hline CHEMBL3191492 & 688759 & 4.45 & 4.9555 & TST & \\
\hline CHEMBL1588933 & 688759 & 4.7 & 4.5042 & TST & \\
\hline CHEMBL1556463 & 688759 & 4.45 & 4.8342 & TRN & \\
\hline CHEMBL1423757 & 688759 & 5.1 & 4.9357 & TRN & \\
\hline CHEMBL1445628 & 688759 & 5.25 & 4.7661 & TST & \\
\hline CHEMBL1507146 & 688759 & 5.15 & 4.8239 & TST & \\
\hline CHEMBL3192679 & 688759 & 4.45 & 4.815 & TRN & \\
\hline CHEMBL1606345 & 688759 & 4.45 & 5.0183 & TRN & \\
\hline CHEMBL1568820 & 688759 & 5.25 & 4.9111 & TRN & \\
\hline CHEMBL1597489 & 688759 & 4.8 & 4.8285 & TRN & \\
\hline CHEMBL1432427 & 688759 & 5.0 & 5.3513 & TRN & \\
\hline CHEMBL1335260 & 688759 & 4.55 & 5.0516 & TRN & \\
\hline CHEMBL1313294 & 688759 & 4.7 & 4.7642 & TST & \\
\hline CHEMBL3208193 & 688759 & 5.75 & 4.8327 & TRN & \\
\hline CHEMBL1424065 & 688759 & 4.95 & 4.8202 & TRN & \\
\hline CHEMBL1596985 & 688759 & 5.9 & 5.766 & TRN & \\
\hline CHEMBL1607661 & 688759 & 4.8 & 4.8746 & TRN & \\
\hline CHEMBL1492101 & 688759 & 5.25 & 4.7206 & TRN & \\
\hline CHEMBL1456518 & 688759 & 5.2 & 5.0168 & TRN & \\
\hline CHEMBL3186408 & 688759 & 6.0 & 5.4406 & TST & \\
\hline
\end{tabular}




\begin{tabular}{|c|c|c|c|c|}
\hline \multicolumn{5}{|c|}{ Supplemental Table S2.txt } \\
\hline CHEMBL1310268 & 688759 & 4.8 & 4.5643 & TRN \\
\hline CHEMBL1365063 & 688759 & 4.5 & 5.003 & TRN \\
\hline CHEMBL1434463 & 688759 & 4.9 & 4.784 & TST \\
\hline CHEMBL1583177 & 688759 & 4.8 & 4.8617 & TST \\
\hline CHEMBL1392142 & 688759 & 5.15 & 5.3429 & TRN \\
\hline CHEMBL1326236 & 688759 & 4.45 & 4.916 & TRN \\
\hline CHEMBL1311570 & 688759 & 4.45 & 4.6433 & TRN \\
\hline CHEMBL1370205 & 688759 & 4.45 & 4.7255 & TRN \\
\hline CHEMBL1502906 & 688759 & 4.75 & 4.6699 & TRN \\
\hline CHEMBL601768 & 688759 & 5.55 & 5.5692 & TRN \\
\hline CHEMBL1340776 & 688759 & 5.7 & 5.3192 & TRN \\
\hline CHEMBL1539307 & 688759 & 5.4 & 5.1202 & TRN \\
\hline CHEMBL378903 & 688759 & 4.45 & 4.6989 & TRN \\
\hline CHEMBL1330516 & 688759 & 5.05 & 5.1353 & TRN \\
\hline CHEMBL1608535 & 688759 & 4.45 & 4.9525 & TST \\
\hline CHEMBL1321963 & 688759 & 4.9 & 4.9573 & TRN \\
\hline CHEMBL1342510 & 688759 & 5.0 & 5.124 & TRN \\
\hline CHEMBL3191170 & 688759 & 5.0 & 5.1166 & TRN \\
\hline CHEMBL1600086 & 688759 & 5.25 & 5.0069 & TRN \\
\hline CHEMBL1529029 & 688759 & 4.45 & 4.5383 & TRN \\
\hline CHEMBL1561126 & 688759 & 5.55 & 5.682 & TRN \\
\hline CHEMBL1535895 & 688759 & 4.75 & 4.7301 & TRN \\
\hline CHEMBL3191063 & 688759 & 4.65 & 4.9227 & TRN \\
\hline CHEMBL3208410 & 688759 & 4.75 & 4.7143 & TRN \\
\hline CHEMBL 3198390 & 688759 & 5.15 & 5.09 & TRN \\
\hline CHEMBL3207933 & 688759 & 5.45 & 5.0365 & TST \\
\hline CHEMBL1444764 & 688759 & 6.0 & 4.9573 & TRN \\
\hline CHEMBL1330250 & 688759 & 6.15 & 5.8901 & TRN \\
\hline CHEMBL1348210 & 688759 & 4.85 & 4.5813 & TST \\
\hline CHEMBL3198598 & 688759 & 5.15 & 4.9345 & TRN \\
\hline CHEMBL1359361 & 688759 & 4.45 & 4.7073 & TRN \\
\hline CHEMBL1965444 & 688759 & 5.3 & 5.3127 & TRN \\
\hline CHEMBL3197665 & 688759 & 5.0 & 4.9616 & TRN \\
\hline CHEMBL421215 & 688759 & 4.85 & 4.8648 & TST \\
\hline CHEMBL1498753 & 688759 & 5.3 & 5.2668 & TRN \\
\hline CHEMBL2006909 & 688759 & 4.45 & 4.8126 & TRN \\
\hline CHEMBL1380516 & 688759 & 7.2503 & 4.9228 & TRN \\
\hline CHEMBL1388691 & 688759 & 4.45 & 4.4552 & TRN \\
\hline CHEMBL1345558 & 688759 & 4.85 & 4.692 & TRN \\
\hline CHEMBL1447251 & 688759 & 5.0 & 5.2477 & TRN \\
\hline CHEMBL1383878 & 688759 & 4.75 & 4.8015 & TST \\
\hline CHEMBL1425228 & 688759 & 4.55 & 4.8057 & TRN \\
\hline CHEMBL1327368 & 688759 & 4.6 & 4.7536 & TST \\
\hline CHEMBL3191437 & 688759 & 4.8 & 4.8715 & TRN \\
\hline CHEMBL1323795 & 688759 & 4.9 & 4.8636 & TRN \\
\hline CHEMBL1534306 & 688759 & 4.45 & 4.6314 & TST \\
\hline CHEMBL1341433 & 688759 & 4.6 & 4.765 & TRN \\
\hline CHEMBL1461579 & 688759 & 4.9 & 5.0151 & TRN \\
\hline
\end{tabular}




\begin{tabular}{|c|c|c|c|c|c|}
\hline & & \multicolumn{4}{|c|}{ Supplemental Table S2.txt } \\
\hline CHEMBL1349442 & 688759 & 4.95 & 5.1056 & TRN & \\
\hline CHEMBL1372596 & 688759 & 4.8 & 5.2119 & TRN & \\
\hline CHEMBL1389061 & 688759 & 5.85 & 5.41200 & 0000000001 & TRN \\
\hline CHEMBL1418435 & 688759 & 5.3 & 4.9942 & TRN & \\
\hline CHEMBL1533590 & 688759 & 4.8 & 4.7868 & TRN & \\
\hline CHEMBL1378785 & 688759 & 5.75 & 5.68 & TRN & \\
\hline CHEMBL1370899 & 688759 & 5.1 & 4.8841 & TRN & \\
\hline CHEMBL1403871 & 688759 & 5.15 & 5.1742 & TRN & \\
\hline CHEMBL1534733 & 688759 & 5.2 & 4.8808 & TST & \\
\hline CHEMBL1496341 & 688759 & 4.45 & 5.4666 & TRN & \\
\hline CHEMBL3197489 & 688759 & 4.65 & 4.4889 & TRN & \\
\hline CHEMBL1438193 & 688759 & 4.65 & 4.7951 & TRN & \\
\hline CHEMBL1469362 & 688759 & 4.45 & 4.705 & TRN & \\
\hline CHEMBL1994913 & 688759 & 4.65 & 4.6337 & TRN & \\
\hline CHEMBL1506384 & 688759 & 4.5 & 4.8511 & TRN & \\
\hline CHEMBL1472238 & 688759 & 5.05 & 4.8221 & TRN & \\
\hline CHEMBL1470256 & 688759 & 5.65 & 5.2854 & TRN & \\
\hline CHEMBL1555178 & 688759 & 4.95 & 5.2895 & TST & \\
\hline CHEMBL3191884 & 688759 & 4.8 & 4.7753 & TST & \\
\hline CHEMBL1583166 & 688759 & 4.9 & 4.7986 & TST & \\
\hline CHEMBL1509267 & 688759 & 4.85 & 4.8079 & TRN & \\
\hline CHEMBL1386680 & 688759 & 4.7 & 4.6029 & TST & \\
\hline CHEMBL1517714 & 688759 & 4.7 & 4.9676 & TST & \\
\hline CHEMBL1499436 & 688759 & 4.85 & 5.2073 & TST & \\
\hline CHEMBL1479951 & 688759 & 4.45 & 4.6751 & TST & \\
\hline CHEMBL38508 & 688759 & 4.45 & 4.7529 & TST & \\
\hline CHEMBL1532593 & 688759 & 4.45 & 5.2301 & TRN & \\
\hline CHEMBL1480251 & 688759 & 5.25 & 4.8355 & TST & \\
\hline CHEMBL1505823 & 688759 & 5.5 & 4.8453 & TRN & \\
\hline CHEMBL1447963 & 688759 & 4.5 & 4.7319 & TRN & \\
\hline CHEMBL1362524 & 688759 & 4.6 & 4.4435 & TRN & \\
\hline CHEMBL1981546 & 688759 & 4.75 & 5.0456 & TRN & \\
\hline CHEMBL3208839 & 688759 & 4.7 & 4.9668 & TST & \\
\hline CHEMBL1399775 & 688759 & 4.45 & 4.5297 & TRN & \\
\hline CHEMBL1568237 & 688759 & 4.9 & 4.96399 & 99999999995 & TRN \\
\hline CHEMBL1584189 & 688759 & 4.9 & 4.902 & TRN & \\
\hline CHEMBL1468088 & 688759 & 4.45 & 5.0508 & TRN & \\
\hline CHEMBL1562570 & 688759 & 4.45 & 5.0641 & TRN & \\
\hline CHEMBL1386178 & 688759 & 5.25 & 5.1333 & TST & \\
\hline CHEMBL1589632 & 688759 & 4.65 & 4.8272 & TRN & \\
\hline CHEMBL1320531 & 688759 & 5.25 & 5.0637 & TRN & \\
\hline CHEMBL1526730 & 688759 & 4.8 & 4.8217 & TST & \\
\hline CHEMBL1559811 & 688759 & 5.0 & 5.5284 & TRN & \\
\hline CHEMBL3189343 & 688759 & 5.55 & 5.51 & TRN & \\
\hline CHEMBL1453441 & 688759 & 4.45 & 4.4976 & TRN & \\
\hline CHEMBL1340302 & 688759 & 5.5 & 4.8321 & TRN & \\
\hline CHEMBL1461209 & 688759 & 5.45 & 4.8295 & TRN & \\
\hline CHEMBL1535908 & 688759 & 4.45 & 4.6742 & TRN & \\
\hline
\end{tabular}




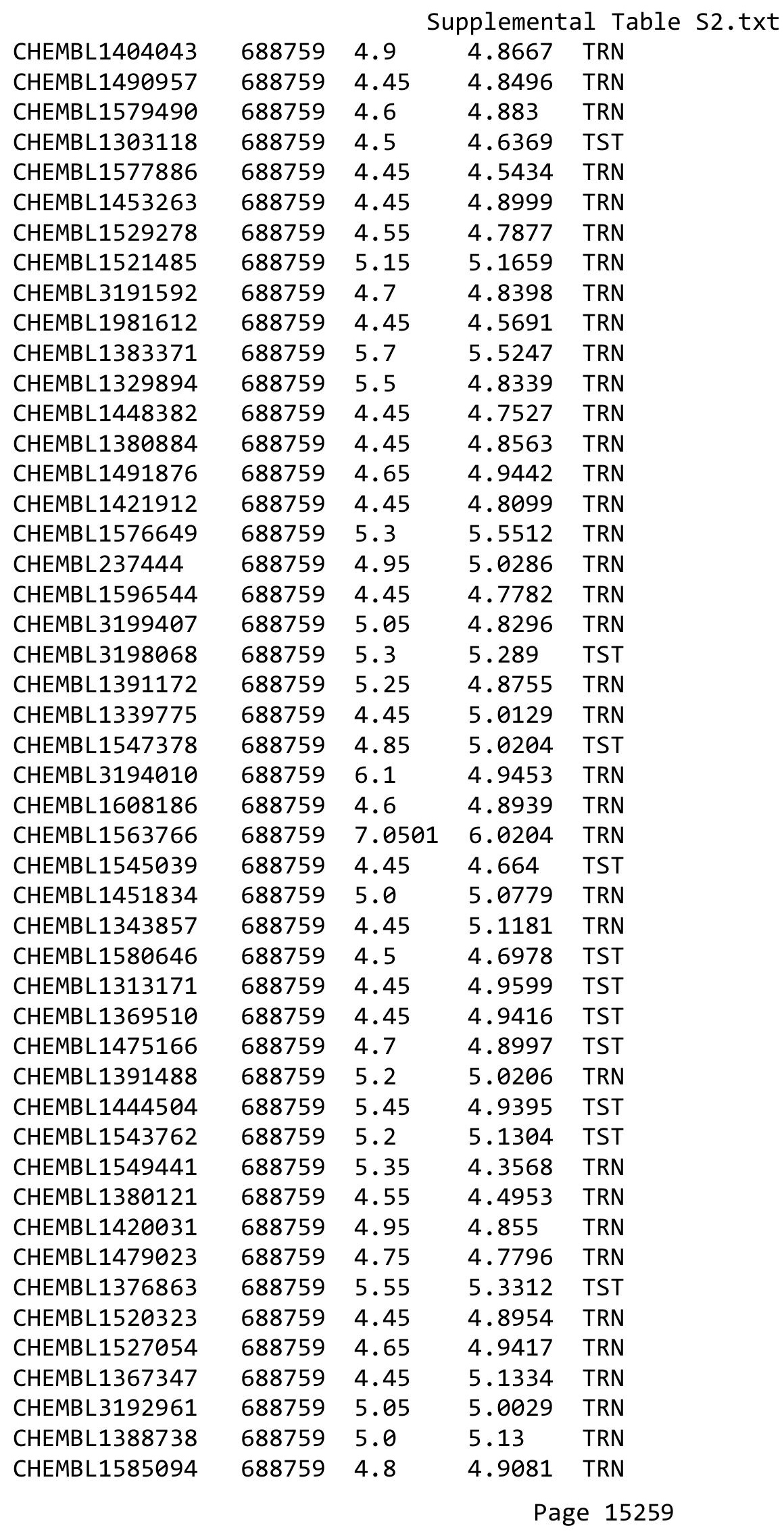




\begin{tabular}{|c|c|c|c|c|}
\hline \multicolumn{5}{|c|}{ Supplemental Table S2.txt } \\
\hline CHEMBL1310629 & 688759 & 4.45 & 4.7249 & TRN \\
\hline CHEMBL1966746 & 688759 & 4.85 & 4.8945 & TRN \\
\hline CHEMBL1575600 & 688759 & 6.25 & 5.5393 & TRN \\
\hline CHEMBL1300417 & 688759 & 4.95 & 4.5882 & TST \\
\hline CHEMBL1482221 & 688759 & 4.7 & 4.5889 & TRN \\
\hline CHEMBL1465227 & 688759 & 4.85 & 4.9262 & TST \\
\hline CHEMBL1348007 & 688759 & 4.45 & 4.8741 & TRN \\
\hline CHEMBL1328470 & 688759 & 5.2 & 4.9823 & TRN \\
\hline CHEMBL1384002 & 688759 & 6.15 & 4.8614 & TST \\
\hline CHEMBL1482901 & 688759 & 4.9 & 5.1849 & TRN \\
\hline CHEMBL1991357 & 688759 & 4.95 & 4.7389 & TRN \\
\hline CHEMBL1525596 & 688759 & 4.65 & 4.8355 & TRN \\
\hline CHEMBL1558795 & 688759 & 4.65 & 4.654 & TRN \\
\hline CHEMBL1497658 & 688759 & 5.3 & 4.8382 & TRN \\
\hline CHEMBL1381886 & 688759 & 4.45 & 5.1014 & TRN \\
\hline CHEMBL1477596 & 688759 & 4.7 & 4.8323 & TRN \\
\hline CHEMBL1510456 & 688759 & 4.9 & 5.0733 & TST \\
\hline CHEMBL180917 & 688759 & 5.0 & 5.0392 & TST \\
\hline CHEMBL3195884 & 688759 & 4.6 & 4.8339 & TRN \\
\hline CHEMBL3199331 & 688759 & 4.9 & 5.0946 & TRN \\
\hline CHEMBL1564441 & 688759 & 4.45 & 4.5387 & TRN \\
\hline CHEMBL1612684 & 688759 & 4.55 & 4.9364 & TRN \\
\hline CHEMBL1550045 & 688759 & 4.45 & 4.4661 & TRN \\
\hline CHEMBL1516860 & 688759 & 4.8 & 4.9121 & TRN \\
\hline CHEMBL1998717 & 688759 & 5.05 & 5.4501 & TRN \\
\hline CHEMBL1506312 & 688759 & 4.7 & 4.5638 & TRN \\
\hline CHEMBL1376134 & 688759 & 5.45 & 4.9152 & TRN \\
\hline CHEMBL 2005895 & 688759 & 5.75 & 5.5978 & TRN \\
\hline CHEMBL1377915 & 688759 & 5.2 & 5.277 & TRN \\
\hline CHEMBL3195645 & 688759 & 4.9 & 4.7186 & TST \\
\hline CHEMBL1519531 & 688759 & 4.45 & 4.848 & TST \\
\hline CHEMBL1381205 & 688759 & 4.85 & 4.9296 & TRN \\
\hline CHEMBL3191365 & 688759 & 4.6 & 4.6642 & TRN \\
\hline CHEMBL1981398 & 688759 & 5.5 & 5.0718 & TRN \\
\hline CHEMBL1429866 & 688759 & 4.45 & 4.5955 & TRN \\
\hline CHEMBL1339806 & 688759 & 5.25 & 4.7223 & TRN \\
\hline CHEMBL1313758 & 688759 & 6.0 & 5.2953 & TRN \\
\hline CHEMBL1460746 & 688759 & 4.45 & 5.4264 & TRN \\
\hline CHEMBL1341080 & 688759 & 4.6 & 4.8098 & TST \\
\hline CHEMBL1426481 & 688759 & 5.35 & 4.9345 & TST \\
\hline CHEMBL1485503 & 688759 & 4.55 & 4.6568 & TST \\
\hline CHEMBL1342451 & 688759 & 4.45 & 4.6302 & TST \\
\hline CHEMBL1577318 & 688759 & 4.95 & 4.7941 & TST \\
\hline CHEMBL1487818 & 688759 & 4.55 & 4.8978 & TRN \\
\hline CHEMBL1607065 & 688759 & 4.9 & 5.0692 & TST \\
\hline CHEMBL601335 & 688759 & 6.0 & 5.1003 & TRN \\
\hline CHEMBL1993544 & 688759 & 5.4 & 4.9651 & TRN \\
\hline CHEMBL1531613 & 688759 & 4.45 & 4.8044 & TRN \\
\hline
\end{tabular}




\begin{tabular}{|c|c|c|c|c|}
\hline \multicolumn{5}{|c|}{ Supplemental Table } \\
\hline CHEMBL 3209845 & 688759 & 5.55 & 5.476 & TRN \\
\hline CHEMBL1480866 & 688759 & 4.45 & 4.6883 & TRN \\
\hline CHEMBL1498303 & 688759 & 4.9 & 4.8495 & TRN \\
\hline CHEMBL1492526 & 688759 & 4.45 & 5.2503 & TRN \\
\hline CHEMBL1575102 & 688759 & 5.0 & 4.9361 & TRN \\
\hline CHEMBL1561446 & 688759 & 4.75 & 4.8993 & TST \\
\hline CHEMBL447876 & 688759 & 5.2 & 5.101 & TST \\
\hline CHEMBL1305241 & 688759 & 4.75 & 4.838 & TRN \\
\hline CHEMBL1509155 & 688759 & 4.9 & 5.0238 & TRN \\
\hline CHEMBL1437994 & 688759 & 4.45 & 4.547 & TRN \\
\hline CHEMBL1342344 & 688759 & 5.25 & 4.8918 & TRN \\
\hline CHEMBL 2006508 & 688759 & 5.55 & 5.2474 & TRN \\
\hline CHEMBL1448294 & 688759 & 4.85 & 4.8561 & TRN \\
\hline CHEMBL1401170 & 688759 & 5.2 & 4.837 & TST \\
\hline CHEMBL1541215 & 688759 & 4.45 & 4.8476 & TST \\
\hline CHEMBL1545363 & 688759 & 5.0 & 4.9434 & TST \\
\hline CHEMBL3198362 & 688759 & 4.8 & 5.1929 & TRN \\
\hline CHEMBL1544221 & 688759 & 5.5 & 4.8874 & TRN \\
\hline CHEMBL237253 & 688759 & 4.75 & 4.9852 & TRN \\
\hline CHEMBL1383635 & 688759 & 4.45 & 4.5371 & TRN \\
\hline CHEMBL3191413 & 688759 & 4.45 & 4.8743 & TRN \\
\hline CHEMBL1388637 & 688759 & 4.5 & 4.6539 & TRN \\
\hline CHEMBL1469054 & 688759 & 5.05 & 4.8638 & TRN \\
\hline CHEMBL1329465 & 688759 & 4.9 & 4.8929 & TRN \\
\hline CHEMBL3194410 & 688759 & 4.45 & 4.7268 & TRN \\
\hline CHEMBL1604692 & 688759 & 5.35 & 4.8718 & TRN \\
\hline CHEMBL1486055 & 688759 & 4.65 & 4.6286 & TRN \\
\hline CHEMBL1488718 & 688759 & 4.6 & 4.5922 & TRN \\
\hline CHEMBL1463639 & 688759 & 4.45 & 4.8234 & TST \\
\hline CHEMBL1323590 & 688759 & 4.75 & 4.8466 & TRN \\
\hline CHEMBL1341197 & 688759 & 4.75 & 4.7625 & TRN \\
\hline CHEMBL1600701 & 688759 & 4.45 & 4.2996 & TRN \\
\hline CHEMBL1560784 & 688759 & 4.45 & 4.5925 & TRN \\
\hline CHEMBL1387313 & 688759 & 4.55 & 4.647 & TST \\
\hline CHEMBL1393635 & 688759 & 4.95 & 5.0009 & TRN \\
\hline CHEMBL1602122 & 688759 & 5.25 & 4.9229 & TRN \\
\hline CHEMBL1577857 & 688759 & 5.4 & 6.0572 & TRN \\
\hline CHEMBL1583950 & 688759 & 5.45 & 4.9695 & TRN \\
\hline CHEMBL1546767 & 688759 & 5.4 & 5.2768 & TRN \\
\hline CHEMBL1606215 & 688759 & 5.4 & 4.9559 & TRN \\
\hline CHEMBL1456293 & 688759 & 4.45 & 4.8262 & TRN \\
\hline CHEMBL1487665 & 688759 & 6.8 & 5.1634 & TST \\
\hline CHEMBL1389480 & 688759 & 5.5 & 4.5516 & TST \\
\hline CHEMBL1454244 & 688759 & 4.45 & 4.7527 & TST \\
\hline CHEMBL1535180 & 688759 & 4.45 & 4.8193 & TRN \\
\hline CHEMBL3210321 & 688759 & 4.95 & 4.7091 & TRN \\
\hline CHEMBL1520053 & 688759 & 4.45 & 4.5262 & TRN \\
\hline CHEMBL1427471 & 688759 & 4.45 & 4.7315 & TST \\
\hline
\end{tabular}




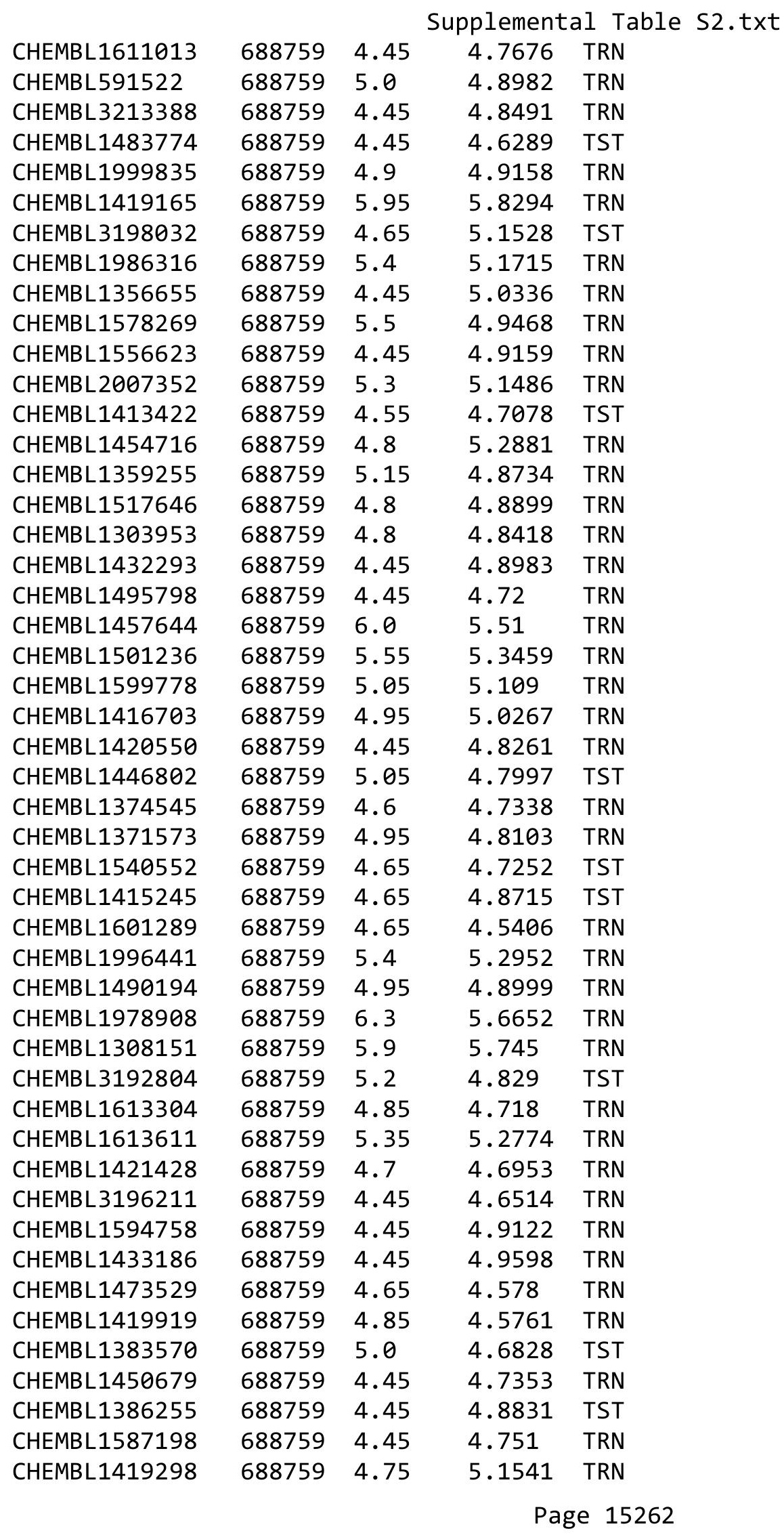




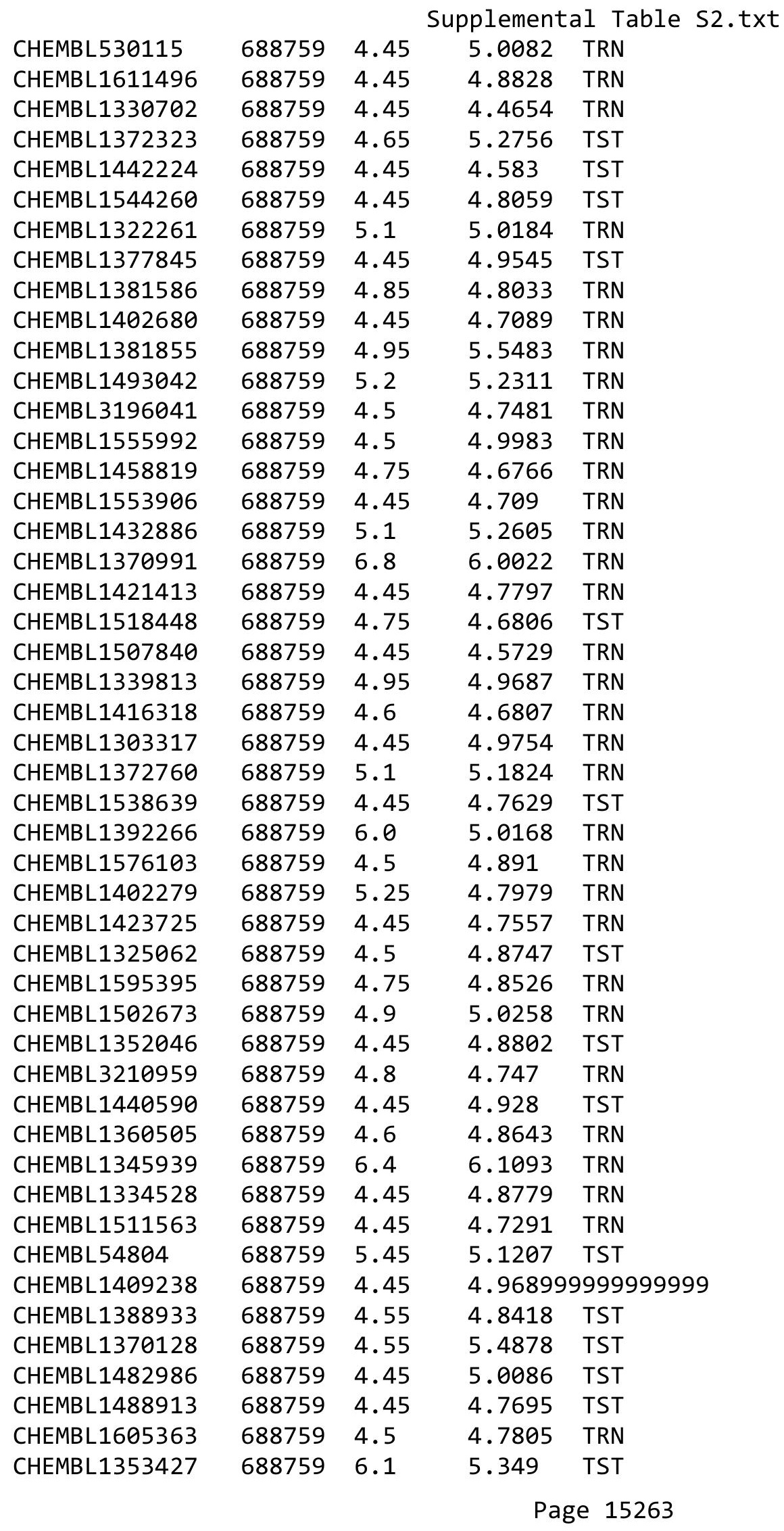




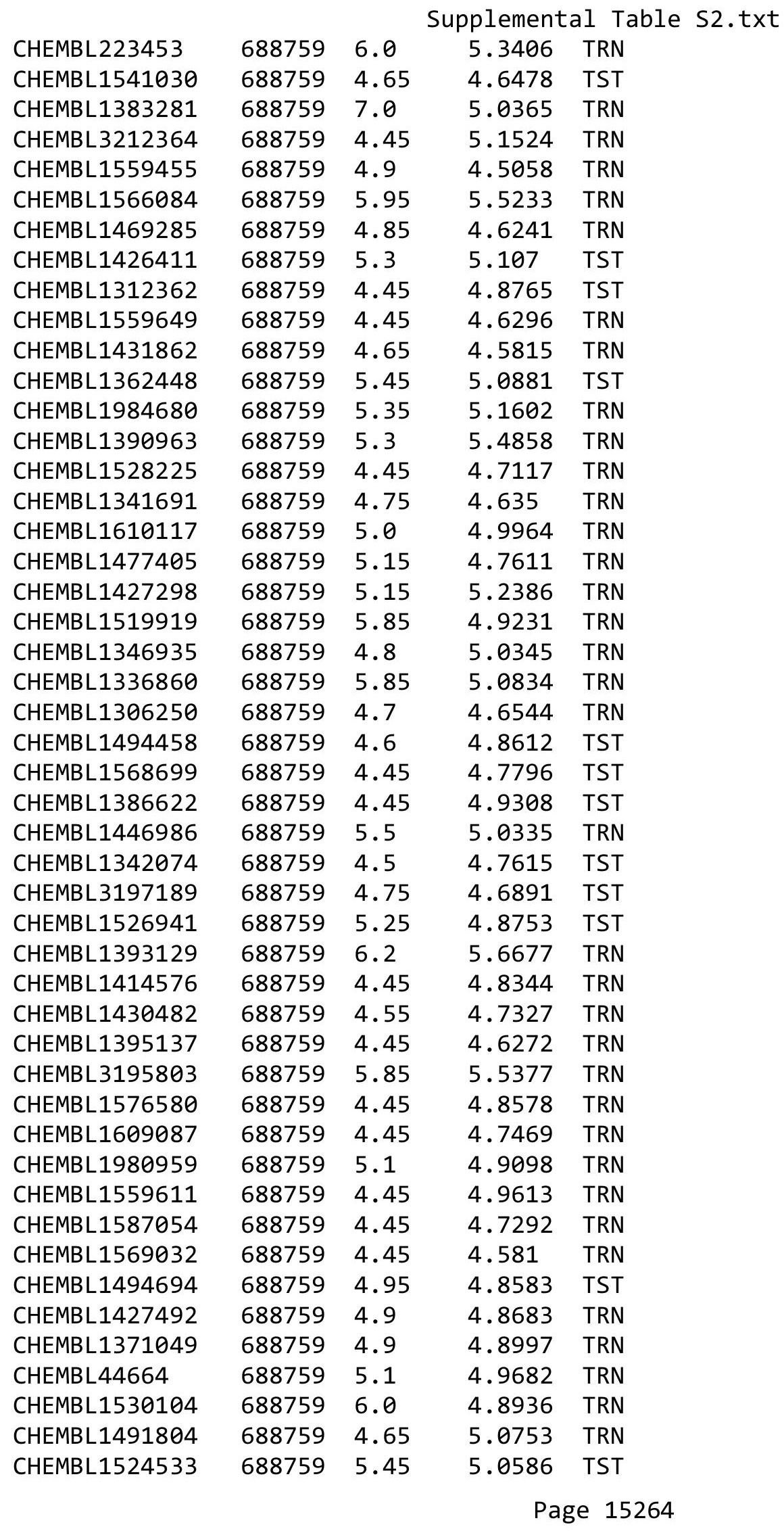




\begin{tabular}{|c|c|c|c|c|}
\hline \multicolumn{5}{|c|}{ Supplemental Table s2.txt } \\
\hline CHEMBL1514691 & 688759 & 5.2 & 4.9514 & TST \\
\hline CHEMBL1469946 & 688759 & 4.95 & 4.5978 & TRN \\
\hline CHEMBL3198407 & 688759 & 5.15 & 5.1735 & TRN \\
\hline CHEMBL 3189196 & 688759 & 4.45 & 4.4982 & TST \\
\hline CHEMBL1397452 & 688759 & 5.7 & 5.2873 & TST \\
\hline CHEMBL3198002 & 688759 & 5.05 & 5.0884 & TRN \\
\hline CHEMBL1570267 & 688759 & 5.0 & 4.952 & TST \\
\hline CHEMBL1418334 & 688759 & 4.65 & 4.8473 & TRN \\
\hline CHEMBL1472418 & 688759 & 6.25 & 5.7846 & TRN \\
\hline CHEMBL1333734 & 688759 & 4.8 & 4.8144 & TRN \\
\hline CHEMBL1309210 & 688759 & 4.45 & 4.773 & TRN \\
\hline CHEMBL 3194498 & 688759 & 4.45 & 4.8464 & TST \\
\hline CHEMBL1347488 & 688759 & 4.45 & 5.1866 & TRN \\
\hline CHEMBL1499561 & 688759 & 6.7001 & 4.6739 & TRN \\
\hline CHEMBL1402856 & 688759 & 4.45 & 4.7466 & TST \\
\hline CHEMBL1586123 & 688759 & 4.45 & 4.8285 & TRN \\
\hline CHEMBL1979455 & 688759 & 5.7 & 5.4912 & TRN \\
\hline CHEMBL1998852 & 688759 & 4.95 & 4.6885 & TRN \\
\hline CHEMBL1550057 & 688759 & 5.25 & 5.3363 & TRN \\
\hline CHEMBL1488059 & 688759 & 4.55 & 4.8441 & TST \\
\hline CHEMBL1412845 & 688759 & 5.2 & 4.7612 & TST \\
\hline CHEMBL1547093 & 688759 & 4.45 & 4.7229 & TST \\
\hline CHEMBL91844 & 688759 & 4.65 & 4.9363 & TST \\
\hline CHEMBL1499960 & 688759 & 4.45 & 4.6983 & TRN \\
\hline CHEMBL1518126 & 688759 & 4.45 & 4.7319 & TRN \\
\hline CHEMBL1359842 & 688759 & 4.65 & 4.6837 & TRN \\
\hline CHEMBL2007601 & 688759 & 5.25 & 5.1006 & TRN \\
\hline CHEMBL1428259 & 688759 & 4.5 & 4.875 & TRN \\
\hline CHEMBL3190739 & 688759 & 4.65 & 4.7094 & TRN \\
\hline CHEMBL1478024 & 688759 & 4.6 & 4.7628 & TRN \\
\hline CHEMBL 2000219 & 688759 & 5.35 & 5.2027 & TRN \\
\hline CHEMBL1985330 & 688759 & 5.25 & 5.2053 & TRN \\
\hline CHEMBL1550366 & 688759 & 4.65 & 4.8655 & TST \\
\hline CHEMBL3198940 & 688759 & 4.95 & 4.6802 & TRN \\
\hline CHEMBL1584661 & 688759 & 4.45 & 4.8259 & TRN \\
\hline CHEMBL1442087 & 688759 & 4.45 & 4.53 & TRN \\
\hline CHEMBL1572024 & 688759 & 4.95 & 5.0494 & TST \\
\hline CHEMBL1559862 & 688759 & 5.2 & 4.942 & TRN \\
\hline CHEMBL1465878 & 688759 & 4.65 & 4.7868 & TRN \\
\hline CHEMBL1429290 & 688759 & 4.65 & 5.1225 & TRN \\
\hline CHEMBL1520777 & 688759 & 4.8 & 4.569 & TST \\
\hline CHEMBL1370034 & 688759 & 6.25 & 4.8523 & TST \\
\hline CHEMBL1381098 & 688759 & 4.9 & 4.9831 & TST \\
\hline CHEMBL1373061 & 688759 & 5.0 & 5.3825 & TRN \\
\hline CHEMBL1305701 & 688759 & 5.25 & 4.7355 & TST \\
\hline CHEMBL1345557 & 688759 & 4.45 & 4.8155 & TRN \\
\hline CHEMBL1304122 & 688759 & 4.45 & 5.0595 & TRN \\
\hline CHEMBL1493818 & 688759 & 4.45 & 4.8385 & TRN \\
\hline
\end{tabular}




\begin{tabular}{|c|c|c|c|c|c|}
\hline & & \multicolumn{4}{|c|}{ Supplemental Table s2.txt } \\
\hline CHEMBL1517823 & 688759 & 5.0 & 4.7 & TST & \\
\hline CHEMBL1608827 & 688759 & 4.45 & 4.9221 & TST & \\
\hline CHEMBL1416655 & 688759 & 4.7 & 4.8954 & TRN & \\
\hline CHEMBL1416769 & 688759 & 4.45 & 4.5986 & TRN & \\
\hline CHEMBL1510080 & 688759 & 5.0 & 5.0599 & TRN & \\
\hline CHEMBL1607527 & 688759 & 4.8 & 4.922 & TRN & \\
\hline CHEMBL1329561 & 688759 & 4.45 & 4.6832 & TRN & \\
\hline CHEMBL3210929 & 688759 & 5.15 & 4.9848 & TRN & \\
\hline CHEMBL1334514 & 688759 & 5.6 & 5.2758 & TRN & \\
\hline CHEMBL2001831 & 688759 & 4.95 & 4.8702 & TRN & \\
\hline CHEMBL1610106 & 688759 & 4.7 & 4.8472 & TST & \\
\hline CHEMBL1380757 & 688759 & 5.0 & 4.8968 & TRN & \\
\hline CHEMBL3193428 & 688759 & 4.6 & 4.7003 & TST & \\
\hline CHEMBL579318 & 688759 & 5.35 & 5.5458 & TRN & \\
\hline CHEMBL1319504 & 688759 & 4.45 & 4.6621 & TRN & \\
\hline CHEMBL1484173 & 688759 & 5.75 & 4.88899 & 9999999999 & TST \\
\hline CHEMBL1437979 & 688759 & 4.95 & 4.8242 & TRN & \\
\hline CHEMBL1361550 & 688759 & 5.35 & 4.9471 & TRN & \\
\hline CHEMBL1529008 & 688759 & 5.15 & 5.0806 & TRN & \\
\hline CHEMBL1522526 & 688759 & 6.25 & 6.0604 & TRN & \\
\hline CHEMBL1450943 & 688759 & 6.5 & 4.9309 & TRN & \\
\hline CHEMBL1348452 & 688759 & 4.55 & 4.6508 & TRN & \\
\hline CHEMBL1574219 & 688759 & 4.75 & 4.7894 & TST & \\
\hline CHEMBL1531805 & 688759 & 4.45 & 4.6643 & TRN & \\
\hline CHEMBL1487401 & 688759 & 6.25 & 6.1565 & TRN & \\
\hline CHEMBL1335557 & 688759 & 4.75 & 4.9846 & TRN & \\
\hline CHEMBL1348582 & 688759 & 4.8 & 5.2677 & TRN & \\
\hline CHEMBL3212718 & 688759 & 5.2 & 5.0746 & TST & \\
\hline CHEMBL1484616 & 688759 & 4.65 & 4.8564 & TRN & \\
\hline CHEMBL1483133 & 688759 & 4.45 & 4.6819 & TRN & \\
\hline CHEMBL1418716 & 688759 & 4.95 & 5.2857 & TRN & \\
\hline CHEMBL1341995 & 688759 & 6.0 & 5.499 & TRN & \\
\hline CHEMBL 3145281 & 688759 & 4.45 & 4.8766 & TRN & \\
\hline CHEMBL3212826 & 688759 & 4.45 & 4.6178 & TRN & \\
\hline CHEMBL1996954 & 688759 & 4.65 & 4.8898 & TRN & \\
\hline CHEMBL1331660 & 688759 & 4.45 & 4.6878 & TRN & \\
\hline CHEMBL1568627 & 688759 & 5.95 & 5.4497 & TRN & \\
\hline CHEMBL1373187 & 688759 & 4.45 & 4.6721 & TRN & \\
\hline CHEMBL1329209 & 688759 & 4.45 & 4.7312 & TST & \\
\hline CHEMBL1331288 & 688759 & 4.6 & 4.9794 & TRN & \\
\hline CHEMBL3189945 & 688759 & 4.6 & 4.6442 & TRN & \\
\hline CHEMBL1528795 & 688759 & 4.45 & 4.4076 & TST & \\
\hline CHEMBL3190513 & 688759 & 5.3 & 4.9704 & TRN & \\
\hline CHEMBL1448328 & 688759 & 4.45 & 4.8943 & TRN & \\
\hline CHEMBL1346613 & 688759 & 4.45 & 4.6727 & TRN & \\
\hline CHEMBL1360207 & 688759 & 5.25 & 5.0692 & TRN & \\
\hline CHEMBL1601883 & 688759 & 4.7 & 4.6492 & TRN & \\
\hline CHEMBL1320418 & 688759 & 4.7 & 4.7774 & TST & \\
\hline
\end{tabular}




\begin{tabular}{|c|c|c|c|c|}
\hline \multicolumn{5}{|c|}{ Supplemental Table S2.txt } \\
\hline CHEMBL1504077 & 688759 & 5.1 & 5.2312 & TRN \\
\hline CHEMBL1541923 & 688759 & 4.65 & 5.0962 & TRN \\
\hline CHEMBL398206 & 688759 & 4.85 & 4.9272 & TRN \\
\hline CHEMBL1544623 & 688759 & 4.45 & 4.9311 & TRN \\
\hline CHEMBL1347211 & 688759 & 4.5 & 4.9067 & TRN \\
\hline CHEMBL1581022 & 688759 & 4.6 & 5.3514 & TRN \\
\hline CHEMBL1306347 & 688759 & 4.95 & 4.9417 & TST \\
\hline CHEMBL1569071 & 688759 & 4.75 & 4.8717 & TRN \\
\hline CHEMBL1540321 & 688759 & 5.15 & 4.8735 & TRN \\
\hline CHEMBL1376288 & 688759 & 4.75 & 5.0151 & TST \\
\hline CHEMBL1342861 & 688759 & 5.6 & 4.7294 & TRN \\
\hline CHEMBL1430093 & 688759 & 4.7 & 4.6753 & TST \\
\hline CHEMBL1973226 & 688759 & 5.0 & 4.8394 & TRN \\
\hline CHEMBL1415532 & 688759 & 5.65 & 5.1802 & TRN \\
\hline CHEMBL1351535 & 688759 & 6.95 & 5.2142 & TRN \\
\hline CHEMBL3196191 & 688759 & 5.65 & 5.2972 & TRN \\
\hline CHEMBL1391715 & 688759 & 4.45 & 4.66 & TST \\
\hline CHEMBL1555591 & 688759 & 5.5 & 5.2529 & TST \\
\hline CHEMBL1450616 & 688759 & 5.5 & 4.8803 & TRN \\
\hline CHEMBL1173823 & 688759 & 4.75 & 4.6498 & TST \\
\hline CHEMBL1564306 & 688759 & 4.95 & 5.0606 & TST \\
\hline CHEMBL3192319 & 688759 & 4.45 & 4.5097 & TRN \\
\hline CHEMBL1572112 & 688759 & 4.95 & 4.7509 & TRN \\
\hline CHEMBL1420037 & 688759 & 6.0 & 5.1239 & TRN \\
\hline CHEMBL1348895 & 688759 & 4.7 & 4.8613 & TRN \\
\hline CHEMBL1506663 & 688759 & 5.0 & 4.886 & TRN \\
\hline CHEMBL1374298 & 688759 & 4.45 & 4.7562 & TST \\
\hline CHEMBL1377059 & 688759 & 4.95 & 4.8637 & TRN \\
\hline CHEMBL 2005664 & 688759 & 4.45 & 4.7391 & TRN \\
\hline CHEMBL1444991 & 688759 & 5.55 & 5.5496 & TST \\
\hline CHEMBL1427379 & 688759 & 4.45 & 4.4509 & TRN \\
\hline CHEMBL1497589 & 688759 & 4.65 & 5.1123 & TRN \\
\hline CHEMBL1450350 & 688759 & 4.45 & 4.9123 & TST \\
\hline CHEMBL1421312 & 688759 & 4.95 & 4.9617 & TRN \\
\hline CHEMBL1300383 & 688759 & 4.5 & 4.8613 & TST \\
\hline CHEMBL1311809 & 688759 & 4.9 & 4.5576 & TST \\
\hline CHEMBL3190223 & 688759 & 4.75 & 4.7262 & TRN \\
\hline CHEMBL 2004322 & 688759 & 4.45 & 4.9757 & TRN \\
\hline CHEMBL1431523 & 688759 & 4.5 & 5.1148 & TRN \\
\hline CHEMBL1982744 & 688759 & 4.6 & 5.0693 & TRN \\
\hline CHEMBL3145303 & 688759 & 8.6576 & 6.3383 & TRN \\
\hline CHEMBL1449811 & 688759 & 5.5 & 5.1331 & TRN \\
\hline CHEMBL3196300 & 688759 & 6.0 & 4.8886 & TRN \\
\hline CHEMBL1469488 & 688759 & 4.7 & 4.6397 & TST \\
\hline CHEMBL1413278 & 688759 & 4.9 & 4.9456 & TRN \\
\hline CHEMBL1585912 & 688759 & 7.4498 & 5.0494 & TRN \\
\hline CHEMBL1368049 & 688759 & 4.65 & 4.8951 & TRN \\
\hline CHEMBL1544508 & 688759 & 4.45 & 4.8617 & TRN \\
\hline
\end{tabular}




\begin{tabular}{|c|c|c|c|c|c|}
\hline \multicolumn{6}{|c|}{ Supplemental Table S2.txt } \\
\hline CHEMBL1342097 & 688759 & 5.0 & 4.9024 & TRN & \\
\hline CHEMBL1375841 & 688759 & 4.45 & 4.575 & TRN & \\
\hline CHEMBL1577585 & 688759 & 4.65 & 4.6127 & TRN & \\
\hline CHEMBL1460094 & 688759 & 5.45 & 5.5017 & TRN & \\
\hline CHEMBL1343248 & 688759 & 6.8 & 5.5376 & TRN & \\
\hline CHEMBL1467287 & 688759 & 4.9 & 4.8948 & TST & \\
\hline CHEMBL1084301 & 688759 & 4.65 & 4.7323 & TRN & \\
\hline CHEMBL3192992 & 688759 & 4.45 & 4.8718 & TRN & \\
\hline CHEMBL1603890 & 688759 & 4.65 & 4.6132 & TST & \\
\hline CHEMBL1536298 & 688759 & 5.3 & 4.869 & TST & \\
\hline CHEMBL1413640 & 688759 & 4.85 & 5.2041 & TRN & \\
\hline CHEMBL1487692 & 688759 & 5.15 & 5.2987 & TST & \\
\hline CHEMBL1429260 & 688759 & 4.45 & 4.9421 & TST & \\
\hline CHEMBL1305951 & 688759 & 4.65 & 5.0723 & TST & \\
\hline CHEMBL1539407 & 688759 & 4.5 & 4.8902 & TRN & \\
\hline CHEMBL1509789 & 688759 & 4.9 & 4.88899 & 9999999999 & TST \\
\hline CHEMBL1599783 & 688759 & 4.45 & 4.694 & TST & \\
\hline CHEMBL1430446 & 688759 & 4.45 & 4.8918 & TRN & \\
\hline CHEMBL1609197 & 688759 & 4.45 & 4.5811 & TRN & \\
\hline CHEMBL3196004 & 688759 & 4.5 & 4.81800 & 00000000005 & TRN \\
\hline CHEMBL1577952 & 688759 & 5.1 & 5.46 & TRN & \\
\hline CHEMBL1303288 & 688759 & 5.3 & 5.2933 & TRN & \\
\hline CHEMBL1310836 & 688759 & 4.45 & 5.175 & TRN & \\
\hline CHEMBL1420307 & 688759 & 4.45 & 5.193 & TRN & \\
\hline CHEMBL468018 & 688759 & 4.45 & 4.8663 & TRN & \\
\hline CHEMBL1525053 & 688759 & 4.65 & 4.6664 & TRN & \\
\hline CHEMBL1469288 & 688759 & 5.5 & 5.1259 & TRN & \\
\hline CHEMBL1376513 & 688759 & 6.25 & 5.0966 & TRN & \\
\hline CHEMBL3212323 & 688759 & 4.45 & 4.7616 & TRN & \\
\hline CHEMBL1588043 & 688759 & 4.45 & 4.7944 & TRN & \\
\hline CHEMBL1391460 & 688759 & 4.8 & 4.7048 & TRN & \\
\hline CHEMBL1374293 & 688759 & 4.95 & 4.9896 & TRN & \\
\hline CHEMBL1424118 & 688759 & 5.5 & 4.9064 & TRN & \\
\hline CHEMBL1562768 & 688759 & 5.2 & 4.8719 & TRN & \\
\hline CHEMBL1461379 & 688759 & 5.15 & 4.8104 & TST & \\
\hline CHEMBL1328854 & 688759 & 6.35 & 5.7609 & TST & \\
\hline CHEMBL3195058 & 688759 & 4.45 & 4.6481 & TRN & \\
\hline CHEMBL1497967 & 688759 & 4.85 & 4.776 & TST & \\
\hline CHEMBL1602810 & 688759 & 4.5 & 4.7985 & TRN & \\
\hline CHEMBL1550032 & 688759 & 5.7 & 4.8835 & TRN & \\
\hline CHEMBL1967395 & 688759 & 5.05 & 4.6151 & TRN & \\
\hline CHEMBL1529596 & 688759 & 5.4 & 5.1798 & TRN & \\
\hline CHEMBL1383757 & 688759 & 5.0 & 4.7668 & TRN & \\
\hline CHEMBL1530741 & 688759 & 4.45 & 4.7849 & TST & \\
\hline CHEMBL1508642 & 688759 & 6.1 & 5.5581 & TRN & \\
\hline CHEMBL1440333 & 688759 & 4.45 & 4.776 & TRN & \\
\hline CHEMBL1334612 & 688759 & 6.1 & 4.9003 & TRN & \\
\hline CHEMBL1367108 & 688759 & 5.2 & 4.9971 & TRN & \\
\hline
\end{tabular}




\begin{tabular}{|c|c|c|c|c|}
\hline \multicolumn{5}{|c|}{ Supplemental Table S2.txt } \\
\hline CHEMBL1461573 & 688759 & 5.35 & 5.2495 & TST \\
\hline CHEMBL1559945 & 688759 & 5.2 & 5.2319 & TRN \\
\hline CHEMBL1348506 & 688759 & 4.85 & 4.8689 & TST \\
\hline CHEMBL1411447 & 688759 & 5.3 & 5.1264 & TRN \\
\hline CHEMBL1546301 & 688759 & 4.95 & 4.8655 & TRN \\
\hline CHEMBL1599401 & 688759 & 4.9 & 5.0561 & TRN \\
\hline CHEMBL1469568 & 688759 & 4.5 & 4.8234 & TST \\
\hline CHEMBL 3192418 & 688759 & 4.45 & 4.9737 & TRN \\
\hline CHEMBL1444259 & 688759 & 5.25 & 5.0368 & TRN \\
\hline CHEMBL1301887 & 688759 & 5.0 & 4.8797 & TRN \\
\hline CHEMBL1560551 & 688759 & 4.95 & 4.9493 & TRN \\
\hline CHEMBL1495966 & 688759 & 4.55 & 4.601 & TRN \\
\hline CHEMBL1558928 & 688759 & 4.6 & 4.5172 & TRN \\
\hline CHEMBL1587517 & 688759 & 4.95 & 4.7749 & TRN \\
\hline CHEMBL129795 & 688759 & 6.0 & 5.4752 & TRN \\
\hline CHEMBL1422470 & 688759 & 4.45 & 4.7043 & TRN \\
\hline CHEMBL1333983 & 688759 & 4.75 & 4.8018 & TRN \\
\hline CHEMBL1479296 & 688759 & 5.4 & 5.2186 & TRN \\
\hline CHEMBL1426425 & 688759 & 4.95 & 5.27 & TRN \\
\hline CHEMBL1305910 & 688759 & 4.45 & 4.5832 & TST \\
\hline CHEMBL1461001 & 688759 & 5.0 & 4.7656 & TRN \\
\hline CHEMBL1430271 & 688759 & 4.65 & 4.5661 & TRN \\
\hline CHEMBL1537947 & 688759 & 5.35 & 5.0547 & TRN \\
\hline CHEMBL1382797 & 688759 & 4.45 & 5.0977 & TRN \\
\hline CHEMBL1346147 & 688759 & 4.45 & 4.6948 & TRN \\
\hline CHEMBL1386322 & 688759 & 4.95 & 5.0945 & TRN \\
\hline CHEMBL1402732 & 688759 & 4.5 & 5.0774 & TRN \\
\hline CHEMBL1389397 & 688759 & 4.75 & 4.793 & TRN \\
\hline CHEMBL3196020 & 688759 & 6.3 & 5.9068 & TRN \\
\hline CHEMBL1592793 & 688759 & 5.5 & 4.883 & TRN \\
\hline CHEMBL1360633 & 688759 & 5.4 & 5.3065 & TST \\
\hline CHEMBL3196254 & 688759 & 4.75 & 5.0453 & TST \\
\hline CHEMBL1386892 & 688759 & 5.3 & 5.0235 & TRN \\
\hline CHEMBL3194752 & 688759 & 5.6 & 5.3679 & TRN \\
\hline CHEMBL1575434 & 688759 & 4.7 & 4.6726 & TST \\
\hline CHEMBL1348465 & 688759 & 4.45 & 4.6377 & TRN \\
\hline CHEMBL3195300 & 688759 & 4.45 & 5.0057 & TRN \\
\hline CHEMBL1452723 & 688759 & 5.55 & 5.5089 & TRN \\
\hline CHEMBL1523558 & 688759 & 4.45 & 4.7238 & TRN \\
\hline CHEMBL1462244 & 688759 & 4.75 & 5.1557 & TRN \\
\hline CHEMBL1461857 & 688759 & 4.95 & 5.0094 & TRN \\
\hline CHEMBL1548433 & 688759 & 4.55 & 5.024 & TRN \\
\hline CHEMBL1407438 & 688759 & 4.65 & 4.8666 & TRN \\
\hline CHEMBL1423286 & 688759 & 6.1 & 5.4114 & TRN \\
\hline CHEMBL1454890 & 688759 & 4.6 & 4.7587 & TST \\
\hline CHEMBL1372853 & 688759 & 4.45 & 4.8126 & TRN \\
\hline CHEMBL1339121 & 688759 & 5.15 & 5.1996 & TRN \\
\hline CHEMBL1403722 & 688759 & 5.25 & 4.9226 & TRN \\
\hline
\end{tabular}




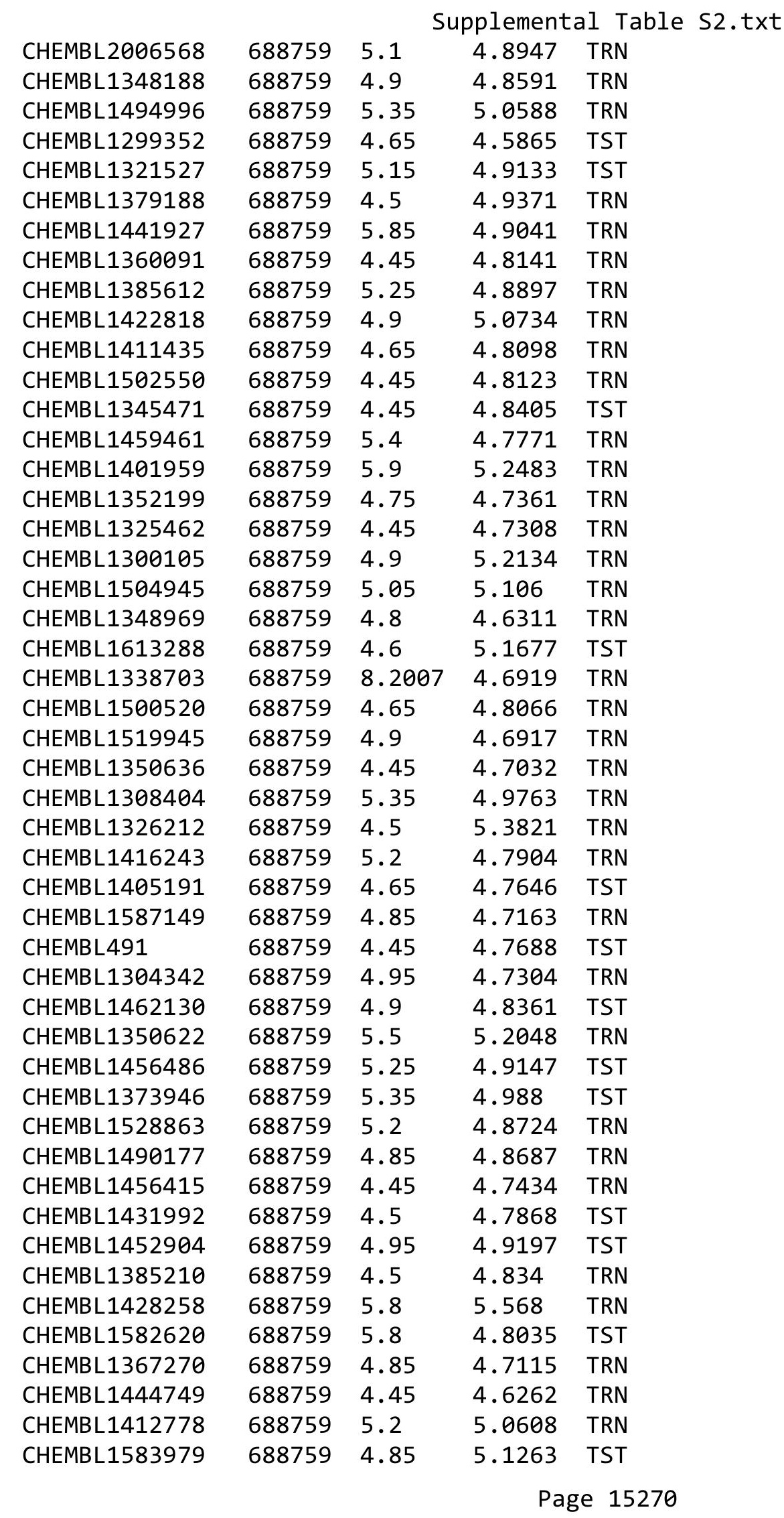




\begin{tabular}{|c|c|c|c|c|c|}
\hline & & \multicolumn{4}{|c|}{ Supplemental Table S2.txt } \\
\hline CHEMBL1531146 & 688759 & 5.35 & 4.9196 & TRN & \\
\hline CHEMBL1587764 & 688759 & 5.4 & 5.1019 & TRN & \\
\hline CHEMBL1303332 & 688759 & 4.6 & 4.8411 & TRN & \\
\hline CHEMBL1995692 & 688759 & 4.6 & 5.13 & TRN & \\
\hline CHEMBL1526752 & 688759 & 4.75 & 4.8388 & TST & \\
\hline CHEMBL1576175 & 688759 & 5.25 & 5.1476 & TRN & \\
\hline CHEMBL1383022 & 688759 & 6.15 & 4.8619 & TRN & \\
\hline CHEMBL1462794 & 688759 & 4.45 & 4.9295 & TRN & \\
\hline CHEMBL 3190780 & 688759 & 5.6 & 5.1323 & TRN & \\
\hline CHEMBL1393068 & 688759 & 4.9 & 4.7828 & TRN & \\
\hline CHEMBL1459083 & 688759 & 5.8 & 5.1527 & TRN & \\
\hline CHEMBL1984924 & 688759 & 4.45 & 4.9841 & TRN & \\
\hline CHEMBL1352435 & 688759 & 4.65 & 4.6887 & TST & \\
\hline CHEMBL1542349 & 688759 & 5.15 & 5.2054 & TRN & \\
\hline CHEMBL1415682 & 688759 & 5.8 & 5.4375 & TRN & \\
\hline CHEMBL1300389 & 688759 & 5.1 & 4.8615 & TRN & \\
\hline CHEMBL1575033 & 688759 & 4.9 & 4.9946 & TST & \\
\hline CHEMBL1578069 & 688759 & 4.9 & 5.0637 & TST & \\
\hline CHEMBL1543467 & 688759 & 4.9 & 4.765 & TRN & \\
\hline CHEMBL1499490 & 688759 & 4.8 & 4.6 & TST & \\
\hline CHEMBL1374333 & 688759 & 5.05 & 4.982 & TRN & \\
\hline CHEMBL1536780 & 688759 & 4.45 & 4.917 & TRN & \\
\hline CHEMBL1569688 & 688759 & 5.4 & 5.3635 & TRN & \\
\hline CHEMBL1588777 & 688759 & 4.45 & 4.9659 & TST & \\
\hline CHEMBL1978995 & 688759 & 5.5 & 5.0199 & TRN & \\
\hline CHEMBL1418269 & 688759 & 5.35 & 5.0259 & TRN & \\
\hline CHEMBL1414923 & 688759 & 5.45 & 4.997 & TRN & \\
\hline CHEMBL1503027 & 688759 & 4.45 & 4.8326 & TRN & \\
\hline CHEMBL1602961 & 688759 & 4.8 & 4.8467 & TST & \\
\hline CHEMBL1577972 & 688759 & 5.45 & 4.795 & TRN & \\
\hline CHEMBL1979360 & 688759 & 5.9 & $5.2360 e$ & 0000000001 & TRN \\
\hline CHEMBL1463787 & 688759 & 4.7 & 4.8697 & TST & \\
\hline CHEMBL3209904 & 688759 & 4.45 & 4.8461 & TST & \\
\hline CHEMBL1372217 & 688759 & 5.15 & 4.8545 & TRN & \\
\hline CHEMBL1596578 & 688759 & 5.25 & 4.869 & TST & \\
\hline CHEMBL1570764 & 688759 & 4.8 & 4.8917 & TST & \\
\hline CHEMBL1465097 & 688759 & 4.65 & 4.4351 & TRN & \\
\hline CHEMBL1510778 & 688759 & 5.25 & 4.8913 & TRN & \\
\hline CHEMBL1565515 & 688759 & 4.45 & 4.9549 & TST & \\
\hline CHEMBL3196102 & 688759 & 4.65 & 5.1501 & TRN & \\
\hline CHEMBL1501005 & 688759 & 5.3 & 4.7726 & TRN & \\
\hline CHEMBL1983451 & 688759 & 5.7 & 5.3678 & TRN & \\
\hline CHEMBL1497693 & 688759 & 4.9 & 4.6929 & TRN & \\
\hline CHEMBL1420333 & 688759 & 4.9 & 5.113 & TST & \\
\hline CHEMBL1579060 & 688759 & 4.45 & 4.7652 & TRN & \\
\hline CHEMBL1393352 & 688759 & 5.5 & 4.9861 & TRN & \\
\hline CHEMBL1308731 & 688759 & 4.45 & 4.5633 & TRN & \\
\hline CHEMBL1307319 & 688759 & 5.25 & 4.7055 & TST & \\
\hline
\end{tabular}




\begin{tabular}{|c|c|c|c|c|c|}
\hline \\
\hline CHEMBL3193437 & 688759 & 6.3 & 5.4919 & TRN & \\
\hline CHEMBL1419563 & 688759 & 4.45 & 4.7527 & TRN & \\
\hline CHEMBL1520460 & 688759 & 4.45 & 4.7218 & TRN & \\
\hline CHEMBL1311015 & 688759 & 4.95 & 5.4434 & TRN & \\
\hline CHEMBL1468078 & 688759 & 4.65 & 5.2028 & TRN & \\
\hline CHEMBL1489362 & 688759 & 4.45 & 4.7808 & TRN & \\
\hline CHEMBL1399232 & 688759 & 4.45 & 4.6257 & TST & \\
\hline CHEMBL1369880 & 688759 & 5.0 & 5.1198 & TST & \\
\hline CHEMBL1561187 & 688759 & 4.45 & 4.2625 & TRN & \\
\hline CHEMBL1523019 & 688759 & 5.55 & 5.0698 & TRN & \\
\hline CHEMBL1377330 & 688759 & 5.25 & 4.6617 & TST & \\
\hline CHEMBL1307262 & 688759 & 4.65 & 4.7748 & TST & \\
\hline CHEMBL1367220 & 688759 & 4.95 & 4.6747 & TRN & \\
\hline CHEMBL1572283 & 688759 & 5.0 & 5.1974 & TRN & \\
\hline CHEMBL1467499 & 688759 & 4.45 & 4.638 & TRN & \\
\hline CHEMBL1310086 & 688759 & 4.45 & 4.769 & TRN & \\
\hline CHEMBL1453175 & 688759 & 5.35 & 5.1482 & TRN & \\
\hline CHEMBL1332928 & 688759 & 4.8 & 5.04899 & 99999999995 & TRN \\
\hline CHEMBL1522254 & 688759 & 4.6 & 4.6828 & TRN & \\
\hline CHEMBL1582862 & 688759 & 6.0 & 5.0787 & TST & \\
\hline CHEMBL1580654 & 688759 & 4.6 & 4.8493 & TRN & \\
\hline CHEMBL1422836 & 688759 & 4.55 & 4.7736 & TRN & \\
\hline CHEMBL1410964 & 688759 & 5.5 & 5.1269 & TRN & \\
\hline CHEMBL1486859 & 688759 & 5.3 & 4.7839 & TST & \\
\hline CHEMBL1330358 & 688759 & 5.3 & 4.7327 & TST & \\
\hline CHEMBL1337413 & 688759 & 6.95 & 4.7633 & TST & \\
\hline CHEMBL3197457 & 688759 & 4.45 & 4.6919 & TRN & \\
\hline CHEMBL1558743 & 688759 & 4.9 & 4.86 & TRN & \\
\hline CHEMBL1544453 & 688759 & 4.65 & 4.8714 & TRN & \\
\hline CHEMBL1354188 & 688759 & 4.45 & 4.7035 & TST & \\
\hline CHEMBL1505972 & 688759 & 4.75 & 4.6532 & TRN & \\
\hline CHEMBL1348139 & 688759 & 4.5 & 5.1051 & TST & \\
\hline CHEMBL1370066 & 688759 & 5.8 & 5.7839 & TRN & \\
\hline CHEMBL1306554 & 688759 & 4.45 & 5.3751 & TRN & \\
\hline CHEMBL1430944 & 688759 & 4.45 & 4.7656 & TRN & \\
\hline CHEMBL1448713 & 688759 & 5.05 & 5.1411 & TRN & \\
\hline CHEMBL1538847 & 688759 & 5.55 & 4.8517 & TRN & \\
\hline CHEMBL1468567 & 688759 & 4.75 & 4.9633 & TRN & \\
\hline CHEMBL1503568 & 688759 & 4.45 & 4.6223 & TRN & \\
\hline CHEMBL1559357 & 688759 & 4.45 & 4.849 & TST & \\
\hline CHEMBL3195343 & 688759 & 5.6 & 5.519 & TST & \\
\hline CHEMBL1421941 & 688759 & 5.45 & 5.1372 & TRN & \\
\hline CHEMBL1314303 & 688759 & 4.6 & 4.8649 & TRN & \\
\hline CHEMBL3196672 & 688759 & 4.85 & 5.0576 & TST & \\
\hline CHEMBL1415184 & 688759 & 5.65 & 5.4984 & TRN & \\
\hline CHEMBL1579933 & 688759 & 4.75 & 4.8494 & TRN & \\
\hline CHEMBL1461225 & 688759 & 6.1 & 5.0693 & TRN & \\
\hline CHEMBL1433185 & 688759 & 5.5 & 5.0691 & TRN & \\
\hline
\end{tabular}




\begin{tabular}{|c|c|c|c|c|c|}
\hline & & \multicolumn{4}{|c|}{ Supplemental Table S2.txt } \\
\hline CHEMBL1996263 & 688759 & 5.35 & 4.9953 & TRN & \\
\hline CHEMBL1546766 & 688759 & 4.9 & 5.0948 & TRN & \\
\hline CHEMBL1505572 & 688759 & 4.45 & 4.5191 & TRN & \\
\hline CHEMBL1491751 & 688759 & 4.6 & 4.7694 & TRN & \\
\hline CHEMBL1573907 & 688759 & 4.65 & 4.8461 & TST & \\
\hline CHEMBL1336397 & 688759 & 4.85 & 4.8705 & TRN & \\
\hline CHEMBL396446 & 688759 & 6.05 & 5.4412 & TRN & \\
\hline CHEMBL1347090 & 688759 & 4.45 & 4.713 & TRN & \\
\hline CHEMBL1387688 & 688759 & 5.45 & 5.2747 & TRN & \\
\hline CHEMBL1331042 & 688759 & 5.5 & 4.9942 & TRN & \\
\hline CHEMBL1605244 & 688759 & 4.65 & 4.7094 & TRN & \\
\hline CHEMBL1496231 & 688759 & 4.65 & 4.9534 & TST & \\
\hline CHEMBL1302127 & 688759 & 4.45 & 5.0625 & TRN & \\
\hline CHEMBL1352202 & 688759 & 4.75 & 4.9593 & TST & \\
\hline CHEMBL1331611 & 688759 & 4.95 & 4.7055 & TRN & \\
\hline CHEMBL1547237 & 688759 & 5.5 & 5.2353 & TRN & \\
\hline CHEMBL3145366 & 688759 & 5.8 & 5.9937 & TRN & \\
\hline CHEMBL1465431 & 688759 & 6.25 & 5.944 & TRN & \\
\hline CHEMBL1471326 & 688759 & 5.0 & 5.0295 & TRN & \\
\hline CHEMBL1538796 & 688759 & 5.05 & 4.7343 & TST & \\
\hline CHEMBL578515 & 688759 & 4.8 & 4.52800 & 00000000005 & TRN \\
\hline CHEMBL1347726 & 688759 & 5.7 & 5.8527 & TRN & \\
\hline CHEMBL3197198 & 688759 & 4.45 & 5.0027 & TST & \\
\hline CHEMBL1339533 & 688759 & 5.45 & 4.9191 & TST & \\
\hline CHEMBL2003595 & 688759 & 4.45 & 4.8865 & TST & \\
\hline CHEMBL1587552 & 688759 & 4.45 & 4.7631 & TST & \\
\hline CHEMBL3208665 & 688759 & 5.8 & 4.8843 & TRN & \\
\hline CHEMBL1539479 & 688759 & 5.65 & 5.325 & TRN & \\
\hline CHEMBL1451096 & 688759 & 4.55 & 5.0008 & TRN & \\
\hline CHEMBL1319900 & 688759 & 4.5 & 4.6404 & TRN & \\
\hline CHEMBL1560423 & 688759 & 4.45 & 4.8485 & TRN & \\
\hline CHEMBL1522808 & 688759 & 4.45 & 5.0189 & TRN & \\
\hline CHEMBL1571116 & 688759 & 5.4 & 4.9143 & TRN & \\
\hline CHEMBL3194550 & 688759 & 5.15 & 4.8493 & TRN & \\
\hline CHEMBL2006628 & 688759 & 5.0 & 4.8581 & TRN & \\
\hline CHEMBL1528593 & 688759 & 4.9 & 5.1092 & TRN & \\
\hline CHEMBL1475234 & 688759 & 4.5 & 4.7618 & TST & \\
\hline CHEMBL1588058 & 688759 & 5.3 & 5.0279 & TST & \\
\hline CHEMBL1399844 & 688759 & 4.45 & 4.4855 & TST & \\
\hline CHEMBL1300404 & 688759 & 4.6 & 4.9278 & TRN & \\
\hline CHEMBL1997543 & 688759 & 5.4 & 5.5337 & TST & \\
\hline CHEMBL1333191 & 688759 & 6.0 & 4.6816 & TRN & \\
\hline CHEMBL1333386 & 688759 & 5.7 & 5.6439 & TRN & \\
\hline CHEMBL2006325 & 688759 & 6.6499 & 5.7695 & TRN & \\
\hline CHEMBL1542954 & 688759 & 5.2 & 4.9836 & TST & \\
\hline CHEMBL1978424 & 688759 & 5.35 & 5.3216 & TRN & \\
\hline CHEMBL3145114 & 688759 & 4.45 & 4.9629 & TRN & \\
\hline CHEMBL1477352 & 688759 & 4.9 & 4.934 & TRN & \\
\hline
\end{tabular}




\begin{tabular}{|c|c|c|c|c|c|}
\hline & & \multicolumn{4}{|c|}{ Supplemental Table S2.txt } \\
\hline CHEMBL1524403 & 688759 & 4.45 & 4.4857 & TRN & \\
\hline CHEMBL1441974 & 688759 & 4.8 & 4.9514 & TST & \\
\hline CHEMBL1557389 & 688759 & 5.2 & 4.7838 & TRN & \\
\hline CHEMBL1519474 & 688759 & 4.45 & 5.0633 & TRN & \\
\hline CHEMBL1536740 & 688759 & 6.2 & 6.0047 & TRN & \\
\hline CHEMBL1542443 & 688759 & 4.45 & 4.9513 & TRN & \\
\hline CHEMBL1545250 & 688759 & 5.4 & 5.4031 & TRN & \\
\hline CHEMBL1373480 & 688759 & 5.25 & 5.1581 & TST & \\
\hline CHEMBL1442847 & 688759 & 4.7 & 4.9802 & TRN & \\
\hline CHEMBL1607665 & 688759 & 5.2 & 5.1138 & TST & \\
\hline CHEMBL1457257 & 688759 & 4.45 & 4.7537 & TRN & \\
\hline CHEMBL1526572 & 688759 & 4.9 & 5.06800 & 00000000005 & TRN \\
\hline CHEMBL1348741 & 688759 & 5.0 & 5.0748 & TRN & \\
\hline CHEMBL1582381 & 688759 & 4.45 & 4.7847 & TRN & \\
\hline CHEMBL3195464 & 688759 & 4.45 & 4.9056 & TRN & \\
\hline CHEMBL1460628 & 688759 & 5.5 & 5.0417 & TST & \\
\hline CHEMBL3192545 & 688759 & 4.45 & 4.9207 & TRN & \\
\hline CHEMBL1469904 & 688759 & 4.7 & 4.8829 & TRN & \\
\hline CHEMBL1389922 & 688759 & 4.45 & 4.9693 & TST & \\
\hline CHEMBL1518699 & 688759 & 5.1 & 4.9602 & TRN & \\
\hline CHEMBL3197533 & 688759 & 4.95 & 4.9526 & TRN & \\
\hline CHEMBL1380866 & 688759 & 5.2 & 4.8977 & TRN & \\
\hline CHEMBL1467505 & 688759 & 5.5 & 5.5884 & TRN & \\
\hline CHEMBL1383774 & 688759 & 5.1 & 4.9552 & TRN & \\
\hline CHEMBL1311170 & 688759 & 4.6 & 4.8137 & TRN & \\
\hline CHEMBL3194258 & 688759 & 5.25 & 4.7383 & TRN & \\
\hline CHEMBL1358016 & 688759 & 4.95 & 5.0553 & TRN & \\
\hline CHEMBL1580496 & 688759 & 5.25 & 4.8298 & TRN & \\
\hline CHEMBL1612507 & 688759 & 4.45 & 4.3582 & TRN & \\
\hline CHEMBL1558144 & 688759 & 4.65 & 4.8416 & TRN & \\
\hline CHEMBL1339652 & 688759 & 4.45 & 5.1184 & TST & \\
\hline CHEMBL1411985 & 688759 & 4.9 & 4.8762 & TRN & \\
\hline CHEMBL1506822 & 688759 & 5.9 & 5.9268 & TRN & \\
\hline CHEMBL1559062 & 688759 & 4.8 & 4.4659 & TRN & \\
\hline CHEMBL1598383 & 688759 & 4.95 & 4.8799 & TST & \\
\hline CHEMBL3197410 & 688759 & 4.5 & 5.1058 & TRN & \\
\hline CHEMBL1325264 & 688759 & 4.55 & 4.9208 & TRN & \\
\hline CHEMBL1504634 & 688759 & 5.75 & 4.6023 & TRN & \\
\hline CHEMBL1580345 & 688759 & 4.65 & 6.3159 & TRN & \\
\hline CHEMBL1364726 & 688759 & 5.15 & 5.0102 & TRN & \\
\hline CHEMBL1403260 & 688759 & 4.6 & 4.978 & TST & \\
\hline CHEMBL3191632 & 688759 & 4.5 & 4.7144 & TRN & \\
\hline CHEMBL3195747 & 688759 & 5.9 & 5.6777 & TRN & \\
\hline CHEMBL1401242 & 688759 & 5.3 & 5.3293 & TRN & \\
\hline CHEMBL1388509 & 688759 & 5.15 & 4.7608 & TRN & \\
\hline CHEMBL1504359 & 688759 & 4.45 & 4.9694 & TRN & \\
\hline CHEMBL1355460 & 688759 & 4.6 & 4.4917 & TRN & \\
\hline CHEMBL1589029 & 688759 & 5.9 & 5.4152 & TRN & \\
\hline
\end{tabular}




\begin{tabular}{|c|c|c|c|c|}
\hline \multicolumn{5}{|c|}{ Supplemental Table S2.txt } \\
\hline CHEMBL1446060 & 688759 & 5.0 & 4.9429 & TRN \\
\hline CHEMBL 3198860 & 688759 & 5.85 & 5.0553 & TRN \\
\hline CHEMBL1458593 & 688759 & 4.65 & 5.0046 & TRN \\
\hline CHEMBL1517836 & 688759 & 4.45 & 4.9632 & TRN \\
\hline CHEMBL1526892 & 688759 & 4.45 & 4.7958 & TRN \\
\hline CHEMBL3191943 & 688759 & 4.45 & 4.6691 & TRN \\
\hline CHEMBL3197131 & 688759 & 4.45 & 4.5184 & TRN \\
\hline CHEMBL3193766 & 688759 & 4.6 & 4.7846 & TRN \\
\hline CHEMBL1489029 & 688759 & 4.45 & 4.93 & TRN \\
\hline CHEMBL3189711 & 688759 & 5.4 & 4.8929 & TRN \\
\hline CHEMBL1586207 & 688759 & 4.85 & 4.8513 & TST \\
\hline CHEMBL1586006 & 688759 & 4.45 & 4.7154 & TST \\
\hline CHEMBL1585267 & 688759 & 4.45 & 4.471 & TRN \\
\hline CHEMBL1374108 & 688759 & 6.0 & 4.7369 & TRN \\
\hline CHEMBL1974432 & 688759 & 5.95 & 5.7974 & TRN \\
\hline CHEMBL1529103 & 688759 & 6.05 & 5.0259 & TRN \\
\hline CHEMBL1510254 & 688759 & 7.8508 & 6.3897 & TRN \\
\hline CHEMBL1376145 & 688759 & 4.7 & 4.8908 & TRN \\
\hline CHEMBL1555805 & 688759 & 4.45 & 5.021 & TST \\
\hline CHEMBL1335404 & 688759 & 5.2 & 5.0714 & TRN \\
\hline CHEMBL1400031 & 688759 & 4.95 & 5.0012 & TRN \\
\hline CHEMBL1521090 & 688759 & 4.65 & 4.9429 & TRN \\
\hline CHEMBL1488192 & 688759 & 5.15 & 4.9671 & TST \\
\hline CHEMBL1321620 & 688759 & 4.45 & 4.8451 & TST \\
\hline CHEMBL1309323 & 688759 & 5.25 & 4.9921 & TRN \\
\hline CHEMBL1530862 & 688759 & 4.95 & 4.9566 & TRN \\
\hline CHEMBL1508673 & 688759 & 4.45 & 4.8328 & TRN \\
\hline CHEMBL1324908 & 688759 & 5.6 & 4.9374 & TRN \\
\hline CHEMBL1418631 & 688759 & 4.45 & 4.9992 & TRN \\
\hline CHEMBL1366842 & 688759 & 5.2 & 4.8821 & TRN \\
\hline CHEMBL1610002 & 688759 & 5.0 & 5.1089 & TST \\
\hline CHEMBL1545435 & 688759 & 5.0 & 5.0663 & TRN \\
\hline CHEMBL3191921 & 688759 & 5.3 & 4.881 & TRN \\
\hline CHEMBL1407212 & 688759 & 4.45 & 4.7014 & TST \\
\hline CHEMBL3197214 & 688759 & 5.55 & 5.3787 & TST \\
\hline CHEMBL1463081 & 688759 & 4.45 & 4.9498 & TRN \\
\hline CHEMBL1611041 & 688759 & 4.45 & 4.4642 & TST \\
\hline CHEMBL1369487 & 688759 & 6.15 & 5.1144 & TRN \\
\hline CHEMBL1320669 & 688759 & 5.9 & 5.2221 & TRN \\
\hline CHEMBL1307575 & 688759 & 4.6 & 4.9738 & TRN \\
\hline CHEMBL1407057 & 688759 & 4.95 & 4.9706 & TRN \\
\hline CHEMBL126077 & 688759 & 4.5 & 4.956 & TST \\
\hline CHEMBL1575622 & 688759 & 4.45 & 4.7443 & TST \\
\hline CHEMBL1496630 & 688759 & 5.55 & 5.1156 & TRN \\
\hline CHEMBL3199452 & 688759 & 5.4 & 5.3009 & TRN \\
\hline CHEMBL1337089 & 688759 & 4.6 & 4.8899 & TRN \\
\hline CHEMBL1535149 & 688759 & 4.9 & 5.0902 & TRN \\
\hline CHEMBL1432745 & 688759 & 5.0 & 5.3407 & TRN \\
\hline
\end{tabular}




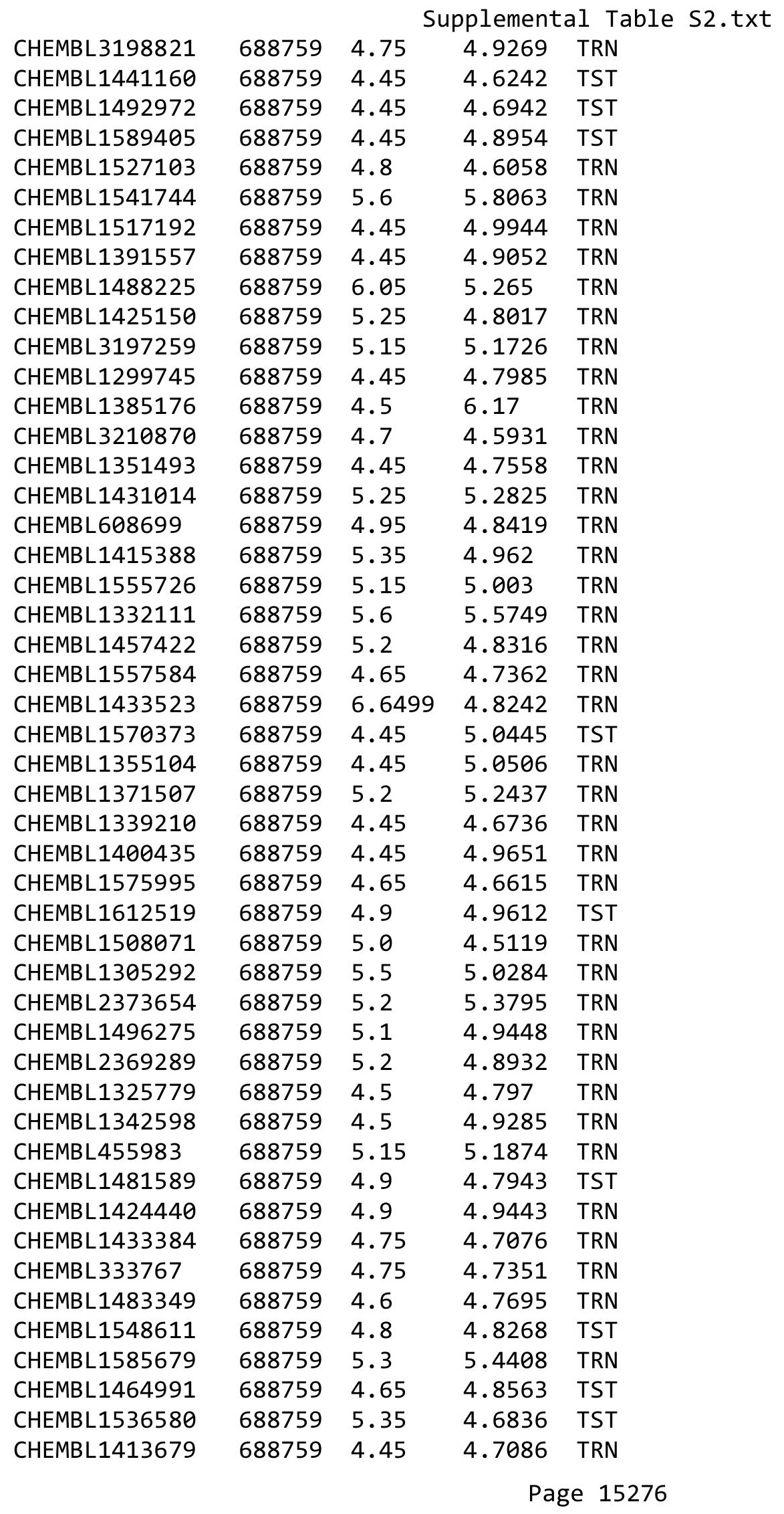




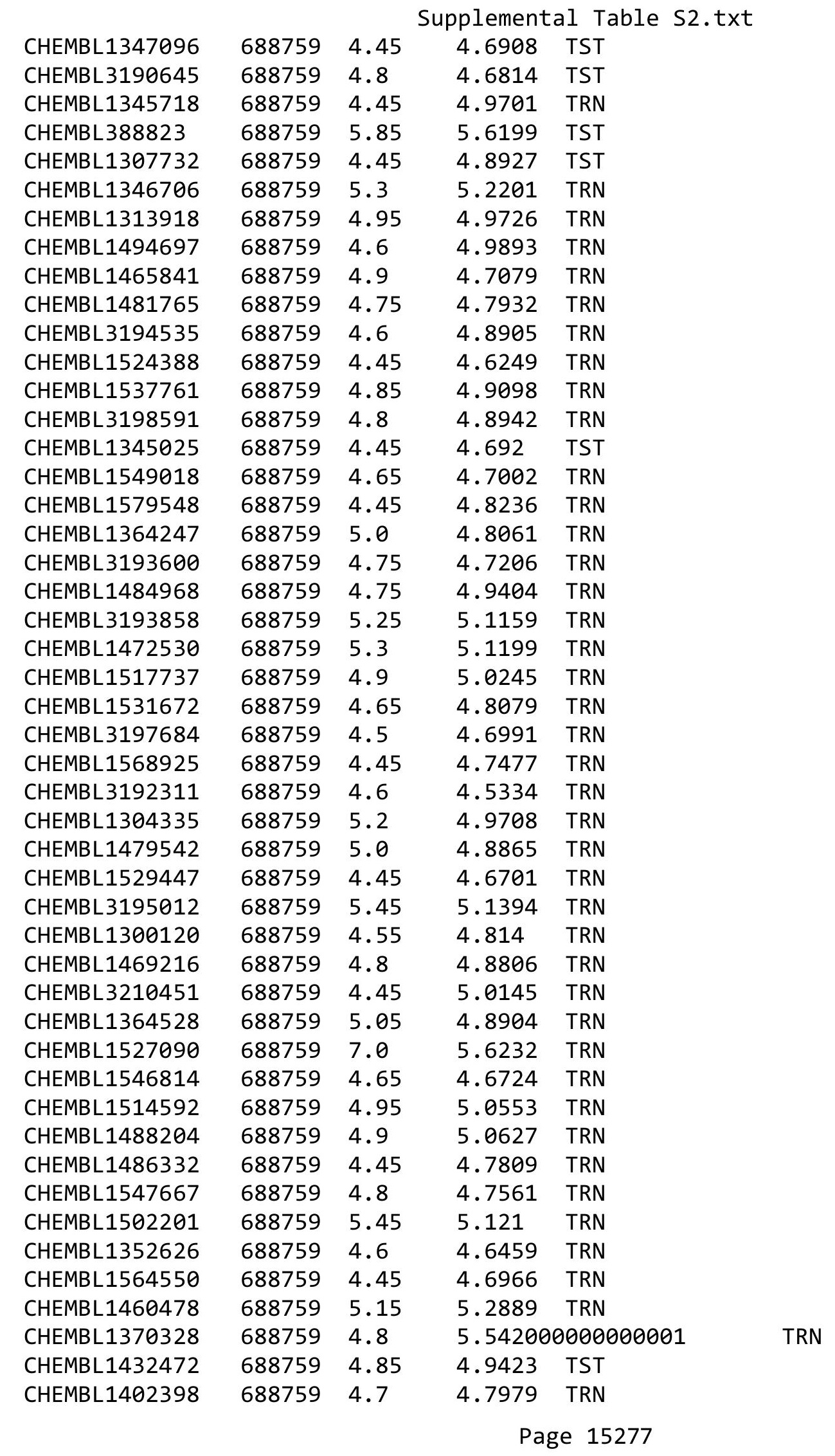




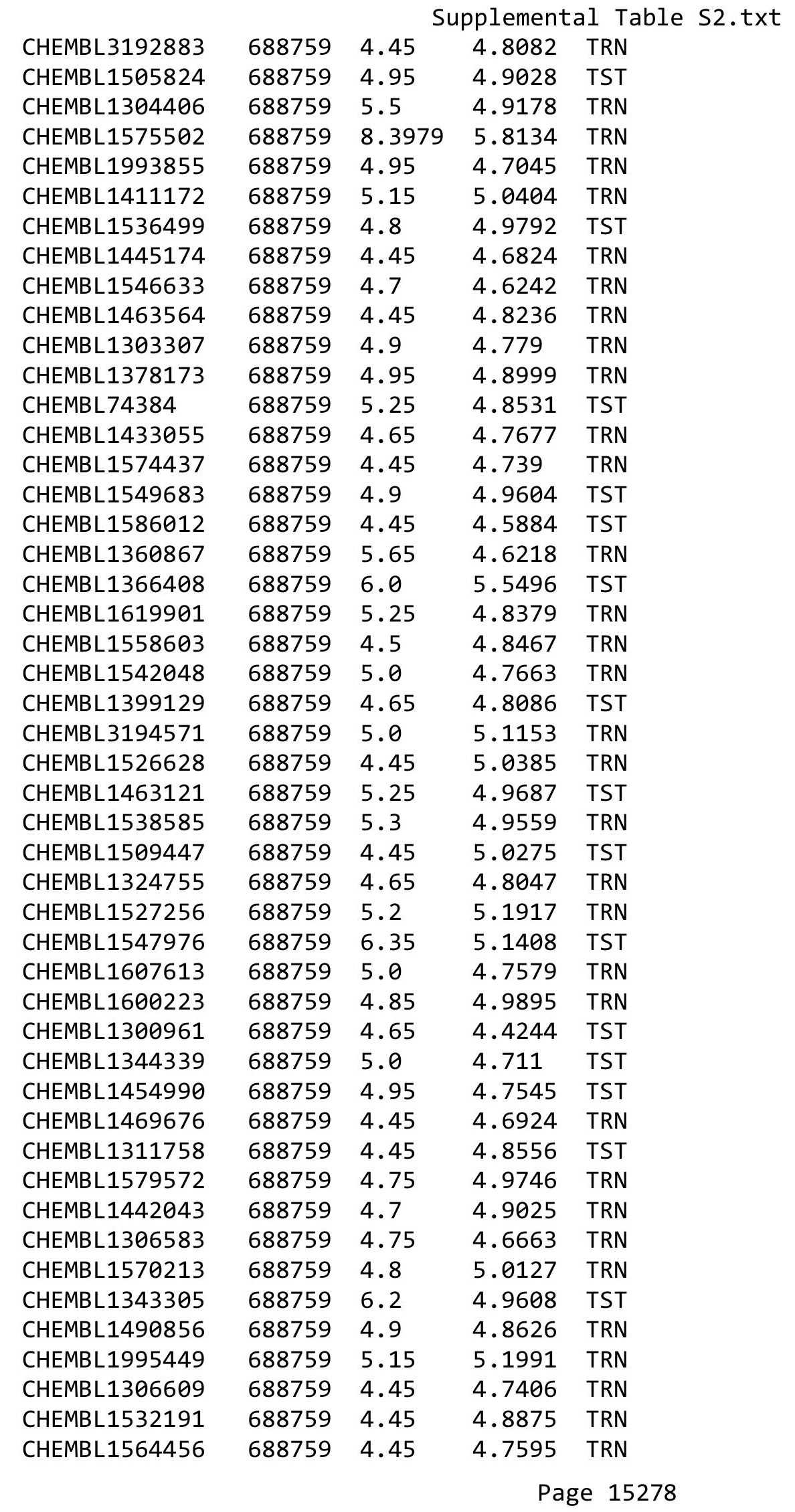




\begin{tabular}{|c|c|c|c|c|}
\hline \multicolumn{5}{|c|}{ Supplemental Table S2.txt } \\
\hline CHEMBL1532576 & 688759 & 4.85 & 4.6912 & TST \\
\hline CHEMBL1477485 & 688759 & 4.75 & 4.586 & TST \\
\hline CHEMBL1525518 & 688759 & 5.5 & 5.2699 & TRN \\
\hline CHEMBL1566287 & 688759 & 5.4 & 4.8458 & TRN \\
\hline CHEMBL1566302 & 688759 & 4.5 & 4.853 & TRN \\
\hline CHEMBL1600513 & 688759 & 4.7 & 4.7795 & TST \\
\hline CHEMBL1499853 & 688759 & 4.45 & 4.959 & TRN \\
\hline CHEMBL1980600 & 688759 & 4.9 & 4.6741 & TST \\
\hline CHEMBL1511000 & 688759 & 4.8 & 4.7505 & TRN \\
\hline CHEMBL3199104 & 688759 & 4.45 & 4.8308 & TRN \\
\hline CHEMBL1502264 & 688759 & 4.85 & 4.7421 & TST \\
\hline CHEMBL1340466 & 688759 & 4.95 & 4.8744 & TRN \\
\hline CHEMBL1487816 & 688759 & 5.55 & 4.6143 & TRN \\
\hline CHEMBL1471700 & 688759 & 4.65 & 4.7753 & TST \\
\hline CHEMBL1424691 & 688759 & 4.45 & 4.504 & TRN \\
\hline CHEMBL1440703 & 688759 & 4.75 & 4.8009 & TST \\
\hline CHEMBL1406036 & 688759 & 5.0 & 5.0322 & TRN \\
\hline CHEMBL1469460 & 688759 & 5.55 & 4.7688 & TST \\
\hline CHEMBL1520782 & 688759 & 4.45 & 4.9055 & TRN \\
\hline CHEMBL1308070 & 688759 & 4.7 & 4.6149 & TRN \\
\hline CHEMBL1319210 & 688759 & 5.7 & 5.5834 & TRN \\
\hline CHEMBL1349635 & 688759 & 6.1 & 5.7148 & TRN \\
\hline CHEMBL1561369 & 688759 & 5.1 & 4.8952 & TRN \\
\hline CHEMBL1385340 & 688759 & 4.45 & 4.8028 & TRN \\
\hline CHEMBL1444114 & 688759 & 5.3 & 4.9562 & TRN \\
\hline CHEMBL1364262 & 688759 & 4.75 & 4.532 & TST \\
\hline CHEMBL1585191 & 688759 & 5.0 & 4.6589 & TST \\
\hline CHEMBL1511596 & 688759 & 5.75 & 4.605 & TRN \\
\hline CHEMBL1567745 & 688759 & 4.45 & 4.8104 & TRN \\
\hline CHEMBL1603092 & 688759 & 5.45 & 5.7499 & TRN \\
\hline CHEMBL411666 & 688759 & 4.6 & 4.6148 & TRN \\
\hline CHEMBL1502031 & 688759 & 4.45 & 4.8664 & TRN \\
\hline CHEMBL1479309 & 688759 & 4.45 & 4.8393 & TRN \\
\hline CHEMBL1499360 & 688759 & 4.55 & 4.863 & TRN \\
\hline CHEMBL1391411 & 688759 & 5.4 & 5.1816 & TRN \\
\hline CHEMBL1408170 & 688759 & 5.2 & 5.2659 & TRN \\
\hline CHEMBL1407952 & 688759 & 5.45 & 5.5082 & TRN \\
\hline CHEMBL1534143 & 688759 & 6.1 & 5.0849 & TST \\
\hline CHEMBL3190175 & 688759 & 4.45 & 4.9248 & TRN \\
\hline CHEMBL1455120 & 688759 & 5.3 & 4.8975 & TRN \\
\hline CHEMBL1550961 & 688759 & 4.6 & 4.47 & TRN \\
\hline CHEMBL1585843 & 688759 & 4.45 & 4.6586 & TRN \\
\hline CHEMBL1965911 & 688759 & 2.9 & 6.055 & TRN \\
\hline CHEMBL1461246 & 688759 & 4.7 & 4.8967 & TRN \\
\hline CHEMBL1499190 & 688759 & 4.65 & 5.1157 & TRN \\
\hline CHEMBL195789 & 688759 & 4.7 & 4.8723 & TRN \\
\hline CHEMBL3197930 & 688759 & 4.85 & 4.735 & TRN \\
\hline CHEMBL1372734 & 688759 & 5.55 & 5.6593 & TRN \\
\hline
\end{tabular}




\begin{tabular}{|c|c|c|c|c|c|}
\hline \multicolumn{6}{|c|}{ Supplemental Table S2.txt } \\
\hline CHEMBL 399121 & 688759 & 5.2 & 4.9478 & TRN & \\
\hline CHEMBL1360330 & 688759 & 4.65 & 4.7533 & TRN & \\
\hline CHEMBL1466471 & 688759 & 4.9 & 4.9547 & TRN & \\
\hline CHEMBL1565523 & 688759 & 4.45 & 4.7628 & TRN & \\
\hline CHEMBL1346655 & 688759 & 4.45 & 4.8553 & TST & \\
\hline CHEMBL1578303 & 688759 & 4.45 & 4.8043 & TRN & \\
\hline CHEMBL3208919 & 688759 & 5.45 & 5.0025 & TRN & \\
\hline CHEMBL1384567 & 688759 & 4.75 & 4.7974 & TST & \\
\hline CHEMBL1571624 & 688759 & 4.95 & 4.985 & TRN & \\
\hline CHEMBL1308718 & 688759 & 4.8 & 4.8118 & TRN & \\
\hline CHEMBL1608628 & 688759 & 4.45 & 4.887 & TST & \\
\hline CHEMBL1452045 & 688759 & 4.45 & 4.8111 & TRN & \\
\hline CHEMBL3195224 & 688759 & 4.8 & 4.7276 & TRN & \\
\hline CHEMBL1386678 & 688759 & 4.45 & 4.742 & TRN & \\
\hline CHEMBL1464020 & 688759 & 4.65 & 4.7385 & TRN & \\
\hline CHEMBL1439196 & 688759 & 5.0 & 5.0693 & TRN & \\
\hline CHEMBL1324015 & 688759 & 4.65 & 4.80399 & 9999999999 & TST \\
\hline CHEMBL1345329 & 688759 & 5.25 & 4.9376 & TST & \\
\hline CHEMBL1361045 & 688759 & 5.2 & 4.9978 & TST & \\
\hline CHEMBL1310610 & 688759 & 4.45 & 4.6708 & TST & \\
\hline CHEMBL1457248 & 688759 & 4.45 & 4.9199 & TST & \\
\hline CHEMBL1349745 & 688759 & 4.45 & 4.7022 & TRN & \\
\hline CHEMBL1334711 & 688759 & 5.45 & 5.3326 & TRN & \\
\hline CHEMBL1564824 & 688759 & 4.45 & 4.7495 & TST & \\
\hline CHEMBL1328966 & 688759 & 6.1 & 6.0847 & TRN & \\
\hline CHEMBL1367991 & 688759 & 4.45 & 4.8152 & TRN & \\
\hline CHEMBL1308451 & 688759 & 4.9 & 4.7885 & TST & \\
\hline CHEMBL1495747 & 688759 & 4.85 & 4.6011 & TRN & \\
\hline CHEMBL1996136 & 688759 & 5.1 & 5.3149 & TRN & \\
\hline CHEMBL1346148 & 688759 & 4.45 & 4.5809 & TRN & \\
\hline CHEMBL1310969 & 688759 & 4.5 & 4.6639 & TRN & \\
\hline CHEMBL1400523 & 688759 & 4.65 & 4.6254 & TRN & \\
\hline CHEMBL 3199844 & 688759 & 4.45 & 4.8361 & TRN & \\
\hline CHEMBL1579667 & 688759 & 4.45 & 4.6561 & TRN & \\
\hline CHEMBL1518707 & 688759 & 4.85 & 5.0504 & TRN & \\
\hline CHEMBL1427464 & 688759 & 4.9 & 5.0428 & TST & \\
\hline CHEMBL1480053 & 688759 & 4.45 & 4.8915 & TST & \\
\hline CHEMBL1609182 & 688759 & 4.45 & 4.7642 & TST & \\
\hline CHEMBL1373552 & 688759 & 4.8 & 4.4629 & TRN & \\
\hline CHEMBL3190921 & 688759 & 4.75 & 4.6056 & TRN & \\
\hline CHEMBL1483765 & 688759 & 5.5 & 5.3115 & TRN & \\
\hline CHEMBL 3212423 & 688759 & 4.65 & 4.9046 & TRN & \\
\hline CHEMBL1488927 & 688759 & 4.9 & 4.6506 & TRN & \\
\hline CHEMBL1420858 & 688759 & 4.45 & 4.8906 & TRN & \\
\hline CHEMBL1601870 & 688759 & 4.95 & 4.8969 & TRN & \\
\hline CHEMBL1577631 & 688759 & 4.45 & 4.753 & TRN & \\
\hline CHEMBL1477241 & 688759 & 4.45 & 5.3047 & TST & \\
\hline CHEMBL3198256 & 688759 & 4.45 & 4.8796 & TRN & \\
\hline
\end{tabular}




\begin{tabular}{|c|c|c|c|c|c|}
\hline \multicolumn{6}{|c|}{ Supplemental Table S2.txt } \\
\hline CHEMBL1601652 & 688759 & 5.3 & 5.3215 & TRN & \\
\hline CHEMBL1464954 & 688759 & 5.6 & 4.7212 & TRN & \\
\hline CHEMBL1478359 & 688759 & 4.45 & 4.9664 & TRN & \\
\hline CHEMBL1588671 & 688759 & 4.45 & 5.074 & TRN & \\
\hline CHEMBL1605758 & 688759 & 4.65 & 4.5504 & TRN & \\
\hline CHEMBL1486623 & 688759 & 4.45 & 4.645 & TST & \\
\hline CHEMBL1582048 & 688759 & 4.5 & $5.1770 e$ & 00000000005 & TRN \\
\hline CHEMBL1328742 & 688759 & 4.45 & 4.9275 & TRN & \\
\hline CHEMBL1539277 & 688759 & 4.85 & 5.007 & TRN & \\
\hline CHEMBL1511302 & 688759 & 4.8 & 4.8087 & TRN & \\
\hline CHEMBL3189647 & 688759 & 4.45 & 4.8791 & TRN & \\
\hline CHEMBL1971532 & 688759 & 4.7 & 4.8714 & TRN & \\
\hline CHEMBL1427160 & 688759 & 4.45 & 4.947 & TRN & \\
\hline CHEMBL1504081 & 688759 & 6.15 & 4.9306 & TRN & \\
\hline CHEMBL1550695 & 688759 & 5.3 & 5.2323 & TRN & \\
\hline CHEMBL1544685 & 688759 & 5.1 & 5.0484 & TRN & \\
\hline CHEMBL3210584 & 688759 & 4.45 & 4.7262 & TRN & \\
\hline CHEMBL1501483 & 688759 & 6.15 & 5.9766 & TRN & \\
\hline CHEMBL1342912 & 688759 & 4.45 & 4.6515 & TRN & \\
\hline CHEMBL1469029 & 688759 & 5.05 & 4.8712 & TRN & \\
\hline CHEMBL1385288 & 688759 & 5.0 & 4.8635 & TRN & \\
\hline CHEMBL1588663 & 688759 & 4.5 & 4.7732 & TST & \\
\hline CHEMBL1520512 & 688759 & 6.15 & 4.9051 & TST & \\
\hline CHEMBL1554602 & 688759 & 4.75 & 5.0652 & TRN & \\
\hline CHEMBL1309978 & 688759 & 4.5 & 4.7489 & TRN & \\
\hline CHEMBL422237 & 688759 & 4.6 & 4.859 & TST & \\
\hline CHEMBL1448063 & 688759 & 4.95 & 4.7753 & TST & \\
\hline CHEMBL1596622 & 688759 & 6.5 & 4.9698 & TRN & \\
\hline CHEMBL1466414 & 688759 & 4.45 & 4.6452 & TRN & \\
\hline CHEMBL1488185 & 688759 & 4.45 & 4.6193 & TRN & \\
\hline CHEMBL1509029 & 688759 & 4.9 & 4.7288 & TRN & \\
\hline CHEMBL1385091 & 688759 & 5.25 & 4.6111 & TST & \\
\hline CHEMBL3209381 & 688759 & 4.75 & 4.7546 & TRN & \\
\hline CHEMBL1566022 & 688759 & 4.45 & 4.8939 & TRN & \\
\hline CHEMBL1403339 & 688759 & 4.55 & 4.4693 & TRN & \\
\hline CHEMBL1370656 & 688759 & 4.7 & 4.8432 & TRN & \\
\hline CHEMBL1537124 & 688759 & 4.45 & 4.586 & TRN & \\
\hline CHEMBL3193975 & 688759 & 6.15 & 5.7188 & TRN & \\
\hline CHEMBL1604928 & 688759 & 5.3 & 4.8383 & TRN & \\
\hline CHEMBL1555483 & 688759 & 5.0 & 4.7453 & TRN & \\
\hline CHEMBL3192398 & 688759 & 5.25 & 4.9795 & TRN & \\
\hline CHEMBL1499650 & 688759 & 4.5 & 5.16799 & 9999999999 & TRN \\
\hline CHEMBL1466699 & 688759 & 5.0 & 4.6023 & TRN & \\
\hline CHEMBL1419825 & 688759 & 4.45 & 4.8195 & TRN & \\
\hline CHEMBL1586959 & 688759 & 4.65 & 4.7241 & TRN & \\
\hline CHEMBL1414460 & 688759 & 4.45 & 5.1128 & TRN & \\
\hline CHEMBL1463761 & 688759 & 4.65 & 4.4949 & TST & \\
\hline CHEMBL1536728 & 688759 & 5.3 & 5.0529 & TRN & \\
\hline
\end{tabular}




\begin{tabular}{|c|c|c|c|c|c|}
\hline & & \multicolumn{4}{|c|}{ Supplemental Table S2.txt } \\
\hline CHEMBL1405339 & 688759 & 5.25 & 4.9826 & TRN & \\
\hline CHEMBL1588613 & 688759 & 4.45 & 4.7873 & TRN & \\
\hline CHEMBL1510164 & 688759 & 5.3 & 4.9445 & TST & \\
\hline CHEMBL1384942 & 688759 & 4.65 & $4.8580 e$ & 00000000005 & TRN \\
\hline CHEMBL1573950 & 688759 & 4.45 & 4.98 & TRN & \\
\hline CHEMBL1397914 & 688759 & 4.95 & 4.7558 & TRN & \\
\hline CHEMBL1420914 & 688759 & 4.95 & 4.9773 & TRN & \\
\hline CHEMBL1607035 & 688759 & 4.95 & 4.9407 & TRN & \\
\hline CHEMBL1330937 & 688759 & 6.2 & 4.8677 & TST & \\
\hline CHEMBL1605001 & 688759 & 4.45 & 4.7111 & TRN & \\
\hline CHEMBL1486565 & 688759 & 4.75 & 4.9535 & TRN & \\
\hline CHEMBL1330251 & 688759 & 6.0 & 5.3865 & TRN & \\
\hline CHEMBL1604200 & 688759 & 5.45 & 4.7588 & TRN & \\
\hline CHEMBL1349790 & 688759 & 4.45 & 4.835 & TST & \\
\hline CHEMBL1404687 & 688759 & 5.1 & 4.9058 & TRN & \\
\hline CHEMBL1463900 & 688759 & 4.45 & 4.8465 & TRN & \\
\hline CHEMBL1600346 & 688759 & 4.45 & 4.8305 & TRN & \\
\hline CHEMBL1537499 & 688759 & 5.35 & 5.386 & TRN & \\
\hline CHEMBL3213215 & 688759 & 4.6 & 4.77 & TRN & \\
\hline CHEMBL1547404 & 688759 & 4.45 & 5.0049 & TRN & \\
\hline CHEMBL1371801 & 688759 & 4.7 & 5.1719 & TRN & \\
\hline CHEMBL1586937 & 688759 & 4.7 & 4.7439 & TRN & \\
\hline CHEMBL 3198338 & 688759 & 4.7 & 4.8067 & TST & \\
\hline CHEMBL1583011 & 688759 & 4.6 & 4.4629 & TRN & \\
\hline CHEMBL1570025 & 688759 & 4.65 & 4.5038 & TRN & \\
\hline CHEMBL1414534 & 688759 & 4.45 & 4.8327 & TRN & \\
\hline CHEMBL1464469 & 688759 & 5.5 & 5.3215 & TRN & \\
\hline CHEMBL 3199645 & 688759 & 5.1 & 5.0243 & TRN & \\
\hline CHEMBL1532453 & 688759 & 4.45 & 4.7921 & TRN & \\
\hline CHEMBL 1500885 & 688759 & 5.35 & 5.3553 & TRN & \\
\hline CHEMBL1505209 & 688759 & 4.75 & 4.9816 & TST & \\
\hline CHEMBL 3191945 & 688759 & 4.45 & 4.5396 & TRN & \\
\hline CHEMBL1547342 & 688759 & 4.55 & 4.6668 & TRN & \\
\hline CHEMBL1489960 & 688759 & 4.8 & 4.6692 & TRN & \\
\hline CHEMBL1420247 & 688759 & 4.6 & 4.886 & TRN & \\
\hline CHEMBL1502943 & 688759 & 5.1 & 4.9176 & TST & \\
\hline CHEMBL1511268 & 688759 & 4.65 & 4.7605 & TST & \\
\hline CHEMBL1416718 & 688759 & 4.9 & 4.7715 & TRN & \\
\hline CHEMBL1560608 & 688759 & 4.45 & 4.6889 & TST & \\
\hline CHEMBL1338471 & 688759 & 4.75 & 4.5302 & TRN & \\
\hline CHEMBL1529310 & 688759 & 6.4 & 6.068 & TRN & \\
\hline CHEMBL1992925 & 688759 & 4.45 & 4.7602 & TRN & \\
\hline CHEMBL3198154 & 688759 & 4.45 & 4.8803 & TRN & \\
\hline CHEMBL1462687 & 688759 & 4.9 & 4.8431 & TRN & \\
\hline CHEMBL1311775 & 688759 & 6.3 & 5.8098 & TRN & \\
\hline CHEMBL1398836 & 688759 & 7.0 & 5.0232 & TRN & \\
\hline CHEMBL1493112 & 688759 & 4.45 & 4.7833 & TRN & \\
\hline CHEMBL1422583 & 688759 & 5.05 & 5.0626 & TRN & \\
\hline
\end{tabular}




\begin{tabular}{|c|c|c|c|c|c|}
\hline \multirow{3}{*}{$\begin{array}{l}\text { CHEMBL } 3193021 \\
\text { CHEMBL } 3190491\end{array}$} & \multirow{3}{*}{$\begin{array}{l}688759 \\
688759\end{array}$} & \multicolumn{4}{|c|}{ Supplemental Table s2.txt } \\
\hline & & 4.55 & \multicolumn{2}{|c|}{4.8180000000000005} & TRN \\
\hline & & 4.5 & 4.8518 & TRN & \\
\hline CHEMBL1560253 & 688759 & 4.65 & 4.7287 & TST & \\
\hline CHEMBL1495303 & 688759 & 4.45 & 4.9501 & TST & \\
\hline CHEMBL1378452 & 688759 & 4.45 & 4.7548 & TST & \\
\hline CHEMBL1406289 & 688759 & 4.45 & 4.838 & TRN & \\
\hline CHEMBL1511276 & 688759 & 6.0 & 5.3214 & TRN & \\
\hline CHEMBL192627 & 688759 & 4.45 & 5.4065 & TST & \\
\hline CHEMBL1499017 & 688759 & 4.7 & 4.4686 & TRN & \\
\hline CHEMBL1459538 & 688759 & 4.45 & 5.1127 & TRN & \\
\hline CHEMBL1469600 & 688759 & 4.95 & 5.0275 & TST & \\
\hline CHEMBL319931 & 688759 & 5.25 & 5.8007 & TRN & \\
\hline CHEMBL1536091 & 688759 & 6.95 & \multicolumn{2}{|c|}{6.257999999999999} & TRN \\
\hline CHEMBL1996523 & 688759 & 4.45 & 5.2468 & TRN & \\
\hline CHEMBL1353281 & 688759 & 4.45 & 4.713 & TRN & \\
\hline CHEMBL1461558 & 688759 & 4.45 & 5.1065 & TST & \\
\hline CHEMBL1365057 & 688759 & 4.6 & 4.6347 & TRN & \\
\hline CHEMBL1584687 & 688759 & 4.65 & 4.7131 & TRN & \\
\hline CHEMBL1587586 & 688759 & 4.9 & 4.8128 & TRN & \\
\hline CHEMBL1320396 & 688759 & 4.45 & 5.4272 & TST & \\
\hline CHEMBL1995503 & 688759 & 5.0 & 5.1837 & TRN & \\
\hline CHEMBL1350107 & 688759 & 5.1 & 5.2583 & TRN & \\
\hline CHEMBL1447125 & 688759 & 4.9 & 4.6432 & TRN & \\
\hline CHEMBL1367044 & 688759 & 5.35 & 4.9186 & TST & \\
\hline CHEMBL1596317 & 688759 & 4.45 & 4.8477 & TST & \\
\hline CHEMBL3198504 & 688759 & 4.45 & 4.6408 & TRN & \\
\hline CHEMBL1987579 & 688759 & 6.15 & 5.6595 & TRN & \\
\hline CHEMBL1439938 & 688759 & 5.3 & 5.2252 & TRN & \\
\hline CHEMBL 3207448 & 688759 & 4.45 & 4.8391 & TRN & \\
\hline CHEMBL1568968 & 688759 & 4.95 & 5.0903 & TRN & \\
\hline CHEMBL3190801 & 688759 & 5.0 & 5.0463 & TRN & \\
\hline CHEMBL1586404 & 688759 & 4.65 & 4.6394 & TRN & \\
\hline CHEMBL3208894 & 688759 & 5.0 & 4.8894 & TRN & \\
\hline CHEMBL1376933 & 688759 & 5.15 & 5.1422 & TRN & \\
\hline CHEMBL1460039 & 688759 & 5.0 & 4.727 & TRN & \\
\hline CHEMBL 2001316 & 688759 & 5.55 & 5.3707 & TRN & \\
\hline CHEMBL1464702 & 688759 & 4.45 & 4.8644 & TRN & \\
\hline CHEMBL1524929 & 688759 & 6.0 & 5.4926 & TRN & \\
\hline CHEMBL3192395 & 688759 & 5.35 & 5.4013 & TRN & \\
\hline CHEMBL1314823 & 688759 & 5.8 & 5.7961 & TRN & \\
\hline CHEMBL1535980 & 688759 & 4.65 & 4.4398 & TRN & \\
\hline CHEMBL1331281 & 688759 & 4.45 & 4.6605 & TRN & \\
\hline CHEMBL3196124 & 688759 & 5.35 & 5.3482 & TRN & \\
\hline CHEMBL1546624 & 688759 & 4.45 & 4.8267 & TRN & \\
\hline CHEMBL3198229 & 688759 & 5.0 & 4.9829 & TRN & \\
\hline CHEMBL1502859 & 688759 & 4.7 & 4.7756 & TRN & \\
\hline CHEMBL1392843 & 688759 & 4.65 & 4.8061 & TST & \\
\hline CHEMBL3190941 & 688759 & 4.8 & 5.2085 & TST & \\
\hline
\end{tabular}




\begin{tabular}{|c|c|c|c|c|}
\hline \multicolumn{5}{|c|}{ Supplemental Table S2.txt } \\
\hline CHEMBL1308911 & 688759 & 4.45 & 4.8533 & TRN \\
\hline CHEMBL1416781 & 688759 & 5.05 & 4.919 & TRN \\
\hline CHEMBL1414178 & 688759 & 5.3 & 4.8847 & TRN \\
\hline CHEMBL1533399 & 688759 & 4.45 & 4.8518 & TRN \\
\hline CHEMBL1423938 & 688759 & 4.65 & 4.7787 & TST \\
\hline CHEMBL1424021 & 688759 & 4.6 & 4.8252 & TST \\
\hline CHEMBL1421726 & 688759 & 4.95 & 4.5332 & TRN \\
\hline CHEMBL489 & 688759 & 4.8 & 4.6012 & TST \\
\hline CHEMBL1342679 & 688759 & 5.0 & 4.7983 & TRN \\
\hline CHEMBL1425137 & 688759 & 4.65 & 4.6074 & TRN \\
\hline CHEMBL1584143 & 688759 & 4.8 & 4.7947 & TST \\
\hline CHEMBL1601712 & 688759 & 5.0 & 4.6658 & TST \\
\hline CHEMBL1971379 & 688759 & 6.2 & 5.7193 & TRN \\
\hline CHEMBL1404372 & 688759 & 4.65 & 5.1001 & TST \\
\hline CHEMBL1391463 & 688759 & 5.55 & 5.1653 & TRN \\
\hline CHEMBL1334369 & 688759 & 4.45 & 4.9036 & TRN \\
\hline CHEMBL1301085 & 688759 & 5.15 & 4.8478 & TST \\
\hline CHEMBL1562405 & 688759 & 4.45 & 4.8638 & TST \\
\hline CHEMBL1557747 & 688759 & 4.65 & 4.9066 & TRN \\
\hline CHEMBL1512198 & 688759 & 5.1 & 5.2107 & TST \\
\hline CHEMBL1500923 & 688759 & 5.6 & 5.2198 & TRN \\
\hline CHEMBL1573671 & 688759 & 4.95 & 4.9299 & TST \\
\hline CHEMBL1508455 & 688759 & 4.45 & 4.475 & TRN \\
\hline CHEMBL1558880 & 688759 & 4.5 & 4.938 & TST \\
\hline CHEMBL1313891 & 688759 & 4.95 & 5.0123 & TRN \\
\hline CHEMBL1372800 & 688759 & 5.0 & 4.814 & TRN \\
\hline CHEMBL1587589 & 688759 & 5.5 & 4.976 & TST \\
\hline CHEMBL 3184468 & 688759 & 4.65 & 5.0521 & TST \\
\hline CHEMBL1362754 & 688759 & 4.65 & 4.815 & TRN \\
\hline CHEMBL1571256 & 688759 & 4.75 & 4.7757 & TST \\
\hline CHEMBL1603544 & 688759 & 4.45 & 4.7486 & TRN \\
\hline CHEMBL1332081 & 688759 & 4.45 & 4.5954 & TRN \\
\hline CHEMBL1384816 & 688759 & 4.45 & 4.9051 & TRN \\
\hline CHEMBL1350429 & 688759 & 4.45 & 5.0405 & TRN \\
\hline CHEMBL1582744 & 688759 & 5.0 & 4.7394 & TRN \\
\hline CHEMBL 3209346 & 688759 & 5.2 & 5.0602 & TRN \\
\hline CHEMBL1535264 & 688759 & 4.6 & 4.7946 & TST \\
\hline CHEMBL1311844 & 688759 & 4.7 & 5.0243 & TRN \\
\hline CHEMBL1556156 & 688759 & 4.65 & 4.4531 & TRN \\
\hline CHEMBL3209362 & 688759 & 4.6 & 4.5407 & TRN \\
\hline CHEMBL1498196 & 688759 & 4.65 & 4.7719 & TRN \\
\hline CHEMBL1443736 & 688759 & 4.9 & 4.6783 & TRN \\
\hline CHEMBL1510680 & 688759 & 4.65 & 4.6023 & TRN \\
\hline CHEMBL1362730 & 688759 & 4.65 & 4.8633 & TST \\
\hline CHEMBL1501062 & 688759 & 6.0 & 5.7065 & TRN \\
\hline CHEMBL3189936 & 688759 & 5.7 & 5.5937 & TRN \\
\hline CHEMBL 1443622 & 688759 & 4.45 & 4.751 & TRN \\
\hline CHEMBL1351121 & 688759 & 5.35 & 5.0207 & TRN \\
\hline
\end{tabular}




\begin{tabular}{|c|c|c|c|c|c|}
\hline \multicolumn{6}{|c|}{ Supplemental Table S2.txt } \\
\hline CHEMBL1404032 & 688759 & 5.85 & 5.4909 & TRN & \\
\hline CHEMBL 3210583 & 688759 & 4.95 & 4.7388 & TRN & \\
\hline CHEMBL1501509 & 688759 & 4.8 & 4.5646 & TRN & \\
\hline CHEMBL1307509 & 688759 & 4.45 & 4.8352 & TST & \\
\hline CHEMBL 3193092 & 688759 & 4.45 & 5.5747 & TRN & \\
\hline CHEMBL1452232 & 688759 & 5.2 & 5.0734 & TRN & \\
\hline CHEMBL1335117 & 688759 & 4.6 & 5.0111 & TST & \\
\hline CHEMBL1348215 & 688759 & 4.7 & 5.1352 & TRN & \\
\hline CHEMBL1413608 & 688759 & 6.0 & 5.7317 & TST & \\
\hline CHEMBL1606282 & 688759 & 4.7 & 4.9394 & TRN & \\
\hline CHEMBL 3195381 & 688759 & 5.35 & 5.2392 & TRN & \\
\hline CHEMBL1562713 & 688759 & 4.9 & 5.0905 & TRN & \\
\hline CHEMBL1541647 & 688759 & 4.65 & 4.7638 & TST & \\
\hline CHEMBL1350157 & 688759 & 5.35 & 5.1172 & TRN & \\
\hline CHEMBL1527367 & 688759 & 4.45 & 4.648 & TRN & \\
\hline CHEMBL1455005 & 688759 & 6.15 & 4.6403 & TRN & \\
\hline CHEMBL1344656 & 688759 & 5.4 & 4.8959 & TRN & \\
\hline CHEMBL1428501 & 688759 & 4.95 & 4.9598 & TRN & \\
\hline CHEMBL1478255 & 688759 & 4.7 & 4.8641 & TRN & \\
\hline CHEMBL1405069 & 688759 & 4.6 & 4.9208 & TRN & \\
\hline CHEMBL1613204 & 688759 & 4.45 & 4.9716 & TST & \\
\hline CHEMBL1510624 & 688759 & 4.45 & 4.7369 & TRN & \\
\hline CHEMBL1375018 & 688759 & 4.8 & 4.9611 & TST & \\
\hline CHEMBL1611512 & 688759 & 4.95 & 4.92899 & 7999999999 & TRN \\
\hline CHEMBL1337788 & 688759 & 4.45 & 4.779 & TRN & \\
\hline CHEMBL1589324 & 688759 & 4.65 & 4.7835 & TRN & \\
\hline CHEMBL1541279 & 688759 & 4.5 & 4.8466 & TST & \\
\hline CHEMBL1412088 & 688759 & 5.35 & 4.6952 & TRN & \\
\hline CHEMBL1516799 & 688759 & 4.45 & 4.6329 & TRN & \\
\hline CHEMBL1368116 & 688759 & 4.45 & 4.7567 & TRN & \\
\hline CHEMBL1560522 & 688759 & 4.45 & 4.8678 & TRN & \\
\hline CHEMBL1565115 & 688759 & 5.15 & 4.8759 & TRN & \\
\hline CHEMBL3190537 & 688759 & 5.25 & 5.0332 & TRN & \\
\hline CHEMBL 3211585 & 688759 & 5.4 & 4.9747 & TRN & \\
\hline CHEMBL1499489 & 688759 & 4.45 & 4.8996 & TRN & \\
\hline CHEMBL1431716 & 688759 & 4.8 & 5.1647 & TRN & \\
\hline CHEMBL1468480 & 688759 & 4.45 & 4.5593 & TRN & \\
\hline CHEMBL1389955 & 688759 & 4.9 & 4.8176 & TRN & \\
\hline CHEMBL1414512 & 688759 & 4.7 & 4.75899 & 99999999995 & TRN \\
\hline CHEMBL1418359 & 688759 & 4.9 & 4.8303 & TST & \\
\hline CHEMBL1465091 & 688759 & 4.45 & 4.901 & TRN & \\
\hline CHEMBL1414720 & 688759 & 5.0 & 4.6625 & TRN & \\
\hline CHEMBL1557783 & 688759 & 4.45 & 4.7019 & TRN & \\
\hline CHEMBL3192659 & 688759 & 5.8 & 5.0257 & TRN & \\
\hline CHEMBL1590547 & 688759 & 4.45 & 4.7047 & TRN & \\
\hline CHEMBL1442145 & 688759 & 4.95 & 4.8375 & TRN & \\
\hline CHEMBL1544598 & 688759 & 5.95 & 4.9972 & TRN & \\
\hline CHEMBL1533621 & 688759 & 5.0 & 4.971 & TRN & \\
\hline
\end{tabular}




\begin{tabular}{|c|c|c|c|c|c|}
\hline \multicolumn{6}{|c|}{ Supplemental Table S2.txt } \\
\hline CHEMBL1545627 & 688759 & 4.85 & 4.9228 & TRN & \\
\hline CHEMBL1339228 & 688759 & 6.1 & 5.612 & TST & \\
\hline CHEMBL1378772 & 688759 & 4.45 & 4.7724 & TRN & \\
\hline CHEMBL1362566 & 688759 & 4.6 & 4.8443 & TRN & \\
\hline CHEMBL1344689 & 688759 & 5.0 & 5.0893 & TRN & \\
\hline CHEMBL1407632 & 688759 & 4.9 & 4.9412 & TRN & \\
\hline CHEMBL1457022 & 688759 & 4.65 & 4.9074 & TRN & \\
\hline CHEMBL1996519 & 688759 & 4.5 & 4.44600 & 0000000001 & TRN \\
\hline CHEMBL1440576 & 688759 & 5.25 & 4.8489 & TST & \\
\hline CHEMBL541231 & 688759 & 4.65 & 4.646 & TST & \\
\hline CHEMBL1299349 & 688759 & 4.45 & 4.8076 & TRN & \\
\hline CHEMBL1404327 & 688759 & 5.45 & 5.3678 & TST & \\
\hline CHEMBL1423821 & 688759 & 6.35 & 5.0517 & TRN & \\
\hline CHEMBL1327359 & 688759 & 4.45 & 4.8727 & TRN & \\
\hline CHEMBL1333930 & 688759 & 5.9 & 4.9807 & TRN & \\
\hline CHEMBL1470236 & 688759 & 5.25 & 5.1055 & TRN & \\
\hline CHEMBL3209925 & 688759 & 5.2 & 4.9288 & TRN & \\
\hline CHEMBL1379776 & 688759 & 4.45 & 5.3213 & TST & \\
\hline CHEMBL1531681 & 688759 & 6.35 & 5.3877 & TRN & \\
\hline CHEMBL1507793 & 688759 & 4.45 & 4.8268 & TRN & \\
\hline CHEMBL1596553 & 688759 & 5.5 & 5.7143 & TRN & \\
\hline CHEMBL1582336 & 688759 & 4.45 & 5.0818 & TRN & \\
\hline CHEMBL1462073 & 688759 & 4.65 & 4.4606 & TRN & \\
\hline CHEMBL3581808 & 1498986 & 5.9666 & 6.5074 & TRN & \\
\hline CHEMBL3402044 & 1498986 & 5.8182 & 4.5857 & TST & \\
\hline CHEMBL3581807 & 1498986 & 5.9788 & 5.4212 & TRN & \\
\hline CHEMBL3581841 & 1498986 & 5.7825 & 6.0193 & TRN & \\
\hline CHEMBL3581822 & 1498986 & 6.8539 & 7.131 & TRN & \\
\hline CHEMBL3581846 & 1498986 & 4.301 & 4.6506 & TST & \\
\hline CHEMBL3581794 & 1498986 & 4.301 & 4.8105 & TST & \\
\hline CHEMBL3580676 & 1498986 & 5.4868 & 5.8029 & TRN & \\
\hline CHEMBL3581838 & 1498986 & 5.6459 & 5.3954 & TRN & \\
\hline CHEMBL535502 & 1498986 & 6.4318 & 6.5996 & TRN & \\
\hline CHEMBL3581853 & 1498986 & 5.8327 & 6.1127 & TRN & \\
\hline CHEMBL3581821 & 1498986 & 6.0315 & 6.3107 & TRN & \\
\hline CHEMBL3581803 & 1498986 & 5.7447 & 4.2532 & TST & \\
\hline CHEMBL 3581827 & 1498986 & 6.2007 & 6.0091 & TRN & \\
\hline CHEMBL3581804 & 1498986 & 4.301 & 4.3736 & TRN & \\
\hline CHEMBL3581795 & 1498986 & 4.301 & 4.5158 & TRN & \\
\hline CHEMBL3581842 & 1498986 & 5.7447 & 4.8868 & TST & \\
\hline CHEMBL3581810 & 1498986 & 5.466 & 5.2656 & TRN & \\
\hline CHEMBL3581802 & 1498986 & 5.9872 & 5.9745 & TRN & \\
\hline CHEMBL3581815 & 1498986 & 4.301 & 4.7344 & TRN & \\
\hline CHEMBL3581796 & 1498986 & 5.7375 & 5.8932 & TRN & \\
\hline CHEMBL3581809 & 1498986 & 5.3947 & 5.5536 & TRN & \\
\hline CHEMBL3581797 & 1498986 & 6.3979 & 6.322 & TRN & \\
\hline CHEMBL3581792 & 1498986 & 5.5986 & 4.0455 & TST & \\
\hline CHEMBL3581828 & 1498986 & 4.301 & 4.3142 & TRN & \\
\hline
\end{tabular}




\begin{tabular}{|c|c|c|c|c|c|}
\hline \multicolumn{6}{|c|}{ Supplemental Table S2.txt } \\
\hline CHEMBL3581801 & 1498986 & 6.284 & 6.5074 & TRN & \\
\hline CHEMBL3581805 & 1498986 & 5.4989 & 5.2581 & TRN & \\
\hline CHEMBL3581852 & 1498986 & 4.301 & 4.6802 & TRN & \\
\hline CHEMBL3581849 & 1498986 & 4.301 & 5.0354 & TST & \\
\hline CHEMBL 3581798 & 1498986 & 5.3788 & 5.5037 & TRN & \\
\hline CHEMBL3581848 & 1498986 & 5.9747 & 5.8377 & TRN & \\
\hline CHEMBL3581825 & 1498986 & 6.4202 & 5.8843 & TRN & \\
\hline CHEMBL3581835 & 1498986 & 7.0 & 6.5882 & TRN & \\
\hline CHEMBL3581787 & 1498986 & 7.0269 & 6.1606 & TRN & \\
\hline CHEMBL 3581837 & 1498986 & 4.301 & 4.4064 & TRN & \\
\hline CHEMBL3581806 & 1498986 & 6.5229 & 6.33799 & 9999999999 & TRN \\
\hline CHEMBL 3581823 & 1498986 & 4.301 & 4.1465 & TRN & \\
\hline CHEMBL3581851 & 1498986 & 6.9208 & 7.0232 & TRN & \\
\hline CHEMBL3581813 & 1498986 & 6.7696 & 6.2665 & TRN & \\
\hline CHEMBL3581793 & 1498986 & 4.301 & 3.9078 & TST & \\
\hline CHEMBL3581817 & 1498986 & 4.301 & 4.2509 & TRN & \\
\hline CHEMBL3581850 & 1498986 & 6.5229 & 6.3109 & TRN & \\
\hline CHEMBL3581839 & 1498986 & 4.301 & 4.8709 & TRN & \\
\hline CHEMBL3581790 & 1498986 & 6.0458 & 4.3252 & TST & \\
\hline CHEMBL3581834 & 1498986 & 4.301 & 4.8569 & TRN & \\
\hline CHEMBL3581847 & 1498986 & 5.5952 & 5.5114 & TRN & \\
\hline CHEMBL3581812 & 1498986 & 5.9172 & 5.6404 & TRN & \\
\hline CHEMBL3581800 & 1498986 & 5.8013 & 5.7317 & TRN & \\
\hline CHEMBL3581830 & 1498986 & 5.7375 & 5.4595 & TRN & \\
\hline CHEMBL3581820 & 1498986 & 6.0132 & 5.8753 & TRN & \\
\hline CHEMBL3581814 & 1498986 & 6.1805 & 5.9414 & TRN & \\
\hline CHEMBL3581826 & 1498986 & 4.301 & 3.9533 & TRN & \\
\hline CHEMBL3581824 & 1498986 & 4.301 & 4.7001 & TRN & \\
\hline CHEMBL3581789 & 1498986 & 5.6383 & 5.6008 & TRN & \\
\hline CHEMBL3581818 & 1498986 & 6.4949 & 6.5827 & TRN & \\
\hline CHEMBL3581791 & 1498986 & 6.8239 & 6.8252 & TRN & \\
\hline CHEMBL3581831 & 1498986 & 4.301 & 3.9167 & TRN & \\
\hline CHEMBL3581829 & 1498986 & 4.301 & 4.0071 & TRN & \\
\hline CHEMBL 3581844 & 1498986 & 4.301 & 4.615 & TST & \\
\hline CHEMBL3581843 & 1498986 & 5.5784 & 4.6328 & TST & \\
\hline CHEMBL3581811 & 1498986 & 4.301 & 4.8575 & TRN & \\
\hline CHEMBL3581819 & 1498986 & 6.4815 & 6.41700 & 0000000001 & TRN \\
\hline CHEMBL3581836 & 1498986 & 5.8633 & 6.4094 & TRN & \\
\hline CHEMBL3581833 & 1498986 & 6.3372 & 5.7829 & TST & \\
\hline CHEMBL3581845 & 1498986 & 4.301 & 4.2398 & TST & \\
\hline CHEMBL3581832 & 1498986 & 5.6459 & 5.2499 & TST & \\
\hline CHEMBL3581788 & 1498986 & 6.6021 & 6.2245 & TST & \\
\hline CHEMBL3581816 & 1498986 & 4.301 & 5.4917 & TST & \\
\hline CHEMBL3581799 & 1498986 & 5.8601 & 6.1759 & TST & \\
\hline CHEMBL3581840 & 1498986 & 5.4737 & 6.1724 & TST & \\
\hline CHEMBL334020 & 48108 & 8.71 & 8.6802 & TRN & \\
\hline CHEMBL330773 & 48108 & 9.31 & 9.1564 & TRN & \\
\hline CHEMBL120031 & 48108 & 8.81 & 8.7434 & TRN & \\
\hline
\end{tabular}




\begin{tabular}{|c|c|c|c|c|}
\hline \multicolumn{5}{|c|}{ Supplemental Table S2.txt } \\
\hline CHEMBL120793 & 48108 & 7.94 & 8.0825 & TRN \\
\hline CHEMBL121267 & 48108 & 8.76 & 8.9306 & TRN \\
\hline CHEMBL332601 & 48108 & 7.47 & 7.3341 & TRN \\
\hline CHEMBL120363 & 48108 & 9.01 & 9.0516 & TRN \\
\hline CHEMBL338278 & 48108 & 8.82 & 9.2584 & TST \\
\hline CHEMBL121331 & 48108 & 9.12 & 9.1104 & TRN \\
\hline CHEMBL121703 & 48108 & 8.54 & 8.4988 & TRN \\
\hline CHEMBL420728 & 48108 & 9.17 & 8.9074 & TRN \\
\hline CHEMBL340107 & 48108 & 8.33 & 8.3506 & TRN \\
\hline CHEMBL120657 & 48108 & 8.42 & 8.4585 & TRN \\
\hline CHEMBL331244 & 48108 & 9.24 & 9.2965 & TRN \\
\hline CHEMBL332595 & 48108 & 8.68 & 8.3372 & TST \\
\hline CHEMBL120296 & 48108 & 9.14 & 8.8583 & TRN \\
\hline CHEMBL333517 & 48108 & 9.02 & 9.1076 & TRN \\
\hline CHEMBL121624 & 48108 & 7.22 & 7.3852 & TRN \\
\hline CHEMBL333930 & 48108 & 8.9 & 8.999 & TRN \\
\hline CHEMBL339879 & 48108 & 8.95 & 8.3042 & TST \\
\hline CHEMBL118622 & 48108 & 9.19 & 9.1128 & TRN \\
\hline CHEMBL331929 & 48108 & 8.08 & 8.1753 & TRN \\
\hline CHEMBL119608 & 48108 & 8.53 & 8.3871 & TRN \\
\hline CHEMBL332646 & 48108 & 8.11 & 8.5283 & TRN \\
\hline CHEMBL331971 & 48108 & 9.02 & 9.0041 & TRN \\
\hline CHEMBL415240 & 48108 & 9.75 & 9.5729 & TRN \\
\hline CHEMBL 278018 & 48108 & 8.81 & 8.7906 & TRN \\
\hline CHEMBL331651 & 48108 & 8.45 & 8.5242 & TST \\
\hline CHEMBL332403 & 48108 & 9.14 & 9.4776 & TRN \\
\hline CHEMBL 331872 & 48108 & 9.65 & 9.6766 & TRN \\
\hline CHEMBL402702 & 48108 & 9.25 & 9.3203 & TRN \\
\hline CHEMBL331975 & 48108 & 9.52 & 9.4607 & TRN \\
\hline CHEMBL331405 & 48108 & 8.72 & 8.6984 & TRN \\
\hline CHEMBL118189 & 48108 & 8.85 & 8.8612 & TRN \\
\hline CHEMBL120168 & 48108 & 8.61 & 8.9492 & TST \\
\hline CHEMBL331688 & 48108 & 8.68 & 8.7868 & TRN \\
\hline CHEMBL121021 & 48108 & 9.48 & 9.0892 & TRN \\
\hline CHEMBL332128 & 48108 & 7.88 & 7.7012 & TRN \\
\hline CHEMBL421271 & 48108 & 9.17 & 9.2227 & TRN \\
\hline CHEMBL120021 & 48108 & 8.95 & 8.976 & TRN \\
\hline CHEMBL331468 & 48108 & 9.53 & 9.5897 & TRN \\
\hline CHEMBL331119 & 48108 & 8.88 & 8.9174 & TRN \\
\hline CHEMBL433028 & 48108 & 8.28 & 8.0288 & TST \\
\hline CHEMBL120015 & 48108 & 8.63 & 8.4183 & TST \\
\hline CHEMBL330854 & 48108 & 8.21 & 8.2271 & TST \\
\hline CHEMBL332568 & 48108 & 9.22 & 9.6212 & TST \\
\hline CHEMBL118954 & 48108 & 9.18 & 8.7171 & TST \\
\hline CHEMBL331262 & 48108 & 8.99 & 9.0774 & TST \\
\hline CHEMBL332850 & 48108 & 8.52 & 9.5963 & TST \\
\hline CHEMBL332902 & 48108 & 9.54 & 9.6118 & TST \\
\hline CHEMBL3646577 & 1528359 & 6.9872 & 7.1552 & TST \\
\hline
\end{tabular}




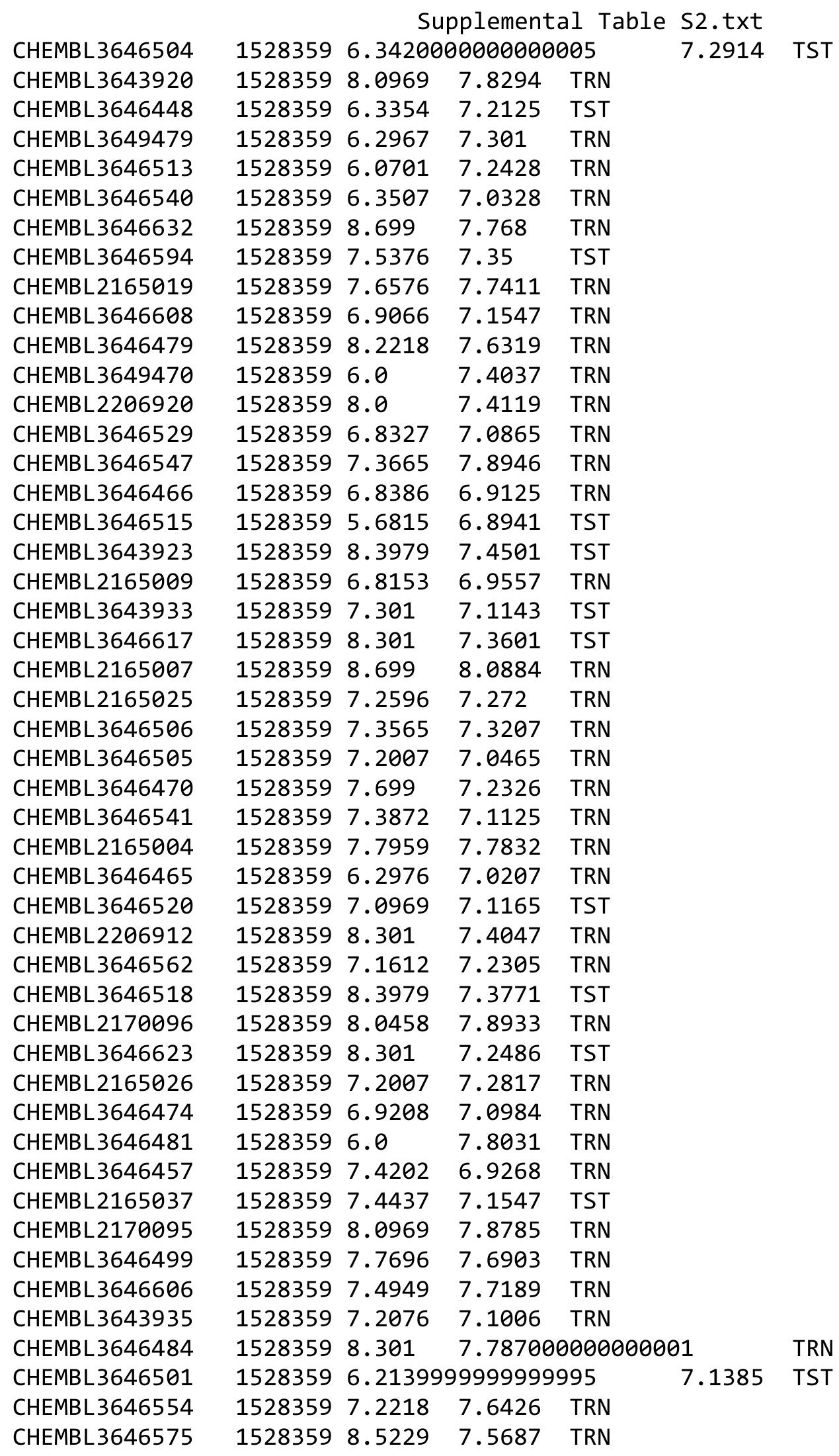

Page 15289 
Supplemental Table S2.txt

\begin{tabular}{|c|c|c|c|c|c|c|}
\hline CHEMBL3646559 & 1528359 & 7.8539 & 7.7441 & TRN & & \\
\hline CHEMBL3646579 & 1528359 & 7.699 & 7.6189 & TRN & & \\
\hline CHEMBL 2165012 & 1528359 & 6.556 & 6.9132 & TRN & & \\
\hline CHEMBL 3646510 & 1528359 & 6.4634 & 7.2285 & TST & & \\
\hline CHEMBL3646607 & 1528359 & 7.6778 & 7.7778 & TRN & & \\
\hline CHEMBL3646537 & 1528359 & \multicolumn{3}{|c|}{6.4510000000000005} & 7.1054 & TRN \\
\hline CHEMBL 2206921 & 1528359 & 8.699 & 7.3039 & TRN & & \\
\hline CHEMBL 2165035 & 1528359 & 6.0958 & 6.4764 & TST & & \\
\hline CHEMBL3646566 & 1528359 & 6.433 & 7.7862 & TRN & & \\
\hline CHEMBL 2170089 & 1528359 & 6.0 & 7.7781 & TRN & & \\
\hline CHEMBL3646604 & 1528359 & 7.5686 & 7.229 & TRN & & \\
\hline CHEMBL 2165018 & 1528359 & 7.7696 & 7.7283 & TRN & & \\
\hline CHEMBL 2206905 & 1528359 & 7.9586 & 7.5866 & TST & & \\
\hline CHEMBL 3646621 & 1528359 & 7.6021 & 7.1147 & TRN & & \\
\hline CHEMBL 2206911 & 1528359 & 6.4895 & 7.2357 & TRN & & \\
\hline CHEMBL3649469 & 1528359 & 6.5544 & 7.5473 & TST & & \\
\hline CHEMBL3646564 & 1528359 & 6.1918 & 7.3223 & TST & & \\
\hline CHEMBL3646636 & 1528359 & 6.0 & 7.615 & TRN & & \\
\hline CHEMBL3643936 & 1528359 & 6.3958 & 6.9693 & TST & & \\
\hline CHEMBL 2165047 & 1528359 & 6.0615 & 6.5463 & TRN & & \\
\hline CHEMBL3646491 & 1528359 & 7.9586 & 7.2599 & TRN & & \\
\hline CHEMBL 2165014 & 1528359 & 6.5884 & 6.968 & TRN & & \\
\hline CHEMBL3646563 & 1528359 & 7.3279 & 7.1675 & TRN & & \\
\hline CHEMBL 3646517 & 1528359 & 8.699 & 7.2754 & TST & & \\
\hline CHEMBL 2165040 & 1528359 & 4.6455 & 5.2418 & TST & & \\
\hline CHEMBL3646550 & 1528359 & 8.0969 & 7.4714 & TST & & \\
\hline CHEMBL3646446 & 1528359 & 6.0 & 7.2746 & TRN & & \\
\hline CHEMBL3646612 & 1528359 & 8.2218 & 7.72 & TRN & & \\
\hline CHEMBL 3646524 & 1528359 & 7.4815 & 7.1443 & TRN & & \\
\hline CHEMBL 2165049 & 1528359 & 7.7447 & 7.0361 & TRN & & \\
\hline CHEMBL3646445 & 1528359 & 7.6383 & 7.6559 & TRN & & \\
\hline CHEMBL 2165042 & 1528359 & 5.8505 & 6.3866 & TST & & \\
\hline CHEMBL3646615 & 1528359 & 7.2596 & 7.5761 & TST & & \\
\hline CHEMBL 2170094 & 1528359 & 6.8894 & 7.8489 & TRN & & \\
\hline CHEMBL3646502 & 1528359 & 8.2218 & 7.4064 & TRN & & \\
\hline CHEMBL3646605 & 1528359 & 7.7447 & 7.724 & TRN & & \\
\hline CHEMBL3646631 & 1528359 & 7.3468 & 7.3113 & TRN & & \\
\hline CHEMBL 2206906 & 1528359 & 8.301 & 7.5784 & TST & & \\
\hline CHEMBL 3646493 & 1528359 & 8.1549 & 7.8362 & TRN & & \\
\hline CHEMBL 3649475 & 1528359 & 7.9208 & 7.8139 & TRN & & \\
\hline CHEMBL3646438 & 1528359 & 7.2441 & 7.1124 & TRN & & \\
\hline CHEMBL 2165033 & 1528359 & 8.0969 & 7.8876 & TRN & & \\
\hline CHEMBL3646451 & 1528359 & 8.0458 & 7.8116 & TRN & & \\
\hline CHEMBL 2206907 & 1528359 & 8.699 & 7.5077 & TST & & \\
\hline CHEMBL3358288 & 1528359 & 7.8239 & 7.2651 & TRN & & \\
\hline CHEMBL3646436 & 1528359 & 7.3768 & 7.125 & TRN & & \\
\hline CHEMBL3646432 & 1528359 & 7.7212 & 7.7089 & TRN & & \\
\hline CHEMBL3646500 & 1528359 & 6.2518 & 7.2666 & TRN & & \\
\hline
\end{tabular}


Supplemental Table S2.txt

\begin{tabular}{|c|c|c|c|c|}
\hline HEMBL & 528359 & 6.8182 & 7.2735 & זעיו \\
\hline & & 7.1612 & 7.2178 & \\
\hline HFMBI & 28359 & 9914 & 0232 & \\
\hline IEMBL 364 & 359 & 91 & & \\
\hline HEMBL 364 & 528359 & 7.3468 & .1928 & \\
\hline HEMBL 364 & 359 & 7.3565 & 2003 & \\
\hline HEMBL 2 & & & 9669 & \\
\hline HEMBL36 & & & 5755 & \\
\hline HEMBL 3646 & 528359 & 6.983 & .0482 & \\
\hline HEMBL 364 & 528359 & 7.3979 & 0149 & \\
\hline HEMBL 364 & 59 & & .3937 & \\
\hline HEMBL; & 59 & 18 & 1143 & \\
\hline HEMBL3 & & & .8519 & \\
\hline HEMBL 364 & 359 & 586 & .9866 & \\
\hline HEMBL 364 & 59 & & 8525 & \\
\hline HEMBL36 & כ) & 7. & 6861 & \\
\hline HEMBL3 & 9 & & 1221 & \\
\hline HEMBL 2 & 59 & & 1942 & \\
\hline HEMBL 216 & & 6 . & 9776 & \\
\hline HEMBL 364 & & & & niv \\
\hline HEMBL; & 59 & 7. & 368 & RN \\
\hline HEM & & & 304 & MIV \\
\hline HEMBL & 59 & & 0765 & \\
\hline HEMBL3 & & & 5979 & TRN \\
\hline HEMBL 216 & & & 966 & I RN \\
\hline HEMBL3 & & & .717 & 「RN \\
\hline HEMBL & & & 96 & II \\
\hline HEMRI & & & 3742 & \\
\hline HEMBL3 & & & 1088 & IRN \\
\hline HEMBL 364 & & 6. & 2276 & TRN \\
\hline HEMBL; & & & 3277 & 「RN \\
\hline HFM & & & 75 & ГST \\
\hline ו & & & 3153 & TRN \\
\hline HEMBL 36 & & & 937 & 「R \\
\hline HEMBL $22 \ell$ & 59 & & 4515 & ГST \\
\hline ᄀ & & 99 & 708 & TRN \\
\hline 0 & & & 24 & ГRN \\
\hline HEMBL3€ & & & 7.1885 & TRN \\
\hline HEMBL2 & 59 & & 243 & $\Gamma R$ \\
\hline LITSL & & & 821 & 11 \\
\hline HEMBL3 & & & 397 & TRN \\
\hline HEMBL3 & 99 & 7. & 7.1279 & RN \\
\hline HEMBL3 & & 8.3979 & .4075 & [RN \\
\hline HEMBL 364 & 59 & 6 & 229 & TR \\
\hline 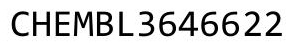 & & & & \\
\hline HEMBL 3 & & 7.6021 & 7.0942 & \\
\hline CHEMBL 36 & 157 & 5.7181 & 6.7479 & \\
\hline CHEMBL3646453 & 1528359 & 5.5646 & 6.8004 & 3 \\
\hline
\end{tabular}

Page 15291 


\begin{tabular}{|c|c|c|c|c|c|c|}
\hline \multicolumn{7}{|c|}{ Supplemental Table s2.txt } \\
\hline CHEMBL3646583 & 1528359 & 6.0 & 7.4006 & TRN & & \\
\hline CHEMBL3643937 & 1528359 & 7.4815 & 7.1841 & TST & & \\
\hline CHEMBL3646496 & 1528359 & 6.75200 & 00000000 & 01 & 7.2586 & TRN \\
\hline CHEMBL 3646635 & 1528359 & 6.5686 & 7.232 & TST & & \\
\hline CHEMBL3646551 & 1528359 & 6.3546 & 7.3593 & TRN & & \\
\hline CHEMBL3357872 & 1528359 & 8.0969 & 7.194 & TRN & & \\
\hline CHEMBL3643919 & 1528359 & 5.2504 & 5.6158 & TST & & \\
\hline CHEMBL 2165020 & 1528359 & 8.0458 & 7.9815 & TRN & & \\
\hline CHEMBL 2165006 & 1528359 & 7.1871 & 7.3013 & TRN & & \\
\hline CHEMBL3643939 & 1528359 & 7.9586 & 7.1493 & TRN & & \\
\hline CHEMBL3357869 & 1528359 & 8.3979 & 7.2172 & TRN & & \\
\hline CHEMBL3646473 & 1528359 & 6.6635 & 7.0944 & TRN & & \\
\hline CHEMBL3646592 & 1528359 & 7.6198 & 7.7707 & TRN & & \\
\hline CHEMBL3643931 & 1528359 & 6.7959 & 7.1726 & TRN & & \\
\hline CHEMBL3646596 & 1528359 & 9.0 & 7.7079 & TRN & & \\
\hline CHEMBL3646516 & 1528359 & 6.3883 & 6.9955 & TST & & \\
\hline CHEMBL3646521 & 1528359 & 6.8153 & 7.1003 & TST & & \\
\hline CHEMBL3646536 & 1528359 & 6.8697 & 7.0477 & TRN & & \\
\hline CHEMBL3646609 & 1528359 & 7.4685 & 7.7303 & TRN & & \\
\hline CHEMBL3646464 & 1528359 & 6.5498 & 6.8919 & TRN & & \\
\hline CHEMBL3646600 & 1528359 & 7.4437 & 7.6619 & TRN & & \\
\hline CHEMBL3643921 & 1528359 & 6.71899 & 99999999 & 99 & 7.2551 & TST \\
\hline CHEMBL3646428 & 1528359 & 7.3768 & 7.0072 & TRN & & \\
\hline CHEMBL 3646528 & 1528359 & 7.0269 & 7.0754 & TRN & & \\
\hline CHEMBL3646558 & 1528359 & 6.3706 & 6.972 & TRN & & \\
\hline CHEMBL3646468 & 1528359 & 8.1549 & 7.8849 & TRN & & \\
\hline CHEMBL3646458 & 1528359 & 6.9469 & 6.9459 & TRN & & \\
\hline CHEMBL3646539 & 1528359 & 7.1675 & 7.2639 & TST & & \\
\hline CHEMBL 3646526 & 1528359 & 7.1675 & 7.1518 & TST & & \\
\hline CHEMBL3646503 & 1528359 & 7.2218 & 7.1521 & TRN & & \\
\hline CHEMBL 2170083 & 1528359 & 6.0 & 7.78299 & 9999999999 & & TRN \\
\hline CHEMBL3646611 & 1528359 & 7.2291 & 7.2122 & TRN & & \\
\hline CHEMBL3646567 & 1528359 & 6.9872 & 7.8135 & TRN & & \\
\hline CHEMBL 2165011 & 1528359 & 6.7011 & 6.9653 & TRN & & \\
\hline CHEMBL3646597 & 1528359 & 6.585 & 7.2443 & TST & & \\
\hline CHEMBL3646477 & 1528359 & 7.3188 & 7.1238 & TRN & & \\
\hline CHEMBL3646555 & 1528359 & 7.9208 & 7.511 & TRN & & \\
\hline CHEMBL2165036 & 1528359 & 5.5032 & 6.0733 & TST & & \\
\hline CHEMBL3646544 & 1528359 & 7.7447 & 7.5825 & TST & & \\
\hline CHEMBL3646618 & 1528359 & 8.5229 & 7.4765 & TRN & & \\
\hline CHEMBL3646595 & 1528359 & 8.699 & 7.6682 & TRN & & \\
\hline CHEMBL3646598 & 1528359 & 7.7212 & 7.70100 & 0000000000 & & TRN \\
\hline CHEMBL 2165022 & 1528359 & 7.1549 & 6.9075 & TRN & & \\
\hline CHEMBL3643938 & 1528359 & 7.0809 & 7.1257 & TRN & & \\
\hline CHEMBL3646431 & 1528359 & 7.0132 & 7.1656 & TRN & & \\
\hline CHEMBL3646531 & 1528359 & 7.3979 & 7.1877 & TRN & & \\
\hline CHEMBL 2165032 & 1528359 & 8.0969 & 7.8523 & TRN & & \\
\hline CHEMBL2206908 & 1528359 & 8.3979 & 7.5532 & TRN & & \\
\hline
\end{tabular}


Supplemental Table S2.txt

\begin{tabular}{|c|c|c|c|c|c|}
\hline CHEMBL3646507 & 1528359 & 8.2218 & 7.7837 & TRN & \\
\hline CHEMBL 3646495 & 1528359 & 6.7496 & 7.3596 & TST & \\
\hline CHEMBL3646488 & 1528359 & 7.6778 & 7.1714 & TRN & \\
\hline CHEMBL3646455 & 1528359 & 6.5986 & 6.8162 & TST & \\
\hline CHEMBL3646616 & 1528359 & 7.0088 & 7.5294 & TRN & \\
\hline CHEMBL3954088 & 1528359 & 8.1549 & 7.3385 & TRN & \\
\hline CHEMBL3643932 & 1528359 & 6.1427 & 7.0422 & TST & \\
\hline CHEMBL3649471 & 1528359 & 7.2291 & 7.4323 & TST & \\
\hline CHEMBL3646546 & 1528359 & 8.0969 & 7.8803 & TRN & \\
\hline CHEMBL3357867 & 1528359 & 7.7696 & 7.2612 & TRN & \\
\hline CHEMBL3643917 & 1528359 & 4.8239 & 5.9924 & TST & \\
\hline CHEMBL3357868 & 1528359 & 8.3979 & 7.2011 & TRN & \\
\hline CHEMBL3646469 & 1528359 & 7.0 & 7.352 & TRN & \\
\hline CHEMBL3646444 & 1528359 & 6.0 & 7.2253 & TRN & \\
\hline CHEMBL 2165053 & 1528359 & 7.4815 & 7.0296 & TST & \\
\hline CHEMBL3646487 & 1528359 & 8.0 & 7.8002 & TRN & \\
\hline CHEMBL 2165052 & 1528359 & 7.8861 & 7.6521 & TST & \\
\hline CHEMBL 3646460 & 1528359 & 7.0132 & 7.2438 & TRN & \\
\hline CHEMBL3649468 & 1528359 & 7.1487 & 7.6069 & TST & \\
\hline CHEMBL 2165030 & 1528359 & 8.301 & 8.0269 & TRN & \\
\hline CHEMBL3646576 & 1528359 & 7.5086 & 7.0553 & TRN & \\
\hline CHEMBL 3646522 & 1528359 & 7.7959 & 7.1168 & TST & \\
\hline CHEMBL3357876 & 1528359 & 6.684 & 7.1412 & TRN & \\
\hline CHEMBL 3358287 & 1528359 & 7.7212 & 7.1508 & TRN & \\
\hline CHEMBL3646601 & 1528359 & 6.0 & 7.2932 & TRN & \\
\hline CHEMBL3643943 & 1528359 & 7.6576 & 7.067 & TRN & \\
\hline CHEMBL 3646523 & 1528359 & 7.284 & 7.8189 & TRN & \\
\hline CHEMBL3649474 & 1528359 & 8.1549 & 7.3969 & TRN & \\
\hline CHEMBL 2165046 & 1528359 & 6.4023 & 6.5562 & TRN & \\
\hline CHEMBL3646478 & 1528359 & 8.301 & \multicolumn{2}{|c|}{7.6339999999999995} & TRN \\
\hline CHEMBL3646589 & 1528359 & 7.2147 & 7.0542 & TRN & \\
\hline CHEMBL 3646498 & 1528359 & 6.2147 & 7.2916 & TST & \\
\hline CHEMBL3646442 & 1528359 & 7.4559 & 7.1368 & TRN & \\
\hline CHEMBL3643934 & 1528359 & 6.9245 & 7.0348 & TST & \\
\hline CHEMBL 2206919 & 1528359 & 7.0706 & 7.4364 & TST & \\
\hline CHEMBL3646572 & 1528359 & 7.9586 & 7.7899 & TRN & \\
\hline CHEMBL 3646549 & 1528359 & 5.8359 & \multicolumn{2}{|c|}{7.587000000000001} & TRN \\
\hline CHEMBL 2170097 & 1528359 & 7.8239 & 7.7696 & TRN & \\
\hline CHEMBL3643925 & 1528359 & 7.2596 & 7.8776 & TRN & \\
\hline CHEMBL3646462 & 1528359 & 7.2924 & 7.0236 & TRN & \\
\hline CHEMBL3646561 & 1528359 & 7.7959 & 7.7098 & TRN & \\
\hline CHEMBL3646545 & 1528359 & 7.3468 & 6.7969 & TRN & \\
\hline CHEMBL3646630 & 1528359 & 7.6198 & 7.2245 & TRN & \\
\hline CHEMBL 3643927 & 1528359 & 7.4437 & 6.9947 & TST & \\
\hline CHEMBL 2206917 & 1528359 & 7.8539 & 7.52 & TST & \\
\hline CHEMBL3646534 & 1528359 & 7.0315 & 7.1817 & TRN & \\
\hline CHEMBL 3646552 & 1528359 & 7.6778 & \multicolumn{2}{|c|}{7.736000000000001} & TRN \\
\hline CHEMBL 3646588 & 1528359 & 9.0 & 7.6134 & TRN & \\
\hline
\end{tabular}


Supplemental Table S2.txt

\begin{tabular}{|c|c|c|c|c|c|}
\hline CHEMBL3639453 & 1528359 & 7.1135 & 7.1447 & TRN & \\
\hline CHEMBL3646620 & 1528359 & 7.7212 & 7.7292 & TRN & \\
\hline CHEMBL3646480 & 1528359 & 8.699 & 8.023 & TRN & \\
\hline CHEMBL 3646625 & 1528359 & 6.4237 & 7.2908 & TRN & \\
\hline CHEMBL3646543 & 1528359 & 8.3979 & 7.5701 & TST & \\
\hline CHEMBL3646565 & 1528359 & 6.8097 & 7.1913 & TST & \\
\hline CHEMBL 2165008 & 1528359 & 6.5751 & 6.8697 & TRN & \\
\hline CHEMBL3646433 & 1528359 & 7.7447 & 7.1644 & TRN & \\
\hline CHEMBL3646553 & 1528359 & 7.9586 & 7.5129 & TRN & \\
\hline CHEMBL3643922 & 1528359 & 5.8022 & 7.7525 & TRN & \\
\hline CHEMBL 3643940 & 1528359 & 7.6383 & 7.1463 & TRN & \\
\hline CHEMBL3646459 & 1528359 & 7.7447 & 6.9105 & TRN & \\
\hline CHEMBL3646439 & 1528359 & 7.4815 & 7.1613 & TRN & \\
\hline CHEMBL 2165050 & 1528359 & 6.4855 & 6.6733 & TRN & \\
\hline CHEMBL3646486 & 1528359 & 7.1938 & 7.4544 & TST & \\
\hline CHEMBL 2206916 & 1528359 & 7.3565 & 7.3715 & TST & \\
\hline CHEMBL3643942 & 1528359 & 7.4559 & 7.1008 & TRN & \\
\hline CHEMBL3646490 & 1528359 & 8.1549 & 7.80399 & 9999999999 & TRN \\
\hline CHEMBL3646560 & 1528359 & 7.0915 & 7.0114 & TRN & \\
\hline CHEMBL3646629 & 1528359 & 7.8539 & 7.397 & TRN & \\
\hline CHEMBL3646475 & 1528359 & 7.2676 & 7.0941 & TRN & \\
\hline CHEMBL 2165010 & 1528359 & 6.983 & 7.1953 & TRN & \\
\hline CHEMBL3357874 & 1528359 & 7.6383 & 7.1765 & TRN & \\
\hline CHEMBL3646580 & 1528359 & 7.3468 & 7.4941 & TRN & \\
\hline CHEMBL3646489 & 1528359 & 7.4815 & 7.2637 & TRN & \\
\hline CHEMBL3646634 & 1528359 & 8.301 & 7.68 & TRN & \\
\hline CHEMBL3646511 & 1528359 & 7.585 & 7.1385 & TRN & \\
\hline CHEMBL 2165017 & 1528359 & 8.0458 & 7.9258 & TRN & \\
\hline CHEMBL3646557 & 1528359 & 8.3979 & 7.1653 & TRN & \\
\hline CHEMBL3646590 & 1528359 & 7.1308 & 7.27 & TRN & \\
\hline CHEMBL3646626 & 1528359 & 7.1249 & 7.3236 & TRN & \\
\hline CHEMBL 2165269 & 1528359 & 6.9706 & 7.0519 & TRN & \\
\hline CHEMBL3646535 & 1528359 & 8.2218 & 7.7412 & TRN & \\
\hline CHEMBL 2165024 & 1528359 & 6.6162 & 6.966 & TRN & \\
\hline CHEMBL3646574 & 1528359 & 8.1549 & 7.7303 & TST & \\
\hline CHEMBL3646613 & 1528359 & 7.1675 & 7.7891 & TRN & \\
\hline CHEMBL3646456 & 1528359 & 7.0088 & 6.8417 & TST & \\
\hline CHEMBL 3646443 & 1528359 & 6.9706 & 7.4159 & TRN & \\
\hline CHEMBL 2165268 & 1528359 & 6.7282 & 6.9349 & TST & \\
\hline CHEMBL3646450 & 1528359 & 8.5229 & 7.4829 & TST & \\
\hline CHEMBL3646494 & 1528359 & 6.0164 & 7.3701 & TST & \\
\hline CHEMBL3646525 & 1528359 & 6.5591 & 7.228 & TRN & \\
\hline CHEMBL3646471 & 1528359 & 6.0 & 7.1066 & TST & \\
\hline CHEMBL3646497 & 1528359 & 6.3401 & 7.2348 & TRN & \\
\hline CHEMBL3646509 & 1528359 & 6.1226 & 7.2477 & TST & \\
\hline CHEMBL3646508 & 1528359 & 6.9066 & 6.8378 & TST & \\
\hline CHEMBL3646519 & 1528359 & 6.1605 & 7.2194 & TST & \\
\hline CHEMBL3646454 & 1528359 & 6.5784 & 7.0465 & TST & \\
\hline
\end{tabular}


Supplemental Table S2.txt

\begin{tabular}{|c|c|c|c|c|c|c|}
\hline CHEMBL 3357863 & 1528359 & 7.7212 & 7.2087 & TRN & & \\
\hline CHEMBL 3646542 & 1528359 & 7.6383 & \multicolumn{3}{|c|}{7.502000000000001} & TST \\
\hline CHEMBL 3646435 & 1528359 & 8.1549 & 7.5627 & TRN & & \\
\hline CHEMBL 2165270 & 1528359 & 7.6198 & 7.4685 & TST & & \\
\hline CHEMBL3646530 & 1528359 & 7.7959 & 7.8121 & TRN & & \\
\hline CHEMBL 3643928 & 1528359 & 6.301 & 7.144 & TRN & & \\
\hline CHEMBL 2165021 & 1528359 & 7.2291 & 6.9817 & TST & & \\
\hline CHEMBL3646485 & 1528359 & 9.0 & 7.7605 & TRN & & \\
\hline CHEMBL3643918 & 1528359 & 4.8239 & 5.8982 & TRN & & \\
\hline CHEMBL3646599 & 1528359 & 7.3565 & 7.7377 & TRN & & \\
\hline CHEMBL 3646585 & 1528359 & 7.9208 & 7.3167 & TRN & & \\
\hline CHEMBL3358285 & 1528359 & 6.718999 & 999999999 & 99 & 7.6796 & TRN \\
\hline CHEMBL3646437 & 1528359 & 8.0458 & 7.1504 & TRN & & \\
\hline CHEMBL 2170098 & 1528359 & 8.0458 & 7.8454 & TRN & & \\
\hline CHEMBL3646527 & 1528359 & 6.7447 & 7.1367 & TRN & & \\
\hline CHEMBL3646582 & 1528359 & 7.6198 & 7.8005 & TRN & & \\
\hline CHEMBL 3646603 & 1528359 & 8.1549 & 7.7253 & TRN & & \\
\hline CHEMBL3646573 & 1528359 & 8.2218 & 7.3449 & TRN & & \\
\hline CHEMBL3643926 & 1528359 & 6.8861 & 6.9563 & TST & & \\
\hline CHEMBL2206914 & 1528359 & 8.2218 & 7.5367 & TST & & \\
\hline CHEMBL3646452 & 1528359 & 6.4449 & 6.7829 & TST & & \\
\hline CHEMBL 3924227 & 1528359 & 8.0458 & 6.5596 & TST & & \\
\hline CHEMBL 3646628 & 1528359 & 8.0458 & 7.2211 & TST & & \\
\hline CHEMBL3646514 & 1528359 & 7.8861 & 7.297999 & 999999999 & & TRN \\
\hline CHEMBL3358286 & 1528359 & 7.2366 & 7.5198 & TRN & & \\
\hline CHEMBL3646548 & 1528359 & 6.7878 & 7.7889 & TRN & & \\
\hline CHEMBL 2165028 & 1528359 & 6.5482 & 6.9239 & TRN & & \\
\hline CHEMBL 3646538 & 1528359 & 7.2291 & 7.0386 & TRN & & \\
\hline CHEMBL3650506 & 1528909 & 8.0825 & 7.9111 & TST & & \\
\hline CHEMBL 3650505 & 1528909 & 8.2632 & 8.1823 & TRN & & \\
\hline CHEMBL 3654165 & 1528909 & 8.9355 & 9.1294 & TST & & \\
\hline CHEMBL 3650594 & 1528909 & 10.4949 & 10.3731 & TRN & & \\
\hline CHEMBL3654057 & 1528909 & 12.0 & 11.5963 & TRN & & \\
\hline CHEMBL3639530 & 1528909 & 9.7799 & 9.5065 & TST & & \\
\hline CHEMBL3654163 & 1528909 & 9.451 & 9.6345 & TST & & \\
\hline CHEMBL3650589 & 1528909 & 9.4802 & 9.4579 & TRN & & \\
\hline CHEMBL3654162 & 1528909 & 10.1612 & 10.4461 & TRN & & \\
\hline CHEMBL3654001 & 1528909 & 9.9788 & 9.9973 & TST & & \\
\hline CHEMBL3650653 & 1528909 & 10.4318 & 10.4311 & TRN & & \\
\hline CHEMBL 3654134 & 1528909 & 7.2388 & 6.8159 & TRN & & \\
\hline CHEMBL3650569 & 1528909 & 6.577999 & 999999999 & 99 & 6.8322 & TRN \\
\hline CHEMBL 3654170 & 1528909 & 10.5229 & 10.4033 & TRN & & \\
\hline CHEMBL 3654064 & 1528909 & 9.8356 & 9.6522 & TST & & \\
\hline CHEMBL3654042 & 1528909 & 9.9547 & 9.7156 & TRN & & \\
\hline CHEMBL 3654125 & 1528909 & 10.9208 & 11.0141 & TRN & & \\
\hline CHEMBL3650607 & 1528909 & 10.5229 & 10.3408 & TRN & & \\
\hline CHEMBL 3650522 & 1528909 & 10.7212 & 10.4112 & TRN & & \\
\hline CHEMBL3654053 & 1528909 & 9.719 & 9.7529 & TRN & & \\
\hline
\end{tabular}


Supplemental Table S2.txt

\begin{tabular}{|c|c|c|c|c|c|c|}
\hline CHEMBL 3650502 & 1528909 & 8.7749 & 8.7956 & TRN & & \\
\hline CHEMBL 3650593 & 1528909 & 10.3768 & 10.2616 & TRN & & \\
\hline CHEMBL3654139 & 1528909 & 10.69900 & 00000006 & 302 & 10.9258 & TRN \\
\hline CHEMBL 3654122 & 1528909 & 10.8539 & 10.9207 & TST & & \\
\hline CHEMBL3653990 & 1528909 & 9.7595 & 9.845 & TRN & & \\
\hline CHEMBL 3654085 & 1528909 & 9.6737 & 9.7586 & TRN & & \\
\hline CHEMBL 3650518 & 1528909 & 10.1549 & 10.1546 & TRN & & \\
\hline CHEMBL 3650497 & 1528909 & 8.7902 & 8.36 & TRN & & \\
\hline CHEMBL 3654043 & 1528909 & 8.9948 & 8.7624 & TRN & & \\
\hline CHEMBL3654114 & 1528909 & 8.5494 & 8.0738 & TRN & & \\
\hline CHEMBL 3650579 & 1528909 & 6.8339 & 6.4961 & TRN & & \\
\hline CHEMBL 3650534 & 1528909 & 10.1427 & 10.0825 & TRN & & \\
\hline CHEMBL 3654016 & 1528909 & 9.9245 & 9.9963 & TST & & \\
\hline CHEMBL3650559 & 1528909 & 6.3463 & 6.7818 & TRN & & \\
\hline CHEMBL3654120 & 1528909 & 10.4815 & 10.3511 & TRN & & \\
\hline CHEMBL3650638 & 1528909 & 10.5086 & 10.5934 & TRN & & \\
\hline CHEMBL3654096 & 1528909 & 12.0 & 11.239 & TRN & & \\
\hline CHEMBL 3654007 & 1528909 & 9.3188 & 9.3471 & TRN & & \\
\hline CHEMBL 3654100 & 1528909 & 8.4763 & 8.5014 & TST & & \\
\hline CHEMBL3654104 & 1528909 & 12.0 & 11.8746 & TRN & & \\
\hline CHEMBL3654002 & 1528909 & 9.04 & 9.0761 & TRN & & \\
\hline CHEMBL 3654054 & 1528909 & 9.6326 & 9.686 & TRN & & \\
\hline CHEMBL 3650587 & 1528909 & 8.4477 & 8.406 & TRN & & \\
\hline CHEMBL 3654074 & 1528909 & 10.2366 & 10.2711 & TRN & & \\
\hline CHEMBL 3654071 & 1528909 & 12.0 & 11.8323 & TST & & \\
\hline CHEMBL3654086 & 1528909 & 10.1675 & 10.0831 & TRN & & \\
\hline CHEMBL 3653984 & 1528909 & 9.644 & 9.4933 & TRN & & \\
\hline CHEMBL 3650567 & 1528909 & 8.2498 & 7.5212 & TRN & & \\
\hline CHEMBL 3654027 & 1528909 & 9.0915 & 9.2685 & TST & & \\
\hline CHEMBL 3654094 & 1528909 & 12.0 & 11.6199 & TRN & & \\
\hline CHEMBL 3654058 & 1528909 & 10.2676 & 10.0464 & TST & & \\
\hline CHEMBL 3653987 & 1528909 & 8.2516 & 8.484 & TRN & & \\
\hline CHEMBL 3654028 & 1528909 & 7.5462 & 7.8572 & TRN & & \\
\hline CHEMBL 3654155 & 1528909 & 9.8633 & 9.7195 & TST & & \\
\hline CHEMBL 3654005 & 1528909 & 10.1612 & 10.0449 & TRN & & \\
\hline CHEMBL 3654014 & 1528909 & 8.9404 & 9.1778 & TRN & & \\
\hline CHEMBL3650519 & 1528909 & 11.30099 & 99999999 & 998 & 10.8921 & TST \\
\hline CHEMBL 3653999 & 1528909 & 9.7055 & 9.5885 & TRN & & \\
\hline CHEMBL 3650585 & 1528909 & 8.1704 & 8.3054 & TRN & & \\
\hline CHEMBL 3650577 & 1528909 & 9.3686 & 9.3966 & TST & & \\
\hline CHEMBL 3650588 & 1528909 & 6.6685 & 6.9433 & TRN & & \\
\hline CHEMBL3654056 & 1528909 & 10.1135 & 10.2141 & TRN & & \\
\hline CHEMBL3654161 & 1528909 & 8.6704 & 9.2327 & TRN & & \\
\hline CHEMBL 3654140 & 1528909 & 9.9431 & 10.2566 & TST & & \\
\hline CHEMBL 3650655 & 1528909 & 10.4437 & 10.4402 & TRN & & \\
\hline CHEMBL 3650668 & 1528909 & 10.6198 & 10.5664 & TRN & & \\
\hline CHEMBL3653997 & 1528909 & 10.4089 & 10.4316 & TRN & & \\
\hline CHEMBL 3650614 & 1528909 & 9.7423 & 10.1467 & TRN & & \\
\hline
\end{tabular}

Page 15296 
Supplemental Table S2.txt

CHEMBL 3650610

CHEMBL 3654036

CHEMBL 3653977

CHEMBL3650549

CHEMBL3654132

CHEMBL 3650660

CHEMBL3654121

CHEMBL 3650558

CHEMBL 3650542

CHEMBL3654116

CHEMBL 3654171

CHEMBL 3654025

CHEMBL 3650504

CHEMBL3654152

CHEMBL 3654055

CHEMBL3654175

CHEMBL3654004

CHEMBL3650645

CHEMBL 3654150

CHEMBL3653996

CHEMBL3654011

CHEMBL 3654102

CHEMBL 3650599

CHEMBL3653989

CHEMBL3650516

CHEMBL3650499

CHEMBL3654010

CHEMBL3654105

CHEMBL 3650520

CHEMBL 3654003

CHEMBL 3650670

CHEMBL 3650552

CHEMBL 3650524

CHEMBL3653976

CHEMBL 3650546

CHEMBL3654097

CHEMBL3653974

CHEMBL 3650627

CHEMBL3653985

CHEMBL 3654012

CHEMBL3639529

CHEMBL3654154

CHEMBL3654046

CHEMBL 3654091

CHEMBL3654129

CHEMBL3654159

CHEMBL3650576

CHEMBL3650521
152890910.173910 .1686 TRN

$\begin{array}{lll}1528909 & 10.0915 & 10.2314 \text { TRN }\end{array}$

$\begin{array}{lll}1528909 & 9.426 & 9.6945\end{array}$ TST

$\begin{array}{llll}1528909 & 9.0931 & 9.2329 & \text { TRN }\end{array}$

$\begin{array}{llll}1528909 & 8.2727 & 8.0335 & \text { TRN }\end{array}$

$\begin{array}{llll}1528909 & 9.8097 & 9.7314 & \text { TRN }\end{array}$

$\begin{array}{lll}1528909 & 12.0 & 12.0212 \text { TRN }\end{array}$

$\begin{array}{llll}1528909 & 6.6207 & 6.7615 & \text { TRN }\end{array}$

$\begin{array}{llll}1528909 & 9.7282 & 9.7339 & \text { TRN }\end{array}$

$\begin{array}{lll}1528909 & 10.2076 & 10.7047\end{array}$

$\begin{array}{llll}1528909 & 9.279 & 9.2989 & \text { TRN }\end{array}$

152890910.167510 .0306 TRN

$\begin{array}{llll}1528909 & 7.8523 & 7.9859 & \text { TRN }\end{array}$

$\begin{array}{lll}1528909 & 10.7447 & 10.7509\end{array}$

$\begin{array}{llll}1528909 & 9.8962 & 9.9342 & \text { TRN }\end{array}$

$\begin{array}{lll}1528909 & 12.0 & 10.5848 \text { TST }\end{array}$

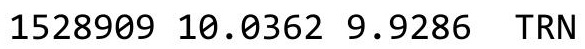

$\begin{array}{llll}1528909 & 9.3028 & 7.0359 & \text { TRN }\end{array}$

$\begin{array}{lll}1528909 & 12.0 & 12.0832\end{array}$

$\begin{array}{lll}1528909 & 10.0044 & 10.176\end{array}$

$\begin{array}{llll}1528909 & 9.7747 & 9.5999 & \text { TRN }\end{array}$

$\begin{array}{lll}1528909 & 10.3768 & 10.6925 \text { TRN }\end{array}$

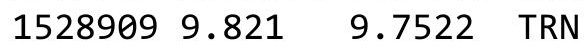

$\begin{array}{llll}1528909 & 8.12 & 8.1978 \text { TRN }\end{array}$

$\begin{array}{llll}1528909 & 8.1443 & 8.2376 & \text { TST }\end{array}$

$\begin{array}{llll}1528909 & 9.2321 & 9.1999 & \text { TRN }\end{array}$

152890910.292410 .1336 TRN

$\begin{array}{llll}1528909 & 9.4237 & 9.4958 & \text { TST }\end{array}$

$\begin{array}{lll}1528909 & 10.8861 & 10.8504\end{array}$

$\begin{array}{llll}1528909 & 9.8508 & 9.8088 & \text { TRN }\end{array}$

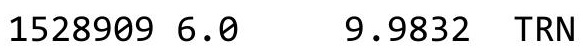

$\begin{array}{llll}1528909 & 7.6899 & 7.7141 & \text { TRN }\end{array}$

$\begin{array}{lll}1528909 & 10.5229 & 10.3892 \text { TRN }\end{array}$

$\begin{array}{llll}1528909 & 8.8735 & 9.0127 & \text { TST }\end{array}$

$\begin{array}{llll}1528909 & 9.3391 & 9.2955 & \text { TRN }\end{array}$

$\begin{array}{llll}1528909 & 10.2441 & 9.9671 & \text { TST }\end{array}$

$\begin{array}{lll}1528909 & 12.0 \quad 11.5587 \text { TRN }\end{array}$

$\begin{array}{llll}1528909 & 9.8962 & 9.9491 & \text { TRN }\end{array}$

$\begin{array}{llll}1528909 & 4.9226 & 5.2845 & \text { TST }\end{array}$

$\begin{array}{llll}1528909 & 9.1726 & 9.3859 & \text { TRN }\end{array}$

$\begin{array}{llll}1528909 & 9.1733 & 9.2812 & \text { TST }\end{array}$

$152890912.0 \quad 11.7506$ TRN

$\begin{array}{lll}1528909 & 10.4318 & 10.1835 \text { TRN }\end{array}$

$\begin{array}{llll}1528909 & 9.9706 & 9.7244 & \text { TST }\end{array}$

$\begin{array}{lll}1528909 & 12.0 \quad 11.6588 \text { TRN }\end{array}$

$\begin{array}{lll}1528909 & 10.4559 & 10.7949 \\ \text { TRN }\end{array}$

$\begin{array}{llll}1528909 & 6.2509 & 6.6592 & \text { TRN }\end{array}$

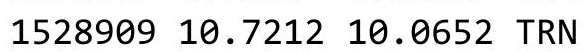




\begin{tabular}{|c|c|c|c|c|c|c|}
\hline \multicolumn{7}{|c|}{ Supplemental Table S2.txt } \\
\hline CHEMBL3653964 & 1528909 & 12.0 & 11.4313 & TRN & & \\
\hline CHEMBL3654147 & 1528909 & 12.0 & 12.1797 & TRN & & \\
\hline CHEMBL3650620 & 1528909 & 9.6517 & 9.8475 & TRN & & \\
\hline CHEMBL3650641 & 1528909 & 10.2518 & 9.9551 & TRN & & \\
\hline CHEMBL3650672 & 1528909 & 9.6576 & 9.7269 & TRN & & \\
\hline CHEMBL3650541 & 1528909 & 9.7352 & 9.6841 & TST & & \\
\hline CHEMBL3654069 & 1528909 & 9.7328 & 9.7516 & TRN & & \\
\hline CHEMBL3650526 & 1528909 & 10.4437 & 10.1294 & TRN & & \\
\hline CHEMBL3650639 & 1528909 & 10.3188 & 10.2398 & TRN & & \\
\hline CHEMBL3654142 & 1528909 & 8.2053 & 8.1862 & TST & & \\
\hline CHEMBL3654101 & 1528909 & 11.0458 & 11.02 & TST & & \\
\hline CHEMBL 3650543 & 1528909 & 9.6576 & 9.8451 & TRN & & \\
\hline CHEMBL3654006 & 1528909 & $8.76100 t$ & 0000000 & $\partial 1$ & 8.8998 & TRN \\
\hline CHEMBL 3650548 & 1528909 & 9.2277 & 9.3742 & TRN & & \\
\hline CHEMBL3650640 & 1528909 & 9.1637 & 9.2292 & TRN & & \\
\hline CHEMBL3654117 & 1528909 & 9.9586 & 10.2519 & TST & & \\
\hline CHEMBL3650517 & 1528909 & 10.6576 & 10.3813 & TRN & & \\
\hline CHEMBL3650487 & 1528909 & 7.5021 & 7.7215 & TRN & & \\
\hline CHEMBL3650647 & 1528909 & 10.1805 & 9.908 & TRN & & \\
\hline CHEMBL3654077 & 1528909 & 9.7033 & 9.7941 & TRN & & \\
\hline CHEMBL3653981 & 1528909 & 10.5686 & 10.3926 & TRN & & \\
\hline CHEMBL3654126 & 1528909 & 12.0 & 11.252 & TST & & \\
\hline CHEMBL3654059 & 1528909 & 7.2866 & 7.4417 & TRN & & \\
\hline CHEMBL3654099 & 1528909 & 10.7696 & 10.8055 & TRN & & \\
\hline CHEMBL3654137 & 1528909 & 7.7459 & 7.78799 & 9999999999 & & TRN \\
\hline CHEMBL3650603 & 1528909 & 9.9586 & 10.1828 & TRN & & \\
\hline CHEMBL3650513 & 1528909 & 10.1487 & 9.8098 & TRN & & \\
\hline CHEMBL3654068 & 1528909 & 9.8097 & 9.6853 & TST & & \\
\hline CHEMBL3654082 & 1528909 & 12.0 & 11.708 & TST & & \\
\hline CHEMBL3650657 & 1528909 & 9.9245 & 9.9298 & TRN & & \\
\hline CHEMBL3650494 & 1528909 & 9.1226 & 8.867 & TRN & & \\
\hline CHEMBL 3650563 & 1528909 & 7.5079 & 7.5566 & TRN & & \\
\hline CHEMBL3650604 & 1528909 & 10.4815 & 10.5175 & TRN & & \\
\hline CHEMBL3650612 & 1528909 & 9.6757 & 9.8543 & TRN & & \\
\hline CHEMBL3654038 & 1528909 & 10.7696 & 10.6052 & TRN & & \\
\hline CHEMBL3650540 & 1528909 & 9.8097 & 9.8554 & TST & & \\
\hline CHEMBL3654111 & 1528909 & 10.7959 & 10.7901 & TST & & \\
\hline CHEMBL3650581 & 1528909 & 7.1465 & 7.3972 & TRN & & \\
\hline CHEMBL3654153 & 1528909 & 10.1135 & 9.701 & TRN & & \\
\hline CHEMBL 3654023 & 1528909 & 9.5591 & 9.7084 & TRN & & \\
\hline CHEMBL 3650578 & 1528909 & 4.9226 & 5.3223 & TRN & & \\
\hline CHEMBL3653972 & 1528909 & 10.1308 & 9.9967 & TRN & & \\
\hline CHEMBL3650539 & 1528909 & 9.8327 & 9.7278 & TRN & & \\
\hline CHEMBL3654160 & 1528909 & 10.4089 & 10.4667 & TRN & & \\
\hline CHEMBL3654052 & 1528909 & 9.5638 & 9.5146 & TRN & & \\
\hline CHEMBL 3654148 & 1528909 & 12.0 & 11.8514 & TRN & & \\
\hline CHEMBL 3650590 & 1528909 & 9.6253 & 9.684 & TRN & & \\
\hline CHEMBL3650601 & 1528909 & 10.0915 & 10.0893 & TRN & & \\
\hline
\end{tabular}

Page 15298 
Supplemental Table S2.txt

CHEMBL3650613

CHEMBL 3650631

CHEMBL3654173

CHEMBL 3654045

CHEMBL 3650663

CHEMBL3654015

CHEMBL3654119

CHEMBL3650536

CHEMBL 3653983

CHEMBL 3654073

CHEMBL3654035

CHEMBL 3654095

CHEMBL3654113

CHEMBL 3650538

CHEMBL3654149

CHEMBL 3653968

CHEMBL3654144

CHEMBL 3650596

CHEMBL3650574

CHEMBL 3654108

CHEMBL3650651

CHEMBL 3650561

CHEMBL 3650489

CHEMBL3654032

CHEMBL 3654044

CHEMBL 3650650

CHEMBL 3654115

CHEMBL3654066

CHEMBL3650602

CHEMBL3654047

CHEMBL3654109

CHEMBL 3650615

CHEMBL3654166

CHEMBL3654048

CHEMBL3654090

CHEMBL3650501

CHEMBL3654128

CHEMBL 3654083

CHEMBL3650595

CHEMBL3654112

CHEMBL3650623

CHEMBL3650662

CHEMBL3650617

CHEMBL 3654158

CHEMBL3650622

CHEMBL 3650575

CHEMBL3650591

CHEMBL 3639494
$152890910.2596 \quad 10.1995$ TRN

$\begin{array}{llll}1528909 & 7.7307 & 8.0729 & \text { TRN }\end{array}$

$\begin{array}{llll}1528909 & 6.0 & 9.6129 & \text { TRN }\end{array}$

$\begin{array}{llll}1528909 & 7.1005 & 7.1034 & \text { TRN }\end{array}$

152890910.26769 .7073 TRN

152890910.300999999999998

152890910.823910 .9605 TRN

152890910.08629 .9306 TRN

$\begin{array}{llll}1528909 & 9.8962 & 9.7501 & \text { TRN }\end{array}$

$\begin{array}{llll}1528909 & 8.3415 & 8.5546 & \text { TRN }\end{array}$

$\begin{array}{llll}1528909 & 9.0287 & 8.8694 & \text { TRN }\end{array}$

$\begin{array}{lll}1528909 & 10.3098 & 10.3505 \\ \text { TRN }\end{array}$

$\begin{array}{llll}1528909 & 8.0192 & 7.6499 & \text { TRN }\end{array}$

$\begin{array}{lll}1528909 & 9.9747 & 10.1859 \text { TRN }\end{array}$

$\begin{array}{lll}1528909 & 12.0 & 11.9723 \text { TST }\end{array}$

$\begin{array}{lll}1528909 & 10.0757 & 10.0867 \text { TRN }\end{array}$

$\begin{array}{lll}1528909 & 12.0 & 11.4346 \text { TRN }\end{array}$

$\begin{array}{lll}1528909 & 10.3768 & 10.3159\end{array}$

$\begin{array}{llll}1528909 & 8.5902 & 8.5623 & \text { TRN }\end{array}$

$\begin{array}{lll}1528909 & 12.0 & 11.6764 \text { TRN }\end{array}$

$\begin{array}{lll}1528909 & 10.3372 & 10.3546 \text { TRN }\end{array}$

$\begin{array}{llll}1528909 & 7.0007 & 6.654 & \text { TRN }\end{array}$

$\begin{array}{llll}1528909 & 8.6066 & 8.5459 & \text { TST }\end{array}$

$\begin{array}{llll}1528909 & 8.7194 & 8.0474 & \text { TRN }\end{array}$

$\begin{array}{llll}1528909 & 7.7642 & 7.7394 & \text { TRN }\end{array}$

$\begin{array}{lll}1528909 & 10.4318 & 10.3742 \text { TRN }\end{array}$

$\begin{array}{llll}1528909 & 9.752 & 9.8482 & \text { TRN }\end{array}$

$\begin{array}{lll}1528909 & 10.3979 & 10.3965\end{array}$

$\begin{array}{lll}1528909 & 13.0 & 12.2215 \text { TRN }\end{array}$

$\begin{array}{llll}1528909 & 8.4974 & 8.6347 & \text { TRN }\end{array}$

$\begin{array}{llll}1528909 & 8.5462 & 9.2537 & \text { TRN }\end{array}$

$\begin{array}{lll}1528909 & 10.1675 & 10.1125 \text { TRN }\end{array}$

$\begin{array}{llll}1528909 & 9.1637 & 9.7611 & \text { TST }\end{array}$

$\begin{array}{lll}1528909 & 9.8827 & 10.0867 \\ 1 R N\end{array}$

$\begin{array}{lll}1528909 & 10.4685 & 10.1508 \text { TRN }\end{array}$

$\begin{array}{llll}1528909 & 8.6043 & 8.5392 & \text { TRN }\end{array}$

$\begin{array}{lll}1528909 & 12.0 & 11.7004\end{array}$

$\begin{array}{llll}1528909 & 9.7375 & 9.6329 & \text { TST }\end{array}$

$\begin{array}{lll}1528909 & 10.4437 & 10.3932 \\ \text { TRN }\end{array}$

$\begin{array}{llll}1528909 & 9.9431 & 9.773 & \text { TST }\end{array}$

$\begin{array}{lll}1528909 & 10.2757 & 10.2051 \text { TRN }\end{array}$

152890910.455910 .4769 TRN

152890910.677810 .7406 TRN

152890910.086210 .2813 TST

$\begin{array}{lll}1528909 & 10.1487 & 10.1479\end{array}$

$\begin{array}{llll}1528909 & 7.7739 & 7.4754 & \text { TRN }\end{array}$

$\begin{array}{lll}1528909 & 10.4089 & 10.2938\end{array}$

$\begin{array}{llll}1528909 & 9.8069 & 9.951 & \text { TRN }\end{array}$
10.0458 TRN 
Supplemental Table S2.txt

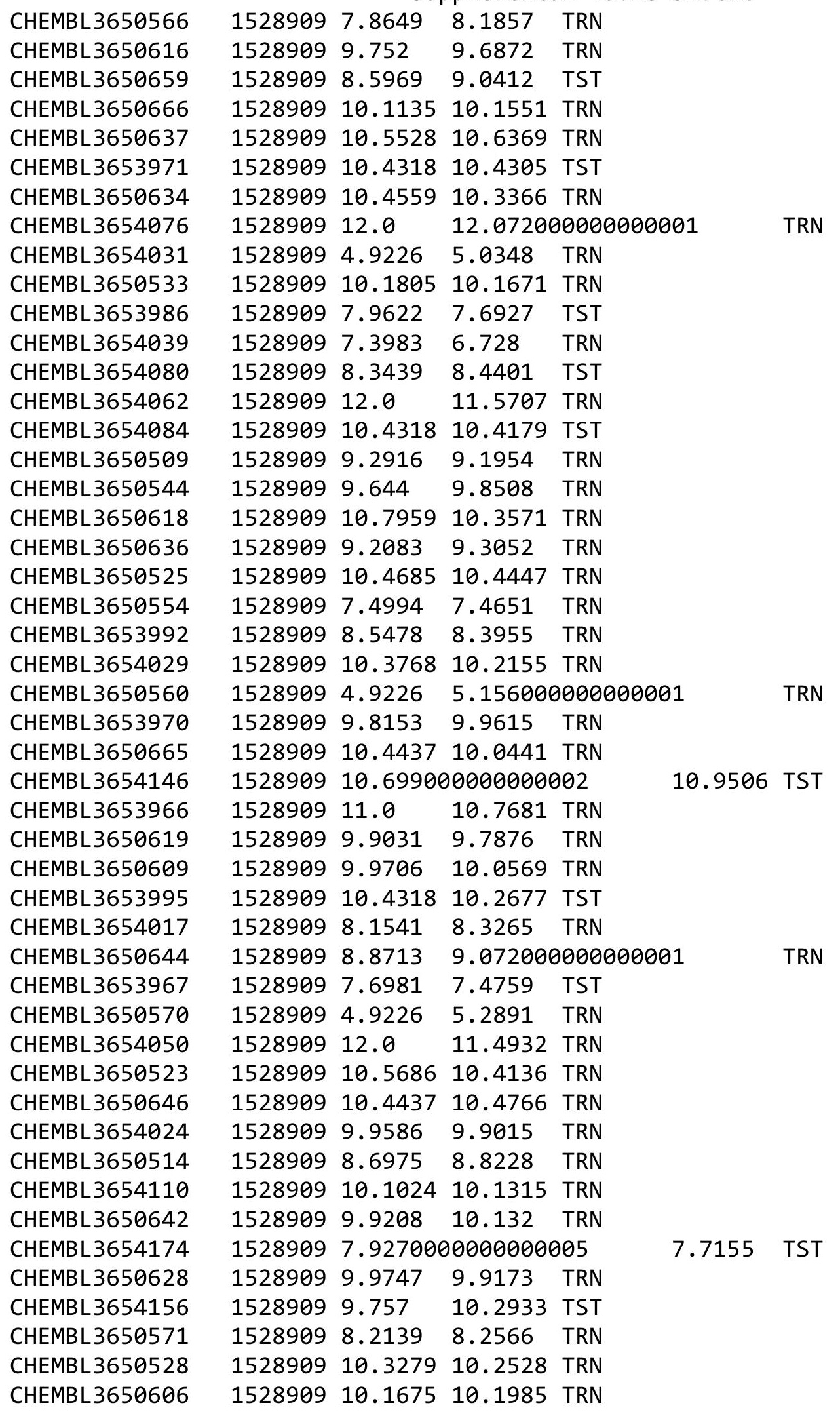

Page 15300 
Supplemental Table S2.txt

\begin{tabular}{|c|c|c|c|c|c|c|c|}
\hline CHEMBL3650551 & 1528909 & 8.0838 & 8.3301 & TRN & & & \\
\hline CHEMBL3650648 & 1528909 & 9.2604 & 9.3479 & TRN & & & \\
\hline CHEMBL 3650535 & 1528909 & 10.1135 & 9.9276 & TST & & & \\
\hline CHEMBL 3650529 & 1528909 & 10.3009 & 999999999 & 998 & 10.2072 & TRN & \\
\hline CHEMBL3654078 & 1528909 & 10.5528 & 10.7215 & TRN & & & \\
\hline CHEMBL3654123 & 1528909 & 8.3419 & 8.9729 & TRN & & & \\
\hline CHEMBL3639493 & 1528909 & 8.2535 & 8.1425 & TRN & & & \\
\hline CHEMBL 3654041 & 1528909 & 8.1221 & 7.2073 & TRN & & & \\
\hline CHEMBL 3654026 & 1528909 & 9.4401 & 9.0281 & TRN & & & \\
\hline CHEMBL3650667 & 1528909 & 9.2581 & 9.4264 & TRN & & & \\
\hline CHEMBL3650583 & 1528909 & 6.1742 & 6.4647 & TRN & & & \\
\hline CHEMBL 3654098 & 1528909 & 9.4145 & 9.3533 & TRN & & & \\
\hline CHEMBL 3650625 & 1528909 & 10.2441 & 10.485 & TRN & & & \\
\hline CHEMBL 3650568 & 1528909 & 8.2788 & 8.301 & TRN & & & \\
\hline CHEMBL3650565 & 1528909 & 4.9226 & 5.2534 & TRN & & & \\
\hline CHEMBL3650500 & 1528909 & 8.5173 & 8.9109 & TRN & & & \\
\hline CHEMBL3653975 & 1528909 & 10.6990 & 000000000 & $\partial 02$ & 10.8540 & 00000000001 & TRN \\
\hline CHEMBL 3650605 & 1528909 & 10.1249 & 10.1848 & TRN & & & \\
\hline CHEMBL3653982 & 1528909 & 7.82799 & 799999999 & 99 & 7.7373 & TST & \\
\hline CHEMBL3653993 & 1528909 & 7.4324 & 7.3245 & TST & & & \\
\hline CHEMBL3654107 & 1528909 & 10.7212 & 10.6086 & TRN & & & \\
\hline CHEMBL3650669 & 1528909 & 10.1938 & 10.2584 & TRN & & & \\
\hline CHEMBL3654018 & 1528909 & 9.9788 & 9.6043 & TST & & & \\
\hline CHEMBL3650492 & 1528909 & 8.5864 & 8.1838 & TRN & & & \\
\hline CHEMBL 3654088 & 1528909 & 12.0 & 11.7312 & TRN & & & \\
\hline CHEMBL3650527 & 1528909 & 10.3279 & 10.2775 & TRN & & & \\
\hline CHEMBL3650491 & 1528909 & 9.104 & 9.0708 & TRN & & & \\
\hline CHEMBL3650531 & 1528909 & 10.2076 & 10.162 & TRN & & & \\
\hline CHEMBL3654079 & 1528909 & 10.5376 & 10.5628 & TST & & & \\
\hline CHEMBL 3650654 & 1528909 & 9.757 & 9.906 & TRN & & & \\
\hline CHEMBL 3650510 & 1528909 & 8.6552 & 8.9019 & TRN & & & \\
\hline CHEMBL3650512 & 1528909 & 9.0443 & 9.0525 & TRN & & & \\
\hline CHEMBL3653969 & 1528909 & 10.1249 & 10.0827 & TRN & & & \\
\hline CHEMBL3654130 & 1528909 & 7.8245 & 6.6513 & TRN & & & \\
\hline CHEMBL 3654030 & 1528909 & 9.3288 & 9.7944 & TRN & & & \\
\hline CHEMBL 3654075 & 1528909 & 9.6882 & 9.7895 & TRN & & & \\
\hline CHEMBL3650530 & 1528909 & 10.2757 & 10.1732 & TRN & & & \\
\hline CHEMBL3654081 & 1528909 & 8.4579 & 8.8702 & TST & & & \\
\hline CHEMBL3650608 & 1528909 & 10.1938 & 10.0062 & TRN & & & \\
\hline CHEMBL 3650488 & 1528909 & 9.0825 & 8.8913 & TST & & & \\
\hline CHEMBL3654022 & 1528909 & 9.7305 & 9.4088 & TRN & & & \\
\hline CHEMBL3654008 & 1528909 & 10.1871 & 9.9271 & TRN & & & \\
\hline CHEMBL3650556 & 1528909 & 6.7226 & 6.697999 & 99999 & 995 & TRN & \\
\hline CHEMBL3650626 & 1528909 & 10.3979 & 10.2529 & TRN & & & \\
\hline CHEMBL 3654157 & 1528909 & 12.0 & 11.4252 & TST & & & \\
\hline CHEMBL3654000 & 1528909 & 9.9066 & 9.7912 & TRN & & & \\
\hline CHEMBL 3653973 & 1528909 & 9.5834 & 9.4312 & TRN & & & \\
\hline CHEMBL3650553 & 1528909 & 7.5003 & 7.3805 & TRN & & & \\
\hline
\end{tabular}

Page 15301 


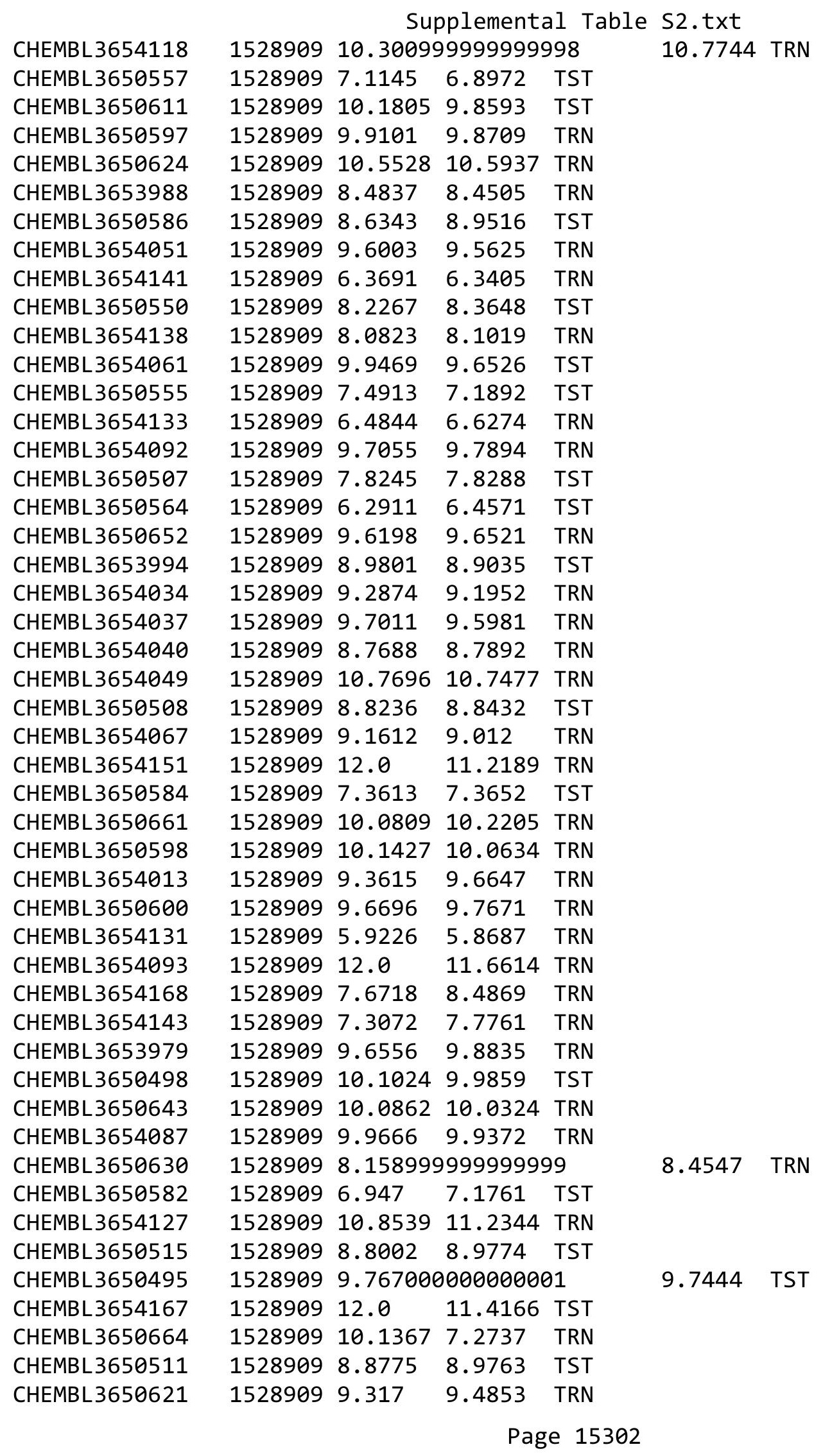


Supplemental Table S2.txt

\begin{tabular}{|c|c|c|c|c|c|c|}
\hline CHEMBL3653965 & 1528909 & 9.6126 & 9.6183 & TRN & & \\
\hline CHEMBL3653991 & 1528909 & 8.9646 & 8.8474 & TST & & \\
\hline CHEMBL 3650572 & 1528909 & 7.9735 & 7.8599 & TST & & \\
\hline CHEMBL 3650649 & 1528909 & 10.7212 & 10.5936 & TRN & & \\
\hline CHEMBL3650547 & 1528909 & 9.28399 & 999999999 & 99 & 9.6285 & TRN \\
\hline CHEMBL 3653980 & 1528909 & 8.5296 & 8.7005 & TST & & \\
\hline CHEMBL 3654072 & 1528909 & 8.5095 & 8.5727 & TST & & \\
\hline CHEMBL 3639528 & 1528909 & 10.0915 & 10.1577 & TRN & & \\
\hline CHEMBL 3653978 & 1528909 & 10.5086 & 10.2589 & TRN & & \\
\hline CHEMBL3654065 & 1528909 & 9.2807 & 9.2798 & TST & & \\
\hline CHEMBL 3654070 & 1528909 & 9.2749 & 9.2396 & TST & & \\
\hline CHEMBL 3654124 & 1528909 & 8.2181 & 9.0029 & TRN & & \\
\hline CHEMBL 3650486 & 1528909 & 8.0781 & 8.0438 & TST & & \\
\hline CHEMBL 3650656 & 1528909 & 9.9508 & 10.0291 & TRN & & \\
\hline CHEMBL 3654019 & 1528909 & 10.0132 & 10.1739 & TST & & \\
\hline CHEMBL 3650532 & 1528909 & 10.2076 & 10.0559 & TRN & & \\
\hline CHEMBL3650573 & 1528909 & 4.9226 & 5.6486 & TST & & \\
\hline CHEMBL 3654060 & 1528909 & 7.8645 & 8.0477 & TST & & \\
\hline CHEMBL 3653998 & 1528909 & 10.1487 & 9.9599 & TRN & & \\
\hline CHEMBL 3650658 & 1528909 & 9.7645 & 9.8189 & TRN & & \\
\hline CHEMBL3654103 & 1528909 & $11.3009 \mathrm{~s}$ & 999999999 & 998 & 11.3724 & TRN \\
\hline CHEMBL3650635 & 1528909 & 9.1427 & 9.4764 & TRN & & \\
\hline CHEMBL3654136 & 1528909 & 12.0 & 11.8739 & TRN & & \\
\hline CHEMBL 3650562 & 1528909 & 6.8276 & 6.8416 & TST & & \\
\hline CHEMBL 3650632 & 1528909 & 10.9208 & 10.5275 & TRN & & \\
\hline CHEMBL 3654009 & 1528909 & 10.4089 & 10.0628 & TRN & & \\
\hline CHEMBL 3650503 & 1528909 & 8.4018 & 8.4 & TST & & \\
\hline CHEMBL 3654172 & 1528909 & 6.0 & 10.2224 & TRN & & \\
\hline CHEMBL 3654145 & 1528909 & 12.0 & 12.0813 & TRN & & \\
\hline CHEMBL 3650537 & 1528909 & 10.0458 & 9.8786 & TRN & & \\
\hline CHEMBL 3650545 & 1528909 & 9.3585 & 9.4365 & TRN & & \\
\hline CHEMBL 3654164 & 1528909 & 9.0241 & 9.1057 & TST & & \\
\hline CHEMBL 3650493 & 1528909 & 8.4621 & 8.3228 & TST & & \\
\hline CHEMBL 3654106 & 1528909 & 8.4226 & 9.0785 & TRN & & \\
\hline CHEMBL 3654135 & 1528909 & 8.634 & 8.8457 & TRN & & \\
\hline CHEMBL3654089 & 1528909 & 9.6234 & 9.5452 & TRN & & \\
\hline CHEMBL3654169 & 1528909 & 9.1427 & 9.124 & TST & & \\
\hline CHEMBL3650633 & 1528909 & 10.2076 & 10.1144 & TRN & & \\
\hline CHEMBL 3650496 & 1528909 & 9.4802 & 9.3278 & TST & & \\
\hline CHEMBL3650629 & 1528909 & 9.1198 & 9.4074 & TRN & & \\
\hline CHEMBL3650580 & 1528909 & 9.0182 & 8.6821 & TST & & \\
\hline CHEMBL3650592 & 1528909 & 7.7585 & 7.9974 & TST & & \\
\hline CHEMBL3650490 & 1528909 & 9.1273 & 9.1304 & TST & & \\
\hline CHEMBL3654033 & 1528909 & 8.9066 & 8.6032 & TRN & & \\
\hline CHEMBL3981584 & 1638896 & 6.0 & 6.6831 & TST & & \\
\hline CHEMBL3956652 & 1638896 & 8.0 & 8.4656 & TST & & \\
\hline CHEMBL 3914322 & 1638896 & 6.0 & 6.0013 & TRN & & \\
\hline CHEMBL3968968 & 1638896 & 7.0 & 6.9963 & TRN & & \\
\hline
\end{tabular}




\begin{tabular}{|c|c|c|c|c|}
\hline & & & ient & $a \perp 1 a$ \\
\hline CHEMBL 3928197 & 1638896 & 8.0 & 7.496 & TRN \\
\hline CHEMBL3972249 & 1638896 & 7.0 & 6.9369 & TRN \\
\hline CHEMBL3929290 & 1638896 & 6.0 & 6.0069 & TRN \\
\hline CHEMBL605976 & 1638896 & 4.0 & 6.8435 & TST \\
\hline CHEMBL3905089 & 1638896 & 8.0 & 7.9919 & TRN \\
\hline CHEMBL3932057 & 1638896 & 6.0 & 6.0043 & TRN \\
\hline CHEMBL3916600 & 1638896 & 7.0 & 7.0297 & TRN \\
\hline CHEMBL3891395 & 1638896 & 6.0 & 5.9991 & TRN \\
\hline CHEMBL 3920254 & 1638896 & 6.0 & 7.7107 & TST \\
\hline CHEMBL3921652 & 1638896 & 7.0 & 6.9998 & TRN \\
\hline CHEMBL3903506 & 1638896 & 7.0 & 7.0049 & TRN \\
\hline CHEMBL3898480 & 1638896 & 7.0 & 6.9987 & TRN \\
\hline CHEMBL598377 & 1638896 & 7.0 & 8.2378 & TST \\
\hline CHEMBL3938265 & 1638896 & 7.0 & 7.0297 & TRN \\
\hline CHEMBL3973966 & 1638896 & 7.0 & 7.5003 & TRN \\
\hline CHEMBL3977186 & 1638896 & 7.0 & 6.989 & TRN \\
\hline CHEMBL3963327 & 1638896 & 7.0 & 7.0026 & TRN \\
\hline CHEMBL3971412 & 1638896 & 8.0 & 7.9978 & TRN \\
\hline CHEMBL596761 & 1638896 & 6.0 & 6.8498 & TST \\
\hline CHEMBL3940740 & 1638896 & 8.0 & 8.4209 & TST \\
\hline CHEMBL 3984573 & 1638896 & 7.0 & 7.0013 & TRN \\
\hline CHEMBL3949983 & 1638896 & 8.0 & 7.9875 & TRN \\
\hline CHEMBL3986286 & 1638896 & 7.0 & 7.496 & TRN \\
\hline CHEMBL 3984477 & 1638896 & 7.0 & 7.0026 & TRN \\
\hline CHEMBL3917093 & 1638896 & 6.0 & 5.9991 & TRN \\
\hline CHEMBL 3984522 & 1638896 & 8.0 & 8.0185 & TRN \\
\hline CHEMBL3899385 & 1638896 & 7.0 & 7.0323 & TRN \\
\hline CHEMBL3971713 & 1638896 & 4.0 & 3.9956 & TRN \\
\hline CHEMBL3917105 & 1638896 & 7.0 & 6.9884 & TRN \\
\hline CHEMBL 3951620 & 1638896 & 8.0 & 6.9997 & TRN \\
\hline CHEMBL3912102 & 1638896 & 8.0 & 8.3273 & TST \\
\hline CHEMBL3956995 & 1638896 & 8.0 & 7.9847 & TRN \\
\hline CHEMBL3900967 & 1638896 & 6.0 & 5.9854 & TRN \\
\hline CHEMBL 3980861 & 1638896 & 8.0 & 8.2799 & TST \\
\hline CHEMBL3950023 & 1638896 & 7.0 & 7.0042 & TRN \\
\hline CHEMBL3947208 & 1638896 & 8.0 & 6.6661 & TST \\
\hline CHEMBL3934468 & 1638896 & 8.0 & 7.5003 & TRN \\
\hline CHEMBL3946124 & 1638896 & 8.0 & 7.9793 & TST \\
\hline CHEMBL 3968341 & 1638896 & 8.0 & 7.3475 & TST \\
\hline CHEMBL3936547 & 1638896 & 7.0 & 6.9987 & TRN \\
\hline CHEMBL3901236 & 1638896 & 7.0 & 6.9987 & TRN \\
\hline CHEMBL3917670 & 1638896 & 7.0 & 6.9998 & TRN \\
\hline CHEMBL3952709 & 1638896 & 7.0 & 6.9884 & TRN \\
\hline CHEMBL3939306 & 1638896 & 7.0 & 7.0016 & TRN \\
\hline CHEMBL3924346 & 1638896 & 7.0 & 7.0018 & TRN \\
\hline CHEMBL 3945421 & 1638896 & 7.0 & 7.005 & TRN \\
\hline CHEMBL3907491 & 1638896 & 7.0 & 7.0062 & TRN \\
\hline CHEMBL3943406 & 1638896 & 8.0 & 8.4656 & TST \\
\hline
\end{tabular}




\begin{tabular}{|c|c|c|c|c|c|c|}
\hline \multicolumn{7}{|c|}{ Supplemental Ia } \\
\hline CHEMBL3984055 & 1638896 & 7.0 & 6.9993 & TRN & & \\
\hline CHEMBL3937516 & 1638896 & 6.0 & 7.7107 & TST & & \\
\hline CHEMBL3905131 & 1638896 & 7.0 & 7.0016 & TRN & & \\
\hline CHEMBL3961102 & 1638896 & 7.0 & 7.0067 & TRN & & \\
\hline CHEMBL3909619 & 1638896 & 8.0 & 8.4656 & TST & & \\
\hline CHEMBL3948072 & 1638896 & 8.0 & 8.0045 & TRN & & \\
\hline CHEMBL3985004 & 1638896 & 6.0 & 6.0069 & TRN & & \\
\hline CHEMBL3902161 & 1638896 & 6.0 & 6.9997 & TRN & & \\
\hline CHEMBL3970784 & 1640162 & 7.7275 & 7.1943 & TRN & & \\
\hline CHEMBL3980414 & 1640162 & 5.6671 & 5.1559 & TRN & & \\
\hline CHEMBL3936876 & 1640162 & 4.6945 & 5.2005 & TRN & & \\
\hline CHEMBL3985693 & 1640162 & 6.3624 & 6.9411 & TRN & & \\
\hline CHEMBL3890649 & 1640162 & 5.5179 & 6.3275 & TRN & & \\
\hline CHEMBL3916782 & 1640162 & 7.0844 & 7.3727 & TRN & & \\
\hline CHEMBL3933016 & 1640162 & 6.2381 & 6.4387 & TRN & & \\
\hline CHEMBL 3889584 & 1640162 & 7.6119 & 6.1014 & TRN & & \\
\hline CHEMBL3895370 & 1640162 & 7.0195 & 6.3362 & TRN & & \\
\hline CHEMBL3896847 & 1640162 & 7.6633 & 7.144 & TRN & & \\
\hline CHEMBL3909490 & 1640162 & 7.2688 & 7.5744 & TRN & & \\
\hline CHEMBL3961450 & 1640162 & 7.2027 & 7.5988 & TRN & & \\
\hline CHEMBL 252124 & 1640162 & 8.4609 & 6.7975 & TST & & \\
\hline CHEMBL 3898024 & 1640162 & 7.9578 & 6.1549 & TST & & \\
\hline CHEMBL3906698 & 1640162 & 8.225 & 7.8133 & TRN & & \\
\hline CHEMBL3908022 & 1640162 & 7.6269 & 7.6228 & TRN & & \\
\hline CHEMBL365617 & 1640162 & 7.9706 & 6.9455 & TST & & \\
\hline CHEMBL 3943099 & 1640162 & 9.1421 & 7.6028 & TRN & & \\
\hline CHEMBL3916268 & 1640162 & 5.3744 & 6.1628 & TRN & & \\
\hline CHEMBL3902028 & 1640162 & 6.01399 & 99999999 & 99 & 7.4971 & TRN \\
\hline CHEMBL 3982842 & 1640162 & 6.6271 & 6.2665 & TST & & \\
\hline CHEMBL3902156 & 1640162 & 7.654 & 7.5511 & TRN & & \\
\hline CHEMBL3929986 & 1640162 & 6.2963 & 5.7852 & TST & & \\
\hline CHEMBL3943106 & 1640162 & 7.0625 & 7.2921 & TRN & & \\
\hline CHEMBL3951501 & 1640162 & 7.1467 & 8.1012 & TRN & & \\
\hline CHEMBL192894 & 1640162 & 6.0449 & 6.6004 & TST & & \\
\hline CHEMBL3979513 & 1640162 & 7.6227 & 5.7681 & TST & & \\
\hline CHEMBL3899246 & 1640162 & 7.9205 & 7.6303 & TRN & & \\
\hline CHEMBL3920953 & 1640162 & 8.4206 & 8.1241 & TRN & & \\
\hline CHEMBL3934788 & 1640162 & 8.2922 & 7.7305 & TRN & & \\
\hline CHEMBL3906699 & 1640162 & 8.2626 & 8.0193 & TRN & & \\
\hline CHEMBL3899564 & 1640162 & 7.4083 & 7.4824 & TRN & & \\
\hline CHEMBL 3898029 & 1640162 & 7.5751 & 6.5114 & TRN & & \\
\hline CHEMBL3969362 & 1640162 & 5.9068 & 6.9276 & TRN & & \\
\hline CHEMBL3903964 & 1640162 & 8.0102 & 7.6944 & TRN & & \\
\hline CHEMBL 3940468 & 1640162 & 7.8431 & 6.6921 & TRN & & \\
\hline CHEMBL3933681 & 1640162 & 5.5487 & 6.1264 & TST & & \\
\hline CHEMBL 3973430 & 1640162 & 6.7093 & 7.3391 & TRN & & \\
\hline CHEMBL3970310 & 1640162 & 6.2892 & 6.4725 & TRN & & \\
\hline CHEMBL3907641 & 1640162 & 8.4194 & 7.9838 & TRN & & \\
\hline
\end{tabular}




\begin{tabular}{|c|c|c|c|c|c|c|}
\hline \multicolumn{7}{|c|}{ Supplemental Table S2.txt } \\
\hline CHEMBL398346 & 1640162 & 10.0 & 6.9625 & TST & & \\
\hline CHEMBL 3981957 & 1640162 & 6.0003 & 5.3926 & TST & & \\
\hline CHEMBL3901758 & 1640162 & 8.3386 & 7.8238 & TRN & & \\
\hline CHEMBL 3899438 & 1640162 & 7.45799 & 99999999 & 99 & 7.9892 & TRN \\
\hline CHEMBL 3931927 & 1640162 & 5.1783 & 5.8292 & TST & & \\
\hline CHEMBL 2042870 & 1640162 & 6.23600 & 00000000 & 01 & 7.0268 & TRN \\
\hline CHEMBL 3889463 & 1640162 & 8.4477 & 7.8581 & TRN & & \\
\hline CHEMBL 3892221 & 1640162 & 8.0756 & 7.831 & TRN & & \\
\hline CHEMBL3966607 & 1640162 & 7.7545 & 7.7205 & TRN & & \\
\hline CHEMBL 3911424 & 1640162 & 8.521 & 7.8927 & TRN & & \\
\hline CHEMBL 3944325 & 1640162 & 8.4697 & 7.7282 & TRN & & \\
\hline CHEMBL 3945793 & 1640162 & 7.82299 & 99999999 & 995 & 7.7126 & TRN \\
\hline CHEMBL3973782 & 1640162 & 6.1322 & 5.9527 & TST & & \\
\hline CHEMBL 3897124 & 1640162 & 7.0939 & 7.5198 & TRN & & \\
\hline CHEMBL 3954162 & 1640162 & 7.4613 & 7.9739 & TRN & & \\
\hline CHEMBL 3983469 & 1640162 & 5.3164 & 6.434 & TST & & \\
\hline CHEMBL 2042857 & 1640162 & 5.8103 & 6.3948 & TRN & & \\
\hline CHEMBL3962733 & 1640162 & 7.4835 & 6.2417 & TST & & \\
\hline CHEMBL 3899839 & 1640162 & 6.7896 & 7.6248 & TRN & & \\
\hline CHEMBL 3942566 & 1640162 & 8.2359 & 7.6003 & TRN & & \\
\hline CHEMBL 3914091 & 1640162 & 7.2545 & 7.9285 & TRN & & \\
\hline CHEMBL 3966503 & 1640162 & 6.3143 & 7.1838 & TRN & & \\
\hline CHEMBL3964633 & 1640162 & 7.01399 & 99999999 & 99 & 5.4523 & TST \\
\hline CHEMBL3900791 & 1640162 & 10.0 & 7.3298 & TST & & \\
\hline CHEMBL 200102 & 1640162 & 8.118 & 7.1732 & TST & & \\
\hline CHEMBL 3961448 & 1637168 & 9.301 & 8.0241 & TRN & & \\
\hline CHEMBL 3924073 & 1637168 & 6.0 & 8.7167 & TRN & & \\
\hline CHEMBL3910626 & 1637168 & 7.301 & 9.2603 & TRN & & \\
\hline CHEMBL 3892627 & 1637168 & 7.301 & 9.0062 & TST & & \\
\hline CHEMBL3900594 & 1637168 & 11.3009 & 99999999 & 998 & 10.4371 & TRN \\
\hline CHEMBL 3907543 & 1637168 & 10.3009 & 99999999 & 998 & 9.6127 & TST \\
\hline CHEMBL3926299 & 1637168 & 10.3009 & 99999999 & 998 & 7.9175 & TRN \\
\hline CHEMBL 3984513 & 1637168 & 10.3009 & 99999999 & 998 & 8.0731 & TST \\
\hline CHEMBL 3940245 & 1637168 & 10.3009 & 99999999 & 998 & 8.2398 & TST \\
\hline CHEMBL3922629 & 1637168 & 6.0 & 8.8183 & TST & & \\
\hline CHEMBL3987097 & 1637168 & 6.0 & 9.0563 & TRN & & \\
\hline CHEMBL3951270 & 1637168 & 9.7959 & 8.7723 & TRN & & \\
\hline CHEMBL 3941697 & 1637168 & 9.301 & 8.5201 & TST & & \\
\hline CHEMBL3895901 & 1637168 & 10.3009 & 99999999 & 998 & 8.2901 & TRN \\
\hline CHEMBL3905492 & 1637168 & 11.3009 & 99999999 & 998 & 7.9821 & TRN \\
\hline CHEMBL 3900230 & 1637168 & 9.301 & 8.4385 & TRN & & \\
\hline CHEMBL3937414 & 1637168 & 7.301 & 9.2159 & TST & & \\
\hline CHEMBL 3917386 & 1637168 & 9.301 & 8.5433 & TST & & \\
\hline CHEMBL3905703 & 1637168 & 11.3009 & 99999999 & 998 & 7.9393 & TRN \\
\hline CHEMBL3935123 & 1637168 & 9.301 & 8.8949 & TRN & & \\
\hline CHEMBL 3926349 & 1637168 & 6.0 & 7.6846 & TRN & & \\
\hline CHEMBL3949785 & 1637168 & 6.0 & 7.8265 & TRN & & \\
\hline CHEMBL3949905 & 1637168 & 7.301 & 9.3936 & TST & & \\
\hline
\end{tabular}


Supplemental Table S2.txt

\begin{tabular}{|c|c|c|c|c|c|c|}
\hline CHEMBL 3947022 & 1637168 & 7.301 & 9.9459 & TST & & \\
\hline CHEMBL 3902406 & 1637168 & \multicolumn{3}{|c|}{ 10.300999999999998 } & 8.9594 & TRN \\
\hline CHEMBL 3891967 & 1637168 & \multicolumn{3}{|c|}{11.300999999999998} & 9.4135 & \\
\hline CHEMBL 3953314 & 1637168 & 7.301 & 7.3195 & TRN & & \\
\hline CHEMBL 3964817 & 1637168 & 6.0 & 8.2269 & TRN & & \\
\hline CHEMBL 3977589 & 1637168 & 9.301 & 9.0549 & TRN & & \\
\hline CHEMBL3897106 & 1637168 & 6.0 & 8.3423 & TRN & & \\
\hline CHEMBL3894084 & 1637168 & \multicolumn{3}{|c|}{10.300999999999998} & 8.0762 & \\
\hline CHEMBL 3889474 & 1637168 & \multicolumn{3}{|c|}{11.300999999999998} & 12.5719 & \\
\hline CHEMBL3933952 & 1637168 & 6.0 & 8.5217 & TRN & & \\
\hline CHEMBL 3980948 & 1637168 & 9.301 & 9.3296 & TST & & \\
\hline CHEMBL 3923850 & 1637168 & 6.0 & 8.713 & TRN & & \\
\hline CHEMBL 3943755 & 1637168 & \multicolumn{3}{|c|}{10.300999999999998} & 9.4694 & \\
\hline CHEMBL 3968024 & 1637168 & \multicolumn{3}{|c|}{10.300999999999998} & 8.1488 & \\
\hline CHEMBL 3930528 & 1637168 & \multicolumn{3}{|c|}{10.300999999999998} & 9.1225 & \\
\hline CHEMBL 3957713 & 1637168 & \multicolumn{3}{|c|}{10.300999999999998} & 8.2836 & \\
\hline CHEMBL 3980445 & 1637168 & 7.301 & 7.9486 & TRN & & \\
\hline CHEMBL 3944030 & 1637168 & 7.301 & 7.3669 & TRN & & \\
\hline CHEMBL 3895822 & 1637168 & \multicolumn{3}{|c|}{10.300999999999998} & 8.4167 & \\
\hline CHEMBL 3986508 & 1637168 & 9.301 & 8.5179 & TRN & & \\
\hline CHEMBL 3897236 & 1637168 & 6.0 & 7.6622 & TRN & & \\
\hline CHEMBL 3929478 & 1637168 & 6.0 & 8.1498 & TST & & \\
\hline CHEMBL 3971247 & 1637168 & 6.0 & 7.4033 & TRN & & \\
\hline CHEMBL3926935 & 1637168 & 9.301 & 9.5698 & TRN & & \\
\hline CHEMBL 3894716 & 1637168 & 6.0 & 8.7186 & TRN & & \\
\hline CHEMBL 3967100 & 1637168 & \multicolumn{3}{|c|}{10.300999999999998} & 8.7149 & TRN \\
\hline CHEMBL 3986043 & 1637168 & 6.0 & 6.5249 & TRN & & \\
\hline CHEMBL 3910977 & 1637168 & 6.0 & 6.6628 & TRN & & \\
\hline CHEMBL3940511 & 1637168 & 6.0 & 8.6985 & TST & & \\
\hline CHEMBL 3891354 & 1637168 & 6.0 & \multicolumn{3}{|c|}{8.863999999999999} & IKIV \\
\hline CHEMBL 3892489 & 1637168 & \multicolumn{3}{|c|}{11.300999999999998} & 9.647 & ThN \\
\hline CHEMBL 3894218 & 1637168 & 9.301 & 8.6841 & TST & & \\
\hline CHEMBL 3955110 & 1637168 & 9.301 & 8.7727 & TRN & & \\
\hline CHEMBL 3898672 & 1637168 & 9.301 & 8.7618 & TRN & & \\
\hline CHEMBL 3927322 & 1637168 & 6.0 & 7.1254 & TRN & & \\
\hline CHEMBL3942853 & 1637168 & \multicolumn{3}{|c|}{10.300999999999998} & 8.39 & TRN \\
\hline CHEMBL3939915 & 1637168 & \multicolumn{3}{|c|}{11.300999999999998} & 11.1284 & TR \\
\hline CHEMBL3969600 & 1637168 & 9.301 & 9.3957 & TRN & & \\
\hline CHEMBL 3962124 & 1637168 & 9.301 & 8.8853 & TRN & & \\
\hline CHEMBL 3933983 & 1637168 & 7.301 & 9.1101 & TRN & & \\
\hline CHEMBL3987033 & 1637168 & \multicolumn{3}{|c|}{10.300999999999998} & 9.0505 & Thiv \\
\hline CHEMBL3970705 & 1637168 & \multicolumn{3}{|c|}{ 10. 300999999999998} & 7.7222 & $1 \mathrm{NI}$ \\
\hline CHEMBL 3961112 & 1637168 & 6.0 & 8.632 & TRN & & \\
\hline CHEMBL 3894404 & 1637168 & 7.301 & 8.3739 & TRN & & \\
\hline CHEMBL 3917838 & 1637168 & 9.301 & 8.4813 & TRN & & \\
\hline CHEMBL 3941485 & 1637168 & 7.301 & 10.4092 & TST & & \\
\hline CHEMBL3921214 & 1637168 & 6.0 & 8.0871 & TRN & & \\
\hline CHEMBL 3908034 & 1637168 & 9.301 & 7.9885 & TRN & & \\
\hline
\end{tabular}




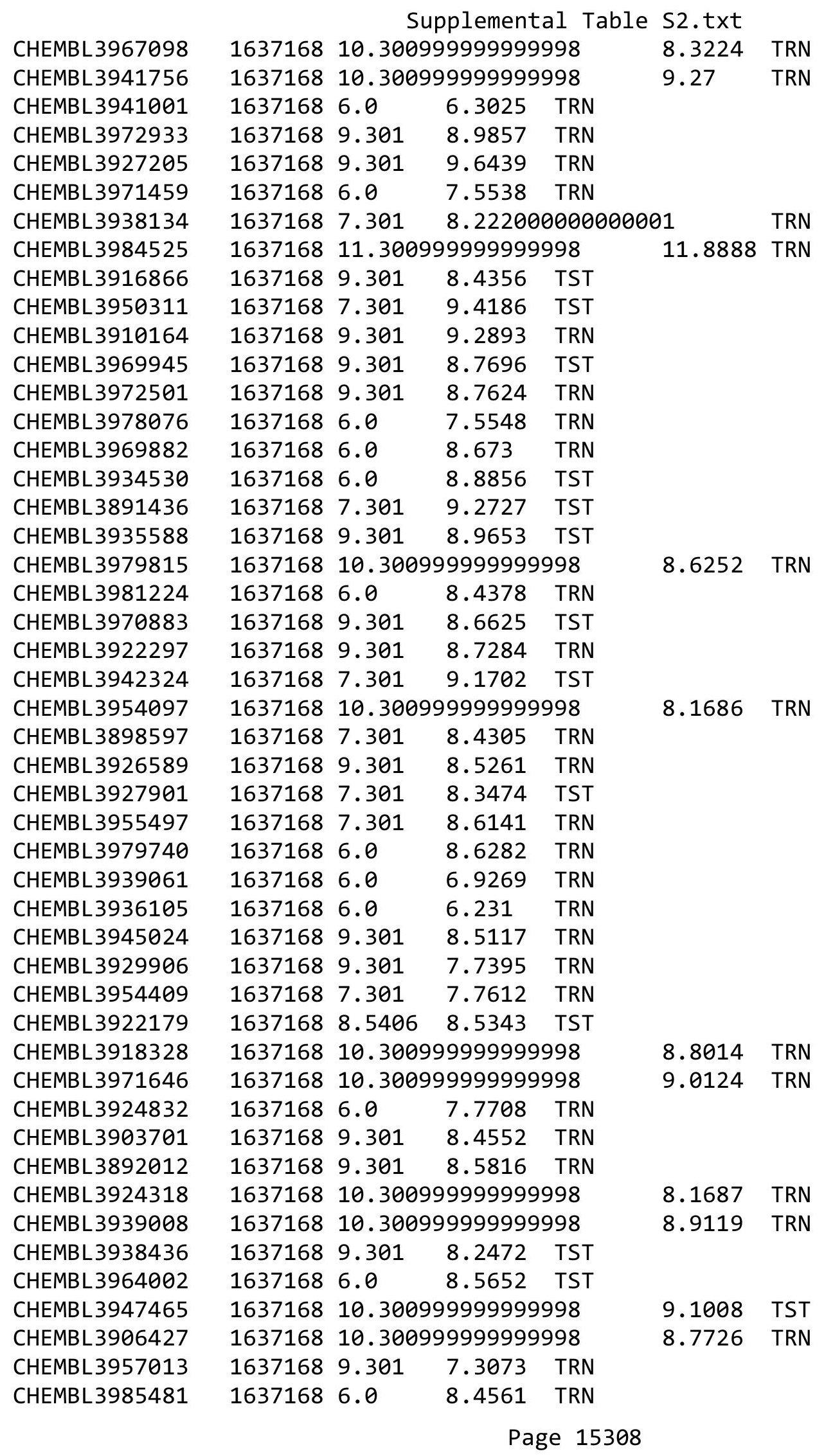




\begin{tabular}{|c|c|c|c|c|c|c|}
\hline \multicolumn{7}{|c|}{ Supplemental Table S2.txt } \\
\hline CHEMBL3960138 & 1637168 & 6.0 & 8.4017 & TST & & \\
\hline CHEMBL3982194 & 1637168 & 9.301 & 8.8394 & TRN & & \\
\hline CHEMBL3952260 & 1637168 & 7.301 & 8.2334 & TRN & & \\
\hline CHEMBL3901430 & 1637168 & 9.301 & 8.6833 & TRN & & \\
\hline CHEMBL3920863 & 1637168 & 6.0 & 7.7941 & TRN & & \\
\hline CHEMBL3926787 & 1637168 & 10.3009 & 99999999 & 998 & 8.7555 & TRN \\
\hline CHEMBL3918159 & 1637168 & 6.0 & 7.2684 & TRN & & \\
\hline CHEMBL3905765 & 1637168 & 10.3009 & 99999999 & 998 & 6.9431 & TRN \\
\hline CHEMBL3907353 & 1637168 & 10.3009 & 99999999 & 998 & 8.0178 & TST \\
\hline CHEMBL3965400 & 1637168 & 10.3009 & 99999999 & 998 & 8.1617 & TRN \\
\hline CHEMBL3901636 & 1637168 & 9.301 & 8.9534 & TRN & & \\
\hline CHEMBL3931604 & 1637168 & 6.0 & 6.2726 & TRN & & \\
\hline CHEMBL3910952 & 1637168 & 9.301 & 8.4325 & TRN & & \\
\hline CHEMBL3941503 & 1637168 & 9.301 & 7.8265 & TRN & & \\
\hline CHEMBL3984711 & 1637168 & 7.301 & 9.3405 & TRN & & \\
\hline CHEMBL3944842 & 1637168 & 10.3009 & 999999995 & 998 & 9.0021 & TRN \\
\hline CHEMBL3908601 & 1637168 & 9.301 & 9.6291 & TRN & & \\
\hline CHEMBL3932423 & 1637168 & 7.301 & 9.3521 & TRN & & \\
\hline CHEMBL3915065 & 1637168 & 6.0 & 8.3695 & TST & & \\
\hline CHEMBL3947411 & 1637168 & 6.0 & 8.2787 & TRN & & \\
\hline CHEMBL3964055 & 1637168 & 6.0 & 7.6403 & TRN & & \\
\hline CHEMBL3969165 & 1637168 & 6.0 & 8.4195 & TST & & \\
\hline CHEMBL3958752 & 1637168 & 7.301 & 8.4176 & TRN & & \\
\hline CHEMBL3910269 & 1637168 & 6.0 & 6.5792 & TRN & & \\
\hline CHEMBL3896496 & 1637168 & 10.3009 & 999999995 & 998 & 9.2107 & TRN \\
\hline CHEMBL3895985 & 1637168 & 6.0 & 8.8417 & TST & & \\
\hline CHEMBL3961775 & 1637168 & 9.301 & 8.9932 & TRN & & \\
\hline CHEMBL3902160 & 1637168 & 6.0 & 8.4516 & TST & & \\
\hline CHEMBL 3932346 & 1637168 & 6.0 & 7.5477 & TRN & & \\
\hline CHEMBL3952397 & 1637168 & 9.301 & 8.3958 & TST & & \\
\hline CHEMBL3915059 & 1637168 & 9.301 & 8.7284 & TST & & \\
\hline CHEMBL3932884 & 1637168 & 7.301 & 10.6918 & TST & & \\
\hline CHEMBL3963265 & 1637168 & 6.0 & 8.0805 & TST & & \\
\hline CHEMBL1469700 & 752529 & 5.399 & 5.7789 & TRN & & \\
\hline CHEMBL1593484 & 752529 & 5.7011 & 5.0257 & TST & & \\
\hline CHEMBL1882945 & 752529 & 4.9978 & 6.9502 & TRN & & \\
\hline CHEMBL1517599 & 752529 & 5.0453 & 5.785 & TST & & \\
\hline CHEMBL1885748 & 752529 & 7.5157 & 7.0027 & TRN & & \\
\hline CHEMBL1409795 & 752529 & 4.7719 & 5.2137 & TRN & & \\
\hline CHEMBL1585059 & 752529 & 5.3143 & 5.7392 & TRN & & \\
\hline CHEMBL1868723 & 752529 & 4.8044 & 5.6863 & TRN & & \\
\hline CHEMBL1713143 & 752529 & 5.9508 & 5.5138 & TRN & & \\
\hline CHEMBL1459203 & 752529 & 5.4935 & 5.8226 & TST & & \\
\hline CHEMBL1318100 & 752529 & 5.4157 & 5.0412 & TRN & & \\
\hline CHEMBL1496823 & 752529 & 4.7891 & 4.9726 & TRN & & \\
\hline CHEMBL1885536 & 752529 & 5.6904 & 6.3946 & TRN & & \\
\hline CHEMBL1476499 & 752529 & 7.9281 & 8.4101 & TRN & & \\
\hline CHEMBL1444580 & 752529 & 6.0691 & 5.2266 & TRN & & \\
\hline
\end{tabular}


Supplemental Table S2.txt

\begin{tabular}{|c|c|c|c|c|}
\hline CHEMBL1574284 & 752529 & 5.6308 & 6.0144 & TRN \\
\hline CHEMBL1459532 & 752529 & 4.7426 & 5.3038 & TRN \\
\hline CHEMBL1729475 & 752529 & 5.6655 & 5.2503 & TRN \\
\hline CHEMBL1734733 & 752529 & 7.9957 & 8.2162 & TRN \\
\hline CHEMBL1431692 & 752529 & 4.8159 & 4.5944 & TRN \\
\hline CHEMBL1473855 & 752529 & 7.5072 & 7.6249 & TRN \\
\hline CHEMBL1898197 & 752529 & 9.71 & 7.1128 & TRN \\
\hline CHEMBL1300063 & 752529 & 6.644 & 5.9842 & TRN \\
\hline CHEMBL1438167 & 752529 & 4.7228 & 5.2357 & TST \\
\hline CHEMBL544348 & 752529 & 4.7481 & 6.1761 & TST \\
\hline CHEMBL1592223 & 752529 & 9.71 & 8.65299 & 999999999 \\
\hline CHEMBL1490818 & 752529 & 5.857 & 5.3882 & TRN \\
\hline CHEMBL1730926 & 752529 & 4.7934 & 5.2162 & TRN \\
\hline CHEMBL1300894 & 752529 & 5.2076 & 4.8685 & TRN \\
\hline CHEMBL1379295 & 752529 & 5.7696 & 5.2157 & TST \\
\hline CHEMBL1726145 & 752529 & 5.8962 & 5.8113 & TRN \\
\hline CHEMBL1569188 & 752529 & 5.1113 & 5.3001 & TRN \\
\hline CHEMBL1568554 & 752529 & 5.064 & 6.0591 & TRN \\
\hline CHEMBL1568183 & 752529 & 5.0716 & 5.186 & TST \\
\hline CHEMBL1583398 & 752529 & 5.2628 & 5.9166 & TRN \\
\hline CHEMBL1352471 & 752529 & 5.6498 & 5.5053 & TRN \\
\hline CHEMBL1326359 & 752529 & 5.1267 & 4.9348 & TRN \\
\hline CHEMBL1555880 & 752529 & 5.0367 & 5.2682 & TRN \\
\hline CHEMBL1704879 & 752529 & 5.6517 & 8.5128 & TRN \\
\hline CHEMBL1591577 & 752529 & 9.71 & 8.6848 & TRN \\
\hline CHEMBL1465247 & 752529 & 4.9935 & 5.0145 & TRN \\
\hline CHEMBL1300394 & 752529 & 5.0146 & 4.3752 & TRN \\
\hline CHEMBL1439045 & 752529 & 4.8611 & 5.1662 & TRN \\
\hline CHEMBL1399528 & 752529 & 6.3872 & 7.5145 & TRN \\
\hline CHEMBL1354134 & 752529 & 8.4425 & 8.2026 & TRN \\
\hline CHEMBL1429141 & 752529 & 5.6108 & 5.70799 & 999999999 \\
\hline CHEMBL1702086 & 752529 & 8.5031 & 8.4364 & TRN \\
\hline CHEMBL1877990 & 752529 & 8.1018 & 6.8187 & TRN \\
\hline CHEMBL1556197 & 752529 & 4.6749 & 5.0609 & TRN \\
\hline CHEMBL1583267 & 752529 & 5.3152 & 5.6406 & TRN \\
\hline CHEMBL1553151 & 752529 & 5.4001 & 5.9894 & TRN \\
\hline CHEMBL1444520 & 752529 & 5.8069 & 5.4779 & TRN \\
\hline CHEMBL1444643 & 752529 & 6.7212 & 6.3883 & TST \\
\hline CHEMBL1724009 & 752529 & 4.9219 & 5.5228 & TRN \\
\hline CHEMBL1448157 & 752529 & 5.0297 & 5.7722 & TST \\
\hline CHEMBL1574454 & 752529 & 6.2062 & 7.4833 & TRN \\
\hline CHEMBL1522508 & 752529 & 5.4045 & 5.8595 & TRN \\
\hline CHEMBL1901314 & 752529 & 8.1568 & 6.3029 & TRN \\
\hline CHEMBL1703897 & 752529 & 4.9927 & 5.9492 & TST \\
\hline CHEMBL1508872 & 752529 & 6.3363 & 6.0573 & TRN \\
\hline CHEMBL1364071 & 752529 & 5.9706 & 5.1516 & TRN \\
\hline CHEMBL1440473 & 752529 & 6.4647 & 6.3152 & TRN \\
\hline CHEMBL1356135 & 752529 & 6.5768 & 7.018 & TRN \\
\hline
\end{tabular}




\begin{tabular}{|c|c|c|c|c|c|c|}
\hline & & \multicolumn{5}{|c|}{ Supplemental Table s2.txt } \\
\hline CHEMBL244857 & 752529 & 4.7368 & 5.2092 & TRN & & \\
\hline CHEMBL1433465 & 752529 & 5.8327 & 7.2057 & TRN & & \\
\hline CHEMBL1467876 & 752529 & 5.2596 & 5.5935 & TRN & & \\
\hline CHEMBL1329994 & 752529 & 5.1475 & 6.2776 & TST & & \\
\hline CHEMBL566722 & 752529 & 7.4949 & 7.9989 & TRN & & \\
\hline CHEMBL1452607 & 752529 & 5.4547 & 5.3329 & TRN & & \\
\hline CHEMBL1515144 & 752529 & 9.71 & 8.5211 & TRN & & \\
\hline CHEMBL1462031 & 752529 & 4.684 & 5.8316 & TST & & \\
\hline CHEMBL1383996 & 752529 & 6.3675 & 5.2986 & TRN & & \\
\hline CHEMBL1611561 & 752529 & 5.2798 & 5.862 & TST & & \\
\hline CHEMBL1899256 & 752529 & 8.3098 & 7.1249 & TRN & & \\
\hline CHEMBL1884711 & 752529 & 6.4145 & 6.2211 & TRN & & \\
\hline CHEMBL1473127 & 752529 & 7.6459 & 8.406 & TRN & & \\
\hline CHEMBL1450567 & 752529 & 5.7352 & 5.954 & TRN & & \\
\hline CHEMBL1357975 & 752529 & 9.71 & 8.4207 & TRN & & \\
\hline CHEMBL1415374 & 752529 & 5.0794 & 6.2054 & TRN & & \\
\hline CHEMBL1899640 & 752529 & 4.8011 & 6.1492 & TRN & & \\
\hline CHEMBL1533622 & 752529 & 5.1475 & 5.6311 & TRN & & \\
\hline CHEMBL1492963 & 752529 & 4.6424 & 5.1156 & TRN & & \\
\hline CHEMBL1573237 & 752529 & 9.71 & 8.45 & TRN & & \\
\hline CHEMBL1481419 & 752529 & 4.8677 & 5.685 & TST & & \\
\hline CHEMBL1556418 & 752529 & 5.0768 & 6.0462 & TRN & & \\
\hline CHEMBL1373964 & 752529 & 4.6649 & 4.8282 & TRN & & \\
\hline CHEMBL1560197 & 752529 & 5.2832 & 5.5091 & TRN & & \\
\hline CHEMBL1610597 & 752529 & 6.7959 & 7.6144 & TRN & & \\
\hline CHEMBL1302093 & 752529 & 5.1831 & 5.2826 & TRN & & \\
\hline CHEMBL1603038 & 752529 & 5.6925 & 5.3444 & TRN & & \\
\hline CHEMBL1312163 & 752529 & 5.3883 & 5.7947 & TRN & & \\
\hline CHEMBL1476609 & 752529 & 7.7932 & 7.6188 & TRN & & \\
\hline CHEMBL1584610 & 752529 & 4.7324 & 4.8414 & TRN & & \\
\hline CHEMBL1545657 & 752529 & 6.1681 & 5.0185 & TRN & & \\
\hline CHEMBL1504891 & 752529 & 5.76200 & 30000000 & 005 & 5.2581 & TRN \\
\hline CHEMBL1540329 & 752529 & 4.9226 & 4.7116 & TRN & & \\
\hline CHEMBL1396483 & 752529 & 9.71 & 8.6885 & TRN & & \\
\hline CHEMBL1894742 & 752529 & 7.1226 & 6.0623 & TRN & & \\
\hline CHEMBL1902528 & 752529 & 7.3958 & 6.1042 & TRN & & \\
\hline CHEMBL1570470 & 752529 & 5.2336 & 5.2272 & TRN & & \\
\hline CHEMBL1411489 & 752529 & 5.3737 & 5.5748 & TRN & & \\
\hline CHEMBL1542509 & 752529 & 4.7886 & 5.8621 & TST & & \\
\hline CHEMBL1474834 & 752529 & 9.71 & 8.5458 & TRN & & \\
\hline CHEMBL1439919 & 752529 & 5.6402 & 4.9031 & TST & & \\
\hline CHEMBL1565963 & 752529 & 5.644 & 5.0619 & TRN & & \\
\hline CHEMBL1395713 & 752529 & 4.6745 & 5.45200 & 0000000001 & & TRN \\
\hline CHEMBL1892019 & 752529 & 8.1694 & 6.4251 & TRN & & \\
\hline CHEMBL1467824 & 752529 & 4.7312 & 5.8223 & TRN & & \\
\hline CHEMBL1410859 & 752529 & 8.0092 & 7.7555 & TRN & & \\
\hline CHEMBL1529610 & 752529 & 5.224 & 5.2425 & TRN & & \\
\hline CHEMBL1607471 & 752529 & 6.32700 & 30000000 & & 6.0519 & TRN \\
\hline & & & & 1531 & & \\
\hline
\end{tabular}




\begin{tabular}{|c|c|c|c|c|c|c|}
\hline & & \multicolumn{5}{|c|}{ Supplemental Table S2.txt } \\
\hline CHEMBL1357429 & 752529 & 5.284 & 7.1068 & TRN & & \\
\hline CHEMBL1390796 & 752529 & 5.4123 & 5.4592 & TRN & & \\
\hline CHEMBL1396654 & 752529 & 8.0026 & 8.2339 & TRN & & \\
\hline CHEMBL1360400 & 752529 & 5.6345 & 5.5187 & TRN & & \\
\hline CHEMBL1564636 & 752529 & 4.9983 & 5.3579 & TST & & \\
\hline CHEMBL1383750 & 752529 & 4.6533 & 4.3468 & TRN & & \\
\hline CHEMBL1579512 & 752529 & 6.3979 & 5.7989 & TST & & \\
\hline CHEMBL1301607 & 752529 & 4.9838 & 4.7753 & TST & & \\
\hline CHEMBL1896205 & 752529 & 4.8184 & 5.2089 & TRN & & \\
\hline CHEMBL1435534 & 752529 & 9.71 & 8.5035 & TRN & & \\
\hline CHEMBL567331 & 752529 & 7.767 & 8.44 & TRN & & \\
\hline CHEMBL408982 & 752529 & 8.1255 & 5.5865 & TST & & \\
\hline CHEMBL1341362 & 752529 & \multicolumn{3}{|c|}{5.172000000000001} & 5.915 & TST \\
\hline CHEMBL566701 & 752529 & 6.8041 & 7.9361 & TRN & & \\
\hline CHEMBL1368493 & 752529 & 4.7291 & 4.9407 & TRN & & \\
\hline CHEMBL1898211 & 752529 & 8.1057 & 6.5362 & TRN & & \\
\hline CHEMBL1555138 & 752529 & 7.2441 & 7.8009 & TRN & & \\
\hline CHEMBL1612677 & 752529 & 7.8601 & 7.9614 & TRN & & \\
\hline CHEMBL1552755 & 752529 & 7.9469 & 8.235 & TRN & & \\
\hline CHEMBL1875932 & 752529 & 5.2636 & 5.8789 & TRN & & \\
\hline CHEMBL269881 & 752529 & 5.767 & 6.1084 & TST & & \\
\hline CHEMBL1565736 & 752529 & 5.8697 & 5.185 & TRN & & \\
\hline CHEMBL1350041 & 752529 & 5.4672 & 4.9084 & TRN & & \\
\hline CHEMBL1450635 & 752529 & 6.4271 & 5.9149 & TRN & & \\
\hline CHEMBL1717028 & 752529 & 4.9859 & 5.309 & TRN & & \\
\hline CHEMBL1872011 & 752529 & 5.6968 & 6.182 & TST & & \\
\hline CHEMBL1904905 & 752529 & 7.6861 & 6.9376 & TST & & \\
\hline CHEMBL1901114 & 752529 & 6.9355 & 5.7636 & TST & & \\
\hline CHEMBL1576388 & 752529 & 4.8139 & 5.2906 & TST & & \\
\hline CHEMBL1440984 & 752529 & 6.1739 & 5.3348 & TST & & \\
\hline CHEMBL1492194 & 752529 & 6.2373 & 5.5348 & TST & & \\
\hline CHEMBL1608304 & 752529 & 5.4609 & 5.2467 & TST & & \\
\hline CHEMBL1718690 & 752529 & 4.7708 & 5.1128 & TST & & \\
\hline CHEMBL1611317 & 752529 & 5.7799 & 6.3202 & TST & & \\
\hline CHEMBL1604973 & 752529 & \multicolumn{3}{|c|}{5.2620000000000005} & 5.5301 & TST \\
\hline CHEMBL1313936 & 752529 & 5.4473 & 5.5104 & TST & & \\
\hline CHEMBL1435542 & 752529 & \multicolumn{3}{|c|}{7.4510000000000005} & 8.2927 & TST \\
\hline CHEMBL1611201 & 752529 & \multicolumn{3}{|c|}{6.1579999999999995} & 7.5339 & TST \\
\hline CHEMBL1450534 & 752529 & 5.5918 & 5.3493 & TST & & \\
\hline CHEMBL1569442 & 752529 & 5.5017 & 6.6073 & TST & & \\
\hline CHEMBL1489830 & 752529 & 4.7036 & 5.5091 & TST & & \\
\hline CHEMBL566197 & 596837 & 8.6383 & 8.496 & TRN & & \\
\hline CHEMBL584484 & 596837 & 5.3932 & 5.3517 & TRN & & \\
\hline CHEMBL566014 & 596837 & 4.4577 & 7.0885 & TST & & \\
\hline CHEMBL566211 & 596837 & 7.0088 & 6.6672 & TRN & & \\
\hline CHEMBL566221 & 596837 & 8.5229 & 8.36 & TRN & & \\
\hline CHEMBL567266 & 596837 & 7.8356 & 7.981 & TRN & & \\
\hline CHEMBL565791 & 596837 & 7.8601 & 8.0858 & TRN & & \\
\hline
\end{tabular}




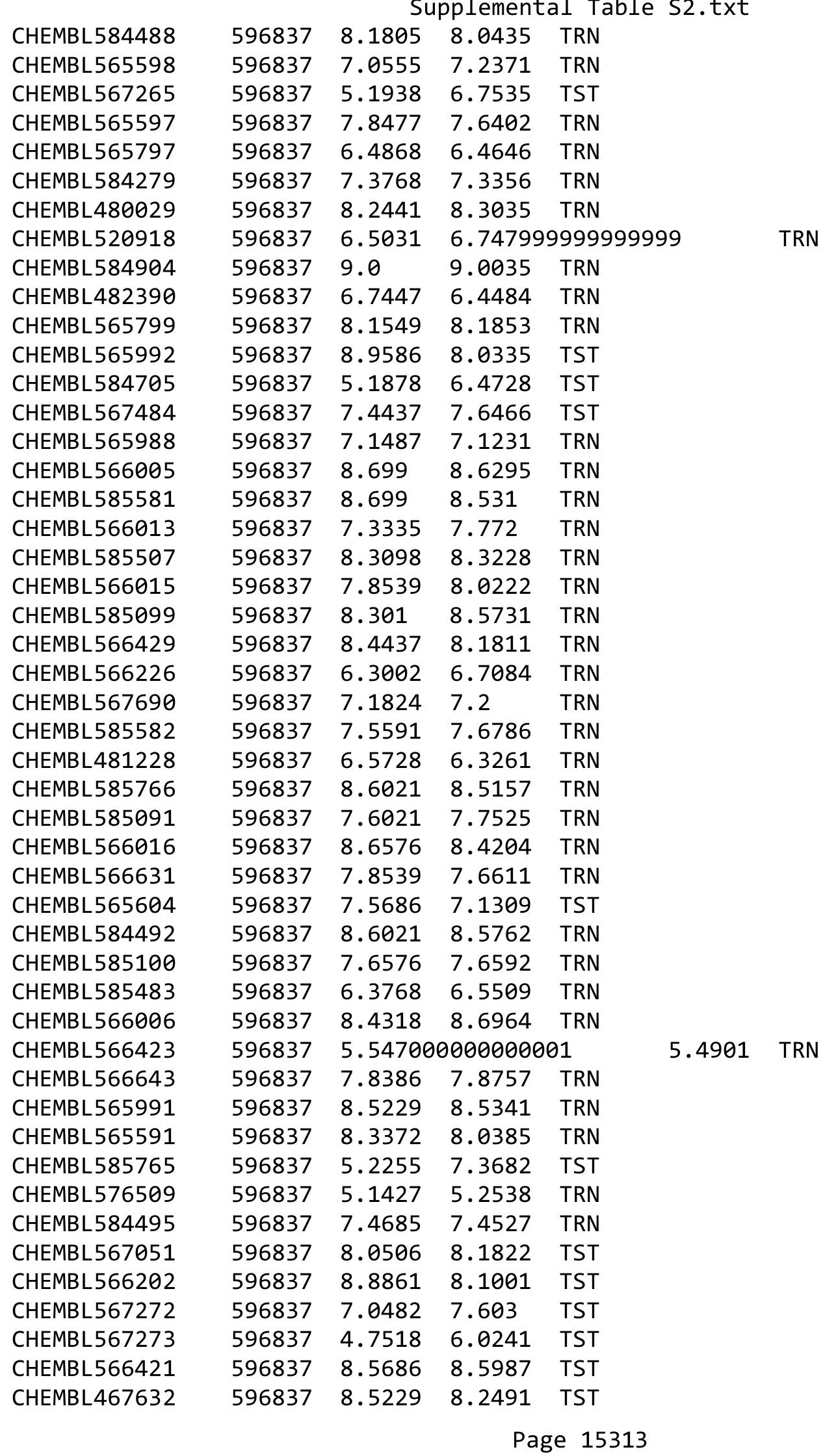




\begin{tabular}{|c|c|c|c|c|c|}
\hline \multicolumn{6}{|c|}{ Supplemental } \\
\hline CHEMBL567905 & 596837 & 8.6198 & 8.4336 & TST & \\
\hline CHEMBL565384 & 596837 & 4.9961 & 6.2455 & TST & \\
\hline CHEMBL62345 & 71198 & 8.4559 & 7.2773 & TRN & \\
\hline CHEMBL 3144541 & 71198 & 4.5229 & 6.435 & TRN & \\
\hline CHEMBL3144539 & 71198 & 7.5229 & 7.5319 & TRN & \\
\hline CHEMBL292471 & 71198 & 7.699 & $6.86600 t$ & 00000000005 & TST \\
\hline CHEMBL3144548 & 71198 & 7.7696 & 7.8725 & TRN & \\
\hline CHEMBL3144550 & 71198 & 7.3372 & 7.6629 & TRN & \\
\hline CHEMBL 294542 & 71198 & 7.5376 & 7.4642 & TRN & \\
\hline CHEMBL64605 & 71198 & 5.585 & 6.6983 & TST & \\
\hline CHEMBL3144552 & 71198 & 7.2596 & 7.4305 & TRN & \\
\hline CHEMBL3144533 & 71198 & 6.7696 & 6.1067 & TRN & \\
\hline CHEMBL413768 & 71198 & 8.6198 & 7.4128 & TST & \\
\hline CHEMBL387073 & 71198 & 8.5376 & 8.206 & TRN & \\
\hline CHEMBL 278447 & 71198 & 8.4559 & 7.0604 & TST & \\
\hline CHEMBL3144536 & 71198 & 8.4089 & 7.6664 & TRN & \\
\hline CHEMBL418123 & 71198 & 7.4089 & 7.034 & TST & \\
\hline CHEMBL 292519 & 71198 & 8.3979 & 6.9792 & TST & \\
\hline CHEMBL3144542 & 71198 & 7.8539 & 7.7235 & TRN & \\
\hline CHEMBL292071 & 71198 & 7.5528 & 7.9994 & TRN & \\
\hline CHEMBL418500 & 71198 & 7.2076 & 6.8621 & TST & \\
\hline CHEMBL3144553 & 71198 & 7.7959 & 7.5642 & TRN & \\
\hline CHEMBL3144563 & 71198 & 7.284 & 7.6426 & TRN & \\
\hline CHEMBL303994 & 71198 & 7.4949 & 6.6007 & TRN & \\
\hline CHEMBL 3144540 & 71198 & 7.1308 & 6.4228 & TRN & \\
\hline CHEMBL 3144555 & 71198 & 7.1024 & 7.5504 & TRN & \\
\hline CHEMBL3144566 & 71198 & 7.0088 & 6.4627 & TRN & \\
\hline CHEMBL60385 & 71198 & 8.0655 & 7.9294 & TRN & \\
\hline CHEMBL 292298 & 71198 & 8.6383 & 7.0463 & TST & \\
\hline CHEMBL 292490 & 71198 & 7.699 & 7.2809 & TRN & \\
\hline CHEMBL 3144531 & 71198 & 6.0706 & 6.1206 & TRN & \\
\hline CHEMBL3144545 & 71198 & 4.5229 & 6.0077 & TRN & \\
\hline CHEMBL3144537 & 71198 & 7.2291 & 7.6289 & TRN & \\
\hline CHEMBL3144544 & 71198 & 6.6198 & 6.152 & TRN & \\
\hline CHEMBL 3144567 & 71198 & 7.0362 & 6.171 & TRN & \\
\hline CHEMBL156559 & 71198 & 9.4089 & 7.0445 & TST & \\
\hline CHEMBL3144561 & 71198 & 7.7696 & 7.7605 & TRN & \\
\hline CHEMBL433640 & 71198 & 8.5229 & 8.0363 & TRN & \\
\hline CHEMBL3144554 & 71198 & 7.699 & 7.8842 & TRN & \\
\hline CHEMBL 3144562 & 71198 & 7.4202 & 7.5807 & TRN & \\
\hline CHEMBL59759 & 71198 & 4.5229 & 6.1573 & TRN & \\
\hline CHEMBL3144551 & 71198 & 7.3468 & 7.6743 & TRN & \\
\hline CHEMBL413548 & 71198 & 7.4202 & 7.6694 & TRN & \\
\hline CHEMBL3144565 & 71198 & 7.6021 & 7.88700 & 00000000005 & TRN \\
\hline CHEMBL 3144534 & 71198 & 6.7959 & 6.3899 & TRN & \\
\hline CHEMBL 293026 & 71198 & 7.1675 & 6.982 & TST & \\
\hline CHEMBL3144535 & 71198 & 7.1612 & 6.644 & TRN & \\
\hline CHEMBL302911 & 71198 & 7.7959 & 7.1694 & TST & \\
\hline
\end{tabular}


Supplemental Table S2.txt

\begin{tabular}{|c|c|c|c|c|}
\hline CHEMBL3144538 & 71198 & 6.6778 & 7.3753 & TRN \\
\hline CHEMBL 3144546 & 71198 & 6.3468 & 6.0977 & TRN \\
\hline CHEMBL 3144564 & 71198 & 8.1427 & 7.90799 & 9999999995 \\
\hline CHEMBL 3144549 & 71198 & 7.0458 & 7.3813 & TRN \\
\hline CHEMBL62887 & 71198 & 7.9586 & 7.102 & TST \\
\hline CHEMBL59404 & 71198 & 7.1024 & 6.8588 & TST \\
\hline CHEMBL433636 & 71198 & 4.5229 & 6.3976 & TST \\
\hline CHEMBL 294304 & 71198 & 7.5229 & 7.3562 & TRN \\
\hline CHEMBL 3144543 & 71198 & 6.5229 & 6.3021 & TRN \\
\hline CHEMBL 3144560 & 71198 & 7.5686 & 7.6616 & TRN \\
\hline CHEMBL524340 & 510189 & 6.9747 & 6.8811 & TRN \\
\hline CHEMBL451315 & 510189 & 6.4535 & 6.1286 & TRN \\
\hline CHEMBL526718 & 510189 & 5.2636 & 5.5085 & TRN \\
\hline CHEMBL509567 & 510189 & 6.5498 & 6.8937 & TRN \\
\hline CHEMBL498834 & 510189 & 5.4711 & 6.0208 & TRN \\
\hline CHEMBL503296 & 510189 & 7.5391 & 6.8886 & TST \\
\hline CHEMBL510064 & 510189 & 5.6536 & 5.8145 & TRN \\
\hline CHEMBL506306 & 510189 & 5.4089 & 5.7833 & TRN \\
\hline CHEMBL447139 & 510189 & 5.3288 & 5.8129 & TRN \\
\hline CHEMBL499657 & 510189 & 6.6778 & 6.2257 & TRN \\
\hline CHEMBL442817 & 510189 & 6.5784 & 6.1667 & TRN \\
\hline CHEMBL508424 & 510189 & 5.8239 & 5.7213 & TRN \\
\hline CHEMBL527076 & 510189 & 6.5436 & 6.1286 & TRN \\
\hline CHEMBL526006 & 510189 & 6.983 & 7.3137 & TRN \\
\hline CHEMBL525037 & 510189 & 6.2418 & 6.0807 & TRN \\
\hline CHEMBL500259 & 510189 & 6.2076 & 5.898 & TST \\
\hline CHEMBL510596 & 510189 & 5.7747 & 5.8277 & TRN \\
\hline CHEMBL525068 & 510189 & 5.4089 & 5.7208 & TRN \\
\hline CHEMBL508595 & 510189 & 6.5072 & 6.349 & TRN \\
\hline CHEMBL525409 & 510189 & 6.5317 & 6.8022 & TRN \\
\hline CHEMBL501595 & 510189 & 6.4724 & 5.8721 & TRN \\
\hline CHEMBL503485 & 510189 & 5.6055 & 5.704 & TRN \\
\hline CHEMBL500011 & 510189 & 6.5302 & 5.9578 & TRN \\
\hline CHEMBL506104 & 510189 & 7.0768 & 6.4173 & TRN \\
\hline CHEMBL500622 & 510189 & 5.8697 & 5.8938 & TRN \\
\hline CHEMBL501519 & 510189 & 6.4802 & 6.1097 & TRN \\
\hline CHEMBL499419 & 510189 & 6.4134 & 6.3185 & TRN \\
\hline CHEMBL527044 & 510189 & 6.098 & 6.159 & TST \\
\hline CHEMBL525432 & 510189 & 5.3915 & 5.6894 & TRN \\
\hline CHEMBL524848 & 510189 & 6.4815 & 6.3115 & TRN \\
\hline CHEMBL508154 & 510189 & 7.0429 & 6.9447 & TST \\
\hline CHEMBL500116 & 510189 & 5.3645 & 5.6508 & TRN \\
\hline CHEMBL502457 & 510189 & 5.3197 & 5.9107 & TRN \\
\hline CHEMBL504804 & 510189 & 6.6968 & 7.2195 & TRN \\
\hline CHEMBL506820 & 510189 & 6.5406 & 6.9647 & TST \\
\hline CHEMBL500793 & 510189 & 6.4868 & 6.1286 & TRN \\
\hline CHEMBL503286 & 510189 & 6.0675 & 5.9147 & TRN \\
\hline CHEMBL501008 & 510189 & 5.684 & 5.7979 & TRN \\
\hline
\end{tabular}




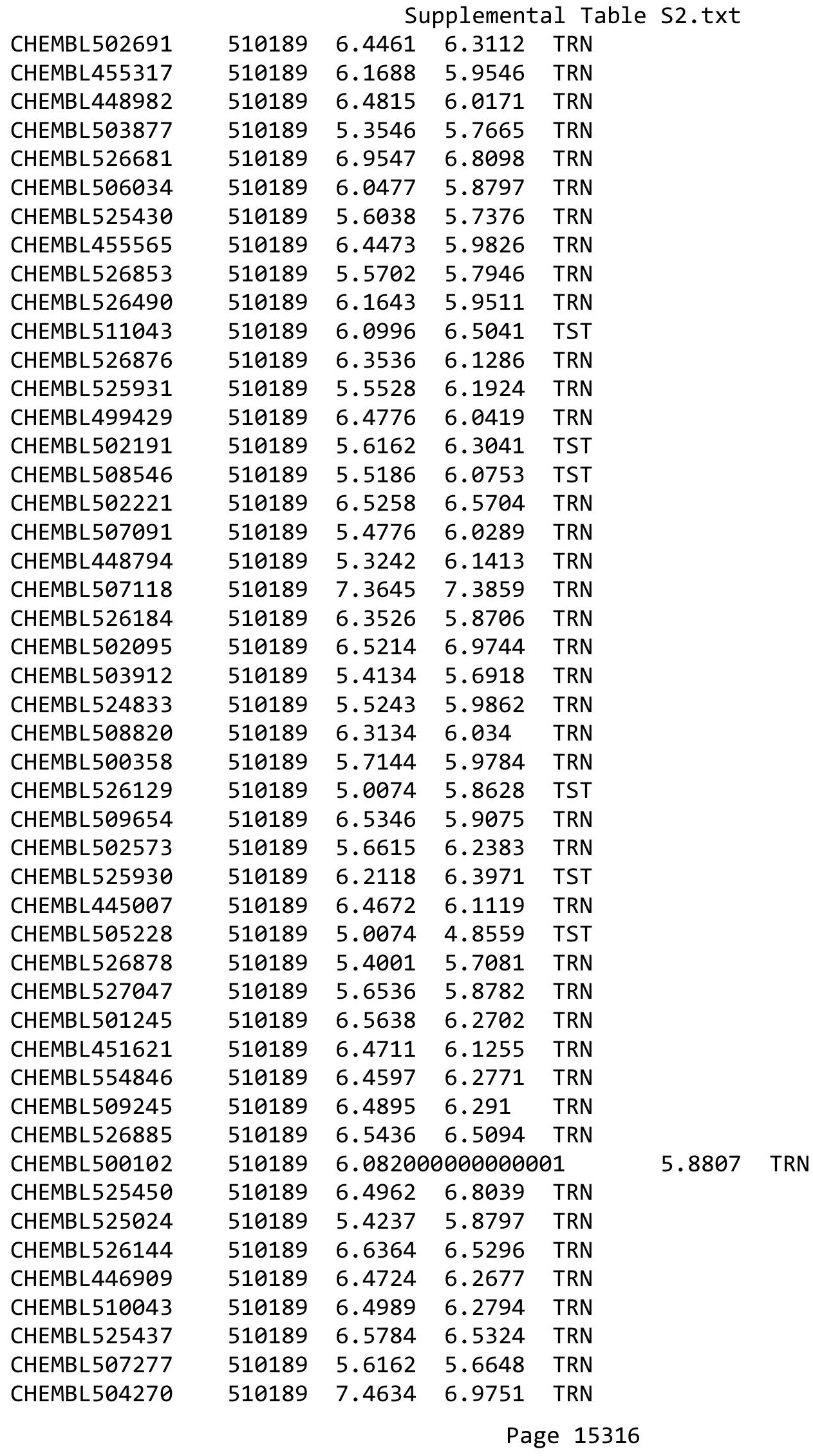




\begin{tabular}{|c|c|c|c|c|c|c|}
\hline \multirow[b]{2}{*}{ CHEMBL453948 } & \multicolumn{6}{|c|}{ Supplemental Table S2.txt } \\
\hline & 510189 & 6.0867 & 6.4329 & TRN & & \\
\hline CHEMBL505745 & 510189 & 7.1605 & 6.5569 & TST & & \\
\hline CHEMBL503207 & 510189 & 5.4921 & 6.1649 & TST & & \\
\hline CHEMBL511090 & 510189 & 5.3152 & 5.8348 & TST & & \\
\hline CHEMBL502851 & 510189 & 7.5867 & 6.6341 & TST & & \\
\hline CHEMBL500546 & 510189 & 5.6576 & 6.1794 & TST & & \\
\hline CHEMBL524857 & 510189 & 5.4949 & 5.973 & TST & & \\
\hline CHEMBL526159 & 510189 & 7.0414 & 7.3547 & TST & & \\
\hline CHEMBL499804 & 510189 & 6.0 & 5.8031 & TST & & \\
\hline CHEMBL509981 & 510189 & 5.308 & 5.8656 & TST & & \\
\hline CHEMBL526486 & 510189 & 6.1215 & 5.9539 & TST & & \\
\hline CHEMBL525787 & 510189 & 6.5086 & 6.1292 & TST & & \\
\hline CHEMBL502360 & 510189 & 5.8447 & 6.2149 & TST & & \\
\hline CHEMBL501160 & 510189 & 5.7235 & 5.9051 & TST & & \\
\hline CHEMBL500039 & 510189 & 6.0177 & 6.1286 & TST & & \\
\hline CHEMBL499096 & 510189 & 5.2857 & 5.8135 & TST & & \\
\hline CHEMBL164952 & 745138 & 7.0655 & 6.9531 & TRN & & \\
\hline CHEMBL1771544 & 745138 & 6.6946 & 6.9457 & TRN & & \\
\hline CHEMBL1771556 & 745138 & 7.8239 & 7.4812 & TRN & & \\
\hline CHEMBL1771553 & 745138 & 5.5607 & 5.9822 & TRN & & \\
\hline CHEMBL1771369 & 745138 & 5.8827 & 6.0925 & TRN & & \\
\hline CHEMBL364361 & 745138 & 5.7496 & 5.7579 & TRN & & \\
\hline CHEMBL1771370 & 745138 & 6.8996 & 6.9261 & TRN & & \\
\hline CHEMBL185999 & 745138 & 5.5129 & 5.4888 & TRN & & \\
\hline CHEMBL365345 & 745138 & 6.3036 & 6.2897 & TST & & \\
\hline CHEMBL1771541 & 745138 & 5.5735 & 5.53100 & 0000000001 & & TRN \\
\hline CHEMBL364145 & 745138 & 6.061 & 6.1714 & TRN & & \\
\hline CHEMBL1771533 & 745138 & 6.8729 & 6.9706 & TRN & & \\
\hline CHEMBL1771549 & 745138 & 5.9586 & 5.7076 & TST & & \\
\hline CHEMBL1771537 & 745138 & 7.0269 & 6.5539 & TRN & & \\
\hline CHEMBL1771545 & 745138 & 6.5986 & 6.4527 & TRN & & \\
\hline CHEMBL1771554 & 745138 & $5.7520 e$ & 30000000 & $\partial 1$ & 5.3004 & TRN \\
\hline CHEMBL186168 & 745138 & 5.9393 & 5.6713 & TRN & & \\
\hline CHEMBL186589 & 745138 & 6.9431 & 6.9929 & TRN & & \\
\hline CHEMBL1771368 & 745138 & 5.6778 & 5.8817 & TRN & & \\
\hline CHEMBL1771551 & 745138 & 7.0132 & 5.2164 & TST & & \\
\hline CHEMBL1771538 & 745138 & 5.5421 & 5.773 & TRN & & \\
\hline CHEMBL1771555 & 745138 & 5.4342 & 5.1552 & TST & & \\
\hline CHEMBL188935 & 745138 & 6.7905 & 6.7297 & TRN & & \\
\hline CHEMBL186078 & 745138 & 7.4089 & 7.3137 & TRN & & \\
\hline CHEMBL187601 & 745138 & 5.284 & 5.4456 & TRN & & \\
\hline CHEMBL1771535 & 745138 & 6.2848 & 6.4166 & TRN & & \\
\hline CHEMBL1771542 & 745138 & 7.0915 & 6.6964 & TRN & & \\
\hline CHEMBL1771366 & 745138 & 6.4089 & 6.1601 & TRN & & \\
\hline CHEMBL163319 & 745138 & 7.1024 & 6.9531 & TRN & & \\
\hline CHEMBL362961 & 745138 & 6.1726 & 5.843 & TST & & \\
\hline CHEMBL1771367 & 745138 & 6.5513 & 6.7698 & TRN & & \\
\hline CHEMBL164903 & 745138 & 6.20206 & 00000000 & & 6.206 & TRN \\
\hline
\end{tabular}


Supplemental Table S2.txt

\begin{tabular}{|c|c|c|c|c|}
\hline AEMBL1771543 & 45138 & 6.7878 & & \\
\hline HEMBL1771552 & 45138 & 6.8508 & 5.2003 & \\
\hline AFMBI 1771532 & 5138 & 71 & & \\
\hline AEMBL364654 & 5138 & 9458 & 3009 & \\
\hline AEMBL186136 & 5138 & 7959 & 2531 & \\
\hline HEMBL187404 & 45138 & .585 & .5672 & \\
\hline HEMBLI & 138 & .983 & 8992 & \\
\hline AEMBL: & & 375 & & 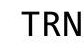 \\
\hline HEMBL 125148 & & .3188 & 5.2885 & \\
\hline HEMBL350410 & 45138 & .4145 & 6.6992 & $\mathrm{~K} \mid$ \\
\hline AEMBL1 & 45138 & 6.2573 & 6.1439 & \\
\hline AEMBL: & 38 & 565 & 651 & \\
\hline IEMBL & & & & DM \\
\hline AEMBL & 38 & 7.0809 & 7.0137 & \\
\hline AEMBL3 & 38 & .4089 & 5.3131 & \\
\hline AEMBL: & 38 & 7.0 & 6.5237 & 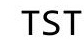 \\
\hline HEMBL & 38 & .4737 & 49 & SI \\
\hline HEMBL & & .2573 & 32 & \\
\hline AEMBL & & 6.4609 & 7.2742 & \\
\hline AEMBL & 38 & .2351 & 6. & 1 \\
\hline AEMBL & 7 & 3.3559 & 09 & 年 \\
\hline HEMBL & & .9601 & 06 & RN \\
\hline HEMBL & & 4.1767 & & \\
\hline AEMBL & & 4.4474 & & \\
\hline AEMBL: & & 57 & & RN \\
\hline IEMBL & & 514 & 37 & \\
\hline IEMBL & & 317 & 28 & 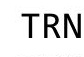 \\
\hline IEMB & & 3.8916 & 79 & \\
\hline AEMBL. & & 5.2122 & & RN \\
\hline HEMBL & 7 & 4.73 & 4. & ГRN \\
\hline AEMBL & & 4.7744 & 4.7745 & $\mathrm{RI}$ \\
\hline HEME & & 3. & 02 & NIV \\
\hline $\mathrm{ME}$ & 7 & 99 & 02 & נח- \\
\hline AEMBL & & 4.2084 & & $\mathrm{RN}$ \\
\hline HEMBL5 & & 3.8503 & 3. & ГRN \\
\hline EMBL & & 4.2195 & & 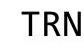 \\
\hline 4 & & 5 & 33 & 年 \\
\hline HEMBL & & 3.4 & 3.4368 & RN \\
\hline HEMBLI & & 3.3287 & 3.3425 & RI \\
\hline AEMBL & & 5.9854 & 46 & TRN \\
\hline CHEMBL & & & 3.8001 & $R$ \\
\hline CHEMBL: & 7 & 6.2477 & 6.2503 & \\
\hline CHEMBL & & 3.2165 & 3.2152 & $\mathrm{RI}$ \\
\hline AEMBL $\angle$ & 57 & 7.0871 & 6.5788 & $S 1$ \\
\hline CHEMBL & 7 & 4.0923 & 4.0952 & $\mathrm{RI}$ \\
\hline CHEMBL & & & 4.4768 & \\
\hline CHEMBL210618 & & 3.35 & 3.3503 & \\
\hline CHEMBL220241 & 54857 & 3.6982 & 3.7021 & \\
\hline
\end{tabular}

Page 15318 


\begin{tabular}{|c|c|c|c|c|c|}
\hline & & \multicolumn{4}{|c|}{ Supplemental Table S2.txt } \\
\hline CHEMBL1590308 & 954857 & 2.6254 & 4.0197 & TST & \\
\hline CHEMBL 222102 & 954857 & 3.398 & 3.3911 & TRN & \\
\hline CHEMBL 2005886 & 954857 & 4.02 & 4.0214 & TRN & \\
\hline CHEMBL 3392440 & 954857 & 3.7559 & 3.7576 & TRN & \\
\hline CHEMBL 209148 & 954857 & 4.2541 & 4.2599 & TRN & \\
\hline CHEMBL1970879 & 954857 & 4.3352 & 4.3355 & TRN & \\
\hline CHEMBL472940 & 954857 & 3.2963 & 3.3009 & TRN & \\
\hline CHEMBL9470 & 954857 & 5.9839 & 5.5339 & TST & \\
\hline CHEMBL 379975 & 954857 & 5.1609 & 5.1605 & TRN & \\
\hline CHEMBL483849 & 954857 & 1.0782 & 1.9883 & TST & \\
\hline CHEMBL1643959 & 954857 & 3.6787 & 3.6746 & TRN & \\
\hline CHEMBL1357247 & 954857 & 4.041 & 4.0404 & TRN & \\
\hline CHEMBL483847 & 954857 & 4.0265 & 4.024 & TRN & \\
\hline CHEMBL1404918 & 954857 & 2.8837 & 2.8759 & TRN & \\
\hline CHEMBL 255342 & 954857 & 3.1771 & 3.1822 & TRN & \\
\hline CHEMBL1516890 & 954857 & 4.3396 & 4.3364 & TRN & \\
\hline CHEMBL221137 & 954857 & 4.9303 & 4.7053 & TST & \\
\hline CHEMBL1230020 & 954857 & 3.7077 & 3.7092 & TRN & \\
\hline CHEMBL1788116 & 954857 & 5.1715 & 5.1669 & TRN & \\
\hline CHEMBL 2363137 & 954857 & 5.6975 & 5.70100 & 00000000005 & TRN \\
\hline CHEMBL 202721 & 954857 & 3.3266 & 3.3297 & TRN & \\
\hline CHEMBL1256459 & 954857 & 7.4968 & 7.4968 & TRN & \\
\hline CHEMBL1186585 & 954857 & 3.4163 & 3.4143 & TRN & \\
\hline CHEMBL 217354 & 954857 & 5.693 & 5.6925 & TRN & \\
\hline CHEMBL 258844 & 954857 & 4.4862 & 4.4844 & TRN & \\
\hline CHEMBL 240954 & 954857 & 3.1221 & 3.5711 & TST & \\
\hline CHEMBL135561 & 954857 & 4.6796 & 4.4061 & TST & \\
\hline CHEMBL515416 & 954857 & 4.7358 & 3.7473 & TST & \\
\hline CHEMBL514499 & 954857 & 6.7317 & 6.2327 & TST & \\
\hline CHEMBL512504 & 954857 & 4.1941 & 4.3026 & TST & \\
\hline CHEMBL 3186408 & 954857 & 4.5038 & 4.0098 & TST & \\
\hline CHEMBL213100 & 954857 & 3.5618 & 5.0268 & TST & \\
\hline CHEMBL509032 & 954857 & 4.1458 & 4.8745 & TST & \\
\hline CHEMBL192566 & 954857 & 6.7007 & 7.4194 & TST & \\
\hline CHEMBL92309 & 954857 & 3.1112 & 3.4249 & TST & \\
\hline CHEMBL585951 & 954857 & 6.1026 & 5.5373 & TST & \\
\hline CHEMBL129056 & 157774 & 8.5229 & 8.4509 & TST & \\
\hline CHEMBL129111 & 157774 & 6.1549 & 6.8195 & TRN & \\
\hline CHEMBL128143 & 157774 & 8.0969 & 7.7796 & TRN & \\
\hline CHEMBL129292 & 157774 & 8.8239 & 8.3977 & TRN & \\
\hline CHEMBL436595 & 157774 & 8.3979 & 7.5806 & TRN & \\
\hline CHEMBL338461 & 157774 & 9.0 & 8.7925 & TRN & \\
\hline CHEMBL434057 & 157774 & 8.3979 & 7.9117 & TRN & \\
\hline CHEMBL129253 & 157774 & 8.2218 & 8.3113 & TRN & \\
\hline CHEMBL 20403 & 157774 & 8.0 & 7.9507 & TST & \\
\hline CHEMBL 340737 & 157774 & 8.1549 & 8.5859 & TRN & \\
\hline CHEMBL129517 & 157774 & 7.7447 & 7.5837 & TRN & \\
\hline CHEMBL130963 & 157774 & 7.3872 & 7.5222 & TRN & \\
\hline
\end{tabular}




\begin{tabular}{|c|c|c|c|c|c|}
\hline \multicolumn{6}{|c|}{ Supplemental Table S2.txt } \\
\hline CHEMBL129018 & 157774 & 8.699 & 8.6817 & TRN & \\
\hline CHEMBL129566 & 157774 & 7.3979 & 7.5289 & TRN & \\
\hline CHEMBL128821 & 157774 & 8.699 & 7.8596 & TRN & \\
\hline CHEMBL128300 & 157774 & 8.699 & 8.6881 & TST & \\
\hline CHEMBL420145 & 157774 & 7.8239 & 7.9207 & TRN & \\
\hline CHEMBL129669 & 157774 & 7.5528 & 7.308 & TRN & \\
\hline CHEMBL338867 & 157774 & 7.0969 & 7.2559 & TRN & \\
\hline CHEMBL340805 & 157774 & 7.6021 & 7.8785 & TRN & \\
\hline CHEMBL127779 & 157774 & 8.699 & 9.5409 & TRN & \\
\hline CHEMBL128271 & 157774 & 5.1549 & 7.973 & TST & \\
\hline CHEMBL99469 & 157774 & 8.699 & 9.055 & TRN & \\
\hline CHEMBL128793 & 157774 & 6.1739 & 7.3122 & TST & \\
\hline CHEMBL128105 & 157774 & 7.7696 & 8.5071 & TST & \\
\hline CHEMBL339953 & 157774 & 7.2291 & 7.4956 & TRN & \\
\hline CHEMBL340957 & 157774 & 7.8239 & 7.3269 & TRN & \\
\hline CHEMBL414375 & 157774 & 8.5229 & 8.0221 & TRN & \\
\hline CHEMBL129916 & 157774 & 8.5229 & 8.1191 & TRN & \\
\hline CHEMBL338549 & 157774 & 6.8239 & 6.46700 & 00000000005 & TRN \\
\hline CHEMBL339970 & 157774 & 9.0 & 9.3087 & TRN & \\
\hline CHEMBL129318 & 157774 & 6.7212 & 7.5645 & TRN & \\
\hline CHEMBL339993 & 157774 & 8.699 & 8.3474 & TRN & \\
\hline CHEMBL97380 & 157774 & 8.5229 & 9.5261 & TST & \\
\hline CHEMBL128094 & 157774 & 7.5686 & 7.7661 & TRN & \\
\hline CHEMBL129258 & 157774 & 5.1549 & 6.20799 & 9999999999 & TRN \\
\hline CHEMBL340795 & 157774 & 8.301 & 8.6064 & TRN & \\
\hline CHEMBL129351 & 157774 & 7.4559 & 7.9764 & TRN & \\
\hline CHEMBL338132 & 157774 & 8.699 & 8.6404 & TST & \\
\hline CHEMBL340333 & 157774 & 7.9586 & 7.8331 & TRN & \\
\hline CHEMBL338489 & 157774 & 7.0506 & 7.5901 & TRN & \\
\hline CHEMBL128716 & 157774 & 8.0 & 7.4681 & TST & \\
\hline CHEMBL128660 & 157774 & 6.2076 & 8.6528 & TST & \\
\hline CHEMBL129478 & 157774 & 8.699 & 7.7813 & TRN & \\
\hline CHEMBL129167 & 157774 & 8.3979 & 7.6714 & TST & \\
\hline CHEMBL421447 & 157774 & 7.585 & 7.9015 & TRN & \\
\hline CHEMBL414244 & 157774 & 8.5229 & 7.2495 & TST & \\
\hline CHEMBL131135 & 157774 & 8.699 & 8.2125 & TRN & \\
\hline CHEMBL128666 & 157774 & 8.0458 & 7.4309 & TST & \\
\hline CHEMBL128751 & 157774 & 8.5229 & 8.1482 & TRN & \\
\hline CHEMBL3920039 & 1641160 & 8.4211 & 8.3879 & TRN & \\
\hline CHEMBL3966257 & 1641160 & 8.6741 & 8.8184 & TRN & \\
\hline CHEMBL3972141 & 1641160 & 9.0655 & 9.0366 & TRN & \\
\hline CHEMBL3934389 & 1641160 & 7.4605 & 7.4301 & TRN & \\
\hline CHEMBL3971265 & 1641160 & 8.2458 & 8.4048 & TRN & \\
\hline CHEMBL 3894928 & 1641160 & 8.6101 & 8.8377 & TRN & \\
\hline CHEMBL 3976967 & 1641160 & 8.2969 & 8.4463 & TST & \\
\hline CHEMBL 3896594 & 1641160 & 8.6434 & 8.9399 & TRN & \\
\hline CHEMBL3910380 & 1641160 & 8.6048 & 8.6688 & TRN & \\
\hline CHEMBL3983865 & 1641160 & 8.3884 & 7.6308 & TRN & \\
\hline
\end{tabular}


Supplemental Table S2.txt

\begin{tabular}{|c|c|c|c|c|c|c|}
\hline CHEMBL 3934972 & 1641160 & 8.6874 & 8.4909 & TRN & & \\
\hline CHEMBL 3927611 & 1641160 & 7.0827 & 6.9267 & TRN & & \\
\hline CHEMBL 3891470 & 1641160 & 7.5902 & 7.7888 & TST & & \\
\hline CHEMBL 3903274 & 1641160 & 9.0026 & 9.1239 & TRN & & \\
\hline CHEMBL 3962812 & 1641160 & 9.3161 & 8.9899 & TRN & & \\
\hline CHEMBL 3940726 & 1641160 & 8.5032 & 8.801 & TRN & & \\
\hline CHEMBL 3932011 & 1641160 & 8.9219 & 8.97299 & 999999999 & & TST \\
\hline CHEMBL3924379 & 1641160 & 8.7326 & 8.7723 & TST & & \\
\hline CHEMBL 3970191 & 1641160 & 8.6639 & 8.7914 & TRN & & \\
\hline CHEMBL 3923479 & 1641160 & 8.7402 & 8.7799 & TRN & & \\
\hline CHEMBL 3922193 & 1641160 & 8.4115 & 8.2572 & TRN & & \\
\hline CHEMBL 3892757 & 1641160 & 7.8716 & 7.7568 & TRN & & \\
\hline CHEMBL 3896098 & 1641160 & 7.8928 & 8.5194 & TST & & \\
\hline CHEMBL 3933272 & 1641160 & 9.8182 & 9.5086 & TST & & \\
\hline CHEMBL 3927672 & 1641160 & 8.8027 & 8.7514 & TRN & & \\
\hline CHEMBL 3960706 & 1641160 & 8.1386 & 8.4411 & TRN & & \\
\hline CHEMBL 3975167 & 1641160 & 7.6558 & 7.9533 & TST & & \\
\hline CHEMBL 3937040 & 1641160 & 8.5745 & 8.3043 & TRN & & \\
\hline CHEMBL 3924576 & 1641160 & 8.9718 & 9.0331 & TST & & \\
\hline CHEMBL 3894464 & 1641160 & 6.9755 & 7.1916 & TRN & & \\
\hline CHEMBL 3919411 & 1641160 & 8.6605 & 8.628 & TRN & & \\
\hline CHEMBL 3966297 & 1641160 & 7.4142 & 7.4216 & TRN & & \\
\hline CHEMBL 3975403 & 1641160 & 3.6021 & 3.9048 & TRN & & \\
\hline CHEMBL 3972341 & 1641160 & 8.4919 & 8.6311 & TRN & & \\
\hline CHEMBL 3940522 & 1641160 & 8.5022 & 7.7375 & TRN & & \\
\hline CHEMBL 3921477 & 1641160 & 6.1944 & 6.7455 & TRN & & \\
\hline CHEMBL 3951813 & 1641160 & 8.6609 & 8.7528 & TRN & & \\
\hline CHEMBL 3910040 & 1641160 & 7.9062 & 7.8782 & TRN & & \\
\hline CHEMBL3976881 & 1641160 & \multicolumn{3}{|c|}{9.341000000000001} & 9.1788 & TST \\
\hline CHEMBL 3956654 & 1641160 & 9.3893 & 8.9832 & TRN & & \\
\hline CHEMBL 3893855 & 1641160 & 8.5674 & 8.6802 & TRN & & \\
\hline CHEMBL 3903630 & 1641160 & 8.2375 & 8.6081 & TST & & \\
\hline CHEMBL 3956712 & 1641160 & 7.8533 & 7.9272 & TST & & \\
\hline CHEMBL3894913 & 1641160 & 8.845 & 8.7594 & TRN & & \\
\hline CHEMBL 3914464 & 1641160 & 9.1512 & 9.0563 & TRN & & \\
\hline CHEMBL3916539 & 1641160 & 8.5364 & 8.6364 & TRN & & \\
\hline CHEMBL3975759 & 1641160 & 8.8677 & 8.8401 & TST & & \\
\hline CHEMBL 3931694 & 1641160 & 8.6517 & 8.6869 & TRN & & \\
\hline CHEMBL 3970403 & 1641160 & 7.5394 & 7.869 & TRN & & \\
\hline CHEMBL 3938806 & 1641160 & 8.6529 & 8.5627 & TRN & & \\
\hline CHEMBL 3969209 & 1641160 & 7.9978 & 8.1174 & TRN & & \\
\hline CHEMBL 3964522 & 1641160 & 8.0416 & 8.1157 & TST & & \\
\hline CHEMBL 3913790 & 1641160 & 8.4026 & 8.385 & TRN & & \\
\hline CHEMBL 3943932 & 1641160 & \multicolumn{3}{|c|}{6.3389999999999995} & 6.6449 & נבו \\
\hline CHEMBL 3925869 & 1641160 & 8.0597 & 8.3341 & TRN & & \\
\hline CHEMBL 3943351 & 1641160 & 8.5414 & 8.5617 & TRN & & \\
\hline CHEMBL 3964430 & 1641160 & 8.7726 & 8.7887 & TRN & & \\
\hline CHEMBL 3948871 & 1641160 & 8.1718 & 8.5047 & TRN & & \\
\hline
\end{tabular}

Page 15321 
Supplemental Table S2.txt

\begin{tabular}{|c|c|c|c|c|}
\hline r & 1160 & & & \\
\hline & 641160 & 9.1325 & 9.1004 & \\
\hline 78 & & & & \\
\hline AEMBL3940053 & & & & M \\
\hline AEMBL3971983 & 160 & & 186 & \\
\hline HEMBL3928316 & 641160 & 137 & . 3849 & \\
\hline HEMBL3970281 & 60 & & & \\
\hline IFMRI 3951474 & & & & RN \\
\hline AEMBL3904667 & & & 8183 & \\
\hline HEMBL3955103 & 60 & & 933 & \\
\hline HEMBL3919205 & 60 & & 69 & \\
\hline IEMBL394 & 50 & & 886 & \\
\hline AEMBL39 & & & & \\
\hline HEMBL3966766 & & & 8.9283 & \\
\hline AEMBL3927963 & 50 & & & \\
\hline AEMBL3889893 & 50 & & 43 & \\
\hline AEMBL3894542 & 80 & & 166 & \\
\hline HEMBL 391 & & & & \\
\hline HEMBL3960515 & & & 8.9133 & \\
\hline AEMBL39 & & 6 & & \\
\hline IEIMBL39 & של & & . 7936 & KIV \\
\hline AEMBL3S & & & 509 & +2 \\
\hline AEMBL3S & & & 45 & \\
\hline AFMRI 396 & & & 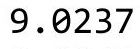 & \\
\hline AEMBL39 & & & 366 & 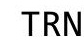 \\
\hline HEMBL39 & 6 & & 888 & RN \\
\hline HEMBL3S & & & 49 & Niv \\
\hline HFMBI $3 c$ & & & 231 & \\
\hline HEMBL3903859 & & & 8.8149 & iv \\
\hline HEMBL3891700 & & & & 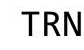 \\
\hline HEMBL 39386 & & & 106 & RN \\
\hline HEMBL; & & & 19 & RN \\
\hline HEMBL; & & & 8.594 & $\mathrm{~N}$ \\
\hline HEMBL 3959581 & & & 177 & IRN \\
\hline HEMBL 3942721 & & & 9.0 & ГRN \\
\hline HEMBL 39 & & & 58 & RIN \\
\hline HFMRI 3 & & & 05 & IRIN \\
\hline HEMBL3 & & & 979 & TRN \\
\hline HEMBL3959933 & & & .5708 & TRN \\
\hline AEMBL3890682 & & & 5425 & $\Gamma \mathrm{RN}$ \\
\hline HEMBL3953527 & 50 & & 8.7441 & \\
\hline HEMBL3902816 & & & 3.5758 & RIN \\
\hline HEMBL3937081 & & & 8.6427 & $\Gamma \mathrm{RN}$ \\
\hline HEMBL3951027 & 60 & & 8.5792 & TST \\
\hline MBL394 & & & 8.5123 & \\
\hline HEMBL 3936445 & & & 3.7173 & \\
\hline LHEMBL 3897780 & & & 8.5943 & \\
\hline CHEMBL3946003 & $164116 e$ & 9.2328 & 9.0955 & ГRN \\
\hline
\end{tabular}

Page 15322 
Supplemental Table S2.txt

\begin{tabular}{|c|c|c|c|c|c|}
\hline CHEMBL3971254 & 1641160 & 8.5964 & 8.6902 & TRN & \\
\hline CHEMBL3931624 & 1641160 & 7.871 & 7.7054 & TRN & \\
\hline CHEMBL3986273 & 1641160 & 8.507 & 8.1279 & TRN & \\
\hline CHEMBL3959652 & 1641160 & 8.9465 & 9.1109 & TRN & \\
\hline CHEMBL3946530 & 1641160 & 7.7345 & 7.9164 & TRN & \\
\hline CHEMBL3928661 & 1641160 & 7.6511 & 7.37 & TRN & \\
\hline CHEMBL3905257 & 1641160 & 9.4101 & 9.5113 & TST & \\
\hline CHEMBL3955962 & 1641160 & 8.0766 & 8.4752 & TRN & \\
\hline CHEMBL3951339 & 1641160 & 3.6021 & 3.0882 & TRN & \\
\hline CHEMBL3987177 & 1641160 & 9.2211 & 9.2234 & TRN & \\
\hline CHEMBL3968536 & 1641160 & 8.2034 & 8.4459 & TST & \\
\hline CHEMBL3910832 & 1641160 & 8.8908 & 9.0316 & TST & \\
\hline CHEMBL3947016 & 1641160 & 8.8841 & 8.7703 & TRN & \\
\hline CHEMBL3904596 & 1641160 & 8.4223 & 8.3612 & TRN & \\
\hline CHEMBL3918963 & 1641160 & 7.4703 & 7.8614 & TRN & \\
\hline CHEMBL3951205 & 1641160 & 8.6494 & 8.9043 & TRN & \\
\hline CHEMBL3945747 & 1641160 & 8.4053 & 8.4359 & TRN & \\
\hline CHEMBL 3984244 & 1641160 & 8.4218 & 8.4885 & TRN & \\
\hline CHEMBL3947696 & 1641160 & 8.8542 & 8.8832 & TST & \\
\hline CHEMBL3964820 & 1641160 & 7.8024 & 7.7776 & TRN & \\
\hline CHEMBL3933886 & 1641160 & 6.8041 & 7.1174 & TRN & \\
\hline CHEMBL3973655 & 1641160 & 6.0 & 6.1101 & TRN & \\
\hline CHEMBL3933060 & 1641160 & 8.7889 & 8.8914 & TRN & \\
\hline CHEMBL3956383 & 1641160 & 8.9706 & 8.7277 & TRN & \\
\hline CHEMBL3909155 & 1641160 & 8.5336 & 8.3501 & TRN & \\
\hline CHEMBL3903846 & 1641160 & 8.8938 & 8.7651 & TRN & \\
\hline CHEMBL3980394 & 1641160 & 8.8268 & 8.8078 & TRN & \\
\hline CHEMBL3889721 & 1641160 & 8.9987 & 9.0509 & TRN & \\
\hline CHEMBL3930988 & 1641160 & 7.6353 & 7.6131 & TRN & \\
\hline CHEMBL3981117 & 1641160 & 8.6021 & 8.472006 & 2000000001 & TRN \\
\hline CHEMBL3981967 & 1641160 & 7.7049 & 7.5989 & TRN & \\
\hline CHEMBL 3967893 & 1641160 & 9.4815 & 9.2489 & TRN & \\
\hline CHEMBL3926287 & 1641160 & 8.6594 & 8.6829 & TRN & \\
\hline CHEMBL 3975494 & 1641160 & 8.6066 & 8.587 & TRN & \\
\hline CHEMBL3913923 & 1641160 & 8.6227 & 8.64 & TRN & \\
\hline CHEMBL3941778 & 1641160 & 8.3796 & 8.5954 & TRN & \\
\hline CHEMBL3969555 & 1641160 & 9.0809 & 8.8819 & TRN & \\
\hline CHEMBL3979418 & 1641160 & 7.9618 & 8.1509 & TRN & \\
\hline CHEMBL 3937164 & 1641160 & 8.0742 & 8.2024 & TST & \\
\hline CHEMBL3942611 & 1641160 & 7.4267 & 7.4124 & TRN & \\
\hline CHEMBL3924392 & 1641160 & 8.7172 & 8.6532 & TRN & \\
\hline CHEMBL3896660 & 1641160 & 8.7708 & 8.7269 & TRN & \\
\hline CHEMBL3942212 & 1641160 & 8.0211 & 8.1316 & TST & \\
\hline CHEMBL 3890463 & 1641160 & 8.4167 & 8.6501 & TST & \\
\hline CHEMBL3982235 & 1641160 & 8.8294 & 8.6794 & TRN & \\
\hline CHEMBL3946071 & 1641160 & 8.8935 & 8.9304 & TST & \\
\hline CHEMBL3978705 & 1641160 & 8.7781 & 8.6211 & TST & \\
\hline CHEMBL3918750 & 1641160 & 8.7364 & 8.8735 & TRN & \\
\hline
\end{tabular}


Supplemental Table S2.txt

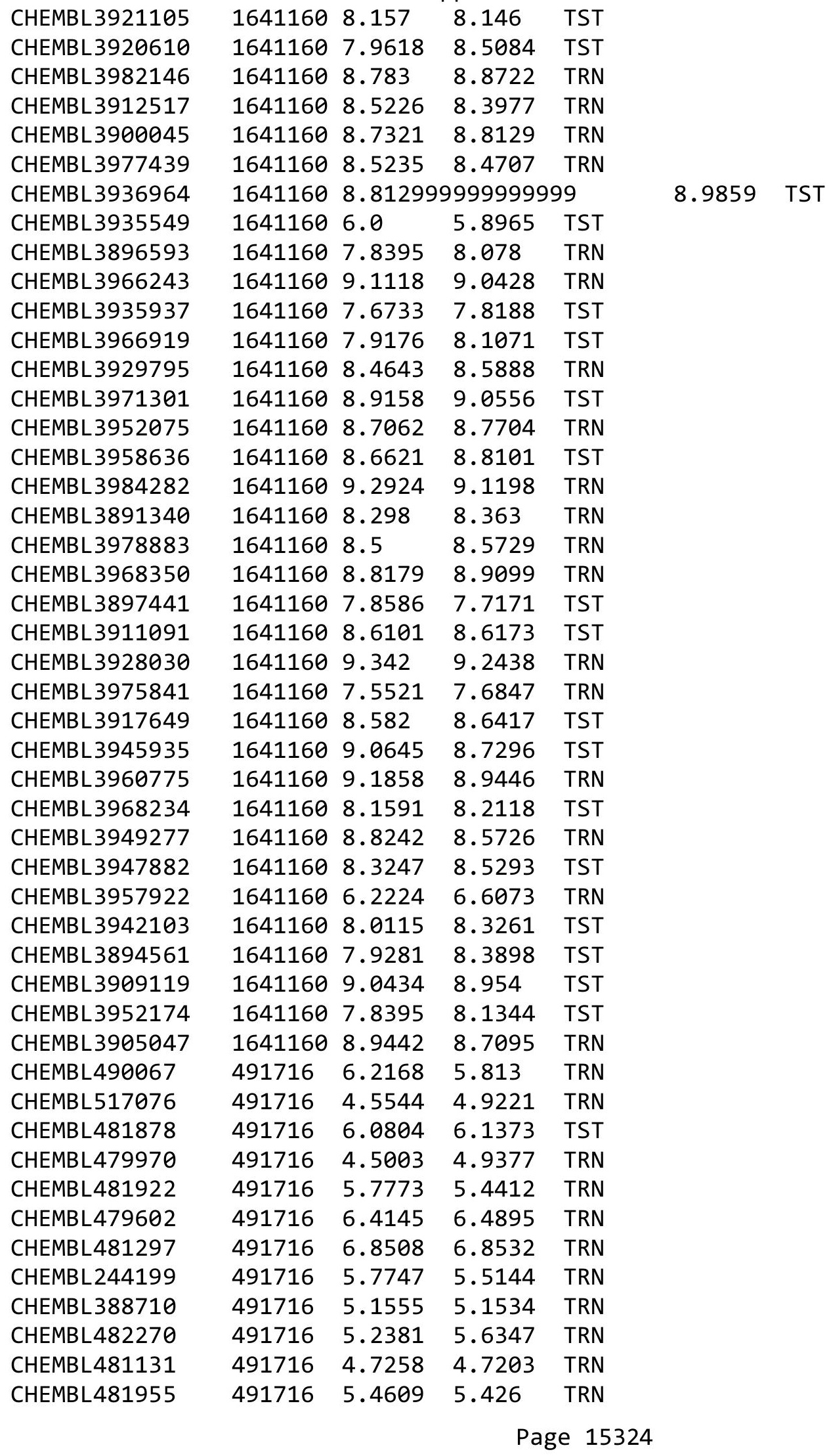




\begin{tabular}{|c|c|c|c|c|c|c|c|}
\hline & \\
\hline CHEMBL480973 & 491716 & 6.1475 & 6.2236 & TRN & & & \\
\hline CHEMBL482287 & 491716 & 6.0241 & 5.2018 & TST & & & \\
\hline CHEMBL445518 & 491716 & 6.3747 & 6.3885 & TRN & & & \\
\hline CHEMBL479611 & 491716 & 5.9136 & 5.9037 & TRN & & & \\
\hline CHEMBL519134 & 491716 & 6.4112 & 6.3965 & TRN & & & \\
\hline CHEMBL443241 & 491716 & 5.0487 & 4.8986 & TRN & & & \\
\hline CHEMBL482094 & 491716 & 4.5884 & 5.5903 & TST & & & \\
\hline CHEMBL479786 & 491716 & 6.2314 & 6.3432 & TRN & & & \\
\hline CHEMBL517384 & 491716 & 6.2299 & 5.8637 & TRN & & & \\
\hline CHEMBL493249 & 491716 & 5.8601 & 5.5102 & TST & & & \\
\hline CHEMBL482096 & 491716 & 6.2277 & 6.455 & TRN & & & \\
\hline CHEMBL482271 & 491716 & 6.2815 & 6.08899 & 99999999 & 995 & TRN & \\
\hline CHEMBL482137 & 491716 & 6.4685 & 6.267 & TRN & & & \\
\hline CHEMBL450723 & 491716 & 5.6038 & 5.8637 & TRN & & & \\
\hline CHEMBL451289 & 491716 & 6.1726 & 6.3755 & TRN & & & \\
\hline CHEMBL479601 & 491716 & 6.6003 & 6.4328 & TRN & & & \\
\hline CHEMBL482281 & 491716 & 5.8097 & 5.8974 & TRN & & & \\
\hline CHEMBL520781 & 491716 & 5.7282 & 5.8053 & TRN & & & \\
\hline CHEMBL471044 & 491716 & 6.4342 & 6.5293 & TRN & & & \\
\hline CHEMBL482136 & 491716 & 6.3002 & 6.2508 & TRN & & & \\
\hline CHEMBL242039 & 491716 & 5.341 & 5.1649 & TRN & & & \\
\hline CHEMBL481148 & 491716 & 6.2757 & 6.4175 & TRN & & & \\
\hline CHEMBL439842 & 491716 & 4.4175 & 4.6125 & TRN & & & \\
\hline CHEMBL482765 & 491716 & 6.7852 & 6.7449 & TRN & & & \\
\hline CHEMBL481136 & 491716 & 6.2708 & 6.12 & TST & & & \\
\hline CHEMBL518961 & 491716 & 6.644 & 6.4591 & TRN & & & \\
\hline CHEMBL480884 & 491716 & 5.1475 & 5.0387 & TRN & & & \\
\hline CHEMBL516915 & 491716 & 6.0521 & 6.3587 & TRN & & & \\
\hline CHEMBL482095 & 491716 & 5.9355 & 5.9446 & TRN & & & \\
\hline CHEMBL481311 & 491716 & 5.2733 & 5.2938 & TRN & & & \\
\hline CHEMBL510856 & 491716 & 6.1397 & 6.1778 & TRN & & & \\
\hline CHEMBL493872 & 491716 & 5.1244 & 4.9995 & TRN & & & \\
\hline CHEMBL481703 & 491716 & 6.2557 & 6.4327 & TST & & & \\
\hline CHEMBL242473 & 491716 & 5.5331 & 5.4873 & TRN & & & \\
\hline CHEMBL479971 & 491716 & 6.11799 & 99999999 & & 5.9383 & TRN & \\
\hline CHEMBL243997 & 491716 & 5.21399 & 99999999 & 995 & 5.12700 & 0000000001 & TRN \\
\hline CHEMBL517997 & 491716 & 6.3036 & 6.0103 & TST & & & \\
\hline CHEMBL482280 & 491716 & 4.98300 & 00000000 & 005 & 5.4852 & TST & \\
\hline CHEMBL482075 & 491716 & 6.0088 & 6.0521 & TST & & & \\
\hline CHEMBL470470 & 491716 & 4.6737 & 5.2339 & TST & & & \\
\hline CHEMBL493871 & 491716 & 5.0123 & 4.917 & TST & & & \\
\hline CHEMBL481319 & 491716 & 5.8069 & 5.9565 & TST & & & \\
\hline CHEMBL487615 & 491716 & 6.6676 & 6.4839 & TST & & & \\
\hline CHEMBL482272 & 491716 & 6.4841 & 6.8255 & TST & & & \\
\hline CHEMBL 2380917 & 958173 & 5.1367 & 5.1554 & TRN & & & \\
\hline CHEMBL2380899 & 958173 & 4.7011 & 4.8468 & TST & & & \\
\hline CHEMBL 2380900 & 958173 & 4.8416 & 4.9599 & TST & & & \\
\hline CHEMBL 2380882 & 958173 & 4.4855 & 4.8424 & TST & & & \\
\hline
\end{tabular}




\begin{tabular}{|c|c|c|c|c|c|c|}
\hline & & \multicolumn{5}{|c|}{ Supplemental Table S2.txt } \\
\hline CHEMBL2381017 & 958173 & 4.4559 & 4.6267 & TRN & & \\
\hline CHEMBL 2381032 & 958173 & 6.0 & 5.7039 & TRN & & \\
\hline CHEMBL2380923 & 958173 & 5.6198 & 5.6673 & TRN & & \\
\hline CHEMBL2380916 & 958173 & 5.1249 & 4.9396 & TST & & \\
\hline CHEMBL2380912 & 958173 & 5.3565 & 5.3644 & TRN & & \\
\hline CHEMBL2381014 & 958173 & 5.2518 & 5.2695 & TRN & & \\
\hline CHEMBL2380919 & 958173 & 5.6198 & 5.4568 & TRN & & \\
\hline CHEMBL2381020 & 958173 & 6.0 & 6.0403 & TRN & & \\
\hline CHEMBL2381035 & 958173 & 5.1739 & 5.1444 & TRN & & \\
\hline CHEMBL2380318 & 958173 & 5.51 & 5.4712 & TRN & & \\
\hline CHEMBL2381040 & 958173 & 6.0 & 6.0809 & TRN & & \\
\hline CHEMBL2380886 & 958173 & 3.0 & 2.8984 & TRN & & \\
\hline CHEMBL2380908 & 958173 & 5.8539 & 5.8216 & TRN & & \\
\hline CHEMBL2380894 & 958173 & 4.9208 & 4.8067 & TRN & & \\
\hline CHEMBL2380906 & 958173 & 5.8539 & 5.7417 & TRN & & \\
\hline CHEMBL2380921 & 958173 & 5.4685 & 5.5418 & TRN & & \\
\hline CHEMBL2381043 & 958173 & 6.0 & 5.9035 & TRN & & \\
\hline CHEMBL2380909 & 958173 & 4.4089 & 4.36 & TRN & & \\
\hline CHEMBL2380883 & 958173 & 4.4056 & 4.8569 & TST & & \\
\hline CHEMBL2381024 & 958173 & 3.0 & 3.0131 & TRN & & \\
\hline CHEMBL2381013 & 958173 & 5.4318 & 4.9538 & TRN & & \\
\hline CHEMBL2380887 & 958173 & \multicolumn{3}{|c|}{4.9830000000000005} & 5.07 & TRN \\
\hline CHEMBL 2381045 & 958173 & 3.0 & 4.4832 & TST & & \\
\hline CHEMBL2380905 & 958173 & 5.1192 & 5.1009 & TRN & & \\
\hline CHEMBL2380884 & 958173 & 4.9245 & 5.2125 & TST & & \\
\hline CHEMBL2381006 & 958173 & 5.5686 & 5.8883 & TRN & & \\
\hline CHEMBL 2380895 & 958173 & 4.8633 & 4.8783 & TRN & & \\
\hline CHEMBL2380898 & 958173 & 4.7055 & 5.1664 & TST & & \\
\hline CHEMBL2380897 & 958173 & 4.9666 & 4.9793 & TRN & & \\
\hline CHEMBL2381038 & 958173 & 5.2147 & 5.4414 & TRN & & \\
\hline CHEMBL2381018 & 958173 & 5.4318 & 5.6097 & TRN & & \\
\hline CHEMBL2380902 & 958173 & 3.0 & 4.1939 & TST & & \\
\hline CHEMBL2380920 & 958173 & 5.6576 & 5.6023 & TRN & & \\
\hline CHEMBL2380925 & 958173 & 5.7447 & 5.8046 & TRN & & \\
\hline CHEMBL2381041 & 958173 & 3.0 & 4.0719 & TST & & \\
\hline CHEMBL2381016 & 958173 & 6.0 & 5.5779 & TRN & & \\
\hline CHEMBL2380881 & 958173 & 6.0 & 5.9474 & TRN & & \\
\hline CHEMBL2380922 & 958173 & 5.4437 & 5.4392 & TRN & & \\
\hline CHEMBL2380891 & 958173 & 4.5186 & 4.5814 & TRN & & \\
\hline CHEMBL2381034 & 958173 & 5.4318 & 5.4156 & TRN & & \\
\hline CHEMBL2380910 & 958173 & 5.284 & 5.2186 & TRN & & \\
\hline CHEMBL2380926 & 958173 & 5.5686 & 5.8349 & TRN & & \\
\hline CHEMBL2381033 & 958173 & 5.0088 & 5.1297 & TRN & & \\
\hline CHEMBL 2380889 & 958173 & 5.0132 & 5.1956 & TRN & & \\
\hline CHEMBL2381015 & 958173 & 5.1367 & 5.154 & TRN & & \\
\hline CHEMBL2381021 & 958173 & 3.0 & 4.4546 & TST & & \\
\hline CHEMBL2380904 & 958173 & 4.7471 & 4.6328 & TRN & & \\
\hline CHEMBL2380913 & 958173 & 4.4672 & 4.5036 & TRN & & \\
\hline
\end{tabular}




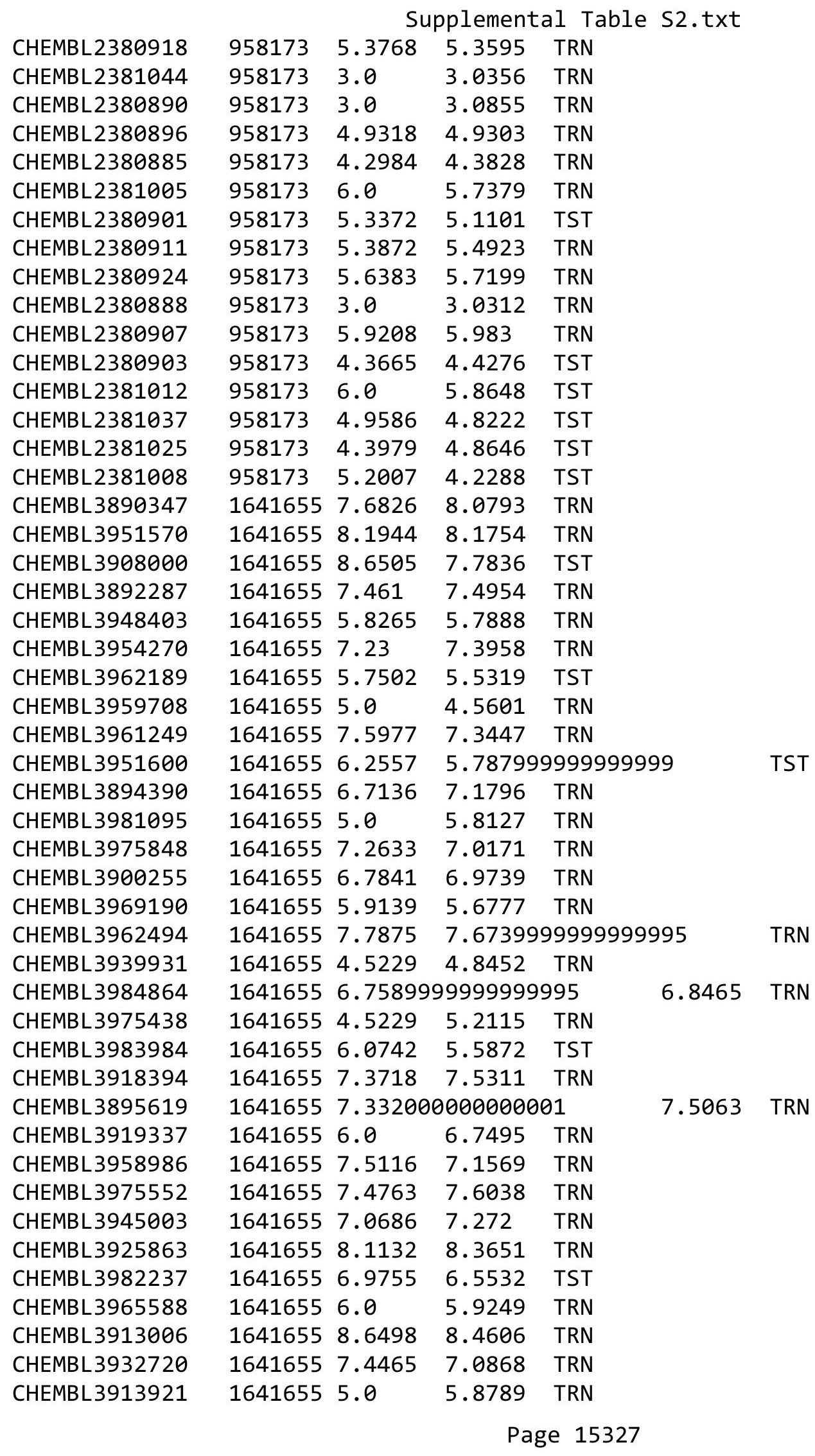


Supplemental Table S2.txt

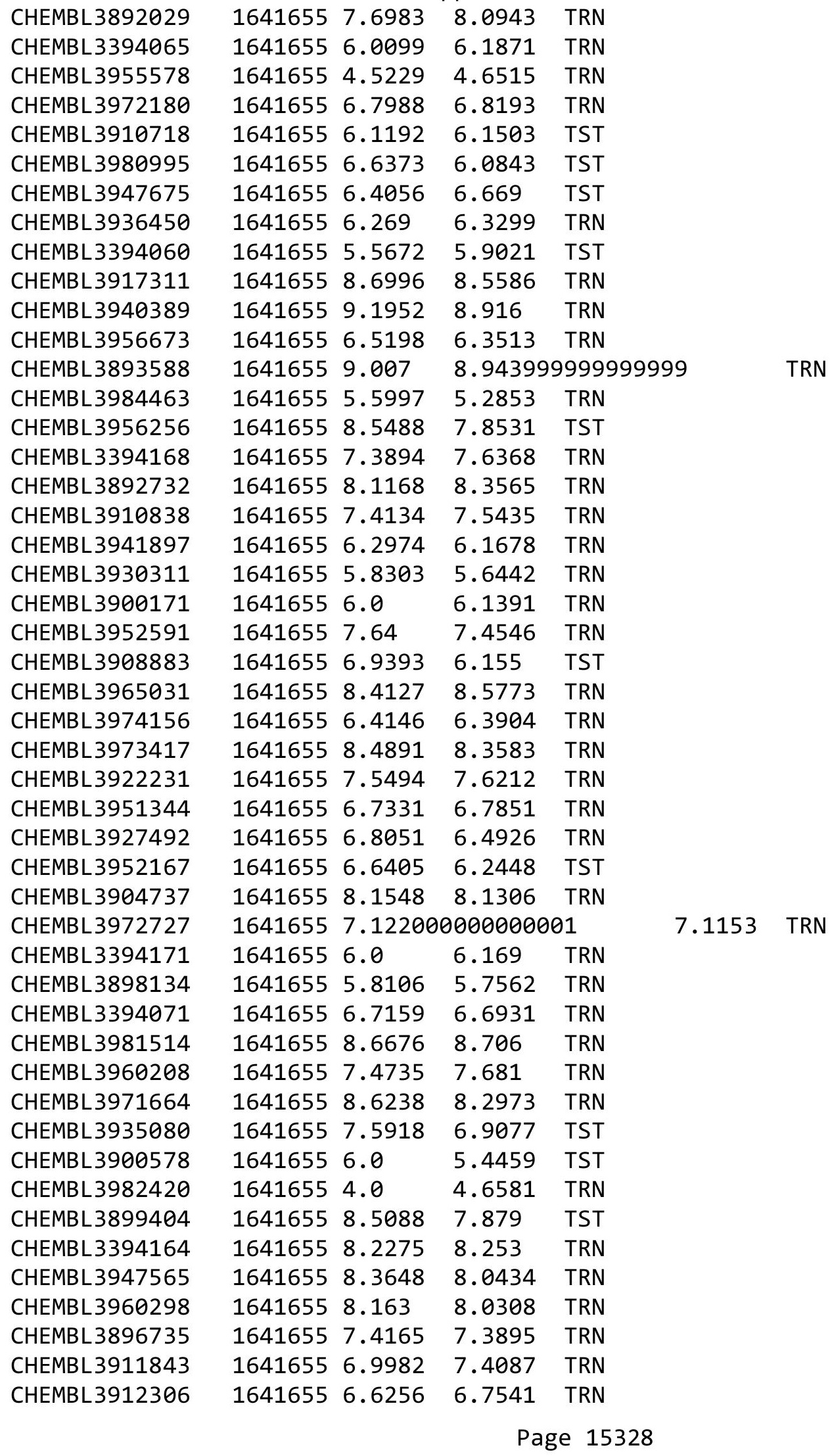


Supplemental Table S2.txt

\begin{tabular}{|c|c|c|c|c|c|c|}
\hline CHEMBL3901647 & 1641655 & 6.0 & 5.5599 & TST & & \\
\hline CHEMBL3980131 & 1641655 & 8.6855 & 8.7216 & TRN & & \\
\hline CHEMBL3942496 & 1641655 & 7.3057 & 6.8318 & TRN & & \\
\hline CHEMBL3977572 & 1641655 & 4.5229 & 5.6537 & TRN & & \\
\hline CHEMBL 3930502 & 1641655 & 6.1612 & 5.815 & TRN & & \\
\hline CHEMBL3920604 & 1641655 & 5.8426 & 5.8471 & TRN & & \\
\hline CHEMBL3914520 & 1641655 & 7.7739 & 7.7805 & TRN & & \\
\hline CHEMBL3902931 & 1641655 & 4.5229 & 5.0231 & TST & & \\
\hline CHEMBL 3982628 & 1641655 & 6.8353 & 6.8101 & TRN & & \\
\hline CHEMBL 3892162 & 1641655 & 4.5229 & 4.6276 & TRN & & \\
\hline CHEMBL3970104 & 1641655 & 7.5849 & 7.5499 & TRN & & \\
\hline CHEMBL3944528 & 1641655 & 7.2314 & 7.2868 & TRN & & \\
\hline CHEMBL3915388 & 1641655 & 5.809 & 5.6847 & TRN & & \\
\hline CHEMBL 3907899 & 1641655 & 7.5203 & \multicolumn{3}{|c|}{7.457999999999999} & \\
\hline CHEMBL 3897313 & 1641655 & \multicolumn{3}{|c|}{6.132000000000001} & 6.513 & \\
\hline CHEMBL 3940277 & 1641655 & 7.0367 & 7.1399 & TRN & & \\
\hline CHEMBL3394172 & 1641655 & 7.6085 & 7.5264 & TRN & & \\
\hline CHEMBL 3890140 & 1641655 & 8.6847 & 8.8 & TRN & & \\
\hline CHEMBL3981152 & 1641655 & 7.4088 & 7.3163 & TRN & & \\
\hline CHEMBL3961854 & 1641655 & 7.7781 & 7.3932 & TRN & & \\
\hline CHEMBL 3910525 & 1641655 & 6.2205 & 6.086 & TRN & & \\
\hline CHEMBL3952561 & 1641655 & 8.4943 & 8.5206 & TRN & & \\
\hline CHEMBL3921086 & 1641655 & \multicolumn{3}{|c|}{6.2989999999999995} & 6.7272 & \\
\hline CHEMBL3893572 & 1641655 & 7.8891 & 8.2225 & TST & & \\
\hline CHEMBL3957441 & 1641655 & 7.0496 & 7.1389 & TRN & & \\
\hline CHEMBL3931494 & 1641655 & 6.1518 & 6.2654 & TST & & \\
\hline CHEMBL3968456 & 1641655 & \multicolumn{3}{|c|}{7.457999999999999} & 7.5165 & \\
\hline CHEMBL3897123 & 1641655 & 6.1752 & 6.1575 & TRN & & \\
\hline CHEMBL3951087 & 1641655 & 6.2524 & 5.7271 & TST & & \\
\hline CHEMBL3394166 & 1641655 & 7.6664 & 7.8693 & TRN & & \\
\hline CHEMBL3919198 & 1641655 & 5.5198 & 5.819 & TRN & & \\
\hline CHEMBL3901441 & 1641655 & 8.263 & 8.4544 & TRN & & \\
\hline CHEMBL3937321 & 1641655 & 7.4324 & 7.0947 & TRN & & \\
\hline CHEMBL 3962808 & 1641655 & 7.9626 & 8.0 & TRN & & \\
\hline CHEMBL3959112 & 1641655 & \multicolumn{3}{|c|}{7.712000000000001} & 7.7995 & v \\
\hline CHEMBL3960832 & 1641655 & 7.108 & 7.0023 & TST & & \\
\hline CHEMBL 3898788 & 1641655 & 6.5017 & 6.4648 & TST & & \\
\hline CHEMBL3961142 & 1641655 & 4.5229 & 4.4021 & TRN & & \\
\hline CHEMBL3950988 & 1641655 & 7.9547 & 7.7848 & TRN & & \\
\hline CHEMBL3949902 & 1641655 & 6.3893 & 6.6323 & TST & & \\
\hline CHEMBL3910677 & 1641655 & 7.2784 & 7.2514 & TRN & & \\
\hline CHEMBL3937011 & 1641655 & 8.971 & 8.9975 & TRN & & \\
\hline CHEMBL3918784 & 1641655 & 6.1635 & 5.7231 & TRN & & \\
\hline CHEMBL3909365 & 1641655 & 7.4965 & 7.6889 & TRN & & \\
\hline CHEMBL3922724 & 1641655 & 7.5995 & 7.5645 & TRN & & \\
\hline CHEMBL 3985653 & 1641655 & 6.5686 & 6.6171 & TST & & \\
\hline CHEMBL 3957552 & 1641655 & 8.082 & 7.7131 & TRN & & \\
\hline CHEMBL3981344 & 1641655 & 7.9694 & 7.7567 & TRN & & \\
\hline
\end{tabular}

Page 15329 
Supplemental Table S2.txt

\begin{tabular}{|c|c|c|c|c|c|c|}
\hline CHEMBL3942045 & 1641655 & 4.5229 & 4.9519 & TRN & & \\
\hline CHEMBL3394062 & 1641655 & 5.7872 & 5.2686 & TST & & \\
\hline CHEMBL3965530 & 1641655 & 5.7349 & 6.0127 & TST & & \\
\hline CHEMBL 3949278 & 1641655 & 7.5255 & 7.3643 & TRN & & \\
\hline CHEMBL3978285 & 1641655 & 8.0549 & 8.2608 & TRN & & \\
\hline CHEMBL3898847 & 1641655 & 7.0581 & 7.159 & TST & & \\
\hline CHEMBL3930004 & 1641655 & 7.3875 & 7.6032 & TRN & & \\
\hline CHEMBL3943596 & 1641655 & 5.0565 & 5.0223 & TRN & & \\
\hline CHEMBL3937933 & 1641655 & 7.871 & 7.6212 & TRN & & \\
\hline CHEMBL3899208 & 1641655 & 8.0648 & 8.0673 & TRN & & \\
\hline CHEMBL3957476 & 1641655 & 6.5214 & 6.0952 & TST & & \\
\hline CHEMBL3946064 & 1641655 & 5.0 & 4.842 & TRN & & \\
\hline CHEMBL3964669 & 1641655 & 7.8713 & 8.1134 & TRN & & \\
\hline CHEMBL3953669 & 1641655 & 5.8719 & 5.6647 & TRN & & \\
\hline CHEMBL3913009 & 1641655 & 7.1623 & 7.0473 & TRN & & \\
\hline CHEMBL3394165 & 1641655 & 7.74299 & 999999999 & & 7.9628 & TRN \\
\hline CHEMBL 3947790 & 1641655 & 6.3979 & 6.306 & TRN & & \\
\hline CHEMBL3904923 & 1641655 & 6.6156 & 6.2936 & TRN & & \\
\hline CHEMBL3394069 & 1641655 & 7.6755 & 7.231 & TRN & & \\
\hline CHEMBL3932201 & 1641655 & 8.3714 & 8.1203 & TRN & & \\
\hline CHEMBL3965804 & 1641655 & 6.8541 & 6.9834 & TRN & & \\
\hline CHEMBL3891145 & 1641655 & 6.0853 & 5.9887 & TRN & & \\
\hline CHEMBL3976832 & 1641655 & 7.545 & 7.7815 & TRN & & \\
\hline CHEMBL3952291 & 1641655 & 6.9114 & 6.8348 & TRN & & \\
\hline CHEMBL3965218 & 1641655 & 8.2859 & 8.2989 & TRN & & \\
\hline CHEMBL3919558 & 1641655 & 7.0399 & 6.6785 & TRN & & \\
\hline CHEMBL3958501 & 1641655 & 4.5229 & 4.7442 & TRN & & \\
\hline CHEMBL3915900 & 1641655 & 5.9141 & 5.9909 & TRN & & \\
\hline CHEMBL 3899451 & 1641655 & 6.4416 & 6.4555 & TRN & & \\
\hline CHEMBL3971473 & 1641655 & 8.7696 & 8.7001 & TRN & & \\
\hline CHEMBL3954897 & 1641655 & 6.6132 & 6.3743 & TRN & & \\
\hline CHEMBL3394167 & 1641655 & 7.99700 & 000000000 & & 8.043 & TRN \\
\hline CHEMBL3394070 & 1641655 & 6.6446 & 6.6054 & TRN & & \\
\hline CHEMBL 3889658 & 1641655 & 6.5642 & 6.7253 & TST & & \\
\hline CHEMBL3394074 & 1641655 & 8.0153 & 7.916 & TRN & & \\
\hline CHEMBL3926288 & 1641655 & 6.6682 & 6.5904 & TRN & & \\
\hline CHEMBL3976511 & 1641655 & 7.2421 & 7.0771 & TRN & & \\
\hline CHEMBL3964167 & 1641655 & 6.9307 & 6.8366 & TRN & & \\
\hline CHEMBL 3985000 & 1641655 & 5.0 & 4.7654 & TST & & \\
\hline CHEMBL3918311 & 1641655 & 6.5385 & 6.1147 & TST & & \\
\hline CHEMBL3912113 & 1641655 & 8.5447 & 8.2123 & TRN & & \\
\hline CHEMBL 3946212 & 1641655 & 8.8162 & 8.6899 & TRN & & \\
\hline CHEMBL3394064 & 1641655 & 6.4589 & 6.3561 & TST & & \\
\hline CHEMBL 3921252 & 1641655 & 7.224 & 7.1901 & TRN & & \\
\hline CHEMBL3959316 & 1641655 & 7.4465 & 7.3784 & TRN & & \\
\hline CHEMBL3912927 & 1641655 & 6.8704 & 6.5893 & TRN & & \\
\hline CHEMBL3967959 & 1641655 & 7.9626 & 8.004 & TRN & & \\
\hline CHEMBL3972469 & 1641655 & 6.6518 & 6.7026 & TRN & & \\
\hline
\end{tabular}


Supplemental Table S2.txt

\begin{tabular}{|c|c|c|c|c|c|c|}
\hline CHEMBL3922191 & 1641655 & 6.2444 & 5.8194 & TST & & \\
\hline CHEMBL 3927004 & 1641655 & 7.66700 & 0000000 & & 7.7889 & TRN \\
\hline CHEMBL3394067 & 1641655 & 6.0 & 5.5935 & TRN & & \\
\hline CHEMBL3939836 & 1641655 & 7.2341 & 7.3778 & TST & & \\
\hline CHEMBL3891857 & 1641655 & 6.347 & 6.3644 & TRN & & \\
\hline CHEMBL3905618 & 1641655 & 8.9784 & 8.7882 & TRN & & \\
\hline CHEMBL3969942 & 1641655 & 8.6207 & 8.4007 & TRN & & \\
\hline CHEMBL3925503 & 1641655 & 6.8108 & 6.8611 & TRN & & \\
\hline CHEMBL3914961 & 1641655 & 7.0966 & 7.4631 & TRN & & \\
\hline CHEMBL3970168 & 1641655 & 8.3181 & 8.5323 & TRN & & \\
\hline CHEMBL3890422 & 1641655 & 6.9824 & 6.9203 & TRN & & \\
\hline CHEMBL3941198 & 1641655 & 8.5289 & 8.2987 & TRN & & \\
\hline CHEMBL3930916 & 1641655 & 7.0522 & 7.4236 & TRN & & \\
\hline CHEMBL3958260 & 1641655 & 5.5792 & 5.4743 & TST & & \\
\hline CHEMBL 3916044 & 1641655 & 4.5229 & 4.5217 & TRN & & \\
\hline CHEMBL3983191 & 1641655 & 6.5243 & 5.7537 & TST & & \\
\hline CHEMBL3924622 & 1641655 & 5.664 & 5.1899 & TRN & & \\
\hline CHEMBL3963322 & 1641655 & 5.6189 & 5.7957 & TRN & & \\
\hline CHEMBL3974432 & 1641655 & 5.55 & 5.5481 & TRN & & \\
\hline CHEMBL3906121 & 1641655 & 6.2058 & 6.3517 & TRN & & \\
\hline CHEMBL3986966 & 1641655 & 6.1311 & 5.6773 & TRN & & \\
\hline CHEMBL3921475 & 1641655 & 7.1898 & 6.8782 & TRN & & \\
\hline CHEMBL3889589 & 1641655 & 6.1858 & 6.0998 & TRN & & \\
\hline CHEMBL3977709 & 1641655 & 6.5959 & 5.8927 & TRN & & \\
\hline CHEMBL 3965556 & 1641655 & 7.8447 & 7.9246 & TRN & & \\
\hline CHEMBL3943843 & 1641655 & 7.7174 & 7.5624 & TRN & & \\
\hline CHEMBL3911316 & 1641655 & 8.4316 & 8.4062 & TRN & & \\
\hline CHEMBL3915869 & 1641655 & 6.4166 & 6.9095 & TRN & & \\
\hline CHEMBL 3967448 & 1641655 & 6.269 & 6.1981 & TRN & & \\
\hline CHEMBL3911670 & 1641655 & 5.9097 & 5.5323 & TRN & & \\
\hline CHEMBL3959910 & 1641655 & 7.1319 & 7.3905 & TRN & & \\
\hline CHEMBL3896794 & 1641655 & 8.3143 & 8.5493 & TRN & & \\
\hline CHEMBL3964497 & 1641655 & 7.5424 & 6.7905 & TST & & \\
\hline CHEMBL3925450 & 1641655 & 6.685 & 6.9259 & TRN & & \\
\hline CHEMBL3937821 & 1641655 & 6.1069 & 6.1705 & TRN & & \\
\hline CHEMBL3970756 & 1641655 & \multicolumn{3}{|c|}{8.937000000000001} & 7.8904 & TRN \\
\hline CHEMBL3942435 & 1641655 & 8.1915 & 8.4248 & TRN & & \\
\hline CHEMBL3910491 & 1641655 & 7.1501 & 6.7443 & TRN & & \\
\hline CHEMBL3394061 & 1641655 & 5.9974 & 6.1847 & TST & & \\
\hline CHEMBL3963493 & 1641655 & 6.1695 & 6.3882 & TRN & & \\
\hline CHEMBL3970964 & 1641655 & 6.4891 & 6.4262 & TST & & \\
\hline CHEMBL3981312 & 1641655 & 6.8411 & 6.8926 & TST & & \\
\hline CHEMBL 3891490 & 1641655 & 6.3378 & 6.2295 & TRN & & \\
\hline CHEMBL3945846 & 1641655 & 7.6126 & 7.6397 & TRN & & \\
\hline CHEMBL3947592 & 1641655 & 6.0677 & 5.6851 & TRN & & \\
\hline CHEMBL3904783 & 1641655 & 8.6467 & 8.5697 & TRN & & \\
\hline CHEMBL 3933275 & 1641655 & 6.8005 & 7.1233 & TRN & & \\
\hline CHEMBL 3938424 & 1641655 & 6.9742 & 6.8718 & TST & & \\
\hline
\end{tabular}


Supplemental Table S2.txt

\begin{tabular}{|c|c|c|c|c|c|}
\hline CHEMBL3900527 & 1641655 & 8.1808 & 7.495 & TST & \\
\hline CHEMBL3934994 & 1641655 & 7.2697 & 7.2348 & TRN & \\
\hline CHEMBL3930132 & 1641655 & 7.0983 & 7.1901 & TRN & \\
\hline CHEMBL3942495 & 1641655 & 7.0945 & 7.0218 & TRN & \\
\hline CHEMBL3939130 & 1641655 & 6.1876 & \multicolumn{2}{|c|}{6.702999999999999} & TRN \\
\hline CHEMBL3915618 & 1641655 & 6.8618 & 6.3287 & TST & \\
\hline CHEMBL3963678 & 1641655 & 5.5371 & 5.3612 & TRN & \\
\hline CHEMBL3901582 & 1641655 & 8.647 & 8.3418 & TRN & \\
\hline CHEMBL3947201 & 1641655 & 8.5575 & 8.2309 & TRN & \\
\hline CHEMBL3981772 & 1641655 & 7.862 & 7.8255 & TRN & \\
\hline CHEMBL3906747 & 1641655 & 6.8511 & 7.1628 & TRN & \\
\hline CHEMBL3965029 & 1641655 & 7.3064 & 7.4907 & TRN & \\
\hline CHEMBL3986124 & 1641655 & 7.6975 & 7.8638 & TRN & \\
\hline CHEMBL3935173 & 1641655 & 7.4896 & 7.3328 & TST & \\
\hline CHEMBL3904314 & 1641655 & 7.5216 & 8.0954 & TST & \\
\hline CHEMBL3932794 & 1641655 & 8.6603 & 8.6656 & TRN & \\
\hline CHEMBL3912741 & 1641655 & 8.3952 & 8.2914 & TRN & \\
\hline CHEMBL3942256 & 1641655 & 7.7082 & 7.9726 & TRN & \\
\hline CHEMBL 3923772 & 1641655 & 7.2439 & 7.4095 & TRN & \\
\hline CHEMBL 3933697 & 1641655 & 7.4526 & 7.65 & TRN & \\
\hline CHEMBL3941886 & 1641655 & 6.2087 & 6.1732 & TRN & \\
\hline CHEMBL3953116 & 1641655 & 7.3302 & \multicolumn{2}{|c|}{6.8839999999999995} & TST \\
\hline CHEMBL3944661 & 1641655 & 6.6118 & 6.0647 & TST & \\
\hline CHEMBL3957081 & 1641655 & 4.5229 & 4.9756 & TRN & \\
\hline CHEMBL 3927342 & 1641655 & 6.1443 & 6.193 & TST & \\
\hline CHEMBL 3957078 & 1641655 & 5.7104 & 5.5465 & TRN & \\
\hline CHEMBL3394073 & 1641655 & 7.9097 & 7.7349 & TRN & \\
\hline CHEMBL3394169 & 1641655 & 6.9415 & 7.2522 & TRN & \\
\hline CHEMBL 3948227 & 1641655 & 7.3559 & 7.8104 & TRN & \\
\hline CHEMBL3394170 & 1641655 & 7.5561 & 7.4786 & TRN & \\
\hline CHEMBL 3985673 & 1641655 & 5.9819 & 5.6382 & TRN & \\
\hline CHEMBL3982185 & 1641655 & 8.2334 & 8.359 & TRN & \\
\hline CHEMBL3918188 & 1641655 & 7.6788 & 7.5053 & TRN & \\
\hline CHEMBL 3896741 & 1641655 & 7.2219 & 6.8118 & TRN & \\
\hline CHEMBL 3943672 & 1641655 & 6.3439 & 6.1708 & TRN & \\
\hline CHEMBL 3903410 & 1641655 & 6.6131 & 6.3249 & TRN & \\
\hline CHEMBL3981553 & 1641655 & 8.112 & 8.2604 & TRN & \\
\hline CHEMBL3901121 & 1641655 & 4.5229 & 4.1015 & TST & \\
\hline CHEMBL 3903651 & 1641655 & 6.0767 & 5.933 & TST & \\
\hline CHEMBL 3895040 & 1641655 & 8.3325 & 8.0461 & TST & \\
\hline CHEMBL3968565 & 1641655 & 7.1998 & 7.2132 & TST & \\
\hline CHEMBL3984537 & 1641655 & 6.9547 & 6.9458 & TST & \\
\hline CHEMBL3946988 & 1641655 & 5.7703 & 5.7033 & TST & \\
\hline CHEMBL 3950062 & 1641655 & 6.2534 & 6.1339 & TST & \\
\hline CHEMBL 3916074 & 1641655 & 6.6745 & 7.0388 & TST & \\
\hline CHEMBL3913664 & 1641655 & 6.6234 & 6.7801 & TST & \\
\hline CHEMBL3894736 & 1641655 & 6.0 & 7.1165 & TST & \\
\hline CHEMBL3967996 & 1641655 & 7.8533 & 7.8098 & TST & \\
\hline
\end{tabular}

Page 15332 
Supplemental Table S2.txt

\begin{tabular}{|c|c|c|c|c|c|}
\hline CHEMBL3938446 & 1641655 & 7.7077 & 7.6423 & TST & \\
\hline CHEMBL3394068 & 1641655 & 7.4299 & 7.3701 & TST & \\
\hline CHEMBL3936230 & 1641655 & 7.624 & 7.4094 & TST & \\
\hline CHEMBL3945136 & 1641655 & 7.0841 & 7.3567 & TST & \\
\hline CHEMBL3930832 & 1641655 & 8.3219 & 8.4505 & TST & \\
\hline CHEMBL3956364 & 1641655 & 6.2668 & 5.9906 & TST & \\
\hline CHEMBL3962369 & 1641655 & 6.5669 & 6.4465 & TST & \\
\hline CHEMBL3924862 & 1641655 & 8.8508 & 8.6916 & TST & \\
\hline CHEMBL3918913 & 1641655 & 6.8396 & 7.1081 & TST & \\
\hline CHEMBL3950989 & 1641655 & 6.4547 & 6.7184 & TST & \\
\hline CHEMBL3939297 & 1641655 & 6.3187 & 6.1426 & TST & \\
\hline CHEMBL3933526 & 1641332 & 5.0 & 5.005 & TRN & \\
\hline CHEMBL3894225 & 1641332 & 6.6402 & 7.1457 & TRN & \\
\hline CHEMBL 3945287 & 1641332 & 9.5229 & 9.4786 & TRN & \\
\hline CHEMBL3964488 & 1641332 & 10.0 & 9.7449 & TRN & \\
\hline CHEMBL3941341 & 1641332 & 7.4318 & 7.4463 & TRN & \\
\hline CHEMBL3902618 & 1641332 & 5.0 & 4.6413 & TRN & \\
\hline CHEMBL3978558 & 1641332 & 9.699 & 9.5019 & TRN & \\
\hline CHEMBL3923925 & 1641332 & 8.1549 & 7.4442 & TST & \\
\hline CHEMBL3977617 & 1641332 & 5.0 & 4.8594 & TRN & \\
\hline CHEMBL3899959 & 1641332 & 6.0424 & 6.1808 & TRN & \\
\hline CHEMBL3959080 & 1641332 & 5.0 & 5.0322 & TST & \\
\hline CHEMBL3938659 & 1641332 & 7.7212 & 7.8326 & TRN & \\
\hline CHEMBL3952597 & 1641332 & 7.0458 & 6.5171 & TRN & \\
\hline CHEMBL3926206 & 1641332 & 5.0 & 5.0877 & TRN & \\
\hline CHEMBL3979615 & 1641332 & 5.0 & 4.8611 & TRN & \\
\hline CHEMBL3894010 & 1641332 & 6.61799 & 999999999 & 99 & 7.3797 \\
\hline CHEMBL3913007 & 1641332 & 6.1759 & 6.145 & TRN & \\
\hline CHEMBL3950423 & 1641332 & 8.1549 & 8.5404 & TRN & \\
\hline CHEMBL3906104 & 1641332 & 6.5969 & 6.6569 & TRN & \\
\hline CHEMBL3954448 & 1641332 & 7.5229 & 7.6887 & TST & \\
\hline CHEMBL3901546 & 1641332 & 6.3635 & 5.5351 & TST & \\
\hline CHEMBL3894741 & 1641332 & 10.0 & 9.2434 & TRN & \\
\hline CHEMBL3899168 & 1641332 & 7.2218 & 7.2551 & TRN & \\
\hline CHEMBL3983880 & 1641332 & 5.0 & 4.689 & TRN & \\
\hline CHEMBL3930937 & 1641332 & 8.2218 & 6.8014 & TST & \\
\hline CHEMBL3935831 & 1641332 & 5.0 & 5.1579 & TRN & \\
\hline CHEMBL 3918145 & 1641332 & 5.0 & 5.3629 & TRN & \\
\hline CHEMBL 3898365 & 1641332 & 5.0 & 4.9153 & TRN & \\
\hline CHEMBL 3892280 & 1641332 & 7.8861 & 7.7105 & TRN & \\
\hline CHEMBL3935328 & 1641332 & 7.8861 & 7.5026 & TRN & \\
\hline CHEMBL3902902 & 1641332 & 6.6596 & 7.0081 & TRN & \\
\hline CHEMBL3951516 & 1641332 & 5.0 & 4.9945 & TRN & \\
\hline CHEMBL3926315 & 1641332 & 8.0969 & 8.1493 & TRN & \\
\hline CHEMBL3914767 & 1641332 & 9.0 & 9.2434 & TRN & \\
\hline CHEMBL3968809 & 1641332 & 8.0 & 8.055 & TRN & \\
\hline CHEMBL3957452 & 1641332 & 5.0 & 5.0829 & TRN & \\
\hline CHEMBL3977888 & 1641332 & 5.0 & 4.9815 & TRN & \\
\hline
\end{tabular}




\begin{tabular}{|c|c|c|c|c|c|c|}
\hline \multicolumn{7}{|c|}{ Supplemental Table S2.txt } \\
\hline CHEMBL 3930331 & 1641332 & 5.0 & 4.9427 & TRN & & \\
\hline CHEMBL 3928078 & 1641332 & 6.4225 & 6.193 & TRN & & \\
\hline CHEMBL3919588 & 1641332 & 8.3979 & 7.9416 & TRN & & \\
\hline CHEMBL3926978 & 1641332 & 7.2366 & 7.6418 & TRN & & \\
\hline CHEMBL 3977941 & 1641332 & 5.0 & 4.9343 & TRN & & \\
\hline CHEMBL3916278 & 1641332 & 5.0 & 4.9186 & TRN & & \\
\hline CHEMBL 3968862 & 1641332 & 6.6308 & 6.6103 & TRN & & \\
\hline CHEMBL3927034 & 1641332 & 5.0 & 5.0988 & TRN & & \\
\hline CHEMBL3899394 & 1641332 & 6.295 & 6.5065 & TRN & & \\
\hline CHEMBL3972650 & 1641332 & 5.0 & 5.2774 & TRN & & \\
\hline CHEMBL 3982752 & 1641332 & 5.0 & 4.7603 & TRN & & \\
\hline CHEMBL 3940857 & 1641332 & 6.2069 & 5.9811 & TRN & & \\
\hline CHEMBL3900505 & 1641332 & 6.4425 & 6.6258 & TRN & & \\
\hline CHEMBL3905757 & 1641332 & 5.0 & 5.0272 & TRN & & \\
\hline CHEMBL 3944073 & 1641332 & 6.4401 & 6.6634 & TST & & \\
\hline CHEMBL3964893 & 1641332 & 5.0 & 5.1575 & TRN & & \\
\hline CHEMBL3896818 & 1641332 & 6.2441 & 6.0887 & TRN & & \\
\hline CHEMBL3892521 & 1641332 & 5.0 & 5.4766 & TRN & & \\
\hline CHEMBL3942501 & 1641332 & 6.3028 & 6.2177 & TRN & & \\
\hline CHEMBL 3918488 & 1641332 & 6.6757 & 6.9815 & TRN & & \\
\hline CHEMBL3933415 & 1641332 & 6.2815 & 6.841 & TRN & & \\
\hline CHEMBL3897913 & 1641332 & 5.0 & 5.1302 & TRN & & \\
\hline CHEMBL 3903407 & 1641332 & 5.0 & 4.888 & TRN & & \\
\hline CHEMBL 3928464 & 1641332 & 6.11799 & 999999999 & 99 & 6.212999999999999 & TRN \\
\hline CHEMBL 3936294 & 1641332 & 6.5114 & 7.0435 & TST & & \\
\hline CHEMBL3970633 & 1641332 & 6.0367 & 5.686 & TRN & & \\
\hline CHEMBL 3971522 & 1641332 & 8.699 & 8.7951 & TST & & \\
\hline CHEMBL 3975856 & 1641332 & 7.2441 & 8.5631 & TST & & \\
\hline CHEMBL3913717 & 1641332 & 9.0 & 7.6387 & TST & & \\
\hline CHEMBL 3902632 & 1641332 & 5.0 & 5.2976 & TRN & & \\
\hline CHEMBL3969110 & 1641332 & 5.0 & 5.3852 & TST & & \\
\hline CHEMBL 3895034 & 1641332 & 7.8539 & 8.1804 & TRN & & \\
\hline CHEMBL 3924869 & 1641332 & 7.7212 & 7.3288 & TRN & & \\
\hline CHEMBL3930891 & 1641332 & 6.4202 & 6.7673 & TRN & & \\
\hline CHEMBL3931310 & 1641332 & 6.3757 & 6.4546 & TRN & & \\
\hline CHEMBL3943990 & 1641332 & 6.6326 & 6.7757 & TRN & & \\
\hline CHEMBL 3945230 & 1641332 & 6.1302 & 5.938 & TRN & & \\
\hline CHEMBL 3909211 & 1641332 & 10.0 & 9.4067 & TRN & & \\
\hline CHEMBL3924937 & 1641332 & 6.3002 & 6.3945 & TRN & & \\
\hline CHEMBL3917338 & 1641332 & 6.2343 & 5.8292 & TRN & & \\
\hline CHEMBL3923044 & 1641332 & 7.0605 & 7.1504 & TRN & & \\
\hline CHEMBL 3972984 & 1641332 & 6.3716 & 6.0394 & TRN & & \\
\hline CHEMBL3903849 & 1641332 & 5.0 & 5.2788 & TRN & & \\
\hline CHEMBL3951698 & 1641332 & 5.0 & 5.1306 & TRN & & \\
\hline CHEMBL 3941020 & 1641332 & 8.0969 & 7.9237 & TRN & & \\
\hline CHEMBL3901568 & 1641332 & 6.2782 & 6.0775 & TRN & & \\
\hline CHEMBL3921932 & 1641332 & 6.3893 & 6.4029 & TRN & & \\
\hline CHEMBL3912911 & 1641332 & 5.0 & 4.8958 & TRN & & \\
\hline
\end{tabular}




\begin{tabular}{|c|c|c|c|c|c|}
\hline \multicolumn{6}{|c|}{ Supplemental Table S2.txt } \\
\hline CHEMBL3939320 & 1641332 & 8.0 & 7.5723 & TRN & \\
\hline CHEMBL3963814 & 1641332 & 5.0 & 5.58 & TST & \\
\hline CHEMBL3929193 & 1641332 & 9.2218 & 9.4067 & TRN & \\
\hline CHEMBL3907071 & 1641332 & 7.9586 & 7.9342 & TRN & \\
\hline CHEMBL 3912857 & 1641332 & 6.4001 & 6.1617 & TRN & \\
\hline CHEMBL3950490 & 1641332 & 5.0 & 4.9655 & TRN & \\
\hline CHEMBL3905128 & 1641332 & 5.0 & 4.925 & TRN & \\
\hline CHEMBL 3891761 & 1641332 & 6.4237 & 6.657999 & 99999999995 & TRN \\
\hline CHEMBL3901241 & 1641332 & 6.4698 & 7.7022 & TST & \\
\hline CHEMBL 3974347 & 1641332 & 6.6655 & 7.242999 & 9999999999 & TRN \\
\hline CHEMBL3915850 & 1641332 & 6.6778 & 6.7122 & TRN & \\
\hline CHEMBL3964361 & 1641332 & 7.2218 & 6.8642 & TRN & \\
\hline CHEMBL3891330 & 1641332 & 7.2924 & 7.1063 & TRN & \\
\hline CHEMBL3942687 & 1641332 & 6.266 & 6.1656 & TRN & \\
\hline CHEMBL3966089 & 1641332 & 6.2076 & 6.3223 & TRN & \\
\hline CHEMBL3946359 & 1641332 & 8.301 & 8.232000 & 0000000001 & TRN \\
\hline CHEMBL3925353 & 1641332 & 5.0 & 4.925 & TRN & \\
\hline CHEMBL3923735 & 1641332 & 9.0458 & 8.5739 & TRN & \\
\hline CHEMBL3951689 & 1641332 & 7.9208 & 7.9545 & TRN & \\
\hline CHEMBL3920602 & 1641332 & 7.9208 & 7.6508 & TRN & \\
\hline CHEMBL3913857 & 1641332 & 5.0 & 5.1936 & TRN & \\
\hline CHEMBL3908218 & 1641332 & 5.0 & 4.9042 & TRN & \\
\hline CHEMBL3921464 & 1641332 & 8.0458 & 7.712000 & 0000000001 & TST \\
\hline CHEMBL 3897213 & 1641332 & 6.475 & 6.7859 & TRN & \\
\hline CHEMBL3912413 & 1641332 & 5.0 & 5.2881 & TRN & \\
\hline CHEMBL3910441 & 1641332 & 5.0 & 5.0355 & TRN & \\
\hline CHEMBL3920915 & 1641332 & 8.2218 & 7.4405 & TST & \\
\hline CHEMBL3934794 & 1641332 & 6.4597 & 5.9821 & TST & \\
\hline CHEMBL3935029 & 1641332 & 6.2441 & 6.3257 & TRN & \\
\hline CHEMBL3937724 & 1641332 & 5.0 & 5.1525 & TRN & \\
\hline CHEMBL3978544 & 1641332 & 6.5258 & 6.5278 & TRN & \\
\hline CHEMBL3930283 & 1641332 & 9.301 & 8.9775 & TRN & \\
\hline CHEMBL3922702 & 1641332 & 7.8239 & 7.8756 & TRN & \\
\hline CHEMBL3937478 & 1641332 & 6.8827 & 6.7081 & TRN & \\
\hline CHEMBL3977347 & 1641332 & 5.0 & 4.9398 & TRN & \\
\hline CHEMBL3979454 & 1641332 & 7.1805 & 7.5654 & TRN & \\
\hline CHEMBL 3956947 & 1641332 & 6.055 & 6.2533 & TRN & \\
\hline CHEMBL3937189 & 1641332 & 6.6696 & 6.1561 & TRN & \\
\hline CHEMBL3954665 & 1641332 & 5.0 & 5.3482 & TRN & \\
\hline CHEMBL3978299 & 1641332 & 7.2518 & 7.1761 & TRN & \\
\hline CHEMBL3985835 & 1641332 & 6.3655 & 6.0438 & TRN & \\
\hline CHEMBL3945285 & 1641332 & 9.699 & 10.1374 & TRN & \\
\hline CHEMBL3945826 & 1641332 & 7.5229 & 8.3482 & TST & \\
\hline CHEMBL3980575 & 1641332 & 5.0 & 4.8873 & TRN & \\
\hline CHEMBL3975564 & 1641332 & 6.4976 & 6.5159 & TRN & \\
\hline CHEMBL3932865 & 1641332 & 7.5086 & 8.3771 & TST & \\
\hline CHEMBL3949482 & 1641332 & 6.6716 & 7.0929 & TRN & \\
\hline CHEMBL3967972 & 1641332 & 6.4123 & 6.2983 & TRN & \\
\hline
\end{tabular}


Supplemental Table S2.txt

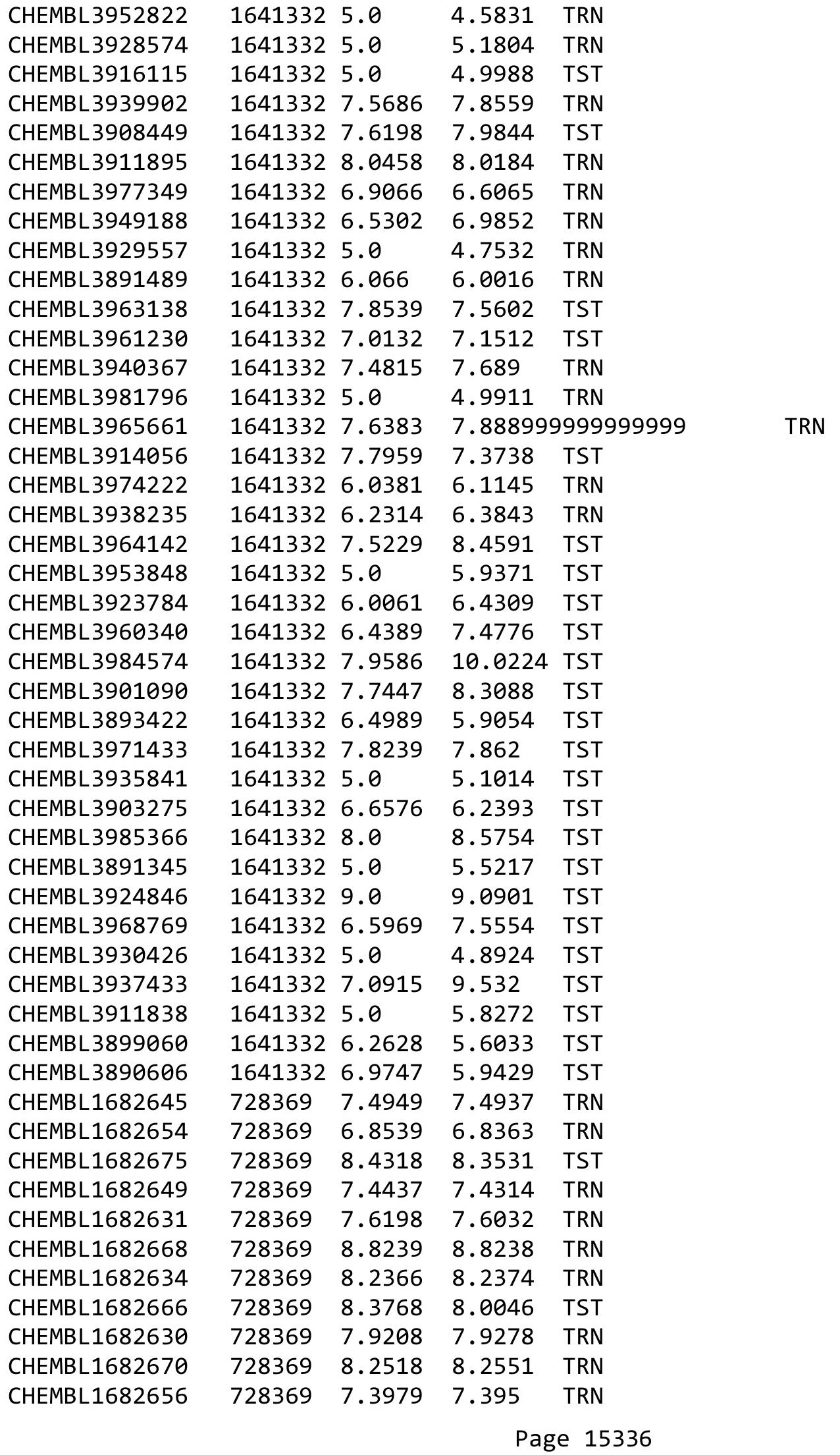


Supplemental Table S2.txt

\begin{tabular}{|c|c|c|c|c|}
\hline CHEMBL1682635 & 728369 & 7.9586 & 7.9724 & TRN \\
\hline CHEMBL1682679 & 728369 & 7.9208 & 8.4844 & TST \\
\hline CHEMBL1682628 & 728369 & 8.2757 & 8.2763 & TRN \\
\hline CHEMBL1682632 & 728369 & 7.4815 & 7.4809 & TRN \\
\hline CHEMBL1682683 & 728369 & 8.7212 & 8.257 & TST \\
\hline CHEMBL1682684 & 728369 & 6.8239 & 8.9546 & TST \\
\hline CHEMBL1682650 & 728369 & 7.4318 & 7.4455 & TRN \\
\hline CHEMBL1682676 & 728369 & 8.7447 & 8.5096 & TST \\
\hline CHEMBL1682665 & 728369 & 6.9586 & 6.9565 & TRN \\
\hline CHEMBL1682641 & 728369 & 7.8861 & 7.8889 & TRN \\
\hline CHEMBL1682662 & 728369 & 8.1367 & 8.1371 & TRN \\
\hline CHEMBL1682674 & 728369 & 8.4815 & 8.3558 & TST \\
\hline CHEMBL1682678 & 728369 & 8.1367 & 8.4629 & TST \\
\hline CHEMBL1682661 & 728369 & 7.0458 & 7.0458 & TRN \\
\hline CHEMBL1682664 & 728369 & 7.0315 & 7.0292 & TRN \\
\hline CHEMBL1682677 & 728369 & 7.7696 & 8.6323 & TST \\
\hline CHEMBL1682663 & 728369 & 6.8539 & 6.8546 & TRN \\
\hline CHEMBL1682637 & 728369 & 8.3372 & 8.3147 & TRN \\
\hline CHEMBL1682673 & 728369 & 8.1079 & 8.1086 & TRN \\
\hline CHEMBL1682655 & 728369 & 7.4949 & 7.5067 & TRN \\
\hline CHEMBL1681797 & 728369 & 8.1249 & 8.1118 & TRN \\
\hline CHEMBL1682658 & 728369 & 6.6778 & 6.6721 & TRN \\
\hline CHEMBL1682653 & 728369 & 6.5686 & 6.5643 & TRN \\
\hline CHEMBL1682681 & 728369 & 8.2366 & 8.4059 & TST \\
\hline CHEMBL1682647 & 728369 & 7.8539 & 7.8623 & TRN \\
\hline CHEMBL1682652 & 728369 & 6.0 & 6.0097 & TRN \\
\hline CHEMBL1682642 & 728369 & 7.6383 & 7.6472 & TRN \\
\hline CHEMBL1682651 & 728369 & 6.4559 & 6.4413 & TRN \\
\hline CHEMBL1682685 & 728369 & 6.8539 & 8.8881 & TST \\
\hline CHEMBL1682629 & 728369 & 7.8539 & 7.8519 & TRN \\
\hline CHEMBL1682636 & 728369 & 7.8239 & 7.8391 & TRN \\
\hline CHEMBL1682626 & 728369 & 7.699 & 7.6954 & TRN \\
\hline CHEMBL1682672 & 728369 & 8.4437 & 7.8484 & TST \\
\hline CHEMBL1682643 & 728369 & 8.2291 & 8.2307 & TRN \\
\hline CHEMBL1682633 & 728369 & 7.301 & 7.3189 & TRN \\
\hline CHEMBL1682669 & 728369 & 8.5528 & 8.5472 & TRN \\
\hline CHEMBL1682682 & 728369 & 8.0605 & 8.4629 & TST \\
\hline CHEMBL1682680 & 728369 & 8.1192 & 8.2925 & TST \\
\hline CHEMBL1682667 & 728369 & 8.2147 & 8.392006 & 0000000001 \\
\hline CHEMBL1682646 & 728369 & 7.1549 & 7.1491 & TRN \\
\hline CHEMBL1682638 & 728369 & 7.5528 & 7.5517 & TRN \\
\hline CHEMBL1682640 & 728369 & 7.7959 & 7.7952 & TRN \\
\hline CHEMBL1682644 & 728369 & 7.1739 & 7.1707 & TRN \\
\hline CHEMBL1682660 & 728369 & 7.3279 & 7.3224 & TRN \\
\hline CHEMBL1682659 & 728369 & 5.7212 & 5.7239 & TRN \\
\hline CHEMBL1682639 & 728369 & 7.6198 & 7.6234 & TRN \\
\hline CHEMBL1682648 & 728369 & 7.1739 & 7.1955 & TRN \\
\hline CHEMBL1682671 & 728369 & 7.9208 & 7.9152 & TRN \\
\hline
\end{tabular}


Supplemental Table S2.txt

\begin{tabular}{|c|c|c|c|c|c|}
\hline CHEMBL1682657 & 728369 & 7.2518 & 7.2558 & TRN & \\
\hline CHEMBL1682627 & 728369 & 7.7447 & 8.1485 & TST & \\
\hline CHEMBL3666281 & 1640310 & 6.3028 & 6.4479 & TRN & \\
\hline CHEMBL3671428 & 1640310 & 6.5686 & 7.2059 & TST & \\
\hline CHEMBL3666291 & 1640310 & 7.4237 & 7.3656 & TRN & \\
\hline CHEMBL3666299 & 1640310 & 7.2823 & 7.4512 & TRN & \\
\hline CHEMBL3661603 & 1640310 & 6.7328 & 6.5993 & TRN & \\
\hline CHEMBL3671454 & 1640310 & 6.4763 & 7.0535 & TST & \\
\hline CHEMBL 3666332 & 1640310 & 7.2684 & 6.931 & TRN & \\
\hline CHEMBL3661475 & 1640310 & 6.4067 & 6.7324 & TRN & \\
\hline CHEMBL 3661534 & 1640310 & 6.6596 & 6.8694 & TRN & \\
\hline CHEMBL3666459 & 1640310 & 6.2314 & 6.2994 & TST & \\
\hline CHEMBL3661627 & 1640310 & 8.0287 & 7.8272 & TRN & \\
\hline CHEMBL3661599 & 1640310 & 6.9101 & 6.4958 & TRN & \\
\hline CHEMBL3661533 & 1640310 & 7.1824 & 7.5536 & TRN & \\
\hline CHEMBL3666326 & 1640310 & 5.8097 & 5.8373 & TRN & \\
\hline CHEMBL3666346 & 1640310 & 5.718999 & 99999999 & 6.1916 & TRN \\
\hline CHEMBL3666406 & 1640310 & 5.3655 & 5.9465 & TRN & \\
\hline CHEMBL 3661521 & 1640310 & 5.8761 & 6.3122 & TRN & \\
\hline CHEMBL3666327 & 1640310 & 5.0088 & 6.3663 & TST & \\
\hline CHEMBL3671433 & 1640310 & 6.4271 & 7.4965 & TRN & \\
\hline CHEMBL3671461 & 1640310 & 8.2168 & 7.5548 & TST & \\
\hline CHEMBL3666444 & 1640310 & 6.7305 & 6.1972 & TRN & \\
\hline CHEMBL3661465 & 1640310 & 7.6421 & 7.4304 & TRN & \\
\hline CHEMBL3666289 & 1640310 & 6.7773 & 7.5554 & TRN & \\
\hline CHEMBL3666464 & 1640310 & 6.9281 & 6.2898 & TST & \\
\hline CHEMBL3666334 & 1640310 & 6.4413 & 7.2071 & TRN & \\
\hline CHEMBL3666275 & 1640310 & 7.4134 & 7.1011 & TRN & \\
\hline CHEMBL3666351 & 1640310 & 5.2487 & 6.9786 & TST & \\
\hline CHEMBL3666324 & 1640310 & 5.0083 & 6.0848 & TRN & \\
\hline CHEMBL3666371 & 1640310 & 6.7825 & 6.0767 & TRN & \\
\hline CHEMBL3661591 & 1640310 & 5.6289 & 5.7271 & TRN & \\
\hline CHEMBL3671437 & 1640310 & 8.8041 & 7.9269 & TRN & \\
\hline CHEMBL 3661528 & 1640310 & 6.4815 & 6.4176 & TST & \\
\hline CHEMBL3666408 & 1640310 & 6.6421 & 6.0341 & TST & \\
\hline CHEMBL3661477 & 1640310 & 6.0419 & 6.1839 & TRN & \\
\hline CHEMBL3661508 & 1640310 & 6.0106 & 6.1315 & TRN & \\
\hline CHEMBL 3666345 & 1640310 & 5.1169 & 5.9458 & TRN & \\
\hline CHEMBL3666375 & 1640310 & 6.8697 & 6.9385 & TRN & \\
\hline CHEMBL3661617 & 1640310 & 7.9031 & 7.8297 & TRN & \\
\hline CHEMBL3666356 & 1640310 & 5.0088 & 5.7921 & TRN & \\
\hline CHEMBL3661535 & 1640310 & 7.2255 & 7.1449 & TRN & \\
\hline CHEMBL3666300 & 1640310 & 6.3686 & 6.7374 & TRN & \\
\hline CHEMBL3671472 & 1640310 & 9.1669 & 7.6989 & TST & \\
\hline CHEMBL3666287 & 1640310 & 7.3655 & 7.0148 & TRN & \\
\hline CHEMBL3671430 & 1640310 & 8.5003 & 7.781006 & 0000000001 & TRN \\
\hline CHEMBL3666407 & 1640310 & 6.0991 & 6.4905 & TRN & \\
\hline CHEMBL3661503 & 1640310 & 7.1864 & 6.7943 & TRN & \\
\hline
\end{tabular}


Supplemental Table S2.txt

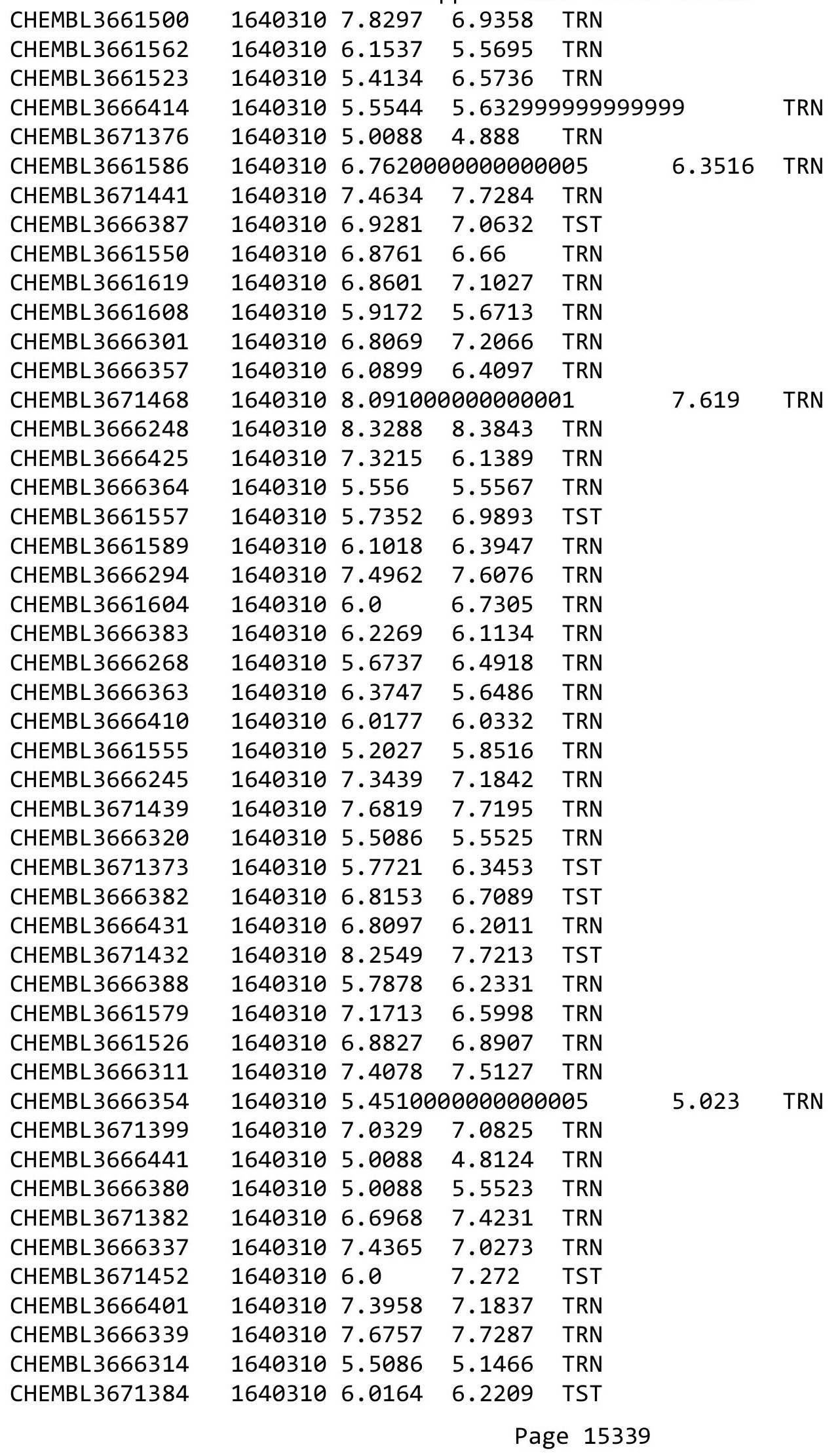


Supplemental Table S2.txt

\begin{tabular}{|c|c|c|c|c|c|c|}
\hline CHEMBL 3671456 & 1640310 & 7.1475 & 7.6603 & TST & & \\
\hline CHEMBL3661594 & 1640310 & 6.317 & 7.0142 & TRN & & \\
\hline CHEMBL3661587 & 1640310 & 5.4473 & 5.6707 & TRN & & \\
\hline CHEMBL3666292 & 1640310 & 7.6946 & 7.044 & TRN & & \\
\hline CHEMBL3661516 & 1640310 & 5.2336 & 5.8715 & TST & & \\
\hline CHEMBL3666423 & 1640310 & 5.0762 & 6.81 & TRN & & \\
\hline CHEMBL3666386 & 1640310 & 5.9136 & 6.757999 & 999999999 & & TST \\
\hline CHEMBL3661532 & 1640310 & 5.0804 & 5.8603 & TRN & & \\
\hline CHEMBL 3671448 & 1640310 & 6.5287 & 8.0454 & TRN & & \\
\hline CHEMBL3666348 & 1640310 & 5.2976 & 5.98 & TRN & & \\
\hline CHEMBL3666256 & 1640310 & 8.2857 & 8.1258 & TRN & & \\
\hline CHEMBL3666298 & 1640310 & 6.2684 & 6.6828 & TRN & & \\
\hline CHEMBL3666255 & 1640310 & 7.4802 & 7.3285 & TRN & & \\
\hline CHEMBL3661538 & 1640310 & 7.1457 & 6.7343 & TRN & & \\
\hline CHEMBL3671466 & 1640310 & 7.82100 & 000000000 & 1 & 5.3652 & TST \\
\hline CHEMBL 3671402 & 1640310 & 8.3439 & 7.8617 & TRN & & \\
\hline CHEMBL3671396 & 1640310 & 8.1367 & 7.1384 & TRN & & \\
\hline CHEMBL 3671394 & 1640310 & 5.0088 & 5.603 & TST & & \\
\hline CHEMBL3666352 & 1640310 & 6.1232 & 6.1794 & TRN & & \\
\hline CHEMBL3661585 & 1640310 & 6.059 & 6.2556 & TRN & & \\
\hline CHEMBL3671436 & 1640310 & 8.5072 & 8.2215 & TRN & & \\
\hline CHEMBL3666307 & 1640310 & 7.00700 & 000000000 & 1 & 7.3581 & TRN \\
\hline CHEMBL3661491 & 1640310 & 8.3134 & 7.8026 & TRN & & \\
\hline CHEMBL3666455 & 1640310 & 5.3546 & 5.3419 & TRN & & \\
\hline CHEMBL 3671370 & 1640310 & 5.0088 & 5.3167 & TRN & & \\
\hline CHEMBL3661623 & 1640310 & 7.0711 & 7.2203 & TRN & & \\
\hline CHEMBL3661495 & 1640310 & 6.6904 & 7.4321 & TRN & & \\
\hline CHEMBL3661590 & 1640310 & 6.3665 & 6.0358 & TRN & & \\
\hline CHEMBL3671403 & 1640310 & 8.0232 & 7.6267 & TRN & & \\
\hline CHEMBL3666394 & 1640310 & 5.0088 & 5.8154 & TRN & & \\
\hline CHEMBL3666272 & 1640310 & 7.4089 & 6.2314 & TRN & & \\
\hline CHEMBL3666415 & 1640310 & 6.6091 & 6.2588 & TRN & & \\
\hline CHEMBL3666305 & 1640310 & 6.2277 & 7.2963 & TST & & \\
\hline CHEMBL3671372 & 1640310 & 5.8508 & 5.9047 & TRN & & \\
\hline CHEMBL3661474 & 1640310 & 5.8013 & 6.3533 & TRN & & \\
\hline CHEMBL3666399 & 1640310 & 7.284 & 6.3164 & TST & & \\
\hline CHEMBL3661485 & 1640310 & 8.055 & 7.8668 & TRN & & \\
\hline CHEMBL 3666329 & 1640310 & 5.5638 & 6.5154 & TST & & \\
\hline CHEMBL3661578 & 1640310 & 6.2373 & 5.6683 & TRN & & \\
\hline CHEMBL3666376 & 1640310 & 5.8665 & 6.2118 & TRN & & \\
\hline CHEMBL3671426 & 1640310 & 8.118 & 7.9429 & TRN & & \\
\hline CHEMBL3666365 & 1640310 & 7.3401 & 6.1528 & TST & & \\
\hline CHEMBL3661600 & 1640310 & 6.9586 & 6.9236 & TRN & & \\
\hline CHEMBL3671375 & 1640310 & 5.5901 & 5.6056 & TRN & & \\
\hline CHEMBL 3661524 & 1640310 & 6.5467 & 6.1369 & TRN & & \\
\hline CHEMBL3671420 & 1640310 & 8.2725 & 8.3567 & TRN & & \\
\hline CHEMBL3661621 & 1640310 & 6.5622 & 6.9845 & TRN & & \\
\hline CHEMBL 3666270 & 1640310 & 6.2541 & 6.9099 & TRN & & \\
\hline
\end{tabular}

Page 15340 
Supplemental Table S2.txt

\begin{tabular}{|c|c|c|c|c|c|}
\hline CHEMBL 3666310 & 1640310 & 6.0783 & 6.3869 & TRN & \\
\hline CHEMBL 3666313 & 1640310 & 5.5086 & 5.99 & TRN & \\
\hline CHEMBL3666456 & 1640310 & 6.1918 & 5.8526 & TRN & \\
\hline CHEMBL 3666266 & 1640310 & 7.1612 & 6.4524 & TRN & \\
\hline CHEMBL 3661461 & 1640310 & 8.4498 & 8.0361 & TRN & \\
\hline CHEMBL3661556 & 1640310 & 6.4895 & 5.9415 & TRN & \\
\hline CHEMBL 3661472 & 1640310 & 7.1918 & 7.2506 & TRN & \\
\hline CHEMBL 3666340 & 1640310 & 7.2034 & 7.8316 & TRN & \\
\hline CHEMBL 3666389 & 1640310 & 5.5784 & 6.3708 & TRN & \\
\hline CHEMBL3666433 & 1640310 & 5.1445 & 4.9898 & TRN & \\
\hline CHEMBL 3666443 & 1640310 & 5.8794 & 5.754 & TRN & \\
\hline CHEMBL 3671407 & 1640310 & 7.2807 & 6.4378 & TRN & \\
\hline CHEMBL3661473 & 1640310 & 6.6925 & 7.3613 & TST & \\
\hline CHEMBL 3666277 & 1640310 & 6.5302 & 6.4118 & TRN & \\
\hline CHEMBL 3661547 & 1640310 & 7.1457 & 7.2689 & TRN & \\
\hline CHEMBL 3666405 & 1640310 & 5.8761 & 5.2572 & TRN & \\
\hline CHEMBL3639653 & 1640310 & 6.6716 & 7.352 & TST & \\
\hline CHEMBL 3666432 & 1640310 & 5.5017 & 6.1343 & TRN & \\
\hline CHEMBL 3661542 & 1640310 & 7.0297 & 7.4132 & TRN & \\
\hline CHEMBL 3666278 & 1640310 & 6.3625 & 6.6702 & TRN & \\
\hline CHEMBL3666315 & 1640310 & 5.0088 & 4.0736 & TRN & \\
\hline CHEMBL 3661488 & 1640310 & 7.9066 & 7.6951 & TRN & \\
\hline CHEMBL3671379 & 1640310 & 5.6308 & 5.8741 & TST & \\
\hline CHEMBL 3661489 & 1640310 & 7.2612 & 7.6834 & TRN & \\
\hline CHEMBL 3671368 & 1640310 & 5.0088 & 5.6411 & TRN & \\
\hline CHEMBL 3671427 & 1640310 & 8.3565 & 8.301 & TST & \\
\hline CHEMBL 3661605 & 1640310 & 6.0 & 6.9123 & TRN & \\
\hline CHEMBL3666446 & 1640310 & 5.6716 & 6.1038 & TRN & \\
\hline CHEMBL 3661541 & 1640310 & 7.1169 & 7.1929 & TRN & \\
\hline CHEMBL 3661548 & 1640310 & 7.0264 & 6.6128 & TRN & \\
\hline CHEMBL3666302 & 1640310 & 5.9136 & 5.7028 & TRN & \\
\hline CHEMBL 3661493 & 1640310 & 7.71 & 7.5403 & TRN & \\
\hline CHEMBL 3661584 & 1640310 & 6.0862 & 6.178 & TRN & \\
\hline CHEMBL 3661614 & 1640310 & 5.5086 & 5.9061 & TST & \\
\hline CHEMBL3661536 & 1640310 & 5.8601 & \multicolumn{2}{|c|}{6.627000000000001} & TRN \\
\hline CHEMBL3666403 & 1640310 & 5.76200 & 000000000 & 5.1361 & TRN \\
\hline CHEMBL 3661618 & 1640310 & 7.8268 & 7.5581 & TRN & \\
\hline CHEMBL 3671395 & 1640310 & 5.3575 & 5.6869 & TST & \\
\hline CHEMBL3666368 & 1640310 & 7.0883 & 6.8922 & TRN & \\
\hline CHEMBL 3666317 & 1640310 & 5.5086 & 5.3239 & TRN & \\
\hline CHEMBL3671465 & 1640310 & 6.52 & 5.3999 & TST & \\
\hline CHEMBL3666279 & 1640310 & 7.2652 & 6.6677 & TRN & \\
\hline CHEMBL 3661460 & 1640310 & 7.2549 & 7.4289 & TRN & \\
\hline CHEMBL3666335 & 1640310 & 6.5969 & 6.7118 & TRN & \\
\hline CHEMBL 3661470 & 1640310 & 6.2464 & 6.534 & TRN & \\
\hline CHEMBL 3666428 & 1640310 & 6.0904 & 6.2406 & TRN & \\
\hline CHEMBL 3671406 & 1640310 & 8.2291 & 7.9409 & TRN & \\
\hline CHEMBL 3666361 & 1640310 & 5.58 & 5.3848 & TRN & \\
\hline
\end{tabular}


Supplemental Table S2.txt

\begin{tabular}{|c|c|c|c|c|c|}
\hline CHEMBL3661564 & 1640310 & 5.5086 & 5.4554 & TRN & \\
\hline CHEMBL3661480 & 1640310 & 7.15 & 5.9652 & TRN & \\
\hline CHEMBL3661593 & 1640310 & 7.9957 & 7.9444 & TRN & \\
\hline CHEMBL 3666424 & 1640310 & 7.4365 & 6.6529 & TST & \\
\hline CHEMBL 3671474 & 1640310 & 6.9508 & 7.3814 & TRN & \\
\hline CHEMBL 3666411 & 1640310 & 5.5622 & 5.937 & TRN & \\
\hline CHEMBL3666417 & 1640310 & 5.2604 & 6.0555 & TST & \\
\hline CHEMBL3661512 & 1640310 & 5.5935 & 5.4014 & TRN & \\
\hline CHEMBL3666312 & 1640310 & 6.7258 & 6.2975 & TRN & \\
\hline CHEMBL3661531 & 1640310 & 6.3045 & 6.9978 & TST & \\
\hline CHEMBL 3666267 & 1640310 & 5.5302 & 6.1079 & TRN & \\
\hline CHEMBL3661478 & 1640310 & 6.4498 & 6.6121 & TRN & \\
\hline CHEMBL 3661514 & 1640310 & 7.2757 & 7.0443 & TRN & \\
\hline CHEMBL 3671385 & 1640310 & 5.9914 & 6.5826 & TRN & \\
\hline CHEMBL3661554 & 1640310 & 5.9666 & 5.692 & TRN & \\
\hline CHEMBL3661622 & 1640310 & 7.0155 & 7.0799 & TRN & \\
\hline CHEMBL 3661484 & 1640310 & 7.6635 & 7.0853 & TRN & \\
\hline CHEMBL 3661464 & 1640310 & 7.9626 & 7.3899 & TRN & \\
\hline CHEMBL 3666377 & 1640310 & 5.1475 & 5.1651 & TRN & \\
\hline CHEMBL3661502 & 1640310 & 8.1175 & 6.5123 & TRN & \\
\hline CHEMBL3671418 & 1640310 & 7.5003 & 8.227 & TST & \\
\hline CHEMBL 3661545 & 1640310 & 6.6345 & 5.938 & TRN & \\
\hline CHEMBL3666247 & 1640310 & 7.4157 & 7.5365 & TRN & \\
\hline CHEMBL3666259 & 1640310 & 8.9626 & 8.4113 & TRN & \\
\hline CHEMBL 3671381 & 1640310 & 7.5884 & 7.0418 & TRN & \\
\hline CHEMBL3666269 & 1640310 & 6.2373 & 5.6051 & TRN & \\
\hline CHEMBL3666319 & 1640310 & 5.5258 & 5.1165 & TRN & \\
\hline CHEMBL 3671463 & 1640310 & 7.4908 & 6.8687 & TRN & \\
\hline CHEMBL 3666458 & 1640310 & 5.5186 & 5.9448 & TRN & \\
\hline CHEMBL3666336 & 1640310 & 6.8097 & 6.7139 & TST & \\
\hline CHEMBL3661540 & 1640310 & 6.2418 & 6.3403 & TRN & \\
\hline CHEMBL 3661527 & 1640310 & 6.1669 & 6.2165 & TRN & \\
\hline CHEMBL 3666370 & 1640310 & 5.1624 & 6.439 & TST & \\
\hline CHEMBL 3666246 & 1640310 & 8.06 & 7.7349 & TRN & \\
\hline CHEMBL 3671400 & 1640310 & 7.3595 & 6.5861 & TRN & \\
\hline CHEMBL3661494 & 1640310 & 7.5918 & 6.8431 & TRN & \\
\hline CHEMBL 3666273 & 1640310 & 6.1568 & 5.9203 & TRN & \\
\hline CHEMBL 3671443 & 1640310 & 8.5346 & 8.1523 & TRN & \\
\hline CHEMBL 3661592 & 1640310 & 7.6556 & 7.9279 & TST & \\
\hline CHEMBL 3666438 & 1640310 & 5.1574 & 5.563 & TRN & \\
\hline CHEMBL3666263 & 1640310 & 7.7747 & 7.74799 & 9999999999 & TRN \\
\hline CHEMBL3661537 & 1640310 & 5.3251 & 5.1999 & TRN & \\
\hline CHEMBL3661505 & 1640310 & 7.3354 & 6.755 & TRN & \\
\hline CHEMBL 3666452 & 1640310 & 6.1244 & 6.33899 & 99999999995 & TST \\
\hline CHEMBL 3671467 & 1640310 & 8.3335 & 7.1326 & TST & \\
\hline CHEMBL3661596 & 1640310 & 6.5003 & 7.4311 & TRN & \\
\hline CHEMBL3671447 & 1640310 & 8.51 & 7.2987 & TRN & \\
\hline CHEMBL 3666402 & 1640310 & 5.0088 & 5.4182 & TRN & \\
\hline
\end{tabular}


Supplemental Table S2.txt

\begin{tabular}{|c|c|c|c|c|c|}
\hline CHEMBL 3671459 & 1640310 & 5.6946 & 7.4687 & TST & \\
\hline CHEMBL 3671412 & 1640310 & 8.8041 & 8.5649 & TRN & \\
\hline CHEMBL3671451 & 1640310 & 7.4353 & 7.8528 & TST & \\
\hline CHEMBL 3661507 & 1640310 & 6.5229 & 6.7303 & TRN & \\
\hline CHEMBL 3661607 & 1640310 & 7.0794 & 6.2819 & TRN & \\
\hline CHEMBL 3666353 & 1640310 & 5.5229 & 6.7769 & TRN & \\
\hline CHEMBL3666316 & 1640310 & 5.5086 & 5.5554 & TRN & \\
\hline CHEMBL3639604 & 1640310 & 6.0783 & 5.9433 & TRN & \\
\hline CHEMBL 3661519 & 1640310 & 6.8297 & 7.2482 & TRN & \\
\hline CHEMBL3666390 & 1640310 & 5.585 & 5.1238 & TRN & \\
\hline CHEMBL3666260 & 1640310 & 7.9136 & 7.9835 & TRN & \\
\hline CHEMBL 3666280 & 1640310 & 6.3575 & 6.211 & TRN & \\
\hline CHEMBL3666297 & 1640310 & 5.8356 & 6.7421 & TST & \\
\hline CHEMBL3661620 & 1640310 & 7.1959 & 7.2691 & TRN & \\
\hline CHEMBL 3661572 & 1640310 & 5.5086 & 6.151 & TRN & \\
\hline CHEMBL 3666264 & 1640310 & 7.1331 & 7.0292 & TRN & \\
\hline CHEMBL3661560 & 1640310 & 6.9586 & 6.896 & TRN & \\
\hline CHEMBL3666265 & 1640310 & 7.0716 & 7.6205 & TRN & \\
\hline CHEMBL 3666318 & 1640310 & 6.9547 & 6.7171 & TRN & \\
\hline CHEMBL 3661490 & 1640310 & 8.2636 & 7.5147 & TRN & \\
\hline CHEMBL 3666409 & 1640310 & 7.0297 & 6.7067 & TRN & \\
\hline CHEMBL3661513 & 1640310 & 6.6326 & 6.7987 & TRN & \\
\hline CHEMBL 3666457 & 1640310 & 7.1871 & 7.0484 & TRN & \\
\hline CHEMBL 3666384 & 1640310 & 6.8794 & 6.9953 & TRN & \\
\hline CHEMBL 3671405 & 1640310 & 8.4056 & 8.5909 & TRN & \\
\hline CHEMBL 3671434 & 1640310 & 5.7932 & 7.2696 & TRN & \\
\hline CHEMBL3666308 & 1640310 & 6.6234 & 7.8183 & TRN & \\
\hline CHEMBL 3666372 & 1640310 & 7.0742 & 7.0131 & TRN & \\
\hline CHEMBL3661583 & 1640310 & 6.0778 & 6.0043 & TRN & \\
\hline CHEMBL 3671422 & 1640310 & 7.6737 & 8.418 & TRN & \\
\hline CHEMBL 3661467 & 1640310 & 7.1986 & 7.162000 & 3000000001 & TRN \\
\hline CHEMBL 3671404 & 1640310 & 8.6478 & 7.9574 & TST & \\
\hline CHEMBL 3671473 & 1640310 & 5.9431 & 6.9286 & TRN & \\
\hline CHEMBL3661613 & 1640310 & 5.7799 & 5.6701 & TRN & \\
\hline CHEMBL3661569 & 1640310 & 5.5867 & 5.1262 & TRN & \\
\hline CHEMBL 3671380 & 1640310 & -0.9912 & 3.848999 & 799999999998 & TRN \\
\hline CHEMBL 3661629 & 1640310 & 7.7167 & 7.2833 & TRN & \\
\hline CHEMBL 3661487 & 1640310 & 7.382000 & 00000000 & 7.0395 & I Kा \\
\hline CHEMBL 3666437 & 1640310 & 5.9706 & 6.8257 & TST & \\
\hline CHEMBL3661486 & 1640310 & 5.9872 & 6.4115 & TRN & \\
\hline CHEMBL3661616 & 1640310 & 8.4425 & 8.2708 & TRN & \\
\hline CHEMBL 3666419 & 1640310 & 6.9706 & 6.1874 & TRN & \\
\hline CHEMBL 3666347 & 1640310 & 5.9872 & 6.4768 & TRN & \\
\hline CHEMBL3666429 & 1640310 & 6.0367 & 6.7187 & TRN & \\
\hline CHEMBL3661573 & 1640310 & 5.5114 & 5.6492 & TRN & \\
\hline CHEMBL 3671409 & 1640310 & 7.5045 & 6.8823 & TST & \\
\hline CHEMBL 3671438 & 1640310 & 7.7471 & 7.7266 & TRN & \\
\hline CHEMBL3661468 & 1640310 & 6.5482 & 6.5696 & TRN & \\
\hline
\end{tabular}

Page 15343 
Supplemental Table S2.txt

\begin{tabular}{|c|c|c|c|c|c|}
\hline CHEMBL 3671410 & 1640310 & 7.6925 & 7.0637 & TRN & \\
\hline CHEMBL3661561 & 1640310 & 5.4597 & 6.5552 & TRN & \\
\hline CHEMBL3666453 & 1640310 & 5.7645 & 6.5102 & TRN & \\
\hline CHEMBL3666369 & 1640310 & 5.0088 & 5.6096 & TRN & \\
\hline CHEMBL 3666349 & 1640310 & 5.6904 & 6.6369 & TRN & \\
\hline CHEMBL 3661497 & 1640310 & 7.3799 & 7.7609 & TRN & \\
\hline CHEMBL3661602 & 1640310 & 6.5654 & 6.6204 & TRN & \\
\hline CHEMBL 3666283 & 1640310 & 5.9957 & 6.4402 & TRN & \\
\hline CHEMBL 3661496 & 1640310 & 7.3675 & 6.8851 & TRN & \\
\hline CHEMBL 3666274 & 1640310 & 6.466 & 7.0422 & TRN & \\
\hline CHEMBL 3666252 & 1640310 & 7.6253 & 7.0527 & TRN & \\
\hline CHEMBL3661504 & 1640310 & 7.4377 & 7.4506 & TRN & \\
\hline CHEMBL 3666322 & 1640310 & 5.0083 & 5.326000 & 00000000005 & TRN \\
\hline CHEMBL 3666262 & 1640310 & 8.0645 & 7.7072 & TRN & \\
\hline CHEMBL 3661510 & 1640310 & 6.9872 & 6.9986 & TRN & \\
\hline CHEMBL 3666293 & 1640310 & 7.2118 & 7.7364 & TRN & \\
\hline CHEMBL3666321 & 1640310 & 5.5086 & 6.0529 & TRN & \\
\hline CHEMBL 3671397 & 1640310 & 7.3197 & 6.9791 & TRN & \\
\hline CHEMBL 3661581 & 1640310 & 5.58 & 5.6594 & TRN & \\
\hline CHEMBL 3671415 & 1640310 & 8.3893 & 8.5733 & TRN & \\
\hline CHEMBL 3671401 & 1640310 & 7.9431 & 7.1723 & TRN & \\
\hline CHEMBL3661525 & 1640310 & 6.0804 & 5.5237 & TRN & \\
\hline CHEMBL3666295 & 1640310 & 7.3215 & 7.1369 & TRN & \\
\hline CHEMBL 3671388 & 1640310 & 8.2636 & 6.6864 & TST & \\
\hline CHEMBL 3666333 & 1640310 & 6.4868 & 6.6985 & TRN & \\
\hline CHEMBL 3661462 & 1640310 & 8.382 & 8.0157 & TRN & \\
\hline CHEMBL3661509 & 1640310 & 6.9914 & 6.6843 & TRN & \\
\hline CHEMBL 3671424 & 1640310 & 7.7932 & 7.6844 & TRN & \\
\hline CHEMBL 3666290 & 1640310 & 5.4908 & 7.0566 & TRN & \\
\hline CHEMBL 3661567 & 1640310 & 5.0083 & 5.7373 & TRN & \\
\hline CHEMBL 3666282 & 1640310 & 6.7932 & 5.9036 & TRN & \\
\hline CHEMBL3661577 & 1640310 & 5.7328 & 5.4754 & TRN & \\
\hline CHEMBL 3666374 & 1640310 & 6.6091 & 6.5673 & TRN & \\
\hline CHEMBL 3661611 & 1640310 & 5.5086 & 5.57 & TRN & \\
\hline CHEMBL3666296 & 1640310 & 6.5243 & 7.305 & TST & \\
\hline CHEMBL3666331 & 1640310 & 6.3458 & 6.2335 & TRN & \\
\hline CHEMBL 3661471 & 1640310 & 6.76200 & 000000000 & 6.8202 & $T$. \\
\hline CHEMBL3666360 & 1640310 & 5.2924 & 5.4377 & TRN & \\
\hline CHEMBL 3661482 & 1640310 & 7.1993 & 6.9981 & TRN & \\
\hline CHEMBL 3661574 & 1640310 & 5.5086 & 6.0145 & TRN & \\
\hline CHEMBL 3671446 & 1640310 & 7.8477 & 8.0177 & TRN & \\
\hline CHEMBL 3661552 & 1640310 & 6.6383 & 6.3499 & TRN & \\
\hline CHEMBL 3671445 & 1640310 & 7.7471 & 7.4792 & TRN & \\
\hline CHEMBL 3661576 & 1640310 & 6.2652 & 6.6183 & TRN & \\
\hline CHEMBL 3671391 & 1640310 & 6.8416 & 5.4014 & TRN & \\
\hline CHEMBL 3661466 & 1640310 & 6.8697 & 6.7635 & TRN & \\
\hline CHEMBL 3666284 & 1640310 & 6.5272 & 6.8604 & TRN & \\
\hline CHEMBL 3666271 & 1640310 & 6.4647 & 6.3659 & TRN & \\
\hline
\end{tabular}

Page 15344 
Supplemental Table S2.txt

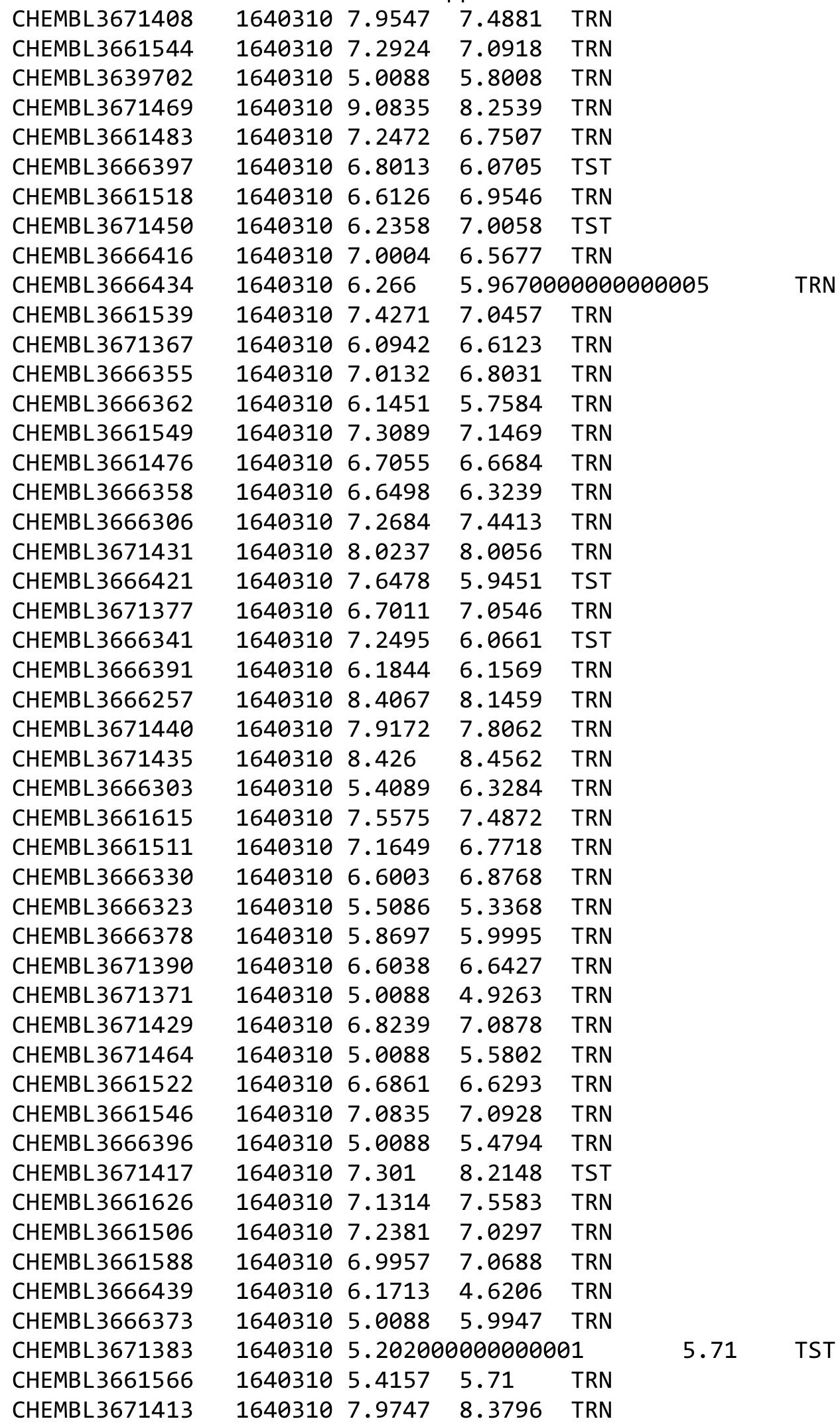


Supplemental Table S2.txt

\begin{tabular}{|c|c|c|c|c|}
\hline CHEMBL 3639603 & 1640310 & 8.4034 & 7.6972 & TRN \\
\hline CHEMBL 3671366 & 1640310 & 7.699 & 5.8549 & TRN \\
\hline CHEMBL 3671457 & 1640310 & 6.8477 & 7.1255 & TRN \\
\hline CHEMBL 3666412 & 1640310 & 6.5272 & 6.0794 & TRN \\
\hline CHEMBL 3666325 & 1640310 & 5.6615 & 5.2868 & TRN \\
\hline CHEMBL 3666253 & 1640310 & 7.4461 & 7.0865 & TRN \\
\hline CHEMBL 3661610 & 1640310 & 6.3354 & 5.9559 & TRN \\
\hline CHEMBL 3671442 & 1640310 & 5.1568 & 6.6709 & TST \\
\hline CHEMBL 3666304 & 1640310 & 5.5784 & 6.065 & TRN \\
\hline CHEMBL3661609 & 1640310 & 6.5436 & 6.2528 & TRN \\
\hline CHEMBL 3661469 & 1640310 & 5.9172 & 6.2841 & TRN \\
\hline CHEMBL 3661568 & 1640310 & 6.6778 & 6.6042 & TRN \\
\hline CHEMBL 3671444 & 1640310 & 8.0223 & 8.2188 & TRN \\
\hline CHEMBL3671455 & 1640310 & 7.5045 & 7.5667 & TST \\
\hline CHEMBL 3671419 & 1640310 & 8.5302 & 8.3098 & TRN \\
\hline CHEMBL 3666418 & 1640310 & 6.6882 & 6.4056 & TRN \\
\hline CHEMBL 3666445 & 1640310 & 5.5214 & 6.0791 & TRN \\
\hline CHEMBL 3671398 & 1640310 & 8.3401 & 7.938 & TRN \\
\hline CHEMBL3661553 & 1640310 & 6.6308 & 6.1227 & TRN \\
\hline CHEMBL 3661479 & 1640310 & 5.5436 & 8.07 & TST \\
\hline CHEMBL 3661515 & 1640310 & 5.284 & 6.0581 & TRN \\
\hline CHEMBL3639652 & 1640310 & 6.52 & 6.4462 & TST \\
\hline CHEMBL 3666261 & 1640310 & 7.9281 & 7.8615 & TRN \\
\hline CHEMBL 3666338 & 1640310 & 6.8153 & 7.5081 & TRN \\
\hline CHEMBL 3671470 & 1640310 & 8.4935 & 7.3976 & TRN \\
\hline CHEMBL 3666400 & 1640310 & 7.1475 & 6.5967 & TRN \\
\hline CHEMBL 3671386 & 1640310 & 5.7878 & 5.9395 & TRN \\
\hline CHEMBL 3661625 & 1640310 & 7.5986 & 7.7585 & TRN \\
\hline CHEMBL3671389 & 1640310 & 5.7878 & 5.1605 & TRN \\
\hline CHEMBL 3671453 & 1640310 & 7.6882 & 7.6863 & TRN \\
\hline CHEMBL 3666436 & 1640310 & 6.1986 & 5.4798 & TRN \\
\hline CHEMBL 3661601 & 1640310 & 6.8894 & 6.5136 & TRN \\
\hline CHEMBL 3666343 & 1640310 & 5.0088 & 4.9938 & TRN \\
\hline CHEMBL3666454 & 1640310 & 5.1379 & 5.6569 & TRN \\
\hline CHEMBL 3661575 & 1640310 & 5.5086 & 5.7196 & TRN \\
\hline CHEMBL 3666250 & 1640310 & 7.4486 & 7.4145 & TRN \\
\hline CHEMBL 3661582 & 1640310 & 6.5575 & 5.7635 & TRN \\
\hline CHEMBL 3666435 & 1640310 & 6.1979 & 5.0759 & TST \\
\hline CHEMBL3671416 & 1640310 & 6.8153 & 8.2917 & TST \\
\hline CHEMBL 3671393 & 1640310 & 5.7235 & 5.2336 & TRN \\
\hline CHEMBL 3661612 & 1640310 & 6.1599 & 5.8349 & TRN \\
\hline CHEMBL 3666430 & 1640310 & 6.5654 & 6.1121 & TRN \\
\hline CHEMBL 3666309 & 1640310 & 6.7799 & 6.976 & TRN \\
\hline CHEMBL 3671449 & 1640310 & 8.7212 & \multicolumn{2}{|c|}{8.302999999999999} \\
\hline CHEMBL 3666392 & 1640310 & 7.1524 & 6.0639 & TRN \\
\hline CHEMBL 3671460 & 1640310 & 8.821 & 7.5233 & TST \\
\hline CHEMBL 3666465 & 1640310 & 6.7167 & 5.7543 & TRN \\
\hline CHEMBL 3661501 & 1640310 & 7.9101 & 7.5732 & TRN \\
\hline
\end{tabular}

Page 15346 
Supplemental Table S2.txt

\begin{tabular}{|c|c|c|c|c|c|}
\hline CHEMBL 3671414 & 1640310 & 8.821 & 8.9746 & TRN & \\
\hline CHEMBL 3671387 & 1640310 & 7.1739 & 7.6483 & TRN & \\
\hline CHEMBL 3661498 & 1640310 & 7.699 & 7.0136 & TRN & \\
\hline CHEMBL 3666393 & 1640310 & 5.0088 & 5.8864 & TRN & \\
\hline CHEMBL3666413 & 1640310 & 6.6289 & 6.4007 & TRN & \\
\hline CHEMBL 3671374 & 1640310 & 6.0716 & 6.3675 & TRN & \\
\hline CHEMBL 3661517 & 1640310 & 6.8447 & 7.0617 & TRN & \\
\hline CHEMBL 3666449 & 1640310 & 5.2924 & 5.0482 & TRN & \\
\hline CHEMBL 3661628 & 1640310 & 7.6459 & 7.5277 & TST & \\
\hline CHEMBL3666460 & 1640310 & 5.6655 & 6.2232 & TST & \\
\hline CHEMBL 3666395 & 1640310 & 8.2857 & 6.4622 & TST & \\
\hline CHEMBL 3666385 & 1640310 & 5.0088 & 6.5187 & TST & \\
\hline CHEMBL 3666254 & 1640310 & 8.4584 & 7.7559 & TST & \\
\hline CHEMBL 3666342 & 1640310 & 5.0088 & 6.3299 & TST & \\
\hline CHEMBL3666344 & 1640310 & 6.0195 & 6.487 & TST & \\
\hline CHEMBL 3661530 & 1640310 & 6.4763 & 6.5103 & TST & \\
\hline CHEMBL3661551 & 1640310 & 6.7595 & 6.3047 & TST & \\
\hline CHEMBL 3666420 & 1640310 & 7.5058 & 6.5636 & TST & \\
\hline CHEMBL 3666379 & 1640310 & 6.75200 & 00000000 & 6.472 & TST \\
\hline CHEMBL3661606 & 1640310 & 6.0 & 8.0482 & TST & \\
\hline CHEMBL3671369 & 1640310 & 7.1898 & 6.0805 & TST & \\
\hline CHEMBL 3666328 & 1640310 & 5.3686 & 5.8406 & TST & \\
\hline CHEMBL 3666381 & 1640310 & 6.8601 & 6.7546 & TST & \\
\hline CHEMBL 3666404 & 1640310 & 6.3458 & 5.4404 & TST & \\
\hline CHEMBL 3666440 & 1640310 & 8.3915 & 7.2139 & TST & \\
\hline CHEMBL 3661563 & 1640310 & 5.5086 & 6.1898 & TST & \\
\hline CHEMBL 3666462 & 1640310 & 6.5045 & 6.1759 & TST & \\
\hline CHEMBL 3671425 & 1640310 & 8.55600 & 300000006 & 8.6148 & TS \\
\hline CHEMBL 3661529 & 1640310 & 6.5058 & 6.4452 & TST & \\
\hline CHEMBL 3666367 & 1640310 & 5.3215 & 6.3245 & TST & \\
\hline CHEMBL 3661580 & 1640310 & 6.1433 & 5.6096 & TST & \\
\hline CHEMBL 3671392 & 1640310 & 7.8996 & 6.6423 & TST & \\
\hline CHEMBL 3666422 & 1640310 & 6.1701 & 6.3002 & TST & \\
\hline CHEMBL 3666451 & 1640310 & 6.7799 & 6.88700 & 30000000005 & TST \\
\hline CHEMBL 3666366 & 1640310 & 6.8861 & 7.0618 & TST & \\
\hline CHEMBL 3671378 & 1640310 & 7.3615 & 7.336 & TST & \\
\hline CHEMBL 3666461 & 1640310 & 6.2749 & 5.9834 & TST & \\
\hline CHEMBL 3666427 & 1640310 & 8.2588 & 6.4144 & TST & \\
\hline CHEMBL 3666251 & 1640310 & 7.1487 & 7.3448 & TST & \\
\hline CHEMBL 3661463 & 1640310 & 7.9172 & 7.4076 & TST & \\
\hline CHEMBL 3666450 & 1640310 & 6.2815 & 6.2761 & TST & \\
\hline CHEMBL 3661565 & 1640310 & 5.8928 & 5.4005 & TST & \\
\hline CHEMBL 3666442 & 1640310 & 5.0088 & 5.0677 & TST & \\
\hline CHEMBL 3661595 & 1640310 & 6.3851 & 7.5911 & TST & \\
\hline CHEMBL 3661559 & 1640310 & 5.4685 & 5.7909 & TST & \\
\hline CHEMBL 3671471 & 1640310 & 8.0092 & 7.2096 & TST & \\
\hline CHEMBL 3661481 & 1640310 & 7.02 & 6.1932 & TST & \\
\hline CHEMBL 3671411 & 1640310 & 7.2907 & 6.7001 & TST & \\
\hline
\end{tabular}




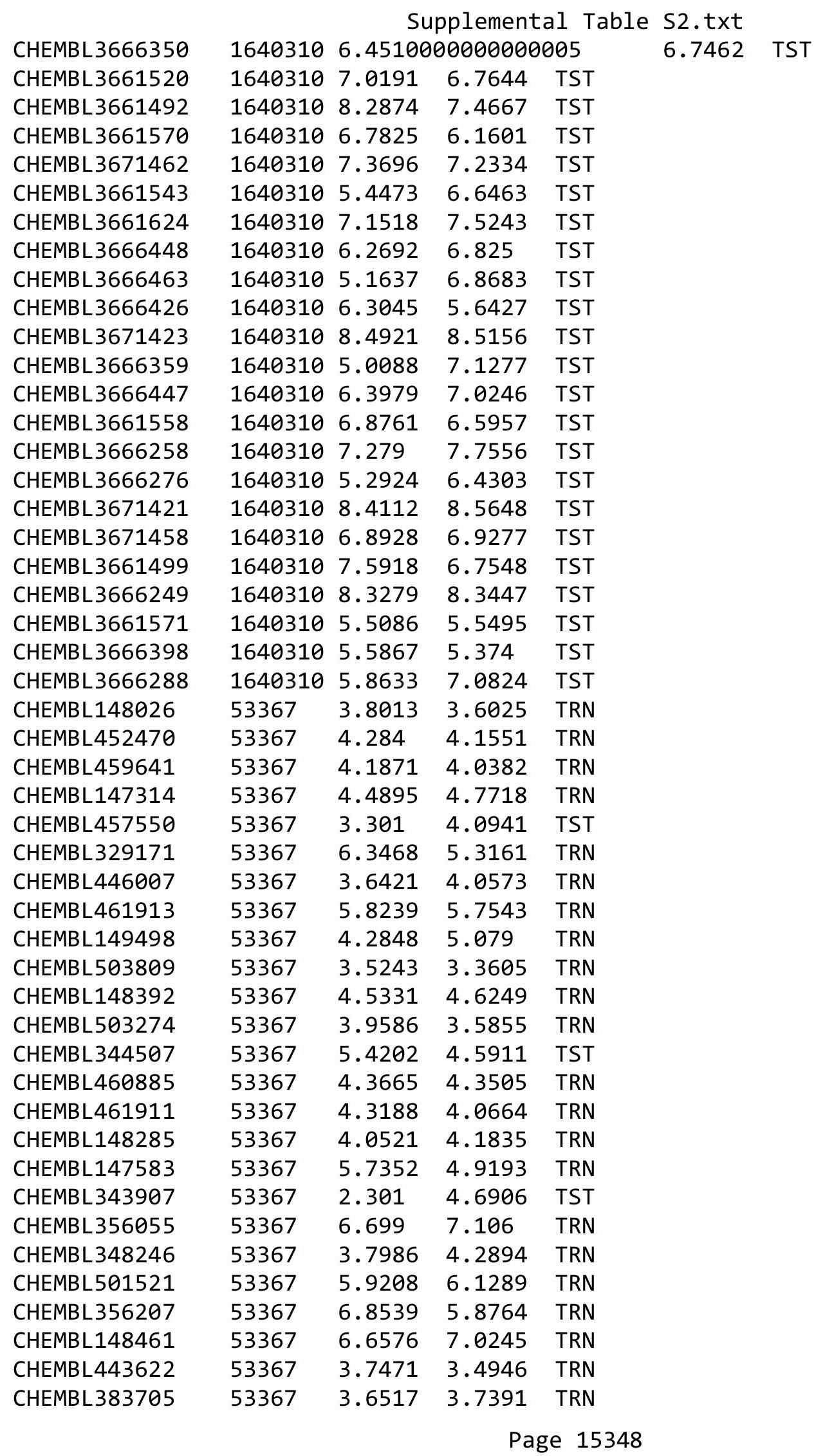




\begin{tabular}{|c|c|c|c|c|c|}
\hline \multicolumn{6}{|c|}{ Supplemental Table S2.txt } \\
\hline CHEMBL434886 & 53367 & 2.301 & 3.5733 & TST & \\
\hline CHEMBL460886 & 53367 & 3.9547 & 3.8455 & TRN & \\
\hline CHEMBL145855 & 53367 & 4.1073 & 4.1856 & TRN & \\
\hline CHEMBL98408 & 53367 & 4.5528 & 4.8429 & TRN & \\
\hline CHEMBL455298 & 53367 & 5.5229 & 5.7327 & TRN & \\
\hline CHEMBL443373 & 53367 & 3.8182 & 3.8675 & TRN & \\
\hline CHEMBL453918 & 53367 & 4.1024 & 4.0285 & TRN & \\
\hline CHEMBL146437 & 53367 & 2.301 & 3.717 & TST & \\
\hline CHEMBL146190 & 53367 & 4.2434 & 4.3713 & TRN & \\
\hline CHEMBL146995 & 53367 & 4.2076 & 4.521 & TRN & \\
\hline CHEMBL403882 & 53367 & 2.301 & 4.6018 & TST & \\
\hline CHEMBL 83418 & 53367 & 4.2291 & 4.0573 & TRN & \\
\hline CHEMBL359211 & 53367 & 4.9626 & 4.9288 & TRN & \\
\hline CHEMBL456298 & 53367 & 5.3098 & 5.0491 & TRN & \\
\hline CHEMBL148002 & 53367 & 2.0 & 3.5441 & TST & \\
\hline CHEMBL145862 & 53367 & 6.2007 & 5.8428 & TRN & \\
\hline CHEMBL343650 & 53367 & 3.6716 & 3.7742 & TST & \\
\hline CHEMBL461291 & 53367 & 3.5406 & 3.7229 & TRN & \\
\hline CHEMBL499101 & 53367 & 2.301 & 3.2848 & TRN & \\
\hline CHEMBL461912 & 53367 & 6.0 & 5.3653 & TRN & \\
\hline CHEMBL146509 & 53367 & 6.3098 & 6.8749 & TRN & \\
\hline CHEMBL501126 & 53367 & 5.0044 & 4.6271 & TRN & \\
\hline CHEMBL319514 & 53367 & 3.9586 & 4.3136 & TRN & \\
\hline CHEMBL148025 & 53367 & 5.0044 & 4.8757 & TRN & \\
\hline CHEMBL461496 & 53367 & 3.1367 & 3.2824 & TRN & \\
\hline CHEMBL511346 & 53367 & 3.8239 & 4.8633 & TST & \\
\hline CHEMBL97180 & 53367 & 6.4815 & 6.5575 & TST & \\
\hline CHEMBL148954 & 53367 & 6.1249 & 5.9464 & TST & \\
\hline CHEMBL97025 & 53367 & 2.0 & 4.1188 & TST & \\
\hline CHEMBL278393 & 53367 & 4.3768 & 4.8757 & TST & \\
\hline CHEMBL343616 & 53367 & 6.2924 & 4.6908 & TST & \\
\hline CHEMBL468470 & 559247 & 8.0458 & 8.0464 & TRN & \\
\hline CHEMBL462041 & 559247 & 6.6498 & 6.6622 & TRN & \\
\hline CHEMBL467634 & 559247 & 7.3665 & 7.3476 & TRN & \\
\hline CHEMBL513165 & 559247 & 4.301 & 4.3208 & TRN & \\
\hline CHEMBL511221 & 559247 & 7.4815 & 7.4686 & TRN & \\
\hline CHEMBL462270 & 559247 & 5.301 & 4.86600 & 00000000005 & TST \\
\hline CHEMBL467007 & 559247 & 7.8539 & 7.8641 & TRN & \\
\hline CHEMBL469308 & 559247 & 6.6308 & 6.6208 & TRN & \\
\hline CHEMBL460373 & 559247 & 8.5229 & 8.5267 & TRN & \\
\hline CHEMBL517044 & 559247 & 7.6778 & 7.6819 & TRN & \\
\hline CHEMBL462042 & 559247 & 6.5622 & 6.5653 & TRN & \\
\hline CHEMBL460980 & 559247 & 7.2291 & 7.777 & TST & \\
\hline CHEMBL516769 & 559247 & 9.0 & 8.995 & TRN & \\
\hline CHEMBL469298 & 559247 & 6.1675 & 6.1601 & TRN & \\
\hline CHEMBL462068 & 559247 & 7.3872 & 7.3976 & TRN & \\
\hline CHEMBL511589 & 559247 & 7.6383 & 7.6424 & TRN & \\
\hline CHEMBL460145 & 559247 & 7.2007 & 7.4994 & TST & \\
\hline
\end{tabular}




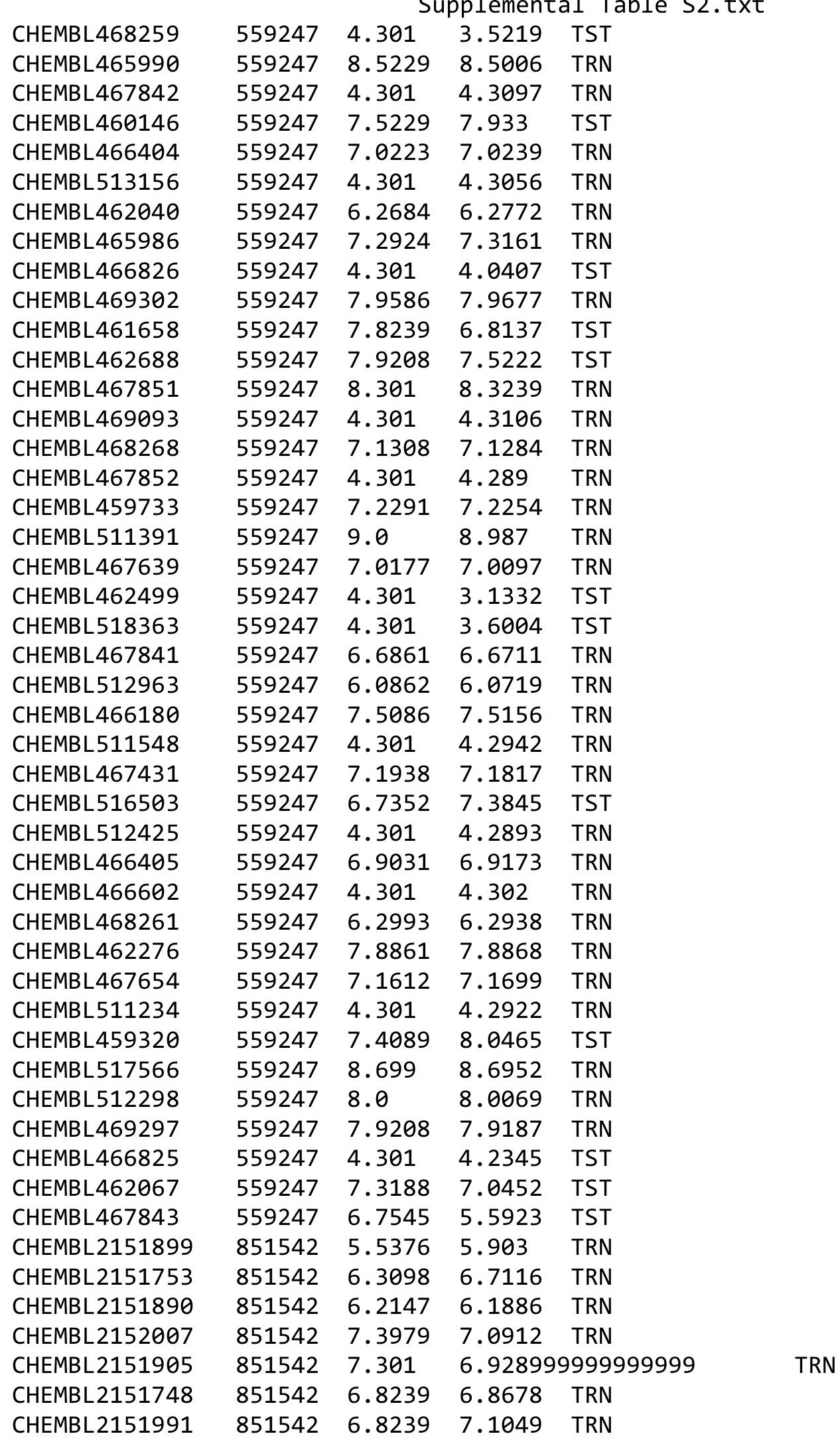

Page 15350 
Supplemental Table S2.txt

\begin{tabular}{|c|c|c|c|c|}
\hline CHEMBL 2152004 & 851542 & 6.0605 & 6.0559 & TRN \\
\hline CHEMBL 2151745 & 851542 & 7.1549 & 6.9578 & TRN \\
\hline CHEMBL2151910 & 851542 & 6.1427 & 6.2768 & TRN \\
\hline CHEMBL 2151754 & 851542 & 6.3098 & 6.416 & TRN \\
\hline CHEMBL 2151744 & 851542 & 6.5528 & 6.5774 & TRN \\
\hline CHEMBL 2151900 & 851542 & 6.2218 & 6.1987 & TRN \\
\hline CHEMBL 2151893 & 851542 & 6.3468 & 6.2652 & TRN \\
\hline CHEMBL418899 & 851542 & 5.6576 & 4.7289 & TST \\
\hline CHEMBL 2151996 & 851542 & 6.3565 & 6.1765 & TRN \\
\hline CHEMBL2151914 & 851542 & 6.2676 & 6.0023 & TRN \\
\hline CHEMBL 2151742 & 851542 & 5.2291 & 5.4576 & TRN \\
\hline CHEMBL 2151997 & 851542 & 6.3872 & 6.2794 & TRN \\
\hline CHEMBL 2151904 & 851542 & 6.4949 & 6.5375 & TRN \\
\hline CHEMBL 2151901 & 851542 & 6.6021 & 6.5116 & TRN \\
\hline CHEMBL 2151747 & 851542 & 6.3098 & 6.3938 & TRN \\
\hline CHEMBL 2151895 & 851542 & 6.3279 & 6.1881 & TRN \\
\hline CHEMBL2151892 & 851542 & 6.8861 & 7.1388 & TRN \\
\hline CHEMBL 2151898 & 851542 & 6.3979 & 6.0959 & TRN \\
\hline CHEMBL 2151756 & 851542 & 4.8752 & 4.8411 & TRN \\
\hline CHEMBL 2151887 & 851542 & 6.6778 & 6.5157 & TRN \\
\hline CHEMBL 2151911 & 851542 & 6.9586 & 6.2167 & TST \\
\hline CHEMBL2151903 & 851542 & 6.301 & 6.6762 & TRN \\
\hline CHEMBL 2151908 & 851542 & 5.6021 & 5.8706 & TRN \\
\hline CHEMBL 2151750 & 851542 & 6.4949 & 6.6689 & TRN \\
\hline CHEMBL2151992 & 851542 & 6.8239 & 6.7319 & TRN \\
\hline CHEMBL 2151743 & 851542 & 5.9208 & 5.7625 & TRN \\
\hline CHEMBL 2152005 & 851542 & 7.301 & 7.3933 & TRN \\
\hline CHEMBL 2151896 & 851542 & 5.2865 & 5.0638 & TRN \\
\hline CHEMBL2151999 & 851542 & 6.0605 & 6.1871 & TRN \\
\hline CHEMBL 2152006 & 851542 & 6.5376 & 6.8337 & TRN \\
\hline CHEMBL1209808 & 851542 & 5.3565 & 4.686 & TST \\
\hline CHEMBL1836702 & 851542 & 5.0223 & 5.0489 & TST \\
\hline CHEMBL2151907 & 851542 & 6.0915 & 5.9318 & TST \\
\hline CHEMBL 2151889 & 851542 & 4.9923 & 4.9005 & TRN \\
\hline CHEMBL 2151752 & 851542 & 7.301 & 7.0494 & TRN \\
\hline CHEMBL2151894 & 851542 & 6.4202 & 6.3729 & TRN \\
\hline CHEMBL 2151749 & 851542 & 7.699 & 7.7842 & TRN \\
\hline CHEMBL2151913 & 851542 & 6.5686 & 6.4291 & TRN \\
\hline CHEMBL 2151897 & 851542 & 5.3979 & 5.5447 & TRN \\
\hline CHEMBL 2151886 & 851542 & 7.1549 & 6.99799 & 9999999999 \\
\hline CHEMBL2151918 & 851542 & 7.3979 & 7.0494 & TRN \\
\hline CHEMBL 2152002 & 851542 & 6.8861 & 6.8443 & TRN \\
\hline CHEMBL2151884 & 851542 & 6.2366 & 6.1376 & TRN \\
\hline CHEMBL 2151917 & 851542 & 3.0 & 3.9606 & TST \\
\hline CHEMBL 2151916 & 851542 & 4.4225 & 4.4287 & TRN \\
\hline CHEMBL2151909 & 851542 & 6.9208 & 6.5004 & TRN \\
\hline CHEMBL 2151912 & 851542 & 6.4949 & 6.5235 & TRN \\
\hline CHEMBL2151906 & 851542 & 6.284 & 5.9055 & TST \\
\hline
\end{tabular}


Supplemental Table S2.txt

\begin{tabular}{|c|c|c|c|c|c|}
\hline CHEMBL 2151994 & 851542 & 6.3098 & 6.6047 & TRN & \\
\hline CHEMBL 2151915 & 851542 & 5.4202 & 5.4586 & TRN & \\
\hline CHEMBL 2151902 & 851542 & 5.6536 & 6.1187 & TRN & \\
\hline CHEMBL 2152001 & 851542 & 6.5686 & 6.2228 & TST & \\
\hline CHEMBL 2151993 & 851542 & 7.3979 & 7.3691 & TST & \\
\hline CHEMBL 2151998 & 851542 & 6.9586 & 6.0125 & TST & \\
\hline CHEMBL 2151891 & 851542 & 6.2218 & 6.8999 & TST & \\
\hline CHEMBL 2152003 & 851542 & 5.4318 & 6.459 & TST & \\
\hline CHEMBL 2151755 & 851542 & 6.585 & 6.3314 & TST & \\
\hline CHEMBL 2151746 & 851542 & 7.5229 & 6.4695 & TST & \\
\hline CHEMBL 2151751 & 851542 & 7.2218 & 6.718 & TST & \\
\hline CHEMBL 2151995 & 851542 & 6.7696 & 6.2635 & TST & \\
\hline CHEMBL 2152000 & 851542 & 6.3665 & 6.9173 & TST & \\
\hline CHEMBL1817761 & 763490 & 9.1612 & 8.5055 & TST & \\
\hline CHEMBL1819553 & 763490 & 7.8861 & 7.8409 & TRN & \\
\hline CHEMBL1817695 & 763490 & 8.7696 & 8.8155 & TRN & \\
\hline CHEMBL1817763 & 763490 & 7.8539 & 7.9554 & TST & \\
\hline CHEMBL1819554 & 763490 & 9.0969 & 9.0224 & TRN & \\
\hline CHEMBL1817754 & 763490 & 9.0044 & 8.7632 & TRN & \\
\hline CHEMBL1819559 & 763490 & 7.6778 & 7.709 & TRN & \\
\hline CHEMBL1819540 & 763490 & 9.8539 & 9.8445 & TRN & \\
\hline CHEMBL1817707 & 763490 & 9.2441 & 9.5181 & TRN & \\
\hline CHEMBL1819550 & 763490 & 8.6576 & 7.9473 & TST & \\
\hline CHEMBL1817704 & 763490 & 9.4202 & 9.3938 & TRN & \\
\hline CHEMBL1817755 & 763490 & 8.8239 & 8.9392 & TRN & \\
\hline CHEMBL1819545 & 763490 & 7.5229 & 7.5341 & TRN & \\
\hline CHEMBL1817768 & 763490 & 8.1135 & 8.1004 & TRN & \\
\hline CHEMBL1817766 & 763490 & 8.1024 & 7.7942 & TST & \\
\hline CHEMBL1817758 & 763490 & 7.8239 & 7.2943 & TST & \\
\hline CHEMBL1819558 & 763490 & 7.4089 & 7.3752 & TRN & \\
\hline CHEMBL1817750 & 763490 & 8.4089 & 8.5095 & TRN & \\
\hline CHEMBL1817701 & 763490 & 8.3188 & 8.2411 & TRN & \\
\hline CHEMBL1819547 & 763490 & 7.7212 & 8.3752 & TST & \\
\hline CHEMBL1817762 & 763490 & 7.9208 & 7.52 & TST & \\
\hline CHEMBL1817697 & 763490 & 8.0969 & \multicolumn{2}{|c|}{8.062000000000001} & TRN \\
\hline CHEMBL1817694 & 763490 & 8.2441 & 8.359 & TRN & \\
\hline CHEMBL1817706 & 763490 & 9.6778 & 9.5652 & TRN & \\
\hline CHEMBL1819546 & 763490 & 5.0 & 7.4936 & TST & \\
\hline CHEMBL1819544 & 763490 & 6.2924 & 6.3626 & TST & \\
\hline CHEMBL1817765 & 763490 & 8.1308 & 8.0988 & TRN & \\
\hline CHEMBL1817700 & 763490 & \multicolumn{3}{|c|}{8.283999999999999} & TRN \\
\hline CHEMBL1817756 & 763490 & 8.585 & 7.9313 & TST & \\
\hline CHEMBL1817757 & 763490 & 8.0 & 7.2862 & TST & \\
\hline CHEMBL1819557 & 763490 & 8.2218 & 8.3075 & TRN & \\
\hline CHEMBL1817767 & 763490 & 7.9208 & 7.6053 & TST & \\
\hline CHEMBL1817691 & 763490 & 7.9208 & 7.8767 & TRN & \\
\hline CHEMBL1817769 & 763490 & 7.9586 & 8.0837 & TRN & \\
\hline CHEMBL1817749 & 763490 & 8.5376 & 8.5534 & TRN & \\
\hline
\end{tabular}




\begin{tabular}{|c|c|c|c|c|}
\hline & \\
\hline & 763490 & 8.8539 & 8.81 & TRN \\
\hline CHEMBL1819543 & 763490 & 9.301 & 9.3486 & TRN \\
\hline CHEMBL1819549 & 763490 & 9.2147 & 9.1824 & TRN \\
\hline CHEMBL1819542 & 763490 & 9.5686 & 9.581 & RN \\
\hline CHEMBL1819541 & 763490 & 9.6383 & 9.6456 & RN \\
\hline CHEMBL1819560 & 763490 & 8.9586 & 8.9464 & TRN \\
\hline CHEMBL1817692 & 763490 & 8.8539 & 8.7999 & RN \\
\hline CHEMBL1817690 & 763490 & 7.1612 & 7.1537 & RN \\
\hline CHEMBL1817693 & 763490 & 8.4437 & 8.3429 & $\mathrm{RN}$ \\
\hline CHEMBL1817698 & 763490 & 8.6778 & 8.6764 & TRN \\
\hline CHEMBL1817705 & 763490 & 9.585 & 9.4602 & TRN \\
\hline CHEMBL1817764 & 763490 & 8.1367 & 8.1901 & RN \\
\hline CHEMBL1819548 & 763490 & 9.2676 & 8.5057 & ST \\
\hline CHEMBL1817760 & 763490 & 7.8239 & 7.8245 & TST \\
\hline CHEMBL1817771 & 763490 & 8.4949 & 8.5436 & TRN \\
\hline CHEMBL1817702 & 763490 & 9.0458 & 9.0632 & TRN \\
\hline CHEMBL1817671 & 763490 & 7.7447 & 7.7616 & RN \\
\hline CHEMBL1819555 & 763490 & 9.6021 & 9.5683 & TRN \\
\hline CHEMBL1817708 & 763490 & 9.0862 & 9.0729 & TRN \\
\hline CHEMBL1817699 & 763490 & 7.7959 & 7.7789 & TRN \\
\hline CHEMBL1817696 & 763490 & 8.3872 & 8.4171 & TRN \\
\hline CHEMBL1819552 & 763490 & 7.9586 & 7.9911 & TRN \\
\hline CHEMBL1817751 & 763490 & 8.5686 & 8.5163 & TRN \\
\hline CHEMBL1819556 & 763490 & 9.0269 & 8.3114 & TST \\
\hline CHEMBL1817703 & 763490 & 7.5229 & 7.5185 & TRN \\
\hline CHEMBL1817759 & 763490 & 7.8539 & 7.0938 & TST \\
\hline CHEMBL1817753 & 763490 & 8.6198 & 8.7492 & TRN \\
\hline CHEMBL1819441 & 763490 & 9.8239 & 9.8196 & TRN \\
\hline CHEMBL1817772 & 763490 & 8.7959 & 8.6925 & TRN \\
\hline CHEMBL1817770 & 763490 & 8.8539 & 8.9138 & TRN \\
\hline CHEMBL1819551 & 763490 & 5.0 & 6.2565 & TST \\
\hline CHEMBL3936639 & 1641888 & 4.9817 & 5.0928 & TRN \\
\hline CHEMBL3920030 & 1641888 & 8.6135 & 8.6685 & TRN \\
\hline CHEMBL3960796 & 1641888 & 7.9776 & 8.3777 & TRN \\
\hline CHEMBL3960822 & 1641888 & 6.2459 & 7.0135 & TST \\
\hline CHEMBL3925436 & 1641888 & 8.649 & 8.5507 & TRN \\
\hline CHEMBL3954316 & 1641888 & 8.5464 & 8.381 & TRN \\
\hline CHEMBL3972861 & 1641888 & 8.046 & 7.8946 & TRN \\
\hline CHEMBL3967005 & 1641888 & 8.582 & 8.5002 & TRN \\
\hline CHEMBL3927052 & 1641888 & 7.6853 & 8.0197 & TRN \\
\hline CHEMBL3910003 & 1641888 & 8.4275 & 7.8457 & TST \\
\hline CHEMBL3901368 & 1641888 & 8.9735 & 8.9767 & TRN \\
\hline CHEMBL3895714 & 1641888 & 8.4076 & 8.4492 & TRN \\
\hline CHEMBL3949157 & 1641888 & 8.1162 & 8.1494 & TRN \\
\hline CHEMBL3940123 & 1641888 & 8.0444 & 8.0722 & TRN \\
\hline CHEMBL3983489 & 1641888 & 7.9974 & 8.4377 & TRN \\
\hline CHEMBL3925629 & 1641888 & 7.4449 & 7.2642 & TRN \\
\hline CHEMBL3957232 & 1641888 & 8.7981 & 8.7599 & TH \\
\hline
\end{tabular}

Page 15353 


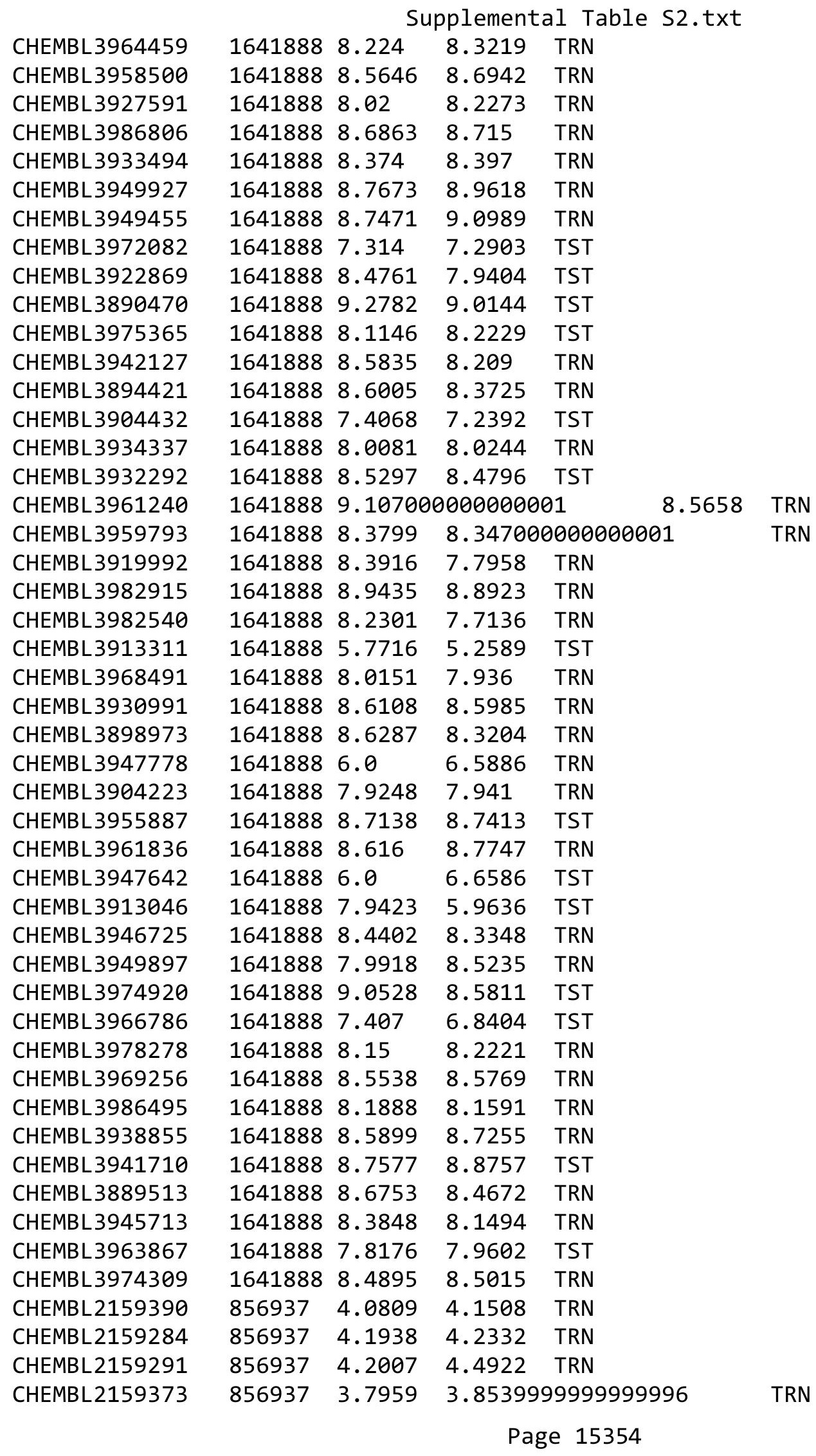


Supplemental Table S2.txt

\begin{tabular}{|c|c|c|c|c|}
\hline CHEMBL 2159281 & 856937 & 5.0691 & 5.0577 & TRN \\
\hline CHEMBL 2159270 & 856937 & 4.7696 & 4.7701 & TRN \\
\hline CHEMBL 2159392 & 856937 & 4.2218 & 4.2056 & TRN \\
\hline CHEMBL 2159371 & 856937 & 3.6517 & 3.7956 & TST \\
\hline CHEMBL 2159387 & 856937 & 4.8069 & 4.8045 & TRN \\
\hline CHEMBL 2159300 & 856937 & 3.6968 & 3.6808 & TRN \\
\hline CHEMBL 2159304 & 856937 & 4.0555 & 4.1252 & TRN \\
\hline CHEMBL 2159271 & 856937 & 5.0862 & 4.6645 & TST \\
\hline CHEMBL 2159362 & 856937 & 3.9031 & 4.2016 & TST \\
\hline CHEMBL 2159274 & 856937 & 6.0 & 4.5245 & TST \\
\hline CHEMBL 2159377 & 856937 & 3.9914 & 4.0846 & TST \\
\hline CHEMBL 2159286 & 856937 & 4.0 & 3.923 & TRN \\
\hline CHEMBL 2159376 & 856937 & 3.9208 & 3.8867 & TRN \\
\hline CHEMBL 2159303 & 856937 & 4.5376 & 4.3528 & TRN \\
\hline CHEMBL 2159290 & 856937 & 5.1308 & 5.1442 & TRN \\
\hline CHEMBL 2159379 & 856937 & 3.7825 & 4.3685 & TST \\
\hline CHEMBL 2159391 & 856937 & 4.5528 & 4.5837 & TRN \\
\hline CHEMBL 2159381 & 856937 & 3.6021 & 3.6761 & TRN \\
\hline CHEMBL 2159385 & 856937 & 3.75699 & 999999999 & 3.7555 \\
\hline CHEMBL 2159364 & 856937 & 5.1308 & 4.3015 & TST \\
\hline CHEMBL 2159301 & 856937 & 4.284 & 4.408 & TRN \\
\hline CHEMBL 2159383 & 856937 & 3.7645 & 3.7524 & TRN \\
\hline CHEMBL 2159375 & 856937 & 3.7825 & 3.8094 & TRN \\
\hline CHEMBL 2159394 & 856937 & 5.3979 & 5.4017 & TRN \\
\hline CHEMBL 2159302 & 856937 & 4.4318 & 4.3121 & TRN \\
\hline CHEMBL 2159292 & 856937 & 4.8861 & 4.6963 & TRN \\
\hline CHEMBL 2159397 & 856937 & 4.9747 & 4.9945 & TRN \\
\hline CHEMBL 2159396 & 856937 & 4.8861 & 4.7701 & TST \\
\hline CHEMBL 2159282 & 856937 & 5.2351 & 5.2427 & TRN \\
\hline CHEMBL 2159393 & 856937 & 4.7447 & 4.7382 & TRN \\
\hline CHEMBL 2159389 & 856937 & 4.9101 & 4.9004 & TRN \\
\hline CHEMBL 2159276 & 856937 & 6.0 & 4.4386 & TST \\
\hline CHEMBL 2159369 & 856937 & 3.6383 & 3.6714 & TST \\
\hline CHEMBL 2159293 & 856937 & 4.8239 & 4.5855 & TRN \\
\hline CHEMBL 2159285 & 856937 & 3.7595 & 3.8107 & TRN \\
\hline CHEMBL 2159388 & 856937 & 4.4949 & 4.4588 & TRN \\
\hline CHEMBL 2159288 & 856937 & 3.9393 & 3.9815 & TRN \\
\hline CHEMBL 2159294 & 856937 & 4.5229 & 4.6732 & TRN \\
\hline CHEMBL 2159283 & 856937 & 4.0706 & 3.9512 & TRN \\
\hline CHEMBL 2159395 & 856937 & 5.1192 & 4.7914 & TST \\
\hline CHEMBL 2159289 & 856937 & 4.8601 & 4.8858 & TRN \\
\hline CHEMBL 2159361 & 856937 & 4.1249 & 4.1689 & TRN \\
\hline CHEMBL 2159374 & 856937 & 4.1487 & 4.1002 & TRN \\
\hline CHEMBL 2159287 & 856937 & 3.9872 & 4.0002 & TRN \\
\hline CHEMBL 2159272 & 856937 & 5.2924 & 4.5767 & TST \\
\hline CHEMBL 2159363 & 856937 & 4.9747 & 4.306999 & 99999999995 \\
\hline CHEMBL 2159305 & 856937 & 4.5229 & 4.4878 & TRN \\
\hline CHEMBL 2159378 & 856937 & 3.6108 & 4.2788 & TST \\
\hline
\end{tabular}




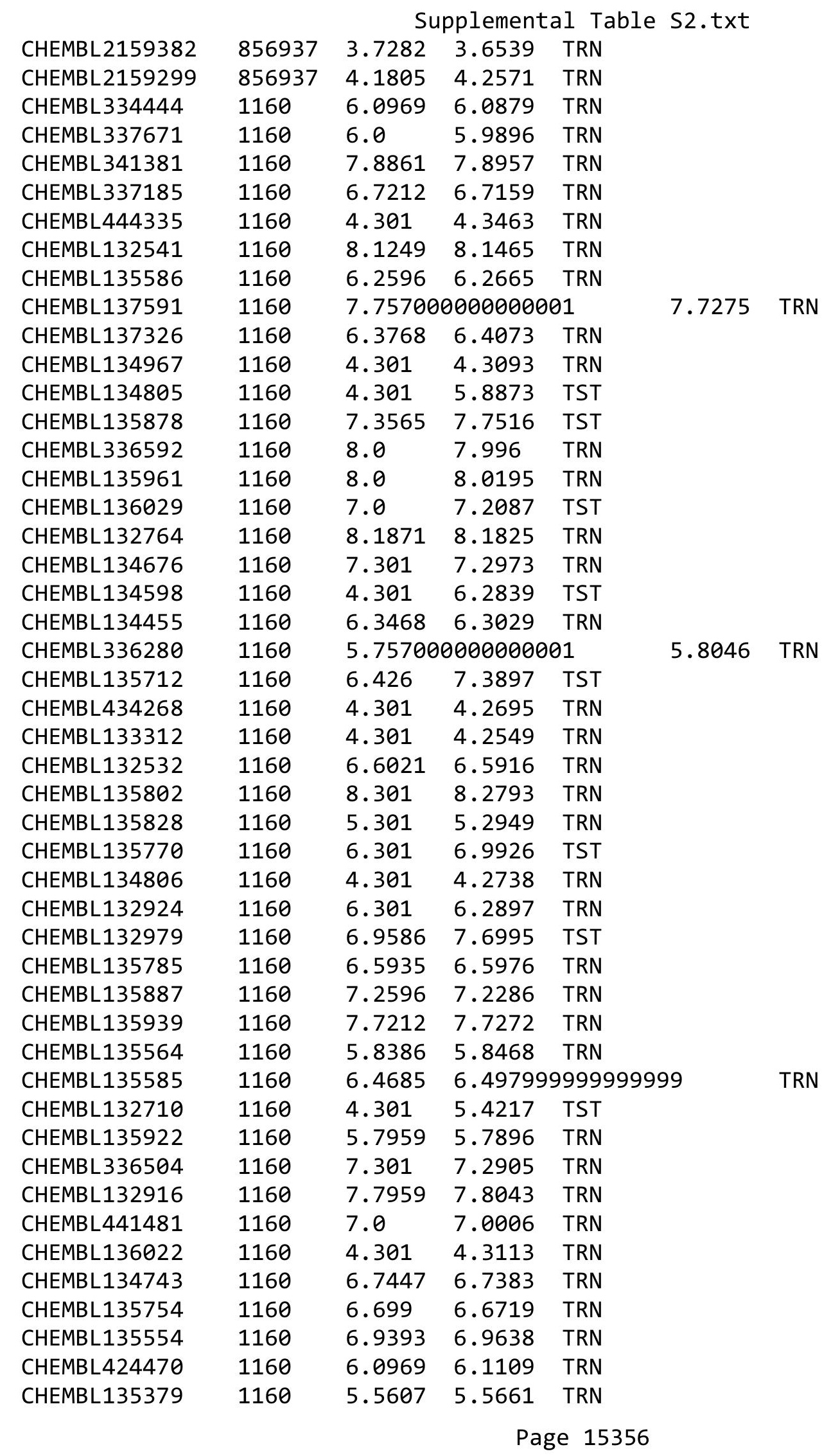




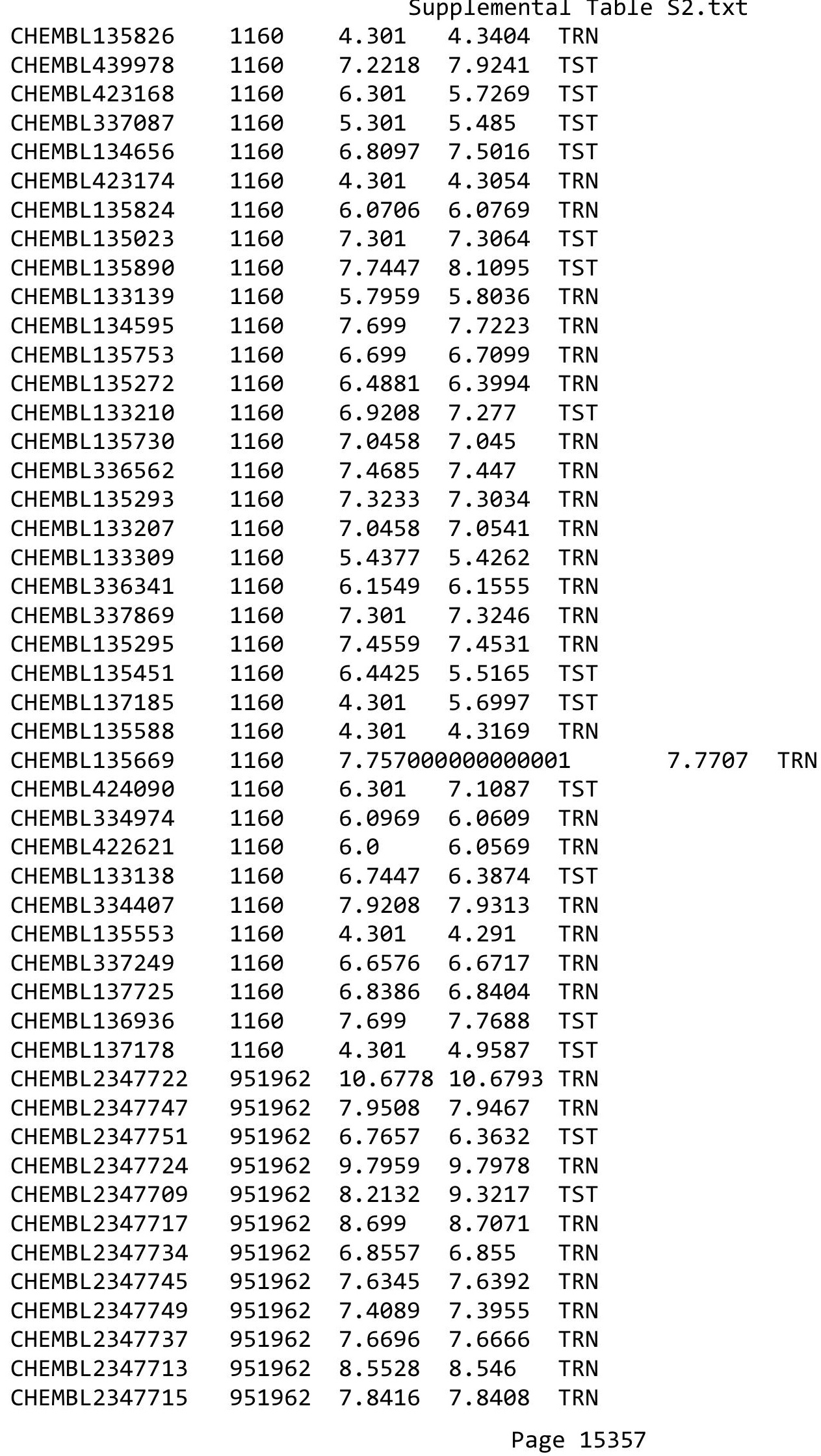




\begin{tabular}{|c|c|c|c|c|c|c|}
\hline \multirow[b]{2}{*}{ CHEMBL 2347742} & & \multicolumn{5}{|c|}{ Supplemental Table S2.txt } \\
\hline & 951962 & 7.3307 & 7.3354 & TRN & & \\
\hline CHEMBL 2347720 & 951962 & 8.9208 & 8.9194 & TRN & & \\
\hline CHEMBL 2347736 & 951962 & 7.7721 & 7.7771 & TRN & & \\
\hline CHEMBL 2347738 & 951962 & 7.3478 & 7.3541 & TRN & & \\
\hline CHEMBL2347752 & 951962 & 6.6209 & 6.612 & TRN & & \\
\hline CHEMBL 2347741 & 951962 & 8.6383 & 8.6299 & TRN & & \\
\hline CHEMBL 2347731 & 951962 & 9.1135 & 9.1174 & TRN & & \\
\hline CHEMBL 2347725 & 951962 & 10.8239 & 10.8208 & TRN & & \\
\hline CHEMBL 2347750 & 951962 & 6.75299 & 999999999 & 99 & 6.7613 & TRN \\
\hline CHEMBL 2347730 & 951962 & 9.0506 & 9.038 & TRN & & \\
\hline CHEMBL 2347718 & 951962 & 8.2518 & 8.2562 & TRN & & \\
\hline CHEMBL 2347726 & 951962 & 9.6383 & 9.6518 & TRN & & \\
\hline CHEMBL 2347743 & 951962 & 5.83 & 5.8292 & TRN & & \\
\hline CHEMBL 2347744 & 951962 & 7.3449 & 7.3349 & TRN & & \\
\hline CHEMBL 2347746 & 951962 & 7.3655 & 7.3743 & TRN & & \\
\hline CHEMBL472525 & 951962 & 7.3595 & 7.3628 & TRN & & \\
\hline CHEMBL2347710 & 951962 & 9.9586 & 9.9524 & TRN & & \\
\hline CHEMBL 2347708 & 951962 & 3.0 & 3.003 & TRN & & \\
\hline CHEMBL 2347748 & 951962 & 6.6998 & 6.693 & TRN & & \\
\hline CHEMBL 2347739 & 951962 & 8.2076 & 8.2236 & TRN & & \\
\hline CHEMBL 2347723 & 951962 & 10.1938 & 10.1912 & TRN & & \\
\hline CHEMBL 2347753 & 951962 & 7.6358 & 5.4391 & TST & & \\
\hline CHEMBL 2347729 & 951962 & 9.9208 & 9.3418 & TST & & \\
\hline CHEMBL 2347732 & 951962 & 6.1558 & 6.1605 & TRN & & \\
\hline CHEMBL 2347719 & 951962 & 9.9586 & 9.1245 & TST & & \\
\hline CHEMBL 2347711 & 951962 & 10.1938 & 10.1141 & TST & & \\
\hline CHEMBL 2347714 & 951962 & 7.8153 & 9.3834 & TST & & \\
\hline CHEMBL 2347721 & 951962 & 9.2924 & 9.0251 & TST & & \\
\hline CHEMBL 2347733 & 951962 & 7.0904 & 7.0917 & TRN & & \\
\hline CHEMBL 2347712 & 951962 & 8.4437 & 8.4341 & TST & & \\
\hline CHEMBL 2347727 & 951962 & 9.7447 & 9.5362 & TST & & \\
\hline CHEMBL 2347707 & 951962 & 3.0 & 5.6066 & TST & & \\
\hline CHEMBL 2347735 & 951962 & 6.0209 & 6.0186 & TRN & & \\
\hline CHEMBL 2347716 & 951962 & 9.5086 & 8.5799 & TST & & \\
\hline CHEMBL 2347728 & 951962 & 9.8861 & 9.1128 & TST & & \\
\hline CHEMBL 2347706 & 951962 & 6.7387 & 6.7424 & TRN & & \\
\hline CHEMBL472524 & 951962 & 5.8579 & 5.853 & TRN & & \\
\hline CHEMBL 2347740 & 951962 & 6.7742 & 6.7678 & TRN & & \\
\hline CHEMBL 2048038 & 826121 & 5.6536 & 5.7976 & TRN & & \\
\hline CHEMBL 2048039 & 826121 & 5.9872 & 5.843 & TRN & & \\
\hline CHEMBL 2047902 & 826121 & 5.7645 & 5.6585 & TST & & \\
\hline CHEMBL 2047895 & 826121 & 5.426 & 5.3185 & TRN & & \\
\hline CHEMBL 2047904 & 826121 & 5.699 & 5.6641 & TRN & & \\
\hline CHEMBL 2048057 & 826121 & 5.5129 & 5.6483 & TRN & & \\
\hline CHEMBL 2047894 & 826121 & 4.0 & 4.0315 & TRN & & \\
\hline CHEMBL 2048055 & 826121 & 4.0 & 5.7295 & TST & & \\
\hline CHEMBL 2047890 & 826121 & 6.1427 & 6.2148 & TRN & & \\
\hline CHEMBL 2047912 & 826121 & 5.9788 & 5.9029 & TRN & & \\
\hline
\end{tabular}




\begin{tabular}{|c|c|c|c|c|c|c|}
\hline \multirow[b]{2}{*}{ CHEMBL 2047909} & \multicolumn{6}{|c|}{ Supplemental Table S2.txt } \\
\hline & 826121 & 6.4437 & 6.4071 & TRN & & \\
\hline CHEMBL 2047889 & 826121 & 6.4685 & 6.2671 & TRN & & \\
\hline CHEMBL2047915 & 826121 & 5.284 & 5.5077 & TRN & & \\
\hline CHEMBL 2047901 & 826121 & \multicolumn{3}{|c|}{5.757000000000001} & 5.4424 & TST \\
\hline CHEMBL 2048054 & 826121 & 6.6021 & 6.6052 & TRN & & \\
\hline CHEMBL 2047910 & 826121 & 6.2924 & 6.2632 & TRN & & \\
\hline CHEMBL 2047893 & 826121 & 5.857 & 5.7817 & TRN & & \\
\hline CHEMBL 2048047 & 826121 & 6.3468 & 6.315 & TRN & & \\
\hline CHEMBL 2048063 & 826121 & 6.2924 & 6.442 & TRN & & \\
\hline CHEMBL 2047914 & 826121 & 6.5376 & 6.5105 & TRN & & \\
\hline CHEMBL 2048042 & 826121 & 6.2676 & 6.3321 & TRN & & \\
\hline CHEMBL 2047905 & 826121 & 5.6383 & 5.58799 & 9999999999 & & TRN \\
\hline CHEMBL 2048056 & 826121 & 5.4306 & 5.6721 & TST & & \\
\hline CHEMBL 2048058 & 826121 & 5.8794 & 6.0142 & TRN & & \\
\hline CHEMBL 2047911 & 826121 & 6.0088 & 5.8383 & TRN & & \\
\hline CHEMBL 2047913 & 826121 & 5.9431 & 5.9845 & TRN & & \\
\hline CHEMBL 2048049 & 826121 & 5.6536 & 5.7592 & TRN & & \\
\hline CHEMBL 2048046 & 826121 & 5.6198 & 5.5523 & TRN & & \\
\hline CHEMBL 2047897 & 826121 & 5.2573 & 5.2148 & TRN & & \\
\hline CHEMBL 2048050 & 826121 & 6.3188 & 6.2225 & TRN & & \\
\hline CHEMBL 2048041 & 826121 & 5.9393 & 5.9628 & TRN & & \\
\hline CHEMBL 2047892 & 826121 & 5.0975 & 5.0654 & TRN & & \\
\hline CHEMBL 2048060 & 826121 & \multicolumn{3}{|c|}{5.821000000000001} & 5.7408 & TST \\
\hline CHEMBL 2047899 & 826121 & 5.8268 & 5.9082 & TRN & & \\
\hline CHEMBL 2048061 & 826121 & 5.5969 & 5.5577 & TRN & & \\
\hline CHEMBL 2047888 & 826121 & 5.5986 & 5.6445 & TRN & & \\
\hline CHEMBL 2048037 & 826121 & 5.3595 & 5.2931 & TRN & & \\
\hline CHEMBL 2047906 & 826121 & 4.0 & 3.9344 & TRN & & \\
\hline CHEMBL 2048040 & 826121 & 6.4089 & 6.3024 & TRN & & \\
\hline CHEMBL 2047896 & 826121 & 5.7878 & 5.83799 & 9999999999 & & TRN \\
\hline CHEMBL 2047907 & 826121 & 5.7595 & 5.8643 & TRN & & \\
\hline CHEMBL 2048044 & 826121 & 6.1675 & 6.08200 & 0000000001 & & TRN \\
\hline CHEMBL 2048059 & 826121 & 6.2218 & 6.1733 & TRN & & \\
\hline CHEMBL 2047891 & 826121 & 5.3809 & 5.6042 & TRN & & \\
\hline CHEMBL 2048048 & 826121 & 5.4001 & 5.7775 & TST & & \\
\hline CHEMBL2047908 & 826121 & 6.2218 & 5.8458 & TST & & \\
\hline CHEMBL 2048062 & 826121 & 5.5513 & 5.4475 & TST & & \\
\hline CHEMBL 2048045 & 826121 & 6.1612 & 5.8156 & TST & & \\
\hline CHEMBL 2047903 & 826121 & 4.0 & 4.2628 & TST & & \\
\hline CHEMBL 2047900 & 826121 & 5.6055 & 5.9171 & TST & & \\
\hline CHEMBL 2047898 & 826121 & 5.9136 & 5.806 & TST & & \\
\hline CHEMBL 2048043 & 826121 & 5.699 & 5.75200 & 0000000001 & & TST \\
\hline CHEMBL 2048053 & 826121 & 6.6021 & 6.6874 & TST & & \\
\hline CHEMBL3112918 & 1290079 & 5.2518 & 5.2318 & TRN & & \\
\hline CHEMBL3112882 & 1290079 & 3.0 & 3.0411 & TRN & & \\
\hline CHEMBL3112884 & 1290079 & 5.4437 & 5.4749 & TRN & & \\
\hline CHEMBL3112920 & 1290079 & 5.2924 & 5.2092 & TRN & & \\
\hline CHEMBL3112887 & 1290079 & 6.0458 & 6.1547 & TRN & & \\
\hline
\end{tabular}


Supplemental Table S2.txt

\begin{tabular}{|c|c|c|c|c|}
\hline HEMB & 290079 & 5.2518 & & בני \\
\hline & 290079 & 5.5376 & 5.5754 & \\
\hline EMRI & 90079 & & & \\
\hline IEMBL & 90079 & 3.0 & & \\
\hline HEMBL3112899 & 290079 & 5.1487 & 2314 & \\
\hline HEMBL3112924 & 290079 & 4.7773 & 788 & \\
\hline 5892 & 290079 & 3.5229 & & \\
\hline AEMBL3112893 & 90079 & & & \\
\hline HEMBL3112909 & 290079 & 5.2518 & 998 & \\
\hline HEMBL3112886 & 290079 & 4.9706 & & \\
\hline HEMBL1688558 & 290079 & 5.6576 & 992 & \\
\hline 2896 & 290079 & 208 & & \\
\hline HEMBL & 290079 & 212 & & \\
\hline HEMBL3112889 & 290079 & 5.6778 & 41 & \\
\hline HEMBL3112917 & 290079 & 5.3768 & & \\
\hline HEMBL; & 2906 & 5 . & 99 & \\
\hline HEMBL & 9 & & & \\
\hline HEMBL. & 290079 & 59 & & \\
\hline HEMBL3 & 290079 & 39 & & \\
\hline AEMBL5 & & & & I KIV \\
\hline HEMBL & 290 & 5 & & ST \\
\hline HEMBL & 9 & & & MIV \\
\hline HEMBL & 290 & 24 & & \\
\hline HEMBL3 & 290079 & 5 . & & I RIV \\
\hline AEMBL6 & 99 & & 03 & IRN \\
\hline HEMBL3 & 296 & & & RN \\
\hline HEMBL & 9 & & & KIN \\
\hline HEME & & 12 & & \\
\hline AEMBL3 & & & & IRN \\
\hline HEMBL1594475 & 2900 & 3 & 26 & ГST \\
\hline HEMBL3 & 290 & & & RN \\
\hline 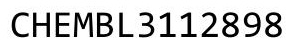 & & & & RN \\
\hline 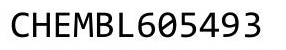 & & & & RN \\
\hline HEMBL1 & & & & 「RN \\
\hline HEMBL $311291 €$ & 2900 & 5 & & RN \\
\hline IFMPI & 90 & 9 & & TRN \\
\hline 0 & & 5 & & ГRN \\
\hline HEMBL3 & & & & TRN \\
\hline HEMBL 5 & 2900 & & & TRN \\
\hline EMBL & 2900 & 3 & & RN \\
\hline HEMBL3 & (1) & 4. & & ГST \\
\hline HEMBL1 & 79 & & 361 & TRN \\
\hline HEMBL3112908 & 290079 & & & {$[R$} \\
\hline HEMBL3 & 2900 & 5. & & TR \\
\hline CHFMRI 3 & & & & \\
\hline HEMBL3112890 & 1290079 & & 5.3099 & \\
\hline CHEMBL3112923 & 1290079 & 5.6383 & 5.4205 & ST \\
\hline CHEMBL3112926 & 1290079 & 4.5735 & 5.103 & TST \\
\hline
\end{tabular}

Page 15360 
Supplemental Table S2.txt

\begin{tabular}{|c|c|c|c|c|c|}
\hline CHEMBL1555271 & 1290079 & 3.0 & 3.1415 & TST & \\
\hline CHEMBL3112891 & 1290079 & 5.9586 & 5.5483 & TST & \\
\hline CHEMBL3112888 & 1290079 & 4.8729 & 5.4993 & TST & \\
\hline CHEMBL3112906 & 1290079 & 5.6021 & 5.9177 & TST & \\
\hline CHEMBL3112925 & 1290079 & 5.1739 & 4.8614 & TST & \\
\hline CHEMBL3646418 & 1536179 & 5.6861 & 6.6469 & TRN & \\
\hline CHEMBL3649319 & 1536179 & 7.6498 & 7.5946 & TRN & \\
\hline CHEMBL3649291 & 1536179 & 7.2534 & 7.3026 & TRN & \\
\hline CHEMBL3649330 & 1536179 & 6.6498 & 7.2989 & TRN & \\
\hline CHEMBL3646306 & 1536179 & 7.3809 & 6.9573 & TST & \\
\hline CHEMBL3646312 & 1536179 & 8.3279 & 7.3739 & TRN & \\
\hline CHEMBL3649268 & 1536179 & 7.8013 & 7.5067 & TRN & \\
\hline CHEMBL3646393 & 1536179 & 6.7496 & 6.8218 & TRN & \\
\hline CHEMBL 3646417 & 1536179 & 7.0052 & 6.5004 & TRN & \\
\hline CHEMBL3649316 & 1536179 & 6.0 & 6.8589 & TRN & \\
\hline CHEMBL3646277 & 1536179 & 7.983 & 7.3135 & TRN & \\
\hline CHEMBL3646400 & 1536179 & 7.1226 & 6.5508 & TST & \\
\hline CHEMBL 3649252 & 1536179 & 6.6459 & 7.3538 & TRN & \\
\hline CHEMBL3649262 & 1536179 & 7.059 & 7.3657 & TRN & \\
\hline CHEMBL 3646346 & 1536179 & 7.7077 & 6.8053 & TRN & \\
\hline CHEMBL3649296 & 1536179 & 8.1791 & 7.4666 & TRN & \\
\hline CHEMBL3649311 & 1536179 & 6.0 & 7.62700 & 0000000001 & $T$ \\
\hline CHEMBL3649277 & 1536179 & 7.6126 & 8.1059 & TRN & \\
\hline CHEMBL 3646252 & 1536179 & 7.1439 & 7.1308 & TRN & \\
\hline CHEMBL3649274 & 1536179 & 7.71899 & 9999999 & 7.3469 & тाит \\
\hline CHEMBL3649336 & 1536179 & 8.0615 & 7.5752 & TRN & \\
\hline CHEMBL3649257 & 1536179 & 6.699 & 6.5262 & TST & \\
\hline CHEMBL3646395 & 1536179 & 6.1415 & 6.6108 & TST & \\
\hline CHEMBL3649259 & 1536179 & 6.5287 & 6.6467 & TST & \\
\hline CHEMBL3649263 & 1536179 & 7.7595 & 7.7551 & TRN & \\
\hline CHEMBL3649351 & 1536179 & 4.0 & 5.8916 & TRN & \\
\hline CHEMBL3646334 & 1536179 & 6.0 & 6.8218 & TRN & \\
\hline CHEMBL3646290 & 1536179 & 7.2118 & 7.148 & TRN & \\
\hline CHEMBL 3649335 & 1536179 & 8.1124 & 7.28299 & & \\
\hline CHEMBL 3646291 & 1536179 & 7.0778 & 7.0288 & TRN & \\
\hline CHEMBL3649307 & 1536179 & 6.0 & 7.6411 & TST & \\
\hline CHEMBL3649287 & 1536179 & 7.0625 & 7.335 & TRN & \\
\hline CHEMBL3646296 & 1536179 & 7.5287 & 7.0122 & TRN & \\
\hline CHEMBL 3649325 & 1536179 & 6.8633 & 6.5199 & TRN & \\
\hline CHEMBL 3649295 & 1536179 & 8.0372 & 7.5635 & TRN & \\
\hline CHEMBL 3649248 & 1536179 & 7.3546 & 6.4562 & TRN & \\
\hline CHEMBL3649282 & 1536179 & 7.5143 & 7.53700 & 0000000001 & RN \\
\hline CHEMBL3649339 & 1536179 & 7.301 & 6.9678 & TRN & \\
\hline CHEMBL3649261 & 1536179 & 7.5751 & 8.1447 & TRN & \\
\hline CHEMBL3646407 & 1536179 & 6.8386 & 6.1348 & TST & \\
\hline CHEMBL3649272 & 1536179 & 7.1925 & 7.2137 & TRN & \\
\hline CHEMBL 3646382 & 1536179 & 6.7852 & 7.0853 & TRN & \\
\hline CHEMBL3649255 & 1536179 & 7.8928 & 7.0702 & TRN & \\
\hline
\end{tabular}

Page 15361 
Supplemental Table S2.txt

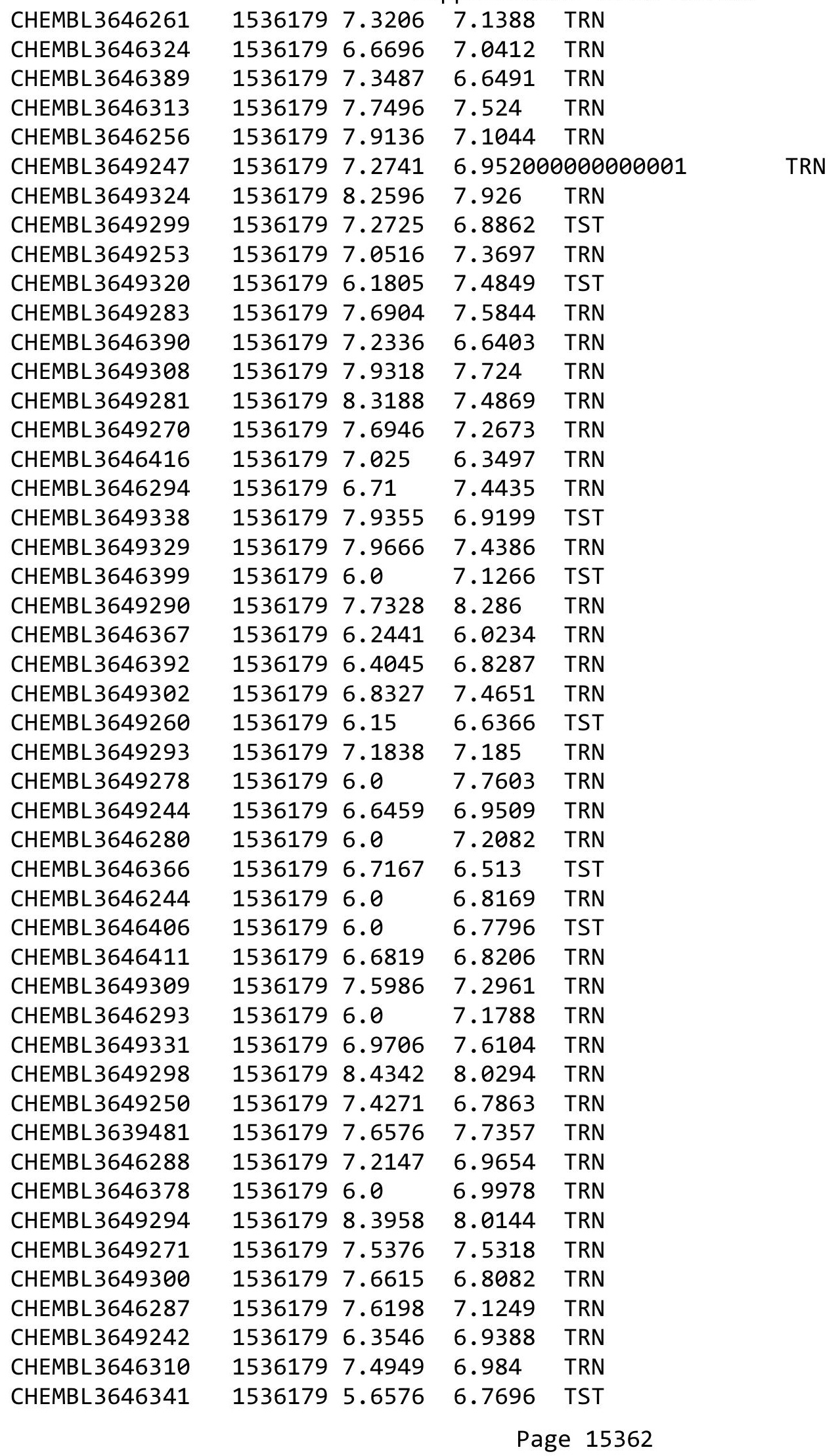


Supplemental Table S2.txt

\begin{tabular}{|c|c|c|c|c|c|}
\hline CHEMBL3649258 & 1536179 & 8.1752 & 6.6976 & TST & \\
\hline CHEMBL3639452 & 1536179 & 7.2924 & 6.7854 & TRN & \\
\hline CHEMBL3649264 & 1536179 & 8.4828 & \multicolumn{2}{|c|}{7.656000000000001} & TRN \\
\hline CHEMBL 3646362 & 1536179 & 6.0 & 6.3246 & TRN & \\
\hline CHEMBL3646275 & 1536179 & 6.0 & 7.1981 & TRN & \\
\hline CHEMBL3646245 & 1536179 & 6.9172 & \multicolumn{2}{|c|}{6.622000000000001} & TRN \\
\hline CHEMBL3649276 & 1536179 & 7.3242 & 7.2193 & TRN & \\
\hline CHEMBL3646302 & 1536179 & 7.3915 & 7.1552 & TRN & \\
\hline CHEMBL 3649286 & 1536179 & 7.4271 & 7.4112 & TRN & \\
\hline CHEMBL3646424 & 1536179 & 5.8069 & 6.7704 & TRN & \\
\hline CHEMBL3649337 & 1536179 & 7.1858 & 7.4117 & TRN & \\
\hline CHEMBL3649280 & 1536179 & 7.9031 & 7.3639 & TRN & \\
\hline CHEMBL3649310 & 1536179 & 7.4789 & 7.3213 & TRN & \\
\hline CHEMBL3646258 & 1536179 & 8.0259 & 7.3719 & TRN & \\
\hline CHEMBL3649266 & 1536179 & 6.0 & 7.3387 & TRN & \\
\hline CHEMBL3646397 & 1536179 & 6.7122 & 6.6027 & TST & \\
\hline CHEMBL3646405 & 1536179 & 6.9355 & 6.9089 & TST & \\
\hline CHEMBL3646273 & 1536179 & 7.8928 & 7.1631 & TRN & \\
\hline CHEMBL 3649285 & 1536179 & 8.2628 & 7.6288 & TRN & \\
\hline CHEMBL3646412 & 1536179 & 7.0186 & 6.5764 & TST & \\
\hline CHEMBL3649292 & 1536179 & 7.9355 & 7.4305 & TRN & \\
\hline CHEMBL 3646243 & 1536179 & 6.5884 & 6.6412 & TRN & \\
\hline CHEMBL 3646410 & 1536179 & 6.0035 & 6.4392 & TRN & \\
\hline CHEMBL3646409 & 1536179 & 6.0 & 6.8282 & TST & \\
\hline CHEMBL3646289 & 1536179 & 6.8761 & 7.0052 & TRN & \\
\hline CHEMBL3649273 & 1536179 & 7.6308 & 7.4309 & TRN & \\
\hline CHEMBL3639451 & 1536179 & 6.8601 & 6.6179 & TRN & \\
\hline CHEMBL3646349 & 1536179 & \multicolumn{2}{|c|}{6.821000000000001} & 6.4729 & TST \\
\hline CHEMBL 3649249 & 1536179 & 7.3565 & 6.7635 & TRN & \\
\hline CHEMBL3646348 & 1536179 & 6.0 & 6.3693 & TRN & \\
\hline CHEMBL3646359 & 1536179 & 6.0 & \multicolumn{2}{|c|}{6.672000000000001} & TST \\
\hline CHEMBL 3649243 & 1536179 & 7.3936 & 7.1505 & TRN & \\
\hline CHEMBL3646318 & 1536179 & 7.0731 & 6.8938 & TRN & \\
\hline CHEMBL 3649315 & 1536179 & 7.7282 & 7.4315 & TRN & \\
\hline CHEMBL3646398 & 1536179 & 6.0 & 6.6108 & TST & \\
\hline CHEMBL3646255 & 1536179 & 7.2676 & 7.2269 & TRN & \\
\hline CHEMBL3646297 & 1536179 & 6.9626 & \multicolumn{2}{|c|}{7.132999999999999} & TRN \\
\hline CHEMBL3649269 & 1536179 & 7.5317 & 7.1797 & TRN & \\
\hline CHEMBL 3649318 & 1536179 & 7.4413 & 7.6492 & TRN & \\
\hline CHEMBL3646365 & 1536179 & 7.2048 & 6.5027 & TRN & \\
\hline CHEMBL3649254 & 1536179 & 7.1278 & 7.2094 & TRN & \\
\hline CHEMBL3649279 & 1536179 & 7.7645 & 7.2165 & TRN & \\
\hline CHEMBL3646368 & 1536179 & 4.0 & 6.4999 & TST & \\
\hline CHEMBL 3646249 & 1536179 & 6.0 & 6.4627 & TST & \\
\hline CHEMBL 3646414 & 1536179 & 6.6055 & 6.4326 & TST & \\
\hline CHEMBL3646309 & 1536179 & 5.6055 & 6.504 & TRN & \\
\hline CHEMBL3649246 & 1536179 & 6.983 & 6.892 & TST & \\
\hline CHEMBL3646355 & 1536179 & 7.3487 & 6.6058 & TST & \\
\hline
\end{tabular}


Supplemental Table S2.txt

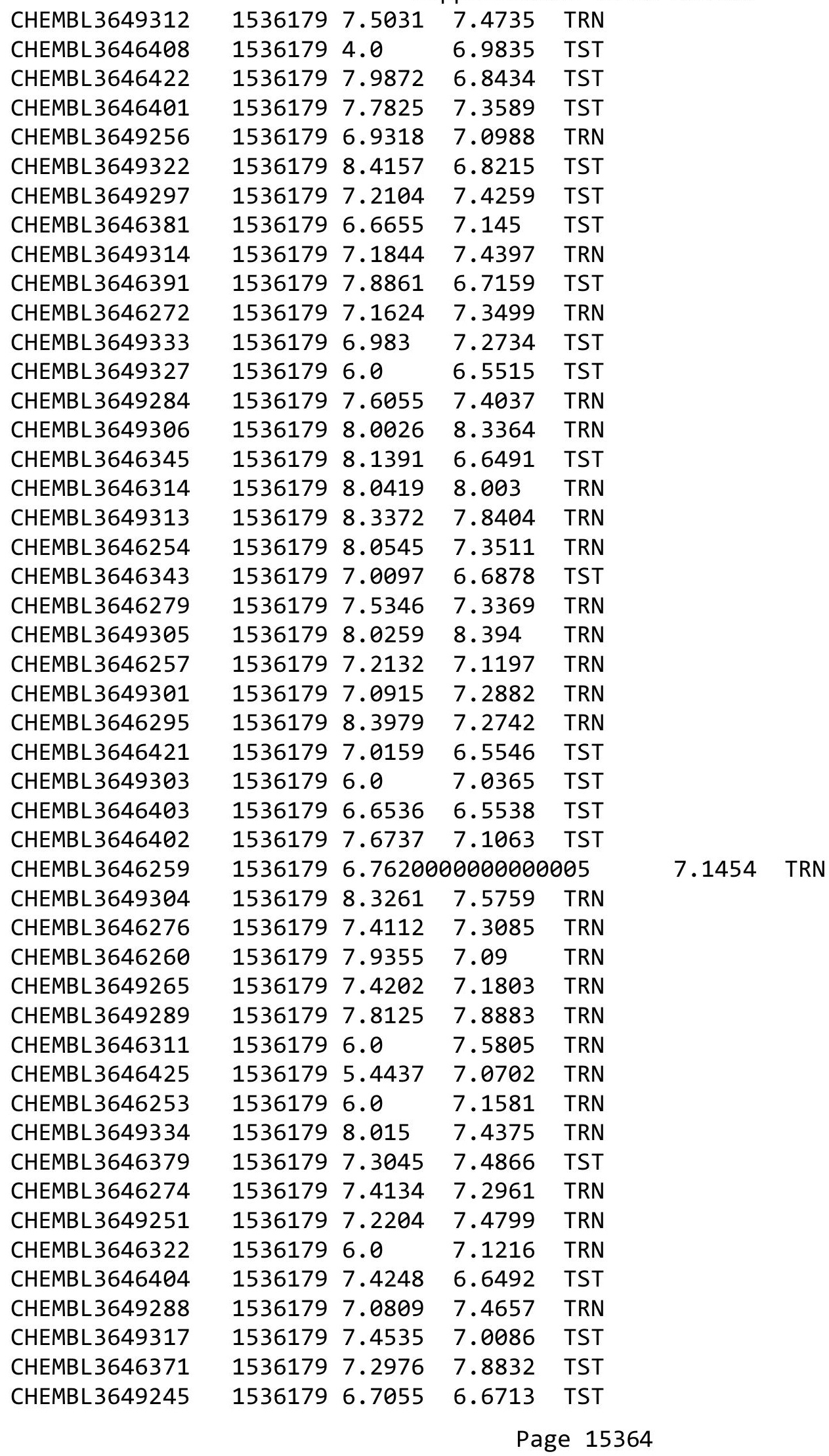


Supplemental Table S2.txt

\begin{tabular}{|c|c|c|c|c|c|}
\hline CHEMBL 3649267 & 1536179 & 8.2218 & 7.5152 & TRN & \\
\hline CHEMBL3649332 & 1536179 & 8.0706 & 7.6648 & TRN & \\
\hline CHEMBL3649275 & 1536179 & 7.284 & 7.2482 & TRN & \\
\hline CHEMBL 3646270 & 1536179 & 7.4295 & 7.1424 & TRN & \\
\hline CHEMBL3953154 & 1640537 & 8.6465 & 8.5865 & TRN & \\
\hline CHEMBL3909625 & 1640537 & 7.6513 & 7.8417 & TRN & \\
\hline CHEMBL3966201 & 1640537 & 8.5685 & 8.45 & TST & \\
\hline CHEMBL3966657 & 1640537 & 8.6092 & 8.4655 & TST & \\
\hline CHEMBL 3937872 & 1640537 & 8.5901 & 8.6043 & TST & \\
\hline CHEMBL3906053 & 1640537 & 7.561 & 7.9295 & TST & \\
\hline CHEMBL3901365 & 1640537 & 7.754 & 7.5947 & TRN & \\
\hline CHEMBL3928644 & 1640537 & 7.7212 & 7.7267 & TRN & \\
\hline CHEMBL3892551 & 1640537 & 7.8176 & 7.8061 & TRN & \\
\hline CHEMBL3985305 & 1640537 & 7.95 & 7.841 & TST & \\
\hline CHEMBL3966285 & 1640537 & 8.3571 & 8.6779 & TST & \\
\hline CHEMBL3910962 & 1640537 & 8.1046 & 7.8686 & TRN & \\
\hline CHEMBL3937844 & 1640537 & 8.1547 & 7.9704 & TRN & \\
\hline CHEMBL3891803 & 1640537 & 8.7897 & 8.419 & TST & \\
\hline CHEMBL3942747 & 1640537 & 8.0214 & 8.4078 & TRN & \\
\hline CHEMBL3974195 & 1640537 & 7.8831 & 7.6827 & TRN & \\
\hline CHEMBL3946739 & 1640537 & 8.5297 & 8.7603 & TRN & \\
\hline CHEMBL3944400 & 1640537 & 7.9083 & 7.8281 & TRN & \\
\hline CHEMBL 3963228 & 1640537 & 7.8887 & 7.6781 & TRN & \\
\hline CHEMBL3909281 & 1640537 & 7.6243 & 7.751 & TRN & \\
\hline CHEMBL3934933 & 1640537 & 8.1052 & 7.7287 & TRN & \\
\hline CHEMBL3957256 & 1640537 & 7.75799 & 99999999 & 8.4169 & TST \\
\hline CHEMBL 3896520 & 1640537 & 7.9289 & 7.7352 & TRN & \\
\hline CHEMBL 3891442 & 1640537 & 7.8861 & 7.7612 & TRN & \\
\hline CHEMBL3927289 & 1640537 & 7.8791 & 7.735 & TRN & \\
\hline CHEMBL3980954 & 1640537 & 8.605 & 8.3672 & TRN & \\
\hline CHEMBL 3984462 & 1640537 & 7.6057 & 7.7091 & TRN & \\
\hline CHEMBL3975673 & 1640537 & 7.6078 & 7.4534 & TRN & \\
\hline CHEMBL3954263 & 1640537 & 8.4974 & 8.5246 & TRN & \\
\hline CHEMBL3965089 & 1640537 & 7.8074 & 7.6781 & TRN & \\
\hline CHEMBL3959647 & 1640537 & 8.0161 & 7.67200 & 0000000001 & 1 \\
\hline CHEMBL3915039 & 1640537 & 7.5086 & 7.2776 & TRN & \\
\hline CHEMBL3965582 & 1640537 & 8.6108 & 8.4086 & TRN & \\
\hline CHEMBL 3986708 & 1640537 & 8.4191 & 8.5079 & TST & \\
\hline CHEMBL3981237 & 1640537 & 6.0 & 7.3485 & TRN & \\
\hline CHEMBL 3891987 & 1640537 & 8.2897 & 8.3542 & TST & \\
\hline CHEMBL3981112 & 1640537 & 8.8404 & 8.6548 & TRN & \\
\hline CHEMBL3906069 & 1640537 & 8.4372 & 8.5839 & TRN & \\
\hline CHEMBL3940461 & 1640537 & 8.7426 & 8.4913 & TRN & \\
\hline CHEMBL3909939 & 1640537 & 8.5854 & 8.5193 & TRN & \\
\hline CHEMBL3945225 & 1640537 & 7.8539 & 7.7592 & TRN & \\
\hline CHEMBL3947704 & 1640537 & 7.6733 & 8.3698 & TRN & \\
\hline CHEMBL3942707 & 1640537 & 7.4324 & 7.8931 & TRN & \\
\hline CHEMBL3900302 & 1640537 & 8.1152 & 7.7255 & TRN & \\
\hline
\end{tabular}

Page 15365 
Supplemental Table S2.txt

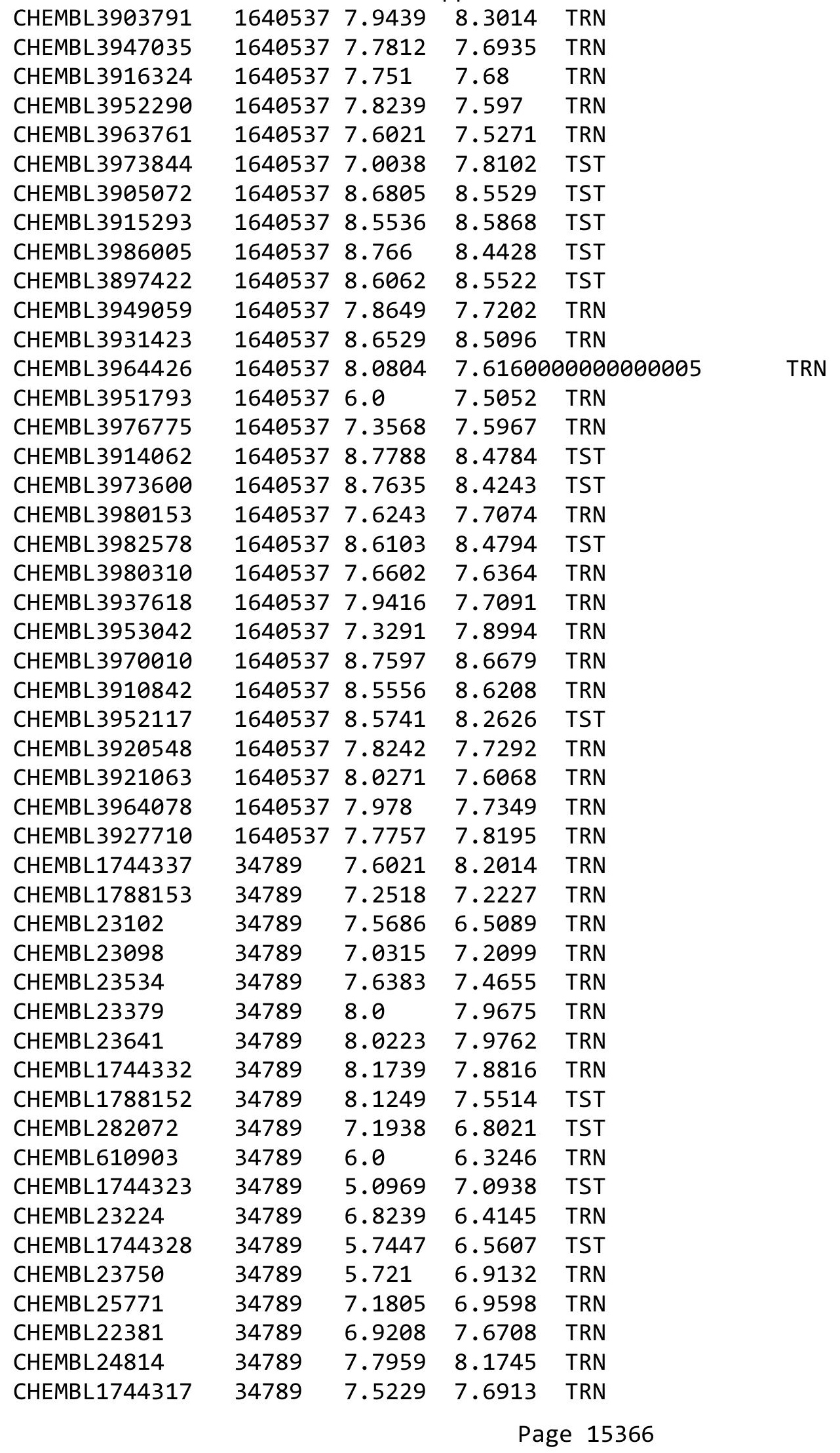




\begin{tabular}{|c|c|c|c|c|c|c|}
\hline \multirow[b]{2}{*}{ CHEMBL23443 } & \multicolumn{6}{|c|}{ Supplemental Table S2.txt } \\
\hline & 34789 & 6.8861 & 7.3956 & TRN & & \\
\hline CHEMBL1744324 & 34789 & 7.6383 & 7.4212 & TRN & & \\
\hline CHEMBL23773 & 34789 & 6.2676 & 6.3611 & TRN & & \\
\hline CHEMBL1744322 & 34789 & 7.0605 & 7.5607 & TST & & \\
\hline CHEMBL23347 & 34789 & 8.0 & 7.5563 & TRN & & \\
\hline CHEMBL1744333 & 34789 & 8.3665 & 7.3602 & TRN & & \\
\hline CHEMBL1788150 & 34789 & 6.0 & 6.4134 & TRN & & \\
\hline CHEMBL1744329 & 34789 & 8.301 & 8.2681 & TRN & & \\
\hline CHEMBL 23251 & 34789 & 7.3768 & 7.0949 & TRN & & \\
\hline CHEMBL1788151 & 34789 & 8.1549 & 7.5879 & TST & & \\
\hline CHEMBL278559 & 34789 & 7.4437 & 7.9572 & TRN & & \\
\hline CHEMBL23527 & 34789 & 6.0 & 6.4479 & TRN & & \\
\hline CHEMBL1744336 & 34789 & 7.699 & 7.6919 & TRN & & \\
\hline CHEMBL 22198 & 34789 & 8.3279 & 8.0582 & TRN & & \\
\hline CHEMBL 1744320 & 34789 & 7.7212 & 7.0056 & TST & & \\
\hline CHEMBL1744334 & 34789 & 8.1135 & 7.6242 & TRN & & \\
\hline CHEMBL22654 & 34789 & 8.1427 & 8.0065 & TRN & & \\
\hline CHEMBL1788147 & 34789 & 7.9208 & 6.8259 & TST & & \\
\hline CHEMBL 277886 & 34789 & 6.5686 & 7.0093 & TRN & & \\
\hline CHEMBL1744331 & 34789 & 7.4685 & 7.5337 & TST & & \\
\hline CHEMBL1744325 & 34789 & 8.1192 & 7.5083 & TST & & \\
\hline CHEMBL1788148 & 34789 & 8.1487 & 7.5514 & TST & & \\
\hline CHEMBL1744326 & 34789 & 7.7212 & 7.5905 & TST & & \\
\hline CHEMBL23555 & 34789 & 6.0 & 6.53100 & 0000000001 & & TRN \\
\hline CHEMBL1744335 & 34789 & 7.585 & 7.6127 & TRN & & \\
\hline CHEMBL1744327 & 34789 & 7.7212 & 7.4889 & TRN & & \\
\hline CHEMBL279938 & 34789 & 7.9208 & 7.7399 & TRN & & \\
\hline CHEMBL1744338 & 34789 & 6.3279 & 7.107 & TRN & & \\
\hline CHEMBL 23727 & 34789 & 7.9586 & 8.0998 & TRN & & \\
\hline CHEMBL 26338 & 34789 & 7.8861 & 7.0746 & TRN & & \\
\hline CHEMBL23136 & 34789 & 6.2676 & 6.3219 & TRN & & \\
\hline CHEMBL23467 & 34789 & 6.2076 & 7.1375 & TST & & \\
\hline CHEMBL282730 & 34789 & 8.0362 & 7.551 & TRN & & \\
\hline CHEMBL1744330 & 34789 & 7.2924 & 7.4047 & TST & & \\
\hline CHEMBL 22652 & 34789 & 7.5229 & 6.8359 & TRN & & \\
\hline CHEMBL39115 & 103104 & 2.79100 & 30000000 & 204 & 2.8729 & TRN \\
\hline CHEMBL289379 & 103104 & 2.9718 & 3.1352 & TST & & \\
\hline CHEMBL 290021 & 103104 & 3.3893 & 3.8158 & TST & & \\
\hline CHEMBL 39608 & 103104 & 3.4629 & 3.6118 & TRN & & \\
\hline CHEMBL 290703 & 103104 & 3.42 & 3.2262 & TRN & & \\
\hline CHEMBL 288680 & 103104 & 3.3164 & 3.5835 & TST & & \\
\hline CHEMBL38690 & 103104 & 2.58600 & 00000000 & 203 & 2.7035 & TRN \\
\hline CHEMBL 290020 & 103104 & 3.4124 & 3.7217 & TST & & \\
\hline CHEMBL38391 & 103104 & 3.1716 & 2.8952 & TRN & & \\
\hline CHEMBL285907 & 103104 & 5.4078 & 4.1877 & TST & & \\
\hline CHEMBL39070 & 103104 & 3.5112 & 3.6464 & TRN & & \\
\hline CHEMBL 288964 & 103104 & 3.2825 & 3.5836 & TRN & & \\
\hline CHEMBL38489 & 103104 & 2.7117 & 3.1093 & TRN & & \\
\hline
\end{tabular}

Page 15367 


\begin{tabular}{|c|c|c|c|c|c|}
\hline \multicolumn{6}{|c|}{ 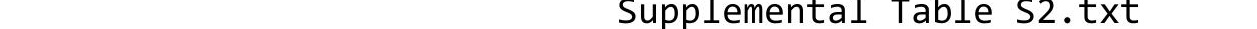 } \\
\hline CHEMBL288587 & 103104 & 3.4343 & 4.5083 & TRN & \\
\hline CHEMBL40059 & 103104 & 2.4542 & 2.5551 & TRN & \\
\hline CHEMBL39499 & 103104 & 2.5842 & 3.2609 & TRN & \\
\hline CHEMBL290648 & 103104 & 3.4016 & 3.6641 & TST & \\
\hline CHEMBL287131 & 103104 & 5.2924 & 3.5698 & TST & \\
\hline CHEMBL39904 & 103104 & 3.6895 & 3.7082 & TRN & \\
\hline CHEMBL290159 & 103104 & 3.568 & 4.2112 & TRN & \\
\hline CHEMBL288161 & 103104 & 2.8982 & 2.9312 & TST & \\
\hline CHEMBL289423 & 103104 & 6.041 & 5.3204 & TRN & \\
\hline CHEMBL289913 & 103104 & 3.3407 & 2.7988 & TRN & \\
\hline CHEMBL291072 & 103104 & 2.7428 & 2.2552 & TRN & \\
\hline CHEMBL39101 & 103104 & 2.7205 & 2.7083 & TRN & \\
\hline CHEMBL291259 & 103104 & 3.3014 & 3.3418 & TST & \\
\hline CHEMBL 38470 & 103104 & 5.7825 & 4.9969 & TRN & \\
\hline CHEMBL287787 & 103104 & 3.3703 & 3.2116 & TRN & \\
\hline CHEMBL 38980 & 103104 & 3.44 & 3.5781 & TRN & \\
\hline CHEMBL289785 & 103104 & 3.4472 & 3.6374 & TRN & \\
\hline CHEMBL288427 & 103104 & 3.2754 & 2.8077 & TRN & \\
\hline CHEMBL273996 & 103104 & 6.1427 & 5.2397 & TRN & \\
\hline CHEMBL289337 & 103104 & 3.3756 & 3.4213 & TST & \\
\hline CHEMBL 38630 & 103104 & 3.4628 & 2.9942 & TRN & \\
\hline CHEMBL289090 & 103104 & 2.7279 & 2.3973 & TRN & \\
\hline CHEMBL289210 & 103104 & 3.2551 & 3.4667 & TRN & \\
\hline CHEMBL39815 & 103104 & 3.4795 & 3.5628 & TRN & \\
\hline CHEMBL39135 & 103104 & 3.2712 & 3.2637 & TRN & \\
\hline CHEMBL290626 & 103104 & 2.5758 & 2.5417 & TRN & \\
\hline CHEMBL289591 & 103104 & 3.5549 & 3.5523 & TRN & \\
\hline CHEMBL287755 & 103104 & 2.8716 & 3.0486 & TST & \\
\hline CHEMBL39462 & 103104 & 3.3751 & 2.8951 & TRN & \\
\hline CHEMBL 38602 & 103104 & 2.9657 & 3.29 & TRN & \\
\hline CHEMBL290902 & 103104 & 2.7184 & 2.6145 & TRN & \\
\hline CHEMBL288339 & 103104 & 2.4439 & 2.2422 & TRN & \\
\hline CHEMBL289608 & 103104 & 2.7897 & 2.9247 & TRN & \\
\hline CHEMBL289726 & 103104 & 3.3542 & 3.8815 & TRN & \\
\hline CHEMBL 39825 & 103104 & 3.4094 & 3.7932 & TRN & \\
\hline CHEMBL40011 & 103104 & 2.7943 & 3.31399 & 99999999996 & TRN \\
\hline CHEMBL39431 & 103104 & 2.5057 & 2.699 & TRN & \\
\hline CHEMBL39105 & 103104 & 3.3116 & 2.9466 & TRN & \\
\hline CHEMBL288706 & 103104 & 2.8323 & 2.998 & TRN & \\
\hline CHEMBL 288727 & 103104 & 3.3497 & 3.3686 & TRN & \\
\hline CHEMBL279411 & 103104 & 2.9207 & 2.7465 & TRN & \\
\hline CHEMBL289208 & 103104 & 2.6573 & 2.6158 & TST & \\
\hline CHEMBL38556 & 103104 & 3.4783 & 3.5532 & TST & \\
\hline CHEMBL39683 & 103104 & 3.0026 & 3.1314 & TRN & \\
\hline CHEMBL39414 & 103104 & 5.091 & 4.0275 & TST & \\
\hline CHEMBL37967 & 103104 & 4.9805 & 4.2715 & TST & \\
\hline CHEMBL509032 & 954506 & 3.8679 & 3.8679 & TRN & \\
\hline CHEMBL449158 & 954506 & 6.1456 & 5.9126 & TST & \\
\hline
\end{tabular}




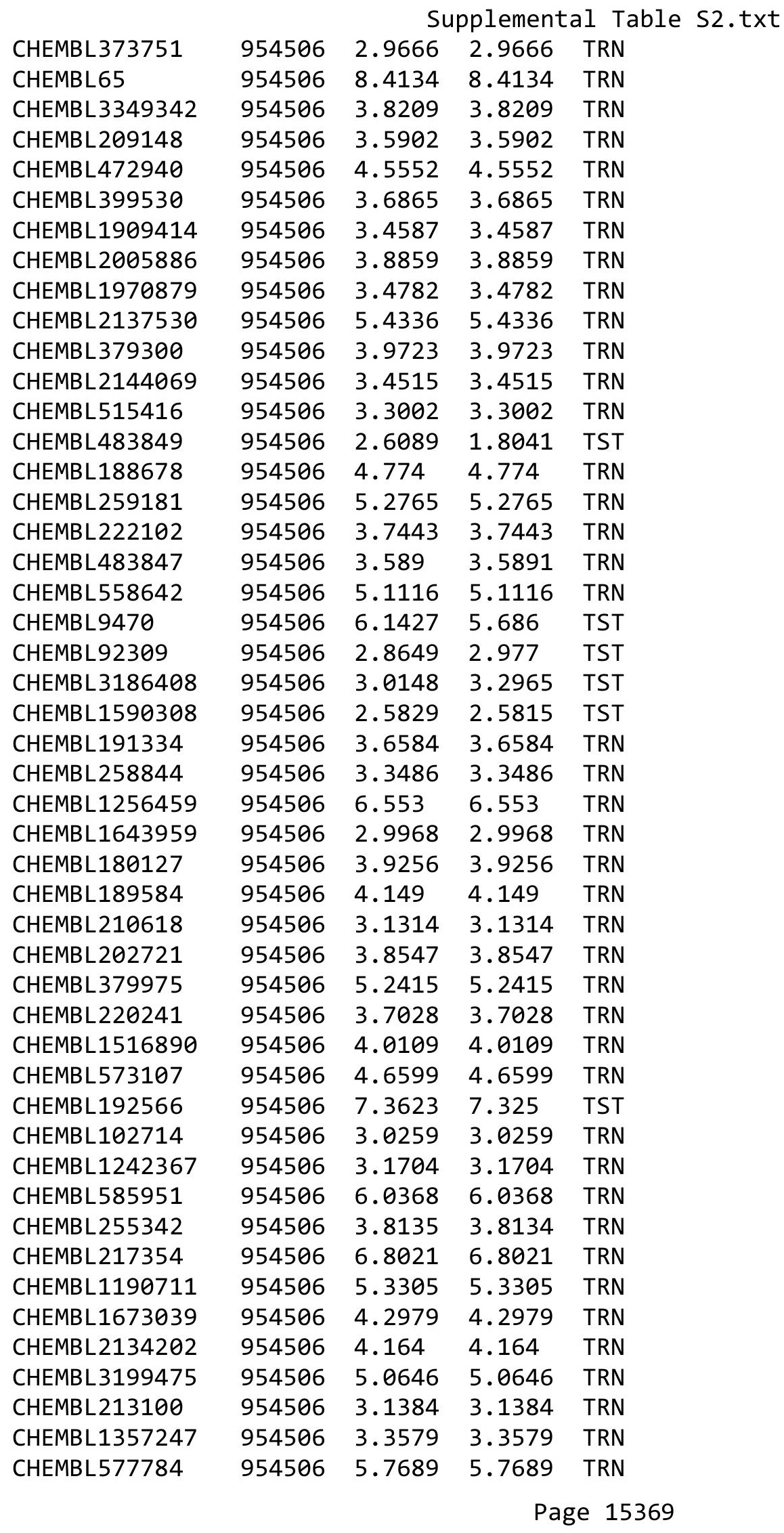




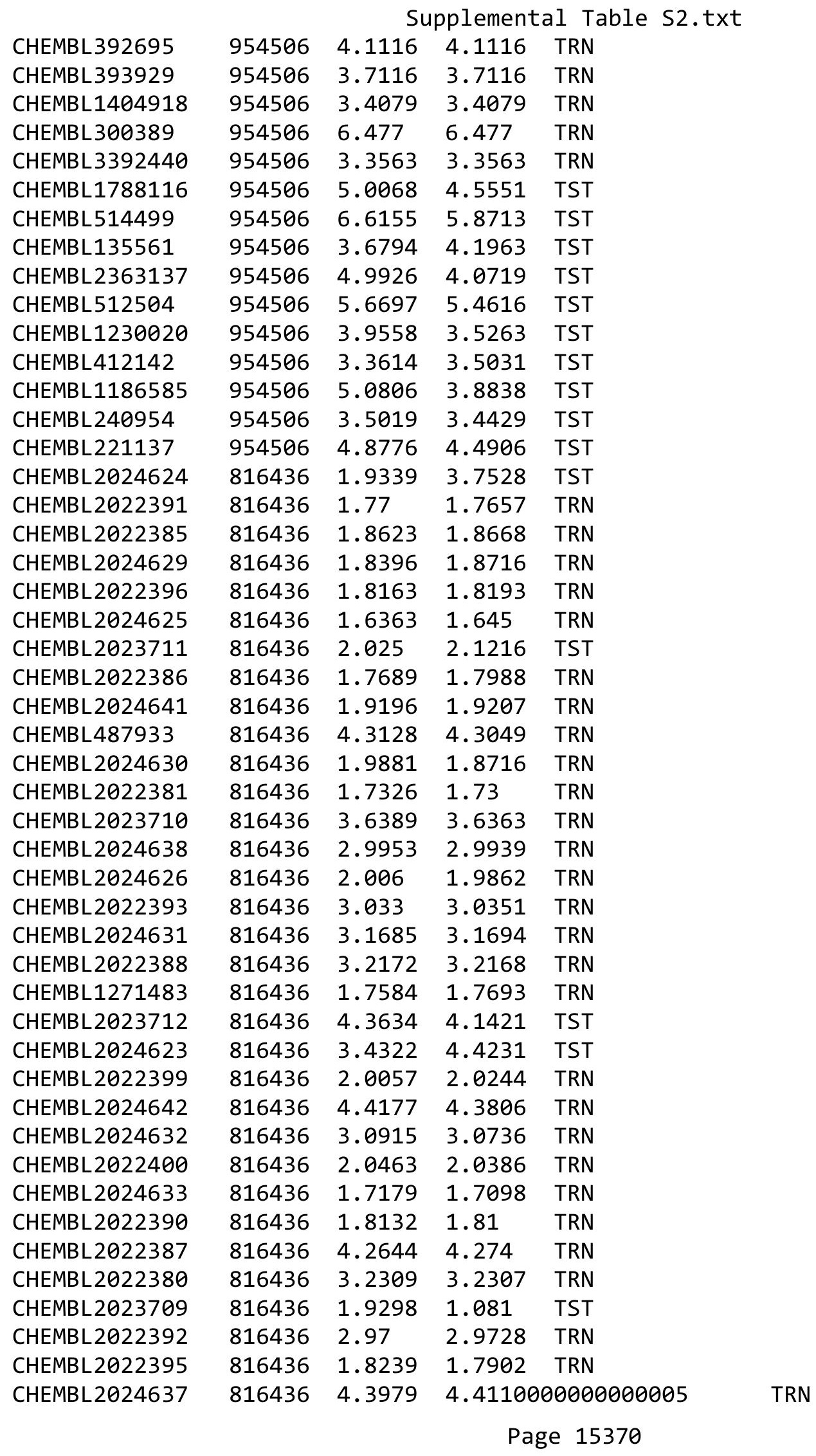


Supplemental Table S2.txt

\begin{tabular}{|c|c|c|c|c|}
\hline CHEMBL2022401 & 816436 & 1.9311 & 0.2978 & TST \\
\hline CHEMBL 2022394 & 816436 & 4.4396 & 2.4693 & TST \\
\hline CHEMBL2022397 & 816436 & 3.1953 & 3.24 & TRN \\
\hline CHEMBL2023706 & 816436 & 1.9992 & 1.9981 & TRN \\
\hline CHEMBL1269516 & 816436 & 1.6973 & 1.6999 & TRN \\
\hline CHEMBL2024635 & 816436 & 4.2412 & 4.2543 & TRN \\
\hline CHEMBL 2024627 & 816436 & 1.7559 & 1.7625 & TRN \\
\hline CHEMBL2023708 & 816436 & 1.9109 & 1.8952 & TRN \\
\hline CHEMBL 2022402 & 816436 & 1.9853 & 1.9875 & TRN \\
\hline CHEMBL 2023707 & 816436 & 1.9651 & 0.3541 & TST \\
\hline CHEMBL450046 & 816436 & 2.8672 & 4.2739 & TST \\
\hline CHEMBL2022383 & 816436 & 1.909 & 1.8988 & TRN \\
\hline CHEMBL2024628 & 816436 & 1.7705 & 1.8716 & TRN \\
\hline CHEMBL 2022384 & 816436 & 2.0942 & 2.0931 & TRN \\
\hline CHEMBL 2024639 & 816436 & 3.8892 & 3.8843 & TRN \\
\hline CHEMBL 2022389 & 816436 & 1.9458 & 1.9426 & TRN \\
\hline CHEMBL2022382 & 816436 & 2.0063 & 1.9968 & TRN \\
\hline CHEMBL 2024634 & 816436 & 1.8563 & 1.8581 & TRN \\
\hline CHEMBL1341255 & 816436 & 3.364 & 4.2554 & TST \\
\hline CHEMBL 2022398 & 816436 & 3.4603 & 4.3204 & TST \\
\hline CHEMBL 2024636 & 816436 & 3.0782 & 2.5094 & TST \\
\hline CHEMBL 2024640 & 816436 & 3.8373 & 3.8843 & TST \\
\hline CHEMBL 2024643 & 816436 & 3.6799 & 3.786 & TST \\
\hline CHEMBL97964 & 36763 & 6.1549 & 6.4064 & TRN \\
\hline CHEMBL317061 & 36763 & 6.2366 & 6.2059 & TRN \\
\hline CHEMBL97295 & 36763 & 6.284 & 5.8447 & TRN \\
\hline CHEMBL97446 & 36763 & 7.5229 & 7.0644 & TRN \\
\hline CHEMBL330463 & 36763 & 6.301 & 6.2437 & TRN \\
\hline CHEMBL328941 & 36763 & 7.3372 & 7.23600 & 0000000001 \\
\hline CHEMBL95198 & 36763 & 6.9586 & 7.2061 & TRN \\
\hline CHEMBL18606 & 36763 & 6.301 & 5.7618 & TRN \\
\hline CHEMBL319353 & 36763 & 6.1079 & 6.7139 & TRN \\
\hline CHEMBL97075 & 36763 & 7.2218 & 7.3169 & TRN \\
\hline CHEMBL94905 & 36763 & 6.7959 & 6.9626 & TRN \\
\hline CHEMBL 907 & 36763 & 3.301 & 5.5578 & TST \\
\hline CHEMBL330533 & 36763 & 7.2757 & 7.1579 & TRN \\
\hline CHEMBL317368 & 36763 & 6.4949 & 6.3124 & TRN \\
\hline CHEMBL97812 & 36763 & 6.5528 & 6.8734 & TRN \\
\hline CHEMBL274712 & 36763 & 6.3468 & 6.3818 & TRN \\
\hline CHEMBL 98126 & 36763 & 6.9586 & 6.7842 & TRN \\
\hline CHEMBL328434 & 36763 & 6.9208 & 6.7823 & TRN \\
\hline CHEMBL321367 & 36763 & 7.0655 & 6.8477 & TRN \\
\hline CHEMBL265012 & 36763 & 6.7212 & 6.9192 & TRN \\
\hline CHEMBL327791 & 36763 & 6.7212 & 6.7769 & TRN \\
\hline CHEMBL94176 & 36763 & 6.301 & 5.9454 & TST \\
\hline CHEMBL316482 & 36763 & 6.7212 & 6.6624 & TRN \\
\hline CHEMBL98068 & 36763 & 6.7959 & 6.9237 & TRN \\
\hline CHEMBL97068 & 36763 & 6.7696 & 6.6012 & TRN \\
\hline
\end{tabular}

Page 15371 


\begin{tabular}{|c|c|c|c|c|c|}
\hline & & \multicolumn{4}{|c|}{ Supplemental Table S2.txt } \\
\hline CHEMBL19018 & 36763 & 4.6383 & 5.8063 & TST & \\
\hline CHEMBL316655 & 36763 & 6.9208 & 7.0 & TRN & \\
\hline CHEMBL329255 & 36763 & 6.5086 & 7.2799 & TRN & \\
\hline CHEMBL314514 & 36763 & 6.1427 & 6.7402 & TRN & \\
\hline CHEMBL97615 & 36763 & 6.8239 & 6.4715 & TRN & \\
\hline CHEMBL319404 & 36763 & 6.7447 & 6.681 & TRN & \\
\hline CHEMBL330165 & 36763 & 6.9586 & 7.1243 & TRN & \\
\hline CHEMBL321086 & 36763 & 5.6383 & 5.7844 & TST & \\
\hline CHEMBL94145 & 36763 & 7.0969 & 6.9264 & TRN & \\
\hline CHEMBL97557 & 36763 & 6.3979 & 6.3331 & TRN & \\
\hline CHEMBL 275160 & 36763 & 6.2291 & \multicolumn{2}{|c|}{5.6979999999999995} & TRN \\
\hline CHEMBL316706 & 36763 & 5.4437 & 5.8772 & TRN & \\
\hline CHEMBL316273 & 36763 & 7.0862 & 6.9423 & TRN & \\
\hline CHEMBL 329099 & 36763 & 6.5686 & 6.9626 & TRN & \\
\hline CHEMBL97897 & 36763 & 6.7959 & 6.3892 & TRN & \\
\hline CHEMBL94910 & 36763 & 6.8239 & 6.5818 & TRN & \\
\hline CHEMBL95955 & 36763 & 6.284 & 6.4044 & TRN & \\
\hline CHEMBL329942 & 36763 & 7.585 & 7.2315 & TRN & \\
\hline CHEMBL 93956 & 36763 & 6.5686 & 6.5245 & TRN & \\
\hline CHEMBL97332 & 36763 & 5.6198 & 5.6735 & TRN & \\
\hline CHEMBL414816 & 36763 & 5.5229 & 5.6306 & TRN & \\
\hline CHEMBL316904 & 36763 & 7.1427 & 6.7461 & TRN & \\
\hline CHEMBL321363 & 36763 & 7.3665 & \multicolumn{2}{|c|}{7.172000000000001} & TRN \\
\hline CHEMBL 327563 & 36763 & 7.1192 & 6.7978 & TRN & \\
\hline CHEMBL329759 & 36763 & 6.3979 & 6.426 & TRN & \\
\hline CHEMBL432392 & 36763 & 6.8861 & \multicolumn{2}{|c|}{6.757999999999999} & TRN \\
\hline CHEMBL432822 & 36763 & 7.3372 & 6.5132 & TRN & \\
\hline CHEMBL97394 & 36763 & 7.4559 & 6.9985 & TRN & \\
\hline CHEMBL93606 & 36763 & 7.0 & 6.5892 & TRN & \\
\hline CHEMBL327191 & 36763 & 6.7696 & 6.9483 & TRN & \\
\hline CHEMBL411487 & 36763 & 6.3665 & \multicolumn{2}{|c|}{6.843999999999999} & TRN \\
\hline CHEMBL328176 & 36763 & 5.8539 & 6.0599 & TRN & \\
\hline CHEMBL318042 & 36763 & 5.0 & 5.9464 & TRN & \\
\hline CHEMBL 97688 & 36763 & 7.0969 & 7.2072 & TRN & \\
\hline CHEMBL319955 & 36763 & 6.3872 & 6.5899 & TRN & \\
\hline CHEMBL98453 & 36763 & 7.0757 & 7.1226 & TRN & \\
\hline CHEMBL329858 & 36763 & 6.301 & 6.216 & TRN & \\
\hline CHEMBL97500 & 36763 & 5.1871 & 5.99 & TRN & \\
\hline CHEMBL97273 & 36763 & 4.9586 & 5.3205 & TRN & \\
\hline CHEMBL329089 & 36763 & 6.8239 & 6.9389 & TRN & \\
\hline CHEMBL314812 & 36763 & 6.2676 & 6.8211 & TRN & \\
\hline CHEMBL317547 & 36763 & 6.6576 & 6.8244 & TRN & \\
\hline CHEMBL94407 & 36763 & 5.0 & 6.0258 & TST & \\
\hline CHEMBL318891 & 36763 & 5.3372 & 5.7534 & TST & \\
\hline CHEMBL98426 & 36763 & 7.0 & 6.8691 & TRN & \\
\hline CHEMBL94355 & 36763 & 5.8239 & 6.2322 & TRN & \\
\hline CHEMBL409058 & 36763 & 6.4202 & 6.6063 & TRN & \\
\hline \multirow[t]{2}{*}{ CHEMBL319313 } & 36763 & 5.284 & \multicolumn{2}{|c|}{5.922000000000001} & TST \\
\hline & & & & 15372 & \\
\hline
\end{tabular}




\begin{tabular}{|c|c|c|c|c|c|}
\hline \multirow[b]{2}{*}{ CHEMBL97464 } & \multicolumn{5}{|c|}{ Supplemental Table s2.txt } \\
\hline & 36763 & 6.7212 & 6.7405 & TRN & \\
\hline CHEMBL97783 & 36763 & 4.6198 & 5.3115 & TST & \\
\hline CHEMBL95197 & 36763 & 6.5229 & 6.5314 & TRN & \\
\hline CHEMBL327988 & 36763 & 6.8861 & 6.8395 & TRN & \\
\hline CHEMBL94582 & 36763 & 6.3468 & 6.2113 & TRN & \\
\hline CHEMBL 292150 & 36763 & 7.7696 & 6.7933 & TRN & \\
\hline CHEMBL279629 & 36763 & 6.5229 & 6.0472 & TRN & \\
\hline CHEMBL316297 & 36763 & 6.301 & 6.5867 & TRN & \\
\hline CHEMBL329693 & 36763 & 7.2596 & 7.2196 & TRN & \\
\hline CHEMBL274710 & 36763 & 6.6198 & 6.3691 & TRN & \\
\hline CHEMBL262296 & 36763 & 7.4559 & 6.9104 & TST & \\
\hline CHEMBL95579 & 36763 & 6.9208 & 6.8802 & TST & \\
\hline CHEMBL320222 & 36763 & 6.041 & 6.4097 & TST & \\
\hline CHEMBL 317864 & 36763 & 6.284 & 6.8922 & TST & \\
\hline CHEMBL98140 & 36763 & 6.8861 & 6.5453 & TST & \\
\hline CHEMBL97020 & 36763 & 7.3468 & 7.0595 & TST & \\
\hline CHEMBL433375 & 36763 & 6.585 & 6.75899 & 99999999995 & TST \\
\hline CHEMBL 316300 & 36763 & 7.4437 & 6.7982 & TST & \\
\hline CHEMBL 97465 & 36763 & 6.4815 & 6.6268 & TST & \\
\hline CHEMBL329290 & 36763 & 7.6021 & 6.967006 & 00000000005 & TST \\
\hline CHEMBL330007 & 36763 & 5.2596 & 6.1779 & TST & \\
\hline CHEMBL 330464 & 36763 & 7.0 & 6.7844 & TST & \\
\hline CHEMBL97271 & 36763 & 7.0605 & 6.9692 & TST & \\
\hline CHEMBL431619 & 36763 & 7.1249 & 6.8067 & TST & \\
\hline CHEMBL327569 & 36763 & 6.1549 & 6.0513 & TST & \\
\hline CHEMBL407919 & 36763 & 6.6576 & 6.9095 & TST & \\
\hline CHEMBL330170 & 36763 & 6.5229 & 6.5269 & TST & \\
\hline CHEMBL3732279 & 1537594 & 5.0 & 5.1464 & TRN & \\
\hline CHEMBL 3732324 & 1537594 & 5.5003 & 6.1748 & TST & \\
\hline CHEMBL3728173 & 1537594 & 6.1986 & 6.4513 & TRN & \\
\hline CHEMBL3732814 & 1537594 & 4.301 & 5.2482 & TRN & \\
\hline CHEMBL3733323 & 1537594 & 6.9872 & 7.0988 & TRN & \\
\hline CHEMBL3728942 & 1537594 & 5.1993 & 5.1285 & TRN & \\
\hline CHEMBL3728035 & 1537594 & 5.8239 & 5.5858 & TRN & \\
\hline CHEMBL3731151 & 1537594 & 5.3335 & 5.1606 & TRN & \\
\hline CHEMBL3731908 & 1537594 & 5.6383 & 5.7023 & TRN & \\
\hline CHEMBL3732463 & 1537594 & 5.699 & 5.7842 & TRN & \\
\hline CHEMBL3729537 & 1537594 & 6.0535 & 5.8918 & TRN & \\
\hline CHEMBL3732639 & 1537594 & 5.9788 & 6.364 & TRN & \\
\hline CHEMBL3731179 & 1537594 & 7.1805 & 6.8822 & TRN & \\
\hline CHEMBL3731820 & 1537594 & 5.382999 & 99999999 & 6.0289 & TST \\
\hline CHEMBL3727999 & 1537594 & 5.1765 & 5.1228 & TRN & \\
\hline CHEMBL3732479 & 1537594 & 7.2676 & 7.142 & TRN & \\
\hline CHEMBL3732027 & 1537594 & 7.4202 & 7.3599 & TRN & \\
\hline CHEMBL3729183 & 1537594 & 5.9872 & 6.0863 & TRN & \\
\hline CHEMBL3728137 & 1537594 & 5.9586 & 5.9148 & TRN & \\
\hline CHEMBL3728093 & 1537594 & 4.6198 & 4.4713 & TRN & \\
\hline CHEMBL3731422 & 1537594 & 9.0 & 8.53399 & 9999999999 & TRN \\
\hline & & & & 15373 & \\
\hline
\end{tabular}


Supplemental Table S2.txt

\begin{tabular}{|c|c|c|c|c|c|}
\hline CHEMBL 3728706 & 1537594 & 6.0757 & 5.9113 & TRN & \\
\hline CHEMBL3728456 & 1537594 & 6.1487 & 5.8045 & TRN & \\
\hline CHEMBL3730264 & 1537594 & 4.7844 & 4.6655 & TRN & \\
\hline CHEMBL3731180 & 1537594 & 6.5901 & 6.212999 & 9999999999 & TRN \\
\hline CHEMBL3730427 & 1537594 & 5.1198 & 5.0756 & TRN & \\
\hline CHEMBL3727786 & 1537594 & 5.6778 & 5.9273 & TRN & \\
\hline CHEMBL3732983 & 1537594 & 7.1249 & 6.9966 & TRN & \\
\hline CHEMBL3731979 & 1537594 & 6.4949 & 7.1771 & TRN & \\
\hline CHEMBL3730091 & 1537594 & 7.4437 & 7.4367 & TRN & \\
\hline CHEMBL3728895 & 1537594 & 5.7696 & 6.1733 & TST & \\
\hline CHEMBL3730386 & 1537594 & 8.301 & 7.7791 & TRN & \\
\hline CHEMBL3733228 & 1537594 & 5.6968 & 6.0151 & TRN & \\
\hline CHEMBL3731721 & 1537594 & 7.1079 & 7.0311 & TRN & \\
\hline CHEMBL3727820 & 1537594 & 6.6198 & 6.7958 & TRN & \\
\hline CHEMBL3732705 & 1537594 & 5.0 & 6.1704 & TST & \\
\hline CHEMBL3733318 & 1537594 & 7.0088 & 7.1299 & TST & \\
\hline CHEMBL3727706 & 1537594 & 6.76200 & 000000000 & 6.909 & TRN \\
\hline CHEMBL3731442 & 1537594 & 5.2343 & 5.9562 & TST & \\
\hline CHEMBL3731998 & 1537594 & 5.3179 & 5.0185 & TRN & \\
\hline CHEMBL3731202 & 1537594 & 5.2441 & 5.1373 & TRN & \\
\hline CHEMBL3731165 & 1537594 & 5.699 & 5.9991 & TRN & \\
\hline CHEMBL3731538 & 1537594 & 5.9318 & 5.551 & TRN & \\
\hline CHEMBL3728250 & 1537594 & 6.8894 & 7.2672 & TRN & \\
\hline CHEMBL3732725 & 1537594 & 7.9208 & 7.8352 & TRN & \\
\hline CHEMBL3732218 & 1537594 & 7.041 & 7.2639 & TRN & \\
\hline CHEMBL3731570 & 1537594 & 6.6778 & 6.734 & TRN & \\
\hline CHEMBL3731199 & 1537594 & 5.8539 & 5.8328 & TRN & \\
\hline CHEMBL3729175 & 1537594 & 7.7212 & \multicolumn{2}{|c|}{ 7. 5889999999999995} & TRN \\
\hline CHEMBL3727466 & 1537594 & 5.8928 & 6.0083 & TRN & \\
\hline CHEMBL3733193 & 1537594 & 5.3372 & 5.7815 & TRN & \\
\hline CHEMBL3731664 & 1537594 & 7.8239 & 7.8839 & TRN & \\
\hline CHEMBL3732308 & 1537594 & 5.3565 & 5.1975 & TRN & \\
\hline CHEMBL3728435 & 1537594 & 8.0969 & 7.8464 & TRN & \\
\hline CHEMBL3729424 & 1537594 & 6.5686 & 6.8098 & TRN & \\
\hline CHEMBL3727685 & 1537594 & 5.3605 & 5.4917 & TRN & \\
\hline CHEMBL3727920 & 1537594 & 6.4145 & 6.715 & TRN & \\
\hline CHEMBL3728229 & 1537594 & 5.9281 & 6.1653 & TRN & \\
\hline CHEMBL3731002 & 1537594 & 7.7959 & 7.6859 & TRN & \\
\hline CHEMBL3731887 & 1537594 & 5.0458 & 5.8511 & TST & \\
\hline CHEMBL3730580 & 1537594 & 5.7959 & 5.8028 & TRN & \\
\hline CHEMBL3732227 & 1537594 & 5.9626 & 6.3957 & TST & \\
\hline CHEMBL3730400 & 1537594 & 6.6576 & 6.2147 & TRN & \\
\hline CHEMBL1995927 & 1537594 & 8.0458 & 6.7595 & TRN & \\
\hline CHEMBL3730512 & 1537594 & 6.4365 & 5.6252 & TST & \\
\hline CHEMBL3732578 & 1537594 & 5.0 & 5.2176 & TRN & \\
\hline CHEMBL3732943 & 1537594 & 5.699 & 6.0202 & TRN & \\
\hline CHEMBL3730340 & 1537594 & 5.5969 & 5.5105 & TRN & \\
\hline CHEMBL3731276 & 1537594 & 5.7212 & 5.5788 & TRN & \\
\hline
\end{tabular}


Supplemental Table S2.txt

\begin{tabular}{|c|c|c|c|c|}
\hline CHEMBL 3727853 & 1537594 & 6.4609 & 6.6826 & TRN \\
\hline CHEMBL3729640 & 1537594 & 6.1302 & 6.0668 & TRN \\
\hline CHEMBL3727376 & 1537594 & 5.7423 & 5.2477 & TRN \\
\hline CHEMBL3731566 & 1537594 & 7.3768 & 6.9623 & TRN \\
\hline CHEMBL3733215 & 1537594 & 6.1772 & 7.1644 & TRN \\
\hline CHEMBL3732615 & 1537594 & 7.1487 & 7.4881 & TRN \\
\hline CHEMBL3730838 & 1537594 & 6.71 & 6.5722 & TRN \\
\hline CHEMBL3732552 & 1537594 & 5.5702 & 5.561 & TRN \\
\hline CHEMBL3731055 & 1537594 & 6.2248 & 6.6033 & TST \\
\hline CHEMBL3728634 & 1537594 & 6.5986 & 6.9844 & TST \\
\hline CHEMBL 3727770 & 1537594 & 6.7212 & 6.2708 & TST \\
\hline CHEMBL3730455 & 1537594 & 7.1805 & 6.6746 & TST \\
\hline CHEMBL3728714 & 1537594 & 6.2441 & 6.5173 & TST \\
\hline CHEMBL3732229 & 1537594 & 6.9031 & 6.8428 & TST \\
\hline CHEMBL3729776 & 1537594 & 7.3872 & 7.237 & TST \\
\hline CHEMBL3729062 & 1537594 & 5.8539 & 5.1816 & TST \\
\hline CHEMBL3733024 & 1537594 & 6.9136 & 7.3067 & TST \\
\hline CHEMBL3732837 & 1537594 & 5.0 & 4.8937 & TST \\
\hline CHEMBL3732863 & 1537594 & 6.2596 & 6.836 & TST \\
\hline CHEMBL3732267 & 1537594 & 6.4056 & 6.8173 & TST \\
\hline CHEMBL3732931 & 1537594 & 6.2549 & 6.58899 & 99999999995 \\
\hline CHEMBL3731901 & 1537594 & 6.2882 & 6.5272 & TST \\
\hline CHEMBL1964290 & 809168 & 4.8 & 5.3409 & TST \\
\hline CHEMBL213505 & 809168 & 5.9 & 4.8546 & TRN \\
\hline CHEMBL1982880 & 809168 & 4.0 & 4.8486 & TRN \\
\hline CHEMBL1987034 & 809168 & 7.5 & 7.1349 & TRN \\
\hline CHEMBL1993941 & 809168 & 4.8 & 5.4716 & TRN \\
\hline CHEMBL377383 & 809168 & 4.8 & 4.5996 & TRN \\
\hline CHEMBL578061 & 809168 & 5.1 & 4.7512 & TRN \\
\hline CHEMBL2005886 & 809168 & 7.1 & 6.7364 & TRN \\
\hline CHEMBL481491 & 809168 & 4.8 & 4.9285 & TST \\
\hline CHEMBL1682345 & 809168 & 6.2 & 5.7129 & TRN \\
\hline CHEMBL1973142 & 809168 & 4.8 & 5.0743 & TRN \\
\hline CHEMBL1973145 & 809168 & 4.3 & 4.5486 & TRN \\
\hline CHEMBL1982924 & 809168 & 4.8 & 5.0486 & TRN \\
\hline CHEMBL 2005936 & 809168 & 4.8 & 5.2559 & TRN \\
\hline CHEMBL1807515 & 809168 & 4.8 & 6.4588 & TRN \\
\hline CHEMBL1971141 & 809168 & 4.8 & 4.7561 & TRN \\
\hline CHEMBL1995813 & 809168 & 4.8 & 6.1111 & TRN \\
\hline CHEMBL1979718 & 809168 & 4.0 & 4.6492 & TRN \\
\hline CHEMBL206236 & 809168 & 4.8 & 4.6447 & TRN \\
\hline CHEMBL523823 & 809168 & 4.0 & 5.2127 & TST \\
\hline CHEMBL1562756 & 809168 & 5.1 & 4.996 & TST \\
\hline CHEMBL 244378 & 809168 & 6.5 & 6.7196 & TRN \\
\hline CHEMBL2001957 & 809168 & 4.8 & 4.6518 & TRN \\
\hline CHEMBL1969372 & 809168 & 4.8 & 4.7061 & TRN \\
\hline CHEMBL1990583 & 809168 & 4.8 & 5.5267 & TRN \\
\hline CHEMBL1986943 & 809168 & 4.8 & 6.4328 & TRN \\
\hline
\end{tabular}




\begin{tabular}{|c|c|c|c|c|c|}
\hline & & & & & \\
\hline CHEMBL 2006263 & 809168 & 4.8 & 5.9253 & TST & \\
\hline CHEMBL1993584 & 809168 & 4.8 & 5.1654 & TRN & \\
\hline CHEMBL1986263 & 809168 & 6.2 & 5.8329 & TRN & \\
\hline CHEMBL 2000114 & 809168 & 4.8 & 5.2113 & TRN & \\
\hline CHEMBL 210618 & 809168 & 4.3 & 4.3712 & TRN & \\
\hline CHEMBL1975647 & 809168 & 4.8 & 5.2147 & TRN & \\
\hline CHEMBL1968380 & 809168 & 5.8 & 4.5186 & TRN & \\
\hline CHEMBL1964644 & 809168 & 4.8 & 4.7813 & TRN & \\
\hline CHEMBL1981782 & 809168 & 4.8 & 5.7844 & TRN & \\
\hline CHEMBL1977681 & 809168 & 6.8 & 5.3385 & TRN & \\
\hline CHEMBL1970142 & 809168 & 4.8 & 5.36299 & 99999999995 & TRN \\
\hline CHEMBL1990912 & 809168 & 4.8 & 4.7619 & TRN & \\
\hline CHEMBL1988163 & 809168 & 6.6 & 6.5446 & TRN & \\
\hline CHEMBL1995592 & 809168 & 4.0 & 4.8021 & TST & \\
\hline CHEMBL2006493 & 809168 & 4.3 & 4.5642 & TST & \\
\hline CHEMBL1982541 & 809168 & 4.0 & 4.7658 & TRN & \\
\hline CHEMBL1996923 & 809168 & 4.3 & 4.5146 & TST & \\
\hline CHEMBL1983449 & 809168 & 6.0 & 4.8967 & TRN & \\
\hline CHEMBL1992323 & 809168 & 4.3 & 4.5437 & TRN & \\
\hline CHEMBL1969735 & 809168 & 4.8 & 4.6612 & TRN & \\
\hline CHEMBL 2003524 & 809168 & 4.0 & 5.482 & TST & \\
\hline CHEMBL 2002649 & 809168 & 6.1 & 6.2476 & TRN & \\
\hline CHEMBL437747 & 809168 & 4.0 & 5.4319 & TRN & \\
\hline CHEMBL1995172 & 809168 & 5.9 & 4.8628 & TST & \\
\hline CHEMBL507936 & 809168 & 4.0 & 4.3639 & TRN & \\
\hline CHEMBL104264 & 809168 & 5.7 & 5.3385 & TST & \\
\hline CHEMBL1994321 & 809168 & 4.5 & 5.2365 & TRN & \\
\hline CHEMBL1997129 & 809168 & 7.8 & 6.865 & TRN & \\
\hline CHEMBL451964 & 809168 & 4.0 & 4.3706 & TRN & \\
\hline CHEMBL1964307 & 809168 & 5.1 & 4.894 & TRN & \\
\hline CHEMBL 2000508 & 809168 & 4.8 & 4.6785 & TRN & \\
\hline CHEMBL1971694 & 809168 & 4.6 & 4.6399 & TST & \\
\hline CHEMBL 2001547 & 809168 & 4.8 & 4.6916 & TRN & \\
\hline CHEMBL 210928 & 809168 & 4.3 & 4.4255 & TRN & \\
\hline CHEMBL1994361 & 809168 & 5.5 & 5.19600 & 2000000001 & TRN \\
\hline CHEMBL1986603 & 809168 & 4.8 & 4.9309 & TST & \\
\hline CHEMBL1972840 & 809168 & 5.8 & 5.8614 & TRN & \\
\hline CHEMBL1977148 & 809168 & 4.8 & 4.9575 & TRN & \\
\hline CHEMBL2003286 & 809168 & 4.8 & 4.7984 & TRN & \\
\hline CHEMBL1992306 & 809168 & 4.8 & 5.1019 & TRN & \\
\hline CHEMBL 2002165 & 809168 & 5.8 & 5.5563 & TRN & \\
\hline CHEMBL 206382 & 809168 & 4.3 & 4.4183 & TRN & \\
\hline CHEMBL1998585 & 809168 & 5.5 & 5.2461 & TRN & \\
\hline CHEMBL127898 & 809168 & 4.8 & 5.1009 & TST & \\
\hline CHEMBL519697 & 809168 & 8.0 & 5.3446 & TST & \\
\hline CHEMBL 2004934 & 809168 & 4.8 & 4.7174 & TRN & \\
\hline CHEMBL1975128 & 809168 & 6.5 & 6.7608 & TRN & \\
\hline CHEMBL 2001485 & 809168 & 4.8 & 5.3241 & TRN & \\
\hline & & & & 15376 & \\
\hline
\end{tabular}




\begin{tabular}{|c|c|c|c|c|}
\hline \multicolumn{5}{|c|}{ Supplemental Table S2.txt } \\
\hline CHEMBL504950 & 809168 & 4.0 & 4.7235 & TRN \\
\hline CHEMBL1966425 & 809168 & 5.8 & 5.6743 & TRN \\
\hline CHEMBL1984363 & 809168 & 4.8 & 5.1582 & TRN \\
\hline CHEMBL1978099 & 809168 & 6.6 & 6.1572 & TRN \\
\hline CHEMBL1977041 & 809168 & 5.4 & 4.9854 & TRN \\
\hline CHEMBL1968070 & 809168 & 5.7 & 5.4373 & TRN \\
\hline CHEMBL1988608 & 809168 & 6.7 & 5.5955 & TRN \\
\hline CHEMBL184847 & 809168 & 4.8 & 5.2771 & TRN \\
\hline CHEMBL1984367 & 809168 & 7.4 & 5.1741 & TRN \\
\hline CHEMBL226898 & 809168 & 7.1 & 6.9842 & TRN \\
\hline CHEMBL1982563 & 809168 & 4.8 & 4.6553 & TRN \\
\hline CHEMBL539474 & 809168 & 4.8 & 6.2325 & TST \\
\hline CHEMBL575824 & 809168 & 4.4 & 4.8588 & TRN \\
\hline CHEMBL1988387 & 809168 & 5.9 & 5.6094 & TRN \\
\hline CHEMBL1989708 & 809168 & 4.8 & 5.31 & TRN \\
\hline CHEMBL1990288 & 809168 & 4.8 & 4.717 & TRN \\
\hline CHEMBL1974803 & 809168 & 4.3 & 4.7526 & TST \\
\hline CHEMBL1970074 & 809168 & 4.3 & 4.6222 & TRN \\
\hline CHEMBL1986970 & 809168 & 4.8 & 6.1643 & TRN \\
\hline CHEMBL1958401 & 809168 & 4.8 & 4.8385 & TRN \\
\hline CHEMBL1984044 & 809168 & 4.3 & 4.7074 & TRN \\
\hline CHEMBL2003456 & 809168 & 4.8 & 5.0178 & TRN \\
\hline CHEMBL1966816 & 809168 & 4.8 & 4.9532 & TRN \\
\hline CHEMBL1972584 & 809168 & 6.4 & 5.7607 & TRN \\
\hline CHEMBL2002992 & 809168 & 4.8 & 4.9755 & TRN \\
\hline CHEMBL560813 & 809168 & 4.8 & 4.7554 & TRN \\
\hline CHEMBL1890036 & 809168 & 4.0 & 4.578 & TST \\
\hline CHEMBL1968791 & 809168 & 6.0 & 4.6047 & TRN \\
\hline CHEMBL326282 & 809168 & 4.0 & 4.4522 & TST \\
\hline CHEMBL2002682 & 809168 & 6.0 & 5.2984 & TST \\
\hline CHEMBL1992732 & 809168 & 4.0 & 4.3879 & TST \\
\hline CHEMBL1971186 & 809168 & 4.8 & 4.7326 & TRN \\
\hline CHEMBL 2003482 & 809168 & 4.8 & 4.8776 & TRN \\
\hline CHEMBL1973211 & 809168 & 4.7 & 5.1129 & TRN \\
\hline CHEMBL1984700 & 809168 & 4.8 & 4.7414 & TRN \\
\hline CHEMBL 2007151 & 809168 & 5.2 & 4.4812 & TRN \\
\hline CHEMBL1972125 & 809168 & 4.9 & 4.78 & TRN \\
\hline CHEMBL1976134 & 809168 & 4.8 & 5.2359 & TRN \\
\hline CHEMBL1965131 & 809168 & 4.8 & 5.4388 & TRN \\
\hline CHEMBL1995448 & 809168 & 4.0 & 4.6035 & TRN \\
\hline CHEMBL1972158 & 809168 & 4.6 & 6.0532 & TRN \\
\hline CHEMBL1974457 & 809168 & 6.2 & 4.7154 & TRN \\
\hline CHEMBL 2006581 & 809168 & 4.0 & 4.3815 & TRN \\
\hline CHEMBL1979855 & 809168 & 4.8 & 4.8739 & TRN \\
\hline CHEMBL1970340 & 809168 & 4.8 & 4.3824 & TRN \\
\hline CHEMBL 2005186 & 809168 & 4.8 & 4.9616 & TRN \\
\hline CHEMBL1975534 & 809168 & 4.8 & 4.9847 & TRN \\
\hline CHEMBL1993424 & 809168 & 4.8 & 6.3645 & TRN \\
\hline
\end{tabular}




\begin{tabular}{|c|c|c|c|c|}
\hline & & & 15 & 11 \\
\hline CHEMBL1966703 & 809168 & 4.8 & 4.8923 & TST \\
\hline CHEMBL1969561 & 809168 & 4.8 & $6.2020 e$ & 0000000001 \\
\hline CHEMBL1975121 & 809168 & 4.8 & 4.6032 & TRN \\
\hline CHEMBL1997023 & 809168 & 4.3 & 4.9313 & TST \\
\hline CHEMBL1964687 & 809168 & 4.3 & 5.7421 & TRN \\
\hline CHEMBL1971943 & 809168 & 4.8 & 4.8311 & TRN \\
\hline CHEMBL1999918 & 809168 & 6.4 & 5.8974 & TRN \\
\hline CHEMBL1974254 & 809168 & 4.8 & 5.2682 & TRN \\
\hline CHEMBL1988537 & 809168 & 4.8 & 5.2766 & TST \\
\hline CHEMBL1969049 & 809168 & 4.8 & 4.7262 & TRN \\
\hline CHEMBL 2005828 & 809168 & 4.8 & 5.5449 & TRN \\
\hline CHEMBL1998611 & 809168 & 4.8 & 5.6709 & TRN \\
\hline CHEMBL485556 & 809168 & 7.7 & 4.59 & TST \\
\hline CHEMBL1975900 & 809168 & 7.1 & 5.5805 & TRN \\
\hline CHEMBL 255822 & 809168 & 4.8 & 4.9646 & TRN \\
\hline CHEMBL1972221 & 809168 & 4.8 & 4.9998 & TRN \\
\hline CHEMBL 2006778 & 809168 & 4.7 & 4.9478 & TRN \\
\hline CHEMBL 378627 & 809168 & 4.3 & 4.3934 & TRN \\
\hline CHEMBL1996979 & 809168 & 4.8 & 5.5452 & TRN \\
\hline CHEMBL1997025 & 809168 & 4.4 & 4.5397 & TRN \\
\hline CHEMBL1968406 & 809168 & 4.8 & 5.7727 & TRN \\
\hline CHEMBL1982476 & 809168 & 4.0 & 5.5957 & TRN \\
\hline CHEMBL1984274 & 809168 & 4.3 & 4.7879 & TST \\
\hline CHEMBL1998545 & 809168 & 4.3 & 4.4528 & TRN \\
\hline CHEMBL1986869 & 809168 & 4.8 & 4.7237 & TRN \\
\hline CHEMBL1682558 & 809168 & 4.8 & 4.8268 & TRN \\
\hline CHEMBL1990496 & 809168 & 4.3 & 4.5128 & TRN \\
\hline CHEMBL1997623 & 809168 & 5.2 & 4.7823 & TRN \\
\hline CHEMBL 2002479 & 809168 & 7.0 & 6.335 & TRN \\
\hline CHEMBL1980371 & 809168 & 5.4 & 5.1725 & TST \\
\hline CHEMBL1993166 & 809168 & 5.8 & 4.6594 & TRN \\
\hline CHEMBL1967094 & 809168 & 7.7 & 6.0552 & TRN \\
\hline CHEMBL1966035 & 809168 & 5.8 & 4.789 & TRN \\
\hline CHEMBL 2003341 & 809168 & 4.8 & 4.7707 & TRN \\
\hline CHEMBL1992644 & 809168 & 3.6 & 4.2599 & TRN \\
\hline CHEMBL1992645 & 809168 & 4.0 & 4.5772 & TST \\
\hline CHEMBL1982992 & 809168 & 4.8 & 4.8625 & TRN \\
\hline CHEMBL1999590 & 809168 & 4.8 & 4.8747 & TST \\
\hline CHEMBL1981079 & 809168 & 5.9 & 5.2159 & TST \\
\hline CHEMBL1980489 & 809168 & 6.5 & 5.4594 & TRN \\
\hline CHEMBL1967116 & 809168 & 4.8 & 5.2557 & TRN \\
\hline CHEMBL 2000832 & 809168 & 6.3 & 5.9083 & TRN \\
\hline CHEMBL1977814 & 809168 & 4.0 & 4.4671 & TST \\
\hline CHEMBL1970709 & 809168 & 4.8 & 4.8968 & TRN \\
\hline CHEMBL1965660 & 809168 & 5.9 & 5.3098 & TST \\
\hline CHEMBL1998112 & 809168 & 4.8 & 4.8309 & TRN \\
\hline CHEMBL1969126 & 809168 & 4.8 & 4.742 & TRN \\
\hline CHEMBL1980896 & 809168 & 4.3 & 4.8072 & TRN \\
\hline
\end{tabular}

TRN 


\begin{tabular}{|c|c|c|c|c|}
\hline & & & גррцement & al lable s \\
\hline CHEMBL1970104 & 809168 & 6.5 & 6.3044 & TRN \\
\hline CHEMBL1991429 & 809168 & 6.0 & 5.591 & TRN \\
\hline CHEMBL1971149 & 809168 & 4.8 & 4.8209 & TRN \\
\hline CHEMBL1999714 & 809168 & 4.8 & 4.6925 & TRN \\
\hline CHEMBL1987533 & 809168 & 4.3 & 4.6051 & TRN \\
\hline CHEMBL1994040 & 809168 & 4.8 & 4.7292 & TRN \\
\hline CHEMBL388978 & 809168 & 8.0 & 8.0018 & TST \\
\hline CHEMBL579246 & 809168 & 4.5 & 5.5473 & TRN \\
\hline CHEMBL398951 & 809168 & 4.8 & 4.9787 & TST \\
\hline CHEMBL1982506 & 809168 & 4.3 & 5.0453 & TST \\
\hline CHEMBL 2004716 & 809168 & 6.3 & 5.6614 & TRN \\
\hline CHEMBL1968127 & 809168 & 4.8 & 4.7197 & TRN \\
\hline CHEMBL1975233 & 809168 & 4.3 & 4.3739 & TRN \\
\hline CHEMBL1985406 & 809168 & 4.8 & 5.5277 & TRN \\
\hline CHEMBL207400 & 809168 & 4.3 & 4.5269 & TST \\
\hline CHEMBL 2000894 & 809168 & 4.8 & 4.6476 & TST \\
\hline CHEMBL1982135 & 809168 & 4.8 & 5.3921 & TRN \\
\hline CHEMBL1976090 & 809168 & 5.8 & 4.9044 & TRN \\
\hline CHEMBL1993243 & 809168 & 4.8 & 5.249 & TRN \\
\hline CHEMBL1992922 & 809168 & 4.7 & 5.8497 & TRN \\
\hline CHEMBL 2004771 & 809168 & 4.8 & 5.3973 & TRN \\
\hline CHEMBL399021 & 809168 & 5.9 & 4.6896 & TRN \\
\hline CHEMBL1997597 & 809168 & 4.8 & 5.1763 & TRN \\
\hline CHEMBL1969537 & 809168 & 5.8 & 5.4379 & TST \\
\hline CHEMBL1976093 & 809168 & 4.8 & 4.6983 & TRN \\
\hline CHEMBL 210032 & 809168 & 4.3 & 4.4281 & TRN \\
\hline CHEMBL1996543 & 809168 & 4.0 & 4.5289 & TRN \\
\hline CHEMBL1975256 & 809168 & 4.8 & 4.6438 & TST \\
\hline CHEMBL508928 & 809168 & 4.3 & 4.9098 & TRN \\
\hline CHEMBL 2004892 & 809168 & 4.8 & 5.2224 & TRN \\
\hline CHEMBL116070 & 809168 & 4.1 & 4.7137 & TRN \\
\hline CHEMBL1970314 & 809168 & 4.8 & 4.9031 & TRN \\
\hline CHEMBL 2004871 & 809168 & 4.8 & 4.7015 & TRN \\
\hline CHEMBL 2004872 & 809168 & 4.8 & 4.7075 & TRN \\
\hline CHEMBL1727312 & 809168 & 4.3 & 4.2564 & TRN \\
\hline CHEMBL1969879 & 809168 & 4.8 & 4.8382 & TRN \\
\hline CHEMBL1981720 & 809168 & 6.3 & 4.8881 & TRN \\
\hline CHEMBL419932 & 809168 & 4.8 & 4.8381 & TRN \\
\hline CHEMBL 262433 & 809168 & 4.8 & 4.789 & TRN \\
\hline CHEMBL 306380 & 809168 & 4.6 & 4.7736 & TRN \\
\hline CHEMBL1966722 & 809168 & 4.8 & 6.2027 & TST \\
\hline CHEMBL1976328 & 809168 & 4.0 & 4.4412 & TRN \\
\hline CHEMBL1975500 & 809168 & 6.5 & 5.267 & TRN \\
\hline CHEMBL394619 & 809168 & 4.3 & 4.7047 & TRN \\
\hline CHEMBL1964399 & 809168 & 7.5 & 6.4323 & TRN \\
\hline CHEMBL1996831 & 809168 & 4.8 & $5.6720 e$ & 0000000001 \\
\hline CHEMBL411903 & 809168 & 6.6 & 5.7598 & TRN \\
\hline CHEMBL1965988 & 809168 & 5.9 & 5.1063 & TRN \\
\hline
\end{tabular}




\begin{tabular}{|c|c|c|c|c|c|}
\hline \\
\hline CHEMBL418203 & 809168 & 4.8 & 5.0229 & TST & \\
\hline CHEMBL1989646 & 809168 & 4.8 & 5.7322 & TRN & \\
\hline CHEMBL1682357 & 809168 & 4.0 & 4.60800 & 00000000005 & TRN \\
\hline CHEMBL225519 & 809168 & 5.0 & 5.1538 & TRN & \\
\hline CHEMBL209534 & 809168 & 4.0 & 4.2808 & TRN & \\
\hline CHEMBL1978200 & 809168 & 4.8 & 4.6982 & TRN & \\
\hline CHEMBL1970522 & 809168 & 4.5 & 4.689 & TRN & \\
\hline CHEMBL402846 & 809168 & 4.3 & 4.5237 & TRN & \\
\hline CHEMBL1966087 & 809168 & 4.3 & 4.4957 & TRN & \\
\hline CHEMBL1964692 & 809168 & 4.8 & 4.7283 & TRN & \\
\hline CHEMBL1996931 & 809168 & 4.8 & 4.6666 & TRN & \\
\hline CHEMBL1964413 & 809168 & 4.3 & 4.6593 & TRN & \\
\hline CHEMBL1973483 & 809168 & 4.8 & 5.29 & TRN & \\
\hline CHEMBL1984432 & 809168 & 4.0 & 4.9321 & TRN & \\
\hline CHEMBL219722 & 809168 & 5.6 & 4.823 & TRN & \\
\hline CHEMBL1997340 & 809168 & 4.8 & 4.8139 & TRN & \\
\hline CHEMBL1522508 & 809168 & 4.8 & 4.7502 & TRN & \\
\hline CHEMBL1989474 & 809168 & 4.8 & 4.7532 & TRN & \\
\hline CHEMBL1090360 & 809168 & 4.8 & 4.8599 & TRN & \\
\hline CHEMBL210887 & 809168 & 4.8 & 4.8815 & TST & \\
\hline CHEMBL458997 & 809168 & 6.5 & 6.6543 & TRN & \\
\hline CHEMBL1971021 & 809168 & 4.8 & 5.0003 & TRN & \\
\hline CHEMBL 227271 & 809168 & 6.0 & 6.9614 & TRN & \\
\hline CHEMBL583144 & 809168 & 4.3 & 4.5776 & TRN & \\
\hline CHEMBL1974310 & 809168 & 6.3 & 5.5566 & TRN & \\
\hline CHEMBL1982660 & 809168 & 4.8 & 4.9401 & TRN & \\
\hline CHEMBL1994693 & 809168 & 4.8 & 5.8926 & TRN & \\
\hline CHEMBL1982957 & 809168 & 6.4 & 6.4631 & TRN & \\
\hline CHEMBL1725279 & 809168 & 6.3 & 5.4395 & TST & \\
\hline CHEMBL1975138 & 809168 & 4.8 & 6.0288 & TST & \\
\hline CHEMBL424872 & 809168 & 4.4 & 4.3673 & TRN & \\
\hline CHEMBL 2006836 & 809168 & 4.3 & 4.7727 & TST & \\
\hline CHEMBL1971947 & 809168 & 4.0 & 4.8562 & TRN & \\
\hline CHEMBL412142 & 809168 & 4.4 & 4.7868 & TST & \\
\hline CHEMBL1980704 & 809168 & 4.8 & 4.8988 & TST & \\
\hline CHEMBL 2003271 & 809168 & 4.8 & 5.4627 & TRN & \\
\hline CHEMBL1966808 & 809168 & 4.8 & 4.6818 & TST & \\
\hline CHEMBL2004447 & 809168 & 4.3 & 4.5409 & TST & \\
\hline CHEMBL1983111 & 809168 & 7.3 & 7.2771 & TST & \\
\hline CHEMBL1973860 & 809168 & 4.8 & 4.7679 & TRN & \\
\hline CHEMBL 260135 & 809168 & 4.3 & 4.53100 & $\partial 000000001$ & TRN \\
\hline CHEMBL 220241 & 809168 & 4.8 & 5.3139 & TRN & \\
\hline CHEMBL1982610 & 809168 & 4.8 & 4.8335 & TST & \\
\hline CHEMBL1986996 & 809168 & 5.4 & 5.308 & TST & \\
\hline CHEMBL1999496 & 809168 & 4.8 & 4.7928 & TRN & \\
\hline CHEMBL 2006933 & 809168 & 6.0 & 4.6169 & TST & \\
\hline CHEMBL1988300 & 809168 & 4.8 & 5.0862 & TRN & \\
\hline CHEMBL1991078 & 809168 & 7.3 & 7.0903 & TRN & \\
\hline
\end{tabular}




\begin{tabular}{|c|c|c|c|c|c|}
\hline \multirow{2}{*}{ CHEMBL1987359 } & \multirow{2}{*}{809168} & \multirow[b]{2}{*}{4.8} & \\
\hline & & & 4.8345 & TST & \\
\hline CHEMBL 2000685 & 809168 & 6.4 & 6.0373 & TRN & \\
\hline CHEMBL1985311 & 809168 & 4.0 & 4.8622 & TRN & \\
\hline CHEMBL1989265 & 809168 & 4.3 & 4.6656 & TST & \\
\hline CHEMBL1969502 & 809168 & 6.9 & 6.4761 & TRN & \\
\hline CHEMBL1965910 & 809168 & 5.5 & 4.5358 & TRN & \\
\hline CHEMBL1682553 & 809168 & 4.3 & 4.4782 & TRN & \\
\hline CHEMBL1971430 & 809168 & 4.4 & 4.4974 & TRN & \\
\hline CHEMBL1997764 & 809168 & 4.8 & 4.9839 & TRN & \\
\hline CHEMBL1983963 & 809168 & 4.6 & 4.9262 & TRN & \\
\hline CHEMBL 2000271 & 809168 & 6.4 & 6.1774 & TRN & \\
\hline CHEMBL1985092 & 809168 & 4.8 & 5.086 & TST & \\
\hline CHEMBL 2004692 & 809168 & 4.3 & 4.4271 & TST & \\
\hline CHEMBL1981410 & 809168 & 4.8 & 5.0469 & TRN & \\
\hline CHEMBL1996234 & 809168 & 4.8 & 4.9434 & TRN & \\
\hline CHEMBL1991434 & 809168 & 4.3 & \multicolumn{2}{|c|}{4.5680000000000005} & TST \\
\hline CHEMBL1967544 & 809168 & 6.3 & 4.8708 & TRN & \\
\hline CHEMBL223367 & 809168 & 4.3 & 5.7037 & TST & \\
\hline CHEMBL407391 & 809168 & 5.4 & 4.9944 & TST & \\
\hline CHEMBL340384 & 809168 & 4.8 & 5.0206 & TST & \\
\hline CHEMBL1996587 & 809168 & 4.8 & 4.7897 & TRN & \\
\hline CHEMBL1964804 & 809168 & 4.8 & 4.7766 & TRN & \\
\hline CHEMBL443962 & 809168 & 4.6 & 4.9246 & TST & \\
\hline CHEMBL 2000354 & 809168 & 4.8 & 4.8717 & TRN & \\
\hline CHEMBL1981107 & 809168 & 3.6 & 4.3856 & TST & \\
\hline CHEMBL 274064 & 809168 & 4.3 & 4.4567 & TRN & \\
\hline CHEMBL1967564 & 809168 & 4.3 & 4.4246 & TRN & \\
\hline CHEMBL592030 & 809168 & 7.7 & 6.5595 & TST & \\
\hline CHEMBL 2000071 & 809168 & 4.4 & \multicolumn{2}{|c|}{5.8420000000000005} & TRN \\
\hline CHEMBL1979176 & 809168 & 4.8 & 4.7773 & TRN & \\
\hline CHEMBL1970317 & 809168 & 6.3 & 5.3504 & TRN & \\
\hline CHEMBL 2000408 & 809168 & 4.8 & 4.7268 & TRN & \\
\hline CHEMBL248757 & 809168 & 4.3 & 5.3714 & TST & \\
\hline CHEMBL1978014 & 809168 & 4.8 & 4.9938 & TRN & \\
\hline CHEMBL1994538 & 809168 & 4.4 & 4.6339 & TRN & \\
\hline CHEMBL1983195 & 809168 & 5.8 & 5.7341 & TST & \\
\hline CHEMBL1975490 & 809168 & 4.8 & 5.2486 & TRN & \\
\hline CHEMBL1964444 & 809168 & 4.8 & 4.6292 & TRN & \\
\hline CHEMBL 2006567 & 809168 & 4.0 & 4.3564 & TRN & \\
\hline CHEMBL1986139 & 809168 & 4.8 & 4.7877 & TRN & \\
\hline CHEMBL383527 & 809168 & 4.0 & 4.3479 & TRN & \\
\hline CHEMBL 1980540 & 809168 & 4.8 & 4.7424 & TRN & \\
\hline CHEMBL1979883 & 809168 & 4.3 & 5.1619 & TRN & \\
\hline CHEMBL1984162 & 809168 & 4.8 & 5.6764 & TRN & \\
\hline CHEMBL491758 & 809168 & 4.8 & 5.6585 & TRN & \\
\hline CHEMBL549730 & 809168 & 6.3 & 4.771 & TRN & \\
\hline CHEMBL1682360 & 809168 & 5.9 & 4.5549 & TRN & \\
\hline \multirow[t]{2}{*}{ CHEMBL1970189 } & 809168 & 4.8 & 4.9024 & TST & \\
\hline & & \multicolumn{4}{|c|}{ Page 15381} \\
\hline
\end{tabular}




\begin{tabular}{|c|c|c|c|c|}
\hline & & & Supplement & \\
\hline CHEMBL1996791 & 809168 & 4.8 & 5.2585 & TRN \\
\hline CHEMBL371206 & 809168 & 4.8 & 5.1089 & TRN \\
\hline CHEMBL1974664 & 809168 & 4.8 & 4.9185 & TST \\
\hline CHEMBL1974288 & 809168 & 4.8 & 4.7548 & TRN \\
\hline CHEMBL196363 & 809168 & 4.1 & 5.1603 & TRN \\
\hline CHEMBL1190711 & 809168 & 4.8 & 4.9639 & TRN \\
\hline CHEMBL1990346 & 809168 & 4.0 & 4.7245 & TRN \\
\hline CHEMBL1968705 & 809168 & 6.0 & 5.4237 & TRN \\
\hline CHEMBL404367 & 809168 & 4.3 & 4.5616 & TRN \\
\hline CHEMBL1966343 & 809168 & 4.8 & 5.3589 & TRN \\
\hline CHEMBL1967887 & 809168 & 4.8 & 5.1855 & TRN \\
\hline CHEMBL 2000568 & 809168 & 6.2 & 4.982 & TRN \\
\hline CHEMBL 2000335 & 809168 & 6.2 & 6.2897 & TRN \\
\hline CHEMBL1988717 & 809168 & 4.8 & 5.3939 & TRN \\
\hline CHEMBL1974328 & 809168 & 7.0 & 5.996 & TRN \\
\hline CHEMBL509032 & 809168 & 8.9 & 7.7699 & TRN \\
\hline CHEMBL1973808 & 809168 & 4.8 & 4.8067 & TRN \\
\hline CHEMBL 2000429 & 809168 & 4.8 & 4.8304 & TRN \\
\hline CHEMBL1989069 & 809168 & 5.2 & 4.9846 & TST \\
\hline CHEMBL1992342 & 809168 & 4.8 & 5.1689 & TRN \\
\hline CHEMBL1988173 & 809168 & 4.8 & 6.4814 & TST \\
\hline CHEMBL1965423 & 809168 & 4.3 & 4.4339 & TRN \\
\hline CHEMBL1983025 & 809168 & 6.1 & 5.0659 & TRN \\
\hline CHEMBL205415 & 809168 & 4.5 & 4.6704 & TRN \\
\hline CHEMBL1977135 & 809168 & 4.8 & 4.6972 & TRN \\
\hline CHEMBL 2001920 & 809168 & 5.9 & 5.6034 & TRN \\
\hline CHEMBL2002322 & 809168 & 4.0 & 4.6807 & TRN \\
\hline CHEMBL1241473 & 809168 & 7.0 & 7.4408 & TRN \\
\hline CHEMBL 2002323 & 809168 & 4.0 & 4.398 & TST \\
\hline CHEMBL1978448 & 809168 & 4.8 & 5.2055 & TST \\
\hline CHEMBL1972258 & 809168 & 4.3 & 4.4442 & TRN \\
\hline CHEMBL 2001257 & 809168 & 4.3 & 5.1274 & TRN \\
\hline CHEMBL 2005548 & 809168 & 6.6 & 4.5631 & TRN \\
\hline CHEMBL1992536 & 809168 & 4.8 & 4.9908 & TRN \\
\hline CHEMBL1992740 & 809168 & 4.3 & 4.5503 & TRN \\
\hline CHEMBL439340 & 809168 & 4.5 & 4.5733 & TRN \\
\hline CHEMBL 2006188 & 809168 & 4.8 & 4.904 & TRN \\
\hline CHEMBL1967531 & 809168 & 4.8 & 5.4835 & TRN \\
\hline CHEMBL1970913 & 809168 & 4.3 & 4.543 & TRN \\
\hline CHEMBL1973893 & 809168 & 4.8 & 5.0004 & TRN \\
\hline CHEMBL1997534 & 809168 & 4.8 & 4.958 & TRN \\
\hline CHEMBL1996500 & 809168 & 4.8 & 4.5765 & TRN \\
\hline CHEMBL1985095 & 809168 & 7.4 & 6.477 & TST \\
\hline CHEMBL1991180 & 809168 & 6.4 & 5.5768 & TST \\
\hline CHEMBL1682540 & 809168 & 4.8 & 4.7742 & TRN \\
\hline CHEMBL1976420 & 809168 & 6.4 & 5.2714 & TST \\
\hline CHEMBL1994864 & 809168 & 6.1 & 4.8374 & TRN \\
\hline CHEMBL413779 & 809168 & 4.0 & 5.8942 & TST \\
\hline
\end{tabular}




\begin{tabular}{|c|c|c|c|c|c|}
\hline \\
\hline CHEMBL 2002446 & 809168 & 5.7 & 4.7963 & TST & \\
\hline CHEMBL497151 & 809168 & 4.8 & 5.6347 & TRN & \\
\hline CHEMBL246970 & 809168 & 4.8 & 5.812 & TRN & \\
\hline CHEMBL340921 & 809168 & 4.2 & 4.4521 & TST & \\
\hline CHEMBL373598 & 809168 & 5.2 & 5.1094 & TST & \\
\hline CHEMBL1999718 & 809168 & 4.8 & 4.7974 & TRN & \\
\hline CHEMBL1276446 & 809168 & 6.8 & 7.2081 & TST & \\
\hline CHEMBL1977346 & 809168 & 5.8 & 5.9117 & TRN & \\
\hline CHEMBL1971649 & 809168 & 4.8 & 4.6791 & TRN & \\
\hline CHEMBL 2003657 & 809168 & 4.0 & 4.3412 & TRN & \\
\hline CHEMBL 2006439 & 809168 & 4.8 & 5.466 & TRN & \\
\hline CHEMBL 2006156 & 809168 & 4.3 & 4.9702 & TST & \\
\hline CHEMBL1969190 & 809168 & 6.5 & 4.8815 & TRN & \\
\hline CHEMBL1973937 & 809168 & 5.4 & $5.3370 e$ & 0000000001 & TRN \\
\hline CHEMBL1991674 & 809168 & 6.4 & 6.1018 & TRN & \\
\hline CHEMBL1982711 & 809168 & 4.8 & 6.1803 & TRN & \\
\hline CHEMBL1984842 & 809168 & 4.0 & 4.4351 & TRN & \\
\hline CHEMBL1969102 & 809168 & 4.0 & 5.0591 & TRN & \\
\hline CHEMBL1682346 & 809168 & 6.2 & 5.9303 & TRN & \\
\hline CHEMBL 2007044 & 809168 & 4.6 & 5.3787 & TST & \\
\hline CHEMBL 2001998 & 809168 & 6.1 & 4.72 & TST & \\
\hline CHEMBL1994241 & 809168 & 4.3 & 5.6911 & TRN & \\
\hline CHEMBL 223460 & 809168 & 4.3 & 5.5002 & TST & \\
\hline CHEMBL1998829 & 809168 & 4.8 & 4.8742 & TRN & \\
\hline CHEMBL50894 & 809168 & 7.7 & 5.3056 & TRN & \\
\hline CHEMBL1988838 & 809168 & 7.0 & 6.4095 & TRN & \\
\hline CHEMBL1981725 & 809168 & 6.1 & 5.3997 & TRN & \\
\hline CHEMBL375284 & 809168 & 4.0 & 4.4195 & TRN & \\
\hline CHEMBL1982866 & 809168 & 4.8 & 4.7231 & TRN & \\
\hline CHEMBL2005792 & 809168 & 4.0 & 4.3934 & TRN & \\
\hline CHEMBL462120 & 809168 & 4.3 & 4.426 & TST & \\
\hline CHEMBL1984206 & 809168 & 4.0 & 4.2459 & TRN & \\
\hline CHEMBL1991577 & 809168 & 5.0 & 4.45 & TRN & \\
\hline CHEMBL1965570 & 809168 & 4.8 & 5.3734 & TRN & \\
\hline CHEMBL 2007592 & 809168 & 4.3 & 4.4295 & TST & \\
\hline CHEMBL210963 & 809168 & 4.3 & 4.3184 & TRN & \\
\hline CHEMBL1082440 & 809168 & 6.0 & 6.1825 & TST & \\
\hline CHEMBL1614705 & 809168 & 4.3 & 4.5736 & TST & \\
\hline CHEMBL1972362 & 809168 & 6.4 & 4.6559 & TRN & \\
\hline CHEMBL1984633 & 809168 & 4.8 & 4.8676 & TRN & \\
\hline CHEMBL1965845 & 809168 & 6.3 & 6.1975 & TRN & \\
\hline CHEMBL 2006715 & 809168 & 6.0 & 5.607 & TRN & \\
\hline CHEMBL1986597 & 809168 & 4.8 & 4.9732 & TRN & \\
\hline CHEMBL1971017 & 809168 & 6.9 & 5.8744 & TRN & \\
\hline CHEMBL1990482 & 809168 & 5.3 & 4.5197 & TRN & \\
\hline CHEMBL1990904 & 809168 & 4.8 & 4.7114 & TRN & \\
\hline CHEMBL 2005475 & 809168 & 7.8 & 5.9795 & TRN & \\
\hline CHEMBL2000104 & 809168 & 6.0 & 4.743 & TRN & \\
\hline & & & & 15383 & \\
\hline
\end{tabular}




\begin{tabular}{|c|c|c|c|c|}
\hline \multirow[b]{2}{*}{ CHEMBL1997349 } & \multicolumn{4}{|c|}{ Supplemental Table S2.txt } \\
\hline & 809168 & 6.0 & 5.449 & TST \\
\hline CHEMBL183844 & 809168 & 4.8 & 4.8526 & TRN \\
\hline CHEMBL220057 & 809168 & 4.7 & 4.8363 & TRN \\
\hline CHEMBL1682545 & 809168 & 4.3 & 4.5316 & TRN \\
\hline CHEMBL 383541 & 809168 & 4.3 & 4.5184 & TRN \\
\hline CHEMBL 2001224 & 809168 & 4.3 & 4.4018 & TRN \\
\hline CHEMBL10 & 809168 & 4.2 & 4.6306 & TRN \\
\hline CHEMBL1976732 & 809168 & 4.8 & 4.9973 & TRN \\
\hline CHEMBL1969506 & 809168 & 4.8 & 4.8423 & TRN \\
\hline CHEMBL1964937 & 809168 & 5.9 & 6.1727 & TRN \\
\hline CHEMBL1980163 & 809168 & 5.9 & 4.7491 & TRN \\
\hline CHEMBL590109 & 809168 & 7.4 & 6.5633 & TST \\
\hline CHEMBL1970879 & 809168 & 6.1 & 5.053 & TRN \\
\hline CHEMBL1989856 & 809168 & 4.0 & 4.6224 & TST \\
\hline CHEMBL 2005899 & 809168 & 6.0 & 4.6784 & TRN \\
\hline CHEMBL1682552 & 809168 & 4.2 & 4.4352 & TRN \\
\hline CHEMBL259850 & 809168 & 4.0 & 4.4076 & TRN \\
\hline CHEMBL1996155 & 809168 & 4.0 & 4.395 & TRN \\
\hline CHEMBL229799 & 809168 & 6.2 & 7.2054 & TRN \\
\hline CHEMBL1682359 & 809168 & 5.0 & 4.5252 & TRN \\
\hline CHEMBL105739 & 809168 & 7.1 & 5.1128 & TRN \\
\hline CHEMBL379300 & 809168 & 6.3 & 6.2336 & TRN \\
\hline CHEMBL 203673 & 809168 & 4.0 & 4.3557 & TRN \\
\hline CHEMBL1969523 & 809168 & 7.7 & 6.5175 & TRN \\
\hline CHEMBL207995 & 809168 & 4.0 & 4.3012 & TRN \\
\hline CHEMBL 2001923 & 809168 & 4.0 & 4.5861 & TRN \\
\hline CHEMBL1986781 & 809168 & 4.8 & 4.7852 & TRN \\
\hline CHEMBL526133 & 809168 & 4.8 & 5.3935 & TRN \\
\hline CHEMBL1979057 & 809168 & 6.5 & 5.6962 & TRN \\
\hline CHEMBL1981045 & 809168 & 4.0 & 4.5902 & TRN \\
\hline CHEMBL387971 & 809168 & 4.5 & 4.5774 & TST \\
\hline CHEMBL1975418 & 809168 & 5.7 & 5.9494 & TRN \\
\hline CHEMBL1992796 & 809168 & 4.0 & 4.4905 & TST \\
\hline CHEMBL1999428 & 809168 & 4.8 & 4.683 & TRN \\
\hline CHEMBL223257 & 809168 & 4.0 & 5.6221 & TST \\
\hline CHEMBL1967560 & 809168 & 4.8 & 4.8502 & TRN \\
\hline CHEMBL 211378 & 809168 & 6.2 & 4.5193 & TRN \\
\hline CHEMBL1516890 & 809168 & 6.2 & 5.6887 & TRN \\
\hline CHEMBL1982465 & 809168 & 4.6 & 5.0911 & TRN \\
\hline CHEMBL 2001751 & 809168 & 7.3 & 7.0194 & TRN \\
\hline CHEMBL 2003420 & 809168 & 4.8 & 5.0631 & TRN \\
\hline CHEMBL1984586 & 809168 & 4.8 & 5.1578 & TRN \\
\hline CHEMBL1999774 & 809168 & 4.0 & 4.4534 & TST \\
\hline CHEMBL1972659 & 809168 & 4.8 & 4.5766 & TST \\
\hline CHEMBL1973395 & 809168 & 5.4 & 6.0352 & TRN \\
\hline CHEMBL 272453 & 809168 & 4.8 & 4.7763 & TRN \\
\hline CHEMBL1970217 & 809168 & 4.8 & 4.7192 & TRN \\
\hline CHEMBL1971801 & 809168 & 5.5 & 4.7388 & TRN \\
\hline
\end{tabular}




\begin{tabular}{|c|c|c|c|c|}
\hline & & & ient & al Ta \\
\hline CHEMBL1968850 & 809168 & 5.6 & 5.3686 & TRN \\
\hline CHEMBL 2005528 & 809168 & 4.8 & 4.9782 & TST \\
\hline CHEMBL185569 & 809168 & 4.6 & 4.7627 & TRN \\
\hline CHEMBL1969843 & 809168 & 4.8 & 4.8623 & TRN \\
\hline CHEMBL 2007002 & 809168 & 4.8 & 5.4551 & TRN \\
\hline CHEMBL1987007 & 809168 & 7.1 & 5.5247 & TRN \\
\hline CHEMBL1969588 & 809168 & 4.8 & 6.9668 & TRN \\
\hline CHEMBL1984711 & 809168 & 4.3 & 5.2165 & TRN \\
\hline CHEMBL1990212 & 809168 & 4.0 & 4.4845 & TRN \\
\hline CHEMBL484390 & 809168 & 7.2 & 5.2986 & TST \\
\hline CHEMBL1979252 & 809168 & 6.2 & 5.3867 & TRN \\
\hline CHEMBL1682341 & 809168 & 5.3 & 5.4863 & TRN \\
\hline CHEMBL 2004290 & 809168 & 4.8 & 5.17 & TRN \\
\hline CHEMBL1986499 & 809168 & 4.8 & 5.6392 & TRN \\
\hline CHEMBL1972937 & 809168 & 4.8 & 4.8151 & TRN \\
\hline CHEMBL1972250 & 809168 & 6.1 & 4.6569 & TST \\
\hline CHEMBL 2000393 & 809168 & 5.9 & 6.4787 & TST \\
\hline CHEMBL 2004072 & 809168 & 4.0 & 4.6994 & TRN \\
\hline CHEMBL 2004311 & 809168 & 4.8 & 5.0368 & TRN \\
\hline CHEMBL1992634 & 809168 & 4.8 & 5.4126 & TRN \\
\hline CHEMBL1242373 & 809168 & 5.9 & 6.1247 & TRN \\
\hline CHEMBL 2000433 & 809168 & 4.0 & 4.6312 & TST \\
\hline CHEMBL1988075 & 809168 & 4.8 & 5.7796 & TRN \\
\hline CHEMBL316264 & 809168 & 4.8 & 4.6593 & TRN \\
\hline CHEMBL1991678 & 809168 & 4.8 & 4.5634 & TRN \\
\hline CHEMBL2001239 & 809168 & 7.7 & 5.5432 & TST \\
\hline CHEMBL1988594 & 809168 & 9.2 & 6.9493 & TRN \\
\hline CHEMBL 2001288 & 809168 & 4.8 & 4.9423 & TRN \\
\hline CHEMBL 260092 & 809168 & 6.6 & 5.2515 & TRN \\
\hline CHEMBL1999811 & 809168 & 4.8 & 5.2207 & TST \\
\hline CHEMBL1965495 & 809168 & 5.1 & 4.9147 & TRN \\
\hline CHEMBL1985074 & 809168 & 4.8 & 5.4959 & TST \\
\hline CHEMBL1982874 & 809168 & 4.8 & 4.6493 & TRN \\
\hline CHEMBL 2000481 & 809168 & 4.8 & 4.8409 & TRN \\
\hline CHEMBL1991725 & 809168 & 4.8 & 4.9474 & TRN \\
\hline CHEMBL1992242 & 809168 & 4.3 & 4.4554 & TRN \\
\hline CHEMBL 2007296 & 809168 & 4.8 & 4.676 & TRN \\
\hline CHEMBL396523 & 809168 & 6.6 & 6.608 & TRN \\
\hline CHEMBL 2007138 & 809168 & 3.6 & 4.2271 & TRN \\
\hline CHEMBL 208637 & 809168 & 4.3 & 4.3242 & TRN \\
\hline CHEMBL1970203 & 809168 & 8.8 & 6.692 & TRN \\
\hline CHEMBL1986530 & 809168 & 4.8 & 4.9632 & TST \\
\hline CHEMBL1999321 & 809168 & 4.8 & 4.8591 & TRN \\
\hline CHEMBL1968590 & 809168 & 4.8 & 5.0434 & TRN \\
\hline CHEMBL1999749 & 809168 & 5.9 & 4.5445 & TRN \\
\hline CHEMBL 2005375 & 809168 & 4.8 & 4.7154 & TRN \\
\hline CHEMBL1984191 & 809168 & 4.8 & 4.8075 & TRN \\
\hline CHEMBL1983006 & 809168 & 4.0 & 4.3053 & TRN \\
\hline
\end{tabular}




\begin{tabular}{|c|c|c|c|c|}
\hline \multicolumn{5}{|c|}{ lemental T } \\
\hline CHEMBL1971029 & 809168 & 6.6 & 7.1952 & TRN \\
\hline CHEMBL1995391 & 809168 & 3.6 & 4.3496 & TRN \\
\hline CHEMBL394790 & 809168 & 4.8 & 4.9875 & TRN \\
\hline CHEMBL226471 & 809168 & 6.2 & 5.7404 & TRN \\
\hline CHEMBL1974702 & 809168 & 4.8 & 5.4773 & TRN \\
\hline CHEMBL1996111 & 809168 & 4.8 & 6.1549 & TRN \\
\hline CHEMBL1965589 & 809168 & 4.8 & 4.766 & TRN \\
\hline CHEMBL1998193 & 809168 & 4.8 & 4.8117 & TRN \\
\hline CHEMBL474432 & 809168 & 6.0 & 6.6024 & TST \\
\hline CHEMBL1988153 & 809168 & 4.8 & 4.7432 & TRN \\
\hline CHEMBL1999556 & 809168 & 6.9 & 5.6172 & TRN \\
\hline CHEMBL1988437 & 809168 & 4.4 & 6.3235 & TST \\
\hline CHEMBL1968245 & 809168 & 4.0 & 4.3811 & TRN \\
\hline CHEMBL1998121 & 809168 & 7.0 & 6.5961 & TRN \\
\hline CHEMBL1979577 & 809168 & 5.8 & 5.1322 & TRN \\
\hline CHEMBL1991800 & 809168 & 4.3 & 4.4719 & TRN \\
\hline CHEMBL1985566 & 809168 & 4.0 & 4.4223 & TRN \\
\hline CHEMBL52387 & 809168 & 4.3 & 4.742 & TST \\
\hline CHEMBL379835 & 809168 & 4.3 & 4.6716 & TST \\
\hline CHEMBL1980802 & 809168 & 4.0 & 5.1049 & TST \\
\hline CHEMBL1979357 & 809168 & 4.8 & 4.7223 & TRN \\
\hline CHEMBL1979554 & 809168 & 7.4 & 5.8213 & TRN \\
\hline CHEMBL1996817 & 809168 & 4.4 & 6.1249 & TRN \\
\hline CHEMBL 2004355 & 809168 & 4.0 & 4.3077 & TRN \\
\hline CHEMBL468280 & 809168 & 4.4 & 4.7016 & TST \\
\hline CHEMBL1990884 & 809168 & 4.8 & 4.9049 & TRN \\
\hline CHEMBL3109278 & 809168 & 7.5 & 6.6764 & TRN \\
\hline CHEMBL256835 & 809168 & 4.1 & 4.618 & TRN \\
\hline CHEMBL1980142 & 809168 & 4.8 & 4.7225 & TRN \\
\hline CHEMBL41783 & 809168 & 4.8 & 4.713 & TRN \\
\hline CHEMBL 2004438 & 809168 & 4.0 & 4.5733 & TRN \\
\hline CHEMBL 2006276 & 809168 & 4.8 & 4.832 & TRN \\
\hline CHEMBL 271381 & 809168 & 4.7 & 4.8916 & TRN \\
\hline CHEMBL 2006785 & 809168 & 4.8 & 4.9248 & TRN \\
\hline CHEMBL1982466 & 809168 & 4.8 & 5.353 & TRN \\
\hline CHEMBL1995740 & 809168 & 5.8 & 5.4654 & TRN \\
\hline CHEMBL1996390 & 809168 & 6.3 & 4.7242 & TRN \\
\hline CHEMBL 234085 & 809168 & 4.8 & 4.8988 & TRN \\
\hline CHEMBL1995832 & 809168 & 4.8 & 4.7113 & TRN \\
\hline CHEMBL1998414 & 809168 & 6.5 & 5.4358 & TRN \\
\hline CHEMBL1969042 & 809168 & 4.8 & 5.0401 & TST \\
\hline CHEMBL 2000345 & 809168 & 6.7 & 5.9298 & TRN \\
\hline CHEMBL1999931 & 809168 & 7.9 & 7.0856 & TRN \\
\hline CHEMBL1991640 & 809168 & 4.0 & 4.7293 & TST \\
\hline CHEMBL 302449 & 809168 & 7.1 & 6.1198 & TST \\
\hline CHEMBL 2007064 & 809168 & 7.3 & 5.9856 & TRN \\
\hline CHEMBL1981047 & 809168 & 4.8 & 7.0092 & TST \\
\hline CHEMBL229968 & 809168 & 6.4 & 6.9298 & TRN \\
\hline
\end{tabular}




\begin{tabular}{|c|c|c|c|c|}
\hline & & & ipplement & al Table S \\
\hline CHEMBL1976240 & 809168 & 6.4 & 5.5763 & TRN \\
\hline CHEMBL1979093 & 809168 & 4.8 & 4.9272 & TRN \\
\hline CHEMBL1968151 & 809168 & 4.8 & 4.711 & TST \\
\hline CHEMBL1381197 & 809168 & 4.0 & 4.5622 & TRN \\
\hline CHEMBL1987009 & 809168 & 7.8 & 6.2086 & TRN \\
\hline CHEMBL379218 & 809168 & 5.9 & 6.4471 & TRN \\
\hline CHEMBL2003817 & 809168 & 6.0 & 4.6091 & TRN \\
\hline CHEMBL336961 & 809168 & 4.0 & 4.5462 & TRN \\
\hline CHEMBL1994830 & 809168 & 4.8 & 4.8095 & TRN \\
\hline CHEMBL1987054 & 809168 & 5.1 & 5.355 & TRN \\
\hline CHEMBL1970083 & 809168 & 5.3 & 5.1355 & TRN \\
\hline CHEMBL 226403 & 809168 & 6.8 & 5.9229 & TRN \\
\hline CHEMBL2005631 & 809168 & 5.4 & 5.2742 & TRN \\
\hline CHEMBL1994938 & 809168 & 4.8 & 5.4516 & TRN \\
\hline CHEMBL1825138 & 809168 & 4.8 & 5.2646 & TST \\
\hline CHEMBL1977223 & 809168 & 5.8 & 5.8753 & TRN \\
\hline CHEMBL1236126 & 809168 & 4.3 & 4.607 & TST \\
\hline CHEMBL1966279 & 809168 & 4.8 & 4.8424 & TRN \\
\hline CHEMBL1997846 & 809168 & 6.5 & 5.2691 & TRN \\
\hline CHEMBL2004419 & 809168 & 4.8 & 4.6903 & TRN \\
\hline CHEMBL1991728 & 809168 & 6.1 & 5.2815 & TRN \\
\hline CHEMBL1975787 & 809168 & 6.4 & 5.67899 & 9999999999 \\
\hline CHEMBL 2002407 & 809168 & 4.0 & 4.5448 & TRN \\
\hline CHEMBL1972489 & 809168 & 4.8 & 4.7633 & TRN \\
\hline CHEMBL1994074 & 809168 & 5.9 & 4.9372 & TRN \\
\hline CHEMBL1992937 & 809168 & 4.9 & 4.886 & TST \\
\hline CHEMBL536151 & 809168 & 4.0 & 4.5968 & TST \\
\hline CHEMBL1972119 & 809168 & 4.8 & 4.8276 & TRN \\
\hline CHEMBL95692 & 809168 & 4.3 & 4.4373 & TRN \\
\hline CHEMBL1090356 & 809168 & 4.8 & 4.823 & TRN \\
\hline CHEMBL1976455 & 809168 & 4.8 & 4.4622 & TRN \\
\hline CHEMBL1983923 & 809168 & 4.8 & 6.1711 & TST \\
\hline CHEMBL1983534 & 809168 & 4.8 & 4.7559 & TRN \\
\hline CHEMBL1982361 & 809168 & 6.1 & 5.4175 & TRN \\
\hline CHEMBL1999112 & 809168 & 4.8 & 5.1091 & TST \\
\hline CHEMBL1982122 & 809168 & 4.8 & 4.7479 & TRN \\
\hline CHEMBL2000801 & 809168 & 4.8 & 4.7031 & TRN \\
\hline CHEMBL1682546 & 809168 & 4.3 & 4.5474 & TRN \\
\hline CHEMBL1991395 & 809168 & 4.4 & 4.5085 & TRN \\
\hline CHEMBL1971245 & 809168 & 4.8 & 5.2149 & TRN \\
\hline CHEMBL1987648 & 809168 & 4.0 & 4.3426 & TRN \\
\hline CHEMBL1996780 & 809168 & 4.0 & 4.3607 & TST \\
\hline CHEMBL1972142 & 809168 & 6.8 & 4.9731 & TRN \\
\hline CHEMBL1966514 & 809168 & 6.0 & 5.1249 & TRN \\
\hline CHEMBL2003638 & 809168 & 7.7 & 7.0413 & TRN \\
\hline CHEMBL296586 & 809168 & 6.2 & 4.9228 & TRN \\
\hline CHEMBL1996066 & 809168 & 4.8 & 4.8196 & TST \\
\hline CHEMBL516429 & 809168 & 6.4 & 6.2213 & TRN \\
\hline
\end{tabular}




\begin{tabular}{|c|c|c|c|c|c|}
\hline \multicolumn{6}{|c|}{ Supplemental Table s2.txt } \\
\hline CHEMBL1993722 & 809168 & 4.2 & 4.8932 & TRN & \\
\hline CHEMBL1970806 & 809168 & 4.3 & 4.4742 & TST & \\
\hline CHEMBL202635 & 809168 & 4.0 & 5.0244 & TRN & \\
\hline CHEMBL1375640 & 809168 & 4.8 & 5.0622 & TST & \\
\hline CHEMBL1979970 & 809168 & 4.4 & 4.5472 & TRN & \\
\hline CHEMBL249282 & 809168 & 4.9 & 5.2382 & TST & \\
\hline CHEMBL1969264 & 809168 & 6.1 & 5.92399 & 99999999995 & TRN \\
\hline CHEMBL1973711 & 809168 & 4.0 & 5.1185 & TST & \\
\hline CHEMBL 2006237 & 809168 & 4.3 & 4.5197 & TST & \\
\hline CHEMBL1967720 & 809168 & 6.3 & 5.5296 & TST & \\
\hline CHEMBL1572266 & 809168 & 4.8 & 4.8385 & TST & \\
\hline CHEMBL1991138 & 809168 & 4.3 & 4.4206 & TST & \\
\hline CHEMBL1969755 & 809168 & 4.3 & 4.4501 & TST & \\
\hline CHEMBL1979516 & 809168 & 4.8 & 5.1861 & TST & \\
\hline CHEMBL1605605 & 809168 & 4.8 & 4.6373 & TST & \\
\hline CHEMBL1989029 & 809168 & 4.8 & 5.0057 & TST & \\
\hline CHEMBL392642 & 809168 & 4.8 & 5.8941 & TST & \\
\hline CHEMBL514499 & 809168 & 4.3 & 5.2131 & TST & \\
\hline CHEMBL1965631 & 809168 & 4.6 & 5.1683 & TST & \\
\hline CHEMBL1980144 & 809168 & 8.5 & 6.8271 & TST & \\
\hline CHEMBL1991188 & 809168 & 4.8 & 4.9091 & TST & \\
\hline CHEMBL1972849 & 809168 & 4.8 & 4.76399 & 9999999999 & TST \\
\hline CHEMBL 377408 & 809168 & 4.0 & 4.3176 & TST & \\
\hline CHEMBL 215152 & 809168 & 5.7 & 4.6719 & TST & \\
\hline CHEMBL231209 & 809168 & 4.8 & 4.8849 & TST & \\
\hline CHEMBL1976220 & 809168 & 4.8 & 4.9994 & TST & \\
\hline CHEMBL 259922 & 809168 & 4.3 & 4.5906 & TST & \\
\hline CHEMBL1997617 & 809168 & 7.2 & 4.9169 & TST & \\
\hline CHEMBL1982383 & 809168 & 4.8 & 4.6673 & TST & \\
\hline CHEMBL1969301 & 809168 & 4.8 & 5.0173 & TST & \\
\hline CHEMBL17370 & 809168 & 4.8 & 4.6788 & TST & \\
\hline CHEMBL1987910 & 809168 & 4.8 & 5.0002 & TST & \\
\hline CHEMBL1983932 & 809168 & 4.8 & 5.2781 & TST & \\
\hline CHEMBL1966069 & 809168 & 4.0 & 5.42899 & 9999999999 & TST \\
\hline CHEMBL1997822 & 809168 & 4.3 & 4.6289 & TST & \\
\hline CHEMBL1991285 & 809168 & 4.3 & 4.6806 & TST & \\
\hline CHEMBL1984038 & 809168 & 4.8 & 4.7585 & TST & \\
\hline CHEMBL 243088 & 809168 & 6.4 & 6.2225 & TST & \\
\hline CHEMBL1993661 & 809168 & 7.1 & 7.7549 & TST & \\
\hline CHEMBL1974416 & 809168 & 4.8 & 5.1682 & TST & \\
\hline CHEMBL3651147 & 1528715 & 5.6778 & 5.6054 & TRN & \\
\hline CHEMBL3651122 & 1528715 & 5.5528 & 5.5551 & TRN & \\
\hline CHEMBL3651136 & 1528715 & 5.4685 & 5.4688 & TRN & \\
\hline CHEMBL3651128 & 1528715 & 4.4318 & 4.4534 & TRN & \\
\hline CHEMBL3651133 & 1528715 & 4.7328 & 4.73600 & 0000000001 & TRN \\
\hline CHEMBL3651096 & 1528715 & 4.5376 & 4.5387 & TRN & \\
\hline CHEMBL3651145 & 1528715 & 3.301 & 3.2789 & TRN & \\
\hline CHEMBL3651132 & 1528715 & 4.7852 & 4.7883 & TRN & \\
\hline
\end{tabular}


Supplemental Table S2.txt

\begin{tabular}{|c|c|c|c|c|c|}
\hline CHEMBL3651111 & 1528715 & 5.2596 & 5.2664 & TRN & \\
\hline CHEMBL3651142 & 1528715 & 5.0915 & 5.0634 & TRN & \\
\hline CHEMBL3651153 & 1528715 & 4.4202 & 5.0258 & TST & \\
\hline CHEMBL3651109 & 1528715 & 5.0458 & 5.0769 & TRN & \\
\hline CHEMBL3651139 & 1528715 & 5.7696 & 5.8228 & TST & \\
\hline CHEMBL3651117 & 1528715 & 5.0706 & 4.0749 & TST & \\
\hline CHEMBL3651130 & 1528715 & 4.6108 & 4.5859 & TRN & \\
\hline CHEMBL3651123 & 1528715 & 5.6021 & 5.7121 & TST & \\
\hline CHEMBL3929030 & 1528715 & 5.0 & 4.9597 & TRN & \\
\hline CHEMBL3651118 & 1528715 & 5.6198 & 5.6428 & TRN & \\
\hline CHEMBL3951323 & 1528715 & 5.8539 & \multicolumn{2}{|c|}{5.872000000000001} & TRN \\
\hline CHEMBL3651134 & 1528715 & 5.5528 & 5.5571 & TRN & \\
\hline CHEMBL3920115 & 1528715 & 5.4949 & 5.5037 & TRN & \\
\hline CHEMBL 3651129 & 1528715 & 5.1549 & 5.1071 & TRN & \\
\hline CHEMBL 3651113 & 1528715 & 5.9208 & 5.8892 & TRN & \\
\hline CHEMBL3651107 & 1528715 & 4.8928 & 4.9098 & TRN & \\
\hline CHEMBL3651100 & 1528715 & 4.7959 & 4.8155 & TRN & \\
\hline CHEMBL3651112 & 1528715 & 4.4711 & 4.4368 & TRN & \\
\hline CHEMBL3651115 & 1528715 & 4.8861 & 4.875 & TRN & \\
\hline CHEMBL3651138 & 1528715 & 4.5751 & \multicolumn{2}{|c|}{4.1530000000000005} & TST \\
\hline CHEMBL3651094 & 1528715 & 4.5086 & 4.5912 & TRN & \\
\hline CHEMBL3651097 & 1528715 & 3.301 & 3.3005 & TRN & \\
\hline CHEMBL3651110 & 1528715 & 5.4202 & 5.4323 & TRN & \\
\hline CHEMBL 3134375 & 1528715 & 3.301 & 3.3368 & TRN & \\
\hline CHEMBL3651121 & 1528715 & 3.301 & 3.2746 & TRN & \\
\hline CHEMBL3651102 & 1528715 & 6.0 & 5.9822 & TRN & \\
\hline CHEMBL3651114 & 1528715 & 5.7959 & 5.7947 & TRN & \\
\hline CHEMBL3651140 & 1528715 & 5.1308 & 5.395 & TST & \\
\hline CHEMBL 3651148 & 1528715 & 5.2291 & 5.3233 & TRN & \\
\hline CHEMBL3651103 & 1528715 & 5.5229 & 5.5186 & TRN & \\
\hline CHEMBL3651104 & 1528715 & 4.9208 & 4.9147 & TRN & \\
\hline CHEMBL 3651124 & 1528715 & 5.7447 & 5.8825 & TST & \\
\hline CHEMBL3651120 & 1528715 & 5.0915 & 5.092 & TRN & \\
\hline CHEMBL3651119 & 1528715 & 4.556 & 4.5363 & TRN & \\
\hline CHEMBL3971292 & 1528715 & 4.7447 & 4.7584 & TRN & \\
\hline CHEMBL3651146 & 1528715 & 5.5229 & 5.4111 & TST & \\
\hline CHEMBL3651108 & 1528715 & 5.5229 & 5.5027 & TRN & \\
\hline CHEMBL3639499 & 1528715 & 4.8861 & 4.8716 & TRN & \\
\hline CHEMBL3651126 & 1528715 & 4.6198 & 4.6262 & TRN & \\
\hline CHEMBL3651152 & 1528715 & 3.301 & 3.2948 & TRN & \\
\hline CHEMBL3651137 & 1528715 & 5.0 & 4.9999 & TRN & \\
\hline CHEMBL3651135 & 1528715 & 5.7447 & 5.7624 & TRN & \\
\hline CHEMBL3651095 & 1528715 & 4.4089 & 4.4156 & TRN & \\
\hline CHEMBL313833 & 1528715 & 5.699 & 5.2184 & TST & \\
\hline CHEMBL3651151 & 1528715 & 4.7959 & 3.5047 & TST & \\
\hline CHEMBL3651101 & 1528715 & 5.5229 & 5.1316 & TST & \\
\hline CHEMBL3651105 & 1528715 & 5.7696 & 4.7268 & TST & \\
\hline CHEMBL 3651141 & 1528715 & 4.6716 & 4.4599 & TST & \\
\hline
\end{tabular}


Supplemental Table S2.txt

\begin{tabular}{|c|c|c|c|c|c|}
\hline CHEMBL 3651125 & 1528715 & 5.6198 & 5.9672 & TST & \\
\hline CHEMBL 3651131 & 1528715 & 4.4112 & 4.3195 & TST & \\
\hline CHEMBL120734 & 809005 & 4.7991 & 4.96 & TRN & \\
\hline CHEMBL 1482468 & 809005 & 4.4058 & \multicolumn{2}{|c|}{4.7330000000000005} & TRN \\
\hline CHEMBL1502830 & 809005 & 4.8351 & 4.2008 & TRN & \\
\hline CHEMBL1305254 & 809005 & 4.6119 & 4.6053 & TST & \\
\hline CHEMBL1358722 & 809005 & 3.1549 & 5.2267 & TST & \\
\hline CHEMBL1901984 & 809005 & 3.1549 & 4.7341 & TST & \\
\hline CHEMBL1443900 & 809005 & 4.2743 & 5.1751 & TRN & \\
\hline CHEMBL1370126 & 809005 & 4.1672 & 4.5526 & TST & \\
\hline CHEMBL1453996 & 809005 & 4.6461 & 4.5744 & TRN & \\
\hline CHEMBL1348931 & 809005 & 4.3378 & 4.4694 & TRN & \\
\hline CHEMBL1706381 & 809005 & 4.221 & 5.3577 & TRN & \\
\hline CHEMBL1409554 & 809005 & 5.4855 & 4.9275 & TRN & \\
\hline CHEMBL1574481 & 809005 & 5.2013 & 4.8839 & TRN & \\
\hline CHEMBL 1505475 & 809005 & 4.2783 & 4.2838 & TRN & \\
\hline CHEMBL1571123 & 809005 & 4.6099 & 4.5504 & TRN & \\
\hline CHEMBL1342907 & 809005 & 5.2048 & \multicolumn{2}{|c|}{4.611000000000001} & TRN \\
\hline CHEMBL1606837 & 809005 & 4.2174 & 4.2859 & TST & \\
\hline CHEMBL1424697 & 809005 & 4.5724 & 4.6537 & TRN & \\
\hline CHEMBL600862 & 809005 & 5.9208 & \multicolumn{2}{|c|}{5.502000000000001} & TRN \\
\hline CHEMBL1727997 & 809005 & 4.2053 & 4.4272 & TRN & \\
\hline CHEMBL1335844 & 809005 & 4.5842 & 4.5892 & TRN & \\
\hline CHEMBL1483511 & 809005 & 3.1549 & 4.3211 & TRN & \\
\hline CHEMBL1721226 & 809005 & 6.2118 & 5.2928 & TST & \\
\hline CHEMBL1383414 & 809005 & 3.1549 & 4.8222 & TRN & \\
\hline CHEMBL1563714 & 809005 & 4.5211 & 4.51 & TST & \\
\hline CHEMBL1613582 & 809005 & 4.6019 & 4.3787 & TRN & \\
\hline CHEMBL1547860 & 809005 & 4.2006 & 4.2512 & TRN & \\
\hline CHEMBL1332454 & 809005 & 4.9805 & 5.1966 & TRN & \\
\hline CHEMBL1392611 & 809005 & 4.4305 & 4.8096 & TRN & \\
\hline CHEMBL1711394 & 809005 & 5.0443 & 4.3205 & TRN & \\
\hline CHEMBL1347861 & 809005 & 5.3872 & 4.5268 & TRN & \\
\hline CHEMBL1612156 & 809005 & 4.176 & 4.3353 & TRN & \\
\hline CHEMBL124006 & 809005 & 5.1068 & 4.2645 & TRN & \\
\hline CHEMBL1369099 & 809005 & 3.1549 & 4.3704 & TRN & \\
\hline CHEMBL1517486 & 809005 & 4.2442 & 4.5808 & TRN & \\
\hline CHEMBL1368413 & 809005 & 4.2437 & 4.7544 & TRN & \\
\hline CHEMBL1464832 & 809005 & 4.4044 & 4.4887 & TRN & \\
\hline CHEMBL1713613 & 809005 & 4.6972 & 4.6761 & TRN & \\
\hline CHEMBL 603020 & 809005 & 5.1494 & 4.3869 & TRN & \\
\hline CHEMBL1876725 & 809005 & 4.87 & 4.419 & TRN & \\
\hline CHEMBL1569058 & 809005 & 4.4441 & 4.4791 & TRN & \\
\hline CHEMBL1339909 & 809005 & 4.5196 & 4.6071 & TRN & \\
\hline CHEMBL1447350 & 809005 & 4.2585 & 4.5759 & TRN & \\
\hline CHEMBL1557454 & 809005 & 4.2841 & 4.5499 & TRN & \\
\hline CHEMBL1338885 & 809005 & 4.9582 & 4.2323 & TRN & \\
\hline CHEMBL1323139 & 809005 & 4.3375 & 4.6699 & TRN & \\
\hline
\end{tabular}




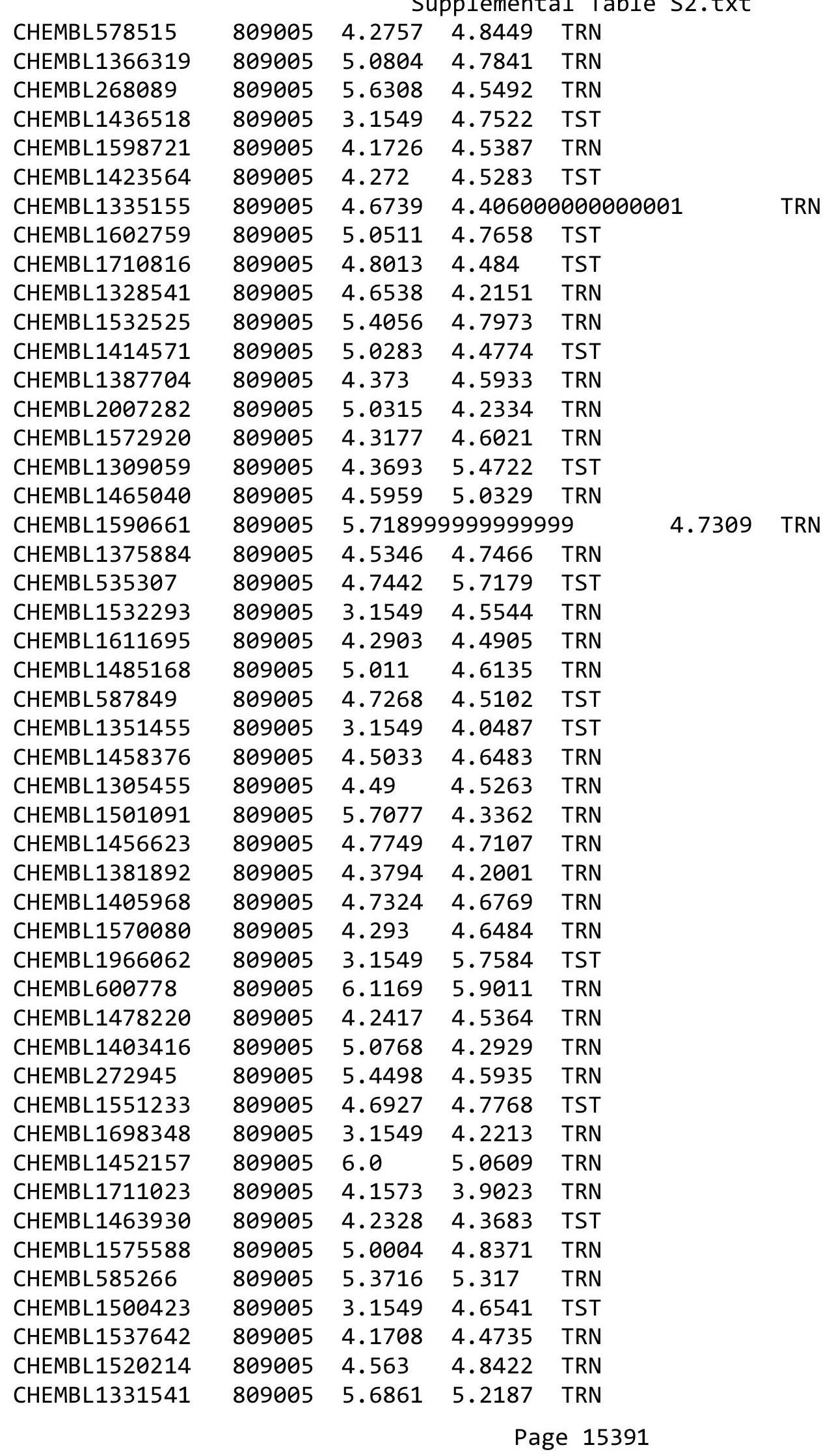




\begin{tabular}{|c|c|c|c|c|c|}
\hline & & \multicolumn{4}{|c|}{ Supplemental Table S2.txt } \\
\hline CHEMBL1510389 & 809005 & 3.1549 & 4.6356 & TRN & \\
\hline CHEMBL 2004475 & 809005 & 4.6153 & 4.6242 & TST & \\
\hline CHEMBL1394624 & 809005 & 5.5317 & 5.0406 & TRN & \\
\hline CHEMBL1539505 & 809005 & 4.226 & 4.1425 & TRN & \\
\hline CHEMBL1374797 & 809005 & 3.1549 & 4.7342 & TRN & \\
\hline CHEMBL1307319 & 809005 & 5.8097 & 4.8272 & TST & \\
\hline CHEMBL1609946 & 809005 & 5.8761 & 4.8349 & TRN & \\
\hline CHEMBL1412298 & 809005 & 5.1844 & 4.3161 & TRN & \\
\hline CHEMBL1725584 & 809005 & 5.0405 & 4.813 & TST & \\
\hline CHEMBL1984723 & 809005 & 3.1549 & 4.5864 & TRN & \\
\hline CHEMBL578929 & 809005 & \multicolumn{3}{|c|}{4.9910000000000005} & TST \\
\hline CHEMBL591363 & 809005 & 5.8327 & 6.0082 & TRN & \\
\hline CHEMBL1535546 & 809005 & 4.9129 & 4.5447 & TRN & \\
\hline CHEMBL1460029 & 809005 & 3.1549 & 4.3592 & TST & \\
\hline CHEMBL268584 & 809005 & 5.5498 & \multicolumn{2}{|c|}{4.638999999999999} & TRN \\
\hline CHEMBL1599441 & 809005 & 3.1549 & 4.5376 & TRN & \\
\hline CHEMBL1340698 & 809005 & 4.3143 & 4.6634 & TRN & \\
\hline CHEMBL593211 & 809005 & 4.2818 & \multicolumn{2}{|c|}{4.8919999999999995} & TRN \\
\hline CHEMBL1549500 & 809005 & 5.6576 & 4.7777 & TRN & \\
\hline CHEMBL1443946 & 809005 & 5.0835 & 4.5759 & TRN & \\
\hline CHEMBL1419822 & 809005 & 4.7368 & 4.5021 & TRN & \\
\hline CHEMBL1578341 & 809005 & 4.6799 & 4.6494 & TRN & \\
\hline CHEMBL1568022 & 809005 & 4.7883 & 4.599 & TRN & \\
\hline CHEMBL1458840 & 809005 & 4.5993 & 4.6152 & TRN & \\
\hline CHEMBL1424801 & 809005 & 3.1549 & 4.3403 & TRN & \\
\hline CHEMBL1702199 & 809005 & 4.6592 & 4.6183 & TRN & \\
\hline CHEMBL1540682 & 809005 & 5.0531 & 5.4281 & TST & \\
\hline CHEMBL1498382 & 809005 & 5.6253 & 4.749 & TRN & \\
\hline CHEMBL1338958 & 809005 & 4.3453 & 4.447 & TST & \\
\hline CHEMBL1550690 & 809005 & 4.4368 & 4.3077 & TRN & \\
\hline CHEMBL1588579 & 809005 & 3.1549 & 4.3784 & TRN & \\
\hline CHEMBL1499127 & 809005 & 4.4987 & 4.1639 & TRN & \\
\hline CHEMBL1573811 & 809005 & 4.2869 & 4.2926 & TRN & \\
\hline CHEMBL1351099 & 809005 & 4.6275 & 4.4048 & TST & \\
\hline CHEMBL1452671 & 809005 & 4.6566 & 4.541 & TRN & \\
\hline CHEMBL580340 & 809005 & 4.8834 & 4.7866 & TRN & \\
\hline CHEMBL1526371 & 809005 & 4.3161 & 4.4814 & TST & \\
\hline CHEMBL1302130 & 809005 & 5.767 & 5.0769 & TRN & \\
\hline CHEMBL1354459 & 809005 & 3.1549 & 4.1757 & TST & \\
\hline CHEMBL1469557 & 809005 & 4.208 & 4.4185 & TRN & \\
\hline CHEMBL1451491 & 809005 & 4.2344 & 4.3111 & TST & \\
\hline CHEMBL1602361 & 809005 & 4.3128 & 4.4877 & TST & \\
\hline CHEMBL1543907 & 809005 & 4.5065 & 4.3722 & TRN & \\
\hline CHEMBL1375365 & 809005 & 3.1549 & 4.2256 & TRN & \\
\hline CHEMBL1869116 & 809005 & 4.4042 & 4.3536 & TRN & \\
\hline CHEMBL1332404 & 809005 & 5.5058 & 5.1651 & TRN & \\
\hline CHEMBL1583665 & 809005 & 5.4225 & 4.5933 & TRN & \\
\hline CHEMBL1725385 & 809005 & 3.1549 & 4.0031 & TRN & \\
\hline
\end{tabular}




\begin{tabular}{|c|c|c|c|c|c|}
\hline \multirow[b]{2}{*}{ CHEMBL47940 } & \multicolumn{5}{|c|}{ Supplemental Table S2.txt } \\
\hline & 809005 & 3.1549 & 4.5106 & TST & \\
\hline CHEMBL1345481 & 809005 & 5.5544 & 4.6535 & TRN & \\
\hline CHEMBL1366727 & 809005 & 5.9547 & 4.8923 & TRN & \\
\hline CHEMBL1429297 & 809005 & 5.1367 & 4.2762 & TRN & \\
\hline CHEMBL306380 & 809005 & 3.1549 & 4.6125 & TST & \\
\hline CHEMBL1878609 & 809005 & 5.7799 & 4.7266 & TRN & \\
\hline CHEMBL1725136 & 809005 & 5.2874 & 4.3941 & TRN & \\
\hline CHEMBL1301851 & 809005 & 3.1549 & 4.4594 & TRN & \\
\hline CHEMBL1352168 & 809005 & 4.8099 & 4.408 & TRN & \\
\hline CHEMBL1369965 & 809005 & 4.461 & 4.5723 & TRN & \\
\hline CHEMBL1321240 & 809005 & 5.1656 & 4.3915 & TRN & \\
\hline CHEMBL1402510 & 809005 & 3.1549 & 4.7141 & TRN & \\
\hline CHEMBL1397089 & 809005 & 4.8438 & 4.9296 & TST & \\
\hline CHEMBL1422386 & 809005 & 5.3487 & 4.6004 & TRN & \\
\hline CHEMBL472437 & 809005 & 4.5802 & 4.85800 & 00000000005 & TST \\
\hline CHEMBL1973156 & 809005 & 4.1891 & 4.2235 & TST & \\
\hline CHEMBL1332925 & 809005 & 4.185 & 4.2301 & TRN & \\
\hline CHEMBL1901445 & 809005 & 4.8586 & 4.2992 & TRN & \\
\hline CHEMBL1429289 & 809005 & 4.2073 & 4.6829 & TST & \\
\hline CHEMBL1408861 & 809005 & 5.3045 & 4.5433 & TRN & \\
\hline CHEMBL1464070 & 809005 & 3.1549 & 4.4029 & TRN & \\
\hline CHEMBL1492214 & 809005 & 4.23 & 3.9512 & TRN & \\
\hline CHEMBL1468351 & 809005 & 4.3253 & 4.3201 & TRN & \\
\hline CHEMBL601547 & 809005 & 4.7298 & 4.559 & TRN & \\
\hline CHEMBL1700186 & 809005 & 3.1549 & 4.3279 & TST & \\
\hline CHEMBL1432816 & 809005 & 3.1549 & 4.4609 & TRN & \\
\hline CHEMBL1312239 & 809005 & 4.32600 & 00000000 & 4.092 & TRN \\
\hline CHEMBL1459468 & 809005 & 5.1824 & 4.8401 & TRN & \\
\hline CHEMBL1396345 & 809005 & 5.5622 & 4.4906 & TRN & \\
\hline CHEMBL1317160 & 809005 & 4.3653 & 4.461 & TRN & \\
\hline CHEMBL1587117 & 809005 & 4.7708 & 4.5781 & TRN & \\
\hline CHEMBL1601830 & 809005 & 5.3363 & 4.5886 & TRN & \\
\hline CHEMBL1439337 & 809005 & 4.3557 & 4.5229 & TST & \\
\hline CHEMBL2355890 & 809005 & 4.7129 & 4.125 & TST & \\
\hline CHEMBL1445650 & 809005 & 5.0101 & 4.7668 & TRN & \\
\hline CHEMBL1466292 & 809005 & 3.1549 & 4.6041 & TRN & \\
\hline CHEMBL578716 & 809005 & 5.0128 & 4.8013 & TST & \\
\hline CHEMBL1337266 & 809005 & 4.3059 & 4.2905 & TRN & \\
\hline CHEMBL1729345 & 809005 & 4.6639 & 4.6932 & TRN & \\
\hline CHEMBL1421029 & 809005 & 4.3175 & 4.64199 & 99999999995 & TRN \\
\hline CHEMBL1398721 & 809005 & 4.6153 & 4.5292 & TRN & \\
\hline CHEMBL1715463 & 809005 & 4.9382 & 4.7345 & TST & \\
\hline CHEMBL1502550 & 809005 & 4.5654 & 4.3854 & TST & \\
\hline CHEMBL1428507 & 809005 & 3.1549 & 4.3412 & TRN & \\
\hline CHEMBL1433325 & 809005 & 4.71 & 4.2745 & TST & \\
\hline CHEMBL1538267 & 809005 & 5.1656 & 4.4372 & TRN & \\
\hline CHEMBL1337862 & 809005 & 4.436 & 4.4588 & TRN & \\
\hline CHEMBL1734661 & 809005 & 4.4244 & 4.1209 & TRN & \\
\hline
\end{tabular}




\begin{tabular}{|c|c|c|c|c|}
\hline \multicolumn{5}{|c|}{ Supplemental Tabl } \\
\hline CHEMBL1567592 & 809005 & 5.1221 & 4.5024 & TRN \\
\hline CHEMBL1588217 & 809005 & 4.1923 & 4.7589 & TRN \\
\hline CHEMBL1323536 & 809005 & 4.9473 & 4.282 & TRN \\
\hline CHEMBL1349747 & 809005 & 4.3141 & 4.0778 & TST \\
\hline CHEMBL1441749 & 809005 & 4.3121 & 4.2338 & TRN \\
\hline CHEMBL 395263 & 809005 & 4.2233 & 4.3019 & TST \\
\hline CHEMBL1499012 & 809005 & 4.4329 & 4.4066 & TRN \\
\hline CHEMBL1377682 & 809005 & 4.1724 & 4.3549 & TRN \\
\hline CHEMBL1546843 & 809005 & 4.195 & 4.5764 & TRN \\
\hline CHEMBL1497797 & 809005 & 4.3517 & 4.633 & TST \\
\hline CHEMBL1544175 & 809005 & 4.5445 & 4.5373 & TRN \\
\hline CHEMBL1535959 & 809005 & 5.3969 & 4.6898 & TRN \\
\hline CHEMBL1529115 & 809005 & 4.9031 & 4.8883 & TRN \\
\hline CHEMBL1879338 & 809005 & 4.636 & 4.4105 & TRN \\
\hline CHEMBL1981103 & 809005 & 5.0888 & 4.564 & TST \\
\hline CHEMBL1586531 & 809005 & 4.5063 & 4.3284 & TRN \\
\hline CHEMBL1340089 & 809005 & 5.0114 & 4.6009 & TRN \\
\hline CHEMBL1388922 & 809005 & 5.2628 & 4.669 & TRN \\
\hline CHEMBL1606291 & 809005 & 5.5719 & 5.3815 & TRN \\
\hline CHEMBL1716472 & 809005 & 5.6091 & 4.49 & TRN \\
\hline CHEMBL528791 & 809005 & 5.7235 & 4.3892 & TRN \\
\hline CHEMBL1522618 & 809005 & 4.6459 & 4.5902 & TRN \\
\hline CHEMBL1422217 & 809005 & 4.6696 & 4.6878 & TRN \\
\hline CHEMBL1329971 & 809005 & 4.4877 & 4.1767 & TRN \\
\hline CHEMBL1873577 & 809005 & 4.6755 & 4.2203 & TRN \\
\hline CHEMBL1320969 & 809005 & 5.1785 & 4.5483 & TST \\
\hline CHEMBL1505604 & 809005 & 4.8196 & 4.7694 & TRN \\
\hline CHEMBL 2002430 & 809005 & 5.0655 & 4.9582 & TST \\
\hline CHEMBL1483380 & 809005 & 4.5819 & 4.4039 & TRN \\
\hline CHEMBL1598843 & 809005 & 4.1595 & 4.2725 & TRN \\
\hline CHEMBL1596126 & 809005 & 4.3108 & 4.6342 & TRN \\
\hline CHEMBL1530557 & 809005 & 5.4868 & 4.5073 & TRN \\
\hline CHEMBL1304363 & 809005 & 4.3229 & 5.1374 & TRN \\
\hline CHEMBL1881757 & 809005 & 3.1549 & 4.19 & TRN \\
\hline CHEMBL1459155 & 809005 & 5.6676 & 4.6021 & TRN \\
\hline CHEMBL1605758 & 809005 & 4.2114 & 4.2659 & TRN \\
\hline CHEMBL1512575 & 809005 & 4.3206 & 4.5136 & TRN \\
\hline CHEMBL1464730 & 809005 & 4.4043 & 4.5515 & TRN \\
\hline CHEMBL1873240 & 809005 & 5.2581 & 4.5508 & TRN \\
\hline CHEMBL1360774 & 809005 & 4.4126 & 4.2265 & TRN \\
\hline CHEMBL1355963 & 809005 & 4.5061 & 4.501 & TST \\
\hline CHEMBL1324082 & 809005 & 5.2388 & 4.5126 & TST \\
\hline CHEMBL1428415 & 809005 & 4.8179 & 5.0882 & TRN \\
\hline CHEMBL1329658 & 809005 & 4.3354 & 4.5762 & TRN \\
\hline CHEMBL1352525 & 809005 & 4.4406 & 4.4212 & TRN \\
\hline CHEMBL1722145 & 809005 & 4.7956 & 4.3015 & TST \\
\hline CHEMBL1505780 & 809005 & 5.3904 & 4.8147 & TRN \\
\hline CHEMBL1999906 & 809005 & 5.1215 & 4.28 & TST \\
\hline
\end{tabular}




\begin{tabular}{|c|c|c|c|c|c|}
\hline & & \multicolumn{4}{|c|}{ Supplemental Table S2.txt } \\
\hline CHEMBL1369137 & 809005 & 4.3296 & 4.4291 & TRN & \\
\hline CHEMBL1524449 & 809005 & 3.1549 & 4.4704 & TRN & \\
\hline CHEMBL1541996 & 809005 & 4.2807 & 4.3276 & TRN & \\
\hline CHEMBL1394722 & 809005 & 7.585 & 4.9243 & TRN & \\
\hline CHEMBL1307901 & 809005 & 3.1549 & 3.7747 & TRN & \\
\hline CHEMBL1493864 & 809005 & 5.7235 & 4.6138 & TRN & \\
\hline CHEMBL1473160 & 809005 & 4.2044 & 4.3636 & TRN & \\
\hline CHEMBL1327783 & 809005 & 4.5642 & 4.6311 & TRN & \\
\hline CHEMBL1581280 & 809005 & 5.4559 & 4.4402 & TRN & \\
\hline CHEMBL1573351 & 809005 & 5.6737 & 4.3257 & TRN & \\
\hline CHEMBL1341970 & 809005 & 4.2862 & 4.311 & TRN & \\
\hline CHEMBL1301042 & 809005 & 3.1549 & $5.3270 e$ & 0000000001 & TRN \\
\hline CHEMBL1719155 & 809005 & 4.4927 & 4.5109 & TST & \\
\hline CHEMBL1301125 & 809005 & 5.3224 & 4.8309 & TST & \\
\hline CHEMBL1524710 & 809005 & 4.2566 & 4.459 & TRN & \\
\hline CHEMBL1983107 & 809005 & 3.1549 & 4.3655 & TST & \\
\hline CHEMBL1499501 & 809005 & 4.5916 & 5.2744 & TRN & \\
\hline CHEMBL1502434 & 809005 & 3.1549 & 5.0516 & TRN & \\
\hline CHEMBL1438737 & 809005 & 4.2463 & 4.7007 & TST & \\
\hline CHEMBL1380787 & 809005 & 4.19 & 4.4588 & TRN & \\
\hline CHEMBL1991164 & 809005 & 4.9614 & 4.279 & TRN & \\
\hline CHEMBL1464261 & 809005 & 4.9492 & 4.2507 & TRN & \\
\hline CHEMBL1580463 & 809005 & 4.3143 & 4.7456 & TRN & \\
\hline CHEMBL1316090 & 809005 & 5.0985 & 4.3382 & TRN & \\
\hline CHEMBL1497939 & 809005 & 5.0462 & 4.6511 & TRN & \\
\hline CHEMBL1341696 & 809005 & 4.5804 & 4.4008 & TRN & \\
\hline CHEMBL1332956 & 809005 & 4.1697 & 4.3455 & TST & \\
\hline CHEMBL606532 & 809005 & 5.5686 & 5.1815 & TRN & \\
\hline CHEMBL1530707 & 809005 & 4.1752 & 4.4281 & TRN & \\
\hline CHEMBL1343966 & 809005 & 3.1549 & 4.8286 & TRN & \\
\hline CHEMBL1334809 & 809005 & 5.0467 & 4.4742 & TRN & \\
\hline CHEMBL1985082 & 809005 & 5.3979 & 5.1353 & TRN & \\
\hline CHEMBL1458548 & 809005 & 4.7838 & 4.6503 & TRN & \\
\hline CHEMBL1516044 & 809005 & 3.1549 & 4.1918 & TRN & \\
\hline CHEMBL1384068 & 809005 & 4.6496 & 4.3932 & TRN & \\
\hline CHEMBL1726140 & 809005 & 4.644 & 4.0755 & TST & \\
\hline CHEMBL 1410758 & 809005 & 5.6635 & 5.2963 & TRN & \\
\hline CHEMBL1450616 & 809005 & 4.6101 & 4.3202 & TRN & \\
\hline CHEMBL1470633 & 809005 & 3.1549 & 4.512 & TRN & \\
\hline CHEMBL1378716 & 809005 & 4.3825 & 4.6187 & TST & \\
\hline CHEMBL1901126 & 809005 & 4.6684 & 4.5955 & TST & \\
\hline CHEMBL1991198 & 809005 & 4.3431 & 4.5502 & TRN & \\
\hline CHEMBL1732062 & 809005 & 4.3064 & 4.521 & TRN & \\
\hline CHEMBL1352586 & 809005 & 4.6158 & 4.636 & TRN & \\
\hline CHEMBL1865502 & 809005 & 3.1549 & 4.7336 & TST & \\
\hline CHEMBL1472168 & 809005 & 3.1549 & 4.1496 & TRN & \\
\hline CHEMBL1585527 & 809005 & 4.3291 & 4.7643 & TRN & \\
\hline CHEMBL1313502 & 809005 & 5.2411 & 4.703 & TRN & \\
\hline
\end{tabular}




\begin{tabular}{|c|c|c|c|c|c|c|}
\hline & & \multicolumn{5}{|c|}{ Supplemental Table S2.txt } \\
\hline CHEMBL1304623 & 809005 & 4.7036 & 4.5835 & TRN & & \\
\hline CHEMBL1531670 & 809005 & 4.2342 & 4.3481 & TST & & \\
\hline CHEMBL1392228 & 809005 & 4.7428 & 4.8383 & TRN & & \\
\hline CHEMBL1579080 & 809005 & 4.2236 & 4.2653 & TRN & & \\
\hline CHEMBL1605956 & 809005 & 4.3371 & 4.5493 & TRN & & \\
\hline CHEMBL1496534 & 809005 & 4.5722 & 4.6247 & TRN & & \\
\hline CHEMBL1334638 & 809005 & 4.3016 & 4.4973 & TRN & & \\
\hline CHEMBL405317 & 809005 & 5.279 & 4.5806 & TRN & & \\
\hline CHEMBL1722002 & 809005 & 5.0794 & 4.8172 & TST & & \\
\hline CHEMBL1570958 & 809005 & 4.7945 & 4.8342 & TRN & & \\
\hline CHEMBL588804 & 809005 & 5.8962 & 5.4715 & TRN & & \\
\hline CHEMBL1318151 & 809005 & 3.1549 & 4.4695 & TST & & \\
\hline CHEMBL1388113 & 809005 & 4.1732 & 4.4108 & TRN & & \\
\hline CHEMBL1880495 & 809005 & 3.1549 & 4.5745 & TST & & \\
\hline CHEMBL1375563 & 809005 & 4.1626 & 4.5767 & TRN & & \\
\hline CHEMBL1571157 & 809005 & 4.5233 & 4.6972 & TRN & & \\
\hline CHEMBL1712452 & 809005 & 3.1549 & 4.0846 & TRN & & \\
\hline CHEMBL1460653 & 809005 & 4.3232 & 4.3835 & TST & & \\
\hline CHEMBL582099 & 809005 & 5.61799 & 99999999 & 99 & 5.3366 & TRN \\
\hline CHEMBL1501755 & 809005 & 3.1549 & 4.2278 & TRN & & \\
\hline CHEMBL1492922 & 809005 & 4.3663 & 4.4469 & TST & & \\
\hline CHEMBL1369594 & 809005 & 5.083 & 4.5391 & TRN & & \\
\hline CHEMBL1607172 & 809005 & 5.3726 & 4.3481 & TRN & & \\
\hline CHEMBL1718295 & 809005 & 3.1549 & 4.0838 & TRN & & \\
\hline CHEMBL1581759 & 809005 & 3.1549 & 4.8388 & TST & & \\
\hline CHEMBL1497597 & 809005 & 4.8441 & 4.6849 & TRN & & \\
\hline CHEMBL1513651 & 809005 & 4.2155 & 4.3644 & TRN & & \\
\hline CHEMBL1609391 & 809005 & 4.2564 & 4.2498 & TRN & & \\
\hline CHEMBL1562060 & 809005 & 4.3856 & 4.3137 & TRN & & \\
\hline CHEMBL1499935 & 809005 & 4.4599 & 4.3017 & TRN & & \\
\hline CHEMBL1413931 & 809005 & 4.7254 & 5.0016 & TRN & & \\
\hline CHEMBL1708906 & 809005 & 4.3383 & 4.2941 & TRN & & \\
\hline CHEMBL1432227 & 809005 & 5.2916 & 4.5865 & TRN & & \\
\hline CHEMBL1567159 & 809005 & 4.5337 & 4.8019 & TRN & & \\
\hline CHEMBL1708171 & 809005 & 4.1988 & 4.1244 & TRN & & \\
\hline CHEMBL1711326 & 809005 & 3.1549 & 4.2102 & TRN & & \\
\hline CHEMBL1330524 & 809005 & 4.2949 & 4.4845 & TRN & & \\
\hline CHEMBL1560784 & 809005 & 4.232 & 4.3241 & TRN & & \\
\hline CHEMBL1336527 & 809005 & 4.2549 & 4.3181 & TRN & & \\
\hline CHEMBL1526446 & 809005 & 4.3463 & 4.2713 & TRN & & \\
\hline CHEMBL1351584 & 809005 & 4.19 & 4.2014 & TRN & & \\
\hline CHEMBL1882159 & 809005 & 4.6546 & 4.3788 & TRN & & \\
\hline CHEMBL1587722 & 809005 & 5.1986 & 4.6124 & TRN & & \\
\hline CHEMBL1486109 & 809005 & 5.1543 & 4.5991 & TRN & & \\
\hline CHEMBL1335146 & 809005 & 4.2934 & 4.5163 & TRN & & \\
\hline CHEMBL265686 & 809005 & 4.5596 & 4.7513 & TRN & & \\
\hline CHEMBL1566940 & 809005 & 5.3615 & 4.4529 & TRN & & \\
\hline CHEMBL1421836 & 809005 & 4.2431 & 4.4344 & TRN & & \\
\hline
\end{tabular}




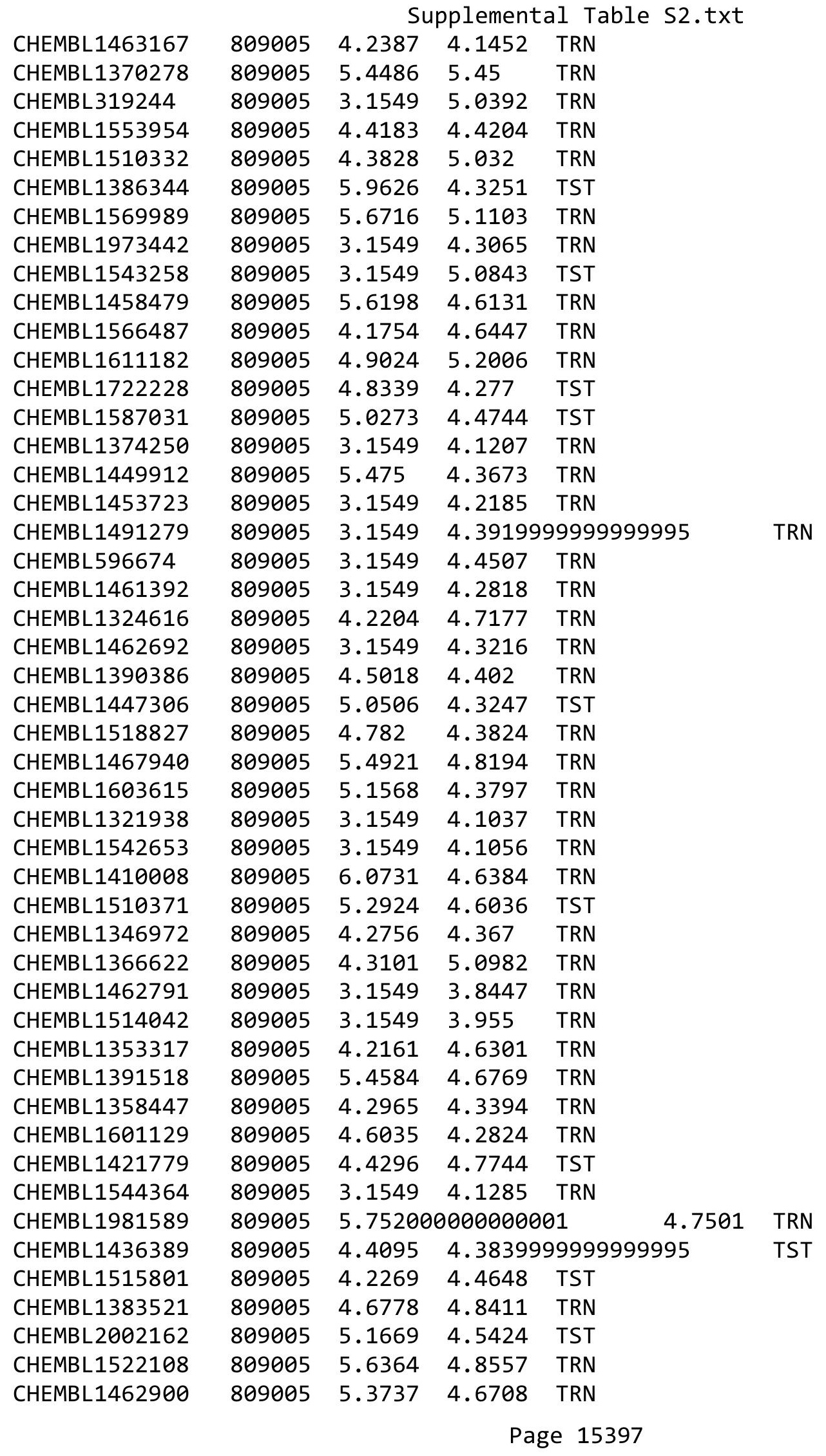




\begin{tabular}{|c|c|c|c|c|c|}
\hline \multicolumn{6}{|c|}{ lemental } \\
\hline CHEMBL453974 & 809005 & 4.3026 & 4.5542 & TST & \\
\hline CHEMBL1469691 & 809005 & 4.3921 & 4.3032 & TRN & \\
\hline CHEMBL1347090 & 809005 & 4.8884 & 4.3809 & TRN & \\
\hline CHEMBL1547430 & 809005 & 4.325 & 4.3475 & TRN & \\
\hline CHEMBL1560590 & 809005 & 4.2399 & 4.5593 & TRN & \\
\hline CHEMBL1437030 & 809005 & 6.0841 & 4.5656 & TRN & \\
\hline CHEMBL1610180 & 809005 & 5.0496 & 4.6227 & TRN & \\
\hline CHEMBL1548253 & 809005 & 4.4219 & 4.3556 & TST & \\
\hline CHEMBL1458022 & 809005 & 5.0511 & 4.675 & TRN & \\
\hline CHEMBL1325594 & 809005 & 4.2417 & 4.1909 & TRN & \\
\hline CHEMBL1534503 & 809005 & 4.5899 & 4.4207 & TRN & \\
\hline CHEMBL1402371 & 809005 & 5.1701 & 4.6632 & TRN & \\
\hline CHEMBL1358740 & 809005 & 4.23 & 4.478 & TST & \\
\hline CHEMBL1885576 & 809005 & 4.3669 & 4.3623 & TRN & \\
\hline CHEMBL1389268 & 809005 & 3.1549 & 5.1221 & TST & \\
\hline CHEMBL1353522 & 809005 & 4.375 & 4.3598 & TST & \\
\hline CHEMBL1545677 & 809005 & 5.7352 & 5.0867 & TRN & \\
\hline CHEMBL1452116 & 809005 & 4.244 & 4.42399 & 99999999995 & TST \\
\hline CHEMBL1872338 & 809005 & 3.1549 & 4.4111 & TST & \\
\hline CHEMBL1460871 & 809005 & 4.8193 & 4.6284 & TRN & \\
\hline CHEMBL1415844 & 809005 & 5.6345 & 4.5514 & TRN & \\
\hline CHEMBL1313222 & 809005 & 4.3432 & 4.30699 & 99999999995 & TRN \\
\hline CHEMBL1369725 & 809005 & 4.3342 & 4.3568 & TRN & \\
\hline CHEMBL1385690 & 809005 & 4.8055 & 4.57100 & 0000000001 & TRN \\
\hline CHEMBL1566205 & 809005 & 6.2277 & 4.8696 & TRN & \\
\hline CHEMBL1979212 & 809005 & 4.2618 & 4.699 & TRN & \\
\hline CHEMBL1882193 & 809005 & 4.3243 & 4.3911 & TRN & \\
\hline CHEMBL1497024 & 809005 & 5.1713 & 4.3635 & TST & \\
\hline CHEMBL1430096 & 809005 & 4.336 & 5.5201 & TST & \\
\hline CHEMBL1720661 & 809005 & 3.1549 & 4.2349 & TRN & \\
\hline CHEMBL1494575 & 809005 & 4.277 & 4.6727 & TST & \\
\hline CHEMBL1493442 & 809005 & 4.6763 & 4.7306 & TRN & \\
\hline CHEMBL1401989 & 809005 & 4.3726 & 4.6126 & TRN & \\
\hline CHEMBL1497019 & 809005 & 4.3741 & 4.3665 & TRN & \\
\hline CHEMBL1331836 & 809005 & 3.1549 & 4.2692 & TST & \\
\hline CHEMBL1311094 & 809005 & 3.1549 & 4.6094 & TST & \\
\hline CHEMBL1299470 & 809005 & 4.5122 & 4.6302 & TRN & \\
\hline CHEMBL1300302 & 809005 & 5.7721 & 4.3639 & TRN & \\
\hline CHEMBL1699284 & 809005 & 5.1073 & 4.6619 & TRN & \\
\hline CHEMBL1564958 & 809005 & 5.6383 & 5.1115 & TRN & \\
\hline CHEMBL203695 & 809005 & 4.276 & 4.6352 & TRN & \\
\hline CHEMBL1305380 & 809005 & 4.3324 & 4.3352 & TRN & \\
\hline CHEMBL1516853 & 809005 & 4.2317 & 4.3528 & TRN & \\
\hline CHEMBL1339536 & 809005 & 4.3134 & 4.066 & TRN & \\
\hline CHEMBL1420175 & 809005 & 4.2598 & 4.3854 & TRN & \\
\hline CHEMBL1408604 & 809005 & 5.2306 & 4.6926 & TRN & \\
\hline CHEMBL1993539 & 809005 & 4.8771 & 4.4555 & TST & \\
\hline CHEMBL1301480 & 809005 & 4.9003 & 4.6194 & TRN & \\
\hline
\end{tabular}




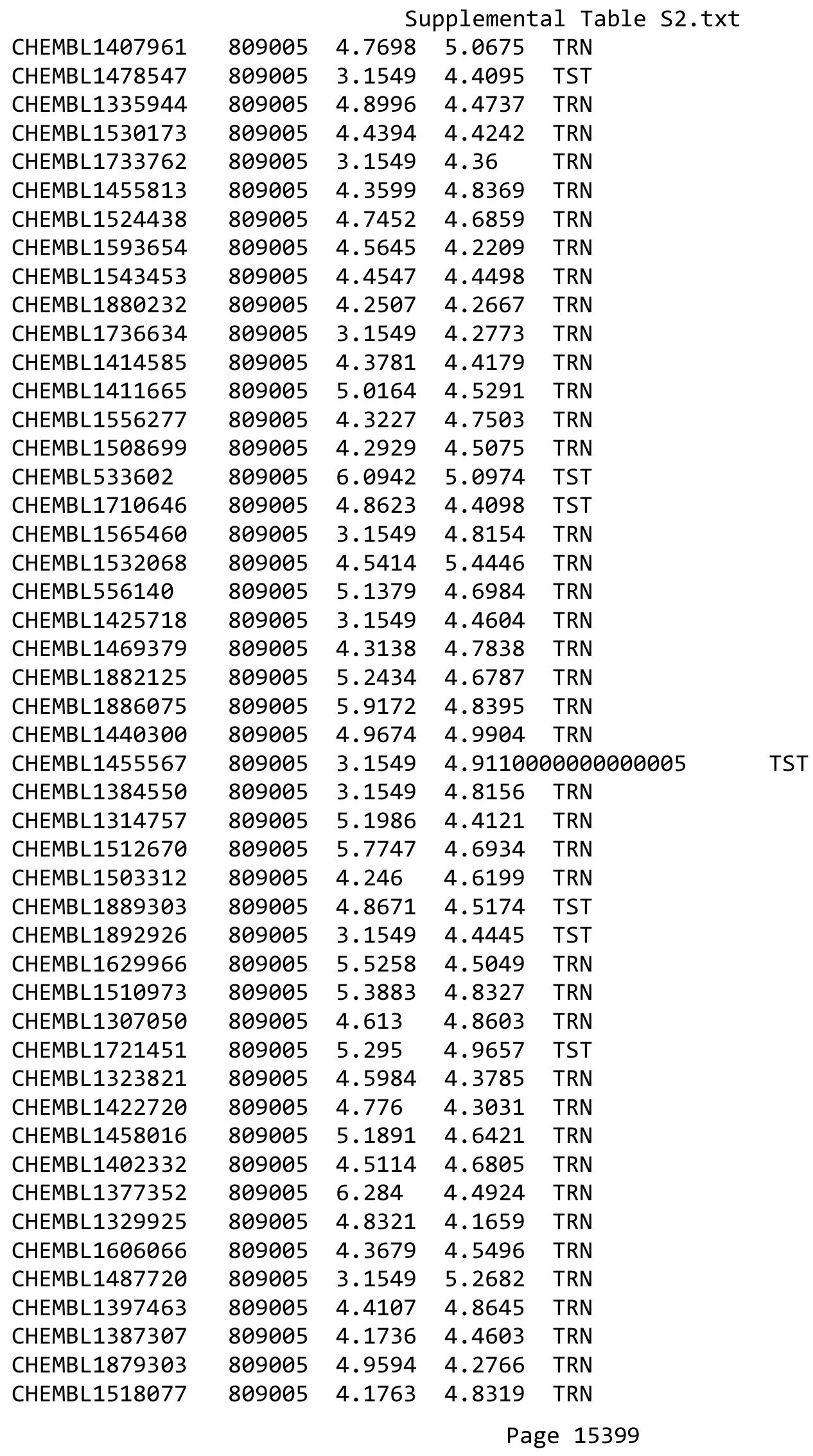


Supplemental Table S2.txt

\begin{tabular}{|c|c|c|c|c|c|}
\hline CHEMBL1345932 & 809005 & 5.5317 & 4.5006 & TRN & \\
\hline CHEMBL1431684 & 809005 & 4.1957 & 4.3139 & TRN & \\
\hline CHEMBL577660 & 809005 & 5.3936 & 4.3891 & TRN & \\
\hline CHEMBL1438590 & 809005 & 4.1592 & 4.4103 & TRN & \\
\hline CHEMBL1898348 & 809005 & 5.2933 & 4.4436 & TRN & \\
\hline CHEMBL1889898 & 809005 & 5.1415 & 4.672 & TST & \\
\hline CHEMBL1722169 & 809005 & 4.1743 & 4.5574 & TRN & \\
\hline CHEMBL1331851 & 809005 & 4.2218 & 4.7124 & TRN & \\
\hline CHEMBL1343490 & 809005 & 4.8847 & 4.7172 & TST & \\
\hline CHEMBL1418818 & 809005 & 4.4289 & 4.4945 & TRN & \\
\hline CHEMBL1519289 & 809005 & 4.6887 & 4.6766 & TRN & \\
\hline CHEMBL1610049 & 809005 & 5.9031 & 4.8419 & TRN & \\
\hline CHEMBL1448732 & 809005 & 4.2358 & 4.5598 & TRN & \\
\hline CHEMBL1574573 & 809005 & 4.3285 & 4.4249 & TRN & \\
\hline CHEMBL590665 & 809005 & 3.1549 & 5.5869 & TRN & \\
\hline CHEMBL1594821 & 809005 & 4.2223 & 4.6311 & TRN & \\
\hline CHEMBL1707874 & 809005 & 3.1549 & 3.9285 & TRN & \\
\hline CHEMBL598263 & 809005 & 3.1549 & 4.6655 & TRN & \\
\hline CHEMBL1344025 & 809005 & 5.4935 & 4.5415 & TRN & \\
\hline CHEMBL1438624 & 809005 & 4.3111 & 4.4598 & TRN & \\
\hline CHEMBL1301371 & 809005 & 4.7565 & 4.5539 & TRN & \\
\hline CHEMBL1581141 & 809005 & 4.3422 & 4.4839 & TRN & \\
\hline CHEMBL1469029 & 809005 & 4.2964 & 4.9272 & TRN & \\
\hline CHEMBL1416089 & 809005 & 4.9718 & 5.2212 & TRN & \\
\hline CHEMBL1597655 & 809005 & 5.7721 & 5.1072 & TRN & \\
\hline CHEMBL1700880 & 809005 & 5.7122 & 4.6848 & TRN & \\
\hline CHEMBL1551507 & 809005 & 4.4579 & 4.1902 & TST & \\
\hline CHEMBL1356084 & 809005 & 3.1549 & 4.31 & TRN & \\
\hline CHEMBL1601133 & 809005 & 5.5086 & 5.2537 & TRN & \\
\hline CHEMBL1526148 & 809005 & 4.468 & 4.3799 & TRN & \\
\hline CHEMBL1569501 & 809005 & 4.2366 & 4.3031 & TRN & \\
\hline CHEMBL1447382 & 809005 & 5.0083 & 4.5999 & TRN & \\
\hline CHEMBL1511215 & 809005 & 4.3066 & 4.7482 & TRN & \\
\hline CHEMBL1563223 & 809005 & 5.4056 & 4.8458 & TRN & \\
\hline CHEMBL1450921 & 809005 & 4.4486 & 4.7348 & TRN & \\
\hline CHEMBL1310930 & 809005 & 5.1811 & 4.4127 & TRN & \\
\hline CHEMBL1605536 & 809005 & $5.7570 e$ & j00000006 & & 4.9021 \\
\hline CHEMBL1597454 & 809005 & 3.1549 & 4.7832 & TRN & \\
\hline CHEMBL1894067 & 809005 & 5.0137 & 4.1609 & TRN & \\
\hline CHEMBL414890 & 809005 & 4.4903 & 4.6576 & TST & \\
\hline CHEMBL1727030 & 809005 & 4.2971 & 4.3721 & TRN & \\
\hline CHEMBL1901877 & 809005 & 4.9559 & 4.3191 & TRN & \\
\hline CHEMBL1561936 & 809005 & 4.5053 & 4.3036 & TRN & \\
\hline CHEMBL1721554 & 809005 & 3.1549 & 4.1483 & TRN & \\
\hline CHEMBL1347469 & 809005 & 4.4708 & 5.239 & TRN & \\
\hline CHEMBL1464631 & 809005 & 4.3949 & 4.3735 & TST & \\
\hline CHEMBL1700729 & 809005 & 4.8788 & 4.3401 & TST & \\
\hline CHEMBL1341270 & 809005 & 6.1215 & 4.7874 & TST & \\
\hline
\end{tabular}


Supplemental Table S2.txt

\begin{tabular}{|c|c|c|c|c|}
\hline CHEMBL1967856 & 809005 & 5.059 & 4.4584 & TRN \\
\hline CHEMBL1834675 & 809005 & 4.9219 & 4.3893 & TST \\
\hline CHEMBL1404398 & 809005 & 5.3645 & 4.6437 & TRN \\
\hline CHEMBL1308497 & 809005 & 4.9027 & 4.5447 & TRN \\
\hline CHEMBL1711797 & 809005 & 5.1555 & 4.6527 & TST \\
\hline CHEMBL1354582 & 809005 & 4.806 & 4.645 & TRN \\
\hline CHEMBL1303653 & 809005 & 4.712 & 4.4108 & TRN \\
\hline CHEMBL1705708 & 809005 & 4.7333 & 4.7412 & TST \\
\hline CHEMBL1483562 & 809005 & 5.015 & 4.5644 & TRN \\
\hline CHEMBL589238 & 809005 & 5.7932 & 4.9016 & TRN \\
\hline CHEMBL1453108 & 809005 & 4.3276 & 4.7536 & TRN \\
\hline CHEMBL1363219 & 809005 & 5.4248 & 4.6204 & TRN \\
\hline CHEMBL1966192 & 809005 & 5.27 & 4.4626 & TST \\
\hline CHEMBL1555866 & 809005 & 4.5203 & 4.319 & TRN \\
\hline CHEMBL1310852 & 809005 & 4.3285 & 4.211 & TRN \\
\hline CHEMBL1300831 & 809005 & 4.365 & 4.8202 & TST \\
\hline CHEMBL1404578 & 809005 & 4.8623 & 4.6248 & TRN \\
\hline CHEMBL1463659 & 809005 & 5.2358 & 5.1142 & TRN \\
\hline CHEMBL1496814 & 809005 & 4.2885 & 4.4713 & TRN \\
\hline CHEMBL1567944 & 809005 & 4.3925 & 5.2503 & TST \\
\hline CHEMBL1567488 & 809005 & 4.2339 & 4.4737 & TRN \\
\hline CHEMBL1366948 & 809005 & 4.2456 & 4.6582 & TST \\
\hline CHEMBL1582580 & 809005 & 4.6036 & 4.8203 & TRN \\
\hline CHEMBL1728642 & 809005 & 4.5106 & 4.798 & TST \\
\hline CHEMBL1565444 & 809005 & 4.4962 & 4.6159 & TRN \\
\hline CHEMBL1575768 & 809005 & 3.1549 & 5.0201 & TST \\
\hline CHEMBL1310479 & 809005 & 3.1549 & 4.8539 & TST \\
\hline CHEMBL1475769 & 809005 & 3.1549 & 4.8366 & TRN \\
\hline CHEMBL599924 & 809005 & 4.9197 & 4.768 & TRN \\
\hline CHEMBL1330184 & 809005 & 3.1549 & 4.5321 & TRN \\
\hline CHEMBL1372484 & 809005 & 3.1549 & 4.2885 & TRN \\
\hline CHEMBL1583471 & 809005 & 5.5482 & 4.8992 & TRN \\
\hline CHEMBL1732831 & 809005 & 3.1549 & 4.60800 & 00000000005 \\
\hline CHEMBL1492648 & 809005 & 4.7962 & 4.6667 & TRN \\
\hline CHEMBL1894596 & 809005 & 4.3135 & 4.467 & TRN \\
\hline CHEMBL1314042 & 809005 & 4.6341 & 4.3871 & TRN \\
\hline CHEMBL1329725 & 809005 & 4.5171 & 4.2519 & TRN \\
\hline CHEMBL1553183 & 809005 & 4.7176 & 4.7374 & TST \\
\hline CHEMBL1972072 & 809005 & 5.1884 & 4.4649 & TRN \\
\hline CHEMBL1541657 & 809005 & 5.0721 & 4.4893 & TRN \\
\hline CHEMBL1978882 & 809005 & 4.7165 & 4.7456 & TST \\
\hline CHEMBL1564737 & 809005 & 5.7986 & 4.3681 & TRN \\
\hline CHEMBL1546607 & 809005 & 4.2113 & 4.5564 & TRN \\
\hline CHEMBL1361913 & 809005 & 4.6085 & 4.1725 & TRN \\
\hline CHEMBL1343392 & 809005 & 4.4794 & 4.6491 & TRN \\
\hline CHEMBL1533399 & 809005 & 5.1209 & 4.6552 & TRN \\
\hline CHEMBL1309979 & 809005 & 4.3741 & 4.0275 & TRN \\
\hline CHEMBL 2006180 & 809005 & 3.1549 & 4.012 & TST \\
\hline
\end{tabular}




\begin{tabular}{|c|c|c|c|c|c|}
\hline \multicolumn{6}{|c|}{ Supplemental Table S2.txt } \\
\hline CHEMBL601135 & 809005 & 4.2609 & 4.3849 & TRN & \\
\hline CHEMBL1572233 & 809005 & 5.2899 & 4.9774 & TRN & \\
\hline CHEMBL1574453 & 809005 & 5.0491 & 4.6339 & TRN & \\
\hline CHEMBL1476734 & 809005 & 5.9208 & 4.5411 & TRN & \\
\hline CHEMBL1338667 & 809005 & 3.1549 & 4.555 & TST & \\
\hline CHEMBL1343814 & 809005 & 4.5184 & 4.4574 & TRN & \\
\hline CHEMBL1477528 & 809005 & 4.394 & 4.481 & TRN & \\
\hline CHEMBL1399478 & 809005 & 5.5272 & 4.9637 & TRN & \\
\hline CHEMBL1417566 & 809005 & 5.5114 & 4.4329 & TRN & \\
\hline CHEMBL1448929 & 809005 & 3.1549 & 4.7528 & TRN & \\
\hline CHEMBL1731360 & 809005 & 3.1549 & 4.3955 & TRN & \\
\hline CHEMBL1423935 & 809005 & 4.5924 & 4.69600 & 0000000001 & TRN \\
\hline CHEMBL1883988 & 809005 & 4.6008 & 4.1541 & TRN & \\
\hline CHEMBL1370024 & 809005 & 5.8601 & 4.3968 & TRN & \\
\hline CHEMBL1905195 & 809005 & 3.1549 & 4.0475 & TST & \\
\hline CHEMBL1300836 & 809005 & 3.1549 & 4.5335 & TST & \\
\hline CHEMBL1516127 & 809005 & 5.2774 & 4.6866 & TRN & \\
\hline CHEMBL1495527 & 809005 & 3.1549 & 4.3085 & TRN & \\
\hline CHEMBL1501632 & 809005 & 5.4377 & 4.9894 & TRN & \\
\hline CHEMBL1577745 & 809005 & 4.7005 & 4.3819 & TRN & \\
\hline CHEMBL1449204 & 809005 & 4.8904 & 4.4588 & TRN & \\
\hline CHEMBL1386067 & 809005 & 3.1549 & 4.4724 & TST & \\
\hline CHEMBL595700 & 809005 & 4.6887 & 4.8849 & TRN & \\
\hline CHEMBL1300959 & 809005 & 4.3355 & 4.6737 & TRN & \\
\hline CHEMBL1459140 & 809005 & 6.0 & 5.1504 & TRN & \\
\hline CHEMBL1432721 & 809005 & 5.6003 & 4.7661 & TRN & \\
\hline CHEMBL1704518 & 809005 & 4.9412 & 4.5498 & TST & \\
\hline CHEMBL1419414 & 809005 & 3.1549 & 4.0574 & TRN & \\
\hline CHEMBL1302158 & 809005 & 4.4111 & 4.3804 & TRN & \\
\hline CHEMBL1534781 & 809005 & 5.3958 & 4.735 & TRN & \\
\hline CHEMBL1530686 & 809005 & 5.4214 & 5.1626 & TRN & \\
\hline CHEMBL1558462 & 809005 & 4.655 & 5.0823 & TRN & \\
\hline CHEMBL1457139 & 809005 & 5.1713 & 5.3231 & TRN & \\
\hline CHEMBL1361883 & 809005 & 5.1694 & 4.6461 & TRN & \\
\hline CHEMBL1707088 & 809005 & 3.1549 & 4.1877 & TRN & \\
\hline CHEMBL1550278 & 809005 & 5.9172 & 5.0728 & TRN & \\
\hline CHEMBL1536041 & 809005 & 4.1852 & 4.2072 & TRN & \\
\hline CHEMBL1434805 & 809005 & 5.3947 & 4.5169 & TRN & \\
\hline CHEMBL1871515 & 809005 & 3.1549 & 4.552 & TST & \\
\hline CHEMBL 2004734 & 809005 & 4.6552 & 4.6929 & TST & \\
\hline CHEMBL1337614 & 809005 & 5.1325 & 4.5863 & TRN & \\
\hline CHEMBL1500252 & 809005 & 3.1549 & 4.5016 & TRN & \\
\hline CHEMBL1312502 & 809005 & 5.1255 & 4.2212 & TRN & \\
\hline CHEMBL1366942 & 809005 & 5.6556 & 5.7847 & TRN & \\
\hline CHEMBL1717596 & 809005 & 4.2422 & 4.5728 & TRN & \\
\hline CHEMBL1412002 & 809005 & 5.6073 & 5.1002 & TRN & \\
\hline CHEMBL1423192 & 809005 & 4.2505 & 4.596 & TRN & \\
\hline CHEMBL1550670 & 809005 & 4.5357 & 4.6498 & TRN & \\
\hline
\end{tabular}


Supplemental Table S2.txt

\begin{tabular}{|c|c|c|c|c|c|}
\hline CHEMBL1361227 & 809005 & 4.9263 & 4.3454 & TRN & \\
\hline CHEMBL1504429 & 809005 & 4.6117 & 4.6431 & TRN & \\
\hline CHEMBL1481192 & 809005 & 4.5909 & 4.3277 & TST & \\
\hline CHEMBL1723968 & 809005 & 4.3391 & 4.3632 & TST & \\
\hline CHEMBL1526851 & 809005 & 3.1549 & 4.4092 & TST & \\
\hline CHEMBL1609580 & 809005 & 4.1585 & 4.4062 & TRN & \\
\hline CHEMBL1482542 & 809005 & 5.7595 & 4.688 & TRN & \\
\hline CHEMBL1315704 & 809005 & 3.1549 & 4.1563 & TST & \\
\hline CHEMBL530361 & 809005 & 4.8592 & 4.9429 & TRN & \\
\hline CHEMBL1482188 & 809005 & 4.4957 & 4.6103 & TST & \\
\hline CHEMBL1565005 & 809005 & 5.6055 & 4.7348 & TRN & \\
\hline CHEMBL367376 & 809005 & 4.2295 & 5.6646 & TST & \\
\hline CHEMBL1896491 & 809005 & 3.1549 & 4.4393 & TRN & \\
\hline CHEMBL1504982 & 809005 & 5.4191 & 4.6183 & TRN & \\
\hline CHEMBL1476739 & 809005 & 4.5594 & 4.6972 & TRN & \\
\hline CHEMBL1352969 & 809005 & 3.1549 & 4.2532 & TST & \\
\hline CHEMBL1875537 & 809005 & 3.1549 & 5.3655 & TST & \\
\hline CHEMBL1734467 & 809005 & 4.6851 & 4.453 & TRN & \\
\hline CHEMBL1417970 & 809005 & 4.6809 & 4.5115 & TRN & \\
\hline CHEMBL1717507 & 809005 & 3.1549 & 4.6161 & TRN & \\
\hline CHEMBL1467359 & 809005 & 4.3406 & 4.0542 & TRN & \\
\hline CHEMBL1484306 & 809005 & 4.2971 & 4.371 & TRN & \\
\hline CHEMBL1430068 & 809005 & 3.1549 & 4.293 & TRN & \\
\hline CHEMBL1464798 & 809005 & 4.38399 & 79999999 & 95 & 4.5161 \\
\hline CHEMBL1544093 & 809005 & 4.45100 & j00000006 & 05 & 4.4826 \\
\hline CHEMBL1886345 & 809005 & 3.1549 & 4.5352 & TST & \\
\hline CHEMBL1443454 & 809005 & 4.7602 & 4.5626 & TRN & \\
\hline CHEMBL1384414 & 809005 & 3.1549 & 4.2503 & TRN & \\
\hline CHEMBL1716027 & 809005 & 4.3785 & 4.1453 & TRN & \\
\hline CHEMBL1300908 & 809005 & 3.1549 & 4.2713 & TRN & \\
\hline CHEMBL1557089 & 809005 & 4.2203 & 4.5057 & TRN & \\
\hline CHEMBL1310132 & 809005 & 5.9914 & 5.4271 & TRN & \\
\hline CHEMBL1514530 & 809005 & 5.767 & 5.5579 & TRN & \\
\hline CHEMBL1435226 & 809005 & 5.7305 & 4.7003 & TRN & \\
\hline CHEMBL1733422 & 809005 & 5.1713 & 4.6437 & TRN & \\
\hline CHEMBL1710184 & 809005 & 4.6291 & 4.4353 & TRN & \\
\hline CHEMBL1334003 & 809005 & 4.493 & 4.6729 & TRN & \\
\hline CHEMBL1349485 & 809005 & 5.2774 & 4.6159 & TRN & \\
\hline CHEMBL1897013 & 809005 & 3.1549 & 4.4042 & TRN & \\
\hline CHEMBL1307349 & 809005 & 3.1549 & 4.0062 & TST & \\
\hline CHEMBL482050 & 809005 & 3.1549 & 4.3942 & TST & \\
\hline CHEMBL1613695 & 809005 & 4.3852 & 4.3739 & TRN & \\
\hline CHEMBL1720610 & 809005 & 3.1549 & 4.3339 & TRN & \\
\hline CHEMBL1501645 & 809005 & 3.1549 & 4.4832 & TRN & \\
\hline CHEMBL1724993 & 809005 & 4.2185 & 4.0359 & TRN & \\
\hline CHEMBL1500469 & 809005 & 4.4795 & 4.8587 & TRN & \\
\hline CHEMBL1474553 & 809005 & 4.9606 & 4.546 & TRN & \\
\hline CHEMBL1335491 & 809005 & 5.251 & 4.7519 & TRN & \\
\hline
\end{tabular}




\begin{tabular}{|c|c|c|c|c|c|c|}
\hline & & \multicolumn{5}{|c|}{ Supplemental Table s2.txt } \\
\hline CHEMBL1559226 & 809005 & 4.4753 & 4.8169 & TST & & \\
\hline CHEMBL1608757 & 809005 & 5.1308 & 4.4036 & TST & & \\
\hline CHEMBL1561146 & 809005 & 3.1549 & 4.3765 & TRN & & \\
\hline CHEMBL1580083 & 809005 & 4.596 & 4.3963 & TRN & & \\
\hline CHEMBL1711814 & 809005 & 5.5834 & 4.6338 & TRN & & \\
\hline CHEMBL1406670 & 809005 & 4.1876 & 3.425 & TST & & \\
\hline CHEMBL1352748 & 809005 & 4.5645 & 4.2644 & TRN & & \\
\hline CHEMBL1734142 & 809005 & 4.3205 & 4.7043 & TST & & \\
\hline CHEMBL1572468 & 809005 & \multicolumn{3}{|c|}{4.5169999999999995} & 4.6504 & TRN \\
\hline CHEMBL1723391 & 809005 & 4.2716 & 4.3342 & TRN & & \\
\hline CHEMBL1565115 & 809005 & 4.5385 & 5.1801 & TRN & & \\
\hline CHEMBL1499893 & 809005 & 4.3038 & 4.6045 & TRN & & \\
\hline CHEMBL1421976 & 809005 & 3.1549 & 4.7329 & TRN & & \\
\hline CHEMBL1988268 & 809005 & 3.1549 & 4.4578 & TRN & & \\
\hline CHEMBL1299281 & 809005 & 3.1549 & 4.6102 & TRN & & \\
\hline CHEMBL1300171 & 809005 & 5.27 & 4.3709 & TRN & & \\
\hline CHEMBL1562926 & 809005 & 5.2549 & 4.9518 & TRN & & \\
\hline CHEMBL1610300 & 809005 & 6.0931 & 4.9917 & TRN & & \\
\hline CHEMBL1712491 & 809005 & 5.6576 & 4.592 & TRN & & \\
\hline CHEMBL1995375 & 809005 & 4.2401 & 4.5769 & TRN & & \\
\hline CHEMBL1566706 & 809005 & 5.2358 & 4.13899 & 9999999999 & & TRN \\
\hline CHEMBL1504035 & 809005 & 4.1603 & 4.4305 & TRN & & \\
\hline CHEMBL1329235 & 809005 & 4.9678 & 5.2242 & TRN & & \\
\hline CHEMBL1312275 & 809005 & 4.3814 & 4.5828 & TRN & & \\
\hline CHEMBL1500615 & 809005 & 4.2552 & 4.4513 & TST & & \\
\hline CHEMBL1891071 & 809005 & 4.6981 & 4.7404 & TRN & & \\
\hline CHEMBL1378232 & 809005 & 3.1549 & 4.7473 & TRN & & \\
\hline CHEMBL1994626 & 809005 & 5.4191 & 4.602 & TRN & & \\
\hline CHEMBL1500686 & 809005 & 4.8928 & 4.2791 & TRN & & \\
\hline CHEMBL1399408 & 809005 & 4.2236 & 4.5497 & TRN & & \\
\hline CHEMBL1543473 & 809005 & 5.1707 & 4.5796 & TRN & & \\
\hline CHEMBL1993889 & 809005 & 3.1549 & 4.6745 & TRN & & \\
\hline CHEMBL1510652 & 809005 & 4.449 & 4.2014 & TRN & & \\
\hline CHEMBL1300618 & 809005 & 4.2346 & 4.1651 & TRN & & \\
\hline CHEMBL1370361 & 809005 & 3.1549 & 4.0059 & TST & & \\
\hline CHEMBL1515132 & 809005 & \multicolumn{3}{|c|}{4.821000000000001} & 4.7528 & TST \\
\hline CHEMBL1563198 & 809005 & 3.1549 & 4.3794 & TRN & & \\
\hline CHEMBL3392492 & 809005 & 5.082 & 4.5306 & TRN & & \\
\hline CHEMBL2003567 & 809005 & 5.2472 & 4.7773 & TRN & & \\
\hline CHEMBL1364390 & 809005 & 4.2298 & 4.2664 & TST & & \\
\hline CHEMBL1312371 & 809005 & 4.5109 & 4.4128 & TRN & & \\
\hline CHEMBL1548322 & 809005 & 3.1549 & 4.323 & TRN & & \\
\hline CHEMBL1300527 & 809005 & 3.1549 & 4.4659 & TRN & & \\
\hline CHEMBL1555876 & 809005 & 5.0066 & 4.9563 & TRN & & \\
\hline CHEMBL1543839 & 809005 & 4.5634 & 4.6157 & TRN & & \\
\hline CHEMBL1896778 & 809005 & 4.9751 & 4.3869 & TRN & & \\
\hline CHEMBL1985527 & 809005 & 4.4357 & 4.9609 & TST & & \\
\hline CHEMBL1490222 & 809005 & 5.3307 & 5.155 & TRN & & \\
\hline
\end{tabular}




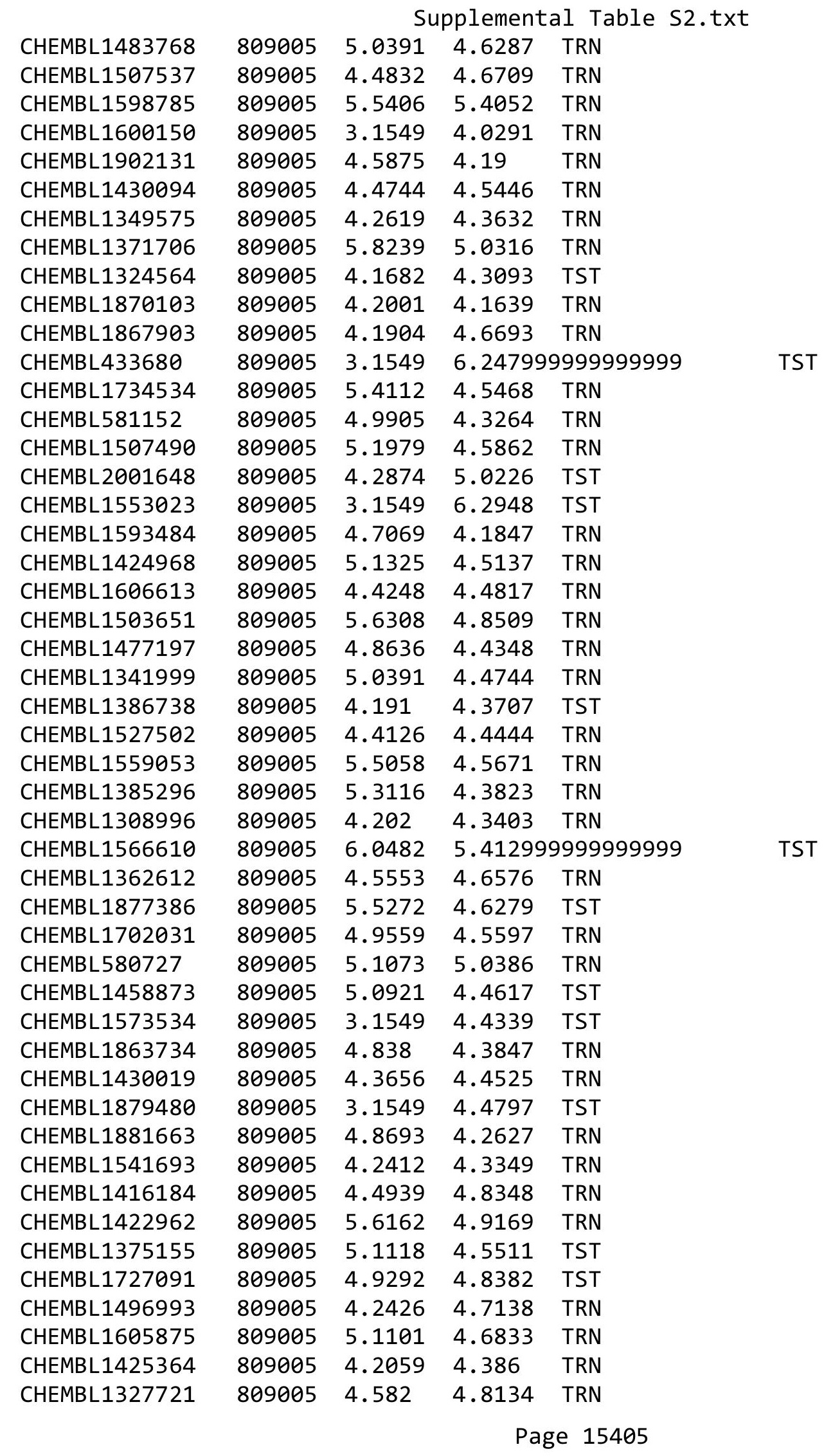




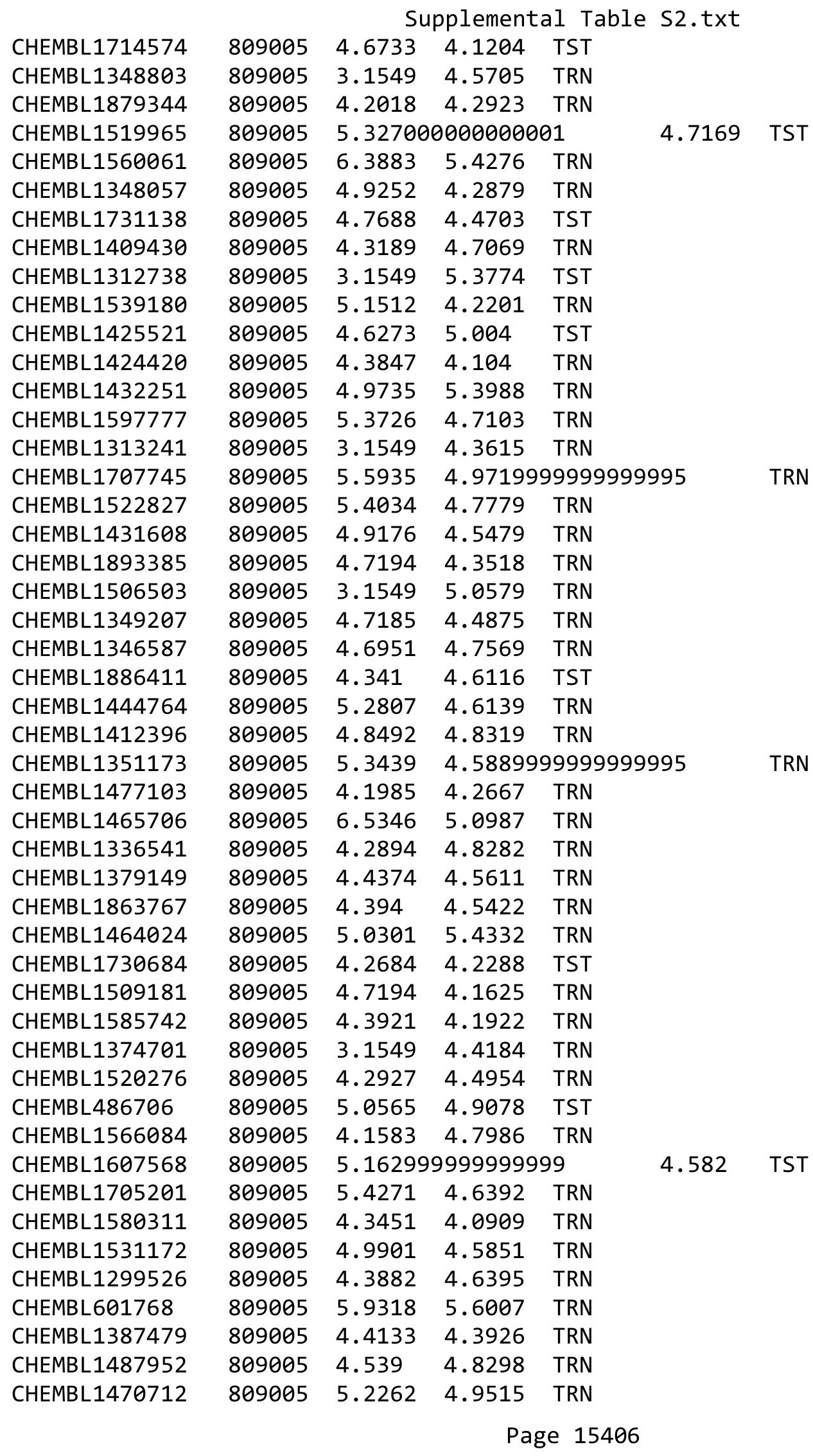




\begin{tabular}{|c|c|c|c|c|c|c|}
\hline & & \multicolumn{5}{|c|}{ Supplemental Table S2.txt } \\
\hline CHEMBL1895200 & 809005 & 4.3812 & 4.7354 & TST & & \\
\hline CHEMBL1453555 & 809005 & 4.1658 & 4.4196 & TRN & & \\
\hline CHEMBL1700777 & 809005 & 4.8312 & 4.2627 & TRN & & \\
\hline CHEMBL1531357 & 809005 & 4.3997 & 4.2401 & TRN & & \\
\hline CHEMBL1602962 & 809005 & 5.4572 & 4.5177 & TRN & & \\
\hline CHEMBL1256655 & 809005 & 4.7224 & 4.7219 & TRN & & \\
\hline CHEMBL1409445 & 809005 & 5.585 & 5.0193 & TRN & & \\
\hline CHEMBL1401779 & 809005 & 3.1549 & 4.6556 & TRN & & \\
\hline CHEMBL1598383 & 809005 & 4.4055 & 4.5543 & TRN & & \\
\hline CHEMBL1598985 & 809005 & 3.1549 & 4.4679 & TRN & & \\
\hline CHEMBL1302286 & 809005 & 4.4152 & 4.2838 & TRN & & \\
\hline CHEMBL1565371 & 809005 & 4.3933 & 4.6171 & TRN & & \\
\hline CHEMBL1594475 & 809005 & 5.5834 & 5.5075 & TRN & & \\
\hline CHEMBL1504634 & 809005 & 3.1549 & 4.2283 & TST & & \\
\hline CHEMBL1718231 & 809005 & 4.207 & 4.5626 & TRN & & \\
\hline CHEMBL1893162 & 809005 & 4.3987 & 4.4821 & TRN & & \\
\hline CHEMBL1522275 & 809005 & 4.5624 & 4.154 & TST & & \\
\hline CHEMBL1449794 & 809005 & 3.1549 & 4.8321 & TST & & \\
\hline CHEMBL1504077 & 809005 & 4.6463 & 4.4945 & TRN & & \\
\hline CHEMBL1554436 & 809005 & 4.1891 & 4.466 & TRN & & \\
\hline CHEMBL1728514 & 809005 & 4.2687 & 4.7125 & TST & & \\
\hline CHEMBL1702773 & 809005 & 4.5847 & 4.2452 & TRN & & \\
\hline CHEMBL1520406 & 809005 & 4.2551 & 4.291 & TRN & & \\
\hline CHEMBL1343711 & 809005 & 5.58 & 4.7053 & TRN & & \\
\hline CHEMBL1525735 & 809005 & 5.1662 & 4.5014 & TRN & & \\
\hline CHEMBL1365328 & 809005 & 4.2815 & 4.1608 & TRN & & \\
\hline CHEMBL1449499 & 809005 & 3.1549 & 4.3896 & TRN & & \\
\hline CHEMBL1606097 & 809005 & 4.9165 & 4.4903 & TST & & \\
\hline CHEMBL1539841 & 809005 & \multicolumn{3}{|c|}{5.382000000000001} & 4.3177 & TRN \\
\hline CHEMBL1369287 & 809005 & 4.8318 & 4.3761 & TST & & \\
\hline CHEMBL1352607 & 809005 & 4.4133 & 4.7463 & TRN & & \\
\hline CHEMBL1526539 & 809005 & 4.9462 & 5.0411 & TST & & \\
\hline CHEMBL1730189 & 809005 & 3.1549 & 4.3069 & TRN & & \\
\hline CHEMBL1720152 & 809005 & 4.4734 & 4.5698 & TRN & & \\
\hline CHEMBL579919 & 809005 & 5.0726 & 4.495 & TRN & & \\
\hline CHEMBL1541828 & 809005 & 4.4072 & 4.5502 & TRN & & \\
\hline CHEMBL1483731 & 809005 & 4.6621 & 4.7767 & TST & & \\
\hline CHEMBL1998498 & 809005 & 4.3101 & 4.0353 & TST & & \\
\hline CHEMBL1612044 & 809005 & 4.9165 & 4.8573 & TRN & & \\
\hline CHEMBL1726266 & 809005 & 4.3376 & 4.7143 & TRN & & \\
\hline CHEMBL1524431 & 809005 & 5.2993 & 4.519 & TRN & & \\
\hline CHEMBL1871319 & 809005 & 4.3407 & 4.399 & TRN & & \\
\hline CHEMBL1538692 & 809005 & 5.4078 & 5.0036 & TRN & & \\
\hline CHEMBL1874456 & 809005 & 4.7411 & 4.30399 & 9999999999 & & TRN \\
\hline CHEMBL1482389 & 809005 & 4.3734 & 4.5078 & TRN & & \\
\hline CHEMBL3392223 & 809005 & 5.4802 & 4.4244 & TST & & \\
\hline CHEMBL1367466 & 809005 & 5.4908 & 4.6529 & TRN & & \\
\hline CHEMBL1473102 & 809005 & 3.1549 & 3.9639 & TRN & & \\
\hline
\end{tabular}


Supplemental Table S2.txt

\begin{tabular}{|c|c|c|c|c|}
\hline HEM & 005 & 4.5302 & 8879 & TS \\
\hline & 09005 & & & \\
\hline HFMBI & 005 & & & \\
\hline IEMBL607553 & 005 & 902 & & \\
\hline HEMBL1700479 & 09005 & 49 & 7032 & \\
\hline HEMBL1581838 & 09005 & & 3525 & \\
\hline HEMBLI & 29005 & & & \\
\hline AEMBL148] & 99005 & & & \\
\hline HEMBL1535665 & 09005 & 147 & 4.8991 & \\
\hline HEMBL1984654 & 09005 & & 1244 & \\
\hline HEMBL156. & 09005 & & & \\
\hline IEME & 29005 & & 17 & \\
\hline AEMBL1 & 005 & & & \\
\hline HEMBL1560954 & 09005 & 027 & 36 & \\
\hline HEMBL1729168 & 09005 & & & \\
\hline AEMBL1 & 09005 & & & \\
\hline AEMBL & 05 & & & \\
\hline AEMBL & 09005 & & & \\
\hline HEMBI 5 & 09005 & & & \\
\hline AEMBL 145 & 005 & & & \\
\hline AEMBL: & 25 & & & \\
\hline HEMBL & 05 & & & \\
\hline HEMBL & 09005 & & & ST \\
\hline HEMBL1 & 09005 & & & . \\
\hline AEMBL1 & 05 & & & RN \\
\hline HEMBL1 & 05 & & & RN \\
\hline HEMBL & $\partial 5$ & & & RN \\
\hline 93 & 005 & & & RN \\
\hline HEMBL1 & 29005 & & & RN \\
\hline AEMBL150 & 29005 & & 89 & TRN \\
\hline AEMBL & 9005 & & & $\mathrm{RN}$ \\
\hline 6 & 95 & & & RN \\
\hline 38 & & & & RN \\
\hline HEMBL136 & & & & RN \\
\hline HEMBL1529783 & 99005 & & & RN \\
\hline IFMDI & 05 & & & . \\
\hline 0 & 5 & & & RN \\
\hline HEMBL1 & & & & RN \\
\hline HEMBL1531 & 09005 & & & RN \\
\hline EMBL & 205 & & & RN \\
\hline HEMBL1 & 9005 & & & \\
\hline & 29005 & & & RN \\
\hline HEMBL1360862 & 29005 & & & RN \\
\hline HEMBL1473791 & 29005 & & & TR \\
\hline CHEMBL1383333 & & & & \\
\hline HEMBL1539522 & 09005 & & & \\
\hline HEMBL 379300 & 09005 & 08 & 894 & \\
\hline CHEMBL 2002411 & 809005 & 3.1549 & 4.4941 & ГRN \\
\hline
\end{tabular}

Page 15408 


\begin{tabular}{|c|c|c|c|c|}
\hline \multicolumn{5}{|c|}{ Supplemental Table s2.txt } \\
\hline CHEMBL1563896 & 809005 & 4.3211 & 4.4694 & TST \\
\hline CHEMBL1570879 & 809005 & 3.1549 & 4.4019 & TRN \\
\hline CHEMBL1436618 & 809005 & 4.4285 & 4.5948 & TRN \\
\hline CHEMBL591876 & 809005 & 5.9547 & 5.6015 & TRN \\
\hline CHEMBL493153 & 809005 & 4.367 & 5.0099 & TRN \\
\hline CHEMBL1304177 & 809005 & 5.1898 & 4.439 & TRN \\
\hline CHEMBL1531933 & 809005 & 4.5093 & 4.4364 & TRN \\
\hline CHEMBL1468672 & 809005 & 5.0655 & 4.544 & TRN \\
\hline CHEMBL 1375338 & 809005 & 4.6112 & 4.5277 & TRN \\
\hline CHEMBL1313883 & 809005 & 4.5211 & 4.5801 & TRN \\
\hline CHEMBL1580472 & 809005 & 4.8658 & 4.3688 & TRN \\
\hline CHEMBL1509727 & 809005 & 4.38 & 4.6526 & TRN \\
\hline CHEMBL1431189 & 809005 & 5.4318 & 4.3902 & TRN \\
\hline CHEMBL1522211 & 809005 & 3.1549 & 4.2452 & TRN \\
\hline CHEMBL1733910 & 809005 & 3.1549 & 4.3352 & TRN \\
\hline CHEMBL548615 & 809005 & 5.4225 & 5.1094 & TRN \\
\hline CHEMBL1446971 & 809005 & 4.6486 & 5.3581 & TRN \\
\hline CHEMBL1966132 & 809005 & 5.1107 & 4.7285 & TRN \\
\hline CHEMBL590927 & 809005 & 5.6326 & 5.3769 & TRN \\
\hline CHEMBL116919 & 809005 & 5.4353 & 4.7142 & TRN \\
\hline CHEMBL1532668 & 809005 & 4.5289 & 5.0022 & TRN \\
\hline CHEMBL1971465 & 809005 & 3.1549 & 4.2078 & TST \\
\hline CHEMBL1521492 & 809005 & 4.3987 & 4.6341 & TRN \\
\hline CHEMBL1486664 & 809005 & 5.4711 & 4.2765 & TRN \\
\hline CHEMBL1716540 & 809005 & 4.7118 & 4.8169 & TST \\
\hline CHEMBL1343705 & 809005 & 5.1986 & 4.4721 & TRN \\
\hline CHEMBL1602160 & 809005 & 4.2297 & 4.6846 & TST \\
\hline CHEMBL1535361 & 809005 & 5.1421 & 4.9332 & TRN \\
\hline CHEMBL1701330 & 809005 & 4.2464 & 4.4173 & TRN \\
\hline CHEMBL1448282 & 809005 & 5.9066 & 5.6152 & TRN \\
\hline CHEMBL1326053 & 809005 & 4.8655 & 4.3023 & TRN \\
\hline CHEMBL1327276 & 809005 & 4.3759 & 4.6997 & TRN \\
\hline CHEMBL1512775 & 809005 & 4.3807 & 4.5444 & TST \\
\hline CHEMBL1492096 & 809005 & 5.4672 & 4.8193 & TRN \\
\hline CHEMBL1548492 & 809005 & 5.6799 & 5.4872 & TRN \\
\hline CHEMBL1322995 & 809005 & 3.1549 & 4.5113 & TRN \\
\hline CHEMBL1889837 & 809005 & 5.0888 & 4.4426 & TRN \\
\hline CHEMBL1425921 & 809005 & 4.7402 & 4.5497 & TRN \\
\hline CHEMBL1442973 & 809005 & 4.2942 & 4.4359 & TRN \\
\hline CHEMBL1501495 & 809005 & 3.1549 & 4.2721 & TRN \\
\hline CHEMBL1302109 & 809005 & 4.3609 & 4.761 & TRN \\
\hline CHEMBL1431651 & 809005 & 4.2694 & 4.3242 & TRN \\
\hline CHEMBL1563650 & 809005 & 3.1549 & 4.8834 & TRN \\
\hline CHEMBL1425438 & 809005 & 4.6411 & 4.7525 & TRN \\
\hline CHEMBL1454819 & 809005 & 4.9038 & 4.3887 & TRN \\
\hline CHEMBL1305077 & 809005 & 4.3064 & 4.5773 & TRN \\
\hline CHEMBL1406419 & 809005 & 4.4733 & 4.4947 & TST \\
\hline CHEMBL1731329 & 809005 & 5.3098 & 4.3849 & TRN \\
\hline
\end{tabular}




\begin{tabular}{|c|c|c|c|c|c|}
\hline & & \multicolumn{4}{|c|}{ Supplemental Table S2.txt } \\
\hline CHEMBL1529190 & 809005 & 5.4989 & 5.1953 & TRN & \\
\hline CHEMBL1710051 & 809005 & 4.176 & 4.586 & TRN & \\
\hline CHEMBL1457902 & 809005 & 5.5346 & 4.7679 & TRN & \\
\hline CHEMBL1387401 & 809005 & 5.7033 & 5.0869 & TRN & \\
\hline CHEMBL1469929 & 809005 & 5.2708 & 4.382 & TRN & \\
\hline CHEMBL1486467 & 809005 & 5.4828 & 4.7079 & TRN & \\
\hline CHEMBL1395785 & 809005 & 4.1897 & 4.3568 & TRN & \\
\hline CHEMBL1608707 & 809005 & 4.1657 & 4.687 & TRN & \\
\hline CHEMBL1475774 & 809005 & 4.6694 & 4.482 & TRN & \\
\hline CHEMBL1975935 & 809005 & 4.4104 & 4.2058 & TRN & \\
\hline CHEMBL1897229 & 809005 & 4.3737 & 4.3868 & TRN & \\
\hline CHEMBL1429108 & 809005 & 4.2506 & 4.3619 & TRN & \\
\hline CHEMBL1607286 & 809005 & 5.0788 & 4.1558 & TRN & \\
\hline CHEMBL1573697 & 809005 & 4.3574 & 4.7432 & TRN & \\
\hline CHEMBL1707900 & 809005 & 5.0511 & 4.625 & TRN & \\
\hline CHEMBL1324027 & 809005 & 4.4431 & 4.5879 & TRN & \\
\hline CHEMBL317115 & 809005 & 5.2725 & 4.7455 & TRN & \\
\hline CHEMBL1699691 & 809005 & 3.1549 & 5.9794 & TST & \\
\hline CHEMBL1358184 & 809005 & 4.3822 & 4.1453 & TRN & \\
\hline CHEMBL1584329 & 809005 & 4.2365 & 4.4166 & TRN & \\
\hline CHEMBL1573994 & 809005 & 4.585 & 5.3726 & TST & \\
\hline CHEMBL585827 & 809005 & 5.6126 & 5.3174 & TRN & \\
\hline CHEMBL1403523 & 809005 & 4.5127 & 4.2547 & TRN & \\
\hline CHEMBL1367597 & 809005 & 5.5361 & 4.6898 & TRN & \\
\hline CHEMBL1511219 & 809005 & 4.5445 & 5.3596 & TRN & \\
\hline CHEMBL1332013 & 809005 & 5.0088 & 4.552 & TRN & \\
\hline CHEMBL579837 & 809005 & 4.2781 & 4.4753 & TRN & \\
\hline CHEMBL1353983 & 809005 & 5.4123 & 5.0638 & TRN & \\
\hline CHEMBL1398686 & 809005 & 4.9622 & 4.6461 & TRN & \\
\hline CHEMBL1405318 & 809005 & 4.1741 & 4.175 & TRN & \\
\hline CHEMBL1338677 & 809005 & 5.5361 & 4.8732 & TRN & \\
\hline CHEMBL1900870 & 809005 & 5.4001 & 5.0064 & TST & \\
\hline CHEMBL1727333 & 809005 & 5.9281 & 4.6139 & TRN & \\
\hline CHEMBL1345388 & 809005 & 5.1965 & 4.4765 & TRN & \\
\hline CHEMBL1391353 & 809005 & 4.2701 & 4.4832 & TRN & \\
\hline CHEMBL1412039 & 809005 & 5.2573 & 4.3862 & TRN & \\
\hline CHEMBL1352995 & 809005 & 4.375 & 4.2986 & TRN & \\
\hline CHEMBL1420393 & 809005 & 3.1549 & 4.7293 & TRN & \\
\hline CHEMBL1462764 & 809005 & 3.1549 & 4.3584 & TRN & \\
\hline CHEMBL1709973 & 809005 & 5.5952 & 4.7566 & TRN & \\
\hline CHEMBL1584502 & 809005 & 4.7158 & 4.6458 & TRN & \\
\hline CHEMBL1336277 & 809005 & 4.3218 & 4.5161 & TRN & \\
\hline CHEMBL1511254 & 809005 & 5.1385 & 4.8697 & TRN & \\
\hline CHEMBL1699532 & 809005 & 5.3595 & 4.3318 & TRN & \\
\hline CHEMBL1866074 & 809005 & 5.0386 & 4.6657 & TRN & \\
\hline CHEMBL1611162 & 809005 & 4.2939 & 4.2694 & TRN & \\
\hline CHEMBL1900730 & 809005 & 5.1851 & 4.75899 & 99999999995 & TRN \\
\hline CHEMBL1313978 & 809005 & 4.5589 & 4.5259 & TRN & \\
\hline
\end{tabular}




\begin{tabular}{|c|c|c|c|c|c|c|}
\hline \multicolumn{7}{|c|}{ Supplemental Table s2.txt } \\
\hline CHEMBL1510339 & 809005 & 4.4753 & 4.6761 & TRN & & \\
\hline CHEMBL1555935 & 809005 & 4.5535 & 5.6177 & TST & & \\
\hline CHEMBL1426340 & 809005 & 5.2976 & 5.3208 & TRN & & \\
\hline CHEMBL1904199 & 809005 & 5.0101 & 4.1849 & TST & & \\
\hline CHEMBL 1494120 & 809005 & 5.3526 & 5.2745 & TRN & & \\
\hline CHEMBL1317315 & 809005 & 3.1549 & 4.477 & TRN & & \\
\hline CHEMBL1384253 & 809005 & 5.4023 & 5.0627 & TRN & & \\
\hline CHEMBL1720855 & 809005 & 5.2899 & 5.6002 & TST & & \\
\hline CHEMBL1541840 & 809005 & 4.553 & 4.3245 & TRN & & \\
\hline CHEMBL1549798 & 809005 & 3.1549 & 3.946 & TRN & & \\
\hline CHEMBL1479496 & 809005 & $4.3660 e$ & 00000000 & 005 & 4.486000000000001 & TRN \\
\hline CHEMBL1324857 & 809005 & 4.1806 & 4.4704 & TRN & & \\
\hline CHEMBL1489033 & 809005 & 3.1549 & 4.3216 & TRN & & \\
\hline CHEMBL1724177 & 809005 & 4.4153 & 4.5845 & TST & & \\
\hline CHEMBL1715327 & 809005 & 3.1549 & 4.2959 & TRN & & \\
\hline CHEMBL1433195 & 809005 & 3.1549 & 4.3411 & TRN & & \\
\hline CHEMBL1529741 & 809005 & 4.467 & 4.7314 & TRN & & \\
\hline CHEMBL607140 & 809005 & 3.1549 & 5.5819 & TRN & & \\
\hline CHEMBL1329129 & 809005 & 5.4295 & 4.5668 & TRN & & \\
\hline CHEMBL1330279 & 809005 & 3.1549 & 5.6988 & TRN & & \\
\hline CHEMBL1729203 & 809005 & 5.9031 & 4.4826 & TST & & \\
\hline CHEMBL1444683 & 809005 & 4.3148 & 4.7816 & TRN & & \\
\hline CHEMBL1550076 & 809005 & 3.1549 & 4.5365 & TRN & & \\
\hline CHEMBL1519450 & 809005 & 5.8962 & 5.3163 & TRN & & \\
\hline CHEMBL543876 & 809005 & 4.4117 & 4.3495 & TRN & & \\
\hline CHEMBL1349225 & 809005 & 4.7421 & 4.4836 & TRN & & \\
\hline CHEMBL1531272 & 809005 & 4.2245 & 4.1366 & TRN & & \\
\hline CHEMBL1501300 & 809005 & 3.1549 & 4.3621 & TRN & & \\
\hline CHEMBL1608578 & 809005 & 4.2305 & 4.2463 & TRN & & \\
\hline CHEMBL1544664 & 809005 & 4.5031 & 4.2102 & TST & & \\
\hline CHEMBL1555271 & 809005 & 5.5751 & 5.472 & TRN & & \\
\hline CHEMBL1574879 & 809005 & 5.2581 & 5.9961 & TRN & & \\
\hline CHEMBL1423474 & 809005 & 3.1549 & 4.2279 & TST & & \\
\hline CHEMBL1547169 & 809005 & 4.3558 & 4.1324 & TRN & & \\
\hline CHEMBL578294 & 809005 & 4.6574 & 4.8359 & TRN & & \\
\hline CHEMBL1413424 & 809005 & 5.6596 & 4.6394 & TRN & & \\
\hline CHEMBL 1575577 & 809005 & 5.3391 & 4.399 & TRN & & \\
\hline CHEMBL1726113 & 809005 & 3.1549 & 3.9037 & TRN & & \\
\hline CHEMBL1372292 & 809005 & 6.2197 & 5.0532 & TRN & & \\
\hline CHEMBL1315948 & 809005 & 4.8356 & 4.4362 & TRN & & \\
\hline CHEMBL1716834 & 809005 & 4.3451 & 4.1351 & TST & & \\
\hline CHEMBL1570765 & 809005 & 5.2076 & 4.954 & TRN & & \\
\hline CHEMBL1724645 & 809005 & 5.2434 & 4.8029 & TST & & \\
\hline CHEMBL1480424 & 809005 & 4.6745 & 4.3306 & TRN & & \\
\hline CHEMBL1304647 & 809005 & $4.6110 e$ & 00000000 & & 4.4914 TRN & \\
\hline CHEMBL1464071 & 809005 & 5.6144 & 4.8698 & TRN & & \\
\hline CHEMBL1497589 & 809005 & 4.2223 & 4.4896 & TRN & & \\
\hline CHEMBL1491222 & 809005 & 3.1549 & 5.0283 & TRN & & \\
\hline
\end{tabular}




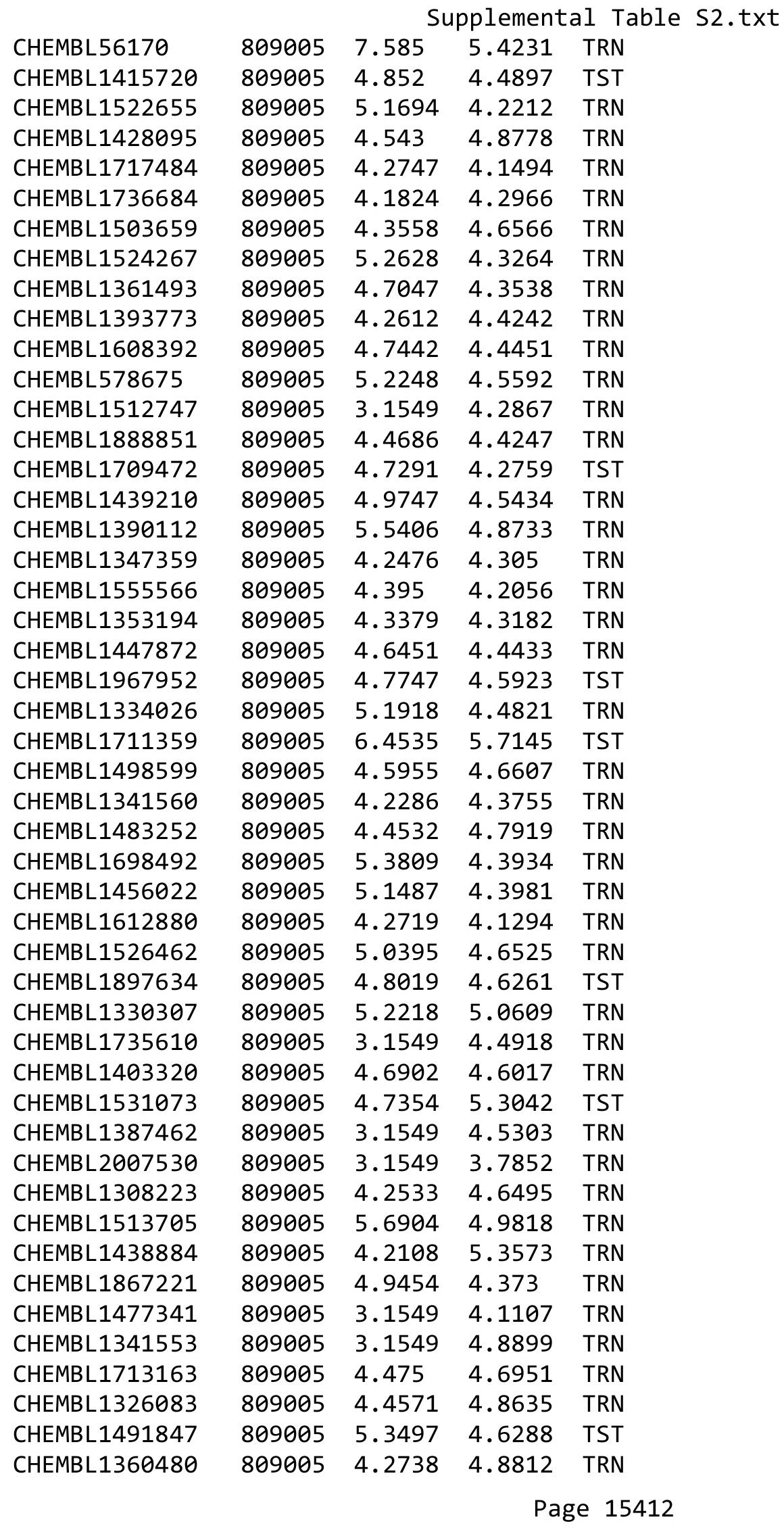




\begin{tabular}{|c|c|c|c|c|c|c|}
\hline & & \multicolumn{5}{|c|}{ Supplemental Table S2.txt } \\
\hline CHEMBL1580910 & 809005 & 4.6381 & 4.5051 & TRN & & \\
\hline CHEMBL588038 & 809005 & 5.5272 & 5.0603 & TST & & \\
\hline CHEMBL1997017 & 809005 & 3.1549 & 4.5172 & TST & & \\
\hline CHEMBL1455102 & 809005 & 3.1549 & 4.1702 & TRN & & \\
\hline CHEMBL1547940 & 809005 & 3.1549 & 4.3164 & TRN & & \\
\hline CHEMBL1565349 & 809005 & 4.2857 & 4.5833 & TRN & & \\
\hline CHEMBL1460352 & 809005 & 5.317 & 4.7242 & TRN & & \\
\hline CHEMBL1474608 & 809005 & 4.6385 & 4.5771 & TST & & \\
\hline CHEMBL1315463 & 809005 & 4.8145 & 4.3283 & TRN & & \\
\hline CHEMBL1504766 & 809005 & 4.6546 & 4.2928 & TRN & & \\
\hline CHEMBL1442788 & 809005 & 4.7042 & 4.8145 & TRN & & \\
\hline CHEMBL1529991 & 809005 & 4.3738 & 4.5776 & TRN & & \\
\hline CHEMBL1608247 & 809005 & 4.2318 & 4.5317 & TRN & & \\
\hline CHEMBL1556615 & 809005 & 4.3609 & 4.3379 & TRN & & \\
\hline CHEMBL1300295 & 809005 & 3.1549 & 4.375 & TRN & & \\
\hline CHEMBL1478826 & 809005 & 3.1549 & 4.9284 & TRN & & \\
\hline CHEMBL1473985 & 809005 & 4.2721 & 4.3935 & TST & & \\
\hline CHEMBL1305642 & 809005 & 4.745 & 4.475 & TRN & & \\
\hline CHEMBL1698464 & 809005 & 5.1878 & 4.9991 & TRN & & \\
\hline CHEMBL1997132 & 809005 & 4.3472 & 4.6074 & TRN & & \\
\hline CHEMBL1564519 & 809005 & 5.5258 & 4.4915 & TRN & & \\
\hline CHEMBL1473402 & 809005 & 5.4486 & 4.9028 & TRN & & \\
\hline CHEMBL1558461 & 809005 & 3.1549 & 4.1175 & TRN & & \\
\hline CHEMBL1896316 & 809005 & 4.6765 & 4.4888 & TRN & & \\
\hline CHEMBL1594119 & 809005 & 5.9666 & 4.8338 & TRN & & \\
\hline CHEMBL338474 & 809005 & 6.0 & 4.9721 & TST & & \\
\hline CHEMBL1575440 & 809005 & 3.1549 & 4.298 & TRN & & \\
\hline CHEMBL1488056 & 809005 & 3.1549 & 4.1308 & TRN & & \\
\hline CHEMBL1408634 & 809005 & 5.5591 & 4.4069 & TRN & & \\
\hline CHEMBL1287980 & 809005 & 4.8353 & 4.7921 & TST & & \\
\hline CHEMBL1536768 & 809005 & 4.2116 & 4.9157 & TRN & & \\
\hline CHEMBL1904727 & 809005 & 4.2781 & 4.9745 & TRN & & \\
\hline CHEMBL1728670 & 809005 & 4.3333 & 4.5044 & TST & & \\
\hline CHEMBL1301232 & 809005 & 4.1917 & 4.4188 & TRN & & \\
\hline CHEMBL1406540 & 809005 & 3.1549 & 4.4492 & TRN & & \\
\hline CHEMBL1492912 & 809005 & 3.1549 & 4.3957 & TRN & & \\
\hline CHEMBL1452421 & 809005 & 5.5935 & 5.2549 & TRN & & \\
\hline CHEMBL1458782 & 809005 & 4.2217 & 4.459 & TRN & & \\
\hline CHEMBL1502771 & 809005 & 4.30699 & 99999999 & 995 & 4.4055 & TRN \\
\hline CHEMBL1419529 & 809005 & 4.2786 & 4.1594 & TRN & & \\
\hline CHEMBL1966666 & 809005 & 4.3977 & 4.4653 & TRN & & \\
\hline CHEMBL1369262 & 809005 & 5.6038 & 5.0922 & TST & & \\
\hline CHEMBL1372112 & 809005 & 4.6645 & 4.4046 & TRN & & \\
\hline CHEMBL3392476 & 809005 & 5.1385 & 4.6456 & TRN & & \\
\hline CHEMBL1876267 & 809005 & 4.8693 & 4.5087 & TST & & \\
\hline CHEMBL1525157 & 809005 & 4.2547 & 4.3994 & TRN & & \\
\hline CHEMBL1434912 & 809005 & 4.4432 & 4.8761 & TRN & & \\
\hline CHEMBL1473229 & 809005 & 5.6073 & 4.5144 & TRN & & \\
\hline
\end{tabular}




\begin{tabular}{|c|c|c|c|c|c|c|}
\hline & & \multicolumn{5}{|c|}{ Supplemental Table S2.txt } \\
\hline CHEMBL1538234 & 809005 & 4.5686 & 4.2533 & TRN & & \\
\hline CHEMBL260148 & 809005 & 4.2099 & 4.6793 & TST & & \\
\hline CHEMBL1368013 & 809005 & 3.1549 & 4.3949 & TRN & & \\
\hline CHEMBL1427185 & 809005 & 4.7962 & 4.7567 & TST & & \\
\hline CHEMBL1711360 & 809005 & 6.1118 & 4.9915 & TRN & & \\
\hline CHEMBL1534387 & 809005 & 3.1549 & 4.8497 & TST & & \\
\hline CHEMBL1495310 & 809005 & 3.1549 & 4.4176 & TST & & \\
\hline CHEMBL1574080 & 809005 & 5.5952 & 4.8421 & TST & & \\
\hline CHEMBL1468075 & 809005 & 4.3863 & 4.7222 & TST & & \\
\hline CHEMBL1514790 & 809005 & 5.0395 & 4.7201 & TST & & \\
\hline CHEMBL1382368 & 809005 & 3.1549 & 4.247 & TST & & \\
\hline CHEMBL1493490 & 809005 & 5.1057 & 4.5677 & TST & & \\
\hline CHEMBL1873503 & 809005 & 5.058 & 4.2623 & TST & & \\
\hline CHEMBL1444328 & 809005 & 4.3377 & 4.7123 & TST & & \\
\hline CHEMBL1443802 & 809005 & 4.8752 & 4.3283 & TST & & \\
\hline CHEMBL1549594 & 809005 & $4.1960 e$ & 00000000 & 01 & 4.2251 & TST \\
\hline CHEMBL1541379 & 809005 & 4.1715 & 4.4377 & TST & & \\
\hline CHEMBL1518893 & 809005 & 4.3039 & 4.38 & TST & & \\
\hline CHEMBL1730238 & 809005 & 4.4115 & 4.879 & TST & & \\
\hline CHEMBL1548439 & 809005 & 4.6407 & 4.4304 & TST & & \\
\hline CHEMBL1725309 & 809005 & 4.3154 & 4.187 & TST & & \\
\hline CHEMBL1524738 & 809005 & 3.1549 & 4.3801 & TST & & \\
\hline CHEMBL1484741 & 809005 & 5.7696 & 4.8122 & TST & & \\
\hline CHEMBL1407690 & 809005 & 4.4127 & 4.6441 & TST & & \\
\hline CHEMBL1340458 & 809005 & 4.5737 & 4.4265 & TST & & \\
\hline CHEMBL1381048 & 809005 & 4.315 & 4.5816 & TST & & \\
\hline CHEMBL1520753 & 809005 & 4.7908 & 4.7312 & TST & & \\
\hline CHEMBL1574349 & 809005 & 5.6696 & 4.4346 & TST & & \\
\hline CHEMBL1975846 & 809005 & 4.4086 & 4.2098 & TST & & \\
\hline CHEMBL1332756 & 809005 & 6.0521 & 5.1887 & TST & & \\
\hline CHEMBL1418643 & 809005 & 4.6572 & 4.8674 & TST & & \\
\hline CHEMBL1603001 & 809005 & 6.1314 & 5.7549 & TST & & \\
\hline CHEMBL1502020 & 809005 & 5.2757 & 4.825 & TST & & \\
\hline CHEMBL1714720 & 809005 & 5.082 & 4.5752 & TST & & \\
\hline CHEMBL1516692 & 809005 & 5.399 & 4.6096 & TST & & \\
\hline CHEMBL1989082 & 809005 & 4.3038 & 4.5176 & TST & & \\
\hline CHEMBL1705098 & 809005 & 5.3224 & 4.7785 & TST & & \\
\hline CHEMBL1732556 & 809005 & 4.6582 & 4.7958 & TST & & \\
\hline CHEMBL1716010 & 809005 & 5.1694 & 4.1396 & TST & & \\
\hline CHEMBL591370 & 809005 & 5.1506 & 4.5207 & TST & & \\
\hline CHEMBL1524692 & 809005 & 4.6743 & 4.1693 & TST & & \\
\hline CHEMBL1409423 & 809005 & 4.2851 & 4.5901 & TST & & \\
\hline CHEMBL1705928 & 809005 & 4.8044 & 4.6982 & TST & & \\
\hline CHEMBL1701308 & 809005 & 4.3491 & 4.454 & TST & & \\
\hline CHEMBL1722300 & 809005 & 4.473 & 4.8926 & TST & & \\
\hline CHEMBL1467697 & 809005 & 4.1925 & 4.5529 & TST & & \\
\hline CHEMBL1472145 & 809005 & 4.7731 & 4.2178 & TST & & \\
\hline CHEMBL1456780 & 809005 & 4.4359 & 4.6999 & TST & & \\
\hline
\end{tabular}




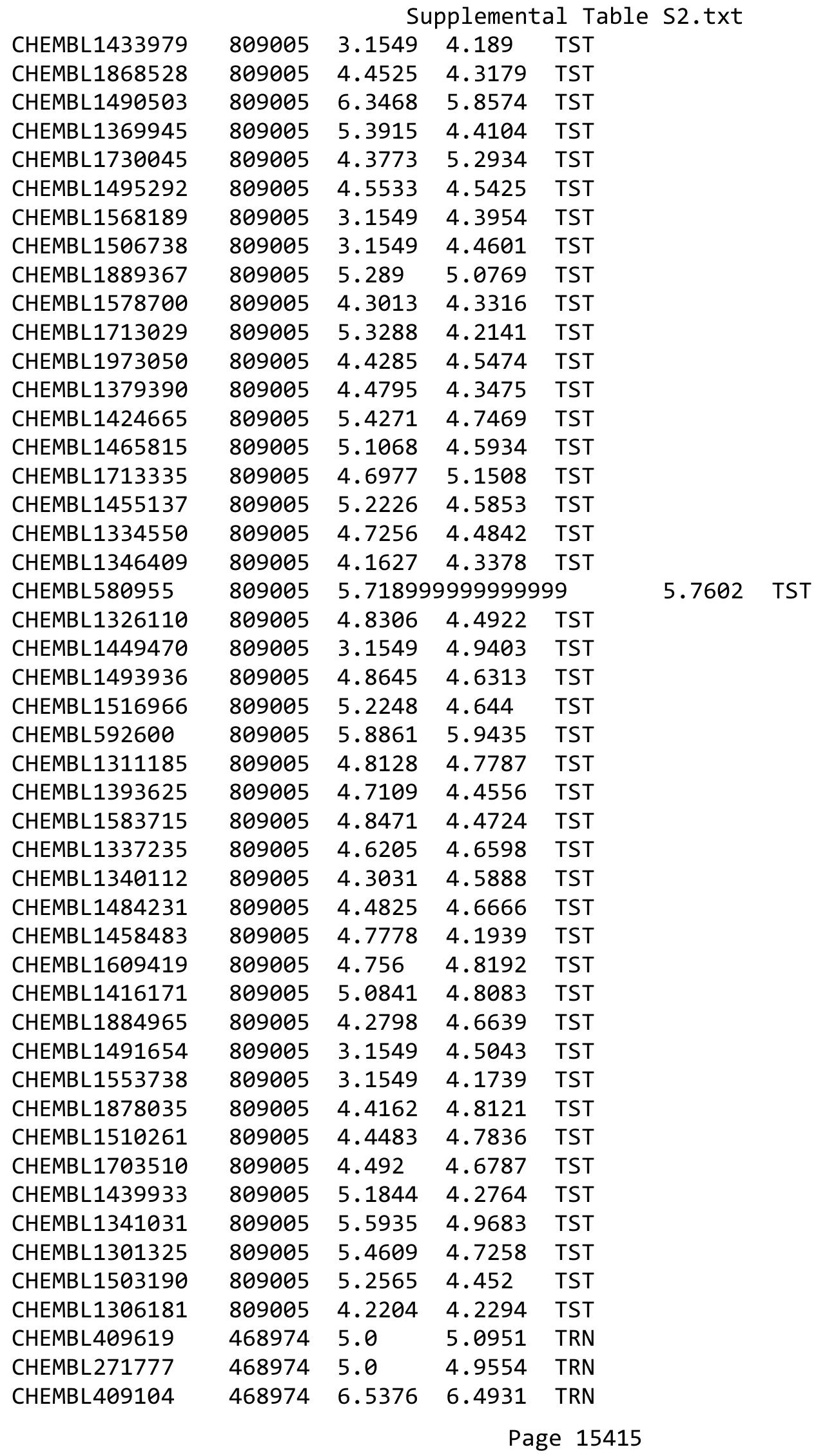




\begin{tabular}{|c|c|c|c|c|c|}
\hline \multicolumn{6}{|c|}{ Supplemental Table S2.txt } \\
\hline CHEMBL271953 & 468974 & 7.2924 & 7.1248 & TRN & \\
\hline CHEMBL271842 & 468974 & 5.8539 & 5.8718 & TRN & \\
\hline CHEMBL409892 & 468974 & 7.9208 & 7.3773 & TST & \\
\hline CHEMBL271182 & 468974 & 6.1805 & 6.1619 & TRN & \\
\hline CHEMBL409690 & 468974 & 7.1135 & 7.0024 & TRN & \\
\hline CHEMBL409731 & 468974 & 7.9208 & 7.9834 & TRN & \\
\hline CHEMBL272387 & 468974 & 6.7696 & 6.73799 & 99999999995 & TRN \\
\hline CHEMBL412097 & 468974 & 6.6576 & 7.016 & TST & \\
\hline CHEMBL269883 & 468974 & 7.7212 & 7.7581 & TRN & \\
\hline CHEMBL411224 & 468974 & 7.7212 & 7.7228 & TRN & \\
\hline CHEMBL272028 & 468974 & 7.2218 & 7.2016 & TRN & \\
\hline CHEMBL429142 & 468974 & 7.7959 & 7.7987 & TRN & \\
\hline CHEMBL412091 & 468974 & 6.8861 & 6.9056 & TRN & \\
\hline CHEMBL411426 & 468974 & 7.4318 & 7.48600 & 0000000001 & TRN \\
\hline CHEMBL 271137 & 468974 & 5.7696 & 5.9896 & TST & \\
\hline CHEMBL411865 & 468974 & 6.8239 & 6.8523 & TRN & \\
\hline CHEMBL 269882 & 468974 & 7.0809 & 6.6549 & TST & \\
\hline CHEMBL410517 & 468974 & 5.0 & 5.0403 & TRN & \\
\hline CHEMBL271183 & 468974 & 6.284 & 6.2277 & TRN & \\
\hline CHEMBL408210 & 468974 & 6.8861 & 6.7942 & TST & \\
\hline CHEMBL272217 & 468974 & 6.5376 & 6.5287 & TRN & \\
\hline CHEMBL405042 & 468974 & 5.6383 & 6.0021 & TST & \\
\hline CHEMBL314397 & 468974 & 6.9586 & 7.0588 & TST & \\
\hline CHEMBL272668 & 468974 & 6.8239 & 6.8835 & TRN & \\
\hline CHEMBL270544 & 468974 & 7.8239 & 7.8083 & TRN & \\
\hline CHEMBL272885 & 468974 & 5.0 & 5.0169 & TRN & \\
\hline CHEMBL 272165 & 468974 & 7.1308 & 7.1814 & TRN & \\
\hline CHEMBL272380 & 468974 & 6.7696 & 6.82700 & 0000000001 & TRN \\
\hline CHEMBL411887 & 468974 & 8.1487 & 8.1649 & TRN & \\
\hline CHEMBL411425 & 468974 & 7.3372 & 7.3634 & TRN & \\
\hline CHEMBL438721 & 468974 & 5.8861 & 5.801 & TRN & \\
\hline CHEMBL 260103 & 468974 & 6.6778 & 6.5771 & TRN & \\
\hline CHEMBL272833 & 468974 & 6.9208 & 6.7654 & TST & \\
\hline CHEMBL 272389 & 468974 & 6.4559 & 6.4933 & TRN & \\
\hline CHEMBL272667 & 468974 & 7.0605 & 7.0716 & TRN & \\
\hline CHEMBL411491 & 468974 & 6.1079 & 6.2313 & TRN & \\
\hline CHEMBL411886 & 468974 & 6.1487 & 6.1468 & TRN & \\
\hline CHEMBL411490 & 468974 & 6.6021 & 6.6551 & TRN & \\
\hline CHEMBL408131 & 468974 & 5.0 & 4.9743 & TRN & \\
\hline CHEMBL269850 & 468974 & 5.5229 & 5.4294 & TST & \\
\hline CHEMBL410293 & 468974 & 6.1308 & 6.0251 & TST & \\
\hline CHEMBL 271136 & 468974 & 8.0315 & 8.0775 & TRN & \\
\hline CHEMBL272414 & 468974 & 5.5528 & 5.3132 & TST & \\
\hline CHEMBL410883 & 468974 & 8.5528 & 8.4205 & TRN & \\
\hline CHEMBL270054 & 468974 & 6.5229 & 6.607 & TRN & \\
\hline CHEMBL271594 & 468974 & 6.1024 & 6.0634 & TRN & \\
\hline CHEMBL 271822 & 468974 & 5.7696 & 5.687 & TRN & \\
\hline CHEMBL271595 & 468974 & 7.5376 & 7.5149 & TST & \\
\hline
\end{tabular}




\begin{tabular}{|c|c|c|c|c|}
\hline \multicolumn{5}{|c|}{ Supplemental Table S2.txt } \\
\hline CHEMBL 273061 & 468974 & 6.5376 & 6.4752 & TRN \\
\hline CHEMBL 271952 & 468974 & 6.8239 & 6.7474 & TST \\
\hline CHEMBL 270132 & 468974 & 7.7696 & 7.7758 & TRN \\
\hline CHEMBL410072 & 468974 & 7.2218 & 7.2242 & TRN \\
\hline CHEMBL409868 & 468974 & 6.8861 & 6.9348 & TRN \\
\hline CHEMBL 271843 & 468974 & 6.4815 & 6.4402 & TRN \\
\hline CHEMBL445945 & 468974 & 7.8239 & 7.67 & TST \\
\hline CHEMBL 271778 & 468974 & 5.0 & 5.0147 & TRN \\
\hline CHEMBL 271160 & 468974 & 7.3872 & 7.3922 & TRN \\
\hline CHEMBL 269827 & 468974 & 8.0 & 8.0037 & TRN \\
\hline CHEMBL 272684 & 468974 & 6.6021 & 6.8248 & TST \\
\hline CHEMBL407709 & 468974 & 7.3665 & 7.3832 & TST \\
\hline CHEMBL 273060 & 468974 & 7.0223 & 7.029 & TRN \\
\hline CHEMBL 269846 & 468974 & 5.0 & 4.8518 & TST \\
\hline CHEMBL 272026 & 468974 & 6.6383 & 6.6351 & TRN \\
\hline CHEMBL411696 & 468974 & 6.2596 & 6.3241 & TRN \\
\hline CHEMBL417709 & 1163 & 8.0044 & 8.1978 & TRN \\
\hline CHEMBL46535 & 1163 & 6.6308 & 6.4298 & TRN \\
\hline CHEMBL46651 & 1163 & 4.0 & 3.8715 & TRN \\
\hline CHEMBL478 & 1163 & 6.8861 & 5.8289 & TST \\
\hline CHEMBL 298286 & 1163 & 4.0 & 3.9791 & TRN \\
\hline CHEMBL 295527 & 1163 & 5.0 & 5.0155 & TRN \\
\hline CHEMBL430567 & 1163 & 6.9208 & 6.7684 & TRN \\
\hline CHEMBL 297887 & 1163 & 7.2336 & 7.2603 & TRN \\
\hline CHEMBL 296724 & 1163 & 5.0 & 5.2518 & TRN \\
\hline CHEMBL42881 & 1163 & 6.301 & 5.9648 & TRN \\
\hline CHEMBL42810 & 1163 & 8.2596 & 8.1767 & TRN \\
\hline CHEMBL44876 & 1163 & 5.0 & 5.0317 & TRN \\
\hline CHEMBL43992 & 1163 & 8.3872 & 8.376 & TRN \\
\hline CHEMBL 9666 & 1163 & 7.1675 & 7.2578 & TST \\
\hline CHEMBL43332 & 1163 & 7.6055 & 7.73 & TRN \\
\hline CHEMBL42219 & 1163 & 4.0 & 3.9302 & TRN \\
\hline CHEMBL46862 & 1163 & 5.0 & 5.1123 & TRN \\
\hline CHEMBL 290039 & 1163 & 7.9469 & 7.9166 & TRN \\
\hline CHEMBL42706 & 1163 & 8.4202 & 8.4287 & TRN \\
\hline CHEMBL46377 & 1163 & 4.0 & 3.9745 & TRN \\
\hline CHEMBL 290203 & 1163 & 7.7167 & 7.3909 & TRN \\
\hline CHEMBL46918 & 1163 & 8.6198 & 8.418 & TRN \\
\hline CHEMBL 289784 & 1163 & 4.0 & 4.3035 & TRN \\
\hline CHEMBL46885 & 1163 & 7.0462 & 7.059 & TRN \\
\hline CHEMBL46470 & 1163 & 7.0691 & 7.1001 & TRN \\
\hline CHEMBL 296413 & 1163 & 7.2373 & 7.2 & TRN \\
\hline CHEMBL42396 & 1163 & 7.1818 & 7.1112 & TRN \\
\hline CHEMBL 297844 & 1163 & 7.2388 & 7.2698 & TRN \\
\hline CHEMBL46802 & 1163 & 6.3788 & 6.3525 & TRN \\
\hline CHEMBL 289873 & 1163 & 8.3565 & 8.4993 & TRN \\
\hline CHEMBL42404 & 1163 & 7.1051 & 7.1358 & TRN \\
\hline CHEMBL45253 & 1163 & 8.2441 & 8.3335 & TRN \\
\hline
\end{tabular}




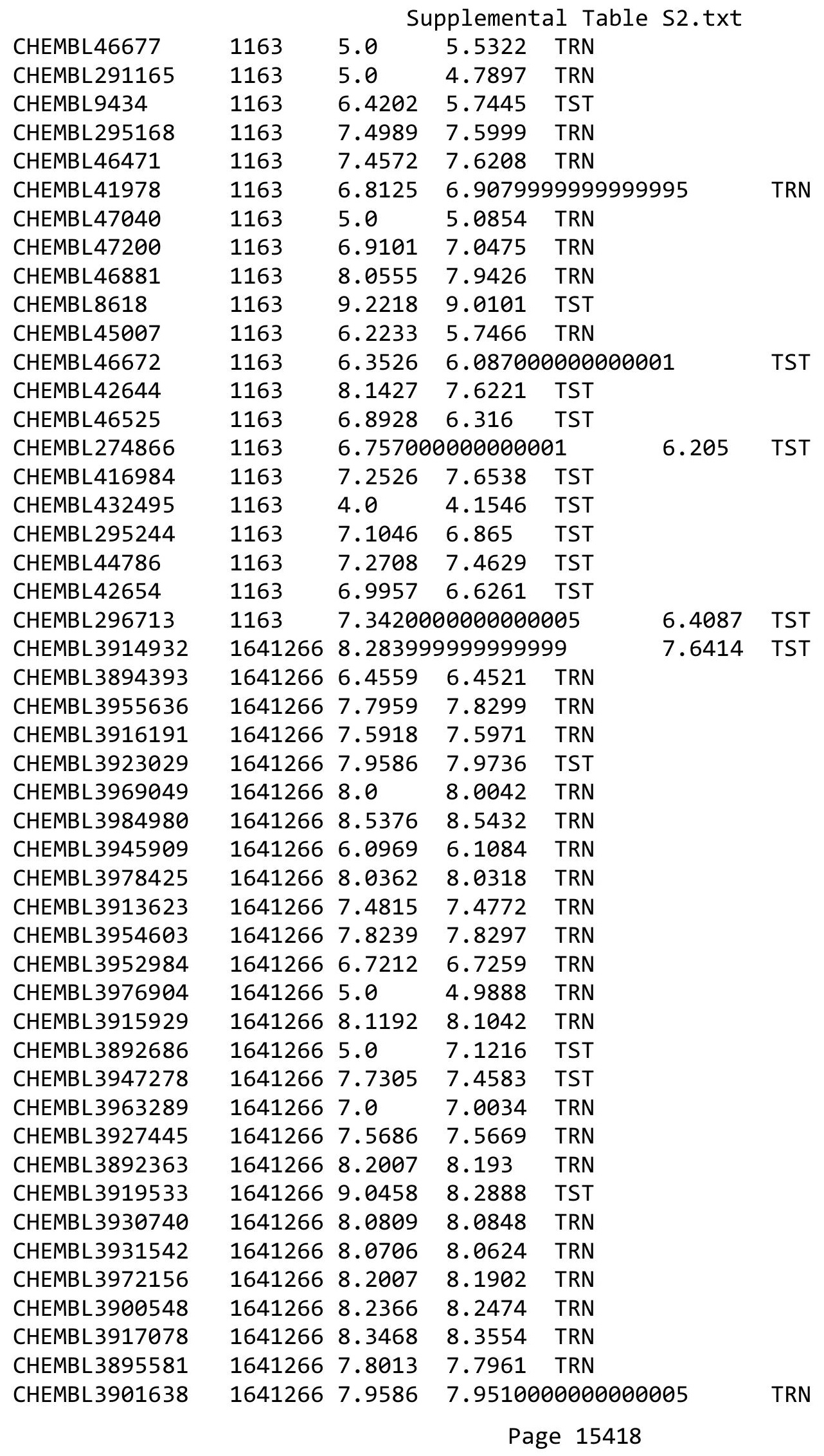


Supplemental Table S2.txt

\begin{tabular}{|c|c|c|c|c|c|}
\hline CHEMBL 3947623 & 1641266 & 8.1805 & 8.1688 & TRN & \\
\hline CHEMBL 3891329 & 1641266 & 8.0 & 8.0394 & TRN & \\
\hline CHEMBL 3905040 & 1641266 & 7.9208 & 7.9224 & TRN & \\
\hline CHEMBL 3969742 & 1641266 & 8.1739 & 8.1291 & TRN & \\
\hline CHEMBL 3925115 & 1641266 & 8.4815 & 8.4749 & TRN & \\
\hline CHEMBL 3907218 & 1641266 & 8.2218 & 8.2277 & TRN & \\
\hline CHEMBL 3970120 & 1641266 & 7.7959 & 7.8128 & TRN & \\
\hline CHEMBL3934529 & 1641266 & 5.0 & 5.0032 & TRN & \\
\hline CHEMBL 3929889 & 1641266 & 8.1871 & 8.1855 & TRN & \\
\hline CHEMBL 3917574 & 1641266 & 7.7447 & 8.621 & TST & \\
\hline CHEMBL 3946391 & 1641266 & 7.7033 & 7.6997 & TRN & \\
\hline CHEMBL 3983247 & 1641266 & 7.7959 & 7.2976 & TST & \\
\hline CHEMBL 3908092 & 1641266 & 8.2441 & 8.2068 & TRN & \\
\hline CHEMBL3940569 & 1641266 & 7.5686 & 7.252999 & 9999999999 & TST \\
\hline CHEMBL 3962648 & 1641266 & 8.1871 & 8.2192 & TRN & \\
\hline CHEMBL 3901034 & 1641266 & 8.041 & 8.0463 & TRN & \\
\hline CHEMBL 3964037 & 1641266 & 7.4202 & 7.4132 & TRN & \\
\hline CHEMBL3963459 & 1641266 & 7.8539 & 7.8546 & TRN & \\
\hline CHEMBL3955609 & 1641266 & 8.0506 & 8.0415 & TRN & \\
\hline CHEMBL 3907535 & 1641266 & 8.1487 & 8.1264 & TRN & \\
\hline CHEMBL 3983859 & 1641266 & 8.6383 & 8.6441 & TRN & \\
\hline CHEMBL 3906567 & 1641266 & 7.8182 & 7.5096 & TST & \\
\hline CHEMBL3978989 & 1641266 & 7.9586 & 7.968 & TRN & \\
\hline CHEMBL 3957308 & 1641266 & 5.7212 & 6.971 & TST & \\
\hline CHEMBL 3922789 & 1641266 & 8.4815 & 8.4847 & TRN & \\
\hline CHEMBL3910594 & 1641266 & 7.6383 & 7.2236 & TST & \\
\hline CHEMBL 3975917 & 1641266 & 8.2596 & 7.3605 & TST & \\
\hline CHEMBL3929705 & 1641266 & 8.2218 & 8.1862 & TRN & \\
\hline CHEMBL3961684 & 1641266 & 7.9431 & 7.9437 & TST & \\
\hline CHEMBL3983342 & 1641266 & 7.6198 & 7.8465 & TST & \\
\hline CHEMBL3926240 & 1641266 & 8.4815 & 6.8218 & TST & \\
\hline CHEMBL 3898162 & 1641266 & 7.9586 & 7.6622 & TST & \\
\hline CHEMBL 3933450 & 1641266 & 8.1549 & 8.1571 & TRN & \\
\hline CHEMBL 3942040 & 1641266 & 8.9586 & 8.0772 & TST & \\
\hline CHEMBL 3931972 & 1641266 & 8.2924 & 8.315 & TRN & \\
\hline CHEMBL3908123 & 1641266 & 8.3188 & 8.312000 & 3000000001 & TRN \\
\hline CHEMBL3906623 & 1641266 & 8.1367 & 8.1233 & TRN & \\
\hline CHEMBL3910080 & 1641266 & 8.2218 & 8.2287 & TRN & \\
\hline CHEMBL 3905389 & 1641266 & 8.4202 & 8.4246 & TRN & \\
\hline CHEMBL3911687 & 1641266 & 8.28399 & 999999999 & 8.3061 & TRN \\
\hline CHEMBL598610 & 1638895 & 7.0 & 7.7365 & TRN & \\
\hline CHEMBL 3899385 & 1638895 & 7.0 & 7.3208 & TRN & \\
\hline CHEMBL 3954393 & 1638895 & 8.0 & 7.3312 & TRN & \\
\hline CHEMBL3945421 & 1638895 & 8.0 & 7.6083 & TRN & \\
\hline CHEMBL 3902161 & 1638895 & 7.0 & 7.34 & TRN & \\
\hline CHEMBL596761 & 1638895 & 7.0 & 7.2037 & TRN & \\
\hline CHEMBL3980430 & 1638895 & 8.0 & 7.5663 & TST & \\
\hline CHEMBL3971713 & 1638895 & 4.0 & 4.8589 & TRN & \\
\hline
\end{tabular}




\begin{tabular}{|c|c|c|c|c|c|}
\hline CHEMBL 3907491 & 1638895 & 7.0 & 6.8122 & TRN & \\
\hline CHEMBL3951620 & 1638895 & 7.0 & 7.34 & TRN & \\
\hline CHEMBL 3959884 & 1638895 & 8.0 & 7.6753 & TRN & \\
\hline CHEMBL3901236 & 1638895 & 7.0 & 6.7977 & TRN & \\
\hline CHEMBL3986286 & 1638895 & 8.0 & 7.4976 & TRN & \\
\hline CHEMBL3928197 & 1638895 & 8.0 & 7.4976 & TRN & \\
\hline CHEMBL3977186 & 1638895 & 7.0 & \multicolumn{2}{|c|}{ 7. 247999999999999} & TRN \\
\hline CHEMBL 3985004 & 1638895 & 6.0 & 6.8361 & TST & \\
\hline CHEMBL604094 & 1638895 & 7.0 & 7.6441 & TST & \\
\hline CHEMBL3956995 & 1638895 & 8.0 & 7.3312 & TRN & \\
\hline CHEMBL3917670 & 1638895 & 8.0 & 7.2098 & TRN & \\
\hline CHEMBL3938265 & 1638895 & 7.0 & 7.6378 & TRN & \\
\hline CHEMBL3939306 & 1638895 & 7.0 & 7.2647 & TRN & \\
\hline CHEMBL3959043 & 1638895 & 7.0 & 7.5622 & TRN & \\
\hline CHEMBL3909900 & 1638895 & 7.0 & 7.6247 & TRN & \\
\hline CHEMBL3961102 & 1638895 & 7.0 & 7.3392 & TRN & \\
\hline CHEMBL3905131 & 1638895 & 7.0 & 7.2647 & TRN & \\
\hline CHEMBL3903506 & 1638895 & 8.0 & 7.6164 & TRN & \\
\hline CHEMBL3936547 & 1638895 & 7.0 & 6.7977 & TRN & \\
\hline CHEMBL3976389 & 1638895 & 8.0 & 7.62 & TRN & \\
\hline CHEMBL596754 & 1638895 & 8.0 & 7.6227 & TRN & \\
\hline CHEMBL 3968380 & 1638895 & 8.0 & 7.5937 & TRN & \\
\hline CHEMBL 3935462 & 1638895 & 8.0 & 7.8459 & TRN & \\
\hline CHEMBL3967530 & 1638895 & 6.0 & 7.1249 & TRN & \\
\hline CHEMBL598164 & 1638895 & 7.0 & 7.6005 & TRN & \\
\hline CHEMBL598799 & 1638895 & 8.0 & 7.808 & TRN & \\
\hline CHEMBL3914322 & 1638895 & 7.0 & 6.7204 & TRN & \\
\hline CHEMBL3984573 & 1638895 & 7.0 & 7.2277 & TRN & \\
\hline CHEMBL3900967 & 1638895 & 8.0 & 7.1784 & TRN & \\
\hline CHEMBL 3924346 & 1638895 & 7.0 & 7.3868 & TRN & \\
\hline CHEMBL597773 & 1638895 & 7.0 & 7.6235 & TRN & \\
\hline CHEMBL3952709 & 1638895 & 7.0 & 7.4066 & TRN & \\
\hline CHEMBL 3917105 & 1638895 & 7.0 & 7.0953 & TRN & \\
\hline CHEMBL605976 & 1638895 & 7.0 & 7.0915 & TST & \\
\hline CHEMBL 3930003 & 1638895 & 8.0 & 7.8742 & TRN & \\
\hline CHEMBL3976961 & 1638895 & 8.0 & 7.5608 & TST & \\
\hline CHEMBL3932057 & 1638895 & 7.0 & 7.2456 & TRN & \\
\hline CHEMBL3929290 & 1638895 & 8.0 & 6.4981 & TRN & \\
\hline CHEMBL3948072 & 1638895 & 8.0 & 7.4497 & TRN & \\
\hline CHEMBL 3898480 & 1638895 & 7.0 & 6.7977 & TRN & \\
\hline CHEMBL3937516 & 1638895 & 8.0 & 7.5239 & TST & \\
\hline CHEMBL3950023 & 1638895 & 7.0 & 6.6955 & TRN & \\
\hline CHEMBL3910297 & 1638895 & 6.0 & 5.9628 & TRN & \\
\hline CHEMBL3901144 & 1638895 & 7.0 & 7.6087 & TST & \\
\hline CHEMBL3901210 & 1638895 & 7.0 & 7.67 & TST & \\
\hline CHEMBL3984055 & 1638895 & 7.0 & 7.0276 & TRN & \\
\hline CHEMBL 3898444 & 1638895 & 7.0 & 7.6826 & TST & \\
\hline CHEMBL3972249 & 1638895 & 7.0 & 7.61700 & 2000000001 & TRN \\
\hline & & & & 15420 & \\
\hline
\end{tabular}




\begin{tabular}{|c|c|c|c|c|}
\hline & & & & \\
\hline CHEMBL3936512 & 1638895 & 8.0 & 7.5663 & TST \\
\hline CHEMBL3985245 & 1638895 & 8.0 & 7.605 & TST \\
\hline CHEMBL598611 & 1638895 & 7.0 & 7.6005 & TST \\
\hline CHEMBL3916600 & 1638895 & 8.0 & 7.6378 & TRN \\
\hline CHEMBL3896110 & 1638895 & 8.0 & 7.5197 & TST \\
\hline CHEMBL3921652 & 1638895 & 7.0 & 7.3772 & TRN \\
\hline CHEMBL597569 & 1638895 & 7.0 & 7.67 & TST \\
\hline CHEMBL3968968 & 1638895 & 7.0 & 6.8584 & TRN \\
\hline CHEMBL3970892 & 1638895 & 8.0 & 7.6798 & TST \\
\hline CHEMBL598377 & 1638895 & 8.0 & 7.7365 & TST \\
\hline CHEMBL3981584 & 1638895 & 7.0 & 7.1742 & TST \\
\hline CHEMBL3917093 & 1638895 & 7.0 & 7.1875 & TRN \\
\hline CHEMBL1964290 & 809275 & 4.0 & 5.2342 & TRN \\
\hline CHEMBL 2003768 & 809275 & 4.0 & 3.9381 & TRN \\
\hline CHEMBL 213505 & 809275 & 6.4 & 6.8386 & TRN \\
\hline CHEMBL1987034 & 809275 & 7.8 & 8.2515 & TRN \\
\hline CHEMBL1993941 & 809275 & 7.2 & 7.1407 & TRN \\
\hline CHEMBL 377383 & 809275 & 4.0 & 3.8391 & TRN \\
\hline CHEMBL 2005886 & 809275 & 6.6 & 6.8297 & TRN \\
\hline CHEMBL481491 & 809275 & 6.6 & 4.4163 & TST \\
\hline CHEMBL1973142 & 809275 & 4.0 & 4.6336 & TRN \\
\hline CHEMBL1973145 & 809275 & 4.0 & 4.4399 & TRN \\
\hline CHEMBL1982924 & 809275 & 6.1 & 6.2499 & TRN \\
\hline CHEMBL 2005936 & 809275 & 4.0 & 4.1783 & TRN \\
\hline CHEMBL1807515 & 809275 & 6.4 & 6.1349 & TRN \\
\hline CHEMBL1971141 & 809275 & 4.0 & 4.276 & TRN \\
\hline CHEMBL1995813 & 809275 & 6.5 & 6.2645 & TRN \\
\hline CHEMBL206236 & 809275 & 4.0 & 4.0622 & TRN \\
\hline CHEMBL 244378 & 809275 & 7.5 & 7.0857 & TRN \\
\hline CHEMBL 2001957 & 809275 & 4.0 & 4.2024 & TRN \\
\hline CHEMBL1969372 & 809275 & 5.3 & 4.2308 & TRN \\
\hline CHEMBL1986943 & 809275 & 6.3 & 6.8385 & TRN \\
\hline CHEMBL2006263 & 809275 & 4.0 & 4.7323 & TRN \\
\hline CHEMBL1993584 & 809275 & 5.7 & 4.3549 & TRN \\
\hline CHEMBL1986263 & 809275 & 6.3 & 5.8213 & TRN \\
\hline CHEMBL 2000114 & 809275 & 6.2 & 5.5534 & TRN \\
\hline CHEMBL210618 & 809275 & 4.0 & 3.9134 & TRN \\
\hline CHEMBL1975647 & 809275 & 4.0 & 4.4192 & TRN \\
\hline CHEMBL1968380 & 809275 & 6.1 & 4.4361 & TRN \\
\hline CHEMBL1964644 & 809275 & 4.0 & 3.972 & TRN \\
\hline CHEMBL1981782 & 809275 & 4.0 & 4.0472 & TRN \\
\hline CHEMBL1977681 & 809275 & 6.4 & 5.3888 & TRN \\
\hline CHEMBL1970142 & 809275 & 8.1 & 7.6348 & TRN \\
\hline CHEMBL1990912 & 809275 & 4.0 & 4.4371 & TRN \\
\hline CHEMBL1988163 & 809275 & 7.6 & 7.0657 & TRN \\
\hline CHEMBL 2006493 & 809275 & 4.0 & 4.0931 & TST \\
\hline CHEMBL1996923 & 809275 & 4.0 & 4.0964 & TST \\
\hline CHEMBL1983449 & 809275 & 4.0 & 3.6683 & TRN \\
\hline
\end{tabular}




\begin{tabular}{|c|c|c|c|c|c|}
\hline & & & plement & Table S & \\
\hline CHEMBL1992323 & 809275 & 4.0 & 4.0564 & TRN & \\
\hline CHEMBL1969735 & 809275 & 4.0 & 4.23300 & 00000000005 & TRN \\
\hline CHEMBL 2002649 & 809275 & 6.2 & 6.6396 & TRN & \\
\hline CHEMBL1995172 & 809275 & 4.0 & 4.395 & TST & \\
\hline CHEMBL1994321 & 809275 & 7.0 & 6.8311 & TRN & \\
\hline CHEMBL1997129 & 809275 & 6.3 & 6.6178 & TRN & \\
\hline CHEMBL1984788 & 809275 & 4.0 & 4.0043 & TRN & \\
\hline CHEMBL1996604 & 809275 & 4.0 & 4.1193 & TRN & \\
\hline CHEMBL 2000508 & 809275 & 4.0 & 4.2285 & TRN & \\
\hline CHEMBL1971694 & 809275 & 4.0 & 3.9285 & TST & \\
\hline CHEMBL 2001547 & 809275 & 4.0 & 4.0498 & TRN & \\
\hline CHEMBL210928 & 809275 & 4.0 & 3.5933 & TRN & \\
\hline CHEMBL1986603 & 809275 & 4.0 & 4.5605 & TST & \\
\hline CHEMBL1977148 & 809275 & 5.3 & 5.6466 & TRN & \\
\hline CHEMBL 2003286 & 809275 & 4.0 & 3.96199 & 99999999997 & TRN \\
\hline CHEMBL1992306 & 809275 & 5.9 & 5.8156 & TRN & \\
\hline CHEMBL 2002165 & 809275 & 7.1 & 7.485 & TRN & \\
\hline CHEMBL2001668 & 809275 & 4.0 & 4.7157 & TST & \\
\hline CHEMBL1979318 & 809275 & 5.5 & 4.4377 & TST & \\
\hline CHEMBL 206382 & 809275 & 4.0 & 4.0419 & TRN & \\
\hline CHEMBL1998585 & 809275 & 7.7 & 6.784 & TRN & \\
\hline CHEMBL127898 & 809275 & 4.0 & 4.7896 & TST & \\
\hline CHEMBL519697 & 809275 & 6.4 & 4.8607 & TRN & \\
\hline CHEMBL 2004934 & 809275 & 4.0 & 3.9357 & TRN & \\
\hline CHEMBL1975128 & 809275 & 4.0 & 4.8204 & TRN & \\
\hline CHEMBL1996048 & 809275 & 6.2 & 5.4267 & TST & \\
\hline CHEMBL1970369 & 809275 & 4.0 & 4.3522 & TRN & \\
\hline CHEMBL461876 & 809275 & 4.0 & 5.3295 & TRN & \\
\hline CHEMBL2001485 & 809275 & 7.4 & 7.2993 & TRN & \\
\hline CHEMBL1966425 & 809275 & 5.3 & 5.0044 & TRN & \\
\hline CHEMBL1984363 & 809275 & 5.7 & 5.6834 & TRN & \\
\hline CHEMBL1978099 & 809275 & 6.5 & 6.4071 & TRN & \\
\hline CHEMBL1988608 & 809275 & 5.1 & 4.467 & TRN & \\
\hline CHEMBL184847 & 809275 & 4.0 & 4.1119 & TRN & \\
\hline CHEMBL1984367 & 809275 & 6.2 & 4.8839 & TRN & \\
\hline CHEMBL178737 & 809275 & 5.5 & 5.0145 & TST & \\
\hline CHEMBL226898 & 809275 & 6.7 & 6.149 & TRN & \\
\hline CHEMBL1982563 & 809275 & 4.0 & 4.1854 & TRN & \\
\hline CHEMBL539474 & 809275 & 4.0 & 4.3532 & TRN & \\
\hline CHEMBL575824 & 809275 & 4.1 & 4.7654 & TRN & \\
\hline CHEMBL1988387 & 809275 & 7.1 & 7.9913 & TRN & \\
\hline CHEMBL1974803 & 809275 & 4.0 & 4.6534 & TRN & \\
\hline CHEMBL1970074 & 809275 & 4.0 & 4.6018 & TRN & \\
\hline CHEMBL1986970 & 809275 & 4.0 & 4.5843 & TRN & \\
\hline CHEMBL 2005112 & 809275 & 5.3 & 4.4192 & TST & \\
\hline CHEMBL1958401 & 809275 & 4.0 & 4.3706 & TRN & \\
\hline CHEMBL1984044 & 809275 & 5.3 & 4.9574 & TRN & \\
\hline CHEMBL2003456 & 809275 & 5.9 & 5.1136 & TRN & \\
\hline
\end{tabular}




\begin{tabular}{|c|c|c|c|c|c|}
\hline \multirow[b]{2}{*}{ CHEMBL1966816 } & \multirow[b]{2}{*}{809275} & \multirow[b]{2}{*}{4.0} & \\
\hline & & & 4.5695 & TRN & \\
\hline CHEMBL 2002992 & 809275 & 5.3 & 4.0772 & TRN & \\
\hline CHEMBL560813 & 809275 & 4.0 & 4.2224 & TRN & \\
\hline CHEMBL207253 & 809275 & 4.0 & 3.9351 & TST & \\
\hline CHEMBL1990635 & 809275 & 5.5 & 5.0329 & TST & \\
\hline CHEMBL1968791 & 809275 & 4.0 & 4.5731 & TRN & \\
\hline CHEMBL2002682 & 809275 & 5.7 & 4.7836 & TST & \\
\hline CHEMBL1971186 & 809275 & 4.0 & 4.1378 & TRN & \\
\hline CHEMBL2003482 & 809275 & 4.0 & 4.0623 & TRN & \\
\hline CHEMBL1973211 & 809275 & 6.7 & 6.9016 & TRN & \\
\hline CHEMBL1984700 & 809275 & 4.0 & 4.2423 & TRN & \\
\hline CHEMBL1972125 & 809275 & 4.1 & 4.0771 & TRN & \\
\hline CHEMBL1461728 & 809275 & 4.0 & 4.398 & TRN & \\
\hline CHEMBL1976134 & 809275 & 5.5 & 5.5946 & TRN & \\
\hline CHEMBL1965131 & 809275 & 4.0 & 4.6645 & TRN & \\
\hline CHEMBL1972158 & 809275 & 4.0 & 4.3772 & TRN & \\
\hline CHEMBL2006580 & 809275 & 5.1 & 4.5516 & TRN & \\
\hline CHEMBL2006481 & 809275 & 4.0 & 4.2719 & TRN & \\
\hline CHEMBL1979855 & 809275 & 4.0 & 4.6275 & TRN & \\
\hline CHEMBL1970340 & 809275 & 4.0 & 4.0051 & TRN & \\
\hline CHEMBL2005186 & 809275 & 4.0 & 4.4734 & TRN & \\
\hline CHEMBL1995927 & 809275 & 4.0 & 4.0895 & TST & \\
\hline CHEMBL1975534 & 809275 & 5.8 & 5.1011 & TRN & \\
\hline CHEMBL1993424 & 809275 & 6.6 & 7.2183 & TRN & \\
\hline CHEMBL1966703 & 809275 & 4.0 & 4.2645 & TST & \\
\hline CHEMBL1969561 & 809275 & 4.0 & 4.51699 & 99999999995 & TRN \\
\hline CHEMBL1975121 & 809275 & 4.0 & 4.0997 & TRN & \\
\hline CHEMBL1997023 & 809275 & 6.0 & 4.5169 & TST & \\
\hline CHEMBL1964687 & 809275 & 7.5 & 6.7677 & TRN & \\
\hline CHEMBL1971943 & 809275 & 6.3 & 4.9391 & TST & \\
\hline CHEMBL1974254 & 809275 & 6.4 & 6.579 & TRN & \\
\hline CHEMBL1988537 & 809275 & 5.7 & 5.2506 & TST & \\
\hline CHEMBL1969049 & 809275 & 4.0 & 3.8164 & TRN & \\
\hline CHEMBL2005828 & 809275 & 6.3 & 5.4565 & TRN & \\
\hline CHEMBL2002240 & 809275 & 4.0 & 4.0939 & TRN & \\
\hline CHEMBL1991143 & 809275 & 4.0 & 4.1902 & TST & \\
\hline CHEMBL1998611 & 809275 & 5.6 & 4.9436 & TRN & \\
\hline CHEMBL1975900 & 809275 & 4.0 & 3.7626 & TRN & \\
\hline CHEMBL 255822 & 809275 & 4.0 & 4.0378 & TRN & \\
\hline CHEMBL1972221 & 809275 & 4.0 & 4.0051 & TRN & \\
\hline CHEMBL 2006778 & 809275 & 7.8 & $7.2420 e$ & 2000000001 & TRN \\
\hline CHEMBL378627 & 809275 & 4.0 & 3.7286 & TRN & \\
\hline CHEMBL1996979 & 809275 & 6.1 & 6.0002 & TRN & \\
\hline CHEMBL1997025 & 809275 & 4.0 & 3.8717 & TRN & \\
\hline CHEMBL1968406 & 809275 & 8.1 & 7.4018 & TRN & \\
\hline CHEMBL1984274 & 809275 & 5.8 & 5.2846 & TST & \\
\hline CHEMBL1998545 & 809275 & 4.0 & 3.713 & TRN & \\
\hline CHEMBL1986869 & 809275 & 4.0 & $3.9930 e$ & 00000000003 & TRN \\
\hline & & & & 15423 & \\
\hline
\end{tabular}




\begin{tabular}{|c|c|c|c|c|}
\hline & & & ipplement & al Table S2 \\
\hline CHEMBL2006010 & 809275 & 4.0 & 4.0372 & TRN \\
\hline CHEMBL1682558 & 809275 & 5.9 & 4.5353 & TRN \\
\hline CHEMBL1990496 & 809275 & 6.8 & 4.7422 & TRN \\
\hline CHEMBL 2002479 & 809275 & 5.5 & 5.1329 & TRN \\
\hline CHEMBL1967094 & 809275 & 6.2 & 5.5383 & TRN \\
\hline CHEMBL1966035 & 809275 & 4.0 & 3.9365 & TRN \\
\hline CHEMBL2003341 & 809275 & 4.0 & 4.091 & TRN \\
\hline CHEMBL1982992 & 809275 & 5.1 & 4.1006 & TRN \\
\hline CHEMBL1999590 & 809275 & 5.6 & 4.9161 & TST \\
\hline CHEMBL1981079 & 809275 & 4.0 & 4.7756 & TRN \\
\hline CHEMBL1972276 & 809275 & 4.0 & 4.2251 & TRN \\
\hline CHEMBL1980489 & 809275 & 4.0 & 3.7763 & TRN \\
\hline CHEMBL1967116 & 809275 & 7.7 & 7.925 & TRN \\
\hline CHEMBL 2000832 & 809275 & 5.0 & 5.7594 & TRN \\
\hline CHEMBL513846 & 809275 & 4.0 & 4.7468 & TRN \\
\hline CHEMBL1970709 & 809275 & 4.0 & 4.1761 & TRN \\
\hline CHEMBL1965660 & 809275 & 5.0 & 5.4237 & TRN \\
\hline CHEMBL1998112 & 809275 & 7.0 & 5.5169 & TRN \\
\hline CHEMBL1969126 & 809275 & 4.0 & 4.3459 & TRN \\
\hline CHEMBL1980896 & 809275 & 4.0 & 5.2457 & TRN \\
\hline CHEMBL1975208 & 809275 & 4.0 & 4.2606 & TST \\
\hline CHEMBL1970104 & 809275 & 6.5 & 6.2227 & TRN \\
\hline CHEMBL1991429 & 809275 & 6.5 & 6.4466 & TRN \\
\hline CHEMBL1964777 & 809275 & 6.2 & 5.0062 & TST \\
\hline CHEMBL1971149 & 809275 & 4.0 & 3.8548 & TRN \\
\hline CHEMBL1999714 & 809275 & 4.0 & 4.1099 & TRN \\
\hline CHEMBL1987533 & 809275 & 4.0 & 3.9959 & TRN \\
\hline CHEMBL1994040 & 809275 & 4.0 & 3.8712 & TRN \\
\hline CHEMBL579246 & 809275 & 5.2 & 5.3004 & TRN \\
\hline CHEMBL 398951 & 809275 & 4.3 & 4.5692 & TRN \\
\hline CHEMBL1982506 & 809275 & 5.7 & 4.9887 & TST \\
\hline CHEMBL2004716 & 809275 & 7.5 & 7.0329 & TRN \\
\hline CHEMBL1968127 & 809275 & 4.0 & 3.7908 & TRN \\
\hline CHEMBL1975233 & 809275 & 4.0 & 4.2728 & TRN \\
\hline CHEMBL1985406 & 809275 & 5.3 & 4.6671 & TRN \\
\hline CHEMBL 207400 & 809275 & 4.0 & 3.88199 & 99999999997 \\
\hline CHEMBL 2000894 & 809275 & 4.0 & 4.6012 & TST \\
\hline CHEMBL 2002553 & 809275 & 4.0 & 4.4431 & TST \\
\hline CHEMBL1982135 & 809275 & 6.0 & 5.6552 & TRN \\
\hline CHEMBL1976090 & 809275 & 6.0 & 5.6156 & TRN \\
\hline CHEMBL1993243 & 809275 & 5.6 & 6.3525 & TRN \\
\hline CHEMBL1992922 & 809275 & 7.1 & 6.8686 & TRN \\
\hline CHEMBL 2004771 & 809275 & 4.0 & 4.846 & TRN \\
\hline CHEMBL1997597 & 809275 & 4.0 & 4.0964 & TRN \\
\hline CHEMBL1969537 & 809275 & 5.7 & 5.3657 & TST \\
\hline CHEMBL1976093 & 809275 & 4.0 & 3.5643 & TRN \\
\hline CHEMBL210032 & 809275 & 4.0 & 4.2244 & TRN \\
\hline CHEMBL1975256 & 809275 & 4.0 & 4.3136 & TST \\
\hline
\end{tabular}




\begin{tabular}{|c|c|c|c|c|}
\hline & & & pplement & al $\mathrm{Ta}$ \\
\hline CHEMBL508928 & 809275 & 6.2 & 5.5761 & TRN \\
\hline CHEMBL1991356 & 809275 & 4.0 & 4.4456 & TRN \\
\hline CHEMBL1983309 & 809275 & 4.0 & 3.9971 & TRN \\
\hline CHEMBL 2004892 & 809275 & 4.0 & 4.433 & TRN \\
\hline CHEMBL1999126 & 809275 & 4.0 & 4.2509 & TST \\
\hline CHEMBL1997503 & 809275 & 4.0 & 4.5722 & TST \\
\hline CHEMBL116070 & 809275 & 6.3 & 4.7025 & TST \\
\hline CHEMBL1990821 & 809275 & 4.0 & 4.6132 & TST \\
\hline CHEMBL1970314 & 809275 & 4.0 & 4.547 & TRN \\
\hline CHEMBL 2004871 & 809275 & 4.0 & 4.0692 & TRN \\
\hline CHEMBL 2004872 & 809275 & 4.0 & 4.0044 & TRN \\
\hline CHEMBL1727312 & 809275 & 4.0 & 3.9353 & TRN \\
\hline CHEMBL1969879 & 809275 & 4.0 & 4.0071 & TRN \\
\hline CHEMBL1981720 & 809275 & 4.0 & 4.1228 & TRN \\
\hline CHEMBL419932 & 809275 & 5.4 & 4.3252 & TRN \\
\hline CHEMBL 262433 & 809275 & 6.6 & 6.3595 & TRN \\
\hline CHEMBL306380 & 809275 & 5.8 & 5.8611 & TRN \\
\hline CHEMBL1966722 & 809275 & 4.0 & 5.3799 & TST \\
\hline CHEMBL1975500 & 809275 & 4.0 & 5.175 & TRN \\
\hline CHEMBL394619 & 809275 & 6.0 & 6.3388 & TRN \\
\hline CHEMBL1996831 & 809275 & 4.0 & 4.585 & TST \\
\hline CHEMBL411903 & 809275 & 6.8 & 6.4286 & TRN \\
\hline CHEMBL1965988 & 809275 & 6.4 & 6.6184 & TRN \\
\hline CHEMBL418203 & 809275 & 4.0 & 4.9543 & TST \\
\hline CHEMBL1989646 & 809275 & 4.0 & 4.2905 & TRN \\
\hline CHEMBL225519 & 809275 & 5.2 & 4.7739 & TRN \\
\hline CHEMBL1978200 & 809275 & 4.0 & 4.3941 & TRN \\
\hline CHEMBL 2006631 & 809275 & 5.9 & 4.3439 & TRN \\
\hline CHEMBL1970522 & 809275 & 4.0 & 4.1362 & TRN \\
\hline CHEMBL1990415 & 809275 & 4.0 & 4.439 & TRN \\
\hline CHEMBL1966087 & 809275 & 4.0 & 4.2295 & TRN \\
\hline CHEMBL1964692 & 809275 & 6.7 & 6.2501 & TRN \\
\hline CHEMBL1996931 & 809275 & 4.0 & 3.4681 & TRN \\
\hline CHEMBL1964413 & 809275 & 4.0 & 4.2684 & TRN \\
\hline CHEMBL1973483 & 809275 & 4.0 & 4.6292 & TRN \\
\hline CHEMBL1970735 & 809275 & 4.0 & 4.1638 & TRN \\
\hline CHEMBL1997340 & 809275 & 4.0 & 4.2612 & TRN \\
\hline CHEMBL 2004365 & 809275 & 5.4 & 4.7895 & TST \\
\hline CHEMBL1522508 & 809275 & 4.0 & 4.2243 & TRN \\
\hline CHEMBL1989474 & 809275 & 4.0 & 4.1517 & TRN \\
\hline CHEMBL1090360 & 809275 & 7.1 & 6.7733 & TRN \\
\hline CHEMBL210887 & 809275 & 4.0 & 4.5422 & TRN \\
\hline CHEMBL458997 & 809275 & 5.8 & 6.1159 & TRN \\
\hline CHEMBL 227271 & 809275 & 5.7 & 6.3156 & TRN \\
\hline CHEMBL1971021 & 809275 & 4.0 & 5.0229 & TRN \\
\hline CHEMBL583144 & 809275 & 4.0 & 4.6159 & TRN \\
\hline CHEMBL1974310 & 809275 & 6.6 & 5.4159 & TST \\
\hline CHEMBL1982660 & 809275 & 6.4 & 5.0845 & TRN \\
\hline
\end{tabular}




\begin{tabular}{|c|c|c|c|c|}
\hline & & & upplement & $d \pm$ \\
\hline CHEMBL1994693 & 809275 & 6.5 & 6.7568 & TRN \\
\hline CHEMBL1982957 & 809275 & 7.5 & 6.9376 & TRN \\
\hline CHEMBL1725279 & 809275 & 5.5 & 5.4274 & TST \\
\hline CHEMBL1975138 & 809275 & 4.0 & 4.9784 & TST \\
\hline CHEMBL424872 & 809275 & 4.0 & 3.8581 & TRN \\
\hline CHEMBL2006836 & 809275 & 4.0 & 3.9604 & TST \\
\hline CHEMBL412142 & 809275 & 5.2 & 4.3013 & TST \\
\hline CHEMBL1980704 & 809275 & 4.0 & 4.1545 & TST \\
\hline CHEMBL 2003271 & 809275 & 5.2 & 4.5652 & TRN \\
\hline CHEMBL1966808 & 809275 & 5.1 & 3.9952 & TST \\
\hline CHEMBL 2004447 & 809275 & 4.0 & 4.0369 & TST \\
\hline CHEMBL1983111 & 809275 & 7.7 & 7.2562 & TST \\
\hline CHEMBL1973860 & 809275 & 4.0 & 4.2391 & TRN \\
\hline CHEMBL1977713 & 809275 & 4.0 & 4.0932 & TRN \\
\hline CHEMBL 260135 & 809275 & 5.8 & 4.3698 & TRN \\
\hline CHEMBL220241 & 809275 & 5.8 & 4.9939 & TRN \\
\hline CHEMBL 2004544 & 809275 & 5.2 & 4.3392 & TST \\
\hline CHEMBL1982610 & 809275 & 4.0 & 4.7189 & TST \\
\hline CHEMBL1999496 & 809275 & 5.4 & 3.9205 & TRN \\
\hline CHEMBL1988300 & 809275 & 5.5 & 5.3836 & TRN \\
\hline CHEMBL1991078 & 809275 & 5.7 & 5.9873 & TRN \\
\hline CHEMBL1987359 & 809275 & 4.0 & 4.3354 & TST \\
\hline CHEMBL1989265 & 809275 & 4.0 & 4.0968 & TST \\
\hline CHEMBL 2004647 & 809275 & 4.0 & 4.6366 & TST \\
\hline CHEMBL1969502 & 809275 & 5.9 & 6.2233 & TRN \\
\hline CHEMBL1682553 & 809275 & 4.0 & 4.5395 & TRN \\
\hline CHEMBL1971430 & 809275 & 4.0 & 4.2686 & TRN \\
\hline CHEMBL1997764 & 809275 & 5.9 & 5.8602 & TRN \\
\hline CHEMBL1983963 & 809275 & 6.6 & 5.8663 & TRN \\
\hline CHEMBL1985092 & 809275 & 4.0 & 4.824 & TST \\
\hline CHEMBL 2004692 & 809275 & 4.0 & 4.0565 & TST \\
\hline CHEMBL1981410 & 809275 & 4.0 & 4.855 & TRN \\
\hline CHEMBL1996234 & 809275 & 4.0 & 4.4293 & TRN \\
\hline CHEMBL1991434 & 809275 & 4.0 & 4.1527 & TRN \\
\hline CHEMBL1967544 & 809275 & 4.0 & 4.3464 & TRN \\
\hline CHEMBL223367 & 809275 & 4.0 & 4.5022 & TST \\
\hline CHEMBL340384 & 809275 & 5.4 & 4.7839 & TST \\
\hline CHEMBL1996587 & 809275 & 5.4 & 4.697 & TRN \\
\hline CHEMBL1964804 & 809275 & 4.0 & 4.5581 & TRN \\
\hline CHEMBL443962 & 809275 & 5.4 & 4.7934 & TST \\
\hline CHEMBL 2000354 & 809275 & 4.0 & 4.2778 & TRN \\
\hline CHEMBL1965507 & 809275 & 7.7 & 6.6995 & TRN \\
\hline CHEMBL 274064 & 809275 & 4.0 & 4.6699 & TRN \\
\hline CHEMBL1967564 & 809275 & 4.0 & 3.8335 & TRN \\
\hline CHEMBL592030 & 809275 & 6.9 & 5.5484 & TST \\
\hline CHEMBL 2000071 & 809275 & 7.4 & 6.9853 & TRN \\
\hline CHEMBL1979176 & 809275 & 4.0 & 4.5061 & TRN \\
\hline CHEMBL 2000408 & 809275 & 4.0 & 4.1158 & TRN \\
\hline
\end{tabular}




\begin{tabular}{|c|c|c|c|c|c|}
\hline \\
\hline CHEMBL 248757 & 809275 & 6.8 & 4.2272 & TST & \\
\hline CHEMBL1978014 & 809275 & 4.0 & 4.0823 & TRN & \\
\hline CHEMBL1994538 & 809275 & 4.0 & 4.0371 & TRN & \\
\hline CHEMBL1983195 & 809275 & 5.4 & 4.5305 & TST & \\
\hline CHEMBL1975490 & 809275 & 5.1 & 5.1199 & TRN & \\
\hline CHEMBL1964444 & 809275 & 4.0 & 4.1831 & TRN & \\
\hline CHEMBL1989957 & 809275 & 4.0 & 4.3767 & TRN & \\
\hline CHEMBL1986139 & 809275 & 4.0 & 4.2633 & TRN & \\
\hline CHEMBL1980540 & 809275 & 4.0 & 4.0295 & TRN & \\
\hline CHEMBL1979883 & 809275 & 6.9 & 6.6973 & TRN & \\
\hline CHEMBL1984162 & 809275 & 7.5 & 7.9153 & TRN & \\
\hline CHEMBL491758 & 809275 & 6.0 & 6.2379 & TRN & \\
\hline CHEMBL549730 & 809275 & 4.0 & 3.7826 & TRN & \\
\hline CHEMBL1970189 & 809275 & 5.7 & 4.0146 & TST & \\
\hline CHEMBL1996791 & 809275 & 6.1 & 5.2889 & TRN & \\
\hline CHEMBL371206 & 809275 & 6.3 & 6.8119 & TRN & \\
\hline CHEMBL1974664 & 809275 & 4.0 & 4.761 & TRN & \\
\hline CHEMBL1974288 & 809275 & 4.0 & 4.0957 & TRN & \\
\hline CHEMBL196363 & 809275 & 7.0 & 6.0511 & TRN & \\
\hline CHEMBL1190711 & 809275 & 6.1 & 5.2098 & TRN & \\
\hline CHEMBL1968705 & 809275 & 5.2 & 4.8485 & TRN & \\
\hline CHEMBL404367 & 809275 & 5.5 & 5.466 & TRN & \\
\hline CHEMBL1966343 & 809275 & 4.0 & 4.3581 & TRN & \\
\hline CHEMBL1967887 & 809275 & 4.0 & 5.0809 & TRN & \\
\hline CHEMBL 2000568 & 809275 & 5.4 & $4.8610 e$ & 0000000001 & TRN \\
\hline CHEMBL2000335 & 809275 & 7.3 & 6.9226 & TRN & \\
\hline CHEMBL1977604 & 809275 & 4.0 & 4.1565 & TST & \\
\hline CHEMBL1988717 & 809275 & 4.0 & 5.9563 & TRN & \\
\hline CHEMBL1974328 & 809275 & 8.3 & 7.0375 & TRN & \\
\hline CHEMBL1985507 & 809275 & 5.4 & 4.34 & TST & \\
\hline CHEMBL509032 & 809275 & 8.3 & 7.8742 & TRN & \\
\hline CHEMBL573339 & 809275 & 4.0 & 4.8068 & TRN & \\
\hline CHEMBL1973808 & 809275 & 4.0 & 4.2217 & TRN & \\
\hline CHEMBL 2000429 & 809275 & 4.0 & 4.6461 & TRN & \\
\hline CHEMBL1972576 & 809275 & 7.4 & 7.322 & TRN & \\
\hline CHEMBL1992555 & 809275 & 4.0 & 4.3371 & TRN & \\
\hline CHEMBL1992342 & 809275 & 4.0 & 4.2792 & TRN & \\
\hline CHEMBL1988173 & 809275 & 5.8 & 4.9807 & TST & \\
\hline CHEMBL1164265 & 809275 & 6.1 & 5.7611 & TST & \\
\hline CHEMBL535331 & 809275 & 4.0 & 4.6143 & TRN & \\
\hline CHEMBL1989805 & 809275 & 5.6 & 5.2047 & TST & \\
\hline CHEMBL1965423 & 809275 & 4.0 & 4.5697 & TRN & \\
\hline CHEMBL1982980 & 809275 & 4.0 & 4.5344 & TST & \\
\hline CHEMBL1983025 & 809275 & 6.2 & 6.1135 & TRN & \\
\hline CHEMBL205415 & 809275 & 5.3 & 4.1918 & TRN & \\
\hline CHEMBL1977135 & 809275 & 4.0 & 4.1626 & TRN & \\
\hline CHEMBL 2001920 & 809275 & 5.9 & 4.9799 & TRN & \\
\hline CHEMBL1241473 & 809275 & 7.8 & 8.0629 & TRN & \\
\hline & & & & 5427 & \\
\hline
\end{tabular}




\begin{tabular}{|c|c|c|c|c|}
\hline & & & lement & al Ta \\
\hline CHEMBL1978448 & 809275 & 4.0 & 4.3745 & TRN \\
\hline CHEMBL 2004513 & 809275 & 5.2 & 4.3186 & TRN \\
\hline CHEMBL1972258 & 809275 & 4.0 & 4.1368 & TRN \\
\hline CHEMBL 2001257 & 809275 & 6.8 & 6.3256 & TRN \\
\hline CHEMBL1992536 & 809275 & 4.0 & 4.0466 & TRN \\
\hline CHEMBL1987793 & 809275 & 5.2 & 5.0574 & TST \\
\hline CHEMBL1992740 & 809275 & 4.0 & 4.1545 & TRN \\
\hline CHEMBL439340 & 809275 & 4.0 & 3.8151 & TRN \\
\hline CHEMBL 2002373 & 809275 & 4.0 & 4.2062 & TRN \\
\hline CHEMBL 2006188 & 809275 & 4.0 & 3.9338 & TRN \\
\hline CHEMBL1967531 & 809275 & 6.4 & 6.5897 & TRN \\
\hline CHEMBL1970913 & 809275 & 4.0 & 3.8248 & TRN \\
\hline CHEMBL1973893 & 809275 & 4.0 & 4.0595 & TRN \\
\hline CHEMBL1995736 & 809275 & 4.0 & 4.3915 & TRN \\
\hline CHEMBL1997534 & 809275 & 6.2 & 4.9634 & TRN \\
\hline CHEMBL1996500 & 809275 & 4.0 & 4.2553 & TRN \\
\hline CHEMBL1985095 & 809275 & 5.8 & 6.0604 & TST \\
\hline CHEMBL1998551 & 809275 & 4.0 & 4.5432 & TRN \\
\hline CHEMBL1977374 & 809275 & 4.0 & 4.5565 & TRN \\
\hline CHEMBL1682540 & 809275 & 4.0 & 4.3044 & TRN \\
\hline CHEMBL1976420 & 809275 & 5.7 & 6.2892 & TST \\
\hline CHEMBL1994864 & 809275 & 4.0 & 3.7355 & TRN \\
\hline CHEMBL 2002446 & 809275 & 5.9 & 5.2704 & TRN \\
\hline CHEMBL497151 & 809275 & 6.1 & 4.8999 & TST \\
\hline CHEMBL1973961 & 809275 & 4.0 & 4.396 & TRN \\
\hline CHEMBL 246970 & 809275 & 5.7 & 4.5456 & TRN \\
\hline CHEMBL340921 & 809275 & 5.2 & 4.2562 & TST \\
\hline CHEMBL1999718 & 809275 & 4.0 & 4.1668 & TRN \\
\hline CHEMBL1276446 & 809275 & 6.9 & 7.1288 & TST \\
\hline CHEMBL1977346 & 809275 & 5.6 & 5.1513 & TRN \\
\hline CHEMBL1971649 & 809275 & 4.0 & 4.8998 & TRN \\
\hline CHEMBL1998435 & 809275 & 4.0 & 4.2876 & TRN \\
\hline CHEMBL2006439 & 809275 & 5.2 & 6.0978 & TRN \\
\hline CHEMBL 2006156 & 809275 & 5.3 & 4.5838 & TST \\
\hline CHEMBL1969190 & 809275 & 5.9 & 6.3104 & TRN \\
\hline CHEMBL1973937 & 809275 & 5.5 & 5.4891 & TRN \\
\hline CHEMBL1991674 & 809275 & 6.9 & 7.0696 & TRN \\
\hline CHEMBL1982711 & 809275 & 6.6 & 6.8696 & TRN \\
\hline CHEMBL1987982 & 809275 & 4.0 & 4.9424 & TST \\
\hline CHEMBL 2007044 & 809275 & 4.0 & 4.6262 & TRN \\
\hline CHEMBL1994241 & 809275 & 5.6 & 6.2017 & TST \\
\hline CHEMBL 223460 & 809275 & 5.2 & 4.5168 & TST \\
\hline CHEMBL1998829 & 809275 & 5.6 & 5.6096 & TRN \\
\hline CHEMBL50894 & 809275 & 4.2 & 6.2523 & TST \\
\hline CHEMBL1988838 & 809275 & 6.7 & 7.4721 & TRN \\
\hline CHEMBL1981725 & 809275 & 6.1 & 6.3307 & TRN \\
\hline CHEMBL1982866 & 809275 & 5.5 & 4.0533 & TRN \\
\hline CHEMBL1968926 & 809275 & 4.0 & 4.1719 & TRN \\
\hline
\end{tabular}




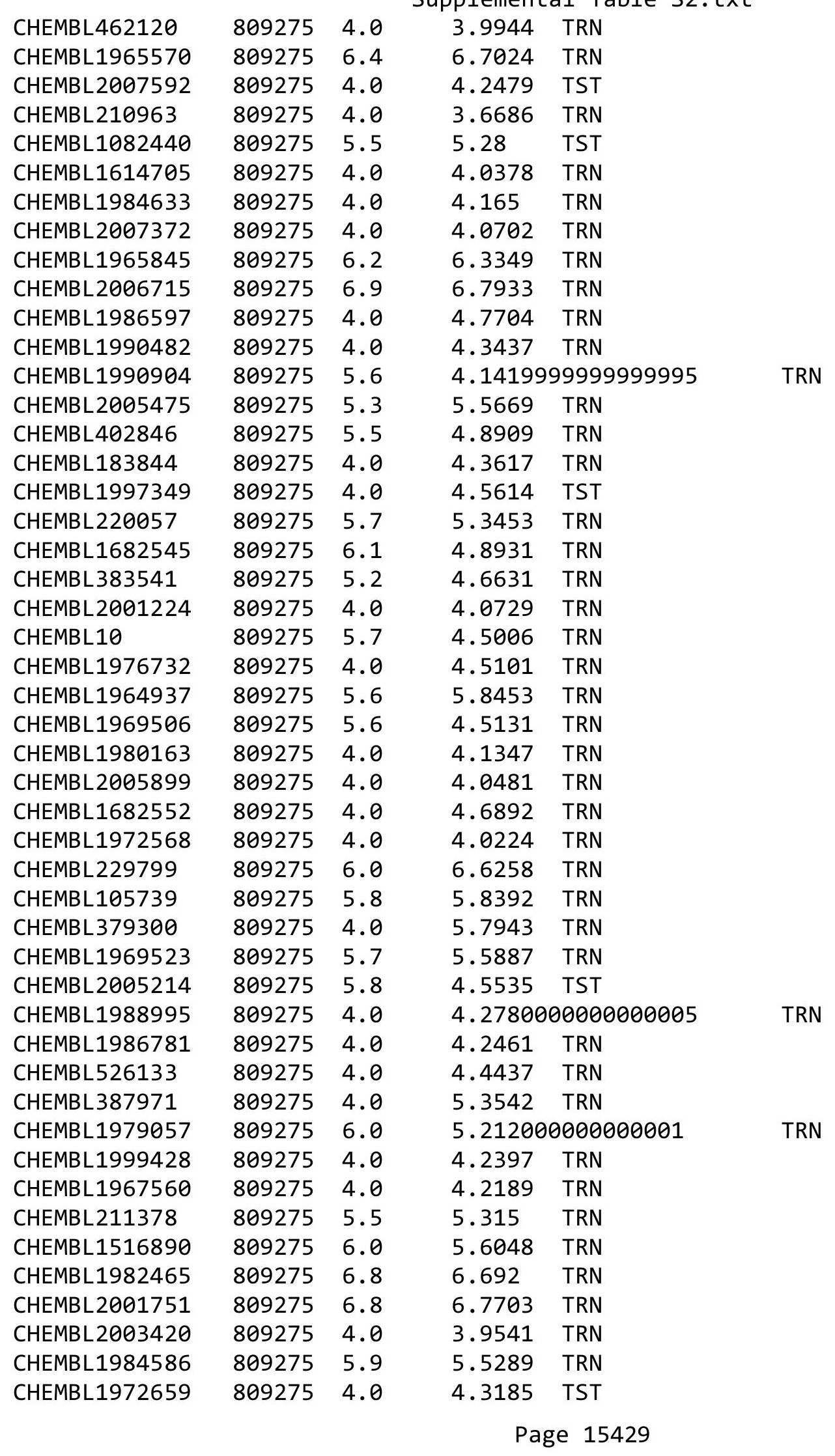




\begin{tabular}{|c|c|c|c|c|c|}
\hline & & & & & \\
\hline CHEMBL 272453 & 809275 & 4.0 & 4.6566 & TRN & \\
\hline CHEMBL1970217 & 809275 & 4.0 & 4.1651 & TRN & \\
\hline CHEMBL 2005528 & 809275 & 4.0 & 4.4949 & TST & \\
\hline CHEMBL185569 & 809275 & 4.0 & 4.7819 & TRN & \\
\hline CHEMBL1969843 & 809275 & 4.0 & 4.1462 & TRN & \\
\hline CHEMBL 2007002 & 809275 & 5.4 & 4.8964 & TRN & \\
\hline CHEMBL1987007 & 809275 & 5.2 & $5.2420 e$ & 0000000001 & TRN \\
\hline CHEMBL1969588 & 809275 & 8.0 & 6.3616 & TRN & \\
\hline CHEMBL1984711 & 809275 & 6.3 & 5.862 & TRN & \\
\hline CHEMBL484390 & 809275 & 6.1 & 4.5705 & TRN & \\
\hline CHEMBL1979252 & 809275 & 4.0 & 3.7182 & TRN & \\
\hline CHEMBL1986499 & 809275 & 4.0 & 4.1902 & TRN & \\
\hline CHEMBL2004290 & 809275 & 7.0 & 6.2356 & TRN & \\
\hline CHEMBL1972937 & 809275 & 4.0 & 4.026 & TRN & \\
\hline CHEMBL2000393 & 809275 & 6.2 & 6.4033 & TST & \\
\hline CHEMBL 2004311 & 809275 & 5.8 & 5.6725 & TRN & \\
\hline CHEMBL1992634 & 809275 & 6.8 & 6.309 & TRN & \\
\hline CHEMBL1242373 & 809275 & 7.2 & 6.9457 & TRN & \\
\hline CHEMBL56543 & 809275 & 5.4 & 4.5311 & TRN & \\
\hline CHEMBL1988075 & 809275 & 6.4 & 6.79899 & 99999999995 & TRN \\
\hline CHEMBL316264 & 809275 & 4.0 & 4.129 & TRN & \\
\hline CHEMBL1991678 & 809275 & 4.0 & 4.3824 & TRN & \\
\hline CHEMBL 2001239 & 809275 & 6.1 & 5.4809 & TST & \\
\hline CHEMBL1988594 & 809275 & 7.1 & 6.9037 & TRN & \\
\hline CHEMBL 2001288 & 809275 & 5.6 & 4.7723 & TRN & \\
\hline CHEMBL1999811 & 809275 & 5.2 & 4.8581 & TST & \\
\hline CHEMBL1985074 & 809275 & 4.0 & 4.2522 & TST & \\
\hline CHEMBL1982874 & 809275 & 4.0 & 5.1546 & TRN & \\
\hline CHEMBL 2000481 & 809275 & 5.1 & 4.6841 & TRN & \\
\hline CHEMBL1991725 & 809275 & 4.0 & 4.7668 & TRN & \\
\hline CHEMBL1992242 & 809275 & 4.0 & 3.7743 & TRN & \\
\hline CHEMBL2007296 & 809275 & 4.0 & 3.8122 & TRN & \\
\hline CHEMBL396523 & 809275 & 7.3 & 7.2111 & TRN & \\
\hline CHEMBL208637 & 809275 & 4.0 & 4.0003 & TRN & \\
\hline CHEMBL1970203 & 809275 & 6.9 & 7.5732 & TRN & \\
\hline CHEMBL1986530 & 809275 & 6.9 & 4.6327 & TST & \\
\hline CHEMBL1965351 & 809275 & 4.0 & 5.1651 & TST & \\
\hline CHEMBL1999321 & 809275 & 4.0 & 4.6038 & TRN & \\
\hline CHEMBL1968590 & 809275 & 5.4 & 5.9311 & TRN & \\
\hline CHEMBL 2005375 & 809275 & 4.0 & 4.4661 & TRN & \\
\hline CHEMBL1984191 & 809275 & 5.7 & 4.2934 & TRN & \\
\hline CHEMBL1972183 & 809275 & 4.0 & 4.3758 & TST & \\
\hline CHEMBL1971029 & 809275 & 8.2 & 8.3607 & TRN & \\
\hline CHEMBL394790 & 809275 & 5.8 & 6.54899 & 99999999995 & TRN \\
\hline CHEMBL226471 & 809275 & 5.4 & 5.3729 & TRN & \\
\hline CHEMBL1996111 & 809275 & 5.4 & 4.6283 & TRN & \\
\hline CHEMBL1974702 & 809275 & 4.0 & 4.5077 & TRN & \\
\hline CHEMBL1965589 & 809275 & 4.0 & 4.2565 & TRN & \\
\hline & & & & 15430 & \\
\hline
\end{tabular}




\begin{tabular}{|c|c|c|c|c|}
\hline & & & pplement & al $\mathrm{Ta}$ \\
\hline CHEMBL1998193 & 809275 & 4.0 & 4.1657 & TRN \\
\hline CHEMBL1988153 & 809275 & 5.3 & 4.6917 & TST \\
\hline CHEMBL1972584 & 809275 & 5.9 & 5.2477 & TRN \\
\hline CHEMBL1988437 & 809275 & 6.6 & 5.8956 & TST \\
\hline CHEMBL1998121 & 809275 & 5.3 & 5.2705 & TRN \\
\hline CHEMBL1979577 & 809275 & 6.7 & 6.4674 & TRN \\
\hline CHEMBL1991800 & 809275 & 4.0 & 3.8742 & TRN \\
\hline CHEMBL52387 & 809275 & 4.0 & 4.0251 & TST \\
\hline CHEMBL379835 & 809275 & 4.0 & 3.8771 & TST \\
\hline CHEMBL1979357 & 809275 & 4.0 & 3.8683 & TRN \\
\hline CHEMBL1996817 & 809275 & 7.9 & 6.9748 & TRN \\
\hline CHEMBL3197315 & 809275 & 4.0 & 3.7994 & TST \\
\hline CHEMBL468280 & 809275 & 4.0 & 4.0441 & TST \\
\hline CHEMBL1990884 & 809275 & 5.2 & 5.5548 & TRN \\
\hline CHEMBL3109278 & 809275 & 7.1 & 7.4686 & TRN \\
\hline CHEMBL 256835 & 809275 & 4.0 & 4.5953 & TRN \\
\hline CHEMBL1970006 & 809275 & 4.0 & 4.5063 & TST \\
\hline CHEMBL1980142 & 809275 & 4.0 & 3.9853 & TRN \\
\hline CHEMBL41783 & 809275 & 4.0 & 3.9888 & TRN \\
\hline CHEMBL2006276 & 809275 & 4.0 & 4.3736 & TRN \\
\hline CHEMBL 271381 & 809275 & 6.2 & 6.0767 & TRN \\
\hline CHEMBL 2006785 & 809275 & 4.0 & 4.2077 & TRN \\
\hline CHEMBL1982466 & 809275 & 7.8 & 7.232 & TRN \\
\hline CHEMBL1995740 & 809275 & 4.0 & 4.2613 & TRN \\
\hline CHEMBL234085 & 809275 & 5.3 & 4.6586 & TRN \\
\hline CHEMBL1995832 & 809275 & 4.0 & 4.3786 & TRN \\
\hline CHEMBL1998414 & 809275 & 5.2 & 4.9896 & TRN \\
\hline CHEMBL1969042 & 809275 & 4.0 & 5.0289 & TST \\
\hline CHEMBL 2000345 & 809275 & 6.4 & 6.2438 & TST \\
\hline CHEMBL1999931 & 809275 & 5.7 & 6.3365 & TRN \\
\hline CHEMBL1375418 & 809275 & 4.0 & 4.5516 & TRN \\
\hline CHEMBL 2007064 & 809275 & 6.1 & 5.8437 & TRN \\
\hline CHEMBL1981047 & 809275 & 7.4 & 6.7474 & TRN \\
\hline CHEMBL229968 & 809275 & 5.8 & 6.237 & TRN \\
\hline CHEMBL1976240 & 809275 & 4.0 & 4.125 & TRN \\
\hline CHEMBL1979093 & 809275 & 5.6 & 5.8975 & TRN \\
\hline CHEMBL1968151 & 809275 & 4.0 & 4.0666 & TST \\
\hline CHEMBL1987009 & 809275 & 6.3 & 5.9255 & TRN \\
\hline CHEMBL379218 & 809275 & 5.8 & 5.7333 & TRN \\
\hline CHEMBL2003817 & 809275 & 5.2 & 4.3606 & TRN \\
\hline CHEMBL1994830 & 809275 & 5.8 & 4.3887 & TST \\
\hline CHEMBL 226403 & 809275 & 4.0 & 4.8488 & TRN \\
\hline CHEMBL 2005631 & 809275 & 7.8 & 7.6319 & TRN \\
\hline CHEMBL1994938 & 809275 & 6.3 & 6.1914 & TRN \\
\hline CHEMBL1977223 & 809275 & 4.0 & 4.1142 & TRN \\
\hline CHEMBL1236126 & 809275 & 4.0 & 3.9729 & TRN \\
\hline CHEMBL1966279 & 809275 & 4.0 & 4.5531 & TRN \\
\hline CHEMBL1997846 & 809275 & 6.3 & 6.5492 & TRN \\
\hline
\end{tabular}




\begin{tabular}{|c|c|c|c|c|c|}
\hline \\
\hline CHEMBL2004419 & 809275 & 4.0 & 4.5521 & TRN & \\
\hline CHEMBL1972489 & 809275 & 4.0 & 4.1091 & TRN & \\
\hline CHEMBL1994074 & 809275 & 5.1 & 4.6331 & TRN & \\
\hline CHEMBL1992937 & 809275 & 6.3 & 5.1031 & TRN & \\
\hline CHEMBL1972119 & 809275 & 4.0 & 3.9446 & TRN & \\
\hline CHEMBL1090356 & 809275 & 6.0 & 5.7615 & TRN & \\
\hline CHEMBL95692 & 809275 & 4.0 & 4.3274 & TRN & \\
\hline CHEMBL1986328 & 809275 & 5.2 & 4.6193 & TST & \\
\hline CHEMBL1976455 & 809275 & 4.0 & 4.5549 & TRN & \\
\hline CHEMBL1983923 & 809275 & 6.3 & 6.0303 & TST & \\
\hline CHEMBL1982361 & 809275 & 4.0 & 3.9744 & TRN & \\
\hline CHEMBL1983534 & 809275 & 4.0 & 4.1873 & TRN & \\
\hline CHEMBL1982122 & 809275 & 4.0 & 4.1286 & TRN & \\
\hline CHEMBL 2000801 & 809275 & 4.0 & 3.7889 & TRN & \\
\hline CHEMBL1999112 & 809275 & 7.0 & 4.8333 & TST & \\
\hline CHEMBL1682546 & 809275 & 4.0 & 4.2656 & TRN & \\
\hline CHEMBL1991395 & 809275 & 4.0 & 3.8695 & TRN & \\
\hline CHEMBL1971245 & 809275 & 5.0 & 5.3487 & TRN & \\
\hline CHEMBL1972142 & 809275 & 5.1 & $4.9860 e$ & 0000000001 & TRN \\
\hline CHEMBL1966514 & 809275 & 6.5 & 6.6802 & TRN & \\
\hline CHEMBL 2003638 & 809275 & 5.5 & 5.9518 & TRN & \\
\hline CHEMBL1996066 & 809275 & 7.2 & 5.3325 & TST & \\
\hline CHEMBL1972152 & 809275 & 4.0 & 4.6823 & TST & \\
\hline CHEMBL1993722 & 809275 & 4.0 & 5.2779 & TRN & \\
\hline CHEMBL1970806 & 809275 & 4.0 & 4.0992 & TST & \\
\hline CHEMBL1375640 & 809275 & 4.0 & 4.2631 & TST & \\
\hline CHEMBL1979970 & 809275 & 5.3 & 4.1933 & TRN & \\
\hline CHEMBL249282 & 809275 & 4.0 & 4.442 & TRN & \\
\hline CHEMBL 2006237 & 809275 & 4.0 & 4.2279 & TRN & \\
\hline CHEMBL1974094 & 809275 & 5.0 & 4.3935 & TST & \\
\hline CHEMBL1967720 & 809275 & 7.5 & 7.6342 & TST & \\
\hline CHEMBL1572266 & 809275 & 4.0 & 4.4661 & TST & \\
\hline CHEMBL1991138 & 809275 & 4.0 & 3.8007 & TST & \\
\hline CHEMBL1969755 & 809275 & 4.0 & 3.6047 & TST & \\
\hline CHEMBL1979516 & 809275 & 7.5 & 7.1374 & TST & \\
\hline CHEMBL1605605 & 809275 & 4.0 & 3.9875 & TST & \\
\hline CHEMBL1972820 & 809275 & 4.0 & 4.2146 & TST & \\
\hline CHEMBL1996208 & 809275 & 4.0 & 4.7254 & TST & \\
\hline CHEMBL1989029 & 809275 & 5.8 & 5.3127 & TST & \\
\hline CHEMBL392642 & 809275 & 6.3 & 4.7309 & TST & \\
\hline CHEMBL514499 & 809275 & 7.9 & 5.586 & TST & \\
\hline CHEMBL1965631 & 809275 & 4.0 & 3.7344 & TST & \\
\hline CHEMBL1980144 & 809275 & 6.7 & 6.7636 & TST & \\
\hline CHEMBL1991188 & 809275 & 5.2 & 4.2031 & TST & \\
\hline CHEMBL1972849 & 809275 & 4.0 & 4.3717 & TST & \\
\hline CHEMBL 377408 & 809275 & 4.0 & 4.329 & TST & \\
\hline CHEMBL 231209 & 809275 & 5.6 & 6.3432 & TST & \\
\hline CHEMBL1975357 & 809275 & 4.0 & 4.5843 & TST & \\
\hline
\end{tabular}




\begin{tabular}{|c|c|c|c|c|}
\hline & & & lemer & $d \perp$ \\
\hline CHEMBL1976220 & 809275 & 6.1 & 6.5212 & TST \\
\hline CHEMBL259922 & 809275 & 4.0 & 3.9375 & TST \\
\hline CHEMBL1997617 & 809275 & 5.4 & 5.6219 & TST \\
\hline CHEMBL1982383 & 809275 & 5.1 & 4.3827 & TST \\
\hline CHEMBL1969301 & 809275 & 5.1 & 4.5613 & TST \\
\hline CHEMBL17370 & 809275 & 5.5 & 4.2168 & TST \\
\hline CHEMBL1987910 & 809275 & 4.0 & 5.4598 & TST \\
\hline CHEMBL1983932 & 809275 & 4.0 & 5.1305 & TST \\
\hline CHEMBL1997822 & 809275 & 6.9 & 6.244 & TST \\
\hline CHEMBL1991285 & 809275 & 4.0 & 4.4163 & TST \\
\hline CHEMBL1984038 & 809275 & 5.7 & 5.015 & TST \\
\hline CHEMBL243088 & 809275 & 6.9 & 6.7376 & TST \\
\hline CHEMBL1974416 & 809275 & 5.8 & 5.9847 & TST \\
\hline CHEMBL 2004615 & 809275 & 5.1 & 4.5906 & TST \\
\hline CHEMBL1984039 & 809275 & 4.0 & 4.5615 & TST \\
\hline CHEMBL1997872 & 809275 & 4.0 & 5.2256 & TST \\
\hline CHEMBL610198 & 688262 & 5.0602 & 5.0953 & TRN \\
\hline CHEMBL1423626 & 688262 & 4.7426 & 4.8926 & TST \\
\hline CHEMBL1459140 & 688262 & 4.8289 & 4.8306 & TRN \\
\hline CHEMBL1521989 & 688262 & 5.1171 & 5.1687 & TRN \\
\hline CHEMBL131037 & 688262 & 4.7742 & 4.7427 & TRN \\
\hline CHEMBL1613578 & 688262 & 5.3504 & 5.3298 & TRN \\
\hline CHEMBL1585527 & 688262 & 5.2272 & 5.249 & TRN \\
\hline CHEMBL1344225 & 688262 & 5.3512 & 5.3296 & TRN \\
\hline CHEMBL1370681 & 688262 & 4.5467 & 4.6718 & TRN \\
\hline CHEMBL1487635 & 688262 & 5.8483 & 5.7789 & TRN \\
\hline CHEMBL 2000517 & 688262 & 5.3735 & 5.2728 & TRN \\
\hline CHEMBL1544423 & 688262 & 4.6794 & 4.6805 & TRN \\
\hline CHEMBL1603615 & 688262 & 3.3028 & 3.3267 & TRN \\
\hline CHEMBL1500227 & 688262 & 4.838 & 4.891 & TRN \\
\hline CHEMBL1595015 & 688262 & 5.6411 & 5.6893 & TRN \\
\hline CHEMBL1367316 & 688262 & 4.6262 & 4.5857 & TRN \\
\hline CHEMBL1605956 & 688262 & 5.0103 & 4.9949 & TRN \\
\hline CHEMBL1440300 & 688262 & 4.9884 & 4.9527 & TRN \\
\hline CHEMBL1547643 & 688262 & 4.5143 & 4.5592 & TRN \\
\hline CHEMBL1343392 & 688262 & 4.9743 & 4.9978 & TRN \\
\hline CHEMBL1468847 & 688262 & 5.1381 & 5.1227 & TRN \\
\hline CHEMBL1309232 & 688262 & 5.1507 & 5.2376 & TRN \\
\hline CHEMBL1333510 & 688262 & 4.6306 & 4.5062 & TRN \\
\hline CHEMBL1486546 & 688262 & 4.8658 & 4.9154 & TRN \\
\hline CHEMBL1365696 & 688262 & 3.3028 & 3.3353 & TRN \\
\hline CHEMBL1374788 & 688262 & 4.8652 & 4.9258 & TRN \\
\hline CHEMBL1563483 & 688262 & 4.8636 & 5.2061 & TST \\
\hline CHEMBL1485010 & 688262 & 4.8655 & 4.9231 & TRN \\
\hline CHEMBL1439384 & 688262 & 5.325 & 5.3888 & TRN \\
\hline CHEMBL1432251 & 688262 & 5.2068 & 5.2326 & TRN \\
\hline CHEMBL1413680 & 688262 & 4.8245 & 5.0381 & TST \\
\hline CHEMBL1340619 & 688262 & 4.9169 & 4.8591 & TRN \\
\hline
\end{tabular}




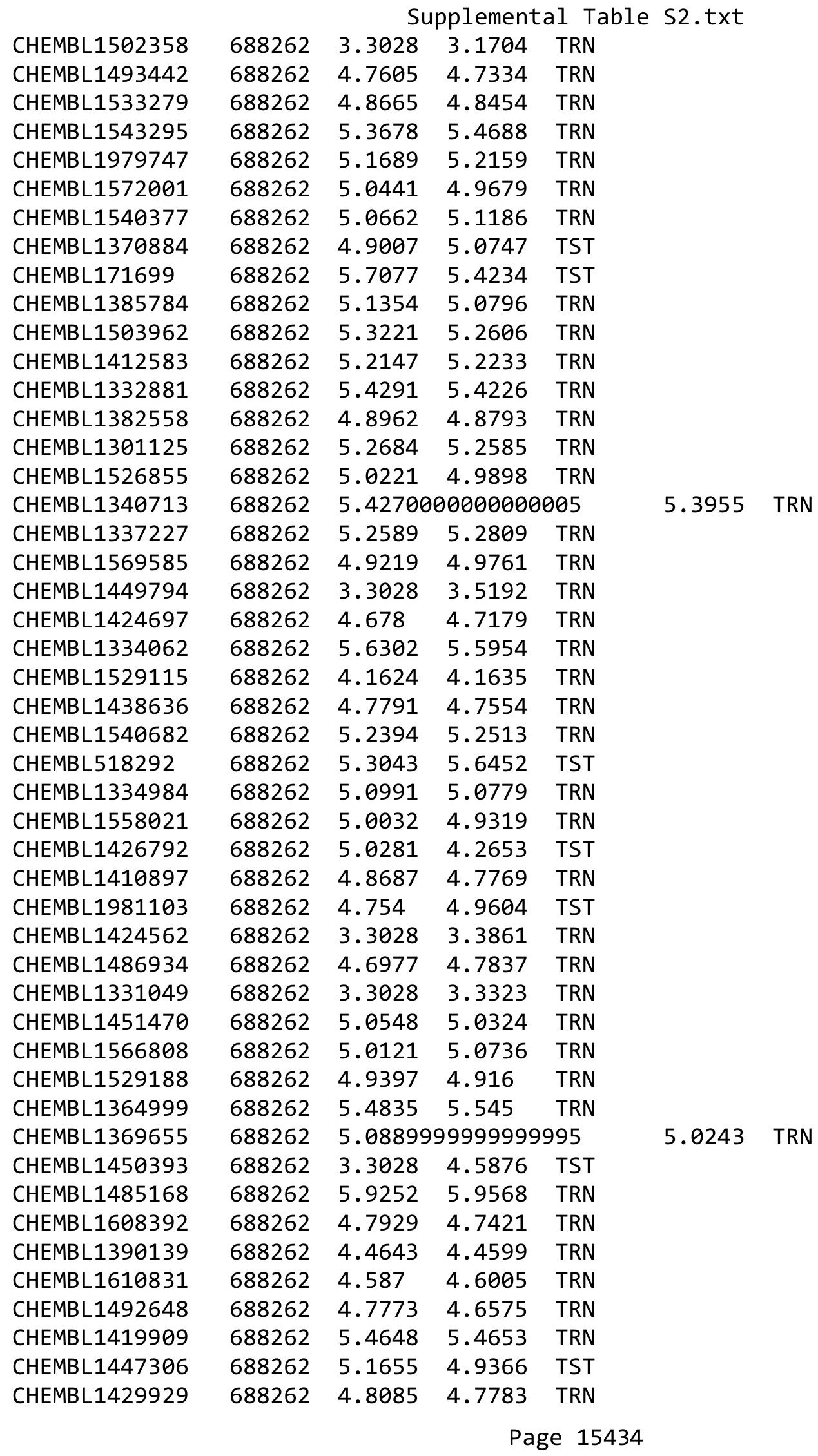




\begin{tabular}{|c|c|c|c|c|c|c|}
\hline & & \multicolumn{5}{|c|}{ Supplemental Table S2.txt } \\
\hline CHEMBL1341981 & 688262 & 4.4098 & 4.2463 & TRN & & \\
\hline CHEMBL1299526 & 688262 & 3.3028 & 3.266 & TRN & & \\
\hline CHEMBL1425921 & 688262 & 4.7423 & 4.6884 & TRN & & \\
\hline CHEMBL1496231 & 688262 & 4.8213 & 4.8451 & TRN & & \\
\hline CHEMBL1999049 & 688262 & 5.1246 & 5.3357 & TST & & \\
\hline CHEMBL1430895 & 688262 & 4.6407 & 4.7054 & TRN & & \\
\hline CHEMBL1535546 & 688262 & 4.9255 & 5.4045 & TST & & \\
\hline CHEMBL1361821 & 688262 & 5.4664 & 5.0569 & TST & & \\
\hline CHEMBL388978 & 688262 & 6.1791 & 5.5024 & TST & & \\
\hline CHEMBL579318 & 688262 & 5.4371 & 4.9859 & TST & & \\
\hline CHEMBL1415555 & 688262 & 3.3028 & 4.7267 & TST & & \\
\hline CHEMBL1303810 & 688262 & 4.8164 & 5.2187 & TST & & \\
\hline CHEMBL1507537 & 688262 & 4.6653 & 4.9568 & TST & & \\
\hline CHEMBL1362503 & 688262 & 5.0102 & 4.7369 & TST & & \\
\hline CHEMBL51931 & 688262 & 5.2993 & 5.4625 & TST & & \\
\hline CHEMBL1480031 & 688262 & 4.2573 & 4.838 & TST & & \\
\hline CHEMBL213580 & 688262 & 5.143 & 4.9866 & TST & & \\
\hline CHEMBL1446971 & 688262 & 4.7251 & 4.3821 & TST & & \\
\hline CHEMBL586135 & 688262 & 6.1169 & 5.0634 & TST & & \\
\hline CHEMBL1369594 & 688262 & 5.1694 & 4.6267 & TST & & \\
\hline CHEMBL237025 & 452894 & 7.1765 & 6.7437 & TRN & & \\
\hline CHEMBL396664 & 452894 & 5.4248 & 5.5282 & TST & & \\
\hline CHEMBL236355 & 452894 & 6.2291 & 6.4782 & TRN & & \\
\hline CHEMBL237032 & 452894 & 5.3401 & 5.1403 & TST & & \\
\hline CHEMBL237222 & 452894 & 3.1726 & 4.3161 & TST & & \\
\hline CHEMBL400028 & 452894 & 5.6073 & 5.6675 & TRN & & \\
\hline CHEMBL237607 & 452894 & 9.699 & 9.1957 & TRN & & \\
\hline CHEMBL237029 & 452894 & 7.9208 & 8.1558 & TRN & & \\
\hline CHEMBL 235706 & 452894 & 3.2648 & 3.2462 & TRN & & \\
\hline CHEMBL237210 & 452894 & 8.9586 & 8.669 & TRN & & \\
\hline CHEMBL235099 & 452894 & 8.9586 & 8.5071 & TRN & & \\
\hline CHEMBL237027 & 452894 & 9.699 & 10.2696 & TRN & & \\
\hline CHEMBL235098 & 452894 & 5.9208 & 5.6987 & TRN & & \\
\hline CHEMBL237599 & 452894 & 6.301 & 6.5946 & TRN & & \\
\hline CHEMBL236148 & 452894 & 9.699 & 9.7491 & TRN & & \\
\hline CHEMBL430174 & 452894 & 4.6405 & 5.2677 & TST & & \\
\hline CHEMBL235707 & 452894 & $5.7620 e$ & j00000006 & 005 & 6.1177 & TRN \\
\hline CHEMBL237165 & 452894 & 8.8239 & 8.6223 & TRN & & \\
\hline CHEMBL236149 & 452894 & 9.3979 & 7.6279 & TRN & & \\
\hline CHEMBL235274 & 452894 & 7.8239 & 7.4248 & TRN & & \\
\hline CHEMBL391222 & 452894 & 8.1079 & 8.27799 & 9999999999 & & I RI \\
\hline CHEMBL237213 & 452894 & 6.4318 & 7.1686 & TST & & \\
\hline CHEMBL237603 & 452894 & 4.397 & 4.9705 & TST & & \\
\hline CHEMBL235055 & 452894 & 4.7899 & 4.2971 & TRN & & \\
\hline CHEMBL391221 & 452894 & 7.1308 & 7.2721 & TRN & & \\
\hline CHEMBL393311 & 452894 & 6.8477 & 7.0423 & TST & & \\
\hline CHEMBL237405 & 452894 & 6.7959 & 7.2984 & TRN & & \\
\hline CHEMBL400222 & 452894 & 6.8962 & 5.7694 & TST & & \\
\hline
\end{tabular}




\begin{tabular}{|c|c|c|c|c|c|c|}
\hline \multirow[b]{2}{*}{ CHEMBL398807 } & \\
\hline & 452894 & 8.8861 & 9.1265 & TRN & & \\
\hline CHEMBL 235028 & 452894 & 3.1726 & 4.3143 & TST & & \\
\hline CHEMBL398789 & 452894 & 6.8539 & 6.1695 & TRN & & \\
\hline CHEMBL393128 & 452894 & 3.5779 & 5.0718 & TST & & \\
\hline CHEMBL 237215 & 452894 & 6.699 & 7.757999 & 99999999 & & TST \\
\hline CHEMBL 235705 & 452894 & 3.9658 & 5.4668 & TRN & & \\
\hline CHEMBL 237403 & 452894 & 8.6576 & 8.2189 & TRN & & \\
\hline CHEMBL 235714 & 452894 & 6.3188 & 5.8639 & TRN & & \\
\hline CHEMBL 237218 & 452894 & 10.6021 & 9.9113 & TRN & & \\
\hline CHEMBL 235067 & 452894 & 6.2147 & 6.5313 & TRN & & \\
\hline CHEMBL 235715 & 452894 & 7.3665 & 7.5128 & TRN & & \\
\hline CHEMBL 237604 & 452894 & 7.6778 & 7.0734 & TRN & & \\
\hline CHEMBL235901 & 452894 & 3.2264 & 3.0219 & TRN & & \\
\hline CHEMBL 398992 & 452894 & 7.2007 & 7.6777 & TRN & & \\
\hline CHEMBL 237023 & 452894 & 7.3565 & 6.761 & TRN & & \\
\hline CHEMBL393310 & 452894 & 6.8239 & 5.9764 & TST & & \\
\hline CHEMBL 238244 & 452894 & 6.4318 & 5.7419 & TST & & \\
\hline CHEMBL238029 & 452894 & 5.9666 & 5.6972 & TST & & \\
\hline CHEMBL428719 & 452894 & 5.4101 & 6.2384 & TRN & & \\
\hline CHEMBL 237212 & 452894 & 7.7212 & 7.5919 & TRN & & \\
\hline CHEMBL391114 & 452894 & 8.0458 & 8.6428 & TRN & & \\
\hline CHEMBL237026 & 452894 & 9.699 & 9.5132 & TRN & & \\
\hline CHEMBL237219 & 452894 & 8.4815 & 9.1388 & TRN & & \\
\hline CHEMBL 235937 & 452894 & 9.699 & 10.2255 & TRN & & \\
\hline CHEMBL 237030 & 452894 & 7.1249 & 7.2159 & TRN & & \\
\hline CHEMBL 237609 & 452894 & 4.6921 & 5.4907 & TST & & \\
\hline CHEMBL 237411 & 452894 & 8.3098 & 8.8316 & TRN & & \\
\hline CHEMBL391115 & 452894 & 6.585 & 6.1223 & TRN & & \\
\hline CHEMBL235936 & 452894 & 6.8539 & 6.9045 & TRN & & \\
\hline CHEMBL 235053 & 452894 & 3.2385 & 3.9222 & TRN & & \\
\hline CHEMBL 237410 & 452894 & 8.7212 & 8.6878 & TRN & & \\
\hline CHEMBL1719740 & 809364 & 3.1024 & 4.3693 & TRN & & \\
\hline CHEMBL1894456 & 809364 & 5.1057 & 4.8981 & TRN & & \\
\hline CHEMBL1722488 & 809364 & $5.82100 €$ & 000000000 & & 5.4435 & TRN \\
\hline CHEMBL1578365 & 809364 & 4.9101 & 4.5083 & TRN & & \\
\hline CHEMBL1557566 & 809364 & 4.8182 & 4.7924 & TRN & & \\
\hline CHEMBL1304960 & 809364 & 5.2774 & 4.6873 & TRN & & \\
\hline CHEMBL1462924 & 809364 & 5.0311 & 4.9313 & TST & & \\
\hline CHEMBL1550633 & 809364 & 5.5784 & 4.6917 & TST & & \\
\hline CHEMBL1981303 & 809364 & 5.341 & 4.9555 & TST & & \\
\hline CHEMBL2361002 & 809364 & 3.1024 & 4.7721 & TST & & \\
\hline CHEMBL1528882 & 809364 & 5.3862 & 4.9449 & TRN & & \\
\hline CHEMBL1511397 & 809364 & 3.1024 & 5.2714 & TST & & \\
\hline CHEMBL1368173 & 809364 & 4.9318 & 4.3174 & TRN & & \\
\hline CHEMBL1582353 & 809364 & 5.4425 & 4.9043 & TRN & & \\
\hline CHEMBL1588045 & 809364 & 4.9914 & 5.0138 & TRN & & \\
\hline CHEMBL1879313 & 809364 & 4.9031 & 4.9201 & TRN & & \\
\hline CHEMBL1419693 & 809364 & $5.20200 €$ & 000000000 & & 4.9467 & TST \\
\hline & & & & 15436 & & \\
\hline
\end{tabular}


Supplemental Table S2.txt

\begin{tabular}{|c|c|c|c|c|}
\hline The & & & & \\
\hline & & .6696 & 4.6097 & \\
\hline$=0$ & & & & \\
\hline AEMBL1 & & & & S \\
\hline AEMBL1710294 & 29364 & 195 & 5605 & \\
\hline HEMBL1865969 & 09364 & 5817 & 5434 & \\
\hline HEMBL1 & 364 & & & \\
\hline IFMBI & & & 1673 & \\
\hline HEMBL1863958 & 64 & & 8434 & \\
\hline HEMBL2001262 & 09364 & 06 & 9259 & \\
\hline HEMBL2002995 & 09364 & 25 & 897 & \\
\hline IEMBL1 & 64 & & 556 & \\
\hline AEMBL1 & & & & \\
\hline HEMBL1 & 64 & & 1851 & \\
\hline HEMBL1 & 64 & & 188 & \\
\hline AEMBL1 & 64 & 24 & 3621 & \\
\hline HEMBLI & 54 & & 952 & \\
\hline HEMBLI & & & & \\
\hline HEMBL1 & 64 & & 7227 & \\
\hline AEMBL1 & & & 501 & \\
\hline AEMBL & 54 & & 629 & \\
\hline AEMBL & & & 904 & 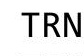 \\
\hline HEMBL & & & 309 & \\
\hline 7670 & 64 & & 431 & \\
\hline AEMBL1 & & & & r. \\
\hline HEMBL: & & & 393 & I RN \\
\hline HEMBL & & & & Niv \\
\hline HFMRI & & & 234 & \\
\hline HEMBL1 & & & & RIV \\
\hline HEMBL1 & & & & s \\
\hline HEMBL1 & & & 847 & RN \\
\hline HEMBL & & & 435 & RN \\
\hline$\triangle 5 M P$ & & & 349 & ST \\
\hline HEMBL1 & & & 575 & IRN \\
\hline HEMBL1330873 & & & 426 & TRN \\
\hline HEMBL & & & 326 & RN \\
\hline HFMRI & & & 896 & I RIV \\
\hline HEMBL & & & 914 & TRN \\
\hline HEMBL1309310 & 309364 & 24 & 5369 & TRN \\
\hline AEMBL1 & & & 015 & ГRN \\
\hline HEMBL1 & & & 138 & \\
\hline CHEMBL1 & & & 6633 & TRN \\
\hline HEMBL1 & & & 9089 & RN \\
\hline AEMBL1 & 09364 & & 4677 & TRN \\
\hline HEMBL1 & & & 5945 & $\mathrm{~N}$ \\
\hline CHEMBL1 & & & 9534 & \\
\hline CHEMBL1571998 & & & .2529 & \\
\hline CHEMBL1408688 & 809364 & 6.4559 & 5.3917 & RN \\
\hline
\end{tabular}

Page 15437 
Supplemental Table S2.txt

\begin{tabular}{|c|c|c|c|c|}
\hline CHEMBL1700311 & 809364 & 4.9914 & 4.6901 & TRN \\
\hline CHEMBL1558819 & 809364 & 5.7077 & 5.2619 & TRN \\
\hline CHEMBL1323071 & 809364 & 5.5686 & 5.1297 & TRN \\
\hline CHEMBL1364287 & 809364 & 5.6126 & 4.6155 & TRN \\
\hline CHEMBL1891615 & 809364 & 5.3575 & 4.8723 & TST \\
\hline CHEMBL1881477 & 809364 & 5.8069 & 4.6994 & TRN \\
\hline CHEMBL1319484 & 809364 & 3.1024 & 4.7398 & TRN \\
\hline CHEMBL1570792 & 809364 & 5.3686 & 4.7256 & TRN \\
\hline CHEMBL1405239 & 809364 & 4.3706 & 5.11 & TRN \\
\hline CHEMBL1307703 & 809364 & 5.4449 & 5.4033 & TRN \\
\hline CHEMBL1409280 & 809364 & 3.1024 & 4.6061 & TRN \\
\hline CHEMBL1733950 & 809364 & 5.9586 & 4.7707 & TRN \\
\hline CHEMBL1721460 & 809364 & 4.4413 & 4.7713 & TST \\
\hline CHEMBL1363579 & 809364 & 4.3675 & 4.9901 & TRN \\
\hline CHEMBL1605288 & 809364 & 5.4711 & 5.4461 & TRN \\
\hline CHEMBL1538790 & 809364 & 5.0595 & 5.228 & TRN \\
\hline CHEMBL1525257 & 809364 & 5.0057 & 5.3594 & TRN \\
\hline CHEMBL1985765 & 809364 & 5.4949 & 4.8374 & TRN \\
\hline CHEMBL1865860 & 809364 & 3.1024 & 4.6561 & TST \\
\hline CHEMBL1721546 & 809364 & 5.0862 & 5.0454 & TST \\
\hline CHEMBL1891356 & 809364 & 5.0691 & 4.7678 & TRN \\
\hline CHEMBL1557763 & 809364 & 5.5287 & 4.9092 & TRN \\
\hline CHEMBL1612775 & 809364 & 4.6904 & 4.9036 & TRN \\
\hline CHEMBL1479872 & 809364 & 3.1024 & 4.3914 & TRN \\
\hline CHEMBL1965966 & 809364 & 3.1024 & 4.9709 & TRN \\
\hline CHEMBL1728704 & 809364 & 5.5391 & 4.6366 & TRN \\
\hline CHEMBL1443499 & 809364 & 5.3872 & 5.1304 & TRN \\
\hline CHEMBL1315337 & 809364 & 5.2815 & 4.5868 & TRN \\
\hline CHEMBL1731097 & 809364 & 3.1024 & 5.1988 & TST \\
\hline CHEMBL1882485 & 809364 & 5.1439 & 4.9782 & TRN \\
\hline CHEMBL1429513 & 809364 & 4.9469 & 4.5886 & TRN \\
\hline CHEMBL1964556 & 809364 & 3.1024 & 5.1286 & TRN \\
\hline CHEMBL1496105 & 809364 & 5.3497 & 5.3474 & TRN \\
\hline CHEMBL1870332 & 809364 & 5.1451 & 4.9779 & TRN \\
\hline CHEMBL1701835 & 809364 & 5.0146 & 4.7811 & TRN \\
\hline CHEMBL1470755 & 809364 & 5.0311 & 4.8555 & TRN \\
\hline CHEMBL1723920 & 809364 & 4.3947 & 4.8748 & TST \\
\hline CHEMBL1420497 & 809364 & 5.4685 & 4.7432 & TRN \\
\hline CHEMBL1337268 & 809364 & 5.2798 & 5.0997 & TRN \\
\hline CHEMBL1713021 & 809364 & 5.4001 & 5.2451 & TRN \\
\hline CHEMBL1711830 & 809364 & 5.3696 & 5.0044 & TRN \\
\hline CHEMBL1503062 & 809364 & 4.7258 & 4.7973 & TRN \\
\hline CHEMBL1391456 & 809364 & 3.1024 & 4.6172 & TRN \\
\hline CHEMBL1985895 & 809364 & 4.9245 & 4.4089 & TRN \\
\hline CHEMBL1414773 & 809364 & 4.4881 & 4.8688 & TRN \\
\hline CHEMBL1414819 & 809364 & 4.7496 & 5.44799 & 99999999995 \\
\hline CHEMBL1346278 & 809364 & 6.0009 & 5.3872 & TRN \\
\hline CHEMBL1547410 & 809364 & 5.3872 & 4.2767 & TRN \\
\hline
\end{tabular}

Page 15438 


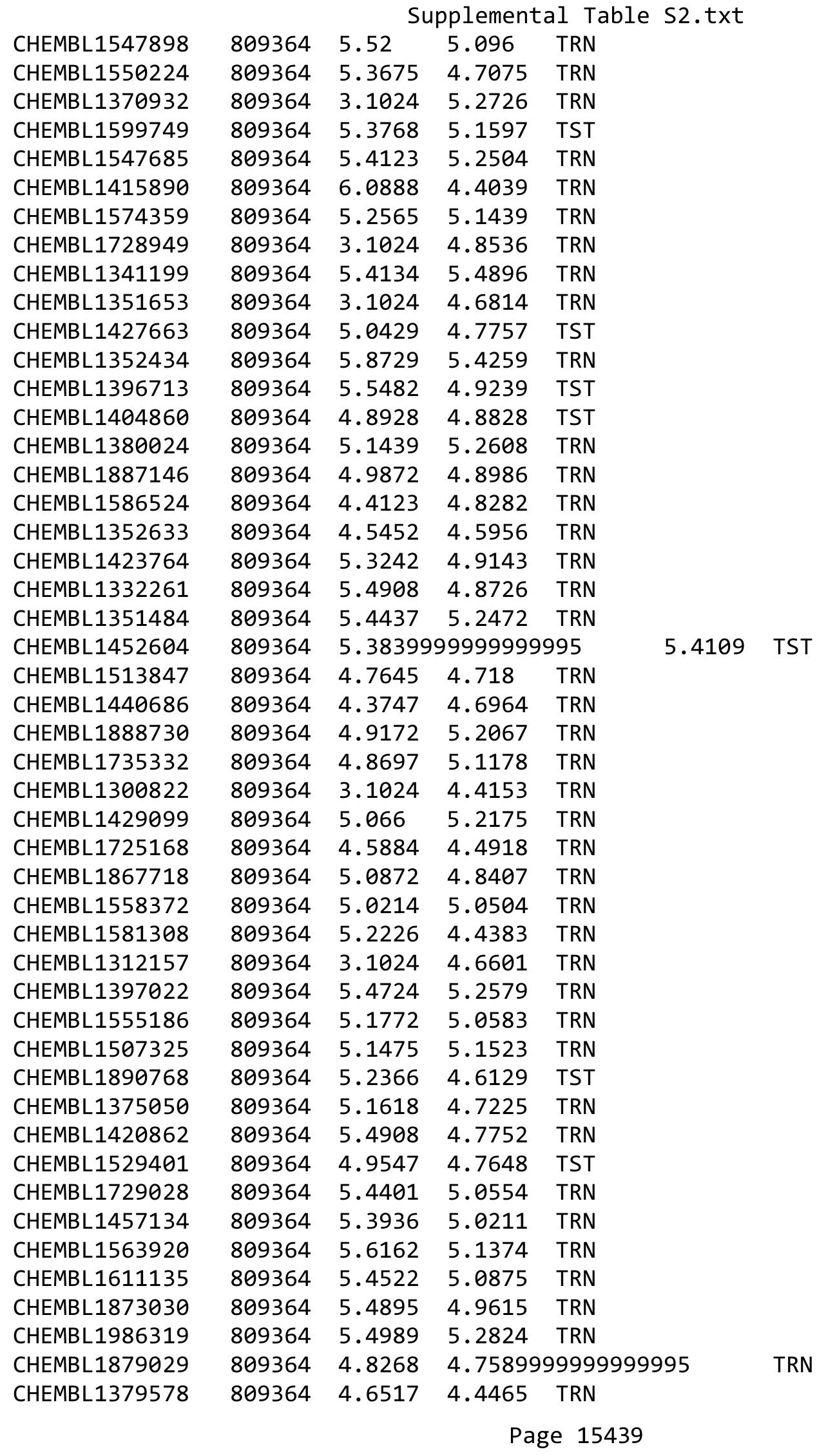




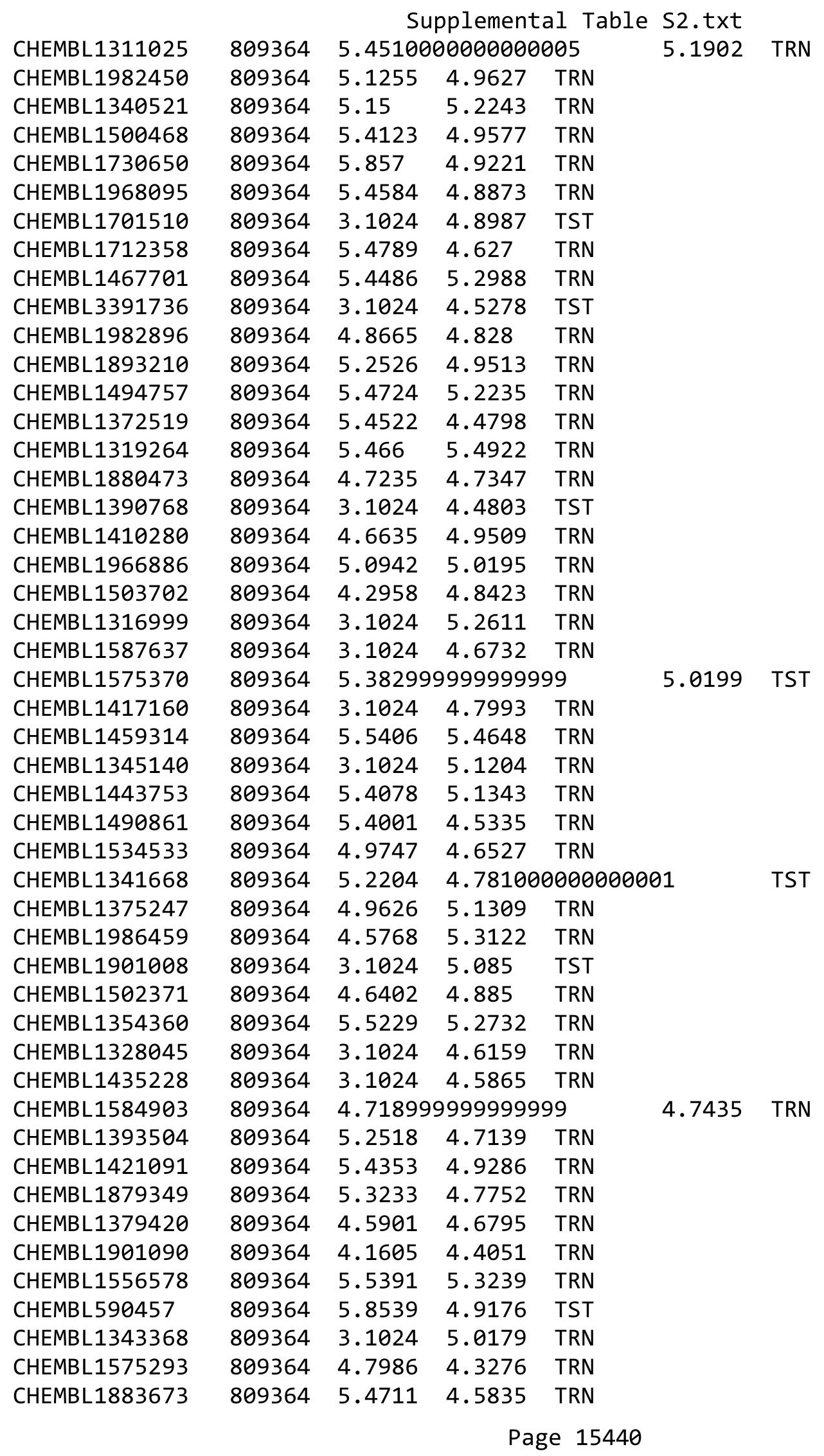


Supplemental Table S2.txt

\begin{tabular}{|c|c|c|c|c|}
\hline 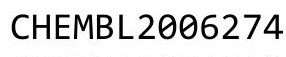 & & & & \\
\hline HEMBL1974112 & 99364 & 0788 & 1599 & \\
\hline HEMBL1480502 & $\partial 9364$ & 024 & 5747 & \\
\hline 553 & 364 & & 3844 & \\
\hline EMBL15 & 364 & & 2213 & \\
\hline HEMBL1495663 & 09364 & 7033 & 5138 & \\
\hline HEMBL1410653 & 09364 & .5817 & .3468 & \\
\hline HEMBL17 & & & & \\
\hline IEMBL19 & 64 & & .2902 & \\
\hline IEMBL16e & & & & \\
\hline HEMBL1511158 & 09364 & 69 & . 9729 & \\
\hline HEMBL1880968 & 364 & & & \\
\hline HEMBL1538976 & & & 86 & \\
\hline AEMBL198 & & & & \\
\hline IEMBL151 & & & & \\
\hline HEMBL198 & 64 & & & \\
\hline HEMBL 20 & 64 & & & \\
\hline HEMBL15 & 54 & 4 & 13 & \\
\hline HEMBL15 & & & 735 & \\
\hline HEMBL1C & & & 34 & \\
\hline HEMBL13. & 64 & & & \\
\hline HEMBL13e & 64 & & & \\
\hline HEMBL15 & 54 & & & \\
\hline HEMBL15 & & & & \\
\hline HEM & & & 94 & RN \\
\hline HEMBL19 & 64 & & & RN \\
\hline HEMBL140 & & & & \\
\hline HEMBL19 & & & & \\
\hline HEMBL19 & & & & \\
\hline HEMBL14 & 54 & & 94 & RN \\
\hline HEMBL199 & & & & ST \\
\hline HEMBL1385111 & 64 & & & RN \\
\hline HEMBL14 & & & & IRN \\
\hline HEM & & & 97 & TRN \\
\hline HEMBL 14 & & & 4.7704 & TST \\
\hline HEMBL1313574 & & & & RN \\
\hline HEMBL1526033 & 64 & & & ГRN \\
\hline TLT & & & & $\ln$ \\
\hline 1 19 & & & 55 & TRN \\
\hline HEMBL $16 €$ & & & & RN \\
\hline HEMBL1992 & 64 & & & ГRN \\
\hline HEMBL15 & & & & $\Gamma \mathrm{F}$ \\
\hline 242 & & & & \\
\hline HEMBL1372308 & & & 8436 & TST \\
\hline HEMBL1903425 & & & 7194 & RN \\
\hline HEMBL170 & 9364 & 5 . & 751 & $N$ \\
\hline HEMBL1468 & & & & \\
\hline НСМD 100050 & & & 7.8344 & \\
\hline
\end{tabular}

Page 15441 
Supplemental Table S2.txt

\begin{tabular}{|c|c|c|c|c|c|}
\hline CHEMBL1731522 & 809364 & 5.9586 & 5.4613 & TRN & \\
\hline CHEMBL 249301 & 809364 & 5.0044 & 5.2259 & TRN & \\
\hline CHEMBL1589231 & 809364 & 5.6421 & 4.8705 & TRN & \\
\hline CHEMBL1975660 & 809364 & 5.0991 & 5.3906 & TST & \\
\hline CHEMBL1540513 & 809364 & 5.7496 & 5.2182 & TRN & \\
\hline CHEMBL1901671 & 809364 & 5.2299 & 4.7735 & TRN & \\
\hline CHEMBL1901020 & 809364 & 5.0119 & 4.63 & TRN & \\
\hline CHEMBL1868131 & 809364 & 5.2565 & 4.553 & TRN & \\
\hline CHEMBL1558069 & 809364 & 5.2612 & 4.9957 & TRN & \\
\hline CHEMBL1385597 & 809364 & 4.8633 & 4.7814 & TRN & \\
\hline CHEMBL1565318 & 809364 & 4.6696 & 4.7306 & TRN & \\
\hline CHEMBL1403619 & 809364 & 5.2857 & 4.6458 & TRN & \\
\hline CHEMBL1993203 & 809364 & 4.5229 & 5.1527 & TRN & \\
\hline CHEMBL1872827 & 809364 & 3.1024 & 4.8697 & TRN & \\
\hline CHEMBL1456075 & 809364 & 5.4737 & 5.3309 & TRN & \\
\hline CHEMBL1481069 & 809364 & 4.1831 & 4.7834 & TRN & \\
\hline CHEMBL1306971 & 809364 & 4.3915 & 5.0897 & TRN & \\
\hline CHEMBL1418287 & 809364 & 3.1024 & 4.4002 & TRN & \\
\hline CHEMBL1580005 & 809364 & 3.1024 & 5.2933 & TRN & \\
\hline CHEMBL1892448 & 809364 & 5.38299 & 99999999 & 9 & 5.0523 \\
\hline CHEMBL1711809 & 809364 & 4.7905 & 4.8851 & TRN & \\
\hline CHEMBL 2002517 & 809364 & 4.9872 & 5.1957 & TRN & \\
\hline CHEMBL1504419 & 809364 & 3.1024 & 4.7397 & TRN & \\
\hline CHEMBL1575354 & 809364 & 5.3233 & 5.1987 & TRN & \\
\hline CHEMBL1588014 & 809364 & 5.2233 & 4.7118 & TRN & \\
\hline CHEMBL1734079 & 809364 & 5.6383 & 4.7465 & TRN & \\
\hline CHEMBL1474877 & 809364 & 5.5735 & 5.1431 & TRN & \\
\hline CHEMBL177938 & 809364 & 4.5058 & 4.8537 & TRN & \\
\hline CHEMBL1722673 & 809364 & 5.5719 & 4.6584 & TST & \\
\hline CHEMBL 1895020 & 809364 & 3.1024 & 4.4055 & TRN & \\
\hline CHEMBL1545864 & 809364 & 5.9031 & 4.8653 & TRN & \\
\hline CHEMBL1507187 & 809364 & 3.1024 & 4.9912 & TRN & \\
\hline CHEMBL1550273 & 809364 & 5.9172 & 4.8178 & TRN & \\
\hline CHEMBL1562798 & 809364 & 5.5361 & 4.7444 & TST & \\
\hline CHEMBL1487042 & 809364 & 5.5003 & 4.9131 & TRN & \\
\hline CHEMBL3391749 & 809364 & 5.4672 & 4.5021 & TST & \\
\hline CHEMBL1474526 & 809364 & 6.1267 & 5.2588 & TRN & \\
\hline CHEMBL1317012 & 809364 & 4.9626 & 5.0039 & TRN & \\
\hline CHEMBL1718951 & 809364 & 5.2041 & 4.8734 & TST & \\
\hline CHEMBL1566701 & 809364 & 5.011 & 4.2169 & TST & \\
\hline CHEMBL1321703 & 809364 & 3.1024 & 4.9237 & TRN & \\
\hline CHEMBL1723414 & 809364 & 5.8041 & 5.1747 & TRN & \\
\hline CHEMBL1455943 & 809364 & 3.1024 & 4.8757 & TRN & \\
\hline CHEMBL1880550 & 809364 & 5.059 & 4.775 & TRN & \\
\hline CHEMBL1730810 & 809364 & 4.9957 & 4.9889 & TST & \\
\hline CHEMBL1408518 & 809364 & 5.1959 & 4.8791 & TRN & \\
\hline CHEMBL1414448 & 809364 & 4.5622 & 5.0191 & TRN & \\
\hline CHEMBL1487964 & 809364 & 5.9706 & 4.9485 & TST & \\
\hline
\end{tabular}




\begin{tabular}{|c|c|c|c|c|c|c|}
\hline & & \multicolumn{5}{|c|}{ Supplemental Table s2.txt } \\
\hline CHEMBL1698139 & 809364 & 4.7959 & 5.0612 & TST & & \\
\hline CHEMBL1873328 & 809364 & 4.8633 & 5.0903 & TRN & & \\
\hline CHEMBL1393529 & 809364 & 5.8013 & 4.7756 & TRN & & \\
\hline CHEMBL1559375 & 809364 & 5.058 & 5.1029 & TRN & & \\
\hline CHEMBL1712645 & 809364 & 5.1733 & 4.4464 & TRN & & \\
\hline CHEMBL1311198 & 809364 & 4.9706 & 4.422 & TRN & & \\
\hline CHEMBL1422847 & 809364 & 5.3429 & 4.8128 & TRN & & \\
\hline CHEMBL1497333 & 809364 & 5.5214 & 5.2902 & TRN & & \\
\hline CHEMBL1470504 & 809364 & 5.1537 & 4.6106 & TRN & & \\
\hline CHEMBL1402745 & 809364 & 4.6757 & 5.1592 & TRN & & \\
\hline CHEMBL1555363 & 809364 & 6.4202 & 5.2417 & TRN & & \\
\hline CHEMBL1878680 & 809364 & 5.3936 & 5.2851 & TRN & & \\
\hline CHEMBL1577620 & 809364 & 6.1249 & 5.6717 & TRN & & \\
\hline CHEMBL56897 & 809364 & \multicolumn{3}{|c|}{6.2139999999999995} & 5.0647 & TST \\
\hline CHEMBL 2005602 & 809364 & 4.8665 & 4.792 & TRN & & \\
\hline CHEMBL1563287 & 809364 & 5.2027 & 4.9412 & TRN & & \\
\hline CHEMBL1572906 & 809364 & 4.9747 & 4.7744 & TRN & & \\
\hline CHEMBL1410428 & 809364 & 5.4935 & 4.5421 & TST & & \\
\hline CHEMBL1348996 & 809364 & 3.1024 & 3.8536 & TRN & & \\
\hline CHEMBL1277891 & 809364 & 5.2684 & 5.5388 & TRN & & \\
\hline CHEMBL1586992 & 809364 & 5.1838 & 4.8644 & TRN & & \\
\hline CHEMBL1322917 & 809364 & 5.3188 & 4.7891 & TRN & & \\
\hline CHEMBL1382123 & 809364 & \multicolumn{3}{|c|}{4.821000000000001} & 4.9216 & TRN \\
\hline CHEMBL1973603 & 809364 & 5.4425 & 4.4382 & TRN & & \\
\hline CHEMBL1439140 & 809364 & 5.266 & 4.7016 & TRN & & \\
\hline CHEMBL1890635 & 809364 & 3.1024 & 5.4094 & TST & & \\
\hline CHEMBL1987417 & 809364 & 5.284 & 4.96 & TRN & & \\
\hline CHEMBL1438732 & 809364 & 5.224 & 5.3337 & TRN & & \\
\hline CHEMBL1472228 & 809364 & 3.1024 & 4.8662 & TRN & & \\
\hline CHEMBL1510895 & 809364 & 5.4248 & 5.0403 & TRN & & \\
\hline CHEMBL1868168 & 809364 & 5.1707 & 5.0137 & TRN & & \\
\hline CHEMBL1489244 & 809364 & 5.1343 & 5.1491 & TRN & & \\
\hline CHEMBL1714012 & 809364 & 4.9626 & 5.2962 & TST & & \\
\hline CHEMBL1456803 & 809364 & 3.1024 & 4.8414 & TRN & & \\
\hline CHEMBL1863599 & 809364 & 4.618 & 5.2456 & TST & & \\
\hline CHEMBL1601471 & 809364 & 4.8761 & 5.1052 & TRN & & \\
\hline CHEMBL1427466 & 809364 & 5.2069 & 5.0545 & TRN & & \\
\hline CHEMBL1900021 & 809364 & 3.1024 & 4.6143 & TST & & \\
\hline CHEMBL1904672 & 809364 & 4.8239 & 5.0563 & TRN & & \\
\hline CHEMBL1348954 & 809364 & 3.1024 & 4.5867 & TST & & \\
\hline CHEMBL1965579 & 809364 & 4.8962 & 5.0722 & TRN & & \\
\hline CHEMBL1969457 & 809364 & 5.0825 & 4.4284 & TRN & & \\
\hline CHEMBL1580522 & 809364 & \multicolumn{3}{|c|}{5.3839999999999995} & 4.5205 & TRN \\
\hline CHEMBL1301826 & 809364 & 5.0434 & 4.813 & TRN & & \\
\hline CHEMBL1366381 & 809364 & 5.6882 & 4.738 & TRN & & \\
\hline CHEMBL1431520 & 809364 & 5.4908 & 4.6254 & TRN & & \\
\hline CHEMBL1467641 & 809364 & 4.6253 & 4.8876 & TRN & & \\
\hline CHEMBL1999359 & 809364 & 5.3072 & 5.0484 & TRN & & \\
\hline
\end{tabular}




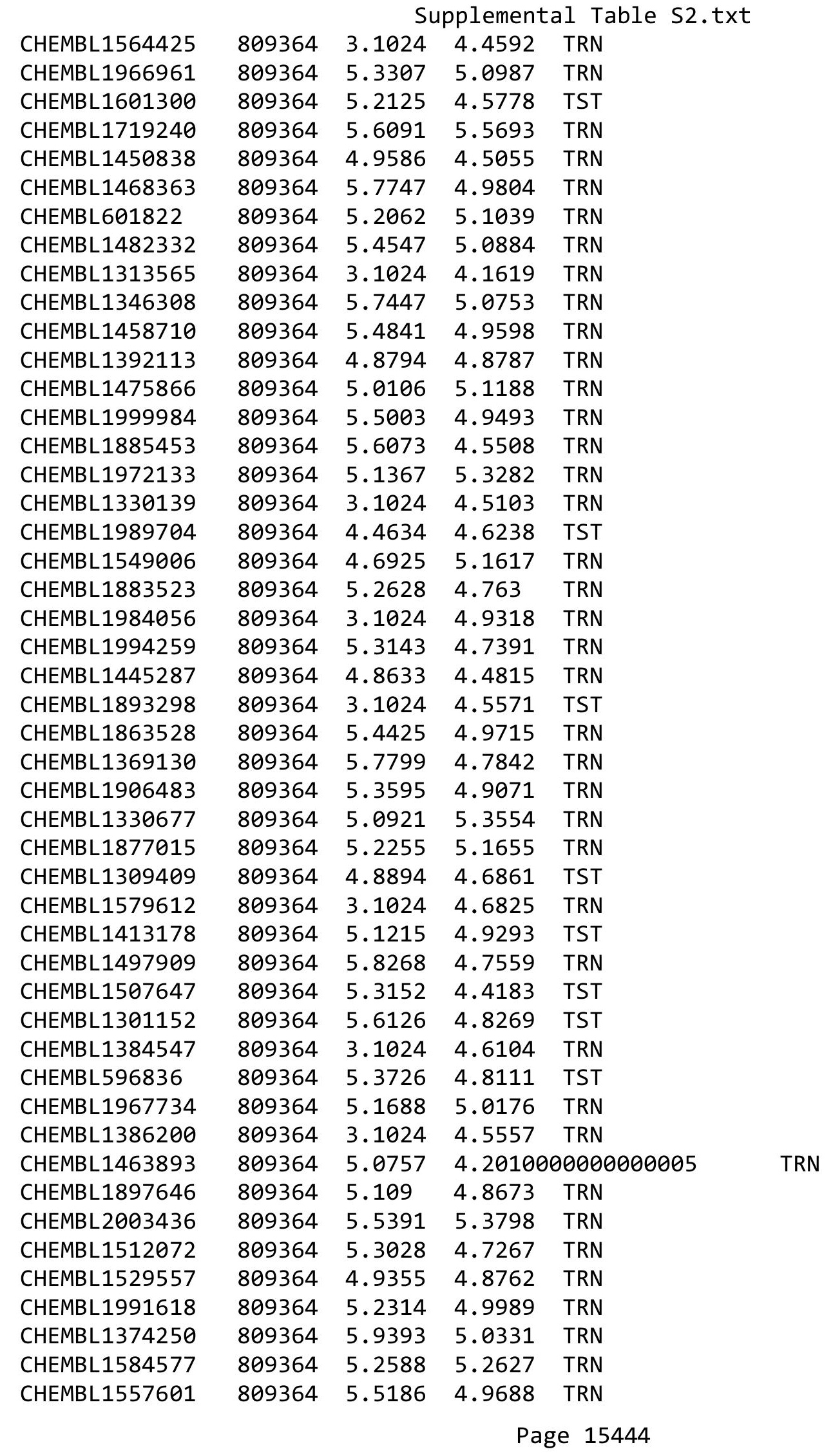


Supplemental Table S2.txt

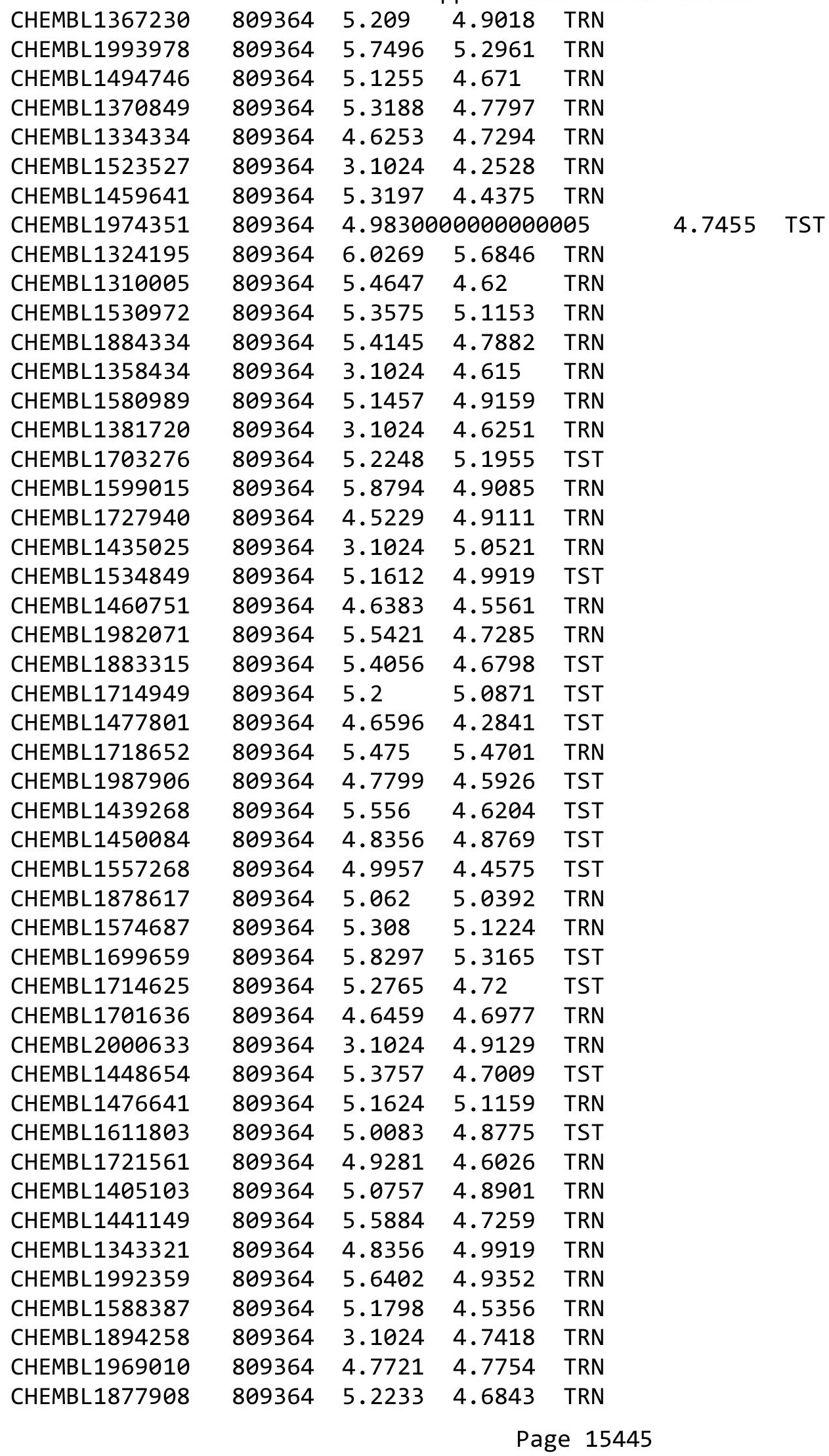


Supplemental Table S2.txt

\begin{tabular}{|c|c|c|c|c|c|}
\hline CHEMBL1503607 & 809364 & 5.767 & 4.5356 & TST & \\
\hline CHEMBL1428612 & 809364 & 5.5817 & 5.0781 & TRN & \\
\hline CHEMBL1990248 & 809364 & 3.1024 & 5.1209 & TST & \\
\hline CHEMBL1558744 & 809364 & 4.9586 & 4.9775 & TRN & \\
\hline CHEMBL1352043 & 809364 & 5.8861 & 5.3101 & TRN & \\
\hline CHEMBL 2006569 & 809364 & 5.1343 & 5.3035 & TRN & \\
\hline CHEMBL1981305 & 809364 & 5.6326 & 5.5872 & TRN & \\
\hline CHEMBL1880451 & 809364 & 5.289 & 4.7714 & TST & \\
\hline CHEMBL1492744 & 809364 & 4.7986 & 4.6829 & TST & \\
\hline CHEMBL1906351 & 809364 & 5.4855 & 4.7707 & TRN & \\
\hline CHEMBL1412745 & 809364 & 5.0711 & 4.7565 & TRN & \\
\hline CHEMBL1570212 & 809364 & 5.6478 & 4.3796 & TRN & \\
\hline CHEMBL1516099 & 809364 & 5.3429 & 5.2909 & TRN & \\
\hline CHEMBL1596732 & 809364 & 5.5086 & 5.2184 & TST & \\
\hline CHEMBL1308563 & 809364 & 5.3449 & 4.7935 & TRN & \\
\hline CHEMBL1362217 & 809364 & 4.8633 & 4.97199 & э99999999995 & TRN \\
\hline CHEMBL1882724 & 809364 & 5.3635 & 5.2021 & TST & \\
\hline CHEMBL1699180 & 809364 & 4.7799 & 5.0138 & TST & \\
\hline CHEMBL1399390 & 809364 & 5.8601 & 5.0101 & TRN & \\
\hline CHEMBL1503376 & 809364 & 5.2366 & 5.1221 & TRN & \\
\hline CHEMBL1300649 & 809364 & 3.1024 & 5.2415 & TRN & \\
\hline CHEMBL1430891 & 809364 & 5.4283 & 4.5498 & TRN & \\
\hline CHEMBL1474285 & 809364 & 5.0814 & 4.9532 & TST & \\
\hline CHEMBL1314090 & 809364 & 4.8894 & 4.784 & TST & \\
\hline CHEMBL1865197 & 809364 & 4.5114 & 4.5202 & TRN & \\
\hline CHEMBL1505157 & 809364 & 4.8894 & 4.717 & TRN & \\
\hline CHEMBL1975975 & 809364 & 4.7212 & 4.6603 & TRN & \\
\hline CHEMBL1408484 & 809364 & 4.6021 & 5.1951 & TRN & \\
\hline CHEMBL1390969 & 809364 & 4.9666 & 4.8094 & TRN & \\
\hline CHEMBL 2004144 & 809364 & 5.1175 & 5.3499 & TRN & \\
\hline CHEMBL1461430 & 809364 & 4.8729 & 4.5614 & TRN & \\
\hline CHEMBL1583472 & 809364 & 4.8268 & 5.0824 & TRN & \\
\hline CHEMBL1311274 & 809364 & 5.9136 & 4.5241 & TRN & \\
\hline CHEMBL1731988 & 809364 & 3.1024 & 4.8798 & TRN & \\
\hline CHEMBL1723682 & 809364 & 5.2733 & 4.4446 & TRN & \\
\hline CHEMBL1372064 & 809364 & 4.8928 & 5.1158 & TRN & \\
\hline CHEMBL1971553 & 809364 & 5.684 & 5.1202 & TRN & \\
\hline CHEMBL1905593 & 809364 & 5.4547 & 4.6297 & TRN & \\
\hline CHEMBL1463672 & 809364 & 3.1024 & 4.6166 & TST & \\
\hline CHEMBL1427949 & 809364 & 5.3958 & 4.6605 & TRN & \\
\hline CHEMBL1339699 & 809364 & 5.2487 & 4.813 & TRN & \\
\hline CHEMBL1506903 & 809364 & 5.6498 & 5.2795 & TRN & \\
\hline CHEMBL1987094 & 809364 & 5.1772 & 5.1558 & TRN & \\
\hline CHEMBL1513925 & 809364 & 5.2668 & 5.0781 & TRN & \\
\hline CHEMBL1603166 & 809364 & 5.4225 & 5.1805 & TRN & \\
\hline CHEMBL1340032 & 809364 & 5.5686 & 5.1948 & TRN & \\
\hline CHEMBL1491734 & 809364 & 5.0031 & 4.7498 & TST & \\
\hline CHEMBL1323249 & 809364 & 3.1024 & 4.459 & TRN & \\
\hline
\end{tabular}




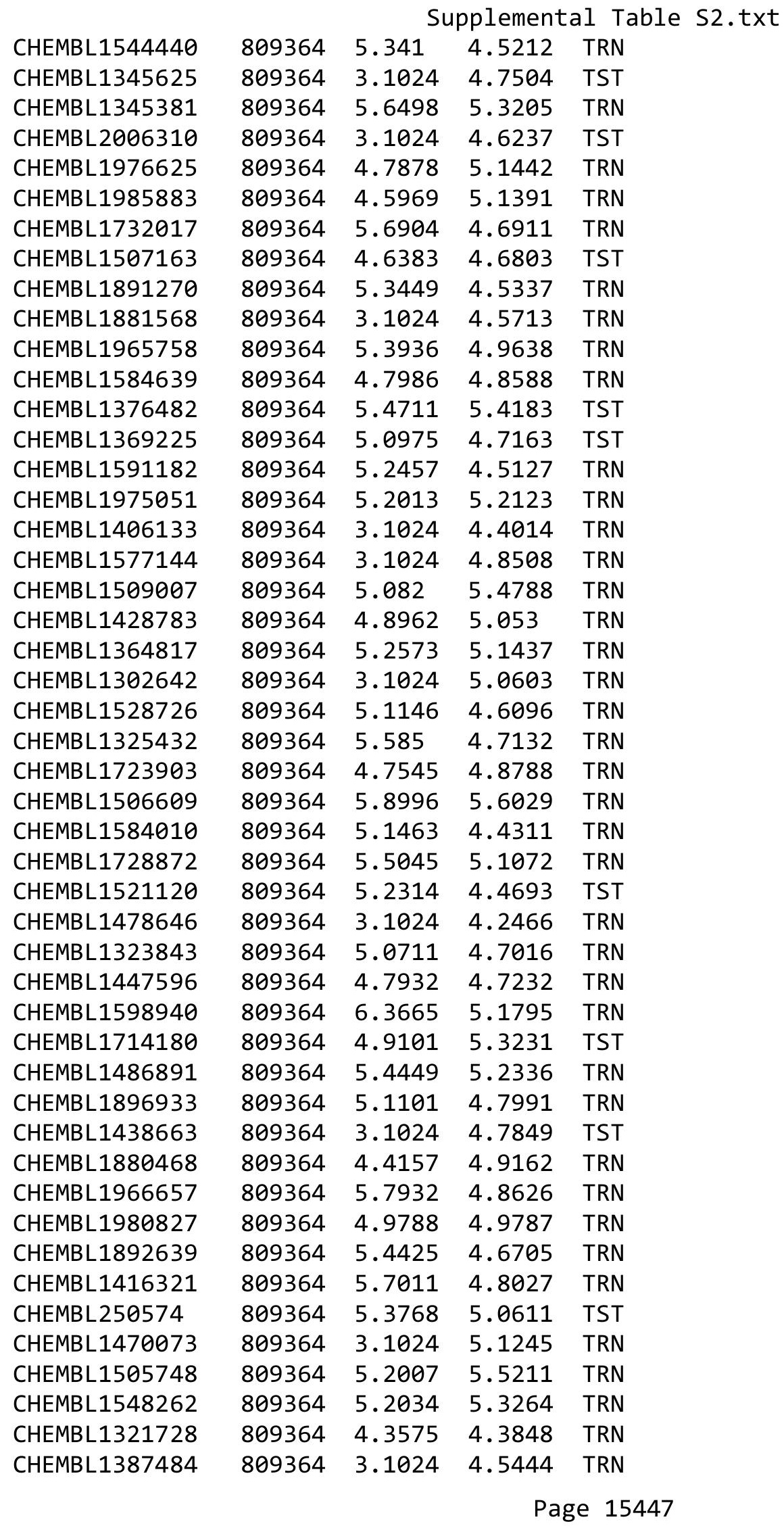




\begin{tabular}{|c|c|c|c|c|c|}
\hline & & \multicolumn{4}{|c|}{ Supplemental Table S2.txt } \\
\hline CHEMBL1554786 & 809364 & 5.5317 & 5.3165 & TRN & \\
\hline CHEMBL1987344 & 809364 & 5.015 & 4.9765 & TRN & \\
\hline CHEMBL1902783 & 809364 & 5.1871 & 4.7346 & TRN & \\
\hline CHEMBL1729533 & 809364 & 5.4056 & 4.8446 & TRN & \\
\hline CHEMBL1365739 & 809364 & 4.9245 & 4.4734 & TRN & \\
\hline CHEMBL1703524 & 809364 & 5.8665 & 5.075 & TRN & \\
\hline CHEMBL1464128 & 809364 & 5.3645 & 4.4456 & TST & \\
\hline CHEMBL1879523 & 809364 & 5.3143 & 4.9711 & TST & \\
\hline CHEMBL1868534 & 809364 & 5.4295 & 5.2882 & TST & \\
\hline CHEMBL1562838 & 809364 & 3.1024 & 5.0604 & TRN & \\
\hline CHEMBL1395840 & 809364 & 5.9666 & 5.1535 & TRN & \\
\hline CHEMBL1352504 & 809364 & 4.9469 & 5.0731 & TRN & \\
\hline CHEMBL1867569 & 809364 & 5.3089 & 4.7461 & TRN & \\
\hline CHEMBL1491564 & 809364 & 5.7033 & 5.6979 & TRN & \\
\hline CHEMBL1450049 & 809364 & 5.1057 & 4.8878 & TST & \\
\hline CHEMBL1476695 & 809364 & 5.2125 & 5.311 & TST & \\
\hline CHEMBL1900199 & 809364 & 4.6402 & 4.8835 & TST & \\
\hline CHEMBL1604372 & 809364 & 4.317 & 5.0881 & TST & \\
\hline CHEMBL1525055 & 809364 & 5.6271 & 5.2431 & TST & \\
\hline CHEMBL1472051 & 809364 & 4.4283 & 4.9406 & TST & \\
\hline CHEMBL1531618 & 809364 & 3.1024 & 4.8855 & TST & \\
\hline CHEMBL1967640 & 809364 & 5.0106 & 4.8746 & TST & \\
\hline CHEMBL1423858 & 809364 & 5.3536 & 4.6504 & TST & \\
\hline CHEMBL1994456 & 809364 & 5.4413 & 5.5421 & TST & \\
\hline CHEMBL 1456690 & 809364 & 4.9957 & 5.4317 & TST & \\
\hline CHEMBL1887390 & 809364 & 4.9547 & 4.90600 & 0000000001 & TST \\
\hline CHEMBL1502259 & 809364 & 4.5867 & 4.9921 & TST & \\
\hline CHEMBL1411635 & 809364 & 3.1024 & 4.6153 & TST & \\
\hline CHEMBL1880018 & 809364 & 5.4425 & 4.6792 & TST & \\
\hline CHEMBL 1604180 & 809364 & 5.6676 & 4.9157 & TST & \\
\hline CHEMBL1904959 & 809364 & 5.2907 & 4.9348 & TST & \\
\hline CHEMBL1493942 & 809364 & 3.1024 & 4.8272 & TST & \\
\hline CHEMBL1549839 & 809364 & 4.7033 & 5.2668 & TST & \\
\hline CHEMBL1314124 & 809364 & 5.2882 & 4.6888 & TST & \\
\hline CHEMBL1365163 & 809364 & 5.3478 & 5.0465 & TST & \\
\hline CHEMBL1699961 & 809364 & 4.8508 & 5.0205 & TST & \\
\hline CHEMBL1453916 & 809364 & 5.4134 & 5.1179 & TST & \\
\hline CHEMBL1524990 & 809364 & 5.0448 & 4.8675 & TST & \\
\hline CHEMBL1448193 & 809364 & 3.1024 & 4.5557 & TST & \\
\hline CHEMBL1595428 & 809364 & 4.7825 & 5.1654 & TST & \\
\hline CHEMBL1870365 & 809364 & 3.1024 & 5.0143 & TST & \\
\hline CHEMBL1985708 & 809364 & 5.0044 & 5.0061 & TST & \\
\hline CHEMBL1867143 & 809364 & 3.1024 & 4.8589 & TST & \\
\hline CHEMBL1878991 & 809364 & 3.1024 & 4.9164 & TST & \\
\hline CHEMBL1530211 & 809364 & 4.399 & 4.5494 & TST & \\
\hline CHEMBL1307821 & 809364 & 5.0872 & 4.8146 & TST & \\
\hline CHEMBL1978228 & 809364 & 6.2924 & 5.2381 & TST & \\
\hline CHEMBL1731294 & 809364 & 6.4815 & 5.1848 & TST & \\
\hline
\end{tabular}


Supplemental Table S2.txt

\begin{tabular}{|c|c|c|c|c|c|}
\hline CHEMBL1599400 & 809364 & 4.9626 & 5.0254 & TST & \\
\hline CHEMBL422237 & 809364 & 4.9172 & 4.6167 & TST & \\
\hline CHEMBL1557060 & 809364 & 5.1675 & 5.0444 & TST & \\
\hline CHEMBL1596782 & 809364 & 4.8239 & 5.0506 & TST & \\
\hline CHEMBL1865363 & 809364 & 5.2 & 4.8065 & TST & \\
\hline CHEMBL1311027 & 809364 & 4.3487 & 4.4206 & TST & \\
\hline CHEMBL1497342 & 809364 & 5.2 & 4.7766 & TST & \\
\hline CHEMBL1467354 & 809364 & 4.7905 & 5.1221 & TST & \\
\hline CHEMBL1524400 & 809364 & 4.8327 & 5.0622 & TST & \\
\hline CHEMBL 2004928 & 809364 & 5.6108 & 4.9916 & TST & \\
\hline CHEMBL1888908 & 809364 & 5.2175 & 4.7462 & TST & \\
\hline CHEMBL1702908 & 809364 & 6.1373 & 4.8442 & TST & \\
\hline CHEMBL1328052 & 809364 & 5.1451 & 5.1198 & TST & \\
\hline CHEMBL1512150 & 809364 & 5.3134 & 5.0525 & TST & \\
\hline CHEMBL1532425 & 809364 & 5.3605 & 5.0624 & TST & \\
\hline CHEMBL1423034 & 809364 & 5.4535 & 5.0223 & TST & \\
\hline CHEMBL1415357 & 809364 & 4.8601 & 5.0502 & TST & \\
\hline CHEMBL1463514 & 809364 & 5.6498 & 4.6758 & TST & \\
\hline CHEMBL1581335 & 809364 & 4.9355 & 4.3645 & TST & \\
\hline CHEMBL102714 & 954841 & 3.0304 & 3.1486 & TRN & \\
\hline CHEMBL1186585 & 954841 & 4.2527 & 4.2028 & TRN & \\
\hline CHEMBL1404918 & 954841 & 3.6314 & 3.3849 & TRN & \\
\hline CHEMBL 213100 & 954841 & 3.7327 & 3.4094 & TRN & \\
\hline CHEMBL 373751 & 954841 & 3.4947 & 4.1438 & TRN & \\
\hline CHEMBL192566 & 954841 & 8.4109 & 9.0242 & TST & \\
\hline CHEMBL 300389 & 954841 & 7.3389 & 7.2063 & TRN & \\
\hline CHEMBL1788116 & 954841 & 4.7516 & 4.6051 & TRN & \\
\hline CHEMBL412142 & 954841 & 3.344 & 3.5136 & TRN & \\
\hline CHEMBL515416 & 954841 & 5.0224 & 4.8161 & TRN & \\
\hline CHEMBL 2137530 & 954841 & 4.7331 & 4.8102 & TRN & \\
\hline CHEMBL 258844 & 954841 & 4.6971 & 4.8188 & TRN & \\
\hline CHEMBL472940 & 954841 & 4.8476 & $4.94300 t$ & 00000000005 & TRN \\
\hline CHEMBL509032 & 954841 & 6.989 & 7.0249 & TRN & \\
\hline CHEMBL393929 & 954841 & 3.8931 & 4.1642 & TRN & \\
\hline CHEMBL3349342 & 954841 & 3.8425 & 3.8626 & TRN & \\
\hline CHEMBL1190711 & 954841 & 5.9316 & 5.7972 & TRN & \\
\hline CHEMBL483847 & 954841 & 3.8844 & 4.1476 & TRN & \\
\hline CHEMBL209148 & 954841 & 5.5067 & 5.4417 & TRN & \\
\hline CHEMBL65 & 954841 & 8.7503 & 9.0015 & TRN & \\
\hline CHEMBL514499 & 954841 & 7.7749 & 7.5988 & TRN & \\
\hline CHEMBL2363137 & 954841 & 4.8149 & 4.8026 & TRN & \\
\hline CHEMBL483849 & 954841 & 2.7283 & 2.1429 & TST & \\
\hline CHEMBL577784 & 954841 & 4.6613 & 5.0596 & TRN & \\
\hline CHEMBL 255342 & 954841 & 3.662 & 3.2664 & TRN & \\
\hline CHEMBL573107 & 954841 & 5.5601 & 5.1779 & TRN & \\
\hline CHEMBL 2005886 & 954841 & 6.7608 & 6.8624 & TRN & \\
\hline CHEMBL1242367 & 954841 & 4.8098 & 4.5357 & TRN & \\
\hline CHEMBL191334 & 954841 & 3.2241 & 3.2666 & TRN & \\
\hline
\end{tabular}


Supplemental Table S2.txt

\begin{tabular}{|c|c|c|c|c|}
\hline CHEMBL 9470 & & 6.0737 & 28 & TST \\
\hline CHEMBL 3186408 & 54841 & 3.4996 & 4.1351 & \\
\hline HEMBL 259181 & & 7626 & 5.4222 & \\
\hline HEMBL180127 & 54841 & 0127 & .7843 & \\
\hline HEMBL 240954 & 54841 & 3.4439 & 3.8891 & \\
\hline HEMBL 188678 & 54841 & .4694 & .3206 & \\
\hline HEMBL3199475 & & .4697 & 5.4608 & \\
\hline HEMBL1230020 & 54 & 5084 & 3.5996 & \\
\hline HEMBL 217354 & 54841 & .6444 & 6.7911 & \\
\hline HEMBL 379300 & 41 & .6549 & 6.5525 & \\
\hline HEMBL1590308 & 41 & 657 & 3.7147 & \\
\hline HEMBL1256 & & 255 & 7.8894 & \\
\hline HEMBL512504 & 54 & 3.8032 & 3.9038 & \\
\hline HEMBL 392695 & 41 & 8203 & 5.7227 & \\
\hline HEMBL1516890 & 54 & 4.8496 & 4.3486 & \\
\hline HEMBL 399530 & 1 & 686 & 766 & \\
\hline HEMBL 213 & & & & \\
\hline HEMBL1643959 & 1 & 458 & 4435 & \\
\hline HEMBL 210618 & 1 & 648 & 2223 & \\
\hline HEMBL 221137 & 52 & 441 & 276 & \\
\hline HEMBL167 & 1 & 54 & 485 & \\
\hline HEMBL18 & & 29 & 21 & \\
\hline HEMBL1357247 & 1 & 673 & 5022 & \\
\hline HEMBL 22210 & 1 & 118 & & \\
\hline HEMBL3392440 & 1 & 3.3773 & 5858 & IRI \\
\hline HEMBL 214 & 1 & 484 & 7216 & RI \\
\hline HEMBL 37 & & & & \\
\hline HEMBL2C & & 21 & 8408 & \\
\hline HEMBL190 & & & 88 & IST \\
\hline HEMBL135561 & 1 & 269 & 4.7753 & ST \\
\hline AEMBL585 & & 527 & 5387 & ST \\
\hline HEMB & & 29 & 14 & \\
\hline HEMBL92309 & & & & TST \\
\hline HEMBL 220241 & & 43 & 309 & is \\
\hline HEMBL44915 & 1 & 2898 & 8388 & IST \\
\hline HEMBL197 & 1 & 021 & 5994 & ST \\
\hline 10 & & & 9983 & RN \\
\hline HEMBL195877 & & 4.3979 & 5.1121 & TST \\
\hline HEMBL 3638 & & 4.3979 & 5111 & TST \\
\hline IEMBL192 & & 949 & 1948 & 「RN \\
\hline HEMBL191807 & & 6.0605 & 6.0602 & \\
\hline CHEMBL195546 & & 7.2676 & 7.2673 & RN \\
\hline HEMBL192029 & & 4.3979 & 4.397 & RN \\
\hline HEMBL1929 & 54 & 4.3979 & 3973 & TR \\
\hline MBL1 & & 208 & 2225 & IRI \\
\hline HEMBL195115 & & 8.6946 & 8.059 & \\
\hline CHEMBL191939 & 312864 & 5.9586 & 5.9595 & \\
\hline CHEMBL194443 & 312864 & 4.3979 & 4.5719 & 3 \\
\hline
\end{tabular}

Page 15450 
Supplemental Table S2.txt

\begin{tabular}{|c|c|c|c|c|c|}
\hline CHEMBL195112 & 312864 & 4.3979 & 4.3982 & TRN & \\
\hline CHEMBL195803 & 312864 & 6.7959 & 6.7962 & TRN & \\
\hline CHEMBL195374 & 312864 & 4.3979 & 4.3976 & TRN & \\
\hline CHEMBL426634 & 312864 & 4.3979 & 5.5609 & TST & \\
\hline CHEMBL195875 & 312864 & 7.1487 & 7.1486 & TRN & \\
\hline CHEMBL195870 & 312864 & 6.3279 & 6.3296 & TRN & \\
\hline CHEMBL192383 & 312864 & 5.4949 & 5.1562 & TST & \\
\hline CHEMBL236139 & 312864 & 5.8539 & 5.8546 & TRN & \\
\hline CHEMBL439855 & 312864 & 7.3979 & 7.3973 & TRN & \\
\hline CHEMBL191768 & 312864 & 6.1805 & 6.1817 & TRN & \\
\hline CHEMBL194449 & 312864 & 6.2924 & 6.2917 & TRN & \\
\hline CHEMBL371621 & 312864 & 4.3979 & 4.398 & TRN & \\
\hline CHEMBL427181 & 312864 & 7.0862 & 7.0864 & TRN & \\
\hline CHEMBL365354 & 312864 & 4.3979 & 4.3977 & TRN & \\
\hline CHEMBL370977 & 312864 & 6.7447 & 6.7444 & TRN & \\
\hline CHEMBL195876 & 312864 & 6.9586 & 6.9584 & TRN & \\
\hline CHEMBL191031 & 312864 & 6.3565 & 6.3562 & TRN & \\
\hline CHEMBL190818 & 312864 & 6.0177 & 6.0178 & TRN & \\
\hline CHEMBL191783 & 312864 & 6.0655 & 6.0652 & TRN & \\
\hline CHEMBL362959 & 312864 & 4.3979 & 4.5725 & TST & \\
\hline CHEMBL 372930 & 312864 & 6.5376 & 6.5375 & TRN & \\
\hline CHEMBL192235 & 312864 & 4.3979 & 4.3983 & TRN & \\
\hline CHEMBL 363632 & 312864 & 6.3665 & 6.3647 & TRN & \\
\hline CHEMBL191247 & 312864 & 8.8861 & 8.8864 & TRN & \\
\hline CHEMBL365128 & 312864 & 5.6198 & 5.6187 & TRN & \\
\hline CHEMBL191657 & 312864 & 5.5686 & 5.5685 & TRN & \\
\hline CHEMBL 365121 & 312864 & 4.3979 & 4.3974 & TRN & \\
\hline CHEMBL191756 & 312864 & 4.3979 & 4.3983 & TRN & \\
\hline CHEMBL372226 & 312864 & 6.2218 & 6.2215 & TRN & \\
\hline CHEMBL194228 & 312864 & 6.0969 & 6.0973 & TRN & \\
\hline CHEMBL191940 & 312864 & 6.6576 & 6.657999 & 799999999995 & TRN \\
\hline CHEMBL195085 & 312864 & 4.3979 & 5.3676 & TST & \\
\hline CHEMBL194924 & 312864 & 5.8894 & 5.8918 & TRN & \\
\hline CHEMBL190874 & 312864 & 9.0 & 8.9999 & TRN & \\
\hline CHEMBL192292 & 312864 & 6.4318 & 6.4307 & TRN & \\
\hline CHEMBL370426 & 312864 & 7.2441 & 7.2438 & TRN & \\
\hline CHEMBL191607 & 312864 & 4.3979 & 4.3977 & TRN & \\
\hline CHEMBL195880 & 312864 & 7.585 & 7.5847 & TRN & \\
\hline CHEMBL263703 & 312864 & 4.3979 & 4.4197 & TST & \\
\hline CHEMBL 370078 & 312864 & 7.0 & 6.9992 & TRN & \\
\hline CHEMBL194280 & 312864 & 5.5376 & 5.5374 & TRN & \\
\hline CHEMBL191628 & 312864 & 4.3979 & 4.3986 & TRN & \\
\hline CHEMBL195257 & 312864 & 4.3979 & 4.6644 & TST & \\
\hline CHEMBL363841 & 312864 & 4.3979 & 5.3612 & TST & \\
\hline CHEMBL191782 & 312864 & 4.3979 & 5.1233 & TST & \\
\hline CHEMBL191708 & 312864 & 4.3979 & 5.6353 & TST & \\
\hline CHEMBL192642 & 312864 & 4.3979 & 5.0017 & TST & \\
\hline CHEMBL192205 & 312864 & 7.0269 & 6.5459 & TST & \\
\hline
\end{tabular}


Supplemental Table S2.txt

\begin{tabular}{|c|c|c|c|c|}
\hline CHEMBL192201 & 312864 & 6.1805 & 6.0895 & TST \\
\hline CHEMBL2042859 & 825804 & 6.2007 & 5.9166 & TRN \\
\hline CHEMBL 2042899 & 825804 & 6.1308 & 5.843 & TRN \\
\hline CHEMBL 2042763 & 825804 & 6.3372 & 6.093 & TRN \\
\hline CHEMBL 2042876 & 825804 & 5.6021 & 5.9048 & TRN \\
\hline CHEMBL 2042878 & 825804 & 6.1487 & 6.4376 & TRN \\
\hline CHEMBL 2042897 & 825804 & 5.9586 & 5.9655 & TRN \\
\hline CHEMBL 2042858 & 825804 & 5.9586 & 5.96399 & 99999999995 \\
\hline CHEMBL 2042872 & 825804 & 5.8539 & 5.6973 & TRN \\
\hline CHEMBL 2042761 & 825804 & 6.4318 & 6.3172 & TRN \\
\hline CHEMBL 2042887 & 825804 & 6.0458 & 6.0157 & TST \\
\hline CHEMBL 2042882 & 825804 & 6.3872 & 6.8007 & TRN \\
\hline CHEMBL 2042861 & 825804 & 6.1192 & 5.8886 & TRN \\
\hline CHEMBL 2042764 & 825804 & 6.7696 & 6.5253 & TRN \\
\hline CHEMBL 2042856 & 825804 & 5.9586 & 5.9453 & TRN \\
\hline CHEMBL 2042766 & 825804 & 6.301 & 6.4405 & TRN \\
\hline CHEMBL2042883 & 825804 & 7.2218 & 6.8061 & TRN \\
\hline CHEMBL 2042767 & 825804 & 6.699 & 6.6692 & TRN \\
\hline CHEMBL2042891 & 825804 & 5.7447 & 5.7956 & TRN \\
\hline CHEMBL 2040870 & 825804 & 6.2366 & 6.0482 & TRN \\
\hline CHEMBL 2042898 & 825804 & 6.2147 & \multicolumn{2}{|c|}{5.922999999999999} \\
\hline CHEMBL 2042884 & 825804 & 4.0605 & 6.2602 & TST \\
\hline CHEMBL 2042871 & 825804 & 5.5229 & 5.8784 & TRN \\
\hline CHEMBL 2042862 & 825804 & 6.3279 & 5.6267 & TRN \\
\hline CHEMBL 2042905 & 825804 & 6.0088 & 5.7017 & TRN \\
\hline CHEMBL 2042765 & 825804 & 6.1675 & 6.1669 & TRN \\
\hline CHEMBL 2042870 & 825804 & 6.6021 & 5.9042 & TRN \\
\hline CHEMBL 2042906 & 825804 & 5.4685 & 5.8611 & TRN \\
\hline CHEMBL2042869 & 825804 & 5.8239 & 5.9314 & TRN \\
\hline CHEMBL 2042893 & 825804 & 6.1805 & 5.8195 & TRN \\
\hline CHEMBL 2042768 & 825804 & 6.4559 & 6.7005 & TRN \\
\hline CHEMBL2042889 & 825804 & 4.2147 & 5.8094 & TST \\
\hline CHEMBL 2042902 & 825804 & 5.8239 & 6.0505 & TRN \\
\hline CHEMBL 2042895 & 825804 & 6.6383 & 5.8872 & TRN \\
\hline CHEMBL 2042896 & 825804 & 6.0458 & 5.9302 & TRN \\
\hline CHEMBL2042863 & 825804 & 5.6383 & 5.7857 & TRN \\
\hline CHEMBL 2042857 & 825804 & 6.4815 & 6.0456 & TRN \\
\hline CHEMBL 2042874 & 825804 & 5.2441 & 6.0456 & TRN \\
\hline CHEMBL 2042866 & 825804 & 5.6198 & 5.8443 & TRN \\
\hline CHEMBL 2042904 & 825804 & 5.4437 & 5.9098 & TRN \\
\hline CHEMBL 2042879 & 825804 & 6.0969 & 6.4572 & TRN \\
\hline CHEMBL 2040871 & 825804 & 3.699 & 5.4684 & TRN \\
\hline CHEMBL 2042900 & 825804 & 5.7696 & 5.5607 & TRN \\
\hline CHEMBL 2042881 & 825804 & 6.1367 & 6.1804 & TRN \\
\hline CHEMBL 2042864 & 825804 & 6.0088 & 6.1433 & TRN \\
\hline CHEMBL 2042769 & 825804 & 6.8239 & 6.6756 & TRN \\
\hline CHEMBL 2042867 & 825804 & 5.8861 & 5.9403 & TRN \\
\hline CHEMBL 2042762 & 825804 & 6.2366 & 6.3392 & TRN \\
\hline
\end{tabular}

Page 15452 


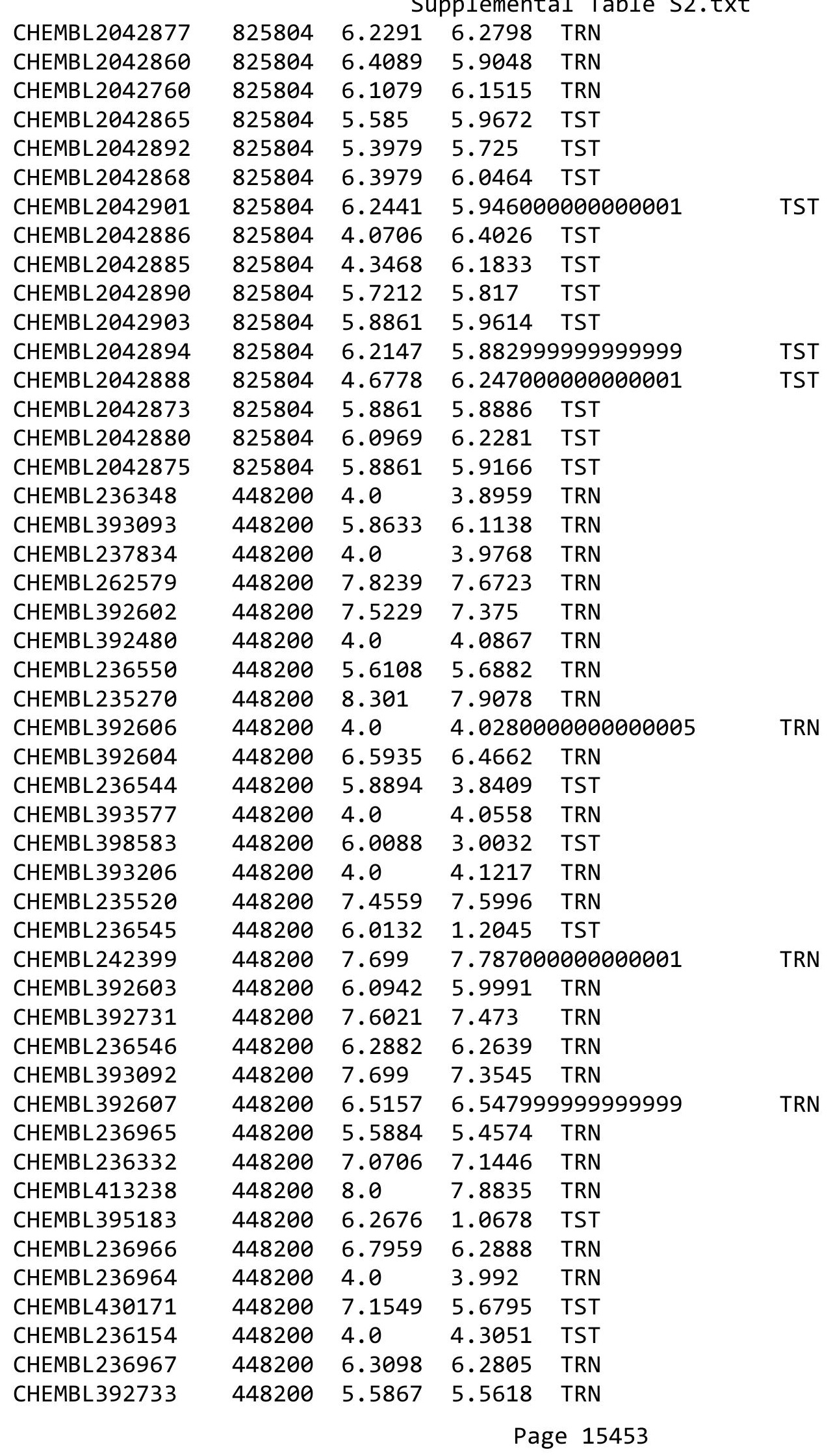




\begin{tabular}{|c|c|c|c|c|c|}
\hline \multicolumn{6}{|c|}{ Supplemental Table S2.txt } \\
\hline CHEMBL 235050 & 448200 & 6.5229 & 6.29 & TRN & \\
\hline CHEMBL236342 & 448200 & 6.7447 & 6.8903 & TRN & \\
\hline CHEMBL235301 & 448200 & 4.0 & 3.9995 & TRN & \\
\hline CHEMBL392815 & 448200 & 6.284 & 6.3701 & TRN & \\
\hline CHEMBL392605 & 448200 & 8.301 & 8.4838 & TRN & \\
\hline CHEMBL392688 & 448200 & 5.8539 & 5.7259 & TRN & \\
\hline CHEMBL392709 & 448200 & 7.3468 & 5.7737 & TST & \\
\hline CHEMBL235269 & 448200 & 8.0 & 8.1903 & TRN & \\
\hline CHEMBL413239 & 448200 & 6.0246 & 6.6251 & TRN & \\
\hline CHEMBL235519 & 448200 & 5.8633 & 6.3734 & TST & \\
\hline CHEMBL262581 & 448200 & 7.0969 & 7.0709 & TRN & \\
\hline CHEMBL236331 & 448200 & 6.0706 & 6.2444 & TRN & \\
\hline CHEMBL 235051 & 448200 & 7.0 & 6.9336 & TRN & \\
\hline CHEMBL 236152 & 448200 & 8.0 & 8.1931 & TRN & \\
\hline CHEMBL235046 & 448200 & 6.2218 & 6.3414 & TRN & \\
\hline CHEMBL 262580 & 448200 & 6.4202 & 6.52 & TRN & \\
\hline CHEMBL236127 & 448200 & 7.7696 & 7.8521 & TRN & \\
\hline CHEMBL392087 & 448200 & 5.767 & 5.7454 & TRN & \\
\hline CHEMBL16745 & 448200 & 7.8239 & 7.9749 & TST & \\
\hline CHEMBL412581 & 448200 & 5.6576 & 3.591 & TST & \\
\hline CHEMBL236750 & 448200 & 5.8013 & 2.9599 & TST & \\
\hline CHEMBL236751 & 448200 & 4.0 & 4.1181 & TST & \\
\hline CHEMBL235302 & 448200 & 4.0 & 6.2481 & TST & \\
\hline CHEMBL 235084 & 448200 & 6.0044 & 6.5524 & TST & \\
\hline CHEMBL236137 & 448200 & 5.7447 & 5.1806 & TST & \\
\hline CHEMBL 3649361 & 1528065 & 4.0 & 6.401 & TRN & \\
\hline CHEMBL 3649307 & 1528065 & 8.2076 & 7.7246 & TRN & \\
\hline CHEMBL3646413 & 1528065 & 7.266 & 6.4464 & TRN & \\
\hline CHEMBL 3646394 & 1528065 & 7.5638 & 7.50700 & 0000000001 & TRN \\
\hline CHEMBL3649359 & 1528065 & 4.0 & 7.2625 & TST & \\
\hline CHEMBL 3646384 & 1528065 & 6.5452 & 6.2611 & TST & \\
\hline CHEMBL3646260 & 1528065 & 8.7235 & 7.8631 & TRN & \\
\hline CHEMBL 3649354 & 1528065 & 4.0 & 6.2593 & TST & \\
\hline CHEMBL3646277 & 1528065 & 6.0 & 7.3926 & TRN & \\
\hline CHEMBL3646390 & 1528065 & 8.2104 & 7.1817 & TRN & \\
\hline CHEMBL 3646348 & 1528065 & 8.1778 & 7.0004 & TRN & \\
\hline CHEMBL3649283 & 1528065 & 8.3215 & 8.0993 & TRN & \\
\hline CHEMBL 3646365 & 1528065 & 7.9431 & 6.1494 & TRN & \\
\hline CHEMBL3649263 & 1528065 & 8.0506 & 8.1999 & TRN & \\
\hline CHEMBL3649293 & 1528065 & 7.1858 & 7.1024 & TRN & \\
\hline CHEMBL3646319 & 1528065 & 8.4522 & 7.0156 & TRN & \\
\hline CHEMBL3649347 & 1528065 & 4.0 & 6.5304 & TRN & \\
\hline CHEMBL3649342 & 1528065 & 4.0 & 6.2225 & TST & \\
\hline CHEMBL3646266 & 1528065 & 8.057 & 7.647 & TRN & \\
\hline CHEMBL 3646354 & 1528065 & 6.5986 & 6.2506 & TRN & \\
\hline CHEMBL3649309 & 1528065 & 8.0506 & 8.0113 & TRN & \\
\hline CHEMBL3649321 & 1528065 & 6.5114 & 7.6445 & TST & \\
\hline CHEMBL 3646268 & 1528065 & 7.8633 & 7.485 & TRN & \\
\hline
\end{tabular}


Supplemental Table S2.txt

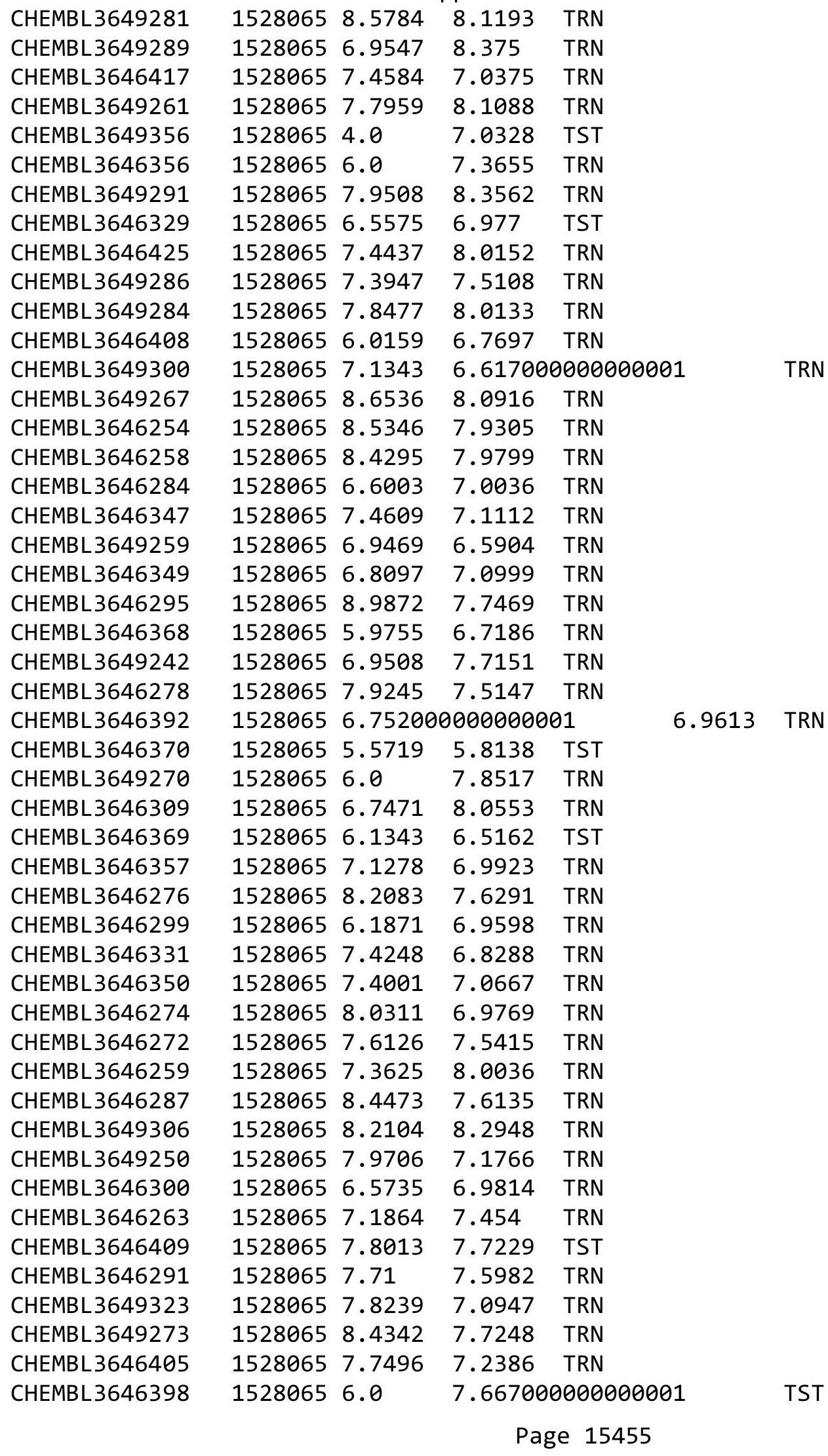


Supplemental Table S2.txt

\begin{tabular}{|c|c|c|c|c|c|}
\hline CHEMBL 3649256 & 1528065 & 7.4895 & 7.8263 & TRN & \\
\hline CHEMBL3646289 & 1528065 & 8.0074 & 7.5375 & TRN & \\
\hline CHEMBL3649314 & 1528065 & 7.699 & 7.99299 & 9999999999 & TRN \\
\hline CHEMBL3646382 & 1528065 & 7.9547 & 6.7609 & TRN & \\
\hline CHEMBL3646367 & 1528065 & 7.5058 & 6.7177 & TRN & \\
\hline CHEMBL3649271 & 1528065 & 7.6696 & 7.9572 & TRN & \\
\hline CHEMBL3646288 & 1528065 & 8.4342 & 7.6439 & TRN & \\
\hline CHEMBL3649245 & 1528065 & 7.3188 & 7.0048 & TRN & \\
\hline CHEMBL3649274 & 1528065 & 8.52 & 7.5408 & TRN & \\
\hline CHEMBL3649280 & 1528065 & 8.0841 & 8.0225 & TRN & \\
\hline CHEMBL3649255 & 1528065 & 8.3605 & 7.7165 & TRN & \\
\hline CHEMBL3649315 & 1528065 & 8.1415 & 7.8793 & TRN & \\
\hline CHEMBL3646249 & 1528065 & 6.0 & 6.3649 & TRN & \\
\hline CHEMBL3646279 & 1528065 & 6.0 & 7.5206 & TRN & \\
\hline CHEMBL3649264 & 1528065 & 8.5817 & 8.1122 & TRN & \\
\hline CHEMBL3646306 & 1528065 & 7.38299 & 79999999 & 8.0125 & TRN \\
\hline CHEMBL3646361 & 1528065 & 6.4815 & 6.2282 & TST & \\
\hline CHEMBL3646420 & 1528065 & 7.5513 & 7.0089 & TRN & \\
\hline CHEMBL3646332 & 1528065 & 5.7878 & 6.757006 & 0000000001 & TRN \\
\hline CHEMBL3646335 & 1528065 & 5.9245 & 6.6378 & TRN & \\
\hline CHEMBL3646343 & 1528065 & 6.0 & 6.9657 & TRN & \\
\hline CHEMBL3639451 & 1528065 & 8.0448 & 7.0609 & TRN & \\
\hline CHEMBL3649322 & 1528065 & 9.0506 & 7.2487 & TRN & \\
\hline CHEMBL3646395 & 1528065 & 6.8861 & 6.8687 & TRN & \\
\hline CHEMBL3646239 & 1528065 & 5.8471 & 5.8963 & TST & \\
\hline CHEMBL3646411 & 1528065 & 7.1367 & 6.59399 & 7999999999 & TRN \\
\hline CHEMBL3646387 & 1528065 & 6.2857 & 5.8466 & TST & \\
\hline CHEMBL3649243 & 1528065 & 8.0061 & 7.4471 & TRN & \\
\hline CHEMBL3646257 & 1528065 & 8.2874 & 7.8412 & TRN & \\
\hline CHEMBL3646407 & 1528065 & 7.2104 & 7.5833 & TST & \\
\hline CHEMBL3646293 & 1528065 & 6.0 & 7.5037 & TRN & \\
\hline CHEMBL3649258 & 1528065 & 8.85700 & 20000000 & 7.2585 & TST \\
\hline CHEMBL3649346 & 1528065 & 4.0 & 6.3246 & TRN & \\
\hline CHEMBL3646298 & 1528065 & 7.2418 & 7.1928 & TRN & \\
\hline CHEMBL3646371 & 1528065 & 8.0899 & 7.5519 & TST & \\
\hline CHEMBL3639452 & 1528065 & 6.0 & 6.9125 & TRN & \\
\hline CHEMBL3649257 & 1528065 & 6.7747 & 6.5455 & TRN & \\
\hline CHEMBL3649320 & 1528065 & 6.7375 & 7.6141 & TST & \\
\hline CHEMBL3646310 & 1528065 & 8.6021 & 8.2137 & TRN & \\
\hline CHEMBL3646330 & 1528065 & 5.7258 & 6.6874 & TRN & \\
\hline CHEMBL3649350 & 1528065 & 4.0 & 5.9275 & TST & \\
\hline CHEMBL3646393 & 1528065 & 6.7055 & 6.9886 & TRN & \\
\hline CHEMBL3649272 & 1528065 & 8.1844 & 7.694 & TRN & \\
\hline CHEMBL3646285 & 1528065 & 7.3936 & 7.7194 & TRN & \\
\hline CHEMBL3646372 & 1528065 & 6.0 & 6.3419 & TRN & \\
\hline CHEMBL3646342 & 1528065 & 7.6162 & 6.9005 & TRN & \\
\hline CHEMBL3646301 & 1528065 & 7.2774 & 7.3774 & TRN & \\
\hline CHEMBL3639481 & 1528065 & 8.2725 & 8.1701 & TRN & \\
\hline
\end{tabular}


Supplemental Table S2.txt

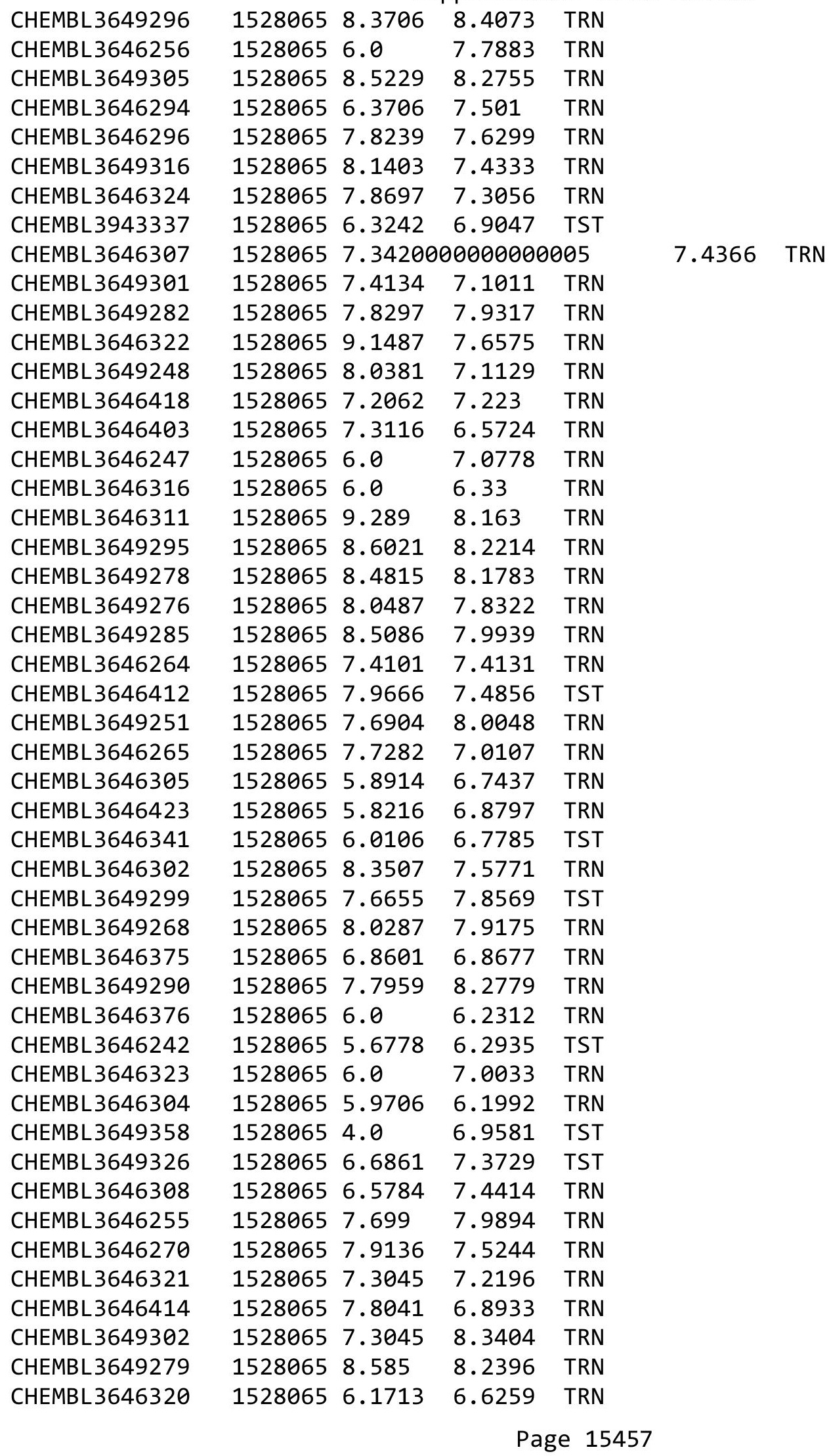


Supplemental Table S2.txt

\begin{tabular}{|c|c|c|c|c|}
\hline CHEMBL 3646245 & 1528065 & 6.0 & 7.151 & TRN \\
\hline CHEMBL 3646353 & 1528065 & 7.6536 & 6.8765 & TRN \\
\hline CHEMBL 3646401 & 1528065 & 7.9747 & 7.6066 & TRN \\
\hline CHEMBL3646399 & 1528065 & 6.0 & 7.6407 & TST \\
\hline CHEMBL 3646359 & 1528065 & 6.644 & 5.8568 & TST \\
\hline CHEMBL3646271 & 1528065 & 7.2182 & 6.7655 & TRN \\
\hline CHEMBL3649313 & 1528065 & 8.4045 & 8.1595 & TRN \\
\hline CHEMBL 3646400 & 1528065 & 7.6162 & 7.4008 & TST \\
\hline CHEMBL 3646416 & 1528065 & 6.4486 & 6.9336 & TRN \\
\hline CHEMBL 3646351 & 1528065 & 7.5406 & 7.0391 & TRN \\
\hline CHEMBL 3646338 & 1528065 & 7.4698 & 6.8955 & TRN \\
\hline CHEMBL3646312 & 1528065 & 9.6861 & 8.1045 & TRN \\
\hline CHEMBL 3649325 & 1528065 & 7.301 & 6.7192 & TRN \\
\hline CHEMBL 3649324 & 1528065 & 6.0 & 8.2773 & TRN \\
\hline CHEMBL 3649328 & 1528065 & 7.0862 & 8.1556 & TRN \\
\hline CHEMBL3649327 & 1528065 & 6.0 & 6.9798 & TRN \\
\hline CHEMBL 3646383 & 1528065 & 7.0246 & 6.8799 & TST \\
\hline CHEMBL 3646281 & 1528065 & 6.5272 & 6.3282 & TRN \\
\hline CHEMBL 3646345 & 1528065 & 8.7545 & 7.2353 & TRN \\
\hline CHEMBL 3646275 & 1528065 & 9.1675 & 7.5942 & TRN \\
\hline CHEMBL3646313 & 1528065 & 8.5421 & 8.1013 & TRN \\
\hline CHEMBL 3646244 & 1528065 & 6.0 & 7.1134 & TRN \\
\hline CHEMBL 3646366 & 1528065 & 7.4868 & 6.7503 & TRN \\
\hline CHEMBL 3646421 & 1528065 & 7.0343 & 7.5479 & TST \\
\hline CHEMBL 3649351 & 1528065 & 4.0 & 6.7484 & TST \\
\hline CHEMBL 3649246 & 1528065 & 7.6234 & 7.4779 & TST \\
\hline CHEMBL 3646248 & 1528065 & 8.7905 & 7.0647 & TST \\
\hline CHEMBL 3649292 & 1528065 & 8.0851 & 8.2064 & TRN \\
\hline CHEMBL3646364 & 1528065 & 7.7595 & 6.1279 & TST \\
\hline CHEMBL 3649249 & 1528065 & 7.7235 & 7.1731 & TST \\
\hline CHEMBL 3646396 & 1528065 & 6.8386 & 6.9664 & TST \\
\hline CHEMBL 3646363 & 1528065 & 6.0991 & 6.2978 & TST \\
\hline CHEMBL 3646388 & 1528065 & 6.4634 & 6.5306 & TST \\
\hline CHEMBL3646286 & 1528065 & 7.2857 & 7.6635 & TRN \\
\hline CHEMBL 3649303 & 1528065 & 8.1192 & 7.6524 & TST \\
\hline CHEMBL 3649353 & 1528065 & 4.0 & 6.9082 & TST \\
\hline CHEMBL3646406 & 1528065 & 8.4023 & 7.4627 & TST \\
\hline CHEMBL 3646314 & 1528065 & 8.1403 & 8.1276 & TRN \\
\hline CHEMBL3646261 & 1528065 & 8.1355 & 7.7685 & TRN \\
\hline CHEMBL 3649252 & 1528065 & 7.3565 & 7.8578 & TRN \\
\hline CHEMBL 3646358 & 1528065 & 6.0996 & 6.6186 & TST \\
\hline CHEMBL 3649294 & 1528065 & 8.7122 & 8.4008 & TRN \\
\hline CHEMBL3649277 & 1528065 & 8.266 & 8.1348 & TRN \\
\hline CHEMBL3646282 & 1528065 & 6.6003 & 6.3144 & TRN \\
\hline CHEMBL 3646424 & 1528065 & 6.1739 & 7.3692 & TRN \\
\hline CHEMBL 3649311 & 1528065 & 8.7305 & 8.15299 & 9999999999 \\
\hline CHEMBL 3646426 & 1528065 & 7.1612 & 7.5187 & TRN \\
\hline CHEMBL3646373 & 1528065 & 7.5607 & 6.9049 & TRN \\
\hline
\end{tabular}

TRN

Page 15458 
Supplemental Table S2.txt

\begin{tabular}{|c|c|c|c|c|}
\hline HEMBL & & 84 & 63 & \\
\hline HFMBI 3649244 & 528065 & 7.3893 & 3251 & \\
\hline HEMBL & & & & \\
\hline HEMBL3646325 & 528065 & 6.0 & 8024 & \\
\hline HEMBL3646355 & 528065 & 6.0 & .1595 & \\
\hline HEMBL; & 528065 & 8.3188 & 532 & \\
\hline HEMBL & 28065 & & & \\
\hline HEMBL36 & 528065 & 8.0894 & 3122 & \\
\hline HEMBL 364 & 528065 & 7.3585 & .7237 & \\
\hline HEMBL3646397 & 528065 & 7.6144 & .0344 & \\
\hline HEMBL 36 & 528065 & 7.857 & 62 & \\
\hline HEMBL3 & & & & \\
\hline HEMBL36 & 528065 & 6.5186 & & \\
\hline HEMBL 364 & 528065 & 7.8327 & 177 & \\
\hline HEMBL 364 & 528065 & 6.5952 & 82 & \\
\hline AEMBL & 65 & 67 & & \\
\hline AEMBL. & & & & \\
\hline HEMBL3 & 528065 & 834 & & \\
\hline HEMBL36 & 065 & 8.2441 & & \\
\hline HEMBL364 & 528065 & 346 & 47 & \\
\hline AEMBL & 65 & & & \\
\hline AEMBL: & & 471 & & RN \\
\hline HEMBL & 65 & 157 & & \\
\hline HEMBL 36 & 65 & 6. & & \\
\hline HEMBL 364 & 528065 & 172 & 65 & $|S|$ \\
\hline AEMBL3 & 528065 & 86 & 19 & ST \\
\hline AEME & & & & RN \\
\hline$\triangle 5 M P$ & & 45 & & \\
\hline AEMBL3 & & & & IRN \\
\hline HEMBL 3646346 & 528065 & 6 & 383 & ГST \\
\hline AEMBL & 65 & 4 & 44 & ST \\
\hline 1 & 55 & & & ST \\
\hline & & & & ST \\
\hline AEMBL 364 & 528065 & & & $\mathrm{R}$ \\
\hline HEMBL3646379 & 528065 & 697 & 394 & TST \\
\hline AFMRI 3 & 528065 & 8. & 12 & RN \\
\hline & & & & RN \\
\hline HEMBL36 & & & & RN \\
\hline AEMBL3649269 & 528065 & 7.939 & & $\Gamma R$ \\
\hline EMBL3 & 065 & 6 & 83 & 「RN \\
\hline HEMBL 36 & 528065 & & & \\
\hline HEMBL 36 & & & & RN \\
\hline HEMBL 364 & & 7.94 & & TRN \\
\hline HEMBL 364 & 528065 & 7. & 337 & TR \\
\hline MBL3 & 165 & & & \\
\hline CHEMBL 364 & 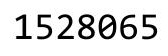 & 7.3468 & 7.8516 & \\
\hline CHEMBL3646339 & .528065 & & 5.6441 & \\
\hline CHEMBL3646337 & 1528065 & 6.9706 & 6.7041 & \\
\hline
\end{tabular}

Page 15459 


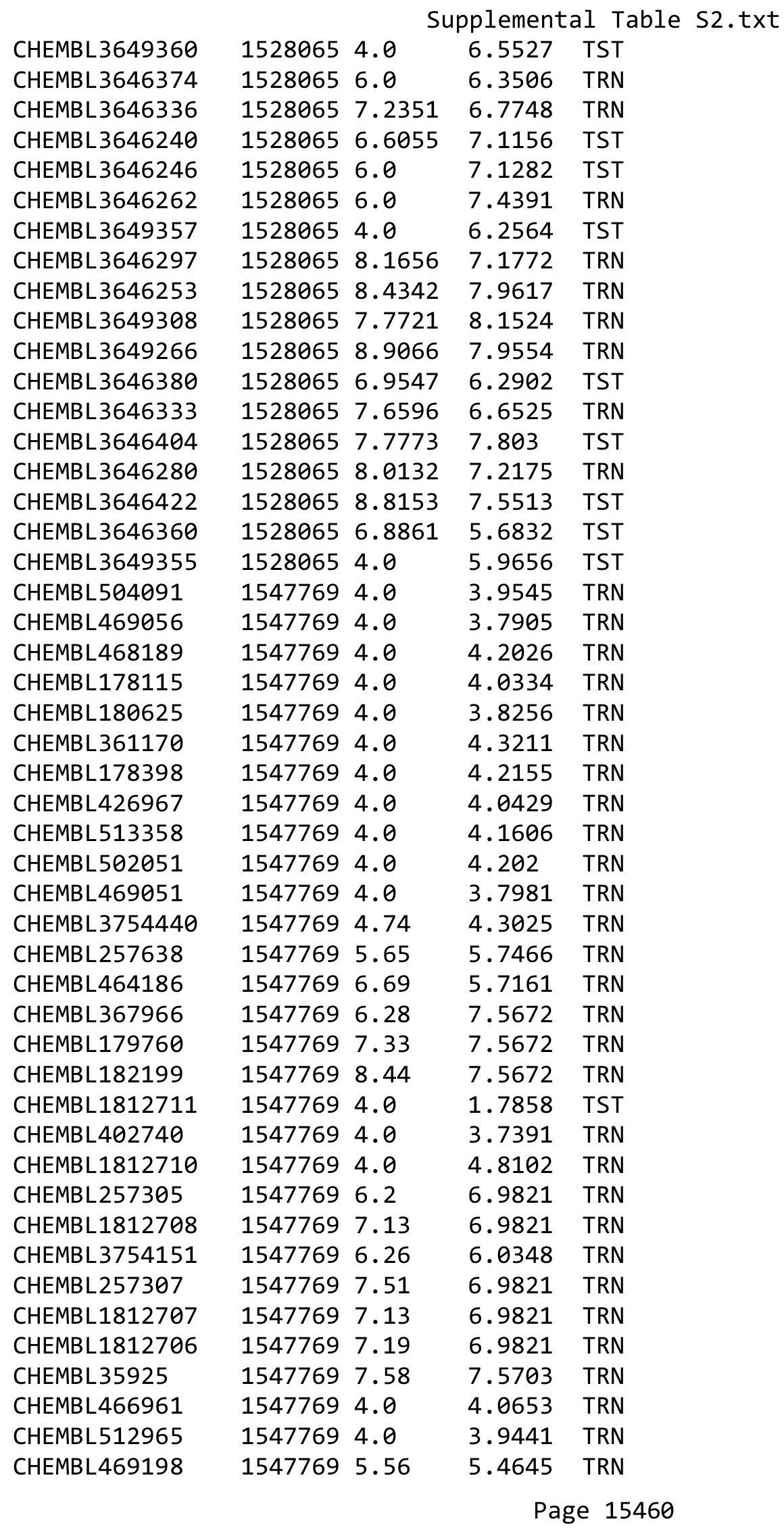




\begin{tabular}{|c|c|c|c|c|}
\hline \multicolumn{5}{|c|}{ Supplemental Table S2.txt } \\
\hline CHEMBL513534 & 1547769 & 5.69 & 5.0263 & TRN \\
\hline CHEMBL466954 & 1547769 & 5.71 & 5.5863 & TRN \\
\hline CHEMBL469241 & 1547769 & 5.98 & 5.5705 & TRN \\
\hline CHEMBL469199 & 1547769 & 6.03 & 5.8334 & TRN \\
\hline CHEMBL3753206 & 1547769 & 4.0 & 3.9858 & TRN \\
\hline CHEMBL3754446 & 1547769 & 4.0 & 4.3266 & TRN \\
\hline CHEMBL220377 & 1547769 & 4.0 & 3.9264 & TRN \\
\hline CHEMBL220309 & 1547769 & 4.0 & 4.1572 & TRN \\
\hline CHEMBL220326 & 1547769 & 4.0 & 4.1049 & TRN \\
\hline CHEMBL222614 & 1547769 & 4.0 & 4.0264 & TRN \\
\hline CHEMBL387376 & 1547769 & 4.0 & 3.7205 & TRN \\
\hline CHEMBL223693 & 1547769 & 4.0 & 4.0483 & TRN \\
\hline CHEMBL173992 & 1547769 & 4.0 & 3.7526 & TRN \\
\hline CHEMBL513787 & 1547769 & 4.0 & 4.2498 & TRN \\
\hline CHEMBL461541 & 1547769 & 4.0 & 4.8199 & TRN \\
\hline CHEMBL460316 & 1547769 & 5.06 & 4.4793 & TRN \\
\hline CHEMBL219681 & 1547769 & 4.0 & 3.2328 & TRN \\
\hline CHEMBL219954 & 1547769 & 4.0 & 3.9135 & TRN \\
\hline CHEMBL 220938 & 1547769 & 4.0 & 3.7545 & TRN \\
\hline CHEMBL373555 & 1547769 & 4.0 & 3.8912 & TRN \\
\hline CHEMBL3754411 & 1547769 & 4.0 & 3.9017 & TRN \\
\hline CHEMBL219659 & 1547769 & 4.0 & 3.9539 & TRN \\
\hline CHEMBL220613 & 1547769 & 4.0 & 3.8557 & TRN \\
\hline CHEMBL 220727 & 1547769 & 4.0 & 4.2735 & TRN \\
\hline CHEMBL 220784 & 1547769 & 4.0 & 4.1729 & TRN \\
\hline CHEMBL 220770 & 1547769 & 4.0 & 4.2891 & TRN \\
\hline CHEMBL3751992 & 1547769 & 4.0 & 4.0254 & TRN \\
\hline CHEMBL373606 & 1547769 & 4.0 & 4.2962 & TRN \\
\hline CHEMBL 219660 & 1547769 & 4.0 & 4.4033 & TRN \\
\hline CHEMBL220378 & 1547769 & 5.74 & 5.1751 & TRN \\
\hline CHEMBL448922 & 1547769 & 4.0 & 4.0765 & TRN \\
\hline CHEMBL460493 & 1547769 & 4.0 & 4.5051 & TRN \\
\hline CHEMBL461363 & 1547769 & 4.0 & 4.1511 & TRN \\
\hline CHEMBL462405 & 1547769 & 4.0 & 4.4592 & TRN \\
\hline CHEMBL448688 & 1547769 & 4.0 & 4.5966 & TRN \\
\hline CHEMBL526161 & 1547769 & 4.0 & 4.2339 & TRN \\
\hline CHEMBL462589 & 1547769 & 5.47 & 5.6749 & TRN \\
\hline CHEMBL462432 & 1547769 & 5.62 & 5.4001 & TRN \\
\hline CHEMBL462302 & 1547769 & 5.63 & 5.4568 & TRN \\
\hline CHEMBL461315 & 1547769 & 5.82 & 6.0077 & TRN \\
\hline CHEMBL461539 & 1547769 & 6.2 & 5.5446 & TRN \\
\hline CHEMBL462423 & 1547769 & 6.24 & 6.3361 & TRN \\
\hline CHEMBL3752580 & 1547769 & 6.32 & 6.5719 & TRN \\
\hline CHEMBL 3753217 & 1547769 & 6.41 & 6.3899 & TRN \\
\hline CHEMBL461544 & 1547769 & 6.67 & 6.3515 & TRN \\
\hline CHEMBL461543 & 1547769 & 6.91 & 6.5807 & TRN \\
\hline CHEMBL461364 & 1547769 & 6.91 & 7.1786 & TRN \\
\hline CHEMBL467796 & 1547769 & 5.57 & 5.5524 & TRN \\
\hline
\end{tabular}




\begin{tabular}{|c|c|c|c|c|}
\hline & & & pplement & al $\mathrm{Ta}$ \\
\hline CHEMBL220125 & 1547769 & 4.0 & 4.3972 & TRN \\
\hline CHEMBL478186 & 1547769 & 4.0 & 4.4464 & TST \\
\hline CHEMBL503109 & 1547769 & 4.0 & 4.2416 & TST \\
\hline CHEMBL476512 & 1547769 & 4.0 & 4.4325 & TST \\
\hline CHEMBL455556 & 1547769 & 4.0 & 5.3463 & TST \\
\hline CHEMBL511422 & 1547769 & 4.0 & 4.4276 & TST \\
\hline CHEMBL468585 & 1547769 & 4.0 & 4.2838 & TST \\
\hline CHEMBL467368 & 1547769 & 4.0 & 4.6962 & TST \\
\hline CHEMBL467141 & 1547769 & 4.0 & 4.6017 & TST \\
\hline CHEMBL456450 & 1547769 & 4.0 & 4.9893 & TST \\
\hline CHEMBL452886 & 1547769 & 4.0 & 4.6347 & TST \\
\hline CHEMBL3754132 & 1547769 & 4.0 & 5.2713 & TST \\
\hline CHEMBL469264 & 1547769 & 4.0 & 5.2674 & TST \\
\hline CHEMBL469263 & 1547769 & 4.0 & 5.1984 & TST \\
\hline CHEMBL511434 & 1547769 & 4.0 & 4.9231 & TST \\
\hline CHEMBL468356 & 1547769 & 4.0 & 4.9666 & TST \\
\hline CHEMBL499698 & 1547769 & 4.0 & 5.3158 & TST \\
\hline CHEMBL3752930 & 1547769 & 4.0 & 4.4914 & TST \\
\hline CHEMBL445514 & 1547769 & 4.0 & 4.3952 & TST \\
\hline CHEMBL517352 & 1547769 & 4.0 & 4.5639 & TST \\
\hline CHEMBL477372 & 1547769 & 4.0 & 4.4412 & TST \\
\hline CHEMBL450158 & 1547769 & 4.0 & 4.269 & TST \\
\hline CHEMBL477371 & 1547769 & 4.0 & 5.022 & TST \\
\hline CHEMBL512816 & 1547769 & 4.0 & 4.2633 & TST \\
\hline CHEMBL469252 & 1547769 & 4.0 & 4.5121 & TST \\
\hline CHEMBL468222 & 1547769 & 4.0 & 4.4196 & TST \\
\hline CHEMBL3754658 & 1547769 & 4.0 & 3.9093 & TRN \\
\hline CHEMBL3754118 & 1547769 & 5.23 & 5.5019 & TRN \\
\hline CHEMBL3753830 & 1547769 & 7.06 & 6.8684 & TRN \\
\hline CHEMBL3753795 & 1547769 & 6.05 & 6.2255 & TRN \\
\hline CHEMBL3752424 & 1547769 & 4.0 & 3.9022 & TRN \\
\hline CHEMBL3753292 & 1547769 & 6.15 & 6.3178 & TRN \\
\hline CHEMBL3752691 & 1547769 & 5.85 & 5.8163 & TRN \\
\hline CHEMBL3754098 & 1547769 & 6.93 & 6.5141 & TRN \\
\hline CHEMBL3752838 & 1547769 & 5.77 & 5.6953 & TRN \\
\hline CHEMBL3753016 & 1547769 & 6.69 & 6.4774 & TRN \\
\hline CHEMBL3752237 & 1547769 & 4.0 & 6.1768 & TST \\
\hline CHEMBL3753568 & 1547769 & 5.91 & 6.5613 & TST \\
\hline CHEMBL3754310 & 1547769 & 4.0 & 5.0221 & TST \\
\hline CHEMBL3752944 & 1547769 & 4.92 & 5.7187 & TST \\
\hline CHEMBL366907 & 1547769 & 5.44 & 5.8937 & TRN \\
\hline CHEMBL175854 & 1547769 & 7.43 & 7.5672 & TRN \\
\hline CHEMBL371831 & 1547769 & 5.62 & 5.431 & TRN \\
\hline CHEMBL3753992 & 1547769 & 6.71 & 6.3175 & TST \\
\hline CHEMBL123724 & 82666 & 4.301 & 5.1029 & TRN \\
\hline CHEMBL421615 & 82666 & 4.301 & 5.2585 & TRN \\
\hline CHEMBL125822 & 82666 & 4.301 & 4.0945 & TRN \\
\hline CHEMBL122022 & 82666 & 4.301 & 4.4894 & TRN \\
\hline
\end{tabular}




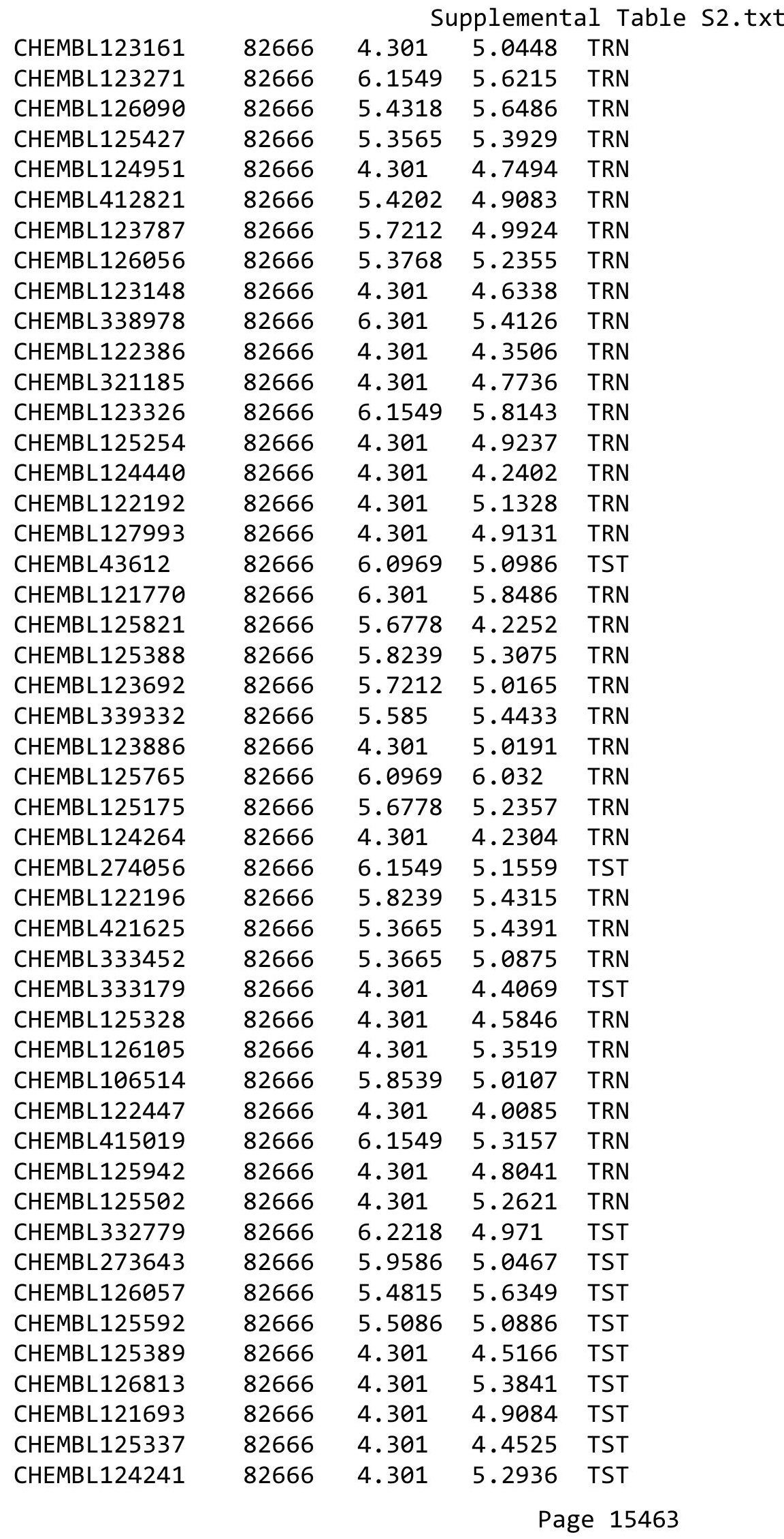




\begin{tabular}{|c|c|c|c|c|c|}
\hline \multicolumn{6}{|c|}{ 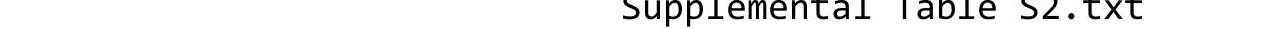 } \\
\hline CHEMBL125762 & 82666 & 4.301 & 5.4225 & TST & \\
\hline CHEMBL286494 & 82666 & 5.7696 & 5.1545 & TST & \\
\hline CHEMBL392767 & 453896 & 4.0 & 4.352 & TST & \\
\hline CHEMBL238735 & 453896 & 5.8996 & 5.9318 & TRN & \\
\hline CHEMBL241667 & 453896 & 6.1024 & 6.2133 & TRN & \\
\hline CHEMBL238522 & 453896 & 6.5686 & 6.4507 & TRN & \\
\hline CHEMBL238526 & 453896 & 6.4559 & 5.8536 & TST & \\
\hline CHEMBL392987 & 453896 & 5.8447 & 5.7798 & TRN & \\
\hline CHEMBL392964 & 453896 & 4.0 & 4.6717 & TST & \\
\hline CHEMBL391127 & 453896 & 6.4437 & 6.3219 & TRN & \\
\hline CHEMBL240209 & 453896 & 6.0362 & 5.9421 & TRN & \\
\hline CHEMBL400216 & 453896 & 6.0315 & 5.9715 & TRN & \\
\hline CHEMBL401040 & 453896 & 5.7282 & 5.8196 & TRN & \\
\hline CHEMBL240643 & 453896 & 6.3565 & 6.4366 & TRN & \\
\hline CHEMBL238938 & 453896 & 4.0 & 3.9191 & TRN & \\
\hline CHEMBL241668 & 453896 & 5.2218 & 5.2529 & TRN & \\
\hline CHEMBL238529 & 453896 & 6.4559 & 6.4648 & TRN & \\
\hline CHEMBL393409 & 453896 & 4.0 & 4.0037 & TRN & \\
\hline CHEMBL241265 & 453896 & 6.3565 & 6.4336 & TRN & \\
\hline CHEMBL238734 & 453896 & 4.0 & 3.9779 & TRN & \\
\hline CHEMBL392986 & 453896 & 4.0 & 3.9964 & TRN & \\
\hline CHEMBL238531 & 453896 & 5.9747 & 5.8537 & TRN & \\
\hline CHEMBL238508 & 453896 & 4.0 & 4.6536 & TRN & \\
\hline CHEMBL392985 & 453896 & 4.0 & 4.0531 & TRN & \\
\hline CHEMBL393964 & 453896 & 4.0 & 4.0827 & TRN & \\
\hline CHEMBL240456 & 453896 & 5.6126 & 5.6028 & TRN & \\
\hline CHEMBL391671 & 453896 & 4.0 & 4.2098 & TRN & \\
\hline CHEMBL394020 & 453896 & 6.4559 & 6.5498 & TRN & \\
\hline CHEMBL240405 & 453896 & 4.0 & 3.8215 & TRN & \\
\hline CHEMBL393418 & 453896 & 5.9508 & 5.9176 & TST & \\
\hline CHEMBL238719 & 453896 & 6.3768 & 6.4649 & TRN & \\
\hline CHEMBL238939 & 453896 & 4.0 & 4.811 & TST & \\
\hline CHEMBL393779 & 453896 & 6.9586 & 6.7284 & TRN & \\
\hline CHEMBL429643 & 453896 & 5.8665 & 5.853 & TRN & \\
\hline CHEMBL240642 & 453896 & 4.0 & 4.4078 & TRN & \\
\hline CHEMBL202011 & 453896 & 6.7959 & 6.4789 & TST & \\
\hline CHEMBL238530 & 453896 & 6.1612 & 6.0475 & TRN & \\
\hline CHEMBL241075 & 453896 & 4.0 & 3.8864 & TRN & \\
\hline CHEMBL238940 & 453896 & 4.0 & 4.0833 & TRN & \\
\hline CHEMBL241313 & 453896 & 5.9101 & 6.0241 & TRN & \\
\hline CHEMBL392513 & 453896 & 6.2518 & 6.1932 & TRN & \\
\hline CHEMBL240606 & 453896 & 4.0 & 4.2044 & TRN & \\
\hline CHEMBL240455 & 453896 & 6.5086 & 6.2512 & TRN & \\
\hline CHEMBL393963 & 453896 & 5.9547 & 5.7717 & TRN & \\
\hline CHEMBL240644 & 453896 & 4.0 & 3.93899 & 99999999996 & TRN \\
\hline CHEMBL241314 & 453896 & 6.2518 & 6.385 & TRN & \\
\hline CHEMBL240818 & 453896 & 5.8416 & 5.5903 & TRN & \\
\hline CHEMBL241466 & 453896 & 5.5935 & 4.9311 & TST & \\
\hline
\end{tabular}




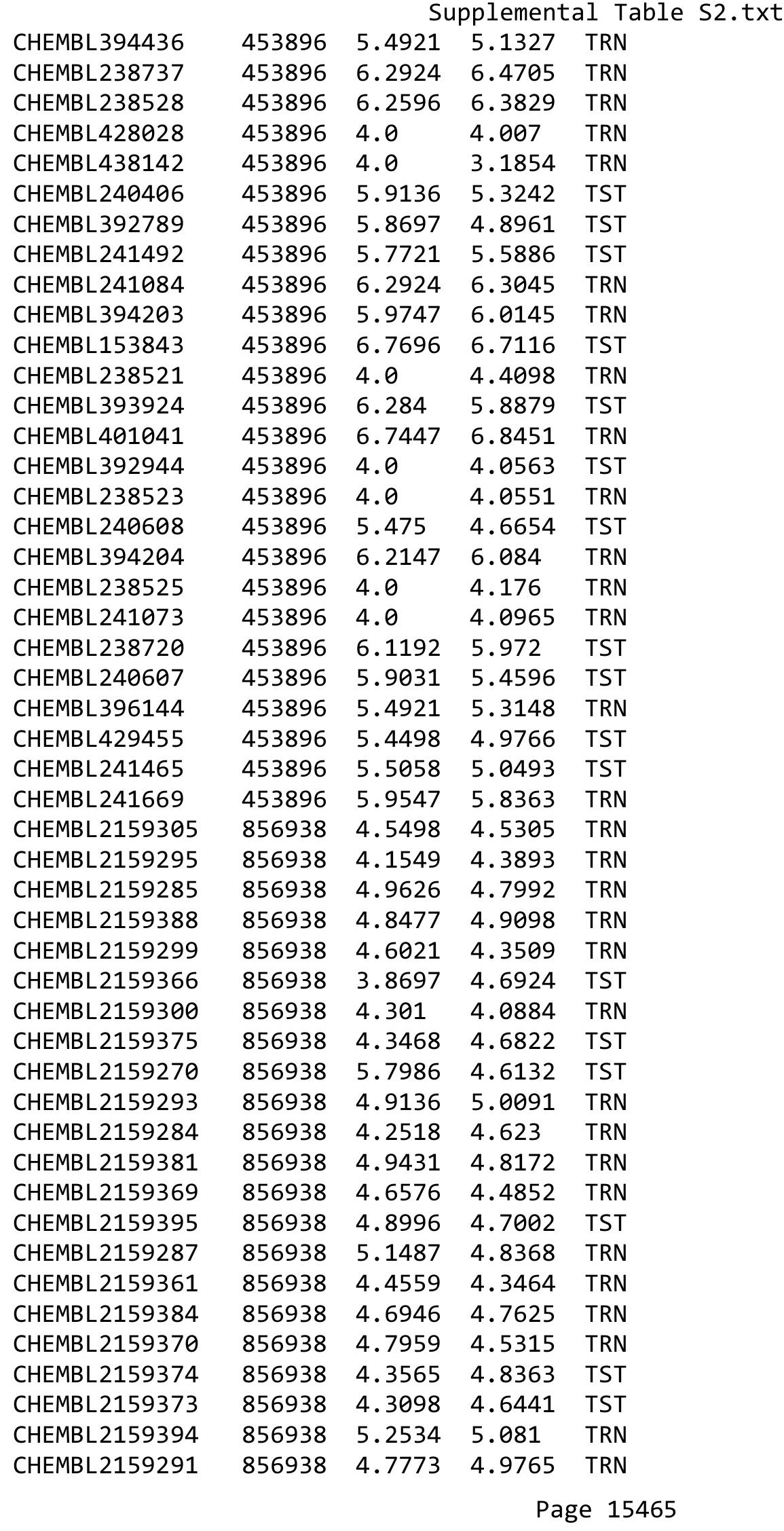


Supplemental Table S2.txt

\begin{tabular}{|c|c|c|c|c|c|}
\hline CHEMBL 2159281 & 856938 & 4.5317 & 4.8086 & TRN & \\
\hline CHEMBL 2159282 & 856938 & 4.7167 & 4.8653 & TRN & \\
\hline CHEMBL2159389 & 856938 & 5.3188 & 4.7576 & TRN & \\
\hline CHEMBL2159292 & 856938 & 4.9101 & 4.7979 & TRN & \\
\hline CHEMBL2159294 & 856938 & 4.9172 & 4.8274 & TRN & \\
\hline CHEMBL 2159286 & 856938 & 4.5784 & 4.5391 & TRN & \\
\hline CHEMBL 2159364 & 856938 & 6.1739 & 4.4271 & TST & \\
\hline CHEMBL2159289 & 856938 & 5.1024 & 5.0674 & TRN & \\
\hline CHEMBL2159397 & 856938 & 4.4815 & 4.7481 & TST & \\
\hline CHEMBL2159376 & 856938 & 4.301 & 4.8773 & TST & \\
\hline CHEMBL 2159303 & 856938 & 4.585 & 4.4927 & TRN & \\
\hline CHEMBL 2159302 & 856938 & 4.5214 & 4.3959 & TRN & \\
\hline CHEMBL2159372 & 856938 & 4.699 & 4.5307 & TRN & \\
\hline CHEMBL2159393 & 856938 & 4.9626 & 4.81800 & 20000000005 & TRN \\
\hline CHEMBL2159383 & 856938 & 4.284 & 4.5675 & TRN & \\
\hline CHEMBL 2159362 & 856938 & 5.4318 & 4.4273 & TST & \\
\hline CHEMBL2159283 & 856938 & 4.5086 & 4.8822 & TRN & \\
\hline CHEMBL2159290 & 856938 & 4.9508 & 4.8859 & TRN & \\
\hline CHEMBL2159390 & 856938 & 4.7696 & 4.9333 & TRN & \\
\hline CHEMBL2159396 & 856938 & 4.8239 & 4.7495 & TST & \\
\hline CHEMBL2159379 & 856938 & 4.2596 & 4.6456 & TRN & \\
\hline CHEMBL2159391 & 856938 & 4.8069 & 4.6948 & TRN & \\
\hline CHEMBL 2159296 & 856938 & 3.8996 & 4.1264 & TRN & \\
\hline CHEMBL2159368 & 856938 & 3.8239 & 4.7067 & TST & \\
\hline CHEMBL2159392 & 856938 & 4.4815 & 4.721 & TRN & \\
\hline CHEMBL2159387 & 856938 & 5.1938 & 5.0038 & TRN & \\
\hline CHEMBL2159301 & 856938 & 4.6596 & 4.5818 & TRN & \\
\hline CHEMBL 2159288 & 856938 & 4.7696 & 4.5765 & TRN & \\
\hline CHEMBL2159363 & 856938 & 6.2757 & 4.3843 & TST & \\
\hline CHEMBL2159298 & 856938 & 3.8928 & 4.0442 & TRN & \\
\hline CHEMBL2159371 & 856938 & 4.699 & 4.5005 & TRN & \\
\hline CHEMBL2159272 & 856938 & 6.2441 & 4.5965 & TST & \\
\hline CHEMBL2159276 & 856938 & 6.0 & 4.4629 & TST & \\
\hline CHEMBL2159380 & 856938 & 4.4685 & 4.705 & TRN & \\
\hline CHEMBL2159377 & 856938 & 4.4437 & 4.6151 & TRN & \\
\hline CHEMBL2159304 & 856938 & 4.4318 & 4.3039 & TRN & \\
\hline CHEMBL 2159271 & 856938 & 6.2218 & 4.5618 & TST & \\
\hline CHEMBL 2159297 & 856938 & 3.9957 & 4.3069 & TRN & \\
\hline CHEMBL2159274 & 856938 & 6.0 & 4.4491 & TST & \\
\hline CHEMBL2159378 & 856938 & 4.3565 & 4.6667 & TRN & \\
\hline CHEMBL2159386 & 856938 & 4.5229 & 4.5441 & TRN & \\
\hline CHEMBL2159385 & 856938 & 4.5702 & 4.5098 & TRN & \\
\hline CHEMBL2159382 & 856938 & 4.8665 & 4.7312 & TRN & \\
\hline CHEMBL3329278 & 1448143 & 5.4685 & 5.0294 & TRN & \\
\hline CHEMBL3329299 & 1448143 & 5.9469 & 6.0738 & TRN & \\
\hline CHEMBL3329304 & 1448143 & 5.6737 & 5.7672 & TRN & \\
\hline CHEMBL3329310 & 1448143 & 6.7696 & 6.8689 & TRN & \\
\hline CHEMBL3329277 & 1448143 & 5.5229 & 5.3542 & TRN & \\
\hline
\end{tabular}


Supplemental Table S2.txt

\begin{tabular}{|c|c|c|c|c|c|}
\hline CHEMBL 3094347 & 1448143 & 7.1249 & 5.5313 & TST & \\
\hline CHEMBL3329289 & 1448143 & 4.6364 & 5.1137 & TST & \\
\hline CHEMBL3329307 & 1448143 & 7.3979 & 6.7951 & TRN & \\
\hline CHEMBL3329313 & 1448143 & 6.8239 & 6.8972 & TRN & \\
\hline CHEMBL3329315 & 1448143 & 5.3098 & 5.4189 & TRN & \\
\hline CHEMBL3329297 & 1448143 & 6.2596 & 5.9915 & TRN & \\
\hline CHEMBL3329306 & 1448143 & 5.3179 & 5.3203 & TRN & \\
\hline CHEMBL3329300 & 1448143 & 5.52 & 5.8954 & TRN & \\
\hline CHEMBL3329302 & 1448143 & 6.0915 & 5.8847 & TRN & \\
\hline CHEMBL3329285 & 1448143 & 5.2757 & 5.2164 & TRN & \\
\hline CHEMBL3329317 & 1448143 & 7.5528 & 7.8506 & TRN & \\
\hline CHEMBL3329273 & 1448143 & 5.1135 & 5.136 & TRN & \\
\hline CHEMBL3329274 & 1448143 & 5.7959 & 5.3829 & TRN & \\
\hline CHEMBL 3329303 & 1448143 & 5.5287 & 5.5286 & TRN & \\
\hline CHEMBL3329283 & 1448143 & 5.1249 & 5.45100 & 30000000005 & TRN \\
\hline CHEMBL3329296 & 1448143 & 4.4789 & 4.9006 & TRN & \\
\hline CHEMBL3329281 & 1448143 & 4.3936 & 4.7275 & TRN & \\
\hline CHEMBL3329311 & 1448143 & 6.9586 & 6.8654 & TRN & \\
\hline CHEMBL 3706672 & 1448143 & 5.0757 & 5.3316 & TST & \\
\hline CHEMBL3329221 & 1448143 & 6.3665 & 6.5209 & TRN & \\
\hline CHEMBL3329301 & 1448143 & 5.1385 & 5.5769 & TRN & \\
\hline CHEMBL3329284 & 1448143 & 5.4559 & 5.32600 & 00000000005 & TRN \\
\hline CHEMBL3329276 & 1448143 & 5.4815 & 5.6272 & TRN & \\
\hline CHEMBL 3329319 & 1448143 & 7.3372 & 7.2476 & TRN & \\
\hline CHEMBL3329275 & 1448143 & 5.6778 & 5.655 & TRN & \\
\hline CHEMBL3329287 & 1448143 & 6.3768 & 5.4765 & TST & \\
\hline CHEMBL3329305 & 1448143 & 6.1805 & 5.7666 & TRN & \\
\hline CHEMBL3329294 & 1448143 & 5.2472 & 5.0787 & TRN & \\
\hline CHEMBL 3329280 & 1448143 & 4.6108 & 4.7443 & TRN & \\
\hline CHEMBL3329279 & 1448143 & 5.4202 & 5.3403 & TRN & \\
\hline CHEMBL 3329288 & 1448143 & 6.0177 & 5.2223 & TST & \\
\hline CHEMBL3329295 & 1448143 & 4.7447 & 4.5738 & TRN & \\
\hline CHEMBL3329298 & 1448143 & 6.2518 & 6.0103 & TRN & \\
\hline CHEMBL3329309 & 1448143 & 6.8239 & 6.8365 & TRN & \\
\hline CHEMBL3329318 & 1448143 & 7.4437 & 7.5172 & TRN & \\
\hline CHEMBL3329314 & 1448143 & 5.699 & 5.8612 & TRN & \\
\hline CHEMBL3329282 & 1448143 & 5.2076 & 5.3735 & TRN & \\
\hline CHEMBL3329312 & 1448143 & 7.4089 & 6.8906 & TST & \\
\hline CHEMBL3329308 & 1448143 & 6.8539 & 6.4884 & TST & \\
\hline CHEMBL3329272 & 1448143 & 5.2218 & 5.4915 & TST & \\
\hline CHEMBL3329293 & 1448143 & 5.289 & 4.9508 & TST & \\
\hline CHEMBL3329286 & 1448143 & 4.8539 & 5.2114 & TST & \\
\hline CHEMBL3329292 & 1448143 & 7.0088 & 6.6436 & TST & \\
\hline CHEMBL3329291 & 1448143 & 7.0044 & 6.4344 & TST & \\
\hline CHEMBL3329316 & 1448143 & 7.0315 & 6.8393 & TST & \\
\hline CHEMBL178710 & 303660 & 8.9208 & 8.7735 & TRN & \\
\hline CHEMBL434138 & 303660 & 8.1079 & 8.1237 & TRN & \\
\hline CHEMBL178188 & 303660 & 8.0223 & 8.0219 & TRN & \\
\hline
\end{tabular}




\begin{tabular}{|c|c|c|c|c|c|}
\hline \multicolumn{6}{|c|}{ Supplemental Table S2.txt } \\
\hline CHEMBL179810 & 303660 & 7.3565 & 7.4815 & TRN & \\
\hline CHEMBL179558 & 303660 & 9.1249 & 9.3399 & TRN & \\
\hline CHEMBL360733 & 303660 & 8.699 & 8.748 & TRN & \\
\hline CHEMBL180224 & 303660 & 7.2366 & 7.5198 & TST & \\
\hline CHEMBL178242 & 303660 & 8.5376 & 8.3567 & TRN & \\
\hline CHEMBL179545 & 303660 & 7.3768 & 7.6676 & TRN & \\
\hline CHEMBL68712 & 303660 & 8.585 & 8.5568 & TRN & \\
\hline CHEMBL427313 & 303660 & 8.3279 & 8.2089 & TRN & \\
\hline CHEMBL360113 & 303660 & 7.9586 & 8.0594 & TRN & \\
\hline CHEMBL178633 & 303660 & 6.9586 & 6.3798 & TRN & \\
\hline CHEMBL179737 & 303660 & 7.9586 & 7.8813 & TRN & \\
\hline CHEMBL179700 & 303660 & 8.3279 & 8.0797 & TRN & \\
\hline CHEMBL179555 & 303660 & 5.0 & 6.0821 & TST & \\
\hline CHEMBL178303 & 303660 & 8.0458 & 7.7783 & TST & \\
\hline CHEMBL179769 & 303660 & 8.0269 & 7.8194 & TRN & \\
\hline CHEMBL360122 & 303660 & 9.5376 & 9.7309 & TRN & \\
\hline CHEMBL178840 & 303660 & 8.1192 & 7.9402 & TRN & \\
\hline CHEMBL359474 & 303660 & 5.301 & 6.3072 & TRN & \\
\hline CHEMBL179000 & 303660 & 7.7696 & 7.8357 & TRN & \\
\hline CHEMBL362485 & 303660 & 8.5086 & 9.2265 & TRN & \\
\hline CHEMBL362620 & 303660 & 8.699 & 8.4462 & TRN & \\
\hline CHEMBL362014 & 303660 & 7.2291 & 7.2044 & TST & \\
\hline CHEMBL178632 & 303660 & 7.4685 & 7.7414 & TRN & \\
\hline CHEMBL178677 & 303660 & 9.699 & 9.6331 & TRN & \\
\hline CHEMBL178856 & 303660 & 8.5686 & 8.3665 & TST & \\
\hline CHEMBL359613 & 303660 & 8.1308 & 7.7565 & TST & \\
\hline CHEMBL 361340 & 303660 & 9.0605 & 8.9176 & TRN & \\
\hline CHEMBL361129 & 303660 & 9.7212 & 9.3259 & TRN & \\
\hline CHEMBL360966 & 303660 & 8.3565 & 7.9194 & TRN & \\
\hline CHEMBL175886 & 303660 & 8.6778 & 8.8067 & TRN & \\
\hline CHEMBL366468 & 303660 & 8.6778 & 8.6152 & TRN & \\
\hline CHEMBL175929 & 303660 & 8.1871 & 8.1967 & TRN & \\
\hline CHEMBL179654 & 303660 & 5.301 & 6.0751 & TRN & \\
\hline CHEMBL178783 & 303660 & 9.1612 & 9.2821 & TRN & \\
\hline CHEMBL13662 & 303660 & 6.3372 & 6.2243 & TST & \\
\hline CHEMBL178992 & 303660 & 8.0706 & 8.1564 & TRN & \\
\hline CHEMBL361114 & 303660 & 9.6778 & 9.2621 & TRN & \\
\hline CHEMBL426234 & 303660 & 8.2757 & 7.8256 & TRN & \\
\hline CHEMBL 362409 & 303660 & 8.8861 & 8.4911 & TRN & \\
\hline CHEMBL368905 & 303660 & 7.699 & 8.1213 & TRN & \\
\hline CHEMBL360562 & 303660 & 6.7696 & 6.1058 & TRN & \\
\hline CHEMBL179712 & 303660 & 9.4089 & 9.3461 & TRN & \\
\hline CHEMBL179924 & 303660 & 8.0458 & $8.2610 e$ & 0000000001 & TRN \\
\hline CHEMBL180174 & 303660 & 9.0555 & 8.9251 & TRN & \\
\hline CHEMBL178956 & 303660 & 8.6778 & 9.2164 & TRN & \\
\hline CHEMBL179048 & 303660 & 7.5686 & 7.3506 & TRN & \\
\hline CHEMBL179474 & 303660 & 9.3372 & 9.73 & TRN & \\
\hline CHEMBL361105 & 303660 & 8.5686 & 8.3351 & TRN & \\
\hline
\end{tabular}




\begin{tabular}{|c|c|c|c|c|c|}
\hline \multicolumn{6}{|c|}{ Supplemental Table s2.txt } \\
\hline CHEMBL175475 & 303660 & 9.301 & 9.1815 & TRN & \\
\hline CHEMBL360311 & 303660 & 8.1549 & 8.3584 & TRN & \\
\hline CHEMBL179430 & 303660 & 7.585 & 8.2212 & TRN & \\
\hline CHEMBL178830 & 303660 & 8.3768 & 8.0452 & TRN & \\
\hline CHEMBL361561 & 303660 & 7.9586 & 7.7674 & TRN & \\
\hline CHEMBL180416 & 303660 & 9.1871 & 9.3406 & TRN & \\
\hline CHEMBL179699 & 303660 & 8.5686 & 8.4072 & TRN & \\
\hline CHEMBL179475 & 303660 & 9.2676 & 9.4547 & TRN & \\
\hline CHEMBL366471 & 303660 & 8.5686 & 8.6121 & TRN & \\
\hline CHEMBL179513 & 303660 & 7.7959 & 7.8764 & TRN & \\
\hline CHEMBL359545 & 303660 & 9.1135 & 8.7726 & TRN & \\
\hline CHEMBL369035 & 303660 & 9.0757 & 9.4252 & TRN & \\
\hline CHEMBL361015 & 303660 & 9.0458 & 8.9953 & TRN & \\
\hline CHEMBL360036 & 303660 & 8.0 & 7.7286 & TST & \\
\hline CHEMBL359650 & 303660 & 8.5528 & 8.4832 & TRN & \\
\hline CHEMBL178831 & 303660 & 9.2676 & 8.4451 & TRN & \\
\hline CHEMBL178942 & 303660 & 8.9208 & 8.5881 & TRN & \\
\hline CHEMBL359906 & 303660 & 8.6021 & 8.8292 & TRN & \\
\hline CHEMBL362869 & 303660 & 8.2218 & 8.0975 & TRN & \\
\hline CHEMBL360912 & 303660 & 8.9208 & 8.8161 & TRN & \\
\hline CHEMBL178670 & 303660 & 8.3468 & 8.0736 & TRN & \\
\hline CHEMBL360345 & 303660 & 7.3979 & 7.3901 & TST & \\
\hline CHEMBL361786 & 303660 & 9.0 & 9.6021 & TRN & \\
\hline CHEMBL180417 & 303660 & 7.5229 & 7.2849 & TRN & \\
\hline CHEMBL361597 & 303660 & 8.0362 & 8.2452 & TRN & \\
\hline CHEMBL179777 & 303660 & 9.2557 & 9.2535 & TRN & \\
\hline CHEMBL180215 & 303660 & 7.0 & 7.00799 & 9999999999 & TST \\
\hline CHEMBL359853 & 303660 & 5.301 & 6.0269 & TRN & \\
\hline CHEMBL 361200 & 303660 & 8.4089 & 8.3892 & TRN & \\
\hline CHEMBL180575 & 303660 & 5.0 & 5.9456 & TST & \\
\hline CHEMBL180464 & 303660 & 8.3768 & 8.4292 & TRN & \\
\hline CHEMBL178738 & 303660 & 8.7447 & 8.4079 & TRN & \\
\hline CHEMBL360262 & 303660 & 5.301 & 6.3059 & TST & \\
\hline CHEMBL 366537 & 303660 & 9.3468 & 9.2939 & TST & \\
\hline CHEMBL362282 & 303660 & 9.585 & 9.0968 & TST & \\
\hline CHEMBL178837 & 303660 & 7.9208 & 7.9194 & TST & \\
\hline CHEMBL362421 & 303660 & 8.1871 & 8.1993 & TST & \\
\hline CHEMBL359638 & 303660 & 5.301 & 6.4172 & TST & \\
\hline CHEMBL 369093 & 303660 & 5.0 & 6.0411 & TST & \\
\hline CHEMBL361754 & 303660 & 5.301 & 6.1772 & TST & \\
\hline CHEMBL178508 & 303660 & 7.6576 & 7.8238 & TST & \\
\hline CHEMBL179664 & 303660 & 7.6383 & 7.2589 & TST & \\
\hline CHEMBL179414 & 303660 & 9.4437 & 9.6912 & TST & \\
\hline CHEMBL440558 & 303660 & 8.3565 & 8.5864 & TST & \\
\hline CHEMBL359616 & 303660 & 7.1938 & 7.3011 & TST & \\
\hline CHEMBL179509 & 303660 & 8.585 & 8.3017 & TST & \\
\hline CHEMBL412142 & 954476 & 3.4902 & 3.5175 & TRN & \\
\hline CHEMBL1590308 & 954476 & 2.8602 & 3.7105 & TST & \\
\hline
\end{tabular}




\begin{tabular}{|c|c|c|c|c|c|c|}
\hline & & & & & & \\
\hline CHEMBL 9470 & 954476 & 6.0629 & 5.3987 & TST & & \\
\hline CHEMBL2144069 & 954476 & 4.3286 & 4.0873 & TRN & & \\
\hline CHEMBL392695 & 954476 & 6.0878 & 6.1458 & TRN & & \\
\hline CHEMBL210618 & 954476 & 3.3953 & 3.2852 & TRN & & \\
\hline CHEMBL213100 & 954476 & 4.3952 & 4.0055 & TRN & & \\
\hline CHEMBL 2134202 & 954476 & 5.1765 & 5.316 & TRN & & \\
\hline CHEMBL1909414 & 954476 & 3.3397 & 3.3368 & TRN & & \\
\hline CHEMBL1186585 & 954476 & 5.3881 & 5.1757 & TRN & & \\
\hline CHEMBL 222102 & 954476 & 3.4061 & 3.5842 & TRN & & \\
\hline CHEMBL393929 & 954476 & 4.2239 & 4.1759 & TRN & & \\
\hline CHEMBL514499 & 954476 & 7.9133 & 8.1089 & TRN & & \\
\hline CHEMBL3349342 & 954476 & 3.3996 & 3.307 & TRN & & \\
\hline CHEMBL 202721 & 954476 & 5.6477 & 5.5212 & TRN & & \\
\hline CHEMBL102714 & 954476 & 3.2382 & 3.2249 & TRN & & \\
\hline CHEMBL1516890 & 954476 & 3.6412 & 3.7707 & TRN & & \\
\hline CHEMBL1230020 & 954476 & 3.3651 & 3.4703 & TRN & & \\
\hline CHEMBL3186408 & 954476 & 3.8104 & 3.7376 & TST & & \\
\hline CHEMBL483849 & 954476 & 2.9246 & 2.7438 & TST & & \\
\hline CHEMBL3199475 & 954476 & 4.0597 & 4.1343 & TRN & & \\
\hline CHEMBL512504 & 954476 & 3.9897 & 3.8665 & TRN & & \\
\hline CHEMBL483847 & 954476 & 4.3821 & 4.5222 & TRN & & \\
\hline CHEMBL209148 & 954476 & 4.9076 & 4.7877 & TRN & & \\
\hline CHEMBL379975 & 954476 & 4.2482 & 4.6002 & TRN & & \\
\hline CHEMBL1970879 & 954476 & 5.2988 & 4.9647 & TRN & & \\
\hline CHEMBL1190711 & 954476 & 5.3864 & 5.1116 & TRN & & \\
\hline CHEMBL573107 & 954476 & 5.1799 & 5.3177 & TRN & & \\
\hline CHEMBL 2005886 & 954476 & 4.4734 & 4.8802 & TRN & & \\
\hline CHEMBL192566 & 954476 & 9.2242 & 8.8492 & TST & & \\
\hline CHEMBL180127 & 954476 & 4.6036 & 4.8012 & TRN & & \\
\hline CHEMBL 2137530 & 954476 & 4.7027 & 4.9669 & TRN & & \\
\hline CHEMBL1404918 & 954476 & 2.8964 & 2.9459 & TRN & & \\
\hline CHEMBL1256459 & 954476 & 8.7122 & 8.6074 & TRN & & \\
\hline CHEMBL515416 & 954476 & 4.5849 & 4.7247 & TRN & & \\
\hline CHEMBL189584 & 954476 & 3.9274 & 4.4342 & TRN & & \\
\hline CHEMBL258844 & 954476 & 5.1123 & 5.2035 & TRN & & \\
\hline CHEMBL1357247 & 954476 & 3.3058 & 3.2361 & TRN & & \\
\hline CHEMBL65 & 954476 & 7.4187 & 7.518 & TRN & & \\
\hline CHEMBL3392440 & 954476 & 3.6922 & 4.0747 & TRN & & \\
\hline CHEMBL 255342 & 954476 & 4.5321 & 3.9474 & TRN & & \\
\hline CHEMBL577784 & 954476 & 5.1257 & 5.4036 & TRN & & \\
\hline CHEMBL1673039 & 954476 & 4.6192 & 4.7009 & TRN & & \\
\hline CHEMBL585951 & 954476 & 5.5179 & 5.7186 & TRN & & \\
\hline CHEMBL300389 & 954476 & 7.2794 & 7.0526 & TRN & & \\
\hline CHEMBL217354 & 954476 & 6.6148 & 6.2218 & TRN & & \\
\hline CHEMBL509032 & 954476 & 5.86600 & 90000000 & 205 & 5.2528 & TRN \\
\hline CHEMBL1643959 & 954476 & 5.6784 & 5.176 & TRN & & \\
\hline CHEMBL188678 & 954476 & 3.9887 & 3.8719 & TRN & & \\
\hline CHEMBL373751 & 954476 & 3.6948 & 3.9518 & TRN & & \\
\hline
\end{tabular}


Supplemental Table S2.txt

\begin{tabular}{|c|c|c|c|c|c|}
\hline CHEMBL1242367 & 954476 & 5.1375 & 5.0681 & TRN & \\
\hline CHEMBL92309 & 954476 & 1.0059 & 3.4018 & TST & \\
\hline CHEMBL221137 & 954476 & 5.274 & 4.9845 & TST & \\
\hline CHEMBL 220241 & 954476 & 4.7644 & 4.8886 & TRN & \\
\hline CHEMBL240954 & 954476 & 4.4193 & 3.8036 & TST & \\
\hline CHEMBL449158 & 954476 & 5.9654 & 6.7591 & TST & \\
\hline CHEMBL379300 & 954476 & 7.5896 & 7.7429 & TRN & \\
\hline CHEMBL191334 & 954476 & 3.9739 & 3.0793 & TST & \\
\hline CHEMBL259181 & 954476 & 5.4344 & 4.5601 & TST & \\
\hline CHEMBL558642 & 954476 & 5.5546 & 4.4475 & TST & \\
\hline CHEMBL 2363137 & 954476 & 6.0914 & 5.0523 & TST & \\
\hline CHEMBL399530 & 954476 & 5.1692 & 4.7434 & TST & \\
\hline CHEMBL135561 & 954476 & 4.6492 & 4.4818 & TST & \\
\hline CHEMBL1788116 & 954476 & 5.9661 & 4.7362 & TST & \\
\hline CHEMBL472940 & 954476 & 4.4758 & 3.9936 & TST & \\
\hline CHEMBL3977960 & 1641120 & 8.3979 & 7.1622 & TST & \\
\hline CHEMBL3977564 & 1641120 & 7.4318 & 7.3578 & TRN & \\
\hline CHEMBL 3909164 & 1641120 & 7.8239 & 8.208 & TRN & \\
\hline CHEMBL 3893372 & 1641120 & 6.9957 & 6.8868 & TRN & \\
\hline CHEMBL3940022 & 1641120 & 7.5229 & 7.3037 & TRN & \\
\hline CHEMBL 3936604 & 1641120 & 6.5751 & 6.5292 & TRN & \\
\hline CHEMBL3926433 & 1641120 & 7.3872 & 7.26 & TRN & \\
\hline CHEMBL 3897626 & 1641120 & 7.6383 & 7.6242 & TRN & \\
\hline CHEMBL 3981293 & 1641120 & 8.301 & 7.6307 & TRN & \\
\hline CHEMBL3945986 & 1641120 & 7.7696 & 7.4331 & TRN & \\
\hline CHEMBL3910254 & 1641120 & 7.8539 & 7.765 & TRN & \\
\hline CHEMBL3932663 & 1641120 & 7.3188 & 7.3022 & TRN & \\
\hline CHEMBL 3934987 & 1641120 & 7.6778 & 7.8382 & TRN & \\
\hline CHEMBL3934695 & 1641120 & 6.2782 & 7.3064 & TST & \\
\hline CHEMBL3971897 & 1641120 & 7.2291 & 7.981 & TST & \\
\hline CHEMBL3970870 & 1641120 & 7.6576 & 7.5433 & TRN & \\
\hline CHEMBL3953233 & 1641120 & 7.1612 & 7.2964 & TRN & \\
\hline CHEMBL 3920972 & 1641120 & 8.0969 & 8.1706 & TRN & \\
\hline CHEMBL3951680 & 1641120 & 7.3279 & 7.3568 & TRN & \\
\hline CHEMBL 3898294 & 1641120 & 7.6576 & 7.2973 & TRN & \\
\hline CHEMBL3919833 & 1641120 & 8.0 & 7.4253 & TST & \\
\hline CHEMBL3982362 & 1641120 & 8.0969 & 7.1931 & TST & \\
\hline CHEMBL 3977723 & 1641120 & 7.4202 & 7.709 & TRN & \\
\hline CHEMBL 3944235 & 1641120 & 7.4559 & 7.41299 & 9999999999 & TRN \\
\hline CHEMBL 3924703 & 1641120 & 6.5986 & 7.2959 & TST & \\
\hline CHEMBL3941078 & 1641120 & 7.9586 & 7.6242 & TRN & \\
\hline CHEMBL3979865 & 1641120 & 7.4559 & 7.7448 & TRN & \\
\hline CHEMBL3899547 & 1641120 & 8.3979 & 7.6262 & TST & \\
\hline CHEMBL3923971 & 1641120 & 8.3979 & 7.7118 & TST & \\
\hline CHEMBL 3922537 & 1641120 & 7.8539 & 7.5074 & TRN & \\
\hline CHEMBL3926797 & 1641120 & 7.2757 & 7.6405 & TRN & \\
\hline CHEMBL3903200 & 1641120 & 6.2168 & 7.5785 & TST & \\
\hline CHEMBL3944314 & 1641120 & 7.4202 & 7.2723 & TST & \\
\hline
\end{tabular}


Supplemental Table S2.txt

\begin{tabular}{|c|c|c|c|c|c|}
\hline CHEMBL3954320 & 1641120 & 6.0 & 8.0658 & TST & \\
\hline CHEMBL3910890 & 1641120 & 6.6162 & 7.3352 & TST & \\
\hline CHEMBL3907326 & 1641120 & 7.3979 & 7.715 & TRN & \\
\hline CHEMBL 3893389 & 1641120 & 7.7447 & 7.4446 & TRN & \\
\hline CHEMBL3927636 & 1641120 & 7.699 & 8.2072 & TRN & \\
\hline CHEMBL 3939264 & 1641120 & 7.5686 & 7.2807 & TRN & \\
\hline CHEMBL 3983170 & 1641120 & 6.6946 & 6.8332 & TRN & \\
\hline CHEMBL3955475 & 1641120 & 7.8539 & 7.8169 & TRN & \\
\hline CHEMBL3925609 & 1641120 & 7.7959 & 7.4874 & TRN & \\
\hline CHEMBL 3930351 & 1641120 & 8.2218 & 7.8661 & TRN & \\
\hline CHEMBL 3890483 & 1641120 & 8.5229 & 7.564 & TRN & \\
\hline CHEMBL 3951251 & 1641120 & 7.8239 & 7.8292 & TRN & \\
\hline CHEMBL 3960777 & 1641120 & 8.2218 & 8.1287 & TRN & \\
\hline CHEMBL 3917531 & 1641120 & 6.0 & 8.1223 & TST & \\
\hline CHEMBL3930759 & 1641120 & 7.6198 & 7.3139 & TRN & \\
\hline CHEMBL 3909824 & 1641120 & 8.1549 & 7.2801 & TST & \\
\hline CHEMBL3943064 & 1641120 & 8.2218 & 8.2074 & TST & \\
\hline CHEMBL 3932086 & 1641120 & 7.3979 & 7.4034 & TRN & \\
\hline CHEMBL 3925723 & 1641120 & 7.9586 & 7.4992 & TRN & \\
\hline CHEMBL3916216 & 1641120 & 7.0757 & 7.1032 & TRN & \\
\hline CHEMBL 3957904 & 1641120 & 8.0969 & 7.9906 & TRN & \\
\hline CHEMBL3899613 & 1641120 & 6.5346 & 7.2565 & TST & \\
\hline CHEMBL 3935823 & 1641120 & 7.7212 & 8.1463 & TRN & \\
\hline CHEMBL 3980935 & 1641120 & 8.1549 & 7.5559 & TRN & \\
\hline CHEMBL 3944635 & 1641120 & 7.2218 & 7.1422 & TRN & \\
\hline CHEMBL3961146 & 1641120 & 7.9586 & 7.7319 & TRN & \\
\hline CHEMBL3889991 & 1641120 & 7.5086 & 7.5284 & TRN & \\
\hline CHEMBL 3914072 & 1641120 & 7.3565 & 7.4349 & TRN & \\
\hline CHEMBL 3984112 & 1641120 & 8.0458 & 7.5674 & TRN & \\
\hline CHEMBL3934609 & 1641120 & 6.9872 & 6.87799 & 9999999999 & TRN \\
\hline CHEMBL 3986089 & 1641120 & 8.0 & 8.0143 & TRN & \\
\hline CHEMBL3923537 & 1641120 & 9.0 & 8.6053 & TRN & \\
\hline CHEMBL 3944701 & 1641120 & 7.2218 & 7.0729 & TRN & \\
\hline CHEMBL3965980 & 1641120 & 8.2218 & 8.2175 & TRN & \\
\hline CHEMBL 3944165 & 1641120 & 8.5229 & 8.4038 & TRN & \\
\hline CHEMBL3948997 & 1641120 & 6.2549 & 7.309 & TST & \\
\hline CHEMBL3957819 & 1641120 & 6.5901 & 7.1113 & TST & \\
\hline CHEMBL3951891 & 1641120 & 6.7375 & 6.6261 & TRN & \\
\hline CHEMBL 3900639 & 1641120 & 7.5229 & 8.3753 & TST & \\
\hline CHEMBL 3893622 & 1641120 & 6.7447 & 6.5526 & TRN & \\
\hline CHEMBL 3907655 & 1641120 & 7.4089 & 7.7142 & TRN & \\
\hline CHEMBL3919769 & 1641120 & 7.3979 & 7.0909 & TRN & \\
\hline CHEMBL3899719 & 1641120 & 6.5935 & 6.6582 & TRN & \\
\hline CHEMBL 3921257 & 1641120 & 6.0 & 7.2127 & TRN & \\
\hline CHEMBL 3962388 & 1641120 & 7.4949 & 7.3984 & TST & \\
\hline CHEMBL 3922062 & 1641120 & 8.1549 & 8.5189 & TRN & \\
\hline CHEMBL3978303 & 1641120 & 7.2218 & 7.0885 & TRN & \\
\hline CHEMBL3954728 & 1641120 & 6.0 & 6.5681 & TRN & \\
\hline
\end{tabular}


Supplemental Table S2.txt

\begin{tabular}{|c|c|c|c|c|}
\hline CHEMBL3969969 & 1641120 & 7.2076 & 7.3428 & TRN \\
\hline CHEMBL3914818 & 1641120 & 6.0 & 6.505 & TRN \\
\hline CHEMBL3918015 & 1641120 & 7.6778 & 7.7276 & TRN \\
\hline CHEMBL3925806 & 1641120 & 6.7799 & 7.5797 & TST \\
\hline CHEMBL3906226 & 1641120 & 7.4437 & 7.7136 & TRN \\
\hline CHEMBL3924511 & 1641120 & 8.0969 & 7.1332 & TRN \\
\hline CHEMBL3944153 & 1641120 & 7.2757 & 6.9738 & TRN \\
\hline CHEMBL3986473 & 1641120 & 7.2518 & 7.1395 & TRN \\
\hline CHEMBL3977226 & 1641120 & 7.1192 & 7.004 & TRN \\
\hline CHEMBL3986062 & 1641120 & 8.0458 & 7.081 & TST \\
\hline CHEMBL3897710 & 1641120 & 7.4949 & 7.6832 & TST \\
\hline CHEMBL3895457 & 1641120 & 6.8508 & 7.1584 & TRN \\
\hline CHEMBL3912223 & 1641120 & 6.0 & 7.4589 & TST \\
\hline CHEMBL3946407 & 1641120 & 6.4776 & 8.3418 & TST \\
\hline CHEMBL3969584 & 1641120 & 7.5086 & 7.5401 & TRN \\
\hline CHEMBL3931741 & 1641120 & 8.3979 & 7.282 & TST \\
\hline CHEMBL3920227 & 1641120 & 7.0088 & 7.1526 & TRN \\
\hline CHEMBL3942068 & 1641120 & 7.3098 & 7.2477 & TRN \\
\hline CHEMBL3914516 & 1641120 & 7.699 & 7.6452 & TRN \\
\hline CHEMBL3953355 & 1641120 & 8.0 & 8.4255 & TRN \\
\hline CHEMBL3954521 & 1641120 & 7.5686 & 7.8246 & TRN \\
\hline CHEMBL3900743 & 1641120 & 6.6556 & 7.966 & TST \\
\hline CHEMBL3986409 & 1641120 & 7.3098 & 7.4753 & TRN \\
\hline CHEMBL3959524 & 1641120 & 8.0458 & 7.5796 & TRN \\
\hline CHEMBL3911292 & 1641120 & 7.2441 & 7.3267 & TRN \\
\hline CHEMBL3919912 & 1641120 & 7.1367 & \multicolumn{2}{|c|}{6.882000000000001} \\
\hline CHEMBL3961983 & 1641120 & 8.0458 & 7.4301 & TRN \\
\hline CHEMBL3962045 & 1641120 & 6.0 & 6.5504 & TRN \\
\hline CHEMBL 3897247 & 1641120 & 6.8153 & \multicolumn{2}{|c|}{7.2010000000000005} \\
\hline CHEMBL3916214 & 1641120 & 8.2218 & 7.3499 & TST \\
\hline CHEMBL3907259 & 1641120 & 8.3979 & 9.1224 & TRN \\
\hline CHEMBL3954331 & 1641120 & 7.4685 & 7.3983 & TRN \\
\hline CHEMBL3959818 & 1641120 & 7.6021 & 7.6893 & TRN \\
\hline CHEMBL3925294 & 1641120 & 6.9031 & \multicolumn{2}{|c|}{7.0729999999999995} \\
\hline CHEMBL3907787 & 1641120 & 7.2757 & 7.1917 & TRN \\
\hline CHEMBL3935194 & 1641120 & 8.1549 & 8.286 & TST \\
\hline CHEMBL3905796 & 1641120 & 6.0 & 6.6548 & TRN \\
\hline CHEMBL3912405 & 1641120 & 7.6778 & 7.7515 & TRN \\
\hline CHEMBL3900034 & 1641120 & 6.0 & 6.4375 & TRN \\
\hline CHEMBL3952183 & 1641120 & 8.3979 & 7.3552 & TST \\
\hline CHEMBL3905073 & 1641120 & 6.8729 & 7.0949 & TRN \\
\hline CHEMBL3916722 & 1641120 & 7.3372 & 7.3729 & TRN \\
\hline CHEMBL3906948 & 1641120 & 7.9208 & 7.4366 & TST \\
\hline CHEMBL3936856 & 1641120 & 7.7212 & 7.5256 & TRN \\
\hline CHEMBL3916602 & 1641120 & 6.8477 & 7.0571 & TRN \\
\hline CHEMBL3967342 & 1641120 & 8.5229 & 7.1507 & TST \\
\hline CHEMBL3891053 & 1641120 & 8.5229 & 8.5418 & TRN \\
\hline CHEMBL3987035 & 1641120 & 6.0 & 6.3772 & TRN \\
\hline
\end{tabular}


Supplemental Table S2.txt

\begin{tabular}{|c|c|c|c|c|c|}
\hline CHEMBL3894470 & 1641120 & 7.7447 & 7.3639 & TRN & \\
\hline CHEMBL3902366 & 1641120 & 6.0 & 7.3439 & TRN & \\
\hline CHEMBL3941912 & 1641120 & 8.0458 & 7.9743 & TRN & \\
\hline CHEMBL3948776 & 1641120 & 8.2218 & 8.0441 & TRN & \\
\hline CHEMBL3893041 & 1641120 & 6.5143 & 7.943 & TST & \\
\hline CHEMBL3931004 & 1641120 & 7.0315 & 6.875 & TRN & \\
\hline CHEMBL3916802 & 1641120 & 7.699 & 7.6679 & TRN & \\
\hline CHEMBL3985970 & 1641120 & 6.8761 & 7.1193 & TRN & \\
\hline CHEMBL479862 & 515688 & 5.6383 & 5.7551 & TRN & \\
\hline CHEMBL480235 & 515688 & 4.9586 & 5.1567 & TRN & \\
\hline CHEMBL520758 & 515688 & 4.6383 & 4.7204 & TRN & \\
\hline CHEMBL481323 & 515688 & 4.0605 & 4.0449 & TRN & \\
\hline CHEMBL480843 & 515688 & 3.1938 & 4.1191 & TST & \\
\hline CHEMBL521097 & 515688 & 3.5952 & 3.5308 & TRN & \\
\hline CHEMBL481215 & 515688 & 4.4685 & 4.09399 & 9999999999 & TRN \\
\hline CHEMBL479451 & 515688 & 4.3665 & 4.4412 & TRN & \\
\hline CHEMBL480431 & 515688 & 4.3372 & 5.3061 & TST & \\
\hline CHEMBL454289 & 515688 & 4.9208 & 5.2057 & TRN & \\
\hline CHEMBL481201 & 515688 & 3.1938 & 3.4237 & TRN & \\
\hline CHEMBL479272 & 515688 & 3.1938 & 3.3157 & TRN & \\
\hline CHEMBL480441 & 515688 & 4.1024 & 4.72199 & 99999999995 & TST \\
\hline CHEMBL480832 & 515688 & 6.9208 & 6.8261 & TRN & \\
\hline CHEMBL519771 & 515688 & 4.3768 & 4.121 & TRN & \\
\hline CHEMBL482400 & 515688 & 3.4056 & 3.4136 & TRN & \\
\hline CHEMBL480225 & 515688 & 3.1938 & 3.1994 & TRN & \\
\hline CHEMBL479273 & 515688 & 3.1938 & 2.8726 & TRN & \\
\hline CHEMBL452186 & 515688 & 4.0223 & 4.1905 & TRN & \\
\hline CHEMBL517067 & 515688 & 4.301 & 3.8104 & TRN & \\
\hline CHEMBL479466 & 515688 & 3.9586 & 3.9462 & TRN & \\
\hline CHEMBL480226 & 515688 & 5.4318 & 5.9762 & TRN & \\
\hline CHEMBL482139 & 515688 & 4.0915 & 4.2036 & TRN & \\
\hline CHEMBL480636 & 515688 & 7.0132 & 6.5097 & TRN & \\
\hline CHEMBL443899 & 515688 & 4.1192 & 4.072 & TRN & \\
\hline CHEMBL480051 & 515688 & 5.4559 & 5.6736 & TRN & \\
\hline CHEMBL481031 & 515688 & 4.301 & 4.0862 & TRN & \\
\hline CHEMBL506548 & 515688 & 4.0132 & 4.0156 & TRN & \\
\hline CHEMBL518771 & 515688 & 3.1938 & 3.1187 & TRN & \\
\hline CHEMBL520115 & 515688 & 4.2757 & 4.3799 & TRN & \\
\hline CHEMBL480831 & 515688 & 6.7959 & 6.9248 & TRN & \\
\hline CHEMBL480432 & 515688 & 3.1938 & 3.7813 & TST & \\
\hline CHEMBL480050 & 515688 & 5.2147 & 4.8979 & TRN & \\
\hline CHEMBL479261 & 515688 & 3.3161 & 3.6195 & TRN & \\
\hline CHEMBL520771 & 515688 & 5.6576 & 5.6621 & TST & \\
\hline CHEMBL480631 & 515688 & 4.9208 & 5.1548 & TRN & \\
\hline CHEMBL479274 & 515688 & 6.699 & 6.2329 & TRN & \\
\hline CHEMBL480844 & 515688 & 5.8861 & 5.7543 & TRN & \\
\hline CHEMBL481610 & 515688 & 4.5528 & 4.4565 & TRN & \\
\hline CHEMBL481216 & 515688 & 3.3585 & 3.5154 & TRN & \\
\hline
\end{tabular}




\begin{tabular}{|c|c|c|c|c|}
\hline & & & pplement & \\
\hline CHEMBL479277 & 515688 & 3.8996 & 4.2263 & TRN \\
\hline CHEMBL482140 & 515688 & 4.4437 & 4.306 & TRN \\
\hline CHEMBL481777 & 515688 & 3.8069 & 4.0046 & TRN \\
\hline CHEMBL479468 & 515688 & 4.0915 & 4.1837 & TST \\
\hline CHEMBL479276 & 515688 & 4.2218 & 4.2608 & TST \\
\hline CHEMBL479726 & 515688 & 7.041 & 6.2118 & TST \\
\hline CHEMBL474066 & 515688 & 3.1938 & 3.9345 & TST \\
\hline CHEMBL519940 & 515688 & 4.4685 & 3.9877 & TST \\
\hline CHEMBL481419 & 515688 & 4.1871 & 3.8315 & TST \\
\hline CHEMBL517223 & 515688 & 3.1938 & 3.7161 & TST \\
\hline CHEMBL480448 & 515688 & 4.5528 & 4.8391 & TST \\
\hline CHEMBL421450 & 88771 & 4.19 & 4.1907 & TRN \\
\hline CHEMBL129120 & 88771 & 4.99 & 4.9773 & TRN \\
\hline CHEMBL338373 & 88771 & 4.68 & 4.6941 & TRN \\
\hline CHEMBL128249 & 88771 & 4.62 & 4.6078 & TRN \\
\hline CHEMBL129286 & 88771 & 4.96 & 4.9439 & TRN \\
\hline CHEMBL433666 & 88771 & 5.11 & 5.1371 & TRN \\
\hline CHEMBL340865 & 88771 & 4.02 & 3.8996 & TST \\
\hline CHEMBL128231 & 88771 & 4.43 & 4.5141 & TRN \\
\hline CHEMBL130134 & 88771 & 5.1 & 5.0951 & TRN \\
\hline CHEMBL128856 & 88771 & 5.1 & 5.1113 & TRN \\
\hline CHEMBL128376 & 88771 & 5.0 & 5.0856 & TRN \\
\hline CHEMBL129055 & 88771 & 3.84 & 3.8197 & TRN \\
\hline CHEMBL129287 & 88771 & 4.3 & 4.3566 & TST \\
\hline CHEMBL129147 & 88771 & 5.37 & 5.3484 & TRN \\
\hline CHEMBL338228 & 88771 & 5.4 & 5.273 & TRN \\
\hline CHEMBL128868 & 88771 & 4.8 & 4.7178 & TRN \\
\hline CHEMBL128850 & 88771 & 4.36 & 4.3507 & TRN \\
\hline CHEMBL128608 & 88771 & 5.2 & 5.2231 & TRN \\
\hline CHEMBL128740 & 88771 & 5.06 & 4.8242 & TST \\
\hline CHEMBL129598 & 88771 & 5.08 & 5.0488 & TRN \\
\hline CHEMBL338145 & 88771 & 4.63 & 4.6342 & TRN \\
\hline CHEMBL339576 & 88771 & 4.85 & 4.8274 & TRN \\
\hline CHEMBL340697 & 88771 & 5.46 & 5.4424 & TRN \\
\hline CHEMBL128550 & 88771 & 3.22 & 3.6919 & TST \\
\hline CHEMBL337606 & 88771 & 5.13 & 5.1566 & TRN \\
\hline CHEMBL127330 & 88771 & 4.92 & 4.9287 & TRN \\
\hline CHEMBL338178 & 88771 & 4.32 & 4.3088 & TRN \\
\hline CHEMBL129462 & 88771 & 3.96 & 3.9384 & TRN \\
\hline CHEMBL132166 & 88771 & 4.38 & 4.3752 & TRN \\
\hline CHEMBL422790 & 88771 & 4.37 & 4.3694 & TRN \\
\hline CHEMBL339551 & 88771 & 4.14 & 4.1384 & TRN \\
\hline CHEMBL338005 & 88771 & 4.3 & 4.289 & TRN \\
\hline CHEMBL338144 & 88771 & 4.72 & 4.7483 & TRN \\
\hline CHEMBL130024 & 88771 & 5.45 & 5.2884 & TST \\
\hline CHEMBL128556 & 88771 & 3.95 & 4.0167 & TST \\
\hline CHEMBL127388 & 88771 & 4.11 & 4.1073 & TRN \\
\hline CHEMBL338628 & 88771 & 3.84 & 3.8415 & TRN \\
\hline
\end{tabular}




\begin{tabular}{|c|c|c|c|c|}
\hline \multicolumn{5}{|c|}{ Supplemental Table S2.txt } \\
\hline CHEMBL341067 & 88771 & 3.75 & 3.7581 & TRN \\
\hline CHEMBL128927 & 88771 & 4.41 & 4.3912 & TRN \\
\hline CHEMBL129812 & 88771 & 4.36 & 4.3473 & TRN \\
\hline CHEMBL129119 & 88771 & 4.9 & 4.9107 & TRN \\
\hline CHEMBL128177 & 88771 & 4.62 & 4.588 & TRN \\
\hline CHEMBL128508 & 88771 & 4.36 & 4.4399 & TRN \\
\hline CHEMBL341232 & 88771 & 3.38 & 3.3932 & TRN \\
\hline CHEMBL419983 & 88771 & 4.68 & 4.2149 & TST \\
\hline CHEMBL132328 & 88771 & 4.47 & 4.2866 & TRN \\
\hline CHEMBL128540 & 88771 & 5.0 & 5.0018 & TRN \\
\hline CHEMBL334547 & 88771 & 4.64 & 4.6422 & TRN \\
\hline CHEMBL339463 & 88771 & 4.49 & 4.7687 & TST \\
\hline CHEMBL129911 & 88771 & 4.22 & 4.2304 & TST \\
\hline CHEMBL128090 & 88771 & 4.3 & 4.3834 & TST \\
\hline CHEMBL339829 & 88771 & 4.23 & 4.1539 & TST \\
\hline CHEMBL129383 & 88771 & 3.95 & 3.8568 & TST \\
\hline CHEMBL131451 & 88771 & 4.15 & 4.1973 & TRN \\
\hline CHEMBL128670 & 88771 & 4.21 & 4.2948 & TST \\
\hline CHEMBL128792 & 88771 & 4.0 & 4.128 & TRN \\
\hline CHEMBL335480 & 88771 & 4.0 & 4.5789 & TST \\
\hline CHEMBL128496 & 88771 & 3.95 & 3.7541 & TST \\
\hline CHEMBL130135 & 88771 & 3.95 & 3.9592 & TRN \\
\hline CHEMBL129778 & 88771 & 4.68 & 4.7305 & TRN \\
\hline CHEMBL131113 & 88771 & 4.4 & 4.4946 & TRN \\
\hline CHEMBL128293 & 88771 & 4.78 & 4.7753 & TRN \\
\hline CHEMBL128247 & 88771 & 4.75 & 4.8653 & TRN \\
\hline CHEMBL 338902 & 88771 & 4.97 & 4.9644 & TRN \\
\hline CHEMBL130882 & 88771 & 4.88 & 4.8511 & TRN \\
\hline CHEMBL340425 & 88771 & 4.61 & 4.631 & TRN \\
\hline CHEMBL128487 & 88771 & 4.71 & 4.7601 & TRN \\
\hline CHEMBL339572 & 88771 & 4.72 & 4.9095 & TST \\
\hline CHEMBL129486 & 88771 & 5.85 & 4.6707 & TST \\
\hline CHEMBL129376 & 88771 & 4.43 & 4.3075 & TRN \\
\hline CHEMBL 339347 & 88771 & 4.92 & 4.8874 & TRN \\
\hline CHEMBL131784 & 88771 & 5.13 & 5.0992 & TRN \\
\hline CHEMBL538398 & 88771 & 3.9 & 4.2378 & TST \\
\hline CHEMBL421441 & 88771 & 3.97 & 4.4321 & TST \\
\hline CHEMBL129173 & 88771 & 5.1 & 5.1338 & TRN \\
\hline CHEMBL131063 & 88771 & 4.4 & 4.3223 & TRN \\
\hline CHEMBL 2024102 & 815989 & 7.1221 & 5.8592 & TRN \\
\hline CHEMBL 2024533 & 815989 & 6.0132 & 5.879 & TRN \\
\hline CHEMBL3969791 & 815989 & 7.5243 & 7.9534 & TRN \\
\hline CHEMBL3925831 & 815989 & 7.8268 & 7.61 & TRN \\
\hline CHEMBL3951468 & 815989 & 6.3002 & 6.45 & TRN \\
\hline CHEMBL3898058 & 815989 & 7.3391 & 7.0537 & TRN \\
\hline CHEMBL3976214 & 815989 & 7.4449 & 6.5828 & TRN \\
\hline CHEMBL 2024536 & 815989 & 7.3429 & 6.2614 & TRN \\
\hline CHEMBL3955485 & 815989 & 8.585 & 8.0572 & TRN \\
\hline
\end{tabular}




\begin{tabular}{|c|c|c|c|c|c|}
\hline \multirow[b]{2}{*}{ CHEMBL2024103 } & \multicolumn{5}{|c|}{ Supplemental Table S2.txt } \\
\hline & 815989 & 7.5834 & 6.767 & TRN & \\
\hline CHEMBL 2024100 & 815989 & 7.8097 & 6.6252 & TST & \\
\hline CHEMBL3917585 & 815989 & 5.2147 & 5.9027 & TRN & \\
\hline CHEMBL3947686 & 815989 & 7.3382 & 7.4901 & TRN & \\
\hline CHEMBL 2022201 & 815989 & 6.2612 & 6.2867 & TRN & \\
\hline CHEMBL3984277 & 815989 & 7.3565 & 7.847 & TRN & \\
\hline CHEMBL3983933 & 815989 & 7.5072 & 7.7351 & TRN & \\
\hline CHEMBL3939002 & 815989 & 7.4486 & 7.2597 & TRN & \\
\hline CHEMBL3900928 & 815989 & 7.3497 & 7.1307 & TRN & \\
\hline CHEMBL 2024535 & 815989 & 5.6946 & 5.5266 & TRN & \\
\hline CHEMBL3965361 & 815989 & 6.3665 & 5.8481 & TRN & \\
\hline CHEMBL3953294 & 815989 & 7.8827 & 8.39 & TRN & \\
\hline CHEMBL3979079 & 815989 & 7.1029 & 6.4331 & TST & \\
\hline CHEMBL3974836 & 815989 & 7.2534 & 6.4851 & TST & \\
\hline CHEMBL 2024532 & 815989 & 5.2941 & 5.7125 & TRN & \\
\hline CHEMBL3950366 & 815989 & 7.3925 & 7.2241 & TRN & \\
\hline CHEMBL 2024097 & 815989 & 6.4698 & 6.3418 & TST & \\
\hline CHEMBL 2022202 & 815989 & 6.1475 & 6.4004 & TST & \\
\hline CHEMBL 2022197 & 815989 & 6.8539 & 6.8283 & TRN & \\
\hline CHEMBL3890425 & 815989 & $5.7620 e$ & 00000006 & 6.5306 & TRN \\
\hline CHEMBL 2024101 & 815989 & 7.5157 & 6.6375 & TST & \\
\hline CHEMBL 2024534 & 815989 & 5.2865 & 5.2574 & TRN & \\
\hline CHEMBL3957140 & 815989 & 6.3161 & 5.8223 & TRN & \\
\hline CHEMBL3903637 & 815989 & 3.699 & 4.2553 & TRN & \\
\hline CHEMBL3904049 & 815989 & 6.4389 & 6.8946 & TRN & \\
\hline CHEMBL3964423 & 815989 & 7.5622 & 6.9696 & TST & \\
\hline CHEMBL3913685 & 815989 & 7.5229 & 7.7566 & TRN & \\
\hline CHEMBL 2024561 & 815989 & 8.8539 & 8.4628 & TRN & \\
\hline CHEMBL 2024545 & 815989 & 7.3344 & 7.57606 & 00000000005 & TRN \\
\hline CHEMBL 2022198 & 815989 & 7.6778 & 7.5235 & TRN & \\
\hline CHEMBL 2024104 & 815989 & 5.1824 & 5.2266 & TRN & \\
\hline CHEMBL3969372 & 815989 & 7.2984 & 6.938 & TRN & \\
\hline CHEMBL3932765 & 815989 & 7.4179 & 6.3234 & TST & \\
\hline CHEMBL3932278 & 815989 & 6.1463 & 6.2771 & TRN & \\
\hline CHEMBL 2024098 & 815989 & 6.8153 & 6.4895 & TST & \\
\hline CHEMBL 2024546 & 815989 & 7.6108 & 8.2195 & TRN & \\
\hline CHEMBL3901995 & 815989 & 6.1494 & 6.71 & TRN & \\
\hline CHEMBL 2024531 & 815989 & 6.0615 & 6.3375 & TRN & \\
\hline CHEMBL 2024099 & 815989 & 6.9508 & 6.5954 & TST & \\
\hline CHEMBL 2022199 & 815989 & 3.699 & 4.5278 & TRN & \\
\hline CHEMBL3965941 & 815989 & 7.2426 & 6.515 & TST & \\
\hline CHEMBL3970647 & 815989 & 7.7696 & 7.8806 & TRN & \\
\hline CHEMBL3895398 & 815989 & 7.3307 & 7.5237 & TST & \\
\hline CHEMBL3934969 & 815989 & 7.6038 & 7.7273 & TST & \\
\hline CHEMBL3973061 & 815989 & 6.9872 & 6.6576 & TST & \\
\hline CHEMBL174346 & 32404 & 5.6946 & 5.8022 & TRN & \\
\hline CHEMBL175219 & 32404 & 4.5229 & 4.4191 & TRN & \\
\hline CHEMBL3216881 & 32404 & 6.3098 & 6.2799 & TRN & \\
\hline
\end{tabular}




\begin{tabular}{|c|c|c|c|c|c|}
\hline & & & & & \\
\hline CHEMBL175218 & 32404 & 6.3487 & 6.3416 & TRN & \\
\hline CHEMBL174027 & 32404 & 6.6861 & 6.5585 & TRN & \\
\hline CHEMBL557186 & 32404 & 4.5229 & 5.9459 & TST & \\
\hline CHEMBL3216631 & 32404 & 7.0353 & 7.0444 & TRN & \\
\hline CHEMBL368299 & 32404 & 5.5421 & 5.5529 & TRN & \\
\hline CHEMBL535357 & 32404 & 7.8327 & 7.876 & TRN & \\
\hline CHEMBL177092 & 32404 & 6.6038 & 6.7742 & TST & \\
\hline CHEMBL369407 & 32404 & 7.8861 & 7.9959 & TRN & \\
\hline CHEMBL173140 & 32404 & 7.8894 & 7.8813 & TRN & \\
\hline CHEMBL173570 & 32404 & 8.1427 & 8.1905 & TRN & \\
\hline CHEMBL177160 & 32404 & 5.699 & 6.9414 & TST & \\
\hline CHEMBL536715 & 32404 & 7.3726 & 7.4542 & TRN & \\
\hline CHEMBL534693 & 32404 & 6.9245 & 6.7096 & TRN & \\
\hline CHEMBL177161 & 32404 & 6.295 & 6.74299 & 9999999999 & TST \\
\hline CHEMBL174512 & 32404 & 7.4881 & 7.1473 & TRN & \\
\hline CHEMBL175279 & 32404 & 5.4685 & 5.8172 & TST & \\
\hline CHEMBL 367848 & 32404 & 4.5229 & 4.5501 & TRN & \\
\hline CHEMBL175271 & 32404 & 7.76200 & 30000000 & 7.7767 & TRN \\
\hline CHEMBL355447 & 32404 & 7.1599 & 7.0715 & TRN & \\
\hline CHEMBL174513 & 32404 & 5.9747 & 6.3226 & TRN & \\
\hline CHEMBL170483 & 32404 & 4.5229 & 6.4489 & TST & \\
\hline CHEMBL368369 & 32404 & 4.5229 & 4.3753 & TRN & \\
\hline CHEMBL172130 & 32404 & 5.8861 & 5.9116 & TST & \\
\hline CHEMBL171296 & 32404 & 7.3947 & 7.3423 & TRN & \\
\hline CHEMBL176567 & 32404 & 7.3947 & 7.6293 & TRN & \\
\hline CHEMBL174178 & 32404 & 4.5229 & 4.4376 & TRN & \\
\hline CHEMBL174204 & 32404 & 4.5229 & 4.7138 & TRN & \\
\hline CHEMBL540615 & 32404 & 7.6861 & 7.6147 & TRN & \\
\hline CHEMBL368408 & 32404 & 7.6737 & 7.5023 & TRN & \\
\hline CHEMBL353160 & 32404 & 7.4841 & 7.4888 & TRN & \\
\hline CHEMBL173504 & 32404 & 6.4413 & 6.8317 & TRN & \\
\hline CHEMBL171898 & 32404 & 7.6162 & 7.6782 & TRN & \\
\hline CHEMBL368541 & 32404 & 4.5229 & 5.9597 & TST & \\
\hline CHEMBL173988 & 32404 & 8.0605 & 7.9857 & TRN & \\
\hline CHEMBL552522 & 32404 & 6.7212 & 6.6309 & TRN & \\
\hline CHEMBL539332 & 32404 & 6.7932 & 6.7831 & TRN & \\
\hline CHEMBL171362 & 32404 & 7.8182 & 7.6973 & TRN & \\
\hline CHEMBL553465 & 32404 & 6.8386 & 7.2904 & TST & \\
\hline CHEMBL174126 & 32404 & 5.9586 & 6.0695 & TRN & \\
\hline CHEMBL427474 & 32404 & 7.7375 & 7.6884 & TRN & \\
\hline CHEMBL171410 & 32404 & 4.5229 & 5.0745 & TST & \\
\hline CHEMBL353329 & 32404 & 7.1337 & 7.3396 & TRN & \\
\hline CHEMBL174934 & 32404 & 7.0106 & 6.9694 & TRN & \\
\hline CHEMBL538812 & 32404 & 5.8239 & 4.8568 & TST & \\
\hline CHEMBL559369 & 32404 & 8.0915 & 7.9435 & TRN & \\
\hline CHEMBL172357 & 32404 & 4.5229 & 5.1331 & TST & \\
\hline CHEMBL172121 & 32404 & 6.4559 & 5.7667 & TST & \\
\hline CHEMBL367555 & 32404 & 5.4828 & 5.4668 & TRN & \\
\hline
\end{tabular}




\begin{tabular}{|c|c|c|c|c|c|c|}
\hline & & \multicolumn{5}{|c|}{ Supplemental Table S2.txt } \\
\hline CHEMBL 373751 & 954899 & 3.0319 & 3.248 & TRN & & \\
\hline CHEMBL 222102 & 954899 & 3.5858 & 3.8838 & TRN & & \\
\hline CHEMBL220241 & 954899 & 4.9132 & 4.9035 & TRN & & \\
\hline CHEMBL192566 & 954899 & 5.9388 & 8.6133 & TST & & \\
\hline CHEMBL1242367 & 954899 & 3.7886 & 3.88 & TRN & & \\
\hline CHEMBL379975 & 954899 & 5.4164 & 5.4796 & TRN & & \\
\hline CHEMBL 3186408 & 954899 & 4.1849 & 3.8193 & TST & & \\
\hline CHEMBL1357247 & 954899 & 2.7225 & 2.737 & TRN & & \\
\hline CHEMBL135561 & 954899 & 4.2004 & 4.0927 & TRN & & \\
\hline CHEMBL209148 & 954899 & 4.9684 & 5.1289 & TRN & & \\
\hline CHEMBL 259181 & 954899 & 4.7659 & 4.7753 & TRN & & \\
\hline CHEMBL449158 & 954899 & 7.1456 & 7.2809 & TST & & \\
\hline CHEMBL1230020 & 954899 & 3.28899 & 99999999 & 997 & 3.2246 & TRN \\
\hline CHEMBL1643959 & 954899 & 3.7636 & 3.8068 & TRN & & \\
\hline CHEMBL188678 & 954899 & 5.8595 & 5.5267 & TRN & & \\
\hline CHEMBL 202721 & 954899 & 5.5859 & 5.4678 & TRN & & \\
\hline CHEMBL585951 & 954899 & 6.2632 & 6.4773 & TRN & & \\
\hline CHEMBL1909414 & 954899 & 4.9858 & 4.8508 & TRN & & \\
\hline CHEMBL483847 & 954899 & 4.5171 & 4.5354 & TRN & & \\
\hline CHEMBL515416 & 954899 & 4.0176 & 3.9079 & TRN & & \\
\hline CHEMBL1256459 & 954899 & 6.8262 & 6.9234 & TRN & & \\
\hline CHEMBL3199475 & 954899 & 4.1298 & 3.9601 & TRN & & \\
\hline CHEMBL1404918 & 954899 & 3.2514 & 3.359 & TRN & & \\
\hline CHEMBL483849 & 954899 & 3.4253 & 3.406 & TRN & & \\
\hline CHEMBL 258844 & 954899 & 4.324 & 4.2365 & TRN & & \\
\hline CHEMBL189584 & 954899 & 4.3874 & 4.4077 & TRN & & \\
\hline CHEMBL92309 & 954899 & 3.8043 & 2.6489 & TST & & \\
\hline CHEMBL65 & 954899 & 8.4278 & 8.4329 & TRN & & \\
\hline CHEMBL240954 & 954899 & 3.7505 & 4.3911 & TST & & \\
\hline CHEMBL 2005886 & 954899 & 6.5438 & 6.6304 & TRN & & \\
\hline CHEMBL1590308 & 954899 & 2.3934 & 3.4683 & TST & & \\
\hline CHEMBL393929 & 954899 & 3.5048 & 3.6881 & TRN & & \\
\hline CHEMBL412142 & 954899 & 3.2816 & 3.3142 & TRN & & \\
\hline CHEMBL221137 & 954899 & 5.0532 & 4.8175 & TST & & \\
\hline CHEMBL191334 & 954899 & 4.7948 & 4.7892 & TRN & & \\
\hline CHEMBL1673039 & 954899 & 5.2887 & 5.1574 & TRN & & \\
\hline CHEMBL514499 & 954899 & 7.5984 & 7.4603 & TRN & & \\
\hline CHEMBL2144069 & 954899 & 6.8113 & 6.8318 & TRN & & \\
\hline CHEMBL577784 & 954899 & 5.5949 & 5.5283 & TRN & & \\
\hline CHEMBL1190711 & 954899 & 5.0221 & 5.0358 & TRN & & \\
\hline CHEMBL392695 & 954899 & 4.3803 & 4.5093 & TRN & & \\
\hline CHEMBL 2363137 & 954899 & 5.4211 & 5.5785 & TRN & & \\
\hline CHEMBL3392440 & 954899 & 3.2686 & 3.1647 & TRN & & \\
\hline CHEMBL180127 & 954899 & 4.8751 & 4.8007 & TRN & & \\
\hline CHEMBL512504 & 954899 & 7.0115 & 6.9645 & TRN & & \\
\hline CHEMBL558642 & 954899 & 3.8033 & 3.6209 & TRN & & \\
\hline CHEMBL472940 & 954899 & 5.0533 & 5.0703 & TRN & & \\
\hline CHEMBL210618 & 954899 & 4.2812 & 4.1026 & TRN & & \\
\hline
\end{tabular}




\begin{tabular}{|c|c|c|c|c|}
\hline & & & & \\
\hline CHEMBL300389 & 954899 & 6.2496 & 6.2942 & $\mathrm{TR}$ \\
\hline HEMBL 213100 & 954899 & .1492 & 3.0088 & \\
\hline HEMBL102714 & 54899 & 3.4133 & 5923 & \\
\hline HEMBL9470 & 54899 & .716 & .4407 & \\
\hline HEMBL3349342 & 54899 & 7.4895 & 2846 & \\
\hline HEMBL1788116 & 954899 & 2766 & 4.0157 & \\
\hline HEMBL1516890 & 954899 & .0688 & 4.1382 & \\
\hline CHEMBL573107 & 954899 & .0537 & 5.4816 & \\
\hline HEMBL509032 & 54899 & .3175 & 5.5971 & \\
\hline CHEMBL379300 & & 6.3007 & & \\
\hline CHEMBL1970879 & 954899 & 3.8915 & 4.0798 & \\
\hline HEMBL1516890 & 954985 & 3.8193 & 3.714 & \\
\hline CHEMBL240954 & 85 & 4.0373 & 4.1638 & \\
\hline HEMBL2. & 85 & 5.2682 & 4915 & \\
\hline HEMBL5 & 85 & 3.2559 & 5049 & \\
\hline HEMBL2363137 & 85 & 3.7965 & 4.2666 & \\
\hline CHEMBL 2144069 & 85 & 3.4127 & 2.8656 & \\
\hline CHEMBL 58 & 954 & 6.188 & 6.0212 & \\
\hline HEMBL1 & 35 & 83 & 2.7168 & \\
\hline HEMBL1 & 35 & 5.0814 & 4.8897 & \\
\hline CHEMBL1242367 & 85 & 3.9244 & 3.8098 & \\
\hline CHEMBL180127 & 954 & 4.5419 & 4.1421 & \\
\hline CHEMBL3 & $95<$ & 6.9502 & 6.7357 & \\
\hline HEMBLS & 5 & 583 & 6.7917 & \\
\hline CHEMBL2 & 35 & 3.2458 & 3.4411 & \\
\hline CHEMBL 1 & 35 & 1747 & 3.133 & \\
\hline CHEMBL55 & 35 & 565 & 0287 & TRN \\
\hline CHEMBL9 & $95<$ & 5 . & 7034 & \\
\hline CHEMBL1 & 5 & 94 & 786 & \\
\hline CHEMBL 1 & 954 & 3.6829 & 3.3219 & \\
\hline CHEMBL3 & 35 & 5.8767 & 5.4183 & \\
\hline CHEMBL44 & 954 & 6.2664 & 6.2694 & TS. \\
\hline CHEMBL1 & 95 & 4.2337 & 4.2465 & RN \\
\hline CHEMBL3 & 5 & 4.6744 & 5.6429 & \\
\hline CHEMBL 2 & 954 & 3.549 & 3.5333 & \\
\hline CHEMBL1970879 & 954985 & 3.6186 & 3.905 & \\
\hline CHEMBL192566 & 954 & 4.7765 & 7.143 & $S$ \\
\hline CHEMBL4 & 95 & 3.7256 & 3.6901 & RI \\
\hline CHEMBL1 & $95<$ & 3.3179 & 3.3291 & \\
\hline CHEMBL 2 & 954 & 4.1144 & 3.4997 & $\mathrm{RN}$ \\
\hline CHEMBL1230020 & 954985 & 3.9687 & 3.6892 & RI \\
\hline CHEMBL1643959 & 954985 & 2.8195 & 2.8764 & $T$ \\
\hline CHEMBL 2 & & 3.3726 & & \\
\hline CHEMBL577784 & 954 & 3.4655 & 3.5549 & \\
\hline CHEMBL65 & 954985 & 6.8289 & 6.3665 & RI \\
\hline CHEMBL334 & 954985 & 3.2459 & 2.9484 & \\
\hline CHEMBL393929 & 954985 & 3.4332 & 3.4627 & \\
\hline CHEMBL258844 & 954985 & 3.9762 & 4.1763 & \\
\hline
\end{tabular}

Page 15480 


\begin{tabular}{|c|c|c|c|c|c|c|}
\hline & & \multicolumn{5}{|c|}{ Supplemental Table S2.txt } \\
\hline CHEMBL512504 & 954985 & 6.6478 & 6.8964 & TRN & & \\
\hline CHEMBL92309 & 954985 & 3.1622 & 2.6891 & TST & & \\
\hline CHEMBL259181 & 954985 & 2.8802 & 3.9883 & TRN & & \\
\hline CHEMBL 3186408 & 954985 & \multicolumn{3}{|c|}{3.2460000000000004} & 3.38 & TST \\
\hline CHEMBL222102 & 954985 & 3.3477 & 3.4082 & TRN & & \\
\hline CHEMBL1909414 & 954985 & 3.665 & 3.6476 & TRN & & \\
\hline CHEMBL3392440 & 954985 & 3.286 & 3.2145 & TRN & & \\
\hline CHEMBL483849 & 954985 & 1.849 & 2.3237 & TRN & & \\
\hline CHEMBL1788116 & 954985 & 3.7696 & 4.1667 & TRN & & \\
\hline CHEMBL1673039 & 954985 & 3.5477 & 4.1623 & TRN & & \\
\hline CHEMBL202721 & 954985 & 3.3942 & 3.4563 & TRN & & \\
\hline CHEMBL188678 & 954985 & 3.8319 & 3.99300 & 00000 & $\partial 03$ & TRN \\
\hline CHEMBL472940 & 954985 & 4.3015 & 4.4373 & TRN & & \\
\hline CHEMBL515416 & 954985 & 5.0422 & 4.2971 & TRN & & \\
\hline CHEMBL373751 & 954985 & 2.9153 & 3.2325 & TRN & & \\
\hline CHEMBL509032 & 954985 & 4.9112 & 4.5682 & TST & & \\
\hline CHEMBL1256459 & 954985 & 6.9863 & 6.4313 & TST & & \\
\hline CHEMBL379975 & 954985 & 4.8125 & 5.14 & TST & & \\
\hline CHEMBL135561 & 954985 & 4.8624 & 3.9246 & TST & & \\
\hline CHEMBL412142 & 954985 & 3.2214 & 3.9055 & TST & & \\
\hline CHEMBL 2005886 & 954985 & \multicolumn{3}{|c|}{4.2330000000000005} & 4.4253 & TST \\
\hline CHEMBL392695 & 954985 & 5.4934 & 4.9402 & TST & & \\
\hline CHEMBL509032 & 954953 & 5.3132 & 5.3717 & TRN & & \\
\hline CHEMBL259181 & 954953 & 5.0308 & 5.0084 & TRN & & \\
\hline CHEMBL102714 & 954953 & 3.3333 & 3.3887 & TRN & & \\
\hline CHEMBL221137 & 954953 & 5.4629 & 4.855 & TST & & \\
\hline CHEMBL240954 & 954953 & 4.4708 & 4.5057 & TST & & \\
\hline CHEMBL1590308 & 954953 & 4.1787 & 3.182 & TST & & \\
\hline CHEMBL220241 & 954953 & 5.0072 & 5.0202 & TRN & & \\
\hline CHEMBL558642 & 954953 & 3.7647 & 3.8061 & TRN & & \\
\hline CHEMBL512504 & 954953 & 6.8886 & 6.8749 & TRN & & \\
\hline CHEMBL379975 & 954953 & 6.315 & 6.3601 & TRN & & \\
\hline CHEMBL573107 & 954953 & 5.7973 & 5.8542 & TRN & & \\
\hline CHEMBL3199475 & 954953 & 6.6682 & 6.7169 & TRN & & \\
\hline CHEMBL 2144069 & 954953 & 5.0226 & 4.8739 & TRN & & \\
\hline CHEMBL3392440 & 954953 & 4.7028 & 4.698 & TRN & & \\
\hline CHEMBL1230020 & 954953 & 4.7744 & 4.7449 & TRN & & \\
\hline CHEMBL 2005886 & 954953 & 3.0267 & 3.0619 & TRN & & \\
\hline CHEMBL1909414 & 954953 & 3.6544 & 3.7566 & TRN & & \\
\hline CHEMBL135561 & 954953 & 4.9137 & 4.8012 & TRN & & \\
\hline CHEMBL1404918 & 954953 & 3.6339 & 3.4938 & TRN & & \\
\hline CHEMBL213100 & 954953 & 4.0983 & 4.2706 & TRN & & \\
\hline CHEMBL202721 & 954953 & 5.9158 & 5.9388 & TRN & & \\
\hline CHEMBL2363137 & 954953 & 3.4354 & 3.3794 & TRN & & \\
\hline CHEMBL1516890 & 954953 & 3.7763 & 3.7232 & TRN & & \\
\hline CHEMBL1242367 & 954953 & 3.9028 & 3.8842 & TRN & & \\
\hline CHEMBL483847 & 954953 & 3.6895 & 3.8002 & TRN & & \\
\hline CHEMBL514499 & 954953 & 8.3213 & 8.2455 & TRN & & \\
\hline
\end{tabular}




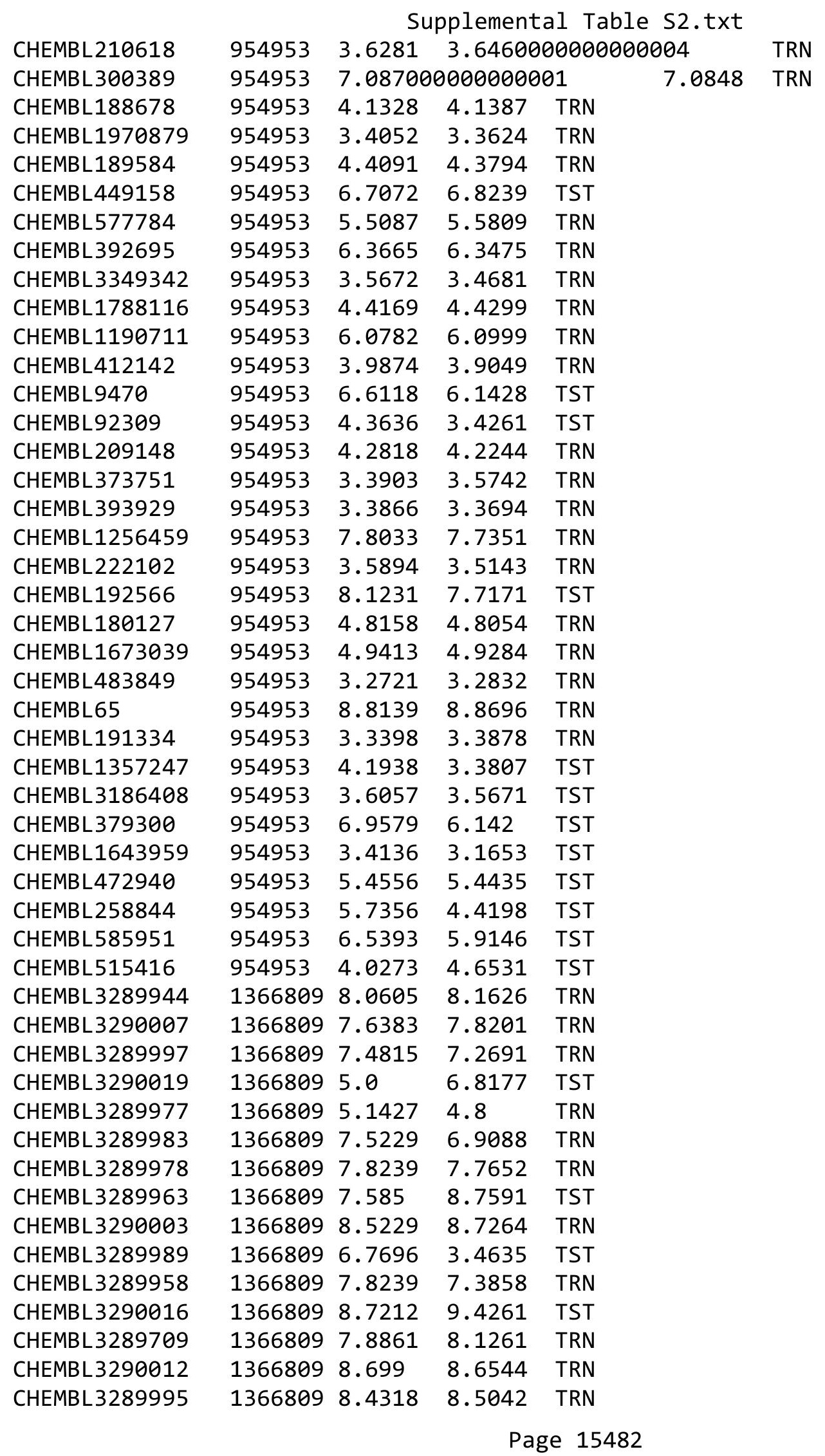


Supplemental Table S2.txt

\begin{tabular}{|c|c|c|c|c|c|}
\hline CHEMBL3289953 & 1366809 & 8.6576 & 8.7163 & TRN & \\
\hline CHEMBL3289980 & 1366809 & 7.2924 & 7.0312 & TRN & \\
\hline CHEMBL3289968 & 1366809 & 7.3565 & 7.6864 & TRN & \\
\hline CHEMBL3289956 & 1366809 & 7.3098 & \multicolumn{2}{|c|}{7.7170000000000005} & TRN \\
\hline CHEMBL3289974 & 1366809 & 6.3979 & 7.0876 & TRN & \\
\hline CHEMBL 3290020 & 1366809 & 5.0 & 6.3493 & TRN & \\
\hline CHEMBL3290001 & 1366809 & 8.041 & 7.9219 & TRN & \\
\hline CHEMBL3289992 & 1366809 & 7.7696 & 7.4014 & TRN & \\
\hline CHEMBL3290005 & 1366809 & 9.0 & 8.7712 & TRN & \\
\hline CHEMBL3290018 & 1366809 & 7.8239 & 7.0728 & TST & \\
\hline CHEMBL 3289949 & 1366809 & 7.3188 & 10.5082 & TST & \\
\hline CHEMBL3289971 & 1366809 & 4.0 & 4.4124 & TRN & \\
\hline CHEMBL3289951 & 1366809 & 8.4949 & 7.6829 & TRN & \\
\hline CHEMBL3290013 & 1366809 & 7.5686 & \multicolumn{2}{|c|}{7.7139999999999995} & TRN \\
\hline CHEMBL3289955 & 1366809 & 8.2218 & 7.9321 & TRN & \\
\hline CHEMBL3289947 & 1366809 & 7.4318 & 7.5429 & TRN & \\
\hline CHEMBL3289973 & 1366809 & 7.2007 & 6.9766 & TRN & \\
\hline CHEMBL 3289993 & 1366809 & 7.8539 & 7.9734 & TRN & \\
\hline CHEMBL 3289948 & 1366809 & 7.5686 & 10.6724 & TST & \\
\hline CHEMBL3289972 & 1366809 & 7.1135 & 6.8758 & TRN & \\
\hline CHEMBL3289965 & 1366809 & 7.5686 & 7.1921 & TST & \\
\hline CHEMBL3290014 & 1366809 & 8.9208 & 8.7876 & TRN & \\
\hline CHEMBL 3286432 & 1366809 & 7.4089 & 7.2159 & TRN & \\
\hline CHEMBL 3289979 & 1366809 & 4.0 & 3.7486 & TRN & \\
\hline CHEMBL3289950 & 1366809 & 7.2518 & 7.4903 & TRN & \\
\hline CHEMBL3289708 & 1366809 & 7.3665 & \multicolumn{2}{|c|}{7.372000000000001} & TRN \\
\hline CHEMBL 3290008 & 1366809 & 9.0 & 8.9275 & TRN & \\
\hline CHEMBL3289961 & 1366809 & 8.0809 & 5.7718 & TST & \\
\hline CHEMBL3290015 & 1366809 & 8.0969 & 8.1741 & TST & \\
\hline CHEMBL 3289988 & 1366809 & 4.0 & 2.7955 & TST & \\
\hline CHEMBL 3290009 & 1366809 & 7.4437 & 7.6518 & TRN & \\
\hline CHEMBL3289982 & 1366809 & 5.8861 & 6.1937 & TRN & \\
\hline CHEMBL3289962 & 1366809 & 7.3565 & 6.4981 & TST & \\
\hline CHEMBL3289999 & 1366809 & 8.0605 & 7.1693 & TRN & \\
\hline CHEMBL3289975 & 1366809 & 7.2596 & 4.0534 & TST & \\
\hline CHEMBL3290021 & 1366809 & 7.6021 & 6.5156 & TRN & \\
\hline CHEMBL 3289946 & 1366809 & 7.5686 & 7.7023 & TRN & \\
\hline CHEMBL 3289984 & 1366809 & 7.2676 & 8.0476 & TRN & \\
\hline CHEMBL3289985 & 1366809 & 4.0 & 3.6119 & TST & \\
\hline CHEMBL 3289970 & 1366809 & 7.2441 & 7.0084 & TRN & \\
\hline CHEMBL3289986 & 1366809 & 7.3372 & 7.2018 & TST & \\
\hline CHEMBL 3290002 & 1366809 & 8.3979 & 7.973 & TRN & \\
\hline CHEMBL3289996 & 1366809 & 7.585 & 7.569 & TRN & \\
\hline CHEMBL 3290004 & 1366809 & \multicolumn{3}{|c|}{8.283999999999999} & TRN \\
\hline CHEMBL 3289998 & 1366809 & 7.1938 & 7.1231 & TRN & \\
\hline CHEMBL3289957 & 1366809 & 7.3188 & 7.7152 & TRN & \\
\hline CHEMBL3289960 & 1366809 & 7.3468 & 7.1501 & TRN & \\
\hline CHEMBL 3290010 & 1366809 & 7.6576 & 7.2611 & TRN & \\
\hline
\end{tabular}

Page 15483 
Supplemental Table S2.txt

\begin{tabular}{|c|c|c|c|c|c|}
\hline CHEMBL3289976 & 1366809 & 8.2757 & 4.5462 & TST & \\
\hline CHEMBL3289987 & 1366809 & 7.0 & 7.8551 & TST & \\
\hline CHEMBL3289990 & 1366809 & 7.699 & 7.4203 & TRN & \\
\hline CHEMBL3289966 & 1366809 & 7.7959 & 7.2057 & TST & \\
\hline CHEMBL3289991 & 1366809 & 7.7959 & 7.858 & TRN & \\
\hline CHEMBL3289964 & 1366809 & 7.3372 & 8.5984 & TST & \\
\hline CHEMBL3289967 & 1366809 & 5.699 & 5.5554 & TRN & \\
\hline CHEMBL3290011 & 1366809 & 7.9586 & 8.294 & TRN & \\
\hline CHEMBL3289954 & 1366809 & 9.0458 & 9.0184 & TRN & \\
\hline CHEMBL3289969 & 1366809 & 4.0 & 4.3507 & TRN & \\
\hline CHEMBL3289952 & 1366809 & 7.7447 & 8.129 & TRN & \\
\hline CHEMBL3289994 & 1366809 & 7.8239 & 7.6588 & TRN & \\
\hline CHEMBL3289981 & 1366809 & 7.8239 & 7.45200 & 0000000001 & TRN \\
\hline CHEMBL3289945 & 1366809 & 8.1079 & 7.905 & TRN & \\
\hline CHEMBL3290006 & 1366809 & 8.9586 & 9.2028 & TRN & \\
\hline CHEMBL 3290000 & 1366809 & 5.0 & 6.2878 & TRN & \\
\hline CHEMBL3290017 & 1366809 & 8.8239 & 10.341 & TST & \\
\hline CHEMBL 2324265 & 941167 & 7.0458 & 6.8766 & TRN & \\
\hline CHEMBL 2323236 & 941167 & 3.6021 & 6.36299 & 99999999995 & TST \\
\hline CHEMBL 2322620 & 941167 & 7.4559 & 7.2986 & TRN & \\
\hline CHEMBL 2324267 & 941167 & 7.0 & 6.9871 & TRN & \\
\hline CHEMBL 2323239 & 941167 & 7.2596 & 7.4413 & TRN & \\
\hline CHEMBL 2323233 & 941167 & 9.0 & 8.564 & TRN & \\
\hline CHEMBL 2324269 & 941167 & 3.6021 & 4.0688 & TRN & \\
\hline CHEMBL 2322630 & 941167 & 6.6778 & 6.8397 & TRN & \\
\hline CHEMBL 2323240 & 941167 & 6.0 & 6.5585 & TRN & \\
\hline CHEMBL 2322633 & 941167 & 4.301 & 4.5841 & TRN & \\
\hline CHEMBL 2323235 & 941167 & 3.6021 & 6.4378 & TST & \\
\hline CHEMBL 2322626 & 941167 & 8.699 & 8.7102 & TRN & \\
\hline CHEMBL1257063 & 941167 & 7.2218 & 6.7139 & TRN & \\
\hline CHEMBL 2324274 & 941167 & 7.6021 & 7.28600 & 00000000005 & TRN \\
\hline CHEMBL 2322623 & 941167 & 8.2596 & 8.2144 & TRN & \\
\hline CHEMBL 2323237 & 941167 & 6.2366 & 5.9559 & TRN & \\
\hline CHEMBL 2322631 & 941167 & 7.0458 & 6.686 & TRN & \\
\hline CHEMBL 2325509 & 941167 & 7.3979 & 7.4767 & TRN & \\
\hline CHEMBL 2325510 & 941167 & \multicolumn{3}{|c|}{6.757000000000001} & TRN \\
\hline CHEMBL 1444402 & 941167 & 5.3979 & 3.9383 & TST & \\
\hline CHEMBL 2324275 & 941167 & 7.8239 & 8.1296 & TRN & \\
\hline CHEMBL 2323241 & 941167 & 5.0 & 5.284 & TRN & \\
\hline CHEMBL 2324270 & 941167 & 5.0 & 5.0726 & TRN & \\
\hline CHEMBL 2323228 & 941167 & 9.3468 & 9.1039 & TRN & \\
\hline CHEMBL 2322629 & 941167 & 8.4559 & 8.43799 & 9999999999 & TRN \\
\hline CHEMBL 2324273 & 941167 & 7.5229 & 7.7006 & TRN & \\
\hline CHEMBL 2325511 & 941167 & 7.301 & 7.8604 & TST & \\
\hline CHEMBL1257090 & 941167 & 7.6021 & 7.8399 & TST & \\
\hline CHEMBL 2325506 & 941167 & 7.0 & 7.5369 & TST & \\
\hline CHEMBL 1257089 & 941167 & 7.3979 & 7.1463 & TST & \\
\hline CHEMBL 2323232 & 941167 & 7.8239 & 8.344 & TRN & \\
\hline
\end{tabular}




\begin{tabular}{|c|c|c|c|c|}
\hline \multicolumn{5}{|c|}{ Supplemental Table S2.txt } \\
\hline CHEMBL 2325505 & 941167 & 7.5229 & 7.3928 & TST \\
\hline CHEMBL 2323238 & 941167 & 6.4559 & 6.5193 & TRN \\
\hline CHEMBL2324276 & 941167 & 7.0458 & 7.4885 & TRN \\
\hline CHEMBL 2322627 & 941167 & 9.5229 & 9.6168 & TRN \\
\hline CHEMBL 2322621 & 941167 & 7.0 & 6.9386 & TRN \\
\hline CHEMBL 2323231 & 941167 & 9.301 & 8.8904 & TRN \\
\hline CHEMBL 2323234 & 941167 & 6.5229 & 5.5474 & TRN \\
\hline CHEMBL2324271 & 941167 & 4.6021 & 4.9467 & TRN \\
\hline CHEMBL 2322632 & 941167 & 9.1249 & 8.5353 & TRN \\
\hline CHEMBL 2323242 & 941167 & 5.0 & 5.3738 & TRN \\
\hline CHEMBL 2324268 & 941167 & 5.585 & 4.3877 & TRN \\
\hline CHEMBL 2322628 & 941167 & 8.8239 & 8.5612 & TRN \\
\hline CHEMBL2322624 & 941167 & 8.8239 & 9.0257 & TRN \\
\hline CHEMBL 2325513 & 941167 & 6.9586 & 7.1411 & TRN \\
\hline CHEMBL 2323230 & 941167 & 9.5229 & 9.1683 & TRN \\
\hline CHEMBL 2325508 & 941167 & 3.6021 & 4.0199 & TRN \\
\hline CHEMBL2325507 & 941167 & 6.6198 & 6.1824 & TRN \\
\hline CHEMBL 2324277 & 941167 & 7.3979 & 6.5307 & TST \\
\hline CHEMBL1581616 & 941167 & 7.8239 & 7.7355 & TST \\
\hline CHEMBL 2324278 & 941167 & 6.6021 & 6.5607 & TST \\
\hline CHEMBL 2323229 & 941167 & 8.5229 & 8.1354 & TRN \\
\hline CHEMBL 2322635 & 941167 & 8.3979 & 9.0041 & TRN \\
\hline CHEMBL 2322622 & 941167 & 7.6021 & 7.9337 & TRN \\
\hline CHEMBL 2323243 & 941167 & 7.5229 & 7.8965 & TRN \\
\hline CHEMBL 2322625 & 941167 & 8.4559 & 8.8359 & TRN \\
\hline CHEMBL 2322619 & 941167 & 6.9208 & 6.559 & TST \\
\hline CHEMBL 2322634 & 941167 & 4.301 & 4.4037 & TRN \\
\hline CHEMBL 2325512 & 941167 & 7.4559 & 7.9413 & TST \\
\hline CHEMBL 2324266 & 941167 & 7.3979 & 7.1025 & TST \\
\hline CHEMBL 2324272 & 941167 & 6.3279 & 6.1028 & TRN \\
\hline CHEMBL 2324279 & 941167 & 7.301 & 7.1386 & TST \\
\hline CHEMBL1257064 & 941167 & 7.5229 & 7.2853 & TST \\
\hline CHEMBL3234178 & 1336411 & 4.1739 & 4.8284 & TRN \\
\hline CHEMBL3234142 & 1336411 & 4.4559 & 4.6762 & TRN \\
\hline CHEMBL3234155 & 1336411 & 2.301 & 3.4607 & TRN \\
\hline CHEMBL3234149 & 1336411 & 4.9508 & 4.7892 & TRN \\
\hline CHEMBL3234438 & 1336411 & 5.0555 & 5.2423 & TRN \\
\hline CHEMBL3234174 & 1336411 & 4.041 & 4.665 & TRN \\
\hline CHEMBL 3234143 & 1336411 & 4.9957 & 5.1895 & TRN \\
\hline CHEMBL3234169 & 1336411 & 3.9788 & 3.7423 & TRN \\
\hline CHEMBL3234181 & 1336411 & 4.2366 & 4.0226 & TRN \\
\hline CHEMBL3234187 & 1336411 & 1.699 & 2.069 & TRN \\
\hline CHEMBL3234183 & 1336411 & 2.6021 & 3.9576 & TST \\
\hline CHEMBL3234170 & 1336411 & 5.0655 & 4.8849 & TRN \\
\hline CHEMBL3234138 & 1336411 & 5.2441 & 4.7903 & TRN \\
\hline CHEMBL3234179 & 1336411 & 4.2366 & 4.9643 & TRN \\
\hline CHEMBL3234180 & 1336411 & 4.0 & 4.4399 & TRN \\
\hline CHEMBL3234435 & 1336411 & 5.2007 & 5.399 & TRN \\
\hline
\end{tabular}


Supplemental Table S2.txt

\begin{tabular}{|c|c|c|c|c|c|}
\hline CHEMBL3234188 & 1336411 & 5.3372 & 5.4571 & TRN & \\
\hline CHEMBL3234153 & 1336411 & 3.9208 & 3.5546 & TRN & \\
\hline CHEMBL3234164 & 1336411 & 4.4559 & 3.9295 & TST & \\
\hline CHEMBL3234182 & 1336411 & 2.6021 & 4.2644 & TST & \\
\hline CHEMBL 3234162 & 1336411 & 2.6021 & 3.4385 & TST & \\
\hline CHEMBL3234159 & 1336411 & 3.2518 & 3.3291 & TRN & \\
\hline CHEMBL3234163 & 1336411 & 2.6021 & 2.9419 & TRN & \\
\hline CHEMBL 3234436 & 1336411 & 5.1739 & 4.2461 & TRN & \\
\hline CHEMBL3234184 & 1336411 & 4.4685 & 3.9595 & TRN & \\
\hline CHEMBL 3234151 & 1336411 & 5.0555 & 4.6963 & TRN & \\
\hline CHEMBL 3234161 & 1336411 & 2.301 & 2.7719 & TRN & \\
\hline CHEMBL3234189 & 1336411 & 5.2076 & 5.1138 & TRN & \\
\hline CHEMBL 3234176 & 1336411 & 4.0506 & 4.1588 & TRN & \\
\hline CHEMBL3234137 & 1336411 & 5.1675 & 4.6178 & TRN & \\
\hline CHEMBL 3234166 & 1336411 & 4.585 & 3.7869 & TRN & \\
\hline CHEMBL3234165 & 1336411 & 3.9914 & 3.4378 & TRN & \\
\hline CHEMBL3234141 & 1336411 & 4.2076 & 4.6963 & TRN & \\
\hline CHEMBL 3234172 & 1336411 & 4.585 & 4.1519 & TST & \\
\hline CHEMBL3234175 & 1336411 & 4.6383 & 4.1056 & TRN & \\
\hline CHEMBL3234437 & 1336411 & 2.6021 & \multicolumn{2}{|c|}{3.7880000000000003} & TRN \\
\hline CHEMBL3234147 & 1336411 & 4.9586 & 5.0159 & TRN & \\
\hline CHEMBL3234171 & 1336411 & 5.1079 & 5.2833 & TRN & \\
\hline CHEMBL 3234177 & 1336411 & 4.585 & 4.1295 & TRN & \\
\hline CHEMBL3234148 & 1336411 & 4.6778 & 4.6423 & TRN & \\
\hline CHEMBL 3234167 & 1336411 & 4.6383 & 3.5754 & TRN & \\
\hline CHEMBL3234186 & 1336411 & 1.699 & 2.0893 & TRN & \\
\hline CHEMBL3234439 & 1336411 & 4.2441 & 4.5225 & TRN & \\
\hline CHEMBL3234154 & 1336411 & 4.2757 & 3.7416 & TRN & \\
\hline CHEMBL3234145 & 1336411 & 5.2076 & 5.2809 & TRN & \\
\hline CHEMBL 3234168 & 1336411 & 4.6576 & \multicolumn{2}{|c|}{4.1419999999999995} & TRN \\
\hline CHEMBL3234140 & 1336411 & 4.6383 & 4.7041 & TST & \\
\hline CHEMBL 3234160 & 1336411 & 2.6021 & 3.4768 & TST & \\
\hline CHEMBL3234185 & 1336411 & 4.2757 & 4.09 & TST & \\
\hline CHEMBL3234152 & 1336411 & 4.4089 & 3.6361 & TST & \\
\hline CHEMBL 3234146 & 1336411 & 4.8861 & 5.3777 & TST & \\
\hline CHEMBL3234139 & 1336411 & 4.1739 & 4.7064 & TST & \\
\hline CHEMBL 3234173 & 1336411 & 4.2441 & 4.6866 & TST & \\
\hline CHEMBL3234144 & 1336411 & 4.9872 & 4.8894 & TST & \\
\hline CHEMBL3234150 & 1336411 & 5.2218 & 4.5075 & TST & \\
\hline CHEMBL3979906 & 1640792 & 9.6024 & 9.8923 & TST & \\
\hline CHEMBL3924124 & 1640792 & 9.9136 & 10.0671 & TRN & \\
\hline CHEMBL 3934607 & 1640792 & 10.5186 & 9.9236 & TRN & \\
\hline CHEMBL3940900 & 1640792 & 10.0996 & 9.3636 & TRN & \\
\hline CHEMBL 3899720 & 1640792 & 10.3645 & 9.4198 & TRN & \\
\hline CHEMBL3938087 & 1640792 & 10.1325 & 9.2634 & TRN & \\
\hline CHEMBL3902181 & 1640792 & 9.8533 & 10.1219 & TRN & \\
\hline CHEMBL 3902954 & 1640792 & 9.4402 & 10.4381 & TRN & \\
\hline CHEMBL3983522 & 1640792 & 9.658 & 9.7639 & TRN & \\
\hline
\end{tabular}




$$
\text { Supplemental Table S2.txt }
$$

\begin{tabular}{|c|c|c|c|c|c|c|}
\hline CHEMBL3936862 & 1640792 & 9.4683 & 9.5991 & TRN & & \\
\hline CHEMBL3903382 & 1640792 & 10.1355 & 9.4371 & TST & & \\
\hline CHEMBL3965246 & 1640792 & 10.2269 & 9.9429 & TST & & \\
\hline CHEMBL3986113 & 1640792 & 9.4666 & 10.0272 & TST & & \\
\hline CHEMBL3892902 & 1640792 & 10.5376 & 10.8279 & TRN & & \\
\hline CHEMBL3917421 & 1640792 & 10.209 & 10.1221 & TRN & & \\
\hline CHEMBL3982275 & 1640792 & 10.1599 & 10.074 & TRN & & \\
\hline CHEMBL3931355 & 1640792 & 10.0223 & 9.5982 & TST & & \\
\hline CHEMBL3958294 & 1640792 & 8.0 & 9.7435 & TST & & \\
\hline CHEMBL3972078 & 1640792 & 10.3072 & 10.0775 & TRN & & \\
\hline CHEMBL3962956 & 1640792 & 10.2314 & 9.2119 & TRN & & \\
\hline CHEMBL3978840 & 1640792 & 9.7307 & 10.1222 & TRN & & \\
\hline CHEMBL3930473 & 1640792 & 10.7670 & 000000000 & 01 & 9.9236 & TRN \\
\hline CHEMBL3966672 & 1640792 & 9.8804 & 9.5704 & TRN & & \\
\hline CHEMBL3975542 & 1640792 & 10.51 & 10.8332 & TRN & & \\
\hline CHEMBL3937342 & 1640792 & 10.5686 & 10.5646 & TRN & & \\
\hline CHEMBL3957130 & 1640792 & 9.9374 & 9.5927 & TST & & \\
\hline CHEMBL3936926 & 1640792 & 8.0 & 9.5371 & TRN & & \\
\hline CHEMBL 3927098 & 1640792 & 10.0195 & 10.1221 & TRN & & \\
\hline CHEMBL3890744 & 1640792 & 6.0 & 8.8969 & TRN & & \\
\hline CHEMBL3944212 & 1640792 & 10.2284 & 10.6006 & TST & & \\
\hline CHEMBL3954223 & 1640792 & 10.4449 & 9.0302 & TRN & & \\
\hline CHEMBL3964924 & 1640792 & 10.2041 & 9.5777 & TRN & & \\
\hline CHEMBL3966731 & 1640792 & 10.1073 & 9.6655 & TRN & & \\
\hline CHEMBL3941883 & 1640792 & 10.0453 & 9.8398 & TRN & & \\
\hline CHEMBL3929061 & 1640792 & 9.9562 & 9.3141 & TRN & & \\
\hline CHEMBL3952280 & 1640792 & 9.7138 & 9.3179 & TST & & \\
\hline CHEMBL3917829 & 1640792 & 9.7462 & 9.6888 & TST & & \\
\hline CHEMBL3931864 & 1640792 & 9.8877 & 9.5704 & TRN & & \\
\hline CHEMBL3962092 & 1640792 & 10.5622 & 9.3767 & TRN & & \\
\hline CHEMBL3965555 & 1640792 & 10.1302 & 9.5777 & TRN & & \\
\hline CHEMBL3956900 & 1640792 & 10.4225 & 9.4942 & TRN & & \\
\hline CHEMBL 3954423 & 1640792 & 10.3036 & 9.0255 & TRN & & \\
\hline CHEMBL3908642 & 1640792 & 9.6985 & 10.0231 & TST & & \\
\hline CHEMBL3901094 & 1640792 & 9.7878 & 9.8339 & TRN & & \\
\hline CHEMBL3977786 & 1640792 & 9.6733 & 9.3204 & TST & & \\
\hline CHEMBL3934813 & 1640792 & 10.0292 & 9.4372 & TST & & \\
\hline CHEMBL3890613 & 1640792 & 6.0 & 9.4911 & TRN & & \\
\hline CHEMBL3896084 & 1640792 & 9.6996 & 9.92 & TRN & & \\
\hline CHEMBL3894029 & 1640792 & 9.6765 & 9.5991 & TRN & & \\
\hline CHEMBL3954037 & 1640792 & 10.1457 & 9.6536 & TRN & & \\
\hline CHEMBL3946230 & 1640792 & 10.5544 & 11.2958 & TRN & & \\
\hline CHEMBL 3970413 & 1640792 & 10.3595 & 10.2951 & TRN & & \\
\hline CHEMBL3917400 & 1640792 & 6.0 & 8.6613 & TRN & & \\
\hline CHEMBL3927734 & 1640792 & 9.7265 & 9.8566 & TST & & \\
\hline CHEMBL3961603 & 1640792 & 10.2596 & 9.2369 & TRN & & \\
\hline CHEMBL3913587 & 1640792 & 10.2255 & 9.8398 & TRN & & \\
\hline CHEMBL 3979765 & 1640792 & 10.4067 & 9.545 & TRN & & \\
\hline
\end{tabular}




\begin{tabular}{|c|c|c|c|c|c|}
\hline \multirow[b]{2}{*}{ CHEMBL 3973483} & \multicolumn{5}{|c|}{ Supplemental Table S2.txt } \\
\hline & 1640792 & 6.0 & 9.2634 & TRN & \\
\hline CHEMBL3965158 & 1640792 & 10.5591 & 9.5951 & TRN & \\
\hline CHEMBL3959353 & 1640792 & 10.1261 & 10.074 & TRN & \\
\hline CHEMBL3940392 & 1640792 & 9.9602 & 9.6968 & TST & \\
\hline CHEMBL3912855 & 1640792 & 9.6073 & 9.7375 & TST & \\
\hline CHEMBL3919622 & 1640792 & 9.8887 & 9.5035 & TRN & \\
\hline CHEMBL3769627 & 1556484 & 3.301 & 3.2143 & TRN & \\
\hline CHEMBL3770970 & 1556484 & 3.301 & 3.9267 & TST & \\
\hline CHEMBL3769969 & 1556484 & 3.301 & 3.1431 & TRN & \\
\hline CHEMBL3771121 & 1556484 & 4.5317 & 4.3307 & TRN & \\
\hline CHEMBL3769967 & 1556484 & 3.301 & 3.2851 & TRN & \\
\hline CHEMBL3769886 & 1556484 & 3.301 & 3.4793 & TRN & \\
\hline CHEMBL3769726 & 1556484 & 3.301 & 3.2386 & TRN & \\
\hline CHEMBL3769467 & 1556484 & 4.757 & 4.1974 & TRN & \\
\hline CHEMBL3770386 & 1556484 & 4.3316 & 3.2812 & TST & \\
\hline CHEMBL3771114 & 1556484 & 3.301 & 3.263 & TRN & \\
\hline CHEMBL3770376 & 1556484 & 4.3449 & 4.1438 & TRN & \\
\hline CHEMBL 3771040 & 1556484 & 3.301 & 3.6845 & TRN & \\
\hline CHEMBL3770552 & 1556484 & 4.4179 & 4.0947 & TRN & \\
\hline CHEMBL3769642 & 1556484 & 3.301 & 3.9072 & TRN & \\
\hline CHEMBL3769625 & 1556484 & 3.301 & 3.9416 & TST & \\
\hline CHEMBL3770881 & 1556484 & 3.301 & 3.2055 & TRN & \\
\hline CHEMBL3769882 & 1556484 & 3.301 & 3.3306 & TRN & \\
\hline CHEMBL3769468 & 1556484 & 4.3072 & 4.0809 & TRN & \\
\hline CHEMBL3769423 & 1556484 & 3.301 & 3.193 & TRN & \\
\hline CHEMBL3769608 & 1556484 & 3.301 & 3.3457 & TRN & \\
\hline CHEMBL3769884 & 1556484 & 3.301 & 3.9297 & TST & \\
\hline CHEMBL3769738 & 1556484 & 3.301 & 3.97300 & 00000000003 & TRN \\
\hline CHEMBL 3770781 & 1556484 & 3.301 & 3.9324 & TRN & \\
\hline CHEMBL3769894 & 1556484 & 4.3335 & 3.6867 & TRN & \\
\hline CHEMBL3770814 & 1556484 & 4.5834 & 4.123 & TRN & \\
\hline CHEMBL333985 & 1556484 & 6.5229 & 3.99 & TST & \\
\hline CHEMBL3771236 & 1556484 & 4.4101 & 4.1191 & TRN & \\
\hline CHEMBL3770932 & 1556484 & 3.301 & 3.9213 & TRN & \\
\hline CHEMBL3770085 & 1556484 & 3.301 & 3.3115 & TRN & \\
\hline CHEMBL3770658 & 1556484 & 3.301 & 4.0307 & TRN & \\
\hline CHEMBL3769955 & 1556484 & 3.301 & 3.4553 & TRN & \\
\hline CHEMBL3770069 & 1556484 & 4.6144 & 4.1798 & TRN & \\
\hline CHEMBL 3770052 & 1556484 & 3.301 & 3.1839 & TRN & \\
\hline CHEMBL3770172 & 1556484 & 4.7852 & 4.3121 & TRN & \\
\hline CHEMBL3771214 & 1556484 & 3.301 & 3.9495 & TRN & \\
\hline CHEMBL3771126 & 1556484 & 3.301 & 3.9594 & TRN & \\
\hline CHEMBL3770089 & 1556484 & 3.301 & 3.2234 & TRN & \\
\hline CHEMBL3771262 & 1556484 & 3.301 & 3.2671 & TRN & \\
\hline CHEMBL3770742 & 1556484 & 3.301 & 3.2204 & TRN & \\
\hline CHEMBL3771257 & 1556484 & 4.341 & 4.3186 & TRN & \\
\hline CHEMBL3770007 & 1556484 & 4.3893 & 4.0646 & TRN & \\
\hline CHEMBL3769549 & 1556484 & 3.301 & 3.2178 & TRN & \\
\hline
\end{tabular}


Supplemental Table S2.txt

\begin{tabular}{|c|c|c|c|c|c|}
\hline CHEMBL3769412 & 1556484 & 3.301 & 3.2329 & TRN & \\
\hline CHEMBL3770335 & 1556484 & 3.301 & 3.2124 & TRN & \\
\hline CHEMBL3771301 & 1556484 & 3.301 & 3.2122 & TRN & \\
\hline CHEMBL 3770937 & 1556484 & 4.3655 & 3.5744 & TST & \\
\hline CHEMBL3770280 & 1556484 & 3.301 & 4.0761 & TST & \\
\hline CHEMBL3770494 & 1556484 & 3.301 & 3.2466 & TST & \\
\hline CHEMBL3769809 & 1556484 & 3.301 & 3.2299 & TST & \\
\hline CHEMBL3771318 & 1556484 & 3.301 & 4.0127 & TST & \\
\hline CHEMBL3770296 & 1556484 & 3.301 & 3.3248 & TST & \\
\hline CHEMBL3770373 & 1556484 & 3.301 & 3.5955 & TST & \\
\hline CHEMBL3771097 & 1556484 & 3.301 & 4.0075 & TST & \\
\hline CHEMBL3771107 & 1556484 & 4.3625 & 4.0065 & TST & \\
\hline CHEMBL1098772 & 632482 & 6.6737 & 6.0323 & TRN & \\
\hline CHEMBL1097809 & 632482 & 6.6091 & 6.7706 & TRN & \\
\hline CHEMBL1096478 & 632482 & 6.8962 & 6.5534 & TRN & \\
\hline CHEMBL1098770 & 632482 & 7.4559 & 6.9195 & TRN & \\
\hline CHEMBL1097800 & 632482 & 7.2676 & 7.0782 & TRN & \\
\hline CHEMBL1094502 & 632482 & 6.9281 & 6.385 & TST & \\
\hline CHEMBL1097801 & 632482 & 6.9431 & 7.1521 & TRN & \\
\hline CHEMBL1097103 & 632482 & 6.7235 & 6.7611 & TRN & \\
\hline CHEMBL1098448 & 632482 & 7.0177 & 6.4903 & TRN & \\
\hline CHEMBL1096340 & 632482 & 4.0 & \multicolumn{2}{|c|}{4.2410000000000005} & TRN \\
\hline CHEMBL1096872 & 632482 & 7.0915 & 7.0064 & TRN & \\
\hline CHEMBL1094193 & 632482 & 6.5086 & 6.24 & TST & \\
\hline CHEMBL1095995 & 632482 & 7.301 & 6.5636 & TRN & \\
\hline CHEMBL1098144 & 632482 & 6.3686 & 6.6414 & TRN & \\
\hline CHEMBL1097537 & 632482 & 6.475 & 6.6881 & TRN & \\
\hline CHEMBL1094699 & 632482 & 6.289 & 6.5628 & TRN & \\
\hline CHEMBL1097183 & 632482 & 5.8447 & 6.4588 & TRN & \\
\hline CHEMBL1097808 & 632482 & 6.8894 & 6.7361 & TRN & \\
\hline CHEMBL1095153 & 632482 & 6.699 & 6.5859 & TRN & \\
\hline CHEMBL1098201 & 632482 & 6.9747 & 7.0578 & TRN & \\
\hline CHEMBL1096541 & 632482 & 6.7375 & 6.3066 & TST & \\
\hline CHEMBL1096873 & 632482 & 6.9066 & 7.437 & TRN & \\
\hline CHEMBL1098142 & 632482 & 7.0555 & 6.6114 & TRN & \\
\hline CHEMBL1097803 & 632482 & 6.9431 & 6.8503 & TRN & \\
\hline CHEMBL1095152 & 632482 & 6.857 & 6.8166 & TRN & \\
\hline CHEMBL1098013 & 632482 & 6.0 & 6.3733 & TRN & \\
\hline CHEMBL1097182 & 632482 & 6.6198 & 7.0628 & TRN & \\
\hline CHEMBL1095987 & 632482 & 6.4989 & 6.7295 & TRN & \\
\hline CHEMBL1094192 & 632482 & 6.9208 & 6.6783 & TRN & \\
\hline CHEMBL1098771 & 632482 & 6.9872 & 6.778 & TRN & \\
\hline CHEMBL1098811 & 632482 & 7.0223 & 6.7266 & TRN & \\
\hline CHEMBL1096787 & 632482 & 5.055 & 6.25 & TRN & \\
\hline CHEMBL1096788 & 632482 & 5.9104 & 6.5666 & TRN & \\
\hline CHEMBL1098484 & 632482 & 6.8665 & 6.6405 & TRN & \\
\hline CHEMBL1098356 & 632482 & 4.0 & 5.5215 & TST & \\
\hline CHEMBL1097535 & 632482 & 6.4559 & 6.6684 & TRN & \\
\hline
\end{tabular}


Supplemental Table S2.txt

\begin{tabular}{|c|c|c|c|c|}
\hline & & & & \\
\hline AEMBL1098143 & 2482 & 6.8416 & 945 & \\
\hline IEMBL1097527 & 2482 & 879 & 0082 & \\
\hline HEMBL1094246 & 2482 & 798 & 3149 & \\
\hline 676 & & & & \\
\hline IEMBL109 & 2482 & 91 & 477 & \\
\hline AEMBL1094491 & 32482 & 031 & 3863 & \\
\hline HEMBL1098467 & 32482 & 129 & 5276 & \\
\hline AEMBL1097529 & & & & \\
\hline IEMBL109 & 82 & & 22 & \\
\hline HEMBL109 & & & 174 & \\
\hline AEMBL1098202 & 632482 & 586 & 5408 & \\
\hline AEMBL1097802 & & & 5887 & \\
\hline IEMBL1096542 & 32 & & 259 & \\
\hline EMBL10 & & & 17 & \\
\hline HEMBL109 & & & 17 & \\
\hline HEMBL109 & 182 & 539 & 752 & 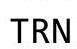 \\
\hline IEMBL10 & & & 22 & RN \\
\hline IEMBLI0S & & & 283 & \\
\hline IEMBL10 & & & 529 & זוס \\
\hline HEMBL10 & & & 895 & \\
\hline HEMBL109 & & & 5917 & $x_{0}+2$ \\
\hline AEMBL109 & & & & ST \\
\hline IEMBL10 & & 47 & 4 & ST \\
\hline EMBL10 & & & 14 & (Niv \\
\hline AFMRI 19 & & & 65 & ST \\
\hline AEMBL10 & & & & RN \\
\hline AEMBL109 & & & & RI \\
\hline AEMBL109 & & 372 & 18 & ST \\
\hline 34 & & & 68 & ST \\
\hline 94 & 39 & & 95 & ST \\
\hline AEMBL3907882 & & & & RN \\
\hline AEMBL3975967 & & & & RN \\
\hline HEMBL394 & & 136 & 97 & $2 \mathrm{~s}$ \\
\hline 66 & & 9. & 52 & Niv \\
\hline & & & & $\mathrm{RN}$ \\
\hline AEMBL3944787 & 641339 & & 769 & $\mathrm{R}$ \\
\hline AEMBL3910570 & 1339 & & 077 & RI \\
\hline IEMBL38 & & & & $S$ \\
\hline 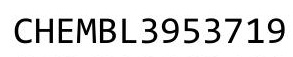 & & 8. & & \\
\hline 41 & & 9 . & 469 & RN \\
\hline HEMBL3944627 & 1339 & 8.6021 & 561 & RN \\
\hline IEMBL 3889645 & 339 & 8. & 389 & $T$ \\
\hline HEMBL 39 & & & 0041 & TR \\
\hline & & 9.6 & & ST \\
\hline CHEMBL 3960357 & & 7.6 & 721 & RN \\
\hline HEMBL3898804 & 1641339 & 8.301 & 8.3667 & $\mathrm{TR}$ \\
\hline HFMRI 3995905 & 1641339 & 7.7212 & 7.7385 & \\
\hline
\end{tabular}

Page 15490 
Supplemental Table S2.txt

\begin{tabular}{|c|c|c|c|c|}
\hline IE & 39 & & 25 & TRN \\
\hline & & 8.6021 & & \\
\hline & & & & \\
\hline AEMBL3943944 & & 6021 & & \\
\hline AEMBL3986561 & 339 & 8.1249 & 1461 & \\
\hline HEMBL3931946 & 641339 & 9.0 & . 9487 & \\
\hline HEMBL3986701 & 39 & 8 . & 9867 & \\
\hline 829 & & 1 & & RN \\
\hline AEMBL3894416 & & 7.4881 & 8.6009 & \\
\hline AEMBL3952318 & 39 & 8.1249 & .0998 & \\
\hline HEMBL3895120 & 39 & 8.301 & . 2016 & \\
\hline IEMBL395 & 39 & 9. & 8228 & \\
\hline IEMBL 396 & & & & RN \\
\hline HEMBL3975150 & 39 & 7.699 & .3508 & \\
\hline AEMBL3906146 & 39 & 596 & .2336 & \\
\hline AEMBL3913931 & 6 & 10.0 & 9.9307 & \\
\hline AEMBL39 & 9 & 01 & .3844 & 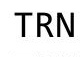 \\
\hline HEMBL39 & & 031 & 28 & \\
\hline AEMBL39 & & 7.5214 & 9.3324 & \\
\hline AEMBL39 & & & 339 & TRN \\
\hline HEIMBLSS & 39 & 9 & 33 & TRN \\
\hline AEMBL39 & & & 25 & RI \\
\hline HEMBL39 & & 8. & 51 & \\
\hline 522 & & 8.92 & 9238 & ונ \\
\hline AEMBL39 & & & & 15 \\
\hline HEMBL 39 & 39 & +9 & 12 & SI \\
\hline AEMBL3S & & & 78 & RN \\
\hline AEMBL39 & & 39 & 97 & DN \\
\hline HEMBL389 & & & & $1 \pi$ \\
\hline HEMBL3970724 & & 8. & 0.0072 & TST \\
\hline HEMBL 39 & & & 385 & RN \\
\hline AFMBI 3 & & 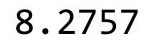 & & RN \\
\hline AEMBL; & & 9 & 358 & $\mathrm{R}$ \\
\hline HEMBL3930018 & & & 0762 & IRN \\
\hline HEMBL3958979 & 39 & 7.9031 & 7.8784 & TRN \\
\hline HEMBL395 & & 8.6021 & 43 & RN \\
\hline HFMRI 3 & & & 49 & RN \\
\hline HEMBL 392 & & & & RN \\
\hline HEMBL3947698 & & 249 & 175 & TRN \\
\hline EMBL39e & & 19 & & RN \\
\hline HEMBL3890924 & 39 & 239 & 43 & DA \\
\hline HEMBL3913331 & & & & RIV \\
\hline HEMBL3964409 & & 7.8239 & 8.3118 & TST \\
\hline AEMBL3987192 & 339 & 8.301 & .0888 & TST \\
\hline EBL392 & & 9 & 7.8079 & 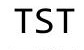 \\
\hline CHEMBL3938680 & & 210 & 8.6021 & ST \\
\hline CHEMBL 3932164 & & 0 & 9.7456 & ST \\
\hline CHEMBL3931131 & 1641339 & 10.0 & 8.5217 & IS \\
\hline
\end{tabular}

Page 15491 
Supplemental Table S2.txt

\begin{tabular}{|c|c|c|c|c|}
\hline CHEMBL3959437 & 1641339 & 9.0 & 8.7461 & TST \\
\hline CHEMBL 3891305 & 1640904 & 7.6021 & 6.7309 & TST \\
\hline CHEMBL 3940486 & 1640904 & 7.3468 & 5.7126 & TRN \\
\hline CHEMBL 3932110 & 1640904 & 7.1135 & 7.2582 & TRN \\
\hline CHEMBL 3962666 & 1640904 & 6.5072 & 6.7618 & TRN \\
\hline CHEMBL 3902141 & 1640904 & 7.4815 & 7.1727 & TRN \\
\hline CHEMBL 3904832 & 1640904 & 7.3372 & 7.2062 & TRN \\
\hline CHEMBL 3976818 & 1640904 & 6.3458 & 6.2434 & TRN \\
\hline CHEMBL 3917040 & 1640904 & 6.4547 & 6.80200 & 0000000005 \\
\hline CHEMBL 3978524 & 1640904 & 6.5157 & 6.983 & TST \\
\hline CHEMBL 3950548 & 1640904 & 7.4949 & 6.9463 & TRN \\
\hline CHEMBL 3899039 & 1640904 & 8.0458 & 7.393 & TRN \\
\hline CHEMBL 3899146 & 1640904 & 6.8633 & 6.5662 & TST \\
\hline CHEMBL 3934146 & 1640904 & 6.4056 & 6.4481 & TRN \\
\hline CHEMBL 3903979 & 1640904 & 6.0 & 7.0537 & TRN \\
\hline CHEMBL3940734 & 1640904 & 6.8416 & 7.0955 & TST \\
\hline CHEMBL 3939442 & 1640904 & 6.6716 & 7.4276 & TRN \\
\hline CHEMBL 3974893 & 1640904 & 6.6615 & 6.8678 & TRN \\
\hline CHEMBL 3892043 & 1640904 & 7.3098 & 6.9195 & TRN \\
\hline CHEMBL3911955 & 1640904 & 6.0 & 6.9034 & TRN \\
\hline CHEMBL3915093 & 1640904 & 8.1549 & 7.8266 & TRN \\
\hline CHEMBL 3904505 & 1640904 & 6.4225 & 6.5508 & TRN \\
\hline CHEMBL 3890397 & 1640904 & 6.0 & 6.9297 & TRN \\
\hline CHEMBL 3981798 & 1640904 & \multicolumn{2}{|c|}{6.821000000000001} & 7.2328 \\
\hline CHEMBL 3964322 & 1640904 & 8.1549 & 7.4588 & TRN \\
\hline CHEMBL 3948485 & 1640904 & 6.8416 & 6.6912 & TRN \\
\hline CHEMBL 3944021 & 1640904 & 6.8794 & 6.7205 & TST \\
\hline CHEMBL 3937614 & 1640904 & 7.3372 & 7.7229 & TRN \\
\hline CHEMBL3904897 & 1640904 & 8.5229 & 6.7974 & TST \\
\hline CHEMBL 3985461 & 1640904 & 7.1487 & 7.1207 & TRN \\
\hline CHEMBL 3897148 & 1640904 & 7.284 & 7.169 & TRN \\
\hline CHEMBL3955836 & 1640904 & 7.0223 & 6.9689 & TST \\
\hline CHEMBL 3905003 & 1640904 & 6.8327 & 7.3105 & TRN \\
\hline CHEMBL3949264 & 1640904 & 7.2518 & 7.6524 & TRN \\
\hline CHEMBL 3908277 & 1640904 & 6.983 & 7.1144 & TRN \\
\hline CHEMBL3970410 & 1640904 & 4.0 & 6.4235 & TRN \\
\hline CHEMBL 3974605 & 1640904 & 7.7959 & 6.4495 & TST \\
\hline CHEMBL3909229 & 1640904 & 7.2366 & 7.0589 & TST \\
\hline CHEMBL3897919 & 1640904 & 6.9626 & 6.8509 & TRN \\
\hline CHEMBL 3962741 & 1640904 & 7.2596 & 7.0333 & TRN \\
\hline CHEMBL3903054 & 1640904 & 7.8239 & 7.6277 & TRN \\
\hline CHEMBL 3914620 & 1640904 & 7.8861 & 7.1164 & TRN \\
\hline CHEMBL3920689 & 1640904 & 6.0004 & 7.5742 & TST \\
\hline CHEMBL3912313 & 1640904 & 7.2366 & 6.9317 & TST \\
\hline CHEMBL 3902502 & 1640904 & 7.5086 & 6.7999 & TRN \\
\hline CHEMBL3985800 & 1640904 & 7.699 & 7.1615 & TRN \\
\hline CHEMBL 3905997 & 1640904 & 6.9547 & 7.0918 & TST \\
\hline CHEMBL 3981496 & 1640904 & 7.9208 & 7.4143 & TRN \\
\hline
\end{tabular}


Supplemental Table S2.txt

\begin{tabular}{|c|c|c|c|c|}
\hline CHEMBL3939348 & 1640904 & 7.1135 & 6.6074 & TST \\
\hline CHEMBL3945174 & 1640904 & 7.2366 & 7.1521 & TST \\
\hline CHEMBL3985972 & 1640904 & 6.767 & 6.9387 & TST \\
\hline CHEMBL3944318 & 1640904 & 6.4089 & 6.6194 & TRN \\
\hline CHEMBL3902830 & 1640904 & 4.0 & 7.2864 & TST \\
\hline CHEMBL3926364 & 1640904 & 8.0 & 6.8685 & TRN \\
\hline CHEMBL3937726 & 1640904 & 6.7423 & 7.2554 & TRN \\
\hline CHEMBL3939906 & 1640904 & 6.0 & 6.6851 & TRN \\
\hline CHEMBL3893868 & 1640904 & 5.3686 & 5.8921 & TRN \\
\hline CHEMBL3946412 & 1640904 & 6.6925 & 7.4463 & TRN \\
\hline CHEMBL3898742 & 1640904 & 7.5376 & 6.8279 & TRN \\
\hline CHEMBL3966594 & 1640904 & 7.1079 & 7.0711 & TRN \\
\hline CHEMBL3913704 & 1640904 & 7.7696 & 7.1229 & TRN \\
\hline CHEMBL3935251 & 1640904 & 7.585 & 7.7724 & TRN \\
\hline CHEMBL3977682 & 1640904 & 7.0362 & 7.3853 & TRN \\
\hline CHEMBL3960337 & 1640904 & 6.8697 & 6.9332 & TRN \\
\hline CHEMBL3962292 & 1640904 & 6.0 & 6.7681 & TRN \\
\hline CHEMBL3914373 & 1640904 & 8.2218 & 7.808 & TRN \\
\hline CHEMBL3970133 & 1640904 & 6.4078 & 7.3849 & TST \\
\hline CHEMBL3900488 & 1640904 & 7.2441 & 7.3017 & TRN \\
\hline CHEMBL3980545 & 1640904 & 7.6021 & 6.9154 & TRN \\
\hline CHEMBL3926630 & 1640904 & 7.585 & 7.907 & TRN \\
\hline CHEMBL3966269 & 1640904 & 7.4318 & 7.3473 & TRN \\
\hline CHEMBL3955925 & 1640904 & 7.3098 & 7.7858 & TRN \\
\hline CHEMBL3923164 & 1640904 & 7.6198 & 6.8346 & TST \\
\hline CHEMBL3931551 & 1640904 & 6.8297 & 6.6186 & TRN \\
\hline CHEMBL3926159 & 1640904 & 6.7055 & 6.6231 & TST \\
\hline CHEMBL3958497 & 1640904 & 6.7905 & 7.2419 & TST \\
\hline CHEMBL3917218 & 1640904 & 7.0862 & 6.3826 & TRN \\
\hline CHEMBL3943835 & 1640904 & 8.0458 & 6.9415 & TST \\
\hline CHEMBL3972615 & 1640904 & 6.7905 & 7.289 & TST \\
\hline CHEMBL3904400 & 1640904 & 7.8861 & 7.6195 & TRN \\
\hline CHEMBL3953445 & 1640904 & 7.3979 & 7.6759 & TRN \\
\hline CHEMBL3895465 & 1640904 & 7.7959 & 7.6185 & TRN \\
\hline CHEMBL3942804 & 1640904 & 6.8447 & 6.937 & TRN \\
\hline CHEMBL3931937 & 1640904 & 7.1739 & 7.279 & TST \\
\hline CHEMBL3928804 & 1640904 & 7.3979 & 6.8899 & TST \\
\hline CHEMBL3948550 & 1640904 & 6.0 & 6.7605 & TRN \\
\hline CHEMBL3902638 & 1640904 & 7.1805 & 7.2259 & TRN \\
\hline CHEMBL3902657 & 1640904 & 6.2565 & 7.001 & TST \\
\hline CHEMBL3895187 & 1640904 & 7.2518 & 7.528 & TRN \\
\hline CHEMBL3927095 & 1640904 & 7.4318 & 7.1516 & TRN \\
\hline CHEMBL3927187 & 1640904 & 6.9872 & 7.0577 & TRN \\
\hline CHEMBL3929856 & 1640904 & 7.301 & 7.1698 & TRN \\
\hline CHEMBL3962654 & 1640904 & 6.0 & 7.1076 & TRN \\
\hline CHEMBL3966759 & 1640904 & 7.4815 & 7.6218 & TRN \\
\hline CHEMBL3900179 & 1640904 & 7.0555 & 7.0057 & TRN \\
\hline CHEMBL3964911 & 1640904 & 7.7959 & 6.8518 & TST \\
\hline
\end{tabular}


Supplemental Table S2.txt

\begin{tabular}{|c|c|c|c|c|c|}
\hline CHEMBL3970405 & 1640904 & 7.4949 & 7.0156 & TRN & \\
\hline CHEMBL3975686 & 1640904 & 7.5528 & 7.0397 & TRN & \\
\hline CHEMBL3985552 & 1640904 & 6.4622 & 6.651 & TRN & \\
\hline CHEMBL3933914 & 1640904 & 6.5901 & 6.96899 & 9999999999 & TRN \\
\hline CHEMBL3908289 & 1640904 & 8.0458 & 7.2276 & TRN & \\
\hline CHEMBL 3913884 & 1640904 & 7.2218 & 6.59399 & 9999999999 & TRN \\
\hline CHEMBL 3927230 & 1640904 & 7.6198 & 7.3206 & TRN & \\
\hline CHEMBL 3959040 & 1640904 & 6.6253 & 5.9231 & TRN & \\
\hline CHEMBL3931975 & 1640904 & 7.585 & 7.5145 & TRN & \\
\hline CHEMBL 3900520 & 1640904 & $6.7570 e$ & 00000000 & 7.1795 & TRN \\
\hline CHEMBL 3939480 & 1640904 & 7.0706 & 7.6585 & TRN & \\
\hline CHEMBL 3897565 & 1640904 & 7.6198 & 6.9382 & TST & \\
\hline CHEMBL3968097 & 1640904 & 7.7959 & 7.4192 & TST & \\
\hline CHEMBL3893527 & 1640904 & 7.2676 & 6.8837 & TRN & \\
\hline CHEMBL 3912742 & 1640904 & 6.8041 & 6.8926 & TRN & \\
\hline CHEMBL 3925055 & 1640904 & 7.0362 & 6.7664 & TST & \\
\hline CHEMBL3964890 & 1640904 & 6.6234 & 6.4664 & TRN & \\
\hline CHEMBL 3972512 & 1640904 & 7.3098 & 6.9425 & TST & \\
\hline CHEMBL3982242 & 1640904 & 7.8861 & 7.4411 & TRN & \\
\hline CHEMBL 3891043 & 1640904 & 7.1612 & 7.0647 & TST & \\
\hline CHEMBL3909463 & 1640904 & 7.1367 & 7.1282 & TST & \\
\hline CHEMBL 3893688 & 1640904 & 6.9747 & 6.8408 & TST & \\
\hline CHEMBL3975531 & 1640904 & 7.4815 & 7.4528 & TRN & \\
\hline CHEMBL 3899224 & 1640904 & 7.3372 & 7.1745 & TRN & \\
\hline CHEMBL 3972489 & 1640904 & 6.4522 & 6.3903 & TRN & \\
\hline CHEMBL3914934 & 1640904 & 7.1024 & 7.2369 & TRN & \\
\hline CHEMBL 3929658 & 1640904 & 7.6576 & 7.2916 & TRN & \\
\hline CHEMBL3965691 & 1640904 & 7.9586 & 7.5057 & TRN & \\
\hline CHEMBL3962822 & 1640904 & 4.0 & \multicolumn{2}{|c|}{5.332000000000001} & TRN \\
\hline CHEMBL3961639 & 1640904 & 6.7773 & 6.9206 & TRN & \\
\hline CHEMBL3900616 & 1640904 & 7.3372 & 7.6317 & TRN & \\
\hline CHEMBL 3954477 & 1640904 & 7.2518 & 6.8582 & TST & \\
\hline CHEMBL3926837 & 1640904 & 7.0506 & 7.0238 & TST & \\
\hline CHEMBL3976586 & 1640904 & 7.6576 & 7.4009 & TRN & \\
\hline CHEMBL3901679 & 1640904 & 7.4559 & 7.4834 & TRN & \\
\hline CHEMBL3904904 & 1640904 & 7.6021 & 6.4468 & TRN & \\
\hline CHEMBL 3930020 & 1640904 & 7.2366 & 7.006 & TRN & \\
\hline CHEMBL 3914974 & 1640904 & 6.2874 & 6.9201 & TST & \\
\hline CHEMBL3899589 & 1640904 & 7.2596 & 7.1402 & TRN & \\
\hline CHEMBL 3922116 & 1640904 & 7.1805 & 7.3444 & TRN & \\
\hline CHEMBL 3907270 & 1640904 & 6.5331 & 7.1199 & TST & \\
\hline CHEMBL3944175 & 1640904 & 6.857 & 7.353 & TRN & \\
\hline CHEMBL 3942958 & 1640904 & 6.2684 & 6.9662 & TRN & \\
\hline CHEMBL3904217 & 1640904 & 7.6021 & 7.5777 & TRN & \\
\hline CHEMBL3916043 & 1640904 & 7.6383 & 7.4311 & TRN & \\
\hline CHEMBL 3962602 & 1640904 & 7.4089 & 7.1291 & TRN & \\
\hline CHEMBL3976979 & 1640904 & 6.4377 & 6.4223 & TST & \\
\hline CHEMBL3949507 & 1640904 & 6.9706 & 6.9028 & TRN & \\
\hline
\end{tabular}


Supplemental Table S2.txt

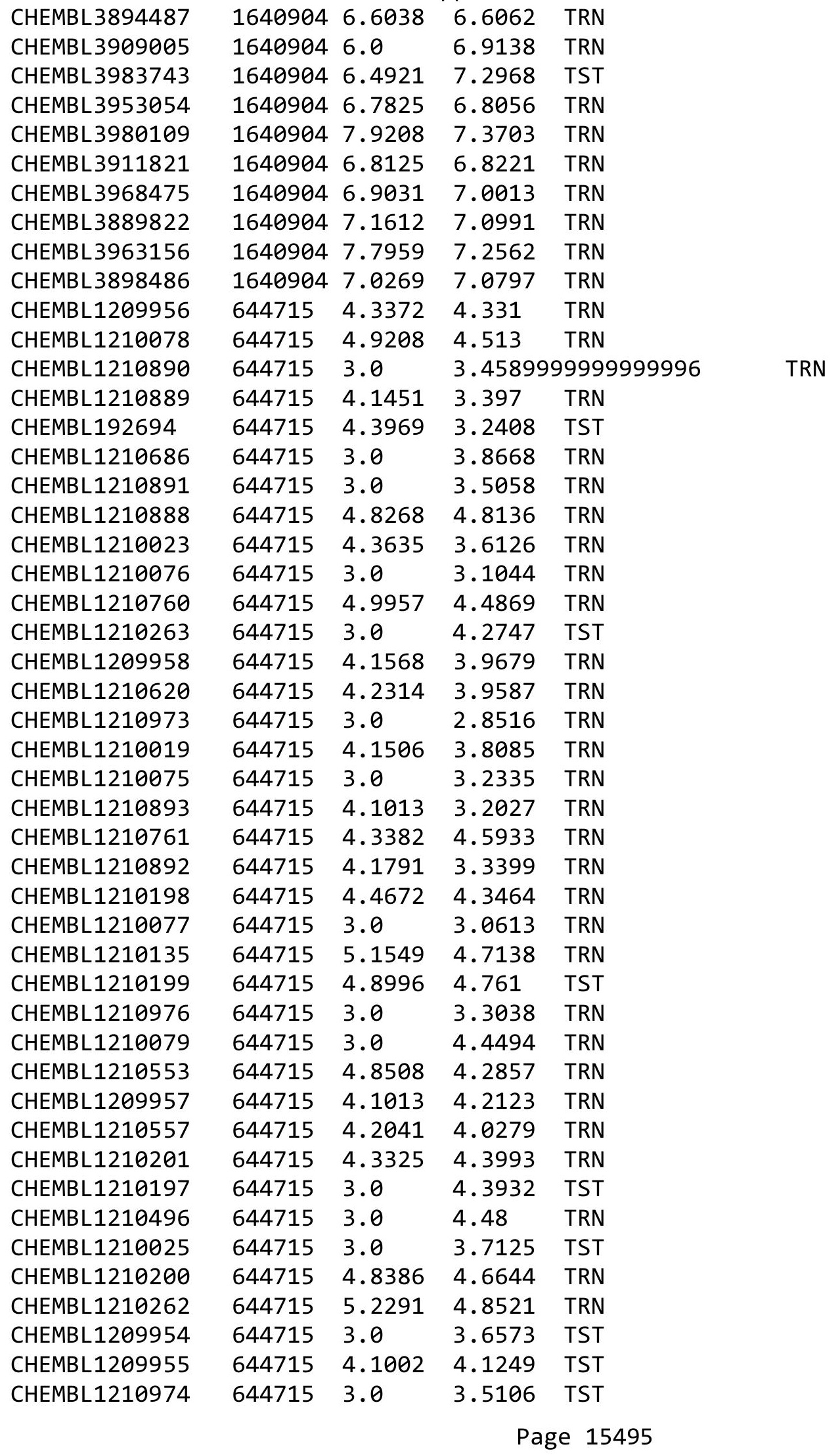




\begin{tabular}{|c|c|c|c|c|c|}
\hline \multicolumn{6}{|c|}{ Supplemental Table S2.txt } \\
\hline CHEMBL1210616 & 644715 & 3.0 & 3.3975 & TRN & \\
\hline CHEMBL1210134 & 644715 & 4.8697 & 4.5003 & TRN & \\
\hline CHEMBL1210024 & 644715 & 4.0706 & 3.6015 & TST & \\
\hline CHEMBL1210978 & 644715 & 3.0 & 3.8479 & TST & \\
\hline CHEMBL1210687 & 644715 & 4.9208 & 4.4907 & TRN & \\
\hline CHEMBL1210132 & 644715 & 3.0 & 4.8775 & TST & \\
\hline CHEMBL1210975 & 644715 & 3.0 & 3.551 & TST & \\
\hline CHEMBL1210555 & 644715 & 3.0 & 3.8148 & TRN & \\
\hline CHEMBL1210617 & 644715 & 3.0 & 3.6186 & TRN & \\
\hline CHEMBL1210759 & 644715 & 4.8996 & 4.4091 & TRN & \\
\hline CHEMBL1210977 & 644715 & 3.0 & 3.6396 & TST & \\
\hline CHEMBL1210828 & 644715 & 4.2823 & 3.7915 & TRN & \\
\hline CHEMBL1210826 & 644715 & 4.7799 & 4.1041 & TRN & \\
\hline CHEMBL1210619 & 644715 & 3.0 & 3.7966 & TRN & \\
\hline CHEMBL1210022 & 644715 & 3.0 & 4.2335 & TST & \\
\hline CHEMBL1210827 & 644715 & 4.301 & 4.2152 & TRN & \\
\hline CHEMBL1210758 & 644715 & 3.0 & 4.229 & TRN & \\
\hline CHEMBL1210133 & 644715 & 4.8962 & 4.6645 & TRN & \\
\hline CHEMBL 3704948 & 1528352 & 6.0 & 6.8436 & TST & \\
\hline CHEMBL 3669040 & 1528352 & 7.4949 & 7.3351 & TRN & \\
\hline CHEMBL 3669031 & 1528352 & 7.5376 & 6.6798 & TST & \\
\hline CHEMBL 3704953 & 1528352 & 6.4498 & 6.5497 & TRN & \\
\hline CHEMBL3704955 & 1528352 & 6.1612 & 6.5414 & TRN & \\
\hline CHEMBL 3704944 & 1528352 & 7.4437 & 7.5805 & TRN & \\
\hline CHEMBL3669026 & 1528352 & 7.6383 & 7.6686 & TRN & \\
\hline CHEMBL3704952 & 1528352 & 6.7011 & 6.3384 & TRN & \\
\hline CHEMBL 3669044 & 1528352 & 7.0915 & 7.131 & TRN & \\
\hline CHEMBL 3704950 & 1528352 & 7.2596 & 6.7178 & TRN & \\
\hline CHEMBL 3704945 & 1528352 & 8.0969 & 7.7148 & TRN & \\
\hline CHEMBL3704959 & 1528352 & 6.0605 & 6.4121 & TRN & \\
\hline CHEMBL3704936 & 1528352 & 6.0 & 7.7582 & TRN & \\
\hline CHEMBL 3669048 & 1528352 & 6.6676 & 7.0204 & TRN & \\
\hline CHEMBL3704965 & 1528352 & 6.7328 & 6.8153 & TRN & \\
\hline CHEMBL3669027 & 1528352 & 7.2676 & 7.5701 & TRN & \\
\hline CHEMBL3704957 & 1528352 & 6.0 & 5.9799 & TRN & \\
\hline CHEMBL3704941 & 1528352 & 7.8539 & 7.92299 & 9999999999 & TRN \\
\hline CHEMBL 3704964 & 1528352 & 7.5528 & 7.4992 & TST & \\
\hline CHEMBL 3669047 & 1528352 & 7.6383 & 7.6539 & TRN & \\
\hline CHEMBL 3704943 & 1528352 & 6.0 & 6.7392 & TRN & \\
\hline CHEMBL3669037 & 1528352 & 7.8861 & 7.6946 & TST & \\
\hline CHEMBL3704961 & 1528352 & 6.0 & 6.5501 & TRN & \\
\hline CHEMBL3905361 & 1528352 & 6.0 & 6.7457 & TST & \\
\hline CHEMBL3669036 & 1528352 & 6.6716 & 6.5072 & TST & \\
\hline CHEMBL3704958 & 1528352 & 7.4949 & 6.9978 & TRN & \\
\hline CHEMBL3704956 & 1528352 & 7.1192 & 6.8445 & TRN & \\
\hline CHEMBL 3669041 & 1528352 & 7.7212 & 7.3217 & TRN & \\
\hline CHEMBL3669042 & 1528352 & 7.284 & 7.1061 & TRN & \\
\hline CHEMBL3669025 & 1528352 & 8.1549 & 8.0734 & TST & \\
\hline
\end{tabular}


Supplemental Table S2.txt

\begin{tabular}{|c|c|c|c|c|c|}
\hline CHEMBL3669051 & 1528352 & 6.9245 & 6.7593 & TRN & \\
\hline CHEMBL3704938 & 1528352 & 7.4559 & 6.6212 & TRN & \\
\hline CHEMBL3669028 & 1528352 & 7.4437 & 6.8018 & TST & \\
\hline CHEMBL 3669034 & 1528352 & 7.2441 & \multicolumn{2}{|c|}{7.002000000000001} & TST \\
\hline CHEMBL3983903 & 1528352 & 4.0 & 6.7863 & TST & \\
\hline CHEMBL3669046 & 1528352 & 7.585 & 7.4115 & TRN & \\
\hline CHEMBL3704942 & 1528352 & 7.7212 & 7.2015 & TRN & \\
\hline CHEMBL3704954 & 1528352 & 7.699 & 6.8123 & TRN & \\
\hline CHEMBL3967710 & 1528352 & 5.7447 & 6.7207 & TST & \\
\hline CHEMBL3956634 & 1528352 & 6.0 & 6.2041 & TST & \\
\hline CHEMBL3669045 & 1528352 & 7.3565 & 7.1749 & TRN & \\
\hline CHEMBL3669023 & 1528352 & 8.0 & \multicolumn{2}{|c|}{7.7589999999999995} & TRN \\
\hline CHEMBL3597969 & 1528352 & 7.9586 & 7.7929 & TRN & \\
\hline CHEMBL3669050 & 1528352 & 7.3565 & 6.5879 & TRN & \\
\hline CHEMBL3669030 & 1528352 & 8.0969 & 7.9552 & TRN & \\
\hline CHEMBL3704966 & 1528352 & 6.4283 & 7.1446 & TST & \\
\hline CHEMBL3669035 & 1528352 & 7.6383 & 7.6646 & TRN & \\
\hline CHEMBL 3640038 & 1528352 & 6.8827 & 6.6171 & TRN & \\
\hline CHEMBL3669049 & 1528352 & 7.5528 & 7.7235 & TRN & \\
\hline CHEMBL 3669032 & 1528352 & 7.8539 & 7.7727 & TST & \\
\hline CHEMBL3704935 & 1528352 & 6.0 & 6.7852 & TRN & \\
\hline CHEMBL3704940 & 1528352 & 8.0 & 7.5624 & TRN & \\
\hline CHEMBL3669043 & 1528352 & 7.0915 & 6.9744 & TRN & \\
\hline CHEMBL3597970 & 1528352 & 8.0969 & 8.0897 & TRN & \\
\hline CHEMBL 3704929 & 1528352 & 7.6021 & 7.2953 & TST & \\
\hline CHEMBL3893886 & 1528352 & 6.0 & 6.1579 & TRN & \\
\hline CHEMBL 3669022 & 1528352 & 6.0 & 6.4538 & TRN & \\
\hline CHEMBL3704951 & 1528352 & 6.0 & 7.0647 & TRN & \\
\hline CHEMBL3704939 & 1528352 & 6.0 & 6.2167 & TRN & \\
\hline CHEMBL3918636 & 1528352 & 5.9586 & 6.5175 & TST & \\
\hline CHEMBL3926734 & 1528352 & 6.0 & 5.774 & TRN & \\
\hline CHEMBL3669033 & 1528352 & 7.2757 & 7.0346 & TRN & \\
\hline CHEMBL3704967 & 1528352 & 6.0 & 6.5981 & TRN & \\
\hline CHEMBL3669024 & 1528352 & 6.0 & 6.6422 & TRN & \\
\hline CHEMBL3669007 & 1528352 & 6.0 & 5.8937 & TST & \\
\hline CHEMBL3704947 & 1528352 & 7.7212 & 7.8803 & TRN & \\
\hline CHEMBL3929103 & 1528352 & 6.0 & 5.8251 & TRN & \\
\hline CHEMBL3704946 & 1528352 & 7.9586 & 7.6037 & TRN & \\
\hline CHEMBL3669029 & 1528352 & 7.5229 & 7.4324 & TRN & \\
\hline CHEMBL3669038 & 1528352 & 7.8539 & \multicolumn{2}{|c|}{7.537000000000001} & TRN \\
\hline CHEMBL3704960 & 1528352 & 8.0458 & 7.5793 & TST & \\
\hline CHEMBL3669039 & 1528352 & 7.699 & 7.6422 & TRN & \\
\hline CHEMBL3645319 & 1642058 & 9.699 & 9.6545 & TRN & \\
\hline CHEMBL3645317 & 1642058 & 9.699 & 9.7772 & TRN & \\
\hline CHEMBL3952427 & 1642058 & 9.5229 & 10.2373 & TST & \\
\hline CHEMBL3645337 & 1642058 & 9.699 & 10.1363 & TRN & \\
\hline CHEMBL 3645334 & 1642058 & 9.5229 & 9.9505 & TRN & \\
\hline CHEMBL 3645357 & 1642058 & 9.699 & 9.9782 & TRN & \\
\hline
\end{tabular}


Supplemental Table S2.txt

\begin{tabular}{|c|c|c|c|c|c|}
\hline CHEMBL3645326 & 1642058 & 10.0 & 9.8237 & TRN & \\
\hline CHEMBL 3645331 & 1642058 & 9.699 & 8.9528 & TRN & \\
\hline CHEMBL3645335 & 1642058 & 10.0 & 9.7845 & TRN & \\
\hline CHEMBL3645311 & 1642058 & 6.0 & 6.6436 & TRN & \\
\hline CHEMBL3645336 & 1642058 & 9.3979 & 9.0156 & TRN & \\
\hline CHEMBL3645351 & 1642058 & 6.0 & 6.1719 & TRN & \\
\hline CHEMBL3645325 & 1642058 & 10.0 & \multicolumn{2}{|c|}{9.636000000000001} & TRN \\
\hline CHEMBL3645296 & 1642058 & 9.699 & 9.8825 & TRN & \\
\hline CHEMBL 3965175 & 1642058 & 10.0 & 9.3186 & TST & \\
\hline CHEMBL3645309 & 1642058 & 10.0 & 9.4614 & TRN & \\
\hline CHEMBL 3645280 & 1642058 & 10.0 & 9.8433 & TRN & \\
\hline CHEMBL3645284 & 1642058 & 10.0 & 10.029 & TRN & \\
\hline CHEMBL 3645278 & 1642058 & 10.0 & 9.9288 & TRN & \\
\hline CHEMBL3645299 & 1642058 & 9.699 & 9.7113 & TRN & \\
\hline CHEMBL3645295 & 1642058 & 10.0 & 9.9206 & TRN & \\
\hline CHEMBL3645362 & 1642058 & 10.0 & 9.6595 & TRN & \\
\hline CHEMBL3645279 & 1642058 & 10.0 & 9.3027 & TRN & \\
\hline CHEMBL 3645358 & 1642058 & 10.0 & 9.5552 & TRN & \\
\hline CHEMBL 3645340 & 1642058 & 9.5229 & 9.8916 & TRN & \\
\hline CHEMBL3645338 & 1642058 & 9.5229 & 9.5634 & TRN & \\
\hline CHEMBL3645286 & 1642058 & 10.0 & 9.9619 & TRN & \\
\hline CHEMBL3645345 & 1642058 & 6.0 & 6.6446 & TRN & \\
\hline CHEMBL 3645289 & 1642058 & 6.0 & 5.6317 & TRN & \\
\hline CHEMBL 3645320 & 1642058 & 6.0 & 6.2486 & TRN & \\
\hline CHEMBL3645330 & 1642058 & 10.0 & 10.0925 & TRN & \\
\hline CHEMBL3645339 & 1642058 & 9.699 & 9.6587 & TRN & \\
\hline CHEMBL3645294 & 1642058 & 9.699 & 9.8713 & TRN & \\
\hline CHEMBL 3645349 & 1642058 & 6.0 & 5.3888 & TRN & \\
\hline CHEMBL3645292 & 1642058 & 9.699 & 9.5501 & TRN & \\
\hline CHEMBL3981221 & 1642058 & 9.699 & 10.1466 & TST & \\
\hline CHEMBL3666068 & 1642058 & 10.0 & 10.0337 & TST & \\
\hline CHEMBL 3645344 & 1642058 & 9.699 & 8.9528 & TRN & \\
\hline CHEMBL 3645327 & 1642058 & 10.0 & 10.0028 & TRN & \\
\hline CHEMBL 3645277 & 1642058 & 10.0 & 9.9996 & TST & \\
\hline CHEMBL3645274 & 1642058 & 10.0 & 10.0704 & TST & \\
\hline CHEMBL3645287 & 1642058 & 10.0 & 10.0511 & TST & \\
\hline CHEMBL3645281 & 1642058 & 6.0 & 5.5481 & TST & \\
\hline CHEMBL3645293 & 1642058 & 10.0 & 10.0163 & TRN & \\
\hline CHEMBL 3645275 & 1642058 & 10.0 & 9.9949 & TST & \\
\hline CHEMBL3645348 & 1642058 & 10.0 & 9.9879 & TRN & \\
\hline CHEMBL3645276 & 1642058 & 10.0 & 9.6578 & TST & \\
\hline CHEMBL3645361 & 1642058 & 6.0 & 8.1049 & TRN & \\
\hline CHEMBL3645288 & 1642058 & 10.0 & 10.0679 & TST & \\
\hline CHEMBL3645324 & 1642058 & 10.0 & 9.527999 & 7999999999 & TRN \\
\hline CHEMBL3896828 & 1642058 & 10.0 & 9.1144 & TST & \\
\hline CHEMBL3645315 & 1642058 & 6.0 & 8.1249 & TRN & \\
\hline CHEMBL3645310 & 1642058 & 9.699 & 10.1094 & TRN & \\
\hline CHEMBL 3645328 & 1642058 & 10.0 & 9.9141 & TRN & \\
\hline
\end{tabular}




\begin{tabular}{|c|c|c|c|c|c|}
\hline \multicolumn{6}{|c|}{ Supplemental Table S2.txt } \\
\hline CHEMBL 3645332 & 1642058 & 6.0 & 5.898 & TRN & \\
\hline CHEMBL3645329 & 1642058 & 9.5229 & 9.7453 & TRN & \\
\hline CHEMBL3645312 & 1642058 & 9.699 & 9.7915 & TRN & \\
\hline CHEMBL3645341 & 1642058 & 6.0 & 5.8732 & TRN & \\
\hline CHEMBL3645356 & 1642058 & 10.0 & 9.4202 & TRN & \\
\hline CHEMBL3645302 & 1642058 & 9.699 & 10.319 & TRN & \\
\hline CHEMBL3892141 & 1642058 & 10.0 & 9.0119 & TST & \\
\hline CHEMBL3645353 & 1642058 & 6.0 & 5.8186 & TRN & \\
\hline CHEMBL3645283 & 1642058 & 10.0 & 10.1086 & TST & \\
\hline CHEMBL3645285 & 1642058 & 10.0 & 9.8313 & TST & \\
\hline CHEMBL3645298 & 1642058 & 10.0 & 10.1293 & TRN & \\
\hline CHEMBL3645359 & 1642058 & 10.0 & 10.0052 & TST & \\
\hline CHEMBL3426704 & 1642058 & 10.0 & 9.8417 & TST & \\
\hline CHEMBL3645322 & 1642058 & 9.699 & 7.9156 & TRN & \\
\hline CHEMBL3645363 & 1642058 & 10.0 & 9.9104 & TST & \\
\hline CHEMBL3649732 & 1640348 & 5.5784 & 5.6731 & TRN & \\
\hline CHEMBL3649724 & 1640348 & 5.8297 & 5.8561 & TRN & \\
\hline CHEMBL3649756 & 1640348 & 6.0315 & 6.1133 & TRN & \\
\hline CHEMBL3649775 & 1640348 & 7.0969 & 7.3563 & TRN & \\
\hline CHEMBL3649723 & 1640348 & 5.8182 & 5.7569 & TRN & \\
\hline CHEMBL3649759 & 1640348 & 6.0315 & 6.6101 & TRN & \\
\hline CHEMBL3649721 & 1640348 & 6.4318 & 6.4925 & TRN & \\
\hline CHEMBL 3649714 & 1640348 & 4.3979 & 5.272 & TST & \\
\hline CHEMBL3649783 & 1640348 & 6.8539 & 6.9733 & TRN & \\
\hline CHEMBL3649735 & 1640348 & 5.5072 & 5.7789 & TST & \\
\hline CHEMBL3649807 & 1640348 & 6.7212 & 6.6782 & TRN & \\
\hline CHEMBL3649769 & 1640348 & 5.8125 & 5.8492 & TST & \\
\hline CHEMBL 3649722 & 1640348 & 6.3372 & 6.0856 & TRN & \\
\hline CHEMBL3649781 & 1640348 & 6.9586 & 7.0906 & TRN & \\
\hline CHEMBL3649789 & 1640348 & 6.9586 & 6.8074 & TRN & \\
\hline CHEMBL3649725 & 1640348 & 5.8125 & 5.6476 & TRN & \\
\hline CHEMBL3649777 & 1640348 & 6.6383 & 6.571006 & 0000000001 & TRN \\
\hline CHEMBL 3649811 & 1640348 & 7.0969 & 6.8746 & TRN & \\
\hline CHEMBL3649750 & 1640348 & 6.585 & 6.6179 & TRN & \\
\hline CHEMBL3649739 & 1640348 & 5.7905 & 5.9063 & TRN & \\
\hline CHEMBL3649797 & 1640348 & 6.7696 & 6.79299 & 9999999999 & TRN \\
\hline CHEMBL3649768 & 1640348 & 6.2676 & 6.2845 & TST & \\
\hline CHEMBL3649764 & 1640348 & 6.7212 & 6.7077 & TRN & \\
\hline CHEMBL3653090 & 1640348 & 6.3872 & 6.3306 & TRN & \\
\hline CHEMBL3649813 & 1640348 & 6.7696 & 6.6808 & TRN & \\
\hline CHEMBL3649717 & 1640348 & 5.9706 & 5.7869 & TST & \\
\hline CHEMBL3649773 & 1640348 & 5.9626 & 5.6311 & TST & \\
\hline CHEMBL3649800 & 1640348 & 6.0458 & 6.0549 & TRN & \\
\hline CHEMBL3649755 & 1640348 & 6.4949 & 6.961 & TRN & \\
\hline CHEMBL3649758 & 1640348 & 7.301 & 7.3771 & TRN & \\
\hline CHEMBL3649798 & 1640348 & 6.3098 & 6.1782 & TST & \\
\hline CHEMBL3649796 & 1640348 & 6.8539 & 6.8672 & TRN & \\
\hline CHEMBL3649795 & 1640348 & 6.7212 & 6.8529 & TRN & \\
\hline
\end{tabular}


Supplemental Table S2.txt

\begin{tabular}{|c|c|c|c|c|c|}
\hline CHEMBL3649734 & 1640348 & 5.5452 & 5.1292 & TRN & \\
\hline CHEMBL 3649810 & 1640348 & 7.1549 & 7.2923 & TRN & \\
\hline CHEMBL3649709 & 1640348 & 6.2218 & 6.5295 & TST & \\
\hline CHEMBL 3649765 & 1640348 & 6.9208 & 6.8264 & TRN & \\
\hline CHEMBL 3649726 & 1640348 & 4.3979 & 4.9854 & TRN & \\
\hline CHEMBL3649737 & 1640348 & 6.6383 & 6.6137 & TRN & \\
\hline CHEMBL3649806 & 1640348 & 7.2218 & \multicolumn{2}{|c|}{7.1160000000000005} & TRN \\
\hline CHEMBL3649754 & 1640348 & 6.2076 & 5.8376 & TST & \\
\hline CHEMBL3649710 & 1640348 & 6.301 & 5.6002 & TRN & \\
\hline CHEMBL3649742 & 1640348 & 4.3979 & 6.6526 & TST & \\
\hline CHEMBL 3649770 & 1640348 & 7.0458 & 6.7464 & TST & \\
\hline CHEMBL 3649718 & 1640348 & 5.4145 & 5.138 & TST & \\
\hline CHEMBL 3649793 & 1640348 & 6.1079 & 6.0101 & TRN & \\
\hline CHEMBL3649767 & 1640348 & 5.9914 & \multicolumn{2}{|c|}{6.1129999999999995} & TRN \\
\hline CHEMBL 3649779 & 1640348 & 7.301 & 7.2993 & TRN & \\
\hline CHEMBL3649799 & 1640348 & 6.1135 & 6.1111 & TRN & \\
\hline CHEMBL3649774 & 1640348 & 5.5229 & \multicolumn{2}{|c|}{6.638999999999999} & TST \\
\hline CHEMBL 3653088 & 1640348 & 7.0 & 7.0755 & TRN & \\
\hline CHEMBL 3649746 & 1640348 & 7.3979 & 7.0886 & TRN & \\
\hline CHEMBL 3639486 & 1640348 & 7.0458 & 7.035 & TRN & \\
\hline CHEMBL 3649716 & 1640348 & 5.9872 & 6.1095 & TST & \\
\hline CHEMBL3649753 & 1640348 & 6.8861 & 6.3865 & TST & \\
\hline CHEMBL 3649803 & 1640348 & 6.2518 & 6.2241 & TRN & \\
\hline CHEMBL 3649740 & 1640348 & $5.4510 e$ & 00000000 & 5.5915 & TRN \\
\hline CHEMBL3649761 & 1640348 & 6.7447 & 6.5269 & TRN & \\
\hline CHEMBL3653091 & 1640348 & 6.7447 & 6.9613 & TRN & \\
\hline CHEMBL3649741 & 1640348 & 5.52 & 5.4695 & TRN & \\
\hline CHEMBL3653089 & 1640348 & 6.7212 & \multicolumn{2}{|c|}{6.832999999999999} & TRN \\
\hline CHEMBL3653092 & 1640348 & 6.2147 & 6.1447 & TRN & \\
\hline CHEMBL3649715 & 1640348 & 4.3979 & 5.3306 & TST & \\
\hline CHEMBL 3649752 & 1640348 & 7.1549 & 7.0424 & TRN & \\
\hline CHEMBL 3649808 & 1640348 & 7.1549 & 7.1046 & TRN & \\
\hline CHEMBL 3649743 & 1640348 & 7.301 & 5.9357 & TST & \\
\hline CHEMBL3649713 & 1640348 & 4.3979 & 5.4243 & TST & \\
\hline CHEMBL3649763 & 1640348 & 6.0362 & 5.8892 & TRN & \\
\hline CHEMBL3649727 & 1640348 & 5.9355 & 5.9545 & TRN & \\
\hline CHEMBL3649771 & 1640348 & 5.9245 & 6.1912 & TST & \\
\hline CHEMBL 3649728 & 1640348 & 5.8447 & 5.8892 & TRN & \\
\hline CHEMBL3649736 & 1640348 & 5.9706 & 6.8707 & TST & \\
\hline CHEMBL3649786 & 1640348 & 6.4949 & 6.4561 & TRN & \\
\hline CHEMBL 3649788 & 1640348 & 6.7447 & 6.6813 & TRN & \\
\hline CHEMBL 3649778 & 1640348 & 7.301 & \multicolumn{2}{|c|}{7.2410000000000005} & TRN \\
\hline CHEMBL3649748 & 1640348 & 6.7959 & 6.7221 & TRN & \\
\hline CHEMBL3649802 & 1640348 & 7.2218 & 7.0968 & TRN & \\
\hline CHEMBL 3649712 & 1640348 & 4.3979 & 5.4791 & TST & \\
\hline CHEMBL 3649747 & 1640348 & 6.6576 & 6.5368 & TRN & \\
\hline CHEMBL3649738 & 1640348 & 6.0315 & 5.9738 & TRN & \\
\hline CHEMBL 3649744 & 1640348 & 7.0 & 5.7548 & TST & \\
\hline
\end{tabular}


Supplemental Table S2.txt

\begin{tabular}{|c|c|c|c|c|}
\hline CHEMBL3649809 & 1640348 & 6.8539 & 6.7001 & TRN \\
\hline CHEMBL3649772 & 1640348 & 4.3979 & 6.1714 & TST \\
\hline CHEMBL 3649801 & 1640348 & 6.1249 & 6.0254 & TRN \\
\hline CHEMBL3639485 & 1640348 & 4.3979 & 4.8071 & TRN \\
\hline CHEMBL3649804 & 1640348 & 6.7447 & 6.7429 & TRN \\
\hline CHEMBL3649731 & 1640348 & 6.4089 & 6.3964 & TRN \\
\hline CHEMBL3649790 & 1640348 & 6.2147 & 6.1049 & TRN \\
\hline CHEMBL 3649760 & 1640348 & 5.7645 & 6.8199 & TST \\
\hline CHEMBL 3649791 & 1640348 & 6.9586 & 7.0069 & TRN \\
\hline CHEMBL3649787 & 1640348 & 6.8239 & \multicolumn{2}{|c|}{7.082000000000001} \\
\hline CHEMBL3649812 & 1640348 & 6.0177 & 5.9986 & TRN \\
\hline CHEMBL3649780 & 1640348 & 7.301 & 7.1965 & TRN \\
\hline CHEMBL 3649751 & 1640348 & 6.2291 & 6.3712 & TRN \\
\hline CHEMBL 3649730 & 1640348 & 4.3979 & 4.4812 & TRN \\
\hline CHEMBL3649711 & 1640348 & 4.3979 & \multicolumn{2}{|c|}{5.303999999999999} \\
\hline CHEMBL3649776 & 1640348 & 7.0 & 7.2342 & TRN \\
\hline CHEMBL3649792 & 1640348 & 6.5686 & 6.561 & TRN \\
\hline CHEMBL3649782 & 1640348 & 6.7447 & 6.6902 & TRN \\
\hline CHEMBL 3649757 & 1640348 & 7.1549 & 6.8704 & TRN \\
\hline CHEMBL3649745 & 1640348 & 4.3979 & 4.5728 & TRN \\
\hline CHEMBL3649805 & 1640348 & 6.9208 & 7.0028 & TRN \\
\hline CHEMBL 3649784 & 1640348 & 6.9586 & 6.9294 & TRN \\
\hline CHEMBL3649719 & 1640348 & 4.3979 & 5.2607 & TST \\
\hline CHEMBL 3649720 & 1640348 & 5.9788 & 6.7381 & TST \\
\hline CHEMBL3649766 & 1640348 & 4.3979 & 4.2962 & TRN \\
\hline CHEMBL3649785 & 1640348 & 7.2218 & 7.1433 & TRN \\
\hline CHEMBL3649729 & 1640348 & 5.9666 & 6.0158 & TRN \\
\hline CHEMBL125431 & 158651 & 7.5376 & 7.4448 & TRN \\
\hline CHEMBL125721 & 158651 & 7.9208 & 6.5905 & TST \\
\hline CHEMBL123667 & 158651 & 7.1135 & 7.2088 & TRN \\
\hline CHEMBL127753 & 158651 & 6.3002 & 6.6033 & TRN \\
\hline CHEMBL125146 & 158651 & 5.5513 & 5.4829 & TRN \\
\hline CHEMBL125811 & 158651 & 8.7959 & 7.1444 & TST \\
\hline CHEMBL125171 & 158651 & 6.9508 & 6.9342 & TRN \\
\hline CHEMBL126699 & 158651 & 9.3979 & 9.4902 & TRN \\
\hline CHEMBL125898 & 158651 & 7.699 & 7.5081 & TRN \\
\hline CHEMBL340200 & 158651 & 5.301 & 5.8379 & TRN \\
\hline CHEMBL125994 & 158651 & 6.7747 & 6.7108 & TRN \\
\hline CHEMBL341258 & 158651 & 8.8539 & 7.0359 & TST \\
\hline CHEMBL124439 & 158651 & 6.0899 & 5.8811 & TRN \\
\hline CHEMBL126173 & 158651 & 5.8386 & 6.2774 & TRN \\
\hline CHEMBL125717 & 158651 & 8.0 & 7.3568 & TST \\
\hline CHEMBL334169 & 158651 & 5.2526 & 5.4489 & TRN \\
\hline CHEMBL59735 & 158651 & 7.4437 & 7.2332 & TRN \\
\hline CHEMBL124983 & 158651 & 6.2487 & 6.2875 & TRN \\
\hline CHEMBL341239 & 158651 & 7.1024 & 6.6033 & TRN \\
\hline CHEMBL125367 & 158651 & 6.7033 & 6.7261 & TRN \\
\hline CHEMBL125761 & 158651 & 6.8386 & 7.0773 & TRN \\
\hline
\end{tabular}

Page 15501 
Supplemental Table S2.txt

\begin{tabular}{|c|c|c|c|c|}
\hline CHEMBL127886 & 158651 & 7.3979 & 6.6401 & TST \\
\hline CHEMBL107599 & 58651 & 9.3979 & 9.5243 & TRN \\
\hline HEMBL340144 & 58651 & 3883 & 4311 & 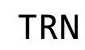 \\
\hline HEMBL338827 & 58651 & 9031 & 8893 & \\
\hline HEMBL121829 & 58651 & 3.699 & 7.0928 & 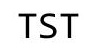 \\
\hline HEMBL124089 & 58651 & . 3979 & 7.3108 & \\
\hline HEMBL338619 & 58651 & .0255 & 5.8405 & \\
\hline HEMBL445636 & 58651 & 3979 & 9.3883 & PN \\
\hline HEMBL124895 & 58651 & 6.7033 & 6.6173 & TRN \\
\hline HEMBL330863 & 58651 & .3979 & 9.4242 & \\
\hline CHEMBL124487 & 58651 & 7.0044 & 6.7261 & \\
\hline HEMBL 125028 & 58651 & 5.6498 & 5.5045 & RN \\
\hline HEMBL 340284 & 58651 & 9.3979 & 7.8758 & \\
\hline HEMBL125805 & 58651 & 8.6198 & 7.235 & \\
\hline HEMBL 333648 & 58651 & 5.8633 & 5.9548 & \\
\hline CHEMBL 339403 & 158651 & 7.301 & 7.3285 & \\
\hline HEMBL 340234 & 58651 & 7.1192 & 7.1514 & RN \\
\hline HEMBL125277 & 58651 & 9.0 & 7.896 & \\
\hline HEMBL124035 & 58651 & 6.3768 & 6.6488 & Th \\
\hline HEMBL127635 & 58651 & 5.8508 & 5.8872 & 10 \\
\hline HEMBL4 & 58651 & 072 & 992 & RN \\
\hline HEMBL1 & 58651 & 959 & 95 & RN \\
\hline HEMBL1 & 58651 & 6.0969 & 6.2772 & TRN \\
\hline HEMBL 340137 & 58651 & 7.585 & 7.1755 & ISI \\
\hline HEMBL125445 & 58651 & 6.1249 & 6.0884 & TRN \\
\hline HEMBL125451 & 58651 & 7. & 6.7952 & TRN \\
\hline HEMBL1 & 58651 & 872 & 1 & $\mathrm{RN}$ \\
\hline LHEMBL 338623 & 58651 & 5.1871 & 4.9923 & TRN \\
\hline HEMBL340157 & 58651 & 7.699 & 7.269 & ISI \\
\hline HEMBL127429 & 58651 & 6.475 & 6.3582 & TRN \\
\hline HEMBL127731 & 58651 & 586 & 913 & TRN \\
\hline CHEMBL1 & 58651 & 38 & 68 & TRN \\
\hline CHEMBL338597 & 158651 & 7.2757 & 357 & TRN \\
\hline HEMBL127786 & 58651 & 6.6655 & 6.8807 & TRN \\
\hline HEMBL419785 & 58651 & 6.06 & 5.9478 & TRN \\
\hline HEMBL444064 & 58651 & 031 & 3889 & TRN \\
\hline CHEMBL1 & 58651 & 586 & 03 & TRN \\
\hline CHEMBL 338330 & 158651 & 6.8386 & 6.7061 & TRN \\
\hline CHEMBL332083 & 58651 & 4.9119 & 6.0069 & TST \\
\hline CHEMBL1 & 58651 & 7.0605 & 6.7981 & TRN \\
\hline CHEMBL122572 & 158651 & 6.8239 & 6.5309 & TRN \\
\hline CHEMBL340235 & 158651 & 6.3726 & 6.5562 & TRN \\
\hline CHEMBL127748 & 158651 & 5.8861 & 6.2798 & TRN \\
\hline CHEMBL339685 & 58651 & 7.3979 & 6.8663 & TST \\
\hline CHEMBL3 & 158651 & & & $T$ \\
\hline CHEMBL124872 & 158651 & 6.1457 & 5.989 & \\
\hline CHEMBL 337920 & 158651 & 5.2111 & 5.3463 & ГRN \\
\hline CHEMBL124827 & 158651 & 6.7496 & 7.055 & 15 \\
\hline
\end{tabular}

Page 15502 
Supplemental Table S2.txt

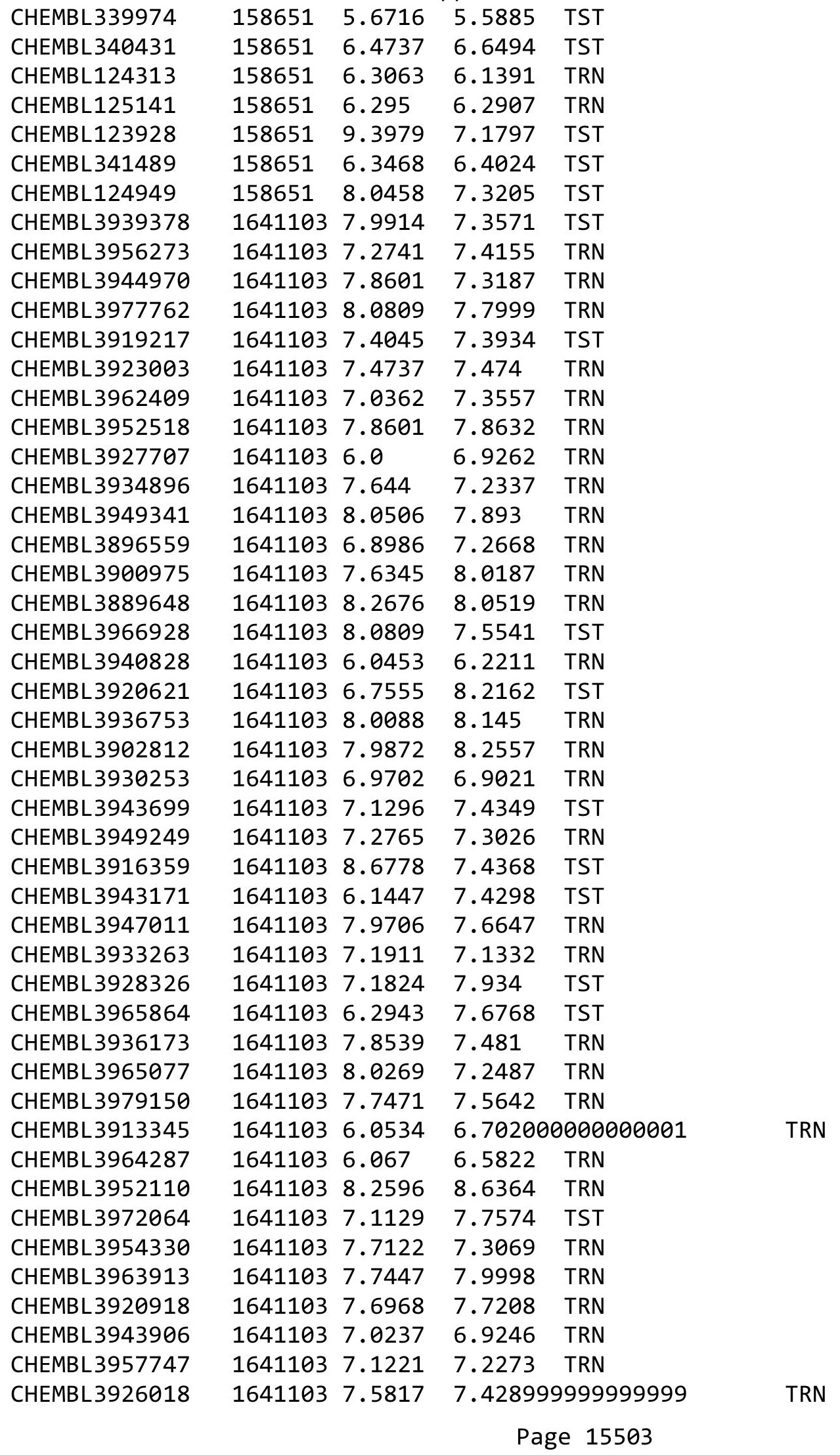


Supplemental Table S2.txt

\begin{tabular}{|c|c|c|c|c|}
\hline CHEMBL3957798 & 1641103 & 8.6383 & 7.2389 & TST \\
\hline CHEMBL3939460 & 1641103 & 7.7645 & 7.9704 & TRN \\
\hline CHEMBL3908029 & 1641103 & 7.3045 & 7.2227 & TRN \\
\hline CHEMBL3943954 & 1641103 & 7.6576 & 8.1035 & TRN \\
\hline CHEMBL3959474 & 1641103 & 7.7852 & 7.9261 & TRN \\
\hline CHEMBL3968778 & 1641103 & 7.3768 & 7.2607 & TRN \\
\hline CHEMBL3964691 & 1641103 & 7.5575 & 7.0339 & TRN \\
\hline CHEMBL3952570 & 1641103 & 7.7825 & 7.7683 & TRN \\
\hline CHEMBL3964721 & 1641103 & 7.2175 & 7.4004 & TRN \\
\hline CHEMBL3942700 & 1641103 & 8.0 & 7.6279 & TRN \\
\hline CHEMBL3913529 & 1641103 & 8.1487 & 7.6354 & TRN \\
\hline CHEMBL3950206 & 1641103 & 6.6664 & 7.1875 & TST \\
\hline CHEMBL3983195 & 1641103 & 8.6576 & 7.4173 & TST \\
\hline CHEMBL3967853 & 1641103 & 7.6253 & \multicolumn{2}{|c|}{6.7829999999999995} \\
\hline CHEMBL3971413 & 1613063 & 7.1427 & 7.1634 & TRN \\
\hline CHEMBL3921555 & 1613063 & 7.7212 & 7.8142 & TRN \\
\hline CHEMBL3933895 & 1613063 & 6.9136 & 6.9057 & TRN \\
\hline CHEMBL3981551 & 1613063 & 7.6021 & 7.6471 & TRN \\
\hline CHEMBL3977926 & 1613063 & 7.0088 & 7.0008 & TRN \\
\hline CHEMBL3967962 & 1613063 & 6.3925 & 6.4426 & TRN \\
\hline CHEMBL3981041 & 1613063 & 6.8962 & 6.9321 & TRN \\
\hline CHEMBL3939985 & 1613063 & 7.6383 & 7.3558 & TRN \\
\hline CHEMBL3923228 & 1613063 & 8.1549 & 8.1089 & TRN \\
\hline CHEMBL3977326 & 1613063 & 7.6778 & 7.4029 & TST \\
\hline CHEMBL3968417 & 1613063 & 8.699 & 8.5959 & TRN \\
\hline CHEMBL3916644 & 1613063 & 6.2933 & 6.316 & TRN \\
\hline CHEMBL3962032 & 1613063 & 6.3757 & 6.5347 & TST \\
\hline CHEMBL3916141 & 1613063 & 6.1267 & 6.0818 & TRN \\
\hline CHEMBL3963723 & 1613063 & 8.2218 & 6.6708 & TST \\
\hline CHEMBL3907533 & 1613063 & 7.585 & 7.6572 & TRN \\
\hline CHEMBL3930506 & 1613063 & 7.8539 & 7.9479 & TRN \\
\hline CHEMBL3948084 & 1613063 & 7.7696 & 7.5843 & TST \\
\hline CHEMBL3921446 & 1613063 & 6.067 & 5.9715 & TRN \\
\hline CHEMBL3948267 & 1613063 & 7.2441 & 7.3374 & TRN \\
\hline CHEMBL3942228 & 1613063 & 8.0969 & 7.9932 & TRN \\
\hline CHEMBL3934034 & 1613063 & 7.4437 & 7.4512 & TRN \\
\hline CHEMBL3969056 & 1613063 & 6.5171 & 6.5032 & TRN \\
\hline CHEMBL3899132 & 1613063 & 7.4202 & 7.3889 & TRN \\
\hline CHEMBL3914227 & 1613063 & 7.1024 & 7.1576 & TRN \\
\hline CHEMBL3919183 & 1613063 & 7.0269 & 6.9486 & TST \\
\hline CHEMBL3980622 & 1613063 & 6.6882 & 6.7296 & TRN \\
\hline CHEMBL3977504 & 1613063 & 6.6968 & 6.7521 & TRN \\
\hline CHEMBL3986103 & 1613063 & 7.6778 & 7.6882 & TRN \\
\hline CHEMBL3958006 & 1613063 & 7.9208 & 7.8779 & TRN \\
\hline CHEMBL3923650 & 1613063 & 6.2823 & 6.2771 & TRN \\
\hline CHEMBL3950549 & 1613063 & 8.699 & 8.1014 & TST \\
\hline CHEMBL3972605 & 1613063 & 6.4647 & 6.4555 & TRN \\
\hline CHEMBL3934539 & 1613063 & 6.8665 & 6.8972 & TRN \\
\hline
\end{tabular}


Supplemental Table S2.txt

\begin{tabular}{|c|c|c|c|c|}
\hline CHEMBL 3946232 & 1613063 & 8.1549 & 7.6473 & TST \\
\hline CHEMBL 3904257 & 1613063 & 7.4318 & 7.3233 & TRN \\
\hline CHEMBL 3942999 & 1613063 & 6.4112 & 6.4546 & TRN \\
\hline CHEMBL 3968839 & 1613063 & 7.2147 & 6.796 & TST \\
\hline CHEMBL 3959248 & 1613063 & 8.1549 & 8.1097 & TRN \\
\hline CHEMBL 3960911 & 1613063 & 6.2848 & 6.142 & TST \\
\hline CHEMBL 3944572 & 1613063 & 6.055 & 6.0771 & TRN \\
\hline CHEMBL 3970738 & 1613063 & 7.1871 & 7.1552 & TRN \\
\hline CHEMBL 3890751 & 1613063 & 7.4437 & 7.3536 & TRN \\
\hline CHEMBL 3944095 & 1613063 & 6.4168 & 6.4343 & TRN \\
\hline CHEMBL 3921129 & 1613063 & 7.6383 & 7.8525 & TRN \\
\hline CHEMBL 3904205 & 1613063 & 6.75700 & 000000000 & 6.6592 \\
\hline CHEMBL 3949347 & 1613063 & 7.3872 & 7.3708 & TRN \\
\hline CHEMBL 3941823 & 1613063 & 7.7696 & 7.787000 & 000000001 \\
\hline CHEMBL 3974571 & 1613063 & 7.6778 & 7.7967 & TST \\
\hline CHEMBL 3922922 & 1613063 & 6.7852 & 6.6996 & TRN \\
\hline CHEMBL3930316 & 1613063 & 8.699 & 8.132 & TST \\
\hline CHEMBL 3930965 & 1613063 & 6.8297 & 6.7709 & TRN \\
\hline CHEMBL 3921347 & 1613063 & 7.1024 & 6.598 & TST \\
\hline CHEMBL 3950966 & 1613063 & 7.8239 & 7.7488 & TRN \\
\hline CHEMBL 3964380 & 1613063 & 7.0655 & 6.3826 & TST \\
\hline CHEMBL3961532 & 1613063 & 7.1739 & 7.161000 & 30000000005 \\
\hline CHEMBL 3890186 & 1613063 & 8.0 & 8.06 & TRN \\
\hline CHEMBL 3932176 & 1613063 & 8.2218 & 8.1424 & TRN \\
\hline CHEMBL 3973028 & 1613063 & 7.0655 & 7.0407 & TRN \\
\hline CHEMBL 3918330 & 1613063 & 7.6576 & 7.944 & TST \\
\hline CHEMBL 3941175 & 1613063 & 6.2269 & 6.2619 & TRN \\
\hline CHEMBL 3896779 & 1613063 & 6.7447 & 6.7117 & TRN \\
\hline CHEMBL3943512 & 1613063 & 7.1871 & 7.0949 & TRN \\
\hline CHEMBL 3951754 & 1613063 & 6.2749 & 6.2282 & TRN \\
\hline CHEMBL 3939300 & 1613063 & 6.1463 & 6.254 & TST \\
\hline CHEMBL 3957801 & 1613063 & 8.0458 & 7.6864 & TST \\
\hline CHEMBL 3936505 & 1613063 & 7.0862 & 7.215 & TRN \\
\hline CHEMBL 3957416 & 1613063 & 7.1612 & 7.1375 & TRN \\
\hline CHEMBL 3962365 & 1613063 & 7.2218 & 7.4439 & TRN \\
\hline CHEMBL 3925158 & 1613063 & 6.9355 & 7.0195 & TRN \\
\hline CHEMBL 3970330 & 1613063 & 7.7959 & 7.7833 & TRN \\
\hline CHEMBL 3958482 & 1613063 & 6.8794 & 6.9258 & TRN \\
\hline CHEMBL417050 & 63342 & 7.0655 & 6.7239 & TRN \\
\hline CHEMBL64039 & 63342 & 8.699 & 8.6533 & TRN \\
\hline CHEMBL302659 & 63342 & 6.4559 & 6.6351 & TRN \\
\hline CHEMBL62951 & 63342 & 6.4559 & 6.6001 & TRN \\
\hline CHEMBL 294127 & 63342 & 5.3188 & 5.4354 & TRN \\
\hline CHEMBL62659 & 63342 & 6.1079 & 6.1877 & TRN \\
\hline CHEMBL62976 & 63342 & 5.284 & 5.5569 & TRN \\
\hline CHEMBL62277 & 63342 & 7.7447 & 7.4394 & TRN \\
\hline CHEMBL 303531 & 63342 & 6.0132 & 6.1384 & TRN \\
\hline CHEMBL294793 & 63342 & 7.0809 & 7.02 & TRN \\
\hline
\end{tabular}




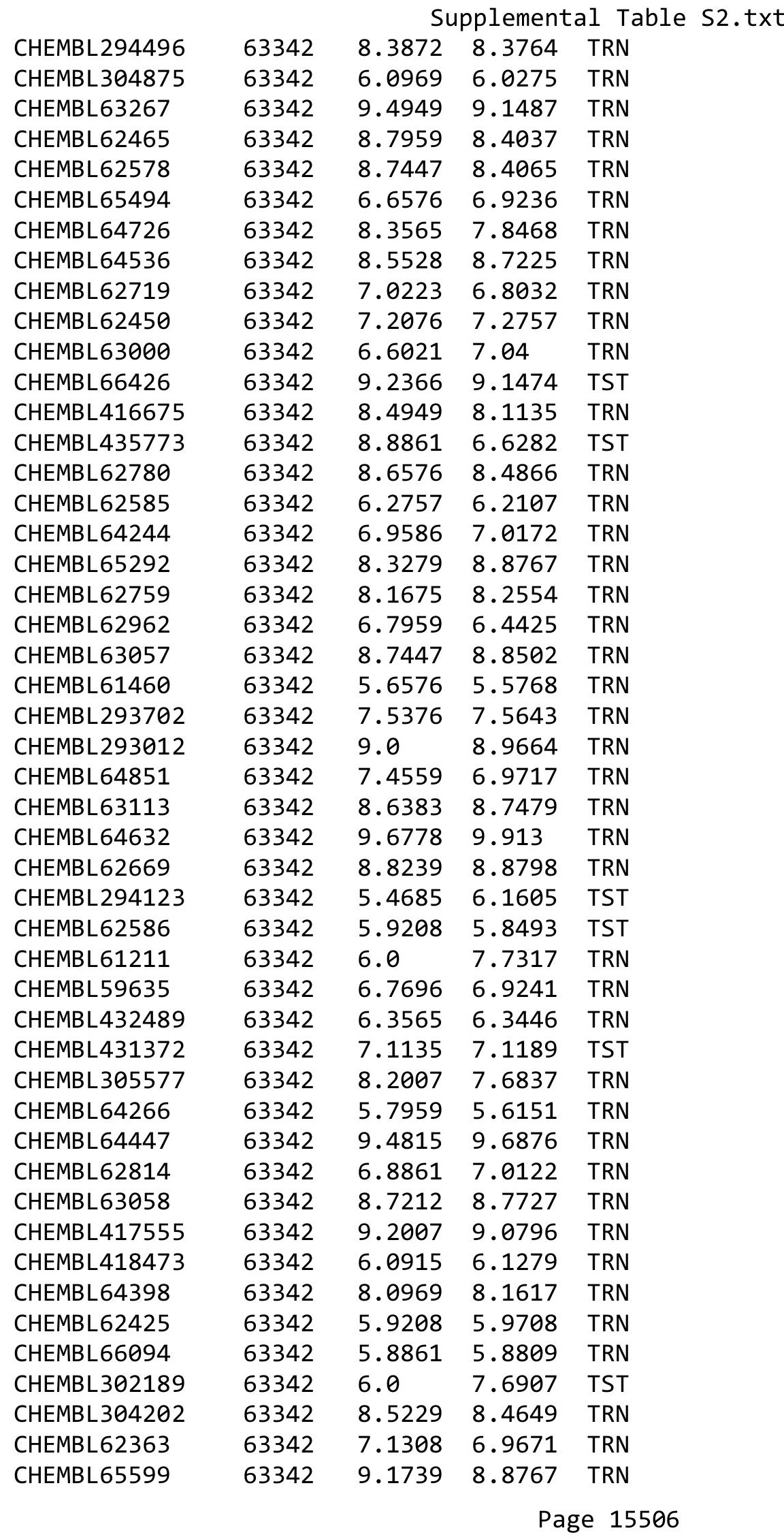




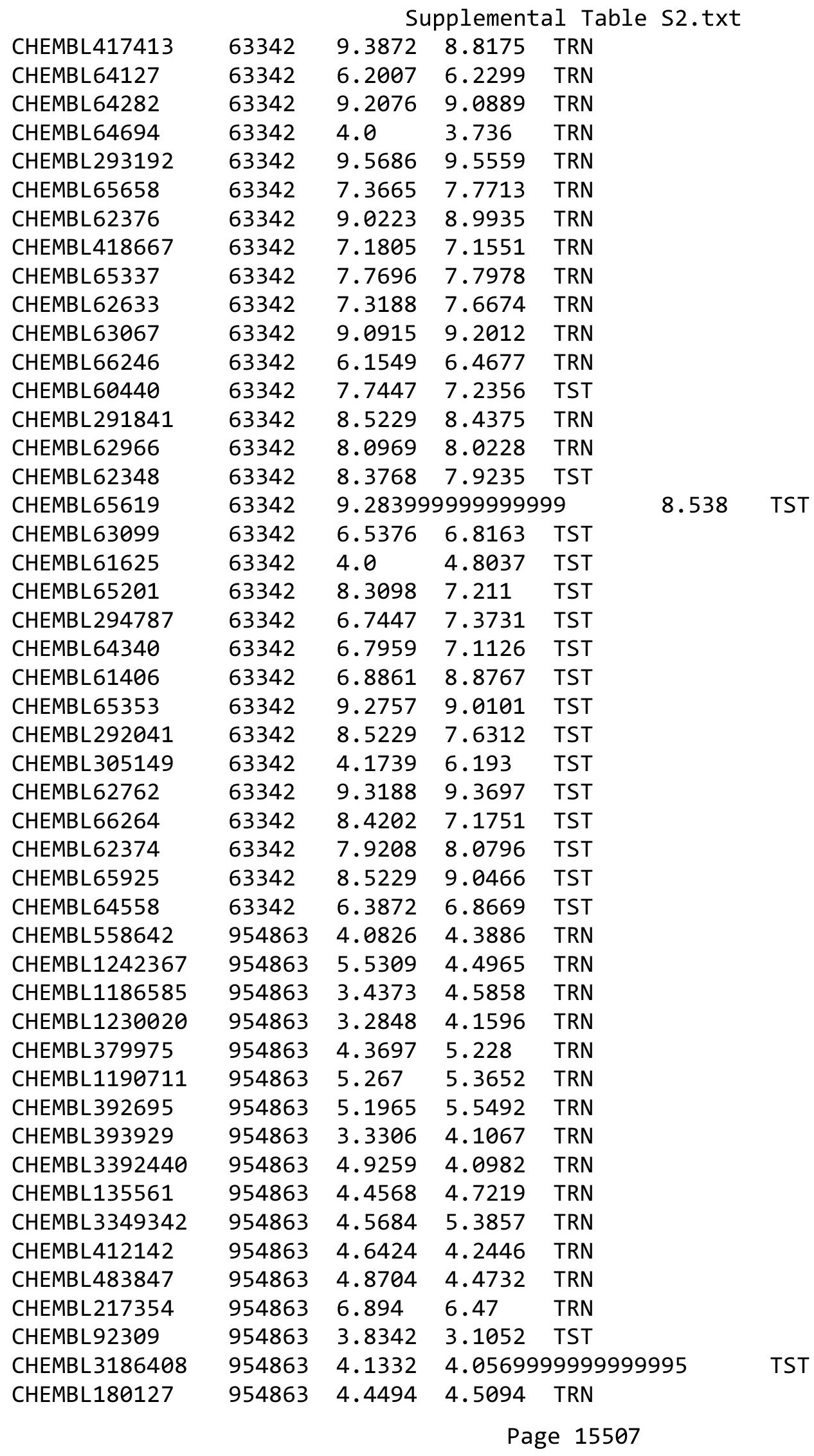




\begin{tabular}{|c|c|c|c|c|c|}
\hline \multicolumn{6}{|c|}{ Supplemental Table S2.txt } \\
\hline CHEMBL191334 & 954863 & 3.7741 & 4.4267 & TRN & \\
\hline CHEMBL259181 & 954863 & 5.1025 & 4.7578 & TRN & \\
\hline CHEMBL 2144069 & 954863 & 4.8477 & 5.2587 & TRN & \\
\hline CHEMBL 2137530 & 954863 & 4.7638 & 5.0574 & TRN & \\
\hline CHEMBL 255342 & 954863 & 3.4876 & 3.7676 & TRN & \\
\hline CHEMBL102714 & 954863 & 3.3117 & 3.6442 & TRN & \\
\hline CHEMBL192566 & 954863 & 9.2602 & 8.7054 & TST & \\
\hline CHEMBL 2005886 & 954863 & 6.0397 & 5.8245 & TRN & \\
\hline CHEMBL449158 & 954863 & 7.1047 & 7.276 & TST & \\
\hline CHEMBL222102 & 954863 & 4.59 & 3.9276 & TRN & \\
\hline CHEMBL1909414 & 954863 & 3.2098 & 4.09399 & 9999999999 & TRN \\
\hline CHEMBL1590308 & 954863 & 4.2471 & 3.6043 & TST & \\
\hline CHEMBL3199475 & 954863 & $3.8080 e$ & 00000000 & 4.6316 & TRN \\
\hline CHEMBL379300 & 954863 & 6.7271 & 6.8926 & TRN & \\
\hline CHEMBL 300389 & 954863 & 7.1071 & 7.3661 & TRN & \\
\hline CHEMBL209148 & 954863 & 4.3981 & 4.8763 & TRN & \\
\hline CHEMBL1788116 & 954863 & 5.4309 & 4.6803 & TRN & \\
\hline CHEMBL220241 & 954863 & 8.2817 & 5.1392 & TRN & \\
\hline CHEMBL213100 & 954863 & 4.8778 & 5.3088 & TRN & \\
\hline CHEMBL1256459 & 954863 & 7.6075 & 7.70700 & 0000000001 & TRN \\
\hline CHEMBL1643959 & 954863 & 4.352 & 3.9882 & TRN & \\
\hline CHEMBL9470 & 954863 & 6.2454 & 6.1782 & TST & \\
\hline CHEMBL515416 & 954863 & 5.5682 & 4.8432 & TRN & \\
\hline CHEMBL483849 & 954863 & 0.9763 & 2.2709 & TST & \\
\hline CHEMBL577784 & 954863 & 5.011 & 5.5407 & TRN & \\
\hline CHEMBL1673039 & 954863 & 5.0681 & 5.1309 & TRN & \\
\hline CHEMBL1357247 & 954863 & 4.1253 & 3.2888 & TRN & \\
\hline CHEMBL512504 & 954863 & 4.2689 & 5.027 & TRN & \\
\hline CHEMBL65 & 954863 & 8.47299 & (99999999 & 8.5441 & TRN \\
\hline CHEMBL202721 & 954863 & 5.4868 & 5.2543 & TRN & \\
\hline CHEMBL240954 & 954863 & 3.4605 & 3.8397 & TST & \\
\hline CHEMBL189584 & 954863 & 3.9963 & 4.822 & TRN & \\
\hline CHEMBL514499 & 954863 & 8.1365 & 7.58899 & 99999999995 & TRN \\
\hline CHEMBL585951 & 954863 & 6.7668 & 6.5494 & TRN & \\
\hline CHEMBL1404918 & 954863 & 2.8888 & 3.0065 & TRN & \\
\hline CHEMBL 2363137 & 954863 & 5.8442 & 5.0938 & TRN & \\
\hline CHEMBL258844 & 954863 & 5.3285 & 4.6165 & TRN & \\
\hline CHEMBL1516890 & 954863 & 4.566 & 4.2353 & TRN & \\
\hline CHEMBL399530 & 954863 & 4.9332 & 4.8132 & TRN & \\
\hline CHEMBL 373751 & 954863 & 3.6562 & 3.9803 & TST & \\
\hline CHEMBL509032 & 954863 & 5.9594 & 6.0072 & TST & \\
\hline CHEMBL1970879 & 954863 & 5.2694 & 5.0719 & TST & \\
\hline CHEMBL472940 & 954863 & 2.8339 & 3.8642 & TST & \\
\hline CHEMBL573107 & 954863 & 5.5013 & 5.3974 & TST & \\
\hline CHEMBL188678 & 954863 & 4.1042 & 4.6177 & TST & \\
\hline CHEMBL221137 & 954863 & 5.4244 & 4.982 & TST & \\
\hline CHEMBL210618 & 954863 & 3.3662 & 3.5922 & TST & \\
\hline CHEMBL 2134202 & 954863 & 3.6756 & 4.5422 & TST & \\
\hline
\end{tabular}




$$
\text { Supplemental Table S2.txt }
$$

\begin{tabular}{|c|c|c|c|c|c|}
\hline CHEMBL3685052 & 1528000 & 6.8794 & 7.8699 & TRN & \\
\hline CHEMBL3689630 & 1528000 & 8.0 & 7.666 & TRN & \\
\hline CHEMBL3685168 & 1528000 & 6.0 & 6.5619 & TRN & \\
\hline CHEMBL 3685009 & 1528000 & 6.0 & 8.3885 & TRN & \\
\hline CHEMBL 3689586 & 1528000 & 6.0 & 7.1391 & TRN & \\
\hline CHEMBL3685176 & 1528000 & 8.1549 & 9.0301 & TRN & \\
\hline CHEMBL3685183 & 1528000 & 7.3872 & 9.131 & TRN & \\
\hline CHEMBL 3685137 & 1528000 & 9.0 & 9.1547 & TRN & \\
\hline CHEMBL 3685023 & 1528000 & 10.3979 & 10.1118 & TRN & \\
\hline CHEMBL3685109 & 1528000 & 8.2218 & 8.0784 & TRN & \\
\hline CHEMBL3689606 & 1528000 & 10.0 & 9.8745 & TRN & \\
\hline CHEMBL3689747 & 1528000 & 7.6576 & 7.2588 & TST & \\
\hline CHEMBL 3685173 & 1528000 & 9.0969 & 9.1414 & TRN & \\
\hline CHEMBL 3689729 & 1528000 & 6.0 & 6.4516 & TRN & \\
\hline CHEMBL 3685143 & 1528000 & 8.3979 & 8.8605 & TRN & \\
\hline CHEMBL 3685148 & 1528000 & 9.0 & 7.3162 & TRN & \\
\hline CHEMBL3639885 & 1528000 & 9.6904 & 9.1128 & TRN & \\
\hline CHEMBL3689708 & 1528000 & 9.2636 & 9.396 & TRN & \\
\hline CHEMBL 3685182 & 1528000 & 9.0 & 8.2507 & TST & \\
\hline CHEMBL 3685075 & 1528000 & 9.2218 & 8.866 & TRN & \\
\hline CHEMBL 3689546 & 1528000 & 9.3979 & 8.5562 & TRN & \\
\hline CHEMBL 3685027 & 1528000 & 8.699 & 7.7149 & TST & \\
\hline CHEMBL3689668 & 1528000 & 9.699 & 8.3847 & TRN & \\
\hline CHEMBL 3689670 & 1528000 & 10.0 & 9.2572 & TRN & \\
\hline CHEMBL3689713 & 1528000 & 6.0 & 6.42 & TRN & \\
\hline CHEMBL 3689607 & 1528000 & 6.0 & 8.0946 & TRN & \\
\hline CHEMBL3685013 & 1528000 & 9.0 & 9.3667 & TRN & \\
\hline CHEMBL 3685000 & 1528000 & 8.699 & 8.963 & TRN & \\
\hline CHEMBL 3685184 & 1528000 & 9.699 & 9.61399 & 9999999999 & TRN \\
\hline CHEMBL 3689600 & 1528000 & 9.5229 & 9.1295 & TRN & \\
\hline CHEMBL 3689660 & 1528000 & 9.5229 & 9.3121 & TRN & \\
\hline CHEMBL 3685130 & 1528000 & 8.699 & 9.3827 & TRN & \\
\hline CHEMBL3689700 & 1528000 & 9.9355 & 9.4689 & TRN & \\
\hline CHEMBL3689633 & 1528000 & 10.0 & 8.355 & TRN & \\
\hline CHEMBL3689657 & 1528000 & 8.301 & 8.7773 & TRN & \\
\hline CHEMBL3689596 & 1528000 & 6.0 & 6.9485 & TRN & \\
\hline CHEMBL 3689697 & 1528000 & 9.8013 & 9.2084 & TRN & \\
\hline CHEMBL3685166 & 1528000 & 6.0 & 7.5087 & TRN & \\
\hline CHEMBL 3689581 & 1528000 & 7.699 & 9.2245 & TRN & \\
\hline CHEMBL3685104 & 1528000 & 8.5229 & 7.7827 & TRN & \\
\hline CHEMBL 3685055 & 1528000 & 10.1549 & 9.6023 & TRN & \\
\hline CHEMBL 3689735 & 1528000 & 7.475 & 6.7869 & TRN & \\
\hline CHEMBL3685089 & 1528000 & 10.5229 & 9.704 & TRN & \\
\hline CHEMBL 3685064 & 1528000 & 7.3768 & 9.1729 & TST & \\
\hline CHEMBL3689589 & 1528000 & 9.0 & 9.2695 & TRN & \\
\hline CHEMBL 3685120 & 1528000 & 7.7447 & 8.6264 & TRN & \\
\hline CHEMBL 3685030 & 1528000 & 8.5229 & 8.1569 & TRN & \\
\hline CHEMBL3689610 & 1528000 & 9.5229 & 8.4134 & TRN & \\
\hline
\end{tabular}




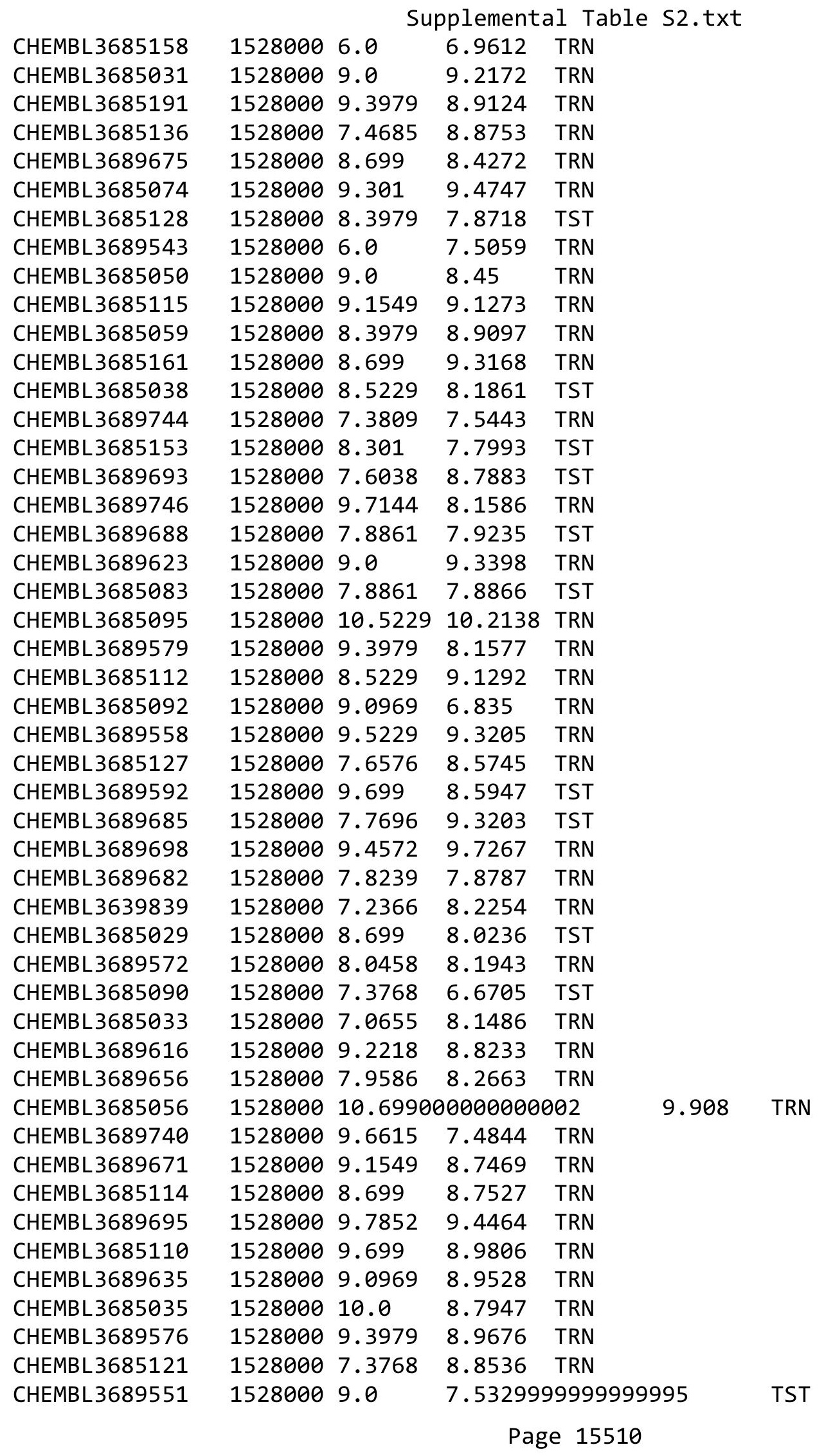


Supplemental Table S2.txt

\begin{tabular}{|c|c|c|c|c|}
\hline HEMBL 36 & & 99 & 14 & TS \\
\hline HFMRI 3685936 & 528000 & 9.0 & .4351 & \\
\hline HEMBL & 28000 & 6.0 & & \\
\hline AEMBL3 & 528000 & 7.9208 & 8623 & \\
\hline HEMBL3685131 & 528000 & 7.3768 & 0976 & \\
\hline HEMBL & 528000 & 10.0 & 7561 & \\
\hline AEMBL: & 28000 & 8.248 & & \\
\hline AEMBL3685132 & 528000 & 8.1549 & 9849 & \\
\hline HEMBL3689613 & 528000 & 6.0 & 8897 & \\
\hline HEMBL3685072 & 528000 & 10.0 & 8.6664 & \\
\hline HEMBL3685125 & 528000 & 7.6778 & 1546 & \\
\hline AEMBL3 & 8000 & 8.2218 & 8504 & \\
\hline HEMBL3 & 528000 & 8.5229 & 2873 & \\
\hline AEMBL3689712 & 528000 & 7.6635 & 0599 & \\
\hline HEMBL3689654 & 528000 & 7.9208 & 8.2076 & \\
\hline AEMBL: & 528000 & 9. & 3176 & \\
\hline AEMBL & 000 & & 932 & \\
\hline HEMBL: & 528000 & 9.699 & 5256 & \\
\hline AEMBL3 & 528000 & & 3373 & \\
\hline AEMBL 36 & 28000 & 458 & 9718 & Th \\
\hline IEMBL & 28000 & 8 & 07 & \\
\hline IEMBL & 00 & 9 & & \\
\hline HEMBL; & 000 & 6.0 & 378 & \\
\hline AEMBL3 & 00 & 16 & 3593 & \\
\hline AEMBL 36 & 528000 & 8.699 & 3294 & $R N$ \\
\hline IEMBL: & 3000 & & 623 & RN \\
\hline IEM & 30 & & 22 & $\mathrm{RN}$ \\
\hline וסMDו & & & 1556 & \\
\hline AEMBL & & & & IRN \\
\hline HEMBL 368 & 528000 & 6. & 133 & RN \\
\hline EMBL & $\partial 00$ & & & \\
\hline 2 & 30 & 79 & 99 & RN \\
\hline & & 229 & & RN \\
\hline AEMBL36 & 528000 & 6. & 513 & RN \\
\hline AEMBL36 & 528000 & 8 . & 2341 & RN \\
\hline IEMPI: 7 & 3000 & 9. & 427 & RN \\
\hline & & & 58 & RN \\
\hline HEMBL & & & 5651 & RN \\
\hline AEMBL 36 & 528000 & $9.397 c$ & 245 & $\Gamma R$ \\
\hline$M B L 3$ & 000 & 6 & 913 & 「RN \\
\hline HEMBL36 & 528000 & 9.379 & 219 & \\
\hline & & 9.0 & & $\mathrm{RN}$ \\
\hline HEMBL36 & 528000 & & 5.8286 & RN \\
\hline AEMBL36 & 528000 & 9 . & 47 & TR \\
\hline HFMRI 36897 & 00 & 7.380 & & \\
\hline HEMBL 36 & 528000 & 9.0 & 8.8024 & \\
\hline HEMBL368504 & .528000 & 7.7959 & 8.9342 & \\
\hline CHEMBL3685076 & 1528000 & 7.699 & 8.3674 & rRN \\
\hline
\end{tabular}

Page 15511 
Supplemental Table S2.txt

\begin{tabular}{|c|c|c|c|c|}
\hline CHEMBL 3685126 & 1528000 & 8.3979 & 9.2743 & TRN \\
\hline CHEMBL 3689669 & 1528000 & 9.0 & 8.9656 & TRN \\
\hline CHEMBL3689659 & 1528000 & 9.5229 & 8.6701 & TRN \\
\hline CHEMBL 3685012 & 1528000 & 9.0 & 8.8646 & TRN \\
\hline CHEMBL 3689552 & 1528000 & 9.0 & 7.1699 & TST \\
\hline CHEMBL3685065 & 1528000 & 7.4815 & 7.9706 & TRN \\
\hline CHEMBL 3689547 & 1528000 & 9.699 & 8.2651 & TRN \\
\hline CHEMBL 3689620 & 1528000 & 9.1549 & 8.7793 & TST \\
\hline CHEMBL 3685117 & 1528000 & 8.3979 & 8.4682 & TRN \\
\hline CHEMBL 3689655 & 1528000 & 9.699 & 8.8705 & TRN \\
\hline CHEMBL 3689595 & 1528000 & 7.3768 & 8.3221 & TST \\
\hline CHEMBL 3689554 & 1528000 & \multicolumn{2}{|c|}{10.699000000000002} & 9.7027 \\
\hline CHEMBL 3689745 & 1528000 & 9.2321 & 8.854 & TRN \\
\hline CHEMBL 3685123 & 1528000 & 9.0 & 7.3004 & TRN \\
\hline CHEMBL 3685094 & 1528000 & 7.8239 & 7.9606 & TST \\
\hline CHEMBL3685159 & 1528000 & 7.9586 & 7.9456 & TRN \\
\hline CHEMBL 3685087 & 1528000 & 9.1549 & 9.2488 & TRN \\
\hline CHEMBL 3689617 & 1528000 & 7.3979 & 8.683 & TRN \\
\hline CHEMBL3689641 & 1528000 & 8.699 & 8.6352 & TRN \\
\hline CHEMBL 3689538 & 1528000 & 9.301 & 9.975 & TRN \\
\hline CHEMBL 3685067 & 1528000 & 9.0458 & 9.6727 & TRN \\
\hline CHEMBL3689662 & 1528000 & 9.5229 & 8.8196 & TRN \\
\hline CHEMBL 3684999 & 1528000 & 6.3809 & 8.1318 & TST \\
\hline CHEMBL 3685041 & 1528000 & 9.5229 & 8.3019 & TRN \\
\hline CHEMBL 3685149 & 1528000 & 8.0458 & 9.2168 & TST \\
\hline CHEMBL 3689696 & 1528000 & 10.1494 & 9.3285 & TRN \\
\hline CHEMBL 3689563 & 1528000 & 6.0 & 7.8599 & TRN \\
\hline CHEMBL 3685051 & 1528000 & 7.466 & 8.5055 & TST \\
\hline CHEMBL3684996 & 1528000 & 6.857 & 7.9378 & TST \\
\hline CHEMBL 3689719 & 1528000 & 10.1409 & 9.6931 & TRN \\
\hline CHEMBL 3685017 & 1528000 & 9.0 & 9.3926 & TRN \\
\hline CHEMBL 3685101 & 1528000 & 6.0 & 8.062000 & 0000000001 \\
\hline CHEMBL 3685162 & 1528000 & 9.699 & 9.9289 & TRN \\
\hline CHEMBL3689573 & 1528000 & 7.7696 & 9.2687 & TST \\
\hline CHEMBL 3689562 & 1528000 & 7.4437 & 7.6679 & TST \\
\hline CHEMBL3689691 & 1528000 & 9.1029 & 9.4286 & TRN \\
\hline CHEMBL 3685086 & 1528000 & 7.3768 & 8.4321 & TRN \\
\hline CHEMBL 3689722 & 1528000 & 10.7305 & 8.961 & TRN \\
\hline CHEMBL 3685019 & 1528000 & 9.3979 & 7.8497 & TRN \\
\hline CHEMBL 3685071 & 1528000 & 7.3768 & 8.2473 & TRN \\
\hline CHEMBL 3685134 & 1528000 & 10.3979 & 9.9514 & TRN \\
\hline CHEMBL 3685014 & 1528000 & 9.0458 & 9.455 & TRN \\
\hline CHEMBL3689736 & 1528000 & 6.0 & 7.4941 & TST \\
\hline CHEMBL 3685007 & 1528000 & 7.8239 & 8.4412 & TRN \\
\hline CHEMBL 3689752 & 1528000 & 7.6198 & 8.1945 & TRN \\
\hline CHEMBL 3689642 & 1528000 & 9.5229 & 8.4421 & TRN \\
\hline CHEMBL 3685080 & 1528000 & 9.5229 & 9.1761 & TRN \\
\hline CHEMBL 3689709 & 1528000 & 8.6162 & 8.346 & TST \\
\hline
\end{tabular}




$$
\text { Supplemental Table S2.txt }
$$

\begin{tabular}{|c|c|c|c|c|c|}
\hline CHEMBL3689582 & 1528000 & 9.0969 & 8.0994 & TRN & \\
\hline CHEMBL3689738 & 1528000 & 9.1512 & 8.2708 & TRN & \\
\hline CHEMBL3685146 & 1528000 & 10.0 & 8.9147 & TRN & \\
\hline CHEMBL3684998 & 1528000 & 7.1427 & 8.0391 & TST & \\
\hline CHEMBL3685181 & 1528000 & 10.1549 & 9.1545 & TRN & \\
\hline CHEMBL3689649 & 1528000 & 10.0969 & 9.0559 & TRN & \\
\hline CHEMBL3689687 & 1528000 & 8.0969 & 8.8856 & TRN & \\
\hline CHEMBL3685006 & 1528000 & 7.585 & 9.0129 & TRN & \\
\hline CHEMBL 3689724 & 1528000 & 7.5969 & 8.0499 & TRN & \\
\hline CHEMBL3685150 & 1528000 & 9.2218 & 9.4591 & TST & \\
\hline CHEMBL3685096 & 1528000 & 10.5229 & 9.7015 & TRN & \\
\hline CHEMBL3689598 & 1528000 & 8.699 & 8.8116 & TRN & \\
\hline CHEMBL3685165 & 1528000 & 8.2218 & 8.4605 & TRN & \\
\hline CHEMBL3685057 & 1528000 & 9.301 & 8.5699 & TRN & \\
\hline CHEMBL3685155 & 1528000 & 10.0 & 8.2717 & TST & \\
\hline CHEMBL3689604 & 1528000 & 6.0 & 8.8259 & TRN & \\
\hline CHEMBL3689679 & 1528000 & 7.3768 & 7.2247 & TRN & \\
\hline CHEMBL 3685070 & 1528000 & 7.5686 & 7.9522 & TRN & \\
\hline CHEMBL 3685190 & 1528000 & 8.1549 & 8.1669 & TRN & \\
\hline CHEMBL3689561 & 1528000 & 7.3768 & 8.1451 & TRN & \\
\hline CHEMBL3689539 & 1528000 & 9.3979 & \multicolumn{2}{|c|}{9.761000000000001} & TRN \\
\hline CHEMBL3639840 & 1528000 & \multicolumn{3}{|c|}{10.699000000000002} & TRN \\
\hline CHEMBL 3685073 & 1528000 & 9.0 & 8.156 & TST & \\
\hline CHEMBL 3689755 & 1528000 & 7.475 & 7.7643 & TRN & \\
\hline CHEMBL3685152 & 1528000 & 8.301 & 8.6917 & TST & \\
\hline CHEMBL3689599 & 1528000 & 8.0 & 8.6226 & TRN & \\
\hline CHEMBL 3685034 & 1528000 & 7.284 & 8.304 & TRN & \\
\hline CHEMBL 3685042 & 1528000 & 8.5229 & 8.1106 & TRN & \\
\hline CHEMBL3689611 & 1528000 & 9.0 & 8.988 & TRN & \\
\hline CHEMBL3685077 & 1528000 & 9.0 & 9.2464 & TRN & \\
\hline CHEMBL3685160 & 1528000 & 9.0 & 7.5529 & TRN & \\
\hline CHEMBL 3689628 & 1528000 & 9.699 & 8.9766 & TRN & \\
\hline CHEMBL3689702 & 1528000 & \multicolumn{2}{|c|}{8.857000000000001} & 9.4651 & TP \\
\hline CHEMBL 3639884 & 1528000 & 8.3979 & 9.3914 & TRN & \\
\hline CHEMBL3685105 & 1528000 & 8.301 & 8.2126 & TRN & \\
\hline CHEMBL 3685020 & 1528000 & 10.5229 & 9.132 & TRN & \\
\hline CHEMBL3685175 & 1528000 & 8.699 & 8.0574 & TRN & \\
\hline CHEMBL3685196 & 1528000 & 7.5686 & 8.4918 & TRN & \\
\hline CHEMBL 3689556 & 1528000 & 6.0 & 6.8795 & TRN & \\
\hline CHEMBL3685116 & 1528000 & 7.4318 & 8.2677 & TRN & \\
\hline CHEMBL3689580 & 1528000 & 8.699 & 9.2674 & TRN & \\
\hline CHEMBL3685103 & 1528000 & 9.0458 & 9.3765 & TRN & \\
\hline CHEMBL3685043 & 1528000 & 8.699 & 7.9017 & TRN & \\
\hline CHEMBL3685113 & 1528000 & 8.699 & 9.2866 & TRN & \\
\hline CHEMBL3689716 & 1528000 & 7.3809 & 6.9433 & TST & \\
\hline CHEMBL3689622 & 1528000 & 7.3768 & 8.2478 & TST & \\
\hline CHEMBL3685100 & 1528000 & 8.699 & 8.9129 & TRN & \\
\hline CHEMBL3689672 & 1528000 & 8.0 & 9.0798 & TRN & \\
\hline
\end{tabular}




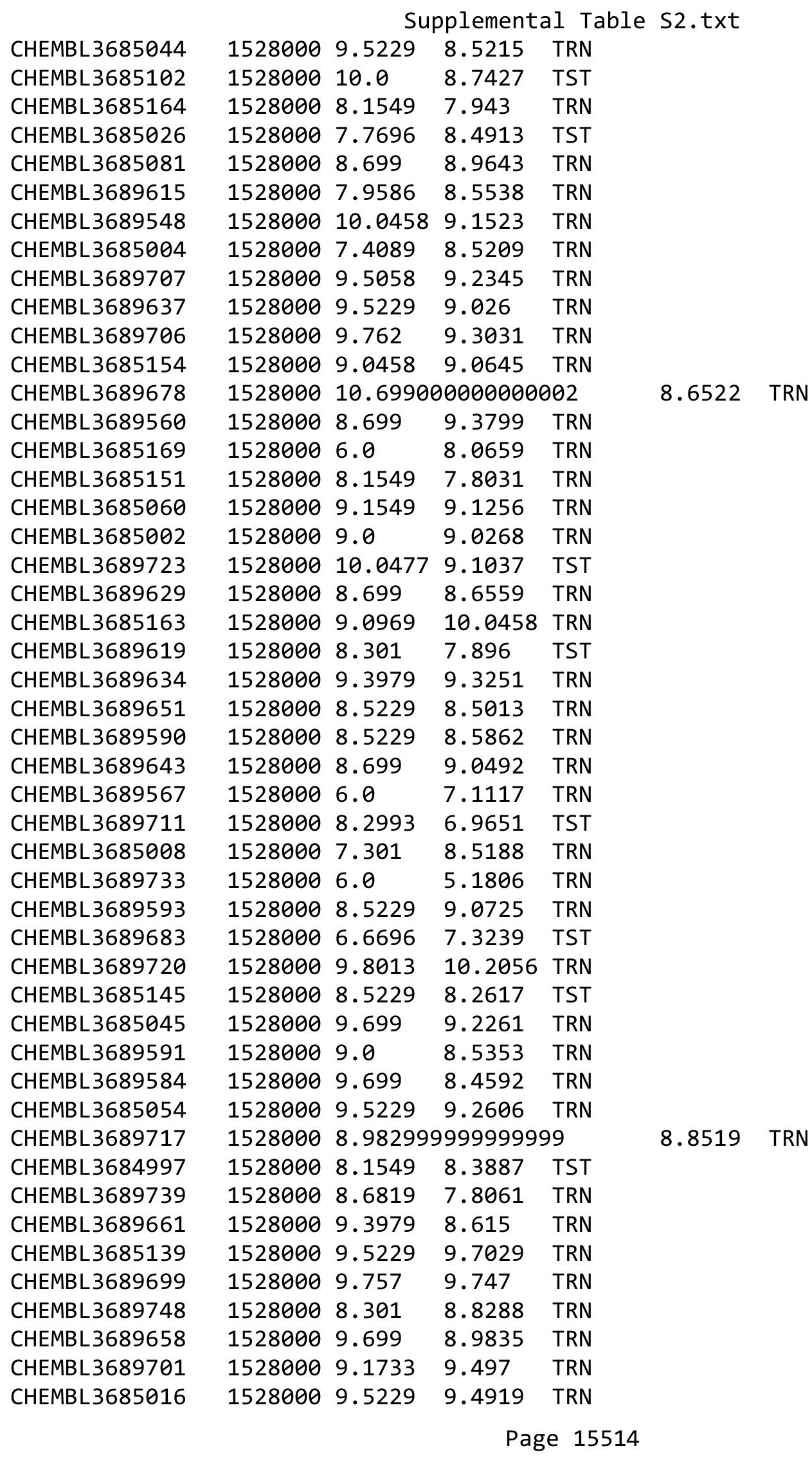


Supplemental Table S2.txt

\begin{tabular}{|c|c|c|c|c|c|}
\hline CHEMBL3685147 & 1528000 & 10.1549 & 9.3392 & TRN & \\
\hline CHEMBL3685171 & 1528000 & 9.0 & 9.208 & TRN & \\
\hline CHEMBL3685022 & 1528000 & 8.5229 & 9.3411 & TRN & \\
\hline CHEMBL3689583 & 1528000 & 9.0 & 9.7465 & TRN & \\
\hline CHEMBL3689646 & 1528000 & 10.0 & 9.0496 & TRN & \\
\hline CHEMBL3685124 & 1528000 & 9.699 & 8.3783 & TRN & \\
\hline CHEMBL3689638 & 1528000 & 7.699 & 9.2739 & TST & \\
\hline CHEMBL3685091 & 1528000 & 7.3768 & 8.5151 & TRN & \\
\hline CHEMBL3689667 & 1528000 & 10.0 & 8.9022 & TRN & \\
\hline CHEMBL3689710 & 1528000 & 8.9872 & 7.7537 & TST & \\
\hline CHEMBL3685015 & 1528000 & 9.0 & 9.625 & TRN & \\
\hline CHEMBL3689594 & 1528000 & 9.5229 & 8.7801 & TRN & \\
\hline CHEMBL3689704 & 1528000 & 9.1475 & 8.9546 & TRN & \\
\hline CHEMBL3685078 & 1528000 & 8.699 & 9.1038 & TRN & \\
\hline CHEMBL3689631 & 1528000 & 6.0 & 6.0062 & TRN & \\
\hline CHEMBL3689680 & 1528000 & 9.5229 & 9.0176 & TRN & \\
\hline CHEMBL3685028 & 1528000 & 6.3947 & 8.2912 & TST & \\
\hline CHEMBL3685107 & 1528000 & 8.0969 & 8.23200 & 0000000001 & TRN \\
\hline CHEMBL3689684 & 1528000 & 8.5229 & 7.8515 & TRN & \\
\hline CHEMBL3685185 & 1528000 & 7.8861 & 7.8392 & TRN & \\
\hline CHEMBL3685099 & 1528000 & 9.699 & 8.7516 & TRN & \\
\hline CHEMBL3689550 & 1528000 & 9.0 & 7.1252 & TST & \\
\hline CHEMBL3689718 & 1528000 & 9.7747 & 8.4845 & TRN & \\
\hline CHEMBL3689612 & 1528000 & 9.301 & 8.6885 & TRN & \\
\hline CHEMBL3689666 & 1528000 & 10.0 & 8.6616 & TRN & \\
\hline CHEMBL3684995 & 1528000 & 8.2218 & 8.1484 & TST & \\
\hline CHEMBL3689625 & 1528000 & 9.0 & 8.4142 & TST & \\
\hline CHEMBL 3685024 & 1528000 & 9.301 & 9.514 & TRN & \\
\hline CHEMBL3689569 & 1528000 & 6.0 & 7.4181 & TRN & \\
\hline CHEMBL3685122 & 1528000 & 7.3768 & 8.094 & TRN & \\
\hline CHEMBL3689721 & 1528000 & 9.5719 & 7.9102 & TRN & \\
\hline CHEMBL3685082 & 1528000 & 7.5686 & 7.6963 & TRN & \\
\hline CHEMBL3685039 & 1528000 & 6.6234 & 8.3392 & TST & \\
\hline CHEMBL3689663 & 1528000 & 9.0 & 8.7698 & TRN & \\
\hline CHEMBL3685093 & 1528000 & 8.3979 & 7.723 & TRN & \\
\hline CHEMBL3689624 & 1528000 & 9.0 & 8.8583 & TST & \\
\hline CHEMBL3685133 & 1528000 & 9.2218 & 8.0799 & TRN & \\
\hline CHEMBL3685061 & 1528000 & 7.8861 & 8.0558 & TRN & \\
\hline CHEMBL3685085 & 1528000 & 9.301 & 9.0671 & TRN & \\
\hline CHEMBL3689614 & 1528000 & 9.0 & 9.1077 & TRN & \\
\hline CHEMBL3689626 & 1528000 & 8.699 & 9.4941 & TRN & \\
\hline CHEMBL3685135 & 1528000 & 7.9586 & 9.5016 & TRN & \\
\hline CHEMBL3685079 & 1528000 & 8.5229 & 8.1554 & TRN & \\
\hline CHEMBL3685106 & 1528000 & 8.301 & 8.2503 & TRN & \\
\hline CHEMBL3685189 & 1528000 & 6.0 & 6.9129 & TRN & \\
\hline CHEMBL3689674 & 1528000 & 8.301 & 8.8413 & TRN & \\
\hline CHEMBL3689575 & 1528000 & 10.3979 & 9.7082 & TRN & \\
\hline CHEMBL3689549 & 1528000 & 9.301 & 8.6645 & TRN & \\
\hline
\end{tabular}




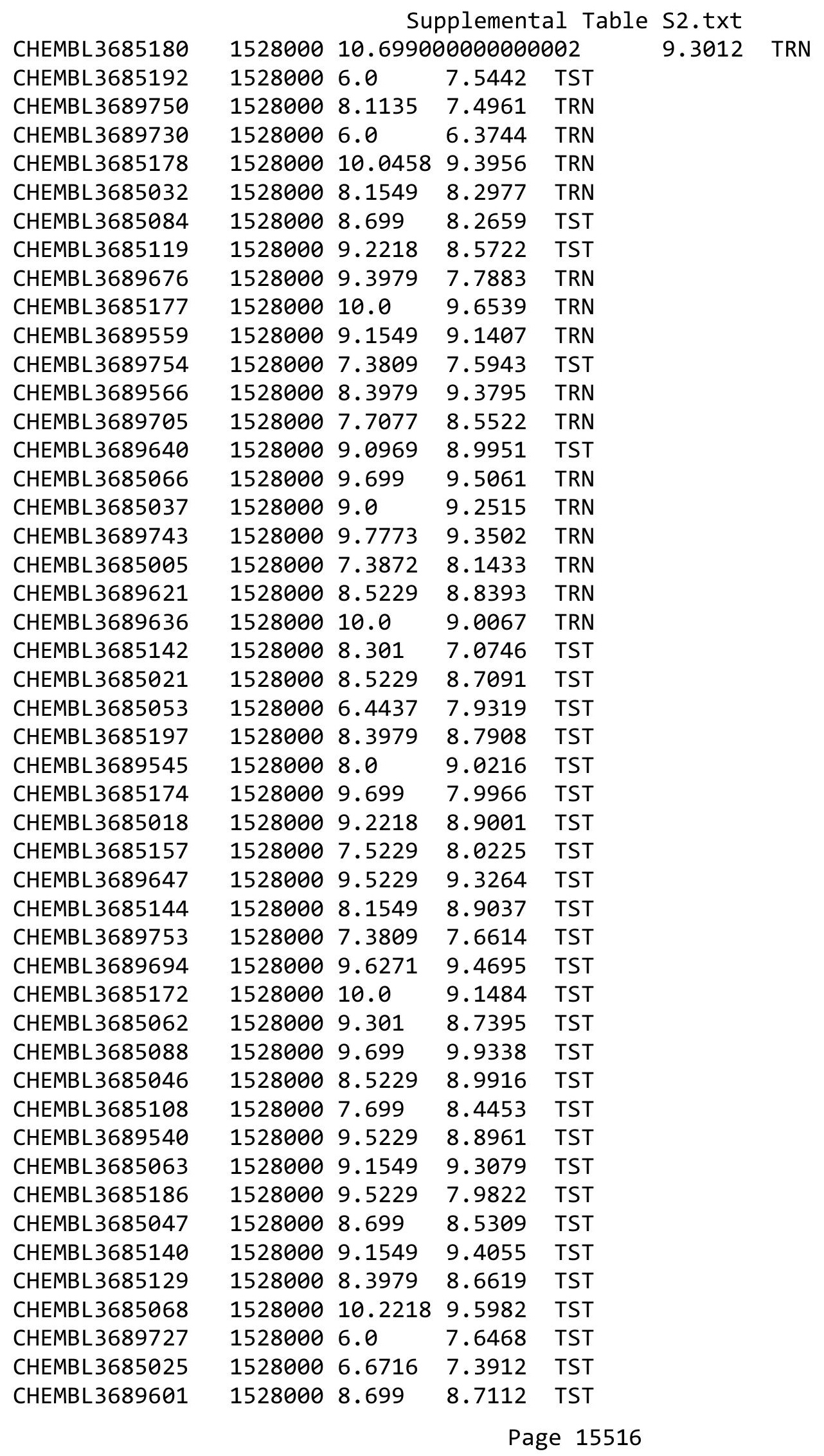


Supplemental Table S2.txt

\begin{tabular}{|c|c|c|c|c|c|}
\hline CHEMBL3685118 & 1528000 & 9.0458 & 8.8198 & TST & \\
\hline CHEMBL 3685156 & 1528000 & 8.5229 & 9.64200 & 0000000001 & TST \\
\hline CHEMBL3689686 & 1528000 & 7.7212 & 8.7005 & TST & \\
\hline CHEMBL3685001 & 1528000 & 6.3565 & 7.8985 & TST & \\
\hline CHEMBL3689639 & 1528000 & 8.301 & 9.1489 & TST & \\
\hline CHEMBL3689574 & 1528000 & 10.5229 & 9.8734 & TST & \\
\hline CHEMBL3685111 & 1528000 & 8.699 & 9.2096 & TST & \\
\hline CHEMBL3689648 & 1528000 & 9.3979 & 9.3084 & TST & \\
\hline CHEMBL 3798788 & 1574259 & 6.3925 & 6.7589 & TST & \\
\hline CHEMBL 3799287 & 1574259 & 8.0 & 7.9872 & TRN & \\
\hline CHEMBL3798995 & 1574259 & 7.7959 & 7.731 & TRN & \\
\hline CHEMBL3798356 & 1574259 & 6.8894 & 6.8942 & TRN & \\
\hline CHEMBL3799789 & 1574259 & 6.9747 & 6.9811 & TRN & \\
\hline CHEMBL3798415 & 1574259 & 6.7825 & 6.5589 & TST & \\
\hline CHEMBL 3798541 & 1574259 & 4.9572 & 6.4051 & TST & \\
\hline CHEMBL3797788 & 1574259 & 7.3665 & 7.3498 & TRN & \\
\hline CHEMBL3797220 & 1574259 & 7.8239 & 7.8258 & TRN & \\
\hline CHEMBL3799871 & 1574259 & 7.1308 & 7.1496 & TRN & \\
\hline CHEMBL 3799132 & 1574259 & 7.6576 & 7.6683 & TRN & \\
\hline CHEMBL 3800563 & 1574259 & 7.2676 & 7.2785 & TRN & \\
\hline CHEMBL3799331 & 1574259 & 8.1549 & 8.1541 & TRN & \\
\hline CHEMBL 3800567 & 1574259 & 6.1765 & 7.0906 & TST & \\
\hline CHEMBL 3797282 & 1574259 & 7.9586 & 7.3203 & TST & \\
\hline CHEMBL 3800552 & 1574259 & 7.3468 & 7.3517 & TRN & \\
\hline CHEMBL 3799306 & 1574259 & 7.585 & 7.7349 & TRN & \\
\hline CHEMBL3800562 & 1574259 & 5.7891 & 7.0115 & TST & \\
\hline CHEMBL3798319 & 1574259 & 7.4815 & 7.4957 & TRN & \\
\hline CHEMBL3797985 & 1574259 & 7.2147 & 6.6219 & TST & \\
\hline CHEMBL 3799590 & 1574259 & 7.0044 & 6.8592 & TST & \\
\hline CHEMBL 3798411 & 1574259 & 7.4949 & 7.4512 & TRN & \\
\hline CHEMBL3799920 & 1574259 & 7.6021 & 7.6131 & TRN & \\
\hline CHEMBL 3800064 & 1574259 & 7.4202 & 7.4185 & TRN & \\
\hline CHEMBL 3797417 & 1574259 & 7.8539 & 7.8604 & TRN & \\
\hline CHEMBL3798880 & 1574259 & 7.9586 & 7.955 & TRN & \\
\hline CHEMBL 3799259 & 1574259 & 7.7212 & 7.8198 & TRN & \\
\hline CHEMBL3798304 & 1574259 & 7.3372 & 7.3267 & TRN & \\
\hline CHEMBL 3799154 & 1574259 & 7.4685 & 7.4643 & TRN & \\
\hline CHEMBL3799810 & 1574259 & 8.0 & 8.0099 & TRN & \\
\hline CHEMBL 3800634 & 1574259 & 7.4815 & 7.4879 & TRN & \\
\hline CHEMBL 3798665 & 1574259 & 7.5528 & 7.5494 & TRN & \\
\hline CHEMBL 3800237 & 1574259 & 7.699 & 7.6999 & TRN & \\
\hline CHEMBL3800151 & 1574259 & 7.9586 & 7.9606 & TRN & \\
\hline CHEMBL 3797264 & 1574259 & 8.2218 & 8.2247 & TRN & \\
\hline CHEMBL3799711 & 1574259 & 7.8239 & 7.8211 & TRN & \\
\hline CHEMBL3798838 & 1574259 & 7.2366 & 7.2476 & TRN & \\
\hline CHEMBL3798902 & 1574259 & 7.6021 & 7.5935 & TRN & \\
\hline CHEMBL 3798821 & 1574259 & 6.2226 & 6.8902 & TST & \\
\hline CHEMBL3798809 & 1574259 & 4.699 & 6.0828 & TST & \\
\hline
\end{tabular}


Supplemental Table S2.txt

\begin{tabular}{|c|c|c|c|c|c|}
\hline CHEMBL3797766 & 1574259 & 7.8861 & 7.7349 & TRN & \\
\hline CHEMBL3799737 & 1574259 & 7.8239 & 7.8245 & TRN & \\
\hline CHEMBL3799918 & 1574259 & 7.8539 & 7.8638 & TRN & \\
\hline CHEMBL3797373 & 1574259 & 7.4559 & 7.4693 & TRN & \\
\hline CHEMBL3799767 & 1574259 & 7.9208 & 7.8198 & TRN & \\
\hline CHEMBL3797520 & 1574259 & 7.7959 & 7.7777 & TRN & \\
\hline CHEMBL3799498 & 1574259 & 7.9586 & 7.9601 & TRN & \\
\hline CHEMBL3797650 & 1574259 & 6.3002 & 7.025 & TST & \\
\hline CHEMBL 3798405 & 1574259 & 7.7959 & 7.7716 & TRN & \\
\hline CHEMBL3798951 & 1574259 & 6.475 & 6.7994 & TST & \\
\hline CHEMBL3799301 & 1574259 & 8.2218 & 8.2373 & TRN & \\
\hline CHEMBL3798055 & 1574259 & 5.2918 & 6.8392 & TST & \\
\hline CHEMBL3799404 & 1574259 & 7.7447 & 7.7483 & TRN & \\
\hline CHEMBL3800600 & 1574259 & 6.0114 & 6.6869 & TST & \\
\hline CHEMBL3799822 & 1574259 & 5.6576 & 6.4217 & TST & \\
\hline CHEMBL3797505 & 1574259 & 7.1805 & 7.18 & TRN & \\
\hline CHEMBL3800397 & 1574259 & 8.2218 & 8.2105 & TRN & \\
\hline CHEMBL3798045 & 1574259 & 8.0969 & 8.1074 & TRN & \\
\hline CHEMBL3798002 & 1574259 & 6.9747 & 6.9672 & TRN & \\
\hline CHEMBL3798985 & 1574259 & 5.6959 & 6.854 & TST & \\
\hline CHEMBL3800114 & 1574259 & 7.6576 & 7.731 & TRN & \\
\hline CHEMBL3799910 & 1574259 & 7.2147 & 7.1979 & TRN & \\
\hline CHEMBL3799607 & 1574259 & 7.5229 & 7.4944 & TRN & \\
\hline CHEMBL3797367 & 1574259 & 7.1612 & 7.1548 & TRN & \\
\hline CHEMBL3799421 & 1574259 & 7.2757 & 7.3149 & TRN & \\
\hline CHEMBL3800077 & 1574259 & 5.7342 & 7.0046 & TST & \\
\hline CHEMBL44240 & 448557 & 4.6402 & 4.7024 & TRN & \\
\hline CHEMBL68688 & 448557 & 7.0 & 6.7079 & TRN & \\
\hline CHEMBL68726 & 448557 & 6.5229 & 6.5741 & TRN & \\
\hline CHEMBL67395 & 448557 & 6.699 & 7.0454 & TRN & \\
\hline CHEMBL236959 & 448557 & 4.9208 & 5.5342 & TST & \\
\hline CHEMBL125473 & 448557 & 4.3979 & 4.8977 & TST & \\
\hline CHEMBL 302020 & 448557 & 5.6198 & 6.1878 & TRN & \\
\hline CHEMBL143959 & 448557 & 4.8239 & 4.7541 & TRN & \\
\hline CHEMBL391077 & 448557 & 5.1079 & 6.3014 & TRN & \\
\hline CHEMBL42381 & 448557 & 5.4023 & 5.7276 & TRN & \\
\hline CHEMBL125791 & 448557 & 5.8239 & 5.5658 & TRN & \\
\hline CHEMBL237396 & 448557 & 7.5229 & 6.7883 & TRN & \\
\hline CHEMBL431556 & 448557 & 6.5229 & 6.92299 & 9999999999 & TRN \\
\hline CHEMBL341275 & 448557 & 4.7959 & 5.5494 & TST & \\
\hline CHEMBL237397 & 448557 & 6.699 & 6.5659 & TRN & \\
\hline CHEMBL238242 & 448557 & 4.8239 & 4.9875 & TRN & \\
\hline CHEMBL338233 & 448557 & 4.9208 & 5.385 & TST & \\
\hline CHEMBL69187 & 448557 & 6.3979 & 6.5556 & TRN & \\
\hline CHEMBL302306 & 448557 & 7.0969 & 7.2211 & TRN & \\
\hline CHEMBL66703 & 448557 & 6.699 & 6.9825 & TST & \\
\hline CHEMBL43764 & 448557 & 5.1681 & 5.3612 & TRN & \\
\hline CHEMBL302786 & 448557 & 7.0 & 7.0697 & TRN & \\
\hline
\end{tabular}




\begin{tabular}{|c|c|c|c|c|}
\hline \multicolumn{5}{|c|}{ Supplemental Table S2.txt } \\
\hline CHEMBL68856 & 448557 & 7.0 & 6.8696 & TRN \\
\hline CHEMBL237206 & 448557 & 5.4437 & 5.834 & TST \\
\hline CHEMBL303833 & 448557 & 6.3979 & 6.6552 & TST \\
\hline CHEMBL127477 & 448557 & 6.0 & 6.3067 & TRN \\
\hline CHEMBL68805 & 448557 & 6.5229 & 6.5503 & TRN \\
\hline CHEMBL419999 & 448557 & 6.5229 & 6.9104 & TRN \\
\hline CHEMBL235525 & 448557 & 7.1549 & 6.268 & TRN \\
\hline CHEMBL419437 & 448557 & 7.0969 & 6.9307 & TRN \\
\hline CHEMBL237627 & 448557 & 7.2218 & 6.9805 & TRN \\
\hline CHEMBL69490 & 448557 & 6.0 & 6.1977 & TRN \\
\hline CHEMBL127895 & 448557 & 6.0 & 5.8306 & TRN \\
\hline CHEMBL69170 & 448557 & 6.1549 & 6.2448 & TRN \\
\hline CHEMBL237163 & 448557 & 7.0458 & 6.999 & TRN \\
\hline CHEMBL340397 & 448557 & 5.0 & 5.0839 & TST \\
\hline CHEMBL308423 & 448557 & 7.0458 & 6.8748 & TST \\
\hline CHEMBL416620 & 448557 & 5.3546 & 5.4839 & TRN \\
\hline CHEMBL393999 & 448557 & 5.2048 & 5.4316 & TST \\
\hline CHEMBL238032 & 448557 & 5.1726 & 4.6709 & TRN \\
\hline CHEMBL44339 & 448557 & 4.8447 & 4.6499 & TRN \\
\hline CHEMBL236960 & 448557 & 4.3391 & 5.7459 & TST \\
\hline CHEMBL68632 & 448557 & 6.699 & 6.6886 & TRN \\
\hline CHEMBL338700 & 448557 & 6.3768 & 6.0215 & TRN \\
\hline CHEMBL127265 & 448557 & 4.301 & 5.3205 & TRN \\
\hline CHEMBL 303472 & 448557 & 7.0 & 6.7111 & TRN \\
\hline CHEMBL432350 & 448557 & 5.6021 & 6.1164 & TRN \\
\hline CHEMBL69885 & 448557 & 7.0969 & 7.1522 & TRN \\
\hline CHEMBL69685 & 448557 & 5.585 & 6.4317 & TST \\
\hline CHEMBL69563 & 448557 & 7.5229 & 6.8402 & TRN \\
\hline CHEMBL296214 & 448557 & 6.1427 & 6.0191 & TRN \\
\hline CHEMBL128189 & 448557 & 4.1871 & 4.8316 & TST \\
\hline CHEMBL68868 & 448557 & 5.8861 & 5.599 & TRN \\
\hline CHEMBL416623 & 448557 & 5.7959 & 6.0845 & TRN \\
\hline CHEMBL303937 & 448557 & 6.699 & 6.8662 & TRN \\
\hline CHEMBL235507 & 448557 & 7.0969 & 6.8633 & TRN \\
\hline CHEMBL305995 & 448557 & 7.0 & 7.148 & TRN \\
\hline CHEMBL305400 & 448557 & 5.4559 & 6.0376 & TRN \\
\hline CHEMBL40419 & 448557 & 5.9508 & 5.7859 & TRN \\
\hline CHEMBL446661 & 448557 & 7.2218 & 6.5252 & TRN \\
\hline CHEMBL67709 & 448557 & 6.5229 & 6.8005 & TRN \\
\hline CHEMBL288060 & 448557 & 6.3188 & 5.7328 & TRN \\
\hline CHEMBL69971 & 448557 & 6.699 & 6.7415 & TRN \\
\hline CHEMBL431366 & 448557 & 6.3979 & 6.2727 & TRN \\
\hline CHEMBL67512 & 448557 & 6.3979 & 6.4395 & TRN \\
\hline CHEMBL340167 & 448557 & 5.0 & 5.3104 & TST \\
\hline CHEMBL129440 & 448557 & 5.8861 & 5.9429 & TRN \\
\hline CHEMBL129298 & 448557 & 4.699 & 4.8182 & TST \\
\hline CHEMBL419781 & 448557 & 6.1805 & 6.0765 & TRN \\
\hline CHEMBL297971 & 448557 & 6.8539 & 6.4703 & TRN \\
\hline
\end{tabular}




\begin{tabular}{|c|c|c|c|c|}
\hline & & & oplement & al $\mathrm{T}$ \\
\hline CHEMBL127187 & 448557 & 4.8239 & 5.3919 & TST \\
\hline CHEMBL68918 & 448557 & 6.301 & 6.3374 & TRN \\
\hline CHEMBL237812 & 448557 & 5.3893 & 5.0087 & TRN \\
\hline CHEMBL66503 & 448557 & 7.0458 & 7.1401 & TRN \\
\hline CHEMBL 71379 & 448557 & 7.0969 & 6.5455 & TRN \\
\hline CHEMBL125629 & 448557 & 6.5229 & 6.6327 & TRN \\
\hline CHEMBL340407 & 448557 & 6.0 & 6.1128 & TRN \\
\hline CHEMBL129398 & 448557 & 5.284 & 5.7208 & TRN \\
\hline CHEMBL 305003 & 448557 & 6.699 & 6.7208 & TRN \\
\hline CHEMBL126745 & 448557 & 4.8239 & 5.5043 & TST \\
\hline CHEMBL 305278 & 448557 & 6.699 & 6.7181 & TST \\
\hline CHEMBL338797 & 448557 & 4.9208 & 5.1292 & TST \\
\hline CHEMBL69699 & 448557 & 7.699 & 6.3972 & TST \\
\hline CHEMBL421654 & 448557 & 4.6021 & 5.4599 & TST \\
\hline CHEMBL296486 & 448557 & 6.041 & 5.7778 & TST \\
\hline CHEMBL1766781 & 743383 & 4.0969 & 4.336 & TRN \\
\hline CHEMBL1766784 & 743383 & 5.5376 & 5.6691 & TRN \\
\hline CHEMBL222102 & 743383 & 7.8861 & 4.7337 & TST \\
\hline CHEMBL1766760 & 743383 & 4.0969 & 3.8191 & TRN \\
\hline CHEMBL1766789 & 743383 & 4.0969 & 3.8844 & TRN \\
\hline CHEMBL479488 & 743383 & 2.7595 & 2.8079 & TST \\
\hline CHEMBL1766768 & 743383 & 4.0969 & 4.3221 & TRN \\
\hline CHEMBL1766798 & 743383 & 4.0969 & 4.4124 & TRN \\
\hline CHEMBL1766797 & 743383 & 4.0969 & 4.1421 & TRN \\
\hline CHEMBL1766793 & 743383 & 4.0969 & 4.3289 & TRN \\
\hline CHEMBL1766782 & 743383 & 4.0969 & 3.9683 & TRN \\
\hline CHEMBL1766801 & 743383 & 6.4202 & 4.6981 & TST \\
\hline CHEMBL1766774 & 743383 & 4.0969 & 4.5378 & TRN \\
\hline CHEMBL1766772 & 743383 & 4.0969 & 4.475 & TRN \\
\hline CHEMBL1766796 & 743383 & 4.0969 & 4.1953 & TRN \\
\hline CHEMBL1766765 & 743383 & 6.4949 & 6.0648 & TRN \\
\hline CHEMBL1766770 & 743383 & 4.0969 & 4.1584 & TRN \\
\hline CHEMBL1766792 & 743383 & 4.0969 & 4.2459 & TRN \\
\hline CHEMBL1765107 & 743383 & 4.0969 & 4.0284 & TRN \\
\hline CHEMBL1766771 & 743383 & 4.0969 & 4.3486 & TRN \\
\hline CHEMBL1766769 & 743383 & 4.0969 & 4.149 & TRN \\
\hline CHEMBL1766783 & 743383 & 4.0969 & 3.9338 & TRN \\
\hline CHEMBL1766776 & 743383 & 4.0969 & 3.8612 & TRN \\
\hline CHEMBL1766802 & 743383 & 6.0757 & 4.6325 & TST \\
\hline CHEMBL1766800 & 743383 & 4.0969 & 3.8287 & TRN \\
\hline CHEMBL1766791 & 743383 & 4.0969 & 4.541 & TRN \\
\hline CHEMBL1766785 & 743383 & 5.585 & 5.5998 & TRN \\
\hline CHEMBL1766767 & 743383 & 4.0969 & 4.3456 & TRN \\
\hline CHEMBL1766762 & 743383 & 4.0969 & 3.7498 & TST \\
\hline CHEMBL1766786 & 743383 & 4.0969 & 4.0388 & TRN \\
\hline CHEMBL1766777 & 743383 & 4.0969 & 3.9499 & TRN \\
\hline CHEMBL1766759 & 743383 & 4.0969 & 4.0787 & TRN \\
\hline CHEMBL1766803 & 743383 & 6.1427 & 4.2827 & TST \\
\hline
\end{tabular}




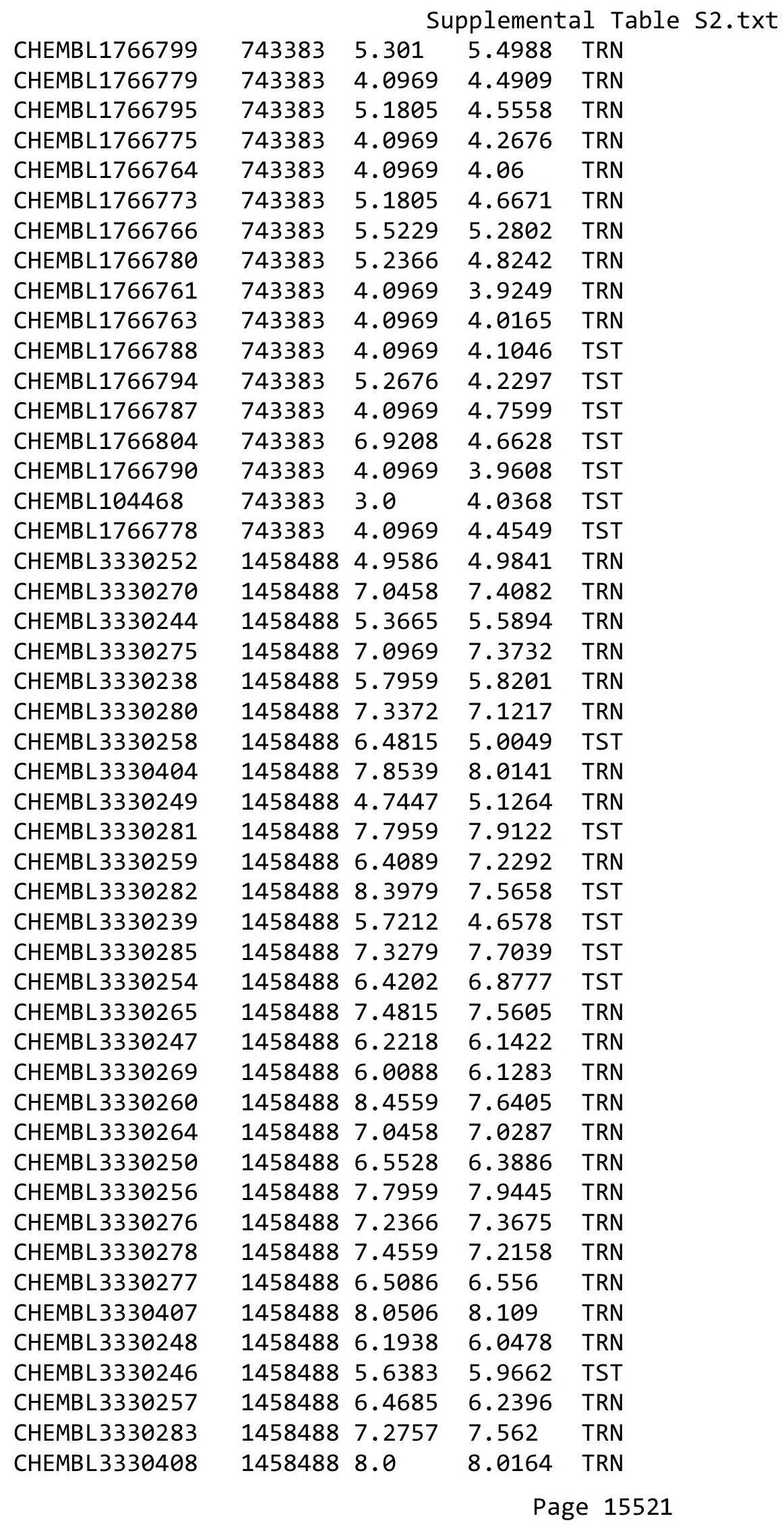


Supplemental Table S2.txt

\begin{tabular}{|c|c|c|c|c|c|}
\hline CHEMBL 3330272 & 1458488 & 7.7447 & 7.5213 & TRN & \\
\hline CHEMBL 3330274 & 1458488 & 7.7696 & 7.7359 & TRN & \\
\hline CHEMBL 3330409 & 1458488 & 8.4437 & 8.3298 & TRN & \\
\hline CHEMBL 3330262 & 1458488 & 6.1487 & 5.6339 & TRN & \\
\hline CHEMBL 3330273 & 1458488 & 7.6021 & 7.6726 & TRN & \\
\hline CHEMBL 3330268 & 1458488 & 4.301 & 4.2885 & TRN & \\
\hline CHEMBL 3330245 & 1458488 & 5.2676 & 5.1741 & TRN & \\
\hline CHEMBL 3330267 & 1458488 & 6.2596 & 6.0314 & TRN & \\
\hline CHEMBL 3330263 & 1458488 & 5.585 & 5.9147 & TRN & \\
\hline CHEMBL 3330253 & 1458488 & 6.2366 & 6.1475 & TRN & \\
\hline CHEMBL 3330255 & 1458488 & 7.4089 & 6.9035 & TRN & \\
\hline CHEMBL 3330251 & 1458488 & 5.3665 & 5.4679 & TRN & \\
\hline CHEMBL 3330261 & 1458488 & 3.301 & 3.3611 & TRN & \\
\hline CHEMBL 3330243 & 1458488 & 5.8539 & 5.6122 & TST & \\
\hline CHEMBL 3330271 & 1458488 & 6.4685 & 6.6951 & TST & \\
\hline CHEMBL 3330266 & 1458488 & 6.6021 & 5.3183 & TST & \\
\hline CHEMBL 3330284 & 1458488 & 7.2147 & 7.4666 & TST & \\
\hline CHEMBL 3330279 & 1458488 & 7.6198 & 7.7007 & TST & \\
\hline CHEMBL 3330410 & 1458488 & 8.5376 & 7.8026 & TST & \\
\hline CHEMBL383994 & 531578 & 6.456 & 6.5469 & TRN & \\
\hline CHEMBL495406 & 531578 & 5.785 & 5.8323 & TRN & \\
\hline CHEMBL495233 & 531578 & 7.65799 & 999999999 & 7.4191 & TRN \\
\hline CHEMBL 220504 & 531578 & 7.824 & 7.927000 & 00000000005 & TRN \\
\hline CHEMBL 374795 & 531578 & 5.614 & 5.5905 & TRN & \\
\hline CHEMBL 374431 & 531578 & 6.409 & 6.5353 & TRN & \\
\hline CHEMBL 218141 & 531578 & 6.77 & 6.7536 & TST & \\
\hline CHEMBL 385177 & 531578 & 5.83899 & 999999999 & 5.7992 & TST \\
\hline CHEMBL 222008 & 531578 & 5.928 & 5.9135 & TRN & \\
\hline CHEMBL 220865 & 531578 & 6.38700 & 000000000 & 6.3366 & TRN \\
\hline CHEMBL 221175 & 531578 & 5.13700 & 000000000 & 5.0955 & TRN \\
\hline CHEMBL 274389 & 531578 & 5.824 & 5.9576 & TRN & \\
\hline CHEMBL 384219 & 531578 & 7.119 & 7.0994 & TRN & \\
\hline CHEMBL 221227 & 531578 & 6.745 & 6.8769 & TRN & \\
\hline CHEMBL218139 & 531578 & 5.796 & 5.782 & TRN & \\
\hline CHEMBL 384951 & 531578 & 6.921 & 6.8377 & TRN & \\
\hline CHEMBL 218219 & 531578 & 7.032 & 7.1085 & TRN & \\
\hline CHEMBL434560 & 531578 & 7.268 & 7.3172 & TRN & \\
\hline CHEMBL 386010 & 531578 & 7.229 & 7.2413 & TRN & \\
\hline CHEMBL 221315 & 531578 & 7.18 & 7.103 & TRN & \\
\hline CHEMBL 220810 & 531578 & 7.032 & 7.0748 & TRN & \\
\hline CHEMBL 220758 & 531578 & 6.585 & 6.5824 & TRN & \\
\hline CHEMBL 220749 & 531578 & 6.086 & 6.0382 & TRN & \\
\hline CHEMBL 375795 & 531578 & 7.018 & 7.0499 & TRN & \\
\hline CHEMBL 221229 & 531578 & \multicolumn{2}{|c|}{7.071000000000001} & 6.9582 & $\mathrm{TR}$ \\
\hline CHEMBL220658 & 531578 & 7.495 & 7.5841 & TRN & \\
\hline CHEMBL 218194 & 531578 & 7.17399 & 999999999 & 7.0829 & TRN \\
\hline CHEMBL 218419 & 531578 & 6.37700 & 000000000 & 6.3205 & TRN \\
\hline CHEMBL 218658 & 531578 & 7.056 & 7.0389 & TRN & \\
\hline
\end{tabular}




\begin{tabular}{|c|c|c|c|c|c|c|c|}
\hline \multicolumn{8}{|c|}{ Supplemental Table S2.txt } \\
\hline CHEMBL374269 & 531578 & 7.638 & 7.5568 & TRN & & & \\
\hline CHEMBL220812 & 531578 & 6.36700 & 00000000 & & 6.3524 & TRN & \\
\hline CHEMBL434368 & 531578 & 6.523 & 6.3543 & TST & & & \\
\hline CHEMBL221075 & 531578 & 6.20799 & 99999999 & & 6.2433 & TRN & \\
\hline CHEMBL374447 & 531578 & 6.276 & 6.2834 & TST & & & \\
\hline CHEMBL220811 & 531578 & 6.495 & 6.4134 & TST & & & \\
\hline CHEMBL220607 & 531578 & 5.70100 & 00000000 & 005 & 5.34200 & 00000000005 & TST \\
\hline CHEMBL220547 & 531578 & 6.244 & 5.8544 & TST & & & \\
\hline CHEMBL218367 & 531578 & 6.602 & 6.3604 & TST & & & \\
\hline CHEMBL387253 & 531578 & 6.569 & 6.4307 & TST & & & \\
\hline CHEMBL219112 & 531578 & 7.09200 & 000000006 & 005 & 6.8204 & TST & \\
\hline CHEMBL374193 & 531578 & & 000000000 & & 7.1501 & TST & \\
\hline CHEMBL221252 & 531578 & 6.36700 & 000000000 & & 6.0872 & TST & \\
\hline CHEMBL221745 & 531578 & 6.699 & 6.5821 & TST & & & \\
\hline CHEMBL221958 & 531578 & 5.28 & 5.2512 & TRN & & & \\
\hline CHEMBL221179 & 531578 & 6.49799 & 999999999 & & 6.4348 & TRN & \\
\hline CHEMBL221128 & 531578 & 7.102 & 7.1158 & TRN & & & \\
\hline CHEMBL220864 & 531578 & 5.53299 & 999999999 & 995 & 5.4649 & TRN & \\
\hline CHEMBL221916 & 531578 & 5.928 & 5.9397 & TRN & & & \\
\hline CHEMBL373740 & 531578 & 5.81 & 5.9021 & TRN & & & \\
\hline CHEMBL376096 & 531578 & 5.65 & 5.6237 & TRN & & & \\
\hline CHEMBL221963 & 531578 & 5.96299 & 999999999 & 99 & 6.0423 & TRN & \\
\hline CHEMBL374855 & 531578 & 5.465 & 5.4707 & TRN & & & \\
\hline CHEMBL123382 & 49489 & 7.0223 & 7.086 & TRN & & & \\
\hline CHEMBL332406 & 49489 & 7.3979 & 7.392 & TRN & & & \\
\hline CHEMBL123233 & 49489 & 4.7447 & 4.6914 & TRN & & & \\
\hline CHEMBL 293774 & 49489 & 7.699 & 7.6417 & TRN & & & \\
\hline CHEMBL124237 & 49489 & 3.0 & 4.2096 & TST & & & \\
\hline CHEMBL 98328 & 49489 & 6.0 & 4.9644 & TST & & & \\
\hline CHEMBL122836 & 49489 & 7.9586 & 7.9489 & TRN & & & \\
\hline CHEMBL450327 & 49489 & 7.7212 & 7.6879 & TRN & & & \\
\hline CHEMBL123105 & 49489 & 4.301 & 4.2058 & TRN & & & \\
\hline CHEMBL306726 & 49489 & 8.301 & 8.2 & TRN & & & \\
\hline CHEMBL331114 & 49489 & 4.5376 & 4.5272 & TRN & & & \\
\hline CHEMBL432223 & 49489 & 8.301 & 8.2228 & TRN & & & \\
\hline CHEMBL55110 & 49489 & 7.9208 & 7.9246 & TRN & & & \\
\hline CHEMBL123775 & 49489 & 8.301 & 8.2158 & TRN & & & \\
\hline CHEMBL330950 & 49489 & 3.0 & 4.5077 & TST & & & \\
\hline CHEMBL55310 & 49489 & 4.0809 & 4.0517 & TRN & & & \\
\hline CHEMBL441084 & 49489 & 7.8861 & 7.9472 & TRN & & & \\
\hline CHEMBL121501 & 49489 & 4.2076 & 4.5556 & TST & & & \\
\hline CHEMBL333532 & 49489 & 5.1549 & 5.2729 & TRN & & & \\
\hline CHEMBL331342 & 49489 & 7.8861 & 7.84 & TRN & & & \\
\hline CHEMBL121729 & 49489 & 4.4437 & 4.2463 & TRN & & & \\
\hline CHEMBL331311 & 49489 & 8.0969 & 8.1508 & TRN & & & \\
\hline CHEMBL123404 & 49489 & 4.1427 & 4.2413 & TRN & & & \\
\hline CHEMBL121916 & 49489 & 6.9872 & 7.0007 & TRN & & & \\
\hline CHEMBL122719 & 49489 & 7.8861 & 7.9488 & TRN & & & \\
\hline
\end{tabular}




\begin{tabular}{|c|c|c|c|c|c|}
\hline \multicolumn{6}{|c|}{ Supplemental Table s2.txt } \\
\hline CHEMBL332755 & 49489 & 8.301 & 8.3058 & TRN & \\
\hline CHEMBL332429 & 49489 & 7.1024 & 7.2612 & TST & \\
\hline CHEMBL333896 & 49489 & 6.8861 & 6.8607 & TRN & \\
\hline CHEMBL121592 & 49489 & 4.4949 & 4.5255 & TRN & \\
\hline CHEMBL122711 & 49489 & 8.2218 & 8.2573 & TRN & \\
\hline CHEMBL440714 & 49489 & 7.6576 & 7.7 & TRN & \\
\hline CHEMBL332858 & 49489 & 7.0969 & 7.1066 & TST & \\
\hline CHEMBL122109 & 49489 & 4.2596 & 5.3349 & TST & \\
\hline CHEMBL 82868 & 49489 & 7.5686 & 7.5431 & TRN & \\
\hline CHEMBL123463 & 49489 & 8.2218 & 8.2372 & TRN & \\
\hline CHEMBL331669 & 49489 & 7.3468 & 7.3048 & TRN & \\
\hline CHEMBL316169 & 49489 & 7.699 & 7.638 & TRN & \\
\hline CHEMBL331308 & 49489 & 3.0 & 4.606 & TST & \\
\hline CHEMBL301469 & 49489 & 4.0969 & 4.123 & TRN & \\
\hline CHEMBL330857 & 49489 & 8.0 & 8.0948 & TRN & \\
\hline CHEMBL262676 & 49489 & 8.2218 & 8.2041 & TRN & \\
\hline CHEMBL332120 & 49489 & 7.6778 & 7.676 & TRN & \\
\hline CHEMBL123443 & 49489 & 7.1612 & 7.4095 & TST & \\
\hline CHEMBL121559 & 49489 & 4.0555 & 4.0658 & TRN & \\
\hline CHEMBL332362 & 49489 & 6.0969 & 5.9319 & TRN & \\
\hline CHEMBL122950 & 49489 & 4.8861 & 4.9394 & TRN & \\
\hline CHEMBL 304281 & 49489 & 8.0 & 7.9743 & TRN & \\
\hline CHEMBL333122 & 49489 & 4.0969 & 4.8789 & TST & \\
\hline CHEMBL120049 & 49489 & 7.4202 & 7.4684 & TRN & \\
\hline CHEMBL 340461 & 49489 & 8.301 & 8.3469 & TRN & \\
\hline CHEMBL122868 & 49489 & 4.699 & 4.9012 & TRN & \\
\hline CHEMBL 293503 & 49489 & 8.301 & 8.3116 & TRN & \\
\hline CHEMBL122925 & 49489 & 6.301 & 5.5848 & TST & \\
\hline CHEMBL122651 & 49489 & 7.6198 & 7.6579 & TRN & \\
\hline CHEMBL 333248 & 49489 & 7.1079 & 7.3179 & TST & \\
\hline CHEMBL332439 & 49489 & 4.2076 & 5.2949 & TST & \\
\hline CHEMBL122831 & 49489 & 7.9586 & 8.0101 & TRN & \\
\hline CHEMBL311336 & 49489 & 7.7696 & 7.6992 & TRN & \\
\hline CHEMBL83508 & 49489 & 6.9208 & 6.84399 & 9999999999 & TRN \\
\hline CHEMBL123167 & 49489 & 7.2676 & 7.2322 & TST & \\
\hline CHEMBL123041 & 49489 & 7.9208 & 8.0104 & TRN & \\
\hline CHEMBL120934 & 49489 & 4.1549 & 4.1939 & TRN & \\
\hline CHEMBL332145 & 49489 & 4.1024 & 4.5545 & TST & \\
\hline CHEMBL123064 & 49489 & 4.4089 & 4.6288 & TST & \\
\hline CHEMBL2372502 & 147866 & 5.2924 & 5.1674 & TRN & \\
\hline CHEMBL2372464 & 147866 & 4.9547 & 4.9592 & TRN & \\
\hline CHEMBL 2372493 & 147866 & 3.0 & 3.1321 & TRN & \\
\hline CHEMBL2372489 & 147866 & 4.8239 & 3.9084 & TRN & \\
\hline CHEMBL 2372483 & 147866 & 5.3372 & 4.9647 & TRN & \\
\hline CHEMBL2372492 & 147866 & 4.8508 & 4.6011 & TRN & \\
\hline CHEMBL2021596 & 147866 & 4.8097 & 4.9478 & TRN & \\
\hline CHEMBL 2370885 & 147866 & 5.6383 & 5.5634 & TRN & \\
\hline CHEMBL 2372506 & 147866 & 4.2518 & 4.6599 & TRN & \\
\hline
\end{tabular}

Page 15524 


\begin{tabular}{|c|c|c|c|c|c|}
\hline \multicolumn{6}{|c|}{ Supplemental Table S2.txt } \\
\hline CHEMBL2372480 & 147866 & 5.6576 & 5.1648 & TRN & \\
\hline CHEMBL 2372472 & 147866 & 4.301 & 4.6392 & TRN & \\
\hline CHEMBL2372473 & 147866 & 3.8861 & 4.1748 & TST & \\
\hline CHEMBL2372457 & 147866 & 5.2518 & 5.7256 & TRN & \\
\hline CHEMBL2372462 & 147866 & 5.699 & 5.1786 & TRN & \\
\hline CHEMBL2372499 & 147866 & 5.8239 & 5.3827 & TRN & \\
\hline CHEMBL2372459 & 147866 & 4.8827 & 4.8551 & TST & \\
\hline CHEMBL 2372494 & 147866 & 5.4685 & 5.2355 & TRN & \\
\hline CHEMBL 2370884 & 147866 & 5.6778 & 5.8774 & TRN & \\
\hline CHEMBL2372481 & 147866 & 5.0969 & 5.45 & TRN & \\
\hline CHEMBL 2372508 & 147866 & 3.5229 & 4.2564 & TST & \\
\hline CHEMBL2372505 & 147866 & 5.2218 & 4.6599 & TRN & \\
\hline CHEMBL2372469 & 147866 & 3.0 & 4.2845 & TRN & \\
\hline CHEMBL 2372482 & 147866 & 4.301 & 4.7343 & TRN & \\
\hline CHEMBL2372486 & 147866 & 5.3665 & 2.4261 & TST & \\
\hline CHEMBL2372463 & 147866 & 3.2676 & 3.1304 & TRN & \\
\hline CHEMBL2372501 & 147866 & 5.8239 & 5.1666 & TST & \\
\hline CHEMBL 2372478 & 147866 & 3.0 & 3.5499 & TRN & \\
\hline CHEMBL 2372503 & 147866 & 5.7212 & 5.2933 & TRN & \\
\hline CHEMBL2372461 & 147866 & 5.0757 & 5.2475 & TRN & \\
\hline CHEMBL 2372477 & 147866 & 4.7932 & 5.1836 & TRN & \\
\hline CHEMBL2372507 & 147866 & 5.7959 & 3.9312 & TST & \\
\hline CHEMBL 2372490 & 147866 & 3.0 & 3.0286 & TRN & \\
\hline CHEMBL 2372496 & 147866 & 4.6383 & 3.6184 & TRN & \\
\hline CHEMBL2372470 & 147866 & 5.699 & 5.3723 & TRN & \\
\hline CHEMBL2372500 & 147866 & 5.3979 & 5.541 & TRN & \\
\hline CHEMBL2372485 & 147866 & 5.2441 & 4.6772 & TRN & \\
\hline CHEMBL2372495 & 147866 & 3.0 & 3.9902 & TRN & \\
\hline CHEMBL2372466 & 147866 & 5.1938 & 5.1159 & TRN & \\
\hline CHEMBL 2372476 & 147866 & 5.0915 & 5.07600 & 00000000005 & TST \\
\hline CHEMBL2372498 & 147866 & 4.8013 & 3.665 & TST & \\
\hline CHEMBL2372497 & 147866 & 5.4685 & 4.8768 & TRN & \\
\hline CHEMBL2372460 & 147866 & 5.0555 & 4.9369 & TRN & \\
\hline CHEMBL 2372456 & 147866 & 5.8861 & 5.356 & TRN & \\
\hline CHEMBL 2370883 & 147866 & 4.7696 & 5.614 & TRN & \\
\hline CHEMBL2372465 & 147866 & 3.5229 & 4.0596 & TRN & \\
\hline CHEMBL 2372479 & 147866 & 4.7212 & 5.2564 & TRN & \\
\hline CHEMBL2372487 & 147866 & 5.7959 & 4.2623 & TST & \\
\hline CHEMBL 2372474 & 147866 & 5.5229 & 4.9294 & TRN & \\
\hline CHEMBL 2372484 & 147866 & 5.6198 & 5.0702 & TST & \\
\hline CHEMBL2372491 & 147866 & 4.3768 & 4.8959 & TRN & \\
\hline CHEMBL 2372475 & 147866 & 5.5686 & 5.7197 & TST & \\
\hline CHEMBL2372458 & 147866 & 5.1549 & 5.7356 & TST & \\
\hline CHEMBL 2372468 & 147866 & 5.0555 & 4.86100 & 0000000001 & TRN \\
\hline CHEMBL 2372488 & 147866 & 5.3979 & 3.8993 & TST & \\
\hline CHEMBL 2372471 & 147866 & 5.3279 & 5.4253 & TRN & \\
\hline CHEMBL 2372504 & 147866 & 5.6778 & 3.8917 & TST & \\
\hline CHEMBL3199359 & 1301667 & 3.158 & 3.4285 & TRN & \\
\hline
\end{tabular}


Supplemental Table S2.txt

\begin{tabular}{|c|c|c|c|c|}
\hline 9684 & & & & \\
\hline & 301667 & 3.158 & & \\
\hline 77 & & & & \\
\hline IEMBL3 & 667 & 002 & & \\
\hline AEMBL1. & 301667 & 122 & & \\
\hline AEMBL3197167 & 301667 & 4.8646 & 0883 & \\
\hline 1967 & 57 & & 771 & \\
\hline 761 & 57 & & & \\
\hline IEMBL13 & 301667 & 4.1122 & & \\
\hline AEMBL3 & 301667 & 4.7948 & 9335 & \\
\hline AEMBL1 & 301667 & 4.563 & 934 & \\
\hline IEMBL: & 301667 & 58 & 697 & \\
\hline EMBL & 57 & & & \\
\hline 2410 & 301667 & 4.9515 & 519 & \\
\hline 6451 & 301667 & 4.8174 & 3711 & \\
\hline 3693 & 67 & & 95 & \\
\hline EMBL: & 57 & & & \\
\hline 3756 & 57 & 959 & & \\
\hline 4017 & 301667 & 4.1123 & 8871 & \\
\hline IEMBL & 67 & 3 . & & \\
\hline 801 & ) & & 48 & \\
\hline EMBL & $3 e$ & & 21 & \\
\hline 73 & 57 & & & \\
\hline 5849 & & 3882 & & \\
\hline IEMBL: & & 3 . & & KN \\
\hline IEMBL & 1 & 3 & & \\
\hline 441 & 36 & 4. & 11 & \\
\hline 69 & 67 & 76 & & RN \\
\hline EMBL & 567 & 673 & & \\
\hline 0855 & 301 & 4. & 97 & RN \\
\hline IEMBL & 67 & 8 & 75 & RI \\
\hline 36 & 7 & 3. & 45 & 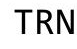 \\
\hline 36 & 67 & 3. & & 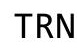 \\
\hline EMBL & 301 & 3 . & & RI \\
\hline IEMBL1 & 301667 & 3. & 4.4041 & $S$ \\
\hline IEMBL & a1 & & 3922 & \\
\hline 25 & & & & V \\
\hline & 57 & & 487 & RIN \\
\hline AEMBL] & 301667 & 3.1579 & & $\mathrm{RN}$ \\
\hline EMBL & 301 & & 568 & \\
\hline 3817 & 67 & 0 & 728 & \\
\hline 2983 & 1301667 & & & $S T$ \\
\hline HEMBL & 301667 & & 3.5737 & RI \\
\hline 6877 & 301667 & 4.5398 & 8155 & $S$ \\
\hline 57 & 301 & 4. & 42 & $\mathrm{R}$ \\
\hline CHEMBL & 301667 & & 3.9756 & \\
\hline CHEMBL & 301667 & 3.6349 & 3.9659 & \\
\hline CHEMBL1448276 & 1301667 & 3.158 & 3.6337 & TR \\
\hline
\end{tabular}

Page 15526 
Supplemental Table S2.txt

\begin{tabular}{|c|c|c|c|c|c|}
\hline CHEMBL3189612 & 1301667 & 3.1579 & 3.9047 & TRN & \\
\hline CHEMBL1362504 & 1301667 & 3.158 & 3.2565 & TRN & \\
\hline CHEMBL1515214 & 1301667 & 5.0512 & 4.0157 & TRN & \\
\hline CHEMBL1569616 & 1301667 & 4.2463 & 3.6968 & TRN & \\
\hline CHEMBL1448503 & 1301667 & 3.158 & 3.9452 & TST & \\
\hline CHEMBL3195351 & 1301667 & 4.6875 & 4.0848 & TRN & \\
\hline CHEMBL 2136674 & 1301667 & 4.7968 & 3.7279 & TRN & \\
\hline CHEMBL1483028 & 1301667 & 3.158 & \multicolumn{2}{|c|}{ 3. 3819999999999997} & TRN \\
\hline CHEMBL1454956 & 1301667 & 4.4375 & 4.3766 & TST & \\
\hline CHEMBL1349147 & 1301667 & 4.904 & 3.9067 & TST & \\
\hline CHEMBL1534873 & 1301667 & 4.3009 & 4.3771 & TRN & \\
\hline CHEMBL1898395 & 1301667 & 4.5323 & 4.1098 & TRN & \\
\hline CHEMBL1303628 & 1301667 & 3.1578 & 4.0084 & TST & \\
\hline CHEMBL531709 & 1301667 & 3.1578 & 3.7957 & TRN & \\
\hline CHEMBL1308000 & 1301667 & 3.1581 & 3.9004 & TRN & \\
\hline CHEMBL1471547 & 1301667 & 3.1579 & 3.5851 & TRN & \\
\hline CHEMBL1326671 & 1301667 & 4.5572 & 3.7565 & TRN & \\
\hline CHEMBL1901182 & 1301667 & 3.1578 & 3.6461 & TRN & \\
\hline CHEMBL1568895 & 1301667 & 3.158 & \multicolumn{2}{|c|}{3.9539999999999997} & TST \\
\hline CHEMBL1319368 & 1301667 & 3.1579 & 3.2701 & TRN & \\
\hline CHEMBL1545173 & 1301667 & 3.1579 & 3.5292 & TST & \\
\hline CHEMBL1581141 & 1301667 & 3.1579 & 3.6234 & TRN & \\
\hline CHEMBL1521021 & 1301667 & 3.635 & 4.5774 & TRN & \\
\hline CHEMBL1699360 & 1301667 & 3.1578 & 3.5469 & TRN & \\
\hline CHEMBL1335870 & 1301667 & 4.8837 & 3.6631 & TRN & \\
\hline CHEMBL1367525 & 1301667 & 3.158 & 3.272 & TRN & \\
\hline CHEMBL3185785 & 1301667 & 3.1579 & 3.7041 & TRN & \\
\hline CHEMBL1309874 & 1301667 & 3.1579 & 3.7101 & TRN & \\
\hline CHEMBL3188669 & 1301667 & 3.1581 & 3.4778 & TRN & \\
\hline CHEMBL1511607 & 1301667 & 3.1581 & 3.1237 & TRN & \\
\hline CHEMBL3192223 & 1301667 & 3.1581 & 3.6621 & TRN & \\
\hline CHEMBL1356476 & 1301667 & 3.158 & 3.1319 & TRN & \\
\hline CHEMBL1383732 & 1301667 & 3.1579 & 3.2738 & TRN & \\
\hline CHEMBL1500131 & 1301667 & 3.158 & 3.8566 & TRN & \\
\hline CHEMBL3182098 & 1301667 & 5.0342 & 4.4627 & TRN & \\
\hline CHEMBL1583419 & 1301667 & 4.1122 & 3.8023 & TRN & \\
\hline CHEMBL1473962 & 1301667 & 4.5941 & 3.5494 & TRN & \\
\hline CHEMBL1586817 & 1301667 & 4.9561 & 4.1236 & TRN & \\
\hline CHEMBL1545908 & 1301667 & 3.1579 & 3.7696 & TRN & \\
\hline CHEMBL1892953 & 1301667 & 3.1587 & 4.609 & TRN & \\
\hline CHEMBL1723427 & 1301667 & 4.9204 & 3.7617 & TRN & \\
\hline CHEMBL1605988 & 1301667 & 3.1578 & 3.91 & TST & \\
\hline CHEMBL2354591 & 1301667 & 4.2771 & 4.183 & TRN & \\
\hline CHEMBL1874900 & 1301667 & 4.9161 & 4.7352 & TRN & \\
\hline CHEMBL3188587 & 1301667 & 3.1579 & 3.4064 & TRN & \\
\hline CHEMBL1449661 & 1301667 & 3.1578 & 3.1543 & TRN & \\
\hline CHEMBL1728523 & 1301667 & 4.112 & 3.9931 & TRN & \\
\hline CHEMBL1506281 & 1301667 & 3.1578 & 3.4151 & TRN & \\
\hline
\end{tabular}


Supplemental Table S2.txt

\begin{tabular}{|c|c|c|c|c|c|}
\hline CHEMBL3145192 & 1301667 & 4.9748 & 3.8107 & TST & \\
\hline CHEMBL3187038 & 1301667 & 3.1578 & 3.9055 & TRN & \\
\hline CHEMBL1970905 & 1301667 & 4.4891 & 4.0419 & TRN & \\
\hline CHEMBL1504766 & 1301667 & 3.1575 & 4.3094 & TRN & \\
\hline CHEMBL1733824 & 1301667 & 4.9013 & 3.9554 & TRN & \\
\hline CHEMBL1526184 & 1301667 & 3.158 & 3.7705 & TST & \\
\hline CHEMBL1600415 & 1301667 & 3.1577 & 4.3595 & TST & \\
\hline CHEMBL2358966 & 1301667 & 4.1126 & 3.5849 & TRN & \\
\hline CHEMBL1890635 & 1301667 & 3.158 & 3.8791 & TRN & \\
\hline CHEMBL1600040 & 1301667 & 4.8695 & 4.5095 & TRN & \\
\hline CHEMBL1583727 & 1301667 & 4.6212 & 3.6006 & TRN & \\
\hline CHEMBL1511563 & 1301667 & 3.1579 & 3.8504 & TRN & \\
\hline CHEMBL1557691 & 1301667 & 3.1579 & 3.7368 & TRN & \\
\hline CHEMBL1609619 & 1301667 & 3.158 & 3.6717 & TST & \\
\hline CHEMBL1505209 & 1301667 & 3.158 & 3.7579 & TST & \\
\hline CHEMBL3184349 & 1301667 & 3.1578 & 2.9196 & TRN & \\
\hline CHEMBL1571201 & 1301667 & 4.7887 & 3.3282 & TRN & \\
\hline CHEMBL1458408 & 1301667 & 3.1582 & 3.633 & TST & \\
\hline CHEMBL1542569 & 1301667 & 3.158 & 3.5903 & TRN & \\
\hline CHEMBL1423469 & 1301667 & 3.1578 & 3.6092 & TRN & \\
\hline CHEMBL1527031 & 1301667 & 4.3926 & 4.1687 & TRN & \\
\hline CHEMBL3182983 & 1301667 & 3.1579 & 3.953006 & 00000000003 & TRN \\
\hline CHEMBL1313561 & 1301667 & 4.4437 & 3.4173 & TRN & \\
\hline CHEMBL1698535 & 1301667 & 3.1578 & 4.0363 & TRN & \\
\hline CHEMBL1896544 & 1301667 & 3.1586 & 3.7768 & TRN & \\
\hline CHEMBL1320912 & 1301667 & 3.158 & 3.1605 & TRN & \\
\hline CHEMBL1366729 & 1301667 & 4.5943 & 4.4887 & TRN & \\
\hline CHEMBL1538014 & 1301667 & 4.7058 & 3.9794 & TRN & \\
\hline CHEMBL1548517 & 1301667 & 3.1577 & 4.1947 & TST & \\
\hline CHEMBL1338171 & 1301667 & 4.9859 & 3.7453 & TRN & \\
\hline CHEMBL1608077 & 1301667 & 4.9333 & 3.4944 & TST & \\
\hline CHEMBL1506571 & 1301667 & 3.1579 & 3.3236 & TRN & \\
\hline CHEMBL1597320 & 1301667 & 4.5612 & 3.6283 & TRN & \\
\hline CHEMBL1306182 & 1301667 & 3.158 & 3.6577 & TRN & \\
\hline CHEMBL1534147 & 1301667 & 4.7373 & 3.3938 & TRN & \\
\hline CHEMBL1877015 & 1301667 & 3.158 & 3.0529 & TRN & \\
\hline CHEMBL1385686 & 1301667 & 3.1583 & 4.2059 & TST & \\
\hline CHEMBL1329279 & 1301667 & 4.4242 & 3.8754 & TRN & \\
\hline CHEMBL3182161 & 1301667 & 3.158 & 3.6901 & TRN & \\
\hline CHEMBL1526021 & 1301667 & 3.1579 & 4.0056 & TRN & \\
\hline CHEMBL3197117 & 1301667 & 3.635 & 4.0165 & TRN & \\
\hline CHEMBL3192842 & 1301667 & 3.158 & 3.5216 & TRN & \\
\hline CHEMBL1707447 & 1301667 & 4.9445 & 3.9049 & TRN & \\
\hline CHEMBL1510469 & 1301667 & 4.5713 & 4.0759 & TRN & \\
\hline CHEMBL3192745 & 1301667 & 3.1579 & 3.7454 & TRN & \\
\hline CHEMBL1721815 & 1301667 & 3.1579 & 3.8121 & TRN & \\
\hline CHEMBL1868450 & 1301667 & 3.1583 & 4.2451 & TRN & \\
\hline CHEMBL1568525 & 1301667 & 3.158 & 3.8208 & TRN & \\
\hline
\end{tabular}


Supplemental Table S2.txt

\begin{tabular}{|c|c|c|c|c|c|}
\hline CHEMBL1731789 & 1301667 & 4.9158 & 3.6911 & TRN & \\
\hline CHEMBL1531151 & 1301667 & 3.158 & 3.5978 & TRN & \\
\hline CHEMBL1468756 & 1301667 & 3.158 & 3.5439 & TRN & \\
\hline CHEMBL1608318 & 1301667 & 4.726 & 4.227 & TRN & \\
\hline CHEMBL1382213 & 1301667 & 3.158 & 3.6529 & TRN & \\
\hline CHEMBL1986557 & 1301667 & 4.8914 & 4.2582 & TRN & \\
\hline CHEMBL1424120 & 1301667 & 3.1579 & 3.2361 & TRN & \\
\hline CHEMBL1731138 & 1301667 & 4.2299 & 3.6946 & TRN & \\
\hline CHEMBL1503729 & 1301667 & 5.0435 & 3.8533 & TST & \\
\hline CHEMBL1897629 & 1301667 & 3.1577 & 3.7412 & TRN & \\
\hline CHEMBL1321129 & 1301667 & 3.1579 & 4.0503 & TRN & \\
\hline CHEMBL3192533 & 1301667 & 4.4884 & 4.2359 & TRN & \\
\hline CHEMBL1467369 & 1301667 & 3.1581 & 3.8395 & TRN & \\
\hline CHEMBL1608929 & 1301667 & 3.158 & 3.5108 & TRN & \\
\hline CHEMBL 2137206 & 1301667 & 4.7328 & 3.7495 & TRN & \\
\hline CHEMBL1900750 & 1301667 & 4.7334 & 3.7671 & TRN & \\
\hline CHEMBL586061 & 1301667 & 3.158 & 3.5293 & TRN & \\
\hline CHEMBL1418782 & 1301667 & 3.158 & 3.5824 & TST & \\
\hline CHEMBL1306985 & 1301667 & 3.1583 & 3.52699 & 99999999997 & TRN \\
\hline CHEMBL1903212 & 1301667 & 4.1123 & 3.7201 & TRN & \\
\hline CHEMBL1720535 & 1301667 & 4.8597 & 3.9016 & TRN & \\
\hline CHEMBL1894622 & 1301667 & 4.369 & 4.5102 & TRN & \\
\hline CHEMBL1336678 & 1301667 & 3.1579 & 3.7712 & TRN & \\
\hline CHEMBL1359055 & 1301667 & 3.1579 & 4.1498 & TST & \\
\hline CHEMBL1391541 & 1301667 & 4.5284 & 4.3958 & TRN & \\
\hline CHEMBL1898370 & 1301667 & 3.1578 & 3.6872 & TRN & \\
\hline CHEMBL1444345 & 1301667 & 4.976 & 4.0756 & TRN & \\
\hline CHEMBL1702964 & 1301667 & 3.1581 & 3.7526 & TRN & \\
\hline CHEMBL1411359 & 1301667 & 3.1582 & 3.887 & TRN & \\
\hline CHEMBL1545902 & 1301667 & 4.1122 & 3.753 & TST & \\
\hline CHEMBL3194223 & 1301667 & 3.1578 & 3.4142 & TRN & \\
\hline CHEMBL1726848 & 1301667 & 3.1585 & 3.1446 & TRN & \\
\hline CHEMBL1374920 & 1301667 & 3.1581 & 3.8787 & TRN & \\
\hline CHEMBL1883149 & 1301667 & 3.1578 & 3.0669 & TRN & \\
\hline CHEMBL3190366 & 1301667 & 3.158 & 3.5839 & TRN & \\
\hline CHEMBL3186340 & 1301667 & 4.6846 & 3.7498 & TRN & \\
\hline CHEMBL 2133525 & 1301667 & 3.1588 & 3.3608 & TRN & \\
\hline CHEMBL1538323 & 1301667 & 3.1578 & 3.785 & TRN & \\
\hline CHEMBL1408161 & 1301667 & 3.1579 & 3.5382 & TRN & \\
\hline CHEMBL1363615 & 1301667 & 4.5445 & 3.8567 & TRN & \\
\hline CHEMBL1724784 & 1301667 & 3.1584 & 3.5704 & TRN & \\
\hline CHEMBL1421192 & 1301667 & 3.1578 & 3.6953 & TRN & \\
\hline CHEMBL1491315 & 1301667 & 3.1576 & 3.7583 & TRN & \\
\hline CHEMBL3185686 & 1301667 & 3.1582 & 3.6305 & TRN & \\
\hline CHEMBL1873230 & 1301667 & 3.158 & 3.5986 & TRN & \\
\hline CHEMBL3183231 & 1301667 & 4.4227 & 3.6459 & TRN & \\
\hline CHEMBL3193593 & 1301667 & 3.1579 & 3.9029 & TRN & \\
\hline CHEMBL1425147 & 1301667 & 3.1577 & 3.7499 & TRN & \\
\hline
\end{tabular}

Page 15529 
Supplemental Table S2.txt

\begin{tabular}{|c|c|c|c|c|}
\hline CHEMBL1519239 & 1301667 & 4.9559 & 3.8599 & TST \\
\hline CHEMBL1386556 & 1301667 & 3.1579 & 3.5169 & TRN \\
\hline CHEMBL1460894 & 1301667 & 3.1579 & 3.4693 & TRN \\
\hline CHEMBL1727418 & 1301667 & 3.1578 & 3.9753 & TRN \\
\hline CHEMBL1341307 & 1301667 & 3.1579 & 4.1769 & TST \\
\hline CHEMBL 3183712 & 1301667 & 4.7844 & 4.2484 & TRN \\
\hline CHEMBL1536759 & 1301667 & 3.158 & 3.5498 & TRN \\
\hline CHEMBL1547261 & 1301667 & 4.1122 & 4.1876 & TRN \\
\hline CHEMBL1536053 & 1301667 & 3.1577 & 3.0919 & TRN \\
\hline CHEMBL 3195360 & 1301667 & 4.6069 & 4.2025 & TRN \\
\hline CHEMBL1517266 & 1301667 & 4.1121 & 3.4897 & TRN \\
\hline CHEMBL1730548 & 1301667 & 3.158 & 3.8972 & TRN \\
\hline CHEMBL1494390 & 1301667 & 4.7539 & 4.0575 & TRN \\
\hline CHEMBL1890869 & 1301667 & 3.1583 & 3.6357 & TRN \\
\hline CHEMBL 1403216 & 1301667 & 3.1579 & 3.0753 & TRN \\
\hline CHEMBL1482044 & 1301667 & 3.1576 & 3.7956 & TST \\
\hline CHEMBL1594922 & 1301667 & 4.6722 & 4.5112 & TRN \\
\hline CHEMBL1881588 & 1301667 & 4.1124 & 3.9457 & TST \\
\hline CHEMBL1518330 & 1301667 & 4.4152 & 3.6985 & TRN \\
\hline CHEMBL 3185636 & 1301667 & 4.1123 & 3.7182 & TRN \\
\hline CHEMBL1319275 & 1301667 & 3.158 & 3.5666 & TRN \\
\hline CHEMBL1498451 & 1301667 & 3.1579 & 3.6833 & TRN \\
\hline CHEMBL1598365 & 1301667 & 4.4888 & 4.0271 & TST \\
\hline CHEMBL67311 & 1301667 & 3.158 & 4.0608 & TRN \\
\hline CHEMBL1997797 & 1301667 & 3.158 & 3.2442 & TRN \\
\hline CHEMBL1376585 & 1301667 & 4.61 & 3.6408 & TST \\
\hline CHEMBL1345528 & 1301667 & 4.1777 & 4.0394 & TST \\
\hline CHEMBL1542473 & 1301667 & 3.1578 & 3.3589 & TST \\
\hline CHEMBL 2136909 & 1301667 & 3.1581 & 3.4287 & TST \\
\hline CHEMBL 3185595 & 1301667 & 4.6181 & 3.6131 & TST \\
\hline CHEMBL1420600 & 1301667 & 3.1579 & 3.3742 & TST \\
\hline CHEMBL1892066 & 1301667 & 3.1584 & 3.5738 & TST \\
\hline CHEMBL1327545 & 1301667 & 3.1579 & 3.1734 & TST \\
\hline CHEMBL 3188643 & 1301667 & 3.1579 & 3.9159 & TST \\
\hline CHEMBL1701427 & 1301667 & 3.158 & 3.6244 & TST \\
\hline CHEMBL1419256 & 1301667 & 4.1121 & 4.0037 & TST \\
\hline CHEMBL 1541177 & 1301667 & 3.1578 & 3.5175 & TST \\
\hline CHEMBL 3193447 & 1301667 & 3.158 & 3.341 & TST \\
\hline CHEMBL1602836 & 1301667 & 4.5892 & 3.3531 & TST \\
\hline CHEMBL 3190770 & 1301667 & 3.1581 & 3.2307 & TST \\
\hline CHEMBL1335571 & 1301667 & 4.3117 & 3.6723 & TST \\
\hline CHEMBL 3190240 & 1301667 & 5.3456 & 3.6062 & TST \\
\hline CHEMBL1479411 & 1301667 & 4.4652 & 4.2569 & TST \\
\hline CHEMBL 2143724 & 1301667 & 5.0422 & 3.6688 & TST \\
\hline CHEMBL1544895 & 1301667 & 3.158 & 3.5337 & TST \\
\hline CHEMBL1362935 & 1301667 & 3.6351 & 3.5464 & TST \\
\hline CHEMBL1422155 & 1301667 & 4.1122 & 4.1728 & TST \\
\hline \multirow[t]{2}{*}{ CHEMBL1414034 } & 1301667 & 4.1123 & 3.75699 & 99999999997 \\
\hline & & & \multicolumn{2}{|c|}{ Page 15530} \\
\hline
\end{tabular}


Supplemental Table S2.txt

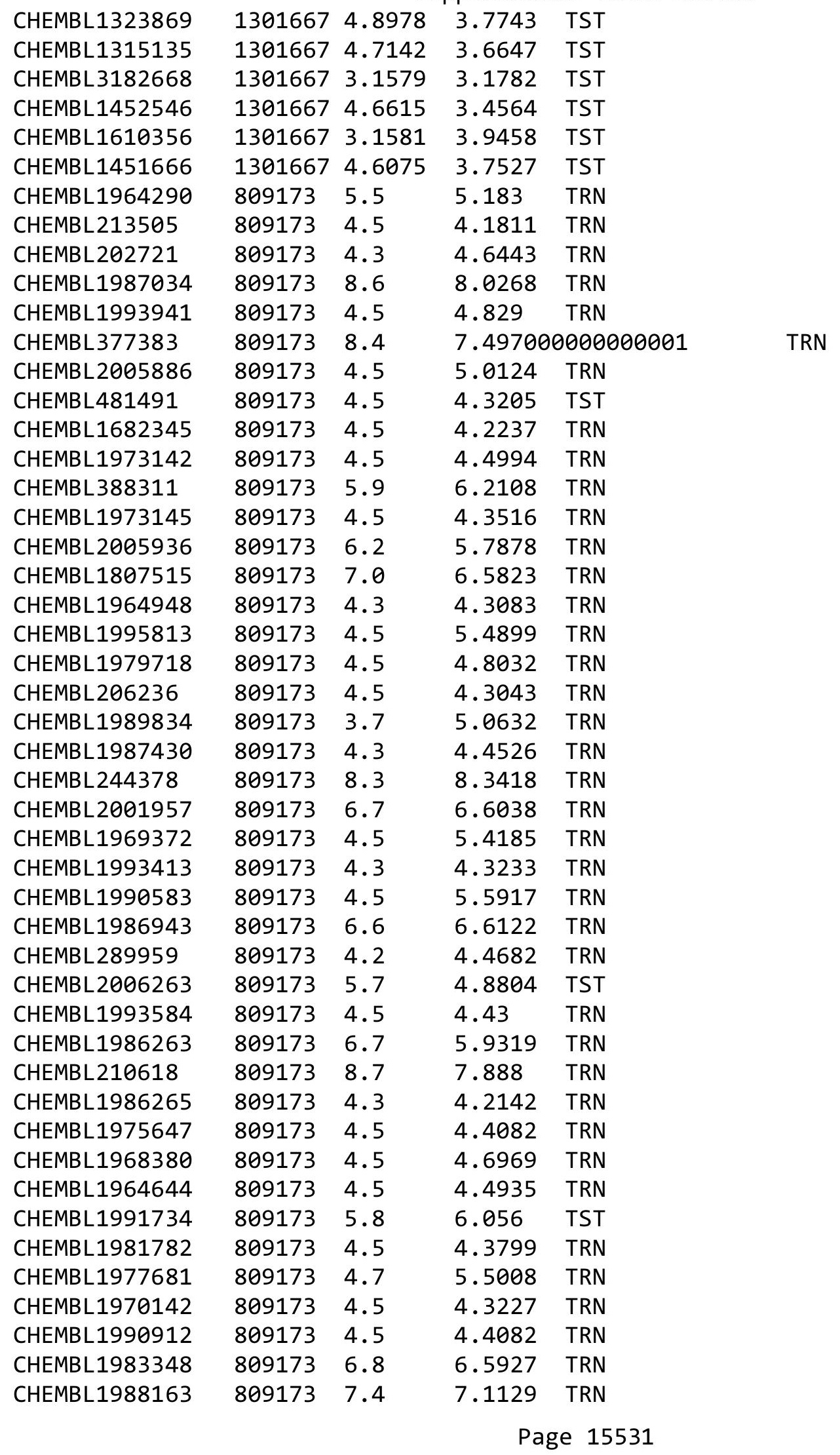




\begin{tabular}{|c|c|c|c|c|}
\hline & & & & \\
\hline CHEMBL1995592 & 809173 & 6.4 & 5.2934 & TST \\
\hline CHEMBL1974480 & 809173 & 5.6 & 5.2386 & TRN \\
\hline CHEMBL1980671 & 809173 & 5.3 & 4.6168 & TRN \\
\hline CHEMBL 2006493 & 809173 & 4.5 & 4.5361 & TST \\
\hline CHEMBL1986177 & 809173 & 4.3 & 4.1372 & TRN \\
\hline CHEMBL1983449 & 809173 & 4.5 & 4.4917 & TRN \\
\hline CHEMBL1992323 & 809173 & 4.5 & 4.4411 & TRN \\
\hline CHEMBL1969735 & 809173 & 6.0 & 5.938 & TRN \\
\hline CHEMBL 2003524 & 809173 & 4.5 & 4.7385 & TST \\
\hline CHEMBL2002649 & 809173 & 4.5 & 5.2664 & TRN \\
\hline CHEMBL1989423 & 809173 & 5.2 & 4.338 & TRN \\
\hline CHEMBL1985367 & 809173 & 6.3 & 4.9364 & TST \\
\hline CHEMBL1996510 & 809173 & 4.3 & 4.8843 & TST \\
\hline CHEMBL437747 & 809173 & 7.4 & 6.3781 & TRN \\
\hline CHEMBL1995172 & 809173 & 4.6 & 4.4747 & TST \\
\hline CHEMBL 2001584 & 809173 & 4.3 & 4.3737 & TRN \\
\hline CHEMBL507936 & 809173 & 4.5 & 4.2508 & TRN \\
\hline CHEMBL1971227 & 809173 & 5.4 & 5.6061 & TST \\
\hline CHEMBL104264 & 809173 & 4.5 & 4.8607 & TST \\
\hline CHEMBL1967998 & 809173 & 7.4 & 7.4346 & TRN \\
\hline CHEMBL1994321 & 809173 & 4.5 & 5.5143 & TRN \\
\hline CHEMBL1978562 & 809173 & 5.7 & 5.5891 & TST \\
\hline CHEMBL1997129 & 809173 & 7.2 & 6.2181 & TRN \\
\hline CHEMBL1984788 & 809173 & 4.5 & 4.2829 & TRN \\
\hline CHEMBL1974875 & 809173 & 4.1 & 4.8502 & TST \\
\hline CHEMBL1964307 & 809173 & 4.5 & 4.397 & TRN \\
\hline CHEMBL1989471 & 809173 & 6.6 & 5.4992 & TST \\
\hline CHEMBL2002099 & 809173 & 4.3 & 4.8796 & TRN \\
\hline CHEMBL 2000508 & 809173 & 5.7 & 5.6528 & TRN \\
\hline CHEMBL1971694 & 809173 & 4.5 & 4.6313 & TST \\
\hline CHEMBL 2001547 & 809173 & 4.5 & 5.7703 & TRN \\
\hline CHEMBL 210928 & 809173 & 8.4 & 7.6601 & TRN \\
\hline CHEMBL1978195 & 809173 & 5.8 & 5.2118 & TRN \\
\hline CHEMBL1986603 & 809173 & 4.5 & 4.4545 & TST \\
\hline CHEMBL1972840 & 809173 & 5.8 & 4.6505 & TRN \\
\hline CHEMBL1977148 & 809173 & 4.5 & 4.5973 & TRN \\
\hline CHEMBL 2003286 & 809173 & 4.5 & 4.3166 & TRN \\
\hline CHEMBL1992306 & 809173 & 4.5 & 4.9001 & TRN \\
\hline CHEMBL 2002165 & 809173 & 4.5 & 5.3588 & TRN \\
\hline CHEMBL1979318 & 809173 & 4.5 & 4.5511 & TRN \\
\hline CHEMBL 206382 & 809173 & 4.5 & 4.3727 & TRN \\
\hline CHEMBL1998585 & 809173 & 4.5 & 5.4295 & TRN \\
\hline CHEMBL127898 & 809173 & 4.5 & 4.6058 & TST \\
\hline CHEMBL519697 & 809173 & 4.5 & 4.6446 & TRN \\
\hline CHEMBL 2004934 & 809173 & 4.5 & 4.4941 & TRN \\
\hline CHEMBL1996345 & 809173 & 4.3 & 4.4337 & TST \\
\hline CHEMBL1975128 & 809173 & 5.9 & 5.1806 & TRN \\
\hline CHEMBL 2004025 & 809173 & 5.9 & 5.3354 & TRN \\
\hline
\end{tabular}




\begin{tabular}{|c|c|c|c|c|c|}
\hline & & & & & \\
\hline CHEMBL1996048 & 809173 & 4.3 & 4.879 & TST & \\
\hline CHEMBL1976158 & 809173 & 4.6 & 4.9273 & TST & \\
\hline CHEMBL461876 & 809173 & 6.8 & 6.4745 & TRN & \\
\hline CHEMBL1965033 & 809173 & 4.3 & 4.1132 & TRN & \\
\hline CHEMBL 2001485 & 809173 & 4.5 & 4.3319 & TRN & \\
\hline CHEMBL1971519 & 809173 & 4.3 & 4.2748 & TRN & \\
\hline CHEMBL504950 & 809173 & 4.5 & 4.02800 & 00000000005 & TRN \\
\hline CHEMBL1997335 & 809173 & 4.3 & 5.8952 & TRN & \\
\hline CHEMBL1966425 & 809173 & 4.5 & 4.7258 & TRN & \\
\hline CHEMBL1984363 & 809173 & 4.5 & 4.3882 & TRN & \\
\hline CHEMBL1978099 & 809173 & 6.5 & 6.6547 & TRN & \\
\hline CHEMBL1977041 & 809173 & 6.1 & 4.7803 & TRN & \\
\hline CHEMBL1968070 & 809173 & 4.5 & 4.3775 & TRN & \\
\hline CHEMBL1988608 & 809173 & 4.5 & 4.7437 & TRN & \\
\hline CHEMBL184847 & 809173 & 4.5 & 4.0885 & TRN & \\
\hline CHEMBL1971132 & 809173 & 4.3 & 4.3162 & TRN & \\
\hline CHEMBL178737 & 809173 & 4.5 & 4.5438 & TST & \\
\hline CHEMBL226898 & 809173 & 4.5 & 4.7491 & TRN & \\
\hline CHEMBL1982563 & 809173 & 6.3 & 6.1168 & TRN & \\
\hline CHEMBL1991377 & 809173 & 4.3 & 4.2367 & TRN & \\
\hline CHEMBL539474 & 809173 & 4.5 & 4.3477 & TST & \\
\hline CHEMBL575824 & 809173 & 4.5 & 4.6785 & TRN & \\
\hline CHEMBL1988387 & 809173 & 4.5 & 5.2946 & TRN & \\
\hline CHEMBL1973868 & 809173 & 4.3 & 4.4462 & TRN & \\
\hline CHEMBL1972462 & 809173 & 4.3 & 4.81800 & 00000000005 & TRN \\
\hline CHEMBL1997759 & 809173 & 4.5 & 4.4438 & TRN & \\
\hline CHEMBL1990288 & 809173 & 6.7 & 5.8702 & TRN & \\
\hline CHEMBL1970074 & 809173 & 4.5 & 4.4876 & TRN & \\
\hline CHEMBL1986970 & 809173 & 4.5 & 4.5239 & TRN & \\
\hline CHEMBL1958401 & 809173 & 4.5 & 4.6577 & TRN & \\
\hline CHEMBL 2003456 & 809173 & 4.5 & 4.4571 & TRN & \\
\hline CHEMBL1966816 & 809173 & 4.5 & 4.3862 & TRN & \\
\hline CHEMBL1972584 & 809173 & 4.5 & 4.7578 & TRN & \\
\hline CHEMBL 2002992 & 809173 & 4.4 & 5.0502 & TRN & \\
\hline CHEMBL560813 & 809173 & 4.5 & 4.6134 & TRN & \\
\hline CHEMBL207253 & 809173 & 6.0 & 5.0146 & TST & \\
\hline CHEMBL1982700 & 809173 & 4.3 & 4.9795 & TST & \\
\hline CHEMBL1968791 & 809173 & 4.5 & 4.0995 & TRN & \\
\hline CHEMBL326282 & 809173 & 4.5 & 4.3553 & TST & \\
\hline CHEMBL1997495 & 809173 & 5.6 & 5.2072 & TRN & \\
\hline CHEMBL1977634 & 809173 & 4.3 & 4.5996 & TRN & \\
\hline CHEMBL1992732 & 809173 & 4.5 & 5.0014 & TST & \\
\hline CHEMBL1971186 & 809173 & 6.8 & 6.221 & TRN & \\
\hline CHEMBL 2003482 & 809173 & 4.6 & 4.6669 & TRN & \\
\hline CHEMBL1976872 & 809173 & 4.1 & 4.6733 & TRN & \\
\hline CHEMBL1969156 & 809173 & 4.9 & 4.3611 & TRN & \\
\hline CHEMBL1973211 & 809173 & 4.5 & 5.5732 & TRN & \\
\hline CHEMBL1984700 & 809173 & 6.0 & 6.2735 & TRN & \\
\hline & & & & 15533 & \\
\hline
\end{tabular}




\begin{tabular}{|c|c|c|c|c|}
\hline & & & Supplement & \\
\hline CHEMBL2007151 & 809173 & 4.5 & 4.1199 & TRN \\
\hline CHEMBL1971606 & 809173 & 4.3 & 4.3873 & TRN \\
\hline CHEMBL1972125 & 809173 & 4.5 & 4.4182 & TRN \\
\hline CHEMBL1461728 & 809173 & 4.5 & 4.4093 & TRN \\
\hline CHEMBL1976134 & 809173 & 6.1 & 5.3238 & TRN \\
\hline CHEMBL1965131 & 809173 & 4.5 & 4.2603 & TRN \\
\hline CHEMBL1972158 & 809173 & 4.5 & 5.0518 & TRN \\
\hline CHEMBL1981215 & 809173 & 4.3 & 4.2999 & TRN \\
\hline CHEMBL1974457 & 809173 & 4.5 & 5.0144 & TRN \\
\hline CHEMBL 2006580 & 809173 & 4.5 & 4.4356 & TRN \\
\hline CHEMBL1999414 & 809173 & 4.3 & 4.5812 & TRN \\
\hline CHEMBL1967336 & 809173 & 4.3 & 4.5462 & TRN \\
\hline CHEMBL1979855 & 809173 & 4.5 & 4.2578 & TRN \\
\hline CHEMBL1970340 & 809173 & 3.6 & 4.3289 & TRN \\
\hline CHEMBL1967992 & 809173 & 4.3 & 4.5668 & TRN \\
\hline CHEMBL 2005186 & 809173 & 4.5 & 4.6426 & TRN \\
\hline CHEMBL1981671 & 809173 & 4.3 & 4.9595 & TRN \\
\hline CHEMBL 2006450 & 809173 & 4.3 & 4.6068 & TRN \\
\hline CHEMBL1975534 & 809173 & 4.5 & 4.6166 & TRN \\
\hline CHEMBL1993424 & 809173 & 4.5 & 5.8978 & TRN \\
\hline CHEMBL1966703 & 809173 & 4.5 & 4.3089 & TST \\
\hline CHEMBL2001987 & 809173 & 4.3 & 4.2824 & TRN \\
\hline CHEMBL1969561 & 809173 & 4.5 & 4.5065 & TRN \\
\hline CHEMBL1994555 & 809173 & 6.5 & 5.2839 & TRN \\
\hline CHEMBL1983640 & 809173 & 4.3 & 4.3581 & TRN \\
\hline CHEMBL1997023 & 809173 & 4.5 & 4.3194 & TST \\
\hline CHEMBL1964687 & 809173 & 4.5 & 4.3034 & TRN \\
\hline CHEMBL1971943 & 809173 & 4.4 & 4.6443 & TRN \\
\hline CHEMBL1999918 & 809173 & 5.7 & 5.9534 & TRN \\
\hline CHEMBL1974254 & 809173 & 4.5 & 4.4624 & TRN \\
\hline CHEMBL1988537 & 809173 & 4.5 & 4.4852 & TST \\
\hline CHEMBL1969049 & 809173 & 4.5 & 4.3459 & TRN \\
\hline CHEMBL 2005828 & 809173 & 4.5 & 4.1936 & TRN \\
\hline CHEMBL 2002240 & 809173 & 6.3 & 5.5519 & TRN \\
\hline CHEMBL1998611 & 809173 & 4.5 & 4.4395 & TRN \\
\hline CHEMBL485556 & 809173 & 4.5 & 4.6282 & TRN \\
\hline CHEMBL1975900 & 809173 & 4.5 & 4.62 & TRN \\
\hline CHEMBL 255822 & 809173 & 4.5 & 4.4342 & TRN \\
\hline CHEMBL1972221 & 809173 & 5.9 & 5.4755 & TRN \\
\hline CHEMBL 2006778 & 809173 & 4.5 & 4.1649 & TRN \\
\hline CHEMBL 378627 & 809173 & 8.5 & 8.1088 & TRN \\
\hline CHEMBL1996979 & 809173 & 4.5 & 5.4677 & TRN \\
\hline CHEMBL1975911 & 809173 & 4.6 & 4.8016 & TRN \\
\hline CHEMBL1997025 & 809173 & 4.5 & 4.2979 & TRN \\
\hline CHEMBL1968406 & 809173 & 4.5 & 4.5479 & TRN \\
\hline CHEMBL1982476 & 809173 & 4.5 & 4.7586 & TRN \\
\hline CHEMBL1998545 & 809173 & 4.5 & 4.466 & TRN \\
\hline CHEMBL1986869 & 809173 & 4.5 & 4.4468 & TRN \\
\hline
\end{tabular}




\begin{tabular}{|c|c|c|c|c|}
\hline & & & & al \\
\hline CHEMBL 2004033 & 809173 & 5.3 & 4.7133 & TST \\
\hline CHEMBL1975923 & 809173 & 5.7 & 5.0436 & TST \\
\hline CHEMBL 2005449 & 809173 & 6.4 & 5.3318 & TRN \\
\hline CHEMBL1987998 & 809173 & 4.3 & 4.3306 & TRN \\
\hline CHEMBL 2006010 & 809173 & 4.5 & 4.143 & TRN \\
\hline CHEMBL1682558 & 809173 & 4.5 & 4.9229 & TRN \\
\hline CHEMBL1971534 & 809173 & 4.2 & 4.8618 & TRN \\
\hline CHEMBL1990496 & 809173 & 6.3 & 5.6026 & TRN \\
\hline CHEMBL 242865 & 809173 & 8.4 & 8.1032 & TRN \\
\hline CHEMBL1997623 & 809173 & 4.5 & 4.2183 & TRN \\
\hline CHEMBL 2002479 & 809173 & 5.6 & 5.3485 & TRN \\
\hline CHEMBL 2002480 & 809173 & 4.3 & 4.5114 & TRN \\
\hline CHEMBL1993166 & 809173 & 4.5 & 4.8921 & TRN \\
\hline CHEMBL1967094 & 809173 & 5.7 & 5.6819 & TRN \\
\hline CHEMBL 2003341 & 809173 & 4.5 & 4.4993 & TRN \\
\hline CHEMBL1992645 & 809173 & 4.5 & 4.9739 & TST \\
\hline CHEMBL550275 & 809173 & 5.6 & 5.0848 & TST \\
\hline CHEMBL1998110 & 809173 & 4.3 & 4.4918 & TRN \\
\hline CHEMBL1999590 & 809173 & 4.5 & 4.8677 & TST \\
\hline CHEMBL1981079 & 809173 & 5.6 & 5.5907 & TRN \\
\hline CHEMBL1978166 & 809173 & 5.7 & 5.5931 & TRN \\
\hline CHEMBL1972276 & 809173 & 4.5 & 4.4384 & TRN \\
\hline CHEMBL1980489 & 809173 & 4.5 & 4.6282 & TRN \\
\hline CHEMBL 2000832 & 809173 & 6.5 & 5.4109 & TRN \\
\hline CHEMBL1967116 & 809173 & 4.5 & 5.1331 & TRN \\
\hline CHEMBL1990590 & 809173 & 4.3 & 4.1478 & TRN \\
\hline CHEMBL1977814 & 809173 & 5.7 & 4.5975 & TST \\
\hline CHEMBL513846 & 809173 & 6.2 & 5.1931 & TRN \\
\hline CHEMBL86755 & 809173 & 5.9 & 5.3396 & TRN \\
\hline CHEMBL1970709 & 809173 & 4.5 & 4.544 & TRN \\
\hline CHEMBL1974617 & 809173 & 4.9 & 4.5794 & TRN \\
\hline CHEMBL1965660 & 809173 & 6.4 & 5.8124 & TRN \\
\hline CHEMBL1992125 & 809173 & 5.3 & 5.5892 & TRN \\
\hline CHEMBL1998112 & 809173 & 4.5 & 4.6278 & TRN \\
\hline CHEMBL1969126 & 809173 & 4.5 & 5.5387 & TRN \\
\hline CHEMBL1980896 & 809173 & 4.5 & 4.4084 & TRN \\
\hline CHEMBL1975208 & 809173 & 4.5 & 4.6108 & TST \\
\hline CHEMBL1178727 & 809173 & 4.2 & 4.4582 & TRN \\
\hline CHEMBL1970104 & 809173 & 5.9 & 4.7988 & TRN \\
\hline CHEMBL1991429 & 809173 & 6.9 & 6.3453 & TRN \\
\hline CHEMBL1964777 & 809173 & 4.5 & 4.5759 & TRN \\
\hline CHEMBL1971149 & 809173 & 5.8 & 5.7666 & TRN \\
\hline CHEMBL1999714 & 809173 & 4.5 & 4.2121 & TRN \\
\hline CHEMBL1987533 & 809173 & 4.5 & 4.4849 & TRN \\
\hline CHEMBL1994040 & 809173 & 6.0 & 5.9349 & TRN \\
\hline CHEMBL 388978 & 809173 & 7.0 & 6.7744 & TST \\
\hline CHEMBL579246 & 809173 & 4.5 & 4.8999 & TRN \\
\hline CHEMBL398951 & 809173 & 4.3 & 4.7061 & TST \\
\hline
\end{tabular}




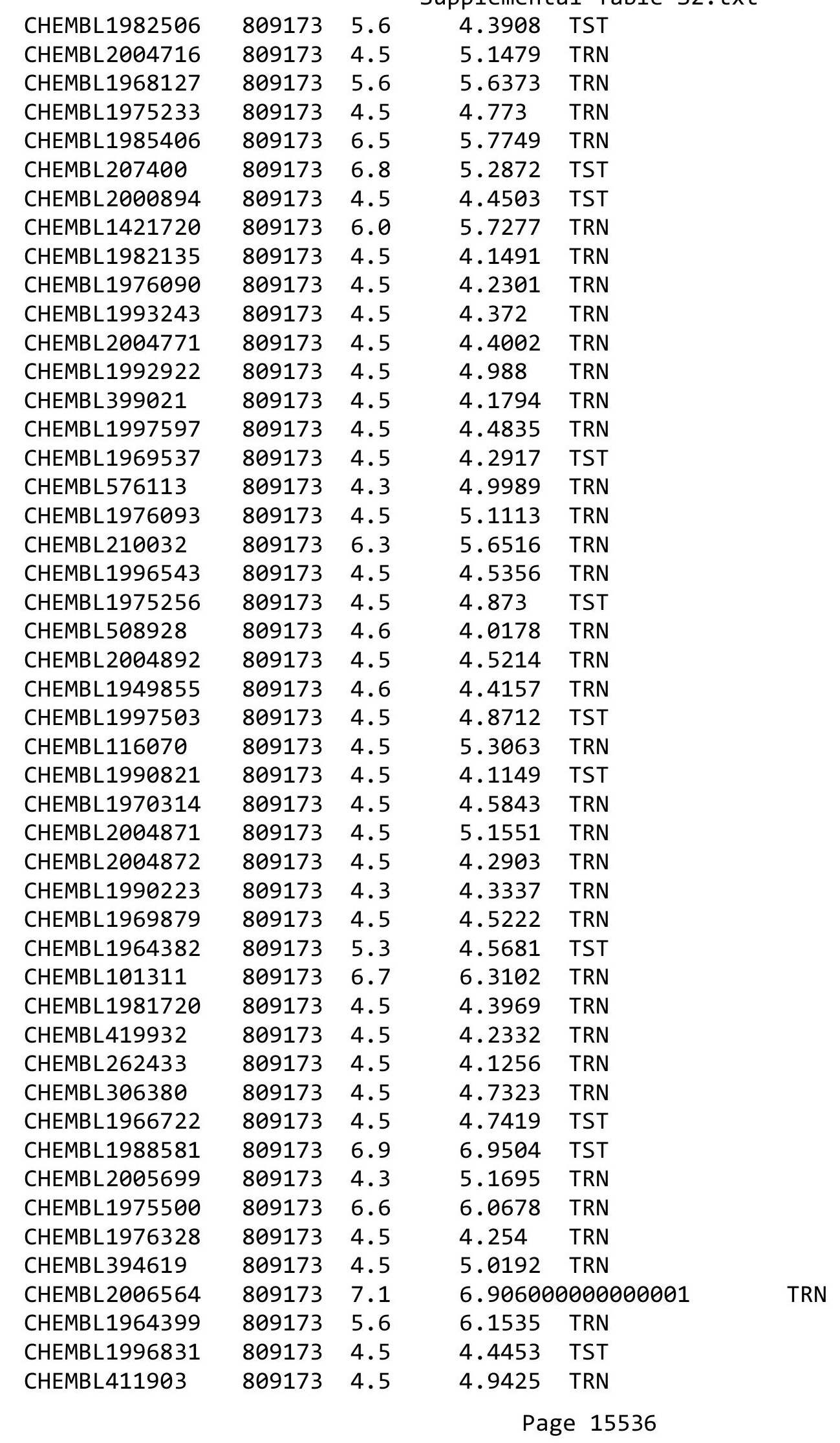




\begin{tabular}{|c|c|c|c|c|c|}
\hline & & & & & \\
\hline CHEMBL1991008 & 809173 & 4.8 & 4.5061 & TRN & \\
\hline CHEMBL1978167 & 809173 & 4.3 & 4.7871 & TST & \\
\hline CHEMBL1965988 & 809173 & 4.5 & 5.2119 & TRN & \\
\hline CHEMBL418203 & 809173 & 4.4 & 5.0336 & TST & \\
\hline CHEMBL1989646 & 809173 & 4.5 & 4.6032 & TRN & \\
\hline CHEMBL1682357 & 809173 & 4.5 & 4.5344 & TRN & \\
\hline CHEMBL225519 & 809173 & 4.4 & 4.7631 & TRN & \\
\hline CHEMBL209534 & 809173 & 8.1 & 7.3901 & TRN & \\
\hline CHEMBL1978200 & 809173 & 5.6 & 5.6994 & TRN & \\
\hline CHEMBL1994159 & 809173 & 4.1 & 4.3544 & TRN & \\
\hline CHEMBL1970522 & 809173 & 4.5 & $4.9110 e$ & 00000000005 & TRN \\
\hline CHEMBL1990415 & 809173 & 4.5 & 4.4328 & TRN & \\
\hline CHEMBL1966087 & 809173 & 4.5 & 4.4187 & TRN & \\
\hline CHEMBL1964692 & 809173 & 4.5 & 4.1987 & TRN & \\
\hline CHEMBL1996931 & 809173 & 4.5 & 4.4388 & TRN & \\
\hline CHEMBL1971223 & 809173 & 4.3 & 5.3638 & TRN & \\
\hline CHEMBL1964413 & 809173 & 4.5 & 4.2838 & TRN & \\
\hline CHEMBL1973483 & 809173 & 4.5 & 4.183 & TRN & \\
\hline CHEMBL1998470 & 809173 & 4.3 & 4.6867 & TRN & \\
\hline CHEMBL1984432 & 809173 & 4.5 & 4.2265 & TRN & \\
\hline CHEMBL1970735 & 809173 & 6.6 & 5.5085 & TRN & \\
\hline CHEMBL 219722 & 809173 & 4.5 & 4.3552 & TRN & \\
\hline CHEMBL1975903 & 809173 & 6.1 & 5.8425 & TRN & \\
\hline CHEMBL1997340 & 809173 & 4.5 & 4.4008 & TRN & \\
\hline CHEMBL1522508 & 809173 & 4.3 & 4.1026 & TRN & \\
\hline CHEMBL1989474 & 809173 & 4.5 & 4.8769 & TRN & \\
\hline CHEMBL1090360 & 809173 & 6.6 & 6.6022 & TRN & \\
\hline CHEMBL 210887 & 809173 & 4.5 & 4.57 & TRN & \\
\hline CHEMBL1988805 & 809173 & 5.7 & 4.7454 & TST & \\
\hline CHEMBL458997 & 809173 & 8.1 & 7.6303 & TRN & \\
\hline CHEMBL1971021 & 809173 & 4.5 & 4.5443 & TRN & \\
\hline CHEMBL 227271 & 809173 & 4.5 & 4.9128 & TRN & \\
\hline CHEMBL583144 & 809173 & 4.5 & 4.302 & TRN & \\
\hline CHEMBL1974310 & 809173 & 5.8 & 5.557 & TRN & \\
\hline CHEMBL1969942 & 809173 & 4.3 & 4.3569 & TRN & \\
\hline CHEMBL1978567 & 809173 & 4.3 & 4.4918 & TRN & \\
\hline CHEMBL1982660 & 809173 & 4.5 & 4.3112 & TRN & \\
\hline CHEMBL1994693 & 809173 & 4.5 & 4.2069 & TRN & \\
\hline CHEMBL1982957 & 809173 & 6.4 & 5.7424 & TRN & \\
\hline CHEMBL1725279 & 809173 & 6.9 & 6.159 & TST & \\
\hline CHEMBL1975138 & 809173 & 4.5 & 4.6419 & TST & \\
\hline CHEMBL424872 & 809173 & 8.4 & 7.9769 & TRN & \\
\hline CHEMBL 2006836 & 809173 & 4.5 & 4.1518 & TST & \\
\hline CHEMBL1971947 & 809173 & 4.5 & 4.4791 & TRN & \\
\hline CHEMBL412142 & 809173 & 4.5 & 4.7139 & TST & \\
\hline CHEMBL1980704 & 809173 & 4.5 & 4.2247 & TST & \\
\hline CHEMBL2003271 & 809173 & 4.5 & 4.6334 & TRN & \\
\hline CHEMBL1966808 & 809173 & 4.5 & 4.1778 & TRN & \\
\hline & & & & 15537 & \\
\hline
\end{tabular}




\begin{tabular}{|c|c|c|c|c|}
\hline & & & pमeme & al Ta \\
\hline CHEMBL 2004447 & 809173 & 4.5 & 4.5174 & TRN \\
\hline CHEMBL1983111 & 809173 & 6.3 & 6.6828 & TRN \\
\hline CHEMBL1973860 & 809173 & 4.5 & 4.3784 & TRN \\
\hline CHEMBL260135 & 809173 & 4.5 & 4.5499 & TRN \\
\hline CHEMBL 220241 & 809173 & 4.5 & 4.4637 & TRN \\
\hline CHEMBL 2004544 & 809173 & 4.5 & 4.6469 & TST \\
\hline CHEMBL1988141 & 809173 & 6.2 & 6.3568 & TST \\
\hline CHEMBL1982610 & 809173 & 4.5 & 4.1336 & TST \\
\hline CHEMBL1977134 & 809173 & 4.3 & 4.3555 & TRN \\
\hline CHEMBL1999496 & 809173 & 4.5 & 4.2058 & TRN \\
\hline CHEMBL 2006933 & 809173 & 4.5 & 4.4118 & TST \\
\hline CHEMBL1985206 & 809173 & 5.7 & 4.5829 & TST \\
\hline CHEMBL1988300 & 809173 & 4.5 & 4.1468 & TRN \\
\hline CHEMBL1991078 & 809173 & 6.2 & 6.7691 & TRN \\
\hline CHEMBL1987359 & 809173 & 4.5 & 4.2715 & TST \\
\hline CHEMBL1977749 & 809173 & 6.7 & 6.0488 & TST \\
\hline CHEMBL1975212 & 809173 & 4.5 & 4.4097 & TRN \\
\hline CHEMBL 2000685 & 809173 & 5.7 & 5.4334 & TRN \\
\hline CHEMBL 2001613 & 809173 & 4.6 & 5.0528 & TST \\
\hline CHEMBL1997275 & 809173 & 4.3 & 4.5762 & TRN \\
\hline CHEMBL1993904 & 809173 & 7.4 & 6.2281 & TRN \\
\hline CHEMBL1980376 & 809173 & 4.4 & 4.2671 & TRN \\
\hline CHEMBL1967513 & 809173 & 4.3 & 4.1248 & TRN \\
\hline CHEMBL 2000724 & 809173 & 4.3 & 4.3357 & TRN \\
\hline CHEMBL1985311 & 809173 & 4.5 & 4.3006 & TRN \\
\hline CHEMBL1989265 & 809173 & 4.5 & 4.4716 & TST \\
\hline CHEMBL1982413 & 809173 & 5.6 & 5.0236 & TST \\
\hline CHEMBL1969502 & 809173 & 4.5 & 4.8393 & TRN \\
\hline CHEMBL1965910 & 809173 & 4.5 & 4.2612 & TRN \\
\hline CHEMBL1682553 & 809173 & 4.5 & 4.394 & TRN \\
\hline CHEMBL1971430 & 809173 & 4.5 & 5.221 & TRN \\
\hline CHEMBL1983963 & 809173 & 4.5 & 4.5952 & TRN \\
\hline CHEMBL 2000271 & 809173 & 6.0 & 5.3129 & TRN \\
\hline CHEMBL1981792 & 809173 & 5.6 & 4.7458 & TRN \\
\hline CHEMBL1987535 & 809173 & 5.4 & 4.9178 & TRN \\
\hline CHEMBL1985092 & 809173 & 4.5 & 4.3021 & TRN \\
\hline CHEMBL 2004692 & 809173 & 4.5 & 4.6957 & TST \\
\hline CHEMBL1981410 & 809173 & 4.5 & 4.2654 & TRN \\
\hline CHEMBL 2002586 & 809173 & 6.1 & 5.2229 & TRN \\
\hline CHEMBL1987815 & 809173 & 5.1 & 4.5173 & TST \\
\hline CHEMBL1996234 & 809173 & 4.5 & 5.2068 & TRN \\
\hline CHEMBL 383264 & 809173 & 4.3 & 4.7533 & TRN \\
\hline CHEMBL 2007421 & 809173 & 4.3 & 5.204 & TST \\
\hline CHEMBL1991434 & 809173 & 4.5 & 4.6867 & TST \\
\hline CHEMBL1967544 & 809173 & 4.5 & 4.5614 & TRN \\
\hline CHEMBL1973138 & 809173 & 4.3 & 4.2859 & TRN \\
\hline CHEMBL 223367 & 809173 & 4.5 & 4.9669 & TST \\
\hline CHEMBL1992673 & 809173 & 4.2 & 4.7086 & TRN \\
\hline
\end{tabular}




\begin{tabular}{|c|c|c|c|c|c|}
\hline \multicolumn{6}{|c|}{ Supplemental Table S2.txt } \\
\hline CHEMBL340384 & 809173 & 4.5 & 4.5818 & TST & \\
\hline CHEMBL1969151 & 809173 & 6.0 & 5.5691 & TRN & \\
\hline CHEMBL1996587 & 809173 & 4.5 & 4.7469 & TRN & \\
\hline CHEMBL1981492 & 809173 & 5.1 & 4.6197 & TRN & \\
\hline CHEMBL1993335 & 809173 & 5.7 & 5.4781 & TST & \\
\hline CHEMBL1988692 & 809173 & 5.5 & 4.9115 & TRN & \\
\hline CHEMBL 2007574 & 809173 & 5.6 & 5.0485 & TRN & \\
\hline CHEMBL1964804 & 809173 & 4.5 & 4.6803 & TRN & \\
\hline CHEMBL443962 & 809173 & 4.5 & 4.4543 & TRN & \\
\hline CHEMBL 2000354 & 809173 & 4.5 & 4.6355 & TRN & \\
\hline CHEMBL1965507 & 809173 & 4.5 & 3.9897 & TRN & \\
\hline CHEMBL 274064 & 809173 & 4.5 & 4.8829 & TRN & \\
\hline CHEMBL1998680 & 809173 & 4.3 & 5.1494 & TRN & \\
\hline CHEMBL1967564 & 809173 & 4.5 & 4.7058 & TRN & \\
\hline CHEMBL592030 & 809173 & 4.6 & 5.0221 & TST & \\
\hline CHEMBL 2000071 & 809173 & 4.5 & 4.6512 & TRN & \\
\hline CHEMBL1979176 & 809173 & 4.5 & 4.1392 & TRN & \\
\hline CHEMBL1970317 & 809173 & 4.5 & 5.008 & TRN & \\
\hline CHEMBL2000408 & 809173 & 5.7 & 5.9679 & TRN & \\
\hline CHEMBL 248757 & 809173 & 4.5 & 4.8522 & TST & \\
\hline CHEMBL1978014 & 809173 & 4.5 & 4.4504 & TRN & \\
\hline CHEMBL 2002736 & 809173 & 4.3 & 4.9395 & TRN & \\
\hline CHEMBL1997007 & 809173 & 6.4 & 6.4869 & TRN & \\
\hline CHEMBL1994538 & 809173 & 4.5 & 4.2346 & TRN & \\
\hline CHEMBL1983195 & 809173 & 4.5 & 4.8406 & TST & \\
\hline CHEMBL1975490 & 809173 & 4.5 & 4.8855 & TRN & \\
\hline CHEMBL1964444 & 809173 & 4.5 & 4.2015 & TRN & \\
\hline CHEMBL 2002690 & 809173 & 4.3 & 4.387 & TRN & \\
\hline CHEMBL 2006567 & 809173 & 7.1 & 6.1107 & TRN & \\
\hline CHEMBL1986139 & 809173 & 4.5 & 4.2506 & TRN & \\
\hline CHEMBL383527 & 809173 & 4.5 & 4.4568 & TRN & \\
\hline CHEMBL1980540 & 809173 & 4.5 & 4.131 & TRN & \\
\hline CHEMBL278041 & 809173 & 6.3 & 5.7893 & TRN & \\
\hline CHEMBL1979883 & 809173 & 4.5 & 5.4125 & TRN & \\
\hline CHEMBL1984162 & 809173 & 4.5 & 4.9592 & TRN & \\
\hline CHEMBL491758 & 809173 & 6.9 & 5.8061 & TRN & \\
\hline CHEMBL1986590 & 809173 & 5.4 & 4.6987 & TRN & \\
\hline CHEMBL549730 & 809173 & 4.5 & 4.564 & TRN & \\
\hline CHEMBL1970189 & 809173 & 4.5 & 4.5968 & TRN & \\
\hline CHEMBL1870106 & 809173 & 4.3 & 4.668 & TRN & \\
\hline CHEMBL1996791 & 809173 & 4.5 & 4.6851 & TRN & \\
\hline CHEMBL371206 & 809173 & 4.5 & 4.88399 & 99999999995 & TRN \\
\hline CHEMBL1974664 & 809173 & 4.5 & 4.8494 & TRN & \\
\hline CHEMBL1998477 & 809173 & 5.4 & 5.1036 & TRN & \\
\hline CHEMBL406845 & 809173 & 5.4 & 5.0644 & TRN & \\
\hline CHEMBL482538 & 809173 & 5.0 & 4.8406 & TRN & \\
\hline CHEMBL1974288 & 809173 & 4.5 & 4.636 & TRN & \\
\hline CHEMBL1984296 & 809173 & 4.3 & 5.0761 & TST & \\
\hline
\end{tabular}




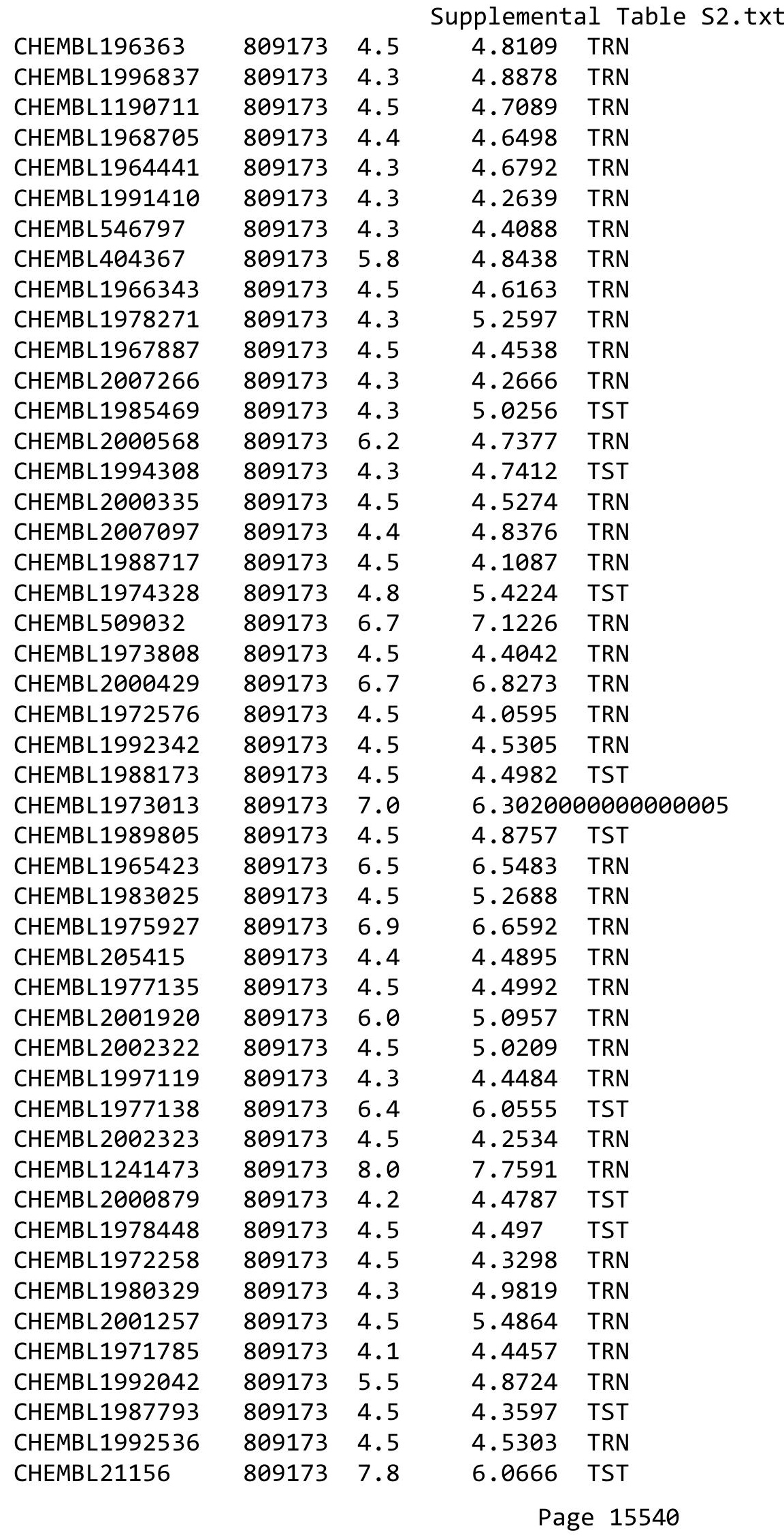




\begin{tabular}{|c|c|c|c|c|}
\hline \multicolumn{5}{|c|}{ lemental T } \\
\hline CHEMBL1992740 & 809173 & 4.5 & 4.8056 & TRN \\
\hline CHEMBL1994724 & 809173 & 4.3 & 4.8509 & TRN \\
\hline CHEMBL1989267 & 809173 & 5.4 & 4.6736 & TRN \\
\hline CHEMBL 2002373 & 809173 & 4.5 & 5.2617 & TRN \\
\hline CHEMBL439340 & 809173 & 4.5 & 4.374 & TRN \\
\hline CHEMBL1974574 & 809173 & 4.3 & 4.9119 & TST \\
\hline CHEMBL 2006188 & 809173 & 4.5 & 4.2695 & TRN \\
\hline CHEMBL1970290 & 809173 & 4.3 & 4.5269 & TRN \\
\hline CHEMBL1967531 & 809173 & 4.5 & 4.2949 & TRN \\
\hline CHEMBL1970913 & 809173 & 4.5 & 4.8687 & TRN \\
\hline CHEMBL1973893 & 809173 & 4.5 & 4.7859 & TRN \\
\hline CHEMBL1997534 & 809173 & 4.5 & 4.4916 & TRN \\
\hline CHEMBL1993877 & 809173 & 5.4 & 5.1461 & TRN \\
\hline CHEMBL1996500 & 809173 & 5.0 & 5.6745 & TRN \\
\hline CHEMBL1985095 & 809173 & 6.9 & 5.5665 & TST \\
\hline CHEMBL1991180 & 809173 & 4.5 & 4.8881 & TST \\
\hline CHEMBL1682540 & 809173 & 4.5 & 4.0551 & TRN \\
\hline CHEMBL1976420 & 809173 & 5.7 & 5.0941 & TRN \\
\hline CHEMBL1998253 & 809173 & 4.3 & 4.87 & TST \\
\hline CHEMBL413779 & 809173 & 4.5 & 5.1847 & TST \\
\hline CHEMBL1981744 & 809173 & 4.3 & 4.086 & TRN \\
\hline CHEMBL1994864 & 809173 & 4.5 & 4.3402 & TRN \\
\hline CHEMBL 2002446 & 809173 & 4.5 & 4.6267 & TST \\
\hline CHEMBL497151 & 809173 & 5.6 & 4.7801 & TRN \\
\hline CHEMBL 2000029 & 809173 & 5.9 & 4.8897 & TRN \\
\hline CHEMBL1973961 & 809173 & 5.5 & 4.9442 & TRN \\
\hline CHEMBL246970 & 809173 & 4.5 & 4.7139 & TRN \\
\hline CHEMBL340921 & 809173 & 4.5 & 4.4083 & TST \\
\hline CHEMBL1994977 & 809173 & 4.3 & 4.2972 & TRN \\
\hline CHEMBL373598 & 809173 & 4.5 & 5.041 & TST \\
\hline CHEMBL2001149 & 809173 & 5.6 & 5.1614 & TRN \\
\hline CHEMBL1999718 & 809173 & 4.5 & 4.4401 & TRN \\
\hline CHEMBL 2005478 & 809173 & 6.2 & 5.2207 & TST \\
\hline CHEMBL1276446 & 809173 & 6.9 & 6.2195 & TST \\
\hline CHEMBL1996646 & 809173 & 5.5 & 5.0405 & TRN \\
\hline CHEMBL1979773 & 809173 & 4.3 & 4.2296 & TRN \\
\hline CHEMBL1977346 & 809173 & 4.5 & 4.5707 & TRN \\
\hline CHEMBL2003657 & 809173 & 6.9 & 6.5203 & TRN \\
\hline CHEMBL1971649 & 809173 & 4.5 & 4.1386 & TRN \\
\hline CHEMBL1996702 & 809173 & 6.2 & 6.1688 & TRN \\
\hline CHEMBL 2007124 & 809173 & 4.3 & 4.2665 & TRN \\
\hline CHEMBL 2006439 & 809173 & 4.5 & 5.3901 & TRN \\
\hline CHEMBL1985681 & 809173 & 5.9 & 4.9976 & TST \\
\hline CHEMBL1969190 & 809173 & 4.5 & 4.7853 & TRN \\
\hline CHEMBL 2002660 & 809173 & 4.3 & 4.3135 & TRN \\
\hline CHEMBL1973937 & 809173 & 4.5 & 5.3612 & TRN \\
\hline CHEMBL1991674 & 809173 & 5.6 & 5.7422 & TRN \\
\hline CHEMBL1982711 & 809173 & 5.8 & 5.0358 & TRN \\
\hline
\end{tabular}




\begin{tabular}{|c|c|c|c|c|}
\hline \multicolumn{5}{|c|}{ Supplemental Table S2.txt } \\
\hline CHEMBL262623 & 809173 & 4.1 & 4.7413 & TRN \\
\hline CHEMBL1984842 & 809173 & 7.4 & 6.4274 & TRN \\
\hline CHEMBL1969102 & 809173 & 4.5 & 4.8278 & TRN \\
\hline CHEMBL 2004118 & 809173 & 6.8 & 6.2616 & TRN \\
\hline CHEMBL1996795 & 809173 & 4.3 & 5.0601 & TST \\
\hline CHEMBL 2007044 & 809173 & 4.5 & 4.8821 & TST \\
\hline CHEMBL 2001998 & 809173 & 4.5 & 4.9095 & TST \\
\hline CHEMBL1994241 & 809173 & 4.5 & 5.3983 & TRN \\
\hline CHEMBL 223460 & 809173 & 4.5 & 5.0248 & TST \\
\hline CHEMBL1998829 & 809173 & 4.5 & 4.5179 & TRN \\
\hline CHEMBL50894 & 809173 & 4.4 & 5.189 & TST \\
\hline CHEMBL1995211 & 809173 & 5.4 & 5.1962 & TRN \\
\hline CHEMBL1988838 & 809173 & 6.5 & 7.0527 & TRN \\
\hline CHEMBL1981725 & 809173 & 5.9 & 6.4292 & TRN \\
\hline CHEMBL 375284 & 809173 & 4.5 & 4.1581 & TRN \\
\hline CHEMBL 2006299 & 809173 & 4.3 & 4.3442 & TRN \\
\hline CHEMBL1965169 & 809173 & 4.3 & 4.3933 & TST \\
\hline CHEMBL1991818 & 809173 & 4.3 & 5.175 & TST \\
\hline CHEMBL1081312 & 809173 & 5.6 & 5.9279 & TRN \\
\hline CHEMBL1965170 & 809173 & 4.3 & 4.9962 & TRN \\
\hline CHEMBL 2005792 & 809173 & 7.3 & 6.2893 & TRN \\
\hline CHEMBL1968926 & 809173 & 4.5 & 4.4687 & TRN \\
\hline CHEMBL1984206 & 809173 & 8.1 & 7.4241 & TRN \\
\hline CHEMBL462120 & 809173 & 4.5 & 4.418 & TRN \\
\hline CHEMBL1991577 & 809173 & 4.5 & 4.6984 & TRN \\
\hline CHEMBL1991867 & 809173 & 4.2 & 4.4239 & TST \\
\hline CHEMBL1986503 & 809173 & 4.3 & 4.413 & TST \\
\hline CHEMBL1965570 & 809173 & 4.5 & 4.3727 & TRN \\
\hline CHEMBL2007592 & 809173 & 5.8 & 4.8122 & TRN \\
\hline CHEMBL1972355 & 809173 & 6.2 & 5.5823 & TRN \\
\hline CHEMBL1997892 & 809173 & 4.3 & 4.1191 & TRN \\
\hline CHEMBL 2001641 & 809173 & 4.7 & 4.5086 & TRN \\
\hline CHEMBL1997193 & 809173 & 6.1 & 4.7559 & TST \\
\hline CHEMBL 210963 & 809173 & 8.5 & 8.3436 & TRN \\
\hline CHEMBL1964902 & 809173 & 4.3 & 5.401 & TRN \\
\hline CHEMBL1082440 & 809173 & 4.5 & 4.5227 & TST \\
\hline CHEMBL1614705 & 809173 & 4.7 & 4.973 & TRN \\
\hline CHEMBL1984633 & 809173 & 4.5 & 4.4861 & TRN \\
\hline CHEMBL1965845 & 809173 & 4.5 & 4.763 & TRN \\
\hline CHEMBL 2007372 & 809173 & 4.5 & 5.6189 & TRN \\
\hline CHEMBL1983715 & 809173 & 8.1 & 7.5538 & TRN \\
\hline CHEMBL1971017 & 809173 & 4.5 & 5.5541 & TRN \\
\hline CHEMBL 2006715 & 809173 & 4.5 & 5.9261 & TRN \\
\hline CHEMBL1986597 & 809173 & 4.5 & 5.0973 & TRN \\
\hline CHEMBL1990482 & 809173 & 4.5 & 4.2728 & TRN \\
\hline CHEMBL1990904 & 809173 & 6.4 & 5.8841 & TRN \\
\hline CHEMBL 2000104 & 809173 & 6.9 & 5.9952 & TRN \\
\hline CHEMBL 2005475 & 809173 & 4.6 & 5.6758 & TRN \\
\hline
\end{tabular}




\begin{tabular}{|c|c|c|c|c|c|}
\hline \multicolumn{6}{|c|}{ Supplemental Table S2.txt } \\
\hline CHEMBL402846 & 809173 & 4.7 & 4.8471 & TRN & \\
\hline CHEMBL1997349 & 809173 & 4.5 & 4.4188 & TST & \\
\hline CHEMBL183844 & 809173 & 4.5 & 3.8813 & TRN & \\
\hline CHEMBL 220057 & 809173 & 4.5 & 4.98600 & 0000000001 & TRN \\
\hline CHEMBL1682545 & 809173 & 4.5 & 4.4579 & TRN & \\
\hline CHEMBL383541 & 809173 & 4.5 & 4.6022 & TRN & \\
\hline CHEMBL 2001224 & 809173 & 4.5 & 4.6098 & TRN & \\
\hline CHEMBL10 & 809173 & 5.9 & 5.9352 & TRN & \\
\hline CHEMBL1976732 & 809173 & 4.5 & 5.0036 & TRN & \\
\hline CHEMBL1969506 & 809173 & 4.5 & 5.0453 & TRN & \\
\hline CHEMBL1980763 & 809173 & 6.9 & 6.1127 & TRN & \\
\hline CHEMBL1964937 & 809173 & 4.5 & 4.5827 & TRN & \\
\hline CHEMBL1980163 & 809173 & 4.5 & 4.4172 & TRN & \\
\hline CHEMBL590109 & 809173 & 6.8 & 5.3376 & TST & \\
\hline CHEMBL1970879 & 809173 & 4.5 & 5.0228 & TRN & \\
\hline CHEMBL1989856 & 809173 & 4.5 & 4.2637 & TST & \\
\hline CHEMBL2005899 & 809173 & 4.5 & 4.5168 & TRN & \\
\hline CHEMBL 2000919 & 809173 & 5.8 & 5.8286 & TRN & \\
\hline CHEMBL1682552 & 809173 & 4.5 & 4.3551 & TRN & \\
\hline CHEMBL 259850 & 809173 & 4.5 & 4.5491 & TRN & \\
\hline CHEMBL 2007479 & 809173 & 4.3 & 4.6245 & TRN & \\
\hline CHEMBL1996155 & 809173 & 4.5 & 4.3855 & TRN & \\
\hline CHEMBL229799 & 809173 & 5.6 & 5.4473 & TRN & \\
\hline CHEMBL105739 & 809173 & 4.5 & 4.1069 & TRN & \\
\hline CHEMBL1972220 & 809173 & 5.4 & 5.6717 & TRN & \\
\hline CHEMBL 379300 & 809173 & 5.8 & 5.2614 & TRN & \\
\hline CHEMBL 203673 & 809173 & 4.5 & 4.2977 & TRN & \\
\hline CHEMBL 2003785 & 809173 & 4.8 & 4.4899 & TST & \\
\hline CHEMBL1973720 & 809173 & 5.9 & 6.2697 & TRN & \\
\hline CHEMBL1969523 & 809173 & 4.5 & 5.5504 & TRN & \\
\hline CHEMBL 207995 & 809173 & 4.5 & 4.9704 & TRN & \\
\hline CHEMBL 2001923 & 809173 & 4.4 & 4.92399 & 99999999995 & TRN \\
\hline CHEMBL1986781 & 809173 & 7.4 & 6.4255 & TRN & \\
\hline CHEMBL1983070 & 809173 & 4.3 & 4.6334 & TRN & \\
\hline CHEMBL526133 & 809173 & 4.5 & 4.2054 & TRN & \\
\hline CHEMBL2003514 & 809173 & 4.3 & 4.4604 & TRN & \\
\hline CHEMBL1989043 & 809173 & 4.3 & 5.0 & TRN & \\
\hline CHEMBL1979057 & 809173 & 4.5 & 4.2589 & TRN & \\
\hline CHEMBL1981045 & 809173 & 6.6 & 5.0379 & TRN & \\
\hline CHEMBL 387971 & 809173 & 4.5 & 4.7126 & TST & \\
\hline CHEMBL1992796 & 809173 & 4.5 & 4.5359 & TRN & \\
\hline CHEMBL1164180 & 809173 & 4.3 & 4.5838 & TST & \\
\hline CHEMBL223257 & 809173 & 4.5 & 5.0397 & TST & \\
\hline CHEMBL1999428 & 809173 & 4.5 & 4.5474 & TRN & \\
\hline CHEMBL1967560 & 809173 & 4.5 & 4.7746 & TRN & \\
\hline CHEMBL1997611 & 809173 & 4.3 & 5.1178 & TST & \\
\hline CHEMBL1516890 & 809173 & 4.5 & 4.9014 & TRN & \\
\hline CHEMBL 211378 & 809173 & 4.5 & 4.1108 & TRN & \\
\hline
\end{tabular}




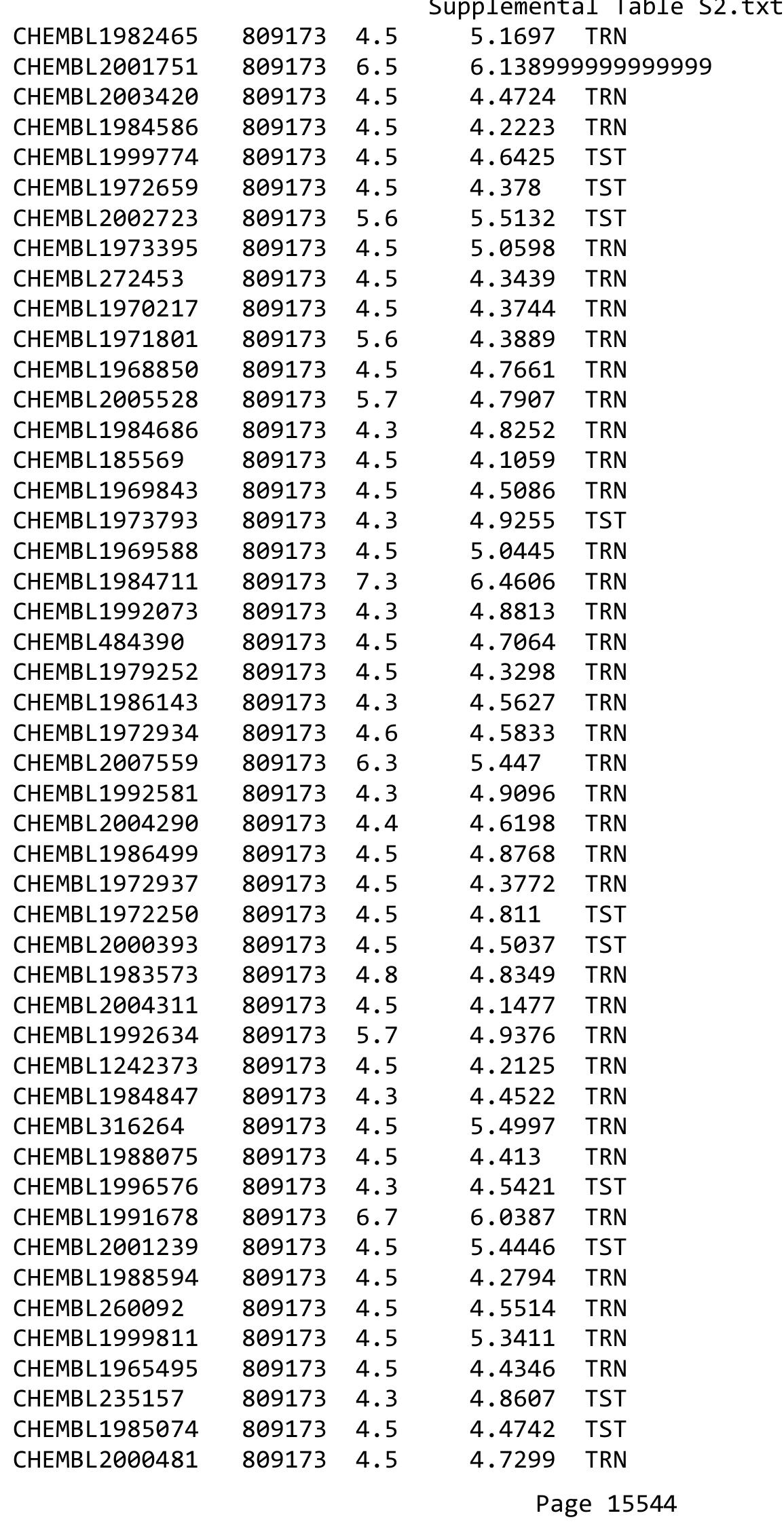

TRN 


\begin{tabular}{|c|c|c|c|c|}
\hline & & & pplement & $\mathrm{a} \perp \mathrm{Ta}$ \\
\hline CHEMBL1982874 & 809173 & 6.4 & 6.3107 & TRN \\
\hline CHEMBL1991725 & 809173 & 6.2 & 5.0638 & TRN \\
\hline CHEMBL1992242 & 809173 & 4.5 & 4.2001 & TRN \\
\hline CHEMBL 2007296 & 809173 & 4.5 & 4.4459 & TRN \\
\hline CHEMBL208637 & 809173 & 6.7 & 6.6074 & TRN \\
\hline CHEMBL396523 & 809173 & 8.3 & 8.2216 & TRN \\
\hline CHEMBL2004159 & 809173 & 4.3 & 4.3238 & TRN \\
\hline CHEMBL1978371 & 809173 & 6.4 & 5.7603 & TST \\
\hline CHEMBL1970203 & 809173 & 4.5 & 4.1591 & TRN \\
\hline CHEMBL1986530 & 809173 & 4.5 & 4.5546 & TST \\
\hline CHEMBL440084 & 809173 & 4.3 & 4.8462 & TRN \\
\hline CHEMBL1999321 & 809173 & 4.5 & 4.3616 & TRN \\
\hline CHEMBL1968590 & 809173 & 4.5 & 4.0907 & TRN \\
\hline CHEMBL1999749 & 809173 & 4.5 & 4.29 & TRN \\
\hline CHEMBL 2005375 & 809173 & 4.5 & 4.7981 & TRN \\
\hline CHEMBL1984191 & 809173 & 4.5 & 5.0968 & TRN \\
\hline CHEMBL1983006 & 809173 & 4.5 & 4.8954 & TRN \\
\hline CHEMBL1966501 & 809173 & 4.3 & 4.1097 & TRN \\
\hline CHEMBL1971029 & 809173 & 6.5 & 7.2311 & TRN \\
\hline CHEMBL394790 & 809173 & 4.5 & 4.305 & TRN \\
\hline CHEMBL 226471 & 809173 & 6.8 & 5.6311 & TRN \\
\hline CHEMBL1974702 & 809173 & 4.5 & 4.3175 & TRN \\
\hline CHEMBL1996111 & 809173 & 4.5 & 4.4642 & TRN \\
\hline CHEMBL1966175 & 809173 & 4.6 & 4.5923 & TRN \\
\hline CHEMBL1965589 & 809173 & 5.7 & 5.8548 & TRN \\
\hline CHEMBL 2007375 & 809173 & 4.3 & 4.3997 & TRN \\
\hline CHEMBL1998193 & 809173 & 4.5 & 4.4164 & TRN \\
\hline CHEMBL379975 & 809173 & 4.3 & 4.9729 & TRN \\
\hline CHEMBL474432 & 809173 & 4.5 & 4.3593 & TST \\
\hline CHEMBL1973016 & 809173 & 4.3 & 4.7514 & TRN \\
\hline CHEMBL1965387 & 809173 & 4.3 & 4.363 & TRN \\
\hline CHEMBL2001539 & 809173 & 5.8 & 4.9939 & TST \\
\hline CHEMBL1997041 & 809173 & 4.4 & 4.6522 & TRN \\
\hline CHEMBL1988153 & 809173 & 4.5 & 4.7877 & TRN \\
\hline CHEMBL550418 & 809173 & 5.9 & 5.1388 & TRN \\
\hline CHEMBL1971289 & 809173 & 5.5 & 5.1297 & TRN \\
\hline CHEMBL1999556 & 809173 & 5.6 & 5.5473 & TRN \\
\hline CHEMBL1988437 & 809173 & 4.8 & 5.0941 & TST \\
\hline CHEMBL1968245 & 809173 & 4.5 & 4.5409 & TRN \\
\hline CHEMBL1979577 & 809173 & 4.5 & 5.2985 & TRN \\
\hline CHEMBL1998121 & 809173 & 5.7 & 5.0236 & TRN \\
\hline CHEMBL1233887 & 809173 & 4.3 & 4.5127 & TST \\
\hline CHEMBL52387 & 809173 & 4.5 & 4.782 & TST \\
\hline CHEMBL1985566 & 809173 & 5.6 & 5.1674 & TRN \\
\hline CHEMBL 2003689 & 809173 & 4.3 & 4.5846 & TRN \\
\hline CHEMBL379835 & 809173 & 6.8 & 5.1172 & TST \\
\hline CHEMBL1979357 & 809173 & 4.5 & 4.3853 & TRN \\
\hline CHEMBL1980802 & 809173 & 4.5 & 4.9175 & TST \\
\hline
\end{tabular}




\begin{tabular}{|c|c|c|c|c|c|}
\hline \\
\hline CHEMBL1996649 & 809173 & 4.3 & 4.258 & TRN & \\
\hline CHEMBL1996817 & 809173 & 4.5 & 5.3701 & TRN & \\
\hline CHEMBL1986756 & 809173 & 4.3 & 4.362 & TRN & \\
\hline CHEMBL2004355 & 809173 & 8.5 & 8.0321 & TRN & \\
\hline CHEMBL468280 & 809173 & 4.5 & 4.4867 & TST & \\
\hline CHEMBL1990884 & 809173 & 4.5 & 4.5154 & TRN & \\
\hline CHEMBL3109278 & 809173 & 4.4 & 4.3999 & TRN & \\
\hline CHEMBL 256835 & 809173 & 4.5 & 5.0558 & TRN & \\
\hline CHEMBL1974998 & 809173 & 4.3 & 4.3521 & TRN & \\
\hline CHEMBL1980142 & 809173 & 4.5 & 4.1498 & TRN & \\
\hline CHEMBL41783 & 809173 & 4.5 & 4.7138 & TRN & \\
\hline CHEMBL 2004438 & 809173 & 4.4 & 4.2834 & TRN & \\
\hline CHEMBL 2006276 & 809173 & 4.5 & 4.8495 & TRN & \\
\hline CHEMBL191003 & 809173 & 6.2 & 5.66299 & 9999999999 & TRN \\
\hline CHEMBL 271381 & 809173 & 4.5 & 4.7188 & TRN & \\
\hline CHEMBL 2006785 & 809173 & 4.5 & 4.3251 & TRN & \\
\hline CHEMBL1982466 & 809173 & 4.5 & 4.2373 & TRN & \\
\hline CHEMBL1973359 & 809173 & 5.8 & 6.55399 & 9999999999 & TST \\
\hline CHEMBL1995740 & 809173 & 4.5 & 5.3006 & TRN & \\
\hline CHEMBL1996390 & 809173 & 4.5 & 5.1152 & TRN & \\
\hline CHEMBL1979690 & 809173 & 7.4 & 7.2105 & TRN & \\
\hline CHEMBL 234085 & 809173 & 4.3 & 4.5891 & TRN & \\
\hline CHEMBL 209082 & 809173 & 5.9 & 6.7094 & TRN & \\
\hline CHEMBL1995832 & 809173 & 6.3 & 6.5991 & TRN & \\
\hline CHEMBL1969042 & 809173 & 4.5 & 4.6706 & TRN & \\
\hline CHEMBL 2000345 & 809173 & 4.5 & 5.2636 & TRN & \\
\hline CHEMBL1999931 & 809173 & 6.4 & 6.8403 & TRN & \\
\hline CHEMBL1976376 & 809173 & 4.3 & 4.4273 & TRN & \\
\hline CHEMBL1991640 & 809173 & 4.5 & 4.6747 & TST & \\
\hline CHEMBL1983575 & 809173 & 6.6 & 6.3006 & TRN & \\
\hline CHEMBL1968868 & 809173 & 4.3 & 4.4646 & TRN & \\
\hline CHEMBL1375418 & 809173 & 4.5 & 3.9491 & TRN & \\
\hline CHEMBL 302449 & 809173 & 7.1 & 5.6505 & TST & \\
\hline CHEMBL2007064 & 809173 & 4.5 & 4.7129 & TRN & \\
\hline CHEMBL1981047 & 809173 & 4.4 & 4.7621 & TRN & \\
\hline CHEMBL229968 & 809173 & 5.6 & 5.595 & TRN & \\
\hline CHEMBL1976196 & 809173 & 5.3 & 4.9189 & TST & \\
\hline CHEMBL1976240 & 809173 & 4.5 & 4.5621 & TRN & \\
\hline CHEMBL1997197 & 809173 & 4.3 & 4.9391 & TRN & \\
\hline CHEMBL1979093 & 809173 & 4.5 & 4.4552 & TRN & \\
\hline CHEMBL1968151 & 809173 & 4.5 & 4.3555 & TRN & \\
\hline CHEMBL1381197 & 809173 & 4.5 & 4.0865 & TRN & \\
\hline CHEMBL1987009 & 809173 & 6.6 & 5.5163 & TRN & \\
\hline CHEMBL379218 & 809173 & 4.5 & 4.9803 & TRN & \\
\hline CHEMBL 2003817 & 809173 & 4.5 & 4.2504 & TRN & \\
\hline CHEMBL336961 & 809173 & 4.5 & 4.5848 & TST & \\
\hline CHEMBL1994830 & 809173 & 4.5 & 5.0781 & TRN & \\
\hline CHEMBL1987054 & 809173 & 4.5 & 4.8938 & TRN & \\
\hline
\end{tabular}




\begin{tabular}{|c|c|c|c|c|c|}
\hline \multirow[b]{2}{*}{ CHEMBL1970083 } & \multirow[b]{2}{*}{809173} & \multirow[b]{2}{*}{4.5} & \\
\hline & & & 5.0906 & TRN & \\
\hline CHEMBL 226403 & 809173 & 6.5 & 5.4832 & TRN & \\
\hline CHEMBL2005631 & 809173 & 4.5 & 4.6426 & TRN & \\
\hline CHEMBL1994938 & 809173 & 4.5 & 4.341 & TRN & \\
\hline CHEMBL1977223 & 809173 & 4.5 & 6.6187 & TRN & \\
\hline CHEMBL1995765 & 809173 & 4.5 & 4.6438 & TST & \\
\hline CHEMBL1966279 & 809173 & 4.5 & 4.6297 & TRN & \\
\hline CHEMBL1236126 & 809173 & 4.5 & 4.3066 & TRN & \\
\hline CHEMBL1984760 & 809173 & 6.3 & 6.2816 & TRN & \\
\hline CHEMBL1997846 & 809173 & 5.6 & 5.3021 & TRN & \\
\hline CHEMBL 2004419 & 809173 & 6.1 & 6.4411 & TRN & \\
\hline CHEMBL1991728 & 809173 & 4.5 & 4.9643 & TRN & \\
\hline CHEMBL360847 & 809173 & 4.3 & 4.6479 & TST & \\
\hline CHEMBL 2007073 & 809173 & 4.3 & 4.8167 & TRN & \\
\hline CHEMBL1995811 & 809173 & 6.3 & 6.2559 & TRN & \\
\hline CHEMBL1975787 & 809173 & 6.0 & 5.6976 & TRN & \\
\hline CHEMBL 2002407 & 809173 & 4.5 & 4.7683 & TRN & \\
\hline CHEMBL1972489 & 809173 & 4.5 & 4.3378 & TRN & \\
\hline CHEMBL1992937 & 809173 & 6.2 & 4.9402 & TST & \\
\hline CHEMBL1972119 & 809173 & 4.5 & 4.1833 & TRN & \\
\hline CHEMBL1986328 & 809173 & 4.5 & 4.7559 & TST & \\
\hline CHEMBL95692 & 809173 & 4.5 & 4.2532 & TRN & \\
\hline CHEMBL1090356 & 809173 & 7.8 & 6.9156 & TRN & \\
\hline CHEMBL 2002450 & 809173 & 4.3 & 4.9 & TRN & \\
\hline CHEMBL1976455 & 809173 & 4.5 & 4.4615 & TRN & \\
\hline CHEMBL261849 & 809173 & 4.3 & 4.4812 & TST & \\
\hline CHEMBL1983923 & 809173 & 4.4 & 4.79 & TRN & \\
\hline CHEMBL1983534 & 809173 & 4.5 & 4.0944 & TRN & \\
\hline CHEMBL1982361 & 809173 & 4.5 & 4.577 & TRN & \\
\hline CHEMBL1999112 & 809173 & 4.5 & 4.7836 & TST & \\
\hline CHEMBL1982122 & 809173 & 4.5 & 4.2586 & TRN & \\
\hline CHEMBL2000801 & 809173 & 4.5 & 4.1688 & TRN & \\
\hline CHEMBL1682546 & 809173 & 4.5 & 4.2305 & TRN & \\
\hline CHEMBL1988872 & 809173 & 4.3 & 5.2835 & TRN & \\
\hline CHEMBL1991395 & 809173 & 6.0 & 5.8002 & TST & \\
\hline CHEMBL1971245 & 809173 & 4.5 & 4.96399 & 99999999995 & TST \\
\hline CHEMBL1996780 & 809173 & 4.5 & 4.5768 & TST & \\
\hline CHEMBL1972142 & 809173 & 4.5 & 5.33799 & 9999999999 & TST \\
\hline CHEMBL1966514 & 809173 & 4.5 & 4.8458 & TST & \\
\hline CHEMBL2003638 & 809173 & 6.1 & 6.7918 & TST & \\
\hline CHEMBL296586 & 809173 & 4.5 & 4.7726 & TST & \\
\hline CHEMBL1996066 & 809173 & 4.5 & 4.363 & TST & \\
\hline CHEMBL1983393 & 809173 & 4.3 & 4.4333 & TST & \\
\hline CHEMBL516429 & 809173 & 5.6 & 4.8447 & TST & \\
\hline CHEMBL1993722 & 809173 & 4.5 & 4.2095 & TST & \\
\hline CHEMBL1970806 & 809173 & 4.5 & 4.1816 & TST & \\
\hline CHEMBL2006674 & 809173 & 4.3 & 4.9828 & TST & \\
\hline CHEMBL1984236 & 809173 & 4.3 & 4.6575 & TST & \\
\hline & & & & 15547 & \\
\hline
\end{tabular}




\begin{tabular}{|c|c|c|c|c|c|}
\hline & & & & & \\
\hline CHEMBL1992371 & 809173 & 5.4 & 4.8714 & TST & \\
\hline CHEMBL1375640 & 809173 & 4.5 & 4.8828 & TST & \\
\hline CHEMBL1979970 & 809173 & 5.8 & 4.9194 & TST & \\
\hline CHEMBL2002599 & 809173 & 4.3 & 4.5098 & TST & \\
\hline CHEMBL 249282 & 809173 & 4.5 & 4.6768 & TST & \\
\hline CHEMBL1967252 & 809173 & 5.3 & 4.6169 & TST & \\
\hline CHEMBL 2004637 & 809173 & 4.3 & 4.4488 & TST & \\
\hline CHEMBL1993374 & 809173 & 6.8 & 6.0872 & TST & \\
\hline CHEMBL1969264 & 809173 & 4.5 & 4.9398 & TST & \\
\hline CHEMBL1994318 & 809173 & 4.3 & 4.6009 & TST & \\
\hline CHEMBL1973711 & 809173 & 4.5 & 4.83 & TST & \\
\hline CHEMBL 2006237 & 809173 & 4.5 & 4.2909 & TST & \\
\hline CHEMBL1999506 & 809173 & 4.3 & 4.26699 & 99999999995 & TST \\
\hline CHEMBL1967720 & 809173 & 4.5 & $5.4520 e$ & 0000000001 & TST \\
\hline CHEMBL1572266 & 809173 & 4.5 & 4.5895 & TST & \\
\hline CHEMBL1991138 & 809173 & 4.5 & 4.2579 & TST & \\
\hline CHEMBL1969755 & 809173 & 4.5 & 4.3895 & TST & \\
\hline CHEMBL1979516 & 809173 & 4.5 & 4.2423 & TST & \\
\hline CHEMBL1972820 & 809173 & 4.5 & 4.4692 & TST & \\
\hline CHEMBL1605605 & 809173 & 4.3 & 4.8509 & TST & \\
\hline CHEMBL1989029 & 809173 & 4.5 & 4.5573 & TST & \\
\hline CHEMBL392642 & 809173 & 4.5 & 5.075 & TST & \\
\hline CHEMBL514499 & 809173 & 4.5 & 4.3577 & TST & \\
\hline CHEMBL1970352 & 809173 & 5.9 & 5.4737 & TST & \\
\hline CHEMBL1965631 & 809173 & 4.5 & 5.9409 & TST & \\
\hline CHEMBL1980144 & 809173 & 4.5 & 4.2048 & TST & \\
\hline CHEMBL1991188 & 809173 & 4.5 & 4.4145 & TST & \\
\hline CHEMBL1980167 & 809173 & 5.8 & 4.8609 & TST & \\
\hline CHEMBL1972849 & 809173 & 4.5 & 4.3928 & TST & \\
\hline CHEMBL 215152 & 809173 & 4.3 & 4.5932 & TST & \\
\hline CHEMBL231209 & 809173 & 4.5 & 4.35 & TST & \\
\hline CHEMBL 2006765 & 809173 & 7.4 & 7.3163 & TST & \\
\hline CHEMBL1976220 & 809173 & 4.5 & 4.4621 & TST & \\
\hline CHEMBL259922 & 809173 & 4.5 & 4.4409 & TST & \\
\hline CHEMBL1997617 & 809173 & 4.5 & 4.3562 & TST & \\
\hline CHEMBL1969301 & 809173 & 4.5 & 4.6161 & TST & \\
\hline CHEMBL1982383 & 809173 & 4.5 & 5.7691 & TST & \\
\hline CHEMBL17370 & 809173 & 4.5 & 5.5135 & TST & \\
\hline CHEMBL1980246 & 809173 & 4.3 & 5.119 & TST & \\
\hline CHEMBL1987910 & 809173 & 4.5 & 4.4022 & TST & \\
\hline CHEMBL1983932 & 809173 & 4.5 & 4.479 & TST & \\
\hline CHEMBL1983980 & 809173 & 5.9 & 5.4955 & TST & \\
\hline CHEMBL1999484 & 809173 & 7.5 & 7.3641 & TST & \\
\hline CHEMBL1973399 & 809173 & 4.1 & 4.5076 & TST & \\
\hline CHEMBL1986899 & 809173 & 5.4 & 4.1942 & TST & \\
\hline CHEMBL1991285 & 809173 & 4.5 & 4.7775 & TST & \\
\hline CHEMBL1997822 & 809173 & 4.5 & 4.456 & TST & \\
\hline CHEMBL243088 & 809173 & 8.4 & 7.6302 & TST & \\
\hline & & & & 15548 & \\
\hline
\end{tabular}




\begin{tabular}{|c|c|c|c|c|}
\hline \multicolumn{5}{|c|}{ Supplemental Table s2.txt } \\
\hline CHEMBL1984038 & 809173 & 4.4 & 5.1324 & TST \\
\hline CHEMBL1993661 & 809173 & 6.9 & 8.0142 & TST \\
\hline CHEMBL2004615 & 809173 & 4.5 & 4.3838 & TST \\
\hline CHEMBL1997872 & 809173 & 4.5 & 4.5614 & TST \\
\hline CHEMBL36108 & 32099 & 6.4202 & 6.6445 & TRN \\
\hline CHEMBL290075 & 32099 & 5.0315 & 4.8073 & TRN \\
\hline CHEMBL34665 & 32099 & 5.1024 & 4.5456 & TRN \\
\hline CHEMBL36920 & 32099 & 5.2441 & 5.3024 & TRN \\
\hline CHEMBL444802 & 32099 & 4.5086 & 4.5793 & TRN \\
\hline CHEMBL34845 & 32099 & 4.6576 & 4.5888 & TRN \\
\hline CHEMBL34976 & 32099 & 5.4437 & 4.9942 & TRN \\
\hline CHEMBL284603 & 32099 & 5.0605 & 5.4668 & TRN \\
\hline CHEMBL286613 & 32099 & 5.0809 & 4.9344 & TRN \\
\hline CHEMBL38344 & 32099 & 4.1739 & 4.577 & TRN \\
\hline CHEMBL 37420 & 32099 & 4.8861 & 4.8155 & TST \\
\hline CHEMBL288077 & 32099 & 6.3979 & 5.3603 & TRN \\
\hline CHEMBL37003 & 32099 & 5.3565 & 5.2698 & TRN \\
\hline CHEMBL34199 & 32099 & 1.699 & 4.8996 & TST \\
\hline CHEMBL287486 & 32099 & 4.4949 & 4.1929 & TRN \\
\hline CHEMBL38109 & 32099 & 4.4318 & 4.3947 & TRN \\
\hline CHEMBL290611 & 32099 & 4.8861 & 4.7498 & TRN \\
\hline CHEMBL36880 & 32099 & 3.3979 & 5.322 & TST \\
\hline CHEMBL1907774 & 32099 & 6.0 & 5.3288 & TST \\
\hline CHEMBL37941 & 32099 & 4.5686 & 4.8335 & TRN \\
\hline CHEMBL285503 & 32099 & 4.1871 & 4.3187 & TRN \\
\hline CHEMBL288405 & 32099 & 3.8861 & 4.1628 & TRN \\
\hline CHEMBL285227 & 32099 & 4.585 & 4.4665 & TRN \\
\hline CHEMBL1907771 & 32099 & 6.0 & 4.4201 & TST \\
\hline CHEMBL287688 & 32099 & 4.5686 & 4.4393 & TRN \\
\hline CHEMBL 285053 & 32099 & 4.7959 & 4.3221 & TRN \\
\hline CHEMBL37733 & 32099 & 4.585 & 4.8007 & TRN \\
\hline CHEMBL 285526 & 32099 & 1.699 & 5.0321 & TST \\
\hline CHEMBL37129 & 32099 & 3.8861 & 4.3819 & TRN \\
\hline CHEMBL35870 & 32099 & 5.3468 & 5.5406 & TRN \\
\hline CHEMBL38284 & 32099 & 4.4202 & 4.8448 & TRN \\
\hline CHEMBL38181 & 32099 & 4.5686 & 4.6659 & TRN \\
\hline CHEMBL 37072 & 32099 & 5.7447 & 5.0438 & TRN \\
\hline CHEMBL35646 & 32099 & 3.8861 & 4.7993 & TST \\
\hline CHEMBL37193 & 32099 & 5.1192 & 4.4466 & TRN \\
\hline CHEMBL34534 & 32099 & 4.1612 & 4.409 & TST \\
\hline CHEMBL439922 & 32099 & 4.0706 & 4.5186 & TST \\
\hline CHEMBL288404 & 32099 & 4.1024 & 4.7786 & TRN \\
\hline CHEMBL285934 & 32099 & 4.7959 & 4.6463 & TRN \\
\hline CHEMBL36915 & 32099 & 4.5376 & 4.5985 & TRN \\
\hline CHEMBL1907952 & 32099 & 6.0 & 4.4427 & TST \\
\hline CHEMBL416599 & 32099 & 3.4089 & 4.9534 & TST \\
\hline CHEMBL38143 & 32099 & 3.4685 & 4.2513 & TRN \\
\hline CHEMBL417691 & 32099 & 4.8539 & 4.669 & TRN \\
\hline
\end{tabular}




\begin{tabular}{|c|c|c|c|c|c|}
\hline \multirow[b]{2}{*}{ CHEMBL37054 } & \multicolumn{5}{|c|}{ Supplemental Table S2.txt } \\
\hline & 32099 & 3.8861 & 4.3086 & TRN & \\
\hline CHEMBL 2000647 & 32099 & 6.0 & $4.5710 e$ & 0000000001 & TST \\
\hline CHEMBL38055 & 32099 & 4.1675 & 4.5916 & TRN & \\
\hline CHEMBL289897 & 32099 & 4.5376 & 4.4878 & TRN & \\
\hline CHEMBL286389 & 32099 & 5.8861 & 5.4467 & TRN & \\
\hline CHEMBL1907775 & 32099 & 6.0 & 4.8378 & TST & \\
\hline CHEMBL37092 & 32099 & 6.0555 & 6.4357 & TRN & \\
\hline CHEMBL 287485 & 32099 & 4.3665 & 4.3209 & TRN & \\
\hline CHEMBL 307943 & 50337 & 5.5229 & 5.5858 & TRN & \\
\hline CHEMBL 308293 & 50337 & 6.3979 & 5.7292 & TRN & \\
\hline CHEMBL419273 & 50337 & 5.9586 & 5.8463 & TRN & \\
\hline CHEMBL77095 & 50337 & 4.6021 & 6.0392 & TRN & \\
\hline CHEMBL77416 & 50337 & 4.6778 & 4.6476 & TRN & \\
\hline CHEMBL 77584 & 50337 & 5.6021 & 4.6782 & TRN & \\
\hline CHEMBL 307941 & 50337 & 4.5229 & 4.2961 & TRN & \\
\hline CHEMBL77458 & 50337 & 4.699 & 5.4219 & TRN & \\
\hline CHEMBL312065 & 50337 & 4.0 & 4.5398 & TRN & \\
\hline CHEMBL 74015 & 50337 & 5.1549 & 5.0464 & TRN & \\
\hline CHEMBL 307944 & 50337 & 5.6021 & 5.228 & TRN & \\
\hline CHEMBL77066 & 50337 & 5.699 & 5.4665 & TRN & \\
\hline CHEMBL 305627 & 50337 & 4.9208 & 4.7746 & TRN & \\
\hline CHEMBL 77540 & 50337 & 6.1549 & 6.3289 & TRN & \\
\hline CHEMBL77697 & 50337 & 5.5229 & 5.7618 & TRN & \\
\hline CHEMBL77002 & 50337 & 4.0 & 4.8257 & TRN & \\
\hline CHEMBL 306498 & 50337 & 6.1549 & 5.6449 & TRN & \\
\hline CHEMBL77264 & 50337 & 6.5229 & 6.2545 & TRN & \\
\hline CHEMBL310036 & 50337 & 4.3979 & 4.4009 & TRN & \\
\hline CHEMBL77469 & 50337 & 5.699 & 4.7104 & TRN & \\
\hline CHEMBL 305901 & 50337 & 5.301 & 4.7794 & TRN & \\
\hline CHEMBL78264 & 50337 & 3.0 & 3.7975 & TRN & \\
\hline CHEMBL76660 & 50337 & 3.0 & 4.2158 & TRN & \\
\hline CHEMBL 309347 & 50337 & 6.0 & 5.8261 & TRN & \\
\hline CHEMBL 76741 & 50337 & 5.1549 & 5.5611 & TRN & \\
\hline CHEMBL 77947 & 50337 & 5.301 & 5.5159 & TRN & \\
\hline CHEMBL 79711 & 50337 & 4.2218 & 5.3222 & TST & \\
\hline CHEMBL77210 & 50337 & 5.2218 & 5.4142 & TRN & \\
\hline CHEMBL 76941 & 50337 & 6.0 & 5.9329 & TRN & \\
\hline CHEMBL 80644 & 50337 & 4.8861 & 4.7099 & TRN & \\
\hline CHEMBL 306263 & 50337 & 5.6383 & 5.3861 & TRN & \\
\hline CHEMBL311935 & 50337 & 4.1612 & 4.6645 & TRN & \\
\hline CHEMBL77211 & 50337 & 5.3979 & 5.4755 & TRN & \\
\hline CHEMBL 77641 & 50337 & 6.6021 & 6.6136 & TRN & \\
\hline CHEMBL75680 & 50337 & 6.8239 & 5.955 & TST & \\
\hline CHEMBL 75756 & 50337 & 3.0 & 4.7856 & TST & \\
\hline CHEMBL78165 & 50337 & 6.3979 & 5.6152 & TST & \\
\hline CHEMBL80785 & 50337 & 5.9208 & 5.8645 & TRN & \\
\hline CHEMBL 76942 & 50337 & 5.8861 & 5.6267 & TST & \\
\hline CHEMBL76740 & 50337 & 6.0 & 5.6411 & TST & \\
\hline
\end{tabular}




\begin{tabular}{|c|c|c|c|c|c|}
\hline \multicolumn{6}{|c|}{ Supplemental Table S2.txt } \\
\hline CHEMBL77267 & 50337 & 5.0969 & 5.2743 & TRN & \\
\hline CHEMBL76559 & 50337 & 5.6383 & 5.3514 & TRN & \\
\hline CHEMBL 78232 & 50337 & 4.0 & 4.8556 & TST & \\
\hline CHEMBL77217 & 50337 & 6.0706 & 5.19600 & 0000000001 & TST \\
\hline CHEMBL74133 & 50337 & 4.301 & 5.984 & TST & \\
\hline CHEMBL76427 & 50337 & 4.6021 & 4.9495 & TST & \\
\hline CHEMBL77590 & 50337 & 4.699 & 4.109 & TRN & \\
\hline CHEMBL 306347 & 50337 & 5.0 & 4.9123 & TST & \\
\hline CHEMBL77019 & 50337 & 5.7447 & 4.8581 & TRN & \\
\hline CHEMBL306355 & 50337 & 6.699 & 5.0188 & TST & \\
\hline CHEMBL 307392 & 50337 & 3.0 & 4.8868 & TST & \\
\hline CHEMBL 9470 & 954845 & 6.5241 & 5.7731 & TST & \\
\hline CHEMBL412142 & 954845 & 4.1442 & 4.1064 & TRN & \\
\hline CHEMBL189584 & 954845 & 4.8755 & 4.9448 & TRN & \\
\hline CHEMBL191334 & 954845 & 4.3343 & 4.2573 & TRN & \\
\hline CHEMBL1190711 & 954845 & 5.7746 & 5.7879 & TRN & \\
\hline CHEMBL1230020 & 954845 & 4.3299 & 4.3185 & TRN & \\
\hline CHEMBL1256459 & 954845 & 7.9237 & 7.9181 & TRN & \\
\hline CHEMBL2363137 & 954845 & 5.3377 & 5.3152 & TRN & \\
\hline CHEMBL 258844 & 954845 & 5.1378 & 5.2093 & TRN & \\
\hline CHEMBL 379300 & 954845 & 6.6656 & 6.6646 & TRN & \\
\hline CHEMBL1970879 & 954845 & 5.4447 & 5.4973 & TRN & \\
\hline CHEMBL1590308 & 954845 & 2.7252 & 3.3076 & TST & \\
\hline CHEMBL 209148 & 954845 & 5.7635 & 5.7624 & TRN & \\
\hline CHEMBL1186585 & 954845 & 4.1981 & 4.169 & TRN & \\
\hline CHEMBL379975 & 954845 & 5.5185 & 5.5265 & TRN & \\
\hline CHEMBL180127 & 954845 & 3.4789 & 3.4808 & TRN & \\
\hline CHEMBL 373751 & 954845 & 3.4756 & 3.5317 & TRN & \\
\hline CHEMBL 255342 & 954845 & 2.9488 & 3.0858 & TRN & \\
\hline CHEMBL393929 & 954845 & 3.8433 & 3.8118 & TRN & \\
\hline CHEMBL 399530 & 954845 & 4.0529 & 4.0862 & TRN & \\
\hline CHEMBL188678 & 954845 & 4.1406 & 4.075 & TRN & \\
\hline CHEMBL 300389 & 954845 & 7.4841 & 7.4722 & TRN & \\
\hline CHEMBL 2137530 & 954845 & 5.2425 & 5.2315 & TRN & \\
\hline CHEMBL3392440 & 954845 & 5.0153 & 5.0338 & TRN & \\
\hline CHEMBL3186408 & 954845 & 3.4012 & 3.4656 & TST & \\
\hline CHEMBL512504 & 954845 & 4.2967 & 4.2419 & TRN & \\
\hline CHEMBL65 & 954845 & 9.9158 & 9.9656 & TRN & \\
\hline CHEMBL3349342 & 954845 & 4.7876 & 4.7842 & TRN & \\
\hline CHEMBL449158 & 954845 & 6.61 & 7.4332 & TST & \\
\hline CHEMBL 2134202 & 954845 & 3.7669 & 3.8028 & TRN & \\
\hline CHEMBL 2144069 & 954845 & 3.6005 & 3.5868 & TRN & \\
\hline CHEMBL210618 & 954845 & 3.7223 & 3.7838 & TRN & \\
\hline CHEMBL515416 & 954845 & 4.348 & 4.3431 & TRN & \\
\hline CHEMBL1404918 & 954845 & 2.985 & 3.0536 & TRN & \\
\hline CHEMBL509032 & 954845 & 6.976 & 6.9668 & TRN & \\
\hline CHEMBL585951 & 954845 & 6.346 & 6.2505 & TRN & \\
\hline CHEMBL1643959 & 954845 & 5.5859 & 5.5791 & TRN & \\
\hline
\end{tabular}




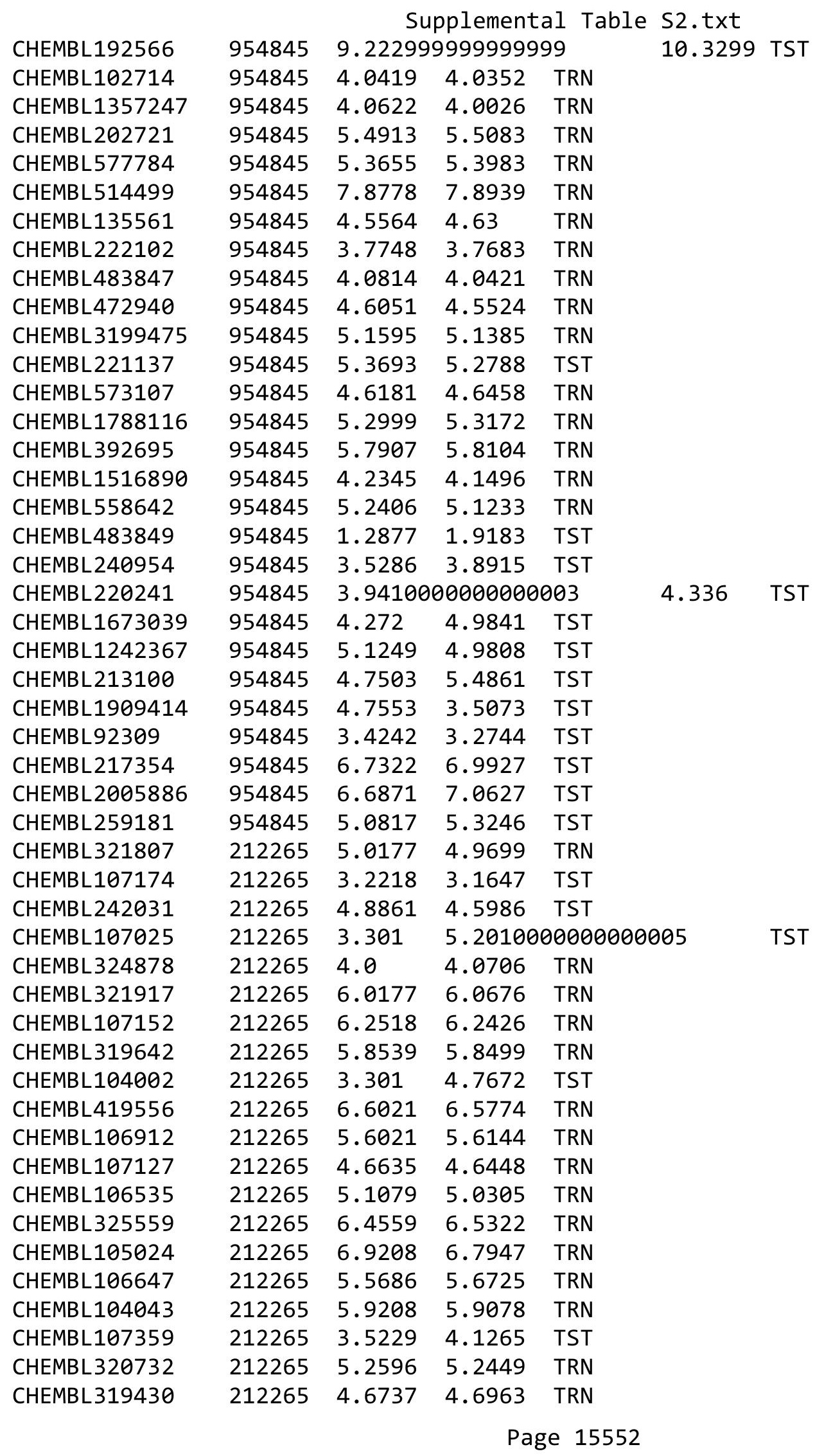




\begin{tabular}{|c|c|c|c|c|}
\hline & & & oplement & al $\mathrm{T}$ \\
\hline CHEMBL321062 & 212265 & 4.699 & 4.8538 & TRN \\
\hline CHEMBL321460 & 212265 & 5.0 & 4.9964 & TRN \\
\hline CHEMBL106989 & 212265 & 5.2518 & 5.182 & TRN \\
\hline CHEMBL104577 & 212265 & 4.5058 & 4.4624 & TRN \\
\hline CHEMBL107450 & 212265 & 3.5229 & 3.5304 & TRN \\
\hline CHEMBL107909 & 212265 & 4.7496 & 4.803 & TRN \\
\hline CHEMBL324666 & 212265 & 6.301 & 6.186 & TRN \\
\hline CHEMBL321146 & 212265 & 6.0 & 6.0475 & TRN \\
\hline CHEMBL323209 & 212265 & 5.2218 & 5.079 & TRN \\
\hline CHEMBL106826 & 212265 & 5.0 & 4.3844 & TST \\
\hline CHEMBL104569 & 212265 & 5.2218 & 5.2142 & TRN \\
\hline CHEMBL320500 & 212265 & 4.7447 & 4.6937 & TRN \\
\hline CHEMBL320834 & 212265 & 5.1367 & 5.144 & TRN \\
\hline CHEMBL106401 & 212265 & 5.301 & 5.3741 & TRN \\
\hline CHEMBL324440 & 212265 & 5.7959 & 5.7951 & TRN \\
\hline CHEMBL104329 & 212265 & 6.7212 & 6.7602 & TRN \\
\hline CHEMBL322224 & 212265 & 3.5229 & 3.582 & TRN \\
\hline CHEMBL106945 & 212265 & 5.6576 & 5.7582 & TRN \\
\hline CHEMBL107954 & 212265 & 3.5229 & 3.4305 & TRN \\
\hline CHEMBL318843 & 212265 & 4.4145 & 4.247 & TRN \\
\hline CHEMBL105614 & 212265 & 6.5229 & 6.5652 & TRN \\
\hline CHEMBL108105 & 212265 & 5.8125 & 5.0224 & TST \\
\hline CHEMBL320155 & 212265 & 4.9208 & 4.3439 & TST \\
\hline CHEMBL104470 & 212265 & 4.6021 & 4.6569 & TRN \\
\hline CHEMBL104671 & 212265 & 4.5229 & 4.5482 & TRN \\
\hline CHEMBL106879 & 212265 & 5.2676 & 5.2896 & TRN \\
\hline CHEMBL107405 & 212265 & 3.301 & 3.303 & TRN \\
\hline CHEMBL104175 & 212265 & 4.2041 & 4.2953 & TRN \\
\hline CHEMBL108276 & 212265 & 4.3372 & 5.0352 & TST \\
\hline CHEMBL108902 & 212265 & 6.7959 & 6.7751 & TRN \\
\hline CHEMBL107004 & 212265 & 5.2596 & 4.6376 & TST \\
\hline CHEMBL323961 & 212265 & 3.5229 & 4.0414 & TST \\
\hline CHEMBL108104 & 212265 & 5.1249 & 5.6738 & TST \\
\hline CHEMBL105660 & 212265 & 3.301 & 4.6453 & TST \\
\hline CHEMBL107950 & 212265 & 6.0757 & 6.016 & TRN \\
\hline CHEMBL107588 & 212265 & 5.4089 & 4.6844 & TST \\
\hline CHEMBL105262 & 212265 & 5.0458 & 5.0194 & TRN \\
\hline CHEMBL106733 & 212265 & 5.3098 & 5.3074 & TRN \\
\hline CHEMBL322571 & 212265 & 4.2314 & 4.2551 & TRN \\
\hline CHEMBL322102 & 212265 & 6.0 & 6.0152 & TRN \\
\hline CHEMBL324869 & 212265 & 5.4815 & 5.4945 & TRN \\
\hline CHEMBL320472 & 212265 & 5.3098 & 5.2817 & TRN \\
\hline CHEMBL321590 & 212265 & 5.8861 & 6.023 & TST \\
\hline CHEMBL106727 & 212265 & 6.5528 & 5.6816 & TST \\
\hline CHEMBL178958 & 311895 & 7.4685 & 7.914 & TRN \\
\hline CHEMBL179766 & 311895 & 7.6383 & 7.7625 & TRN \\
\hline CHEMBL424959 & 311895 & 8.0088 & 8.168 & TRN \\
\hline CHEMBL360933 & 311895 & 7.4855 & 8.0919 & TRN \\
\hline
\end{tabular}




\begin{tabular}{|c|c|c|c|c|c|}
\hline & & \multicolumn{4}{|c|}{ Supplemental Table S2.txt } \\
\hline CHEMBL175492 & 311895 & 6.8877 & 7.3147 & TRN & \\
\hline CHEMBL178096 & 311895 & 6.301 & 6.4619 & TRN & \\
\hline CHEMBL179363 & 311895 & 8.9208 & 8.7846 & TRN & \\
\hline CHEMBL361343 & 311895 & 8.3188 & 8.4182 & TRN & \\
\hline CHEMBL179123 & 311895 & 8.9586 & 8.9036 & TRN & \\
\hline CHEMBL175840 & 311895 & 8.6778 & 8.2221 & TRN & \\
\hline CHEMBL178265 & 311895 & 5.5528 & 6.3549 & TRN & \\
\hline CHEMBL367754 & 311895 & 5.6443 & 5.6799 & TRN & \\
\hline CHEMBL179652 & 311895 & 8.8539 & 8.2586 & TST & \\
\hline CHEMBL179659 & 311895 & 7.8962 & 8.3695 & TRN & \\
\hline CHEMBL368234 & 311895 & 6.1958 & 5.725 & TRN & \\
\hline CHEMBL369088 & 311895 & 8.5686 & 8.2103 & TRN & \\
\hline CHEMBL360979 & 311895 & 8.3098 & 7.8714 & TST & \\
\hline CHEMBL179607 & 311895 & 8.1612 & 7.9062 & TRN & \\
\hline CHEMBL179052 & 311895 & 8.3665 & 8.2385 & TRN & \\
\hline CHEMBL175933 & 311895 & 7.8069 & 7.4756 & TRN & \\
\hline CHEMBL180516 & 311895 & 8.0862 & 8.5435 & TRN & \\
\hline CHEMBL359630 & 311895 & 6.8283 & 7.1505 & TRN & \\
\hline CHEMBL2112990 & 311895 & 6.9352 & 6.9917 & TRN & \\
\hline CHEMBL440935 & 311895 & 8.2291 & 8.0048 & TRN & \\
\hline CHEMBL179164 & 311895 & 7.8239 & 8.161 & TST & \\
\hline CHEMBL179577 & 311895 & 8.699 & 7.9319 & TRN & \\
\hline CHEMBL180415 & 311895 & 8.0315 & 8.7952 & TRN & \\
\hline CHEMBL 360519 & 311895 & 8.5376 & 8.6749 & TRN & \\
\hline CHEMBL362611 & 311895 & 8.7696 & 8.4778 & TRN & \\
\hline CHEMBL369299 & 311895 & 8.7959 & 8.1703 & TRN & \\
\hline CHEMBL179527 & 311895 & 8.7212 & 8.4721 & TRN & \\
\hline CHEMBL178654 & 311895 & 8.6021 & 8.5298 & TRN & \\
\hline CHEMBL 360780 & 311895 & 7.9586 & 7.6298 & TRN & \\
\hline CHEMBL360958 & 311895 & 8.3768 & 8.6793 & TRN & \\
\hline CHEMBL179633 & 311895 & 7.0655 & 7.0679 & TRN & \\
\hline CHEMBL179969 & 311895 & $7.1720 €$ & 30000000 & 6.7036 & TST \\
\hline CHEMBL175621 & 311895 & 7.2 & 7.4105 & TRN & \\
\hline CHEMBL360028 & 311895 & 8.4815 & 8.5309 & TRN & \\
\hline CHEMBL434720 & 311895 & 8.5686 & 8.3541 & TRN & \\
\hline CHEMBL175552 & 311895 & 7.4685 & 7.6792 & TRN & \\
\hline CHEMBL368702 & 311895 & 7.8041 & 8.5758 & TRN & \\
\hline CHEMBL179310 & 311895 & 7.5528 & 8.1839 & TST & \\
\hline CHEMBL153763 & 311895 & 7.699 & 7.749 & TRN & \\
\hline CHEMBL362618 & 311895 & 7.4225 & 7.63299 & 9999999999 & TRN \\
\hline CHEMBL362824 & 311895 & 8.4949 & 8.2531 & TRN & \\
\hline CHEMBL180018 & 311895 & 8.4089 & 7.7731 & TRN & \\
\hline CHEMBL179458 & 311895 & 6.3979 & 7.2304 & TST & \\
\hline CHEMBL178922 & 311895 & 5.9208 & 8.0426 & TST & \\
\hline CHEMBL175556 & 311895 & 8.0044 & 8.5808 & TRN & \\
\hline CHEMBL179313 & 311895 & 9.3979 & 8.2081 & TRN & \\
\hline CHEMBL178312 & 311895 & 8.2757 & 8.6287 & TRN & \\
\hline CHEMBL359629 & 311895 & 7.8962 & 8.1886 & TRN & \\
\hline
\end{tabular}




\begin{tabular}{|c|c|c|c|c|c|}
\hline \multicolumn{6}{|c|}{ Supplemental Table S } \\
\hline CHEMBL359660 & 311895 & 7.7077 & 7.7762 & TRN & \\
\hline CHEMBL178290 & 311895 & 8.4815 & 8.4529 & TRN & \\
\hline CHEMBL179726 & 311895 & 8.4202 & 8.3044 & TRN & \\
\hline CHEMBL175513 & 311895 & 7.9586 & 7.7675 & TRN & \\
\hline CHEMBL362232 & 311895 & 8.6576 & 8.4378 & TRN & \\
\hline CHEMBL359705 & 311895 & 5.119 & 5.7306 & TRN & \\
\hline CHEMBL179923 & 311895 & 8.5528 & 8.2601 & TRN & \\
\hline CHEMBL179074 & 311895 & 6.961 & 7.2756 & TST & \\
\hline CHEMBL179572 & 311895 & 8.8239 & 7.9063 & TRN & \\
\hline CHEMBL367792 & 311895 & 5.3817 & 4.9591 & TRN & \\
\hline CHEMBL360211 & 311895 & 8.4949 & 8.415 & TRN & \\
\hline CHEMBL180227 & 311895 & 8.4685 & 8.025 & TST & \\
\hline CHEMBL178199 & 311895 & 7.4962 & 7.8982 & TRN & \\
\hline CHEMBL175558 & 311895 & 7.3354 & 7.4522 & TRN & \\
\hline CHEMBL178573 & 311895 & 7.5528 & 8.1115 & TST & \\
\hline CHEMBL426051 & 311895 & 8.4815 & 8.44399 & 9999999999 & TST \\
\hline CHEMBL175557 & 311895 & 7.341 & 8.3109 & TST & \\
\hline CHEMBL180175 & 311895 & 8.8861 & 8.0841 & TST & \\
\hline CHEMBL178144 & 311895 & 8.2441 & 8.2342 & TST & \\
\hline CHEMBL175726 & 311895 & 8.1079 & 8.1993 & TST & \\
\hline CHEMBL176199 & 311895 & 8.4318 & 8.6274 & TST & \\
\hline CHEMBL179521 & 311895 & 4.301 & 7.1104 & TST & \\
\hline CHEMBL 362233 & 311895 & 7.0969 & 7.7723 & TST & \\
\hline CHEMBL427314 & 311895 & 7.3979 & 7.3612 & TST & \\
\hline CHEMBL 367492 & 311895 & 8.0269 & 7.8299 & TST & \\
\hline CHEMBL420833 & 753959 & 6.63 & 6.8777 & TRN & \\
\hline CHEMBL1796645 & 753959 & 8.82 & 8.5404 & TRN & \\
\hline CHEMBL1796646 & 753959 & 8.08 & 8.6258 & TRN & \\
\hline CHEMBL1796647 & 753959 & 7.68 & 7.8724 & TRN & \\
\hline CHEMBL1796648 & 753959 & 8.28 & 8.074 & TRN & \\
\hline CHEMBL1795359 & 753959 & 8.72 & 8.6393 & TRN & \\
\hline CHEMBL1796649 & 753959 & 7.6 & 7.8311 & TRN & \\
\hline CHEMBL1796650 & 753959 & 7.07 & 6.8895 & TRN & \\
\hline CHEMBL1796651 & 753959 & 7.37 & 7.2171 & TRN & \\
\hline CHEMBL1796652 & 753959 & 8.0 & 7.6182 & TST & \\
\hline CHEMBL1796653 & 753959 & 6.96 & 6.4079 & TRN & \\
\hline CHEMBL1796654 & 753959 & 7.96 & 7.8804 & TRN & \\
\hline CHEMBL1796655 & 753959 & 7.19 & 7.1958 & TRN & \\
\hline CHEMBL1796656 & 753959 & 7.57 & 7.5133 & TRN & \\
\hline CHEMBL1796657 & 753959 & 7.05 & 6.8857 & TRN & \\
\hline CHEMBL1796658 & 753959 & 5.7 & 5.6842 & TRN & \\
\hline CHEMBL1796659 & 753959 & 6.01 & 5.8833 & TRN & \\
\hline CHEMBL1796660 & 753959 & 5.17 & 5.8544 & TRN & \\
\hline CHEMBL1796661 & 753959 & 6.82 & 6.7683 & TRN & \\
\hline CHEMBL1796662 & 753959 & 5.54 & 5.8487 & TRN & \\
\hline CHEMBL1796663 & 753959 & 7.08 & 7.3061 & TRN & \\
\hline CHEMBL1796664 & 753959 & 8.32 & 7.7596 & TRN & \\
\hline CHEMBL1671889 & 753959 & 7.37 & 7.5138 & TRN & \\
\hline
\end{tabular}




\begin{tabular}{|c|c|c|c|c|c|}
\hline \multirow[b]{2}{*}{ CHEMBL1796665 } & & \multicolumn{4}{|c|}{ Supplemental Table s2.txt } \\
\hline & 753959 & 7.23 & 7.8573 & TST & \\
\hline CHEMBL1796666 & 753959 & 7.27 & 8.0463 & TST & \\
\hline CHEMBL1796667 & 753959 & 7.17 & 7.5507 & TST & \\
\hline CHEMBL1796668 & 753959 & 7.29 & 7.2412 & TST & \\
\hline CHEMBL1796669 & 753959 & 7.82 & 7.3377 & TST & \\
\hline CHEMBL1796670 & 753959 & 7.38 & 7.4034 & TST & \\
\hline CHEMBL1796671 & 753959 & 7.74 & 7.7267 & TST & \\
\hline CHEMBL1796672 & 753959 & 7.77 & 7.1377 & TST & \\
\hline CHEMBL1796673 & 753959 & 7.28 & 6.7778 & TST & \\
\hline CHEMBL1796674 & 753959 & 8.6 & 8.4 & TST & \\
\hline CHEMBL1796675 & 753959 & 8.89 & 8.7915 & TST & \\
\hline CHEMBL1796676 & 753959 & 8.12 & 8.3054 & TST & \\
\hline CHEMBL 28937 & 753959 & 7.07 & 7.2098 & TRN & \\
\hline CHEMBL360229 & 753959 & 7.26 & 6.9871 & TRN & \\
\hline CHEMBL182347 & 753959 & 7.21 & 7.24799 & 9999999999 & TRN \\
\hline CHEMBL180547 & 753959 & 7.26 & 7.6745 & TRN & \\
\hline CHEMBL180255 & 753959 & 7.29 & 7.5913 & TRN & \\
\hline CHEMBL180801 & 753959 & 7.06 & 7.5278 & TRN & \\
\hline CHEMBL183480 & 753959 & 7.88 & 7.9272 & TRN & \\
\hline CHEMBL182389 & 753959 & 7.76 & 8.0087 & TRN & \\
\hline CHEMBL183759 & 753959 & 7.22 & 7.01200 & 00000000005 & TRN \\
\hline CHEMBL359517 & 753959 & 7.22 & 7.5951 & TRN & \\
\hline CHEMBL180550 & 753959 & 8.08 & 8.0356 & TRN & \\
\hline CHEMBL180139 & 753959 & 7.79 & 7.9703 & TRN & \\
\hline CHEMBL180754 & 753959 & 7.92 & 7.7443 & TRN & \\
\hline CHEMBL359540 & 753959 & 7.2 & 7.0259 & TRN & \\
\hline CHEMBL181901 & 753959 & 7.74 & 7.8905 & TRN & \\
\hline CHEMBL182978 & 753959 & 8.39 & 8.1843 & TRN & \\
\hline CHEMBL360084 & 753959 & 7.31 & 7.5115 & TRN & \\
\hline CHEMBL182512 & 753959 & 7.72 & 7.6787 & TRN & \\
\hline CHEMBL262819 & 753959 & 7.95 & 7.6403 & TRN & \\
\hline CHEMBL361616 & 753959 & 7.88 & 7.6888 & TRN & \\
\hline CHEMBL183140 & 753959 & 7.92 & 7.8013 & TRN & \\
\hline CHEMBL180536 & 753959 & 7.69 & 7.5205 & TRN & \\
\hline CHEMBL183291 & 753959 & 7.88 & 7.6412 & TRN & \\
\hline CHEMBL368903 & 753959 & 7.48 & 7.5885 & TRN & \\
\hline CHEMBL183666 & 753959 & 8.12 & 8.1175 & TRN & \\
\hline CHEMBL181444 & 753959 & 7.21 & 7.2184 & TRN & \\
\hline CHEMBL 369304 & 753959 & 7.56 & 7.6639 & TRN & \\
\hline CHEMBL362174 & 753959 & 7.72 & 7.46200 & 0000000001 & TRN \\
\hline CHEMBL182944 & 753959 & 7.09 & 7.6436 & TRN & \\
\hline CHEMBL360574 & 753959 & 7.82 & 7.4594 & TRN & \\
\hline CHEMBL362381 & 753959 & 7.88 & 7.7017 & TRN & \\
\hline CHEMBL425337 & 753959 & 7.15 & 7.0477 & TRN & \\
\hline CHEMBL361734 & 753959 & 7.42 & 7.4875 & TRN & \\
\hline CHEMBL362044 & 753959 & 7.49 & 7.4826 & TRN & \\
\hline CHEMBL1796853 & 753959 & 7.53 & 8.058 & TST & \\
\hline CHEMBL360525 & 753959 & 9.09 & 9.043 & TRN & \\
\hline
\end{tabular}




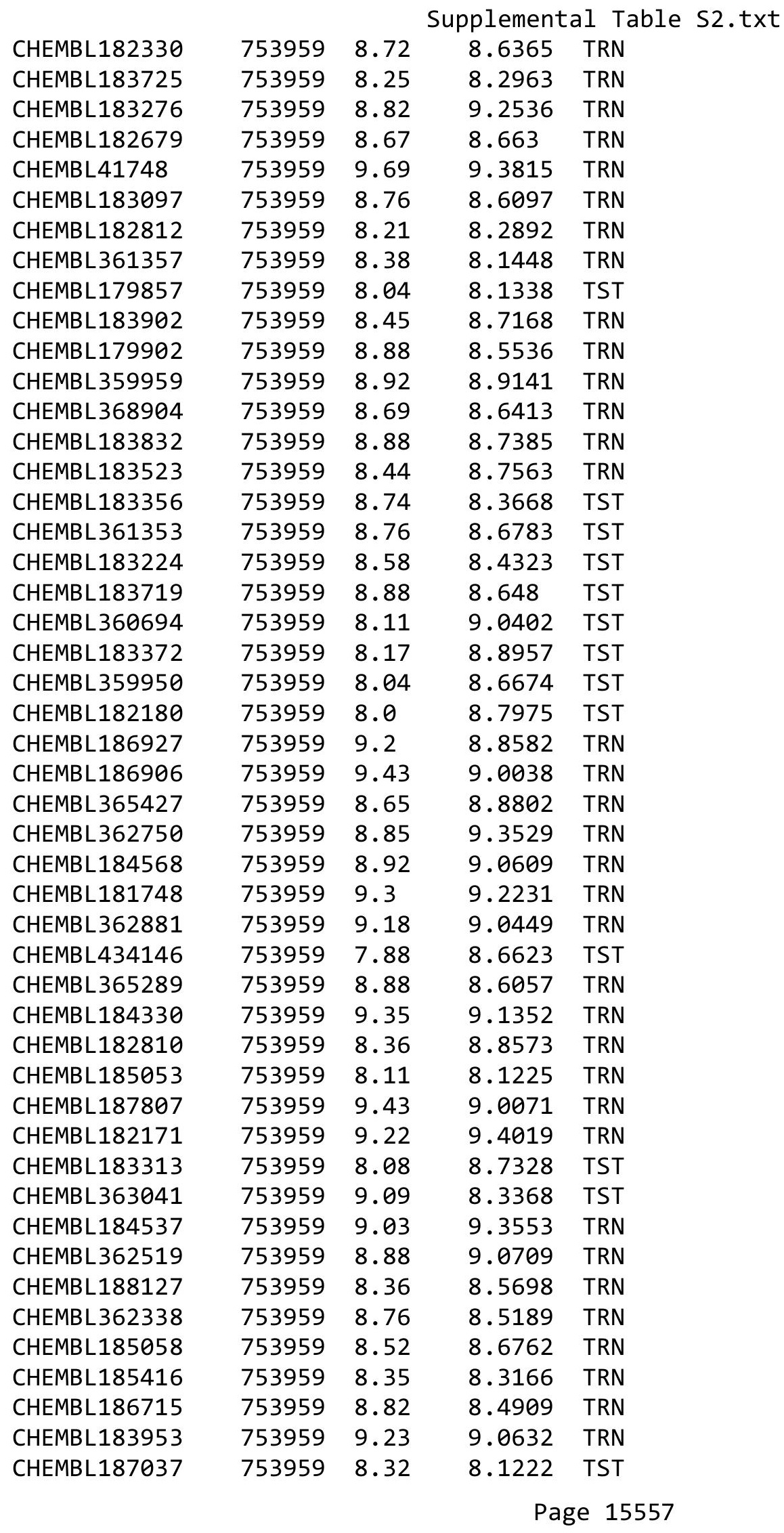




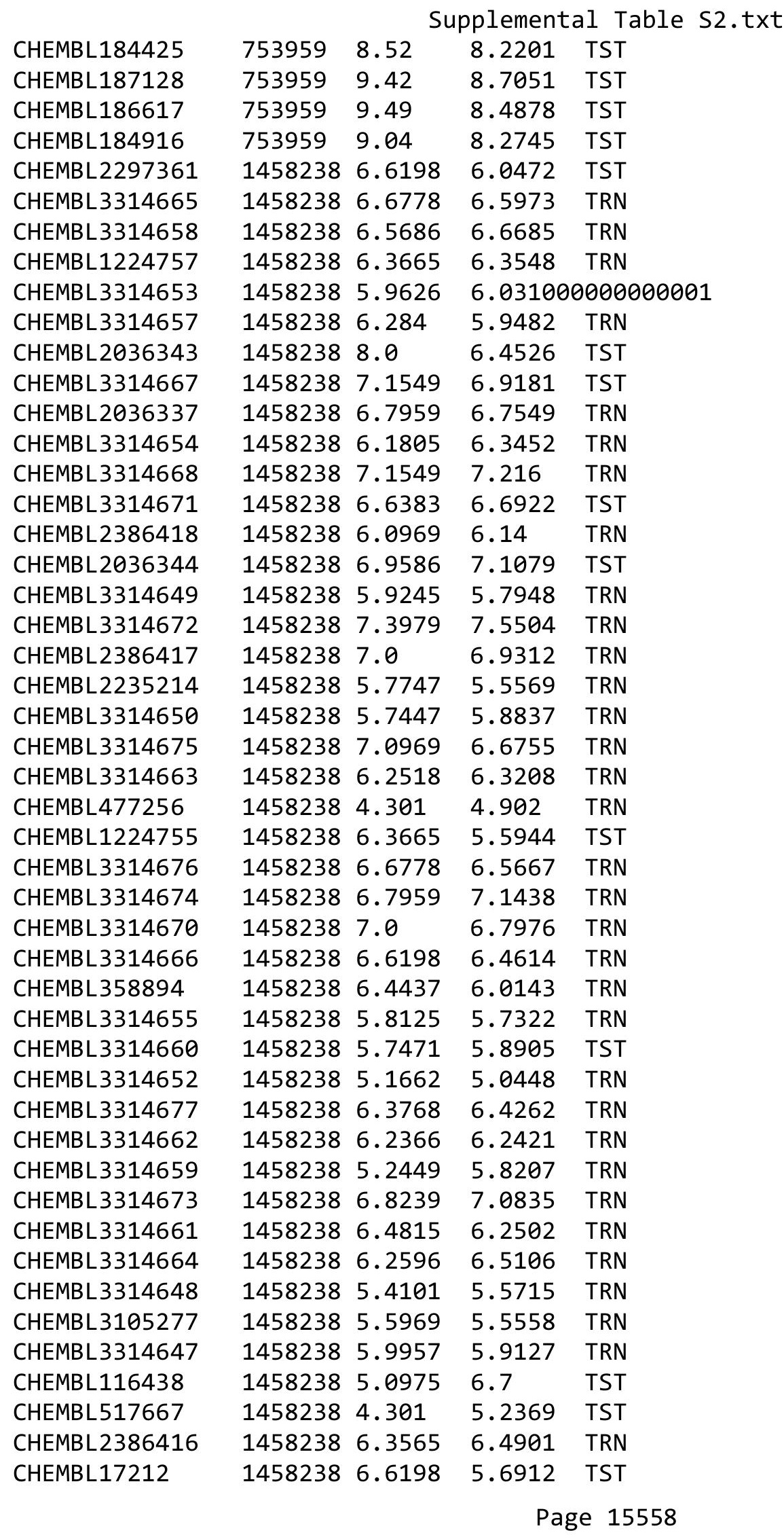


Supplemental Table S2.txt

\begin{tabular}{|c|c|c|c|c|c|}
\hline CHEMBL472887 & 1458238 & 5.2328 & 5.1706 & TRN & \\
\hline CHEMBL 379849 & 1458238 & 6.4949 & 6.2521 & TST & \\
\hline CHEMBL 2036345 & 1458238 & 3.3979 & 6.3974 & TST & \\
\hline CHEMBL1257317 & 1458238 & 6.2441 & 6.4176 & TRN & \\
\hline CHEMBL3314656 & 1458238 & 6.2291 & 6.2872 & TRN & \\
\hline CHEMBL3314651 & 1458238 & 5.9318 & 5.7444 & TRN & \\
\hline CHEMBL3314669 & 1458238 & 6.9586 & 6.6275 & TRN & \\
\hline CHEMBL 392538 & 442727 & 6.699 & 6.9413 & TST & \\
\hline CHEMBL391584 & 442727 & 6.5229 & 6.5219 & TRN & \\
\hline CHEMBL233387 & 442727 & 6.2218 & 6.2091 & TRN & \\
\hline CHEMBL234436 & 442727 & 6.0969 & 6.101 & TRN & \\
\hline CHEMBL234418 & 442727 & 6.699 & 6.6967 & TRN & \\
\hline CHEMBL391503 & 442727 & 7.0458 & 7.0465 & TRN & \\
\hline CHEMBL393461 & 442727 & 6.699 & 6.6995 & TRN & \\
\hline CHEMBL 233787 & 442727 & 4.301 & 4.3011 & TRN & \\
\hline CHEMBL392537 & 442727 & 4.8239 & 4.8245 & TRN & \\
\hline CHEMBL395396 & 442727 & 6.5229 & 6.5264 & TRN & \\
\hline CHEMBL394323 & 442727 & 6.699 & 6.7044 & TRN & \\
\hline CHEMBL 233837 & 442727 & 6.5229 & 6.5238 & TRN & \\
\hline CHEMBL234405 & 442727 & 6.699 & 6.7905 & TST & \\
\hline CHEMBL393928 & 442727 & 6.8861 & 6.8845 & TRN & \\
\hline CHEMBL392727 & 442727 & 6.3979 & 6.393 & TRN & \\
\hline CHEMBL 236418 & 442727 & 6.6021 & 6.6024 & TRN & \\
\hline CHEMBL 234455 & 442727 & 6.0 & 6.0018 & TRN & \\
\hline CHEMBL234264 & 442727 & 6.8861 & 6.8842 & TRN & \\
\hline CHEMBL233836 & 442727 & 6.0 & 6.0005 & TRN & \\
\hline CHEMBL 234230 & 442727 & 6.8239 & 6.8253 & TRN & \\
\hline CHEMBL394117 & 442727 & 6.699 & 6.70799 & 9999999999 & TRN \\
\hline CHEMBL236417 & 442727 & 6.1549 & 6.1554 & TRN & \\
\hline CHEMBL234407 & 442727 & 5.699 & 5.3949 & TST & \\
\hline CHEMBL 393074 & 442727 & 5.8861 & 5.8863 & TRN & \\
\hline CHEMBL 233788 & 442727 & 5.3979 & 5.4003 & TRN & \\
\hline CHEMBL 234406 & 442727 & 6.301 & 6.3039 & TRN & \\
\hline CHEMBL 233377 & 442727 & 6.699 & 6.7025 & TRN & \\
\hline CHEMBL394324 & 442727 & 6.301 & 6.3031 & TRN & \\
\hline CHEMBL 233382 & 442727 & 6.301 & 6.2994 & TRN & \\
\hline CHEMBL 234435 & 442727 & 5.699 & 6.5125 & TST & \\
\hline CHEMBL450880 & 442727 & 7.0 & 6.9952 & TRN & \\
\hline CHEMBL 234229 & 442727 & 5.7959 & 5.7913 & TRN & \\
\hline CHEMBL233381 & 442727 & 6.0 & 5.999 & TRN & \\
\hline CHEMBL 233378 & 442727 & 6.699 & 6.8031 & TST & \\
\hline CHEMBL392497 & 442727 & 6.8239 & 6.822 & TRN & \\
\hline CHEMBL234419 & 442727 & 6.5229 & 6.521 & TRN & \\
\hline CHEMBL395344 & 442727 & 6.3979 & 6.2861 & TST & \\
\hline CHEMBL233215 & 442727 & 6.699 & 6.7007 & TRN & \\
\hline CHEMBL391585 & 442727 & 5.6383 & 5.6378 & TRN & \\
\hline CHEMBL 233379 & 442727 & 6.301 & 6.4759 & TST & \\
\hline CHEMBL234266 & 442727 & 5.6383 & 6.0933 & TST & \\
\hline
\end{tabular}


Supplemental Table S2.txt

\begin{tabular}{|c|c|c|c|c|c|}
\hline CHEMBL398064 & 442727 & 6.3979 & 6.3941 & TRN & \\
\hline CHEMBL429622 & 442727 & 6.0 & 6.4994 & TST & \\
\hline CHEMBL233386 & 442727 & 6.0458 & 6.0493 & TRN & \\
\hline CHEMBL395343 & 442727 & 5.5229 & 6.1913 & TST & \\
\hline CHEMBL 234453 & 442727 & 6.9208 & 6.8145 & TST & \\
\hline CHEMBL234420 & 442727 & 6.0 & 6.8806 & TST & \\
\hline CHEMBL 234621 & 442727 & 6.5229 & 6.5218 & TRN & \\
\hline CHEMBL234265 & 442727 & 6.4559 & 6.4556 & TRN & \\
\hline CHEMBL395397 & 442727 & 6.6021 & 6.6011 & TRN & \\
\hline CHEMBL391505 & 442727 & 7.0 & 6.7887 & TST & \\
\hline CHEMBL233206 & 442727 & 6.6021 & 6.6028 & TRN & \\
\hline CHEMBL3661296 & 1528427 & 6.5874 & 6.7286 & TRN & \\
\hline CHEMBL3661311 & 1528427 & 6.5102 & 6.2626 & TRN & \\
\hline CHEMBL3661306 & 1528427 & 6.1194 & 6.2587 & TRN & \\
\hline CHEMBL3661295 & 1528427 & 6.6438 & \multicolumn{2}{|c|}{6.742999999999999} & TRN \\
\hline CHEMBL 3661278 & 1528427 & 6.8729 & 6.8443 & TRN & \\
\hline CHEMBL3661206 & 1528427 & 6.0877 & 6.2272 & TRN & \\
\hline CHEMBL3661274 & 1528427 & 7.1314 & 7.0737 & TRN & \\
\hline CHEMBL3661293 & 1528427 & 6.265 & 6.2905 & TRN & \\
\hline CHEMBL3943985 & 1528427 & 6.4624 & 6.6322 & TRN & \\
\hline CHEMBL3661254 & 1528427 & 6.1563 & 6.0012 & TRN & \\
\hline CHEMBL3661268 & 1528427 & 6.3683 & 6.3466 & TRN & \\
\hline CHEMBL3661229 & 1528427 & 6.4184 & 6.4962 & TRN & \\
\hline CHEMBL3661312 & 1528427 & 6.1677 & 6.1459 & TRN & \\
\hline CHEMBL3661313 & 1528427 & 6.6385 & 6.5656 & TRN & \\
\hline CHEMBL3661281 & 1528427 & 6.4203 & 6.4539 & TRN & \\
\hline CHEMBL3661220 & 1528427 & 6.3061 & 6.3453 & TRN & \\
\hline CHEMBL3661205 & 1528427 & 5.9378 & 5.9712 & TRN & \\
\hline CHEMBL3661315 & 1528427 & 6.7256 & 6.8569 & TRN & \\
\hline CHEMBL3661219 & 1528427 & 6.176 & 5.7501 & TRN & \\
\hline CHEMBL3665858 & 1528427 & 7.5719 & 7.4496 & TRN & \\
\hline CHEMBL3661288 & 1528427 & 6.5805 & 6.7164 & TRN & \\
\hline CHEMBL3661209 & 1528427 & 6.2541 & 6.221 & TRN & \\
\hline CHEMBL3661267 & 1528427 & 6.8099 & 6.6521 & TRN & \\
\hline CHEMBL3661284 & 1528427 & 6.9003 & 6.8245 & TRN & \\
\hline CHEMBL3665862 & 1528427 & 7.7721 & 7.475 & TRN & \\
\hline CHEMBL3661202 & 1528427 & 5.3995 & 5.3777 & TRN & \\
\hline CHEMBL3661231 & 1528427 & 7.2573 & 7.3513 & TRN & \\
\hline CHEMBL3661259 & 1528427 & 6.1751 & 6.2259 & TST & \\
\hline CHEMBL3661227 & 1528427 & 7.3936 & 7.5213 & TRN & \\
\hline CHEMBL3661307 & 1528427 & 6.4566 & 6.6792 & TST & \\
\hline CHEMBL3639601 & 1528427 & 6.9698 & 7.1735 & TRN & \\
\hline CHEMBL3661208 & 1528427 & 5.5036 & 5.9719 & TRN & \\
\hline CHEMBL 3661314 & 1528427 & 6.8814 & 6.8945 & TST & \\
\hline CHEMBL3661264 & 1528427 & 6.604 & 6.5304 & TRN & \\
\hline CHEMBL3665857 & 1528427 & 7.2418 & 7.3487 & TRN & \\
\hline CHEMBL3661201 & 1528427 & 6.0458 & 5.9867 & TRN & \\
\hline CHEMBL3661261 & 1528427 & 6.7597 & 6.6892 & TRN & \\
\hline
\end{tabular}

Page 15560 
Supplemental Table S2.txt

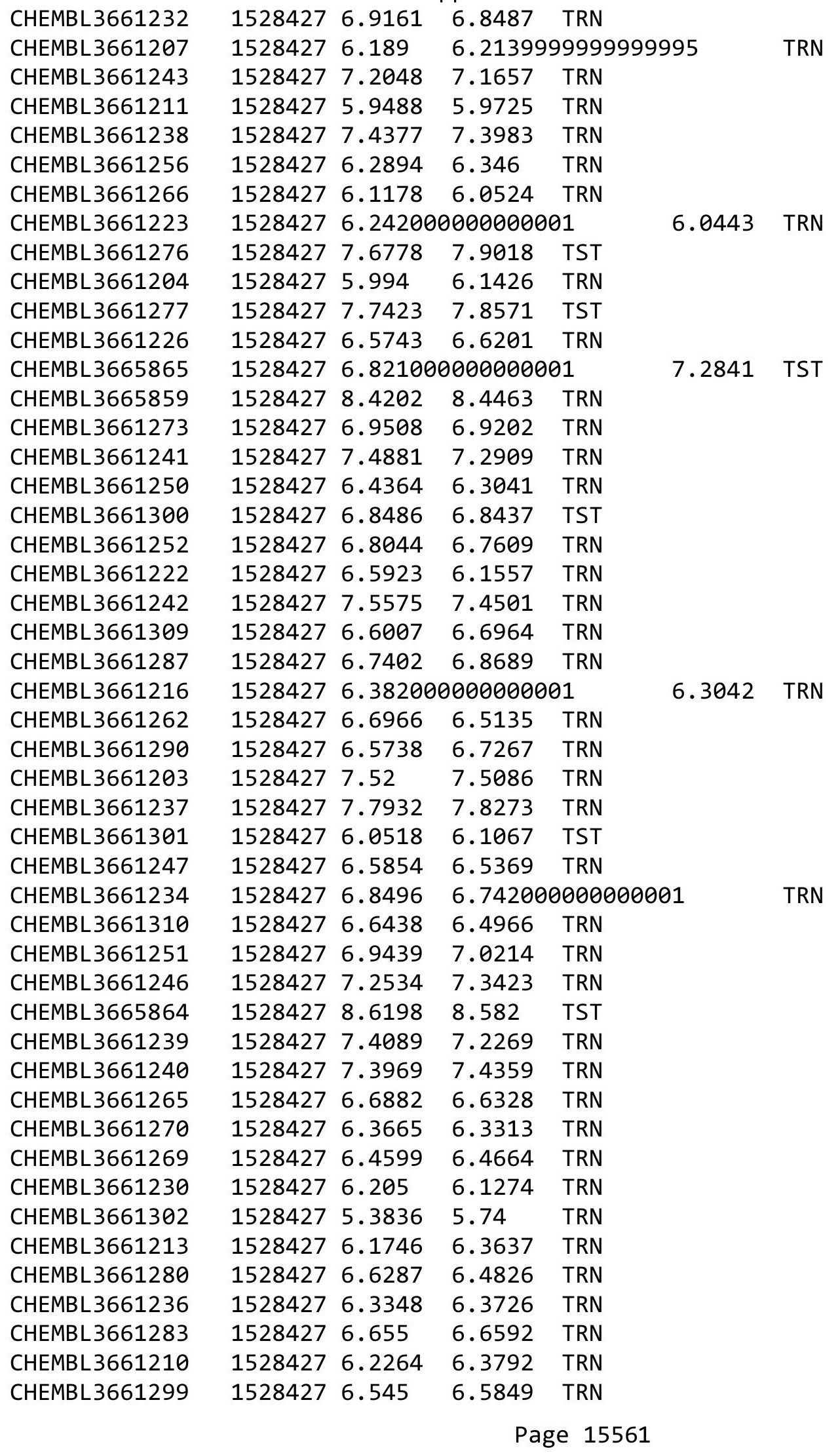


Supplemental Table S2.txt

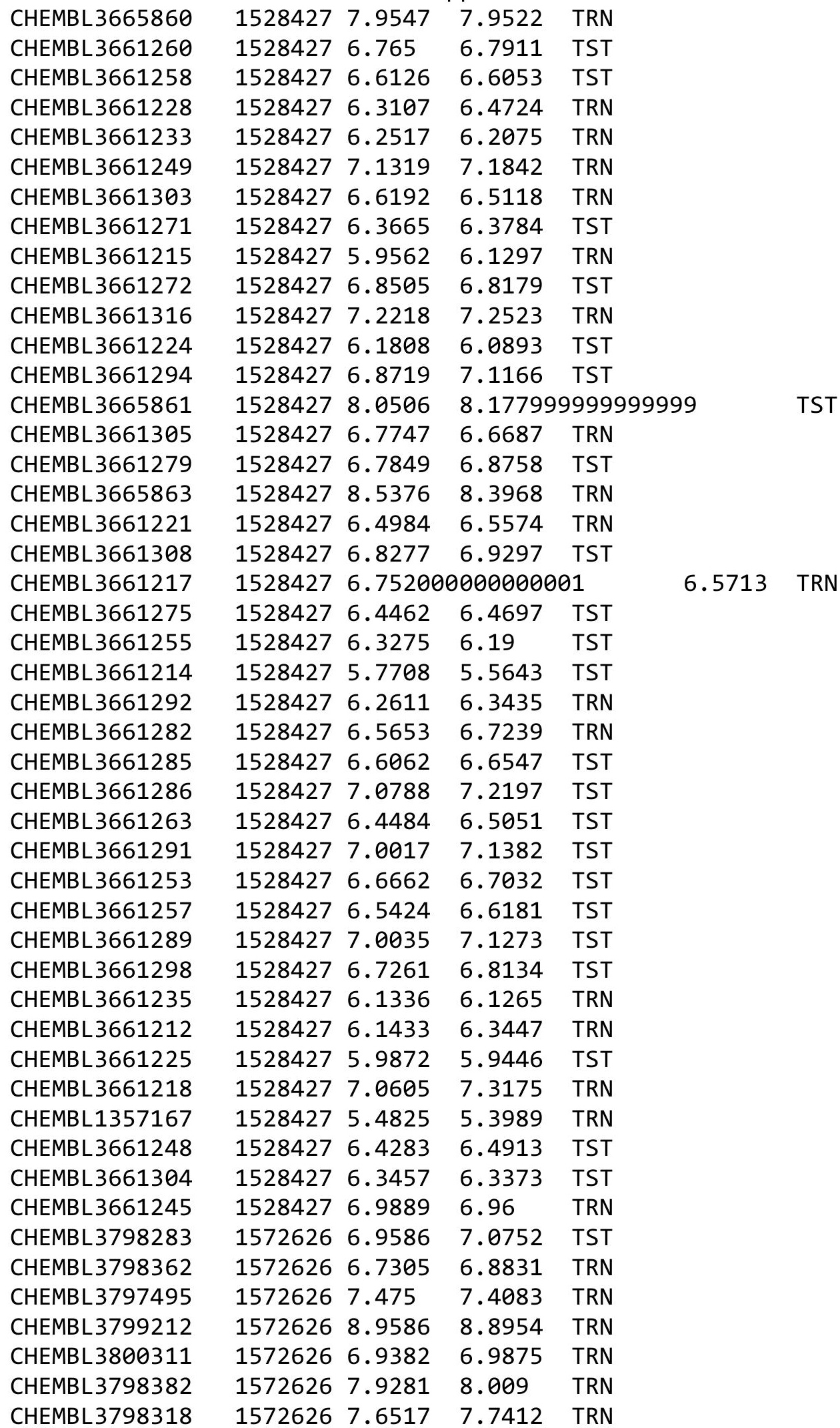

Page 15562 
Supplemental Table S2.txt

\begin{tabular}{|c|c|c|c|c|c|}
\hline CHEMBL 3800105 & 1572626 & 8.6778 & 8.7609 & TRN & \\
\hline CHEMBL 3800307 & 1572626 & 7.2565 & 6.9062 & TRN & \\
\hline CHEMBL3797571 & 1572626 & 9.0 & 8.7778 & TRN & \\
\hline CHEMBL3799592 & 1572626 & 8.7447 & 8.5541 & TST & \\
\hline CHEMBL3798726 & 1572626 & 9.2218 & 9.1266 & TRN & \\
\hline CHEMBL3798129 & 1572626 & 8.4318 & 8.3738 & TRN & \\
\hline CHEMBL3799307 & 1572626 & 8.8539 & 8.539 & TRN & \\
\hline CHEMBL3799742 & 1572626 & 7.8356 & 7.8682 & TRN & \\
\hline CHEMBL 3797440 & 1572626 & 7.7352 & 7.6398 & TRN & \\
\hline CHEMBL3798294 & 1572626 & 7.6216 & 7.6494 & TRN & \\
\hline CHEMBL3799159 & 1572626 & 7.1226 & 6.9483 & TST & \\
\hline CHEMBL3797212 & 1572626 & 8.4559 & 8.3763 & TRN & \\
\hline CHEMBL3800399 & 1572626 & 7.064 & 6.6664 & TST & \\
\hline CHEMBL3797855 & 1572626 & 7.8665 & 8.6594 & TST & \\
\hline CHEMBL3797823 & 1572626 & 7.6478 & 7.5529 & TRN & \\
\hline CHEMBL3799679 & 1572626 & 7.4647 & 7.4566 & TRN & \\
\hline CHEMBL3797558 & 1572626 & 8.0605 & 8.3718 & TRN & \\
\hline CHEMBL3799581 & 1572626 & 7.3716 & 8.3339 & TST & \\
\hline CHEMBL3797689 & 1572626 & 6.2069 & 6.3722 & TST & \\
\hline CHEMBL3800432 & 1572626 & 6.9626 & 6.9899 & TRN & \\
\hline CHEMBL3797656 & 1572626 & 6.9957 & 7.196006 & 0000000001 & TRN \\
\hline CHEMBL3799073 & 1572626 & 7.4437 & 7.4221 & TRN & \\
\hline CHEMBL3798853 & 1572626 & 8.283999 & 79999999ऽ & 8.4981 & TRN \\
\hline CHEMBL 3800080 & 1572626 & 8.6198 & 8.5837 & TRN & \\
\hline CHEMBL3798886 & 1572626 & 8.1308 & 8.3426 & TST & \\
\hline CHEMBL3798632 & 1572626 & 8.0605 & 8.068 & TRN & \\
\hline CHEMBL 3800037 & 1572626 & 7.8665 & 7.8445 & TRN & \\
\hline CHEMBL3797472 & 1572626 & 7.8928 & 7.9183 & TRN & \\
\hline CHEMBL3798587 & 1572626 & 6.466 & 7.4929 & TST & \\
\hline CHEMBL3798419 & 1572626 & 8.0655 & 7.7832 & TRN & \\
\hline CHEMBL 3799824 & 1572626 & 8.5376 & 7.6989 & TST & \\
\hline CHEMBL 3798778 & 1572626 & 7.1337 & 6.894 & TST & \\
\hline CHEMBL3799396 & 1572626 & 10.0969 & 10.1749 & TRN & \\
\hline CHEMBL3408213 & 1572626 & 8.301 & 8.2332 & TRN & \\
\hline CHEMBL3797317 & 1572626 & 7.8239 & 7.7526 & TRN & \\
\hline CHEMBL3799579 & 1572626 & 8.3979 & 8.4306 & TRN & \\
\hline CHEMBL3798804 & 1572626 & 8.2757 & 7.934 & TRN & \\
\hline CHEMBL3798987 & 1572626 & 7.4498 & 7.7432 & TRN & \\
\hline CHEMBL 3798712 & 1572626 & 5.4643 & 6.3503 & TST & \\
\hline CHEMBL3798611 & 1572626 & 9.1549 & 9.2461 & TRN & \\
\hline CHEMBL3799116 & 1572626 & 7.8386 & 7.9548 & TRN & \\
\hline CHEMBL3800533 & 1572626 & 7.2343 & 7.2769 & TRN & \\
\hline CHEMBL3798430 & 1572626 & 7.71 & 7.7505 & TRN & \\
\hline CHEMBL 3798944 & 1572626 & 7.8827 & 8.0442 & TRN & \\
\hline CHEMBL3798663 & 1572626 & 8.3372 & 8.2949 & TRN & \\
\hline CHEMBL3799826 & 1572626 & 7.6234 & 7.7991 & TRN & \\
\hline CHEMBL3798568 & 1572626 & 7.8962 & 8.2348 & TST & \\
\hline CHEMBL 3800210 & 1572626 & 7.6383 & 7.5661 & TST & \\
\hline
\end{tabular}


Supplemental Table S2.txt

\begin{tabular}{|c|c|c|}
\hline 260 & & \\
\hline CHEMBL3660234 & 527941 & 4.0 \\
\hline HEMBL3660244 & 27941 & \\
\hline AEMBL 3664805 & 941 & \\
\hline EMBL3660212 & 27941 & \\
\hline AEMBL3660232 & 527941 & 4.0 \\
\hline HEMBL3660222 & .527941 & \\
\hline AEMBL3660266 & 527941 & \\
\hline IEMBL 3664801 & 527941 & \\
\hline HEMBL 3664812 & 527941 & 4.0 \\
\hline HEMBL3660229 & 527941 & \\
\hline HEMBL3660233 & 1527941 & 4.0 \\
\hline HEMBL3660241 & 1527941 & \\
\hline AEMBL3660243 & 1527941 & \\
\hline AEMBL3660210 & 1527941 & \\
\hline AEMBL3660221 & 1527941 & \\
\hline HEMBL3664797 & 527941 & \\
\hline HEMBL 366 & 1527941 & .0 \\
\hline HEMBL36 & 1527941 & 4.0 \\
\hline AEMBL36 & 1527941 & 3.52 \\
\hline AEMBL3660209 & 1527941 & \\
\hline AEMBL3660227 & 1527941 & \\
\hline AEMBL3660257 & 1527941 & \\
\hline AEMBL36 & 1527941 & \\
\hline AEMBL 36 & 1527941 & \\
\hline AEMBL3660261 & 1527941 & \\
\hline CHEMBL 3660224 & 1527941 & \\
\hline AEMBL 3660245 & 1527941 & \\
\hline AEMBL: & 1527941 & \\
\hline 0231 & 1527941 & 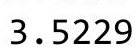 \\
\hline AEMBL3664808 & 1527941 & 4.0 \\
\hline CHEMBL 3660215 & 1527941 & 0 \\
\hline AEMBL 3660230 & 1941 & \\
\hline CHEMBL; & 527941 & 4.0 \\
\hline CHEMBL: & 1527941 & \\
\hline CHEMBL3664796 & 1527941 & \\
\hline CHEMBL 3660219 & 1527941 & \\
\hline CHEMBL: & 941 & \\
\hline CHEMBL 36 & 527941 & 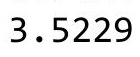 \\
\hline CHEMBL 3660228 & 1527941 & ני \\
\hline CHEMBL3660259 & 1527941 & $81-1 \cdot 2 \cdot 1 \cdot$ \\
\hline CHEMBL 3660225 & 1527941 & 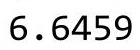 \\
\hline CHEMBL366 & 1527941 & \\
\hline CHEMBL 3664810 & 1527941 & 4.0 \\
\hline CHEMBL 3664807 & 1527941 & 3.52 \\
\hline CHEMBL 3660253 & 1527941 & \\
\hline CHEMBL 3660263 & 1527941 & \\
\hline CHEMBL366021 & & \\
\hline
\end{tabular}

5.7121 TRN

5.4539 TST

4.4051 TRN

5.2966 TRN

4.671 TST

3.7406 TST

6.3555 TRN

6.7107 TRN

5.8462 TRN

5.0391 TRN

6.0115 TRN

3.7965 TRN

5.9446 TRN

0.7373 TST

5.8631 TRN

5.1858 TRN

3.8186 TRN

4.2803 TRN

4.4099 TST

4.3375 TST

6.0827 TRN

5.0758 TRN

2.9426 TRN

4.3551 TST

6.8968 TRN

3.9471 TST

6.9695 TRN

4.2792 TST

3.1131 TRN

3.9125 TRN

4.1048 TRN

6.8737 TRN

5.544 TRN

4.6867 TRN

5.0218 TRN

5.092 TST

3.5275 TRN

6.9717 TRN

4.9825 TST

3.8811 TST

6.3203 TRN

6.4494 TRN

6.3948 TRN

3.9982 TRN

4.765 TST

4.0138 TST

$5.787000000000001 \quad$ TRN

7.2913 TRN

Page 15564 
Supplemental Table S2.txt

\begin{tabular}{|c|c|c|c|c|}
\hline CHEMBL 3660255 & 1527941 & 7.2518 & 7.1062 & TRN \\
\hline CHEMBL3664803 & 1527941 & 3.5229 & 5.0604 & TST \\
\hline CHEMBL3664799 & 1527941 & 3.5229 & 4.2272 & TRN \\
\hline CHEMBL3660213 & 1527941 & 5.5391 & 6.1046 & TRN \\
\hline CHEMBL3660239 & 1527941 & 5.5834 & 6.0788 & TRN \\
\hline CHEMBL3660264 & 1527941 & 6.6655 & 5.8705 & TRN \\
\hline CHEMBL3664800 & 1527941 & 4.0 & 4.0533 & TRN \\
\hline CHEMBL3664811 & 1527941 & 5.6696 & 5.85 & TRN \\
\hline CHEMBL3664813 & 1527941 & 6.1273 & 5.4487 & TRN \\
\hline CHEMBL3660223 & 1527941 & 5.9872 & 5.2674 & TRN \\
\hline CHEMBL 3660250 & 1527941 & 4.0 & 4.5042 & TRN \\
\hline CHEMBL 3660240 & 1527941 & 5.2526 & 4.8935 & TRN \\
\hline CHEMBL 3660211 & 1527941 & 3.5229 & 3.4023 & TRN \\
\hline CHEMBL3660236 & 1527941 & 5.5784 & 5.476 & TRN \\
\hline CHEMBL3660235 & 1527941 & 5.1805 & 5.6459 & TRN \\
\hline CHEMBL3664806 & 1527941 & 3.5229 & 3.7605 & TRN \\
\hline CHEMBL3660248 & 1527941 & 4.0 & 4.3551 & TST \\
\hline CHEMBL 3660242 & 1527941 & 5.7144 & 5.1175 & TRN \\
\hline CHEMBL3660218 & 1527941 & 3.5229 & 3.983 & TRN \\
\hline CHEMBL3660265 & 1527941 & 4.0 & 4.1772 & TRN \\
\hline CHEMBL3660208 & 1527941 & 5.4609 & 5.1419 & TRN \\
\hline CHEMBL3660262 & 1527941 & 3.5229 & 4.0037 & TST \\
\hline CHEMBL3660246 & 1527941 & 3.5229 & 4.3494 & TST \\
\hline CHEMBL3660238 & 1527941 & 5.9547 & 5.4351 & TRN \\
\hline CHEMBL 3660214 & 1527941 & 7.4202 & 7.2542 & TRN \\
\hline CHEMBL3660220 & 1527941 & 5.0462 & 6.4051 & TST \\
\hline CHEMBL3664802 & 1527941 & 5.1694 & 5.15799 & 99999999995 \\
\hline CHEMBL3660256 & 1527941 & 6.4101 & 6.5548 & TRN \\
\hline CHEMBL3660252 & 1527941 & 4.0 & 4.0343 & TRN \\
\hline CHEMBL1817700 & 763491 & 7.5528 & 7.5384 & TRN \\
\hline CHEMBL1817764 & 763491 & 6.4559 & 6.3591 & TRN \\
\hline CHEMBL1817749 & 763491 & 7.4318 & 7.4743 & TRN \\
\hline CHEMBL1817765 & 763491 & 6.4202 & 6.6878 & TRN \\
\hline CHEMBL1817754 & 763491 & 6.9208 & 7.1424 & TRN \\
\hline CHEMBL1817690 & 763491 & 6.2676 & 6.2611 & TRN \\
\hline CHEMBL1817752 & 763491 & 6.6021 & 6.8528 & TRN \\
\hline CHEMBL1819540 & 763491 & 7.8239 & 7.8077 & TRN \\
\hline CHEMBL1817757 & 763491 & 6.2757 & 6.3027 & TST \\
\hline CHEMBL1817753 & 763491 & 7.1871 & 6.9598 & TRN \\
\hline CHEMBL1819550 & 763491 & 6.6778 & 6.9039 & TST \\
\hline CHEMBL1817702 & 763491 & 7.3372 & 7.2607 & TRN \\
\hline CHEMBL1817755 & 763491 & 7.5086 & 7.3075 & TRN \\
\hline CHEMBL1817671 & 763491 & 6.0177 & 6.0463 & TRN \\
\hline CHEMBL1817696 & 763491 & 7.2518 & 7.3265 & TRN \\
\hline CHEMBL1817762 & 763491 & 6.2924 & 6.8906 & TST \\
\hline CHEMBL1817694 & 763491 & 7.5229 & 7.4245 & TRN \\
\hline CHEMBL1819555 & 763491 & 8.0969 & 8.0071 & TRN \\
\hline CHEMBL1819441 & 763491 & 7.7959 & 7.8206 & TRN \\
\hline
\end{tabular}


Supplemental Table S2.txt

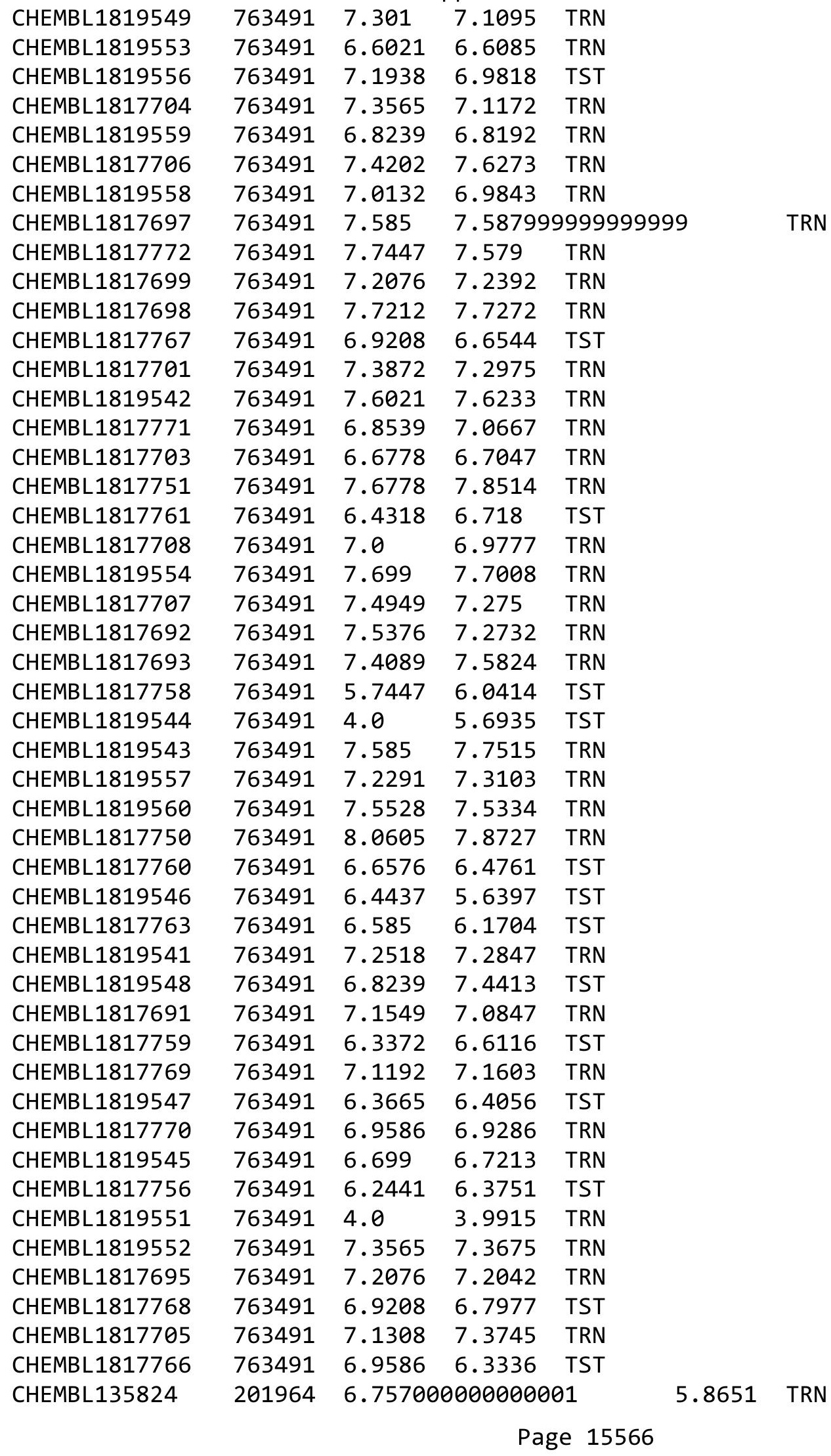




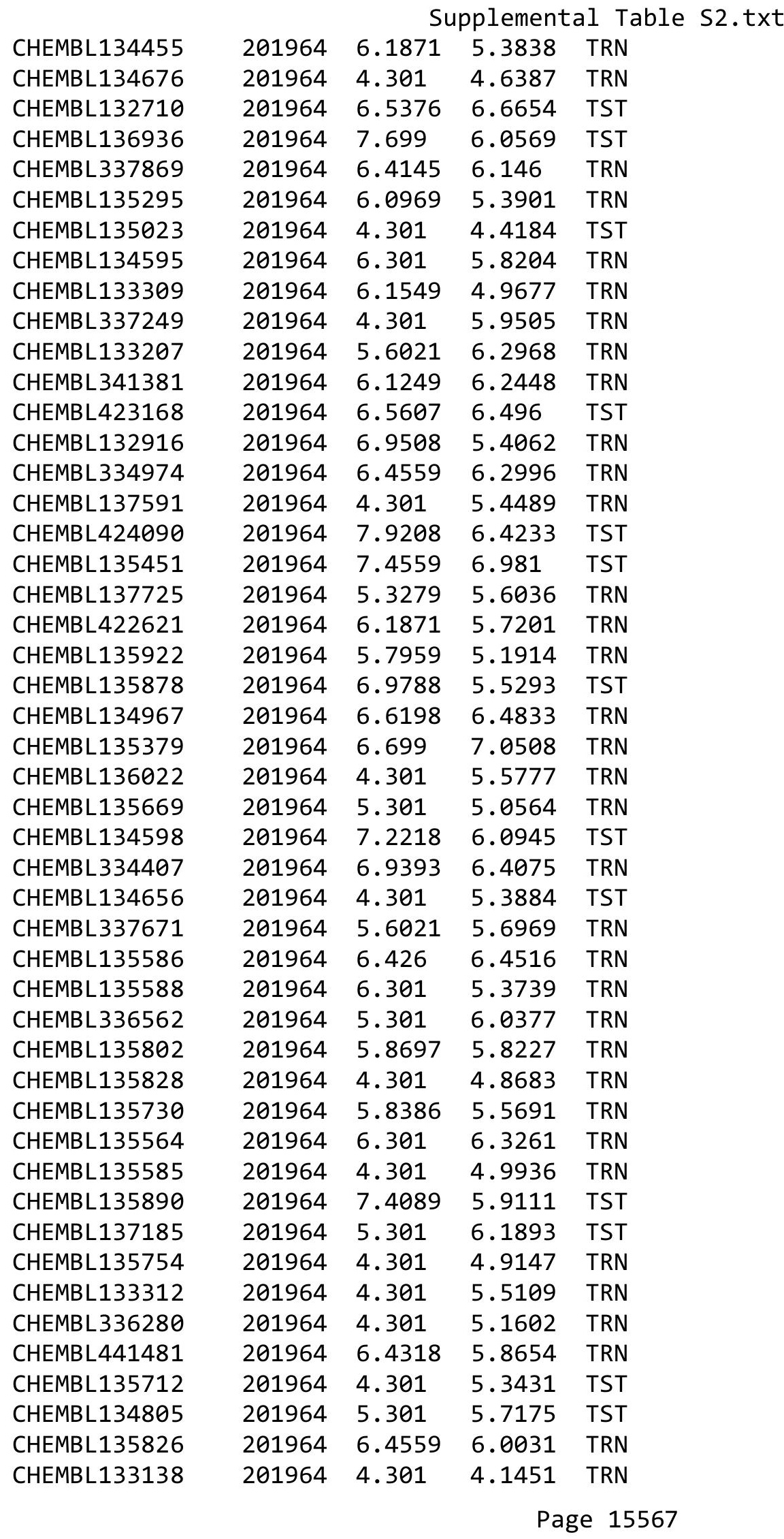




\begin{tabular}{|c|c|c|c|c|c|}
\hline \multicolumn{6}{|c|}{ Supplemental Table S2.txt } \\
\hline CHEMBL135293 & 201964 & 4.301 & 5.6291 & TRN & \\
\hline CHEMBL132979 & 201964 & 6.3098 & 5.3876 & TST & \\
\hline CHEMBL136029 & 201964 & 6.301 & 5.4467 & TST & \\
\hline CHEMBL135785 & 201964 & 6.3372 & 5.8674 & TRN & \\
\hline CHEMBL135887 & 201964 & 5.1871 & 6.2775 & TRN & \\
\hline CHEMBL337185 & 201964 & 6.7212 & 6.6059 & TRN & \\
\hline CHEMBL423174 & 201964 & 4.301 & 3.9731 & TRN & \\
\hline CHEMBL135753 & 201964 & 4.301 & 5.6573 & TRN & \\
\hline CHEMBL135272 & 201964 & 6.301 & 6.0567 & TRN & \\
\hline CHEMBL137326 & 201964 & 6.4202 & 6.6811 & TRN & \\
\hline CHEMBL134743 & 201964 & 6.8239 & 6.2738 & TRN & \\
\hline CHEMBL337087 & 201964 & 7.301 & 6.6885 & TST & \\
\hline CHEMBL135939 & 201964 & 5.9031 & 5.87200 & 0000000001 & TRN \\
\hline CHEMBL135553 & 201964 & 4.301 & 4.9614 & TRN & \\
\hline CHEMBL439978 & 201964 & 7.0223 & 5.818 & TST & \\
\hline CHEMBL137178 & 201964 & 5.9393 & 4.8935 & TST & \\
\hline CHEMBL336504 & 201964 & 4.301 & 4.5347 & TRN & \\
\hline CHEMBL133210 & 201964 & 4.301 & 4.3606 & TST & \\
\hline CHEMBL132924 & 201964 & 6.5607 & 6.8098 & TRN & \\
\hline CHEMBL336341 & 201964 & 6.6576 & 6.3656 & TRN & \\
\hline CHEMBL132532 & 201964 & 6.0 & 5.8111 & TRN & \\
\hline CHEMBL424470 & 201964 & 6.5229 & 5.3318 & TRN & \\
\hline CHEMBL132541 & 201964 & 6.0969 & 5.7203 & TRN & \\
\hline CHEMBL134806 & 201964 & 8.0 & 7.33299 & 9999999999 & TRN \\
\hline CHEMBL 334444 & 201964 & 4.301 & 4.6186 & TRN & \\
\hline CHEMBL444335 & 201964 & 5.9393 & 5.8251 & TRN & \\
\hline CHEMBL135554 & 201964 & 4.301 & 5.1326 & TRN & \\
\hline CHEMBL135770 & 201964 & 6.301 & 5.9409 & TST & \\
\hline CHEMBL132764 & 201964 & 6.0223 & 5.6733 & TRN & \\
\hline CHEMBL434268 & 201964 & 5.6021 & 4.7972 & TRN & \\
\hline CHEMBL336592 & 201964 & 4.301 & 5.2663 & TST & \\
\hline CHEMBL133139 & 201964 & 5.8239 & 5.2374 & TRN & \\
\hline CHEMBL135961 & 201964 & 5.6021 & 5.3465 & TRN & \\
\hline CHEMBL3915096 & 1642273 & 8.699 & 7.7577 & TRN & \\
\hline CHEMBL 3929098 & 1642273 & 8.0 & 7.9976 & TRN & \\
\hline CHEMBL3892176 & 1642273 & 8.0 & 8.1008 & TRN & \\
\hline CHEMBL3965442 & 1642273 & 8.699 & 8.578 & TRN & \\
\hline CHEMBL3924601 & 1642273 & 5.0 & 6.4858 & TRN & \\
\hline CHEMBL3935375 & 1642273 & 8.699 & 8.5051 & TRN & \\
\hline CHEMBL 3982805 & 1642273 & 8.699 & 8.8707 & TRN & \\
\hline CHEMBL3899645 & 1642273 & 7.301 & 7.7327 & TRN & \\
\hline CHEMBL3948194 & 1642273 & 8.0 & 7.982 & TST & \\
\hline CHEMBL3898470 & 1642273 & 8.301 & 8.4325 & TRN & \\
\hline CHEMBL3975280 & 1642273 & 8.699 & 8.432 & TRN & \\
\hline CHEMBL 3907045 & 1642273 & 8.301 & 8.5532 & TRN & \\
\hline CHEMBL3966923 & 1642273 & 8.0 & 6.9733 & TST & \\
\hline CHEMBL3932350 & 1642273 & 8.699 & 8.7225 & TRN & \\
\hline CHEMBL3911069 & 1642273 & 8.699 & 8.1708 & TRN & \\
\hline
\end{tabular}


Supplemental Table S2.txt

\begin{tabular}{|c|c|c|c|c|}
\hline HEMBL3954119 & 642273 & 7.699 & 7.7648 & TR \\
\hline HEMBL3935002 & 642273 & 7.699 & 8.1679 & \\
\hline HFMBL & 542273 & 7.301 & 1868 & \\
\hline HEMBL3892670 & 642273 & 8.699 & 6125 & $R N$ \\
\hline HEMBL3908546 & 642273 & 8.699 & 1904 & \\
\hline HEMBL3904434 & 642273 & 8.699 & .4421 & \\
\hline HEMBL3933115 & 642273 & 8.699 & .7527 & \\
\hline AEMBL3967584 & 273 & 7.301 & 0868 & $\mathrm{RN}$ \\
\hline HEMBL3952455 & 1642273 & 8.0 & 8.0287 & \\
\hline HEMBL3896574 & 642273 & 8.0 & .2573 & \\
\hline HEMBL3971936 & 642273 & 8.699 & .4442 & \\
\hline HEMBL394 & 273 & 8.0 & .2049 & \\
\hline HEMBL 390 & 273 & 4 & 5549 & RN \\
\hline HEMBL3901039 & 273 & 5.0 & 5.0015 & RN \\
\hline HEMBL391. & 73 & 8.699 & 1537 & \\
\hline HEMBL396 & 64 & 7.699 & .5525 & RN \\
\hline HEMBL398 & 73 & 8.699 & 3882 & RN \\
\hline HEMBL 388 & 73 & 8.0 & 1364 & \\
\hline HEMBL393. & 273 & 8.0 & 7.8611 & $2 \mathrm{~N}$ \\
\hline HEMBL 389 & 73 & 99 & 302 & TRN \\
\hline HEMBL396 & 64 & 7.301 & 223 & RN \\
\hline HEMBL 39 & 3 & 99 & 16 & RN \\
\hline HEMBL 392 & 73 & 8.699 & 69 & RN \\
\hline HEMBL3926 & 273 & 8.301 & 8922 & TRN \\
\hline HEMBL 397 & 73 & 7.699 & & TST \\
\hline HEMBL 394 & 64 & 8.301 & 85 & RN \\
\hline HEMBL392 & 3 & 7.699 & 13 & RN \\
\hline HEMBL 389 & 73 & 7.0 & 757 & RN \\
\hline HEMBL3974350 & 73 & 8.699 & 1789 & TRN \\
\hline HEMBL3928389 & 64 & 8.699 & & TRN \\
\hline HEMBL389 & 64 & 8.699 & 127 & RN \\
\hline HEMBL39 & 16 & 7.699 & 174 & TRN \\
\hline HEMBL390 & 73 & 7.301 & $\partial 29$ & RN \\
\hline HEMBL3986981 & 64 & 8.699 & 177 & TRN \\
\hline HEMBL3941707 & 64 & 8.699 & 5084 & TRN \\
\hline HEMBL395 & 64 & 8.699 & 3035 & $\Gamma \mathrm{RN}$ \\
\hline HEMBL3 & 73 & 99 & 026 & $\Gamma \mathrm{RN}$ \\
\hline CHEMBL 391 & 164 & 8.699 & 5736 & TRN \\
\hline HEMBL3894129 & 64 & 7.301 & 5772 & TST \\
\hline HEMBL 395 & 64 & 8.301 & & TST \\
\hline CHEMBL 389 & 164 & 7.301 & 06 & PN \\
\hline CHEMBL3889853 & 164 & 8.699 & 5323 & $\Gamma \mathrm{RN}$ \\
\hline CHEMBL 3926549 & 164 & 7.699 & 7.1478 & TRN \\
\hline HEMBL3981963 & 164 & 7.699 & 178 & TRN \\
\hline EMBL389 & 64 & 8.699 & & $\mathrm{~N}$ \\
\hline CHEMBL 394 & 164 & 8.699 & 1945 & \\
\hline CHEMBL3920980 & 1642273 & 8.699 & & RIV \\
\hline CHEMBL3971896 & 1642273 & 8.699 & 8.8441 & ГRN \\
\hline
\end{tabular}

Page 15569 
Supplemental Table S2.txt

\begin{tabular}{|c|c|c|c|c|c|}
\hline CHEMBL3897579 & 1642273 & 8.0 & 7.6347 & TRN & \\
\hline CHEMBL3898958 & 1642273 & 7.301 & 6.6485 & TST & \\
\hline CHEMBL3928548 & 1642273 & 8.301 & 7.4334 & TST & \\
\hline CHEMBL3912145 & 1642273 & 7.301 & 7.7087 & TRN & \\
\hline CHEMBL3942122 & 1642273 & 8.699 & 8.215 & TST & \\
\hline CHEMBL3961668 & 1642273 & 8.699 & 8.4533 & TRN & \\
\hline CHEMBL3901621 & 1642273 & 8.699 & 8.6069 & TRN & \\
\hline CHEMBL3906918 & 1642273 & 8.699 & 8.2215 & TRN & \\
\hline CHEMBL3958881 & 1642273 & 7.699 & 6.9084 & TST & \\
\hline CHEMBL3940192 & 1642273 & 8.699 & 8.6812 & TRN & \\
\hline CHEMBL3928192 & 1642273 & 7.699 & 6.2934 & TST & \\
\hline CHEMBL3949300 & 1642273 & 8.699 & 8.1384 & TRN & \\
\hline CHEMBL3946639 & 1642273 & 8.699 & 8.4305 & TRN & \\
\hline CHEMBL3932107 & 1642273 & 8.699 & 8.4716 & TRN & \\
\hline CHEMBL3968717 & 1642273 & 5.0 & 5.2847 & TRN & \\
\hline CHEMBL3904353 & 1642273 & 7.0 & 4.6352 & TST & \\
\hline CHEMBL3937080 & 1642273 & 8.699 & 8.2609 & TRN & \\
\hline CHEMBL3975901 & 1642273 & 8.699 & 8.6511 & TRN & \\
\hline CHEMBL3963488 & 1642273 & 8.699 & 8.3629 & TST & \\
\hline CHEMBL3948742 & 1642273 & 7.0 & 6.2988 & TRN & \\
\hline CHEMBL3889834 & 1642273 & 8.301 & 7.691 & TST & \\
\hline CHEMBL 3937170 & 1642273 & 7.301 & 6.1939 & TST & \\
\hline CHEMBL3917972 & 1642273 & 7.699 & 7.8268 & TRN & \\
\hline CHEMBL3936573 & 1642273 & 7.699 & 7.8124 & TRN & \\
\hline CHEMBL3956331 & 1642273 & 8.301 & 8.4976 & TRN & \\
\hline CHEMBL3950487 & 1642273 & 5.0 & 4.4618 & TST & \\
\hline CHEMBL3957554 & 1642273 & 8.301 & 8.7097 & TRN & \\
\hline CHEMBL3902048 & 1642273 & 7.301 & \multicolumn{2}{|c|}{6.672000000000001} & TST \\
\hline CHEMBL3971195 & 1642273 & 8.0 & 6.7907 & TST & \\
\hline CHEMBL3972759 & 1642273 & 5.0 & 5.0102 & TRN & \\
\hline CHEMBL3928184 & 1642273 & 7.0 & 4.7281 & TST & \\
\hline CHEMBL3943268 & 1642273 & 8.699 & 8.7614 & TRN & \\
\hline CHEMBL3955195 & 1642273 & 8.699 & 8.1073 & TRN & \\
\hline CHEMBL3919894 & 1642273 & 8.301 & 8.7252 & TRN & \\
\hline CHEMBL 3895587 & 1642273 & 8.699 & 8.5018 & TRN & \\
\hline CHEMBL3950186 & 1642273 & 8.699 & 8.5519 & TST & \\
\hline CHEMBL3974734 & 1642273 & 5.0 & 5.3193 & TRN & \\
\hline CHEMBL 3946772 & 1642273 & 8.699 & 8.2279 & TST & \\
\hline CHEMBL3923581 & 1642273 & 8.699 & 8.7049 & TRN & \\
\hline CHEMBL3899566 & 1642273 & 8.699 & 8.7689 & TRN & \\
\hline CHEMBL3896031 & 1642273 & 8.699 & 8.8162 & TRN & \\
\hline CHEMBL3939030 & 1642273 & 8.301 & 9.0124 & TRN & \\
\hline CHEMBL3893960 & 1642273 & 7.0 & 6.6893 & TRN & \\
\hline CHEMBL3954762 & 1642273 & 7.301 & 7.9613 & TRN & \\
\hline CHEMBL3979330 & 1642273 & 8.699 & 8.7907 & TRN & \\
\hline CHEMBL3982199 & 1642273 & 7.699 & 8.4763 & TRN & \\
\hline CHEMBL3966943 & 1642273 & 8.699 & 8.3777 & TST & \\
\hline \multirow[t]{2}{*}{ CHEMBL3957442 } & 1642273 & 5.0 & \multirow{2}{*}{\multicolumn{2}{|c|}{$\begin{array}{r}7.2979999999999 \\
\text { Page } 15570\end{array}$}} & TRN \\
\hline & & & & & \\
\hline
\end{tabular}


Supplemental Table S2.txt

\begin{tabular}{|c|c|c|c|c|}
\hline CHEMBL3901273 & 1642273 & 8.301 & 7.5683 & TRN \\
\hline CHEMBL3959184 & 1642273 & 7.699 & 6.6722 & TST \\
\hline CHEMBL3910134 & 1642273 & 8.301 & 8.1012 & TRN \\
\hline CHEMBL3982124 & 1642273 & 8.301 & 8.6221 & TRN \\
\hline CHEMBL3962392 & 1642273 & 8.699 & 8.5896 & TRN \\
\hline CHEMBL3980132 & 1642273 & 7.699 & 8.4942 & TRN \\
\hline CHEMBL3914879 & 1642273 & 8.699 & 8.7082 & TRN \\
\hline CHEMBL3914954 & 1642273 & 7.301 & 6.9 & TRN \\
\hline CHEMBL3915406 & 1642273 & 8.699 & 8.4319 & TST \\
\hline CHEMBL3942382 & 1642273 & 7.301 & 8.2635 & TRN \\
\hline CHEMBL3936925 & 1642273 & 8.699 & 8.5282 & TRN \\
\hline CHEMBL3949502 & 1642273 & 7.699 & 7.5251 & TST \\
\hline CHEMBL3901728 & 1642273 & 8.699 & 8.3018 & TRN \\
\hline CHEMBL3933520 & 1642273 & 8.699 & 8.5491 & TST \\
\hline CHEMBL 3892608 & 1642273 & 5.0 & 6.2791 & TST \\
\hline CHEMBL3970653 & 1642273 & 8.699 & 8.4896 & TRN \\
\hline CHEMBL3947737 & 1642273 & 8.699 & 8.7984 & TRN \\
\hline CHEMBL3918815 & 1642273 & 8.699 & 8.7018 & TST \\
\hline CHEMBL3890853 & 1642273 & 8.699 & 8.5566 & TRN \\
\hline CHEMBL3934545 & 1642273 & 8.301 & 8.0818 & TRN \\
\hline CHEMBL3908536 & 1642273 & 8.699 & 8.3379 & TRN \\
\hline CHEMBL3954373 & 1642273 & 8.301 & 8.5827 & TRN \\
\hline CHEMBL3975221 & 1642273 & 8.0 & 7.7193 & TST \\
\hline CHEMBL3944283 & 1642273 & 8.0 & 7.2671 & TRN \\
\hline CHEMBL 3908380 & 1642273 & 8.699 & 8.3984 & TRN \\
\hline CHEMBL3927886 & 1642273 & 8.699 & 8.537 & TST \\
\hline CHEMBL3979231 & 1642273 & 8.0 & 7.2189 & TST \\
\hline CHEMBL3980333 & 1642273 & 7.0 & 6.8673 & TRN \\
\hline CHEMBL3912131 & 1642273 & 7.301 & 7.7522 & TST \\
\hline CHEMBL 3899700 & 1642273 & 7.0 & 5.3424 & TST \\
\hline CHEMBL3915483 & 1642273 & 7.301 & 7.4338 & TRN \\
\hline CHEMBL3906560 & 1642273 & 8.0 & 7.5575 & TST \\
\hline CHEMBL3971472 & 1642273 & 8.0 & 8.2938 & TRN \\
\hline CHEMBL3975819 & 1642273 & 5.0 & 3.7703 & TRN \\
\hline CHEMBL3975406 & 1642273 & 7.5229 & 6.3618 & TST \\
\hline CHEMBL3967797 & 1642273 & 8.699 & 7.9821 & TRN \\
\hline CHEMBL3964456 & 1642273 & 7.699 & 7.5533 & TST \\
\hline CHEMBL3899477 & 1642273 & 8.699 & 8.1816 & TRN \\
\hline CHEMBL3943967 & 1642273 & 8.0 & 8.2556 & TRN \\
\hline CHEMBL3965861 & 1642273 & 8.0 & 7.9949 & TRN \\
\hline CHEMBL3918922 & 1642273 & 8.699 & 8.4269 & TRN \\
\hline CHEMBL3933674 & 1642273 & 8.301 & 8.0918 & TST \\
\hline CHEMBL3913196 & 1642273 & 7.0 & 7.5094 & TST \\
\hline CHEMBL3967319 & 1642273 & 8.0 & 8.5786 & TRN \\
\hline CHEMBL3985139 & 1642273 & 8.699 & 8.5103 & TRN \\
\hline CHEMBL189584 & 954571 & 4.3506 & 4.2248 & TRN \\
\hline CHEMBL1256459 & 954571 & 7.1978 & 7.3032 & TRN \\
\hline CHEMBL259181 & 954571 & 3.4785 & 3.55899 & 99999999997 \\
\hline
\end{tabular}




\begin{tabular}{|c|c|c|c|c|c|c|}
\hline \multirow[b]{2}{*}{ CHEMBL1970879 } & \multicolumn{6}{|c|}{ Supplemental Table S2.txt } \\
\hline & 954571 & 6.4685 & 6.4139 & TRN & & \\
\hline CHEMBL65 & 954571 & 7.761 & 7.9081 & TRN & & \\
\hline CHEMBL3392440 & 954571 & 3.8231 & 3.8238 & TRN & & \\
\hline CHEMBL1673039 & 954571 & 5.13399 & 79999999 & 995 & 5.0091 & TRN \\
\hline CHEMBL449158 & 954571 & 6.6257 & 7.2033 & TST & & \\
\hline CHEMBL 220241 & 954571 & 5.0927 & 5.1263 & TRN & & \\
\hline CHEMBL 240954 & 954571 & 3.5194 & 3.3159 & TST & & \\
\hline CHEMBL 2144069 & 954571 & 3.93399 & 99999999 & 997 & 4.0415 & TRN \\
\hline CHEMBL 213100 & 954571 & 6.4464 & 6.5681 & TRN & & \\
\hline CHEMBL1909414 & 954571 & 3.502 & 3.3507 & TRN & & \\
\hline CHEMBL3349342 & 954571 & 5.2146 & 5.2599 & TRN & & \\
\hline CHEMBL1788116 & 954571 & 5.2786 & 5.2504 & TRN & & \\
\hline CHEMBL180127 & 954571 & 3.8654 & 3.9907 & TRN & & \\
\hline CHEMBL102714 & 954571 & 2.9964 & 3.2259 & TRN & & \\
\hline CHEMBL 209148 & 954571 & 5.1482 & 4.8708 & TRN & & \\
\hline CHEMBL483847 & 954571 & 4.4953 & 4.5405 & TRN & & \\
\hline CHEMBL188678 & 954571 & 4.3171 & 4.3642 & TRN & & \\
\hline CHEMBL1357247 & 954571 & 3.3703 & 3.3641 & TRN & & \\
\hline CHEMBL 255342 & 954571 & 3.2953 & 3.25399 & 9999999999 & 96 & TRN \\
\hline CHEMBL512504 & 954571 & 4.0077 & 3.8111 & TRN & & \\
\hline CHEMBL577784 & 954571 & 5.2525 & 5.1939 & TRN & & \\
\hline CHEMBL573107 & 954571 & 4.842 & 4.8981 & TRN & & \\
\hline CHEMBL9470 & 954571 & 6.1273 & 5.581 & TST & & \\
\hline CHEMBL 202721 & 954571 & 4.18 & 4.2544 & TRN & & \\
\hline CHEMBL221137 & 954571 & 4.7595 & 4.4493 & TST & & \\
\hline CHEMBL1516890 & 954571 & 4.21399 & 99999999 & 995 & 4.1027 & TRN \\
\hline CHEMBL 222102 & 954571 & 3.6959 & 3.7907 & TRN & & \\
\hline CHEMBL472940 & 954571 & 2.8896 & 2.7915 & TRN & & \\
\hline CHEMBL514499 & 954571 & 7.0094 & 6.8329 & TRN & & \\
\hline CHEMBL1230020 & 954571 & 3.3715 & 3.3339 & TRN & & \\
\hline CHEMBL191334 & 954571 & 3.0471 & 3.1074 & TRN & & \\
\hline CHEMBL2363137 & 954571 & 4.4848 & 4.49100 & 0000000000 & 05 & TRN \\
\hline CHEMBL412142 & 954571 & 4.315 & 4.5075 & TRN & & \\
\hline CHEMBL 258844 & 954571 & 5.1063 & 4.8611 & TRN & & \\
\hline CHEMBL558642 & 954571 & 3.6211 & 3.40199 & 9999999999 & 97 & TRN \\
\hline CHEMBL 2005886 & 954571 & 5.4649 & 5.3579 & TRN & & \\
\hline CHEMBL192566 & 954571 & 7.4869 & 8.1385 & TST & & \\
\hline CHEMBL1242367 & 954571 & 4.8638 & 4.6641 & TRN & & \\
\hline CHEMBL1404918 & 954571 & 2.9034 & 2.7012 & TRN & & \\
\hline CHEMBL392695 & 954571 & 5.558 & 5.324 & TRN & & \\
\hline CHEMBL 210618 & 954571 & 3.6169 & 3.5483 & TRN & & \\
\hline CHEMBL135561 & 954571 & 4.3066 & 4.5842 & TRN & & \\
\hline CHEMBL 373751 & 954571 & 3.4251 & 3.7562 & TRN & & \\
\hline CHEMBL1186585 & 954571 & 3.3933 & 3.5565 & TRN & & \\
\hline CHEMBL1643959 & 954571 & 3.6308 & 3.8581 & TRN & & \\
\hline CHEMBL1190711 & 954571 & 3.9641 & 3.9879 & TRN & & \\
\hline CHEMBL393929 & 954571 & 3.6566 & 3.8248 & TRN & & \\
\hline CHEMBL379975 & 954571 & 3.8556 & 4.3871 & TST & & \\
\hline
\end{tabular}




\begin{tabular}{|c|c|c|c|c|c|c|}
\hline & & \multicolumn{5}{|c|}{ Supplemental Table S2.txt } \\
\hline CHEMBL 3186408 & 954571 & 3.6525 & 3.784 & TST & & \\
\hline CHEMBL92309 & 954571 & 3.3587 & 2.7617 & TST & & \\
\hline CHEMBL300389 & 954571 & 7.5555 & 7.1436 & TST & & \\
\hline CHEMBL1590308 & 954571 & 3.6538 & 3.8096 & TST & & \\
\hline CHEMBL585951 & 954571 & 6.5365 & 6.32 & TST & & \\
\hline CHEMBL515416 & 954571 & 4.5032 & 4.7907 & TST & & \\
\hline CHEMBL 379300 & 954571 & 6.9366 & 6.4575 & TST & & \\
\hline CHEMBL3199475 & 954571 & 4.2101 & 3.9503 & TST & & \\
\hline CHEMBL483849 & 954571 & 2.8552 & 1.7621 & TST & & \\
\hline CHEMBL509032 & 954571 & 5.3704 & 5.7801 & TST & & \\
\hline CHEMBL3934004 & 1641458 & 6.5686 & 6.8912 & TRN & & \\
\hline CHEMBL 3979878 & 1641458 & \multicolumn{3}{|c|}{6.4510000000000005} & 6.5192 & TRN \\
\hline CHEMBL 3987028 & 1641458 & 6.3372 & 6.0996 & TRN & & \\
\hline CHEMBL 3925475 & 1641458 & 6.2907 & 6.2822 & TRN & & \\
\hline CHEMBL 3927431 & 1641458 & 6.5376 & 6.7143 & TRN & & \\
\hline CHEMBL3948888 & 1641458 & 6.466 & 6.6364 & TST & & \\
\hline CHEMBL3907352 & 1641458 & 7.8447 & 7.4662 & TRN & & \\
\hline CHEMBL3939936 & 1641458 & 6.8153 & 7.0037 & TRN & & \\
\hline CHEMBL3891499 & 1641458 & 6.0 & 6.9678 & TRN & & \\
\hline CHEMBL3976135 & 1641458 & 6.9469 & 6.5785 & TRN & & \\
\hline CHEMBL3973625 & 1641458 & 6.5272 & 7.099 & TRN & & \\
\hline CHEMBL3917288 & 1641458 & 7.1568 & 6.688 & TRN & & \\
\hline CHEMBL 3908394 & 1641458 & 6.6383 & 6.5683 & TRN & & \\
\hline CHEMBL 3909887 & 1641458 & 6.3645 & 7.3076 & TRN & & \\
\hline CHEMBL 3984549 & 1641458 & 7.4559 & 7.3509 & TRN & & \\
\hline CHEMBL 3930856 & 1641458 & 6.2628 & 6.4944 & TRN & & \\
\hline CHEMBL3906093 & 1641458 & 5.9788 & 6.4857 & TRN & & \\
\hline CHEMBL 3904772 & 1641458 & 6.5607 & 6.9832 & TRN & & \\
\hline CHEMBL3895764 & 1641458 & 6.5214 & 7.2054 & TRN & & \\
\hline CHEMBL 3962747 & 1641458 & 7.4634 & 7.2905 & TRN & & \\
\hline CHEMBL 3964902 & 1641458 & 7.0395 & 6.8121 & TRN & & \\
\hline CHEMBL3911077 & 1641458 & 6.9281 & 7.3687 & TRN & & \\
\hline CHEMBL 3902448 & 1641458 & 7.9626 & 7.4023 & TRN & & \\
\hline CHEMBL3973810 & 1641458 & 6.7258 & 6.5437 & TRN & & \\
\hline CHEMBL 3907632 & 1641458 & 7.4672 & 6.7544 & TRN & & \\
\hline CHEMBL3917289 & 1641458 & 7.1379 & 6.8875 & TRN & & \\
\hline CHEMBL3947663 & 1641458 & 6.0 & 6.7344 & TRN & & \\
\hline CHEMBL3936518 & 1641458 & 6.7212 & 6.3788 & TRN & & \\
\hline CHEMBL 3926182 & 1641458 & 5.9318 & 6.4476 & TRN & & \\
\hline CHEMBL 3984165 & 1641458 & 6.61799 & 99999999 & 99 & 6.3817 & TRN \\
\hline CHEMBL 3917226 & 1641458 & 7.025 & 6.891 & TRN & & \\
\hline CHEMBL3916702 & 1641458 & 8.7696 & 7.5176 & TRN & & \\
\hline CHEMBL3942369 & 1641458 & 6.2749 & 6.4753 & TRN & & \\
\hline CHEMBL3976687 & 1641458 & 7.7399 & 6.8816 & TRN & & \\
\hline CHEMBL 3946834 & 1641458 & 5.4685 & 7.261 & TRN & & \\
\hline CHEMBL 3904579 & 1641458 & 7.6757 & 6.2994 & TRN & & \\
\hline CHEMBL3941757 & 1641458 & 6.7282 & 7.3332 & TRN & & \\
\hline CHEMBL3897156 & 1641458 & 5.8239 & 6.88 & TRN & & \\
\hline
\end{tabular}


Supplemental Table S2.txt

\begin{tabular}{|c|c|c|c|c|c|}
\hline CHEMBL 3968286 & 1641458 & 5.857 & 7.2546 & TST & \\
\hline CHEMBL3954001 & 1641458 & 7.38200 & 00000006 & 7.6328 & TRN \\
\hline CHEMBL3904171 & 1641458 & 8.567 & \multicolumn{2}{|c|}{7.0920000000000005} & TRN \\
\hline CHEMBL 3926584 & 1641458 & 7.426 & 7.1571 & TRN & \\
\hline CHEMBL3927325 & 1641458 & 6.0 & 7.2691 & TRN & \\
\hline CHEMBL 3971027 & 1641458 & \multicolumn{3}{|c|}{7.2620000000000005} & TRN \\
\hline CHEMBL3901773 & 1641458 & 5.8041 & 6.8118 & TST & \\
\hline CHEMBL 3944549 & 1641458 & 6.7905 & 6.4933 & TRN & \\
\hline CHEMBL 3984115 & 1641458 & 5.8539 & 6.4042 & TRN & \\
\hline CHEMBL3912753 & 1641458 & 6.0 & 7.4298 & TRN & \\
\hline CHEMBL 3950841 & 1641458 & 7.4283 & 7.0672 & TRN & \\
\hline CHEMBL 3899880 & 1641458 & 6.9706 & 6.7757 & TRN & \\
\hline CHEMBL 3919210 & 1641458 & 8.2782 & 7.3582 & TRN & \\
\hline CHEMBL 3913770 & 1641458 & 6.1158 & 7.0399 & TRN & \\
\hline CHEMBL3894694 & 1641458 & 7.1325 & 7.0271 & TRN & \\
\hline CHEMBL3963923 & 1641458 & 6.3862 & 7.1279 & TST & \\
\hline CHEMBL3973749 & 1641458 & 6.3161 & 6.7682 & TRN & \\
\hline CHEMBL 3900849 & 1641458 & 6.0 & 6.6068 & TRN & \\
\hline CHEMBL3913901 & 1641458 & 7.6055 & 7.5395 & TST & \\
\hline CHEMBL3911881 & 1641458 & 6.7055 & 6.22 & TRN & \\
\hline CHEMBL3928521 & 1641458 & 8.1073 & 7.0766 & TRN & \\
\hline CHEMBL3929016 & 1641458 & 6.0 & 6.5833 & TRN & \\
\hline CHEMBL3950553 & 1641458 & 6.0 & 6.6733 & TST & \\
\hline CHEMBL 3955544 & 1641458 & 5.6421 & 6.8222 & TRN & \\
\hline CHEMBL 3974682 & 1641458 & 5.4597 & 7.1653 & TRN & \\
\hline CHEMBL3964715 & 1641458 & 7.8182 & 7.6242 & TRN & \\
\hline CHEMBL3985215 & 1641458 & 8.1778 & 7.0975 & TRN & \\
\hline CHEMBL3968321 & 1641458 & 7.0809 & 7.0654 & TRN & \\
\hline CHEMBL 3967167 & 1641458 & 6.684 & 7.051 & TRN & \\
\hline CHEMBL 3967226 & 1641458 & 7.6737 & 7.4616 & TRN & \\
\hline CHEMBL 3936366 & 1641458 & 5.9508 & 6.4605 & TST & \\
\hline CHEMBL 3986258 & 1641458 & 6.6556 & 6.8725 & TST & \\
\hline CHEMBL3966179 & 1641458 & 8.1451 & 7.4595 & TRN & \\
\hline CHEMBL3902059 & 1641458 & 7.0477 & 7.1728 & TRN & \\
\hline CHEMBL3935301 & 1641458 & 6.4023 & 6.837006 & 0000000001 & TRN \\
\hline CHEMBL3923357 & 1641458 & 7.0635 & 6.2266 & TRN & \\
\hline CHEMBL 3908248 & 1641458 & 6.6757 & 6.8832 & TST & \\
\hline CHEMBL3941164 & 1641458 & 6.0 & 6.877006 & 0000000001 & TST \\
\hline CHEMBL3960839 & 1641458 & 7.5498 & 6.737 & TST & \\
\hline CHEMBL3894192 & 1641458 & 5.857 & 6.5575 & TST & \\
\hline CHEMBL 3977642 & 1641458 & 7.2182 & 7.116006 & 00000000005 & I KI \\
\hline CHEMBL3936364 & 1641458 & 5.3429 & 6.6115 & TST & \\
\hline CHEMBL3903504 & 1641458 & 7.0017 & 6.8863 & TRN & \\
\hline CHEMBL3917189 & 1641458 & 7.1343 & 7.1264 & TRN & \\
\hline CHEMBL3916439 & 1641458 & 6.9706 & 6.8674 & TRN & \\
\hline CHEMBL 3967222 & 1641458 & 5.3595 & 6.4097 & TRN & \\
\hline CHEMBL 3893722 & 1641458 & 5.9031 & 7.2248 & TRN & \\
\hline CHEMBL 3917048 & 1641458 & 6.3625 & 6.8374 & TRN & \\
\hline
\end{tabular}


Supplemental Table S2.txt

\begin{tabular}{|c|c|c|c|c|c|}
\hline CHEMBL3970525 & 1641458 & 7.1451 & 6.6996 & TST & \\
\hline CHEMBL3895756 & 1641458 & 8.0841 & 7.544 & TRN & \\
\hline CHEMBL3976174 & 1641458 & 5.5969 & 6.3817 & TRN & \\
\hline CHEMBL3916618 & 1641458 & 7.9788 & 7.0522 & TST & \\
\hline CHEMBL3947497 & 1641458 & 7.0443 & 6.6198 & TRN & \\
\hline CHEMBL3979604 & 1641458 & 7.6556 & 7.151 & TRN & \\
\hline CHEMBL3909374 & 1641458 & 7.5346 & 7.1994 & TRN & \\
\hline CHEMBL3980050 & 1641458 & 6.1361 & 6.4258 & TRN & \\
\hline CHEMBL3917697 & 1641458 & 6.8477 & 6.6703 & TRN & \\
\hline CHEMBL3947005 & 1641458 & 7.2676 & \multicolumn{2}{|c|}{7.242999999999999} & TRN \\
\hline CHEMBL3902867 & 1641458 & 7.4622 & 7.3971 & TRN & \\
\hline CHEMBL3925003 & 1641458 & 8.2457 & 6.9201 & TRN & \\
\hline CHEMBL3922010 & 1641458 & 5.8633 & 6.7045 & TRN & \\
\hline CHEMBL3916494 & 1641458 & 6.6819 & 7.3584 & TST & \\
\hline CHEMBL3908433 & 1641458 & 5.5607 & 6.3865 & TST & \\
\hline CHEMBL3954058 & 1641458 & 6.5452 & 7.0047 & TST & \\
\hline CHEMBL3911660 & 1641458 & 6.6216 & 7.1625 & TRN & \\
\hline CHEMBL 3952423 & 1641458 & 6.0114 & 6.6008 & TRN & \\
\hline CHEMBL3897309 & 1641458 & 6.4609 & 6.8412 & TRN & \\
\hline CHEMBL3924738 & 1641458 & 6.1169 & 6.5285 & TRN & \\
\hline CHEMBL3901081 & 1641458 & 6.0 & 6.3269 & TST & \\
\hline CHEMBL3919011 & 1641458 & 8.317 & 7.289 & TRN & \\
\hline CHEMBL3964677 & 1641458 & 6.5058 & 7.0558 & TRN & \\
\hline CHEMBL3930457 & 1641458 & 6.0665 & 6.5512 & TST & \\
\hline CHEMBL3920259 & 1641458 & 7.6536 & 7.1742 & TRN & \\
\hline CHEMBL3949779 & 1641458 & 6.5017 & 6.6155 & TRN & \\
\hline CHEMBL3910749 & 1641458 & 6.8633 & 7.3524 & TRN & \\
\hline CHEMBL3911953 & 1641458 & 7.5421 & 7.0726 & TST & \\
\hline CHEMBL3980559 & 1641458 & 7.0132 & 7.1558 & TRN & \\
\hline CHEMBL3896935 & 1641458 & 7.6676 & 7.1192 & TRN & \\
\hline CHEMBL3908271 & 1641458 & 7.3206 & \multicolumn{2}{|c|}{6.156000000000001} & TRN \\
\hline CHEMBL3921865 & 1641458 & 6.1831 & 6.6618 & TRN & \\
\hline CHEMBL3978685 & 1641458 & 7.1397 & 7.0716 & TRN & \\
\hline CHEMBL3939765 & 1641458 & 6.0 & 7.2854 & TST & \\
\hline CHEMBL3913312 & 1641458 & 6.7799 & 6.3801 & TST & \\
\hline CHEMBL3949112 & 1641458 & 6.3969 & 6.5267 & TRN & \\
\hline CHEMBL3983510 & 1641458 & 7.0137 & 6.9851 & TRN & \\
\hline CHEMBL3978041 & 1641458 & 6.9957 & 7.0967 & TST & \\
\hline CHEMBL 3894990 & 1641458 & 6.0 & \multicolumn{2}{|c|}{6.872000000000001} & TST \\
\hline CHEMBL3959952 & 1641458 & 5.9788 & 6.0897 & TRN & \\
\hline CHEMBL3954653 & 1641458 & 6.983 & 6.9524 & TRN & \\
\hline CHEMBL3978668 & 1641458 & 8.4461 & 7.0895 & TRN & \\
\hline CHEMBL3964823 & 1641458 & 7.4377 & 7.191 & TRN & \\
\hline CHEMBL3893203 & 1641458 & 6.0 & 6.8977 & TST & \\
\hline CHEMBL3919698 & 1641458 & 7.1681 & 7.0828 & TRN & \\
\hline CHEMBL3931134 & 1641458 & 6.9914 & 6.7942 & TRN & \\
\hline CHEMBL3979529 & 1641458 & 6.15799 & 999999999 & 6.9171 & TRN \\
\hline CHEMBL3954173 & 1641458 & 7.7235 & 6.874 & TRN & \\
\hline
\end{tabular}


Supplemental Table S2.txt

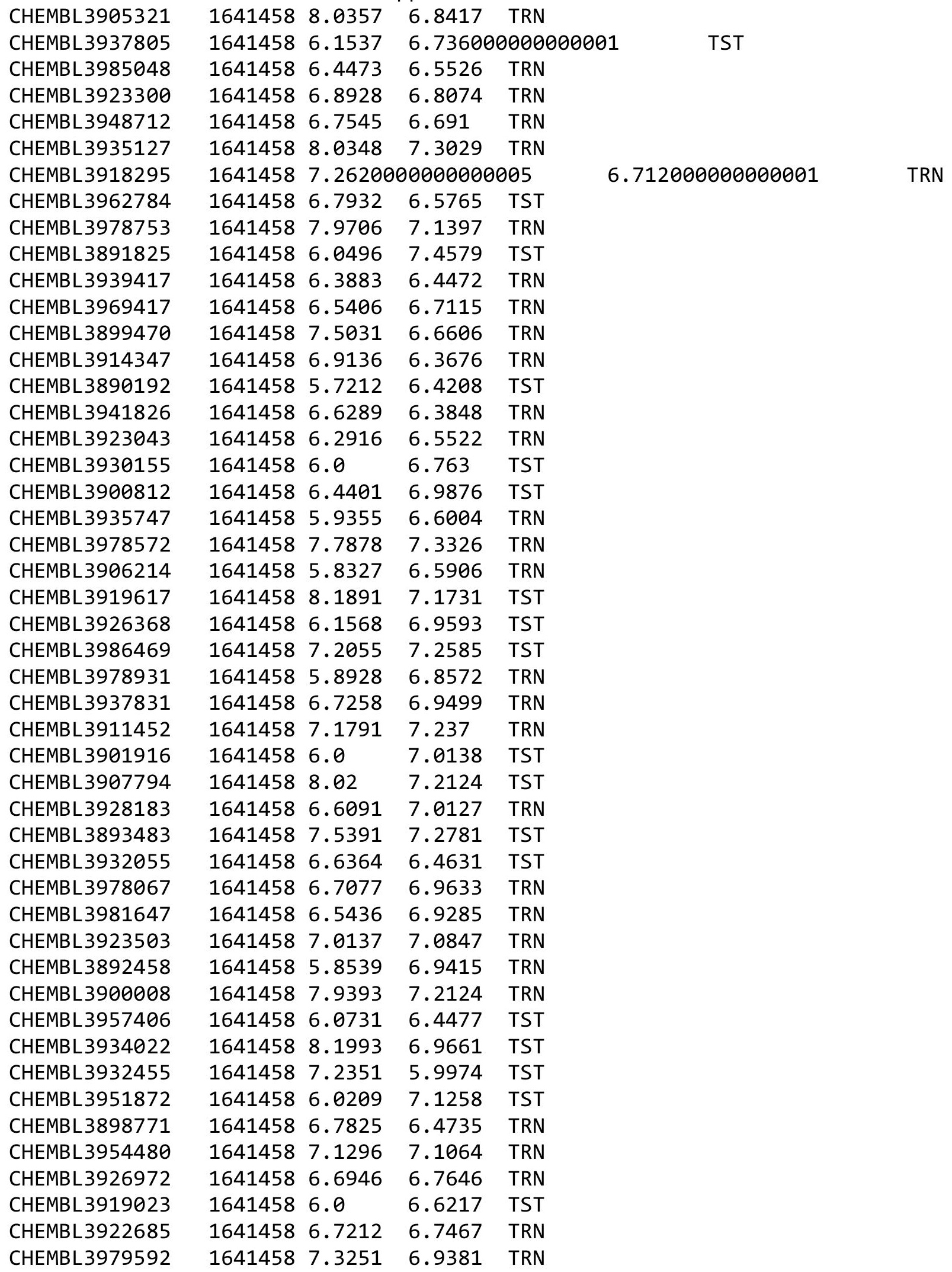

Page 15576 
Supplemental Table S2.txt

\begin{tabular}{|c|c|c|c|c|}
\hline CHEMBL3945953 & 1641458 & 6.7905 & 6.8343 & TST \\
\hline CHEMBL3939302 & 1641458 & 7.1965 & 7.5033 & TST \\
\hline CHEMBL3979898 & 1641458 & 6.644 & 7.0569 & TRN \\
\hline CHEMBL3941056 & 1641458 & 7.684 & 7.2161 & TRN \\
\hline CHEMBL3921916 & 1641458 & 6.6162 & 6.6168 & TRN \\
\hline CHEMBL3939907 & 1641458 & 8.4976 & 6.9292 & TST \\
\hline CHEMBL3959490 & 1641458 & 7.6055 & 6.6317 & TRN \\
\hline CHEMBL3956124 & 1641458 & 7.8996 & 7.1379 & TST \\
\hline CHEMBL3976093 & 1641458 & 7.0768 & 6.9698 & TRN \\
\hline CHEMBL3902179 & 1641458 & 6.9957 & 7.1058 & TRN \\
\hline CHEMBL3933892 & 1641458 & 6.5591 & 7.216 & TST \\
\hline CHEMBL3957918 & 1641458 & 6.6615 & 6.75299 & 9999999999 \\
\hline CHEMBL3901904 & 1641458 & 8.1643 & 6.8995 & TRN \\
\hline CHEMBL 76779 & 65464 & 6.3279 & 6.2938 & TRN \\
\hline CHEMBL310944 & 65464 & 5.7212 & 5.5568 & TST \\
\hline CHEMBL 309692 & 65464 & 8.5528 & 7.8827 & TRN \\
\hline CHEMBL312551 & 65464 & 6.0044 & 5.9476 & TRN \\
\hline CHEMBL80532 & 65464 & 6.5686 & 6.5438 & TRN \\
\hline CHEMBL310739 & 65464 & 8.4202 & 7.081 & TST \\
\hline CHEMBL 78853 & 65464 & 6.3098 & 6.3379 & TST \\
\hline CHEMBL80180 & 65464 & 6.0757 & 6.1654 & TRN \\
\hline CHEMBL81593 & 65464 & 5.7447 & 5.9259 & TRN \\
\hline CHEMBL80945 & 65464 & 4.0458 & 4.1578 & TRN \\
\hline CHEMBL80317 & 65464 & 6.3098 & 6.0952 & TRN \\
\hline CHEMBL 79054 & 65464 & 4.8539 & 6.1395 & TST \\
\hline CHEMBL312685 & 65464 & 6.9208 & 6.9559 & TRN \\
\hline CHEMBL 76576 & 65464 & 5.4202 & 5.399 & TRN \\
\hline CHEMBL420029 & 65464 & 6.6198 & 6.9287 & TRN \\
\hline CHEMBL80129 & 65464 & 5.0506 & 5.0012 & TRN \\
\hline CHEMBL78499 & 65464 & 6.1135 & 6.0604 & TRN \\
\hline CHEMBL 79080 & 65464 & 4.7212 & 4.9542 & TRN \\
\hline CHEMBL80506 & 65464 & 6.2076 & 6.1897 & TRN \\
\hline CHEMBL 78601 & 65464 & 5.0 & 4.9951 & TRN \\
\hline CHEMBL309397 & 65464 & 6.9586 & 6.8696 & TST \\
\hline CHEMBL 80438 & 65464 & 7.1487 & 6.9702 & TST \\
\hline CHEMBL 78830 & 65464 & 7.2757 & 7.1342 & TRN \\
\hline CHEMBL 78552 & 65464 & 5.699 & 5.8045 & TRN \\
\hline CHEMBL80807 & 65464 & 6.5686 & 7.0483 & TRN \\
\hline CHEMBL 312670 & 65464 & 6.301 & 5.9339 & TRN \\
\hline CHEMBL311742 & 65464 & 7.5376 & 7.7798 & TRN \\
\hline CHEMBL80857 & 65464 & 8.8539 & 7.4242 & TST \\
\hline CHEMBL 76420 & 65464 & 6.1427 & 6.1455 & TRN \\
\hline CHEMBL 78080 & 65464 & 7.1024 & 6.7493 & TRN \\
\hline CHEMBL421523 & 65464 & 5.6021 & 6.9282 & TST \\
\hline CHEMBL79031 & 65464 & 6.6383 & 6.6945 & TRN \\
\hline CHEMBL 78563 & 65464 & 8.0915 & 7.6768 & TRN \\
\hline CHEMBL 77090 & 65464 & 6.0 & 6.3344 & TST \\
\hline CHEMBL25970 & 65464 & 4.8539 & 4.7184 & TRN \\
\hline
\end{tabular}




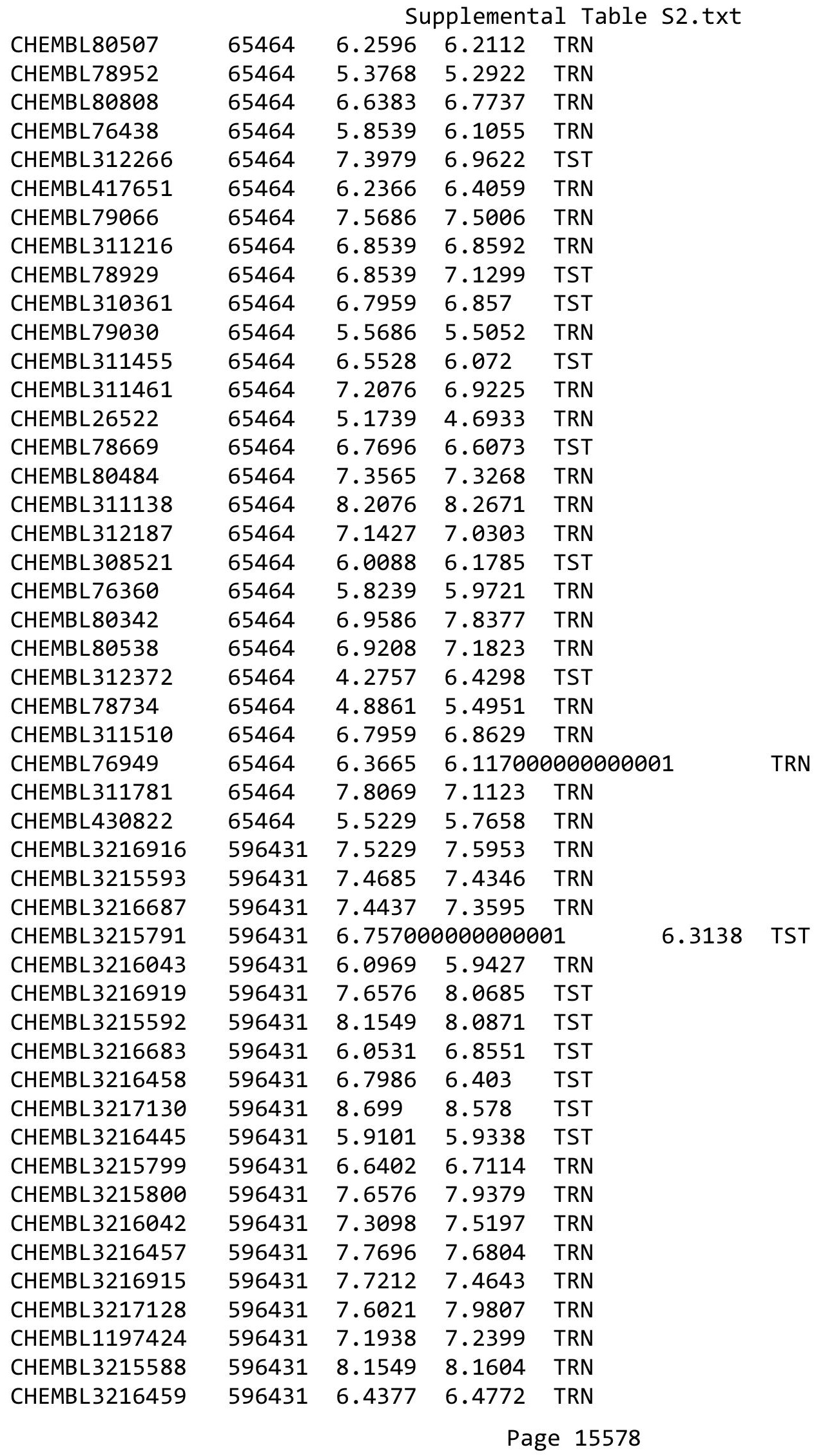




\begin{tabular}{|c|c|c|c|c|}
\hline & & & oplement & al Ta \\
\hline CHEMBL3216451 & 596431 & 5.2782 & 5.5462 & TRN \\
\hline CHEMBL3216248 & 596431 & 7.284 & 7.0685 & TRN \\
\hline CHEMBL3216463 & 596431 & 6.9031 & 6.8961 & TRN \\
\hline CHEMBL3216692 & 596431 & 7.9586 & 7.9476 & TRN \\
\hline CHEMBL3216454 & 596431 & 7.0223 & 7.0363 & TRN \\
\hline CHEMBL3216922 & 596431 & 8.1549 & 8.112 & TRN \\
\hline CHEMBL3215801 & 596431 & 7.585 & 7.4962 & TRN \\
\hline CHEMBL3216688 & 596431 & 6.9281 & 6.9591 & TRN \\
\hline CHEMBL3216686 & 596431 & 8.699 & 8.8358 & TRN \\
\hline CHEMBL569952 & 596431 & 7.5528 & 7.4347 & TRN \\
\hline CHEMBL3216456 & 596431 & 6.9747 & 6.8848 & TRN \\
\hline CHEMBL3215795 & 596431 & 7.3665 & 7.2916 & TRN \\
\hline CHEMBL3216249 & 596431 & 9.2218 & 8.9789 & TRN \\
\hline CHEMBL3216243 & 596431 & 7.7959 & 7.9458 & TRN \\
\hline CHEMBL3216685 & 596431 & 7.0757 & 7.2997 & TRN \\
\hline CHEMBL3216046 & 596431 & 8.0 & 8.0329 & TRN \\
\hline CHEMBL3216449 & 596431 & 7.6198 & 7.2119 & TST \\
\hline CHEMBL3216691 & 596431 & 8.301 & 8.3189 & TRN \\
\hline CHEMBL3216039 & 596431 & 5.0491 & 5.7906 & TST \\
\hline CHEMBL3216920 & 596431 & 8.699 & 8.7225 & TRN \\
\hline CHEMBL1197423 & 596431 & 7.8539 & 7.7397 & TRN \\
\hline CHEMBL3215803 & 596431 & 6.7696 & 6.348 & TST \\
\hline CHEMBL3216040 & 596431 & 7.6778 & 7.5944 & TRN \\
\hline CHEMBL3215793 & 596431 & 8.0458 & 8.1634 & TRN \\
\hline CHEMBL 3217131 & 596431 & 7.2596 & 7.4038 & TRN \\
\hline CHEMBL1198787 & 596431 & 7.2366 & 7.1466 & TST \\
\hline CHEMBL3216045 & 596431 & 8.5229 & 8.4185 & TRN \\
\hline CHEMBL3216450 & 596431 & 8.3979 & 8.1421 & TRN \\
\hline CHEMBL3215590 & 596431 & 7.7696 & 7.5257 & TST \\
\hline CHEMBL1197563 & 596431 & 8.1549 & 8.1585 & TST \\
\hline CHEMBL3216921 & 596431 & 7.5528 & 7.3862 & TRN \\
\hline CHEMBL 3216044 & 596431 & 8.699 & 8.5928 & TRN \\
\hline CHEMBL3216693 & 596431 & 8.0458 & 8.0443 & TRN \\
\hline CHEMBL3216241 & 596431 & 6.1314 & 5.7881 & TRN \\
\hline CHEMBL3215792 & 596431 & 5.9245 & 6.006 & TRN \\
\hline CHEMBL3216690 & 596431 & 7.3872 & 6.9205 & TST \\
\hline CHEMBL3216918 & 596431 & 6.71 & 6.8927 & TRN \\
\hline CHEMBL 3216242 & 596431 & 7.4202 & 7.5807 & TRN \\
\hline CHEMBL3215594 & 596431 & 7.8861 & 7.8825 & TRN \\
\hline CHEMBL 3215589 & 596431 & 6.4881 & 6.4066 & TST \\
\hline CHEMBL364224 & 321562 & 7.5229 & 7.6964 & TRN \\
\hline CHEMBL196658 & 321562 & 7.9586 & 6.6937 & TRN \\
\hline CHEMBL382076 & 321562 & 8.1249 & 7.608 & TRN \\
\hline CHEMBL194685 & 321562 & 9.1249 & 8.6705 & TRN \\
\hline CHEMBL380601 & 321562 & 8.3979 & 7.7066 & TST \\
\hline CHEMBL555246 & 321562 & 9.1192 & 8.3234 & TST \\
\hline CHEMBL194461 & 321562 & 8.6576 & 7.9063 & TRN \\
\hline CHEMBL196443 & 321562 & 8.1549 & 8.3232 & TRN \\
\hline
\end{tabular}




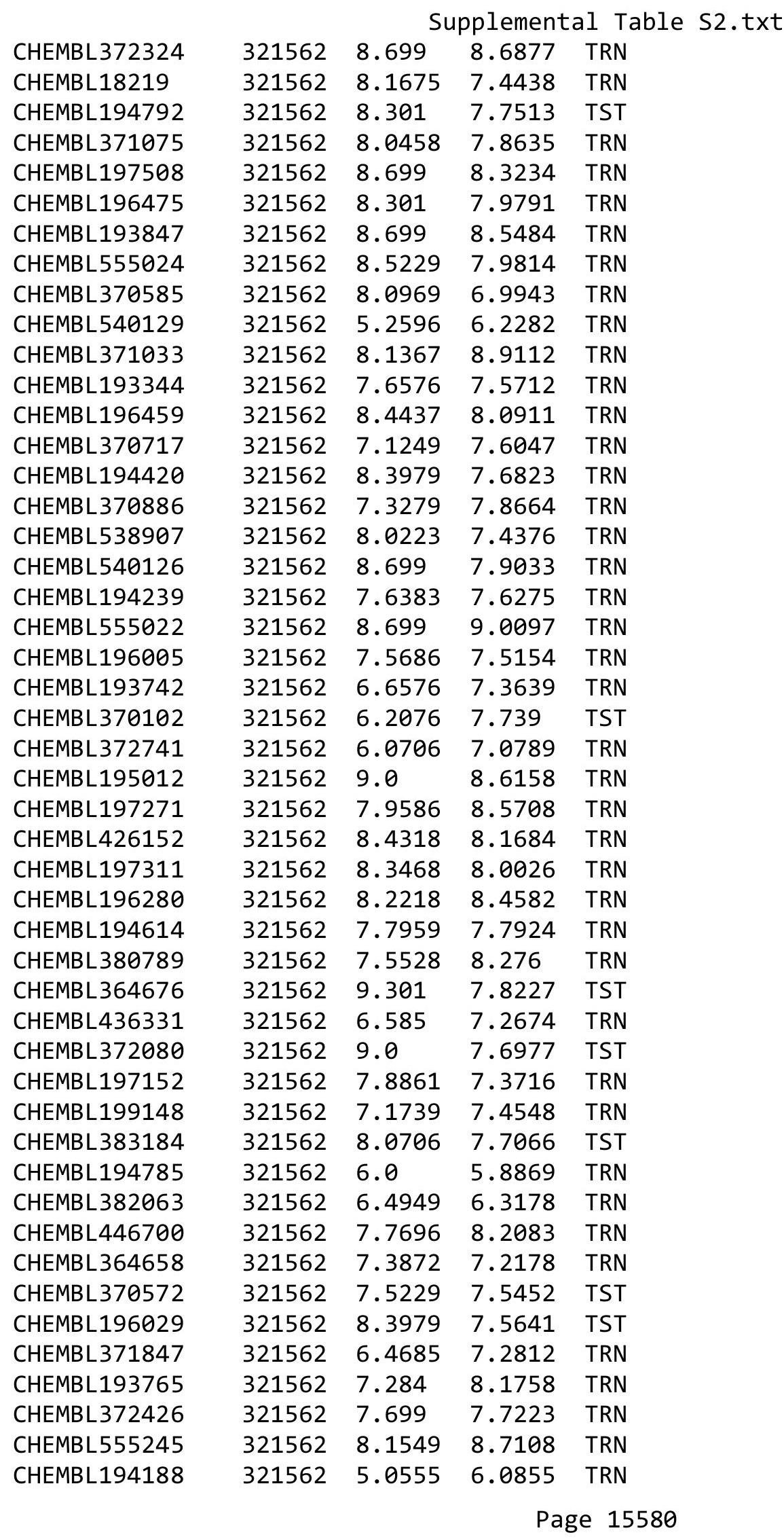




\begin{tabular}{|c|c|c|c|c|}
\hline \multicolumn{5}{|c|}{ Supplemental Table S2.txt } \\
\hline CHEMBL196032 & 321562 & 8.6383 & 8.209 & TRN \\
\hline CHEMBL426998 & 321562 & 8.1249 & 8.1035 & TRN \\
\hline CHEMBL193439 & 321562 & 8.3979 & 9.0186 & TST \\
\hline CHEMBL372088 & 321562 & 8.0706 & 7.8575 & TST \\
\hline CHEMBL540128 & 321562 & 8.2441 & 7.9814 & TST \\
\hline CHEMBL370103 & 321562 & 9.5229 & 7.8586 & TST \\
\hline CHEMBL611748 & 321562 & 8.5229 & 8.3031 & TST \\
\hline CHEMBL196159 & 321562 & 7.3768 & 7.1202 & TST \\
\hline CHEMBL383368 & 321562 & 6.0315 & 6.7132 & TST \\
\hline CHEMBL372572 & 321562 & 7.3468 & 8.7102 & TST \\
\hline CHEMBL221137 & 954998 & 4.8877 & 5.3078 & TST \\
\hline CHEMBL3199475 & 954998 & 6.0467 & 6.024 & TRN \\
\hline CHEMBL558642 & 954998 & 4.3863 & 4.3669 & TRN \\
\hline CHEMBL191334 & 954998 & 3.5489 & 3.5575 & TRN \\
\hline CHEMBL217354 & 954998 & 6.3725 & 6.2229 & TRN \\
\hline CHEMBL192566 & 954998 & 8.3335 & 9.4682 & TST \\
\hline CHEMBL1190711 & 954998 & 5.7394 & 5.7815 & TRN \\
\hline CHEMBL1643959 & 954998 & 5.1387 & 5.2741 & TRN \\
\hline CHEMBL577784 & 954998 & 5.8323 & 5.7636 & TRN \\
\hline CHEMBL222102 & 954998 & 4.066 & 3.8312 & TRN \\
\hline CHEMBL514499 & 954998 & 7.8066 & 7.7485 & TRN \\
\hline CHEMBL1516890 & 954998 & 4.6378 & 4.5328 & TRN \\
\hline CHEMBL210618 & 954998 & 3.6597 & 3.6202 & TRN \\
\hline CHEMBL585951 & 954998 & 6.4564 & 6.4473 & TRN \\
\hline CHEMBL1909414 & 954998 & 3.5018 & 3.464 & TRN \\
\hline CHEMBL472940 & 954998 & 4.6172 & 4.6249 & TRN \\
\hline CHEMBL1186585 & 954998 & 3.3127 & 3.3494 & TRN \\
\hline CHEMBL 2363137 & 954998 & 5.3343 & 5.306 & TRN \\
\hline CHEMBL412142 & 954998 & 3.4729 & 3.3832 & TRN \\
\hline CHEMBL300389 & 954998 & 7.7786 & 7.8485 & TRN \\
\hline CHEMBL 255342 & 954998 & 3.2169 & 3.2808 & TRN \\
\hline CHEMBL 2134202 & 954998 & 3.5038 & 3.5536 & TRN \\
\hline CHEMBL3392440 & 954998 & 4.3086 & 4.3312 & TRN \\
\hline CHEMBL202721 & 954998 & 5.0223 & 5.0003 & TRN \\
\hline CHEMBL 240954 & 954998 & 4.2842 & 3.7977 & TST \\
\hline CHEMBL1788116 & 954998 & 4.5753 & 4.5578 & TRN \\
\hline CHEMBL449158 & 954998 & 6.4708 & 7.07 & TST \\
\hline CHEMBL 3186408 & 954998 & 3.3617 & 4.0201 & TST \\
\hline CHEMBL 2137530 & 954998 & 4.5771 & 4.6617 & TRN \\
\hline CHEMBL220241 & 954998 & 4.1932 & 4.1622 & TRN \\
\hline CHEMBL209148 & 954998 & 5.0271 & 4.9458 & TRN \\
\hline CHEMBL 2144069 & 954998 & 5.2471 & 5.1934 & TRN \\
\hline CHEMBL483849 & 954998 & 2.931 & 2.7478 & TST \\
\hline CHEMBL573107 & 954998 & 5.1635 & 5.1931 & TRN \\
\hline CHEMBL3349342 & 954998 & 4.7781 & 4.7601 & TRN \\
\hline CHEMBL 373751 & 954998 & 3.352 & 3.4105 & TRN \\
\hline CHEMBL135561 & 954998 & 4.7451 & 4.6573 & TRN \\
\hline CHEMBL1357247 & 954998 & 3.6531 & 3.6049 & TRN \\
\hline
\end{tabular}




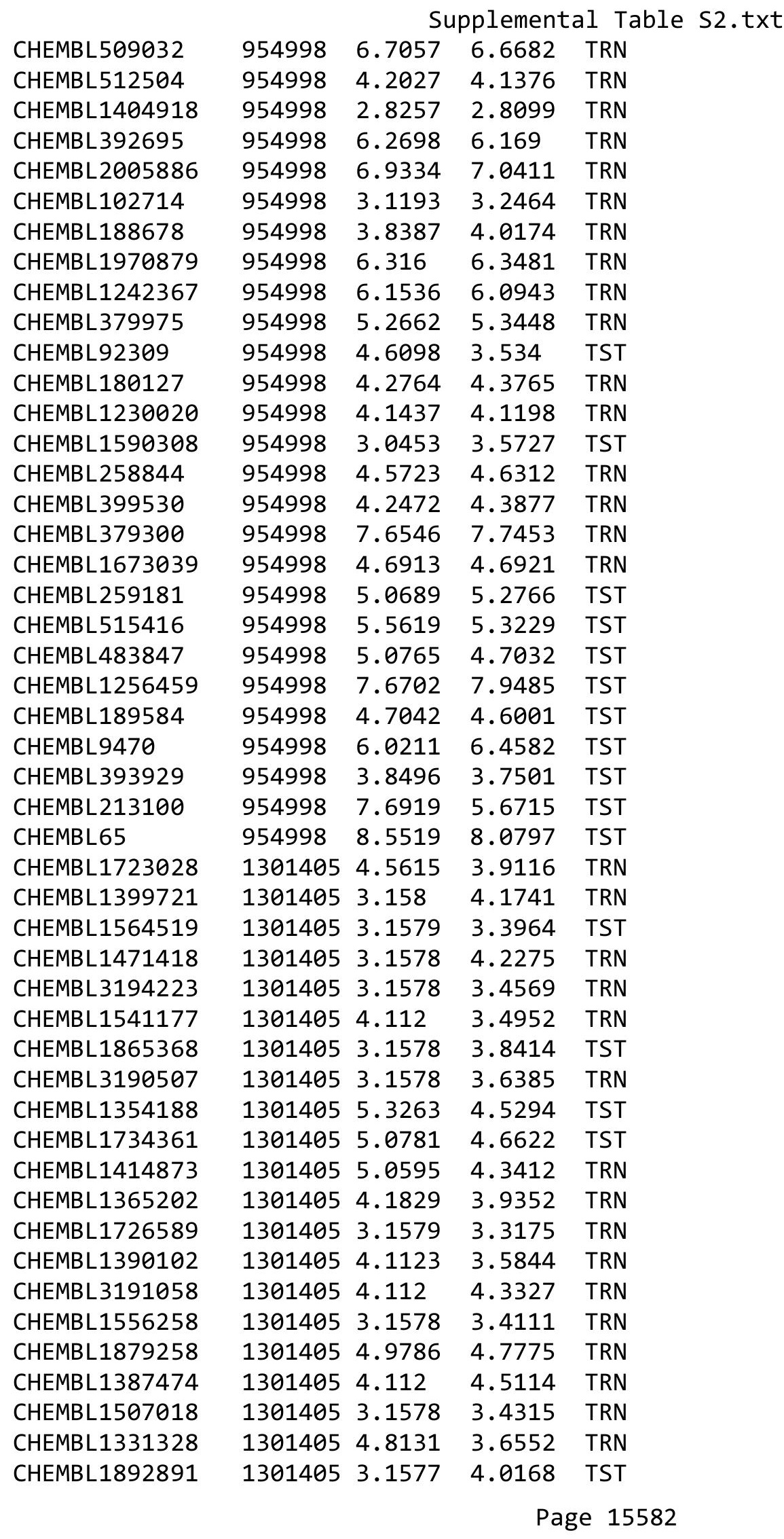


Supplemental Table S2.txt

\begin{tabular}{|c|c|c|c|c|}
\hline CHEMBL1314100 & 1301405 & 5.0415 & 4.6216 & TRN \\
\hline CHEMBL3198383 & 1301405 & 3.1582 & 3.57 & TRN \\
\hline CHEMBL1339121 & 1301405 & 4.8267 & 5.0185 & TRN \\
\hline CHEMBL1542349 & 1301405 & 4.1122 & 3.8976 & TRN \\
\hline CHEMBL3199869 & 1301405 & 4.4277 & 3.7497 & TRN \\
\hline CHEMBL3193700 & 1301405 & 4.5996 & 4.0842 & TRN \\
\hline CHEMBL1872282 & 1301405 & 3.1578 & 4.1939 & TST \\
\hline CHEMBL1548862 & 1301405 & 4.1122 & 4.3378 & TRN \\
\hline CHEMBL3183423 & 1301405 & 3.158 & 3.2962 & TRN \\
\hline CHEMBL1302531 & 1301405 & 4.9336 & 3.7794 & TRN \\
\hline CHEMBL1709472 & 1301405 & 4.5892 & 3.2906 & TRN \\
\hline CHEMBL1705776 & 1301405 & 3.158 & 3.489 & TRN \\
\hline CHEMBL1725768 & 1301405 & 5.227 & 4.1076 & TRN \\
\hline CHEMBL1598969 & 1301405 & 3.158 & 3.2672 & TRN \\
\hline CHEMBL1598365 & 1301405 & 3.1579 & 4.0889 & TRN \\
\hline CHEMBL1557691 & 1301405 & 3.1579 & 3.6765 & TST \\
\hline CHEMBL1716263 & 1301405 & 3.1578 & 3.6361 & TRN \\
\hline CHEMBL1372805 & 1301405 & 4.9968 & 4.0019 & TRN \\
\hline CHEMBL3196102 & 1301405 & 3.158 & 4.5604 & TST \\
\hline CHEMBL1392937 & 1301405 & 3.1581 & 3.8521 & TRN \\
\hline CHEMBL1360535 & 1301405 & 4.711 & 4.4704 & TST \\
\hline CHEMBL1884247 & 1301405 & 4.1122 & 3.4437 & TRN \\
\hline CHEMBL1731138 & 1301405 & 3.1578 & 3.6844 & TRN \\
\hline CHEMBL1536544 & 1301405 & 3.1578 & 4.1256 & TRN \\
\hline CHEMBL1515432 & 1301405 & 4.7328 & 4.4703 & TST \\
\hline CHEMBL1580116 & 1301405 & 4.9034 & 4.6802 & TRN \\
\hline CHEMBL1459330 & 1301405 & 4.9194 & 4.7676 & TRN \\
\hline CHEMBL3182418 & 1301405 & 3.1579 & 3.1322 & TRN \\
\hline CHEMBL1569954 & 1301405 & 3.1578 & 3.3028 & TRN \\
\hline CHEMBL1700254 & 1301405 & 4.9127 & \multicolumn{2}{|c|}{3.8510000000000004} \\
\hline CHEMBL1879111 & 1301405 & 3.1579 & 3.952 & TST \\
\hline CHEMBL1505057 & 1301405 & 3.1578 & 3.7944 & TRN \\
\hline CHEMBL1464485 & 1301405 & 3.1578 & \multicolumn{2}{|c|}{3.4610000000000003} \\
\hline CHEMBL1704794 & 1301405 & 4.9096 & 3.8412 & TST \\
\hline CHEMBL1472578 & 1301405 & 4.1122 & 4.1429 & TRN \\
\hline CHEMBL1367596 & 1301405 & 4.8219 & 4.166 & TST \\
\hline CHEMBL1313030 & 1301405 & 4.9895 & 3.5151 & TST \\
\hline CHEMBL1415308 & 1301405 & 4.8829 & 4.3578 & TRN \\
\hline CHEMBL 2136964 & 1301405 & 3.158 & 3.3122 & TRN \\
\hline CHEMBL1490638 & 1301405 & 3.1579 & 3.5708 & TRN \\
\hline CHEMBL1565496 & 1301405 & 4.9323 & 4.6946 & TRN \\
\hline CHEMBL1344800 & 1301405 & 4.1122 & 4.3343 & TRN \\
\hline CHEMBL1529744 & 1301405 & 3.1579 & 3.319 & TRN \\
\hline CHEMBL1608318 & 1301405 & 4.6554 & 4.2469 & TRN \\
\hline CHEMBL3199359 & 1301405 & 3.158 & 3.6524 & TRN \\
\hline CHEMBL1440953 & 1301405 & 3.1579 & 3.7145 & TRN \\
\hline CHEMBL456230 & 1301405 & 3.1581 & 3.9854 & TRN \\
\hline CHEMBL1556868 & 1301405 & 4.7686 & 4.0969 & TRN \\
\hline
\end{tabular}

Page 15583 
Supplemental Table S2.txt

\begin{tabular}{|c|c|c|c|c|}
\hline 387 & & & & $T R_{2}$ \\
\hline HEMBL1342393 & & 3.158 & 3.7573 & \\
\hline & & & & \\
\hline 166 & 01 & & & \\
\hline IEMBL1904243 & 3014 & 158 & & \\
\hline AEMBL1362333 & 301405 & 3.1579 & & \\
\hline AEMBL1C & 3014 & & & \\
\hline 441 & 301405 & & & \\
\hline IEMBL & 301405 & & & \\
\hline AEMBL1322496 & 301405 & 3.158 & & \\
\hline AEMBL2133252 & 301405 & 3.158 & & \\
\hline IEMBL1 & 3014 & 33 & & \\
\hline EMBL: & & & & RN \\
\hline AEMBL1 & 3014 & & & \\
\hline IEMBL1 & 3014 & 78 & & \\
\hline IEMBL1568078 & Je & 79 & & \\
\hline IEMBL3 & 301 & & & 年 \\
\hline IEMBL3 & & & & ST \\
\hline AEMBL1 & 301 & & & ST \\
\hline IEMBL: & 201 & & & \\
\hline 82277 & 301 & & & KIV \\
\hline IEMBL] & 301 & & & RN \\
\hline IEMBL: & & & & \\
\hline 937 & > & & & \\
\hline IEMBL & 36 & & & iv \\
\hline 810 & 301 & & & SI \\
\hline IEMBL: & 30 & 2 & & RN \\
\hline 996 & ard & & & \\
\hline 66 & & & & ST \\
\hline IEMBL1 & . & & & rRN \\
\hline IEMBL & 301 & & & RN \\
\hline EMBL & $30+2$ & & & RN \\
\hline 65 & 2011 & & & \\
\hline IEMBL1: & & & & RN \\
\hline AEMBL1609332 & 3014 & & & TR \\
\hline IEMBL & 01 & & & RN \\
\hline 22 & $3 a 1+2$ & & & RN \\
\hline & & & & RIN \\
\hline AEMBL1379134 & 3014 & & & TRN \\
\hline IEMBL? & 3014 & & & TRN \\
\hline IEMBL] & 301 & & & TST \\
\hline 1 & & & & rRN \\
\hline HEMBL1360489 & 3014 & & 71 & TST \\
\hline EMBL1885808 & 3014 & 1579 & & RN \\
\hline 320 & 301 & & & nIV \\
\hline HEMBL & 301 & & & $\cdots$ \\
\hline CHEMBL1327593 & 301 & 3.1581 & & $\mathrm{RN}$ \\
\hline CHEMBL1342518 & 130140 & 3.1581 & 4.6026 & TST \\
\hline
\end{tabular}

Page 15584 
Supplemental Table S2.txt

\begin{tabular}{|c|c|c|c|c|}
\hline$\theta$ & & & & \\
\hline & 301405 & & & \\
\hline EMRI & 5 & & & \\
\hline IEMBL138 & & & & \\
\hline AEMBL3189131 & 301405 & 17 & 9777 & \\
\hline HEMBL 3192 & 301405 & & 817 & \\
\hline HEMBL: & 301 & & & \\
\hline AEMBL189 & 25 & & & 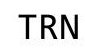 \\
\hline HEMBL1426168 & 301405 & & 5802 & \\
\hline HEMBL3185731 & 301405 & & & \\
\hline HEMBL154€ & 3014 & & & \\
\hline HEMBL1 & 301 & & 5 & \\
\hline HEMBL1 & 5 & & & \\
\hline HEMBL1505089 & 301405 & & 3712 & 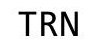 \\
\hline AEMBL1897794 & 301405 & & & \\
\hline HEMBL1 & 301 & & 301 & \\
\hline HEMBL & 36 & & & RN \\
\hline HEMBL1 & 301 & & 06 & \\
\hline HEMBL1 & 301405 & & 1177 & \\
\hline AEMBL1 & 201 & & & I KIV \\
\hline HEMBL & 30 & & & RI \\
\hline HEM & 30 & & & RN \\
\hline HEMBL; & 95 & & & $\mathrm{RN}$ \\
\hline HEMBL1 & 301405 & & & TRN \\
\hline AEMBL151: & 35 & & & I RN \\
\hline HEMBL3 & 30 & & & 「RN \\
\hline HEMBL & 30 & & & $\mathrm{RN}$ \\
\hline 56 & 20 & & & \\
\hline AEMBLI & & & & $\mid$ \\
\hline HEMBL 3182 & 3014 & & 81 & TRN \\
\hline HEMBL1 & 30 & & & RN \\
\hline $15 \mathrm{M}$ & 13 & & & \\
\hline 8 & & & & 「RN \\
\hline HEMBL150 & $301<$ & & & $\mathrm{RN}$ \\
\hline HEMBL1390546 & 3014 & & & RN \\
\hline IFMPI- & 30 & & & TRN \\
\hline 4 & م & & & ГRN \\
\hline HEMBL 318 & & & & 「RN \\
\hline HEMBL159€ & 301 & & & TST \\
\hline 1 & 30 & & & 「RN \\
\hline HEMBL1 & 30 & & & TRN \\
\hline HEMBL1 & 20 & & & 「RN \\
\hline HEMBL1510525 & 301405 & 4.7 & 0437 & RN \\
\hline HEMBL1 & 301405 & & & TR \\
\hline CHEMBL1567029 & & & & ST \\
\hline HEMBL3 & 301 & & 5816 & \\
\hline CHEMBL 3184105 & 13014 & 3.158 & 4577 & \\
\hline CHEMBL1882496 & 1301405 & 3.1578 & 3.2021 & \\
\hline
\end{tabular}

Page 15585 
Supplemental Table S2.txt

\begin{tabular}{|c|c|c|c|c|c|c|}
\hline CHEMBL1893620 & 1301405 & 5.0507 & 4.9675 & TRN & & \\
\hline CHEMBL1377629 & 1301405 & 5.0554 & 4.9811 & TRN & & \\
\hline CHEMBL1881685 & 1301405 & 4.7643 & 4.7195 & TRN & & \\
\hline CHEMBL1444205 & 1301405 & 3.1579 & 3.4552 & TRN & & \\
\hline CHEMBL1341108 & 1301405 & 5.1292 & 4.1498 & TRN & & \\
\hline CHEMBL1321181 & 1301405 & 5.1138 & 3.7024 & TRN & & \\
\hline CHEMBL3183981 & 1301405 & 5.0126 & 3.6736 & TRN & & \\
\hline CHEMBL1360018 & 1301405 & 3.1579 & 3.9566 & TRN & & \\
\hline CHEMBL1395386 & 1301405 & 3.158 & 3.7733 & TRN & & \\
\hline CHEMBL1408046 & 1301405 & 3.158 & 4.1126 & TST & & \\
\hline CHEMBL1523835 & 1301405 & 4.74 & 4.1196 & TST & & \\
\hline CHEMBL1340694 & 1301405 & 4.8809 & 3.8518 & TRN & & \\
\hline CHEMBL1500199 & 1301405 & 4.9206 & 4.448 & TRN & & \\
\hline CHEMBL1579548 & 1301405 & 3.158 & 3.8814 & TRN & & \\
\hline CHEMBL1520460 & 1301405 & 3.1579 & 3.986 & TRN & & \\
\hline CHEMBL1526349 & 1301405 & 3.158 & 4.0855 & TST & & \\
\hline CHEMBL1468925 & 1301405 & 4.8356 & 4.309 & TRN & & \\
\hline CHEMBL1309608 & 1301405 & 3.1579 & 3.5515 & TRN & & \\
\hline CHEMBL1301475 & 1301405 & 3.158 & 3.6737 & TRN & & \\
\hline CHEMBL1900400 & 1301405 & 5.0714 & 4.4852 & TRN & & \\
\hline CHEMBL1371370 & 1301405 & 5.2837 & 4.5388 & TRN & & \\
\hline CHEMBL1346062 & 1301405 & 4.1122 & 4.2988 & TRN & & \\
\hline CHEMBL1870067 & 1301405 & \multicolumn{3}{|c|}{4.9830000000000005} & 4.4429 & TRN \\
\hline CHEMBL1338847 & 1301405 & 5.0601 & 3.6153 & TRN & & \\
\hline CHEMBL1510676 & 1301405 & 4.7768 & 4.2909 & TST & & \\
\hline CHEMBL3187645 & 1301405 & 4.1119 & 3.9803 & TRN & & \\
\hline CHEMBL1576810 & 1301405 & 4.5605 & 4.2592 & TRN & & \\
\hline CHEMBL 2004592 & 1301405 & 3.1579 & 3.3768 & TRN & & \\
\hline CHEMBL1339991 & 1301405 & 4.8883 & 4.6559 & TRN & & \\
\hline CHEMBL3183645 & 1301405 & 3.1581 & 3.359 & TRN & & \\
\hline CHEMBL1584720 & 1301405 & 5.1276 & 4.6301 & TRN & & \\
\hline CHEMBL1610051 & 1301405 & 4.8949 & 5.1544 & TRN & & \\
\hline CHEMBL1573057 & 1301405 & 3.1579 & 4.3381 & TST & & \\
\hline CHEMBL1416769 & 1301405 & 4.1122 & 4.1186 & TRN & & \\
\hline CHEMBL1543659 & 1301405 & 5.0763 & 3.7119 & TRN & & \\
\hline CHEMBL1575715 & 1301405 & 4.7736 & 4.4248 & TRN & & \\
\hline CHEMBL 3190022 & 1301405 & 3.158 & 4.5187 & TST & & \\
\hline CHEMBL1343752 & 1301405 & 3.1579 & 3.7001 & TRN & & \\
\hline CHEMBL1891222 & 1301405 & 5.0197 & 3.8858 & TRN & & \\
\hline CHEMBL1890686 & 1301405 & 4.9491 & 4.979 & TST & & \\
\hline CHEMBL1433203 & 1301405 & 3.158 & 3.7259 & TST & & \\
\hline CHEMBL1905891 & 1301405 & 4.112 & 4.56 & TST & & \\
\hline CHEMBL1898802 & 1301405 & 5.0953 & 4.5677 & TST & & \\
\hline CHEMBL3196661 & 1301405 & 3.158 & 3.7983 & TST & & \\
\hline CHEMBL1544580 & 1301405 & 3.158 & 3.8418 & TST & & \\
\hline CHEMBL1540038 & 1301405 & 3.1581 & 4.5962 & TST & & \\
\hline CHEMBL1383622 & 1301405 & 3.1579 & 4.2602 & TST & & \\
\hline CHEMBL1883149 & 1301405 & 3.1578 & 3.3953 & TST & & \\
\hline
\end{tabular}

Page 15586 
Supplemental Table S2.txt

\begin{tabular}{|c|c|c|c|c|c|}
\hline CHEMBL1309498 & 1301405 & 4.9625 & 4.461 & TST & \\
\hline CHEMBL1449661 & 1301405 & 3.1578 & 3.3259 & TST & \\
\hline CHEMBL1310332 & 1301405 & 3.158 & 4.9216 & TST & \\
\hline CHEMBL1613092 & 1301405 & 3.1582 & 4.3351 & TST & \\
\hline CHEMBL1498140 & 1301405 & 3.1578 & 3.7414 & TST & \\
\hline CHEMBL1893852 & 1301405 & 3.1578 & 3.0669 & TST & \\
\hline CHEMBL1538808 & 1301405 & 4.1122 & 4.1672 & TST & \\
\hline CHEMBL1320796 & 1301405 & 4.353 & 3.4581 & TST & \\
\hline CHEMBL1904601 & 1301405 & 5.1049 & 4.1174 & TST & \\
\hline CHEMBL1877001 & 1301405 & 5.1199 & 5.0278 & TST & \\
\hline CHEMBL1488756 & 1301405 & 4.4318 & 4.4061 & TST & \\
\hline CHEMBL3192775 & 1301405 & 3.1579 & 3.9117 & TST & \\
\hline CHEMBL1901350 & 1301405 & 4.8079 & 4.8467 & TST & \\
\hline CHEMBL599255 & 1301405 & 5.2571 & 4.3205 & TST & \\
\hline CHEMBL3978852 & 1641495 & 7.4123 & 7.2908 & TRN & \\
\hline CHEMBL3977143 & 1641495 & 7.0706 & 7.3882 & TRN & \\
\hline CHEMBL3954169 & 1641495 & 7.4685 & 7.3642 & TRN & \\
\hline CHEMBL3960735 & 1641495 & 7.3565 & 7.7344 & TRN & \\
\hline CHEMBL3928356 & 1641495 & 8.699 & 8.7194 & TRN & \\
\hline CHEMBL3954528 & 1641495 & 7.4437 & 7.2545 & TRN & \\
\hline CHEMBL3950809 & 1641495 & 7.4685 & 7.2515 & TRN & \\
\hline CHEMBL3978408 & 1641495 & 7.3979 & 7.21299 & 9999999999 & TRN \\
\hline CHEMBL3959688 & 1641495 & 7.5686 & 7.3651 & TRN & \\
\hline CHEMBL3930081 & 1641495 & 7.699 & 7.9219 & TRN & \\
\hline CHEMBL3963434 & 1641495 & 7.3768 & 7.4742 & TST & \\
\hline CHEMBL3982908 & 1641495 & 7.4202 & 7.3468 & TRN & \\
\hline CHEMBL3963060 & 1641495 & 9.2218 & 9.2586 & TRN & \\
\hline CHEMBL3891192 & 1641495 & 8.0458 & 7.8275 & TRN & \\
\hline CHEMBL3905585 & 1641495 & 9.0 & 8.639 & TRN & \\
\hline CHEMBL3924067 & 1641495 & 7.4437 & 7.4859 & TRN & \\
\hline CHEMBL3955969 & 1641495 & 8.5229 & 8.3201 & TRN & \\
\hline CHEMBL3956077 & 1641495 & 7.3665 & 7.8769 & TST & \\
\hline CHEMBL3901911 & 1641495 & 7.4318 & 7.4058 & TST & \\
\hline CHEMBL3974915 & 1641495 & 7.3872 & 7.2811 & TRN & \\
\hline CHEMBL3981456 & 1641495 & 7.2291 & 7.4237 & TST & \\
\hline CHEMBL3944439 & 1641495 & 7.3665 & 7.182 & TRN & \\
\hline CHEMBL3983164 & 1641495 & 7.041 & 7.2133 & TRN & \\
\hline CHEMBL3927583 & 1641495 & 7.4949 & 7.4088 & TRN & \\
\hline CHEMBL3937686 & 1641495 & 7.4202 & 7.6244 & TRN & \\
\hline CHEMBL3894293 & 1641495 & 7.3979 & 7.2419 & TRN & \\
\hline CHEMBL3926673 & 1641495 & 7.1871 & 7.5443 & TRN & \\
\hline CHEMBL3948759 & 1641495 & 7.3279 & 7.1714 & TRN & \\
\hline CHEMBL3964540 & 1641495 & 7.4437 & 7.376 & TRN & \\
\hline CHEMBL3950499 & 1641495 & 7.0915 & 7.319 & TRN & \\
\hline CHEMBL3983855 & 1641495 & 7.4685 & 7.4797 & TRN & \\
\hline CHEMBL3899290 & 1641495 & 7.1249 & 7.2908 & TRN & \\
\hline CHEMBL3917713 & 1641495 & 7.284 & 7.3143 & TRN & \\
\hline CHEMBL3958602 & 1641495 & 7.2076 & 7.4513 & TRN & \\
\hline
\end{tabular}


Supplemental Table S2.txt

\begin{tabular}{|c|c|c|c|c|c|}
\hline CHEMBL3972714 & 1641495 & 7.3279 & 7.2442 & TRN & \\
\hline CHEMBL3963966 & 1641495 & 7.3279 & 6.6868 & TRN & \\
\hline CHEMBL3890457 & 1641495 & 7.4685 & 7.4112 & TRN & \\
\hline CHEMBL3893830 & 1641495 & 7.3279 & 7.2966 & TRN & \\
\hline CHEMBL3950852 & 1641495 & 7.3979 & 7.4148 & TRN & \\
\hline CHEMBL3950675 & 1641495 & 7.5229 & 7.3631 & TRN & \\
\hline CHEMBL3922976 & 1641495 & 8.3979 & 8.3336 & TST & \\
\hline CHEMBL3894148 & 1641495 & 7.3872 & 7.2408 & TRN & \\
\hline CHEMBL3890749 & 1641495 & 7.0362 & 7.3407 & TST & \\
\hline CHEMBL3954053 & 1641495 & 7.3468 & 7.3536 & TRN & \\
\hline CHEMBL3957103 & 1641495 & 6.857 & 7.279 & TST & \\
\hline CHEMBL3977550 & 1641495 & 8.7212 & 8.6118 & TRN & \\
\hline CHEMBL3924995 & 1641495 & 7.2441 & 7.234 & TRN & \\
\hline CHEMBL 3893226 & 1641495 & 7.5229 & 7.6577 & TRN & \\
\hline CHEMBL3929847 & 1641495 & 6.9872 & 6.9747 & TST & \\
\hline CHEMBL3962790 & 1641495 & 7.1612 & 7.3154 & TRN & \\
\hline CHEMBL3907694 & 1641495 & 6.5171 & 7.2716 & TST & \\
\hline CHEMBL3978232 & 1641495 & 6.8928 & 7.057 & TST & \\
\hline CHEMBL3962620 & 1641495 & 7.3372 & 7.4515 & TRN & \\
\hline CHEMBL3935000 & 1641495 & 7.0 & 7.7156 & TST & \\
\hline CHEMBL3949130 & 1641495 & 7.4949 & 7.2226 & TRN & \\
\hline CHEMBL3919450 & 1641495 & 8.3979 & 8.2316 & TRN & \\
\hline CHEMBL3908762 & 1641495 & 7.1427 & 7.48799 & 99999999995 & TRN \\
\hline CHEMBL3905123 & 1641495 & 7.6198 & 7.6941 & TRN & \\
\hline CHEMBL3946524 & 1641495 & 7.7212 & 7.7804 & TRN & \\
\hline CHEMBL3931309 & 1641495 & 7.9586 & 7.6459 & TST & \\
\hline CHEMBL3967503 & 1641495 & 9.1549 & 8.605 & TRN & \\
\hline CHEMBL3902786 & 1641495 & 7.1739 & 7.2592 & TRN & \\
\hline CHEMBL3927928 & 1641495 & 7.4815 & 7.6358 & TST & \\
\hline CHEMBL 3954302 & 1641495 & 7.6778 & 7.657 & TRN & \\
\hline CHEMBL3947992 & 1641495 & 7.1871 & 7.3876 & TRN & \\
\hline CHEMBL3968121 & 1641495 & 7.0757 & 7.4988 & TST & \\
\hline CHEMBL3945010 & 1641495 & 7.3768 & 7.3949 & TST & \\
\hline CHEMBL3964853 & 1641495 & 8.0458 & 8.325 & TRN & \\
\hline CHEMBL3983021 & 1641495 & 7.0315 & 7.2083 & TST & \\
\hline CHEMBL3893978 & 1641495 & 7.4559 & 7.3016 & TRN & \\
\hline CHEMBL3945536 & 1641495 & 7.2676 & 7.3357 & TRN & \\
\hline CHEMBL3889592 & 1641495 & 7.1549 & 7.2077 & TRN & \\
\hline CHEMBL3903099 & 1641495 & 7.3279 & 7.2905 & TST & \\
\hline CHEMBL3936857 & 1641495 & 7.4089 & 7.3122 & TST & \\
\hline CHEMBL3922164 & 1641495 & 7.3188 & 7.3391 & TST & \\
\hline CHEMBL3941079 & 1641495 & 7.4949 & 7.358 & TRN & \\
\hline CHEMBL3959530 & 1641495 & 7.3565 & 7.3299 & TRN & \\
\hline CHEMBL3979101 & 1641495 & 7.5528 & 7.4458 & TRN & \\
\hline CHEMBL3895927 & 1641495 & 9.0 & 8.8515 & TRN & \\
\hline CHEMBL3902980 & 1641495 & 7.6021 & 7.5381 & TST & \\
\hline CHEMBL3903270 & 1641495 & 7.4089 & 7.3654 & TRN & \\
\hline CHEMBL 3894304 & 1641495 & 7.2076 & 7.45 & TST & \\
\hline
\end{tabular}


Supplemental Table S2.txt

\begin{tabular}{|c|c|c|c|c|c|c|}
\hline CHEMBL3926536 & 1641495 & 7.3768 & 7.4019 & TST & & \\
\hline CHEMBL 3965742 & 1641495 & 7.2007 & 7.3255 & TRN & & \\
\hline CHEMBL3913968 & 1641495 & 7.284 & 7.225 & TRN & & \\
\hline CHEMBL 3979127 & 1641495 & 7.5686 & 7.3594 & TRN & & \\
\hline CHEMBL3947268 & 1641495 & 6.0 & 7.6194 & TRN & & \\
\hline CHEMBL38093 & 157713 & 6.4949 & 6.7513 & TRN & & \\
\hline CHEMBL290074 & 157713 & 9.8861 & 9.9203 & TRN & & \\
\hline CHEMBL 287546 & 157713 & 9.0605 & 8.743 & TRN & & \\
\hline CHEMBL37593 & 157713 & 10.0 & 10.1809 & TRN & & \\
\hline CHEMBL432093 & 157713 & 9.3872 & 8.9698 & TST & & \\
\hline CHEMBL36725 & 157713 & 8.0088 & 7.7166 & TRN & & \\
\hline CHEMBL289934 & 157713 & 7.4815 & 7.1117 & TRN & & \\
\hline CHEMBL37701 & 157713 & 7.8539 & 7.8882 & TRN & & \\
\hline CHEMBL36437 & 157713 & 9.4202 & 9.182 & TRN & & \\
\hline CHEMBL39432 & 157713 & 6.4949 & 5.5684 & TST & & \\
\hline CHEMBL 289350 & 157713 & 5.6198 & 5.8883 & TRN & & \\
\hline CHEMBL37618 & 157713 & 7.3565 & 7.1488 & TRN & & \\
\hline CHEMBL284942 & 157713 & \multicolumn{3}{|c|}{10.699000000000002} & 10.6956 & TRN \\
\hline CHEMBL38281 & 157713 & 8.2518 & 8.45 & TRN & & \\
\hline CHEMBL285417 & 157713 & 9.8539 & 9.7839 & TRN & & \\
\hline CHEMBL285871 & 157713 & 9.3098 & 9.3186 & TRN & & \\
\hline CHEMBL286672 & 157713 & 10.0969 & 10.1458 & TRN & & \\
\hline CHEMBL284941 & 157713 & 9.5086 & 9.5544 & TRN & & \\
\hline CHEMBL37947 & 157713 & 5.4202 & 5.2911 & TRN & & \\
\hline CHEMBL416964 & 157713 & 8.8539 & 8.8266 & TRN & & \\
\hline CHEMBL286159 & 157713 & 9.6198 & 9.3296 & TRN & & \\
\hline CHEMBL 285282 & 157713 & 8.3098 & 8.2663 & TRN & & \\
\hline CHEMBL288515 & 157713 & 5.8239 & 7.3134 & TST & & \\
\hline CHEMBL37033 & 157713 & 7.9586 & 7.9606 & TRN & & \\
\hline CHEMBL288254 & 157713 & \multicolumn{3}{|c|}{10.699000000000002} & 10.3744 & TRN \\
\hline CHEMBL39747 & 157713 & 6.7328 & 6.892 & TRN & & \\
\hline CHEMBL288513 & 157713 & 6.8041 & 6.6039 & TRN & & \\
\hline CHEMBL40052 & 157713 & 6.2668 & 6.3618 & TRN & & \\
\hline CHEMBL290362 & 157713 & 10.0969 & 10.1809 & TRN & & \\
\hline CHEMBL36862 & 157713 & 8.7696 & 9.1284 & TRN & & \\
\hline CHEMBL290888 & 157713 & 5.5229 & 4.5494 & TST & & \\
\hline CHEMBL366576 & 157713 & 10.2218 & 10.1855 & TRN & & \\
\hline CHEMBL 286693 & 157713 & 9.041 & 9.5481 & TRN & & \\
\hline CHEMBL287923 & 157713 & 9.3188 & 9.5825 & TRN & & \\
\hline CHEMBL286671 & 157713 & 10.5229 & 10.6756 & TRN & & \\
\hline CHEMBL116517 & 157713 & \multicolumn{3}{|c|}{10.699000000000002} & 10.7517 & TRN \\
\hline CHEMBL36581 & 157713 & 9.5528 & 9.4206 & TRN & & \\
\hline CHEMBL286304 & 157713 & 6.6383 & 7.131 & TRN & & \\
\hline CHEMBL 288261 & 157713 & 9.8239 & 9.8265 & TRN & & \\
\hline CHEMBL290254 & 157713 & 10.0 & 10.0273 & TRN & & \\
\hline CHEMBL284136 & 157713 & 9.9208 & 9.8933 & TRN & & \\
\hline CHEMBL37472 & 157713 & 8.9208 & 9.245 & TRN & & \\
\hline CHEMBL277389 & 157713 & 9.8539 & 9.8678 & TRN & & \\
\hline
\end{tabular}




\begin{tabular}{|c|c|c|c|c|c|c|}
\hline & & \multicolumn{5}{|c|}{ Supplemental Table S2.txt } \\
\hline CHEMBL38339 & 157713 & 7.9586 & 8.0459 & TRN & & \\
\hline CHEMBL287520 & 157713 & 7.3979 & 7.1117 & TRN & & \\
\hline CHEMBL288239 & 157713 & 7.1805 & 7.4469 & TRN & & \\
\hline CHEMBL39749 & 157713 & 7.8239 & 7.8618 & TRN & & \\
\hline CHEMBL39979 & 157713 & 7.0 & 6.9552 & TRN & & \\
\hline CHEMBL286390 & 157713 & 9.6021 & 9.3533 & TRN & & \\
\hline CHEMBL38314 & 157713 & 10.5686 & 9.9857 & TST & & \\
\hline CHEMBL36900 & 157713 & 11.0 & 11.0318 & TRN & & \\
\hline CHEMBL36380 & 157713 & 5.6198 & 6.4622 & TST & & \\
\hline CHEMBL39526 & 157713 & 7.9208 & 7.5499 & TRN & & \\
\hline CHEMBL289393 & 157713 & 8.7959 & 8.7511 & TRN & & \\
\hline CHEMBL38059 & 157713 & 6.3372 & 6.4069 & TRN & & \\
\hline CHEMBL289715 & 157713 & 7.6383 & 7.8437 & TRN & & \\
\hline CHEMBL289762 & 157713 & 9.5229 & 9.5112 & TRN & & \\
\hline CHEMBL284340 & 157713 & 10.0458 & 9.6728 & TRN & & \\
\hline CHEMBL446395 & 157713 & 10.0 & 9.8799 & TRN & & \\
\hline CHEMBL36481 & 157713 & 6.0132 & 6.4246 & TST & & \\
\hline CHEMBL290331 & 157713 & 10.2218 & 10.2938 & TRN & & \\
\hline CHEMBL416783 & 157713 & 10.69906 & 0000000 & 202 & 10.6898 & TRN \\
\hline CHEMBL36751 & 157713 & 6.6968 & 6.7019 & TST & & \\
\hline CHEMBL36939 & 157713 & 8.585 & 8.7471 & TRN & & \\
\hline CHEMBL39592 & 157713 & 8.0969 & 8.1182 & TRN & & \\
\hline CHEMBL286794 & 157713 & 8.2076 & 7.8196 & TRN & & \\
\hline CHEMBL290809 & 157713 & 6.3872 & 6.6264 & TST & & \\
\hline CHEMBL289473 & 157713 & 10.2218 & 9.9395 & TRN & & \\
\hline CHEMBL288045 & 157713 & 6.4815 & 6.5716 & TRN & & \\
\hline CHEMBL264852 & 157713 & 10.0 & 9.8705 & TST & & \\
\hline CHEMBL431321 & 157713 & 9.1871 & 9.4206 & TRN & & \\
\hline CHEMBL37118 & 157713 & 7.4815 & 9.3286 & TST & & \\
\hline CHEMBL289907 & 157713 & 8.8539 & 8.7245 & TST & & \\
\hline CHEMBL287818 & 157713 & 6.9586 & 6.9862 & TST & & \\
\hline CHEMBL37083 & 157713 & 7.8539 & 8.0217 & TST & & \\
\hline CHEMBL431910 & 157713 & 6.5528 & 6.5555 & TST & & \\
\hline CHEMBL37639 & 157713 & 7.8239 & 7.882006 & 0000000001 & & TST \\
\hline CHEMBL416612 & 157713 & 10.2218 & 9.1393 & TST & & \\
\hline CHEMBL291004 & 157713 & 10.5229 & 10.0238 & TST & & \\
\hline CHEMBL286596 & 157713 & 7.6383 & 7.358 & TST & & \\
\hline CHEMBL290864 & 157713 & 7.0044 & 8.7354 & TST & & \\
\hline CHEMBL37313 & 157713 & 7.9208 & 7.9113 & TST & & \\
\hline CHEMBL223543 & 430991 & 7.4318 & 7.0225 & TRN & & \\
\hline CHEMBL224672 & 430991 & 6.8861 & 6.9041 & TRN & & \\
\hline CHEMBL225589 & 430991 & 7.7959 & 7.70799 & 9999999999 & & TRN \\
\hline CHEMBL374135 & 430991 & 3.0 & 4.2908 & TRN & & \\
\hline CHEMBL224617 & 430991 & 8.301 & 7.2191 & TRN & & \\
\hline CHEMBL386565 & 430991 & 8.0 & 7.2871 & TST & & \\
\hline CHEMBL389655 & 430991 & 7.301 & 7.0715 & TRN & & \\
\hline CHEMBL224200 & 430991 & 7.0862 & 6.6537 & TST & & \\
\hline CHEMBL225032 & 430991 & 9.0 & 7.0715 & TRN & & \\
\hline
\end{tabular}




\begin{tabular}{|c|c|c|c|c|c|}
\hline \\
\hline CHEMBL224084 & 430991 & 8.0458 & 7.4442 & TRN & \\
\hline CHEMBL376372 & 430991 & 7.0044 & 6.7695 & TRN & \\
\hline CHEMBL224673 & 430991 & 7.3565 & 7.505 & TRN & \\
\hline CHEMBL374167 & 430991 & 6.3904 & 6.95 & TRN & \\
\hline CHEMBL225439 & 430991 & 5.0706 & 6.1518 & TRN & \\
\hline CHEMBL224377 & 430991 & 5.8356 & 6.737 & TST & \\
\hline CHEMBL225126 & 430991 & 6.9469 & 6.8645 & TRN & \\
\hline CHEMBL223399 & 430991 & 7.8861 & 7.0715 & TRN & \\
\hline CHEMBL224798 & 430991 & 6.7375 & 6.7345 & TRN & \\
\hline CHEMBL387976 & 430991 & 6.9957 & 7.138 & TRN & \\
\hline CHEMBL389870 & 430991 & 7.4089 & 8.3885 & TRN & \\
\hline CHEMBL223819 & 430991 & 6.475 & 7.2513 & TST & \\
\hline CHEMBL385336 & 430991 & 8.5229 & 7.4426 & TRN & \\
\hline CHEMBL426018 & 430991 & 6.7447 & 7.2014 & TRN & \\
\hline CHEMBL390391 & 430991 & 6.5143 & 6.8458 & TRN & \\
\hline CHEMBL 224898 & 430991 & 7.3468 & 7.6055 & TRN & \\
\hline CHEMBL426190 & 430991 & 7.3098 & 7.1402 & TRN & \\
\hline CHEMBL386935 & 430991 & 7.585 & 7.101 & TRN & \\
\hline CHEMBL224315 & 430991 & 6.8539 & 7.2966 & TRN & \\
\hline CHEMBL224088 & 430991 & 7.3872 & 6.8581 & TRN & \\
\hline CHEMBL389918 & 430991 & 6.0227 & 6.95700 & 3000000001 & TRN \\
\hline CHEMBL387687 & 430991 & 7.0605 & 5.1694 & TRN & \\
\hline CHEMBL225201 & 430991 & 7.0757 & 7.4661 & TRN & \\
\hline CHEMBL225125 & 430991 & 7.1487 & 7.4139 & TRN & \\
\hline CHEMBL386408 & 430991 & 6.7773 & 6.6367 & TST & \\
\hline CHEMBL374815 & 430991 & 7.0088 & 7.2892 & TRN & \\
\hline CHEMBL385776 & 430991 & 6.7773 & 7.2656 & TRN & \\
\hline CHEMBL388087 & 430991 & 6.5513 & 7.0907 & TRN & \\
\hline CHEMBL225438 & 430991 & 6.9136 & 7.6646 & TRN & \\
\hline CHEMBL225590 & 430991 & 8.3979 & 7.6917 & TRN & \\
\hline CHEMBL224356 & 430991 & 7.7696 & 7.6969 & TRN & \\
\hline CHEMBL388827 & 430991 & 6.317 & 7.0397 & TRN & \\
\hline CHEMBL223868 & 430991 & 6.857 & 6.8896 & TRN & \\
\hline CHEMBL223496 & 430991 & 8.301 & 7.8141 & TRN & \\
\hline CHEMBL375439 & 430991 & 6.6003 & 7.3799 & TRN & \\
\hline CHEMBL 225124 & 430991 & 7.6383 & 7.7822 & TST & \\
\hline CHEMBL224375 & 430991 & 7.4949 & 6.7107 & TST & \\
\hline CHEMBL224135 & 430991 & 6.1993 & 7.4453 & TST & \\
\hline CHEMBL389897 & 430991 & 7.301 & 7.4539 & TST & \\
\hline CHEMBL224615 & 430991 & 7.699 & 7.3944 & TST & \\
\hline CHEMBL 224322 & 430991 & 7.1192 & 7.4053 & TST & \\
\hline CHEMBL223869 & 430991 & 7.3665 & 7.1475 & TST & \\
\hline CHEMBL374180 & 430991 & 7.7212 & 6.8129 & TST & \\
\hline CHEMBL364601 & 306667 & 8.5229 & 7.2449 & TST & \\
\hline CHEMBL184699 & 306667 & 6.6576 & 7.3219 & TRN & \\
\hline CHEMBL186658 & 306667 & 5.6757 & 6.0312 & TRN & \\
\hline CHEMBL186923 & 306667 & 6.7447 & 6.2282 & TRN & \\
\hline CHEMBL184129 & 306667 & 7.0969 & 7.0498 & TST & \\
\hline
\end{tabular}




\begin{tabular}{|c|c|c|c|c|c|}
\hline & & & oplement & al Table Sz & \\
\hline CHEMBL184244 & 306667 & 5.9872 & 6.3907 & TRN & \\
\hline CHEMBL186889 & 306667 & 5.8125 & 5.9586 & TRN & \\
\hline CHEMBL182515 & 306667 & 7.1549 & 7.38200 & 0000000001 & TRN \\
\hline CHEMBL363057 & 306667 & 5.51 & 5.9262 & TST & \\
\hline CHEMBL184235 & 306667 & 6.8539 & 7.0984 & TRN & \\
\hline CHEMBL360756 & 306667 & 8.301 & 7.4035 & TRN & \\
\hline CHEMBL184575 & 306667 & 5.7471 & 5.7472 & TRN & \\
\hline CHEMBL183987 & 306667 & 5.9469 & 5.7696 & TRN & \\
\hline CHEMBL187688 & 306667 & 5.9957 & 6.2358 & TRN & \\
\hline CHEMBL184382 & 306667 & 4.8297 & 4.6734 & TRN & \\
\hline CHEMBL184352 & 306667 & 5.4248 & 5.5683 & TRN & \\
\hline CHEMBL184414 & 306667 & 7.301 & 6.8356 & TRN & \\
\hline CHEMBL184082 & 306667 & 6.0506 & 6.2054 & TRN & \\
\hline CHEMBL184180 & 306667 & 6.6576 & 6.8961 & TRN & \\
\hline CHEMBL185921 & 306667 & 5.6716 & 5.83799 & 9999999999 & TRN \\
\hline CHEMBL186718 & 306667 & 6.4437 & 7.0372 & TRN & \\
\hline CHEMBL186922 & 306667 & 6.6576 & 7.1111 & TST & \\
\hline CHEMBL184118 & 306667 & 5.3872 & 5.8094 & TRN & \\
\hline CHEMBL186618 & 306667 & 7.699 & 7.3356 & TRN & \\
\hline CHEMBL186851 & 306667 & 6.7447 & 6.6113 & TRN & \\
\hline CHEMBL184254 & 306667 & 6.3768 & 6.0551 & TRN & \\
\hline CHEMBL187280 & 306667 & 7.301 & 6.3597 & TRN & \\
\hline CHEMBL186682 & 306667 & 5.9957 & 6.6641 & TRN & \\
\hline CHEMBL185597 & 306667 & 6.7959 & 6.5658 & TST & \\
\hline CHEMBL435098 & 306667 & 6.6198 & 5.9822 & TRN & \\
\hline CHEMBL184906 & 306667 & 5.466 & 5.7256 & TRN & \\
\hline CHEMBL425536 & 306667 & 6.3372 & 6.0339 & TRN & \\
\hline CHEMBL184231 & 306667 & 4.4989 & 4.9334 & TRN & \\
\hline CHEMBL365271 & 306667 & 7.699 & 7.46700 & 00000000005 & TRN \\
\hline CHEMBL186905 & 306667 & 6.0362 & 6.2161 & TRN & \\
\hline CHEMBL186698 & 306667 & 4.9809 & 5.6924 & TST & \\
\hline CHEMBL186612 & 306667 & 5.8665 & 6.2176 & TRN & \\
\hline CHEMBL363922 & 306667 & 6.0969 & 5.9135 & TRN & \\
\hline CHEMBL184392 & 306667 & 5.9393 & 5.9336 & TRN & \\
\hline CHEMBL184227 & 306667 & 7.699 & 7.84200 & 00000000005 & TRN \\
\hline CHEMBL184188 & 306667 & 6.0362 & 5.915 & TRN & \\
\hline CHEMBL186719 & 306667 & 8.301 & 7.2936 & TST & \\
\hline CHEMBL183923 & 306667 & 7.0 & 6.6387 & TRN & \\
\hline CHEMBL187144 & 306667 & 5.2358 & 5.5041 & TRN & \\
\hline CHEMBL 363083 & 306667 & 6.8239 & 6.9995 & TST & \\
\hline CHEMBL185510 & 306667 & 6.6198 & 6.6375 & TST & \\
\hline CHEMBL186645 & 306667 & 6.0969 & 6.0138 & TRN & \\
\hline CHEMBL185605 & 306667 & 4.8729 & 5.4648 & TRN & \\
\hline CHEMBL186550 & 306667 & 6.2007 & 6.3576 & TRN & \\
\hline CHEMBL 363085 & 306667 & 4.9172 & 4.7455 & TRN & \\
\hline CHEMBL363901 & 306667 & 5.7033 & 5.9443 & TRN & \\
\hline CHEMBL184078 & 306667 & 8.301 & 8.0159 & TRN & \\
\hline CHEMBL184753 & 306667 & 6.8539 & 7.0366 & TRN & \\
\hline
\end{tabular}




\begin{tabular}{|c|c|c|c|c|c|}
\hline & & & oplementa & al Table S & \\
\hline CHEMBL184913 & 306667 & 6.3768 & 5.9984 & TRN & \\
\hline CHEMBL186767 & 306667 & 5.699 & 5.7851 & TST & \\
\hline CHEMBL183731 & 306667 & 6.3468 & 6.19799 & 99999999995 & TRN \\
\hline CHEMBL184642 & 306667 & 8.0 & 7.269 & TST & \\
\hline CHEMBL183929 & 306667 & 5.0209 & 4.4279 & TRN & \\
\hline CHEMBL365199 & 306667 & 6.4559 & 6.3889 & TST & \\
\hline CHEMBL361517 & 306667 & 7.5229 & 7.1721 & TST & \\
\hline CHEMBL187960 & 306667 & 7.0 & 7.7023 & TST & \\
\hline CHEMBL186850 & 306667 & 6.4949 & 7.2413 & TST & \\
\hline CHEMBL363723 & 306667 & 5.3883 & 6.0955 & TST & \\
\hline CHEMBL139666 & 31764 & 7.6576 & 7.7057 & TRN & \\
\hline CHEMBL140199 & 31764 & 7.4685 & 5.7246 & TRN & \\
\hline CHEMBL143633 & 31764 & 7.8861 & 7.8154 & TRN & \\
\hline CHEMBL357435 & 31764 & 6.1739 & 5.7633 & TRN & \\
\hline CHEMBL143903 & 31764 & 6.2676 & 7.16799 & 9999999999 & TRN \\
\hline CHEMBL143098 & 31764 & 7.7212 & 7.5683 & TRN & \\
\hline CHEMBL342339 & 31764 & 6.9208 & 6.359 & TRN & \\
\hline CHEMBL 357074 & 31764 & 6.3665 & 6.9782 & TRN & \\
\hline CHEMBL422647 & 31764 & 8.1938 & 7.1996 & TRN & \\
\hline CHEMBL140042 & 31764 & 6.1805 & 5.8855 & TRN & \\
\hline CHEMBL140375 & 31764 & 5.0 & 5.3504 & TRN & \\
\hline CHEMBL140750 & 31764 & 7.284 & 6.8613 & TRN & \\
\hline CHEMBL 344057 & 31764 & 7.7212 & 7.4769 & TRN & \\
\hline CHEMBL357460 & 31764 & 6.8239 & 6.7702 & TRN & \\
\hline CHEMBL142989 & 31764 & 7.5086 & 7.0733 & TRN & \\
\hline CHEMBL142274 & 31764 & 7.0506 & 6.7999 & TRN & \\
\hline CHEMBL 2111988 & 31764 & 7.5528 & 6.8997 & TRN & \\
\hline CHEMBL143708 & 31764 & 5.6576 & 7.0688 & TST & \\
\hline CHEMBL143387 & 31764 & 6.3372 & 6.7197 & TRN & \\
\hline CHEMBL 2111987 & 31764 & 6.3279 & 6.5153 & TRN & \\
\hline CHEMBL142110 & 31764 & 5.3098 & 6.985 & TST & \\
\hline CHEMBL423187 & 31764 & 5.0862 & 5.2602 & TRN & \\
\hline CHEMBL142704 & 31764 & 5.2291 & 6.5757 & TST & \\
\hline CHEMBL143863 & 31764 & 6.7696 & 7.3672 & TST & \\
\hline CHEMBL143117 & 31764 & 4.2291 & 6.4261 & TST & \\
\hline CHEMBL143569 & 31764 & 6.1427 & 6.4929 & TST & \\
\hline CHEMBL142934 & 31764 & 5.3768 & 6.5111 & TST & \\
\hline CHEMBL142647 & 31764 & 5.6576 & 5.7546 & TRN & \\
\hline CHEMBL358550 & 31764 & 5.5086 & 5.7257 & TRN & \\
\hline CHEMBL 358792 & 31764 & 7.5686 & 7.2494 & TRN & \\
\hline CHEMBL143234 & 31764 & 8.4949 & 7.602 & TRN & \\
\hline CHEMBL140980 & 31764 & 5.4949 & 5.7101 & TRN & \\
\hline CHEMBL422476 & 31764 & 9.0 & 7.4847 & TRN & \\
\hline CHEMBL342887 & 31764 & 5.9586 & 6.5757 & TRN & \\
\hline CHEMBL143551 & 31764 & 6.8239 & 7.2838 & TRN & \\
\hline CHEMBL142790 & 31764 & 7.4949 & 7.4723 & TRN & \\
\hline CHEMBL142879 & 31764 & 6.9586 & 6.9038 & TRN & \\
\hline CHEMBL344526 & 31764 & 7.4318 & 6.9305 & TST & \\
\hline
\end{tabular}




\begin{tabular}{|c|c|c|c|c|c|}
\hline \multicolumn{6}{|c|}{ Supplemental Table S2.txt } \\
\hline CHEMBL143241 & 31764 & 6.6198 & 7.6129 & TRN & \\
\hline CHEMBL356286 & 31764 & 6.2007 & 7.501 & TRN & \\
\hline CHEMBL142599 & 31764 & 7.5528 & 7.1459 & TST & \\
\hline CHEMBL335376 & 31764 & 5.3372 & 6.2405 & TRN & \\
\hline CHEMBL357206 & 31764 & 6.8069 & 6.7935 & TRN & \\
\hline CHEMBL424485 & 31764 & 5.6778 & 7.0164 & TST & \\
\hline CHEMBL341864 & 31764 & 8.1871 & 7.1834 & TRN & \\
\hline CHEMBL143211 & 31764 & 7.1079 & 7.5766 & TRN & \\
\hline CHEMBL143872 & 31764 & 6.3768 & 6.3539 & TRN & \\
\hline CHEMBL140012 & 31764 & 7.301 & 7.1687 & TST & \\
\hline CHEMBL142512 & 31764 & 5.5229 & 6.7064 & TRN & \\
\hline CHEMBL422824 & 31764 & 6.0 & 6.6154 & TRN & \\
\hline CHEMBL141013 & 31764 & 6.699 & 6.8808 & TST & \\
\hline CHEMBL345068 & 31764 & 7.6383 & 7.2187 & TRN & \\
\hline CHEMBL342786 & 31764 & 6.0605 & 6.5218 & TST & \\
\hline CHEMBL141390 & 31764 & 6.6576 & 6.812 & TRN & \\
\hline CHEMBL342524 & 31764 & 6.3565 & 7.4687 & TST & \\
\hline CHEMBL141135 & 31764 & 6.6021 & 7.0133 & TRN & \\
\hline CHEMBL342974 & 31764 & 6.699 & 6.9655 & TST & \\
\hline CHEMBL356545 & 31764 & 6.3279 & 6.782 & TRN & \\
\hline CHEMBL142542 & 31764 & 5.6576 & 5.4314 & TRN & \\
\hline CHEMBL356789 & 31764 & 5.9586 & 7.1462 & TST & \\
\hline CHEMBL139898 & 31764 & 5.2147 & 5.6698 & TRN & \\
\hline CHEMBL143231 & 31764 & 6.7959 & 5.99 & TRN & \\
\hline CHEMBL344245 & 31764 & 5.3468 & 5.7317 & TRN & \\
\hline CHEMBL 3930614 & 1641301 & 6.1805 & 4.1457 & TRN & \\
\hline CHEMBL3927846 & 1641301 & 5.4949 & 4.995 & TRN & \\
\hline CHEMBL 3904867 & 1641301 & 4.0 & 4.4384 & TRN & \\
\hline CHEMBL3965830 & 1641301 & 6.6198 & 4.9088 & TRN & \\
\hline CHEMBL3983864 & 1641301 & 6.2676 & 4.2032 & TST & \\
\hline CHEMBL 3952585 & 1641301 & 4.0 & 4.4957 & TRN & \\
\hline CHEMBL3982394 & 1641301 & 4.0 & 4.1933 & TRN & \\
\hline CHEMBL 3921520 & 1641301 & 5.0888 & 4.9035 & TRN & \\
\hline CHEMBL 3930324 & 1641301 & 4.0 & 4.4968 & TRN & \\
\hline CHEMBL3950371 & 1641301 & 4.0 & 3.9717 & TST & \\
\hline CHEMBL3913360 & 1641301 & 4.0 & 3.8861 & TRN & \\
\hline CHEMBL3895515 & 1641301 & 4.0 & 4.7607 & TRN & \\
\hline CHEMBL 3926390 & 1641301 & 4.0 & 3.944 & TRN & \\
\hline CHEMBL3911735 & 1641301 & 6.1612 & 4.8645 & TRN & \\
\hline CHEMBL3976944 & 1641301 & 4.0 & 3.9822 & TRN & \\
\hline CHEMBL 3974290 & 1641301 & 7.0969 & 4.6804 & TST & \\
\hline CHEMBL 3945371 & 1641301 & 5.064 & 5.0183 & TRN & \\
\hline CHEMBL3971953 & 1641301 & 5.0477 & 4.8794 & TRN & \\
\hline CHEMBL3962890 & 1641301 & 4.0 & 4.1616 & TRN & \\
\hline CHEMBL3934175 & 1641301 & 3.3768 & 5.1162 & TRN & \\
\hline CHEMBL 3956243 & 1641301 & 4.0 & 4.4297 & TRN & \\
\hline CHEMBL3929020 & 1641301 & 4.0 & 3.97600 & 00000000004 & TRN \\
\hline CHEMBL 3897340 & 1641301 & 4.0 & 4.467 & TRN & \\
\hline
\end{tabular}




\begin{tabular}{|c|c|c|c|c|c|}
\hline \multicolumn{6}{|c|}{ Supplemental Table S2.txt } \\
\hline CHEMBL 3977341 & 1641301 & 4.0 & 5.0984 & TRN & \\
\hline CHEMBL 3958514 & 1641301 & 4.0 & 3.9869 & TRN & \\
\hline CHEMBL3905217 & 1641301 & 5.1871 & 4.4973 & TRN & \\
\hline CHEMBL3942759 & 1641301 & 4.0 & 3.9913 & TRN & \\
\hline CHEMBL3906198 & 1641301 & 5.3188 & 5.2012 & TRN & \\
\hline CHEMBL 3960698 & 1641301 & 3.3768 & 5.2138 & TRN & \\
\hline CHEMBL 3936029 & 1641301 & 4.0 & 3.9561 & TRN & \\
\hline CHEMBL3957606 & 1641301 & 4.0 & 5.0432 & TRN & \\
\hline CHEMBL 3902168 & 1641301 & 4.0 & 5.0738 & TRN & \\
\hline CHEMBL3941184 & 1641301 & 6.1739 & 5.1955 & TRN & \\
\hline CHEMBL 3958100 & 1641301 & 7.0458 & 4.1825 & TST & \\
\hline CHEMBL 3958774 & 1641301 & 4.0 & 4.6421 & TRN & \\
\hline CHEMBL3943971 & 1641301 & 6.0757 & 4.9892 & TRN & \\
\hline CHEMBL 3912253 & 1641301 & 5.1141 & 4.9341 & TRN & \\
\hline CHEMBL 3943652 & 1641301 & 6.7447 & 5.1286 & TRN & \\
\hline CHEMBL 3915356 & 1641301 & 5.1707 & 4.2599 & TRN & \\
\hline CHEMBL 3932183 & 1641301 & 4.0 & 4.5044 & TRN & \\
\hline CHEMBL 3957380 & 1641301 & 4.0 & 5.0044 & TRN & \\
\hline CHEMBL 3904458 & 1641301 & 4.0 & 4.4759 & TRN & \\
\hline CHEMBL 3945637 & 1641301 & 4.0 & 4.0968 & TST & \\
\hline CHEMBL 3896734 & 1641301 & 4.0 & 3.9875 & TRN & \\
\hline CHEMBL 3894586 & 1641301 & 4.0 & 4.3923 & TRN & \\
\hline CHEMBL3977416 & 1641301 & 4.0 & 3.9775 & TST & \\
\hline CHEMBL 3910177 & 1641301 & 5.7375 & 4.949 & TRN & \\
\hline CHEMBL3983340 & 1641301 & 4.0 & 4.1137 & TRN & \\
\hline CHEMBL 3943326 & 1641301 & 4.0 & 4.2366 & TRN & \\
\hline CHEMBL 3957524 & 1641301 & 4.0 & 4.0944 & TST & \\
\hline CHEMBL3920667 & 1641301 & 6.699 & 5.1706 & TRN & \\
\hline CHEMBL 3899289 & 1641301 & 4.0 & 4.4469 & TRN & \\
\hline CHEMBL3921148 & 1641301 & 4.0 & 5.0807 & TRN & \\
\hline CHEMBL3907911 & 1641301 & 5.4056 & 4.8363 & TRN & \\
\hline CHEMBL 3985485 & 1641301 & 4.0 & 4.8419 & TRN & \\
\hline CHEMBL 3955509 & 1641301 & 4.0 & 3.95600 & 00000000004 & TRN \\
\hline CHEMBL3939403 & 1641301 & 4.0 & 4.3154 & TST & \\
\hline CHEMBL 3931341 & 1641301 & 5.3468 & 4.4277 & TRN & \\
\hline CHEMBL3900016 & 1641301 & 5.7423 & 4.2312 & TRN & \\
\hline CHEMBL 3986695 & 1641301 & 4.0 & 4.5795 & TRN & \\
\hline CHEMBL3915486 & 1641301 & 4.0 & 4.2944 & TST & \\
\hline CHEMBL 3926870 & 1641301 & 4.0 & 4.7987 & TRN & \\
\hline CHEMBL3952365 & 1641301 & 6.6904 & 5.1185 & TRN & \\
\hline CHEMBL 3983422 & 1641301 & 3.8539 & 4.9833 & TRN & \\
\hline CHEMBL3894216 & 1641301 & 4.0 & 4.3546 & TST & \\
\hline CHEMBL3940006 & 1641301 & 4.0 & 4.1188 & TST & \\
\hline CHEMBL3977410 & 1641301 & 4.0 & 4.4896 & TRN & \\
\hline CHEMBL3916964 & 1641301 & 4.0 & 4.7788 & TRN & \\
\hline CHEMBL 3978476 & 1641301 & 6.9393 & 5.2026 & TRN & \\
\hline CHEMBL3898396 & 1641301 & 4.0 & 4.9102 & TRN & \\
\hline CHEMBL3971927 & 1641301 & 4.0 & 4.5067 & TRN & \\
\hline
\end{tabular}


Supplemental Table S2.txt

\begin{tabular}{|c|c|c|c|c|c|}
\hline CHEMBL3969700 & 1641301 & 7.3979 & 4.6725 & TST & \\
\hline CHEMBL3969848 & 1641301 & 4.0 & 4.0951 & TST & \\
\hline CHEMBL 3973738 & 1641301 & 5.4685 & 5.0586 & TRN & \\
\hline CHEMBL3974719 & 1641301 & 5.0915 & 4.0251 & TRN & \\
\hline CHEMBL3936997 & 1641301 & 4.0 & 4.4452 & TRN & \\
\hline CHEMBL3957813 & 1641301 & 4.0 & 5.0215 & TST & \\
\hline CHEMBL3896898 & 1641301 & 4.0 & 4.1822 & TST & \\
\hline CHEMBL 3894420 & 1641301 & 4.0 & 4.4414 & TRN & \\
\hline CHEMBL3944976 & 1641301 & 4.0 & 4.1691 & TST & \\
\hline CHEMBL3900808 & 1641301 & 4.0 & 4.10800 & 00000000005 & TRN \\
\hline CHEMBL3979393 & 1641301 & 4.0 & 4.8847 & TRN & \\
\hline CHEMBL3937947 & 1641301 & 4.0 & 3.9923 & TRN & \\
\hline CHEMBL3936746 & 1641301 & 4.0 & 3.9378 & TST & \\
\hline CHEMBL 3975021 & 1641301 & 4.0 & 4.2075 & TST & \\
\hline CHEMBL 3968450 & 1641301 & 4.0 & 3.9303 & TST & \\
\hline CHEMBL3911785 & 1641301 & 4.0 & 5.0129 & TRN & \\
\hline CHEMBL3930097 & 1641301 & 4.0 & 5.0348 & TRN & \\
\hline CHEMBL3903362 & 1641301 & 5.2676 & 4.9382 & TRN & \\
\hline CHEMBL3897610 & 1641301 & 3.6778 & 4.9574 & TRN & \\
\hline CHEMBL 3894411 & 1641301 & 5.3872 & 4.4717 & TRN & \\
\hline CHEMBL3969161 & 1641301 & 4.0 & 4.2006 & TST & \\
\hline CHEMBL3943139 & 1641301 & 5.4202 & 5.1227 & TRN & \\
\hline CHEMBL3893051 & 1641301 & 4.0 & 3.9585 & TRN & \\
\hline CHEMBL3944623 & 1641301 & 5.1487 & 4.9869 & TRN & \\
\hline CHEMBL 3983209 & 1641301 & 4.0 & 3.9253 & TRN & \\
\hline CHEMBL3936647 & 1641301 & 4.0 & 4.0455 & TRN & \\
\hline CHEMBL3913525 & 1641301 & 4.0 & 4.1545 & TRN & \\
\hline CHEMBL 3945781 & 1641301 & 5.0044 & 4.5189 & TRN & \\
\hline CHEMBL3901058 & 1641301 & 4.0 & 4.2774 & TST & \\
\hline CHEMBL 3948463 & 1641301 & 6.041 & 5.115 & TRN & \\
\hline CHEMBL3960295 & 1641301 & 4.0 & 4.0021 & TST & \\
\hline CHEMBL3933872 & 1641301 & 4.0 & 4.1792 & TST & \\
\hline CHEMBL3915692 & 1641301 & 7.301 & 5.1928 & TRN & \\
\hline CHEMBL3897394 & 1641301 & 4.0 & 4.1575 & TST & \\
\hline CHEMBL 3896261 & 1641301 & 4.0 & \multicolumn{2}{|c|}{3.9339999999999997} & TRN \\
\hline CHEMBL3971941 & 1641301 & 4.0 & 4.8654 & TRN & \\
\hline CHEMBL 3918083 & 1641301 & 4.0 & 4.2031 & TRN & \\
\hline CHEMBL 3965825 & 1641301 & 5.3768 & 4.6114 & TRN & \\
\hline CHEMBL 3972458 & 1641301 & 4.0 & 3.9426 & TST & \\
\hline CHEMBL 3902769 & 1641301 & 4.0 & 3.9251 & TST & \\
\hline CHEMBL3938905 & 1641301 & 4.0 & 3.9822 & TST & \\
\hline CHEMBL 3906690 & 1641301 & 6.1249 & 4.3014 & TST & \\
\hline CHEMBL 3903264 & 1641301 & 4.0 & 4.461 & TRN & \\
\hline CHEMBL3952055 & 1641301 & 4.0 & 4.8633 & TRN & \\
\hline CHEMBL 3972302 & 1641301 & 5.1487 & 5.0215 & TRN & \\
\hline CHEMBL 3948754 & 1641301 & 5.4318 & 4.4928 & TRN & \\
\hline CHEMBL 3985500 & 1641301 & 4.0 & 4.5073 & TRN & \\
\hline CHEMBL3968062 & 1641301 & 4.0 & 4.0357 & TST & \\
\hline
\end{tabular}


Supplemental Table S2.txt

\begin{tabular}{|c|c|c|c|c|c|}
\hline CHEMBL3925964 & 1641301 & 5.082 & 4.942 & TRN & \\
\hline CHEMBL3973835 & 1641301 & 4.0 & 4.9283 & TRN & \\
\hline CHEMBL3933648 & 1641301 & 5.1669 & 4.9355 & TRN & \\
\hline CHEMBL3957046 & 1641301 & 4.0 & 3.9463 & TST & \\
\hline CHEMBL3922599 & 1641301 & 5.1805 & 4.9617 & TRN & \\
\hline CHEMBL3892978 & 1641301 & 7.2218 & 4.9167 & TRN & \\
\hline CHEMBL3955693 & 1641301 & 4.0 & 3.9643 & TST & \\
\hline CHEMBL3930717 & 1641301 & 5.0044 & 5.0498 & TRN & \\
\hline CHEMBL3957705 & 1641301 & 4.0 & 3.9488 & TST & \\
\hline CHEMBL3893217 & 1641301 & 4.0 & 5.0911 & TRN & \\
\hline CHEMBL3903356 & 1641301 & 4.0 & 4.9321 & TRN & \\
\hline CHEMBL3971778 & 1641301 & 5.5751 & 4.8421 & TRN & \\
\hline CHEMBL3968848 & 1641301 & 5.4377 & 4.5181 & TRN & \\
\hline CHEMBL3978993 & 1641301 & 3.8539 & 5.0212 & TRN & \\
\hline CHEMBL3955998 & 1641301 & 5.4908 & 4.9733 & TRN & \\
\hline CHEMBL3902884 & 1641301 & 4.0 & 5.0831 & TRN & \\
\hline CHEMBL3909066 & 1641301 & 4.0 & 4.1205 & TRN & \\
\hline CHEMBL3970742 & 1641301 & 6.3372 & 5.0784 & TRN & \\
\hline CHEMBL3977851 & 1641301 & 4.0 & 4.8408 & TRN & \\
\hline CHEMBL3909733 & 1641301 & 4.0 & 5.0232 & TST & \\
\hline CHEMBL3986218 & 1641301 & 4.0 & 3.9479 & TST & \\
\hline CHEMBL3985957 & 1641301 & 7.2218 & 5.2255 & TRN & \\
\hline CHEMBL 3890048 & 1641301 & 4.0 & 3.9864 & TST & \\
\hline CHEMBL3976803 & 1641301 & 4.0 & 5.1095 & TRN & \\
\hline CHEMBL 3977520 & 1641301 & 4.0 & 4.2214 & TRN & \\
\hline CHEMBL3964326 & 1641301 & 5.1739 & 4.8817 & TRN & \\
\hline CHEMBL3910633 & 1641301 & 5.1739 & 4.0427 & TST & \\
\hline CHEMBL 3953885 & 1641301 & 4.0 & 3.9768 & TRN & \\
\hline CHEMBL3985507 & 1641301 & 4.0 & 4.0037 & TST & \\
\hline CHEMBL3931509 & 1641301 & 4.0 & 4.276 & TRN & \\
\hline CHEMBL 3945880 & 1641301 & 5.2815 & 4.9502 & TRN & \\
\hline CHEMBL3915757 & 1641301 & 4.0 & 4.435 & TRN & \\
\hline CHEMBL3969812 & 1641301 & 5.0132 & 4.9755 & TRN & \\
\hline CHEMBL3975228 & 1641301 & 5.0132 & 4.5361 & TRN & \\
\hline CHEMBL3966822 & 1641301 & 4.0 & 4.4864 & TRN & \\
\hline CHEMBL3964712 & 1641301 & 4.0 & \multicolumn{2}{|c|}{3.9789999999999996} & TRN \\
\hline CHEMBL 3948183 & 1641301 & 4.0 & 3.9714 & TST & \\
\hline CHEMBL3915918 & 1641301 & 5.6234 & 5.0118 & TRN & \\
\hline CHEMBL3946529 & 1641301 & 4.0 & 4.3508 & TRN & \\
\hline CHEMBL3983001 & 1641301 & 4.0 & 4.1651 & TST & \\
\hline CHEMBL3906870 & 1641301 & 4.0 & 4.3718 & TST & \\
\hline CHEMBL3986705 & 1641301 & 5.3665 & 4.8557 & TRN & \\
\hline CHEMBL3949004 & 1641301 & 4.0 & 4.4922 & TRN & \\
\hline CHEMBL3924707 & 1641301 & 4.0 & 4.7737 & TRN & \\
\hline CHEMBL3931268 & 1641301 & 4.0 & 4.5517 & TST & \\
\hline CHEMBL3649583 & 1528363 & 6.5883 & 7.1568 & TST & \\
\hline CHEMBL3649558 & 1528363 & 7.7338 & 7.6939 & TRN & \\
\hline CHEMBL3649551 & 1528363 & 8.5086 & 8.5696 & TRN & \\
\hline
\end{tabular}

Page 15597 
Supplemental Table S2.txt

\begin{tabular}{|c|c|c|c|c|}
\hline CHEMBL3649526 & 1528363 & 8.3979 & 8.5116 & TRN \\
\hline CHEMBL 3649537 & 1528363 & 6.9586 & 7.0122 & TRN \\
\hline CHEMBL3649581 & 1528363 & 8.1302 & \multicolumn{2}{|c|}{7.9079999999999995} \\
\hline CHEMBL 3649523 & 1528363 & 7.8729 & 7.7043 & TRN \\
\hline CHEMBL 3649578 & 1528363 & 9.2757 & 9.2211 & TRN \\
\hline CHEMBL3649533 & 1528363 & 6.1461 & 6.3119 & TRN \\
\hline CHEMBL 3649545 & 1528363 & 7.6234 & 6.8442 & TST \\
\hline CHEMBL 3649539 & 1528363 & 7.8386 & 7.9155 & TRN \\
\hline CHEMBL 3649554 & 1528363 & 8.2472 & 8.2949 & TRN \\
\hline CHEMBL3649544 & 1528363 & 6.1172 & 6.1295 & TRN \\
\hline CHEMBL 3649536 & 1528363 & 5.8423 & 5.6789 & TRN \\
\hline CHEMBL 3649527 & 1528363 & 5.9644 & 5.84 & TRN \\
\hline CHEMBL 3649522 & 1528363 & 7.1938 & 7.1693 & TRN \\
\hline CHEMBL 3649521 & 1528363 & 7.7959 & 7.6225 & TRN \\
\hline CHEMBL 3649548 & 1528363 & 7.4841 & 7.6981 & TST \\
\hline CHEMBL 3649555 & 1528363 & 8.4237 & 8.3929 & TRN \\
\hline CHEMBL 3649559 & 1528363 & 7.8598 & 7.9526 & TRN \\
\hline CHEMBL 3649562 & 1528363 & 7.7747 & 8.076 & TST \\
\hline CHEMBL 3649535 & 1528363 & 7.6882 & 7.7156 & TRN \\
\hline CHEMBL 3649550 & 1528363 & 8.7696 & 8.7585 & TRN \\
\hline CHEMBL 3649560 & 1528363 & 6.6262 & 6.6086 & TRN \\
\hline CHEMBL 3649525 & 1528363 & 6.398 & 6.3821 & TRN \\
\hline CHEMBL 3649552 & 1528363 & 7.0655 & 7.1112 & TRN \\
\hline CHEMBL 3649565 & 1528363 & 6.18 & 6.6253 & TST \\
\hline CHEMBL 3649561 & 1528363 & 6.5857 & 6.6092 & TRN \\
\hline CHEMBL 3649577 & 1528363 & 9.1549 & 9.1804 & TRN \\
\hline CHEMBL3649571 & 1528363 & 7.1328 & 7.1628 & TRN \\
\hline CHEMBL 3649531 & 1528363 & 7.1367 & 7.109 & TRN \\
\hline CHEMBL 3649556 & 1528363 & 7.3383 & 7.2762 & TRN \\
\hline CHEMBL 3649573 & 1528363 & 6.745 & 6.5122 & TST \\
\hline CHEMBL 3649564 & 1528363 & 8.4318 & 8.4224 & TRN \\
\hline CHEMBL3649580 & 1528363 & 7.2658 & 7.3911 & TRN \\
\hline CHEMBL 3649541 & 1528363 & 7.6716 & 7.6482 & TRN \\
\hline CHEMBL 3649563 & 1528363 & 6.8677 & 6.8961 & TRN \\
\hline CHEMBL 3649566 & 1528363 & 7.8383 & 8.5134 & TST \\
\hline CHEMBL 3649542 & 1528363 & 7.1085 & 7.1104 & TRN \\
\hline CHEMBL3649569 & 1528363 & 6.3955 & 6.6125 & TRN \\
\hline CHEMBL 3649546 & 1528363 & 7.9586 & 7.9604 & TRN \\
\hline CHEMBL 3649528 & 1528363 & 6.7226 & 7.6294 & TST \\
\hline CHEMBL 3649529 & 1528363 & 5.6476 & 5.7445 & TRN \\
\hline CHEMBL 3649540 & 1528363 & 6.694 & 6.7117 & TRN \\
\hline CHEMBL3649567 & 1528363 & 6.4286 & 7.0069 & TST \\
\hline CHEMBL 3649547 & 1528363 & 7.7144 & 8.2119 & TST \\
\hline CHEMBL3649532 & 1528363 & 6.1813 & 7.1166 & TST \\
\hline CHEMBL 3649575 & 1528363 & 8.4672 & 8.4222 & TRN \\
\hline CHEMBL 3649524 & 1528363 & 6.3791 & 7.0428 & TST \\
\hline CHEMBL3649538 & 1528363 & 6.6472 & 8.2251 & TST \\
\hline CHEMBL3649534 & 1528363 & 6.6836 & 6.8356 & TRN \\
\hline
\end{tabular}


Supplemental Table S2.txt

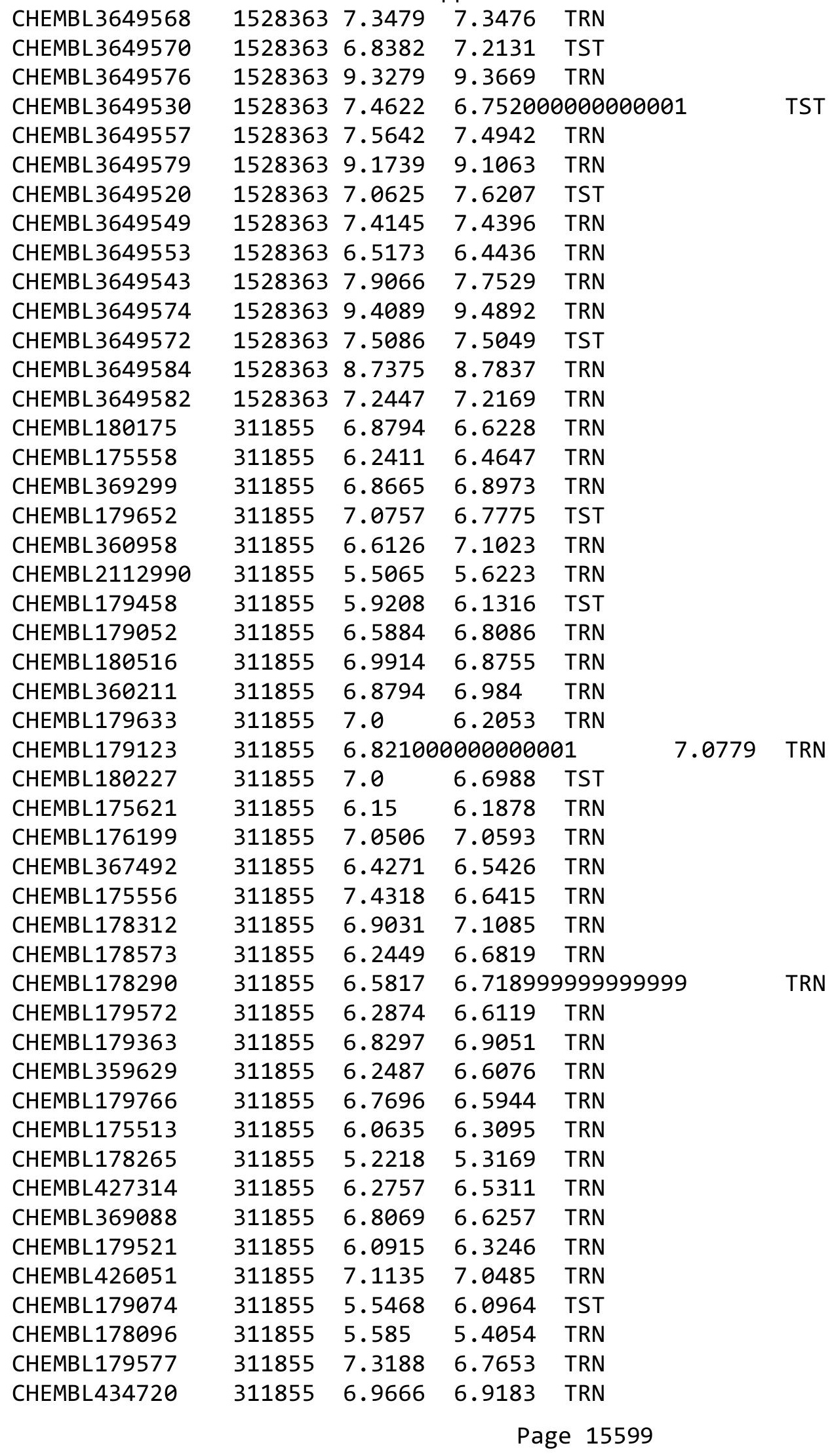




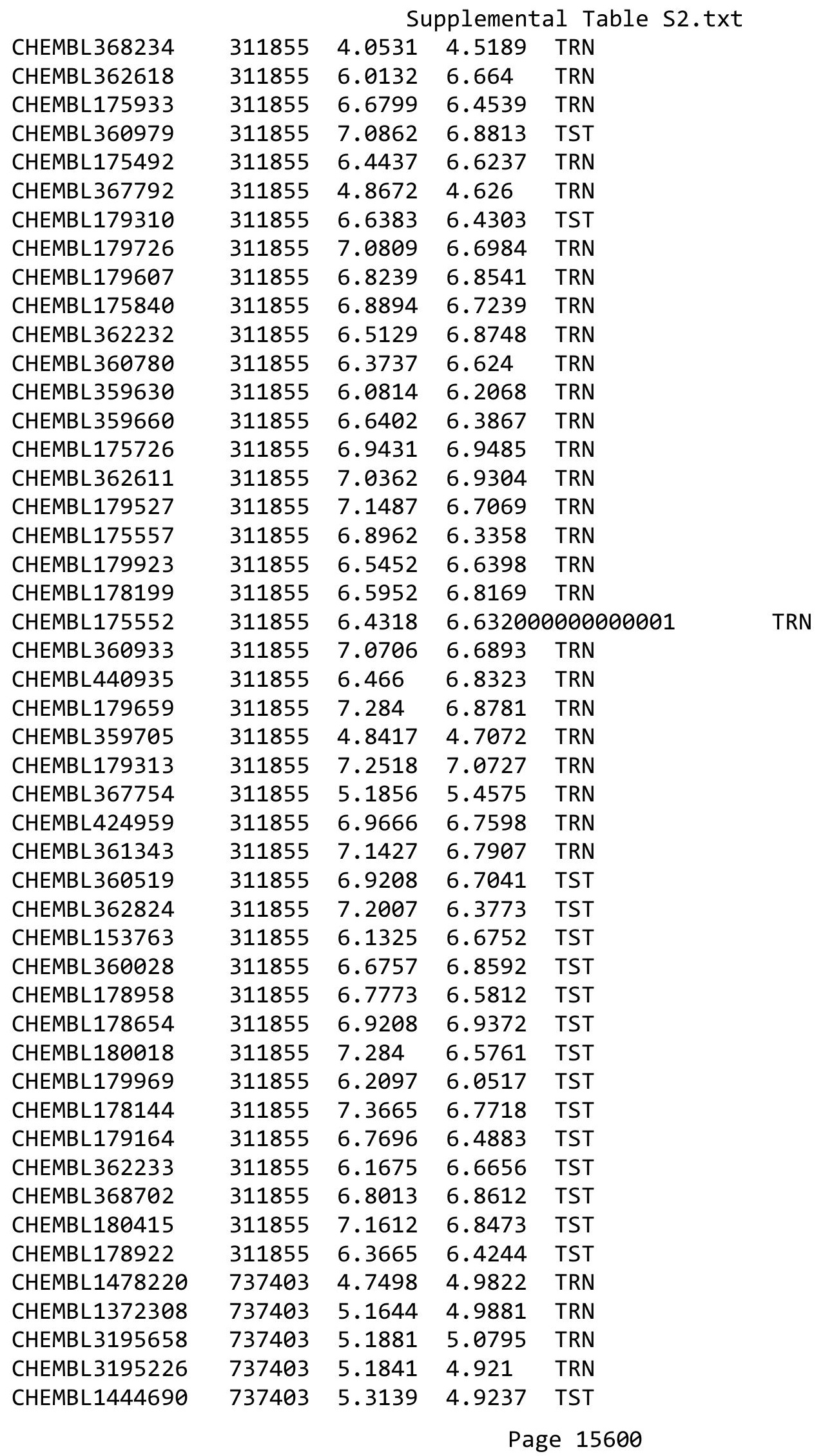




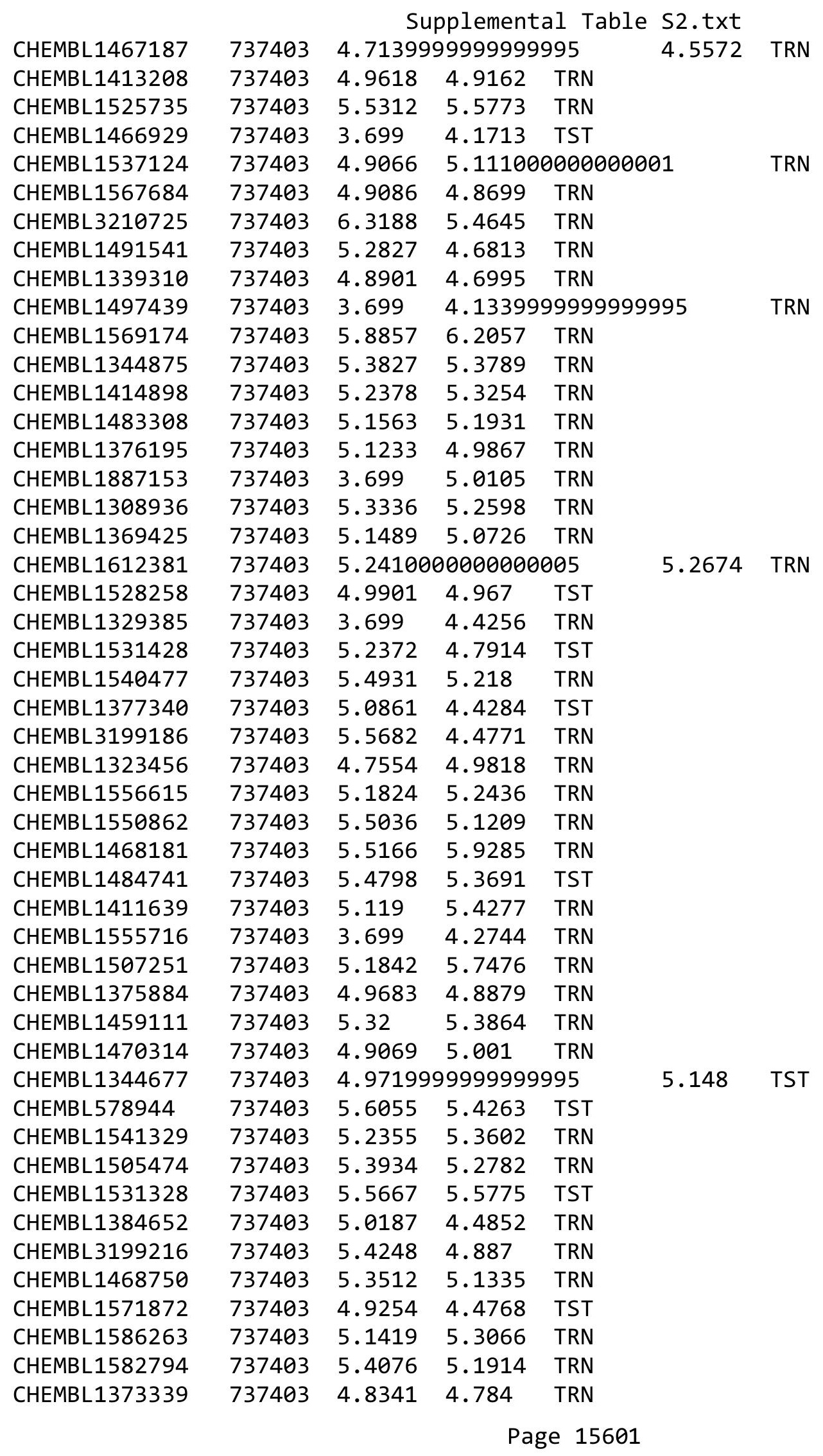


Supplemental Table S2.txt

\begin{tabular}{|c|c|c|c|c|}
\hline CHEMBL1333821 & 737403 & 5.7149 & 5.2527 & TRN \\
\hline CHEMBL1344292 & 737403 & 5.0805 & 5.0495 & TRN \\
\hline CHEMBL1544947 & 737403 & 5.3609 & 5.1808 & TRN \\
\hline CHEMBL1454614 & 737403 & 4.9863 & 5.0787 & TST \\
\hline CHEMBL1433943 & 737403 & 5.0361 & 4.9882 & TRN \\
\hline CHEMBL1332756 & 737403 & 3.699 & 4.4698 & TRN \\
\hline CHEMBL1598561 & 737403 & 4.8583 & 5.0735 & TRN \\
\hline CHEMBL1466286 & 737403 & 4.9041 & 5.2227 & TRN \\
\hline CHEMBL1369671 & 737403 & 5.034 & 5.165 & TRN \\
\hline CHEMBL1611369 & 737403 & 5.1662 & 5.2596 & TRN \\
\hline CHEMBL1415184 & 737403 & 6.2154 & 5.7312 & TST \\
\hline CHEMBL590706 & 737403 & 5.1982 & 5.2575 & TST \\
\hline CHEMBL1447831 & 737403 & 5.2774 & 5.3011 & TRN \\
\hline CHEMBL1583914 & 737403 & 5.5334 & 5.4506 & TRN \\
\hline CHEMBL1311887 & 737403 & 4.9156 & 5.2486 & TRN \\
\hline CHEMBL1304363 & 737403 & 5.3791 & 5.0373 & TRN \\
\hline CHEMBL1415844 & 737403 & 5.2038 & 5.3076 & TRN \\
\hline CHEMBL1440735 & 737403 & 3.699 & 4.2295 & TST \\
\hline CHEMBL1549094 & 737403 & 4.8136 & 4.935 & TST \\
\hline CHEMBL1588806 & 737403 & 4.9857 & 5.0123 & TRN \\
\hline CHEMBL1442136 & 737403 & 5.2705 & 5.2544 & TRN \\
\hline CHEMBL1379291 & 737403 & 5.3973 & 5.2065 & TRN \\
\hline CHEMBL3196263 & 737403 & 5.2206 & 5.3138 & TRN \\
\hline CHEMBL1456373 & 737403 & 5.1442 & 5.2141 & TRN \\
\hline CHEMBL272945 & 737403 & 5.2859 & 5.1602 & TRN \\
\hline CHEMBL1445071 & 737403 & 3.699 & 4.4312 & TRN \\
\hline CHEMBL472646 & 737403 & 5.0928 & 5.2277 & TST \\
\hline CHEMBL579621 & 737403 & 5.0013 & 4.9316 & TRN \\
\hline CHEMBL1387990 & 737403 & 4.7204 & 4.5361 & TST \\
\hline CHEMBL1512575 & 737403 & 5.2618 & 5.3879 & TRN \\
\hline CHEMBL1604919 & 737403 & 5.1561 & 5.1565 & TST \\
\hline CHEMBL1382616 & 737403 & 5.1557 & 5.0142 & TRN \\
\hline CHEMBL1306839 & 737403 & 4.8096 & 4.8826 & TRN \\
\hline CHEMBL1321987 & 737403 & 5.1251 & 5.192 & TRN \\
\hline CHEMBL1407708 & 737403 & 5.2429 & 5.0831 & TST \\
\hline CHEMBL1597042 & 737403 & 3.699 & 4.5322 & TST \\
\hline CHEMBL1349713 & 737403 & 5.2151 & 5.4797 & TRN \\
\hline CHEMBL1416682 & 737403 & 4.8057 & 5.1243 & TST \\
\hline CHEMBL1420606 & 737403 & 5.035 & 4.2794 & TRN \\
\hline CHEMBL 2006780 & 737403 & 5.6753 & 5.2539 & TRN \\
\hline CHEMBL1302109 & 737403 & 4.8789 & 5.2493 & TRN \\
\hline CHEMBL1472748 & 737403 & 4.7433 & 5.0109 & TRN \\
\hline CHEMBL1431769 & 737403 & 5.1575 & 4.8488 & TRN \\
\hline CHEMBL1525546 & 737403 & 5.1978 & 4.5708 & TST \\
\hline CHEMBL1304065 & 737403 & 5.2343 & 5.1519 & TRN \\
\hline CHEMBL1421605 & 737403 & 5.0362 & 5.0355 & TST \\
\hline CHEMBL1319304 & 737403 & 5.8962 & 5.7539 & TRN \\
\hline CHEMBL1332013 & 737403 & 4.883 & 5.0201 & TST \\
\hline
\end{tabular}


Supplemental Table S2.txt

\begin{tabular}{|c|c|c|c|c|c|}
\hline CHEMBL1301733 & 737403 & 5.1563 & 5.1029 & TRN & \\
\hline CHEMBL1456848 & 737403 & 5.391 & 4.7599 & TRN & \\
\hline CHEMBL1475198 & 737403 & 5.3282 & 5.2053 & TRN & \\
\hline CHEMBL1525940 & 737403 & 3.699 & 4.2586 & TRN & \\
\hline CHEMBL1993613 & 737403 & 4.9077 & 4.5176 & TRN & \\
\hline CHEMBL1467115 & 737403 & 5.1699 & 5.0501 & TRN & \\
\hline CHEMBL1360862 & 737403 & 5.1196 & 5.3502 & TRN & \\
\hline CHEMBL1385296 & 737403 & 4.9307 & 5.2057 & TRN & \\
\hline CHEMBL1493633 & 737403 & 5.3285 & 5.2567 & TRN & \\
\hline CHEMBL1462357 & 737403 & 5.3146 & 5.0739 & TRN & \\
\hline CHEMBL1442742 & 737403 & 5.4223 & 5.072 & TRN & \\
\hline CHEMBL1612227 & 737403 & 5.1597 & 5.2838 & TRN & \\
\hline CHEMBL1478256 & 737403 & 4.699 & 4.536000 & 00000000005 & TRN \\
\hline CHEMBL3145280 & 737403 & 3.699 & 4.3429 & TRN & \\
\hline CHEMBL1425054 & 737403 & 3.699 & 4.9601 & TRN & \\
\hline CHEMBL1453730 & 737403 & 5.0693 & 5.2352 & TRN & \\
\hline CHEMBL1470676 & 737403 & 4.9002 & 5.0246 & TRN & \\
\hline CHEMBL1528004 & 737403 & 5.4111 & 5.0715 & TRN & \\
\hline CHEMBL1529494 & 737403 & 4.8005 & 4.5174 & TRN & \\
\hline CHEMBL1602759 & 737403 & 5.1884 & 4.8724 & TST & \\
\hline CHEMBL1437979 & 737403 & 5.2936 & 5.3577 & TRN & \\
\hline CHEMBL1581233 & 737403 & 4.7776 & 4.7702 & TRN & \\
\hline CHEMBL1440314 & 737403 & 4.7394 & 4.7156 & TRN & \\
\hline CHEMBL1495890 & 737403 & 5.3364 & 5.1772 & TST & \\
\hline CHEMBL1506308 & 737403 & 5.2463 & 5.1918 & TRN & \\
\hline CHEMBL1571360 & 737403 & 4.7448 & 4.3825 & TRN & \\
\hline CHEMBL1330503 & 737403 & 3.699 & 4.8837 & TRN & \\
\hline CHEMBL1504685 & 737403 & 5.4484 & 5.3743 & TST & \\
\hline CHEMBL1349185 & 737403 & 3.699 & 4.0121 & TRN & \\
\hline CHEMBL1347270 & 737403 & 5.4911 & 5.3381 & TRN & \\
\hline CHEMBL1306900 & 737403 & 5.2178 & 5.0071 & TST & \\
\hline CHEMBL1347274 & 737403 & 5.4639 & 5.3884 & TRN & \\
\hline CHEMBL1366153 & 737403 & 3.699 & 4.7344 & TRN & \\
\hline CHEMBL1424118 & 737403 & 5.1136 & 5.0049 & TST & \\
\hline CHEMBL1349532 & 737403 & 5.2248 & 4.5362 & TRN & \\
\hline CHEMBL1479888 & 737403 & 5.3915 & 5.1248 & TST & \\
\hline CHEMBL588028 & 737403 & 5.1674 & 5.0173 & TRN & \\
\hline CHEMBL1578700 & 737403 & 5.2569 & 5.272 & TRN & \\
\hline CHEMBL1318773 & 737403 & 5.1749 & 4.9829 & TST & \\
\hline CHEMBL1608077 & 737403 & 5.4037 & 5.3025 & TRN & \\
\hline CHEMBL1332003 & 737403 & 5.7077 & 4.1973 & TRN & \\
\hline CHEMBL1468075 & 737403 & 4.7473 & 5.0738 & TRN & \\
\hline CHEMBL3192230 & 737403 & 3.699 & 4.5434 & TRN & \\
\hline CHEMBL1502883 & 737403 & 5.9266 & 5.2278 & TRN & \\
\hline CHEMBL1497078 & 737403 & 5.0869 & 5.1815 & TRN & \\
\hline CHEMBL3193234 & 737403 & 3.699 & 4.6535 & TRN & \\
\hline CHEMBL1350780 & 737403 & \multicolumn{3}{|c|}{5.502000000000001} & $\mathrm{TRI}$ \\
\hline CHEMBL1525315 & 737403 & 4.8735 & 5.1189 & TRN & \\
\hline
\end{tabular}




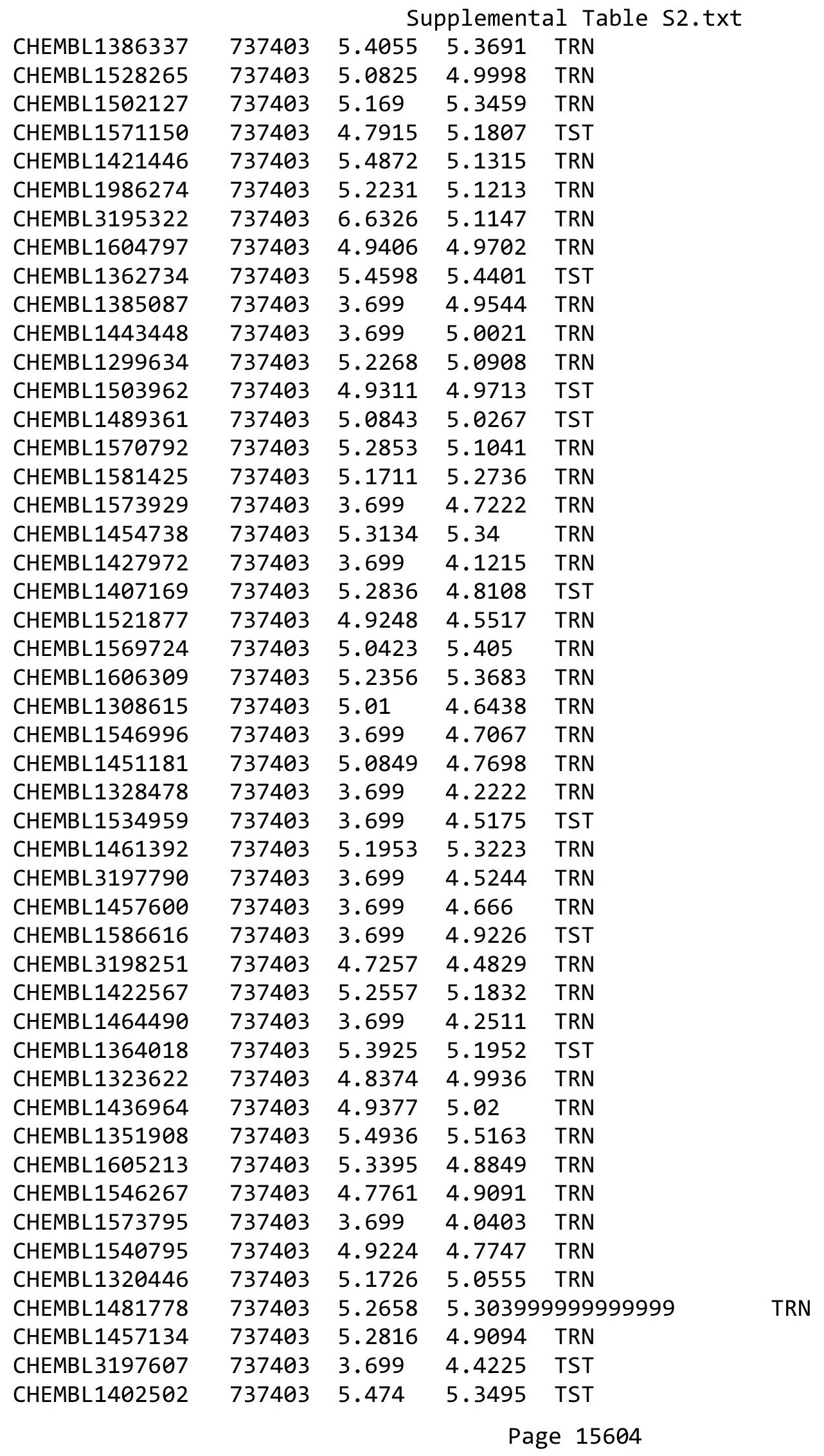


Supplemental Table S2.txt

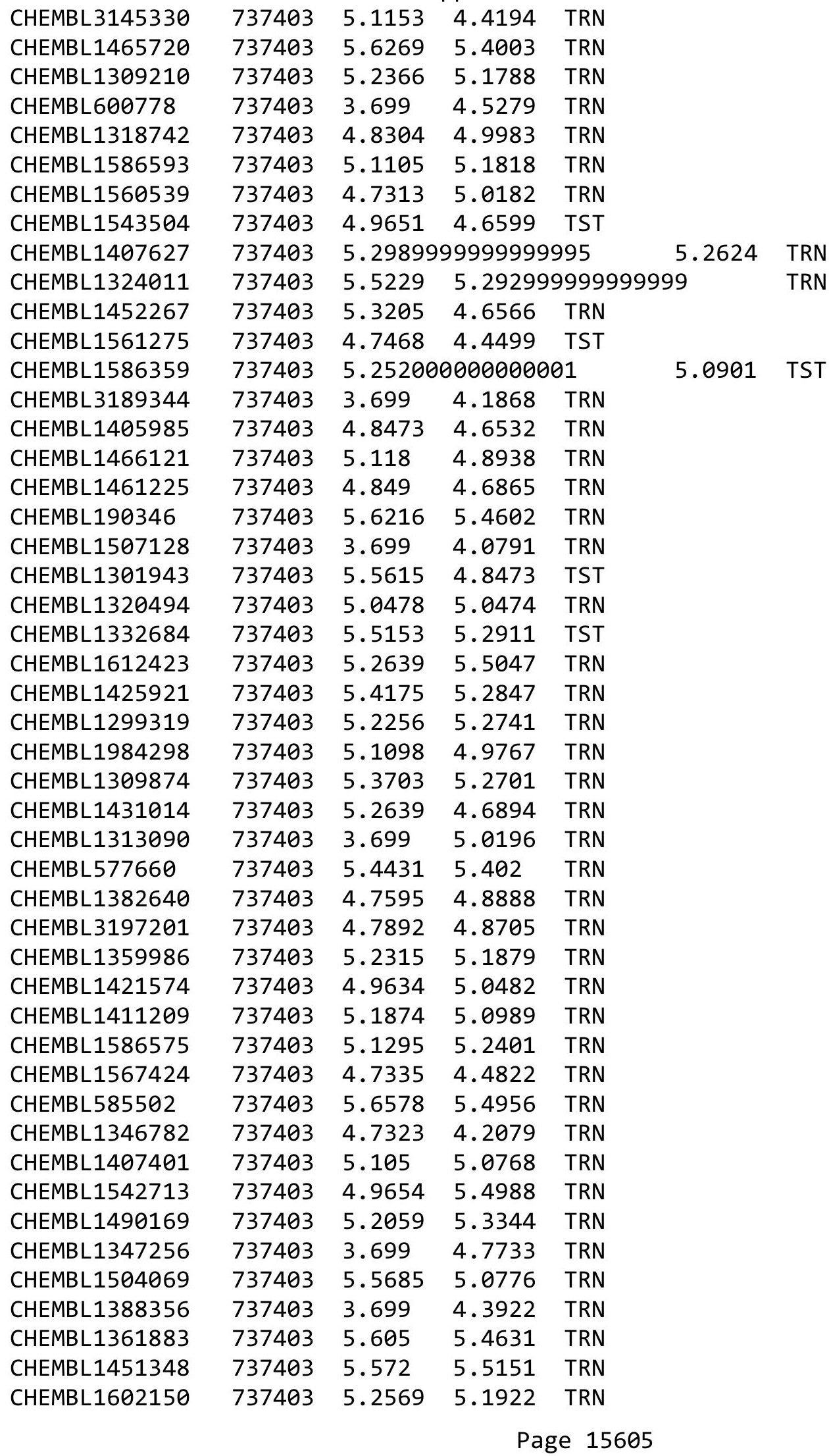




\begin{tabular}{|c|c|c|c|c|c|c|}
\hline & & \multicolumn{5}{|c|}{ Supplemental Table S2.txt } \\
\hline CHEMBL1329069 & 737403 & 5.3029 & 5.2948 & TRN & & \\
\hline CHEMBL1570135 & 737403 & 5.2946 & 5.2461 & TRN & & \\
\hline CHEMBL1427059 & 737403 & 5.4184 & 5.4618 & TRN & & \\
\hline CHEMBL1379347 & 737403 & 5.3703 & 5.3509 & TRN & & \\
\hline CHEMBL1434502 & 737403 & 4.7986 & 4.4834 & TRN & & \\
\hline CHEMBL1313978 & 737403 & 5.3485 & 5.2464 & TRN & & \\
\hline CHEMBL1567973 & 737403 & 5.0537 & 4.9478 & TST & & \\
\hline CHEMBL1489105 & 737403 & 4.8776 & 4.4909 & TRN & & \\
\hline CHEMBL1347586 & 737403 & 3.699 & 4.8263 & TST & & \\
\hline CHEMBL1334593 & 737403 & 5.1506 & 4.3632 & TST & & \\
\hline CHEMBL1407286 & 737403 & 5.1634 & 5.4057 & TRN & & \\
\hline CHEMBL1497803 & 737403 & 4.8989 & 4.5077 & TRN & & \\
\hline CHEMBL1997659 & 737403 & 4.7502 & 4.8012 & TRN & & \\
\hline CHEMBL1450208 & 737403 & 4.8878 & 5.0602 & TRN & & \\
\hline CHEMBL1501375 & 737403 & 5.3837 & 4.7074 & TRN & & \\
\hline CHEMBL1507713 & 737403 & 5.9408 & 5.4932 & TRN & & \\
\hline CHEMBL1346468 & 737403 & 5.2148 & 4.7144 & TRN & & \\
\hline CHEMBL1393096 & 737403 & 5.0795 & 5.13 & TRN & & \\
\hline CHEMBL1361922 & 737403 & 5.16700 & 20000000 & & 5.3777 & TST \\
\hline CHEMBL1414053 & 737403 & 5.5444 & 4.9636 & TRN & & \\
\hline CHEMBL1472304 & 737403 & 5.0872 & 5.2978 & TRN & & \\
\hline CHEMBL1383777 & 737403 & 4.8332 & 4.8609 & TRN & & \\
\hline CHEMBL1606583 & 737403 & 5.3118 & 5.1341 & TRN & & \\
\hline CHEMBL1555482 & 737403 & 5.4789 & 5.1743 & TRN & & \\
\hline CHEMBL1598294 & 737403 & 3.699 & 5.0206 & TRN & & \\
\hline CHEMBL1565083 & 737403 & 5.0907 & 5.4006 & TRN & & \\
\hline CHEMBL1589670 & 737403 & 5.6185 & 4.96 & TRN & & \\
\hline CHEMBL1982381 & 737403 & 5.2069 & 5.0113 & TRN & & \\
\hline CHEMBL1481689 & 737403 & 4.8452 & 5.195 & TRN & & \\
\hline CHEMBL1482357 & 737403 & 4.9982 & 4.2599 & TRN & & \\
\hline CHEMBL1299281 & 737403 & 5.2036 & 5.0188 & TRN & & \\
\hline CHEMBL1444020 & 737403 & 5.1419 & 5.2447 & TRN & & \\
\hline CHEMBL1568614 & 737403 & 3.699 & 4.3016 & TRN & & \\
\hline CHEMBL3195189 & 737403 & 5.2145 & 5.3814 & TRN & & \\
\hline CHEMBL1610725 & 737403 & 5.6211 & 5.2735 & TRN & & \\
\hline CHEMBL1560379 & 737403 & 5.4239 & 5.3648 & TST & & \\
\hline CHEMBL1413565 & 737403 & 5.0183 & 4.7789 & TRN & & \\
\hline CHEMBL454580 & 737403 & 5.3326 & 4.7356 & TST & & \\
\hline CHEMBL1595790 & 737403 & 5.3266 & 6.2098 & TST & & \\
\hline CHEMBL1455507 & 737403 & 5.2982 & 5.2692 & TRN & & \\
\hline CHEMBL1302130 & 737403 & 5.4414 & 5.4768 & TRN & & \\
\hline CHEMBL1544114 & 737403 & 5.46899 & 99999999 & 99 & 5.2043 & TRN \\
\hline CHEMBL1562819 & 737403 & 5.0589 & 5.0073 & TRN & & \\
\hline CHEMBL1556239 & 737403 & 5.0285 & 4.4776 & TST & & \\
\hline CHEMBL1333987 & 737403 & 5.3762 & 4.5893 & TRN & & \\
\hline CHEMBL1384893 & 737403 & 4.9036 & 5.2512 & TRN & & \\
\hline CHEMBL1428415 & 737403 & 5.084 & 4.8604 & TRN & & \\
\hline CHEMBL1468596 & 737403 & 5.125 & 5.391 & TRN & & \\
\hline
\end{tabular}




\begin{tabular}{|c|c|c|c|c|c|c|}
\hline & & \multicolumn{5}{|c|}{ Supplemental Table S2.txt } \\
\hline CHEMBL1337833 & 737403 & 5.1024 & 5.1019 & TRN & & \\
\hline CHEMBL1401029 & 737403 & 3.699 & 4.0563 & TRN & & \\
\hline CHEMBL1583236 & 737403 & 5.4594 & 5.3362 & TRN & & \\
\hline CHEMBL1312200 & 737403 & 4.9924 & 4.5052 & TRN & & \\
\hline CHEMBL1480238 & 737403 & 5.7174 & 5.4005 & TRN & & \\
\hline CHEMBL1572157 & 737403 & 4.8345 & 4.3049 & TRN & & \\
\hline CHEMBL1491893 & 737403 & 4.9801 & 4.8943 & TST & & \\
\hline CHEMBL1306524 & 737403 & 5.7199 & 5.4564 & TRN & & \\
\hline CHEMBL1991112 & 737403 & 4.849 & 4.1615 & TST & & \\
\hline CHEMBL1418948 & 737403 & 5.1755 & 5.2234 & TST & & \\
\hline CHEMBL1382232 & 737403 & 5.267 & 4.4858 & TRN & & \\
\hline CHEMBL1575051 & 737403 & 5.2798 & 5.4108 & TRN & & \\
\hline CHEMBL1516853 & 737403 & 5.2811 & 5.2507 & TRN & & \\
\hline CHEMBL321747 & 737403 & 5.0344 & 4.7455 & TRN & & \\
\hline CHEMBL1967099 & 737403 & 3.699 & 4.4011 & TRN & & \\
\hline CHEMBL1509707 & 737403 & 5.0652 & 5.0732 & TRN & & \\
\hline CHEMBL1595779 & 737403 & 5.29799 & 99999999 & 99 & 5.4415 & TRN \\
\hline CHEMBL1426245 & 737403 & 4.7566 & 5.1003 & TRN & & \\
\hline CHEMBL1351159 & 737403 & 4.8222 & 5.0684 & TRN & & \\
\hline CHEMBL1400385 & 737403 & 5.1218 & 5.0183 & TRN & & \\
\hline CHEMBL1530557 & 737403 & 5.4052 & 5.5699 & TRN & & \\
\hline CHEMBL1351584 & 737403 & 5.3538 & 5.0452 & TRN & & \\
\hline CHEMBL1523659 & 737403 & $5.2010 e$ & 30000000 & 005 & 5.0439 & TRN \\
\hline CHEMBL1374797 & 737403 & 4.9345 & 4.6854 & TRN & & \\
\hline CHEMBL1603938 & 737403 & 5.3076 & 4.23600 & 0000000001 & & TRN \\
\hline CHEMBL1586285 & 737403 & 5.1583 & 5.0991 & TRN & & \\
\hline CHEMBL1439315 & 737403 & 6.15799 & 99999999 & 995 & 5.4324 & TRN \\
\hline CHEMBL1558928 & 737403 & 4.9657 & 4.9642 & TRN & & \\
\hline CHEMBL1446827 & 737403 & 3.699 & 4.3716 & TRN & & \\
\hline CHEMBL1550184 & 737403 & 4.9116 & 5.1322 & TST & & \\
\hline CHEMBL1611106 & 737403 & 5.3218 & 5.0506 & TST & & \\
\hline CHEMBL1418614 & 737403 & 5.0368 & 5.0801 & TRN & & \\
\hline CHEMBL1415786 & 737403 & 3.699 & 4.2756 & TST & & \\
\hline CHEMBL1431608 & 737403 & 5.1871 & 5.1486 & TRN & & \\
\hline CHEMBL1303635 & 737403 & 5.0843 & 4.7804 & TST & & \\
\hline CHEMBL1342894 & 737403 & 5.1078 & 5.1443 & TST & & \\
\hline CHEMBL1994623 & 737403 & 3.699 & 4.1528 & TRN & & \\
\hline CHEMBL1493896 & 737403 & 5.0762 & 4.8617 & TRN & & \\
\hline CHEMBL1484482 & 737403 & 5.0536 & 4.8337 & TRN & & \\
\hline CHEMBL1565526 & 737403 & 5.6247 & 4.9507 & TRN & & \\
\hline CHEMBL1968085 & 737403 & 3.699 & 4.4703 & TRN & & \\
\hline CHEMBL 3194944 & 737403 & 6.9872 & 5.7063 & TRN & & \\
\hline CHEMBL1558180 & 737403 & 3.699 & 4.2891 & TRN & & \\
\hline CHEMBL1374703 & 737403 & 3.699 & 4.2547 & TRN & & \\
\hline CHEMBL1322356 & 737403 & 4.8385 & 4.4784 & TRN & & \\
\hline CHEMBL1544150 & 737403 & 3.699 & 4.5787 & TRN & & \\
\hline CHEMBL1498038 & 737403 & 5.2914 & 5.3778 & TRN & & \\
\hline CHEMBL1449912 & 737403 & 5.301 & 5.1218 & TST & & \\
\hline
\end{tabular}




\begin{tabular}{|c|c|c|c|c|}
\hline \multicolumn{5}{|c|}{ Supplemental Table S2.txt } \\
\hline CHEMBL1519375 & 737403 & 4.7899 & 4.5185 & TST \\
\hline CHEMBL1325644 & 737403 & 5.3404 & 4.6062 & TRN \\
\hline CHEMBL1372398 & 737403 & 5.71 & 5.4674 & TRN \\
\hline CHEMBL1543588 & 737403 & 4.9068 & 4.7003 & TST \\
\hline CHEMBL1374160 & 737403 & 5.515 & 5.1869 & TRN \\
\hline CHEMBL1486619 & 737403 & 5.7625 & 5.5354 & TRN \\
\hline CHEMBL1540815 & 737403 & 5.1318 & 5.0107 & TRN \\
\hline CHEMBL1457068 & 737403 & 3.699 & 4.231 & TRN \\
\hline CHEMBL1505956 & 737403 & 5.8324 & 5.3683 & TRN \\
\hline CHEMBL1375966 & 737403 & 5.5038 & 5.1719 & TRN \\
\hline CHEMBL 1348555 & 737403 & 4.8123 & 4.9512 & TST \\
\hline CHEMBL1542558 & 737403 & 3.699 & 4.4319 & TRN \\
\hline CHEMBL1447125 & 737403 & 5.0237 & 4.9394 & TST \\
\hline CHEMBL257286 & 737403 & 5.7371 & 5.0821 & TRN \\
\hline CHEMBL1378118 & 737403 & 5.1601 & 5.1623 & TRN \\
\hline CHEMBL1325227 & 737403 & 5.4839 & 5.3747 & TRN \\
\hline CHEMBL1573242 & 737403 & 5.2363 & 5.0752 & TRN \\
\hline CHEMBL1346232 & 737403 & 4.9123 & 5.0473 & TRN \\
\hline CHEMBL1529741 & 737403 & 4.936 & 5.1681 & TST \\
\hline CHEMBL1416848 & 737403 & 5.4445 & 5.2963 & TRN \\
\hline CHEMBL1332761 & 737403 & 5.079 & 4.9061 & TRN \\
\hline CHEMBL1398541 & 737403 & 5.2906 & 4.8251 & TRN \\
\hline CHEMBL1520241 & 737403 & 5.9274 & 5.3096 & TRN \\
\hline CHEMBL1599782 & 737403 & 5.1473 & 4.7398 & TRN \\
\hline CHEMBL1996376 & 737403 & 3.699 & 4.4579 & TST \\
\hline CHEMBL1335978 & 737403 & 5.0106 & 4.3315 & TRN \\
\hline CHEMBL3197098 & 737403 & 4.797 & 4.8389 & TRN \\
\hline CHEMBL1424366 & 737403 & 3.699 & 4.8285 & TRN \\
\hline CHEMBL1406480 & 737403 & 5.2213 & 5.1464 & TRN \\
\hline CHEMBL1536767 & 737403 & 5.1757 & 5.0649 & TRN \\
\hline CHEMBL1520131 & 737403 & 5.0714 & 5.0249 & TRN \\
\hline CHEMBL1444822 & 737403 & 3.699 & 4.9785 & TST \\
\hline CHEMBL1611774 & 737403 & 5.1 & 5.0168 & TST \\
\hline CHEMBL1351458 & 737403 & 5.2357 & 4.9853 & TRN \\
\hline CHEMBL1409963 & 737403 & 4.885 & 5.0181 & TST \\
\hline CHEMBL1460585 & 737403 & 5.2798 & 4.3152 & TRN \\
\hline CHEMBL1377693 & 737403 & 5.0669 & 5.1946 & TRN \\
\hline CHEMBL1568877 & 737403 & 5.2163 & 5.131 & TRN \\
\hline CHEMBL495005 & 737403 & 5.2159 & 5.0765 & TRN \\
\hline CHEMBL1445206 & 737403 & 5.1704 & 4.2758 & TRN \\
\hline CHEMBL1310479 & 737403 & 4.8848 & 4.8782 & TRN \\
\hline CHEMBL1380661 & 737403 & 5.2847 & 4.4583 & TRN \\
\hline CHEMBL1549092 & 737403 & 3.699 & 4.3542 & TRN \\
\hline CHEMBL1299637 & 737403 & 3.699 & 4.5842 & TST \\
\hline CHEMBL1386754 & 737403 & 5.0916 & 5.2965 & TRN \\
\hline CHEMBL1345481 & 737403 & 5.1505 & 5.0692 & TRN \\
\hline CHEMBL1409423 & 737403 & 5.3646 & 5.3175 & TRN \\
\hline CHEMBL1486981 & 737403 & 5.5173 & 4.9576 & TRN \\
\hline
\end{tabular}



Supplemental Table S2.txt

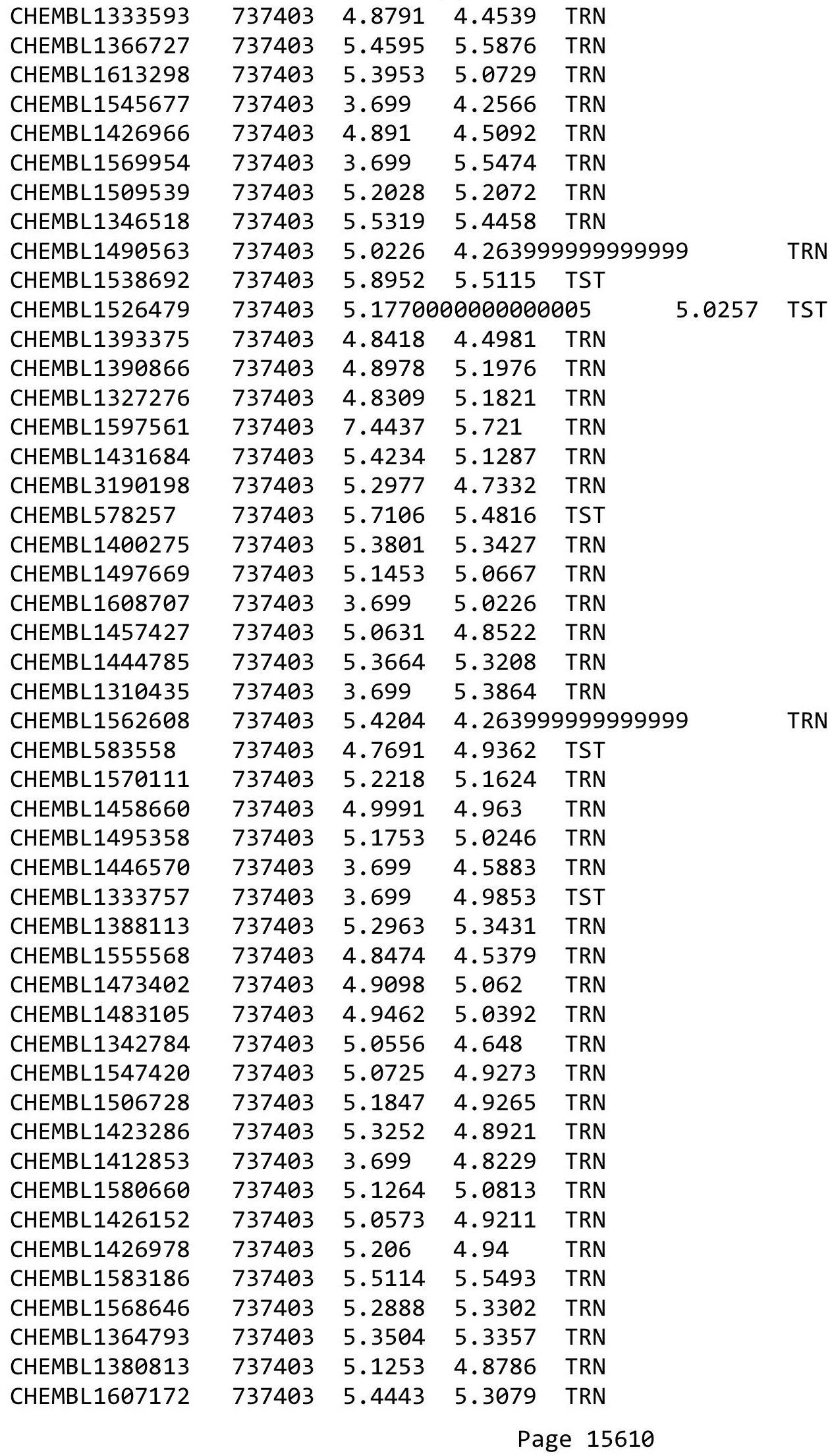





\begin{tabular}{|c|c|c|c|c|c|}
\hline \multicolumn{6}{|c|}{ Supplemental Table S2.txt } \\
\hline CHEMBL1361509 & 737403 & 5.2678 & 4.8594 & TST & \\
\hline CHEMBL1522043 & 737403 & 5.1315 & 5.1201 & TST & \\
\hline CHEMBL1455542 & 737403 & 5.5875 & 5.6521 & TST & \\
\hline CHEMBL1495687 & 737403 & 5.4285 & 5.1262 & TST & \\
\hline CHEMBL1427335 & 737403 & 3.699 & 5.1508 & TST & \\
\hline CHEMBL1446989 & 737403 & 4.8784 & 5.0309 & TST & \\
\hline CHEMBL1301855 & 737403 & 3.699 & 4.7843 & TST & \\
\hline CHEMBL3189325 & 737403 & 3.699 & 4.4712 & TST & \\
\hline CHEMBL1509029 & 737403 & 4.984 & 5.0439 & TST & \\
\hline CHEMBL1394121 & 737403 & 3.699 & 4.4171 & TST & \\
\hline CHEMBL1580556 & 737403 & 6.058 & 5.2675 & TST & \\
\hline CHEMBL 3644381 & 1640352 & 4.0 & 4.2368 & TRN & \\
\hline CHEMBL3702384 & 1640352 & 5.8539 & 5.7151 & TRN & \\
\hline CHEMBL3702427 & 1640352 & 4.0 & 3.9732 & TRN & \\
\hline CHEMBL3702405 & 1640352 & 4.0 & 3.3947 & TST & \\
\hline CHEMBL3702421 & 1640352 & 4.0 & 4.6367 & TST & \\
\hline CHEMBL3702417 & 1640352 & 4.0 & 4.7147 & TRN & \\
\hline CHEMBL3702366 & 1640352 & 5.8861 & 5.8384 & TRN & \\
\hline CHEMBL3702410 & 1640352 & 5.7959 & 5.3493 & TRN & \\
\hline CHEMBL3702393 & 1640352 & 5.4685 & 4.0926 & TST & \\
\hline CHEMBL3702404 & 1640352 & 4.0 & 4.3106 & TRN & \\
\hline CHEMBL3702390 & 1640352 & 5.7959 & 4.5404 & TST & \\
\hline CHEMBL3644364 & 1640352 & 4.0 & 3.4256 & TST & \\
\hline CHEMBL 3702441 & 1640352 & 5.4111 & 5.1376 & TRN & \\
\hline CHEMBL3702407 & 1640352 & 5.0506 & 4.6266 & TRN & \\
\hline CHEMBL 3644414 & 1640352 & 4.0 & 4.1413 & TRN & \\
\hline CHEMBL 3644410 & 1640352 & 4.0 & 3.6848 & TRN & \\
\hline CHEMBL 3702447 & 1640352 & 5.2321 & 5.0304 & TRN & \\
\hline CHEMBL 3702392 & 1640352 & 4.0 & 3.5804 & TRN & \\
\hline CHEMBL3702418 & 1640352 & 4.0 & 3.9131 & TRN & \\
\hline CHEMBL3702386 & 1640352 & 7.8239 & 5.7646 & TST & \\
\hline CHEMBL 3644428 & 1640352 & 6.1475 & 6.2485 & TRN & \\
\hline CHEMBL3702449 & 1640352 & 5.8239 & 5.5653 & TST & \\
\hline CHEMBL3702409 & 1640352 & 5.5086 & 6.2398 & TST & \\
\hline CHEMBL3644384 & 1640352 & 4.0 & 4.10800 & 00000000005 & TRN \\
\hline CHEMBL3644394 & 1640352 & 6.0506 & 5.9967 & TRN & \\
\hline CHEMBL3644429 & 1640352 & 5.8239 & 5.7621 & TRN & \\
\hline CHEMBL 3644380 & 1640352 & 5.7169 & 4.7706 & TRN & \\
\hline CHEMBL3922521 & 1640352 & 4.0 & 4.194 & TRN & \\
\hline CHEMBL3644404 & 1640352 & 5.4815 & 5.6856 & TRN & \\
\hline CHEMBL3702376 & 1640352 & 4.0 & 4.2019 & TST & \\
\hline CHEMBL3644431 & 1640352 & 4.0 & 4.7619 & TRN & \\
\hline CHEMBL3702454 & 1640352 & 5.2291 & 5.2153 & TRN & \\
\hline CHEMBL3644406 & 1640352 & 7.3872 & 7.0024 & TRN & \\
\hline CHEMBL3644422 & 1640352 & 6.2518 & 6.3099 & TRN & \\
\hline CHEMBL3702403 & 1640352 & 4.0 & 4.154 & TRN & \\
\hline CHEMBL3702398 & 1640352 & 5.6383 & 5.1491 & TRN & \\
\hline CHEMBL 3640012 & 1640352 & 4.0 & 3.8553 & TST & \\
\hline
\end{tabular}




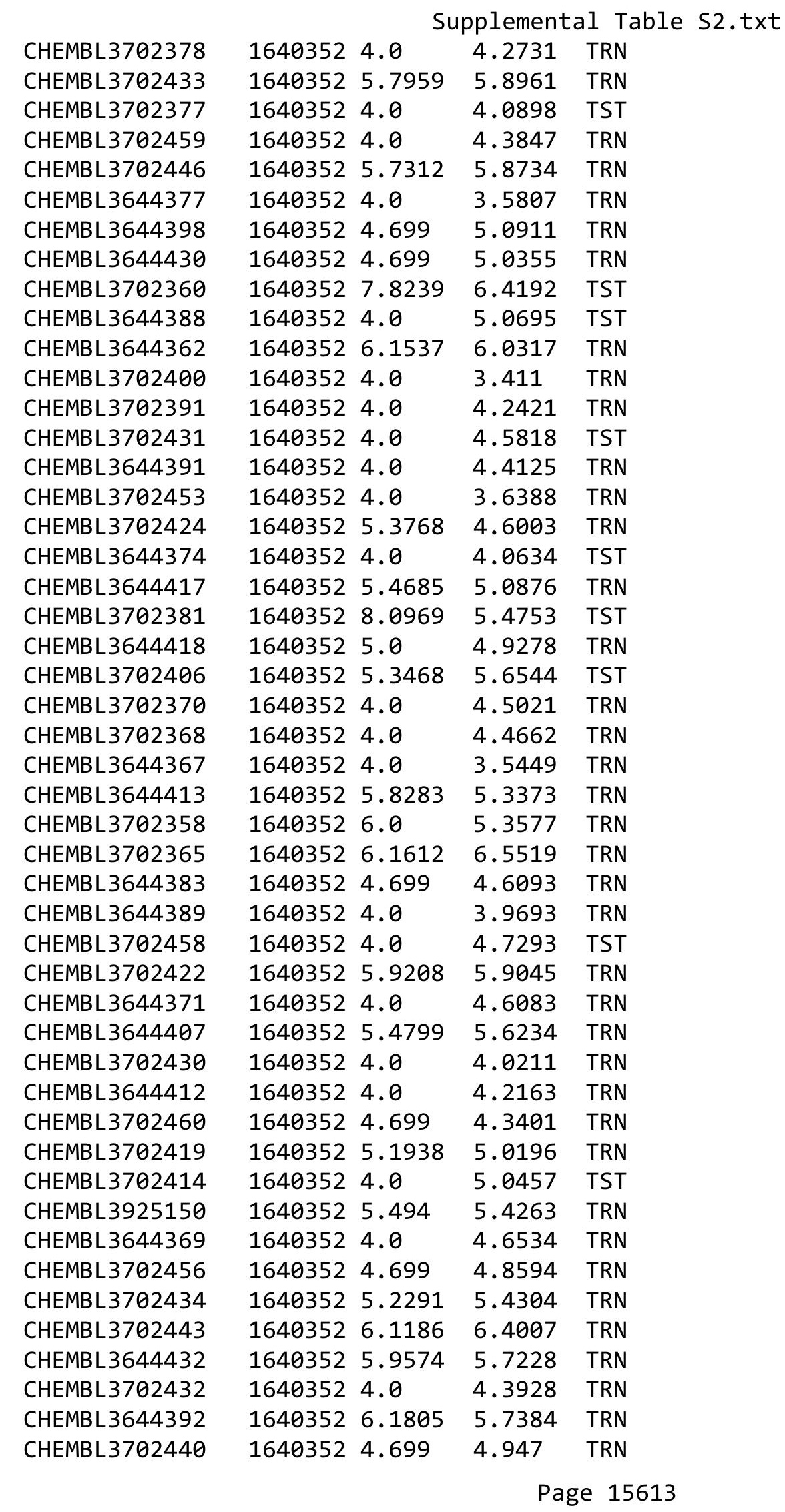


Supplemental Table S2.txt

\begin{tabular}{|c|c|c|c|c|c|}
\hline CHEMBL 3702448 & 1640352 & 6.1871 & 5.9196 & TST & \\
\hline CHEMBL3702423 & 1640352 & 6.7696 & 6.5539 & TRN & \\
\hline CHEMBL 3644378 & 1640352 & 4.0 & 4.43199 & 99999999995 & TST \\
\hline CHEMBL 3702402 & 1640352 & 4.0 & 4.4277 & TRN & \\
\hline CHEMBL3702442 & 1640352 & 5.7093 & 5.7054 & TRN & \\
\hline CHEMBL 3644375 & 1640352 & 4.0 & 4.1415 & TRN & \\
\hline CHEMBL 3702416 & 1640352 & 4.0 & 4.4035 & TST & \\
\hline CHEMBL 3702382 & 1640352 & 5.8539 & 5.7046 & TRN & \\
\hline CHEMBL 3702411 & 1640352 & 5.4949 & 5.6456 & TRN & \\
\hline CHEMBL3702438 & 1640352 & 4.699 & 5.0189 & TRN & \\
\hline CHEMBL3702399 & 1640352 & 4.0 & 4.4085 & TRN & \\
\hline CHEMBL 3702362 & 1640352 & 6.6778 & 6.9692 & TRN & \\
\hline CHEMBL3702380 & 1640352 & 5.3188 & 5.4593 & TST & \\
\hline CHEMBL 3644395 & 1640352 & 6.3098 & 5.93 & TRN & \\
\hline CHEMBL3644370 & 1640352 & 4.0 & 4.1828 & TST & \\
\hline CHEMBL 3644411 & 1640352 & 4.699 & 4.6595 & TRN & \\
\hline CHEMBL3702363 & 1640352 & 4.0 & 4.6778 & TRN & \\
\hline CHEMBL3702385 & 1640352 & 7.0315 & 6.3076 & TST & \\
\hline CHEMBL3644372 & 1640352 & 5.8861 & 5.8099 & TRN & \\
\hline CHEMBL3702452 & 1640352 & 5.8239 & 5.8552 & TRN & \\
\hline CHEMBL 3702444 & 1640352 & 5.9776 & 6.3825 & TRN & \\
\hline CHEMBL 3644365 & 1640352 & 6.0894 & 5.8132 & TRN & \\
\hline CHEMBL3702389 & 1640352 & 7.6576 & 5.6899 & TST & \\
\hline CHEMBL3702428 & 1640352 & 4.0 & 4.0274 & TRN & \\
\hline CHEMBL3644425 & 1640352 & 5.6383 & 5.4457 & TRN & \\
\hline CHEMBL 3702451 & 1640352 & 6.1965 & 6.4641 & TRN & \\
\hline CHEMBL3644390 & 1640352 & 4.0 & 4.4087 & TRN & \\
\hline CHEMBL3702445 & 1640352 & 4.0 & 3.9324 & TRN & \\
\hline CHEMBL3644416 & 1640352 & 6.0 & \multicolumn{2}{|c|}{5.672999999999999} & TRN \\
\hline CHEMBL 3644405 & 1640352 & 5.9226 & 6.4609 & TRN & \\
\hline CHEMBL3702461 & 1640352 & 5.083 & 5.0921 & TRN & \\
\hline CHEMBL 3702450 & 1640352 & 6.6576 & 6.0179 & TRN & \\
\hline CHEMBL3702462 & 1640352 & 4.9211 & 4.9971 & TRN & \\
\hline CHEMBL 3702364 & 1640352 & 6.0269 & 5.8229 & TRN & \\
\hline CHEMBL3702455 & 1640352 & 5.6198 & 5.4695 & TRN & \\
\hline CHEMBL3702374 & 1640352 & 5.284 & 5.2217 & TRN & \\
\hline CHEMBL3702396 & 1640352 & 4.0 & 5.5316 & TST & \\
\hline CHEMBL 3913043 & 1640352 & 5.6821 & 5.572 & TRN & \\
\hline CHEMBL 3644409 & 1640352 & 4.0 & \multicolumn{2}{|c|}{4.196000000000001} & TRN \\
\hline CHEMBL3702361 & 1640352 & 5.5157 & 5.7972 & TRN & \\
\hline CHEMBL3702397 & 1640352 & 5.6576 & 5.8032 & TST & \\
\hline CHEMBL3702415 & 1640352 & 5.8539 & 4.9875 & TST & \\
\hline CHEMBL 3644433 & 1640352 & 4.699 & 4.8855 & TRN & \\
\hline CHEMBL3702367 & 1640352 & 6.2757 & 6.12 & TRN & \\
\hline CHEMBL3702394 & 1640352 & 4.0 & 5.4313 & TST & \\
\hline CHEMBL3702372 & 1640352 & 6.0969 & 4.7965 & TST & \\
\hline CHEMBL 3644403 & 1640352 & 4.699 & 4.5078 & TRN & \\
\hline CHEMBL3639432 & 1640352 & 6.1726 & 6.7787 & TRN & \\
\hline
\end{tabular}


Supplemental Table S2.txt

\begin{tabular}{|c|c|c|c|c|c|}
\hline CHEMBL3702387 & 1640352 & 5.1612 & 4.772 & TST & \\
\hline CHEMBL3644382 & 1640352 & 4.0 & 3.9485 & TRN & \\
\hline CHEMBL3702412 & 1640352 & 4.0 & 4.3555 & TRN & \\
\hline CHEMBL 3644421 & 1640352 & 6.5391 & 6.3825 & TRN & \\
\hline CHEMBL 3644401 & 1640352 & 6.2916 & 6.1744 & TRN & \\
\hline CHEMBL3644376 & 1640352 & 5.1347 & 4.3787 & TRN & \\
\hline CHEMBL3702465 & 1640352 & 6.162999 & 99999999 & 5.7396 & TRN \\
\hline CHEMBL 3644415 & 1640352 & 6.3958 & 5.6053 & TRN & \\
\hline CHEMBL3644386 & 1640352 & 4.0 & 4.2836 & TRN & \\
\hline CHEMBL3644400 & 1640352 & 6.6459 & 6.0086 & TRN & \\
\hline CHEMBL3644419 & 1640352 & 4.0 & 4.6196 & TRN & \\
\hline CHEMBL 3702371 & 1640352 & 4.0 & 5.0345 & TST & \\
\hline CHEMBL3702429 & 1640352 & 4.0 & 3.7254 & TRN & \\
\hline CHEMBL 3644387 & 1640352 & 5.0315 & 5.8 & TST & \\
\hline CHEMBL3702420 & 1640352 & 4.0 & 5.2209 & TST & \\
\hline CHEMBL3702375 & 1640352 & 4.0 & 3.1422 & TST & \\
\hline CHEMBL3644366 & 1640352 & 4.2218 & $3.81100 t$ & 00000000004 & TRN \\
\hline CHEMBL 3702463 & 1640352 & 4.7401 & 4.6224 & TRN & \\
\hline CHEMBL3644399 & 1640352 & 5.6304 & 5.9625 & TRN & \\
\hline CHEMBL3702395 & 1640352 & 4.0 & 4.3782 & TST & \\
\hline CHEMBL3644423 & 1640352 & 5.4815 & 5.4743 & TRN & \\
\hline CHEMBL3702359 & 1640352 & 6.8239 & 4.9858 & TST & \\
\hline CHEMBL3644402 & 1640352 & 5.7841 & 5.9105 & TRN & \\
\hline CHEMBL3702379 & 1640352 & 4.0 & 4.6593 & TST & \\
\hline CHEMBL3702413 & 1640352 & 5.8239 & 5.7638 & TRN & \\
\hline CHEMBL3702401 & 1640352 & 4.0 & 5.2218 & TST & \\
\hline CHEMBL3644427 & 1640352 & 4.699 & 4.8839 & TRN & \\
\hline CHEMBL3702373 & 1640352 & 5.5528 & 4.5396 & TST & \\
\hline CHEMBL 3644368 & 1640352 & 4.0 & 3.5101 & TRN & \\
\hline CHEMBL3702439 & 1640352 & 4.0 & 4.0361 & TRN & \\
\hline CHEMBL3702357 & 1640352 & 7.5686 & 6.3317 & TST & \\
\hline CHEMBL 3644373 & 1640352 & 4.0 & 3.8832 & TRN & \\
\hline CHEMBL3702369 & 1640352 & 5.4559 & 5.2228 & TST & \\
\hline CHEMBL3644379 & 1640352 & 4.0 & 4.45100 & 00000000005 & TRN \\
\hline CHEMBL 3702408 & 1640352 & 5.1871 & 5.4921 & TST & \\
\hline CHEMBL3644424 & 1640352 & 5.7447 & 5.7847 & TRN & \\
\hline CHEMBL 3702426 & 1640352 & 4.0 & 4.1205 & TRN & \\
\hline CHEMBL3702457 & 1640352 & 4.0 & 4.5935 & TRN & \\
\hline CHEMBL 3644408 & 1640352 & 5.6844 & 5.7408 & TRN & \\
\hline CHEMBL3702467 & 1640352 & 6.251 & 5.7513 & TRN & \\
\hline CHEMBL501521 & 492003 & 4.6364 & 4.637 & TRN & \\
\hline CHEMBL 383705 & 492003 & 5.2676 & 5.2663 & TRN & \\
\hline CHEMBL461506 & 492003 & 3.6073 & 3.6026 & TRN & \\
\hline CHEMBL459643 & 492003 & 3.9281 & 3.9268 & TRN & \\
\hline CHEMBL446007 & 492003 & 3.4271 & 3.431 & TRN & \\
\hline CHEMBL452470 & 492003 & 4.284 & 4.2844 & TRN & \\
\hline CHEMBL501126 & 492003 & 4.4089 & 4.4125 & TRN & \\
\hline CHEMBL453918 & 492003 & 4.6778 & 4.6765 & TRN & \\
\hline
\end{tabular}


Supplemental Table S2.txt

\begin{tabular}{|c|c|c|c|c|}
\hline CHEMBL461289 & 492003 & 4.8962 & 4.8957 & TRN \\
\hline HEMBL461291 & 192003 & 4.8239 & 4.8238 & \\
\hline HEMBL 4 & 2003 & 318 & 33 & \\
\hline HEMBL98408 & 92003 & 7696 & 7624 & \\
\hline HEMBL461913 & 192003 & 4.2924 & 2932 & \\
\hline HEMBL 459438 & 492003 & 4.0088 & 0078 & \\
\hline HEMBL4 & 92003 & 5.6576 & 5.657 & \\
\hline HEMBL5 & 492003 & 315 & 4.0305 & PN \\
\hline HEMBL459642 & 492003 & 4.8069 & 4.8038 & RIN \\
\hline HEMBL443373 & 492003 & 3.7258 & 3.7259 & \\
\hline HEMBL452029 & 492003 & 3.5436 & 3.5433 & RN \\
\hline HEMBL4 & 492003 & 198 & 6188 & RN \\
\hline HEMBL 9 & 492003 & 696 & 7704 & $\mathrm{RN}$ \\
\hline HEMBL511346 & 492003 & 4.3615 & 4.3615 & TRN \\
\hline HEMBL443622 & 492003 & 3872 & 3886 & TRN \\
\hline HEMBL9 & 492 & 3.7825 & 22 & II \\
\hline HEMBL5 & 23 & 5.6021 & 026 & RN \\
\hline HEMBL 5 & 492003 & 2. & 3005 & TRN \\
\hline HEMBL4 & 492003 & 383 & 545 & TRN \\
\hline HEMBL4 & 03 & & 936 & TRN \\
\hline HEMBL4 & 492 & 08 & 07 & I RN \\
\hline HEMBL & 33 & 32 & 88 & 「RN \\
\hline HEMBL5 & 492 & 7.6576 & 2109 & TST \\
\hline HEMBL 9 & 03 & & 5334 & TST \\
\hline HEMBL4 & 03 & 39 & 8241 & $\mathrm{IR}^{2}$ \\
\hline HEMBL4 & 492 & & 468 & TST \\
\hline HEMBL & 492 & 47 & 723 & 「RN \\
\hline HEMBL & 492 & 932 & 7906 & 「RN \\
\hline HEMBL4 & 492 & 76 & 2971 & TRN \\
\hline HEMBL4 & 492 & 3.7212 & & TRN \\
\hline HEMBL $\angle$ & 492 & 59 & & TRN \\
\hline HEM & 49 & $\partial 6$ & 13 & TRN \\
\hline HEMBL & 49 & & 92 & TRN \\
\hline HEMBL4C & 492 & 5.4559 & 578 & TRN \\
\hline HEMBL469890 & 492 & & 0032 & TRN \\
\hline HEMBL 4 & 492 & 5 & 414 & TST \\
\hline HEM & 49 & 2. & 78 & TST \\
\hline HEMBL4 & 492 & 6.27 & 6.5414 & TST \\
\hline HEMBL 83418 & 492 & 4.1739 & & TST \\
\hline HEMBL4 & 492 & & 402 & TST \\
\hline HEMBL4 & 492 & 18 & 4888 & TST \\
\hline CHEMBL4 & 492 & 4.0269 & 5495 & TST \\
\hline HEMBL499101 & 492003 & 3.9136 & 3.7553 & TST \\
\hline CHEMBL4 & 492 & 2 & 9519 & TST \\
\hline CHEMBL4 & 492 & & 7218 & TST \\
\hline CHEMBL395268 & 1641629 & 5.4437 & 5.1448 & Niv \\
\hline CHEMBL389793 & 1641629 & 8.041 & 8.251 & RN \\
\hline CHEMBL3980100 & 1641629 & 6.6576 & 6.9824 & IRI \\
\hline
\end{tabular}

Page 15616 
Supplemental Table S2.txt

\begin{tabular}{|c|c|c|c|c|c|}
\hline CHEMBL3940563 & 1641629 & 4.3872 & 4.0619 & TRN & \\
\hline CHEMBL3924469 & 1641629 & 7.7696 & 7.3959 & TST & \\
\hline CHEMBL3890597 & 1641629 & 7.1308 & 5.9863 & TST & \\
\hline CHEMBL3979983 & 1641629 & 7.0088 & 7.3852 & TRN & \\
\hline CHEMBL3971818 & 1641629 & 6.0 & 5.1492 & TRN & \\
\hline CHEMBL3902437 & 1641629 & 7.9208 & 7.8805 & TRN & \\
\hline CHEMBL3924822 & 1641629 & 6.2596 & 5.7053 & TRN & \\
\hline CHEMBL3959596 & 1641629 & 5.2147 & 4.7284 & TRN & \\
\hline CHEMBL3975559 & 1641629 & 6.9208 & 6.9978 & TST & \\
\hline CHEMBL3981135 & 1641629 & 5.5528 & 5.5172 & TRN & \\
\hline CHEMBL3982512 & 1641629 & 5.0 & 5.7433 & TRN & \\
\hline CHEMBL3939173 & 1641629 & 7.699 & 7.9438 & TRN & \\
\hline CHEMBL3926421 & 1641629 & 6.8539 & 6.7588 & TRN & \\
\hline CHEMBL3957210 & 1641629 & 5.2007 & 5.1135 & TRN & \\
\hline CHEMBL 3943483 & 1641629 & 4.7447 & 5.5353 & TRN & \\
\hline CHEMBL3970710 & 1641629 & 6.6021 & 7.171 & TST & \\
\hline CHEMBL3911212 & 1641629 & 7.4559 & 7.3169 & TRN & \\
\hline CHEMBL3950193 & 1641629 & 7.7959 & 7.3724 & TST & \\
\hline CHEMBL3917646 & 1641629 & 8.4815 & 7.8227 & TRN & \\
\hline CHEMBL 3941444 & 1641629 & 6.0177 & 6.186 & TST & \\
\hline CHEMBL3957113 & 1641629 & 8.2366 & 7.1976 & TRN & \\
\hline CHEMBL3912600 & 1641629 & 5.0 & 5.58299 & 9999999999 & TRN \\
\hline CHEMBL3904132 & 1641629 & 5.6198 & 5.6399 & TRN & \\
\hline CHEMBL3985928 & 1641629 & 6.0 & 6.3741 & TST & \\
\hline CHEMBL 3955277 & 1641629 & 5.0 & 5.0979 & TST & \\
\hline CHEMBL3903060 & 1641629 & 5.4318 & 4.6236 & TST & \\
\hline CHEMBL3980617 & 1641629 & 6.0458 & 5.5069 & TRN & \\
\hline CHEMBL3907336 & 1641629 & 7.7447 & 7.2004 & TRN & \\
\hline CHEMBL3890960 & 1641629 & 6.4089 & 6.2788 & TRN & \\
\hline CHEMBL3925006 & 1641629 & 6.4202 & 6.4578 & TRN & \\
\hline CHEMBL3890900 & 1641629 & 8.2007 & 7.734 & TRN & \\
\hline CHEMBL3910922 & 1641629 & 7.3372 & 7.8959 & TRN & \\
\hline CHEMBL3973470 & 1641629 & 6.4815 & 6.7981 & TRN & \\
\hline CHEMBL 3925444 & 1641629 & 7.3143 & 7.0484 & TRN & \\
\hline CHEMBL3916335 & 1641629 & 6.8539 & 7.1565 & TRN & \\
\hline CHEMBL3913380 & 1641629 & 8.2757 & 8.7029 & TRN & \\
\hline CHEMBL3933677 & 1641629 & 6.0 & 6.2679 & TRN & \\
\hline CHEMBL3928723 & 1641629 & 6.0 & \multicolumn{2}{|c|}{6.053999999999999} & TRN \\
\hline CHEMBL3918818 & 1641629 & 7.0 & 7.4406 & TRN & \\
\hline CHEMBL3978925 & 1641629 & 6.0458 & 5.7122 & TRN & \\
\hline CHEMBL3898696 & 1641629 & 4.6576 & 6.5939 & TST & \\
\hline CHEMBL3926701 & 1641629 & 4.699 & 4.9998 & TRN & \\
\hline CHEMBL3963726 & 1641629 & 8.0223 & 8.5399 & TRN & \\
\hline CHEMBL3978726 & 1641629 & 7.9586 & 7.3187 & TRN & \\
\hline CHEMBL3898311 & 1641629 & 7.5086 & 7.021 & TRN & \\
\hline CHEMBL 3895371 & 1641629 & 6.0088 & 5.8308 & TST & \\
\hline CHEMBL3897076 & 1641629 & 6.0 & 6.3645 & TRN & \\
\hline CHEMBL3947793 & 1641629 & 6.7447 & 6.8648 & TST & \\
\hline
\end{tabular}


Supplemental Table S2.txt

\begin{tabular}{|c|c|c|c|c|c|}
\hline CHEMBL3952049 & 1641629 & 6.6198 & 6.7672 & TRN & \\
\hline CHEMBL3969877 & 1641629 & 5.9586 & 6.1885 & TRN & \\
\hline CHEMBL3980986 & 1641629 & 6.2007 & 6.9525 & TST & \\
\hline CHEMBL3928221 & 1641629 & 8.2218 & 8.0609 & TRN & \\
\hline CHEMBL 3906864 & 1641629 & 6.8239 & 7.0933 & TRN & \\
\hline CHEMBL3952707 & 1641629 & 6.0655 & \multicolumn{2}{|c|}{6.132000000000001} & TRN \\
\hline CHEMBL 3920854 & 1641629 & 8.3565 & 8.2244 & TRN & \\
\hline CHEMBL 3942270 & 1641629 & 8.8861 & 8.5214 & TRN & \\
\hline CHEMBL 3942101 & 1641629 & 8.0088 & 8.0653 & TRN & \\
\hline CHEMBL3915527 & 1641629 & 6.3468 & 6.8514 & TRN & \\
\hline CHEMBL 3954789 & 1641629 & 7.0862 & 6.3956 & TRN & \\
\hline CHEMBL3909284 & 1641629 & 7.3565 & 6.9707 & TRN & \\
\hline CHEMBL 3955537 & 1641629 & 8.2147 & 7.9963 & TRN & \\
\hline CHEMBL3930449 & 1641629 & 7.0 & 6.83 & TRN & \\
\hline CHEMBL3945682 & 1641629 & 6.8539 & 5.763 & TST & \\
\hline CHEMBL 3926002 & 1641629 & 6.3468 & 7.1367 & TST & \\
\hline CHEMBL3943324 & 1641629 & 6.2291 & \multicolumn{2}{|c|}{6.457999999999999} & TRN \\
\hline CHEMBL 3898177 & 1641629 & 6.9586 & 6.2892 & TRN & \\
\hline CHEMBL 3933114 & 1641629 & 5.0 & 4.9166 & TST & \\
\hline CHEMBL 3948645 & 1641629 & 8.3768 & 6.6803 & TRN & \\
\hline CHEMBL 3931490 & 1641629 & 6.6778 & 6.6982 & TRN & \\
\hline CHEMBL3946845 & 1641629 & 7.7696 & 7.5727 & TST & \\
\hline CHEMBL 3954289 & 1641629 & 5.0 & 5.749 & TRN & \\
\hline CHEMBL 3918746 & 1641629 & 5.0 & 5.9284 & TST & \\
\hline CHEMBL 3984858 & 1641629 & 6.0088 & 6.7868 & TST & \\
\hline CHEMBL 3948802 & 1641629 & 6.5376 & 6.9789 & TRN & \\
\hline CHEMBL3935634 & 1641629 & 5.301 & 5.182 & TRN & \\
\hline CHEMBL 3897398 & 1641629 & 7.2441 & 6.7365 & TRN & \\
\hline CHEMBL 3943364 & 1641629 & 6.0 & 5.8195 & TRN & \\
\hline CHEMBL 3937903 & 1641629 & 6.9208 & 8.8795 & TST & \\
\hline CHEMBL 3912387 & 1641629 & 6.0458 & 6.4053 & TRN & \\
\hline CHEMBL3895399 & 1641629 & 6.8239 & 6.8428 & TRN & \\
\hline CHEMBL3923416 & 1641629 & 6.0 & 4.8868 & TST & \\
\hline CHEMBL 3927667 & 1641629 & 6.6383 & 6.3458 & TRN & \\
\hline CHEMBL 3897464 & 1641629 & 7.0605 & 6.5859 & TRN & \\
\hline CHEMBL3926609 & 1641629 & 6.2757 & 6.1795 & TST & \\
\hline CHEMBL3909726 & 1641629 & 5.0 & 5.6019 & TRN & \\
\hline CHEMBL 3903505 & 1641629 & 7.0088 & 6.6499 & TRN & \\
\hline CHEMBL3929936 & 1641629 & 5.4437 & 5.8048 & TRN & \\
\hline CHEMBL3955557 & 1641629 & 6.6778 & 5.7263 & TST & \\
\hline CHEMBL 3945452 & 1641629 & 5.7212 & 5.8306 & TRN & \\
\hline CHEMBL3948604 & 1641629 & 6.3468 & 6.352 & TRN & \\
\hline CHEMBL3980046 & 1641629 & 7.9208 & 8.1475 & TRN & \\
\hline CHEMBL 3985746 & 1641629 & 6.0 & 7.0824 & TRN & \\
\hline CHEMBL 3960695 & 1641629 & 6.5528 & 6.2101 & TRN & \\
\hline CHEMBL 3947951 & 1641629 & 8.2757 & 7.0108 & TST & \\
\hline CHEMBL3906550 & 1641629 & 5.4437 & 5.4878 & TRN & \\
\hline CHEMBL 3965942 & 1641629 & 5.0 & 4.8112 & TST & \\
\hline
\end{tabular}


Supplemental Table S2.txt

\begin{tabular}{|c|c|c|c|c|c|}
\hline CHEMBL3902792 & 1641629 & 7.4202 & 6.8931 & TRN & \\
\hline CHEMBL3911701 & 1641629 & 6.0 & 6.8705 & TRN & \\
\hline CHEMBL3890677 & 1641629 & 6.8539 & 6.7325 & TRN & \\
\hline CHEMBL3912418 & 1641629 & 6.8539 & 6.7229 & TRN & \\
\hline CHEMBL 3932074 & 1641629 & 7.8539 & 7.1454 & TRN & \\
\hline CHEMBL3921005 & 1641629 & 6.5528 & 6.4391 & TRN & \\
\hline CHEMBL3962524 & 1641629 & 7.1675 & 7.159 & TRN & \\
\hline CHEMBL3962590 & 1641629 & 5.3665 & 5.4798 & TRN & \\
\hline CHEMBL3961312 & 1641629 & 6.0 & 6.2295 & TRN & \\
\hline CHEMBL 3954244 & 1641629 & 7.301 & 7.8913 & TST & \\
\hline CHEMBL3890380 & 1641629 & 5.4815 & 5.8629 & TRN & \\
\hline CHEMBL3921570 & 1641629 & 7.6198 & 7.2655 & TRN & \\
\hline CHEMBL3971063 & 1641629 & 6.5528 & 6.5186 & TRN & \\
\hline CHEMBL3983970 & 1641629 & 7.6021 & 8.0499 & TST & \\
\hline CHEMBL 3953723 & 1641629 & 5.0 & 4.8516 & TST & \\
\hline CHEMBL3891397 & 1641629 & 5.4559 & 5.45799 & 9999999999 & TRN \\
\hline CHEMBL3923658 & 1641629 & 7.9208 & 7.3638 & TRN & \\
\hline CHEMBL 3890023 & 1641629 & 5.0 & 5.5546 & TRN & \\
\hline CHEMBL3910593 & 1641629 & 5.0 & 6.0223 & TST & \\
\hline CHEMBL 3897364 & 1641629 & 7.2218 & 6.925 & TRN & \\
\hline CHEMBL3978117 & 1641629 & 4.6198 & 6.0902 & TST & \\
\hline CHEMBL3898667 & 1641629 & 6.4089 & 5.8516 & TRN & \\
\hline CHEMBL3933669 & 1641629 & 7.1612 & 7.276 & TRN & \\
\hline CHEMBL3972838 & 1641629 & 6.7212 & 6.777 & TRN & \\
\hline CHEMBL3966415 & 1641629 & 5.8539 & 6.1996 & TRN & \\
\hline CHEMBL3930957 & 1641629 & 8.3372 & 7.3389 & TST & \\
\hline CHEMBL3964354 & 1641629 & 8.6021 & 7.7117 & TST & \\
\hline CHEMBL 3897227 & 1641629 & 6.0 & 5.6825 & TRN & \\
\hline CHEMBL3965499 & 1641629 & 3.0 & 4.993 & TST & \\
\hline CHEMBL3927038 & 1641629 & 7.3872 & 6.3742 & TRN & \\
\hline CHEMBL3916166 & 1641629 & 8.1427 & 6.8242 & TST & \\
\hline CHEMBL3912761 & 1641629 & 5.0 & 5.7938 & TRN & \\
\hline CHEMBL 3934344 & 1641629 & 7.3979 & 7.2517 & TRN & \\
\hline CHEMBL 3962484 & 1641629 & 6.699 & 6.4747 & TST & \\
\hline CHEMBL 3972143 & 1641629 & 4.6576 & 5.1498 & TRN & \\
\hline CHEMBL3923949 & 1641629 & 6.1938 & 5.8683 & TRN & \\
\hline CHEMBL 3950737 & 1641629 & 6.0 & 5.7012 & TRN & \\
\hline CHEMBL 3957511 & 1641629 & 8.699 & 7.2604 & TST & \\
\hline CHEMBL3982464 & 1641629 & 6.0 & 7.7939 & TRN & \\
\hline CHEMBL 3964486 & 1641629 & 6.0 & 6.1844 & TRN & \\
\hline CHEMBL3918502 & 1641629 & 8.2366 & 7.8295 & TRN & \\
\hline CHEMBL 3964807 & 1641629 & 5.4685 & 5.7841 & TRN & \\
\hline CHEMBL 3940443 & 1641629 & 7.9586 & 8.6956 & TST & \\
\hline CHEMBL3983537 & 1641629 & 6.699 & 6.2022 & TST & \\
\hline CHEMBL 3932716 & 1641629 & 7.8861 & 7.8685 & TST & \\
\hline CHEMBL3896838 & 1641629 & 7.4622 & 6.7991 & TST & \\
\hline CHEMBL3896155 & 1641629 & 6.699 & 6.2475 & TST & \\
\hline CHEMBL3892541 & 1641629 & 5.1427 & 5.1291 & TRN & \\
\hline
\end{tabular}


Supplemental Table S2.txt

\begin{tabular}{|c|c|c|c|c|c|}
\hline CHEMBL3915541 & 1641629 & 4.6383 & 4.868 & TRN & \\
\hline CHEMBL3903752 & 1641629 & 6.8861 & 6.3558 & TRN & \\
\hline CHEMBL3927659 & 1641629 & 7.1024 & 6.8905 & TRN & \\
\hline CHEMBL 3935270 & 1641629 & 7.3143 & 7.8732 & TRN & \\
\hline CHEMBL3943267 & 1641629 & 6.0862 & \multicolumn{2}{|c|}{6.202000000000001} & TRN \\
\hline CHEMBL3905106 & 1641629 & 7.5086 & 7.4919 & TRN & \\
\hline CHEMBL3943412 & 1641629 & 6.9208 & 6.5529 & TRN & \\
\hline CHEMBL3986206 & 1641629 & 7.9586 & 6.335 & TST & \\
\hline CHEMBL 3986088 & 1641629 & 5.4949 & 6.3943 & TRN & \\
\hline CHEMBL3966664 & 1641629 & 7.4815 & 6.6291 & TST & \\
\hline CHEMBL 3954920 & 1641629 & 7.4815 & 7.2017 & TST & \\
\hline CHEMBL3915352 & 1641629 & 8.3979 & 8.211 & TRN & \\
\hline CHEMBL3929756 & 1641629 & 9.0458 & 8.6702 & TRN & \\
\hline CHEMBL3972358 & 1641629 & 8.3872 & 7.6694 & TRN & \\
\hline CHEMBL 3933117 & 1641629 & 7.8861 & 7.4725 & TRN & \\
\hline CHEMBL 3912083 & 1641629 & 6.1739 & 5.9538 & TRN & \\
\hline CHEMBL3969257 & 1641629 & 6.2518 & 6.3548 & TRN & \\
\hline CHEMBL 3913479 & 1641629 & 7.1805 & 6.629 & TST & \\
\hline CHEMBL3896291 & 1641629 & 8.8539 & \multicolumn{2}{|c|}{8.783999999999999} & TRN \\
\hline CHEMBL 3902191 & 1641629 & 7.7212 & 7.7361 & TRN & \\
\hline CHEMBL 3957495 & 1641629 & 5.5086 & 5.7352 & TRN & \\
\hline CHEMBL3917507 & 1641629 & 5.4202 & 5.4471 & TRN & \\
\hline CHEMBL3918219 & 1641629 & 5.0 & \multicolumn{2}{|c|}{5.497999999999999} & TRN \\
\hline CHEMBL3986294 & 1641629 & 6.0862 & 5.8224 & TRN & \\
\hline CHEMBL 3964273 & 1641629 & 8.585 & 8.5472 & TST & \\
\hline CHEMBL 3959450 & 1641629 & 5.0 & 5.1523 & TRN & \\
\hline CHEMBL3956142 & 1641629 & 5.0 & 5.2997 & TRN & \\
\hline CHEMBL3933781 & 1641629 & 6.0 & \multicolumn{2}{|c|}{ 7. 3629999999999995} & TRN \\
\hline CHEMBL3945395 & 1641629 & 6.5229 & 6.0919 & TRN & \\
\hline CHEMBL 3900800 & 1641629 & 6.699 & 6.2857 & TRN & \\
\hline CHEMBL 3915463 & 1641629 & 6.0 & 5.8372 & TRN & \\
\hline CHEMBL3916736 & 1641629 & 6.6198 & 6.345 & TRN & \\
\hline CHEMBL3957591 & 1641629 & 7.1079 & 7.2848 & TRN & \\
\hline CHEMBL3921032 & 1641629 & 3.0 & 2.7829 & TRN & \\
\hline CHEMBL 3894729 & 1641629 & 6.3372 & 7.0824 & TST & \\
\hline CHEMBL3987086 & 1641629 & 3.0 & 3.2252 & TRN & \\
\hline CHEMBL 3911009 & 1641629 & 6.4949 & 6.84 & TRN & \\
\hline CHEMBL3906331 & 1641629 & 8.4685 & 8.1781 & TRN & \\
\hline CHEMBL3912917 & 1641629 & 6.2076 & 6.0342 & TRN & \\
\hline CHEMBL3928625 & 1641629 & 6.0 & 7.3262 & TRN & \\
\hline CHEMBL 3960104 & 1641629 & 7.3468 & 7.1439 & TRN & \\
\hline CHEMBL 3924259 & 1641629 & 6.0 & 6.1195 & TRN & \\
\hline CHEMBL3936628 & 1641629 & 5.8239 & 5.813 & TRN & \\
\hline CHEMBL3932608 & 1641629 & 8.4685 & 6.9318 & TST & \\
\hline CHEMBL3982276 & 1641629 & 6.4437 & 6.8617 & TRN & \\
\hline CHEMBL 3936890 & 1641629 & 6.0 & 7.1701 & TRN & \\
\hline CHEMBL3968511 & 1641629 & 5.0 & 5.5547 & TRN & \\
\hline CHEMBL3899332 & 1641629 & 6.3372 & 5.6302 & TRN & \\
\hline
\end{tabular}

Page 15620 


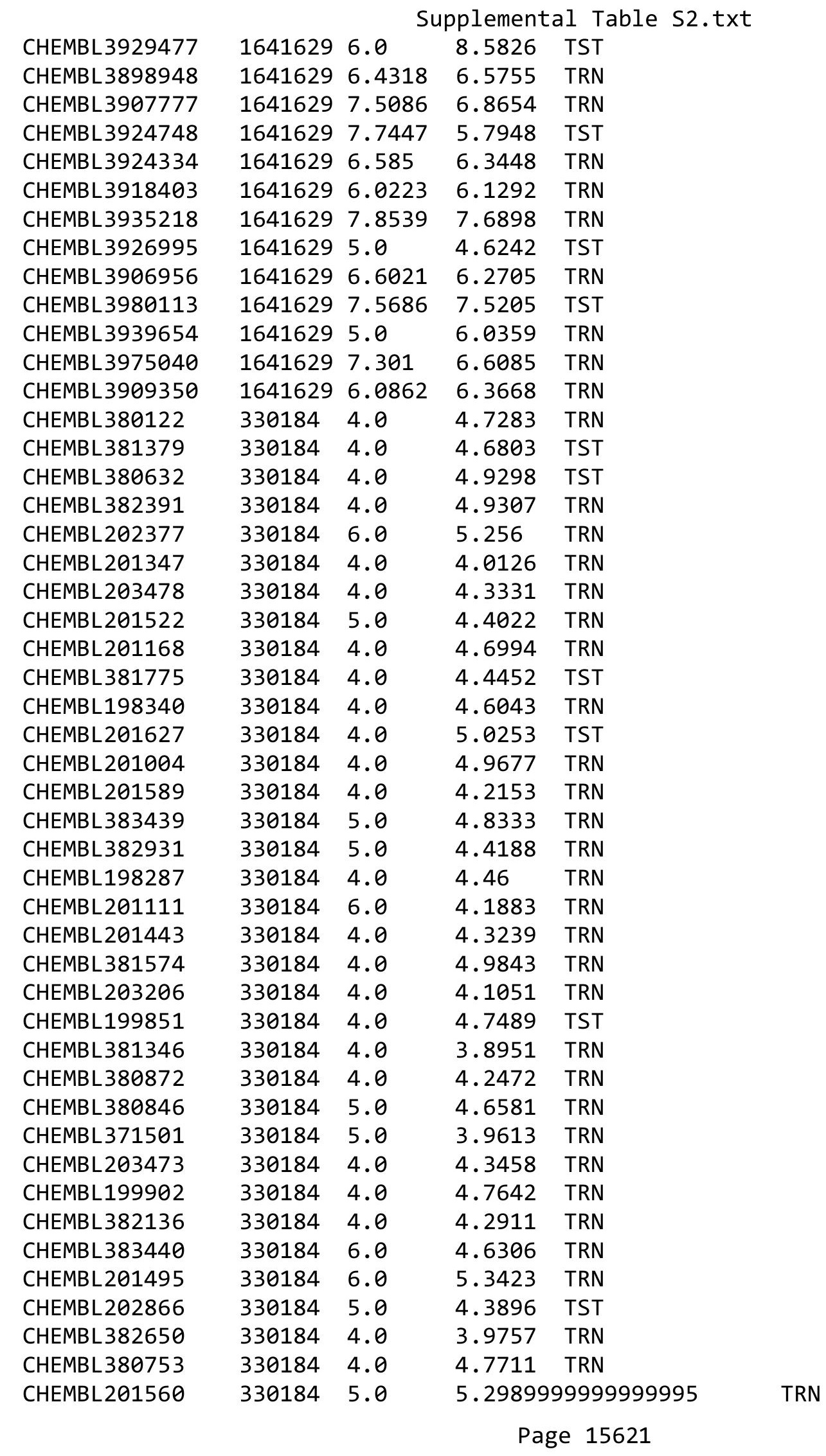




\begin{tabular}{|c|c|c|c|c|c|}
\hline & & & & & \\
\hline CHEMBL535156 & 330184 & 4.0 & 4.293 & TRN & \\
\hline CHEMBL379034 & 330184 & 4.0 & 4.8783 & TRN & \\
\hline CHEMBL202040 & 330184 & 4.0 & 4.5506 & TRN & \\
\hline CHEMBL536050 & 330184 & 6.0 & 5.3808 & TRN & \\
\hline CHEMBL203201 & 330184 & 4.0 & 4.4155 & TRN & \\
\hline CHEMBL382424 & 330184 & 5.0 & 4.9633 & TST & \\
\hline CHEMBL201486 & 330184 & 5.0 & 4.5097 & TST & \\
\hline CHEMBL372197 & 330184 & 4.0 & 4.5902 & TRN & \\
\hline CHEMBL380824 & 330184 & 5.0 & 4.896 & TRN & \\
\hline CHEMBL202988 & 330184 & 4.0 & 4.1575 & TRN & \\
\hline CHEMBL437894 & 330184 & 5.0 & 4.2215 & TRN & \\
\hline CHEMBL383317 & 330184 & 5.0 & 4.5653 & TRN & \\
\hline CHEMBL382160 & 330184 & 4.0 & 4.5477 & TST & \\
\hline CHEMBL201029 & 330184 & 5.0 & 5.1724 & TRN & \\
\hline CHEMBL201276 & 330184 & 4.0 & 5.0453 & TST & \\
\hline CHEMBL201498 & 330184 & 5.0 & 4.6555 & TRN & \\
\hline CHEMBL200990 & 330184 & 5.0 & 4.6475 & TRN & \\
\hline CHEMBL 200981 & 330184 & 6.0 & 5.6626 & TRN & \\
\hline CHEMBL381956 & 330184 & 4.0 & 4.2116 & TRN & \\
\hline CHEMBL200068 & 330184 & 4.0 & 4.7413 & TST & \\
\hline CHEMBL382215 & 330184 & 6.0 & 5.3808 & TRN & \\
\hline CHEMBL 380750 & 330184 & 6.0 & 4.9598 & TRN & \\
\hline CHEMBL 201348 & 330184 & 6.0 & 5.3774 & TRN & \\
\hline CHEMBL381713 & 330184 & 4.0 & 4.2323 & TST & \\
\hline CHEMBL379035 & 330184 & 4.0 & 5.36799 & 9999999999 & TRN \\
\hline CHEMBL 201274 & 330184 & 4.0 & 3.9846 & TRN & \\
\hline CHEMBL381345 & 330184 & 7.0 & 5.6564 & TRN & \\
\hline CHEMBL201754 & 330184 & 5.0 & 4.249 & TST & \\
\hline CHEMBL381856 & 330184 & 4.0 & 5.0245 & TRN & \\
\hline CHEMBL198286 & 330184 & 5.0 & 4.3054 & TRN & \\
\hline CHEMBL 201500 & 330184 & 4.0 & 4.6594 & TST & \\
\hline CHEMBL203097 & 330184 & 4.0 & 4.9538 & TST & \\
\hline CHEMBL201471 & 330184 & 4.0 & 4.5637 & TST & \\
\hline CHEMBL372596 & 330184 & 4.0 & 4.3149 & TST & \\
\hline CHEMBL 203146 & 330184 & 4.0 & 4.8209 & TST & \\
\hline CHEMBL2171072 & 865017 & 3.8239 & 3.7097 & TST & \\
\hline CHEMBL2170859 & 865017 & 7.0969 & 6.6779 & TST & \\
\hline CHEMBL 2171063 & 865017 & 7.699 & 6.1633 & TRN & \\
\hline CHEMBL 2170904 & 865017 & 7.5229 & 7.3422 & TRN & \\
\hline CHEMBL 2171083 & 865017 & 10.0 & 9.2944 & TRN & \\
\hline CHEMBL 2170874 & 865017 & 7.301 & 6.4296 & TRN & \\
\hline CHEMBL 2171081 & 865017 & 10.0 & 7.8773 & TRN & \\
\hline CHEMBL 2171067 & 865017 & 8.0 & 6.98600 & 0000000001 & TRN \\
\hline CHEMBL 2171055 & 865017 & 3.8239 & 5.0563 & TRN & \\
\hline CHEMBL1090974 & 865017 & 3.8239 & 6.3082 & TRN & \\
\hline CHEMBL 2171052 & 865017 & 3.8239 & 4.5096 & TST & \\
\hline CHEMBL 2171073 & 865017 & 3.8239 & 5.4797 & TRN & \\
\hline CHEMBL 2170875 & 865017 & 8.0 & 7.8043 & TRN & \\
\hline
\end{tabular}


Supplemental Table S2.txt

\begin{tabular}{|c|c|c|c|c|}
\hline CHEMBL 2170865 & 865017 & 7.3979 & 8.1726 & TRN \\
\hline CHEMBL 2170901 & 865017 & 5.9208 & 7.9186 & TST \\
\hline CHEMBL 2170896 & 865017 & 6.6576 & 7.5871 & TRN \\
\hline CHEMBL 2170889 & 865017 & 7.301 & 7.1785 & TST \\
\hline CHEMBL 2170861 & 865017 & 7.0969 & 8.0098 & TRN \\
\hline CHEMBL582392 & 865017 & 6.041 & 5.973 & TST \\
\hline CHEMBL 2171070 & 865017 & 10.0 & 10.0512 & TRN \\
\hline CHEMBL 2170864 & 865017 & 3.8239 & 6.517 & TST \\
\hline CHEMBL 2170902 & 865017 & 3.8239 & 5.417999 & 9999999999 \\
\hline CHEMBL 2170863 & 865017 & 3.8239 & 6.1503 & TST \\
\hline CHEMBL 2170900 & 865017 & 3.8239 & 6.5018 & TST \\
\hline CHEMBL 2170867 & 865017 & 6.7447 & 7.7935 & TRN \\
\hline CHEMBL 2171082 & 865017 & 10.0 & 9.3934 & TRN \\
\hline CHEMBL 2170860 & 865017 & 6.9586 & 7.8591 & TRN \\
\hline CHEMBL 2170882 & 865017 & 10.0 & 8.9835 & TRN \\
\hline CHEMBL1093370 & 865017 & 7.2218 & 6.8699 & TRN \\
\hline CHEMBL 2171058 & 865017 & 3.8239 & 5.1156 & TRN \\
\hline CHEMBL 2170899 & 865017 & 3.8239 & 6.9142 & TST \\
\hline CHEMBL 2171059 & 865017 & 10.0 & 5.4797 & TRN \\
\hline CHEMBL 2170887 & 865017 & 6.699 & 6.8062 & TRN \\
\hline CHEMBL 2170877 & 865017 & 8.0 & 7.7587 & TRN \\
\hline CHEMBL 2170888 & 865017 & 6.8239 & 6.5684 & TRN \\
\hline CHEMBL 2171074 & 865017 & 5.2366 & 4.4683 & TRN \\
\hline CHEMBL 2171062 & 865017 & 5.2007 & 4.43 & TRN \\
\hline CHEMBL 2170891 & 865017 & 10.0 & 8.1001 & TRN \\
\hline CHEMBL 2171061 & 865017 & 10.0 & 5.5097 & TRN \\
\hline CHEMBL 2170895 & 865017 & 8.0 & 8.1984 & TRN \\
\hline CHEMBL 2170862 & 865017 & 6.3468 & 6.922999 & 9999999999 \\
\hline CHEMBL 2170858 & 865017 & 3.8239 & 5.4542 & TST \\
\hline CHEMBL 2170866 & 865017 & 7.699 & 8.4174 & TRN \\
\hline CHEMBL 2170881 & 865017 & 6.2596 & 6.5815 & TST \\
\hline CHEMBL 2170879 & 865017 & 6.9208 & 6.2837 & TRN \\
\hline CHEMBL 2171077 & 865017 & 6.7447 & 7.9559 & TRN \\
\hline CHEMBL 2171076 & 865017 & 3.8239 & 3.4604 & TRN \\
\hline CHEMBL 2171060 & 865017 & 5.7447 & 6.5519 & TRN \\
\hline CHEMBL 2170886 & 865017 & 5.7212 & 6.3148 & TRN \\
\hline CHEMBL 2170871 & 865017 & 7.301 & 7.9261 & TRN \\
\hline CHEMBL 2170883 & 865017 & 6.7696 & 6.6834 & TRN \\
\hline CHEMBL1093727 & 865017 & 5.1135 & 6.0311 & TRN \\
\hline CHEMBL 2171065 & 865017 & 3.8239 & 4.6274 & TRN \\
\hline CHEMBL 2170868 & 865017 & 7.0 & 6.9394 & TST \\
\hline CHEMBL 2171057 & 865017 & 7.699 & 7.0323 & TRN \\
\hline CHEMBL 2170878 & 865017 & 6.9586 & 6.6727 & TRN \\
\hline CHEMBL 2171051 & 865017 & 6.3279 & 6.456 & TRN \\
\hline CHEMBL 2170890 & 865017 & 8.0 & 7.231 & TRN \\
\hline CHEMBL 2171068 & 865017 & 6.5376 & 7.8778 & TRN \\
\hline CHEMBL 2171085 & 865017 & 10.0 & 8.6733 & TRN \\
\hline CHEMBL 2170880 & 865017 & 7.5229 & 6.9473 & TST \\
\hline
\end{tabular}




\begin{tabular}{|c|c|c|c|c|c|c|}
\hline & & \multicolumn{5}{|c|}{ Supplemental Table S2.txt } \\
\hline CHEMBL 2171054 & 865017 & 5.8239 & 4.2339 & TRN & & \\
\hline CHEMBL 2170894 & 865017 & 3.8239 & 3.3043 & TST & & \\
\hline CHEMBL 2171075 & 865017 & 3.8239 & 3.2965 & TST & & \\
\hline CHEMBL 2170897 & 865017 & 10.0 & 8.2415 & TRN & & \\
\hline CHEMBL 2170893 & 865017 & 3.8239 & 3.1652 & TRN & & \\
\hline CHEMBL 2170873 & 865017 & 3.8239 & 6.6333 & TRN & & \\
\hline CHEMBL 2170905 & 865017 & 3.8239 & 4.4343 & TRN & & \\
\hline CHEMBL 2171066 & 865017 & 3.8239 & 4.6811 & TRN & & \\
\hline CHEMBL 2171056 & 865017 & 3.8239 & 5.5859 & TST & & \\
\hline CHEMBL 2171080 & 865017 & 10.0 & 9.2579 & TRN & & \\
\hline CHEMBL 2171078 & 865017 & 10.0 & 9.0008 & TRN & & \\
\hline CHEMBL 2171064 & 865017 & 5.0555 & 4.5211 & TRN & & \\
\hline CHEMBL 2170884 & 865017 & 8.0 & 8.0962 & TRN & & \\
\hline CHEMBL1093371 & 865017 & 3.8239 & 5.8043 & TRN & & \\
\hline CHEMBL 2170872 & 865017 & 6.9586 & 7.6279 & TRN & & \\
\hline CHEMBL 2170898 & 865017 & 5.2924 & 5.9893 & TRN & & \\
\hline CHEMBL1092774 & 865017 & 6.6778 & 7.2552 & TRN & & \\
\hline CHEMBL 2170876 & 865017 & 6.9208 & 6.2539 & TRN & & \\
\hline CHEMBL 2170885 & 865017 & 7.0 & 6.0215 & TRN & & \\
\hline CHEMBL 2170892 & 865017 & 8.0 & 7.4427 & TRN & & \\
\hline CHEMBL 2171084 & 865017 & 10.0 & 9.3233 & TRN & & \\
\hline CHEMBL 2170869 & 865017 & 5.7447 & 6.2039 & TST & & \\
\hline CHEMBL 2171071 & 865017 & 5.7959 & 7.8773 & TRN & & \\
\hline CHEMBL 2170903 & 865017 & 3.8239 & 4.5858 & TST & & \\
\hline CHEMBL1093726 & 865017 & 3.8239 & 7.4184 & TRN & & \\
\hline CHEMBL 2171053 & 865017 & 3.8239 & 5.3639 & TRN & & \\
\hline CHEMBL1093728 & 865017 & 5.6383 & 6.4998 & TRN & & \\
\hline CHEMBL 2171079 & 865017 & 9.0 & 8.7378 & TRN & & \\
\hline CHEMBL 2171069 & 865017 & 3.8239 & 5.8944 & TST & & \\
\hline CHEMBL 2170870 & 865017 & 3.8239 & 6.0153 & TST & & \\
\hline CHEMBL 1213174 & 646869 & 5.5229 & 5.2802 & TRN & & \\
\hline CHEMBL1213390 & 646869 & 4.4089 & 4.6736 & TRN & & \\
\hline CHEMBL1213873 & 646869 & 6.0 & 5.2989 & TRN & & \\
\hline CHEMBL328540 & 646869 & 3.821 & 4.8036 & TST & & \\
\hline CHEMBL1213089 & 646869 & 3.9031 & 5.1404 & TRN & & \\
\hline CHEMBL1213180 & 646869 & 4.2676 & 4.7801 & TST & & \\
\hline CHEMBL1213258 & 646869 & 5.0 & 4.8648 & TRN & & \\
\hline CHEMBL1213061 & 646869 & 3.8069 & 5.1114 & TRN & & \\
\hline CHEMBL1213360 & 646869 & 5.699 & 5.17 & TST & & \\
\hline CHEMBL1213181 & 646869 & 4.1367 & 4.6576 & TRN & & \\
\hline CHEMBL1213946 & 646869 & 4.1675 & 5.17 & TST & & \\
\hline CHEMBL1213064 & 646869 & 5.5229 & 5.1799 & TRN & & \\
\hline CHEMBL1213319 & 646869 & 5.3979 & 4.6222 & TRN & & \\
\hline CHEMBL1213362 & 646869 & 3.85699 & 99999999 & 998 & 5.2573 & TST \\
\hline CHEMBL1213182 & 646869 & 5.5229 & 4.796 & TRN & & \\
\hline CHEMBL 1213259 & 646869 & 6.0 & 5.3243 & TRN & & \\
\hline CHEMBL1213088 & 646869 & 5.5229 & 5.1934 & TRN & & \\
\hline CHEMBL1213041 & 646869 & 6.0 & 4.8026 & TRN & & \\
\hline
\end{tabular}




\begin{tabular}{|c|c|c|c|c|}
\hline \multicolumn{5}{|c|}{ Supplemental Table S2.txt } \\
\hline CHEMBL1213063 & 646869 & 4.0044 & 4.8948 & TST \\
\hline CHEMBL1213264 & 646869 & 4.6383 & 4.8554 & TST \\
\hline CHEMBL1213177 & 646869 & 4.4437 & 4.6441 & TRN \\
\hline CHEMBL1213125 & 646869 & 5.2218 & 4.8283 & TST \\
\hline CHEMBL1213060 & 646869 & 5.3979 & 4.8412 & TST \\
\hline CHEMBL1213391 & 646869 & 4.5229 & 4.5264 & TRN \\
\hline CHEMBL1213037 & 646869 & 4.6021 & 4.6993 & TRN \\
\hline CHEMBL1213314 & 646869 & 4.2007 & 4.5992 & TRN \\
\hline CHEMBL1213091 & 646869 & 4.4559 & 5.1639 & TRN \\
\hline CHEMBL1213176 & 646869 & 6.0 & 4.9003 & TRN \\
\hline CHEMBL 1213356 & 646869 & 3.6253 & 4.4936 & TRN \\
\hline CHEMBL1213389 & 646869 & 5.699 & 4.705 & TRN \\
\hline CHEMBL1213175 & 646869 & 5.3979 & 4.9231 & TRN \\
\hline CHEMBL1212945 & 646869 & 6.0 & 5.2573 & TST \\
\hline CHEMBL1213358 & 646869 & 6.0 & 5.17 & TST \\
\hline CHEMBL1213357 & 646869 & 5.1549 & 5.2573 & TST \\
\hline CHEMBL1213313 & 646869 & 4.0088 & 4.8626 & TRN \\
\hline CHEMBL1213942 & 646869 & 5.2218 & 5.2154 & TRN \\
\hline CHEMBL1213945 & 646869 & 5.5229 & 5.2475 & TRN \\
\hline CHEMBL1213036 & 646869 & 4.3188 & 4.8236 & TST \\
\hline CHEMBL1213128 & 646869 & 6.0 & 5.2511 & TRN \\
\hline CHEMBL1213944 & 646869 & 5.0 & 5.2415 & TRN \\
\hline CHEMBL1213388 & 646869 & 4.8239 & 4.6081 & TRN \\
\hline CHEMBL1213040 & 646869 & 4.8239 & 4.6411 & TRN \\
\hline CHEMBL1213262 & 646869 & 5.0458 & 5.3137 & TRN \\
\hline CHEMBL 1213355 & 646869 & 4.8861 & 4.723 & TRN \\
\hline CHEMBL1213039 & 646869 & 4.7447 & 4.8921 & TRN \\
\hline CHEMBL1213311 & 646869 & 5.0 & 4.7877 & TST \\
\hline CHEMBL1213874 & 646869 & 5.3979 & 5.3042 & TRN \\
\hline CHEMBL1213387 & 646869 & 4.4815 & 4.6598 & TRN \\
\hline CHEMBL1213090 & 646869 & 5.5229 & 5.1594 & TRN \\
\hline CHEMBL1213943 & 646869 & 5.0 & 5.2098 & TRN \\
\hline CHEMBL1213363 & 646869 & 5.699 & 4.6204 & TRN \\
\hline CHEMBL1213361 & 646869 & 4.7447 & 4.5906 & TRN \\
\hline CHEMBL1213038 & 646869 & 3.983 & 4.8367 & TRN \\
\hline CHEMBL1213126 & 646869 & 4.4437 & 5.1813 & TRN \\
\hline CHEMBL1213260 & 646869 & 3.9172 & 4.752 & TRN \\
\hline CHEMBL1212942 & 646869 & 3.7375 & 5.1778 & TRN \\
\hline CHEMBL1213317 & 646869 & 5.301 & 4.5855 & TRN \\
\hline CHEMBL1213263 & 646869 & 5.699 & 4.7983 & TST \\
\hline CHEMBL1213127 & 646869 & 5.699 & 5.23 & TRN \\
\hline CHEMBL1213087 & 646869 & 3.8633 & 5.0771 & TRN \\
\hline CHEMBL1213359 & 646869 & 5.699 & 5.2573 & TST \\
\hline CHEMBL1213364 & 646869 & 4.0969 & 4.6023 & TRN \\
\hline CHEMBL1213062 & 646869 & 6.0 & 5.2681 & TRN \\
\hline CHEMBL 1213129 & 646869 & 5.699 & 5.2665 & TRN \\
\hline CHEMBL1212944 & 646869 & 4.7212 & 4.5944 & TRN \\
\hline CHEMBL318275 & 646869 & 4.2924 & 4.8608 & TST \\
\hline
\end{tabular}




\begin{tabular}{|c|c|c|c|c|}
\hline \multicolumn{5}{|c|}{ Supplemental Table S2.txt } \\
\hline CHEMBL1213318 & 646869 & 4.1675 & 4.5154 & TRN \\
\hline CHEMBL1213261 & 646869 & 5.301 & 5.3192 & TRN \\
\hline CHEMBL1213312 & 646869 & 4.1871 & 4.8894 & TST \\
\hline CHEMBL3700542 & 1528572 & 6.9172 & 6.8379 & TRN \\
\hline CHEMBL1682280 & 1528572 & 8.0 & 8.0983 & TRN \\
\hline CHEMBL3700397 & 1528572 & 6.6778 & 6.9365 & TRN \\
\hline CHEMBL3700515 & 1528572 & 7.1549 & 6.8466 & TRN \\
\hline CHEMBL3700554 & 1528572 & 7.1192 & 7.2663 & TRN \\
\hline CHEMBL 3700504 & 1528572 & 6.0 & 5.9299 & TRN \\
\hline CHEMBL1649759 & 1528572 & 5.301 & 5.5123 & TRN \\
\hline CHEMBL3700541 & 1528572 & 7.0458 & 6.9448 & TRN \\
\hline CHEMBL3700406 & 1528572 & 4.9031 & 5.7952 & TST \\
\hline CHEMBL3700549 & 1528572 & 6.8962 & 7.0897 & TRN \\
\hline CHEMBL3696944 & 1528572 & 6.7447 & 7.5483 & TST \\
\hline CHEMBL3700457 & 1528572 & 8.2218 & 7.8653 & TRN \\
\hline CHEMBL1682281 & 1528572 & 8.2218 & 8.2066 & TRN \\
\hline CHEMBL3700546 & 1528572 & 7.041 & 7.0502 & TRN \\
\hline CHEMBL1652711 & 1528572 & 5.3979 & 6.7111 & TST \\
\hline CHEMBL3696943 & 1528572 & 5.699 & 5.7098 & TST \\
\hline CHEMBL3700530 & 1528572 & 6.6003 & 6.2572 & TRN \\
\hline CHEMBL3700456 & 1528572 & 5.1249 & 7.7834 & TST \\
\hline CHEMBL3700516 & 1528572 & 6.8996 & 6.5388 & TRN \\
\hline CHEMBL3700502 & 1528572 & 6.0 & 6.1577 & TRN \\
\hline CHEMBL1682284 & 1528572 & 7.0605 & 6.9804 & TRN \\
\hline CHEMBL3700526 & 1528572 & 6.4401 & 6.7309 & TRN \\
\hline CHEMBL3700417 & 1528572 & 8.1549 & 8.3139 & TRN \\
\hline CHEMBL3700518 & 1528572 & 6.8894 & 6.6945 & TRN \\
\hline CHEMBL3700496 & 1528572 & 6.0 & 5.8557 & TRN \\
\hline CHEMBL 3700454 & 1528572 & 7.2291 & 7.138 & TRN \\
\hline CHEMBL1649760 & 1528572 & 6.1481 & 6.0682 & TST \\
\hline CHEMBL3700392 & 1528572 & 6.0 & 5.9038 & TRN \\
\hline CHEMBL 3700443 & 1528572 & 6.9431 & 6.902 & TRN \\
\hline CHEMBL3700381 & 1528572 & 6.0 & 7.3337 & TST \\
\hline CHEMBL1649770 & 1528572 & 8.1549 & 8.0905 & TRN \\
\hline CHEMBL3700473 & 1528572 & 5.1249 & 5.026 & TRN \\
\hline CHEMBL3700425 & 1528572 & 7.585 & 7.0237 & TRN \\
\hline CHEMBL3700415 & 1528572 & 6.0 & 6.8151 & TRN \\
\hline CHEMBL3700524 & 1528572 & 6.2604 & 5.6225 & TRN \\
\hline CHEMBL3700560 & 1528572 & 5.4685 & 7.0183 & TST \\
\hline CHEMBL1652737 & 1528572 & 8.5229 & 8.0247 & TRN \\
\hline CHEMBL3700484 & 1528572 & 7.4815 & 7.4537 & TRN \\
\hline CHEMBL 3700440 & 1528572 & 6.767 & 7.1629 & TRN \\
\hline CHEMBL3696945 & 1528572 & 5.6021 & 5.3634 & TST \\
\hline CHEMBL 3700441 & 1528572 & 6.9706 & 7.0023 & TRN \\
\hline CHEMBL3700485 & 1528572 & 7.699 & 7.1241 & TRN \\
\hline CHEMBL 3700421 & 1528572 & 5.301 & 5.1284 & TRN \\
\hline CHEMBL1652704 & 1528572 & 8.5229 & 8.0244 & TRN \\
\hline CHEMBL 3700414 & 1528572 & 7.284 & 6.9334 & TST \\
\hline
\end{tabular}


Supplemental Table S2.txt

\begin{tabular}{|c|c|c|c|c|}
\hline CHEMBL 3700403 & 1528572 & 6.0 & 5.9337 & TRN \\
\hline CHEMBL 3700429 & 1528572 & 7.0506 & 6.2547 & TRN \\
\hline CHEMBL3639992 & 1528572 & 6.9208 & 6.7002 & TRN \\
\hline CHEMBL 3700438 & 1528572 & 7.0809 & 7.3679 & TRN \\
\hline CHEMBL1682287 & 1528572 & 8.3979 & 7.8347 & TRN \\
\hline CHEMBL1652708 & 1528572 & 8.301 & 8.1285 & TRN \\
\hline CHEMBL 3700499 & 1528572 & 6.0 & 5.5233 & TST \\
\hline CHEMBL 3700520 & 1528572 & 7.0915 & 7.1907 & TRN \\
\hline CHEMBL1682298 & 1528572 & 5.1249 & 6.0298 & TRN \\
\hline CHEMBL 3700402 & 1528572 & 6.0 & 5.841 & TRN \\
\hline CHEMBL 3700490 & 1528572 & 6.0 & 6.0872 & TRN \\
\hline CHEMBL 3700552 & 1528572 & 7.4559 & 7.2292 & TRN \\
\hline CHEMBL 3700475 & 1528572 & 7.6383 & 7.871 & TRN \\
\hline CHEMBL 3700436 & 1528572 & 7.699 & 7.3745 & TRN \\
\hline CHEMBL 3700525 & 1528572 & 6.6198 & 6.38700 & 0000000005 \\
\hline CHEMBL 3700398 & 1528572 & 6.1739 & 6.74100 & 0000000005 \\
\hline CHEMBL 3700543 & 1528572 & 6.5513 & 6.6488 & TRN \\
\hline CHEMBL 3700523 & 1528572 & 6.2993 & 5.9378 & TRN \\
\hline CHEMBL 3700511 & 1528572 & 6.8697 & 7.4684 & TRN \\
\hline CHEMBL 3700393 & 1528572 & 5.8239 & 5.715 & TST \\
\hline CHEMBL 3700540 & 1528572 & 6.8069 & 6.8224 & TRN \\
\hline CHEMBL 3700487 & 1528572 & 6.0 & 6.6758 & TST \\
\hline CHEMBL 3700434 & 1528572 & 8.0458 & 7.4367 & TRN \\
\hline CHEMBL3696946 & 1528572 & 6.0 & 5.6399 & TST \\
\hline CHEMBL3700394 & 1528572 & 6.0 & 6.7729 & TRN \\
\hline CHEMBL3700548 & 1528572 & 6.8069 & 6.7047 & TRN \\
\hline CHEMBL 3700558 & 1528572 & 6.6904 & 6.3525 & TRN \\
\hline CHEMBL 3700508 & 1528572 & 6.0 & 5.9427 & TRN \\
\hline CHEMBL3700547 & 1528572 & 6.5918 & 6.7222 & TRN \\
\hline CHEMBL 3700447 & 1528572 & 5.1249 & 5.7314 & TRN \\
\hline CHEMBL3700466 & 1528572 & 6.4486 & 6.8582 & TRN \\
\hline CHEMBL 3700401 & 1528572 & 6.0 & 6.5267 & TRN \\
\hline CHEMBL 3700557 & 1528572 & 6.8508 & 6.3274 & TRN \\
\hline CHEMBL3700536 & 1528572 & 6.6556 & 6.7515 & TRN \\
\hline CHEMBL3700453 & 1528572 & 8.2218 & 7.5965 & TRN \\
\hline CHEMBL 3700464 & 1528572 & 6.7747 & 6.57299 & 9999999995 \\
\hline CHEMBL3700396 & 1528572 & 5.9586 & 5.7796 & TRN \\
\hline CHEMBL3700519 & 1528572 & 6.9872 & 7.0868 & TRN \\
\hline CHEMBL3700562 & 1528572 & 7.4318 & 6.9014 & TRN \\
\hline CHEMBL3700517 & 1528572 & 6.4034 & 6.7153 & TRN \\
\hline CHEMBL3700481 & 1528572 & 7.0315 & 7.6542 & TRN \\
\hline CHEMBL3700422 & 1528572 & 7.2924 & 6.8235 & TRN \\
\hline CHEMBL3700538 & 1528572 & 6.7282 & 7.0304 & TRN \\
\hline CHEMBL3700395 & 1528572 & 6.8239 & 6.9928 & TRN \\
\hline CHEMBL 3700497 & 1528572 & 6.0 & 6.0965 & TRN \\
\hline CHEMBL1682292 & 1528572 & 7.8861 & 7.3833 & TRN \\
\hline CHEMBL1652738 & 1528572 & 8.3979 & 8.2007 & TRN \\
\hline CHEMBL3700413 & 1528572 & 7.3279 & 6.972 & TST \\
\hline
\end{tabular}




\begin{tabular}{|c|c|c|c|c|}
\hline \multicolumn{5}{|c|}{ le s2.txt } \\
\hline CHEMBL 3700491 & 1528572 & 6.0 & 6.2852 & TRN \\
\hline CHEMBL3696948 & 1528572 & 4.0 & 5.9264 & TST \\
\hline CHEMBL 3700384 & 1528572 & 6.0 & 6.4415 & TRN \\
\hline CHEMBL 3700544 & 1528572 & 7.2147 & 6.482 & TRN \\
\hline CHEMBL3700492 & 1528572 & 6.0 & 6.0379 & TRN \\
\hline CHEMBL3700493 & 1528572 & 6.0 & 6.2678 & TRN \\
\hline CHEMBL3700459 & 1528572 & 6.9914 & 7.4476 & TRN \\
\hline CHEMBL3700411 & 1528572 & 4.6021 & 5.4902 & TRN \\
\hline CHEMBL 3700488 & 1528572 & 6.0 & 6.9434 & TST \\
\hline CHEMBL3700550 & 1528572 & 6.8601 & 6.8622 & TRN \\
\hline CHEMBL3700391 & 1528572 & 4.301 & 4.9812 & TST \\
\hline CHEMBL3696947 & 1528572 & 4.0 & 4.7861 & TST \\
\hline CHEMBL3700469 & 1528572 & 5.1249 & 5.4434 & TRN \\
\hline CHEMBL 3700505 & 1528572 & 6.0 & 6.1936 & TRN \\
\hline CHEMBL3700510 & 1528572 & 6.0 & 5.3521 & TRN \\
\hline CHEMBL3700467 & 1528572 & 6.9872 & 7.0613 & TRN \\
\hline CHEMBL3700498 & 1528572 & 6.0 & 6.0895 & TRN \\
\hline CHEMBL 3700514 & 1528572 & 7.4949 & 7.0745 & TRN \\
\hline CHEMBL 3700561 & 1528572 & 6.0 & 6.6557 & TRN \\
\hline CHEMBL3700506 & 1528572 & 6.0 & 6.2741 & TRN \\
\hline CHEMBL3700529 & 1528572 & 6.5406 & 5.9974 & TRN \\
\hline CHEMBL 3700449 & 1528572 & 7.5528 & 7.6823 & TRN \\
\hline CHEMBL 3700462 & 1528572 & 7.4559 & 7.0061 & TRN \\
\hline CHEMBL1652705 & 1528572 & 7.7959 & 7.6363 & TRN \\
\hline CHEMBL3700437 & 1528572 & 8.1549 & 7.8454 & TRN \\
\hline CHEMBL3700500 & 1528572 & 6.0 & 6.2857 & TRN \\
\hline CHEMBL1682295 & 1528572 & 7.0655 & 7.3844 & TRN \\
\hline CHEMBL 3700472 & 1528572 & 5.1249 & 4.8155 & TRN \\
\hline CHEMBL 3700390 & 1528572 & 6.0 & 6.2369 & TRN \\
\hline CHEMBL3700386 & 1528572 & 6.0 & 6.3895 & TST \\
\hline CHEMBL1652716 & 1528572 & 6.0 & 7.0803 & TST \\
\hline CHEMBL1682296 & 1528572 & 7.3372 & 7.4032 & TRN \\
\hline CHEMBL 3700405 & 1528572 & 6.0458 & 5.7902 & TST \\
\hline CHEMBL3700463 & 1528572 & 5.1249 & 6.6894 & TST \\
\hline CHEMBL3700551 & 1528572 & 6.9355 & 6.7744 & TRN \\
\hline CHEMBL3700423 & 1528572 & 7.1612 & 6.8262 & TRN \\
\hline CHEMBL3700477 & 1528572 & 7.8539 & 7.4123 & TRN \\
\hline CHEMBL 3700432 & 1528572 & 6.8416 & 7.3198 & TRN \\
\hline CHEMBL3700418 & 1528572 & 8.301 & 8.1781 & TRN \\
\hline CHEMBL3700537 & 1528572 & 6.8633 & 6.7739 & TRN \\
\hline CHEMBL3700385 & 1528572 & 6.0 & 7.5216 & TST \\
\hline CHEMBL3700501 & 1528572 & 6.0 & 6.3173 & TRN \\
\hline CHEMBL1652693 & 1528572 & 5.7959 & 6.4233 & TRN \\
\hline CHEMBL3700455 & 1528572 & 7.585 & 7.0911 & TRN \\
\hline CHEMBL3639993 & 1528572 & 6.0 & 6.0421 & TRN \\
\hline CHEMBL1682293 & 1528572 & 7.5686 & 6.8568 & TRN \\
\hline CHEMBL3700399 & 1528572 & 6.0132 & 7.0659 & TST \\
\hline CHEMBL3700513 & 1528572 & 7.1675 & 7.1411 & TRN \\
\hline
\end{tabular}


Supplemental Table S2.txt

\begin{tabular}{|c|c|c|c|c|c|}
\hline CHEMBL3700489 & 1528572 & 6.0 & 5.42 & TST & \\
\hline CHEMBL 3700451 & 1528572 & 5.1249 & 6.1881 & TRN & \\
\hline CHEMBL 3700426 & 1528572 & 7.2518 & 6.7686 & TRN & \\
\hline CHEMBL3700452 & 1528572 & 6.3072 & 6.5764 & TRN & \\
\hline CHEMBL1652710 & 1528572 & 8.1549 & 8.0044 & TRN & \\
\hline CHEMBL 3700531 & 1528572 & 6.5186 & \multicolumn{2}{|c|}{6.178999999999999} & TRN \\
\hline CHEMBL1682288 & 1528572 & 7.7447 & 7.3903 & TRN & \\
\hline CHEMBL3700430 & 1528572 & 7.2218 & 7.3517 & TRN & \\
\hline CHEMBL 3700521 & 1528572 & 7.5528 & 7.1193 & TRN & \\
\hline CHEMBL 3700522 & 1528572 & 6.4202 & 6.2444 & TRN & \\
\hline CHEMBL 3700419 & 1528572 & 5.301 & 4.8213 & TRN & \\
\hline CHEMBL 3700470 & 1528572 & 6.2899 & 7.192 & TRN & \\
\hline CHEMBL1652701 & 1528572 & 7.7959 & 8.0143 & TST & \\
\hline CHEMBL 3700482 & 1528572 & 8.0 & 7.8321 & TRN & \\
\hline CHEMBL 3700533 & 1528572 & 6.5129 & 6.1333 & TRN & \\
\hline CHEMBL3700435 & 1528572 & 7.7447 & 7.5461 & TRN & \\
\hline CHEMBL 3700534 & 1528572 & 6.7167 & 6.8794 & TRN & \\
\hline CHEMBL 3700494 & 1528572 & 6.0 & 6.0567 & TRN & \\
\hline CHEMBL3700471 & 1528572 & 7.5686 & 7.6989 & TRN & \\
\hline CHEMBL 3700404 & 1528572 & 6.0 & 6.2763 & TRN & \\
\hline CHEMBL3700479 & 1528572 & 5.1249 & 5.0043 & TRN & \\
\hline CHEMBL1652697 & 1528572 & 6.0 & \multicolumn{2}{|c|}{7.507000000000001} & TRN \\
\hline CHEMBL 3700564 & 1528572 & 6.8356 & 7.2855 & TST & \\
\hline CHEMBL3700412 & 1528572 & 6.1864 & 5.5948 & TST & \\
\hline CHEMBL1652742 & 1528572 & 7.3468 & 6.8963 & TST & \\
\hline CHEMBL3700424 & 1528572 & 7.699 & 7.2662 & TRN & \\
\hline CHEMBL 3700420 & 1528572 & 5.301 & 4.897 & TRN & \\
\hline CHEMBL 3700407 & 1528572 & 6.0 & 6.6499 & TST & \\
\hline CHEMBL3700444 & 1528572 & 7.301 & 7.3239 & TRN & \\
\hline CHEMBL 3700445 & 1528572 & 6.6696 & 7.1767 & TRN & \\
\hline CHEMBL3700535 & 1528572 & 6.4365 & 6.0561 & TST & \\
\hline CHEMBL 3700400 & 1528572 & 6.0 & 6.4592 & TST & \\
\hline CHEMBL3700389 & 1528572 & 6.0 & 6.7885 & TST & \\
\hline CHEMBL1682286 & 1528572 & 6.7645 & 7.0971 & TRN & \\
\hline CHEMBL 3700545 & 1528572 & 6.6162 & 6.5621 & TST & \\
\hline CHEMBL3700433 & 1528572 & 6.6021 & 6.8075 & TRN & \\
\hline CHEMBL 3700555 & 1528572 & 6.8827 & 7.2002 & TST & \\
\hline CHEMBL3700507 & 1528572 & 6.0 & 6.2156 & TST & \\
\hline CHEMBL1682301 & 1528572 & 6.7328 & 7.1231 & TRN & \\
\hline CHEMBL 3700486 & 1528572 & 6.7033 & 6.97 & TRN & \\
\hline CHEMBL1682289 & 1528572 & 5.1249 & 6.3034 & TRN & \\
\hline CHEMBL 3700528 & 1528572 & 6.6253 & 6.3287 & TST & \\
\hline CHEMBL 3700383 & 1528572 & 6.0 & 6.5919 & TST & \\
\hline CHEMBL 3700448 & 1528572 & 5.1249 & 4.2712 & TRN & \\
\hline CHEMBL3700476 & 1528572 & 7.8239 & 7.3517 & TRN & \\
\hline CHEMBL3700565 & 1528572 & 7.3565 & 7.2988 & TST & \\
\hline CHEMBL3700458 & 1528572 & 7.9586 & 7.4269 & TRN & \\
\hline CHEMBL 3700428 & 1528572 & 6.9706 & 6.3543 & TRN & \\
\hline
\end{tabular}


Supplemental Table S2.txt

\begin{tabular}{|c|c|c|c|c|c|}
\hline CHEMBL3700539 & 1528572 & 6.475 & 6.4982 & TST & \\
\hline CHEMBL1682290 & 1528572 & 7.5229 & 7.2819 & TRN & \\
\hline CHEMBL3700410 & 1528572 & 6.0 & 5.7889 & TRN & \\
\hline CHEMBL3700527 & 1528572 & 6.4976 & 5.805 & TST & \\
\hline CHEMBL1682291 & 1528572 & 6.8729 & 7.1338 & TRN & \\
\hline CHEMBL3700559 & 1528572 & 5.3279 & 6.9193 & TST & \\
\hline CHEMBL1652703 & 1528572 & 8.0458 & 7.7506 & TRN & \\
\hline CHEMBL3700532 & 1528572 & 6.6498 & 6.7686 & TST & \\
\hline CHEMBL3700465 & 1528572 & 6.1637 & 6.5264 & TST & \\
\hline CHEMBL3700460 & 1528572 & 6.8729 & 7.0078 & TRN & \\
\hline CHEMBL1682285 & 1528572 & 7.9586 & 7.4776 & TRN & \\
\hline CHEMBL3700503 & 1528572 & 6.0 & 6.3766 & TST & \\
\hline CHEMBL3700387 & 1528572 & 6.0 & 7.2564 & TST & \\
\hline CHEMBL 3700442 & 1528572 & 6.4572 & 6.941 & TRN & \\
\hline CHEMBL1652706 & 1528572 & 6.0 & 7.4927 & TRN & \\
\hline CHEMBL 3700450 & 1528572 & 7.6778 & 7.5909 & TRN & \\
\hline CHEMBL3700431 & 1528572 & 7.3979 & 7.3685 & TRN & \\
\hline CHEMBL3700409 & 1528572 & 6.0 & 5.4755 & TRN & \\
\hline CHEMBL3700512 & 1528572 & 7.1549 & 7.1325 & TST & \\
\hline CHEMBL3700478 & 1528572 & 5.1249 & 6.3082 & TRN & \\
\hline CHEMBL 3700483 & 1528572 & 7.4559 & 6.9136 & TRN & \\
\hline CHEMBL3700468 & 1528572 & 5.1249 & 5.8116 & TRN & \\
\hline CHEMBL1652715 & 1528572 & 6.0 & 7.194 & TST & \\
\hline CHEMBL3700382 & 1528572 & 6.0 & 6.0392 & TST & \\
\hline CHEMBL3700416 & 1528572 & 8.301 & 8.1551 & TRN & \\
\hline CHEMBL3700509 & 1528572 & 6.0 & 5.88 & TST & \\
\hline CHEMBL3700553 & 1528572 & 6.8962 & 7.2279 & TST & \\
\hline CHEMBL3700495 & 1528572 & 6.0 & 5.7854 & TST & \\
\hline CHEMBL3700388 & 1528572 & 6.0 & 5.7224 & TST & \\
\hline CHEMBL 3700427 & 1528572 & 6.7878 & 6.2102 & TRN & \\
\hline CHEMBL3700563 & 1528572 & 6.9208 & 7.1821 & TST & \\
\hline CHEMBL 3700480 & 1528572 & 7.8539 & 7.25299 & 9999999999 & TRN \\
\hline CHEMBL3700461 & 1528572 & 7.7447 & 7.6083 & TRN & \\
\hline CHEMBL3700556 & 1528572 & 6.5391 & 6.5376 & TST & \\
\hline CHEMBL1682283 & 1528572 & 8.2218 & 8.128 & TRN & \\
\hline CHEMBL3700408 & 1528572 & 6.0 & 6.1002 & TST & \\
\hline CHEMBL1682282 & 1528572 & 8.2218 & 8.1493 & TRN & \\
\hline CHEMBL3700446 & 1528572 & 5.1249 & 5.4511 & TRN & \\
\hline CHEMBL 3700474 & 1528572 & 5.1249 & 6.3045 & TRN & \\
\hline CHEMBL1652714 & 1528572 & 5.5528 & 6.9477 & TST & \\
\hline CHEMBL3700439 & 1528572 & 7.284 & 7.3092 & TRN & \\
\hline CHEMBL1090507 & 626787 & 9.0458 & 9.0439 & TRN & \\
\hline CHEMBL1089095 & 626787 & 9.699 & 9.3541 & TRN & \\
\hline CHEMBL1088823 & 626787 & 9.301 & 9.3884 & TRN & \\
\hline CHEMBL1093124 & 626787 & 9.0458 & 8.8664 & TRN & \\
\hline CHEMBL1093559 & 626787 & 9.5229 & 9.3484 & TRN & \\
\hline CHEMBL1089807 & 626787 & 8.4685 & 8.4221 & TRN & \\
\hline CHEMBL1089313 & 626787 & 7.9355 & 8.4379 & TRN & \\
\hline
\end{tabular}




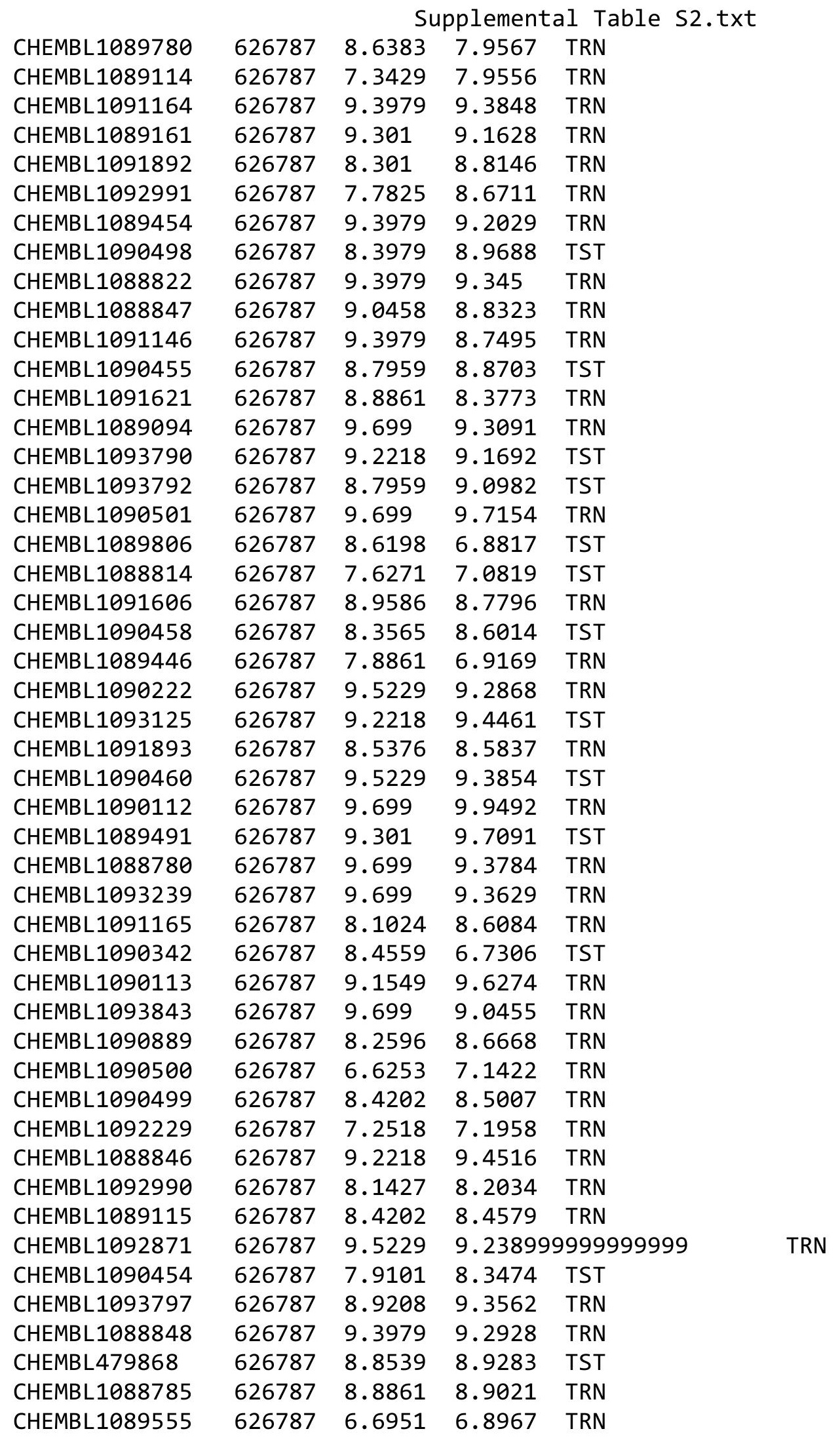

Page 15631 


\begin{tabular}{|c|c|c|c|c|c|}
\hline & & \multicolumn{4}{|c|}{ Supplemental Table S2.txt } \\
\hline CHEMBL1091622 & 626787 & 8.8861 & 8.8939 & TRN & \\
\hline CHEMBL1093791 & 626787 & 9.0458 & 9.1294 & TST & \\
\hline CHEMBL1093240 & 626787 & 7.9355 & 8.611 & TRN & \\
\hline CHEMBL1088815 & 626787 & 9.5229 & 9.6804 & TRN & \\
\hline CHEMBL1090888 & 626787 & 8.5686 & 9.0668 & TRN & \\
\hline CHEMBL1091145 & 626787 & 9.1549 & 9.2227 & TRN & \\
\hline CHEMBL1093897 & 626787 & 10.0 & 9.3666 & TRN & \\
\hline CHEMBL1092230 & 626787 & 9.301 & 9.3901 & TRN & \\
\hline CHEMBL1090102 & 626787 & 7.8633 & 6.5277 & TST & \\
\hline CHEMBL1089455 & 626787 & 9.2218 & 9.0757 & TST & \\
\hline CHEMBL1090459 & 626787 & 9.2218 & 8.9757 & TST & \\
\hline CHEMBL1093133 & 626787 & 9.0 & 8.8682 & TST & \\
\hline CHEMBL585507 & 626787 & 8.3098 & 8.3268 & TRN & \\
\hline CHEMBL1089481 & 626787 & 8.1871 & 8.1538 & TRN & \\
\hline CHEMBL3646650 & 1528635 & 6.0 & 6.0107 & TRN & \\
\hline CHEMBL 3644100 & 1528635 & 7.585 & 7.567 & TRN & \\
\hline CHEMBL 3644130 & 1528635 & 7.6778 & 7.6753 & TRN & \\
\hline CHEMBL3644111 & 1528635 & 6.0 & 5.9873 & TRN & \\
\hline CHEMBL3646641 & 1528635 & 6.6615 & 6.6479 & TRN & \\
\hline CHEMBL3644064 & 1528635 & 6.0 & 6.0684 & TRN & \\
\hline CHEMBL 3644135 & 1528635 & 6.0 & 5.956 & TRN & \\
\hline CHEMBL 3644110 & 1528635 & 7.4318 & 7.4625 & TRN & \\
\hline CHEMBL3644133 & 1528635 & 6.0 & 6.0391 & TRN & \\
\hline CHEMBL 3646679 & 1528635 & 3.426 & 3.4298 & TRN & \\
\hline CHEMBL 3646684 & 1528635 & 3.426 & 5.6953 & TST & \\
\hline CHEMBL 3644063 & 1528635 & 6.0 & 5.9869 & TRN & \\
\hline CHEMBL3644129 & 1528635 & 6.0 & 5.9992 & TRN & \\
\hline CHEMBL3644113 & 1528635 & 5.0632 & 5.0534 & TRN & \\
\hline CHEMBL3646678 & 1528635 & 5.0178 & 4.9898 & TRN & \\
\hline CHEMBL 3644085 & 1528635 & 5.76200 & 30000000 & 5.7906 & TRN \\
\hline CHEMBL 3646677 & 1528635 & 3.426 & 3.4421 & TRN & \\
\hline CHEMBL 3644101 & 1528635 & 7.0605 & 7.0748 & TRN & \\
\hline CHEMBL 3644125 & 1528635 & 6.0 & 6.0303 & TRN & \\
\hline CHEMBL3646664 & 1528635 & 6.0 & 5.9875 & TRN & \\
\hline CHEMBL3646656 & 1528635 & 6.0947 & 5.61100 & 0000000001 & TST \\
\hline CHEMBL 3644127 & 1528635 & 6.0 & 6.0095 & TRN & \\
\hline CHEMBL3644103 & 1528635 & 6.0 & 5.9884 & TRN & \\
\hline CHEMBL 3644058 & 1528635 & 6.0 & 5.9885 & TRN & \\
\hline CHEMBL3646661 & 1528635 & 6.0 & 5.9815 & TRN & \\
\hline CHEMBL3646675 & 1528635 & 3.426 & 3.4347 & TRN & \\
\hline CHEMBL 3646676 & 1528635 & 7.0 & 7.0002 & TRN & \\
\hline CHEMBL3646658 & 1528635 & 6.0 & 5.9886 & TRN & \\
\hline CHEMBL3646638 & 1528635 & 6.0 & 6.032 & TRN & \\
\hline CHEMBL3646671 & 1528635 & 6.0 & 6.0118 & TRN & \\
\hline CHEMBL3646652 & 1528635 & 6.0 & 5.4901 & TST & \\
\hline CHEMBL 3646685 & 1528635 & 6.0 & 5.9952 & TRN & \\
\hline CHEMBL3646692 & 1528635 & 7.4559 & 5.7615 & TST & \\
\hline CHEMBL3644119 & 1528635 & 6.0 & 5.9776 & TRN & \\
\hline
\end{tabular}




\begin{tabular}{|c|c|c|c|c|c|c|}
\hline \multicolumn{7}{|c|}{ Supplemental Table S2.txt } \\
\hline CHEMBL 3644141 & 1528635 & 6.0 & 5.973 & TRN & & \\
\hline CHEMBL3644149 & 1528635 & 6.0 & 5.9811 & TRN & & \\
\hline CHEMBL3646668 & 1528635 & 6.0 & 6.0023 & TRN & & \\
\hline CHEMBL 3644102 & 1528635 & 6.5376 & 6.5617 & TRN & & \\
\hline CHEMBL3646665 & 1528635 & 6.0 & 5.9951 & TRN & & \\
\hline CHEMBL3646681 & 1528635 & 6.8386 & 5.9894 & TST & & \\
\hline CHEMBL3646642 & 1528635 & 6.0 & 6.028 & TRN & & \\
\hline CHEMBL3646693 & 1528635 & 6.7447 & 5.8433 & TST & & \\
\hline CHEMBL3644092 & 1528635 & 6.3696 & 6.3219 & TRN & & \\
\hline CHEMBL3644090 & 1528635 & 6.0 & 5.9621 & TRN & & \\
\hline CHEMBL3646694 & 1528635 & 7.0 & 6.1021 & TST & & \\
\hline CHEMBL3646683 & 1528635 & 6.2118 & 5.9923 & TST & & \\
\hline CHEMBL3644060 & 1528635 & 6.0 & 5.7568 & TST & & \\
\hline CHEMBL3644109 & 1528635 & 5.8722 & 5.8811 & TRN & & \\
\hline CHEMBL3644116 & 1528635 & 6.0 & 5.9817 & TRN & & \\
\hline CHEMBL3646682 & 1528635 & 3.426 & 4.9869 & TST & & \\
\hline CHEMBL3644143 & 1528635 & 6.0 & 6.0251 & TRN & & \\
\hline CHEMBL 3644104 & 1528635 & 7.1805 & 7.1803 & TRN & & \\
\hline CHEMBL3644095 & 1528635 & 7.1079 & 7.1156 & TRN & & \\
\hline CHEMBL3646654 & 1528635 & 6.0 & 5.6828 & TST & & \\
\hline CHEMBL3644086 & 1528635 & 6.0 & 6.0111 & TRN & & \\
\hline CHEMBL 3644057 & 1528635 & 7.2596 & 4.9741 & TST & & \\
\hline CHEMBL3644061 & 1528635 & 6.0 & 5.9786 & TRN & & \\
\hline CHEMBL 3646680 & 1528635 & 6.9355 & 6.2748 & TST & & \\
\hline CHEMBL3644114 & 1528635 & 6.0 & 6.0556 & TST & & \\
\hline CHEMBL3639455 & 1528635 & 6.0 & 6.0445 & TST & & \\
\hline CHEMBL 2408542 & 972803 & 5.0585 & 4.9554 & TRN & & \\
\hline CHEMBL 2408540 & 972803 & 5.71899 & 99999999 & 99 & 5.8519 & TRN \\
\hline CHEMBL 2408553 & 972803 & 5.6778 & 5.8633 & TRN & & \\
\hline CHEMBL 2408536 & 972803 & 5.6799 & 5.9385 & TRN & & \\
\hline CHEMBL 2408559 & 972803 & 4.6782 & 5.3328 & TST & & \\
\hline CHEMBL 2408544 & 972803 & 6.2291 & 6.1465 & TRN & & \\
\hline CHEMBL 2408517 & 972803 & 5.5452 & 5.6657 & TRN & & \\
\hline CHEMBL 2408516 & 972803 & 4.8371 & 4.6769 & TRN & & \\
\hline CHEMBL 2408529 & 972803 & 5.7773 & 5.6336 & TRN & & \\
\hline CHEMBL 2408361 & 972803 & 5.2495 & 5.2314 & TST & & \\
\hline CHEMBL 2408524 & 972803 & 5.2269 & 4.9165 & TRN & & \\
\hline CHEMBL 2408364 & 972803 & 3.3979 & 4.8007 & TRN & & \\
\hline CHEMBL 2408526 & 972803 & 5.6289 & 5.2129 & TRN & & \\
\hline CHEMBL 2408359 & 972803 & 4.8386 & 5.4306 & TST & & \\
\hline CHEMBL 2408558 & 972803 & 3.3979 & 5.085 & TST & & \\
\hline CHEMBL 2408528 & 972803 & 6.1805 & 5.7254 & TRN & & \\
\hline CHEMBL 2408545 & 972803 & 5.6478 & 5.8354 & TRN & & \\
\hline CHEMBL 2408515 & 972803 & 5.5114 & 5.3861 & TST & & \\
\hline CHEMBL 2408520 & 972803 & 5.5735 & 5.6496 & TRN & & \\
\hline CHEMBL 2408532 & 972803 & 5.9586 & 5.4399 & TST & & \\
\hline CHEMBL 2408362 & 972803 & 4.945 & 4.6767 & TRN & & \\
\hline CHEMBL 2408519 & 972803 & 6.1549 & 6.0176 & TRN & & \\
\hline
\end{tabular}


Supplemental Table S2.txt

\begin{tabular}{|c|c|c|c|c|}
\hline CHEMBL 2408551 & 972803 & 5.5391 & 5.3861 & TRN \\
\hline CHEMBL 2408531 & 972803 & 5.7825 & 5.8885 & TRN \\
\hline CHEMBL 2408365 & 972803 & 5.4622 & 5.7178 & TRN \\
\hline CHEMBL 2408549 & 972803 & 5.3372 & 5.0994 & TST \\
\hline CHEMBL 2408541 & 972803 & 5.4191 & 5.5004 & TST \\
\hline CHEMBL 2408535 & 972803 & 5.5834 & 5.2363 & TRN \\
\hline CHEMBL 2408556 & 972803 & 3.3979 & 5.0731 & TST \\
\hline CHEMBL 2408527 & 972803 & 5.6882 & 5.9971 & TRN \\
\hline CHEMBL 2408513 & 972803 & 5.5784 & 5.3547 & TRN \\
\hline CHEMBL 2408546 & 972803 & 5.6716 & 5.7984 & TRN \\
\hline CHEMBL 2408512 & 972803 & 5.5302 & 5.4346 & TRN \\
\hline CHEMBL 2408534 & 972803 & 5.6696 & 5.5995 & TRN \\
\hline CHEMBL 2408555 & 972803 & 6.0315 & 6.0333 & TRN \\
\hline CHEMBL 2408533 & 972803 & 4.9658 & 4.9653 & TST \\
\hline CHEMBL 2408552 & 972803 & 6.1938 & 6.1237 & TRN \\
\hline CHEMBL 2408538 & 972803 & 5.5229 & 5.6155 & TRN \\
\hline CHEMBL 2408521 & 972803 & 5.5287 & 5.5877 & TRN \\
\hline CHEMBL 2408550 & 972803 & 5.6383 & 5.8038 & TRN \\
\hline CHEMBL 2408547 & 972803 & 6.0088 & 6.0207 & TRN \\
\hline CHEMBL 2408525 & 972803 & 5.6091 & 5.6463 & TRN \\
\hline CHEMBL 2408360 & 972803 & 4.76399 & 99999999 & 5.358 \\
\hline CHEMBL 2408523 & 972803 & 5.7773 & 5.4629 & TST \\
\hline CHEMBL 2408530 & 972803 & 5.5544 & 5.6492 & TRN \\
\hline CHEMBL 2408518 & 972803 & 4.914 & 5.1847 & TRN \\
\hline CHEMBL 2408548 & 972803 & 5.9508 & 5.6254 & TST \\
\hline CHEMBL 2408543 & 972803 & 5.4067 & 5.3701 & TRN \\
\hline CHEMBL 2408363 & 972803 & 5.5935 & 5.406006 & 000000001 \\
\hline CHEMBL 2408557 & 972803 & 4.9642 & 5.2772 & TST \\
\hline CHEMBL 2408522 & 972803 & 6.2218 & 5.8947 & TRN \\
\hline CHEMBL 2408554 & 972803 & 5.6615 & 5.812 & TRN \\
\hline CHEMBL 2408514 & 972803 & 5.6091 & 5.6405 & TRN \\
\hline CHEMBL 2408539 & 972803 & 6.284 & 5.7877 & TRN \\
\hline CHEMBL 2408537 & 972803 & 5.6716 & 5.6786 & TRN \\
\hline CHEMBL3354581 & 1451729 & 6.0862 & 6.004 & TRN \\
\hline CHEMBL3353951 & 1451729 & 5.8861 & 6.047006 & 000000001 \\
\hline CHEMBL3354594 & 1451729 & 6.7447 & 6.5897 & TRN \\
\hline CHEMBL 3354574 & 1451729 & 4.0 & 5.2117 & TST \\
\hline CHEMBL3354595 & 1451729 & 7.041 & 7.0616 & TRN \\
\hline CHEMBL 3354570 & 1451729 & 6.0315 & 5.9689 & TRN \\
\hline CHEMBL3354572 & 1451729 & 4.0 & 5.1492 & TST \\
\hline CHEMBL3353930 & 1451729 & 6.1805 & 6.1552 & TRN \\
\hline CHEMBL3353944 & 1451729 & 6.585 & 6.7793 & TRN \\
\hline CHEMBL3354576 & 1451729 & 6.0809 & 5.7344 & TRN \\
\hline CHEMBL3353932 & 1451729 & 6.301 & 6.4588 & TRN \\
\hline CHEMBL3354600 & 1451729 & 6.3768 & 6.4715 & TRN \\
\hline CHEMBL3354582 & 1451729 & 6.3468 & 6.0217 & TRN \\
\hline CHEMBL3353943 & 1451729 & 4.0 & 3.9484 & TRN \\
\hline CHEMBL3353949 & 1451729 & 6.3565 & 6.2921 & TRN \\
\hline
\end{tabular}

Page 15634 


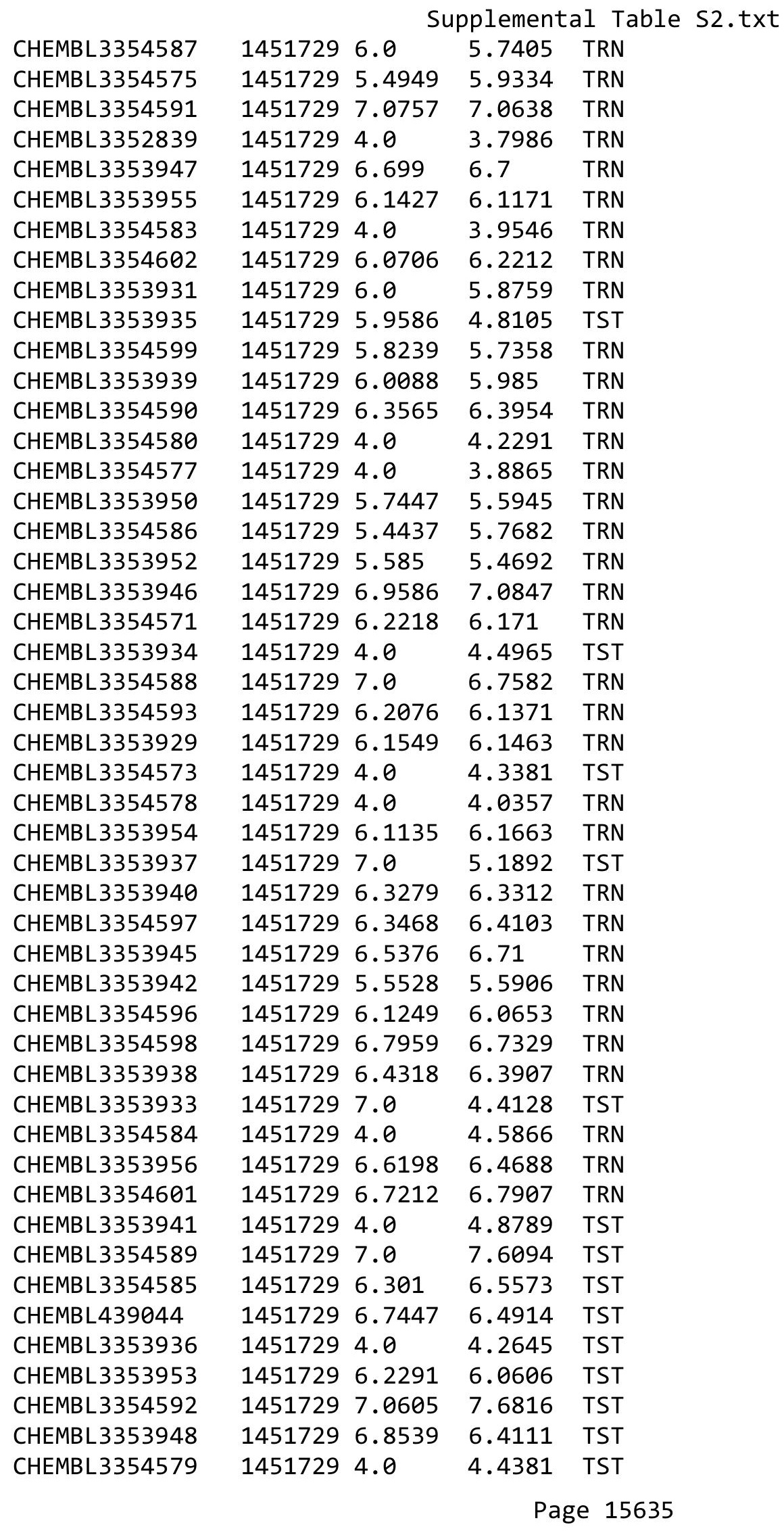


Supplemental Table S2.txt

\begin{tabular}{|c|c|c|c|c|c|}
\hline CHEMBL3716120 & 1537035 & 8.7799 & 8.2587 & TRN & \\
\hline CHEMBL3719264 & 1537035 & 9.0362 & 8.3934 & TRN & \\
\hline CHEMBL3715054 & 1537035 & 8.3429 & 8.7051 & TRN & \\
\hline CHEMBL3715604 & 1537035 & 9.2518 & 9.0278 & TRN & \\
\hline CHEMBL3718606 & 1537035 & 8.2 & 8.6622 & TRN & \\
\hline CHEMBL3718869 & 1537035 & 8.1343 & 8.6041 & TST & \\
\hline CHEMBL3716388 & 1537035 & 9.2757 & 8.9796 & TRN & \\
\hline CHEMBL3716224 & 1537035 & 5.504 & 8.2292 & TST & \\
\hline CHEMBL3716555 & 1537035 & 9.3468 & 8.7491 & TST & \\
\hline CHEMBL3716332 & 1537035 & 9.1487 & 8.7459 & TST & \\
\hline CHEMBL3714996 & 1537035 & 8.9872 & 8.7102 & TRN & \\
\hline CHEMBL3716899 & 1537035 & 9.2441 & 9.1772 & TRN & \\
\hline CHEMBL3715826 & 1537035 & 9.2518 & 9.5476 & TRN & \\
\hline CHEMBL 3716576 & 1537035 & 9.3872 & 8.9766 & TST & \\
\hline CHEMBL3717308 & 1537035 & 9.5376 & 9.1015 & TRN & \\
\hline CHEMBL3719106 & 1537035 & 9.3188 & 8.5596 & TRN & \\
\hline CHEMBL3715013 & 1537035 & 9.6383 & 8.9858 & TRN & \\
\hline CHEMBL3719349 & 1537035 & 8.7852 & 8.5278 & TRN & \\
\hline CHEMBL3716026 & 1537035 & 8.8996 & 8.588 & TRN & \\
\hline CHEMBL3717065 & 1537035 & 8.0434 & 8.7535 & TRN & \\
\hline CHEMBL3716323 & 1537035 & 8.9586 & 8.8022 & TRN & \\
\hline CHEMBL3717430 & 1537035 & 9.4559 & 8.8612 & TST & \\
\hline CHEMBL3717597 & 1537035 & 9.1612 & 8.7886 & TRN & \\
\hline CHEMBL3718901 & 1537035 & 9.0223 & 8.6343 & TRN & \\
\hline CHEMBL3715196 & 1537035 & 8.6904 & 9.0518 & TRN & \\
\hline CHEMBL3716818 & 1537035 & 9.1308 & 8.6962 & TRN & \\
\hline CHEMBL3717884 & 1537035 & 8.8894 & 8.6808 & TRN & \\
\hline CHEMBL3715948 & 1537035 & 8.0685 & 8.2554 & TRN & \\
\hline CHEMBL 3716344 & 1537035 & 8.9136 & 8.9134 & TRN & \\
\hline CHEMBL3716806 & 1537035 & 8.7258 & 9.1858 & TRN & \\
\hline CHEMBL3717959 & 1537035 & 9.1612 & 8.7758 & TRN & \\
\hline CHEMBL 3717040 & 1537035 & 8.7305 & 8.4981 & TRN & \\
\hline CHEMBL3719331 & 1537035 & 8.9747 & 8.6359 & TRN & \\
\hline CHEMBL 3718355 & 1537035 & 9.5086 & 9.0194 & TST & \\
\hline CHEMBL3718854 & 1537035 & 9.4202 & 9.2968 & TRN & \\
\hline CHEMBL3718187 & 1537035 & 8.9245 & 8.8947 & TRN & \\
\hline CHEMBL3715723 & 1537035 & 8.8297 & 9.392000 & 0000000001 & TRN \\
\hline CHEMBL3717423 & 1537035 & 8.3615 & 8.2147 & TRN & \\
\hline CHEMBL3715775 & 1537035 & 8.9747 & 8.5706 & TST & \\
\hline CHEMBL3716636 & 1537035 & 9.2218 & 8.7073 & TRN & \\
\hline CHEMBL3715722 & 1537035 & 9.3098 & 8.7958 & TRN & \\
\hline CHEMBL3719033 & 1537035 & 8.85700 & 000000000 & 9.054 & TST \\
\hline CHEMBL3719074 & 1537035 & 9.4437 & 8.9912 & TRN & \\
\hline CHEMBL3715555 & 1537035 & 8.8327 & 9.0503 & TRN & \\
\hline CHEMBL3716719 & 1537035 & 8.8447 & 9.046 & TRN & \\
\hline CHEMBL3719244 & 1537035 & 9.0 & 9.3679 & TRN & \\
\hline CHEMBL3717220 & 1537035 & 9.1427 & 8.9622 & TST & \\
\hline CHEMBL3715991 & 1537035 & 9.2441 & 9.109 & TRN & \\
\hline
\end{tabular}


Supplemental Table S2.txt

\begin{tabular}{|c|c|c|}
\hline & & \\
\hline HEMBL3716704 & 537035 & \\
\hline AEMBL 3717838 & 35 & .9666 \\
\hline 23 & & 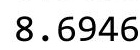 \\
\hline AEMBL 371 & & 516 \\
\hline AEMBL3717928 & 37035 & 455 \\
\hline HEMBL 3717518 & 537035 & 9.443 \\
\hline HEMBL3717498 & 35 & 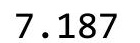 \\
\hline AEMBL3715416 & & 8.9172 \\
\hline AEMBL37 & & 8.6615 \\
\hline HEMBL3714876 & 35 & 8.6615 \\
\hline HEMBL3714990 & 53 & 9.443 \\
\hline HEMBL3718111 & & 8 \\
\hline AEMBL3 & & 312 \\
\hline HEMBL3 3 & & \\
\hline HEMBL3716559 & 35 & 8.37 \\
\hline HEMBL3718880 & & \\
\hline HEMBL37 & - & 8.8041 \\
\hline HEMBL3 & & 8.7721 \\
\hline HEMBL3 & & 8.4248 \\
\hline HEMBL3717515 & & 8.36 \\
\hline HEMBL3715976 & & 8 \\
\hline HEMBL3 & 15 & 8 \\
\hline HEMBL3 & & 8 \\
\hline HEMBL3 & & 8 \\
\hline HEMBL37 & & 8 \\
\hline HEMBL3718990 & & 9.301 \\
\hline HEMBL37 & 15 & 8 \\
\hline HEMBL & & 8 \\
\hline HEMBL3 & 35 & 8.6556 \\
\hline HEMBL37 & & 8. \\
\hline HEMBL 3717703 & ז- & 9.119 \\
\hline HEMBL3 & & \\
\hline 09 & 15 & 7 \\
\hline HEMBL3 & 35 & 8.8297 \\
\hline HEMBL3717105 & $-5+2$ & 9.173 \\
\hline HEMBL3715980 & -8 & 8.422 \\
\hline HEMBL & & 8 \\
\hline HFMRI 3 & 5 & 9. \\
\hline HEMBL3 & 35 & 9.6383 \\
\hline HEMBL3719049 & 537 & 9.070 \\
\hline HEMBL3718163 & 153 & 7.173 \\
\hline CHEM & & 9.327 \\
\hline CHEMBL3 & 153 & 8.759 \\
\hline CHEMBL37 & 153 & 8.987 \\
\hline AEMBL3716715 & 1537 & 7.655 \\
\hline CHEMBL 37 & 153 & 8.9 \\
\hline 1070 & & \\
\hline
\end{tabular}

$\begin{array}{ll}8.4934 & \text { TRN } \\ 8.6558 & \text { TRN } \\ 8.8721 & \text { TRN } \\ 8.7194 & \text { TRN } \\ 8.8006 & \text { TRN } \\ 8.4664 & \text { TRN } \\ 9.1076 & \text { TRN } \\ 8.0658 & \text { TRN } \\ 8.9537 & \text { TRN } \\ 8.7648 & \text { TRN } \\ 8.8168 & \text { TRN } \\ 9.0893 & \text { TST } \\ 8.2635 & \text { TRN } \\ 8.1564 & \text { TRN } \\ 8.7496 & \text { TRN } \\ 8.2521 & \text { TRN } \\ 9.4518 & \text { TRN } \\ 8.9597 & \text { TRN } \\ 8.8237 & \text { TRN } \\ 8.6143 & \text { TST } \\ 8.0301 & \text { TRN } \\ 8.755 & \text { TRN } \\ 8.3695 & \text { TRN } \\ 8.7348 & \text { TRN } \\ 9.1278 & \text { TRN } \\ 8.6144 & \text { TRN } \\ 9.2555 & \text { TRN } \\ 9.1034 & \text { TRN } \\ 8.482000000000001 \\ 8.8066 & \text { TST } \\ 8.7163 & \text { TRN } \\ 8.8316 & \text { TRN } \\ 9.4794 & \text { TRN } \\ 8.1943 & \text { TRN } \\ 8.9041 & \text { TRN } \\ 9.0934 & \text { TRN } \\ 8.9277 & \text { TRN } \\ 8.4073 & \text { TRN } \\ 9.0656 & \text { TRN } \\ 8.8605 & \text { TST } \\ 8.9363 & \text { TST } \\ 7.9438 & \text { TRN } \\ 9.1272 & \text { TRN } \\ 8.4261 & \text { TRN } \\ 8.9135 & \text { TRN } \\ 8.332 & \text { TST } \\ 8.7582 & \text { TRN } \\ 8.867 & \text { TST } \\ & \end{array}$


Supplemental Table S2.txt

\begin{tabular}{|c|c|c|c|c|c|c|}
\hline CHEMBL3718180 & 1537035 & 8.0615 & 8.3485 & TST & & \\
\hline CHEMBL3715863 & 1537035 & 8.7986 & 8.5538 & TST & & \\
\hline CHEMBL3718243 & 1537035 & 8.4724 & 8.2392 & TST & & \\
\hline CHEMBL3716397 & 1537035 & 9.0757 & 9.5955 & TST & & \\
\hline CHEMBL3716460 & 1537035 & 9.1612 & 9.1375 & TST & & \\
\hline CHEMBL3719340 & 1537035 & 8.9626 & 8.9291 & TST & & \\
\hline CHEMBL3715116 & 1537035 & 8.8794 & 8.7406 & TST & & \\
\hline CHEMBL 3716664 & 1537035 & 8.1433 & 8.3291 & TST & & \\
\hline CHEMBL3717253 & 1537035 & 8.8153 & 9.1578 & TST & & \\
\hline CHEMBL3234051 & 1336281 & 6.6925 & 7.0002 & TRN & & \\
\hline CHEMBL 3234085 & 1336281 & 6.8097 & 6.5268 & TRN & & \\
\hline CHEMBL3234092 & 1336281 & 4.5445 & 5.3726 & TRN & & \\
\hline CHEMBL 3234058 & 1336281 & 6.0088 & 6.2263 & TRN & & \\
\hline CHEMBL 3234066 & 1336281 & 4.4974 & 5.7959 & TST & & \\
\hline CHEMBL3234049 & 1336281 & 6.7375 & 7.0984 & TRN & & \\
\hline CHEMBL 3234068 & 1336281 & 8.4815 & 8.1513 & TRN & & \\
\hline CHEMBL3234096 & 1336281 & 4.6863 & 5.3559 & TRN & & \\
\hline CHEMBL3234069 & 1336281 & 8.3565 & 7.7651 & TRN & & \\
\hline CHEMBL3234056 & 1336281 & 6.2306 & 6.8053 & TRN & & \\
\hline CHEMBL3234065 & 1336281 & 4.5445 & 5.2881 & TRN & & \\
\hline CHEMBL3234045 & 1336281 & 7.0132 & 7.5352 & TST & & \\
\hline CHEMBL 3234043 & 1336281 & 7.6289 & 7.5237 & TRN & & \\
\hline CHEMBL 3234077 & 1336281 & 7.2596 & 7.9815 & TRN & & \\
\hline CHEMBL 3234093 & 1336281 & 7.1192 & 7.3978 & TRN & & \\
\hline CHEMBL 3234088 & 1336281 & 6.1986 & 6.5148 & TRN & & \\
\hline CHEMBL3234059 & 1336281 & 5.9041 & 5.7125 & TRN & & \\
\hline CHEMBL 3234078 & 1336281 & 7.1079 & 7.381 & TRN & & \\
\hline CHEMBL 3234042 & 1336281 & 7.8239 & 7.2406 & TRN & & \\
\hline CHEMBL 3234071 & 1336281 & 8.2007 & 7.5827 & TRN & & \\
\hline CHEMBL3234086 & 1336281 & \multicolumn{3}{|c|}{6.7620000000000005} & 6.8667 & TRN \\
\hline CHEMBL 3234063 & 1336281 & 5.7773 & 6.1864 & TST & & \\
\hline CHEMBL 3234062 & 1336281 & 5.7943 & 6.3393 & TST & & \\
\hline CHEMBL 3234082 & 1336281 & 6.8729 & 6.5782 & TRN & & \\
\hline CHEMBL 3234053 & 1336281 & \multicolumn{3}{|c|}{6.382000000000001} & 6.199 & TRN \\
\hline CHEMBL172 & 1336281 & 8.0757 & 7.9314 & TST & & \\
\hline CHEMBL3234094 & 1336281 & 7.699 & 7.9865 & TRN & & \\
\hline CHEMBL 3234061 & 1336281 & 5.8268 & 5.4128 & TRN & & \\
\hline CHEMBL 3234087 & 1336281 & 6.5017 & 7.3024 & TRN & & \\
\hline CHEMBL 3234083 & 1336281 & 6.8356 & 5.5834 & TRN & & \\
\hline CHEMBL 3234055 & 1336281 & 6.3089 & 5.8199 & TRN & & \\
\hline CHEMBL3234046 & 1336281 & 6.9281 & 7.4144 & TRN & & \\
\hline CHEMBL 3234074 & 1336281 & 7.9586 & 7.8935 & TRN & & \\
\hline CHEMBL 3234090 & 1336281 & 4.6925 & 5.7706 & TRN & & \\
\hline CHEMBL 3234075 & 1336281 & 7.7212 & 7.6599 & TRN & & \\
\hline CHEMBL 3234041 & 1336281 & 7.8539 & 7.7908 & TRN & & \\
\hline CHEMBL3234057 & 1336281 & 6.059 & 5.9602 & TRN & & \\
\hline CHEMBL3234097 & 1336281 & 6.1752 & 6.5782 & TRN & & \\
\hline CHEMBL 3234073 & 1336281 & 7.9586 & 7.5258 & TRN & & \\
\hline
\end{tabular}

Page 15638 
Supplemental Table S2.txt

\begin{tabular}{|c|c|c|c|c|}
\hline CHEMBL 3234044 & 1336281 & 7.5528 & 7.1213 & TRN \\
\hline CHEMBL 3234079 & 1336281 & 7.0044 & 7.5393 & TRN \\
\hline CHEMBL3234070 & 1336281 & 8.2596 & 7.8495 & TRN \\
\hline CHEMBL3234048 & 1336281 & 6.8601 & 5.9703 & TRN \\
\hline CHEMBL3234081 & 1336281 & 6.9706 & 6.9382 & TRN \\
\hline CHEMBL 3234098 & 1336281 & 6.1355 & 7.1134 & TST \\
\hline CHEMBL 3234076 & 1336281 & 7.585 & 7.4926 & TRN \\
\hline CHEMBL 3234084 & 1336281 & 6.8182 & 6.6436 & TRN \\
\hline CHEMBL3234054 & 1336281 & 6.3851 & 6.2407 & TRN \\
\hline CHEMBL3234089 & 1336281 & 6.1232 & 5.8587 & TRN \\
\hline CHEMBL 3234095 & 1336281 & 4.633 & 6.2711 & TST \\
\hline CHEMBL 3234091 & 1336281 & 5.9698 & 5.4793 & TRN \\
\hline CHEMBL 3234047 & 1336281 & 6.9136 & 7.2612 & TST \\
\hline CHEMBL 3234060 & 1336281 & 5.8462 & 5.9107 & TST \\
\hline CHEMBL3234072 & 1336281 & 8.1427 & 7.5093 & TST \\
\hline CHEMBL 3234050 & 1336281 & 6.7167 & 6.2675 & TST \\
\hline CHEMBL3234067 & 1336281 & 9.2366 & 7.5135 & TST \\
\hline CHEMBL 3234064 & 1336281 & 4.5532 & 5.885 & TST \\
\hline CHEMBL3234052 & 1336281 & 6.6091 & 7.2191 & TST \\
\hline CHEMBL3234080 & 1336281 & 7.0177 & 7.167006 & 0000000001 \\
\hline CHEMBL255342 & 955075 & 4.4144 & 4.3768 & TRN \\
\hline CHEMBL1242367 & 955075 & 3.7231 & 3.7205 & TRN \\
\hline CHEMBL1186585 & 955075 & 4.1502 & 4.1334 & TRN \\
\hline CHEMBL373751 & 955075 & 4.1664 & 4.1542 & TRN \\
\hline CHEMBL483847 & 955075 & 3.8726 & 3.8746 & TRN \\
\hline CHEMBL1357247 & 955075 & 3.3053 & 3.3072 & TRN \\
\hline CHEMBL3392440 & 955075 & 4.2941 & 4.2733 & TRN \\
\hline CHEMBL 2363137 & 955075 & 5.1357 & 5.1424 & TRN \\
\hline CHEMBL509032 & 955075 & 5.8624 & 5.8443 & TRN \\
\hline CHEMBL 9470 & 955075 & 6.499 & 6.1587 & TST \\
\hline CHEMBL259181 & 955075 & 5.0919 & 5.1107 & TRN \\
\hline CHEMBL221137 & 955075 & 4.777 & 5.5023 & TST \\
\hline CHEMBL573107 & 955075 & 4.24 & 4.2317 & TRN \\
\hline CHEMBL180127 & 955075 & 4.3481 & 4.3179 & TRN \\
\hline CHEMBL1256459 & 955075 & 7.3209 & 7.3145 & TRN \\
\hline CHEMBL213100 & 955075 & 4.7202 & 4.7147 & TRN \\
\hline CHEMBL449158 & 955075 & 6.4493 & 6.1304 & TST \\
\hline CHEMBL 3186408 & 955075 & 4.0188 & 4.0805 & TST \\
\hline CHEMBL2005886 & 955075 & 5.1988 & 5.2062 & TRN \\
\hline CHEMBL577784 & 955075 & 5.3961 & 5.4224 & TRN \\
\hline CHEMBL65 & 955075 & 7.5406 & 7.4999 & TRN \\
\hline CHEMBL1404918 & 955075 & 2.9013 & 2.877 & TRN \\
\hline CHEMBL 379300 & 955075 & 6.4785 & 6.4703 & TRN \\
\hline CHEMBL514499 & 955075 & 7.6576 & 7.6755 & TRN \\
\hline CHEMBL92309 & 955075 & 3.1808 & 3.5797 & TST \\
\hline CHEMBL558642 & 955075 & 4.0573 & 4.0561 & TRN \\
\hline CHEMBL483849 & 955075 & 0.99 & 2.531 & TST \\
\hline CHEMBL1516890 & 955075 & 3.9476 & 3.9453 & TRN \\
\hline
\end{tabular}




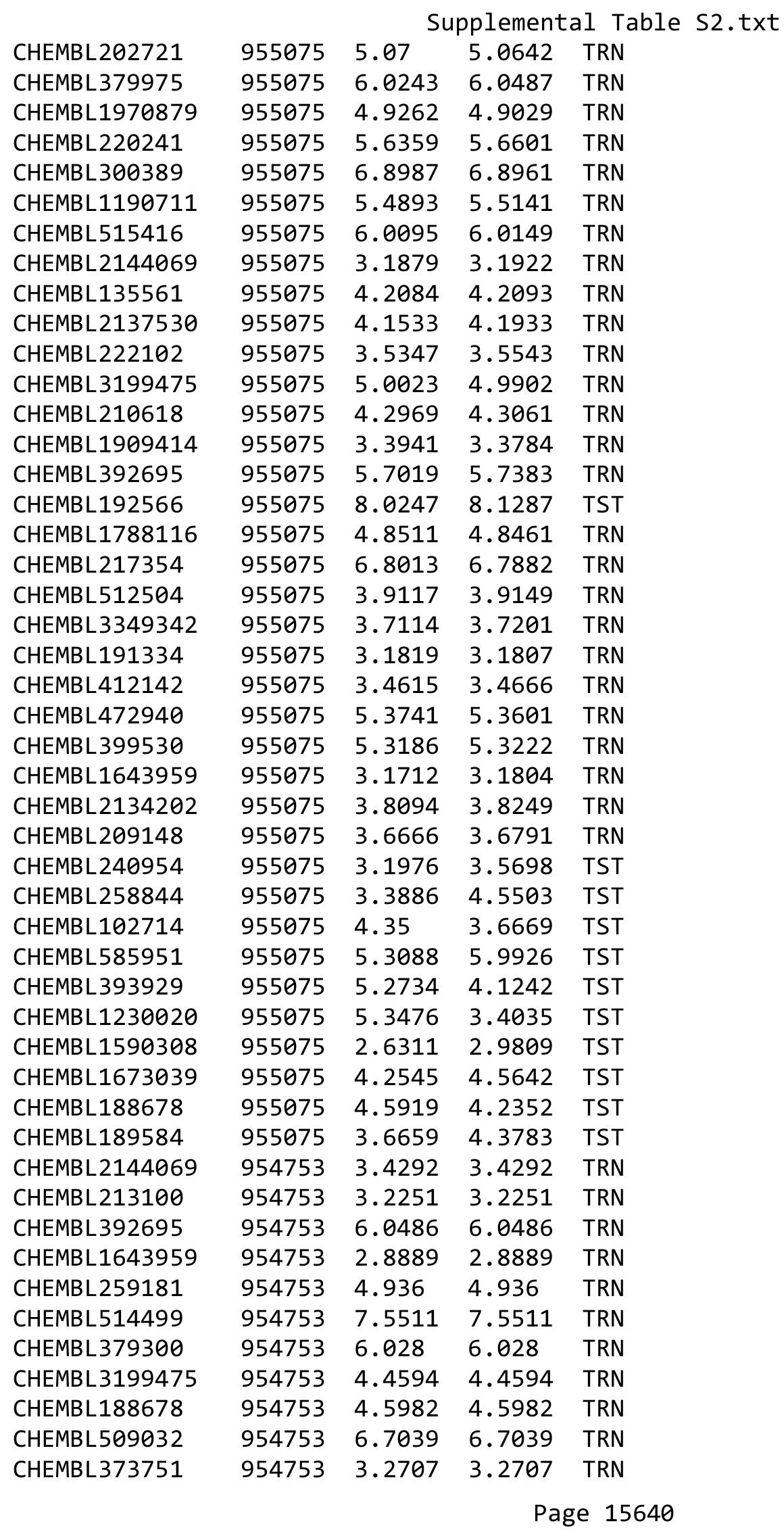




\begin{tabular}{|c|c|c|c|c|c|c|}
\hline \multicolumn{7}{|c|}{ Supplemental Table S2.txt } \\
\hline CHEMBL577784 & 954753 & 3.7456 & 3.7456 & TRN & & \\
\hline CHEMBL483849 & 954753 & 3.1122 & 3.1122 & TRN & & \\
\hline CHEMBL65 & 954753 & 7.20700 & 30000000 & & 7.207000000000001 & TRN \\
\hline CHEMBL 3186408 & 954753 & 4.5606 & 3.7317 & TST & & \\
\hline CHEMBL1190711 & 954753 & 5.5375 & 5.5375 & TRN & & \\
\hline CHEMBL573107 & 954753 & 4.3975 & 4.3975 & TRN & & \\
\hline CHEMBL412142 & 954753 & 3.2586 & 3.2586 & TRN & & \\
\hline CHEMBL3349342 & 954753 & 3.6749 & 3.6749 & TRN & & \\
\hline CHEMBL1970879 & 954753 & 3.9252 & 3.9252 & TRN & & \\
\hline CHEMBL512504 & 954753 & 3.793 & 3.793 & TRN & & \\
\hline CHEMBL9470 & 954753 & 6.4151 & 5.4318 & TST & & \\
\hline CHEMBL379975 & 954753 & 5.739 & 5.739 & TRN & & \\
\hline CHEMBL192566 & 954753 & 7.3191 & 7.7349 & TST & & \\
\hline CHEMBL 202721 & 954753 & 3.5293 & 3.5293 & TRN & & \\
\hline CHEMBL558642 & 954753 & 3.8996 & 3.8996 & TRN & & \\
\hline CHEMBL135561 & 954753 & 3.6781 & 3.6781 & TRN & & \\
\hline CHEMBL220241 & 954753 & 3.5123 & 3.5123 & TRN & & \\
\hline CHEMBL191334 & 954753 & 3.3343 & 3.3343 & TRN & & \\
\hline CHEMBL1516890 & 954753 & 4.0337 & 4.0337 & TRN & & \\
\hline CHEMBL483847 & 954753 & 4.1822 & 4.1822 & TRN & & \\
\hline CHEMBL 2363137 & 954753 & 4.755 & 4.755 & TRN & & \\
\hline CHEMBL1590308 & 954753 & 3.2818 & 3.0966 & TST & & \\
\hline CHEMBL393929 & 954753 & 3.5871 & 3.5871 & TRN & & \\
\hline CHEMBL 222102 & 954753 & 3.4524 & 3.4524 & TRN & & \\
\hline CHEMBL3392440 & 954753 & 3.7928 & 3.7928 & TRN & & \\
\hline CHEMBL 2005886 & 954753 & 6.0295 & 6.0295 & TRN & & \\
\hline CHEMBL 240954 & 954753 & 3.9898 & 3.5534 & TST & & \\
\hline CHEMBL 209148 & 954753 & 4.19 & 4.19 & TRN & & \\
\hline CHEMBL180127 & 954753 & 4.5378 & 4.5378 & TRN & & \\
\hline CHEMBL102714 & 954753 & 3.5372 & 3.5372 & TRN & & \\
\hline CHEMBL92309 & 954753 & 1.1247 & 2.9898 & TST & & \\
\hline CHEMBL1673039 & 954753 & 4.7357 & 4.7357 & TRN & & \\
\hline CHEMBL1788116 & 954753 & 3.12899 & 99999999 & 996 & 3.1289999999999996 & TRN \\
\hline CHEMBL1230020 & 954753 & 3.4859 & 3.4859 & TRN & & \\
\hline CHEMBL1404918 & 954753 & 3.0427 & 3.0427 & TRN & & \\
\hline CHEMBL221137 & 954753 & 4.7663 & 4.4877 & TST & & \\
\hline CHEMBL472940 & 954753 & 3.4081 & 3.4081 & TRN & & \\
\hline CHEMBL189584 & 954753 & 4.351 & 4.351 & TRN & & \\
\hline CHEMBL449158 & 954753 & 6.1366 & 6.189 & TST & & \\
\hline CHEMBL585951 & 954753 & 6.2857 & 6.2857 & TRN & & \\
\hline CHEMBL 300389 & 954753 & 7.0817 & 7.0817 & TRN & & \\
\hline CHEMBL210618 & 954753 & 3.7905 & 2.7789 & TST & & \\
\hline CHEMBL1256459 & 954753 & 6.8832 & 7.2653 & TST & & \\
\hline CHEMBL1909414 & 954753 & 3.7452 & 3.2894 & TST & & \\
\hline CHEMBL1242367 & 954753 & 3.4683 & 4.18 & TST & & \\
\hline CHEMBL515416 & 954753 & 4.9986 & 4.5643 & TST & & \\
\hline CHEMBL1357247 & 954753 & 3.0105 & 2.7044 & TST & & \\
\hline CHEMBL 258844 & 954753 & 4.7297 & 4.4344 & TST & & \\
\hline
\end{tabular}


Supplemental Table S2.txt

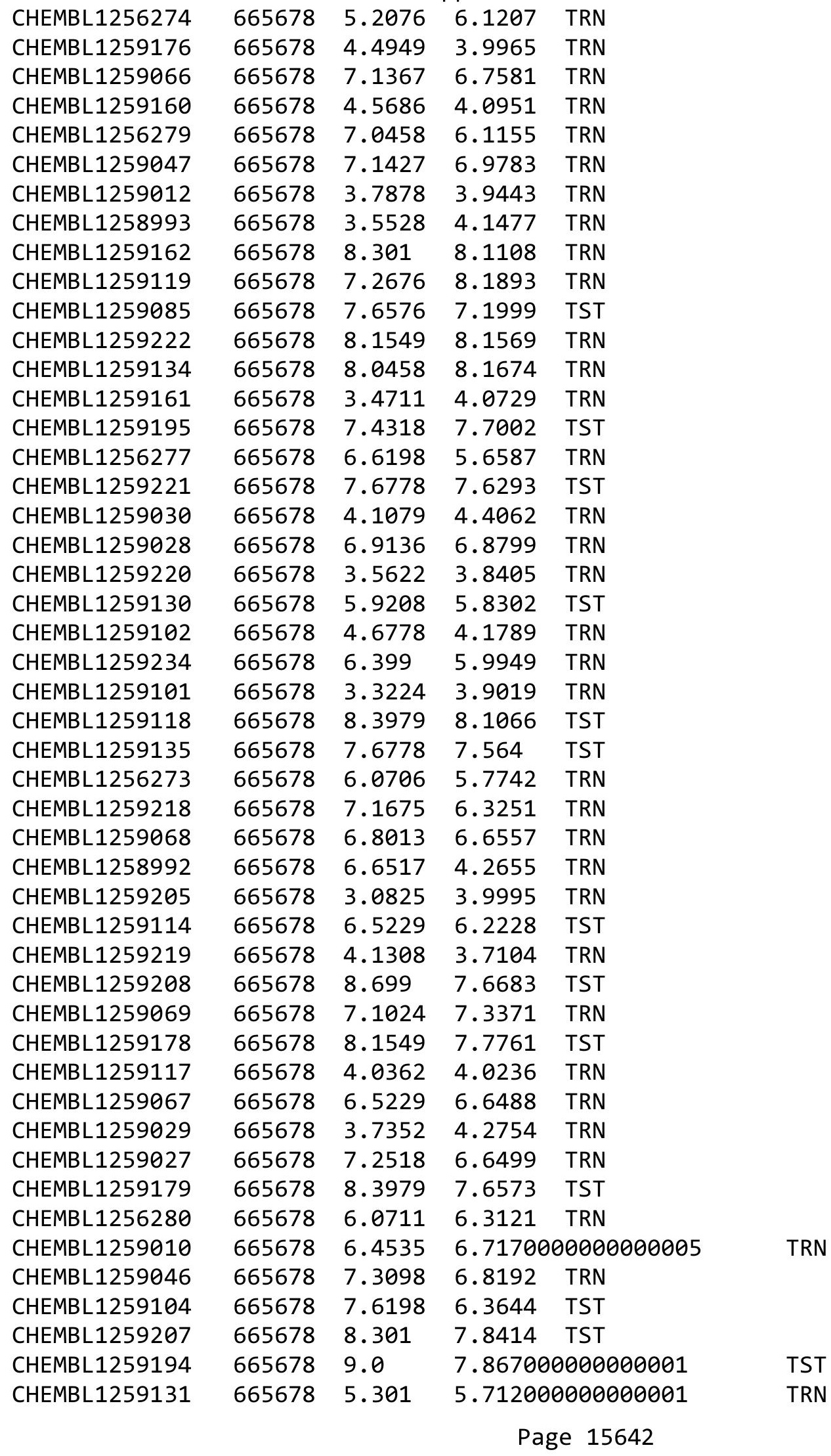




\begin{tabular}{|c|c|c|c|c|c|}
\hline \multicolumn{6}{|c|}{ Supplemental Table S2.txt } \\
\hline CHEMBL1259048 & 665678 & 3.8356 & 4.1574 & TRN & \\
\hline CHEMBL1259149 & 665678 & 8.5229 & 7.9675 & TST & \\
\hline CHEMBL1259103 & 665678 & 6.5114 & 6.2431 & TST & \\
\hline CHEMBL1259009 & 665678 & 5.3883 & 6.74200 & 0000000001 & TRN \\
\hline CHEMBL1259193 & 665678 & 4.6383 & 4.0833 & TRN & \\
\hline CHEMBL1259175 & 665678 & 5.3595 & 5.7106 & TRN & \\
\hline CHEMBL1259235 & 665678 & 6.2857 & 5.4007 & TRN & \\
\hline CHEMBL1259084 & 665678 & 6.3645 & 6.8961 & TRN & \\
\hline CHEMBL1259206 & 665678 & 3.4948 & 4.1823 & TRN & \\
\hline CHEMBL 1256278 & 665678 & 6.2441 & 5.7728 & TRN & \\
\hline CHEMBL1259132 & 665678 & 3.1487 & 4.0304 & TRN & \\
\hline CHEMBL1259238 & 665678 & 7.9208 & 7.8283 & TST & \\
\hline CHEMBL1256276 & 665678 & 6.0969 & 5.8245 & TRN & \\
\hline CHEMBL1258994 & 665678 & 3.6556 & 4.2399 & TRN & \\
\hline CHEMBL186567 & 311953 & 5.727 & 5.7262 & TRN & \\
\hline CHEMBL363114 & 311953 & 6.0726 & 6.0727 & TST & \\
\hline CHEMBL184739 & 311953 & 6.644 & 6.66100 & 00000000005 & TRN \\
\hline CHEMBL189092 & 311953 & 8.6198 & 8.5822 & TRN & \\
\hline CHEMBL362289 & 311953 & 7.2218 & 7.2271 & TRN & \\
\hline CHEMBL186081 & 311953 & 9.0 & 8.875 & TST & \\
\hline CHEMBL186983 & 311953 & 6.7077 & 6.732 & TRN & \\
\hline CHEMBL185704 & 311953 & 6.3019 & 6.2805 & TRN & \\
\hline CHEMBL186997 & 311953 & 6.4401 & 6.5269 & TST & \\
\hline CHEMBL188321 & 311953 & 4.5229 & 4.5205 & TRN & \\
\hline CHEMBL364159 & 311953 & 8.4318 & 8.4744 & TRN & \\
\hline CHEMBL426627 & 311953 & 5.6205 & 5.6793 & TRN & \\
\hline CHEMBL189702 & 311953 & 7.7212 & 7.7168 & TRN & \\
\hline CHEMBL365487 & 311953 & 7.2076 & 7.1979 & TRN & \\
\hline CHEMBL188356 & 311953 & 7.2441 & 7.4208 & TST & \\
\hline CHEMBL189406 & 311953 & 5.7867 & 5.7673 & TRN & \\
\hline CHEMBL188891 & 311953 & 6.1898 & 6.235 & TRN & \\
\hline CHEMBL188573 & 311953 & 6.0 & 5.9949 & TRN & \\
\hline CHEMBL189227 & 311953 & 4.5229 & 4.5222 & TRN & \\
\hline CHEMBL189648 & 311953 & 7.6576 & 7.6655 & TRN & \\
\hline CHEMBL361294 & 311953 & 5.6745 & 5.6821 & TRN & \\
\hline CHEMBL188724 & 311953 & 6.7905 & 6.7709 & TRN & \\
\hline CHEMBL185956 & 311953 & 6.0 & 6.0166 & TRN & \\
\hline CHEMBL186143 & 311953 & 7.1549 & 7.115 & TRN & \\
\hline CHEMBL189034 & 311953 & 6.8861 & 7.1471 & TST & \\
\hline CHEMBL188682 & 311953 & 7.8539 & 7.8684 & TRN & \\
\hline CHEMBL359983 & 311953 & 6.0 & 5.9996 & TRN & \\
\hline CHEMBL181650 & 311953 & 8.1487 & 8.135 & TRN & \\
\hline CHEMBL364121 & 311953 & 8.2441 & 8.2353 & TRN & \\
\hline CHEMBL187298 & 311953 & 4.5229 & 4.4901 & TRN & \\
\hline CHEMBL425183 & 311953 & 6.1945 & 6.1327 & TRN & \\
\hline CHEMBL362118 & 311953 & 7.1079 & 6.8668 & TST & \\
\hline CHEMBL185767 & 311953 & 5.9104 & 5.9282 & TRN & \\
\hline CHEMBL188939 & 311953 & 6.0 & 5.9518 & TRN & \\
\hline
\end{tabular}




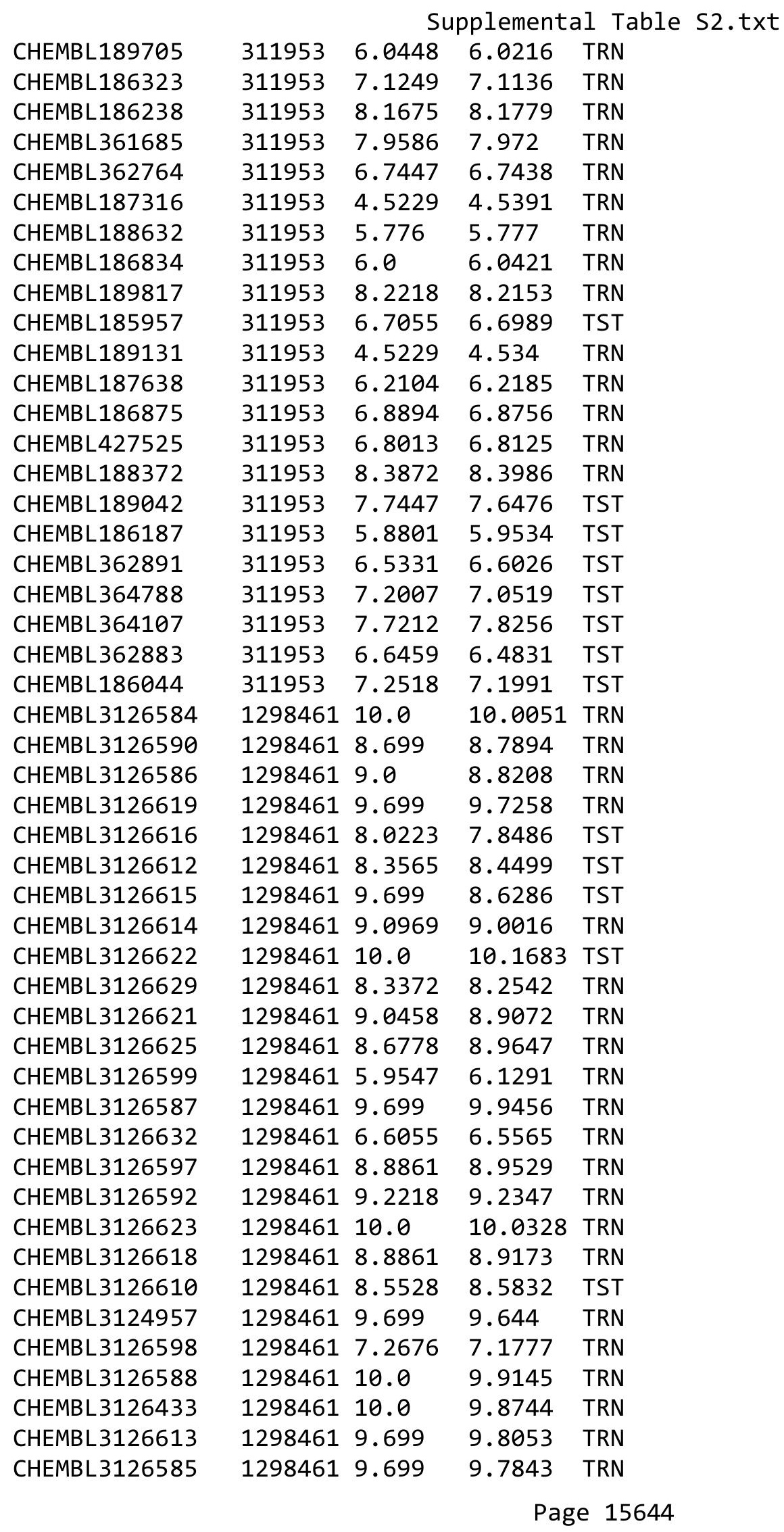


Supplemental Table S2.txt

\begin{tabular}{|c|c|c|c|c|c|}
\hline CHEMBL3126601 & 1298461 & 8.6778 & 8.613 & TRN & \\
\hline CHEMBL3126605 & 1298461 & 9.699 & 9.5526 & TRN & \\
\hline CHEMBL3126603 & 1298461 & 9.5229 & 9.668 & TRN & \\
\hline CHEMBL 3126602 & 1298461 & 9.1549 & 9.2572 & TRN & \\
\hline CHEMBL 3126604 & 1298461 & 8.7447 & 8.6701 & TRN & \\
\hline CHEMBL3126591 & 1298461 & 9.3979 & 9.3621 & TRN & \\
\hline CHEMBL3126630 & 1298461 & 8.4089 & 8.3254 & TRN & \\
\hline CHEMBL3126600 & 1298461 & 7.0655 & 7.351 & TRN & \\
\hline CHEMBL 3126593 & 1298461 & 8.7212 & 8.7233 & TRN & \\
\hline CHEMBL3126607 & 1298461 & 10.0 & 9.8701 & TRN & \\
\hline CHEMBL3126434 & 1298461 & 9.5229 & 9.0123 & TRN & \\
\hline CHEMBL3126596 & 1298461 & 9.0458 & 9.192 & TRN & \\
\hline CHEMBL3126606 & 1298461 & 8.0757 & 8.0211 & TRN & \\
\hline CHEMBL 3126436 & 1298461 & 10.0 & 10.2338 & TRN & \\
\hline CHEMBL3126608 & 1298461 & 9.5229 & 9.307 & TRN & \\
\hline CHEMBL3126435 & 1298461 & 9.3979 & 9.5343 & TRN & \\
\hline CHEMBL3126617 & 1298461 & 9.301 & 9.9751 & TST & \\
\hline CHEMBL 3126620 & 1298461 & 10.0 & 9.1587 & TST & \\
\hline CHEMBL 3126624 & 1298461 & 9.699 & 10.1246 & TST & \\
\hline CHEMBL3126631 & 1298461 & 7.6383 & 7.411000 & 00000000005 & TST \\
\hline CHEMBL3126611 & 1298461 & 9.699 & 9.383 & TST & \\
\hline CHEMBL3126609 & 1298461 & 7.6383 & 8.4748 & TST & \\
\hline CHEMBL3126589 & 1298461 & 9.5229 & 9.8684 & TST & \\
\hline CHEMBL 3126626 & 1298461 & 9.1549 & 9.5932 & TST & \\
\hline CHEMBL372956 & 1640188 & 8.6861 & 8.4958 & TRN & \\
\hline CHEMBL3959350 & 1640188 & 7.5229 & 7.2836 & TRN & \\
\hline CHEMBL3955803 & 1640188 & 8.9031 & 8.8314 & TRN & \\
\hline CHEMBL190142 & 1640188 & 8.8416 & 8.6185 & TRN & \\
\hline CHEMBL3904655 & 1640188 & 8.6216 & 8.7147 & TRN & \\
\hline CHEMBL3972799 & 1640188 & 9.15299 & 999999999 & 9.0713 & TRN \\
\hline CHEMBL550453 & 1640188 & 8.1068 & 8.3382 & TRN & \\
\hline CHEMBL557915 & 1640188 & 8.7773 & 8.854 & TRN & \\
\hline CHEMBL 383361 & 1640188 & 9.0259 & 9.0791 & TRN & \\
\hline CHEMBL 3958789 & 1640188 & 8.4815 & 8.5234 & TRN & \\
\hline CHEMBL3961484 & 1640188 & 9.0926 & 8.971 & TRN & \\
\hline CHEMBL93087 & 1640188 & 7.1397 & 7.1404 & TST & \\
\hline CHEMBL316053 & 1640188 & 7.4237 & 7.2529 & TST & \\
\hline CHEMBL196551 & 1640188 & 8.0721 & 8.0143 & TRN & \\
\hline CHEMBL198654 & 1640188 & 8.3298 & 8.4545 & TRN & \\
\hline CHEMBL370614 & 1640188 & 8.9788 & 8.8499 & TRN & \\
\hline CHEMBL564248 & 1640188 & 8.8356 & 8.9092 & TRN & \\
\hline CHEMBL3907419 & 1640188 & 8.3401 & 8.5396 & TRN & \\
\hline CHEMBL 372568 & 1640188 & 6.4342 & 6.4829 & TRN & \\
\hline CHEMBL 364284 & 1640188 & 9.7235 & 9.7165 & TRN & \\
\hline CHEMBL196539 & 1640188 & 9.1325 & 9.1509 & TRN & \\
\hline CHEMBL 3986101 & 1640188 & 9.0088 & 9.0593 & TRN & \\
\hline CHEMBL196589 & 1640188 & 7.0311 & 7.2533 & TRN & \\
\hline CHEMBL1235423 & 1640188 & 7.5622 & 7.2953 & TST & \\
\hline
\end{tabular}


Supplemental Table S2.txt

\begin{tabular}{|c|c|c|c|c|}
\hline CHEMBL3979386 & 1640188 & 8.9872 & 8.958 & TRN \\
\hline CHEMBL194810 & 1640188 & 7.8697 & 7.9551 & TRN \\
\hline CHEMBL3910588 & 1640188 & 9.15 & 9.008 & TRN \\
\hline CHEMBL3304291 & 1640188 & 8.2899 & 8.6034 & TRN \\
\hline CHEMBL196492 & 1640188 & 8.3585 & 8.1655 & TRN \\
\hline CHEMBL370176 & 1640188 & 6.7773 & 6.9791 & TRN \\
\hline CHEMBL3956658 & 1640188 & 8.1373 & 8.3387 & TRN \\
\hline CHEMBL3942651 & 1640188 & 5.4763 & 5.6335 & TST \\
\hline CHEMBL194186 & 1640188 & 9.1945 & 9.0774 & TRN \\
\hline CHEMBL3968842 & 1640188 & 8.5243 & 8.6722 & TRN \\
\hline CHEMBL48813 & 1640188 & 8.8153 & 8.7438 & TST \\
\hline CHEMBL436293 & 1640188 & 7.1343 & 6.9182 & TRN \\
\hline CHEMBL194889 & 1640188 & 6.3862 & 6.3504 & TRN \\
\hline CHEMBL3305961 & 1640188 & 7.6778 & 7.902 & TRN \\
\hline CHEMBL197547 & 1640188 & 7.4034 & 7.3061 & TRN \\
\hline CHEMBL196162 & 1640188 & 8.4547 & 7.6898 & TRN \\
\hline CHEMBL198421 & 1640188 & 6.6216 & 6.7279 & TRN \\
\hline CHEMBL3928201 & 1640188 & 7.644 & 7.4537 & TST \\
\hline CHEMBL381866 & 1640188 & 8.3893 & 8.4301 & TRN \\
\hline CHEMBL3960154 & 1640188 & 9.1931 & 9.0354 & TST \\
\hline CHEMBL371106 & 1640188 & 7.5544 & 7.7624 & TRN \\
\hline CHEMBL3974641 & 1640188 & 7.5436 & 7.3876 & TST \\
\hline CHEMBL120413 & 1640188 & 7.3325 & 6.8937 & TST \\
\hline CHEMBL3957468 & 1640188 & 7.9208 & 7.9937 & TRN \\
\hline CHEMBL3966335 & 1640188 & 6.1169 & 6.0497 & TST \\
\hline CHEMBL197377 & 1640188 & 9.2306 & 9.1112 & TRN \\
\hline CHEMBL3912108 & 1640188 & 8.8539 & 8.4715 & TST \\
\hline CHEMBL196669 & 1640188 & 5.2472 & 5.3552 & TST \\
\hline CHEMBL197624 & 1640188 & 7.4841 & 7.4335 & TST \\
\hline CHEMBL3972969 & 1640188 & 8.1612 & 8.3516 & TST \\
\hline CHEMBL 3582080 & 1499863 & 7.3468 & 7.313 & TRN \\
\hline CHEMBL3582052 & 1499863 & 5.9666 & 5.9256 & TRN \\
\hline CHEMBL2236603 & 1499863 & 6.8539 & 6.6947 & TRN \\
\hline CHEMBL3582071 & 1499863 & 6.7212 & 7.0853 & TRN \\
\hline CHEMBL3582056 & 1499863 & 7.4685 & 7.9104 & TRN \\
\hline CHEMBL3582067 & 1499863 & 6.5686 & 6.48 & TRN \\
\hline CHEMBL3582062 & 1499863 & 8.0 & 7.5378 & TRN \\
\hline CHEMBL3582082 & 1499863 & 6.3979 & 6.5308 & TST \\
\hline CHEMBL3582039 & 1499863 & 6.5528 & 6.3441 & TRN \\
\hline CHEMBL3582044 & 1499863 & 5.6576 & 6.1729 & TRN \\
\hline CHEMBL3582079 & 1499863 & 7.3468 & 6.9195 & TRN \\
\hline CHEMBL3582040 & 1499863 & 3.4318 & 3.4125 & TRN \\
\hline CHEMBL3582063 & 1499863 & 5.4949 & 6.1412 & TRN \\
\hline CHEMBL2236598 & 1499863 & 5.3098 & 5.3192 & TRN \\
\hline CHEMBL3582054 & 1499863 & 4.6007 & 4.6464 & TRN \\
\hline CHEMBL3582048 & 1499863 & 2.9547 & 3.14899 & 99999999996 \\
\hline CHEMBL3582078 & 1499863 & 5.4559 & 4.2796 & TST \\
\hline CHEMBL3582070 & 1499863 & 7.7447 & 7.7198 & TRN \\
\hline
\end{tabular}

Page 15646 
Supplemental Table S2.txt

\begin{tabular}{|c|c|c|c|c|c|}
\hline CHEMBL 2236600 & 1499863 & 6.6021 & 6.6704 & TRN & \\
\hline CHEMBL 3582060 & 1499863 & 6.2924 & 6.4749 & TRN & \\
\hline CHEMBL3582049 & 1499863 & 4.4949 & 4.6014 & TRN & \\
\hline CHEMBL3582057 & 1499863 & 7.7959 & 7.8459 & TRN & \\
\hline CHEMBL 3582058 & 1499863 & 6.2676 & 6.2046 & TRN & \\
\hline CHEMBL3582065 & 1499863 & 6.6576 & 6.5381 & TRN & \\
\hline CHEMBL3582069 & 1499863 & 7.301 & 7.6156 & TRN & \\
\hline CHEMBL3582072 & 1499863 & 7.0177 & 6.8519 & TRN & \\
\hline CHEMBL3582068 & 1499863 & 5.1549 & 5.0301 & TRN & \\
\hline CHEMBL 3582043 & 1499863 & 3.4318 & 3.4999 & TRN & \\
\hline CHEMBL3582076 & 1499863 & 4.4949 & 4.3713 & TRN & \\
\hline CHEMBL 2236589 & 1499863 & 5.8539 & 5.895 & TRN & \\
\hline CHEMBL3582066 & 1499863 & 5.6383 & 5.3689 & TRN & \\
\hline CHEMBL 2236601 & 1499863 & 7.7212 & 7.7915 & TRN & \\
\hline CHEMBL 3582073 & 1499863 & 6.8861 & 6.8964 & TST & \\
\hline CHEMBL3582051 & 1499863 & 5.8861 & 5.5657 & TRN & \\
\hline CHEMBL3582053 & 1499863 & 5.5086 & 5.44600 & 0000000001 & TRN \\
\hline CHEMBL 3238130 & 1499863 & 7.0969 & 6.8094 & TST & \\
\hline CHEMBL 3582045 & 1499863 & 5.4318 & 4.7741 & TRN & \\
\hline CHEMBL497501 & 1499863 & 7.9208 & 7.1191 & TST & \\
\hline CHEMBL 3582041 & 1499863 & 5.8539 & 5.8022 & TRN & \\
\hline CHEMBL 2236602 & 1499863 & 4.7959 & 4.8064 & TRN & \\
\hline CHEMBL3582075 & 1499863 & 3.9208 & 4.3522 & TRN & \\
\hline CHEMBL3582064 & 1499863 & 6.9586 & 6.8712 & TRN & \\
\hline CHEMBL498713 & 1499863 & 7.4815 & 7.6795 & TST & \\
\hline CHEMBL 3582038 & 1499863 & 6.1549 & 5.8092 & TRN & \\
\hline CHEMBL 3582047 & 1499863 & 4.9586 & 5.1359 & TRN & \\
\hline CHEMBL3582050 & 1499863 & 2.9547 & 3.0732 & TRN & \\
\hline CHEMBL2236599 & 1499863 & 7.8239 & 6.8407 & TST & \\
\hline CHEMBL 3582077 & 1499863 & 4.8539 & 4.5769 & TST & \\
\hline CHEMBL3582059 & 1499863 & 6.3468 & 7.9558 & TST & \\
\hline CHEMBL 3582061 & 1499863 & 6.1938 & 5.8056 & TST & \\
\hline CHEMBL2236588 & 1499863 & 7.4202 & 7.9486 & TST & \\
\hline CHEMBL3582081 & 1499863 & 4.7959 & 6.8283 & TST & \\
\hline CHEMBL 3582042 & 1499863 & 3.4318 & 4.0608 & TST & \\
\hline CHEMBL3582046 & 1499863 & 5.2596 & 5.2474 & TST & \\
\hline CHEMBL 3948059 & 1536038 & 9.5302 & 9.5359 & TRN & \\
\hline CHEMBL3695553 & 1536038 & 8.7122 & 8.786 & TST & \\
\hline CHEMBL 3691461 & 1536038 & 9.1778 & 8.7502 & TST & \\
\hline CHEMBL 3695542 & 1536038 & 8.2832 & 8.2785 & TRN & \\
\hline CHEMBL3904129 & 1536038 & 9.2684 & 9.2643 & TRN & \\
\hline CHEMBL 3695567 & 1536038 & 8.5607 & 8.5614 & TRN & \\
\hline CHEMBL 3691392 & 1536038 & 8.5969 & 8.5956 & TRN & \\
\hline CHEMBL 3695561 & 1536038 & 8.9431 & 8.9357 & TRN & \\
\hline CHEMBL3691394 & 1536038 & 8.8508 & 8.8462 & TRN & \\
\hline CHEMBL3691454 & 1536038 & 6.0 & 6.023 & TRN & \\
\hline CHEMBL 3695560 & 1536038 & 8.4672 & 8.4679 & TRN & \\
\hline CHEMBL 3695557 & 1536038 & 9.3696 & 9.3703 & TRN & \\
\hline
\end{tabular}


Supplemental Table S2.txt

\begin{tabular}{|c|c|c|c|c|}
\hline W & & & & \\
\hline HEMBL3890184 & & 9.6596 & & \\
\hline 96 & & & & \\
\hline AEMBL & 38 & & & \\
\hline HEMBL & 36038 & 6.0 & & \\
\hline HEMBL3691419 & 536038 & 8.4855 & 855 & \\
\hline 944 & 338 & & & \\
\hline 555 & & & & \\
\hline AEMBL3691465 & 536038 & 6.0 & & \\
\hline HEMBL3896811 & 36038 & 9. & & \\
\hline HEMBL3691409 & 6038 & & 46 & \\
\hline IEMBL36 & & 77 & 42 & \\
\hline IEMBL3 & & & & \\
\hline AEMBL3982111 & 536038 & 10.1096 & 10.113 & \\
\hline AEMBL36 & 6038 & 388 & & \\
\hline AEMBL3691390 & 38 & 9 & 41 & \\
\hline AEMBL3 & & & 32 & \\
\hline AEMBL3 & & & & \\
\hline AEMBL3S & 338 & 9. & 9.3154 & \\
\hline AEMBL3S & 38 & & & \\
\hline AEMBL: & 38 & & 17 & 1SI \\
\hline AEMBL & & & & RN \\
\hline HEMBL; & & & & \\
\hline 937 & & 9. & & \\
\hline AEMBL3S & & & & I RIV \\
\hline AEMBL & 38 & & & | \\
\hline AEMBL & & & & NIV \\
\hline AFMRI : & 38 & & & \\
\hline AEMBL3 & & & & RIV \\
\hline HEMBL3960644 & 38 & & & I RN \\
\hline HEMBL3 & 360 & & & RN \\
\hline HEMBL & & & & RN \\
\hline 19 & 38 & 8 & 24 & 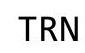 \\
\hline HEMBL3695515 & & & & is \\
\hline HEMBL3908866 & 36038 & & & TR \\
\hline HEMBL36 & 38 & & & $\mid$ \\
\hline HCMP - & & 16 & 9. & ST \\
\hline HEMBL & & 8 . & & IST \\
\hline HEMBL3960909 & 536038 & 8.5346 & 351 & TRN \\
\hline HEMBL 390 & 36038 & 9 . & & RN \\
\hline HEMBL38 & 6038 & 041 & & \\
\hline HEMBL3695496 & & & 7.9425 & זית \\
\hline HEMBL3983637 & 536038 & 9.4622 & & TRN \\
\hline AEMBL3691444 & 536038 & 8.2197 & 8.1024 & rS \\
\hline 1. & 0 & 9 & 7.2192 & IS \\
\hline HEMBL36 & & & & \\
\hline HEMBL 36 & & 3.342 & 8.2068 & \\
\hline CHEMBL3957010 & 1536038 & 9.4157 & 9.4184 & ГRN \\
\hline
\end{tabular}

Page 15648 
Supplemental Table S2.txt

\begin{tabular}{|c|c|c|c|c|c|}
\hline CHEMBL 3695564 & 1536038 & 9.5901 & 9.5914 & TRN & \\
\hline CHEMBL3695536 & 1536038 & 9.0 & 8.8565 & TST & \\
\hline CHEMBL3695563 & 1536038 & 9.5768 & 9.58 & TRN & \\
\hline CHEMBL3964235 & 1536038 & 9.5544 & 9.5596 & TRN & \\
\hline CHEMBL3892187 & 1536038 & 7.8601 & 7.86 & TRN & \\
\hline CHEMBL1459300 & 1301881 & 3.5229 & 3.5204 & TRN & \\
\hline CHEMBL 2141104 & 1301881 & 3.5229 & 3.5095 & TRN & \\
\hline CHEMBL1316018 & 1301881 & 3.5229 & 3.5306 & TRN & \\
\hline CHEMBL1713168 & 1301881 & 4.5272 & 4.5224 & TRN & \\
\hline CHEMBL1425879 & 1301881 & 3.5229 & 3.5287 & TRN & \\
\hline CHEMBL 2133259 & 1301881 & 3.5229 & 2.9825 & TST & \\
\hline CHEMBL1512350 & 1301881 & 3.5229 & 3.5222 & TRN & \\
\hline CHEMBL1346363 & 1301881 & 3.5229 & 3.5339 & TRN & \\
\hline CHEMBL1371396 & 1301881 & 5.6517 & 3.4352 & TST & \\
\hline CHEMBL 2143030 & 1301881 & 4.558 & 4.5662 & TRN & \\
\hline CHEMBL1504645 & 1301881 & 3.5229 & 3.5177 & TRN & \\
\hline CHEMBL1506296 & 1301881 & 3.5229 & 3.5116 & TRN & \\
\hline CHEMBL1726836 & 1301881 & 3.5229 & 3.5234 & TRN & \\
\hline CHEMBL3188716 & 1301881 & 3.5229 & 3.8134 & TST & \\
\hline CHEMBL1719984 & 1301881 & 3.5229 & 3.5347 & TRN & \\
\hline CHEMBL1374123 & 1301881 & 3.5229 & 3.5272 & TRN & \\
\hline CHEMBL2136014 & 1301881 & 4.6617 & 4.6628 & TRN & \\
\hline CHEMBL1301892 & 1301881 & 3.5229 & \multicolumn{2}{|c|}{ 3. 5189999999999997} & TRN \\
\hline CHEMBL1523953 & 1301881 & 4.758 & 4.7535 & TRN & \\
\hline CHEMBL1732851 & 1301881 & 3.5229 & 3.525 & TRN & \\
\hline CHEMBL1468539 & 1301881 & 3.5229 & 3.5223 & TRN & \\
\hline CHEMBL1489752 & 1301881 & 4.8274 & 4.8279 & TRN & \\
\hline CHEMBL 250711 & 1301881 & 4.7421 & 4.7428 & TRN & \\
\hline CHEMBL1717489 & 1301881 & 3.5229 & 4.7915 & TST & \\
\hline CHEMBL1502562 & 1301881 & 3.5229 & 3.5299 & TRN & \\
\hline CHEMBL 3187780 & 1301881 & 3.5229 & 3.5245 & TRN & \\
\hline CHEMBL2135963 & 1301881 & 4.6007 & 4.199 & TST & \\
\hline CHEMBL2360179 & 1301881 & 3.5229 & 3.5167 & TRN & \\
\hline CHEMBL1368400 & 1301881 & 3.5229 & 3.8364 & TST & \\
\hline CHEMBL1880572 & 1301881 & 3.5229 & 3.5257 & TRN & \\
\hline CHEMBL2139733 & 1301881 & 3.5229 & 3.5203 & TRN & \\
\hline CHEMBL1499964 & 1301881 & 5.058 & 5.0569 & TRN & \\
\hline CHEMBL1348501 & 1301881 & 3.5229 & 3.5229 & TRN & \\
\hline CHEMBL1598399 & 1301881 & 3.5229 & \multicolumn{2}{|c|}{3.5189999999999997} & TRN \\
\hline CHEMBL1306645 & 1301881 & 3.5229 & 3.4968 & TRN & \\
\hline CHEMBL477936 & 1301881 & 5.3778 & 5.3832 & TRN & \\
\hline CHEMBL1464810 & 1301881 & 3.5229 & 3.525 & TRN & \\
\hline CHEMBL1879779 & 1301881 & 3.5229 & 3.5169 & TRN & \\
\hline CHEMBL1340850 & 1301881 & 3.5229 & 3.523 & TRN & \\
\hline CHEMBL578329 & 1301881 & 4.6271 & 4.6263 & TRN & \\
\hline CHEMBL1333944 & 1301881 & 3.5229 & 3.5173 & TRN & \\
\hline CHEMBL1471489 & 1301881 & 3.5229 & 3.5127 & TRN & \\
\hline CHEMBL1723784 & 1301881 & 3.5229 & 3.5228 & TRN & \\
\hline
\end{tabular}

Page 15649 
Supplemental Table S2.txt

\begin{tabular}{|c|c|c|c|c|}
\hline 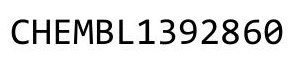 & & & & \\
\hline & & & & \\
\hline 12 & & & & \\
\hline EMBL & 881 & 075 & 091 & \\
\hline AEMBL1481652 & 301881 & 5758 & 5719 & \\
\hline HEMBL 2134842 & 301881 & 3.5229 & 5298 & \\
\hline 917 & 81 & 229 & 228 & \\
\hline IEMBL 3187171 & & & & \\
\hline HEMBL2139297 & 301881 & 3.5229 & 5267 & \\
\hline HEMBL1709306 & 301881 & 229 & 263 & \\
\hline AEMBL21241 & 301881 & 024 & 2979 & \\
\hline IEMBL1 & 81 & & 249 & \\
\hline AEMBL 213 & & & & \\
\hline HEMBL1894479 & 301881 & 3.5229 & 5335 & \\
\hline HEMBL1323487 & 301881 & & & \\
\hline HEMBL158 & 81 & & 214 & ГRN \\
\hline AEMBL & 31 & & & 年 \\
\hline AEMBL1 & 81 & & 49 & \\
\hline HEMBL1507117 & 81 & & 546 & \\
\hline AEMBL418068 & 81 & 29 & 176 & I KIV \\
\hline HEMBL & 36 & & 342 & ГRN \\
\hline HEMBL & $\perp$ & & 97 & MIV \\
\hline AEMBL & 81 & & 222 & \\
\hline HEMBL156 & & & & \\
\hline AEMBL1733106 & 81 & 3. & 52 & RN \\
\hline AEMBL1 & 81 & & 746 & RN \\
\hline HEM & & & 13 & KIV \\
\hline 31 & & & & RN \\
\hline HEMBL150 & & & & IRN \\
\hline HEMBL1884108 & 381 & 3. & 238 & TRN \\
\hline AEMBL154 & 30 & & 95 & TRN \\
\hline JEN & & & & 「RN \\
\hline 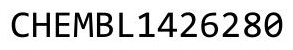 & & & & ST \\
\hline AEMBL 2356 & 31 & & 198 & 「RN \\
\hline AEMBL1 & 381 & 29 & & RN \\
\hline 1 & 30 & & & TRN \\
\hline 10 & & & & ГRN \\
\hline HEMBL1 & & & & RN \\
\hline HEMBL1605764 & 30 & 29 & 267 & ГRN \\
\hline$T 16$ & 81 & & & RN \\
\hline HEMBL1 & 30 & & 45 & TRN \\
\hline HEMBL1444560 & & 29 & 196 & 「RN \\
\hline HEMBL1 & 381 & 29 & & $\mathrm{R}$ \\
\hline HEMBL1 & 81 & 59 & & TS \\
\hline CHEMBL1724900 & & & & \\
\hline HEMBL1471166 & 130 & & & \\
\hline HEMBL 1447881 & 130 & .5229 & 5277 & RN \\
\hline LHEMBL1905013 & 1301881 & 3.5229 & 4.1535 & TST \\
\hline
\end{tabular}

Page 15650 
Supplemental Table S2.txt

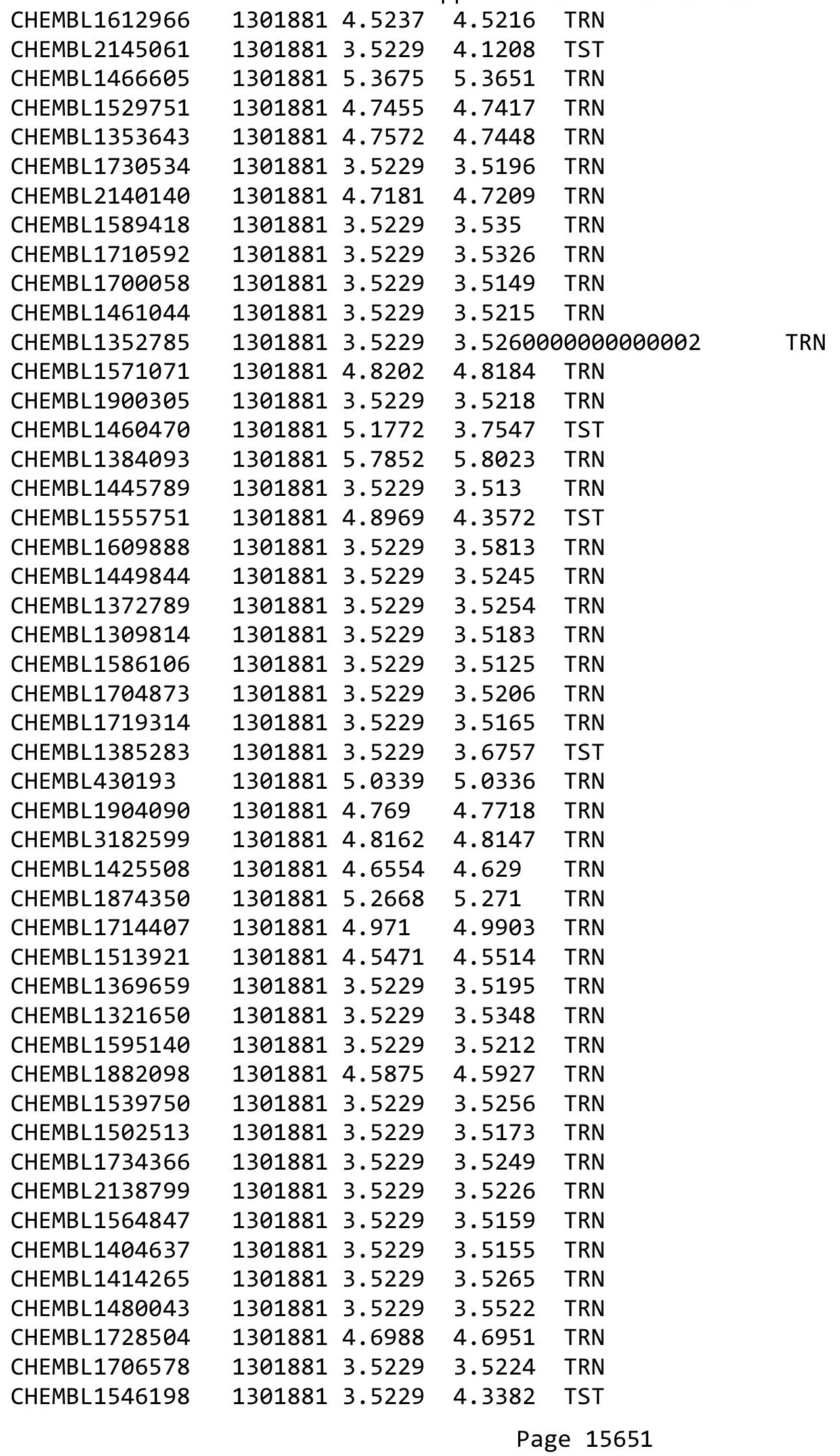


Supplemental Table S2.txt

\begin{tabular}{|c|c|c|c|c|}
\hline CHEMBL1409702 & 1301881 & 3.5229 & 3.5177 & TRN \\
\hline CHEMBL1461325 & 1301881 & 3.5229 & 4.2357 & TST \\
\hline CHEMBL1542137 & 1301881 & 3.5229 & 3.5246 & TRN \\
\hline CHEMBL1361287 & 1301881 & 3.5229 & 3.5279 & TRN \\
\hline CHEMBL1347992 & 1301881 & 4.5525 & 4.5564 & TRN \\
\hline CHEMBL 2142038 & 1301881 & 4.601 & 4.5984 & TRN \\
\hline CHEMBL1728975 & 1301881 & 3.5229 & 3.5308 & TRN \\
\hline CHEMBL1500095 & 1301881 & 3.5229 & 3.5197 & TRN \\
\hline CHEMBL3188164 & 1301881 & 3.5229 & 3.5246 & TRN \\
\hline CHEMBL1733603 & 1301881 & 3.5229 & 3.5261 & TRN \\
\hline CHEMBL1349324 & 1301881 & 4.5991 & 4.5992 & TRN \\
\hline CHEMBL1491012 & 1301881 & 3.5229 & 3.5169 & TRN \\
\hline CHEMBL1256695 & 1301881 & 3.5229 & 3.52100 & 00000000004 \\
\hline CHEMBL1388392 & 1301881 & 3.5229 & 3.4773 & TRN \\
\hline CHEMBL1711272 & 1301881 & 3.5229 & 3.5293 & TRN \\
\hline CHEMBL1426779 & 1301881 & 3.5229 & 3.5238 & TRN \\
\hline CHEMBL1874338 & 1301881 & 3.5229 & 3.5197 & TRN \\
\hline CHEMBL1389801 & 1301881 & 3.5229 & 3.5164 & TRN \\
\hline CHEMBL1575990 & 1301881 & 3.5229 & 3.5248 & TRN \\
\hline CHEMBL1586329 & 1301881 & 3.5229 & 3.676 & TST \\
\hline CHEMBL1610382 & 1301881 & 4.8681 & 4.5856 & TST \\
\hline CHEMBL1590885 & 1301881 & 3.5229 & 3.4816 & TST \\
\hline CHEMBL 2133541 & 1301881 & 3.5229 & 3.6111 & TST \\
\hline CHEMBL1414432 & 1301881 & 3.5229 & 3.24399 & 99999999998 \\
\hline CHEMBL1886244 & 1301881 & 3.5229 & 4.1417 & TST \\
\hline CHEMBL1711008 & 1301881 & 3.5229 & 3.9729 & TST \\
\hline CHEMBL1471317 & 1301881 & 4.5769 & 3.3452 & TST \\
\hline CHEMBL3185460 & 1301881 & 3.5229 & 3.412 & TST \\
\hline CHEMBL1413866 & 1301881 & 5.3391 & 4.029 & TST \\
\hline CHEMBL1456929 & 1301881 & 4.6649 & 4.234 & TST \\
\hline CHEMBL1730412 & 1301881 & 3.5229 & 4.4573 & TST \\
\hline CHEMBL1372387 & 1301881 & 5.295 & 3.9768 & TST \\
\hline CHEMBL3188598 & 1301881 & 3.5229 & 3.7945 & TST \\
\hline CHEMBL1527791 & 1301881 & 3.5229 & 3.3343 & TST \\
\hline CHEMBL1455871 & 1301881 & 3.5229 & 3.57800 & 00000000003 \\
\hline CHEMBL1570961 & 1301881 & 4.7464 & 4.5894 & TST \\
\hline CHEMBL1423883 & 1301881 & 3.5229 & 4.0 & TST \\
\hline CHEMBL1729254 & 1301881 & 4.8035 & 4.1485 & TST \\
\hline CHEMBL1369654 & 1301881 & 4.8077 & 4.8981 & TST \\
\hline CHEMBL1389365 & 1301881 & 3.5229 & 3.8066 & TST \\
\hline CHEMBL1336699 & 1301881 & 4.5706 & 4.0123 & TST \\
\hline CHEMBL1376190 & 1301881 & 3.5229 & 4.5819 & TST \\
\hline CHEMBL1398901 & 1301881 & 3.5229 & 3.7087 & TST \\
\hline CHEMBL3181799 & 1301881 & 4.8989 & 4.5567 & TST \\
\hline CHEMBL1700602 & 1301881 & 3.5229 & 4.1865 & TST \\
\hline CHEMBL1327345 & 1301881 & 3.5229 & 3.648 & TST \\
\hline CHEMBL1867232 & 1301881 & 3.5229 & 4.5407 & TST \\
\hline CHEMBL267287 & 223295 & 5.699 & 5.7718 & TST \\
\hline
\end{tabular}




\begin{tabular}{|c|c|}
\hline CHEMBL 7107 & 223295 \\
\hline CHEMBL 7099 & 223295 \\
\hline CHEMBL275295 & 223295 \\
\hline CHEMBL266116 & 223295 \\
\hline CHEMBL7097 & 223295 \\
\hline CHEMBL 7145 & 223295 \\
\hline CHEMBL7399 & 223295 \\
\hline CHEMBL7727 & 223295 \\
\hline CHEMBL440452 & 223295 \\
\hline CHEMBL 7678 & 223295 \\
\hline CHEMBL269760 & 223295 \\
\hline CHEMBL 7745 & 223295 \\
\hline CHEMBL266777 & 223295 \\
\hline CHEMBL 7517 & 223295 \\
\hline CHEMBL267470 & 223295 \\
\hline CHEMBL268586 & 223295 \\
\hline CHEMBL267867 & 223295 \\
\hline CHEMBL 7696 & 223295 \\
\hline CHEMBL 7273 & 223295 \\
\hline CHEMBL 7267 & 223295 \\
\hline CHEMBL 7619 & 223295 \\
\hline CHEMBL 7685 & 223295 \\
\hline CHEMBL 7123 & 223295 \\
\hline CHEMBL7711 & 223295 \\
\hline CHEMBL266721 & 223295 \\
\hline CHEMBL269588 & 223295 \\
\hline CHEMBL 266547 & 223295 \\
\hline CHEMBL266053 & 223295 \\
\hline CHEMBL267472 & 223295 \\
\hline CHEMBL412900 & 223295 \\
\hline CHEMBL 7445 & 223295 \\
\hline CHEMBL 266052 & 223295 \\
\hline CHEMBL7734 & 223295 \\
\hline CHEMBL266592 & 223295 \\
\hline CHEMBL267272 & 223295 \\
\hline CHEMBL7657 & 223295 \\
\hline CHEMBL 274302 & 223295 \\
\hline CHEMBL7311 & 223295 \\
\hline CHEMBL 7507 & 223295 \\
\hline CHEMBL273767 & 223295 \\
\hline CHEMBL 7660 & 223295 \\
\hline CHEMBL 7477 & 223295 \\
\hline CHEMBL 7589 & 223295 \\
\hline CHEMBL7351 & 223295 \\
\hline CHEMBL 7601 & 223295 \\
\hline CHEMBL 7647 & 223295 \\
\hline CHEMBL 7606 & 223295 \\
\hline CHEMBL 7491 & 223295 \\
\hline
\end{tabular}

Supplemental Table S2.txt

6.49496 .5552 TRN

$\begin{array}{lll}5.5528 & 5.4999 & \text { TRN }\end{array}$

$\begin{array}{lll}6.1367 & 4.959 & \text { TST }\end{array}$

$\begin{array}{lll}7.7212 & 7.7849 & \text { TRN }\end{array}$

$\begin{array}{lll}7.1675 & 7.24 & \text { TRN }\end{array}$

$\begin{array}{llll}6.9208 & 6.8356 & \text { TRN }\end{array}$

$\begin{array}{llll}6.5376 & 6.5855 & \text { TRN }\end{array}$

$\begin{array}{llll}6.3188 & 6.2917 & \text { TRN }\end{array}$

$\begin{array}{lll}6.3768 & 6.3895 & \text { TRN }\end{array}$

$\begin{array}{llll}7.1805 & 7.307 & \text { TRN }\end{array}$

$\begin{array}{llll}6.7447 & 6.6971 & \text { TRN }\end{array}$

$\begin{array}{llll}6.7959 & 6.8029 & \text { TRN }\end{array}$

$\begin{array}{lll}7.5528 & 7.5184 & \text { TRN }\end{array}$

$\begin{array}{lll}5.585 & 5.5531 & \text { TRN }\end{array}$

$\begin{array}{lll}5.8539 & 5.9658 \text { TRN }\end{array}$

$\begin{array}{lll}6.5376 & 6.4954 & \text { TRN }\end{array}$

$\begin{array}{llll}5.9208 & 5.8862 & \text { TRN }\end{array}$

$\begin{array}{llll}5.3979 & 5.6044 & \text { TST }\end{array}$

$\begin{array}{lll}7.7212 & 7.6159 & \text { TRN }\end{array}$

$8.0458 \quad 8.0772$ TRN

6.85396 .7195 TRN

$\begin{array}{lll}7.3279 & 7.3995 & \text { TRN }\end{array}$

$\begin{array}{lll}5.0 & 5.0905 & \text { TRN }\end{array}$

$\begin{array}{lll}6.5376 & 6.5259 & \text { TRN }\end{array}$

$\begin{array}{llll}7.5528 & 7.6133 & \text { TRN }\end{array}$

$\begin{array}{llll}6.3665 & 6.3423 & \text { TRN }\end{array}$

$\begin{array}{llll}7.2218 & 7.1667 & \text { TRN }\end{array}$

$\begin{array}{llll}7.2441 & 7.2908 & \text { TRN }\end{array}$

$\begin{array}{lll}6.0 & 6.0471 & \text { TRN }\end{array}$

$\begin{array}{lll}6.5528 & 6.6044 & \text { TRN }\end{array}$

$\begin{array}{llll}4.4815 & 4.4599 & \text { TRN }\end{array}$

$\begin{array}{lll}7.1487 & 7.1494 & \text { TRN }\end{array}$

$6.9208 \quad 6.9372$ TRN

6.52295 .7086 TST

$\begin{array}{llll}6.3279 & 6.3394 & \text { TRN }\end{array}$

$\begin{array}{llll}6.8539 & 6.7613 & \text { TRN }\end{array}$

5.49495 .5393 TRN

$\begin{array}{llll}5.2924 & 5.3273 & \text { TRN }\end{array}$

$6.1024 \quad 5.1648$ TST

$\begin{array}{lll}7.2924 & 7.1023 & \text { TRN }\end{array}$

$\begin{array}{lll}5.0969 & 5.7399 & \text { TST }\end{array}$

$\begin{array}{lll}7.1871 & 7.2169 & \text { TRN }\end{array}$

$\begin{array}{llll}5.8539 & 5.8053 & \text { TRN }\end{array}$

$\begin{array}{lll}7.2596 & 7.4392 & \text { TST }\end{array}$

$\begin{array}{llll}6.8861 & 6.4596 & \text { TST }\end{array}$

$\begin{array}{lll}6.9208 & 6.792000000000001 & \text { TST }\end{array}$

$5.6778 \quad 5.9676 \quad$ TST

$\begin{array}{lll}6.5528 & 6.4529 & \text { TST }\end{array}$

Page 15653 


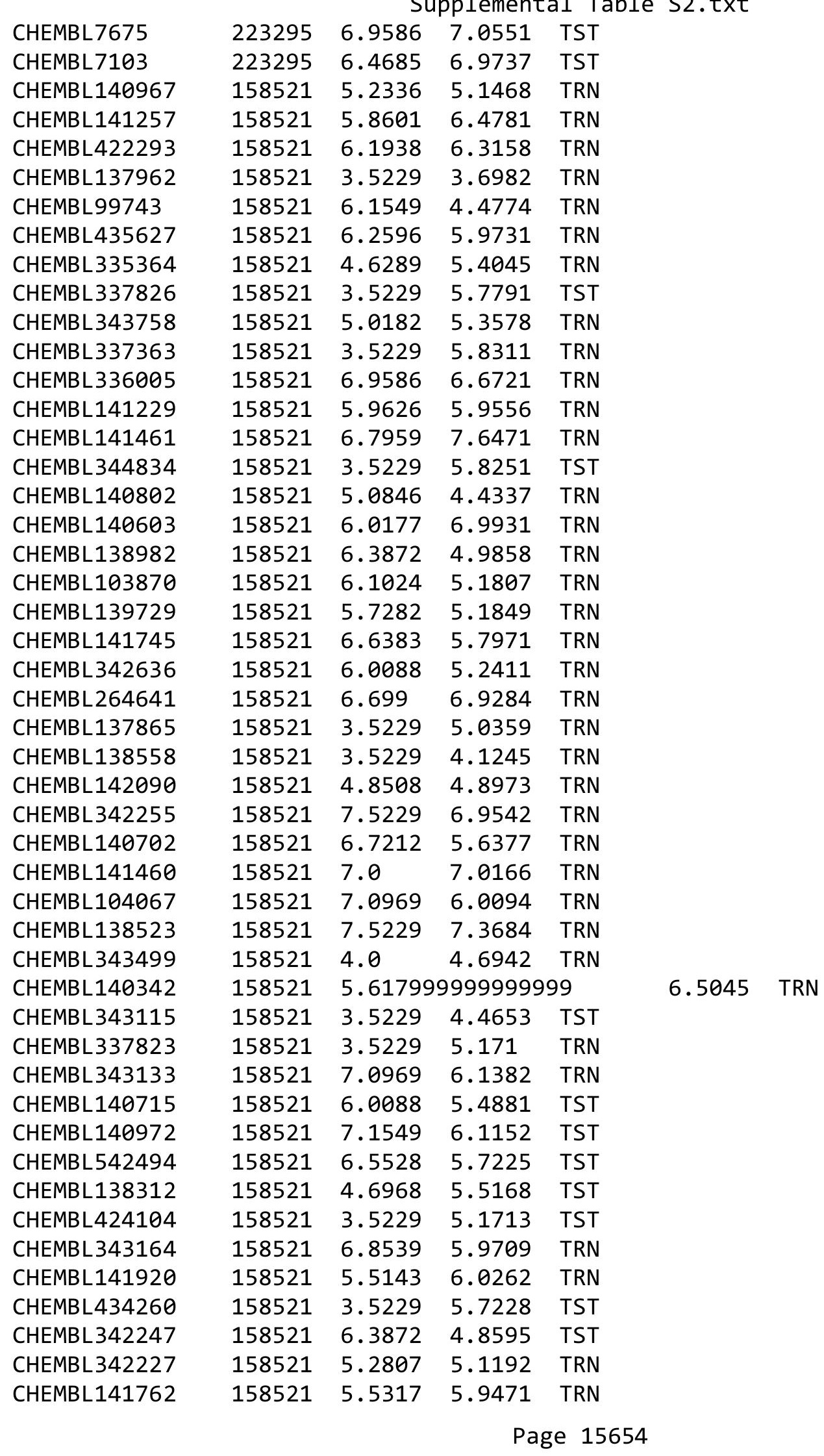


Supplemental Table S2.txt

\begin{tabular}{|c|c|c|c|c|}
\hline CHEMBL336491 & 158521 & 3.5229 & 4.4122 & TRN \\
\hline CHEMBL105280 & 158521 & 7.5229 & 6.7135 & TRN \\
\hline CHEMBL138425 & 158521 & 3.5229 & 4.3006 & TRN \\
\hline CHEMBL319894 & 158521 & 6.2596 & 6.4192 & TST \\
\hline CHEMBL141453 & 158521 & 6.4202 & 6.0808 & TRN \\
\hline CHEMBL138376 & 158521 & 6.1308 & 6.3296 & TRN \\
\hline CHEMBL102346 & 158521 & 7.0969 & 6.1747 & TRN \\
\hline CHEMBL140964 & 158521 & 6.4685 & 6.5402 & TST \\
\hline CHEMBL323336 & 158521 & 6.2757 & 6.3412 & TRN \\
\hline CHEMBL341973 & 158521 & 5.8962 & 5.1203 & TRN \\
\hline CHEMBL138980 & 158521 & 4.0 & 6.0794 & TST \\
\hline CHEMBL138566 & 158521 & 6.4815 & 5.9787 & TST \\
\hline CHEMBL345107 & 158521 & 6.1871 & 6.1512 & TRN \\
\hline CHEMBL141852 & 158521 & 6.2596 & 5.0264 & TST \\
\hline CHEMBL341602 & 158521 & 6.0177 & 5.72 & TST \\
\hline CHEMBL140457 & 158521 & 3.5229 & 4.9549 & TRN \\
\hline CHEMBL104325 & 158521 & 5.9586 & 5.1168 & TRN \\
\hline CHEMBL289959 & 809182 & 3.9 & 3.9343 & TRN \\
\hline CHEMBL 2006263 & 809182 & 4.9 & 4.7789 & TST \\
\hline CHEMBL1993584 & 809182 & 4.9 & 4.7015 & TRN \\
\hline CHEMBL1986263 & 809182 & 4.9 & 5.0191 & TRN \\
\hline CHEMBL 2000114 & 809182 & 4.9 & 4.6873 & TRN \\
\hline CHEMBL 210618 & 809182 & 4.9 & 5.1243 & TRN \\
\hline CHEMBL1975647 & 809182 & 4.9 & 5.5505 & TRN \\
\hline CHEMBL1968380 & 809182 & 4.9 & 4.8255 & TRN \\
\hline CHEMBL1964644 & 809182 & 4.9 & 4.912 & TRN \\
\hline CHEMBL1981782 & 809182 & 4.9 & 4.6673 & TRN \\
\hline CHEMBL1970142 & 809182 & 8.1 & 7.8851 & TRN \\
\hline CHEMBL1990912 & 809182 & 4.9 & 4.7653 & TRN \\
\hline CHEMBL1988163 & 809182 & 4.9 & 5.8581 & TRN \\
\hline CHEMBL1995592 & 809182 & 4.9 & 5.7782 & TST \\
\hline CHEMBL 2000934 & 809182 & 6.7 & 4.9086 & TRN \\
\hline CHEMBL1982541 & 809182 & 6.0 & 5.4176 & TRN \\
\hline CHEMBL1992323 & 809182 & 4.9 & 4.548 & TST \\
\hline CHEMBL1969735 & 809182 & 4.9 & 4.7878 & TRN \\
\hline CHEMBL 2003524 & 809182 & 4.9 & 5.3093 & TST \\
\hline CHEMBL 2002649 & 809182 & 4.9 & 5.1932 & TRN \\
\hline CHEMBL1996510 & 809182 & 4.2 & 4.8399 & TST \\
\hline CHEMBL437747 & 809182 & 4.9 & 5.0282 & TRN \\
\hline CHEMBL1995172 & 809182 & 4.2 & 4.5238 & TST \\
\hline CHEMBL507936 & 809182 & 4.9 & 6.0001 & TRN \\
\hline CHEMBL104264 & 809182 & 4.9 & 4.2774 & TST \\
\hline CHEMBL1994321 & 809182 & 7.7 & 7.3099 & TRN \\
\hline CHEMBL1997129 & 809182 & 4.9 & 5.1062 & TRN \\
\hline CHEMBL1964307 & 809182 & 4.9 & 6.2984 & TRN \\
\hline CHEMBL 2000508 & 809182 & 4.9 & 4.6276 & TRN \\
\hline CHEMBL2001547 & 809182 & 4.9 & 4.97 & TRN \\
\hline CHEMBL 210928 & 809182 & 4.9 & 5.0968 & TRN \\
\hline
\end{tabular}




\begin{tabular}{|c|c|c|c|c|c|}
\hline & & \multicolumn{4}{|c|}{ Supplemental Table S2.txt } \\
\hline CHEMBL1994361 & 809182 & 4.9 & 4.9642 & TRN & \\
\hline CHEMBL1972840 & 809182 & 4.9 & 5.0584 & TRN & \\
\hline CHEMBL1977148 & 809182 & 8.8 & 8.7383 & TRN & \\
\hline CHEMBL2003286 & 809182 & 4.9 & 4.73300 & 00000000005 & TRN \\
\hline CHEMBL2002165 & 809182 & 7.4 & 7.6255 & TRN & \\
\hline CHEMBL1998585 & 809182 & 7.4 & 6.83899 & 99999999995 & TRN \\
\hline CHEMBL519697 & 809182 & 4.9 & 4.2843 & TST & \\
\hline CHEMBL 2004934 & 809182 & 4.9 & 5.1716 & TRN & \\
\hline CHEMBL2000652 & 809182 & 9.1 & 8.0303 & TRN & \\
\hline CHEMBL1975128 & 809182 & 4.9 & 4.6959 & TRN & \\
\hline CHEMBL1996048 & 809182 & 6.4 & 5.0191 & TST & \\
\hline CHEMBL461876 & 809182 & 4.9 & 4.98 & TST & \\
\hline CHEMBL2001485 & 809182 & 7.1 & 7.3285 & TRN & \\
\hline CHEMBL504950 & 809182 & 4.9 & 4.6888 & TRN & \\
\hline CHEMBL1984363 & 809182 & 4.9 & 6.4219 & TRN & \\
\hline CHEMBL1978099 & 809182 & 5.9 & 6.2239 & TRN & \\
\hline CHEMBL1977041 & 809182 & 6.0 & 6.7455 & TRN & \\
\hline CHEMBL1968070 & 809182 & 4.9 & 4.7971 & TRN & \\
\hline CHEMBL1988608 & 809182 & 4.9 & 4.5137 & TRN & \\
\hline CHEMBL184847 & 809182 & 4.9 & 4.9061 & TRN & \\
\hline CHEMBL1984367 & 809182 & 4.9 & 4.6924 & TRN & \\
\hline CHEMBL226898 & 809182 & 4.9 & 4.8878 & TRN & \\
\hline CHEMBL1982563 & 809182 & 4.9 & 4.8987 & TRN & \\
\hline CHEMBL539474 & 809182 & 5.9 & 5.0412 & TST & \\
\hline CHEMBL575824 & 809182 & 4.9 & 4.9797 & TRN & \\
\hline CHEMBL1988387 & 809182 & 8.0 & 8.1926 & TRN & \\
\hline CHEMBL1990288 & 809182 & 4.9 & 4.8574 & TRN & \\
\hline CHEMBL1970074 & 809182 & 6.4 & 6.709 & TRN & \\
\hline CHEMBL1825138 & 809182 & 4.9 & 5.59 & TST & \\
\hline CHEMBL1986970 & 809182 & 4.9 & 4.6859 & TRN & \\
\hline CHEMBL1958401 & 809182 & 4.9 & 4.9584 & TRN & \\
\hline CHEMBL 2003456 & 809182 & 4.9 & 4.7572 & TRN & \\
\hline CHEMBL1966816 & 809182 & 4.9 & 5.5624 & TRN & \\
\hline CHEMBL1972584 & 809182 & 4.9 & 5.518 & TRN & \\
\hline CHEMBL 2002992 & 809182 & 4.9 & 4.3741 & TRN & \\
\hline CHEMBL560813 & 809182 & 4.9 & 4.715 & TRN & \\
\hline CHEMBL1968791 & 809182 & 6.3 & 6.1011 & TRN & \\
\hline CHEMBL326282 & 809182 & 4.9 & 4.6212 & TST & \\
\hline CHEMBL1992732 & 809182 & 4.9 & 4.9795 & TST & \\
\hline CHEMBL1971186 & 809182 & 4.9 & 4.6635 & TRN & \\
\hline CHEMBL2003482 & 809182 & 4.9 & 4.7097 & TRN & \\
\hline CHEMBL1976872 & 809182 & 3.9 & 4.4026 & TST & \\
\hline CHEMBL1969156 & 809182 & 3.9 & 4.6612 & TST & \\
\hline CHEMBL1973211 & 809182 & 7.8 & 7.4184 & TRN & \\
\hline CHEMBL1984700 & 809182 & 4.9 & 4.9103 & TRN & \\
\hline CHEMBL2007151 & 809182 & 6.8 & 5.9836 & TRN & \\
\hline CHEMBL1998953 & 809182 & 6.0 & 4.5507 & TRN & \\
\hline CHEMBL1972125 & 809182 & 4.9 & 4.8253 & TRN & \\
\hline
\end{tabular}




\begin{tabular}{|c|c|c|c|c|c|}
\hline & & & & & \\
\hline CHEMBL1976134 & 809182 & 4.9 & 5.0888 & TRN & \\
\hline CHEMBL1965131 & 809182 & 4.9 & 4.4688 & TST & \\
\hline CHEMBL1972158 & 809182 & 4.9 & 4.6508 & TRN & \\
\hline CHEMBL 2006581 & 809182 & 4.9 & 5.1611 & TRN & \\
\hline CHEMBL1970340 & 809182 & 4.9 & 4.3004 & TRN & \\
\hline CHEMBL 2005186 & 809182 & 4.9 & 4.7211 & TRN & \\
\hline CHEMBL1975534 & 809182 & 4.9 & 4.739 & TRN & \\
\hline CHEMBL1993424 & 809182 & 4.9 & 5.6687 & TRN & \\
\hline CHEMBL1966703 & 809182 & 4.9 & 5.2079 & TST & \\
\hline CHEMBL1969561 & 809182 & 4.9 & 4.5736 & TRN & \\
\hline CHEMBL1975121 & 809182 & 4.9 & 4.85800 & 00000000005 & TRN \\
\hline CHEMBL1997023 & 809182 & 4.9 & 4.2706 & TST & \\
\hline CHEMBL1964687 & 809182 & 4.9 & 5.4397 & TRN & \\
\hline CHEMBL1971943 & 809182 & 6.5 & 5.1132 & TST & \\
\hline CHEMBL1999918 & 809182 & 4.9 & 4.6906 & TRN & \\
\hline CHEMBL1974254 & 809182 & 8.1 & 8.4913 & TRN & \\
\hline CHEMBL1988537 & 809182 & 4.9 & 4.6514 & TST & \\
\hline CHEMBL1969049 & 809182 & 4.9 & 5.0254 & TRN & \\
\hline CHEMBL 2005828 & 809182 & 4.9 & 5.7056 & TRN & \\
\hline CHEMBL1998611 & 809182 & 4.9 & 5.1054 & TST & \\
\hline CHEMBL485556 & 809182 & 6.0 & 4.8657 & TST & \\
\hline CHEMBL1975900 & 809182 & 4.9 & 4.8839 & TRN & \\
\hline CHEMBL 255822 & 809182 & 4.9 & 4.6127 & TRN & \\
\hline CHEMBL1972221 & 809182 & 4.9 & 4.8906 & TRN & \\
\hline CHEMBL2006778 & 809182 & 6.5 & 6.9006 & TRN & \\
\hline CHEMBL 378627 & 809182 & 4.9 & 5.1693 & TRN & \\
\hline CHEMBL1996979 & 809182 & 6.2 & 5.6071 & TRN & \\
\hline CHEMBL1968406 & 809182 & 4.9 & 5.3578 & TRN & \\
\hline CHEMBL1982476 & 809182 & 8.3 & 7.6701 & TRN & \\
\hline CHEMBL1998545 & 809182 & 4.9 & 4.8183 & TRN & \\
\hline CHEMBL1986869 & 809182 & 4.9 & 4.7075 & TRN & \\
\hline CHEMBL1682558 & 809182 & 4.9 & 4.9259 & TRN & \\
\hline CHEMBL1990496 & 809182 & 4.7 & 4.8863 & TRN & \\
\hline CHEMBL1997623 & 809182 & 7.6 & 7.0558 & TRN & \\
\hline CHEMBL 2002479 & 809182 & 4.9 & 4.3223 & TRN & \\
\hline CHEMBL1967094 & 809182 & 4.9 & 4.4796 & TRN & \\
\hline CHEMBL 2003341 & 809182 & 4.9 & 4.7667 & TRN & \\
\hline CHEMBL1992644 & 809182 & 4.5 & 4.6625 & TRN & \\
\hline CHEMBL1999590 & 809182 & 4.9 & 5.0362 & TST & \\
\hline CHEMBL1981079 & 809182 & 4.9 & 4.7548 & TST & \\
\hline CHEMBL1978166 & 809182 & 6.3 & 7.0261 & TRN & \\
\hline CHEMBL1980489 & 809182 & 4.9 & 5.0455 & TRN & \\
\hline CHEMBL 2000832 & 809182 & 4.9 & 4.6851 & TRN & \\
\hline CHEMBL1967116 & 809182 & 9.0 & 7.9154 & TRN & \\
\hline CHEMBL1970709 & 809182 & 4.9 & 4.7717 & TRN & \\
\hline CHEMBL1965660 & 809182 & 4.9 & 4.7591 & TST & \\
\hline CHEMBL1998112 & 809182 & 4.9 & 5.2522 & TRN & \\
\hline CHEMBL1993996 & 809182 & 9.1 & 8.352 & TRN & \\
\hline & & & & 15657 & \\
\hline
\end{tabular}




\begin{tabular}{|c|c|c|c|c|}
\hline & & & Supplement & \\
\hline CHEMBL1969126 & 809182 & 4.9 & 4.5443 & TRN \\
\hline CHEMBL1980896 & 809182 & 4.9 & 5.6278 & TRN \\
\hline CHEMBL1970104 & 809182 & 5.0 & 5.4603 & TRN \\
\hline CHEMBL1991429 & 809182 & 6.1 & 5.6268 & TRN \\
\hline CHEMBL1971149 & 809182 & 4.9 & 4.8121 & TRN \\
\hline CHEMBL1999714 & 809182 & 4.9 & 4.7345 & TRN \\
\hline CHEMBL1994040 & 809182 & 4.9 & 4.9896 & TRN \\
\hline CHEMBL 388978 & 809182 & 6.8 & 6.5585 & TST \\
\hline CHEMBL579246 & 809182 & 4.9 & 5.2083 & TRN \\
\hline CHEMBL398951 & 809182 & 4.9 & 4.9676 & TST \\
\hline CHEMBL1982506 & 809182 & 4.9 & 5.2189 & TST \\
\hline CHEMBL 2004716 & 809182 & 7.6 & 7.2908 & TRN \\
\hline CHEMBL1968127 & 809182 & 4.9 & 4.832 & TRN \\
\hline CHEMBL1975233 & 809182 & 4.9 & 5.2571 & TRN \\
\hline CHEMBL1985406 & 809182 & 4.9 & 4.7296 & TRN \\
\hline CHEMBL 2007603 & 809182 & 4.2 & 4.8459 & TRN \\
\hline CHEMBL207400 & 809182 & 4.9 & 4.7906 & TST \\
\hline CHEMBL 2000894 & 809182 & 4.9 & 5.1078 & TST \\
\hline CHEMBL1982135 & 809182 & 4.9 & 4.8754 & TRN \\
\hline CHEMBL1976090 & 809182 & 4.9 & 4.6578 & TRN \\
\hline CHEMBL1993243 & 809182 & 4.9 & 6.3936 & TRN \\
\hline CHEMBL1992922 & 809182 & 4.9 & 4.7556 & TRN \\
\hline CHEMBL 2004771 & 809182 & 6.4 & 4.5912 & TRN \\
\hline CHEMBL399021 & 809182 & 6.0 & 5.6791 & TRN \\
\hline CHEMBL1997597 & 809182 & 4.9 & 5.0151 & TRN \\
\hline CHEMBL1969537 & 809182 & 4.9 & 5.0755 & TST \\
\hline CHEMBL1976093 & 809182 & 4.9 & 4.9394 & TRN \\
\hline CHEMBL1975256 & 809182 & 4.9 & 4.762 & TST \\
\hline CHEMBL508928 & 809182 & 8.3 & 7.441 & TRN \\
\hline CHEMBL 2004892 & 809182 & 4.9 & 5.0411 & TRN \\
\hline CHEMBL116070 & 809182 & 4.9 & 4.8218 & TRN \\
\hline CHEMBL1970314 & 809182 & 4.9 & 4.6104 & TRN \\
\hline CHEMBL 2004871 & 809182 & 4.9 & 4.7531 & TRN \\
\hline CHEMBL2004872 & 809182 & 4.9 & 4.8537 & TRN \\
\hline CHEMBL1727312 & 809182 & 4.2 & 4.3831 & TRN \\
\hline CHEMBL1969879 & 809182 & 4.9 & 4.7233 & TRN \\
\hline CHEMBL1981720 & 809182 & 4.9 & 4.9926 & TRN \\
\hline CHEMBL419932 & 809182 & 4.9 & 4.7936 & TRN \\
\hline CHEMBL262433 & 809182 & 4.9 & 6.0723 & TRN \\
\hline CHEMBL373798 & 809182 & 9.6 & 8.0808 & TRN \\
\hline CHEMBL 306380 & 809182 & 6.3 & 5.7841 & TRN \\
\hline CHEMBL1966722 & 809182 & 4.9 & 4.3283 & TST \\
\hline CHEMBL1975500 & 809182 & 4.9 & 4.6947 & TRN \\
\hline CHEMBL1976328 & 809182 & 4.9 & 5.5443 & TRN \\
\hline CHEMBL394619 & 809182 & 6.6 & 6.3337 & TRN \\
\hline CHEMBL1964399 & 809182 & 4.9 & 5.3612 & TRN \\
\hline CHEMBL1996831 & 809182 & 4.9 & 4.33 & TST \\
\hline CHEMBL411903 & 809182 & 6.7 & 7.0144 & TRN \\
\hline
\end{tabular}




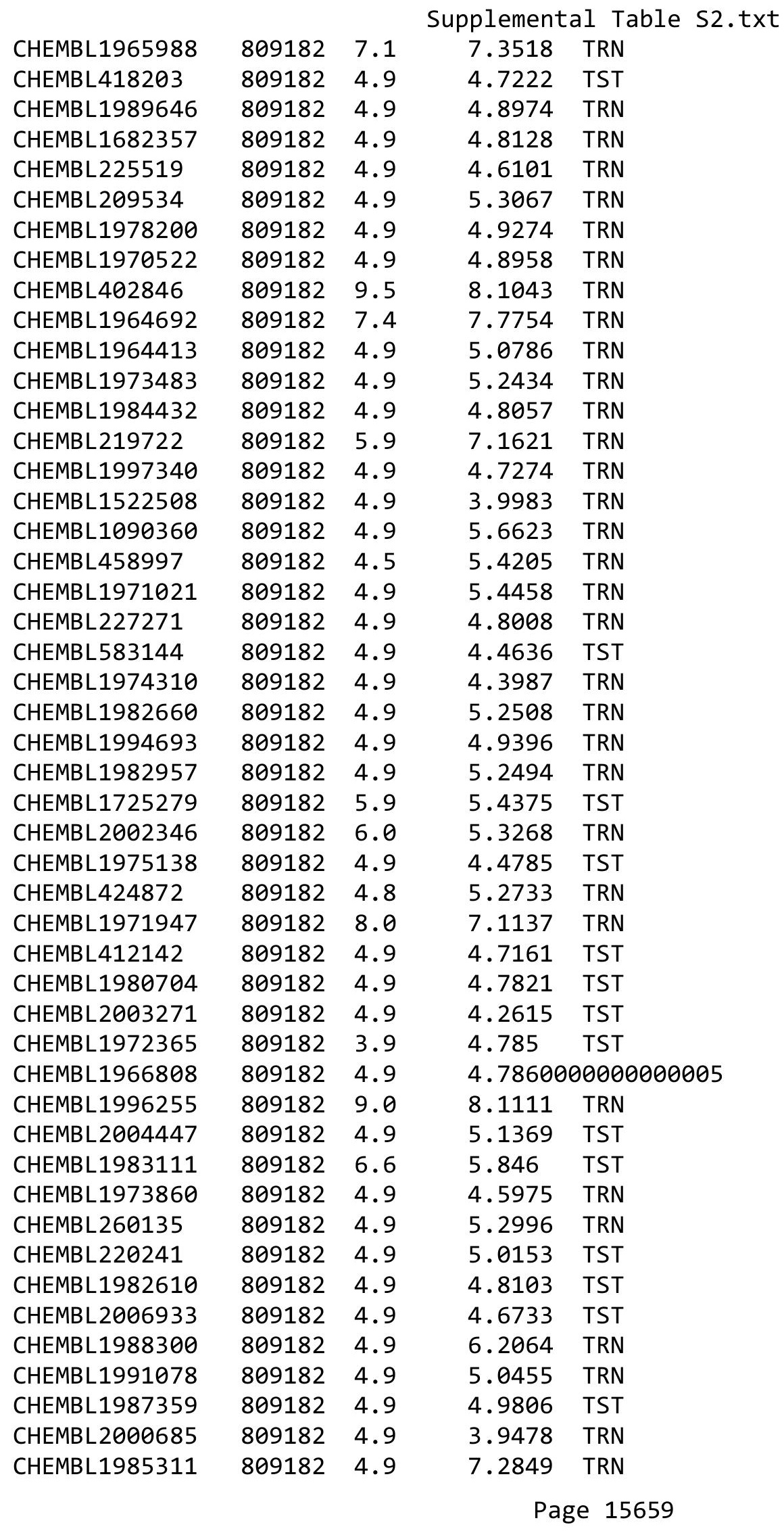




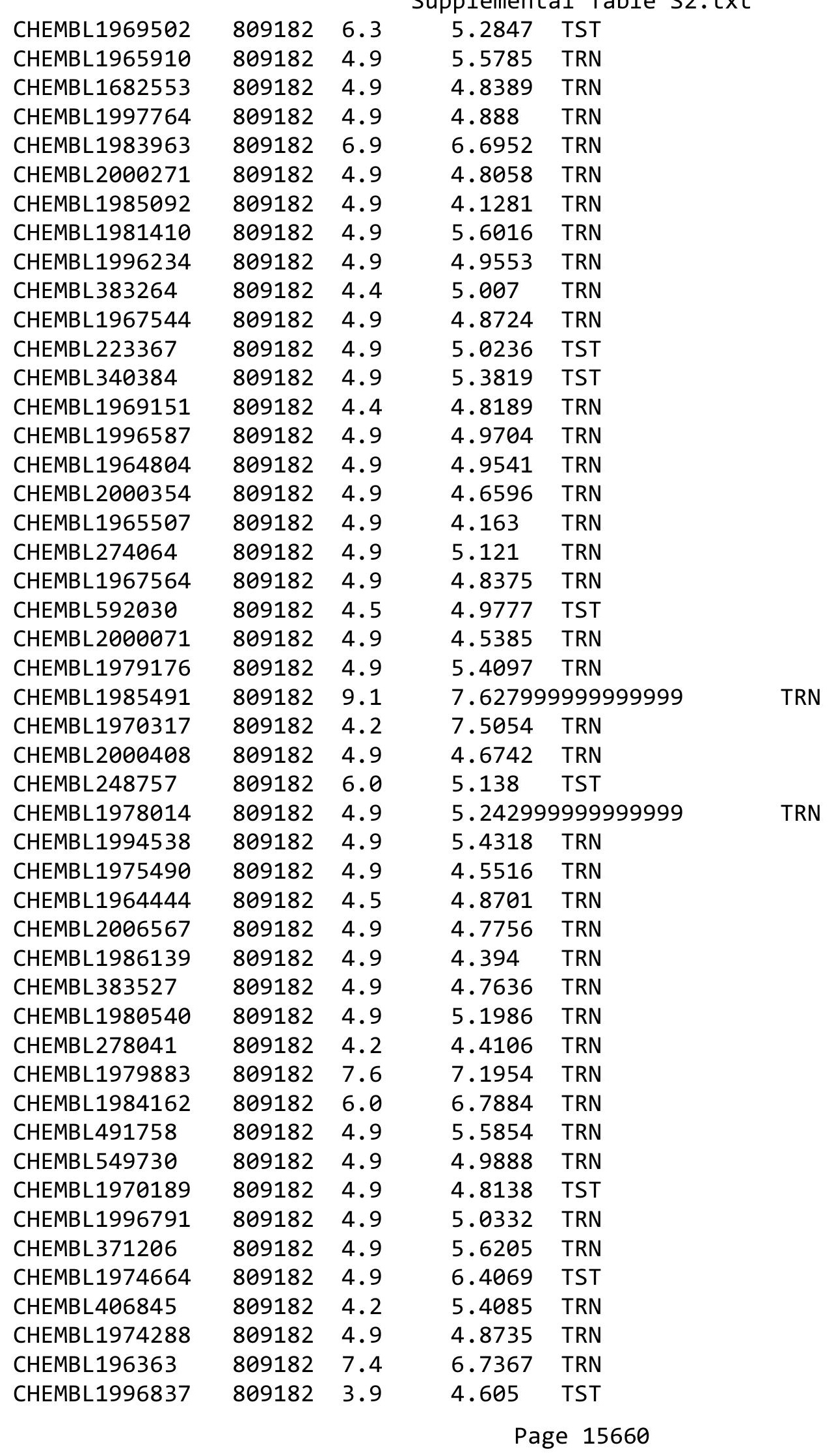




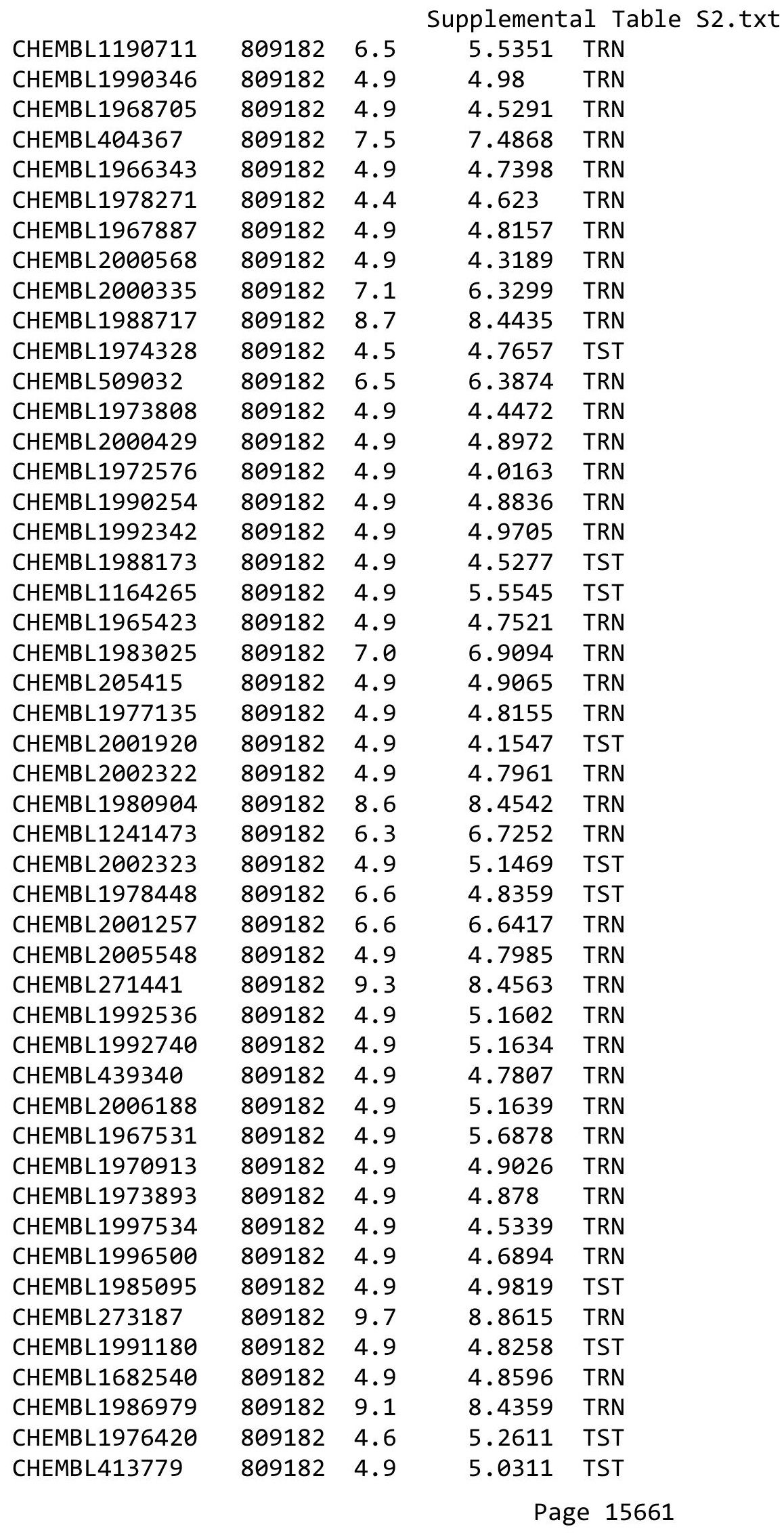




\begin{tabular}{|c|c|c|c|c|c|}
\hline \multirow[b]{2}{*}{ CHEMBL 2002446} & \multicolumn{5}{|c|}{ Supplemental Table S2.txt } \\
\hline & 809182 & 7.7 & 7.2057 & TST & \\
\hline CHEMBL497151 & 809182 & 4.9 & 4.5360 & 00000000005 & TRN \\
\hline CHEMBL1973961 & 809182 & 4.9 & 4.9482 & TRN & \\
\hline CHEMBL 246970 & 809182 & 4.9 & 4.7066 & TRN & \\
\hline CHEMBL340921 & 809182 & 4.9 & 5.2021 & TST & \\
\hline CHEMBL1994977 & 809182 & 4.4 & 4.6286 & TRN & \\
\hline CHEMBL373598 & 809182 & 4.9 & 5.0675 & TST & \\
\hline CHEMBL1999718 & 809182 & 4.9 & 5.3472 & TRN & \\
\hline CHEMBL1276446 & 809182 & 4.9 & 6.1544 & TST & \\
\hline CHEMBL1977346 & 809182 & 4.9 & 4.9524 & TRN & \\
\hline CHEMBL1971649 & 809182 & 4.9 & 5.901 & TRN & \\
\hline CHEMBL 2003657 & 809182 & 4.9 & 4.8877 & TRN & \\
\hline CHEMBL 2006439 & 809182 & 4.9 & 5.1833 & TRN & \\
\hline CHEMBL1969190 & 809182 & 4.9 & 6.2082 & TRN & \\
\hline CHEMBL1973937 & 809182 & 6.6 & 6.7126 & TRN & \\
\hline CHEMBL1991674 & 809182 & 4.6 & 4.6721 & TRN & \\
\hline CHEMBL1982711 & 809182 & 4.9 & 4.3628 & TRN & \\
\hline CHEMBL1984842 & 809182 & 4.9 & 4.7859 & TRN & \\
\hline CHEMBL1969102 & 809182 & 8.9 & 7.8665 & TRN & \\
\hline CHEMBL1682346 & 809182 & 4.9 & 4.8502 & TRN & \\
\hline CHEMBL 2007044 & 809182 & 4.9 & 4.8045 & TST & \\
\hline CHEMBL2001998 & 809182 & 4.9 & 5.1169 & TST & \\
\hline CHEMBL1994241 & 809182 & 4.9 & 4.9941 & TRN & \\
\hline CHEMBL 223460 & 809182 & 4.9 & 5.1561 & TST & \\
\hline CHEMBL50894 & 809182 & 4.9 & 5.6632 & TRN & \\
\hline CHEMBL1988838 & 809182 & 4.9 & 6.3209 & TRN & \\
\hline CHEMBL1981725 & 809182 & 7.1 & 6.4458 & TRN & \\
\hline CHEMBL1982753 & 809182 & 4.2 & 4.4807 & TST & \\
\hline CHEMBL375284 & 809182 & 4.9 & 6.1494 & TRN & \\
\hline CHEMBL1982866 & 809182 & 4.9 & 4.7987 & TRN & \\
\hline CHEMBL 2005792 & 809182 & 4.9 & 4.7977 & TRN & \\
\hline CHEMBL1984206 & 809182 & 4.9 & 5.2878 & TRN & \\
\hline CHEMBL1965570 & 809182 & 6.1 & 6.9315 & TRN & \\
\hline CHEMBL 2007592 & 809182 & 4.9 & 4.6946 & TST & \\
\hline CHEMBL 210963 & 809182 & 4.9 & 5.135 & TRN & \\
\hline CHEMBL1082440 & 809182 & 4.9 & 4.7596 & TST & \\
\hline CHEMBL1614705 & 809182 & 4.9 & 4.9385 & TST & \\
\hline CHEMBL1972362 & 809182 & 4.9 & 4.7551 & TRN & \\
\hline CHEMBL1984633 & 809182 & 4.9 & 4.9561 & TRN & \\
\hline CHEMBL1965845 & 809182 & 4.9 & 4.8394 & TRN & \\
\hline CHEMBL 2006715 & 809182 & 4.9 & 5.5324 & TRN & \\
\hline CHEMBL1986597 & 809182 & 4.9 & 4.9927 & TRN & \\
\hline CHEMBL1971017 & 809182 & 4.9 & 4.6574 & TRN & \\
\hline CHEMBL1990482 & 809182 & 4.9 & 4.6856 & TRN & \\
\hline CHEMBL1990904 & 809182 & 4.9 & 4.953 & TRN & \\
\hline CHEMBL 2005475 & 809182 & 4.9 & 4.7729 & TRN & \\
\hline CHEMBL 2000104 & 809182 & 4.9 & 4.9878 & TRN & \\
\hline CHEMBL183844 & 809182 & 4.9 & 5.5068 & TRN & \\
\hline
\end{tabular}




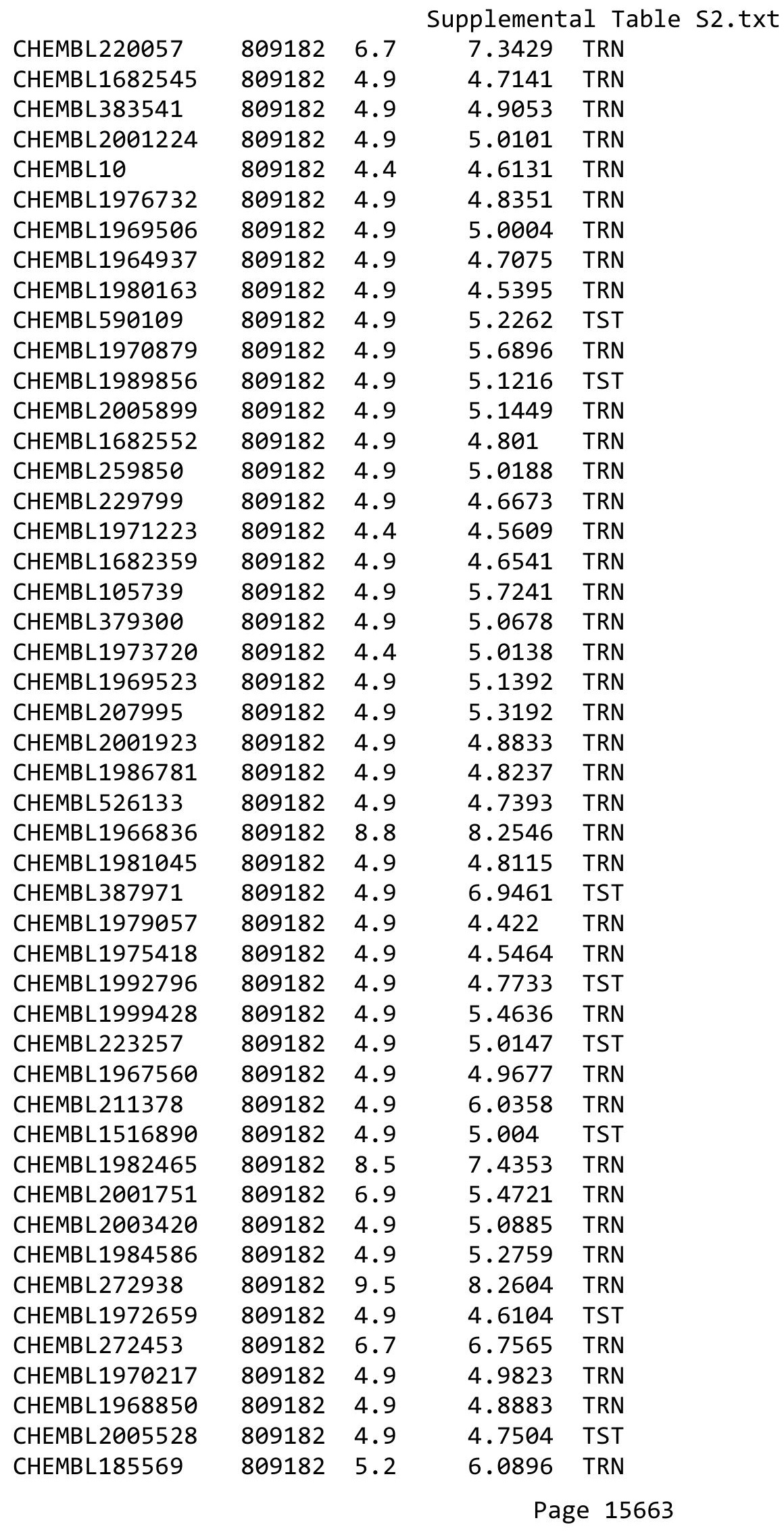




\begin{tabular}{|c|c|c|c|c|c|}
\hline \multirow{3}{*}{$\begin{array}{l}\text { CHEMBL1969843 } \\
\text { CHEMBL } 2007002\end{array}$} & \multirow{3}{*}{$\begin{array}{l}809182 \\
809182\end{array}$} & \multicolumn{4}{|c|}{ Supplemental Table S2.txt } \\
\hline & & 4.9 & \multicolumn{2}{|c|}{4.8180000000000005} & TRN \\
\hline & & 4.9 & 4.6134 & TRN & \\
\hline CHEMBL1987007 & 809182 & 4.9 & 5.1063 & TRN & \\
\hline CHEMBL1969588 & 809182 & 4.9 & 5.7097 & TRN & \\
\hline CHEMBL1984711 & 809182 & 4.9 & 5.9384 & TRN & \\
\hline CHEMBL1992073 & 809182 & 4.2 & 4.8187 & TST & \\
\hline CHEMBL484390 & 809182 & 4.9 & 4.3748 & TST & \\
\hline CHEMBL1979252 & 809182 & 4.9 & 5.2427 & TRN & \\
\hline CHEMBL1682341 & 809182 & 4.9 & 4.6387 & TRN & \\
\hline CHEMBL 2004290 & 809182 & 8.5 & 8.1703 & TRN & \\
\hline CHEMBL1986499 & 809182 & 4.9 & 4.8855 & TRN & \\
\hline CHEMBL1972937 & 809182 & 4.9 & 4.6948 & TRN & \\
\hline CHEMBL1972250 & 809182 & 4.9 & 4.9888 & TST & \\
\hline CHEMBL 2000393 & 809182 & 4.9 & 4.7321 & TST & \\
\hline CHEMBL403402 & 809182 & 9.1 & 8.7375 & TRN & \\
\hline CHEMBL 2004311 & 809182 & 4.9 & 5.5559 & TRN & \\
\hline CHEMBL1992634 & 809182 & 4.9 & 4.4752 & TRN & \\
\hline CHEMBL1242373 & 809182 & 4.9 & 5.2274 & TRN & \\
\hline CHEMBL1988075 & 809182 & 6.2 & 6.8643 & TRN & \\
\hline CHEMBL316264 & 809182 & 4.9 & 4.5226 & TRN & \\
\hline CHEMBL1991678 & 809182 & 4.9 & 4.698 & TRN & \\
\hline CHEMBL2001239 & 809182 & 4.9 & 4.8104 & TST & \\
\hline CHEMBL1988594 & 809182 & 4.9 & 4.1655 & TRN & \\
\hline CHEMBL 2001288 & 809182 & 4.9 & 4.7141 & TRN & \\
\hline CHEMBL 260092 & 809182 & 9.0 & 6.8076 & TRN & \\
\hline CHEMBL1999811 & 809182 & 4.9 & 4.458 & TST & \\
\hline CHEMBL1965495 & 809182 & 4.9 & 5.433 & TRN & \\
\hline CHEMBL235157 & 809182 & 4.4 & 5.0477 & TST & \\
\hline CHEMBL1985074 & 809182 & 4.9 & 4.584 & TST & \\
\hline CHEMBL1982874 & 809182 & 4.9 & 4.6984 & TRN & \\
\hline CHEMBL 2000481 & 809182 & 4.9 & 4.2071 & TRN & \\
\hline CHEMBL1991725 & 809182 & 4.9 & 5.0904 & TRN & \\
\hline CHEMBL1992242 & 809182 & 4.9 & 5.4467 & TRN & \\
\hline CHEMBL 2007296 & 809182 & 4.9 & 4.9857 & TRN & \\
\hline CHEMBL396523 & 809182 & 4.9 & 5.1137 & TRN & \\
\hline CHEMBL1970203 & 809182 & 4.9 & 4.2952 & TRN & \\
\hline CHEMBL1986530 & 809182 & 4.9 & 4.7083 & TST & \\
\hline CHEMBL440084 & 809182 & 4.2 & 4.2794 & TRN & \\
\hline CHEMBL1999321 & 809182 & 4.9 & 5.6089 & TRN & \\
\hline CHEMBL385478 & 809182 & 4.9 & 5.2516 & TRN & \\
\hline CHEMBL1968590 & 809182 & 6.3 & 6.5759 & TRN & \\
\hline CHEMBL1999749 & 809182 & 4.9 & 5.2989 & TRN & \\
\hline CHEMBL2005375 & 809182 & 4.9 & 4.81800 & 00000000005 & TRN \\
\hline CHEMBL1984191 & 809182 & 4.9 & 4.5227 & TRN & \\
\hline CHEMBL1983006 & 809182 & 4.9 & 5.3353 & TRN & \\
\hline CHEMBL1971029 & 809182 & 7.1 & 6.2358 & TRN & \\
\hline CHEMBL394790 & 809182 & 6.1 & 5.7659 & TRN & \\
\hline CHEMBL226471 & 809182 & 4.9 & 4.599 & TRN & \\
\hline
\end{tabular}




\begin{tabular}{|c|c|c|c|c|}
\hline & & & Supplement & al \\
\hline CHEMBL1974702 & 809182 & 4.9 & 4.5407 & TST \\
\hline CHEMBL1996111 & 809182 & 4.9 & 4.4242 & TRN \\
\hline CHEMBL1965589 & 809182 & 4.9 & 4.9253 & TRN \\
\hline CHEMBL1998193 & 809182 & 4.9 & 5.2566 & TRN \\
\hline CHEMBL474432 & 809182 & 4.9 & 6.2042 & TST \\
\hline CHEMBL2001539 & 809182 & 3.9 & 4.2648 & TST \\
\hline CHEMBL1988153 & 809182 & 4.9 & 5.0786 & TRN \\
\hline CHEMBL1999556 & 809182 & 4.9 & 4.8293 & TRN \\
\hline CHEMBL1988437 & 809182 & 8.0 & 5.6713 & TST \\
\hline CHEMBL1968245 & 809182 & 4.9 & 4.7612 & TRN \\
\hline CHEMBL1998121 & 809182 & 4.9 & 4.867 & TRN \\
\hline CHEMBL1979577 & 809182 & 7.4 & 7.1849 & TRN \\
\hline CHEMBL1233887 & 809182 & 4.4 & 4.9392 & TST \\
\hline CHEMBL1991800 & 809182 & 4.9 & 4.9525 & TRN \\
\hline CHEMBL1980802 & 809182 & 4.9 & 4.8348 & TST \\
\hline CHEMBL1979357 & 809182 & 4.9 & 4.998 & TRN \\
\hline CHEMBL1979554 & 809182 & 4.9 & 4.7523 & TRN \\
\hline CHEMBL1996817 & 809182 & 4.9 & 5.3026 & TRN \\
\hline CHEMBL409349 & 809182 & 8.8 & 7.251 & TRN \\
\hline CHEMBL 2004355 & 809182 & 4.9 & 5.3354 & TRN \\
\hline CHEMBL468280 & 809182 & 4.9 & 4.855 & TST \\
\hline CHEMBL1990884 & 809182 & 4.9 & 5.8978 & TRN \\
\hline CHEMBL3109278 & 809182 & 4.5 & 5.7736 & TRN \\
\hline CHEMBL256835 & 809182 & 4.9 & 4.7589 & TRN \\
\hline CHEMBL1974998 & 809182 & 4.4 & 4.5174 & TRN \\
\hline CHEMBL1980142 & 809182 & 4.9 & 5.3309 & TRN \\
\hline CHEMBL41783 & 809182 & 4.9 & 4.9068 & TRN \\
\hline CHEMBL 2004438 & 809182 & 6.8 & 6.0915 & TRN \\
\hline CHEMBL191003 & 809182 & 7.1 & 5.6377 & TRN \\
\hline CHEMBL 271381 & 809182 & 6.9 & 6.349 & TRN \\
\hline CHEMBL 2006785 & 809182 & 4.9 & 4.5365 & TST \\
\hline CHEMBL1982466 & 809182 & 8.1 & 8.0145 & TRN \\
\hline CHEMBL1994638 & 809182 & 9.0 & 8.0596 & TRN \\
\hline CHEMBL1995740 & 809182 & 4.9 & 4.9244 & TRN \\
\hline CHEMBL1985888 & 809182 & 9.1 & 8.2922 & TRN \\
\hline CHEMBL1986943 & 809182 & 4.9 & 5.159 & TRN \\
\hline CHEMBL 234085 & 809182 & 4.3 & 4.5755 & TRN \\
\hline CHEMBL1995832 & 809182 & 4.9 & 4.8762 & TRN \\
\hline CHEMBL1969042 & 809182 & 4.9 & 4.7567 & TRN \\
\hline CHEMBL 2000345 & 809182 & 4.9 & 4.9696 & TRN \\
\hline CHEMBL1999931 & 809182 & 4.9 & 4.5054 & TRN \\
\hline CHEMBL 302449 & 809182 & 4.9 & 5.7358 & TST \\
\hline CHEMBL 2007064 & 809182 & 4.9 & 5.5124 & TRN \\
\hline CHEMBL1981047 & 809182 & 4.9 & 5.9255 & TRN \\
\hline CHEMBL229968 & 809182 & 4.9 & 4.7318 & TRN \\
\hline CHEMBL1976240 & 809182 & 4.9 & 4.9969 & TRN \\
\hline CHEMBL1979093 & 809182 & 6.3 & 6.7273 & TRN \\
\hline CHEMBL1968151 & 809182 & 4.9 & 4.7154 & TST \\
\hline
\end{tabular}




\begin{tabular}{|c|c|c|c|c|}
\hline \multicolumn{5}{|c|}{ lemental T } \\
\hline CHEMBL1987009 & 809182 & 4.9 & 4.8294 & TRN \\
\hline CHEMBL379218 & 809182 & 4.9 & 4.7509 & TRN \\
\hline CHEMBL 2003817 & 809182 & 4.9 & 5.3109 & TRN \\
\hline CHEMBL336961 & 809182 & 4.9 & 5.0193 & TRN \\
\hline CHEMBL1994830 & 809182 & 4.9 & 5.0576 & TRN \\
\hline CHEMBL1987054 & 809182 & 6.9 & 6.6247 & TRN \\
\hline CHEMBL1970083 & 809182 & 7.2 & 7.6305 & TRN \\
\hline CHEMBL226403 & 809182 & 4.9 & 4.3582 & TRN \\
\hline CHEMBL 2005631 & 809182 & 8.5 & 7.8656 & TRN \\
\hline CHEMBL1994938 & 809182 & 6.4 & 6.9152 & TRN \\
\hline CHEMBL1977223 & 809182 & 4.9 & 4.5665 & TRN \\
\hline CHEMBL1966279 & 809182 & 4.9 & 4.4181 & TRN \\
\hline CHEMBL1997846 & 809182 & 4.9 & 4.5391 & TRN \\
\hline CHEMBL 2004419 & 809182 & 4.9 & 4.8977 & TRN \\
\hline CHEMBL 2007073 & 809182 & 4.4 & 4.6204 & TRN \\
\hline CHEMBL 1975787 & 809182 & 4.9 & 4.7301 & TRN \\
\hline CHEMBL 2002407 & 809182 & 4.9 & 5.3205 & TRN \\
\hline CHEMBL1994074 & 809182 & 4.9 & 4.5983 & TRN \\
\hline CHEMBL1992937 & 809182 & 4.9 & 4.9898 & TST \\
\hline CHEMBL1985566 & 809182 & 4.9 & 4.7917 & TRN \\
\hline CHEMBL1972119 & 809182 & 4.9 & 5.3416 & TRN \\
\hline CHEMBL95692 & 809182 & 4.9 & 4.8953 & TRN \\
\hline CHEMBL1090356 & 809182 & 4.9 & 5.6028 & TRN \\
\hline CHEMBL1986507 & 809182 & 9.0 & 7.4703 & TRN \\
\hline CHEMBL1976455 & 809182 & 4.9 & 5.1015 & TRN \\
\hline CHEMBL1983923 & 809182 & 6.4 & 5.7254 & TST \\
\hline CHEMBL1983534 & 809182 & 4.9 & 4.6207 & TRN \\
\hline CHEMBL1982361 & 809182 & 4.9 & 5.169 & TRN \\
\hline CHEMBL1999112 & 809182 & 4.9 & 4.8435 & TST \\
\hline CHEMBL1982122 & 809182 & 4.9 & 4.6772 & TRN \\
\hline CHEMBL 2000801 & 809182 & 4.9 & 5.7242 & TRN \\
\hline CHEMBL1682546 & 809182 & 4.9 & 4.6421 & TRN \\
\hline CHEMBL1991395 & 809182 & 4.9 & 4.8713 & TRN \\
\hline CHEMBL1971245 & 809182 & 6.1 & 5.7931 & TRN \\
\hline CHEMBL1987648 & 809182 & 4.9 & 4.7989 & TRN \\
\hline CHEMBL1996780 & 809182 & 4.9 & 5.0883 & TST \\
\hline CHEMBL1972142 & 809182 & 4.9 & 4.654 & TRN \\
\hline CHEMBL1966514 & 809182 & 7.3 & 6.9472 & TRN \\
\hline CHEMBL 2003638 & 809182 & 4.9 & 4.6506 & TRN \\
\hline CHEMBL 296586 & 809182 & 4.9 & 5.5175 & TRN \\
\hline CHEMBL1996066 & 809182 & 6.1 & 5.5405 & TST \\
\hline CHEMBL516429 & 809182 & 6.2 & 5.2875 & TRN \\
\hline CHEMBL1993722 & 809182 & 4.9 & 6.0751 & TRN \\
\hline CHEMBL1375640 & 809182 & 4.9 & 4.5553 & TST \\
\hline CHEMBL1979970 & 809182 & 4.9 & 4.9965 & TRN \\
\hline CHEMBL249282 & 809182 & 4.9 & 4.8656 & TST \\
\hline CHEMBL1969264 & 809182 & 4.9 & 4.6803 & TRN \\
\hline CHEMBL1973711 & 809182 & 4.9 & 4.7618 & TST \\
\hline
\end{tabular}




\begin{tabular}{|c|c|c|c|c|}
\hline & & & & \\
\hline CHEMBL1967720 & 809182 & 7.4 & 7.5465 & TRN \\
\hline CHEMBL1572266 & 809182 & 4.9 & 5.559 & TST \\
\hline CHEMBL1991138 & 809182 & 4.9 & 5.3745 & TRN \\
\hline CHEMBL1979516 & 809182 & 7.6 & 6.9465 & TRN \\
\hline CHEMBL1605605 & 809182 & 4.9 & 4.743 & TRN \\
\hline CHEMBL1996208 & 809182 & 4.4 & 5.3104 & TST \\
\hline CHEMBL1989029 & 809182 & 4.9 & 5.0267 & TST \\
\hline CHEMBL392642 & 809182 & 4.9 & 4.893 & TRN \\
\hline CHEMBL514499 & 809182 & 6.9 & 6.1177 & TST \\
\hline CHEMBL1965631 & 809182 & 4.9 & 4.716 & TRN \\
\hline CHEMBL1980144 & 809182 & 4.9 & 4.1228 & TRN \\
\hline CHEMBL1991188 & 809182 & 4.9 & 5.013 & TRN \\
\hline CHEMBL1972849 & 809182 & 4.9 & 4.7687 & TRN \\
\hline CHEMBL377408 & 809182 & 5.8 & 5.1494 & TRN \\
\hline CHEMBL215152 & 809182 & 4.9 & 4.9711 & TRN \\
\hline CHEMBL231209 & 809182 & 4.9 & 5.4643 & TRN \\
\hline CHEMBL1976220 & 809182 & 6.4 & 5.7692 & TRN \\
\hline CHEMBL259922 & 809182 & 6.2 & 5.0465 & TST \\
\hline CHEMBL1997617 & 809182 & 7.8 & 6.5436 & TRN \\
\hline CHEMBL1982383 & 809182 & 4.9 & 5.0806 & TRN \\
\hline CHEMBL1969301 & 809182 & 4.9 & 4.3099 & TST \\
\hline CHEMBL17370 & 809182 & 4.9 & 4.48600 & 0000000001 \\
\hline CHEMBL1987910 & 809182 & 4.9 & 5.928 & TRN \\
\hline CHEMBL374044 & 809182 & 9.1 & 8.5188 & TRN \\
\hline CHEMBL1983932 & 809182 & 4.9 & 4.9484 & TRN \\
\hline CHEMBL1999484 & 809182 & 7.2 & 5.5358 & TST \\
\hline CHEMBL404366 & 809182 & 9.8 & 7.9763 & TST \\
\hline CHEMBL1966069 & 809182 & 4.9 & 4.5615 & TST \\
\hline CHEMBL1997822 & 809182 & 6.2 & 6.3369 & TST \\
\hline CHEMBL1991285 & 809182 & 4.9 & 5.5988 & TST \\
\hline CHEMBL243088 & 809182 & 4.9 & 5.2705 & TST \\
\hline CHEMBL1984038 & 809182 & 4.5 & 4.8563 & TST \\
\hline CHEMBL1993661 & 809182 & 4.6 & 6.0558 & TST \\
\hline CHEMBL1974416 & 809182 & 4.9 & 5.3431 & TST \\
\hline CHEMBL1964290 & 809182 & 4.9 & 4.7849 & TST \\
\hline CHEMBL213505 & 809182 & 4.9 & 5.8361 & TST \\
\hline CHEMBL1987034 & 809182 & 6.2 & 5.8748 & TST \\
\hline CHEMBL1993941 & 809182 & 8.3 & 7.7408 & TST \\
\hline CHEMBL377383 & 809182 & 4.9 & 5.1217 & TST \\
\hline CHEMBL578061 & 809182 & 5.9 & 5.1046 & TST \\
\hline CHEMBL 2005886 & 809182 & 5.0 & 5.7536 & TST \\
\hline CHEMBL481491 & 809182 & 4.9 & 5.0462 & TST \\
\hline CHEMBL1682345 & 809182 & 4.9 & 4.5503 & TST \\
\hline CHEMBL1973142 & 809182 & 4.9 & 4.8104 & TST \\
\hline CHEMBL1973145 & 809182 & 4.9 & 6.8248 & TST \\
\hline CHEMBL1982924 & 809182 & 4.9 & 4.822 & TST \\
\hline CHEMBL 2005936 & 809182 & 4.9 & 4.4426 & TST \\
\hline CHEMBL1807515 & 809182 & 4.9 & 5.0235 & TST \\
\hline
\end{tabular}

TRN 


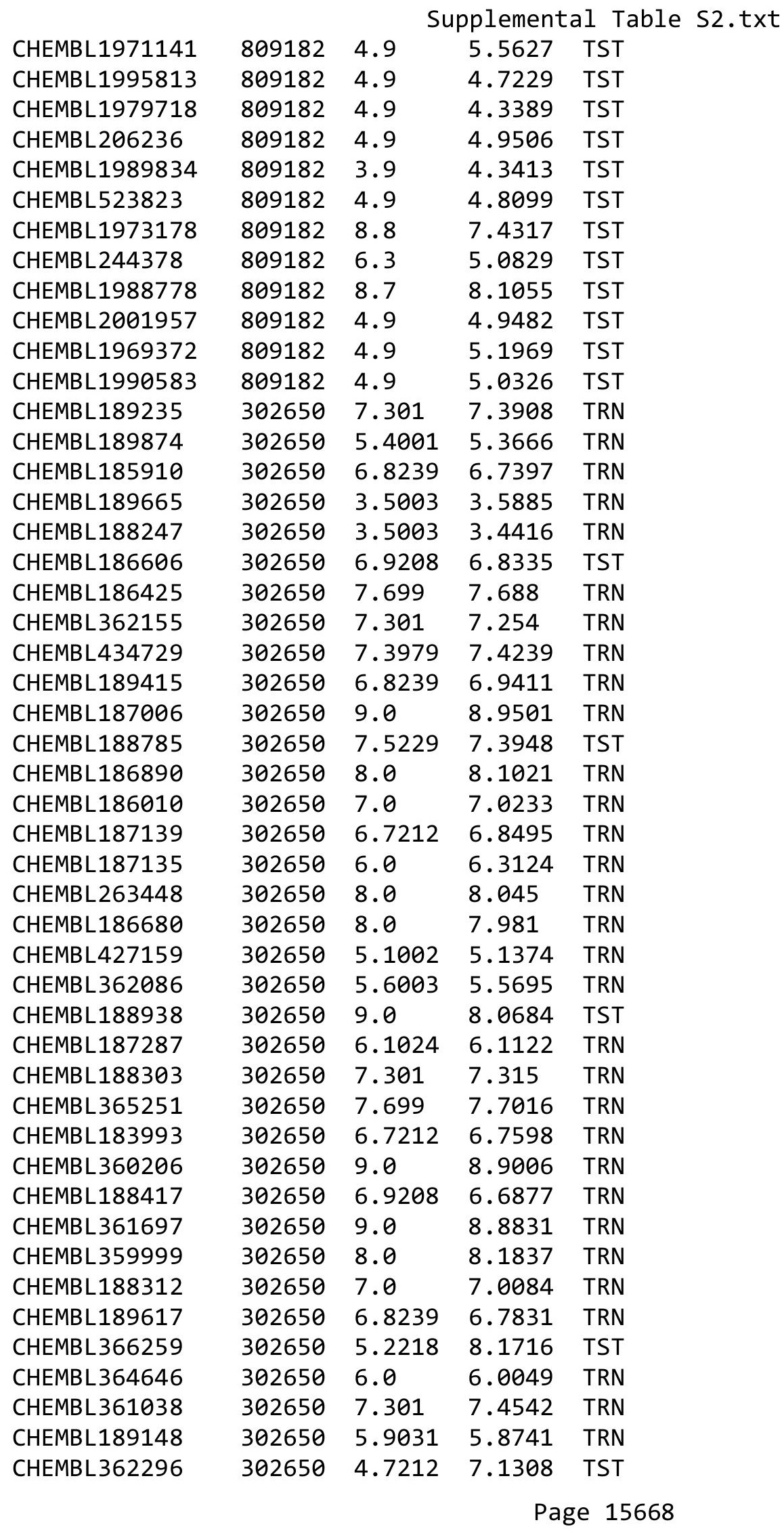




\begin{tabular}{|c|c|c|c|c|c|}
\hline \multicolumn{6}{|c|}{ Supplemental Table s2.txt } \\
\hline CHEMBL189455 & 302650 & 9.0 & 8.6994 & TST & \\
\hline CHEMBL183064 & 302650 & 8.0 & 7.9704 & TRN & \\
\hline CHEMBL186101 & 302650 & 9.0 & 9.0418 & TRN & \\
\hline CHEMBL189352 & 302650 & 7.301 & 7.8724 & TST & \\
\hline CHEMBL189343 & 302650 & 7.699 & 7.5813 & TRN & \\
\hline CHEMBL186054 & 302650 & 8.0 & 7.9669 & TRN & \\
\hline CHEMBL189288 & 302650 & 7.3979 & 7.3365 & TRN & \\
\hline CHEMBL186116 & 302650 & 5.3002 & 5.2888 & TRN & \\
\hline CHEMBL187750 & 302650 & 8.0 & 7.9904 & TRN & \\
\hline CHEMBL361894 & 302650 & 9.0 & 8.7504 & TST & \\
\hline CHEMBL359794 & 302650 & 9.0 & 9.022 & TRN & \\
\hline CHEMBL365248 & 302650 & 7.301 & 7.2885 & TRN & \\
\hline CHEMBL364197 & 302650 & 7.5229 & 7.4271 & TRN & \\
\hline CHEMBL185516 & 302650 & 4.6383 & 6.98 & TST & \\
\hline CHEMBL365229 & 302650 & 9.0 & 8.9805 & TRN & \\
\hline CHEMBL439850 & 302650 & 8.0 & 8.071 & TRN & \\
\hline CHEMBL182493 & 302650 & 7.699 & 7.6748 & TRN & \\
\hline CHEMBL363125 & 302650 & 9.0 & 8.7361 & TRN & \\
\hline CHEMBL359554 & 302650 & 8.0 & 7.9653 & TRN & \\
\hline CHEMBL186195 & 302650 & 5.8013 & 5.9366 & TRN & \\
\hline CHEMBL189135 & 302650 & 3.5003 & 3.41399 & 99999999997 & TRN \\
\hline CHEMBL188784 & 302650 & 3.5003 & 3.4728 & TRN & \\
\hline CHEMBL185871 & 302650 & 6.9208 & 6.8729 & TRN & \\
\hline CHEMBL182326 & 302650 & 8.0 & 8.0724 & TRN & \\
\hline CHEMBL184510 & 302650 & 9.0 & 8.9632 & TRN & \\
\hline CHEMBL434158 & 302650 & 7.301 & 7.2575 & TRN & \\
\hline CHEMBL434337 & 302650 & 8.0 & 8.6544 & TST & \\
\hline CHEMBL180593 & 302650 & 7.0969 & 6.3578 & TST & \\
\hline CHEMBL188794 & 302650 & 4.5086 & 4.4907 & TRN & \\
\hline CHEMBL188257 & 302650 & 5.3002 & 5.2864 & TRN & \\
\hline CHEMBL365840 & 302650 & 3.5003 & 3.4556 & TRN & \\
\hline CHEMBL364587 & 302650 & 7.301 & 7.7204 & TST & \\
\hline CHEMBL364539 & 302650 & 6.1024 & 6.1429 & TRN & \\
\hline CHEMBL186826 & 302650 & 6.1024 & 6.1164 & TRN & \\
\hline CHEMBL186213 & 302650 & 4.5003 & 4.5264 & TRN & \\
\hline CHEMBL188426 & 302650 & 5.5003 & 6.0011 & TST & \\
\hline CHEMBL186288 & 302650 & 7.1549 & 7.13700 & 00000000005 & TST \\
\hline CHEMBL 360408 & 302650 & 8.0 & 8.0965 & TRN & \\
\hline CHEMBL186166 & 302650 & 7.699 & 7.8088 & TRN & \\
\hline CHEMBL188205 & 302650 & 6.2007 & 6.7439 & TST & \\
\hline CHEMBL365297 & 302650 & 8.0 & 7.9826 & TRN & \\
\hline CHEMBL187081 & 302650 & 8.0 & 8.4131 & TST & \\
\hline CHEMBL360866 & 302650 & 4.7011 & 8.2982 & TST & \\
\hline CHEMBL184657 & 302650 & 6.2007 & 5.9015 & TRN & \\
\hline CHEMBL 273870 & 302650 & 3.7001 & 6.73 & TST & \\
\hline CHEMBL185939 & 302650 & 3.5003 & 3.705 & TRN & \\
\hline CHEMBL359963 & 302650 & 7.5229 & 7.8405 & TST & \\
\hline CHEMBL186476 & 302650 & 8.0 & 8.0358 & TRN & \\
\hline
\end{tabular}




\begin{tabular}{|c|c|c|c|c|c|}
\hline \multirow{3}{*}{$\begin{array}{l}\text { CHEMBL188665 } \\
\text { CHEMBL189459 }\end{array}$} & \multicolumn{5}{|c|}{ Supplemental Table S2.txt } \\
\hline & 302650 & 9.0 & \multicolumn{2}{|c|}{8.677999999999999} & TST \\
\hline & 302650 & 7.699 & 7.6408 & TRN & \\
\hline CHEMBL364370 & 302650 & 8.0 & 8.7256 & TST & \\
\hline CHEMBL186708 & 302650 & 9.0 & 8.8043 & TST & \\
\hline CHEMBL185044 & 302650 & 3.7001 & 6.6596 & TST & \\
\hline CHEMBL184656 & 302650 & 6.5086 & 6.3337 & TRN & \\
\hline CHEMBL187272 & 302650 & 3.5003 & 3.4326 & TRN & \\
\hline CHEMBL361723 & 302650 & 7.5229 & 7.7714 & TRN & \\
\hline CHEMBL3589729 & 1503357 & 7.2218 & 7.2071 & TRN & \\
\hline CHEMBL3589879 & 1503357 & 6.1938 & 6.0988 & TRN & \\
\hline CHEMBL3589731 & 1503357 & 6.5884 & 6.6821 & TRN & \\
\hline CHEMBL3589732 & 1503357 & 6.1391 & 6.1423 & TRN & \\
\hline CHEMBL3589719 & 1503357 & 6.684 & 6.8482 & TRN & \\
\hline CHEMBL3589736 & 1503357 & 5.6753 & 5.6883 & TRN & \\
\hline CHEMBL3589716 & 1503357 & 6.5952 & 6.5801 & TRN & \\
\hline CHEMBL3589874 & 1503357 & 7.7258 & 7.5858 & TRN & \\
\hline CHEMBL3589718 & 1503357 & 5.2567 & 5.1905 & TRN & \\
\hline CHEMBL3589877 & 1503357 & 7.3382 & 7.402 & TRN & \\
\hline CHEMBL3589872 & 1503357 & 6.9626 & 7.4327 & TST & \\
\hline CHEMBL3589712 & 1503357 & 7.1733 & 6.9966 & TRN & \\
\hline CHEMBL3589876 & 1503357 & 7.209 & 7.0888 & TRN & \\
\hline CHEMBL3589862 & 1503357 & 5.7003 & 6.2447 & TST & \\
\hline CHEMBL3589714 & 1503357 & 7.2557 & 7.2186 & TRN & \\
\hline CHEMBL3589866 & 1503357 & 6.0921 & 6.9486 & TST & \\
\hline CHEMBL87381 & 1503357 & 6.3242 & 6.3463 & TRN & \\
\hline CHEMBL3589871 & 1503357 & 7.3288 & 7.4843 & TRN & \\
\hline CHEMBL3589721 & 1503357 & 6.4271 & 6.3007 & TRN & \\
\hline CHEMBL3589730 & 1503357 & 6.7932 & 6.6655 & TRN & \\
\hline CHEMBL3589875 & 1503357 & 5.6265 & 5.6692 & TRN & \\
\hline CHEMBL 20730 & 1503357 & 6.9508 & 6.8923 & TRN & \\
\hline CHEMBL3589863 & 1503357 & 6.7852 & 7.2745 & TST & \\
\hline CHEMBL3590031 & 1503357 & 6.1858 & 7.00200 & 2000000001 & TST \\
\hline CHEMBL3589734 & 1503357 & 5.6821 & 5.6438 & TRN & \\
\hline CHEMBL3589724 & 1503357 & 7.0545 & 6.8594 & TRN & \\
\hline CHEMBL3589865 & 1503357 & 6.9666 & 7.0415 & TRN & \\
\hline CHEMBL473129 & 1503357 & 6.5467 & 6.5471 & TRN & \\
\hline CHEMBL3589873 & 1503357 & 6.8729 & 6.9183 & TRN & \\
\hline CHEMBL3589722 & 1503357 & 5.6998 & 5.7205 & TRN & \\
\hline CHEMBL3589728 & 1503357 & 6.2604 & 6.6591 & TST & \\
\hline CHEMBL3589711 & 1503357 & 7.0665 & 7.1173 & TRN & \\
\hline CHEMBL3589870 & 1503357 & 6.7773 & 6.57799 & 9999999999 & TRN \\
\hline CHEMBL3589715 & 1503357 & 6.5528 & 7.16299 & 9999999999 & TST \\
\hline CHEMBL3589733 & 1503357 & 5.4409 & 5.4558 & TRN & \\
\hline CHEMBL3589725 & 1503357 & 6.1445 & 6.3398 & TRN & \\
\hline CHEMBL3589727 & 1503357 & 6.7799 & 7.2482 & TST & \\
\hline CHEMBL87379 & 1503357 & 7.0159 & 7.1021 & TRN & \\
\hline CHEMBL264437 & 1503357 & 7.1129 & 7.0637 & TRN & \\
\hline CHEMBL3589878 & 1503357 & 6.2652 & 6.5426 & TRN & \\
\hline
\end{tabular}




\begin{tabular}{|c|c|c|c|c|c|c|c|}
\hline \multicolumn{8}{|c|}{ Supplemental Table S2.txt } \\
\hline CHEMBL 3589868 & 1503357 & 5.4793 & 5.4258 & TRN & & & \\
\hline CHEMBL 3589867 & 1503357 & 5.32700 & 000000000 & & 5.5167 & TST & \\
\hline CHEMBL3589735 & 1503357 & 5.8598 & 5.5473 & TST & & & \\
\hline CHEMBL3589717 & 1503357 & 6.9872 & 7.0976 & TRN & & & \\
\hline CHEMBL3590029 & 1503357 & 6.15799 & 999999999 & 995 & 6.29200 & 0000000001 & TST \\
\hline CHEMBL3589723 & 1503357 & 6.7852 & $6.71200 e$ & 000000000 & & TRN & \\
\hline CHEMBL 3589864 & 1503357 & 5.7378 & 5.7452 & TST & & & \\
\hline CHEMBL3589720 & 1503357 & 7.341 & 7.2019 & TRN & & & \\
\hline CHEMBL3590030 & 1503357 & 6.8013 & 7.1802 & TST & & & \\
\hline CHEMBL3589869 & 1503357 & 7.2749 & 7.3482 & TRN & & & \\
\hline CHEMBL1089853 & 1503357 & 6.1367 & 6.1959 & TRN & & & \\
\hline CHEMBL3589713 & 1503357 & 5.9825 & 6.141 & TRN & & & \\
\hline CHEMBL3589726 & 1503357 & 5.8945 & 6.3159 & TST & & & \\
\hline CHEMBL3955419 & 1528016 & 5.3468 & 5.4912 & TRN & & & \\
\hline CHEMBL3645172 & 1528016 & 7.4949 & 6.794 & TRN & & & \\
\hline CHEMBL3642612 & 1528016 & 5.1739 & 6.1104 & TRN & & & \\
\hline CHEMBL1241481 & 1528016 & 6.6402 & 6.2732 & TRN & & & \\
\hline CHEMBL 3645171 & 1528016 & 7.5686 & 6.6772 & TRN & & & \\
\hline CHEMBL1526260 & 1528016 & 5.8239 & 5.6778 & TST & & & \\
\hline CHEMBL 3642607 & 1528016 & 6.8268 & 6.8446 & TRN & & & \\
\hline CHEMBL3937030 & 1528016 & 6.8861 & 5.2493 & TST & & & \\
\hline CHEMBL1601822 & 1528016 & 6.5784 & 5.3692 & TST & & & \\
\hline CHEMBL 3907072 & 1528016 & 5.6021 & 5.5333 & TRN & & & \\
\hline CHEMBL3642599 & 1528016 & 5.1135 & 5.5218 & TRN & & & \\
\hline CHEMBL1589705 & 1528016 & 6.7825 & 5.947 & TRN & & & \\
\hline CHEMBL1241578 & 1528016 & 6.75700 & 000000000 & & 6.7267 & TRN & \\
\hline CHEMBL3642623 & 1528016 & 6.8539 & 6.9449 & TRN & & & \\
\hline CHEMBL 3642602 & 1528016 & 5.1549 & 5.3211 & TRN & & & \\
\hline CHEMBL3919635 & 1528016 & 5.0915 & 4.6487 & TRN & & & \\
\hline CHEMBL 3642613 & 1528016 & 6.0883 & 6.2581 & TRN & & & \\
\hline CHEMBL 3645173 & 1528016 & 6.3615 & 6.3682 & TRN & & & \\
\hline CHEMBL 3642633 & 1528016 & 5.8239 & 5.881 & TRN & & & \\
\hline CHEMBL 3645176 & 1528016 & 5.63899 & 999999999 & & 6.4363 & TRN & \\
\hline CHEMBL3642601 & 1528016 & 5.5376 & 5.4335 & TRN & & & \\
\hline CHEMBL1570219 & 1528016 & 5.704 & 5.3194 & TST & & & \\
\hline CHEMBL3645169 & 1528016 & 6.2967 & 6.5157 & TRN & & & \\
\hline CHEMBL 3642620 & 1528016 & 5.2441 & 5.0599 & TRN & & & \\
\hline CHEMBL 3642609 & 1528016 & 5.1024 & 5.2953 & TRN & & & \\
\hline CHEMBL3645164 & 1528016 & 6.7878 & 6.5172 & TRN & & & \\
\hline CHEMBL584726 & 1528016 & 5.6424 & 6.0813 & TRN & & & \\
\hline CHEMBL 3642600 & 1528016 & 7.4045 & 7.1146 & TRN & & & \\
\hline CHEMBL1376633 & 1528016 & 5.4896 & 5.6772 & TST & & & \\
\hline CHEMBL3949846 & 1528016 & 5.301 & 4.7986 & TRN & & & \\
\hline CHEMBL3936271 & 1528016 & 7.2147 & 5.771 & TST & & & \\
\hline CHEMBL 3642622 & 1528016 & 5.3979 & 5.0241 & TRN & & & \\
\hline CHEMBL 3642634 & 1528016 & 5.0707 & 5.4973 & TRN & & & \\
\hline CHEMBL3950821 & 1528016 & 5.2291 & 5.4203 & TRN & & & \\
\hline CHEMBL 3642604 & 1528016 & 6.556 & 6.8057 & TRN & & & \\
\hline
\end{tabular}


Supplemental Table S2.txt

\begin{tabular}{|c|c|c|c|c|c|}
\hline CHEMBL1312649 & 1528016 & 5.8901 & 6.0924 & TST & \\
\hline CHEMBL1610040 & 1528016 & 6.0315 & 5.58299 & 7999999999 & TRN \\
\hline CHEMBL 3645162 & 1528016 & 5.0 & 5.7059 & TRN & \\
\hline CHEMBL3645163 & 1528016 & 6.7825 & 7.0031 & TRN & \\
\hline CHEMBL 3642611 & 1528016 & 6.8069 & 6.6268 & TRN & \\
\hline CHEMBL 3645170 & 1528016 & 6.7959 & 6.8786 & TRN & \\
\hline CHEMBL1233882 & 1528016 & 6.6576 & 6.4892 & TRN & \\
\hline CHEMBL 3642614 & 1528016 & 6.3468 & 6.2769 & TRN & \\
\hline CHEMBL3645175 & 1528016 & 6.0794 & 6.2708 & TRN & \\
\hline CHEMBL 3642636 & 1528016 & 5.4387 & 5.4492 & TRN & \\
\hline CHEMBL 3645167 & 1528016 & 6.6536 & 6.4487 & TRN & \\
\hline CHEMBL 3642618 & 1528016 & 5.5913 & 6.5631 & TRN & \\
\hline CHEMBL 3642616 & 1528016 & 5.0969 & 5.1857 & TRN & \\
\hline CHEMBL3645168 & 1528016 & 7.4318 & 6.9201 & TRN & \\
\hline CHEMBL 3642610 & 1528016 & 5.2518 & 5.2977 & TRN & \\
\hline CHEMBL 3642635 & 1528016 & 5.3386 & 5.4766 & TRN & \\
\hline CHEMBL 3645177 & 1528016 & 6.7595 & 6.4356 & TRN & \\
\hline CHEMBL 3642619 & 1528016 & 6.1427 & 6.7893 & TST & \\
\hline CHEMBL 3645174 & 1528016 & 7.2676 & 6.5109 & TST & \\
\hline CHEMBL 3642605 & 1528016 & 5.2924 & 6.7772 & TST & \\
\hline CHEMBL3951035 & 1528016 & 5.83 & 5.1768 & TST & \\
\hline CHEMBL 3645165 & 1528016 & 6.6144 & 6.2827 & TST & \\
\hline CHEMBL 3642632 & 1528016 & 6.04 & 6.2673 & TST & \\
\hline CHEMBL 3642617 & 1528016 & 5.5528 & 4.9197 & TST & \\
\hline CHEMBL 3645166 & 1528016 & 7.3098 & 6.6877 & TST & \\
\hline CHEMBL1713176 & 1495345 & 4.3261 & 4.3183 & TRN & \\
\hline CHEMBL3559893 & 1495345 & 4.6005 & 4.6214 & TRN & \\
\hline CHEMBL3561806 & 1495345 & 3.301 & 3.3253 & TRN & \\
\hline CHEMBL3561414 & 1495345 & 4.301 & 4.1545 & TRN & \\
\hline CHEMBL1500845 & 1495345 & 4.4202 & 4.2214 & TST & \\
\hline CHEMBL 3560457 & 1495345 & 3.301 & 3.5546 & TRN & \\
\hline CHEMBL3561865 & 1495345 & 5.4802 & 5.9155 & TRN & \\
\hline CHEMBL 3560869 & 1495345 & 5.3045 & 4.7299 & TST & \\
\hline CHEMBL1422224 & 1495345 & 3.301 & 3.0598 & TRN & \\
\hline CHEMBL 3559934 & 1495345 & 3.301 & 3.3895 & TRN & \\
\hline CHEMBL 3560293 & 1495345 & 4.301 & 4.4023 & TRN & \\
\hline CHEMBL 3560029 & 1495345 & 6.0809 & 5.9199 & TRN & \\
\hline CHEMBL 3561688 & 1495345 & 4.7392 & 4.2097 & TRN & \\
\hline CHEMBL1610450 & 1495345 & 3.301 & 5.2269 & TST & \\
\hline CHEMBL 3561912 & 1495345 & 5.3242 & 4.9992 & TRN & \\
\hline CHEMBL 3560807 & 1495345 & 7.4082 & 7.4198 & TRN & \\
\hline CHEMBL3560289 & 1495345 & 3.301 & 2.7862 & TST & \\
\hline CHEMBL3559953 & 1495345 & 3.301 & 3.0817 & TST & \\
\hline CHEMBL3560899 & 1495345 & 3.301 & 3.8835 & TRN & \\
\hline CHEMBL 3561920 & 1495345 & 4.301 & 4.1607 & TRN & \\
\hline CHEMBL 3560347 & 1495345 & 4.301 & 4.1076 & TRN & \\
\hline CHEMBL3561576 & 1495345 & 3.301 & 3.1631 & TRN & \\
\hline CHEMBL3560273 & 1495345 & 3.301 & 3.3275 & TRN & \\
\hline
\end{tabular}


Supplemental Table S2.txt

\begin{tabular}{|c|c|c|c|c|}
\hline & & & 2 & \\
\hline CHEMP - & 495345 & & 4037 & \\
\hline IEMBL: & 5345 & 3.301 & & \\
\hline IEMBL3 & 5345 & 7.4082 & 691 & \\
\hline AEMBL1442924 & 95345 & 5.7645 & 3711 & \\
\hline AEMBL3 & 345 & 3.301 & & \\
\hline 56 & & 3.301 & & \\
\hline 50156 & 495345 & 4.3325 & & \\
\hline 60867 & 495345 & 4.3477 & 61 & \\
\hline 61807 & 5345 & 4.3205 & & \\
\hline AEMBL & 345 & 4.301 & & \\
\hline 9997 & 345 & 7.4082 & & \\
\hline 9994 & 495345 & 4.301 & & \\
\hline 51433 & 345 & 3.301 & & \\
\hline 9873 & 45 & 3.301 & & \\
\hline 859 & 45 & 593 & & \\
\hline 152 & & & & \\
\hline 1028 & 345 & 4.301 & & \\
\hline 9776 & 345 & 5.6383 & & \\
\hline 1279 & 345 & 7.4 & & \\
\hline 62 & 45 & 3 . & & \\
\hline 31 & 15 & & & \\
\hline 0019 & 345 & 4. & & \\
\hline 1662 & 345 & & & \\
\hline 1661 & 345 & 4. & & \\
\hline 73 & 45 & & & \\
\hline 0 & 5 & & & \\
\hline 62 & & & & \\
\hline & & & & \\
\hline 9784 & 345 & 4. & & \\
\hline 86 & 5 & 5 . & & \\
\hline & & & & \\
\hline & & & & \\
\hline 1490 & 345 & & & \\
\hline 50363 & 345 & & & \\
\hline 155 & 45 & 4. & & \\
\hline & & & & \\
\hline & & & & \\
\hline 1524 & 345 & & & \\
\hline 771 & 345 & & & \\
\hline 0651 & 345 & 882 & & \\
\hline & & 5.2774 & & \\
\hline 868 & 345 & $\lfloor 25$ & & $R$ \\
\hline 51366 & 1495345 & 3.301 & & R \\
\hline & & & & \\
\hline 50722 & 1495345 & .6326 & & \\
\hline 51476 & 1495345 & 5.2218 & 5.4874 & \\
\hline CHEMBL3559910 & 1495345 & 4.6198 & 3.823 & \\
\hline
\end{tabular}

Page 15673 
Supplemental Table S2.txt

\begin{tabular}{|c|c|c|c|c|c|}
\hline CHEMBL3561056 & 1495345 & 5.6126 & \multicolumn{2}{|c|}{5.5729999999999995} & \multirow[t]{2}{*}{ TRN } \\
\hline CHEMBL3559804 & 1495345 & 4.3883 & 4.5666 & TST & \\
\hline CHEMBL3560405 & 1495345 & 4.3982 & 4.5972 & TST & \\
\hline CHEMBL3559868 & 1495345 & 3.301 & 3.1634 & TRN & \\
\hline CHEMBL3560850 & 1495345 & 5.1979 & 2.0888 & TST & \\
\hline CHEMBL3561660 & 1495345 & 3.301 & 3.5805 & TRN & \\
\hline CHEMBL3561474 & 1495345 & 3.301 & 3.8313 & TRN & \\
\hline CHEMBL3561680 & 1495345 & 4.9948 & 5.2154 & TRN & \\
\hline CHEMBL3559746 & 1495345 & 5.1972 & 5.1421 & TRN & \\
\hline CHEMBL3560773 & 1495345 & 4.9855 & 4.6631 & TST & \\
\hline CHEMBL3561770 & 1495345 & 4.5589 & 7.255 & TST & \\
\hline CHEMBL3559858 & 1495345 & 3.301 & 3.2407 & TRN & \\
\hline CHEMBL3560345 & 1495345 & 4.8233 & 4.7177 & TRN & \\
\hline CHEMBL3560065 & 1495345 & 4.8225 & 4.8958 & TRN & \\
\hline CHEMBL 3561371 & 1495345 & 4.301 & 4.0795 & TRN & \\
\hline CHEMBL3560136 & 1495345 & 7.4082 & 7.2706 & TST & \\
\hline CHEMBL3561086 & 1495345 & 4.8259 & 5.0768 & TRN & \\
\hline CHEMBL3561377 & 1495345 & 4.301 & 3.7427 & TRN & \\
\hline CHEMBL1611438 & 1495345 & 6.1612 & 6.5588 & TST & \\
\hline CHEMBL3561905 & 1495345 & 4.9825 & 6.6877 & TST & \\
\hline CHEMBL3560496 & 1495345 & 3.301 & 3.2288 & TRN & \\
\hline CHEMBL3561729 & 1495345 & 3.301 & 4.4749 & TST & \\
\hline CHEMBL3560764 & 1495345 & 3.301 & 3.2739 & TRN & \\
\hline CHEMBL1331469 & 1495345 & 5.7167 & 5.42 & TRN & \\
\hline CHEMBL3561283 & 1495345 & 5.6503 & 5.59200 & 00000000005 & TRN \\
\hline CHEMBL3559918 & 1495345 & 7.4082 & 7.2596 & TRN & \\
\hline CHEMBL3561791 & 1495345 & 4.9694 & 4.6699 & TRN & \\
\hline CHEMBL3561464 & 1495345 & 3.301 & 3.4485 & TST & \\
\hline CHEMBL3560577 & 1495345 & 5.7959 & 7.7302 & TST & \\
\hline CHEMBL1585648 & 688750 & 4.3394 & 4.9137 & TST & \\
\hline CHEMBL1344654 & 688750 & 5.0217 & 4.9549 & TST & \\
\hline CHEMBL1450480 & 688750 & 5.1522 & 4.945 & TRN & \\
\hline CHEMBL1479543 & 688750 & 5.0991 & 4.4767 & TRN & \\
\hline CHEMBL 3207415 & 688750 & 5.6565 & 4.391 & TRN & \\
\hline CHEMBL1580965 & 688750 & 4.9362 & 4.8914 & TRN & \\
\hline CHEMBL1305761 & 688750 & 4.7901 & 4.5394 & TRN & \\
\hline CHEMBL1579617 & 688750 & 3.301 & 4.4579 & TRN & \\
\hline CHEMBL1582222 & 688750 & 4.4534 & 4.3247 & TRN & \\
\hline CHEMBL1331003 & 688750 & 4.8251 & 4.6166 & TRN & \\
\hline CHEMBL1325301 & 688750 & 5.3097 & 4.6927 & TRN & \\
\hline CHEMBL1509141 & 688750 & 3.301 & 5.1407 & TRN & \\
\hline CHEMBL1482957 & 688750 & 5.1331 & 4.24106 & 00000000005 & TRN \\
\hline CHEMBL1324397 & 688750 & 5.0954 & 4.6954 & TST & \\
\hline CHEMBL1372818 & 688750 & 3.301 & 4.8098 & TRN & \\
\hline CHEMBL1365262 & 688750 & 5.1143 & 4.5191 & TRN & \\
\hline CHEMBL3198178 & 688750 & 5.0543 & 4.8211 & TRN & \\
\hline CHEMBL1451598 & 688750 & 7.3979 & 5.5259 & TRN & \\
\hline CHEMBL1214345 & 688750 & 4.8343 & 4.4003 & TRN & \\
\hline
\end{tabular}

Page 15674 
Supplemental Table S2.txt

\begin{tabular}{|c|c|c|c|c|}
\hline r & & 3979 & 9061 & \\
\hline UГMDI 1752 & 88750 & & 5.0014 & \\
\hline & & & & \\
\hline AEMBL150e & 750 & & & $\mathrm{MI}$ \\
\hline AEMBL1544648 & 750 & & 2648 & \\
\hline HEMBL1495238 & 88750 & 4639 & 8721 & \\
\hline & 750 & & 732 & \\
\hline IFMR $15^{\circ}$ & & & 5812 & \\
\hline AEMBL14492 & 750 & 39 & 3793 & \\
\hline HEMBL1376048 & 750 & .301 & 9489 & \\
\hline HEMBL1469659 & 50 & & 309 & \\
\hline IEMBL1491 & & & 3066 & \\
\hline AEMBL1389 & & & & \\
\hline AEMBL1327866 & 750 & & $\partial 619$ & \\
\hline AEMBL1448 & 50 & & & \\
\hline AEMBL1601 & 50 & & 9076 & \\
\hline HEMBL 200 & & & 425 & \\
\hline HEMBL1438 & & & & \\
\hline AEMBL1589345 & 50 & & 7828 & \\
\hline IEMBL146 & & & 301 & \\
\hline FEMBI & & & 59 & \\
\hline HEMBL14 & & & 77 & וד \\
\hline HEMBL14 & & & 34 & \\
\hline HFMRI 1422225 & 750 & & 3829 & \\
\hline AEMBL1414 & & & & IRIV \\
\hline HEMBL1 & & & 395 & KIV \\
\hline HEMBL1 & & & 47 & RN \\
\hline HFMBI 1 & 50 & & 938 & \\
\hline AEMBL & & & 354 & $\mathrm{in}$ \\
\hline HEMBL1556603 & & & 523 & TRN \\
\hline HEMBL1 & & & 226 & RN \\
\hline HEMBL & & & 323 & RN \\
\hline HEMPI & 50 & & 266 & $x_{0}$ \\
\hline HEMBL3192657 & & & 508 & IRN \\
\hline HEMBL1598043 & & & 533 & TST \\
\hline HEMBL154 & & & 169 & TRN \\
\hline HᄃMDI - & & & 052 & $\Gamma \mathrm{RN}$ \\
\hline HEMBL1380796 & & & 159 & ГRN \\
\hline HEMBL1385286 & 88750 & & 3525 & TRN \\
\hline AEMBL13765 & 50 & & 759 & TRN \\
\hline HEMBL1 & & & 856 & \\
\hline CHEMBL2000230 & 88750 & & 5905 & \\
\hline HEMBL1401534 & 3750 & 894 & 9759 & TRN \\
\hline AEMBL1345090 & 88750 & 3.301 & 909 & TST \\
\hline HEMBL319 & 88750 & & 53 & $r$ \\
\hline HEMBL1 & & & 2828 & \\
\hline CHEMBL1338593 & & 5.0598 & 4.9011 & \\
\hline CHEMBL1581949 & 688750 & 3.301 & 4.6308 & \\
\hline
\end{tabular}

Page 15675 


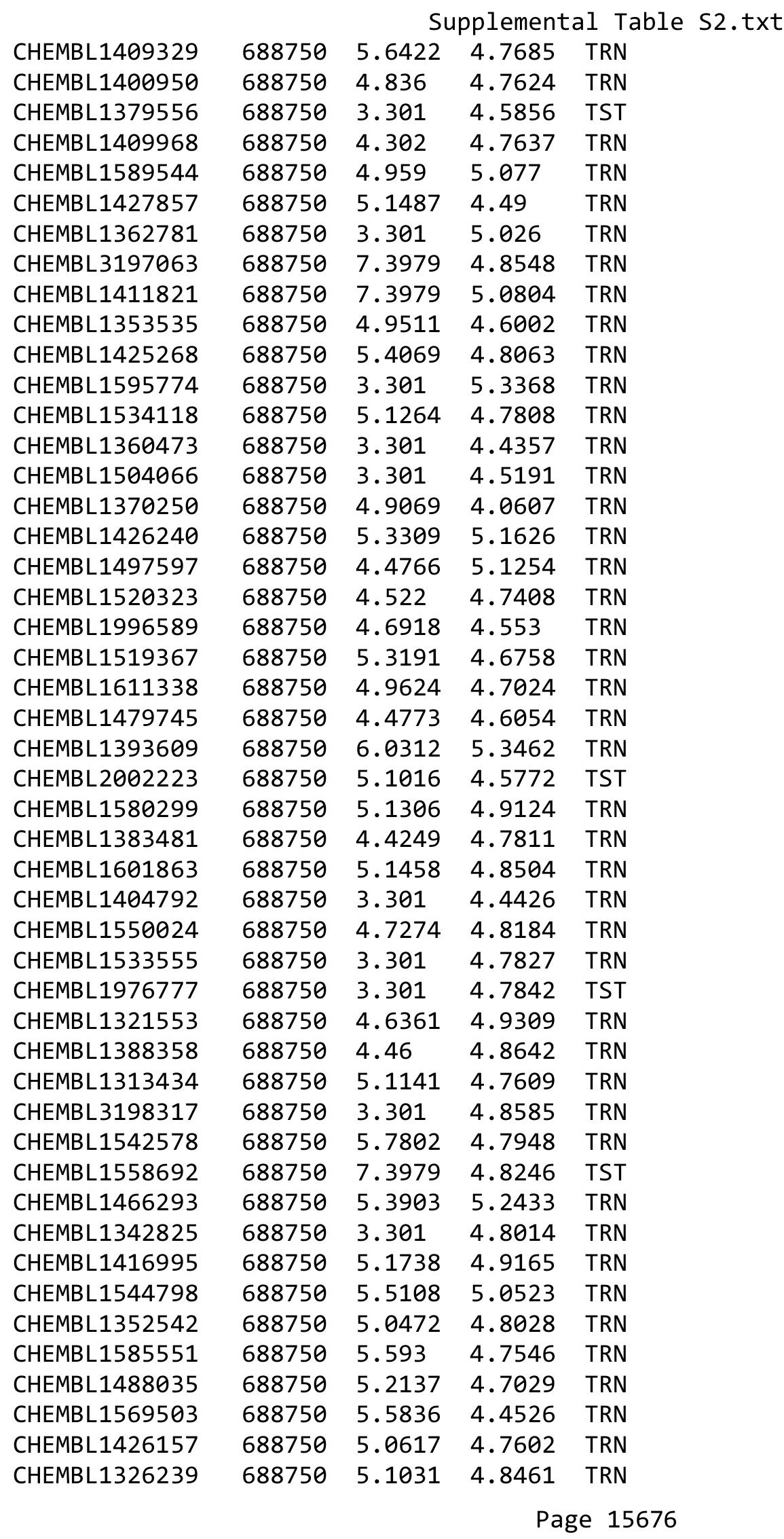




\begin{tabular}{|c|c|c|c|c|c|}
\hline & & \multicolumn{4}{|c|}{ Supplemental Table S2.txt } \\
\hline CHEMBL1430430 & 688750 & 5.471 & 4.607 & TRN & \\
\hline CHEMBL1353252 & 688750 & 4.7208 & 5.0464 & TRN & \\
\hline CHEMBL1330135 & 688750 & 5.419 & 4.5265 & TRN & \\
\hline CHEMBL1543349 & 688750 & 5.473 & 4.8268 & TRN & \\
\hline CHEMBL1610117 & 688750 & 3.301 & 4.6318 & TRN & \\
\hline CHEMBL1352671 & 688750 & 3.301 & 4.6755 & TRN & \\
\hline CHEMBL1498136 & 688750 & 5.4557 & 4.5591 & TRN & \\
\hline CHEMBL1588345 & 688750 & 7.3979 & 5.2664 & TRN & \\
\hline CHEMBL1568131 & 688750 & 3.301 & 4.50899 & 99999999995 & TRN \\
\hline CHEMBL1417524 & 688750 & 5.5706 & 5.4949 & TRN & \\
\hline CHEMBL1341809 & 688750 & 4.8682 & 4.8913 & TRN & \\
\hline CHEMBL1469542 & 688750 & 5.271 & 5.0463 & TRN & \\
\hline CHEMBL1383741 & 688750 & 3.301 & 4.9725 & TRN & \\
\hline CHEMBL3208127 & 688750 & 4.867 & 4.582 & TRN & \\
\hline CHEMBL3213308 & 688750 & 3.301 & 4.6573 & TRN & \\
\hline CHEMBL1477421 & 688750 & 3.301 & 4.5757 & TRN & \\
\hline CHEMBL1312561 & 688750 & 3.301 & 4.4313 & TRN & \\
\hline CHEMBL1610519 & 688750 & 4.8677 & 4.441 & TRN & \\
\hline CHEMBL1448876 & 688750 & 6.0377 & 4.4886 & TRN & \\
\hline CHEMBL1594456 & 688750 & 4.7167 & 4.9757 & TRN & \\
\hline CHEMBL373784 & 688750 & 3.301 & 4.6662 & TRN & \\
\hline CHEMBL1467604 & 688750 & 4.6124 & 5.0832 & TRN & \\
\hline CHEMBL1543801 & 688750 & 5.1089 & 4.5062 & TRN & \\
\hline CHEMBL1549513 & 688750 & 5.1434 & 4.8532 & TST & \\
\hline CHEMBL1426817 & 688750 & 5.2066 & 4.8706 & TRN & \\
\hline CHEMBL1525017 & 688750 & 5.1262 & 4.8371 & TRN & \\
\hline CHEMBL3197753 & 688750 & 4.7302 & 4.8662 & TST & \\
\hline CHEMBL1319003 & 688750 & 3.301 & 4.8045 & TRN & \\
\hline CHEMBL1353442 & 688750 & 4.8452 & 4.8566 & TRN & \\
\hline CHEMBL 3213771 & 688750 & 4.7963 & 4.373 & TRN & \\
\hline CHEMBL1588465 & 688750 & 5.3502 & 4.5798 & TRN & \\
\hline CHEMBL1431524 & 688750 & 5.0461 & 4.9483 & TRN & \\
\hline CHEMBL1421317 & 688750 & 5.4774 & 4.9971 & TRN & \\
\hline CHEMBL1490119 & 688750 & 3.301 & 4.3564 & TRN & \\
\hline CHEMBL1525318 & 688750 & 5.0069 & 4.8834 & TRN & \\
\hline CHEMBL1531389 & 688750 & 6.0953 & 5.2011 & TRN & \\
\hline CHEMBL 1386270 & 688750 & 4.4357 & 4.4596 & TRN & \\
\hline CHEMBL3193999 & 688750 & 4.8693 & 4.6828 & TRN & \\
\hline CHEMBL1324275 & 688750 & 3.301 & 4.6644 & TRN & \\
\hline CHEMBL1305070 & 688750 & 5.1679 & 5.5201 & TRN & \\
\hline CHEMBL1467356 & 688750 & 5.0589 & 4.8993 & TRN & \\
\hline CHEMBL1328224 & 688750 & 5.3673 & 4.6466 & TRN & \\
\hline CHEMBL1605677 & 688750 & 3.301 & 4.4651 & TST & \\
\hline CHEMBL605959 & 688750 & 4.8626 & 4.7418 & TRN & \\
\hline CHEMBL1372911 & 688750 & 5.4871 & 4.8274 & TRN & \\
\hline CHEMBL1549845 & 688750 & 5.0523 & 4.7725 & TST & \\
\hline CHEMBL1557159 & 688750 & 5.1916 & 5.1877 & TST & \\
\hline CHEMBL1373194 & 688750 & 3.301 & 4.9384 & TST & \\
\hline
\end{tabular}




\begin{tabular}{|c|c|c|c|c|c|c|}
\hline & & \multicolumn{5}{|c|}{ Supplemental Table S2.txt } \\
\hline CHEMBL1605254 & 688750 & 3.301 & 4.852 & TRN & & \\
\hline CHEMBL1373474 & 688750 & 5.5489 & 4.8185 & TST & & \\
\hline CHEMBL1609786 & 688750 & 5.4967 & 5.1133 & TRN & & \\
\hline CHEMBL1326919 & 688750 & 7.3979 & 4.8464 & TRN & & \\
\hline CHEMBL1332282 & 688750 & 4.9332 & 5.1929 & TRN & & \\
\hline CHEMBL1310272 & 688750 & 5.1541 & 5.0893 & TRN & & \\
\hline CHEMBL1386259 & 688750 & 4.7521 & 4.5941 & TRN & & \\
\hline CHEMBL1542491 & 688750 & 5.2295 & 4.9307 & TST & & \\
\hline CHEMBL1608186 & 688750 & 5.0934 & 4.7277 & TRN & & \\
\hline CHEMBL1320260 & 688750 & 5.1356 & 5.2718 & TRN & & \\
\hline CHEMBL1522943 & 688750 & 4.8465 & 4.4507 & TRN & & \\
\hline CHEMBL1393523 & 688750 & 4.6926 & 4.6432 & TRN & & \\
\hline CHEMBL1548948 & 688750 & 5.306 & 4.3495 & TRN & & \\
\hline CHEMBL1455733 & 688750 & 4.7023 & 4.4815 & TRN & & \\
\hline CHEMBL1541807 & 688750 & 5.5463 & 5.2279 & TRN & & \\
\hline CHEMBL1421559 & 688750 & 7.3979 & 4.8096 & TRN & & \\
\hline CHEMBL1433040 & 688750 & 4.825 & 4.734 & TRN & & \\
\hline CHEMBL3198038 & 688750 & 5.3297 & 4.3637 & TST & & \\
\hline CHEMBL1578946 & 688750 & 3.301 & 4.7903 & TRN & & \\
\hline CHEMBL 3213346 & 688750 & 4.9642 & 4.5949 & TRN & & \\
\hline CHEMBL1372933 & 688750 & 5.03100 & 00000000 & 01 & 4.8 & TST \\
\hline CHEMBL1313596 & 688750 & 4.8539 & 5.2873 & TRN & & \\
\hline CHEMBL1349074 & 688750 & 5.4047 & 4.9121 & TRN & & \\
\hline CHEMBL1517815 & 688750 & 4.9005 & 5.0132 & TST & & \\
\hline CHEMBL1448074 & 688750 & 4.6286 & 4.7527 & TRN & & \\
\hline CHEMBL1427233 & 688750 & 4.8712 & 5.1013 & TRN & & \\
\hline CHEMBL1310523 & 688750 & 5.1946 & 5.098 & TRN & & \\
\hline CHEMBL1333388 & 688750 & 5.1879 & 4.7851 & TRN & & \\
\hline CHEMBL1366913 & 688750 & 3.301 & 4.8499 & TRN & & \\
\hline CHEMBL1578664 & 688750 & 5.141 & 4.9823 & TRN & & \\
\hline CHEMBL1466714 & 688750 & 4.8729 & 5.0752 & TRN & & \\
\hline CHEMBL1499320 & 688750 & 5.2814 & 4.8691 & TRN & & \\
\hline CHEMBL1569932 & 688750 & 4.8948 & 4.6076 & TRN & & \\
\hline CHEMBL1312198 & 688750 & 4.6407 & 4.9307 & TRN & & \\
\hline CHEMBL1537789 & 688750 & 4.4651 & 5.2759 & TRN & & \\
\hline CHEMBL1580526 & 688750 & 4.599 & 5.063 & TRN & & \\
\hline CHEMBL1509990 & 688750 & 5.1017 & 5.092 & TRN & & \\
\hline CHEMBL1480237 & 688750 & 7.3979 & 4.6797 & TRN & & \\
\hline CHEMBL1371842 & 688750 & 5.1086 & 5.079 & TRN & & \\
\hline CHEMBL1391519 & 688750 & 5.0043 & 5.1222 & TRN & & \\
\hline CHEMBL1344956 & 688750 & 3.301 & 4.4665 & TRN & & \\
\hline CHEMBL1416439 & 688750 & 5.0821 & 4.5625 & TST & & \\
\hline CHEMBL1399167 & 688750 & 5.1313 & 4.4471 & TRN & & \\
\hline CHEMBL 3194162 & 688750 & 3.301 & 4.6393 & TRN & & \\
\hline CHEMBL1600056 & 688750 & 5.0463 & 4.8748 & TST & & \\
\hline CHEMBL1571923 & 688750 & 3.301 & 4.9802 & TRN & & \\
\hline CHEMBL1304631 & 688750 & 4.9311 & 5.0041 & TRN & & \\
\hline CHEMBL1419498 & 688750 & 5.0225 & 5.2801 & TRN & & \\
\hline
\end{tabular}


Supplemental Table S2.txt

\begin{tabular}{|c|c|c|c|c|}
\hline ים & & & & 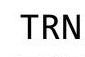 \\
\hline HEMBL1466789 & 88750 & 5.4472 & & \\
\hline HEMBL1408704 & 8750 & 3181 & 5486 & \\
\hline AEMBL1427968 & 38750 & & & \\
\hline 766 & 8750 & & & \\
\hline IEMBL1607656 & 88750 & & 133 & \\
\hline HEMBL1414761 & 88750 & .0264 & 4.9791 & \\
\hline HEMBL1479240 & 88750 & & 4.7275 & \\
\hline IEMBL13 & 38750 & & 4.4784 & \\
\hline EMBL: & 8750 & & & \\
\hline HEMBL1486562 & 88750 & & 4.5878 & \\
\hline HEMBL1453148 & 88750 & & 5.1466 & \\
\hline AEMBL1: & 38750 & & 203 & \\
\hline IEMBL31 & 8750 & & 4.8823 & RN \\
\hline IEMBL15 & & & 898 & \\
\hline HEMBL14 & 38750 & & 4.8255 & \\
\hline IEMBL31 & 50 & & 645 & \\
\hline HEMBL16 & 88750 & 5 . & 4.9 & \\
\hline EMBL15 & 50 & & 4. & $\mathrm{RN}$ \\
\hline IEMBL13 & & & & \\
\hline 52 & 50 & & 676 & \\
\hline IEMBL15 & 50 & & & \\
\hline AEMBL13 & 0 & & 4.7 & RIN \\
\hline EMBL1 & & & 43 & $\mathrm{RN}$ \\
\hline FM & & & & \\
\hline 141 & 50 & & 202 & Iv \\
\hline IEMBL199 & 0 & & & $\mathrm{~N}$ \\
\hline IEMBL1 & $\theta$ & & 4.4 & RN \\
\hline |EM & & & 4. & RN \\
\hline 86 & 50 & & 642 & RN \\
\hline & & & 558 & IN \\
\hline IEMBL1323 & 0 & & 4. & TRN \\
\hline IEMBL1 & 0 & & 198 & ST \\
\hline 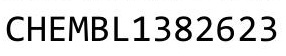 & & & 4. & RN \\
\hline 5 & 0 & 3. & 49 & RN \\
\hline IEMBL136 & & & 4.6093 & RN \\
\hline IEMBL1464644 & 88750 & & 479 & RN \\
\hline 1 & & & & RN \\
\hline כ & $\theta$ & 4 & 4. & ST \\
\hline & & & 4.7 & RN \\
\hline AEMBL1452872 & 88750 & & 4.6595 & TRN \\
\hline AEMBL158 & 88750 & & 4. & TS \\
\hline & & & & RN \\
\hline (15) & 0 & & 4.8512 & $\mathrm{RN}$ \\
\hline HEMBL1534195 & & & 4.9805 & RN \\
\hline IEMBL1308004 & 88750 & 41 & 5.1816 & $\mathrm{~N}$ \\
\hline HEMBL1320023 & 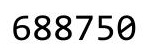 & & 4.7771 & $\mathrm{~N}$ \\
\hline CHEMBL137283 & & 7.3979 & 4.7385 & \\
\hline
\end{tabular}

Page 15679 


\begin{tabular}{|c|c|c|c|c|}
\hline \multicolumn{5}{|c|}{ Supplemental Table S2.txt } \\
\hline CHEMBL1613288 & 688750 & 3.301 & 4.2893 & TRN \\
\hline CHEMBL1499210 & 688750 & 5.3076 & 5.0753 & TRN \\
\hline CHEMBL1468246 & 688750 & 4.897 & 4.6527 & TRN \\
\hline CHEMBL1459936 & 688750 & 7.3979 & 5.3761 & TRN \\
\hline CHEMBL1482885 & 688750 & 7.3979 & 4.8683 & TRN \\
\hline CHEMBL1412616 & 688750 & 3.301 & 5.0827 & TRN \\
\hline CHEMBL1341778 & 688750 & 5.1403 & 5.4365 & TRN \\
\hline CHEMBL1464902 & 688750 & 3.301 & 4.9075 & TRN \\
\hline CHEMBL1341833 & 688750 & 4.6188 & 4.7978 & TRN \\
\hline CHEMBL1525030 & 688750 & 3.301 & 4.3135 & TRN \\
\hline CHEMBL1491387 & 688750 & 3.301 & 4.4848 & TRN \\
\hline CHEMBL1304118 & 688750 & 4.3144 & 4.4819 & TRN \\
\hline CHEMBL1534596 & 688750 & 3.301 & 4.9432 & TRN \\
\hline CHEMBL1441211 & 688750 & 4.3072 & 4.5706 & TRN \\
\hline CHEMBL1346640 & 688750 & 5.0788 & 5.0352 & TRN \\
\hline CHEMBL1394030 & 688750 & 5.3915 & 4.7557 & TRN \\
\hline CHEMBL1348169 & 688750 & 5.1275 & 4.8241 & TRN \\
\hline CHEMBL1604170 & 688750 & 3.301 & 4.3501 & TRN \\
\hline CHEMBL1605350 & 688750 & 5.2895 & 4.6517 & TRN \\
\hline CHEMBL1462418 & 688750 & 4.3872 & 4.2118 & TRN \\
\hline CHEMBL1528647 & 688750 & 6.1096 & 5.3256 & TRN \\
\hline CHEMBL1361363 & 688750 & 5.5983 & 5.037 & TRN \\
\hline CHEMBL1595065 & 688750 & 4.8841 & 4.6456 & TRN \\
\hline CHEMBL591404 & 688750 & 5.1362 & 5.3055 & TRN \\
\hline CHEMBL1509530 & 688750 & 5.4905 & 5.1269 & TRN \\
\hline CHEMBL3196867 & 688750 & 5.6226 & 4.8804 & TRN \\
\hline CHEMBL1421432 & 688750 & 4.4734 & 4.7791 & TRN \\
\hline CHEMBL1324476 & 688750 & 5.1986 & 4.9822 & TST \\
\hline CHEMBL1491400 & 688750 & 4.7533 & 4.7712 & TRN \\
\hline CHEMBL1555805 & 688750 & 4.7987 & 4.7794 & TRN \\
\hline CHEMBL1333399 & 688750 & 4.9675 & 5.0694 & TRN \\
\hline CHEMBL1504063 & 688750 & 5.3007 & 5.305 & TRN \\
\hline CHEMBL1419617 & 688750 & 4.9452 & 4.8621 & TRN \\
\hline CHEMBL1450043 & 688750 & 5.6718 & 5.2765 & TRN \\
\hline CHEMBL1378300 & 688750 & 5.7876 & 4.8488 & TRN \\
\hline CHEMBL1519930 & 688750 & 4.881 & 4.6989 & TRN \\
\hline CHEMBL1998281 & 688750 & 5.5056 & 4.9565 & TST \\
\hline CHEMBL1364180 & 688750 & 4.9178 & 5.0315 & TRN \\
\hline CHEMBL3199530 & 688750 & 5.0489 & 5.0315 & TRN \\
\hline CHEMBL1420812 & 688750 & 3.301 & 4.3362 & TRN \\
\hline CHEMBL1507621 & 688750 & 5.1656 & 5.1767 & TRN \\
\hline CHEMBL1525340 & 688750 & 4.8589 & 5.1306 & TRN \\
\hline CHEMBL1568020 & 688750 & 4.6992 & 4.7336 & TRN \\
\hline CHEMBL1511282 & 688750 & 7.3979 & 5.1053 & TRN \\
\hline CHEMBL1501666 & 688750 & 4.9881 & 4.707 & TRN \\
\hline CHEMBL1452537 & 688750 & 5.1619 & 4.9238 & TRN \\
\hline CHEMBL1448495 & 688750 & 3.301 & 4.6092 & TRN \\
\hline CHEMBL3189409 & 688750 & 4.5532 & 4.5547 & TST \\
\hline
\end{tabular}


Supplemental Table S2.txt

\begin{tabular}{|c|c|c|c|c|}
\hline-5 & & & 7298 & \\
\hline HEMBL1421187 & 88750 & .9952 & 5.1064 & \\
\hline 77 & & & 729 & \\
\hline AEMBL1404979 & & & 0112 & \\
\hline AEMBL1420418 & 750 & 301 & 5874 & \\
\hline HEMBL1375153 & 88750 & .1223 & 8857 & \\
\hline HEMBL326 & 750 & & 512 & \\
\hline 315 & & & 943 & \\
\hline AEMBL1347786 & 750 & & 862 & \\
\hline HEMBL1392785 & 50 & 06 & 7519 & \\
\hline HEMBL1468165 & 50 & & 267 & \\
\hline IEMBL14 & & 31 & 3964 & \\
\hline AEMBL14 & & & & \\
\hline HEMBL1446344 & 50 & 979 & 9692 & \\
\hline AEMBL13 & & & 572 & \\
\hline AEMBL13 & 50 & 79 & & \\
\hline HEMBL1C & 50 & & 997 & \\
\hline HEMBL5 5 & & & & \\
\hline HEMBL13 & 50 & & 1566 & \\
\hline IEMBL15 & & & & \\
\hline HEMBII & & & 65 & \\
\hline AEMBL13 & & & & \\
\hline HEMBL31 & & & 65 & \\
\hline 318 & & & & \\
\hline AEMBL1: & & & & ( \\
\hline HEMBL1 & & & 29 & KIV \\
\hline HEMBL: & & & 26 & Niv \\
\hline AFMRI 1 & 50 & & 49 & \\
\hline AEMBL13 & & & & TIV \\
\hline HEMBL1311122 & & & & IRN \\
\hline HEMBL1 & & & 177 & SI \\
\hline HEMBL & & & 382 & ST \\
\hline $15 M P I$ & 50 & & 358 & ST \\
\hline HEMBL1301945 & & & & IR \\
\hline HEMBL1462265 & & 607 & 473 & TRN \\
\hline HEMBL & & & & NIV \\
\hline HFMBI & & & 04 & RN \\
\hline HEMBL1 & & & 578 & RN \\
\hline HEMBL1545341 & 88750 & 1 & 3792 & TRN \\
\hline AEMBL130672 & & & 338 & $\mathrm{TR}$ \\
\hline HEMBL1 & & 12 & 974 & I IN \\
\hline CHEMBL1596681 & & .1438 & 574 & IST \\
\hline HEMBL1444883 & & & 595 & RN \\
\hline AEMBL1504385 & 38750 & 68 & 1875 & TRN \\
\hline HEMBL15 & 50 & 28 & 5032 & $\mathrm{~N}$ \\
\hline HEMBL3 & & 4.7295 & 4458 & \\
\hline CHEMBL 314512 & 88750 & 3.301 & 7203 & \\
\hline HEMBL137384 & 688750 & 4.5924 & 4.592 & ГRN \\
\hline
\end{tabular}

Page 15681 


\begin{tabular}{|c|c|c|c|c|c|}
\hline & & \multicolumn{4}{|c|}{ Supplemental Table S2.txt } \\
\hline CHEMBL1975809 & 688750 & 4.9643 & 4.7837 & TRN & \\
\hline CHEMBL1482431 & 688750 & 5.4759 & 4.6735 & TRN & \\
\hline CHEMBL1385374 & 688750 & 5.9818 & 4.5901 & TRN & \\
\hline CHEMBL1572329 & 688750 & 4.8768 & 4.3516 & TRN & \\
\hline CHEMBL1548408 & 688750 & 5.3224 & 4.7153 & TRN & \\
\hline CHEMBL1444355 & 688750 & 5.2742 & 4.477 & TRN & \\
\hline CHEMBL579424 & 688750 & 5.4066 & 4.697 & TRN & \\
\hline CHEMBL3192411 & 688750 & 4.8471 & 4.4427 & TRN & \\
\hline CHEMBL1460334 & 688750 & 5.7398 & 5.21399 & 99999999995 & TRN \\
\hline CHEMBL1308322 & 688750 & 3.301 & 4.9304 & TRN & \\
\hline CHEMBL1605788 & 688750 & 5.6011 & 4.9939 & TRN & \\
\hline CHEMBL1564523 & 688750 & 5.3098 & 5.0972 & TRN & \\
\hline CHEMBL1493047 & 688750 & 5.2489 & 4.8084 & TRN & \\
\hline CHEMBL1582910 & 688750 & 5.4182 & 5.1267 & TRN & \\
\hline CHEMBL1313653 & 688750 & 5.2145 & 5.1857 & TST & \\
\hline CHEMBL1429036 & 688750 & 5.745 & 4.9172 & TRN & \\
\hline CHEMBL1510161 & 688750 & 3.301 & 4.777 & TST & \\
\hline CHEMBL1441131 & 688750 & 5.6646 & 4.9046 & TRN & \\
\hline CHEMBL1348402 & 688750 & 3.301 & 4.6932 & TRN & \\
\hline CHEMBL1582544 & 688750 & 4.9424 & 4.7322 & TST & \\
\hline CHEMBL1529364 & 688750 & 4.333 & 4.9687 & TRN & \\
\hline CHEMBL1381242 & 688750 & 5.2413 & 4.9483 & TRN & \\
\hline CHEMBL1493575 & 688750 & 4.9019 & 4.9536 & TRN & \\
\hline CHEMBL1468968 & 688750 & 5.1116 & 5.0055 & TST & \\
\hline CHEMBL1360952 & 688750 & 4.6138 & 4.762 & TST & \\
\hline CHEMBL1379983 & 688750 & 4.7478 & 4.7224 & TRN & \\
\hline CHEMBL1502867 & 688750 & 5.5779 & 5.0882 & TRN & \\
\hline CHEMBL3195309 & 688750 & 5.019 & 4.7297 & TRN & \\
\hline CHEMBL1448592 & 688750 & 4.9436 & 4.793 & TST & \\
\hline CHEMBL1486737 & 688750 & 7.3979 & 4.97 & TRN & \\
\hline CHEMBL1320203 & 688750 & 7.3979 & 5.1179 & TRN & \\
\hline CHEMBL1566345 & 688750 & 5.3978 & 5.5177 & TRN & \\
\hline CHEMBL1600820 & 688750 & 5.14 & 4.6484 & TRN & \\
\hline CHEMBL1519498 & 688750 & 5.0459 & 4.4671 & TRN & \\
\hline CHEMBL1299435 & 688750 & 4.688 & 4.7771 & TRN & \\
\hline CHEMBL1604971 & 688750 & 5.1787 & 4.5385 & TRN & \\
\hline CHEMBL1974348 & 688750 & 3.301 & 4.6569 & TRN & \\
\hline CHEMBL1443192 & 688750 & 5.1982 & 4.9268 & TST & \\
\hline CHEMBL1370379 & 688750 & 3.301 & 4.8553 & TST & \\
\hline CHEMBL1972249 & 688750 & 5.2928 & 4.66100 & 00000000005 & TST \\
\hline CHEMBL1563896 & 688750 & 4.8764 & 5.0643 & TRN & \\
\hline CHEMBL1549455 & 688750 & 3.301 & 4.716 & TRN & \\
\hline CHEMBL1438178 & 688750 & 5.2573 & 4.7955 & TRN & \\
\hline CHEMBL1485525 & 688750 & 6.1325 & 5.3226 & TRN & \\
\hline CHEMBL1314032 & 688750 & 5.6309 & 4.9421 & TRN & \\
\hline CHEMBL1568109 & 688750 & 5.1334 & 4.6343 & TST & \\
\hline CHEMBL1613404 & 688750 & 5.0537 & 4.8775 & TRN & \\
\hline CHEMBL1567371 & 688750 & 3.301 & 4.512 & TRN & \\
\hline
\end{tabular}


Supplemental Table S2.txt

\begin{tabular}{|c|c|c|c|c|}
\hline CHEMBL1580660 & 688750 & 5.3008 & 5.0367 & TST \\
\hline CHEMBL1537428 & 688750 & 5.6194 & 4.519 & TRN \\
\hline CHEMBL3212425 & 688750 & 5.0202 & 4.6539 & TST \\
\hline CHEMBL1584754 & 688750 & 5.79899 & 79999999 & 4.332 \\
\hline CHEMBL1489924 & 688750 & 4.8405 & 4.6216 & TRN \\
\hline CHEMBL1322330 & 688750 & 4.9375 & 4.9491 & TRN \\
\hline CHEMBL1488012 & 688750 & 3.301 & 4.7693 & TRN \\
\hline CHEMBL1305111 & 688750 & 3.301 & 4.8873 & TRN \\
\hline CHEMBL1418997 & 688750 & 4.3337 & 4.354 & TRN \\
\hline CHEMBL1526081 & 688750 & 4.8241 & 4.74100 & 00000000005 \\
\hline CHEMBL1345979 & 688750 & 4.8259 & 4.743 & TST \\
\hline CHEMBL1559545 & 688750 & 5.0663 & 4.7128 & TRN \\
\hline CHEMBL1572080 & 688750 & 4.6447 & 5.5501 & TRN \\
\hline CHEMBL1448795 & 688750 & 5.1836 & 4.529 & TRN \\
\hline CHEMBL3392017 & 688750 & 3.301 & 5.1194 & TRN \\
\hline CHEMBL1441855 & 688750 & 3.301 & 5.0419 & TRN \\
\hline CHEMBL1534310 & 688750 & 5.2422 & 4.9241 & TRN \\
\hline CHEMBL1452182 & 688750 & 4.5407 & 4.9702 & TRN \\
\hline CHEMBL1517892 & 688750 & 4.7656 & 4.4852 & TRN \\
\hline CHEMBL165418 & 688750 & 3.301 & 4.8098 & TRN \\
\hline CHEMBL1478054 & 688750 & 4.9705 & 4.7053 & TRN \\
\hline CHEMBL1378549 & 688750 & 5.2393 & 4.9075 & TRN \\
\hline CHEMBL3189832 & 688750 & 5.4453 & 4.8655 & TST \\
\hline CHEMBL1426552 & 688750 & 4.9542 & 4.8522 & TRN \\
\hline CHEMBL1458909 & 688750 & 5.0093 & 5.2019 & TRN \\
\hline CHEMBL1321933 & 688750 & 5.4394 & 5.2409 & TRN \\
\hline CHEMBL1544057 & 688750 & 3.301 & 4.8187 & TRN \\
\hline CHEMBL1346061 & 688750 & 5.8477 & 4.9449 & TRN \\
\hline CHEMBL3194499 & 688750 & 5.2223 & 4.8704 & TST \\
\hline CHEMBL1458074 & 688750 & 4.8738 & 5.0312 & TRN \\
\hline CHEMBL3211143 & 688750 & 4.6616 & 4.4087 & TRN \\
\hline CHEMBL1495740 & 688750 & 5.2969 & 4.9848 & TRN \\
\hline CHEMBL1548833 & 688750 & 3.301 & 4.841 & TRN \\
\hline CHEMBL1493953 & 688750 & 5.1011 & 5.2508 & TRN \\
\hline CHEMBL1493628 & 688750 & 4.8258 & 5.1587 & TRN \\
\hline CHEMBL3207689 & 688750 & 3.301 & 4.6589 & TRN \\
\hline CHEMBL1538715 & 688750 & 4.961 & 4.6929 & TRN \\
\hline CHEMBL1336098 & 688750 & 4.604 & 5.2999 & TRN \\
\hline CHEMBL1446705 & 688750 & 4.6556 & 4.7185 & TRN \\
\hline CHEMBL1598721 & 688750 & 4.7185 & 5.2425 & TRN \\
\hline CHEMBL1484741 & 688750 & 5.2279 & 4.9632 & TRN \\
\hline CHEMBL1994510 & 688750 & 5.2946 & 4.6683 & TRN \\
\hline CHEMBL1330318 & 688750 & 4.8867 & 4.5969 & TRN \\
\hline CHEMBL3213287 & 688750 & 5.1815 & 4.3659 & TRN \\
\hline CHEMBL1526421 & 688750 & 3.301 & 4.2773 & TRN \\
\hline CHEMBL1391545 & 688750 & 5.0535 & 5.0267 & TRN \\
\hline CHEMBL1307384 & 688750 & 3.301 & 5.2524 & TRN \\
\hline CHEMBL1462662 & 688750 & 4.5597 & 4.4232 & TRN \\
\hline
\end{tabular}


Supplemental Table S2.txt

\begin{tabular}{|c|c|c|c|c|c|}
\hline CHEMBL256202 & 688750 & 4.7257 & 5.2927 & TRN & \\
\hline CHEMBL1424500 & 688750 & 5.0321 & 4.6149 & TRN & \\
\hline CHEMBL1500619 & 688750 & 4.9169 & 5.0191 & TRN & \\
\hline CHEMBL1366367 & 688750 & 4.9561 & 4.2734 & TRN & \\
\hline CHEMBL1423872 & 688750 & 4.793 & 4.4863 & TST & \\
\hline CHEMBL1320983 & 688750 & 4.9598 & 4.748 & TRN & \\
\hline CHEMBL1370165 & 688750 & 3.301 & 4.806 & TRN & \\
\hline CHEMBL1391764 & 688750 & 4.9122 & 5.3809 & TST & \\
\hline CHEMBL1580998 & 688750 & 5.2265 & 4.5813 & TRN & \\
\hline CHEMBL1565820 & 688750 & 4.6179 & 4.7151 & TRN & \\
\hline CHEMBL1313074 & 688750 & 4.8921 & 5.0375 & TST & \\
\hline CHEMBL1584337 & 688750 & 4.9462 & 4.6028 & TRN & \\
\hline CHEMBL1423304 & 688750 & 5.2267 & 4.5288 & TRN & \\
\hline CHEMBL1578997 & 688750 & 4.9674 & 4.8768 & TRN & \\
\hline CHEMBL1311039 & 688750 & 5.1057 & 4.6587 & TRN & \\
\hline CHEMBL1305050 & 688750 & 3.301 & 5.0355 & TRN & \\
\hline CHEMBL1479490 & 688750 & 3.301 & 4.7198 & TRN & \\
\hline CHEMBL1481613 & 688750 & 3.301 & 4.6367 & TRN & \\
\hline CHEMBL1463403 & 688750 & 7.3979 & 4.8461 & TRN & \\
\hline CHEMBL1471276 & 688750 & 3.301 & 4.7911 & TRN & \\
\hline CHEMBL1427793 & 688750 & 5.4378 & 4.5485 & TST & \\
\hline CHEMBL1360102 & 688750 & 4.8862 & 4.8339 & TRN & \\
\hline CHEMBL1364075 & 688750 & 5.0919 & 4.9661 & TRN & \\
\hline CHEMBL1543504 & 688750 & 4.8448 & 4.6855 & TST & \\
\hline CHEMBL3194588 & 688750 & 3.301 & 4.6248 & TRN & \\
\hline CHEMBL1300170 & 688750 & 7.3979 & 5.1572 & TRN & \\
\hline CHEMBL1519276 & 688750 & 3.301 & 4.5926 & TRN & \\
\hline CHEMBL1448881 & 688750 & 4.9111 & 4.8059 & TRN & \\
\hline CHEMBL1610299 & 688750 & 3.301 & 4.8365 & TRN & \\
\hline CHEMBL1471907 & 688750 & 4.8735 & 4.1887 & TRN & \\
\hline CHEMBL1410745 & 688750 & 5.6083 & 4.7202 & TRN & \\
\hline CHEMBL1345112 & 688750 & 4.9988 & 5.0 & TRN & \\
\hline CHEMBL1431286 & 688750 & 4.7855 & 4.9605 & TRN & \\
\hline CHEMBL1546518 & 688750 & 5.0288 & 4.10800 & 00000000005 & TRN \\
\hline CHEMBL1366209 & 688750 & 6.0377 & 5.1227 & TRN & \\
\hline CHEMBL1595646 & 688750 & 5.4074 & 4.7736 & TST & \\
\hline CHEMBL1414867 & 688750 & 5.261 & 5.143 & TRN & \\
\hline CHEMBL1349465 & 688750 & 5.3788 & 5.2938 & TRN & \\
\hline CHEMBL1522084 & 688750 & 4.9886 & 4.8177 & TRN & \\
\hline CHEMBL 1454500 & 688750 & 5.3964 & 4.8768 & TRN & \\
\hline CHEMBL1454798 & 688750 & 5.2885 & 5.0122 & TRN & \\
\hline CHEMBL1307467 & 688750 & 4.7318 & 4.8828 & TRN & \\
\hline CHEMBL1611622 & 688750 & 5.1963 & 4.7347 & TRN & \\
\hline CHEMBL 1404580 & 688750 & 7.3979 & 4.5855 & TRN & \\
\hline CHEMBL1587437 & 688750 & 4.5869 & 4.8511 & TRN & \\
\hline CHEMBL1389841 & 688750 & 3.301 & 4.2869 & TRN & \\
\hline CHEMBL1423724 & 688750 & 5.1444 & 4.9498 & TRN & \\
\hline CHEMBL1534430 & 688750 & 4.8828 & 4.9681 & TRN & \\
\hline
\end{tabular}




\begin{tabular}{|c|c|c|c|c|c|c|}
\hline & & \multicolumn{5}{|c|}{ Supplemental Table S2.txt } \\
\hline CHEMBL1331691 & 688750 & 3.301 & 4.8147 & TRN & & \\
\hline CHEMBL1359861 & 688750 & 4.8798 & 5.3387 & TRN & & \\
\hline CHEMBL1469710 & 688750 & 4.9617 & 5.3623 & TRN & & \\
\hline CHEMBL1545049 & 688750 & 5.1139 & 4.9738 & TRN & & \\
\hline CHEMBL1574619 & 688750 & 3.301 & 5.1554 & TRN & & \\
\hline CHEMBL1585260 & 688750 & 5.1515 & 4.8593 & TRN & & \\
\hline CHEMBL1576377 & 688750 & 4.9702 & 4.9617 & TRN & & \\
\hline CHEMBL1442309 & 688750 & 5.3312 & 5.1469 & TRN & & \\
\hline CHEMBL1588062 & 688750 & 3.301 & 4.363 & TRN & & \\
\hline CHEMBL1600299 & 688750 & 5.0914 & 4.8678 & TRN & & \\
\hline CHEMBL1362939 & 688750 & 3.301 & 4.7476 & TRN & & \\
\hline CHEMBL1319097 & 688750 & 3.301 & 4.9473 & TRN & & \\
\hline CHEMBL3195027 & 688750 & 3.301 & 4.2427 & TRN & & \\
\hline CHEMBL1374583 & 688750 & 3.301 & 4.5475 & TRN & & \\
\hline CHEMBL1327125 & 688750 & 3.301 & 4.8869 & TRN & & \\
\hline CHEMBL1303355 & 688750 & 4.5855 & 4.5658 & TRN & & \\
\hline CHEMBL1482585 & 688750 & 5.3479 & 4.7629 & TRN & & \\
\hline CHEMBL1523891 & 688750 & 3.301 & 4.5749 & TRN & & \\
\hline CHEMBL1499048 & 688750 & 5.6481 & 4.9992 & TRN & & \\
\hline CHEMBL1322699 & 688750 & \multicolumn{3}{|c|}{6.172000000000001} & 4.6954 & TRN \\
\hline CHEMBL1299742 & 688750 & 5.4665 & 4.4511 & TRN & & \\
\hline CHEMBL1307240 & 688750 & 5.0063 & 5.0888 & TST & & \\
\hline CHEMBL1458609 & 688750 & 3.301 & 4.3603 & TRN & & \\
\hline CHEMBL1569124 & 688750 & 3.301 & 5.0226 & TRN & & \\
\hline CHEMBL1462609 & 688750 & 5.2028 & 4.5278 & TRN & & \\
\hline CHEMBL1489457 & 688750 & 4.7325 & 4.9526 & TRN & & \\
\hline CHEMBL1365398 & 688750 & 3.301 & 4.7752 & TRN & & \\
\hline CHEMBL1384697 & 688750 & 4.7431 & 4.8938 & TRN & & \\
\hline CHEMBL1433052 & 688750 & 5.801 & \multicolumn{3}{|c|}{4.696000000000001} & TST \\
\hline CHEMBL1579489 & 688750 & 3.301 & 4.4347 & TRN & & \\
\hline CHEMBL1429703 & 688750 & 5.2323 & 4.5882 & TRN & & \\
\hline CHEMBL3195524 & 688750 & 4.8525 & 4.4662 & TST & & \\
\hline CHEMBL1488150 & 688750 & 5.0433 & 4.7926 & TRN & & \\
\hline CHEMBL1564502 & 688750 & 7.3979 & 4.9582 & TST & & \\
\hline CHEMBL81935 & 688750 & 5.1062 & 4.3866 & TRN & & \\
\hline CHEMBL1321706 & 688750 & 5.4191 & 4.5188 & TRN & & \\
\hline CHEMBL1588585 & 688750 & 3.301 & 4.8847 & TRN & & \\
\hline CHEMBL1303294 & 688750 & 4.806 & 4.2873 & TST & & \\
\hline CHEMBL1453574 & 688750 & 5.7023 & 4.6593 & TRN & & \\
\hline CHEMBL1585749 & 688750 & 5.06 & 4.6736 & TRN & & \\
\hline CHEMBL1584221 & 688750 & 3.301 & 5.0968 & TRN & & \\
\hline CHEMBL1429396 & 688750 & 3.301 & 4.9501 & TRN & & \\
\hline CHEMBL1428261 & 688750 & 4.8728 & 4.8535 & TRN & & \\
\hline CHEMBL1308774 & 688750 & \multicolumn{3}{|c|}{5.502999999999999} & 5.1402 & TRN \\
\hline CHEMBL1484171 & 688750 & 4.8845 & 4.6436 & TRN & & \\
\hline CHEMBL1460500 & 688750 & 3.301 & 4.4848 & TST & & \\
\hline CHEMBL1417708 & 688750 & 4.6054 & 4.5197 & TRN & & \\
\hline CHEMBL1367830 & 688750 & 5.3989 & 4.8152 & TRN & & \\
\hline
\end{tabular}




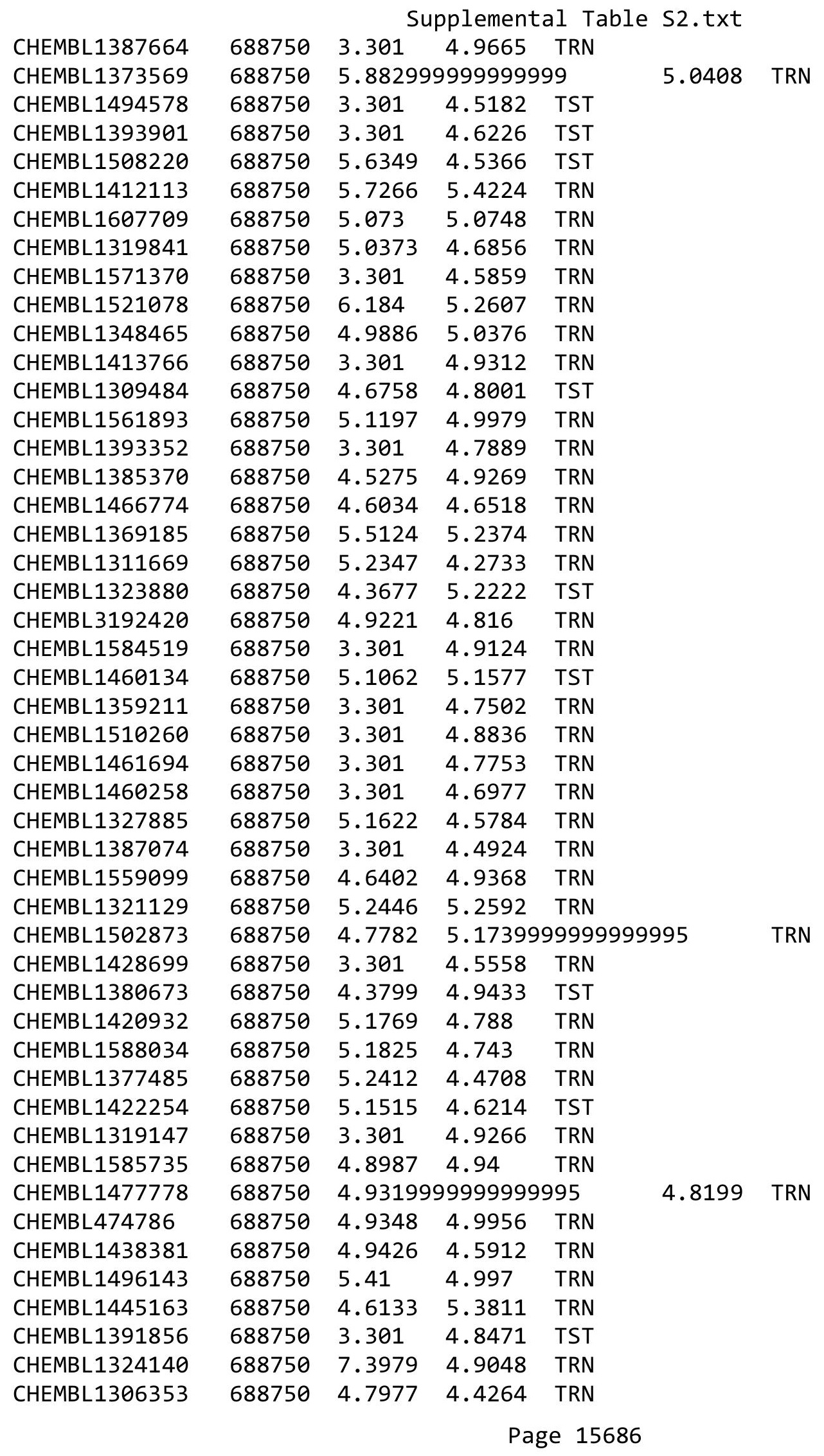




\begin{tabular}{|c|c|c|c|c|c|c|}
\hline & & \multicolumn{5}{|c|}{ Supplemental Table S2.txt } \\
\hline CHEMBL1542282 & 688750 & 3.301 & 4.7744 & TRN & & \\
\hline CHEMBL1612095 & 688750 & 4.7944 & 4.9781 & TRN & & \\
\hline CHEMBL1466115 & 688750 & 4.9654 & 4.9329 & TST & & \\
\hline CHEMBL1471083 & 688750 & 5.4898 & 4.8589 & TRN & & \\
\hline CHEMBL1381852 & 688750 & 5.04 & 4.9823 & TRN & & \\
\hline CHEMBL1323832 & 688750 & 4.8343 & 4.933 & TST & & \\
\hline CHEMBL1346621 & 688750 & 4.9159 & 4.6882 & TRN & & \\
\hline CHEMBL 3214588 & 688750 & 5.3573 & 4.6132 & TRN & & \\
\hline CHEMBL1544637 & 688750 & 4.9117 & 4.3284 & TRN & & \\
\hline CHEMBL1410498 & 688750 & 4.7806 & 4.7237 & TST & & \\
\hline CHEMBL1503103 & 688750 & 3.301 & 4.7582 & TRN & & \\
\hline CHEMBL1451147 & 688750 & 7.3979 & 5.1937 & TRN & & \\
\hline CHEMBL1407173 & 688750 & 5.2064 & 5.0373 & TST & & \\
\hline CHEMBL1330051 & 688750 & 5.0787 & 4.8516 & TST & & \\
\hline CHEMBL1320223 & 688750 & 4.5353 & 5.0039 & TRN & & \\
\hline CHEMBL1526192 & 688750 & 4.925 & 4.4986 & TRN & & \\
\hline CHEMBL1479812 & 688750 & 7.3979 & 5.2579 & TRN & & \\
\hline CHEMBL1426364 & 688750 & 3.301 & 5.1955 & TRN & & \\
\hline CHEMBL3209333 & 688750 & 3.301 & 4.5392 & TRN & & \\
\hline CHEMBL1370398 & 688750 & 5.4767 & 4.8492 & TRN & & \\
\hline CHEMBL1608861 & 688750 & 4.4061 & 4.7256 & TRN & & \\
\hline CHEMBL1439185 & 688750 & \multicolumn{3}{|c|}{5.992000000000001} & .6159 & TST \\
\hline CHEMBL3190280 & 688750 & 3.301 & 4.6342 & TRN & & \\
\hline CHEMBL1300437 & 688750 & 3.301 & 4.6162 & TRN & & \\
\hline CHEMBL212314 & 688750 & 4.9123 & 4.7383 & TST & & \\
\hline CHEMBL1418962 & 688750 & 7.3979 & 4.8699 & TST & & \\
\hline CHEMBL1608597 & 688750 & 4.6162 & 5.082 & TRN & & \\
\hline CHEMBL1427458 & 688750 & 3.301 & 4.6963 & TRN & & \\
\hline CHEMBL1612190 & 688750 & 3.301 & 4.7566 & TRN & & \\
\hline CHEMBL1367285 & 688750 & 3.301 & 4.7723 & TRN & & \\
\hline CHEMBL1299406 & 688750 & 3.301 & 4.644 & TRN & & \\
\hline CHEMBL1584988 & 688750 & 4.6429 & 4.8802 & TST & & \\
\hline CHEMBL1612529 & 688750 & 3.301 & 4.9963 & TRN & & \\
\hline CHEMBL1498224 & 688750 & 4.9813 & 5.6079 & TRN & & \\
\hline CHEMBL1529826 & 688750 & 3.301 & 4.7819 & TRN & & \\
\hline CHEMBL1460265 & 688750 & 3.301 & 4.9137 & TRN & & \\
\hline CHEMBL1410085 & 688750 & 3.301 & 4.4402 & TRN & & \\
\hline CHEMBL1457905 & 688750 & 5.21 & 5.282 & TRN & & \\
\hline CHEMBL1581556 & 688750 & 3.301 & 4.9469 & TRN & & \\
\hline CHEMBL1424755 & 688750 & 3.301 & 4.7482 & TST & & \\
\hline CHEMBL1388030 & 688750 & 3.301 & 4.1698 & TRN & & \\
\hline CHEMBL1304995 & 688750 & 7.3979 & 5.3655 & TRN & & \\
\hline CHEMBL1387044 & 688750 & 4.9674 & 4.6579 & TRN & & \\
\hline CHEMBL1456765 & 688750 & 7.3979 & 5.16700 & 0000000001 & & TRN \\
\hline CHEMBL1578592 & 688750 & 5.3898 & 4.7688 & TRN & & \\
\hline CHEMBL1535791 & 688750 & 4.4557 & 4.5566 & TRN & & \\
\hline CHEMBL1399944 & 688750 & 3.301 & 4.9904 & TRN & & \\
\hline CHEMBL1493506 & 688750 & 4.5858 & 4.5955 & TRN & & \\
\hline
\end{tabular}




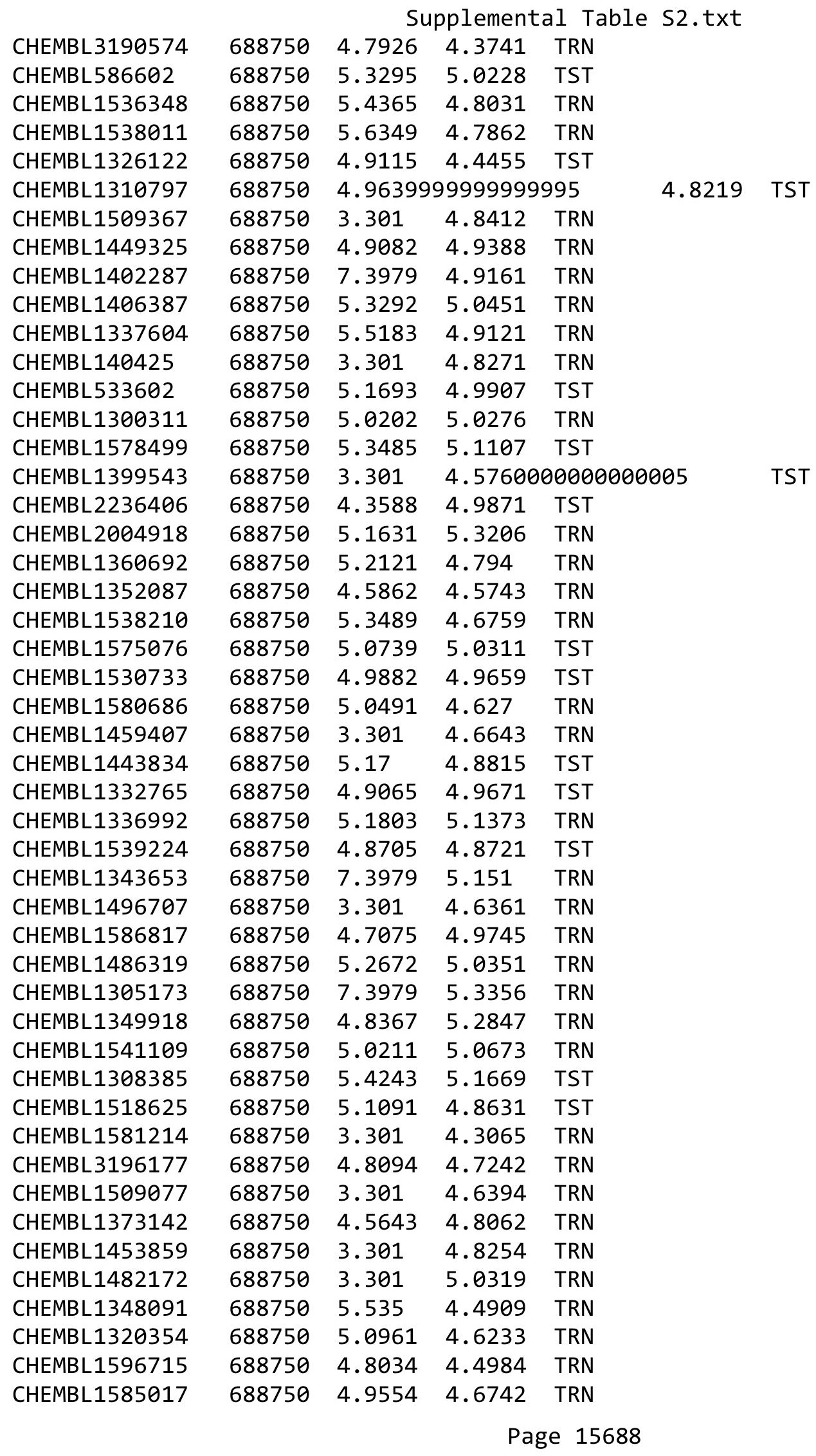




\begin{tabular}{|c|c|c|c|c|c|}
\hline & & \multicolumn{4}{|c|}{ Supplemental Table S2.txt } \\
\hline CHEMBL1393264 & 688750 & 3.301 & 4.6704 & TRN & \\
\hline CHEMBL1610610 & 688750 & 4.4876 & 4.7588 & TRN & \\
\hline CHEMBL1424585 & 688750 & 4.5905 & 4.8497 & TRN & \\
\hline CHEMBL 3198863 & 688750 & 4.8991 & 4.5738 & TST & \\
\hline CHEMBL1584720 & 688750 & 5.1014 & 4.8316 & TRN & \\
\hline CHEMBL1333828 & 688750 & 5.1961 & 4.6135 & TRN & \\
\hline CHEMBL1347472 & 688750 & 4.579 & 5.0645 & TRN & \\
\hline CHEMBL1305074 & 688750 & 3.301 & 4.3839 & TRN & \\
\hline CHEMBL 3210000 & 688750 & 4.7227 & 4.1297 & TRN & \\
\hline CHEMBL1564012 & 688750 & 4.92 & 4.5795 & TRN & \\
\hline CHEMBL1340633 & 688750 & 5.5425 & 4.3534 & TRN & \\
\hline CHEMBL1416104 & 688750 & 5.2718 & 4.6241 & TRN & \\
\hline CHEMBL1340253 & 688750 & 5.3326 & 4.7534 & TRN & \\
\hline CHEMBL1349182 & 688750 & 4.72199 & 99999999 & 4.9865 & TRN \\
\hline CHEMBL1597060 & 688750 & 5.3227 & 4.42399 & 99999999995 & TST \\
\hline CHEMBL1519259 & 688750 & 5.0677 & 4.856 & TRN & \\
\hline CHEMBL1330352 & 688750 & 4.9797 & 5.2668 & TRN & \\
\hline CHEMBL1467721 & 688750 & 3.301 & 4.8675 & TST & \\
\hline CHEMBL1391726 & 688750 & 7.3979 & 5.1374 & TRN & \\
\hline CHEMBL1605642 & 688750 & 5.6926 & 5.0949 & TRN & \\
\hline CHEMBL1330638 & 688750 & 3.301 & 4.8274 & TST & \\
\hline CHEMBL1457753 & 688750 & 4.941 & 4.9204 & TRN & \\
\hline CHEMBL1559796 & 688750 & 4.9745 & 4.4717 & TST & \\
\hline CHEMBL1413854 & 688750 & 6.0482 & 5.0079 & TRN & \\
\hline CHEMBL1479567 & 688750 & 4.9314 & 5.0404 & TRN & \\
\hline CHEMBL1542885 & 688750 & 4.6822 & 4.7968 & TRN & \\
\hline CHEMBL1352894 & 688750 & 4.7394 & 5.0453 & TRN & \\
\hline CHEMBL1438738 & 688750 & 4.9011 & 4.3744 & TRN & \\
\hline CHEMBL 1486883 & 688750 & 4.9358 & 4.6328 & TRN & \\
\hline CHEMBL1484489 & 688750 & 3.301 & 4.3876 & TRN & \\
\hline CHEMBL1335658 & 688750 & 3.301 & 5.2013 & TRN & \\
\hline CHEMBL1465721 & 688750 & 4.7838 & 5.0146 & TRN & \\
\hline CHEMBL1394043 & 688750 & 5.5206 & 4.3672 & TRN & \\
\hline CHEMBL1402382 & 688750 & 5.3801 & 4.7419 & TST & \\
\hline CHEMBL1305451 & 688750 & 3.301 & 4.8782 & TST & \\
\hline CHEMBL 3189460 & 688750 & 5.1649 & 4.5486 & TRN & \\
\hline CHEMBL1596696 & 688750 & 3.301 & 4.827 & TRN & \\
\hline CHEMBL1408575 & 688750 & 4.9978 & 4.6821 & TRN & \\
\hline CHEMBL1383033 & 688750 & 4.7876 & 4.8454 & TRN & \\
\hline CHEMBL1413523 & 688750 & 5.0406 & 5.0955 & TRN & \\
\hline CHEMBL 3197173 & 688750 & 7.3979 & 4.461 & TRN & \\
\hline CHEMBL1416972 & 688750 & 5.0161 & 4.9699 & TRN & \\
\hline CHEMBL1506708 & 688750 & 5.5145 & 4.8605 & TST & \\
\hline CHEMBL1401890 & 688750 & 3.301 & 5.0338 & TRN & \\
\hline CHEMBL1578120 & 688750 & 4.7808 & 4.5629 & TRN & \\
\hline CHEMBL1305181 & 688750 & 4.7178 & 5.1712 & TRN & \\
\hline CHEMBL1399773 & 688750 & 3.301 & 4.8836 & TST & \\
\hline CHEMBL1351340 & 688750 & 3.301 & 4.6326 & TRN & \\
\hline
\end{tabular}




\begin{tabular}{|c|c|c|c|c|c|c|}
\hline & & \multicolumn{5}{|c|}{ Supplemental Table S2.txt } \\
\hline CHEMBL1980384 & 688750 & 3.301 & 4.783 & TRN & & \\
\hline CHEMBL1609569 & 688750 & 5.642 & 4.877 & TRN & & \\
\hline CHEMBL1391757 & 688750 & 4.7252 & 4.3239 & TRN & & \\
\hline CHEMBL1427748 & 688750 & 6.1434 & 4.6276 & TRN & & \\
\hline CHEMBL1448911 & 688750 & 5.2042 & 4.4378 & TST & & \\
\hline CHEMBL1410228 & 688750 & 4.8631 & 5.2983 & TRN & & \\
\hline CHEMBL3213837 & 688750 & 7.3979 & 4.739 & TRN & & \\
\hline CHEMBL1550387 & 688750 & 5.6379 & 5.3545 & TRN & & \\
\hline CHEMBL1350606 & 688750 & 5.0205 & 4.5251 & TRN & & \\
\hline CHEMBL1608778 & 688750 & 5.4918 & 4.6813 & TST & & \\
\hline CHEMBL1324586 & 688750 & 7.3979 & 5.0081 & TRN & & \\
\hline CHEMBL1463422 & 688750 & 5.3091 & 4.9695 & TRN & & \\
\hline CHEMBL1440502 & 688750 & 4.4134 & 4.9413 & TRN & & \\
\hline CHEMBL1470581 & 688750 & 5.0809 & 4.7746 & TST & & \\
\hline CHEMBL1537995 & 688750 & 4.9323 & 5.1364 & TRN & & \\
\hline CHEMBL1416682 & 688750 & 5.5281 & 4.9389 & TRN & & \\
\hline CHEMBL1458448 & 688750 & 4.8741 & 4.9409 & TRN & & \\
\hline CHEMBL1576971 & 688750 & 3.301 & 4.5351 & TRN & & \\
\hline CHEMBL1352489 & 688750 & 4.8446 & 4.7685 & TST & & \\
\hline CHEMBL1330322 & 688750 & 4.3721 & 5.0158 & TRN & & \\
\hline CHEMBL1302784 & 688750 & 5.1317 & 4.863 & TRN & & \\
\hline CHEMBL1498854 & 688750 & 3.301 & 4.5583 & TRN & & \\
\hline CHEMBL1594527 & 688750 & 5.0227 & 5.073 & TRN & & \\
\hline CHEMBL1414508 & 688750 & 5.8464 & 4.7585 & TRN & & \\
\hline CHEMBL1481083 & 688750 & 5.0082 & 4.8891 & TRN & & \\
\hline CHEMBL3198812 & 688750 & 5.0223 & 4.8019 & TRN & & \\
\hline CHEMBL1402848 & 688750 & 5.0057 & 4.8741 & TST & & \\
\hline CHEMBL1599628 & 688750 & 4.3492 & 4.8545 & TRN & & \\
\hline CHEMBL1606087 & 688750 & 5.8664 & 4.7224 & TRN & & \\
\hline CHEMBL1600754 & 688750 & 4.3529 & 4.5043 & TRN & & \\
\hline CHEMBL 3209257 & 688750 & 5.6129 & 4.7371 & TRN & & \\
\hline CHEMBL3190750 & 688750 & 4.6392 & 4.227 & TRN & & \\
\hline CHEMBL1343488 & 688750 & 4.792 & 4.2341 & TRN & & \\
\hline CHEMBL1598605 & 688750 & $5.3670 e$ & 30000000 & $\partial 1$ & 5.0787 & TRN \\
\hline CHEMBL1532819 & 688750 & 6.2161 & 5.1789 & TRN & & \\
\hline CHEMBL1517782 & 688750 & 4.5082 & 4.4873 & TRN & & \\
\hline CHEMBL1519862 & 688750 & 5.5246 & 4.8503 & TRN & & \\
\hline CHEMBL1347895 & 688750 & 4.9779 & 4.916 & TRN & & \\
\hline CHEMBL1536448 & 688750 & 5.1789 & 4.9788 & TRN & & \\
\hline CHEMBL1488340 & 688750 & 4.6474 & 4.8295 & TRN & & \\
\hline CHEMBL1499012 & 688750 & 3.301 & 4.9492 & TRN & & \\
\hline CHEMBL1334036 & 688750 & 5.26 & 4.9467 & TRN & & \\
\hline CHEMBL1511432 & 688750 & 5.6227 & 4.9177 & TRN & & \\
\hline CHEMBL1456517 & 688750 & 4.6472 & 4.8077 & TRN & & \\
\hline CHEMBL1305142 & 688750 & 5.7874 & 4.5328 & TRN & & \\
\hline CHEMBL1541366 & 688750 & 4.8455 & 5.155 & TST & & \\
\hline CHEMBL1481347 & 688750 & 5.1727 & 4.9574 & TST & & \\
\hline CHEMBL1502223 & 688750 & 3.301 & 5.2541 & TRN & & \\
\hline
\end{tabular}




\begin{tabular}{|c|c|c|c|c|}
\hline & & & pplement & al $\mathrm{T}$ \\
\hline CHEMBL1607489 & 688750 & 4.7321 & 4.843 & TRN \\
\hline CHEMBL1389118 & 688750 & 3.301 & 4.0661 & TRN \\
\hline CHEMBL1985073 & 688750 & 4.9515 & 5.0231 & TRN \\
\hline CHEMBL1543659 & 688750 & 5.1454 & 5.1469 & TRN \\
\hline CHEMBL1576436 & 688750 & 4.7516 & 4.8724 & TST \\
\hline CHEMBL1481370 & 688750 & 3.301 & 5.0131 & TRN \\
\hline CHEMBL1484311 & 688750 & 3.301 & 4.5436 & TRN \\
\hline CHEMBL1536734 & 688750 & 5.1564 & 4.6476 & TRN \\
\hline CHEMBL1599032 & 688750 & 3.301 & 5.0325 & TRN \\
\hline CHEMBL1583886 & 688750 & 3.301 & 4.7297 & TRN \\
\hline CHEMBL1482453 & 688750 & 6.1346 & 4.9317 & TRN \\
\hline CHEMBL1446306 & 688750 & 5.3423 & 5.2696 & TRN \\
\hline CHEMBL1605568 & 688750 & 5.2432 & 5.2452 & TRN \\
\hline CHEMBL1610438 & 688750 & 4.5972 & 5.0564 & TRN \\
\hline CHEMBL1385264 & 688750 & 5.981 & 4.8434 & TST \\
\hline CHEMBL1313485 & 688750 & 3.301 & 4.6756 & TRN \\
\hline CHEMBL1612956 & 688750 & 3.301 & 4.7315 & TRN \\
\hline CHEMBL1352564 & 688750 & 5.1386 & 4.4461 & TRN \\
\hline CHEMBL1323364 & 688750 & 4.5561 & 4.6217 & TST \\
\hline CHEMBL1399250 & 688750 & 4.8403 & 4.5292 & TRN \\
\hline CHEMBL1582703 & 688750 & 5.1777 & 4.9084 & TRN \\
\hline CHEMBL1410479 & 688750 & 5.74 & 5.1731 & TRN \\
\hline CHEMBL1506934 & 688750 & 3.301 & 4.6718 & TRN \\
\hline CHEMBL1502943 & 688750 & 4.9639 & 4.3447 & TST \\
\hline CHEMBL1523527 & 688750 & 3.301 & 4.5436 & TRN \\
\hline CHEMBL1349308 & 688750 & 4.9191 & 4.8543 & TRN \\
\hline CHEMBL1392636 & 688750 & 4.9564 & 4.5896 & TRN \\
\hline CHEMBL1359985 & 688750 & 3.301 & 4.8967 & TST \\
\hline CHEMBL1541672 & 688750 & 5.2783 & 4.7512 & TRN \\
\hline CHEMBL 2001381 & 688750 & 5.2868 & 4.6833 & TRN \\
\hline CHEMBL1516491 & 688750 & 3.301 & 4.9471 & TRN \\
\hline CHEMBL1440918 & 688750 & 4.569 & 4.8626 & TRN \\
\hline CHEMBL1463050 & 688750 & 3.301 & 4.7367 & TRN \\
\hline CHEMBL1427736 & 688750 & 4.618 & 4.7813 & TRN \\
\hline CHEMBL1470835 & 688750 & 5.5097 & 5.2037 & TST \\
\hline CHEMBL1405705 & 688750 & 4.8432 & 4.6767 & TRN \\
\hline CHEMBL1503432 & 688750 & 4.584 & 4.7819 & TRN \\
\hline CHEMBL1562771 & 688750 & 4.6365 & 4.7061 & TST \\
\hline CHEMBL1425914 & 688750 & 3.301 & 4.7602 & TRN \\
\hline CHEMBL1420004 & 688750 & 4.8392 & 4.7324 & TRN \\
\hline CHEMBL1369125 & 688750 & 5.2228 & 4.9747 & TRN \\
\hline CHEMBL1496874 & 688750 & 4.7114 & 4.2916 & TRN \\
\hline CHEMBL1580709 & 688750 & 5.2889 & 4.8277 & TRN \\
\hline CHEMBL1986741 & 688750 & 5.0188 & 4.71 & TRN \\
\hline CHEMBL1571756 & 688750 & 4.6689 & 4.966 & TRN \\
\hline CHEMBL1401655 & 688750 & 5.4267 & 4.6611 & TRN \\
\hline CHEMBL1402020 & 688750 & 3.301 & 4.499 & TRN \\
\hline CHEMBL1517776 & 688750 & 5.6518 & 5.0715 & TRN \\
\hline
\end{tabular}


Supplemental Table S2.txt

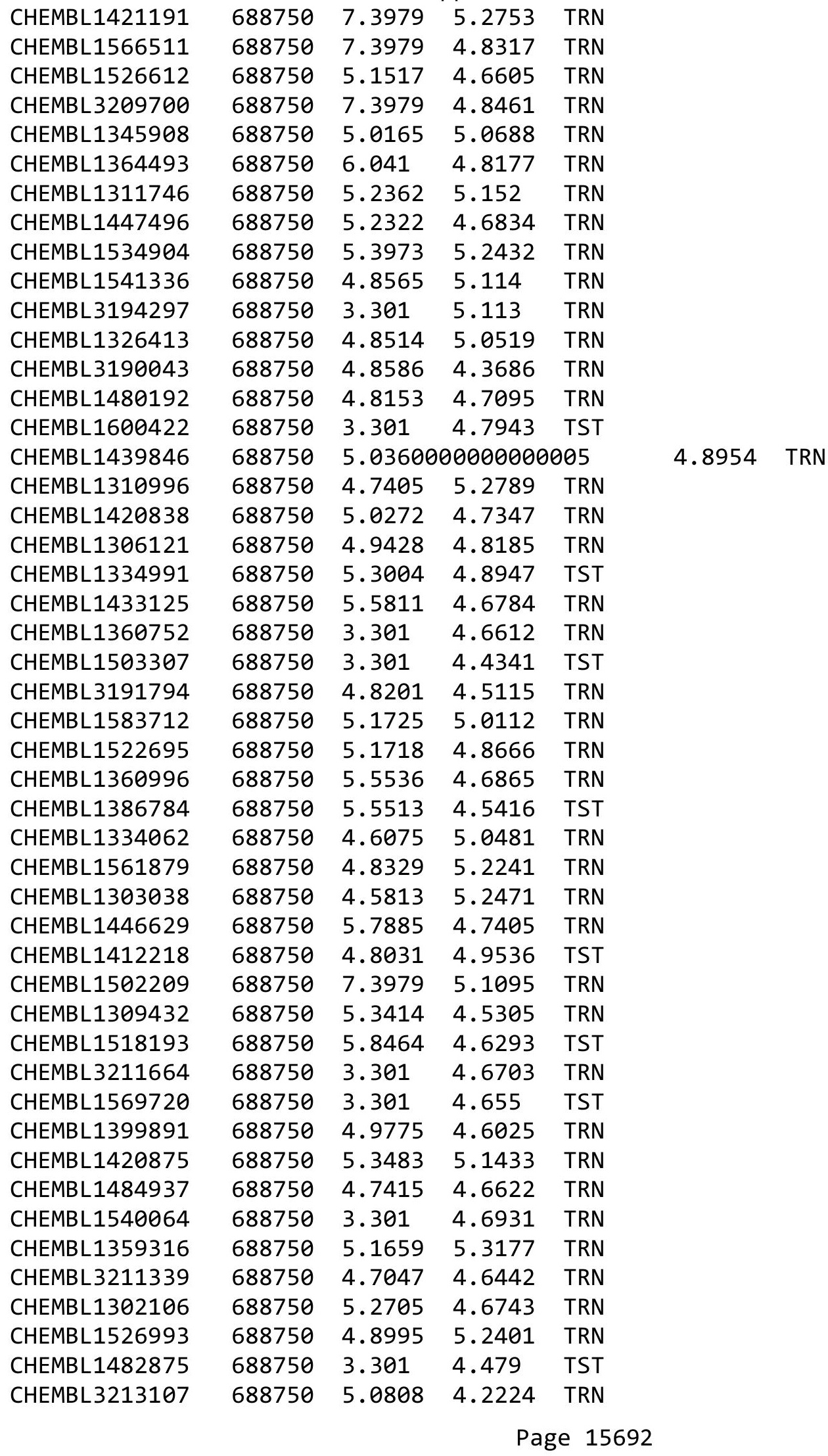


Supplemental Table S2.txt

\begin{tabular}{|c|c|c|c|c|c|c|}
\hline CHEMBL1438267 & 688750 & 4.5127 & 5.0434 & TRN & & \\
\hline CHEMBL1336586 & 688750 & 7.3979 & 4.9095 & TRN & & \\
\hline CHEMBL1528570 & 688750 & 5.2279 & 4.7345 & TST & & \\
\hline CHEMBL1507497 & 688750 & 4.9425 & 4.5111 & TRN & & \\
\hline CHEMBL1353330 & 688750 & 4.6072 & 5.2079 & TRN & & \\
\hline CHEMBL1442487 & 688750 & 7.3979 & 4.79 & TRN & & \\
\hline CHEMBL1469637 & 688750 & 5.0122 & 4.5828 & TRN & & \\
\hline CHEMBL1598464 & 688750 & 5.3638 & 4.6006 & TRN & & \\
\hline CHEMBL1979957 & 688750 & 4.4106 & 4.6669 & TST & & \\
\hline CHEMBL1345338 & 688750 & 5.2923 & 4.9695 & TRN & & \\
\hline CHEMBL1980399 & 688750 & 5.1786 & 4.3187 & TRN & & \\
\hline CHEMBL1405615 & 688750 & 4.7363 & 4.5383 & TRN & & \\
\hline CHEMBL1600183 & 688750 & 4.9738 & 4.5407 & TRN & & \\
\hline CHEMBL1487337 & 688750 & 5.4956 & 4.5364 & TST & & \\
\hline CHEMBL259516 & 688750 & 3.301 & 4.5398 & TRN & & \\
\hline CHEMBL1469653 & 688750 & 5.3884 & 5.2569 & TRN & & \\
\hline CHEMBL1569566 & 688750 & 5.2107 & 4.5823 & TRN & & \\
\hline CHEMBL1324079 & 688750 & 4.8021 & 4.7917 & TRN & & \\
\hline CHEMBL1578542 & 688750 & 3.301 & 4.711 & TRN & & \\
\hline CHEMBL1313141 & 688750 & 4.4176 & 4.9593 & TRN & & \\
\hline CHEMBL1416319 & 688750 & 3.301 & 4.6667 & TRN & & \\
\hline CHEMBL1549791 & 688750 & 5.5244 & 5.0697 & TRN & & \\
\hline CHEMBL1524203 & 688750 & 5.294 & 4.9254 & TRN & & \\
\hline CHEMBL510279 & 688750 & 5.301 & 4.731 & TST & & \\
\hline CHEMBL1400345 & 688750 & 7.3979 & 5.2823 & TRN & & \\
\hline CHEMBL1563043 & 688750 & 5.047 & 4.27 & TRN & & \\
\hline CHEMBL1301720 & 688750 & 3.301 & 4.797 & TRN & & \\
\hline CHEMBL1594883 & 688750 & 3.301 & 4.8335 & TRN & & \\
\hline CHEMBL1463051 & 688750 & 5.6254 & 4.5545 & TRN & & \\
\hline CHEMBL1548475 & 688750 & 5.6456 & 4.9002 & TRN & & \\
\hline CHEMBL1382924 & 688750 & 5.9534 & 4.8473 & TRN & & \\
\hline CHEMBL1418192 & 688750 & 5.2177 & 4.8384 & TRN & & \\
\hline CHEMBL1509703 & 688750 & 4.6064 & 4.7655 & TRN & & \\
\hline CHEMBL1502002 & 688750 & 4.7221 & 4.8412 & TRN & & \\
\hline CHEMBL3210608 & 688750 & 3.301 & 4.6594 & TRN & & \\
\hline CHEMBL1384216 & 688750 & 5.2173 & 4.7135 & TRN & & \\
\hline CHEMBL1375293 & 688750 & 5.0591 & 5.0198 & TRN & & \\
\hline CHEMBL1604091 & 688750 & \multicolumn{3}{|c|}{5.0360000000000005} & 4.8253 & TST \\
\hline CHEMBL1574490 & 688750 & 3.301 & 4.1608 & TRN & & \\
\hline CHEMBL1303961 & 688750 & 5.1661 & 4.5175 & TST & & \\
\hline CHEMBL1378652 & 688750 & 4.9176 & 4.4015 & TRN & & \\
\hline CHEMBL1374511 & 688750 & 5.1362 & 5.3688 & TRN & & \\
\hline CHEMBL1438936 & 688750 & 4.9978 & 4.5798 & TRN & & \\
\hline CHEMBL1523020 & 688750 & 5.228 & 4.6373 & TRN & & \\
\hline CHEMBL1458713 & 688750 & 3.301 & 4.8583 & TST & & \\
\hline CHEMBL1478950 & 688750 & 5.0049 & 4.8807 & TRN & & \\
\hline CHEMBL1469847 & 688750 & 4.8069 & 4.3484 & TST & & \\
\hline CHEMBL1347093 & 688750 & 4.9186 & 4.9401 & TRN & & \\
\hline
\end{tabular}

Page 15693 


\begin{tabular}{|c|c|c|c|c|c|}
\hline & & \multicolumn{4}{|c|}{ Supplemental Table S2.txt } \\
\hline CHEMBL1527057 & 688750 & 4.7537 & 5.1435 & TRN & \\
\hline CHEMBL3191881 & 688750 & 5.6421 & 4.6753 & TRN & \\
\hline CHEMBL1426782 & 688750 & 4.5995 & 4.6902 & TRN & \\
\hline CHEMBL1545385 & 688750 & 5.147 & 4.3609 & TRN & \\
\hline CHEMBL1309257 & 688750 & 7.3979 & 4.9288 & TRN & \\
\hline CHEMBL1557622 & 688750 & 3.301 & 4.4811 & TRN & \\
\hline CHEMBL1307549 & 688750 & 4.7768 & 5.2718 & TRN & \\
\hline CHEMBL3197533 & 688750 & 4.9418 & 4.8814 & TRN & \\
\hline CHEMBL3197099 & 688750 & 5.5176 & 4.9764 & TRN & \\
\hline CHEMBL 1607676 & 688750 & 4.93 & 4.9796 & TRN & \\
\hline CHEMBL1499282 & 688750 & 5.4129 & 4.9177 & TRN & \\
\hline CHEMBL1411391 & 688750 & 5.2197 & 4.9753 & TRN & \\
\hline CHEMBL1339685 & 688750 & 3.301 & 4.9651 & TRN & \\
\hline CHEMBL3196737 & 688750 & 5.4568 & 4.5631 & TRN & \\
\hline CHEMBL1311928 & 688750 & 5.5905 & 5.1605 & TST & \\
\hline CHEMBL1604694 & 688750 & 5.0694 & 4.5223 & TRN & \\
\hline CHEMBL1270953 & 688750 & 3.301 & 5.0411 & TRN & \\
\hline CHEMBL1321333 & 688750 & 5.4128 & 4.90300 & 00000000005 & TRN \\
\hline CHEMBL1306253 & 688750 & 3.301 & 4.4148 & TRN & \\
\hline CHEMBL3199639 & 688750 & 4.6516 & 4.4272 & TRN & \\
\hline CHEMBL1477203 & 688750 & 4.5824 & 4.6134 & TRN & \\
\hline CHEMBL1383938 & 688750 & 4.4406 & 4.7386 & TRN & \\
\hline CHEMBL1343006 & 688750 & 5.2636 & 4.6458 & TRN & \\
\hline CHEMBL1306609 & 688750 & 4.4615 & 4.9348 & TRN & \\
\hline CHEMBL3191570 & 688750 & 5.3956 & 4.7453 & TRN & \\
\hline CHEMBL1441807 & 688750 & 4.7259 & 4.77 & TRN & \\
\hline CHEMBL1428174 & 688750 & 3.301 & 4.8993 & TRN & \\
\hline CHEMBL1509378 & 688750 & 5.1654 & 4.9852 & TRN & \\
\hline CHEMBL1567389 & 688750 & 5.0926 & 5.0679 & TRN & \\
\hline CHEMBL1440418 & 688750 & 5.6558 & 5.1134 & TRN & \\
\hline CHEMBL1532844 & 688750 & 5.1278 & 4.9357 & TRN & \\
\hline CHEMBL1563013 & 688750 & 4.9838 & 4.9252 & TRN & \\
\hline CHEMBL1549266 & 688750 & 5.3596 & 5.6108 & TRN & \\
\hline CHEMBL1365192 & 688750 & 4.6837 & 4.6025 & TRN & \\
\hline CHEMBL1385676 & 688750 & 4.9307 & 4.7698 & TRN & \\
\hline CHEMBL1339843 & 688750 & 5.0175 & 4.9496 & TST & \\
\hline CHEMBL1399997 & 688750 & 3.301 & 4.6241 & TRN & \\
\hline CHEMBL1465581 & 688750 & 5.0016 & 4.5655 & TRN & \\
\hline CHEMBL1443380 & 688750 & 3.301 & 5.1645 & TST & \\
\hline CHEMBL1462559 & 688750 & 4.8292 & 5.2359 & TRN & \\
\hline CHEMBL1173673 & 688750 & 3.301 & 4.5402 & TRN & \\
\hline CHEMBL1388691 & 688750 & 3.301 & 4.6306 & TRN & \\
\hline CHEMBL1433227 & 688750 & 5.1027 & 4.6509 & TRN & \\
\hline CHEMBL1408029 & 688750 & 4.985 & 5.088 & TST & \\
\hline CHEMBL1576055 & 688750 & 3.301 & 4.6958 & TRN & \\
\hline CHEMBL1506889 & 688750 & 5.75 & 5.1998 & TRN & \\
\hline CHEMBL 233347 & 688750 & 4.8499 & 4.261 & TRN & \\
\hline CHEMBL1565737 & 688750 & 5.1219 & 4.7685 & TRN & \\
\hline
\end{tabular}




\begin{tabular}{|c|c|c|c|c|c|}
\hline \multicolumn{6}{|c|}{ Supplemental Table S2.txt } \\
\hline CHEMBL1374838 & 688750 & 5.481 & 5.0616 & TRN & \\
\hline CHEMBL1483192 & 688750 & 5.8205 & 4.4488 & TRN & \\
\hline CHEMBL1557120 & 688750 & 5.5479 & 4.7364 & TRN & \\
\hline CHEMBL1454616 & 688750 & 3.301 & 5.1298 & TRN & \\
\hline CHEMBL1546524 & 688750 & 4.7627 & 4.6659 & TRN & \\
\hline CHEMBL1412104 & 688750 & 5.4993 & 4.7513 & TRN & \\
\hline CHEMBL1333407 & 688750 & 5.2119 & 5.0179 & TRN & \\
\hline CHEMBL3198457 & 688750 & 5.7993 & 4.7366 & TRN & \\
\hline CHEMBL1584716 & 688750 & 4.6194 & 4.7382 & TRN & \\
\hline CHEMBL1504960 & 688750 & 5.3034 & 4.6232 & TST & \\
\hline CHEMBL1509537 & 688750 & 5.2166 & 4.8829 & TST & \\
\hline CHEMBL1968859 & 688750 & 3.301 & 4.8032 & TRN & \\
\hline CHEMBL1490642 & 688750 & 5.066 & 4.7319 & TRN & \\
\hline CHEMBL1432044 & 688750 & 3.301 & 4.8633 & TST & \\
\hline CHEMBL1422845 & 688750 & 5.0122 & 4.6555 & TST & \\
\hline CHEMBL1440481 & 688750 & 4.7074 & 4.8656 & TST & \\
\hline CHEMBL1429225 & 688750 & 7.3979 & 4.6651 & TST & \\
\hline CHEMBL3197930 & 688750 & 4.4579 & 4.8865 & TST & \\
\hline CHEMBL1379369 & 688750 & 4.9942 & 5.1194 & TST & \\
\hline CHEMBL1326328 & 688750 & 5.1683 & 4.6023 & TST & \\
\hline CHEMBL1595277 & 688750 & 5.0915 & 5.0472 & TST & \\
\hline CHEMBL1606479 & 688750 & 3.301 & 4.4235 & TST & \\
\hline CHEMBL1517677 & 688750 & 5.2736 & 4.8038 & TST & \\
\hline CHEMBL1565396 & 688750 & 4.9723 & 4.8574 & TST & \\
\hline CHEMBL1412007 & 688750 & 4.7649 & 4.5265 & TST & \\
\hline CHEMBL1487973 & 688750 & 5.4291 & 4.60800 & 00000000005 & TST \\
\hline CHEMBL1604393 & 688750 & 7.3979 & 4.5096 & TST & \\
\hline CHEMBL1564814 & 688750 & 5.0172 & 4.7644 & TST & \\
\hline CHEMBL1358863 & 688750 & 5.9626 & 4.3582 & TST & \\
\hline CHEMBL3213919 & 688750 & 4.5174 & 4.8246 & TST & \\
\hline CHEMBL1372826 & 688750 & 3.301 & 4.7638 & TST & \\
\hline CHEMBL1504323 & 688750 & 4.3654 & 4.7083 & TST & \\
\hline CHEMBL1404786 & 688750 & 5.7605 & 4.6746 & TST & \\
\hline CHEMBL1577373 & 688750 & 5.4125 & 4.6712 & TST & \\
\hline CHEMBL1598713 & 688750 & 5.1927 & 4.9753 & TST & \\
\hline CHEMBL1446695 & 688750 & 3.301 & 4.4777 & TST & \\
\hline CHEMBL1495216 & 688750 & 5.1676 & 4.8015 & TST & \\
\hline CHEMBL1483613 & 688750 & 4.8988 & 4.5838 & TST & \\
\hline CHEMBL1535185 & 688750 & 5.4821 & 4.8933 & TST & \\
\hline CHEMBL1466307 & 688750 & 4.9652 & 4.7814 & TST & \\
\hline CHEMBL 2005973 & 688750 & 3.301 & 4.9661 & TST & \\
\hline CHEMBL1603948 & 688750 & 3.301 & 5.0826 & TST & \\
\hline CHEMBL1370340 & 688750 & 3.301 & 4.7106 & TST & \\
\hline CHEMBL 1365650 & 688750 & 4.5347 & 5.0983 & TST & \\
\hline CHEMBL1478587 & 688750 & 5.4266 & 4.8606 & TST & \\
\hline CHEMBL1338186 & 688750 & 7.3979 & 5.0413 & TST & \\
\hline CHEMBL1403307 & 688750 & 3.301 & 4.9761 & TST & \\
\hline CHEMBL1409926 & 688750 & 4.8301 & 5.1372 & TST & \\
\hline
\end{tabular}


Supplemental Table S2.txt

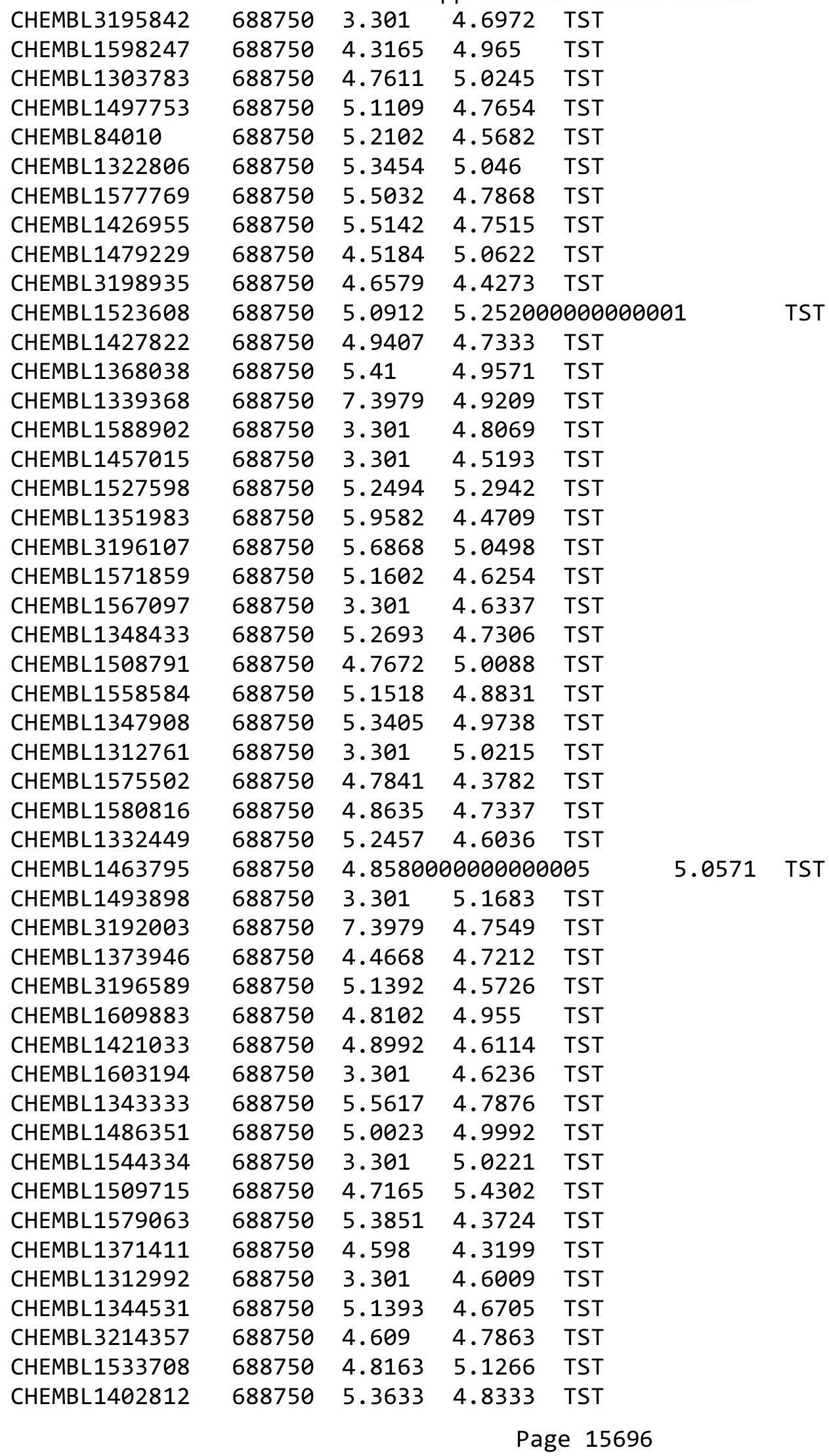




\begin{tabular}{|c|c|c|c|c|c|}
\hline & & \multicolumn{4}{|c|}{ Supplemental Table S2.txt } \\
\hline CHEMBL1346170 & 688750 & 3.301 & 4.6239 & TST & \\
\hline CHEMBL1331552 & 688750 & 4.7609 & 4.9939 & TST & \\
\hline CHEMBL1530636 & 688750 & 4.5348 & 5.1334 & TST & \\
\hline CHEMBL1482773 & 688750 & 5.1284 & 4.6529 & TST & \\
\hline CHEMBL1480465 & 688750 & 5.24 & 4.9681 & TST & \\
\hline CHEMBL1567424 & 688750 & 3.301 & 4.5911 & TST & \\
\hline CHEMBL1300045 & 688750 & 5.0286 & 5.3607 & TST & \\
\hline CHEMBL1613616 & 688750 & 5.2798 & 4.6101 & TST & \\
\hline CHEMBL1459147 & 688750 & 5.4018 & 4.9779 & TST & \\
\hline CHEMBL3197578 & 688750 & 5.0451 & 4.4988 & TST & \\
\hline CHEMBL3194272 & 688750 & 4.6005 & 4.7332 & TST & \\
\hline CHEMBL1509354 & 688750 & 3.301 & 5.0748 & TST & \\
\hline CHEMBL1506141 & 688750 & 3.301 & 4.8544 & TST & \\
\hline CHEMBL1420122 & 688750 & 7.3979 & 4.8537 & TST & \\
\hline CHEMBL1300177 & 688750 & 5.1741 & 4.7183 & TST & \\
\hline CHEMBL1447492 & 688750 & 5.9258 & 4.4863 & TST & \\
\hline CHEMBL1438937 & 688750 & 3.301 & 4.8422 & TST & \\
\hline CHEMBL1543893 & 688750 & 4.9677 & 4.7074 & TST & \\
\hline CHEMBL340416 & 688750 & 3.301 & 4.9529 & TST & \\
\hline CHEMBL1508351 & 688750 & 4.9249 & 5.1116 & TST & \\
\hline CHEMBL1312315 & 688750 & 3.301 & 4.7558 & TST & \\
\hline CHEMBL1520240 & 688750 & 5.5883 & 5.1693 & TST & \\
\hline CHEMBL1387189 & 688750 & 4.6207 & 4.7846 & TST & \\
\hline CHEMBL1611650 & 688750 & 4.6553 & 4.6309 & TST & \\
\hline CHEMBL1461701 & 688750 & 7.3979 & 4.9212 & TST & \\
\hline CHEMBL1467250 & 688750 & 5.113 & 4.8607 & TST & \\
\hline CHEMBL1347587 & 688750 & 3.301 & 4.92399 & 99999999995 & TST \\
\hline CHEMBL1964891 & 688750 & 5.4419 & 4.7471 & TST & \\
\hline CHEMBL1319924 & 688750 & 3.301 & 5.0385 & TST & \\
\hline CHEMBL 2001396 & 688750 & 4.6575 & 4.7592 & TST & \\
\hline CHEMBL1420908 & 688750 & 5.1237 & 5.1324 & TST & \\
\hline CHEMBL1310649 & 688750 & 3.301 & 4.8946 & TST & \\
\hline CHEMBL1581708 & 688750 & 4.9549 & 5.0604 & TST & \\
\hline CHEMBL1420034 & 688750 & 4.7993 & 5.2009 & TST & \\
\hline CHEMBL536166 & 688750 & 4.7766 & 5.0228 & TST & \\
\hline CHEMBL1377693 & 688750 & 4.3182 & 5.0887 & TST & \\
\hline CHEMBL1490435 & 688750 & 4.7769 & 5.1915 & TST & \\
\hline CHEMBL1501050 & 688750 & 4.8178 & 4.6735 & TST & \\
\hline CHEMBL1533240 & 688750 & 3.301 & 5.03 & TST & \\
\hline CHEMBL1526946 & 688750 & 4.617 & 5.28 & TST & \\
\hline CHEMBL1408764 & 688750 & 4.63399 & 99999999 & 4.7808 & TST \\
\hline CHEMBL1519241 & 688750 & 4.734 & 4.5499 & TST & \\
\hline CHEMBL1486748 & 688750 & 4.9667 & 4.876 & TST & \\
\hline CHEMBL1421903 & 688750 & 4.5748 & 4.9621 & TST & \\
\hline CHEMBL1603478 & 688750 & 4.7464 & 4.9515 & TST & \\
\hline CHEMBL 1377510 & 688750 & 4.842 & 4.7538 & TST & \\
\hline CHEMBL1344549 & 688750 & 4.513 & 4.73300 & 20000000005 & TST \\
\hline CHEMBL467257 & 500573 & 9.1549 & 9.1902 & TRN & \\
\hline
\end{tabular}




\begin{tabular}{|c|c|c|c|c|c|}
\hline \multicolumn{6}{|c|}{ Supplemental Table S2.txt } \\
\hline CHEMBL468739 & 500573 & 8.4815 & 8.6086 & TRN & \\
\hline CHEMBL466460 & 500573 & 7.5528 & 7.5858 & TRN & \\
\hline CHEMBL512613 & 500573 & 9.0458 & 9.1208 & TRN & \\
\hline CHEMBL467687 & 500573 & 9.1549 & 9.1244 & TRN & \\
\hline CHEMBL468103 & 500573 & 5.0458 & 5.3485 & TST & \\
\hline CHEMBL466656 & 500573 & 9.1249 & 9.0992 & TRN & \\
\hline CHEMBL466461 & 500573 & 7.3098 & 7.4226 & TRN & \\
\hline CHEMBL492383 & 500573 & 8.4437 & 8.7031 & TRN & \\
\hline CHEMBL466249 & 500573 & 9.0969 & 9.0762 & TRN & \\
\hline CHEMBL466663 & 500573 & 5.9755 & 5.9276 & TRN & \\
\hline CHEMBL466059 & 500573 & 9.301 & 9.3235 & TRN & \\
\hline CHEMBL466664 & 500573 & 6.2403 & 6.2289 & TRN & \\
\hline CHEMBL513822 & 500573 & 7.7447 & 7.8966 & TRN & \\
\hline CHEMBL466208 & 500573 & 8.3979 & 8.6537 & TRN & \\
\hline CHEMBL468096 & 500573 & 9.0969 & 9.082 & TRN & \\
\hline CHEMBL467682 & 500573 & 6.7055 & 4.9531 & TST & \\
\hline CHEMBL513655 & 500573 & 8.1192 & 8.1251 & TRN & \\
\hline CHEMBL493989 & 500573 & 8.8539 & 8.9859 & TRN & \\
\hline CHEMBL493178 & 500573 & 7.7959 & 7.9268 & TRN & \\
\hline CHEMBL466060 & 500573 & 9.0969 & 9.1515 & TRN & \\
\hline CHEMBL499159 & 500573 & 9.2218 & 9.0553 & TRN & \\
\hline CHEMBL467459 & 500573 & 8.8861 & 8.7733 & TRN & \\
\hline CHEMBL493179 & 500573 & 8.0969 & 8.1136 & TRN & \\
\hline CHEMBL511433 & 500573 & 9.0458 & 8.8371 & TRN & \\
\hline CHEMBL466445 & 500573 & 8.1612 & 8.1916 & TRN & \\
\hline CHEMBL513645 & 500573 & 8.3979 & 8.2383 & TRN & \\
\hline CHEMBL512061 & 500573 & 9.5229 & 9.4415 & TRN & \\
\hline CHEMBL469138 & 500573 & 9.3979 & 9.2679 & TRN & \\
\hline CHEMBL466657 & 500573 & 7.8962 & 7.8547 & TRN & \\
\hline CHEMBL468738 & 500573 & 7.9172 & 7.9592 & TRN & \\
\hline CHEMBL467262 & 500573 & 9.2218 & 9.2584 & TRN & \\
\hline CHEMBL468708 & 500573 & 7.0458 & 7.0874 & TRN & \\
\hline CHEMBL513148 & 500573 & 8.6576 & 8.6685 & TRN & \\
\hline CHEMBL466052 & 500573 & 8.7959 & 8.8394 & TRN & \\
\hline CHEMBL494167 & 500573 & 8.7696 & 8.7238 & TRN & \\
\hline CHEMBL494824 & 500573 & 9.1549 & 9.087 & TRN & \\
\hline CHEMBL511729 & 500573 & 8.1675 & 7.955 & TRN & \\
\hline CHEMBL468731 & 500573 & 9.301 & 9.39299 & 9999999999 & TRN \\
\hline CHEMBL469125 & 500573 & 6.8386 & 6.9754 & TST & \\
\hline CHEMBL466237 & 500573 & 9.3979 & 9.2548 & TRN & \\
\hline CHEMBL512275 & 500573 & 9.0 & 8.8508 & TRN & \\
\hline CHEMBL512468 & 500573 & 5.8778 & 6.15799 & 99999999995 & TST \\
\hline CHEMBL 2093894 & 500573 & 8.7212 & 8.2766 & TST & \\
\hline CHEMBL494823 & 500573 & 8.9208 & 8.8759 & TRN & \\
\hline CHEMBL512237 & 500573 & 8.8539 & 8.6919 & TRN & \\
\hline CHEMBL513823 & 500573 & 8.4559 & 8.3654 & TRN & \\
\hline CHEMBL468095 & 500573 & 8.699 & 8.8104 & TRN & \\
\hline CHEMBL466024 & 500573 & 9.2218 & 9.3919 & TRN & \\
\hline
\end{tabular}




\begin{tabular}{|c|c|c|c|c|c|}
\hline \multirow[b]{2}{*}{ CHEMBL492384 } & \multicolumn{5}{|c|}{ Supplemental Table s2.txt } \\
\hline & 500573 & 9.0458 & 9.1888 & TRN & \\
\hline CHEMBL512243 & 500573 & 8.3279 & 8.1499 & TRN & \\
\hline CHEMBL468102 & 500573 & 7.2111 & 6.4008 & TST & \\
\hline CHEMBL466625 & 500573 & 7.301 & 7.312 & TRN & \\
\hline CHEMBL512081 & 500573 & 9.5229 & 9.56899 & 9999999999 & TST \\
\hline CHEMBL511895 & 500573 & 8.6198 & 9.0659 & TST & \\
\hline CHEMBL467482 & 500573 & 8.2596 & 8.3245 & TST & \\
\hline CHEMBL466045 & 500573 & 7.9586 & 8.4618 & TST & \\
\hline CHEMBL468101 & 500573 & 9.301 & 9.4438 & TST & \\
\hline CHEMBL468737 & 500573 & 8.8861 & 9.113 & TST & \\
\hline CHEMBL467460 & 500573 & 8.4089 & 8.4022 & TST & \\
\hline CHEMBL253680 & 500573 & 9.301 & 9.7017 & TST & \\
\hline CHEMBL493177 & 500573 & 8.5528 & 8.1245 & TST & \\
\hline CHEMBL440498 & 500573 & 9.5229 & 8.1019 & TST & \\
\hline CHEMBL1834796 & 772988 & 7.5376 & 7.5399 & TRN & \\
\hline CHEMBL1834794 & 772988 & 7.8861 & 7.8828 & TRN & \\
\hline CHEMBL1834787 & 772988 & 7.5229 & 7.522 & TRN & \\
\hline CHEMBL1834797 & 772988 & 7.7212 & 7.7207 & TRN & \\
\hline CHEMBL1834780 & 772988 & 6.6383 & 6.6384 & TRN & \\
\hline CHEMBL1834649 & 772988 & 3.6021 & 3.6025 & TRN & \\
\hline CHEMBL1834852 & 772988 & 7.6383 & 7.6403 & TRN & \\
\hline CHEMBL1834784 & 772988 & 6.1871 & 6.1866 & TRN & \\
\hline CHEMBL1834650 & 772988 & 5.6819 & 5.6807 & TRN & \\
\hline CHEMBL1834634 & 772988 & 7.9208 & 7.9229 & TRN & \\
\hline CHEMBL1834646 & 772988 & 6.2757 & 6.2769 & TRN & \\
\hline CHEMBL1834648 & 772988 & 6.699 & 6.7008 & TRN & \\
\hline CHEMBL1833983 & 772988 & 5.0 & 4.9996 & TRN & \\
\hline CHEMBL1834635 & 772988 & 7.8861 & 7.8919 & TRN & \\
\hline CHEMBL1834633 & 772988 & 7.9208 & 7.9185 & TRN & \\
\hline CHEMBL1834788 & 772988 & 8.2218 & 8.2187 & TRN & \\
\hline CHEMBL1834631 & 772988 & 7.9208 & 7.9215 & TRN & \\
\hline CHEMBL1834641 & 772988 & 5.585 & 5.5848 & TRN & \\
\hline CHEMBL1834581 & 772988 & 6.2924 & 6.2917 & TRN & \\
\hline CHEMBL1834636 & 772988 & 7.2007 & 6.4033 & TST & \\
\hline CHEMBL1834782 & 772988 & 6.0362 & 6.03700 & 0000000001 & TRN \\
\hline CHEMBL1834642 & 772988 & 6.2924 & 6.2932 & TRN & \\
\hline CHEMBL1834853 & 772988 & 7.5086 & 7.2107 & TST & \\
\hline CHEMBL1834791 & 772988 & 8.1549 & 8.1593 & TRN & \\
\hline CHEMBL1834779 & 772988 & 7.2757 & 7.274 & TRN & \\
\hline CHEMBL1834639 & 772988 & 6.9208 & 6.9218 & TRN & \\
\hline CHEMBL1834652 & 772988 & 7.6778 & 7.6742 & TRN & \\
\hline CHEMBL1834719 & 772988 & 7.5686 & 7.572 & TRN & \\
\hline CHEMBL1834786 & 772988 & 8.301 & 8.3026 & TRN & \\
\hline CHEMBL1834651 & 772988 & 7.4437 & 7.4416 & TRN & \\
\hline CHEMBL1834795 & 772988 & 7.5376 & 7.5398 & TRN & \\
\hline CHEMBL1834849 & 772988 & 6.3188 & 6.6359 & TST & \\
\hline CHEMBL1834790 & 772988 & 8.0458 & 8.0421 & TRN & \\
\hline CHEMBL1834638 & 772988 & 6.4815 & 6.4815 & TRN & \\
\hline
\end{tabular}


Supplemental Table S2.txt

\begin{tabular}{|c|c|c|c|c|c|}
\hline CHEMBL1834792 & 772988 & 7.7959 & 6.9838 & TST & \\
\hline CHEMBL1834637 & 772988 & 6.4318 & 6.4313 & TRN & \\
\hline CHEMBL1834793 & 772988 & 7.5528 & 7.553 & TRN & \\
\hline CHEMBL1834785 & 772988 & 7.7212 & 7.7202 & TRN & \\
\hline CHEMBL1834799 & 772988 & 8.301 & 8.3013 & TRN & \\
\hline CHEMBL1834580 & 772988 & 6.5376 & 6.5383 & TRN & \\
\hline CHEMBL1834721 & 772988 & 7.8239 & 7.8244 & TRN & \\
\hline CHEMBL 2092884 & 772988 & 7.7959 & 7.795 & TRN & \\
\hline CHEMBL1834783 & 772988 & 6.7696 & 7.7485 & TST & \\
\hline CHEMBL1834644 & 772988 & 7.5686 & 7.5681 & TRN & \\
\hline CHEMBL1834781 & 772988 & 7.2518 & 7.2503 & TRN & \\
\hline CHEMBL1834850 & 772988 & 5.8539 & 5.8533 & TRN & \\
\hline CHEMBL1834854 & 772988 & 7.5086 & 7.8291 & TST & \\
\hline CHEMBL1834645 & 772988 & 7.4949 & 7.4948 & TRN & \\
\hline CHEMBL1834643 & 772988 & 7.3565 & 7.3548 & TRN & \\
\hline CHEMBL1834640 & 772988 & 7.8861 & 7.8848 & TRN & \\
\hline CHEMBL1834717 & 772988 & 7.2596 & 7.325 & TST & \\
\hline CHEMBL1834720 & 772988 & 7.5376 & 7.0973 & TST & \\
\hline CHEMBL1834851 & 772988 & 6.699 & 7.0479 & TST & \\
\hline CHEMBL1834632 & 772988 & 8.2218 & 7.6313 & TST & \\
\hline CHEMBL1834798 & 772988 & 7.7447 & 7.909 & TST & \\
\hline CHEMBL1834647 & 772988 & 6.8539 & 6.8719 & TST & \\
\hline CHEMBL1834718 & 772988 & 7.0862 & 7.3217 & TST & \\
\hline CHEMBL1834579 & 772988 & 5.2676 & 6.0547 & TST & \\
\hline CHEMBL1834789 & 772988 & 7.2518 & 7.6679 & TST & \\
\hline CHEMBL590299 & 1527814 & 6.5901 & 6.48 & TRN & \\
\hline CHEMBL 3679704 & 1527814 & 7.6038 & 7.1353 & TST & \\
\hline CHEMBL602554 & 1527814 & 6.8097 & 6.8713 & TRN & \\
\hline CHEMBL603166 & 1527814 & 6.1475 & 6.2326 & TRN & \\
\hline CHEMBL1083671 & 1527814 & 6.4486 & 6.4384 & TRN & \\
\hline CHEMBL1085271 & 1527814 & 6.4547 & 6.4374 & TRN & \\
\hline CHEMBL 3679698 & 1527814 & 7.2967 & 7.6838 & TRN & \\
\hline CHEMBL1086441 & 1527814 & 7.1469 & \multicolumn{2}{|c|}{7.207000000000001} & TRN \\
\hline CHEMBL3679699 & 1527814 & 6.209 & 5.6172 & TST & \\
\hline CHEMBL3679692 & 1527814 & 6.3372 & 6.2556 & TRN & \\
\hline CHEMBL590021 & 1527814 & 7.3516 & 7.3708 & TRN & \\
\hline CHEMBL1085844 & 1527814 & 5.8182 & 5.8425 & TRN & \\
\hline CHEMBL590752 & 1527814 & 6.9747 & 6.9355 & TRN & \\
\hline CHEMBL608374 & 1527814 & 6.6696 & 6.5301 & TRN & \\
\hline CHEMBL590992 & 1527814 & 7.9747 & 7.9263 & TRN & \\
\hline CHEMBL1083079 & 1527814 & 6.8827 & 6.9368 & TRN & \\
\hline CHEMBL 3679705 & 1527814 & 7.0511 & 6.9882 & TRN & \\
\hline CHEMBL1085547 & 1527814 & 7.7696 & 7.5652 & TRN & \\
\hline CHEMBL602721 & 1527814 & 6.6038 & 6.5212 & TRN & \\
\hline CHEMBL1083674 & 1527814 & 7.1918 & 7.1285 & TRN & \\
\hline CHEMBL590277 & 1527814 & 6.1952 & 6.1458 & TRN & \\
\hline CHEMBL1083975 & 1527814 & 7.9431 & 7.9737 & TRN & \\
\hline CHEMBL 3679708 & 1527814 & 7.7545 & 7.8699 & TRN & \\
\hline
\end{tabular}

Page 15700 
Supplemental Table S2.txt

\begin{tabular}{|c|c|c|c|c|c|}
\hline CHEMBL 3639785 & 1527814 & 7.9706 & 7.9544 & TRN & \\
\hline CHEMBL 3679700 & 1527814 & 6.2741 & 5.8659 & TST & \\
\hline CHEMBL1083978 & 1527814 & 7.2125 & 7.0806 & TRN & \\
\hline CHEMBL1084259 & 1527814 & 6.9872 & 6.9039 & TRN & \\
\hline CHEMBL1083979 & 1527814 & 6.6536 & 6.6617 & TRN & \\
\hline CHEMBL590751 & 1527814 & 7.75200 & 000000000 & 7.9273 & TRN \\
\hline CHEMBL601947 & 1527814 & 6.4522 & 6.5781 & TRN & \\
\hline CHEMBL1082502 & 1527814 & 5.983 & 5.9985 & TRN & \\
\hline CHEMBL 3679695 & 1527814 & 5.8477 & 5.9401 & TRN & \\
\hline CHEMBL1083369 & 1527814 & 6.6253 & 6.6334 & TRN & \\
\hline CHEMBL591937 & 1527814 & 6.266 & 6.0911 & TST & \\
\hline CHEMBL1086006 & 1527814 & 6.5331 & 6.4194 & TRN & \\
\hline CHEMBL603167 & 1527814 & 7.7799 & 7.6889 & TRN & \\
\hline CHEMBL1085546 & 1527814 & 6.3615 & 6.3651 & TRN & \\
\hline CHEMBL3679693 & 1527814 & 6.2612 & 6.595 & TST & \\
\hline CHEMBL3679694 & 1527814 & 6.1367 & 6.701000 & 30000000005 & TST \\
\hline CHEMBL589545 & 1527814 & 6.2503 & 6.2041 & TRN & \\
\hline CHEMBL 3679701 & 1527814 & 6.3089 & 5.9934 & TST & \\
\hline CHEMBL1085769 & 1527814 & 7.76200 & 900000000 & 7.6838 & TRN \\
\hline CHEMBL1085015 & 1527814 & 6.7747 & 6.8108 & TRN & \\
\hline CHEMBL601465 & 1527814 & 7.2757 & 7.2454 & TRN & \\
\hline CHEMBL1085545 & 1527814 & 6.9626 & 7.1006 & TRN & \\
\hline CHEMBL590514 & 1527814 & 7.0114 & 6.8335 & TRN & \\
\hline CHEMBL592686 & 1527814 & 6.9245 & 6.9933 & TRN & \\
\hline CHEMBL591739 & 1527814 & 7.9626 & 8.0497 & TRN & \\
\hline CHEMBL3679707 & 1527814 & 6.4908 & 6.591 & TRN & \\
\hline CHEMBL590020 & 1527814 & 7.7399 & 7.7413 & TRN & \\
\hline CHEMBL1085770 & 1527814 & 6.9547 & 6.5901 & TST & \\
\hline CHEMBL1083690 & 1527814 & 7.3665 & 7.3196 & TRN & \\
\hline CHEMBL1085272 & 1527814 & 7.1878 & 7.1855 & TRN & \\
\hline CHEMBL590041 & 1527814 & 7.6038 & 7.6772 & TRN & \\
\hline CHEMBL590991 & 1527814 & 7.2343 & 7.2794 & TRN & \\
\hline CHEMBL 3679697 & 1527814 & 6.6968 & 6.7647 & TRN & \\
\hline CHEMBL3679691 & 1527814 & 7.1391 & 7.218 & TRN & \\
\hline CHEMBL590271 & 1527814 & 7.6615 & 7.7072 & TRN & \\
\hline CHEMBL3679702 & 1527814 & 6.5834 & 7.2008 & TST & \\
\hline CHEMBL3679696 & 1527814 & 5.9101 & 5.8665 & TRN & \\
\hline CHEMBL1083673 & 1527814 & 6.7545 & 6.4579 & TST & \\
\hline CHEMBL591950 & 1527814 & 6.7212 & 6.68 & TRN & \\
\hline CHEMBL1083980 & 1527814 & 6.5654 & 6.4389 & TRN & \\
\hline CHEMBL601510 & 1527814 & 8.4547 & 8.1013 & TRN & \\
\hline CHEMBL590042 & 1527814 & 7.3439 & 7.4994 & TRN & \\
\hline CHEMBL591714 & 1527814 & 6.4214 & 6.3737 & TRN & \\
\hline CHEMBL605905 & 1527814 & 8.15299 & 999999999 & 8.0416 & TRN \\
\hline CHEMBL1085771 & 1527814 & 7.8729 & 7.6614 & TRN & \\
\hline CHEMBL591949 & 1527814 & 8.3915 & 8.3546 & TRN & \\
\hline CHEMBL590296 & 1527814 & 7.5186 & 7.4698 & TRN & \\
\hline CHEMBL591738 & 1527814 & 6.8356 & 6.9171 & TRN & \\
\hline
\end{tabular}


Supplemental Table S2.txt

\begin{tabular}{|c|c|c|c|c|c|c|}
\hline CHEMBL1084440 & 1527814 & 7.1226 & 7.3212 & TRN & & \\
\hline CHEMBL1082416 & 1527814 & 6.1549 & 6.1676 & TRN & & \\
\hline CHEMBL1085273 & 1527814 & 5.767 & 6.3466 & TST & & \\
\hline CHEMBL606689 & 1527814 & 6.9872 & 6.994 & TRN & & \\
\hline CHEMBL589980 & 1527814 & 6.1203 & 6.1658 & TRN & & \\
\hline CHEMBL1082759 & 1527814 & 6.6946 & 6.7135 & TRN & & \\
\hline CHEMBL591490 & 1527814 & 6.3516 & 6.2152 & TST & & \\
\hline CHEMBL1085772 & 1527814 & 5.7282 & 5.8271 & TRN & & \\
\hline CHEMBL3679703 & 1527814 & 6.3958 & 6.4122 & TST & & \\
\hline CHEMBL1085529 & 1527814 & 6.8729 & 6.8353 & TRN & & \\
\hline CHEMBL1082417 & 1527814 & 5.9431 & 5.9107 & TRN & & \\
\hline CHEMBL1086192 & 1527814 & 7.1101 & 6.9487 & TST & & \\
\hline CHEMBL1085528 & 1527814 & 6.091 & 6.1747 & TRN & & \\
\hline CHEMBL3679706 & 1527814 & 7.6055 & 7.7115 & TRN & & \\
\hline CHEMBL1083370 & 1527814 & 6.5867 & 6.5876 & TRN & & \\
\hline CHEMBL1084166 & 1527814 & 7.1463 & 6.9566 & TST & & \\
\hline CHEMBL589324 & 1527814 & 6.9136 & 6.7483 & TST & & \\
\hline CHEMBL1085297 & 1527814 & 7.15 & 7.1026 & TST & & \\
\hline CHEMBL3679709 & 1527814 & 8.2557 & 8.0776 & TST & & \\
\hline CHEMBL589300 & 1527814 & 7.0883 & 6.7895 & TST & & \\
\hline CHEMBL606750 & 1527814 & 7.8416 & 7.6943 & TST & & \\
\hline CHEMBL600982 & 1527814 & 7.4389 & 7.2597 & TST & & \\
\hline CHEMBL1084258 & 1527814 & 7.0825 & 6.8722 & TST & & \\
\hline CHEMBL1085544 & 1527814 & 6.9586 & 6.6618 & TST & & \\
\hline CHEMBL591485 & 1527814 & \multicolumn{3}{|c|}{6.117999999999999} & 6.0253 & TST \\
\hline CHEMBL602524 & 1527814 & 6.8996 & 7.5973 & TST & & \\
\hline CHEMBL54344 & 68746 & 2.5367 & 3.221 & TRN & & \\
\hline CHEMBL98110 & 68746 & 5.0 & 4.5019 & TRN & & \\
\hline CHEMBL125706 & 68746 & 4.1427 & 4.5887 & TRN & & \\
\hline CHEMBL299563 & 68746 & \multicolumn{3}{|c|}{ 3. 2239999999999998} & 2.9158 & TRN \\
\hline CHEMBL333503 & 68746 & 1.5989 & 3.5544 & TRN & & \\
\hline CHEMBL125188 & 68746 & 3.9586 & 3.0761 & TRN & & \\
\hline CHEMBL417549 & 68746 & 3.7721 & 3.9674 & TRN & & \\
\hline CHEMBL301247 & 68746 & 4.9208 & 4.3807 & TRN & & \\
\hline CHEMBL294192 & 68746 & 4.8539 & 5.2306 & TRN & & \\
\hline CHEMBL125029 & 68746 & 2.9197 & 3.3629 & TRN & & \\
\hline CHEMBL127588 & 68746 & 2.045 & 2.9991 & TRN & & \\
\hline CHEMBL55358 & 68746 & 3.9586 & 3.5646 & TRN & & \\
\hline CHEMBL125887 & 68746 & 4.7959 & 3.7796 & TRN & & \\
\hline CHEMBL301065 & 68746 & 4.6198 & 4.9247 & TRN & & \\
\hline CHEMBL299717 & 68746 & 4.4559 & 3.9469 & TRN & & \\
\hline CHEMBL54472 & 68746 & 4.8861 & 3.4953 & TST & & \\
\hline CHEMBL124647 & 68746 & 4.2007 & 3.8357 & TRN & & \\
\hline CHEMBL55608 & 68746 & 4.8861 & 4.283 & TRN & & \\
\hline CHEMBL340034 & 68746 & 5.1367 & 3.6919 & TST & & \\
\hline CHEMBL56556 & 68746 & 2.5501 & 3.0371 & TRN & & \\
\hline CHEMBL56253 & 68746 & 4.3279 & 4.1207 & TST & & \\
\hline CHEMBL55352 & 68746 & 4.0809 & 3.3243 & TRN & & \\
\hline
\end{tabular}

Page 15702 


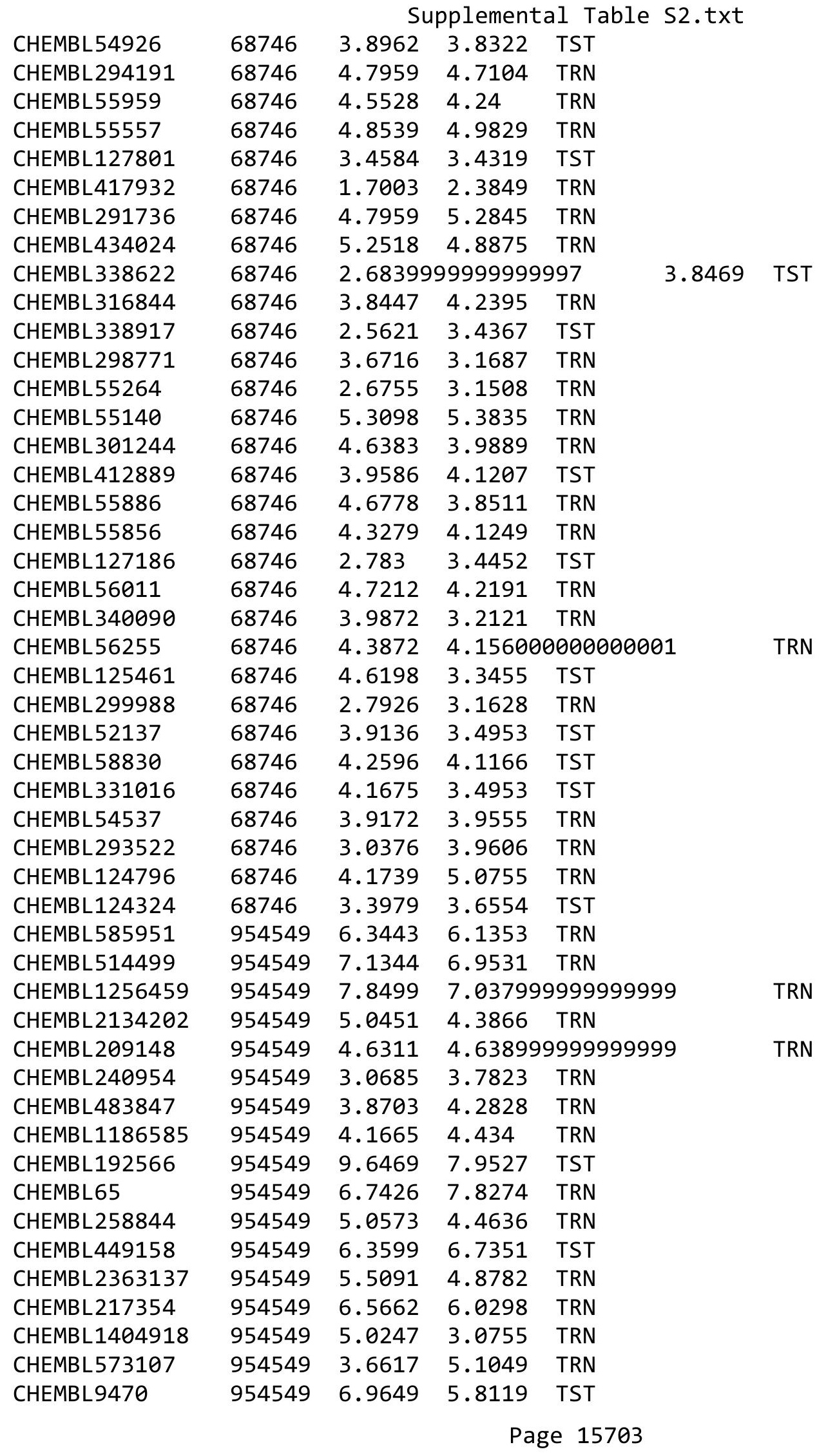




\begin{tabular}{|c|c|c|c|c|c|}
\hline \multicolumn{6}{|c|}{ Supplemental Table S2.txt } \\
\hline CHEMBL1357247 & 954549 & 3.8853 & 3.3198 & TRN & \\
\hline CHEMBL 2144069 & 954549 & 3.6561 & 4.9326 & TRN & \\
\hline CHEMBL 373751 & 954549 & 3.321 & 3.88 & TRN & \\
\hline CHEMBL 3199475 & 954549 & 3.9684 & 4.4918 & TRN & \\
\hline CHEMBL1190711 & 954549 & 4.8255 & 5.1 & TRN & \\
\hline CHEMBL300389 & 954549 & 6.8704 & 6.7882 & TRN & \\
\hline CHEMBL 259181 & 954549 & 5.5315 & 4.58899 & 99999999995 & TRN \\
\hline CHEMBL1788116 & 954549 & 5.1317 & 4.495 & TRN & \\
\hline CHEMBL1242367 & 954549 & 3.9567 & 4.3139 & TRN & \\
\hline CHEMBL 2005886 & 954549 & 5.3175 & 5.4493 & TRN & \\
\hline CHEMBL399530 & 954549 & 5.165 & 4.6359 & TRN & \\
\hline CHEMBL483849 & 954549 & 0.802 & 2.4005 & TRN & \\
\hline CHEMBL 213100 & 954549 & 3.8536 & 4.8936 & TRN & \\
\hline CHEMBL515416 & 954549 & 5.8543 & 4.6131 & TRN & \\
\hline CHEMBL412142 & 954549 & 5.5782 & 4.1249 & TRN & \\
\hline CHEMBL1970879 & 954549 & 3.7773 & 4.7312 & TRN & \\
\hline CHEMBL221137 & 954549 & 5.2485 & 4.7763 & TST & \\
\hline CHEMBL 379300 & 954549 & 6.5585 & 6.369 & TRN & \\
\hline CHEMBL 255342 & 954549 & 3.7628 & 3.7433 & TST & \\
\hline CHEMBL 210618 & 954549 & 3.2769 & 3.5759 & TRN & \\
\hline CHEMBL 2137530 & 954549 & 4.8467 & 4.8275 & TRN & \\
\hline CHEMBL1230020 & 954549 & 2.9605 & 4.0689 & TRN & \\
\hline CHEMBL3186408 & 954549 & 4.8032 & 3.9456 & TST & \\
\hline CHEMBL180127 & 954549 & 4.3901 & 4.3219 & TRN & \\
\hline CHEMBL92309 & 954549 & 3.9213 & 3.1343 & TST & \\
\hline CHEMBL1516890 & 954549 & 3.9375 & 4.1435 & TRN & \\
\hline CHEMBL509032 & 954549 & 5.9356 & 5.6204 & TRN & \\
\hline CHEMBL1590308 & 954549 & 3.0888 & 3.5533 & TST & \\
\hline CHEMBL 3392440 & 954549 & 6.0465 & 4.0023 & TRN & \\
\hline CHEMBL1643959 & 954549 & 3.3317 & 3.8465 & TRN & \\
\hline CHEMBL102714 & 954549 & 3.0317 & 3.6778 & TRN & \\
\hline CHEMBL1673039 & 954549 & 4.5401 & 4.863 & TRN & \\
\hline CHEMBL188678 & 954549 & 4.5675 & 4.4832 & TRN & \\
\hline CHEMBL558642 & 954549 & 5.269 & 4.2569 & TST & \\
\hline CHEMBL135561 & 954549 & 4.3119 & 4.5344 & TST & \\
\hline CHEMBL512504 & 954549 & 4.6496 & 4.8796 & TST & \\
\hline CHEMBL392695 & 954549 & 5.044 & 5.2155 & TST & \\
\hline CHEMBL472940 & 954549 & 4.8308 & 3.8209 & TST & \\
\hline CHEMBL 220241 & 954549 & 4.4868 & 4.8334 & TST & \\
\hline CHEMBL222102 & 954549 & 3.5373 & 3.8855 & TST & \\
\hline CHEMBL1271801 & 674830 & 7.2596 & 7.4007 & TRN & \\
\hline CHEMBL 1271800 & 674830 & 7.5086 & 7.3941 & TRN & \\
\hline CHEMBL1271581 & 674830 & 4.0 & 3.9804 & TRN & \\
\hline CHEMBL1272026 & 674830 & 5.7178 & 5.6255 & TRN & \\
\hline CHEMBL1271914 & 674830 & 7.2076 & 7.2322 & TRN & \\
\hline CHEMBL1272079 & 674830 & 4.0 & 4.07 & TRN & \\
\hline CHEMBL1269807 & 674830 & 6.2147 & 6.1533 & TRN & \\
\hline CHEMBL1271474 & 674830 & 5.555 & 5.5333 & TRN & \\
\hline
\end{tabular}




\begin{tabular}{|c|c|c|c|c|}
\hline & & \multicolumn{3}{|c|}{ Supplemental Table S2.txt } \\
\hline CHEMBL1271967 & 674830 & 7.5086 & 7.3797 & TRN \\
\hline CHEMBL1271912 & 674830 & 7.0088 & 6.9386 & TRN \\
\hline CHEMBL1272292 & 674830 & 4.0 & 3.9544 & TST \\
\hline CHEMBL1272129 & 674830 & 7.6198 & 7.5828 & TRN \\
\hline CHEMBL1271740 & 674830 & 6.2418 & 6.2296 & TRN \\
\hline CHEMBL1272239 & 674830 & 6.9172 & 6.9328 & TRN \\
\hline CHEMBL1271857 & 674830 & 4.0 & 4.0829 & TRN \\
\hline CHEMBL1271685 & 674830 & 4.0 & 3.8735 & TRN \\
\hline CHEMBL1272293 & 674830 & 4.0 & 4.1915 & TRN \\
\hline CHEMBL1271799 & 674830 & 4.0 & 3.0708 & TST \\
\hline CHEMBL1272184 & 674830 & 7.2441 & 7.0735 & TRN \\
\hline CHEMBL1271970 & 674830 & 6.9431 & 6.9512 & TRN \\
\hline CHEMBL1271579 & 674830 & 5.0 & 4.9605 & TRN \\
\hline CHEMBL1271738 & 674830 & 4.0 & 3.9334 & TRN \\
\hline CHEMBL1272023 & 674830 & 7.9208 & 8.1111 & TRN \\
\hline CHEMBL1271473 & 674830 & 4.0 & 3.9323 & TRN \\
\hline CHEMBL1272080 & 674830 & 4.0 & 4.0718 & TRN \\
\hline CHEMBL1269808 & 674830 & 4.0 & 4.0368 & TRN \\
\hline CHEMBL1271739 & 674830 & 4.0 & 3.966 & TRN \\
\hline CHEMBL1272183 & 674830 & 7.2366 & 7.2089 & TRN \\
\hline CHEMBL1272130 & 674830 & 7.3098 & 7.3461 & TRN \\
\hline CHEMBL1271525 & 674830 & 7.3565 & 7.4042 & TRN \\
\hline CHEMBL1269043 & 674830 & 5.5964 & 5.4943 & TRN \\
\hline CHEMBL1271737 & 674830 & 6.8239 & 6.7835 & TRN \\
\hline CHEMBL1271969 & 674830 & 7.2518 & 7.4362 & TRN \\
\hline CHEMBL1272024 & 674830 & 7.3468 & 7.1924 & TRN \\
\hline CHEMBL1271856 & 674830 & 4.0 & 4.15600 & 0000000001 \\
\hline CHEMBL1271913 & 674830 & 7.3188 & 7.5738 & TST \\
\hline CHEMBL1271741 & 674830 & 4.0 & 3.8554 & TST \\
\hline CHEMBL1271797 & 674830 & 5.4437 & 5.5385 & TRN \\
\hline CHEMBL1271855 & 674830 & 4.0 & 3.1044 & TST \\
\hline CHEMBL1271633 & 674830 & 4.0 & 3.4933 & TST \\
\hline CHEMBL1271580 & 674830 & 6.8729 & 6.7595 & TRN \\
\hline CHEMBL1269063 & 674830 & 4.0 & 4.1004 & TRN \\
\hline CHEMBL1271854 & 674830 & 4.0 & 3.8131 & TST \\
\hline CHEMBL1272082 & 674830 & 7.4559 & 7.6482 & TST \\
\hline CHEMBL1271968 & 674830 & 7.5528 & 7.7246 & TRN \\
\hline CHEMBL1271684 & 674830 & 4.0 & 3.5737 & TST \\
\hline CHEMBL1272027 & 674830 & 4.0 & 3.6328 & TST \\
\hline CHEMBL1269065 & 674830 & 4.0 & 3.7599 & TST \\
\hline CHEMBL1272131 & 674830 & 5.0 & 5.0037 & TRN \\
\hline CHEMBL1272081 & 674830 & 4.0 & 3.9707 & TST \\
\hline CHEMBL1271798 & 674830 & 4.0 & 4.1103 & TRN \\
\hline CHEMBL1269064 & 674830 & 4.0 & 3.9188 & TRN \\
\hline CHEMBL1271911 & 674830 & 4.0 & 3.6737 & TST \\
\hline CHEMBL99779 & 51337 & 3.569 & 5.2553 & TST \\
\hline CHEMBL121543 & 51337 & 5.699 & 5.8692 & TRN \\
\hline CHEMBL316485 & 51337 & 3.886 & 3.9051 & TST \\
\hline
\end{tabular}




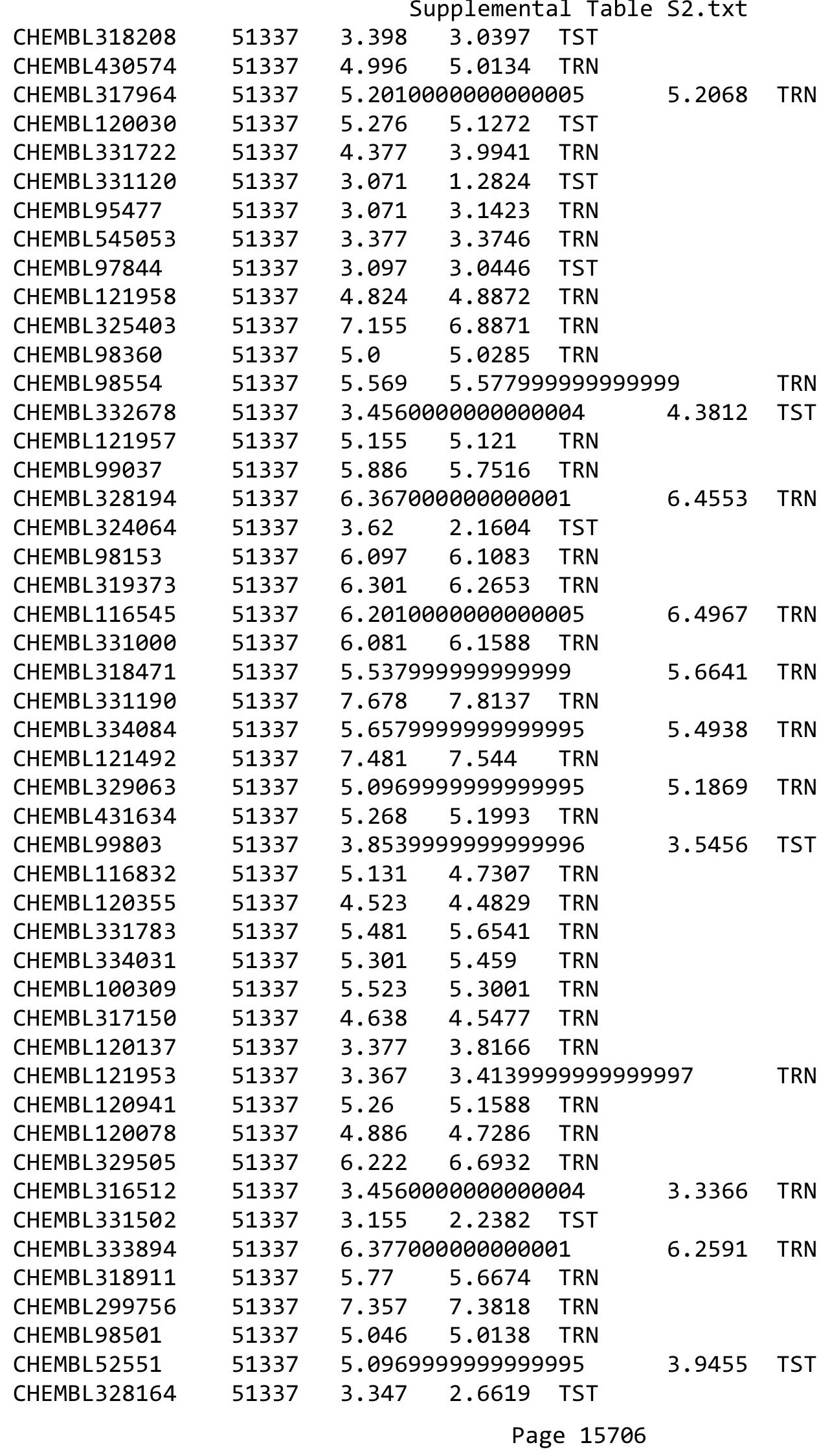




\begin{tabular}{|c|c|c|c|c|c|c|}
\hline \multicolumn{7}{|c|}{ Supplemental Table S2.txt } \\
\hline CHEMBL323657 & 51337 & 5.398 & 5.2304 & TRN & & \\
\hline CHEMBL95827 & 51337 & 5.678 & 5.6116 & TRN & & \\
\hline CHEMBL99423 & 51337 & 3.0 & 3.0162 & TRN & & \\
\hline CHEMBL333006 & 51337 & 6.921 & 6.8031 & TRN & & \\
\hline CHEMBL332359 & 51337 & 6.0 & 5.766 & TRN & & \\
\hline CHEMBL120497 & 51337 & 5.77 & 5.9877 & TST & & \\
\hline CHEMBL100312 & 51337 & 3.097 & 2.1534 & TST & & \\
\hline CHEMBL419054 & 51337 & 5.022 & 4.9942 & TRN & & \\
\hline CHEMBL333066 & 51337 & 4.523 & 4.94 & TRN & & \\
\hline CHEMBL325654 & 51337 & 7.222 & 7.03299 & 9999 & 995 & TRN \\
\hline CHEMBL119989 & 51337 & 4.46899 & 99999999 & & 4.4961 & TRN \\
\hline CHEMBL331759 & 51337 & $3.0660 e$ & 00000000 & 203 & 0.8834 & TST \\
\hline CHEMBL119932 & 51337 & 3.347 & 3.7494 & TRN & & \\
\hline CHEMBL119963 & 51337 & 7.0 & 6.9205 & TRN & & \\
\hline CHEMBL328627 & 51337 & 3.585 & 3.3012 & TST & & \\
\hline CHEMBL330398 & 51337 & 3.398 & 3.3933 & TRN & & \\
\hline CHEMBL118406 & 51337 & 4.398 & 4.33 & TRN & & \\
\hline CHEMBL120664 & 51337 & 5.081 & 4.645 & TST & & \\
\hline CHEMBL118162 & 51337 & 6.495 & 5.6579 & TST & & \\
\hline CHEMBL1727313 & 737457 & 3.0 & 4.1744 & TRN & & \\
\hline CHEMBL1505867 & 737457 & 5.2716 & 4.7963 & TRN & & \\
\hline CHEMBL1544838 & 737457 & 4.9914 & 5.0239 & TRN & & \\
\hline CHEMBL1600176 & 737457 & 3.0 & 4.6318 & TRN & & \\
\hline CHEMBL1363085 & 737457 & 5.3401 & 4.5525 & TRN & & \\
\hline CHEMBL1517284 & 737457 & 5.083 & 5.035 & TST & & \\
\hline CHEMBL1599992 & 737457 & 5.4365 & 4.7216 & TRN & & \\
\hline CHEMBL1703256 & 737457 & 4.5751 & 5.2722 & TST & & \\
\hline CHEMBL1363961 & 737457 & 5.3696 & 5.1 & TST & & \\
\hline CHEMBL1722165 & 737457 & 3.0 & 4.4904 & TRN & & \\
\hline CHEMBL1407064 & 737457 & 4.9066 & 5.36 & TRN & & \\
\hline CHEMBL1408451 & 737457 & 6.0 & 5.8902 & TRN & & \\
\hline CHEMBL1327409 & 737457 & 5.3526 & 5.5854 & TRN & & \\
\hline CHEMBL1609295 & 737457 & 4.6364 & 5.4892 & TST & & \\
\hline CHEMBL1411230 & 737457 & 5.4763 & 4.9003 & TRN & & \\
\hline CHEMBL1466979 & 737457 & 3.0 & 4.6412 & TRN & & \\
\hline CHEMBL1531603 & 737457 & 6.6162 & 5.9524 & TRN & & \\
\hline CHEMBL1366670 & 737457 & 5.1255 & 5.3896 & TRN & & \\
\hline CHEMBL1497466 & 737457 & 4.8416 & 5.2271 & TRN & & \\
\hline CHEMBL1699515 & 737457 & 4.9066 & 4.5563 & TRN & & \\
\hline CHEMBL1609596 & 737457 & 5.0645 & 5.2486 & TRN & & \\
\hline CHEMBL1711577 & 737457 & 4.3224 & 4.9896 & TST & & \\
\hline CHEMBL1373057 & 737457 & 5.3799 & 4.9848 & TRN & & \\
\hline CHEMBL1605701 & 737457 & 3.0 & 4.94 & TST & & \\
\hline CHEMBL1716980 & 737457 & 3.0 & 4.4799 & TRN & & \\
\hline CHEMBL1727861 & 737457 & 5.3279 & 5.0398 & TRN & & \\
\hline CHEMBL1606954 & 737457 & 6.1308 & 5.8925 & TRN & & \\
\hline CHEMBL1507415 & 737457 & 5.2588 & 4.9416 & TRN & & \\
\hline CHEMBL1570846 & 737457 & 5.4486 & 4.6509 & TRN & & \\
\hline
\end{tabular}


Supplemental Table S2.txt

\begin{tabular}{|c|c|c|c|c|c|}
\hline CHEMBL1452776 & 737457 & 4.7747 & 5.3894 & TRN & \\
\hline CHEMBL1594910 & 737457 & 5.3478 & 4.617 & TRN & \\
\hline CHEMBL1698744 & 737457 & 5.3072 & 4.6059 & TRN & \\
\hline CHEMBL1703721 & 737457 & 4.7721 & 4.1699 & TRN & \\
\hline CHEMBL1335027 & 737457 & 4.0615 & 4.4993 & TRN & \\
\hline CHEMBL1728719 & 737457 & 4.9031 & 5.0648 & TRN & \\
\hline CHEMBL1431176 & 737457 & 5.3595 & 4.0328 & TRN & \\
\hline CHEMBL 3212503 & 737457 & 4.4202 & 5.2132 & TST & \\
\hline CHEMBL1562738 & 737457 & 5.0496 & 5.226 & TRN & \\
\hline CHEMBL1708559 & 737457 & 4.1871 & 5.0041 & TST & \\
\hline CHEMBL1412551 & 737457 & 5.0862 & 4.7886 & TRN & \\
\hline CHEMBL1705908 & 737457 & 3.0 & 4.5296 & TRN & \\
\hline CHEMBL1531156 & 737457 & 3.0 & 4.9194 & TST & \\
\hline CHEMBL3189343 & 737457 & 6.6576 & 5.254 & TST & \\
\hline CHEMBL1338487 & 737457 & 3.0 & 4.9598 & TST & \\
\hline CHEMBL1707381 & 737457 & 5.475 & 5.1318 & TRN & \\
\hline CHEMBL1520235 & 737457 & 5.5186 & 4.4407 & TRN & \\
\hline CHEMBL1461999 & 737457 & 5.3354 & 4.7094 & TRN & \\
\hline CHEMBL1409617 & 737457 & 5.3516 & 4.8142 & TRN & \\
\hline CHEMBL1701809 & 737457 & 5.4179 & 4.7532 & TRN & \\
\hline CHEMBL1703161 & 737457 & 5.4584 & 5.1556 & TRN & \\
\hline CHEMBL1328938 & 737457 & 5.3893 & 5.0767 & TRN & \\
\hline CHEMBL1339179 & 737457 & 4.1469 & 4.1123 & TRN & \\
\hline CHEMBL1565196 & 737457 & 4.7496 & 4.7861 & TRN & \\
\hline CHEMBL1701765 & 737457 & 3.0 & 4.3467 & TRN & \\
\hline CHEMBL1333813 & 737457 & 6.0 & 5.457999 & 9999999999 & TST \\
\hline CHEMBL1457385 & 737457 & 5.0752 & 4.8961 & TRN & \\
\hline CHEMBL1411223 & 737457 & 4.7496 & 5.1302 & TRN & \\
\hline CHEMBL1721064 & 737457 & 3.0 & 4.5881 & TRN & \\
\hline CHEMBL1719462 & 737457 & 5.0888 & 4.6735 & TRN & \\
\hline CHEMBL1527436 & 737457 & 4.8239 & 4.9491 & TRN & \\
\hline CHEMBL1532795 & 737457 & 6.0 & 5.7076 & TRN & \\
\hline CHEMBL1518655 & 737457 & 4.9747 & 5.4521 & TRN & \\
\hline CHEMBL1362009 & 737457 & 5.2328 & 5.3869 & TST & \\
\hline CHEMBL1708865 & 737457 & 4.3497 & 5.0049 & TST & \\
\hline CHEMBL1459448 & 737457 & 5.4989 & 4.7865 & TRN & \\
\hline CHEMBL1720121 & 737457 & 5.3536 & 4.7033 & TRN & \\
\hline CHEMBL1582381 & 737457 & 5.3585 & 5.1424 & TST & \\
\hline CHEMBL1478526 & 737457 & 4.71 & 4.8766 & TRN & \\
\hline CHEMBL1722831 & 737457 & 5.38299 & 99999999 & 5.2486 & TST \\
\hline CHEMBL1412070 & 737457 & 5.1851 & 4.9466 & TRN & \\
\hline CHEMBL1486827 & 737457 & 3.0 & 5.3134 & TST & \\
\hline CHEMBL1470219 & 737457 & 4.9914 & 5.0351 & TRN & \\
\hline CHEMBL1335905 & 737457 & 5.4101 & 5.4566 & TRN & \\
\hline CHEMBL1566691 & 737457 & 5.0921 & 4.8773 & TRN & \\
\hline CHEMBL1569923 & 737457 & 4.9872 & 5.329 & TRN & \\
\hline CHEMBL1305463 & 737457 & 5.3063 & 5.2235 & TRN & \\
\hline CHEMBL1457695 & 737457 & 4.9101 & 5.495 & TRN & \\
\hline
\end{tabular}




\begin{tabular}{|c|c|c|c|c|c|}
\hline & & \multicolumn{4}{|c|}{ Supplemental Table S2.txt } \\
\hline CHEMBL260311 & 737457 & 4.5784 & 5.0067 & TST & \\
\hline CHEMBL1730966 & 737457 & 4.1481 & 3.9847 & TRN & \\
\hline CHEMBL1722880 & 737457 & 3.0 & 4.2761 & TRN & \\
\hline CHEMBL1299371 & 737457 & 5.2526 & 4.8614 & TRN & \\
\hline CHEMBL1524101 & 737457 & 3.0 & 4.8764 & TST & \\
\hline CHEMBL1333085 & 737457 & 5.0164 & 4.5204 & TRN & \\
\hline CHEMBL1443401 & 737457 & 4.4342 & 3.9312 & TRN & \\
\hline CHEMBL1701841 & 737457 & 5.3019 & 4.6543 & TRN & \\
\hline CHEMBL1403384 & 737457 & 5.4949 & 4.789 & TRN & \\
\hline CHEMBL1731255 & 737457 & 4.5918 & 4.9058 & TRN & \\
\hline CHEMBL585591 & 737457 & 5.7144 & 5.6838 & TST & \\
\hline CHEMBL1529827 & 737457 & 4.2644 & 5.7645 & TST & \\
\hline CHEMBL1408713 & 737457 & 6.0 & 4.9714 & TRN & \\
\hline CHEMBL1413142 & 737457 & 5.3958 & 5.5619 & TRN & \\
\hline CHEMBL586135 & 737457 & 4.8539 & 5.1727 & TRN & \\
\hline CHEMBL1478726 & 737457 & 4.8508 & 4.9107 & TRN & \\
\hline CHEMBL1450091 & 737457 & 4.9508 & 5.4218 & TRN & \\
\hline CHEMBL1408338 & 737457 & 5.2351 & 5.0663 & TRN & \\
\hline CHEMBL1725848 & 737457 & 5.3134 & 4.8381 & TRN & \\
\hline CHEMBL1537356 & 737457 & 4.9626 & 5.0269 & TRN & \\
\hline CHEMBL1460778 & 737457 & 4.0872 & 4.9201 & TRN & \\
\hline CHEMBL1566209 & 737457 & 4.9281 & 5.0333 & TRN & \\
\hline CHEMBL1412460 & 737457 & 5.5482 & 4.7993 & TST & \\
\hline CHEMBL1546307 & 737457 & 5.4214 & 5.392 & TST & \\
\hline CHEMBL1479664 & 737457 & 6.5229 & 5.1837 & TST & \\
\hline CHEMBL1570963 & 737457 & 5.1192 & 4.3518 & TST & \\
\hline CHEMBL1537181 & 737457 & 4.8539 & 4.9022 & TST & \\
\hline CHEMBL323958 & 217298 & 4.6021 & 4.6043 & TRN & \\
\hline CHEMBL113720 & 217298 & 4.5229 & 4.8423 & TRN & \\
\hline CHEMBL326798 & 217298 & 4.4815 & 4.4043 & TST & \\
\hline CHEMBL114234 & 217298 & 5.0969 & 5.1389 & TRN & \\
\hline CHEMBL112619 & 217298 & 4.3979 & 4.1618 & TRN & \\
\hline CHEMBL114678 & 217298 & 5.1549 & 5.25700 & 0000000001 & TRN \\
\hline CHEMBL 325410 & 217298 & 6.3979 & 6.6287 & TRN & \\
\hline CHEMBL325904 & 217298 & 4.2218 & 4.6405 & TRN & \\
\hline CHEMBL324113 & 217298 & 5.699 & 5.6124 & TRN & \\
\hline CHEMBL114391 & 217298 & 3.9208 & 4.1351 & TRN & \\
\hline CHEMBL114708 & 217298 & 5.301 & 4.8938 & TRN & \\
\hline CHEMBL431870 & 217298 & 3.4559 & 3.6589 & TRN & \\
\hline CHEMBL326625 & 217298 & 5.5686 & 5.2497 & TRN & \\
\hline CHEMBL326539 & 217298 & 6.9208 & 6.6262 & TRN & \\
\hline CHEMBL432437 & 217298 & 6.301 & 6.2595 & TRN & \\
\hline CHEMBL114882 & 217298 & 5.8239 & 5.4873 & TRN & \\
\hline CHEMBL 2372105 & 217298 & 6.5229 & 6.7894 & TRN & \\
\hline CHEMBL326394 & 217298 & 6.6383 & 6.7018 & TRN & \\
\hline CHEMBL115932 & 217298 & 8.0969 & 5.1996 & TST & \\
\hline CHEMBL115597 & 217298 & 5.8239 & 5.5593 & TST & \\
\hline CHEMBL113731 & 217298 & 5.4437 & 5.4626 & TRN & \\
\hline
\end{tabular}




\begin{tabular}{|c|c|c|c|c|}
\hline & & & pplement & al $\mathrm{T}$ \\
\hline CHEMBL112704 & 217298 & 3.6021 & 3.5468 & TRN \\
\hline CHEMBL323250 & 217298 & 4.301 & 4.2178 & TST \\
\hline CHEMBL114486 & 217298 & 3.7399 & 3.5446 & TRN \\
\hline CHEMBL112675 & 217298 & 6.699 & 6.6289 & TRN \\
\hline CHEMBL115715 & 217298 & 4.0969 & 3.9837 & TRN \\
\hline CHEMBL420864 & 217298 & 5.2218 & 4.9175 & TRN \\
\hline CHEMBL115443 & 217298 & 4.8539 & 5.1058 & TRN \\
\hline CHEMBL114369 & 217298 & 4.9788 & 5.1022 & TRN \\
\hline CHEMBL112321 & 217298 & 3.6778 & 4.1212 & TRN \\
\hline CHEMBL324283 & 217298 & 4.0 & 4.0601 & TRN \\
\hline CHEMBL324281 & 217298 & 4.8239 & 4.5485 & TRN \\
\hline CHEMBL114151 & 217298 & 4.8239 & 4.4956 & TRN \\
\hline CHEMBL116286 & 217298 & 5.5229 & 4.8378 & TST \\
\hline CHEMBL115882 & 217298 & 4.6021 & 4.2934 & TRN \\
\hline CHEMBL 326500 & 217298 & 6.301 & 5.5078 & TST \\
\hline CHEMBL326953 & 217298 & 4.3979 & 4.641 & TRN \\
\hline CHEMBL116053 & 217298 & 5.301 & 5.3133 & TRN \\
\hline CHEMBL110964 & 217298 & 4.7212 & 5.1866 & TRN \\
\hline CHEMBL 325753 & 217298 & 5.0458 & 5.1013 & TRN \\
\hline CHEMBL419038 & 217298 & 4.8239 & 5.7352 & TST \\
\hline CHEMBL333631 & 217298 & 6.5086 & 6.6148 & TRN \\
\hline CHEMBL 325280 & 217298 & 6.9208 & 6.46 & TRN \\
\hline CHEMBL115504 & 217298 & 6.2218 & 6.3125 & TRN \\
\hline CHEMBL 323810 & 217298 & 3.6021 & 3.6844 & TRN \\
\hline CHEMBL325366 & 217298 & 4.0 & 4.0575 & TRN \\
\hline CHEMBL114767 & 217298 & 5.3279 & 5.5239 & TRN \\
\hline CHEMBL424064 & 217298 & 5.2007 & 5.4187 & TRN \\
\hline CHEMBL115564 & 217298 & 6.0 & 5.9116 & TRN \\
\hline CHEMBL1790844 & 217298 & 6.4949 & 6.3964 & TRN \\
\hline CHEMBL113100 & 217298 & 4.0969 & 3.8297 & TRN \\
\hline CHEMBL325911 & 217298 & 5.7212 & 5.428 & TST \\
\hline CHEMBL114583 & 217298 & 4.7696 & 5.2335 & TST \\
\hline CHEMBL115881 & 217298 & 3.8996 & 4.8491 & TST \\
\hline CHEMBL432796 & 217298 & 7.699 & 6.8001 & TST \\
\hline CHEMBL112936 & 217298 & 3.6778 & 3.6124 & TST \\
\hline CHEMBL441822 & 217298 & 6.0269 & 4.837 & TST \\
\hline CHEMBL 324503 & 217298 & 3.0 & 3.4353 & TST \\
\hline CHEMBL439598 & 217298 & 5.3768 & 4.5096 & TST \\
\hline CHEMBL 2418173 & 978483 & 5.6383 & 5.4625 & TRN \\
\hline CHEMBL 2418183 & 978483 & 3.6021 & 3.6341 & TRN \\
\hline CHEMBL 2418174 & 978483 & 3.6021 & 3.6859 & TRN \\
\hline CHEMBL2418190 & 978483 & 3.6021 & 3.4162 & TRN \\
\hline CHEMBL 2418158 & 978483 & 3.6021 & 3.5831 & TRN \\
\hline CHEMBL 2418150 & 978483 & 3.6021 & 3.9036 & TST \\
\hline CHEMBL2418163 & 978483 & 3.6021 & 3.5852 & TRN \\
\hline CHEMBL 2418181 & 978483 & 5.585 & 4.7611 & TST \\
\hline CHEMBL2418146 & 978483 & 3.6021 & 3.3433 & TST \\
\hline CHEMBL2418157 & 978483 & 3.6021 & 3.929 & TST \\
\hline
\end{tabular}




\begin{tabular}{|c|c|c|c|c|c|}
\hline & & \multicolumn{4}{|c|}{ Supplemental Table S2.txt } \\
\hline CHEMBL 2418180 & 978483 & 3.6021 & 3.4958 & TRN & \\
\hline CHEMBL 2418143 & 978483 & 3.6021 & 2.4635 & TST & \\
\hline CHEMBL 2418179 & 978483 & 3.6021 & 3.5381 & TRN & \\
\hline CHEMBL 2418171 & 978483 & 3.6021 & 3.5668 & TRN & \\
\hline CHEMBL 2418165 & 978483 & 3.6021 & 3.5289 & TRN & \\
\hline CHEMBL236232 & 978483 & 3.301 & 3.3477 & TRN & \\
\hline CHEMBL 2418172 & 978483 & 5.8539 & 5.9048 & TRN & \\
\hline CHEMBL 2418166 & 978483 & 3.6021 & 3.5945 & TRN & \\
\hline CHEMBL 2418164 & 978483 & 3.6021 & 3.6211 & TRN & \\
\hline CHEMBL 2418156 & 978483 & 3.6021 & 2.7268 & TST & \\
\hline CHEMBL 2418176 & 978483 & 3.6021 & 3.6178 & TRN & \\
\hline CHEMBL 2418178 & 978483 & 3.6021 & 3.7666 & TRN & \\
\hline CHEMBL 2418140 & 978483 & 3.301 & 4.1092 & TST & \\
\hline CHEMBL 2418167 & 978483 & 3.6021 & 3.5866 & TRN & \\
\hline CHEMBL 2418145 & 978483 & 3.6021 & 3.5691 & TRN & \\
\hline CHEMBL 2418160 & 978483 & 3.6021 & 3.6613 & TRN & \\
\hline CHEMBL 2418141 & 978483 & 3.6021 & 3.5862 & TRN & \\
\hline CHEMBL 2418161 & 978483 & 3.6021 & 4.0065 & TST & \\
\hline CHEMBL 2418155 & 978483 & 5.2007 & 4.8726 & TST & \\
\hline CHEMBL 2418191 & 978483 & 3.6021 & 3.6777 & TRN & \\
\hline CHEMBL 2418151 & 978483 & 3.6021 & 2.9366 & TST & \\
\hline CHEMBL 2418153 & 978483 & 3.6021 & 3.6179 & TRN & \\
\hline CHEMBL 2418144 & 978483 & 3.6021 & 3.7967 & TST & \\
\hline CHEMBL 2418192 & 978483 & 3.6021 & 3.7429 & TRN & \\
\hline CHEMBL 2418175 & 978483 & 3.6021 & 3.5791 & TRN & \\
\hline CHEMBL 2418152 & 978483 & 3.6021 & 4.2358 & TST & \\
\hline CHEMBL 2418139 & 978483 & 5.0132 & 5.07600 & 00000000005 & TRN \\
\hline CHEMBL 2418182 & 978483 & 5.4949 & 5.4703 & TRN & \\
\hline CHEMBL 2418177 & 978483 & 3.6021 & 3.5564 & TRN & \\
\hline CHEMBL 2418147 & 978483 & 3.6021 & 2.1099 & TST & \\
\hline CHEMBL 2418154 & 978483 & 3.6021 & 3.57800 & 00000000003 & TRN \\
\hline CHEMBL 2418162 & 978483 & 3.6021 & 3.6408 & TRN & \\
\hline CHEMBL 2418185 & 978483 & 3.6021 & 3.5302 & TRN & \\
\hline CHEMBL 2418188 & 978483 & 3.6021 & 3.5963 & TRN & \\
\hline CHEMBL 2418184 & 978483 & 3.6021 & 3.7152 & TRN & \\
\hline CHEMBL 2418170 & 978483 & 3.6021 & 3.6776 & TRN & \\
\hline CHEMBL 2418149 & 978483 & 4.7986 & 5.0283 & TST & \\
\hline CHEMBL 2418168 & 978483 & 3.6021 & 3.6151 & TRN & \\
\hline CHEMBL 2418142 & 978483 & 3.6021 & 3.6627 & TRN & \\
\hline CHEMBL 2418186 & 978483 & 3.6021 & 3.5288 & TRN & \\
\hline CHEMBL 2418187 & 978483 & 3.6021 & 3.6522 & TRN & \\
\hline CHEMBL 2418169 & 978483 & 3.6021 & 3.6291 & TRN & \\
\hline CHEMBL 2418159 & 978483 & 3.6021 & 3.5792 & TRN & \\
\hline CHEMBL 2418194 & 978483 & 3.6021 & 3.5826 & TRN & \\
\hline CHEMBL 2418148 & 978483 & 4.8447 & 5.1116 & TST & \\
\hline CHEMBL 2418193 & 978483 & 3.6021 & 3.5058 & TRN & \\
\hline CHEMBL 2418189 & 978483 & 3.6021 & 3.6113 & TRN & \\
\hline CHEMBL3715373 & 1536901 & 7.09 & 6.8752 & TST & \\
\hline
\end{tabular}




\begin{tabular}{|c|c|c|c|c|c|}
\hline \multicolumn{6}{|c|}{ Supplemental Table S2.txt } \\
\hline CHEMBL 3716562 & 1536901 & 7.58 & 7.7576 & TRN & \\
\hline CHEMBL 3717702 & 1536901 & 8.36 & 7.5945 & TST & \\
\hline CHEMBL 3715993 & 1536901 & 8.11 & 7.5315 & TRN & \\
\hline CHEMBL 3715344 & 1536901 & 6.86 & 7.311 & TRN & \\
\hline CHEMBL 3719191 & 1536901 & 7.93 & 7.1831 & TRN & \\
\hline CHEMBL 3718916 & 1536901 & 7.75 & 7.0802 & TRN & \\
\hline CHEMBL 3718512 & 1536901 & 6.63 & 7.4699 & TRN & \\
\hline CHEMBL 3718483 & 1536901 & 5.38 & 7.1144 & TST & \\
\hline CHEMBL 3716240 & 1536901 & 7.5 & 6.8082 & TRN & \\
\hline CHEMBL3714951 & 1536901 & 5.94 & 6.4738 & TST & \\
\hline CHEMBL 3718485 & 1536901 & 8.14 & 7.5102 & TRN & \\
\hline CHEMBL 3716874 & 1536901 & 5.7 & 6.7016 & TRN & \\
\hline CHEMBL 3718318 & 1536901 & 7.8 & 7.61700 & 0000000001 & TRN \\
\hline CHEMBL 3715582 & 1536901 & 8.16 & 7.8318 & TRN & \\
\hline CHEMBL 3717520 & 1536901 & 8.25 & 7.5169 & TRN & \\
\hline CHEMBL3715819 & 1536901 & 6.26 & 6.4264 & TRN & \\
\hline CHEMBL 3717189 & 1536901 & 5.6 & 7.0416 & TRN & \\
\hline CHEMBL 3716021 & 1536901 & 5.53 & 7.2324 & TRN & \\
\hline CHEMBL 3717359 & 1536901 & 6.29 & 6.9405 & TRN & \\
\hline CHEMBL 3717333 & 1536901 & 7.37 & 7.5288 & TRN & \\
\hline CHEMBL3718926 & 1536901 & 5.9 & 6.8603 & TRN & \\
\hline CHEMBL 3714799 & 1536901 & 7.57 & 6.8889 & TRN & \\
\hline CHEMBL3716655 & 1536901 & 7.85 & 7.1318 & TRN & \\
\hline CHEMBL 3717475 & 1536901 & 8.38 & 7.5611 & TRN & \\
\hline CHEMBL 3716898 & 1536901 & 7.55 & 7.2505 & TRN & \\
\hline CHEMBL 3717302 & 1536901 & 7.12 & 7.2758 & TRN & \\
\hline CHEMBL3718099 & 1536901 & 8.04 & 7.2899 & TRN & \\
\hline CHEMBL 3718340 & 1536901 & 5.38 & 6.4688 & TRN & \\
\hline CHEMBL 3719366 & 1536901 & 5.17 & 5.8901 & TRN & \\
\hline CHEMBL3716694 & 1536901 & 5.86 & 6.4896 & TRN & \\
\hline CHEMBL3719115 & 1536901 & 5.53 & 6.0818 & TST & \\
\hline CHEMBL 3715532 & 1536901 & 6.86 & 6.3782 & TRN & \\
\hline CHEMBL3719108 & 1536901 & 8.3 & 7.7028 & TRN & \\
\hline CHEMBL 3719164 & 1536901 & 7.28 & 6.8105 & TRN & \\
\hline CHEMBL 3719087 & 1536901 & 8.11 & 7.3275 & TRN & \\
\hline CHEMBL 3717098 & 1536901 & 7.12 & 6.9187 & TRN & \\
\hline CHEMBL 3719282 & 1536901 & 5.3 & 6.7207 & TRN & \\
\hline CHEMBL 3715247 & 1536901 & 6.82 & 6.9073 & TRN & \\
\hline CHEMBL 3717840 & 1536901 & 7.97 & 6.3256 & TST & \\
\hline CHEMBL 3717005 & 1536901 & 8.3 & 7.3971 & TRN & \\
\hline CHEMBL 3718104 & 1536901 & 8.01 & 7.1202 & TRN & \\
\hline CHEMBL 3718582 & 1536901 & 5.91 & 6.8529 & TRN & \\
\hline CHEMBL3719321 & 1536901 & 7.33 & 7.2908 & TRN & \\
\hline CHEMBL 3715920 & 1536901 & 7.38 & 7.0591 & TRN & \\
\hline CHEMBL3715780 & 1536901 & 5.4 & 6.3681 & TST & \\
\hline CHEMBL 3715517 & 1536901 & 5.35 & 6.8876 & TRN & \\
\hline CHEMBL 3717456 & 1536901 & 6.99 & 6.7516 & TRN & \\
\hline CHEMBL3716775 & 1536901 & 6.16 & 6.6097 & TRN & \\
\hline
\end{tabular}




\begin{tabular}{|c|c|c|c|c|}
\hline \multicolumn{5}{|c|}{ Supplemental Table S2.txt } \\
\hline CHEMBL3716011 & 1536901 & 6.31 & 6.4413 & TRN \\
\hline CHEMBL 3718448 & 1536901 & 6.5 & 6.6489 & TRN \\
\hline CHEMBL3716152 & 1536901 & 6.69 & 6.7203 & TRN \\
\hline CHEMBL3718769 & 1536901 & 7.28 & 6.9383 & TRN \\
\hline CHEMBL3715167 & 1536901 & 6.05 & 6.9717 & TRN \\
\hline CHEMBL3717107 & 1536901 & 6.88 & 6.6399 & TST \\
\hline CHEMBL3718218 & 1536901 & 5.35 & 6.7356 & TST \\
\hline CHEMBL 3717540 & 1536901 & 5.87 & 5.1221 & TRN \\
\hline CHEMBL 3718795 & 1536901 & 5.4 & 4.9943 & TRN \\
\hline CHEMBL 3717240 & 1536901 & 5.34 & 5.2305 & TRN \\
\hline CHEMBL3716219 & 1536901 & 5.35 & 5.2805 & TRN \\
\hline CHEMBL 3717286 & 1536901 & 5.93 & 5.2789 & TRN \\
\hline CHEMBL3718938 & 1536901 & 5.59 & 5.2394 & TRN \\
\hline CHEMBL 3716972 & 1536901 & 5.56 & 5.1735 & TRN \\
\hline CHEMBL3718617 & 1536901 & 5.87 & 5.0667 & TST \\
\hline CHEMBL3716333 & 1536901 & 5.44 & 4.9907 & TST \\
\hline CHEMBL3718216 & 1536901 & 5.35 & 5.381 & TST \\
\hline CHEMBL3717879 & 1536901 & 5.49 & 5.3393 & TST \\
\hline CHEMBL 3716485 & 1536901 & 5.62 & 5.28 & TST \\
\hline CHEMBL3714811 & 1536901 & 5.69 & 5.2947 & TST \\
\hline CHEMBL3715326 & 1536901 & 5.51 & 5.3109 & TST \\
\hline CHEMBL3715648 & 1536901 & 5.66 & 5.221 & TST \\
\hline CHEMBL 3717505 & 1536901 & 5.2 & 5.5679 & TST \\
\hline CHEMBL 3716538 & 1536901 & 6.31 & 5.3221 & TST \\
\hline CHEMBL1964290 & 809115 & 5.9 & 5.3911 & TRN \\
\hline CHEMBL1230164 & 809115 & 5.3 & 4.7726 & TRN \\
\hline CHEMBL 2003768 & 809115 & 4.0 & 4.6039 & TRN \\
\hline CHEMBL213505 & 809115 & 5.9 & 5.5606 & TRN \\
\hline CHEMBL 202721 & 809115 & 4.5 & 4.7378 & TRN \\
\hline CHEMBL1987034 & 809115 & 7.2 & 7.2747 & TRN \\
\hline CHEMBL1993941 & 809115 & 6.7 & 6.5982 & TRN \\
\hline CHEMBL1980435 & 809115 & 6.0 & 5.8419 & TRN \\
\hline CHEMBL1989293 & 809115 & 6.1 & 5.7308 & TRN \\
\hline CHEMBL377383 & 809115 & 4.0 & 3.6994 & TRN \\
\hline CHEMBL2005886 & 809115 & 7.3 & 6.9005 & TRN \\
\hline CHEMBL481491 & 809115 & 5.1 & 4.9704 & TST \\
\hline CHEMBL1973142 & 809115 & 6.1 & 6.0473 & TST \\
\hline CHEMBL388311 & 809115 & 8.3 & 8.3884 & TRN \\
\hline CHEMBL2007009 & 809115 & 5.2 & 4.4929 & TST \\
\hline CHEMBL1973145 & 809115 & 4.0 & 4.651 & TRN \\
\hline CHEMBL1982924 & 809115 & 6.8 & 7.0702 & TRN \\
\hline CHEMBL2005936 & 809115 & 6.2 & 5.8583 & TRN \\
\hline CHEMBL1807515 & 809115 & 7.2 & 8.1546 & TRN \\
\hline CHEMBL1964948 & 809115 & 4.3 & 4.1204 & TRN \\
\hline CHEMBL1971141 & 809115 & 4.0 & 5.189 & TRN \\
\hline CHEMBL1995813 & 809115 & 7.5 & 7.8964 & TRN \\
\hline CHEMBL 206236 & 809115 & 5.3 & 5.5078 & TRN \\
\hline CHEMBL1964288 & 809115 & 7.0 & 6.9282 & TRN \\
\hline
\end{tabular}




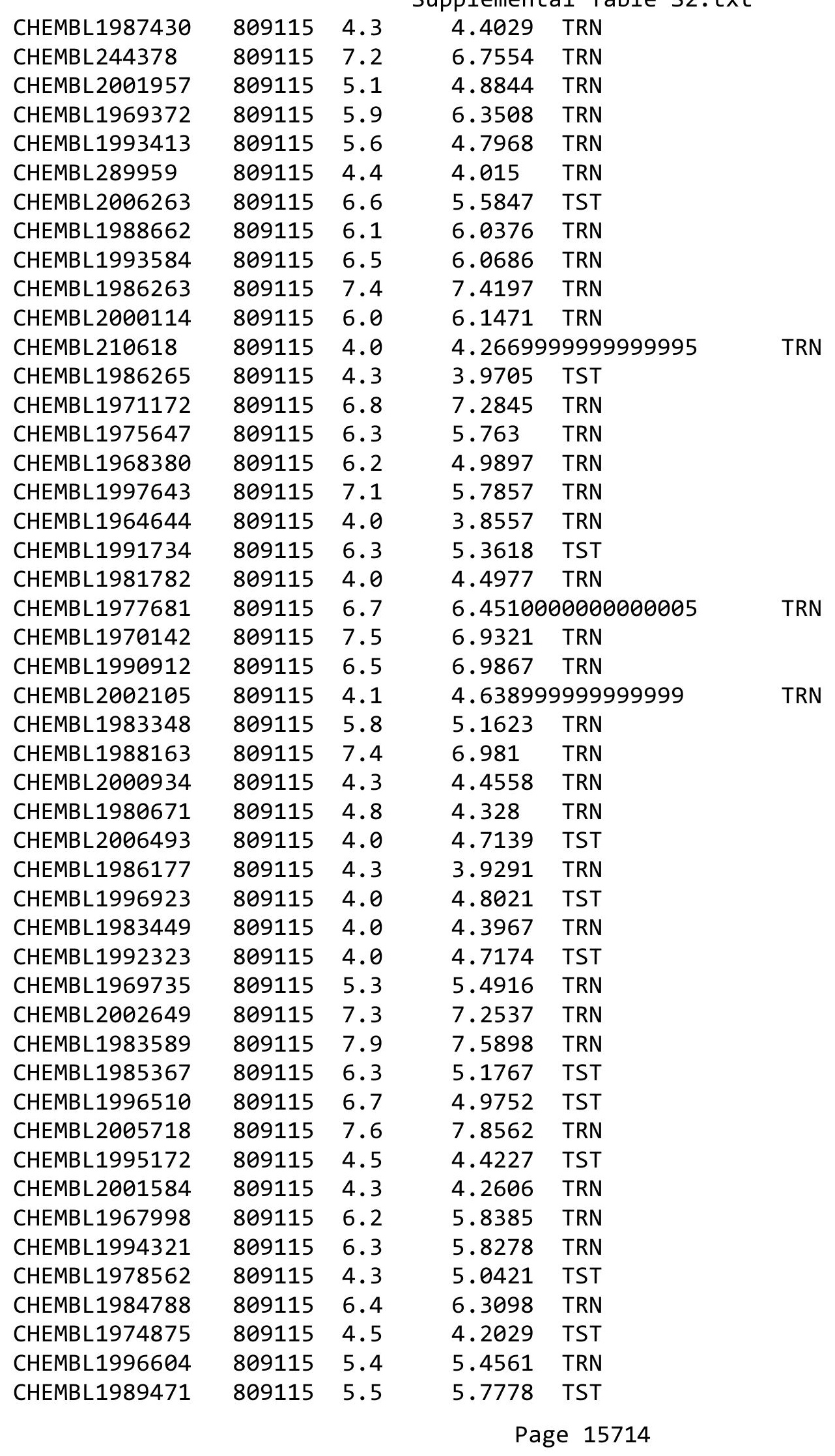




\begin{tabular}{|c|c|c|c|c|}
\hline \multicolumn{5}{|r|}{ Il Table } \\
\hline CHEMBL 2000508 & 809115 & 6.7 & 6.3914 & TRN \\
\hline CHEMBL1971694 & 809115 & 4.0 & 4.5369 & TST \\
\hline CHEMBL 2001547 & 809115 & 5.6 & 5.3734 & TRN \\
\hline CHEMBL210928 & 809115 & 4.0 & 3.4873 & TRN \\
\hline CHEMBL1978195 & 809115 & 4.3 & 4.9373 & TRN \\
\hline CHEMBL1986603 & 809115 & 6.9 & 5.0668 & TST \\
\hline CHEMBL1977148 & 809115 & 5.7 & 6.2088 & TRN \\
\hline CHEMBL1966842 & 809115 & 5.5 & 5.7378 & TRN \\
\hline CHEMBL 2004443 & 809115 & 4.0 & 4.9601 & TRN \\
\hline CHEMBL 2003286 & 809115 & 5.6 & 5.7108 & TRN \\
\hline CHEMBL1992306 & 809115 & 5.0 & 4.9578 & TRN \\
\hline CHEMBL 2002165 & 809115 & 7.0 & 6.9019 & TRN \\
\hline CHEMBL 2001668 & 809115 & 4.0 & 4.9179 & TRN \\
\hline CHEMBL1979318 & 809115 & 4.0 & 4.3444 & TST \\
\hline CHEMBL206382 & 809115 & 5.5 & 5.7023 & TRN \\
\hline CHEMBL1998585 & 809115 & 6.1 & 6.1367 & TRN \\
\hline CHEMBL127898 & 809115 & 4.0 & 5.0992 & TST \\
\hline CHEMBL519697 & 809115 & 5.7 & 5.7173 & TRN \\
\hline CHEMBL 2004934 & 809115 & 5.2 & 4.6933 & TRN \\
\hline CHEMBL1987261 & 809115 & 6.8 & 7.9505 & TRN \\
\hline CHEMBL1981947 & 809115 & 5.1 & 4.8767 & TST \\
\hline CHEMBL1968459 & 809115 & 7.8 & 7.3252 & TRN \\
\hline CHEMBL1996345 & 809115 & 7.0 & 5.0757 & TST \\
\hline CHEMBL1975128 & 809115 & 6.3 & 6.819 & TRN \\
\hline CHEMBL 2004025 & 809115 & 4.3 & 4.9821 & TST \\
\hline CHEMBL1996048 & 809115 & 7.4 & 6.9611 & TRN \\
\hline CHEMBL1970369 & 809115 & 4.0 & 3.7229 & TRN \\
\hline CHEMBL1976158 & 809115 & 4.6 & 5.0968 & TST \\
\hline CHEMBL461876 & 809115 & 4.3 & 5.0134 & TST \\
\hline CHEMBL1965033 & 809115 & 4.3 & 4.4996 & TRN \\
\hline CHEMBL 2001485 & 809115 & 6.9 & 6.6124 & TRN \\
\hline CHEMBL1971519 & 809115 & 4.7 & 4.9213 & TRN \\
\hline CHEMBL1997335 & 809115 & 6.4 & 6.3705 & TRN \\
\hline CHEMBL1966425 & 809115 & 5.2 & 5.596 & TRN \\
\hline CHEMBL1984363 & 809115 & 5.2 & 5.5195 & TRN \\
\hline CHEMBL1978099 & 809115 & 5.9 & 5.9253 & TRN \\
\hline CHEMBL1988608 & 809115 & 5.3 & 5.0832 & TRN \\
\hline CHEMBL184847 & 809115 & 5.5 & 5.4372 & TRN \\
\hline CHEMBL1971132 & 809115 & 4.3 & 3.8253 & TST \\
\hline CHEMBL1984367 & 809115 & 6.0 & 5.9458 & TRN \\
\hline CHEMBL1985723 & 809115 & 6.8 & 7.78799 & 9999999999 \\
\hline CHEMBL178737 & 809115 & 5.5 & 4.8338 & TST \\
\hline CHEMBL1982563 & 809115 & 5.6 & 5.6683 & TRN \\
\hline CHEMBL1991377 & 809115 & 4.3 & 4.4916 & TRN \\
\hline CHEMBL539474 & 809115 & 6.4 & 4.6985 & TST \\
\hline CHEMBL575824 & 809115 & 6.0 & 5.7298 & TRN \\
\hline CHEMBL1988387 & 809115 & 7.5 & 7.1125 & TRN \\
\hline CHEMBL1973868 & 809115 & 6.0 & 5.5145 & TRN \\
\hline
\end{tabular}




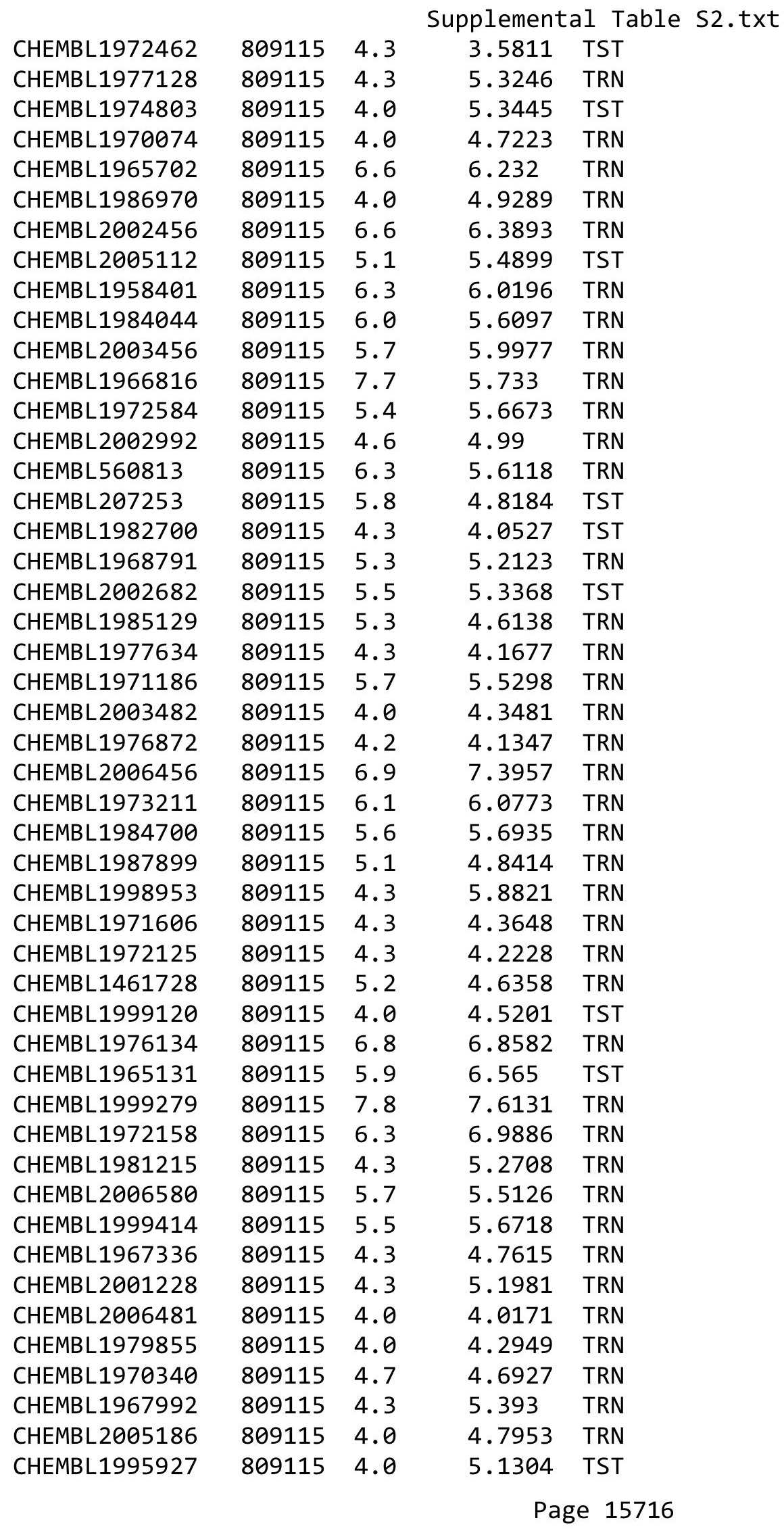




\begin{tabular}{|c|c|c|c|c|c|}
\hline & & & & & \\
\hline CHEMBL1981671 & 809115 & 4.3 & 4.4735 & TRN & \\
\hline CHEMBL 2006450 & 809115 & 4.3 & 4.7046 & TRN & \\
\hline CHEMBL1975534 & 809115 & 5.5 & 5.4604 & TRN & \\
\hline CHEMBL1993424 & 809115 & 6.6 & 6.97 & TRN & \\
\hline CHEMBL1966703 & 809115 & 4.0 & 4.5903 & TST & \\
\hline CHEMBL2001987 & 809115 & 4.3 & 4.6096 & TRN & \\
\hline CHEMBL 243518 & 809115 & 6.7 & 5.8101 & TRN & \\
\hline CHEMBL1969561 & 809115 & 5.2 & 5.1652 & TRN & \\
\hline CHEMBL1994555 & 809115 & 5.5 & 4.8389 & TST & \\
\hline CHEMBL1997554 & 809115 & 7.6 & 6.2409 & TRN & \\
\hline CHEMBL1983640 & 809115 & 5.8 & 5.5956 & TRN & \\
\hline CHEMBL1997023 & 809115 & 5.1 & 4.6408 & TST & \\
\hline CHEMBL1964687 & 809115 & 5.4 & 5.7604 & TRN & \\
\hline CHEMBL1971943 & 809115 & 4.7 & 5.3236 & TRN & \\
\hline CHEMBL1974254 & 809115 & 7.2 & 6.8522 & TRN & \\
\hline CHEMBL1997924 & 809115 & 7.1 & 6.8581 & TRN & \\
\hline CHEMBL1988537 & 809115 & 5.9 & 5.534 & TST & \\
\hline CHEMBL1969049 & 809115 & 4.0 & 4.7334 & TRN & \\
\hline CHEMBL 2005828 & 809115 & 6.4 & 6.5567 & TRN & \\
\hline CHEMBL 2002240 & 809115 & 5.1 & 5.0514 & TRN & \\
\hline CHEMBL1978267 & 809115 & 4.3 & 4.6869 & TRN & \\
\hline CHEMBL1971485 & 809115 & 5.8 & 4.728 & TRN & \\
\hline CHEMBL1991143 & 809115 & 4.0 & 4.3514 & TST & \\
\hline CHEMBL1980178 & 809115 & 6.8 & 6.6679 & TRN & \\
\hline CHEMBL1998611 & 809115 & 6.5 & 5.6415 & TST & \\
\hline CHEMBL1975900 & 809115 & 5.3 & 4.8855 & TRN & \\
\hline CHEMBL 255822 & 809115 & 5.7 & 5.7977 & TRN & \\
\hline CHEMBL1972221 & 809115 & 4.0 & 4.1484 & TRN & \\
\hline CHEMBL 2006778 & 809115 & 8.5 & 8.0082 & TRN & \\
\hline CHEMBL1981511 & 809115 & 6.1 & 5.4849 & TRN & \\
\hline CHEMBL 378627 & 809115 & 4.0 & 4.4072 & TRN & \\
\hline CHEMBL1996979 & 809115 & 7.3 & 7.7332 & TRN & \\
\hline CHEMBL1997025 & 809115 & 6.2 & 6.2622 & TRN & \\
\hline CHEMBL1968406 & 809115 & 5.5 & 5.829 & TRN & \\
\hline CHEMBL1975921 & 809115 & 4.3 & 4.8896 & TRN & \\
\hline CHEMBL1984274 & 809115 & 5.9 & 4.6646 & TST & \\
\hline CHEMBL1998545 & 809115 & 4.0 & 4.6858 & TRN & \\
\hline CHEMBL1986869 & 809115 & 4.0 & 4.6433 & TRN & \\
\hline CHEMBL1975923 & 809115 & 4.6 & 4.3583 & TST & \\
\hline CHEMBL 2005449 & 809115 & 4.3 & 5.0984 & TRN & \\
\hline CHEMBL1987998 & 809115 & 4.3 & 4.0172 & TST & \\
\hline CHEMBL 2006010 & 809115 & 4.0 & 4.5467 & TRN & \\
\hline CHEMBL1682558 & 809115 & 6.4 & 5.5323 & TRN & \\
\hline CHEMBL1971534 & 809115 & 4.6 & 4.8222 & TRN & \\
\hline CHEMBL1990496 & 809115 & 6.7 & 6.5664 & TRN & \\
\hline CHEMBL242865 & 809115 & 4.3 & 4.6641 & TRN & \\
\hline CHEMBL1998068 & 809115 & 8.0 & 7.3416 & TRN & \\
\hline CHEMBL2002479 & 809115 & 5.6 & 6.00700 & 2000000001 & TRN \\
\hline & & & & 15717 & \\
\hline
\end{tabular}




\begin{tabular}{|c|c|c|c|c|}
\hline & & & pplement & al $\mathrm{Ta}$ \\
\hline CHEMBL 2002480 & 809115 & 4.3 & 4.755 & TRN \\
\hline CHEMBL1967094 & 809115 & 5.9 & 6.3853 & TRN \\
\hline CHEMBL1966035 & 809115 & 4.0 & 4.2247 & TRN \\
\hline CHEMBL 2003341 & 809115 & 5.4 & 5.1757 & TRN \\
\hline CHEMBL1990708 & 809115 & 4.0 & 5.2045 & TRN \\
\hline CHEMBL1982992 & 809115 & 5.7 & 5.2649 & TRN \\
\hline CHEMBL1998110 & 809115 & 4.3 & 4.1651 & TRN \\
\hline CHEMBL1999590 & 809115 & 6.3 & 5.3601 & TST \\
\hline CHEMBL1981079 & 809115 & 4.7 & 5.6599 & TRN \\
\hline CHEMBL1978166 & 809115 & 6.1 & 6.1937 & TRN \\
\hline CHEMBL1972276 & 809115 & 4.0 & 4.6689 & TRN \\
\hline CHEMBL1980489 & 809115 & 5.2 & 4.3395 & TRN \\
\hline CHEMBL2000832 & 809115 & 6.7 & 6.2094 & TRN \\
\hline CHEMBL1967116 & 809115 & 7.0 & 7.1382 & TRN \\
\hline CHEMBL1990590 & 809115 & 4.3 & 4.6893 & TRN \\
\hline CHEMBL1977814 & 809115 & 4.3 & 4.8184 & TST \\
\hline CHEMBL513846 & 809115 & 5.4 & 5.4038 & TRN \\
\hline CHEMBL1970709 & 809115 & 4.0 & 4.0076 & TRN \\
\hline CHEMBL1974617 & 809115 & 4.7 & 4.3372 & TRN \\
\hline CHEMBL1965660 & 809115 & 5.8 & 5.9827 & TRN \\
\hline CHEMBL1992125 & 809115 & 5.9 & 5.9648 & TRN \\
\hline CHEMBL1998112 & 809115 & 5.4 & 5.7985 & TRN \\
\hline CHEMBL1972290 & 809115 & 7.4 & 8.214 & TRN \\
\hline CHEMBL1969126 & 809115 & 7.2 & 6.7143 & TRN \\
\hline CHEMBL1980896 & 809115 & 5.0 & 5.1262 & TRN \\
\hline CHEMBL1975208 & 809115 & 4.0 & 3.7479 & TST \\
\hline CHEMBL1970104 & 809115 & 6.5 & 6.8116 & TRN \\
\hline CHEMBL1991429 & 809115 & 7.3 & 7.2455 & TRN \\
\hline CHEMBL1967612 & 809115 & 4.2 & 4.2645 & TST \\
\hline CHEMBL1964777 & 809115 & 5.9 & 5.7551 & TRN \\
\hline CHEMBL1971149 & 809115 & 4.0 & 5.1954 & TRN \\
\hline CHEMBL1999714 & 809115 & 4.0 & 3.8593 & TRN \\
\hline CHEMBL1987533 & 809115 & 4.0 & 4.4763 & TRN \\
\hline CHEMBL1994040 & 809115 & 5.8 & 5.3672 & TRN \\
\hline CHEMBL388978 & 809115 & 8.8 & 7.5174 & TST \\
\hline CHEMBL1984548 & 809115 & 7.4 & 7.6785 & TRN \\
\hline CHEMBL579246 & 809115 & 6.2 & 6.0535 & TRN \\
\hline CHEMBL398951 & 809115 & 4.4 & 4.5477 & TST \\
\hline CHEMBL1982506 & 809115 & 5.4 & 5.7528 & TST \\
\hline CHEMBL2004716 & 809115 & 6.5 & 6.7593 & TRN \\
\hline CHEMBL1968127 & 809115 & 5.4 & 5.0613 & TRN \\
\hline CHEMBL1975233 & 809115 & 5.8 & 4.4767 & TRN \\
\hline CHEMBL1985406 & 809115 & 5.8 & 6.0741 & TRN \\
\hline CHEMBL 2007603 & 809115 & 4.3 & 4.8065 & TRN \\
\hline CHEMBL 207400 & 809115 & 4.0 & 4.6047 & TST \\
\hline CHEMBL 2000894 & 809115 & 5.7 & 5.7809 & TRN \\
\hline CHEMBL1421720 & 809115 & 4.3 & 4.618 & TRN \\
\hline CHEMBL1968130 & 809115 & 4.3 & 4.6627 & TST \\
\hline
\end{tabular}




\begin{tabular}{|c|c|c|c|c|c|}
\hline \multicolumn{6}{|c|}{ Supplemental Table S2.txt } \\
\hline CHEMBL 2002553 & 809115 & 4.0 & 3.9778 & TST & \\
\hline CHEMBL1982135 & 809115 & 5.7 & 6.0067 & TRN & \\
\hline CHEMBL1976090 & 809115 & 6.1 & 5.6377 & TRN & \\
\hline CHEMBL1993243 & 809115 & 7.4 & 6.7668 & TRN & \\
\hline CHEMBL 2004771 & 809115 & 6.7 & 5.7299 & TRN & \\
\hline CHEMBL1992922 & 809115 & 6.4 & 6.7665 & TRN & \\
\hline CHEMBL1997597 & 809115 & 5.1 & 5.1837 & TRN & \\
\hline CHEMBL1969537 & 809115 & 6.1 & 5.8507 & TST & \\
\hline CHEMBL576113 & 809115 & 4.3 & 4.4487 & TRN & \\
\hline CHEMBL1976093 & 809115 & 4.0 & 5.2882 & TRN & \\
\hline CHEMBL 210032 & 809115 & 5.4 & 5.131 & TRN & \\
\hline CHEMBL1975256 & 809115 & 4.0 & 3.9587 & TST & \\
\hline CHEMBL508928 & 809115 & 6.6 & 6.4009 & TRN & \\
\hline CHEMBL1991356 & 809115 & 6.8 & 4.8717 & TST & \\
\hline CHEMBL1983309 & 809115 & 4.0 & 4.5805 & TRN & \\
\hline CHEMBL 2004892 & 809115 & 5.3 & 5.19 & TRN & \\
\hline CHEMBL1949855 & 809115 & 4.9 & 5.0049 & TST & \\
\hline CHEMBL1999126 & 809115 & 4.0 & 5.5268 & TST & \\
\hline CHEMBL1997503 & 809115 & 6.6 & 4.8459 & TST & \\
\hline CHEMBL1972339 & 809115 & 6.6 & 8.1147 & TRN & \\
\hline CHEMBL116070 & 809115 & 5.9 & 5.1514 & TRN & \\
\hline CHEMBL1990821 & 809115 & 4.0 & 5.0473 & TST & \\
\hline CHEMBL1968340 & 809115 & 5.5 & 6.2321 & TRN & \\
\hline CHEMBL1970314 & 809115 & 5.9 & 5.8778 & TRN & \\
\hline CHEMBL 2004871 & 809115 & 5.4 & 5.8889 & TRN & \\
\hline CHEMBL 2004872 & 809115 & 4.0 & 4.5668 & TRN & \\
\hline CHEMBL1727312 & 809115 & 4.0 & 3.5419 & TRN & \\
\hline CHEMBL1990223 & 809115 & 4.3 & 4.0671 & TST & \\
\hline CHEMBL1969879 & 809115 & 4.0 & 3.9586 & TRN & \\
\hline CHEMBL1964382 & 809115 & 4.3 & 4.5718 & TST & \\
\hline CHEMBL101311 & 809115 & 5.6 & 4.8454 & TRN & \\
\hline CHEMBL1981720 & 809115 & 6.2 & 5.9207 & TRN & \\
\hline CHEMBL1967704 & 809115 & 7.1 & 7.0544 & TRN & \\
\hline CHEMBL419932 & 809115 & 6.1 & 6.305 & TRN & \\
\hline CHEMBL262433 & 809115 & 5.2 & 5.6106 & TRN & \\
\hline CHEMBL306380 & 809115 & 5.8 & 5.3582 & TRN & \\
\hline CHEMBL1966722 & 809115 & 5.4 & 5.1777 & TST & \\
\hline CHEMBL1983595 & 809115 & 4.3 & 4.9895 & TRN & \\
\hline CHEMBL1988581 & 809115 & 6.8 & 5.74299 & 9999999999 & TST \\
\hline CHEMBL 2005699 & 809115 & 4.3 & 3.9635 & TRN & \\
\hline CHEMBL1975500 & 809115 & 6.3 & 6.4178 & TRN & \\
\hline CHEMBL394619 & 809115 & 5.6 & $5.8770 e$ & 0000000001 & TRN \\
\hline CHEMBL 2006564 & 809115 & 5.8 & $5.3260 e$ & 00000000005 & TRN \\
\hline CHEMBL1996831 & 809115 & 5.4 & 5.5814 & TST & \\
\hline CHEMBL411903 & 809115 & 6.9 & 6.7742 & TRN & \\
\hline CHEMBL1991008 & 809115 & 4.6 & 4.9039 & TRN & \\
\hline CHEMBL1980253 & 809115 & 7.7 & 7.4705 & TRN & \\
\hline CHEMBL1978167 & 809115 & 4.3 & 4.9008 & TST & \\
\hline
\end{tabular}




\begin{tabular}{|c|c|c|c|c|c|}
\hline \\
\hline CHEMBL1965988 & 809115 & 6.1 & 6.5376 & TRN & \\
\hline CHEMBL1969221 & 809115 & 7.1 & 6.6524 & TRN & \\
\hline CHEMBL418203 & 809115 & 4.4 & 4.8796 & TST & \\
\hline CHEMBL1989646 & 809115 & 6.0 & $5.9570 e$ & 0000000001 & TRN \\
\hline CHEMBL225519 & 809115 & 4.5 & 6.3035 & TRN & \\
\hline CHEMBL1978200 & 809115 & 6.2 & 5.8008 & TRN & \\
\hline CHEMBL1994159 & 809115 & 4.1 & 4.715 & TRN & \\
\hline CHEMBL2006631 & 809115 & 4.0 & 4.306 & TRN & \\
\hline CHEMBL1970522 & 809115 & 6.0 & 5.4923 & TRN & \\
\hline CHEMBL1990415 & 809115 & 5.6 & 5.6447 & TRN & \\
\hline CHEMBL1966087 & 809115 & 5.2 & 5.0425 & TRN & \\
\hline CHEMBL1986767 & 809115 & 5.9 & $5.5310 e$ & 3000000001 & TRN \\
\hline CHEMBL1996931 & 809115 & 4.0 & 4.5172 & TRN & \\
\hline CHEMBL1964692 & 809115 & 6.1 & 6.0473 & TRN & \\
\hline CHEMBL1971223 & 809115 & 4.3 & 4.3475 & TRN & \\
\hline CHEMBL1964413 & 809115 & 4.0 & 3.9891 & TRN & \\
\hline CHEMBL1973483 & 809115 & 5.5 & 4.9872 & TRN & \\
\hline CHEMBL1998470 & 809115 & 6.1 & 5.3173 & TRN & \\
\hline CHEMBL1996980 & 809115 & 8.2 & 7.7016 & TRN & \\
\hline CHEMBL1995428 & 809115 & 4.3 & 5.3178 & TRN & \\
\hline CHEMBL1970735 & 809115 & 5.2 & 4.5985 & TRN & \\
\hline CHEMBL1975903 & 809115 & 6.1 & 5.2389 & TRN & \\
\hline CHEMBL1994669 & 809115 & 7.4 & 8.1271 & TRN & \\
\hline CHEMBL1997340 & 809115 & 4.0 & 3.5811 & TRN & \\
\hline CHEMBL 2004365 & 809115 & 6.0 & 5.1642 & TST & \\
\hline CHEMBL1522508 & 809115 & 4.6 & 4.0526 & TRN & \\
\hline CHEMBL1989474 & 809115 & 5.4 & 5.3094 & TRN & \\
\hline CHEMBL1090360 & 809115 & 7.3 & 6.5044 & TRN & \\
\hline CHEMBL 226232 & 809115 & 7.0 & 6.4577 & TRN & \\
\hline CHEMBL 210887 & 809115 & 6.7 & 5.5964 & TRN & \\
\hline CHEMBL1988805 & 809115 & 5.9 & 4.7331 & TST & \\
\hline CHEMBL458997 & 809115 & 4.4 & 5.2062 & TRN & \\
\hline CHEMBL1971021 & 809115 & 4.0 & 3.9283 & TRN & \\
\hline CHEMBL 227271 & 809115 & 8.2 & 8.0514 & TRN & \\
\hline CHEMBL583144 & 809115 & 6.1 & 5.2676 & TST & \\
\hline CHEMBL1974310 & 809115 & 5.9 & 5.9735 & TRN & \\
\hline CHEMBL1969942 & 809115 & 5.9 & 4.6739 & TRN & \\
\hline CHEMBL1978567 & 809115 & 4.3 & 4.1651 & TRN & \\
\hline CHEMBL1982660 & 809115 & 7.2 & 5.9294 & TRN & \\
\hline CHEMBL1994693 & 809115 & 5.9 & 6.614 & TRN & \\
\hline CHEMBL1725279 & 809115 & 6.5 & 6.5475 & TST & \\
\hline CHEMBL1975138 & 809115 & 5.4 & 5.4543 & TST & \\
\hline CHEMBL 2005767 & 809115 & 5.9 & 6.0441 & TRN & \\
\hline CHEMBL424872 & 809115 & 4.2 & 3.8457 & TRN & \\
\hline CHEMBL 2006836 & 809115 & 4.0 & 5.0275 & TST & \\
\hline CHEMBL412142 & 809115 & 4.0 & 4.7319 & TST & \\
\hline CHEMBL1985153 & 809115 & 4.0 & 4.669 & TRN & \\
\hline CHEMBL1980704 & 809115 & 4.0 & 4.4542 & TST & \\
\hline
\end{tabular}




\begin{tabular}{|c|c|c|c|c|c|}
\hline & & \multicolumn{4}{|c|}{ Supplemental Table S2.txt } \\
\hline CHEMBL 2003271 & 809115 & 6.1 & \multicolumn{2}{|c|}{6.247000000000001} & TST \\
\hline CHEMBL1966808 & 809115 & 4.0 & 5.6801 & TST & \\
\hline CHEMBL 2004447 & 809115 & 4.0 & 4.3741 & TST & \\
\hline CHEMBL1992231 & 809115 & 4.3 & 4.0451 & TRN & \\
\hline CHEMBL1983111 & 809115 & 7.0 & \multicolumn{2}{|c|}{6.422999999999999} & TRN \\
\hline CHEMBL1973860 & 809115 & 6.4 & 6.1321 & TRN & \\
\hline CHEMBL1977713 & 809115 & 4.0 & 4.2073 & TRN & \\
\hline CHEMBL260135 & 809115 & 4.0 & 5.083 & TRN & \\
\hline CHEMBL 220241 & 809115 & 4.0 & 4.7599 & TRN & \\
\hline CHEMBL 2004544 & 809115 & 5.7 & 5.143 & TST & \\
\hline CHEMBL1983157 & 809115 & 6.5 & 6.2968 & TRN & \\
\hline CHEMBL1988141 & 809115 & 4.3 & 4.8941 & TST & \\
\hline CHEMBL1982610 & 809115 & 5.1 & 5.0208 & TRN & \\
\hline CHEMBL1989569 & 809115 & 5.7 & 5.4296 & TRN & \\
\hline CHEMBL1966040 & 809115 & 7.5 & 7.3488 & TRN & \\
\hline CHEMBL1977134 & 809115 & 4.3 & 4.4007 & TRN & \\
\hline CHEMBL1999496 & 809115 & 4.0 & 4.6424 & TRN & \\
\hline CHEMBL1970873 & 809115 & 3.5 & 4.0403 & TRN & \\
\hline CHEMBL1985206 & 809115 & 4.3 & 4.7033 & TST & \\
\hline CHEMBL375293 & 809115 & 5.2 & 6.0103 & TST & \\
\hline CHEMBL1988300 & 809115 & 6.5 & 6.6117 & TRN & \\
\hline CHEMBL1991078 & 809115 & 6.3 & 6.3664 & TRN & \\
\hline CHEMBL1987359 & 809115 & 4.0 & 4.119 & TST & \\
\hline CHEMBL1977749 & 809115 & 6.2 & 5.5502 & TST & \\
\hline CHEMBL1975212 & 809115 & 5.0 & 4.8534 & TRN & \\
\hline CHEMBL 2001613 & 809115 & 4.7 & 4.7458 & TRN & \\
\hline CHEMBL1997275 & 809115 & 4.3 & 5.312 & TRN & \\
\hline CHEMBL1993904 & 809115 & 5.6 & 4.8093 & TRN & \\
\hline CHEMBL1994438 & 809115 & 7.1 & 6.8371 & TRN & \\
\hline CHEMBL1980376 & 809115 & 5.0 & 4.9634 & TRN & \\
\hline CHEMBL1967513 & 809115 & 4.3 & 4.5305 & TRN & \\
\hline CHEMBL 2000724 & 809115 & 4.3 & 4.5933 & TRN & \\
\hline CHEMBL1989265 & 809115 & 4.0 & 3.9254 & TST & \\
\hline CHEMBL1982413 & 809115 & 4.3 & 5.4255 & TRN & \\
\hline CHEMBL 2004647 & 809115 & 4.0 & 3.7382 & TST & \\
\hline CHEMBL1969502 & 809115 & 6.5 & 6.1852 & TRN & \\
\hline CHEMBL1996447 & 809115 & 6.6 & 6.3794 & TRN & \\
\hline CHEMBL1682553 & 809115 & 5.5 & 5.0849 & TRN & \\
\hline CHEMBL1971430 & 809115 & 5.7 & 6.1342 & TRN & \\
\hline CHEMBL1983963 & 809115 & 6.4 & 6.2846 & TRN & \\
\hline CHEMBL1997764 & 809115 & 6.7 & 7.4235 & TRN & \\
\hline CHEMBL1981792 & 809115 & 4.3 & 4.6307 & TRN & \\
\hline CHEMBL1987535 & 809115 & 6.1 & 5.8139 & TRN & \\
\hline CHEMBL1985092 & 809115 & 6.0 & 6.4596 & TRN & \\
\hline CHEMBL 2004692 & 809115 & 4.0 & 3.8365 & TST & \\
\hline CHEMBL1981410 & 809115 & 4.0 & $5.1610 e$ & 00000000005 & TRN \\
\hline CHEMBL 2002586 & 809115 & 4.3 & 4.668 & TRN & \\
\hline CHEMBL1996234 & 809115 & 4.0 & 4.5488 & TRN & \\
\hline
\end{tabular}




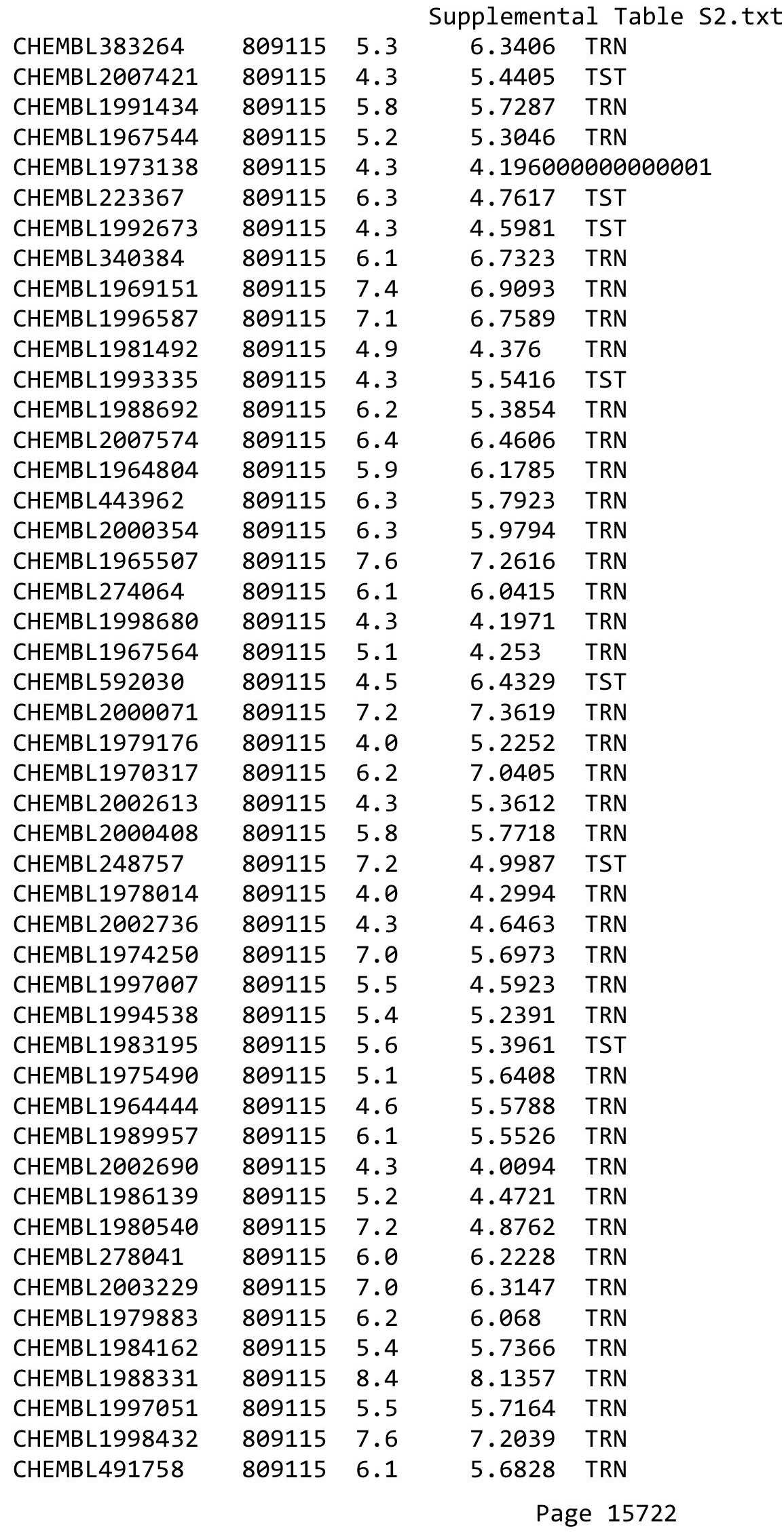

TRN 


\begin{tabular}{|c|c|c|c|c|c|}
\hline \\
\hline CHEMBL1986590 & 809115 & 5.6 & 5.2838 & TRN & \\
\hline CHEMBL549730 & 809115 & 4.0 & 4.4491 & TRN & \\
\hline CHEMBL1998826 & 809115 & 6.9 & 6.7628 & TRN & \\
\hline CHEMBL1970189 & 809115 & 4.0 & 4.3981 & TST & \\
\hline CHEMBL1870106 & 809115 & 4.5 & 4.359 & TRN & \\
\hline CHEMBL1996791 & 809115 & 5.1 & 5.0755 & TRN & \\
\hline CHEMBL371206 & 809115 & 5.0 & 5.7679 & TRN & \\
\hline CHEMBL1974664 & 809115 & 6.3 & 5.525 & TST & \\
\hline CHEMBL406845 & 809115 & 4.3 & 4.6422 & TRN & \\
\hline CHEMBL1974288 & 809115 & 5.7 & 5.1528 & TRN & \\
\hline CHEMBL482538 & 809115 & 5.4 & 5.4767 & TRN & \\
\hline CHEMBL1984296 & 809115 & 4.3 & 5.4466 & TST & \\
\hline CHEMBL213207 & 809115 & 7.7 & 7.66299 & 9999999999 & TRN \\
\hline CHEMBL196363 & 809115 & 6.1 & 5.6891 & TRN & \\
\hline CHEMBL1996837 & 809115 & 4.0 & 4.4522 & TST & \\
\hline CHEMBL1190711 & 809115 & 7.0 & 6.9526 & TRN & \\
\hline CHEMBL1968705 & 809115 & 4.5 & 4.8614 & TRN & \\
\hline CHEMBL1964441 & 809115 & 5.7 & 5.5468 & TRN & \\
\hline CHEMBL1991410 & 809115 & 4.3 & 4.7822 & TRN & \\
\hline CHEMBL546797 & 809115 & 4.3 & 4.8775 & TRN & \\
\hline CHEMBL404367 & 809115 & 6.0 & 6.0081 & TRN & \\
\hline CHEMBL1966343 & 809115 & 5.5 & 5.6118 & TRN & \\
\hline CHEMBL1978271 & 809115 & 4.3 & 4.3858 & TRN & \\
\hline CHEMBL1967887 & 809115 & 7.7 & 7.5393 & TRN & \\
\hline CHEMBL 2007266 & 809115 & 4.3 & 4.7079 & TRN & \\
\hline CHEMBL1985469 & 809115 & 4.3 & 4.4616 & TST & \\
\hline CHEMBL 2000568 & 809115 & 6.3 & 5.5642 & TRN & \\
\hline CHEMBL1994308 & 809115 & 4.3 & 3.9309 & TRN & \\
\hline CHEMBL2000335 & 809115 & 6.0 & 5.9943 & TRN & \\
\hline CHEMBL1977604 & 809115 & 4.0 & 3.6625 & TST & \\
\hline CHEMBL1993648 & 809115 & 8.5 & 7.4727 & TRN & \\
\hline CHEMBL1988717 & 809115 & 5.4 & 5.2554 & TRN & \\
\hline CHEMBL1974328 & 809115 & 7.3 & 6.7159 & TRN & \\
\hline CHEMBL509032 & 809115 & 6.5 & 6.2315 & TRN & \\
\hline CHEMBL243298 & 809115 & 4.3 & 5.4246 & TRN & \\
\hline CHEMBL1971951 & 809115 & 5.9 & 5.7453 & TRN & \\
\hline CHEMBL1973808 & 809115 & 6.0 & 4.8074 & TRN & \\
\hline CHEMBL2000429 & 809115 & 5.7 & 5.6643 & TRN & \\
\hline CHEMBL1972576 & 809115 & 7.3 & 7.4705 & TRN & \\
\hline CHEMBL1992555 & 809115 & 4.0 & 4.2104 & TRN & \\
\hline CHEMBL1992342 & 809115 & 5.1 & 5.0239 & TRN & \\
\hline CHEMBL 2003682 & 809115 & 7.2 & 6.2291 & TRN & \\
\hline CHEMBL1988173 & 809115 & 6.2 & 5.692 & TST & \\
\hline CHEMBL1973013 & 809115 & 5.6 & 4.9962 & TST & \\
\hline CHEMBL1164265 & 809115 & 6.7 & 5.9567 & TST & \\
\hline CHEMBL535331 & 809115 & 5.6 & 4.967 & TRN & \\
\hline CHEMBL1989805 & 809115 & 6.5 & 5.4314 & TST & \\
\hline CHEMBL1966204 & 809115 & 5.9 & 6.0159 & TRN & \\
\hline & & & & 15723 & \\
\hline
\end{tabular}




\begin{tabular}{|c|c|c|c|c|c|}
\hline \\
\hline CHEMBL1982980 & 809115 & 4.0 & 4.7541 & TST & \\
\hline CHEMBL1965423 & 809115 & 7.5 & 7.0329 & TRN & \\
\hline CHEMBL1983025 & 809115 & 5.6 & 5.7812 & TRN & \\
\hline CHEMBL1975927 & 809115 & 4.3 & 5.4266 & TRN & \\
\hline CHEMBL205415 & 809115 & 4.5 & 4.8942 & TRN & \\
\hline CHEMBL1999153 & 809115 & 7.7 & 7.9326 & TRN & \\
\hline CHEMBL1969473 & 809115 & 6.1 & 6.24799 & 9999999999 & TRN \\
\hline CHEMBL1977135 & 809115 & 5.3 & 5.2667 & TRN & \\
\hline CHEMBL 2001920 & 809115 & 6.2 & 5.6911 & TRN & \\
\hline CHEMBL1985654 & 809115 & 7.7 & 7.2473 & TRN & \\
\hline CHEMBL1997119 & 809115 & 4.2 & 4.0952 & TRN & \\
\hline CHEMBL1977138 & 809115 & 6.2 & 6.0804 & TST & \\
\hline CHEMBL1241473 & 809115 & 7.8 & 7.2141 & TRN & \\
\hline CHEMBL1978448 & 809115 & 4.6 & 3.4451 & TST & \\
\hline CHEMBL1972258 & 809115 & 5.6 & 5.5527 & TRN & \\
\hline CHEMBL 2004513 & 809115 & 4.0 & 4.2411 & TRN & \\
\hline CHEMBL1969483 & 809115 & 4.3 & 4.3131 & TRN & \\
\hline CHEMBL1983855 & 809115 & 7.1 & 7.4039 & TRN & \\
\hline CHEMBL1980329 & 809115 & 7.7 & 7.08899 & 99999999995 & TRN \\
\hline CHEMBL 2004515 & 809115 & 5.4 & 5.0635 & TRN & \\
\hline CHEMBL 2001257 & 809115 & 5.9 & 5.2795 & TRN & \\
\hline CHEMBL1992042 & 809115 & 4.3 & 5.3429 & TST & \\
\hline CHEMBL1987793 & 809115 & 5.2 & 5.2716 & TST & \\
\hline CHEMBL1992536 & 809115 & 4.0 & 4.6331 & TRN & \\
\hline CHEMBL21156 & 809115 & 4.3 & 6.0288 & TST & \\
\hline CHEMBL1992740 & 809115 & 4.0 & 4.0498 & TRN & \\
\hline CHEMBL1994724 & 809115 & 5.3 & 4.4075 & TRN & \\
\hline CHEMBL1989267 & 809115 & 6.6 & 6.5999 & TRN & \\
\hline CHEMBL 2002373 & 809115 & 5.7 & 5.8309 & TRN & \\
\hline CHEMBL439340 & 809115 & 4.0 & 3.3937 & TRN & \\
\hline CHEMBL1974574 & 809115 & 4.3 & 3.8957 & TST & \\
\hline CHEMBL 2006188 & 809115 & 4.0 & 4.6512 & TRN & \\
\hline CHEMBL1970290 & 809115 & 4.3 & 4.9716 & TRN & \\
\hline CHEMBL1967531 & 809115 & 5.8 & 6.0416 & TRN & \\
\hline CHEMBL1970913 & 809115 & 5.0 & 4.367 & TRN & \\
\hline CHEMBL1973893 & 809115 & 4.0 & 4.3813 & TRN & \\
\hline CHEMBL 2004631 & 809115 & 6.0 & 6.2615 & TRN & \\
\hline CHEMBL1995736 & 809115 & 5.2 & 4.808 & TRN & \\
\hline CHEMBL1997534 & 809115 & 7.2 & 7.064 & TRN & \\
\hline CHEMBL1993877 & 809115 & 5.6 & 5.1041 & TRN & \\
\hline CHEMBL1985095 & 809115 & 7.1 & 6.5376 & TST & \\
\hline CHEMBL1996500 & 809115 & 5.6 & 5.3692 & TRN & \\
\hline CHEMBL1998551 & 809115 & 6.3 & 6.3489 & TRN & \\
\hline CHEMBL1977374 & 809115 & 6.5 & 6.4951 & TRN & \\
\hline CHEMBL1682540 & 809115 & 4.0 & 5.2297 & TRN & \\
\hline CHEMBL1983315 & 809115 & 6.8 & 7.379 & TRN & \\
\hline CHEMBL1976420 & 809115 & 6.4 & 5.3095 & TST & \\
\hline CHEMBL1998253 & 809115 & 4.3 & 4.0626 & TST & \\
\hline
\end{tabular}




\begin{tabular}{|c|c|c|c|c|}
\hline & & & ple & \\
\hline CHEMBL1994864 & 809115 & 4.0 & 4.5955 & TRN \\
\hline CHEMBL1981744 & 809115 & 4.3 & 4.6789 & TRN \\
\hline CHEMBL 2002446 & 809115 & 6.1 & 5.9675 & TST \\
\hline CHEMBL497151 & 809115 & 6.4 & 6.0774 & TRN \\
\hline CHEMBL 2000029 & 809115 & 5.4 & 6.0278 & TRN \\
\hline CHEMBL1973961 & 809115 & 4.3 & 4.005 & TRN \\
\hline CHEMBL246970 & 809115 & 6.0 & 5.9945 & TRN \\
\hline CHEMBL340921 & 809115 & 5.5 & 5.9402 & TRN \\
\hline CHEMBL1994977 & 809115 & 4.5 & 4.187 & TRN \\
\hline CHEMBL 2001149 & 809115 & 4.3 & 5.3701 & TRN \\
\hline CHEMBL1999718 & 809115 & 4.0 & 4.205 & TRN \\
\hline CHEMBL1987073 & 809115 & 4.6 & 5.1898 & TRN \\
\hline CHEMBL 2000078 & 809115 & 4.3 & 4.7044 & TRN \\
\hline CHEMBL 2005478 & 809115 & 4.3 & 5.6636 & TST \\
\hline CHEMBL1996646 & 809115 & 5.9 & 5.834 & TRN \\
\hline CHEMBL1995712 & 809115 & 6.5 & 5.9095 & TRN \\
\hline CHEMBL1979773 & 809115 & 4.3 & 4.3745 & TRN \\
\hline CHEMBL1977346 & 809115 & 5.2 & 5.2683 & TRN \\
\hline CHEMBL1971649 & 809115 & 5.5 & 5.2216 & TRN \\
\hline CHEMBL1992723 & 809115 & 4.5 & 4.4292 & TRN \\
\hline CHEMBL 2005482 & 809115 & 6.8 & 5.9555 & TRN \\
\hline CHEMBL1996702 & 809115 & 5.8 & 5.8096 & TRN \\
\hline CHEMBL1997909 & 809115 & 4.3 & 5.105 & TRN \\
\hline CHEMBL 2007124 & 809115 & 4.3 & 4.1685 & TRN \\
\hline CHEMBL1975440 & 809115 & 7.4 & 6.5929 & TRN \\
\hline CHEMBL1998435 & 809115 & 5.9 & 5.8447 & TRN \\
\hline CHEMBL 2006439 & 809115 & 6.9 & 6.2405 & TRN \\
\hline CHEMBL 2006156 & 809115 & 5.4 & 5.4094 & TST \\
\hline CHEMBL1985681 & 809115 & 6.5 & 5.3486 & TST \\
\hline CHEMBL1969190 & 809115 & 5.5 & 6.3469 & TRN \\
\hline CHEMBL 2002660 & 809115 & 4.3 & 4.3492 & TRN \\
\hline CHEMBL1973937 & 809115 & 5.8 & 5.8124 & TRN \\
\hline CHEMBL1991674 & 809115 & 6.9 & 7.8266 & TRN \\
\hline CHEMBL1982711 & 809115 & 7.3 & 7.1253 & TRN \\
\hline CHEMBL 262623 & 809115 & 6.1 & 5.1766 & TRN \\
\hline CHEMBL1987982 & 809115 & 4.0 & 5.0463 & TST \\
\hline CHEMBL1984842 & 809115 & 5.4 & 4.7531 & TRN \\
\hline CHEMBL 2004118 & 809115 & 5.7 & 4.9976 & TRN \\
\hline CHEMBL1996795 & 809115 & 4.3 & 4.6214 & TST \\
\hline CHEMBL1994241 & 809115 & 7.4 & 6.9528 & TRN \\
\hline CHEMBL 2007044 & 809115 & 6.3 & 4.2598 & TST \\
\hline CHEMBL223460 & 809115 & 6.8 & 4.5938 & TST \\
\hline CHEMBL1998829 & 809115 & 6.7 & 7.0119 & TRN \\
\hline CHEMBL50894 & 809115 & 7.4 & 5.4157 & TST \\
\hline CHEMBL1995211 & 809115 & 5.5 & 5.8924 & TRN \\
\hline CHEMBL1988838 & 809115 & 6.2 & 6.3173 & TRN \\
\hline CHEMBL1981725 & 809115 & 7.0 & 6.1867 & TRN \\
\hline CHEMBL1982753 & 809115 & 6.5 & 5.6214 & TRN \\
\hline
\end{tabular}




\begin{tabular}{|c|c|c|c|c|c|}
\hline \multicolumn{6}{|c|}{ Supplemental Table S2.txt } \\
\hline CHEMBL 2006299 & 809115 & 4.3 & 4.9906 & TRN & \\
\hline CHEMBL1972346 & 809115 & 6.3 & 5.8286 & TST & \\
\hline CHEMBL1980562 & 809115 & 7.3 & 7.0521 & TRN & \\
\hline CHEMBL1965169 & 809115 & 4.3 & 5.1758 & TST & \\
\hline CHEMBL1991818 & 809115 & 5.5 & 4.806 & TST & \\
\hline CHEMBL1081312 & 809115 & 6.2 & 5.8256 & TRN & \\
\hline CHEMBL1965170 & 809115 & 6.1 & 6.4628 & TRN & \\
\hline CHEMBL1982866 & 809115 & 5.6 & 5.4153 & TRN & \\
\hline CHEMBL 2004156 & 809115 & 4.0 & 4.9999 & TRN & \\
\hline CHEMBL 2005792 & 809115 & 5.9 & 5.1065 & TRN & \\
\hline CHEMBL1968926 & 809115 & 5.5 & 5.50200 & 0000000001 & TRN \\
\hline CHEMBL462120 & 809115 & 5.3 & 4.795 & TST & \\
\hline CHEMBL1991867 & 809115 & 4.3 & 4.3557 & TST & \\
\hline CHEMBL1979933 & 809115 & 4.3 & 4.7584 & TRN & \\
\hline CHEMBL1986503 & 809115 & 4.3 & 4.863 & TST & \\
\hline CHEMBL 2007592 & 809115 & 5.2 & 5.1319 & TST & \\
\hline CHEMBL1965570 & 809115 & 6.6 & 6.8249 & TRN & \\
\hline CHEMBL1972355 & 809115 & 5.3 & 6.0336 & TST & \\
\hline CHEMBL1997892 & 809115 & 4.3 & 4.157 & TRN & \\
\hline CHEMBL 2001641 & 809115 & 4.4 & 4.213 & TRN & \\
\hline CHEMBL1976936 & 809115 & 8.0 & 7.6546 & TRN & \\
\hline CHEMBL1997193 & 809115 & 4.3 & 4.9435 & TST & \\
\hline CHEMBL210963 & 809115 & 4.0 & 3.8419 & TRN & \\
\hline CHEMBL1964902 & 809115 & 4.3 & 4.0676 & TRN & \\
\hline CHEMBL1082440 & 809115 & 5.9 & 5.95 & TST & \\
\hline CHEMBL1614705 & 809115 & 6.0 & 5.0428 & TRN & \\
\hline CHEMBL1984633 & 809115 & 4.0 & 4.1795 & TRN & \\
\hline CHEMBL1982400 & 809115 & 7.4 & 7.0383 & TRN & \\
\hline CHEMBL1972988 & 809115 & 6.1 & 5.9946 & TRN & \\
\hline CHEMBL1965845 & 809115 & 7.3 & 7.195 & TRN & \\
\hline CHEMBL 2007372 & 809115 & 4.0 & 4.8313 & TRN & \\
\hline CHEMBL1983715 & 809115 & 6.5 & 5.7757 & TRN & \\
\hline CHEMBL 2006715 & 809115 & 7.0 & 7.2637 & TRN & \\
\hline CHEMBL1986597 & 809115 & 6.2 & 6.2515 & TRN & \\
\hline CHEMBL1990482 & 809115 & 6.0 & 6.2314 & TRN & \\
\hline CHEMBL1990904 & 809115 & 6.6 & 6.2753 & TRN & \\
\hline CHEMBL 2005475 & 809115 & 5.4 & 6.3298 & TRN & \\
\hline CHEMBL1987448 & 809115 & 7.0 & 7.4156 & TRN & \\
\hline CHEMBL402846 & 809115 & 5.7 & 5.926 & TRN & \\
\hline CHEMBL1997349 & 809115 & 5.9 & 5.6546 & TST & \\
\hline CHEMBL183844 & 809115 & 4.0 & 5.1219 & TRN & \\
\hline CHEMBL220057 & 809115 & 5.8 & 6.0731 & TRN & \\
\hline CHEMBL1682545 & 809115 & 6.3 & 5.8197 & TRN & \\
\hline CHEMBL383541 & 809115 & 6.4 & 5.5038 & TRN & \\
\hline CHEMBL 2001224 & 809115 & 4.0 & 3.9943 & TRN & \\
\hline CHEMBL10 & 809115 & 6.4 & 6.0941 & TRN & \\
\hline CHEMBL1976732 & 809115 & 6.2 & 6.5394 & TRN & \\
\hline CHEMBL1982982 & 809115 & 5.7 & 5.5327 & TRN & \\
\hline
\end{tabular}




\begin{tabular}{|c|c|c|c|c|c|}
\hline \multicolumn{6}{|c|}{ Supplemental Table S2.txt } \\
\hline CHEMBL 2005216 & 809115 & 7.8 & 7.187 & TRN & \\
\hline CHEMBL1969506 & 809115 & 5.8 & 4.5693 & TRN & \\
\hline CHEMBL1980763 & 809115 & 5.4 & 5.1588 & TRN & \\
\hline CHEMBL1964937 & 809115 & 6.8 & 6.9591 & TRN & \\
\hline CHEMBL1980163 & 809115 & 4.0 & 4.3773 & TRN & \\
\hline CHEMBL1977931 & 809115 & 4.3 & 4.3384 & TRN & \\
\hline CHEMBL 2005899 & 809115 & 4.0 & 4.32 & TRN & \\
\hline CHEMBL1972568 & 809115 & 5.7 & 5.5571 & TRN & \\
\hline CHEMBL1682552 & 809115 & 4.0 & 4.8109 & TRN & \\
\hline CHEMBL 2007479 & 809115 & 4.3 & 4.3225 & TRN & \\
\hline CHEMBL1995635 & 809115 & 5.3 & 4.7755 & TST & \\
\hline CHEMBL1987745 & 809115 & 6.1 & 5.7311 & TRN & \\
\hline CHEMBL105739 & 809115 & 6.7 & 6.5538 & TRN & \\
\hline CHEMBL1972220 & 809115 & 7.6 & 6.8075 & TRN & \\
\hline CHEMBL 379300 & 809115 & 7.3 & 7.8334 & TRN & \\
\hline CHEMBL 2003785 & 809115 & 4.1 & 4.2921 & TRN & \\
\hline CHEMBL1973720 & 809115 & 7.7 & 7.55200 & 00000000005 & TRN \\
\hline CHEMBL1969523 & 809115 & 6.6 & 5.6861 & TRN & \\
\hline CHEMBL1988995 & 809115 & 6.4 & 6.2781 & TRN & \\
\hline CHEMBL 2001923 & 809115 & 4.3 & 4.8159 & TRN & \\
\hline CHEMBL1986781 & 809115 & 5.8 & 5.2931 & TRN & \\
\hline CHEMBL1983070 & 809115 & 4.3 & 4.5617 & TRN & \\
\hline CHEMBL 2003514 & 809115 & 4.3 & 4.0804 & TRN & \\
\hline CHEMBL526133 & 809115 & 6.2 & 5.4141 & TRN & \\
\hline CHEMBL1989043 & 809115 & 4.3 & 3.8806 & TRN & \\
\hline CHEMBL1979057 & 809115 & 6.1 & 6.233 & TRN & \\
\hline CHEMBL387971 & 809115 & 5.7 & 5.4917 & TST & \\
\hline CHEMBL1164180 & 809115 & 5.7 & 5.3952 & TST & \\
\hline CHEMBL1999428 & 809115 & 5.8 & 4.7479 & TRN & \\
\hline CHEMBL1967560 & 809115 & 4.0 & 4.0696 & TRN & \\
\hline CHEMBL1997611 & 809115 & 4.3 & 4.1413 & TST & \\
\hline CHEMBL1516890 & 809115 & 6.5 & 7.0703 & TRN & \\
\hline CHEMBL211378 & 809115 & 5.9 & 5.6404 & TRN & \\
\hline CHEMBL1682358 & 809115 & 6.3 & 5.71899 & 9999999999 & TRN \\
\hline CHEMBL1982465 & 809115 & 6.0 & 5.8566 & TRN & \\
\hline CHEMBL 2001751 & 809115 & 8.4 & 8.116 & TRN & \\
\hline CHEMBL 2003420 & 809115 & 4.0 & 4.3274 & TRN & \\
\hline CHEMBL1984586 & 809115 & 5.5 & 5.7922 & TRN & \\
\hline CHEMBL1972659 & 809115 & 4.0 & 4.7237 & TST & \\
\hline CHEMBL 272453 & 809115 & 4.0 & 5.0111 & TRN & \\
\hline CHEMBL1970217 & 809115 & 5.6 & 4.4827 & TRN & \\
\hline CHEMBL 2005528 & 809115 & 6.2 & 5.3632 & TST & \\
\hline CHEMBL1984686 & 809115 & 4.3 & 4.6974 & TRN & \\
\hline CHEMBL 2006113 & 809115 & 5.7 & 5.4608 & TST & \\
\hline CHEMBL185569 & 809115 & 6.4 & 5.9256 & TRN & \\
\hline CHEMBL1969843 & 809115 & 4.0 & 4.418 & TRN & \\
\hline CHEMBL 2007002 & 809115 & 7.9 & 7.2839 & TRN & \\
\hline CHEMBL1987007 & 809115 & 5.6 & 5.5177 & TRN & \\
\hline
\end{tabular}




\begin{tabular}{|c|c|c|c|c|c|}
\hline \\
\hline CHEMBL1973793 & 809115 & 5.4 & 4.6386 & TST & \\
\hline CHEMBL1984711 & 809115 & 5.3 & 5.5513 & TRN & \\
\hline CHEMBL1992073 & 809115 & 4.3 & 4.1204 & TRN & \\
\hline CHEMBL484390 & 809115 & 5.4 & 5.3895 & TRN & \\
\hline CHEMBL1979252 & 809115 & 4.0 & 4.4117 & TRN & \\
\hline CHEMBL1986143 & 809115 & 4.3 & 4.6796 & TRN & \\
\hline CHEMBL1972934 & 809115 & 4.6 & 4.3187 & TRN & \\
\hline CHEMBL 2007559 & 809115 & 4.3 & 4.1388 & TRN & \\
\hline CHEMBL1992581 & 809115 & 6.0 & 5.5335 & TRN & \\
\hline CHEMBL 2004290 & 809115 & 7.0 & 6.6162 & TRN & \\
\hline CHEMBL1986499 & 809115 & 6.1 & 7.00200 & 0000000001 & TRN \\
\hline CHEMBL1972937 & 809115 & 4.0 & 4.7076 & TRN & \\
\hline CHEMBL 2000393 & 809115 & 5.6 & 6.8842 & TST & \\
\hline CHEMBL1089101 & 809115 & 5.7 & 6.0307 & TRN & \\
\hline CHEMBL 2001477 & 809115 & 5.4 & 5.4042 & TRN & \\
\hline CHEMBL 2004311 & 809115 & 5.1 & 5.0888 & TRN & \\
\hline CHEMBL1992634 & 809115 & 8.1 & 8.1354 & TRN & \\
\hline CHEMBL1242373 & 809115 & 5.6 & 6.0767 & TRN & \\
\hline CHEMBL56543 & 809115 & 4.1 & 5.6233 & TST & \\
\hline CHEMBL1984847 & 809115 & 4.3 & 4.4867 & TRN & \\
\hline CHEMBL316264 & 809115 & 6.2 & 6.3307 & TRN & \\
\hline CHEMBL1988075 & 809115 & 6.6 & 6.6817 & TRN & \\
\hline CHEMBL1996576 & 809115 & 4.3 & 4.2247 & TST & \\
\hline CHEMBL1988076 & 809115 & 5.8 & 5.3587 & TRN & \\
\hline CHEMBL1991678 & 809115 & 5.7 & 5.3107 & TRN & \\
\hline CHEMBL 2001239 & 809115 & 6.3 & 5.1859 & TRN & \\
\hline CHEMBL1988594 & 809115 & 7.1 & 7.5337 & TRN & \\
\hline CHEMBL 2001288 & 809115 & 4.0 & 4.1666 & TRN & \\
\hline CHEMBL1992363 & 809115 & 6.8 & 6.4077 & TRN & \\
\hline CHEMBL1999811 & 809115 & 6.0 & 6.01 & TRN & \\
\hline CHEMBL235157 & 809115 & 4.3 & 4.813 & TST & \\
\hline CHEMBL1985074 & 809115 & 5.1 & 5.3521 & TST & \\
\hline CHEMBL 2000481 & 809115 & 6.1 & 6.0399 & TRN & \\
\hline CHEMBL1982874 & 809115 & 7.1 & 6.864 & TRN & \\
\hline CHEMBL1991725 & 809115 & 4.0 & 5.1024 & TRN & \\
\hline CHEMBL1992242 & 809115 & 4.0 & 4.0803 & TRN & \\
\hline CHEMBL1982271 & 809115 & 7.9 & 7.1022 & TRN & \\
\hline CHEMBL 2007296 & 809115 & 4.0 & 4.9108 & TRN & \\
\hline CHEMBL208637 & 809115 & 5.3 & 4.4813 & TRN & \\
\hline CHEMBL 2004159 & 809115 & 4.3 & 4.4417 & TRN & \\
\hline CHEMBL396523 & 809115 & 6.9 & 6.75700 & 0000000001 & TRN \\
\hline CHEMBL1978371 & 809115 & 4.3 & 4.5321 & TST & \\
\hline CHEMBL1970203 & 809115 & 7.2 & 7.0747 & TRN & \\
\hline CHEMBL1986530 & 809115 & 6.3 & 5.4563 & TST & \\
\hline CHEMBL440084 & 809115 & 4.3 & 4.9622 & TRN & \\
\hline CHEMBL1999321 & 809115 & 4.0 & 4.3057 & TRN & \\
\hline CHEMBL 2007336 & 809115 & 5.9 & 5.4061 & TRN & \\
\hline CHEMBL1968590 & 809115 & 6.5 & 7.0088 & TRN & \\
\hline
\end{tabular}




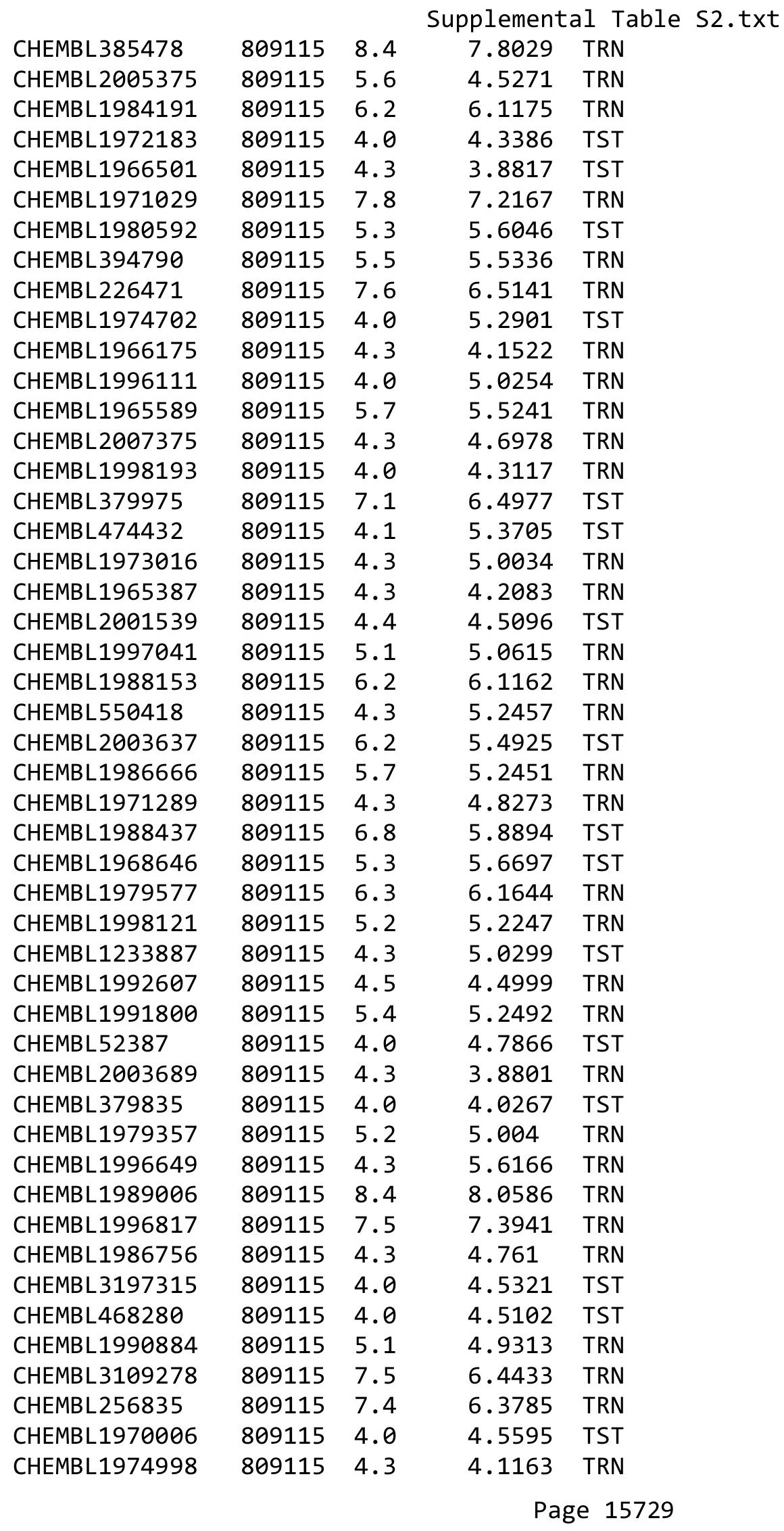




\begin{tabular}{|c|c|c|c|c|c|}
\hline \multicolumn{6}{|c|}{ Supplemental Table S2.txt } \\
\hline CHEMBL1980142 & 809115 & 4.0 & 4.8863 & TRN & \\
\hline CHEMBL41783 & 809115 & 4.0 & 3.9527 & TRN & \\
\hline CHEMBL 2004438 & 809115 & 4.3 & 4.3115 & TRN & \\
\hline CHEMBL 2006276 & 809115 & 5.9 & 5.6042 & TRN & \\
\hline CHEMBL191003 & 809115 & 4.4 & 4.5911 & TRN & \\
\hline CHEMBL271381 & 809115 & 5.9 & 6.2909 & TRN & \\
\hline CHEMBL 2006785 & 809115 & 4.0 & 4.8913 & TST & \\
\hline CHEMBL1982466 & 809115 & 7.3 & 6.8932 & TRN & \\
\hline CHEMBL1973359 & 809115 & 6.4 & 5.9225 & TST & \\
\hline CHEMBL1995740 & 809115 & 5.5 & 4.8589 & TRN & \\
\hline CHEMBL1990162 & 809115 & 5.3 & 5.4718 & TRN & \\
\hline CHEMBL1992220 & 809115 & 8.2 & 7.8491 & TRN & \\
\hline CHEMBL1986943 & 809115 & 7.5 & 7.8733 & TRN & \\
\hline CHEMBL1979690 & 809115 & 6.4 & 5.9925 & TRN & \\
\hline CHEMBL234085 & 809115 & 4.3 & 3.9375 & TRN & \\
\hline CHEMBL1998414 & 809115 & 5.1 & 4.805 & TRN & \\
\hline CHEMBL1995832 & 809115 & 6.1 & 5.74100 & 00000000005 & TRN \\
\hline CHEMBL1969042 & 809115 & 6.6 & 6.5731 & TRN & \\
\hline CHEMBL 2000345 & 809115 & 7.4 & 7.5068 & TRN & \\
\hline CHEMBL1999931 & 809115 & 7.7 & 6.4518 & TRN & \\
\hline CHEMBL1076555 & 809115 & 6.0 & 5.9453 & TRN & \\
\hline CHEMBL1976376 & 809115 & 4.3 & 5.1517 & TRN & \\
\hline CHEMBL1988622 & 809115 & 5.1 & 5.2258 & TRN & \\
\hline CHEMBL1983575 & 809115 & 6.2 & 6.0206 & TRN & \\
\hline CHEMBL1375418 & 809115 & 5.1 & 5.3479 & TRN & \\
\hline CHEMBL1968868 & 809115 & 4.3 & 4.5325 & TRN & \\
\hline CHEMBL 2007064 & 809115 & 6.8 & 6.0609 & TRN & \\
\hline CHEMBL1981047 & 809115 & 5.7 & 6.2685 & TRN & \\
\hline CHEMBL1976196 & 809115 & 4.3 & 4.7923 & TST & \\
\hline CHEMBL1976240 & 809115 & 5.7 & 5.2503 & TRN & \\
\hline CHEMBL1987948 & 809115 & 6.7 & 6.4084 & TRN & \\
\hline CHEMBL1997197 & 809115 & 4.3 & 4.8262 & TRN & \\
\hline CHEMBL1983630 & 809115 & 4.1 & 4.6947 & TRN & \\
\hline CHEMBL1968151 & 809115 & 5.2 & 5.5721 & TST & \\
\hline CHEMBL1979093 & 809115 & 5.5 & 6.5085 & TRN & \\
\hline CHEMBL1987009 & 809115 & 6.2 & 7.0955 & TRN & \\
\hline CHEMBL379218 & 809115 & 8.2 & 8.3096 & TRN & \\
\hline CHEMBL 2003817 & 809115 & 5.7 & 4.9947 & TRN & \\
\hline CHEMBL1994830 & 809115 & 6.6 & 5.8997 & TRN & \\
\hline CHEMBL 226403 & 809115 & 6.8 & 6.7241 & TRN & \\
\hline CHEMBL2005631 & 809115 & 6.6 & 6.2195 & TRN & \\
\hline CHEMBL1994938 & 809115 & 7.6 & 7.3612 & TRN & \\
\hline CHEMBL1977223 & 809115 & 4.0 & 5.0392 & TRN & \\
\hline CHEMBL1995765 & 809115 & 4.2 & 4.5734 & TST & \\
\hline CHEMBL1966279 & 809115 & 5.8 & 5.8891 & TRN & \\
\hline CHEMBL1236126 & 809115 & 5.3 & 4.8463 & TRN & \\
\hline CHEMBL1997846 & 809115 & 5.7 & 6.8346 & TRN & \\
\hline CHEMBL1984760 & 809115 & 4.3 & 4.7782 & TRN & \\
\hline
\end{tabular}




\begin{tabular}{|c|c|c|c|c|c|}
\hline \multicolumn{6}{|c|}{ Supplemental Table S2.txt } \\
\hline CHEMBL2004419 & 809115 & 5.6 & 6.6343 & TRN & \\
\hline CHEMBL360847 & 809115 & 4.3 & 4.5329 & TST & \\
\hline CHEMBL2007073 & 809115 & 4.3 & 4.2648 & TRN & \\
\hline CHEMBL1995811 & 809115 & 5.7 & 4.8836 & TRN & \\
\hline CHEMBL1972489 & 809115 & 5.2 & 4.8131 & TRN & \\
\hline CHEMBL1994074 & 809115 & 7.0 & 6.89 & TRN & \\
\hline CHEMBL1992937 & 809115 & 4.4 & 5.3055 & TST & \\
\hline CHEMBL451401 & 809115 & 4.3 & 4.6806 & TRN & \\
\hline CHEMBL1968930 & 809115 & 7.3 & 7.3412 & TRN & \\
\hline CHEMBL1972119 & 809115 & 4.0 & 4.7485 & TRN & \\
\hline CHEMBL1986328 & 809115 & 5.7 & 5.1855 & TST & \\
\hline CHEMBL95692 & 809115 & 6.1 & 6.0735 & TRN & \\
\hline CHEMBL1090356 & 809115 & 5.6 & 5.7607 & TRN & \\
\hline CHEMBL1976455 & 809115 & 5.2 & 5.2452 & TRN & \\
\hline CHEMBL 261849 & 809115 & 4.3 & 4.68 & TST & \\
\hline CHEMBL1983923 & 809115 & 5.4 & 5.3428 & TRN & \\
\hline CHEMBL1983534 & 809115 & 6.1 & 5.8752 & TRN & \\
\hline CHEMBL1970950 & 809115 & 6.2 & 5.1186 & TRN & \\
\hline CHEMBL1982361 & 809115 & 5.1 & 4.5828 & TRN & \\
\hline CHEMBL1999112 & 809115 & 5.8 & 5.5159 & TST & \\
\hline CHEMBL 2000801 & 809115 & 4.0 & 3.9669 & TRN & \\
\hline CHEMBL1982122 & 809115 & 6.1 & 5.2952 & TRN & \\
\hline CHEMBL1682546 & 809115 & 4.0 & 5.3187 & TRN & \\
\hline CHEMBL1988872 & 809115 & 4.3 & 4.565 & TRN & \\
\hline CHEMBL1991395 & 809115 & 5.7 & 5.6415 & TRN & \\
\hline CHEMBL1971245 & 809115 & 4.0 & 5.2712 & TRN & \\
\hline CHEMBL1972142 & 809115 & 7.0 & 6.1319 & TRN & \\
\hline CHEMBL1966514 & 809115 & 6.3 & 6.7861 & TRN & \\
\hline CHEMBL2003638 & 809115 & 6.3 & 6.2854 & TRN & \\
\hline CHEMBL1983393 & 809115 & 6.2 & 4.7138 & TRN & \\
\hline CHEMBL1972152 & 809115 & 4.0 & 4.7095 & TST & \\
\hline CHEMBL1970806 & 809115 & 4.0 & 5.0073 & TST & \\
\hline CHEMBL1993722 & 809115 & 5.8 & 5.6822 & TRN & \\
\hline CHEMBL2006674 & 809115 & 4.3 & 4.2392 & TST & \\
\hline CHEMBL1984236 & 809115 & 5.9 & 4.4969 & TST & \\
\hline CHEMBL1992371 & 809115 & 5.3 & 5.0892 & TRN & \\
\hline CHEMBL1375640 & 809115 & 5.8 & 5.2297 & TST & \\
\hline CHEMBL1979970 & 809115 & 4.1 & 4.1964 & TRN & \\
\hline CHEMBL2002599 & 809115 & 4.3 & 4.375 & TRN & \\
\hline CHEMBL249282 & 809115 & 6.8 & 4.7653 & TST & \\
\hline CHEMBL1967252 & 809115 & 5.6 & 6.5686 & TRN & \\
\hline CHEMBL1992473 & 809115 & 5.9 & 5.0318 & TRN & \\
\hline CHEMBL1970821 & 809115 & 8.5 & $7.8210 e$ & 2000000001 & TRN \\
\hline CHEMBL 2004637 & 809115 & 5.3 & 4.9608 & TRN & \\
\hline CHEMBL1993374 & 809115 & 4.3 & 4.0404 & TST & \\
\hline CHEMBL1994318 & 809115 & 4.3 & 4.30699 & 99999999995 & TRN \\
\hline CHEMBL 2006237 & 809115 & 4.0 & 4.9223 & TST & \\
\hline CHEMBL1974094 & 809115 & 5.8 & 5.0237 & TST & \\
\hline
\end{tabular}




\begin{tabular}{|c|c|c|c|c|c|}
\hline \\
\hline CHEMBL1999506 & 809115 & 4.3 & 4.0486 & TST & \\
\hline CHEMBL1967720 & 809115 & 6.7 & 7.1549 & TST & \\
\hline CHEMBL2005509 & 809115 & 7.9 & 7.8698 & TST & \\
\hline CHEMBL1572266 & 809115 & 4.0 & 4.0282 & TST & \\
\hline CHEMBL1991138 & 809115 & 4.0 & 4.834 & TST & \\
\hline CHEMBL1979516 & 809115 & 6.4 & 5.8953 & TST & \\
\hline CHEMBL1969755 & 809115 & 4.0 & 4.6344 & TST & \\
\hline CHEMBL1972820 & 809115 & 4.0 & 3.5933 & TST & \\
\hline CHEMBL1605605 & 809115 & 4.3 & 4.4256 & TST & \\
\hline CHEMBL1996208 & 809115 & 4.2 & 4.4188 & TST & \\
\hline CHEMBL1989029 & 809115 & 5.8 & 5.8871 & TST & \\
\hline CHEMBL392642 & 809115 & 6.5 & 5.9143 & TST & \\
\hline CHEMBL514499 & 809115 & 6.6 & 4.966 & TST & \\
\hline CHEMBL1970352 & 809115 & 4.3 & 4.2705 & TST & \\
\hline CHEMBL1965631 & 809115 & 4.0 & 4.5891 & TST & \\
\hline CHEMBL1980144 & 809115 & 7.0 & 7.03299 & 99999999995 & TST \\
\hline CHEMBL1991188 & 809115 & 5.1 & 4.9322 & TST & \\
\hline CHEMBL1682554 & 809115 & 5.8 & 5.3859 & TST & \\
\hline CHEMBL1980167 & 809115 & 4.3 & 5.0051 & TST & \\
\hline CHEMBL1972849 & 809115 & 6.7 & 6.4084 & TST & \\
\hline CHEMBL 377408 & 809115 & 4.3 & 4.2577 & TST & \\
\hline CHEMBL1986855 & 809115 & 8.1 & 9.4342 & TST & \\
\hline CHEMBL215152 & 809115 & 5.5 & 4.2552 & TST & \\
\hline CHEMBL 231209 & 809115 & 5.7 & 6.25 & TST & \\
\hline CHEMBL1975357 & 809115 & 4.0 & 4.4617 & TST & \\
\hline CHEMBL1976220 & 809115 & 5.7 & 5.9179 & TST & \\
\hline CHEMBL1989136 & 809115 & 5.9 & 5.6625 & TST & \\
\hline CHEMBL 2006765 & 809115 & 6.2 & 5.4079 & TST & \\
\hline CHEMBL 259922 & 809115 & 4.0 & 3.24300 & 00000000003 & TST \\
\hline CHEMBL1997617 & 809115 & 6.6 & 5.9217 & TST & \\
\hline CHEMBL1969301 & 809115 & 6.4 & 5.4216 & TST & \\
\hline CHEMBL1982383 & 809115 & 5.9 & 5.718 & TST & \\
\hline CHEMBL17370 & 809115 & 6.2 & 6.4057 & TST & \\
\hline CHEMBL1980246 & 809115 & 4.3 & 4.5902 & TST & \\
\hline CHEMBL1987910 & 809115 & 5.3 & 4.9463 & TST & \\
\hline CHEMBL1983932 & 809115 & 8.0 & 5.5452 & TST & \\
\hline CHEMBL1983980 & 809115 & 5.3 & 4.6778 & TST & \\
\hline CHEMBL1999484 & 809115 & 4.6 & 5.9722 & TST & \\
\hline CHEMBL1986899 & 809115 & 4.3 & 5.7131 & TST & \\
\hline CHEMBL1991285 & 809115 & 5.6 & 4.2851 & TST & \\
\hline CHEMBL1997822 & 809115 & 7.4 & 7.3159 & TST & \\
\hline CHEMBL 243088 & 809115 & 6.7 & 6.2685 & TST & \\
\hline CHEMBL1984038 & 809115 & 4.3 & 4.7166 & TST & \\
\hline CHEMBL1974416 & 809115 & 6.8 & 7.3177 & TST & \\
\hline CHEMBL1993661 & 809115 & 6.4 & 6.5943 & TST & \\
\hline CHEMBL 2004615 & 809115 & 5.1 & 4.5969 & TST & \\
\hline CHEMBL1984039 & 809115 & 4.0 & 4.9085 & TST & \\
\hline CHEMBL1997872 & 809115 & 6.8 & 5.625 & TST & \\
\hline
\end{tabular}


Supplemental Table S2.txt

\begin{tabular}{|c|c|c|c|c|}
\hline CHEMBL3666116 & 1528695 & 4.8477 & 4.8326 & TRN \\
\hline CHEMBL1809158 & 1528695 & 6.2291 & 6.5823 & TRN \\
\hline CHEMBL3666106 & 1528695 & 5.1249 & 5.1735 & TRN \\
\hline CHEMBL1809170 & 1528695 & 6.3565 & 6.4249 & TRN \\
\hline CHEMBL3666108 & 1528695 & 5.9957 & 5.8849 & TRN \\
\hline CHEMBL3666097 & 1528695 & 5.2314 & 5.087 & TST \\
\hline CHEMBL3666155 & 1528695 & 5.3851 & 5.9218 & TRN \\
\hline CHEMBL3666176 & 1528695 & 6.0 & 5.7708 & TRN \\
\hline CHEMBL1809183 & 1528695 & 5.6861 & 5.8255 & TRN \\
\hline CHEMBL1809185 & 1528695 & 5.0088 & 5.1712 & TRN \\
\hline CHEMBL3666189 & 1528695 & 4.0 & 6.1526 & TST \\
\hline CHEMBL1809176 & 1528695 & 5.8601 & 5.7387 & TRN \\
\hline CHEMBL3666076 & 1528695 & 6.6383 & 6.4734 & TRN \\
\hline CHEMBL 3666136 & 1528695 & 5.6198 & 5.64 & TRN \\
\hline CHEMBL1809159 & 1528695 & 6.6576 & 6.2491 & TRN \\
\hline CHEMBL3666081 & 1528695 & 6.2518 & 6.2675 & TRN \\
\hline CHEMBL1809154 & 1528695 & 6.1487 & 5.91299 & 9999999999 \\
\hline CHEMBL3666162 & 1528695 & 6.1675 & 6.23 & TRN \\
\hline CHEMBL3666070 & 1528695 & 6.3468 & 6.1924 & TRN \\
\hline CHEMBL1809184 & 1528695 & 5.4547 & 5.4664 & TRN \\
\hline CHEMBL3666161 & 1528695 & 4.3474 & 5.4543 & TST \\
\hline CHEMBL3666111 & 1528695 & 5.0429 & 5.7288 & TRN \\
\hline CHEMBL3639650 & 1528695 & 6.5229 & 4.73600 & 0000000001 \\
\hline CHEMBL3666089 & 1528695 & 5.5171 & 5.2397 & TRN \\
\hline CHEMBL 3666163 & 1528695 & 3.2924 & 5.083 & TST \\
\hline CHEMBL3666137 & 1528695 & 5.7773 & 5.5233 & TRN \\
\hline CHEMBL3666164 & 1528695 & 5.7825 & 5.6539 & TRN \\
\hline CHEMBL3666175 & 1528695 & 6.1549 & 6.053 & TRN \\
\hline CHEMBL3666138 & 1528695 & 5.1024 & 4.7303 & TRN \\
\hline CHEMBL3666109 & 1528695 & 5.7959 & 5.4574 & TRN \\
\hline CHEMBL3666146 & 1528695 & 5.8447 & 5.2689 & TST \\
\hline CHEMBL3666142 & 1528695 & 5.567 & 4.8376 & TST \\
\hline CHEMBL3666084 & 1528695 & 5.3516 & 6.19600 & 0000000001 \\
\hline CHEMBL 3666156 & 1528695 & 6.4202 & 5.9415 & TRN \\
\hline CHEMBL3666105 & 1528695 & 5.4949 & 5.4693 & TRN \\
\hline CHEMBL3666183 & 1528695 & 4.0 & 5.5392 & TST \\
\hline CHEMBL3666069 & 1528695 & 6.0655 & 6.1946 & TRN \\
\hline CHEMBL3666182 & 1528695 & 5.3851 & 5.4348 & TRN \\
\hline CHEMBL3666128 & 1528695 & 4.6383 & 5.5741 & TST \\
\hline CHEMBL1809189 & 1528695 & 5.2147 & 5.1378 & TRN \\
\hline CHEMBL3666147 & 1528695 & 6.1805 & 5.0579 & TST \\
\hline CHEMBL1809168 & 1528695 & 6.6383 & 5.8632 & TST \\
\hline CHEMBL3666130 & 1528695 & 3.5229 & 4.1253 & TRN \\
\hline CHEMBL3666174 & 1528695 & 6.5229 & 6.4311 & TRN \\
\hline CHEMBL3666158 & 1528695 & 5.3747 & 5.4593 & TRN \\
\hline CHEMBL1809187 & 1528695 & 6.0269 & 6.62299 & 9999999999 \\
\hline CHEMBL3666087 & 1528695 & 5.8327 & 5.8767 & TRN \\
\hline CHEMBL3666149 & 1528695 & 6.0506 & 6.1475 & TRN \\
\hline
\end{tabular}


Supplemental Table S2.txt

\begin{tabular}{|c|c|c|c|c|c|}
\hline CHEMBL1809174 & 1528695 & 5.8928 & 5.829 & TRN & \\
\hline CHEMBL1809186 & 1528695 & 6.1675 & 6.4092 & TST & \\
\hline CHEMBL3956239 & 1528695 & 4.0 & 4.0729 & TRN & \\
\hline CHEMBL3666103 & 1528695 & 5.8327 & 5.8748 & TRN & \\
\hline CHEMBL1809163 & 1528695 & 6.0809 & 5.6768 & TRN & \\
\hline CHEMBL 3666090 & 1528695 & 6.5229 & 5.9224 & TRN & \\
\hline CHEMBL3666100 & 1528695 & 5.6198 & 5.436 & TRN & \\
\hline CHEMBL3666151 & 1528695 & 5.0074 & 5.4888 & TST & \\
\hline CHEMBL3666112 & 1528695 & 5.1118 & 5.414 & TRN & \\
\hline CHEMBL3956587 & 1528695 & 4.0 & 3.9247 & TRN & \\
\hline CHEMBL3666079 & 1528695 & 5.6925 & 5.5698 & TRN & \\
\hline CHEMBL1809162 & 1528695 & 6.1675 & 6.1447 & TRN & \\
\hline CHEMBL3666179 & 1528695 & 6.0506 & 6.2036 & TRN & \\
\hline CHEMBL3666143 & 1528695 & 6.2218 & 4.9528 & TST & \\
\hline CHEMBL 3666154 & 1528695 & 3.2924 & 5.932 & TST & \\
\hline CHEMBL3666180 & 1528695 & 6.2218 & 6.2789 & TRN & \\
\hline CHEMBL3666129 & 1528695 & 3.5229 & 5.0269 & TST & \\
\hline CHEMBL1809182 & 1528695 & 5.2708 & 5.4389 & TRN & \\
\hline CHEMBL1809181 & 1528695 & 4.9393 & 5.0026 & TRN & \\
\hline CHEMBL3666120 & 1528695 & 6.4089 & 5.8004 & TRN & \\
\hline CHEMBL3666110 & 1528695 & 5.426 & 5.8281 & TRN & \\
\hline CHEMBL1809153 & 1528695 & 4.0 & 3.9838 & TRN & \\
\hline CHEMBL3666127 & 1528695 & 4.5229 & 5.2953 & TRN & \\
\hline CHEMBL1809173 & 1528695 & 6.7959 & 6.3392 & TST & \\
\hline CHEMBL3666132 & 1528695 & 3.5229 & 3.762 & TRN & \\
\hline CHEMBL3666104 & 1528695 & 5.3179 & 5.225 & TST & \\
\hline CHEMBL3666177 & 1528695 & 5.1791 & 5.3514 & TRN & \\
\hline CHEMBL3666123 & 1528695 & 5.0915 & 5.354 & TRN & \\
\hline CHEMBL 3890618 & 1528695 & 6.1024 & 4.9678 & TST & \\
\hline CHEMBL3666101 & 1528695 & 5.6253 & 5.5334 & TRN & \\
\hline CHEMBL3666086 & 1528695 & 6.3372 & 5.9855 & TRN & \\
\hline CHEMBL3666099 & 1528695 & 5.6289 & 5.8671 & TRN & \\
\hline CHEMBL3666135 & 1528695 & 3.5229 & 5.3151 & TST & \\
\hline CHEMBL1809155 & 1528695 & 6.1487 & 5.94600 & 0000000001 & TRN \\
\hline CHEMBL1236391 & 1528695 & 6.2291 & 6.3425 & TRN & \\
\hline CHEMBL3666077 & 1528695 & 6.2518 & 6.2152 & TRN & \\
\hline CHEMBL3666181 & 1528695 & 6.1805 & 6.0738 & TRN & \\
\hline CHEMBL3932179 & 1528695 & 4.0 & 3.8626 & TRN & \\
\hline CHEMBL1809171 & 1528695 & 7.0458 & 6.1952 & TST & \\
\hline CHEMBL3666119 & 1528695 & 6.1675 & 6.2547 & TRN & \\
\hline CHEMBL3975914 & 1528695 & 4.0 & 4.015 & TRN & \\
\hline CHEMBL3666170 & 1528695 & 6.3188 & 5.1317 & TST & \\
\hline CHEMBL1809161 & 1528695 & 6.4202 & 6.5521 & TRN & \\
\hline CHEMBL3666118 & 1528695 & 6.3979 & 6.3108 & TRN & \\
\hline CHEMBL3666117 & 1528695 & 4.8327 & 4.7712 & TRN & \\
\hline CHEMBL3666166 & 1528695 & 4.699 & 4.6489 & TST & \\
\hline CHEMBL3666095 & 1528695 & 6.3665 & 6.1258 & TRN & \\
\hline CHEMBL3666091 & 1528695 & 4.7852 & 4.7375 & TRN & \\
\hline
\end{tabular}

Page 15734 
Supplemental Table S2.txt

\begin{tabular}{|c|c|c|c|c|c|c|}
\hline CHEMBL3666094 & 1528695 & 5.2725 & 5.7686 & TRN & & \\
\hline CHEMBL1809179 & 1528695 & 6.0655 & 6.2617 & TRN & & \\
\hline CHEMBL3666093 & 1528695 & 5.2175 & 5.3882 & TRN & & \\
\hline CHEMBL3666131 & 1528695 & 5.1278 & 4.9548 & TRN & & \\
\hline CHEMBL 3666124 & 1528695 & 5.3546 & 5.1593 & TRN & & \\
\hline CHEMBL3666114 & 1528695 & 5.9101 & 5.6304 & TRN & & \\
\hline CHEMBL1809157 & 1528695 & 6.5086 & 6.4842 & TRN & & \\
\hline CHEMBL3666098 & 1528695 & 3.5229 & 5.3099 & TST & & \\
\hline CHEMBL3666145 & 1528695 & 6.0506 & 4.6586 & TST & & \\
\hline CHEMBL3666159 & 1528695 & 5.6882 & 5.6142 & TRN & & \\
\hline CHEMBL3666168 & 1528695 & 6.1739 & 6.2117 & TRN & & \\
\hline CHEMBL3666082 & 1528695 & 6.1739 & 6.2226 & TRN & & \\
\hline CHEMBL3666102 & 1528695 & 5.7447 & 5.4342 & TRN & & \\
\hline CHEMBL1809177 & 1528695 & 6.2441 & 5.7874 & TRN & & \\
\hline CHEMBL 3666080 & 1528695 & 5.6925 & 5.6005 & TRN & & \\
\hline CHEMBL3666088 & 1528695 & 5.2865 & 5.5074 & TRN & & \\
\hline CHEMBL3666144 & 1528695 & 5.7645 & 4.9223 & TST & & \\
\hline CHEMBL3666125 & 1528695 & 3.5229 & 3.5584 & TST & & \\
\hline CHEMBL1809180 & 1528695 & 5.3449 & 5.6005 & TRN & & \\
\hline CHEMBL 3666148 & 1528695 & 4.8327 & 5.0739 & TST & & \\
\hline CHEMBL3666122 & 1528695 & 6.5086 & 5.8472 & TRN & & \\
\hline CHEMBL3666078 & 1528695 & 5.5391 & 5.6894 & TRN & & \\
\hline CHEMBL3967341 & 1528695 & 6.2147 & 5.1095 & TST & & \\
\hline CHEMBL3666185 & 1528695 & 4.0 & 5.4104 & TST & & \\
\hline CHEMBL3666075 & 1528695 & 6.585 & 6.5043 & TRN & & \\
\hline CHEMBL3666126 & 1528695 & 5.3468 & 6.6867 & TST & & \\
\hline CHEMBL3666134 & 1528695 & 4.8539 & 4.9896 & TRN & & \\
\hline CHEMBL3666073 & 1528695 & 5.5719 & 5.5481 & TRN & & \\
\hline CHEMBL3666190 & 1528695 & 6.0362 & 6.1078 & TRN & & \\
\hline CHEMBL 3666133 & 1528695 & \multicolumn{3}{|c|}{5.821000000000001} & 5.1148 & TRN \\
\hline CHEMBL3666113 & 1528695 & 6.7959 & 6.6978 & TST & & \\
\hline CHEMBL 3666152 & 1528695 & 5.5834 & 5.9463 & TST & & \\
\hline CHEMBL3666107 & 1528695 & 5.6383 & 5.8255 & TRN & & \\
\hline CHEMBL1809172 & 1528695 & 6.3098 & 5.7534 & TST & & \\
\hline CHEMBL3666141 & 1528695 & 4.5229 & 4.2991 & TRN & & \\
\hline CHEMBL3666074 & 1528695 & 6.2676 & 6.2921 & TRN & & \\
\hline CHEMBL 3666178 & 1528695 & 5.082 & 5.1019 & TRN & & \\
\hline CHEMBL3666139 & 1528695 & 5.2782 & 5.5612 & TRN & & \\
\hline CHEMBL3666096 & 1528695 & 6.0506 & 5.8348 & TRN & & \\
\hline CHEMBL1809178 & 1528695 & 6.2518 & 5.7763 & TRN & & \\
\hline CHEMBL3666085 & 1528695 & 5.8069 & 5.7858 & TRN & & \\
\hline CHEMBL1809167 & 1528695 & 6.4437 & 5.5272 & TST & & \\
\hline CHEMBL3666121 & 1528695 & 5.2248 & 5.416 & TRN & & \\
\hline CHEMBL3666115 & 1528695 & 5.8041 & 5.6364 & TRN & & \\
\hline CHEMBL3666071 & 1528695 & 6.1549 & 6.1219 & TRN & & \\
\hline CHEMBL3666165 & 1528695 & 4.699 & 5.7864 & TST & & \\
\hline CHEMBL3666153 & 1528695 & 6.3768 & 6.376 & TRN & & \\
\hline CHEMBL 3666157 & 1528695 & 6.0809 & 6.0318 & TRN & & \\
\hline
\end{tabular}


Supplemental Table S2.txt

\begin{tabular}{|c|c|c|c|c|c|}
\hline CHEMBL3666083 & 1528695 & 5.5498 & 5.8377 & TRN & \\
\hline CHEMBL3666160 & 1528695 & 6.0362 & 6.0941 & TRN & \\
\hline CHEMBL3666072 & 1528695 & 5.9957 & 6.2582 & TRN & \\
\hline CHEMBL 3666184 & 1528695 & 5.6676 & 5.7876 & TRN & \\
\hline CHEMBL3666092 & 1528695 & 5.3054 & 5.3732 & TRN & \\
\hline CHEMBL3666169 & 1528695 & 4.0 & 4.9679 & TST & \\
\hline CHEMBL1809151 & 1528695 & 6.2518 & 6.2171 & TRN & \\
\hline CHEMBL3666140 & 1528695 & 4.9393 & 5.475 & TRN & \\
\hline CHEMBL3666150 & 1528695 & 6.1135 & 6.1549 & TRN & \\
\hline CHEMBL474682 & 985246 & 4.0362 & 4.6685 & TST & \\
\hline CHEMBL 2430038 & 985246 & 4.7696 & 4.9007 & TST & \\
\hline CHEMBL1255773 & 985246 & 4.1938 & 4.2009 & TRN & \\
\hline CHEMBL1801959 & 985246 & 5.1079 & 4.5747 & TRN & \\
\hline CHEMBL 33943 & 985246 & 4.7447 & 5.14 & TRN & \\
\hline CHEMBL 2429955 & 985246 & 4.8539 & 4.7586 & TRN & \\
\hline CHEMBL126669 & 985246 & 8.3768 & 8.2173 & TRN & \\
\hline CHEMBL 2430043 & 985246 & 4.5686 & 4.9302 & TRN & \\
\hline CHEMBL2430040 & 985246 & 4.3872 & 5.3182 & TST & \\
\hline CHEMBL2430041 & 985246 & 4.3872 & 4.8991 & TRN & \\
\hline CHEMBL61592 & 985246 & 4.7959 & 4.7488 & TRN & \\
\hline CHEMBL318170 & 985246 & 5.1871 & 4.9637 & TRN & \\
\hline CHEMBL 2430042 & 985246 & 5.0088 & 5.2768 & TRN & \\
\hline CHEMBL2429869 & 985246 & 4.6198 & 4.4415 & TRN & \\
\hline CHEMBL1801961 & 985246 & 4.2366 & 4.6712 & TST & \\
\hline CHEMBL 276473 & 985246 & 3.6383 & 3.5443 & TRN & \\
\hline CHEMBL128000 & 985246 & 8.3372 & \multicolumn{3}{|c|}{7.9670000000000005} \\
\hline CHEMBL129795 & 985246 & 4.4559 & \multicolumn{2}{|c|}{4.3660000000000005} & TRN \\
\hline CHEMBL375905 & 985246 & 4.1192 & 4.6135 & TRN & \\
\hline CHEMBL339587 & 985246 & 7.6383 & 7.5961 & TRN & \\
\hline CHEMBL127409 & 985246 & 6.8539 & 7.3908 & TRN & \\
\hline CHEMBL129371 & 985246 & 3.8539 & 3.7476 & TRN & \\
\hline CHEMBL130640 & 985246 & 4.7696 & 4.9737 & TRN & \\
\hline CHEMBL2429962 & 985246 & 6.0 & 4.9537 & TRN & \\
\hline CHEMBL 2429959 & 985246 & 5.2757 & 5.3419 & TRN & \\
\hline CHEMBL465457 & 985246 & 4.8239 & 4.8959 & TST & \\
\hline CHEMBL126657 & 985246 & 5.0506 & 5.215 & TRN & \\
\hline CHEMBL465025 & 985246 & 5.0458 & 5.2293 & TRN & \\
\hline CHEMBL2429961 & 985246 & 4.9586 & 5.0137 & TRN & \\
\hline CHEMBL390381 & 985246 & 5.3279 & 4.9911 & TRN & \\
\hline CHEMBL104732 & 985246 & 4.5686 & 4.6602 & TST & \\
\hline CHEMBL2429960 & 985246 & 5.3979 & 5.1459 & TRN & \\
\hline CHEMBL 2429956 & 985246 & 4.5686 & 4.868 & TRN & \\
\hline CHEMBL341135 & 985246 & 8.3979 & 8.1634 & TRN & \\
\hline CHEMBL129510 & 985246 & 7.3665 & 7.4977 & TRN & \\
\hline CHEMBL1999124 & 985246 & 4.4089 & 4.6415 & TRN & \\
\hline CHEMBL144626 & 985246 & 5.0 & 4.9258 & TST & \\
\hline CHEMBL 2429957 & 985246 & 5.6198 & 5.0923 & TRN & \\
\hline CHEMBL106771 & 985246 & 4.6383 & 4.6938 & TST & \\
\hline
\end{tabular}




\begin{tabular}{|c|c|c|c|c|c|}
\hline \multicolumn{6}{|c|}{ Supplemental Table S2.txt } \\
\hline CHEMBL105310 & 985246 & 3.3979 & 3.5443 & TRN & \\
\hline CHEMBL2429954 & 985246 & 4.4202 & 5.0683 & TRN & \\
\hline CHEMBL338066 & 985246 & 4.0 & 4.2101 & TRN & \\
\hline CHEMBL7976 & 985246 & 4.3665 & 4.1081 & TRN & \\
\hline CHEMBL504473 & 985246 & 3.3979 & 4.7624 & TST & \\
\hline CHEMBL 2429958 & 985246 & 4.7959 & 4.3483 & TRN & \\
\hline CHEMBL2430039 & 985246 & 5.1079 & 5.0258 & TST & \\
\hline CHEMBL105496 & 985246 & 4.699 & 4.6868 & TRN & \\
\hline CHEMBL 262070 & 985246 & 3.4318 & 4.6527 & TST & \\
\hline CHEMBL104575 & 985246 & 4.3872 & 4.8044 & TRN & \\
\hline CHEMBL126804 & 985246 & 4.3768 & 4.098 & TRN & \\
\hline CHEMBL130639 & 985246 & 4.9208 & 5.3658 & TST & \\
\hline CHEMBL 227560 & 985246 & 4.0706 & 4.5172 & TST & \\
\hline CHEMBL3414908 & 1473763 & 3.699 & 3.5966 & TRN & \\
\hline CHEMBL1951164 & 1473763 & 5.5229 & 5.4833 & TST & \\
\hline CHEMBL1951180 & 1473763 & 3.699 & 3.9118 & TRN & \\
\hline CHEMBL1951187 & 1473763 & 6.3979 & 6.2763 & TRN & \\
\hline CHEMBL3415067 & 1473763 & 6.3665 & 6.28299 & 99999999995 & TRN \\
\hline CHEMBL1951172 & 1473763 & 4.8239 & 4.8026 & TRN & \\
\hline CHEMBL 2207600 & 1473763 & 7.3979 & 6.6612 & TST & \\
\hline CHEMBL 3414906 & 1473763 & 3.699 & 3.7396 & TRN & \\
\hline CHEMBL1951166 & 1473763 & 4.8239 & 5.9331 & TST & \\
\hline CHEMBL 2207606 & 1473763 & 8.0 & 7.728 & TRN & \\
\hline CHEMBL1951186 & 1473763 & 6.301 & 6.2567 & TRN & \\
\hline CHEMBL3415072 & 1473763 & 7.301 & 7.1522 & TRN & \\
\hline CHEMBL 2207602 & 1473763 & 7.3979 & 6.5677 & TST & \\
\hline CHEMBL3414904 & 1473763 & 7.0 & 7.0033 & TRN & \\
\hline CHEMBL1951174 & 1473763 & 4.7696 & 4.7815 & TRN & \\
\hline CHEMBL1951185 & 1473763 & 6.0458 & 6.0095 & TRN & \\
\hline CHEMBL1951163 & 1473763 & 4.699 & 4.6538 & TRN & \\
\hline CHEMBL3414899 & 1473763 & 6.301 & 6.3066 & TRN & \\
\hline CHEMBL3414900 & 1473763 & 5.699 & 5.8429 & TRN & \\
\hline CHEMBL2207601 & 1473763 & 7.699 & 6.8976 & TST & \\
\hline CHEMBL1951173 & 1473763 & 5.301 & 5.3648 & TRN & \\
\hline CHEMBL1951178 & 1473763 & 5.3979 & 5.4149 & TRN & \\
\hline CHEMBL1951177 & 1473763 & 3.699 & 5.2531 & TST & \\
\hline CHEMBL1951170 & 1473763 & 3.699 & 5.0639 & TST & \\
\hline CHEMBL1951176 & 1473763 & 5.0 & 4.9298 & TRN & \\
\hline CHEMBL3414903 & 1473763 & 7.0458 & 7.1412 & TRN & \\
\hline CHEMBL3415071 & 1473763 & 6.1675 & 6.1445 & TRN & \\
\hline CHEMBL3414907 & 1473763 & 4.0 & 4.0644 & TRN & \\
\hline CHEMBL1951183 & 1473763 & 5.5229 & 5.7356 & TRN & \\
\hline CHEMBL3414897 & 1473763 & 5.8239 & 5.6059 & TRN & \\
\hline CHEMBL1951171 & 1473763 & 4.6021 & 4.6164 & TRN & \\
\hline CHEMBL3414902 & 1473763 & 6.301 & 6.6127 & TRN & \\
\hline CHEMBL2207599 & 1473763 & 7.3979 & 7.0131 & TST & \\
\hline CHEMBL 2207605 & 1473763 & 7.5229 & 7.5472 & TRN & \\
\hline CHEMBL3415069 & 1473763 & 6.3979 & 6.4082 & TRN & \\
\hline
\end{tabular}

Page 15737 
Supplemental Table S2.txt

\begin{tabular}{|c|c|c|c|c|}
\hline HEN & & & & \\
\hline & 473763 & 7.0458 & .0342 & \\
\hline 503 & 3763 & 8.0 & 1814 & \\
\hline HEMBL195 & 3763 & 5.699 & 6298 & \\
\hline AEMBL 34 & 473763 & 3239 & 3153 & \\
\hline HEMBL3415116 & 473763 & 6.3188 & .2593 & \\
\hline HEMBL & & 458 & 991 & \\
\hline 182 & & 5.5229 & & \\
\hline AEMBL19 & & 4.3979 & 2787 & \\
\hline HEMBL1951184 & 473763 & 6.6021 & . 3872 & \\
\hline AEMBL19 & & 4.0969 & .7585 & \\
\hline IEMBL3. & & & 101 & \\
\hline AEMBL & & 9 & 081 & \\
\hline HEMBL2 & & 7.2218 & 7.2312 & \\
\hline AEMBL34 & 53 & 6.301 & 2792 & \\
\hline AEMBL3 3 & 3 & 99 & 3063 & \\
\hline AEMBL3 & & 218 & 997 & 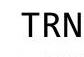 \\
\hline HEMBL3 & & 99 & 881 & \\
\hline HEMBL3L & & 3.699 & 4.2987 & \\
\hline IEMBL1 & & 778 & 3948 & \\
\hline HEMBL & & 3. & 197 & ISI \\
\hline AEMBL & & 1 & 089 & \\
\hline HEMBL; & & 6 . & 885 & \\
\hline AEMBL & & 6.9031 & & \\
\hline AEMBL3 & & & & Tu \\
\hline HEMBL; & & 47 & 378 & 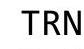 \\
\hline AEME & & 15 & 69 & Niv \\
\hline $\mathrm{AFMBI}=$ & & 46 & 388 & \\
\hline HEMBL33 & & 6.5058 & 303 & TIV \\
\hline HEMBL 331 & & & & I RIV \\
\hline HEMBL 2 & & 3 & 201 & RIV \\
\hline HEMBL & & 4 & 55 & ST \\
\hline HEMBL & & 38 & 29 & RN \\
\hline HEMBL331 & & 539 & 3962 & IRN \\
\hline HEMBL3319346 & & 6.1203 & 5.4634 & ГRN \\
\hline HEMBL3 & & 882 & 938 & \\
\hline HEMR I & & 586 & & ST \\
\hline HEMBL3 & & & 025 & RN \\
\hline HEMBL3319310 & & 6.341 & 324 & $\Gamma \mathrm{RN}$ \\
\hline IEMBL3 & & 021 & 563 & IRN \\
\hline HEMBL3 & & 809 & 126 & \\
\hline HEMBL 3 & & 6.5719 & & RIN \\
\hline HEMBL 33 & & 5.0 & 5.4168 & $\Gamma \mathrm{RN}$ \\
\hline AEMBL3319315 & 827 & 5.9208 & 5381 & TRN \\
\hline MBL3 & & 7 & 6.7446 & $\mathrm{~N}$ \\
\hline HEMBL3 & & & 6.3025 & \\
\hline HEMBL 33 & & 3.6021 & 5.316 & \\
\hline HEMBL3318200 & 1446827 & 3.6021 & 4.9708 & \\
\hline
\end{tabular}

Page 15738 
Supplemental Table S2.txt

\begin{tabular}{|c|c|c|c|c|}
\hline CHEMBL 3318203 & 1446827 & 6.9666 & 5.1081 & TRN \\
\hline CHEMBL3318204 & 1446827 & 3.6021 & 5.1796 & TRN \\
\hline CHEMBL3319340 & 1446827 & 6.4353 & 6.7112 & TRN \\
\hline CHEMBL3319335 & 1446827 & 5.0706 & 4.5187 & TRN \\
\hline CHEMBL3319325 & 1446827 & 3.301 & 4.5514 & TRN \\
\hline CHEMBL3319324 & 1446827 & 6.4737 & 5.6932 & TRN \\
\hline CHEMBL3319343 & 1446827 & 6.7055 & 6.1697 & TST \\
\hline CHEMBL1976236 & 1446827 & 4.8239 & 6.3457 & TRN \\
\hline CHEMBL3319309 & 1446827 & 7.6198 & 6.9463 & TRN \\
\hline CHEMBL3319345 & 1446827 & 3.6021 & 6.1889 & TST \\
\hline CHEMBL3319321 & 1446827 & 4.8239 & 5.7354 & TRN \\
\hline CHEMBL3319352 & 1446827 & 6.4989 & 6.0028 & TRN \\
\hline CHEMBL3319353 & 1446827 & 5.0 & 5.3265 & TRN \\
\hline CHEMBL3318205 & 1446827 & 6.1898 & 5.086 & TRN \\
\hline CHEMBL3319305 & 1446827 & 5.71 & 6.6165 & TRN \\
\hline CHEMBL3319354 & 1446827 & 5.7905 & 6.1277 & TRN \\
\hline CHEMBL3318198 & 1446827 & 5.9626 & 6.3135 & TST \\
\hline CHEMBL 3319342 & 1446827 & 5.9706 & 5.6337 & TST \\
\hline CHEMBL3319316 & 1446827 & 5.556 & 6.6099 & TST \\
\hline CHEMBL3319333 & 1446827 & 5.9872 & 4.3452 & TRN \\
\hline CHEMBL3319344 & 1446827 & 6.0721 & 6.2793 & TST \\
\hline CHEMBL3319319 & 1446827 & 5.8356 & 6.3448 & TST \\
\hline CHEMBL3319349 & 1446827 & 5.7077 & 5.3532 & TST \\
\hline CHEMBL3318201 & 1446827 & 5.2976 & 4.8452 & TRN \\
\hline CHEMBL3319334 & 1446827 & 4.8239 & 4.4894 & TRN \\
\hline CHEMBL3319307 & 1446827 & 6.7077 & 6.8848 & TST \\
\hline CHEMBL3319320 & 1446827 & 3.6021 & \multicolumn{2}{|c|}{6.122000000000001} \\
\hline CHEMBL3319332 & 1446827 & 3.301 & 4.1814 & TRN \\
\hline CHEMBL3319347 & 1446827 & 3.301 & 5.4096 & TST \\
\hline CHEMBL3319312 & 1446827 & 6.4935 & 6.3775 & TST \\
\hline CHEMBL3318202 & 1446827 & 6.3279 & 5.0628 & TRN \\
\hline CHEMBL3319351 & 1446827 & 6.3595 & 6.0023 & TRN \\
\hline CHEMBL3319348 & 1446827 & 6.983 & 6.4307 & TST \\
\hline CHEMBL3319314 & 1446827 & 6.1824 & 6.6267 & TST \\
\hline CHEMBL3319323 & 1446827 & 6.9101 & 5.6796 & TRN \\
\hline CHEMBL3319331 & 1446827 & 3.6021 & 4.2712 & TRN \\
\hline CHEMBL3319330 & 1446827 & 3.6021 & 4.4198 & TRN \\
\hline CHEMBL180646 & 305650 & 10.2007 & 10.3629 & TRN \\
\hline CHEMBL181274 & 305650 & 10.1938 & 10.1082 & TRN \\
\hline CHEMBL359598 & 305650 & 10.5528 & 10.5656 & TRN \\
\hline CHEMBL181027 & 305650 & 9.0506 & 9.5164 & TRN \\
\hline CHEMBL181623 & 305650 & 10.3188 & 10.4095 & TRN \\
\hline CHEMBL359542 & 305650 & 8.9547 & 8.667 & TRN \\
\hline CHEMBL264344 & 305650 & 10.2518 & 9.5881 & TRN \\
\hline CHEMBL360355 & 305650 & 9.8239 & 9.6043 & TRN \\
\hline CHEMBL180623 & 305650 & 8.2899 & 8.7081 & TRN \\
\hline CHEMBL447233 & 305650 & 9.0044 & 8.8499 & TRN \\
\hline CHEMBL181768 & 305650 & 9.8861 & 10.0371 & TRN \\
\hline
\end{tabular}




\begin{tabular}{|c|c|c|c|c|c|c|}
\hline \multirow[b]{2}{*}{ CHEMBL178339 } & \multicolumn{6}{|c|}{ Supplemental Table S2.txt } \\
\hline & 305650 & 8.9101 & 8.8405 & TRN & & \\
\hline CHEMBL361613 & 305650 & 10.1871 & 10.2522 & TRN & & \\
\hline CHEMBL434147 & 305650 & 9.2076 & 9.2576 & TRN & & \\
\hline CHEMBL179066 & 305650 & 9.3372 & 9.5584 & TRN & & \\
\hline CHEMBL359643 & 305650 & 9.0362 & 8.7071 & TRN & & \\
\hline CHEMBL179551 & 305650 & 10.5086 & 10.3024 & TRN & & \\
\hline CHEMBL178775 & 305650 & 9.1367 & 9.0499 & TRN & & \\
\hline CHEMBL178280 & 305650 & 8.9666 & 9.1731 & TRN & & \\
\hline CHEMBL361825 & 305650 & 10.1739 & 10.1033 & TRN & & \\
\hline CHEMBL181295 & 305650 & 8.757 & 9.2433 & TRN & & \\
\hline CHEMBL361983 & 305650 & 8.7696 & 8.9495 & TRN & & \\
\hline CHEMBL181948 & 305650 & 8.7144 & 8.8083 & TRN & & \\
\hline CHEMBL425699 & 305650 & 8.7959 & 8.9073 & TST & & \\
\hline CHEMBL433771 & 305650 & 9.6576 & 9.7098 & TRN & & \\
\hline CHEMBL180763 & 305650 & 9.6383 & 9.5921 & TRN & & \\
\hline CHEMBL443565 & 305650 & 9.5086 & 9.0596 & TST & & \\
\hline CHEMBL182103 & 305650 & 8.7212 & 8.4522 & TRN & & \\
\hline CHEMBL362191 & 305650 & 9.3979 & 9.4579 & TRN & & \\
\hline CHEMBL366927 & 305650 & 10.3009 & 999999999 & 998 & 10.1065 & TRN \\
\hline CHEMBL 369290 & 305650 & 10.6021 & 10.2673 & TRN & & \\
\hline CHEMBL180273 & 305650 & 9.7212 & 9.93 & TRN & & \\
\hline CHEMBL360020 & 305650 & 8.7399 & 8.6385 & TRN & & \\
\hline CHEMBL424789 & 305650 & 9.5376 & 9.9786 & TRN & & \\
\hline CHEMBL360915 & 305650 & 9.0458 & 8.7941 & TRN & & \\
\hline CHEMBL441118 & 305650 & 10.3279 & 10.2466 & TRN & & \\
\hline CHEMBL178674 & 305650 & 9.0555 & 9.5262 & TRN & & \\
\hline CHEMBL367356 & 305650 & 11.0605 & 10.713 & TRN & & \\
\hline CHEMBL362213 & 305650 & 10.0605 & 9.2505 & TST & & \\
\hline CHEMBL178514 & 305650 & 10.6021 & 10.5656 & TRN & & \\
\hline CHEMBL181775 & 305650 & 9.6576 & 9.476 & TST & & \\
\hline CHEMBL360788 & 305650 & 10.8861 & 10.7703 & TST & & \\
\hline CHEMBL362074 & 305650 & 9.9586 & 10.0746 & TST & & \\
\hline CHEMBL360956 & 305650 & 9.1739 & 9.3923 & TST & & \\
\hline CHEMBL178116 & 305650 & 10.2218 & 9.4827 & TST & & \\
\hline CHEMBL181763 & 305650 & 9.2076 & 9.9059 & TST & & \\
\hline CHEMBL180669 & 305650 & 9.9586 & 10.0475 & TST & & \\
\hline CHEMBL181396 & 305650 & 8.9431 & 9.3347 & TST & & \\
\hline CHEMBL179503 & 305650 & 9.9586 & 9.9021 & TST & & \\
\hline CHEMBL220238 & 305650 & 9.0088 & 9.274 & TST & & \\
\hline CHEMBL1812546 & 761928 & 4.3979 & 3.5092 & TRN & & \\
\hline CHEMBL1812533 & 761928 & 4.3979 & 3.5154 & TRN & & \\
\hline CHEMBL1812518 & 761928 & 2.699 & 2.8141 & TRN & & \\
\hline CHEMBL1812503 & 761928 & 2.699 & 3.0915 & TRN & & \\
\hline CHEMBL1812504 & 761928 & 2.699 & 2.8226 & TRN & & \\
\hline CHEMBL441669 & 761928 & 3.0969 & 2.9208 & TRN & & \\
\hline CHEMBL1812532 & 761928 & 3.0969 & 3.1891 & TRN & & \\
\hline CHEMBL171548 & 761928 & 3.0 & 3.1489 & TRN & & \\
\hline CHEMBL1812515 & 761928 & 3.0969 & 2.8991 & TRN & & \\
\hline
\end{tabular}


Supplemental Table S2.txt

\begin{tabular}{|c|c|c|c|c|c|}
\hline CHEMBL1812510 & 761928 & 2.699 & 2.8915 & TRN & \\
\hline CHEMBL1812528 & 761928 & 4.699 & 2.9944 & TRN & \\
\hline CHEMBL1812534 & 761928 & 2.699 & 3.4649 & TRN & \\
\hline CHEMBL1812524 & 761928 & 2.699 & 2.9205 & TRN & \\
\hline CHEMBL1812539 & 761928 & 4.699 & 3.6085 & TRN & \\
\hline CHEMBL1812653 & 761928 & 2.699 & 2.8765 & TST & \\
\hline CHEMBL1812501 & 761928 & 3.0969 & 3.0492 & TST & \\
\hline CHEMBL1812544 & 761928 & 3.0969 & 3.1643 & TRN & \\
\hline CHEMBL1812497 & 761928 & 3.0969 & 2.8948 & TRN & \\
\hline CHEMBL1812552 & 761928 & 3.0969 & 3.4553 & TRN & \\
\hline CHEMBL1812512 & 761928 & 3.0969 & 3.0659 & TRN & \\
\hline CHEMBL1812656 & 761928 & 3.0969 & 3.1143 & TST & \\
\hline CHEMBL355606 & 761928 & 3.0969 & 3.2328 & TRN & \\
\hline CHEMBL1812498 & 761928 & 3.0969 & 2.9186 & TRN & \\
\hline CHEMBL1812519 & 761928 & 2.699 & 2.7948 & TRN & \\
\hline CHEMBL435072 & 761928 & 3.699 & 3.3903 & TRN & \\
\hline CHEMBL1812511 & 761928 & 2.699 & 2.8127 & TRN & \\
\hline CHEMBL1812540 & 761928 & 4.3979 & 3.5713 & TRN & \\
\hline CHEMBL1812549 & 761928 & 3.0969 & 3.4466 & TRN & \\
\hline CHEMBL168956 & 761928 & 3.0969 & 3.2007 & TRN & \\
\hline CHEMBL176991 & 761928 & 3.0969 & 3.2324 & TST & \\
\hline CHEMBL1812509 & 761928 & 2.699 & 2.9008 & TRN & \\
\hline CHEMBL1812526 & 761928 & 2.3979 & 3.0634 & TRN & \\
\hline CHEMBL1812506 & 761928 & 3.0969 & 3.0638 & TRN & \\
\hline CHEMBL1812547 & 761928 & 2.3979 & 3.4915 & TRN & \\
\hline CHEMBL445966 & 761928 & 2.3979 & 3.1668 & TRN & \\
\hline CHEMBL166509 & 761928 & 3.0 & 3.0691 & TRN & \\
\hline CHEMBL1812529 & 761928 & 2.699 & 2.8875 & TRN & \\
\hline CHEMBL1812507 & 761928 & 4.3979 & 3.0084 & TRN & \\
\hline CHEMBL1812535 & 761928 & 4.3979 & 3.5893 & TRN & \\
\hline CHEMBL1812500 & 761928 & 3.0969 & 2.8645 & TST & \\
\hline CHEMBL1812513 & 761928 & 4.699 & 3.0076 & TRN & \\
\hline CHEMBL1812553 & 761928 & 3.0969 & 2.88199 & 99999999997 & TST \\
\hline CHEMBL1812514 & 761928 & 2.699 & 2.9006 & TRN & \\
\hline CHEMBL1812548 & 761928 & 4.0 & 3.5335 & TRN & \\
\hline CHEMBL1812550 & 761928 & 3.0969 & 3.4189 & TRN & \\
\hline CHEMBL1812505 & 761928 & 2.699 & 2.8124 & TRN & \\
\hline CHEMBL46724 & 761928 & 3.0969 & 3.1915 & TST & \\
\hline CHEMBL1812531 & 761928 & 4.0 & 3.4416 & TRN & \\
\hline CHEMBL1812522 & 761928 & 2.699 & 2.9158 & TRN & \\
\hline CHEMBL1812516 & 761928 & 2.699 & 2.9537 & TRN & \\
\hline CHEMBL1812521 & 761928 & 2.699 & 2.9958 & TRN & \\
\hline CHEMBL1812654 & 761928 & 3.0969 & 3.2205 & TST & \\
\hline CHEMBL1812520 & 761928 & 3.3979 & 3.0654 & TRN & \\
\hline CHEMBL1812508 & 761928 & 2.699 & \multicolumn{2}{|c|}{2.9619999999999997} & TRN \\
\hline CHEMBL1812499 & 761928 & 3.0969 & 2.8524 & TRN & \\
\hline CHEMBL1812517 & 761928 & 2.699 & 2.9494 & TRN & \\
\hline CHEMBL1812536 & 761928 & 2.699 & 3.583 & TRN & \\
\hline
\end{tabular}




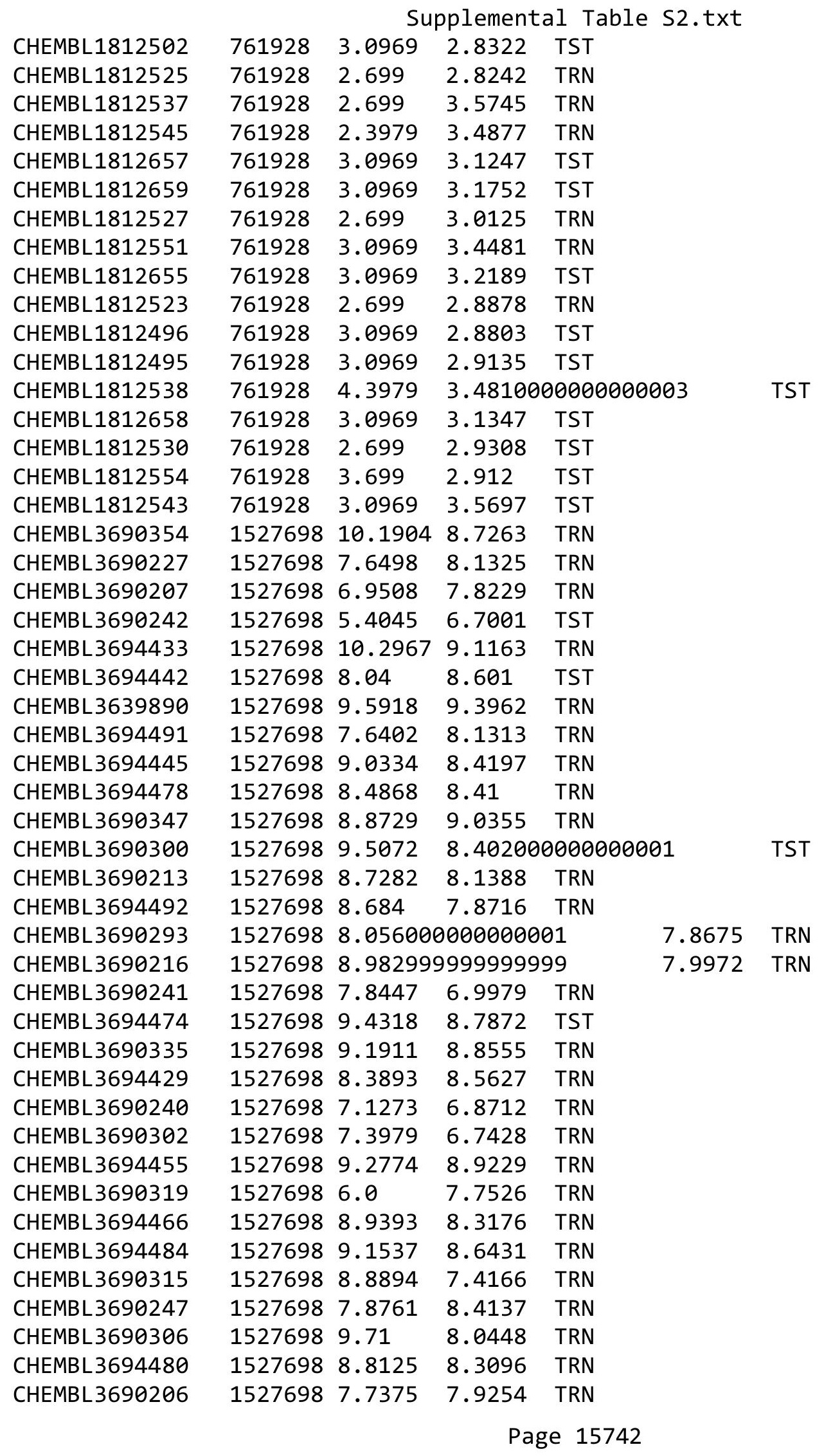


Supplemental Table S2.txt

\begin{tabular}{|c|c|c|c|c|c|}
\hline CHEMBL 3690317 & 1527698 & 8.8962 & 8.9704 & TRN & \\
\hline CHEMBL 3639891 & 1527698 & 9.757 & 8.8545 & TRN & \\
\hline CHEMBL 3690307 & 1527698 & 7.9355 & 8.2866 & TST & \\
\hline CHEMBL 3690279 & 1527698 & 6.0 & 7.1347 & TRN & \\
\hline CHEMBL3690305 & 1527698 & 6.0 & 8.4131 & TRN & \\
\hline CHEMBL 3690261 & 1527698 & 8.8539 & 8.1168 & TRN & \\
\hline CHEMBL 3690355 & 1527698 & 10.5452 & 8.3129 & TRN & \\
\hline CHEMBL 3690298 & 1527698 & 6.0 & 5.523 & TRN & \\
\hline CHEMBL 3690282 & 1527698 & 8.0013 & 7.6676 & TRN & \\
\hline CHEMBL3690243 & 1527698 & 7.5622 & 8.2957 & TRN & \\
\hline CHEMBL 3690229 & 1527698 & 8.1605 & 7.9661 & TRN & \\
\hline CHEMBL 3690308 & 1527698 & 9.1599 & 9.4454 & TST & \\
\hline CHEMBL3319210 & 1527698 & 9.8013 & 9.1748 & TRN & \\
\hline CHEMBL 3694465 & 1527698 & 9.1586 & 8.4726 & TRN & \\
\hline CHEMBL3694435 & 1527698 & 9.0969 & 8.3917 & TRN & \\
\hline CHEMBL 3690316 & 1527698 & 9.2062 & 9.4167 & TRN & \\
\hline CHEMBL3694432 & 1527698 & 10.2255 & 8.33 & TRN & \\
\hline CHEMBL 3694468 & 1527698 & 9.2 & 7.7807 & TRN & \\
\hline CHEMBL 3694451 & 1527698 & 7.9872 & 8.1303 & TRN & \\
\hline CHEMBL3694473 & 1527698 & 9.1267 & 9.0011 & TRN & \\
\hline CHEMBL 3690200 & 1527698 & 9.1192 & 8.6419 & TRN & \\
\hline CHEMBL 3694470 & 1527698 & 7.2373 & 9.1144 & TST & \\
\hline CHEMBL 3690351 & 1527698 & 6.0 & 6.2356 & TRN & \\
\hline CHEMBL 3694428 & 1527698 & 8.8069 & 9.9653 & TRN & \\
\hline CHEMBL 3694443 & 1527698 & 9.6615 & 9.0786 & TRN & \\
\hline CHEMBL 3690272 & 1527698 & 8.7852 & 8.1095 & TRN & \\
\hline CHEMBL 3690303 & 1527698 & 6.0 & 6.6686 & TRN & \\
\hline CHEMBL 3690332 & 1527698 & 9.5719 & 8.4615 & TRN & \\
\hline CHEMBL 3690266 & 1527698 & 8.6556 & 8.8945 & TRN & \\
\hline CHEMBL 3690202 & 1527698 & 8.2097 & 8.0218 & TRN & \\
\hline CHEMBL 3690357 & 1527698 & 8.6345 & 8.1972 & TRN & \\
\hline CHEMBL 3690252 & 1527698 & 9.466000 & 00000006 & 1 & 8.8311 \\
\hline CHEMBL 3694476 & 1527698 & 8.6402 & 8.6014 & TRN & \\
\hline CHEMBL 3694454 & 1527698 & 8.5544 & 8.3488 & TRN & \\
\hline CHEMBL 3690197 & 1527698 & 7.3497 & 7.0637 & TRN & \\
\hline CHEMBL 3694461 & 1527698 & 6.3799 & 7.7106 & TST & \\
\hline CHEMBL 3690258 & 1527698 & 7.3526 & 8.9884 & TRN & \\
\hline CHEMBL 3639933 & 1527698 & 7.4962 & 8.1154 & TST & \\
\hline CHEMBL 3690280 & 1527698 & 9.5735 & 8.61 & TST & \\
\hline CHEMBL 3690224 & 1527698 & 5.7932 & 7.726 & TST & \\
\hline CHEMBL 3690263 & 1527698 & 8.4377 & 8.1202 & TRN & \\
\hline CHEMBL 3690210 & 1527698 & 7.1409 & 8.0113 & TRN & \\
\hline CHEMBL3690312 & 1527698 & 8.9355 & 8.4049 & TRN & \\
\hline CHEMBL 3690225 & 1527698 & 7.0052 & 9.6908 & TST & \\
\hline CHEMBL 3690285 & 1527698 & 8.3768 & 8.6141 & TRN & \\
\hline CHEMBL 3690269 & 1527698 & 8.5003 & 8.218 & TRN & \\
\hline CHEMBL 3690226 & 1527698 & 6.5638 & 7.8991 & TRN & \\
\hline CHEMBL 3690301 & 1527698 & 6.0 & 6.1447 & TRN & \\
\hline
\end{tabular}


Supplemental Table S2.txt

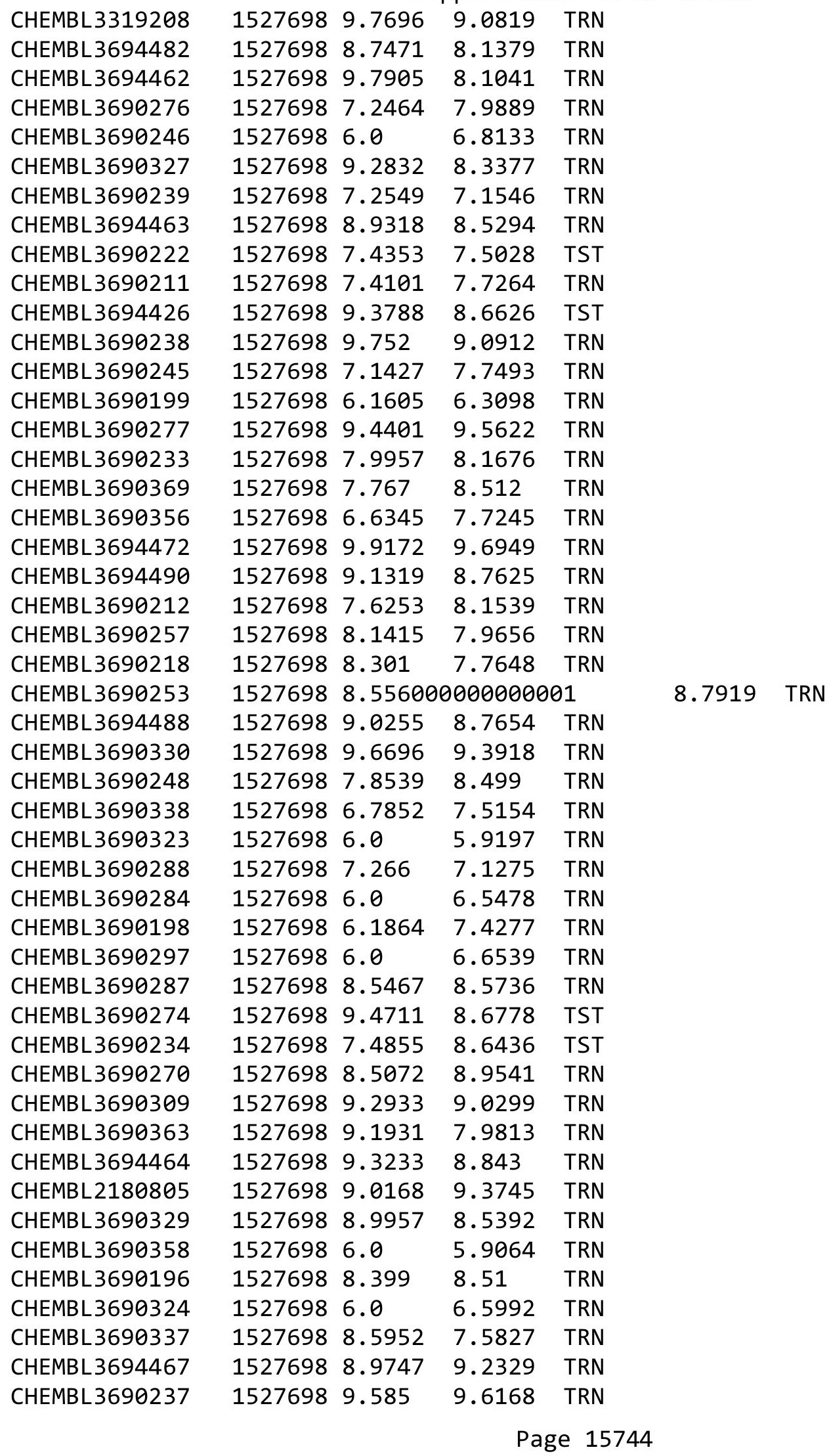


Supplemental Table S2.txt

\begin{tabular}{|c|c|c|c|c|}
\hline 4459 & 527698 & 6.9245 & 7.0245 & ונכו \\
\hline & & & 8.2343 & \\
\hline HEMRI & 27698 & 238 & & \\
\hline IEMBL & & 7595 & 69 & \\
\hline AEMBL3690232 & 527698 & 3726 & 3378 & \\
\hline HEMBL369 & 527698 & 8.684 & 75 & \\
\hline HEMBL & & & 85 & \\
\hline HEMBL369 & & & 85 & \\
\hline HEMBL3694485 & 527698 & 8.8601 & 8.5649 & \\
\hline HEMBL 3698 & 527698 & 7.6517 & .1604 & \\
\hline HEMBL 369 & 98 & 6.0 & 6.0442 & \\
\hline HEMBL & 98 & 97 & .4563 & \\
\hline AEMBL & & & & \\
\hline HEMBL 3698 & 527698 & 383 & 8.6528 & \\
\hline HEMBL 369 & 98 & & & \\
\hline HEMBL36 & 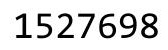 & 8 . & 8.8173 & \\
\hline HEMBL & & & & \\
\hline HEMBL; & & 94 & 03 & \\
\hline HEMBL 369 & 98 & 605 & 8.3194 & \\
\hline HEMBL369 & & 6. & & \\
\hline HEMBL & 98 & & 34 & ו \\
\hline HEM & & & & 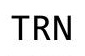 \\
\hline AEMBL & 98 & 894 & 93 & \\
\hline HEMBL 369 & & 6. & & II \\
\hline HEMBL 369 & & 8 & & SI \\
\hline HEMBL & & 16 & & RN \\
\hline HEME & & & & ו \\
\hline 30 & & 6 & 8 & RN \\
\hline AEMBL & & & & RIN \\
\hline HEMBL369 & & 8. & 8.7036 & RN \\
\hline AEMBL & & & & ו \\
\hline 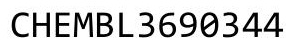 & & 6 & & ST \\
\hline 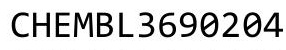 & & & 079 & TRN \\
\hline HEMBL 369 & & & & RN \\
\hline HEMBL 369 & 98 & & 31 & ST \\
\hline JEMP & & & 56 & RN \\
\hline 5 & & & & RN \\
\hline HEMBL 369 & & 9.7747 & & TRN \\
\hline HEMBL 369 & 98 & & & $\mathrm{RN}$ \\
\hline 9 & & & & ST \\
\hline HEMBL3 & & & 25 & ST \\
\hline HEMBL3 & 98 & 9 & 767 & RN \\
\hline HEMBL 369 & & & & ST \\
\hline HEMBL369 & 98 & 8 . & & TS \\
\hline 4 & & & & TST \\
\hline HEMBL3 & & & .8557 & \\
\hline HEMBL 369 & 698 & 9.567 & 9.4568 & N \\
\hline CHEMBL3690214 & 152769 & 9.5186 & 8.6857 & TST \\
\hline
\end{tabular}

Page 15745 
Supplemental Table S2.txt

\begin{tabular}{|c|c|c|c|c|}
\hline CHEMBL 3690244 & 1527698 & 7.2284 & 8.2179 & TST \\
\hline CHEMBL3690268 & 1527698 & 8.6073 & 8.4469 & TST \\
\hline CHEMBL3690289 & 1527698 & 8.6737 & 7.7063 & TST \\
\hline CHEMBL3690221 & 1527698 & 6.9281 & 7.9045 & TST \\
\hline CHEMBL3690255 & 1527698 & 9.1739 & 8.7992 & TRN \\
\hline CHEMBL3694489 & 1527698 & 8.9431 & 8.4034 & TRN \\
\hline CHEMBL3690299 & 1527698 & 9.3098 & 7.95299 & 9999999999 \\
\hline CHEMBL 3690260 & 1527698 & 8.7747 & 8.2495 & TST \\
\hline CHEMBL3690359 & 1527698 & 6.0 & 6.9854 & TRN \\
\hline CHEMBL 3690251 & 1527698 & 8.8297 & 8.2989 & TRN \\
\hline CHEMBL3690275 & 1527698 & 9.7471 & 9.1186 & TST \\
\hline CHEMBL3690295 & 1527698 & 7.5045 & 7.1801 & TST \\
\hline CHEMBL 3694434 & 1527698 & 8.7878 & 8.5139 & TRN \\
\hline CHEMBL3694479 & 1527698 & 9.7721 & 7.6745 & TST \\
\hline CHEMBL 3694477 & 1527698 & 9.0448 & 9.0547 & TST \\
\hline CHEMBL3690217 & 1527698 & 7.5751 & 7.9726 & TST \\
\hline CHEMBL3690201 & 1527698 & 8.202 & 9.1394 & TRN \\
\hline CHEMBL 3690281 & 1527698 & 8.9957 & 9.1356 & TRN \\
\hline CHEMBL 3690271 & 1527698 & 8.5302 & 8.8985 & TRN \\
\hline CHEMBL3690336 & 1527698 & 6.0 & 8.7134 & TRN \\
\hline CHEMBL3690273 & 1527698 & 9.6038 & 9.1608 & TST \\
\hline CHEMBL 2071607 & 1527698 & 6.9508 & 6.5356 & TST \\
\hline CHEMBL 3694483 & 1527698 & 8.7305 & 7.897 & TRN \\
\hline CHEMBL3690364 & 1527698 & 8.0186 & 8.8027 & TRN \\
\hline CHEMBL3690328 & 1527698 & 8.6038 & 7.6938 & TST \\
\hline CHEMBL3694458 & 1527698 & 6.3778 & 8.1053 & TRN \\
\hline CHEMBL3690348 & 1527698 & 6.2874 & 8.2348 & TST \\
\hline CHEMBL 3690349 & 1527698 & 6.0 & 7.2571 & TRN \\
\hline CHEMBL3690230 & 1527698 & 7.8928 & 7.1768 & TRN \\
\hline CHEMBL 3690290 & 1527698 & 6.0 & 7.7956 & TRN \\
\hline CHEMBL3694481 & 1527698 & 8.3862 & 8.2477 & TRN \\
\hline CHEMBL3690286 & 1527698 & 7.3401 & 8.2329 & TRN \\
\hline CHEMBL 3690220 & 1527698 & 8.1785 & 8.8952 & TST \\
\hline CHEMBL3690203 & 1527698 & 8.7932 & 8.5189 & TRN \\
\hline CHEMBL3690231 & 1527698 & 7.3575 & 8.3597 & TST \\
\hline CHEMBL1420705 & 688477 & 2.3092 & 3.1751 & TRN \\
\hline CHEMBL1485127 & 688477 & 4.9052 & 4.4074 & TRN \\
\hline CHEMBL1459717 & 688477 & 4.691 & 5.2898 & TRN \\
\hline CHEMBL1588600 & 688477 & 4.6021 & 4.9769 & TRN \\
\hline CHEMBL1489368 & 688477 & 5.9872 & 4.3518 & TST \\
\hline CHEMBL494255 & 688477 & 6.2291 & 4.5514 & TST \\
\hline CHEMBL1544035 & 688477 & 4.7867 & 5.8158 & TRN \\
\hline CHEMBL1444036 & 688477 & 4.0706 & 5.2542 & TRN \\
\hline CHEMBL1324571 & 688477 & 4.9087 & 5.5189 & TRN \\
\hline CHEMBL1507636 & 688477 & 4.7286 & 4.9711 & TRN \\
\hline CHEMBL270297 & 688477 & 5.1146 & 5.1441 & TST \\
\hline CHEMBL3209768 & 688477 & 8.0 & 5.7991 & TRN \\
\hline CHEMBL1584440 & 688477 & 6.0269 & 4.9101 & TRN \\
\hline
\end{tabular}


Supplemental Table S2.txt

\begin{tabular}{|c|c|c|c|c|}
\hline CHEMBL1339327 & 688477 & 4.6021 & 5.0068 & TRN \\
\hline CHEMBL1485668 & 688477 & 4.1064 & 3.9866 & TRN \\
\hline CHEMBL534353 & 688477 & 4.9059 & 4.9064 & TRN \\
\hline CHEMBL1428721 & 688477 & 2.889 & 3.9327 & TRN \\
\hline CHEMBL1459947 & 688477 & 5.1707 & 4.9034 & TST \\
\hline CHEMBL1599636 & 688477 & 4.9516 & 4.9701 & TRN \\
\hline CHEMBL3196344 & 688477 & 4.8041 & 6.20200 & 0000000001 \\
\hline CHEMBL1510156 & 688477 & 5.8097 & 4.9333 & TRN \\
\hline CHEMBL3194976 & 688477 & 5.4001 & 4.3341 & TST \\
\hline CHEMBL1443819 & 688477 & 8.6778 & 6.3336 & TRN \\
\hline CHEMBL1362861 & 688477 & 4.9087 & 5.0219 & TRN \\
\hline CHEMBL1393825 & 688477 & 5.9626 & 5.6264 & TRN \\
\hline CHEMBL548615 & 688477 & 4.6449 & 6.1151 & TRN \\
\hline CHEMBL1610717 & 688477 & 5.1938 & 4.2298 & TRN \\
\hline CHEMBL1508570 & 688477 & 4.803 & 4.7959 & TRN \\
\hline CHEMBL1422950 & 688477 & 6.1249 & 4.5535 & TRN \\
\hline CHEMBL1612666 & 688477 & 5.1391 & 4.4569 & TRN \\
\hline CHEMBL1558216 & 688477 & 3.0185 & 3.9941 & TST \\
\hline CHEMBL1321025 & 688477 & 4.8945 & 5.591 & TRN \\
\hline CHEMBL1564551 & 688477 & 4.7943 & 3.8334 & TRN \\
\hline CHEMBL1494120 & 688477 & 6.2076 & 6.5564 & TRN \\
\hline CHEMBL1480976 & 688477 & 5.0535 & 6.4667 & TRN \\
\hline CHEMBL1429944 & 688477 & 5.6676 & 4.8455 & TRN \\
\hline CHEMBL1577840 & 688477 & 6.1079 & 4.2837 & TST \\
\hline CHEMBL1465665 & 688477 & 3.4647 & 4.3566 & TRN \\
\hline CHEMBL1460750 & 688477 & 6.7959 & 5.6091 & TRN \\
\hline CHEMBL1391781 & 688477 & 6.6576 & 5.3927 & TST \\
\hline CHEMBL1508654 & 688477 & 5.1314 & 5.6596 & TRN \\
\hline CHEMBL1459746 & 688477 & 6.4202 & 4.9371 & TRN \\
\hline CHEMBL1529000 & 688477 & 0.1307 & 4.1299 & TRN \\
\hline CHEMBL1372266 & 688477 & 4.9562 & 4.6887 & TRN \\
\hline CHEMBL1326482 & 688477 & 4.7036 & 4.4899 & TRN \\
\hline CHEMBL1992346 & 688477 & 4.9751 & 4.9952 & TST \\
\hline CHEMBL1579035 & 688477 & 6.7696 & 4.9575 & TRN \\
\hline CHEMBL1453212 & 688477 & 6.0757 & 4.9042 & TRN \\
\hline CHEMBL1471740 & 688477 & 5.3625 & 4.6966 & TRN \\
\hline CHEMBL3211435 & 688477 & 4.7918 & 3.0358 & TRN \\
\hline CHEMBL1599907 & 688477 & 5.71 & 5.3016 & TRN \\
\hline CHEMBL1403894 & 688477 & 5.5317 & 5.1384 & TRN \\
\hline CHEMBL1599863 & 688477 & 5.5058 & 6.3212 & TRN \\
\hline CHEMBL1465899 & 688477 & 4.6021 & 6.2198 & TRN \\
\hline CHEMBL1481403 & 688477 & 5.1244 & 4.6999 & TRN \\
\hline CHEMBL1604713 & 688477 & 3.4057 & 3.6678 & TRN \\
\hline CHEMBL1563867 & 688477 & 6.2757 & 5.5774 & TRN \\
\hline CHEMBL1386067 & 688477 & \multicolumn{3}{|c|}{5.172000000000001} \\
\hline CHEMBL1531114 & 688477 & 7.3979 & 4.8996 & TRN \\
\hline CHEMBL1372698 & 688477 & 4.3647 & 5.9502 & TRN \\
\hline CHEMBL1528061 & 688477 & 4.8976 & 5.5545 & TRN \\
\hline
\end{tabular}




\begin{tabular}{|c|c|c|c|c|c|c|}
\hline & & & & & & \\
\hline CHEMBL1353015 & 688477 & 5.7235 & 4.1201 & TRN & & \\
\hline CHEMBL3192398 & 688477 & 5.1574 & 5.4917 & TRN & & \\
\hline CHEMBL1597855 & 688477 & 4.9531 & 4.6132 & TRN & & \\
\hline CHEMBL1322695 & 688477 & 5.317 & 5.6414 & TRN & & \\
\hline CHEMBL1376861 & 688477 & 4.9069 & 4.22 & TRN & & \\
\hline CHEMBL1601988 & 688477 & 2.142 & 4.138 & TRN & & \\
\hline CHEMBL1528853 & 688477 & 4.4688 & 4.0048 & TRN & & \\
\hline CHEMBL1372241 & 688477 & 4.758999 & 99999999 & 995 & .8965 & TST \\
\hline CHEMBL 3197200 & 688477 & 7.699 & 7.532 & TRN & & \\
\hline CHEMBL1454183 & 688477 & 5.5784 & 4.0701 & TST & & \\
\hline CHEMBL 2004241 & 688477 & 6.585 & 4.5112 & TRN & & \\
\hline CHEMBL1387704 & 688477 & 5.8794 & 5.4232 & TRN & & \\
\hline CHEMBL3212629 & 688477 & 5.9872 & 4.8825 & TRN & & \\
\hline CHEMBL1438981 & 688477 & 5.0894 & 4.4204 & TRN & & \\
\hline CHEMBL1413351 & 688477 & 4.8125 & 4.1782 & TRN & & \\
\hline CHEMBL1600969 & 688477 & 4.6409 & 6.9037 & TRN & & \\
\hline CHEMBL1299328 & 688477 & 2.2856 & 4.6636 & TRN & & \\
\hline CHEMBL1423097 & 688477 & 2.603999 & 99999999 & 996 & .7397 & TRN \\
\hline CHEMBL1442726 & 688477 & 4.9031 & 4.2634 & TRN & & \\
\hline CHEMBL1500656 & 688477 & 2.9305 & 3.8753 & TRN & & \\
\hline CHEMBL1444103 & 688477 & 8.0 & 4.9708 & TRN & & \\
\hline CHEMBL1542678 & 688477 & 2.485 & 3.2541 & TRN & & \\
\hline CHEMBL1612814 & 688477 & 4.8601 & 5.2873 & TST & & \\
\hline CHEMBL1588516 & 688477 & 4.8677 & 4.7797 & TRN & & \\
\hline CHEMBL1574026 & 688477 & 7.5229 & 5.4241 & TRN & & \\
\hline CHEMBL1319238 & 688477 & 5.0526 & 5.1086 & TRN & & \\
\hline CHEMBL1427365 & 688477 & 4.6021 & 5.0007 & TRN & & \\
\hline CHEMBL1456712 & 688477 & 4.6021 & 5.0083 & TST & & \\
\hline CHEMBL1494074 & 688477 & 6.7212 & 6.5869 & TRN & & \\
\hline CHEMBL1427765 & 688477 & 4.3258 & 4.6323 & TRN & & \\
\hline CHEMBL1481654 & 688477 & 3.5575 & 4.7912 & TRN & & \\
\hline CHEMBL1417080 & 688477 & 5.3809 & 5.38299 & 9999999999 & & TRN \\
\hline CHEMBL1979539 & 688477 & 5.2111 & 5.9109 & TRN & & \\
\hline CHEMBL1577044 & 688477 & 5.0009 & 4.4779 & TRN & & \\
\hline CHEMBL1480866 & 688477 & 5.3625 & 3.3903 & TRN & & \\
\hline CHEMBL1383244 & 688477 & 4.6021 & 4.4878 & TRN & & \\
\hline CHEMBL1446981 & 688477 & 5.4498 & 5.5769 & TRN & & \\
\hline CHEMBL1498736 & 688477 & 5.1433 & 5.1838 & TRN & & \\
\hline CHEMBL 2004475 & 688477 & 4.9201 & 5.2276 & TST & & \\
\hline CHEMBL1609356 & 688477 & 4.3268 & 4.7937 & TRN & & \\
\hline CHEMBL1399821 & 688477 & 6.4089 & 5.1158 & TRN & & \\
\hline CHEMBL1422553 & 688477 & 1.8144 & 4.9444 & TST & & \\
\hline CHEMBL1321494 & 688477 & 6.4202 & 5.552006 & 0000000000 & & TRN \\
\hline CHEMBL1578853 & 688477 & 1.0229 & 3.8512 & TRN & & \\
\hline CHEMBL1319663 & 688477 & 0.8604 & 3.2048 & TRN & & \\
\hline CHEMBL1478901 & 688477 & $3.73100 e$ & 900000006 & 003 & .5905 & TRN \\
\hline CHEMBL1466635 & 688477 & 4.8976 & 5.0903 & TRN & & \\
\hline CHEMBL1546972 & 688477 & 6.5376 & 4.6282 & TRN & & \\
\hline
\end{tabular}




\begin{tabular}{|c|c|c|c|c|c|}
\hline & & \multicolumn{4}{|c|}{ Supplemental Table S2.txt } \\
\hline CHEMBL1381155 & 688477 & 5.6198 & 5.4883 & TRN & \\
\hline CHEMBL1302008 & 688477 & 3.0824 & 3.6847 & TRN & \\
\hline CHEMBL1366929 & 688477 & 5.5287 & 5.4808 & TRN & \\
\hline CHEMBL1575594 & 688477 & 4.9348 & 4.6104 & TST & \\
\hline CHEMBL1433182 & 688477 & 6.0 & 5.4803 & TRN & \\
\hline CHEMBL1971185 & 688477 & 2.7307 & 5.191 & TRN & \\
\hline CHEMBL1563104 & 688477 & 4.9003 & 4.3451 & TRN & \\
\hline CHEMBL1384554 & 688477 & 2.3664 & 3.8879 & TST & \\
\hline CHEMBL338474 & 688477 & 6.3768 & 4.7762 & TST & \\
\hline CHEMBL1400741 & 688477 & 4.2634 & 5.3913 & TRN & \\
\hline CHEMBL1328861 & 688477 & 3.3106 & 4.5928 & TRN & \\
\hline CHEMBL1412615 & 688477 & 4.6021 & 5.2878 & TRN & \\
\hline CHEMBL1380447 & 688477 & 3.8256 & 4.6235 & TRN & \\
\hline CHEMBL1493936 & 688477 & 8.0 & 6.3781 & TST & \\
\hline CHEMBL1439938 & 688477 & 3.7403 & 4.6891 & TRN & \\
\hline CHEMBL1564354 & 688477 & 5.9626 & 5.2841 & TRN & \\
\hline CHEMBL1493420 & 688477 & -0.214 & 3.5684 & TRN & \\
\hline CHEMBL1506014 & 688477 & 4.8778 & 4.8709 & TRN & \\
\hline CHEMBL1581794 & 688477 & 5.6144 & 4.6955 & TRN & \\
\hline CHEMBL1483654 & 688477 & 6.0915 & 5.9112 & TRN & \\
\hline CHEMBL1603902 & 688477 & 4.8371 & 4.8375 & TRN & \\
\hline CHEMBL1399698 & 688477 & 5.8477 & 5.2907 & TST & \\
\hline CHEMBL1335610 & 688477 & 5.699 & 5.6859 & TRN & \\
\hline CHEMBL1542911 & 688477 & 5.1068 & 5.0461 & TRN & \\
\hline CHEMBL1389973 & 688477 & 5.0273 & 5.3487 & TRN & \\
\hline CHEMBL1492017 & 688477 & 6.2518 & 5.2492 & TST & \\
\hline CHEMBL1377737 & 688477 & 6.2518 & 6.8232 & TRN & \\
\hline CHEMBL1341246 & 688477 & 4.9582 & 4.5312 & TRN & \\
\hline CHEMBL1442077 & 688477 & 8.0 & 5.4222 & TRN & \\
\hline CHEMBL1348322 & 688477 & 4.9559 & 4.8998 & TRN & \\
\hline CHEMBL1506485 & 688477 & 4.9097 & 6.0826 & TRN & \\
\hline CHEMBL1526871 & 688477 & 4.7156 & 4.4364 & TST & \\
\hline CHEMBL1393655 & 688477 & 7.0458 & 5.7075 & TRN & \\
\hline CHEMBL1564238 & 688477 & 5.0491 & 4.2917 & TRN & \\
\hline CHEMBL1546843 & 688477 & 6.5686 & 5.5626 & TRN & \\
\hline CHEMBL1307185 & 688477 & 5.9208 & 4.8981 & TST & \\
\hline CHEMBL1986619 & 688477 & 6.2147 & 3.97399 & 99999999998 & TST \\
\hline CHEMBL1425092 & 688477 & 4.3214 & 5.19600 & 0000000001 & TST \\
\hline CHEMBL1441597 & 688477 & 4.3322 & 4.6038 & TST & \\
\hline CHEMBL1558070 & 688477 & 5.6498 & 4.566 & TST & \\
\hline CHEMBL1468918 & 688477 & 3.3301 & 5.0283 & TST & \\
\hline CHEMBL1393752 & 688477 & 5.1445 & 3.3049 & TST & \\
\hline CHEMBL1420393 & 688477 & 5.7747 & 5.4428 & TST & \\
\hline CHEMBL1537480 & 688477 & 3.3551 & 4.6991 & TST & \\
\hline CHEMBL1338305 & 688477 & 5.0186 & 4.0478 & TST & \\
\hline CHEMBL1464853 & 688477 & 5.6162 & 4.7179 & TST & \\
\hline CHEMBL1500242 & 688477 & 5.7773 & 4.5888 & TST & \\
\hline CHEMBL1550485 & 688477 & 6.8861 & 4.9512 & TST & \\
\hline
\end{tabular}




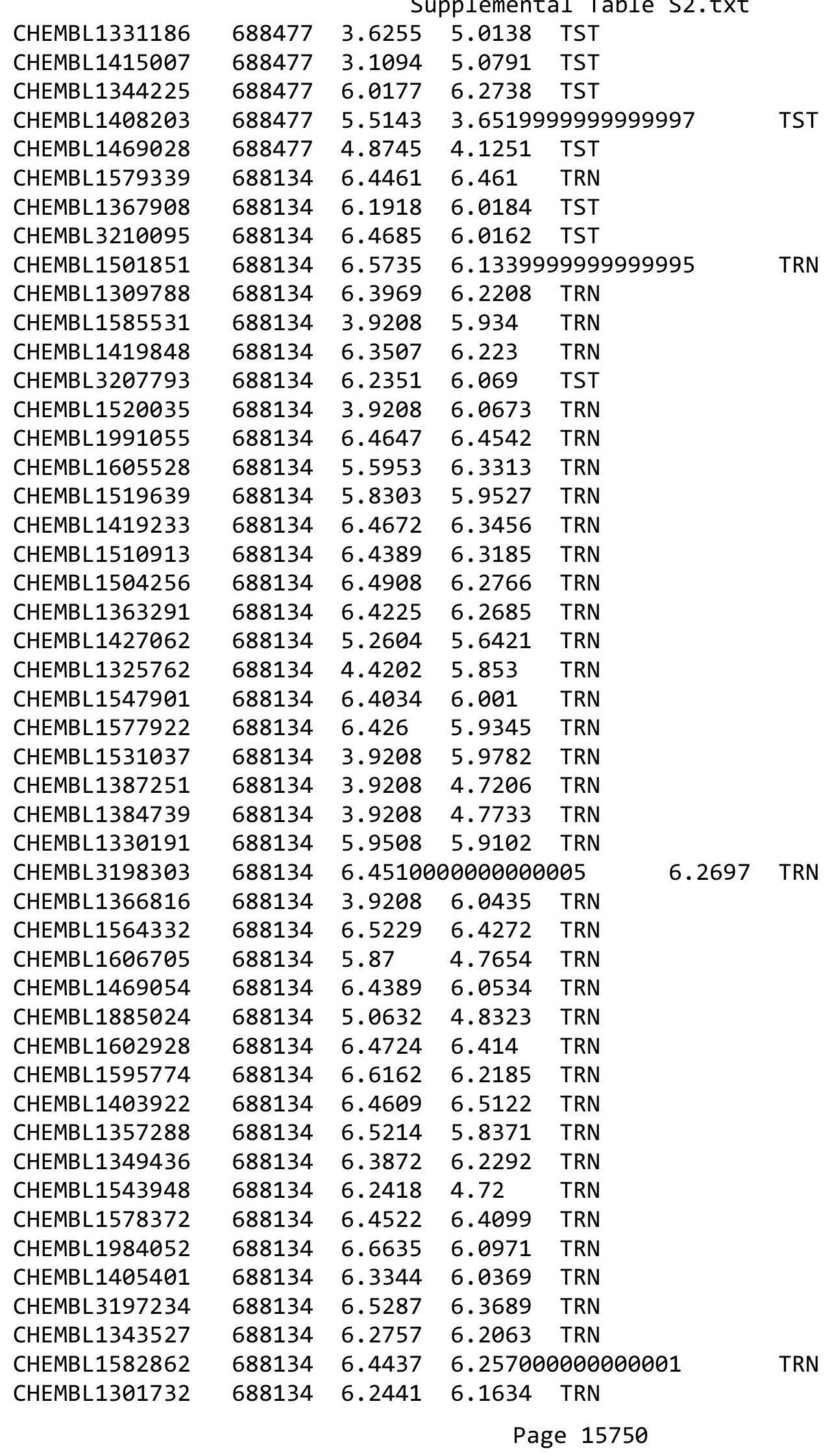


Supplemental Table S2.txt

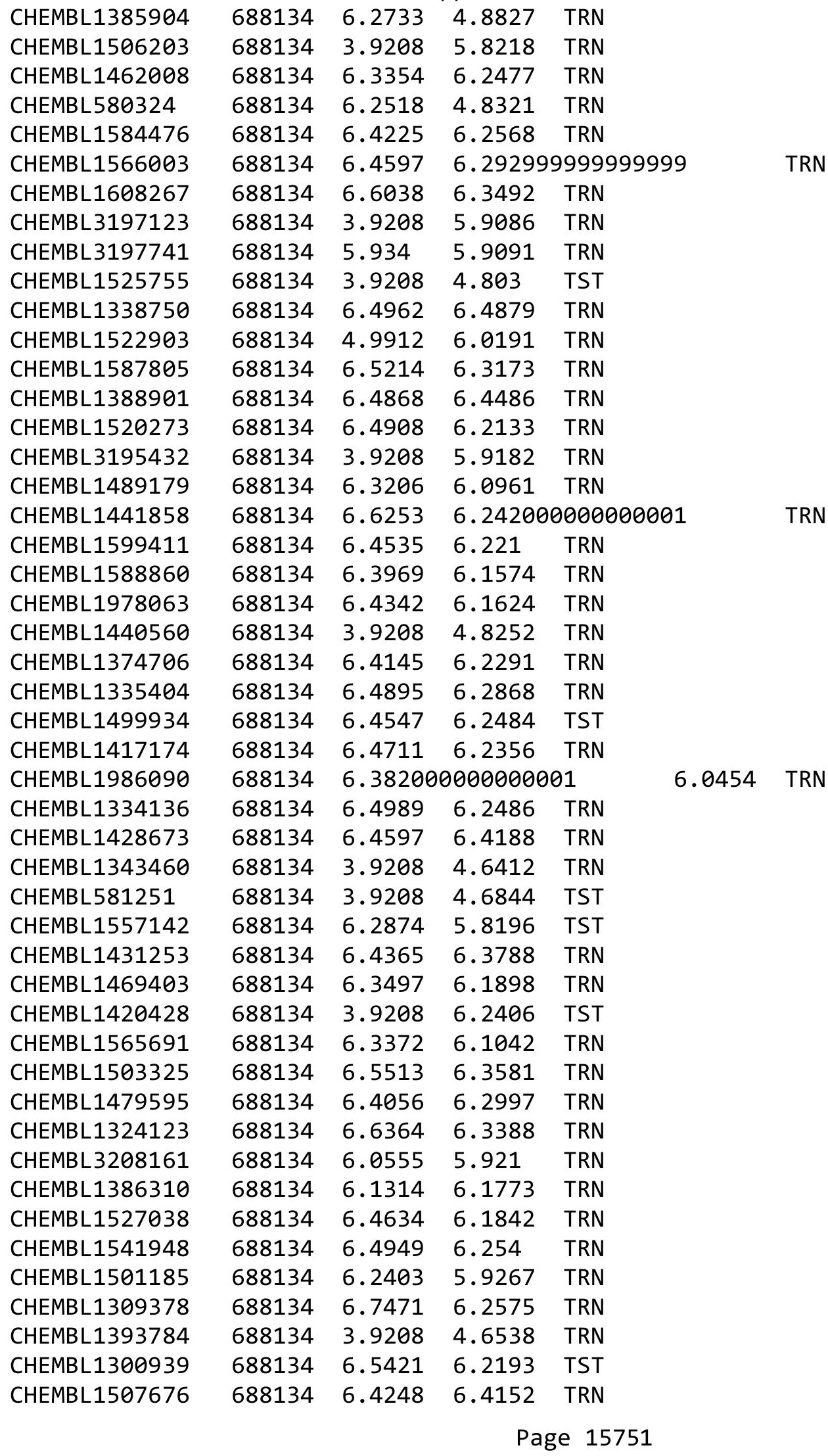


Supplemental Table S2.txt

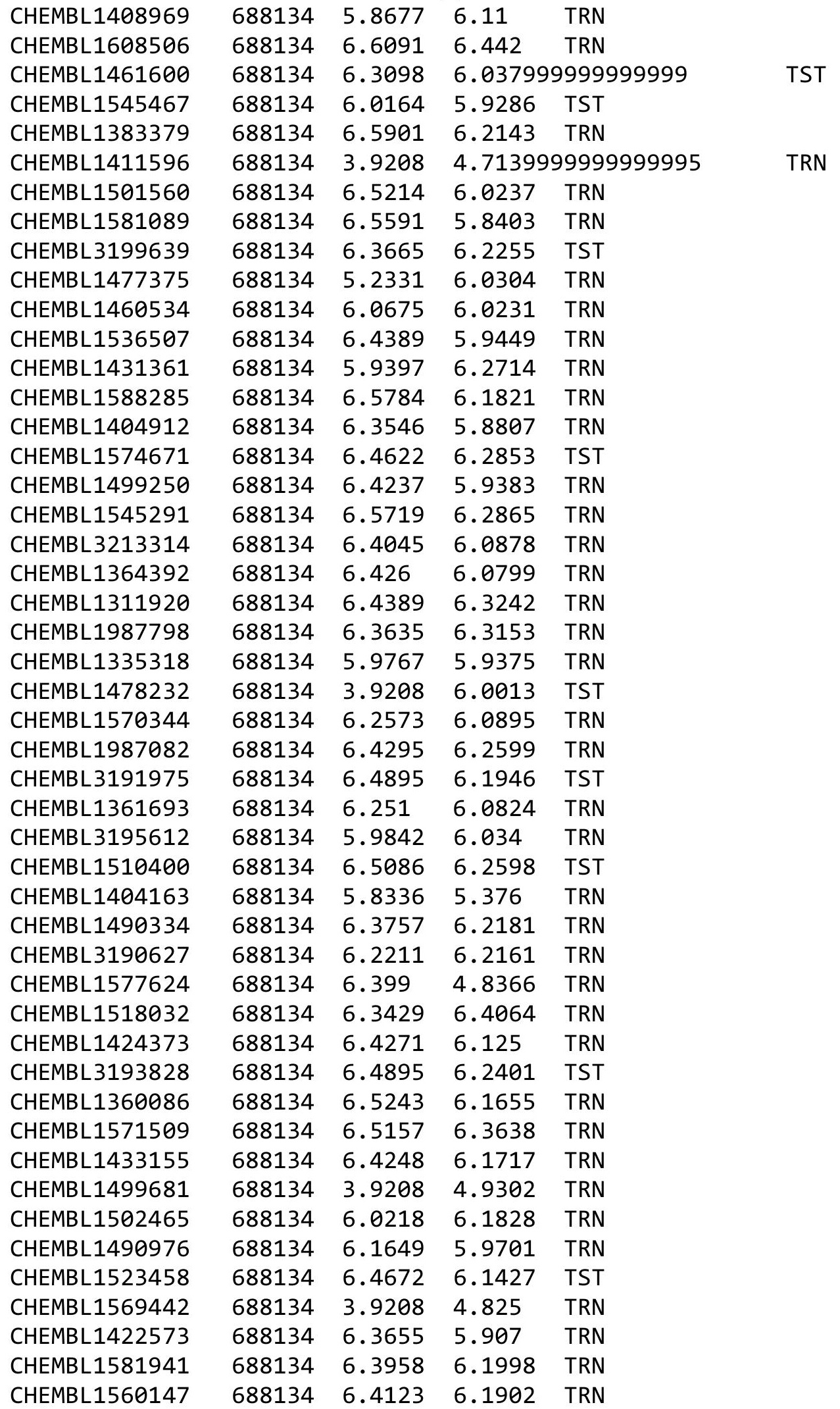

Page 15752 


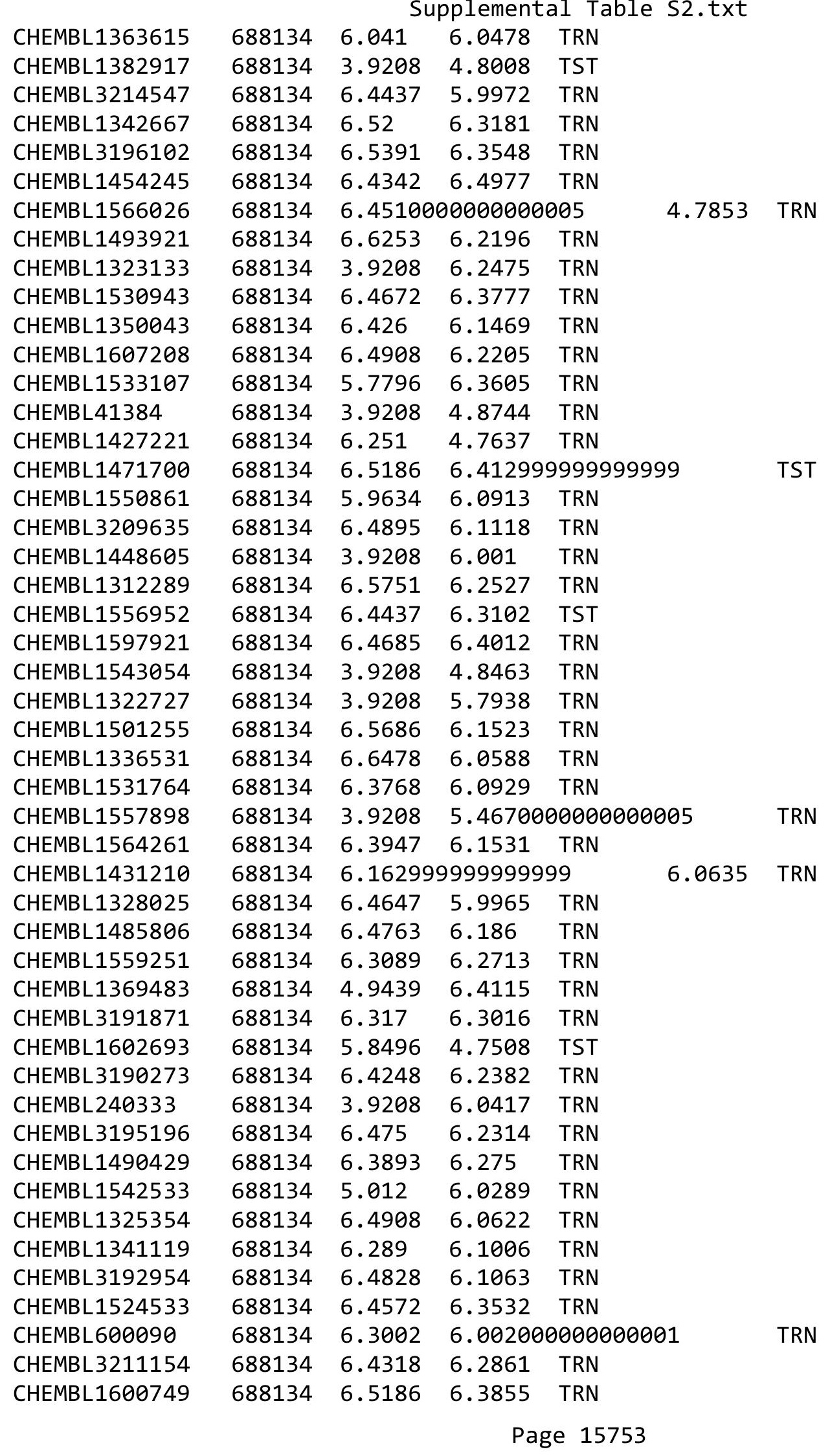




\begin{tabular}{|c|c|c|c|c|c|}
\hline & & & & & \\
\hline CHEMBL1321104 & 688134 & 6.1831 & 4.7159 & TRN & \\
\hline CHEMBL1572118 & 688134 & 6.0696 & 5.9257 & TRN & \\
\hline CHEMBL1422230 & 688134 & 6.4634 & 6.2239 & TRN & \\
\hline CHEMBL1327977 & 688134 & 6.3585 & 5.4286 & TRN & \\
\hline CHEMBL1495474 & 688134 & 6.4353 & 5.92700 & 00000000005 & TRN \\
\hline CHEMBL1390789 & 688134 & 6.5302 & 6.0818 & TRN & \\
\hline CHEMBL3197870 & 688134 & 6.3635 & 6.0654 & TRN & \\
\hline CHEMBL1441319 & 688134 & 5.8277 & 6.1812 & TRN & \\
\hline CHEMBL1586026 & 688134 & 6.6271 & 6.2413 & TRN & \\
\hline CHEMBL1523841 & 688134 & 6.5751 & 6.3925 & TST & \\
\hline CHEMBL1561135 & 688134 & 6.317 & 5.9189 & TRN & \\
\hline CHEMBL1377188 & 688134 & 3.9208 & 4.6591 & TRN & \\
\hline CHEMBL1401361 & 688134 & 5.0854 & 6.2907 & TST & \\
\hline CHEMBL1511008 & 688134 & 6.0348 & 6.0515 & TST & \\
\hline CHEMBL1355755 & 688134 & 6.4012 & 5.9582 & TST & \\
\hline CHEMBL1545433 & 688134 & 3.9208 & 4.7871 & TST & \\
\hline CHEMBL3213101 & 688134 & 6.3925 & 6.2098 & TST & \\
\hline CHEMBL1328527 & 688134 & 6.7212 & 6.1252 & TST & \\
\hline CHEMBL1327517 & 688134 & 3.9208 & 4.6407 & TST & \\
\hline CHEMBL1392667 & 688134 & 6.3925 & 6.1103 & TST & \\
\hline CHEMBL1381195 & 688134 & 3.9208 & 5.8741 & TST & \\
\hline CHEMBL1575402 & 688134 & 6.4763 & 6.0918 & TST & \\
\hline CHEMBL3191398 & 688134 & 5.8713 & 4.8384 & TST & \\
\hline CHEMBL1586145 & 688134 & 6.3904 & 6.0341 & TST & \\
\hline CHEMBL1364646 & 688134 & 6.4711 & 6.2643 & TST & \\
\hline CHEMBL1572929 & 688134 & 3.9208 & 4.7482 & TST & \\
\hline CHEMBL1476311 & 688134 & 5.4307 & 5.9702 & TST & \\
\hline CHEMBL1323422 & 688134 & 6.556 & 6.3418 & TST & \\
\hline CHEMBL473106 & 688134 & 6.58 & 6.2783 & TST & \\
\hline CHEMBL1461878 & 688134 & 3.9208 & 4.8102 & TST & \\
\hline CHEMBL1424754 & 688134 & 6.3958 & 6.0862 & TST & \\
\hline CHEMBL1358014 & 688134 & 5.7783 & 5.9665 & TST & \\
\hline CHEMBL1402437 & 688134 & 6.1884 & 5.8225 & TST & \\
\hline CHEMBL1451684 & 688134 & 3.9208 & 6.3051 & TST & \\
\hline CHEMBL3195212 & 688134 & 6.5186 & 6.3028 & TST & \\
\hline CHEMBL1606344 & 688134 & 6.0691 & 4.8272 & TST & \\
\hline CHEMBL1491745 & 688134 & 3.9208 & 5.7227 & TST & \\
\hline CHEMBL1310825 & 688134 & 5.8239 & 4.9334 & TST & \\
\hline CHEMBL1494524 & 688134 & 6.3242 & 6.07100 & 0000000001 & TST \\
\hline CHEMBL1339785 & 688134 & 6.1884 & 5.9609 & TST & \\
\hline CHEMBL1468618 & 688134 & 6.1739 & 6.0857 & TST & \\
\hline CHEMBL3191418 & 688134 & 3.9208 & 4.8175 & TST & \\
\hline CHEMBL1464721 & 688134 & 6.8268 & 4.8242 & TST & \\
\hline CHEMBL1518080 & 688134 & 3.9208 & 6.2632 & TST & \\
\hline CHEMBL1583879 & 688134 & 6.5467 & 6.3401 & TST & \\
\hline CHEMBL1977589 & 688134 & 6.4908 & 6.3928 & TST & \\
\hline CHEMBL1423951 & 688134 & 6.2118 & 5.4005 & TST & \\
\hline CHEMBL1485052 & 688134 & 5.959 & 4.7952 & TST & \\
\hline
\end{tabular}


Supplemental Table S2.txt

\begin{tabular}{|c|c|c|c|c|c|}
\hline CHEMBL 2408904 & 1642120 & 7.3979 & 6.0811 & TRN & \\
\hline CHEMBL 2408898 & 1642120 & 6.0 & 5.9788 & TRN & \\
\hline CHEMBL 2408922 & 1642120 & 6.0 & 6.3711 & TRN & \\
\hline CHEMBL 3893566 & 1642120 & 5.301 & 5.8908 & TRN & \\
\hline CHEMBL3900802 & 1642120 & 6.699 & 5.9977 & TRN & \\
\hline CHEMBL 2408918 & 1642120 & 7.0 & \multicolumn{2}{|c|}{6.281000000000001} & TRN \\
\hline CHEMBL 3974202 & 1642120 & 6.0 & 5.5822 & TST & \\
\hline CHEMBL 3898233 & 1642120 & 5.0 & 4.5069 & TRN & \\
\hline CHEMBL 2408916 & 1642120 & 5.6021 & \multicolumn{2}{|c|}{6.0089999999999995} & TRN \\
\hline CHEMBL3923350 & 1642120 & 5.0 & 5.601 & TST & \\
\hline CHEMBL 2408906 & 1642120 & 5.0 & 5.8608 & TRN & \\
\hline CHEMBL3946507 & 1642120 & 5.0 & 5.852 & TRN & \\
\hline CHEMBL3970497 & 1642120 & 5.6021 & 4.8271 & TRN & \\
\hline CHEMBL 3961304 & 1642120 & 5.0 & 4.4923 & TRN & \\
\hline CHEMBL3915178 & 1642120 & 5.0 & 5.6608 & TST & \\
\hline CHEMBL 2408921 & 1642120 & 7.0 & 6.1344 & TRN & \\
\hline CHEMBL3975602 & 1642120 & 4.0 & 4.7447 & TRN & \\
\hline CHEMBL3934516 & 1642120 & 6.0 & 5.7018 & TST & \\
\hline CHEMBL 3920009 & 1642120 & 6.0 & 5.8182 & TRN & \\
\hline CHEMBL3963225 & 1642120 & 5.0 & 4.8526 & TRN & \\
\hline CHEMBL 2408914 & 1642120 & 5.0 & \multicolumn{2}{|c|}{6.082999999999999} & TRN \\
\hline CHEMBL3920677 & 1642120 & 5.0 & 5.4981 & TST & \\
\hline CHEMBL 2408902 & 1642120 & 5.0 & 5.9043 & TRN & \\
\hline CHEMBL 2408901 & 1642120 & 6.3979 & 6.1014 & TRN & \\
\hline CHEMBL3931539 & 1642120 & 5.0 & 4.5534 & TRN & \\
\hline CHEMBL 2408900 & 1642120 & 5.8239 & 6.0097 & TRN & \\
\hline CHEMBL 2408919 & 1642120 & 7.0 & 5.9626 & TRN & \\
\hline CHEMBL2408911 & 1642120 & 5.301 & 5.4188 & TST & \\
\hline CHEMBL 3921574 & 1642120 & 6.6478 & 6.1132 & TRN & \\
\hline CHEMBL3928775 & 1642120 & 5.0 & 5.4036 & TRN & \\
\hline CHEMBL3959031 & 1642120 & 5.0 & 5.2335 & TRN & \\
\hline CHEMBL2408908 & 1642120 & 6.8239 & 6.0028 & TST & \\
\hline CHEMBL3901496 & 1642120 & 7.0 & 5.5641 & TST & \\
\hline CHEMBL 3913213 & 1642120 & 5.0 & 5.2805 & TRN & \\
\hline CHEMBL3943150 & 1642120 & 5.0 & 5.1829 & TRN & \\
\hline CHEMBL 2408903 & 1642120 & 5.0 & 5.8051 & TRN & \\
\hline CHEMBL2408910 & 1642120 & 5.301 & 6.0422 & TRN & \\
\hline CHEMBL3919703 & 1642120 & 6.5607 & 5.4291 & TST & \\
\hline CHEMBL3922764 & 1642120 & 5.0 & 5.2762 & TRN & \\
\hline CHEMBL3937799 & 1642120 & 5.0 & 5.1606 & TRN & \\
\hline CHEMBL3917979 & 1642120 & 5.0 & 5.1709 & TRN & \\
\hline CHEMBL 2408907 & 1642120 & 5.0 & 5.6543 & TRN & \\
\hline CHEMBL3929814 & 1642120 & 6.0 & 5.6234 & TRN & \\
\hline CHEMBL 2408912 & 1642120 & 7.0 & 6.3543 & TRN & \\
\hline CHEMBL3960800 & 1642120 & 7.0 & 6.0192 & TRN & \\
\hline CHEMBL3962819 & 1642120 & 7.5229 & 5.7848 & TST & \\
\hline CHEMBL3938833 & 1642120 & 7.301 & 5.5861 & TST & \\
\hline CHEMBL2408899 & 1642120 & 6.0 & 6.1397 & TRN & \\
\hline
\end{tabular}




\begin{tabular}{|c|c|c|c|c|c|c|}
\hline \multicolumn{7}{|c|}{ Supplemental Table S2.txt } \\
\hline CHEMBL3913999 & 1642120 & 5.0 & 5.0871 & TST & & \\
\hline CHEMBL 2408905 & 1642120 & 6.5229 & 6.0019 & TST & & \\
\hline CHEMBL3923166 & 1640700 & 6.8871 & 6.9352 & TRN & & \\
\hline CHEMBL3968585 & 1640700 & 6.9933 & 6.8621 & TRN & & \\
\hline CHEMBL3929065 & 1640700 & 6.9395 & 7.0246 & TRN & & \\
\hline CHEMBL3929886 & 1640700 & 7.29200 & 000000006 & & 6.9135 & TRN \\
\hline CHEMBL 2177731 & 1640700 & 6.391 & 5.9614 & TST & & \\
\hline CHEMBL3915378 & 1640700 & 7.1026 & 6.6206 & TST & & \\
\hline CHEMBL3913308 & 1640700 & 8.1349 & 7.9903 & TRN & & \\
\hline CHEMBL3984163 & 1640700 & 8.8097 & 6.1963 & TST & & \\
\hline CHEMBL3979891 & 1640700 & 6.1953 & 6.2018 & TRN & & \\
\hline CHEMBL3937579 & 1640700 & 6.5884 & 6.7202 & TRN & & \\
\hline CHEMBL3975376 & 1640700 & 4.0 & 5.4778 & TST & & \\
\hline CHEMBL3905301 & 1640700 & 6.4623 & 6.4111 & TRN & & \\
\hline CHEMBL3978220 & 1640700 & 6.609 & 6.6311 & TRN & & \\
\hline CHEMBL3890598 & 1640700 & 6.5686 & 6.5054 & TRN & & \\
\hline CHEMBL3986921 & 1640700 & 6.2119 & 6.1558 & TRN & & \\
\hline CHEMBL3929792 & 1640700 & 7.0083 & 7.0664 & TRN & & \\
\hline CHEMBL3950662 & 1640700 & 6.7285 & 6.7806 & TST & & \\
\hline CHEMBL3981189 & 1640700 & 8.6576 & 6.7631 & TST & & \\
\hline CHEMBL3980690 & 1640700 & 7.2227 & 7.2791 & TRN & & \\
\hline CHEMBL 3917782 & 1640700 & 7.3219 & 5.4675 & TST & & \\
\hline CHEMBL3919813 & 1640700 & 7.3716 & 7.3649 & TRN & & \\
\hline CHEMBL3903684 & 1640700 & 6.7315 & 5.9396 & TST & & \\
\hline CHEMBL3985249 & 1640700 & 6.58299 & 999999999 & & 6.6962 & TRN \\
\hline CHEMBL3918656 & 1640700 & 5.7084 & 5.752000 & 0000000001 & & TRN \\
\hline CHEMBL3923353 & 1640700 & 6.63700 & 000000000 & $005 \quad \epsilon$ & 6.5511 & TRN \\
\hline CHEMBL3979246 & 1640700 & 7.6131 & 7.6941 & TRN & & \\
\hline CHEMBL 3923815 & 1640700 & 6.6598 & 6.6618 & TRN & & \\
\hline CHEMBL 2177735 & 1640700 & 7.806 & 6.7799 & TST & & \\
\hline CHEMBL3915494 & 1640700 & 7.2175 & 7.0781 & TRN & & \\
\hline CHEMBL3964570 & 1640700 & 7.1249 & 7.1099 & TRN & & \\
\hline CHEMBL3929222 & 1640700 & 6.3872 & 6.3861 & TRN & & \\
\hline CHEMBL3926161 & 1640700 & 6.3113 & 6.2772 & TRN & & \\
\hline CHEMBL3900807 & 1640700 & 7.4419 & 7.5066 & TRN & & \\
\hline CHEMBL 2177732 & 1640700 & 6.4544 & 6.1378 & TST & & \\
\hline CHEMBL3952392 & 1640700 & 6.6679 & 7.3749 & TST & & \\
\hline CHEMBL3892963 & 1640700 & 7.0479 & 6.994 & TRN & & \\
\hline CHEMBL3919960 & 1640700 & 6.5524 & 6.2879 & TRN & & \\
\hline CHEMBL3977076 & 1640700 & 5.9797 & 5.9824 & TRN & & \\
\hline CHEMBL 2177733 & 1640700 & 6.8952 & 6.075 & TST & & \\
\hline CHEMBL3901945 & 1640700 & 6.6783 & 6.6095 & TRN & & \\
\hline CHEMBL3985714 & 1640700 & 7.0576 & 6.9892 & TRN & & \\
\hline CHEMBL 3984821 & 1640700 & 6.4566 & 6.3694 & TRN & & \\
\hline CHEMBL3981889 & 1640700 & 6.051 & 5.8064 & TST & & \\
\hline CHEMBL3920882 & 1640700 & 6.5348 & 6.513 & TRN & & \\
\hline CHEMBL3913758 & 1640700 & 6.7975 & 6.7844 & TRN & & \\
\hline CHEMBL3903715 & 1640700 & 6.2222 & 6.1676 & TRN & & \\
\hline
\end{tabular}


Supplemental Table S2.txt

\begin{tabular}{|c|c|c|c|c|c|}
\hline CHEMBL3916676 & 1640700 & 6.8202 & 6.7469 & TRN & \\
\hline CHEMBL3894630 & 1640700 & 7.1861 & 7.1238 & TRN & \\
\hline CHEMBL3986432 & 1640700 & 7.2472 & 7.2529 & TRN & \\
\hline CHEMBL3952000 & 1640700 & 6.3541 & 6.3271 & TRN & \\
\hline CHEMBL3914923 & 1640700 & 7.1474 & 7.2847 & TRN & \\
\hline CHEMBL3923420 & 1640700 & 6.9872 & 8.0199 & TST & \\
\hline CHEMBL3911254 & 1640700 & 7.2163 & 6.9155 & TRN & \\
\hline CHEMBL3908627 & 1640700 & 5.859 & 5.9464 & TRN & \\
\hline CHEMBL3905313 & 1640700 & 6.7555 & 6.8922 & TRN & \\
\hline CHEMBL3901153 & 1640700 & 6.1574 & 6.2735 & TRN & \\
\hline CHEMBL3892872 & 1640700 & 6.0437 & 6.3056 & TRN & \\
\hline CHEMBL3924222 & 1640700 & 6.4332 & 6.5382 & TRN & \\
\hline CHEMBL3961355 & 1640700 & 5.456 & 5.7152 & TRN & \\
\hline CHEMBL3972639 & 1640700 & 6.0 & 6.2447 & TRN & \\
\hline CHEMBL3907020 & 1640700 & 7.3233 & 7.1978 & TRN & \\
\hline CHEMBL3939408 & 1640700 & 6.0227 & 5.7947 & TST & \\
\hline CHEMBL3931568 & 1640700 & 7.1945 & 7.1379 & TRN & \\
\hline CHEMBL 3937801 & 1640700 & 6.2267 & 7.8227 & TST & \\
\hline CHEMBL3957270 & 1640700 & 7.0531 & 6.7638 & TRN & \\
\hline CHEMBL3940590 & 1640700 & 6.3367 & 8.3868 & TST & \\
\hline CHEMBL3897146 & 1640700 & 6.5765 & 6.5189 & TST & \\
\hline CHEMBL 3910580 & 1640700 & 7.0747 & 6.9943 & TRN & \\
\hline CHEMBL3891682 & 1640700 & 6.7115 & 6.7728 & TRN & \\
\hline CHEMBL 3917171 & 1640700 & 6.7247 & 6.6081 & TRN & \\
\hline CHEMBL3911581 & 1640700 & 8.7825 & 8.8886 & TRN & \\
\hline CHEMBL 2177734 & 1640700 & 7.6073 & 6.9959 & TST & \\
\hline CHEMBL3936569 & 1640700 & 6.5136 & 6.47 & TRN & \\
\hline CHEMBL3924486 & 1640700 & 6.8051 & 7.2416 & TRN & \\
\hline CHEMBL3920431 & 1640700 & 6.0 & 5.9747 & TRN & \\
\hline CHEMBL3951309 & 1640700 & 7.8254 & 8.2745 & TST & \\
\hline CHEMBL3906417 & 1640700 & 6.079 & 6.1259 & TRN & \\
\hline CHEMBL3972012 & 1640700 & 6.3208 & 6.0882 & TRN & \\
\hline CHEMBL3942514 & 1640700 & 6.2149 & 6.0708 & TRN & \\
\hline CHEMBL 2177726 & 1640700 & 9.0 & 8.5767 & TST & \\
\hline CHEMBL3925678 & 1640700 & 5.8998 & 6.0706 & TRN & \\
\hline CHEMBL3938263 & 1640700 & 6.8494 & 6.8788 & TRN & \\
\hline CHEMBL3903578 & 1640700 & 7.3752 & 6.9016 & TST & \\
\hline CHEMBL3973270 & 1640700 & 6.2223 & 6.7036 & TRN & \\
\hline CHEMBL3963552 & 1640700 & 6.3629 & 6.2779 & TRN & \\
\hline CHEMBL1652492 & 714443 & 4.9208 & 3.5394 & TST & \\
\hline CHEMBL1652529 & 714443 & 4.2441 & 4.2465 & TRN & \\
\hline CHEMBL1652508 & 714443 & 4.3372 & 4.22199 & 99999999995 & TRN \\
\hline CHEMBL1652509 & 714443 & 4.4685 & 4.4752 & TRN & \\
\hline CHEMBL1652514 & 714443 & 2.7959 & 2.8756 & TRN & \\
\hline CHEMBL1652506 & 714443 & 4.1487 & 3.951 & TRN & \\
\hline CHEMBL1652531 & 714443 & 4.6576 & 4.5971 & TRN & \\
\hline CHEMBL1652523 & 714443 & 4.6198 & 4.5501 & TRN & \\
\hline CHEMBL1652491 & 714443 & 4.4685 & 3.2165 & TST & \\
\hline
\end{tabular}


Supplemental Table S2.txt

\begin{tabular}{|c|c|c|c|c|}
\hline CHEMBL1652520 & 714443 & 4.4559 & 4.2917 & TRN \\
\hline CHEMBL1652519 & 714443 & 3.0915 & 3.3426 & TRN \\
\hline CHEMBL1652495 & 714443 & 2.0223 & 1.9052 & TRN \\
\hline CHEMBL1652507 & 714443 & 2.9586 & 3.0188 & TRN \\
\hline CHEMBL1652534 & 714443 & 4.7447 & 4.7622 & TRN \\
\hline CHEMBL1652527 & 714443 & 4.7212 & 4.5613 & TRN \\
\hline CHEMBL1652498 & 714443 & 3.5686 & 3.8053 & TRN \\
\hline CHEMBL1652524 & 714443 & 4.585 & 4.6099 & TRN \\
\hline CHEMBL1652484 & 714443 & 4.2076 & 4.1127 & TRN \\
\hline CHEMBL1652535 & 714443 & 4.5528 & 4.4281 & TRN \\
\hline CHEMBL452545 & 714443 & 3.4437 & 3.4624 & TRN \\
\hline CHEMBL1652511 & 714443 & 1.7447 & 3.5968 & TST \\
\hline CHEMBL1652504 & 714443 & 3.1308 & 3.1733 & TRN \\
\hline CHEMBL1652497 & 714443 & 1.6198 & 1.8941 & TST \\
\hline CHEMBL1652512 & 714443 & 3.0862 & 3.1081 & TRN \\
\hline CHEMBL1652496 & 714443 & 2.5528 & 2.8221 & TST \\
\hline CHEMBL1652521 & 714443 & 4.2518 & 4.2487 & TRN \\
\hline CHEMBL1652500 & 714443 & 2.699 & 2.82 & TRN \\
\hline CHEMBL1652501 & 714443 & 3.1079 & 2.9425 & TRN \\
\hline CHEMBL1652515 & 714443 & 4.2596 & 4.3812 & TRN \\
\hline CHEMBL1652522 & 714443 & 4.5686 & 4.6201 & TRN \\
\hline CHEMBL1652502 & 714443 & 2.9586 & 3.0005 & TRN \\
\hline CHEMBL1652485 & 714443 & 3.2076 & 3.1498 & TRN \\
\hline CHEMBL1652525 & 714443 & 4.3188 & 4.3291 & TRN \\
\hline CHEMBL1652532 & 714443 & 4.585 & 4.6076 & TRN \\
\hline CHEMBL1652533 & 714443 & 4.2076 & 4.2466 & TRN \\
\hline CHEMBL1652513 & 714443 & 3.3665 & 3.3112 & TRN \\
\hline CHEMBL1652503 & 714443 & 3.0 & 3.0845 & TRN \\
\hline CHEMBL1652499 & 714443 & 3.284 & 3.3953 & TRN \\
\hline CHEMBL1652516 & 714443 & 1.7696 & 1.6881 & TRN \\
\hline CHEMBL1652528 & 714443 & 3.6576 & 3.859 & TRN \\
\hline CHEMBL1652518 & 714443 & 2.0177 & 1.9056 & TRN \\
\hline CHEMBL452807 & 714443 & 2.0 & 3.0323 & TST \\
\hline CHEMBL1652526 & 714443 & 4.6576 & 4.6692 & TRN \\
\hline CHEMBL1652494 & 714443 & 1.6383 & 2.806 & TST \\
\hline CHEMBL1652510 & 714443 & 3.9586 & 4.3633 & TST \\
\hline CHEMBL1649612 & 714443 & 2.9208 & 3.4772 & TST \\
\hline CHEMBL1652530 & 714443 & 2.6576 & 4.8002 & TST \\
\hline CHEMBL1652505 & 714443 & 2.8861 & 3.1965 & TST \\
\hline CHEMBL1652493 & 714443 & 4.9208 & 2.9959 & TST \\
\hline CHEMBL1652517 & 714443 & 4.2366 & 3.1755 & TST \\
\hline CHEMBL426396 & 195671 & 6.7696 & 6.78700 & 0000000001 \\
\hline CHEMBL268871 & 195671 & 7.699 & 7.7263 & TRN \\
\hline CHEMBL177192 & 195671 & 5.7328 & 5.7311 & TRN \\
\hline CHEMBL367052 & 195671 & 7.4318 & 7.4288 & TRN \\
\hline CHEMBL173280 & 195671 & 2.5229 & 4.7168 & TST \\
\hline CHEMBL174364 & 195671 & 7.0132 & 7.0044 & TRN \\
\hline CHEMBL171919 & 195671 & 7.9586 & 7.9649 & TRN \\
\hline
\end{tabular}

Page 15758 


\begin{tabular}{|c|c|c|c|c|c|c|}
\hline & & \multicolumn{5}{|c|}{ Supplemental Table S2.txt } \\
\hline CHEMBL367204 & 195671 & 5.4685 & 5.4762 & TRN & & \\
\hline CHEMBL176957 & 195671 & 7.4685 & 7.4375 & TRN & & \\
\hline CHEMBL174311 & 195671 & \multicolumn{3}{|c|}{6.718999999999999} & 6.7177 & TRN \\
\hline CHEMBL368116 & 195671 & 7.8861 & 7.8585 & TRN & & \\
\hline CHEMBL98159 & 195671 & 6.8861 & 6.8826 & TRN & & \\
\hline CHEMBL177016 & 195671 & 7.4815 & 7.4892 & TRN & & \\
\hline CHEMBL176637 & 195671 & 6.6882 & 6.6766 & TRN & & \\
\hline CHEMBL172773 & 195671 & 5.2676 & 5.3034 & TST & & \\
\hline CHEMBL367850 & 195671 & 4.0 & 6.0763 & TST & & \\
\hline CHEMBL176972 & 195671 & 7.2076 & 7.2142 & TRN & & \\
\hline CHEMBL353328 & 195671 & 4.301 & 4.3051 & TRN & & \\
\hline CHEMBL172861 & 195671 & 7.6198 & 7.6451 & TRN & & \\
\hline CHEMBL175235 & 195671 & 5.0757 & 5.0765 & TRN & & \\
\hline CHEMBL439655 & 195671 & 3.585 & 3.5883 & TRN & & \\
\hline CHEMBL177074 & 195671 & 4.8697 & 4.8655 & TRN & & \\
\hline CHEMBL177898 & 195671 & 6.3546 & 6.358 & TRN & & \\
\hline CHEMBL175162 & 195671 & 7.8239 & 7.8213 & TRN & & \\
\hline CHEMBL176631 & 195671 & 7.0555 & \multicolumn{3}{|c|}{7.071000000000001} & TRN \\
\hline CHEMBL174267 & 195671 & 5.9586 & 5.9625 & TRN & & \\
\hline CHEMBL175089 & 195671 & 5.9031 & 5.9047 & TRN & & \\
\hline CHEMBL172311 & 195671 & 7.5229 & 7.5458 & TRN & & \\
\hline CHEMBL415320 & 195671 & 6.6778 & 6.6484 & TRN & & \\
\hline CHEMBL174953 & 195671 & 6.5086 & 6.5067 & TRN & & \\
\hline CHEMBL174899 & 195671 & 4.382 & 4.3831 & TRN & & \\
\hline CHEMBL95426 & 195671 & 6.4318 & 5.7013 & TST & & \\
\hline CHEMBL177174 & 195671 & 5.6778 & 5.6625 & TRN & & \\
\hline CHEMBL83622 & 195671 & 7.6383 & 7.5918 & TRN & & \\
\hline CHEMBL176443 & 195671 & 7.3979 & 7.4086 & TRN & & \\
\hline CHEMBL173589 & 195671 & 7.0809 & 7.1107 & TRN & & \\
\hline CHEMBL176982 & 195671 & 4.7959 & 4.7861 & TRN & & \\
\hline CHEMBL367515 & 195671 & 4.3468 & 4.353 & TRN & & \\
\hline CHEMBL176362 & 195671 & 7.8239 & 7.8332 & TRN & & \\
\hline CHEMBL173635 & 195671 & 6.4145 & 6.6141 & TST & & \\
\hline CHEMBL175531 & 195671 & 5.7696 & 5.7783 & TRN & & \\
\hline CHEMBL177271 & 195671 & 7.8539 & 7.8664 & TRN & & \\
\hline CHEMBL176594 & 195671 & 7.3188 & 7.319 & TRN & & \\
\hline CHEMBL176814 & 195671 & 5.8539 & 5.8454 & TRN & & \\
\hline CHEMBL177191 & 195671 & \multicolumn{3}{|c|}{6.752000000000001} & 6.7549 & TRN \\
\hline CHEMBL99235 & 195671 & 7.8539 & 7.8331 & TRN & & \\
\hline CHEMBL173868 & 195671 & 2.5229 & 4.4187 & TST & & \\
\hline CHEMBL173575 & 195671 & 7.284 & 7.2755 & TRN & & \\
\hline CHEMBL174130 & 195671 & 7.5376 & 6.9241 & TST & & \\
\hline CHEMBL177256 & 195671 & 6.7645 & 6.8576 & TST & & \\
\hline CHEMBL174419 & 195671 & 7.5229 & 7.0515 & TST & & \\
\hline CHEMBL171920 & 195671 & 7.4089 & 7.0315 & TST & & \\
\hline CHEMBL176463 & 195671 & 7.2366 & 5.8679 & TST & & \\
\hline CHEMBL 82439 & 195671 & 5.4318 & 5.1902 & TST & & \\
\hline CHEMBL172583 & 195671 & 7.3665 & 7.5166 & TST & & \\
\hline
\end{tabular}




\begin{tabular}{|c|c|c|c|c|c|}
\hline & & & & & \\
\hline CHEMBL 329720 & 195671 & 7.5528 & 7.6441 & TST & \\
\hline CHEMBL173529 & 195671 & 5.6108 & 4.954 & TST & \\
\hline CHEMBL409248 & 467655 & 7.585 & 7.2931 & TRN & \\
\hline CHEMBL 261298 & 467655 & 8.6021 & 7.1481 & TRN & \\
\hline CHEMBL401595 & 467655 & 6.3372 & 5.7844 & TRN & \\
\hline CHEMBL403641 & 467655 & 6.4202 & 7.08200 & 0000000001 & TRN \\
\hline CHEMBL403642 & 467655 & 7.7959 & 6.8586 & TRN & \\
\hline CHEMBL436646 & 467655 & 5.7447 & 5.6413 & TRN & \\
\hline CHEMBL 257408 & 467655 & 7.1135 & 7.2706 & TRN & \\
\hline CHEMBL259995 & 467655 & 7.3279 & 7.5226 & TRN & \\
\hline CHEMBL 259741 & 467655 & 7.2676 & 7.3798 & TRN & \\
\hline CHEMBL399631 & 467655 & 6.4685 & 5.8838 & TST & \\
\hline CHEMBL408675 & 467655 & 7.6778 & 7.1008 & TRN & \\
\hline CHEMBL403189 & 467655 & 7.1549 & 7.6816 & TRN & \\
\hline CHEMBL 253963 & 467655 & 7.041 & 6.9118 & TRN & \\
\hline CHEMBL411288 & 467655 & 7.4685 & 7.1496 & TRN & \\
\hline CHEMBL 260084 & 467655 & 6.2218 & 6.79799 & 9999999999 & TRN \\
\hline CHEMBL409672 & 467655 & 6.2924 & 6.4181 & TRN & \\
\hline CHEMBL410687 & 467655 & 7.1249 & 6.7652 & TRN & \\
\hline CHEMBL256949 & 467655 & 7.585 & 6.9876 & TRN & \\
\hline CHEMBL 258028 & 467655 & 6.1612 & 6.4074 & TRN & \\
\hline CHEMBL 259781 & 467655 & 7.301 & 7.2099 & TST & \\
\hline CHEMBL 255901 & 467655 & 7.3188 & 7.1095 & TST & \\
\hline CHEMBL 254164 & 467655 & 6.5376 & 5.9719 & TST & \\
\hline CHEMBL402234 & 467655 & 7.5528 & 7.4668 & TRN & \\
\hline CHEMBL 256324 & 467655 & 6.3188 & 6.3095 & TRN & \\
\hline CHEMBL265924 & 467655 & 8.6021 & 7.0188 & TST & \\
\hline CHEMBL402125 & 467655 & 6.8539 & 6.7951 & TRN & \\
\hline CHEMBL410688 & 467655 & 7.0315 & 6.7685 & TST & \\
\hline CHEMBL 265190 & 467655 & 6.7212 & 6.2559 & TST & \\
\hline CHEMBL 262327 & 467655 & 6.7447 & 6.5778 & TST & \\
\hline CHEMBL 256323 & 467655 & 6.8239 & 6.9214 & TRN & \\
\hline CHEMBL 256948 & 467655 & 8.0 & 7.6029 & TRN & \\
\hline CHEMBL 260083 & 467655 & 6.585 & 6.96700 & 00000000005 & TST \\
\hline CHEMBL 258899 & 467655 & 6.5229 & 7.0809 & TST & \\
\hline CHEMBL 259335 & 467655 & 6.3979 & 6.7696 & TST & \\
\hline CHEMBL259349 & 467655 & 7.0132 & 6.6662 & TST & \\
\hline CHEMBL401825 & 467655 & 8.6021 & 7.0573 & TST & \\
\hline CHEMBL 257409 & 467655 & 7.0362 & 6.9218 & TRN & \\
\hline CHEMBL258459 & 467655 & 7.2291 & 7.3182 & TRN & \\
\hline CHEMBL 258237 & 467655 & 6.3098 & 6.5531 & TRN & \\
\hline CHEMBL 257195 & 467655 & 5.9208 & 6.8996 & TRN & \\
\hline CHEMBL 256918 & 467655 & 7.2676 & 7.0066 & TRN & \\
\hline CHEMBL411407 & 467655 & 7.1192 & 7.319 & TRN & \\
\hline CHEMBL261698 & 467655 & 6.9586 & 6.977 & TRN & \\
\hline CHEMBL 265447 & 467655 & 6.6576 & 6.7843 & TRN & \\
\hline CHEMBL 258027 & 467655 & 6.3468 & 6.4076 & TRN & \\
\hline CHEMBL261697 & 467655 & 5.6021 & 6.4375 & TRN & \\
\hline
\end{tabular}




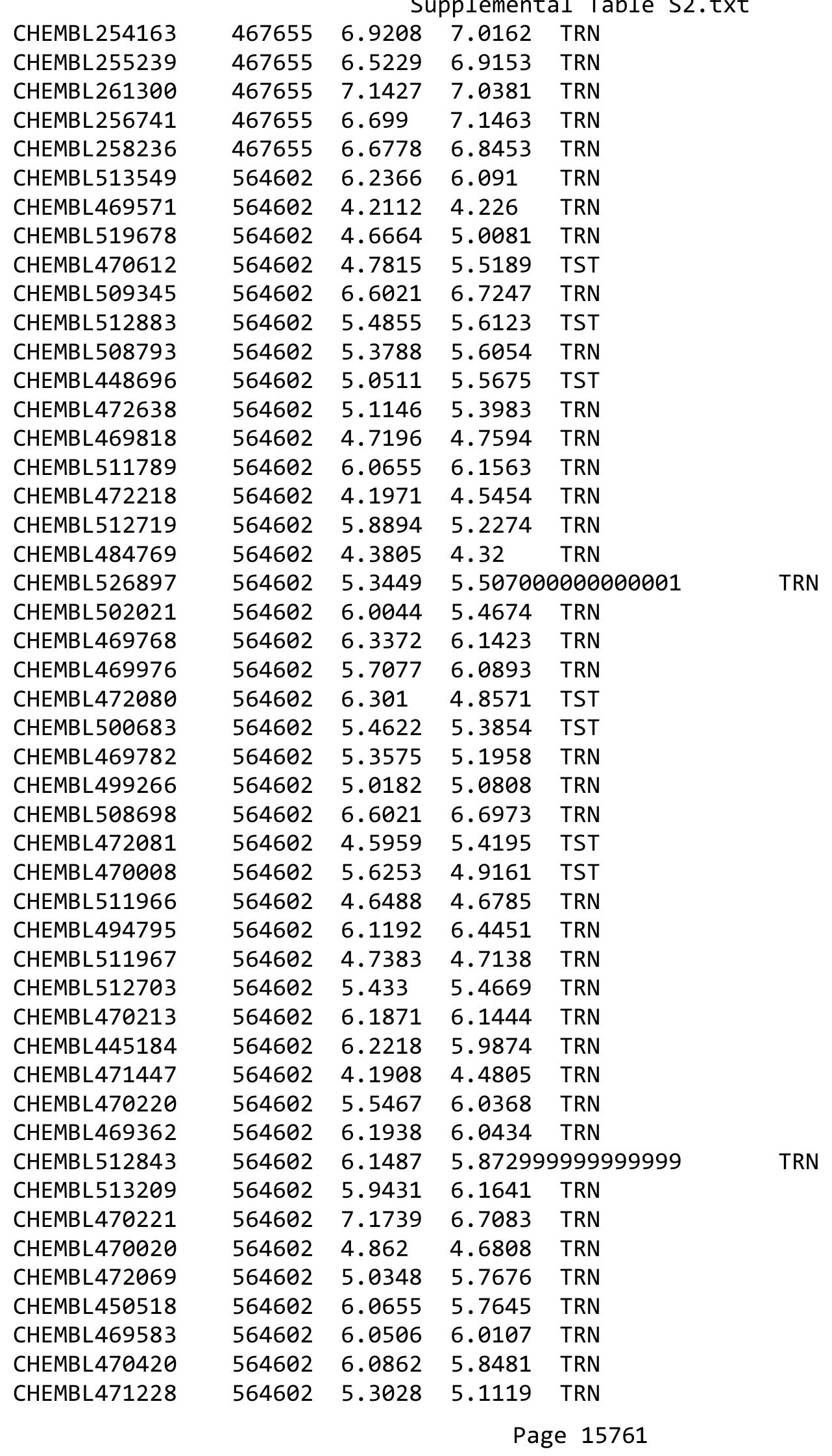




\begin{tabular}{|c|c|c|c|c|c|}
\hline \multicolumn{6}{|c|}{ Supplemental Table s2.txt } \\
\hline CHEMBL469783 & 564602 & 5.4737 & 5.0868 & TRN & \\
\hline CHEMBL453410 & 564602 & 6.0969 & 6.2516 & TST & \\
\hline CHEMBL471221 & 564602 & 6.4202 & 5.6901 & TST & \\
\hline CHEMBL470226 & 564602 & 8.8539 & 6.067 & TST & \\
\hline CHEMBL469350 & 564602 & 6.041 & 5.0803 & TST & \\
\hline CHEMBL471232 & 564602 & 6.1549 & 5.6698 & TST & \\
\hline CHEMBL484410 & 564602 & 5.5421 & 5.1892 & TST & \\
\hline CHEMBL281111 & 77277 & 3.0 & 3.1231 & TRN & \\
\hline CHEMBL 25607 & 77277 & 3.0 & 2.8956 & TRN & \\
\hline CHEMBL284016 & 77277 & 3.0 & 3.0602 & TRN & \\
\hline CHEMBL 277233 & 77277 & 3.0 & 3.0636 & TRN & \\
\hline CHEMBL2093921 & 77277 & 6.1549 & 4.1341 & TST & \\
\hline CHEMBL 279744 & 77277 & 3.0 & 2.9526 & TST & \\
\hline CHEMBL22264 & 77277 & 3.0 & 2.9683 & TRN & \\
\hline CHEMBL278766 & 77277 & 3.0 & 3.0461 & TRN & \\
\hline CHEMBL 282268 & 77277 & 3.0 & 3.043 & TRN & \\
\hline CHEMBL22995 & 77277 & 4.3979 & 4.4511 & TRN & \\
\hline CHEMBL23032 & 77277 & 3.0 & 3.3158 & TRN & \\
\hline CHEMBL22787 & 77277 & 3.0 & 3.1368 & TST & \\
\hline CHEMBL23020 & 77277 & 3.0 & 2.9744 & TRN & \\
\hline CHEMBL 276979 & 77277 & 3.0 & 3.04100 & 00000000004 & TRN \\
\hline CHEMBL22263 & 77277 & 4.5229 & 4.4235 & TRN & \\
\hline CHEMBL 278997 & 77277 & 3.0 & 3.0398 & TRN & \\
\hline CHEMBL 282023 & 77277 & 3.0 & 2.8402 & TRN & \\
\hline CHEMBL22954 & 77277 & 3.0 & 2.905 & TRN & \\
\hline CHEMBL 280386 & 77277 & 3.0 & 3.0391 & TRN & \\
\hline CHEMBL 277221 & 77277 & 3.0 & 3.0198 & TRN & \\
\hline CHEMBL22941 & 77277 & 4.6576 & 4.5426 & TRN & \\
\hline CHEMBL22714 & 77277 & 3.0 & 3.1211 & TRN & \\
\hline CHEMBL435567 & 77277 & 4.6576 & 4.4149 & TST & \\
\hline CHEMBL 281171 & 77277 & 4.4949 & 4.7511 & TST & \\
\hline CHEMBL22289 & 77277 & 3.0 & 2.8926 & TRN & \\
\hline CHEMBL 25044 & 77277 & 3.0 & 3.0174 & TRN & \\
\hline CHEMBL282937 & 77277 & 3.0 & 3.0137 & TRN & \\
\hline CHEMBL277486 & 77277 & 3.0 & 3.0369 & TRN & \\
\hline CHEMBL22887 & 77277 & 3.0 & 2.8327 & TRN & \\
\hline CHEMBL 280131 & 77277 & 3.0 & 2.9538 & TRN & \\
\hline CHEMBL 22792 & 77277 & 4.4949 & 4.4745 & TRN & \\
\hline CHEMBL25388 & 77277 & 3.0 & 2.8976 & TRN & \\
\hline CHEMBL23023 & 77277 & 3.0 & 2.9696 & TRN & \\
\hline CHEMBL25100 & 77277 & 3.0 & 3.2255 & TST & \\
\hline CHEMBL22850 & 77277 & 4.4949 & 4.2898 & TRN & \\
\hline CHEMBL283158 & 77277 & 3.0 & 2.93899 & 99999999996 & TRN \\
\hline CHEMBL 278162 & 77277 & 4.4318 & 4.4348 & TRN & \\
\hline CHEMBL22681 & 77277 & 3.0 & 3.1747 & TST & \\
\hline CHEMBL22368 & 77277 & 3.0 & 2.9499 & TST & \\
\hline CHEMBL25270 & 77277 & 4.4949 & 4.6717 & TRN & \\
\hline CHEMBL 277222 & 77277 & 3.0 & 2.9899 & TRN & \\
\hline
\end{tabular}




\begin{tabular}{|c|c|c|c|c|c|}
\hline \multicolumn{6}{|c|}{ Supplemental Table S2.txt } \\
\hline CHEMBL25329 & 77277 & 3.0 & 3.0898 & TRN & \\
\hline CHEMBL22658 & 77277 & 4.5229 & 3.3404 & TST & \\
\hline CHEMBL513232 & 77277 & 5.5376 & 3.74 & TST & \\
\hline CHEMBL22503 & 77277 & 4.9208 & 4.9058 & TRN & \\
\hline CHEMBL277866 & 77277 & 3.0 & 3.0552 & TRN & \\
\hline CHEMBL22997 & 77277 & 4.0 & 3.9641 & TST & \\
\hline CHEMBL22402 & 77277 & 3.0 & 3.0375 & TRN & \\
\hline CHEMBL281627 & 77277 & 3.0 & 2.6073 & TST & \\
\hline CHEMBL22262 & 77277 & 3.0 & 3.2471 & TST & \\
\hline CHEMBL28471 & 122731 & 4.6716 & 4.0161 & TRN & \\
\hline CHEMBL29351 & 122731 & 4.3788 & 4.6338 & TRN & \\
\hline CHEMBL444786 & 122731 & 3.6021 & 2.7799 & TST & \\
\hline CHEMBL281980 & 122731 & 2.301 & 2.1229 & TRN & \\
\hline CHEMBL28251 & 122731 & 5.6757 & 5.3767 & TRN & \\
\hline CHEMBL283707 & 122731 & 4.76699 & 99999999 & 4.6413 & TRN \\
\hline CHEMBL280639 & 122731 & 2.301 & 2.35699 & 99999999998 & TRN \\
\hline CHEMBL30145 & 122731 & 3.6459 & 3.5803 & TRN & \\
\hline CHEMBL30247 & 122731 & 4.9245 & 4.9635 & TRN & \\
\hline CHEMBL29701 & 122731 & 3.6676 & 3.2091 & TST & \\
\hline CHEMBL282370 & 122731 & 2.301 & 2.7389 & TRN & \\
\hline CHEMBL28755 & 122731 & 4.3851 & 4.2659 & TRN & \\
\hline CHEMBL29042 & 122731 & 2.301 & 2.9475 & TRN & \\
\hline CHEMBL29845 & 122731 & 2.301 & 3.0193 & TRN & \\
\hline CHEMBL29787 & 122731 & 4.4609 & 4.35 & TRN & \\
\hline CHEMBL29573 & 122731 & 4.6234 & 4.6651 & TRN & \\
\hline CHEMBL281870 & 122731 & 5.0264 & 4.8395 & TRN & \\
\hline CHEMBL30022 & 122731 & 5.2798 & 5.6103 & TRN & \\
\hline CHEMBL25902 & 122731 & 4.279 & 3.02100 & 00000000004 & TST \\
\hline CHEMBL281551 & 122731 & 3.31699 & 99999999 & $997 \quad 2.6823$ & TST \\
\hline CHEMBL29539 & 122731 & 6.3279 & 6.4595 & TRN & \\
\hline CHEMBL282831 & 122731 & 4.4067 & 4.0275 & TST & \\
\hline CHEMBL29493 & 122731 & 4.4023 & 4.7065 & TST & \\
\hline CHEMBL29563 & 122731 & 4.6737 & 4.4741 & TRN & \\
\hline CHEMBL28613 & 122731 & 3.7696 & 2.7907 & TST & \\
\hline CHEMBL30095 & 122731 & 5.0964 & 4.8722 & TRN & \\
\hline CHEMBL28855 & 122731 & 3.8697 & 3.8539 & TRN & \\
\hline CHEMBL29733 & 122731 & 2.301 & 2.375 & TRN & \\
\hline CHEMBL28614 & 122731 & 2.301 & 0.4722 & TST & \\
\hline CHEMBL282399 & 122731 & 5.0545 & 4.702 & TRN & \\
\hline CHEMBL29542 & 122731 & 4.9172 & 4.7868 & TRN & \\
\hline CHEMBL29251 & 122731 & 4.4461 & 4.5952 & TRN & \\
\hline CHEMBL28689 & 122731 & 4.4895 & 4.7136 & TRN & \\
\hline CHEMBL28189 & 122731 & 2.301 & 1.8727 & TRN & \\
\hline CHEMBL28861 & 122731 & 2.301 & 2.5876 & TRN & \\
\hline CHEMBL281704 & 122731 & 3.6421 & 2.5264 & TST & \\
\hline CHEMBL286704 & 122731 & 4.262 & 4.1987 & TRN & \\
\hline CHEMBL284405 & 122731 & 4.4815 & 3.92 & TRN & \\
\hline CHEMBL282326 & 122731 & 2.301 & 2.151 & TRN & \\
\hline
\end{tabular}




\begin{tabular}{|c|c|c|c|c|c|}
\hline \multicolumn{6}{|c|}{ Supplemental Table S2.txt } \\
\hline CHEMBL30098 & 122731 & 4.2218 & 4.0632 & TRN & \\
\hline CHEMBL29077 & 122731 & 3.6021 & 2.6355 & TST & \\
\hline CHEMBL28667 & 122731 & 4.3063 & 3.5496 & TST & \\
\hline CHEMBL29737 & 122731 & 4.2411 & 3.4309 & TST & \\
\hline CHEMBL28591 & 122731 & 4.3737 & 3.9133 & TRN & \\
\hline CHEMBL413538 & 122731 & 4.2933 & 3.9354 & TRN & \\
\hline CHEMBL30096 & 122731 & 3.7545 & 3.0499 & TST & \\
\hline CHEMBL286526 & 122731 & 4.0526 & 3.4895 & TST & \\
\hline CHEMBL 28190 & 122731 & 2.301 & 3.0276 & TRN & \\
\hline CHEMBL27535 & 122731 & 4.2708 & 4.545 & TRN & \\
\hline CHEMBL417294 & 122731 & 4.3696 & 4.4568 & TRN & \\
\hline CHEMBL282962 & 122731 & 4.3363 & 4.2414 & TRN & \\
\hline CHEMBL284878 & 122731 & 4.0953 & 3.8834 & TRN & \\
\hline CHEMBL417299 & 122731 & 4.0 & 4.7551 & TRN & \\
\hline CHEMBL287179 & 122731 & 2.301 & 1.9079 & TRN & \\
\hline CHEMBL 282171 & 122731 & 4.5482 & 4.6778 & TRN & \\
\hline CHEMBL29170 & 122731 & 3.762 & 3.9426 & TRN & \\
\hline CHEMBL3641001 & 1528015 & 8.301 & 7.859 & TRN & \\
\hline CHEMBL3645956 & 1528015 & 8.821 & 8.4524 & TST & \\
\hline CHEMBL3645801 & 1528015 & 6.0 & 7.3684 & TRN & \\
\hline CHEMBL3645972 & 1528015 & 8.9957 & 9.3797 & TRN & \\
\hline CHEMBL 3645874 & 1528015 & 8.644 & 9.2026 & TRN & \\
\hline CHEMBL 3641010 & 1528015 & 9.2218 & 8.5709 & TRN & \\
\hline CHEMBL3640975 & 1528015 & 7.3565 & 8.6312 & TST & \\
\hline CHEMBL3643251 & 1528015 & 8.1918 & 8.1699 & TRN & \\
\hline CHEMBL3643128 & 1528015 & 7.7696 & 7.8264 & TRN & \\
\hline CHEMBL3643276 & 1528015 & 8.8182 & 8.68100 & 0000000001 & TRN \\
\hline CHEMBL3643164 & 1528015 & 8.5229 & 8.7432 & TST & \\
\hline CHEMBL 3648867 & 1528015 & 8.15 & 7.6969 & TRN & \\
\hline CHEMBL 3645884 & 1528015 & 8.6383 & 8.8619 & TRN & \\
\hline CHEMBL3645969 & 1528015 & 8.6757 & 8.2638 & TST & \\
\hline CHEMBL3643117 & 1528015 & 7.6198 & 7.8706 & TRN & \\
\hline CHEMBL3645779 & 1528015 & 8.1079 & 7.9811 & TRN & \\
\hline CHEMBL 3648875 & 1528015 & 7.9747 & 8.3431 & TRN & \\
\hline CHEMBL3643263 & 1528015 & 9.3372 & 8.2201 & TRN & \\
\hline CHEMBL3643186 & 1528015 & 7.7447 & 7.9722 & TST & \\
\hline CHEMBL3643124 & 1528015 & 7.8539 & 7.9409 & TST & \\
\hline CHEMBL3640980 & 1528015 & 8.0969 & 8.4338 & TST & \\
\hline CHEMBL3641016 & 1528015 & 9.0757 & 8.5002 & TRN & \\
\hline CHEMBL3643074 & 1528015 & 8.699 & 8.3501 & TRN & \\
\hline CHEMBL3645910 & 1528015 & 10.1549 & 8.5394 & TRN & \\
\hline CHEMBL 3648880 & 1528015 & 8.2321 & 7.6054 & TRN & \\
\hline CHEMBL3645987 & 1528015 & 8.0496 & 7.865 & TRN & \\
\hline CHEMBL3643120 & 1528015 & 7.9208 & 7.5237 & TRN & \\
\hline CHEMBL3643100 & 1528015 & 8.1549 & 7.9449 & TRN & \\
\hline CHEMBL3643115 & 1528015 & 7.8861 & 7.5655 & TRN & \\
\hline CHEMBL3645904 & 1528015 & 7.9385 & 7.8112 & TRN & \\
\hline CHEMBL3640954 & 1528015 & 7.4685 & 8.2144 & TST & \\
\hline
\end{tabular}


Supplemental Table S2.txt

\begin{tabular}{|c|c|c|c|c|}
\hline HEMBL & & & 38 & \\
\hline HFMRI 3613966 & $=20915$ & 8.699 & & \\
\hline HEMBL & & 8894 & & \\
\hline HEMBL 364 & 528015 & 699 & 2888 & \\
\hline HEMBL3645980 & 528015 & 8.7747 & .7102 & \\
\hline HEMBL & 528015 & .7878 & 3527 & \\
\hline AEMBL & & .5686 & 7021 & RN \\
\hline HEMBL36 & 528015 & 214 & 8584 & \\
\hline HEMBL 364 & 528015 & 8.5229 & .7807 & \\
\hline HEMBL364 & 528015 & 8.699 & 8.3291 & \\
\hline HEMBL3 & 528015 & 301 & 1732 & \\
\hline AEMBL3 & & 555 & 6228 & RN \\
\hline HEMBL3 & 528015 & 3565 & 1757 & \\
\hline AEMBL36 & 528015 & 8.699 & 8444 & \\
\hline HEMBL363 & 528015 & 2218 & 8583 & \\
\hline AEMBL: & 8015 & 229 & 3767 & \\
\hline AEMBL & & 258 & 46 & \\
\hline HEMBL & 528015 & 599 & 7235 & \\
\hline AEMBL3 & 528015 & 327 & 7177 & \\
\hline AEMBL36 & 528015 & 7.5931 & 372 & KIV \\
\hline AEMBL & 8015 & & 033 & RN \\
\hline AEMBL & & & 501 & RN \\
\hline HEMBL & 15 & 229 & 4508 & RN \\
\hline AEMBL3 & & 932 & & \\
\hline HEMBL3 & 28015 & 549 & 481 & RN \\
\hline EMBL: & J & 066 & & RN \\
\hline IEM & & 79 & & $\mathrm{RN}$ \\
\hline וסMDו & & & & RN \\
\hline AEMBL & & & & IRN \\
\hline AEMBL 36 & 528015 & 696 & 374 & ГST \\
\hline IEMBL & 3015 & 979 & 758 & RN \\
\hline 3 & & & & RN \\
\hline & & 212 & & RN \\
\hline AEMBL36 & 528015 & & & 「RN \\
\hline AEMBL36 & 528015 & & 3265 & RN \\
\hline IEMPI: 7 & 5 & & 22 & RN \\
\hline & & & & RN \\
\hline HEMBL & & & 574 & RN \\
\hline AEMBL36 & 528015 & 969 & 3658 & $\Gamma \mathrm{R}$ \\
\hline EMBL & 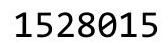 & 56 & 7071 & RN \\
\hline HEMBL3 & L & 969 & 7395 & \\
\hline & & & 9.2809 & RN \\
\hline HEMBL36 & & & & RN \\
\hline AEMBL36 & 52 & 63 & 181 & TR \\
\hline met & & & & N \\
\hline HEMBL 36 & & 7.8239 & 7.4022 & \\
\hline HEMBL 36 & $-\operatorname{son}$ & 8.3152 & 8.3895 & \\
\hline CHEMBL3643170 & 1528015 & 8.3979 & 8.7989 & ГST \\
\hline
\end{tabular}

Page 15765 
Supplemental Table S2.txt

\begin{tabular}{|c|c|c|c|c|}
\hline . & 528015 & .8928 & & \\
\hline & 528015 & 7.983 & .3622 & \\
\hline & & & & \\
\hline AEMBL & 28015 & & $50 s$ & \\
\hline AEMBL3639447 & 528015 & 7655 & 4771 & \\
\hline HEMBL3643090 & 528015 & 8.3979 & .1442 & \\
\hline 41 & 528015 & 784 & 3104 & \\
\hline 57 & 8015 & & 4078 & \\
\hline AEMBL36 & 528015 & 8069 & 6392 & \\
\hline HEMBL 364 & 528015 & 8.4067 & 7901 & \\
\hline AEMBL364 & 528015 & 7.2441 & 1568 & \\
\hline IEMBL & 28015 & 34 & 844 & \\
\hline HEMBL; & & & 179 & \\
\hline HEMBL3E & 528015 & 51 & 5606 & \\
\hline AEMBL36 & 528015 & & 351 & \\
\hline AEMBL36 & 28015 & 69 & 5349 & \\
\hline AEMBL3 & 8015 & 36 & 117 & \\
\hline HEMBL3 & & & 614 & \\
\hline HEMBL36 & 528015 & 92 & 2298 & \\
\hline IEMBL3 & 3015 & & & \\
\hline HEMBL= & 8015 & 21 & 071 & Niv \\
\hline HEMBL: & 8015 & & 457 & RN \\
\hline HEMBL; & 8015 & & 33 & \\
\hline 22 & 528015 & 59 & & \\
\hline AEMBL36 & 3015 & 9. & & TST \\
\hline HEMBL; & 8015 & 9 & & RN \\
\hline HEMBL & 15 & & & Non \\
\hline AFMRI & 15 & & 95 & \\
\hline HEMBL3 & & & & RIV \\
\hline HEMBL36 & 528015 & & 713 & I RN \\
\hline HEMBL3 & 3015 & & 075 & RN \\
\hline HEMBL & 15 & & 724 & ST \\
\hline HEMPI & 15 & & 341 & $\mathrm{R}$ \\
\hline HEMBL36 & 528015 & & 169 & IRN \\
\hline HEMBL 364 & 528015 & 979 & 3127 & TRN \\
\hline HEMBL3 & 28015 & & 2761 & RN \\
\hline HFMRI & 5 & & 579 & $\Gamma \mathrm{RN}$ \\
\hline HEMBL; & & & 522 & IRN \\
\hline HEMBL 36 & 528015 & & 2603 & TRN \\
\hline EMBL & 528015 & & 7108 & RN \\
\hline HEMBL36 & 528015 & & 4294 & \\
\hline CHEMBL 36 & & & 8.1534 & ГST \\
\hline HEMBL36 & 528015 & & 8.1149 & TST \\
\hline HEMBL 364 & 528015 & 585 & 7311 & TRN \\
\hline 1. & 528015 & & 2845 & 13 \\
\hline HEMBL36 & תמת & & .5972 & \\
\hline HEMBL 36 & 528015 & 7.961 & 8.0342 & \\
\hline CHEMBL3645897 & 1528015 & 7.8517 & 7.8509 & ГRN \\
\hline
\end{tabular}

Page 15766 
Supplemental Table S2.txt

\begin{tabular}{|c|c|c|c|c|c|}
\hline CHEMBL 3643065 & 1528015 & 8.699 & 8.3854 & TRN & \\
\hline CHEMBL 3643174 & 1528015 & 7.3372 & 7.8223 & TST & \\
\hline CHEMBL 3643095 & 1528015 & 6.0 & 7.7049 & TRN & \\
\hline CHEMBL 3643137 & 1528015 & 7.585 & 7.588999 & 99999999995 & TRN \\
\hline CHEMBL 3643224 & 1528015 & 9.0269 & 8.4056 & TRN & \\
\hline CHEMBL 3643273 & 1528015 & 8.4449 & 8.3268 & TRN & \\
\hline CHEMBL 3645982 & 1528015 & 8.8894 & 8.4257 & TRN & \\
\hline CHEMBL 3645915 & 1528015 & 9.1367 & 9.1148 & TRN & \\
\hline CHEMBL 3645772 & 1528015 & 8.6162 & 8.179 & TST & \\
\hline CHEMBL 3645901 & 1528015 & 8.0531 & 7.7 & TRN & \\
\hline CHEMBL 3645986 & 1528015 & 8.2255 & 7.641 & TRN & \\
\hline CHEMBL 3648883 & 1528015 & 6.0 & 7.0744 & TRN & \\
\hline CHEMBL 3643158 & 1528015 & 6.0 & 7.7233 & TRN & \\
\hline CHEMBL 3640935 & 1528015 & 8.699 & 8.3915 & TRN & \\
\hline CHEMBL 3645977 & 1528015 & 9.28399 & 999999999 & 8.346 & TST \\
\hline CHEMBL 3640973 & 1528015 & 7.5528 & 7.8184 & TRN & \\
\hline CHEMBL 3645948 & 1528015 & 8.4168 & 9.195 & TRN & \\
\hline CHEMBL 3645953 & 1528015 & 8.0083 & 7.7904 & TRN & \\
\hline CHEMBL 3645875 & 1528015 & 8.4828 & 8.3383 & TRN & \\
\hline CHEMBL 3643245 & 1528015 & 8.1403 & 8.5499 & TRN & \\
\hline CHEMBL 3645921 & 1528015 & 8.3605 & 8.6947 & TRN & \\
\hline CHEMBL 3645896 & 1528015 & 7.2559 & 6.7113 & TRN & \\
\hline CHEMBL 3645954 & 1528015 & 8.4202 & 8.3918 & TRN & \\
\hline CHEMBL 3645865 & 1528015 & 6.5581 & 7.8938 & TRN & \\
\hline CHEMBL 3645985 & 1528015 & 8.0114 & 7.7766 & TST & \\
\hline CHEMBL 3640964 & 1528015 & 7.8861 & 8.3569 & TRN & \\
\hline CHEMBL 3643190 & 1528015 & 8.3979 & 8.5418 & TST & \\
\hline CHEMBL 3645791 & 1528015 & 8.9101 & 8.033999 & 9999999999 & RN \\
\hline CHEMBL 3643240 & 1528015 & 8.1778 & 7.5309 & TST & \\
\hline CHEMBL 3643180 & 1528015 & 8.0 & 8.0009 & TRN & \\
\hline CHEMBL 3648877 & 1528015 & \multicolumn{3}{|c|}{7.997000000000001} & t \\
\hline CHEMBL 3645830 & 1528015 & 9.2291 & 8.8486 & TST & \\
\hline CHEMBL 3640996 & 1528015 & 8.0969 & 7.9194 & TRN & \\
\hline CHEMBL3645879 & 1528015 & 8.6003 & 8.0981 & TST & \\
\hline CHEMBL 3643106 & 1528015 & 8.0 & 7.8462 & TRN & \\
\hline CHEMBL 3643221 & 1528015 & 8.1238 & 9.0545 & TRN & \\
\hline CHEMBL 3645851 & 1528015 & 8.5072 & 8.2608 & TRN & \\
\hline CHEMBL 3645855 & 1528015 & 8.3279 & 7.8173 & TRN & \\
\hline CHEMBL 3643142 & 1528015 & 8.301 & 8.3396 & TRN & \\
\hline CHEMBL 3645782 & 1528015 & 8.5421 & 8.4702 & TRN & \\
\hline CHEMBL 3645849 & 1528015 & 8.3344 & 7.8032 & TRN & \\
\hline CHEMBL 3645974 & 1528015 & 9.4949 & 9.1041 & TRN & \\
\hline CHEMBL 3645869 & 1528015 & 8.4225 & 8.6346 & TRN & \\
\hline CHEMBL 3643110 & 1528015 & 7.5528 & 7.6299 & TRN & \\
\hline CHEMBL 3643262 & 1528015 & 8.9626 & 8.4203 & TRN & \\
\hline CHEMBL 3643191 & 1528015 & 8.301 & 7.8947 & TST & \\
\hline CHEMBL 3645815 & 1528015 & 6.0 & 7.8583 & TRN & \\
\hline CHEMBL 3643172 & 1528015 & 8.5229 & 8.227 & TRN & \\
\hline
\end{tabular}

Page 15767 
Supplemental Table S2.txt

\begin{tabular}{|c|c|c|c|c|}
\hline HEMBL & 528015 & 6.0 & 7.2522 & \\
\hline & 528015 & 7.7959 & 8.3625 & \\
\hline - & & & & \\
\hline AEMBL & 8015 & & & \\
\hline AEMBL3 & 528015 & 8.757 & 9908 & \\
\hline HEMBL 3643243 & 528015 & 7.1245 & .4267 & \\
\hline 09 & 28015 & & & \\
\hline 94 & 28015 & & & \\
\hline AEMBL36 & 528015 & & 3.1282 & \\
\hline HEMBL 364 & 528015 & 8.0114 & .4038 & \\
\hline AEMBL364 & 528015 & 8.8356 & . 3911 & \\
\hline IEMBL3 & 28015 & 8 & 6953 & \\
\hline AEMBL & 8015 & & & \\
\hline HEMBL36 & 528015 & & . 6792 & \\
\hline AEMBL36 & 528015 & & .9225 & \\
\hline AEMBL36 & 528015 & 8. & 8.9 & \\
\hline AEMBL3 & 8015 & & 29 & \\
\hline HEMBL 3 & & & & \\
\hline HEMBL36 & 528015 & & 8.1614 & \\
\hline AEMBL36 & 528015 & 6 . & & RN \\
\hline HEMBL & 8015 & & 63 & \\
\hline AEMBL & 8615 & & & \\
\hline HEMBL & 8015 & 8 & & \\
\hline HEMBL & 528015 & 6.0 & & \\
\hline AEMBL36 & 8015 & 8 & 67 & NIV \\
\hline HEMBL3 & 8015 & & 97 & RN \\
\hline HEMBL. & 15 & & & \\
\hline AFMB : & 3015 & 7. & 97 & ST \\
\hline HEMBL36 & 528015 & & & RIV \\
\hline HEMBL 36 & 528015 & & 38 & I RN \\
\hline HEMBL3 & 8015 & 7 & 14 & \\
\hline AFMB & 15 & 6 & & RN \\
\hline HEMBL & & 6 & & RN \\
\hline HEMBL36 & 528015 & & & IRN \\
\hline HEMBL 364 & 528015 & & 6214 & TST \\
\hline HEMBL3C & 28015 & 2 & 59 & RN \\
\hline HCMDI & 5 & & & RN \\
\hline HEMBL36 & & & & $\mathrm{RN}$ \\
\hline HEMBL 364 & 528015 & 9.3468 & 2996 & TST \\
\hline AEMBL3 & 528015 & & 6097 & RN \\
\hline HEMBL36 & 528015 & 8. & 8.2224 & \\
\hline CHEMBL 3 & & & & ST \\
\hline HEMBL36 & 528015 & 7.9241 & 8.2317 & $\mathrm{RN}$ \\
\hline HEMBL 364 & 528015 & 8.5229 & .4329 & RN \\
\hline MBL & 8015 & & 7.8022 & \\
\hline HEMBL36 & 528015 & & & \\
\hline HEMBL 36 & 528015 & 8.8327 & 8.0427 & \\
\hline HEMBL3643114 & 1528015 & 8.0458 & 8.1982 & ГRN \\
\hline
\end{tabular}

Page 15768 
Supplemental Table S2.txt

\begin{tabular}{|c|c|c|c|c|}
\hline CHEMBL 3645936 & 1528015 & 8.7852 & 8.8056 & TRN \\
\hline CHEMBL 3645824 & 1528015 & 8.757 & 8.7433 & TST \\
\hline CHEMBL 3643277 & 1528015 & 8.4389 & 8.4491 & TRN \\
\hline CHEMBL 3643070 & 1528015 & 8.0969 & 7.8385 & TRN \\
\hline CHEMBL 3643068 & 1528015 & 8.699 & 7.8903 & TRN \\
\hline CHEMBL 3645942 & 1528015 & 8.5607 & 8.5412 & TRN \\
\hline CHEMBL 3645845 & 1528015 & 8.6757 & 8.4397 & TRN \\
\hline CHEMBL 3645808 & 1528015 & 7.7673 & 8.2202 & TRN \\
\hline CHEMBL 3643244 & 1528015 & 7.2914 & 7.5534 & TRN \\
\hline CHEMBL 3645789 & 1528015 & 7.8147 & 8.0663 & TST \\
\hline CHEMBL 3643220 & 1528015 & 9.0269 & 8.5715 & TRN \\
\hline CHEMBL 3645939 & 1528015 & 7.9813 & 7.7724 & TRN \\
\hline CHEMBL 3643104 & 1528015 & 8.2218 & 8.4784 & TRN \\
\hline CHEMBL 3643217 & 1528015 & 8.6696 & 8.9618 & TRN \\
\hline CHEMBL 3639398 & 1528015 & 7.1675 & 7.6354 & TRN \\
\hline CHEMBL 3643182 & 1528015 & 7.9586 & 8.0691 & TRN \\
\hline CHEMBL 3645850 & 1528015 & 8.2848 & 7.9885 & TRN \\
\hline CHEMBL 3645887 & 1528015 & 8.7077 & 8.6582 & TRN \\
\hline CHEMBL 3645814 & 1528015 & 6.0 & 7.8513 & TRN \\
\hline CHEMBL 3643093 & 1528015 & 8.1549 & 7.9522 & TRN \\
\hline CHEMBL 3643132 & 1528015 & 7.8861 & 7.6296 & TRN \\
\hline CHEMBL 3640974 & 1528015 & 7.5086 & 8.512 & TST \\
\hline CHEMBL 3643073 & 1528015 & 8.699 & 8.4511 & TRN \\
\hline CHEMBL 3648879 & 1528015 & 8.1524 & 7.7345 & TRN \\
\hline CHEMBL 3643099 & 1528015 & 8.3979 & 8.5875 & TRN \\
\hline CHEMBL 3643228 & 1528015 & 7.6796 & 7.7987 & TST \\
\hline CHEMBL 3643233 & 1528015 & 7.397 & 7.5376 & TRN \\
\hline CHEMBL 3645885 & 1528015 & 8.821 & 8.4619 & TRN \\
\hline CHEMBL 3643238 & 1528015 & 7.9038 & 8.2948 & TRN \\
\hline CHEMBL 3645950 & 1528015 & 8.0731 & 8.3767 & TRN \\
\hline CHEMBL 3643157 & 1528015 & 6.0 & 7.8009 & TRN \\
\hline CHEMBL 3640969 & 1528015 & 6.9626 & 8.4925 & TST \\
\hline CHEMBL 3645881 & 1528015 & 8.2434 & 7.1605 & TRN \\
\hline CHEMBL 3643118 & 1528015 & 7.7696 & 7.9424 & TRN \\
\hline CHEMBL 3640998 & 1528015 & 8.0458 & 7.7862 & TRN \\
\hline CHEMBL 3645975 & 1528015 & 9.2518 & 9.3106 & TRN \\
\hline CHEMBL 3645958 & 1528015 & 8.8996 & 8.7258 & TRN \\
\hline CHEMBL 3643071 & 1528015 & 9.0 & 8.5792 & TRN \\
\hline CHEMBL 3640967 & 1528015 & 7.8861 & 7.8062 & TRN \\
\hline CHEMBL 3643197 & 1528015 & 7.9208 & 7.891 & TST \\
\hline CHEMBL 3645886 & 1528015 & 8.4572 & 8.375 & TRN \\
\hline CHEMBL 3645872 & 1528015 & 8.9547 & 8.7861 & TRN \\
\hline CHEMBL 3645794 & 1528015 & 7.9574 & 8.2646 & TRN \\
\hline CHEMBL 3643143 & 1528015 & 6.0 & 7.4962 & TRN \\
\hline CHEMBL 3643113 & 1528015 & 8.301 & 7.986006 & 0000000001 \\
\hline CHEMBL 3639419 & 1528015 & 8.699 & 7.8252 & TST \\
\hline CHEMBL 3640928 & 1528015 & 8.0969 & 8.5595 & TST \\
\hline CHEMBL 3645898 & 1528015 & 7.8413 & 8.1069 & TRN \\
\hline
\end{tabular}

Page 15769 
Supplemental Table S2.txt

\begin{tabular}{|c|c|c|c|c|}
\hline CHEMBL3645967 & 1528015 & 9.5528 & 9.0584 & TRN \\
\hline CHEMBL3643133 & 1528015 & 8.0969 & 7.5292 & TRN \\
\hline CHEMBL3640978 & 1528015 & 7.4815 & 7.5433 & TRN \\
\hline CHEMBL3643146 & 1528015 & 6.0 & 7.7331 & TRN \\
\hline CHEMBL3645927 & 1528015 & 9.1739 & 7.9849 & TST \\
\hline CHEMBL3643246 & 1528015 & 6.0 & 6.7639 & TRN \\
\hline CHEMBL3645847 & 1528015 & 7.727 & 8.5213 & TRN \\
\hline CHEMBL3640927 & 1528015 & 7.9586 & 8.4501 & TST \\
\hline CHEMBL3640960 & 1528015 & 7.4949 & 8.137 & TST \\
\hline CHEMBL3645844 & 1528015 & 7.636 & 8.8074 & TST \\
\hline CHEMBL3643181 & 1528015 & 8.0969 & 8.1697 & TRN \\
\hline CHEMBL3645842 & 1528015 & 8.1675 & 7.8494 & TRN \\
\hline CHEMBL3643125 & 1528015 & 6.0 & 7.5877 & TRN \\
\hline CHEMBL3643189 & 1528015 & 9.0 & 8.2347 & TRN \\
\hline CHEMBL3643175 & 1528015 & 7.7959 & 7.6877 & TST \\
\hline CHEMBL 3640948 & 1528015 & 7.2007 & 8.3462 & TST \\
\hline CHEMBL3643230 & 1528015 & 8.3468 & 8.1484 & TRN \\
\hline CHEMBL3645899 & 1528015 & 7.8768 & 7.9514 & TRN \\
\hline CHEMBL3643105 & 1528015 & 7.9208 & 7.8233 & TRN \\
\hline CHEMBL3643061 & 1528015 & 9.0 & 8.6834 & TRN \\
\hline CHEMBL3643062 & 1528015 & 9.0 & 8.3242 & TRN \\
\hline CHEMBL3643242 & 1528015 & 7.0532 & 6.8147 & TRN \\
\hline CHEMBL3645859 & 1528015 & 8.7144 & 8.6244 & TRN \\
\hline CHEMBL3643236 & 1528015 & 7.9914 & 7.9829 & TRN \\
\hline CHEMBL3640970 & 1528015 & 8.3979 & 8.2986 & TRN \\
\hline CHEMBL3643156 & 1528015 & 6.0 & 8.1591 & TRN \\
\hline CHEMBL 3643148 & 1528015 & 6.0 & 7.0701 & TRN \\
\hline CHEMBL3643218 & 1528015 & 8.6676 & 9.0035 & TRN \\
\hline CHEMBL 3645964 & 1528015 & 9.2518 & 9.0664 & TRN \\
\hline CHEMBL3643135 & 1528015 & 7.7959 & 8.3517 & TRN \\
\hline CHEMBL3645989 & 1528015 & 8.0146 & 7.6948 & TRN \\
\hline CHEMBL3643086 & 1528015 & 8.301 & 8.3635 & TRN \\
\hline CHEMBL3641014 & 1528015 & 7.7447 & 8.1498 & TRN \\
\hline CHEMBL 3640931 & 1528015 & 7.5229 & 8.141 & TST \\
\hline CHEMBL3645834 & 1528015 & 7.8655 & 9.2777 & TRN \\
\hline CHEMBL3640985 & 1528015 & 8.3979 & 7.6303 & TRN \\
\hline CHEMBL3640943 & 1528015 & 7.5376 & 8.3047 & TST \\
\hline CHEMBL3645790 & 1528015 & 8.3458 & 7.8368 & TRN \\
\hline CHEMBL3645988 & 1528015 & 8.1884 & 7.8711 & TST \\
\hline CHEMBL3640990 & 1528015 & 8.5229 & 8.6769 & TRN \\
\hline CHEMBL3643167 & 1528015 & 8.3979 & 9.0273 & TST \\
\hline CHEMBL3648876 & 1528015 & 8.2832 & 8.3395 & TRN \\
\hline CHEMBL3643254 & 1528015 & 7.4895 & 7.7341 & TRN \\
\hline CHEMBL3643193 & 1528015 & 8.1549 & 7.6537 & TST \\
\hline CHEMBL3643123 & 1528015 & 7.7696 & 7.8149 & TRN \\
\hline CHEMBL 3645983 & 1528015 & 8.6517 & 8.6198 & TRN \\
\hline CHEMBL3645774 & 1528015 & 7.9825 & \multicolumn{2}{|c|}{7.827999999999999} \\
\hline CHEMBL3643162 & 1528015 & 6.0 & 7.7923 & TRN \\
\hline
\end{tabular}


Supplemental Table S2.txt

\begin{tabular}{|c|c|c|c|c|c|c|}
\hline CHEMBL3640952 & 1528015 & 7.699 & 8.4633 & TST & & \\
\hline CHEMBL3645836 & 1528015 & $8.7670 e$ & 00000000 & & 8.4462 & TRN \\
\hline CHEMBL3645882 & 1528015 & 8.5467 & 8.2989 & TRN & & \\
\hline CHEMBL 3645952 & 1528015 & 8.1701 & 9.0352 & TRN & & \\
\hline CHEMBL3643179 & 1528015 & 7.8861 & 8.4246 & TRN & & \\
\hline CHEMBL3643225 & 1528015 & $8.4660 e$ & 00000000 & & 8.8728 & TST \\
\hline CHEMBL3645860 & 1528015 & 8.3288 & 8.3727 & TRN & & \\
\hline CHEMBL3643089 & 1528015 & 8.3979 & 8.6459 & TRN & & \\
\hline CHEMBL3645888 & 1528015 & 8.6696 & 9.0336 & TRN & & \\
\hline CHEMBL3645919 & 1528015 & 8.9281 & 8.201 & TST & & \\
\hline CHEMBL 3640988 & 1528015 & 8.3979 & 8.5411 & TRN & & \\
\hline CHEMBL3643187 & 1528015 & 9.0 & 8.2897 & TST & & \\
\hline CHEMBL3643107 & 1528015 & 7.7959 & 7.9721 & TRN & & \\
\hline CHEMBL3645955 & 1528015 & 8.2565 & 8.4664 & TRN & & \\
\hline CHEMBL3640972 & 1528015 & 7.7696 & 8.2952 & TRN & & \\
\hline CHEMBL3640963 & 1528015 & 7.6198 & 8.547 & TST & & \\
\hline CHEMBL3643196 & 1528015 & 7.8861 & 8.0709 & TST & & \\
\hline CHEMBL3640926 & 1528015 & 7.6198 & 8.5866 & TST & & \\
\hline CHEMBL3645917 & 1528015 & 8.9469 & 8.7166 & TRN & & \\
\hline CHEMBL3645821 & 1528015 & 9.2676 & 9.2781 & TRN & & \\
\hline CHEMBL3645786 & 1528015 & 8.015 & 8.5502 & TRN & & \\
\hline CHEMBL3645912 & 1528015 & 9.5376 & 9.2536 & TRN & & \\
\hline CHEMBL3641011 & 1528015 & 8.5229 & 7.8977 & TRN & & \\
\hline CHEMBL3645916 & 1528015 & 9.3279 & 8.6157 & TRN & & \\
\hline CHEMBL3643116 & 1528015 & 8.2218 & 7.1499 & TRN & & \\
\hline CHEMBL3643078 & 1528015 & 8.5229 & 8.2769 & TRN & & \\
\hline CHEMBL 3643241 & 1528015 & 8.0526 & 7.7691 & TST & & \\
\hline CHEMBL 3645827 & 1528015 & 9.1549 & 9.1511 & TRN & & \\
\hline CHEMBL3645906 & 1528015 & 9.1739 & 9.1835 & TRN & & \\
\hline CHEMBL3648869 & 1528015 & 8.3536 & 7.7026 & TST & & \\
\hline CHEMBL3643267 & 1528015 & 8.7496 & 7.5412 & TRN & & \\
\hline CHEMBL3890827 & 1528015 & 7.7212 & 8.0865 & TST & & \\
\hline CHEMBL3645867 & 1528015 & 8.7011 & 8.8619 & TRN & & \\
\hline CHEMBL 3641008 & 1528015 & 9.0 & 8.4393 & TRN & & \\
\hline CHEMBL 3645848 & 1528015 & 7.4072 & 8.2495 & TRN & & \\
\hline CHEMBL3643092 & 1528015 & 8.5229 & 8.8342 & TRN & & \\
\hline CHEMBL3643213 & 1528015 & 7.6198 & 8.2173 & TST & & \\
\hline CHEMBL 3643195 & 1528015 & 8.0 & 8.1584 & TST & & \\
\hline CHEMBL 3643212 & 1528015 & 8.5229 & 8.2353 & TRN & & \\
\hline CHEMBL 3641017 & 1528015 & 8.699 & 8.4608 & TRN & & \\
\hline CHEMBL3643136 & 1528015 & 6.0 & 8.0263 & TST & & \\
\hline CHEMBL3643250 & 1528015 & 7.479 & 7.2542 & TRN & & \\
\hline CHEMBL3645812 & 1528015 & 7.7762 & 8.5336 & TST & & \\
\hline CHEMBL3643111 & 1528015 & 8.2218 & 8.054 & TRN & & \\
\hline CHEMBL3643161 & 1528015 & 6.0 & 8.133 & TST & & \\
\hline CHEMBL3640992 & 1528015 & 8.1549 & 8.5403 & TRN & & \\
\hline CHEMBL3643252 & 1528015 & 8.3152 & 8.0506 & TRN & & \\
\hline CHEMBL3645918 & 1528015 & 9.0969 & 8.1576 & TST & & \\
\hline
\end{tabular}


Supplemental Table S2.txt

\begin{tabular}{|c|c|c|c|c|}
\hline CHEMBL 3648882 & 1528015 & 9.1805 & 8.2968 & TST \\
\hline CHEMBL 3643208 & 1528015 & 7.7696 & 7.3538 & TRN \\
\hline CHEMBL 3645978 & 1528015 & 9.4089 & 8.4476 & TST \\
\hline CHEMBL 3645799 & 1528015 & 8.2321 & 8.3941 & TRN \\
\hline CHEMBL 3643171 & 1528015 & 7.5086 & 7.4033 & TRN \\
\hline CHEMBL 3645771 & 1528015 & 8.7399 & 7.9087 & TST \\
\hline CHEMBL 3645914 & 1528015 & 9.699 & 8.5959 & TRN \\
\hline CHEMBL 3645857 & 1528015 & 8.4647 & 7.9665 & TRN \\
\hline CHEMBL 3643266 & 1528015 & 7.90799 & 79999999ऽ & 6.8841 \\
\hline CHEMBL 3643064 & 1528015 & 8.3979 & 8.1055 & TRN \\
\hline CHEMBL 3640989 & 1528015 & 7.5686 & 7.67399 & 99999999995 \\
\hline CHEMBL 3643083 & 1528015 & 7.4815 & 7.4402 & TRN \\
\hline CHEMBL 3643280 & 1528015 & 8.5702 & 7.4114 & TRN \\
\hline CHEMBL 3645905 & 1528015 & 9.0 & 8.7135 & TRN \\
\hline CHEMBL 3641003 & 1528015 & 9.0 & 8.381 & TRN \\
\hline CHEMBL 3640993 & 1528015 & 8.0969 & 7.6051 & TRN \\
\hline CHEMBL 3643153 & 1528015 & 6.0 & 6.8398 & TRN \\
\hline CHEMBL 3645769 & 1528015 & 8.4647 & 8.7082 & TRN \\
\hline CHEMBL 3645913 & 1528015 & 9.6021 & 8.8765 & TRN \\
\hline CHEMBL 3643147 & 1528015 & 6.0 & 7.7249 & TRN \\
\hline CHEMBL 3643101 & 1528015 & 8.1549 & 7.7226 & TRN \\
\hline CHEMBL 3643201 & 1528015 & 8.0969 & 7.6875 & TST \\
\hline CHEMBL 3645822 & 1528015 & 8.8665 & 8.5819 & TST \\
\hline CHEMBL 3648885 & 1528015 & 8.9393 & 8.6075 & TRN \\
\hline CHEMBL 3645971 & 1528015 & 9.1675 & 9.157 & TRN \\
\hline CHEMBL 3640976 & 1528015 & 8.5229 & 8.5017 & TRN \\
\hline CHEMBL 3645929 & 1528015 & 8.8097 & 8.8953 & TRN \\
\hline CHEMBL 3643102 & 1528015 & 7.4089 & 7.7498 & TRN \\
\hline CHEMBL 3643069 & 1528015 & 9.0 & 7.9334 & TRN \\
\hline CHEMBL 3643271 & 1528015 & 8.5784 & 8.1112 & TRN \\
\hline CHEMBL 3645792 & 1528015 & 8.7375 & 8.7694 & TRN \\
\hline CHEMBL 3645788 & 1528015 & 8.2233 & 8.7846 & TST \\
\hline CHEMBL 3645832 & 1528015 & 9.2757 & 8.7073 & TRN \\
\hline CHEMBL 3648866 & 1528015 & 7.9423 & 7.5367 & TRN \\
\hline CHEMBL 3640959 & 1528015 & 7.1024 & 8.2367 & TST \\
\hline CHEMBL 3645823 & 1528015 & 9.0506 & 8.7726 & TST \\
\hline CHEMBL 3645795 & 1528015 & 8.2933 & 8.0253 & TRN \\
\hline CHEMBL 3645862 & 1528015 & 7.6996 & 8.0814 & TRN \\
\hline CHEMBL 3640956 & 1528015 & 7.6576 & 8.3601 & TST \\
\hline CHEMBL 3645807 & 1528015 & 7.8447 & 8.1006 & TRN \\
\hline CHEMBL 3645951 & 1528015 & 7.8567 & 8.435 & TRN \\
\hline CHEMBL 3643184 & 1528015 & 8.301 & 8.1163 & TST \\
\hline CHEMBL 3645809 & 1528015 & 8.02 & 8.0147 & TRN \\
\hline CHEMBL 3643237 & 1528015 & 7.9259 & 7.0224 & TRN \\
\hline CHEMBL 3643199 & 1528015 & 8.0 & 7.9199 & TST \\
\hline CHEMBL 3645846 & 1528015 & 8.0655 & 8.7047 & TRN \\
\hline CHEMBL 3641007 & 1528015 & 8.5229 & 8.4156 & TST \\
\hline CHEMBL 3643163 & 1528015 & 8.3979 & 8.1848 & TST \\
\hline
\end{tabular}


Supplemental Table S2.txt

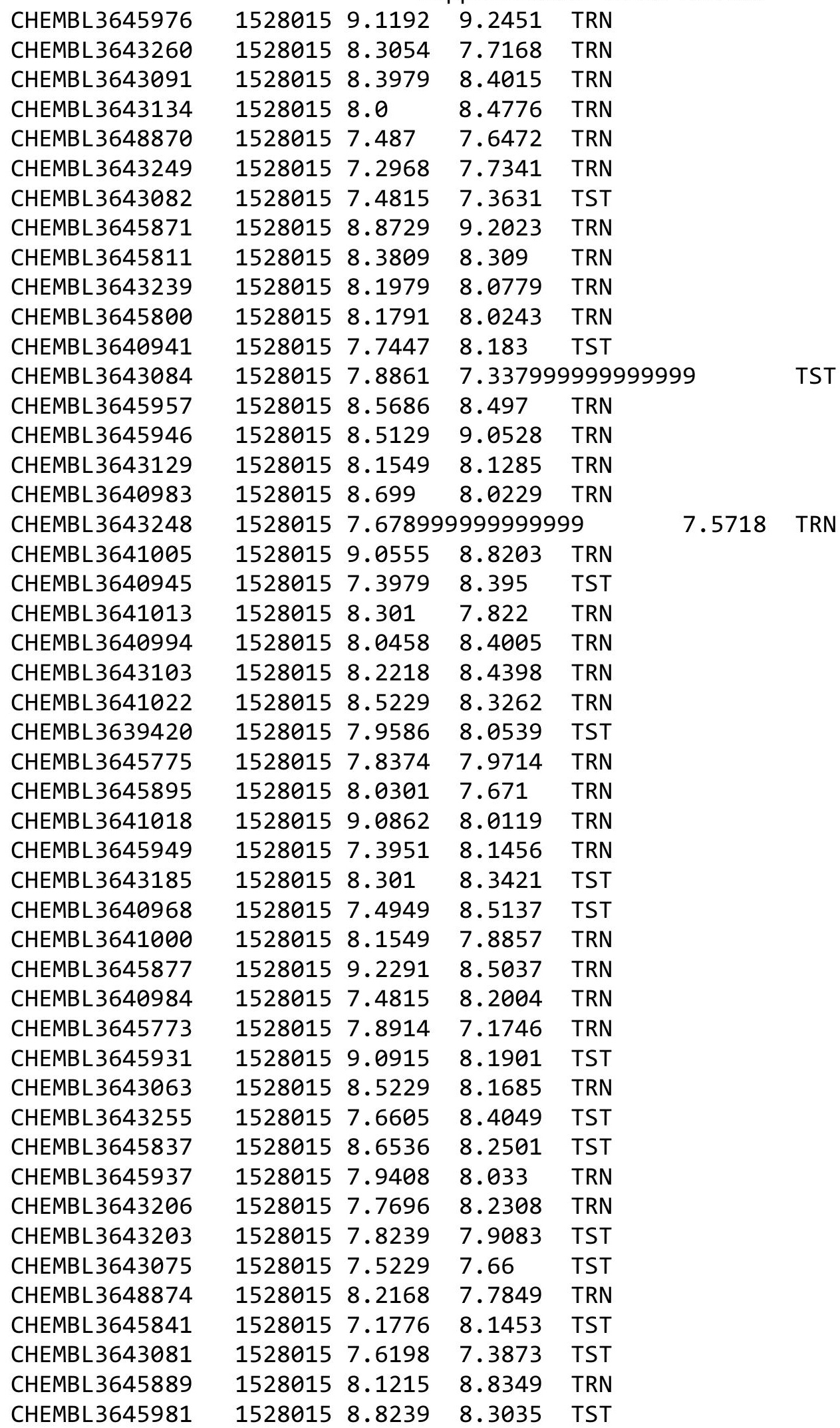

Page 15773 
Supplemental Table S2.txt

\begin{tabular}{|c|c|c|c|c|}
\hline HEMBL: & & 1 & & \\
\hline HFMRI 3613131 & 528915 & 8.0969 & 4817 & \\
\hline HEMBL & & $\partial 862$ & 5655 & \\
\hline AEMBL3643119 & 528015 & 8861 & 892 & \\
\hline HEMBL3643130 & 528015 & 8.3979 & .901 & \\
\hline HEMBL3 & 528015 & 9.2924 & 6703 & \\
\hline HEMBL; & & 8.5654 & & \\
\hline HEMBL3 & 528015 & 4004 & 4531 & \\
\hline HEMBL 364 & 528015 & 8.6055 & 8142 & \\
\hline HEMBL364 & 528015 & 9.0 & .1719 & \\
\hline HEMBL36 & 528015 & 8.0458 & 6643 & \\
\hline HEMBL3 & & & & \\
\hline HEMBL3 & 528015 & 799 & 3385 & \\
\hline HEMBL 36 & 528015 & 612 & 7908 & \\
\hline HEMBL364 & 528015 & 8.699 & 5819 & \\
\hline AEMBL & 28015 & & 237 & \\
\hline AEMBL. & 8015 & & & IIV \\
\hline HEMBL & 528015 & 7905 & 887 & \\
\hline HEMBL36 & 528015 & 616 & 1057 & \\
\hline AEMBL36 & 528015 & 9. & 7571 & KIV \\
\hline AEMBL: & 8015 & & 333 & RN \\
\hline AEMBL & & 59 & 26 & NIV \\
\hline HEMBL & 15 & 229 & 094 & $\mathrm{RN}$ \\
\hline AEMBL3 & & & & \\
\hline HEMBL3 & 528015 & 996 & 726 & | \\
\hline IEMBL: & 5 & 528 & 55 & ST \\
\hline AEME & & & & $\mathrm{RN}$ \\
\hline AСMP & & & & RN \\
\hline AEMBL & & & & IRN \\
\hline AEMBL36 & 528015 & 7. & & $\mathrm{RN}$ \\
\hline AEMBL: & 528015 & 52 & 48 & $\mathrm{RN}$ \\
\hline$I 5 M$ & & & $\partial 9$ & RN \\
\hline & & & & TST \\
\hline AEMBL36 & 15 & & & TST \\
\hline HEMBL36 & 528015 & 258 & 598 & 「RN \\
\hline$A F M B I=$ & 528015 & 62 & 351 & RN \\
\hline & & & & ST \\
\hline HEMBL3 & & & 182 & TRN \\
\hline AEMBL36 & 528015 & 7. & & TST \\
\hline EMBL3 & 15 & 908 & 564 & 「RN \\
\hline HEMBL36 & 5 & 765 & 152 & No \\
\hline & & 7.8576 & & 「RN \\
\hline HEMBL36 & & & 611 & TRN \\
\hline AEMBL36 & 528 & 8.0969 & 986 & TS \\
\hline met & & 924 & 329 & ונכ \\
\hline HEMBL 36 & - & 3.2218 & 8.5018 & \\
\hline CHEMBL 36 & 50010 & 8.5719 & 8.5448 & \\
\hline CHEMBL3643183 & 1528015 & 8.1549 & 7.782 & ГST \\
\hline
\end{tabular}

Page 15774 
Supplemental Table S2.txt

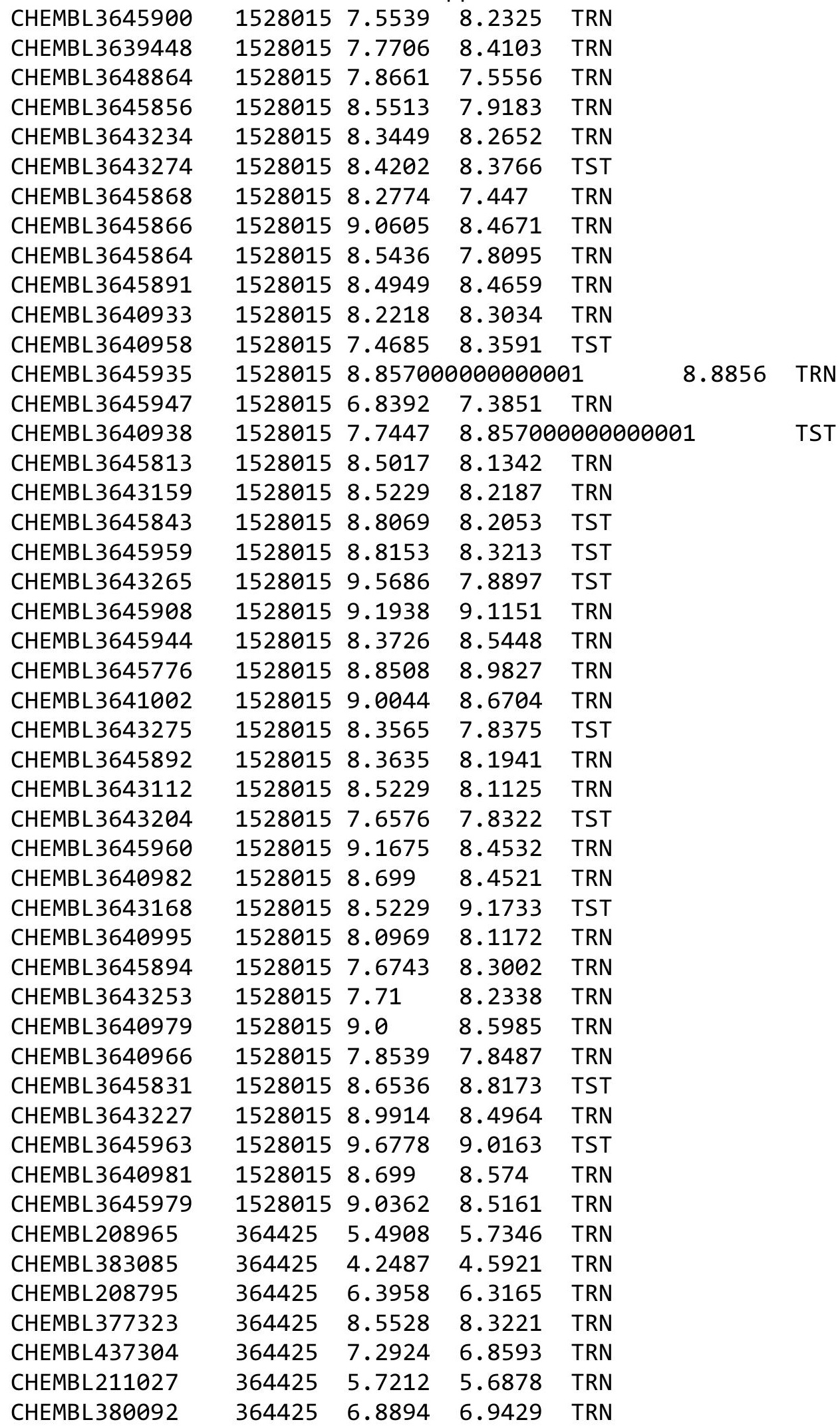

Page 15775 


\begin{tabular}{|c|c|c|c|c|c|}
\hline \multicolumn{6}{|c|}{ oplemental Table } \\
\hline CHEMBL377103 & 364425 & 6.0 & 7.0308 & TST & \\
\hline CHEMBL208580 & 364425 & 8.0 & 7.5327 & TST & \\
\hline CHEMBL209203 & 364425 & 7.0088 & 6.8602 & TST & \\
\hline CHEMBL378569 & 364425 & 5.6757 & 5.2916 & TRN & \\
\hline CHEMBL210280 & 364425 & 5.6234 & 5.6391 & TRN & \\
\hline CHEMBL385135 & 364425 & 6.8508 & 6.6991 & TRN & \\
\hline CHEMBL266830 & 364425 & 5.4815 & 5.6088 & TRN & \\
\hline CHEMBL378454 & 364425 & 4.3979 & 5.3324 & TRN & \\
\hline CHEMBL208959 & 364425 & 6.2358 & 6.5953 & TRN & \\
\hline CHEMBL359880 & 364425 & 7.0605 & 7.12700 & 3000000001 & TRN \\
\hline CHEMBL 207274 & 364425 & 6.9547 & 7.3023 & TRN & \\
\hline CHEMBL379703 & 364425 & 6.9666 & 7.0619 & TRN & \\
\hline CHEMBL377160 & 364425 & 8.4685 & 8.2784 & TST & \\
\hline CHEMBL207535 & 364425 & 5.4711 & 5.2576 & TRN & \\
\hline CHEMBL210698 & 364425 & 8.1549 & 9.0936 & TST & \\
\hline CHEMBL209517 & 364425 & 6.4283 & 6.4746 & TRN & \\
\hline CHEMBL210377 & 364425 & 7.4815 & 7.136 & TRN & \\
\hline CHEMBL377017 & 364425 & 6.7375 & 6.8081 & TRN & \\
\hline CHEMBL209347 & 364425 & 8.7959 & 8.9935 & TST & \\
\hline CHEMBL207136 & 364425 & 4.9473 & 4.5309 & TRN & \\
\hline CHEMBL 377148 & 364425 & 4.6238 & 4.5498 & TRN & \\
\hline CHEMBL210391 & 364425 & 5.9101 & 5.6626 & TRN & \\
\hline CHEMBL381078 & 364425 & 5.7799 & 5.7799 & TRN & \\
\hline CHEMBL210141 & 364425 & 6.9586 & 6.5798 & TRN & \\
\hline CHEMBL378187 & 364425 & 8.8239 & 8.0633 & TST & \\
\hline CHEMBL 209570 & 364425 & 7.1487 & 7.0707 & TST & \\
\hline CHEMBL208757 & 364425 & 7.3188 & 7.7136 & TRN & \\
\hline CHEMBL210623 & 364425 & 5.9626 & 6.1258 & TST & \\
\hline CHEMBL210412 & 364425 & 5.9431 & 6.0586 & TRN & \\
\hline CHEMBL379750 & 364425 & 8.7212 & 9.2245 & TST & \\
\hline CHEMBL 377404 & 364425 & 7.585 & 7.5739 & TRN & \\
\hline CHEMBL208669 & 364425 & 6.8827 & 6.9643 & TRN & \\
\hline CHEMBL208777 & 364425 & 8.6778 & 9.1415 & TST & \\
\hline CHEMBL439152 & 364425 & 9.5229 & 8.5684 & TST & \\
\hline CHEMBL379295 & 364425 & 6.1624 & 6.0816 & TRN & \\
\hline CHEMBL 208910 & 364425 & 8.8861 & 8.2888 & TST & \\
\hline CHEMBL383988 & 364425 & 7.8861 & 7.5604 & TRN & \\
\hline CHEMBL210251 & 364425 & 3.3979 & 4.3689 & TRN & \\
\hline CHEMBL537199 & 364425 & 5.475 & 5.5805 & TRN & \\
\hline CHEMBL 207592 & 364425 & 5.9469 & 5.8651 & TRN & \\
\hline CHEMBL 210442 & 364425 & 6.7328 & 6.8546 & TRN & \\
\hline CHEMBL 209569 & 364425 & 9.0458 & 8.1177 & TST & \\
\hline CHEMBL 207593 & 364425 & 6.51 & 6.391 & TRN & \\
\hline CHEMBL441472 & 364425 & 9.3979 & 8.4797 & TST & \\
\hline CHEMBL 208692 & 364425 & 6.8794 & 6.9591 & TRN & \\
\hline CHEMBL209116 & 364425 & 5.0841 & 6.2453 & TRN & \\
\hline CHEMBL 210263 & 364425 & 7.585 & 7.1492 & TRN & \\
\hline CHEMBL 380281 & 364425 & 6.9101 & 6.8513 & TRN & \\
\hline
\end{tabular}




\begin{tabular}{|c|c|c|c|c|c|}
\hline & & \\
\hline CHEMBL210302 & 364425 & 6.3665 & 6.1514 & TRN & \\
\hline CHEMBL207715 & 364425 & 5.6861 & 5.1505 & TRN & \\
\hline CHEMBL427394 & 364425 & 6.5735 & 6.3504 & TRN & \\
\hline CHEMBL380205 & 364425 & 6.0 & 6.654 & TST & \\
\hline CHEMBL210711 & 364425 & 6.1884 & 6.0688 & TRN & \\
\hline CHEMBL377610 & 364425 & 3.3979 & 3.2675 & TRN & \\
\hline CHEMBL210214 & 364425 & 7.301 & 7.5634 & TRN & \\
\hline CHEMBL210536 & 364425 & 6.3363 & 6.4461 & TRN & \\
\hline CHEMBL210669 & 364425 & 7.1938 & 7.2474 & TRN & \\
\hline CHEMBL210235 & 364425 & 5.2013 & 5.6533 & TRN & \\
\hline CHEMBL210993 & 364425 & 7.3372 & 7.9851 & TST & \\
\hline CHEMBL210716 & 364425 & 5.8633 & 5.2985 & TRN & \\
\hline CHEMBL210847 & 364425 & 6.3072 & 5.822 & TRN & \\
\hline CHEMBL378021 & 364425 & 5.4078 & 5.2475 & TRN & \\
\hline CHEMBL210445 & 364425 & 6.4881 & 6.7852 & TRN & \\
\hline CHEMBL379215 & 364425 & 5.8097 & 5.9209 & TST & \\
\hline CHEMBL379131 & 364425 & 8.8539 & 8.6475 & TST & \\
\hline CHEMBL209268 & 364425 & 7.0269 & 6.7646 & TRN & \\
\hline CHEMBL378565 & 364425 & 7.5229 & 7.8729 & TST & \\
\hline CHEMBL380215 & 364425 & 6.7799 & 7.1362 & TRN & \\
\hline CHEMBL210492 & 364425 & 5.2373 & 4.9878 & TRN & \\
\hline CHEMBL210975 & 364425 & 6.6556 & 6.5016 & TRN & \\
\hline CHEMBL 210086 & 364425 & 7.5376 & 7.4725 & TRN & \\
\hline CHEMBL271066 & 465006 & 8.2 & 6.011 & TST & \\
\hline CHEMBL408169 & 465006 & 6.4 & 5.9712 & TST & \\
\hline CHEMBL272702 & 465006 & 5.0 & 6.2276 & TST & \\
\hline CHEMBL272379 & 465006 & 5.1 & 6.0439 & TST & \\
\hline CHEMBL 257534 & 465006 & 4.6 & 5.5633 & TST & \\
\hline CHEMBL256652 & 465006 & 5.3 & 5.9082 & TST & \\
\hline CHEMBL257536 & 465006 & 7.2 & 5.6449 & TST & \\
\hline CHEMBL401576 & 465006 & 6.9 & 6.8953 & TST & \\
\hline CHEMBL403181 & 465006 & 6.0 & 6.059 & TRN & \\
\hline CHEMBL 256475 & 465006 & 5.2 & 5.2768 & TRN & \\
\hline CHEMBL257946 & 465006 & 6.1 & 5.9685 & TRN & \\
\hline CHEMBL401728 & 465006 & 6.0 & 6.0079 & TRN & \\
\hline CHEMBL270567 & 465006 & 6.3 & 6.2052 & TRN & \\
\hline CHEMBL271083 & 465006 & 6.7 & 6.8124 & TRN & \\
\hline CHEMBL 270227 & 465006 & 7.0 & 6.9773 & TRN & \\
\hline CHEMBL255620 & 465006 & 4.7 & 4.7768 & TRN & \\
\hline CHEMBL255826 & 465006 & 5.3 & 5.2204 & TRN & \\
\hline CHEMBL255619 & 465006 & 6.0 & 5.8304 & TRN & \\
\hline CHEMBL273166 & 465006 & 5.9 & 6.126 & TRN & \\
\hline CHEMBL256472 & 465006 & 3.8 & 3.74300 & 00000000003 & TRN \\
\hline CHEMBL256473 & 465006 & 5.9 & 6.0086 & TRN & \\
\hline CHEMBL 258090 & 465006 & 5.6 & 5.6049 & TRN & \\
\hline CHEMBL402016 & 465006 & 6.0 & 6.0239 & TRN & \\
\hline CHEMBL256651 & 465006 & 5.9 & 5.79899 & 99999999995 & TRN \\
\hline CHEMBL271096 & 465006 & 6.6 & 6.5759 & TRN & \\
\hline & & & & 15777 & \\
\hline
\end{tabular}




\begin{tabular}{|c|c|c|c|c|}
\hline & & & & \\
\hline CHEMBL272302 & 465006 & 4.8 & 5.9346 & TST \\
\hline CHEMBL270209 & 465006 & 3.2 & 4.8026 & TST \\
\hline CHEMBL269995 & 465006 & 5.0 & 5.0128 & TST \\
\hline CHEMBL439065 & 465006 & 5.4 & 5.7801 & TST \\
\hline CHEMBL256653 & 465006 & 4.3 & 5.1881 & TST \\
\hline CHEMBL429132 & 465006 & 6.1 & 6.0195 & TRN \\
\hline CHEMBL271280 & 465006 & 4.4 & 4.9053 & TRN \\
\hline CHEMBL272695 & 465006 & 6.0 & 5.3528 & TRN \\
\hline CHEMBL256016 & 465006 & 5.4 & 5.4314 & TRN \\
\hline CHEMBL256015 & 465006 & 5.7 & 5.7097 & TRN \\
\hline CHEMBL402826 & 465006 & 6.2 & 6.135 & TRN \\
\hline CHEMBL272546 & 465006 & 5.2 & 5.113 & TRN \\
\hline CHEMBL 272545 & 465006 & 5.3 & 5.3779 & TRN \\
\hline CHEMBL271844 & 465006 & 5.4 & 5.4634 & TRN \\
\hline CHEMBL255621 & 465006 & 5.2 & 5.1551 & TRN \\
\hline CHEMBL255827 & 465006 & 4.5 & 4.2261 & TRN \\
\hline CHEMBL269959 & 465006 & 4.0 & 4.5363 & TRN \\
\hline CHEMBL255618 & 465006 & 5.7 & 5.8877 & TRN \\
\hline CHEMBL255417 & 465006 & 5.5 & 5.3815 & TRN \\
\hline CHEMBL273165 & 465006 & 5.0 & 4.8671 & TRN \\
\hline CHEMBL257525 & 465006 & 6.0 & 5.9764 & TRN \\
\hline CHEMBL257524 & 465006 & 5.4 & 5.4183 & TRN \\
\hline CHEMBL270239 & 465006 & 4.9 & 4.8319 & TRN \\
\hline CHEMBL257900 & 465006 & 6.4 & 6.3101 & TRN \\
\hline CHEMBL401777 & 465006 & 5.6 & 5.685 & TRN \\
\hline CHEMBL257901 & 465006 & 4.9 & 5.1394 & TRN \\
\hline CHEMBL408208 & 465006 & 6.2 & 6.1741 & TRN \\
\hline CHEMBL272378 & 465006 & 5.6 & 5.6302 & TRN \\
\hline CHEMBL402015 & 465006 & 5.2 & 5.1082 & TRN \\
\hline CHEMBL256650 & 465006 & 4.3 & 4.2261 & TRN \\
\hline CHEMBL271097 & 465006 & 6.6 & 6.6085 & TRN \\
\hline CHEMBL269994 & 465006 & 5.8 & 6.0367 & TRN \\
\hline CHEMBL 256481 & 465006 & 5.8 & 5.5819 & TRN \\
\hline CHEMBL257369 & 465006 & 6.6 & 6.5484 & TRN \\
\hline CHEMBL256482 & 465006 & 5.8 & 5.9037 & TRN \\
\hline CHEMBL271072 & 465006 & 5.3 & 5.4445 & TRN \\
\hline CHEMBL271073 & 465006 & 4.3 & 4.1993 & TRN \\
\hline CHEMBL402087 & 465006 & 6.6 & 6.5282 & TRN \\
\hline CHEMBL401752 & 465006 & 6.3 & 6.0823 & TRN \\
\hline CHEMBL272694 & 465006 & 5.3 & 5.5565 & TRN \\
\hline CHEMBL255566 & 465006 & 6.4 & 6.45799 & 9999999999 \\
\hline CHEMBL255778 & 465006 & 5.9 & 5.8634 & TRN \\
\hline CHEMBL255806 & 465006 & 5.6 & 5.4958 & TRN \\
\hline CHEMBL255567 & 465006 & 5.9 & 6.0883 & TRN \\
\hline CHEMBL271631 & 465006 & 6.6 & 6.4377 & TRN \\
\hline CHEMBL256471 & 465006 & 5.5 & 5.3891 & TRN \\
\hline CHEMBL271632 & 465006 & 5.6 & 5.7702 & TRN \\
\hline CHEMBL256477 & 465006 & 6.0 & 5.9298 & TRN \\
\hline
\end{tabular}




\begin{tabular}{|c|c|c|c|c|c|}
\hline & & & & & \\
\hline CHEMBL272086 & 465006 & 5.6 & 5.2974 & TST & \\
\hline CHEMBL 272300 & 465006 & 4.4 & 4.8679 & TST & \\
\hline CHEMBL270852 & 465006 & 5.4 & 6.0552 & TST & \\
\hline CHEMBL270853 & 465006 & 4.5 & 5.4715 & TST & \\
\hline CHEMBL272478 & 465006 & 5.4 & 6.1416 & TST & \\
\hline CHEMBL273199 & 465006 & 5.7 & 6.8065 & TST & \\
\hline CHEMBL85606 & 465006 & 5.7 & 6.5299 & TST & \\
\hline CHEMBL379975 & 954775 & 3.9719 & 3.9594 & TRN & \\
\hline CHEMBL3349342 & 954775 & 4.372 & 4.3773 & TRN & \\
\hline CHEMBL3199475 & 954775 & 3.5683 & 3.5718 & TRN & \\
\hline CHEMBL512504 & 954775 & 4.172 & 4.1809 & TRN & \\
\hline CHEMBL392695 & 954775 & 3.3792 & 3.3714 & TRN & \\
\hline CHEMBL1788116 & 954775 & 2.9432 & 2.9395 & TRN & \\
\hline CHEMBL577784 & 954775 & 3.8357 & 3.8283 & TRN & \\
\hline CHEMBL1190711 & 954775 & 2.8125 & 2.8175 & TRN & \\
\hline CHEMBL191334 & 954775 & 3.5843 & 3.5851 & TRN & \\
\hline CHEMBL2005886 & 954775 & 3.0095 & 3.0026 & TRN & \\
\hline CHEMBL1357247 & 954775 & 2.6349 & 2.64600 & 20000000004 & TRN \\
\hline CHEMBL2144069 & 954775 & 4.0525 & 4.0476 & TRN & \\
\hline CHEMBL393929 & 954775 & 3.8587 & 3.8655 & TRN & \\
\hline CHEMBL1673039 & 954775 & 2.7926 & 2.7811 & TRN & \\
\hline CHEMBL483847 & 954775 & 3.4612 & 3.4608 & TRN & \\
\hline CHEMBL180127 & 954775 & 2.3991 & 2.4083 & TRN & \\
\hline CHEMBL213100 & 954775 & 3.7084 & 3.7118 & TRN & \\
\hline CHEMBL379300 & 954775 & 3.836999 & 99999999 & 3.8375 & TRN \\
\hline CHEMBL102714 & 954775 & 2.9749 & 2.9852 & TRN & \\
\hline CHEMBL3186408 & 954775 & 2.9284 & 3.5688 & TST & \\
\hline CHEMBL221137 & 954775 & 2.2087 & 3.8047 & TST & \\
\hline CHEMBL255342 & 954775 & 3.9601 & 3.9377 & TRN & \\
\hline CHEMBL1970879 & 954775 & 2.8595 & 2.8632 & TRN & \\
\hline CHEMBL 2134202 & 954775 & 4.2768 & 4.247 & TRN & \\
\hline CHEMBL1590308 & 954775 & 2.9627 & 3.072 & TST & \\
\hline CHEMBL189584 & 954775 & 3.7675 & 3.7722 & TRN & \\
\hline CHEMBL 300389 & 954775 & 5.4985 & 5.5006 & TRN & \\
\hline CHEMBL1256459 & 954775 & 4.1097 & 4.1153 & TRN & \\
\hline CHEMBL483849 & 954775 & 2.1957 & 1.9593 & TST & \\
\hline CHEMBL573107 & 954775 & 4.8233 & 4.8262 & TRN & \\
\hline CHEMBL65 & 954775 & 7.4504 & 7.4603 & TRN & \\
\hline CHEMBL135561 & 954775 & 3.8387 & 3.8458 & TRN & \\
\hline CHEMBL258844 & 954775 & 3.4287 & 3.4308 & TRN & \\
\hline CHEMBL222102 & 954775 & 3.178 & 3.1926 & TRN & \\
\hline CHEMBL514499 & 954775 & 4.5066 & 4.511 & TRN & \\
\hline CHEMBL192566 & 954775 & 3.8817 & 5.7648 & TST & \\
\hline CHEMBL2137530 & 954775 & 4.9781 & 5.0006 & TRN & \\
\hline CHEMBL472940 & 954775 & 2.2801 & 2.2755 & TRN & \\
\hline CHEMBL1909414 & 954775 & 3.1 & 3.1129 & TRN & \\
\hline CHEMBL449158 & 954775 & 5.8549 & 6.0659 & TST & \\
\hline CHEMBL558642 & 954775 & 2.5045 & 2.4933 & TRN & \\
\hline
\end{tabular}





\begin{tabular}{|c|c|c|c|c|c|}
\hline \\
\hline CHEMBL1355634 & 688643 & 5.0 & 5.0076 & TRN & \\
\hline CHEMBL1522155 & 688643 & 5.3 & 5.2812 & TRN & \\
\hline CHEMBL1475108 & 688643 & 5.4 & 5.2528 & TRN & \\
\hline CHEMBL1329326 & 688643 & 6.1 & 5.895 & TRN & \\
\hline CHEMBL1367030 & 688643 & 6.2 & 6.155 & TRN & \\
\hline CHEMBL1255935 & 688643 & 4.5 & 4.7017 & TST & \\
\hline CHEMBL1495077 & 688643 & 5.1 & 5.1295 & TRN & \\
\hline CHEMBL1357551 & 688643 & 4.6 & 4.5489 & TRN & \\
\hline CHEMBL1562791 & 688643 & 4.7 & 4.7077 & TRN & \\
\hline CHEMBL1356395 & 688643 & 5.5 & 5.5781 & TST & \\
\hline CHEMBL1396211 & 688643 & 4.4 & 4.4096 & TRN & \\
\hline CHEMBL1533572 & 688643 & 4.6 & 4.6297 & TRN & \\
\hline CHEMBL21241 & 688643 & 5.2 & 5.26200 & 20000000005 & TST \\
\hline CHEMBL1327793 & 688643 & 5.6 & 5.6283 & TST & \\
\hline CHEMBL1257080 & 688643 & 4.4 & 5.1269 & TST & \\
\hline CHEMBL1357982 & 688643 & 5.2 & 4.9602 & TRN & \\
\hline CHEMBL1235966 & 688643 & 7.5003 & 7.3482 & TRN & \\
\hline CHEMBL1255865 & 688643 & 7.0 & 6.8362 & TRN & \\
\hline CHEMBL1572167 & 688643 & 4.9 & 4.9615 & TST & \\
\hline CHEMBL1330718 & 688643 & 4.7 & 4.6537 & TRN & \\
\hline CHEMBL1608975 & 688643 & 5.5 & 5.4809 & TRN & \\
\hline CHEMBL1374028 & 688643 & 5.8 & 5.7293 & TST & \\
\hline CHEMBL1606892 & 688643 & 4.4 & 4.6133 & TRN & \\
\hline CHEMBL102714 & 688643 & 4.5 & 5.2501 & TST & \\
\hline CHEMBL1327945 & 688643 & 4.8 & 4.8349 & TRN & \\
\hline CHEMBL1368395 & 688643 & 6.0 & 6.1453 & TRN & \\
\hline CHEMBL1400043 & 688643 & 4.4 & 4.2957 & TRN & \\
\hline CHEMBL1354403 & 688643 & 4.9 & 5.2001 & TRN & \\
\hline CHEMBL1401672 & 688643 & 4.7 & 4.6065 & TRN & \\
\hline CHEMBL1590106 & 688643 & 4.6 & 4.9446 & TRN & \\
\hline CHEMBL1354112 & 688643 & 5.4 & 5.3317 & TRN & \\
\hline CHEMBL1373998 & 688643 & 5.5 & 5.5222 & TST & \\
\hline CHEMBL1373007 & 688643 & 4.6 & 4.8285 & TST & \\
\hline CHEMBL1456015 & 688643 & 4.4 & 4.3944 & TRN & \\
\hline CHEMBL1448192 & 688643 & 5.5 & 5.5258 & TRN & \\
\hline CHEMBL1339015 & 688643 & 7.6003 & 5.3459 & TRN & \\
\hline CHEMBL1568178 & 688643 & 4.7 & 4.7085 & TRN & \\
\hline CHEMBL1474471 & 688643 & 5.0 & 5.0701 & TRN & \\
\hline CHEMBL1407 & 688643 & 6.0 & 5.3593 & TRN & \\
\hline CHEMBL1894909 & 688643 & 5.6 & 5.4666 & TRN & \\
\hline CHEMBL1372873 & 688643 & 5.5 & 5.4504 & TST & \\
\hline CHEMBL1452389 & 688643 & 6.9 & 6.5904 & TRN & \\
\hline CHEMBL1363967 & 688643 & 7.5003 & 7.0045 & TRN & \\
\hline CHEMBL29197 & 688643 & 5.0 & 4.9409 & TRN & \\
\hline CHEMBL1591543 & 688643 & 5.0 & 4.8715 & TRN & \\
\hline CHEMBL1322686 & 688643 & 5.0 & 4.9681 & TRN & \\
\hline CHEMBL1456454 & 688643 & 4.7 & 4.7203 & TRN & \\
\hline CHEMBL1527622 & 688643 & 7.1002 & 6.7502 & TST & \\
\hline
\end{tabular}




\begin{tabular}{|c|c|c|c|c|c|}
\hline & & & & & \\
\hline CHEMBL1488574 & 688643 & 4.5 & 4.5155 & TRN & \\
\hline CHEMBL81977 & 688643 & 4.7 & 4.7233 & TST & \\
\hline CHEMBL1600292 & 688643 & 5.4 & 5.2986 & TST & \\
\hline CHEMBL1322976 & 688643 & 5.5 & 5.3763 & TST & \\
\hline CHEMBL1525349 & 688643 & 5.2 & 5.4496 & TRN & \\
\hline CHEMBL52387 & 688643 & 4.5 & 4.7269 & TRN & \\
\hline CHEMBL76904 & 688643 & 4.7 & 4.5408 & TRN & \\
\hline CHEMBL1315504 & 688643 & 4.8 & 4.7038 & TRN & \\
\hline CHEMBL1355010 & 688643 & 4.7 & 4.6011 & TRN & \\
\hline CHEMBL585986 & 688643 & 5.5 & 5.7111 & TST & \\
\hline CHEMBL1256775 & 688643 & 4.5 & 4.7134 & TRN & \\
\hline CHEMBL321691 & 688643 & 5.4 & 5.4269 & TRN & \\
\hline CHEMBL1603852 & 688643 & 4.7 & 4.6541 & TRN & \\
\hline CHEMBL1516054 & 688643 & 6.1 & 6.07299 & 99999999995 & TRN \\
\hline CHEMBL1355292 & 688643 & 5.3 & 5.6026 & TRN & \\
\hline CHEMBL1365455 & 688643 & 6.0 & 7.8535 & TRN & \\
\hline CHEMBL1600612 & 688643 & 5.0 & 5.0601 & TRN & \\
\hline CHEMBL1446467 & 688643 & 5.4 & 5.3068 & TRN & \\
\hline CHEMBL1512722 & 688643 & 6.1 & 6.0173 & TRN & \\
\hline CHEMBL285932 & 688643 & 5.4 & 5.4176 & TST & \\
\hline CHEMBL1447538 & 688643 & 5.5 & 5.5865 & TRN & \\
\hline CHEMBL1361552 & 688643 & 4.7 & 4.707 & TRN & \\
\hline CHEMBL1326322 & 688643 & 4.4 & 4.408 & TRN & \\
\hline CHEMBL1320141 & 688643 & 5.5 & 5.4735 & TRN & \\
\hline CHEMBL1590245 & 688643 & 5.4 & 5.4927 & TRN & \\
\hline CHEMBL1356094 & 688643 & 6.8 & 6.3746 & TST & \\
\hline CHEMBL1256996 & 688643 & 6.0 & 6.0893 & TRN & \\
\hline CHEMBL1554465 & 688643 & 5.1 & 4.9028 & TRN & \\
\hline CHEMBL1434447 & 688643 & 5.1 & 5.4433 & TRN & \\
\hline CHEMBL288096 & 688643 & 4.8 & 4.8894 & TRN & \\
\hline CHEMBL1452722 & 688643 & 5.3 & 5.2592 & TST & \\
\hline CHEMBL62 & 688643 & 6.0 & $5.9970 e$ & 0000000001 & TRN \\
\hline CHEMBL1556377 & 688643 & 5.5 & 5.2981 & TRN & \\
\hline CHEMBL1366732 & 688643 & 4.7 & 4.6614 & TRN & \\
\hline CHEMBL1377111 & 688643 & 6.0 & 5.9384 & TRN & \\
\hline CHEMBL1515982 & 688643 & 5.3 & 5.3037 & TRN & \\
\hline CHEMBL1604883 & 688643 & 5.5 & 5.4065 & TST & \\
\hline CHEMBL1436536 & 688643 & 4.9 & 5.0697 & TRN & \\
\hline CHEMBL203722 & 688643 & 5.9 & 5.7702 & TST & \\
\hline CHEMBL1515001 & 688643 & 5.2 & 5.2255 & TRN & \\
\hline CHEMBL1395355 & 688643 & 5.4 & 5.2968 & TRN & \\
\hline CHEMBL366489 & 688643 & 5.4 & 5.3588 & TRN & \\
\hline CHEMBL1314222 & 688643 & 4.7 & 4.6711 & TRN & \\
\hline CHEMBL1435450 & 688643 & 4.6 & 4.5878 & TRN & \\
\hline CHEMBL1358342 & 688643 & 4.4 & 4.3999 & TRN & \\
\hline CHEMBL242171 & 688643 & 4.5 & 5.17299 & 9999999999 & TRN \\
\hline CHEMBL1407257 & 688643 & 6.3 & 6.2537 & TRN & \\
\hline CHEMBL440084 & 688643 & 4.9 & 4.9768 & TRN & \\
\hline & & & & 15782 & \\
\hline
\end{tabular}




\begin{tabular}{|c|c|c|c|c|c|}
\hline \multirow[b]{2}{*}{ CHEMBL1395421 } & \multicolumn{5}{|c|}{ Supplemental Table S2.txt } \\
\hline & 688643 & 8.2007 & 7.5926 & TST & \\
\hline CHEMBL119264 & 688643 & 5.3 & 5.4381 & TRN & \\
\hline CHEMBL1369796 & 688643 & 4.7 & 4.7328 & TRN & \\
\hline CHEMBL1316760 & 688643 & 4.9 & 4.7931 & TRN & \\
\hline CHEMBL1356941 & 688643 & 4.6 & 4.6039 & TRN & \\
\hline CHEMBL1552249 & 688643 & 7.8013 & 7.2443 & TRN & \\
\hline CHEMBL1437282 & 688643 & 5.5 & 5.4665 & TRN & \\
\hline CHEMBL1591374 & 688643 & 4.6 & 4.6053 & TRN & \\
\hline CHEMBL1257081 & 688643 & 4.8 & 5.3897 & TRN & \\
\hline CHEMBL1354319 & 688643 & 5.0 & 4.8294 & TRN & \\
\hline CHEMBL 1355256 & 688643 & 4.7 & 4.5957 & TRN & \\
\hline CHEMBL1316714 & 688643 & 4.4 & 4.4915 & TRN & \\
\hline CHEMBL1526053 & 688643 & 5.5 & 5.2103 & TRN & \\
\hline CHEMBL1335140 & 688643 & 5.3 & 5.1497 & TRN & \\
\hline CHEMBL1255583 & 688643 & 6.0 & 5.8095 & TRN & \\
\hline CHEMBL187216 & 688643 & 5.4 & 5.3971 & TRN & \\
\hline CHEMBL1257075 & 688643 & 6.0 & 5.7652 & TRN & \\
\hline CHEMBL1437075 & 688643 & 4.7 & 4.6073 & TRN & \\
\hline CHEMBL1253921 & 688643 & 7.4001 & 5.058 & TRN & \\
\hline CHEMBL1593353 & 688643 & 4.7 & 4.5833 & TRN & \\
\hline CHEMBL491748 & 688643 & 5.6 & 5.494 & TRN & \\
\hline CHEMBL1553404 & 688643 & 4.4 & 4.3856 & TRN & \\
\hline CHEMBL1325408 & 688643 & 5.4 & 5.3874 & TRN & \\
\hline CHEMBL1482759 & 688643 & 6.7001 & 6.4525 & TRN & \\
\hline CHEMBL1412163 & 688643 & 5.4 & 5.3353 & TRN & \\
\hline CHEMBL 1318447 & 688643 & 4.4 & 4.5314 & TRN & \\
\hline CHEMBL1410759 & 688643 & 5.5 & 5.53600 & 00000000005 & TRN \\
\hline CHEMBL1474016 & 688643 & 6.2 & 6.2306 & TRN & \\
\hline CHEMBL1551139 & 688643 & 5.0 & 4.8638 & TRN & \\
\hline CHEMBL1567020 & 688643 & 7.3002 & 6.7538 & TST & \\
\hline CHEMBL1515355 & 688643 & 4.7 & 4.5812 & TRN & \\
\hline CHEMBL1327915 & 688643 & 4.7 & 4.6214 & TRN & \\
\hline CHEMBL 2373666 & 688643 & 5.3 & 5.5135 & TRN & \\
\hline CHEMBL1557234 & 688643 & 4.6 & 4.5228 & TRN & \\
\hline CHEMBL345083 & 688643 & 4.5 & 5.2613 & TST & \\
\hline CHEMBL1331410 & 688643 & 4.9 & 4.8309 & TRN & \\
\hline CHEMBL1594227 & 688643 & 4.6 & 4.7324 & TRN & \\
\hline CHEMBL1317928 & 688643 & 5.5 & 5.5379 & TRN & \\
\hline CHEMBL1256750 & 688643 & 4.4 & 5.155 & TRN & \\
\hline CHEMBL1315079 & 688643 & 4.8 & 5.4201 & TRN & \\
\hline CHEMBL1318824 & 688643 & 5.5 & 5.6395 & TST & \\
\hline CHEMBL486817 & 688643 & 4.8 & 5.1854 & TRN & \\
\hline CHEMBL1592470 & 688643 & 4.9 & 5.396 & TRN & \\
\hline CHEMBL1318042 & 688643 & 4.7 & 4.7198 & TRN & \\
\hline CHEMBL1236872 & 688643 & 4.4 & 5.1602 & TRN & \\
\hline CHEMBL 1208858 & 688643 & 7.4001 & 7.0963 & TST & \\
\hline CHEMBL1395899 & 688643 & 4.4 & 4.32100 & 0000000001 & TRN \\
\hline CHEMBL1526697 & 688643 & 5.0 & 4.9548 & TRN & \\
\hline & & & & 15783 & \\
\hline
\end{tabular}




\begin{tabular}{|c|c|c|c|c|}
\hline & & & upplement & al $\mathrm{Ta}$ \\
\hline CHEMBL182310 & 688643 & 4.7 & 4.7517 & TRN \\
\hline CHEMBL63426 & 688643 & 6.0 & 5.9523 & TST \\
\hline CHEMBL1602476 & 688643 & 4.7 & 4.785 & TST \\
\hline CHEMBL1317885 & 688643 & 5.0 & 5.0904 & TRN \\
\hline CHEMBL1395620 & 688643 & 5.4 & 5.3851 & TRN \\
\hline CHEMBL1531899 & 688643 & 4.4 & 4.4077 & TRN \\
\hline CHEMBL25236 & 688643 & 6.0 & 5.8497 & TRN \\
\hline CHEMBL1529490 & 688643 & 6.0 & 6.3974 & TRN \\
\hline CHEMBL1395997 & 688643 & 5.3 & 5.2251 & TRN \\
\hline CHEMBL1200766 & 688643 & 5.4 & 5.3796 & TRN \\
\hline CHEMBL1609178 & 688643 & 5.5 & 5.6613 & TRN \\
\hline CHEMBL1512742 & 688643 & 5.9 & 5.95 & TRN \\
\hline CHEMBL1433559 & 688643 & 4.5 & 4.4896 & TRN \\
\hline CHEMBL1160730 & 688643 & 5.5 & 5.6811 & TRN \\
\hline CHEMBL1554622 & 688643 & 4.7 & 4.681 & TRN \\
\hline CHEMBL 1438000 & 688643 & 5.7 & 5.8556 & TRN \\
\hline CHEMBL586946 & 688643 & 6.1 & 5.8418 & TRN \\
\hline CHEMBL1484896 & 688643 & 4.4 & 4.5551 & TRN \\
\hline CHEMBL1397914 & 688643 & 4.6 & 4.5844 & TRN \\
\hline CHEMBL1318307 & 688643 & 5.6 & 5.6612 & TST \\
\hline CHEMBL1601416 & 688643 & 4.9 & 4.8543 & TRN \\
\hline CHEMBL1336796 & 688643 & 5.5 & 5.4383 & TST \\
\hline CHEMBL1436324 & 688643 & 6.0 & 5.9279 & TRN \\
\hline CHEMBL1440157 & 688643 & 5.6 & 5.6106 & TRN \\
\hline CHEMBL1593867 & 688643 & 5.1 & 5.1456 & TRN \\
\hline CHEMBL1486009 & 688643 & 5.0 & 4.8816 & TRN \\
\hline CHEMBL1554937 & 688643 & 4.8 & 4.8197 & TRN \\
\hline CHEMBL534084 & 688643 & 4.9 & 5.1256 & TRN \\
\hline CHEMBL 1600586 & 688643 & 5.5 & 5.3856 & TRN \\
\hline CHEMBL1553070 & 688643 & 5.1 & 4.967 & TRN \\
\hline CHEMBL104264 & 688643 & 4.6 & 4.8657 & TRN \\
\hline CHEMBL 274844 & 688643 & 5.1 & 5.245 & TRN \\
\hline CHEMBL1515366 & 688643 & 5.3 & 5.1571 & TRN \\
\hline CHEMBL1371127 & 688643 & 6.8 & 6.5043 & TRN \\
\hline CHEMBL1551970 & 688643 & 5.6 & 5.6496 & TRN \\
\hline CHEMBL1493644 & 688643 & 4.6 & 4.5242 & TRN \\
\hline CHEMBL1435077 & 688643 & 4.6 & 4.8218 & TRN \\
\hline CHEMBL1515736 & 688643 & 5.5 & 5.5158 & TRN \\
\hline CHEMBL520992 & 688643 & 4.6 & 4.5998 & TRN \\
\hline CHEMBL1529478 & 688643 & 4.6 & 4.6485 & TRN \\
\hline CHEMBL1356280 & 688643 & 6.2 & 6.1439 & TRN \\
\hline CHEMBL1355651 & 688643 & 4.9 & 4.8491 & TRN \\
\hline CHEMBL1595142 & 688643 & 7.0 & 7.039 & TRN \\
\hline CHEMBL1192187 & 688643 & 6.0 & 5.8165 & TRN \\
\hline CHEMBL1412847 & 688643 & 4.6 & 4.3271 & TRN \\
\hline CHEMBL1552227 & 688643 & 4.8 & 4.8276 & TRN \\
\hline CHEMBL1359181 & 688643 & 4.6 & 4.7779 & TRN \\
\hline CHEMBL1514161 & 688643 & 5.6 & 5.6221 & TRN \\
\hline
\end{tabular}




\begin{tabular}{|c|c|c|c|c|c|}
\hline & & \multicolumn{4}{|c|}{ Supplemental Table S2.txt } \\
\hline CHEMBL1319789 & 688643 & 5.7 & 5.7245 & TRN & \\
\hline CHEMBL1365882 & 688643 & 5.2 & 5.22 & TRN & \\
\hline CHEMBL1410016 & 688643 & 6.0 & 5.977 & TRN & \\
\hline CHEMBL1322757 & 688643 & 4.4 & 4.5052 & TRN & \\
\hline CHEMBL1479817 & 688643 & 4.7 & 4.6942 & TRN & \\
\hline CHEMBL 7257 & 688643 & 4.7 & 4.9601 & TRN & \\
\hline CHEMBL1317537 & 688643 & 6.0 & 5.8082 & TRN & \\
\hline CHEMBL1410676 & 688643 & 6.1 & 5.99799 & 9999999999 & TRN \\
\hline CHEMBL1315417 & 688643 & 5.0 & 5.1336 & TST & \\
\hline CHEMBL1356794 & 688643 & 5.4 & 5.2548 & TRN & \\
\hline CHEMBL1554577 & 688643 & 5.9 & 5.9104 & TRN & \\
\hline CHEMBL1511986 & 688643 & 4.6 & 4.5678 & TRN & \\
\hline CHEMBL1522796 & 688643 & 5.5 & 5.5825 & TST & \\
\hline CHEMBL1593213 & 688643 & 5.0 & 5.1379 & TST & \\
\hline CHEMBL1360434 & 688643 & 4.4 & 4.4083 & TRN & \\
\hline CHEMBL1356505 & 688643 & 4.8 & 4.7629 & TRN & \\
\hline CHEMBL1256839 & 688643 & 6.0 & 5.8457 & TRN & \\
\hline CHEMBL1372363 & 688643 & 4.6 & 4.6399 & TRN & \\
\hline CHEMBL 27441 & 688643 & 6.6 & 6.4721 & TST & \\
\hline CHEMBL1255867 & 688643 & 4.6 & 4.7022 & TRN & \\
\hline CHEMBL1437095 & 688643 & 5.0 & 5.0673 & TRN & \\
\hline CHEMBL1473379 & 688643 & 4.7 & 4.8554 & TRN & \\
\hline CHEMBL1512391 & 688643 & 6.0 & 5.8087 & TRN & \\
\hline CHEMBL1483263 & 688643 & 6.0 & 5.4214 & TST & \\
\hline CHEMBL1357184 & 688643 & 5.5 & 5.4395 & TRN & \\
\hline CHEMBL1591508 & 688643 & 5.3 & 5.4273 & TRN & \\
\hline CHEMBL53206 & 688643 & 6.3 & 6.4054 & TRN & \\
\hline CHEMBL1529665 & 688643 & 7.0 & 6.6444 & TST & \\
\hline CHEMBL1591896 & 688643 & 5.0 & 5.1134 & TRN & \\
\hline CHEMBL1372371 & 688643 & 4.7 & 4.6798 & TRN & \\
\hline CHEMBL1412225 & 688643 & 5.7 & 5.6656 & TRN & \\
\hline CHEMBL1611893 & 688643 & 7.4001 & 7.0004 & TRN & \\
\hline CHEMBL1402381 & 688643 & 5.9 & 6.2818 & TRN & \\
\hline CHEMBL1480903 & 688643 & 4.5 & 4.6444 & TRN & \\
\hline CHEMBL1446716 & 688643 & 6.9 & 6.8495 & TST & \\
\hline CHEMBL1315457 & 688643 & 5.1 & 5.3168 & TST & \\
\hline CHEMBL1439183 & 688643 & 4.4 & 4.4976 & TRN & \\
\hline CHEMBL1477169 & 688643 & 5.9 & 5.933 & TRN & \\
\hline CHEMBL1437783 & 688643 & 6.6 & 6.6093 & TRN & \\
\hline CHEMBL1394258 & 688643 & 4.4 & 4.295 & TRN & \\
\hline CHEMBL1397466 & 688643 & 4.9 & 4.7633 & TST & \\
\hline CHEMBL1338985 & 688643 & 4.6 & 4.5262 & TRN & \\
\hline CHEMBL1398537 & 688643 & 4.5 & 4.5365 & TRN & \\
\hline CHEMBL1555567 & 688643 & 4.6 & 4.7191 & TRN & \\
\hline CHEMBL 275006 & 688643 & 6.0 & 5.8113 & TRN & \\
\hline CHEMBL1316222 & 688643 & 5.5 & 5.5934 & TST & \\
\hline CHEMBL1589893 & 688643 & 4.9 & 4.8095 & TRN & \\
\hline CHEMBL242385 & 688643 & 4.6 & 5.0401 & TRN & \\
\hline
\end{tabular}




\begin{tabular}{|c|c|c|c|c|c|}
\hline \multicolumn{6}{|c|}{ Supplemental Table S2.txt } \\
\hline CHEMBL1483855 & 688643 & 5.2 & 5.1186 & TRN & \\
\hline CHEMBL1609889 & 688643 & 4.8 & 4.8295 & TRN & \\
\hline CHEMBL1492063 & 688643 & 5.5 & 5.5206 & TRN & \\
\hline CHEMBL1495251 & 688643 & 4.9 & 4.919 & TRN & \\
\hline CHEMBL1608410 & 688643 & 5.1 & 5.6201 & TST & \\
\hline CHEMBL1314505 & 688643 & 4.6 & 4.876 & TRN & \\
\hline CHEMBL1416912 & 688643 & 4.6 & 4.5884 & TRN & \\
\hline CHEMBL1364243 & 688643 & 6.0 & 6.1606 & TRN & \\
\hline CHEMBL242383 & 688643 & 4.7 & 5.0639 & TRN & \\
\hline CHEMBL1446523 & 688643 & 5.5 & 5.5825 & TRN & \\
\hline CHEMBL1439040 & 688643 & 5.3 & 5.3762 & TST & \\
\hline CHEMBL1527579 & 688643 & 5.5 & 5.6224 & TRN & \\
\hline CHEMBL1405461 & 688643 & 5.0 & 5.1817 & TRN & \\
\hline CHEMBL1361905 & 688643 & 4.7 & 4.6941 & TRN & \\
\hline CHEMBL1600269 & 688643 & 4.7 & 4.7479 & TRN & \\
\hline CHEMBL1411164 & 688643 & 6.1 & 6.2501 & TRN & \\
\hline CHEMBL1321899 & 688643 & 4.7 & 4.6967 & TRN & \\
\hline CHEMBL1594030 & 688643 & 4.5 & 4.5647 & TRN & \\
\hline CHEMBL196677 & 688643 & 4.4 & 5.2 & TST & \\
\hline CHEMBL1606038 & 688643 & 5.4 & 5.4608 & TRN & \\
\hline CHEMBL1411146 & 688643 & 4.4 & 4.5504 & TRN & \\
\hline CHEMBL1605356 & 688643 & 4.4 & 4.3367 & TRN & \\
\hline CHEMBL1401324 & 688643 & 6.9 & 6.61100 & 0000000001 & TRN \\
\hline CHEMBL1440145 & 688643 & 5.1 & 5.1965 & TRN & \\
\hline CHEMBL1200462 & 688643 & 6.0 & 6.0129 & TRN & \\
\hline CHEMBL1355840 & 688643 & 4.7 & 4.5449 & TRN & \\
\hline CHEMBL105739 & 688643 & 6.4 & 6.1919 & TRN & \\
\hline CHEMBL1561366 & 688643 & 5.2 & 5.1722 & TRN & \\
\hline CHEMBL1516028 & 688643 & 4.9 & 5.04899 & 99999999995 & TRN \\
\hline CHEMBL1399994 & 688643 & 6.3 & 6.2025 & TRN & \\
\hline CHEMBL1453980 & 688643 & 4.4 & 4.6169 & TRN & \\
\hline CHEMBL1397225 & 688643 & 5.0 & 5.0351 & TRN & \\
\hline CHEMBL 2062333 & 688643 & 4.5 & 4.7296 & TST & \\
\hline CHEMBL1332636 & 688643 & 5.4 & 5.48 & TRN & \\
\hline CHEMBL15134 & 688643 & 6.0 & 6.0495 & TST & \\
\hline CHEMBL1317055 & 688643 & 5.4 & 5.4463 & TRN & \\
\hline CHEMBL1434199 & 688643 & 6.0 & 5.935 & TRN & \\
\hline CHEMBL1534734 & 688643 & 5.1 & 5.13899 & 9999999999 & TRN \\
\hline CHEMBL35482 & 688643 & 5.1 & 5.1357 & TRN & \\
\hline CHEMBL1317235 & 688643 & 5.0 & 5.4032 & TST & \\
\hline CHEMBL1404408 & 688643 & 4.8 & 4.7998 & TRN & \\
\hline CHEMBL1362517 & 688643 & 6.7001 & 6.5758 & TRN & \\
\hline CHEMBL1516068 & 688643 & 7.8013 & 7.4762 & TRN & \\
\hline CHEMBL1330087 & 688643 & 6.0 & 6.1311 & TRN & \\
\hline CHEMBL1602394 & 688643 & 4.5 & 4.5057 & TRN & \\
\hline CHEMBL1435381 & 688643 & 4.5 & 4.4896 & TST & \\
\hline CHEMBL1358541 & 688643 & 4.8 & 5.2536 & TRN & \\
\hline CHEMBL1594329 & 688643 & 4.4 & 4.3527 & TRN & \\
\hline
\end{tabular}




\begin{tabular}{|c|c|c|c|c|}
\hline \multicolumn{5}{|c|}{ Supplemental Table S2.txt } \\
\hline CHEMBL1256746 & 688643 & 4.6 & 4.7841 & TRN \\
\hline CHEMBL1516388 & 688643 & 4.5 & 4.7175 & TST \\
\hline CHEMBL1591908 & 688643 & 5.2 & 5.2307 & TRN \\
\hline CHEMBL1514071 & 688643 & 4.9 & 4.8953 & TRN \\
\hline CHEMBL 227298 & 688643 & 5.5 & 5.5034 & TRN \\
\hline CHEMBL1474613 & 688643 & 4.4 & 4.5339 & TRN \\
\hline CHEMBL544115 & 688643 & 4.6 & 4.8301 & TRN \\
\hline CHEMBL98350 & 688643 & 4.6 & 4.7598 & TRN \\
\hline CHEMBL1512210 & 688643 & 4.6 & 4.6021 & TRN \\
\hline CHEMBL1602926 & 688643 & 5.5 & 5.5449 & TRN \\
\hline CHEMBL1597169 & 688643 & 5.6 & 5.5473 & TRN \\
\hline CHEMBL1324151 & 688643 & 5.5 & 5.6834 & TRN \\
\hline CHEMBL1399619 & 688643 & 5.1 & 5.1969 & TST \\
\hline CHEMBL1437486 & 688643 & 5.2 & 5.2095 & TRN \\
\hline CHEMBL1402251 & 688643 & 5.2 & 5.2251 & TST \\
\hline CHEMBL1556742 & 688643 & 5.4 & 5.3706 & TST \\
\hline CHEMBL475376 & 688643 & 4.9 & 5.035 & TRN \\
\hline CHEMBL1402277 & 688643 & 6.1 & 6.7031 & TRN \\
\hline CHEMBL512908 & 688643 & 5.5 & 5.5328 & TST \\
\hline CHEMBL1256364 & 688643 & 4.5 & 4.6368 & TRN \\
\hline CHEMBL 21396 & 688643 & 4.7 & 5.1211 & TST \\
\hline CHEMBL1553498 & 688643 & 8.2007 & 7.6453 & TRN \\
\hline CHEMBL1611974 & 688643 & 5.4 & 5.0793 & TST \\
\hline CHEMBL1256957 & 688643 & 6.0 & 5.8913 & TRN \\
\hline CHEMBL1394472 & 688643 & 5.5 & 5.4688 & TRN \\
\hline CHEMBL1323549 & 688643 & 4.4 & 4.4934 & TRN \\
\hline CHEMBL1515287 & 688643 & 4.6 & 4.636 & TRN \\
\hline CHEMBL1363367 & 688643 & 5.5 & 5.5122 & TST \\
\hline CHEMBL122701 & 688643 & 4.5 & 5.1063 & TRN \\
\hline CHEMBL1316219 & 688643 & 4.9 & 5.1019 & TRN \\
\hline CHEMBL1565751 & 688643 & 5.8 & 5.6901 & TRN \\
\hline CHEMBL1408856 & 688643 & 4.9 & 4.8923 & TRN \\
\hline CHEMBL1357429 & 688643 & 4.7 & 4.7375 & TRN \\
\hline CHEMBL16687 & 688643 & 4.9 & 4.8991 & TST \\
\hline CHEMBL1322233 & 688643 & 5.9 & 5.6638 & TRN \\
\hline CHEMBL1591556 & 688643 & 7.3002 & 6.9249 & TST \\
\hline CHEMBL 1200450 & 688643 & 6.0 & 5.9756 & TST \\
\hline CHEMBL1397752 & 688643 & 6.2 & 6.2259 & TRN \\
\hline CHEMBL164 & 688643 & 4.7 & 4.7894 & TRN \\
\hline CHEMBL1488420 & 688643 & 5.9 & 5.8923 & TRN \\
\hline CHEMBL328710 & 688643 & 4.5 & 5.5817 & TRN \\
\hline CHEMBL 20730 & 688643 & 6.0 & 5.9257 & TRN \\
\hline CHEMBL1452057 & 688643 & 4.7 & 4.7726 & TRN \\
\hline CHEMBL1374710 & 688643 & 4.7 & 4.5847 & TRN \\
\hline CHEMBL1591189 & 688643 & 5.4 & 5.4736 & TRN \\
\hline CHEMBL1338163 & 688643 & 5.3 & 5.1104 & TRN \\
\hline CHEMBL180966 & 688643 & 4.5 & 4.71 & TRN \\
\hline CHEMBL1565525 & 688643 & 4.9 & 4.7339 & TRN \\
\hline
\end{tabular}




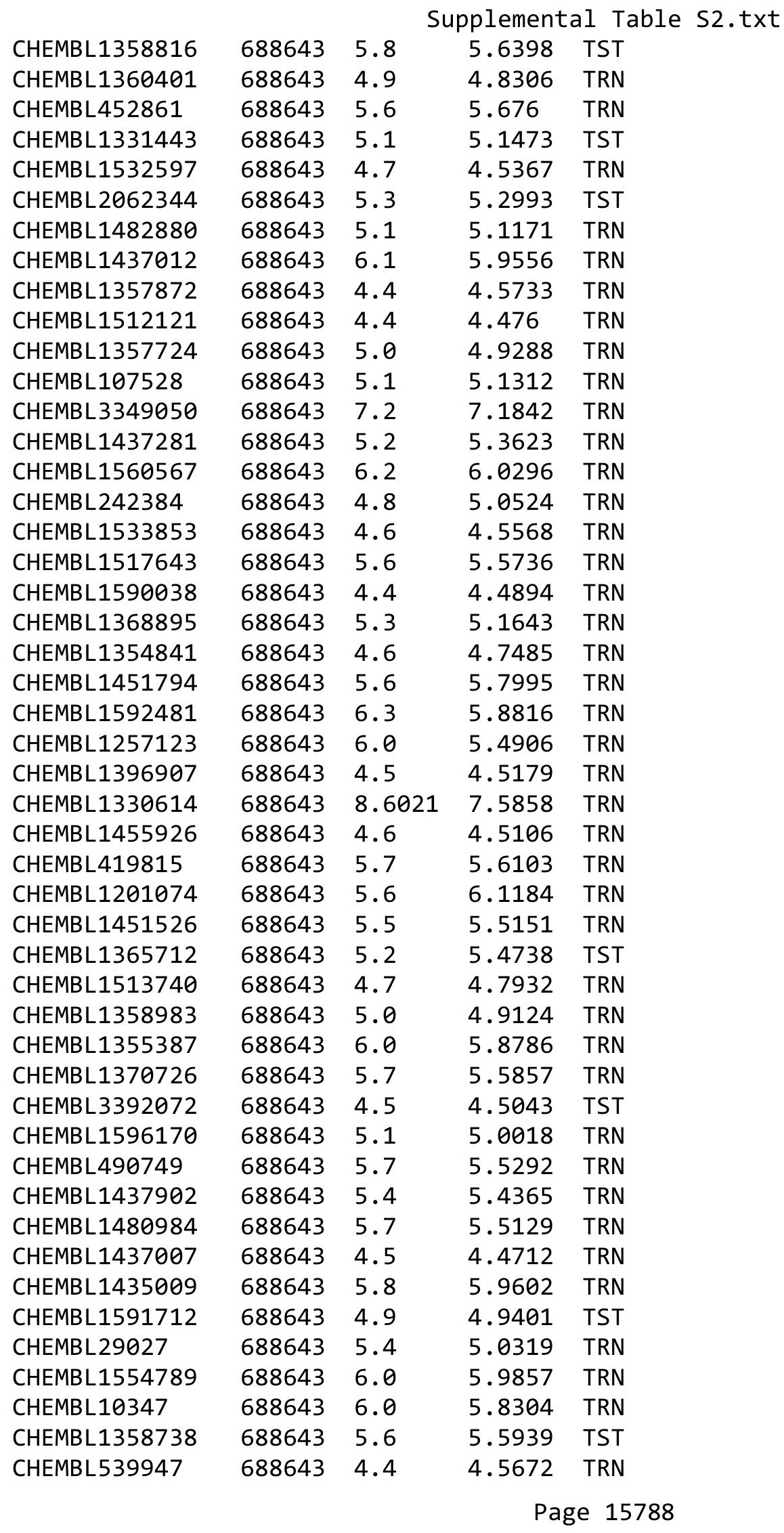




\begin{tabular}{|c|c|c|c|c|c|}
\hline \multicolumn{6}{|c|}{ Supplemental Table S2.txt } \\
\hline CHEMBL1371696 & 688643 & 5.9 & 5.9523 & TRN & \\
\hline CHEMBL1571995 & 688643 & 5.5 & 5.5694 & TRN & \\
\hline CHEMBL1358568 & 688643 & 6.0 & 6.0792 & TRN & \\
\hline CHEMBL1452894 & 688643 & 4.4 & 4.3652 & TRN & \\
\hline CHEMBL1397169 & 688643 & 7.1002 & 6.73799 & 99999999995 & TST \\
\hline CHEMBL1572747 & 688643 & 4.9 & 4.8051 & TRN & \\
\hline CHEMBL1435216 & 688643 & 5.6 & 5.7006 & TRN & \\
\hline CHEMBL 1255747 & 688643 & 4.5 & 4.7801 & TRN & \\
\hline CHEMBL1454284 & 688643 & 4.6 & 5.6105 & TST & \\
\hline CHEMBL1531754 & 688643 & 6.0 & 5.8673 & TRN & \\
\hline CHEMBL1374913 & 688643 & 4.7 & 4.7949 & TRN & \\
\hline CHEMBL1434747 & 688643 & 4.5 & 4.5246 & TRN & \\
\hline CHEMBL1396829 & 688643 & 5.4 & 5.5286 & TRN & \\
\hline CHEMBL1396203 & 688643 & 5.0 & 5.0118 & TRN & \\
\hline CHEMBL1331634 & 688643 & 6.0 & 6.1455 & TRN & \\
\hline CHEMBL1568250 & 688643 & 4.7 & 4.9019 & TRN & \\
\hline CHEMBL1481017 & 688643 & 4.8 & 4.8804 & TRN & \\
\hline CHEMBL1331914 & 688643 & 5.4 & 5.5741 & TST & \\
\hline CHEMBL1552332 & 688643 & 4.7 & 4.6196 & TRN & \\
\hline CHEMBL1594217 & 688643 & 5.1 & 5.2386 & TRN & \\
\hline CHEMBL1598334 & 688643 & 7.6003 & 7.2755 & TRN & \\
\hline CHEMBL1328533 & 688643 & 4.6 & 4.5134 & TRN & \\
\hline CHEMBL1473754 & 688643 & 4.8 & 4.6933 & TRN & \\
\hline CHEMBL1514517 & 688643 & 5.0 & 4.9599 & TRN & \\
\hline CHEMBL1363551 & 688643 & 5.7 & 5.6963 & TST & \\
\hline CHEMBL1491744 & 688643 & 5.0 & 4.8757 & TRN & \\
\hline CHEMBL 1453542 & 688643 & 4.9 & 4.9263 & TRN & \\
\hline CHEMBL1571545 & 688643 & 6.5 & 5.3608 & TST & \\
\hline CHEMBL521971 & 688643 & 4.6 & 4.6759 & TRN & \\
\hline CHEMBL1414251 & 688643 & 5.3 & 5.1384 & TRN & \\
\hline CHEMBL1489211 & 688643 & 4.8 & 4.7236 & TRN & \\
\hline CHEMBL1597410 & 688643 & 4.7 & 4.5428 & TRN & \\
\hline CHEMBL1593589 & 688643 & 4.8 & 4.7995 & TRN & \\
\hline CHEMBL1613194 & 688643 & 5.1 & 5.2882 & TRN & \\
\hline CHEMBL1603582 & 688643 & 5.0 & 4.6827 & TST & \\
\hline CHEMBL137803 & 688643 & 5.0 & 5.5037 & TST & \\
\hline CHEMBL1480806 & 688643 & 5.2 & 5.1359 & TRN & \\
\hline CHEMBL1233960 & 688643 & 5.7 & 5.5903 & TRN & \\
\hline CHEMBL1355963 & 688643 & 5.0 & 5.3576 & TST & \\
\hline CHEMBL490743 & 688643 & 4.9 & 4.8935 & TRN & \\
\hline CHEMBL1435509 & 688643 & 5.0 & 5.1435 & TRN & \\
\hline CHEMBL30432 & 688643 & 4.5 & 4.6652 & TRN & \\
\hline CHEMBL1256661 & 688643 & 5.7 & 5.8189 & TRN & \\
\hline CHEMBL3189190 & 688643 & 5.4 & 5.5337 & TRN & \\
\hline CHEMBL1399561 & 688643 & 5.6 & 5.8828 & TRN & \\
\hline CHEMBL 276140 & 688643 & 4.5 & 4.6769 & TST & \\
\hline CHEMBL1562777 & 688643 & 5.1 & 5.078 & TRN & \\
\hline CHEMBL1256678 & 688643 & 5.0 & 5.1462 & TST & \\
\hline
\end{tabular}




\begin{tabular}{|c|c|c|c|c|}
\hline \multicolumn{5}{|c|}{ Supplemental Table S2.txt } \\
\hline CHEMBL1322743 & 688643 & 6.0 & 5.9517 & TRN \\
\hline CHEMBL1329059 & 688643 & 5.1 & 5.3603 & TRN \\
\hline CHEMBL1479470 & 688643 & 4.9 & 4.9417 & TRN \\
\hline CHEMBL1411264 & 688643 & 6.0 & 6.1041 & TRN \\
\hline CHEMBL1318638 & 688643 & 5.8 & 6.1118 & TRN \\
\hline CHEMBL1438164 & 688643 & 4.9 & 4.8051 & TRN \\
\hline CHEMBL123 & 688643 & 6.0 & 5.1798 & TRN \\
\hline CHEMBL1472649 & 688643 & 6.3 & 6.2273 & TRN \\
\hline CHEMBL1533467 & 688643 & 7.3002 & 7.3742 & TRN \\
\hline CHEMBL1592209 & 688643 & 4.7 & 4.6951 & TRN \\
\hline CHEMBL1358570 & 688643 & 5.2 & 5.3077 & TST \\
\hline CHEMBL1565564 & 688643 & 4.7 & 4.6511 & TRN \\
\hline CHEMBL1446743 & 688643 & 4.8 & 5.092 & TST \\
\hline CHEMBL1327466 & 688643 & 5.7 & 5.6421 & TRN \\
\hline CHEMBL545523 & 688643 & 4.7 & 4.6637 & TRN \\
\hline CHEMBL1338329 & 688643 & 6.4 & 5.3506 & TRN \\
\hline CHEMBL554041 & 688643 & 5.5 & 5.4893 & TRN \\
\hline CHEMBL1357199 & 688643 & 4.6 & 4.6806 & TRN \\
\hline CHEMBL1334477 & 688643 & 4.7 & 4.7291 & TRN \\
\hline CHEMBL1354408 & 688643 & 4.6 & 4.5326 & TRN \\
\hline CHEMBL1449726 & 688643 & 5.6 & 5.6246 & TRN \\
\hline CHEMBL1521356 & 688643 & 5.6 & 5.4657 & TST \\
\hline CHEMBL1599266 & 688643 & 5.1 & 5.1193 & TST \\
\hline CHEMBL73824 & 688643 & 4.9 & 5.0882 & TRN \\
\hline CHEMBL369230 & 688643 & 5.1 & 5.4678 & TST \\
\hline CHEMBL541585 & 688643 & 4.5 & 4.6469 & TRN \\
\hline CHEMBL1401859 & 688643 & 5.0 & 4.886 & TRN \\
\hline CHEMBL1316464 & 688643 & 4.8 & 4.8315 & TRN \\
\hline CHEMBL 299683 & 688643 & 5.1 & 5.2645 & TRN \\
\hline CHEMBL189724 & 688643 & 5.6 & 5.7381 & TRN \\
\hline CHEMBL1523894 & 688643 & 5.9 & 5.8657 & TST \\
\hline CHEMBL405358 & 688643 & 5.4 & 5.1671 & TRN \\
\hline CHEMBL1597037 & 688643 & 5.1 & 4.9392 & TRN \\
\hline CHEMBL1355139 & 688643 & 4.9 & 5.0097 & TRN \\
\hline CHEMBL1438323 & 688643 & 5.1 & 5.1916 & TRN \\
\hline CHEMBL1371311 & 688643 & 5.4 & 5.4351 & TRN \\
\hline CHEMBL1324697 & 688643 & 4.6 & 4.7526 & TRN \\
\hline CHEMBL1516170 & 688643 & 4.4 & 4.3505 & TRN \\
\hline CHEMBL1591219 & 688643 & 4.4 & 5.3243 & TST \\
\hline CHEMBL1330466 & 688643 & 5.4 & 5.4861 & TRN \\
\hline CHEMBL1332759 & 688643 & 4.4 & 4.4165 & TRN \\
\hline CHEMBL1395027 & 688643 & 4.4 & 4.6423 & TRN \\
\hline CHEMBL1590261 & 688643 & 4.4 & 4.445 & TRN \\
\hline CHEMBL1356029 & 688643 & 5.1 & 4.9165 & TRN \\
\hline CHEMBL 8674 & 688643 & 6.7001 & 5.1657 & TST \\
\hline CHEMBL1565818 & 688643 & 5.2 & 5.3748 & TRN \\
\hline CHEMBL1552985 & 688643 & 5.1 & 5.0686 & TRN \\
\hline CHEMBL1553740 & 688643 & 4.4 & 4.4944 & TRN \\
\hline
\end{tabular}




\begin{tabular}{|c|c|c|c|c|}
\hline \multicolumn{5}{|c|}{ Supplemental Tabl } \\
\hline CHEMBL1568086 & 688643 & 4.9 & 4.8574 & TRN \\
\hline CHEMBL1591140 & 688643 & 4.9 & 4.8527 & TRN \\
\hline CHEMBL1358402 & 688643 & 4.6 & 5.4468 & TST \\
\hline CHEMBL94734 & 688643 & 5.5 & 5.9244 & TRN \\
\hline CHEMBL1554851 & 688643 & 4.7 & 4.6773 & TRN \\
\hline CHEMBL1436957 & 688643 & 4.6 & 4.7014 & TRN \\
\hline CHEMBL1235242 & 688643 & 4.9 & 5.2021 & TRN \\
\hline CHEMBL1416452 & 688643 & 4.7 & 5.0329 & TRN \\
\hline CHEMBL1562663 & 688643 & 5.0 & 5.0187 & TRN \\
\hline CHEMBL1553047 & 688643 & 6.8 & 6.9929 & TRN \\
\hline CHEMBL1418420 & 688643 & 4.7 & 4.6941 & TRN \\
\hline CHEMBL1327681 & 688643 & 5.0 & 4.9662 & TRN \\
\hline CHEMBL1314247 & 688643 & 4.4 & 4.4377 & TRN \\
\hline CHEMBL1415521 & 688643 & 5.0 & 4.9569 & TRN \\
\hline CHEMBL1321846 & 688643 & 5.0 & 4.9057 & TRN \\
\hline CHEMBL1554306 & 688643 & 5.8 & 5.8823 & TST \\
\hline CHEMBL1331778 & 688643 & 5.5 & 5.4203 & TST \\
\hline CHEMBL510009 & 688643 & 5.4 & 5.2262 & TRN \\
\hline CHEMBL1456714 & 688643 & 7.6003 & 7.0944 & TRN \\
\hline CHEMBL1449884 & 688643 & 5.6 & 5.704 & TRN \\
\hline CHEMBL1356439 & 688643 & 4.9 & 4.873 & TRN \\
\hline CHEMBL1591971 & 688643 & 4.8 & 4.7583 & TRN \\
\hline CHEMBL1475620 & 688643 & 5.0 & 5.1271 & TRN \\
\hline CHEMBL1330422 & 688643 & 4.6 & 4.6709 & TRN \\
\hline CHEMBL1319517 & 688643 & 5.3 & 5.5934 & TRN \\
\hline CHEMBL1591381 & 688643 & 5.0 & 5.0654 & TRN \\
\hline CHEMBL543557 & 688643 & 4.7 & 4.9524 & TRN \\
\hline CHEMBL1567251 & 688643 & 4.7 & 4.5604 & TRN \\
\hline CHEMBL1593930 & 688643 & 5.4 & 5.5098 & TRN \\
\hline CHEMBL50112 & 688643 & 4.9 & 4.9649 & TRN \\
\hline CHEMBL1590060 & 688643 & 4.8 & 4.7767 & TRN \\
\hline CHEMBL1591107 & 688643 & 4.9 & 4.8983 & TRN \\
\hline CHEMBL1316749 & 688643 & 5.1 & 5.1373 & TRN \\
\hline CHEMBL1402656 & 688643 & 4.4 & 4.4283 & TRN \\
\hline CHEMBL1436817 & 688643 & 5.1 & 5.1326 & TRN \\
\hline CHEMBL544713 & 688643 & 6.9 & 6.9309 & TRN \\
\hline CHEMBL 1408334 & 688643 & 5.6 & 6.0558 & TRN \\
\hline CHEMBL151 & 688643 & 4.5 & 4.8892 & TRN \\
\hline CHEMBL1520603 & 688643 & 5.4 & 5.3284 & TRN \\
\hline CHEMBL1331710 & 688643 & 5.8 & 5.7549 & TST \\
\hline CHEMBL1450805 & 688643 & 6.5 & 6.6024 & TRN \\
\hline CHEMBL1401483 & 688643 & 5.1 & 5.2442 & TRN \\
\hline CHEMBL20963 & 688643 & 4.9 & 5.086 & TRN \\
\hline CHEMBL1256797 & 688643 & 4.4 & 4.7477 & TRN \\
\hline CHEMBL1398586 & 688643 & 5.5 & 5.6004 & TRN \\
\hline CHEMBL1356834 & 688643 & 4.5 & 4.4685 & TRN \\
\hline CHEMBL1314962 & 688643 & 5.3 & 5.4726 & TST \\
\hline CHEMBL1316056 & 688643 & 4.9 & 4.9757 & TRN \\
\hline
\end{tabular}




\begin{tabular}{|c|c|c|c|c|c|}
\hline & & & & & \\
\hline CHEMBL113180 & 688643 & 6.0 & 5.6773 & TRN & \\
\hline CHEMBL1477492 & 688643 & 4.4 & 4.445 & TRN & \\
\hline CHEMBL1554976 & 688643 & 4.6 & 4.525 & TRN & \\
\hline CHEMBL1398456 & 688643 & 4.6 & 4.7971 & TST & \\
\hline CHEMBL1473205 & 688643 & 6.0 & 5.2535 & TRN & \\
\hline CHEMBL1440242 & 688643 & 5.4 & 5.5909 & TRN & \\
\hline CHEMBL1529028 & 688643 & 5.4 & 5.3373 & TRN & \\
\hline CHEMBL523283 & 688643 & 5.4 & 5.2387 & TRN & \\
\hline CHEMBL1437876 & 688643 & 5.0 & 5.0902 & TRN & \\
\hline CHEMBL1317620 & 688643 & 6.3 & 6.273 & TRN & \\
\hline CHEMBL1319049 & 688643 & 6.0 & 6.1554 & TRN & \\
\hline CHEMBL585861 & 688643 & 4.9 & 4.7863 & TRN & \\
\hline CHEMBL48278 & 688643 & 4.7 & 4.7945 & TRN & \\
\hline CHEMBL1473029 & 688643 & 5.5 & 5.3147 & TRN & \\
\hline CHEMBL1558526 & 688643 & 5.0 & 4.8727 & TRN & \\
\hline CHEMBL 242172 & 688643 & 4.6 & 5.1062 & TRN & \\
\hline CHEMBL1316623 & 688643 & 5.0 & 5.09399 & 9999999999 & TST \\
\hline CHEMBL1321275 & 688643 & 5.5 & 5.3474 & TRN & \\
\hline CHEMBL1355088 & 688643 & 5.1 & 5.2708 & TRN & \\
\hline CHEMBL1445094 & 688643 & 4.9 & 4.90600 & 2000000001 & TRN \\
\hline CHEMBL441948 & 688643 & 4.4 & 4.6991 & TRN & \\
\hline CHEMBL1512190 & 688643 & 4.4 & 4.3951 & TRN & \\
\hline CHEMBL1492346 & 688643 & 7.4001 & 7.1529 & TRN & \\
\hline CHEMBL1433883 & 688643 & 4.7 & 4.8231 & TRN & \\
\hline CHEMBL3351063 & 688643 & 5.5 & 5.4529 & TST & \\
\hline CHEMBL1454751 & 688643 & 5.5 & 5.5793 & TRN & \\
\hline CHEMBL1551387 & 688643 & 4.6 & 4.6622 & TRN & \\
\hline CHEMBL1360650 & 688643 & 5.2 & 5.522 & TRN & \\
\hline CHEMBL1552098 & 688643 & 5.7 & 5.8663 & TRN & \\
\hline CHEMBL1596698 & 688643 & 5.3 & 5.30200 & 00000000005 & TRN \\
\hline CHEMBL15060 & 688643 & 4.6 & 4.8964 & TRN & \\
\hline CHEMBL1256656 & 688643 & 6.0 & 5.8119 & TRN & \\
\hline CHEMBL567175 & 688643 & 6.0 & 6.1641 & TRN & \\
\hline CHEMBL1573532 & 688643 & 5.5 & 5.5032 & TRN & \\
\hline CHEMBL1336782 & 688643 & 5.4 & 5.4224 & TRN & \\
\hline CHEMBL1612582 & 688643 & 4.6 & 4.5198 & TRN & \\
\hline CHEMBL1529384 & 688643 & 5.5 & 5.5334 & TRN & \\
\hline CHEMBL1515985 & 688643 & 5.1 & 4.9863 & TRN & \\
\hline CHEMBL1369874 & 688643 & 6.0 & 5.2651 & TRN & \\
\hline CHEMBL1495395 & 688643 & 5.4 & 5.3446 & TRN & \\
\hline CHEMBL540294 & 688643 & 4.5 & 4.7483 & TST & \\
\hline CHEMBL1531837 & 688643 & 4.6 & 4.6815 & TRN & \\
\hline CHEMBL1354325 & 688643 & 4.8 & 4.9318 & TST & \\
\hline CHEMBL1473752 & 688643 & 4.7 & 4.6755 & TRN & \\
\hline CHEMBL1323124 & 688643 & 4.5 & 4.4513 & TRN & \\
\hline CHEMBL1590818 & 688643 & 5.1 & 4.9981 & TRN & \\
\hline CHEMBL1437138 & 688643 & 7.6003 & 7.6771 & TRN & \\
\hline CHEMBL491940 & 688643 & 5.1 & 5.0762 & TRN & \\
\hline
\end{tabular}




\begin{tabular}{|c|c|c|c|c|c|}
\hline \multicolumn{6}{|c|}{ Supplemental Table S2.txt } \\
\hline CHEMBL1572173 & 688643 & 4.6 & 4.6507 & TRN & \\
\hline CHEMBL1256735 & 688643 & 4.5 & 4.7673 & TRN & \\
\hline CHEMBL1237212 & 688643 & 4.5 & 5.1766 & TST & \\
\hline CHEMBL1360890 & 688643 & 4.9 & 4.8867 & TRN & \\
\hline CHEMBL1317059 & 688643 & 4.7 & 5.5146 & TST & \\
\hline CHEMBL1568735 & 688643 & 6.4 & 6.1586 & TRN & \\
\hline CHEMBL1318264 & 688643 & 5.5 & 5.3837 & TRN & \\
\hline CHEMBL1600210 & 688643 & 4.5 & 4.4068 & TRN & \\
\hline CHEMBL1592388 & 688643 & 4.8 & 4.6868 & TRN & \\
\hline CHEMBL10009 & 688643 & 4.4 & 4.58 & TRN & \\
\hline CHEMBL67378 & 688643 & 6.0 & 5.8504 & TST & \\
\hline CHEMBL1433455 & 688643 & 4.8 & 4.9978 & TRN & \\
\hline CHEMBL1395417 & 688643 & 4.5 & 4.4836 & TRN & \\
\hline CHEMBL1484253 & 688643 & 4.7 & 4.6158 & TRN & \\
\hline CHEMBL1445026 & 688643 & 5.5 & 5.4006 & TRN & \\
\hline CHEMBL1443376 & 688643 & 4.8 & 4.8694 & TST & \\
\hline CHEMBL536480 & 688643 & 5.7 & 5.6011 & TRN & \\
\hline CHEMBL192566 & 688643 & 4.4 & 4.6599 & TST & \\
\hline CHEMBL1414185 & 688643 & 5.3 & 5.3177 & TST & \\
\hline CHEMBL1601121 & 688643 & 4.4 & 4.3846 & TRN & \\
\hline CHEMBL1553941 & 688643 & 4.4 & 4.3323 & TRN & \\
\hline CHEMBL1513324 & 688643 & 4.7 & 4.7266 & TRN & \\
\hline CHEMBL1511845 & 688643 & 7.699 & 7.2246 & TRN & \\
\hline CHEMBL1442987 & 688643 & 6.0 & 6.1601 & TRN & \\
\hline CHEMBL 76232 & 688643 & 5.0 & 5.1929 & TRN & \\
\hline CHEMBL1453244 & 688643 & 4.9 & 4.8739 & TRN & \\
\hline CHEMBL1161461 & 688643 & 4.8 & 5.3108 & TST & \\
\hline CHEMBL86676 & 688643 & 6.0 & 5.0710 & 0000000001 & TRN \\
\hline CHEMBL1314465 & 688643 & 5.7 & 5.744 & TRN & \\
\hline CHEMBL330129 & 688643 & 4.9 & 5.1704 & TRN & \\
\hline CHEMBL1534082 & 688643 & 4.7 & 4.6393 & TRN & \\
\hline CHEMBL1474302 & 688643 & 4.6 & 4.6519 & TRN & \\
\hline CHEMBL1454544 & 688643 & 5.1 & 4.9633 & TRN & \\
\hline CHEMBL1601095 & 688643 & 5.0 & 5.0741 & TRN & \\
\hline CHEMBL1374763 & 688643 & 5.6 & 5.5223 & TRN & \\
\hline CHEMBL3199929 & 688643 & 5.8 & 5.7246 & TST & \\
\hline CHEMBL1320607 & 688643 & 5.5 & 4.8953 & TRN & \\
\hline CHEMBL1516211 & 688643 & 5.0 & 5.1643 & TRN & \\
\hline CHEMBL1476871 & 688643 & 6.6 & 6.5923 & TRN & \\
\hline CHEMBL1396559 & 688643 & 4.7 & 4.7554 & TRN & \\
\hline CHEMBL1594704 & 688643 & 4.5 & 4.6081 & TRN & \\
\hline CHEMBL1519829 & 688643 & 4.9 & 5.1286 & TRN & \\
\hline CHEMBL1472753 & 688643 & 4.4 & 4.4031 & TRN & \\
\hline CHEMBL1430037 & 688643 & 4.4 & 4.4794 & TRN & \\
\hline CHEMBL1357422 & 688643 & 5.2 & 5.315 & TRN & \\
\hline CHEMBL1415406 & 688643 & 4.9 & 4.9689 & TRN & \\
\hline CHEMBL1475008 & 688643 & 5.9 & 5.6221 & TRN & \\
\hline CHEMBL1513669 & 688643 & 5.3 & 5.2169 & TRN & \\
\hline
\end{tabular}




\begin{tabular}{|c|c|c|c|c|c|}
\hline \multicolumn{6}{|c|}{ Supplemental Table S2.txt } \\
\hline CHEMBL1479792 & 688643 & 4.9 & 4.8624 & TRN & \\
\hline CHEMBL1553731 & 688643 & 5.5 & 5.4604 & TRN & \\
\hline CHEMBL1492205 & 688643 & 4.4 & 4.3267 & TRN & \\
\hline CHEMBL539027 & 688643 & 6.0 & 5.8688 & TRN & \\
\hline CHEMBL1255655 & 688643 & 4.9 & 5.0217 & TST & \\
\hline CHEMBL1591209 & 688643 & 5.1 & 5.0221 & TRN & \\
\hline CHEMBL1412872 & 688643 & 5.9 & 5.1796 & TRN & \\
\hline CHEMBL1314564 & 688643 & 5.4 & 5.352 & TRN & \\
\hline CHEMBL1478614 & 688643 & 5.4 & 5.5413 & TST & \\
\hline CHEMBL1327247 & 688643 & 4.4 & 4.4843 & TRN & \\
\hline CHEMBL1611348 & 688643 & 5.0 & 5.0626 & TRN & \\
\hline CHEMBL1396230 & 688643 & 4.4 & 4.4422 & TRN & \\
\hline CHEMBL1472933 & 688643 & 6.0 & 6.0515 & TRN & \\
\hline CHEMBL1516015 & 688643 & 4.6 & 4.9464 & TRN & \\
\hline CHEMBL1330357 & 688643 & 4.5 & 4.8168 & TST & \\
\hline CHEMBL405912 & 688643 & 5.1 & 5.088 & TRN & \\
\hline CHEMBL83899 & 688643 & 4.9 & 5.0657 & TRN & \\
\hline CHEMBL1551847 & 688643 & 4.7 & 5.2535 & TRN & \\
\hline CHEMBL1315700 & 688643 & 4.5 & 4.4871 & TRN & \\
\hline CHEMBL1496934 & 688643 & 4.4 & 4.3388 & TRN & \\
\hline CHEMBL391997 & 688643 & 6.0 & 5.03 & TST & \\
\hline CHEMBL1331521 & 688643 & 4.4 & 5.1869 & TRN & \\
\hline CHEMBL1515540 & 688643 & 5.0 & 5.1032 & TRN & \\
\hline CHEMBL1552362 & 688643 & 5.0 & 3.6543 & TRN & \\
\hline CHEMBL1523120 & 688643 & 5.5 & 5.61600 & 00000000005 & TST \\
\hline CHEMBL1531070 & 688643 & 4.7 & 4.6406 & TRN & \\
\hline CHEMBL1396822 & 688643 & 4.7 & 4.7691 & TST & \\
\hline CHEMBL1336166 & 688643 & 4.6 & 4.7175 & TST & \\
\hline CHEMBL1569585 & 688643 & 4.4 & 4.5135 & TRN & \\
\hline CHEMBL1496569 & 688643 & 5.3 & 5.2681 & TRN & \\
\hline CHEMBL1512802 & 688643 & 4.5 & 4.5077 & TRN & \\
\hline CHEMBL1513870 & 688643 & 5.5 & 5.7239 & TRN & \\
\hline CHEMBL1515295 & 688643 & 4.7 & 4.8119 & TRN & \\
\hline CHEMBL559612 & 688643 & 4.5 & 5.5422 & TST & \\
\hline CHEMBL1607010 & 688643 & 4.7 & 4.65300 & 00000000005 & TRN \\
\hline CHEMBL1355703 & 688643 & 5.4 & 5.4943 & TRN & \\
\hline CHEMBL1557048 & 688643 & 5.0 & 5.0357 & TRN & \\
\hline CHEMBL1320315 & 688643 & 5.4 & 5.4847 & TST & \\
\hline CHEMBL1607905 & 688643 & 4.8 & 5.4237 & TST & \\
\hline CHEMBL1397009 & 688643 & 5.0 & 4.883 & TRN & \\
\hline CHEMBL1435698 & 688643 & 5.0 & 4.8852 & TRN & \\
\hline CHEMBL1358161 & 688643 & 5.0 & 5.0638 & TRN & \\
\hline CHEMBL1325766 & 688643 & 5.6 & 5.4608 & TRN & \\
\hline CHEMBL1487318 & 688643 & 5.4 & 5.4347 & TRN & \\
\hline CHEMBL1730100 & 688643 & 4.6 & 5.3201 & TST & \\
\hline CHEMBL1395337 & 688643 & 4.4 & 4.5242 & TRN & \\
\hline CHEMBL1354693 & 688643 & 4.8 & 4.6346 & TRN & \\
\hline CHEMBL1560764 & 688643 & 5.5 & 5.6388 & TRN & \\
\hline
\end{tabular}




\begin{tabular}{|c|c|c|c|c|}
\hline \multicolumn{5}{|c|}{ Supplement } \\
\hline CHEMBL1493388 & 688643 & 5.5 & 5.6309 & TRN \\
\hline CHEMBL1479506 & 688643 & 5.0 & 5.0235 & TRN \\
\hline CHEMBL1559163 & 688643 & 5.5 & 5.4444 & TRN \\
\hline CHEMBL123904 & 688643 & 4.9 & 4.9039 & TST \\
\hline CHEMBL1363481 & 688643 & 4.7 & 4.7247 & TRN \\
\hline CHEMBL1355224 & 688643 & 4.5 & 4.9829 & TRN \\
\hline CHEMBL1394499 & 688643 & 5.8 & 5.7652 & TRN \\
\hline CHEMBL1412044 & 688643 & 5.5 & 5.5446 & TST \\
\hline CHEMBL1435787 & 688643 & 5.0 & 5.1292 & TRN \\
\hline CHEMBL1437648 & 688643 & 5.9 & 5.7726 & TRN \\
\hline CHEMBL1611225 & 688643 & 7.8996 & 7.8366 & TRN \\
\hline CHEMBL479014 & 688643 & 6.6 & 6.28700 & 0000000001 \\
\hline CHEMBL1364404 & 688643 & 5.2 & 5.1816 & TRN \\
\hline CHEMBL1434006 & 688643 & 4.7 & 4.579 & TRN \\
\hline CHEMBL1557498 & 688643 & 4.8 & 4.6068 & TRN \\
\hline CHEMBL1187592 & 688643 & 4.7 & 5.4543 & TRN \\
\hline CHEMBL 2374026 & 688643 & 5.5 & 5.1259 & TST \\
\hline CHEMBL1317451 & 688643 & 4.4 & 4.3832 & TRN \\
\hline CHEMBL1314674 & 688643 & 4.6 & 4.5826 & TRN \\
\hline CHEMBL1514953 & 688643 & 4.4 & 4.4802 & TRN \\
\hline CHEMBL1478772 & 688643 & 4.9 & 4.9312 & TRN \\
\hline CHEMBL1357401 & 688643 & 4.5 & 4.5856 & TRN \\
\hline CHEMBL1593371 & 688643 & 5.1 & 4.862 & TRN \\
\hline CHEMBL1476227 & 688643 & 5.6 & 5.5333 & TRN \\
\hline CHEMBL1596235 & 688643 & 5.7 & 5.564 & TRN \\
\hline CHEMBL1369242 & 688643 & 5.6 & 5.5965 & TST \\
\hline CHEMBL1369973 & 688643 & 4.5 & 4.5101 & TRN \\
\hline CHEMBL1562420 & 688643 & 7.8013 & 7.1298 & TST \\
\hline CHEMBL428768 & 688643 & 4.5 & 4.6142 & TRN \\
\hline CHEMBL1473875 & 688643 & 5.7 & 5.9411 & TRN \\
\hline CHEMBL1594947 & 688643 & 5.2 & 5.2933 & TRN \\
\hline CHEMBL1437776 & 688643 & 4.7 & 4.8246 & TRN \\
\hline CHEMBL1395431 & 688643 & 4.7 & 4.8422 & TRN \\
\hline CHEMBL1435053 & 688643 & 5.6 & 5.5015 & TST \\
\hline CHEMBL87385 & 688643 & 5.0 & 5.2708 & TRN \\
\hline CHEMBL1601957 & 688643 & 6.2 & 6.0441 & TRN \\
\hline CHEMBL491977 & 688643 & 5.4 & 5.3042 & TRN \\
\hline CHEMBL13790 & 688643 & 6.0 & 5.8336 & TRN \\
\hline CHEMBL1592507 & 688643 & 5.4 & 5.482 & TRN \\
\hline CHEMBL1331122 & 688643 & 6.0 & 5.9901 & TST \\
\hline CHEMBL1572683 & 688643 & 6.5 & 6.409 & TRN \\
\hline CHEMBL1612590 & 688643 & 5.3 & 5.642 & TST \\
\hline CHEMBL1567472 & 688643 & 5.7 & 5.6929 & TRN \\
\hline CHEMBL1452272 & 688643 & 7.4001 & 7.0513 & TRN \\
\hline CHEMBL608555 & 688643 & 4.8 & 5.0779 & TRN \\
\hline CHEMBL230056 & 688643 & 6.0 & 5.2259 & TRN \\
\hline CHEMBL 8260 & 688643 & 4.5 & 4.993 & TRN \\
\hline CHEMBL1399528 & 688643 & 5.0 & 4.9795 & TRN \\
\hline
\end{tabular}




\begin{tabular}{|c|c|c|c|c|}
\hline \multicolumn{5}{|c|}{ Supplemental Table s2.txt } \\
\hline CHEMBL1327187 & 688643 & 5.5 & 5.5246 & TRN \\
\hline CHEMBL1524577 & 688643 & 7.1002 & 6.6886 & TRN \\
\hline CHEMBL1405464 & 688643 & 5.2 & 5.2716 & TRN \\
\hline CHEMBL1596872 & 688643 & 4.8 & 4.7447 & TRN \\
\hline CHEMBL1190214 & 688643 & 5.3 & 5.4325 & TST \\
\hline CHEMBL1514280 & 688643 & 5.9 & 5.9724 & TRN \\
\hline CHEMBL1433939 & 688643 & 5.1 & 5.3244 & TST \\
\hline CHEMBL1378731 & 688643 & 5.4 & 5.4344 & TRN \\
\hline CHEMBL1515997 & 688643 & 6.1 & 6.0874 & TRN \\
\hline CHEMBL1472779 & 688643 & 4.8 & 4.8781 & TRN \\
\hline CHEMBL1330396 & 688643 & 5.7 & 5.5684 & TRN \\
\hline CHEMBL1256878 & 688643 & 6.0 & 5.7797 & TRN \\
\hline CHEMBL1256851 & 688643 & 7.3002 & 7.0463 & TRN \\
\hline CHEMBL1486915 & 688643 & 4.7 & 4.6508 & TRN \\
\hline CHEMBL1411360 & 688643 & 5.5 & 5.5946 & TST \\
\hline CHEMBL1318461 & 688643 & 5.4 & 5.4434 & TRN \\
\hline CHEMBL1476078 & 688643 & 5.1 & 5.0885 & TRN \\
\hline CHEMBL445102 & 688643 & 6.0 & 6.4113 & TRN \\
\hline CHEMBL 310310 & 688643 & 6.0 & 6.2672 & TRN \\
\hline CHEMBL1526837 & 688643 & 5.3 & 5.2463 & TST \\
\hline CHEMBL1514397 & 688643 & 6.0 & 6.0982 & TRN \\
\hline CHEMBL1370189 & 688643 & 5.6 & 5.4465 & TRN \\
\hline CHEMBL146855 & 688643 & 6.0 & 5.7669 & TST \\
\hline CHEMBL1567725 & 688643 & 4.9 & 4.8707 & TRN \\
\hline CHEMBL1491009 & 688643 & 5.3 & 5.5783 & TRN \\
\hline CHEMBL1316348 & 688643 & 4.7 & 4.4928 & TRN \\
\hline CHEMBL1364168 & 688643 & 4.9 & 4.8021 & TRN \\
\hline CHEMBL1515449 & 688643 & 5.1 & 5.0831 & TRN \\
\hline CHEMBL1414592 & 688643 & 5.5 & 5.676 & TRN \\
\hline CHEMBL1325735 & 688643 & 4.7 & 4.8042 & TRN \\
\hline CHEMBL1397523 & 688643 & 7.3002 & 5.5696 & TST \\
\hline CHEMBL1372657 & 688643 & 6.4 & 6.2383 & TST \\
\hline CHEMBL1416426 & 688643 & 5.1 & 5.067 & TRN \\
\hline CHEMBL1559654 & 688643 & 4.9 & 4.8581 & TRN \\
\hline CHEMBL1314255 & 688643 & 4.4 & 4.4894 & TRN \\
\hline CHEMBL1437778 & 688643 & 5.3 & 5.4243 & TRN \\
\hline CHEMBL1398467 & 688643 & 4.4 & 4.4428 & TRN \\
\hline CHEMBL1373634 & 688643 & 5.4 & 5.653 & TRN \\
\hline CHEMBL1366433 & 688643 & 4.4 & 4.3584 & TRN \\
\hline CHEMBL1316709 & 688643 & 4.8 & 4.63899 & 9999999999 \\
\hline CHEMBL1257083 & 688643 & 4.4 & 4.6413 & TRN \\
\hline CHEMBL 9843 & 688643 & 4.5 & 5.0946 & TRN \\
\hline CHEMBL1442173 & 688643 & 4.4 & 4.4459 & TRN \\
\hline CHEMBL1573862 & 688643 & 5.0 & 4.9964 & TRN \\
\hline CHEMBL1435917 & 688643 & 5.3 & 5.2722 & TRN \\
\hline CHEMBL1607106 & 688643 & 5.5 & 5.5784 & TRN \\
\hline CHEMBL1255966 & 688643 & 6.1 & 6.0932 & TRN \\
\hline CHEMBL292477 & 688643 & 8.2007 & 7.8041 & TRN \\
\hline
\end{tabular}




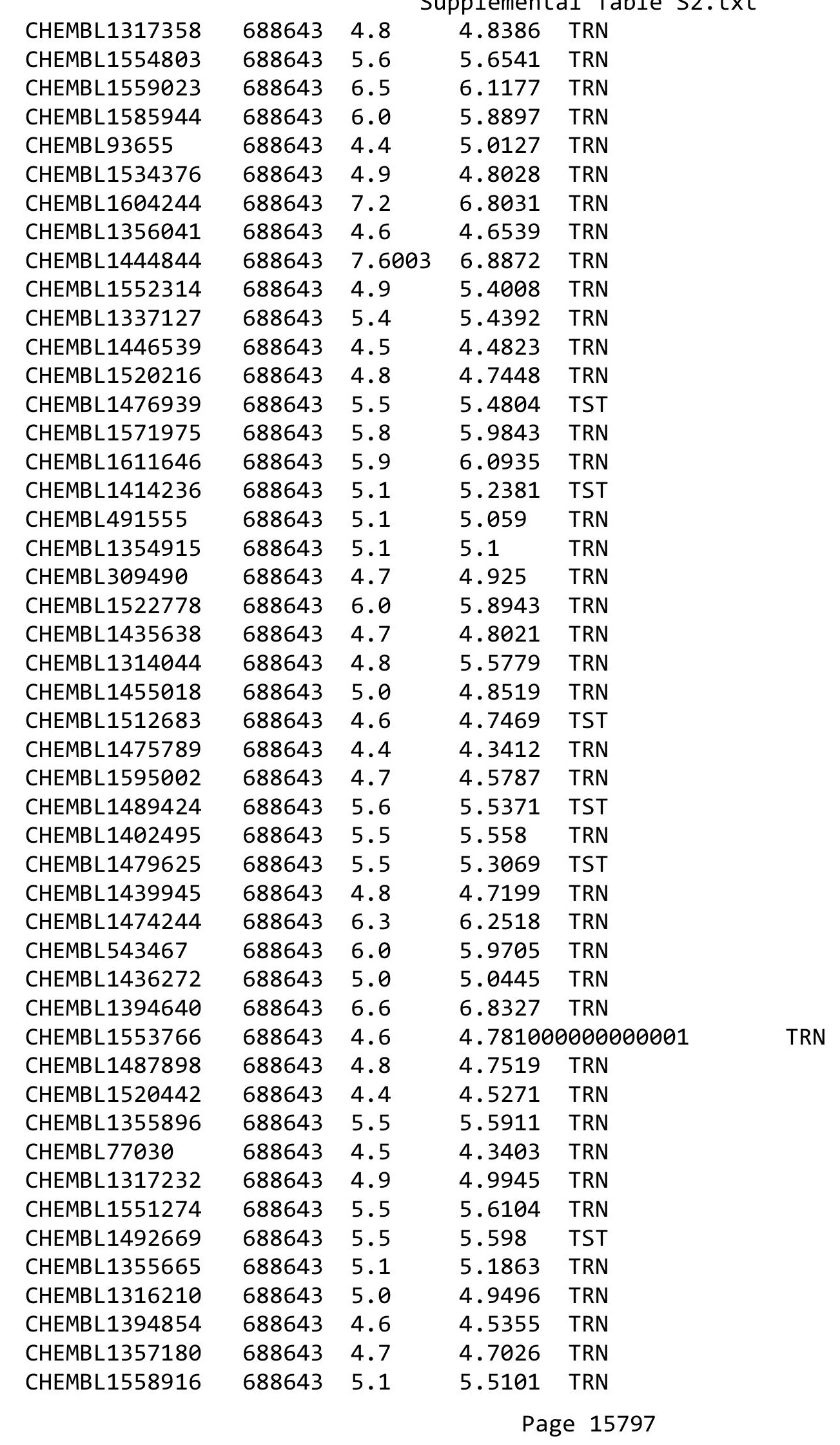




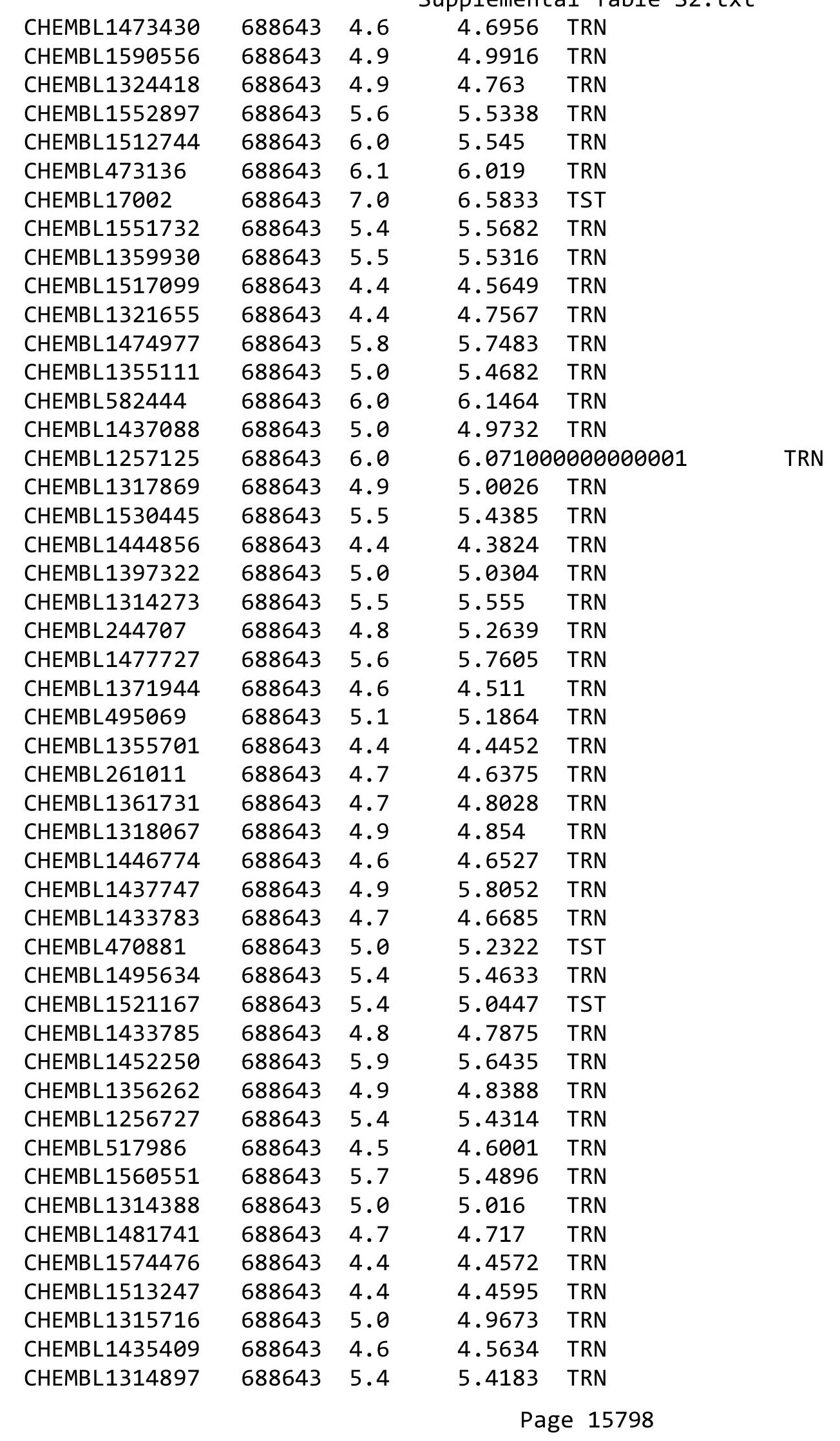




\begin{tabular}{|c|c|c|c|c|c|}
\hline & & & & & \\
\hline CHEMBL1411808 & 688643 & 5.5 & 5.2086 & TRN & \\
\hline CHEMBL1357857 & 688643 & 4.7 & 4.6336 & TRN & \\
\hline CHEMBL1358487 & 688643 & 5.4 & 5.6419 & TRN & \\
\hline CHEMBL1315725 & 688643 & 5.8 & 5.7883 & TST & \\
\hline CHEMBL1529151 & 688643 & 5.4 & 5.2734 & TRN & \\
\hline CHEMBL462880 & 688643 & 5.2 & 5.4276 & TRN & \\
\hline CHEMBL490742 & 688643 & 4.7 & 4.5939 & TRN & \\
\hline CHEMBL1356733 & 688643 & 4.6 & 4.6238 & TRN & \\
\hline CHEMBL1514143 & 688643 & 5.0 & 5.1841 & TRN & \\
\hline CHEMBL1336175 & 688643 & 5.8 & $5.9920 e$ & 0000000001 & TRN \\
\hline CHEMBL1256910 & 688643 & 4.5 & 4.743 & TRN & \\
\hline CHEMBL1395415 & 688643 & 4.5 & 4.4742 & TRN & \\
\hline CHEMBL1512540 & 688643 & 4.8 & 4.7794 & TRN & \\
\hline CHEMBL1552607 & 688643 & 6.1 & 6.0203 & TRN & \\
\hline CHEMBL1395089 & 688643 & 4.8 & 4.8836 & TRN & \\
\hline CHEMBL1447909 & 688643 & 4.9 & 4.8641 & TRN & \\
\hline CHEMBL1324882 & 688643 & 4.4 & 4.3475 & TRN & \\
\hline CHEMBL1475191 & 688643 & 5.0 & 5.3269 & TRN & \\
\hline CHEMBL1396282 & 688643 & 5.6 & 5.6943 & TRN & \\
\hline CHEMBL1085765 & 688643 & 5.5 & 5.6937 & TRN & \\
\hline CHEMBL1395974 & 688643 & 5.5 & 5.6434 & TRN & \\
\hline CHEMBL1516514 & 688643 & 5.9 & 5.1359 & TRN & \\
\hline CHEMBL1492577 & 688643 & 5.4 & 5.3688 & TRN & \\
\hline CHEMBL1318114 & 688643 & 5.1 & 5.1881 & TRN & \\
\hline CHEMBL1441608 & 688643 & 4.7 & 4.7239 & TRN & \\
\hline CHEMBL64569 & 688643 & 5.5 & 5.4876 & TRN & \\
\hline CHEMBL536950 & 688643 & 4.5 & 4.6637 & TST & \\
\hline CHEMBL1474927 & 688643 & 4.8 & 4.6364 & TRN & \\
\hline CHEMBL492127 & 688643 & 4.9 & 5.0915 & TRN & \\
\hline CHEMBL 34730 & 688643 & 4.4 & 4.7915 & TRN & \\
\hline CHEMBL1594150 & 688643 & 5.9 & 5.9525 & TST & \\
\hline CHEMBL1355146 & 688643 & 4.8 & 4.9495 & TRN & \\
\hline CHEMBL1434098 & 688643 & 4.8 & 4.7559 & TRN & \\
\hline CHEMBL1519261 & 688643 & 4.7 & 4.6473 & TRN & \\
\hline CHEMBL1256180 & 688643 & 4.4 & 4.6189 & TRN & \\
\hline CHEMBL1441287 & 688643 & 4.6 & 4.5799 & TRN & \\
\hline CHEMBL1527221 & 688643 & 4.8 & 4.6915 & TRN & \\
\hline CHEMBL1315609 & 688643 & 5.7 & 5.4945 & TRN & \\
\hline CHEMBL1400521 & 688643 & 5.5 & 5.5418 & TST & \\
\hline CHEMBL1552405 & 688643 & 4.7 & 4.6242 & TRN & \\
\hline CHEMBL1324871 & 688643 & 5.3 & 5.3632 & TST & \\
\hline CHEMBL1551200 & 688643 & 4.6 & 4.8554 & TRN & \\
\hline CHEMBL1493496 & 688643 & 4.5 & 4.5267 & TRN & \\
\hline CHEMBL580421 & 688643 & 5.6 & 5.5566 & TST & \\
\hline CHEMBL1568744 & 688643 & 6.0 & 5.8699 & TRN & \\
\hline CHEMBL1489359 & 688643 & 5.4 & 5.4383 & TST & \\
\hline CHEMBL1474272 & 688643 & 4.8 & 4.8106 & TRN & \\
\hline CHEMBL1532921 & 688643 & 5.8 & $5.6620 e$ & 2000000001 & TRN \\
\hline & & & & 15799 & \\
\hline
\end{tabular}




\begin{tabular}{|c|c|c|c|c|}
\hline \multicolumn{5}{|c|}{ Supplemental Table S2.txt } \\
\hline CHEMBL1454793 & 688643 & 5.1 & 4.7627 & TRN \\
\hline CHEMBL1565125 & 688643 & 4.8 & 5.0197 & TRN \\
\hline CHEMBL1397877 & 688643 & 4.4 & 4.4488 & TRN \\
\hline CHEMBL1373587 & 688643 & 6.1 & 5.9184 & TST \\
\hline CHEMBL1480161 & 688643 & 4.6 & 4.7205 & TRN \\
\hline CHEMBL1559279 & 688643 & 4.7 & 4.5838 & TRN \\
\hline CHEMBL1592876 & 688643 & 5.4 & 5.4452 & TRN \\
\hline CHEMBL1474468 & 688643 & 5.1 & 4.9398 & TRN \\
\hline CHEMBL45244 & 688643 & 5.0 & 5.0546 & TRN \\
\hline CHEMBL1553939 & 688643 & 5.0 & 5.1942 & TRN \\
\hline CHEMBL1357445 & 688643 & 7.0 & 7.1071 & TRN \\
\hline CHEMBL 21031 & 688643 & 6.6 & 6.5471 & TRN \\
\hline CHEMBL58033 & 688643 & 6.0 & 6.0852 & TRN \\
\hline CHEMBL1434082 & 688643 & 4.8 & 4.6529 & TRN \\
\hline CHEMBL1605688 & 688643 & 4.6 & 4.6874 & TRN \\
\hline CHEMBL1406851 & 688643 & 5.5 & 5.4581 & TRN \\
\hline CHEMBL1395137 & 688643 & 4.4 & 4.4031 & TRN \\
\hline CHEMBL 2373602 & 688643 & 6.0 & 6.1324 & TRN \\
\hline CHEMBL1314367 & 688643 & 5.4 & 5.357 & TRN \\
\hline CHEMBL1327411 & 688643 & 5.5 & 5.6789 & TRN \\
\hline CHEMBL1395992 & 688643 & 5.3 & 5.419 & TRN \\
\hline CHEMBL1335033 & 688643 & 5.7 & 5.182 & TST \\
\hline CHEMBL1526170 & 688643 & 4.6 & 4.5757 & TRN \\
\hline CHEMBL1331288 & 688643 & 4.4 & 4.5841 & TRN \\
\hline CHEMBL1413858 & 688643 & 4.6 & 4.6696 & TRN \\
\hline CHEMBL177809 & 688643 & 5.1 & 5.0837 & TRN \\
\hline CHEMBL1376191 & 688643 & 5.9 & 5.8839 & TRN \\
\hline CHEMBL1436054 & 688643 & 6.2 & 6.0075 & TRN \\
\hline CHEMBL1555537 & 688643 & 5.7 & 5.6986 & TST \\
\hline CHEMBL1413161 & 688643 & 5.0 & 4.8815 & TRN \\
\hline CHEMBL 372797 & 688643 & 4.7 & 4.9036 & TRN \\
\hline CHEMBL 319244 & 688643 & 4.4 & 4.6156 & TRN \\
\hline CHEMBL1399489 & 688643 & 4.7 & 4.625 & TRN \\
\hline CHEMBL1335471 & 688643 & 4.9 & 4.8458 & TRN \\
\hline CHEMBL1593096 & 688643 & 6.2 & 6.0355 & TRN \\
\hline CHEMBL1402049 & 688643 & 5.4 & 5.4507 & TRN \\
\hline CHEMBL 1317741 & 688643 & 5.4 & 5.4928 & TRN \\
\hline CHEMBL1526068 & 688643 & 7.1002 & 5.3548 & TRN \\
\hline CHEMBL56 & 688643 & 6.0 & 6.1174 & TRN \\
\hline CHEMBL1339065 & 688643 & 5.3 & 5.2956 & TRN \\
\hline CHEMBL1494883 & 688643 & 6.8 & 6.9407 & TRN \\
\hline CHEMBL1572834 & 688643 & 4.4 & 4.3596 & TRN \\
\hline CHEMBL1374501 & 688643 & 5.4 & 5.2414 & TRN \\
\hline CHEMBL495068 & 688643 & 4.7 & 4.7441 & TRN \\
\hline CHEMBL1592227 & 688643 & 5.3 & 5.1794 & TRN \\
\hline CHEMBL1354734 & 688643 & 4.9 & 5.1183 & TST \\
\hline CHEMBL1514390 & 688643 & 4.9 & 4.8817 & TRN \\
\hline CHEMBL1437711 & 688643 & 6.0 & 6.0146 & TRN \\
\hline
\end{tabular}




\begin{tabular}{|c|c|c|c|c|c|}
\hline \multicolumn{6}{|c|}{ Supplemental Table S2.txt } \\
\hline CHEMBL1321094 & 688643 & 4.6 & 4.5541 & TRN & \\
\hline CHEMBL1366831 & 688643 & 5.4 & 5.4604 & TRN & \\
\hline CHEMBL1362079 & 688643 & 4.4 & 4.3949 & TRN & \\
\hline CHEMBL1589925 & 688643 & 4.9 & 4.9854 & TRN & \\
\hline CHEMBL1496013 & 688643 & 6.0 & 5.8625 & TRN & \\
\hline CHEMBL1375753 & 688643 & 5.4 & 5.1776 & TRN & \\
\hline CHEMBL1354713 & 688643 & 5.0 & 4.9855 & TRN & \\
\hline CHEMBL491953 & 688643 & 4.9 & 4.8955 & TRN & \\
\hline CHEMBL1601506 & 688643 & 5.5 & 5.5911 & TRN & \\
\hline CHEMBL1476791 & 688643 & 4.4 & 4.5254 & TRN & \\
\hline CHEMBL1356166 & 688643 & 4.7 & 4.7042 & TRN & \\
\hline CHEMBL1331525 & 688643 & 4.8 & 4.8715 & TRN & \\
\hline CHEMBL1557657 & 688643 & 4.8 & 4.8977 & TRN & \\
\hline CHEMBL1482426 & 688643 & 4.4 & 4.4239 & TRN & \\
\hline CHEMBL1560798 & 688643 & 5.5 & 5.4981 & TRN & \\
\hline CHEMBL1315637 & 688643 & 5.0 & 4.9736 & TRN & \\
\hline CHEMBL1481402 & 688643 & 5.4 & 5.3763 & TST & \\
\hline CHEMBL1415080 & 688643 & 6.5 & 6.8759 & TRN & \\
\hline CHEMBL253998 & 688643 & 4.5 & 5.3805 & TRN & \\
\hline CHEMBL1513115 & 688643 & 5.7 & 5.54700 & 0000000001 & TRN \\
\hline CHEMBL1607228 & 688643 & 5.0 & 4.9792 & TRN & \\
\hline CHEMBL1366926 & 688643 & 5.1 & 4.9856 & TRN & \\
\hline CHEMBL1395058 & 688643 & 5.3 & 5.3362 & TRN & \\
\hline CHEMBL1453749 & 688643 & 4.9 & 5.2674 & TRN & \\
\hline CHEMBL441282 & 688643 & 6.0 & 4.9948 & TST & \\
\hline CHEMBL1589942 & 688643 & 5.5 & 5.5893 & TST & \\
\hline CHEMBL1372997 & 688643 & 4.9 & 5.0561 & TRN & \\
\hline CHEMBL1436049 & 688643 & 5.8 & 5.6519 & TRN & \\
\hline CHEMBL1514748 & 688643 & 4.9 & 4.9431 & TRN & \\
\hline CHEMBL1516485 & 688643 & 7.6003 & 7.2377 & TST & \\
\hline CHEMBL1408879 & 688643 & 5.5 & 5.4442 & TRN & \\
\hline CHEMBL1590458 & 688643 & 4.4 & 4.4778 & TRN & \\
\hline CHEMBL1344070 & 688643 & 6.6 & 6.5423 & TRN & \\
\hline CHEMBL1446922 & 688643 & 8.0 & 7.9486 & TRN & \\
\hline CHEMBL1493707 & 688643 & 5.7 & 5.6241 & TRN & \\
\hline CHEMBL1601805 & 688643 & 5.4 & 5.4936 & TRN & \\
\hline CHEMBL1475990 & 688643 & 5.5 & 5.6772 & TRN & \\
\hline CHEMBL321820 & 688643 & 4.4 & 4.6788 & TST & \\
\hline CHEMBL1512919 & 688643 & 4.6 & 4.6308 & TRN & \\
\hline CHEMBL1356630 & 688643 & 4.7 & 4.9243 & TRN & \\
\hline CHEMBL1526268 & 688643 & 5.4 & 5.523 & TRN & \\
\hline CHEMBL1558135 & 688643 & 4.5 & 4.6548 & TRN & \\
\hline CHEMBL1562612 & 688643 & 5.5 & 5.5361 & TRN & \\
\hline CHEMBL1476511 & 688643 & 4.8 & 4.8272 & TRN & \\
\hline CHEMBL1558777 & 688643 & 4.8 & 4.7911 & TRN & \\
\hline CHEMBL159096 & 688643 & 5.0 & 5.1625 & TST & \\
\hline CHEMBL1319286 & 688643 & 4.7 & 4.6259 & TRN & \\
\hline CHEMBL1517241 & 688643 & 4.9 & 4.96 & TRN & \\
\hline
\end{tabular}




\begin{tabular}{|c|c|c|c|c|c|}
\hline \multicolumn{6}{|c|}{ Supplemental Table S2.txt } \\
\hline CHEMBL395808 & 688643 & 4.5 & 5.197 & TRN & \\
\hline CHEMBL1525602 & 688643 & 5.1 & 4.9166 & TRN & \\
\hline CHEMBL1527466 & 688643 & 6.0 & 6.1506 & TRN & \\
\hline CHEMBL1314286 & 688643 & 6.0 & 5.8626 & TST & \\
\hline CHEMBL1256720 & 688643 & 4.4 & 4.64 & TRN & \\
\hline CHEMBL1436925 & 688643 & 5.0 & 5.0977 & TRN & \\
\hline CHEMBL10 & 688643 & 4.4 & 4.6679 & TST & \\
\hline CHEMBL1568575 & 688643 & 4.4 & 4.4146 & TRN & \\
\hline CHEMBL1316893 & 688643 & 4.7 & 4.6153 & TRN & \\
\hline CHEMBL1476712 & 688643 & 4.4 & 4.4054 & TRN & \\
\hline CHEMBL1564545 & 688643 & 4.6 & 4.7231 & TRN & \\
\hline CHEMBL1513160 & 688643 & 4.4 & 4.484 & TRN & \\
\hline CHEMBL1414910 & 688643 & 5.5 & 5.4557 & TRN & \\
\hline CHEMBL1314956 & 688643 & 7.1002 & 6.8907 & TRN & \\
\hline CHEMBL471226 & 688643 & 5.4 & 5.4611 & TST & \\
\hline CHEMBL1372133 & 688643 & 4.7 & 4.6717 & TRN & \\
\hline CHEMBL1568129 & 688643 & 5.1 & 4.9914 & TRN & \\
\hline CHEMBL492611 & 688643 & 4.7 & 4.547 & TRN & \\
\hline CHEMBL107201 & 688643 & 4.8 & 4.8744 & TRN & \\
\hline CHEMBL492122 & 688643 & 4.5 & 4.4768 & TRN & \\
\hline CHEMBL1526455 & 688643 & 4.4 & 4.9103 & TRN & \\
\hline CHEMBL1358384 & 688643 & 5.2 & 5.3921 & TST & \\
\hline CHEMBL1552095 & 688643 & 6.0 & 5.8783 & TRN & \\
\hline CHEMBL1435477 & 688643 & 6.0 & 6.3254 & TRN & \\
\hline CHEMBL1604925 & 688643 & 6.0 & 6.4525 & TST & \\
\hline CHEMBL1332504 & 688643 & 5.8 & 5.6689 & TRN & \\
\hline CHEMBL1597209 & 688643 & 4.8 & 4.6828 & TRN & \\
\hline CHEMBL1552066 & 688643 & 5.1 & 5.1161 & TRN & \\
\hline CHEMBL1573063 & 688643 & 4.5 & 4.4659 & TRN & \\
\hline CHEMBL1473188 & 688643 & 5.2 & 5.2569 & TRN & \\
\hline CHEMBL1476267 & 688643 & 5.1 & 5.3267 & TRN & \\
\hline CHEMBL1590601 & 688643 & 5.1 & 5.4365 & TRN & \\
\hline CHEMBL1553977 & 688643 & 5.4 & 5.4479 & TRN & \\
\hline CHEMBL1256647 & 688643 & 6.3 & 6.2559 & TRN & \\
\hline CHEMBL1592327 & 688643 & 4.7 & 4.7044 & TRN & \\
\hline CHEMBL1256646 & 688643 & 5.5 & 5.4913 & TRN & \\
\hline CHEMBL1373818 & 688643 & 4.6 & 4.75899 & 99999999995 & TST \\
\hline CHEMBL1516103 & 688643 & 5.8 & 5.6946 & TRN & \\
\hline CHEMBL1604074 & 688643 & 6.0 & 5.9335 & TRN & \\
\hline CHEMBL1445792 & 688643 & 5.4 & 5.3568 & TRN & \\
\hline CHEMBL1316055 & 688643 & 5.0 & 5.1417 & TRN & \\
\hline CHEMBL1436355 & 688643 & 6.5 & 6.3406 & TRN & \\
\hline CHEMBL1567435 & 688643 & 5.5 & 5.4298 & TRN & \\
\hline CHEMBL1569583 & 688643 & 5.5 & 5.5366 & TRN & \\
\hline CHEMBL1475255 & 688643 & 5.1 & 5.0283 & TRN & \\
\hline CHEMBL1475689 & 688643 & 4.6 & 4.5604 & TRN & \\
\hline CHEMBL1592117 & 688643 & 6.5 & 6.2191 & TRN & \\
\hline CHEMBL581886 & 688643 & 5.0 & 5.3381 & TRN & \\
\hline
\end{tabular}




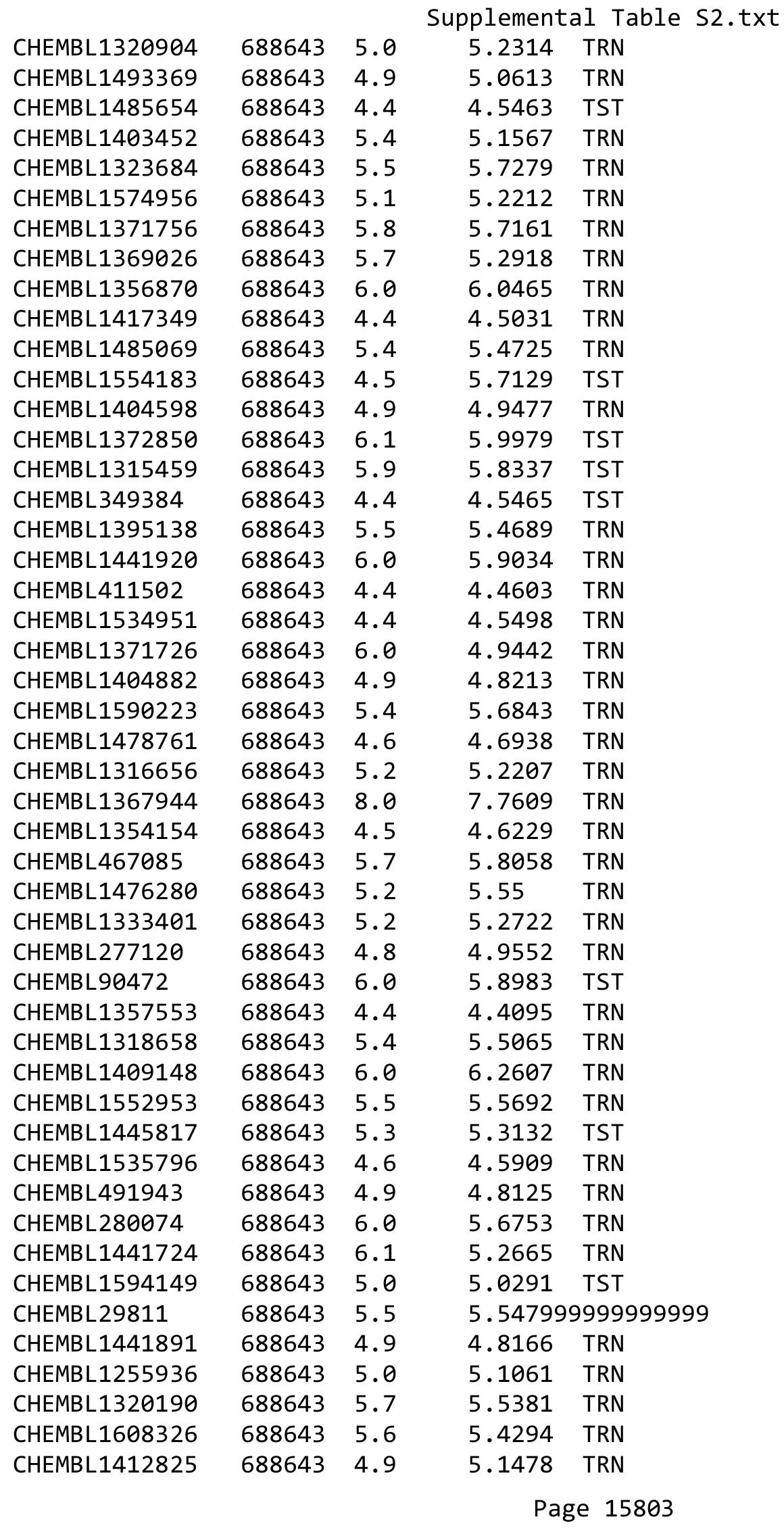




\begin{tabular}{|c|c|c|c|c|c|}
\hline & & & & & \\
\hline CHEMBL1434975 & 688643 & 5.9 & 5.8119 & TST & \\
\hline CHEMBL1321919 & 688643 & 5.4 & 5.32700 & 0000000001 & TRN \\
\hline CHEMBL1400543 & 688643 & 6.0 & 6.0513 & TRN & \\
\hline CHEMBL1516187 & 688643 & 6.1 & 5.9954 & TRN & \\
\hline CHEMBL1564927 & 688643 & 5.4 & 5.4925 & TST & \\
\hline CHEMBL1512878 & 688643 & 5.2 & 5.1057 & TRN & \\
\hline CHEMBL1596241 & 688643 & 4.4 & 4.5348 & TRN & \\
\hline CHEMBL243664 & 688643 & 4.9 & 5.0059 & TRN & \\
\hline CHEMBL1317950 & 688643 & 5.9 & 6.0109 & TST & \\
\hline CHEMBL1256654 & 688643 & 6.0 & 5.8866 & TRN & \\
\hline CHEMBL1590191 & 688643 & 4.4 & 4.9471 & TRN & \\
\hline CHEMBL85194 & 688643 & 4.9 & 5.0256 & TST & \\
\hline CHEMBL1476051 & 688643 & 4.5 & 4.4902 & TRN & \\
\hline CHEMBL1448562 & 688643 & 8.1024 & 7.9095 & TRN & \\
\hline CHEMBL1489182 & 688643 & 5.0 & 4.9909 & TRN & \\
\hline CHEMBL1590980 & 688643 & 6.7001 & 6.6046 & TRN & \\
\hline CHEMBL73310 & 688643 & 4.8 & 4.92399 & 99999999995 & TRN \\
\hline CHEMBL1473480 & 688643 & 6.3 & 6.475 & TRN & \\
\hline CHEMBL1454049 & 688643 & 5.0 & 4.9134 & TRN & \\
\hline CHEMBL32503 & 688643 & 5.4 & 5.3462 & TST & \\
\hline CHEMBL1368773 & 688643 & 6.1 & 6.1644 & TST & \\
\hline CHEMBL283130 & 688643 & 5.3 & 5.4721 & TRN & \\
\hline CHEMBL1314625 & 688643 & 4.9 & 4.9019 & TRN & \\
\hline CHEMBL137648 & 688643 & 5.5 & 5.5666 & TRN & \\
\hline CHEMBL1474461 & 688643 & 4.9 & 5.1556 & TRN & \\
\hline CHEMBL1377686 & 688643 & 5.1 & 5.3839 & TRN & \\
\hline CHEMBL1357722 & 688643 & 4.8 & 5.0706 & TRN & \\
\hline CHEMBL1513511 & 688643 & 4.7 & 4.6717 & TRN & \\
\hline CHEMBL101168 & 688643 & 4.5 & 4.5796 & TRN & \\
\hline CHEMBL 275938 & 688643 & 4.4 & 4.727 & TST & \\
\hline CHEMBL1397517 & 688643 & 5.5 & 5.5761 & TRN & \\
\hline CHEMBL1551310 & 688643 & 5.6 & 5.4119 & TRN & \\
\hline CHEMBL1552864 & 688643 & 4.6 & 4.6125 & TRN & \\
\hline CHEMBL1368942 & 688643 & 4.4 & 4.3344 & TRN & \\
\hline CHEMBL1330404 & 688643 & 4.4 & 4.8304 & TRN & \\
\hline CHEMBL1359320 & 688643 & 5.1 & 5.1433 & TRN & \\
\hline CHEMBL1396693 & 688643 & 4.9 & 4.8234 & TRN & \\
\hline CHEMBL1354596 & 688643 & 4.8 & 4.7002 & TRN & \\
\hline CHEMBL1554459 & 688643 & 5.5 & 5.5597 & TRN & \\
\hline CHEMBL464467 & 688643 & 4.5 & 5.47 & TRN & \\
\hline CHEMBL1519225 & 688643 & 4.8 & 4.7613 & TRN & \\
\hline CHEMBL1567295 & 688643 & 4.7 & 4.6119 & TRN & \\
\hline CHEMBL1408836 & 688643 & 6.3 & 6.0043 & TRN & \\
\hline CHEMBL112816 & 688643 & 6.0 & 5.2257 & TRN & \\
\hline CHEMBL1373326 & 688643 & 4.7 & 4.797 & TRN & \\
\hline CHEMBL1400976 & 688643 & 5.2 & 5.3239 & TRN & \\
\hline CHEMBL1519978 & 688643 & 4.4 & 4.4925 & TRN & \\
\hline CHEMBL1443703 & 688643 & 5.4 & 5.40799 & 99999999995 & TRN \\
\hline & & & & 15804 & \\
\hline
\end{tabular}




\begin{tabular}{|c|c|c|c|c|c|}
\hline \multirow{2}{*}{ CHEMBL1376952 } & \multirow{2}{*}{688643} & \\
\hline & & 5.5 & 5.5218 & TRN & \\
\hline CHEMBL1322414 & 688643 & 5.4 & 5.4407 & TRN & \\
\hline CHEMBL567331 & 688643 & 6.4 & 5.7109 & TRN & \\
\hline CHEMBL1512025 & 688643 & 5.4 & 5.5278 & TST & \\
\hline CHEMBL1446323 & 688643 & 4.6 & 4.5286 & TRN & \\
\hline CHEMBL1372330 & 688643 & 6.0 & 6.1745 & TRN & \\
\hline CHEMBL1318262 & 688643 & 5.0 & 4.9076 & TRN & \\
\hline CHEMBL1531699 & 688643 & 5.0 & 4.9542 & TRN & \\
\hline CHEMBL 3350578 & 688643 & 5.5 & 5.5892 & TST & \\
\hline CHEMBL1376723 & 688643 & 4.5 & 4.6222 & TRN & \\
\hline CHEMBL1336932 & 688643 & 5.0 & 5.0283 & TRN & \\
\hline CHEMBL1357016 & 688643 & 4.4 & 4.6052 & TRN & \\
\hline CHEMBL1395862 & 688643 & 4.9 & 4.9298 & TRN & \\
\hline CHEMBL490717 & 688643 & 4.9 & 4.9841 & TRN & \\
\hline CHEMBL251904 & 688643 & 6.0 & 6.5802 & TRN & \\
\hline CHEMBL1399055 & 688643 & 4.6 & 4.6433 & TRN & \\
\hline CHEMBL1594078 & 688643 & 4.9 & 4.74 & TRN & \\
\hline CHEMBL1413343 & 688643 & 4.9 & 4.6886 & TRN & \\
\hline CHEMBL471728 & 688643 & 5.9 & 5.875 & TST & \\
\hline CHEMBL1315965 & 688643 & 4.4 & 4.4295 & TRN & \\
\hline CHEMBL1446815 & 688643 & 5.0 & 5.1597 & TRN & \\
\hline CHEMBL1590354 & 688643 & 4.4 & 4.415 & TRN & \\
\hline CHEMBL68534 & 688643 & 4.6 & 3.8199 & TRN & \\
\hline CHEMBL1329108 & 688643 & 6.2 & 6.2584 & TRN & \\
\hline CHEMBL1557564 & 688643 & 4.6 & 4.6748 & TRN & \\
\hline CHEMBL1515788 & 688643 & 6.0 & 6.0074 & TRN & \\
\hline CHEMBL1513078 & 688643 & 4.6 & 5.1343 & TRN & \\
\hline CHEMBL1398800 & 688643 & 5.4 & 5.17206 & 0000000001 & TRN \\
\hline CHEMBL1477982 & 688643 & 4.6 & 4.8005 & TRN & \\
\hline CHEMBL1321511 & 688643 & 5.5 & 5.5804 & TRN & \\
\hline CHEMBL1515717 & 688643 & 5.0 & 5.0139 & TRN & \\
\hline CHEMBL442956 & 688643 & 5.4 & 5.136 & TRN & \\
\hline CHEMBL1361725 & 688643 & 6.2 & 6.4994 & TRN & \\
\hline CHEMBL363332 & 688643 & 5.4 & 5.4707 & TRN & \\
\hline CHEMBL1520292 & 688643 & 4.4 & 4.3851 & TRN & \\
\hline CHEMBL1332803 & 688643 & 5.4 & 5.401 & TRN & \\
\hline CHEMBL1516787 & 688643 & 5.0 & 5.0671 & TRN & \\
\hline CHEMBL1437408 & 688643 & 5.3 & 5.2515 & TRN & \\
\hline CHEMBL1451315 & 688643 & 4.6 & 4.4689 & TRN & \\
\hline CHEMBL1327256 & 688643 & 4.6 & 5.4168 & TRN & \\
\hline CHEMBL1514440 & 688643 & 6.0 & 4.7274 & TRN & \\
\hline CHEMBL1589842 & 688643 & 5.5 & 5.6483 & TRN & \\
\hline CHEMBL1435032 & 688643 & 4.8 & 4.7404 & TRN & \\
\hline CHEMBL1599163 & 688643 & 4.4 & 4.4034 & TRN & \\
\hline CHEMBL1598680 & 688643 & 6.0 & 5.6931 & TRN & \\
\hline CHEMBL1524305 & 688643 & 4.6 & 4.6202 & TRN & \\
\hline CHEMBL1334959 & 688643 & 4.5 & 4.4907 & TRN & \\
\hline CHEMBL1525886 & 688643 & 5.5 & 5.6168 & TRN & \\
\hline & & & & 15805 & \\
\hline
\end{tabular}




\begin{tabular}{|c|c|c|c|c|}
\hline & & & Supplement & \\
\hline CHEMBL1479730 & 688643 & 4.8 & 4.8385 & TRN \\
\hline CHEMBL1473760 & 688643 & 4.4 & 4.4239 & TRN \\
\hline CHEMBL1452065 & 688643 & 4.5 & 4.4887 & TRN \\
\hline CHEMBL1479203 & 688643 & 6.9 & 6.9715 & TRN \\
\hline CHEMBL1592966 & 688643 & 6.3 & 6.6082 & TRN \\
\hline CHEMBL86931 & 688643 & 4.5 & 4.7188 & TRN \\
\hline CHEMBL1402827 & 688643 & 4.7 & 4.7852 & TRN \\
\hline CHEMBL1364980 & 688643 & 5.0 & 5.074 & TRN \\
\hline CHEMBL1322026 & 688643 & 6.2 & 6.1524 & TRN \\
\hline CHEMBL1395226 & 688643 & 4.7 & 4.5676 & TRN \\
\hline CHEMBL1436832 & 688643 & 4.7 & 4.581 & TRN \\
\hline CHEMBL 27403 & 688643 & 4.6 & 4.7186 & TRN \\
\hline CHEMBL1554194 & 688643 & 4.8 & 4.8354 & TRN \\
\hline CHEMBL1444914 & 688643 & 4.8 & 4.8318 & TRN \\
\hline CHEMBL1496596 & 688643 & 4.7 & 4.6948 & TRN \\
\hline CHEMBL1517187 & 688643 & 4.4 & 4.4896 & TST \\
\hline CHEMBL297784 & 688643 & 6.0 & 5.7814 & TST \\
\hline CHEMBL1269022 & 688643 & 5.7 & 5.6148 & TST \\
\hline CHEMBL249669 & 688643 & 6.0 & 5.7647 & TST \\
\hline CHEMBL1789998 & 688643 & 5.1 & 5.245 & TST \\
\hline CHEMBL1366020 & 688643 & 4.8 & 4.9411 & TRN \\
\hline CHEMBL1557213 & 688643 & 5.5 & 5.6217 & TRN \\
\hline CHEMBL1182777 & 688643 & 4.8 & 4.8788 & TST \\
\hline CHEMBL1330296 & 688643 & 4.8 & 4.9428 & TRN \\
\hline CHEMBL1256740 & 688643 & 6.0 & 6.0514 & TST \\
\hline CHEMBL1789988 & 688643 & 5.5 & 5.4956 & TRN \\
\hline CHEMBL 20377 & 688643 & 6.1 & 6.3978 & TRN \\
\hline CHEMBL1484447 & 688643 & 4.4 & 4.5628 & TRN \\
\hline CHEMBL1454809 & 688643 & 5.4 & 5.3515 & TRN \\
\hline CHEMBL1410004 & 688643 & 5.6 & 5.6298 & TRN \\
\hline CHEMBL1398528 & 688643 & 5.6 & 5.5593 & TRN \\
\hline CHEMBL1328943 & 688643 & 5.5 & 5.5819 & TRN \\
\hline CHEMBL1376143 & 688643 & 4.9 & 4.8234 & TRN \\
\hline CHEMBL1368892 & 688643 & 4.7 & 4.6546 & TRN \\
\hline CHEMBL1436761 & 688643 & 4.6 & 4.7656 & TRN \\
\hline CHEMBL1414698 & 688643 & 4.9 & 4.9123 & TRN \\
\hline CHEMBL1373907 & 688643 & 4.4 & 4.3959 & TRN \\
\hline CHEMBL1330317 & 688643 & 5.1 & 5.0584 & TRN \\
\hline CHEMBL1594372 & 688643 & 5.0 & 5.056 & TRN \\
\hline CHEMBL1354563 & 688643 & 4.9 & 4.8965 & TRN \\
\hline CHEMBL1527029 & 688643 & 5.1 & 5.3553 & TRN \\
\hline CHEMBL1518571 & 688643 & 5.2 & 5.3204 & TST \\
\hline CHEMBL1613725 & 688643 & 4.4 & 4.4487 & TRN \\
\hline CHEMBL1318400 & 688643 & 6.0 & 6.1857 & TRN \\
\hline CHEMBL1397308 & 688643 & 4.8 & 5.3316 & TRN \\
\hline CHEMBL1514729 & 688643 & 6.4 & 6.0823 & TRN \\
\hline CHEMBL16410 & 688643 & 4.6 & 4.8917 & TRN \\
\hline CHEMBL1451058 & 688643 & 4.5 & 5.183 & TRN \\
\hline
\end{tabular}




\begin{tabular}{|c|c|c|c|c|}
\hline \multicolumn{5}{|c|}{ Supplemental Table s2.txt } \\
\hline CHEMBL1605255 & 688643 & 4.7 & 4.6422 & TRN \\
\hline CHEMBL1528565 & 688643 & 7.3002 & 6.9047 & TST \\
\hline CHEMBL567332 & 688643 & 4.8 & 4.6811 & TRN \\
\hline CHEMBL1336727 & 688643 & 4.5 & 4.7878 & TRN \\
\hline CHEMBL490718 & 688643 & 4.7 & 4.5886 & TRN \\
\hline CHEMBL1435444 & 688643 & 4.6 & 4.8966 & TRN \\
\hline CHEMBL1316285 & 688643 & 4.4 & 4.398 & TRN \\
\hline CHEMBL1365367 & 688643 & 4.9 & 4.7348 & TRN \\
\hline CHEMBL66654 & 688643 & 4.4 & 5.0576 & TST \\
\hline CHEMBL1484261 & 688643 & 5.6 & 5.5994 & TRN \\
\hline CHEMBL1335862 & 688643 & 5.4 & 5.4523 & TRN \\
\hline CHEMBL305195 & 688643 & 6.0 & 6.0654 & TRN \\
\hline CHEMBL1601019 & 688643 & 4.8 & 4.6655 & TRN \\
\hline CHEMBL1396583 & 688643 & 5.5 & 5.4371 & TRN \\
\hline CHEMBL1553185 & 688643 & 5.4 & 5.3753 & TRN \\
\hline CHEMBL1515829 & 688643 & 4.6 & 4.612 & TRN \\
\hline CHEMBL1394419 & 688643 & 4.4 & 5.3632 & TST \\
\hline CHEMBL1590048 & 688643 & 4.6 & 4.7068 & TRN \\
\hline CHEMBL1327355 & 688643 & 4.8 & 4.828 & TRN \\
\hline CHEMBL1450317 & 688643 & 5.5 & 5.6168 & TRN \\
\hline CHEMBL37081 & 688643 & 4.9 & 4.5433 & TRN \\
\hline CHEMBL117405 & 688643 & 6.0 & 5.9126 & TRN \\
\hline CHEMBL1521453 & 688643 & 6.0 & 5.8709 & TST \\
\hline CHEMBL1406879 & 688643 & 4.7 & 4.6185 & TRN \\
\hline CHEMBL1376736 & 688643 & 5.0 & 4.8776 & TRN \\
\hline CHEMBL474415 & 688643 & 5.9 & 5.8173 & TRN \\
\hline CHEMBL1314799 & 688643 & 4.9 & 4.7926 & TRN \\
\hline CHEMBL1473030 & 688643 & 6.0 & $6.1220 e$ & 3000000001 \\
\hline CHEMBL1396595 & 688643 & 4.7 & 4.6074 & TRN \\
\hline CHEMBL1317066 & 688643 & 7.1002 & 6.8165 & TRN \\
\hline CHEMBL1400309 & 688643 & 5.2 & 5.0771 & TRN \\
\hline CHEMBL587849 & 688643 & 5.4 & 5.4195 & TRN \\
\hline CHEMBL 87418 & 688643 & 5.6 & 5.6433 & TRN \\
\hline CHEMBL1396384 & 688643 & 4.4 & 4.5601 & TRN \\
\hline CHEMBL407874 & 688643 & 6.3 & 6.1634 & TRN \\
\hline CHEMBL1364859 & 688643 & 5.1 & 5.0256 & TRN \\
\hline CHEMBL1394923 & 688643 & 6.9 & 6.8024 & TRN \\
\hline CHEMBL189438 & 688643 & 6.0 & 6.3589 & TRN \\
\hline CHEMBL441618 & 688643 & 6.3 & $5.4510 e$ & 00000000005 \\
\hline CHEMBL1603100 & 688643 & 5.5 & 5.5209 & TRN \\
\hline CHEMBL1365537 & 688643 & 6.1 & 5.9947 & TRN \\
\hline CHEMBL1334465 & 688643 & 4.5 & 4.6403 & TST \\
\hline CHEMBL1317504 & 688643 & 4.7 & 4.6672 & TRN \\
\hline CHEMBL1354398 & 688643 & 6.0 & 5.8379 & TRN \\
\hline CHEMBL1412390 & 688643 & 4.5 & 4.6388 & TRN \\
\hline CHEMBL1256687 & 688643 & 6.2 & 5.9775 & TRN \\
\hline CHEMBL1590992 & 688643 & 5.7 & 5.56 & TRN \\
\hline CHEMBL1397902 & 688643 & 5.4 & 5.4078 & TRN \\
\hline
\end{tabular}




\begin{tabular}{|c|c|c|c|c|}
\hline \multicolumn{5}{|c|}{ Supplemental Table S2.txt } \\
\hline CHEMBL1593592 & 688643 & 4.4 & 4.5102 & TRN \\
\hline CHEMBL1441607 & 688643 & 5.3 & 5.0902 & TST \\
\hline CHEMBL1533033 & 688643 & 5.1 & 5.3009 & TRN \\
\hline CHEMBL432527 & 688643 & 6.0 & 5.5042 & TRN \\
\hline CHEMBL1361847 & 688643 & 5.1 & 5.1905 & TRN \\
\hline CHEMBL1551066 & 688643 & 5.1 & 5.0038 & TRN \\
\hline CHEMBL44297 & 688643 & 4.5 & 4.7756 & TST \\
\hline CHEMBL552439 & 688643 & 5.4 & 5.3308 & TST \\
\hline CHEMBL1415465 & 688643 & 5.0 & 4.723 & TRN \\
\hline CHEMBL1546193 & 688643 & 5.1 & 5.3137 & TST \\
\hline CHEMBL1395605 & 688643 & 4.6 & 4.5663 & TRN \\
\hline CHEMBL1434801 & 688643 & 4.4 & 4.4826 & TRN \\
\hline CHEMBL3209702 & 688643 & 5.2 & 5.3279 & TRN \\
\hline CHEMBL303516 & 688643 & 5.3 & 5.4631 & TST \\
\hline CHEMBL1435540 & 688643 & 6.7001 & 6.5077 & TRN \\
\hline CHEMBL1440302 & 688643 & 5.8 & 5.9359 & TRN \\
\hline CHEMBL1552277 & 688643 & 4.9 & 5.0371 & TRN \\
\hline CHEMBL509150 & 688643 & 4.5 & 4.4828 & TRN \\
\hline CHEMBL1713992 & 688643 & 6.0 & 5.8706 & TST \\
\hline CHEMBL1475151 & 688643 & 5.5 & 5.6039 & TRN \\
\hline CHEMBL1255659 & 688643 & 4.8 & 4.8787 & TRN \\
\hline CHEMBL1441737 & 688643 & 4.7 & 4.6358 & TRN \\
\hline CHEMBL1489663 & 688643 & 5.4 & 5.4901 & TRN \\
\hline CHEMBL1490740 & 688643 & 4.7 & 4.8014 & TRN \\
\hline CHEMBL1414269 & 688643 & 4.9 & 4.7289 & TRN \\
\hline CHEMBL491978 & 688643 & 4.7 & 4.6435 & TRN \\
\hline CHEMBL1592202 & 688643 & 4.4 & 4.6316 & TRN \\
\hline CHEMBL1481747 & 688643 & 4.6 & 4.6148 & TRN \\
\hline CHEMBL19439 & 688643 & 6.0 & 5.9132 & TRN \\
\hline CHEMBL1356023 & 688643 & 5.6 & 5.6922 & TRN \\
\hline CHEMBL1408138 & 688643 & 5.5 & 5.4666 & TRN \\
\hline CHEMBL1556218 & 688643 & 5.1 & 5.2729 & TRN \\
\hline CHEMBL566899 & 688643 & 5.0 & 5.0191 & TRN \\
\hline CHEMBL1414688 & 688643 & 7.6003 & 5.194 & TRN \\
\hline CHEMBL1473707 & 688643 & 6.0 & 5.1827 & TRN \\
\hline CHEMBL513116 & 688643 & 6.0 & 5.9118 & TRN \\
\hline CHEMBL 1360740 & 688643 & 5.7 & 5.4691 & TRN \\
\hline CHEMBL1378704 & 688643 & 4.6 & 4.7006 & TRN \\
\hline CHEMBL1490786 & 688643 & 4.8 & 4.7436 & TRN \\
\hline CHEMBL1611220 & 688643 & 7.6003 & 7.1541 & TST \\
\hline CHEMBL93403 & 688643 & 4.5 & 4.6578 & TRN \\
\hline CHEMBL1327054 & 688643 & 5.5 & 5.157 & TST \\
\hline CHEMBL1405762 & 688643 & 5.6 & 5.7416 & TRN \\
\hline CHEMBL1257078 & 688643 & 7.8013 & 7.58 & TRN \\
\hline CHEMBL1256737 & 688643 & 6.0 & 6.2294 & TRN \\
\hline CHEMBL1512850 & 688643 & 5.6 & 5.6676 & TRN \\
\hline CHEMBL1565927 & 688643 & 5.5 & 5.3077 & TRN \\
\hline CHEMBL1439485 & 688643 & 5.1 & 4.9936 & TRN \\
\hline
\end{tabular}




\begin{tabular}{|c|c|c|c|c|c|}
\hline \multicolumn{6}{|c|}{ Supplemental Table S2.txt } \\
\hline CHEMBL1456312 & 688643 & 6.4 & 6.1377 & TRN & \\
\hline CHEMBL1555238 & 688643 & 4.8 & 4.8212 & TRN & \\
\hline CHEMBL1333531 & 688643 & 4.9 & 5.0277 & TRN & \\
\hline CHEMBL1395098 & 688643 & 5.0 & 5.0748 & TRN & \\
\hline CHEMBL31741 & 688643 & 5.2 & 5.2459 & TRN & \\
\hline CHEMBL1474681 & 688643 & 5.0 & 5.053 & TRN & \\
\hline CHEMBL1414948 & 688643 & 4.8 & 4.8607 & TRN & \\
\hline CHEMBL1334652 & 688643 & 4.9 & 5.1327 & TRN & \\
\hline CHEMBL1328339 & 688643 & 6.0 & 6.0273 & TRN & \\
\hline CHEMBL1553204 & 688643 & 5.3 & 5.5521 & TRN & \\
\hline CHEMBL1365701 & 688643 & 5.9 & 6.032 & TRN & \\
\hline CHEMBL1366737 & 688643 & 4.9 & 4.9502 & TRN & \\
\hline CHEMBL472656 & 688643 & 5.4 & 5.4299 & TST & \\
\hline CHEMBL1591451 & 688643 & 5.9 & 5.91706 & 2000000001 & TRN \\
\hline CHEMBL1433752 & 688643 & 5.3 & 5.3294 & TRN & \\
\hline CHEMBL448966 & 688643 & 4.8 & 4.6839 & TRN & \\
\hline CHEMBL1328480 & 688643 & 6.1 & 6.0681 & TRN & \\
\hline CHEMBL1398250 & 688643 & 5.4 & 5.5152 & TRN & \\
\hline CHEMBL1487735 & 688643 & 4.6 & 4.5702 & TRN & \\
\hline CHEMBL1433777 & 688643 & 6.1 & 6.1112 & TRN & \\
\hline CHEMBL1320485 & 688643 & 5.7 & 5.8715 & TRN & \\
\hline CHEMBL51085 & 688643 & 6.0 & 5.3548 & TST & \\
\hline CHEMBL1319506 & 688643 & 4.4 & 4.4999 & TRN & \\
\hline CHEMBL1565311 & 688643 & 6.5 & 6.4355 & TRN & \\
\hline CHEMBL1594020 & 688643 & 6.4 & 6.3963 & TRN & \\
\hline CHEMBL34704 & 688643 & 6.0 & 5.7657 & TST & \\
\hline CHEMBL1402894 & 688643 & 5.2 & 5.3267 & TRN & \\
\hline CHEMBL1437667 & 688643 & 4.7 & 4.6791 & TRN & \\
\hline CHEMBL1514375 & 688643 & 4.5 & 4.7562 & TST & \\
\hline CHEMBL608109 & 688643 & 5.7 & 5.6227 & TRN & \\
\hline CHEMBL1323563 & 688643 & 4.9 & 4.8587 & TRN & \\
\hline CHEMBL1318495 & 688643 & 5.3 & 5.2917 & TRN & \\
\hline CHEMBL434119 & 688643 & 5.6 & 5.5739 & TST & \\
\hline CHEMBL1602710 & 688643 & 4.6 & 4.5532 & TRN & \\
\hline CHEMBL1324494 & 688643 & 4.5 & 4.4779 & TRN & \\
\hline CHEMBL1789995 & 688643 & 6.3 & 6.1516 & TRN & \\
\hline CHEMBL26138 & 688643 & 4.4 & 5.0754 & TST & \\
\hline CHEMBL1369863 & 688643 & 5.1 & 4.9032 & TRN & \\
\hline CHEMBL1555164 & 688643 & 5.5 & 5.5693 & TRN & \\
\hline CHEMBL1486638 & 688643 & 5.6 & 5.4979 & TST & \\
\hline CHEMBL1514923 & 688643 & 6.6 & 6.3501 & TRN & \\
\hline CHEMBL1560758 & 688643 & 4.9 & 4.8727 & TRN & \\
\hline CHEMBL1332931 & 688643 & 5.5 & 5.1377 & TRN & \\
\hline CHEMBL200309 & 688643 & 5.6 & 5.6208 & TRN & \\
\hline CHEMBL1481160 & 688643 & 6.7001 & 6.6216 & TST & \\
\hline CHEMBL1554141 & 688643 & 5.5 & 5.5653 & TRN & \\
\hline CHEMBL1605510 & 688643 & 6.8 & 7.0662 & TRN & \\
\hline CHEMBL1600497 & 688643 & 6.3 & 6.4149 & TRN & \\
\hline
\end{tabular}




\begin{tabular}{|c|c|c|c|c|c|}
\hline \multicolumn{6}{|c|}{ Supplemental Table S2.txt } \\
\hline CHEMBL1394343 & 688643 & 5.1 & 5.2926 & TST & \\
\hline CHEMBL47940 & 688643 & 4.5 & 4.7624 & TST & \\
\hline CHEMBL1552270 & 688643 & 6.9 & 6.5422 & TRN & \\
\hline CHEMBL1478946 & 688643 & 4.7 & 4.792 & TRN & \\
\hline CHEMBL1256749 & 688643 & 6.9 & 6.7123 & TST & \\
\hline CHEMBL289233 & 688643 & 6.3 & 6.0608 & TRN & \\
\hline CHEMBL1394765 & 688643 & 4.4 & 4.3939 & TRN & \\
\hline CHEMBL489737 & 688643 & 5.0 & 5.0476 & TRN & \\
\hline CHEMBL1478530 & 688643 & 4.5 & 4.7587 & TST & \\
\hline CHEMBL1555308 & 688643 & 5.1 & 5.4731 & TRN & \\
\hline CHEMBL1553218 & 688643 & 6.2 & 6.2593 & TRN & \\
\hline CHEMBL1568491 & 688643 & 4.4 & 4.3861 & TRN & \\
\hline CHEMBL1536058 & 688643 & 5.4 & 5.6341 & TST & \\
\hline CHEMBL1334321 & 688643 & 5.7 & 5.3614 & TRN & \\
\hline CHEMBL1444367 & 688643 & 5.5 & 5.5264 & TRN & \\
\hline CHEMBL265177 & 688643 & 5.5 & 5.4825 & TST & \\
\hline CHEMBL556001 & 688643 & 6.6 & 6.5592 & TRN & \\
\hline CHEMBL1570500 & 688643 & 5.4 & 5.1749 & TST & \\
\hline CHEMBL1573957 & 688643 & 7.8013 & 7.28799 & 9999999999 & TRN \\
\hline CHEMBL1404451 & 688643 & 5.9 & 5.6943 & TRN & \\
\hline CHEMBL 293749 & 688643 & 4.4 & 4.285 & TRN & \\
\hline CHEMBL 8145 & 688643 & 4.8 & 5.2202 & TRN & \\
\hline CHEMBL1315373 & 688643 & 4.9 & 5.0682 & TRN & \\
\hline CHEMBL1454920 & 688643 & 4.9 & 4.8934 & TRN & \\
\hline CHEMBL1552165 & 688643 & 4.4 & 4.6885 & TRN & \\
\hline CHEMBL1316401 & 688643 & 5.3 & 5.4956 & TRN & \\
\hline CHEMBL1446990 & 688643 & 5.9 & 6.1488 & TRN & \\
\hline CHEMBL1288014 & 688643 & 5.6 & 5.62 & TRN & \\
\hline CHEMBL1515774 & 688643 & 5.6 & 5.6185 & TRN & \\
\hline CHEMBL1597692 & 688643 & 6.0 & 6.1484 & TRN & \\
\hline CHEMBL1446110 & 688643 & 5.4 & 5.5004 & TRN & \\
\hline CHEMBL221137 & 688643 & 6.0 & 5.6714 & TST & \\
\hline CHEMBL1332450 & 688643 & 5.4 & 5.3679 & TRN & \\
\hline CHEMBL1441981 & 688643 & 5.7 & 5.5255 & TRN & \\
\hline CHEMBL1592663 & 688643 & 5.9 & 5.8699 & TST & \\
\hline CHEMBL1435823 & 688643 & 4.4 & 4.3593 & TRN & \\
\hline CHEMBL909 & 688643 & 6.9 & 6.8005 & TRN & \\
\hline CHEMBL1358009 & 688643 & 5.8 & 5.6723 & TRN & \\
\hline CHEMBL1594350 & 688643 & 5.5 & 5.5463 & TRN & \\
\hline CHEMBL1590857 & 688643 & 4.6 & 4.5985 & TRN & \\
\hline CHEMBL1256359 & 688643 & 4.9 & 4.9418 & TST & \\
\hline CHEMBL1256667 & 688643 & 4.5 & 4.7431 & TST & \\
\hline CHEMBL1255832 & 688643 & 4.7 & 5.7624 & TRN & \\
\hline CHEMBL1355788 & 688643 & 5.4 & 5.3308 & TRN & \\
\hline CHEMBL 282489 & 688643 & 4.4 & 4.655 & TRN & \\
\hline CHEMBL1256836 & 688643 & 4.8 & 5.0991 & TRN & \\
\hline CHEMBL574181 & 688643 & 4.4 & 4.6153 & TRN & \\
\hline CHEMBL1405759 & 688643 & 4.5 & 4.8527 & TST & \\
\hline
\end{tabular}




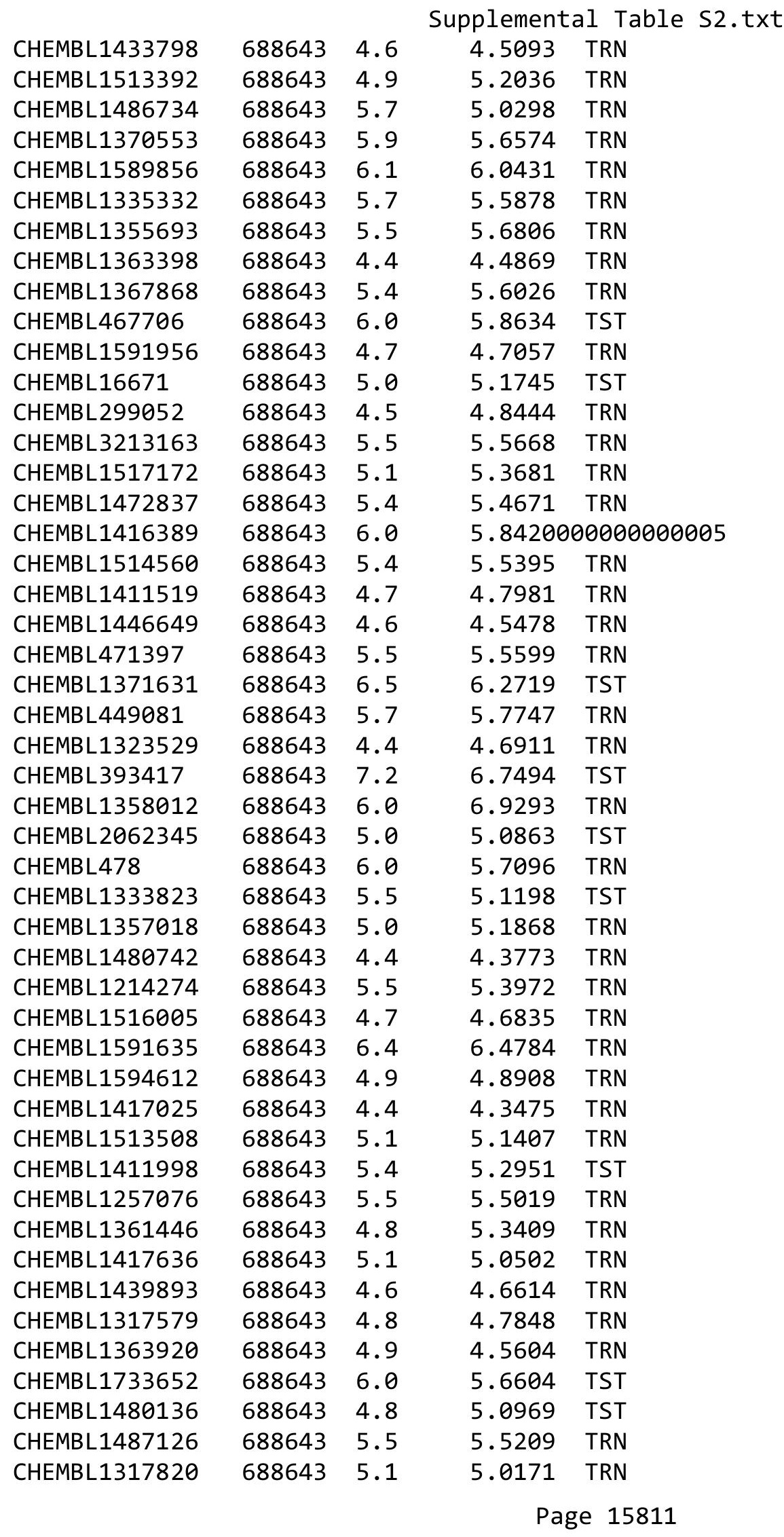




\begin{tabular}{|c|c|c|c|c|c|}
\hline \\
\hline CHEMBL1357293 & 688643 & 5.1 & 4.9224 & TRN & \\
\hline CHEMBL1551133 & 688643 & 4.9 & 4.7535 & TRN & \\
\hline CHEMBL1354934 & 688643 & 5.3 & 5.2564 & TRN & \\
\hline CHEMBL1551913 & 688643 & 4.4 & 4.4129 & TRN & \\
\hline CHEMBL270299 & 688643 & 4.5 & 6.26 & TST & \\
\hline CHEMBL1555028 & 688643 & 4.4 & 4.4241 & TRN & \\
\hline CHEMBL 21823 & 688643 & 5.1 & 5.1984 & TRN & \\
\hline CHEMBL375126 & 688643 & 5.4 & 5.3477 & TST & \\
\hline CHEMBL1476729 & 688643 & 5.0 & 4.9847 & TRN & \\
\hline CHEMBL1362501 & 688643 & 5.5 & 5.2149 & TST & \\
\hline CHEMBL1473055 & 688643 & 4.4 & 4.3647 & TRN & \\
\hline CHEMBL1358380 & 688643 & 5.7 & 5.6629 & TRN & \\
\hline CHEMBL1316408 & 688643 & 5.6 & $5.4520 e$ & 0000000001 & TRN \\
\hline CHEMBL516075 & 688643 & 5.5 & 5.3499 & TRN & \\
\hline CHEMBL1514045 & 688643 & 4.4 & 4.461 & TRN & \\
\hline CHEMBL1452716 & 688643 & 6.0 & 5.6608 & TRN & \\
\hline CHEMBL1437056 & 688643 & 4.8 & 4.7072 & TRN & \\
\hline CHEMBL1527332 & 688643 & 4.8 & 4.7168 & TRN & \\
\hline CHEMBL475375 & 688643 & 4.6 & 4.647 & TRN & \\
\hline CHEMBL1473990 & 688643 & 6.2 & 6.1467 & TRN & \\
\hline CHEMBL1407146 & 688643 & 5.7 & 5.7009 & TRN & \\
\hline CHEMBL1437488 & 688643 & 6.0 & 4.9035 & TRN & \\
\hline CHEMBL1613233 & 688643 & 5.0 & 5.0922 & TRN & \\
\hline CHEMBL1600520 & 688643 & 4.8 & 5.1257 & TRN & \\
\hline CHEMBL1609440 & 688643 & 5.0 & 5.1324 & TRN & \\
\hline CHEMBL1416705 & 688643 & 4.4 & 4.5048 & TRN & \\
\hline CHEMBL1448896 & 688643 & 5.5 & 5.5111 & TRN & \\
\hline CHEMBL1395252 & 688643 & 4.7 & 4.8392 & TRN & \\
\hline CHEMBL1526032 & 688643 & 5.0 & 5.0461 & TRN & \\
\hline CHEMBL1408878 & 688643 & 4.6 & 4.5726 & TRN & \\
\hline CHEMBL153036 & 688643 & 6.0 & 5.9826 & TRN & \\
\hline CHEMBL1491036 & 688643 & 5.5 & 5.6793 & TRN & \\
\hline CHEMBL165 & 688643 & 6.0 & 4.9937 & TRN & \\
\hline CHEMBL1366667 & 688643 & 5.4 & 5.3716 & TRN & \\
\hline CHEMBL1515918 & 688643 & 4.7 & 4.685 & TRN & \\
\hline CHEMBL1335890 & 688643 & 6.0 & 6.2765 & TRN & \\
\hline CHEMBL1330957 & 688643 & 6.5 & 6.3287 & TST & \\
\hline CHEMBL1551021 & 688643 & 5.5 & 5.4966 & TRN & \\
\hline CHEMBL1355835 & 688643 & 4.4 & 4.4258 & TRN & \\
\hline CHEMBL1322864 & 688643 & 6.5 & 6.2337 & TST & \\
\hline CHEMBL1395375 & 688643 & 5.3 & 5.5265 & TRN & \\
\hline CHEMBL1373610 & 688643 & 4.4 & 4.4753 & TRN & \\
\hline CHEMBL136906 & 688643 & 5.4 & 5.3831 & TST & \\
\hline CHEMBL365739 & 688643 & 6.0 & 5.8894 & TST & \\
\hline CHEMBL16857 & 688643 & 6.0 & 5.9242 & TRN & \\
\hline CHEMBL1256876 & 688643 & 4.5 & 4.6699 & TRN & \\
\hline CHEMBL1552752 & 688643 & 4.9 & 4.8472 & TRN & \\
\hline CHEMBL 259073 & 688643 & 4.4 & 4.5865 & TRN & \\
\hline
\end{tabular}




\begin{tabular}{|c|c|c|c|c|c|}
\hline \\
\hline CHEMBL1613562 & 688643 & 5.2 & 5.2824 & TRN & \\
\hline CHEMBL1338229 & 688643 & 6.0 & 5.9742 & TRN & \\
\hline CHEMBL1448044 & 688643 & 5.2 & 5.1487 & TRN & \\
\hline CHEMBL1480219 & 688643 & 4.4 & 4.433 & TRN & \\
\hline CHEMBL1317244 & 688643 & 5.6 & 5.345 & TRN & \\
\hline CHEMBL1410841 & 688643 & 5.6 & 5.3628 & TST & \\
\hline CHEMBL1551652 & 688643 & 5.4 & 5.2808 & TRN & \\
\hline CHEMBL1512702 & 688643 & 5.2 & 5.5096 & TRN & \\
\hline CHEMBL1512250 & 688643 & 4.5 & 4.4594 & TRN & \\
\hline CHEMBL88147 & 688643 & 5.0 & 4.98 & TST & \\
\hline CHEMBL1356657 & 688643 & 4.6 & 4.4894 & TRN & \\
\hline CHEMBL1553694 & 688643 & 5.2 & 5.1561 & TRN & \\
\hline CHEMBL1397548 & 688643 & 4.6 & 4.4604 & TRN & \\
\hline CHEMBL1343187 & 688643 & 5.5 & 5.4868 & TRN & \\
\hline CHEMBL1442701 & 688643 & 5.8 & 5.8208 & TRN & \\
\hline CHEMBL1437448 & 688643 & 4.9 & 4.8814 & TRN & \\
\hline CHEMBL1256914 & 688643 & 5.5 & 5.5078 & TRN & \\
\hline CHEMBL1357850 & 688643 & 4.9 & 4.8861 & TRN & \\
\hline CHEMBL 88272 & 688643 & 7.0 & 6.7159 & TRN & \\
\hline CHEMBL1552764 & 688643 & 4.8 & 4.955 & TRN & \\
\hline CHEMBL113830 & 688643 & 6.0 & 6.0254 & TRN & \\
\hline CHEMBL1451697 & 688643 & 5.3 & 5.1648 & TRN & \\
\hline CHEMBL1329488 & 688643 & 5.2 & 5.3106 & TST & \\
\hline CHEMBL1354626 & 688643 & 5.6 & 5.6493 & TRN & \\
\hline CHEMBL1335465 & 688643 & 4.9 & 5.1656 & TRN & \\
\hline CHEMBL1487191 & 688643 & 5.1 & 5.0208 & TRN & \\
\hline CHEMBL1565360 & 688643 & 4.6 & 4.67 & TRN & \\
\hline CHEMBL1533335 & 688643 & 4.7 & 4.7062 & TRN & \\
\hline CHEMBL39 & 688643 & 5.0 & 4.955 & TRN & \\
\hline CHEMBL1357491 & 688643 & 4.4 & 4.3867 & TRN & \\
\hline CHEMBL259325 & 688643 & 5.6 & 5.36100 & 0000000001 & TRN \\
\hline CHEMBL14276 & 688643 & 6.6 & 5.0324 & TST & \\
\hline CHEMBL608828 & 688643 & 4.8 & 4.9653 & TRN & \\
\hline CHEMBL1333783 & 688643 & 4.7 & 4.6773 & TRN & \\
\hline CHEMBL244948 & 688643 & 5.1 & 5.1953 & TRN & \\
\hline CHEMBL1409758 & 688643 & 5.0 & 4.8887 & TRN & \\
\hline CHEMBL1486821 & 688643 & 5.2 & 5.3898 & TRN & \\
\hline CHEMBL172064 & 688643 & 5.6 & 5.5675 & TRN & \\
\hline CHEMBL1374363 & 688643 & 5.5 & 5.5528 & TRN & \\
\hline CHEMBL1443628 & 688643 & 5.8 & 5.6298 & TRN & \\
\hline CHEMBL1610944 & 688643 & 4.8 & 5.1721 & TRN & \\
\hline CHEMBL1487371 & 688643 & 5.3 & 5.4472 & TRN & \\
\hline CHEMBL1399897 & 688643 & 4.7 & 5.5451 & TST & \\
\hline CHEMBL1590321 & 688643 & 6.8 & 7.0158 & TRN & \\
\hline CHEMBL3209999 & 688643 & 5.4 & 5.5143 & TRN & \\
\hline CHEMBL1446905 & 688643 & 6.5 & 6.0935 & TRN & \\
\hline CHEMBL1553768 & 688643 & 6.0 & 6.0554 & TRN & \\
\hline CHEMBL1316265 & 688643 & 6.9 & 6.4566 & TRN & \\
\hline & & & & 15813 & \\
\hline
\end{tabular}




\begin{tabular}{|c|c|c|c|c|c|}
\hline \\
\hline CHEMBL1256873 & 688643 & 4.5 & 4.6459 & TST & \\
\hline CHEMBL 275854 & 688643 & 6.0 & 5.9226 & TRN & \\
\hline CHEMBL1473099 & 688643 & 4.8 & 4.7425 & TRN & \\
\hline CHEMBL1484006 & 688643 & 6.0 & 6.1661 & TRN & \\
\hline CHEMBL1411049 & 688643 & 4.7 & 4.7148 & TRN & \\
\hline CHEMBL325238 & 688643 & 7.4001 & 7.086 & TRN & \\
\hline CHEMBL1474151 & 688643 & 4.4 & 4.4836 & TRN & \\
\hline CHEMBL 278041 & 688643 & 6.0 & 5.1932 & TST & \\
\hline CHEMBL446774 & 688643 & 5.2 & 5.2927 & TST & \\
\hline CHEMBL1358115 & 688643 & 5.5 & 5.5877 & TRN & \\
\hline CHEMBL150 & 688643 & 6.0 & 4.9968 & TRN & \\
\hline CHEMBL1356843 & 688643 & 5.2 & 5.0328 & TRN & \\
\hline CHEMBL1520770 & 688643 & 5.5 & 5.3786 & TRN & \\
\hline CHEMBL1450619 & 688643 & 5.6 & 5.4394 & TRN & \\
\hline CHEMBL1554745 & 688643 & 5.1 & 5.2075 & TRN & \\
\hline CHEMBL1356998 & 688643 & 4.8 & 4.865 & TRN & \\
\hline CHEMBL1554654 & 688643 & 6.5 & 6.3844 & TRN & \\
\hline CHEMBL1290409 & 688643 & 5.4 & 5.3952 & TRN & \\
\hline CHEMBL1592364 & 688643 & 4.9 & 5.0164 & TRN & \\
\hline CHEMBL1553325 & 688643 & 6.0 & 6.0453 & TRN & \\
\hline CHEMBL1493037 & 688643 & 4.9 & 5.1882 & TST & \\
\hline CHEMBL1475366 & 688643 & 5.6 & 5.5245 & TRN & \\
\hline CHEMBL1417448 & 688643 & 4.7 & 4.731 & TRN & \\
\hline CHEMBL1454280 & 688643 & 8.1024 & 5.141 & TRN & \\
\hline CHEMBL577635 & 688643 & 5.4 & 5.5517 & TRN & \\
\hline CHEMBL269550 & 688643 & 4.5 & 4.5869 & TRN & \\
\hline CHEMBL118109 & 688643 & 7.6003 & 7.2221 & TRN & \\
\hline CHEMBL1438748 & 688643 & 4.7 & 4.8216 & TRN & \\
\hline CHEMBL1369871 & 688643 & 5.0 & 4.9727 & TRN & \\
\hline CHEMBL1571785 & 688643 & 7.2 & 5.7903 & TRN & \\
\hline CHEMBL1474114 & 688643 & 4.7 & 4.7265 & TRN & \\
\hline CHEMBL1316314 & 688643 & 6.2 & 6.1137 & TRN & \\
\hline CHEMBL250428 & 688643 & 5.3 & 5.2616 & TRN & \\
\hline CHEMBL1553491 & 688643 & 5.2 & 5.07600 & 00000000005 & TRN \\
\hline CHEMBL444309 & 688643 & 5.8 & 5.7901 & TRN & \\
\hline CHEMBL1552635 & 688643 & 4.9 & 4.8891 & TRN & \\
\hline CHEMBL1366699 & 688643 & 4.8 & 4.8022 & TRN & \\
\hline CHEMBL1255662 & 688643 & 4.7 & 4.8395 & TRN & \\
\hline CHEMBL15192 & 688643 & 4.8 & 4.9519 & TST & \\
\hline CHEMBL1330385 & 688643 & 4.9 & 4.8277 & TRN & \\
\hline CHEMBL1486304 & 688643 & 6.0 & 5.86700 & 0000000001 & TRN \\
\hline CHEMBL1398637 & 688643 & 4.9 & 5.0342 & TRN & \\
\hline CHEMBL490744 & 688643 & 4.4 & 4.4163 & TRN & \\
\hline CHEMBL1483789 & 688643 & 5.4 & 5.4871 & TRN & \\
\hline CHEMBL1329940 & 688643 & 5.3 & 5.4035 & TST & \\
\hline CHEMBL1603113 & 688643 & 5.0 & 5.1032 & TRN & \\
\hline CHEMBL1591847 & 688643 & 4.6 & 4.7037 & TRN & \\
\hline CHEMBL1333556 & 688643 & 4.8 & 4.908 & TST & \\
\hline
\end{tabular}




\begin{tabular}{|c|c|c|c|c|c|}
\hline \multicolumn{6}{|c|}{ Supplemental Table S2.txt } \\
\hline CHEMBL1322702 & 688643 & 4.5 & 4.6707 & TRN & \\
\hline CHEMBL1362931 & 688643 & 4.7 & 4.6283 & TRN & \\
\hline CHEMBL389390 & 688643 & 6.0 & 6.0314 & TRN & \\
\hline CHEMBL1256754 & 688643 & 6.3 & 6.2608 & TRN & \\
\hline CHEMBL1527317 & 688643 & 5.5 & 5.4833 & TRN & \\
\hline CHEMBL1554910 & 688643 & 6.3 & 6.3981 & TRN & \\
\hline CHEMBL1317805 & 688643 & 5.1 & 5.0534 & TRN & \\
\hline CHEMBL1530645 & 688643 & 4.4 & 4.4219 & TRN & \\
\hline CHEMBL1610955 & 688643 & 4.9 & 5.0783 & TRN & \\
\hline CHEMBL1327232 & 688643 & 4.7 & 4.7244 & TRN & \\
\hline CHEMBL1362892 & 688643 & 4.9 & 4.8252 & TRN & \\
\hline CHEMBL1456076 & 688643 & 5.1 & 5.079 & TRN & \\
\hline CHEMBL1173475 & 688643 & 6.0 & 4.9342 & TRN & \\
\hline CHEMBL492130 & 688643 & 5.1 & 5.1573 & TRN & \\
\hline CHEMBL1499077 & 688643 & 5.9 & 6.0529 & TRN & \\
\hline CHEMBL1473472 & 688643 & 4.9 & 4.6587 & TRN & \\
\hline CHEMBL1482575 & 688643 & 4.7 & 4.6353 & TRN & \\
\hline CHEMBL1495875 & 688643 & 4.7 & 4.7146 & TRN & \\
\hline CHEMBL1358416 & 688643 & 5.5 & 5.5995 & TRN & \\
\hline CHEMBL1330758 & 688643 & 5.1 & 5.12799 & 9999999999 & TRN \\
\hline CHEMBL491976 & 688643 & 4.9 & 5.04899 & 99999999995 & TRN \\
\hline CHEMBL1515117 & 688643 & 5.7 & 5.6551 & TRN & \\
\hline CHEMBL1591460 & 688643 & 4.9 & 4.8075 & TRN & \\
\hline CHEMBL453019 & 688643 & 7.3002 & 5.3189 & TRN & \\
\hline CHEMBL143324 & 688643 & 4.6 & 5.3055 & TRN & \\
\hline CHEMBL1328292 & 688643 & 5.4 & 5.3838 & TST & \\
\hline CHEMBL1553902 & 688643 & 4.9 & 4.8424 & TRN & \\
\hline CHEMBL1482582 & 688643 & 5.0 & 4.9699 & TRN & \\
\hline CHEMBL1475945 & 688643 & 5.5 & 5.6291 & TRN & \\
\hline CHEMBL1553422 & 688643 & 4.5 & 4.6893 & TRN & \\
\hline CHEMBL1610387 & 688643 & 5.2 & 5.215 & TRN & \\
\hline CHEMBL1591380 & 688643 & 4.7 & $4.6160 e$ & 00000000005 & TRN \\
\hline CHEMBL3212919 & 688643 & 5.6 & 5.6674 & TRN & \\
\hline CHEMBL340807 & 688643 & 6.0 & 5.5254 & TRN & \\
\hline CHEMBL1162107 & 688643 & 5.5 & 5.3904 & TST & \\
\hline CHEMBL1485500 & 688643 & 5.5 & 5.3949 & TRN & \\
\hline CHEMBL103469 & 688643 & 5.0 & 5.0344 & TRN & \\
\hline CHEMBL1557053 & 688643 & 5.5 & 5.5915 & TRN & \\
\hline CHEMBL1410635 & 688643 & 4.5 & 4.5531 & TRN & \\
\hline CHEMBL545050 & 688643 & 8.2007 & 7.636 & TST & \\
\hline CHEMBL1357674 & 688643 & 4.6 & 4.8029 & TST & \\
\hline CHEMBL1450573 & 688643 & 6.2 & 6.1936 & TST & \\
\hline CHEMBL1439401 & 688643 & 4.6 & 4.5991 & TRN & \\
\hline CHEMBL28992 & 688643 & 4.4 & 4.6801 & TRN & \\
\hline CHEMBL1412305 & 688643 & 7.8013 & 7.6481 & TRN & \\
\hline CHEMBL258893 & 688643 & 4.6 & 4.9119 & TRN & \\
\hline CHEMBL1453208 & 688643 & 6.0 & 5.1397 & TRN & \\
\hline CHEMBL1232474 & 688643 & 6.7001 & 6.5018 & TST & \\
\hline
\end{tabular}




\begin{tabular}{|c|c|c|c|c|c|}
\hline & & & & & \\
\hline CHEMBL1494294 & 688643 & 4.4 & 4.742 & TRN & \\
\hline CHEMBL1317163 & 688643 & 5.9 & 5.7421 & TRN & \\
\hline CHEMBL1473116 & 688643 & 6.2 & 6.2364 & TRN & \\
\hline CHEMBL1360310 & 688643 & 4.6 & 4.5354 & TRN & \\
\hline CHEMBL1494218 & 688643 & 5.5 & 5.5742 & TRN & \\
\hline CHEMBL1318316 & 688643 & 5.8 & 5.9957 & TRN & \\
\hline CHEMBL476135 & 688643 & 5.5 & 5.5471 & TST & \\
\hline CHEMBL399491 & 688643 & 5.1 & 5.2266 & TST & \\
\hline CHEMBL1590378 & 688643 & 6.0 & 5.8571 & TRN & \\
\hline CHEMBL1512740 & 688643 & 4.9 & 4.8587 & TRN & \\
\hline CHEMBL1337108 & 688643 & 4.8 & 4.706 & TRN & \\
\hline CHEMBL1479727 & 688643 & 4.9 & 5.0927 & TRN & \\
\hline CHEMBL1314434 & 688643 & 4.6 & 4.5929 & TRN & \\
\hline CHEMBL1528011 & 688643 & 5.3 & 5.5353 & TRN & \\
\hline CHEMBL1591992 & 688643 & 6.2 & 6.4402 & TRN & \\
\hline CHEMBL1486399 & 688643 & 4.4 & 4.3614 & TRN & \\
\hline CHEMBL1406082 & 688643 & 5.0 & 4.9072 & TRN & \\
\hline CHEMBL26320 & 688643 & 6.0 & 6.0957 & TRN & \\
\hline CHEMBL1605152 & 688643 & 5.4 & 5.5336 & TRN & \\
\hline CHEMBL1457332 & 688643 & 5.7 & 5.981 & TRN & \\
\hline CHEMBL1564113 & 688643 & 4.9 & 4.8995 & TRN & \\
\hline CHEMBL1512833 & 688643 & 4.7 & 4.8094 & TRN & \\
\hline CHEMBL1365934 & 688643 & 5.2 & 5.2113 & TRN & \\
\hline CHEMBL1592803 & 688643 & 5.6 & 5.6487 & TRN & \\
\hline CHEMBL1527565 & 688643 & 5.4 & 5.1408 & TST & \\
\hline CHEMBL1448542 & 688643 & 6.6 & 6.1049 & TRN & \\
\hline CHEMBL258465 & 688643 & 5.7 & 5.6438 & TRN & \\
\hline CHEMBL45068 & 688643 & 6.0 & 4.5711 & TST & \\
\hline CHEMBL1515410 & 688643 & 4.4 & 4.55399 & 7999999999 & TRN \\
\hline CHEMBL1476850 & 688643 & 5.1 & 5.42299 & 9999999999 & TRN \\
\hline CHEMBL1599118 & 688643 & 5.0 & 4.7716 & TRN & \\
\hline CHEMBL1318766 & 688643 & 5.4 & 5.4455 & TST & \\
\hline CHEMBL1496125 & 688643 & 5.5 & 5.4947 & TRN & \\
\hline CHEMBL1613623 & 688643 & 6.0 & 5.2397 & TRN & \\
\hline CHEMBL 241862 & 688643 & 5.5 & 4.8821 & TRN & \\
\hline CHEMBL1363568 & 688643 & 4.7 & 4.7478 & TRN & \\
\hline CHEMBL305881 & 688643 & 6.0 & 5.8728 & TRN & \\
\hline CHEMBL1514779 & 688643 & 5.0 & 5.0056 & TRN & \\
\hline CHEMBL1403623 & 688643 & 4.5 & 7.2116 & TRN & \\
\hline CHEMBL1593432 & 688643 & 5.0 & 5.0471 & TRN & \\
\hline CHEMBL1475541 & 688643 & 4.6 & 4.6168 & TRN & \\
\hline CHEMBL1494099 & 688643 & 6.3 & 6.4509 & TRN & \\
\hline CHEMBL1477964 & 688643 & 4.7 & 4.643 & TRN & \\
\hline CHEMBL39947 & 688643 & 6.0 & 6.6078 & TRN & \\
\hline CHEMBL1594421 & 688643 & 4.4 & 4.4137 & TRN & \\
\hline CHEMBL 3436365 & 688643 & 5.5 & 5.6078 & TRN & \\
\hline CHEMBL1316075 & 688643 & 4.4 & 4.4601 & TRN & \\
\hline CHEMBL8618 & 688643 & 6.0 & 5.8572 & TRN & \\
\hline
\end{tabular}




\begin{tabular}{|c|c|c|c|c|c|}
\hline \multicolumn{6}{|c|}{ Supplemental Table S2.txt } \\
\hline CHEMBL1515221 & 688643 & 4.9 & 4.9567 & TRN & \\
\hline CHEMBL 7162 & 688643 & 7.3002 & 6.7534 & TST & \\
\hline CHEMBL1317998 & 688643 & 5.0 & 5.1452 & TRN & \\
\hline CHEMBL1433551 & 688643 & 5.5 & 5.6161 & TRN & \\
\hline CHEMBL1553114 & 688643 & 4.8 & 4.7395 & TRN & \\
\hline CHEMBL540848 & 688643 & 6.0 & 5.8561 & TRN & \\
\hline CHEMBL1554664 & 688643 & 5.0 & 4.9419 & TRN & \\
\hline CHEMBL425403 & 688643 & 5.8 & 5.8216 & TST & \\
\hline CHEMBL64119 & 688643 & 5.1 & 5.2264 & TST & \\
\hline CHEMBL287689 & 688643 & 5.6 & 5.5599 & TST & \\
\hline CHEMBL39317 & 688643 & 6.9 & 6.5381 & TRN & \\
\hline CHEMBL1451224 & 688643 & 5.8 & 6.0092 & TRN & \\
\hline CHEMBL1404907 & 688643 & 4.5 & 4.5957 & TRN & \\
\hline CHEMBL 72365 & 688643 & 4.4 & 5.4037 & TRN & \\
\hline CHEMBL1397257 & 688643 & 5.6 & 5.393 & TRN & \\
\hline CHEMBL1480779 & 688643 & 7.6003 & 7.5836 & TRN & \\
\hline CHEMBL1483427 & 688643 & 4.6 & 4.5174 & TRN & \\
\hline CHEMBL1610228 & 688643 & 5.2 & 5.1233 & TRN & \\
\hline CHEMBL598263 & 688643 & 6.0 & 5.9057 & TRN & \\
\hline CHEMBL1408427 & 688643 & 4.6 & 4.6659 & TRN & \\
\hline CHEMBL1436979 & 688643 & 5.4 & 5.6575 & TRN & \\
\hline CHEMBL1433486 & 688643 & 6.0 & 6.1367 & TRN & \\
\hline CHEMBL1396975 & 688643 & 4.9 & 4.8706 & TRN & \\
\hline CHEMBL1365994 & 688643 & 4.4 & $4.4030 e$ & 00000000005 & TRN \\
\hline CHEMBL1474317 & 688643 & 5.2 & 5.0139 & TRN & \\
\hline CHEMBL1491104 & 688643 & 4.4 & 4.3952 & TRN & \\
\hline CHEMBL1607443 & 688643 & 6.1 & 5.8476 & TRN & \\
\hline CHEMBL1316897 & 688643 & 5.1 & 5.1284 & TRN & \\
\hline CHEMBL1439866 & 688643 & 4.8 & 4.9931 & TST & \\
\hline CHEMBL1413371 & 688643 & 4.6 & 4.7896 & TRN & \\
\hline CHEMBL1529496 & 688643 & 5.1 & 5.2451 & TRN & \\
\hline CHEMBL1591573 & 688643 & 4.7 & 4.6711 & TRN & \\
\hline CHEMBL1558834 & 688643 & 5.0 & 4.9778 & TRN & \\
\hline CHEMBL1485000 & 688643 & 6.2 & 6.2595 & TRN & \\
\hline CHEMBL1316956 & 688643 & 5.9 & 5.9252 & TRN & \\
\hline CHEMBL1516622 & 688643 & 5.6 & 5.7222 & TRN & \\
\hline CHEMBL1450926 & 688643 & 5.0 & 5.0068 & TRN & \\
\hline CHEMBL 2374062 & 688643 & 4.7 & 4.8632 & TST & \\
\hline CHEMBL 1255837 & 688643 & 6.0 & 5.1929 & TRN & \\
\hline CHEMBL1440842 & 688643 & 5.5 & 5.5683 & TRN & \\
\hline CHEMBL1555396 & 688643 & 4.7 & 4.6343 & TRN & \\
\hline CHEMBL3211338 & 688643 & 5.4 & 5.4093 & TRN & \\
\hline CHEMBL188641 & 688643 & 5.8 & 5.7045 & TST & \\
\hline CHEMBL1453216 & 688643 & 5.3 & 5.1824 & TRN & \\
\hline CHEMBL1533121 & 688643 & 4.4 & 5.0993 & TRN & \\
\hline CHEMBL1591170 & 688643 & 7.2 & 7.3661 & TRN & \\
\hline CHEMBL1374696 & 688643 & 6.0 & 5.8106 & TRN & \\
\hline CHEMBL1437990 & 688643 & 5.4 & 5.5779 & TRN & \\
\hline
\end{tabular}




\begin{tabular}{|c|c|c|c|c|c|}
\hline \multirow[b]{2}{*}{ CHEMBL1626274 } & \multirow{2}{*}{688643} & \\
\hline & & 6.0 & 5.9307 & TRN & \\
\hline CHEMBL1368632 & 688643 & 6.2 & \multicolumn{2}{|c|}{5.912000000000001} & TRN \\
\hline CHEMBL1408735 & 688643 & 4.9 & 4.8042 & TRN & \\
\hline CHEMBL1370480 & 688643 & 5.8 & 6.0234 & TRN & \\
\hline CHEMBL1435544 & 688643 & 4.9 & 5.0593 & TRN & \\
\hline CHEMBL1320565 & 688643 & 4.5 & 4.5 & TRN & \\
\hline CHEMBL1515815 & 688643 & 5.9 & 6.1059 & TRN & \\
\hline CHEMBL1317461 & 688643 & 6.2 & 5.9794 & TRN & \\
\hline CHEMBL1256866 & 688643 & 4.5 & 4.796 & TRN & \\
\hline CHEMBL1323759 & 688643 & 4.6 & 4.4925 & TRN & \\
\hline CHEMBL1337419 & 688643 & 5.5 & \multicolumn{2}{|c|}{5.497000000000001} & TST \\
\hline CHEMBL1397406 & 688643 & 4.7 & 4.6595 & TRN & \\
\hline CHEMBL1554826 & 688643 & 4.6 & 4.621 & TRN & \\
\hline CHEMBL1461491 & 688643 & 6.0 & 5.982 & TRN & \\
\hline CHEMBL1435276 & 688643 & 5.0 & 5.2442 & TRN & \\
\hline CHEMBL1405627 & 688643 & 4.8 & 4.7232 & TRN & \\
\hline CHEMBL1558843 & 688643 & 6.3 & 6.2685 & TRN & \\
\hline CHEMBL1596499 & 688643 & 4.6 & 4.5996 & TRN & \\
\hline CHEMBL1591903 & 688643 & 5.4 & 5.524 & TRN & \\
\hline CHEMBL1395278 & 688643 & 5.6 & 5.6191 & TRN & \\
\hline CHEMBL1590391 & 688643 & 5.1 & 5.5517 & TST & \\
\hline CHEMBL336467 & 688643 & 4.4 & 4.6077 & TST & \\
\hline CHEMBL1448005 & 688643 & 5.4 & 5.5049 & TRN & \\
\hline CHEMBL1396936 & 688643 & 4.7 & 4.6382 & TRN & \\
\hline CHEMBL1358731 & 688643 & 4.4 & 4.9915 & TRN & \\
\hline CHEMBL1528648 & 688643 & 4.5 & 4.7781 & TRN & \\
\hline CHEMBL1323355 & 688643 & 7.2 & 7.53 & TRN & \\
\hline CHEMBL1492229 & 688643 & 4.8 & 4.7322 & TRN & \\
\hline CHEMBL1605605 & 688643 & 4.8 & 4.8941 & TST & \\
\hline CHEMBL1555122 & 688643 & 4.9 & 4.7422 & TRN & \\
\hline CHEMBL1593019 & 688643 & 5.0 & 4.9674 & TRN & \\
\hline CHEMBL1595872 & 688643 & 5.5 & 5.5311 & TST & \\
\hline CHEMBL1611496 & 688643 & 5.0 & 5.0438 & TRN & \\
\hline CHEMBL1356113 & 688643 & 5.4 & 5.4314 & TRN & \\
\hline CHEMBL1324530 & 688643 & 4.4 & 4.4822 & TRN & \\
\hline CHEMBL491547 & 688643 & 5.0 & 4.8829 & TRN & \\
\hline CHEMBL1322050 & 688643 & 5.8 & 5.7613 & TRN & \\
\hline CHEMBL541543 & 688643 & 6.2 & 6.0457 & TST & \\
\hline CHEMBL1530982 & 688643 & 4.7 & 4.6078 & TRN & \\
\hline CHEMBL 28140 & 688643 & 6.0 & 5.8819 & TRN & \\
\hline CHEMBL274438 & 688643 & 4.4 & 4.4505 & TRN & \\
\hline CHEMBL1448712 & 688643 & 5.6 & 5.3742 & TRN & \\
\hline CHEMBL1399922 & 688643 & 4.8 & 4.9727 & TRN & \\
\hline CHEMBL1609160 & 688643 & 5.6 & 5.70299 & 9999999999 & TRN \\
\hline CHEMBL1405922 & 688643 & 6.8 & 6.5937 & TRN & \\
\hline CHEMBL316611 & 688643 & 5.7 & 5.5602 & TRN & \\
\hline CHEMBL1370526 & 688643 & 6.7001 & 6.8179 & TRN & \\
\hline CHEMBL1314906 & 688643 & 4.7 & 4.5704 & TRN & \\
\hline & & & & 15818 & \\
\hline
\end{tabular}




\begin{tabular}{|c|c|c|c|c|c|}
\hline \multirow[b]{2}{*}{ CHEMBL1493039 } & \multirow[b]{2}{*}{688643} & \\
\hline & & 5.6 & 5.5061 & TST & \\
\hline CHEMBL289277 & 688643 & 6.0 & 5.3853 & TST & \\
\hline CHEMBL1256186 & 688643 & 4.6 & 4.7995 & TST & \\
\hline CHEMBL1566458 & 688643 & 5.5 & 5.3068 & TRN & \\
\hline CHEMBL242948 & 688643 & 4.5 & \multicolumn{2}{|c|}{5.3870000000000005} & TST \\
\hline CHEMBL1395412 & 688643 & 4.5 & 4.9312 & TST & \\
\hline CHEMBL1356348 & 688643 & 5.3 & 5.3041 & TST & \\
\hline CHEMBL1485629 & 688643 & 4.5 & 4.5824 & TST & \\
\hline CHEMBL208484 & 688643 & 5.0 & \multicolumn{2}{|c|}{5.3020000000000005} & TRN \\
\hline CHEMBL1553662 & 688643 & 6.0 & 6.0739 & TRN & \\
\hline CHEMBL1476407 & 688643 & 5.1 & 5.1399 & TRN & \\
\hline CHEMBL1400637 & 688643 & 4.6 & 4.9188 & TRN & \\
\hline CHEMBL1473190 & 688643 & 7.1002 & 5.3744 & TST & \\
\hline CHEMBL476833 & 688643 & 4.9 & 5.1645 & TST & \\
\hline CHEMBL1435086 & 688643 & 4.6 & 4.6937 & TRN & \\
\hline CHEMBL1256709 & 688643 & 6.0 & 6.107 & TRN & \\
\hline CHEMBL1315991 & 688643 & 4.4 & 4.4865 & TRN & \\
\hline CHEMBL1567098 & 688643 & 5.4 & \multicolumn{2}{|c|}{5.486000000000001} & TRN \\
\hline CHEMBL1399058 & 688643 & 6.3 & 5.9647 & TRN & \\
\hline CHEMBL1473753 & 688643 & 5.1 & 5.0236 & TRN & \\
\hline CHEMBL1571410 & 688643 & 5.5 & 5.5832 & TRN & \\
\hline CHEMBL1553173 & 688643 & 4.4 & 4.4803 & TRN & \\
\hline CHEMBL1373723 & 688643 & 5.1 & 5.0226 & TRN & \\
\hline CHEMBL1328708 & 688643 & 4.8 & 5.6795 & TST & \\
\hline CHEMBL1357231 & 688643 & 4.8 & 4.7972 & TRN & \\
\hline CHEMBL1396862 & 688643 & 6.0 & 6.2374 & TRN & \\
\hline CHEMBL1255749 & 688643 & 4.5 & 4.7164 & TST & \\
\hline CHEMBL1515706 & 688643 & 5.5 & 5.5621 & TRN & \\
\hline CHEMBL1435254 & 688643 & 4.4 & 4.4011 & TRN & \\
\hline CHEMBL1336469 & 688643 & 5.0 & 5.2575 & TRN & \\
\hline CHEMBL1592500 & 688643 & 6.0 & 5.5435 & TRN & \\
\hline CHEMBL1490268 & 688643 & 4.4 & 4.4671 & TRN & \\
\hline CHEMBL565856 & 688643 & 6.3 & 6.1397 & TRN & \\
\hline CHEMBL1598394 & 688643 & 4.4 & 4.331 & TRN & \\
\hline CHEMBL1365665 & 688643 & 5.2 & 5.3163 & TRN & \\
\hline CHEMBL1437690 & 688643 & 4.5 & 4.5962 & TRN & \\
\hline CHEMBL1364182 & 688643 & 4.7 & 4.6419 & TRN & \\
\hline CHEMBL1564194 & 688643 & 4.9 & 4.9394 & TRN & \\
\hline CHEMBL1397782 & 688643 & 4.6 & 4.6051 & TRN & \\
\hline CHEMBL541847 & 688643 & 5.2 & 5.1512 & TRN & \\
\hline CHEMBL1476430 & 688643 & 4.9 & 4.7799 & TRN & \\
\hline CHEMBL1396010 & 688643 & 4.6 & 3.9438 & TRN & \\
\hline CHEMBL1593443 & 688643 & 7.3002 & 7.4068 & TRN & \\
\hline CHEMBL490913 & 688643 & 4.7 & 4.63899 & 9999999999 & TRN \\
\hline CHEMBL1593827 & 688643 & 5.4 & 5.3457 & TRN & \\
\hline CHEMBL1449575 & 688643 & 5.0 & 5.007 & TRN & \\
\hline CHEMBL277525 & 688643 & 5.2 & 5.1348 & TRN & \\
\hline \multirow[t]{2}{*}{ CHEMBL406835 } & 688643 & 4.7 & 5.1958 & TRN & \\
\hline & & \multicolumn{4}{|c|}{ Page 15819} \\
\hline
\end{tabular}




\begin{tabular}{|c|c|c|c|c|c|}
\hline \multicolumn{6}{|c|}{ Supplemental Table S2.txt } \\
\hline CHEMBL24983 & 688643 & 4.5 & 4.6884 & TST & \\
\hline CHEMBL45281 & 688643 & 5.8 & 5.6485 & TST & \\
\hline CHEMBL1410075 & 688643 & 5.6 & 5.7362 & TRN & \\
\hline CHEMBL 398673 & 688643 & 6.0 & 5.8043 & TST & \\
\hline CHEMBL1591190 & 688643 & 4.9 & 4.8611 & TRN & \\
\hline CHEMBL1473405 & 688643 & 4.9 & 4.9358 & TRN & \\
\hline CHEMBL1256835 & 688643 & 6.0 & 5.9906 & TRN & \\
\hline CHEMBL1603884 & 688643 & 5.4 & 5.3465 & TRN & \\
\hline CHEMBL1445946 & 688643 & 5.5 & 5.1719 & TRN & \\
\hline CHEMBL1332463 & 688643 & 4.9 & 4.897 & TRN & \\
\hline CHEMBL1318310 & 688643 & 5.0 & 5.17 & TRN & \\
\hline CHEMBL1595371 & 688643 & 6.2 & 6.0496 & TRN & \\
\hline CHEMBL1441222 & 688643 & 5.5 & 5.5483 & TRN & \\
\hline CHEMBL1256885 & 688643 & 6.0 & 6.0187 & TRN & \\
\hline CHEMBL1476334 & 688643 & 4.5 & 4.6406 & TRN & \\
\hline CHEMBL1478504 & 688643 & 5.9 & 5.9231 & TRN & \\
\hline CHEMBL1398137 & 688643 & 4.6 & 4.6229 & TRN & \\
\hline CHEMBL1604135 & 688643 & 5.6 & 5.3332 & TST & \\
\hline CHEMBL1408703 & 688643 & 4.4 & 4.4429 & TRN & \\
\hline CHEMBL1513654 & 688643 & 7.2 & 6.9858 & TRN & \\
\hline CHEMBL24909 & 688643 & 4.4 & 4.6518 & TRN & \\
\hline CHEMBL463783 & 688643 & 5.4 & 5.4157 & TRN & \\
\hline CHEMBL323197 & 688643 & 4.5 & 5.2724 & TRN & \\
\hline CHEMBL1561927 & 688643 & 5.4 & 5.2885 & TST & \\
\hline CHEMBL1256390 & 688643 & 5.7 & 5.55200 & 00000000005 & TRN \\
\hline CHEMBL1552194 & 688643 & 4.4 & 4.3338 & TRN & \\
\hline CHEMBL1438690 & 688643 & 5.4 & 5.4568 & TRN & \\
\hline CHEMBL1482184 & 688643 & 6.0 & 5.9115 & TST & \\
\hline CHEMBL388342 & 688643 & 6.0 & 5.7878 & TRN & \\
\hline CHEMBL22870 & 688643 & 4.4 & 5.4452 & TRN & \\
\hline CHEMBL1480853 & 688643 & 5.4 & 5.4465 & TRN & \\
\hline CHEMBL1367656 & 688643 & 5.4 & 5.5894 & TRN & \\
\hline CHEMBL1414232 & 688643 & 5.5 & 5.6469 & TRN & \\
\hline CHEMBL1474568 & 688643 & 4.9 & 4.9293 & TRN & \\
\hline CHEMBL1393664 & 688643 & 6.2 & 6.1533 & TRN & \\
\hline CHEMBL1319093 & 688643 & 4.9 & 4.8759 & TRN & \\
\hline CHEMBL1478249 & 688643 & 5.5 & 5.5607 & TRN & \\
\hline CHEMBL1612346 & 688643 & 6.2 & 6.0745 & TRN & \\
\hline CHEMBL536803 & 688643 & 4.5 & 4.703 & TRN & \\
\hline CHEMBL1559126 & 688643 & 4.7 & 4.6548 & TRN & \\
\hline CHEMBL1446522 & 688643 & 5.4 & 5.23799 & 99999999995 & TST \\
\hline CHEMBL375270 & 688643 & 5.0 & 4.9545 & TST & \\
\hline CHEMBL1315292 & 688643 & 4.4 & 4.4225 & TRN & \\
\hline CHEMBL1437831 & 688643 & 4.5 & 4.7609 & TST & \\
\hline CHEMBL1567238 & 688643 & 5.6 & 5.4717 & TRN & \\
\hline CHEMBL1593796 & 688643 & 5.6 & 5.6934 & TRN & \\
\hline CHEMBL1597474 & 688643 & 4.6 & 4.6378 & TRN & \\
\hline CHEMBL1592760 & 688643 & 4.8 & 4.7931 & TRN & \\
\hline
\end{tabular}




\begin{tabular}{|c|c|c|c|c|c|}
\hline & & & & & \\
\hline CHEMBL1317633 & 688643 & 4.4 & 5.39 & TST & \\
\hline CHEMBL1591876 & 688643 & 5.2 & 5.055 & TRN & \\
\hline CHEMBL1520907 & 688643 & 7.4001 & 5.3625 & TST & \\
\hline CHEMBL1590173 & 688643 & 5.7 & 5.5547 & TRN & \\
\hline CHEMBL1393947 & 688643 & 5.3 & 5.2821 & TRN & \\
\hline CHEMBL1573058 & 688643 & 4.9 & 4.79899 & 99999999995 & TRN \\
\hline CHEMBL1318480 & 688643 & 4.8 & 5.2286 & TRN & \\
\hline CHEMBL1356842 & 688643 & 5.3 & 5.2026 & TRN & \\
\hline CHEMBL1522752 & 688643 & 5.5 & 5.1913 & TST & \\
\hline CHEMBL1434848 & 688643 & 4.4 & 4.5431 & TRN & \\
\hline CHEMBL1358122 & 688643 & 4.8 & 4.7237 & TRN & \\
\hline CHEMBL1357968 & 688643 & 4.7 & 4.6184 & TRN & \\
\hline CHEMBL1433762 & 688643 & 5.7 & 5.7335 & TRN & \\
\hline CHEMBL1354190 & 688643 & 5.3 & 5.3946 & TST & \\
\hline CHEMBL 225230 & 688643 & 5.0 & 4.9049 & TRN & \\
\hline CHEMBL1369212 & 688643 & 6.0 & 6.11799 & 9999999999 & TRN \\
\hline CHEMBL1399394 & 688643 & 4.7 & 4.618 & TRN & \\
\hline CHEMBL1475028 & 688643 & 5.4 & 5.3367 & TRN & \\
\hline CHEMBL1523314 & 688643 & 5.9 & 6.1704 & TRN & \\
\hline CHEMBL1476303 & 688643 & 4.9 & 4.9129 & TRN & \\
\hline CHEMBL26318 & 688643 & 5.0 & 5.3548 & TST & \\
\hline CHEMBL287327 & 688643 & 4.9 & 4.8962 & TST & \\
\hline CHEMBL1590031 & 688643 & 5.5 & 5.4983 & TST & \\
\hline CHEMBL428784 & 688643 & 5.1 & 5.1051 & TST & \\
\hline CHEMBL1316461 & 688643 & 5.6 & 6.0457 & TRN & \\
\hline CHEMBL1688558 & 688643 & 6.5 & 6.3249 & TRN & \\
\hline CHEMBL1434954 & 688643 & 5.5 & 5.4147 & TST & \\
\hline CHEMBL1592289 & 688643 & 4.9 & 4.9652 & TRN & \\
\hline CHEMBL1448228 & 688643 & 5.5 & 5.4695 & TST & \\
\hline CHEMBL491742 & 688643 & 4.6 & 4.552 & TRN & \\
\hline CHEMBL1377507 & 688643 & 6.8 & 6.2232 & TST & \\
\hline CHEMBL1256911 & 688643 & 4.6 & 4.7686 & TRN & \\
\hline CHEMBL1592982 & 688643 & 5.6 & 5.6617 & TRN & \\
\hline CHEMBL3392050 & 688643 & 4.6 & 4.5043 & TST & \\
\hline CHEMBL22075 & 688643 & 6.6 & 6.5621 & TRN & \\
\hline CHEMBL1525180 & 688643 & 5.0 & 5.0275 & TRN & \\
\hline CHEMBL491909 & 688643 & 4.9 & 4.8866 & TRN & \\
\hline CHEMBL1554278 & 688643 & 5.5 & 5.6204 & TST & \\
\hline CHEMBL1320619 & 688643 & 5.9 & 5.85 & TRN & \\
\hline CHEMBL1358628 & 688643 & 6.0 & 5.9291 & TRN & \\
\hline CHEMBL115225 & 688643 & 7.0 & 6.7625 & TRN & \\
\hline CHEMBL 1257002 & 688643 & 6.0 & 5.9499 & TST & \\
\hline CHEMBL1437159 & 688643 & 4.4 & 4.521 & TRN & \\
\hline CHEMBL 74121 & 688643 & 6.0 & 5.7482 & TST & \\
\hline CHEMBL1256663 & 688643 & 5.9 & 5.9252 & TRN & \\
\hline CHEMBL611207 & 688643 & 7.0 & 7.2265 & TRN & \\
\hline CHEMBL1603322 & 688643 & 4.8 & 4.9161 & TRN & \\
\hline CHEMBL1358796 & 688643 & 6.3 & 6.3116 & TRN & \\
\hline & & & & 15821 & \\
\hline
\end{tabular}




\begin{tabular}{|c|c|c|c|c|}
\hline \multicolumn{5}{|c|}{ Supplemental Table S2.txt } \\
\hline CHEMBL1594134 & 688643 & 4.9 & 4.9567 & TRN \\
\hline CHEMBL1368572 & 688643 & 5.4 & 5.4478 & TRN \\
\hline CHEMBL1368474 & 688643 & 5.0 & 5.0088 & TRN \\
\hline CHEMBL1356346 & 688643 & 4.5 & 4.8584 & TRN \\
\hline CHEMBL1335409 & 688643 & 5.3 & 5.3715 & TST \\
\hline CHEMBL1563147 & 688643 & 5.4 & 5.3025 & TRN \\
\hline CHEMBL1551518 & 688643 & 4.7 & 4.7439 & TRN \\
\hline CHEMBL1436532 & 688643 & 6.0 & 5.6853 & TRN \\
\hline CHEMBL1407527 & 688643 & 4.6 & 4.6593 & TRN \\
\hline CHEMBL1321624 & 688643 & 4.4 & 5.3724 & TST \\
\hline CHEMBL1554717 & 688643 & 4.8 & 4.981 & TRN \\
\hline CHEMBL1528848 & 688643 & 8.3979 & 5.5522 & TRN \\
\hline CHEMBL1397636 & 688643 & 4.6 & 4.5998 & TRN \\
\hline CHEMBL1480687 & 688643 & 5.2 & 5.1383 & TRN \\
\hline CHEMBL428814 & 688643 & 4.7 & 4.7376 & TRN \\
\hline CHEMBL1592213 & 688643 & 4.5 & 4.5676 & TRN \\
\hline CHEMBL1359713 & 688643 & 5.3 & 5.6535 & TST \\
\hline CHEMBL1529009 & 688643 & 4.9 & 4.9911 & TRN \\
\hline CHEMBL1403793 & 688643 & 6.6 & 6.2704 & TRN \\
\hline CHEMBL1606990 & 688643 & 6.4 & 6.105 & TRN \\
\hline CHEMBL 258405 & 688643 & 4.7 & 4.8373 & TST \\
\hline CHEMBL332898 & 688643 & 5.7 & 5.5206 & TRN \\
\hline CHEMBL1447149 & 688643 & 5.5 & 5.3813 & TRN \\
\hline CHEMBL1317748 & 688643 & 7.0 & 7.2257 & TRN \\
\hline CHEMBL1512708 & 688643 & 5.8 & 5.7122 & TRN \\
\hline CHEMBL1398138 & 688643 & 6.7001 & 6.6693 & TST \\
\hline CHEMBL1517999 & 688643 & 6.8 & 6.9576 & TRN \\
\hline CHEMBL140 & 688643 & 4.8 & 4.955 & TRN \\
\hline CHEMBL491952 & 688643 & 4.4 & 4.4319 & TRN \\
\hline CHEMBL1243269 & 688643 & 6.0 & 5.966 & TRN \\
\hline CHEMBL1256392 & 688643 & 4.5 & 4.7034 & TRN \\
\hline CHEMBL 265698 & 688643 & 5.5 & 5.1522 & TRN \\
\hline CHEMBL1322216 & 688643 & 4.6 & 4.5594 & TRN \\
\hline CHEMBL1369140 & 688643 & 5.3 & 5.271 & TST \\
\hline CHEMBL1552403 & 688643 & 5.4 & 5.5227 & TST \\
\hline CHEMBL1514149 & 688643 & 5.0 & 4.9074 & TRN \\
\hline CHEMBL1446112 & 688643 & 4.5 & 4.516 & TRN \\
\hline CHEMBL38576 & 688643 & 7.8996 & 7.2733 & TRN \\
\hline CHEMBL1574966 & 688643 & 6.0 & 5.8768 & TRN \\
\hline CHEMBL1499 & 688643 & 4.5 & 5.4382 & TST \\
\hline CHEMBL1590508 & 688643 & 5.8 & 5.7805 & TRN \\
\hline CHEMBL447507 & 688643 & 4.9 & 4.7587 & TRN \\
\hline CHEMBL1397596 & 688643 & 5.3 & 5.3778 & TRN \\
\hline CHEMBL1604036 & 688643 & 6.2 & 6.0345 & TST \\
\hline CHEMBL1365609 & 688643 & 4.7 & 4.7907 & TRN \\
\hline CHEMBL1318786 & 688643 & 5.7 & 5.7195 & TRN \\
\hline CHEMBL1554612 & 688643 & 5.5 & 5.4855 & TST \\
\hline CHEMBL1356060 & 688643 & 5.6 & 5.5627 & TRN \\
\hline
\end{tabular}




\begin{tabular}{|c|c|c|c|c|c|}
\hline & & & & & \\
\hline CHEMBL2009961 & 688643 & 5.8 & 5.7846 & TST & \\
\hline CHEMBL429095 & 688643 & 6.0 & 4.6805 & TST & \\
\hline CHEMBL50267 & 688643 & 4.9 & 5.1932 & TST & \\
\hline CHEMBL1343047 & 688643 & 5.9 & 5.1721 & TRN & \\
\hline CHEMBL1328389 & 688643 & 6.9 & 6.6306 & TRN & \\
\hline CHEMBL1331786 & 688643 & 6.0 & 5.9117 & TRN & \\
\hline CHEMBL1490172 & 688643 & 5.2 & 5.2208 & TST & \\
\hline CHEMBL1320469 & 688643 & 4.4 & 4.3955 & TRN & \\
\hline CHEMBL1436045 & 688643 & 4.9 & 5.0447 & TRN & \\
\hline CHEMBL1433485 & 688643 & 5.4 & 5.4977 & TRN & \\
\hline CHEMBL1513633 & 688643 & 4.9 & 4.796 & TRN & \\
\hline CHEMBL523167 & 688643 & 4.6 & 4.8879 & TRN & \\
\hline CHEMBL598270 & 688643 & 6.5 & 6.3308 & TST & \\
\hline CHEMBL1304918 & 688643 & 5.5 & 5.4112 & TST & \\
\hline CHEMBL1451057 & 688643 & 5.4 & 5.4446 & TRN & \\
\hline CHEMBL1314545 & 688643 & 4.9 & 4.9647 & TST & \\
\hline CHEMBL1553139 & 688643 & 5.4 & 5.1358 & TRN & \\
\hline CHEMBL1406274 & 688643 & 5.6 & 5.5859 & TRN & \\
\hline CHEMBL1321338 & 688643 & 5.4 & 5.2782 & TRN & \\
\hline CHEMBL1255866 & 688643 & 4.6 & 4.8503 & TRN & \\
\hline CHEMBL1559860 & 688643 & 7.0 & 6.6478 & TRN & \\
\hline CHEMBL1488990 & 688643 & 4.7 & 4.6412 & TRN & \\
\hline CHEMBL90882 & 688643 & 7.4001 & 6.9085 & TRN & \\
\hline CHEMBL1440487 & 688643 & 4.8 & 4.9465 & TRN & \\
\hline CHEMBL1528605 & 688643 & 5.1 & 5.3083 & TST & \\
\hline CHEMBL1516468 & 688643 & 5.4 & 5.4316 & TRN & \\
\hline CHEMBL 277362 & 688643 & 4.4 & 4.63899 & 9999999999 & TRN \\
\hline CHEMBL1553530 & 688643 & 5.2 & 5.107 & TRN & \\
\hline CHEMBL1514719 & 688643 & 4.6 & 4.59699 & 99999999995 & TRN \\
\hline CHEMBL1435934 & 688643 & 5.5 & 5.5506 & TRN & \\
\hline CHEMBL1551777 & 688643 & 4.9 & 4.7467 & TRN & \\
\hline CHEMBL1200938 & 688643 & 6.0 & 5.9936 & TRN & \\
\hline CHEMBL1256998 & 688643 & 5.9 & 5.8179 & TRN & \\
\hline CHEMBL1439400 & 688643 & 5.1 & 5.3062 & TRN & \\
\hline CHEMBL1370426 & 688643 & 6.5 & 5.459 & TST & \\
\hline CHEMBL1474241 & 688643 & 5.6 & 5.9212 & TRN & \\
\hline CHEMBL1437171 & 688643 & 5.5 & 5.5059 & TST & \\
\hline CHEMBL1479741 & 688643 & 6.0 & 5.8841 & TRN & \\
\hline CHEMBL1357089 & 688643 & 6.5 & 7.0097 & TRN & \\
\hline CHEMBL1437325 & 688643 & 4.9 & 4.7452 & TRN & \\
\hline CHEMBL1533214 & 688643 & 4.6 & 5.0938 & TRN & \\
\hline CHEMBL1394113 & 688643 & 4.9 & 4.9618 & TRN & \\
\hline CHEMBL1332929 & 688643 & 4.6 & 4.6437 & TRN & \\
\hline CHEMBL1605496 & 688643 & 5.5 & 5.2208 & TRN & \\
\hline CHEMBL1566044 & 688643 & 5.5 & 5.5098 & TRN & \\
\hline CHEMBL1320820 & 688643 & 5.0 & 4.8593 & TRN & \\
\hline CHEMBL 304008 & 688643 & 5.6 & 5.5812 & TST & \\
\hline CHEMBL1364611 & 688643 & 4.8 & 4.6451 & TRN & \\
\hline & & & & 15823 & \\
\hline
\end{tabular}




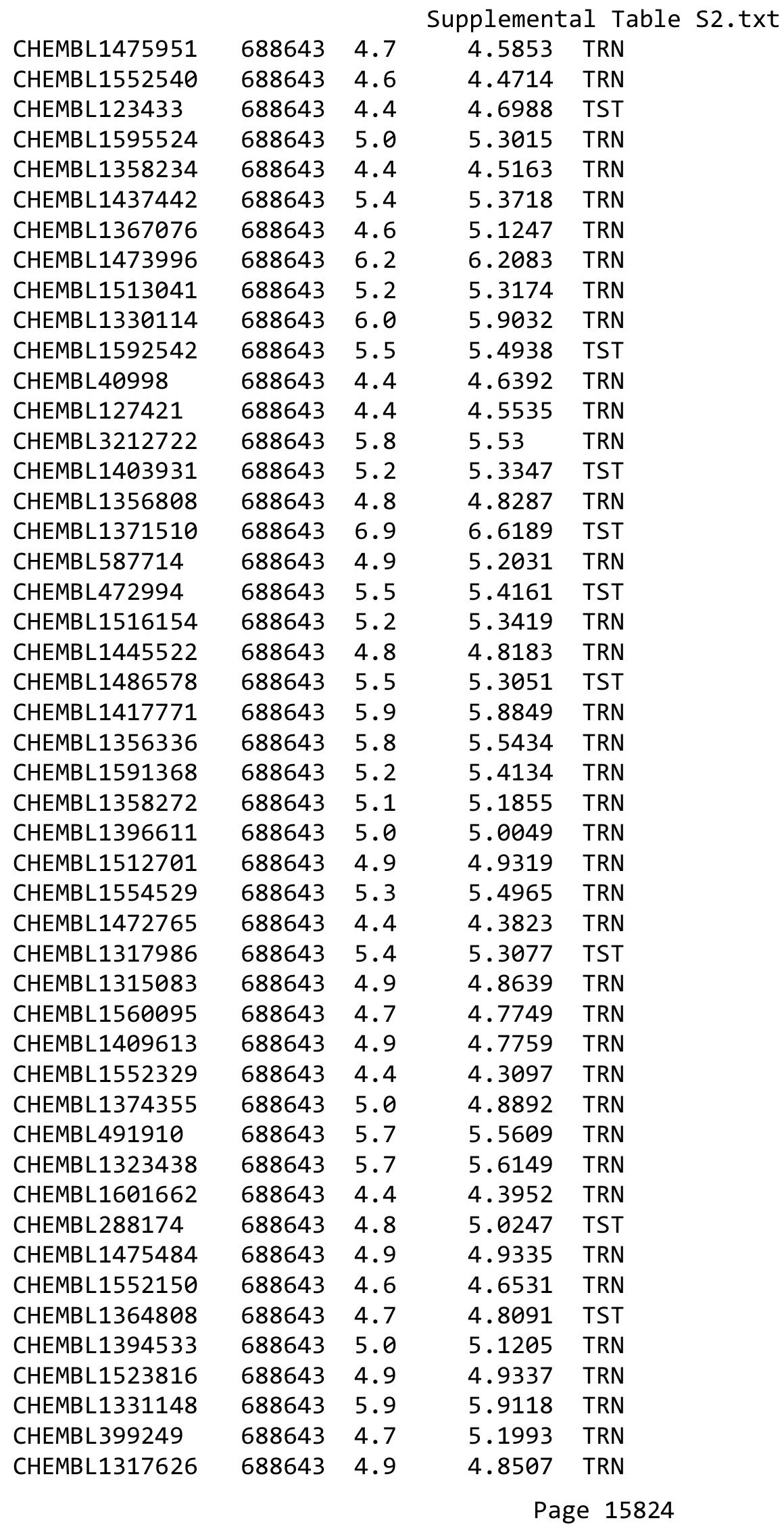




\begin{tabular}{|c|c|c|c|c|}
\hline & & & ient & al Ta \\
\hline CHEMBL1552677 & 688643 & 4.6 & 4.488 & TRN \\
\hline CHEMBL1574693 & 688643 & 5.4 & 5.4458 & TRN \\
\hline CHEMBL1480633 & 688643 & 5.3 & 5.6796 & TRN \\
\hline CHEMBL1314971 & 688643 & 4.4 & 4.4188 & TRN \\
\hline CHEMBL489943 & 688643 & 6.4 & 5.9401 & TRN \\
\hline CHEMBL 79140 & 688643 & 5.1 & 5.1003 & TRN \\
\hline CHEMBL1363622 & 688643 & 4.6 & 4.5429 & TRN \\
\hline CHEMBL1725279 & 688643 & 6.4 & 6.2098 & TST \\
\hline CHEMBL1435837 & 688643 & 5.7 & 5.4809 & TRN \\
\hline CHEMBL1448726 & 688643 & 4.4 & 4.3233 & TRN \\
\hline CHEMBL1335466 & 688643 & 5.4 & 5.5191 & TRN \\
\hline CHEMBL1473715 & 688643 & 5.6 & 5.5324 & TRN \\
\hline CHEMBL1532230 & 688643 & 4.4 & 4.4769 & TRN \\
\hline CHEMBL1355831 & 688643 & 4.8 & 5.0105 & TRN \\
\hline CHEMBL1487748 & 688643 & 6.0 & 6.1211 & TRN \\
\hline CHEMBL1552707 & 688643 & 5.1 & 4.9287 & TRN \\
\hline CHEMBL 280822 & 688643 & 5.6 & 5.6741 & TRN \\
\hline CHEMBL1596743 & 688643 & 5.6 & 5.4783 & TRN \\
\hline CHEMBL1365427 & 688643 & 4.4 & 4.4096 & TRN \\
\hline CHEMBL1369062 & 688643 & 4.7 & 4.7412 & TRN \\
\hline CHEMBL 1564178 & 688643 & 5.5 & 5.403 & TRN \\
\hline CHEMBL1378755 & 688643 & 5.0 & 4.8178 & TRN \\
\hline CHEMBL52 & 688643 & 6.0 & 4.7126 & TRN \\
\hline CHEMBL1603595 & 688643 & 4.5 & 4.6236 & TRN \\
\hline CHEMBL1481781 & 688643 & 4.5 & 4.7532 & TRN \\
\hline CHEMBL119841 & 688643 & 4.8 & 4.7118 & TRN \\
\hline CHEMBL1601163 & 688643 & 5.0 & 4.9858 & TRN \\
\hline CHEMBL501701 & 688643 & 4.4 & 4.5243 & TRN \\
\hline CHEMBL521970 & 688643 & 5.0 & 4.9905 & TRN \\
\hline CHEMBL1355909 & 688643 & 4.7 & 4.6473 & TRN \\
\hline CHEMBL 260374 & 688643 & 6.0 & 5.9474 & TST \\
\hline CHEMBL1554721 & 688643 & 5.2 & 5.1357 & TRN \\
\hline CHEMBL1358602 & 688643 & 5.5 & 5.6025 & TRN \\
\hline CHEMBL1566780 & 688643 & 4.7 & 4.7822 & TRN \\
\hline CHEMBL1356744 & 688643 & 4.9 & 4.7985 & TRN \\
\hline CHEMBL1320947 & 688643 & 5.5 & 5.358 & TRN \\
\hline CHEMBL1405538 & 688643 & 5.0 & 5.1242 & TRN \\
\hline CHEMBL1363347 & 688643 & 5.4 & 5.7298 & TRN \\
\hline CHEMBL1451823 & 688643 & 5.7 & 5.3216 & TRN \\
\hline CHEMBL1515246 & 688643 & 4.4 & 4.5858 & TRN \\
\hline CHEMBL1474989 & 688643 & 4.4 & 4.4513 & TRN \\
\hline CHEMBL1356107 & 688643 & 7.0 & 6.6299 & TRN \\
\hline CHEMBL3186408 & 688643 & 4.4 & 5.2995 & TST \\
\hline CHEMBL400598 & 688643 & 5.8 & 6.0465 & TRN \\
\hline CHEMBL1410399 & 688643 & 5.5 & 5.7154 & TST \\
\hline CHEMBL1332346 & 688643 & 4.7 & 4.5346 & TRN \\
\hline CHEMBL1533537 & 688643 & 4.9 & 4.7973 & TRN \\
\hline CHEMBL131091 & 688643 & 4.7 & 5.3952 & TST \\
\hline
\end{tabular}




\begin{tabular}{|c|c|c|c|c|}
\hline \multicolumn{5}{|c|}{ Supplemental Table S2.txt } \\
\hline CHEMBL1476711 & 688643 & 4.9 & 4.9054 & TRN \\
\hline CHEMBL1394371 & 688643 & 4.8 & 4.7205 & TRN \\
\hline CHEMBL1570633 & 688643 & 4.6 & 4.5818 & TRN \\
\hline CHEMBL1317494 & 688643 & 4.8 & 4.6853 & TRN \\
\hline CHEMBL1599378 & 688643 & 4.9 & 5.1149 & TRN \\
\hline CHEMBL1600620 & 688643 & 7.0 & 7.0152 & TRN \\
\hline CHEMBL1473211 & 688643 & 5.2 & 5.3672 & TRN \\
\hline CHEMBL1484127 & 688643 & 6.1 & 6.0469 & TRN \\
\hline CHEMBL1555118 & 688643 & 4.6 & 4.6285 & TRN \\
\hline CHEMBL546257 & 688643 & 6.0 & 5.8282 & TRN \\
\hline CHEMBL1554579 & 688643 & 5.3 & 5.3443 & TRN \\
\hline CHEMBL1558245 & 688643 & 5.5 & 5.6122 & TRN \\
\hline CHEMBL1373954 & 688643 & 5.6 & 5.5988 & TRN \\
\hline CHEMBL1535207 & 688643 & 5.2 & 5.2041 & TST \\
\hline CHEMBL1551981 & 688643 & 6.4 & 6.2668 & TRN \\
\hline CHEMBL1414899 & 688643 & 5.3 & 5.2715 & TRN \\
\hline CHEMBL1472561 & 688643 & 5.0 & 5.1386 & TST \\
\hline CHEMBL1355855 & 688643 & 7.8996 & 7.375 & TRN \\
\hline CHEMBL1516476 & 688643 & 6.0 & 5.8129 & TRN \\
\hline CHEMBL242341 & 688643 & 5.0 & 5.5211 & TRN \\
\hline CHEMBL1329435 & 688643 & 5.6 & 5.1117 & TRN \\
\hline CHEMBL1255578 & 688643 & 5.4 & 5.3465 & TST \\
\hline CHEMBL1551915 & 688643 & 4.4 & 5.3823 & TST \\
\hline CHEMBL1592464 & 688643 & 6.2 & 6.2375 & TRN \\
\hline CHEMBL1473191 & 688643 & 5.4 & 5.4757 & TST \\
\hline CHEMBL1491258 & 688643 & 6.0 & 5.893 & TRN \\
\hline CHEMBL1317860 & 688643 & 5.3 & 5.3219 & TRN \\
\hline CHEMBL448741 & 688643 & 6.0 & 5.7541 & TRN \\
\hline CHEMBL1574160 & 688643 & 4.7 & 4.6817 & TRN \\
\hline CHEMBL1379086 & 688643 & 5.4 & 5.4874 & TRN \\
\hline CHEMBL1570480 & 688643 & 5.4 & 5.4774 & TST \\
\hline CHEMBL1256974 & 688643 & 4.6 & 4.7722 & TST \\
\hline CHEMBL1564011 & 688643 & 5.4 & 5.5258 & TRN \\
\hline CHEMBL1359917 & 688643 & 7.5003 & 7.2358 & TRN \\
\hline CHEMBL1590270 & 688643 & 6.8 & 6.9196 & TRN \\
\hline CHEMBL407232 & 688643 & 6.0 & 4.9307 & TST \\
\hline CHEMBL1338249 & 688643 & 5.7 & 5.6278 & TRN \\
\hline CHEMBL1613513 & 688643 & 4.6 & 4.4852 & TRN \\
\hline CHEMBL1395634 & 688643 & 5.5 & 5.5804 & TRN \\
\hline CHEMBL1442106 & 688643 & 4.8 & 4.8979 & TRN \\
\hline CHEMBL1473498 & 688643 & 5.9 & 5.7098 & TRN \\
\hline CHEMBL399121 & 688643 & 6.0 & 5.113 & TRN \\
\hline CHEMBL1317932 & 688643 & 5.5 & 5.5006 & TRN \\
\hline CHEMBL1443491 & 688643 & 5.3 & 5.4027 & TRN \\
\hline CHEMBL1555067 & 688643 & 5.1 & 5.2522 & TST \\
\hline CHEMBL1535470 & 688643 & 5.2 & 5.2187 & TST \\
\hline CHEMBL1488197 & 688643 & 7.0 & 7.154 & TRN \\
\hline CHEMBL1437011 & 688643 & 5.5 & 5.443 & TRN \\
\hline
\end{tabular}




\begin{tabular}{|c|c|c|c|c|}
\hline & & & 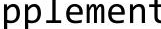 & al Ta \\
\hline CHEMBL1599748 & 688643 & 5.6 & 5.6049 & TRN \\
\hline CHEMBL1402088 & 688643 & 5.1 & 5.5792 & TRN \\
\hline CHEMBL1456872 & 688643 & 4.9 & 4.7672 & TRN \\
\hline CHEMBL1358583 & 688643 & 5.7 & 5.6072 & TRN \\
\hline CHEMBL1607623 & 688643 & 6.0 & 5.8568 & TRN \\
\hline CHEMBL1256659 & 688643 & 4.9 & 5.0503 & TRN \\
\hline CHEMBL1446146 & 688643 & 5.3 & 5.1835 & TST \\
\hline CHEMBL1593486 & 688643 & 5.4 & 5.5744 & TRN \\
\hline CHEMBL1433886 & 688643 & 5.5 & 5.4779 & TRN \\
\hline CHEMBL1360942 & 688643 & 5.2 & 5.2215 & TST \\
\hline CHEMBL126077 & 688643 & 4.5 & 5.2601 & TST \\
\hline CHEMBL1434111 & 688643 & 5.0 & 4.8285 & TRN \\
\hline CHEMBL1551122 & 688643 & 4.4 & 4.4562 & TRN \\
\hline CHEMBL1396577 & 688643 & 4.8 & 4.8371 & TRN \\
\hline CHEMBL283196 & 688643 & 4.9 & 5.3248 & TRN \\
\hline CHEMBL 1255758 & 688643 & 5.4 & 5.4773 & TST \\
\hline CHEMBL1457262 & 688643 & 5.3 & 5.4424 & TRN \\
\hline CHEMBL1316979 & 688643 & 5.0 & 5.0064 & TRN \\
\hline CHEMBL1324022 & 688643 & 6.1 & 6.1668 & TRN \\
\hline CHEMBL1334357 & 688643 & 5.4 & 5.4147 & TST \\
\hline CHEMBL 845 & 688643 & 5.2 & 5.2761 & TRN \\
\hline CHEMBL1438138 & 688643 & 5.4 & 5.2483 & TRN \\
\hline CHEMBL1475487 & 688643 & 4.4 & 4.5564 & TRN \\
\hline CHEMBL1395661 & 688643 & 6.0 & 5.966 & TRN \\
\hline CHEMBL1454512 & 688643 & 5.2 & 5.4849 & TRN \\
\hline CHEMBL1519435 & 688643 & 5.1 & 5.0314 & TRN \\
\hline CHEMBL1592571 & 688643 & 4.7 & 4.6387 & TRN \\
\hline CHEMBL1473123 & 688643 & 4.7 & 4.8287 & TRN \\
\hline CHEMBL1434149 & 688643 & 4.8 & 4.7951 & TRN \\
\hline CHEMBL1334543 & 688643 & 4.8 & 4.8413 & TRN \\
\hline CHEMBL1474230 & 688643 & 5.4 & 5.3676 & TST \\
\hline CHEMBL1358297 & 688643 & 4.4 & 4.7478 & TST \\
\hline CHEMBL1492558 & 688643 & 5.1 & 5.0839 & TRN \\
\hline CHEMBL1570894 & 688643 & 5.3 & 5.3465 & TRN \\
\hline CHEMBL1327673 & 688643 & 6.2 & 6.05 & TRN \\
\hline CHEMBL281622 & 688643 & 5.0 & 5.1147 & TRN \\
\hline CHEMBL1518035 & 688643 & 4.7 & 4.6775 & TRN \\
\hline CHEMBL1606199 & 688643 & 4.4 & 4.4282 & TRN \\
\hline CHEMBL1593162 & 688643 & 5.3 & 5.336 & TRN \\
\hline CHEMBL371811 & 688643 & 4.6 & 4.6707 & TST \\
\hline CHEMBL490577 & 688643 & 4.5 & 4.4113 & TRN \\
\hline CHEMBL1409682 & 688643 & 5.5 & 5.6707 & TRN \\
\hline CHEMBL1476139 & 688643 & 4.9 & 5.2989 & TRN \\
\hline CHEMBL1552519 & 688643 & 4.8 & 4.7955 & TRN \\
\hline CHEMBL1551051 & 688643 & 5.6 & 5.4495 & TRN \\
\hline CHEMBL1490998 & 688643 & 4.8 & 5.0404 & TRN \\
\hline CHEMBL1319783 & 688643 & 4.4 & 4.5078 & TRN \\
\hline CHEMBL 1256178 & 688643 & 4.4 & 4.5976 & TST \\
\hline
\end{tabular}




\begin{tabular}{|c|c|c|c|c|}
\hline \multicolumn{5}{|c|}{ Supplemental Table S2.txt } \\
\hline CHEMBL1455203 & 688643 & 5.1 & 5.3123 & TRN \\
\hline CHEMBL1440715 & 688643 & 4.7 & 4.6277 & TRN \\
\hline CHEMBL1330951 & 688643 & 6.8 & 6.9088 & TRN \\
\hline CHEMBL1593765 & 688643 & 6.0 & 5.9529 & TRN \\
\hline CHEMBL1332471 & 688643 & 4.9 & 4.6754 & TRN \\
\hline CHEMBL1475860 & 688643 & 5.5 & 5.6477 & TRN \\
\hline CHEMBL1426948 & 688643 & 4.5 & 4.7371 & TRN \\
\hline CHEMBL323356 & 688643 & 4.4 & 5.0181 & TST \\
\hline CHEMBL1457494 & 688643 & 5.3 & 5.2385 & TRN \\
\hline CHEMBL1514110 & 688643 & 4.7 & 4.8166 & TRN \\
\hline CHEMBL1331363 & 688643 & 5.1 & 5.0518 & TRN \\
\hline CHEMBL1356485 & 688643 & 4.4 & 4.6065 & TRN \\
\hline CHEMBL1493040 & 688643 & 5.1 & 5.2752 & TRN \\
\hline CHEMBL 267014 & 688643 & 6.0 & 5.7521 & TRN \\
\hline CHEMBL1551488 & 688643 & 5.1 & 5.3013 & TST \\
\hline CHEMBL1448979 & 688643 & 6.1 & 5.9328 & TRN \\
\hline CHEMBL1611999 & 688643 & 4.9 & 5.0623 & TRN \\
\hline CHEMBL1534248 & 688643 & 5.4 & 5.4765 & TRN \\
\hline CHEMBL1371572 & 688643 & 4.4 & 4.5782 & TRN \\
\hline CHEMBL1317172 & 688643 & 4.8 & 4.7 & TRN \\
\hline CHEMBL1408013 & 688643 & 7.0 & 7.0662 & TRN \\
\hline CHEMBL85251 & 688643 & 4.9 & 5.0629 & TRN \\
\hline CHEMBL1528170 & 688643 & 4.6 & 4.5159 & TRN \\
\hline CHEMBL1495854 & 688643 & 4.7 & 4.6395 & TRN \\
\hline CHEMBL1472523 & 688643 & 7.1002 & 6.7979 & TRN \\
\hline CHEMBL90769 & 688643 & 5.9 & 5.6619 & TST \\
\hline CHEMBL1478279 & 688643 & 5.2 & 4.9246 & TRN \\
\hline CHEMBL11684 & 688643 & 6.9 & 6.5214 & TST \\
\hline CHEMBL1256943 & 688643 & 5.0 & 5.0901 & TRN \\
\hline CHEMBL333985 & 688643 & 4.4 & 4.5588 & TST \\
\hline CHEMBL106437 & 688643 & 8.2007 & 7.8447 & TRN \\
\hline CHEMBL1415728 & 688643 & 4.6 & 4.5225 & TRN \\
\hline CHEMBL1256751 & 688643 & 4.5 & 4.7194 & TRN \\
\hline CHEMBL1473925 & 688643 & 5.5 & 5.6146 & TRN \\
\hline CHEMBL1443163 & 688643 & 5.2 & 5.1452 & TST \\
\hline CHEMBL1397766 & 688643 & 4.5 & 4.8454 & TRN \\
\hline CHEMBL1316463 & 688643 & 4.8 & 5.3729 & TRN \\
\hline CHEMBL1492579 & 688643 & 9.0 & 4.9919 & TRN \\
\hline CHEMBL1370622 & 688643 & 4.7 & 4.7982 & TRN \\
\hline CHEMBL1553399 & 688643 & 5.7 & 5.6043 & TST \\
\hline CHEMBL1513077 & 688643 & 4.7 & 4.6197 & TRN \\
\hline CHEMBL1400491 & 688643 & 4.4 & 4.4169 & TRN \\
\hline CHEMBL1332033 & 688643 & 5.3 & 5.1157 & TRN \\
\hline CHEMBL129795 & 688643 & 4.8 & 4.9092 & TRN \\
\hline CHEMBL1438371 & 688643 & 5.4 & 5.2923 & TRN \\
\hline CHEMBL1436125 & 688643 & 5.8 & 5.7805 & TRN \\
\hline CHEMBL1396261 & 688643 & 5.0 & 5.0159 & TRN \\
\hline CHEMBL1318411 & 688643 & 5.5 & 5.84 & TRN \\
\hline
\end{tabular}




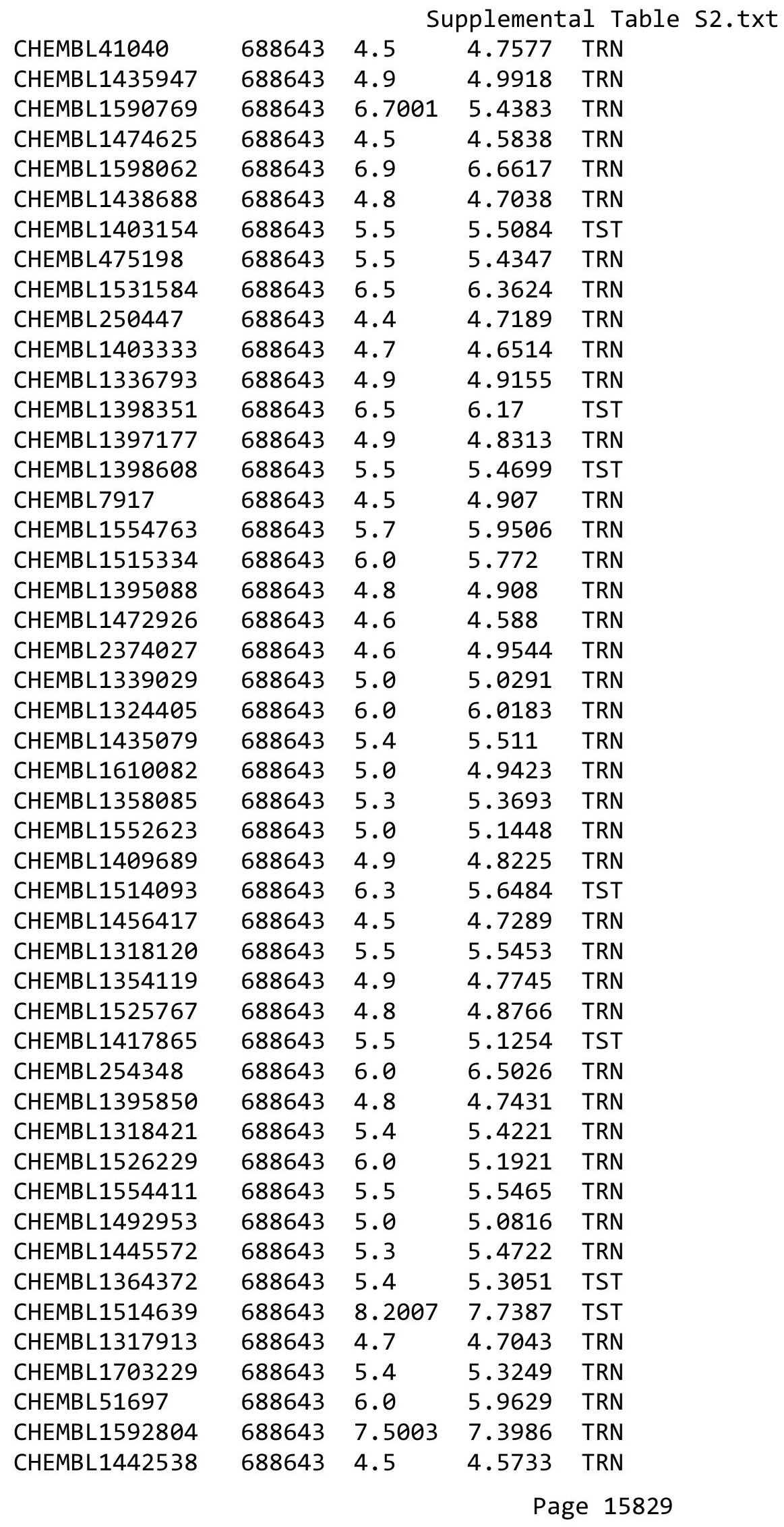




\begin{tabular}{|c|c|c|c|c|c|}
\hline \multicolumn{6}{|c|}{ Supplemental Table S2.txt } \\
\hline CHEMBL1590663 & 688643 & 4.7 & 4.6921 & TRN & \\
\hline CHEMBL1437013 & 688643 & 4.9 & 4.8638 & TRN & \\
\hline CHEMBL1358197 & 688643 & 4.9 & 4.7455 & TRN & \\
\hline CHEMBL1530613 & 688643 & 5.8 & 5.6862 & TST & \\
\hline CHEMBL1435702 & 688643 & 5.8 & 5.648 & TRN & \\
\hline CHEMBL1397206 & 688643 & 5.4 & 5.3422 & TRN & \\
\hline CHEMBL1589879 & 688643 & 5.2 & 5.2714 & TRN & \\
\hline CHEMBL1358263 & 688643 & 4.8 & 4.7137 & TRN & \\
\hline CHEMBL1601633 & 688643 & 4.8 & 4.9773 & TRN & \\
\hline CHEMBL1357221 & 688643 & 6.0 & 6.0927 & TRN & \\
\hline CHEMBL1555314 & 688643 & 4.6 & 4.626 & TRN & \\
\hline CHEMBL1445893 & 688643 & 5.4 & 5.2624 & TRN & \\
\hline CHEMBL1437700 & 688643 & 5.5 & 5.4925 & TRN & \\
\hline CHEMBL1590197 & 688643 & 4.4 & 4.4442 & TRN & \\
\hline CHEMBL1356304 & 688643 & 5.2 & 5.4328 & TST & \\
\hline CHEMBL1596952 & 688643 & 4.4 & 4.3714 & TRN & \\
\hline CHEMBL1378764 & 688643 & 4.9 & 4.8138 & TRN & \\
\hline CHEMBL 76897 & 688643 & 4.4 & 4.533 & TRN & \\
\hline CHEMBL1612158 & 688643 & 4.8 & 4.7112 & TRN & \\
\hline CHEMBL1397558 & 688643 & 5.2 & 5.1232 & TRN & \\
\hline CHEMBL1611820 & 688643 & 4.8 & 4.7412 & TRN & \\
\hline CHEMBL1439665 & 688643 & 4.5 & 4.4392 & TRN & \\
\hline CHEMBL2373669 & 688643 & 5.3 & 5.2153 & TRN & \\
\hline CHEMBL1396358 & 688643 & 4.4 & 4.4484 & TRN & \\
\hline CHEMBL1358018 & 688643 & 4.4 & 5.0064 & TRN & \\
\hline CHEMBL1591964 & 688643 & 4.7 & 4.6153 & TRN & \\
\hline CHEMBL157351 & 688643 & 4.4 & 4.54899 & 99999999995 & TRN \\
\hline CHEMBL 293349 & 688643 & 4.5 & 4.999 & TRN & \\
\hline CHEMBL 2062336 & 688643 & 8.0 & 7.8258 & TRN & \\
\hline CHEMBL1358462 & 688643 & 4.9 & 4.8549 & TRN & \\
\hline CHEMBL1415790 & 688643 & 4.6 & 4.5963 & TRN & \\
\hline CHEMBL1413637 & 688643 & 5.0 & 5.0161 & TRN & \\
\hline CHEMBL1317306 & 688643 & 7.0 & 7.0967 & TRN & \\
\hline CHEMBL1318285 & 688643 & 5.5 & 5.5273 & TST & \\
\hline CHEMBL1394187 & 688643 & 5.4 & 5.3361 & TRN & \\
\hline CHEMBL18132 & 688643 & 5.1 & 5.2689 & TST & \\
\hline CHEMBL1590821 & 688643 & 4.5 & 4.4411 & TRN & \\
\hline CHEMBL1605426 & 688643 & 4.6 & 4.7214 & TRN & \\
\hline CHEMBL1593889 & 688643 & 5.5 & 5.5117 & TRN & \\
\hline CHEMBL313833 & 688643 & 6.0 & 5.8708 & TST & \\
\hline CHEMBL1319251 & 688643 & 5.5 & 5.1267 & TRN & \\
\hline CHEMBL1436715 & 688643 & 5.0 & 4.8899 & TRN & \\
\hline CHEMBL1480008 & 688643 & 4.7 & 4.8286 & TRN & \\
\hline CHEMBL303579 & 688643 & 4.4 & 4.7551 & TRN & \\
\hline CHEMBL1591677 & 688643 & 5.0 & 4.851 & TRN & \\
\hline CHEMBL491578 & 688643 & 6.3 & 6.1144 & TRN & \\
\hline CHEMBL1403505 & 688643 & 4.7 & 4.7747 & TRN & \\
\hline CHEMBL113142 & 688643 & 5.0 & 5.12799 & 9999999999 & TST \\
\hline & & & & 15830 & \\
\hline
\end{tabular}




\begin{tabular}{|c|c|c|c|c|}
\hline \multicolumn{5}{|c|}{ Supplemental Table S2.txt } \\
\hline CHEMBL1981840 & 688643 & 5.3 & 5.3178 & TST \\
\hline CHEMBL1558569 & 688643 & 4.6 & 4.5206 & TRN \\
\hline CHEMBL18879 & 688643 & 8.2007 & 7.5342 & TST \\
\hline CHEMBL489935 & 688643 & 5.3 & 5.2061 & TRN \\
\hline CHEMBL1593596 & 688643 & 5.5 & 5.584 & TST \\
\hline CHEMBL1255649 & 688643 & 6.0 & 5.7622 & TST \\
\hline CHEMBL1559246 & 688643 & 4.4 & 4.4379 & TRN \\
\hline CHEMBL272005 & 688643 & 4.5 & 5.1959 & TRN \\
\hline CHEMBL1354414 & 688643 & 5.5 & 5.3034 & TRN \\
\hline CHEMBL32142 & 688643 & 4.6 & 4.6907 & TST \\
\hline CHEMBL1400667 & 688643 & 6.4 & 6.135 & TST \\
\hline CHEMBL1606018 & 688643 & 5.5 & 5.3137 & TST \\
\hline CHEMBL1411081 & 688643 & 6.0 & 5.7826 & TRN \\
\hline CHEMBL492610 & 688643 & 4.9 & 4.8611 & TRN \\
\hline CHEMBL399705 & 688643 & 5.0 & 5.1528 & TST \\
\hline CHEMBL1358806 & 688643 & 5.5 & 5.6227 & TRN \\
\hline CHEMBL994 & 688643 & 5.1 & 5.2091 & TRN \\
\hline CHEMBL1328324 & 688643 & 4.4 & 4.6094 & TST \\
\hline CHEMBL1593438 & 688643 & 4.7 & 4.7999 & TRN \\
\hline CHEMBL1436024 & 688643 & 4.9 & 4.7792 & TRN \\
\hline CHEMBL491771 & 688643 & 4.9 & 4.7733 & TRN \\
\hline CHEMBL1361750 & 688643 & 5.0 & 4.9062 & TRN \\
\hline CHEMBL1513643 & 688643 & 6.2 & 6.0975 & TST \\
\hline CHEMBL489534 & 688643 & 5.1 & 4.9893 & TRN \\
\hline CHEMBL1524520 & 688643 & 4.9 & 4.8092 & TRN \\
\hline CHEMBL1358137 & 688643 & 5.4 & 5.3851 & TST \\
\hline CHEMBL1317458 & 688643 & 7.1002 & 6.754 & TRN \\
\hline CHEMBL 266084 & 688643 & 4.9 & 5.0472 & TRN \\
\hline CHEMBL1409720 & 688643 & 5.5 & 5.5538 & TRN \\
\hline CHEMBL1408343 & 688643 & 5.4 & 5.3863 & TRN \\
\hline CHEMBL1489528 & 688643 & 4.6 & 4.6646 & TRN \\
\hline CHEMBL1396615 & 688643 & 4.7 & 4.5761 & TRN \\
\hline CHEMBL1354272 & 688643 & 4.9 & 4.8469 & TRN \\
\hline CHEMBL1324667 & 688643 & 4.5 & 4.4628 & TRN \\
\hline CHEMBL41680 & 688643 & 6.0 & 4.5219 & TST \\
\hline CHEMBL1356652 & 688643 & 4.4 & 4.4667 & TRN \\
\hline CHEMBL1396561 & 688643 & 4.9 & 4.865 & TRN \\
\hline CHEMBL 296586 & 688643 & 6.4 & 6.1487 & TST \\
\hline CHEMBL1567854 & 688643 & 5.4 & 5.5613 & TRN \\
\hline CHEMBL171064 & 688643 & 4.5 & 4.6771 & TST \\
\hline CHEMBL1592211 & 688643 & 4.4 & 4.489 & TRN \\
\hline CHEMBL1326787 & 688643 & 8.0 & 5.4648 & TRN \\
\hline CHEMBL1451119 & 688643 & 5.4 & 5.2864 & TRN \\
\hline CHEMBL1399313 & 688643 & 4.9 & 4.837 & TRN \\
\hline CHEMBL1612893 & 688643 & 5.1 & 5.1199 & TRN \\
\hline CHEMBL1571138 & 688643 & 5.5 & 5.5297 & TRN \\
\hline CHEMBL1256971 & 688643 & 6.0 & 5.1005 & TST \\
\hline CHEMBL1315184 & 688643 & 4.8 & 4.7774 & TRN \\
\hline
\end{tabular}




\begin{tabular}{|c|c|c|c|c|c|}
\hline \multicolumn{6}{|c|}{ Supplemental Table S2.txt } \\
\hline CHEMBL1593717 & 688643 & 5.3 & 5.3921 & TST & \\
\hline CHEMBL1407769 & 688643 & 5.7 & 5.8252 & TRN & \\
\hline CHEMBL1592212 & 688643 & 6.1 & 6.1568 & TRN & \\
\hline CHEMBL1362630 & 688643 & 5.1 & 5.0949 & TST & \\
\hline CHEMBL1317786 & 688643 & 4.9 & 5.011 & TRN & \\
\hline CHEMBL1512978 & 688643 & 6.9 & 6.7319 & TST & \\
\hline CHEMBL1369822 & 688643 & 4.4 & 4.3079 & TRN & \\
\hline CHEMBL1566670 & 688643 & 4.4 & 4.6881 & TRN & \\
\hline CHEMBL1495694 & 688643 & 4.6 & 4.9234 & TRN & \\
\hline CHEMBL1357157 & 688643 & 4.6 & 4.6009 & TRN & \\
\hline CHEMBL1609403 & 688643 & 5.8 & 5.5715 & TST & \\
\hline CHEMBL1408954 & 688643 & 5.4 & 5.3959 & TRN & \\
\hline CHEMBL1611823 & 688643 & 5.5 & 5.62200 & 0000000001 & TRN \\
\hline CHEMBL1396374 & 688643 & 4.7 & 4.7594 & TRN & \\
\hline CHEMBL1472899 & 688643 & 4.9 & 5.1172 & TRN & \\
\hline CHEMBL1514821 & 688643 & 6.0 & 6.0423 & TRN & \\
\hline CHEMBL1475284 & 688643 & 4.9 & 5.0467 & TRN & \\
\hline CHEMBL1396326 & 688643 & 4.4 & 4.4927 & TRN & \\
\hline CHEMBL1358694 & 688643 & 4.6 & 4.5848 & TRN & \\
\hline CHEMBL1397443 & 688643 & 5.5 & 5.3973 & TST & \\
\hline CHEMBL1335617 & 688643 & 5.2 & 5.3049 & TRN & \\
\hline CHEMBL1516107 & 688643 & 5.3 & 5.1792 & TRN & \\
\hline CHEMBL1455438 & 688643 & 4.4 & 4.395 & TRN & \\
\hline CHEMBL1488305 & 688643 & 4.4 & 3.662 & TRN & \\
\hline CHEMBL1494878 & 688643 & 6.5 & 6.5916 & TRN & \\
\hline CHEMBL1611012 & 688643 & 7.4001 & 5.3091 & TST & \\
\hline CHEMBL1438674 & 688643 & 4.9 & 4.9164 & TRN & \\
\hline CHEMBL131921 & 688643 & 4.5 & 6.4002 & TRN & \\
\hline CHEMBL23957 & 688643 & 5.4 & 5.4055 & TST & \\
\hline CHEMBL1718952 & 688643 & 5.6 & 5.8958 & TRN & \\
\hline CHEMBL1436540 & 688643 & 4.4 & 4.3867 & TRN & \\
\hline CHEMBL1513166 & 688643 & 6.2 & 6.2452 & TRN & \\
\hline CHEMBL311158 & 688643 & 6.0 & 4.6586 & TRN & \\
\hline CHEMBL1590909 & 688643 & 4.9 & 4.8896 & TRN & \\
\hline CHEMBL1436992 & 688643 & 4.8 & 4.8322 & TRN & \\
\hline CHEMBL1335889 & 688643 & 5.5 & 5.1787 & TRN & \\
\hline CHEMBL188 & 688643 & 4.8 & 5.0135 & TST & \\
\hline CHEMBL1256959 & 688643 & 6.0 & 5.82 & TRN & \\
\hline CHEMBL117 & 688643 & 4.9 & 4.9197 & TRN & \\
\hline CHEMBL1434085 & 688643 & 4.9 & 5.0306 & TRN & \\
\hline CHEMBL1481170 & 688643 & 5.6 & 5.6762 & TST & \\
\hline CHEMBL1608337 & 688643 & 5.1 & 5.2214 & TST & \\
\hline CHEMBL1377140 & 688643 & 5.4 & 5.3188 & TRN & \\
\hline CHEMBL1320662 & 688643 & 4.9 & 4.7361 & TRN & \\
\hline CHEMBL1318356 & 688643 & 5.2 & 5.5726 & TRN & \\
\hline CHEMBL1256666 & 688643 & 4.5 & 4.794 & TRN & \\
\hline CHEMBL1396202 & 688643 & 5.1 & 5.0125 & TRN & \\
\hline CHEMBL444422 & 688643 & 4.5 & 4.6883 & TRN & \\
\hline
\end{tabular}




\begin{tabular}{|c|c|c|c|c|c|}
\hline \multicolumn{6}{|c|}{ Supplemental Table S2.txt } \\
\hline CHEMBL1337781 & 688643 & 5.1 & 5.1504 & TRN & \\
\hline CHEMBL1256695 & 688643 & 6.0 & 5.8623 & TRN & \\
\hline CHEMBL1396100 & 688643 & 4.9 & 4.9814 & TRN & \\
\hline CHEMBL476672 & 688643 & 5.8 & 5.7766 & TRN & \\
\hline CHEMBL12014 & 688643 & 6.0 & 4.9922 & TRN & \\
\hline CHEMBL1570413 & 688643 & 4.7 & 4.6919 & TRN & \\
\hline CHEMBL1418094 & 688643 & 5.6 & 5.5821 & TST & \\
\hline CHEMBL434063 & 688643 & 7.5003 & 7.0739 & TST & \\
\hline CHEMBL1452408 & 688643 & 5.0 & 4.8686 & TRN & \\
\hline CHEMBL1356628 & 688643 & 4.7 & 4.6891 & TRN & \\
\hline CHEMBL1356138 & 688643 & 4.4 & 4.3662 & TRN & \\
\hline CHEMBL1474876 & 688643 & 5.5 & 5.6346 & TRN & \\
\hline CHEMBL1515802 & 688643 & 5.3 & 5.4067 & TRN & \\
\hline CHEMBL1361285 & 688643 & 9.0 & 5.3237 & TRN & \\
\hline CHEMBL1337629 & 688643 & 5.4 & 5.4695 & TST & \\
\hline CHEMBL1315424 & 688643 & 5.3 & 5.263 & TRN & \\
\hline CHEMBL1566105 & 688643 & 5.4 & 5.364 & TST & \\
\hline CHEMBL1363467 & 688643 & 4.7 & 4.6133 & TRN & \\
\hline CHEMBL1315318 & 688643 & 5.1 & 5.0353 & TRN & \\
\hline CHEMBL331372 & 688643 & 4.9 & 5.0458 & TRN & \\
\hline CHEMBL1476049 & 688643 & 4.8 & 4.7871 & TRN & \\
\hline CHEMBL1318553 & 688643 & 6.0 & 5.9642 & TST & \\
\hline CHEMBL345124 & 688643 & 5.2 & 5.2436 & TST & \\
\hline CHEMBL1454229 & 688643 & 5.4 & 5.4598 & TST & \\
\hline CHEMBL1590763 & 688643 & 5.0 & 4.8489 & TRN & \\
\hline CHEMBL1475338 & 688643 & 5.1 & 5.0259 & TRN & \\
\hline CHEMBL1096400 & 688643 & 5.3 & 5.3346 & TRN & \\
\hline CHEMBL1376290 & 688643 & 5.4 & 5.7662 & TRN & \\
\hline CHEMBL1413701 & 688643 & 4.4 & 4.5881 & TRN & \\
\hline CHEMBL1488167 & 688643 & 5.9 & 6.0472 & TRN & \\
\hline CHEMBL1335397 & 688643 & 5.8 & 4.9518 & TST & \\
\hline CHEMBL489738 & 688643 & 5.3 & 5.1217 & TRN & \\
\hline CHEMBL1409830 & 688643 & 4.7 & 4.6182 & TRN & \\
\hline CHEMBL1416812 & 688643 & 6.2 & 5.9808 & TRN & \\
\hline CHEMBL1474445 & 688643 & 5.4 & 5.4936 & TST & \\
\hline CHEMBL1526733 & 688643 & 5.5 & 5.2887 & TRN & \\
\hline CHEMBL1402241 & 688643 & 5.5 & 5.5562 & TRN & \\
\hline CHEMBL1522486 & 688643 & 4.8 & 5.2321 & TRN & \\
\hline CHEMBL1555348 & 688643 & 5.5 & 5.5742 & TRN & \\
\hline CHEMBL1603418 & 688643 & 4.8 & 4.6999 & TRN & \\
\hline CHEMBL1556283 & 688643 & 4.6 & 4.6277 & TRN & \\
\hline CHEMBL1315129 & 688643 & 7.2 & 7.3741 & TRN & \\
\hline CHEMBL1213137 & 688643 & 5.3 & $5.2970 e$ & 0000000001 & TRN \\
\hline CHEMBL1334327 & 688643 & 5.5 & 5.5345 & TRN & \\
\hline CHEMBL1553034 & 688643 & 5.7 & 5.9319 & TRN & \\
\hline CHEMBL1554637 & 688643 & 4.7 & 4.7103 & TRN & \\
\hline CHEMBL1556431 & 688643 & 4.4 & 4.3665 & TRN & \\
\hline CHEMBL157754 & 688643 & 5.5 & 5.5161 & TRN & \\
\hline
\end{tabular}




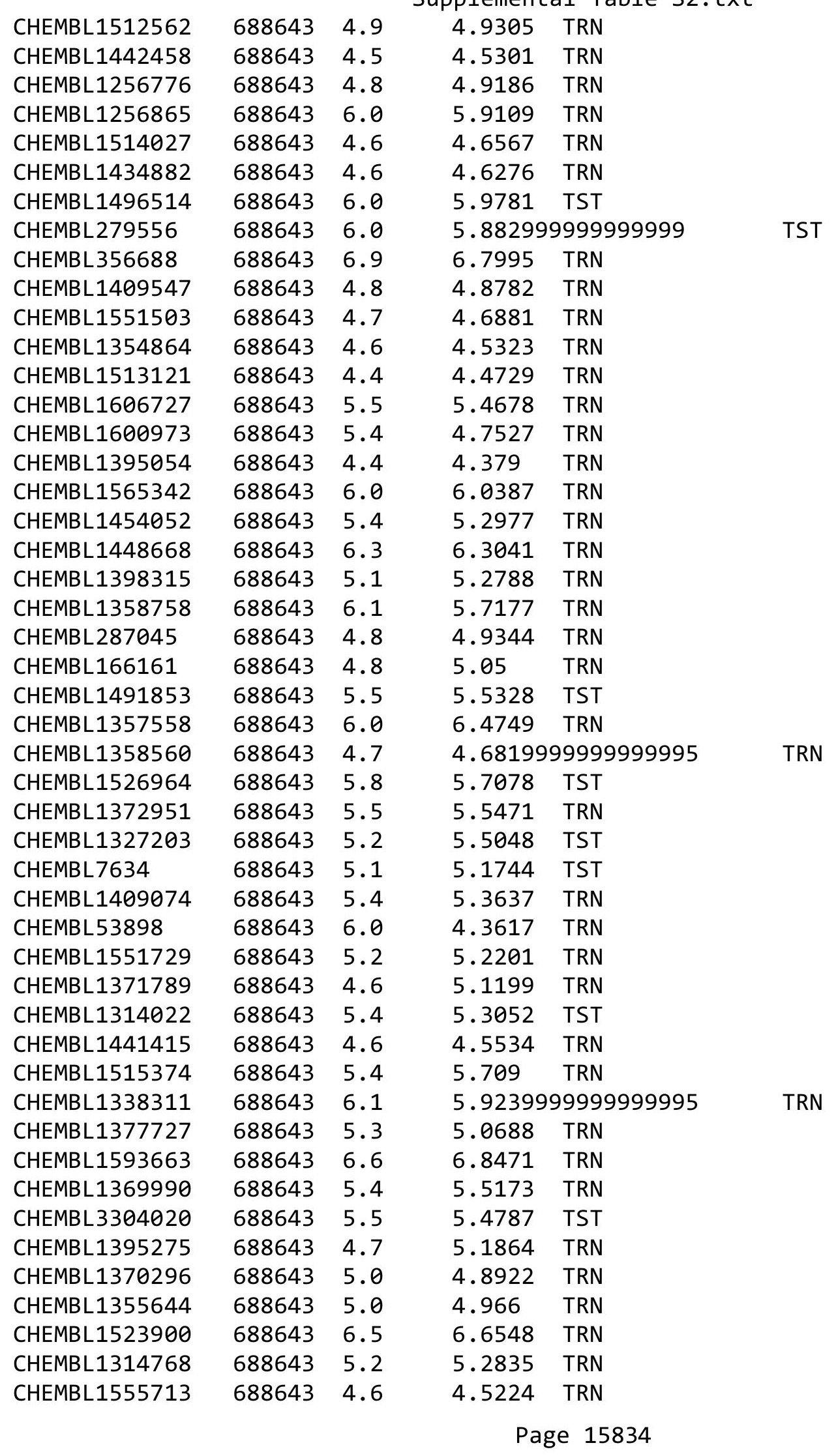




\begin{tabular}{|c|c|c|c|c|c|}
\hline \\
\hline CHEMBL1514634 & 688643 & 5.5 & 5.8025 & TST & \\
\hline CHEMBL522600 & 688643 & 5.7 & 5.6545 & TRN & \\
\hline CHEMBL1606796 & 688643 & 5.0 & 5.0499 & TRN & \\
\hline CHEMBL1476526 & 688643 & 5.4 & $5.4460 e$ & 3000000001 & TRN \\
\hline CHEMBL 275097 & 688643 & 7.2 & 7.2249 & TRN & \\
\hline CHEMBL1720282 & 688643 & 5.3 & 5.3721 & TRN & \\
\hline CHEMBL1593805 & 688643 & 5.1 & 5.3224 & TRN & \\
\hline CHEMBL1590968 & 688643 & 5.1 & 5.2057 & TRN & \\
\hline CHEMBL1329927 & 688643 & 6.0 & 5.9638 & TRN & \\
\hline CHEMBL1418655 & 688643 & 5.5 & 5.5342 & TRN & \\
\hline CHEMBL122270 & 688643 & 6.0 & 6.0642 & TRN & \\
\hline CHEMBL1256770 & 688643 & 5.1 & 5.2295 & TRN & \\
\hline CHEMBL1534566 & 688643 & 5.0 & 5.1509 & TRN & \\
\hline CHEMBL1514272 & 688643 & 4.4 & 4.3285 & TRN & \\
\hline CHEMBL1555014 & 688643 & 4.4 & 4.4112 & TRN & \\
\hline CHEMBL83954 & 688643 & 6.9 & 6.4665 & TRN & \\
\hline CHEMBL1395344 & 688643 & 4.7 & 4.698 & TRN & \\
\hline CHEMBL1355089 & 688643 & 6.4 & 6.097 & TRN & \\
\hline CHEMBL1445984 & 688643 & 4.9 & 4.8553 & TRN & \\
\hline CHEMBL1440943 & 688643 & 4.4 & 4.3206 & TRN & \\
\hline CHEMBL1480516 & 688643 & 6.0 & 5.9798 & TRN & \\
\hline CHEMBL1555255 & 688643 & 5.5 & 5.569 & TRN & \\
\hline CHEMBL338115 & 688643 & 6.2 & 6.0402 & TRN & \\
\hline CHEMBL1526543 & 688643 & 6.0 & 5.10800 & 30000000005 & TST \\
\hline CHEMBL1557821 & 688643 & 5.0 & 4.8903 & TRN & \\
\hline CHEMBL1602812 & 688643 & 4.8 & 4.8745 & TRN & \\
\hline CHEMBL1357648 & 688643 & 5.1 & 5.2081 & TRN & \\
\hline CHEMBL1319120 & 688643 & 5.6 & 5.6436 & TRN & \\
\hline CHEMBL1436160 & 688643 & 4.7 & 4.6782 & TRN & \\
\hline CHEMBL1472955 & 688643 & 4.7 & 4.6618 & TRN & \\
\hline CHEMBL1396407 & 688643 & 5.0 & 4.9234 & TRN & \\
\hline CHEMBL1357444 & 688643 & 5.0 & 5.0364 & TRN & \\
\hline CHEMBL1397833 & 688643 & 6.0 & 5.0583 & TST & \\
\hline CHEMBL1447959 & 688643 & 4.7 & 4.6622 & TRN & \\
\hline CHEMBL 267548 & 688643 & 4.6 & 4.779 & TST & \\
\hline CHEMBL1416476 & 688643 & 5.4 & 5.33 & TRN & \\
\hline CHEMBL1496576 & 688643 & 5.0 & 4.9095 & TRN & \\
\hline CHEMBL1551557 & 688643 & 4.7 & 4.704 & TRN & \\
\hline CHEMBL1318045 & 688643 & 4.7 & 4.6614 & TRN & \\
\hline CHEMBL1594761 & 688643 & 5.3 & 5.2722 & TRN & \\
\hline CHEMBL1480350 & 688643 & 4.4 & 4.4598 & TRN & \\
\hline CHEMBL1403982 & 688643 & 5.8 & 5.6497 & TRN & \\
\hline CHEMBL1331657 & 688643 & 5.1 & 5.159 & TRN & \\
\hline CHEMBL1609324 & 688643 & 4.9 & 4.8676 & TRN & \\
\hline CHEMBL1396898 & 688643 & 4.7 & 4.6333 & TRN & \\
\hline CHEMBL1369036 & 688643 & 5.1 & 5.1851 & TRN & \\
\hline CHEMBL1435080 & 688643 & 4.7 & 4.6594 & TRN & \\
\hline CHEMBL1527958 & 688643 & 6.4 & 6.505 & TRN & \\
\hline
\end{tabular}




\begin{tabular}{|c|c|c|c|c|}
\hline & & & & $a \perp 1$ \\
\hline CHEMBL1551979 & 688643 & 5.4 & 5.1656 & TRN \\
\hline CHEMBL1433950 & 688643 & 5.7 & 5.4639 & TRN \\
\hline CHEMBL1288013 & 688643 & 5.5 & 5.58899 & 99999999995 \\
\hline CHEMBL1394956 & 688643 & 4.4 & 4.4533 & TRN \\
\hline CHEMBL1484337 & 688643 & 4.7 & 4.72 & TRN \\
\hline CHEMBL73451 & 688643 & 6.4 & 6.5876 & TRN \\
\hline CHEMBL1374334 & 688643 & 5.5 & 5.5136 & TRN \\
\hline CHEMBL1355408 & 688643 & 5.5 & 5.4488 & TRN \\
\hline CHEMBL1434817 & 688643 & 5.5 & 5.374 & TRN \\
\hline CHEMBL1408760 & 688643 & 4.4 & 4.5143 & TRN \\
\hline CHEMBL1318509 & 688643 & 5.1 & 5.0654 & TST \\
\hline CHEMBL1493168 & 688643 & 6.8 & 6.8767 & TST \\
\hline CHEMBL1446009 & 688643 & 4.4 & 4.0863 & TST \\
\hline CHEMBL450493 & 688643 & 4.9 & 4.81 & TST \\
\hline CHEMBL33103 & 688643 & 4.8 & 4.734 & TST \\
\hline CHEMBL1373464 & 688643 & 4.5 & 4.6604 & TST \\
\hline CHEMBL1358614 & 688643 & 4.9 & 4.7502 & TST \\
\hline CHEMBL1395935 & 688643 & 5.5 & 5.6352 & TST \\
\hline CHEMBL1354901 & 688643 & 6.2 & 6.4376 & TST \\
\hline CHEMBL1601305 & 688643 & 4.4 & 4.3808 & TST \\
\hline CHEMBL1515194 & 688643 & 4.4 & 4.3746 & TST \\
\hline CHEMBL1414780 & 688643 & 5.1 & 5.3049 & TST \\
\hline CHEMBL1564864 & 688643 & 4.7 & 5.5319 & TST \\
\hline CHEMBL 375672 & 688643 & 5.4 & 5.3616 & TST \\
\hline CHEMBL1317712 & 688643 & 4.9 & 4.7148 & TST \\
\hline CHEMBL1372282 & 688643 & 6.1 & 5.947 & TST \\
\hline CHEMBL1450716 & 688643 & 4.4 & 4.4996 & TST \\
\hline CHEMBL1435301 & 688643 & 4.6 & 4.6288 & TST \\
\hline CHEMBL1525112 & 688643 & 4.7 & 4.8052 & TST \\
\hline CHEMBL1610945 & 688643 & 6.0 & 5.9682 & TST \\
\hline CHEMBL1322064 & 688643 & 5.1 & 5.1728 & TST \\
\hline CHEMBL1321005 & 688643 & 6.0 & 6.1169 & TST \\
\hline CHEMBL87285 & 688643 & 4.9 & 5.1959 & TST \\
\hline CHEMBL1355712 & 688643 & 6.1 & 6.0768 & TST \\
\hline CHEMBL1407012 & 688643 & 5.0 & 5.2089 & TST \\
\hline CHEMBL1516249 & 688643 & 4.8 & 4.6911 & TST \\
\hline CHEMBL1331351 & 688643 & 4.7 & 4.8429 & TST \\
\hline CHEMBL1256924 & 688643 & 4.5 & 4.6519 & TST \\
\hline CHEMBL1326619 & 688643 & 5.7 & 5.268 & TST \\
\hline CHEMBL1323215 & 688643 & 5.1 & 5.3008 & TST \\
\hline CHEMBL542493 & 688643 & 4.5 & 4.7725 & TST \\
\hline CHEMBL 250053 & 688643 & 6.0 & 4.9181 & TST \\
\hline CHEMBL1593923 & 688643 & 5.5 & 5.5602 & TST \\
\hline CHEMBL1437804 & 688643 & 5.0 & 5.0912 & TST \\
\hline CHEMBL1514836 & 688643 & 4.6 & 4.7806 & TST \\
\hline CHEMBL1256995 & 688643 & 6.0 & 5.7836 & TST \\
\hline CHEMBL1514604 & 688643 & 5.8 & 5.8133 & TST \\
\hline CHEMBL 3084891 & 688643 & 4.6 & 5.0334 & TST \\
\hline
\end{tabular}

TRN 


\begin{tabular}{|c|c|c|c|c|c|}
\hline \multirow[b]{2}{*}{ CHEMBL1410859 } & \multirow[b]{2}{*}{688643} & \multicolumn{4}{|c|}{ able sz. } \\
\hline & & 4.8 & 4.7866 & TST & \\
\hline CHEMBL1256916 & 688643 & 6.6 & \multicolumn{2}{|c|}{7.0360000000000005} & \multirow[t]{2}{*}{ TST } \\
\hline CHEMBL1552172 & 688643 & 4.4 & 4.4798 & TST & \\
\hline CHEMBL1476362 & 688643 & 4.6 & 5.3244 & TST & \\
\hline CHEMBL1551618 & 688643 & 4.4 & 4.8781 & TST & \\
\hline CHEMBL164660 & 688643 & 5.7 & 5.2823 & TST & \\
\hline CHEMBL1256693 & 688643 & 4.9 & 5.1185 & TST & \\
\hline CHEMBL1551834 & 688643 & 4.7 & 4.6496 & TST & \\
\hline CHEMBL1516262 & 688643 & 4.4 & 4.5336 & TST & \\
\hline CHEMBL1318228 & 688643 & 4.6 & 4.5655 & TST & \\
\hline CHEMBL1436031 & 688643 & 5.0 & 5.1041 & TST & \\
\hline CHEMBL1356135 & 688643 & 6.9 & 6.7547 & TST & \\
\hline CHEMBL492132 & 688643 & 5.6 & 5.5533 & TST & \\
\hline CHEMBL1399481 & 688643 & 4.7 & 4.6316 & TST & \\
\hline CHEMBL1376212 & 688643 & 5.5 & 5.4567 & TST & \\
\hline CHEMBL1563840 & 688643 & 6.0 & 5.3308 & TST & \\
\hline CHEMBL1554023 & 688643 & 5.2 & 5.3087 & TST & \\
\hline CHEMBL1514910 & 688643 & 4.7 & 5.4487 & TST & \\
\hline CHEMBL1409461 & 688643 & 5.3 & \multicolumn{2}{|c|}{5.3629999999999995} & TST \\
\hline CHEMBL1410865 & 688643 & 6.0 & 6.3045 & TST & \\
\hline CHEMBL1526828 & 688643 & 5.1 & 5.0098 & TST & \\
\hline CHEMBL2373608 & 688643 & 5.5 & 5.3124 & TST & \\
\hline CHEMBL1318041 & 688643 & 5.1 & 5.0363 & TST & \\
\hline CHEMBL1592936 & 688643 & 6.6 & 6.3611 & TST & \\
\hline CHEMBL1314486 & 688643 & 4.4 & 4.4153 & TST & \\
\hline CHEMBL491548 & 688643 & 4.6 & 4.5327 & TST & \\
\hline CHEMBL1358409 & 688643 & 5.4 & 5.4806 & TST & \\
\hline CHEMBL38288 & 688643 & 4.7 & 4.7643 & TST & \\
\hline CHEMBL12129 & 688643 & 5.3 & 5.6186 & TST & \\
\hline CHEMBL264931 & 688643 & 5.1 & 5.27 & TST & \\
\hline CHEMBL1475562 & 688643 & 5.1 & 4.9862 & TST & \\
\hline CHEMBL565654 & 688643 & 5.0 & 4.9552 & TST & \\
\hline CHEMBL1369318 & 688643 & 4.8 & 4.6887 & TST & \\
\hline CHEMBL1790009 & 688643 & 5.2 & 5.2898 & TST & \\
\hline CHEMBL23327 & 688643 & 4.4 & 5.034 & TST & \\
\hline CHEMBL1439839 & 688643 & 4.4 & 4.3966 & TST & \\
\hline CHEMBL1573964 & 688643 & 5.1 & 5.1372 & TST & \\
\hline CHEMBL1322959 & 688643 & 5.2 & 5.2255 & TST & \\
\hline CHEMBL346898 & 688643 & 6.1 & 6.0025 & TST & \\
\hline CHEMBL291536 & 688643 & 5.0 & 4.9827 & TST & \\
\hline CHEMBL1333156 & 688643 & 5.2 & 5.0244 & TST & \\
\hline CHEMBL1314211 & 688643 & 4.7 & 4.7675 & TST & \\
\hline CHEMBL1399249 & 688643 & 4.6 & 4.8296 & TST & \\
\hline CHEMBL1359691 & 688643 & 5.1 & 4.9996 & TST & \\
\hline CHEMBL1374544 & 688643 & 5.8 & 5.7422 & TST & \\
\hline CHEMBL1415957 & 688643 & 4.6 & 4.5285 & TST & \\
\hline CHEMBL1398299 & 688643 & 5.2 & 5.3599 & TST & \\
\hline CHEMBL1574626 & 688643 & 4.9 & 4.9564 & TST & \\
\hline & & & & 15837 & \\
\hline
\end{tabular}




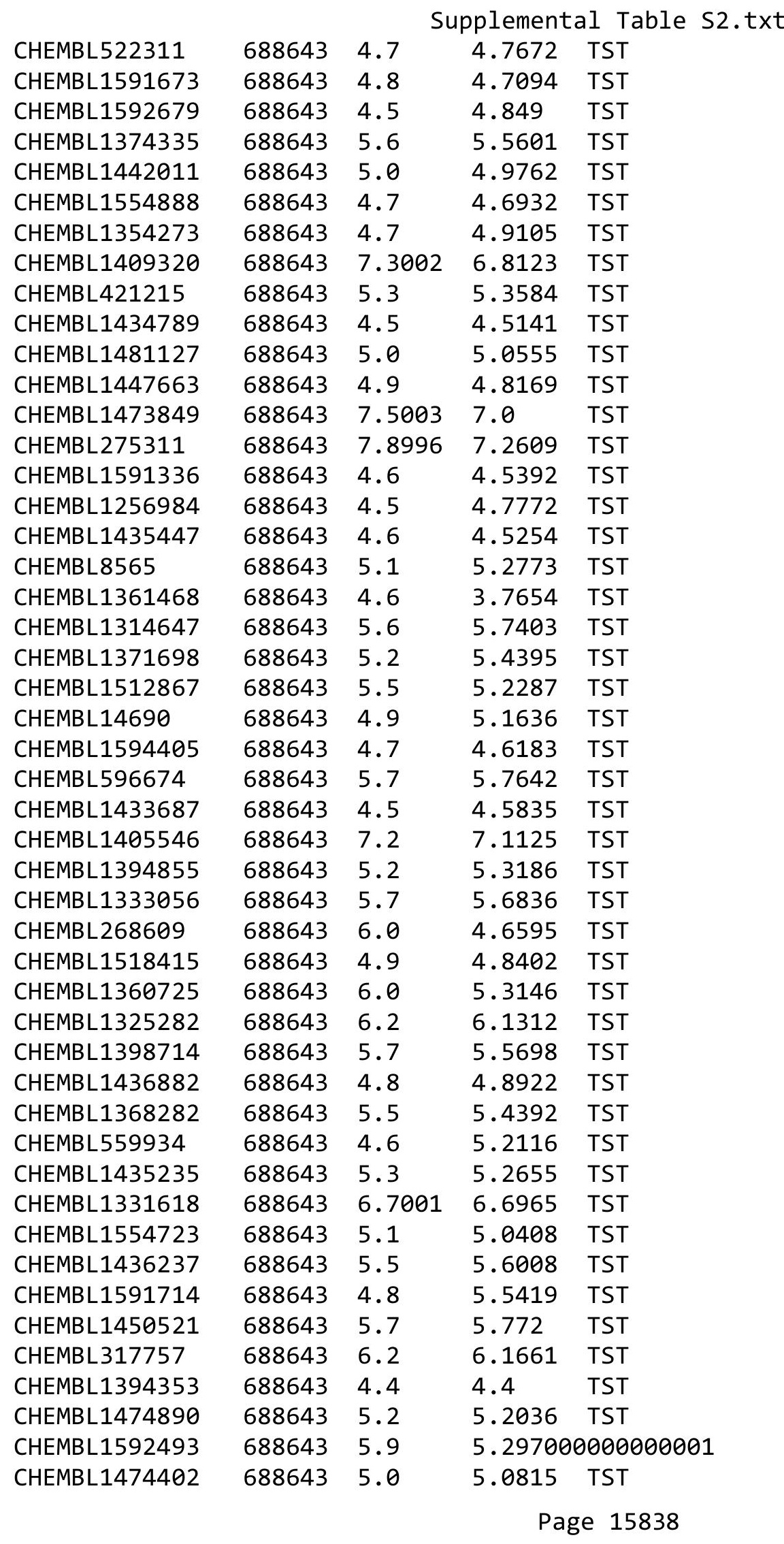




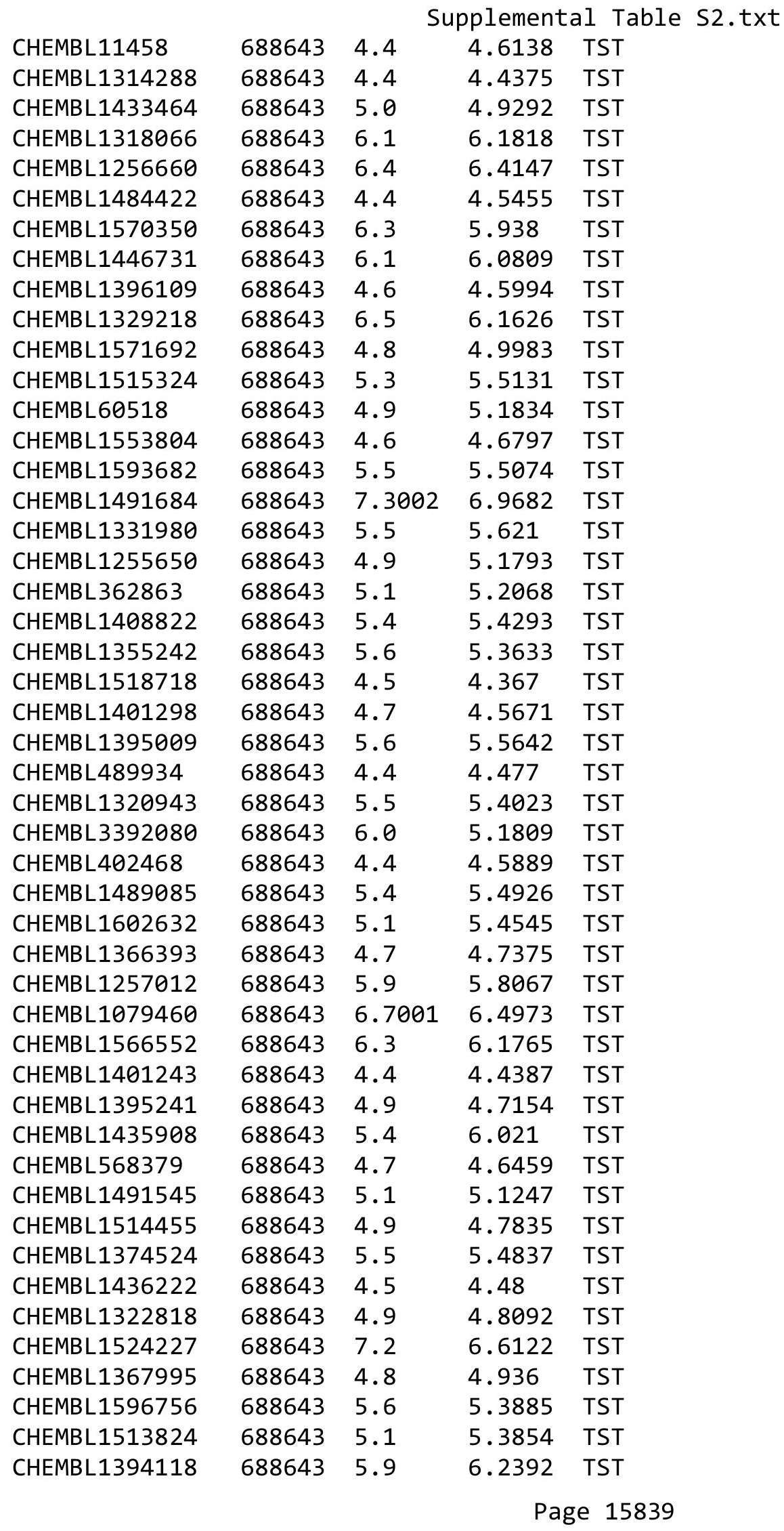




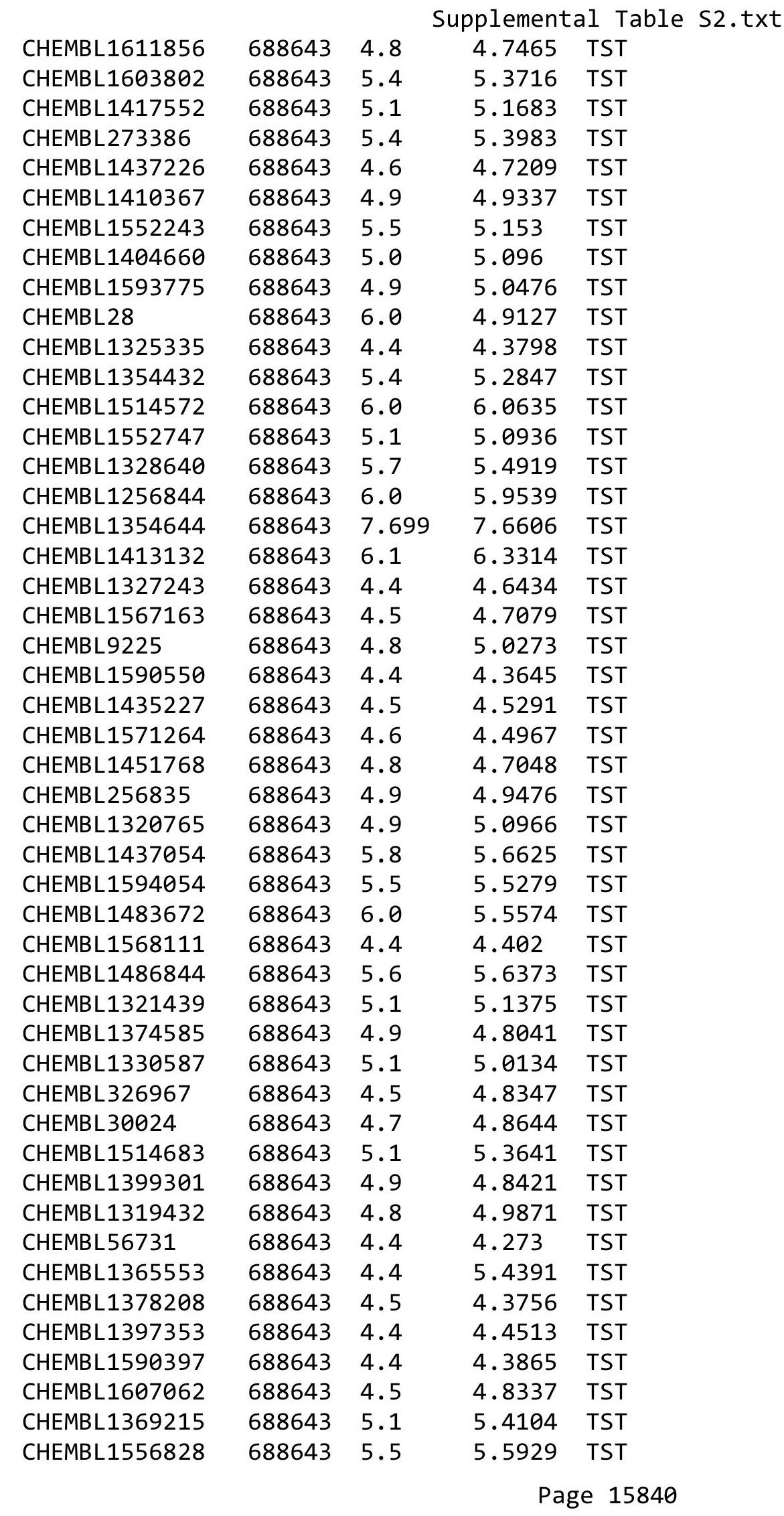




\begin{tabular}{|c|c|c|c|c|}
\hline & & & pplement & $d \perp$ \\
\hline CHEMBL1570851 & 688643 & 5.5 & 5.3686 & TST \\
\hline CHEMBL576997 & 688643 & 6.0 & 6.0388 & TST \\
\hline CHEMBL1484196 & 688643 & 4.4 & 4.3277 & TST \\
\hline CHEMBL1363801 & 688643 & 4.7 & 4.6365 & TST \\
\hline CHEMBL1552854 & 688643 & 5.7 & 5.5304 & TST \\
\hline CHEMBL1492411 & 688643 & 4.8 & 4.8312 & TST \\
\hline CHEMBL1394137 & 688643 & 4.4 & 4.467 & TST \\
\hline CHEMBL1436169 & 688643 & 5.1 & 5.0178 & TST \\
\hline CHEMBL1256869 & 688643 & 4.5 & 4.7642 & TST \\
\hline CHEMBL1395429 & 688643 & 5.0 & 5.1996 & TST \\
\hline CHEMBL1438566 & 688643 & 6.0 & 4.8491 & TST \\
\hline CHEMBL3207783 & 688643 & 5.1 & 5.2665 & TST \\
\hline CHEMBL492193 & 688643 & 6.0 & 5.0992 & TST \\
\hline CHEMBL1475079 & 688643 & 4.7 & 4.6563 & TST \\
\hline CHEMBL1607885 & 688643 & 4.9 & 4.949 & TST \\
\hline CHEMBL1568854 & 688643 & 4.4 & 4.4395 & TST \\
\hline CHEMBL1395219 & 688643 & 4.6 & 4.4635 & TST \\
\hline CHEMBL1591879 & 688643 & 5.5 & 5.4874 & TST \\
\hline CHEMBL1529330 & 688643 & 5.4 & 5.2133 & TST \\
\hline CHEMBL1592438 & 688643 & 4.9 & 4.841 & TST \\
\hline CHEMBL1736254 & 688643 & 5.8 & 5.6911 & TST \\
\hline CHEMBL1533139 & 688643 & 4.6 & 4.5577 & TST \\
\hline CHEMBL1486947 & 688643 & 5.6 & 5.568 & TST \\
\hline CHEMBL1437491 & 688643 & 4.9 & 4.993 & TST \\
\hline CHEMBL1314808 & 688643 & 4.9 & 5.7026 & TST \\
\hline CHEMBL1600780 & 688643 & 6.0 & 5.9485 & TST \\
\hline CHEMBL1554960 & 688643 & 5.5 & 5.4123 & TST \\
\hline CHEMBL500996 & 688643 & 4.5 & 4.9507 & TST \\
\hline CHEMBL1595576 & 688643 & 5.0 & 4.9569 & TST \\
\hline CHEMBL1572239 & 688643 & 5.2 & 5.3719 & TST \\
\hline CHEMBL1396792 & 688643 & 4.6 & 4.5614 & TST \\
\hline CHEMBL1556700 & 688643 & 4.4 & 4.4322 & TST \\
\hline CHEMBL1551090 & 688643 & 4.6 & 4.5961 & TST \\
\hline CHEMBL1317373 & 688643 & 4.5 & 4.4442 & TST \\
\hline CHEMBL1395029 & 688643 & 4.4 & 4.4114 & TST \\
\hline CHEMBL1593365 & 688643 & 4.4 & 4.4858 & TST \\
\hline CHEMBL1394774 & 688643 & 4.8 & 4.6696 & TST \\
\hline CHEMBL1372037 & 688643 & 4.9 & 5.1185 & TST \\
\hline CHEMBL19259 & 688643 & 7.8996 & 7.3552 & TST \\
\hline CHEMBL1337960 & 688643 & 5.3 & 5.2289 & TST \\
\hline CHEMBL1475311 & 688643 & 5.6 & 5.3967 & TST \\
\hline CHEMBL492121 & 688643 & 5.6 & 5.5532 & TST \\
\hline CHEMBL1256511 & 688643 & 5.4 & 5.0937 & TST \\
\hline CHEMBL1494182 & 688643 & 4.7 & 4.8983 & TST \\
\hline CHEMBL1319672 & 688643 & 6.2 & 5.905 & TST \\
\hline CHEMBL1475200 & 688643 & 8.2007 & 5.4989 & TST \\
\hline CHEMBL605003 & 688643 & 4.5 & 4.7759 & TST \\
\hline CHEMBL1476851 & 688643 & 4.4 & 4.6029 & TST \\
\hline
\end{tabular}




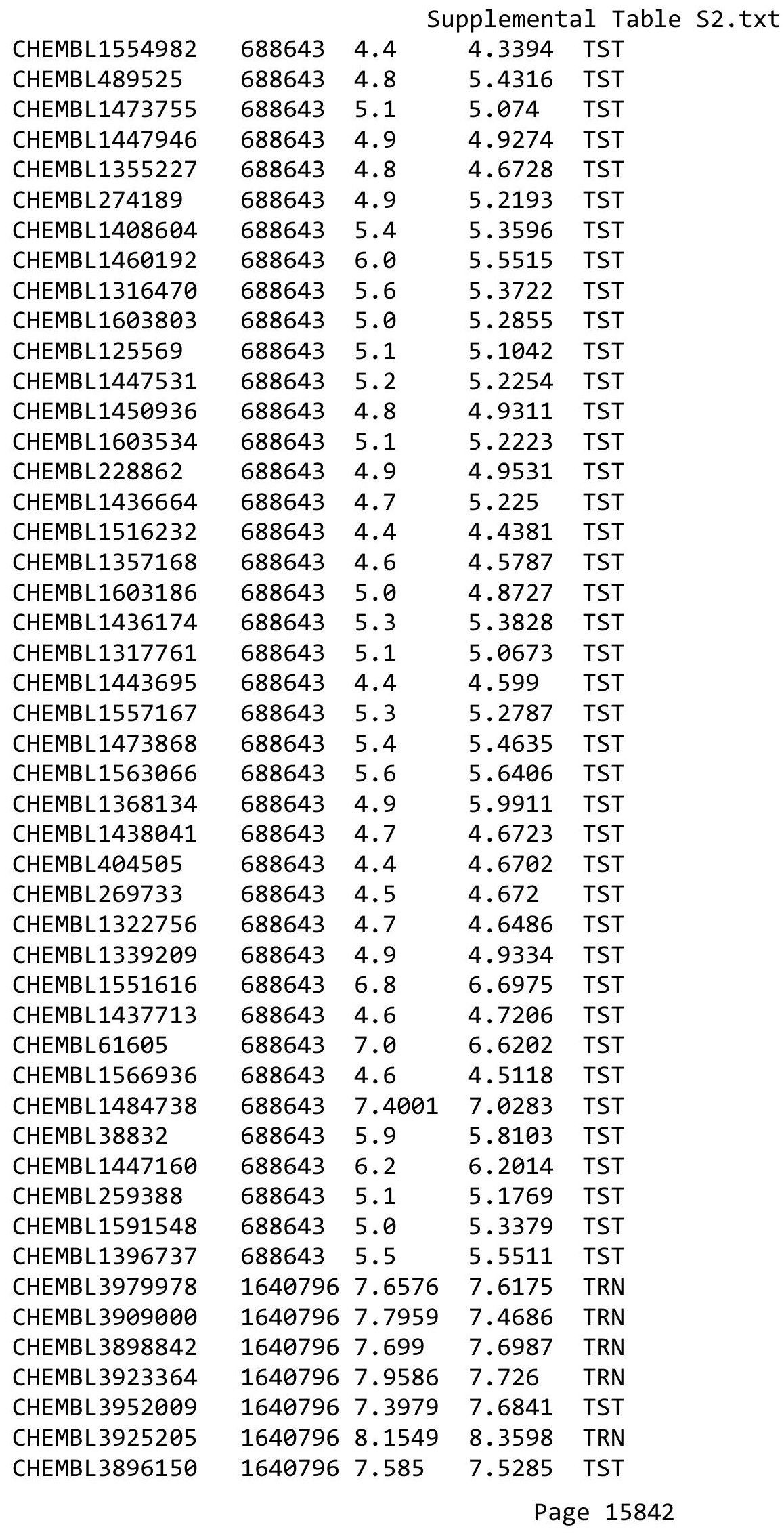


Supplemental Table S2.txt

\begin{tabular}{|c|c|c|}
\hline AEMBL3928863 & & \\
\hline & & .0969 \\
\hline IFMRI = & & 6.0 \\
\hline IEMBL3 & & 958 \\
\hline AEMBL3935023 & ב & \\
\hline HEMBL3917379 & 640796 & 7.61 \\
\hline AEMBL3932237 & & 7.638 \\
\hline IEMBL 3898204 & & 8397 \\
\hline AEMBL3905102 & & 221 \\
\hline HEMBL3956295 & 6 & 95 \\
\hline HEMBL3903884 & 16 & 9.0 \\
\hline AEMBL3963827 & & .920 \\
\hline IEMBL 3914356 & & .886 \\
\hline HEMBL3967392 & 16 & 9.0 \\
\hline AEMBL3984169 & 6 & 8.221 \\
\hline AEMBL3953089 & 16 & 15 \\
\hline AEMBL3966701 & 16 & 8.397 \\
\hline AEMBL3936239 & 16 & 7.3565 \\
\hline HEMBL3980874 & 16 & 397 \\
\hline IEMBL3 & & 366 \\
\hline AEMBL; & 16 & 6.0 \\
\hline 79444 & 16 & 6.0 \\
\hline 90672 & & 8.699 \\
\hline AEMBL3903697 & 16 & 7.721 \\
\hline AEMBL3949873 & & 7.920 \\
\hline IEMBL3943493 & 16 & 7.568 \\
\hline IEMBL & 16 & 7.769 \\
\hline IEMBL & 16 & 9.0 \\
\hline IEMBL3935180 & 16 & 9.0 \\
\hline AEMBL3973012 & 16 & 9.0 \\
\hline AEMBL3987026 & & 8.522 \\
\hline IEMBL & 16 & 7.795 \\
\hline IEMB & 16 & 7.4685 \\
\hline AEMBL3940702 & 16 & 8.699 \\
\hline HEMBL3957977 & 16 & 9.0 \\
\hline AEMBL3926281 & 16 & 7.958 \\
\hline AEMBL & 16 & 8.096 \\
\hline HEMBL & 16 & 7.6198 \\
\hline HEMBL3967508 & 16 & 7.387 \\
\hline AEMBL3974585 & 16 & 8.522 \\
\hline CHEMBL 3 & 16 & 7.7959 \\
\hline CHEMBL 3943279 & 16 & 7.699 \\
\hline CHEMBL3951026 & 16 & 8.5229 \\
\hline CHEMBL3941232 & 16 & 8.096 \\
\hline CHEMBL 3980052 & 164 & 7.468 \\
\hline CHEMBL 3970295 & 164 & 8.221 \\
\hline CHEMBL39104 & 64 & 7.769 \\
\hline CHEMBL394 & & 0 \\
\hline
\end{tabular}

$\begin{array}{ll}8.219 & \text { TRN } \\ 7.8653 & \text { TRN } \\ 7.0467 & \text { TRN } \\ 7.7318 & \text { TRN } \\ 8.0876 & \text { TRN }\end{array}$

7.6593 TST

7.8724 TRN

8.021 TRN

8.3989 TRN

8.1446 TRN

8.3062 TRN

8.3143 TRN

7.669 TRN

8.6251 TRN

7.6717 TRN

7.8831 TRN

8.2205 TRN

7.7061 TRN

8.4808 TRN

7.1001 TRN

6.7422 TRN

6.6353 TRN

8.0112 TRN

7.4861 TRN

7.4692 TST

7.6672 TRN

7.3202 TST

9.1979 TRN

8.7227 TRN

9.2803 TRN

8.3745 TRN

7.7362 TRN

7.4831 TST

9.1089 TRN

9.2603 TRN

7.0765 TRN

8.12 TRN

7.7026 TRN

7.5609 TST

8.5794 TRN

7.9787 TST

7.8337 TRN

8.2401 TRN

8.4711 TRN

7.5814 TST

8.3388 TST

7.9665 TST

$9.197000000000001 \quad$ TST

Page 15843 
Supplemental Table S2.txt

\begin{tabular}{|c|c|c|c|c|c|}
\hline CHEMBL 3970786 & 1640796 & 8.0969 & 8.5643 & TST & \\
\hline CHEMBL3963636 & 1640796 & 7.699 & 8.3923 & TST & \\
\hline CHEMBL3971118 & 1640796 & 9.0 & 8.5123 & TST & \\
\hline CHEMBL54344 & 64687 & 4.2034 & 2.6368 & TST & \\
\hline CHEMBL54714 & 64687 & 4.0605 & 4.1102 & TRN & \\
\hline CHEMBL52306 & 64687 & 2.699 & 2.6496 & TST & \\
\hline CHEMBL55222 & 64687 & 2.699 & 2.8946 & TST & \\
\hline CHEMBL54004 & 64687 & 4.8761 & 4.2983 & TRN & \\
\hline CHEMBL56253 & 64687 & 4.7959 & 2.8781 & TST & \\
\hline CHEMBL55779 & 64687 & 2.699 & 2.5304 & TST & \\
\hline CHEMBL52621 & 64687 & 2.699 & 2.7093 & TRN & \\
\hline CHEMBL55027 & 64687 & 4.5452 & 4.5661 & TRN & \\
\hline CHEMBL293116 & 64687 & 2.699 & 2.7031 & TRN & \\
\hline CHEMBL 298852 & 64687 & 4.9586 & 4.2983 & TRN & \\
\hline CHEMBL 301572 & 64687 & 2.699 & 2.2082 & TST & \\
\hline CHEMBL55352 & 64687 & 2.699 & 2.4049 & TST & \\
\hline CHEMBL55856 & 64687 & 4.433 & 4.4429 & TRN & \\
\hline CHEMBL291736 & 64687 & 2.699 & 2.8174 & TRN & \\
\hline CHEMBL431735 & 64687 & 4.8069 & 4.75899 & 99999999995 & TRN \\
\hline CHEMBL 300361 & 64687 & 2.699 & 3.1946 & TST & \\
\hline CHEMBL56028 & 64687 & 3.7645 & 3.6771 & TRN & \\
\hline CHEMBL56047 & 64687 & 4.1487 & 2.7844 & TST & \\
\hline CHEMBL56556 & 64687 & 2.699 & 2.7579 & TRN & \\
\hline CHEMBL55889 & 64687 & 2.699 & 2.7044 & TRN & \\
\hline CHEMBL55810 & 64687 & 4.1308 & 4.2983 & TRN & \\
\hline CHEMBL431139 & 64687 & 2.699 & 2.6893 & TRN & \\
\hline CHEMBL417198 & 64687 & 2.699 & 2.6669 & TRN & \\
\hline CHEMBL55886 & 64687 & 2.699 & 2.6105 & TRN & \\
\hline CHEMBL54056 & 64687 & 2.699 & 2.6567 & TRN & \\
\hline CHEMBL299491 & 64687 & 2.699 & 2.8096 & TRN & \\
\hline CHEMBL58830 & 64687 & 4.4449 & 2.8568 & TST & \\
\hline CHEMBL416301 & 64687 & 4.1959 & 4.2983 & TRN & \\
\hline CHEMBL52251 & 64687 & 4.5072 & 3.5885 & TRN & \\
\hline CHEMBL 293479 & 64687 & 5.0575 & 5.0585 & TRN & \\
\hline CHEMBL56255 & 64687 & 2.699 & 2.8907 & TRN & \\
\hline CHEMBL54926 & 64687 & 2.699 & 2.6979 & TST & \\
\hline CHEMBL52620 & 64687 & 3.752 & 3.78899 & 99999999997 & TRN \\
\hline CHEMBL55959 & 64687 & 4.1938 & 4.1969 & TRN & \\
\hline CHEMBL298771 & 64687 & 2.699 & 2.7275 & TRN & \\
\hline CHEMBL301854 & 64687 & 4.0173 & 3.9739 & TRN & \\
\hline CHEMBL417549 & 64687 & 3.8665 & 3.5885 & TRN & \\
\hline CHEMBL433833 & 64687 & 4.4413 & 4.2233 & TRN & \\
\hline CHEMBL299988 & 64687 & 3.8041 & 3.6493 & TRN & \\
\hline CHEMBL55572 & 64687 & 2.699 & 4.2983 & TRN & \\
\hline CHEMBL55988 & 64687 & 4.2708 & 3.0556 & TST & \\
\hline CHEMBL52761 & 64687 & 2.699 & 2.6092 & TRN & \\
\hline CHEMBL 291727 & 64687 & 2.699 & 2.727 & TRN & \\
\hline CHEMBL53982 & 64687 & 5.1878 & 5.1511 & TRN & \\
\hline
\end{tabular}




\begin{tabular}{|c|c|c|c|c|c|}
\hline & & \multicolumn{4}{|c|}{ Supplemental Table S2.txt } \\
\hline CHEMBL417932 & 64687 & 2.699 & 2.7215 & TRN & \\
\hline CHEMBL56704 & 64687 & 2.699 & 2.6022 & TST & \\
\hline CHEMBL301247 & 64687 & 2.699 & 2.6472 & TRN & \\
\hline CHEMBL55371 & 64687 & 5.1805 & 5.1899 & TRN & \\
\hline CHEMBL417419 & 64687 & 2.699 & 2.7067 & TRN & \\
\hline CHEMBL294478 & 64687 & 2.699 & 2.6664 & TRN & \\
\hline CHEMBL298547 & 64687 & 4.6517 & 4.2983 & TRN & \\
\hline CHEMBL56011 & 64687 & 3.8697 & 3.8992 & TRN & \\
\hline CHEMBL55359 & 64687 & 2.699 & 2.6355 & TRN & \\
\hline CHEMBL54747 & 64687 & 4.9066 & 4.8295 & TRN & \\
\hline CHEMBL52137 & 64687 & 2.699 & 2.2549 & TST & \\
\hline CHEMBL55608 & 64687 & 2.699 & 2.7231 & TRN & \\
\hline CHEMBL54537 & 64687 & 4.3458 & 4.5264 & TRN & \\
\hline CHEMBL434978 & 64687 & 5.4001 & 5.3839 & TRN & \\
\hline CHEMBL55464 & 64687 & 4.6882 & 4.704 & TRN & \\
\hline CHEMBL55221 & 64687 & 2.699 & 3.0916 & TST & \\
\hline CHEMBL55140 & 64687 & 2.699 & 2.7284 & TRN & \\
\hline CHEMBL55353 & 64687 & 4.3251 & 3.0306 & TST & \\
\hline CHEMBL301954 & 64687 & 3.7122 & 3.8996 & TST & \\
\hline CHEMBL301471 & 64687 & 2.699 & 2.7022 & TRN & \\
\hline CHEMBL294191 & 64687 & 2.699 & $2.7560 e$ & 00000000002 & TRN \\
\hline CHEMBL434024 & 64687 & 2.699 & 2.7051 & TRN & \\
\hline CHEMBL301065 & 64687 & 4.2218 & 4.2741 & TRN & \\
\hline CHEMBL54480 & 64687 & 4.1851 & 4.2037 & TRN & \\
\hline CHEMBL54124 & 64687 & 2.699 & 2.742 & TRN & \\
\hline CHEMBL55557 & 64687 & 2.699 & 2.6667 & TRN & \\
\hline CHEMBL54888 & 64687 & 3.8794 & 4.2233 & TRN & \\
\hline CHEMBL293522 & 64687 & 2.699 & 2.7478 & TRN & \\
\hline CHEMBL299717 & 64687 & 2.699 & 2.7668 & TRN & \\
\hline CHEMBL 301244 & 64687 & 3.8447 & 3.7587 & TRN & \\
\hline CHEMBL56254 & 64687 & 2.699 & 3.5885 & TRN & \\
\hline CHEMBL56078 & 64687 & 4.6635 & 4.6779 & TRN & \\
\hline CHEMBL430963 & 64687 & 4.4034 & 4.3453 & TRN & \\
\hline CHEMBL412889 & 64687 & 4.8097 & 2.8781 & TST & \\
\hline CHEMBL300532 & 64687 & 4.3546 & 4.3134 & TRN & \\
\hline CHEMBL55837 & 64687 & 4.3565 & 4.2983 & TRN & \\
\hline CHEMBL299443 & 64687 & 2.699 & 2.6955 & TRN & \\
\hline CHEMBL292224 & 64687 & 3.9469 & 2.9179 & TST & \\
\hline CHEMBL299563 & 64687 & 2.699 & 2.4968 & TST & \\
\hline CHEMBL55264 & 64687 & 4.5302 & 4.2983 & TST & \\
\hline CHEMBL54472 & 64687 & 2.699 & 2.2549 & TST & \\
\hline CHEMBL300755 & 64687 & 4.7167 & 4.7592 & TRN & \\
\hline CHEMBL54925 & 64687 & 2.699 & 2.7036 & TRN & \\
\hline CHEMBL55582 & 64687 & 2.699 & 3.3901 & TST & \\
\hline CHEMBL56073 & 64687 & 4.6308 & 4.4755 & TRN & \\
\hline CHEMBL294192 & 64687 & 2.699 & 2.5939 & TRN & \\
\hline CHEMBL55358 & 64687 & 2.699 & 2.9332 & TST & \\
\hline CHEMBL55518 & 64687 & 2.699 & 2.6537 & TRN & \\
\hline
\end{tabular}


Supplemental Table S2.txt

\begin{tabular}{|c|c|c|c|c|c|}
\hline CHEMBL301857 & 64687 & 2.699 & 2.7056 & TRN & \\
\hline CHEMBL 3896319 & 1528762 & 9.251 & 9.126 & TRN & \\
\hline CHEMBL 3960644 & 1528762 & 9.2097 & 8.5475 & TRN & \\
\hline CHEMBL 3959259 & 1528762 & 8.4283 & 9.3051 & TRN & \\
\hline CHEMBL3691423 & 1528762 & 8.3449 & 8.68 & TST & \\
\hline CHEMBL 3691393 & 1528762 & 9.4828 & 8.2236 & TRN & \\
\hline CHEMBL 3968510 & 1528762 & 9.3565 & 8.962 & TRN & \\
\hline CHEMBL 3691434 & 1528762 & 8.5258 & 7.7903 & TRN & \\
\hline CHEMBL 3904129 & 1528762 & 9.5935 & 9.1179 & TRN & \\
\hline CHEMBL3691464 & 1528762 & 7.9957 & 7.5844 & TRN & \\
\hline CHEMBL 3695558 & 1528762 & 9.4389 & 8.8766 & TRN & \\
\hline CHEMBL 3695500 & 1528762 & 9.0788 & 8.4359 & TRN & \\
\hline CHEMBL 3691418 & 1528762 & 8.5686 & 9.1688 & TST & \\
\hline CHEMBL 3691463 & 1528762 & 8.5391 & 9.0625 & TST & \\
\hline CHEMBL3695498 & 1528762 & 9.1952 & 8.5405 & TRN & \\
\hline CHEMBL 3695499 & 1528762 & 8.8268 & 8.2345 & TST & \\
\hline CHEMBL3691417 & 1528762 & 10.0 & 9.2525 & TST & \\
\hline CHEMBL 3977015 & 1528762 & 7.7825 & 8.7061 & TRN & \\
\hline CHEMBL 3695519 & 1528762 & 9.5768 & 9.3328 & TRN & \\
\hline CHEMBL3691433 & 1528762 & 8.9281 & 8.8707 & TST & \\
\hline CHEMBL 3934637 & 1528762 & 9.8416 & 9.0346 & TRN & \\
\hline CHEMBL 3964235 & 1528762 & 9.5686 & 9.1041 & TRN & \\
\hline CHEMBL 3691414 & 1528762 & 8.4157 & 7.9658 & TRN & \\
\hline CHEMBL 3695540 & 1528762 & 8.4248 & 8.6644 & TRN & \\
\hline CHEMBL 3691432 & 1528762 & 6.8761 & 8.1452 & TRN & \\
\hline CHEMBL 3695494 & 1528762 & 8.762 & 8.7192 & TST & \\
\hline CHEMBL 3691430 & 1528762 & 9.4535 & 8.4441 & TRN & \\
\hline CHEMBL 3691422 & 1528762 & 8.7471 & 8.1212 & TST & \\
\hline CHEMBL 3691444 & 1528762 & 8.4486 & 8.2258 & TRN & \\
\hline CHEMBL 3959319 & 1528762 & 6.0 & 8.3777 & TRN & \\
\hline CHEMBL 3934605 & 1528762 & 7.7545 & 9.0529 & TRN & \\
\hline CHEMBL 3956447 & 1528762 & 8.8069 & 8.6657 & TRN & \\
\hline CHEMBL 3913131 & 1528762 & 8.8182 & 8.3922 & TRN & \\
\hline CHEMBL 3929438 & 1528762 & 8.4535 & 8.5393 & TRN & \\
\hline CHEMBL 3691453 & 1528762 & 6.0 & 8.417 & TRN & \\
\hline CHEMBL 3695508 & 1528762 & 8.8447 & 9.1107 & TRN & \\
\hline CHEMBL 3695503 & 1528762 & 9.0255 & 8.7693 & TRN & \\
\hline CHEMBL 3695566 & 1528762 & 6.0 & 8.7843 & TRN & \\
\hline CHEMBL 3695551 & 1528762 & 7.9469 & 8.3886 & TRN & \\
\hline CHEMBL 3695502 & 1528762 & 9.4737 & 9.1872 & TRN & \\
\hline CHEMBL 3938955 & 1528762 & 9.9101 & 9.5746 & TRN & \\
\hline CHEMBL 3973105 & 1528762 & 8.6126 & 8.1018 & TRN & \\
\hline CHEMBL 3983637 & 1528762 & 9.4449 & 9.5824 & TRN & \\
\hline CHEMBL 3691429 & 1528762 & 8.8697 & 9.1215 & TRN & \\
\hline CHEMBL 3929935 & 1528762 & 6.0 & 8.5559 & TRN & \\
\hline CHEMBL 3695510 & 1528762 & 8.1938 & 8.5388 & TRN & \\
\hline CHEMBL 3695515 & 1528762 & 9.34100 & 000000000 & 11 & 9.2358 \\
\hline CHEMBL 3951164 & 1528762 & 7.6326 & 8.6662 & TRN & \\
\hline
\end{tabular}


Supplemental Table S2.txt

\begin{tabular}{|c|c|c|c|c|}
\hline CHEMBL 3691466 & 1528762 & 8.0434 & 7.9166 & TST \\
\hline CHEMBL 3695501 & 1528762 & 8.0964 & 7.8034 & TST \\
\hline CHEMBL3951882 & 1528762 & 9.8477 & 9.2759 & TRN \\
\hline CHEMBL 3695564 & 1528762 & 9.7122 & 9.0212 & TRN \\
\hline CHEMBL 3691475 & 1528762 & 8.8416 & 9.3605 & TRN \\
\hline CHEMBL3691473 & 1528762 & 8.9666 & 8.684 & TRN \\
\hline CHEMBL3695559 & 1528762 & 8.0737 & 8.4093 & TRN \\
\hline CHEMBL3691472 & 1528762 & 8.2899 & 8.5644 & TRN \\
\hline CHEMBL 3695531 & 1528762 & 8.9957 & 7.5312 & TRN \\
\hline CHEMBL3960909 & 1528762 & 8.7496 & 8.3896 & TRN \\
\hline CHEMBL 3695542 & 1528762 & 8.6655 & 8.2132 & TRN \\
\hline CHEMBL3911937 & 1528762 & 9.6271 & 8.6417 & TRN \\
\hline CHEMBL3971996 & 1528762 & 9.7878 & 8.8783 & TRN \\
\hline CHEMBL 3695506 & 1528762 & 8.8697 & 8.6613 & TRN \\
\hline CHEMBL3691391 & 1528762 & 6.0 & 8.2765 & TRN \\
\hline CHEMBL3695507 & 1528762 & 8.5768 & 8.5742 & TST \\
\hline CHEMBL3691442 & 1528762 & 8.1669 & 8.3003 & TRN \\
\hline CHEMBL 3695509 & 1528762 & 8.567 & 8.2262 & TRN \\
\hline CHEMBL3973103 & 1528762 & 9.76700 & 000000000 & 8.6859 \\
\hline CHEMBL 3691438 & 1528762 & 8.1367 & 7.92 & TRN \\
\hline CHEMBL 3919003 & 1528762 & 6.0 & 6.8337 & TST \\
\hline CHEMBL3691474 & 1528762 & 8.7258 & 8.8211 & TRN \\
\hline CHEMBL 3691394 & 1528762 & 8.9508 & 8.4197 & TRN \\
\hline CHEMBL3691465 & 1528762 & 6.0 & 6.8182 & TRN \\
\hline CHEMBL 3957010 & 1528762 & 9.5129 & 8.7576 & TRN \\
\hline CHEMBL 3920255 & 1528762 & 9.644 & 9.139 & TRN \\
\hline CHEMBL 3958677 & 1528762 & 10.757 & 9.031 & TRN \\
\hline CHEMBL 3691390 & 1528762 & 9.2924 & 8.3455 & TRN \\
\hline CHEMBL3695495 & 1528762 & 7.699 & 7.846 & TRN \\
\hline CHEMBL 3948059 & 1528762 & 9.7077 & 9.2677 & TRN \\
\hline CHEMBL 3691468 & 1528762 & 8.1858 & 8.6062 & TRN \\
\hline CHEMBL 3695567 & 1528762 & 8.6904 & 8.4217 & TRN \\
\hline CHEMBL 3691420 & 1528762 & 7.8697 & 8.7078 & TRN \\
\hline CHEMBL3695562 & 1528762 & 9.2518 & 8.2318 & TRN \\
\hline CHEMBL 3691454 & 1528762 & 6.0 & 7.3052 & TRN \\
\hline CHEMBL3691467 & 1528762 & 7.9355 & 9.001 & TRN \\
\hline CHEMBL3695527 & 1528762 & 8.0009 & 9.189 & TRN \\
\hline CHEMBL 3695521 & 1528762 & 9.3098 & 8.4052 & TRN \\
\hline CHEMBL 3691424 & 1528762 & 8.6596 & 8.7672 & TST \\
\hline CHEMBL 3898525 & 1528762 & 9.4318 & 9.4397 & TRN \\
\hline CHEMBL 3913497 & 1528762 & 10.1568 & 9.3873 & TRN \\
\hline CHEMBL 3695536 & 1528762 & 9.0434 & 8.9038 & TST \\
\hline CHEMBL 3695523 & 1528762 & 8.8239 & 8.6878 & TRN \\
\hline CHEMBL3695554 & 1528762 & 8.3737 & 8.0504 & TRN \\
\hline CHEMBL 3691437 & 1528762 & 9.0482 & 8.1901 & TRN \\
\hline CHEMBL 3691411 & 1528762 & 9.4908 & 8.312999 & 9999999999 \\
\hline CHEMBL 3695492 & 1528762 & 9.0182 & 9.1649 & TRN \\
\hline CHEMBL 3695518 & 1528762 & 6.0 & 8.4354 & TRN \\
\hline
\end{tabular}


Supplemental Table S2.txt

\begin{tabular}{|c|c|c|c|c|}
\hline - & & & & \\
\hline & & 10.0477 & 9.1944 & \\
\hline & 762 & & 6881 & \\
\hline IEMBL & & & & \\
\hline AEMBL & 528762 & 48 & 4583 & \\
\hline HEMBL3691419 & 528762 & 8.6478 & 8.73 & \\
\hline & & 605 & 4447 & \\
\hline 57 & & & 2108 & \\
\hline AEMBL & 762 & 6.0 & 8.8591 & \\
\hline HEMBL3890184 & 528762 & 6.0 & 9092 & \\
\hline HEMBL3695496 & 762 & 8.16 & 7056 & \\
\hline IEMBL: & 62 & & 3707 & \\
\hline EMBL & & & 1944 & \\
\hline AEMBL 369 & 62 & 086 & 8.612 & \\
\hline AEMBL3695511 & 62 & 8 & 538 & \\
\hline AEMBL3691 & $2<$ & 9 & 2003 & \\
\hline AEMBL & 2 & 10.6198 & 085 & \\
\hline HEMBL & & & 556 & \\
\hline AEMBL3 & & 9.5482 & 7197 & \\
\hline IEMBL3 & & 8 . & 928 & \\
\hline AEIMBL. & 22 & & 453 & \\
\hline AEMBL & & & 802 & וד \\
\hline AEMBL & & & 948 & \\
\hline 553 & & & 1899 & \\
\hline HEMBL 369 & & & & TST \\
\hline AEMBL & & & 316 & RN \\
\hline AEME & & & 521 & וד \\
\hline AFMBI & & & .053 & \\
\hline AEMBL3 & & & 1258 & RIV \\
\hline HEMBL 3944 & & & 23 & $\Gamma \mathrm{RN}$ \\
\hline HEMBL & & & 7623 & RN \\
\hline AEME & & & 296 & KIN \\
\hline 92 & & 9. & 201 & TRN \\
\hline HEMBL3695514 & & 8 . & 3736 & 15 \\
\hline HEMBL3691409 & 52 & 9.3546 & 7066 & TST \\
\hline HEMBL3639944 & & 15 & 2682 & ГST \\
\hline 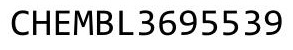 & & & & ST \\
\hline HEMBL & & & 4878 & ST \\
\hline HEMBL3695561 & 62 & 496 & 4444 & TRN \\
\hline IEMBL3 & & 14 & 889 & RN \\
\hline HEMBL3 & & 27 & 1008 & \\
\hline HEMBL3900890 & & & 313 & RIV \\
\hline HEMBL3899556 & 762 & 8.9245 & 8.5288 & RN \\
\hline AEMBL3982111 & 762 & 10.0223 & 967 & TR \\
\hline 1 & & & 149 & 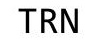 \\
\hline HEMBL 369 & & & 9744 & \\
\hline HEMBL3901223 & & 8.0119 & 8.2081 & \\
\hline CHEMBL3911327 & 1528762 & 8.4101 & 8.4866 & ГRN \\
\hline
\end{tabular}

Page 15848 
Supplemental Table S2.txt

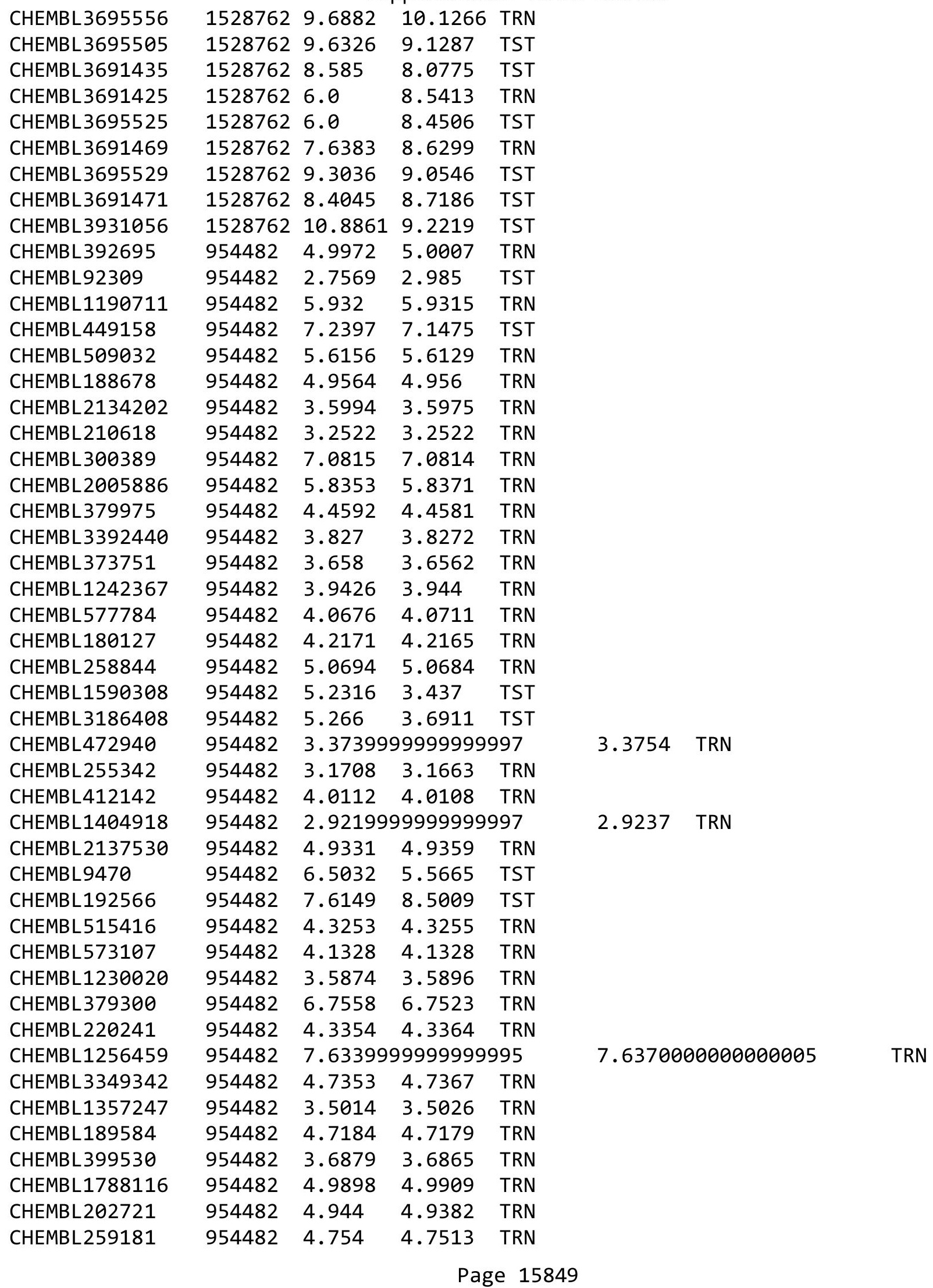


Supplemental Table S2.txt

\begin{tabular}{|c|c|c|c|c|}
\hline CHEMBL3199475 & 954482 & 4.819 & 4.8198 & TRN \\
\hline CHEMBL1643959 & 954482 & 4.2633 & 4.2615 & TRN \\
\hline CHEMBL 2363137 & 954482 & 5.1704 & 5.1699 & TRN \\
\hline CHEMBL585951 & 954482 & 6.4086 & 6.40600 & 0000000001 \\
\hline CHEMBL483849 & 954482 & 2.536 & 1.8319 & TST \\
\hline CHEMBL213100 & 954482 & 6.4558 & 6.4571 & TRN \\
\hline CHEMBL209148 & 954482 & 5.0507 & 5.0519 & TRN \\
\hline CHEMBL483847 & 954482 & 4.1264 & 4.1277 & TRN \\
\hline CHEMBL1186585 & 954482 & 4.3125 & 4.3174 & TRN \\
\hline CHEMBL65 & 954482 & 8.0014 & 8.0022 & TRN \\
\hline CHEMBL191334 & 954482 & 5.2412 & 5.2408 & TRN \\
\hline CHEMBL135561 & 954482 & 4.4021 & 4.3977 & TRN \\
\hline CHEMBL240954 & 954482 & 4.3386 & 3.5394 & TST \\
\hline CHEMBL1673039 & 954482 & 4.8521 & 4.8558 & TRN \\
\hline CHEMBL512504 & 954482 & 3.9301 & 3.9308 & TRN \\
\hline CHEMBL217354 & 954482 & 6.1324 & 6.1314 & TRN \\
\hline CHEMBL 2144069 & 954482 & 4.3184 & 4.3172 & TRN \\
\hline CHEMBL1970879 & 954482 & 6.1218 & 5.3896 & TST \\
\hline CHEMBL393929 & 954482 & 3.6852 & 3.7104 & TST \\
\hline CHEMBL221137 & 954482 & 5.0295 & 4.546 & TST \\
\hline CHEMBL558642 & 954482 & 4.2893 & 4.6365 & TST \\
\hline CHEMBL102714 & 954482 & 3.7099 & 3.5944 & TST \\
\hline CHEMBL514499 & 954482 & 6.7264 & 6.8394 & TST \\
\hline CHEMBL1909414 & 954482 & 3.5029 & 3.7841 & TST \\
\hline CHEMBL1516890 & 954482 & 4.9206 & 4.1678 & TST \\
\hline CHEMBL222102 & 954482 & 3.4347 & 4.0985 & TST \\
\hline CHEMBL229541 & 439367 & 8.3979 & 8.3381 & TRN \\
\hline CHEMBL227292 & 439367 & 4.699 & 4.7697 & TRN \\
\hline CHEMBL227167 & 439367 & 6.8239 & 6.729 & TRN \\
\hline CHEMBL375267 & 439367 & 7.0458 & 7.0069 & TRN \\
\hline CHEMBL229708 & 439367 & 4.699 & 4.7278 & TRN \\
\hline CHEMBL229592 & 439367 & 5.2218 & 5.2042 & TRN \\
\hline CHEMBL226949 & 439367 & 8.2924 & 8.3084 & TRN \\
\hline CHEMBL226809 & 439367 & 8.1549 & 8.1587 & TRN \\
\hline CHEMBL390592 & 439367 & 7.4559 & 7.4769 & TRN \\
\hline CHEMBL229540 & 439367 & 9.0 & 9.0669 & TRN \\
\hline CHEMBL227293 & 439367 & 6.699 & 6.6623 & TRN \\
\hline CHEMBL229647 & 439367 & 5.5086 & 6.769 & TST \\
\hline CHEMBL436982 & 439367 & 8.585 & 8.6008 & TRN \\
\hline CHEMBL229489 & 439367 & 8.3768 & 8.4741 & TRN \\
\hline CHEMBL226885 & 439367 & 8.1739 & 8.122 & TRN \\
\hline CHEMBL229147 & 439367 & 6.0 & 6.75799 & 9999999999 \\
\hline CHEMBL387957 & 439367 & 5.2218 & 5.2422 & TRN \\
\hline CHEMBL229435 & 439367 & 8.4949 & 8.4088 & TRN \\
\hline CHEMBL226950 & 439367 & 7.9586 & 7.9804 & TRN \\
\hline CHEMBL227046 & 439367 & 9.1249 & 9.0145 & TRN \\
\hline CHEMBL389034 & 439367 & 8.4815 & 8.5064 & TRN \\
\hline CHEMBL226808 & 439367 & 7.8861 & 7.8754 & TRN \\
\hline
\end{tabular}




\begin{tabular}{|c|c|c|c|c|c|}
\hline & & & & & \\
\hline CHEMBL227115 & 439367 & 8.2518 & 7.6845 & TST & \\
\hline CHEMBL229148 & 439367 & 3.0 & 6.4798 & TST & \\
\hline CHEMBL227294 & 439367 & 7.2007 & 7.25899 & 99999999995 & TRN \\
\hline CHEMBL229482 & 439367 & 5.4559 & 5.4754 & TRN & \\
\hline CHEMBL227328 & 439367 & 3.301 & 6.3017 & TST & \\
\hline CHEMBL226811 & 439367 & 7.2218 & 7.2439 & TRN & \\
\hline CHEMBL375914 & 439367 & 8.6198 & 7.6174 & TST & \\
\hline CHEMBL229490 & 439367 & 8.6021 & 8.6552 & TRN & \\
\hline CHEMBL227005 & 439367 & 8.5528 & 8.6469 & TRN & \\
\hline CHEMBL226951 & 439367 & 6.9208 & 6.8979 & TRN & \\
\hline CHEMBL387986 & 439367 & 8.4815 & 8.4312 & TRN & \\
\hline CHEMBL229268 & 439367 & 5.1549 & 6.2726 & TST & \\
\hline CHEMBL227253 & 439367 & 8.7212 & 8.8625 & TRN & \\
\hline CHEMBL387681 & 439367 & 8.6576 & 8.5777 & TRN & \\
\hline CHEMBL227327 & 439367 & 7.1249 & 7.124 & TRN & \\
\hline CHEMBL376397 & 439367 & 5.6021 & 6.4438 & TST & \\
\hline CHEMBL229266 & 439367 & 7.4559 & 7.4022 & TRN & \\
\hline CHEMBL376396 & 439367 & 6.699 & 6.7128 & TRN & \\
\hline CHEMBL229485 & 439367 & 5.6021 & 6.3215 & TST & \\
\hline CHEMBL227273 & 439367 & 7.5086 & 7.3012 & TRN & \\
\hline CHEMBL427285 & 439367 & 7.7212 & 7.8629 & TRN & \\
\hline CHEMBL227274 & 439367 & 8.0 & 8.0087 & TRN & \\
\hline CHEMBL229591 & 439367 & 8.8239 & 8.6891 & TRN & \\
\hline CHEMBL229964 & 439367 & 7.8539 & 7.9005 & TRN & \\
\hline CHEMBL229146 & 439367 & 8.5229 & 8.5407 & TRN & \\
\hline CHEMBL226883 & 439367 & 9.0458 & 9.1379 & TRN & \\
\hline CHEMBL388986 & 439367 & 4.0 & 4.1208 & TRN & \\
\hline CHEMBL229322 & 439367 & 5.7447 & 6.3901 & TST & \\
\hline CHEMBL226859 & 439367 & 7.6021 & 7.53299 & 99999999995 & TRN \\
\hline CHEMBL229650 & 439367 & 5.8239 & 5.8521 & TRN & \\
\hline CHEMBL226991 & 439367 & 8.699 & 8.6745 & TRN & \\
\hline CHEMBL436979 & 439367 & 7.3979 & 7.4442 & TRN & \\
\hline CHEMBL441879 & 439367 & 8.5686 & 8.5845 & TRN & \\
\hline CHEMBL367859 & 439367 & 7.6021 & 7.6146 & TRN & \\
\hline CHEMBL227166 & 439367 & 6.5229 & 6.5524 & TRN & \\
\hline CHEMBL227219 & 439367 & 8.0969 & 8.1976 & TRN & \\
\hline CHEMBL226810 & 439367 & 8.301 & 8.2398 & TRN & \\
\hline CHEMBL229323 & 439367 & 6.0969 & 6.6985 & TST & \\
\hline CHEMBL227062 & 439367 & 8.7696 & 8.7429 & TRN & \\
\hline CHEMBL387680 & 439367 & 5.2757 & 5.4756 & TRN & \\
\hline CHEMBL389212 & 439367 & 7.8239 & 7.8136 & TRN & \\
\hline CHEMBL388985 & 439367 & 6.699 & 6.8076 & TRN & \\
\hline CHEMBL227220 & 439367 & 8.4949 & 7.981 & TST & \\
\hline CHEMBL390374 & 439367 & 8.3979 & 8.3645 & TRN & \\
\hline CHEMBL410598 & 439367 & 9.4202 & 9.1861 & TST & \\
\hline CHEMBL375023 & 439367 & 8.3979 & 8.3228 & TRN & \\
\hline CHEMBL375026 & 439367 & 5.699 & 7.9557 & TST & \\
\hline CHEMBL441878 & 439367 & 7.4437 & 7.3038 & TST & \\
\hline
\end{tabular}




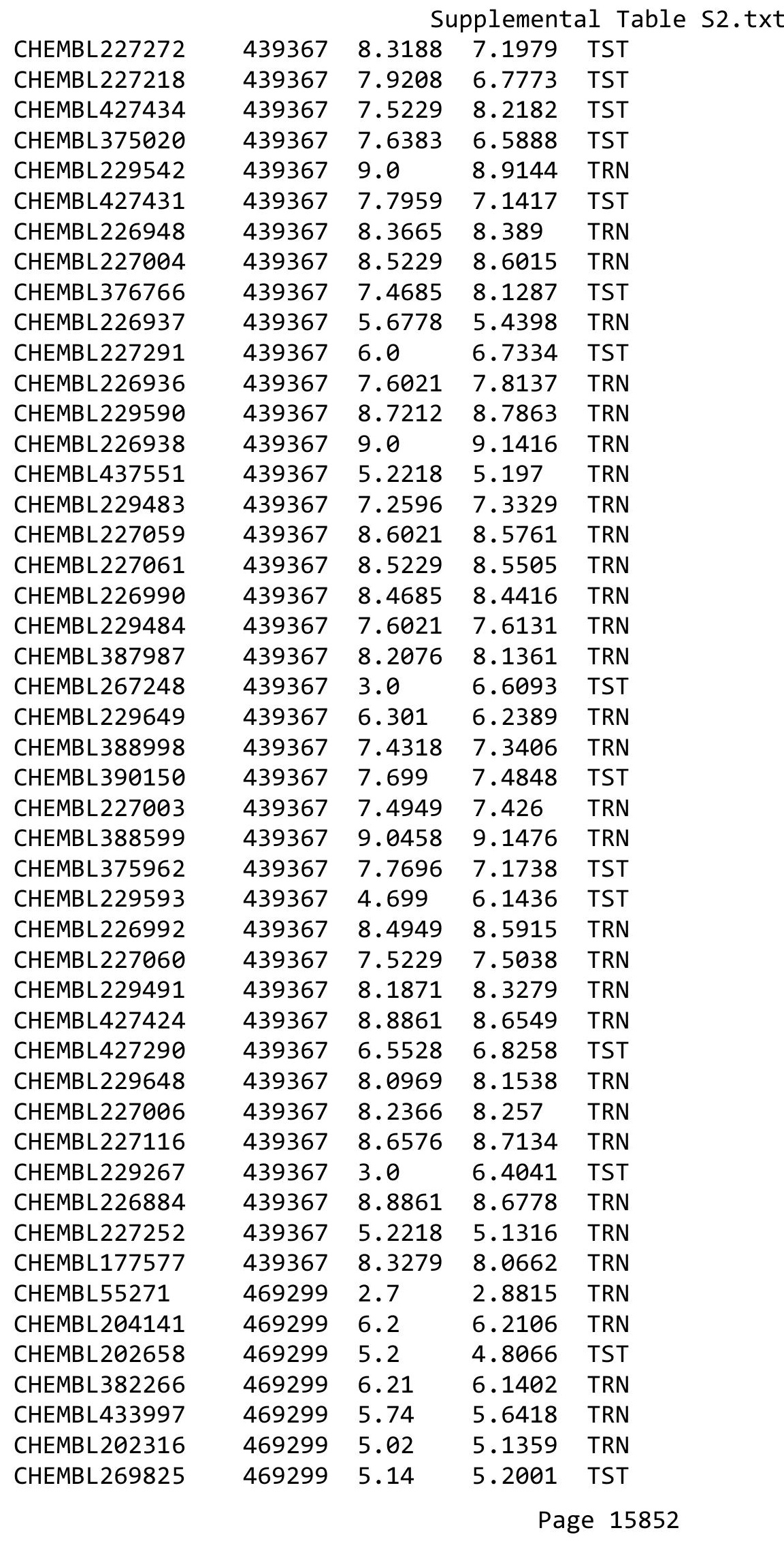




\begin{tabular}{|c|c|c|c|c|c|}
\hline & & \multicolumn{4}{|c|}{ Supplemental Table s2.txt } \\
\hline CHEMBL272624 & 469299 & 4.71 & 4.9742 & TRN & \\
\hline CHEMBL411130 & 469299 & 4.57 & 4.5544 & TRN & \\
\hline CHEMBL406729 & 469299 & 5.74 & 5.2408 & TST & \\
\hline CHEMBL271133 & 469299 & 5.66 & 5.4026 & TST & \\
\hline CHEMBL409826 & 469299 & 5.25 & 5.0486 & TST & \\
\hline CHEMBL273111 & 469299 & 5.18 & 5.3643 & TRN & \\
\hline CHEMBL270963 & 469299 & 5.19 & 5.1902 & TRN & \\
\hline CHEMBL270115 & 469299 & 6.11 & 5.9275 & TRN & \\
\hline CHEMBL409931 & 469299 & 6.01 & 5.8056 & TRN & \\
\hline CHEMBL271399 & 469299 & 5.45 & 5.4834 & TST & \\
\hline CHEMBL270525 & 469299 & 4.98 & 5.194 & TST & \\
\hline CHEMBL409699 & 469299 & 5.58 & 4.4871 & TST & \\
\hline CHEMBL271724 & 469299 & 5.21 & 4.9507 & TST & \\
\hline CHEMBL272782 & 469299 & 5.62 & 5.5124 & TST & \\
\hline CHEMBL256209 & 469299 & 6.54 & 5.8924 & TST & \\
\hline CHEMBL256419 & 469299 & 5.1 & 5.2366 & TST & \\
\hline CHEMBL257296 & 469299 & 6.22 & 5.3653 & TST & \\
\hline CHEMBL407177 & 469299 & 5.92 & 4.8295 & TST & \\
\hline CHEMBL55997 & 469299 & 3.22 & \multicolumn{2}{|c|}{3.2430000000000003} & TRN \\
\hline CHEMBL55757 & 469299 & 4.22 & 4.0797 & TRN & \\
\hline CHEMBL300851 & 469299 & 4.22 & 4.3924 & TRN & \\
\hline CHEMBL57064 & 469299 & 3.37 & 3.1891 & TRN & \\
\hline CHEMBL55186 & 469299 & 4.05 & 3.9027 & TRN & \\
\hline CHEMBL55187 & 469299 & 4.3 & 4.42 & TRN & \\
\hline CHEMBL291983 & 469299 & 4.52 & 4.7597 & TRN & \\
\hline CHEMBL56135 & 469299 & 4.7 & 4.8314 & TRN & \\
\hline CHEMBL299001 & 469299 & 5.0 & \multicolumn{2}{|c|}{4.9030000000000005} & TRN \\
\hline CHEMBL55951 & 469299 & 4.15 & 4.1159 & TRN & \\
\hline CHEMBL301055 & 469299 & 3.52 & 3.4098 & TRN & \\
\hline CHEMBL432894 & 469299 & 2.46 & 2.3288 & TRN & \\
\hline CHEMBL292436 & 469299 & 1.1 & 1.2656 & TRN & \\
\hline CHEMBL299271 & 469299 & 2.62 & 2.6143 & TRN & \\
\hline CHEMBL298823 & 469299 & 2.27 & 2.2441 & TRN & \\
\hline CHEMBL58988 & 469299 & 2.52 & 2.3802 & TRN & \\
\hline CHEMBL53684 & 469299 & 2.52 & \multicolumn{2}{|c|}{2.5069999999999997} & TRN \\
\hline CHEMBL57223 & 469299 & 1.7 & 1.6759 & TRN & \\
\hline CHEMBL293989 & 469299 & 3.27 & 3.2001 & TRN & \\
\hline CHEMBL293780 & 469299 & 2.3 & 2.2914 & TRN & \\
\hline CHEMBL433488 & 469299 & 2.52 & 2.5822 & TRN & \\
\hline CHEMBL291532 & 469299 & 3.23 & 3.2496 & TRN & \\
\hline CHEMBL301086 & 469299 & 2.39 & 2.4855 & TRN & \\
\hline CHEMBL53896 & 469299 & 2.02 & 1.8341 & TRN & \\
\hline CHEMBL54600 & 469299 & 3.4 & 3.4287 & TRN & \\
\hline CHEMBL54444 & 469299 & 2.64 & 2.6299 & TRN & \\
\hline CHEMBL55043 & 469299 & 1.6 & 1.7565 & TRN & \\
\hline CHEMBL55199 & 469299 & 3.05 & 3.0071 & TRN & \\
\hline CHEMBL55308 & 469299 & 3.22 & 3.1861 & TRN & \\
\hline CHEMBL1964290 & 809184 & 4.3 & 4.4303 & TRN & \\
\hline
\end{tabular}




\begin{tabular}{|c|c|c|c|c|}
\hline & & & CII & al Ta \\
\hline CHEMBL 2003768 & 809184 & 4.3 & 4.4384 & TRN \\
\hline CHEMBL 213505 & 809184 & 4.3 & 4.6468 & TRN \\
\hline CHEMBL 202721 & 809184 & 4.3 & 4.165 & TRN \\
\hline CHEMBL1982880 & 809184 & 4.3 & 4.5639 & TRN \\
\hline CHEMBL1987034 & 809184 & 7.8 & 6.6915 & TRN \\
\hline CHEMBL1993941 & 809184 & 5.4 & 4.5005 & TRN \\
\hline CHEMBL1980435 & 809184 & 6.1 & 5.9499 & TRN \\
\hline CHEMBL 377383 & 809184 & 4.3 & 4.3434 & TRN \\
\hline CHEMBL578061 & 809184 & 3.9 & 4.2173 & TRN \\
\hline CHEMBL 2005886 & 809184 & 6.8 & 6.3622 & TRN \\
\hline CHEMBL481491 & 809184 & 4.3 & 4.4738 & TST \\
\hline CHEMBL1682345 & 809184 & 4.3 & 4.4854 & TRN \\
\hline CHEMBL1973142 & 809184 & 4.3 & 4.4026 & TST \\
\hline CHEMBL388311 & 809184 & 7.5 & 7.1041 & TRN \\
\hline CHEMBL1973145 & 809184 & 4.3 & 4.0825 & TRN \\
\hline CHEMBL1982924 & 809184 & 4.3 & 4.3028 & TRN \\
\hline CHEMBL 2005936 & 809184 & 4.3 & 4.7987 & TRN \\
\hline CHEMBL1807515 & 809184 & 6.5 & 7.0293 & TRN \\
\hline CHEMBL1964948 & 809184 & 4.3 & 4.7489 & TRN \\
\hline CHEMBL1971141 & 809184 & 4.3 & 4.3365 & TRN \\
\hline CHEMBL1995813 & 809184 & 7.0 & 6.4718 & TRN \\
\hline CHEMBL1979718 & 809184 & 4.3 & 4.712 & TRN \\
\hline CHEMBL206236 & 809184 & 4.3 & 4.3643 & TRN \\
\hline CHEMBL523823 & 809184 & 4.3 & 4.5253 & TST \\
\hline CHEMBL1562756 & 809184 & 4.3 & 4.6873 & TST \\
\hline CHEMBL1987430 & 809184 & 4.3 & 4.4894 & TRN \\
\hline CHEMBL 244378 & 809184 & 5.9 & 5.6103 & TRN \\
\hline CHEMBL 2001957 & 809184 & 4.3 & 4.5431 & TRN \\
\hline CHEMBL1969372 & 809184 & 4.3 & 4.1638 & TRN \\
\hline CHEMBL1993413 & 809184 & 4.3 & 4.0983 & TRN \\
\hline CHEMBL1990583 & 809184 & 4.3 & 4.5398 & TRN \\
\hline CHEMBL1986943 & 809184 & 7.6 & 7.4526 & TRN \\
\hline CHEMBL 2006263 & 809184 & 4.3 & 4.7397 & TST \\
\hline CHEMBL1993584 & 809184 & 4.3 & 4.3373 & TRN \\
\hline CHEMBL1986263 & 809184 & 4.4 & 4.8579 & TRN \\
\hline CHEMBL 2000114 & 809184 & 4.3 & 4.6585 & TRN \\
\hline CHEMBL 210618 & 809184 & 4.3 & 4.1546 & TRN \\
\hline CHEMBL1986265 & 809184 & 4.3 & 4.3089 & TRN \\
\hline CHEMBL1971172 & 809184 & 5.5 & 6.1524 & TRN \\
\hline CHEMBL1975647 & 809184 & 4.3 & 4.502 & TRN \\
\hline CHEMBL1968380 & 809184 & 4.3 & 4.8865 & TRN \\
\hline CHEMBL1964644 & 809184 & 4.3 & 3.9035 & TRN \\
\hline CHEMBL1991734 & 809184 & 5.9 & 5.6297 & TST \\
\hline CHEMBL1981782 & 809184 & 4.3 & 4.5997 & TRN \\
\hline CHEMBL1977681 & 809184 & 4.3 & 4.3047 & TRN \\
\hline CHEMBL1970142 & 809184 & 4.3 & 4.5248 & TRN \\
\hline CHEMBL1990912 & 809184 & 4.3 & 3.9478 & TRN \\
\hline CHEMBL1991782 & 809184 & 3.0 & 3.2369 & TRN \\
\hline
\end{tabular}




\begin{tabular}{|c|c|c|c|c|c|}
\hline \multicolumn{6}{|c|}{ Supplemental Table S2.txt } \\
\hline CHEMBL 2002105 & 809184 & 4.2 & 4.3572 & TRN & \\
\hline CHEMBL1983348 & 809184 & 7.2 & 6.1068 & TRN & \\
\hline CHEMBL1988163 & 809184 & 6.3 & 6.0485 & TRN & \\
\hline CHEMBL1995592 & 809184 & 4.3 & 4.4098 & TST & \\
\hline CHEMBL1974480 & 809184 & 5.4 & 4.9813 & TRN & \\
\hline CHEMBL1980671 & 809184 & 4.2 & 4.3325 & TRN & \\
\hline CHEMBL 2006493 & 809184 & 4.3 & 4.1308 & TST & \\
\hline CHEMBL1986177 & 809184 & 4.3 & 4.1026 & TRN & \\
\hline CHEMBL1982541 & 809184 & 4.3 & 4.3472 & TRN & \\
\hline CHEMBL1996923 & 809184 & 4.3 & 4.0036 & TST & \\
\hline CHEMBL1983449 & 809184 & 4.3 & 4.6427 & TRN & \\
\hline CHEMBL1992323 & 809184 & 4.3 & 4.1961 & TST & \\
\hline CHEMBL1969735 & 809184 & 4.3 & 4.5155 & TRN & \\
\hline CHEMBL 2003524 & 809184 & 4.3 & 4.1742 & TST & \\
\hline CHEMBL 2002649 & 809184 & 4.3 & 4.9744 & TRN & \\
\hline CHEMBL1983589 & 809184 & 7.7 & 7.1847 & TRN & \\
\hline CHEMBL1985367 & 809184 & 4.3 & 4.7707 & TST & \\
\hline CHEMBL1996510 & 809184 & 5.7 & 5.2118 & TST & \\
\hline CHEMBL437747 & 809184 & 4.3 & 4.9259 & TRN & \\
\hline CHEMBL 2005718 & 809184 & 6.3 & 6.4179 & TRN & \\
\hline CHEMBL1995172 & 809184 & 4.3 & 4.1108 & TST & \\
\hline CHEMBL 2001584 & 809184 & 4.3 & 4.24100 & 00000000005 & TRN \\
\hline CHEMBL507936 & 809184 & 4.3 & 4.0808 & TRN & \\
\hline CHEMBL104264 & 809184 & 4.3 & 4.8575 & TST & \\
\hline CHEMBL1967998 & 809184 & 6.9 & 7.1004 & TRN & \\
\hline CHEMBL1994321 & 809184 & 4.3 & 4.2517 & TRN & \\
\hline CHEMBL1978562 & 809184 & 5.4 & 5.0357 & TST & \\
\hline CHEMBL1997129 & 809184 & 4.3 & 4.9136 & TRN & \\
\hline CHEMBL1984788 & 809184 & 4.3 & 4.4581 & TRN & \\
\hline CHEMBL451964 & 809184 & 4.3 & 4.5522 & TRN & \\
\hline CHEMBL1964307 & 809184 & 4.3 & 4.5014 & TRN & \\
\hline CHEMBL1989471 & 809184 & 5.7 & 4.7667 & TST & \\
\hline CHEMBL 2000508 & 809184 & 4.3 & 4.0856 & TRN & \\
\hline CHEMBL1971694 & 809184 & 4.3 & 4.1817 & TST & \\
\hline CHEMBL 2001547 & 809184 & 4.3 & 4.5646 & TRN & \\
\hline CHEMBL210928 & 809184 & 4.3 & 4.3564 & TRN & \\
\hline CHEMBL1978195 & 809184 & 4.3 & 4.7263 & TRN & \\
\hline CHEMBL1994361 & 809184 & 4.3 & 4.3002 & TRN & \\
\hline CHEMBL1986603 & 809184 & 4.3 & 4.42399 & 99999999995 & TST \\
\hline CHEMBL1972840 & 809184 & 4.3 & 4.8616 & TRN & \\
\hline CHEMBL1977148 & 809184 & 4.3 & 4.5733 & TRN & \\
\hline CHEMBL1966842 & 809184 & 5.5 & 4.6944 & TRN & \\
\hline CHEMBL 2003286 & 809184 & 4.3 & 3.9017 & TRN & \\
\hline CHEMBL1992306 & 809184 & 4.3 & 4.4259 & TRN & \\
\hline CHEMBL 2002165 & 809184 & 5.8 & 4.7097 & TRN & \\
\hline CHEMBL 2001668 & 809184 & 4.3 & 4.3842 & TST & \\
\hline CHEMBL1979318 & 809184 & 4.3 & 4.3485 & TRN & \\
\hline CHEMBL206382 & 809184 & 4.3 & 4.1575 & TRN & \\
\hline
\end{tabular}




\begin{tabular}{|c|c|c|c|c|c|}
\hline & & & & & \\
\hline CHEMBL1998585 & 809184 & 4.3 & 4.828 & TRN & \\
\hline CHEMBL127898 & 809184 & 4.3 & 4.3493 & TST & \\
\hline CHEMBL519697 & 809184 & 4.3 & 4.5234 & TRN & \\
\hline CHEMBL 2004934 & 809184 & 4.3 & 4.3614 & TRN & \\
\hline CHEMBL1987261 & 809184 & 6.2 & 6.2512 & TRN & \\
\hline CHEMBL1996345 & 809184 & 4.3 & 4.0668 & TST & \\
\hline CHEMBL1975128 & 809184 & 5.8 & 5.039 & TRN & \\
\hline CHEMBL 2004025 & 809184 & 4.3 & 4.6444 & TST & \\
\hline CHEMBL1996048 & 809184 & 6.0 & 5.2704 & TST & \\
\hline CHEMBL1970369 & 809184 & 4.3 & 4.2305 & TRN & \\
\hline CHEMBL1976158 & 809184 & 4.6 & 4.54899 & 99999999995 & TST \\
\hline CHEMBL461876 & 809184 & 4.3 & 5.7987 & TST & \\
\hline CHEMBL1965033 & 809184 & 4.3 & 4.3046 & TRN & \\
\hline CHEMBL 2001485 & 809184 & 4.3 & 4.7173 & TRN & \\
\hline CHEMBL1971519 & 809184 & 4.3 & 4.5274 & TRN & \\
\hline CHEMBL504950 & 809184 & 4.3 & 4.2019 & TRN & \\
\hline CHEMBL1997335 & 809184 & 5.7 & 5.5712 & TRN & \\
\hline CHEMBL1966425 & 809184 & 4.3 & 5.0531 & TRN & \\
\hline CHEMBL1984363 & 809184 & 4.3 & 4.3511 & TRN & \\
\hline CHEMBL1978099 & 809184 & 5.3 & 5.32600 & 00000000005 & TRN \\
\hline CHEMBL1977041 & 809184 & 5.5 & 4.1205 & TRN & \\
\hline CHEMBL1968070 & 809184 & 4.3 & 4.2311 & TRN & \\
\hline CHEMBL1988608 & 809184 & 4.3 & 4.2505 & TRN & \\
\hline CHEMBL184847 & 809184 & 4.3 & 4.1725 & TRN & \\
\hline CHEMBL1971132 & 809184 & 4.3 & 4.315 & TRN & \\
\hline CHEMBL1984367 & 809184 & 4.3 & 4.1934 & TRN & \\
\hline CHEMBL1985723 & 809184 & 6.5 & 6.5791 & TRN & \\
\hline CHEMBL178737 & 809184 & 4.3 & 4.3595 & TST & \\
\hline CHEMBL226898 & 809184 & 6.4 & 6.6457 & TRN & \\
\hline CHEMBL1982563 & 809184 & 4.3 & 4.5366 & TRN & \\
\hline CHEMBL1991377 & 809184 & 4.3 & 4.3539 & TRN & \\
\hline CHEMBL539474 & 809184 & 5.4 & 4.8124 & TST & \\
\hline CHEMBL575824 & 809184 & 4.3 & 4.5444 & TRN & \\
\hline CHEMBL1988387 & 809184 & 5.5 & 4.9917 & TRN & \\
\hline CHEMBL1973868 & 809184 & 4.3 & 4.0814 & TRN & \\
\hline CHEMBL1972462 & 809184 & 4.3 & 4.2278 & TRN & \\
\hline CHEMBL1977128 & 809184 & 6.1 & 5.9043 & TRN & \\
\hline CHEMBL1997759 & 809184 & 4.3 & 4.3796 & TRN & \\
\hline CHEMBL1990288 & 809184 & 4.3 & 4.4728 & TRN & \\
\hline CHEMBL1989708 & 809184 & 4.3 & 4.7158 & TRN & \\
\hline CHEMBL1974803 & 809184 & 4.3 & 4.5552 & TST & \\
\hline CHEMBL1970074 & 809184 & 4.3 & 4.7899 & TRN & \\
\hline CHEMBL1965702 & 809184 & 7.0 & 6.98 & TRN & \\
\hline CHEMBL1984500 & 809184 & 3.0 & 3.4781 & TRN & \\
\hline CHEMBL1986970 & 809184 & 4.3 & 4.5723 & TRN & \\
\hline CHEMBL 2005112 & 809184 & 4.3 & 4.5422 & TST & \\
\hline CHEMBL1958401 & 809184 & 4.3 & 4.6632 & TRN & \\
\hline CHEMBL1984044 & 809184 & 4.3 & 4.3539 & TRN & \\
\hline & & & & 15856 & \\
\hline
\end{tabular}




\begin{tabular}{|c|c|c|c|c|}
\hline \multicolumn{5}{|c|}{ plemental T } \\
\hline CHEMBL 2003456 & 809184 & 4.3 & 4.0322 & TRN \\
\hline CHEMBL1966816 & 809184 & 4.3 & 4.8781 & TRN \\
\hline CHEMBL1972584 & 809184 & 5.8 & 5.5718 & TRN \\
\hline CHEMBL 2002992 & 809184 & 5.8 & 4.6805 & TRN \\
\hline CHEMBL560813 & 809184 & 4.3 & 3.9105 & TRN \\
\hline CHEMBL1982700 & 809184 & 4.3 & 4.56 & TST \\
\hline CHEMBL1968791 & 809184 & 4.3 & 4.6177 & TRN \\
\hline CHEMBL326282 & 809184 & 4.3 & 4.3729 & TST \\
\hline CHEMBL 2002682 & 809184 & 4.3 & 5.1561 & TST \\
\hline CHEMBL1977634 & 809184 & 4.3 & 4.5101 & TRN \\
\hline CHEMBL1992732 & 809184 & 4.3 & 4.1965 & TST \\
\hline CHEMBL1971186 & 809184 & 4.3 & 4.5358 & TRN \\
\hline CHEMBL 2003482 & 809184 & 4.3 & 4.0215 & TRN \\
\hline CHEMBL 2006456 & 809184 & 7.1 & 7.1262 & TRN \\
\hline CHEMBL1973211 & 809184 & 4.3 & 4.2611 & TRN \\
\hline CHEMBL 1984700 & 809184 & 4.3 & 4.6724 & TRN \\
\hline CHEMBL 2007151 & 809184 & 4.3 & 4.8236 & TRN \\
\hline CHEMBL1971606 & 809184 & 4.3 & 4.2922 & TRN \\
\hline CHEMBL1972125 & 809184 & 4.3 & 4.1068 & TRN \\
\hline CHEMBL1461728 & 809184 & 4.3 & 4.1116 & TRN \\
\hline CHEMBL1976134 & 809184 & 4.3 & 4.7828 & TRN \\
\hline CHEMBL1965131 & 809184 & 4.3 & 4.4566 & TST \\
\hline CHEMBL1972158 & 809184 & 4.3 & 4.7944 & TRN \\
\hline CHEMBL1981215 & 809184 & 4.3 & 4.3736 & TRN \\
\hline CHEMBL1974457 & 809184 & 4.3 & 3.9586 & TRN \\
\hline CHEMBL 2006580 & 809184 & 4.3 & 4.0163 & TRN \\
\hline CHEMBL1999414 & 809184 & 5.4 & 5.3213 & TRN \\
\hline CHEMBL1967336 & 809184 & 4.3 & 4.0229 & TRN \\
\hline CHEMBL 2001228 & 809184 & 4.3 & 4.2817 & TRN \\
\hline CHEMBL 2006581 & 809184 & 4.3 & 4.5072 & TRN \\
\hline CHEMBL 2006481 & 809184 & 4.3 & 4.0728 & TRN \\
\hline CHEMBL1979855 & 809184 & 4.3 & 4.5239 & TRN \\
\hline CHEMBL1970340 & 809184 & 4.3 & 3.8773 & TRN \\
\hline CHEMBL1967992 & 809184 & 4.3 & 3.9252 & TRN \\
\hline CHEMBL 2005186 & 809184 & 4.3 & 4.7216 & TRN \\
\hline CHEMBL1995927 & 809184 & 4.3 & 4.3693 & TST \\
\hline CHEMBL1981671 & 809184 & 4.3 & 4.375 & TRN \\
\hline CHEMBL 2006450 & 809184 & 4.3 & 4.1625 & TRN \\
\hline CHEMBL1975534 & 809184 & 4.3 & 4.4243 & TRN \\
\hline CHEMBL1993424 & 809184 & 4.3 & 5.2321 & TRN \\
\hline CHEMBL1966703 & 809184 & 4.3 & 4.3241 & TST \\
\hline CHEMBL 2001987 & 809184 & 4.3 & 4.4603 & TRN \\
\hline CHEMBL1969561 & 809184 & 4.3 & 4.4082 & TRN \\
\hline CHEMBL1994555 & 809184 & 5.6 & 4.7359 & TST \\
\hline CHEMBL1975121 & 809184 & 4.3 & 4.3025 & TRN \\
\hline CHEMBL1983640 & 809184 & 4.3 & 4.1128 & TRN \\
\hline CHEMBL1997023 & 809184 & 4.3 & 4.1902 & TST \\
\hline CHEMBL1964687 & 809184 & 4.3 & 4.2366 & TRN \\
\hline
\end{tabular}




\begin{tabular}{|c|c|c|c|c|c|}
\hline \multicolumn{6}{|c|}{ בد" } \\
\hline CHEMBL1971943 & 809184 & 4.4 & 4.7453 & TRN & \\
\hline CHEMBL1999918 & 809184 & 5.4 & 4.6436 & TRN & \\
\hline CHEMBL1974254 & 809184 & 4.3 & 4.7786 & TRN & \\
\hline CHEMBL1997924 & 809184 & 7.3 & 6.5352 & TRN & \\
\hline CHEMBL1988537 & 809184 & 4.3 & 4.4087 & TST & \\
\hline CHEMBL1969049 & 809184 & 4.3 & 4.398 & TRN & \\
\hline CHEMBL 2005828 & 809184 & 4.3 & 4.3073 & TRN & \\
\hline CHEMBL 2002240 & 809184 & 4.3 & 4.254 & TRN & \\
\hline CHEMBL1978267 & 809184 & 4.3 & 4.3583 & TRN & \\
\hline CHEMBL1971485 & 809184 & 4.3 & 4.0878 & TRN & \\
\hline CHEMBL1991143 & 809184 & 4.3 & 4.2459 & TST & \\
\hline CHEMBL1980178 & 809184 & 6.8 & 6.6243 & TRN & \\
\hline CHEMBL1998611 & 809184 & 4.3 & 4.5008 & TST & \\
\hline CHEMBL485556 & 809184 & 4.3 & 4.519 & TRN & \\
\hline CHEMBL1975900 & 809184 & 4.3 & 4.4885 & TRN & \\
\hline CHEMBL 255822 & 809184 & 4.3 & 3.8177 & TRN & \\
\hline CHEMBL1972221 & 809184 & 4.3 & 4.1071 & TRN & \\
\hline CHEMBL 2006778 & 809184 & 4.3 & 4.4788 & TRN & \\
\hline CHEMBL 378627 & 809184 & 4.3 & 4.2759 & TRN & \\
\hline CHEMBL1996979 & 809184 & 4.3 & 4.6316 & TRN & \\
\hline CHEMBL1997025 & 809184 & 4.3 & 4.3168 & TRN & \\
\hline CHEMBL1968406 & 809184 & 4.3 & 4.4898 & TRN & \\
\hline CHEMBL1975921 & 809184 & 4.4 & 4.3125 & TRN & \\
\hline CHEMBL1982476 & 809184 & 4.3 & 4.7406 & TRN & \\
\hline CHEMBL1984274 & 809184 & 4.3 & 4.6123 & TST & \\
\hline CHEMBL1998545 & 809184 & 4.3 & $4.2860 t$ & 00000000005 & TRN \\
\hline CHEMBL1986869 & 809184 & 4.3 & 4.4465 & TRN & \\
\hline CHEMBL1975923 & 809184 & 4.6 & 4.7321 & TST & \\
\hline CHEMBL2005449 & 809184 & 6.0 & 5.4192 & TRN & \\
\hline CHEMBL1987998 & 809184 & 4.3 & 4.2278 & TRN & \\
\hline CHEMBL 2006010 & 809184 & 4.3 & 4.1838 & TRN & \\
\hline CHEMBL1682558 & 809184 & 4.3 & 3.8179 & TRN & \\
\hline CHEMBL1971534 & 809184 & 4.1 & 4.1297 & TRN & \\
\hline CHEMBL1990496 & 809184 & 4.3 & 4.3162 & TRN & \\
\hline CHEMBL242865 & 809184 & 5.3 & 5.28 & TRN & \\
\hline CHEMBL1997623 & 809184 & 4.3 & 4.2972 & TRN & \\
\hline CHEMBL 2002479 & 809184 & 5.5 & 5.2689 & TRN & \\
\hline CHEMBL 2002480 & 809184 & 4.6 & 4.1257 & TST & \\
\hline CHEMBL1983884 & 809184 & 3.0 & 4.3319 & TST & \\
\hline CHEMBL1993166 & 809184 & 4.3 & 4.9846 & TRN & \\
\hline CHEMBL1967094 & 809184 & 4.3 & 4.1195 & TRN & \\
\hline CHEMBL1966035 & 809184 & 4.3 & 4.405 & TRN & \\
\hline CHEMBL 2003341 & 809184 & 4.3 & 4.4 & TRN & \\
\hline CHEMBL1992644 & 809184 & 3.9 & 3.9399 & TRN & \\
\hline CHEMBL1992645 & 809184 & 4.3 & 4.3499 & TST & \\
\hline CHEMBL1982992 & 809184 & 4.3 & 4.248 & TRN & \\
\hline CHEMBL1998110 & 809184 & 4.3 & 3.8406 & TRN & \\
\hline CHEMBL1999590 & 809184 & 4.3 & 4.4976 & TST & \\
\hline & & & & 15858 & \\
\hline
\end{tabular}




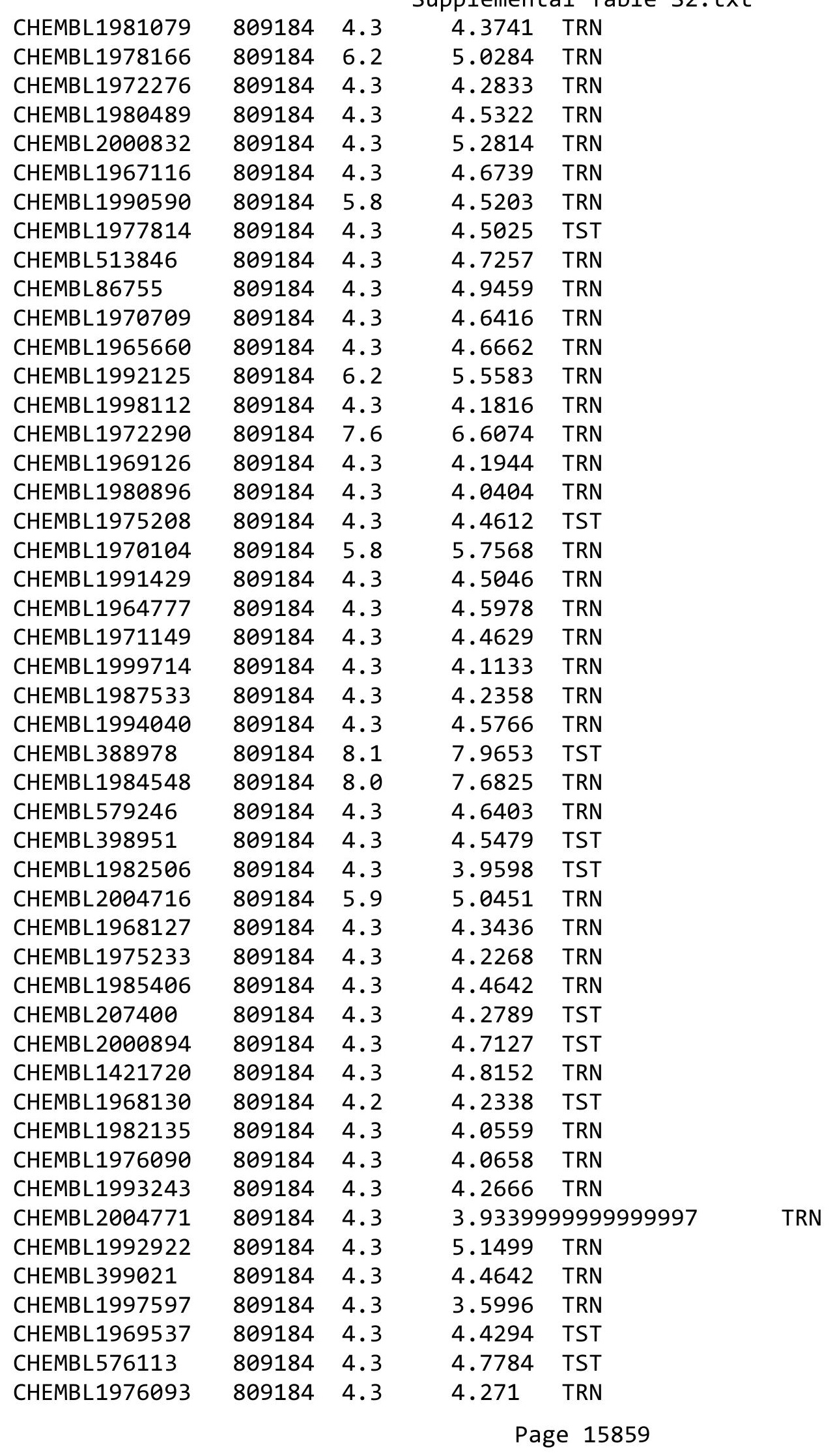




\begin{tabular}{|c|c|c|c|c|}
\hline \multicolumn{5}{|c|}{ ipplemental T } \\
\hline CHEMBL1996543 & 809184 & 4.3 & 4.3789 & TRN \\
\hline CHEMBL1975256 & 809184 & 4.3 & 4.1913 & TST \\
\hline CHEMBL508928 & 809184 & 4.3 & 4.4482 & TRN \\
\hline CHEMBL1991356 & 809184 & 4.3 & 4.0533 & TST \\
\hline CHEMBL1983309 & 809184 & 4.3 & 4.357 & TRN \\
\hline CHEMBL 2004892 & 809184 & 4.3 & 3.8389 & TRN \\
\hline CHEMBL1949855 & 809184 & 4.8 & 4.5134 & TST \\
\hline CHEMBL1999126 & 809184 & 4.3 & 4.4534 & TST \\
\hline CHEMBL1997503 & 809184 & 4.3 & 4.8479 & TST \\
\hline CHEMBL1972339 & 809184 & 7.1 & 5.7915 & TRN \\
\hline CHEMBL116070 & 809184 & 4.3 & 4.2301 & TRN \\
\hline CHEMBL1990821 & 809184 & 4.3 & 4.6493 & TST \\
\hline CHEMBL1970314 & 809184 & 4.3 & 4.1584 & TRN \\
\hline CHEMBL 2004871 & 809184 & 4.3 & 4.0981 & TRN \\
\hline CHEMBL 2004872 & 809184 & 4.3 & 4.1846 & TRN \\
\hline CHEMBL1727312 & 809184 & 4.3 & 3.7622 & TRN \\
\hline CHEMBL1990223 & 809184 & 4.3 & 4.1597 & TRN \\
\hline CHEMBL1969879 & 809184 & 4.3 & 4.418 & TRN \\
\hline CHEMBL1964382 & 809184 & 4.3 & 4.4902 & TST \\
\hline CHEMBL101311 & 809184 & 5.9 & 5.0731 & TRN \\
\hline CHEMBL1981720 & 809184 & 4.3 & 3.8161 & TRN \\
\hline CHEMBL419932 & 809184 & 4.3 & 4.4144 & TRN \\
\hline CHEMBL 262433 & 809184 & 4.3 & 4.3206 & TRN \\
\hline CHEMBL306380 & 809184 & 4.3 & 4.725 & TRN \\
\hline CHEMBL1966722 & 809184 & 5.7 & 4.7705 & TST \\
\hline CHEMBL1983595 & 809184 & 6.1 & 5.8283 & TRN \\
\hline CHEMBL1988581 & 809184 & 6.8 & 6.1994 & TST \\
\hline CHEMBL 2005699 & 809184 & 4.3 & 4.3602 & TRN \\
\hline CHEMBL1975500 & 809184 & 4.3 & 4.7321 & TRN \\
\hline CHEMBL1976328 & 809184 & 4.3 & 4.1296 & TRN \\
\hline CHEMBL394619 & 809184 & 4.3 & 4.3568 & TRN \\
\hline CHEMBL 2006564 & 809184 & 7.3 & 6.785 & TRN \\
\hline CHEMBL1964399 & 809184 & 4.3 & 4.7901 & TRN \\
\hline CHEMBL1996831 & 809184 & 4.3 & 4.4734 & TST \\
\hline CHEMBL411903 & 809184 & 4.3 & 4.4825 & TRN \\
\hline CHEMBL1980253 & 809184 & 6.9 & 6.685 & TRN \\
\hline CHEMBL1978167 & 809184 & 4.3 & 4.9419 & TST \\
\hline CHEMBL1965988 & 809184 & 4.3 & 4.6732 & TRN \\
\hline CHEMBL418203 & 809184 & 4.3 & 4.316 & TST \\
\hline CHEMBL1989646 & 809184 & 4.3 & 4.4534 & TRN \\
\hline CHEMBL1682357 & 809184 & 4.3 & 4.3508 & TRN \\
\hline CHEMBL225519 & 809184 & 4.3 & 4.1322 & TRN \\
\hline CHEMBL209534 & 809184 & 4.3 & 4.2218 & TRN \\
\hline CHEMBL1978200 & 809184 & 4.3 & 4.5597 & TRN \\
\hline CHEMBL1970522 & 809184 & 4.3 & 3.9727 & TRN \\
\hline CHEMBL1990415 & 809184 & 4.3 & 4.4089 & TRN \\
\hline CHEMBL1966087 & 809184 & 4.3 & 4.4113 & TRN \\
\hline CHEMBL1996931 & 809184 & 4.3 & 4.4368 & TRN \\
\hline
\end{tabular}




\begin{tabular}{|c|c|c|c|c|}
\hline \multicolumn{5}{|c|}{ plemental T } \\
\hline CHEMBL1964692 & 809184 & 4.3 & 4.7705 & TRN \\
\hline CHEMBL1964413 & 809184 & 4.3 & 4.1886 & TRN \\
\hline CHEMBL1973483 & 809184 & 4.3 & 4.2557 & TRN \\
\hline CHEMBL1998470 & 809184 & 4.3 & 4.6791 & TRN \\
\hline CHEMBL1996980 & 809184 & 7.4 & 7.3914 & TRN \\
\hline CHEMBL1984432 & 809184 & 4.3 & 4.3458 & TRN \\
\hline CHEMBL1970735 & 809184 & 4.3 & 4.4369 & TRN \\
\hline CHEMBL219722 & 809184 & 4.3 & 4.3601 & TRN \\
\hline CHEMBL1975903 & 809184 & 4.3 & 4.3257 & TRN \\
\hline CHEMBL1994669 & 809184 & 8.1 & 7.7084 & TRN \\
\hline CHEMBL 1997340 & 809184 & 4.3 & 4.1252 & TRN \\
\hline CHEMBL 2004365 & 809184 & 4.3 & 4.7516 & TST \\
\hline CHEMBL1522508 & 809184 & 4.3 & 3.9575 & TRN \\
\hline CHEMBL1989474 & 809184 & 4.3 & 4.1452 & TRN \\
\hline CHEMBL1090360 & 809184 & 4.3 & 4.1743 & TRN \\
\hline CHEMBL 210887 & 809184 & 4.3 & 4.363 & TRN \\
\hline CHEMBL1988805 & 809184 & 4.3 & 4.3514 & TST \\
\hline CHEMBL458997 & 809184 & 5.5 & 5.9168 & TRN \\
\hline CHEMBL1971021 & 809184 & 4.3 & 4.3536 & TRN \\
\hline CHEMBL 227271 & 809184 & 7.3 & 6.5462 & TRN \\
\hline CHEMBL583144 & 809184 & 4.3 & 4.3008 & TST \\
\hline CHEMBL1974310 & 809184 & 4.3 & 4.6445 & TRN \\
\hline CHEMBL1969942 & 809184 & 4.3 & 4.2625 & TRN \\
\hline CHEMBL1978567 & 809184 & 4.3 & 3.8406 & TRN \\
\hline CHEMBL1982660 & 809184 & 4.3 & 4.3136 & TRN \\
\hline CHEMBL1994693 & 809184 & 4.3 & 4.254 & TRN \\
\hline CHEMBL1982957 & 809184 & 6.2 & 5.2087 & TRN \\
\hline CHEMBL1725279 & 809184 & 4.3 & 4.9506 & TST \\
\hline CHEMBL1975138 & 809184 & 4.3 & 4.7063 & TST \\
\hline CHEMBL424872 & 809184 & 4.3 & 4.172 & TRN \\
\hline CHEMBL 2006836 & 809184 & 4.3 & 4.5173 & TST \\
\hline CHEMBL412142 & 809184 & 4.3 & 4.3282 & TST \\
\hline CHEMBL1980704 & 809184 & 4.3 & 4.5024 & TST \\
\hline CHEMBL 2003271 & 809184 & 4.3 & 4.6313 & TST \\
\hline CHEMBL1966808 & 809184 & 4.3 & 4.3199 & TST \\
\hline CHEMBL 2004447 & 809184 & 4.3 & 4.1699 & TRN \\
\hline CHEMBL1992231 & 809184 & 5.5 & 5.0129 & TRN \\
\hline CHEMBL1983111 & 809184 & 7.0 & 7.1212 & TRN \\
\hline CHEMBL1973860 & 809184 & 4.3 & 3.7815 & TRN \\
\hline CHEMBL 260135 & 809184 & 4.3 & 3.7513 & TRN \\
\hline CHEMBL220241 & 809184 & 4.3 & 4.2623 & TRN \\
\hline CHEMBL 2004544 & 809184 & 4.3 & 4.6121 & TST \\
\hline CHEMBL1988141 & 809184 & 6.1 & 5.3974 & TST \\
\hline CHEMBL1982610 & 809184 & 4.3 & 4.4003 & TST \\
\hline CHEMBL1977134 & 809184 & 4.3 & 4.5736 & TRN \\
\hline CHEMBL1999496 & 809184 & 4.3 & 4.292 & TRN \\
\hline CHEMBL 2006933 & 809184 & 4.3 & 4.1802 & TST \\
\hline CHEMBL1985206 & 809184 & 4.3 & 4.5025 & TST \\
\hline
\end{tabular}




\begin{tabular}{|c|c|c|c|c|c|}
\hline & & & & & \\
\hline CHEMBL1988300 & 809184 & 4.3 & 3.8781 & TRN & \\
\hline CHEMBL1991078 & 809184 & 6.3 & 6.5409 & TRN & \\
\hline CHEMBL1987359 & 809184 & 4.3 & 4.1886 & TST & \\
\hline CHEMBL1977749 & 809184 & 4.3 & 4.5168 & TST & \\
\hline CHEMBL 2000685 & 809184 & 6.0 & 5.2179 & TRN & \\
\hline CHEMBL2001613 & 809184 & 4.3 & 4.4894 & TRN & \\
\hline CHEMBL1997275 & 809184 & 4.3 & $4.5710 e$ & 0000000001 & TRN \\
\hline CHEMBL1993904 & 809184 & 5.7 & 5.1868 & TRN & \\
\hline CHEMBL1994438 & 809184 & 7.5 & 6.9774 & TRN & \\
\hline CHEMBL1967513 & 809184 & 4.3 & 4.3575 & TRN & \\
\hline CHEMBL 2000724 & 809184 & 4.3 & 4.3328 & TRN & \\
\hline CHEMBL1985311 & 809184 & 4.3 & 4.5225 & TRN & \\
\hline CHEMBL1989265 & 809184 & 4.3 & 4.3992 & TST & \\
\hline CHEMBL1982413 & 809184 & 4.3 & $4.9460 e$ & $\partial 000000001$ & TRN \\
\hline CHEMBL1969502 & 809184 & 4.3 & 4.9184 & TRN & \\
\hline CHEMBL1965910 & 809184 & 5.4 & 4.7513 & TRN & \\
\hline CHEMBL1682553 & 809184 & 4.3 & 4.7049 & TRN & \\
\hline CHEMBL1971430 & 809184 & 4.3 & 4.4543 & TRN & \\
\hline CHEMBL1983963 & 809184 & 4.3 & 4.038 & TRN & \\
\hline CHEMBL1997764 & 809184 & 4.3 & 4.3849 & TRN & \\
\hline CHEMBL 2000271 & 809184 & 6.0 & 6.0289 & TRN & \\
\hline CHEMBL1981792 & 809184 & 4.3 & 4.5285 & TRN & \\
\hline CHEMBL1987535 & 809184 & 4.3 & 5.1026 & TRN & \\
\hline CHEMBL1985092 & 809184 & 4.3 & 4.4394 & TRN & \\
\hline CHEMBL 2004692 & 809184 & 4.3 & 4.1428 & TST & \\
\hline CHEMBL1981410 & 809184 & 4.3 & 4.3908 & TRN & \\
\hline CHEMBL 2002586 & 809184 & 5.4 & 5.5072 & TRN & \\
\hline CHEMBL1996234 & 809184 & 4.3 & 4.4238 & TRN & \\
\hline CHEMBL 2007421 & 809184 & 4.3 & 6.0582 & TST & \\
\hline CHEMBL1991434 & 809184 & 4.3 & 4.3563 & TST & \\
\hline CHEMBL1967544 & 809184 & 5.4 & 4.9796 & TRN & \\
\hline CHEMBL1973138 & 809184 & 4.3 & 4.3189 & TRN & \\
\hline CHEMBL223367 & 809184 & 4.3 & 5.5745 & TST & \\
\hline CHEMBL 340384 & 809184 & 4.3 & 4.7918 & TST & \\
\hline CHEMBL1969151 & 809184 & 7.3 & 7.4058 & TRN & \\
\hline CHEMBL1996587 & 809184 & 4.3 & 4.1009 & TRN & \\
\hline CHEMBL1993335 & 809184 & 5.9 & 5.3431 & TST & \\
\hline CHEMBL1988692 & 809184 & 5.4 & 4.8041 & TRN & \\
\hline CHEMBL 2007574 & 809184 & 5.6 & 5.8417 & TRN & \\
\hline CHEMBL1964804 & 809184 & 4.3 & 4.0245 & TRN & \\
\hline CHEMBL443962 & 809184 & 4.3 & 3.9326 & TST & \\
\hline CHEMBL 2000354 & 809184 & 4.3 & 4.2753 & TRN & \\
\hline CHEMBL1965507 & 809184 & 4.3 & 4.311 & TRN & \\
\hline CHEMBL 274064 & 809184 & 4.3 & 4.713 & TRN & \\
\hline CHEMBL1998680 & 809184 & 4.3 & 4.368 & TRN & \\
\hline CHEMBL1967564 & 809184 & 4.3 & 4.0895 & TRN & \\
\hline CHEMBL592030 & 809184 & 5.6 & 5.5173 & TST & \\
\hline CHEMBL 2000071 & 809184 & 4.5 & 4.9546 & TRN & \\
\hline & & & & 15862 & \\
\hline
\end{tabular}




\begin{tabular}{|c|c|c|c|c|c|}
\hline \multirow[b]{2}{*}{ CHEMBL1979176 } & \multirow{2}{*}{809184} & \\
\hline & & 4.3 & 3.8734 & TRN & \\
\hline CHEMBL1970317 & 809184 & 4.3 & 4.3764 & TRN & \\
\hline CHEMBL2002613 & 809184 & 5.6 & 5.5261 & TRN & \\
\hline CHEMBL2000408 & 809184 & 4.3 & 4.5032 & TRN & \\
\hline CHEMBL 248757 & 809184 & 4.3 & 4.7168 & TST & \\
\hline CHEMBL1978014 & 809184 & 4.3 & 4.2103 & TRN & \\
\hline CHEMBL 2002736 & 809184 & 4.3 & 4.3855 & TRN & \\
\hline CHEMBL1997007 & 809184 & 5.8 & 5.4292 & TRN & \\
\hline CHEMBL1994538 & 809184 & 4.3 & 4.2032 & TRN & \\
\hline CHEMBL1983195 & 809184 & 4.3 & 4.5154 & TST & \\
\hline CHEMBL1975490 & 809184 & 4.3 & 4.9614 & TRN & \\
\hline CHEMBL1964444 & 809184 & 4.3 & $4.8180 e$ & 00000000005 & TRN \\
\hline CHEMBL 2002690 & 809184 & 4.3 & 4.1189 & TRN & \\
\hline CHEMBL 2006567 & 809184 & 4.3 & 4.2891 & TRN & \\
\hline CHEMBL1986139 & 809184 & 4.3 & 3.9925 & TRN & \\
\hline CHEMBL383527 & 809184 & 4.3 & 4.5018 & TRN & \\
\hline CHEMBL1980540 & 809184 & 4.3 & 4.28 & TRN & \\
\hline CHEMBL 278041 & 809184 & 4.3 & 4.4171 & TRN & \\
\hline CHEMBL1979883 & 809184 & 4.3 & 4.3995 & TRN & \\
\hline CHEMBL1984162 & 809184 & 5.9 & 5.7946 & TRN & \\
\hline CHEMBL1997051 & 809184 & 4.3 & 4.726 & TRN & \\
\hline CHEMBL1998432 & 809184 & 7.0 & 7.5032 & TRN & \\
\hline CHEMBL491758 & 809184 & 4.3 & 4.7078 & TRN & \\
\hline CHEMBL1986590 & 809184 & 4.3 & 4.9851 & TRN & \\
\hline CHEMBL549730 & 809184 & 4.3 & 4.3662 & TRN & \\
\hline CHEMBL1682360 & 809184 & 4.3 & 4.4458 & TRN & \\
\hline CHEMBL1970189 & 809184 & 4.3 & 4.3685 & TRN & \\
\hline CHEMBL1870106 & 809184 & 4.3 & 4.8902 & TRN & \\
\hline CHEMBL1996791 & 809184 & 4.3 & 4.6678 & TRN & \\
\hline CHEMBL371206 & 809184 & 4.3 & 4.268 & TRN & \\
\hline CHEMBL1974664 & 809184 & 4.3 & 4.4945 & TST & \\
\hline CHEMBL406845 & 809184 & 4.3 & 4.7762 & TRN & \\
\hline CHEMBL1974288 & 809184 & 5.6 & 4.5347 & TRN & \\
\hline CHEMBL482538 & 809184 & 4.1 & 4.4313 & TRN & \\
\hline CHEMBL1984296 & 809184 & 5.4 & 5.0084 & TST & \\
\hline CHEMBL196363 & 809184 & 4.3 & 4.5284 & TRN & \\
\hline CHEMBL1190711 & 809184 & 4.3 & 4.3565 & TRN & \\
\hline CHEMBL1990346 & 809184 & 4.3 & 4.4771 & TRN & \\
\hline CHEMBL1968705 & 809184 & 4.3 & 4.4572 & TRN & \\
\hline CHEMBL1991410 & 809184 & 4.3 & 4.0742 & TRN & \\
\hline CHEMBL1964441 & 809184 & 4.3 & 4.3362 & TRN & \\
\hline CHEMBL546797 & 809184 & 4.3 & 4.1974 & TRN & \\
\hline CHEMBL404367 & 809184 & 4.3 & 4.3231 & TRN & \\
\hline CHEMBL1966343 & 809184 & 4.3 & 4.3448 & TRN & \\
\hline CHEMBL1978271 & 809184 & 4.3 & 4.4648 & TRN & \\
\hline CHEMBL1967887 & 809184 & 4.3 & 5.2297 & TRN & \\
\hline CHEMBL 2007266 & 809184 & 4.3 & 4.01 & TRN & \\
\hline CHEMBL1985469 & 809184 & 4.3 & 4.3294 & TST & \\
\hline & & & & 15863 & \\
\hline
\end{tabular}




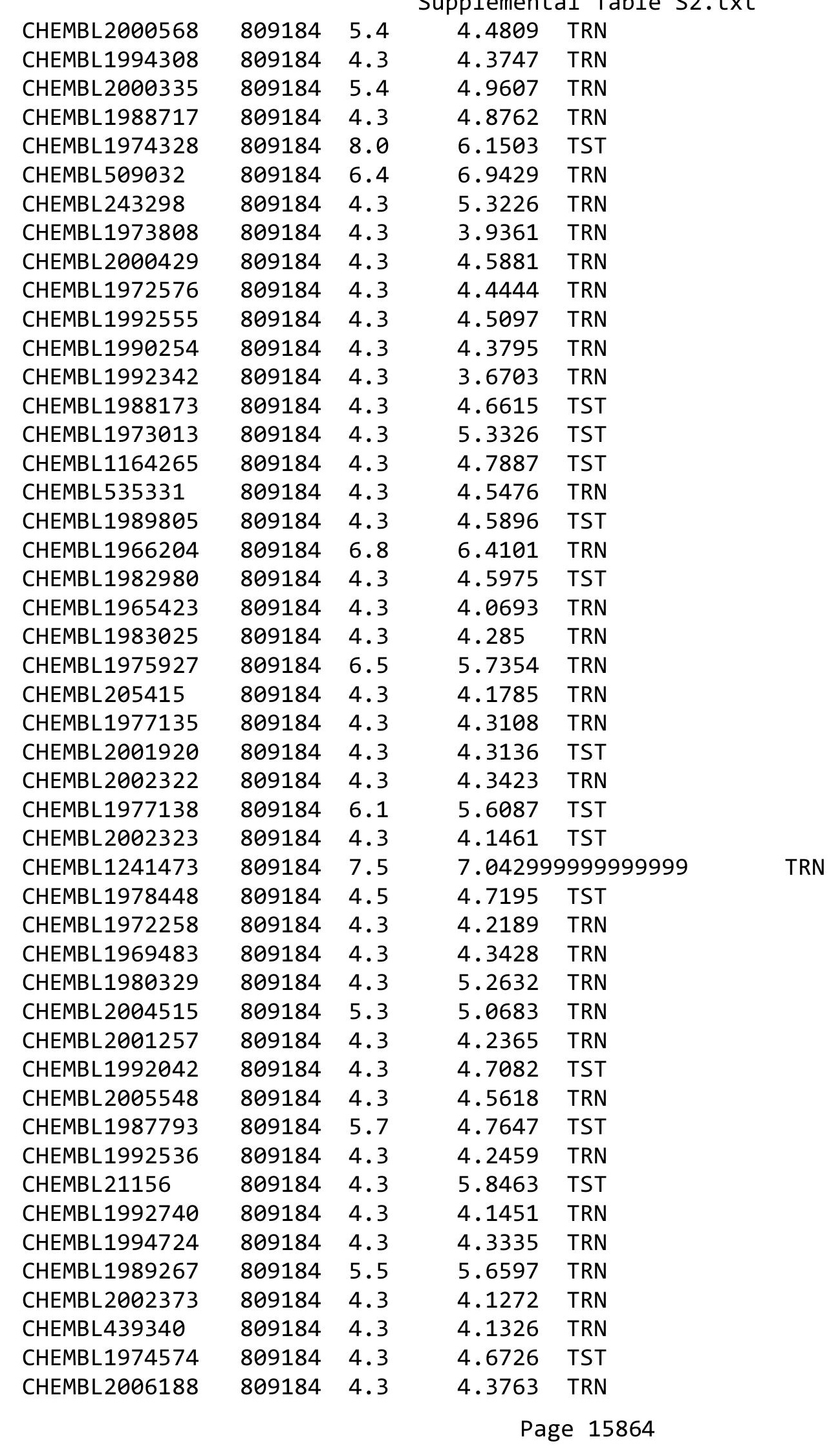




\begin{tabular}{|c|c|c|c|c|c|}
\hline \\
\hline CHEMBL1970290 & 809184 & 6.3 & 5.5845 & TRN & \\
\hline CHEMBL1967531 & 809184 & 4.3 & 4.2713 & TRN & \\
\hline CHEMBL1970913 & 809184 & 4.3 & 4.3145 & TRN & \\
\hline CHEMBL1973893 & 809184 & 4.3 & 4.231 & TRN & \\
\hline CHEMBL1995736 & 809184 & 4.3 & 4.3722 & TRN & \\
\hline CHEMBL1997534 & 809184 & 4.3 & 4.4025 & TRN & \\
\hline CHEMBL1993877 & 809184 & 6.3 & 5.3519 & TRN & \\
\hline CHEMBL1985095 & 809184 & 4.3 & 5.2007 & TST & \\
\hline CHEMBL1996500 & 809184 & 4.3 & 4.5153 & TRN & \\
\hline CHEMBL1998551 & 809184 & 4.3 & 4.274 & TRN & \\
\hline CHEMBL1977374 & 809184 & 4.3 & 4.3988 & TRN & \\
\hline CHEMBL1973363 & 809184 & 5.4 & 4.8294 & TRN & \\
\hline CHEMBL1991180 & 809184 & 5.7 & 4.9212 & TST & \\
\hline CHEMBL1682540 & 809184 & 4.3 & 4.2135 & TRN & \\
\hline CHEMBL1976420 & 809184 & 5.8 & 4.7005 & TST & \\
\hline CHEMBL1998253 & 809184 & 4.3 & 4.478 & TST & \\
\hline CHEMBL413779 & 809184 & 5.5 & 5.4402 & TST & \\
\hline CHEMBL1994864 & 809184 & 4.3 & 4.4591 & TRN & \\
\hline CHEMBL1981744 & 809184 & 4.3 & 4.36600 & 30000000005 & TRN \\
\hline CHEMBL 2002446 & 809184 & 4.3 & 4.5955 & TST & \\
\hline CHEMBL497151 & 809184 & 4.3 & 4.5615 & TRN & \\
\hline CHEMBL 2000029 & 809184 & 5.5 & 5.3314 & TRN & \\
\hline CHEMBL1973961 & 809184 & 4.3 & 4.4707 & TRN & \\
\hline CHEMBL 246970 & 809184 & 4.3 & 4.6306 & TRN & \\
\hline CHEMBL340921 & 809184 & 4.3 & 4.6245 & TST & \\
\hline CHEMBL1994977 & 809184 & 4.3 & 4.5666 & TRN & \\
\hline CHEMBL373598 & 809184 & 4.3 & 5.3838 & TST & \\
\hline CHEMBL 2001149 & 809184 & 5.4 & 4.7005 & TRN & \\
\hline CHEMBL1999718 & 809184 & 4.3 & 3.7823 & TRN & \\
\hline CHEMBL1987073 & 809184 & 5.8 & 6.1182 & TRN & \\
\hline CHEMBL 2000078 & 809184 & 4.3 & 4.3549 & TRN & \\
\hline CHEMBL1276446 & 809184 & 6.7 & 5.0947 & TST & \\
\hline CHEMBL 2005478 & 809184 & 5.6 & 5.0383 & TST & \\
\hline CHEMBL1996646 & 809184 & 5.5 & 5.7034 & TRN & \\
\hline CHEMBL1995712 & 809184 & 6.4 & 6.6754 & TRN & \\
\hline CHEMBL1979773 & 809184 & 5.8 & 4.8185 & TRN & \\
\hline CHEMBL 1977346 & 809184 & 4.3 & 4.3333 & TRN & \\
\hline CHEMBL 2003657 & 809184 & 4.3 & 4.084 & TRN & \\
\hline CHEMBL1971649 & 809184 & 4.3 & 4.1835 & TRN & \\
\hline CHEMBL 2005482 & 809184 & 4.3 & 4.4648 & TRN & \\
\hline CHEMBL1996702 & 809184 & 6.2 & 5.1269 & TRN & \\
\hline CHEMBL1997909 & 809184 & 4.3 & 4.391 & TRN & \\
\hline CHEMBL 2007124 & 809184 & 4.3 & 4.3092 & TRN & \\
\hline CHEMBL1998435 & 809184 & 4.3 & 3.9474 & TRN & \\
\hline CHEMBL 2006439 & 809184 & 4.7 & 5.8381 & TRN & \\
\hline CHEMBL 2006156 & 809184 & 4.3 & 4.3494 & TST & \\
\hline CHEMBL1985681 & 809184 & 4.3 & 4.9843 & TST & \\
\hline CHEMBL1969190 & 809184 & 4.3 & 4.5542 & TRN & \\
\hline
\end{tabular}




\begin{tabular}{|c|c|c|c|c|}
\hline \multicolumn{5}{|c|}{ Supplemental Tab } \\
\hline CHEMBL 2002660 & 809184 & 4.3 & 4.7016 & TRN \\
\hline CHEMBL1973937 & 809184 & 4.3 & 4.649 & TRN \\
\hline CHEMBL1991674 & 809184 & 7.0 & 6.7572 & TRN \\
\hline CHEMBL1982711 & 809184 & 4.3 & 5.0586 & TRN \\
\hline CHEMBL 262623 & 809184 & 4.0 & 4.1012 & TRN \\
\hline CHEMBL1984842 & 809184 & 4.3 & 4.5586 & TRN \\
\hline CHEMBL1969102 & 809184 & 4.3 & 4.7143 & TRN \\
\hline CHEMBL 2004118 & 809184 & 5.7 & 5.551 & TRN \\
\hline CHEMBL1682346 & 809184 & 4.3 & 4.7552 & TRN \\
\hline CHEMBL1996795 & 809184 & 4.3 & 4.4617 & TST \\
\hline CHEMBL1994241 & 809184 & 4.3 & 4.4431 & TRN \\
\hline CHEMBL 2007044 & 809184 & 4.3 & 4.9698 & TST \\
\hline CHEMBL 2001998 & 809184 & 4.3 & 4.5751 & TST \\
\hline CHEMBL223460 & 809184 & 4.3 & 5.3395 & TST \\
\hline CHEMBL1998829 & 809184 & 4.3 & 4.1422 & TRN \\
\hline CHEMBL50894 & 809184 & 6.1 & 4.6992 & TRN \\
\hline CHEMBL1995211 & 809184 & 6.0 & 5.1894 & TRN \\
\hline CHEMBL1988838 & 809184 & 6.2 & 5.9874 & TRN \\
\hline CHEMBL1981725 & 809184 & 6.4 & 4.9062 & TRN \\
\hline CHEMBL375284 & 809184 & 4.3 & 4.2053 & TRN \\
\hline CHEMBL 2006299 & 809184 & 4.3 & 4.5419 & TRN \\
\hline CHEMBL1980562 & 809184 & 6.9 & 6.9257 & TRN \\
\hline CHEMBL1965169 & 809184 & 4.3 & 4.5486 & TST \\
\hline CHEMBL1991818 & 809184 & 4.3 & 4.7305 & TST \\
\hline CHEMBL1081312 & 809184 & 6.2 & 5.7113 & TRN \\
\hline CHEMBL1965170 & 809184 & 4.3 & 4.5222 & TRN \\
\hline CHEMBL1982866 & 809184 & 4.3 & 3.9963 & TRN \\
\hline CHEMBL 2005792 & 809184 & 4.3 & 4.5344 & TRN \\
\hline CHEMBL1968926 & 809184 & 4.3 & 4.162 & TRN \\
\hline CHEMBL1984206 & 809184 & 4.3 & 4.4275 & TRN \\
\hline CHEMBL462120 & 809184 & 4.3 & 4.1926 & TST \\
\hline CHEMBL1991577 & 809184 & 4.3 & 4.5226 & TRN \\
\hline CHEMBL1979933 & 809184 & 4.3 & 5.3465 & TRN \\
\hline CHEMBL1986503 & 809184 & 4.3 & 4.3936 & TST \\
\hline CHEMBL 2007592 & 809184 & 4.3 & 4.1466 & TST \\
\hline CHEMBL1965570 & 809184 & 4.3 & 4.5259 & TRN \\
\hline CHEMBL1972355 & 809184 & 4.3 & 5.4437 & TST \\
\hline CHEMBL1997892 & 809184 & 4.3 & 4.3667 & TRN \\
\hline CHEMBL 2001641 & 809184 & 4.0 & 4.4582 & TRN \\
\hline CHEMBL1976936 & 809184 & 7.1 & 6.8451 & TRN \\
\hline CHEMBL1997193 & 809184 & 5.7 & 4.6518 & TST \\
\hline CHEMBL210963 & 809184 & 4.3 & 4.2783 & TRN \\
\hline CHEMBL1964902 & 809184 & 4.3 & 4.2758 & TRN \\
\hline CHEMBL1082440 & 809184 & 4.3 & 4.7325 & TST \\
\hline CHEMBL1614705 & 809184 & 4.3 & 4.2772 & TRN \\
\hline CHEMBL1972362 & 809184 & 4.3 & 4.2989 & TRN \\
\hline CHEMBL1984633 & 809184 & 4.3 & 3.9656 & TRN \\
\hline CHEMBL1972988 & 809184 & 4.3 & 4.8916 & TRN \\
\hline
\end{tabular}




\begin{tabular}{|c|c|c|c|c|}
\hline \multicolumn{5}{|c|}{ plemental T } \\
\hline CHEMBL1965845 & 809184 & 4.3 & 4.6616 & TRN \\
\hline CHEMBL 2007372 & 809184 & 4.3 & 4.397 & TRN \\
\hline CHEMBL1983715 & 809184 & 6.2 & 6.6488 & TRN \\
\hline CHEMBL1982167 & 809184 & 4.3 & 4.428 & TRN \\
\hline CHEMBL1971017 & 809184 & 4.3 & 4.6093 & TRN \\
\hline CHEMBL 2006715 & 809184 & 4.3 & 4.4037 & TRN \\
\hline CHEMBL1986597 & 809184 & 4.3 & 4.3754 & TRN \\
\hline CHEMBL1990482 & 809184 & 4.3 & 3.7173 & TRN \\
\hline CHEMBL1990904 & 809184 & 4.3 & 4.3727 & TRN \\
\hline CHEMBL 2000104 & 809184 & 4.3 & 4.2715 & TRN \\
\hline CHEMBL 2005475 & 809184 & 4.3 & 4.3011 & TRN \\
\hline CHEMBL1987448 & 809184 & 6.0 & 6.2198 & TRN \\
\hline CHEMBL402846 & 809184 & 4.3 & 4.2246 & TRN \\
\hline CHEMBL1997349 & 809184 & 4.3 & 4.9065 & TST \\
\hline CHEMBL183844 & 809184 & 4.3 & 3.9667 & TRN \\
\hline CHEMBL220057 & 809184 & 4.3 & 4.3509 & TRN \\
\hline CHEMBL1682545 & 809184 & 4.3 & 3.5797 & TRN \\
\hline CHEMBL383541 & 809184 & 4.3 & 4.4077 & TRN \\
\hline CHEMBL 2001224 & 809184 & 4.3 & 4.4388 & TRN \\
\hline CHEMBL10 & 809184 & 4.3 & 4.1677 & TRN \\
\hline CHEMBL1976732 & 809184 & 4.3 & 4.2577 & TRN \\
\hline CHEMBL 2005216 & 809184 & 7.6 & 6.7404 & TRN \\
\hline CHEMBL1969506 & 809184 & 4.3 & 4.4683 & TRN \\
\hline CHEMBL1980763 & 809184 & 5.5 & 5.3626 & TRN \\
\hline CHEMBL1964937 & 809184 & 4.3 & 4.8541 & TRN \\
\hline CHEMBL1980163 & 809184 & 4.3 & 4.1288 & TRN \\
\hline CHEMBL590109 & 809184 & 5.9 & 5.437 & TST \\
\hline CHEMBL1977931 & 809184 & 4.3 & 4.4458 & TRN \\
\hline CHEMBL1970879 & 809184 & 6.3 & 5.5773 & TRN \\
\hline CHEMBL1989856 & 809184 & 4.3 & 4.2768 & TST \\
\hline CHEMBL 2005899 & 809184 & 4.3 & 4.3089 & TRN \\
\hline CHEMBL1972568 & 809184 & 4.3 & 4.2186 & TRN \\
\hline CHEMBL1682552 & 809184 & 4.3 & 4.7201 & TRN \\
\hline CHEMBL 259850 & 809184 & 4.3 & 3.9192 & TRN \\
\hline CHEMBL 2007479 & 809184 & 4.3 & 4.0206 & TRN \\
\hline CHEMBL1996155 & 809184 & 4.3 & 4.4396 & TRN \\
\hline CHEMBL229799 & 809184 & 7.5 & 6.9867 & TRN \\
\hline CHEMBL105739 & 809184 & 4.3 & 4.599 & TRN \\
\hline CHEMBL1682359 & 809184 & 4.3 & 4.2428 & TRN \\
\hline CHEMBL1972220 & 809184 & 4.3 & 5.2164 & TRN \\
\hline CHEMBL379300 & 809184 & 5.8 & 6.3707 & TRN \\
\hline CHEMBL203673 & 809184 & 4.3 & 4.4876 & TRN \\
\hline CHEMBL 2003785 & 809184 & 4.7 & 4.7855 & TST \\
\hline CHEMBL1973720 & 809184 & 7.4 & 7.8741 & TRN \\
\hline CHEMBL1969523 & 809184 & 4.3 & 4.7074 & TRN \\
\hline CHEMBL1988995 & 809184 & 4.3 & 4.3127 & TRN \\
\hline CHEMBL207995 & 809184 & 4.3 & 4.3911 & TRN \\
\hline CHEMBL 2001923 & 809184 & 4.3 & 4.5281 & TRN \\
\hline
\end{tabular}




\begin{tabular}{|c|c|c|c|c|}
\hline \multicolumn{5}{|c|}{ lemental T } \\
\hline CHEMBL1986781 & 809184 & 4.3 & 4.5965 & TRN \\
\hline CHEMBL1983070 & 809184 & 6.3 & 4.5928 & TRN \\
\hline CHEMBL 2003514 & 809184 & 4.3 & 4.1371 & TRN \\
\hline CHEMBL526133 & 809184 & 4.3 & 4.1606 & TRN \\
\hline CHEMBL1989043 & 809184 & 4.3 & 4.7973 & TRN \\
\hline CHEMBL1979057 & 809184 & 4.3 & 4.0884 & TRN \\
\hline CHEMBL1981045 & 809184 & 4.3 & 4.6399 & TRN \\
\hline CHEMBL387971 & 809184 & 4.3 & 4.3959 & TST \\
\hline CHEMBL1975418 & 809184 & 4.3 & 4.8964 & TRN \\
\hline CHEMBL1992796 & 809184 & 4.3 & 4.6351 & TST \\
\hline CHEMBL 1164180 & 809184 & 4.3 & 5.08 & TST \\
\hline CHEMBL223257 & 809184 & 4.3 & 5.4357 & TST \\
\hline CHEMBL1999428 & 809184 & 4.3 & 4.4134 & TRN \\
\hline CHEMBL1967560 & 809184 & 4.3 & 4.7113 & TRN \\
\hline CHEMBL1997611 & 809184 & 4.3 & 4.8701 & TST \\
\hline CHEMBL 1516890 & 809184 & 4.3 & 4.6522 & TRN \\
\hline CHEMBL211378 & 809184 & 4.3 & 4.1274 & TRN \\
\hline CHEMBL1982465 & 809184 & 4.3 & 4.1215 & TRN \\
\hline CHEMBL 2001751 & 809184 & 5.9 & 6.4042 & TRN \\
\hline CHEMBL 2003420 & 809184 & 4.3 & 4.115 & TRN \\
\hline CHEMBL 1984586 & 809184 & 4.3 & 4.1673 & TRN \\
\hline CHEMBL1999774 & 809184 & 4.3 & 4.2007 & TST \\
\hline CHEMBL1972659 & 809184 & 4.3 & 4.5384 & TST \\
\hline CHEMBL 2002723 & 809184 & 5.5 & 5.0166 & TST \\
\hline CHEMBL1973395 & 809184 & 5.4 & 5.2868 & TRN \\
\hline CHEMBL 272453 & 809184 & 4.3 & 4.3819 & TRN \\
\hline CHEMBL1970217 & 809184 & 4.3 & 4.4004 & TRN \\
\hline CHEMBL1971801 & 809184 & 4.3 & 4.0956 & TRN \\
\hline CHEMBL1968850 & 809184 & 4.3 & 4.1103 & TRN \\
\hline CHEMBL 2005528 & 809184 & 4.3 & 3.9468 & TST \\
\hline CHEMBL1984686 & 809184 & 4.3 & 4.3928 & TRN \\
\hline CHEMBL185569 & 809184 & 4.3 & 4.2272 & TRN \\
\hline CHEMBL1969843 & 809184 & 4.3 & 4.1381 & TRN \\
\hline CHEMBL 2007002 & 809184 & 4.3 & 4.3768 & TRN \\
\hline CHEMBL1987007 & 809184 & 4.3 & 4.5877 & TRN \\
\hline CHEMBL1973793 & 809184 & 5.4 & 4.1907 & TST \\
\hline CHEMBL1969588 & 809184 & 5.7 & 6.3834 & TRN \\
\hline CHEMBL1984711 & 809184 & 6.0 & 4.5927 & TRN \\
\hline CHEMBL1990212 & 809184 & 4.3 & 4.522 & TRN \\
\hline CHEMBL1992073 & 809184 & 5.6 & 5.2647 & TRN \\
\hline CHEMBL484390 & 809184 & 4.3 & 4.5659 & TRN \\
\hline CHEMBL1979252 & 809184 & 4.3 & 4.5708 & TRN \\
\hline CHEMBL1986143 & 809184 & 4.3 & 4.3178 & TRN \\
\hline CHEMBL 2007559 & 809184 & 6.3 & 5.1122 & TRN \\
\hline CHEMBL1992581 & 809184 & 4.3 & 4.6308 & TRN \\
\hline CHEMBL1682341 & 809184 & 4.3 & 4.5644 & TRN \\
\hline CHEMBL 2004290 & 809184 & 4.3 & 4.3361 & TRN \\
\hline CHEMBL1986499 & 809184 & 4.3 & 4.8284 & TRN \\
\hline
\end{tabular}




\begin{tabular}{|c|c|c|c|c|}
\hline \multicolumn{5}{|c|}{ olemental Table s } \\
\hline CHEMBL1972937 & 809184 & 4.3 & 4.3166 & TRN \\
\hline CHEMBL1972250 & 809184 & 4.3 & 4.6872 & TST \\
\hline CHEMBL 2000393 & 809184 & 5.3 & 5.2954 & TST \\
\hline CHEMBL 2004311 & 809184 & 4.3 & 4.2244 & TRN \\
\hline CHEMBL1992634 & 809184 & 4.3 & 4.8565 & TRN \\
\hline CHEMBL1242373 & 809184 & 4.3 & 4.3329 & TRN \\
\hline CHEMBL1984847 & 809184 & 4.3 & 4.7434 & TRN \\
\hline CHEMBL316264 & 809184 & 4.3 & 4.0676 & TRN \\
\hline CHEMBL1988075 & 809184 & 4.3 & 4.4766 & TRN \\
\hline CHEMBL1996576 & 809184 & 4.3 & 4.2293 & TST \\
\hline CHEMBL 1988076 & 809184 & 4.3 & 4.4571 & TRN \\
\hline CHEMBL1991678 & 809184 & 4.3 & 4.4878 & TRN \\
\hline CHEMBL 2001239 & 809184 & 5.9 & 5.0832 & TRN \\
\hline CHEMBL1988594 & 809184 & 4.3 & 4.372 & TRN \\
\hline CHEMBL 2001288 & 809184 & 4.3 & 4.5419 & TRN \\
\hline CHEMBL1992363 & 809184 & 7.0 & 6.7971 & TRN \\
\hline CHEMBL260092 & 809184 & 4.3 & 4.127 & TRN \\
\hline CHEMBL1999811 & 809184 & 4.3 & 4.1301 & TRN \\
\hline CHEMBL1965495 & 809184 & 4.3 & 4.1756 & TRN \\
\hline CHEMBL1985074 & 809184 & 4.3 & 4.4149 & TST \\
\hline CHEMBL 2000481 & 809184 & 4.3 & 4.67899 & 9999999999 \\
\hline CHEMBL1982874 & 809184 & 4.3 & 4.2225 & TRN \\
\hline CHEMBL1991725 & 809184 & 4.3 & 4.3981 & TRN \\
\hline CHEMBL1992242 & 809184 & 4.3 & 4.2124 & TRN \\
\hline CHEMBL1982271 & 809184 & 7.5 & 7.3394 & TRN \\
\hline CHEMBL 2007296 & 809184 & 4.3 & 4.4756 & TRN \\
\hline CHEMBL208637 & 809184 & 4.3 & 4.1864 & TRN \\
\hline CHEMBL 2007138 & 809184 & 3.9 & 3.8895 & TRN \\
\hline CHEMBL 2004159 & 809184 & 4.3 & 4.3892 & TRN \\
\hline CHEMBL396523 & 809184 & 5.5 & 5.4674 & TRN \\
\hline CHEMBL1978371 & 809184 & 4.3 & 4.5432 & TST \\
\hline CHEMBL1970203 & 809184 & 4.3 & 4.3725 & TRN \\
\hline CHEMBL1986530 & 809184 & 4.3 & 4.1339 & TST \\
\hline CHEMBL440084 & 809184 & 4.3 & 4.4786 & TRN \\
\hline CHEMBL1999321 & 809184 & 4.3 & 4.0581 & TRN \\
\hline CHEMBL1968590 & 809184 & 4.3 & 4.165 & TRN \\
\hline CHEMBL1999749 & 809184 & 4.3 & 4.3664 & TRN \\
\hline CHEMBL 2005375 & 809184 & 4.3 & 4.6964 & TRN \\
\hline CHEMBL1984191 & 809184 & 4.3 & 4.3848 & TRN \\
\hline CHEMBL1983006 & 809184 & 4.3 & 4.258 & TRN \\
\hline CHEMBL1972183 & 809184 & 4.3 & 4.4178 & TRN \\
\hline CHEMBL1971029 & 809184 & 7.7 & 6.902 & TRN \\
\hline CHEMBL1995391 & 809184 & 3.9 & 4.0975 & TRN \\
\hline CHEMBL 394790 & 809184 & 4.3 & 4.3975 & TRN \\
\hline CHEMBL226471 & 809184 & 4.3 & 3.9799 & TRN \\
\hline CHEMBL1974702 & 809184 & 4.3 & 4.4076 & TST \\
\hline CHEMBL1966175 & 809184 & 4.3 & 5.0702 & TRN \\
\hline CHEMBL1996111 & 809184 & 4.3 & 4.5541 & TRN \\
\hline
\end{tabular}




\begin{tabular}{|c|c|c|c|c|c|}
\hline \\
\hline CHEMBL1965589 & 809184 & 4.3 & 4.5841 & TRN & \\
\hline CHEMBL 2007375 & 809184 & 4.3 & 4.3948 & TRN & \\
\hline CHEMBL1998193 & 809184 & 4.3 & 3.9802 & TRN & \\
\hline CHEMBL379975 & 809184 & 6.0 & 5.9288 & TST & \\
\hline CHEMBL474432 & 809184 & 4.3 & 4.9286 & TST & \\
\hline CHEMBL1973016 & 809184 & 4.3 & 4.2672 & TRN & \\
\hline CHEMBL1965387 & 809184 & 4.3 & 3.9368 & TRN & \\
\hline CHEMBL2001539 & 809184 & 4.3 & 4.3646 & TST & \\
\hline CHEMBL1997041 & 809184 & 5.1 & 4.8976 & TRN & \\
\hline CHEMBL1988153 & 809184 & 4.3 & 4.5527 & TRN & \\
\hline CHEMBL550418 & 809184 & 4.3 & 4.7327 & TRN & \\
\hline CHEMBL1986666 & 809184 & 6.0 & 5.7391 & TRN & \\
\hline CHEMBL1971289 & 809184 & 4.3 & 4.4658 & TRN & \\
\hline CHEMBL1999556 & 809184 & 4.3 & 4.55699 & 99999999995 & TRN \\
\hline CHEMBL1988437 & 809184 & 5.6 & 4.6641 & TST & \\
\hline CHEMBL1968245 & 809184 & 4.3 & 4.4132 & TRN & \\
\hline CHEMBL1979577 & 809184 & 4.3 & 4.3989 & TRN & \\
\hline CHEMBL1998121 & 809184 & 5.7 & 4.9385 & TRN & \\
\hline CHEMBL1233887 & 809184 & 4.3 & 4.122 & TST & \\
\hline CHEMBL1991800 & 809184 & 4.3 & 4.5267 & TRN & \\
\hline CHEMBL52387 & 809184 & 4.3 & 4.8782 & TST & \\
\hline CHEMBL1985566 & 809184 & 4.3 & 4.5494 & TRN & \\
\hline CHEMBL 2003689 & 809184 & 4.3 & 4.4265 & TRN & \\
\hline CHEMBL379835 & 809184 & 4.3 & 4.2346 & TST & \\
\hline CHEMBL1979357 & 809184 & 4.3 & 4.4805 & TRN & \\
\hline CHEMBL1980802 & 809184 & 4.3 & 5.1036 & TST & \\
\hline CHEMBL1996649 & 809184 & 5.3 & 5.2509 & TRN & \\
\hline CHEMBL1996817 & 809184 & 6.2 & 5.0842 & TRN & \\
\hline CHEMBL1979554 & 809184 & 4.3 & 4.7428 & TRN & \\
\hline CHEMBL1986756 & 809184 & 4.3 & 4.4215 & TRN & \\
\hline CHEMBL3197315 & 809184 & 4.3 & 4.1672 & TST & \\
\hline CHEMBL 2004355 & 809184 & 4.3 & 4.2429 & TRN & \\
\hline CHEMBL468280 & 809184 & 4.3 & 4.0676 & TST & \\
\hline CHEMBL1990884 & 809184 & 4.3 & 4.4558 & TRN & \\
\hline CHEMBL3109278 & 809184 & 4.5 & 5.0149 & TRN & \\
\hline CHEMBL256835 & 809184 & 4.3 & 4.5449 & TRN & \\
\hline CHEMBL1974998 & 809184 & 4.3 & 4.6871 & TRN & \\
\hline CHEMBL1980142 & 809184 & 4.3 & 4.2876 & TRN & \\
\hline CHEMBL41783 & 809184 & 4.3 & 4.1074 & TRN & \\
\hline CHEMBL 2004438 & 809184 & 4.3 & 4.0798 & TRN & \\
\hline CHEMBL 2006276 & 809184 & 4.3 & 4.208 & TRN & \\
\hline CHEMBL191003 & 809184 & 5.9 & 5.7582 & TRN & \\
\hline CHEMBL271381 & 809184 & 4.3 & 4.5062 & TRN & \\
\hline CHEMBL 2006785 & 809184 & 4.3 & 4.3164 & TST & \\
\hline CHEMBL1982466 & 809184 & 4.3 & 4.5156 & TRN & \\
\hline CHEMBL1973359 & 809184 & 6.1 & 5.4533 & TST & \\
\hline CHEMBL1995740 & 809184 & 4.3 & 4.712 & TRN & \\
\hline CHEMBL1996390 & 809184 & 4.3 & 4.0117 & TRN & \\
\hline
\end{tabular}




\begin{tabular}{|c|c|c|c|c|c|}
\hline & & & & & \\
\hline CHEMBL1990162 & 809184 & 6.6 & 6.1813 & TRN & \\
\hline CHEMBL1992220 & 809184 & 7.6 & 7.379 & TRN & \\
\hline CHEMBL1979690 & 809184 & 6.9 & 7.0617 & TRN & \\
\hline CHEMBL 234085 & 809184 & 4.3 & 4.5561 & TRN & \\
\hline CHEMBL1998414 & 809184 & 4.3 & 4.4135 & TRN & \\
\hline CHEMBL1995832 & 809184 & 4.3 & 4.6339 & TRN & \\
\hline CHEMBL1969042 & 809184 & 4.3 & 4.3128 & TRN & \\
\hline CHEMBL 2000345 & 809184 & 4.3 & 4.5427 & TRN & \\
\hline CHEMBL1999931 & 809184 & 6.5 & 6.4953 & TRN & \\
\hline CHEMBL1976376 & 809184 & 4.3 & 4.2766 & TRN & \\
\hline CHEMBL1991640 & 809184 & 4.3 & 4.729 & TST & \\
\hline CHEMBL1983575 & 809184 & 6.8 & 5.6714 & TRN & \\
\hline CHEMBL1375418 & 809184 & 4.3 & 4.3698 & TRN & \\
\hline CHEMBL1968868 & 809184 & 4.3 & 4.29899 & 99999999995 & TRN \\
\hline CHEMBL 302449 & 809184 & 7.2 & 5.0196 & TST & \\
\hline CHEMBL 2007064 & 809184 & 4.3 & 4.5627 & TRN & \\
\hline CHEMBL1981047 & 809184 & 5.5 & 5.3935 & TRN & \\
\hline CHEMBL229968 & 809184 & 7.1 & 6.5919 & TRN & \\
\hline CHEMBL1976196 & 809184 & 4.3 & 4.4649 & TST & \\
\hline CHEMBL1976240 & 809184 & 4.3 & 4.6755 & TRN & \\
\hline CHEMBL1987948 & 809184 & 6.8 & $6.5710 e$ & 0000000001 & TRN \\
\hline CHEMBL1997197 & 809184 & 4.3 & 4.2255 & TRN & \\
\hline CHEMBL1968151 & 809184 & 4.3 & 4.3703 & TST & \\
\hline CHEMBL1979093 & 809184 & 4.3 & 4.5351 & TRN & \\
\hline CHEMBL1381197 & 809184 & 4.3 & 4.2554 & TRN & \\
\hline CHEMBL1987009 & 809184 & 4.3 & 4.3929 & TRN & \\
\hline CHEMBL379218 & 809184 & 5.6 & 6.4713 & TRN & \\
\hline CHEMBL 2003817 & 809184 & 4.3 & 3.4422 & TRN & \\
\hline CHEMBL336961 & 809184 & 4.3 & 4.2241 & TRN & \\
\hline CHEMBL1994830 & 809184 & 4.3 & 4.2297 & TRN & \\
\hline CHEMBL1987054 & 809184 & 5.5 & 5.6655 & TRN & \\
\hline CHEMBL1970083 & 809184 & 4.3 & 4.5603 & TRN & \\
\hline CHEMBL226403 & 809184 & 4.3 & 3.9213 & TRN & \\
\hline CHEMBL 2005631 & 809184 & 4.3 & 4.8679 & TRN & \\
\hline CHEMBL1994938 & 809184 & 4.3 & 4.4209 & TRN & \\
\hline CHEMBL1977223 & 809184 & 5.4 & 5.1293 & TRN & \\
\hline CHEMBL1995765 & 809184 & 4.2 & 4.3147 & TST & \\
\hline CHEMBL1966279 & 809184 & 4.3 & 4.6503 & TRN & \\
\hline CHEMBL1236126 & 809184 & 4.3 & 4.2996 & TRN & \\
\hline CHEMBL1997846 & 809184 & 6.1 & 5.9979 & TRN & \\
\hline CHEMBL1984760 & 809184 & 6.2 & 5.5569 & TRN & \\
\hline CHEMBL 2004419 & 809184 & 4.3 & 4.1948 & TRN & \\
\hline CHEMBL1991728 & 809184 & 5.6 & 4.954 & TRN & \\
\hline CHEMBL360847 & 809184 & 4.3 & 4.6779 & TST & \\
\hline CHEMBL2007073 & 809184 & 4.3 & 4.5091 & TRN & \\
\hline CHEMBL1995811 & 809184 & 5.5 & 5.4684 & TRN & \\
\hline CHEMBL1975787 & 809184 & 4.3 & 4.372 & TRN & \\
\hline CHEMBL 2002407 & 809184 & 4.3 & 4.1532 & TRN & \\
\hline & & & & 15871 & \\
\hline
\end{tabular}




\begin{tabular}{l} 
CHEMBL1972489 \\
CHEMBL1994074 \\
CHEMBL1992937 \\
CHEMBL1968930 \\
CHEMBL1972119 \\
CHEMBL1986328 \\
CHEMBL95692 \\
CHEMBL1090356 \\
CHEMBL1976455 \\
CHEMBL261849 \\
CHEMBL1983923 \\
CHEMBL1983534 \\
CHEMBL1982361 \\
CHEMBL1999112 \\
CHEMBL2000801 \\
CHEMBL1982122 \\
CHEMBL1682546 \\
CHEMBL1988872 \\
CHEMBL1991395 \\
CHEMBL1971245 \\
CHEMBL1987648 \\
CHEMBL1996780 \\
CHEMBL1972142 \\
CHEMBL1966514 \\
CHEMBL2003638 \\
CHEMBL296586 \\
CHEMBL1996066 \\
CHEMBL1983393 \\
CHEMBL516429 \\
CHEMBL1970806 \\
CHEMBL1993722 \\
CHEMBL2006674 \\
CHEMBL1984236 \\
CHEMBL1992371 \\
CHEMBL1375640 \\
CHEMBL1979970 \\
CHEMBL 2002599 \\
CHEMBL 249282 \\
CHEMBL1967252 \\
CHEMBL2004637 \\
CHEMBL1993374 \\
CHEMBL1969264 \\
CHEMBL1994318 \\
CHEMBL1973711 \\
CHEMBL 199965067 \\
\hline
\end{tabular}

Supplemental Table S2.txt

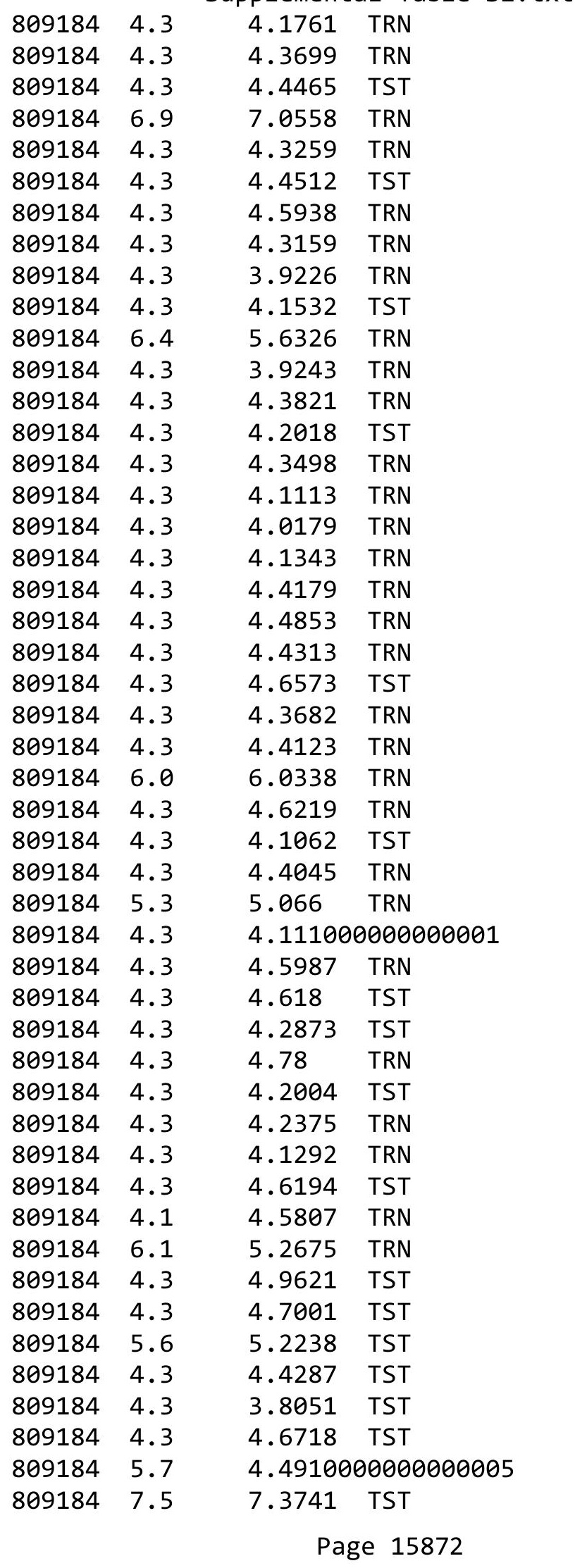

TST

\section{TST}




\begin{tabular}{|c|c|c|c|c|}
\hline & & & plement & \\
\hline CHEMBL1572266 & 809184 & 4.3 & 4.1744 & TST \\
\hline CHEMBL1991138 & 809184 & 4.5 & 4.1402 & TST \\
\hline CHEMBL1979516 & 809184 & 4.3 & 4.6926 & TST \\
\hline CHEMBL1969755 & 809184 & 4.3 & 4.314 & TST \\
\hline CHEMBL1972820 & 809184 & 4.3 & 4.327 & TST \\
\hline CHEMBL1605605 & 809184 & 4.3 & 4.7012 & TST \\
\hline CHEMBL1996208 & 809184 & 4.3 & 4.7651 & TST \\
\hline CHEMBL1989029 & 809184 & 4.3 & 4.5558 & TST \\
\hline CHEMBL392642 & 809184 & 4.3 & 4.7284 & TST \\
\hline CHEMBL514499 & 809184 & 4.3 & 5.0334 & TST \\
\hline CHEMBL1970352 & 809184 & 4.3 & 4.7423 & TST \\
\hline CHEMBL1965631 & 809184 & 4.3 & 4.8399 & TST \\
\hline CHEMBL1980144 & 809184 & 4.3 & 4.4374 & TST \\
\hline CHEMBL1991188 & 809184 & 4.3 & 4.1201 & TST \\
\hline CHEMBL1980167 & 809184 & 4.3 & 4.7782 & TST \\
\hline CHEMBL1972849 & 809184 & 4.3 & 4.2245 & TST \\
\hline CHEMBL377408 & 809184 & 4.3 & 4.4886 & TST \\
\hline CHEMBL1986855 & 809184 & 7.3 & 6.0827 & TST \\
\hline CHEMBL215152 & 809184 & 4.3 & 4.3594 & TST \\
\hline CHEMBL231209 & 809184 & 4.3 & 4.4219 & TST \\
\hline CHEMBL1976220 & 809184 & 4.3 & 4.3756 & TST \\
\hline CHEMBL 2006765 & 809184 & 7.4 & 6.7268 & TST \\
\hline CHEMBL259922 & 809184 & 4.3 & 4.3733 & TST \\
\hline CHEMBL1997617 & 809184 & 6.7 & 4.9261 & TST \\
\hline CHEMBL1969301 & 809184 & 5.7 & 4.4979 & TST \\
\hline CHEMBL1982383 & 809184 & 4.3 & 4.4858 & TST \\
\hline CHEMBL17370 & 809184 & 4.3 & 4.1695 & TST \\
\hline CHEMBL1980246 & 809184 & 4.3 & 4.4298 & TST \\
\hline CHEMBL1987910 & 809184 & 4.3 & 4.5001 & TST \\
\hline CHEMBL1983932 & 809184 & 4.3 & 4.5338 & TST \\
\hline CHEMBL1983980 & 809184 & 5.3 & 5.3356 & TST \\
\hline CHEMBL1999484 & 809184 & 6.3 & 6.6789 & TST \\
\hline CHEMBL1966069 & 809184 & 4.3 & 4.5003 & TST \\
\hline CHEMBL1986899 & 809184 & 4.3 & 4.2105 & TST \\
\hline CHEMBL1991285 & 809184 & 4.3 & 4.2307 & TST \\
\hline CHEMBL1997822 & 809184 & 4.3 & 4.1896 & TST \\
\hline CHEMBL 243088 & 809184 & 5.5 & 5.2804 & TST \\
\hline CHEMBL1984038 & 809184 & 4.3 & 4.2433 & TST \\
\hline CHEMBL1974416 & 809184 & 4.3 & 4.434 & TST \\
\hline CHEMBL1993661 & 809184 & 8.8 & 7.8875 & TST \\
\hline CHEMBL 2004615 & 809184 & 4.3 & 4.3434 & TST \\
\hline CHEMBL1997872 & 809184 & 4.3 & 4.3722 & TST \\
\hline CHEMBL3222087 & 1332010 & 7.6478 & 7.5576 & TRN \\
\hline CHEMBL3222069 & 1332010 & 7.1029 & 6.8606 & TRN \\
\hline CHEMBL3217800 & 1332010 & 8.041 & 7.9842 & TRN \\
\hline CHEMBL3222076 & 1332010 & 7.5436 & 7.5325 & TRN \\
\hline CHEMBL3222079 & 1332010 & 7.3645 & 7.4296 & TRN \\
\hline CHEMBL 3217874 & 1332010 & 4.0 & 4.5197 & TRN \\
\hline
\end{tabular}


Supplemental Table S2.txt

\begin{tabular}{|c|c|c|}
\hline - & & \\
\hline & 332010 & \\
\hline 82 & & \\
\hline AEMBL3222098 & & \\
\hline AEMBL3217881 & 32010 & \\
\hline HEMBL3222096 & 332010 & 5 \\
\hline HEMBL; & 32010 & \\
\hline 91 & 32010 & \\
\hline AEMBL3222108 & 32010 & \\
\hline HEMBL322 & 32010 & \\
\hline AEMBL3 & 32010 & \\
\hline IEMBL & 2010 & 87 \\
\hline AEMBL & 010 & \\
\hline HEMBL3 & 2010 & \\
\hline AEMBL3 & 2010 & \\
\hline AEMBL3 & 10 & \\
\hline HEMBL3 & 10 & \\
\hline HEMBL & 010 & \\
\hline HEMBL3 & 2010 & \\
\hline HEMBL3 & $\partial 10$ & \\
\hline HEMBL & 10 & 7.2644 \\
\hline HEMBL: & 10 & 6 \\
\hline HEMBL; & 010 & \\
\hline HEMBL3 & 010 & \\
\hline HEMBL3 & & \\
\hline HEMBL & 10 & 7. \\
\hline HEMBL; & 10 & 7 \\
\hline HEMBL3 & 10 & 8. \\
\hline HEMBL3 & & \\
\hline HEMBL32 & & \\
\hline HEMBL3 & $\partial 10$ & 6 \\
\hline HEMBL & 10 & 757 \\
\hline HEMBL3 & 10 & 586 \\
\hline HEMBL32 & 2010 & 6.0022 \\
\hline HEMBL3222073 & 32010 & 6.017 \\
\hline HEMBL & $\partial 10$ & \\
\hline HEMBL & 10 & 6 \\
\hline HEMBL3 & 10 & 8.1871 \\
\hline HEMBL3222054 & 332010 & 7.559 \\
\hline HEMBL32 & 332010 & 6.823 \\
\hline HEMBL3 & 10 & \\
\hline CHEMBL3 & 1332010 & 7.705 \\
\hline CHEMBL3 & 332010 & 6.903 \\
\hline HEMBL 32 & 332010 & 7.374 \\
\hline CHEMBL 32 & 332010 & 4.866 \\
\hline CHEMBL3 & & 7.598 \\
\hline CHEMBL3 & 332010 & 7.769 \\
\hline & 2320 & 10 \\
\hline
\end{tabular}

7.1852 TST

6.8121 TRN

6.8669 TRN

6.5784 TRN

6.432 TRN

6.7405 TST

7.4328 TRN

7.4802 TST

7.0747 TRN

6.7404 TRN

7.6951 TRN

6.1597 TRN

7.2895 TRN

7.907 TRN

7.4258 TST

8.1389 TRN

6.3069 TRN

5.3336 TRN

7.1033 TRN

7.2584 TRN

6.1898 TRN

6.9802 TST

$7.5089999999999995 \quad$ TST

7.313 TST

8.2088 TRN

7.4995 TRN

7.4126 TRN

7.8626 TRN

7.1706 TRN

7.1857 TRN

6.0901 TRN

8.1041 TRN

7.6791 TRN

6.0479 TRN

6.5511 TRN

6.9786 TRN

7.1337 TRN

8.1786 TRN

7.4603 TRN

6.9806 TRN

7.0026 TRN

7.0361 TRN

6.8639 TRN

6.6662 TRN

6.8509 TRN

7.808 TRN

7.8176 TRN

4.6688 TRN

Page 15874 


\begin{tabular}{|c|c|c|c|c|}
\hline \multicolumn{5}{|c|}{ Supplemental Table S2.txt } \\
\hline CHEMBL 3217875 & 1332010 & 4.0 & 4.4063 & TRN \\
\hline CHEMBL3217867 & 1332010 & 4.0 & 7.0857 & TRN \\
\hline CHEMBL3222063 & 1332010 & 6.5229 & 6.9221 & TRN \\
\hline CHEMBL3222052 & 1332010 & 7.5834 & 7.3371 & TRN \\
\hline CHEMBL3222053 & 1332010 & 7.5406 & 7.3449 & TRN \\
\hline CHEMBL3222047 & 1332010 & 6.8539 & 7.7204 & TST \\
\hline CHEMBL 3222056 & 1332010 & 7.4841 & 7.0983 & TRN \\
\hline CHEMBL3217866 & 1332010 & 7.8794 & 7.4138 & TRN \\
\hline CHEMBL3222085 & 1332010 & 8.0 & 7.9402 & TRN \\
\hline CHEMBL3222088 & 1332010 & 7.5229 & 7.3764 & TRN \\
\hline CHEMBL 3222090 & 1332010 & 6.4437 & 7.0254 & TST \\
\hline CHEMBL 3222051 & 1332010 & 7.5513 & 7.2952 & TRN \\
\hline CHEMBL3222092 & 1332010 & 6.6198 & 7.5866 & TST \\
\hline CHEMBL 3222080 & 1332010 & 7.6536 & 7.5453 & TRN \\
\hline CHEMBL 3217870 & 1332010 & 6.4089 & 6.1468 & TRN \\
\hline CHEMBL 3222048 & 1332010 & 7.2557 & 7.6583 & TST \\
\hline CHEMBL 3222095 & 1332010 & 7.0501 & 7.3449 & TST \\
\hline CHEMBL3222106 & 1332010 & 6.4559 & 6.4114 & TRN \\
\hline CHEMBL3222105 & 1332010 & 6.9208 & 6.9055 & TRN \\
\hline CHEMBL 3217878 & 1332010 & 5.4248 & 5.3696 & TRN \\
\hline CHEMBL3217873 & 1332010 & 5.9706 & 5.2224 & TRN \\
\hline CHEMBL3222110 & 1332010 & 7.1898 & 7.2396 & TST \\
\hline CHEMBL3222068 & 1332010 & 8.0605 & 7.6867 & TST \\
\hline CHEMBL3222101 & 1332010 & 6.6198 & 7.2746 & TST \\
\hline CHEMBL3222078 & 1332010 & 6.2147 & 6.9408 & TST \\
\hline CHEMBL3222055 & 1332010 & 7.5376 & 7.2795 & TST \\
\hline CHEMBL3217876 & 1332010 & 4.0 & 5.3016 & TST \\
\hline CHEMBL3222094 & 1332010 & 6.6778 & 6.4242 & TST \\
\hline CHEMBL3222066 & 1332010 & 8.1427 & 8.0275 & TST \\
\hline CHEMBL3222102 & 1332010 & 6.4559 & 6.7283 & TST \\
\hline CHEMBL3222104 & 1332010 & 6.9586 & 6.1958 & TST \\
\hline CHEMBL 3668087 & 1528397 & 8.0 & 8.2285 & TRN \\
\hline CHEMBL3668127 & 1528397 & 8.0 & 8.0348 & TRN \\
\hline CHEMBL3668056 & 1528397 & 7.0 & 7.7834 & TRN \\
\hline CHEMBL 3668084 & 1528397 & 8.0 & 7.8753 & TRN \\
\hline CHEMBL3668094 & 1528397 & 7.0 & 7.3245 & TRN \\
\hline CHEMBL3668098 & 1528397 & 7.0 & 7.6625 & TST \\
\hline CHEMBL3673091 & 1528397 & 8.0 & 7.2258 & TRN \\
\hline CHEMBL 3668075 & 1528397 & 8.0 & 7.2409 & TRN \\
\hline CHEMBL 3673074 & 1528397 & 8.0 & 7.7884 & TRN \\
\hline CHEMBL3668085 & 1528397 & 8.0 & 7.9672 & TRN \\
\hline CHEMBL3668113 & 1528397 & 7.0 & 7.4478 & TRN \\
\hline CHEMBL3668040 & 1528397 & 8.0 & 7.7664 & TRN \\
\hline CHEMBL 3673079 & 1528397 & 8.0 & 7.5636 & TRN \\
\hline CHEMBL3668047 & 1528397 & 6.0 & 8.1629 & TST \\
\hline CHEMBL3668093 & 1528397 & 7.0 & 7.3944 & TRN \\
\hline CHEMBL3639719 & 1528397 & 7.0 & 7.5477 & TRN \\
\hline CHEMBL 3668070 & 1528397 & 8.0 & 8.0089 & TST \\
\hline
\end{tabular}




\begin{tabular}{|c|c|c|c|c|c|}
\hline CHEMBL 3668053 & 1528397 & 8.0 & 8.1725 & TST & \\
\hline CHEMBL3668126 & 1528397 & 8.0 & 7.71200 & 0000000001 & TRN \\
\hline CHEMBL3668064 & 1528397 & 8.0 & 7.7158 & TRN & \\
\hline CHEMBL 3668028 & 1528397 & 8.0 & 7.4139 & TRN & \\
\hline CHEMBL3668118 & 1528397 & 7.0 & 6.94600 & 0000000001 & TRN \\
\hline CHEMBL3668086 & 1528397 & 8.0 & 8.2435 & TRN & \\
\hline CHEMBL3668107 & 1528397 & 8.0 & 7.7569 & TST & \\
\hline CHEMBL3668065 & 1528397 & 8.0 & 7.5636 & TST & \\
\hline CHEMBL3668076 & 1528397 & 8.0 & 7.42 & TRN & \\
\hline CHEMBL3668032 & 1528397 & 8.0 & 7.3692 & TRN & \\
\hline CHEMBL3673073 & 1528397 & 8.0 & 7.5649 & TRN & \\
\hline CHEMBL 3673075 & 1528397 & 7.0 & 7.5111 & TRN & \\
\hline CHEMBL3668105 & 1528397 & 8.0 & 7.5719 & TRN & \\
\hline CHEMBL3668111 & 1528397 & 8.0 & 7.9583 & TRN & \\
\hline CHEMBL3668116 & 1528397 & 8.0 & 7.5055 & TRN & \\
\hline CHEMBL3668110 & 1528397 & 7.0 & 7.4348 & TRN & \\
\hline CHEMBL 3668078 & 1528397 & 8.0 & 7.8218 & TST & \\
\hline CHEMBL3673071 & 1528397 & 8.0 & 8.1014 & TRN & \\
\hline CHEMBL3668080 & 1528397 & 8.0 & 7.5824 & TRN & \\
\hline CHEMBL3673081 & 1528397 & 7.0 & 7.4902 & TRN & \\
\hline CHEMBL3668117 & 1528397 & 7.0 & 7.4501 & TRN & \\
\hline CHEMBL 3668024 & 1528397 & 4.0 & 7.73 & TST & \\
\hline CHEMBL272811 & 1528397 & 8.0 & 7.733 & TRN & \\
\hline CHEMBL3639668 & 1528397 & 8.0 & 7.5862 & TST & \\
\hline CHEMBL3668095 & 1528397 & 7.0 & 7.0867 & TRN & \\
\hline CHEMBL3668082 & 1528397 & 8.0 & 7.9823 & TRN & \\
\hline CHEMBL3668062 & 1528397 & 8.0 & 7.5718 & TRN & \\
\hline CHEMBL3668069 & 1528397 & 8.0 & 8.1335 & TST & \\
\hline CHEMBL3668046 & 1528397 & 4.0 & 7.818 & TST & \\
\hline CHEMBL3668039 & 1528397 & 8.0 & 7.6901 & TRN & \\
\hline CHEMBL3668124 & 1528397 & 7.0 & 7.5185 & TRN & \\
\hline CHEMBL3668041 & 1528397 & 7.0 & 7.2167 & TRN & \\
\hline CHEMBL3668081 & 1528397 & 7.0 & 7.1146 & TRN & \\
\hline CHEMBL3668061 & 1528397 & 8.0 & 7.4143 & TRN & \\
\hline CHEMBL3668092 & 1528397 & 8.0 & 7.7265 & TRN & \\
\hline CHEMBL3668067 & 1528397 & 8.0 & 8.0321 & TRN & \\
\hline CHEMBL3639669 & 1528397 & 7.0 & 7.6146 & TRN & \\
\hline CHEMBL3668115 & 1528397 & 8.0 & 7.6203 & TRN & \\
\hline CHEMBL3668079 & 1528397 & 8.0 & 7.6629 & TRN & \\
\hline CHEMBL3668104 & 1528397 & 8.0 & 7.54299 & 9999999999 & TRN \\
\hline CHEMBL3668123 & 1528397 & 7.0 & 7.5137 & TRN & \\
\hline CHEMBL3668063 & 1528397 & 8.0 & 7.532 & TRN & \\
\hline CHEMBL3668073 & 1528397 & 7.0 & 7.4713 & TRN & \\
\hline CHEMBL3673087 & 1528397 & 5.0 & 7.2649 & TRN & \\
\hline CHEMBL3668072 & 1528397 & 8.0 & 7.6651 & TRN & \\
\hline CHEMBL3668114 & 1528397 & 8.0 & 7.6652 & TRN & \\
\hline CHEMBL3668030 & 1528397 & 8.0 & 7.9487 & TRN & \\
\hline CHEMBL3673085 & 1528397 & 8.0 & 7.6146 & TRN & \\
\hline
\end{tabular}




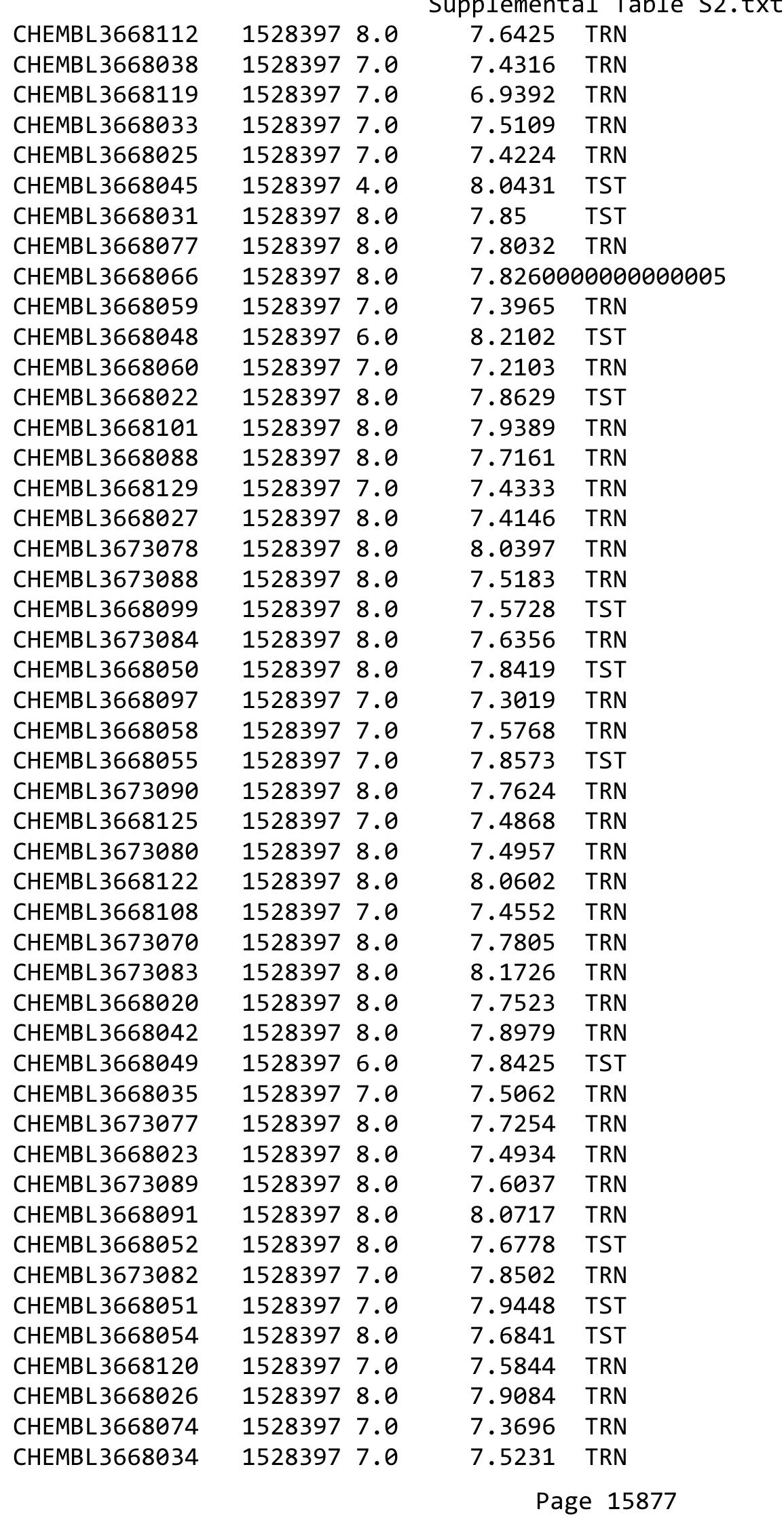




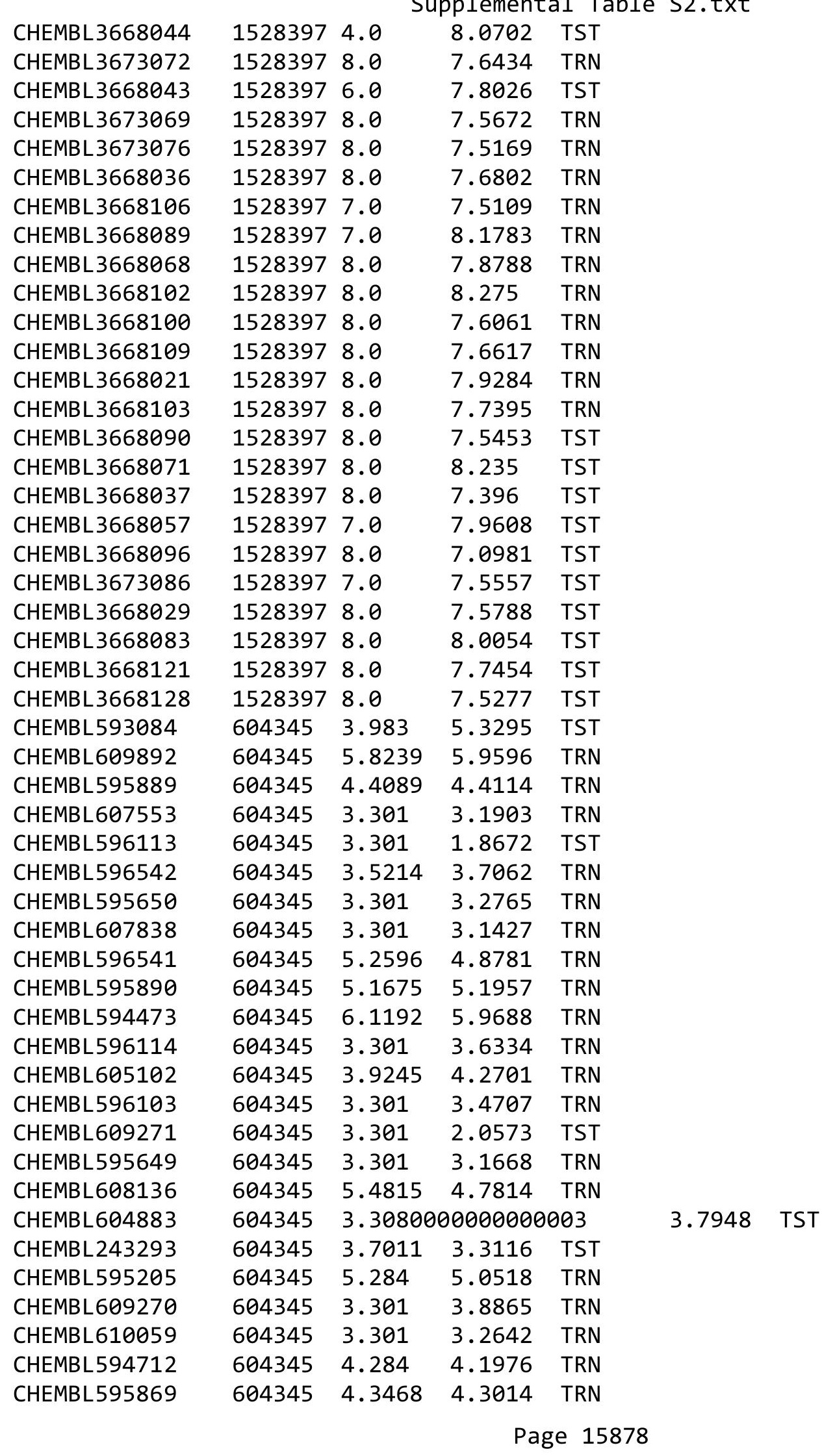




\begin{tabular}{|c|c|c|c|c|c|}
\hline \multirow[b]{2}{*}{ CHEMBL602589 } & \multicolumn{5}{|c|}{ Supplemental Table S2.txt } \\
\hline & 604345 & 5.0315 & 5.0402 & TRN & \\
\hline CHEMBL596334 & 604345 & 4.7471 & 3.4252 & TST & \\
\hline CHEMBL593329 & 604345 & 5.3468 & 5.4674 & TRN & \\
\hline CHEMBL593337 & 604345 & 3.301 & 3.0443 & TRN & \\
\hline CHEMBL610481 & 604345 & 3.7305 & 4.0218 & TST & \\
\hline CHEMBL593085 & 604345 & 3.6596 & 3.6847 & TRN & \\
\hline CHEMBL610744 & 604345 & 3.301 & 3.4919 & TST & \\
\hline CHEMBL595642 & 604345 & 3.301 & 3.1919 & TRN & \\
\hline CHEMBL594501 & 604345 & 4.2518 & 4.51399 & 9999999999 & TRN \\
\hline CHEMBL595437 & 604345 & 3.7799 & 3.806 & TRN & \\
\hline CHEMBL608718 & 604345 & 3.9626 & 3.6603 & TST & \\
\hline CHEMBL608402 & 604345 & 3.301 & 4.0664 & TRN & \\
\hline CHEMBL595444 & 604345 & 3.301 & 2.5954 & TST & \\
\hline CHEMBL593304 & 604345 & 3.301 & 1.9472 & TST & \\
\hline CHEMBL594498 & 604345 & 4.585 & 3.3845 & TST & \\
\hline CHEMBL608381 & 604345 & 3.301 & 3.198 & TRN & \\
\hline CHEMBL609599 & 604345 & 3.9393 & 3.9787 & TRN & \\
\hline CHEMBL595865 & 604345 & 5.2441 & 5.1148 & TRN & \\
\hline CHEMBL595438 & 604345 & 3.301 & 3.412 & TRN & \\
\hline CHEMBL595640 & 604345 & 3.301 & 3.4629 & TRN & \\
\hline CHEMBL596104 & 604345 & 4.2147 & 3.8793 & TRN & \\
\hline CHEMBL594274 & 604345 & 4.7696 & 4.32600 & 00000000005 & TST \\
\hline CHEMBL593093 & 604345 & 4.7696 & 4.8379 & TRN & \\
\hline CHEMBL611956 & 604345 & 4.3188 & 4.3501 & TRN & \\
\hline CHEMBL610198 & 604345 & 3.301 & 3.4054 & TRN & \\
\hline CHEMBL594711 & 604345 & 3.301 & 3.6232 & TRN & \\
\hline CHEMBL595436 & 604345 & 2.0 & 1.9225 & TRN & \\
\hline CHEMBL593310 & 604345 & 4.8239 & 4.6524 & TRN & \\
\hline CHEMBL593687 & 604345 & 5.3565 & 5.8748 & TRN & \\
\hline CHEMBL593067 & 604345 & 5.0177 & 4.8668 & TRN & \\
\hline CHEMBL608988 & 604345 & 4.8539 & 4.3645 & TST & \\
\hline CHEMBL595443 & 604345 & 3.301 & 3.8272 & TRN & \\
\hline CHEMBL596540 & 604345 & 5.4318 & 4.76699 & 99999999995 & TST \\
\hline CHEMBL607981 & 604345 & 4.3768 & 4.4758 & TRN & \\
\hline CHEMBL595623 & 604345 & 3.301 & 3.3572 & TRN & \\
\hline CHEMBL595648 & 604345 & 3.3925 & 3.6698 & TST & \\
\hline CHEMBL106771 & 604345 & 4.2924 & 4.1906 & TST & \\
\hline CHEMBL604473 & 604345 & 5.0458 & 5.5689 & TRN & \\
\hline CHEMBL609750 & 604345 & 4.1675 & 4.2307 & TRN & \\
\hline CHEMBL596322 & 604345 & 4.9208 & 4.9886 & TST & \\
\hline CHEMBL594492 & 604345 & 4.2676 & 4.2102 & TRN & \\
\hline CHEMBL593068 & 604345 & 4.8539 & 5.0778 & TRN & \\
\hline CHEMBL608679 & 604345 & 3.301 & 2.21199 & 99999999997 & TST \\
\hline CHEMBL610482 & 604345 & 3.301 & 3.3479 & TRN & \\
\hline CHEMBL594499 & 604345 & 3.301 & 3.3587 & TRN & \\
\hline CHEMBL595641 & 604345 & 3.301 & 3.35600 & 00000000003 & TRN \\
\hline CHEMBL596102 & 604345 & 4.5229 & 4.4635 & TRN & \\
\hline CHEMBL610764 & 604345 & 3.301 & 2.931 & TRN & \\
\hline
\end{tabular}




\begin{tabular}{|c|c|c|c|c|c|}
\hline & & \multicolumn{4}{|c|}{ Supplemental Table S2.txt } \\
\hline CHEMBL593932 & 604345 & 3.301 & 3.4369 & TRN & \\
\hline CHEMBL593305 & 604345 & 6.0 & 4.7733 & TRN & \\
\hline CHEMBL1163024 & 604345 & 4.4559 & 3.5373 & TST & \\
\hline CHEMBL594493 & 604345 & 4.6576 & 4.5187 & TRN & \\
\hline CHEMBL595445 & 604345 & 4.2076 & 3.9591 & TRN & \\
\hline CHEMBL611644 & 604345 & 5.0506 & 4.9307 & TRN & \\
\hline CHEMBL608987 & 604345 & 5.5086 & 5.1142 & TRN & \\
\hline CHEMBL610743 & 604345 & 3.301 & 3.174 & TRN & \\
\hline CHEMBL3422835 & 1474093 & 6.7696 & 6.5584 & TRN & \\
\hline CHEMBL2251560 & 1474093 & 5.7696 & 6.0201 & TRN & \\
\hline CHEMBL 3422795 & 1474093 & 4.9469 & 5.1823 & TRN & \\
\hline CHEMBL3422825 & 1474093 & 4.7423 & 5.1351 & TST & \\
\hline CHEMBL3422800 & 1474093 & 4.9208 & 4.8584 & TRN & \\
\hline CHEMBL3422815 & 1474093 & 4.9626 & 4.9557 & TRN & \\
\hline CHEMBL3422817 & 1474093 & 4.9431 & 4.456 & TRN & \\
\hline CHEMBL3422809 & 1474093 & 5.3565 & 6.3096 & TRN & \\
\hline CHEMBL3422826 & 1474093 & 5.5086 & 5.1876 & TST & \\
\hline CHEMBL3422807 & 1474093 & 5.9872 & 5.9891 & TRN & \\
\hline CHEMBL3422818 & 1474093 & 4.7721 & 5.4625 & TRN & \\
\hline CHEMBL3422833 & 1474093 & 5.8239 & 5.8219 & TRN & \\
\hline CHEMBL 3422831 & 1474093 & 4.0 & 4.5546 & TRN & \\
\hline CHEMBL3422827 & 1474093 & 5.7212 & 5.5406 & TRN & \\
\hline CHEMBL3422816 & 1474093 & 4.9431 & 4.4832 & TRN & \\
\hline CHEMBL3422805 & 1474093 & 5.0605 & 5.7053 & TRN & \\
\hline CHEMBL3422796 & 1474093 & 6.6198 & 5.2596 & TRN & \\
\hline CHEMBL 3422799 & 1474093 & 6.585 & 6.0657 & TRN & \\
\hline CHEMBL3422801 & 1474093 & 4.8041 & 4.7604 & TRN & \\
\hline CHEMBL3422812 & 1474093 & 4.8447 & 5.46899 & 9999999999 & TRN \\
\hline CHEMBL 3422840 & 1474093 & 6.3979 & 6.2579 & TRN & \\
\hline CHEMBL 3422804 & 1474093 & 4.3335 & 5.0641 & TRN & \\
\hline CHEMBL3422822 & 1474093 & 4.585 & 4.9365 & TST & \\
\hline CHEMBL3422794 & 1474093 & 5.8239 & 5.311 & TRN & \\
\hline CHEMBL 3422797 & 1474093 & 4.3979 & 4.9401 & TRN & \\
\hline CHEMBL3422819 & 1474093 & 4.9431 & 4.4992 & TRN & \\
\hline CHEMBL3422830 & 1474093 & 5.9586 & 5.4452 & TRN & \\
\hline CHEMBL3422828 & 1474093 & 4.0 & 5.4256 & TRN & \\
\hline CHEMBL3422814 & 1474093 & 5.2441 & 5.0372 & TRN & \\
\hline CHEMBL 3422806 & 1474093 & 6.0223 & 6.1481 & TRN & \\
\hline CHEMBL3422811 & 1474093 & 6.3279 & 6.065 & TRN & \\
\hline CHEMBL 258405 & 1474093 & 7.2366 & 5.7558 & TRN & \\
\hline CHEMBL3422837 & 1474093 & 7.1367 & 6.2126 & TRN & \\
\hline CHEMBL3422802 & 1474093 & 5.0809 & 5.2041 & TRN & \\
\hline CHEMBL3422839 & 1474093 & 5.699 & 5.5267 & TRN & \\
\hline CHEMBL3422832 & 1474093 & 5.1871 & 4.9683 & TRN & \\
\hline CHEMBL3422808 & 1474093 & 5.4949 & 5.8958 & TRN & \\
\hline CHEMBL 3422834 & 1474093 & 5.9788 & 5.82100 & 0000000001 & TRN \\
\hline CHEMBL 3422843 & 1474093 & 6.2218 & 5.6628 & TST & \\
\hline CHEMBL3422821 & 1474093 & 4.4698 & 5.095 & TST & \\
\hline
\end{tabular}


Supplemental Table S2.txt

\begin{tabular}{|c|c|c|c|c|}
\hline CHEMBL 3422842 & 1474093 & 6.7696 & 5.4862 & TST \\
\hline CHEMBL 3422803 & 1474093 & 4.6576 & 4.5592 & TRN \\
\hline CHEMBL3422820 & 1474093 & 5.4559 & 5.4193 & TST \\
\hline CHEMBL 3422813 & 1474093 & 4.1649 & 4.8902 & TRN \\
\hline CHEMBL3422810 & 1474093 & 5.8239 & 6.0671 & TRN \\
\hline CHEMBL 3422841 & 1474093 & 5.2147 & 5.0503 & TST \\
\hline CHEMBL 3422836 & 1474093 & 6.8539 & 6.2309 & TST \\
\hline CHEMBL3422824 & 1474093 & 5.1805 & 4.651 & TST \\
\hline CHEMBL3422798 & 1474093 & 5.8539 & 6.0015 & TRN \\
\hline CHEMBL3422838 & 1474093 & 6.3665 & 5.3739 & TST \\
\hline CHEMBL1451030 & 1474093 & 5.0809 & \multicolumn{2}{|c|}{5.127000000000001} \\
\hline CHEMBL 3422829 & 1474093 & 5.7447 & 4.9904 & TST \\
\hline CHEMBL3422823 & 1474093 & 5.2441 & 5.2185 & TST \\
\hline CHEMBL3422844 & 1474093 & 4.0 & 4.9882 & TST \\
\hline CHEMBL546168 & 817944 & 3.4948 & 3.6798 & TRN \\
\hline CHEMBL601806 & 817944 & 3.4948 & 4.1412 & TST \\
\hline CHEMBL546162 & 817944 & 3.4948 & 4.0502 & TRN \\
\hline CHEMBL609628 & 817944 & 4.7138 & 4.9156 & TRN \\
\hline CHEMBL527593 & 817944 & 3.4948 & \multicolumn{2}{|c|}{3.5039999999999996} \\
\hline CHEMBL 2028068 & 817944 & 3.4948 & 3.9794 & TST \\
\hline CHEMBL586033 & 817944 & 5.41 & 5.1652 & TRN \\
\hline CHEMBL591395 & 817944 & 3.4948 & 4.0928 & TRN \\
\hline CHEMBL1744512 & 817944 & 4.9385 & 3.4441 & TRN \\
\hline CHEMBL534190 & 817944 & 3.4948 & 3.4489 & TRN \\
\hline CHEMBL535079 & 817944 & 3.4948 & 3.6934 & TRN \\
\hline CHEMBL532560 & 817944 & 3.4948 & 3.6317 & TRN \\
\hline CHEMBL592550 & 817944 & 3.4948 & 3.8437 & TRN \\
\hline CHEMBL529874 & 817944 & 4.6732 & 3.3164 & TST \\
\hline CHEMBL 2028041 & 817944 & 3.4948 & 4.3465 & TRN \\
\hline CHEMBL531222 & 817944 & 3.4948 & 3.4704 & TRN \\
\hline CHEMBL529732 & 817944 & 3.4948 & 3.2275 & TRN \\
\hline CHEMBL597262 & 817944 & 3.4948 & 3.3698 & TRN \\
\hline CHEMBL537071 & 817944 & 3.4948 & 3.9013 & TRN \\
\hline CHEMBL592786 & 817944 & 3.4948 & 3.6251 & TRN \\
\hline CHEMBL580188 & 817944 & 3.4948 & 3.3098 & TRN \\
\hline CHEMBL592044 & 817944 & 4.4949 & 3.9992 & TST \\
\hline CHEMBL596856 & 817944 & 3.4948 & 3.9447 & TRN \\
\hline CHEMBL529348 & 817944 & 3.4948 & 4.2226 & TRN \\
\hline CHEMBL 2028061 & 817944 & 3.4948 & 3.556 & TRN \\
\hline CHEMBL600030 & 817944 & 3.4948 & 3.5363 & TRN \\
\hline CHEMBL533999 & 817944 & 3.4948 & 3.3778 & TRN \\
\hline CHEMBL597857 & 817944 & 3.4948 & 3.8508 & TRN \\
\hline CHEMBL2028058 & 817944 & 3.4948 & 4.2584 & TRN \\
\hline CHEMBL582666 & 817944 & 3.4948 & 4.5646 & TRN \\
\hline CHEMBL577874 & 817944 & 4.9137 & 4.1709 & TRN \\
\hline CHEMBL2028044 & 817944 & 3.4948 & 3.5967 & TRN \\
\hline CHEMBL547443 & 817944 & 3.4948 & 4.2495 & TRN \\
\hline \multirow[t]{2}{*}{ CHEMBL605281 } & 817944 & 3.4948 & $3.4360 e$ & 20000000004 \\
\hline & & & \multicolumn{2}{|c|}{ Page 15881} \\
\hline
\end{tabular}




\begin{tabular}{|c|c|c|c|c|c|}
\hline & & & oplement & & \\
\hline CHEMBL527620 & 817944 & 4.7862 & 4.1331 & TRN & \\
\hline CHEMBL1738986 & 817944 & 3.4948 & 4.22199 & 99999999995 & TRN \\
\hline CHEMBL588481 & 817944 & 5.3949 & 4.6569 & TRN & \\
\hline CHEMBL 2028060 & 817944 & 3.4948 & 3.6757 & TRN & \\
\hline CHEMBL532510 & 817944 & 3.4948 & 3.4265 & TRN & \\
\hline CHEMBL603945 & 817944 & 3.4948 & 4.1855 & TRN & \\
\hline CHEMBL525692 & 817944 & 3.4948 & 3.6817 & TRN & \\
\hline CHEMBL532879 & 817944 & 3.4948 & 3.6381 & TRN & \\
\hline CHEMBL586031 & 817944 & 5.0053 & 5.0442 & TST & \\
\hline CHEMBL602413 & 817944 & 4.9441 & 4.8503 & TRN & \\
\hline CHEMBL1623028 & 817944 & 3.4948 & 4.2555 & TRN & \\
\hline CHEMBL580353 & 817944 & 3.4948 & 3.5711 & TRN & \\
\hline CHEMBL585983 & 817944 & 3.4948 & 3.7407 & TRN & \\
\hline CHEMBL49055 & 817944 & 4.5952 & 4.6458 & TRN & \\
\hline CHEMBL530973 & 817944 & 3.4948 & 3.35600 & 00000000003 & TRN \\
\hline CHEMBL533855 & 817944 & 4.9723 & 4.4481 & TRN & \\
\hline CHEMBL524784 & 817944 & 3.4948 & 3.736 & TRN & \\
\hline CHEMBL586178 & 817944 & 3.4948 & 3.4615 & TRN & \\
\hline CHEMBL535556 & 817944 & 3.4948 & 4.0664 & TRN & \\
\hline CHEMBL528437 & 817944 & 5.0312 & 4.4089 & TRN & \\
\hline CHEMBL601814 & 817944 & 3.4948 & 3.5121 & TRN & \\
\hline CHEMBL581225 & 817944 & 4.8604 & 4.5197 & TST & \\
\hline CHEMBL578508 & 817944 & 3.4948 & 3.4517 & TRN & \\
\hline CHEMBL601492 & 817944 & 3.4948 & 4.2367 & TRN & \\
\hline CHEMBL586000 & 817944 & 3.4948 & 3.6025 & TRN & \\
\hline CHEMBL581475 & 817944 & 3.4948 & 3.3631 & TRN & \\
\hline CHEMBL590919 & 817944 & 4.5827 & 4.4714 & TRN & \\
\hline CHEMBL589951 & 817944 & 3.4948 & 3.4691 & TRN & \\
\hline CHEMBL585622 & 817944 & 5.401 & 4.94 & TRN & \\
\hline CHEMBL602409 & 817944 & 3.4948 & 3.4249 & TRN & \\
\hline CHEMBL590675 & 817944 & 3.4948 & 3.8621 & TRN & \\
\hline CHEMBL 2028049 & 817944 & 3.4948 & 3.6098 & TRN & \\
\hline CHEMBL607688 & 817944 & 3.4948 & 4.0637 & TRN & \\
\hline CHEMBL602946 & 817944 & 4.9847 & 4.5102 & TRN & \\
\hline CHEMBL582552 & 817944 & 3.4948 & 3.94199 & 99999999997 & TRN \\
\hline CHEMBL533917 & 817944 & 4.9265 & 5.4669 & TRN & \\
\hline CHEMBL599886 & 817944 & 5.1973 & 3.3711 & TST & \\
\hline CHEMBL602586 & 817944 & 3.4948 & 4.293 & TST & \\
\hline CHEMBL 2028043 & 817944 & 5.4523 & 4.5617 & TRN & \\
\hline CHEMBL602366 & 817944 & 3.4948 & 3.4166 & TRN & \\
\hline CHEMBL596852 & 817944 & 5.3227 & 5.3982 & TRN & \\
\hline CHEMBL601825 & 817944 & 3.4948 & 3.4145 & TRN & \\
\hline CHEMBL549216 & 817944 & 4.7592 & 4.2141 & TRN & \\
\hline CHEMBL 206540 & 817944 & 3.4948 & 3.438 & TRN & \\
\hline CHEMBL601612 & 817944 & 3.4948 & 3.9454 & TST & \\
\hline CHEMBL 2021322 & 817944 & 3.4948 & 4.066 & TRN & \\
\hline CHEMBL592305 & 817944 & 3.4948 & 3.4693 & TST & \\
\hline CHEMBL600174 & 817944 & 3.4948 & 3.5068 & TRN & \\
\hline
\end{tabular}




\begin{tabular}{|c|c|c|c|c|c|}
\hline & & \multicolumn{4}{|c|}{ Supplemental Table s2.txt } \\
\hline CHEMBL590683 & 817944 & 3.4948 & 4.3333 & TRN & \\
\hline CHEMBL589224 & 817944 & 4.7428 & 3.8065 & TST & \\
\hline CHEMBL591147 & 817944 & 3.4948 & 3.5319 & TRN & \\
\hline CHEMBL601348 & 817944 & 3.4948 & 3.6172 & TST & \\
\hline CHEMBL582547 & 817944 & 4.6239 & 4.8355 & TRN & \\
\hline CHEMBL588516 & 817944 & 3.4948 & 3.3978 & TRN & \\
\hline CHEMBL 2028053 & 817944 & 3.4948 & 3.5204 & TRN & \\
\hline CHEMBL606531 & 817944 & 3.4948 & 3.72600 & 00000000004 & TRN \\
\hline CHEMBL580876 & 817944 & 3.4948 & 3.3329 & TRN & \\
\hline CHEMBL586078 & 817944 & 3.4948 & 3.4985 & TRN & \\
\hline CHEMBL578952 & 817944 & 3.4948 & 3.3369 & TRN & \\
\hline CHEMBL546994 & 817944 & 3.4948 & 3.3926 & TRN & \\
\hline CHEMBL609036 & 817944 & 3.4948 & 4.4066 & TRN & \\
\hline CHEMBL596643 & 817944 & 3.4948 & 3.4125 & TRN & \\
\hline CHEMBL577014 & 817944 & 4.8532 & 4.4807 & TRN & \\
\hline CHEMBL582119 & 817944 & 3.4948 & 3.4971 & TST & \\
\hline CHEMBL531611 & 817944 & 4.7897 & 4.1169 & TRN & \\
\hline CHEMBL1198307 & 817944 & 5.0738 & 4.9187 & TRN & \\
\hline CHEMBL580381 & 817944 & 3.4948 & 3.4586 & TRN & \\
\hline CHEMBL2028066 & 817944 & 3.4948 & 4.1915 & TST & \\
\hline CHEMBL531290 & 817944 & 3.4948 & 4.2373 & TST & \\
\hline CHEMBL603686 & 817944 & 3.4948 & 4.1418 & TRN & \\
\hline CHEMBL124006 & 817944 & 5.5429 & 5.3237 & TRN & \\
\hline CHEMBL588859 & 817944 & 3.4948 & 3.4138 & TRN & \\
\hline CHEMBL582478 & 817944 & 4.8561 & 4.2508 & TRN & \\
\hline CHEMBL588855 & 817944 & 5.83899 & 99999999 & 4.8259 & TRN \\
\hline CHEMBL547269 & 817944 & 5.2627 & 4.3166 & TRN & \\
\hline CHEMBL600904 & 817944 & 3.4948 & 3.5226 & TRN & \\
\hline CHEMBL581489 & 817944 & 3.4948 & 3.3676 & TRN & \\
\hline CHEMBL605751 & 817944 & 6.4096 & 5.027 & TRN & \\
\hline CHEMBL1459149 & 817944 & 3.4948 & 3.735 & TST & \\
\hline CHEMBL589205 & 817944 & 3.4948 & 3.6813 & TRN & \\
\hline CHEMBL532987 & 817944 & 3.4948 & 3.7904 & TRN & \\
\hline CHEMBL525826 & 817944 & 4.5793 & 4.4613 & TRN & \\
\hline CHEMBL1740701 & 817944 & 3.4948 & 3.64600 & 00000000004 & TRN \\
\hline CHEMBL527730 & 817944 & 5.3179 & 4.5697 & TRN & \\
\hline CHEMBL590435 & 817944 & 3.4948 & 3.2494 & TRN & \\
\hline CHEMBL600235 & 817944 & 5.25299 & 79999999 & 4.6495 & TRN \\
\hline CHEMBL604389 & 817944 & 3.4948 & 3.64300 & 00000000002 & TRN \\
\hline CHEMBL606159 & 817944 & 3.4948 & 3.7793 & TRN & \\
\hline CHEMBL459199 & 817944 & 3.4948 & 4.3266 & TRN & \\
\hline CHEMBL580819 & 817944 & 3.4948 & 3.3981 & TRN & \\
\hline CHEMBL581860 & 817944 & 5.3042 & 4.8691 & TRN & \\
\hline CHEMBL607308 & 817944 & 4.7206 & 3.9178 & TRN & \\
\hline CHEMBL589922 & 817944 & 3.4948 & 3.7876 & TRN & \\
\hline CHEMBL524930 & 817944 & 3.4948 & 4.1514 & TRN & \\
\hline CHEMBL547825 & 817944 & 4.8379 & 4.5118 & TRN & \\
\hline CHEMBL531060 & 817944 & 3.4948 & 3.6441 & TRN & \\
\hline
\end{tabular}


Supplemental Table S2.txt

\begin{tabular}{|c|c|c|c|c|}
\hline 492 & 17944 & 4.6755 & 3.4336 & TR \\
\hline HEMBL600356 & 17944 & 3.4948 & 3.5841 & \\
\hline HFMBI & 7944 & 948 & & \\
\hline HEMBL601156 & .7944 & 4948 & & \\
\hline HEMBL1615697 & 17944 & 4948 & 744 & \\
\hline HEMBL 578933 & 17944 & .0733 & 2107 & \\
\hline HEMBLS & .7944 & 1812 & 385 & \\
\hline AEMBL602179 & 17944 & & & RN \\
\hline HEMBL597855 & 17944 & 5.1201 & 1854 & RN \\
\hline HEMBL590201 & 17944 & 1948 & 3.715 & \\
\hline HEMBL 602580 & 17944 & .3821 & 718 & \\
\hline HEMBL599100 & .7944 & 3.4948 & 527 & \\
\hline HEMBL2 & 7944 & & & \\
\hline HEMBL530308 & 17944 & 4948 & 3425 & \\
\hline HEMBL580159 & 17944 & 9992 & 42 & \\
\hline HEMBL 582767 & 17944 & 5.3949 & 13 & \\
\hline HEMBL5 & 7944 & 3.4948 & & RN \\
\hline HEMBL2 & 7944 & 3.4948 & & \\
\hline HEMBL545880 & 7944 & 948 & 4.0695 & \\
\hline HEMBL5 & 9944 & 18 & & \\
\hline HEMBL5 & 7944 & 4 & 4. & ונכ \\
\hline HEMBL: & 7944 & 48 & 3 . & RN \\
\hline HEMBL5 & 7944 & 3. & & \\
\hline HEMBL5 & 7944 & 948 & & \\
\hline HEMBL5 & 44 & 72 & & N \\
\hline HEMBL5 & 7944 & 48 & 4. & RN \\
\hline HEMBLS & 944 & 48 & 3 . & RN \\
\hline HEMBL1 & 7944 & 48 & & RN \\
\hline HEMBL582286 & 944 & 948 & & TRN \\
\hline HEMBL600374 & 944 & 28 & & TRN \\
\hline HEMBL582070 & 7944 & 48 & 63 & $\mathrm{RN}$ \\
\hline HEMBL5 & 944 & 48 & & TRN \\
\hline HEMBL $€$ & 944 & 48 & 67 & 「RN \\
\hline HEMBL 2028063 & 7944 & 4.7928 & & TRN \\
\hline HEMBL601528 & 17944 & 3.4948 & 3.5442 & TRN \\
\hline HEMBL5 & 944 & & & $\Gamma \mathrm{RN}$ \\
\hline HEMBL5 & 944 & 59 & 4. & $\Gamma \mathrm{RN}$ \\
\hline HEMBL6 & 944 & 48 & 278 & TRN \\
\hline HEMBL525106 & 17944 & 4.5594 & 4.5703 & TRN \\
\hline HEMBL579294 & .7944 & & 0527 & TRN \\
\hline CHEMBL 5 & 7944 & 3.4948 & & $\Gamma \mathrm{RN}$ \\
\hline CHEMBL601378 & 17944 & 3.4948 & 4.7142 & TRN \\
\hline CHEMBL592338 & 17944 & 3.4948 & 3.458 & TRN \\
\hline HEMBL585839 & 17944 & 3.4948 & 3.3518 & TRN \\
\hline CHEMBL600549 & 17944 & 3.4948 & 3.4256 & TRN \\
\hline CHEMBL5 & 7944 & & 3.2097 & \\
\hline CHEMBL202804 & 17944 & 3.4948 & 3.7248 & \\
\hline CHEMBL10835 & 817944 & 3.4948 & .4193 & IRI \\
\hline
\end{tabular}

Page 15884 


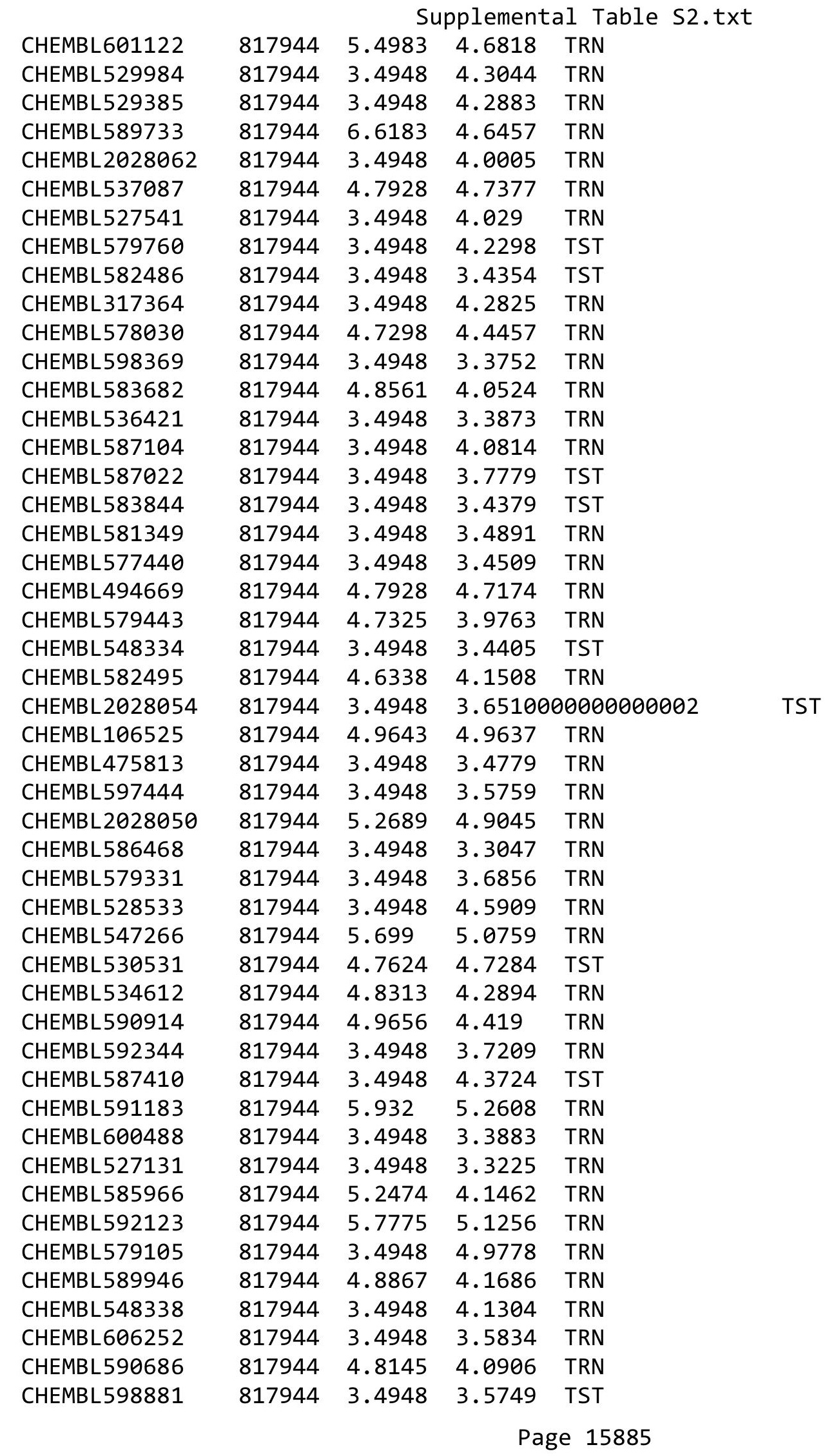




\begin{tabular}{|c|c|c|c|c|c|}
\hline \multicolumn{6}{|c|}{ Supplemental Table S2.txt } \\
\hline CHEMBL547488 & 817944 & 3.4948 & 3.5478 & TRN & \\
\hline CHEMBL549208 & 817944 & 4.5688 & 3.8828 & TRN & \\
\hline CHEMBL587892 & 817944 & 4.8121 & 4.5855 & TRN & \\
\hline CHEMBL1619026 & 817944 & 3.4948 & 3.9738 & TRN & \\
\hline CHEMBL 2028045 & 817944 & 3.4948 & 3.7437 & TRN & \\
\hline CHEMBL 2028057 & 817944 & 3.4948 & 3.8394 & TRN & \\
\hline CHEMBL597248 & 817944 & 5.4732 & 4.9334 & TRN & \\
\hline CHEMBL589920 & 817944 & 3.4948 & 4.8394 & TRN & \\
\hline CHEMBL587485 & 817944 & 3.4948 & 3.3799 & TRN & \\
\hline CHEMBL534283 & 817944 & 3.4948 & 4.4588 & TST & \\
\hline CHEMBL547614 & 817944 & 3.4948 & 3.3412 & TST & \\
\hline CHEMBL604323 & 817944 & 3.4948 & 3.4659 & TRN & \\
\hline CHEMBL533017 & 817944 & 3.4948 & 3.38 & TRN & \\
\hline CHEMBL590933 & 817944 & 5.3979 & 4.836 & TRN & \\
\hline CHEMBL534319 & 817944 & 5.3918 & 5.1124 & TRN & \\
\hline CHEMBL1545915 & 817944 & 3.4948 & 3.5163 & TRN & \\
\hline CHEMBL533921 & 817944 & 3.4948 & 3.5628 & TRN & \\
\hline CHEMBL529968 & 817944 & 3.4948 & 3.4754 & TRN & \\
\hline CHEMBL584676 & 817944 & 3.4948 & 3.3559 & TRN & \\
\hline CHEMBL587371 & 817944 & 3.4948 & 3.5707 & TRN & \\
\hline CHEMBL590182 & 817944 & 3.4948 & 3.4136 & TRN & \\
\hline CHEMBL601158 & 817944 & 3.4948 & 3.4411 & TRN & \\
\hline CHEMBL548469 & 817944 & 3.4948 & 4.3409 & TRN & \\
\hline CHEMBL602127 & 817944 & 3.4948 & 3.9296 & TRN & \\
\hline CHEMBL585243 & 817944 & 3.4948 & 3.7108 & TRN & \\
\hline CHEMBL588155 & 817944 & 4.5717 & 3.9729 & TRN & \\
\hline CHEMBL548901 & 817944 & 3.4948 & 4.1259 & TRN & \\
\hline CHEMBL602312 & 817944 & 4.8022 & 4.6461 & TRN & \\
\hline CHEMBL577011 & 817944 & 3.4948 & 3.4362 & TRN & \\
\hline CHEMBL470514 & 817944 & 3.4948 & 4.82100 & 0000000001 & TRN \\
\hline CHEMBL609156 & 817944 & 3.4948 & 3.3667 & TRN & \\
\hline CHEMBL584841 & 817944 & 3.4948 & 4.2229 & TRN & \\
\hline CHEMBL580388 & 817944 & 3.4948 & 3.5907 & TST & \\
\hline CHEMBL590888 & 817944 & 5.1201 & 4.4951 & TST & \\
\hline CHEMBL580249 & 817944 & 3.4948 & 3.3633 & TRN & \\
\hline CHEMBL587923 & 817944 & 4.8036 & 4.291 & TRN & \\
\hline CHEMBL528734 & 817944 & 3.4948 & 3.5896 & TRN & \\
\hline CHEMBL532597 & 817944 & 3.4948 & 3.3993 & TRN & \\
\hline CHEMBL586442 & 817944 & 3.4948 & 3.2636 & TRN & \\
\hline CHEMBL579459 & 817944 & 4.5916 & 3.9526 & TST & \\
\hline CHEMBL533598 & 817944 & 5.1087 & 4.3447 & TRN & \\
\hline CHEMBL526800 & 817944 & 4.78 & 4.0326 & TRN & \\
\hline CHEMBL592808 & 817944 & 3.4948 & 4.3372 & TRN & \\
\hline CHEMBL535730 & 817944 & 4.7928 & 4.2323 & TST & \\
\hline CHEMBL601771 & 817944 & 3.4948 & 3.5679 & TST & \\
\hline CHEMBL602940 & 817944 & 4.545 & 4.0737 & TST & \\
\hline CHEMBL547476 & 817944 & 3.4948 & 3.443 & TRN & \\
\hline CHEMBL532015 & 817944 & 3.4948 & 3.4045 & TRN & \\
\hline
\end{tabular}




\begin{tabular}{|c|c|c|c|c|c|}
\hline \multicolumn{6}{|c|}{ Supplemental Table S2.txt } \\
\hline CHEMBL583555 & 817944 & 4.9441 & 4.3748 & TST & \\
\hline CHEMBL600906 & 817944 & 3.4948 & 3.3436 & TRN & \\
\hline CHEMBL611070 & 817944 & 3.4948 & 3.4126 & TRN & \\
\hline CHEMBL2028047 & 817944 & 3.4948 & 4.4256 & TRN & \\
\hline CHEMBL 2028064 & 817944 & 6.1852 & 4.7683 & TST & \\
\hline CHEMBL589060 & 817944 & 3.4948 & 3.383 & TRN & \\
\hline CHEMBL525519 & 817944 & 3.4948 & 4.2463 & TRN & \\
\hline CHEMBL601580 & 817944 & 3.4948 & 4.6034 & TRN & \\
\hline CHEMBL532155 & 817944 & 3.4948 & 3.6653 & TRN & \\
\hline CHEMBL581175 & 817944 & 3.4948 & 3.9721 & TRN & \\
\hline CHEMBL586962 & 817944 & 3.4948 & 3.6052 & TRN & \\
\hline CHEMBL546799 & 817944 & 3.4948 & 4.0842 & TRN & \\
\hline CHEMBL261095 & 817944 & 3.4948 & 3.3955 & TRN & \\
\hline CHEMBL534288 & 817944 & 3.4948 & 4.3012 & TRN & \\
\hline CHEMBL600444 & 817944 & 3.4948 & 3.9956 & TRN & \\
\hline CHEMBL591393 & 817944 & 5.3454 & 4.5265 & TRN & \\
\hline CHEMBL584235 & 817944 & 4.7897 & 4.5157 & TRN & \\
\hline CHEMBL 2028067 & 817944 & 4.9966 & 4.5468 & TRN & \\
\hline CHEMBL590212 & 817944 & 4.7253 & 4.2875 & TRN & \\
\hline CHEMBL 261693 & 817944 & 3.4948 & 3.2631 & TRN & \\
\hline CHEMBL532079 & 817944 & 3.4948 & 4.1464 & TRN & \\
\hline CHEMBL580516 & 817944 & 5.4042 & 4.7094 & TRN & \\
\hline CHEMBL581194 & 817944 & 5.3181 & 4.2442 & TRN & \\
\hline CHEMBL584015 & 817944 & 4.9874 & 4.6373 & TRN & \\
\hline CHEMBL530978 & 817944 & 5.3979 & 4.2092 & TRN & \\
\hline CHEMBL549210 & 817944 & 5.3478 & 4.1253 & TRN & \\
\hline CHEMBL587083 & 817944 & 3.4948 & 4.2177 & TRN & \\
\hline CHEMBL589236 & 817944 & 3.4948 & 3.4213 & TRN & \\
\hline CHEMBL585686 & 817944 & 3.4948 & 3.4237 & TRN & \\
\hline CHEMBL530223 & 817944 & 3.4948 & 4.1891 & TRN & \\
\hline CHEMBL585264 & 817944 & 3.4948 & 4.0667 & TST & \\
\hline CHEMBL591362 & 817944 & 5.5184 & 5.157 & TRN & \\
\hline CHEMBL580654 & 817944 & 3.4948 & 3.4469 & TRN & \\
\hline CHEMBL529603 & 817944 & 3.4948 & 3.4558 & TRN & \\
\hline CHEMBL 2028048 & 817944 & 4.5779 & 3.8395 & TRN & \\
\hline CHEMBL588732 & 817944 & 3.4948 & 3.6455 & TRN & \\
\hline CHEMBL525486 & 817944 & 5.0723 & 4.5306 & TRN & \\
\hline CHEMBL548209 & 817944 & 4.9418 & 4.5006 & TRN & \\
\hline CHEMBL579315 & 817944 & 3.4948 & 3.4542 & TRN & \\
\hline CHEMBL 2028052 & 817944 & 3.4948 & $3.5410 e$ & 00000000004 & TRN \\
\hline CHEMBL532525 & 817944 & 3.4948 & 3.7538 & TRN & \\
\hline CHEMBL586933 & 817944 & 3.4948 & 3.2118 & TRN & \\
\hline CHEMBL592332 & 817944 & 3.4948 & 3.5732 & TRN & \\
\hline CHEMBL529919 & 817944 & 3.4948 & 3.5171 & TRN & \\
\hline CHEMBL591128 & 817944 & 3.4948 & 3.7318 & TRN & \\
\hline CHEMBL586344 & 817944 & 3.4948 & 3.4887 & TST & \\
\hline CHEMBL528245 & 817944 & 3.4948 & 3.845 & TRN & \\
\hline CHEMBL589916 & 817944 & 3.4948 & 3.3796 & TRN & \\
\hline
\end{tabular}




\begin{tabular}{|c|c|c|c|c|c|}
\hline & & \multicolumn{4}{|c|}{ Supplemental Table s2.txt } \\
\hline CHEMBL601566 & 817944 & 3.4948 & 3.5915 & TST & \\
\hline CHEMBL319952 & 817944 & 3.4948 & 4.1414 & TRN & \\
\hline CHEMBL601743 & 817944 & 3.4948 & 4.4521 & TRN & \\
\hline CHEMBL548374 & 817944 & 4.8461 & 4.6589 & TRN & \\
\hline CHEMBL585431 & 817944 & 3.4948 & 3.3855 & TRN & \\
\hline CHEMBL603943 & 817944 & 3.4948 & 3.39899 & 99999999996 & TRN \\
\hline CHEMBL602211 & 817944 & 3.4948 & 3.5368 & TRN & \\
\hline CHEMBL591641 & 817944 & 3.4948 & 3.6332 & TRN & \\
\hline CHEMBL591887 & 817944 & 3.4948 & 3.91600 & 00000000004 & TRN \\
\hline CHEMBL589723 & 817944 & 4.5394 & 4.4751 & TRN & \\
\hline CHEMBL526587 & 817944 & 3.4948 & 3.4448 & TRN & \\
\hline CHEMBL1460047 & 817944 & 4.5594 & 3.4177 & TST & \\
\hline CHEMBL546531 & 817944 & 4.9224 & 4.5318 & TRN & \\
\hline CHEMBL586704 & 817944 & 4.5216 & 3.6826 & TRN & \\
\hline CHEMBL1616787 & 817944 & 4.9727 & 4.468 & TRN & \\
\hline CHEMBL 2028059 & 817944 & 4.5779 & 3.8867 & TRN & \\
\hline CHEMBL579300 & 817944 & 3.4948 & 4.1949 & TRN & \\
\hline CHEMBL586026 & 817944 & 3.4948 & 4.5936 & TST & \\
\hline CHEMBL600706 & 817944 & 3.4948 & 3.4353 & TRN & \\
\hline CHEMBL587989 & 817944 & 3.4948 & 3.5892 & TRN & \\
\hline CHEMBL581187 & 817944 & 3.4948 & 3.7391 & TRN & \\
\hline CHEMBL604982 & 817944 & 3.4948 & 3.6052 & TRN & \\
\hline CHEMBL601786 & 817944 & 3.4948 & 3.9401 & TRN & \\
\hline CHEMBL602764 & 817944 & 3.4948 & 3.4009 & TRN & \\
\hline CHEMBL590944 & 817944 & 3.4948 & 4.1222 & TRN & \\
\hline CHEMBL1485159 & 817944 & 3.4948 & 4.0757 & TRN & \\
\hline CHEMBL1623897 & 817944 & 3.4948 & 3.5082 & TST & \\
\hline CHEMBL589422 & 817944 & 3.4948 & 4.075 & TST & \\
\hline CHEMBL524973 & 817944 & 4.805 & 4.4093 & TST & \\
\hline CHEMBL535514 & 817944 & 3.4948 & 3.4442 & TST & \\
\hline CHEMBL581874 & 817944 & 3.4948 & 3.5746 & TST & \\
\hline CHEMBL601534 & 817944 & 5.3549 & 4.3227 & TST & \\
\hline CHEMBL590159 & 817944 & 3.4948 & 3.8003 & TST & \\
\hline CHEMBL580580 & 817944 & 3.4948 & 4.5779 & TST & \\
\hline CHEMBL95606 & 817944 & 3.4948 & 3.5148 & TST & \\
\hline CHEMBL608855 & 817944 & 3.4948 & 3.8187 & TST & \\
\hline CHEMBL529773 & 817944 & 5.16200 & 00000000 & 4.1112 & TST \\
\hline CHEMBL580757 & 817944 & 3.4948 & 3.4136 & TST & \\
\hline CHEMBL602234 & 817944 & 4.8084 & 4.7135 & TST & \\
\hline CHEMBL578294 & 817944 & 4.8683 & 5.0241 & TST & \\
\hline CHEMBL601957 & 817944 & 4.5149 & 4.508 & TST & \\
\hline CHEMBL1437888 & 817944 & 5.4567 & 4.9865 & TST & \\
\hline CHEMBL577445 & 817944 & 3.4948 & 3.60699 & 99999999998 & TST \\
\hline CHEMBL527234 & 817944 & 3.4948 & 3.4098 & TST & \\
\hline CHEMBL529640 & 817944 & 3.4948 & 4.1804 & TST & \\
\hline CHEMBL586310 & 817944 & 3.4948 & 3.3382 & TST & \\
\hline CHEMBL584240 & 817944 & 3.4948 & 3.5376 & TST & \\
\hline CHEMBL532141 & 817944 & 4.8169 & 4.3564 & TST & \\
\hline
\end{tabular}




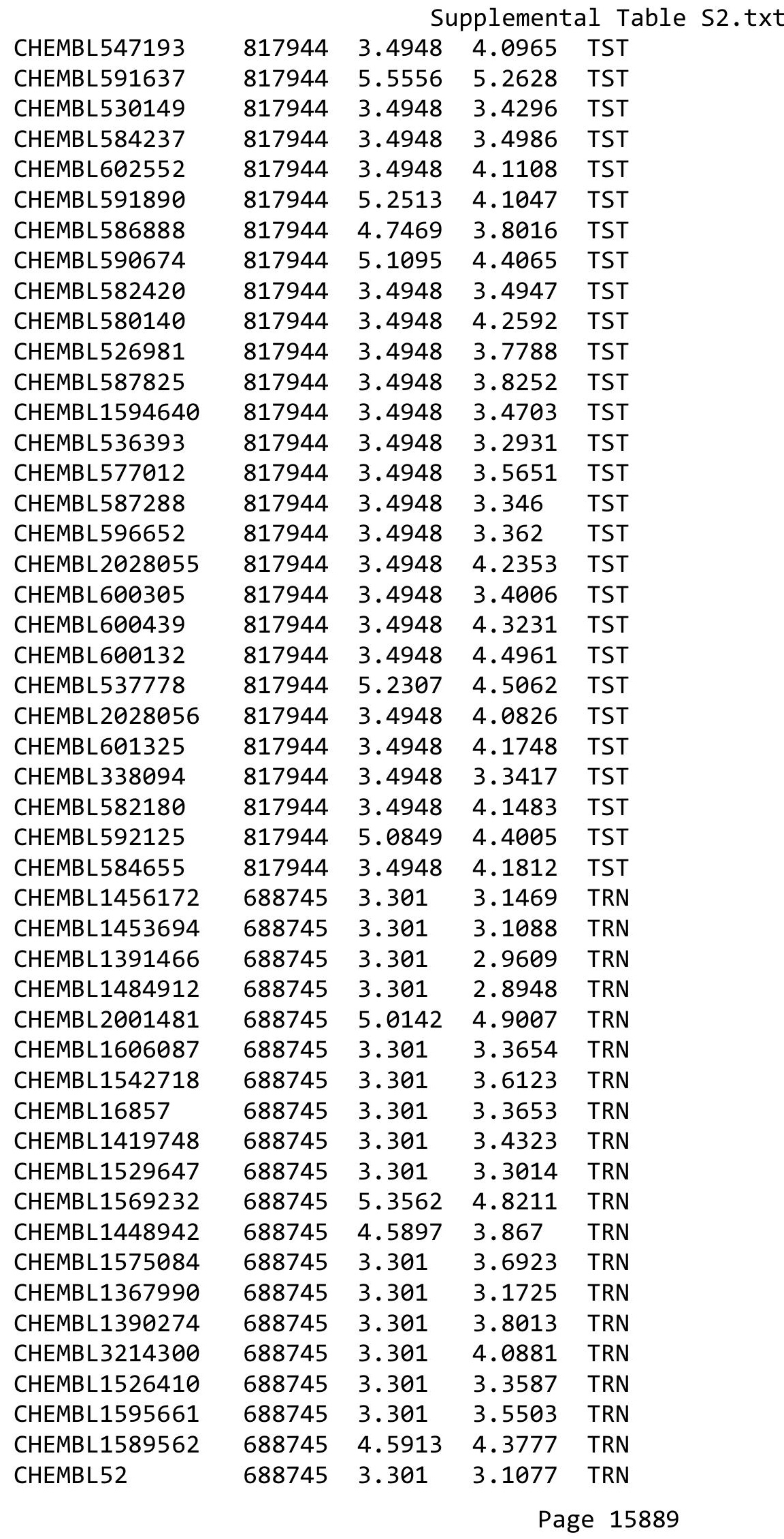




\begin{tabular}{|c|c|c|c|c|c|c|}
\hline & & \multicolumn{5}{|c|}{ Supplemental Table S2.txt } \\
\hline CHEMBL1523317 & 688745 & 3.301 & 3.3588 & TRN & & \\
\hline CHEMBL 3190482 & 688745 & 3.301 & 3.9098 & TRN & & \\
\hline CHEMBL1328512 & 688745 & 4.6089 & 4.1079 & TRN & & \\
\hline CHEMBL1598223 & 688745 & 5.5021 & 3.5165 & TST & & \\
\hline CHEMBL3216654 & 688745 & 3.301 & 3.3773 & TRN & & \\
\hline CHEMBL3199764 & 688745 & 3.301 & 3.4772 & TRN & & \\
\hline CHEMBL1439609 & 688745 & 3.301 & 3.3361 & TST & & \\
\hline CHEMBL1369154 & 688745 & 3.301 & 3.222 & TST & & \\
\hline CHEMBL1438583 & 688745 & 3.301 & 3.5253 & TST & & \\
\hline CHEMBL1332240 & 688745 & 4.9722 & 4.8006 & TRN & & \\
\hline CHEMBL1724937 & 688745 & 3.6021 & 4.0081 & TST & & \\
\hline CHEMBL1430492 & 688745 & 3.301 & 3.2854 & TRN & & \\
\hline CHEMBL1502394 & 688745 & 3.301 & 3.8819 & TST & & \\
\hline CHEMBL1544329 & 688745 & 5.0498 & 4.907 & TRN & & \\
\hline CHEMBL166209 & 688745 & 3.301 & 4.28 & TRN & & \\
\hline CHEMBL1558400 & 688745 & 4.5236 & 3.3401 & TST & & \\
\hline CHEMBL1348066 & 688745 & 3.301 & 3.6034 & TRN & & \\
\hline CHEMBL1501269 & 688745 & 4.3415 & 3.6871 & TRN & & \\
\hline CHEMBL 2003304 & 688745 & \multicolumn{3}{|c|}{5.1370000000000005} & 3.9354 & TST \\
\hline CHEMBL1385512 & 688745 & 5.2991 & 4.8123 & TRN & & \\
\hline CHEMBL1602413 & 688745 & 3.301 & 2.8539 & TRN & & \\
\hline CHEMBL1200938 & 688745 & 3.301 & 3.5664 & TRN & & \\
\hline CHEMBL1498522 & 688745 & 3.301 & 3.5704 & TRN & & \\
\hline CHEMBL1582991 & 688745 & 3.301 & 3.1457 & TRN & & \\
\hline CHEMBL1583664 & 688745 & 3.301 & 3.5829 & TRN & & \\
\hline CHEMBL1384321 & 688745 & 4.301 & 4.3821 & TST & & \\
\hline CHEMBL1502839 & 688745 & 6.0692 & 3.8533 & TST & & \\
\hline CHEMBL1366915 & 688745 & 4.7425 & 3.2173 & TST & & \\
\hline CHEMBL1306960 & 688745 & 7.1072 & 4.1652 & TST & & \\
\hline CHEMBL1376878 & 688745 & 3.301 & 3.0668 & TST & & \\
\hline CHEMBL564467 & 1290682 & 3.301 & 3.9141 & TST & & \\
\hline CHEMBL3113335 & 1290682 & 4.3706 & 4.0076 & TRN & & \\
\hline CHEMBL 3113307 & 1290682 & 5.6198 & 5.5642 & TRN & & \\
\hline CHEMBL 226093 & 1290682 & 4.426 & 4.3316 & TRN & & \\
\hline CHEMBL3113305 & 1290682 & 4.5452 & 4.5386 & TRN & & \\
\hline CHEMBL3113301 & 1290682 & 4.8729 & 4.9329 & TRN & & \\
\hline CHEMBL3113298 & 1290682 & 4.9101 & 4.9086 & TRN & & \\
\hline CHEMBL 3113324 & 1290682 & 4.4168 & 4.3762 & TST & & \\
\hline CHEMBL3113326 & 1290682 & 4.3468 & 4.2076 & TST & & \\
\hline CHEMBL3113333 & 1290682 & 3.301 & 3.2714 & TRN & & \\
\hline CHEMBL3113098 & 1290682 & 4.7747 & 4.7508 & TRN & & \\
\hline CHEMBL550866 & 1290682 & 4.3188 & 4.3287 & TRN & & \\
\hline CHEMBL3113313 & 1290682 & 5.2147 & 5.2 & TRN & & \\
\hline CHEMBL 3113294 & 1290682 & 4.7959 & 4.7875 & TRN & & \\
\hline CHEMBL3113306 & 1290682 & 4.5031 & 4.4841 & TRN & & \\
\hline CHEMBL3113303 & 1290682 & 4.7447 & 4.735 & TRN & & \\
\hline CHEMBL3113315 & 1290682 & 4.7305 & 4.7349 & TRN & & \\
\hline CHEMBL3113292 & 1290682 & 4.9281 & 4.9109 & TRN & & \\
\hline
\end{tabular}


Supplemental Table S2.txt

\begin{tabular}{|c|c|c|c|c|}
\hline 312 & 90682 & & 904 & \\
\hline & 290682 & 5.0223 & 5.0281 & \\
\hline & & & & \\
\hline IEMBL 3113302 & 290682 & & & \\
\hline AEMBL 3113291 & 290682 & 4.9747 & 292 & \\
\hline 13322 & 290682 & 4.5 & 15 & \\
\hline 3300 & 290682 & & & \\
\hline 3099 & 290682 & & & \\
\hline AEMBL558129 & 290682 & 3.301 & 312 & \\
\hline 13304 & 290682 & & & \\
\hline 3100 & 290682 & & & \\
\hline 332 & 290682 & 3. & & \\
\hline 42 & 290682 & & & \\
\hline 13329 & 290682 & & 775 & \\
\hline 13331 & 290682 & & & \\
\hline 39 & 290682 & & & \\
\hline 328 & 290682 & & & \\
\hline 3317 & 290682 & & & \\
\hline 3295 & 290682 & & & \\
\hline 3200 & 290682 & & & \\
\hline 32 & 1290682 & & & \\
\hline 325 & 582 & & & \\
\hline 310 & 290682 & & & \\
\hline 2302 & 290682 & & & \\
\hline 70 & 82 & & & \\
\hline 330 & 1290682 & & & \\
\hline 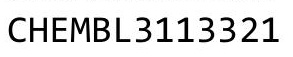 & 2 & & & \\
\hline 318 & 290682 & & & \\
\hline 211 & 290682 & & & \\
\hline 3096 & 90682 & & & \\
\hline 80 & 290682 & & & \\
\hline 7 & 32 & & & \\
\hline 6 & 32 & & & \\
\hline 3327 & 82 & & & \\
\hline 3299 & 90682 & & & \\
\hline & 582 & & & \\
\hline $\mathrm{CHE}$ & 32 & & & \\
\hline ra & 32 & & & \\
\hline CHEMBL & 290682 & & & - \\
\hline 333 & 90682 & & & \\
\hline 316 & 1290682 & & & \\
\hline 256 & 458976 & & & \\
\hline CHEMBL & 58976 & & & \\
\hline EMBL & 58976 & & & R \\
\hline 57 & 58976 & & & \\
\hline 088 & 458976 & & & \\
\hline 9057 & 458976 & 5.6778 & 5.6848 & \\
\hline CHEMBL 363840 & 58976 & 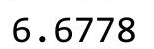 & .2582 & \\
\hline
\end{tabular}

Page 15891 


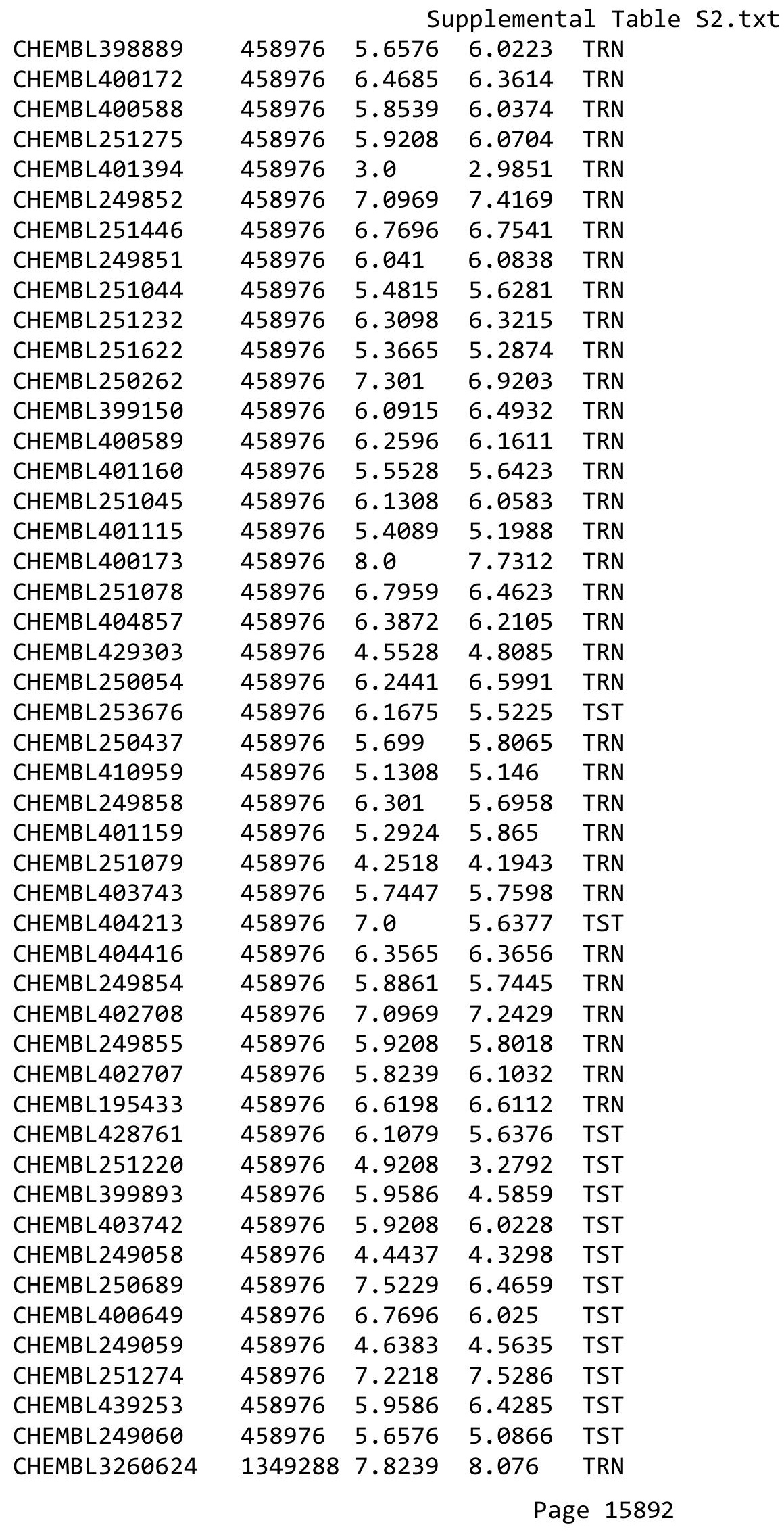


Supplemental Table S2.txt

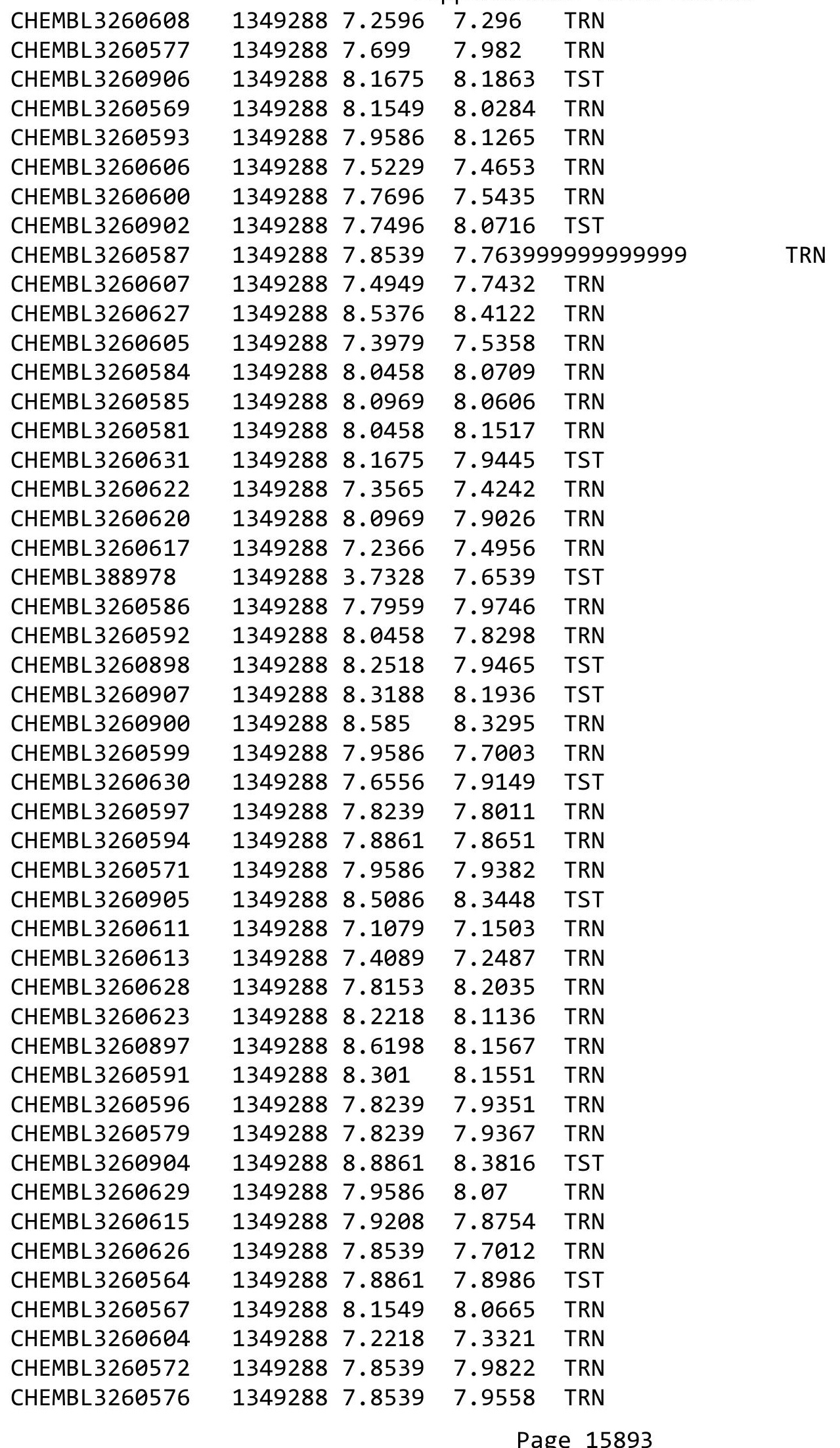


Supplemental Table S2.txt

\begin{tabular}{|c|c|c|c|c|}
\hline CHEMBL3260612 & 1349288 & 7.3279 & 7.4267 & TRN \\
\hline CHEMBL3260610 & 1349288 & 7.2291 & 7.2851 & TRN \\
\hline CHEMBL3260583 & 1349288 & 8.301 & 8.1306 & TRN \\
\hline CHEMBL3260595 & 1349288 & 7.7696 & 7.7309 & TRN \\
\hline CHEMBL226838 & 1349288 & 7.2676 & 8.0797 & TST \\
\hline CHEMBL3260588 & 1349288 & 7.6383 & 7.8798 & TRN \\
\hline CHEMBL3260616 & 1349288 & 7.7447 & 7.92399 & 99999999995 \\
\hline CHEMBL3260582 & 1349288 & 8.2218 & 8.1429 & TRN \\
\hline CHEMBL3260590 & 1349288 & 7.9208 & 7.9853 & TRN \\
\hline CHEMBL3260598 & 1349288 & 7.7696 & 7.7094 & TRN \\
\hline CHEMBL3260566 & 1349288 & 7.8861 & 7.8084 & TRN \\
\hline CHEMBL3260575 & 1349288 & 8.0 & 8.0251 & TRN \\
\hline CHEMBL3260565 & 1349288 & 7.6778 & 7.9343 & TST \\
\hline CHEMBL3260603 & 1349288 & 7.3188 & 7.2171 & TRN \\
\hline CHEMBL3260621 & 1349288 & 7.7696 & 7.6514 & TRN \\
\hline CHEMBL3260601 & 1349288 & 7.7959 & 7.4833 & TRN \\
\hline CHEMBL3260618 & 1349288 & 7.6778 & 7.8228 & TRN \\
\hline CHEMBL492634 & 1349288 & 7.7696 & 7.9689 & TST \\
\hline CHEMBL3260899 & 1349288 & 8.0915 & 7.9558 & TST \\
\hline CHEMBL3260573 & 1349288 & 7.8539 & 7.6285 & TRN \\
\hline CHEMBL3260589 & 1349288 & 8.1549 & 8.1108 & TRN \\
\hline CHEMBL 3260574 & 1349288 & 7.9208 & 7.7996 & TRN \\
\hline CHEMBL3260578 & 1349288 & 7.5229 & 7.755 & TRN \\
\hline CHEMBL3260602 & 1349288 & 7.3372 & 7.4553 & TRN \\
\hline CHEMBL3260570 & 1349288 & 7.8539 & 7.9681 & TRN \\
\hline CHEMBL3260619 & 1349288 & 8.0 & 8.02 & TRN \\
\hline CHEMBL 3260580 & 1349288 & 7.3979 & 7.7968 & TST \\
\hline CHEMBL3260903 & 1349288 & 8.4815 & 8.1227 & TST \\
\hline CHEMBL3260625 & 1349288 & 7.8539 & 7.9662 & TST \\
\hline CHEMBL3260568 & 1349288 & 8.0458 & 7.8082 & TST \\
\hline CHEMBL3260609 & 1349288 & 7.6021 & 7.5742 & TST \\
\hline CHEMBL3260614 & 1349288 & 8.0458 & 8.031 & TST \\
\hline CHEMBL3260901 & 1349288 & 8.3098 & 8.2417 & TST \\
\hline CHEMBL1214133 & 646978 & 7.0706 & 6.9007 & TRN \\
\hline CHEMBL1213693 & 646978 & 6.0605 & 6.103 & TRN \\
\hline CHEMBL1214001 & 646978 & 8.699 & 8.67 & TRN \\
\hline CHEMBL1214138 & 646978 & 5.8894 & 5.8606 & TRN \\
\hline CHEMBL1214056 & 646978 & 7.7212 & 7.6242 & TRN \\
\hline CHEMBL1213951 & 646978 & 7.1938 & 7.1855 & TRN \\
\hline CHEMBL1213689 & 646978 & 7.5229 & 7.5336 & TRN \\
\hline CHEMBL1213694 & 646978 & 6.9586 & 6.354 & TST \\
\hline CHEMBL1213695 & 646978 & 5.3872 & 5.3867 & TRN \\
\hline CHEMBL1214616 & 646978 & 7.6198 & 6.3667 & TST \\
\hline CHEMBL1214612 & 646978 & 8.3979 & 8.2841 & TRN \\
\hline CHEMBL1214130 & 646978 & 6.8729 & 6.8154 & TRN \\
\hline CHEMBL1214136 & 646978 & 6.8239 & 6.676 & TRN \\
\hline CHEMBL1212951 & 646978 & 7.0458 & 7.0205 & TRN \\
\hline CHEMBL1214619 & 646978 & 8.0 & 7.4143 & TST \\
\hline
\end{tabular}


Supplemental Table S2.txt

\begin{tabular}{|c|c|c|c|c|}
\hline 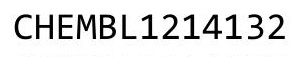 & & & & \\
\hline HEMBL1214057 & 46978 & 198 & 604 & \\
\hline AEMBL1213690 & 78 & 747 & 3042 & \\
\hline EMBL1214 & & 229 & 489 & \\
\hline EMBL1214378 & & & 606 & \\
\hline AEMBL1214617 & 46978 & & 5385 & \\
\hline AEMBL1214613 & 46978 & 192 & .8011 & \\
\hline HEMBL1214439 & & & 355 & \\
\hline EMBL1213884 & & & 149 & \\
\hline IEMBL1213696 & & & 253 & \\
\hline AEMBL1214615 & 78 & & 5886 & \\
\hline AEMBL1214379 & & & 546 & \\
\hline AEMBL1214252 & & & 519 & \\
\hline AEMBL1214381 & & & & \\
\hline HEMBL1214324 & & & & \\
\hline AEMBL1214198 & & & 961 & \\
\hline AEMBL1214438 & & & & \\
\hline HEMBL1214055 & & & 26 & \\
\hline HEMBL1213998 & & & & \\
\hline AEMBL1214562 & & & & \\
\hline AEMBL1214505 & & & 852 & \\
\hline AEMBL1212949 & & & 976 & \\
\hline IEMBL1091849 & & & 58 & \\
\hline AEMBL1214134 & & & & \\
\hline AEMBL1213821 & & & 322 & \\
\hline AEMBL1214197 & & & & \\
\hline IEMBL1213692 & & & & \\
\hline IEMBL1213753 & & & & \\
\hline AFMBI 1214 & & & & \\
\hline 1214251 & & & 058 & \\
\hline AEMBL1213755 & & & 471 & \\
\hline HEMBL1213822 & & & 965 & \\
\hline 12137 & & & & \\
\hline 121 & & & 24 & \\
\hline AEMBL1092541 & & & 45 & \\
\hline AEMBL1214380 & & & 649 & F \\
\hline AEMBL1214382 & & & 306 & \\
\hline 1213756 & & & & \\
\hline 1213886 & & & 25 & \\
\hline HEMBL1214564 & & & & ГST \\
\hline AEMBL1213823 & & & 148 & TR \\
\hline AEMBL1214C & & & 685 & \\
\hline 12143 & & & 787 & \\
\hline HEMBL1213691 & & & .4214 & r \\
\hline AEMBL1213757 & & & .6019 & rs \\
\hline AEMBL1214325 & & 7. & 7.1833 & TP \\
\hline 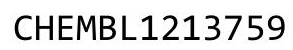 & & & & \\
\hline & & 5.96 & 6.7569 & \\
\hline
\end{tabular}

Page 15895 


\begin{tabular}{|c|c|c|c|c|c|}
\hline \multirow[b]{2}{*}{ CHEMBL1213824 } & \multirow{2}{*}{646978} & \\
\hline & & 8.2218 & 7.7782 & TST & \\
\hline CHEMBL1214383 & 646978 & 4.7696 & 4.9332 & TRN & \\
\hline CHEMBL1214561 & 646978 & 6.2366 & 6.218 & TRN & \\
\hline CHEMBL1214440 & 646978 & 7.2924 & 6.4749 & TST & \\
\hline CHEMBL1214137 & 646978 & 6.8761 & 6.0007 & TST & \\
\hline CHEMBL1214131 & 646978 & 7.1135 & 7.4121 & TRN & \\
\hline CHEMBL1214250 & 646978 & 6.6536 & 6.2458 & TRN & \\
\hline CHEMBL1214135 & 646978 & 7.0044 & 6.9406 & TRN & \\
\hline CHEMBL1214618 & 646978 & 7.4685 & 6.6878 & TST & \\
\hline CHEMBL1214441 & 646978 & 7.3979 & 7.2917 & TRN & \\
\hline CHEMBL1213952 & 646978 & 8.3979 & 8.0602 & TST & \\
\hline CHEMBL1214563 & 646978 & 7.6778 & 6.9367 & TST & \\
\hline CHEMBL1213885 & 646978 & 6.7212 & 6.8509 & TRN & \\
\hline CHEMBL1214000 & 646978 & 8.699 & 8.4837 & TRN & \\
\hline CHEMBL1213999 & 646978 & 8.3979 & 8.3602 & TRN & \\
\hline CHEMBL1214139 & 646978 & 7.2291 & 6.4331 & TST & \\
\hline CHEMBL1214506 & 646978 & 6.1938 & 6.272 & TRN & \\
\hline CHEMBL1214196 & 646978 & 5.6402 & 5.6574 & TRN & \\
\hline CHEMBL1213754 & 646978 & 7.6021 & 7.5555 & TRN & \\
\hline CHEMBL1214504 & 646978 & 6.9788 & 6.1209 & TST & \\
\hline CHEMBL1214129 & 646978 & 8.301 & 7.9281 & TST & \\
\hline CHEMBL1214385 & 646978 & 5.8633 & 5.897 & TRN & \\
\hline CHEMBL1256247 & 665348 & 5.5229 & 5.6378 & TRN & \\
\hline CHEMBL1258013 & 665348 & 7.9101 & 7.9608 & TRN & \\
\hline CHEMBL1255621 & 665348 & 5.6682 & 6.004 & TRN & \\
\hline CHEMBL582429 & 665348 & 6.3439 & 6.3611 & TRN & \\
\hline CHEMBL1258014 & 665348 & 8.2197 & 7.9608 & TRN & \\
\hline CHEMBL1256383 & 665348 & 5.6855 & 4.9226 & TRN & \\
\hline CHEMBL1257785 & 665348 & 4.0696 & 5.5495 & TST & \\
\hline CHEMBL1258246 & 665348 & 7.4045 & 7.50899 & 99999999995 & TRN \\
\hline CHEMBL1256108 & 665348 & 3.87899 & 79999999 & 5.0082 & TST \\
\hline CHEMBL1258247 & 665348 & 7.5017 & 7.7569 & TRN & \\
\hline CHEMBL1256613 & 665348 & 6.2449 & 6.4024 & TRN & \\
\hline CHEMBL1257902 & 665348 & 6.7773 & 6.8065 & TRN & \\
\hline CHEMBL1255774 & 665348 & 6.9508 & 6.8952 & TRN & \\
\hline CHEMBL1257312 & 665348 & 7.8894 & 7.6391 & TRN & \\
\hline CHEMBL1256317 & 665348 & 4.0356 & 3.9611 & TRN & \\
\hline CHEMBL1257544 & 665348 & 6.1349 & 5.8925 & TRN & \\
\hline CHEMBL528486 & 665348 & 6.5406 & 6.4385 & TRN & \\
\hline CHEMBL1258012 & 665348 & 7.1002 & 7.226 & TRN & \\
\hline CHEMBL1257313 & 665348 & 7.4023 & 7.25 & TRN & \\
\hline CHEMBL1256569 & 665348 & 6.6655 & 6.4396 & TRN & \\
\hline CHEMBL1256382 & 665348 & 6.5421 & 6.4495 & TRN & \\
\hline CHEMBL1258134 & 665348 & 5.6664 & 5.4599 & TRN & \\
\hline CHEMBL1257542 & 665348 & 5.191 & 5.4126 & TRN & \\
\hline CHEMBL1256509 & 665348 & 6.6126 & 5.7173 & TRN & \\
\hline CHEMBL1256316 & 665348 & 6.032 & 5.7552 & TRN & \\
\hline CHEMBL527822 & 665348 & 8.066 & 7.08200 & 0000000001 & ISI \\
\hline & & & & 13090 & \\
\hline
\end{tabular}


Supplemental Table S2.txt

\begin{tabular}{|c|c|c|c|c|c|}
\hline CHEMBL1258132 & 665348 & 6.6253 & 6.7909 & TRN & \\
\hline CHEMBL1256318 & 665348 & 5.0816 & 4.7795 & TRN & \\
\hline CHEMBL1256381 & 665348 & 4.0258 & 4.7725 & TRN & \\
\hline CHEMBL1256109 & 665348 & 3.3497 & 4.2496 & TST & \\
\hline CHEMBL1256345 & 665348 & 4.0426 & 4.4209 & TRN & \\
\hline CHEMBL1257429 & 665348 & 4.0451 & 3.9619 & TRN & \\
\hline CHEMBL1257663 & 665348 & 4.0757 & 6.0272 & TST & \\
\hline CHEMBL1257428 & 665348 & 5.3373 & 5.2781 & TRN & \\
\hline CHEMBL1255729 & 665348 & 7.317 & 7.2449 & TRN & \\
\hline CHEMBL1255622 & 665348 & 4.0555 & 6.4183 & TST & \\
\hline CHEMBL1257786 & 665348 & 4.0757 & 5.9949 & TST & \\
\hline CHEMBL1256347 & 665348 & 5.0886 & 5.5028 & TRN & \\
\hline CHEMBL1255730 & 665348 & 6.7471 & 6.8204 & TRN & \\
\hline CHEMBL1256444 & 665348 & 5.6071 & 5.169 & TRN & \\
\hline CHEMBL1255775 & 665348 & 7.0635 & 7.1425 & TRN & \\
\hline CHEMBL1256346 & 665348 & 4.0158 & 3.8753 & TRN & \\
\hline CHEMBL1256570 & 665348 & 4.033 & 4.1426 & TRN & \\
\hline CHEMBL1256443 & 665348 & 6.2007 & 5.6632 & TRN & \\
\hline CHEMBL1257903 & 665348 & 7.5817 & 7.5856 & TRN & \\
\hline CHEMBL1256445 & 665348 & 5.6639 & 5.6953 & TRN & \\
\hline CHEMBL1258133 & 665348 & 7.0283 & 7.077999 & 999999999 & TRN \\
\hline CHEMBL1255731 & 665348 & 7.2472 & 6.9699 & TRN & \\
\hline CHEMBL1256614 & 665348 & 4.0852 & 4.2442 & TRN & \\
\hline CHEMBL1258248 & 665348 & 7.2097 & 6.2732 & TST & \\
\hline CHEMBL1255574 & 665348 & 4.0555 & 6.0267 & TST & \\
\hline CHEMBL1256615 & 665348 & 4.0852 & 4.064 & TRN & \\
\hline CHEMBL1255776 & 665348 & 5.4983 & 5.4547 & TRN & \\
\hline CHEMBL1256508 & 665348 & 5.2955 & 5.8891 & TRN & \\
\hline CHEMBL1256507 & 665348 & 4.055 & 3.8882 & TRN & \\
\hline CHEMBL1255728 & 665348 & 6.4342 & 6.5466 & TRN & \\
\hline CHEMBL1256315 & 665348 & 6.0731 & 6.3763 & TRN & \\
\hline CHEMBL1257901 & 665348 & 4.0696 & 5.6619 & TST & \\
\hline CHEMBL1256571 & 665348 & 6.1811 & 5.9101 & TRN & \\
\hline CHEMBL1256246 & 665348 & 4.042 & 4.2618 & TRN & \\
\hline CHEMBL1256168 & 665348 & 4.2998 & 5.3156 & TRN & \\
\hline CHEMBL1257314 & 665348 & 6.9918 & 7.3855 & TRN & \\
\hline CHEMBL1256167 & 665348 & 6.1481 & 5.955 & TRN & \\
\hline CHEMBL1257662 & 665348 & 4.0696 & 6.1817 & TST & \\
\hline CHEMBL537807 & 665348 & 7.61799 & 9999999 & 7.5578 & TRN \\
\hline CHEMBL 1257784 & 665348 & 4.0696 & 6.2099 & TST & \\
\hline CHEMBL1256248 & 665348 & 5.8526 & 5.9681 & TST & \\
\hline CHEMBL1256166 & 665348 & 6.2286 & 6.0904 & TST & \\
\hline CHEMBL1257427 & 665348 & 4.0783 & 5.1202 & TST & \\
\hline CHEMBL529769 & 665348 & 7.0306 & 7.2263 & TST & \\
\hline CHEMBL1257661 & 665348 & 4.6501 & 4.3619 & TST & \\
\hline CHEMBL1257543 & 665348 & 4.0482 & 4.6 & TST & \\
\hline CHEMBL1522827 & 752368 & 4.3862 & 4.9379 & TRN & \\
\hline CHEMBL3192181 & 752368 & 4.7597 & 4.7371 & TRN & \\
\hline
\end{tabular}

Page 15897 


\begin{tabular}{|c|c|c|c|c|}
\hline & & & pplement & al $\mathrm{T}$ \\
\hline CHEMBL1427463 & 752368 & 4.6714 & 4.5947 & TRN \\
\hline CHEMBL1500966 & 752368 & 5.2958 & 4.5656 & TRN \\
\hline CHEMBL1452426 & 752368 & 3.6855 & 4.8548 & TRN \\
\hline CHEMBL1900376 & 752368 & 5.5498 & 4.4884 & TRN \\
\hline CHEMBL1980322 & 752368 & 4.8348 & 4.7393 & TRN \\
\hline CHEMBL1527600 & 752368 & 4.0606 & 4.5479 & TRN \\
\hline CHEMBL1341497 & 752368 & 5.3872 & 4.9091 & TRN \\
\hline CHEMBL1541177 & 752368 & 4.671 & 4.6088 & TRN \\
\hline CHEMBL1504701 & 752368 & 6.0883 & 5.4439 & TRN \\
\hline CHEMBL1717138 & 752368 & 5.3028 & 5.9506 & TRN \\
\hline CHEMBL1331851 & 752368 & 4.0877 & 4.7034 & TRN \\
\hline CHEMBL1552207 & 752368 & 4.3685 & 4.3067 & TRN \\
\hline CHEMBL1889367 & 752368 & 4.9344 & 4.6599 & TRN \\
\hline CHEMBL1547261 & 752368 & 4.5585 & 4.3723 & TRN \\
\hline CHEMBL1591222 & 752368 & 4.5659 & 4.7448 & TRN \\
\hline CHEMBL1901897 & 752368 & 3.9659 & 4.7041 & TRN \\
\hline CHEMBL1477623 & 752368 & 4.2748 & 4.4801 & TRN \\
\hline CHEMBL1394624 & 752368 & 4.8844 & 4.6861 & TRN \\
\hline CHEMBL1472016 & 752368 & 4.5226 & 4.5535 & TRN \\
\hline CHEMBL1535532 & 752368 & 4.9784 & 4.7885 & TRN \\
\hline CHEMBL1599290 & 752368 & 3.967 & 4.9286 & TST \\
\hline CHEMBL1388121 & 752368 & 4.5219 & 5.2091 & TRN \\
\hline CHEMBL1577983 & 752368 & 5.9393 & 4.5893 & TRN \\
\hline CHEMBL1978830 & 752368 & 6.5406 & 4.7623 & TRN \\
\hline CHEMBL1406398 & 752368 & 4.6115 & 4.7319 & TRN \\
\hline CHEMBL1596434 & 752368 & 3.5568 & 4.1591 & TRN \\
\hline CHEMBL1698316 & 752368 & 6.1007 & 6.0602 & TRN \\
\hline CHEMBL1971144 & 752368 & 3.8941 & 4.5574 & TRN \\
\hline CHEMBL 1713163 & 752368 & 5.0232 & 4.615 & TRN \\
\hline CHEMBL1993020 & 752368 & 4.5653 & 4.4642 & TRN \\
\hline CHEMBL1880417 & 752368 & 6.3526 & 6.2886 & TRN \\
\hline CHEMBL1450526 & 752368 & 4.9893 & 4.6227 & TRN \\
\hline CHEMBL224367 & 752368 & 3.9251 & 5.1151 & TRN \\
\hline CHEMBL1323794 & 752368 & 4.2607 & 4.1602 & TRN \\
\hline CHEMBL1439588 & 752368 & 4.1102 & 4.6641 & TST \\
\hline CHEMBL1572496 & 752368 & 3.9676 & 4.6543 & TRN \\
\hline CHEMBL1587842 & 752368 & 4.5572 & 4.5416 & TST \\
\hline CHEMBL1729751 & 752368 & 4.5214 & 4.1659 & TRN \\
\hline CHEMBL 1875537 & 752368 & 4.2912 & 5.1503 & TST \\
\hline CHEMBL3190911 & 752368 & 5.0386 & 4.6978 & TRN \\
\hline CHEMBL1888076 & 752368 & 5.3675 & 5.9506 & TRN \\
\hline CHEMBL1318556 & 752368 & 4.3534 & 4.1606 & TRN \\
\hline CHEMBL1717079 & 752368 & 6.1952 & 5.7274 & TRN \\
\hline CHEMBL1417731 & 752368 & 5.3925 & 4.885 & TRN \\
\hline CHEMBL1366310 & 752368 & 4.5267 & 4.5119 & TRN \\
\hline CHEMBL1599458 & 752368 & 4.4163 & 4.4025 & TRN \\
\hline CHEMBL1878035 & 752368 & 5.5258 & 5.1265 & TRN \\
\hline CHEMBL1423387 & 752368 & 4.7902 & 4.7712 & TRN \\
\hline
\end{tabular}




\begin{tabular}{|c|c|c|c|c|c|}
\hline & & & & & \\
\hline CHEMBL1173475 & 752368 & 3.6326 & 4.675 & TST & \\
\hline CHEMBL1711432 & 752368 & 4.4631 & 4.5931 & TRN & \\
\hline CHEMBL1539340 & 752368 & 4.5264 & 4.3592 & TRN & \\
\hline CHEMBL1899451 & 752368 & 4.5396 & 5.003 & TST & \\
\hline CHEMBL1705854 & 752368 & 5.1925 & 5.1729 & TRN & \\
\hline CHEMBL1307349 & 752368 & 5.2487 & 4.5628 & TST & \\
\hline CHEMBL3194777 & 752368 & 4.1538 & 4.5046 & TST & \\
\hline CHEMBL1880333 & 752368 & 4.0383 & 4.3815 & TRN & \\
\hline CHEMBL1718568 & 752368 & 4.4903 & 4.8654 & TRN & \\
\hline CHEMBL1896407 & 752368 & 6.1343 & 5.1524 & TRN & \\
\hline CHEMBL1362860 & 752368 & 3.4598 & 4.2359 & TRN & \\
\hline CHEMBL1497323 & 752368 & 4.2675 & 4.832 & TST & \\
\hline CHEMBL2354875 & 752368 & 4.6916 & 4.6133 & TRN & \\
\hline CHEMBL1514340 & 752368 & 3.7852 & 4.6393 & TRN & \\
\hline CHEMBL1906369 & 752368 & 5.9431 & 4.9246 & TRN & \\
\hline CHEMBL1492729 & 752368 & 4.6017 & 4.8578 & TST & \\
\hline CHEMBL1256751 & 752368 & 4.6169 & 4.2967 & TRN & \\
\hline CHEMBL1481616 & 752368 & 4.5524 & 4.7933 & TRN & \\
\hline CHEMBL1500035 & 752368 & 4.5629 & 4.90300 & 00000000005 & TRN \\
\hline CHEMBL1991388 & 752368 & 3.9496 & 4.4829 & TRN & \\
\hline CHEMBL1411665 & 752368 & 4.7742 & 4.9193 & TRN & \\
\hline CHEMBL3189416 & 752368 & 4.5198 & 4.6155 & TRN & \\
\hline CHEMBL1583665 & 752368 & 5.7878 & 4.885 & TRN & \\
\hline CHEMBL1345971 & 752368 & $4.3610 €$ & 00000000 & 4.621 & TRN \\
\hline CHEMBL1312275 & 752368 & 4.5712 & 4.8424 & TRN & \\
\hline CHEMBL1498801 & 752368 & 4.5302 & 4.5903 & TRN & \\
\hline CHEMBL1392509 & 752368 & 4.0919 & 4.3785 & TRN & \\
\hline CHEMBL1352721 & 752368 & 3.7498 & 4.58899 & 99999999995 & TRN \\
\hline CHEMBL140053 & 752368 & 4.1774 & 4.8208 & TRN & \\
\hline CHEMBL1343265 & 752368 & 5.4078 & 4.9477 & TRN & \\
\hline CHEMBL1316074 & 752368 & 3.7304 & 4.9245 & TRN & \\
\hline CHEMBL3213965 & 752368 & 6.8327 & 5.3489 & TRN & \\
\hline CHEMBL1331913 & 752368 & 4.4032 & 5.1879 & TRN & \\
\hline CHEMBL1316462 & 752368 & 4.8496 & 4.5348 & TRN & \\
\hline CHEMBL1605795 & 752368 & 5.0146 & 4.7901 & TRN & \\
\hline CHEMBL1359964 & 752368 & 4.5308 & 4.4633 & TRN & \\
\hline CHEMBL1426340 & 752368 & 5.0472 & 4.5781 & TRN & \\
\hline CHEMBL3198332 & 752368 & 4.8807 & 4.829 & TRN & \\
\hline CHEMBL1713017 & 752368 & 4.9626 & 4.7489 & TRN & \\
\hline CHEMBL1902169 & 752368 & 4.9694 & 5.0145 & TRN & \\
\hline CHEMBL1310617 & 752368 & 6.2716 & 4.8437 & TST & \\
\hline CHEMBL1387790 & 752368 & 4.7902 & 5.1373 & TST & \\
\hline CHEMBL1698608 & 752368 & 5.2857 & 5.5479 & TST & \\
\hline CHEMBL1701797 & 752368 & 5.7696 & 5.5402 & TST & \\
\hline CHEMBL1562280 & 752368 & 6.1113 & 4.9302 & TST & \\
\hline CHEMBL1536459 & 752368 & 4.126 & 3.8491 & TST & \\
\hline CHEMBL 2358182 & 752368 & 5.3925 & 4.706 & TST & \\
\hline CHEMBL1335661 & 752368 & 4.0409 & 4.6683 & TST & \\
\hline & & & & 15899 & \\
\hline
\end{tabular}


Supplemental Table S2.txt

\begin{tabular}{|c|c|c|c|c|}
\hline HEM & 58 & 052 & 18 & $\mathrm{~T}$ \\
\hline HEMBL1509213 & 52368 & 4.3161 & 4.4983 & \\
\hline .0020 & 2368 & & & \\
\hline AEMBL1545435 & 2368 & 4.8111 & 319 & \\
\hline HEMBL1449083 & 52368 & 75 & 5918 & \\
\hline HEMBL1399478 & 52368 & 4.2214 & 3309 & \\
\hline HEMBL1608194 & 52368 & 4.4856 & 754 & \\
\hline AEMBL1461441 & 52368 & & & \\
\hline HEMBL590643 & 52368 & 295 & & \\
\hline HEMBL2448693 & 93443 & 6.0 & 916 & \\
\hline HEMBL 2448696 & 93443 & 4 . & 3. & \\
\hline HEMBL 2448738 & 43 & 15 & 58 & \\
\hline HEMBL2448699 & & 3 . & & \\
\hline HEMBL2448727 & 93443 & 385 & 968 & \\
\hline HEMBL2448734 & 43 & & & \\
\hline HEMBL 2448708 & 3 & 4. & 36 & \\
\hline HEMBL2448726 & 3 & & 47 & \\
\hline HEMBL2448691 & 3 & 3 & & \\
\hline HEMBL2448690 & 43 & 3. & 3305 & \\
\hline HEMBL2448707 & 13 & & & ST \\
\hline HEMBL2448702 & 3 & & & \\
\hline HEMBL 2448 & 3 & & & \\
\hline HEMBL 2448718 & 3 & 3 & & \\
\hline HEMBL2448713 & 43 & 3. & & \\
\hline HEMBL2448703 & & & & \\
\hline HEMBL2448710 & 3 & 4. & & ST \\
\hline HEMBL 244 & 3 & & & RN \\
\hline HEMBL2448719 & 3 & 6 & 74 & RN \\
\hline HEMBL1552686 & & 3. & & RIN \\
\hline HEMBL2448732 & & & & RIN \\
\hline HEMBL2448714 & & & 147 & RN \\
\hline HEMBL2 2 & כ & 6 & & RN \\
\hline HEMBL2 2 & 3 & 3. & 83 & RN \\
\hline HEMBL2448700 & & & 3064 & ST \\
\hline HEMBL2448711 & 3 & 4. & 3377 & RN \\
\hline HEMBL2448701 & & & 86 & RN \\
\hline HFMBI 2 & & 6. & & ST \\
\hline HEMBL2448731 & & 3. & 377 & RN \\
\hline HEMBL2448724 & 93 & & 3928 & $\mathrm{RN}$ \\
\hline AEMBL2 24 & & & & $\mathrm{RN}$ \\
\hline HEMBL2448744 & 3 & 6 & 174 & RN \\
\hline CHEMBL 2448697 & & 4.3 & & ST \\
\hline CHEMBL2448712 & 993443 & 3.0 & & RN \\
\hline HEMBL2448723 & 93 & 3. & 803 & RN \\
\hline MBL2 2 & 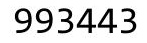 & 4. & & \\
\hline HEMBL2448735 & 993 & & 1.5339 & \\
\hline CHEMBL1321912 & 993443 & $4.1 \varepsilon$ & .9729 & \\
\hline CHEMBL 2448742 & 993443 & 4.1976 & 4.4678 & ГRN \\
\hline
\end{tabular}

Page 15900 


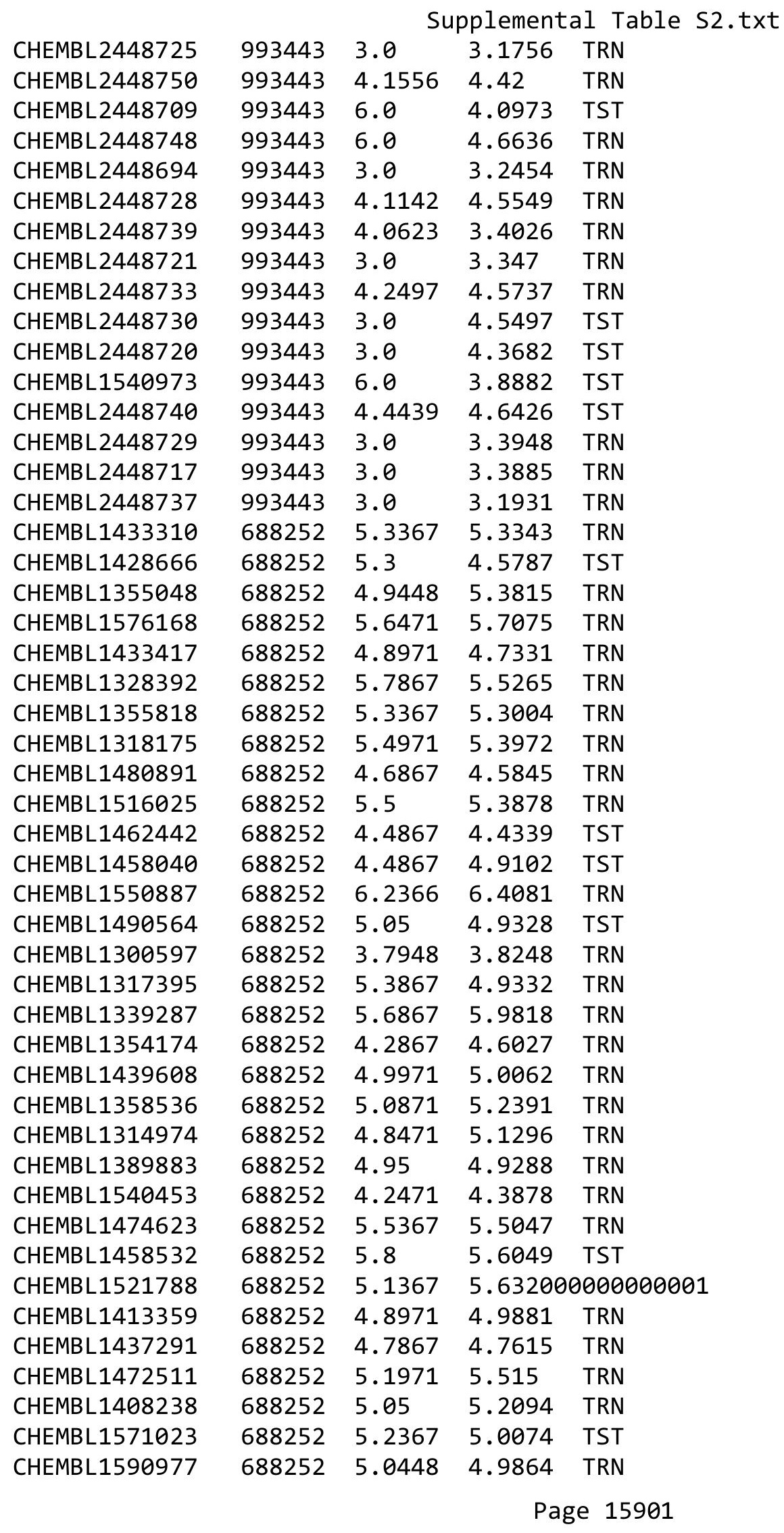




\begin{tabular}{|c|c|c|c|c|c|}
\hline \multicolumn{6}{|c|}{ Supplemental Table S2.txt } \\
\hline CHEMBL1323898 & 688252 & 4.7 & 4.8845 & TST & \\
\hline CHEMBL129795 & 688252 & 4.95 & 4.9521 & TST & \\
\hline CHEMBL1508879 & 688252 & 5.0867 & 4.9368 & TST & \\
\hline CHEMBL1519545 & 688252 & 4.5867 & 5.2709 & TST & \\
\hline CHEMBL1397663 & 688252 & 5.9867 & 5.9741 & TRN & \\
\hline CHEMBL1433363 & 688252 & 4.9 & 5.2127 & TRN & \\
\hline CHEMBL1299329 & 688252 & 5.6971 & 5.5512 & TRN & \\
\hline CHEMBL1554954 & 688252 & 4.8367 & 5.3874 & TRN & \\
\hline CHEMBL1488228 & 688252 & 4.4867 & 4.6707 & TST & \\
\hline CHEMBL1354095 & 688252 & 5.8867 & 5.9623 & TRN & \\
\hline CHEMBL3196175 & 688252 & 5.0367 & 5.2734 & TST & \\
\hline CHEMBL1315035 & 688252 & 6.0 & 5.7829 & TRN & \\
\hline CHEMBL1358030 & 688252 & 4.4867 & 4.8131 & TRN & \\
\hline CHEMBL1550906 & 688252 & 6.0867 & 5.7745 & TRN & \\
\hline CHEMBL1446531 & 688252 & 5.1 & 5.3774 & TST & \\
\hline CHEMBL1559576 & 688252 & 5.1867 & 4.8456 & TST & \\
\hline CHEMBL1354202 & 688252 & 5.0 & 4.7881 & TRN & \\
\hline CHEMBL1354203 & 688252 & 5.0371 & 4.522 & TRN & \\
\hline CHEMBL1393924 & 688252 & 5.4867 & 5.0952 & TRN & \\
\hline CHEMBL1591268 & 688252 & 5.5971 & 5.6004 & TRN & \\
\hline CHEMBL1398519 & 688252 & 6.1367 & 6.1789 & TRN & \\
\hline CHEMBL1336452 & 688252 & 6.0 & 5.7084 & TRN & \\
\hline CHEMBL1532388 & 688252 & 5.1867 & 5.1923 & TRN & \\
\hline CHEMBL1590268 & 688252 & 4.3371 & 4.9836 & TRN & \\
\hline CHEMBL1358037 & 688252 & 5.2367 & 4.9722 & TRN & \\
\hline CHEMBL1569657 & 688252 & 4.4867 & 4.7166 & TST & \\
\hline CHEMBL1358917 & 688252 & 5.3867 & 5.2622 & TRN & \\
\hline CHEMBL1433325 & 688252 & 6.1971 & 5.5481 & TRN & \\
\hline CHEMBL1511850 & 688252 & 4.9471 & 5.0302 & TRN & \\
\hline CHEMBL1397527 & 688252 & 4.7867 & 4.4608 & TRN & \\
\hline CHEMBL1433347 & 688252 & 4.7371 & 5.1576 & TRN & \\
\hline CHEMBL1589695 & 688252 & 4.1371 & 5.0478 & TRN & \\
\hline CHEMBL1589806 & 688252 & 5.4867 & 5.2057 & TRN & \\
\hline CHEMBL1579805 & 688252 & 5.0 & 4.9283 & TST & \\
\hline CHEMBL1472850 & 688252 & 5.5971 & 5.28799 & 9999999999 & TRN \\
\hline CHEMBL1461153 & 688252 & 4.5867 & 4.4201 & TRN & \\
\hline CHEMBL1315685 & 688252 & 5.0867 & 4.5989 & TRN & \\
\hline CHEMBL1358575 & 688252 & 5.6471 & 5.7291 & TRN & \\
\hline CHEMBL1354148 & 688252 & 5.6 & 5.697 & TRN & \\
\hline CHEMBL117108 & 688252 & 6.0 & 5.23 & TRN & \\
\hline CHEMBL1436605 & 688252 & 5.3367 & 5.19799 & 99999999995 & TRN \\
\hline CHEMBL1332880 & 688252 & 4.4867 & 4.6007 & TRN & \\
\hline CHEMBL1412828 & 688252 & 5.0867 & 4.6936 & TRN & \\
\hline CHEMBL1575888 & 688252 & 5.1 & 5.3887 & TST & \\
\hline CHEMBL1361379 & 688252 & 6.4866 & 6.0769 & TRN & \\
\hline CHEMBL1354132 & 688252 & 5.5971 & 5.8707 & TRN & \\
\hline CHEMBL1511986 & 688252 & 4.8 & 4.9136 & TRN & \\
\hline CHEMBL1523867 & 688252 & 8.6021 & 5.6003 & TST & \\
\hline
\end{tabular}




\begin{tabular}{|c|c|c|c|c|c|}
\hline & & & & & \\
\hline CHEMBL1400476 & 688252 & 6.1867 & 5.9883 & TRN & \\
\hline CHEMBL1452154 & 688252 & 5.0 & 4.8009 & TRN & \\
\hline CHEMBL1589703 & 688252 & 6.0471 & 5.8862 & TRN & \\
\hline CHEMBL1314035 & 688252 & 6.1471 & 5.9507 & TRN & \\
\hline CHEMBL1433409 & 688252 & 6.0 & 6.3321 & TRN & \\
\hline CHEMBL1559154 & 688252 & 4.4867 & 4.1239 & TST & \\
\hline CHEMBL1371623 & 688252 & 5.0 & 4.6426 & TRN & \\
\hline CHEMBL1317425 & 688252 & 5.5367 & 5.5923 & TRN & \\
\hline CHEMBL1354978 & 688252 & 6.0 & 5.9009 & TRN & \\
\hline CHEMBL1529019 & 688252 & 5.3867 & 5.25799 & 9999999999 & TRN \\
\hline CHEMBL1461549 & 688252 & 5.4867 & 5.3753 & TRN & \\
\hline CHEMBL1394015 & 688252 & 5.0867 & 4.9249 & TRN & \\
\hline CHEMBL1610733 & 688252 & 4.9 & 4.5111 & TST & \\
\hline CHEMBL1592410 & 688252 & 5.4367 & 5.2825 & TRN & \\
\hline CHEMBL1363195 & 688252 & 5.5867 & 5.558 & TRN & \\
\hline CHEMBL3392418 & 688252 & 5.5867 & 5.0828 & TRN & \\
\hline CHEMBL1474764 & 688252 & 5.6471 & 5.1249 & TRN & \\
\hline CHEMBL1442507 & 688252 & 5.0 & 4.6511 & TST & \\
\hline CHEMBL1314058 & 688252 & 5.8867 & 6.1019 & TRN & \\
\hline CHEMBL1433148 & 688252 & 4.9367 & 4.779 & TRN & \\
\hline CHEMBL1672340 & 688252 & 4.8867 & 4.6195 & TRN & \\
\hline CHEMBL1393956 & 688252 & 5.9367 & 5.8583 & TRN & \\
\hline CHEMBL1411146 & 688252 & 5.05 & 5.19799 & 99999999995 & TRN \\
\hline CHEMBL1551018 & 688252 & 4.7867 & 4.5967 & TRN & \\
\hline CHEMBL1475540 & 688252 & 4.6367 & 5.49100 & 00000000005 & TST \\
\hline CHEMBL1356231 & 688252 & 5.3367 & 4.996 & TRN & \\
\hline CHEMBL1396821 & 688252 & 5.2867 & 5.2926 & TRN & \\
\hline CHEMBL1433344 & 688252 & 4.9448 & 5.2182 & TRN & \\
\hline CHEMBL1535519 & 688252 & 4.8867 & 4.7459 & TRN & \\
\hline CHEMBL1354216 & 688252 & 5.8971 & 6.1802 & TRN & \\
\hline CHEMBL3194903 & 688252 & 4.85 & 4.6517 & TST & \\
\hline CHEMBL1433316 & 688252 & 6.0 & 5.9758 & TRN & \\
\hline CHEMBL1672258 & 688252 & 4.95 & 4.8959 & TRN & \\
\hline CHEMBL1487749 & 688252 & 5.6867 & 5.5451 & TRN & \\
\hline CHEMBL1434480 & 688252 & 4.1867 & 4.4637 & TRN & \\
\hline CHEMBL1464228 & 688252 & 4.5867 & 4.6381 & TST & \\
\hline CHEMBL1314160 & 688252 & 5.2371 & 5.388 & TRN & \\
\hline CHEMBL1433280 & 688252 & 4.1971 & 4.6748 & TRN & \\
\hline CHEMBL1436663 & 688252 & 6.0971 & 6.0332 & TRN & \\
\hline CHEMBL1553244 & 688252 & 4.6948 & 4.6544 & TRN & \\
\hline CHEMBL1473976 & 688252 & 4.1371 & 4.937 & TST & \\
\hline CHEMBL1314131 & 688252 & 6.0867 & 5.7108 & TRN & \\
\hline CHEMBL1394831 & 688252 & 4.3471 & 5.2497 & TST & \\
\hline CHEMBL1492491 & 688252 & 4.85 & 4.7985 & TST & \\
\hline CHEMBL1386329 & 688252 & 5.3 & 4.9384 & TST & \\
\hline CHEMBL1318417 & 688252 & 5.3867 & 5.3664 & TRN & \\
\hline CHEMBL1474351 & 688252 & 5.9871 & 5.335 & TST & \\
\hline CHEMBL1477517 & 688252 & 4.4867 & 4.5389 & TST & \\
\hline
\end{tabular}




\begin{tabular}{|c|c|c|c|c|c|}
\hline \multicolumn{6}{|c|}{ Supplemental Table S2.txt } \\
\hline CHEMBL1375146 & 688252 & 4.7867 & 4.835 & TRN & \\
\hline CHEMBL1394007 & 688252 & 4.7371 & 5.1042 & TST & \\
\hline CHEMBL1984581 & 688252 & 5.1867 & 5.6435 & TST & \\
\hline CHEMBL1550970 & 688252 & 5.5971 & 5.5744 & TRN & \\
\hline CHEMBL1579681 & 688252 & 3.8948 & 3.8288 & TRN & \\
\hline CHEMBL1314134 & 688252 & 5.9971 & 4.96899 & 9999999999 & TRN \\
\hline CHEMBL1415959 & 688252 & 5.8471 & 5.9222 & TRN & \\
\hline CHEMBL1434224 & 688252 & 5.6971 & 5.705 & TRN & \\
\hline CHEMBL1432838 & 688252 & 4.3371 & 4.3054 & TRN & \\
\hline CHEMBL1396417 & 688252 & 5.5971 & 5.9025 & TRN & \\
\hline CHEMBL1376659 & 688252 & 4.1448 & 4.8627 & TRN & \\
\hline CHEMBL1330113 & 688252 & 6.0 & 4.5058 & TST & \\
\hline CHEMBL1550875 & 688252 & 5.1371 & 4.9672 & TST & \\
\hline CHEMBL1314119 & 688252 & 5.9471 & 6.2172 & TRN & \\
\hline CHEMBL1394027 & 688252 & 5.5471 & 5.0766 & TRN & \\
\hline CHEMBL1472565 & 688252 & 6.5367 & 6.3474 & TRN & \\
\hline CHEMBL1474062 & 688252 & 5.6971 & 5.7337 & TRN & \\
\hline CHEMBL1511908 & 688252 & 5.7867 & 5.9105 & TRN & \\
\hline CHEMBL1393949 & 688252 & 5.1867 & 4.9469 & TRN & \\
\hline CHEMBL1591152 & 688252 & 5.2471 & 5.1585 & TST & \\
\hline CHEMBL72650 & 688252 & 4.9971 & 5.0476 & TRN & \\
\hline CHEMBL1431629 & 688252 & 4.0471 & 4.4279 & TRN & \\
\hline CHEMBL1354192 & 688252 & 6.4366 & 6.501 & TRN & \\
\hline CHEMBL1314061 & 688252 & 5.4367 & 5.3262 & TRN & \\
\hline CHEMBL1589972 & 688252 & 4.8867 & 4.9108 & TRN & \\
\hline CHEMBL1354117 & 688252 & 5.9371 & 5.2886 & TST & \\
\hline CHEMBL1512531 & 688252 & 4.8867 & 5.13899 & 9999999999 & TRN \\
\hline CHEMBL1551017 & 688252 & 4.1971 & 4.5371 & TRN & \\
\hline CHEMBL1370189 & 688252 & 4.8 & 4.6672 & TRN & \\
\hline CHEMBL1586373 & 688252 & 5.0867 & 4.96 & TRN & \\
\hline CHEMBL1363835 & 688252 & 5.3971 & 5.2789 & TRN & \\
\hline CHEMBL1433377 & 688252 & 5.7471 & 5.4884 & TST & \\
\hline CHEMBL1476627 & 688252 & 6.1367 & 6.3441 & TRN & \\
\hline CHEMBL1435323 & 688252 & 6.3867 & 6.051 & TRN & \\
\hline CHEMBL1396722 & 688252 & 5.5971 & 5.879 & TRN & \\
\hline CHEMBL1672334 & 688252 & 5.4867 & 5.6792 & TRN & \\
\hline CHEMBL1355183 & 688252 & 5.0367 & 4.8394 & TRN & \\
\hline CHEMBL1591395 & 688252 & 5.9471 & 5.3136 & TST & \\
\hline CHEMBL1433940 & 688252 & 5.5971 & 5.8338 & TRN & \\
\hline CHEMBL140151 & 688252 & 5.6871 & 5.2955 & TST & \\
\hline CHEMBL1416949 & 688252 & 4.1867 & 4.4332 & TRN & \\
\hline CHEMBL1381698 & 688252 & 5.1 & 5.1483 & TRN & \\
\hline CHEMBL1393958 & 688252 & 3.9971 & 5.3144 & TST & \\
\hline CHEMBL1314133 & 688252 & 5.6971 & 5.8358 & TRN & \\
\hline CHEMBL1441515 & 688252 & 4.6367 & 5.0916 & TRN & \\
\hline CHEMBL1560083 & 688252 & 5.2471 & 5.1351 & TRN & \\
\hline CHEMBL1511846 & 688252 & 5.5367 & 5.0778 & TRN & \\
\hline CHEMBL1512558 & 688252 & 5.1367 & 5.5885 & TRN & \\
\hline
\end{tabular}




\begin{tabular}{|c|c|c|c|c|c|}
\hline & & \multicolumn{4}{|c|}{ Supplemental Table S2.txt } \\
\hline CHEMBL1398115 & 688252 & 5.2948 & 5.2422 & TRN & \\
\hline CHEMBL1395506 & 688252 & 6.4366 & 6.02 & TRN & \\
\hline CHEMBL1553985 & 688252 & 5.4367 & 5.0694 & TRN & \\
\hline CHEMBL1448951 & 688252 & 6.0 & 4.8585 & TRN & \\
\hline CHEMBL1672349 & 688252 & 3.7867 & 4.9365 & TRN & \\
\hline CHEMBL 3210588 & 688252 & 5.3367 & 5.5293 & TST & \\
\hline CHEMBL1473257 & 688252 & 5.4867 & 5.9453 & TRN & \\
\hline CHEMBL1433694 & 688252 & 3.6948 & 4.6386 & TRN & \\
\hline CHEMBL1495153 & 688252 & 5.9 & 5.5725 & TST & \\
\hline CHEMBL1358203 & 688252 & 5.5367 & 4.7828 & TRN & \\
\hline CHEMBL1456760 & 688252 & 5.15 & 4.8247 & TST & \\
\hline CHEMBL1513111 & 688252 & 5.9867 & 5.7646 & TRN & \\
\hline CHEMBL1511806 & 688252 & 5.2471 & 5.5598 & TRN & \\
\hline CHEMBL1366141 & 688252 & 3.7448 & 4.7196 & TRN & \\
\hline CHEMBL1597603 & 688252 & 4.5367 & 4.6903 & TST & \\
\hline CHEMBL1501221 & 688252 & 5.0867 & 4.9755 & TRN & \\
\hline CHEMBL1331855 & 688252 & 5.55 & 4.99 & TST & \\
\hline CHEMBL1437489 & 688252 & 5.7471 & 5.4406 & TST & \\
\hline CHEMBL1367254 & 688252 & 5.4948 & 5.5893 & TRN & \\
\hline CHEMBL1551983 & 688252 & 5.4867 & 5.0944 & TRN & \\
\hline CHEMBL1406908 & 688252 & 5.9367 & 5.81 & TRN & \\
\hline CHEMBL1474725 & 688252 & 4.4867 & 4.9509 & TRN & \\
\hline CHEMBL588327 & 688252 & 5.5367 & 5.5608 & TST & \\
\hline CHEMBL1434302 & 688252 & 4.0971 & 4.40600 & 0000000001 & TRN \\
\hline CHEMBL1513215 & 688252 & 5.0867 & 5.2146 & TRN & \\
\hline CHEMBL1436541 & 688252 & 4.3971 & 5.3105 & TST & \\
\hline CHEMBL1433327 & 688252 & 3.6948 & 4.3667 & TRN & \\
\hline CHEMBL1515695 & 688252 & 4.6367 & 4.5688 & TST & \\
\hline CHEMBL1335016 & 688252 & 5.2867 & 5.0019 & TRN & \\
\hline CHEMBL1589742 & 688252 & 5.8971 & 4.9506 & TST & \\
\hline CHEMBL1393882 & 688252 & 6.0 & 5.979 & TRN & \\
\hline CHEMBL1550940 & 688252 & 6.0867 & 5.8735 & TRN & \\
\hline CHEMBL1472525 & 688252 & 4.0371 & 5.2306 & TST & \\
\hline CHEMBL1346506 & 688252 & 3.7948 & 3.9157 & TRN & \\
\hline CHEMBL1434754 & 688252 & 6.5367 & 6.0655 & TRN & \\
\hline CHEMBL1472535 & 688252 & 6.0867 & 5.9685 & TRN & \\
\hline CHEMBL1385222 & 688252 & 4.5867 & 5.1774 & TRN & \\
\hline CHEMBL1536781 & 688252 & 5.1867 & 5.17899 & 9999999999 & TST \\
\hline CHEMBL1357660 & 688252 & 5.2471 & 5.5137 & TST & \\
\hline CHEMBL1488093 & 688252 & 5.1367 & 5.2444 & TRN & \\
\hline CHEMBL1551334 & 688252 & 5.6471 & 5.42299 & 9999999999 & TRN \\
\hline CHEMBL1436910 & 688252 & 5.3867 & 5.2731 & TRN & \\
\hline CHEMBL1434805 & 688252 & 5.0867 & 4.4902 & TRN & \\
\hline CHEMBL1474621 & 688252 & 5.6471 & 5.3672 & TRN & \\
\hline CHEMBL1450529 & 688252 & 4.4471 & 4.7364 & TRN & \\
\hline CHEMBL1314076 & 688252 & 5.6471 & 5.5271 & TST & \\
\hline CHEMBL1515820 & 688252 & 5.9971 & 5.6904 & TRN & \\
\hline CHEMBL1353362 & 688252 & 5.2367 & 5.02 & TRN & \\
\hline
\end{tabular}




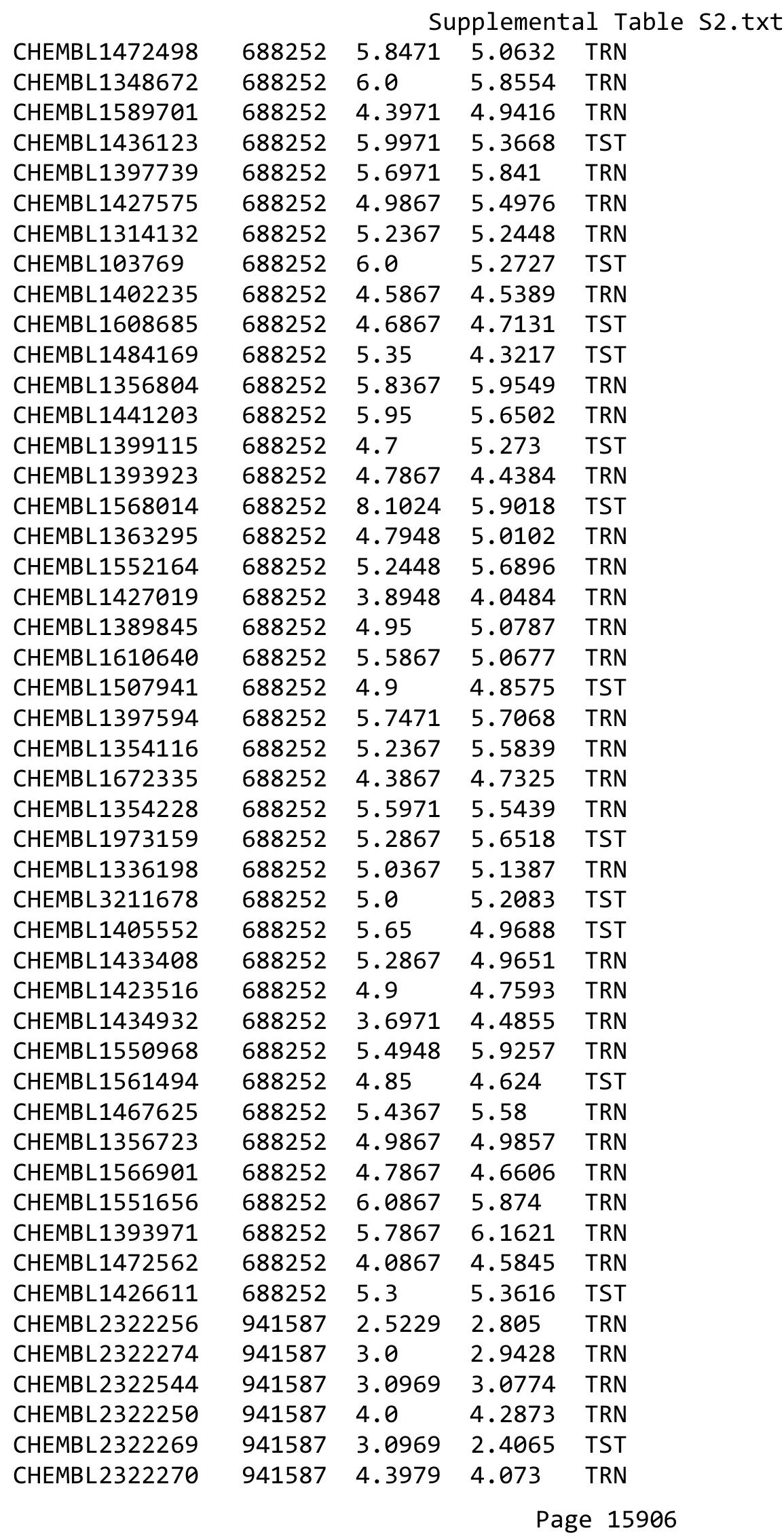




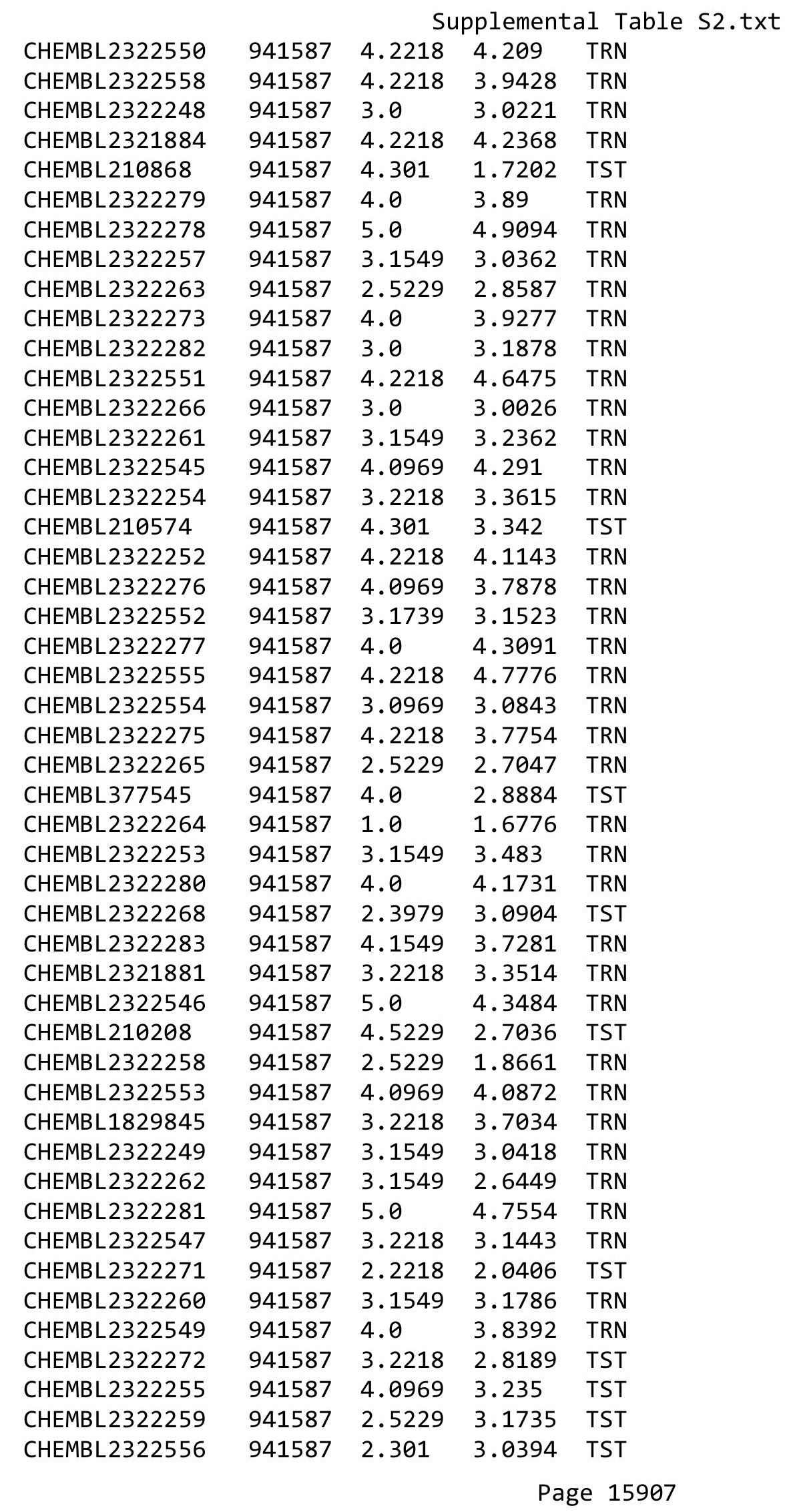




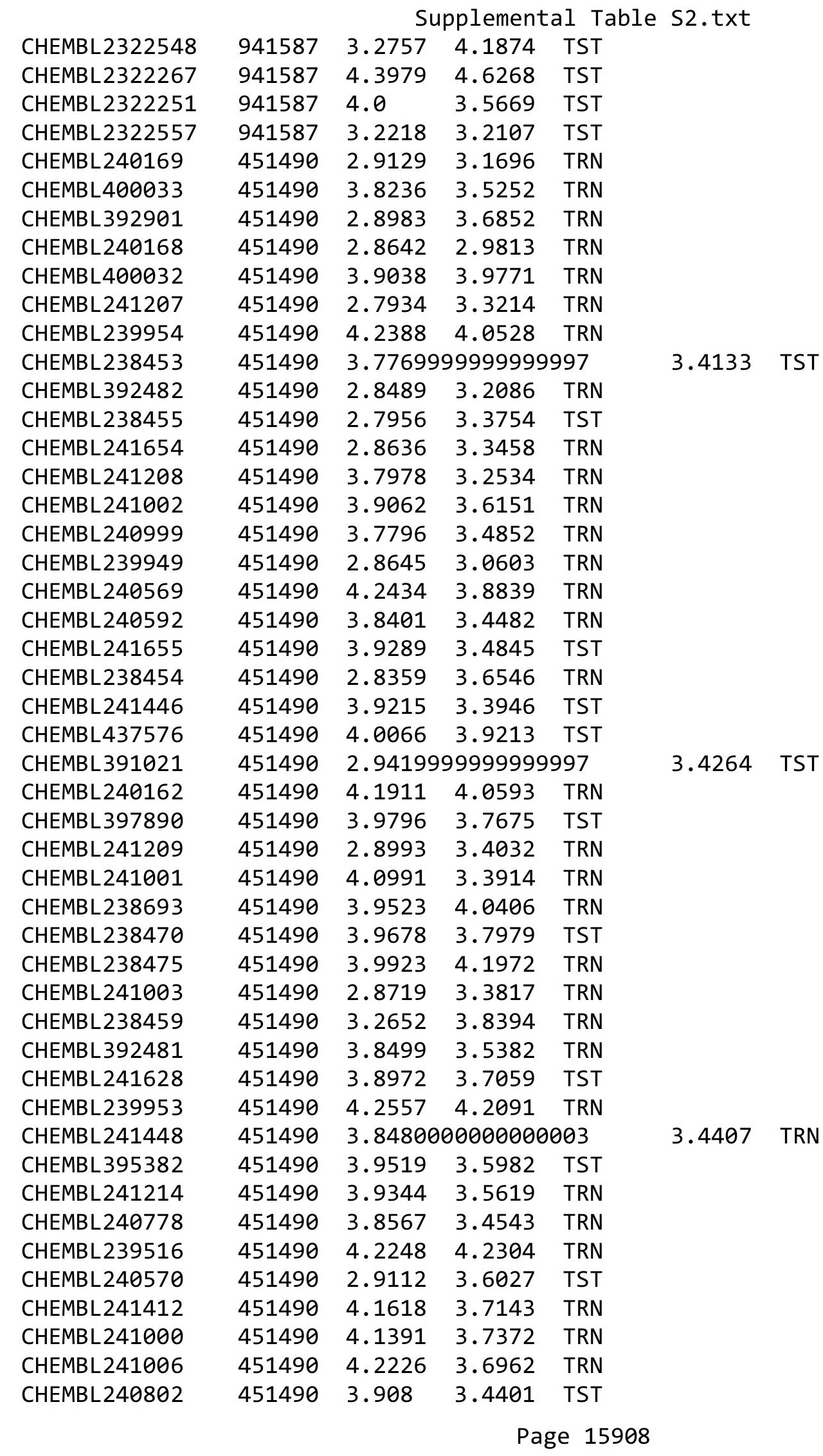




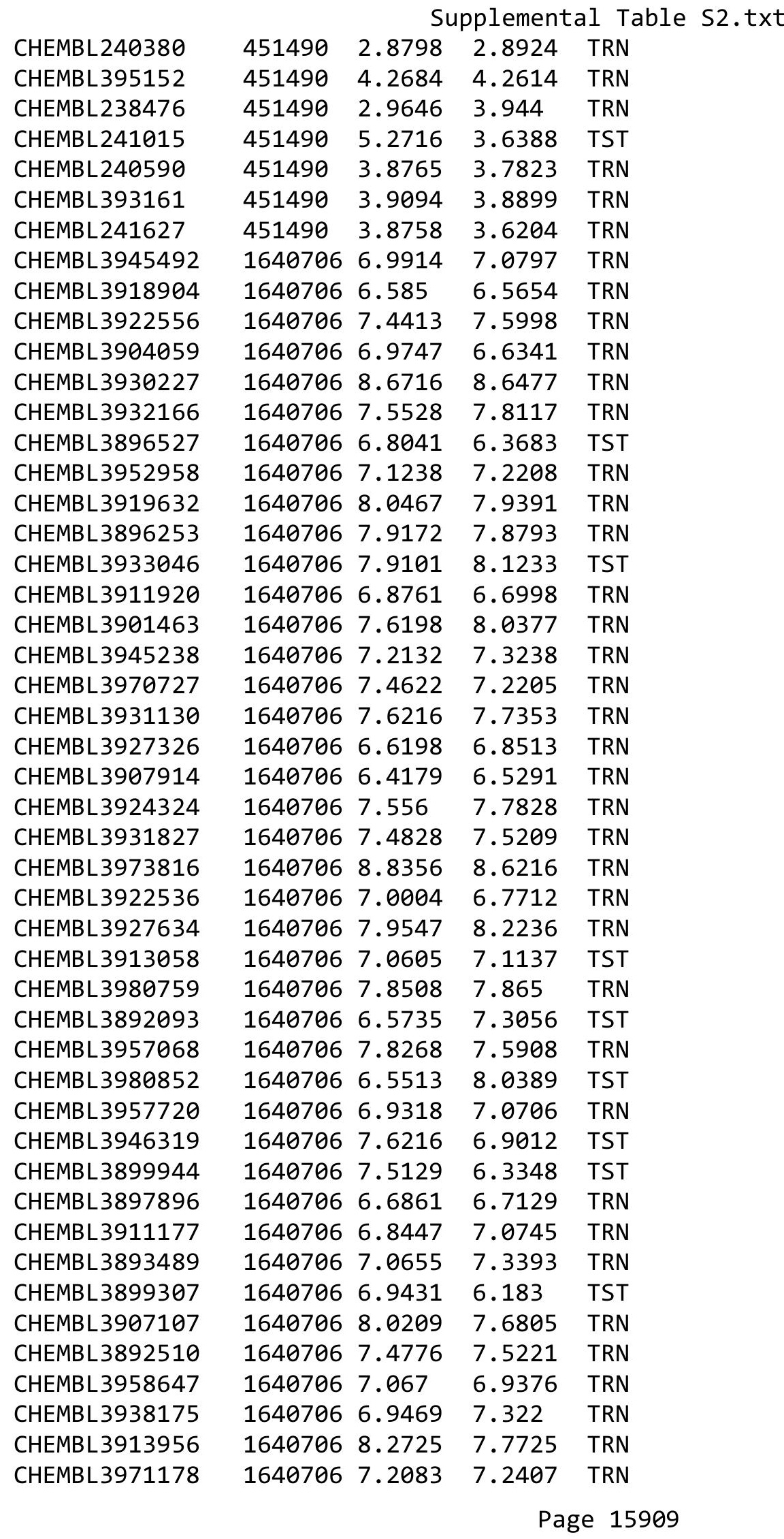


Supplemental Table S2.txt

\begin{tabular}{|c|c|c|c|c|c|}
\hline CHEMBL3916484 & 1640706 & 7.7595 & 7.7395 & TRN & \\
\hline CHEMBL3975741 & 1640706 & 7.5719 & 7.6982 & TRN & \\
\hline CHEMBL3974055 & 1640706 & 6.7696 & 6.9224 & TRN & \\
\hline CHEMBL3986627 & 1640706 & 7.4622 & 7.4343 & TRN & \\
\hline CHEMBL 3908851 & 1640706 & 7.4473 & 7.3792 & TRN & \\
\hline CHEMBL 3943574 & 1640706 & 7.0809 & 6.9281 & TRN & \\
\hline CHEMBL3917406 & 1640706 & 8.4622 & 7.9722 & TRN & \\
\hline CHEMBL3946517 & 1640706 & 8.0783 & 7.8625 & TRN & \\
\hline CHEMBL3904411 & 1640706 & 8.3851 & 8.0997 & TRN & \\
\hline CHEMBL3935543 & 1640706 & 8.5143 & 8.1904 & TRN & \\
\hline CHEMBL 3927933 & 1640706 & 7.5391 & 7.5978 & TRN & \\
\hline CHEMBL 3897064 & 1640706 & 7.0804 & 6.7561 & TST & \\
\hline CHEMBL3947459 & 1640706 & $7.7620 e$ & 00000000 & 7.6682 & TRN \\
\hline CHEMBL3893310 & 1640706 & 7.2924 & 7.2172 & TRN & \\
\hline CHEMBL 3923146 & 1640706 & 8.1296 & 8.2013 & TRN & \\
\hline CHEMBL 3980674 & 1640706 & 7.3915 & 7.5377 & TRN & \\
\hline CHEMBL3949039 & 1640706 & 7.2175 & 6.8174 & TRN & \\
\hline CHEMBL 3987083 & 1640706 & 6.4989 & 6.3843 & TRN & \\
\hline CHEMBL3958170 & 1640706 & 8.4123 & 7.9161 & TRN & \\
\hline CHEMBL 3943061 & 1640706 & 8.1319 & 8.1849 & TRN & \\
\hline CHEMBL3944335 & 1640706 & 7.6162 & 7.6373 & TRN & \\
\hline CHEMBL 3928567 & 1640706 & 8.1487 & 8.0334 & TRN & \\
\hline CHEMBL3939131 & 1640706 & 7.3516 & 7.2651 & TRN & \\
\hline CHEMBL 3934094 & 1640706 & 8.2503 & 8.2839 & TRN & \\
\hline CHEMBL 3925571 & 1640706 & 8.2161 & 8.3439 & TRN & \\
\hline CHEMBL3938818 & 1640706 & 8.1096 & 7.7296 & TRN & \\
\hline CHEMBL 3952372 & 1640706 & \multicolumn{3}{|c|}{7.082000000000001} & TRN \\
\hline CHEMBL3923117 & 1640706 & 7.0605 & 7.1699 & TRN & \\
\hline CHEMBL 3913543 & 1640706 & 7.6696 & 7.8533 & TST & \\
\hline CHEMBL 3972375 & 1640706 & 7.6144 & \multicolumn{2}{|c|}{7.297999999999999} & TRN \\
\hline CHEMBL3927822 & 1640706 & 7.699 & 7.4793 & TRN & \\
\hline CHEMBL 3945374 & 1640706 & 8.3556 & 8.3574 & TRN & \\
\hline CHEMBL3970089 & 1640706 & 6.5719 & 6.3943 & TRN & \\
\hline CHEMBL 3890996 & 1640706 & 7.1175 & 7.5655 & TST & \\
\hline CHEMBL 3960287 & 1640706 & 8.3298 & 8.1137 & TRN & \\
\hline CHEMBL3902138 & 1640706 & 7.8894 & 7.7171 & TRN & \\
\hline CHEMBL 3921036 & 1640706 & 6.7423 & 6.6341 & TST & \\
\hline CHEMBL 3945607 & 1640706 & 7.6925 & 7.1921 & TST & \\
\hline CHEMBL3957907 & 1640706 & 8.1169 & \multicolumn{2}{|c|}{8.181000000000001} & TRN \\
\hline CHEMBL 3978127 & 1640706 & 7.9031 & 7.6915 & TRN & \\
\hline CHEMBL 3938830 & 1640706 & 7.8153 & 8.0278 & TRN & \\
\hline CHEMBL 3915585 & 1640706 & 6.9914 & 7.0952 & TRN & \\
\hline CHEMBL 3930411 & 1640706 & 8.1403 & 8.4671 & TRN & \\
\hline CHEMBL3952819 & 1640706 & 8.054 & 7.9175 & TRN & \\
\hline CHEMBL3907315 & 1640706 & 7.8069 & 7.5364 & TRN & \\
\hline CHEMBL 3898256 & 1640706 & 6.4089 & 7.1222 & TRN & \\
\hline CHEMBL 3908655 & 1640706 & 6.4789 & 7.0461 & TST & \\
\hline CHEMBL3892894 & 1640706 & 6.7447 & 6.4491 & TRN & \\
\hline
\end{tabular}


Supplemental Table S2.txt

\begin{tabular}{|c|c|c|c|c|c|}
\hline CHEMBL 3898086 & 1640706 & 6.7033 & 6.8417 & TRN & \\
\hline CHEMBL 3968760 & 1640706 & 7.4045 & \multicolumn{2}{|c|}{7.412999999999999} & TRN \\
\hline CHEMBL3908559 & 1640706 & 8.3098 & 8.2639 & TRN & \\
\hline CHEMBL 3986230 & 1640706 & 6.2596 & 7.2172 & TST & \\
\hline CHEMBL 3893168 & 1640706 & 7.8327 & 7.7574 & TRN & \\
\hline CHEMBL 3908228 & 1640706 & 8.0353 & 8.0175 & TRN & \\
\hline CHEMBL 3928738 & 1640706 & 7.1427 & 7.0408 & TRN & \\
\hline CHEMBL3952991 & 1640706 & 7.6326 & 7.9093 & TRN & \\
\hline CHEMBL 3918690 & 1640706 & 7.0706 & 8.3256 & TST & \\
\hline CHEMBL 3924037 & 1640706 & 8.015 & 8.2123 & TST & \\
\hline CHEMBL 3935645 & 1640706 & 7.7721 & 6.6169 & TST & \\
\hline CHEMBL 3901853 & 1640706 & 7.6498 & 7.7495 & TRN & \\
\hline CHEMBL 3982986 & 1640706 & 7.0443 & 7.1927 & TRN & \\
\hline CHEMBL3983359 & 1640706 & 7.644 & 7.4286 & TRN & \\
\hline CHEMBL 3940422 & 1640706 & 7.2588 & 7.3307 & TRN & \\
\hline CHEMBL 3942352 & 1640706 & 6.3706 & 6.7845 & TRN & \\
\hline CHEMBL 3912243 & 1640706 & \multicolumn{2}{|c|}{6.821000000000001} & 6.8982 & TRN \\
\hline CHEMBL 3979798 & 1640706 & 7.1746 & 7.4019 & TRN & \\
\hline CHEMBL3928887 & 1640706 & 7.6402 & 7.4531 & TRN & \\
\hline CHEMBL 3901247 & 1640706 & 8.2218 & \multicolumn{2}{|c|}{8.232999999999999} & TRN \\
\hline CHEMBL3907599 & 1640706 & 7.7375 & 7.7566 & TRN & \\
\hline CHEMBL 3955079 & 1640706 & 7.6198 & 7.9875 & TRN & \\
\hline CHEMBL 3959076 & 1640706 & 7.2062 & 7.4526 & TRN & \\
\hline CHEMBL3911663 & 1640706 & 7.2798 & 7.5442 & TRN & \\
\hline CHEMBL 3984809 & 1640706 & 8.055 & 7.9945 & TRN & \\
\hline CHEMBL 3974955 & 1640706 & 7.0526 & 7.0834 & TST & \\
\hline CHEMBL 3921304 & 1640706 & 7.2976 & 7.3079 & TRN & \\
\hline CHEMBL 3910761 & 1640706 & 6.6576 & 6.8167 & TRN & \\
\hline CHEMBL3948394 & 1640706 & 7.2314 & 7.4267 & TST & \\
\hline CHEMBL 3941661 & 1640706 & 8.3778 & 7.9826 & TRN & \\
\hline CHEMBL 3907002 & 1640706 & 7.2457 & 7.0171 & TRN & \\
\hline CHEMBL 3975808 & 1640706 & 8.025 & 8.0818 & TRN & \\
\hline CHEMBL3944602 & 1640706 & 8.4045 & 8.4787 & TRN & \\
\hline CHEMBL3891580 & 1640706 & 7.4389 & 7.3044 & TRN & \\
\hline CHEMBL 3906098 & 1640706 & \multicolumn{3}{|c|}{ 7.617999999999999 } & TRN \\
\hline CHEMBL 3895483 & 1640706 & 8.1931 & 8.1215 & TRN & \\
\hline CHEMBL3985472 & 1640706 & 7.3862 & 7.8626 & TRN & \\
\hline CHEMBL3941395 & 1640706 & 6.4949 & 6.4861 & TRN & \\
\hline CHEMBL 3963445 & 1640706 & 6.5317 & 6.7579 & TRN & \\
\hline CHEMBL 3933127 & 1640706 & 6.8477 & 6.2848 & TST & \\
\hline CHEMBL 3973373 & 1640706 & 7.2487 & 7.176 & TRN & \\
\hline CHEMBL 3969775 & 1640706 & 7.8386 & $7.82700 e$ & 0000000001 & TRN \\
\hline CHEMBL 3934362 & 1640706 & 6.699 & 6.5829 & TRN & \\
\hline CHEMBL 3954060 & 1640706 & 7.1494 & 7.2462 & TRN & \\
\hline CHEMBL 3957948 & 1640706 & 7.5171 & 7.5138 & TRN & \\
\hline CHEMBL 3901734 & 1640706 & 8.1512 & 8.3432 & TRN & \\
\hline CHEMBL 3890963 & 1640706 & 7.6003 & 7.5941 & TRN & \\
\hline CHEMBL 3916295 & 1640706 & 6.4283 & 6.9106 & TRN & \\
\hline
\end{tabular}


Supplemental Table S2.txt

\begin{tabular}{|c|c|c|c|c|c|}
\hline CHEMBL 3984025 & 1640706 & 6.8097 & 6.9551 & TRN & \\
\hline CHEMBL 3937180 & 1640706 & 7.6478 & 7.54200 & 0000000001 & TRN \\
\hline CHEMBL 3930974 & 1640706 & 7.8861 & 7.8591 & TRN & \\
\hline CHEMBL 3961504 & 1640706 & 7.3686 & 7.2532 & TRN & \\
\hline CHEMBL 3962500 & 1640706 & 6.9747 & 7.215 & TRN & \\
\hline CHEMBL 3922654 & 1640706 & 7.5952 & 7.2797 & TRN & \\
\hline CHEMBL 3977788 & 1640706 & 7.1824 & 7.3163 & TRN & \\
\hline CHEMBL 3983702 & 1640706 & 7.4685 & 7.9082 & TRN & \\
\hline CHEMBL 3932678 & 1640706 & 6.5258 & 6.5376 & TRN & \\
\hline CHEMBL 3957686 & 1640706 & 6.5436 & 6.7341 & TRN & \\
\hline CHEMBL 3984309 & 1640706 & 7.1952 & 7.1525 & TRN & \\
\hline CHEMBL 3959680 & 1640706 & 7.5072 & 7.478 & TRN & \\
\hline CHEMBL 3961266 & 1640706 & 7.7721 & 7.5766 & TRN & \\
\hline CHEMBL 3952975 & 1640706 & 7.58 & 7.3235 & TRN & \\
\hline CHEMBL 3939724 & 1640706 & 7.7167 & 7.7383 & TRN & \\
\hline CHEMBL 3913665 & 1640706 & 7.983 & 7.9388 & TRN & \\
\hline CHEMBL 3952165 & 1640706 & 7.7471 & 7.3438 & TRN & \\
\hline CHEMBL 3966570 & 1640706 & 7.3335 & 6.7899 & TST & \\
\hline CHEMBL 3940368 & 1640706 & 7.2248 & 7.146 & TRN & \\
\hline CHEMBL 3961288 & 1640706 & 6.5129 & 7.7672 & TST & \\
\hline CHEMBL 3973832 & 1640706 & 6.6198 & 6.5414 & TRN & \\
\hline CHEMBL 3953133 & 1640706 & 6.9626 & 6.768 & TRN & \\
\hline CHEMBL 3958676 & 1640706 & 7.3969 & \multicolumn{2}{|c|}{7.736000000000001} & \\
\hline CHEMBL 3931456 & 1640706 & 7.5045 & 8.0243 & TST & \\
\hline CHEMBL 3986520 & 1640706 & 6.9431 & 7.0478 & TRN & \\
\hline CHEMBL 3928569 & 1640706 & 6.684 & 6.6443 & TRN & \\
\hline CHEMBL 3962187 & 1640706 & 7.6635 & 7.8001 & TRN & \\
\hline CHEMBL 3907061 & 1640706 & 6.5622 & 6.4539 & TST & \\
\hline CHEMBL 3971237 & 1640706 & 6.9469 & 7.0162 & TRN & \\
\hline CHEMBL 3950368 & 1640706 & 8.3675 & 7.4718 & TST & \\
\hline CHEMBL 3972291 & 1640706 & 7.4559 & 6.6393 & TST & \\
\hline CHEMBL 3901263 & 1640706 & 8.0453 & 8.089 & TRN & \\
\hline CHEMBL 3982290 & 1640706 & 7.3799 & 7.3855 & TRN & \\
\hline CHEMBL 3976726 & 1640706 & 8.0287 & 7.6961 & TRN & \\
\hline CHEMBL 3945936 & 1640706 & 7.9914 & 7.6936 & TST & \\
\hline CHEMBL 3960174 & 1640706 & 6.3716 & 6.4749 & TRN & \\
\hline CHEMBL 3903137 & 1640706 & 6.4547 & 6.5487 & TST & \\
\hline CHEMBL 3972816 & 1640706 & 8.1232 & 7.8051 & TRN & \\
\hline CHEMBL 3940164 & 1640706 & \multicolumn{3}{|c|}{6.4510000000000005} & \\
\hline CHEMBL 3942788 & 1640706 & 7.1463 & 7.3988 & TRN & \\
\hline CHEMBL 3920593 & 1640706 & 7.0742 & 7.4576 & TRN & \\
\hline CHEMBL 3910783 & 1640706 & 6.6861 & 7.78600 & 00000000005 & 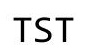 \\
\hline CHEMBL 3917599 & 1640706 & 7.0737 & 7.0428 & TRN & \\
\hline CHEMBL 3931045 & 1640706 & 7.5157 & 7.5087 & TRN & \\
\hline CHEMBL 3955433 & 1640706 & 6.8697 & 6.6877 & TST & \\
\hline CHEMBL 3902470 & 1640706 & 6.9208 & 7.0295 & TRN & \\
\hline CHEMBL 3980784 & 1640706 & 6.8013 & 6.6524 & TRN & \\
\hline CHEMBL 3950144 & 1640706 & 7.2604 & 7.3363 & TRN & \\
\hline
\end{tabular}

Page 15912 
Supplemental Table S2.txt

\begin{tabular}{|c|c|c|c|c|}
\hline CHEMBL3969275 & 1640706 & 7.0783 & 6.9156 & TST \\
\hline CHEMBL3916578 & 1640706 & 6.8601 & 8.0836 & TST \\
\hline CHEMBL 3892692 & 1640706 & 6.7852 & 7.8794 & TST \\
\hline CHEMBL 3899817 & 1640706 & 7.5287 & 7.2344 & TST \\
\hline CHEMBL3918531 & 1640706 & 6.7258 & 6.651 & TST \\
\hline CHEMBL 3985184 & 1640706 & 7.6596 & 7.4142 & TST \\
\hline CHEMBL3977857 & 1640706 & 7.2848 & 7.9216 & TST \\
\hline CHEMBL 3971198 & 1640706 & 6.8477 & 6.8548 & TST \\
\hline CHEMBL 3970196 & 1640706 & 6.6517 & 7.7485 & TST \\
\hline CHEMBL 3985583 & 1640706 & 7.9747 & 7.6134 & TST \\
\hline CHEMBL 3946967 & 1640706 & 7.1273 & 8.0802 & TST \\
\hline CHEMBL3929804 & 1640706 & 8.0851 & 8.0288 & TST \\
\hline CHEMBL3978845 & 1640706 & 7.9469 & 8.2368 & TST \\
\hline CHEMBL 3958212 & 1640706 & 6.3625 & 7.3983 & TST \\
\hline CHEMBL 3978405 & 1640706 & 7.3665 & 7.62799 & 9999999999 \\
\hline CHEMBL3923729 & 1640706 & 6.4413 & 7.308 & TST \\
\hline CHEMBL 3930908 & 1640706 & 7.9281 & 7.5191 & TST \\
\hline CHEMBL3908456 & 1640706 & 7.7447 & 7.1119 & TST \\
\hline CHEMBL 3972540 & 1641802 & 6.0 & 6.0384 & TRN \\
\hline CHEMBL3892343 & 1641802 & 6.9698 & 6.019 & TRN \\
\hline CHEMBL 3966580 & 1641802 & 6.0 & 6.1104 & TRN \\
\hline CHEMBL 3961473 & 1641802 & 6.0 & 6.0096 & TRN \\
\hline CHEMBL 3897670 & 1641802 & 6.6517 & 6.2167 & TRN \\
\hline CHEMBL3909336 & 1641802 & 6.0 & 6.7179 & TRN \\
\hline CHEMBL3906674 & 1641802 & 6.36 & 6.1377 & TRN \\
\hline CHEMBL 3950859 & 1641802 & 6.0 & 6.0014 & TRN \\
\hline CHEMBL 3898235 & 1641802 & 8.0655 & 6.3233 & TRN \\
\hline CHEMBL3958148 & 1641802 & 6.0 & 6.2511 & TRN \\
\hline CHEMBL3940118 & 1641802 & 6.0 & 6.8018 & TRN \\
\hline CHEMBL 3897882 & 1641802 & 6.0 & 6.2683 & TST \\
\hline CHEMBL 3930799 & 1641802 & 6.8545 & 7.1883 & TRN \\
\hline CHEMBL 3962000 & 1641802 & 7.1024 & 8.0032 & TRN \\
\hline CHEMBL3895163 & 1641802 & 6.0 & 6.6015 & TRN \\
\hline CHEMBL 3961327 & 1641802 & 6.0 & 5.9571 & TRN \\
\hline CHEMBL 3933767 & 1641802 & 6.0 & 6.1061 & TRN \\
\hline CHEMBL3899466 & 1641802 & 7.5421 & 6.4529 & TST \\
\hline CHEMBL3955928 & 1641802 & 6.0 & 6.1005 & TRN \\
\hline CHEMBL 3905143 & 1641802 & 7.9508 & 6.6019 & TST \\
\hline CHEMBL 3969766 & 1641802 & 6.3287 & 6.5334 & TRN \\
\hline CHEMBL3981755 & 1641802 & 6.0 & 6.2317 & TST \\
\hline CHEMBL 3902937 & 1641802 & 6.0 & 6.7154 & TRN \\
\hline CHEMBL3939812 & 1641802 & 7.4698 & 7.2957 & TRN \\
\hline CHEMBL3956816 & 1641802 & 6.0 & 6.2098 & TRN \\
\hline CHEMBL3972747 & 1641802 & 7.0048 & 6.1614 & TST \\
\hline CHEMBL 3937624 & 1641802 & 6.0 & 6.2329 & TST \\
\hline CHEMBL 3968834 & 1641802 & 6.0 & 6.1922 & TRN \\
\hline CHEMBL 3964495 & 1641802 & 6.0 & \multicolumn{2}{|c|}{7.5120000000000005} \\
\hline CHEMBL3961909 & 1641802 & 7.7011 & 7.171 & TRN \\
\hline
\end{tabular}


Supplemental Table S2.txt

\begin{tabular}{|c|c|c|c|}
\hline HEMBL3931306 & 1641802 & 8.699 & 7.5648 \\
\hline CHEMBL 3940223 & 1641802 & 6.2421 & 6.6299 \\
\hline HEMBL3965296 & 1641802 & 6.7854 & 9998 \\
\hline CHEMBL 3953996 & 1641802 & 6.0 & 6.0742 \\
\hline HEMBL3919697 & 1641802 & 6.2754 & 6.7284 \\
\hline CHEMBL3978893 & 1641802 & 6.0 & 6.1533 \\
\hline HEMBL3946705 & 1641802 & 6.0 & 6.5006 \\
\hline HEMBL3912734 & 1641802 & 6.0 & \\
\hline HEMBL3908283 & 1641802 & 7.9172 & 7.5062 \\
\hline HEMBL3943288 & 1641802 & 6.0 & 6.1633 \\
\hline CHEMBL3949403 & 1641802 & 7.4711 & 6.7303 \\
\hline HEMBL3892270 & 1641802 & 6.0 & 6.1327 \\
\hline CHEMBL 3953874 & 1641802 & 8.0506 & \\
\hline HEMBL3926168 & 1641802 & 6.0 & 6.7985 \\
\hline HEMBL3962541 & 1641802 & 6.3518 & 6.0897 \\
\hline CHEMBL3980771 & 1641802 & 6.0 & 6.3951 \\
\hline HEMBL3953795 & 164 & 7.4921 & 6. \\
\hline HEMBL 394 & 164 & 6.0 & \\
\hline HEMBL3959940 & 1641802 & 6.0 & 6.6612 \\
\hline HEMBL3895209 & 164 & 7.7595 & \\
\hline HEMBL397 & 164 & 6.5214 & 6 . \\
\hline HEMBL3938688 & 164 & 6.4781 & 7. \\
\hline CHEMBL3919295 & 164 & 7.063 & 6. \\
\hline HEMBL3932806 & 1641802 & 6.0 & \\
\hline HEMBL3955327 & 164 & 6.0 & 6.7 \\
\hline CHEMBL3981329 & 164 & 6.0 & 6 . \\
\hline CHEMBL 39 & 164 & 6.0 & 6 . \\
\hline CHEMBL3967429 & 164 & 6.0 & 6. \\
\hline HEMBL3981341 & 1641802 & 6.0 & 6.6 \\
\hline CHEMBL 3974317 & 1641802 & 6.0 & 6.2 \\
\hline CHEMBL3931556 & 1641802 & 6.4113 & 6 . \\
\hline CHEMBL39 & 164 & 6 & 6. \\
\hline CHEMBL 3896237 & 164 & 7.4295 & 6. \\
\hline CHEMBL3967467 & 1641802 & 7.8447 & 6.5 \\
\hline CHEMBL 3980401 & 1641802 & 7.129 & 6.4694 \\
\hline CHEMBL397 & 164 & 6.52 & 74 \\
\hline CHEMBL397 & 164 & 7.6757 & 7.4 \\
\hline CHEMBL3899662 & 1641802 & 6.4471 & 6.1644 \\
\hline CHEMBL 3926157 & 1641802 & 6.0282 & 6.3252 \\
\hline CHEMBL 3920184 & 1641802 & 6.0 & 6.5644 \\
\hline CHEMBL3928311 & 1641802 & 6.0 & 6.1917 \\
\hline CHEMBL3949834 & 1641802 & 6.0 & 6.1057 \\
\hline CHEMBL3965872 & 1641802 & 7.1124 & 7.0551 \\
\hline CHEMBL 3977519 & 1641802 & 6.0 & 6.0186 \\
\hline CHEMBL 3940581 & 1641802 & 6.7918 & 6.2321 \\
\hline CHEMBL 3946625 & 1641802 & 6.0 & 5.8682 \\
\hline CHEMBL3929676 & 1641802 & 8.6576 & 8.0979 \\
\hline CHEMBL3972804 & 1641802 & 6.5787 & 6.9517 \\
\hline
\end{tabular}

Page 15914 
Supplemental Table S2.txt

\begin{tabular}{|c|c|c|c|c|}
\hline HEMBL3955924 & 641802 & 6.2889 & 6.1546 & TRN \\
\hline HEMBL3941282 & 641802 & 6.0 & 6.7327 & TRN \\
\hline HEMBL 3905191 & 302 & 7.9706 & 9232 & {$[\mathrm{RNN}$} \\
\hline HEMBL3987195 & 641802 & 6.0 & 9962 & DN \\
\hline HEMBL3894043 & 641802 & 6.0 & 5224 & ST \\
\hline HEMBL3911543 & 641802 & 6.0 & .5261 & \\
\hline HEMBL3986755 & 641802 & 7.8125 & .074 & \\
\hline AEMBL3897929 & 641802 & 6.0 & .4269 & ST \\
\hline HEMBL3903421 & 1641802 & 7.1273 & .2672 & ST \\
\hline HEMBL3917238 & 641802 & 7.6799 & 7.4833 & TRN \\
\hline HEMBL 3948286 & 802 & 6.0 & .1447 & \\
\hline HEMBL3939944 & 802 & 7.8416 & 7.0491 & \\
\hline HEMBL3917393 & 802 & 6.0 & 6.5128 & \\
\hline HEMBL3986707 & 802 & 6.0 & 1387 & \\
\hline HEMBL3973903 & 802 & 7.2472 & 1603 & \\
\hline HEMBL3980823 & 302 & 7.2161 & 6.8806 & \\
\hline HEMBL3934404 & 302 & 7.8125 & 7.5805 & KIN \\
\hline HEMBL3924926 & 302 & 6.7144 & 6.1057 & \\
\hline HEMBL3972348 & 302 & 6.1526 & 6.3255 & RN \\
\hline HEMBL3912433 & 302 & 7.5331 & & 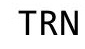 \\
\hline HEMBL3963721 & 302 & 6.0 & 5433 & 151 \\
\hline HEMBL39 & 302 & 7.3478 & 759 & RN \\
\hline HEMBL 26 & 42 & 4.9101 & 186 & RN \\
\hline HEMBL 354765 & 42 & 5.1871 & 1942 & $\Gamma \mathrm{RN}$ \\
\hline HEMBL 352423 & 42 & 5.2076 & & 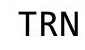 \\
\hline HEMBL44e & 42 & 5.0605 & 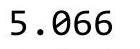 & RN \\
\hline HEMBL35 & 42 & 6. & 529 & RN \\
\hline HEMBL16 & 42 & 315 & 506 & 「RN \\
\hline HEMBL169773 & 42 & 778 & 5846 & IR \\
\hline HEMBL 352540 & 42 & 4.2676 & 306 & $\mathrm{IR}$ \\
\hline HEMBL16ऽ & 42 & 5.2596 & 562 & RN \\
\hline HEMBL4 & 42 & 547 & 07 & ST \\
\hline HEMBL1 & 42 & 14 & 688 & 「RN \\
\hline HEMBL443037 & 426 & 4.6459 & 3194 & is \\
\hline HEMBL 352413 & 426 & 5.1871 & 5.1661 & TST \\
\hline HEMBL408162 & $42 \epsilon$ & 3.6198 & 5863 & TRN \\
\hline HEMBL 3 & & 36 & 192 & TRN \\
\hline HEMBL169 & & 5.1487 & 331 & TST \\
\hline HEMBL168487 & 426 & 5.1079 & 5.1689 & TST \\
\hline HEMBL169678 & $42 \epsilon$ & 5.9586 & 5.7807 & TST \\
\hline HEMBL353437 & 426 & 5.6021 & 6088 & TRN \\
\hline CHEMBL353498 & & 6.3872 & 5.3682 & TRN \\
\hline CHEMBL352691 & 426 & 5.4202 & 5.4411 & TRN \\
\hline HEMBL355324 & 426 & 5.7959 & 5.8429 & TRN \\
\hline EMBL167 & $42 \epsilon$ & 4.7496 & & ISI \\
\hline CHEMBL172395 & & .9136 & 9085 & \\
\hline CHEMBL354630 & 42682 & 6.2076 & 1982 & \\
\hline CHEMBL355016 & 42682 & 5.1612 & 5.3402 & TST \\
\hline
\end{tabular}

Page 15915 


\begin{tabular}{|c|c|c|c|c|c|}
\hline \multicolumn{6}{|c|}{ Supplemental Table S2.txt } \\
\hline CHEMBL441495 & 42682 & 5.5528 & 5.5583 & TRN & \\
\hline CHEMBL 264845 & 42682 & 5.4202 & 5.4447 & TRN & \\
\hline CHEMBL353646 & 42682 & 6.4815 & 6.4253 & TRN & \\
\hline CHEMBL354032 & 42682 & 5.7212 & 5.7188 & TRN & \\
\hline CHEMBL 279627 & 42682 & 6.0 & 5.8835 & TRN & \\
\hline CHEMBL353730 & 42682 & 5.7959 & 5.7171 & TRN & \\
\hline CHEMBL171114 & 42682 & 5.5528 & 5.534 & TRN & \\
\hline CHEMBL168853 & 42682 & 4.8928 & 4.9063 & TST & \\
\hline CHEMBL169224 & 42682 & 6.0 & 6.0172 & TRN & \\
\hline CHEMBL168225 & 42682 & 5.7212 & 5.6648 & TRN & \\
\hline CHEMBL262491 & 42682 & 4.1079 & 4.08899 & 99999999995 & TRN \\
\hline CHEMBL433537 & 42682 & 5.6778 & 5.6021 & TRN & \\
\hline CHEMBL169762 & 42682 & 4.9957 & 4.9269 & TRN & \\
\hline CHEMBL172036 & 42682 & 5.3098 & 5.2875 & TRN & \\
\hline CHEMBL168996 & 42682 & 4.8601 & 5.0094 & TST & \\
\hline CHEMBL169755 & 42682 & 5.0177 & 4.6083 & TST & \\
\hline CHEMBL354684 & 42682 & 5.3768 & 5.3358 & TRN & \\
\hline CHEMBL169673 & 42682 & 5.4949 & 5.3105 & TST & \\
\hline CHEMBL355890 & 42682 & 5.6198 & 5.6379 & TRN & \\
\hline CHEMBL168937 & 42682 & 4.8996 & 5.5784 & TST & \\
\hline CHEMBL355871 & 42682 & 5.8239 & 5.7621 & TRN & \\
\hline CHEMBL168321 & 42682 & 5.7959 & 5.8374 & TRN & \\
\hline CHEMBL169529 & 42682 & 5.2076 & 4.9968 & TRN & \\
\hline CHEMBL352352 & 42682 & 5.3665 & 5.3679 & TRN & \\
\hline CHEMBL168527 & 42682 & 5.7959 & 5.7972 & TRN & \\
\hline CHEMBL169630 & 42682 & 6.4815 & 6.4734 & TRN & \\
\hline CHEMBL353114 & 42682 & 5.3768 & 5.3298 & TRN & \\
\hline CHEMBL168495 & 42682 & 5.5376 & 5.4283 & TRN & \\
\hline CHEMBL352360 & 42682 & 4.9136 & 4.9273 & TRN & \\
\hline CHEMBL424547 & 42682 & 5.4685 & 5.4934 & TRN & \\
\hline CHEMBL352692 & 42682 & 5.3372 & 5.4118 & TRN & \\
\hline CHEMBL354943 & 42682 & 5.6383 & 5.801 & TRN & \\
\hline CHEMBL422909 & 42682 & 4.4202 & 4.283 & TST & \\
\hline CHEMBL169563 & 42682 & 5.1192 & 5.0967 & TST & \\
\hline CHEMBL 368730 & 42682 & 5.585 & 5.6019 & TRN & \\
\hline CHEMBL355549 & 42682 & 5.3768 & 5.3797 & TRN & \\
\hline CHEMBL418037 & 42682 & 6.0706 & 5.9999 & TRN & \\
\hline CHEMBL354052 & 42682 & 6.1427 & 6.1446 & TRN & \\
\hline CHEMBL355181 & 42682 & 5.699 & 5.6857 & TRN & \\
\hline CHEMBL 353103 & 42682 & 5.0555 & 4.6893 & TST & \\
\hline CHEMBL172615 & 42682 & 5.699 & 5.6974 & TST & \\
\hline CHEMBL170951 & 42682 & 5.8239 & 5.9038 & TRN & \\
\hline CHEMBL353817 & 42682 & 5.5376 & 5.5451 & TRN & \\
\hline CHEMBL169404 & 42682 & 5.4202 & 5.5399 & TRN & \\
\hline CHEMBL169942 & 42682 & 5.0362 & 5.7269 & TST & \\
\hline CHEMBL1494188 & 737622 & 4.5654 & 3.8254 & TRN & \\
\hline CHEMBL1320575 & 737622 & 4.262 & 4.0272 & TRN & \\
\hline CHEMBL3198224 & 737622 & 3.0969 & 4.0456 & TRN & \\
\hline
\end{tabular}

Page 15916 


\begin{tabular}{|c|c|c|c|c|}
\hline \multicolumn{5}{|c|}{ Supplemental Table S2.txt } \\
\hline CHEMBL1456075 & 737622 & 3.0969 & 4.2889 & TRN \\
\hline CHEMBL1608402 & 737622 & 5.1506 & 4.4304 & TRN \\
\hline CHEMBL1333858 & 737622 & 3.0969 & 4.5988 & TRN \\
\hline CHEMBL1334041 & 737622 & 3.0969 & 3.5144 & TST \\
\hline CHEMBL1544054 & 737622 & 3.0969 & 3.5124 & TRN \\
\hline CHEMBL1428662 & 737622 & 3.0969 & 5.1201 & TRN \\
\hline CHEMBL1403324 & 737622 & 5.7545 & 4.9625 & TRN \\
\hline CHEMBL1721523 & 737622 & 4.3279 & 4.1286 & TRN \\
\hline CHEMBL1704298 & 737622 & 3.0969 & 4.4685 & TRN \\
\hline CHEMBL1300952 & 737622 & 5.9747 & 5.029 & TRN \\
\hline CHEMBL1727813 & 737622 & 3.0969 & 3.5184 & TST \\
\hline CHEMBL1344784 & 737622 & 3.0969 & 3.3561 & TRN \\
\hline CHEMBL1597161 & 737622 & 4.9393 & 3.3612 & TRN \\
\hline CHEMBL1553841 & 737622 & 3.0969 & 3.4445 & TRN \\
\hline CHEMBL1612757 & 737622 & 3.0969 & 3.6146 & TRN \\
\hline CHEMBL1582024 & 737622 & 3.0969 & 4.0729 & TRN \\
\hline CHEMBL1730563 & 737622 & 4.9281 & 4.4548 & TST \\
\hline CHEMBL1602481 & 737622 & 3.0969 & 3.2509 & TRN \\
\hline CHEMBL1528660 & 737622 & 6.6198 & 5.1616 & TRN \\
\hline CHEMBL1890899 & 737622 & 4.6799 & 5.1508 & TRN \\
\hline CHEMBL1568851 & 737622 & 5.1355 & 3.6922 & TRN \\
\hline CHEMBL1411133 & 737622 & 4.2255 & 4.1551 & TRN \\
\hline CHEMBL1596277 & 737622 & 3.0969 & 3.5935 & TST \\
\hline CHEMBL1507572 & 737622 & 3.0969 & 3.3342 & TRN \\
\hline CHEMBL1716010 & 737622 & 4.4461 & 3.9693 & TST \\
\hline CHEMBL1541316 & 737622 & 4.6126 & 4.5753 & TRN \\
\hline CHEMBL1305586 & 737622 & 3.0969 & 3.4131 & TRN \\
\hline CHEMBL1552306 & 737622 & 3.0969 & 4.1491 & TRN \\
\hline CHEMBL1572520 & 737622 & 3.0969 & 3.5807 & TRN \\
\hline CHEMBL1494391 & 737622 & 3.0969 & 3.3968 & TRN \\
\hline CHEMBL3212183 & 737622 & 3.0969 & 3.5419 & TRN \\
\hline CHEMBL 3190420 & 737622 & 3.0969 & 3.6596 & TRN \\
\hline CHEMBL1397386 & 737622 & 4.4413 & 4.0555 & TST \\
\hline CHEMBL1387015 & 737622 & 3.0969 & 4.0438 & TRN \\
\hline CHEMBL1733981 & 737622 & 3.0969 & 3.3502 & TRN \\
\hline CHEMBL1369231 & 737622 & 6.3372 & 4.7967 & TRN \\
\hline CHEMBL1424292 & 737622 & 3.0969 & 3.3915 & TRN \\
\hline CHEMBL1467489 & 737622 & 3.0969 & 3.4552 & TRN \\
\hline CHEMBL1399076 & 737622 & 3.0969 & 3.1948 & TRN \\
\hline CHEMBL1589649 & 737622 & 4.4389 & 4.0135 & TRN \\
\hline CHEMBL1313532 & 737622 & 3.0969 & 3.2169 & TRN \\
\hline CHEMBL77705 & 737622 & 3.0969 & 3.3167 & TST \\
\hline CHEMBL1607086 & 737622 & 5.7328 & 5.4369 & TRN \\
\hline CHEMBL1299637 & 737622 & 5.9469 & 6.313 & TRN \\
\hline CHEMBL1412180 & 737622 & 3.0969 & 3.6268 & TST \\
\hline CHEMBL1347158 & 737622 & 3.0969 & 3.5697 & TRN \\
\hline CHEMBL1578168 & 737622 & 3.0969 & 3.575 & TST \\
\hline CHEMBL1370849 & 737622 & 5.2774 & 4.4975 & TRN \\
\hline
\end{tabular}


Supplemental Table S2.txt

\begin{tabular}{|c|c|c|c|c|}
\hline . & & & & \\
\hline HEMBL1327993 & 37622 & 969 & 661 & \\
\hline AEMBL1561496 & 7622 & 482 & 523 & \\
\hline AEMBL14 & 7622 & & & \\
\hline IEMBL1473114 & 37622 & 69 & & \\
\hline AEMBL1471715 & 37622 & 969 & 986 & \\
\hline AEMBL3197976 & 37622 & 969 & 5129 & \\
\hline HEMBL1432867 & & & & \\
\hline AEMBL1533857 & 37622 & & & \\
\hline AEMBL191750 & 37622 & & & \\
\hline AEMBL1498980 & 37622 & 4.2097 & 4222 & \\
\hline HEMBL1348824 & 37622 & 969 & .2168 & \\
\hline AEMBL1348010 & 22 & & 32 & \\
\hline AEMBL1321043 & 37622 & & 81 & \\
\hline AEMBL1705361 & 22 & & & \\
\hline AEMBL3210100 & 37622 & 69 & 62 & \\
\hline AEMBL1469676 & 37622 & & & \\
\hline AEMBL1583137 & 2 & & & \\
\hline AEMBL16 & 22 & & & \\
\hline HEMBL173 & 2 & & & \\
\hline AEMBL1471436 & 22 & 81 & & \\
\hline AEMBL1405953 & & & & \\
\hline AEMBL1539923 & 2 & & & \\
\hline HEMBL130 & 2 & & & \\
\hline AEMBL 32 & & & & \\
\hline AEMBL1384841 & 2 & & & \\
\hline AEMBL1302442 & 22 & & & \\
\hline IEMBL1613126 & 2 & & & \\
\hline AFMBI 15 & 2 & & & \\
\hline 908 & 2 & 99 & & \\
\hline AEMBL1541251 & 2 & & & \\
\hline AEMBL3195661 & 22 & & & \\
\hline 348 & & & & \\
\hline 46 & 2 & & & \\
\hline HEMBL1547825 & & & & 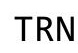 \\
\hline HEMBL1443643 & 37622 & & & $\mathrm{RI}$ \\
\hline AEMBL1610300 & 37622 & & & \\
\hline & 2 & & 52 & \\
\hline 711 & 2 & & 15 & \\
\hline HEMBL1388599 & 37622 & & & RN \\
\hline AEMBL1707441 & 37622 & & 913 & $S$ \\
\hline HEMBL 145 & 37622 & & 955 & $S$ \\
\hline HEIMGL $13 \angle 0 S 14$ & 376 & & 3094 & \\
\hline CHEMBL1478292 & & & & \\
\hline AEMBL1420469 & 37622 & & 3.8273 & RN \\
\hline AEMBL1461141 & 37622 & 4. & 5208 & $\mathrm{R}$ \\
\hline EMBL1431151 & & & & \\
\hline HEMBL153454 & & & & \\
\hline
\end{tabular}

Page 15918 
Supplemental Table S2.txt

\begin{tabular}{|c|c|c|c|c|c|c|}
\hline CHEMBL3197447 & 737622 & 3.0969 & 3.4983 & TRN & & \\
\hline CHEMBL1364853 & 737622 & 5.3072 & 3.5484 & TRN & & \\
\hline CHEMBL1504183 & 737622 & 3.0969 & 3.3102 & TST & & \\
\hline CHEMBL1409822 & 737622 & 6.0506 & 5.1575 & TRN & & \\
\hline CHEMBL1521793 & 737622 & 6.4089 & 4.5684 & TRN & & \\
\hline CHEMBL1352723 & 737622 & 3.0969 & 3.5096 & TRN & & \\
\hline CHEMBL3197039 & 737622 & \multicolumn{3}{|c|}{4.1530000000000005} & 4.8457 & TRN \\
\hline CHEMBL514760 & 737622 & 3.0969 & 3.3816 & TRN & & \\
\hline CHEMBL1371504 & 737622 & 3.0969 & 3.9871 & TRN & & \\
\hline CHEMBL1371372 & 737622 & 3.0969 & 3.4046 & TRN & & \\
\hline CHEMBL1469670 & 737622 & 6.1367 & 5.0934 & TRN & & \\
\hline CHEMBL1378086 & 737622 & 3.0969 & 4.8139 & TRN & & \\
\hline CHEMBL1452159 & 737622 & 6.1192 & 5.4413 & TRN & & \\
\hline CHEMBL1730195 & 737622 & 3.0969 & 3.3394 & TRN & & \\
\hline CHEMBL1604602 & 737622 & 3.0969 & 3.4329 & TRN & & \\
\hline CHEMBL3198534 & 737622 & 3.0969 & 4.6699 & TRN & & \\
\hline CHEMBL117804 & 737622 & 4.1925 & 4.164 & TST & & \\
\hline CHEMBL1996630 & 737622 & 3.0969 & 3.4463 & TRN & & \\
\hline CHEMBL1424269 & 737622 & 4.2628 & 4.4423 & TRN & & \\
\hline CHEMBL1360938 & 737622 & 4.1373 & 3.4009 & TRN & & \\
\hline CHEMBL1596384 & 737622 & 3.0969 & 3.4966 & TRN & & \\
\hline CHEMBL1519480 & 737622 & 3.0969 & 4.6065 & TRN & & \\
\hline CHEMBL1412855 & 737622 & 5.2306 & 4.5597 & TRN & & \\
\hline CHEMBL3207905 & 737622 & 3.0969 & 4.7522 & TRN & & \\
\hline CHEMBL1347156 & 737622 & 5.0773 & 4.0576 & TRN & & \\
\hline CHEMBL1456623 & 737622 & 5.5391 & 4.6443 & TST & & \\
\hline CHEMBL1409494 & 737622 & 4.3979 & 3.4664 & TRN & & \\
\hline CHEMBL1363955 & 737622 & 5.38299 & 99999999 & 9 & 4.178 & Tr \\
\hline CHEMBL1730681 & 737622 & 4.5045 & 4.2103 & TST & & \\
\hline CHEMBL1584403 & 737622 & 3.0969 & 3.1986 & TRN & & \\
\hline CHEMBL3189935 & 737622 & 3.0969 & 5.0598 & TRN & & \\
\hline CHEMBL1407064 & 737622 & 3.0969 & 3.4592 & TRN & & \\
\hline CHEMBL1430579 & 737622 & 3.0969 & 4.9394 & TRN & & \\
\hline CHEMBL1598762 & 737622 & 3.0969 & 3.5429 & TRN & & \\
\hline CHEMBL1464197 & 737622 & 3.0969 & 4.2894 & TST & & \\
\hline CHEMBL1349387 & 737622 & 5.3179 & 4.409 & TRN & & \\
\hline CHEMBL1698398 & 737622 & 4.6904 & 4.5588 & TRN & & \\
\hline CHEMBL1497097 & 737622 & 3.0969 & 3.4156 & TRN & & \\
\hline CHEMBL1366394 & 737622 & 3.0969 & 3.391 & TRN & & \\
\hline CHEMBL1313816 & 737622 & 3.0969 & 3.6896 & TRN & & \\
\hline CHEMBL1419661 & 737622 & 5.3915 & 4.3393 & TRN & & \\
\hline CHEMBL3208118 & 737622 & 4.644 & 4.1096 & TRN & & \\
\hline CHEMBL1529883 & 737622 & 3.0969 & 3.4881 & TRN & & \\
\hline CHEMBL1311956 & 737622 & 3.0969 & 4.2225 & TRN & & \\
\hline CHEMBL414840 & 737622 & 3.0969 & 4.4319 & TRN & & \\
\hline CHEMBL1572139 & 737622 & 3.0969 & 4.3918 & TRN & & \\
\hline CHEMBL1486981 & 737622 & 5.284 & 4.4801 & TRN & & \\
\hline CHEMBL1542780 & 737622 & 3.0969 & 3.5161 & TRN & & \\
\hline
\end{tabular}


Supplemental Table S2.txt

\begin{tabular}{|c|c|c|c|c|c|}
\hline CHEMBL1413363 & 737622 & 4.9318 & 4.6757 & TRN & \\
\hline CHEMBL1436569 & 737622 & 3.0969 & 4.6402 & TRN & \\
\hline CHEMBL1318556 & 737622 & 4.7447 & 4.4098 & TRN & \\
\hline CHEMBL1326942 & 737622 & 3.0969 & 4.5595 & TRN & \\
\hline CHEMBL1423158 & 737622 & 3.0969 & 3.5972 & TRN & \\
\hline CHEMBL1496891 & 737622 & 3.0969 & 6.355 & TRN & \\
\hline CHEMBL1313238 & 737622 & 5.8356 & 4.5095 & TRN & \\
\hline CHEMBL1377943 & 737622 & 3.0969 & 4.4446 & TRN & \\
\hline CHEMBL1377924 & 737622 & 5.7545 & 4.7855 & TRN & \\
\hline CHEMBL1965654 & 737622 & 6.6819 & 5.3126 & TST & \\
\hline CHEMBL1574176 & 737622 & 3.0969 & 4.0397 & TRN & \\
\hline CHEMBL1518647 & 737622 & 5.2204 & 4.3413 & TRN & \\
\hline CHEMBL1521435 & 737622 & 3.0969 & 3.4457 & TRN & \\
\hline CHEMBL1328161 & 737622 & 5.5376 & 4.6613 & TRN & \\
\hline CHEMBL1509078 & 737622 & 5.0752 & 4.5889 & TRN & \\
\hline CHEMBL607309 & 737622 & 4.3002 & 3.8319 & TRN & \\
\hline CHEMBL1321343 & 737622 & 3.0969 & 3.5532 & TST & \\
\hline CHEMBL1699107 & 737622 & 3.0969 & 4.6987 & TRN & \\
\hline CHEMBL512578 & 737622 & 3.0969 & 3.5664 & TST & \\
\hline CHEMBL 2003998 & 737622 & 3.0969 & 4.4496 & TRN & \\
\hline CHEMBL1576870 & 737622 & 7.7959 & 6.0519 & TRN & \\
\hline CHEMBL3189918 & 737622 & 4.4498 & 4.3288 & TRN & \\
\hline CHEMBL582030 & 737622 & 4.7905 & 4.0581 & TRN & \\
\hline CHEMBL1341261 & 737622 & 4.1481 & 3.50399 & & TRN \\
\hline CHEMBL1490470 & 737622 & 4.8297 & 5.8784 & TRN & \\
\hline CHEMBL1484886 & 737622 & 3.0969 & 3.675 & TRN & \\
\hline CHEMBL1438842 & 737622 & 3.0969 & 5.478 & TRN & \\
\hline CHEMBL1564224 & 737622 & 5.064 & 4.6608 & TRN & \\
\hline CHEMBL1477125 & 737622 & 3.0969 & 3.477 & TRN & \\
\hline CHEMBL1393156 & 737622 & 6.284 & 5.3448 & TRN & \\
\hline CHEMBL1313520 & 737622 & 7.7959 & 6.2815 & TRN & \\
\hline CHEMBL1542873 & 737622 & 5.2055 & 3.9603 & TRN & \\
\hline CHEMBL1324718 & 737622 & 3.0969 & 3.384 & TRN & \\
\hline CHEMBL1518428 & 737622 & 4.5867 & 4.3051 & TRN & \\
\hline CHEMBL1538560 & 737622 & 3.0969 & 3.4445 & TRN & \\
\hline CHEMBL3190354 & 737622 & 3.0969 & 3.5251 & TST & \\
\hline CHEMBL1446437 & 737622 & 5.8297 & 4.7642 & TRN & \\
\hline CHEMBL1386431 & 737622 & 4.9208 & 4.1284 & TRN & \\
\hline CHEMBL1520650 & 737622 & 5.8861 & 4.3906 & TRN & \\
\hline CHEMBL1304776 & 737622 & 3.0969 & 3.6111 & TRN & \\
\hline CHEMBL1587181 & 737622 & 5.8962 & 4.9304 & TST & \\
\hline CHEMBL1372555 & 737622 & 3.0969 & 4.2175 & TRN & \\
\hline CHEMBL1455409 & 737622 & 4.752 & 4.4455 & TRN & \\
\hline CHEMBL1525213 & 737622 & 3.0969 & 3.9209 & TRN & \\
\hline CHEMBL1485824 & 737622 & 3.0969 & 4.461 & TRN & \\
\hline CHEMBL1454384 & 737622 & 3.0969 & 3.6203 & TRN & \\
\hline CHEMBL1470315 & 737622 & 3.0969 & 3.9558 & TRN & \\
\hline CHEMBL1611371 & 737622 & 5.8477 & 4.6932 & TST & \\
\hline
\end{tabular}




\begin{tabular}{|c|c|c|c|c|c|}
\hline \multirow[b]{2}{*}{ CHEMBL1389966 } & \multicolumn{5}{|c|}{ Supplemental Table S2.txt } \\
\hline & 737622 & 5.1811 & 3.6342 & TRN & \\
\hline CHEMBL1506962 & 737622 & 4.684 & 3.9127 & TRN & \\
\hline CHEMBL1507520 & 737622 & 4.1073 & 4.4306 & TRN & \\
\hline CHEMBL1414465 & 737622 & 3.0969 & 4.1107 & TRN & \\
\hline CHEMBL1730695 & 737622 & 3.0969 & 3.4781 & TRN & \\
\hline CHEMBL1565949 & 737622 & 3.0969 & 3.4046 & TST & \\
\hline CHEMBL583351 & 737622 & 3.0969 & 3.3561 & TRN & \\
\hline CHEMBL1610614 & 737622 & 4.9788 & 4.3155 & TRN & \\
\hline CHEMBL1376346 & 737622 & 3.0969 & 3.5739 & TST & \\
\hline CHEMBL1967256 & 737622 & 3.0969 & 3.4957 & TRN & \\
\hline CHEMBL1719312 & 737622 & 5.0273 & 4.2473 & TST & \\
\hline CHEMBL1545954 & 737622 & 5.15 & 4.5103 & TRN & \\
\hline CHEMBL1440051 & 737622 & 5.5017 & 4.9678 & TRN & \\
\hline CHEMBL1419363 & 737622 & 3.0969 & 3.4552 & TRN & \\
\hline CHEMBL1412930 & 737622 & 3.0969 & 3.5428 & TRN & \\
\hline CHEMBL1578584 & 737622 & 4.1938 & 5.3514 & TRN & \\
\hline CHEMBL1608905 & 737622 & 3.0969 & 3.3205 & TRN & \\
\hline CHEMBL1402289 & 737622 & 4.3625 & 4.1884 & TRN & \\
\hline CHEMBL1455877 & 737622 & 4.4976 & 3.3133 & TRN & \\
\hline CHEMBL3197177 & 737622 & 4.4237 & 5.9331 & TRN & \\
\hline CHEMBL1331700 & 737622 & 3.0969 & 4.3323 & TRN & \\
\hline CHEMBL600313 & 737622 & 4.3391 & 3.58100 & 00000000004 & TST \\
\hline CHEMBL1488229 & 737622 & 6.1549 & 4.8868 & TRN & \\
\hline CHEMBL1418371 & 737622 & 6.4437 & 4.4816 & TRN & \\
\hline CHEMBL1496657 & 737622 & 4.4473 & 3.2456 & TRN & \\
\hline CHEMBL1413424 & 737622 & 3.0969 & 3.3745 & TRN & \\
\hline CHEMBL1575808 & 737622 & 3.0969 & 4.6267 & TRN & \\
\hline CHEMBL1476823 & 737622 & 3.0969 & 3.384 & TRN & \\
\hline CHEMBL1559811 & 737622 & 6.6383 & 5.8297 & TRN & \\
\hline CHEMBL3211093 & 737622 & 6.0555 & 4.5644 & TRN & \\
\hline CHEMBL1478067 & 737622 & 4.4647 & 3.5269 & TST & \\
\hline CHEMBL1580381 & 737622 & 3.0969 & 3.2006 & TRN & \\
\hline CHEMBL587856 & 737622 & 3.0969 & 3.5029 & TRN & \\
\hline CHEMBL1422720 & 737622 & 5.6478 & 4.7656 & TRN & \\
\hline CHEMBL1589463 & 737622 & 4.399 & 3.385 & TRN & \\
\hline CHEMBL1373623 & 737622 & 3.0969 & 3.2426 & TRN & \\
\hline CHEMBL1545864 & 737622 & 4.5086 & 4.4977 & TRN & \\
\hline CHEMBL1506520 & 737622 & 3.0969 & 3.4483 & TRN & \\
\hline CHEMBL1572914 & 737622 & 5.6655 & 4.4869 & TRN & \\
\hline CHEMBL2369258 & 737622 & 3.0969 & 3.5037 & TST & \\
\hline CHEMBL1404247 & 737622 & 3.0969 & 3.2903 & TRN & \\
\hline CHEMBL1711464 & 737622 & 3.0969 & 4.4247 & TRN & \\
\hline CHEMBL1428362 & 737622 & 4.7305 & 3.9916 & TRN & \\
\hline CHEMBL1447345 & 737622 & 4.2976 & 3.2026 & TRN & \\
\hline CHEMBL1353529 & 737622 & 4.7144 & 4.2306 & TST & \\
\hline CHEMBL1408398 & 737622 & 4.3307 & 4.1613 & TRN & \\
\hline CHEMBL1351755 & 737622 & 6.3279 & 5.2142 & TRN & \\
\hline CHEMBL1383331 & 737622 & 3.0969 & 3.3898 & TRN & \\
\hline
\end{tabular}




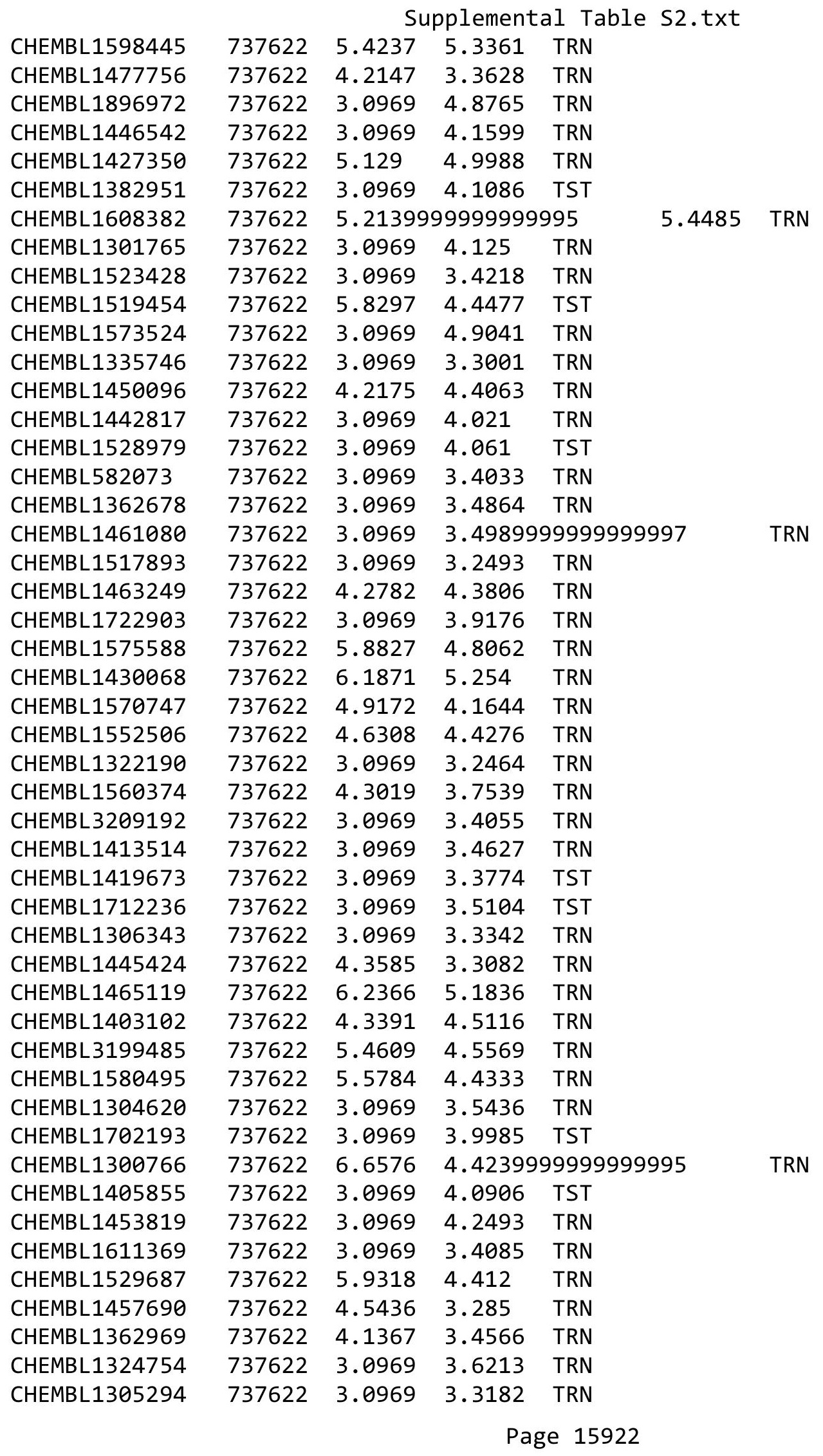


Supplemental Table S2.txt

\begin{tabular}{|c|c|c|c|c|}
\hline 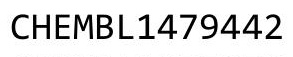 & & & & \\
\hline HEMBL1357976 & 37622 & .0969 & 8453 & \\
\hline HEMBL1533676 & 37622 & 5969 & 39 & \\
\hline 11 & & & & \\
\hline AEMBL1302818 & 22 & & & \\
\hline HEMBL1581420 & 37622 & 331 & 55 & \\
\hline HEMBL1328214 & 37622 & .0969 & .4949 & \\
\hline HEMBL1329037 & 22 & & & \\
\hline HEMBL140 & 22 & 969 & .4041 & \\
\hline AEMBL3197 & & & & \\
\hline HEMBL1345991 & 37622 & 2969 & 4984 & \\
\hline HEMBL 602987 & 37622 & 969 & 4626 & \\
\hline HEMBL1442S & 22 & .4078 & 82 & \\
\hline HEMBL157 & 22 & 39 & & \\
\hline HEMBL156 & 22 & & & \\
\hline HEMBL1712805 & 37622 & 969 & 4249 & \\
\hline HEMBL1461209 & & 969 & & \\
\hline HEMBL152 & 2 & 969 & 04 & \\
\hline L15 & 22 & 969 & & \\
\hline HEMBL31 & 2 & 281 & & \\
\hline HEMBL1379472 & 22 & 3002 & & \\
\hline AEMBL1319621 & & 59 & & \\
\hline HEMBL17C & 2 & 062 & 24 & \\
\hline L13 & & 85 & & \\
\hline 8 & 2 & 59 & & RN \\
\hline L431525 & & 69 & & ST \\
\hline HEMBL1568892 & & & & RN \\
\hline HEMBL1485 & 2 & 7 & & \\
\hline L5e & 2 & & & ST \\
\hline AEMBL13 & 2 & 59 & & RN \\
\hline AEMBL148 & & 59 & & RN \\
\hline HEMBL1472889 & 2 & 969 & & RN \\
\hline AEMBL13 & & 32 & & RN \\
\hline 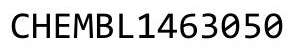 & 2 & 2 & & RN \\
\hline 8 & 2 & 97 & & RN \\
\hline AEMBL1503612 & 37 & 986 & & RN \\
\hline AEMBL1306844 & 37 & 969 & & RN \\
\hline 55 & 2 & 69 & & RN \\
\hline HᄃMP 12 & 2 & 28 & & RIN \\
\hline EMMBL14 & 2 & & & RN \\
\hline AEMBL1559383 & 37 & 3979 & & RN \\
\hline AEMBL14 & 2 & 83 & & RN \\
\hline $17 x$ & & 59 & & \\
\hline HEMBL1503607 & & & & RN \\
\hline HEMBL1445134 & 2 & 145 & & RN \\
\hline IEMBL14331 & 737 & 4.2083 & 332 & RN \\
\hline 21 & & & & \\
\hline & $737 €$ & & & \\
\hline
\end{tabular}

Page 15923 
Supplemental Table S2.txt

\begin{tabular}{|c|c|c|c|c|}
\hline CHEMBL1430446 & 737622 & 3.0969 & 3.3889 & TRN \\
\hline CHEMBL1900850 & 737622 & 7.7959 & 5.9327 & TST \\
\hline CHEMBL3193468 & 737622 & 4.4535 & 5.0466 & TRN \\
\hline CHEMBL1507548 & 737622 & 3.0969 & 4.5068 & TRN \\
\hline CHEMBL1369200 & 737622 & 4.7212 & 4.1616 & TRN \\
\hline CHEMBL1523794 & 737622 & 3.0969 & 3.4302 & TRN \\
\hline CHEMBL1387790 & 737622 & 5.8013 & 5.3757 & TRN \\
\hline CHEMBL1350753 & 737622 & 4.1433 & 4.3759 & TRN \\
\hline CHEMBL1503124 & 737622 & 3.0969 & 6.3641 & TRN \\
\hline CHEMBL1454683 & 737622 & 3.0969 & 4.0096 & TRN \\
\hline CHEMBL1352270 & 737622 & 6.4815 & 4.6708 & TRN \\
\hline CHEMBL1305438 & 737622 & 4.6819 & 4.2641 & TRN \\
\hline CHEMBL1379578 & 737622 & 4.1952 & 3.2555 & TRN \\
\hline CHEMBL1371241 & 737622 & 3.0969 & 4.6724 & TRN \\
\hline CHEMBL1335749 & 737622 & 3.0969 & 4.3305 & TST \\
\hline CHEMBL1526910 & 737622 & 5.4976 & 4.4811 & TRN \\
\hline CHEMBL1448789 & 737622 & 5.6904 & 4.3337 & TRN \\
\hline CHEMBL1533110 & 737622 & 3.0969 & 3.3411 & TRN \\
\hline CHEMBL145557 & 737622 & 3.0969 & 3.5099 & TRN \\
\hline CHEMBL1402278 & 737622 & 4.3925 & 4.2396 & TRN \\
\hline CHEMBL1412162 & 737622 & 4.4461 & 4.0597 & TRN \\
\hline CHEMBL1606813 & 737622 & 3.0969 & 3.6574 & TRN \\
\hline CHEMBL1429636 & 737622 & 4.7852 & 4.18 & TST \\
\hline CHEMBL1711360 & 737622 & 4.1555 & 4.0492 & TST \\
\hline CHEMBL1325260 & 737622 & 5.1302 & 4.4012 & TRN \\
\hline CHEMBL1379416 & 737622 & 4.1752 & 4.7087 & TRN \\
\hline CHEMBL1343497 & 737622 & 3.0969 & 3.1948 & TRN \\
\hline CHEMBL1484661 & 737622 & 6.4685 & 3.5183 & TRN \\
\hline CHEMBL1546693 & 737622 & 4.6216 & 4.2267 & TST \\
\hline CHEMBL1305304 & 737622 & 6.6021 & 5.8048 & TRN \\
\hline CHEMBL1546342 & 737622 & 3.0969 & 3.2576 & TRN \\
\hline CHEMBL1428877 & 737622 & 3.0969 & 3.2886 & TRN \\
\hline CHEMBL1416637 & 737622 & 6.0862 & 5.0565 & TST \\
\hline CHEMBL1447724 & 737622 & 4.6216 & 4.2424 & TRN \\
\hline CHEMBL1357675 & 737622 & 3.0969 & 4.3238 & TRN \\
\hline CHEMBL1503666 & 737622 & 3.0969 & 4.4309 & TRN \\
\hline CHEMBL1505655 & 737622 & 6.4815 & 4.8738 & TRN \\
\hline CHEMBL1724339 & 737622 & 3.0969 & 4.5209 & TRN \\
\hline CHEMBL1521044 & 737622 & 5.4647 & 4.3215 & TRN \\
\hline CHEMBL1484158 & 737622 & 5.289 & 5.0058 & TRN \\
\hline CHEMBL1709070 & 737622 & 3.0969 & 3.7224 & TRN \\
\hline CHEMBL1480380 & 737622 & 3.0969 & 3.2146 & TRN \\
\hline CHEMBL1377807 & 737622 & 4.2147 & 4.0793 & TRN \\
\hline CHEMBL1364289 & 737622 & 3.0969 & 5.0267 & TRN \\
\hline CHEMBL1555599 & 737622 & 3.0969 & 3.3412 & TRN \\
\hline CHEMBL1392896 & 737622 & 3.0969 & \multicolumn{2}{|c|}{3.4530000000000003} \\
\hline CHEMBL1705775 & 737622 & 4.5317 & 4.2939 & TRN \\
\hline CHEMBL1554602 & 737622 & 4.9586 & 4.2684 & TRN \\
\hline
\end{tabular}


Supplemental Table S2.txt

\begin{tabular}{|c|c|c|c|c|}
\hline HEMBL & 622 & 5.1029 & & \\
\hline & 37622 & 3.0969 & & \\
\hline & 22 & & & \\
\hline EMBL1 & 522 & 969 & & \\
\hline IEMBL1351128 & 37622 & & & \\
\hline HEMBL600121 & 37622 & 0372 & 004 & \\
\hline AEMBL1513846 & 622 & 969 & 315 & \\
\hline EMBL & 522 & & & \\
\hline AEMBL1382246 & 37622 & 3969 & 901 & \\
\hline AEMBL1713181 & 37622 & 969 & 983 & \\
\hline AEMBL1 & 37622 & 799 & 956 & \\
\hline EMBL & 7622 & 031 & 701 & \\
\hline EMBL & & & & \\
\hline AEMBL1392403 & 37622 & 1427 & & \\
\hline IEMBL1377607 & 622 & & 443 & \\
\hline IEMBL? & 22 & 59 & 64 & \\
\hline AEMBL & 22 & & 721 & \\
\hline AEMBL] & 22 & & & \\
\hline 24352 & 37622 & & 161 & \\
\hline EMBL1 & & & & \\
\hline 689 & 22 & & 99 & \\
\hline EMB & 22 & & & \\
\hline EMBL & 22 & & 73 & \\
\hline 609 & 622 & & 102 & \\
\hline EMBL1 & 2 & & & ST \\
\hline IEMBL & 22 & 6 & 79 & \\
\hline AEMBL & 22 & & & \\
\hline FMBI & 22 & 25 & 36 & \\
\hline EMBL1 & & & 267 & \\
\hline AEMBL1719240 & 22 & 1 & 796 & \\
\hline IEMBL: & 22 & & 321 & ST \\
\hline AFMB & 2 & & 44 & \\
\hline & 2 & 99 & 21 & \\
\hline EMBL1346443 & & & 3.7753 & \\
\hline AEMBL1486790 & 37622 & 59 & 3.5191 & ST \\
\hline AEMBL1 & 22 & & 365 & \\
\hline IFMD & 2 & & & \\
\hline & & & 4.1232 & \\
\hline IEMBL1723778 & 37622 & & 814 & SI \\
\hline MBL1 & 22 & 969 & 952 & S \\
\hline HEMBL1 & 22 & 31 & 4.3094 & \\
\hline 295 & & & & \\
\hline HEMBL1441617 & 37622 & & 7347 & ST \\
\hline EMBL1393397 & 37622 & 302 & 88 & S \\
\hline & & 69 & 298 & \\
\hline HEMBL1 & 2 & & .3158 & \\
\hline HEMBL151871 & 37622 & & 4.4539 & \\
\hline HEMBL1423463 & 737622 & 5.2373 & 4.1974 & \\
\hline
\end{tabular}

Page 15925 


\begin{tabular}{|c|c|c|c|c|c|c|}
\hline \multirow[b]{2}{*}{ CHEMBL1431035 } & & \multicolumn{5}{|c|}{ Supplemental Table S2.txt } \\
\hline & 737622 & 4.4034 & 3.8732 & TST & & \\
\hline CHEMBL1366006 & 737622 & 5.8182 & 4.3137 & TST & & \\
\hline CHEMBL1352850 & 737622 & 5.76200 & 00000000 & 005 & 4.9654 & TST \\
\hline CHEMBL1717272 & 737622 & 3.0969 & 3.3364 & TST & & \\
\hline CHEMBL1385709 & 737622 & 3.0969 & 3.2066 & TST & & \\
\hline CHEMBL1534042 & 737622 & 3.0969 & 3.5329 & TST & & \\
\hline CHEMBL1415303 & 737622 & 4.1524 & 3.8169 & TST & & \\
\hline CHEMBL1472681 & 737622 & 6.1079 & 5.2028 & TST & & \\
\hline CHEMBL1704636 & 737622 & 3.0969 & 3.3486 & TST & & \\
\hline CHEMBL1362588 & 737622 & 5.9245 & 4.395 & TST & & \\
\hline CHEMBL1498710 & 737622 & 3.0969 & 3.5772 & TST & & \\
\hline CHEMBL1549107 & 737622 & 3.0969 & 3.2542 & TST & & \\
\hline CHEMBL1559707 & 737622 & 3.0969 & 3.5434 & TST & & \\
\hline CHEMBL1529440 & 737622 & 3.0969 & 3.531 & TST & & \\
\hline CHEMBL3209594 & 737622 & 3.0969 & 3.9394 & TST & & \\
\hline CHEMBL1734009 & 737622 & 4.2857 & 3.873 & TST & & \\
\hline CHEMBL3192670 & 737622 & 4.1739 & 3.5108 & TST & & \\
\hline CHEMBL1423968 & 737622 & 5.1818 & 5.0805 & TST & & \\
\hline CHEMBL1436389 & 737622 & 5.9469 & 4.9218 & TST & & \\
\hline CHEMBL 73497 & 53177 & 5.0 & 4.9115 & TRN & & \\
\hline CHEMBL306971 & 53177 & 6.0 & 5.8905 & TRN & & \\
\hline CHEMBL305631 & 53177 & 5.0 & 5.4379 & TST & & \\
\hline CHEMBL70425 & 53177 & 6.9208 & 6.99 & TRN & & \\
\hline CHEMBL73590 & 53177 & 8.7959 & 8.619 & TRN & & \\
\hline CHEMBL 72643 & 53177 & 5.0 & 5.0543 & TRN & & \\
\hline CHEMBL 74622 & 53177 & 6.3188 & 6.1824 & TRN & & \\
\hline CHEMBL75494 & 53177 & 7.5686 & 7.6146 & TRN & & \\
\hline CHEMBL73302 & 53177 & 6.1427 & 6.1463 & TRN & & \\
\hline CHEMBL306566 & 53177 & 7.4271 & 7.3747 & TRN & & \\
\hline CHEMBL 73327 & 53177 & 5.0 & 5.0448 & TRN & & \\
\hline CHEMBL307501 & 53177 & 5.0 & 4.9841 & TRN & & \\
\hline CHEMBL310477 & 53177 & 6.5229 & 6.6331 & TRN & & \\
\hline CHEMBL308041 & 53177 & 5.0 & 6.1311 & TST & & \\
\hline CHEMBL312304 & 53177 & 8.0 & 7.8673 & TRN & & \\
\hline CHEMBL 73897 & 53177 & 5.0 & 5.0019 & TRN & & \\
\hline CHEMBL 74405 & 53177 & 7.1612 & 7.2033 & TRN & & \\
\hline CHEMBL 74888 & 53177 & 6.3625 & 6.2845 & TRN & & \\
\hline CHEMBL 73583 & 53177 & 7.4437 & 7.5144 & TRN & & \\
\hline CHEMBL 72869 & 53177 & 5.0 & 5.03 & TRN & & \\
\hline CHEMBL 306843 & 53177 & 5.0 & 5.0318 & TRN & & \\
\hline CHEMBL307188 & 53177 & 5.0 & 5.1582 & TRN & & \\
\hline CHEMBL 307242 & 53177 & 5.0 & 4.9752 & TRN & & \\
\hline CHEMBL73032 & 53177 & 5.0 & 5.053 & TRN & & \\
\hline CHEMBL 2115150 & 53177 & 6.0 & 6.1018 & TST & & \\
\hline CHEMBL306053 & 53177 & 6.9626 & 6.9891 & TRN & & \\
\hline CHEMBL 70260 & 53177 & 6.3468 & 6.2665 & TRN & & \\
\hline CHEMBL 74057 & 53177 & 5.0 & 5.3538 & TST & & \\
\hline CHEMBL 75377 & 53177 & 5.0 & 5.0034 & TRN & & \\
\hline
\end{tabular}




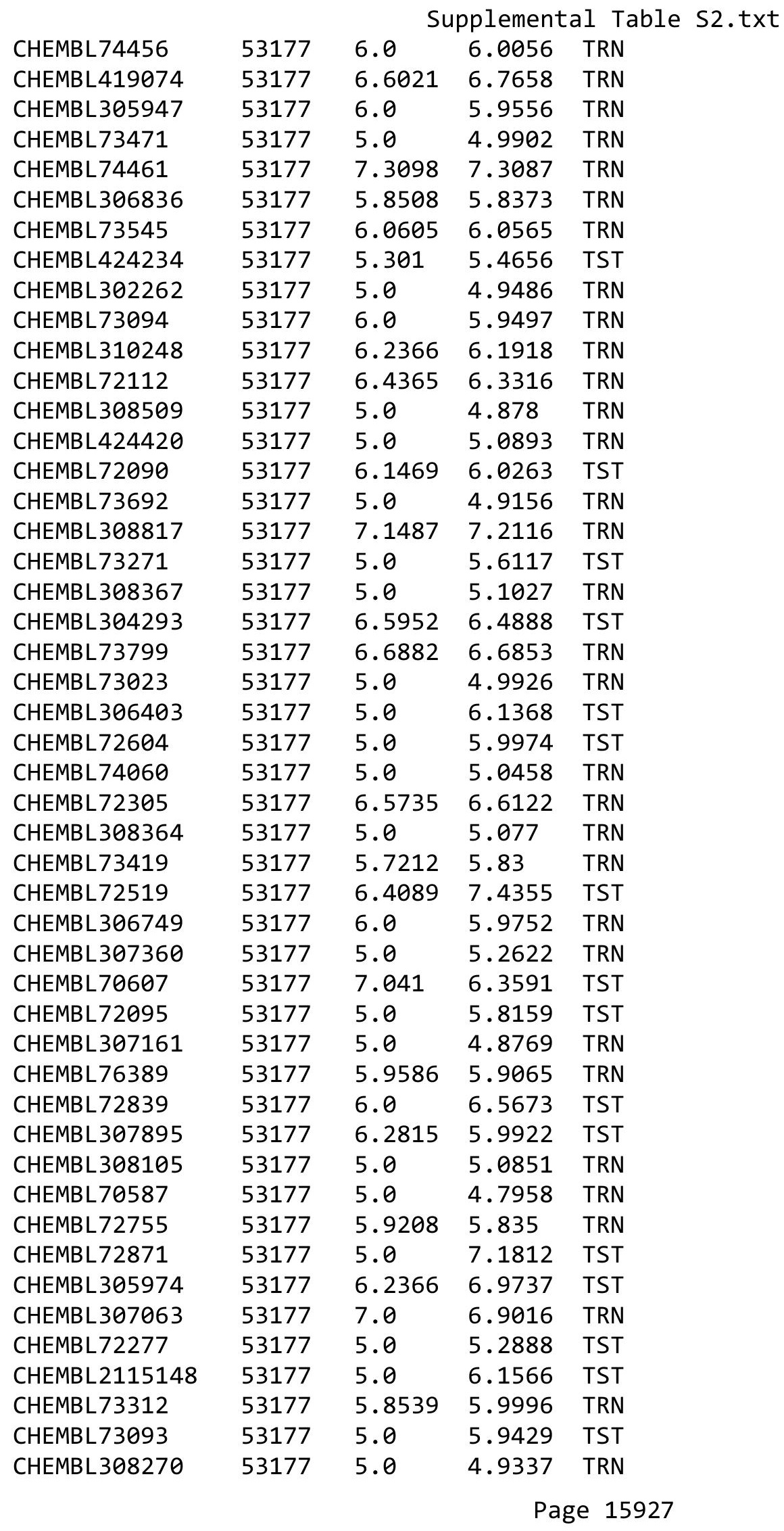




\begin{tabular}{|c|c|c|c|c|c|c|}
\hline & & \multicolumn{5}{|c|}{ Supplemental Table S2.txt } \\
\hline CHEMBL431564 & 53177 & 7.2924 & 7.4089 & TRN & & \\
\hline CHEMBL307436 & 53177 & 5.0 & 5.2597 & TST & & \\
\hline CHEMBL72341 & 53177 & 7.4881 & 7.6149 & TRN & & \\
\hline CHEMBL306404 & 53177 & 6.301 & 6.1488 & TRN & & \\
\hline CHEMBL74061 & 53177 & 5.0 & 5.0546 & TRN & & \\
\hline CHEMBL73063 & 53177 & 6.1669 & 6.2869 & TRN & & \\
\hline CHEMBL 70849 & 53177 & 5.8684 & 5.7608 & TRN & & \\
\hline CHEMBL1975961 & 688845 & 4.2711 & 4.0253 & TRN & & \\
\hline CHEMBL1495227 & 688845 & 3.9789 & 4.1379 & TRN & & \\
\hline CHEMBL 2006545 & 688845 & 4.3479 & 4.2972 & TRN & & \\
\hline CHEMBL1524515 & 688845 & 4.4587 & 4.4937 & TRN & & \\
\hline CHEMBL1362047 & 688845 & 2.8239 & 4.2473 & TRN & & \\
\hline CHEMBL199405 & 688845 & 4.5237 & 4.3771 & TRN & & \\
\hline CHEMBL1332952 & 688845 & 4.6976 & 4.5232 & TRN & & \\
\hline CHEMBL1331702 & 688845 & 4.0653 & 4.0348 & TRN & & \\
\hline CHEMBL1578054 & 688845 & 3.8509 & 4.1244 & TRN & & \\
\hline CHEMBL1472455 & 688845 & 4.0867 & 4.2934 & TRN & & \\
\hline CHEMBL1393472 & 688845 & 4.51399 & 99999999 & 99 & 3.5132 & TRN \\
\hline CHEMBL1608917 & 688845 & 2.8239 & 4.1238 & TRN & & \\
\hline CHEMBL1322645 & 688845 & 4.065 & 4.2381 & TST & & \\
\hline CHEMBL532239 & 688845 & 4.7216 & 4.7976 & TRN & & \\
\hline CHEMBL584269 & 688845 & 4.8221 & 4.8744 & TRN & & \\
\hline CHEMBL524376 & 688845 & 4.4532 & 4.6967 & TRN & & \\
\hline CHEMBL1568905 & 688845 & 3.9173 & 3.9648 & TST & & \\
\hline CHEMBL 209101 & 688845 & 4.0626 & 3.9953 & TRN & & \\
\hline CHEMBL3190599 & 688845 & 3.8279 & 4.1313 & TRN & & \\
\hline CHEMBL1403744 & 688845 & 4.2532 & 4.1112 & TST & & \\
\hline CHEMBL1514790 & 688845 & 4.6608 & 4.4816 & TST & & \\
\hline CHEMBL1521960 & 688845 & 5.4415 & 4.6905 & TST & & \\
\hline CHEMBL1326371 & 688845 & 5.9547 & 4.7873 & TRN & & \\
\hline CHEMBL1460004 & 688845 & 4.0937 & 4.3294 & TRN & & \\
\hline CHEMBL1605613 & 688845 & 4.0741 & 3.9989 & TRN & & \\
\hline CHEMBL217920 & 688845 & 3.9751 & 3.9952 & TRN & & \\
\hline CHEMBL1458376 & 688845 & 3.9887 & 4.1408 & TRN & & \\
\hline CHEMBL1500500 & 688845 & 4.1065 & 4.3819 & TRN & & \\
\hline CHEMBL51931 & 688845 & 4.7218 & 4.3191 & TRN & & \\
\hline CHEMBL1435878 & 688845 & 4.3297 & 4.0292 & TRN & & \\
\hline CHEMBL600121 & 688845 & 4.0964 & 4.27 & TRN & & \\
\hline CHEMBL1539127 & 688845 & 4.4016 & 4.1862 & TRN & & \\
\hline CHEMBL1324762 & 688845 & 2.8239 & 3.6169 & TRN & & \\
\hline CHEMBL1586075 & 688845 & 2.8239 & 3.9203 & TRN & & \\
\hline CHEMBL290077 & 688845 & 5.4252 & 4.3471 & TST & & \\
\hline CHEMBL1429304 & 688845 & 3.9695 & 4.0125 & TRN & & \\
\hline CHEMBL1605784 & 688845 & 4.0865 & 4.2906 & TRN & & \\
\hline CHEMBL1484218 & 688845 & 4.1843 & 4.029 & TRN & & \\
\hline CHEMBL1988121 & 688845 & 4.0383 & 4.3028 & TRN & & \\
\hline CHEMBL1485275 & 688845 & 6.0 & 5.7144 & TST & & \\
\hline CHEMBL1378190 & 688845 & 4.3952 & 3.9058 & TRN & & \\
\hline
\end{tabular}




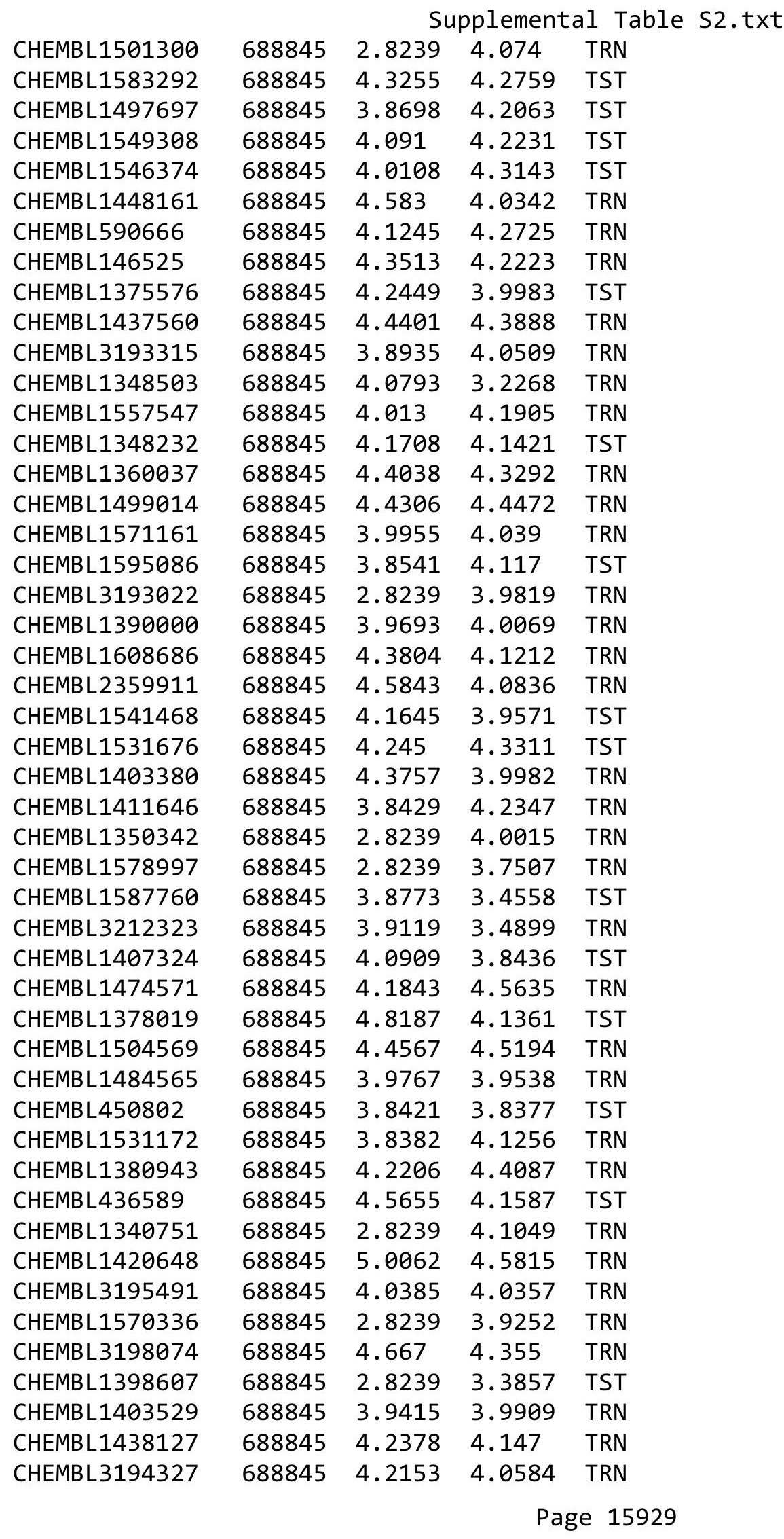




\begin{tabular}{|c|c|c|c|c|c|}
\hline \multicolumn{6}{|c|}{ Supplemental Table S2.txt } \\
\hline CHEMBL585828 & 688845 & 4.1474 & 4.1612 & TST & \\
\hline CHEMBL1416618 & 688845 & 4.1888 & 4.1607 & TST & \\
\hline CHEMBL3192856 & 688845 & 3.9481 & 3.9164 & TRN & \\
\hline CHEMBL1327205 & 688845 & 4.3003 & 4.07600 & 00000000005 & TRN \\
\hline CHEMBL1541657 & 688845 & 2.8239 & 4.2634 & TST & \\
\hline CHEMBL1318993 & 688845 & 4.103 & 4.1086 & TRN & \\
\hline CHEMBL601578 & 688845 & 4.1374 & 4.3515 & TRN & \\
\hline CHEMBL3197818 & 688845 & 4.3388 & 4.0477 & TRN & \\
\hline CHEMBL1330520 & 688845 & 4.3456 & 4.4497 & TRN & \\
\hline CHEMBL1523680 & 688845 & 2.8239 & 3.6019 & TRN & \\
\hline CHEMBL1427617 & 688845 & 4.4061 & 4.4202 & TRN & \\
\hline CHEMBL1594936 & 688845 & 4.1866 & 3.5549 & TRN & \\
\hline CHEMBL578061 & 688845 & 4.1729 & 4.3252 & TRN & \\
\hline CHEMBL1623028 & 688845 & 4.2677 & 4.4584 & TRN & \\
\hline CHEMBL1479316 & 688845 & 4.6087 & 4.473 & TRN & \\
\hline CHEMBL1303357 & 688845 & 4.1481 & 4.12 & TRN & \\
\hline CHEMBL1392287 & 688845 & 2.8239 & 4.2805 & TRN & \\
\hline CHEMBL1201074 & 688845 & 3.8828 & 4.1017 & TRN & \\
\hline CHEMBL1403240 & 688845 & 4.0978 & 4.0853 & TRN & \\
\hline CHEMBL1569910 & 688845 & 4.6334 & 3.9203 & TRN & \\
\hline CHEMBL1353170 & 688845 & 4.5496 & 4.3924 & TRN & \\
\hline CHEMBL3193701 & 688845 & 4.6855 & 4.325 & TRN & \\
\hline CHEMBL1611421 & 688845 & 3.9204 & 3.5289 & TST & \\
\hline CHEMBL1455056 & 688845 & 4.1602 & 4.0074 & TRN & \\
\hline CHEMBL1572031 & 688845 & 4.0838 & 3.9064 & TRN & \\
\hline CHEMBL1441196 & 688845 & 5.1292 & 4.7643 & TRN & \\
\hline CHEMBL1563862 & 688845 & 2.8239 & 4.0898 & TRN & \\
\hline CHEMBL3190369 & 688845 & 4.6135 & 4.5298 & TST & \\
\hline CHEMBL606167 & 688845 & 4.6775 & 4.7199 & TST & \\
\hline CHEMBL1558968 & 688845 & 3.9222 & 4.2315 & TRN & \\
\hline CHEMBL1979727 & 688845 & 2.8239 & 3.8882 & TRN & \\
\hline CHEMBL1433069 & 688845 & 4.6864 & 4.0742 & TRN & \\
\hline CHEMBL1580218 & 688845 & 2.8239 & 3.9864 & TRN & \\
\hline CHEMBL1483355 & 688845 & 4.5469 & 4.0573 & TRN & \\
\hline CHEMBL1413197 & 688845 & 2.8239 & 3.2331 & TRN & \\
\hline CHEMBL1481347 & 688845 & 3.842 & 4.6872 & TRN & \\
\hline CHEMBL586135 & 688845 & 4.99 & 4.5586 & TST & \\
\hline CHEMBL492886 & 688845 & 4.1104 & 4.1904 & TRN & \\
\hline CHEMBL1539637 & 688845 & 4.7022 & 4.3476 & TST & \\
\hline CHEMBL1330954 & 688845 & 3.8731 & 4.0931 & TRN & \\
\hline CHEMBL1532828 & 688845 & 4.596 & 4.6428 & TRN & \\
\hline CHEMBL1340487 & 688845 & 3.9921 & 3.6696 & TRN & \\
\hline CHEMBL1612112 & 688845 & 3.8687 & 3.9545 & TRN & \\
\hline CHEMBL1403875 & 688845 & 3.8417 & 4.0182 & TRN & \\
\hline CHEMBL1490887 & 688845 & 4.1165 & 4.2407 & TST & \\
\hline CHEMBL1301082 & 688845 & 3.8349 & 4.3749 & TRN & \\
\hline CHEMBL1501385 & 688845 & 2.8239 & 4.166 & TRN & \\
\hline CHEMBL1588476 & 688845 & 4.1443 & 4.0478 & TST & \\
\hline
\end{tabular}




\begin{tabular}{|c|c|c|c|c|c|c|}
\hline \multirow[b]{2}{*}{ CHEMBL1329129 } & \multirow[b]{2}{*}{688845} & \multicolumn{5}{|c|}{ Supplemental Table S2.txt } \\
\hline & & 4.7356 & 4.4789 & TRN & & \\
\hline CHEMBL1556072 & 688845 & 2.8239 & 4.1047 & TST & & \\
\hline CHEMBL1481342 & 688845 & 4.0665 & 3.7891 & TRN & & \\
\hline CHEMBL1410641 & 688845 & 5.0887 & 3.9304 & TST & & \\
\hline CHEMBL3190555 & 688845 & \multicolumn{3}{|c|}{3.8310000000000004} & 4.1331 & TRN \\
\hline CHEMBL1974537 & 688845 & 2.8239 & 3.8008 & TST & & \\
\hline CHEMBL1468954 & 688845 & 4.6967 & 4.16 & TRN & & \\
\hline CHEMBL1521896 & 688845 & 5.0946 & 4.5537 & TRN & & \\
\hline CHEMBL1522486 & 688845 & 6.0 & 5.3116 & TRN & & \\
\hline CHEMBL3189342 & 688845 & 4.8957 & 4.5407 & TRN & & \\
\hline CHEMBL1314977 & 688845 & 2.8239 & 3.6411 & TRN & & \\
\hline CHEMBL1489929 & 688845 & 4.0117 & 4.0871 & TRN & & \\
\hline CHEMBL1487428 & 688845 & \multicolumn{3}{|c|}{3.8930000000000002} & 3.5357 & TRN \\
\hline CHEMBL 3197272 & 688845 & 4.3771 & 3.9931 & TRN & & \\
\hline CHEMBL1594766 & 688845 & 4.1562 & 4.2355 & TRN & & \\
\hline CHEMBL1424474 & 688845 & 3.9704 & 4.0785 & TRN & & \\
\hline CHEMBL1475023 & 688845 & 4.3316 & 3.9659 & TRN & & \\
\hline CHEMBL1564731 & 688845 & 3.9703 & 3.9994 & TRN & & \\
\hline CHEMBL1982032 & 688845 & 5.0237 & 4.2303 & TST & & \\
\hline CHEMBL578928 & 688845 & 4.1085 & 4.2594 & TRN & & \\
\hline CHEMBL1558070 & 688845 & 4.7589 & 4.2923 & TST & & \\
\hline CHEMBL1559564 & 688845 & 4.6791 & 4.2261 & TRN & & \\
\hline CHEMBL1378768 & 688845 & 4.4354 & 4.4093 & TRN & & \\
\hline CHEMBL587892 & 688845 & 4.1641 & 4.3672 & TRN & & \\
\hline CHEMBL 309016 & 688845 & 4.2728 & 3.9509 & TRN & & \\
\hline CHEMBL1496705 & 688845 & 4.7801 & 4.761 & TRN & & \\
\hline CHEMBL1409001 & 688845 & 2.8239 & 4.6226 & TRN & & \\
\hline CHEMBL1443946 & 688845 & 4.4431 & 4.0978 & TRN & & \\
\hline CHEMBL1532668 & 688845 & 4.7067 & 4.3302 & TST & & \\
\hline CHEMBL3191293 & 688845 & 4.8273 & 4.3133 & TRN & & \\
\hline CHEMBL1483252 & 688845 & 4.3169 & 4.3594 & TRN & & \\
\hline CHEMBL1392912 & 688845 & 4.4966 & 4.2129 & TRN & & \\
\hline CHEMBL1447782 & 688845 & 4.1052 & 4.2111 & TRN & & \\
\hline CHEMBL1573817 & 688845 & 4.2341 & 4.1787 & TRN & & \\
\hline CHEMBL1091556 & 688845 & 4.0821 & 3.5688 & TRN & & \\
\hline CHEMBL3191363 & 688845 & 4.1757 & 3.8995 & TRN & & \\
\hline CHEMBL3196295 & 688845 & 4.1448 & 3.7814 & TRN & & \\
\hline CHEMBL1345775 & 688845 & 3.9462 & 4.0636 & TRN & & \\
\hline CHEMBL1348468 & 688845 & 4.1667 & 4.0713 & TRN & & \\
\hline CHEMBL186248 & 688845 & 4.4038 & 3.4962 & TRN & & \\
\hline CHEMBL1451747 & 688845 & 4.0964 & 4.1913 & TST & & \\
\hline CHEMBL1197835 & 688845 & 2.8239 & 3.8259 & TRN & & \\
\hline CHEMBL1200567 & 688845 & 5.7053 & 5.437 & TST & & \\
\hline CHEMBL3198512 & 688845 & 3.8824 & 3.6438 & TST & & \\
\hline CHEMBL1589539 & 688845 & 4.3303 & 3.3349 & TRN & & \\
\hline CHEMBL1335155 & 688845 & 4.0693 & 4.0673 & TRN & & \\
\hline CHEMBL3198649 & 688845 & 3.8667 & 3.8975 & TRN & & \\
\hline CHEMBL1598087 & 688845 & 4.0025 & 3.5524 & TRN & & \\
\hline
\end{tabular}




\begin{tabular}{|c|c|c|c|c|c|c|}
\hline & & & oplement & או & $S 2 . t x$ & \\
\hline CHEMBL1986678 & 688845 & 4.3543 & 4.0235 & TRN & & \\
\hline CHEMBL1428563 & 688845 & 4.05399 & 99999999 & 99 & 4.3782 & TST \\
\hline CHEMBL1522007 & 688845 & 5.7058 & 4.7251 & TRN & & \\
\hline CHEMBL1597839 & 688845 & 3.8459 & 4.002 & TRN & & \\
\hline CHEMBL1308783 & 688845 & 4.381 & 3.6293 & TRN & & \\
\hline CHEMBL1433269 & 688845 & 3.9649 & 4.0938 & TST & & \\
\hline CHEMBL1604346 & 688845 & 2.8239 & 4.0696 & TST & & \\
\hline CHEMBL1304363 & 688845 & 4.6669 & 4.4128 & TRN & & \\
\hline CHEMBL1979106 & 688845 & 4.3349 & 4.3946 & TRN & & \\
\hline CHEMBL1365234 & 688845 & 4.1214 & 3.5679 & TST & & \\
\hline CHEMBL1503034 & 688845 & 4.4212 & 4.2543 & TRN & & \\
\hline CHEMBL546344 & 688845 & 4.4813 & 4.5215 & TRN & & \\
\hline CHEMBL1572280 & 688845 & 4.4944 & 4.3831 & TST & & \\
\hline CHEMBL1496555 & 688845 & 2.8239 & 3.8817 & TRN & & \\
\hline CHEMBL1986690 & 688845 & 4.2643 & 4.1544 & TRN & & \\
\hline CHEMBL1335384 & 688845 & 4.2617 & 4.2858 & TRN & & \\
\hline CHEMBL3192021 & 688845 & 4.0099 & 3.5061 & TRN & & \\
\hline CHEMBL1582934 & 688845 & 4.4365 & 4.0789 & TRN & & \\
\hline CHEMBL1306583 & 688845 & 4.1038 & 4.2178 & TRN & & \\
\hline CHEMBL1396209 & 688845 & 4.8063 & 4.5253 & TST & & \\
\hline CHEMBL591404 & 688845 & 4.7732 & 4.5473 & TRN & & \\
\hline CHEMBL1318861 & 688845 & 5.0416 & 5.3172 & TST & & \\
\hline CHEMBL1347071 & 688845 & 4.5715 & 4.5434 & TRN & & \\
\hline CHEMBL1542590 & 688845 & 3.9006 & 4.1413 & TRN & & \\
\hline CHEMBL1958251 & 688845 & 4.6572 & 4.4825 & TRN & & \\
\hline CHEMBL1600851 & 688845 & 3.8638 & 3.9959 & TRN & & \\
\hline CHEMBL1315061 & 688845 & 5.6824 & 5.3772 & TST & & \\
\hline CHEMBL1342852 & 688845 & 5.4501 & 4.7474 & TRN & & \\
\hline CHEMBL1491847 & 688845 & 4.8293 & 4.6068 & TST & & \\
\hline CHEMBL1423096 & 688845 & 4.1259 & 3.9803 & TST & & \\
\hline CHEMBL1513972 & 688845 & 4.7085 & 4.4952 & TST & & \\
\hline CHEMBL1310009 & 688845 & 4.0223 & 4.2574 & TRN & & \\
\hline CHEMBL3190747 & 688845 & 4.4161 & 4.0289 & TRN & & \\
\hline CHEMBL1597177 & 688845 & 4.6472 & 4.416 & TST & & \\
\hline CHEMBL1338743 & 688845 & 4.0845 & 4.2245 & TRN & & \\
\hline CHEMBL 2006730 & 688845 & 4.2403 & 3.9033 & TRN & & \\
\hline CHEMBL1382900 & 688845 & 2.8239 & 3.8607 & TST & & \\
\hline CHEMBL1400005 & 688845 & 4.224 & 4.0313 & TST & & \\
\hline CHEMBL1478852 & 688845 & 2.8239 & 4.4313 & TST & & \\
\hline CHEMBL3195334 & 688845 & 4.2881 & 4.0399 & TST & & \\
\hline CHEMBL1600855 & 688845 & 4.7141 & 4.4756 & TRN & & \\
\hline CHEMBL3191149 & 688845 & 4.4296 & 4.4063 & TRN & & \\
\hline CHEMBL1550897 & 688845 & 4.3399 & 4.3017 & TRN & & \\
\hline CHEMBL1563943 & 688845 & 4.4463 & 4.4141 & TRN & & \\
\hline CHEMBL1575043 & 688845 & 2.8239 & 3.8624 & TRN & & \\
\hline CHEMBL1472891 & 688845 & 3.8969 & 4.0787 & TRN & & \\
\hline CHEMBL1542057 & 688845 & 4.006 & 3.9606 & TRN & & \\
\hline CHEMBL1575531 & 688845 & 2.8239 & 3.9913 & TRN & & \\
\hline
\end{tabular}




\begin{tabular}{|c|c|c|c|c|c|}
\hline \multicolumn{6}{|c|}{ Supplemental Table S2.txt } \\
\hline CHEMBL1342436 & 688845 & 4.2853 & 4.4296 & TST & \\
\hline CHEMBL1971144 & 688845 & 4.5492 & 4.3335 & TRN & \\
\hline CHEMBL3196837 & 688845 & 4.4691 & 4.143 & TRN & \\
\hline CHEMBL1419803 & 688845 & 4.3151 & 4.1208 & TRN & \\
\hline CHEMBL1440636 & 688845 & 3.9561 & 4.0801 & TRN & \\
\hline CHEMBL1330558 & 688845 & 4.916 & 4.6262 & TRN & \\
\hline CHEMBL1573754 & 688845 & 4.0224 & 4.3352 & TST & \\
\hline CHEMBL3039775 & 688845 & 4.695 & 4.3051 & TRN & \\
\hline CHEMBL1971727 & 688845 & 4.3037 & 4.235 & TRN & \\
\hline CHEMBL1304297 & 688845 & 2.8239 & 3.9415 & TRN & \\
\hline CHEMBL1335846 & 688845 & 4.4618 & 4.3995 & TST & \\
\hline CHEMBL1966224 & 688845 & 2.8239 & 3.6049 & TRN & \\
\hline CHEMBL1581182 & 688845 & 4.5494 & 4.6563 & TRN & \\
\hline CHEMBL1583082 & 688845 & 3.8294 & 4.1281 & TRN & \\
\hline CHEMBL1452648 & 688845 & 4.5401 & 4.3031 & TRN & \\
\hline CHEMBL589694 & 688845 & 2.8239 & 3.431 & TRN & \\
\hline CHEMBL578872 & 688845 & 3.9764 & 4.0449 & TST & \\
\hline CHEMBL3213876 & 688845 & 4.4764 & 4.2962 & TRN & \\
\hline CHEMBL 3190268 & 688845 & 3.9659 & 3.9645 & TRN & \\
\hline CHEMBL1485332 & 688845 & 2.8239 & 4.0035 & TRN & \\
\hline CHEMBL11908 & 688845 & 4.1368 & 4.0403 & TRN & \\
\hline CHEMBL3192398 & 688845 & 4.4825 & 4.0448 & TRN & \\
\hline CHEMBL1596066 & 688845 & 3.9134 & 3.98100 & 00000000003 & TRN \\
\hline CHEMBL 3196257 & 688845 & 4.2191 & 4.1238 & TRN & \\
\hline CHEMBL1565898 & 688845 & 3.9891 & 4.0056 & TRN & \\
\hline CHEMBL1321310 & 688845 & 4.0603 & 3.8683 & TRN & \\
\hline CHEMBL1360870 & 688845 & 4.0213 & 4.1926 & TST & \\
\hline CHEMBL1329197 & 688845 & 4.1652 & 4.2591 & TRN & \\
\hline CHEMBL1483161 & 688845 & 4.399 & 4.3016 & TST & \\
\hline CHEMBL172 & 688845 & 4.043 & 4.2057 & TST & \\
\hline CHEMBL1524435 & 688845 & 4.9727 & 4.3387 & TRN & \\
\hline CHEMBL1983581 & 688845 & 4.0255 & 3.9731 & TRN & \\
\hline CHEMBL1580083 & 688845 & 4.4029 & 3.9217 & TRN & \\
\hline CHEMBL1470633 & 688845 & 4.4378 & 4.1077 & TRN & \\
\hline CHEMBL1389994 & 688845 & 4.4294 & 4.3418 & TRN & \\
\hline CHEMBL1440518 & 688845 & 4.2859 & 4.3468 & TRN & \\
\hline CHEMBL 3193714 & 688845 & 3.8736 & 3.5334 & TRN & \\
\hline CHEMBL3194811 & 688845 & 4.1517 & 4.02800 & 00000000005 & TRN \\
\hline CHEMBL 3190330 & 688845 & 4.6243 & 4.4213 & TRN & \\
\hline CHEMBL1520233 & 688845 & 2.8239 & 4.4085 & TRN & \\
\hline CHEMBL1370195 & 688845 & 2.8239 & 3.5866 & TST & \\
\hline CHEMBL1549574 & 688845 & 4.1052 & 4.1815 & TRN & \\
\hline CHEMBL1501309 & 688845 & 4.7867 & 4.5296 & TRN & \\
\hline CHEMBL1478460 & 688845 & 4.5065 & 4.4137 & TRN & \\
\hline CHEMBL1600807 & 688845 & 2.8239 & 4.0739 & TRN & \\
\hline CHEMBL1313044 & 688845 & 4.0292 & 4.1576 & TRN & \\
\hline CHEMBL1481934 & 688845 & 4.8492 & 4.4181 & TRN & \\
\hline CHEMBL1309827 & 688845 & 7.6383 & 3.5378 & TST & \\
\hline
\end{tabular}




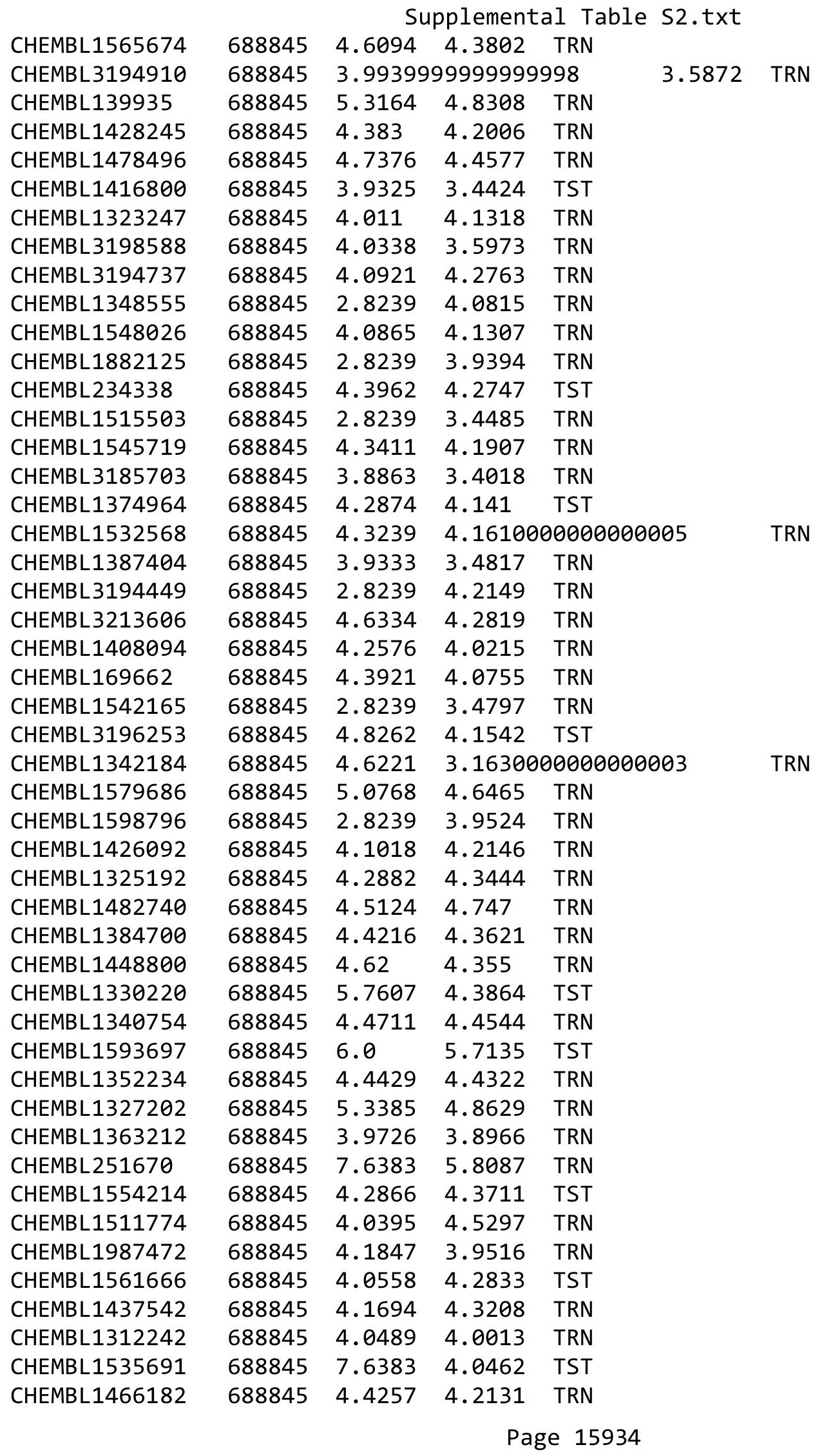




\begin{tabular}{|c|c|c|c|c|c|}
\hline \multirow[b]{2}{*}{ CHEMBL1460809 } & \multicolumn{5}{|c|}{ Supplemental Table s2.txt } \\
\hline & 688845 & 3.8412 & 4.0396 & TST & \\
\hline CHEMBL1592917 & 688845 & 4.3791 & 4.4261 & TST & \\
\hline CHEMBL1440490 & 688845 & 3.8825 & 4.2767 & TRN & \\
\hline CHEMBL1385206 & 688845 & 5.4569 & 4.9513 & TRN & \\
\hline CHEMBL1454171 & 688845 & 4.3614 & 4.3069 & TST & \\
\hline CHEMBL3192690 & 688845 & 4.2387 & 4.05699 & 99999999995 & TRN \\
\hline CHEMBL1616787 & 688845 & 2.8239 & 4.3531 & TRN & \\
\hline CHEMBL299228 & 688845 & 4.0926 & 4.1528 & TRN & \\
\hline CHEMBL1581725 & 688845 & 2.8239 & 4.2 & TRN & \\
\hline CHEMBL1368458 & 688845 & 4.4263 & 4.3702 & TRN & \\
\hline CHEMBL1607938 & 688845 & 3.8264 & 4.1627 & TRN & \\
\hline CHEMBL1599208 & 688845 & 4.4737 & 4.1381 & TRN & \\
\hline CHEMBL1372734 & 688845 & 4.398 & 4.1638 & TRN & \\
\hline CHEMBL1410230 & 688845 & 4.3608 & 4.2408 & TRN & \\
\hline CHEMBL1596681 & 688845 & 4.4356 & 4.6872 & TRN & \\
\hline CHEMBL1561133 & 688845 & 4.1786 & 4.2811 & TST & \\
\hline CHEMBL1613582 & 688845 & 3.8365 & 4.1197 & TRN & \\
\hline CHEMBL1377733 & 688845 & 2.8239 & 3.9241 & TST & \\
\hline CHEMBL1993199 & 688845 & 4.3039 & 4.1189 & TRN & \\
\hline CHEMBL1330992 & 688845 & 4.118 & 4.102 & TRN & \\
\hline CHEMBL1986151 & 688845 & 4.5381 & 4.1731 & TRN & \\
\hline CHEMBL1996730 & 688845 & 4.8174 & 4.5825 & TRN & \\
\hline CHEMBL1504354 & 688845 & 2.8239 & 4.0742 & TRN & \\
\hline CHEMBL 2004056 & 688845 & 4.4096 & 4.2373 & TRN & \\
\hline CHEMBL 2001316 & 688845 & 3.8651 & 3.4059 & TRN & \\
\hline CHEMBL1481601 & 688845 & 4.9523 & 4.2485 & TRN & \\
\hline CHEMBL566933 & 688845 & 4.4762 & 4.3908 & TRN & \\
\hline CHEMBL1584438 & 688845 & 4.2135 & 4.2103 & TRN & \\
\hline CHEMBL104270 & 688845 & 7.6383 & 6.251 & TRN & \\
\hline CHEMBL1359859 & 688845 & 4.0453 & 3.9519 & TRN & \\
\hline CHEMBL1520621 & 688845 & 2.8239 & 4.0123 & TRN & \\
\hline CHEMBL1439747 & 688845 & 4.0923 & 4.03 & TST & \\
\hline CHEMBL1328072 & 688845 & 4.2094 & 3.5479 & TRN & \\
\hline CHEMBL3192651 & 688845 & 4.5429 & 4.4052 & TRN & \\
\hline CHEMBL3190958 & 688845 & 4.1441 & 4.0166 & TRN & \\
\hline CHEMBL1373092 & 688845 & 4.1034 & 4.1395 & TRN & \\
\hline CHEMBL1518557 & 688845 & 3.858 & 4.1992 & TRN & \\
\hline CHEMBL3211290 & 688845 & 4.6996 & 4.4552 & TRN & \\
\hline CHEMBL1542594 & 688845 & 4.4198 & 4.3848 & TST & \\
\hline CHEMBL1390787 & 688845 & 4.2077 & 4.0218 & TRN & \\
\hline CHEMBL1338004 & 688845 & 4.7414 & 4.9716 & TRN & \\
\hline CHEMBL1326171 & 688845 & 2.8239 & 4.0073 & TRN & \\
\hline CHEMBL1313622 & 688845 & 4.1271 & 4.1827 & TRN & \\
\hline CHEMBL52101 & 688845 & 4.2691 & 4.3293 & TRN & \\
\hline CHEMBL 2369277 & 688845 & 4.4399 & 4.3801 & TRN & \\
\hline CHEMBL3194579 & 688845 & 4.2301 & 4.4295 & TRN & \\
\hline CHEMBL1986183 & 688845 & 4.1662 & 4.0411 & TST & \\
\hline CHEMBL1502777 & 688845 & 3.8414 & 4.0938 & TRN & \\
\hline
\end{tabular}

Page 15935 


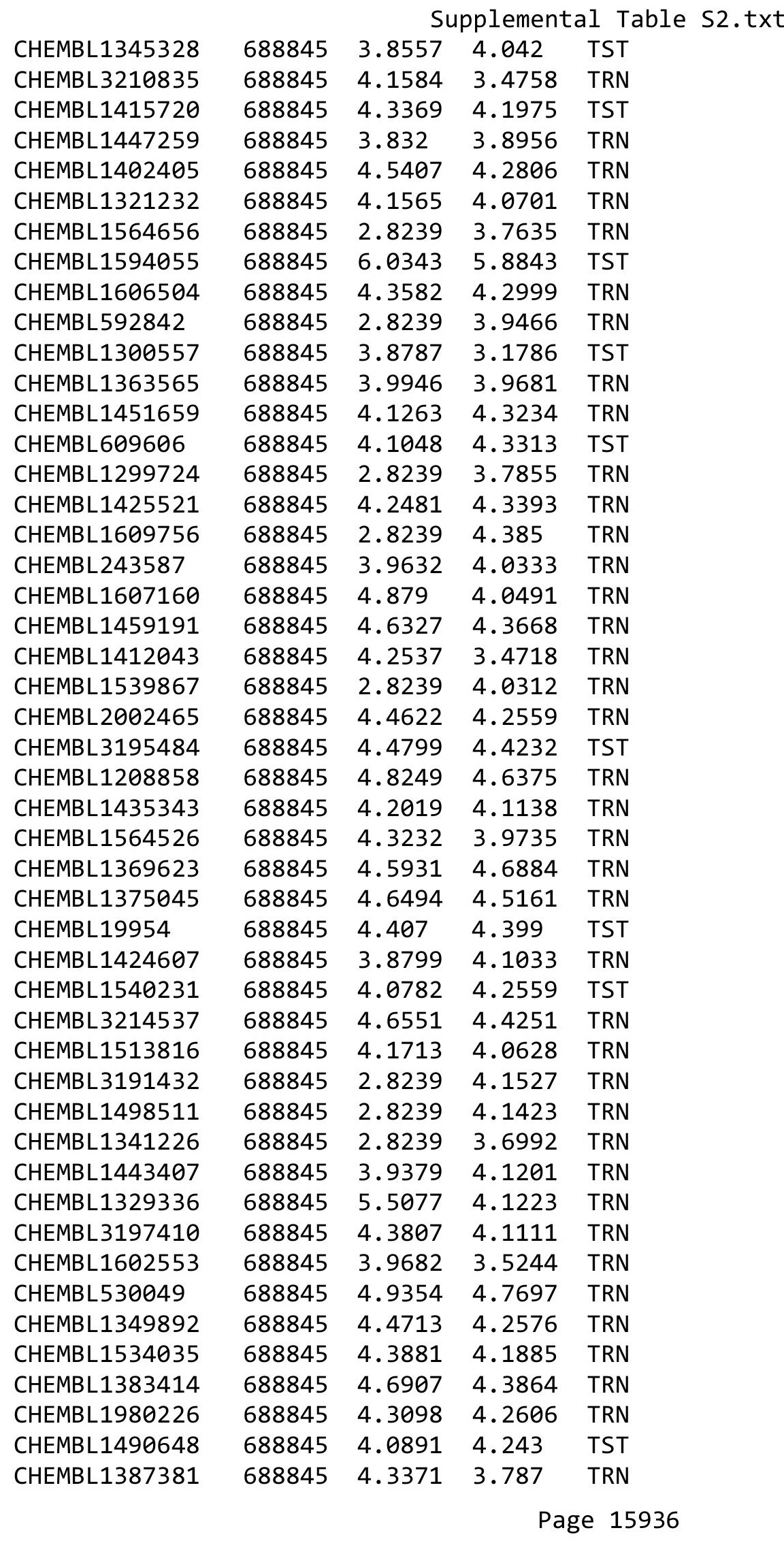




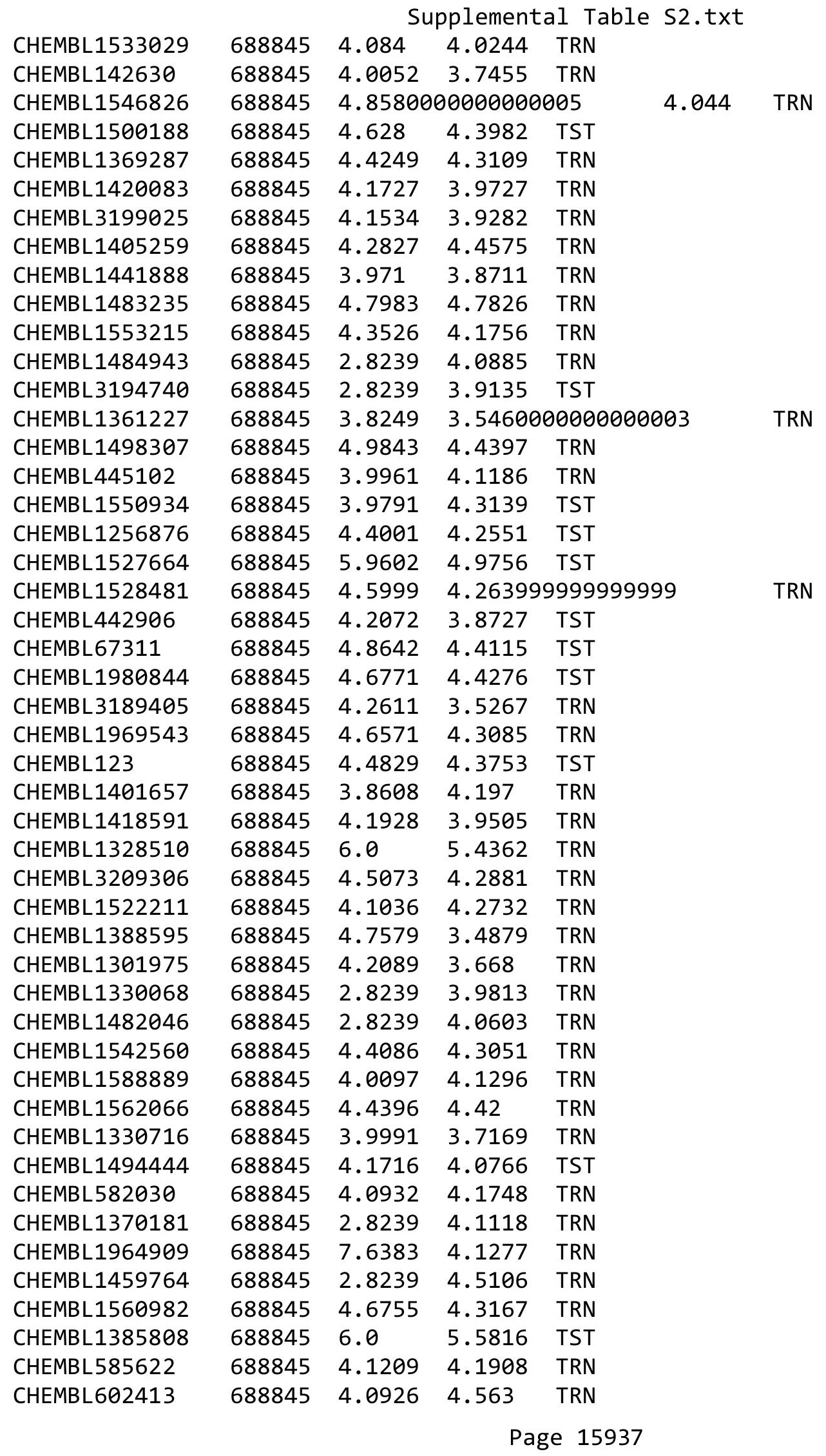




\begin{tabular}{|c|c|c|c|c|c|}
\hline & & \multicolumn{4}{|c|}{ Supplemental Table s2.txt } \\
\hline CHEMBL3197977 & 688845 & 4.0825 & 3.9851 & TRN & \\
\hline CHEMBL3199665 & 688845 & 4.5409 & 3.5797 & TRN & \\
\hline CHEMBL1600045 & 688845 & 3.8843 & 4.1001 & TRN & \\
\hline CHEMBL1421414 & 688845 & 3.8525 & 3.665 & TST & \\
\hline CHEMBL1589425 & 688845 & 4.7834 & 4.4581 & TRN & \\
\hline CHEMBL1409219 & 688845 & 4.0852 & 3.5548 & TRN & \\
\hline CHEMBL548615 & 688845 & 4.697 & 4.4868 & TRN & \\
\hline CHEMBL1378952 & 688845 & 4.4978 & 4.4637 & TRN & \\
\hline CHEMBL1904459 & 688845 & 4.4705 & 4.1626 & TRN & \\
\hline CHEMBL1484328 & 688845 & 4.6133 & 4.0026 & TRN & \\
\hline CHEMBL1555739 & 688845 & 4.2003 & 4.0952 & TRN & \\
\hline CHEMBL1366004 & 688845 & 4.0711 & 4.3673 & TRN & \\
\hline CHEMBL429095 & 688845 & 3.9134 & 4.0462 & TRN & \\
\hline CHEMBL1984298 & 688845 & 4.6027 & 3.7503 & TRN & \\
\hline CHEMBL3191530 & 688845 & 4.2115 & 4.2099 & TRN & \\
\hline CHEMBL603020 & 688845 & 4.775 & 4.7727 & TRN & \\
\hline CHEMBL1342357 & 688845 & 4.4199 & 4.2495 & TRN & \\
\hline CHEMBL1308051 & 688845 & 3.8535 & 3.983 & TRN & \\
\hline CHEMBL1385558 & 688845 & 4.4096 & 4.29 & TRN & \\
\hline CHEMBL2373661 & 688845 & 5.0318 & 4.7984 & TST & \\
\hline CHEMBL1382265 & 688845 & 4.0959 & 4.1723 & TRN & \\
\hline CHEMBL1200847 & 688845 & 4.7893 & 4.2771 & TRN & \\
\hline CHEMBL1477547 & 688845 & 4.0863 & 4.1805 & TRN & \\
\hline CHEMBL1502014 & 688845 & 4.112 & 4.1725 & TST & \\
\hline CHEMBL1525481 & 688845 & 4.104 & 4.0693 & TRN & \\
\hline CHEMBL441986 & 688845 & 3.9091 & 4.0911 & TST & \\
\hline CHEMBL1572436 & 688845 & 4.5902 & 4.27800 & 00000000005 & TRN \\
\hline CHEMBL3195570 & 688845 & 4.4505 & 4.1579 & TRN & \\
\hline CHEMBL1376732 & 688845 & 3.8659 & 3.9612 & TRN & \\
\hline CHEMBL1424729 & 688845 & 4.0026 & 4.2218 & TST & \\
\hline CHEMBL1389330 & 688845 & 2.8239 & 4.1282 & TRN & \\
\hline CHEMBL1568414 & 688845 & 4.6744 & 4.3177 & TRN & \\
\hline CHEMBL1412114 & 688845 & 3.9735 & 4.2934 & TRN & \\
\hline CHEMBL1347193 & 688845 & 4.0438 & 4.5382 & TRN & \\
\hline CHEMBL283849 & 688845 & 6.3526 & 5.4607 & TRN & \\
\hline CHEMBL1403593 & 688845 & 4.3322 & 3.7001 & TRN & \\
\hline CHEMBL1457463 & 688845 & 4.3846 & 4.2117 & TRN & \\
\hline CHEMBL1336722 & 688845 & 4.3082 & 4.4084 & TST & \\
\hline CHEMBL1572266 & 688845 & 6.4559 & 6.2528 & TRN & \\
\hline CHEMBL3196547 & 688845 & 4.4232 & 4.2977 & TRN & \\
\hline CHEMBL1411080 & 688845 & 3.8314 & 3.9522 & TRN & \\
\hline CHEMBL1398181 & 688845 & 4.3141 & 4.1862 & TRN & \\
\hline CHEMBL1408942 & 688845 & 2.8239 & 4.1282 & TRN & \\
\hline CHEMBL1404984 & 688845 & 3.9885 & 4.0804 & TRN & \\
\hline CHEMBL1309128 & 688845 & 4.01399 & 99999999 & 3.5715 & TRN \\
\hline CHEMBL1544460 & 688845 & 3.8929 & 4.35 & TRN & \\
\hline CHEMBL606166 & 688845 & 3.9208 & 4.24100 & 20000000005 & TST \\
\hline CHEMBL1572896 & 688845 & 3.8396 & 4.0774 & TRN & \\
\hline
\end{tabular}




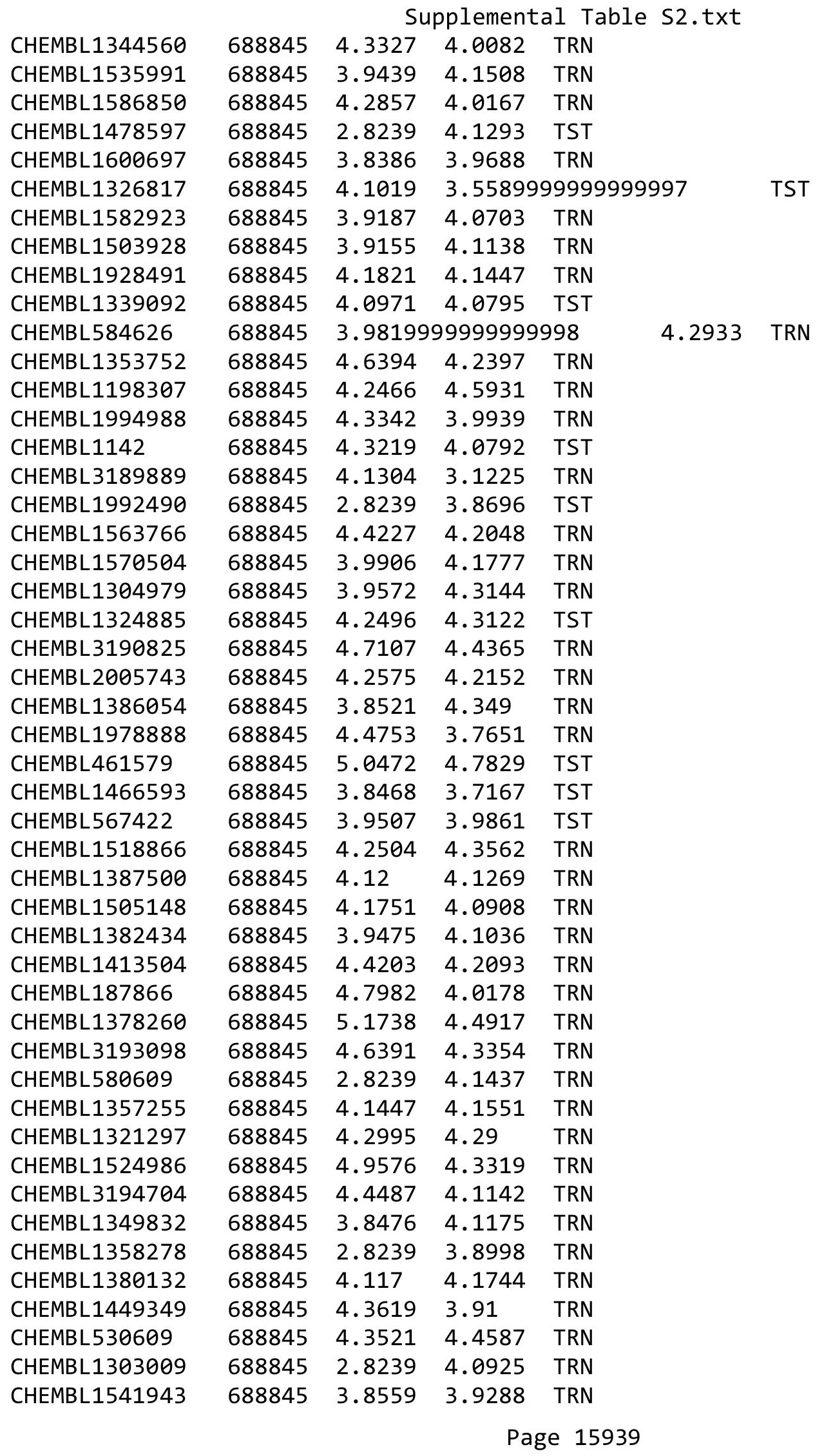




\begin{tabular}{|c|c|c|c|c|c|c|}
\hline & & \multicolumn{5}{|c|}{ Supplemental Table S2.txt } \\
\hline CHEMBL3145245 & 688845 & 4.2712 & 4.0457 & TRN & & \\
\hline CHEMBL1478435 & 688845 & 3.8449 & 3.7546 & TRN & & \\
\hline CHEMBL1568848 & 688845 & 4.3188 & 4.2529 & TRN & & \\
\hline CHEMBL1530234 & 688845 & 4.1055 & 4.0354 & TRN & & \\
\hline CHEMBL3194689 & 688845 & 3.9429 & 3.4907 & TRN & & \\
\hline CHEMBL1430673 & 688845 & 4.4398 & 4.0104 & TRN & & \\
\hline CHEMBL1419585 & 688845 & $3.8680 e$ & 00000000 & 203 & 4.0872 & TRN \\
\hline CHEMBL3195459 & 688845 & 4.6413 & 4.3402 & TRN & & \\
\hline CHEMBL1398224 & 688845 & 4.4088 & 4.3313 & TST & & \\
\hline CHEMBL1455197 & 688845 & 4.1609 & 3.9734 & TRN & & \\
\hline CHEMBL1576581 & 688845 & 5.0711 & 4.7443 & TRN & & \\
\hline CHEMBL153535 & 688845 & 4.1251 & 4.0019 & TRN & & \\
\hline CHEMBL1541209 & 688845 & 2.8239 & 3.7087 & TRN & & \\
\hline CHEMBL1388836 & 688845 & 4.4681 & 4.3465 & TRN & & \\
\hline CHEMBL1331050 & 688845 & 3.8369 & 3.5165 & TRN & & \\
\hline CHEMBL3195549 & 688845 & 4.883 & 4.334 & TRN & & \\
\hline CHEMBL1964793 & 688845 & 4.5558 & 4.4637 & TRN & & \\
\hline CHEMBL1595024 & 688845 & 4.6444 & 4.4187 & TRN & & \\
\hline CHEMBL1415035 & 688845 & 4.2146 & 4.0803 & TRN & & \\
\hline CHEMBL1326203 & 688845 & 4.1871 & 4.3481 & TRN & & \\
\hline CHEMBL520667 & 688845 & 4.2631 & 4.0309 & TRN & & \\
\hline CHEMBL1386615 & 688845 & 4.0205 & 3.7002 & TRN & & \\
\hline CHEMBL1314743 & 688845 & 4.5642 & 4.2721 & TRN & & \\
\hline CHEMBL1471206 & 688845 & 2.8239 & 3.8464 & TRN & & \\
\hline CHEMBL1499792 & 688845 & 4.4659 & 4.4161 & TRN & & \\
\hline CHEMBL1449490 & 688845 & 4.1108 & 4.2112 & TST & & \\
\hline CHEMBL1460656 & 688845 & 4.2692 & 4.0846 & TRN & & \\
\hline CHEMBL1457139 & 688845 & 4.4588 & 4.4592 & TRN & & \\
\hline CHEMBL3195943 & 688845 & 4.8838 & 4.4536 & TRN & & \\
\hline CHEMBL1403921 & 688845 & 3.9193 & 3.6398 & TRN & & \\
\hline CHEMBL1454391 & 688845 & 4.1608 & 3.9577 & TRN & & \\
\hline CHEMBL1425438 & 688845 & 4.1376 & 4.0134 & TRN & & \\
\hline CHEMBL1588107 & 688845 & 4.4434 & 4.2679 & TRN & & \\
\hline CHEMBL1501653 & 688845 & 4.5536 & 4.4506 & TRN & & \\
\hline CHEMBL3196358 & 688845 & 4.3003 & 4.1289 & TRN & & \\
\hline CHEMBL1543738 & 688845 & 4.1048 & 3.4389 & TRN & & \\
\hline CHEMBL1256737 & 688845 & 4.2546 & 4.2835 & TRN & & \\
\hline CHEMBL1497059 & 688845 & 3.8823 & 3.9736 & TST & & \\
\hline CHEMBL581257 & 688845 & 4.3669 & 4.2553 & TST & & \\
\hline CHEMBL 1440037 & 688845 & 4.0707 & 4.2627 & TRN & & \\
\hline CHEMBL1507898 & 688845 & 4.0762 & 4.2125 & TRN & & \\
\hline CHEMBL1359781 & 688845 & 3.8619 & 3.7803 & TRN & & \\
\hline CHEMBL1459734 & 688845 & 4.5404 & 4.4266 & TRN & & \\
\hline CHEMBL1440235 & 688845 & 4.0792 & 4.3189 & TRN & & \\
\hline CHEMBL1312441 & 688845 & 3.9417 & 4.1608 & TRN & & \\
\hline CHEMBL1242180 & 688845 & 4.7096 & 4.4967 & TST & & \\
\hline CHEMBL1993190 & 688845 & 4.055 & 3.6 & TRN & & \\
\hline CHEMBL1738986 & 688845 & 4.4112 & 4.2649 & TRN & & \\
\hline
\end{tabular}




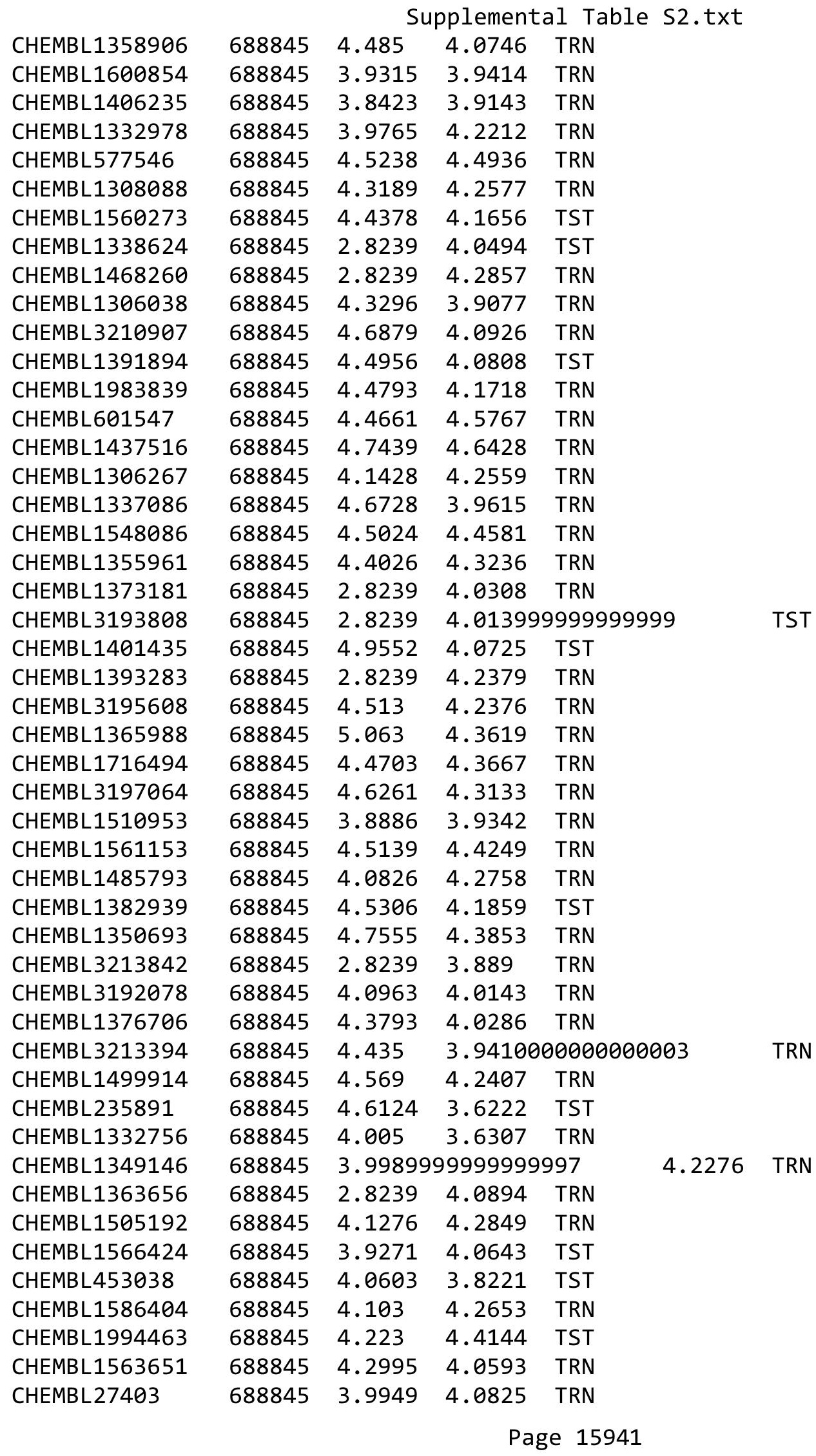




\begin{tabular}{|c|c|c|c|c|c|}
\hline \multicolumn{6}{|c|}{ Supplemental Table S2.txt } \\
\hline CHEMBL1611650 & 688845 & 4.4723 & 4.3517 & TRN & \\
\hline CHEMBL1563084 & 688845 & 2.8239 & 3.5332 & TST & \\
\hline CHEMBL1397507 & 688845 & 4.72 & 4.6776 & TST & \\
\hline CHEMBL1604283 & 688845 & 6.0 & 5.5076 & TST & \\
\hline CHEMBL 1578376 & 688845 & 3.9013 & 3.8012 & TRN & \\
\hline CHEMBL1520808 & 688845 & 4.1755 & 4.1177 & TRN & \\
\hline CHEMBL1710 & 688845 & 3.906 & 4.1773 & TRN & \\
\hline CHEMBL582444 & 688845 & 4.3786 & 4.3841 & TRN & \\
\hline CHEMBL1326083 & 688845 & 4.473 & 4.2688 & TRN & \\
\hline CHEMBL1328570 & 688845 & 2.8239 & 3.9907 & TRN & \\
\hline CHEMBL1971965 & 688845 & 4.6835 & 4.3574 & TRN & \\
\hline CHEMBL 2004417 & 688845 & 4.606 & 4.3518 & TRN & \\
\hline CHEMBL3190546 & 688845 & 4.4736 & 4.08899 & 99999999995 & TRN \\
\hline CHEMBL1501558 & 688845 & 4.4695 & 4.3528 & TRN & \\
\hline CHEMBL1539359 & 688845 & 4.2049 & 4.2786 & TRN & \\
\hline CHEMBL1395220 & 688845 & 4.1001 & 4.0999 & TRN & \\
\hline CHEMBL1463614 & 688845 & 4.435 & 4.4857 & TRN & \\
\hline CHEMBL1427717 & 688845 & 4.7392 & 3.9494 & TRN & \\
\hline CHEMBL1443977 & 688845 & 4.4729 & 3.8853 & TRN & \\
\hline CHEMBL1564901 & 688845 & 4.1381 & 3.8795 & TST & \\
\hline CHEMBL1423463 & 688845 & 4.1684 & 4.4012 & TRN & \\
\hline CHEMBL1384387 & 688845 & 4.4406 & 4.4581 & TRN & \\
\hline CHEMBL1610733 & 688845 & 2.8239 & 4.0187 & TRN & \\
\hline CHEMBL1363502 & 688845 & 4.041 & 3.7488 & TRN & \\
\hline CHEMBL3199413 & 688845 & 3.9735 & 4.073 & TRN & \\
\hline CHEMBL 2000750 & 688845 & 4.5733 & 4.1596 & TRN & \\
\hline CHEMBL1322008 & 688845 & 4.1393 & 4.20100 & 00000000005 & TRN \\
\hline CHEMBL68997 & 688845 & 4.4258 & 4.3284 & TRN & \\
\hline CHEMBL1373533 & 688845 & 3.9964 & 4.0945 & TRN & \\
\hline CHEMBL1339613 & 688845 & 4.2658 & 4.3152 & TRN & \\
\hline CHEMBL1300729 & 688845 & 2.8239 & 4.046 & TRN & \\
\hline CHEMBL1472253 & 688845 & 4.2465 & 3.8969 & TRN & \\
\hline CHEMBL1378707 & 688845 & 4.0447 & 4.2011 & TRN & \\
\hline CHEMBL580183 & 688845 & 4.2432 & 3.9999 & TRN & \\
\hline CHEMBL414400 & 688845 & 5.5929 & 4.9388 & TRN & \\
\hline CHEMBL81324 & 688845 & 3.8407 & 4.0238 & TRN & \\
\hline CHEMBL 1495602 & 688845 & 4.0202 & 4.2409 & TST & \\
\hline CHEMBL1308845 & 688845 & 4.088 & 4.2029 & TRN & \\
\hline CHEMBL1527341 & 688845 & 4.5951 & 4.7046 & TRN & \\
\hline CHEMBL1479530 & 688845 & 4.8989 & 4.2175 & TST & \\
\hline CHEMBL1521705 & 688845 & 5.1152 & 4.7375 & TRN & \\
\hline CHEMBL1598775 & 688845 & 4.1145 & 4.3022 & TRN & \\
\hline CHEMBL1339036 & 688845 & 2.8239 & 3.8365 & TRN & \\
\hline CHEMBL1530942 & 688845 & 3.8452 & 4.0469 & TST & \\
\hline CHEMBL3190286 & 688845 & 3.8747 & 3.8689 & TRN & \\
\hline CHEMBL3191484 & 688845 & 3.9875 & 3.8931 & TRN & \\
\hline CHEMBL1524052 & 688845 & 4.2528 & 4.183 & TRN & \\
\hline CHEMBL1307428 & 688845 & 2.8239 & 3.9312 & TRN & \\
\hline
\end{tabular}




\begin{tabular}{|c|c|c|c|c|c|c|}
\hline & & \multicolumn{5}{|c|}{ Supplemental Table S2.txt } \\
\hline CHEMBL1478103 & 688845 & 4.0813 & 4.3409 & TRN & & \\
\hline CHEMBL 3144932 & 688845 & 4.3142 & 3.505 & TRN & & \\
\hline CHEMBL1422217 & 688845 & 4.0776 & 4.2043 & TRN & & \\
\hline CHEMBL1550442 & 688845 & 4.2816 & 4.2715 & TRN & & \\
\hline CHEMBL1490728 & 688845 & 4.3422 & 4.245 & TRN & & \\
\hline CHEMBL1301509 & 688845 & 3.8676 & 4.0592 & TST & & \\
\hline CHEMBL1611026 & 688845 & 2.8239 & 4.0797 & TRN & & \\
\hline CHEMBL3191309 & 688845 & 4.3137 & 4.2583 & TRN & & \\
\hline CHEMBL591137 & 688845 & 4.4615 & 4.4736 & TRN & & \\
\hline CHEMBL1507990 & 688845 & 4.1753 & 4.1991 & TRN & & \\
\hline CHEMBL1460853 & 688845 & 3.9376 & 3.9998 & TRN & & \\
\hline CHEMBL 3195094 & 688845 & 4.7064 & 4.2223 & TRN & & \\
\hline CHEMBL1388274 & 688845 & 4.369 & 4.3044 & TRN & & \\
\hline CHEMBL1544371 & 688845 & 4.3202 & 4.3451 & TRN & & \\
\hline CHEMBL3195766 & 688845 & 3.9603 & 3.5793 & TRN & & \\
\hline CHEMBL1393092 & 688845 & 4.375 & 3.8785 & TST & & \\
\hline CHEMBL1975118 & 688845 & 4.5273 & 4.3341 & TRN & & \\
\hline CHEMBL345124 & 688845 & 4.2723 & 3.5551 & TST & & \\
\hline CHEMBL1507242 & 688845 & 2.8239 & 4.0343 & TRN & & \\
\hline CHEMBL1350506 & 688845 & 3.932 & 4.2378 & TRN & & \\
\hline CHEMBL1321398 & 688845 & 4.4997 & 4.4384 & TST & & \\
\hline CHEMBL3197991 & 688845 & 4.3566 & 4.078 & TRN & & \\
\hline CHEMBL1573630 & 688845 & 4.4079 & 4.0449 & TRN & & \\
\hline CHEMBL1433109 & 688845 & 4.0974 & 4.0971 & TST & & \\
\hline CHEMBL1418885 & 688845 & 4.292 & 4.3609 & TRN & & \\
\hline CHEMBL1429241 & 688845 & 4.0564 & 3.4977 & TRN & & \\
\hline CHEMBL 3190482 & 688845 & 4.0796 & 4.1499 & TRN & & \\
\hline CHEMBL601757 & 688845 & 6.1073 & 5.1781 & TST & & \\
\hline CHEMBL1391048 & 688845 & 4.1208 & 4.3964 & TRN & & \\
\hline CHEMBL3198170 & 688845 & 4.09 & 3.9024 & TRN & & \\
\hline CHEMBL193872 & 688845 & 4.8991 & 4.8353 & TST & & \\
\hline CHEMBL1304293 & 688845 & 3.89300 & 00000000 & 002 & 4.1969 & TRN \\
\hline CHEMBL1448592 & 688845 & 4.7183 & 4.4171 & TST & & \\
\hline CHEMBL3196495 & 688845 & 4.6958 & 4.2253 & TRN & & \\
\hline CHEMBL1495072 & 688845 & 4.2013 & 4.3037 & TRN & & \\
\hline CHEMBL1470669 & 688845 & 4.6279 & 3.4875 & TRN & & \\
\hline CHEMBL428064 & 688845 & 5.9322 & 5.1956 & TRN & & \\
\hline CHEMBL1583127 & 688845 & 4.6233 & 4.2526 & TRN & & \\
\hline CHEMBL1580272 & 688845 & 5.2931 & 4.7183 & TRN & & \\
\hline CHEMBL602363 & 688845 & 4.1762 & 4.0944 & TST & & \\
\hline CHEMBL1548109 & 688845 & 4.3047 & 4.5074 & TRN & & \\
\hline CHEMBL1382888 & 688845 & 3.9122 & 3.3793 & TRN & & \\
\hline CHEMBL571501 & 688845 & 4.4009 & 3.5503 & TRN & & \\
\hline CHEMBL1395962 & 688845 & 4.3651 & 4.3229 & TRN & & \\
\hline CHEMBL1440420 & 688845 & 3.8956 & 4.1441 & TRN & & \\
\hline CHEMBL1609529 & 688845 & 4.4637 & 4.5725 & TRN & & \\
\hline CHEMBL1384026 & 688845 & 4.1389 & 4.1429 & TRN & & \\
\hline CHEMBL1362990 & 688845 & 2.8239 & 3.93 & TRN & & \\
\hline
\end{tabular}




\begin{tabular}{|c|c|c|c|c|c|}
\hline \multicolumn{6}{|c|}{ Supplemental Table S2.txt } \\
\hline CHEMBL1405964 & 688845 & 3.9446 & 4.874 & TRN & \\
\hline CHEMBL1384935 & 688845 & 4.2017 & 4.2209 & TRN & \\
\hline CHEMBL598270 & 688845 & 4.0967 & 4.2276 & TRN & \\
\hline CHEMBL 3196546 & 688845 & 3.8866 & 4.0068 & TRN & \\
\hline CHEMBL 3196813 & 688845 & 4.3331 & 4.0738 & TRN & \\
\hline CHEMBL1304172 & 688845 & 4.419 & 4.532 & TRN & \\
\hline CHEMBL1995193 & 688845 & 4.0493 & 3.7955 & TRN & \\
\hline CHEMBL1482500 & 688845 & 4.5654 & 4.3517 & TRN & \\
\hline CHEMBL66953 & 688845 & 4.7573 & 4.3977 & TRN & \\
\hline CHEMBL3197662 & 688845 & 4.4756 & 4.1478 & TRN & \\
\hline CHEMBL1382479 & 688845 & 4.261 & 4.0702 & TRN & \\
\hline CHEMBL1984876 & 688845 & 4.2641 & 4.263999 & 9999999999 & TRN \\
\hline CHEMBL1351158 & 688845 & 4.8468 & 4.8919 & TRN & \\
\hline CHEMBL578512 & 688845 & 6.1302 & 5.2002 & TST & \\
\hline CHEMBL1375232 & 688845 & 3.9505 & 4.013 & TRN & \\
\hline CHEMBL1984581 & 688845 & 2.8239 & 3.9739 & TST & \\
\hline CHEMBL1452301 & 688845 & 4.0553 & 4.2046 & TRN & \\
\hline CHEMBL1328567 & 688845 & 4.0514 & 3.2671 & TRN & \\
\hline CHEMBL1543548 & 688845 & 3.9676 & 4.034 & TRN & \\
\hline CHEMBL1406274 & 688845 & 6.0 & 5.2276 & TRN & \\
\hline CHEMBL3192432 & 688845 & 4.3163 & 4.3121 & TRN & \\
\hline CHEMBL1587596 & 688845 & 4.8254 & 4.5905 & TRN & \\
\hline CHEMBL1305911 & 688845 & 4.3626 & 4.1602 & TRN & \\
\hline CHEMBL1987461 & 688845 & 4.3313 & 3.7003 & TRN & \\
\hline CHEMBL1565592 & 688845 & 4.6545 & 4.3211 & TRN & \\
\hline CHEMBL1579201 & 688845 & 2.8239 & 4.0354 & TRN & \\
\hline CHEMBL1543256 & 688845 & 2.8239 & 4.1165 & TRN & \\
\hline CHEMBL1380091 & 688845 & 4.1681 & 4.2194 & TRN & \\
\hline CHEMBL1468104 & 688845 & 3.8867 & 4.128 & TST & \\
\hline CHEMBL1559687 & 688845 & 4.4592 & 3.9979 & TRN & \\
\hline CHEMBL1556805 & 688845 & 4.4475 & 4.2259 & TST & \\
\hline CHEMBL1500643 & 688845 & 4.7627 & 4.1702 & TRN & \\
\hline CHEMBL525826 & 688845 & 4.0731 & 4.4399 & TRN & \\
\hline CHEMBL1586895 & 688845 & 2.8239 & 3.9239 & TRN & \\
\hline CHEMBL1342066 & 688845 & 2.8239 & 4.1079 & TRN & \\
\hline CHEMBL1426788 & 688845 & 4.1287 & 4.2215 & TRN & \\
\hline CHEMBL1485234 & 688845 & 4.1266 & 3.8153 & TRN & \\
\hline CHEMBL1555833 & 688845 & 4.0824 & 4.0845 & TRN & \\
\hline CHEMBL1981612 & 688845 & 4.5193 & 4.3597 & TRN & \\
\hline CHEMBL1478652 & 688845 & 2.8239 & 4.4072 & TRN & \\
\hline CHEMBL1311401 & 688845 & 4.0955 & 4.2234 & TST & \\
\hline CHEMBL3193897 & 688845 & 4.5384 & 4.0304 & TRN & \\
\hline CHEMBL1528425 & 688845 & 4.9252 & 4.6047 & TRN & \\
\hline CHEMBL1509380 & 688845 & 4.8045 & 4.9451 & TRN & \\
\hline CHEMBL3197284 & 688845 & 3.9514 & 4.0446 & TST & \\
\hline CHEMBL1485551 & 688845 & 3.9573 & 4.1465 & TRN & \\
\hline CHEMBL 3213802 & 688845 & 3.9426 & 3.8113 & TST & \\
\hline CHEMBL570345 & 688845 & 4.8549 & 4.2739 & TRN & \\
\hline
\end{tabular}


Supplemental Table S2.txt

\begin{tabular}{|c|c|c|c|c|}
\hline HEM & & 4.5952 & & \\
\hline & & & & \\
\hline HEMR 1 & 5 & & & \\
\hline IEMBL1 & 38845 & & & \\
\hline HEMBL1448340 & 88845 & 383 & 046 & \\
\hline HEMBL31994 & 88845 & & $\partial 256$ & \\
\hline IEMBL] & 8845 & & & \\
\hline AEMBL1542886 & 8845 & & & \\
\hline HEMBL1570835 & 88845 & 006 & .4012 & \\
\hline HEMBL463175 & 88845 & 693 & .301 & \\
\hline HEMBL14569 & 88845 & & & \\
\hline IEMBL15 & 845 & & 48 & T \\
\hline AEMBL 5285 & & & & \\
\hline HEMBL1331185 & 88845 & & 3309 & \\
\hline HEMBL1487183 & 8845 & & & \\
\hline AEMBL151: & 5 & & & \\
\hline AEMBL25 & & & & \\
\hline HEMBL130 & 845 & & & \\
\hline HEMBL3196305 & 845 & & & \\
\hline AEMBL15872 & & & & \\
\hline HEMBL13 & 5 & & & RIN \\
\hline AEMBL & & & & MIV \\
\hline HEMBL] & 15 & & & RN \\
\hline HEMBL1604 & 45 & & & \\
\hline HEMBL5818 & 45 & & & RN \\
\hline HEMBL 31 & 845 & & & RN \\
\hline HEM & & & & RN \\
\hline AEMPI - & 15 & & & RN \\
\hline AEMBL134ع & & & & IRN \\
\hline AEMBL15053: & 8845 & & 9267 & TST \\
\hline AEMBL1: & 45 & & 44 & 「RN \\
\hline HEM & 5 & & & RN \\
\hline $15 \mathrm{M}$ & & & & TRN \\
\hline HEMBL1421542 & & & & ГST \\
\hline HEMBL580340 & 8845 & & 501 & ГRN \\
\hline JEMRI 58 & 45 & & & TRN \\
\hline 10 & 5 & & 33 & ГRN \\
\hline HEMBL15289 & & & & TST \\
\hline HEMBL15376 & 8845 & & & $\Gamma R$ \\
\hline EMBL1 & 15 & & & RN \\
\hline HEMBL1308 & 45 & & 07 & TRN \\
\hline HEMBL13212 & 845 & & 3.1318 & 「RN \\
\hline HEMBL1564 & 5 & & 2788 & TST \\
\hline HEMBL1587£ & 45 & & & TR \\
\hline CHFMPI 11629 & & & & \\
\hline HEMBL1532831 & & & & \\
\hline HEMBL1370471 & & 4.6714 & 4.7432 & \\
\hline HEMBL1458722 & 688845 & 4.1034 & 4.2257 & $\pi$ \\
\hline
\end{tabular}

Page 15945 
Supplemental Table S2.txt

\begin{tabular}{|c|c|c|c|c|c|}
\hline CHEMBL1382884 & 688845 & 4.6977 & 4.3869 & TST & \\
\hline CHEMBL 1587753 & 688845 & 6.2358 & 5.073 & TST & \\
\hline CHEMBL1388616 & 688845 & 3.8662 & 4.022 & TST & \\
\hline CHEMBL1464975 & 688845 & 4.3239 & 4.066 & TST & \\
\hline CHEMBL1379600 & 688845 & 3.8274 & 4.0185 & TST & \\
\hline CHEMBL1964405 & 688845 & 4.3396 & 4.0591 & TST & \\
\hline CHEMBL 1446900 & 688845 & 3.8518 & 4.0117 & TST & \\
\hline CHEMBL1502346 & 688845 & 3.8754 & 4.0756 & TST & \\
\hline CHEMBL 71936 & 688845 & 4.2977 & 3.5104 & TST & \\
\hline CHEMBL581870 & 688845 & 4.1929 & 4.3186 & TST & \\
\hline CHEMBL1469216 & 688845 & 3.9026 & 3.93399 & 99999999997 & TST \\
\hline CHEMBL1342570 & 688845 & 4.2298 & 4.2201 & TST & \\
\hline CHEMBL1999984 & 688845 & 4.6804 & 3.7057 & TST & \\
\hline CHEMBL1538611 & 688845 & 3.8871 & 3.6372 & TST & \\
\hline CHEMBL1330113 & 688845 & 6.0 & 5.2011 & TST & \\
\hline CHEMBL1315701 & 688845 & 4.4415 & 3.9818 & TST & \\
\hline CHEMBL1386044 & 688845 & 4.4348 & 4.0273 & TST & \\
\hline CHEMBL1486325 & 688845 & 4.1077 & 3.4418 & TST & \\
\hline CHEMBL1596605 & 688845 & 4.1139 & 4.0604 & TST & \\
\hline CHEMBL1411779 & 688845 & 4.3583 & 4.0479 & TST & \\
\hline CHEMBL1505275 & 688845 & 5.2485 & 4.6388 & TST & \\
\hline CHEMBL1416171 & 688845 & 4.1181 & 4.2431 & TST & \\
\hline CHEMBL 1428566 & 688845 & 3.9397 & 4.1948 & TST & \\
\hline CHEMBL532641 & 688845 & 4.1119 & 4.5351 & TST & \\
\hline CHEMBL1346881 & 688845 & 3.863 & 4.251 & TST & \\
\hline CHEMBL1582968 & 688845 & 4.0877 & 4.0934 & TST & \\
\hline CHEMBL935 & 688845 & 4.5072 & 4.2847 & TST & \\
\hline CHEMBL458019 & 688845 & 7.6383 & 5.4142 & TST & \\
\hline CHEMBL 3197506 & 688845 & 4.5572 & 4.0889 & TST & \\
\hline CHEMBL334707 & 688845 & 5.8356 & 5.0045 & TST & \\
\hline CHEMBL1445085 & 688845 & 4.0218 & 4.1468 & TST & \\
\hline CHEMBL1981840 & 688845 & 4.188 & 4.0709 & TST & \\
\hline CHEMBL1542959 & 688845 & 6.3556 & 5.0658 & TST & \\
\hline CHEMBL1495292 & 688845 & 4.2278 & 3.9037 & TST & \\
\hline CHEMBL 1413726 & 688845 & 4.1108 & 4.1815 & TST & \\
\hline CHEMBL1326318 & 688845 & 3.9823 & 3.9506 & TST & \\
\hline CHEMBL 1401989 & 688845 & 2.8239 & 4.1943 & TST & \\
\hline CHEMBL1472251 & 688845 & 4.0468 & 4.1935 & TST & \\
\hline CHEMBL1466250 & 688845 & \multicolumn{2}{|c|}{4.071000000000001} & 3.8535 & TST \\
\hline CHEMBL1349822 & 688845 & 4.1959 & 4.0385 & TST & \\
\hline CHEMBL591126 & 688845 & 4.7036 & 4.5761 & TST & \\
\hline CHEMBL599890 & 688845 & 4.607 & 4.2871 & TST & \\
\hline CHEMBL1408130 & 688845 & 2.8239 & 4.0061 & TST & \\
\hline CHEMBL531322 & 688845 & 3.8639 & 4.4213 & TST & \\
\hline CHEMBL1598572 & 688845 & 4.021 & 4.1115 & TST & \\
\hline CHEMBL1977877 & 688845 & 4.4769 & 4.3222 & TST & \\
\hline CHEMBL 2369168 & 688845 & 4.4764 & 4.3214 & TST & \\
\hline CHEMBL1401052 & 688845 & 4.0249 & 4.0161 & TST & \\
\hline
\end{tabular}





\begin{tabular}{|c|c|c|c|c|c|}
\hline & & \multicolumn{4}{|c|}{ Supplemental Table S2.txt } \\
\hline CHEMBL238939 & 453895 & 5.2765 & 4.6881 & TST & \\
\hline CHEMBL392944 & 453895 & 4.0 & 4.2942 & TRN & \\
\hline CHEMBL241084 & 453895 & 6.4559 & 6.4722 & TRN & \\
\hline CHEMBL391127 & 453895 & 6.6021 & 6.4091 & TRN & \\
\hline CHEMBL240643 & 453895 & 6.5376 & 6.6195 & TRN & \\
\hline CHEMBL438142 & 453895 & 4.0 & 4.6458 & TRN & \\
\hline CHEMBL429643 & 453895 & 5.9469 & 6.0118 & TRN & \\
\hline CHEMBL393963 & 453895 & 6.2518 & 5.7571 & TRN & \\
\hline CHEMBL 240818 & 453895 & 6.0605 & 5.8071 & TRN & \\
\hline CHEMBL392767 & 453895 & 5.2204 & 5.4386 & TST & \\
\hline CHEMBL392986 & 453895 & 4.0 & 4.0702 & TRN & \\
\hline CHEMBL392987 & 453895 & 5.9393 & 6.2688 & TRN & \\
\hline CHEMBL240607 & 453895 & 6.0132 & 5.6933 & TST & \\
\hline CHEMBL 240608 & 453895 & 5.9245 & 5.4227 & TST & \\
\hline CHEMBL 238940 & 453895 & 4.0 & 3.9813 & TRN & \\
\hline CHEMBL 241313 & 453895 & 5.9508 & 6.154 & TRN & \\
\hline CHEMBL241265 & 453895 & 6.6778 & 6.3902 & TRN & \\
\hline CHEMBL 238528 & 453895 & 6.4318 & 6.64 & TRN & \\
\hline CHEMBL401040 & 453895 & 6.1367 & 6.1101 & TRN & \\
\hline CHEMBL393964 & 453895 & 5.3737 & 4.8554 & TST & \\
\hline CHEMBL 238522 & 453895 & 6.7447 & 6.9034 & TRN & \\
\hline CHEMBL393409 & 453895 & 5.2541 & 5.272 & TRN & \\
\hline CHEMBL 238521 & 453895 & 6.6021 & 5.5584 & TRN & \\
\hline CHEMBL393779 & 453895 & 7.0605 & 7.0761 & TRN & \\
\hline CHEMBL241669 & 453895 & 6.1192 & 6.2078 & TRN & \\
\hline CHEMBL241667 & 453895 & 6.1871 & 6.49100 & 00000000005 & TRN \\
\hline CHEMBL240606 & 453895 & 5.4855 & 4.7253 & TST & \\
\hline CHEMBL 241465 & 453895 & 5.644 & 5.4144 & TST & \\
\hline CHEMBL 238526 & 453895 & 6.6383 & 6.393 & TST & \\
\hline CHEMBL238525 & 453895 & 5.3675 & 4.763 & TRN & \\
\hline CHEMBL 238523 & 453895 & 5.4237 & 4.8233 & TRN & \\
\hline CHEMBL 238508 & 453895 & 4.0 & 4.7888 & TST & \\
\hline CHEMBL240405 & 453895 & 5.2366 & 4.7801 & TST & \\
\hline CHEMBL 394020 & 453895 & 6.5376 & 6.6515 & TRN & \\
\hline CHEMBL240406 & 453895 & 6.0269 & 5.5656 & TST & \\
\hline CHEMBL241073 & 453895 & 4.0 & 4.4763 & TRN & \\
\hline CHEMBL240644 & 453895 & 4.0 & 4.4889 & TRN & \\
\hline CHEMBL394436 & 453895 & 5.6861 & 5.4884 & TRN & \\
\hline CHEMBL153843 & 453895 & 7.4949 & 6.6084 & TST & \\
\hline CHEMBL238735 & 453895 & 6.0223 & 6.2736 & TRN & \\
\hline CHEMBL1460869 & 737264 & 4.6763 & 4.8201 & TRN & \\
\hline CHEMBL1479255 & 737264 & 4.63 & 4.9786 & TRN & \\
\hline CHEMBL322970 & 737264 & 5.255 & 5.0129 & TRN & \\
\hline CHEMBL1512748 & 737264 & 4.67899 & 99999999 & 4.939 & TST \\
\hline CHEMBL1387710 & 737264 & 5.1513 & 5.0664 & TRN & \\
\hline CHEMBL3189492 & 737264 & 5.2565 & 4.9177 & TRN & \\
\hline CHEMBL561114 & 737264 & 5.6432 & 4.7718 & TRN & \\
\hline CHEMBL1341816 & 737264 & 4.9007 & 4.6259 & TRN & \\
\hline
\end{tabular}




\begin{tabular}{|c|c|c|c|c|c|c|}
\hline & & \multicolumn{5}{|c|}{ Supplemental Table S2.txt } \\
\hline CHEMBL1989440 & 737264 & 4.5826 & 4.5565 & TRN & & \\
\hline CHEMBL1459203 & 737264 & 5.7151 & 5.2916 & TRN & & \\
\hline CHEMBL1550992 & 737264 & 4.2775 & 4.931 & TRN & & \\
\hline CHEMBL1725853 & 737264 & 4.3988 & 4.6253 & TRN & & \\
\hline CHEMBL1698845 & 737264 & 4.9093 & 4.8587 & TST & & \\
\hline CHEMBL1602923 & 737264 & 4.7636 & 4.5833 & TRN & & \\
\hline CHEMBL1407544 & 737264 & 4.6871 & 4.7927 & TRN & & \\
\hline CHEMBL328834 & 737264 & 4.8345 & 4.7634 & TST & & \\
\hline CHEMBL16288 & 737264 & 5.0665 & 4.7183 & TST & & \\
\hline CHEMBL1310617 & 737264 & 5.5289 & 5.8385 & TRN & & \\
\hline CHEMBL3197032 & 737264 & 4.4355 & 4.8146 & TRN & & \\
\hline CHEMBL3193790 & 737264 & 4.7594 & 4.8608 & TRN & & \\
\hline CHEMBL1728023 & 737264 & 5.7726 & 4.7943 & TRN & & \\
\hline CHEMBL1731237 & 737264 & 4.4848 & 4.9199 & TRN & & \\
\hline CHEMBL1329661 & 737264 & 5.376 & 5.0666 & TRN & & \\
\hline CHEMBL1734146 & 737264 & 5.1353 & 5.0614 & TRN & & \\
\hline CHEMBL1575202 & 737264 & \multicolumn{3}{|c|}{4.6530000000000005} & 5.1301 & TRN \\
\hline CHEMBL1464354 & 737264 & 5.1475 & 4.794 & TRN & & \\
\hline CHEMBL1730302 & 737264 & 4.5592 & 4.8434 & TST & & \\
\hline CHEMBL1509862 & 737264 & 5.0858 & 5.4821 & TRN & & \\
\hline CHEMBL1491396 & 737264 & 4.8174 & 5.2657 & TRN & & \\
\hline CHEMBL1709889 & 737264 & 5.0755 & 4.726 & TRN & & \\
\hline CHEMBL1928483 & 737264 & 4.927 & 5.0053 & TRN & & \\
\hline CHEMBL1346456 & 737264 & 5.6592 & 4.7665 & TRN & & \\
\hline CHEMBL77064 & 737264 & 6.3344 & 5.6749 & TRN & & \\
\hline CHEMBL1393021 & 737264 & 4.5324 & 4.8103 & TST & & \\
\hline CHEMBL 300389 & 737264 & 6.4237 & 6.2999 & TRN & & \\
\hline CHEMBL1404540 & 737264 & 5.5602 & 4.796 & TRN & & \\
\hline CHEMBL1448093 & 737264 & 4.6727 & 4.965 & TRN & & \\
\hline CHEMBL1450770 & 737264 & 4.9698 & 4.8511 & TRN & & \\
\hline CHEMBL1611838 & 737264 & 4.4867 & 4.9782 & TRN & & \\
\hline CHEMBL1605666 & 737264 & 4.6507 & 4.7306 & TRN & & \\
\hline CHEMBL1541596 & 737264 & 4.999 & 4.9527 & TST & & \\
\hline CHEMBL1403024 & 737264 & 4.4088 & 4.663 & TRN & & \\
\hline CHEMBL1389177 & 737264 & 4.6867 & 4.7129 & TRN & & \\
\hline CHEMBL3192954 & 737264 & \multicolumn{3}{|c|}{4.7010000000000005} & 4.9381 & In \\
\hline CHEMBL1985333 & 737264 & 4.8035 & 4.7088 & TRN & & \\
\hline CHEMBL1722444 & 737264 & 4.3637 & 4.9776 & TST & & \\
\hline CHEMBL1482760 & 737264 & 4.9087 & 4.9587 & TRN & & \\
\hline CHEMBL225903 & 737264 & 4.785 & 4.7123 & TRN & & \\
\hline CHEMBL1305254 & 737264 & 4.8325 & 4.8907 & TST & & \\
\hline CHEMBL1352038 & 737264 & \multicolumn{3}{|c|}{ 4.2219999999999995 } & 4.7629 & I RI \\
\hline CHEMBL1526851 & 737264 & 4.6297 & 4.8862 & TRN & & \\
\hline CHEMBL1462373 & 737264 & 4.7565 & 4.7673 & TRN & & \\
\hline CHEMBL1481543 & 737264 & 4.9294 & 4.7519 & TRN & & \\
\hline CHEMBL1417732 & 737264 & 4.6738 & 4.5782 & TRN & & \\
\hline CHEMBL261692 & 737264 & 6.5719 & 4.8817 & TRN & & \\
\hline CHEMBL557419 & 737264 & 4.775 & 4.7254 & TRN & & \\
\hline
\end{tabular}


Supplemental Table S2.txt

\begin{tabular}{|c|c|c|c|c|c|c|}
\hline CHEMBL1601353 & 737264 & 5.4972 & 4.8586 & \multicolumn{2}{|l|}{ TST } & \\
\hline CHEMBL415270 & 737264 & 5.4731 & \multicolumn{3}{|c|}{5.537999999999999} & TRN \\
\hline CHEMBL1451924 & 737264 & 3.8882 & 4.8144 & \multicolumn{2}{|l|}{ TRN } & \\
\hline CHEMBL1708376 & 737264 & 5.1327 & 5.0468 & \multicolumn{2}{|l|}{ TST } & \\
\hline CHEMBL1470568 & 737264 & 4.6697 & 4.8001 & \multicolumn{2}{|l|}{ TRN } & \\
\hline CHEMBL66953 & 737264 & 4.6342 & 4.7749 & \multicolumn{2}{|l|}{ TRN } & \\
\hline CHEMBL1421146 & 737264 & 4.0435 & 4.8262 & \multicolumn{2}{|l|}{ TRN } & \\
\hline CHEMBL 306783 & 737264 & 6.5607 & 5.6777 & \multicolumn{2}{|l|}{ TRN } & \\
\hline CHEMBL1722954 & 737264 & 4.1569 & 4.9248 & \multicolumn{2}{|l|}{ TST } & \\
\hline CHEMBL16482 & 737264 & 3.7342 & 4.7162 & \multicolumn{3}{|l|}{ TST } \\
\hline CHEMBL 3189250 & 737264 & 5.8292 & 5.3204 & \multicolumn{3}{|l|}{ TRN } \\
\hline CHEMBL102397 & 737264 & \multicolumn{3}{|c|}{5.252999999999999} & 4.8106 & TST \\
\hline CHEMBL 78223 & 737264 & 5.0251 & 5.426 & \multicolumn{3}{|l|}{ TRN } \\
\hline CHEMBL1464645 & 737264 & 4.7294 & 4.7625 & \multicolumn{3}{|l|}{ TRN } \\
\hline CHEMBL1304418 & 737264 & 4.7566 & 5.1275 & \multicolumn{3}{|l|}{ TRN } \\
\hline CHEMBL1607989 & 737264 & 4.2138 & 4.9344 & \multicolumn{3}{|l|}{ TRN } \\
\hline CHEMBL1704558 & 737264 & 4.3849 & 4.6999 & \multicolumn{3}{|l|}{ TRN } \\
\hline CHEMBL1725944 & 737264 & 4.846 & 5.0272 & \multicolumn{3}{|l|}{ TRN } \\
\hline CHEMBL1973571 & 737264 & 4.7095 & 4.7093 & \multicolumn{3}{|l|}{ TRN } \\
\hline CHEMBL1359848 & 737264 & 5.4047 & 5.0236 & \multicolumn{3}{|l|}{ TRN } \\
\hline CHEMBL1735186 & 737264 & 4.0498 & 5.0454 & \multicolumn{3}{|l|}{ TST } \\
\hline CHEMBL 309978 & 737264 & 5.232 & 5.5028 & TRN & & \\
\hline CHEMBL1732383 & 737264 & 4.4593 & 4.6424 & TRN & & \\
\hline CHEMBL80895 & 737264 & 5.5862 & 5.8014 & TRN & & \\
\hline CHEMBL1727014 & 737264 & 4.7544 & 4.6952 & TRN & & \\
\hline CHEMBL1392570 & 737264 & 5.0568 & 4.6664 & TST & & \\
\hline CHEMBL1457634 & 737264 & 4.8877 & 4.6964 & TST & & \\
\hline CHEMBL1406948 & 737264 & 4.0931 & 5.2199 & TST & & \\
\hline CHEMBL1589205 & 737264 & 4.5062 & 4.9868 & TST & & \\
\hline CHEMBL 1448387 & 737264 & 4.7568 & 4.9201 & TST & & \\
\hline CHEMBL193872 & 737264 & 4.3857 & 4.8939 & TST & & \\
\hline CHEMBL1557629 & 737264 & 4.5274 & 4.906006 & 0000000001 & & TST \\
\hline CHEMBL 3972463 & 1528304 & 7.6778 & 6.9889 & TRN & & \\
\hline CHEMBL 3964909 & 1528304 & 6.9172 & 6.8276 & TST & & \\
\hline CHEMBL 3653716 & 1528304 & 5.5834 & 5.8732 & TRN & & \\
\hline CHEMBL 3657454 & 1528304 & 5.3716 & 5.8013 & TRN & & \\
\hline CHEMBL 3653661 & 1528304 & 5.7235 & 6.0091 & TST & & \\
\hline CHEMBL 3653665 & 1528304 & 6.2518 & 5.7213 & TST & & \\
\hline CHEMBL 2152916 & 1528304 & 4.8386 & 6.2942 & TRN & & \\
\hline CHEMBL1373468 & 1528304 & 8.9208 & 6.4357 & TST & & \\
\hline CHEMBL 3653725 & 1528304 & 5.1726 & 6.5047 & TRN & & \\
\hline CHEMBL 3897786 & 1528304 & 7.7033 & 6.7677 & TRN & & \\
\hline CHEMBL 3653708 & 1528304 & 7.0 & 6.5586 & TST & & \\
\hline CHEMBL1601183 & 1528304 & 7.6021 & 6.1859 & TST & & \\
\hline CHEMBL 3945110 & 1528304 & 7.6198 & 6.4357 & TRN & & \\
\hline CHEMBL 3961886 & 1528304 & 7.699 & 6.5739 & TRN & & \\
\hline CHEMBL 3657431 & 1528304 & 7.6778 & 7.0787 & TRN & & \\
\hline CHEMBL 3981097 & 1528304 & 7.6383 & 5.94600 & 000000 & & \\
\hline & & & & 15950 & & \\
\hline
\end{tabular}


Supplemental Table S2.txt

\begin{tabular}{|c|c|c|c|c|}
\hline CHEMBL3913558 & 1528304 & 7.3279 & 6.3281 & TST \\
\hline CHEMBL3657436 & 1528304 & 6.1993 & 6.4237 & TRN \\
\hline CHEMBL3919032 & 1528304 & 7.2924 & 6.7133 & TRN \\
\hline CHEMBL3653660 & 1528304 & 5.8861 & 5.6451 & TST \\
\hline CHEMBL3934490 & 1528304 & 6.7878 & 6.3788 & TST \\
\hline CHEMBL3657444 & 1528304 & 5.5834 & \multicolumn{2}{|c|}{5.827000000000001} \\
\hline CHEMBL3986744 & 1528304 & 7.1938 & 6.6641 & TRN \\
\hline CHEMBL3946842 & 1528304 & 7.6576 & 6.3176 & TRN \\
\hline CHEMBL3653659 & 1528304 & 5.7696 & 5.8249 & TRN \\
\hline CHEMBL3653690 & 1528304 & 7.0 & 6.2827 & TRN \\
\hline CHEMBL3959097 & 1528304 & 7.6576 & 6.7745 & TRN \\
\hline CHEMBL3653692 & 1528304 & 5.7545 & 5.5166 & TRN \\
\hline CHEMBL3657441 & 1528304 & 4.7144 & 5.763 & TRN \\
\hline CHEMBL3917003 & 1528304 & 7.4685 & 6.5547 & TRN \\
\hline CHEMBL3653689 & 1528304 & 5.1232 & 5.193 & TRN \\
\hline CHEMBL3945121 & 1528304 & 7.6021 & 6.782 & TRN \\
\hline CHEMBL3653694 & 1528304 & 6.3893 & 6.3322 & TST \\
\hline CHEMBL3987125 & 1528304 & 7.6576 & 7.183 & TRN \\
\hline CHEMBL3653700 & 1528304 & 6.0 & 6.0585 & TST \\
\hline CHEMBL3653702 & 1528304 & 6.0 & 6.5353 & TST \\
\hline CHEMBL3936953 & 1528304 & 5.3054 & 6.4615 & TRN \\
\hline CHEMBL3653721 & 1528304 & 6.3969 & 5.8141 & TRN \\
\hline CHEMBL3653729 & 1528304 & 4.7878 & 5.2325 & TRN \\
\hline CHEMBL3653723 & 1528304 & 5.0013 & 7.0232 & TRN \\
\hline CHEMBL3657457 & 1528304 & 5.7747 & 5.7738 & TRN \\
\hline CHEMBL1361136 & 1528304 & 7.6383 & 6.1054 & TST \\
\hline CHEMBL3657432 & 1528304 & 7.6198 & 6.9445 & TRN \\
\hline CHEMBL3653707 & 1528304 & 8.0 & 5.6079 & TST \\
\hline CHEMBL 2152917 & 1528304 & 6.0 & 6.9371 & TRN \\
\hline CHEMBL3657445 & 1528304 & 6.1261 & 7.2173 & TRN \\
\hline CHEMBL3653711 & 1528304 & 7.2076 & 6.4675 & TRN \\
\hline CHEMBL3948423 & 1528304 & 6.0747 & 5.9493 & TRN \\
\hline CHEMBL3933883 & 1528304 & 7.1805 & 7.4935 & TRN \\
\hline CHEMBL3920021 & 1528304 & 7.699 & 6.2704 & TST \\
\hline CHEMBL3957561 & 1528304 & 6.7235 & 6.7113 & TRN \\
\hline CHEMBL3923132 & 1528304 & 6.1965 & 6.7713 & TRN \\
\hline CHEMBL 3653714 & 1528304 & 6.0 & 6.6111 & TRN \\
\hline CHEMBL3907727 & 1528304 & 5.2314 & 6.5455 & TRN \\
\hline CHEMBL3917335 & 1528304 & 7.4318 & 6.9246 & TRN \\
\hline CHEMBL3972810 & 1528304 & 7.6021 & 7.2286 & TRN \\
\hline CHEMBL3657455 & 1528304 & 5.1733 & 5.505 & TRN \\
\hline CHEMBL3653709 & 1528304 & 4.1215 & 5.0852 & TST \\
\hline CHEMBL3653658 & 1528304 & 6.129 & 6.2886 & TRN \\
\hline CHEMBL3904970 & 1528304 & 7.0506 & 6.6758 & TRN \\
\hline CHEMBL3963582 & 1528304 & 7.6778 & 6.8921 & TRN \\
\hline CHEMBL3985516 & 1528304 & 6.7258 & 6.0704 & TRN \\
\hline CHEMBL3653712 & 1528304 & 5.1798 & 5.2731 & TRN \\
\hline CHEMBL3657456 & 1528304 & 4.7878 & 5.6562 & TRN \\
\hline
\end{tabular}


Supplemental Table S2.txt

\begin{tabular}{|c|c|c|c|c|c|}
\hline CHEMBL 3657428 & 1528304 & 7.6576 & 7.06 & TRN & \\
\hline CHEMBL3926971 & 1528304 & 7.3565 & 7.4739 & TRN & \\
\hline CHEMBL3653722 & 1528304 & 4.7878 & 7.0526 & TRN & \\
\hline CHEMBL3653664 & 1528304 & 5.1898 & 5.5588 & TST & \\
\hline CHEMBL 3952823 & 1528304 & 7.5686 & 7.1909 & TRN & \\
\hline CHEMBL3653666 & 1528304 & 6.9508 & 6.2004 & TRN & \\
\hline CHEMBL 3657443 & 1528304 & 7.4685 & 6.768 & TRN & \\
\hline CHEMBL3657420 & 1528304 & 4.8125 & 6.7115 & TRN & \\
\hline CHEMBL3653715 & 1528304 & 6.2815 & 5.9524 & TRN & \\
\hline CHEMBL 3657458 & 1528304 & 5.1643 & 5.4063 & TRN & \\
\hline CHEMBL 3657452 & 1528304 & 5.4949 & 5.5843 & TRN & \\
\hline CHEMBL 3653662 & 1528304 & 6.9508 & 5.8247 & TST & \\
\hline CHEMBL3653696 & 1528304 & 6.1713 & 5.6821 & TST & \\
\hline CHEMBL 2152914 & 1528304 & 5.1124 & 7.0457 & TRN & \\
\hline CHEMBL3657453 & 1528304 & 5.4389 & 5.4876 & TRN & \\
\hline CHEMBL 3981574 & 1528304 & 7.585 & 7.1047 & TRN & \\
\hline CHEMBL3653657 & 1528304 & 6.8041 & 5.8166 & TRN & \\
\hline CHEMBL3653691 & 1528304 & 6.8386 & 6.1588 & TRN & \\
\hline CHEMBL 3657460 & 1528304 & 5.7447 & 5.6144 & TRN & \\
\hline CHEMBL3657430 & 1528304 & 7.6778 & 7.621 & TRN & \\
\hline CHEMBL3653701 & 1528304 & 6.0 & 5.5634 & TST & \\
\hline CHEMBL 3653713 & 1528304 & 6.5467 & 6.742006 & 0000000001 & TRN \\
\hline CHEMBL 3917387 & 1528304 & 7.5528 & 7.1079 & TRN & \\
\hline CHEMBL 3657459 & 1528304 & 5.7033 & 5.4773 & TRN & \\
\hline CHEMBL 3653710 & 1528304 & 6.4881 & 6.5923 & TRN & \\
\hline CHEMBL3653693 & 1528304 & 7.2757 & 6.9382 & TRN & \\
\hline CHEMBL 3653733 & 1528304 & 7.6383 & 6.9383 & TST & \\
\hline CHEMBL 3951608 & 1528304 & 6.0 & 6.37799 & 9999999999 & TST \\
\hline CHEMBL1527785 & 688264 & 2.0 & 2.2732 & TRN & \\
\hline CHEMBL1526738 & 688264 & 2.0 & 1.92400 & 00000000002 & TRN \\
\hline CHEMBL1460247 & 688264 & 4.8972 & 4.4399 & TRN & \\
\hline CHEMBL1353818 & 688264 & 4.8752 & 5.334 & TRN & \\
\hline CHEMBL1313988 & 688264 & 4.8889 & 5.6506 & TRN & \\
\hline CHEMBL1561092 & 688264 & 5.1569 & 3.9441 & TRN & \\
\hline CHEMBL1581991 & 688264 & 4.9008 & 4.8906 & TRN & \\
\hline CHEMBL1564765 & 688264 & 2.0 & 2.15199 & 99999999997 & TRN \\
\hline CHEMBL1417293 & 688264 & 4.8809 & 4.4762 & TRN & \\
\hline CHEMBL3208556 & 688264 & 5.1857 & 5.0225 & TST & \\
\hline CHEMBL1577591 & 688264 & 4.9904 & 2.8963 & TST & \\
\hline CHEMBL1319476 & 688264 & 4.7934 & 4.2155 & TRN & \\
\hline CHEMBL1550695 & 688264 & 4.6003 & 4.4379 & TRN & \\
\hline CHEMBL1307769 & 688264 & 4.7409 & 4.6422 & TRN & \\
\hline CHEMBL1569996 & 688264 & 4.9031 & 4.0004 & TRN & \\
\hline CHEMBL1408587 & 688264 & 4.8681 & 4.8422 & TRN & \\
\hline CHEMBL1426255 & 688264 & 4.7558 & 4.5236 & TRN & \\
\hline CHEMBL1408465 & 688264 & 4.9828 & 4.4198 & TRN & \\
\hline CHEMBL1576191 & 688264 & 5.1733 & 5.2473 & TST & \\
\hline CHEMBL1304031 & 688264 & 4.8211 & 5.5101 & TRN & \\
\hline
\end{tabular}




\begin{tabular}{|c|c|c|c|c|c|c|}
\hline & & \multicolumn{5}{|c|}{ Supplemental Table s2.txt } \\
\hline CHEMBL1598249 & 688264 & 4.7233 & 3.8249 & TRN & & \\
\hline CHEMBL1511524 & 688264 & 4.6365 & 5.0977 & TRN & & \\
\hline CHEMBL1613213 & 688264 & 4.5703 & 5.2147 & TRN & & \\
\hline CHEMBL1339786 & 688264 & 4.9055 & 4.6291 & TRN & & \\
\hline CHEMBL1528250 & 688264 & 4.8804 & 5.1065 & TRN & & \\
\hline CHEMBL1463175 & 688264 & 4.4249 & 4.3602 & TRN & & \\
\hline CHEMBL1532971 & 688264 & 5.1085 & 4.8564 & TRN & & \\
\hline CHEMBL1432305 & 688264 & 4.8975 & 5.6481 & TST & & \\
\hline CHEMBL1324684 & 688264 & 4.6308 & 3.8854 & TST & & \\
\hline CHEMBL1606800 & 688264 & 4.8909 & 4.3642 & TRN & & \\
\hline CHEMBL1437982 & 688264 & 5.2058 & 4.6297 & TRN & & \\
\hline CHEMBL1453481 & 688264 & 4.8981 & 5.3722 & TRN & & \\
\hline CHEMBL1480971 & 688264 & \multicolumn{3}{|c|}{4.4830000000000005} & 4.3513 & TRN \\
\hline CHEMBL1300638 & 688264 & 5.072 & 4.2003 & TRN & & \\
\hline CHEMBL1528686 & 688264 & 2.0 & 2.0098 & TRN & & \\
\hline CHEMBL1608446 & 688264 & 4.8943 & 5.4555 & TRN & & \\
\hline CHEMBL1587923 & 688264 & 4.8992 & 4.5814 & TRN & & \\
\hline CHEMBL1518870 & 688264 & 5.485 & 5.2721 & TRN & & \\
\hline CHEMBL1384353 & 688264 & 4.5414 & 4.5574 & TRN & & \\
\hline CHEMBL1521144 & 688264 & 5.0036 & 4.3423 & TRN & & \\
\hline CHEMBL1568150 & 688264 & 5.1947 & 4.157 & TST & & \\
\hline CHEMBL1556666 & 688264 & 4.9534 & 4.8205 & TRN & & \\
\hline CHEMBL1530757 & 688264 & 5.8008 & 5.4574 & TRN & & \\
\hline CHEMBL1323312 & 688264 & 4.8736 & 4.7336 & TRN & & \\
\hline CHEMBL1464608 & 688264 & 4.8909 & 4.2401 & TRN & & \\
\hline CHEMBL1573401 & 688264 & \multicolumn{3}{|c|}{4.888999999999999} & 5.8112 & TRN \\
\hline CHEMBL1531388 & 688264 & 4.8404 & 4.86 & TRN & & \\
\hline CHEMBL1346307 & 688264 & 4.6528 & 3.9929 & TRN & & \\
\hline CHEMBL1543264 & 688264 & 4.6466 & 4.599 & TRN & & \\
\hline CHEMBL1542391 & 688264 & 4.8858 & 5.4408 & TRN & & \\
\hline CHEMBL1478573 & 688264 & 2.0 & 3.1989 & TRN & & \\
\hline CHEMBL1584293 & 688264 & 2.0 & 2.6779 & TRN & & \\
\hline CHEMBL1467405 & 688264 & 5.1712 & 5.3095 & TST & & \\
\hline CHEMBL1307479 & 688264 & 4.8881 & 4.909 & TRN & & \\
\hline CHEMBL1304004 & 688264 & 2.0 & 3.0848 & TRN & & \\
\hline CHEMBL1446466 & 688264 & 2.0 & 3.5978 & TRN & & \\
\hline CHEMBL1349056 & 688264 & 4.9612 & 5.29 & TRN & & \\
\hline CHEMBL1559853 & 688264 & 4.6372 & 3.9307 & TRN & & \\
\hline CHEMBL1543412 & 688264 & 4.8941 & 4.5528 & TRN & & \\
\hline CHEMBL1369482 & 688264 & 5.0381 & 4.8816 & TST & & \\
\hline CHEMBL1581188 & 688264 & 5.1568 & 5.1372 & TRN & & \\
\hline CHEMBL1370066 & 688264 & 4.8366 & 4.823 & TRN & & \\
\hline CHEMBL1452992 & 688264 & 4.6291 & 4.6194 & TRN & & \\
\hline CHEMBL1533181 & 688264 & 4.8972 & 5.3098 & TRN & & \\
\hline CHEMBL1447305 & 688264 & \multicolumn{3}{|c|}{ 4.763999999999999 } & 5.2305 & TRN \\
\hline CHEMBL1532316 & 688264 & 2.0 & 2.5282 & TRN & & \\
\hline CHEMBL389704 & 688264 & 4.9024 & 5.3677 & TST & & \\
\hline CHEMBL3192559 & 688264 & 5.1004 & 3.1561 & TST & & \\
\hline
\end{tabular}




\begin{tabular}{|c|c|c|c|c|c|c|}
\hline & & \multicolumn{5}{|c|}{ Supplemental Table S2.txt } \\
\hline CHEMBL1382890 & 688264 & 4.875 & 4.1188 & TRN & & \\
\hline CHEMBL1369446 & 688264 & 2.0 & 2.3632 & TRN & & \\
\hline CHEMBL1545080 & 688264 & 4.8934 & 3.7445 & TRN & & \\
\hline CHEMBL1342889 & 688264 & 4.8117 & 5.3698 & TRN & & \\
\hline CHEMBL372840 & 688264 & 5.0353 & 5.2855 & TST & & \\
\hline CHEMBL1412578 & 688264 & 2.0 & 2.8307 & TRN & & \\
\hline CHEMBL1559291 & 688264 & 4.4926 & 4.3847 & TRN & & \\
\hline CHEMBL1410971 & 688264 & \multicolumn{3}{|c|}{4.9030000000000005} & 4.0297 & TRN \\
\hline CHEMBL1326366 & 688264 & 4.8929 & 5.2661 & TRN & & \\
\hline CHEMBL1464070 & 688264 & 4.9364 & 4.4875 & TRN & & \\
\hline CHEMBL1550294 & 688264 & 5.3225 & 5.2233 & TRN & & \\
\hline CHEMBL548615 & 688264 & 4.6111 & 4.8385 & TRN & & \\
\hline CHEMBL1531523 & 688264 & 2.0 & 3.1206 & TRN & & \\
\hline CHEMBL1446603 & 688264 & 4.8228 & 4.7147 & TST & & \\
\hline CHEMBL1458873 & 688264 & 4.8355 & 4.3148 & TST & & \\
\hline CHEMBL1468795 & 688264 & 4.9034 & 6.3793 & TST & & \\
\hline CHEMBL1460232 & 688264 & 4.7611 & 3.6373 & TST & & \\
\hline CHEMBL1392657 & 688264 & 4.8953 & 4.0026 & TST & & \\
\hline CHEMBL1606317 & 688264 & 4.9216 & 4.7972 & TST & & \\
\hline CHEMBL1462377 & 688264 & 4.67399 & و9999999 & 995 & 3.3137 & TST \\
\hline CHEMBL 213432 & 688264 & 1.69099 & 99999999 & 998 & 3.7658 & TST \\
\hline CHEMBL1344053 & 688264 & 5.1242 & 3.7422 & TST & & \\
\hline CHEMBL1353908 & 688264 & 4.731 & 4.308 & TST & & \\
\hline CHEMBL1500466 & 688264 & 4.9415 & 3.4518 & TST & & \\
\hline CHEMBL1456029 & 688264 & 5.1789 & 4.7039 & TST & & \\
\hline CHEMBL259067 & 688264 & 4.8992 & 3.469 & TST & & \\
\hline CHEMBL1801563 & 754944 & 8.8239 & 7.3924 & TRN & & \\
\hline CHEMBL1801867 & 754944 & 7.0458 & 7.2174 & TST & & \\
\hline CHEMBL1801569 & 754944 & 7.2518 & 8.7305 & TRN & & \\
\hline CHEMBL1801566 & 754944 & 8.9208 & 8.4097 & TRN & & \\
\hline CHEMBL1801871 & 754944 & 5.1427 & 7.3104 & TST & & \\
\hline CHEMBL1801557 & 754944 & 4.0 & 6.3032 & TRN & & \\
\hline CHEMBL1801565 & 754944 & 7.9208 & 8.459 & TRN & & \\
\hline CHEMBL1801855 & 754944 & 8.5376 & 6.8039 & TRN & & \\
\hline CHEMBL1801938 & 754944 & 6.8861 & 6.7878 & TRN & & \\
\hline CHEMBL1801550 & 754944 & 7.5229 & 6.5722 & TRN & & \\
\hline CHEMBL1801941 & 754944 & 7.4685 & 6.6338 & TRN & & \\
\hline CHEMBL1801567 & 754944 & 8.585 & 9.0454 & TRN & & \\
\hline CHEMBL1801866 & 754944 & 5.9208 & 7.2303 & TST & & \\
\hline CHEMBL1801937 & 754944 & 8.4437 & 6.8958 & TRN & & \\
\hline CHEMBL1801558 & 754944 & 6.3768 & 7.2286 & TRN & & \\
\hline CHEMBL1801862 & 754944 & 9.1024 & 9.4443 & TRN & & \\
\hline CHEMBL1801868 & 754944 & 4.0 & 8.3375 & TST & & \\
\hline CHEMBL1801556 & 754944 & 7.8239 & 6.3995 & TRN & & \\
\hline CHEMBL1801861 & 754944 & 8.4202 & 8.2585 & TRN & & \\
\hline CHEMBL1801869 & 754944 & 6.2218 & 7.7415 & TST & & \\
\hline CHEMBL1801858 & 754944 & 4.0 & 5.5809 & TRN & & \\
\hline CHEMBL1801865 & 754944 & 5.5528 & 7.0067 & TST & & \\
\hline
\end{tabular}


Supplemental Table S2.txt

\begin{tabular}{|c|c|c|c|c|}
\hline CHEMBL1801551 & 754944 & 6.6021 & 6.5812 & TRN \\
\hline CHEMBL1801553 & 754944 & 7.5086 & 6.8846 & TRN \\
\hline CHEMBL1801860 & 754944 & 7.9208 & 8.6232 & TRN \\
\hline CHEMBL1801863 & 754944 & 9.5229 & 9.5731 & TRN \\
\hline CHEMBL1801552 & 754944 & 8.8539 & 6.9154 & TRN \\
\hline CHEMBL1801859 & 754944 & 4.0 & 6.0362 & TRN \\
\hline CHEMBL1801555 & 754944 & 6.4815 & 6.5603 & TRN \\
\hline CHEMBL1801571 & 754944 & 6.1805 & 8.2175 & TRN \\
\hline CHEMBL1801857 & 754944 & 5.585 & 5.7759 & TRN \\
\hline CHEMBL1801870 & 754944 & 7.5376 & 7.807 & TST \\
\hline CHEMBL1801939 & 754944 & 4.0 & 5.6419 & TRN \\
\hline CHEMBL1801554 & 754944 & 4.0 & 6.2388 & TRN \\
\hline CHEMBL1801560 & 754944 & 8.3768 & 7.4949 & TRN \\
\hline CHEMBL1801559 & 754944 & 8.2147 & 7.1946 & TRN \\
\hline CHEMBL1801549 & 754944 & 6.8239 & 6.4378 & TRN \\
\hline CHEMBL1801548 & 754944 & 7.0088 & 6.8833 & TRN \\
\hline CHEMBL1801564 & 754944 & 6.9586 & 6.7114 & TRN \\
\hline CHEMBL1801568 & 754944 & 7.8861 & 7.9367 & TRN \\
\hline CHEMBL1801864 & 754944 & 9.3468 & 9.0435 & TRN \\
\hline CHEMBL1801940 & 754944 & 7.0706 & 6.6556 & TRN \\
\hline CHEMBL1801854 & 754944 & 6.6778 & 6.9763 & TRN \\
\hline CHEMBL123756 & 754944 & 9.5086 & 9.28399 & 9999999999 \\
\hline CHEMBL1801856 & 754944 & 6.0223 & 6.5493 & TRN \\
\hline CHEMBL1801561 & 754944 & 8.8861 & 6.3597 & TRN \\
\hline CHEMBL1801547 & 754944 & 7.3098 & 6.7405 & TST \\
\hline CHEMBL1801570 & 754944 & 7.9208 & 8.7076 & TST \\
\hline CHEMBL1801935 & 754944 & 7.9586 & 8.0707 & TST \\
\hline CHEMBL1801934 & 754944 & 9.2596 & 8.164 & TST \\
\hline CHEMBL1801936 & 754944 & 7.6021 & 7.88399 & 99999999995 \\
\hline CHEMBL1801933 & 754944 & 7.3979 & 7.9014 & TST \\
\hline CHEMBL1801562 & 754944 & 8.7212 & 7.3404 & TST \\
\hline CHEMBL1421227 & 688128 & 4.55 & 4.6036 & TRN \\
\hline CHEMBL1300347 & 688128 & 4.6 & 4.4823 & TRN \\
\hline CHEMBL1351369 & 688128 & 4.05 & 4.7281 & TRN \\
\hline CHEMBL1449108 & 688128 & 4.3 & 4.5439 & TRN \\
\hline CHEMBL600175 & 688128 & 4.35 & 4.5116 & TST \\
\hline CHEMBL1576312 & 688128 & 5.1 & 4.5143 & TRN \\
\hline CHEMBL1452080 & 688128 & 5.4 & 4.724 & TRN \\
\hline CHEMBL1390550 & 688128 & 5.4 & 4.5589 & TRN \\
\hline CHEMBL3196182 & 688128 & 5.1 & 4.6953 & TST \\
\hline CHEMBL 1452450 & 688128 & 4.45 & 4.4019 & TRN \\
\hline CHEMBL1337258 & 688128 & 4.8 & 4.5973 & TRN \\
\hline CHEMBL1481420 & 688128 & 4.4 & 4.5647 & TRN \\
\hline CHEMBL1473495 & 688128 & 5.5 & 4.5791 & TST \\
\hline CHEMBL 2373641 & 688128 & 5.35 & 4.8421 & TRN \\
\hline CHEMBL44664 & 688128 & 5.6 & 4.992 & TRN \\
\hline CHEMBL3193288 & 688128 & 4.35 & 4.7294 & TST \\
\hline CHEMBL1544313 & 688128 & 4.4 & 5.3141 & TRN \\
\hline
\end{tabular}




\begin{tabular}{|c|c|c|c|c|c|}
\hline \multicolumn{6}{|c|}{ Supplemental Table S2.txt } \\
\hline CHEMBL1595221 & 688128 & 5.9 & 5.2978 & TRN & \\
\hline CHEMBL1318497 & 688128 & 4.45 & 4.8803 & TRN & \\
\hline CHEMBL1510129 & 688128 & 5.1 & 4.7537 & TRN & \\
\hline CHEMBL1503300 & 688128 & 5.35 & 4.7661 & TST & \\
\hline CHEMBL1441636 & 688128 & 4.7 & 4.5067 & TRN & \\
\hline CHEMBL1421076 & 688128 & 4.3 & 4.5946 & TRN & \\
\hline CHEMBL1503841 & 688128 & 4.55 & 4.942 & TRN & \\
\hline CHEMBL1500334 & 688128 & 6.15 & 4.4819 & TRN & \\
\hline CHEMBL1403337 & 688128 & 4.35 & 4.6777 & TST & \\
\hline CHEMBL1519630 & 688128 & 4.45 & 4.8981 & TRN & \\
\hline CHEMBL1527616 & 688128 & 4.5 & 4.6528 & TST & \\
\hline CHEMBL1554025 & 688128 & 4.4 & 4.6004 & TRN & \\
\hline CHEMBL1436088 & 688128 & 5.4 & 4.5981 & TRN & \\
\hline CHEMBL1561127 & 688128 & 4.3 & 4.3734 & TRN & \\
\hline CHEMBL1333512 & 688128 & 4.2 & 4.5222 & TRN & \\
\hline CHEMBL1603275 & 688128 & 4.4 & 4.9335 & TRN & \\
\hline CHEMBL1485713 & 688128 & 4.45 & 4.4105 & TRN & \\
\hline CHEMBL1349349 & 688128 & 4.3 & 4.8406 & TRN & \\
\hline CHEMBL1402943 & 688128 & 4.9 & 4.8157 & TRN & \\
\hline CHEMBL1466504 & 688128 & 4.65 & 4.6446 & TST & \\
\hline CHEMBL1542222 & 688128 & 4.45 & 4.4491 & TRN & \\
\hline CHEMBL1403830 & 688128 & 4.4 & 4.5971 & TRN & \\
\hline CHEMBL1578584 & 688128 & 4.35 & 4.4375 & TRN & \\
\hline CHEMBL1511011 & 688128 & 4.05 & 4.6823 & TRN & \\
\hline CHEMBL1526473 & 688128 & 4.2 & 4.5467 & TRN & \\
\hline CHEMBL 2373631 & 688128 & 4.8 & 4.9509 & TRN & \\
\hline CHEMBL1546041 & 688128 & 4.9 & 4.55699 & 99999999995 & TRN \\
\hline CHEMBL1402433 & 688128 & 4.35 & 4.2404 & TRN & \\
\hline CHEMBL1435780 & 688128 & 4.5 & 4.735 & TRN & \\
\hline CHEMBL1324524 & 688128 & 4.25 & 4.5203 & TST & \\
\hline CHEMBL1988303 & 688128 & 4.35 & 4.3725 & TST & \\
\hline CHEMBL1536183 & 688128 & 4.35 & 5.0238 & TRN & \\
\hline CHEMBL1457915 & 688128 & 5.2 & 4.6318 & TST & \\
\hline CHEMBL1442671 & 688128 & 4.35 & 4.6626 & TRN & \\
\hline CHEMBL1493010 & 688128 & 4.3 & 4.5684 & TRN & \\
\hline CHEMBL1448862 & 688128 & 4.35 & 4.2034 & TRN & \\
\hline CHEMBL1491190 & 688128 & 4.3 & 4.5215 & TRN & \\
\hline CHEMBL1495375 & 688128 & 4.05 & 4.444 & TRN & \\
\hline CHEMBL1576791 & 688128 & 5.45 & 5.3074 & TRN & \\
\hline CHEMBL1421801 & 688128 & 4.25 & 4.6309 & TRN & \\
\hline CHEMBL1518221 & 688128 & 4.35 & 4.6111 & TRN & \\
\hline CHEMBL1600800 & 688128 & 4.3 & 4.66 & TRN & \\
\hline CHEMBL1339103 & 688128 & 4.1 & 4.5791 & TRN & \\
\hline CHEMBL1572498 & 688128 & 4.3 & 4.4242 & TRN & \\
\hline CHEMBL505390 & 688128 & 4.45 & 4.7041 & TRN & \\
\hline CHEMBL1605613 & 688128 & 4.35 & 4.4843 & TRN & \\
\hline CHEMBL1463417 & 688128 & 4.05 & 4.5867 & TRN & \\
\hline CHEMBL1374721 & 688128 & 5.4 & 4.5969 & TRN & \\
\hline
\end{tabular}




\begin{tabular}{|c|c|c|c|c|}
\hline \multicolumn{5}{|c|}{ Supplemental Table S2.txt } \\
\hline CHEMBL 3195774 & 688128 & 4.4 & 4.3887 & TST \\
\hline CHEMBL1452095 & 688128 & 4.75 & 4.7747 & TRN \\
\hline CHEMBL1966298 & 688128 & 4.3 & 4.5494 & TST \\
\hline CHEMBL1595449 & 688128 & 4.5 & 4.6374 & TST \\
\hline CHEMBL1445086 & 688128 & 4.4 & 4.4295 & TRN \\
\hline CHEMBL1404964 & 688128 & 4.05 & 4.8154 & TST \\
\hline CHEMBL1319748 & 688128 & 4.65 & 4.6933 & TST \\
\hline CHEMBL1449790 & 688128 & 6.05 & 4.6716 & TRN \\
\hline CHEMBL1412815 & 688128 & 4.0 & 4.3413 & TRN \\
\hline CHEMBL1428203 & 688128 & 4.3 & 4.4986 & TRN \\
\hline CHEMBL1474594 & 688128 & 5.3 & 4.2894 & TST \\
\hline CHEMBL1590736 & 688128 & 4.85 & 4.9652 & TRN \\
\hline CHEMBL1388261 & 688128 & 4.35 & 4.3476 & TRN \\
\hline CHEMBL1491126 & 688128 & 4.1 & 4.529 & TRN \\
\hline CHEMBL1428271 & 688128 & 5.0 & 4.5917 & TRN \\
\hline CHEMBL1577121 & 688128 & 4.85 & 4.4754 & TRN \\
\hline CHEMBL1303771 & 688128 & 5.5 & 4.9337 & TRN \\
\hline CHEMBL1533207 & 688128 & 4.45 & 4.8044 & TST \\
\hline CHEMBL1431588 & 688128 & 4.05 & 4.2667 & TRN \\
\hline CHEMBL1581233 & 688128 & 4.45 & 4.8438 & TRN \\
\hline CHEMBL1312729 & 688128 & 4.15 & 4.7159 & TRN \\
\hline CHEMBL1408490 & 688128 & 4.55 & 4.4089 & TRN \\
\hline CHEMBL 3197557 & 688128 & 4.35 & 4.8581 & TRN \\
\hline CHEMBL1451156 & 688128 & 4.7 & 4.5544 & TRN \\
\hline CHEMBL1309035 & 688128 & 6.45 & 5.2503 & TRN \\
\hline CHEMBL1529479 & 688128 & 4.4 & 4.6446 & TRN \\
\hline CHEMBL1347080 & 688128 & 4.25 & 4.513 & TRN \\
\hline CHEMBL1416041 & 688128 & 5.75 & 4.6643 & TRN \\
\hline CHEMBL1589963 & 688128 & 4.35 & 4.7154 & TRN \\
\hline CHEMBL1502297 & 688128 & 4.85 & 4.6607 & TRN \\
\hline CHEMBL1482059 & 688128 & 5.25 & 4.5559 & TRN \\
\hline CHEMBL1340861 & 688128 & 4.05 & 4.5573 & TRN \\
\hline CHEMBL601757 & 688128 & 4.8 & 5.0048 & TRN \\
\hline CHEMBL1439111 & 688128 & 4.7 & 4.7169 & TRN \\
\hline CHEMBL1490187 & 688128 & 4.8 & 4.6298 & TRN \\
\hline CHEMBL1328214 & 688128 & 4.35 & 4.3874 & TRN \\
\hline CHEMBL1332181 & 688128 & 5.8 & 4.5222 & TRN \\
\hline CHEMBL1539522 & 688128 & 4.95 & 5.2429 & TRN \\
\hline CHEMBL1423904 & 688128 & 4.85 & 4.6213 & TRN \\
\hline CHEMBL1477014 & 688128 & 6.05 & 5.1608 & TRN \\
\hline CHEMBL1338304 & 688128 & 6.35 & 5.3661 & TRN \\
\hline CHEMBL1327576 & 688128 & 4.45 & 4.5714 & TST \\
\hline CHEMBL1582349 & 688128 & 4.4 & 4.5049 & TRN \\
\hline CHEMBL1443539 & 688128 & 4.5 & 4.8689 & TST \\
\hline CHEMBL1377975 & 688128 & 4.45 & 4.5142 & TRN \\
\hline CHEMBL3196104 & 688128 & 4.45 & 4.5816 & TST \\
\hline CHEMBL1350955 & 688128 & 4.35 & 4.61100 & 0000000001 \\
\hline CHEMBL1427282 & 688128 & 4.4 & 4.6358 & TRN \\
\hline
\end{tabular}




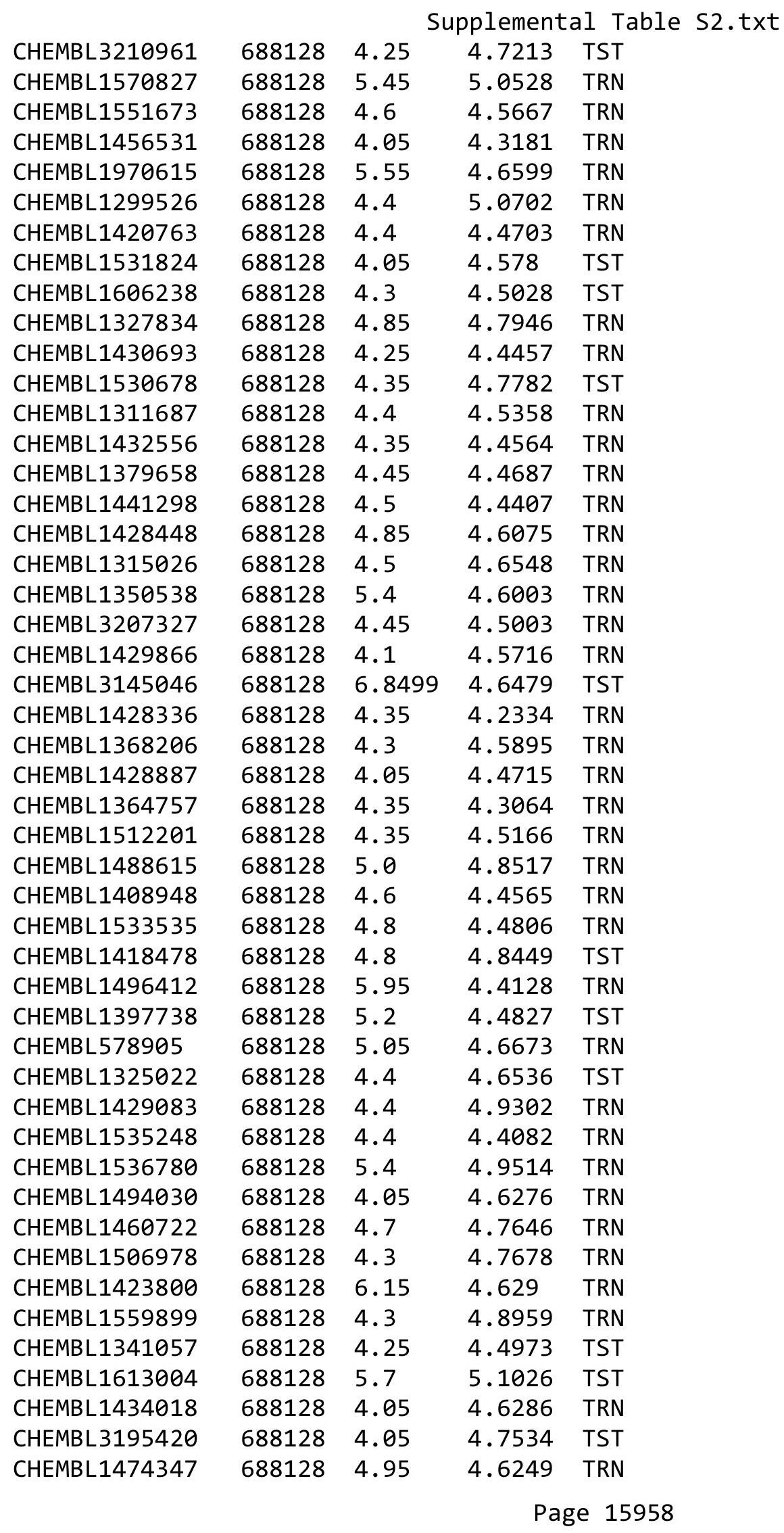




\begin{tabular}{|c|c|c|c|c|}
\hline & & & pplemen & al $\mathrm{T}$ \\
\hline CHEMBL1494458 & 688128 & 4.6 & 4.7122 & TRN \\
\hline CHEMBL1334178 & 688128 & 5.5 & 5.2065 & TRN \\
\hline CHEMBL1453699 & 688128 & 4.9 & 4.7818 & TRN \\
\hline CHEMBL1403551 & 688128 & 4.55 & 4.4134 & TRN \\
\hline CHEMBL1984764 & 688128 & 4.4 & 4.4773 & TST \\
\hline CHEMBL1362190 & 688128 & 4.25 & 4.5103 & TRN \\
\hline CHEMBL1539727 & 688128 & 7.0 & 5.3994 & TRN \\
\hline CHEMBL1315381 & 688128 & 5.35 & 4.5494 & TRN \\
\hline CHEMBL1377059 & 688128 & 4.1 & 4.927 & TRN \\
\hline CHEMBL1453629 & 688128 & 4.65 & 4.6146 & TST \\
\hline CHEMBL1490424 & 688128 & 4.35 & 4.6058 & TRN \\
\hline CHEMBL1508545 & 688128 & 4.4 & 4.4062 & TRN \\
\hline CHEMBL1612858 & 688128 & 4.4 & 4.7021 & TRN \\
\hline CHEMBL1327164 & 688128 & 4.45 & 4.5612 & TRN \\
\hline CHEMBL1574906 & 688128 & 4.85 & 5.006 & TST \\
\hline CHEMBL1386893 & 688128 & 4.3 & 4.3448 & TRN \\
\hline CHEMBL1414256 & 688128 & 4.25 & 4.9751 & TST \\
\hline CHEMBL1336751 & 688128 & 4.35 & 4.7251 & TRN \\
\hline CHEMBL1514080 & 688128 & 4.95 & 5.0181 & TRN \\
\hline CHEMBL1521989 & 688128 & 5.1 & 4.8628 & TRN \\
\hline CHEMBL1365952 & 688128 & 4.05 & 4.6619 & TST \\
\hline CHEMBL1545287 & 688128 & 4.45 & 4.6906 & TST \\
\hline CHEMBL1606988 & 688128 & 5.95 & 4.3422 & TRN \\
\hline CHEMBL1551116 & 688128 & 4.6 & 4.8698 & TRN \\
\hline CHEMBL1588052 & 688128 & 5.0 & 4.7537 & TRN \\
\hline CHEMBL1306701 & 688128 & 4.75 & 4.7948 & TST \\
\hline CHEMBL1436544 & 688128 & 4.6 & 4.3877 & TRN \\
\hline CHEMBL1493968 & 688128 & 4.35 & 4.5662 & TRN \\
\hline CHEMBL1605538 & 688128 & 4.95 & 4.8055 & TRN \\
\hline CHEMBL3144999 & 688128 & 4.4 & 5.086 & TRN \\
\hline CHEMBL1576381 & 688128 & 4.35 & 4.5687 & TRN \\
\hline CHEMBL1589910 & 688128 & 4.35 & 4.3405 & TST \\
\hline CHEMBL1595465 & 688128 & 4.35 & 4.6242 & TRN \\
\hline CHEMBL1425892 & 688128 & 5.4 & 4.4506 & TRN \\
\hline CHEMBL1611890 & 688128 & 4.05 & 4.5988 & TST \\
\hline CHEMBL1601232 & 688128 & 4.45 & 4.4024 & TRN \\
\hline CHEMBL1562476 & 688128 & 5.6 & 4.7165 & TRN \\
\hline CHEMBL1569824 & 688128 & 5.1 & 4.851 & TRN \\
\hline CHEMBL1315734 & 688128 & 4.4 & 4.3789 & TRN \\
\hline CHEMBL1346206 & 688128 & 4.5 & 4.489 & TRN \\
\hline CHEMBL1339351 & 688128 & 4.4 & 4.8942 & TRN \\
\hline CHEMBL1441602 & 688128 & 4.4 & 4.5712 & TST \\
\hline CHEMBL1499602 & 688128 & 4.25 & 4.3673 & TRN \\
\hline CHEMBL1577950 & 688128 & 4.5 & 4.7785 & TST \\
\hline CHEMBL3211923 & 688128 & 4.4 & 4.6228 & TST \\
\hline CHEMBL1439210 & 688128 & 5.0 & 4.8239 & TRN \\
\hline CHEMBL1465776 & 688128 & 4.4 & 4.7277 & TRN \\
\hline CHEMBL1447832 & 688128 & 4.85 & 4.6721 & TRN \\
\hline
\end{tabular}




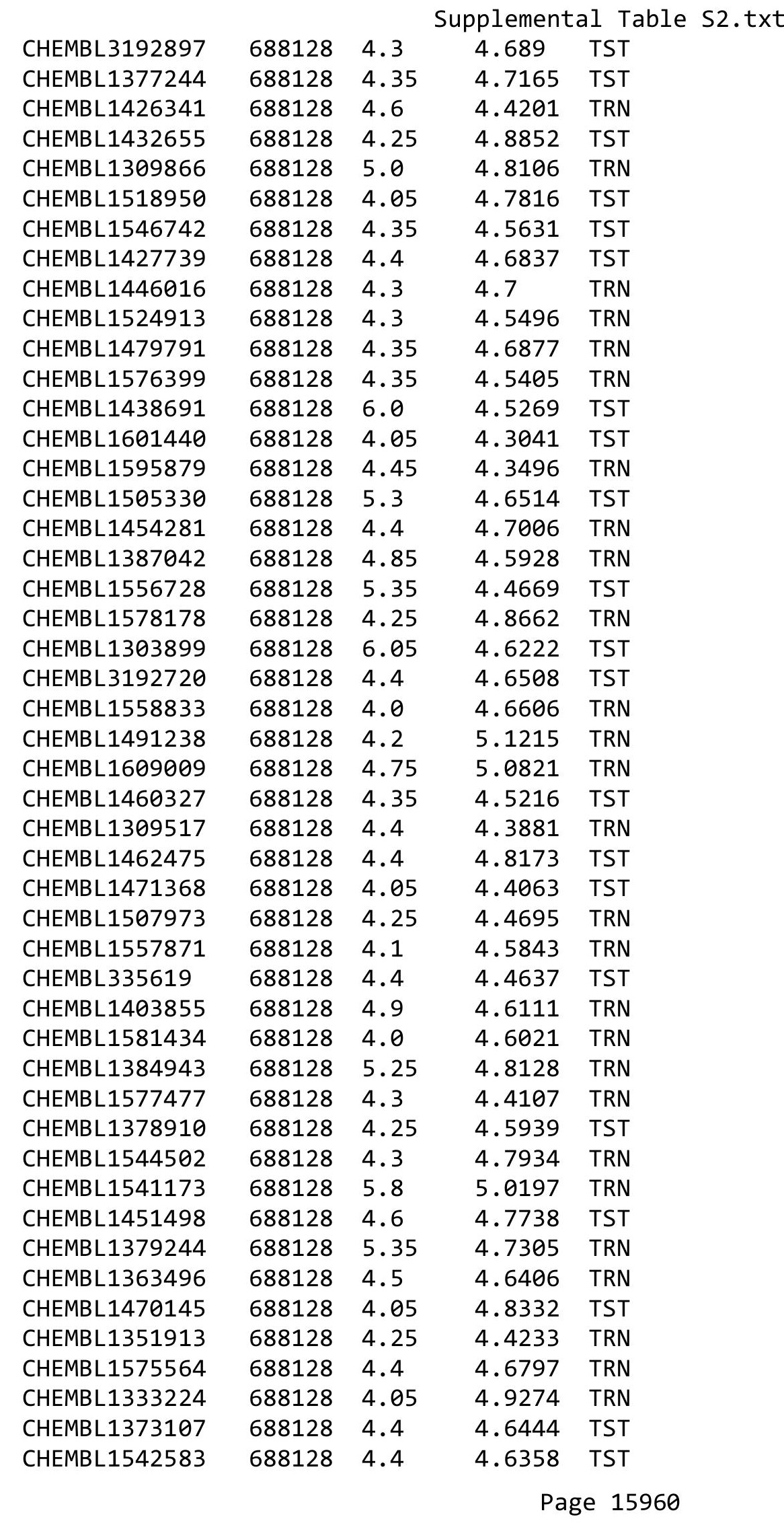




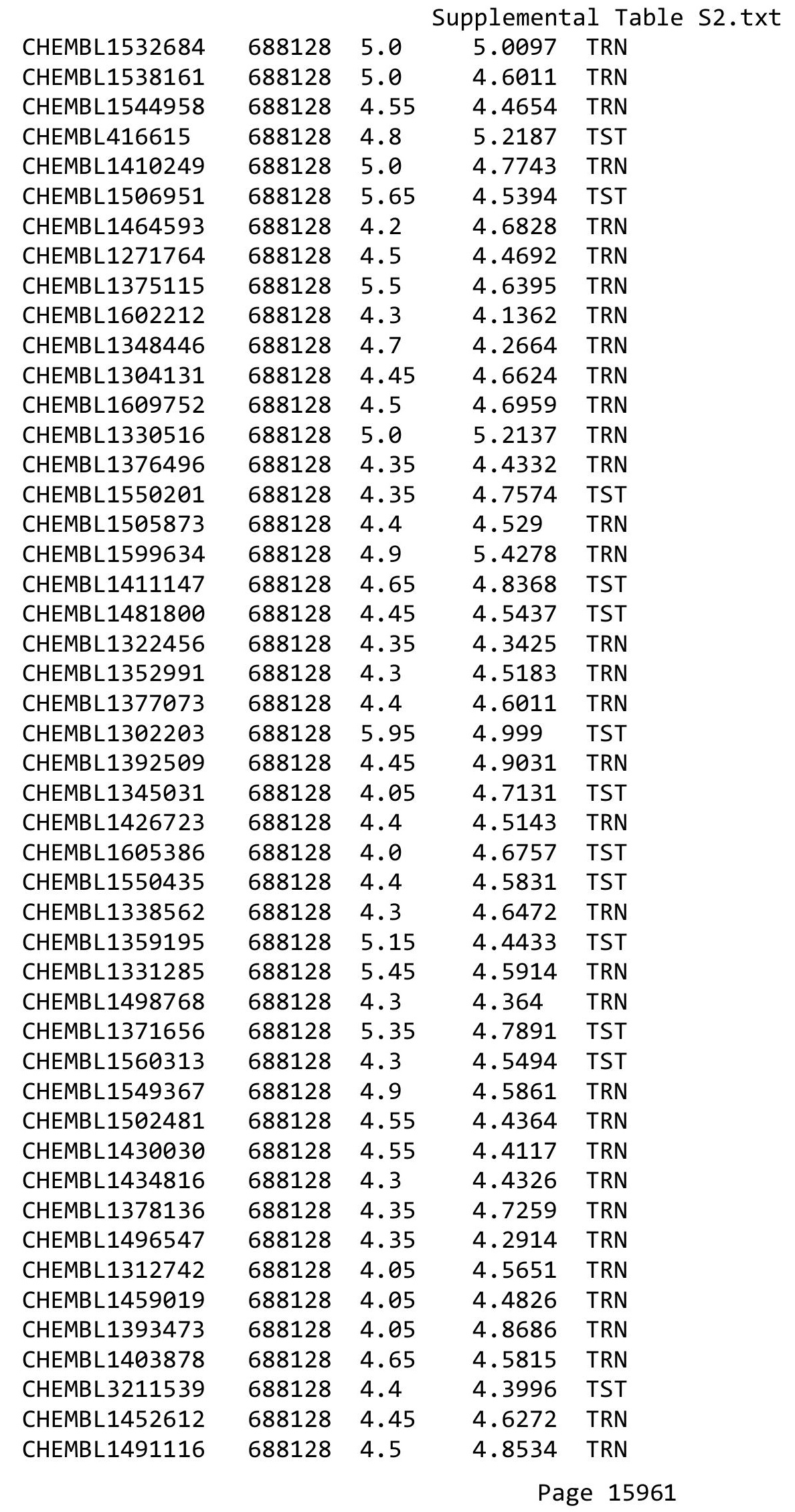




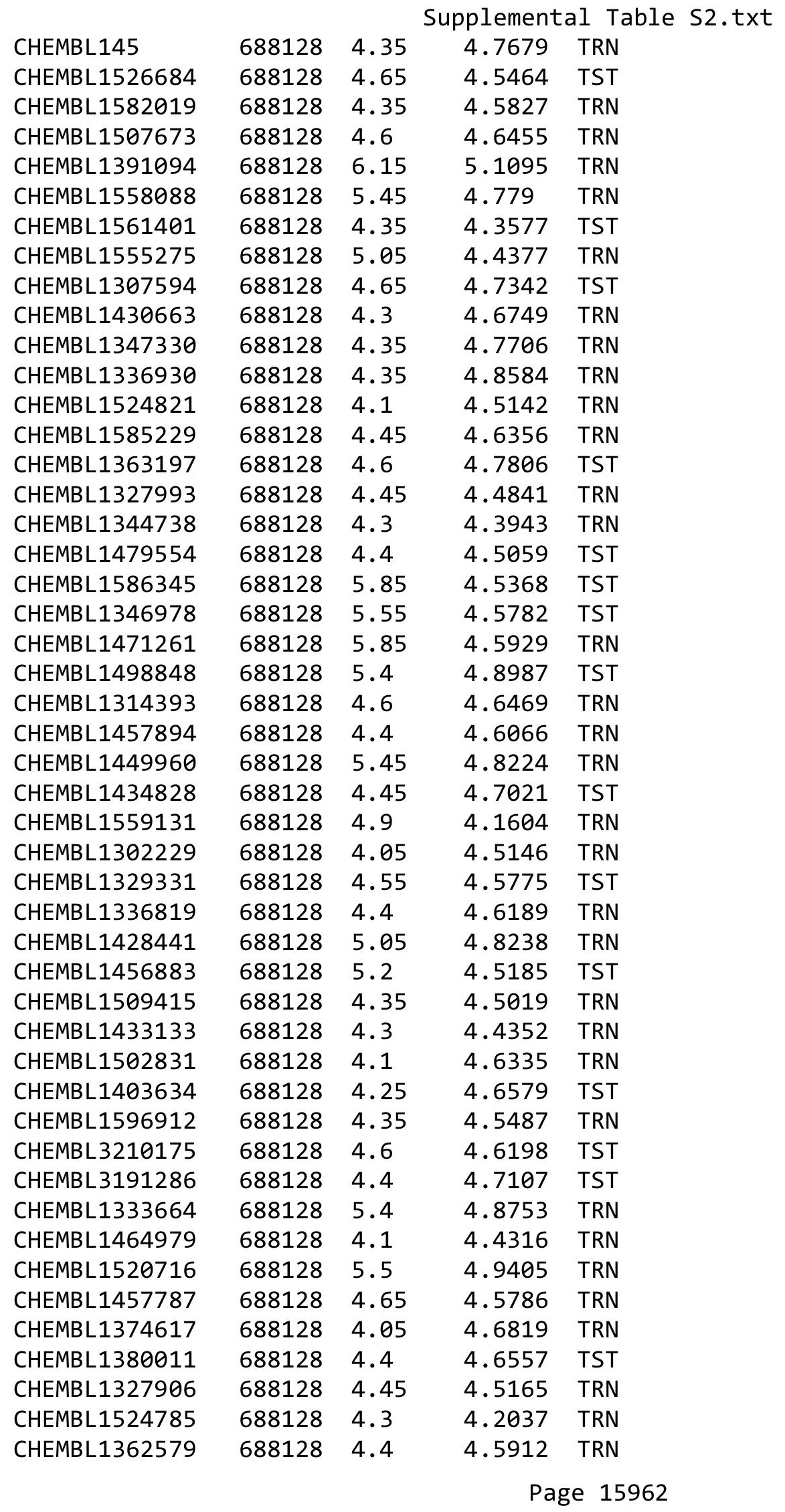




\begin{tabular}{|c|c|c|c|c|}
\hline \multicolumn{5}{|c|}{ Supplemental Table S2.txt } \\
\hline CHEMBL1594991 & 688128 & 6.0 & 5.1225 & TRN \\
\hline CHEMBL1314479 & 688128 & 5.25 & 4.5083 & TRN \\
\hline CHEMBL1348953 & 688128 & 4.65 & 4.3659 & TRN \\
\hline CHEMBL1393757 & 688128 & 4.05 & 4.3572 & TRN \\
\hline CHEMBL1305660 & 688128 & 4.45 & 4.2856 & TRN \\
\hline CHEMBL3189658 & 688128 & 4.35 & 4.4595 & TRN \\
\hline CHEMBL1465387 & 688128 & 4.95 & 4.6318 & TRN \\
\hline CHEMBL1332333 & 688128 & 4.7 & 4.6418 & TST \\
\hline CHEMBL1472414 & 688128 & 4.3 & 4.7038 & TST \\
\hline CHEMBL1428314 & 688128 & 4.4 & 4.4652 & TRN \\
\hline CHEMBL1533772 & 688128 & 4.4 & 4.4155 & TRN \\
\hline CHEMBL1531819 & 688128 & 4.9 & 4.4581 & TRN \\
\hline CHEMBL1416513 & 688128 & 4.6 & 4.51 & TRN \\
\hline CHEMBL1463418 & 688128 & 4.3 & 4.6706 & TST \\
\hline CHEMBL1477177 & 688128 & 4.35 & 4.455 & TST \\
\hline CHEMBL1534116 & 688128 & 4.3 & 4.5118 & TRN \\
\hline CHEMBL1306585 & 688128 & 4.25 & 4.6517 & TST \\
\hline CHEMBL1406179 & 688128 & 4.35 & 4.7258 & TRN \\
\hline CHEMBL1375350 & 688128 & 4.25 & 4.7809 & TRN \\
\hline CHEMBL1407876 & 688128 & 4.9 & 4.9814 & TRN \\
\hline CHEMBL3194107 & 688128 & 4.95 & 4.6732 & TRN \\
\hline CHEMBL1478825 & 688128 & 4.4 & 4.6972 & TRN \\
\hline CHEMBL1308599 & 688128 & 4.4 & 4.5561 & TRN \\
\hline CHEMBL1527415 & 688128 & 4.1 & 4.5503 & TRN \\
\hline CHEMBL1517782 & 688128 & 4.9 & 4.9146 & TRN \\
\hline CHEMBL1426948 & 688128 & 4.4 & 4.4132 & TST \\
\hline CHEMBL1536873 & 688128 & 4.9 & 4.9335 & TRN \\
\hline CHEMBL1597822 & 688128 & 4.4 & 4.6526 & TRN \\
\hline CHEMBL1343017 & 688128 & 4.35 & 4.3527 & TRN \\
\hline CHEMBL1596728 & 688128 & 4.7 & 4.5222 & TRN \\
\hline CHEMBL1509674 & 688128 & 5.55 & 4.6799 & TRN \\
\hline CHEMBL1529115 & 688128 & 6.5 & 4.9348 & TST \\
\hline CHEMBL1309419 & 688128 & 4.95 & 4.7172 & TRN \\
\hline CHEMBL1544905 & 688128 & 4.4 & 4.8595 & TST \\
\hline CHEMBL1475813 & 688128 & 4.35 & 4.5287 & TRN \\
\hline CHEMBL1576173 & 688128 & 4.35 & 4.8003 & TRN \\
\hline CHEMBL1391243 & 688128 & 4.05 & 4.4666 & TRN \\
\hline CHEMBL1350249 & 688128 & 5.05 & 4.9686 & TRN \\
\hline CHEMBL1612384 & 688128 & 4.4 & 4.7118 & TRN \\
\hline CHEMBL1584049 & 688128 & 4.2 & 4.5905 & TRN \\
\hline CHEMBL1340601 & 688128 & 4.3 & 4.6132 & TRN \\
\hline CHEMBL1475447 & 688128 & 4.25 & 4.5052 & TST \\
\hline CHEMBL1577942 & 688128 & 4.45 & 4.6201 & TRN \\
\hline CHEMBL1399010 & 688128 & 4.3 & 5.0165 & TRN \\
\hline CHEMBL450003 & 688128 & 4.3 & 4.5523 & TRN \\
\hline CHEMBL1555581 & 688128 & 6.0 & 4.7444 & TST \\
\hline CHEMBL1559327 & 688128 & 4.4 & 4.5103 & TRN \\
\hline CHEMBL1333817 & 688128 & 4.55 & 5.0174 & TRN \\
\hline
\end{tabular}




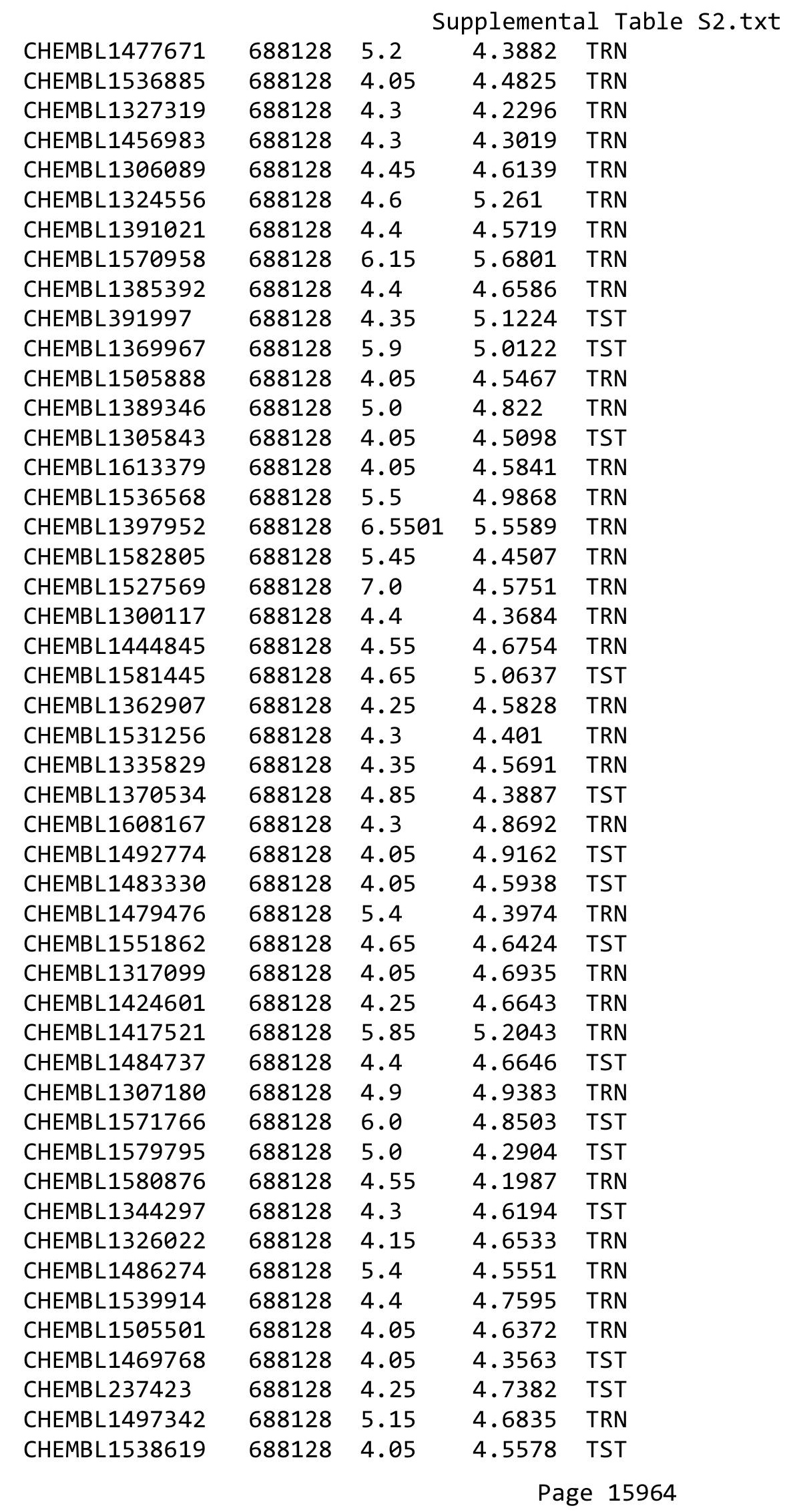




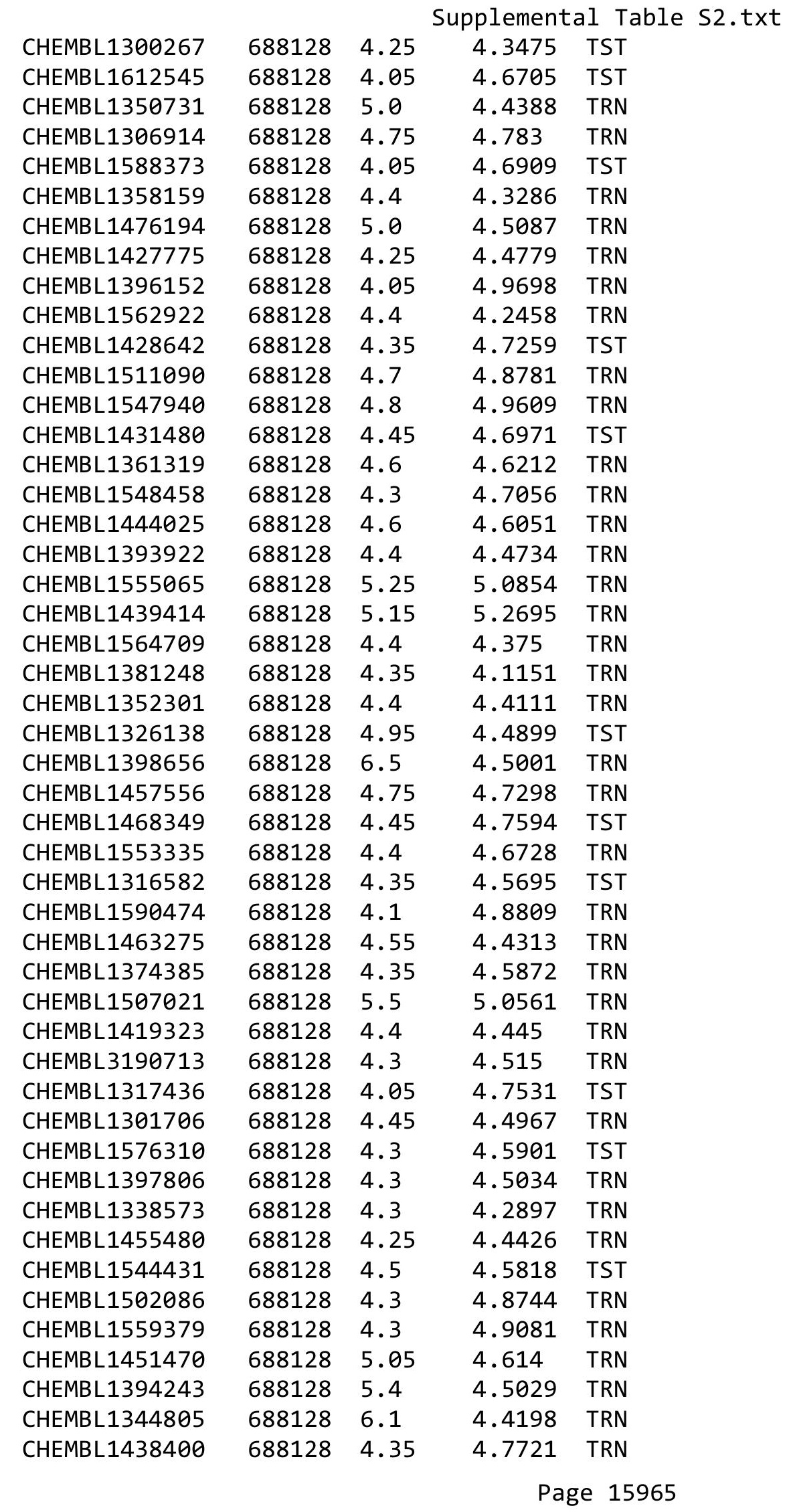




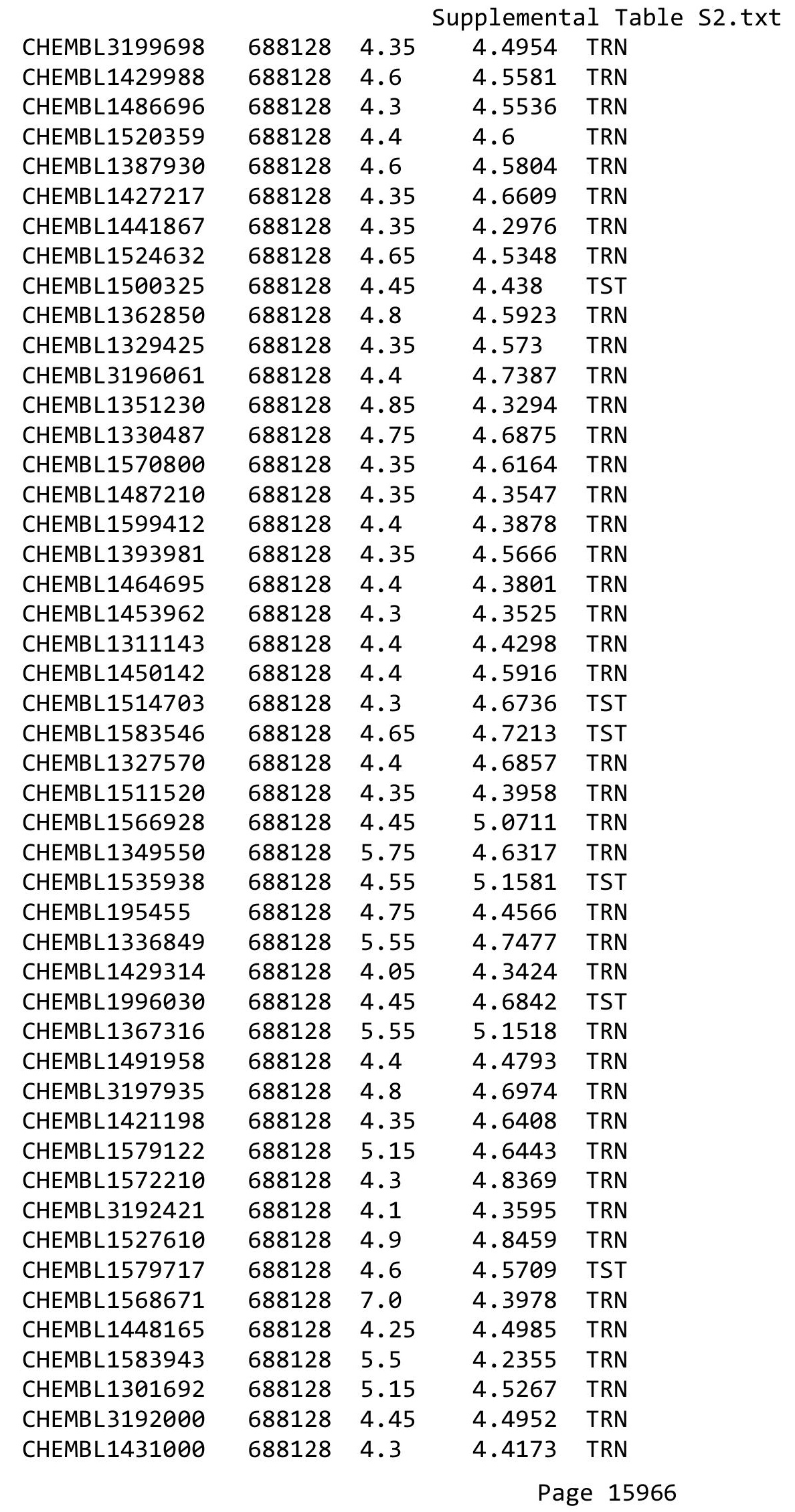




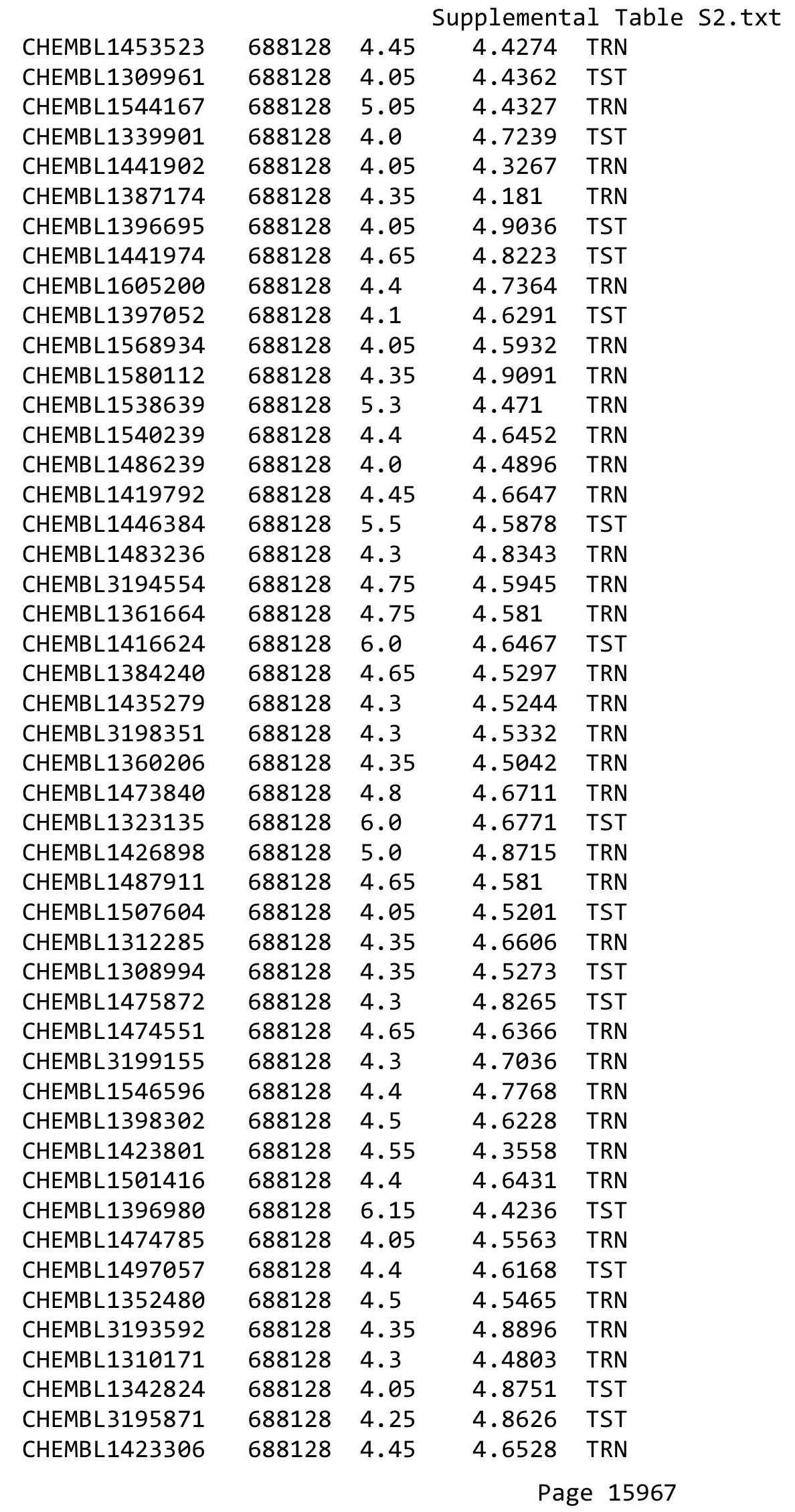




\begin{tabular}{|c|c|c|c|c|}
\hline \multicolumn{5}{|c|}{ Supplemental Table S2.txt } \\
\hline CHEMBL444293 & 688128 & 4.35 & 4.8769 & TRN \\
\hline CHEMBL1548537 & 688128 & 4.35 & 4.5596 & TRN \\
\hline CHEMBL3191886 & 688128 & 4.2 & 4.6999 & TST \\
\hline CHEMBL1370965 & 688128 & 4.1 & 4.5642 & TRN \\
\hline CHEMBL1598087 & 688128 & 4.45 & 4.7878 & TRN \\
\hline CHEMBL1436147 & 688128 & 4.3 & 4.4158 & TRN \\
\hline CHEMBL1372868 & 688128 & 4.3 & 4.7028 & TRN \\
\hline CHEMBL1448578 & 688128 & 4.3 & 4.8298 & TRN \\
\hline CHEMBL1498436 & 688128 & 4.4 & 4.9307 & TRN \\
\hline CHEMBL1523343 & 688128 & 5.35 & 4.6923 & TRN \\
\hline CHEMBL3192792 & 688128 & 4.3 & 4.9243 & TST \\
\hline CHEMBL1564403 & 688128 & 5.55 & 5.0787 & TRN \\
\hline CHEMBL1573268 & 688128 & 6.15 & 4.4205 & TRN \\
\hline CHEMBL1591269 & 688128 & 4.25 & 4.6529 & TST \\
\hline CHEMBL1998946 & 688128 & 5.1 & 4.6465 & TRN \\
\hline CHEMBL3392037 & 688128 & 4.05 & 4.2886 & TST \\
\hline CHEMBL1488340 & 688128 & 4.35 & 4.7096 & TRN \\
\hline CHEMBL1569837 & 688128 & 4.35 & 4.9876 & TRN \\
\hline CHEMBL1411521 & 688128 & 4.65 & 4.605 & TRN \\
\hline CHEMBL1299702 & 688128 & 5.0 & 4.5458 & TRN \\
\hline CHEMBL1367299 & 688128 & 4.8 & 4.495 & TRN \\
\hline CHEMBL1595693 & 688128 & 4.4 & 4.7323 & TRN \\
\hline CHEMBL1380648 & 688128 & 4.4 & 4.7742 & TST \\
\hline CHEMBL1463284 & 688128 & 4.3 & 4.6174 & TRN \\
\hline CHEMBL1599657 & 688128 & 4.65 & 4.6004 & TST \\
\hline CHEMBL1546394 & 688128 & 5.15 & 5.0594 & TRN \\
\hline CHEMBL1439279 & 688128 & 4.3 & 4.4717 & TST \\
\hline CHEMBL1375934 & 688128 & 4.75 & 4.8813 & TRN \\
\hline CHEMBL1300803 & 688128 & 4.95 & 4.1424 & TRN \\
\hline CHEMBL1607432 & 688128 & 4.3 & 4.4449 & TRN \\
\hline CHEMBL3211290 & 688128 & 4.35 & 4.9029 & TRN \\
\hline CHEMBL1419955 & 688128 & 4.8 & 4.3266 & TRN \\
\hline CHEMBL1368609 & 688128 & 4.75 & 4.8249 & TST \\
\hline CHEMBL1460955 & 688128 & 4.4 & 4.5634 & TRN \\
\hline CHEMBL1347418 & 688128 & 4.3 & 4.3 & TRN \\
\hline CHEMBL1477160 & 688128 & 4.6 & 4.3892 & TST \\
\hline CHEMBL1459063 & 688128 & 4.45 & 4.5817 & TRN \\
\hline CHEMBL1443679 & 688128 & 4.05 & 4.6081 & TST \\
\hline CHEMBL1413693 & 688128 & 5.3 & 4.5652 & TRN \\
\hline CHEMBL542493 & 688128 & 5.8 & 4.9721 & TST \\
\hline CHEMBL1526216 & 688128 & 4.05 & 4.5956 & TRN \\
\hline CHEMBL1601526 & 688128 & 5.75 & 5.0107 & TRN \\
\hline CHEMBL1388652 & 688128 & 4.35 & 4.8604 & TST \\
\hline CHEMBL1484414 & 688128 & 4.05 & 4.6602 & TST \\
\hline CHEMBL1470841 & 688128 & 4.45 & 4.2275 & TRN \\
\hline CHEMBL1335280 & 688128 & 4.05 & 4.2306 & TST \\
\hline CHEMBL1470249 & 688128 & 4.3 & 4.7749 & TRN \\
\hline CHEMBL1388626 & 688128 & 5.35 & 4.7853 & TRN \\
\hline
\end{tabular}




\begin{tabular}{|c|c|c|c|c|}
\hline \multicolumn{5}{|c|}{ Supplemental Table S2.txt } \\
\hline CHEMBL1371239 & 688128 & 4.3 & 4.6314 & TRN \\
\hline CHEMBL1322457 & 688128 & 6.0 & 4.3188 & TRN \\
\hline CHEMBL1512468 & 688128 & 4.0 & 4.5542 & TST \\
\hline CHEMBL1431126 & 688128 & 7.0 & 4.5295 & TST \\
\hline CHEMBL1331102 & 688128 & 4.35 & 4.7694 & TST \\
\hline CHEMBL 2374070 & 688128 & 4.9 & 5.1805 & TRN \\
\hline CHEMBL1609318 & 688128 & 4.45 & 4.7812 & TRN \\
\hline CHEMBL1569644 & 688128 & 4.4 & 4.3637 & TRN \\
\hline CHEMBL3199559 & 688128 & 4.45 & 4.4963 & TST \\
\hline CHEMBL1459079 & 688128 & 4.85 & 4.9079 & TST \\
\hline CHEMBL1351289 & 688128 & 4.05 & 4.8839 & TRN \\
\hline CHEMBL1339825 & 688128 & 4.85 & 4.4809 & TST \\
\hline CHEMBL1406954 & 688128 & 5.0 & 4.3456 & TRN \\
\hline CHEMBL1375757 & 688128 & 4.05 & 4.5286 & TRN \\
\hline CHEMBL1399375 & 688128 & 4.35 & 4.5101 & TRN \\
\hline CHEMBL1422720 & 688128 & 5.0 & 4.8483 & TRN \\
\hline CHEMBL1442287 & 688128 & 4.55 & 4.4273 & TRN \\
\hline CHEMBL1508092 & 688128 & 4.05 & 4.6801 & TST \\
\hline CHEMBL1411011 & 688128 & 4.0 & 4.5234 & TST \\
\hline CHEMBL1437535 & 688128 & 4.4 & 4.5752 & TST \\
\hline CHEMBL1504382 & 688128 & 4.45 & 4.6967 & TRN \\
\hline CHEMBL139935 & 688128 & 5.5 & 5.398 & TRN \\
\hline CHEMBL1369918 & 688128 & 4.25 & 4.4845 & TRN \\
\hline CHEMBL1504010 & 688128 & 4.3 & 4.5854 & TRN \\
\hline CHEMBL1446345 & 688128 & 4.25 & 4.6267 & TRN \\
\hline CHEMBL1507625 & 688128 & 4.35 & 4.7552 & TRN \\
\hline CHEMBL1469633 & 688128 & 4.75 & 4.9887 & TRN \\
\hline CHEMBL1421663 & 688128 & 4.05 & 4.6785 & TRN \\
\hline CHEMBL1299466 & 688128 & 4.0 & 4.5954 & TST \\
\hline CHEMBL1447462 & 688128 & 5.5 & 4.9011 & TST \\
\hline CHEMBL1518924 & 688128 & 4.4 & 4.7358 & TRN \\
\hline CHEMBL1500258 & 688128 & 4.35 & 4.4061 & TRN \\
\hline CHEMBL1418105 & 688128 & 4.65 & 4.6396 & TRN \\
\hline CHEMBL1607291 & 688128 & 4.4 & 4.32 & TRN \\
\hline CHEMBL1422767 & 688128 & 4.75 & 4.6581 & TRN \\
\hline CHEMBL1574827 & 688128 & 4.6 & 4.5944 & TRN \\
\hline CHEMBL1567743 & 688128 & 4.3 & 4.4709 & TRN \\
\hline CHEMBL1607470 & 688128 & 4.4 & 4.442 & TST \\
\hline CHEMBL1452314 & 688128 & 4.4 & 5.0316 & TST \\
\hline CHEMBL1549941 & 688128 & 4.35 & 4.9739 & TRN \\
\hline CHEMBL599890 & 688128 & 4.35 & 4.6793 & TRN \\
\hline CHEMBL1548912 & 688128 & 4.3 & 4.5168 & TST \\
\hline CHEMBL1446111 & 688128 & 4.35 & 4.7259 & TRN \\
\hline CHEMBL1554625 & 688128 & 4.35 & 4.4191 & TRN \\
\hline CHEMBL1489403 & 688128 & 6.0 & 4.6596 & TRN \\
\hline CHEMBL1364138 & 688128 & 5.35 & 4.6077 & TRN \\
\hline CHEMBL1359080 & 688128 & 4.4 & 4.5284 & TRN \\
\hline CHEMBL1542450 & 688128 & 4.4 & 4.7147 & TRN \\
\hline
\end{tabular}




\begin{tabular}{|c|c|c|c|c|}
\hline \multicolumn{5}{|c|}{ Supplemental Table } \\
\hline CHEMBL1340518 & 688128 & 4.25 & 4.2855 & TRN \\
\hline CHEMBL1444005 & 688128 & 4.45 & 4.8909 & TRN \\
\hline CHEMBL1349803 & 688128 & 4.35 & 4.3834 & TRN \\
\hline CHEMBL1494423 & 688128 & 4.25 & 4.5315 & TRN \\
\hline CHEMBL1324618 & 688128 & 4.6 & 4.507 & TRN \\
\hline CHEMBL1558988 & 688128 & 4.35 & 4.4594 & TRN \\
\hline CHEMBL1406405 & 688128 & 4.4 & 4.4747 & TST \\
\hline CHEMBL1473369 & 688128 & 4.3 & 4.4468 & TST \\
\hline CHEMBL1444103 & 688128 & 5.6 & 4.9229 & TST \\
\hline CHEMBL1468129 & 688128 & 4.45 & 4.4497 & TST \\
\hline CHEMBL1300494 & 688128 & 4.3 & 4.4219 & TRN \\
\hline CHEMBL1341607 & 688128 & 4.4 & 4.3764 & TRN \\
\hline CHEMBL1308553 & 688128 & 4.4 & 4.4062 & TRN \\
\hline CHEMBL1459531 & 688128 & 4.85 & 4.7472 & TRN \\
\hline CHEMBL1413841 & 688128 & 5.5 & 4.6 & TST \\
\hline CHEMBL1568794 & 688128 & 4.4 & 4.4252 & TRN \\
\hline CHEMBL1541904 & 688128 & 4.25 & 4.7313 & TRN \\
\hline CHEMBL1423121 & 688128 & 4.45 & 4.5077 & TRN \\
\hline CHEMBL1591105 & 688128 & 4.25 & 4.6135 & TST \\
\hline CHEMBL1520970 & 688128 & 4.55 & 4.8034 & TRN \\
\hline CHEMBL1406989 & 688128 & 4.95 & 4.6888 & TRN \\
\hline CHEMBL1368779 & 688128 & 4.3 & 4.805 & TRN \\
\hline CHEMBL1416698 & 688128 & 5.15 & 4.6506 & TRN \\
\hline CHEMBL1498324 & 688128 & 4.4 & 4.7407 & TRN \\
\hline CHEMBL1525805 & 688128 & 4.35 & 4.5943 & TST \\
\hline CHEMBL1304828 & 688128 & 5.5 & 4.9202 & TRN \\
\hline CHEMBL3196552 & 688128 & 4.95 & 4.5218 & TST \\
\hline CHEMBL3196147 & 688128 & 4.55 & 4.5668 & TRN \\
\hline CHEMBL1573585 & 688128 & 4.3 & 4.3222 & TRN \\
\hline CHEMBL1534773 & 688128 & 4.3 & 4.5374 & TRN \\
\hline CHEMBL1538084 & 688128 & 4.3 & 4.8616 & TST \\
\hline CHEMBL1577394 & 688128 & 4.65 & 4.6806 & TST \\
\hline CHEMBL1330506 & 688128 & 4.4 & 4.4529 & TRN \\
\hline CHEMBL2007419 & 688128 & 4.25 & 4.9157 & TRN \\
\hline CHEMBL1383557 & 688128 & 4.3 & 4.8187 & TST \\
\hline CHEMBL1454551 & 688128 & 4.5 & 4.4742 & TRN \\
\hline CHEMBL1352275 & 688128 & 4.45 & 4.694 & TST \\
\hline CHEMBL1579738 & 688128 & 4.65 & 4.7743 & TRN \\
\hline CHEMBL1441911 & 688128 & 4.9 & 4.5823 & TST \\
\hline CHEMBL1308282 & 688128 & 4.35 & 4.4118 & TRN \\
\hline CHEMBL1470912 & 688128 & 4.3 & 4.37 & TRN \\
\hline CHEMBL1345808 & 688128 & 4.3 & 4.6484 & TRN \\
\hline CHEMBL267233 & 688128 & 4.45 & 4.7898 & TRN \\
\hline CHEMBL1511442 & 688128 & 4.05 & 4.6427 & TRN \\
\hline CHEMBL1532948 & 688128 & 4.35 & 4.1189 & TRN \\
\hline CHEMBL1322046 & 688128 & 4.25 & 4.5899 & TRN \\
\hline CHEMBL1367356 & 688128 & 4.95 & 4.6338 & TST \\
\hline CHEMBL1438503 & 688128 & 4.45 & 4.5958 & TRN \\
\hline
\end{tabular}




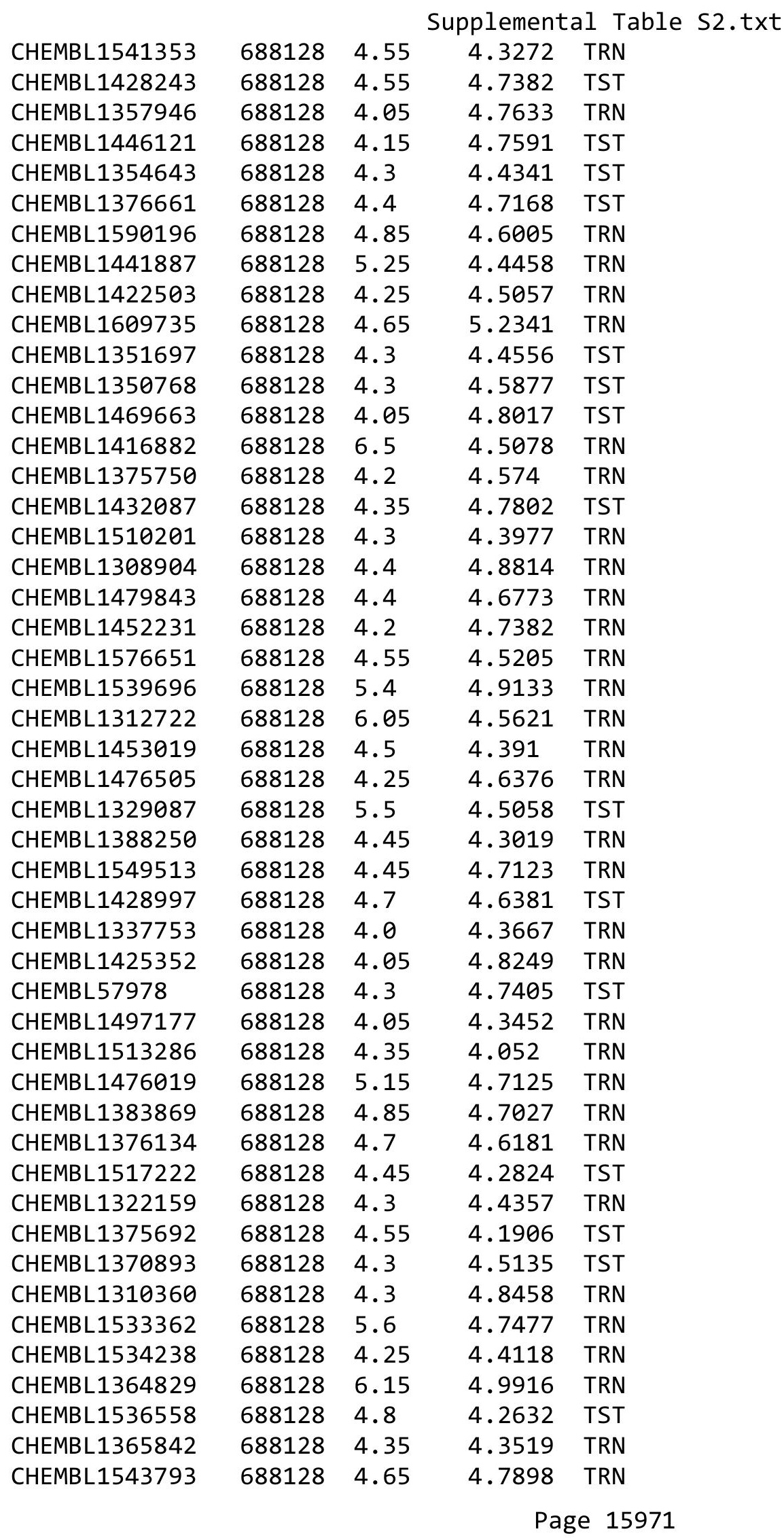




\begin{tabular}{|c|c|c|c|c|c|}
\hline \\
\hline CHEMBL1486825 & 688128 & 4.3 & 4.4591 & TRN & \\
\hline CHEMBL1356435 & 688128 & 4.95 & 4.7509 & TRN & \\
\hline CHEMBL1329974 & 688128 & 5.75 & 4.746 & TRN & \\
\hline CHEMBL1442764 & 688128 & 4.8 & 4.6235 & TRN & \\
\hline CHEMBL1607554 & 688128 & 4.4 & 4.8861 & TST & \\
\hline CHEMBL1606582 & 688128 & 4.0 & 4.6914 & TRN & \\
\hline CHEMBL1352194 & 688128 & 4.3 & 4.5197 & TST & \\
\hline CHEMBL1376611 & 688128 & 4.85 & 4.6391 & TRN & \\
\hline CHEMBL1406427 & 688128 & 4.4 & 4.6162 & TRN & \\
\hline CHEMBL1457037 & 688128 & 4.65 & 4.5056 & TST & \\
\hline CHEMBL1478361 & 688128 & 4.25 & 4.5295 & TRN & \\
\hline CHEMBL1513045 & 688128 & 4.35 & 4.6046 & TRN & \\
\hline CHEMBL1497838 & 688128 & 5.2 & 4.6614 & TST & \\
\hline CHEMBL1419721 & 688128 & 5.4 & 4.8793 & TRN & \\
\hline CHEMBL312586 & 688128 & 4.0 & 4.9376 & TRN & \\
\hline CHEMBL1327880 & 688128 & 4.1 & 5.0069 & TST & \\
\hline CHEMBL1504207 & 688128 & 4.25 & 5.0843 & TRN & \\
\hline CHEMBL1431722 & 688128 & 5.4 & 4.4112 & TRN & \\
\hline CHEMBL1331605 & 688128 & 4.7 & 4.9396 & TRN & \\
\hline CHEMBL1337335 & 688128 & 5.45 & 4.4781 & TRN & \\
\hline CHEMBL1408874 & 688128 & 4.0 & 4.8812 & TRN & \\
\hline CHEMBL1524820 & 688128 & 4.25 & 4.5247 & TRN & \\
\hline CHEMBL1343352 & 688128 & 4.45 & 4.79 & TRN & \\
\hline CHEMBL1983389 & 688128 & 4.9 & 4.5742 & TST & \\
\hline CHEMBL1613104 & 688128 & 4.5 & 4.572 & TST & \\
\hline CHEMBL1419941 & 688128 & 4.45 & 4.6783 & TRN & \\
\hline CHEMBL1458132 & 688128 & 4.95 & 4.6333 & TRN & \\
\hline CHEMBL1606488 & 688128 & 4.95 & 4.8117 & TRN & \\
\hline CHEMBL1594989 & 688128 & 4.35 & 4.5279 & TRN & \\
\hline CHEMBL1597912 & 688128 & 4.3 & 4.7219 & TRN & \\
\hline CHEMBL1374566 & 688128 & 4.4 & 4.84699 & 99999999995 & TRN \\
\hline CHEMBL1394618 & 688128 & 4.35 & 4.6666 & TRN & \\
\hline CHEMBL1378900 & 688128 & 4.0 & 4.4108 & TRN & \\
\hline CHEMBL1364880 & 688128 & 4.2 & 4.409 & TRN & \\
\hline CHEMBL1353554 & 688128 & 4.7 & 5.0396 & TST & \\
\hline CHEMBL1405938 & 688128 & 4.1 & 4.5844 & TRN & \\
\hline CHEMBL1439860 & 688128 & 4.5 & 4.4652 & TRN & \\
\hline CHEMBL1377284 & 688128 & 4.1 & 5.0267 & TRN & \\
\hline CHEMBL1600558 & 688128 & 4.25 & 4.2969 & TST & \\
\hline CHEMBL1406655 & 688128 & 4.3 & 4.2961 & TST & \\
\hline CHEMBL1387686 & 688128 & 4.25 & 4.4284 & TRN & \\
\hline CHEMBL1408737 & 688128 & 4.95 & 4.8252 & TRN & \\
\hline CHEMBL1493649 & 688128 & 4.55 & 4.4831 & TRN & \\
\hline CHEMBL1367148 & 688128 & 5.1 & 4.8583 & TRN & \\
\hline CHEMBL1376920 & 688128 & 4.6 & 4.8896 & TRN & \\
\hline CHEMBL1522275 & 688128 & 6.0 & 4.9707 & TST & \\
\hline CHEMBL1335965 & 688128 & 5.2 & 4.8665 & TRN & \\
\hline CHEMBL1478187 & 688128 & 4.2 & 4.3875 & TRN & \\
\hline & & & & 2 & \\
\hline
\end{tabular}




\begin{tabular}{|c|c|c|c|c|c|}
\hline & & \multicolumn{4}{|c|}{ Supplemental Table S2.txt } \\
\hline CHEMBL1993855 & 688128 & 4.05 & 4.6556 & TRN & \\
\hline CHEMBL3192073 & 688128 & 6.0 & 4.7292 & TRN & \\
\hline CHEMBL1511883 & 688128 & 4.5 & 4.774 & TRN & \\
\hline CHEMBL1426860 & 688128 & 4.25 & 5.2106 & TST & \\
\hline CHEMBL1408580 & 688128 & 5.1 & 4.7221 & TRN & \\
\hline CHEMBL1522443 & 688128 & 5.45 & 5.1399 & TRN & \\
\hline CHEMBL1304870 & 688128 & 4.35 & 4.7767 & TRN & \\
\hline CHEMBL1415815 & 688128 & 4.1 & 4.6201 & TRN & \\
\hline CHEMBL1477803 & 688128 & 4.45 & 4.9396 & TRN & \\
\hline CHEMBL1359477 & 688128 & 4.3 & 4.3561 & TRN & \\
\hline CHEMBL1299850 & 688128 & 4.4 & 4.4805 & TRN & \\
\hline CHEMBL1570964 & 688128 & 4.35 & 4.6246 & TRN & \\
\hline CHEMBL1462693 & 688128 & 4.4 & 4.3505 & TRN & \\
\hline CHEMBL1606423 & 688128 & 4.65 & 4.5456 & TRN & \\
\hline CHEMBL1325819 & 688128 & 4.5 & 4.393 & TRN & \\
\hline CHEMBL1430606 & 688128 & 4.0 & 4.5193 & TST & \\
\hline CHEMBL1584970 & 688128 & 4.35 & 4.5874 & TRN & \\
\hline CHEMBL1556631 & 688128 & 4.8 & 4.5846 & TRN & \\
\hline CHEMBL1320447 & 688128 & 4.75 & 4.6813 & TRN & \\
\hline CHEMBL1485530 & 688128 & 5.0 & 4.6022 & TRN & \\
\hline CHEMBL1517746 & 688128 & 4.3 & 4.744 & TRN & \\
\hline CHEMBL1419113 & 688128 & 4.05 & 4.2512 & TRN & \\
\hline CHEMBL1344806 & 688128 & 4.3 & 4.5561 & TRN & \\
\hline CHEMBL1483507 & 688128 & 5.05 & 4.5326 & TRN & \\
\hline CHEMBL1306855 & 688128 & 4.3 & 4.7787 & TRN & \\
\hline CHEMBL3192847 & 688128 & 5.8 & 4.7793 & TRN & \\
\hline CHEMBL1498708 & 688128 & 4.65 & 4.7533 & TRN & \\
\hline CHEMBL1479920 & 688128 & 4.3 & 4.38399 & 99999999995 & TRN \\
\hline CHEMBL1362646 & 688128 & 4.45 & 4.6287 & TRN & \\
\hline CHEMBL1498288 & 688128 & 4.25 & 4.6021 & TRN & \\
\hline CHEMBL1321748 & 688128 & 4.3 & 4.3578 & TRN & \\
\hline CHEMBL1509134 & 688128 & 4.4 & 4.6366 & TST & \\
\hline CHEMBL1301722 & 688128 & 6.0 & 4.7291 & TST & \\
\hline CHEMBL1489898 & 688128 & 5.05 & 4.6835 & TST & \\
\hline CHEMBL1503034 & 688128 & 5.35 & 5.0672 & TRN & \\
\hline CHEMBL1338449 & 688128 & 4.65 & 4.3963 & TRN & \\
\hline CHEMBL1553004 & 688128 & 4.35 & 4.2828 & TRN & \\
\hline CHEMBL406341 & 688128 & 4.9 & 5.0489 & TRN & \\
\hline CHEMBL1316426 & 688128 & 4.45 & 4.6593 & TRN & \\
\hline CHEMBL1336249 & 688128 & 4.3 & 4.6471 & TRN & \\
\hline CHEMBL3198401 & 688128 & 4.3 & 4.9665 & TRN & \\
\hline CHEMBL1529471 & 688128 & 4.8 & 4.9149 & TRN & \\
\hline CHEMBL1492714 & 688128 & 5.5 & 4.7766 & TRN & \\
\hline CHEMBL1507417 & 688128 & 4.45 & 4.5155 & TRN & \\
\hline CHEMBL1580311 & 688128 & 5.4 & 5.0206 & TRN & \\
\hline CHEMBL1349259 & 688128 & 4.3 & 4.3776 & TST & \\
\hline CHEMBL1341913 & 688128 & 6.0 & 4.5729 & TRN & \\
\hline CHEMBL1430519 & 688128 & 4.5 & 4.5482 & TRN & \\
\hline
\end{tabular}




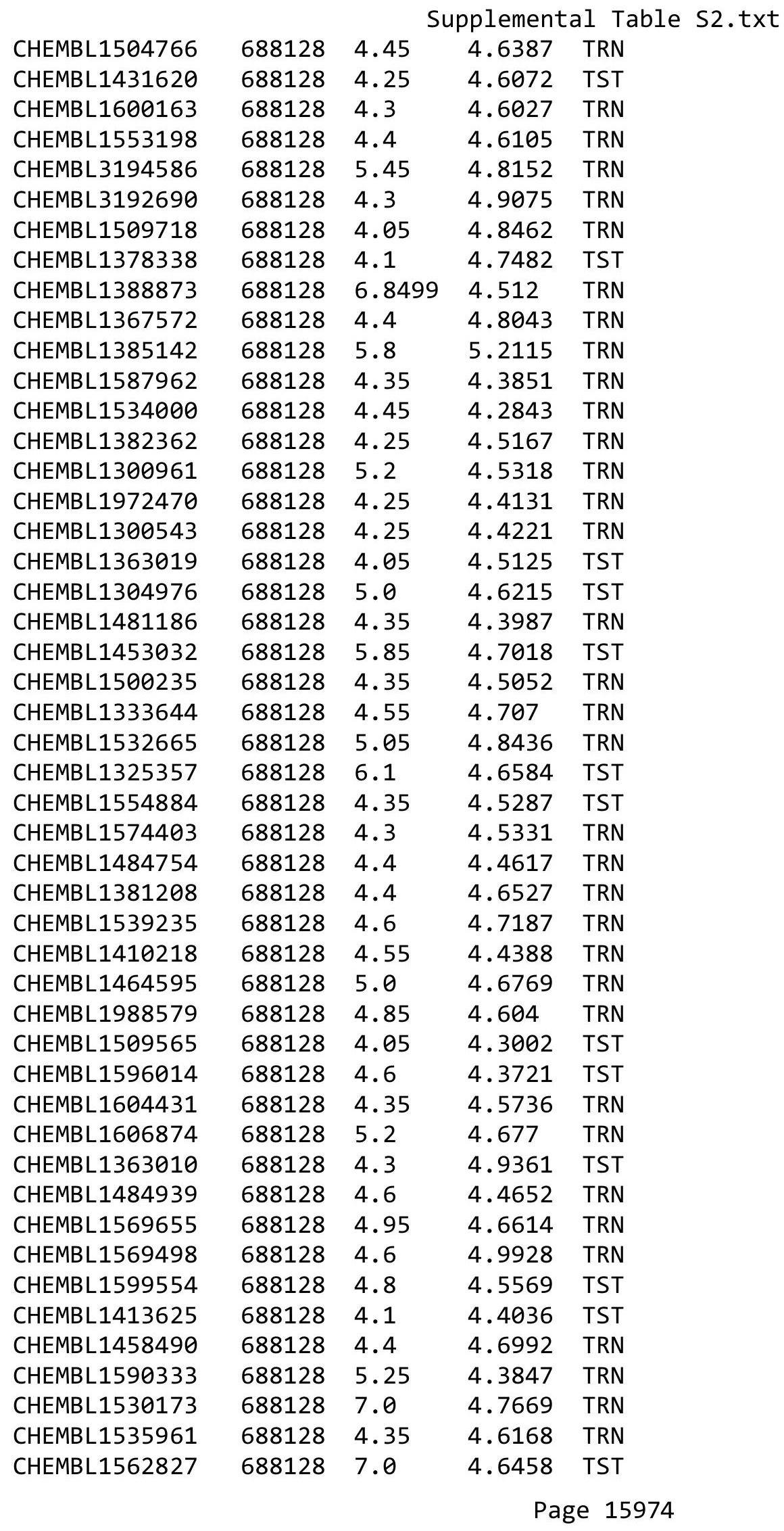




\begin{tabular}{|c|c|c|c|c|}
\hline \multicolumn{5}{|c|}{ Supplemental Table S2.txt } \\
\hline CHEMBL1353515 & 688128 & 6.2 & 5.309 & TRN \\
\hline CHEMBL1389707 & 688128 & 4.4 & 4.6796 & TRN \\
\hline CHEMBL1396413 & 688128 & 4.05 & 4.6347 & TRN \\
\hline CHEMBL1348220 & 688128 & 6.8499 & 5.0028 & TRN \\
\hline CHEMBL1450987 & 688128 & 4.35 & 4.4579 & TRN \\
\hline CHEMBL1332702 & 688128 & 4.35 & 4.5294 & TRN \\
\hline CHEMBL1471648 & 688128 & 4.5 & 4.7563 & TRN \\
\hline CHEMBL1497949 & 688128 & 4.35 & 4.7189 & TRN \\
\hline CHEMBL1449731 & 688128 & 4.05 & 4.6575 & TST \\
\hline CHEMBL1448428 & 688128 & 4.0 & 4.8488 & TST \\
\hline CHEMBL1396253 & 688128 & 4.3 & 4.5539 & TRN \\
\hline CHEMBL1567708 & 688128 & 4.4 & 4.613 & TRN \\
\hline CHEMBL1362023 & 688128 & 4.5 & 4.6772 & TRN \\
\hline CHEMBL 3198071 & 688128 & 4.55 & 4.5296 & TRN \\
\hline CHEMBL1452324 & 688128 & 4.3 & 4.7154 & TRN \\
\hline CHEMBL1586353 & 688128 & 4.35 & 4.4934 & TRN \\
\hline CHEMBL1537136 & 688128 & 4.25 & 4.5169 & TRN \\
\hline CHEMBL1568445 & 688128 & 5.05 & 4.7741 & TRN \\
\hline CHEMBL1562387 & 688128 & 4.0 & 4.6109 & TST \\
\hline CHEMBL1569790 & 688128 & 4.5 & 4.3449 & TRN \\
\hline CHEMBL1458109 & 688128 & 4.4 & 4.6877 & TRN \\
\hline CHEMBL1362248 & 688128 & 4.35 & 5.0168 & TST \\
\hline CHEMBL1472710 & 688128 & 4.4 & 4.5401 & TRN \\
\hline CHEMBL1506885 & 688128 & 4.05 & 4.5255 & TRN \\
\hline CHEMBL1302329 & 688128 & 4.55 & 4.6835 & TRN \\
\hline CHEMBL1988969 & 688128 & 5.55 & 4.6061 & TRN \\
\hline CHEMBL1578345 & 688128 & 5.7 & 4.803 & TRN \\
\hline CHEMBL1391618 & 688128 & 4.55 & 4.4606 & TRN \\
\hline CHEMBL1496994 & 688128 & 4.55 & 4.5076 & TRN \\
\hline CHEMBL1342646 & 688128 & 4.3 & 4.374 & TRN \\
\hline CHEMBL1493804 & 688128 & 4.05 & 4.4558 & TRN \\
\hline CHEMBL1319869 & 688128 & 5.85 & 4.751 & TST \\
\hline CHEMBL1299975 & 688128 & 4.1 & 4.7613 & TRN \\
\hline CHEMBL1387051 & 688128 & 4.5 & 4.6377 & TRN \\
\hline CHEMBL1578775 & 688128 & 4.9 & 4.4843 & TRN \\
\hline CHEMBL1452394 & 688128 & 4.75 & 4.2349 & TRN \\
\hline CHEMBL1363219 & 688128 & 5.1 & 4.9288 & TRN \\
\hline CHEMBL1405648 & 688128 & 4.15 & 4.3847 & TRN \\
\hline CHEMBL1519469 & 688128 & 4.35 & 4.5512 & TST \\
\hline CHEMBL1377696 & 688128 & 4.45 & 4.582 & TST \\
\hline CHEMBL1413859 & 688128 & 4.85 & 5.2086 & TRN \\
\hline CHEMBL1523807 & 688128 & 4.3 & 4.5897 & TRN \\
\hline CHEMBL1388237 & 688128 & 4.65 & 4.8049 & TRN \\
\hline CHEMBL1337016 & 688128 & 4.6 & 4.6382 & TRN \\
\hline CHEMBL1555304 & 688128 & 4.45 & 4.5116 & TRN \\
\hline CHEMBL1464798 & 688128 & 5.2 & 5.2201 & TRN \\
\hline CHEMBL1520772 & 688128 & 4.3 & 4.3679 & TRN \\
\hline CHEMBL1569475 & 688128 & 4.6 & 4.5481 & TRN \\
\hline
\end{tabular}




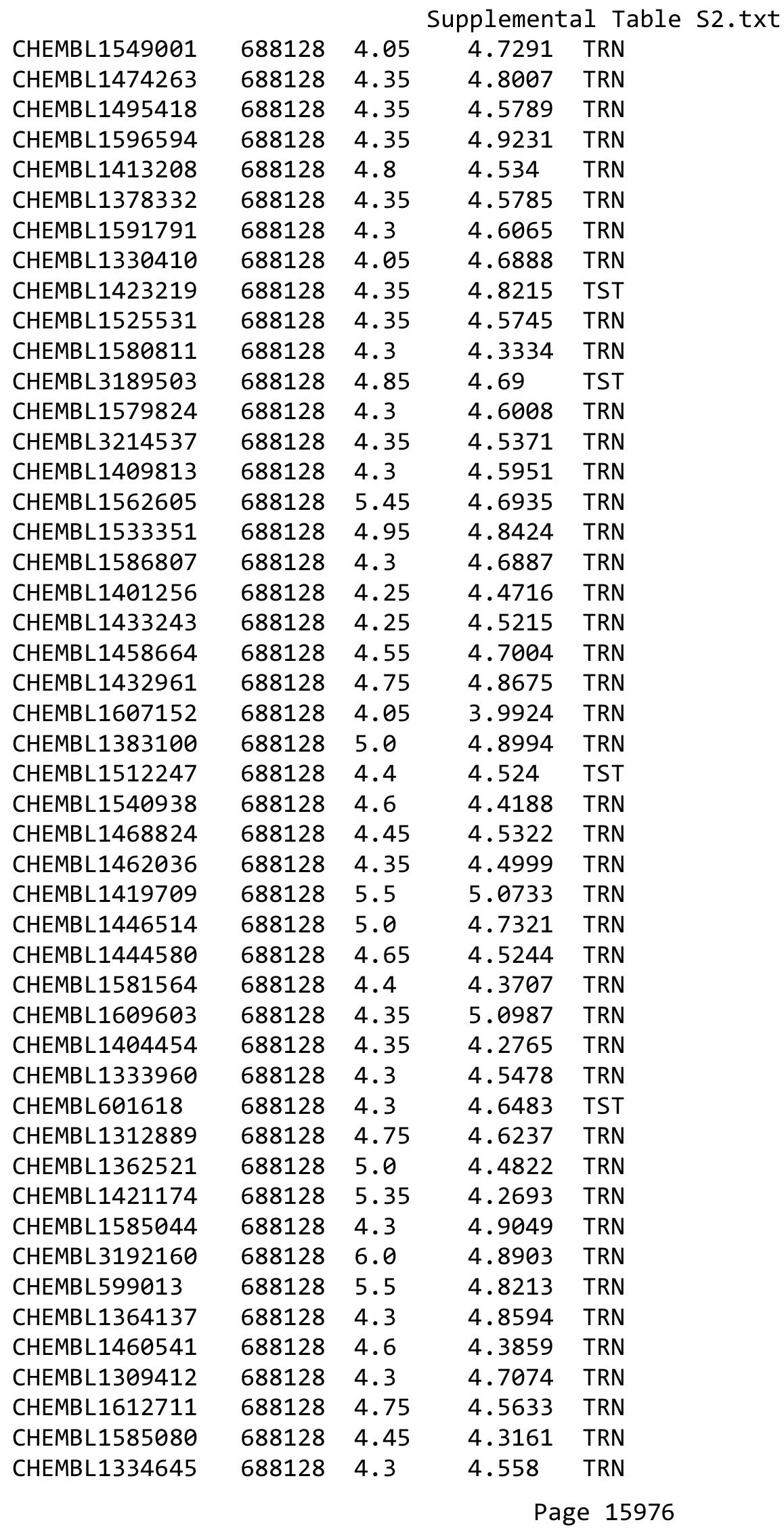




\begin{tabular}{|c|c|c|c|c|c|}
\hline \\
\hline CHEMBL1497070 & 688128 & 4.4 & 4.5454 & TST & \\
\hline CHEMBL1439291 & 688128 & 4.5 & 4.8828 & TRN & \\
\hline CHEMBL1494490 & 688128 & 4.4 & 4.6361 & TST & \\
\hline CHEMBL1429363 & 688128 & 4.85 & 4.7166 & TRN & \\
\hline CHEMBL1354776 & 688128 & 4.05 & 4.5237 & TRN & \\
\hline CHEMBL1612713 & 688128 & 4.35 & 4.5819 & TST & \\
\hline CHEMBL1528411 & 688128 & 4.4 & 4.5693 & TRN & \\
\hline CHEMBL1460942 & 688128 & 4.4 & 4.4813 & TST & \\
\hline CHEMBL1403071 & 688128 & 4.7 & 4.6673 & TST & \\
\hline CHEMBL1439904 & 688128 & 5.4 & 4.6578 & TRN & \\
\hline CHEMBL1585944 & 688128 & 4.4 & 4.9655 & TRN & \\
\hline CHEMBL1426171 & 688128 & 4.95 & 4.6984 & TRN & \\
\hline CHEMBL1465565 & 688128 & 4.3 & 4.6108 & TST & \\
\hline CHEMBL1385958 & 688128 & 4.3 & 4.7232 & TRN & \\
\hline CHEMBL1601691 & 688128 & 6.1 & 4.5667 & TRN & \\
\hline CHEMBL1480511 & 688128 & 4.55 & 4.42399 & 99999999995 & TRN \\
\hline CHEMBL1530358 & 688128 & 4.35 & 4.5344 & TRN & \\
\hline CHEMBL1612734 & 688128 & 4.4 & 4.4497 & TRN & \\
\hline CHEMBL1497815 & 688128 & 4.4 & 4.2361 & TRN & \\
\hline CHEMBL1318916 & 688128 & 4.45 & 4.5771 & TRN & \\
\hline CHEMBL1468757 & 688128 & 5.55 & 4.5508 & TST & \\
\hline CHEMBL1511230 & 688128 & 4.05 & 4.7036 & TRN & \\
\hline CHEMBL1470974 & 688128 & 4.05 & 4.4793 & TST & \\
\hline CHEMBL1312167 & 688128 & 4.85 & 4.973 & TRN & \\
\hline CHEMBL1325009 & 688128 & 4.5 & 4.4616 & TRN & \\
\hline CHEMBL1312404 & 688128 & 4.4 & 4.8646 & TST & \\
\hline CHEMBL1487067 & 688128 & 6.3 & 4.382 & TST & \\
\hline CHEMBL1392050 & 688128 & 4.45 & 4.7471 & TRN & \\
\hline CHEMBL1505936 & 688128 & 4.35 & 4.493 & TST & \\
\hline CHEMBL1604203 & 688128 & 4.5 & 4.481 & TRN & \\
\hline CHEMBL1367653 & 688128 & 4.35 & 4.7219 & TRN & \\
\hline CHEMBL339561 & 688128 & 4.05 & 4.9517 & TST & \\
\hline CHEMBL1424482 & 688128 & 5.5 & 4.5431 & TRN & \\
\hline CHEMBL1318721 & 688128 & 5.0 & 4.6506 & TRN & \\
\hline CHEMBL1309821 & 688128 & 4.35 & 4.7774 & TRN & \\
\hline CHEMBL1537429 & 688128 & 4.4 & 4.5005 & TRN & \\
\hline CHEMBL1454649 & 688128 & 4.4 & 4.412 & TST & \\
\hline CHEMBL1383513 & 688128 & 4.55 & 4.5922 & TRN & \\
\hline CHEMBL1323236 & 688128 & 4.35 & 4.5386 & TRN & \\
\hline CHEMBL1357301 & 688128 & 4.4 & 4.6351 & TST & \\
\hline CHEMBL1436144 & 688128 & 4.9 & 4.7294 & TST & \\
\hline CHEMBL1527052 & 688128 & 4.05 & 4.5381 & TST & \\
\hline CHEMBL1459530 & 688128 & 4.25 & 4.6986 & TRN & \\
\hline CHEMBL1438686 & 688128 & 4.3 & 4.3604 & TRN & \\
\hline CHEMBL1302338 & 688128 & 4.05 & 4.7615 & TST & \\
\hline CHEMBL1503620 & 688128 & 4.05 & 4.6634 & TST & \\
\hline CHEMBL1350384 & 688128 & 6.95 & 4.7572 & TRN & \\
\hline CHEMBL1478116 & 688128 & 6.15 & 4.2921 & TST & \\
\hline
\end{tabular}




\begin{tabular}{|c|c|c|c|c|c|}
\hline \multicolumn{6}{|c|}{ Supplemental Table s2.txt } \\
\hline CHEMBL1471337 & 688128 & 4.3 & 4.8081 & TRN & \\
\hline CHEMBL1399746 & 688128 & 4.35 & 4.4708 & TRN & \\
\hline CHEMBL1500915 & 688128 & 4.4 & 4.7198 & TRN & \\
\hline CHEMBL1474005 & 688128 & 4.45 & 4.6733 & TRN & \\
\hline CHEMBL1328429 & 688128 & 4.3 & 4.5308 & TRN & \\
\hline CHEMBL1604423 & 688128 & 4.35 & 4.5011 & TRN & \\
\hline CHEMBL1336147 & 688128 & 4.25 & 4.6755 & TRN & \\
\hline CHEMBL1347976 & 688128 & 4.05 & 4.3225 & TST & \\
\hline CHEMBL1558087 & 688128 & 4.4 & 4.5766 & TRN & \\
\hline CHEMBL1466562 & 688128 & 4.35 & 4.3499 & TST & \\
\hline CHEMBL1430415 & 688128 & 4.75 & 4.5107 & TRN & \\
\hline CHEMBL1492966 & 688128 & 4.4 & 4.8833 & TRN & \\
\hline CHEMBL1533621 & 688128 & 4.5 & 5.2583 & TRN & \\
\hline CHEMBL1424398 & 688128 & 6.1 & 5.2285 & TRN & \\
\hline CHEMBL1500563 & 688128 & 6.0 & 4.7229 & TRN & \\
\hline CHEMBL1609766 & 688128 & 4.25 & 4.4563 & TRN & \\
\hline CHEMBL1305675 & 688128 & 4.35 & 4.4043 & TRN & \\
\hline CHEMBL1532104 & 688128 & 4.3 & 4.8181 & TRN & \\
\hline CHEMBL1547094 & 688128 & 4.25 & 4.5965 & TRN & \\
\hline CHEMBL1381258 & 688128 & 4.0 & 4.5411 & TRN & \\
\hline CHEMBL3212874 & 688128 & 4.35 & 4.5277 & TRN & \\
\hline CHEMBL1414563 & 688128 & 4.8 & 4.8768 & TRN & \\
\hline CHEMBL1421056 & 688128 & 4.4 & 4.7757 & TRN & \\
\hline CHEMBL1594872 & 688128 & 4.05 & 4.4958 & TRN & \\
\hline CHEMBL1510246 & 688128 & 4.9 & 4.6846 & TRN & \\
\hline CHEMBL1355122 & 688128 & 4.05 & 4.5988 & TST & \\
\hline CHEMBL1309966 & 688128 & 4.3 & 4.5287 & TRN & \\
\hline CHEMBL3194427 & 688128 & 4.5 & 4.6283 & TST & \\
\hline CHEMBL1440397 & 688128 & 4.6 & 4.7188 & TRN & \\
\hline CHEMBL1409850 & 688128 & 4.05 & 4.6195 & TRN & \\
\hline CHEMBL1321076 & 688128 & 5.05 & 4.6219 & TRN & \\
\hline CHEMBL1491638 & 688128 & 4.55 & 4.7618 & TRN & \\
\hline CHEMBL1512017 & 688128 & 4.25 & 4.5137 & TRN & \\
\hline CHEMBL1384075 & 688128 & 4.3 & 4.4517 & TRN & \\
\hline CHEMBL1612708 & 688128 & 5.4 & 4.4519 & TST & \\
\hline CHEMBL1454331 & 688128 & 5.2 & 4.7967 & TRN & \\
\hline CHEMBL1452774 & 688128 & 4.6 & 4.7816 & TRN & \\
\hline CHEMBL17201 & 688128 & 4.6 & 4.52 & TRN & \\
\hline CHEMBL1562803 & 688128 & 5.25 & 4.4246 & TST & \\
\hline CHEMBL1966114 & 688128 & 4.35 & 4.5805 & TRN & \\
\hline CHEMBL1495949 & 688128 & 5.1 & 4.9393 & TRN & \\
\hline CHEMBL1396400 & 688128 & 4.35 & 4.605 & TRN & \\
\hline CHEMBL1313868 & 688128 & 4.45 & 4.5269 & TRN & \\
\hline CHEMBL1310162 & 688128 & 4.65 & 4.6073 & TRN & \\
\hline CHEMBL1426835 & 688128 & 4.4 & 4.4689 & TRN & \\
\hline CHEMBL1312522 & 688128 & 4.35 & 4.505 & TRN & \\
\hline CHEMBL1422342 & 688128 & 4.45 & 4.67399 & 99999999995 & TRN \\
\hline CHEMBL1394977 & 688128 & 4.35 & 4.5892 & TRN & \\
\hline
\end{tabular}




\begin{tabular}{|c|c|c|c|c|}
\hline \multicolumn{5}{|c|}{ Supplemental Table S2.txt } \\
\hline CHEMBL 3212972 & 688128 & 6.2 & 5.5052 & TRN \\
\hline CHEMBL3213251 & 688128 & 4.95 & 4.6849 & TRN \\
\hline CHEMBL1497364 & 688128 & 4.45 & 4.5648 & TST \\
\hline CHEMBL1415810 & 688128 & 4.6 & 5.0429 & TRN \\
\hline CHEMBL1454890 & 688128 & 4.3 & 4.5359 & TST \\
\hline CHEMBL1400000 & 688128 & 4.4 & 4.7593 & TRN \\
\hline CHEMBL1384528 & 688128 & 4.4 & 4.5104 & TST \\
\hline CHEMBL1976567 & 688128 & 4.85 & 4.7803 & TRN \\
\hline CHEMBL 3191761 & 688128 & 4.4 & 4.4162 & TRN \\
\hline CHEMBL1527786 & 688128 & 5.4 & 4.4793 & TRN \\
\hline CHEMBL1613375 & 688128 & 4.9 & 4.8423 & TRN \\
\hline CHEMBL585269 & 688128 & 4.1 & 4.2771 & TRN \\
\hline CHEMBL1521711 & 688128 & 4.35 & 4.6459 & TRN \\
\hline CHEMBL 3192031 & 688128 & 4.25 & 4.2935 & TST \\
\hline CHEMBL1312725 & 688128 & 4.45 & 4.404 & TRN \\
\hline CHEMBL1428214 & 688128 & 4.0 & 4.4618 & TRN \\
\hline CHEMBL1318889 & 688128 & 5.05 & 4.812 & TRN \\
\hline CHEMBL1539379 & 688128 & 4.35 & 4.6807 & TRN \\
\hline CHEMBL1328719 & 688128 & 4.4 & 4.4024 & TRN \\
\hline CHEMBL1439200 & 688128 & 4.55 & 5.0351 & TRN \\
\hline CHEMBL1524709 & 688128 & 4.75 & 4.5404 & TRN \\
\hline CHEMBL1529269 & 688128 & 5.9 & 4.3798 & TRN \\
\hline CHEMBL1309474 & 688128 & 4.4 & 4.6706 & TST \\
\hline CHEMBL1349699 & 688128 & 4.4 & 4.6563 & TST \\
\hline CHEMBL1509757 & 688128 & 4.35 & 4.3634 & TRN \\
\hline CHEMBL1593378 & 688128 & 4.35 & 4.5664 & TST \\
\hline CHEMBL1562256 & 688128 & 4.35 & 4.6173 & TRN \\
\hline CHEMBL1560380 & 688128 & 4.05 & 4.9704 & TST \\
\hline CHEMBL1566993 & 688128 & 4.0 & 4.6308 & TRN \\
\hline CHEMBL1532631 & 688128 & 4.35 & 5.0571 & TST \\
\hline CHEMBL1498633 & 688128 & 4.6 & 4.4053 & TRN \\
\hline CHEMBL1371869 & 688128 & 4.2 & 4.9223 & TST \\
\hline CHEMBL 3212947 & 688128 & 4.5 & 4.8943 & TST \\
\hline CHEMBL1574443 & 688128 & 6.15 & 4.6269 & TRN \\
\hline CHEMBL1532150 & 688128 & 5.0 & 4.9125 & TRN \\
\hline CHEMBL1509356 & 688128 & 4.1 & 4.4883 & TST \\
\hline CHEMBL1565738 & 688128 & 4.7 & 4.5938 & TRN \\
\hline CHEMBL1359057 & 688128 & 4.4 & 4.6396 & TST \\
\hline CHEMBL1562943 & 688128 & 4.45 & 4.6533 & TRN \\
\hline CHEMBL1605886 & 688128 & 4.3 & 4.29 & TRN \\
\hline CHEMBL1537486 & 688128 & 4.35 & 4.5361 & TRN \\
\hline CHEMBL1492157 & 688128 & 5.3 & 5.0895 & TRN \\
\hline CHEMBL1459822 & 688128 & 4.05 & 4.4231 & TRN \\
\hline CHEMBL1597060 & 688128 & 4.05 & 4.591 & TST \\
\hline CHEMBL1438852 & 688128 & 4.35 & 4.2832 & TRN \\
\hline CHEMBL3210161 & 688128 & 4.25 & 4.7779 & TRN \\
\hline CHEMBL1576454 & 688128 & 4.35 & 4.6402 & TRN \\
\hline CHEMBL1353387 & 688128 & 4.5 & 4.6814 & TRN \\
\hline
\end{tabular}




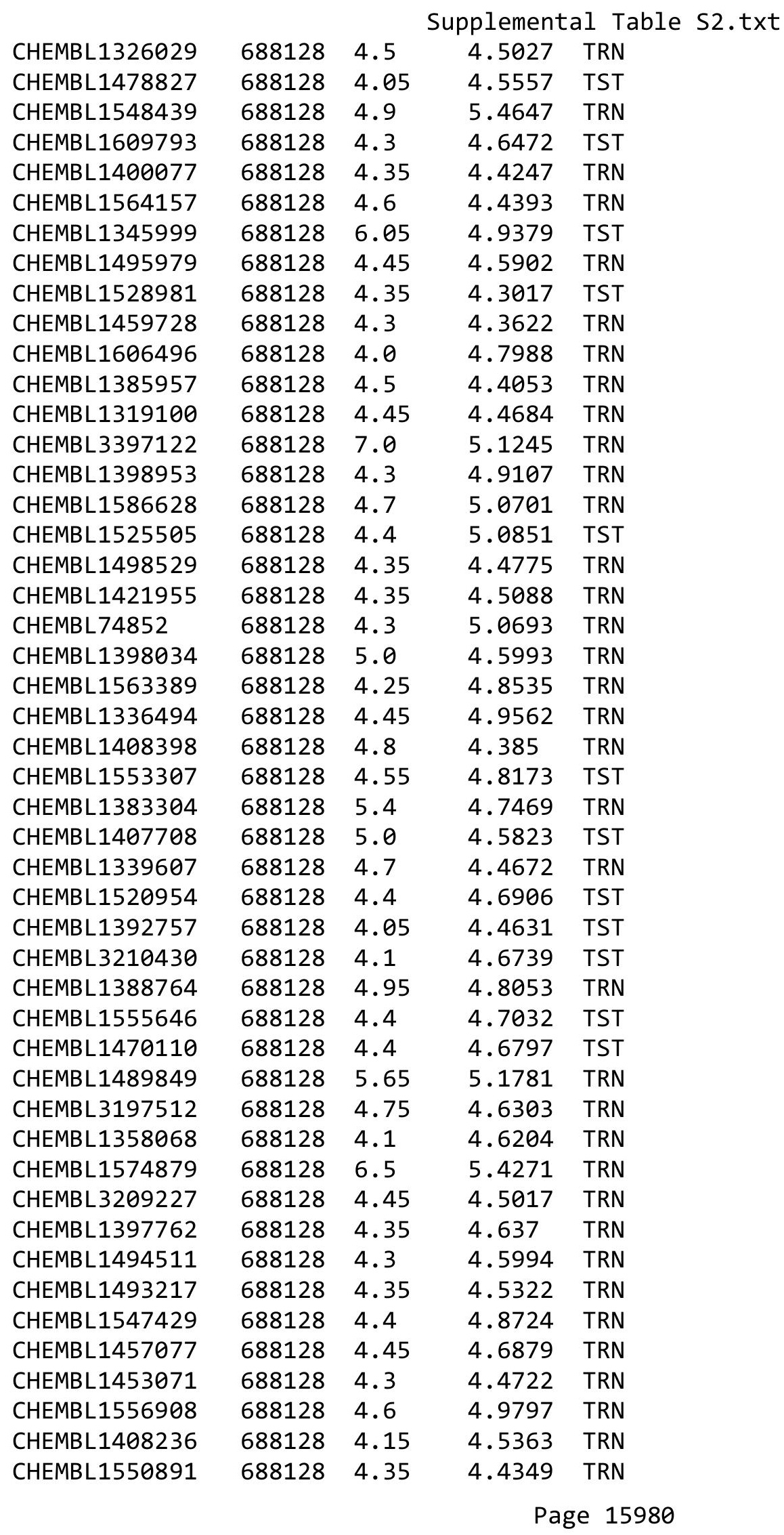




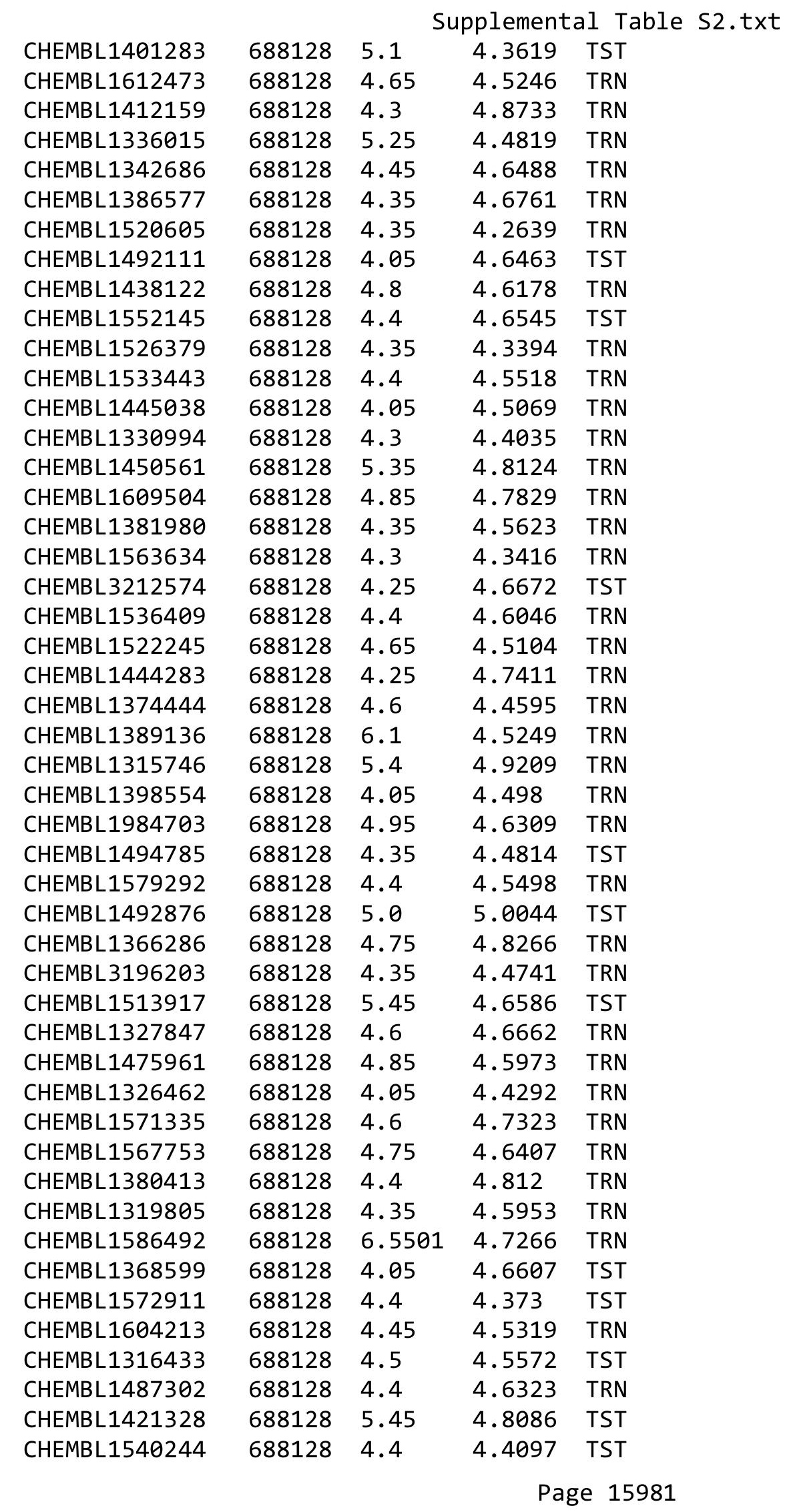




\begin{tabular}{|c|c|c|c|c|}
\hline \multicolumn{5}{|c|}{ Supplemental Table S2.txt } \\
\hline CHEMBL3192219 & 688128 & 4.35 & 4.6788 & TRN \\
\hline CHEMBL1549316 & 688128 & 4.85 & 4.7787 & TRN \\
\hline CHEMBL1479544 & 688128 & 4.35 & 4.6329 & TRN \\
\hline CHEMBL1486669 & 688128 & 4.35 & 4.8642 & TST \\
\hline CHEMBL 1465758 & 688128 & 4.15 & 4.6069 & TRN \\
\hline CHEMBL1571894 & 688128 & 4.5 & 4.3205 & TRN \\
\hline CHEMBL1362526 & 688128 & 5.2 & 4.8048 & TRN \\
\hline CHEMBL1611029 & 688128 & 5.35 & 4.5226 & TST \\
\hline CHEMBL1510735 & 688128 & 4.05 & 4.3487 & TRN \\
\hline CHEMBL1560930 & 688128 & 4.45 & 5.148 & TRN \\
\hline CHEMBL1577622 & 688128 & 4.3 & 4.5527 & TRN \\
\hline CHEMBL1372855 & 688128 & 4.0 & 4.4879 & TRN \\
\hline CHEMBL3189728 & 688128 & 4.1 & 4.6049 & TRN \\
\hline CHEMBL1336682 & 688128 & 3.95 & 4.6634 & TRN \\
\hline CHEMBL1491821 & 688128 & 4.05 & 4.598 & TST \\
\hline CHEMBL1433367 & 688128 & 4.05 & 4.44 & TRN \\
\hline CHEMBL1612574 & 688128 & 4.85 & 4.6439 & TRN \\
\hline CHEMBL1392501 & 688128 & 4.55 & 4.7597 & TRN \\
\hline CHEMBL1338943 & 688128 & 5.55 & 4.8697 & TRN \\
\hline CHEMBL1488262 & 688128 & 4.25 & 4.4853 & TRN \\
\hline CHEMBL1571285 & 688128 & 4.4 & 4.6405 & TRN \\
\hline CHEMBL1607380 & 688128 & 4.7 & 4.7602 & TRN \\
\hline CHEMBL1385841 & 688128 & 5.45 & 4.9023 & TRN \\
\hline CHEMBL1348681 & 688128 & 4.55 & 4.7383 & TRN \\
\hline CHEMBL1448605 & 688128 & 5.5 & 4.6081 & TST \\
\hline CHEMBL1339303 & 688128 & 4.5 & 5.1799 & TST \\
\hline CHEMBL1456687 & 688128 & 6.1 & 4.7289 & TRN \\
\hline CHEMBL1429243 & 688128 & 5.0 & 4.7671 & TST \\
\hline CHEMBL1571582 & 688128 & 4.3 & 4.3768 & TRN \\
\hline CHEMBL1968954 & 688128 & 5.95 & 4.5008 & TST \\
\hline CHEMBL1351743 & 688128 & 4.05 & 4.5798 & TRN \\
\hline CHEMBL1979849 & 688128 & 6.1 & 4.9249 & TRN \\
\hline CHEMBL1376590 & 688128 & 6.45 & 4.7779 & TRN \\
\hline CHEMBL1427436 & 688128 & 5.9 & 5.1867 & TRN \\
\hline CHEMBL1417030 & 688128 & 4.45 & 4.3681 & TST \\
\hline CHEMBL1420492 & 688128 & 4.4 & 4.5201 & TRN \\
\hline CHEMBL3211314 & 688128 & 3.95 & 4.7028 & TST \\
\hline CHEMBL1321871 & 688128 & 5.0 & 4.5135 & TRN \\
\hline CHEMBL1541747 & 688128 & 4.3 & 4.5465 & TRN \\
\hline CHEMBL1554116 & 688128 & 4.5 & 4.6531 & TRN \\
\hline CHEMBL1407965 & 688128 & 5.35 & 4.8024 & TST \\
\hline CHEMBL1468562 & 688128 & 4.3 & 4.7706 & TRN \\
\hline CHEMBL1382998 & 688128 & 4.5 & 4.721 & TST \\
\hline CHEMBL1301122 & 688128 & 4.05 & 4.9195 & TST \\
\hline CHEMBL1344361 & 688128 & 5.4 & 4.5339 & TRN \\
\hline CHEMBL1465678 & 688128 & 4.3 & 4.6184 & TRN \\
\hline CHEMBL1588970 & 688128 & 5.05 & 4.7187 & TRN \\
\hline CHEMBL3199701 & 688128 & 4.3 & 4.4625 & TRN \\
\hline
\end{tabular}




\begin{tabular}{|c|c|c|c|c|c|}
\hline \multicolumn{6}{|c|}{ Supplemental Table S2.txt } \\
\hline CHEMBL1316148 & 688128 & 4.25 & 4.6606 & TRN & \\
\hline CHEMBL1394768 & 688128 & 5.4 & 4.6769 & TST & \\
\hline CHEMBL1539793 & 688128 & 4.3 & 4.1913 & TRN & \\
\hline CHEMBL1450998 & 688128 & 5.05 & 4.6185 & TRN & \\
\hline CHEMBL1499155 & 688128 & 5.55 & 4.6211 & TRN & \\
\hline CHEMBL1531620 & 688128 & 5.05 & 4.731 & TST & \\
\hline CHEMBL1604547 & 688128 & 4.5 & 4.3829 & TRN & \\
\hline CHEMBL1461513 & 688128 & 4.55 & 4.6728 & TRN & \\
\hline CHEMBL1223305 & 688128 & 4.3 & 4.4184 & TRN & \\
\hline CHEMBL1315784 & 688128 & 4.95 & 5.0219 & TRN & \\
\hline CHEMBL1330585 & 688128 & 4.4 & 4.5915 & TRN & \\
\hline CHEMBL1467755 & 688128 & 4.4 & 4.9399 & TRN & \\
\hline CHEMBL1441408 & 688128 & 4.3 & 4.8952 & TST & \\
\hline CHEMBL 3210442 & 688128 & 4.6 & $4.2810 e$ & 0000000001 & TST \\
\hline CHEMBL1333892 & 688128 & 4.85 & 4.9707 & TRN & \\
\hline CHEMBL3195250 & 688128 & 5.2 & 4.7789 & TRN & \\
\hline CHEMBL1320848 & 688128 & 4.35 & 4.7767 & TST & \\
\hline CHEMBL1347319 & 688128 & 4.75 & 4.4959 & TRN & \\
\hline CHEMBL1400768 & 688128 & 4.3 & 4.69 & TRN & \\
\hline CHEMBL1372447 & 688128 & 5.4 & 4.885 & TRN & \\
\hline CHEMBL1352938 & 688128 & 4.05 & 4.3641 & TRN & \\
\hline CHEMBL1411616 & 688128 & 4.35 & 4.5375 & TRN & \\
\hline CHEMBL1418671 & 688128 & 4.4 & 4.5124 & TRN & \\
\hline CHEMBL1326936 & 688128 & 4.25 & 4.5883 & TRN & \\
\hline CHEMBL1308654 & 688128 & 5.5 & 4.9905 & TRN & \\
\hline CHEMBL1386197 & 688128 & 6.1 & 4.7329 & TST & \\
\hline CHEMBL1433041 & 688128 & 6.3 & 5.2155 & TRN & \\
\hline CHEMBL1359000 & 688128 & 4.3 & 4.6475 & TRN & \\
\hline CHEMBL1565120 & 688128 & 4.05 & 4.6545 & TRN & \\
\hline CHEMBL1585685 & 688128 & 5.0 & 4.8227 & TRN & \\
\hline CHEMBL1507679 & 688128 & 5.4 & 4.6747 & TRN & \\
\hline CHEMBL1485605 & 688128 & 5.3 & 5.1363 & TRN & \\
\hline CHEMBL1351395 & 688128 & 4.65 & 4.817 & TRN & \\
\hline CHEMBL1567556 & 688128 & 4.95 & 4.7893 & TRN & \\
\hline CHEMBL1451059 & 688128 & 5.5 & 5.0578 & TST & \\
\hline CHEMBL1346135 & 688128 & 4.35 & 4.4395 & TRN & \\
\hline CHEMBL233531 & 688128 & 6.1 & 4.55 & TST & \\
\hline CHEMBL1379274 & 688128 & 5.85 & 4.9315 & TST & \\
\hline CHEMBL1439003 & 688128 & 4.7 & 4.7301 & TRN & \\
\hline CHEMBL1585801 & 688128 & 5.65 & 4.544 & TRN & \\
\hline CHEMBL1351465 & 688128 & 5.5 & 4.8503 & TRN & \\
\hline CHEMBL1364283 & 688128 & 5.4 & 4.4677 & TRN & \\
\hline CHEMBL1529104 & 688128 & 5.0 & 4.5817 & TRN & \\
\hline CHEMBL1493185 & 688128 & 4.25 & 4.3253 & TRN & \\
\hline CHEMBL1337100 & 688128 & 4.5 & 4.5126 & TRN & \\
\hline CHEMBL1451329 & 688128 & 4.5 & 4.73 & TRN & \\
\hline CHEMBL1514476 & 688128 & 4.05 & 4.5058 & TST & \\
\hline CHEMBL1503476 & 688128 & 4.4 & 4.5972 & TRN & \\
\hline
\end{tabular}




\begin{tabular}{|c|c|c|c|c|}
\hline \multicolumn{5}{|c|}{ pplemen } \\
\hline CHEMBL1311353 & 688128 & 4.4 & 4.9921 & TST \\
\hline CHEMBL1477427 & 688128 & 5.05 & 4.5501 & TRN \\
\hline CHEMBL1467274 & 688128 & 5.0 & 4.5143 & TST \\
\hline CHEMBL1391390 & 688128 & 4.4 & 4.2476 & TRN \\
\hline CHEMBL1501590 & 688128 & 4.55 & 4.4826 & TST \\
\hline CHEMBL1560184 & 688128 & 4.7 & 4.6904 & TRN \\
\hline CHEMBL1524973 & 688128 & 4.6 & 4.5788 & TRN \\
\hline CHEMBL1559496 & 688128 & 5.5 & 4.7531 & TRN \\
\hline CHEMBL1583717 & 688128 & 4.6 & 4.6469 & TRN \\
\hline CHEMBL1497770 & 688128 & 4.3 & 4.4749 & TRN \\
\hline CHEMBL1449331 & 688128 & 4.55 & 4.7302 & TST \\
\hline CHEMBL3193158 & 688128 & 4.35 & 4.2824 & TRN \\
\hline CHEMBL1406412 & 688128 & 4.05 & 4.9149 & TST \\
\hline CHEMBL1396156 & 688128 & 4.4 & 4.5377 & TST \\
\hline CHEMBL1542261 & 688128 & 4.3 & 4.3211 & TRN \\
\hline CHEMBL1481192 & 688128 & 4.9 & 5.3703 & TRN \\
\hline CHEMBL1559535 & 688128 & 4.65 & 4.0927 & TST \\
\hline CHEMBL1464053 & 688128 & 4.85 & 4.4585 & TRN \\
\hline CHEMBL1386493 & 688128 & 5.5 & 4.7188 & TRN \\
\hline CHEMBL1495791 & 688128 & 4.3 & 4.5817 & TRN \\
\hline CHEMBL1413708 & 688128 & 4.5 & 4.5092 & TRN \\
\hline CHEMBL1444758 & 688128 & 4.05 & 4.6493 & TRN \\
\hline CHEMBL1440311 & 688128 & 4.35 & 4.4151 & TRN \\
\hline CHEMBL1566786 & 688128 & 4.85 & 4.7277 & TRN \\
\hline CHEMBL1403926 & 688128 & 5.4 & 4.4892 & TRN \\
\hline CHEMBL1448457 & 688128 & 4.0 & 4.6097 & TRN \\
\hline CHEMBL1549492 & 688128 & 4.25 & 4.8195 & TRN \\
\hline CHEMBL1595015 & 688128 & 4.7 & 4.7896 & TRN \\
\hline CHEMBL1541748 & 688128 & 4.6 & 4.4064 & TRN \\
\hline CHEMBL1446855 & 688128 & 4.4 & 4.6999 & TRN \\
\hline CHEMBL1323550 & 688128 & 4.3 & 4.204 & TRN \\
\hline CHEMBL1437416 & 688128 & 4.45 & 4.5058 & TST \\
\hline CHEMBL1471902 & 688128 & 4.7 & 4.5341 & TRN \\
\hline CHEMBL1455378 & 688128 & 4.05 & 4.2812 & TST \\
\hline CHEMBL1531544 & 688128 & 4.35 & 4.6404 & TRN \\
\hline CHEMBL1577173 & 688128 & 4.35 & 4.6964 & TRN \\
\hline CHEMBL1459125 & 688128 & 4.25 & 4.7451 & TRN \\
\hline CHEMBL1514704 & 688128 & 4.35 & 4.7614 & TRN \\
\hline CHEMBL3213103 & 688128 & 5.3 & 4.9964 & TST \\
\hline CHEMBL1299750 & 688128 & 5.1 & 4.8921 & TST \\
\hline CHEMBL1560020 & 688128 & 4.25 & 4.3892 & TRN \\
\hline CHEMBL1514817 & 688128 & 6.45 & 5.2736 & TRN \\
\hline CHEMBL1544590 & 688128 & 4.3 & 4.4057 & TRN \\
\hline CHEMBL1519754 & 688128 & 4.5 & 4.522 & TRN \\
\hline CHEMBL405110 & 688128 & 4.5 & 4.8755 & TST \\
\hline CHEMBL1326350 & 688128 & 4.45 & 4.7075 & TST \\
\hline CHEMBL1400643 & 688128 & 4.25 & 4.5929 & TRN \\
\hline CHEMBL1321547 & 688128 & 4.35 & 4.2811 & TRN \\
\hline
\end{tabular}




\begin{tabular}{|c|c|c|c|c|c|}
\hline & & \multicolumn{4}{|c|}{ Supplemental Table S2.txt } \\
\hline CHEMBL1510425 & 688128 & 4.3 & 4.73 & TRN & \\
\hline CHEMBL1325028 & 688128 & 4.0 & 4.5519 & TRN & \\
\hline CHEMBL1488104 & 688128 & 4.7 & 4.3469 & TRN & \\
\hline CHEMBL1612061 & 688128 & 4.55 & 4.7864 & TST & \\
\hline CHEMBL1434131 & 688128 & 4.65 & 4.5248 & TRN & \\
\hline CHEMBL3211903 & 688128 & 4.3 & 4.4699 & TRN & \\
\hline CHEMBL1548049 & 688128 & 5.95 & 4.6816 & TRN & \\
\hline CHEMBL1611522 & 688128 & 4.55 & 4.5014 & TST & \\
\hline CHEMBL1597166 & 688128 & 4.45 & 4.5701 & TRN & \\
\hline CHEMBL1456411 & 688128 & 4.4 & 4.76 & TST & \\
\hline CHEMBL1610195 & 688128 & 4.05 & 4.6653 & TST & \\
\hline CHEMBL1493114 & 688128 & 4.3 & 4.39 & TST & \\
\hline CHEMBL1309032 & 688128 & 4.35 & 4.7613 & TRN & \\
\hline CHEMBL1256191 & 688128 & 4.45 & 4.9179 & TST & \\
\hline CHEMBL1511046 & 688128 & 4.55 & 4.4866 & TRN & \\
\hline CHEMBL3192240 & 688128 & 4.3 & 4.47 & TST & \\
\hline CHEMBL1347850 & 688128 & 4.55 & 4.8604 & TRN & \\
\hline CHEMBL1434012 & 688128 & 4.75 & 4.8179 & TRN & \\
\hline CHEMBL1454279 & 688128 & 4.15 & 4.5644 & TRN & \\
\hline CHEMBL1450304 & 688128 & 5.2 & 4.6746 & TST & \\
\hline CHEMBL3212177 & 688128 & 4.65 & 4.6478 & TRN & \\
\hline CHEMBL1365619 & 688128 & 4.4 & 4.7689 & TST & \\
\hline CHEMBL1529182 & 688128 & 4.25 & 4.38 & TST & \\
\hline CHEMBL1362369 & 688128 & 4.8 & 4.4932 & TRN & \\
\hline CHEMBL1518998 & 688128 & 4.9 & 4.6279 & TRN & \\
\hline CHEMBL1567271 & 688128 & 5.9 & 4.7595 & TRN & \\
\hline CHEMBL1977747 & 688128 & 4.95 & 4.88899 & 9999999999 & TRN \\
\hline CHEMBL1504965 & 688128 & 4.4 & 4.5883 & TRN & \\
\hline CHEMBL1531140 & 688128 & 4.05 & 4.5752 & TRN & \\
\hline CHEMBL1334484 & 688128 & 5.0 & 4.9278 & TST & \\
\hline CHEMBL1305963 & 688128 & 4.3 & 4.4821 & TRN & \\
\hline CHEMBL1582513 & 688128 & 4.55 & 4.6839 & TRN & \\
\hline CHEMBL1382069 & 688128 & 4.5 & 4.6648 & TRN & \\
\hline CHEMBL1515322 & 688128 & 4.05 & 4.4218 & TST & \\
\hline CHEMBL1529788 & 688128 & 4.35 & 4.526 & TST & \\
\hline CHEMBL1442427 & 688128 & 4.05 & 4.6585 & TRN & \\
\hline CHEMBL1424420 & 688128 & 5.2 & 4.598 & TRN & \\
\hline CHEMBL1549820 & 688128 & 4.95 & 4.5646 & TRN & \\
\hline CHEMBL1552503 & 688128 & 4.05 & 4.6386 & TST & \\
\hline CHEMBL1426791 & 688128 & 4.8 & 4.6367 & TRN & \\
\hline CHEMBL3195450 & 688128 & 4.4 & 4.4153 & TRN & \\
\hline CHEMBL1407961 & 688128 & 5.7 & 5.2659 & TRN & \\
\hline CHEMBL1369138 & 688128 & 4.65 & 4.688 & TRN & \\
\hline CHEMBL1527051 & 688128 & 4.35 & 4.6999 & TST & \\
\hline CHEMBL1481663 & 688128 & 4.45 & 4.6779 & TRN & \\
\hline CHEMBL1581234 & 688128 & 4.4 & 4.6014 & TST & \\
\hline CHEMBL1520738 & 688128 & 4.35 & 4.5705 & TRN & \\
\hline CHEMBL1395715 & 688128 & 4.35 & 4.3867 & TRN & \\
\hline
\end{tabular}




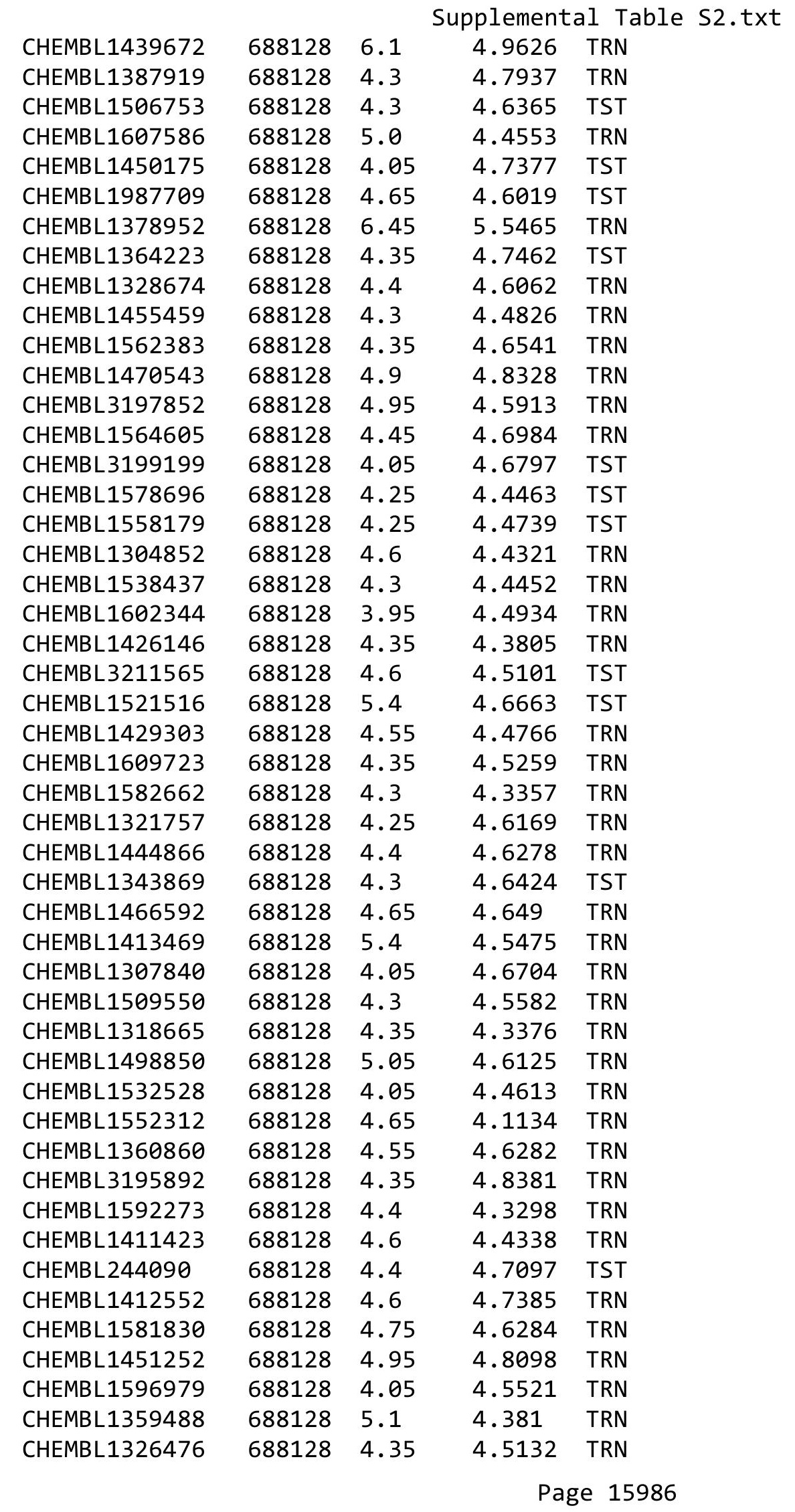




\begin{tabular}{|c|c|c|c|c|}
\hline \multicolumn{5}{|c|}{ Supplemental Table S2.txt } \\
\hline CHEMBL1480673 & 688128 & 4.45 & 4.9719 & TST \\
\hline CHEMBL1502312 & 688128 & 4.35 & 5.1943 & TRN \\
\hline CHEMBL1302961 & 688128 & 4.5 & 4.8239 & TRN \\
\hline CHEMBL1543725 & 688128 & 4.05 & 4.6677 & TST \\
\hline CHEMBL1606797 & 688128 & 4.35 & 4.9051 & TRN \\
\hline CHEMBL1612735 & 688128 & 4.45 & 4.6406 & TRN \\
\hline CHEMBL1439743 & 688128 & 4.9 & 4.6207 & TST \\
\hline CHEMBL1581082 & 688128 & 4.4 & 4.6553 & TRN \\
\hline CHEMBL1315946 & 688128 & 4.9 & 4.6851 & TRN \\
\hline CHEMBL1526408 & 688128 & 4.35 & 4.5895 & TRN \\
\hline CHEMBL1529175 & 688128 & 4.55 & 4.6212 & TRN \\
\hline CHEMBL1428843 & 688128 & 4.35 & 4.1849 & TRN \\
\hline CHEMBL1507170 & 688128 & 4.65 & 4.5057 & TRN \\
\hline CHEMBL1595027 & 688128 & 4.4 & 4.4929 & TST \\
\hline CHEMBL1588558 & 688128 & 4.45 & 4.5716 & TRN \\
\hline CHEMBL1306076 & 688128 & 4.3 & 4.7396 & TST \\
\hline CHEMBL1487782 & 688128 & 4.35 & 4.5312 & TST \\
\hline CHEMBL1345316 & 688128 & 4.05 & 4.5138 & TRN \\
\hline CHEMBL1580879 & 688128 & 4.4 & 4.3319 & TRN \\
\hline CHEMBL1488050 & 688128 & 5.6 & 4.927 & TRN \\
\hline CHEMBL1609258 & 688128 & 5.35 & 4.6076 & TRN \\
\hline CHEMBL1589719 & 688128 & 4.5 & 4.2488 & TST \\
\hline CHEMBL1602852 & 688128 & 5.15 & 4.6399 & TRN \\
\hline CHEMBL1421485 & 688128 & 4.6 & 4.6167 & TST \\
\hline CHEMBL1383591 & 688128 & 4.85 & 4.5274 & TRN \\
\hline CHEMBL1376472 & 688128 & 4.5 & 4.6955 & TRN \\
\hline CHEMBL1611970 & 688128 & 4.25 & 4.4616 & TRN \\
\hline CHEMBL1475463 & 688128 & 4.45 & 4.5357 & TST \\
\hline CHEMBL3195503 & 688128 & 5.15 & 4.6839 & TRN \\
\hline CHEMBL1382993 & 688128 & 4.55 & 4.6904 & TRN \\
\hline CHEMBL1477363 & 688128 & 5.45 & 4.5832 & TRN \\
\hline CHEMBL1352820 & 688128 & 4.5 & 4.4208 & TRN \\
\hline CHEMBL3199284 & 688128 & 4.1 & 4.5341 & TST \\
\hline CHEMBL1543633 & 688128 & 4.45 & 4.6421 & TST \\
\hline CHEMBL1505850 & 688128 & 4.45 & 4.6726 & TRN \\
\hline CHEMBL1402669 & 688128 & 4.35 & 4.56 & TRN \\
\hline CHEMBL1518077 & 688128 & 5.15 & 5.2934 & TRN \\
\hline CHEMBL1575895 & 688128 & 4.3 & 4.6528 & TRN \\
\hline CHEMBL1441650 & 688128 & 5.9 & 4.7849 & TRN \\
\hline CHEMBL1540947 & 688128 & 5.45 & 4.6975 & TST \\
\hline CHEMBL1587329 & 688128 & 4.05 & 4.5029 & TRN \\
\hline CHEMBL1544464 & 688128 & 4.35 & 4.5039 & TST \\
\hline CHEMBL1551679 & 688128 & 4.25 & 4.6412 & TRN \\
\hline CHEMBL1305418 & 688128 & 4.1 & 4.7884 & TST \\
\hline CHEMBL1505177 & 688128 & 5.95 & 4.8979 & TRN \\
\hline CHEMBL1569736 & 688128 & 4.4 & 4.5795 & TRN \\
\hline CHEMBL1550039 & 688128 & 5.0 & 4.5425 & TRN \\
\hline CHEMBL1470643 & 688128 & 4.35 & 4.4129 & TRN \\
\hline
\end{tabular}




\begin{tabular}{|c|c|c|c|c|}
\hline \multicolumn{5}{|c|}{ Supplemental Table } \\
\hline CHEMBL1325868 & 688128 & 4.85 & 4.5191 & TRN \\
\hline CHEMBL1442388 & 688128 & 4.7 & 4.7091 & TRN \\
\hline CHEMBL1567442 & 688128 & 5.35 & 4.9283 & TRN \\
\hline CHEMBL3191267 & 688128 & 4.4 & 4.7592 & TST \\
\hline CHEMBL1337631 & 688128 & 4.1 & 4.6144 & TST \\
\hline CHEMBL1413248 & 688128 & 4.4 & 4.3539 & TRN \\
\hline CHEMBL1305810 & 688128 & 5.3 & 4.5465 & TST \\
\hline CHEMBL1461355 & 688128 & 4.05 & 4.832 & TST \\
\hline CHEMBL1400276 & 688128 & 4.7 & 4.3488 & TRN \\
\hline CHEMBL1564838 & 688128 & 4.4 & 4.5758 & TRN \\
\hline CHEMBL3194629 & 688128 & 4.35 & 4.8044 & TRN \\
\hline CHEMBL1338667 & 688128 & 4.8 & 4.8592 & TST \\
\hline CHEMBL1466994 & 688128 & 4.5 & 4.4278 & TST \\
\hline CHEMBL1483297 & 688128 & 4.45 & 4.5803 & TRN \\
\hline CHEMBL1454080 & 688128 & 4.05 & 4.5797 & TST \\
\hline CHEMBL1435412 & 688128 & 4.65 & 4.6242 & TST \\
\hline CHEMBL1355924 & 688128 & 4.4 & 4.4915 & TRN \\
\hline CHEMBL1534729 & 688128 & 4.95 & 4.6434 & TRN \\
\hline CHEMBL1377848 & 688128 & 4.3 & 4.2924 & TRN \\
\hline CHEMBL1501864 & 688128 & 4.65 & 4.7415 & TRN \\
\hline CHEMBL1320094 & 688128 & 4.05 & 4.6039 & TST \\
\hline CHEMBL1373479 & 688128 & 4.55 & 4.657 & TRN \\
\hline CHEMBL1562493 & 688128 & 4.35 & 4.8445 & TRN \\
\hline CHEMBL1625328 & 688128 & 4.3 & 4.6667 & TRN \\
\hline CHEMBL1585410 & 688128 & 5.25 & 4.7779 & TRN \\
\hline CHEMBL1418713 & 688128 & 4.1 & 4.3418 & TST \\
\hline CHEMBL1392310 & 688128 & 4.1 & 4.5683 & TRN \\
\hline CHEMBL1396249 & 688128 & 4.05 & 4.8201 & TRN \\
\hline CHEMBL1469830 & 688128 & 5.45 & 5.067 & TRN \\
\hline CHEMBL1526058 & 688128 & 4.4 & 4.3899 & TRN \\
\hline CHEMBL1535313 & 688128 & 4.05 & 4.4982 & TST \\
\hline CHEMBL1330742 & 688128 & 4.55 & 4.6923 & TRN \\
\hline CHEMBL1583268 & 688128 & 4.4 & 4.3574 & TRN \\
\hline CHEMBL1400349 & 688128 & 4.45 & 4.671 & TRN \\
\hline CHEMBL1453489 & 688128 & 4.45 & 4.7297 & TRN \\
\hline CHEMBL1502135 & 688128 & 4.85 & 4.666 & TRN \\
\hline CHEMBL1531308 & 688128 & 6.05 & 4.9948 & TST \\
\hline CHEMBL1573738 & 688128 & 4.05 & 4.4128 & TRN \\
\hline CHEMBL1337235 & 688128 & 4.8 & 5.1821 & TRN \\
\hline CHEMBL1486017 & 688128 & 5.0 & 4.7019 & TRN \\
\hline CHEMBL1448512 & 688128 & 4.05 & 4.4864 & TST \\
\hline CHEMBL1584189 & 688128 & 4.3 & 4.6167 & TRN \\
\hline CHEMBL1602774 & 688128 & 4.75 & 4.7687 & TST \\
\hline CHEMBL1321384 & 688128 & 6.0 & 4.6028 & TRN \\
\hline CHEMBL1328511 & 688128 & 4.35 & 4.8729 & TRN \\
\hline CHEMBL1607926 & 688128 & 4.35 & 4.3796 & TRN \\
\hline CHEMBL1346216 & 688128 & 3.95 & 4.6012 & TRN \\
\hline CHEMBL1581601 & 688128 & 4.0 & 4.6196 & TRN \\
\hline
\end{tabular}




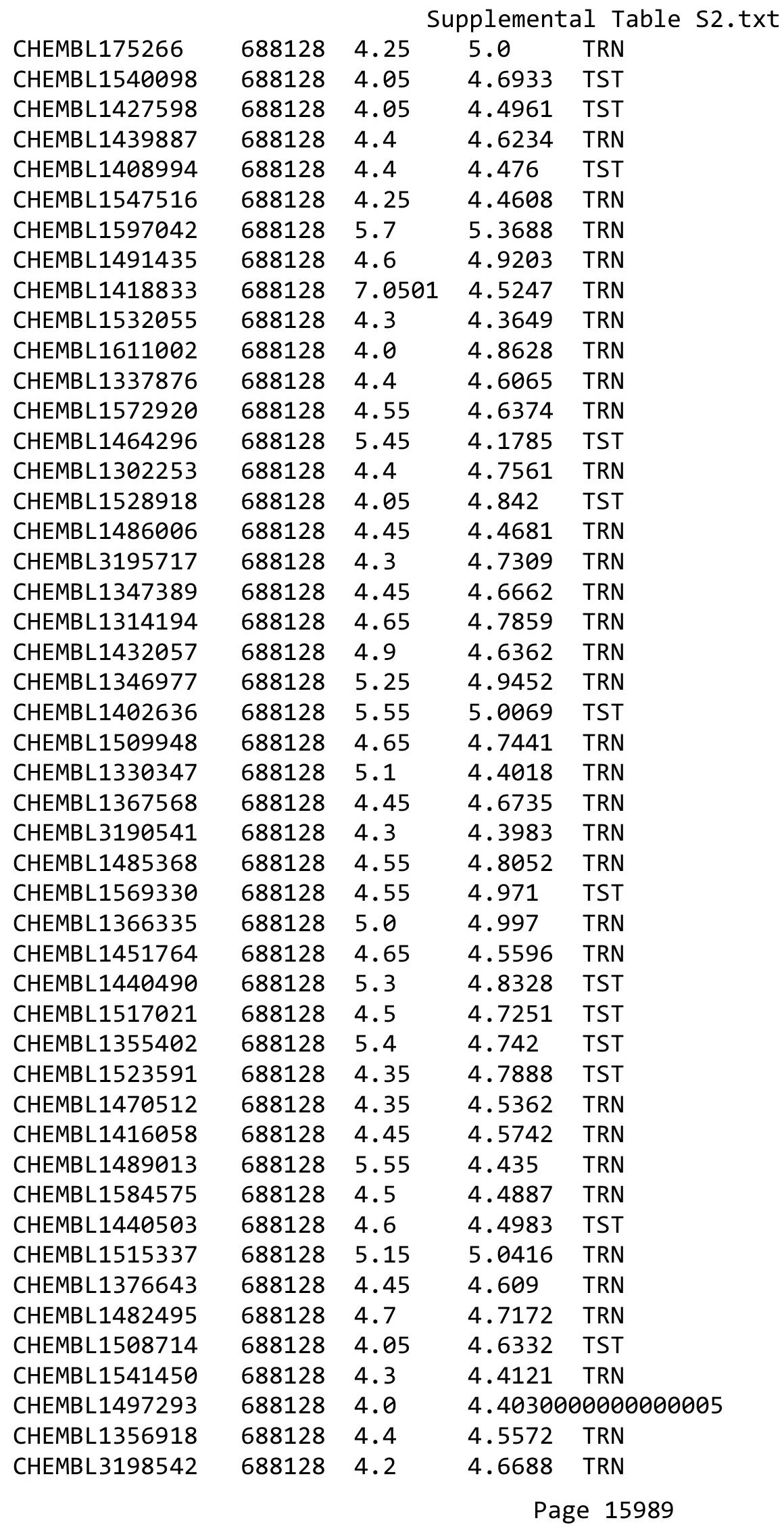

TRN 


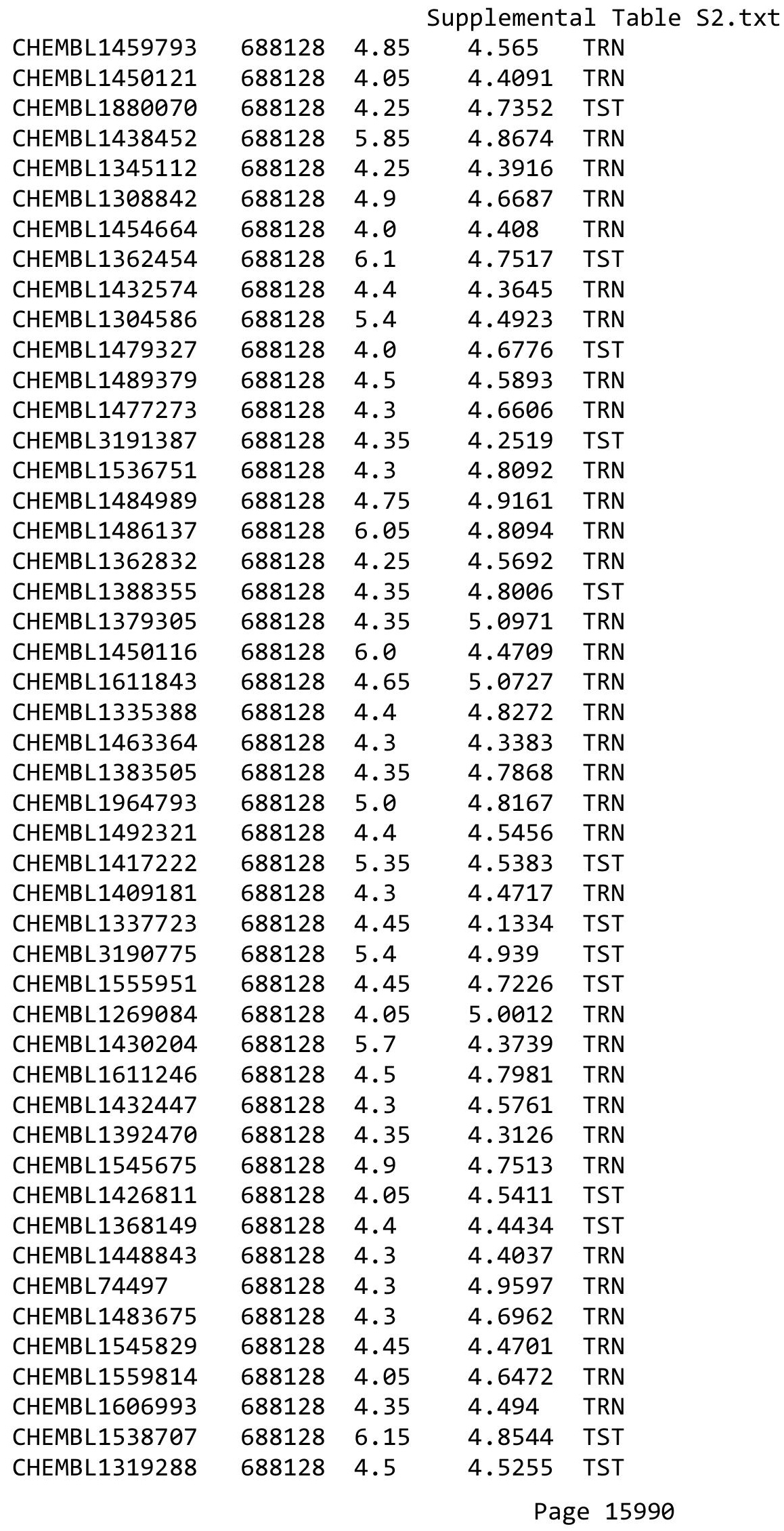




\begin{tabular}{|c|c|c|c|c|c|}
\hline \multicolumn{6}{|c|}{ Supplemental Table S2.txt } \\
\hline CHEMBL1563024 & 688128 & 4.4 & 4.5792 & TRN & \\
\hline CHEMBL1411751 & 688128 & 5.85 & 4.4505 & TRN & \\
\hline CHEMBL1327418 & 688128 & 4.95 & 4.458 & TRN & \\
\hline CHEMBL1547171 & 688128 & 4.55 & 4.6766 & TST & \\
\hline CHEMBL1727447 & 688128 & 4.95 & 4.8726 & TRN & \\
\hline CHEMBL1483080 & 688128 & 4.65 & 5.1866 & TRN & \\
\hline CHEMBL1521975 & 688128 & 5.8 & 4.7872 & TRN & \\
\hline CHEMBL1348884 & 688128 & 4.05 & 4.4931 & TRN & \\
\hline CHEMBL1467835 & 688128 & 5.4 & 4.7362 & TRN & \\
\hline CHEMBL1303141 & 688128 & 4.9 & 4.7819 & TRN & \\
\hline CHEMBL1302848 & 688128 & 4.25 & 4.7051 & TRN & \\
\hline CHEMBL1521227 & 688128 & 4.4 & 4.7129 & TRN & \\
\hline CHEMBL1534271 & 688128 & 4.65 & 4.6873 & TST & \\
\hline CHEMBL3191903 & 688128 & 4.65 & 4.4495 & TST & \\
\hline CHEMBL1376339 & 688128 & 4.3 & 4.6909 & TRN & \\
\hline CHEMBL1596989 & 688128 & 4.05 & 4.3762 & TRN & \\
\hline CHEMBL1382492 & 688128 & 4.0 & 4.5807 & TRN & \\
\hline CHEMBL1444849 & 688128 & 4.6 & 4.6294 & TRN & \\
\hline CHEMBL1328655 & 688128 & 5.95 & 4.5748 & TST & \\
\hline CHEMBL1506958 & 688128 & 5.25 & $4.7410 e$ & 00000000005 & TRN \\
\hline CHEMBL3214041 & 688128 & 4.25 & 4.6823 & TST & \\
\hline CHEMBL1493248 & 688128 & 5.75 & 5.0664 & TST & \\
\hline CHEMBL1544048 & 688128 & 4.3 & 4.3778 & TRN & \\
\hline CHEMBL1538058 & 688128 & 4.3 & 4.5463 & TRN & \\
\hline CHEMBL1528943 & 688128 & 4.25 & 4.9204 & TRN & \\
\hline CHEMBL1563687 & 688128 & 4.3 & 4.4516 & TST & \\
\hline CHEMBL1493146 & 688128 & 4.05 & 4.6987 & TRN & \\
\hline CHEMBL1520852 & 688128 & 5.55 & 5.2111 & TRN & \\
\hline CHEMBL1608036 & 688128 & 4.05 & 4.2168 & TRN & \\
\hline CHEMBL1994973 & 688128 & 4.55 & 4.5281 & TRN & \\
\hline CHEMBL1351518 & 688128 & 4.95 & 4.7705 & TRN & \\
\hline CHEMBL1403980 & 688128 & 6.1 & 4.9924 & TRN & \\
\hline CHEMBL1513301 & 688128 & 5.1 & 5.0343 & TRN & \\
\hline CHEMBL1413313 & 688128 & 4.3 & 4.5305 & TRN & \\
\hline CHEMBL1571320 & 688128 & 4.3 & 4.4123 & TRN & \\
\hline CHEMBL1430829 & 688128 & 4.3 & 4.2391 & TRN & \\
\hline CHEMBL1469930 & 688128 & 4.45 & 4.5336 & TRN & \\
\hline CHEMBL1447544 & 688128 & 5.2 & 4.5727 & TRN & \\
\hline CHEMBL1548678 & 688128 & 6.1 & 4.7724 & TST & \\
\hline CHEMBL1465957 & 688128 & 4.35 & 4.527 & TRN & \\
\hline CHEMBL1301846 & 688128 & 4.5 & 4.6751 & TRN & \\
\hline CHEMBL1333462 & 688128 & 5.5 & 4.9996 & TRN & \\
\hline CHEMBL1430784 & 688128 & 4.05 & 4.2721 & TRN & \\
\hline CHEMBL1584194 & 688128 & 5.3 & 4.7184 & TRN & \\
\hline CHEMBL1328413 & 688128 & 4.6 & 4.7155 & TRN & \\
\hline CHEMBL1373543 & 688128 & 4.1 & 4.332 & TST & \\
\hline CHEMBL1496303 & 688128 & 4.35 & 4.724 & TRN & \\
\hline CHEMBL1533766 & 688128 & 4.95 & 4.4798 & TRN & \\
\hline
\end{tabular}




\begin{tabular}{|c|c|c|c|c|c|}
\hline \multicolumn{6}{|c|}{ Supplemental Table S2.txt } \\
\hline CHEMBL1360079 & 688128 & 4.3 & 4.3734 & TRN & \\
\hline CHEMBL3211851 & 688128 & 4.65 & 4.481 & TRN & \\
\hline CHEMBL1430312 & 688128 & 6.8499 & 4.5854 & TRN & \\
\hline CHEMBL1606971 & 688128 & 4.35 & 4.3782 & TRN & \\
\hline CHEMBL1546140 & 688128 & 5.0 & 4.7087 & TRN & \\
\hline CHEMBL1301107 & 688128 & 4.25 & 4.7103 & TST & \\
\hline CHEMBL1458682 & 688128 & 4.3 & 4.5955 & TRN & \\
\hline CHEMBL1323275 & 688128 & 4.4 & 4.561 & TST & \\
\hline CHEMBL1559105 & 688128 & 4.3 & 4.2591 & TRN & \\
\hline CHEMBL3192757 & 688128 & 4.7 & 4.7166 & TRN & \\
\hline CHEMBL 3193178 & 688128 & 4.45 & 4.6936 & TRN & \\
\hline CHEMBL1537303 & 688128 & 4.35 & 4.7843 & TRN & \\
\hline CHEMBL3189525 & 688128 & 5.4 & 4.547 & TRN & \\
\hline CHEMBL1543916 & 688128 & 4.35 & 4.2203 & TRN & \\
\hline CHEMBL1493923 & 688128 & 4.05 & 4.7025 & TST & \\
\hline CHEMBL1462066 & 688128 & 4.3 & 4.5092 & TST & \\
\hline CHEMBL1350246 & 688128 & 4.4 & 4.5337 & TST & \\
\hline CHEMBL1441968 & 688128 & 7.699 & 4.2448 & TRN & \\
\hline CHEMBL1578917 & 688128 & 5.75 & 4.4118 & TRN & \\
\hline CHEMBL1975419 & 688128 & 6.8 & 4.9139 & TRN & \\
\hline CHEMBL1426444 & 688128 & 5.4 & 4.7232 & TST & \\
\hline CHEMBL1578876 & 688128 & 4.35 & 4.6026 & TRN & \\
\hline CHEMBL1447308 & 688128 & 4.4 & 4.5582 & TRN & \\
\hline CHEMBL1441377 & 688128 & 4.7 & 4.592 & TRN & \\
\hline CHEMBL3209563 & 688128 & 5.4 & 4.5428 & TST & \\
\hline CHEMBL1536378 & 688128 & 4.4 & 4.5902 & TRN & \\
\hline CHEMBL1510668 & 688128 & 4.1 & 4.7569 & TST & \\
\hline CHEMBL1510278 & 688128 & 4.35 & 4.4265 & TST & \\
\hline CHEMBL601385 & 688128 & 4.3 & 4.6107 & TST & \\
\hline CHEMBL1519753 & 688128 & 4.05 & 4.6821 & TRN & \\
\hline CHEMBL1522514 & 688128 & 5.65 & 4.5427 & TRN & \\
\hline CHEMBL1554945 & 688128 & 4.4 & 4.5777 & TRN & \\
\hline CHEMBL1255944 & 688128 & 6.1 & 5.0667 & TRN & \\
\hline CHEMBL1359506 & 688128 & 4.3 & 4.4586 & TRN & \\
\hline CHEMBL1313160 & 688128 & 4.85 & 4.7324 & TRN & \\
\hline CHEMBL1420717 & 688128 & 4.3 & 4.4857 & TRN & \\
\hline CHEMBL1443979 & 688128 & 4.7 & 4.6551 & TRN & \\
\hline CHEMBL1572924 & 688128 & 5.65 & 4.8938 & TRN & \\
\hline CHEMBL1402286 & 688128 & 5.1 & 4.6998 & TRN & \\
\hline CHEMBL1411400 & 688128 & 4.6 & 4.7205 & TRN & \\
\hline CHEMBL3195543 & 688128 & 4.35 & 4.44600 & 0000000001 & TRN \\
\hline CHEMBL1384433 & 688128 & 5.35 & 4.6567 & TST & \\
\hline CHEMBL3212204 & 688128 & 4.3 & 4.6897 & TRN & \\
\hline CHEMBL1556948 & 688128 & 4.55 & 4.452 & TRN & \\
\hline CHEMBL1323683 & 688128 & 4.75 & 4.7707 & TRN & \\
\hline CHEMBL1434949 & 688128 & 4.85 & 4.4626 & TRN & \\
\hline CHEMBL1401673 & 688128 & 4.3 & 4.577 & TRN & \\
\hline CHEMBL1539547 & 688128 & 4.05 & 4.5424 & TRN & \\
\hline
\end{tabular}




\begin{tabular}{|c|c|c|c|c|c|}
\hline CHEMBL1449914 & 688128 & 4.4 & 4.7369 & TRN & \\
\hline CHEMBL1386778 & 688128 & 5.1 & \multicolumn{2}{|c|}{4.5889999999999995} & TST \\
\hline CHEMBL1401087 & 688128 & 4.5 & 4.3056 & TST & \\
\hline CHEMBL1406686 & 688128 & 4.7 & 4.507 & TST & \\
\hline CHEMBL1326813 & 688128 & 4.4 & 4.7588 & TRN & \\
\hline CHEMBL1526933 & 688128 & 4.45 & 5.0085 & TRN & \\
\hline CHEMBL3195864 & 688128 & 4.7 & 4.8571 & TRN & \\
\hline CHEMBL1510551 & 688128 & 4.05 & 4.6172 & TRN & \\
\hline CHEMBL1327813 & 688128 & 4.35 & 4.3926 & TRN & \\
\hline CHEMBL1384697 & 688128 & 5.45 & 4.4694 & TST & \\
\hline CHEMBL1390729 & 688128 & 4.45 & 4.6588 & TRN & \\
\hline CHEMBL1603051 & 688128 & 4.9 & 4.199 & TRN & \\
\hline CHEMBL1463155 & 688128 & 4.4 & \multicolumn{2}{|c|}{4.656000000000001} & TRN \\
\hline CHEMBL1487004 & 688128 & 4.3 & 4.7065 & TST & \\
\hline CHEMBL1383339 & 688128 & 4.45 & 4.6452 & TRN & \\
\hline CHEMBL1463065 & 688128 & 6.9 & 4.5799 & TST & \\
\hline CHEMBL3109023 & 688128 & 5.6 & 4.7061 & TRN & \\
\hline CHEMBL1419523 & 688128 & 6.0 & 5.0994 & TRN & \\
\hline CHEMBL1380746 & 688128 & 4.25 & 5.1173 & TST & \\
\hline CHEMBL1406241 & 688128 & 5.4 & 4.6311 & TRN & \\
\hline CHEMBL1971815 & 688128 & 4.35 & 4.5553 & TRN & \\
\hline CHEMBL1509825 & 688128 & 4.05 & 4.7225 & TST & \\
\hline CHEMBL1475283 & 688128 & 4.05 & 4.6925 & TRN & \\
\hline CHEMBL1320191 & 688128 & 4.5 & 4.6177 & TRN & \\
\hline CHEMBL1432787 & 688128 & 5.5 & 5.1263 & TRN & \\
\hline CHEMBL1332057 & 688128 & 4.4 & 4.6709 & TRN & \\
\hline CHEMBL1458311 & 688128 & 5.15 & 4.4124 & TST & \\
\hline CHEMBL1466232 & 688128 & 4.05 & 4.5845 & TRN & \\
\hline CHEMBL1431351 & 688128 & 4.35 & 4.5359 & TRN & \\
\hline CHEMBL1499017 & 688128 & 4.05 & 4.6091 & TRN & \\
\hline CHEMBL1301475 & 688128 & 4.35 & 4.7698 & TST & \\
\hline CHEMBL1978364 & 688128 & 4.9 & 4.6913 & TRN & \\
\hline CHEMBL1423859 & 688128 & 4.65 & 4.2032 & TRN & \\
\hline CHEMBL1339735 & 688128 & 4.3 & 4.5888 & TRN & \\
\hline CHEMBL1493543 & 688128 & 4.35 & 4.5605 & TRN & \\
\hline CHEMBL1508878 & 688128 & 4.15 & 4.8253 & TST & \\
\hline CHEMBL1539866 & 688128 & 4.4 & 4.5301 & TRN & \\
\hline CHEMBL1467743 & 688128 & 4.45 & 4.4942 & TRN & \\
\hline CHEMBL3199456 & 688128 & 4.35 & 4.8365 & TRN & \\
\hline CHEMBL1352220 & 688128 & 4.05 & 4.5961 & TRN & \\
\hline CHEMBL1319198 & 688128 & 4.3 & 4.2642 & TRN & \\
\hline CHEMBL1523077 & 688128 & 4.85 & 4.8159 & TRN & \\
\hline CHEMBL3198600 & 688128 & 4.35 & 4.7149 & TST & \\
\hline CHEMBL1540358 & 688128 & 4.4 & 4.5561 & TST & \\
\hline CHEMBL1590749 & 688128 & 4.45 & 4.5056 & TST & \\
\hline CHEMBL1990716 & 688128 & 6.25 & 4.8465 & TST & \\
\hline CHEMBL1302639 & 688128 & 5.35 & 4.7752 & TRN & \\
\hline CHEMBL1325061 & 688128 & 4.7 & 4.5271 & TRN & \\
\hline
\end{tabular}




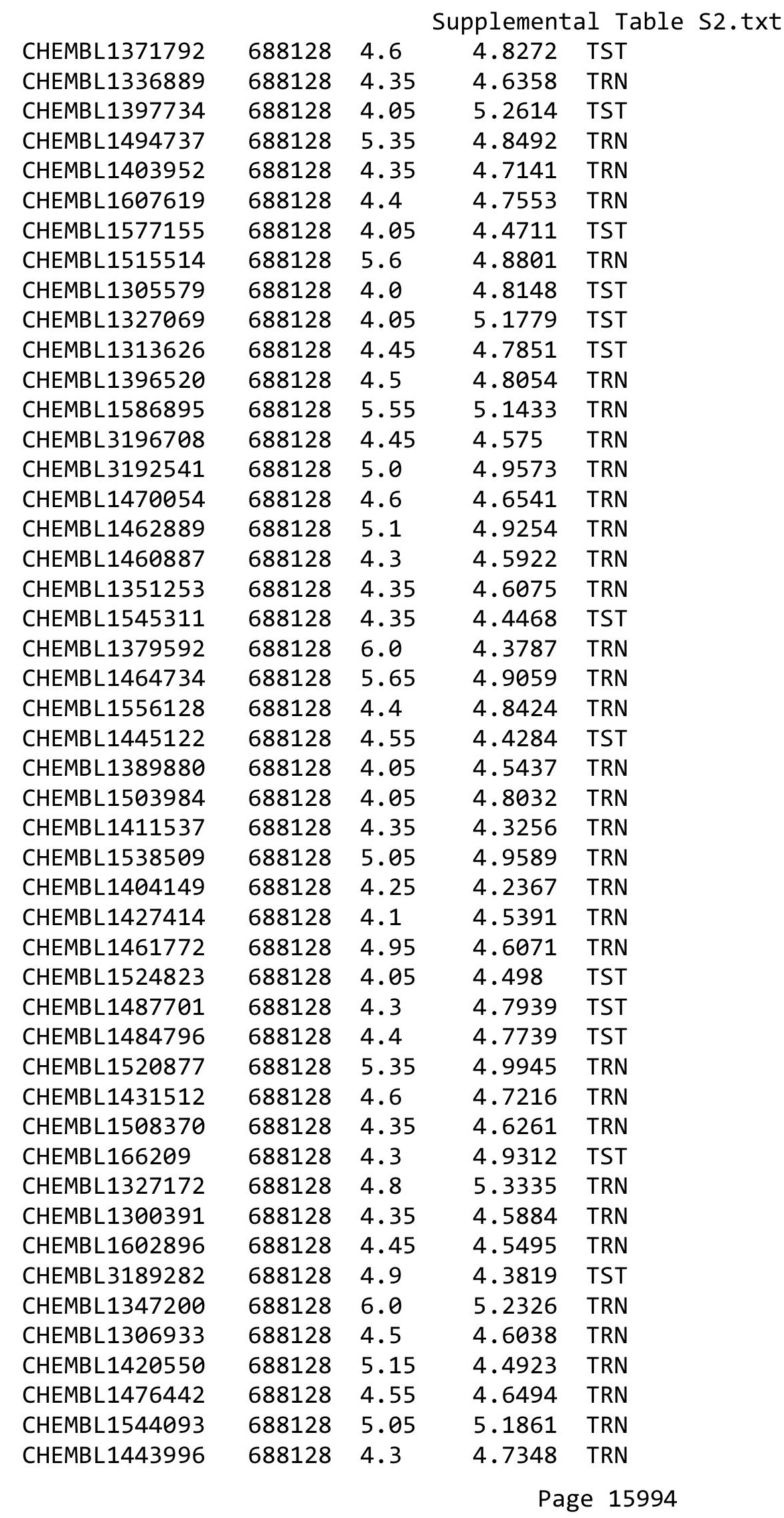




\begin{tabular}{|c|c|c|c|c|}
\hline \multicolumn{5}{|c|}{ Supplemental Table } \\
\hline CHEMBL1517792 & 688128 & 4.35 & 4.626 & TRN \\
\hline CHEMBL1341372 & 688128 & 4.35 & 4.3629 & TRN \\
\hline CHEMBL1491673 & 688128 & 6.35 & 5.0846 & TRN \\
\hline CHEMBL1478160 & 688128 & 4.3 & 4.5224 & TRN \\
\hline CHEMBL1369591 & 688128 & 4.4 & 4.7284 & TRN \\
\hline CHEMBL1575390 & 688128 & 4.9 & 4.4535 & TRN \\
\hline CHEMBL1601937 & 688128 & 4.4 & 4.461 & TRN \\
\hline CHEMBL3191910 & 688128 & 4.3 & 4.7851 & TST \\
\hline CHEMBL1449477 & 688128 & 4.35 & 4.593 & TRN \\
\hline CHEMBL1544364 & 688128 & 4.55 & 4.7676 & TRN \\
\hline CHEMBL1606493 & 688128 & 4.55 & 4.5308 & TRN \\
\hline CHEMBL1420548 & 688128 & 5.65 & 5.2167 & TRN \\
\hline CHEMBL3212593 & 688128 & 4.7 & 4.6755 & TRN \\
\hline CHEMBL1465527 & 688128 & 5.35 & 4.7104 & TST \\
\hline CHEMBL1380803 & 688128 & 4.6 & 4.5683 & TRN \\
\hline CHEMBL1431881 & 688128 & 4.4 & 4.7434 & TRN \\
\hline CHEMBL1986381 & 688128 & 5.1 & 4.4756 & TST \\
\hline CHEMBL1585340 & 688128 & 4.45 & 4.8005 & TST \\
\hline CHEMBL1345308 & 688128 & 4.3 & 4.2879 & TST \\
\hline CHEMBL1450165 & 688128 & 5.1 & 4.6536 & TRN \\
\hline CHEMBL1570004 & 688128 & 5.45 & 5.3579 & TRN \\
\hline CHEMBL1472794 & 688128 & 4.65 & 5.0128 & TRN \\
\hline CHEMBL1471850 & 688128 & 4.4 & 4.6169 & TRN \\
\hline CHEMBL1322910 & 688128 & 4.75 & 4.3293 & TRN \\
\hline CHEMBL570345 & 688128 & 7.0 & 4.9722 & TST \\
\hline CHEMBL1403783 & 688128 & 4.4 & 4.4918 & TRN \\
\hline CHEMBL1493791 & 688128 & 5.2 & 4.9208 & TRN \\
\hline CHEMBL1320441 & 688128 & 4.4 & 4.7252 & TRN \\
\hline CHEMBL1306289 & 688128 & 4.35 & 4.6121 & TRN \\
\hline CHEMBL3213732 & 688128 & 4.05 & 4.776 & TST \\
\hline CHEMBL1414928 & 688128 & 5.3 & 5.0356 & TST \\
\hline CHEMBL1435646 & 688128 & 5.5 & 4.8623 & TRN \\
\hline CHEMBL1419642 & 688128 & 4.85 & 4.8224 & TRN \\
\hline CHEMBL1301875 & 688128 & 4.05 & 4.7265 & TST \\
\hline CHEMBL1308751 & 688128 & 5.55 & 4.999 & TRN \\
\hline CHEMBL1311692 & 688128 & 4.05 & 4.4908 & TRN \\
\hline CHEMBL1598471 & 688128 & 4.35 & 4.8334 & TRN \\
\hline CHEMBL1551198 & 688128 & 4.4 & 4.5025 & TRN \\
\hline CHEMBL1576855 & 688128 & 4.4 & 4.6731 & TRN \\
\hline CHEMBL1340126 & 688128 & 4.65 & 4.6694 & TST \\
\hline CHEMBL1314810 & 688128 & 4.35 & 4.5243 & TRN \\
\hline CHEMBL1600200 & 688128 & 5.05 & 4.967 & TRN \\
\hline CHEMBL1431459 & 688128 & 4.35 & 4.654 & TST \\
\hline CHEMBL1494562 & 688128 & 4.4 & 4.7121 & TST \\
\hline CHEMBL1390246 & 688128 & 4.1 & 5.3364 & TST \\
\hline CHEMBL1214410 & 688128 & 4.5 & 4.5327 & TRN \\
\hline CHEMBL1388485 & 688128 & 4.35 & 4.5974 & TRN \\
\hline CHEMBL1411804 & 688128 & 4.95 & 4.8096 & TRN \\
\hline
\end{tabular}




\begin{tabular}{|c|c|c|c|c|c|}
\hline \\
\hline CHEMBL1407420 & 688128 & 4.4 & 4.5012 & TRN & \\
\hline CHEMBL1519058 & 688128 & 4.1 & 4.4603 & TRN & \\
\hline CHEMBL1522062 & 688128 & 4.5 & 4.5183 & TRN & \\
\hline CHEMBL1429800 & 688128 & 4.05 & $4.7810 €$ & 0000000001 & TRN \\
\hline CHEMBL1543588 & 688128 & 5.0 & 5.0129 & TRN & \\
\hline CHEMBL1525964 & 688128 & 4.4 & 4.5908 & TRN & \\
\hline CHEMBL1416808 & 688128 & 4.8 & 4.7041 & TRN & \\
\hline CHEMBL1346121 & 688128 & 4.1 & 4.647 & TRN & \\
\hline CHEMBL1335821 & 688128 & 4.35 & 4.6975 & TRN & \\
\hline CHEMBL1504608 & 688128 & 4.3 & 4.5096 & TRN & \\
\hline CHEMBL1364671 & 688128 & 5.4 & 4.5598 & TRN & \\
\hline CHEMBL1506627 & 688128 & 5.1 & 4.8217 & TRN & \\
\hline CHEMBL1381055 & 688128 & 4.5 & 4.9375 & TRN & \\
\hline CHEMBL1304105 & 688128 & 4.75 & 4.7593 & TRN & \\
\hline CHEMBL1508646 & 688128 & 4.05 & 4.4127 & TRN & \\
\hline CHEMBL3197751 & 688128 & 4.25 & 4.6732 & TST & \\
\hline CHEMBL1540989 & 688128 & 4.7 & 4.3902 & TRN & \\
\hline CHEMBL3195384 & 688128 & 4.45 & 4.4013 & TRN & \\
\hline CHEMBL1411914 & 688128 & 4.1 & 4.511 & TST & \\
\hline CHEMBL1553639 & 688128 & 4.3 & 4.5402 & TST & \\
\hline CHEMBL1305656 & 688128 & 4.25 & 4.572 & TRN & \\
\hline CHEMBL1341756 & 688128 & 5.6 & 5.0403 & TRN & \\
\hline CHEMBL1540404 & 688128 & 4.25 & 4.8919 & 99999999995 & TST \\
\hline CHEMBL3196363 & 688128 & 5.0 & 4.5853 & TRN & \\
\hline CHEMBL 1459078 & 688128 & 4.35 & 4.8394 & TRN & \\
\hline CHEMBL3195943 & 688128 & 4.4 & 4.5527 & TRN & \\
\hline CHEMBL1613278 & 688128 & 4.4 & 4.5959 & TRN & \\
\hline CHEMBL1570286 & 688128 & 4.05 & 4.8581 & TST & \\
\hline CHEMBL1272069 & 688128 & 4.3 & 4.5403 & TRN & \\
\hline CHEMBL1461473 & 688128 & 4.45 & 4.3422 & TST & \\
\hline CHEMBL1412968 & 688128 & 5.1 & 4.7427 & TRN & \\
\hline CHEMBL1554125 & 688128 & 4.45 & 4.5716 & TST & \\
\hline CHEMBL1342110 & 688128 & 4.3 & 4.5237 & TRN & \\
\hline CHEMBL1405994 & 688128 & 4.4 & 4.5088 & TST & \\
\hline CHEMBL1505216 & 688128 & 6.15 & 4.9239 & TRN & \\
\hline CHEMBL1335717 & 688128 & 4.45 & 4.6182 & TRN & \\
\hline CHEMBL1547628 & 688128 & 4.3 & 4.6571 & TRN & \\
\hline CHEMBL1339904 & 688128 & 5.25 & 4.9333 & TRN & \\
\hline CHEMBL1608050 & 688128 & 4.3 & 4.59399 & 9999999999 & TST \\
\hline CHEMBL 1495700 & 688128 & 4.85 & 4.6673 & TRN & \\
\hline CHEMBL1528156 & 688128 & 4.35 & 4.6798 & TRN & \\
\hline CHEMBL1548326 & 688128 & 4.4 & 4.3676 & TRN & \\
\hline CHEMBL1318199 & 688128 & 6.0 & 4.7702 & TRN & \\
\hline CHEMBL 3208140 & 688128 & 4.25 & 4.4683 & TRN & \\
\hline CHEMBL1571708 & 688128 & 4.65 & 4.8063 & TRN & \\
\hline CHEMBL1416961 & 688128 & 4.35 & 4.4447 & TRN & \\
\hline CHEMBL1609520 & 688128 & 4.5 & 4.5904 & TRN & \\
\hline CHEMBL1338881 & 688128 & 4.65 & 4.5375 & TST & \\
\hline
\end{tabular}




\begin{tabular}{|c|c|c|c|c|c|}
\hline & & \multicolumn{4}{|c|}{ Supplemental Table S2.txt } \\
\hline CHEMBL1335282 & 688128 & 4.45 & 4.5663 & TRN & \\
\hline CHEMBL1471978 & 688128 & 4.05 & 4.7173 & TRN & \\
\hline CHEMBL1341179 & 688128 & 4.25 & 4.4519 & TRN & \\
\hline CHEMBL1533435 & 688128 & 4.4 & 4.7186 & TRN & \\
\hline CHEMBL1404809 & 688128 & 4.4 & 4.7318 & TRN & \\
\hline CHEMBL1458127 & 688128 & 4.8 & 4.9001 & TRN & \\
\hline CHEMBL1325464 & 688128 & 4.35 & 4.4489 & TRN & \\
\hline CHEMBL1339997 & 688128 & 4.6 & 4.6404 & TRN & \\
\hline CHEMBL1495613 & 688128 & 4.5 & 4.23 & TRN & \\
\hline CHEMBL3208488 & 688128 & 4.3 & 4.7056 & TRN & \\
\hline CHEMBL1319543 & 688128 & 4.4 & 4.4509 & TRN & \\
\hline CHEMBL1509378 & 688128 & 4.55 & 4.5695 & TRN & \\
\hline CHEMBL1373418 & 688128 & 4.0 & 4.657 & TRN & \\
\hline CHEMBL1453065 & 688128 & 4.95 & 4.5619 & TRN & \\
\hline CHEMBL1502002 & 688128 & 4.35 & 4.6764 & TST & \\
\hline CHEMBL1339711 & 688128 & 4.5 & 4.5923 & TRN & \\
\hline CHEMBL1416519 & 688128 & 4.3 & 4.5336 & TRN & \\
\hline CHEMBL1395647 & 688128 & 5.45 & 4.5347 & TRN & \\
\hline CHEMBL1418487 & 688128 & 4.3 & 4.61600 & 00000000005 & TST \\
\hline CHEMBL1348614 & 688128 & 5.45 & 4.6874 & TRN & \\
\hline CHEMBL1387375 & 688128 & 4.3 & 4.3149 & TRN & \\
\hline CHEMBL1471205 & 688128 & 4.9 & 4.5682 & TST & \\
\hline CHEMBL1402857 & 688128 & 5.4 & 4.6082 & TRN & \\
\hline CHEMBL1300828 & 688128 & 4.65 & 4.6849 & TRN & \\
\hline CHEMBL1348406 & 688128 & 4.9 & 5.28 & TRN & \\
\hline CHEMBL1556899 & 688128 & 5.0 & 4.6864 & TST & \\
\hline CHEMBL1380549 & 688128 & 4.4 & 4.6559 & TRN & \\
\hline CHEMBL1508385 & 688128 & 4.7 & 4.4812 & TST & \\
\hline CHEMBL1495172 & 688128 & 4.95 & 4.8257 & TRN & \\
\hline CHEMBL1584182 & 688128 & 5.75 & 5.0815 & TRN & \\
\hline CHEMBL1350202 & 688128 & 4.35 & 4.5201 & TRN & \\
\hline CHEMBL1338412 & 688128 & 4.25 & 4.7555 & TRN & \\
\hline CHEMBL1417322 & 688128 & 5.1 & 4.658 & TRN & \\
\hline CHEMBL1526433 & 688128 & 4.3 & 4.5454 & TST & \\
\hline CHEMBL1436685 & 688128 & 4.45 & 4.655 & TRN & \\
\hline CHEMBL1545509 & 688128 & 4.3 & 4.8102 & TRN & \\
\hline CHEMBL3199385 & 688128 & 4.05 & 4.6704 & TST & \\
\hline CHEMBL600881 & 688128 & 4.05 & 4.4606 & TRN & \\
\hline CHEMBL1497078 & 688128 & 4.95 & 4.7295 & TRN & \\
\hline CHEMBL1516601 & 688128 & 4.45 & 4.7981 & TRN & \\
\hline CHEMBL1378052 & 688128 & 4.1 & 4.2385 & TST & \\
\hline CHEMBL1559523 & 688128 & 5.1 & 4.4351 & TRN & \\
\hline CHEMBL1498904 & 688128 & 4.55 & 4.5512 & TST & \\
\hline CHEMBL1346326 & 688128 & 4.25 & 4.6123 & TRN & \\
\hline CHEMBL1429730 & 688128 & 4.05 & 4.546 & TRN & \\
\hline CHEMBL1431042 & 688128 & 4.45 & 5.0237 & TRN & \\
\hline CHEMBL1485854 & 688128 & 4.35 & 4.5289 & TRN & \\
\hline CHEMBL1895724 & 688128 & 4.75 & 4.5557 & TST & \\
\hline
\end{tabular}




\begin{tabular}{|c|c|c|c|c|}
\hline \multicolumn{5}{|c|}{ Supplemental Table S2.txt } \\
\hline CHEMBL1390448 & 688128 & 6.0 & 4.6044 & TRN \\
\hline CHEMBL1390506 & 688128 & 5.1 & 4.3361 & TRN \\
\hline CHEMBL1592868 & 688128 & 5.45 & 4.2847 & TST \\
\hline CHEMBL1564155 & 688128 & 4.4 & 4.8236 & TRN \\
\hline CHEMBL1346506 & 688128 & 4.05 & 4.6162 & TRN \\
\hline CHEMBL1442329 & 688128 & 4.35 & 4.8769 & TRN \\
\hline CHEMBL1510553 & 688128 & 4.4 & 4.3896 & TRN \\
\hline CHEMBL1342337 & 688128 & 5.05 & 4.8792 & TRN \\
\hline CHEMBL1414704 & 688128 & 4.95 & 5.1395 & TRN \\
\hline CHEMBL1409897 & 688128 & 4.05 & 4.4779 & TRN \\
\hline CHEMBL1613708 & 688128 & 4.75 & 4.7099 & TRN \\
\hline CHEMBL1369042 & 688128 & 4.3 & 4.5277 & TRN \\
\hline CHEMBL1374313 & 688128 & 5.6 & 4.4563 & TRN \\
\hline CHEMBL1382561 & 688128 & 5.45 & 4.7284 & TRN \\
\hline CHEMBL1426049 & 688128 & 4.35 & 4.4228 & TST \\
\hline CHEMBL1574056 & 688128 & 5.4 & 4.6277 & TST \\
\hline CHEMBL1434939 & 688128 & 4.35 & 4.5915 & TRN \\
\hline CHEMBL1438309 & 688128 & 4.35 & 4.5493 & TRN \\
\hline CHEMBL1381848 & 688128 & 4.35 & 4.7708 & TST \\
\hline CHEMBL1480536 & 688128 & 4.3 & 4.6679 & TRN \\
\hline CHEMBL1577453 & 688128 & 5.5 & 4.769 & TRN \\
\hline CHEMBL1482909 & 688128 & 5.25 & 5.0765 & TRN \\
\hline CHEMBL1430159 & 688128 & 4.45 & 4.6005 & TRN \\
\hline CHEMBL1396112 & 688128 & 4.05 & 4.7103 & TST \\
\hline CHEMBL1480895 & 688128 & 5.55 & 4.6315 & TRN \\
\hline CHEMBL1445384 & 688128 & 4.25 & 4.5751 & TST \\
\hline CHEMBL1339860 & 688128 & 4.8 & 4.7802 & TRN \\
\hline CHEMBL1417867 & 688128 & 5.35 & 4.9028 & TRN \\
\hline CHEMBL1429158 & 688128 & 4.3 & 4.8284 & TRN \\
\hline CHEMBL1334840 & 688128 & 6.15 & 4.8391 & TRN \\
\hline CHEMBL1353399 & 688128 & 4.4 & 4.5098 & TST \\
\hline CHEMBL1426821 & 688128 & 4.9 & 4.8716 & TRN \\
\hline CHEMBL1596242 & 688128 & 4.3 & 4.8358 & TRN \\
\hline CHEMBL1980614 & 688128 & 4.35 & 4.4608 & TRN \\
\hline CHEMBL1369633 & 688128 & 6.1 & 4.7461 & TST \\
\hline CHEMBL1328029 & 688128 & 5.65 & 5.067 & TRN \\
\hline CHEMBL1976000 & 688128 & 4.45 & 4.5463 & TRN \\
\hline CHEMBL1411879 & 688128 & 4.3 & 4.648 & TRN \\
\hline CHEMBL1361913 & 688128 & 6.25 & 4.9452 & TST \\
\hline CHEMBL1333736 & 688128 & 4.05 & 4.6505 & TST \\
\hline CHEMBL1341786 & 688128 & 4.0 & 4.6022 & TRN \\
\hline CHEMBL1364849 & 688128 & 5.45 & 4.6074 & TRN \\
\hline CHEMBL1550142 & 688128 & 4.3 & 4.3596 & TRN \\
\hline CHEMBL1506007 & 688128 & 4.35 & 4.8355 & TST \\
\hline CHEMBL1387139 & 688128 & 4.4 & 4.5677 & TRN \\
\hline CHEMBL1585033 & 688128 & 4.0 & 4.5173 & TRN \\
\hline CHEMBL1480960 & 688128 & 5.0 & 4.7422 & TRN \\
\hline CHEMBL1377155 & 688128 & 4.65 & 4.6041 & TRN \\
\hline
\end{tabular}




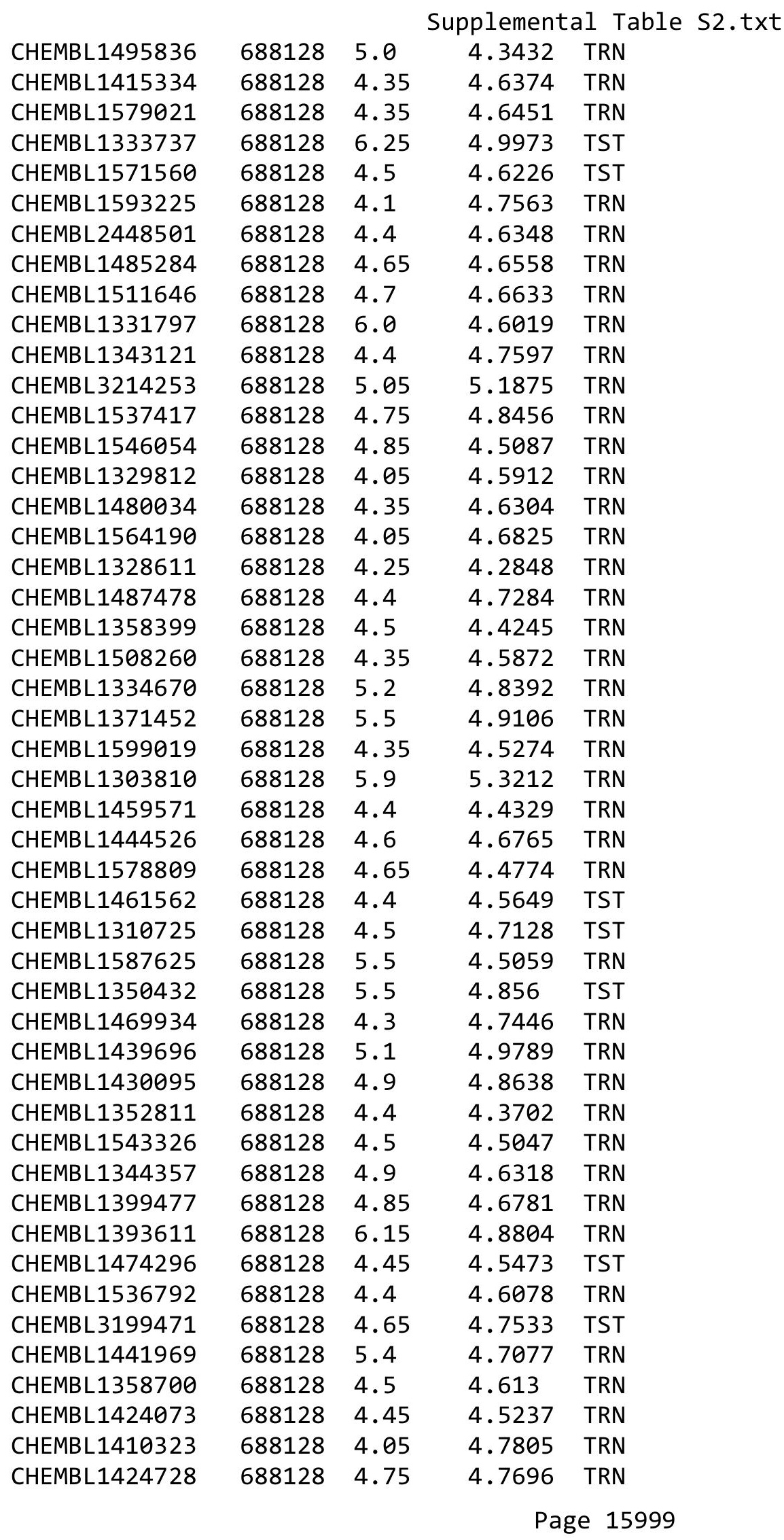




\begin{tabular}{|c|c|c|c|c|}
\hline \multicolumn{5}{|c|}{ Supplemental Table } \\
\hline CHEMBL1441819 & 688128 & 4.35 & 4.9493 & TST \\
\hline CHEMBL1336054 & 688128 & 4.85 & 4.9816 & TRN \\
\hline CHEMBL1368667 & 688128 & 4.0 & 4.4171 & TRN \\
\hline CHEMBL1501753 & 688128 & 5.55 & 4.6677 & TRN \\
\hline CHEMBL1438333 & 688128 & 6.1 & 4.6955 & TST \\
\hline CHEMBL1406857 & 688128 & 5.6 & 4.288 & TST \\
\hline CHEMBL1396808 & 688128 & 4.1 & 4.6358 & TRN \\
\hline CHEMBL1409606 & 688128 & 4.95 & 4.876 & TST \\
\hline CHEMBL1452678 & 688128 & 4.1 & 4.8269 & TRN \\
\hline CHEMBL1384259 & 688128 & 4.25 & 4.6326 & TST \\
\hline CHEMBL553751 & 688128 & 4.35 & 4.9218 & TST \\
\hline CHEMBL1465040 & 688128 & 5.5 & 5.0216 & TRN \\
\hline CHEMBL1563481 & 688128 & 4.4 & 4.7179 & TRN \\
\hline CHEMBL1341261 & 688128 & 5.45 & 4.3911 & TRN \\
\hline CHEMBL1439363 & 688128 & 4.4 & 4.9672 & TRN \\
\hline CHEMBL1565573 & 688128 & 4.5 & 4.5276 & TRN \\
\hline CHEMBL3214091 & 688128 & 4.3 & 4.5931 & TST \\
\hline CHEMBL1369329 & 688128 & 4.55 & 4.478 & TRN \\
\hline CHEMBL1381715 & 688128 & 5.5 & 4.6216 & TRN \\
\hline CHEMBL1312080 & 688128 & 4.35 & 4.2378 & TRN \\
\hline CHEMBL1492598 & 688128 & 4.05 & 4.4017 & TRN \\
\hline CHEMBL1604080 & 688128 & 4.55 & 4.3345 & TST \\
\hline CHEMBL1476925 & 688128 & 4.3 & 4.6171 & TRN \\
\hline CHEMBL1384838 & 688128 & 4.25 & 4.7308 & TRN \\
\hline CHEMBL1480398 & 688128 & 5.95 & 4.707 & TST \\
\hline CHEMBL1461392 & 688128 & 4.55 & 4.0989 & TRN \\
\hline CHEMBL1562672 & 688128 & 4.75 & 5.0472 & TST \\
\hline CHEMBL1323162 & 688128 & 4.35 & 4.5097 & TRN \\
\hline CHEMBL1429843 & 688128 & 4.2 & 4.5354 & TRN \\
\hline CHEMBL1526999 & 688128 & 4.55 & 4.5245 & TRN \\
\hline CHEMBL1512894 & 688128 & 4.05 & 4.575 & TST \\
\hline CHEMBL1474888 & 688128 & 4.25 & 4.5645 & TRN \\
\hline CHEMBL1605393 & 688128 & 5.05 & 4.6002 & TRN \\
\hline CHEMBL1510744 & 688128 & 4.6 & 4.7061 & TST \\
\hline CHEMBL1532131 & 688128 & 4.75 & 4.6361 & TRN \\
\hline CHEMBL1380958 & 688128 & 5.15 & 5.0569 & TRN \\
\hline CHEMBL1407444 & 688128 & 4.3 & 4.5253 & TRN \\
\hline CHEMBL1362024 & 688128 & 4.4 & 4.4596 & TRN \\
\hline CHEMBL1380602 & 688128 & 5.0 & 4.5144 & TRN \\
\hline CHEMBL1510922 & 688128 & 4.25 & 4.7681 & TRN \\
\hline CHEMBL1331366 & 688128 & 4.3 & 4.6929 & TRN \\
\hline CHEMBL1366105 & 688128 & 4.35 & 4.8753 & TRN \\
\hline CHEMBL1496532 & 688128 & 5.15 & 4.9189 & TRN \\
\hline CHEMBL1501755 & 688128 & 4.45 & 4.7724 & TRN \\
\hline CHEMBL1370962 & 688128 & 4.25 & 4.6766 & TRN \\
\hline CHEMBL1356410 & 688128 & 4.3 & 4.7688 & TRN \\
\hline CHEMBL1344854 & 688128 & 4.7 & 4.5308 & TRN \\
\hline CHEMBL1574604 & 688128 & 4.25 & 4.6364 & TRN \\
\hline
\end{tabular}




\begin{tabular}{|c|c|c|c|c|c|}
\hline & & \multicolumn{4}{|c|}{ Supplemental Table S2.txt } \\
\hline CHEMBL1380659 & 688128 & 4.35 & 4.374 & TRN & \\
\hline CHEMBL1471350 & 688128 & 4.05 & 4.6646 & TST & \\
\hline CHEMBL1401196 & 688128 & 5.6 & 4.5269 & TST & \\
\hline CHEMBL1611074 & 688128 & 4.45 & 4.8274 & TRN & \\
\hline CHEMBL1352427 & 688128 & 4.35 & 4.5669 & TRN & \\
\hline CHEMBL1402971 & 688128 & 5.8 & 4.497 & TRN & \\
\hline CHEMBL1559448 & 688128 & 4.35 & 4.8538 & TST & \\
\hline CHEMBL1550687 & 688128 & 4.35 & 4.7883 & TRN & \\
\hline CHEMBL1448394 & 688128 & 4.4 & 4.5368 & TRN & \\
\hline CHEMBL1371202 & 688128 & 4.45 & 4.7497 & TRN & \\
\hline CHEMBL1404599 & 688128 & 4.25 & 4.3883 & TRN & \\
\hline CHEMBL1374007 & 688128 & 4.5 & 4.7537 & TRN & \\
\hline CHEMBL1444106 & 688128 & 4.95 & 4.3468 & TST & \\
\hline CHEMBL1453773 & 688128 & 4.5 & 4.70100 & 00000000005 & TRN \\
\hline CHEMBL1572914 & 688128 & 5.3 & 5.0161 & TRN & \\
\hline CHEMBL1461875 & 688128 & 4.4 & 4.508 & TRN & \\
\hline CHEMBL1320992 & 688128 & 5.6 & 4.6341 & TRN & \\
\hline CHEMBL1482476 & 688128 & 4.35 & 4.6057 & TST & \\
\hline CHEMBL1564546 & 688128 & 4.45 & 4.4254 & TRN & \\
\hline CHEMBL1333107 & 688128 & 4.55 & 4.5804 & TRN & \\
\hline CHEMBL3194200 & 688128 & 4.4 & 4.7415 & TRN & \\
\hline CHEMBL1421016 & 688128 & 5.3 & 4.5326 & TST & \\
\hline CHEMBL1547717 & 688128 & 4.55 & 4.562 & TRN & \\
\hline CHEMBL1439938 & 688128 & 4.4 & 4.5466 & TST & \\
\hline CHEMBL1427043 & 688128 & 4.05 & 4.3511 & TST & \\
\hline CHEMBL1347989 & 688128 & 4.4 & 4.6356 & TRN & \\
\hline CHEMBL1486278 & 688128 & 6.1 & 4.8176 & TRN & \\
\hline CHEMBL1479729 & 688128 & 6.15 & 4.8524 & TRN & \\
\hline CHEMBL3183391 & 688128 & 4.4 & 4.6791 & TRN & \\
\hline CHEMBL1341399 & 688128 & 5.1 & 4.8636 & TRN & \\
\hline CHEMBL1361652 & 688128 & 4.35 & 4.7391 & TRN & \\
\hline CHEMBL1576346 & 688128 & 4.7 & 4.6183 & TRN & \\
\hline CHEMBL1488106 & 688128 & 4.95 & 4.8437 & TRN & \\
\hline CHEMBL1582878 & 688128 & 4.25 & 4.7652 & TRN & \\
\hline CHEMBL1419002 & 688128 & 5.25 & 4.6831 & TRN & \\
\hline CHEMBL1300399 & 688128 & 4.4 & 5.1912 & TRN & \\
\hline CHEMBL1473717 & 688128 & 4.05 & 5.0375 & TRN & \\
\hline CHEMBL1413985 & 688128 & 4.8 & 4.9188 & TRN & \\
\hline CHEMBL1329371 & 688128 & 5.75 & 4.5184 & TST & \\
\hline CHEMBL1409586 & 688128 & 5.1 & 4.8959 & TRN & \\
\hline CHEMBL1562629 & 688128 & 5.1 & 4.9595 & TRN & \\
\hline CHEMBL1357803 & 688128 & 6.1 & 4.5201 & TRN & \\
\hline CHEMBL1335551 & 688128 & 4.45 & 5.1368 & TRN & \\
\hline CHEMBL1499451 & 688128 & 4.45 & 4.8331 & TRN & \\
\hline CHEMBL1410824 & 688128 & 4.3 & 4.3978 & TRN & \\
\hline CHEMBL3212060 & 688128 & 4.3 & 4.5853 & TRN & \\
\hline CHEMBL1318818 & 688128 & 4.3 & 4.7188 & TRN & \\
\hline CHEMBL1419849 & 688128 & 4.3 & 4.4546 & TRN & \\
\hline
\end{tabular}




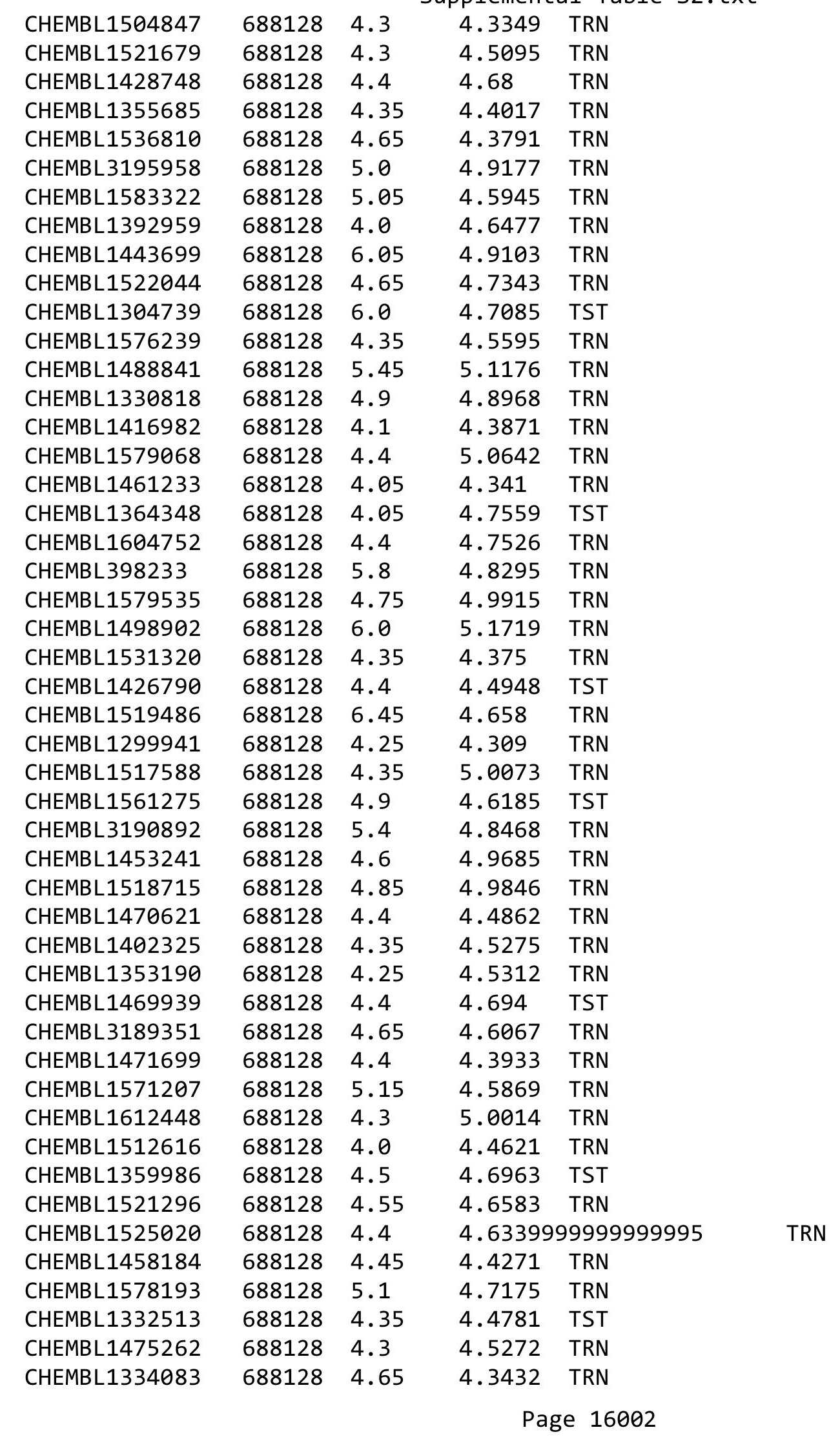




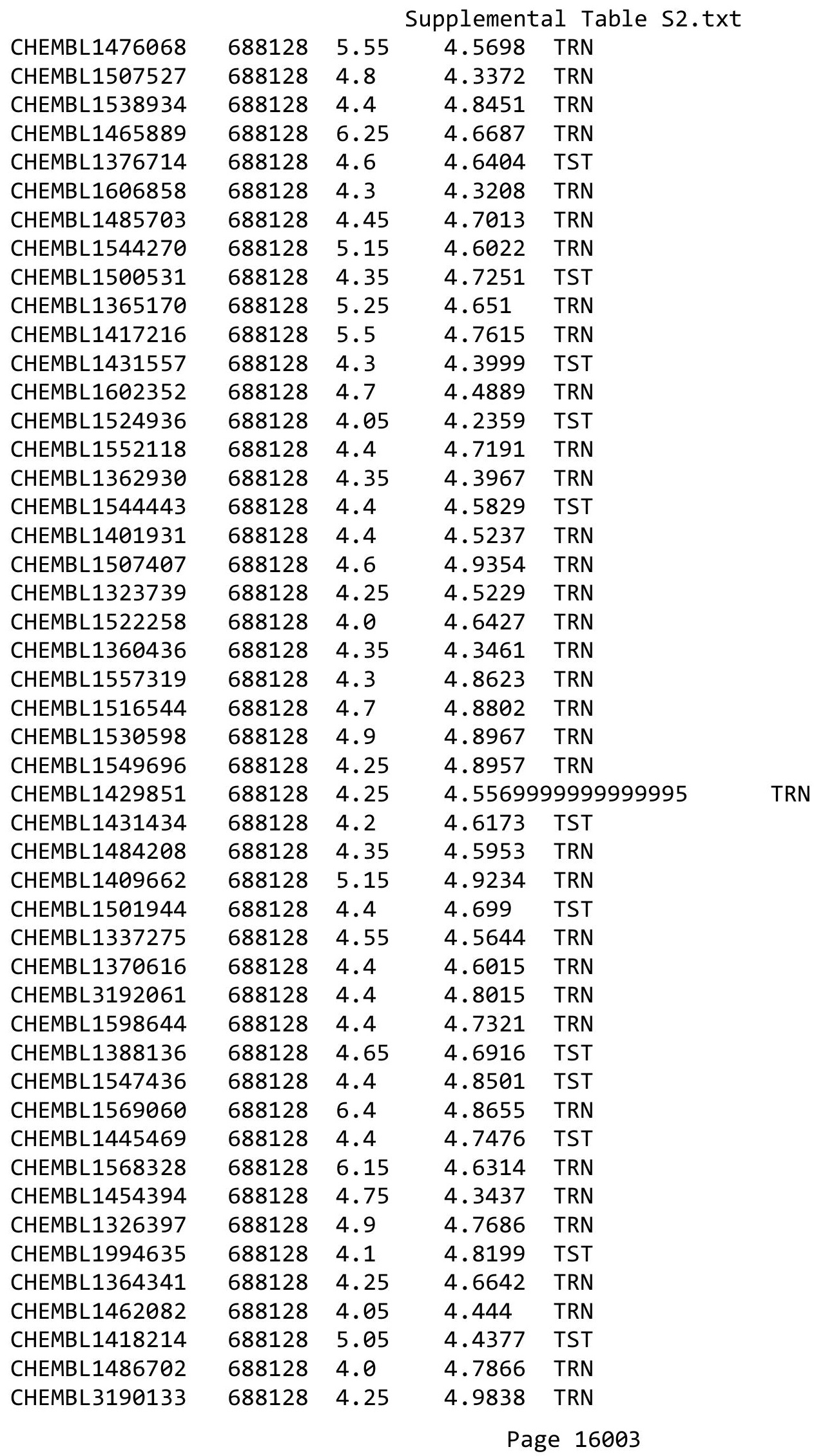




\begin{tabular}{|c|c|c|c|c|}
\hline & & & pplement & al $\mathrm{Ta}$ \\
\hline CHEMBL1494004 & 688128 & 4.4 & 4.5821 & TRN \\
\hline CHEMBL1453415 & 688128 & 5.45 & 5.376 & TRN \\
\hline CHEMBL1607719 & 688128 & 4.55 & 4.4818 & TRN \\
\hline CHEMBL1405494 & 688128 & 4.4 & 4.6337 & TST \\
\hline CHEMBL1533966 & 688128 & 4.5 & 4.4743 & TRN \\
\hline CHEMBL1324698 & 688128 & 4.75 & 4.4419 & TRN \\
\hline CHEMBL1563301 & 688128 & 4.3 & 4.8578 & TST \\
\hline CHEMBL1407126 & 688128 & 4.55 & 4.2903 & TRN \\
\hline CHEMBL1609660 & 688128 & 4.05 & 4.5216 & TRN \\
\hline CHEMBL1534621 & 688128 & 4.15 & 4.5614 & TST \\
\hline CHEMBL1521008 & 688128 & 4.5 & 4.7984 & TST \\
\hline CHEMBL1501265 & 688128 & 4.7 & 4.4918 & TRN \\
\hline CHEMBL1455108 & 688128 & 4.35 & 4.6433 & TST \\
\hline CHEMBL1332208 & 688128 & 4.25 & 4.3056 & TRN \\
\hline CHEMBL1514269 & 688128 & 4.35 & 4.6093 & TRN \\
\hline CHEMBL1612502 & 688128 & 5.0 & 5.211 & TRN \\
\hline CHEMBL1613403 & 688128 & 5.4 & 4.5144 & TRN \\
\hline CHEMBL1469759 & 688128 & 4.55 & 4.5192 & TST \\
\hline CHEMBL1383273 & 688128 & 4.5 & 4.7269 & TRN \\
\hline CHEMBL1366760 & 688128 & 4.25 & 4.5692 & TRN \\
\hline CHEMBL1599409 & 688128 & 4.6 & 4.6376 & TRN \\
\hline CHEMBL1429895 & 688128 & 4.0 & 4.3033 & TRN \\
\hline CHEMBL1427899 & 688128 & 4.35 & 4.5491 & TRN \\
\hline CHEMBL1302039 & 688128 & 4.35 & 4.7431 & TRN \\
\hline CHEMBL1390463 & 688128 & 4.0 & 4.3816 & TRN \\
\hline CHEMBL1525562 & 688128 & 4.45 & 4.5047 & TRN \\
\hline CHEMBL1578082 & 688128 & 4.25 & 4.9039 & TRN \\
\hline CHEMBL1426071 & 688128 & 4.3 & 4.317 & TRN \\
\hline CHEMBL3197450 & 688128 & 4.25 & 4.676 & TRN \\
\hline CHEMBL1344396 & 688128 & 4.65 & 4.4103 & TRN \\
\hline CHEMBL1432927 & 688128 & 4.05 & 4.5653 & TST \\
\hline CHEMBL1487985 & 688128 & 4.45 & 4.4304 & TST \\
\hline CHEMBL1421472 & 688128 & 4.9 & 4.4126 & TST \\
\hline CHEMBL1431543 & 688128 & 4.5 & 4.7814 & TRN \\
\hline CHEMBL1329222 & 688128 & 4.95 & 4.3694 & TRN \\
\hline CHEMBL1547401 & 688128 & 4.75 & 4.4558 & TRN \\
\hline CHEMBL1453652 & 688128 & 4.35 & 4.5324 & TST \\
\hline CHEMBL1518653 & 688128 & 4.3 & 4.4728 & TRN \\
\hline CHEMBL1508233 & 688128 & 4.45 & 4.4422 & TRN \\
\hline CHEMBL1541519 & 688128 & 5.0 & 4.8869 & TST \\
\hline CHEMBL1390412 & 688128 & 4.35 & 4.5697 & TRN \\
\hline CHEMBL1606385 & 688128 & 4.3 & 4.5051 & TRN \\
\hline CHEMBL1344131 & 688128 & 4.25 & 4.7435 & TRN \\
\hline CHEMBL 2000888 & 688128 & 5.05 & 4.766 & TRN \\
\hline CHEMBL1469894 & 688128 & 6.15 & 4.6142 & TST \\
\hline CHEMBL1481651 & 688128 & 4.75 & 4.348 & TRN \\
\hline CHEMBL1354918 & 688128 & 4.9 & 4.6342 & TRN \\
\hline CHEMBL1416365 & 688128 & 4.5 & 4.4119 & TRN \\
\hline
\end{tabular}




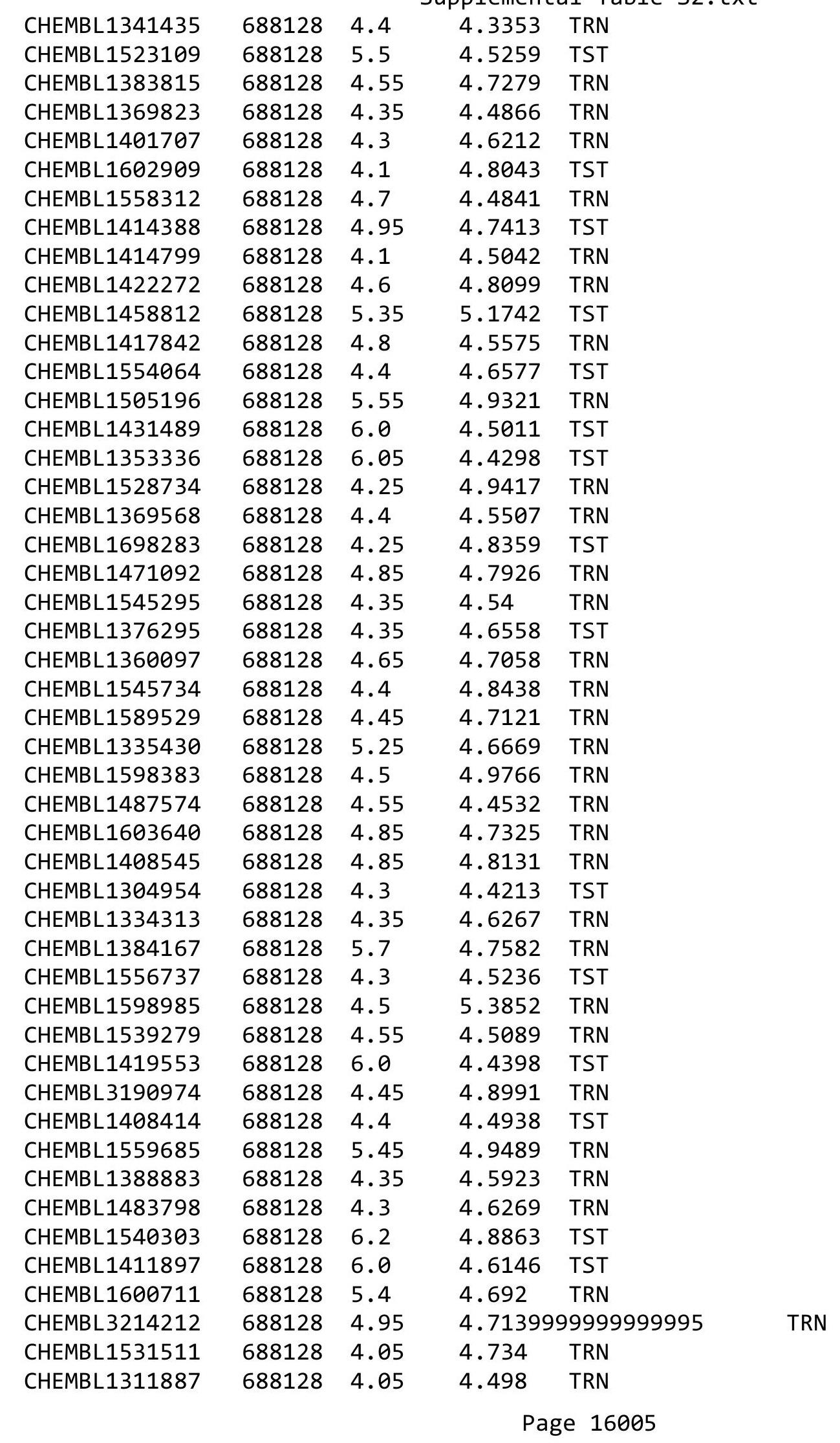




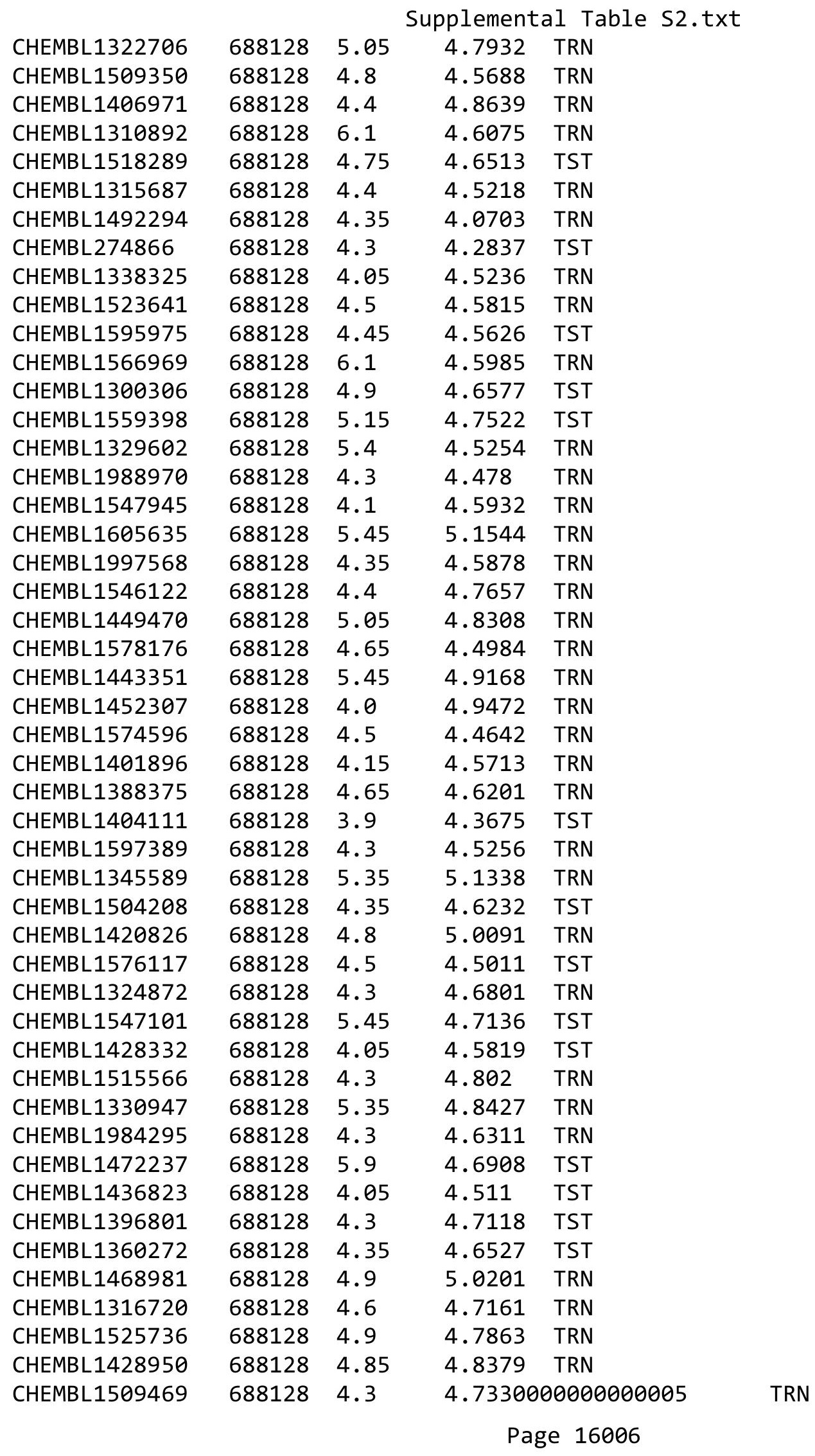




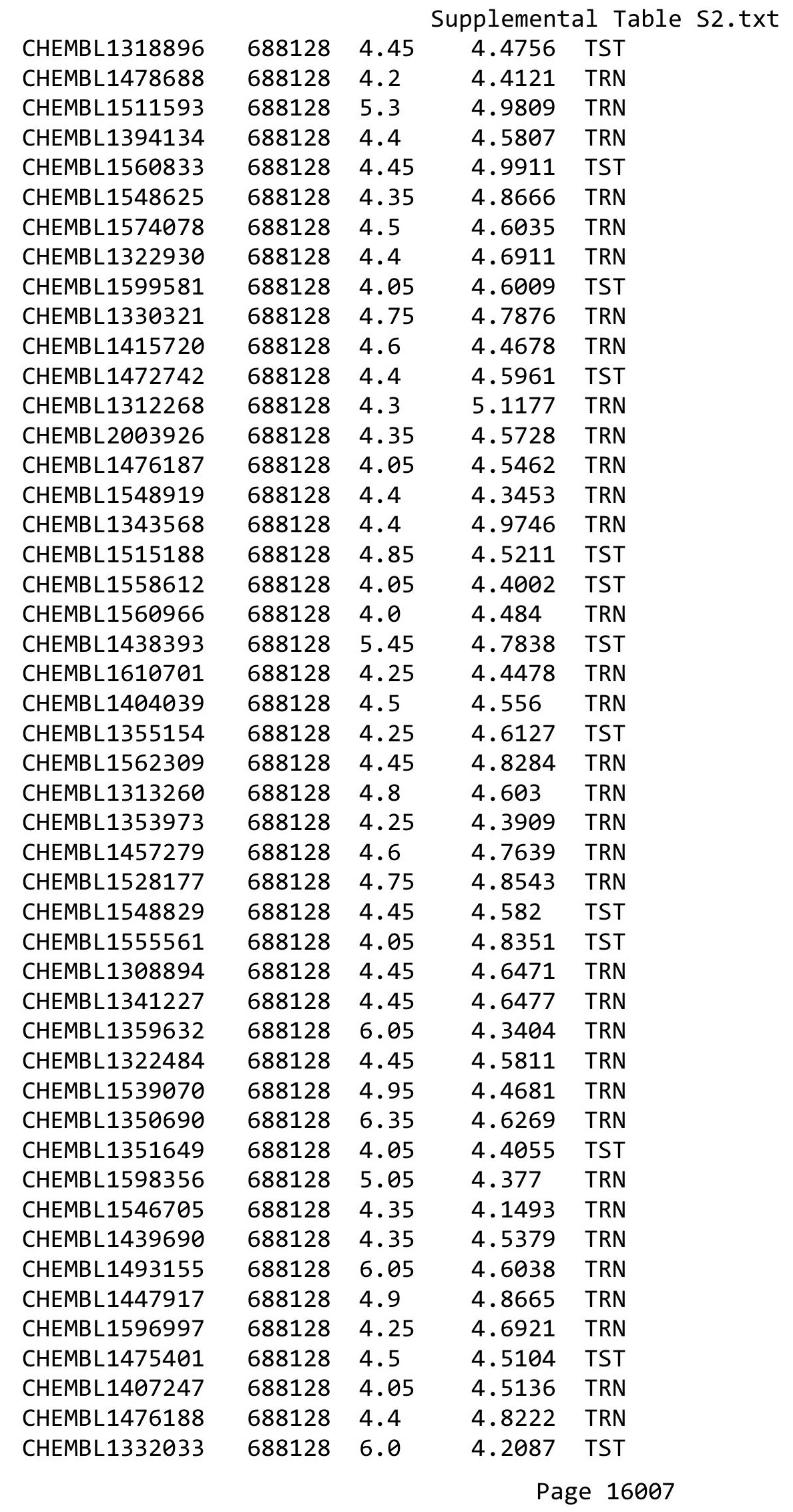




\begin{tabular}{|c|c|c|c|c|}
\hline & & & upplemen & al $\mathrm{T}$ \\
\hline CHEMBL1475488 & 688128 & 4.5 & 4.8349 & TRN \\
\hline CHEMBL1445820 & 688128 & 6.4 & 4.9863 & TRN \\
\hline CHEMBL1471370 & 688128 & 4.35 & 4.3258 & TRN \\
\hline CHEMBL1557622 & 688128 & 6.95 & 5.7282 & TRN \\
\hline CHEMBL1586970 & 688128 & 4.4 & 4.4677 & TRN \\
\hline CHEMBL1510969 & 688128 & 4.3 & 4.7374 & TRN \\
\hline CHEMBL1572275 & 688128 & 4.4 & 4.5037 & TRN \\
\hline CHEMBL1308531 & 688128 & 4.4 & 4.8664 & TRN \\
\hline CHEMBL1477769 & 688128 & 5.95 & 5.2294 & TRN \\
\hline CHEMBL1475294 & 688128 & 4.6 & 4.7217 & TRN \\
\hline CHEMBL1421756 & 688128 & 5.05 & 4.8048 & TRN \\
\hline CHEMBL1309078 & 688128 & 4.45 & 4.5151 & TST \\
\hline CHEMBL1485276 & 688128 & 4.25 & 4.4107 & TRN \\
\hline CHEMBL1307669 & 688128 & 4.6 & 4.6637 & TRN \\
\hline CHEMBL1313065 & 688128 & 4.4 & 4.8359 & TRN \\
\hline CHEMBL1446668 & 688128 & 5.85 & 4.9343 & TRN \\
\hline CHEMBL1533166 & 688128 & 4.3 & 4.4099 & TRN \\
\hline CHEMBL1527639 & 688128 & 4.35 & 4.7928 & TRN \\
\hline CHEMBL1525053 & 688128 & 5.75 & 4.7004 & TRN \\
\hline CHEMBL3212929 & 688128 & 4.0 & 4.8763 & TST \\
\hline CHEMBL1375943 & 688128 & 4.3 & 4.6664 & TRN \\
\hline CHEMBL1437829 & 688128 & 5.5 & 4.6648 & TRN \\
\hline CHEMBL1515179 & 688128 & 4.5 & 4.5158 & TRN \\
\hline CHEMBL1469468 & 688128 & 4.35 & 4.6863 & TRN \\
\hline CHEMBL1560307 & 688128 & 4.5 & 4.6671 & TST \\
\hline CHEMBL1361276 & 688128 & 6.05 & 4.6702 & TST \\
\hline CHEMBL1514191 & 688128 & 4.0 & 4.5393 & TST \\
\hline CHEMBL1371085 & 688128 & 4.35 & 4.5547 & TRN \\
\hline CHEMBL549640 & 688128 & 4.3 & 4.7925 & TRN \\
\hline CHEMBL1383486 & 688128 & 4.05 & 4.5482 & TRN \\
\hline CHEMBL1467558 & 688128 & 4.25 & 4.4154 & TRN \\
\hline CHEMBL3191721 & 688128 & 4.35 & 4.2944 & TRN \\
\hline CHEMBL1550771 & 688128 & 4.3 & 4.4302 & TST \\
\hline CHEMBL1387171 & 688128 & 4.95 & 4.6926 & TRN \\
\hline CHEMBL1478341 & 688128 & 4.2 & 4.9102 & TST \\
\hline CHEMBL1375334 & 688128 & 4.3 & 5.1949 & TRN \\
\hline CHEMBL1307206 & 688128 & 5.05 & 4.5421 & TRN \\
\hline CHEMBL1489775 & 688128 & 4.0 & 4.6176 & TRN \\
\hline CHEMBL1506107 & 688128 & 4.0 & 4.5843 & TST \\
\hline CHEMBL1606062 & 688128 & 5.35 & 4.6044 & TRN \\
\hline CHEMBL1561938 & 688128 & 4.35 & 4.9262 & TST \\
\hline CHEMBL1535698 & 688128 & 4.3 & 4.5491 & TRN \\
\hline CHEMBL1337860 & 688128 & 5.05 & 4.8493 & TRN \\
\hline CHEMBL1457445 & 688128 & 4.35 & 4.6223 & TRN \\
\hline CHEMBL1485932 & 688128 & 4.05 & 4.5173 & TRN \\
\hline CHEMBL1421320 & 688128 & 4.35 & 4.3204 & TRN \\
\hline CHEMBL1343037 & 688128 & 5.15 & 4.5957 & TRN \\
\hline CHEMBL1385413 & 688128 & 6.0 & 5.4007 & TRN \\
\hline
\end{tabular}




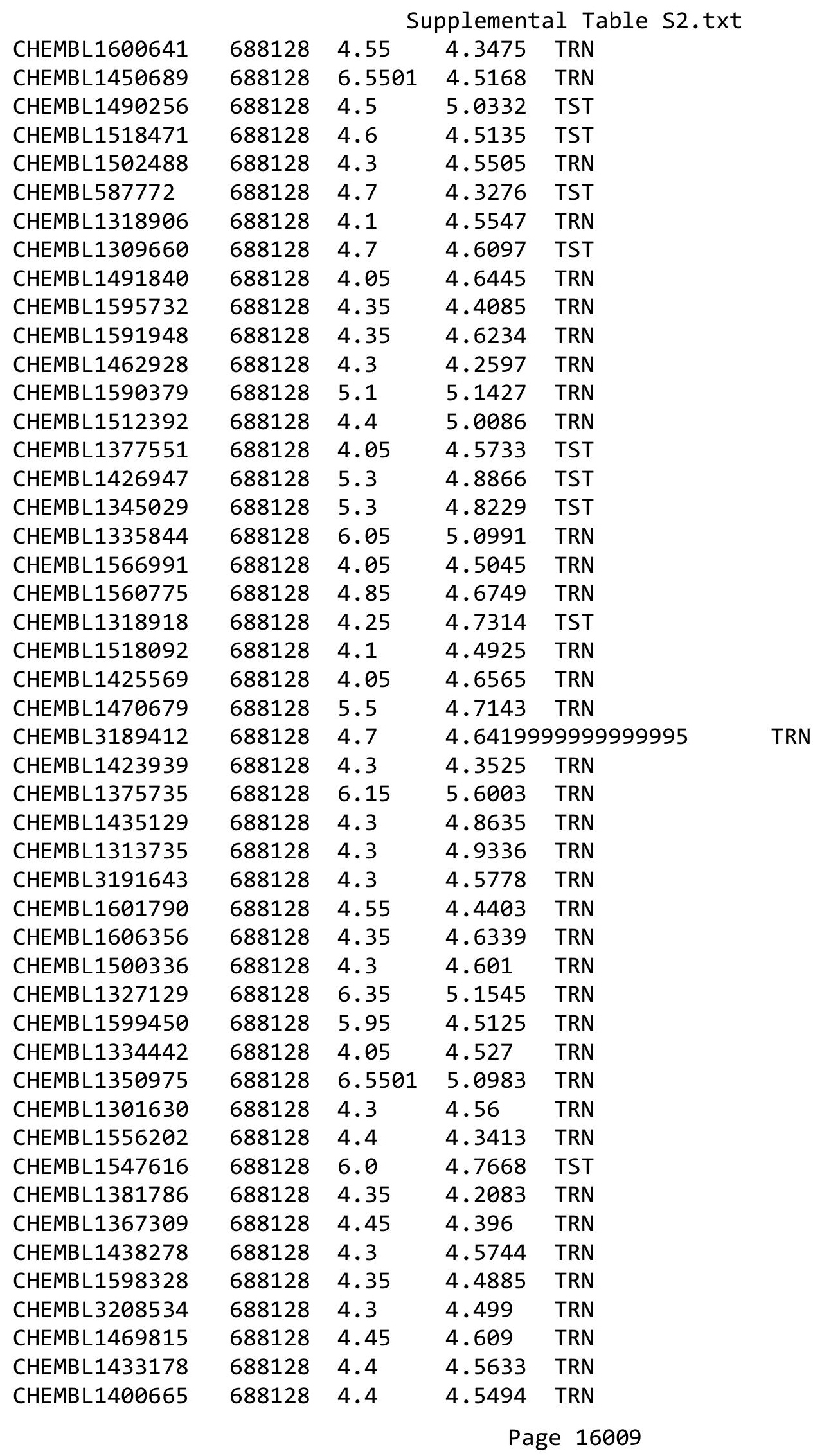




\begin{tabular}{|c|c|c|c|c|c|}
\hline & & & & & \\
\hline CHEMBL1485894 & 688128 & 4.3 & 4.5315 & TRN & \\
\hline CHEMBL1348306 & 688128 & 4.6 & 4.7386 & TRN & \\
\hline CHEMBL1358144 & 688128 & 4.4 & 4.426 & TRN & \\
\hline CHEMBL1602168 & 688128 & 4.85 & 4.4934 & TRN & \\
\hline CHEMBL1509622 & 688128 & 4.4 & $4.7410 e$ & 20000000005 & TRN \\
\hline CHEMBL1496187 & 688128 & 4.55 & 4.5842 & TRN & \\
\hline CHEMBL1301673 & 688128 & 5.05 & 5.2848 & TRN & \\
\hline CHEMBL1964614 & 688128 & 4.3 & 5.0742 & TST & \\
\hline CHEMBL1559785 & 688128 & 4.4 & 4.5951 & TST & \\
\hline CHEMBL1522190 & 688128 & 4.35 & 4.4479 & TRN & \\
\hline CHEMBL1515574 & 688128 & 6.05 & 4.4143 & TRN & \\
\hline CHEMBL1478731 & 688128 & 4.75 & 5.0172 & TRN & \\
\hline CHEMBL1305087 & 688128 & 4.5 & 4.7431 & TST & \\
\hline CHEMBL1529482 & 688128 & 4.65 & 4.8481 & TST & \\
\hline CHEMBL1429579 & 688128 & 4.85 & 4.4831 & TRN & \\
\hline CHEMBL1451538 & 688128 & 4.3 & 4.6147 & TRN & \\
\hline CHEMBL1446243 & 688128 & 4.7 & 4.5809 & TRN & \\
\hline CHEMBL1308002 & 688128 & 4.3 & 4.7643 & TRN & \\
\hline CHEMBL1373189 & 688128 & 4.4 & 4.8838 & TRN & \\
\hline CHEMBL1318660 & 688128 & 4.55 & 4.5983 & TST & \\
\hline CHEMBL1529239 & 688128 & 4.35 & 4.4349 & TRN & \\
\hline CHEMBL1391717 & 688128 & 4.4 & 4.7447 & TRN & \\
\hline CHEMBL1418605 & 688128 & 4.05 & 4.5957 & TRN & \\
\hline CHEMBL1360477 & 688128 & 4.4 & 4.4431 & TRN & \\
\hline CHEMBL1473669 & 688128 & 4.5 & 4.5578 & TRN & \\
\hline CHEMBL1486203 & 688128 & 5.7 & 4.7666 & TRN & \\
\hline CHEMBL3212175 & 688128 & 4.45 & 4.7997 & TST & \\
\hline CHEMBL1376711 & 688128 & 4.5 & 5.3163 & TRN & \\
\hline CHEMBL1443295 & 688128 & 4.3 & 4.6844 & TRN & \\
\hline CHEMBL1562394 & 688128 & 4.05 & 4.5651 & TRN & \\
\hline CHEMBL1452017 & 688128 & 4.3 & 4.4498 & TST & \\
\hline CHEMBL1445627 & 688128 & 5.45 & 4.4883 & TST & \\
\hline CHEMBL1400754 & 688128 & 4.6 & 4.5311 & TRN & \\
\hline CHEMBL1444166 & 688128 & 4.45 & 4.6122 & TRN & \\
\hline CHEMBL1531774 & 688128 & 4.05 & 4.3746 & TST & \\
\hline CHEMBL1347617 & 688128 & 4.55 & 4.8101 & TRN & \\
\hline CHEMBL1325425 & 688128 & 4.05 & 4.5684 & TRN & \\
\hline CHEMBL1606478 & 688128 & 4.95 & 4.5685 & TRN & \\
\hline CHEMBL1604282 & 688128 & 4.7 & 4.6956 & TRN & \\
\hline CHEMBL1415104 & 688128 & 4.35 & 4.8259 & TRN & \\
\hline CHEMBL1470748 & 688128 & 4.45 & 4.5085 & TRN & \\
\hline CHEMBL1461980 & 688128 & 4.35 & 4.7829 & TST & \\
\hline CHEMBL3195059 & 688128 & 4.25 & 4.7246 & TRN & \\
\hline CHEMBL1499815 & 688128 & 4.35 & 4.4985 & TRN & \\
\hline CHEMBL1579039 & 688128 & 4.75 & 4.6 & TRN & \\
\hline CHEMBL1372617 & 688128 & 4.35 & 4.574 & TRN & \\
\hline CHEMBL 1355544 & 688128 & 6.2 & 4.499 & TRN & \\
\hline CHEMBL1437341 & 688128 & 4.75 & 4.6266 & TRN & \\
\hline & & & & 16010 & \\
\hline
\end{tabular}




\begin{tabular}{|c|c|c|c|c|c|}
\hline \multicolumn{6}{|c|}{ Supplemental Table S2.txt } \\
\hline CHEMBL1600156 & 688128 & 5.0 & 4.496 & TRN & \\
\hline CHEMBL1567426 & 688128 & 4.3 & 4.4402 & TRN & \\
\hline CHEMBL1404806 & 688128 & 4.45 & 4.488 & TRN & \\
\hline CHEMBL1426409 & 688128 & 5.05 & 4.7173 & TRN & \\
\hline CHEMBL1458996 & 688128 & 4.05 & 4.1155 & TST & \\
\hline CHEMBL1405720 & 688128 & 4.5 & 4.4795 & TRN & \\
\hline CHEMBL1582338 & 688128 & 5.45 & 4.6392 & TST & \\
\hline CHEMBL1989662 & 688128 & 5.0 & 4.6917 & TST & \\
\hline CHEMBL1393135 & 688128 & 4.7 & 4.6511 & TRN & \\
\hline CHEMBL1468844 & 688128 & 4.4 & 4.7589 & TRN & \\
\hline CHEMBL1329416 & 688128 & 4.55 & 4.7184 & TST & \\
\hline CHEMBL1462474 & 688128 & 4.75 & 4.8094 & TRN & \\
\hline CHEMBL1387467 & 688128 & 4.4 & 4.5788 & TRN & \\
\hline CHEMBL1303069 & 688128 & 4.25 & 4.6626 & TRN & \\
\hline CHEMBL1516515 & 688128 & 5.6 & 4.6781 & TST & \\
\hline CHEMBL1559433 & 688128 & 4.35 & 4.7649 & TRN & \\
\hline CHEMBL1455912 & 688128 & 4.75 & 4.6599 & TRN & \\
\hline CHEMBL2005947 & 688128 & 4.6 & 4.38399 & 99999999995 & TRN \\
\hline CHEMBL3193260 & 688128 & 4.1 & 4.8215 & TRN & \\
\hline CHEMBL3193712 & 688128 & 4.7 & 4.5274 & TRN & \\
\hline CHEMBL1318996 & 688128 & 4.45 & 4.5075 & TRN & \\
\hline CHEMBL1306581 & 688128 & 6.1 & 4.6903 & TRN & \\
\hline CHEMBL1547032 & 688128 & 4.6 & 4.6944 & TRN & \\
\hline CHEMBL1448140 & 688128 & 4.6 & 4.337 & TRN & \\
\hline CHEMBL1403028 & 688128 & 5.5 & 5.2946 & TRN & \\
\hline CHEMBL1471610 & 688128 & 4.35 & 4.8396 & TST & \\
\hline CHEMBL1584430 & 688128 & 4.4 & 4.5729 & TRN & \\
\hline CHEMBL1313101 & 688128 & 4.8 & 4.7239 & TRN & \\
\hline CHEMBL1437177 & 688128 & 4.05 & 4.6706 & TST & \\
\hline CHEMBL1365424 & 688128 & 4.4 & 4.5086 & TRN & \\
\hline CHEMBL1532126 & 688128 & 4.6 & 4.3243 & TRN & \\
\hline CHEMBL3209634 & 688128 & 5.3 & 4.5921 & TRN & \\
\hline CHEMBL1372179 & 688128 & 4.45 & 4.8236 & TRN & \\
\hline CHEMBL1375884 & 688128 & 5.15 & 5.4972 & TRN & \\
\hline CHEMBL1542129 & 688128 & 4.25 & 4.5785 & TRN & \\
\hline CHEMBL1423649 & 688128 & 4.3 & 4.9253 & TST & \\
\hline CHEMBL1543190 & 688128 & 4.65 & 4.7982 & TRN & \\
\hline CHEMBL1427004 & 688128 & 6.5501 & 5.3906 & TRN & \\
\hline CHEMBL1438994 & 688128 & 4.55 & 4.4102 & TRN & \\
\hline CHEMBL1429524 & 688128 & 4.0 & 4.5785 & TRN & \\
\hline CHEMBL1523076 & 688128 & 4.35 & 4.8426 & TST & \\
\hline CHEMBL1420015 & 688128 & 4.35 & 4.7627 & TRN & \\
\hline CHEMBL1606662 & 688128 & 4.4 & 4.6518 & TRN & \\
\hline CHEMBL1339996 & 688128 & 4.4 & 4.3567 & TRN & \\
\hline CHEMBL1373750 & 688128 & 4.4 & 4.5828 & TST & \\
\hline CHEMBL3196799 & 688128 & 4.45 & 4.6031 & TRN & \\
\hline CHEMBL1609408 & 688128 & 5.4 & 4.8178 & TRN & \\
\hline CHEMBL1512388 & 688128 & 4.95 & 4.6667 & TRN & \\
\hline
\end{tabular}




\begin{tabular}{|c|c|c|c|c|}
\hline \multicolumn{5}{|c|}{ Supplemental Table S2.txt } \\
\hline CHEMBL1509247 & 688128 & 5.35 & 4.755 & TRN \\
\hline CHEMBL1389539 & 688128 & 5.0 & 4.6711 & TRN \\
\hline CHEMBL1536241 & 688128 & 4.7 & 4.4645 & TRN \\
\hline CHEMBL1539340 & 688128 & 4.3 & 4.442 & TRN \\
\hline CHEMBL1443645 & 688128 & 5.45 & 4.6919 & TRN \\
\hline CHEMBL1360759 & 688128 & 4.8 & 4.6418 & TRN \\
\hline CHEMBL1507251 & 688128 & 4.4 & 4.6877 & TRN \\
\hline CHEMBL1565367 & 688128 & 4.35 & 4.5976 & TRN \\
\hline CHEMBL1419669 & 688128 & 4.35 & 4.2718 & TRN \\
\hline CHEMBL1530525 & 688128 & 6.3 & 4.6207 & TRN \\
\hline CHEMBL1399435 & 688128 & 4.3 & 4.4341 & TRN \\
\hline CHEMBL1486635 & 688128 & 4.35 & 4.6717 & TST \\
\hline CHEMBL1346012 & 688128 & 5.1 & 4.3517 & TRN \\
\hline CHEMBL1985827 & 688128 & 4.4 & 4.5931 & TRN \\
\hline CHEMBL1500858 & 688128 & 4.1 & 4.3093 & TRN \\
\hline CHEMBL1595476 & 688128 & 5.1 & 4.6513 & TRN \\
\hline CHEMBL1562534 & 688128 & 4.3 & 4.5115 & TRN \\
\hline CHEMBL1566316 & 688128 & 5.25 & 4.7036 & TST \\
\hline CHEMBL1545742 & 688128 & 5.5 & 4.6216 & TST \\
\hline CHEMBL1318998 & 688128 & 4.7 & 4.9471 & TRN \\
\hline CHEMBL1443791 & 688128 & 6.5501 & 4.9103 & TRN \\
\hline CHEMBL1522027 & 688128 & 6.2 & 5.1237 & TRN \\
\hline CHEMBL1551499 & 688128 & 5.5 & 4.9142 & TRN \\
\hline CHEMBL1577550 & 688128 & 4.5 & 4.7765 & TRN \\
\hline CHEMBL1357259 & 688128 & 5.9 & 4.322 & TST \\
\hline CHEMBL1299495 & 688128 & 4.3 & 4.4507 & TRN \\
\hline CHEMBL1363353 & 688128 & 4.4 & 4.5872 & TST \\
\hline CHEMBL1378306 & 688128 & 4.45 & 4.5456 & TRN \\
\hline CHEMBL1560180 & 688128 & 5.4 & 4.6867 & TRN \\
\hline CHEMBL1470155 & 688128 & 4.4 & 4.4241 & TRN \\
\hline CHEMBL3207555 & 688128 & 4.65 & 4.5729 & TST \\
\hline CHEMBL1357122 & 688128 & 4.4 & 4.495 & TST \\
\hline CHEMBL1312014 & 688128 & 4.7 & 4.4289 & TRN \\
\hline CHEMBL3214101 & 688128 & 4.05 & 4.5405 & TRN \\
\hline CHEMBL1459449 & 688128 & 4.4 & 4.6914 & TRN \\
\hline CHEMBL1305892 & 688128 & 4.05 & 4.5838 & TRN \\
\hline CHEMBL1560406 & 688128 & 4.85 & 4.5434 & TST \\
\hline CHEMBL1571187 & 688128 & 4.35 & 4.6674 & TRN \\
\hline CHEMBL1484914 & 688128 & 4.3 & 4.2614 & TRN \\
\hline CHEMBL1371643 & 688128 & 4.55 & 4.1688 & TRN \\
\hline CHEMBL566062 & 688128 & 4.5 & 4.1924 & TRN \\
\hline CHEMBL1333169 & 688128 & 5.3 & 4.5027 & TRN \\
\hline CHEMBL1416638 & 688128 & 4.35 & 4.5079 & TRN \\
\hline CHEMBL1379380 & 688128 & 4.4 & 4.5334 & TRN \\
\hline CHEMBL1522377 & 688128 & 5.85 & 4.3492 & TRN \\
\hline CHEMBL1470160 & 688128 & 4.4 & 4.8063 & TRN \\
\hline CHEMBL1559630 & 688128 & 4.35 & 4.3377 & TRN \\
\hline CHEMBL1487927 & 688128 & 4.6 & 4.4872 & TRN \\
\hline
\end{tabular}




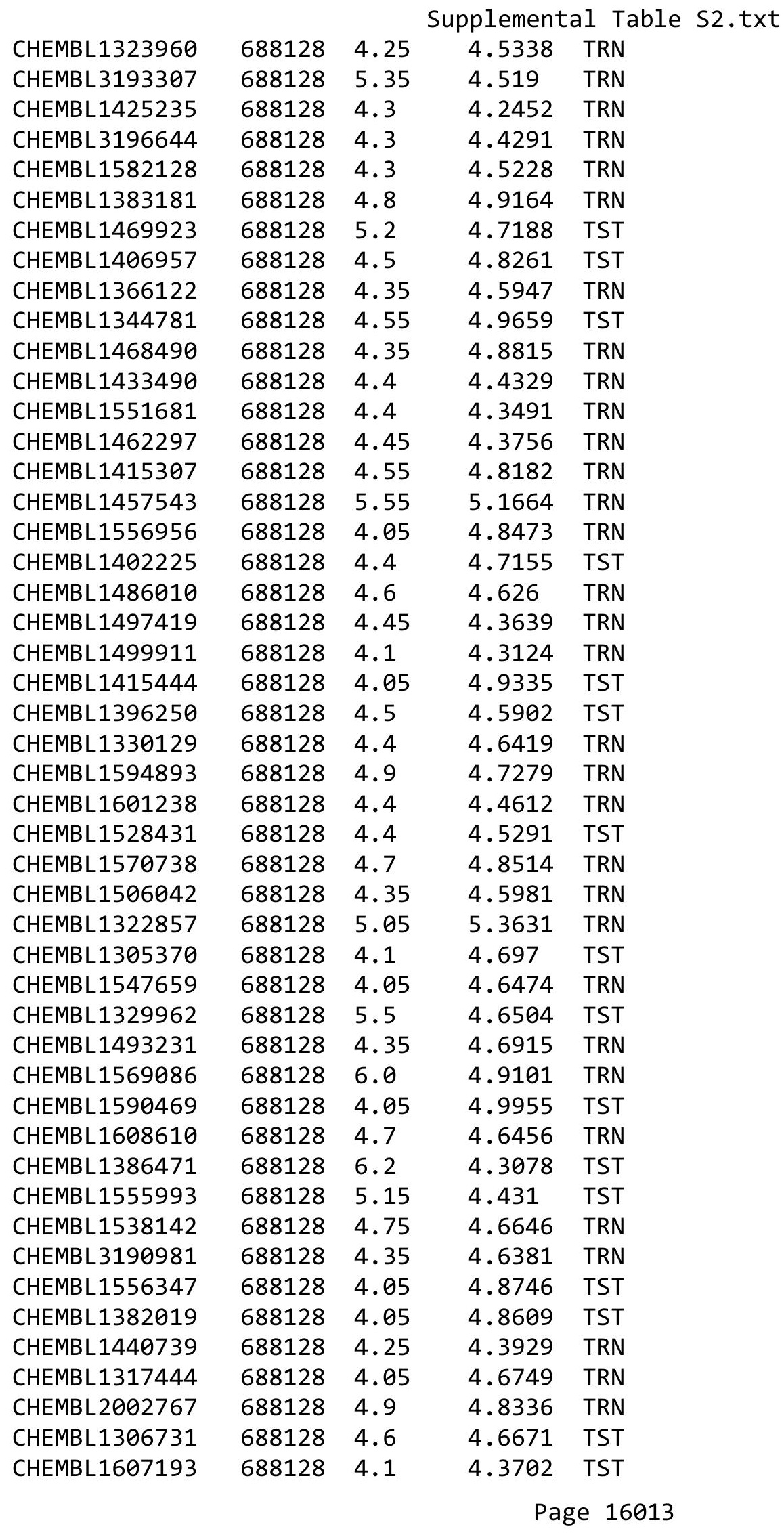




\begin{tabular}{|c|c|c|c|c|c|}
\hline \multicolumn{6}{|c|}{ Supplemental Table S2.txt } \\
\hline CHEMBL1999359 & 688128 & 5.25 & 4.7866 & TST & \\
\hline CHEMBL1480022 & 688128 & 4.05 & 4.4504 & TRN & \\
\hline CHEMBL1312229 & 688128 & 4.45 & 4.4731 & TRN & \\
\hline CHEMBL1418969 & 688128 & 4.4 & 4.5573 & TST & \\
\hline CHEMBL376426 & 688128 & 5.85 & 4.797 & TRN & \\
\hline CHEMBL1460748 & 688128 & 4.75 & 4.8956 & TST & \\
\hline CHEMBL1463978 & 688128 & 4.6 & 4.731 & TRN & \\
\hline CHEMBL1367689 & 688128 & 5.05 & 5.1223 & TRN & \\
\hline CHEMBL1608484 & 688128 & 4.4 & 4.6124 & TRN & \\
\hline CHEMBL1361097 & 688128 & 4.35 & 4.3206 & TRN & \\
\hline CHEMBL1371328 & 688128 & 4.05 & 4.533 & TRN & \\
\hline CHEMBL1344370 & 688128 & 5.05 & 5.147 & TRN & \\
\hline CHEMBL1587529 & 688128 & 5.05 & 4.4723 & TRN & \\
\hline CHEMBL1449287 & 688128 & 6.5501 & 4.3346 & TRN & \\
\hline CHEMBL1521683 & 688128 & 4.3 & 4.5806 & TST & \\
\hline CHEMBL1578850 & 688128 & 5.5 & 4.5106 & TST & \\
\hline CHEMBL1306824 & 688128 & 4.4 & 4.6243 & TRN & \\
\hline CHEMBL1442339 & 688128 & 4.4 & 4.7587 & TRN & \\
\hline CHEMBL1529853 & 688128 & 4.3 & 4.7006 & TST & \\
\hline CHEMBL1521012 & 688128 & 4.4 & 4.6131 & TST & \\
\hline CHEMBL1608799 & 688128 & 4.05 & 4.4763 & TRN & \\
\hline CHEMBL1531879 & 688128 & 4.4 & 4.69 & TST & \\
\hline CHEMBL1566623 & 688128 & 4.05 & 4.7089 & TRN & \\
\hline CHEMBL1605016 & 688128 & 4.3 & 4.5681 & TRN & \\
\hline CHEMBL1521511 & 688128 & 4.85 & 4.8228 & TRN & \\
\hline CHEMBL1576746 & 688128 & 4.35 & 5.0407 & TRN & \\
\hline CHEMBL1364896 & 688128 & 6.3 & 4.9974 & TST & \\
\hline CHEMBL1425343 & 688128 & 4.4 & 4.6603 & TRN & \\
\hline CHEMBL1341646 & 688128 & 4.3 & 4.4263 & TRN & \\
\hline CHEMBL1590757 & 688128 & 4.25 & 4.6014 & TRN & \\
\hline CHEMBL1974201 & 688128 & 4.6 & 4.7085 & TRN & \\
\hline CHEMBL1314144 & 688128 & 4.7 & 4.5017 & TRN & \\
\hline CHEMBL1596762 & 688128 & 4.0 & 4.6071 & TRN & \\
\hline CHEMBL1323873 & 688128 & 4.25 & 4.8444 & TST & \\
\hline CHEMBL3198152 & 688128 & 4.3 & 4.5189 & TST & \\
\hline CHEMBL1559392 & 688128 & 4.0 & 4.2049 & TRN & \\
\hline CHEMBL1516043 & 688128 & 4.05 & 4.5077 & TRN & \\
\hline CHEMBL1524720 & 688128 & 4.85 & 4.7523 & TST & \\
\hline CHEMBL1490101 & 688128 & 4.35 & 4.6972 & TRN & \\
\hline CHEMBL1520677 & 688128 & 4.35 & 4.7691 & TRN & \\
\hline CHEMBL1511683 & 688128 & 4.3 & 4.6702 & TRN & \\
\hline CHEMBL514988 & 688128 & 4.65 & 4.7687 & TRN & \\
\hline CHEMBL1394865 & 688128 & 4.3 & 4.8877 & TRN & \\
\hline CHEMBL1322515 & 688128 & 4.35 & 4.80399 & 9999999999 & TRN \\
\hline CHEMBL1410837 & 688128 & 4.6 & 4.4803 & TRN & \\
\hline CHEMBL1306176 & 688128 & 5.2 & 4.6743 & TRN & \\
\hline CHEMBL1577068 & 688128 & 4.45 & 4.6416 & TRN & \\
\hline CHEMBL3191122 & 688128 & 4.05 & 4.7592 & TST & \\
\hline
\end{tabular}




\begin{tabular}{|c|c|c|c|c|}
\hline \multicolumn{5}{|c|}{ Supplemental Table S2.txt } \\
\hline CHEMBL1598089 & 688128 & 5.25 & 4.7617 & TRN \\
\hline CHEMBL1481067 & 688128 & 4.45 & 4.2803 & TRN \\
\hline CHEMBL1515926 & 688128 & 4.35 & 4.7883 & TRN \\
\hline CHEMBL1355885 & 688128 & 4.25 & 4.6961 & TST \\
\hline CHEMBL1332502 & 688128 & 4.4 & 4.3789 & TRN \\
\hline CHEMBL1534006 & 688128 & 4.8 & 4.6466 & TRN \\
\hline CHEMBL3192090 & 688128 & 6.2 & 4.5927 & TST \\
\hline CHEMBL1376022 & 688128 & 4.35 & 4.4747 & TRN \\
\hline CHEMBL1405808 & 688128 & 4.4 & 4.8999 & TRN \\
\hline CHEMBL1487118 & 688128 & 4.35 & 4.6277 & TRN \\
\hline CHEMBL1457258 & 688128 & 4.0 & 4.6443 & TST \\
\hline CHEMBL229760 & 688128 & 4.0 & 4.7477 & TST \\
\hline CHEMBL1413459 & 688128 & 4.25 & 4.3242 & TRN \\
\hline CHEMBL1533444 & 688128 & 5.4 & 5.0865 & TRN \\
\hline CHEMBL1603684 & 688128 & 4.4 & 4.4369 & TST \\
\hline CHEMBL1457955 & 688128 & 4.3 & 4.7582 & TRN \\
\hline CHEMBL1435338 & 688128 & 4.5 & 4.7129 & TRN \\
\hline CHEMBL1489193 & 688128 & 6.6499 & 4.5029 & TRN \\
\hline CHEMBL1576687 & 688128 & 5.05 & 4.6056 & TRN \\
\hline CHEMBL1504050 & 688128 & 4.4 & 4.378 & TRN \\
\hline CHEMBL1494138 & 688128 & 4.0 & 4.6519 & TRN \\
\hline CHEMBL1494390 & 688128 & 4.55 & 5.1064 & TRN \\
\hline CHEMBL1272096 & 688128 & 4.4 & 4.3298 & TRN \\
\hline CHEMBL1473686 & 688128 & 5.3 & 4.7884 & TRN \\
\hline CHEMBL1594883 & 688128 & 4.05 & 4.8909 & TRN \\
\hline CHEMBL1302833 & 688128 & 4.3 & 4.5276 & TRN \\
\hline CHEMBL1396397 & 688128 & 5.4 & 4.6425 & TST \\
\hline CHEMBL1561027 & 688128 & 4.35 & 4.3037 & TRN \\
\hline CHEMBL1469017 & 688128 & 4.45 & 4.671 & TST \\
\hline CHEMBL1362315 & 688128 & 4.45 & 4.5835 & TRN \\
\hline CHEMBL1300569 & 688128 & 4.35 & 4.5783 & TRN \\
\hline CHEMBL3190665 & 688128 & 4.3 & 4.655 & TRN \\
\hline CHEMBL1407971 & 688128 & 4.3 & 4.8132 & TRN \\
\hline CHEMBL1338179 & 688128 & 4.8 & 4.7362 & TRN \\
\hline CHEMBL1327334 & 688128 & 4.45 & 4.5391 & TRN \\
\hline CHEMBL1468730 & 688128 & 4.65 & 4.768 & TRN \\
\hline CHEMBL1563983 & 688128 & 4.55 & 4.7227 & TRN \\
\hline CHEMBL1517425 & 688128 & 4.35 & 5.0453 & TST \\
\hline CHEMBL3197427 & 688128 & 4.35 & 4.5367 & TRN \\
\hline CHEMBL1565606 & 688128 & 5.15 & 4.7199 & TST \\
\hline CHEMBL1371945 & 688128 & 4.6 & 4.6706 & TRN \\
\hline CHEMBL1382792 & 688128 & 4.15 & 4.8377 & TRN \\
\hline CHEMBL1411414 & 688128 & 4.45 & 4.599 & TST \\
\hline CHEMBL1525346 & 688128 & 5.1 & 4.3538 & TST \\
\hline CHEMBL1348837 & 688128 & 4.35 & 5.0583 & TRN \\
\hline CHEMBL1422072 & 688128 & 4.4 & 4.4803 & TRN \\
\hline CHEMBL1378376 & 688128 & 4.45 & 4.7932 & TRN \\
\hline CHEMBL1538523 & 688128 & 4.65 & 4.5112 & TRN \\
\hline
\end{tabular}




\begin{tabular}{|c|c|c|c|c|}
\hline \multicolumn{5}{|c|}{ Supplemental Table S2.txt } \\
\hline CHEMBL1585295 & 688128 & 4.6 & 4.7208 & TRN \\
\hline CHEMBL3209215 & 688128 & 4.9 & 4.6757 & TRN \\
\hline CHEMBL1557702 & 688128 & 4.65 & 4.4754 & TST \\
\hline CHEMBL1519279 & 688128 & 4.4 & 4.5723 & TRN \\
\hline CHEMBL1509027 & 688128 & 4.35 & 4.5804 & TRN \\
\hline CHEMBL1306125 & 688128 & 4.3 & 4.5439 & TRN \\
\hline CHEMBL1569496 & 688128 & 5.3 & 4.5999 & TST \\
\hline CHEMBL1503793 & 688128 & 5.15 & 4.8855 & TRN \\
\hline CHEMBL1312667 & 688128 & 4.5 & 4.356 & TRN \\
\hline CHEMBL1580966 & 688128 & 4.8 & 4.3018 & TRN \\
\hline CHEMBL1461574 & 688128 & 6.05 & 4.6678 & TRN \\
\hline CHEMBL1441405 & 688128 & 4.05 & 4.3741 & TST \\
\hline CHEMBL1491822 & 688128 & 5.0 & 4.8269 & TRN \\
\hline CHEMBL1311399 & 688128 & 5.1 & 4.2637 & TRN \\
\hline CHEMBL1309769 & 688128 & 4.3 & 4.4832 & TRN \\
\hline CHEMBL1610321 & 688128 & 4.25 & 4.5811 & TST \\
\hline CHEMBL1477661 & 688128 & 4.4 & 4.4685 & TRN \\
\hline CHEMBL1306153 & 688128 & 4.05 & 4.5571 & TST \\
\hline CHEMBL1588255 & 688128 & 4.35 & 5.2499 & TRN \\
\hline CHEMBL1325877 & 688128 & 6.45 & 4.9931 & TST \\
\hline CHEMBL1504634 & 688128 & 4.35 & 4.7037 & TST \\
\hline CHEMBL3197929 & 688128 & 6.9 & 4.6714 & TST \\
\hline CHEMBL1352791 & 688128 & 4.05 & 4.5614 & TRN \\
\hline CHEMBL1376392 & 688128 & 5.5 & 4.8635 & TRN \\
\hline CHEMBL1562639 & 688128 & 4.6 & 4.6609 & TRN \\
\hline CHEMBL1342209 & 688128 & 4.45 & 4.4296 & TST \\
\hline CHEMBL1309509 & 688128 & 4.35 & 4.5975 & TRN \\
\hline CHEMBL1491717 & 688128 & 6.15 & 5.374 & TRN \\
\hline CHEMBL1489517 & 688128 & 4.05 & 4.3369 & TST \\
\hline CHEMBL1559010 & 688128 & 4.4 & 4.8812 & TST \\
\hline CHEMBL1426404 & 688128 & 4.3 & 4.7811 & TST \\
\hline CHEMBL1445748 & 688128 & 5.55 & 4.43 & TRN \\
\hline CHEMBL 3198443 & 688128 & 4.4 & 4.5477 & TRN \\
\hline CHEMBL1607098 & 688128 & 4.65 & 4.7971 & TRN \\
\hline CHEMBL1585390 & 688128 & 6.35 & 5.6765 & TRN \\
\hline CHEMBL1338058 & 688128 & 4.4 & 4.4081 & TRN \\
\hline CHEMBL1438700 & 688128 & 4.45 & 4.7886 & TRN \\
\hline CHEMBL1391782 & 688128 & 5.8 & 4.6125 & TST \\
\hline CHEMBL1381465 & 688128 & 4.3 & 4.4747 & TRN \\
\hline CHEMBL1432163 & 688128 & 5.35 & 4.7816 & TRN \\
\hline CHEMBL1429878 & 688128 & 4.3 & 4.3604 & TRN \\
\hline CHEMBL1327650 & 688128 & 4.8 & 4.8442 & TST \\
\hline CHEMBL1334564 & 688128 & 4.35 & 4.2976 & TRN \\
\hline CHEMBL1448475 & 688128 & 4.4 & 4.6559 & TRN \\
\hline CHEMBL1402899 & 688128 & 5.05 & 4.4993 & TRN \\
\hline CHEMBL1360031 & 688128 & 4.4 & 4.7805 & TST \\
\hline CHEMBL1458889 & 688128 & 4.35 & 4.5181 & TRN \\
\hline CHEMBL1522500 & 688128 & 5.2 & 4.5566 & TRN \\
\hline
\end{tabular}




\begin{tabular}{|c|c|c|c|c|c|}
\hline \multirow{2}{*}{ CHEMBL1453897 } & \multirow{2}{*}{688128} & \\
\hline & & 4.7 & 4.7507 & TRN & \\
\hline CHEMBL1507891 & 688128 & 4.3 & 4.5845 & TRN & \\
\hline CHEMBL1497777 & 688128 & 4.05 & 4.7785 & TST & \\
\hline CHEMBL1305182 & 688128 & 5.1 & 4.7607 & TST & \\
\hline CHEMBL1586334 & 688128 & 6.1 & 4.777 & TST & \\
\hline CHEMBL1492739 & 688128 & 5.4 & 4.2438 & TRN & \\
\hline CHEMBL1575062 & 688128 & 4.25 & \multicolumn{2}{|c|}{4.5360000000000005} & TRN \\
\hline CHEMBL1444334 & 688128 & 4.5 & 4.7019 & TRN & \\
\hline CHEMBL3196569 & 688128 & 5.85 & 4.4475 & TST & \\
\hline CHEMBL1351927 & 688128 & 4.45 & 4.276 & TRN & \\
\hline CHEMBL1382494 & 688128 & 4.5 & 4.7751 & TRN & \\
\hline CHEMBL1536616 & 688128 & 4.35 & 4.4026 & TRN & \\
\hline CHEMBL1333601 & 688128 & 4.05 & 4.606 & TST & \\
\hline CHEMBL1378125 & 688128 & 4.35 & 4.4163 & TRN & \\
\hline CHEMBL1570603 & 688128 & 4.3 & 4.5054 & TRN & \\
\hline CHEMBL1599729 & 688128 & 4.35 & 4.4321 & TRN & \\
\hline CHEMBL1349676 & 688128 & 4.3 & 4.62 & TRN & \\
\hline CHEMBL1396708 & 688128 & 4.0 & 4.8415 & TRN & \\
\hline CHEMBL1310308 & 688128 & 4.45 & 4.1471 & TRN & \\
\hline CHEMBL1373347 & 688128 & 4.8 & 4.6867 & TRN & \\
\hline CHEMBL1419223 & 688128 & 4.7 & 4.75 & TRN & \\
\hline CHEMBL1371680 & 688128 & 5.3 & 4.3786 & TST & \\
\hline CHEMBL1500045 & 688128 & 4.4 & 4.3114 & TRN & \\
\hline CHEMBL1461678 & 688128 & 4.25 & 4.7382 & TRN & \\
\hline CHEMBL449690 & 688128 & 4.45 & 4.8694 & TST & \\
\hline CHEMBL1514795 & 688128 & 5.0 & 4.7245 & TRN & \\
\hline CHEMBL1582064 & 688128 & 4.3 & 4.8625 & TRN & \\
\hline CHEMBL1331613 & 688128 & 4.3 & 4.6551 & TRN & \\
\hline CHEMBL1302306 & 688128 & 6.0 & 4.6709 & TRN & \\
\hline CHEMBL1367492 & 688128 & 5.65 & 4.4852 & TST & \\
\hline CHEMBL1351880 & 688128 & 4.2 & 4.5752 & TRN & \\
\hline CHEMBL1576457 & 688128 & 4.6 & 4.5711 & TRN & \\
\hline CHEMBL1599574 & 688128 & 4.6 & 4.5457 & TRN & \\
\hline CHEMBL1354552 & 688128 & 4.45 & 4.7877 & TRN & \\
\hline CHEMBL1505898 & 688128 & 4.4 & 4.7564 & TST & \\
\hline CHEMBL1520214 & 688128 & 6.25 & 5.8226 & TRN & \\
\hline CHEMBL1432636 & 688128 & 4.45 & 4.6753 & TST & \\
\hline CHEMBL3189714 & 688128 & 4.45 & 5.3011 & TRN & \\
\hline CHEMBL3199292 & 688128 & 4.6 & 4.322 & TRN & \\
\hline CHEMBL1537814 & 688128 & 4.05 & 4.6896 & TRN & \\
\hline CHEMBL1597375 & 688128 & 4.5 & 4.7821 & TRN & \\
\hline CHEMBL1605870 & 688128 & 4.85 & 4.45100 & 0000000005 & TRN \\
\hline CHEMBL1387578 & 688128 & 4.45 & 4.5673 & TRN & \\
\hline CHEMBL1543839 & 688128 & 5.15 & 5.312 & TRN & \\
\hline CHEMBL1509021 & 688128 & 4.35 & 4.6256 & TST & \\
\hline CHEMBL1439180 & 688128 & 4.95 & 4.8776 & TRN & \\
\hline CHEMBL1607306 & 688128 & 4.5 & 4.9479 & TST & \\
\hline \multirow[t]{2}{*}{ CHEMBL1544664 } & 688128 & 5.4 & 4.9444 & TRN & \\
\hline & & \multicolumn{4}{|c|}{ Page 16017} \\
\hline
\end{tabular}




\begin{tabular}{|c|c|c|c|c|c|}
\hline \multicolumn{6}{|c|}{ Supplemental Table S2.txt } \\
\hline CHEMBL1450596 & 688128 & 4.05 & 4.3634 & TST & \\
\hline CHEMBL3208046 & 688128 & 5.05 & 4.4794 & TRN & \\
\hline CHEMBL1411054 & 688128 & 5.4 & 4.5947 & TRN & \\
\hline CHEMBL1580994 & 688128 & 4.05 & 4.584 & TRN & \\
\hline CHEMBL1462483 & 688128 & 4.45 & 4.5842 & TRN & \\
\hline CHEMBL1423529 & 688128 & 4.35 & 4.8763 & TRN & \\
\hline CHEMBL1467442 & 688128 & 5.6 & 4.7833 & TRN & \\
\hline CHEMBL1533699 & 688128 & 4.05 & 4.3887 & TRN & \\
\hline CHEMBL1338167 & 688128 & 4.35 & 4.5464 & TRN & \\
\hline CHEMBL1327137 & 688128 & 4.5 & 4.6981 & TRN & \\
\hline CHEMBL1464492 & 688128 & 4.75 & 4.641 & TRN & \\
\hline CHEMBL1419032 & 688128 & 4.25 & 4.9382 & TRN & \\
\hline CHEMBL1988133 & 688128 & 4.0 & 4.5085 & TRN & \\
\hline CHEMBL1374174 & 688128 & 4.35 & 4.4786 & TRN & \\
\hline CHEMBL1533532 & 688128 & 4.05 & 4.5092 & TRN & \\
\hline CHEMBL1560364 & 688128 & 4.25 & 4.5015 & TRN & \\
\hline CHEMBL1550298 & 688128 & 4.45 & 4.5309 & TRN & \\
\hline CHEMBL1302791 & 688128 & 4.85 & 4.66100 & 00000000005 & TRN \\
\hline CHEMBL1303737 & 688128 & 4.3 & 4.806 & TST & \\
\hline CHEMBL1622566 & 688128 & 4.95 & 5.1145 & TRN & \\
\hline CHEMBL1471107 & 688128 & 4.35 & 4.773 & TRN & \\
\hline CHEMBL1502318 & 688128 & 4.35 & 4.2782 & TRN & \\
\hline CHEMBL3191180 & 688128 & 4.35 & 4.4808 & TRN & \\
\hline CHEMBL1323401 & 688128 & 4.05 & 4.3827 & TRN & \\
\hline CHEMBL1599127 & 688128 & 4.7 & 4.588 & TST & \\
\hline CHEMBL1327327 & 688128 & 4.05 & 4.5567 & TRN & \\
\hline CHEMBL1453501 & 688128 & 6.5 & 4.9453 & TST & \\
\hline CHEMBL1456617 & 688128 & 4.3 & 4.4648 & TST & \\
\hline CHEMBL1588003 & 688128 & 4.2 & 4.5587 & TST & \\
\hline CHEMBL1526586 & 688128 & 4.25 & 4.82600 & 00000000005 & TRN \\
\hline CHEMBL1335404 & 688128 & 4.3 & 4.5806 & TRN & \\
\hline CHEMBL1405956 & 688128 & 4.4 & 4.5709 & TST & \\
\hline CHEMBL1355972 & 688128 & 4.8 & 4.584 & TST & \\
\hline CHEMBL1389703 & 688128 & 5.45 & 4.8564 & TRN & \\
\hline CHEMBL1313979 & 688128 & 4.85 & 4.2925 & TRN & \\
\hline CHEMBL1344469 & 688128 & 5.1 & 4.5881 & TRN & \\
\hline CHEMBL1464549 & 688128 & 4.05 & 4.478 & TRN & \\
\hline CHEMBL1576329 & 688128 & 4.4 & 4.5802 & TST & \\
\hline CHEMBL1544598 & 688128 & 4.35 & 4.9159 & TST & \\
\hline CHEMBL490107 & 688128 & 4.8 & 4.8155 & TRN & \\
\hline CHEMBL1317726 & 688128 & 4.3 & 4.22199 & 99999999995 & TRN \\
\hline CHEMBL1317061 & 688128 & 4.05 & 4.5774 & TRN & \\
\hline CHEMBL1431704 & 688128 & 4.3 & 4.4627 & TST & \\
\hline CHEMBL1570209 & 688128 & 4.6 & 4.4919 & TRN & \\
\hline CHEMBL1418198 & 688128 & 4.4 & 4.7722 & TST & \\
\hline CHEMBL1350826 & 688128 & 4.1 & 4.6023 & TST & \\
\hline CHEMBL1450422 & 688128 & 5.15 & 4.997 & TRN & \\
\hline CHEMBL1457791 & 688128 & 4.05 & 4.6898 & TST & \\
\hline
\end{tabular}




\begin{tabular}{|c|c|c|c|c|c|}
\hline \multicolumn{6}{|c|}{ Supplemental Table S2.txt } \\
\hline CHEMBL1302031 & 688128 & 4.0 & 4.4695 & TRN & \\
\hline CHEMBL1563382 & 688128 & 4.55 & 4.585 & TRN & \\
\hline CHEMBL1458689 & 688128 & 5.7 & 4.8905 & TRN & \\
\hline CHEMBL1397690 & 688128 & 4.45 & 4.5471 & TST & \\
\hline CHEMBL1374699 & 688128 & 4.15 & 4.9346 & TRN & \\
\hline CHEMBL1331335 & 688128 & 4.05 & 4.3818 & TRN & \\
\hline CHEMBL1456104 & 688128 & 4.25 & 4.6513 & TRN & \\
\hline CHEMBL1331176 & 688128 & 4.6 & 4.5779 & TRN & \\
\hline CHEMBL1534310 & 688128 & 4.25 & 4.3103 & TST & \\
\hline CHEMBL1405891 & 688128 & 4.4 & 4.4077 & TRN & \\
\hline CHEMBL 3211505 & 688128 & 4.4 & 4.4395 & TST & \\
\hline CHEMBL1350065 & 688128 & 4.05 & 4.6884 & TST & \\
\hline CHEMBL1597824 & 688128 & 4.3 & 4.6346 & TRN & \\
\hline CHEMBL1313063 & 688128 & 4.75 & 4.7602 & TRN & \\
\hline CHEMBL1435493 & 688128 & 4.85 & 4.6309 & TST & \\
\hline CHEMBL1559158 & 688128 & 4.05 & 4.7707 & TRN & \\
\hline CHEMBL1412839 & 688128 & 6.35 & 4.7709 & TST & \\
\hline CHEMBL1465828 & 688128 & 4.45 & 4.711 & TST & \\
\hline CHEMBL1407234 & 688128 & 4.95 & 4.9618 & TRN & \\
\hline CHEMBL1461266 & 688128 & 4.7 & 4.6068 & TRN & \\
\hline CHEMBL1490739 & 688128 & 4.4 & 4.4559 & TRN & \\
\hline CHEMBL1612679 & 688128 & 4.1 & 4.7538 & TST & \\
\hline CHEMBL1496498 & 688128 & 4.35 & 4.8023 & TST & \\
\hline CHEMBL1316155 & 688128 & 6.0 & 4.9884 & TRN & \\
\hline CHEMBL1598773 & 688128 & 4.35 & 4.2694 & TRN & \\
\hline CHEMBL1390647 & 688128 & 5.5 & 4.8255 & TRN & \\
\hline CHEMBL1393037 & 688128 & 4.05 & 4.8099 & TST & \\
\hline CHEMBL1572129 & 688128 & 4.35 & 4.7725 & TRN & \\
\hline CHEMBL1377938 & 688128 & 4.45 & $4.5360 e$ & 00000000005 & TRN \\
\hline CHEMBL1345499 & 688128 & 4.7 & 4.62 & TRN & \\
\hline CHEMBL1424987 & 688128 & 4.45 & 4.8484 & TRN & \\
\hline CHEMBL1301888 & 688128 & 5.9 & 4.8135 & TRN & \\
\hline CHEMBL1531088 & 688128 & 4.45 & 4.5806 & TST & \\
\hline CHEMBL1464389 & 688128 & 4.7 & 4.6613 & TRN & \\
\hline CHEMBL1393654 & 688128 & 4.3 & 4.7189 & TRN & \\
\hline CHEMBL1314192 & 688128 & 5.35 & 5.0734 & TRN & \\
\hline CHEMBL1330395 & 688128 & 4.45 & 4.7996 & TST & \\
\hline CHEMBL1470573 & 688128 & 4.35 & 4.4155 & TRN & \\
\hline CHEMBL1584438 & 688128 & 4.4 & 4.6836 & TRN & \\
\hline CHEMBL1987895 & 688128 & 5.35 & 4.7057 & TRN & \\
\hline CHEMBL1496868 & 688128 & 4.4 & 4.6488 & TRN & \\
\hline CHEMBL1571852 & 688128 & 4.6 & 5.0613 & TRN & \\
\hline CHEMBL1389485 & 688128 & 5.6 & 5.263 & TRN & \\
\hline CHEMBL1444999 & 688128 & 4.85 & 4.4976 & TRN & \\
\hline CHEMBL1440796 & 688128 & 4.25 & 4.4362 & TRN & \\
\hline CHEMBL1523695 & 688128 & 4.5 & 4.5523 & TRN & \\
\hline CHEMBL 2002882 & 688128 & 4.6 & 4.5685 & TST & \\
\hline CHEMBL1589425 & 688128 & 4.75 & 4.7456 & TST & \\
\hline
\end{tabular}




\begin{tabular}{|c|c|c|c|c|c|}
\hline \multicolumn{6}{|c|}{ Supplemental Table S2.txt } \\
\hline CHEMBL1434776 & 688128 & 4.5 & 4.9312 & TRN & \\
\hline CHEMBL1490225 & 688128 & 4.65 & 4.6316 & TRN & \\
\hline CHEMBL1338821 & 688128 & 4.3 & 4.4088 & TRN & \\
\hline CHEMBL1401000 & 688128 & 5.1 & 4.4413 & TRN & \\
\hline CHEMBL 3194845 & 688128 & 4.45 & 4.7312 & TST & \\
\hline CHEMBL3197471 & 688128 & 4.35 & 4.4934 & TRN & \\
\hline CHEMBL1363264 & 688128 & 4.1 & 4.6712 & TRN & \\
\hline CHEMBL1435148 & 688128 & 4.3 & 4.5856 & TRN & \\
\hline CHEMBL1310015 & 688128 & 4.95 & 4.893 & TRN & \\
\hline CHEMBL1577118 & 688128 & 4.75 & 4.6977 & TRN & \\
\hline CHEMBL1589770 & 688128 & 4.3 & 4.6204 & TRN & \\
\hline CHEMBL1316437 & 688128 & 4.5 & 4.4547 & TRN & \\
\hline CHEMBL1335677 & 688128 & 4.9 & 4.705 & TST & \\
\hline CHEMBL1601150 & 688128 & 4.95 & 5.01 & TRN & \\
\hline CHEMBL1325950 & 688128 & 4.85 & 4.9352 & TST & \\
\hline CHEMBL1565466 & 688128 & 4.3 & 4.534 & TRN & \\
\hline CHEMBL 2001933 & 688128 & 4.7 & 4.8788 & TRN & \\
\hline CHEMBL1358527 & 688128 & 4.35 & 4.8574 & TRN & \\
\hline CHEMBL1324109 & 688128 & 4.3 & 4.6165 & TST & \\
\hline CHEMBL1428610 & 688128 & 4.35 & 4.6459 & TRN & \\
\hline CHEMBL1591869 & 688128 & 4.25 & 4.6528 & TST & \\
\hline CHEMBL1307360 & 688128 & 4.35 & 4.7395 & TRN & \\
\hline CHEMBL1484370 & 688128 & 4.45 & 4.7104 & TST & \\
\hline CHEMBL1525669 & 688128 & 4.9 & 5.0063 & TRN & \\
\hline CHEMBL1400776 & 688128 & 4.05 & 4.2601 & TRN & \\
\hline CHEMBL1342645 & 688128 & 4.35 & 4.6097 & TST & \\
\hline CHEMBL304953 & 688128 & 4.4 & 4.6767 & TRN & \\
\hline CHEMBL1378305 & 688128 & 6.0 & 4.8641 & TRN & \\
\hline CHEMBL1478733 & 688128 & 4.65 & 4.6906 & TRN & \\
\hline CHEMBL1511145 & 688128 & 4.35 & 4.2031 & TST & \\
\hline CHEMBL1385357 & 688128 & 4.4 & 4.5061 & TRN & \\
\hline CHEMBL1570051 & 688128 & 5.5 & 4.89199 & 99999999995 & TRN \\
\hline CHEMBL1562724 & 688128 & 4.35 & 4.5736 & TRN & \\
\hline CHEMBL1411008 & 688128 & 5.0 & 4.5225 & TRN & \\
\hline CHEMBL167513 & 688128 & 4.5 & 4.3361 & TRN & \\
\hline CHEMBL1499980 & 688128 & 4.6 & 4.4473 & TRN & \\
\hline CHEMBL1317919 & 688128 & 6.0 & 5.3717 & TRN & \\
\hline CHEMBL1605306 & 688128 & 4.55 & 4.5371 & TRN & \\
\hline CHEMBL1604411 & 688128 & 4.1 & 4.7025 & TRN & \\
\hline CHEMBL1427633 & 688128 & 5.5 & 5.0623 & TRN & \\
\hline CHEMBL1374288 & 688128 & 6.0 & 4.9963 & TRN & \\
\hline CHEMBL1519229 & 688128 & 4.9 & 4.5121 & TRN & \\
\hline CHEMBL1441288 & 688128 & 4.55 & 4.6527 & TRN & \\
\hline CHEMBL1468753 & 688128 & 4.4 & 4.2285 & TRN & \\
\hline CHEMBL1319467 & 688128 & 5.85 & 5.1999 & TRN & \\
\hline CHEMBL1359359 & 688128 & 5.45 & 4.7603 & TST & \\
\hline CHEMBL1362566 & 688128 & 5.9 & 5.1574 & TRN & \\
\hline CHEMBL1586065 & 688128 & 5.8 & 4.6506 & TRN & \\
\hline
\end{tabular}




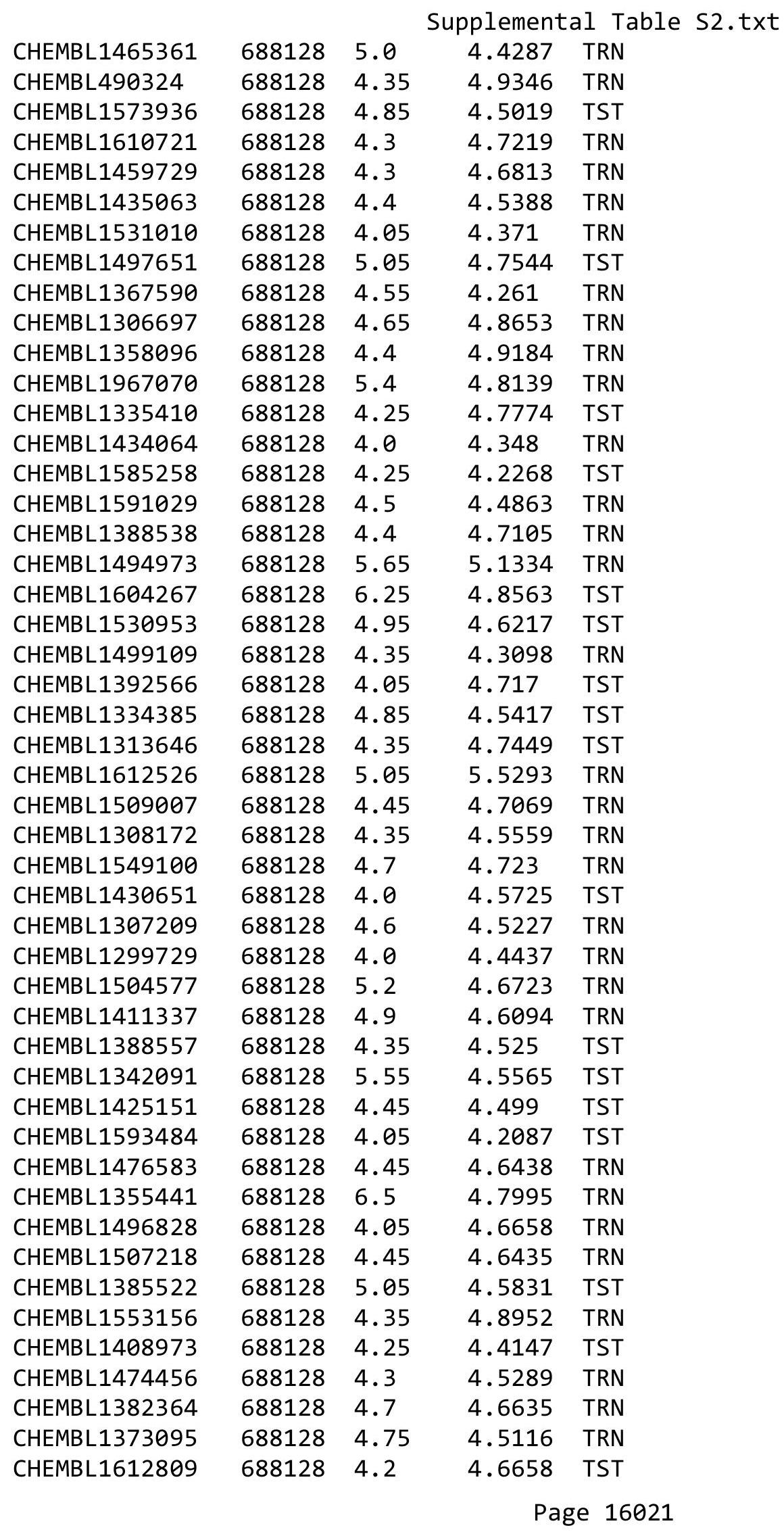




\begin{tabular}{|c|c|c|c|c|c|}
\hline \multicolumn{6}{|c|}{ Supplemental Table S2.txt } \\
\hline CHEMBL1606645 & 688128 & 4.1 & 4.6077 & TST & \\
\hline CHEMBL1490938 & 688128 & 4.35 & 4.789 & TRN & \\
\hline CHEMBL1402174 & 688128 & 4.3 & 4.4619 & TRN & \\
\hline CHEMBL1418382 & 688128 & 4.35 & 4.59399 & 9999999999 & TRN \\
\hline CHEMBL1576417 & 688128 & 6.1 & 4.9013 & TST & \\
\hline CHEMBL1345110 & 688128 & 4.6 & 4.4778 & TRN & \\
\hline CHEMBL1495602 & 688128 & 4.05 & 4.8506 & TST & \\
\hline CHEMBL1505049 & 688128 & 5.25 & 4.5167 & TST & \\
\hline CHEMBL1305013 & 688128 & 4.85 & 4.7472 & TST & \\
\hline CHEMBL1604166 & 688128 & 4.1 & 4.5415 & TST & \\
\hline CHEMBL1534795 & 688128 & 6.45 & 5.0556 & TRN & \\
\hline CHEMBL1434983 & 688128 & 4.35 & 4.4293 & TRN & \\
\hline CHEMBL1355009 & 688128 & 4.3 & 4.579 & TRN & \\
\hline CHEMBL1475388 & 688128 & 4.5 & 4.8692 & TRN & \\
\hline CHEMBL1322066 & 688128 & 4.6 & 4.5925 & TRN & \\
\hline CHEMBL1341970 & 688128 & 5.55 & 4.9253 & TRN & \\
\hline CHEMBL 1605526 & 688128 & 4.3 & 4.7177 & TRN & \\
\hline CHEMBL1341629 & 688128 & 5.5 & 4.7461 & TRN & \\
\hline CHEMBL3193606 & 688128 & 6.05 & 4.7972 & TRN & \\
\hline CHEMBL1475697 & 688128 & 4.35 & 4.5663 & TRN & \\
\hline CHEMBL1585298 & 688128 & 5.65 & 4.4634 & TRN & \\
\hline CHEMBL1528726 & 688128 & 4.85 & 5.0893 & TRN & \\
\hline CHEMBL1576130 & 688128 & 4.5 & 4.7648 & TST & \\
\hline CHEMBL1461347 & 688128 & 4.35 & 4.3447 & TRN & \\
\hline CHEMBL1401183 & 688128 & 5.4 & 4.7115 & TRN & \\
\hline CHEMBL1611025 & 688128 & 4.55 & 4.7432 & TRN & \\
\hline CHEMBL1401764 & 688128 & 5.2 & 4.6622 & TRN & \\
\hline CHEMBL1368454 & 688128 & 4.65 & 4.4864 & TST & \\
\hline CHEMBL2369205 & 688128 & 4.55 & 4.7267 & TRN & \\
\hline CHEMBL1452301 & 688128 & 6.5501 & 4.9782 & TRN & \\
\hline CHEMBL1529116 & 688128 & 4.25 & 4.3816 & TST & \\
\hline CHEMBL1306129 & 688128 & 4.4 & 4.3309 & TRN & \\
\hline CHEMBL1338905 & 688128 & 4.4 & 4.2948 & TRN & \\
\hline CHEMBL1499617 & 688128 & 4.35 & 4.8377 & TST & \\
\hline CHEMBL3193893 & 688128 & 4.25 & 4.8447 & TST & \\
\hline CHEMBL1536843 & 688128 & 7.0 & 4.3772 & TRN & \\
\hline CHEMBL 2006519 & 688128 & 4.85 & 4.6977 & TRN & \\
\hline CHEMBL1345539 & 688128 & 4.45 & 4.5662 & TRN & \\
\hline CHEMBL1582738 & 688128 & 4.35 & 4.3987 & TRN & \\
\hline CHEMBL1528063 & 688128 & 5.0 & 4.748 & TRN & \\
\hline CHEMBL1448198 & 688128 & 4.1 & 4.8314 & TST & \\
\hline CHEMBL1334010 & 688128 & 4.3 & 4.6435 & TRN & \\
\hline CHEMBL1406375 & 688128 & 4.05 & 4.5313 & TST & \\
\hline CHEMBL1336014 & 688128 & 4.05 & 4.5808 & TRN & \\
\hline CHEMBL1302593 & 688128 & 4.6 & 4.5793 & TRN & \\
\hline CHEMBL1377858 & 688128 & 4.0 & 4.547 & TST & \\
\hline CHEMBL1524876 & 688128 & 4.6 & 4.4505 & TRN & \\
\hline CHEMBL1333618 & 688128 & 5.35 & 4.8427 & TRN & \\
\hline
\end{tabular}




\begin{tabular}{|c|c|c|c|c|c|}
\hline \\
\hline CHEMBL1452388 & 688128 & 4.3 & 4.5779 & TRN & \\
\hline CHEMBL1549819 & 688128 & 4.3 & 4.5283 & TRN & \\
\hline CHEMBL1496584 & 688128 & 4.4 & 4.5651 & TRN & \\
\hline CHEMBL1312003 & 688128 & 5.8 & 4.6752 & TST & \\
\hline CHEMBL1328629 & 688128 & 5.4 & 5.0624 & TRN & \\
\hline CHEMBL1311148 & 688128 & 5.75 & 4.5989 & TRN & \\
\hline CHEMBL1445933 & 688128 & 4.35 & 4.5901 & TRN & \\
\hline CHEMBL1422155 & 688128 & 4.25 & 4.5649 & TRN & \\
\hline CHEMBL1311367 & 688128 & 4.4 & 4.6954 & TRN & \\
\hline CHEMBL1336255 & 688128 & 4.3 & 5.0689 & TST & \\
\hline CHEMBL1451931 & 688128 & 4.55 & 4.9723 & TRN & \\
\hline CHEMBL1309830 & 688128 & 4.25 & 4.3988 & TRN & \\
\hline CHEMBL1442395 & 688128 & 4.75 & 4.5963 & TRN & \\
\hline CHEMBL1489222 & 688128 & 4.6 & 4.6539 & TRN & \\
\hline CHEMBL1503912 & 688128 & 4.85 & 4.5951 & TRN & \\
\hline CHEMBL1457918 & 688128 & 4.8 & 4.5341 & TRN & \\
\hline CHEMBL1509600 & 688128 & 4.45 & 4.3649 & TRN & \\
\hline CHEMBL1465951 & 688128 & 4.6 & 4.7859 & TRN & \\
\hline CHEMBL1350619 & 688128 & 4.3 & 4.6882 & TST & \\
\hline CHEMBL1402730 & 688128 & 4.4 & 4.6435 & TRN & \\
\hline CHEMBL1355295 & 688128 & 4.1 & 4.3868 & TST & \\
\hline CHEMBL1446387 & 688128 & 4.3 & 4.3868 & TRN & \\
\hline CHEMBL1548760 & 688128 & 4.3 & 4.519 & TRN & \\
\hline CHEMBL1380950 & 688128 & 4.45 & 4.6172 & TST & \\
\hline CHEMBL1459153 & 688128 & 4.4 & $4.4830 e$ & 00000000005 & TRN \\
\hline CHEMBL605003 & 688128 & 4.3 & 4.7947 & TST & \\
\hline CHEMBL1563392 & 688128 & 4.3 & 4.5734 & TRN & \\
\hline CHEMBL1321832 & 688128 & 4.3 & 4.6309 & TRN & \\
\hline CHEMBL1409492 & 688128 & 4.65 & 4.5829 & TRN & \\
\hline CHEMBL1310269 & 688128 & 4.85 & 4.7706 & TRN & \\
\hline CHEMBL1432889 & 688128 & 4.3 & 4.4697 & TST & \\
\hline CHEMBL1316564 & 688128 & 4.3 & 4.3675 & TST & \\
\hline CHEMBL1611545 & 688128 & 4.3 & $4.3660 e$ & 00000000005 & TST \\
\hline CHEMBL1476794 & 688128 & 4.3 & 4.6825 & TRN & \\
\hline CHEMBL1539155 & 688128 & 5.2 & 5.0315 & TRN & \\
\hline CHEMBL1502042 & 688128 & 4.0 & 4.6581 & TRN & \\
\hline CHEMBL1608044 & 688128 & 4.45 & 4.4338 & TST & \\
\hline CHEMBL1716494 & 688128 & 4.6 & 4.5918 & TRN & \\
\hline CHEMBL1300750 & 688128 & 4.95 & 4.4036 & TST & \\
\hline CHEMBL1380316 & 688128 & 4.85 & 4.7889 & TRN & \\
\hline CHEMBL1375467 & 688128 & 4.35 & 4.5176 & TRN & \\
\hline CHEMBL1498278 & 688128 & 4.6 & 4.8191 & TRN & \\
\hline CHEMBL1416184 & 688128 & 7.0 & 5.8824 & TRN & \\
\hline CHEMBL1590449 & 688128 & 4.4 & 4.6411 & TRN & \\
\hline CHEMBL1583744 & 688128 & 4.4 & 4.4259 & TRN & \\
\hline CHEMBL1410439 & 688128 & 4.3 & 4.4148 & TRN & \\
\hline CHEMBL1584807 & 688128 & 4.3 & 4.7065 & TRN & \\
\hline CHEMBL1485538 & 688128 & 6.1 & 5.2678 & TRN & \\
\hline & & & & 6023 & \\
\hline
\end{tabular}




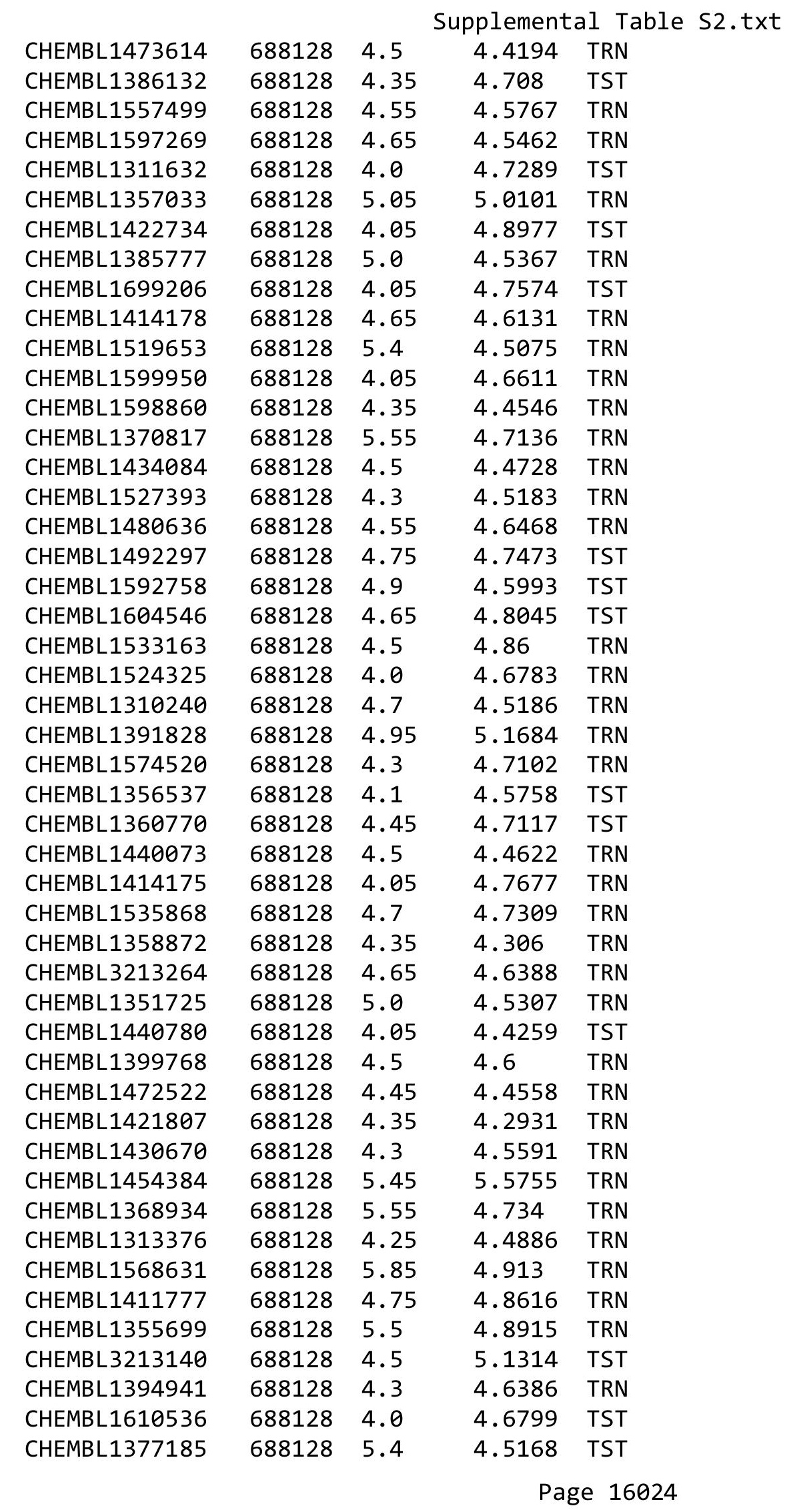




\begin{tabular}{|c|c|c|c|c|c|}
\hline \multicolumn{6}{|c|}{ Supplemental Table s2.txt } \\
\hline CHEMBL1302722 & 688128 & 5.6 & 4.833 & TRN & \\
\hline CHEMBL1438214 & 688128 & 4.0 & 4.524 & TRN & \\
\hline CHEMBL164968 & 688128 & 5.2 & 4.7891 & TRN & \\
\hline CHEMBL1318369 & 688128 & 4.35 & 4.5814 & TRN & \\
\hline CHEMBL1609772 & 688128 & 4.35 & 4.2594 & TRN & \\
\hline CHEMBL516702 & 688128 & 5.45 & 4.2724 & TST & \\
\hline CHEMBL1434654 & 688128 & 4.35 & 4.6756 & TRN & \\
\hline CHEMBL1392258 & 688128 & 4.3 & 4.6375 & TRN & \\
\hline CHEMBL 2003559 & 688128 & 4.05 & 4.7973 & TST & \\
\hline CHEMBL1378258 & 688128 & 4.95 & 4.8938 & TRN & \\
\hline CHEMBL1383018 & 688128 & 4.4 & $4.6160 e$ & 00000000005 & TRN \\
\hline CHEMBL1305083 & 688128 & 4.4 & 4.785 & TST & \\
\hline CHEMBL1421040 & 688128 & 4.35 & 4.5635 & TRN & \\
\hline CHEMBL1580712 & 688128 & 4.4 & 4.26699 & 99999999995 & TST \\
\hline CHEMBL1484506 & 688128 & 4.25 & 4.5688 & TST & \\
\hline CHEMBL1540858 & 688128 & 4.35 & 4.7147 & TRN & \\
\hline CHEMBL1612401 & 688128 & 4.3 & 4.8431 & TRN & \\
\hline CHEMBL1374427 & 688128 & 4.45 & 4.8512 & TRN & \\
\hline CHEMBL1335761 & 688128 & 4.3 & 4.6663 & TRN & \\
\hline CHEMBL1415281 & 688128 & 4.55 & 4.6019 & TRN & \\
\hline CHEMBL1454009 & 688128 & 4.05 & 4.7825 & TST & \\
\hline CHEMBL1593891 & 688128 & 4.3 & 4.3758 & TRN & \\
\hline CHEMBL1505193 & 688128 & 4.25 & 4.5169 & TRN & \\
\hline CHEMBL1555026 & 688128 & 4.0 & 4.8969 & TRN & \\
\hline CHEMBL1430622 & 688128 & 4.4 & 4.5378 & TRN & \\
\hline CHEMBL1472448 & 688128 & 4.45 & 4.5169 & TRN & \\
\hline CHEMBL1360063 & 688128 & 5.2 & 4.5214 & TRN & \\
\hline CHEMBL1418057 & 688128 & 4.7 & 4.6305 & TST & \\
\hline CHEMBL1600246 & 688128 & 4.3 & 4.4575 & TRN & \\
\hline CHEMBL1998229 & 688128 & 4.05 & 4.5041 & TRN & \\
\hline CHEMBL6816 & 688128 & 5.4 & 4.6487 & TST & \\
\hline CHEMBL3197786 & 688128 & 4.6 & 4.7734 & TRN & \\
\hline CHEMBL1572362 & 688128 & 5.1 & 5.0903 & TRN & \\
\hline CHEMBL1342581 & 688128 & 4.75 & 4.8452 & TRN & \\
\hline CHEMBL1458278 & 688128 & 4.6 & 4.8392 & TRN & \\
\hline CHEMBL1576354 & 688128 & 4.65 & 4.5462 & TRN & \\
\hline CHEMBL1497553 & 688128 & 4.5 & 4.6116 & TRN & \\
\hline CHEMBL1560672 & 688128 & 4.2 & 4.6678 & TRN & \\
\hline CHEMBL1369885 & 688128 & 5.1 & 4.7314 & TRN & \\
\hline CHEMBL1547643 & 688128 & 4.6 & 4.6156 & TST & \\
\hline CHEMBL1467915 & 688128 & 4.45 & 4.3224 & TRN & \\
\hline CHEMBL1532129 & 688128 & 4.3 & 4.5926 & TRN & \\
\hline CHEMBL1511985 & 688128 & 5.55 & 4.7937 & TST & \\
\hline CHEMBL1335176 & 688128 & 4.95 & 4.9939 & TST & \\
\hline CHEMBL1401422 & 688128 & 4.65 & 4.7101 & TRN & \\
\hline CHEMBL1410699 & 688128 & 4.3 & 4.9186 & TRN & \\
\hline CHEMBL1427156 & 688128 & 4.4 & 4.596 & TRN & \\
\hline CHEMBL1447513 & 688128 & 4.35 & 4.4823 & TRN & \\
\hline
\end{tabular}




\begin{tabular}{|c|c|c|c|c|}
\hline & & & upplement & al Table S2. \\
\hline CHEMBL1606268 & 688128 & 4.05 & 4.4253 & TST \\
\hline CHEMBL1402617 & 688128 & 4.35 & 4.6184 & TRN \\
\hline CHEMBL1324322 & 688128 & 4.85 & 4.7493 & TRN \\
\hline CHEMBL1555794 & 688128 & 4.05 & 4.3873 & TST \\
\hline CHEMBL1351986 & 688128 & 4.05 & 4.5213 & TRN \\
\hline CHEMBL1424085 & 688128 & 4.85 & 4.8384 & TRN \\
\hline CHEMBL3199316 & 688128 & 4.4 & 4.8734 & TST \\
\hline CHEMBL1380040 & 688128 & 4.3 & 4.5975 & TRN \\
\hline CHEMBL1428419 & 688128 & 4.6 & 4.6831 & TRN \\
\hline CHEMBL1469500 & 688128 & 4.55 & 4.6134 & TRN \\
\hline CHEMBL1428618 & 688128 & 4.3 & 4.8491 & TRN \\
\hline CHEMBL1530872 & 688128 & 4.55 & 4.595 & TST \\
\hline CHEMBL1609658 & 688128 & 4.6 & 4.2907 & TST \\
\hline CHEMBL1337377 & 688128 & 4.45 & 4.3861 & TRN \\
\hline CHEMBL1360958 & 688128 & 4.4 & 4.6529 & TRN \\
\hline CHEMBL1485619 & 688128 & 6.35 & 4.4778 & TST \\
\hline CHEMBL1323314 & 688128 & 4.65 & 4.4524 & TRN \\
\hline CHEMBL1299484 & 688128 & 4.05 & 4.3725 & TST \\
\hline CHEMBL1611634 & 688128 & 4.6 & 4.6117 & TRN \\
\hline CHEMBL1496459 & 688128 & 4.35 & 4.6343 & TRN \\
\hline CHEMBL1321238 & 688128 & 5.85 & 5.1045 & TRN \\
\hline CHEMBL1516685 & 688128 & 4.85 & 4.62 & TRN \\
\hline CHEMBL1358212 & 688128 & 5.35 & 5.3048 & TRN \\
\hline CHEMBL1564589 & 688128 & 4.05 & 4.6382 & TST \\
\hline CHEMBL1333336 & 688128 & 6.95 & 5.3525 & TRN \\
\hline CHEMBL1452206 & 688128 & 4.7 & 4.6402 & TRN \\
\hline CHEMBL1455014 & 688128 & 5.6 & 4.6828 & TRN \\
\hline CHEMBL3190931 & 688128 & 4.05 & 4.4513 & TRN \\
\hline CHEMBL1360180 & 688128 & 4.55 & 4.659 & TRN \\
\hline CHEMBL1424505 & 688128 & 4.05 & 4.855 & TST \\
\hline CHEMBL1385596 & 688128 & 4.05 & 4.4547 & TST \\
\hline CHEMBL1555246 & 688128 & 6.05 & 5.0548 & TRN \\
\hline CHEMBL1574133 & 688128 & 4.35 & 4.6227 & TRN \\
\hline CHEMBL1594437 & 688128 & 4.35 & 4.4572 & TRN \\
\hline CHEMBL1355795 & 688128 & 4.3 & 4.4952 & TRN \\
\hline CHEMBL1548338 & 688128 & 4.3 & 4.7758 & TST \\
\hline CHEMBL1340380 & 688128 & 4.4 & 4.5102 & TST \\
\hline CHEMBL1406998 & 688128 & 4.65 & 4.7782 & TRN \\
\hline CHEMBL1427278 & 688128 & 4.05 & 4.5963 & TRN \\
\hline CHEMBL1467673 & 688128 & 4.75 & 4.3322 & TST \\
\hline CHEMBL1378569 & 688128 & 4.3 & 4.8119 & TRN \\
\hline CHEMBL1367986 & 688128 & 4.65 & 4.8763 & TRN \\
\hline CHEMBL3194273 & 688128 & 4.15 & 4.3863 & TRN \\
\hline CHEMBL1580827 & 688128 & 4.25 & 4.53600 & 00000000005 \\
\hline CHEMBL1395925 & 688128 & 4.05 & 4.4839 & TRN \\
\hline CHEMBL1327447 & 688128 & 5.7 & 4.3852 & TRN \\
\hline CHEMBL1309152 & 688128 & 4.9 & 4.4791 & TRN \\
\hline CHEMBL1499465 & 688128 & 4.35 & 4.7631 & TRN \\
\hline
\end{tabular}




\begin{tabular}{|c|c|c|c|c|}
\hline \multicolumn{5}{|c|}{ Supplemental Table S2.txt } \\
\hline CHEMBL1378905 & 688128 & 4.05 & 4.4994 & TST \\
\hline CHEMBL1521717 & 688128 & 4.4 & 4.4083 & TST \\
\hline CHEMBL1340090 & 688128 & 4.25 & 4.5676 & TRN \\
\hline CHEMBL399293 & 688128 & 5.45 & 4.7536 & TST \\
\hline CHEMBL1456091 & 688128 & 5.75 & 4.5926 & TST \\
\hline CHEMBL1569494 & 688128 & 5.15 & 4.7331 & TST \\
\hline CHEMBL1402779 & 688128 & 4.05 & 4.7136 & TRN \\
\hline CHEMBL1496402 & 688128 & 4.3 & 4.4153 & TST \\
\hline CHEMBL1596769 & 688128 & 4.35 & 4.465 & TRN \\
\hline CHEMBL1593637 & 688128 & 4.3 & 4.8684 & TRN \\
\hline CHEMBL1565479 & 688128 & 4.9 & 4.6818 & TRN \\
\hline CHEMBL1486806 & 688128 & 4.4 & 4.7124 & TRN \\
\hline CHEMBL1498610 & 688128 & 6.4 & 4.7647 & TRN \\
\hline CHEMBL1347506 & 688128 & 5.4 & 4.5565 & TST \\
\hline CHEMBL1560367 & 688128 & 4.4 & 4.5155 & TRN \\
\hline CHEMBL1424746 & 688128 & 4.95 & 5.2911 & TRN \\
\hline CHEMBL455284 & 688128 & 4.4 & 4.6665 & TST \\
\hline CHEMBL1316063 & 688128 & 4.4 & 4.7668 & TRN \\
\hline CHEMBL1323902 & 688128 & 4.3 & 4.5817 & TRN \\
\hline CHEMBL1370582 & 688128 & 4.0 & 4.5255 & TRN \\
\hline CHEMBL3197141 & 688128 & 4.4 & 4.8242 & TRN \\
\hline CHEMBL1317908 & 688128 & 4.0 & 4.5203 & TRN \\
\hline CHEMBL1404207 & 688128 & 4.75 & 4.6245 & TRN \\
\hline CHEMBL1572739 & 688128 & 4.7 & 4.2929 & TRN \\
\hline CHEMBL1356532 & 688128 & 4.05 & 4.4788 & TST \\
\hline CHEMBL1543836 & 688128 & 4.3 & 4.8688 & TST \\
\hline CHEMBL1407301 & 688128 & 4.85 & 4.8582 & TRN \\
\hline CHEMBL1544074 & 688128 & 4.4 & 4.3655 & TRN \\
\hline CHEMBL1413696 & 688128 & 4.65 & 4.5866 & TRN \\
\hline CHEMBL1558109 & 688128 & 5.0 & 4.5846 & TRN \\
\hline CHEMBL1558442 & 688128 & 5.15 & 4.8227 & TRN \\
\hline CHEMBL1588765 & 688128 & 4.55 & 4.4796 & TRN \\
\hline CHEMBL1607263 & 688128 & 5.2 & 4.8236 & TRN \\
\hline CHEMBL1607565 & 688128 & 4.05 & 4.6893 & TRN \\
\hline CHEMBL1524013 & 688128 & 4.0 & 4.6552 & TRN \\
\hline CHEMBL1302308 & 688128 & 4.3 & 4.6138 & TRN \\
\hline CHEMBL1382410 & 688128 & 4.7 & 4.9343 & TRN \\
\hline CHEMBL1544433 & 688128 & 4.6 & 4.5733 & TRN \\
\hline CHEMBL1446678 & 688128 & 5.85 & 4.9318 & TRN \\
\hline CHEMBL1487938 & 688128 & 5.35 & 4.9287 & TRN \\
\hline CHEMBL1330037 & 688128 & 6.0 & 4.6435 & TRN \\
\hline CHEMBL1543661 & 688128 & 4.35 & 4.7465 & TRN \\
\hline CHEMBL1571914 & 688128 & 5.0 & 4.552 & TRN \\
\hline CHEMBL1419195 & 688128 & 4.3 & 4.4625 & TRN \\
\hline CHEMBL1541680 & 688128 & 4.65 & 4.7162 & TST \\
\hline CHEMBL1507735 & 688128 & 4.0 & 4.5606 & TST \\
\hline CHEMBL1464821 & 688128 & 4.35 & 4.9197 & TST \\
\hline CHEMBL1369357 & 688128 & 4.25 & 4.548 & TRN \\
\hline
\end{tabular}




\begin{tabular}{|c|c|c|c|c|}
\hline \multicolumn{5}{|c|}{ Supplemental Table S2.txt } \\
\hline CHEMBL1420789 & 688128 & 4.05 & 4.6587 & TRN \\
\hline CHEMBL 3193357 & 688128 & 4.3 & 4.709 & TRN \\
\hline CHEMBL1536141 & 688128 & 4.3 & 4.9733 & TRN \\
\hline CHEMBL1413586 & 688128 & 4.5 & 4.8049 & TRN \\
\hline CHEMBL1396334 & 688128 & 4.4 & 4.7383 & TST \\
\hline CHEMBL1407756 & 688128 & 5.9 & 4.8526 & TRN \\
\hline CHEMBL1526265 & 688128 & 4.4 & 4.9091 & TRN \\
\hline CHEMBL1585182 & 688128 & 4.5 & 4.5523 & TRN \\
\hline CHEMBL1542999 & 688128 & 3.95 & 4.6548 & TRN \\
\hline CHEMBL1338241 & 688128 & 4.4 & 4.8063 & TRN \\
\hline CHEMBL1551217 & 688128 & 4.05 & 4.4694 & TRN \\
\hline CHEMBL1486528 & 688128 & 5.45 & 4.9914 & TRN \\
\hline CHEMBL1580187 & 688128 & 4.55 & 4.7124 & TST \\
\hline CHEMBL1519723 & 688128 & 4.65 & 4.8498 & TST \\
\hline CHEMBL1299907 & 688128 & 5.55 & 4.9072 & TRN \\
\hline CHEMBL1321310 & 688128 & 4.1 & 4.2147 & TRN \\
\hline CHEMBL1335865 & 688128 & 4.05 & 4.5585 & TRN \\
\hline CHEMBL1549213 & 688128 & 5.85 & 4.6465 & TRN \\
\hline CHEMBL1389188 & 688128 & 4.65 & 4.5766 & TRN \\
\hline CHEMBL1464959 & 688128 & 4.4 & 4.5808 & TRN \\
\hline CHEMBL1532825 & 688128 & 5.1 & 4.4744 & TRN \\
\hline CHEMBL1484409 & 688128 & 4.3 & 4.551 & TRN \\
\hline CHEMBL1486277 & 688128 & 4.65 & 4.4711 & TRN \\
\hline CHEMBL1563766 & 688128 & 4.5 & 5.0382 & TRN \\
\hline CHEMBL1389819 & 688128 & 4.05 & 4.5697 & TRN \\
\hline CHEMBL1500443 & 688128 & 4.75 & 5.2419 & TST \\
\hline CHEMBL1563076 & 688128 & 5.55 & 4.5122 & TRN \\
\hline CHEMBL1390283 & 688128 & 4.4 & 4.5486 & TST \\
\hline CHEMBL1453701 & 688128 & 4.05 & 4.4949 & TRN \\
\hline CHEMBL1506417 & 688128 & 4.4 & 4.8887 & TRN \\
\hline CHEMBL1517493 & 688128 & 4.35 & 4.8635 & TST \\
\hline CHEMBL1436627 & 688128 & 4.6 & 4.3621 & TRN \\
\hline CHEMBL1367784 & 688128 & 4.25 & 4.6732 & TST \\
\hline CHEMBL1544567 & 688128 & 4.3 & 4.9671 & TST \\
\hline CHEMBL1426592 & 688128 & 4.3 & 5.1079 & TST \\
\hline CHEMBL1459546 & 688128 & 6.0 & 4.7233 & TRN \\
\hline CHEMBL1424333 & 688128 & 5.1 & 4.9366 & TRN \\
\hline CHEMBL1482282 & 688128 & 4.4 & 4.5404 & TRN \\
\hline CHEMBL1468182 & 688128 & 4.75 & 4.3679 & TRN \\
\hline CHEMBL1571345 & 688128 & 4.35 & 4.569 & TRN \\
\hline CHEMBL1333641 & 688128 & 4.65 & 4.6952 & TRN \\
\hline CHEMBL1382669 & 688128 & 4.25 & 4.7262 & TRN \\
\hline CHEMBL1349223 & 688128 & 4.25 & 4.7455 & TRN \\
\hline CHEMBL1410146 & 688128 & 4.3 & 4.328 & TRN \\
\hline CHEMBL1475932 & 688128 & 4.05 & 4.8326 & TRN \\
\hline CHEMBL1504662 & 688128 & 6.05 & 4.3606 & TRN \\
\hline CHEMBL1572299 & 688128 & 4.45 & 4.6255 & TRN \\
\hline CHEMBL1381445 & 688128 & 4.65 & 4.6242 & TRN \\
\hline
\end{tabular}




\begin{tabular}{|c|c|c|c|c|}
\hline \multicolumn{5}{|c|}{ Supplemental Table S2.txt } \\
\hline CHEMBL1398380 & 688128 & 5.45 & 4.81 & TRN \\
\hline CHEMBL1349800 & 688128 & 5.75 & 4.5606 & TST \\
\hline CHEMBL1304181 & 688128 & 5.45 & 4.8923 & TRN \\
\hline CHEMBL1607577 & 688128 & 5.05 & 4.5975 & TST \\
\hline CHEMBL1575042 & 688128 & 4.3 & 4.7999 & TST \\
\hline CHEMBL1352919 & 688128 & 5.9 & 4.9814 & TRN \\
\hline CHEMBL3191525 & 688128 & 4.3 & 4.4064 & TST \\
\hline CHEMBL1339797 & 688128 & 4.85 & 4.8251 & TST \\
\hline CHEMBL1343506 & 688128 & 4.7 & 4.8348 & TRN \\
\hline CHEMBL1372193 & 688128 & 4.35 & 4.5098 & TRN \\
\hline CHEMBL1939687 & 688128 & 4.6 & 4.7917 & TRN \\
\hline CHEMBL1552739 & 688128 & 4.7 & 4.5294 & TRN \\
\hline CHEMBL1450508 & 688128 & 4.4 & 4.2435 & TRN \\
\hline CHEMBL1339111 & 688128 & 6.05 & 4.5378 & TRN \\
\hline CHEMBL1586720 & 688128 & 5.5 & 4.6864 & TRN \\
\hline CHEMBL1409874 & 688128 & 5.0 & 4.6454 & TRN \\
\hline CHEMBL1605397 & 688128 & 5.4 & 4.9383 & TST \\
\hline CHEMBL1408468 & 688128 & 4.05 & 4.8887 & TRN \\
\hline CHEMBL1972621 & 688128 & 4.75 & 4.5883 & TRN \\
\hline CHEMBL1412628 & 688128 & 4.6 & 4.2954 & TRN \\
\hline CHEMBL3191395 & 688128 & 4.4 & 4.4028 & TRN \\
\hline CHEMBL1589269 & 688128 & 4.35 & 4.3525 & TRN \\
\hline CHEMBL1462168 & 688128 & 5.75 & 4.9683 & TRN \\
\hline CHEMBL1601130 & 688128 & 4.05 & 4.4795 & TRN \\
\hline CHEMBL1402972 & 688128 & 4.4 & 4.6888 & TST \\
\hline CHEMBL1541013 & 688128 & 4.05 & 4.598 & TRN \\
\hline CHEMBL1373090 & 688128 & 5.8 & 4.9709 & TRN \\
\hline CHEMBL1469574 & 688128 & 4.1 & 4.8678 & TRN \\
\hline CHEMBL1558487 & 688128 & 4.05 & 4.6251 & TST \\
\hline CHEMBL1533397 & 688128 & 4.35 & 4.8257 & TRN \\
\hline CHEMBL1337160 & 688128 & 4.4 & 4.7557 & TRN \\
\hline CHEMBL316589 & 688128 & 4.35 & 5.0233 & TST \\
\hline CHEMBL1503824 & 688128 & 4.65 & 4.7386 & TST \\
\hline CHEMBL1324887 & 688128 & 4.45 & 4.4003 & TRN \\
\hline CHEMBL1584029 & 688128 & 4.05 & 4.4132 & TST \\
\hline CHEMBL1512088 & 688128 & 4.4 & 4.8464 & TRN \\
\hline CHEMBL1518186 & 688128 & 4.25 & 4.5439 & TRN \\
\hline CHEMBL1385077 & 688128 & 4.05 & 4.4307 & TST \\
\hline CHEMBL1596960 & 688128 & 4.35 & 4.6152 & TST \\
\hline CHEMBL1346985 & 688128 & 4.45 & 4.6957 & TRN \\
\hline CHEMBL1326838 & 688128 & 4.9 & 4.3399 & TRN \\
\hline CHEMBL1364755 & 688128 & 5.1 & 4.4376 & TST \\
\hline CHEMBL1350240 & 688128 & 5.1 & 4.8453 & TRN \\
\hline CHEMBL1384247 & 688128 & 4.85 & 4.9758 & TRN \\
\hline CHEMBL1352850 & 688128 & 4.5 & 5.0279 & TST \\
\hline CHEMBL1500193 & 688128 & 4.65 & 4.5629 & TRN \\
\hline CHEMBL1435710 & 688128 & 4.05 & 4.4963 & TRN \\
\hline CHEMBL1413010 & 688128 & 4.4 & 4.4959 & TST \\
\hline
\end{tabular}




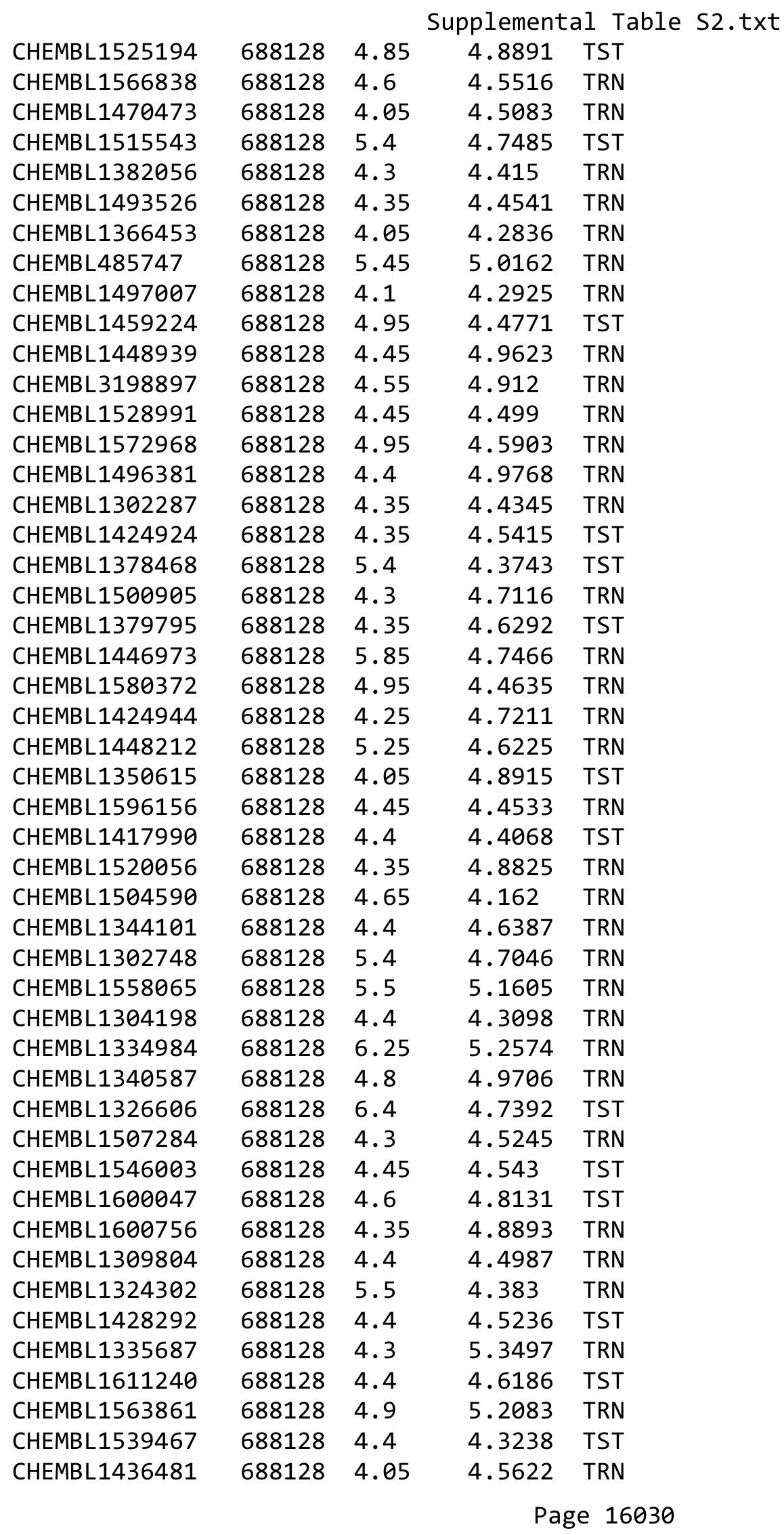




\begin{tabular}{|c|c|c|c|c|}
\hline \multicolumn{5}{|c|}{ Supplemental Table S2.txt } \\
\hline CHEMBL559797 & 688128 & 4.3 & 4.6658 & TST \\
\hline CHEMBL1534499 & 688128 & 4.4 & 5.1176 & TRN \\
\hline CHEMBL1496444 & 688128 & 4.55 & 4.4209 & TRN \\
\hline CHEMBL1557901 & 688128 & 4.05 & 4.9245 & TRN \\
\hline CHEMBL1596911 & 688128 & 6.1 & 4.5611 & TST \\
\hline CHEMBL3213876 & 688128 & 4.5 & 4.7987 & TRN \\
\hline CHEMBL1539953 & 688128 & 5.0 & 4.9372 & TRN \\
\hline CHEMBL1327167 & 688128 & 4.7 & 4.6002 & TRN \\
\hline CHEMBL1302762 & 688128 & 4.5 & 4.4082 & TRN \\
\hline CHEMBL1313990 & 688128 & 5.55 & 4.7131 & TRN \\
\hline CHEMBL 1466500 & 688128 & 4.6 & 4.373 & TRN \\
\hline CHEMBL1491689 & 688128 & 4.4 & 4.5738 & TST \\
\hline CHEMBL1310961 & 688128 & 4.7 & 4.3108 & TST \\
\hline CHEMBL1428407 & 688128 & 4.0 & 4.6685 & TST \\
\hline CHEMBL1300242 & 688128 & 4.35 & 5.1207 & TRN \\
\hline CHEMBL 1403300 & 688128 & 5.0 & 4.6802 & TRN \\
\hline CHEMBL1599135 & 688128 & 6.1 & 4.4183 & TRN \\
\hline CHEMBL1490492 & 688128 & 4.35 & 4.6019 & TRN \\
\hline CHEMBL1416741 & 688128 & 5.35 & 4.6222 & TRN \\
\hline CHEMBL1383199 & 688128 & 4.25 & 4.6258 & TST \\
\hline CHEMBL1565585 & 688128 & 6.8 & 4.5237 & TST \\
\hline CHEMBL1470524 & 688128 & 4.4 & 4.7496 & TRN \\
\hline CHEMBL1334032 & 688128 & 4.45 & 4.5424 & TRN \\
\hline CHEMBL1425576 & 688128 & 4.35 & 4.5562 & TST \\
\hline CHEMBL1490479 & 688128 & 4.05 & 4.566 & TRN \\
\hline CHEMBL1487952 & 688128 & 6.0 & 5.4626 & TRN \\
\hline CHEMBL1484657 & 688128 & 5.05 & 4.5201 & TRN \\
\hline CHEMBL1498106 & 688128 & 4.6 & 4.5245 & TRN \\
\hline CHEMBL1453619 & 688128 & 4.4 & 4.7469 & TST \\
\hline CHEMBL1510959 & 688128 & 6.6 & 4.3566 & TST \\
\hline CHEMBL312858 & 688128 & 4.35 & 4.798 & TRN \\
\hline CHEMBL1466281 & 688128 & 4.0 & 4.5788 & TST \\
\hline CHEMBL1486616 & 688128 & 4.7 & 4.8091 & TRN \\
\hline CHEMBL1383917 & 688128 & 4.4 & 4.6226 & TRN \\
\hline CHEMBL1572626 & 688128 & 4.3 & 4.3961 & TRN \\
\hline CHEMBL1579564 & 688128 & 4.05 & 5.0058 & TRN \\
\hline CHEMBL1399300 & 688128 & 5.35 & 4.3616 & TRN \\
\hline CHEMBL1595018 & 688128 & 4.35 & 4.6729 & TRN \\
\hline CHEMBL1361392 & 688128 & 4.4 & 4.5387 & TRN \\
\hline CHEMBL1352592 & 688128 & 5.55 & 4.5459 & TST \\
\hline CHEMBL1562669 & 688128 & 4.35 & 4.7049 & TRN \\
\hline CHEMBL1506777 & 688128 & 4.65 & 4.382 & TRN \\
\hline CHEMBL1300695 & 688128 & 4.95 & 4.8446 & TRN \\
\hline CHEMBL1484215 & 688128 & 4.45 & 4.4513 & TRN \\
\hline CHEMBL1601394 & 688128 & 4.15 & 4.5732 & TST \\
\hline CHEMBL1541706 & 688128 & 4.05 & 4.7909 & TRN \\
\hline CHEMBL1336304 & 688128 & 5.5 & 5.1122 & TRN \\
\hline CHEMBL1423368 & 688128 & 5.4 & 4.4059 & TRN \\
\hline
\end{tabular}




\begin{tabular}{|c|c|c|c|c|c|}
\hline \multicolumn{6}{|c|}{ Supplemental Table S2.txt } \\
\hline CHEMBL1571596 & 688128 & 5.7 & 4.6966 & TST & \\
\hline CHEMBL1305255 & 688128 & 4.1 & 4.6149 & TST & \\
\hline CHEMBL1560938 & 688128 & 4.9 & 4.4997 & TRN & \\
\hline CHEMBL1357170 & 688128 & 4.05 & 4.5932 & TST & \\
\hline CHEMBL254833 & 688128 & 4.2 & 4.6713 & TRN & \\
\hline CHEMBL1483721 & 688128 & 4.4 & 4.6345 & TRN & \\
\hline CHEMBL1367700 & 688128 & 4.3 & 4.417 & TRN & \\
\hline CHEMBL1478575 & 688128 & 4.25 & 4.6611 & TRN & \\
\hline CHEMBL1425108 & 688128 & 5.95 & 4.625 & TRN & \\
\hline CHEMBL1557816 & 688128 & 4.45 & 4.4291 & TST & \\
\hline CHEMBL1479382 & 688128 & 4.35 & 4.4063 & TRN & \\
\hline CHEMBL1449730 & 688128 & 4.3 & 4.7221 & TRN & \\
\hline CHEMBL1539032 & 688128 & 4.05 & 4.4958 & TRN & \\
\hline CHEMBL1389524 & 688128 & 4.05 & $4.6610 e$ & 00000000005 & TRN \\
\hline CHEMBL3392033 & 688128 & 5.1 & 4.5645 & TRN & \\
\hline CHEMBL1502268 & 688128 & 4.6 & 4.7803 & TST & \\
\hline CHEMBL1404082 & 688128 & 4.3 & 4.3986 & TRN & \\
\hline CHEMBL1587596 & 688128 & 5.35 & 5.0077 & TRN & \\
\hline CHEMBL1550307 & 688128 & 4.45 & 4.3289 & TRN & \\
\hline CHEMBL1363990 & 688128 & 4.05 & 4.4575 & TRN & \\
\hline CHEMBL1596479 & 688128 & 5.2 & 4.5038 & TRN & \\
\hline CHEMBL1308688 & 688128 & 4.4 & 4.7705 & TRN & \\
\hline CHEMBL1572765 & 688128 & 6.2 & 4.6043 & TRN & \\
\hline CHEMBL1362316 & 688128 & 4.7 & 4.7479 & TRN & \\
\hline CHEMBL1505566 & 688128 & 4.4 & 4.2012 & TRN & \\
\hline CHEMBL1599268 & 688128 & 6.0 & 4.8587 & TRN & \\
\hline CHEMBL1512931 & 688128 & 4.1 & 4.5324 & TRN & \\
\hline CHEMBL1471090 & 688128 & 4.3 & 4.7753 & TRN & \\
\hline CHEMBL1349645 & 688128 & 4.35 & 4.2984 & TRN & \\
\hline CHEMBL1388278 & 688128 & 4.6 & 4.9218 & TRN & \\
\hline CHEMBL1323854 & 688128 & 4.0 & 4.8798 & TRN & \\
\hline CHEMBL1314267 & 688128 & 4.1 & 4.5353 & TST & \\
\hline CHEMBL1543339 & 688128 & 4.65 & 4.6258 & TRN & \\
\hline CHEMBL1325187 & 688128 & 4.45 & 4.5618 & TRN & \\
\hline CHEMBL1526642 & 688128 & 4.3 & 4.4058 & TRN & \\
\hline CHEMBL1374857 & 688128 & 4.3 & 4.525 & TST & \\
\hline CHEMBL1326064 & 688128 & 4.35 & 4.3684 & TRN & \\
\hline CHEMBL1299485 & 688128 & 4.0 & 4.3395 & TRN & \\
\hline CHEMBL1544911 & 688128 & 4.1 & 4.8312 & TST & \\
\hline CHEMBL1481931 & 688128 & 4.45 & 4.2586 & TRN & \\
\hline CHEMBL1563340 & 688128 & 4.5 & 4.6378 & TRN & \\
\hline CHEMBL1531740 & 688128 & 4.15 & 4.4718 & TRN & \\
\hline CHEMBL1464555 & 688128 & 4.4 & $4.1930 e$ & 00000000005 & TRN \\
\hline CHEMBL1612984 & 688128 & 4.45 & 4.6248 & TRN & \\
\hline CHEMBL1307837 & 688128 & 5.0 & 4.4576 & TRN & \\
\hline CHEMBL1566507 & 688128 & 4.6 & 4.7673 & TRN & \\
\hline CHEMBL1342188 & 688128 & 4.35 & 4.6204 & TST & \\
\hline CHEMBL1472072 & 688128 & 4.05 & 4.6662 & TRN & \\
\hline
\end{tabular}




\begin{tabular}{|c|c|c|c|c|}
\hline \multicolumn{5}{|c|}{ Supplemental Table s2.txt } \\
\hline CHEMBL1393588 & 688128 & 4.4 & 4.7477 & TRN \\
\hline CHEMBL1464619 & 688128 & 4.65 & 4.6118 & TRN \\
\hline CHEMBL1578957 & 688128 & 4.1 & 4.4763 & TST \\
\hline CHEMBL1499826 & 688128 & 4.4 & 4.4578 & TRN \\
\hline CHEMBL1417083 & 688128 & 4.4 & 4.3759 & TRN \\
\hline CHEMBL1540975 & 688128 & 4.4 & 4.6464 & TRN \\
\hline CHEMBL1547868 & 688128 & 4.0 & 4.68 & TST \\
\hline CHEMBL1583833 & 688128 & 4.3 & 4.5547 & TRN \\
\hline CHEMBL1547957 & 688128 & 4.05 & 4.7084 & TRN \\
\hline CHEMBL1985797 & 688128 & 4.4 & 4.731 & TRN \\
\hline CHEMBL1346288 & 688128 & 4.4 & 4.6411 & TRN \\
\hline CHEMBL1521015 & 688128 & 4.25 & 4.8325 & TST \\
\hline CHEMBL1431450 & 688128 & 4.4 & 4.7561 & TRN \\
\hline CHEMBL1403809 & 688128 & 4.2 & 4.5739 & TRN \\
\hline CHEMBL1582831 & 688128 & 5.5 & 5.5524 & TRN \\
\hline CHEMBL1538471 & 688128 & 4.8 & 4.7775 & TRN \\
\hline CHEMBL1393390 & 688128 & 4.4 & 4.5913 & TRN \\
\hline CHEMBL1473186 & 688128 & 4.45 & 4.8054 & TRN \\
\hline CHEMBL1455137 & 688128 & 4.15 & 4.6755 & TRN \\
\hline CHEMBL1462093 & 688128 & 4.85 & 4.2245 & TRN \\
\hline CHEMBL1311808 & 688128 & 4.35 & 4.3966 & TRN \\
\hline CHEMBL3196468 & 688128 & 5.4 & 4.546 & TST \\
\hline CHEMBL1359356 & 688128 & 4.25 & 4.5203 & TST \\
\hline CHEMBL1578341 & 688128 & 5.4 & 5.0297 & TST \\
\hline CHEMBL1526397 & 688128 & 4.3 & 4.8393 & TRN \\
\hline CHEMBL1425215 & 688128 & 4.3 & 4.41 & TRN \\
\hline CHEMBL1340363 & 688128 & 6.1 & 4.8893 & TRN \\
\hline CHEMBL1551972 & 688128 & 4.5 & 4.3568 & TRN \\
\hline CHEMBL1404561 & 688128 & 4.3 & 4.4684 & TRN \\
\hline CHEMBL1525739 & 688128 & 4.05 & 4.5145 & TRN \\
\hline CHEMBL1533320 & 688128 & 4.05 & 4.0682 & TST \\
\hline CHEMBL1428880 & 688128 & 4.05 & 4.2287 & TRN \\
\hline CHEMBL1393609 & 688128 & 4.05 & 4.4937 & TST \\
\hline CHEMBL1504988 & 688128 & 4.05 & 4.4134 & TRN \\
\hline CHEMBL1607897 & 688128 & 4.9 & 4.8066 & TST \\
\hline CHEMBL1513697 & 688128 & 4.1 & 4.5823 & TST \\
\hline CHEMBL3208640 & 688128 & 4.4 & 4.8034 & TST \\
\hline CHEMBL135814 & 688128 & 4.05 & 4.5812 & TRN \\
\hline CHEMBL1491175 & 688128 & 4.5 & 4.646 & TRN \\
\hline CHEMBL1467695 & 688128 & 4.45 & 4.8166 & TRN \\
\hline CHEMBL1468462 & 688128 & 4.15 & 4.6762 & TRN \\
\hline CHEMBL1571761 & 688128 & 4.05 & 5.027 & TRN \\
\hline CHEMBL1971458 & 688128 & 4.3 & 4.734 & TRN \\
\hline CHEMBL1436867 & 688128 & 4.6 & 4.5802 & TST \\
\hline CHEMBL1537440 & 688128 & 4.4 & 4.3251 & TRN \\
\hline CHEMBL1529147 & 688128 & 4.3 & 4.6608 & TST \\
\hline CHEMBL1373289 & 688128 & 5.4 & 4.8983 & TST \\
\hline CHEMBL1305705 & 688128 & 4.05 & 4.6463 & TRN \\
\hline
\end{tabular}




\begin{tabular}{|c|c|c|c|c|c|}
\hline & & \multicolumn{4}{|c|}{ Supplemental Table S2.txt } \\
\hline CHEMBL1604749 & 688128 & 4.35 & 4.5755 & TRN & \\
\hline CHEMBL1314619 & 688128 & 4.35 & 4.9084 & TRN & \\
\hline CHEMBL1595330 & 688128 & 4.3 & 4.5354 & TST & \\
\hline CHEMBL1351611 & 688128 & 5.35 & 4.9435 & TRN & \\
\hline CHEMBL1575822 & 688128 & 4.05 & 4.5011 & TRN & \\
\hline CHEMBL1429429 & 688128 & 5.75 & 5.1756 & TST & \\
\hline CHEMBL1538203 & 688128 & 4.05 & 4.6852 & TRN & \\
\hline CHEMBL1369433 & 688128 & 4.6 & 5.4251 & TRN & \\
\hline CHEMBL1493753 & 688128 & 5.1 & 4.5321 & TRN & \\
\hline CHEMBL1587071 & 688128 & 5.5 & 4.383 & TST & \\
\hline CHEMBL1488285 & 688128 & 5.75 & 4.9447 & TRN & \\
\hline CHEMBL1435612 & 688128 & 4.35 & 4.703 & TRN & \\
\hline CHEMBL1560932 & 688128 & 4.35 & 4.4015 & TRN & \\
\hline CHEMBL1303579 & 688128 & 4.4 & 4.523 & TRN & \\
\hline CHEMBL1412930 & 688128 & 4.3 & 4.4144 & TST & \\
\hline CHEMBL1470798 & 688128 & 4.3 & 4.3506 & TRN & \\
\hline CHEMBL1414295 & 688128 & 4.35 & 4.6338 & TRN & \\
\hline CHEMBL1363355 & 688128 & 4.4 & 4.3481 & TRN & \\
\hline CHEMBL1422140 & 688128 & 5.85 & 4.7881 & TRN & \\
\hline CHEMBL1406563 & 688128 & 5.4 & 4.6556 & TST & \\
\hline CHEMBL1365835 & 688128 & 4.35 & 4.5813 & TRN & \\
\hline CHEMBL1349915 & 688128 & 5.45 & 5.0072 & TRN & \\
\hline CHEMBL1511139 & 688128 & 4.85 & 4.6924 & TRN & \\
\hline CHEMBL1355127 & 688128 & 6.1 & 4.6568 & TRN & \\
\hline CHEMBL1565136 & 688128 & 5.1 & 4.5782 & TST & \\
\hline CHEMBL1605973 & 688128 & 4.1 & 4.8449 & TST & \\
\hline CHEMBL1506204 & 688128 & 4.7 & 4.6458 & TRN & \\
\hline CHEMBL1329550 & 688128 & 4.6 & 4.6492 & TRN & \\
\hline CHEMBL1334495 & 688128 & 4.6 & 4.45100 & 00000000005 & TRN \\
\hline CHEMBL1448220 & 688128 & 4.05 & 4.7041 & TRN & \\
\hline CHEMBL1416800 & 688128 & 5.45 & 4.698 & TRN & \\
\hline CHEMBL1481305 & 688128 & 5.1 & 4.7928 & TRN & \\
\hline CHEMBL581251 & 688128 & 4.5 & 4.6742 & TST & \\
\hline CHEMBL1551155 & 688128 & 4.7 & 5.2142 & TRN & \\
\hline CHEMBL1577878 & 688128 & 4.4 & 4.5025 & TRN & \\
\hline CHEMBL1418885 & 688128 & 5.5 & 5.1001 & TRN & \\
\hline CHEMBL1442480 & 688128 & 4.3 & 4.3398 & TST & \\
\hline CHEMBL1326518 & 688128 & 4.4 & 4.7569 & TRN & \\
\hline CHEMBL1361596 & 688128 & 6.0 & 4.9755 & TRN & \\
\hline CHEMBL1488439 & 688128 & 4.85 & 4.9559 & TRN & \\
\hline CHEMBL1479827 & 688128 & 4.05 & 4.916 & TST & \\
\hline CHEMBL1353862 & 688128 & 4.35 & 4.3816 & TRN & \\
\hline CHEMBL1374538 & 688128 & 4.05 & 4.6181 & TST & \\
\hline CHEMBL1462539 & 688128 & 6.05 & 4.5899 & TST & \\
\hline CHEMBL1501805 & 688128 & 6.35 & 5.0666 & TRN & \\
\hline CHEMBL1481632 & 688128 & 4.35 & 4.5539 & TRN & \\
\hline CHEMBL1352598 & 688128 & 4.75 & 4.4543 & TRN & \\
\hline CHEMBL1491296 & 688128 & 4.3 & 4.5364 & TRN & \\
\hline
\end{tabular}




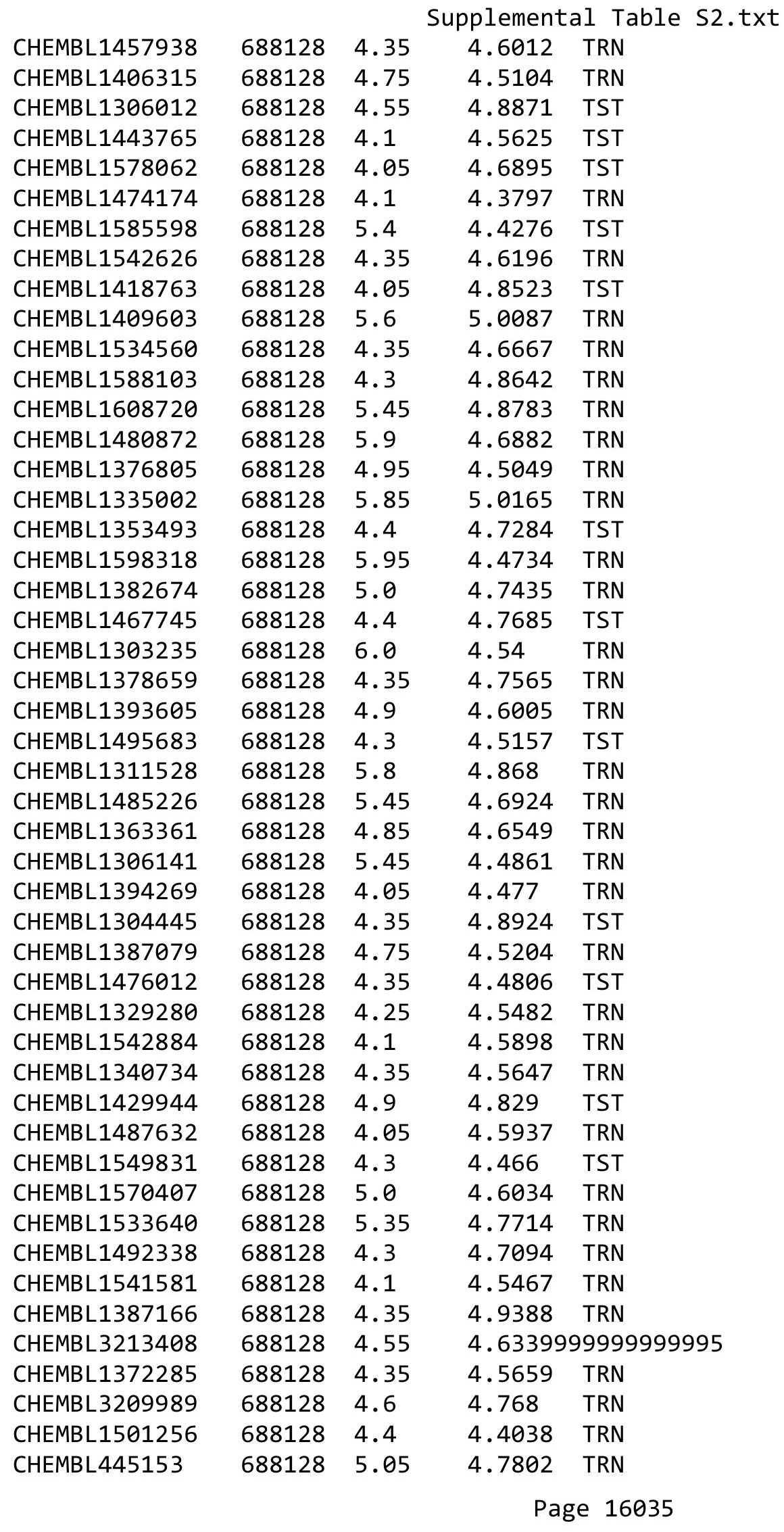




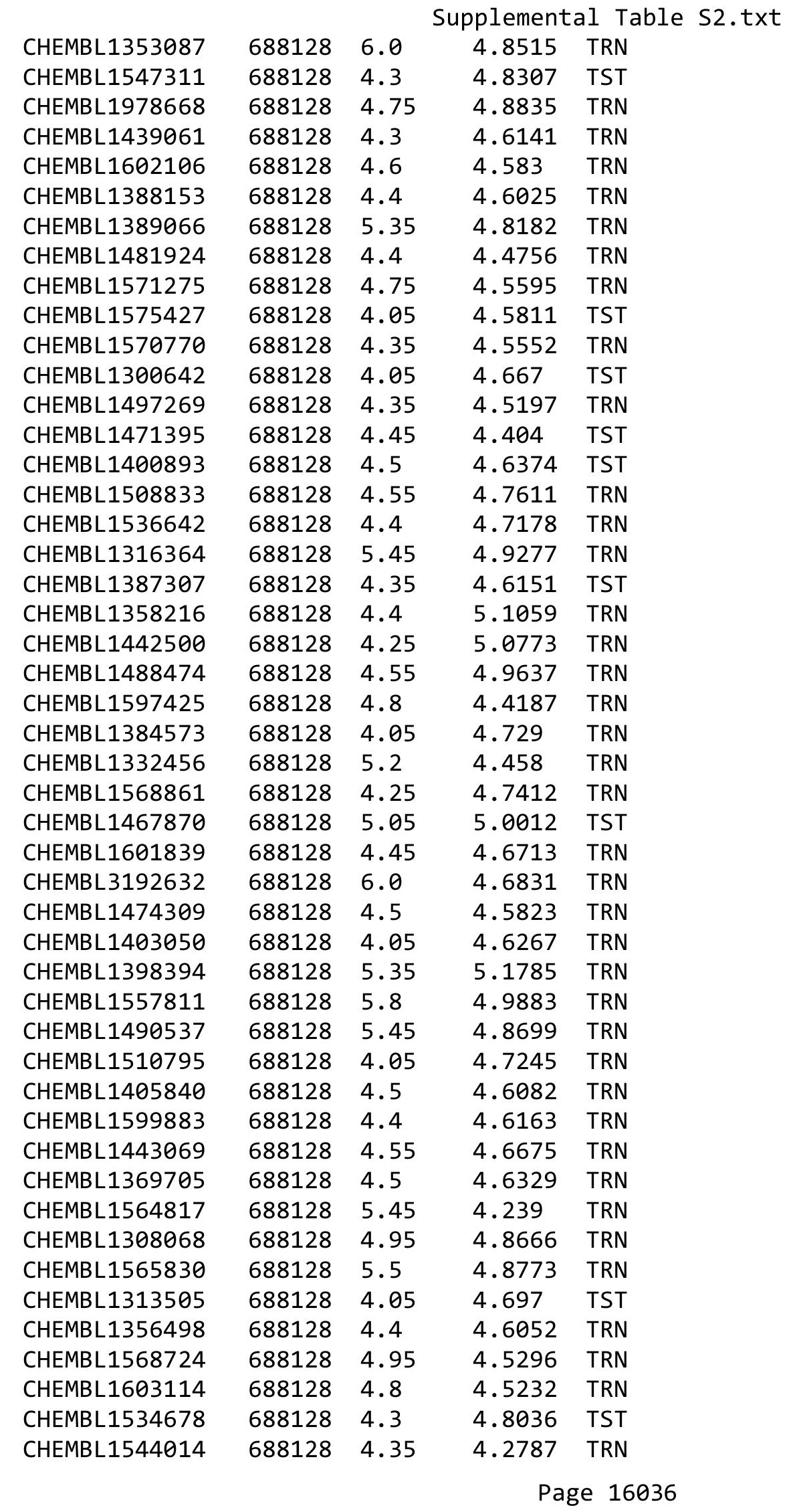




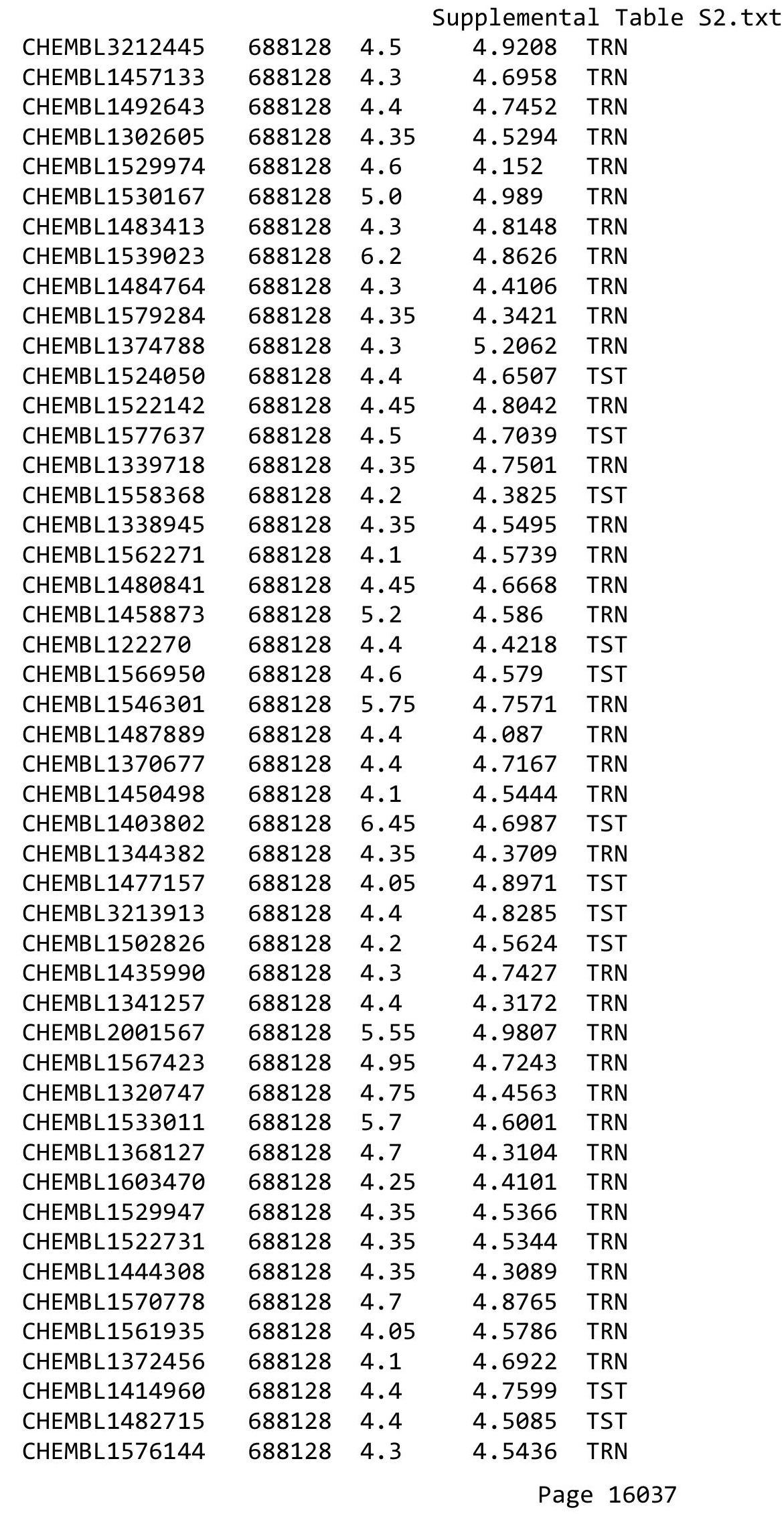




\begin{tabular}{|c|c|c|c|c|c|}
\hline \multicolumn{6}{|c|}{ Supplemental Table s2.txt } \\
\hline CHEMBL1200938 & 688128 & 6.0 & 4.7794 & TRN & \\
\hline CHEMBL1328634 & 688128 & 5.75 & 5.2953 & TRN & \\
\hline CHEMBL1542074 & 688128 & 5.8 & 4.5877 & TST & \\
\hline CHEMBL1516596 & 688128 & 4.85 & 4.317 & TRN & \\
\hline CHEMBL1469380 & 688128 & 4.3 & 4.7515 & TST & \\
\hline CHEMBL3194441 & 688128 & 5.4 & 4.7999 & TRN & \\
\hline CHEMBL1471102 & 688128 & 6.1 & 4.6493 & TST & \\
\hline CHEMBL1549276 & 688128 & 4.3 & 4.8986 & TRN & \\
\hline CHEMBL1393688 & 688128 & 4.55 & 4.2371 & TST & \\
\hline CHEMBL1503033 & 688128 & 4.85 & 5.0815 & TRN & \\
\hline CHEMBL1540159 & 688128 & 4.3 & 4.6681 & TRN & \\
\hline CHEMBL1318583 & 688128 & 4.45 & 4.2749 & TRN & \\
\hline CHEMBL1402026 & 688128 & 4.35 & 4.7234 & TST & \\
\hline CHEMBL1530741 & 688128 & 5.4 & 4.7225 & TRN & \\
\hline CHEMBL1460351 & 688128 & 4.35 & 4.7198 & TRN & \\
\hline CHEMBL3145088 & 688128 & 5.7 & 4.7822 & TST & \\
\hline CHEMBL1596306 & 688128 & 4.4 & 4.4741 & TRN & \\
\hline CHEMBL1602759 & 688128 & 6.3 & 5.3258 & TRN & \\
\hline CHEMBL1437779 & 688128 & 4.05 & 4.6643 & TRN & \\
\hline CHEMBL1356087 & 688128 & 5.5 & 5.0791 & TRN & \\
\hline CHEMBL1569581 & 688128 & 6.1 & 4.7095 & TST & \\
\hline CHEMBL1583163 & 688128 & 4.3 & 4.5848 & TST & \\
\hline CHEMBL1472490 & 688128 & 4.35 & 4.5082 & TST & \\
\hline CHEMBL1524672 & 688128 & 5.45 & 4.6938 & TST & \\
\hline CHEMBL3214368 & 688128 & 4.3 & 4.3865 & TST & \\
\hline CHEMBL1419828 & 688128 & 4.85 & 4.4379 & TRN & \\
\hline CHEMBL1321572 & 688128 & 4.35 & 4.7139 & TRN & \\
\hline CHEMBL1419273 & 688128 & 4.65 & 5.112 & TRN & \\
\hline CHEMBL1578945 & 688128 & 4.05 & 4.7431 & TST & \\
\hline CHEMBL3195115 & 688128 & 4.6 & 4.981 & TRN & \\
\hline CHEMBL1604540 & 688128 & 5.45 & 4.6929 & TRN & \\
\hline CHEMBL1394292 & 688128 & 4.1 & 4.5585 & TRN & \\
\hline CHEMBL1967099 & 688128 & 4.7 & 4.533 & TRN & \\
\hline CHEMBL1568308 & 688128 & 5.3 & $4.6080 e$ & 00000000005 & TRN \\
\hline CHEMBL1533416 & 688128 & 4.5 & 4.3845 & TRN & \\
\hline CHEMBL1603177 & 688128 & 4.3 & 4.4169 & TRN & \\
\hline CHEMBL3192178 & 688128 & 4.3 & 4.4171 & TRN & \\
\hline CHEMBL1369992 & 688128 & 5.45 & 4.4921 & TST & \\
\hline CHEMBL1445127 & 688128 & 4.4 & 4.6925 & TRN & \\
\hline CHEMBL1569550 & 688128 & 4.45 & 4.7787 & TRN & \\
\hline CHEMBL1610637 & 688128 & 5.65 & 4.7741 & TRN & \\
\hline CHEMBL1438361 & 688128 & 4.05 & 4.4759 & TRN & \\
\hline CHEMBL1313924 & 688128 & 5.05 & 4.7343 & TRN & \\
\hline CHEMBL1490628 & 688128 & 4.1 & 4.7087 & TRN & \\
\hline CHEMBL1426892 & 688128 & 4.4 & 4.662 & TST & \\
\hline CHEMBL1549746 & 688128 & 4.3 & 4.3268 & TRN & \\
\hline CHEMBL1489879 & 688128 & 4.75 & 4.6455 & TRN & \\
\hline CHEMBL3213075 & 688128 & 5.4 & 4.5785 & TRN & \\
\hline
\end{tabular}




\begin{tabular}{|c|c|c|c|c|c|}
\hline \multicolumn{6}{|c|}{ Supplemental Table s2.txt } \\
\hline CHEMBL1601151 & 688128 & 4.6 & 4.6092 & TRN & \\
\hline CHEMBL1333743 & 688128 & 4.4 & 4.6522 & TRN & \\
\hline CHEMBL1456946 & 688128 & 4.85 & 4.5014 & TRN & \\
\hline CHEMBL1985591 & 688128 & 4.75 & 4.6553 & TRN & \\
\hline CHEMBL1576754 & 688128 & 5.35 & 4.9425 & TRN & \\
\hline CHEMBL1428282 & 688128 & 4.35 & 4.5415 & TRN & \\
\hline CHEMBL1482850 & 688128 & 4.25 & 4.7647 & TST & \\
\hline CHEMBL 3213580 & 688128 & 4.4 & 4.7002 & TRN & \\
\hline CHEMBL1348989 & 688128 & 4.5 & 4.4389 & TRN & \\
\hline CHEMBL1475164 & 688128 & 5.65 & 4.8895 & TRN & \\
\hline CHEMBL1538591 & 688128 & 4.3 & 4.3489 & TRN & \\
\hline CHEMBL1575143 & 688128 & 6.45 & 4.6067 & TST & \\
\hline CHEMBL1503500 & 688128 & 4.35 & 4.3551 & TRN & \\
\hline CHEMBL1435705 & 688128 & 4.25 & 4.8785 & TRN & \\
\hline CHEMBL1542620 & 688128 & 4.45 & 4.4799 & TRN & \\
\hline CHEMBL1522314 & 688128 & 7.0 & 4.8937 & TRN & \\
\hline CHEMBL1538686 & 688128 & 4.25 & 4.6818 & TRN & \\
\hline CHEMBL1345516 & 688128 & 4.3 & 4.6973 & TST & \\
\hline CHEMBL1310113 & 688128 & 4.8 & 4.4346 & TRN & \\
\hline CHEMBL1494067 & 688128 & 4.4 & 4.7015 & TRN & \\
\hline CHEMBL3211206 & 688128 & 4.35 & 4.6368 & TRN & \\
\hline CHEMBL1514534 & 688128 & 5.5 & 4.8484 & TRN & \\
\hline CHEMBL1479752 & 688128 & 4.4 & 4.6617 & TRN & \\
\hline CHEMBL1399976 & 688128 & 4.85 & 4.4317 & TRN & \\
\hline CHEMBL1404387 & 688128 & 4.8 & 4.7009 & TRN & \\
\hline CHEMBL1341524 & 688128 & 4.6 & 4.8061 & TRN & \\
\hline CHEMBL1570637 & 688128 & 5.3 & 5.2433 & TST & \\
\hline CHEMBL1426338 & 688128 & 4.0 & 4.5288 & TRN & \\
\hline CHEMBL1446517 & 688128 & 5.4 & 4.8039 & TST & \\
\hline CHEMBL1553760 & 688128 & 4.55 & 4.3341 & TRN & \\
\hline CHEMBL1363844 & 688128 & 4.75 & 4.4853 & TST & \\
\hline CHEMBL1380111 & 688128 & 4.35 & 4.5793 & TST & \\
\hline CHEMBL1497427 & 688128 & 4.9 & 4.6124 & TRN & \\
\hline CHEMBL1399950 & 688128 & 4.0 & 4.5612 & TST & \\
\hline CHEMBL1308009 & 688128 & 4.45 & 4.7378 & TRN & \\
\hline CHEMBL3208743 & 688128 & 4.4 & 4.7456 & TST & \\
\hline CHEMBL1419468 & 688128 & 4.35 & 4.567 & TRN & \\
\hline CHEMBL1468152 & 688128 & 4.4 & 4.9989 & TRN & \\
\hline CHEMBL1586459 & 688128 & 4.35 & 4.77800 & 00000000005 & \\
\hline CHEMBL1394871 & 688128 & 4.3 & 4.4943 & TRN & \\
\hline CHEMBL1586726 & 688128 & 4.4 & 4.5406 & TRN & \\
\hline CHEMBL1420841 & 688128 & 4.0 & 4.4675 & TST & \\
\hline CHEMBL1306846 & 688128 & 4.3 & 5.0257 & TRN & \\
\hline CHEMBL1510664 & 688128 & 4.7 & 4.9586 & TST & \\
\hline CHEMBL1359549 & 688128 & 4.4 & 4.8236 & TRN & \\
\hline CHEMBL1536278 & 688128 & 6.0 & 4.9521 & TRN & \\
\hline CHEMBL1474902 & 688128 & 5.1 & 5.129 & TRN & \\
\hline CHEMBL3212638 & 688128 & 4.45 & 4.5121 & TST & \\
\hline
\end{tabular}




\begin{tabular}{|c|c|c|c|c|c|}
\hline & & \multicolumn{4}{|c|}{ Supplemental Table s2.txt } \\
\hline CHEMBL3207893 & 688128 & 4.4 & 4.694 & TRN & \\
\hline CHEMBL 3198160 & 688128 & 4.25 & 4.7521 & TRN & \\
\hline CHEMBL1366689 & 688128 & 4.0 & 4.734 & TRN & \\
\hline CHEMBL1338332 & 688128 & 5.0 & 4.7913 & TRN & \\
\hline CHEMBL1383845 & 688128 & 5.4 & 4.8042 & TRN & \\
\hline CHEMBL1402905 & 688128 & 4.4 & 4.5019 & TRN & \\
\hline CHEMBL1491014 & 688128 & 6.1 & 4.6498 & TRN & \\
\hline CHEMBL3199451 & 688128 & 4.55 & 4.6882 & TRN & \\
\hline CHEMBL1541675 & 688128 & 4.35 & 4.5429 & TRN & \\
\hline CHEMBL166415 & 688128 & 4.3 & 4.8051 & TST & \\
\hline CHEMBL1325422 & 688128 & 3.95 & 4.6207 & TRN & \\
\hline CHEMBL1485480 & 688128 & 4.55 & 4.7223 & TST & \\
\hline CHEMBL1331283 & 688128 & 4.05 & 4.6035 & TRN & \\
\hline CHEMBL1359232 & 688128 & 4.05 & 4.5705 & TRN & \\
\hline CHEMBL1425175 & 688128 & 4.75 & 4.82 & TRN & \\
\hline CHEMBL1352626 & 688128 & 5.05 & 4.6659 & TRN & \\
\hline CHEMBL1492493 & 688128 & 6.8 & 4.2929 & TRN & \\
\hline CHEMBL1376855 & 688128 & 4.1 & 4.7427 & TST & \\
\hline CHEMBL1421466 & 688128 & 4.6 & 4.6345 & TRN & \\
\hline CHEMBL1506907 & 688128 & 4.4 & 4.6512 & TRN & \\
\hline CHEMBL1509182 & 688128 & 4.3 & 4.98 & TRN & \\
\hline CHEMBL1523699 & 688128 & 5.85 & 5.2373 & TRN & \\
\hline CHEMBL3195858 & 688128 & 4.05 & 4.4765 & TST & \\
\hline CHEMBL1473453 & 688128 & 4.45 & 4.3919 & TRN & \\
\hline CHEMBL1415547 & 688128 & 4.4 & 4.6513 & TRN & \\
\hline CHEMBL1313717 & 688128 & 4.4 & 4.793 & TST & \\
\hline CHEMBL1553556 & 688128 & 4.35 & 4.5854 & TRN & \\
\hline CHEMBL1505341 & 688128 & 4.45 & 4.4911 & TST & \\
\hline CHEMBL1362890 & 688128 & 4.7 & 4.9282 & TRN & \\
\hline CHEMBL1468499 & 688128 & 4.65 & 4.8027 & TRN & \\
\hline CHEMBL1472513 & 688128 & 6.5 & 5.1320 & 0000000001 & TRN \\
\hline CHEMBL1597942 & 688128 & 4.6 & 4.606 & TRN & \\
\hline CHEMBL1367851 & 688128 & 4.65 & 4.7147 & TRN & \\
\hline CHEMBL1610322 & 688128 & 4.15 & 4.3159 & TRN & \\
\hline CHEMBL1339493 & 688128 & 4.5 & 4.5819 & TRN & \\
\hline CHEMBL1512015 & 688128 & 4.35 & 4.83 & TRN & \\
\hline CHEMBL1369099 & 688128 & 5.3 & 4.8251 & TRN & \\
\hline CHEMBL1564875 & 688128 & 4.65 & 4.5454 & TRN & \\
\hline CHEMBL1405414 & 688128 & 5.55 & 5.0191 & TRN & \\
\hline CHEMBL1497123 & 688128 & 4.35 & 4.2331 & TRN & \\
\hline CHEMBL1451216 & 688128 & 5.05 & 5.1207 & TST & \\
\hline CHEMBL1589050 & 688128 & 4.35 & 4.6148 & TRN & \\
\hline CHEMBL1340535 & 688128 & 5.8 & 4.7366 & TRN & \\
\hline CHEMBL1508955 & 688128 & 4.4 & 4.4396 & TST & \\
\hline CHEMBL1598098 & 688128 & 4.45 & 4.5023 & TRN & \\
\hline CHEMBL3211409 & 688128 & 4.3 & 4.5726 & TST & \\
\hline CHEMBL1362734 & 688128 & 5.4 & 5.2228 & TRN & \\
\hline CHEMBL1409426 & 688128 & 4.25 & 4.7053 & TRN & \\
\hline
\end{tabular}




\begin{tabular}{|c|c|c|c|c|}
\hline \multicolumn{5}{|c|}{ Supplemental Tabl } \\
\hline CHEMBL1531875 & 688128 & 5.35 & 4.4736 & TST \\
\hline CHEMBL1526332 & 688128 & 4.3 & 4.5083 & TRN \\
\hline CHEMBL1411867 & 688128 & 4.35 & 4.5679 & TRN \\
\hline CHEMBL1585095 & 688128 & 4.05 & 4.7173 & TST \\
\hline CHEMBL1441993 & 688128 & 4.35 & 4.5186 & TRN \\
\hline CHEMBL1445717 & 688128 & 6.0 & 4.8973 & TRN \\
\hline CHEMBL1300047 & 688128 & 5.55 & 5.3082 & TRN \\
\hline CHEMBL1311809 & 688128 & 4.35 & 4.4611 & TRN \\
\hline CHEMBL1442779 & 688128 & 4.25 & 4.5626 & TRN \\
\hline CHEMBL1392389 & 688128 & 4.25 & 4.6811 & TST \\
\hline CHEMBL1586738 & 688128 & 4.3 & 4.4904 & TRN \\
\hline CHEMBL1557832 & 688128 & 5.5 & 5.2624 & TRN \\
\hline CHEMBL 3208357 & 688128 & 4.3 & 4.6207 & TRN \\
\hline CHEMBL1481763 & 688128 & 4.0 & 4.4033 & TST \\
\hline CHEMBL 3190104 & 688128 & 4.45 & 4.9179 & TRN \\
\hline CHEMBL1366717 & 688128 & 4.35 & 4.5683 & TRN \\
\hline CHEMBL1566471 & 688128 & 4.4 & 4.6225 & TRN \\
\hline CHEMBL1414222 & 688128 & 4.7 & 4.8355 & TRN \\
\hline CHEMBL1595235 & 688128 & 4.8 & 4.9329 & TRN \\
\hline CHEMBL1410883 & 688128 & 4.1 & 4.3435 & TST \\
\hline CHEMBL1551917 & 688128 & 5.1 & 4.8259 & TRN \\
\hline CHEMBL1600891 & 688128 & 4.35 & 4.3623 & TRN \\
\hline CHEMBL1368166 & 688128 & 4.85 & 4.3909 & TRN \\
\hline CHEMBL1445943 & 688128 & 4.7 & 4.806 & TRN \\
\hline CHEMBL1520159 & 688128 & 4.35 & 4.4477 & TST \\
\hline CHEMBL1370873 & 688128 & 5.45 & 4.6718 & TRN \\
\hline CHEMBL1429992 & 688128 & 4.9 & 4.8096 & TRN \\
\hline CHEMBL1461989 & 688128 & 4.65 & 4.5427 & TRN \\
\hline CHEMBL1612042 & 688128 & 4.45 & 5.4056 & TST \\
\hline CHEMBL1501558 & 688128 & 5.35 & 5.5131 & TRN \\
\hline CHEMBL1466334 & 688128 & 4.35 & 5.0957 & TRN \\
\hline CHEMBL1480879 & 688128 & 4.05 & 4.5186 & TRN \\
\hline CHEMBL1328768 & 688128 & 4.85 & 4.8334 & TST \\
\hline CHEMBL1569896 & 688128 & 4.45 & 4.7398 & TRN \\
\hline CHEMBL1472003 & 688128 & 5.4 & 4.7903 & TRN \\
\hline CHEMBL3195623 & 688128 & 4.4 & 4.5643 & TRN \\
\hline CHEMBL3197262 & 688128 & 4.4 & 4.7824 & TRN \\
\hline CHEMBL1440231 & 688128 & 4.35 & 4.6957 & TRN \\
\hline CHEMBL1573082 & 688128 & 5.8 & 4.5803 & TRN \\
\hline CHEMBL1434716 & 688128 & 4.45 & 4.6155 & TST \\
\hline CHEMBL1326032 & 688128 & 4.3 & 4.6891 & TRN \\
\hline CHEMBL1508382 & 688128 & 4.75 & 4.7687 & TST \\
\hline CHEMBL1329770 & 688128 & 5.6 & 5.1878 & TRN \\
\hline CHEMBL3190631 & 688128 & 4.3 & 4.5255 & TRN \\
\hline CHEMBL1320701 & 688128 & 4.05 & 4.6307 & TST \\
\hline CHEMBL1312698 & 688128 & 4.45 & 4.8781 & TST \\
\hline CHEMBL1544683 & 688128 & 4.35 & 4.7831 & TST \\
\hline CHEMBL1307587 & 688128 & 4.5 & 4.4568 & TRN \\
\hline
\end{tabular}




\begin{tabular}{|c|c|c|c|c|c|}
\hline & & \multicolumn{4}{|c|}{ Supplemental Table S2.txt } \\
\hline CHEMBL1529512 & 688128 & 4.1 & 4.9346 & TST & \\
\hline CHEMBL1324679 & 688128 & 4.05 & 4.5221 & TRN & \\
\hline CHEMBL1588434 & 688128 & 4.4 & 4.8974 & TRN & \\
\hline CHEMBL 3210083 & 688128 & 4.35 & 4.3479 & TST & \\
\hline CHEMBL1387416 & 688128 & 4.6 & 4.61600 & 00000000005 & TRN \\
\hline CHEMBL1558005 & 688128 & 4.55 & 4.6693 & TRN & \\
\hline CHEMBL1477477 & 688128 & 4.35 & 4.3831 & TRN & \\
\hline CHEMBL1398169 & 688128 & 4.95 & 4.9015 & TRN & \\
\hline CHEMBL1585844 & 688128 & 4.6 & 4.7639 & TST & \\
\hline CHEMBL1343069 & 688128 & 6.0 & 5.0662 & TRN & \\
\hline CHEMBL1547498 & 688128 & 4.45 & 4.6623 & TRN & \\
\hline CHEMBL1537576 & 688128 & 4.1 & 4.57100 & 2000000001 & TRN \\
\hline CHEMBL1358059 & 688128 & 5.4 & 4.5093 & TRN & \\
\hline CHEMBL51085 & 688128 & 4.35 & 4.8969 & TST & \\
\hline CHEMBL1553011 & 688128 & 4.45 & 4.7337 & TRN & \\
\hline CHEMBL1575386 & 688128 & 4.4 & 4.5156 & TRN & \\
\hline CHEMBL1497591 & 688128 & 4.35 & 4.7612 & TRN & \\
\hline CHEMBL1309000 & 688128 & 5.65 & 5.2851 & TRN & \\
\hline CHEMBL1559159 & 688128 & 4.4 & 4.7723 & TST & \\
\hline CHEMBL1354906 & 688128 & 4.85 & 4.5769 & TRN & \\
\hline CHEMBL1485592 & 688128 & 6.1 & 4.474 & TST & \\
\hline CHEMBL1489956 & 688128 & 5.3 & 5.013 & TST & \\
\hline CHEMBL1485454 & 688128 & 4.05 & 4.7598 & TST & \\
\hline CHEMBL1430584 & 688128 & 4.35 & 5.0897 & TST & \\
\hline CHEMBL3196760 & 688128 & 6.9 & 4.7738 & TRN & \\
\hline CHEMBL1365142 & 688128 & 4.45 & 4.3346 & TRN & \\
\hline CHEMBL1562719 & 688128 & 4.65 & 4.3506 & TRN & \\
\hline CHEMBL1403291 & 688128 & 5.75 & 4.6363 & TRN & \\
\hline CHEMBL1510740 & 688128 & 4.35 & 4.5252 & TRN & \\
\hline CHEMBL1573902 & 688128 & 4.4 & 4.5977 & TRN & \\
\hline CHEMBL1528715 & 688128 & 6.15 & 4.7694 & TST & \\
\hline CHEMBL1310248 & 688128 & 4.45 & 4.7386 & TRN & \\
\hline CHEMBL1586196 & 688128 & 5.65 & 4.5249 & TST & \\
\hline CHEMBL1489099 & 688128 & 4.05 & 4.7609 & TRN & \\
\hline CHEMBL1381518 & 688128 & 4.65 & 4.6309 & TRN & \\
\hline CHEMBL1565029 & 688128 & 4.6 & 4.556 & TRN & \\
\hline CHEMBL1534974 & 688128 & 4.5 & 4.5584 & TRN & \\
\hline CHEMBL1300192 & 688128 & 4.6 & 4.5913 & TRN & \\
\hline CHEMBL1367933 & 688128 & 5.2 & 4.6095 & TST & \\
\hline CHEMBL1495442 & 688128 & 4.4 & 4.3676 & TRN & \\
\hline CHEMBL1595521 & 688128 & 5.35 & 4.7664 & TST & \\
\hline CHEMBL1578925 & 688128 & 4.0 & 4.6722 & TRN & \\
\hline CHEMBL1534636 & 688128 & 4.35 & 4.7577 & TST & \\
\hline CHEMBL1458047 & 688128 & 4.05 & 4.76 & TRN & \\
\hline CHEMBL1573754 & 688128 & 4.95 & 4.4976 & TST & \\
\hline CHEMBL1372604 & 688128 & 4.35 & 4.5226 & TRN & \\
\hline CHEMBL1352888 & 688128 & 4.25 & 4.2402 & TRN & \\
\hline CHEMBL1587024 & 688128 & 4.05 & 4.4371 & TRN & \\
\hline
\end{tabular}




\begin{tabular}{|c|c|c|c|c|}
\hline \multicolumn{5}{|c|}{ olemental I } \\
\hline CHEMBL1404000 & 688128 & 4.5 & 4.6144 & TST \\
\hline CHEMBL1380776 & 688128 & 4.6 & 4.5512 & TRN \\
\hline CHEMBL1396580 & 688128 & 4.35 & 4.7292 & TRN \\
\hline CHEMBL1308482 & 688128 & 4.25 & 4.5873 & TST \\
\hline CHEMBL1301528 & 688128 & 4.5 & 4.7426 & TRN \\
\hline CHEMBL1412563 & 688128 & 5.2 & 4.6222 & TRN \\
\hline CHEMBL1300007 & 688128 & 4.75 & 4.5931 & TRN \\
\hline CHEMBL1336377 & 688128 & 4.4 & 4.5857 & TRN \\
\hline CHEMBL1341030 & 688128 & 5.2 & 4.4218 & TST \\
\hline CHEMBL1361441 & 688128 & 4.4 & 4.4958 & TRN \\
\hline CHEMBL1505930 & 688128 & 4.1 & 4.5595 & TRN \\
\hline CHEMBL1332924 & 688128 & 4.35 & 4.6314 & TRN \\
\hline CHEMBL192009 & 688128 & 4.6 & 4.7061 & TRN \\
\hline CHEMBL1496259 & 688128 & 4.3 & 4.4676 & TRN \\
\hline CHEMBL1383075 & 688128 & 4.3 & 4.6888 & TRN \\
\hline CHEMBL1215100 & 688128 & 5.85 & 4.7745 & TRN \\
\hline CHEMBL1372303 & 688128 & 4.9 & 4.4424 & TRN \\
\hline CHEMBL1611402 & 688128 & 4.1 & 4.2571 & TRN \\
\hline CHEMBL1394870 & 688128 & 4.05 & 4.3461 & TRN \\
\hline CHEMBL1423597 & 688128 & 5.6 & 5.0293 & TRN \\
\hline CHEMBL1581356 & 688128 & 4.3 & 4.8052 & TRN \\
\hline CHEMBL1986893 & 688128 & 4.4 & 4.7656 & TST \\
\hline CHEMBL1601657 & 688128 & 4.3 & 4.6414 & TST \\
\hline CHEMBL1590647 & 688128 & 4.3 & 4.6297 & TST \\
\hline CHEMBL1476059 & 688128 & 6.1 & 4.4398 & TRN \\
\hline CHEMBL1343585 & 688128 & 4.05 & 4.6704 & TST \\
\hline CHEMBL1496674 & 688128 & 4.2 & 4.7325 & TRN \\
\hline CHEMBL3191137 & 688128 & 4.3 & 4.199 & TRN \\
\hline CHEMBL1558011 & 688128 & 4.4 & 4.6868 & TST \\
\hline CHEMBL1496605 & 688128 & 6.4 & 4.1955 & TST \\
\hline CHEMBL1457004 & 688128 & 4.3 & 4.7406 & TRN \\
\hline CHEMBL1587671 & 688128 & 4.35 & 4.5486 & TRN \\
\hline CHEMBL1607032 & 688128 & 4.35 & 4.4903 & TRN \\
\hline CHEMBL1378644 & 688128 & 4.45 & 4.9166 & TRN \\
\hline CHEMBL 3208371 & 688128 & 4.35 & 4.6231 & TRN \\
\hline CHEMBL1458501 & 688128 & 4.05 & 4.6461 & TRN \\
\hline CHEMBL1313231 & 688128 & 4.4 & 4.7594 & TST \\
\hline CHEMBL1392176 & 688128 & 4.55 & 4.6299 & TST \\
\hline CHEMBL1529978 & 688128 & 4.9 & 4.7286 & TRN \\
\hline CHEMBL 1480853 & 688128 & 4.35 & 4.63399 & 99999999995 \\
\hline CHEMBL1414391 & 688128 & 4.35 & 4.6719 & TST \\
\hline CHEMBL1399971 & 688128 & 4.35 & 4.5945 & TRN \\
\hline CHEMBL1463876 & 688128 & 4.45 & 4.4646 & TRN \\
\hline CHEMBL1599132 & 688128 & 4.0 & 4.7645 & TST \\
\hline CHEMBL1420384 & 688128 & 4.05 & 4.4612 & TST \\
\hline CHEMBL1350028 & 688128 & 4.35 & 4.4265 & TRN \\
\hline CHEMBL1544759 & 688128 & 4.4 & 4.6427 & TST \\
\hline CHEMBL1404930 & 688128 & 4.3 & 4.4006 & TRN \\
\hline
\end{tabular}




\begin{tabular}{|c|c|c|c|c|c|}
\hline \\
\hline CHEMBL1327552 & 688128 & 4.3 & 4.5681 & TST & \\
\hline CHEMBL3145192 & 688128 & 5.1 & 5.3595 & TRN & \\
\hline CHEMBL1364540 & 688128 & 5.45 & 4.5074 & TST & \\
\hline CHEMBL1454592 & 688128 & 4.0 & 4.67399 & 99999999995 & TRN \\
\hline CHEMBL1330727 & 688128 & 4.9 & 4.6347 & TRN & \\
\hline CHEMBL1384686 & 688128 & 4.05 & 4.2882 & TRN & \\
\hline CHEMBL1568684 & 688128 & 4.75 & 4.819 & TRN & \\
\hline CHEMBL1417890 & 688128 & 4.35 & 4.6321 & TRN & \\
\hline CHEMBL1562950 & 688128 & 4.5 & 4.4085 & TRN & \\
\hline CHEMBL1423152 & 688128 & 4.05 & 4.5402 & TRN & \\
\hline CHEMBL1495722 & 688128 & 6.0 & 4.9159 & TST & \\
\hline CHEMBL1312656 & 688128 & 4.3 & 4.8935 & TRN & \\
\hline CHEMBL1442788 & 688128 & 5.45 & 4.8144 & TST & \\
\hline CHEMBL1534171 & 688128 & 4.45 & 4.5224 & TRN & \\
\hline CHEMBL257359 & 688128 & 4.95 & 4.8962 & TRN & \\
\hline CHEMBL1589426 & 688128 & 4.35 & 4.3951 & TRN & \\
\hline CHEMBL1339049 & 688128 & 4.25 & 4.5122 & TRN & \\
\hline CHEMBL3194933 & 688128 & 4.05 & 4.7499 & TRN & \\
\hline CHEMBL1360040 & 688128 & 4.3 & 4.4691 & TRN & \\
\hline CHEMBL1325451 & 688128 & 5.15 & 4.9041 & TST & \\
\hline CHEMBL1300000 & 688128 & 6.05 & 4.864 & TRN & \\
\hline CHEMBL1514264 & 688128 & 4.35 & 4.6398 & TRN & \\
\hline CHEMBL562036 & 688128 & 4.3 & 4.449 & TRN & \\
\hline CHEMBL1368728 & 688128 & 4.3 & 4.7289 & TRN & \\
\hline CHEMBL1484303 & 688128 & 4.5 & 5.23799 & 99999999995 & TST \\
\hline CHEMBL1549978 & 688128 & 4.4 & 4.8063 & TRN & \\
\hline CHEMBL1392392 & 688128 & 4.55 & 4.5663 & TRN & \\
\hline CHEMBL1528621 & 688128 & 4.05 & 4.731 & TST & \\
\hline CHEMBL1610198 & 688128 & 4.6 & 4.3571 & TST & \\
\hline CHEMBL1529146 & 688128 & 5.5 & 5.0423 & TRN & \\
\hline CHEMBL1576815 & 688128 & 4.35 & 4.7946 & TST & \\
\hline CHEMBL1568540 & 688128 & 4.3 & 4.6048 & TRN & \\
\hline CHEMBL1586859 & 688128 & 4.35 & 4.5258 & TRN & \\
\hline CHEMBL1997581 & 688128 & 4.9 & 4.5865 & TRN & \\
\hline CHEMBL1424070 & 688128 & 7.0 & 4.382 & TRN & \\
\hline CHEMBL3196672 & 688128 & 5.55 & 4.4791 & TRN & \\
\hline CHEMBL1367420 & 688128 & 4.4 & 4.5145 & TRN & \\
\hline CHEMBL1401211 & 688128 & 6.25 & 5.0466 & TRN & \\
\hline CHEMBL1316502 & 688128 & 4.4 & 4.3761 & TRN & \\
\hline CHEMBL 1460586 & 688128 & 4.6 & 4.7269 & TRN & \\
\hline CHEMBL1485148 & 688128 & 4.3 & 5.3563 & TRN & \\
\hline CHEMBL1360902 & 688128 & 6.5 & 5.1668 & TRN & \\
\hline CHEMBL1403156 & 688128 & 4.8 & 4.7895 & TRN & \\
\hline CHEMBL1583319 & 688128 & 5.2 & 4.7485 & TRN & \\
\hline CHEMBL1985664 & 688128 & 4.45 & 4.7901 & TST & \\
\hline CHEMBL1369455 & 688128 & 4.55 & 4.4109 & TRN & \\
\hline CHEMBL1535150 & 688128 & 4.5 & 4.8497 & TRN & \\
\hline CHEMBL1434906 & 688128 & 4.75 & 4.6182 & TRN & \\
\hline
\end{tabular}




\begin{tabular}{|c|c|c|c|c|c|}
\hline \multirow{2}{*}{ CHEMBL1549495 } & \multirow{2}{*}{688128} & \\
\hline & & 4.6 & 4.4737 & \multicolumn{2}{|l|}{ TRN } \\
\hline CHEMBL1301917 & 688128 & 4.6 & 4.6619 & \multicolumn{2}{|l|}{ TRN } \\
\hline CHEMBL1415990 & 688128 & 4.8 & 4.3925 & \multicolumn{2}{|l|}{ TRN } \\
\hline CHEMBL1415203 & 688128 & 4.35 & 4.6401 & \multicolumn{2}{|l|}{ TRN } \\
\hline CHEMBL1607948 & 688128 & 4.5 & 4.8037 & \multicolumn{2}{|l|}{ TRN } \\
\hline CHEMBL1500890 & 688128 & 4.4 & 4.4702 & \multicolumn{2}{|l|}{ TRN } \\
\hline CHEMBL3194608 & 688128 & 4.65 & 4.5564 & \multicolumn{2}{|l|}{ TST } \\
\hline CHEMBL1381433 & 688128 & 5.05 & 5.3213 & \multicolumn{2}{|l|}{ TRN } \\
\hline CHEMBL1499170 & 688128 & 5.0 & 4.5698 & \multicolumn{2}{|l|}{ TRN } \\
\hline CHEMBL1593508 & 688128 & 4.55 & 4.4959 & \multicolumn{2}{|l|}{ TRN } \\
\hline CHEMBL1346260 & 688128 & 4.55 & 4.8065 & \multicolumn{2}{|l|}{ TST } \\
\hline CHEMBL3190473 & 688128 & 4.35 & 4.5864 & \multicolumn{2}{|l|}{ TRN } \\
\hline CHEMBL1353013 & 688128 & 5.45 & 5.4234 & \multicolumn{2}{|l|}{ TRN } \\
\hline CHEMBL1304402 & 688128 & 5.9 & 5.3671 & \multicolumn{2}{|l|}{ TRN } \\
\hline CHEMBL 2000633 & 688128 & 5.8 & 4.8178 & \multicolumn{2}{|l|}{ TRN } \\
\hline CHEMBL1597805 & 688128 & 4.0 & 4.4065 & \multicolumn{2}{|l|}{ TST } \\
\hline CHEMBL1546783 & 688128 & 4.35 & 4.567 & \multicolumn{2}{|l|}{ TRN } \\
\hline CHEMBL1602429 & 688128 & 4.25 & 4.4467 & \multicolumn{2}{|l|}{ TST } \\
\hline CHEMBL1561321 & 688128 & 4.2 & 5.26399 & 9999999999 & TST \\
\hline CHEMBL1483768 & 688128 & 4.4 & 4.7358 & TRN & \\
\hline CHEMBL3192298 & 688128 & 4.4 & 4.6587 & TST & \\
\hline CHEMBL1583296 & 688128 & 4.0 & 4.4692 & TRN & \\
\hline CHEMBL1357482 & 688128 & 4.2 & 4.5897 & TRN & \\
\hline CHEMBL1312576 & 688128 & 4.05 & 4.6201 & TST & \\
\hline CHEMBL1602465 & 688128 & 4.45 & 4.5538 & TRN & \\
\hline CHEMBL1346987 & 688128 & 4.35 & 4.4322 & TRN & \\
\hline CHEMBL1608468 & 688128 & 4.35 & 4.4102 & TRN & \\
\hline CHEMBL1549698 & 688128 & 4.3 & 4.4632 & TRN & \\
\hline CHEMBL1546199 & 688128 & 4.35 & 4.8645 & TST & \\
\hline CHEMBL1533452 & 688128 & 4.3 & 4.3673 & TRN & \\
\hline CHEMBL1544101 & 688128 & 4.25 & 4.5313 & TRN & \\
\hline CHEMBL39878 & 688128 & 4.3 & 4.5314 & TRN & \\
\hline CHEMBL1589626 & 688128 & 4.45 & 4.632 & TRN & \\
\hline CHEMBL1399074 & 688128 & 4.8 & 4.8606 & TST & \\
\hline CHEMBL1321487 & 688128 & 5.45 & 4.6266 & TST & \\
\hline CHEMBL1399943 & 688128 & 4.4 & 5.1279 & 9999999999 & TRN \\
\hline CHEMBL1542048 & 688128 & 4.5 & 4.7619 & TRN & \\
\hline CHEMBL1396518 & 688128 & 4.65 & 4.6984 & TRN & \\
\hline CHEMBL1300165 & 688128 & 4.5 & 4.4951 & TRN & \\
\hline CHEMBL1594034 & 688128 & 4.35 & 4.7377 & TRN & \\
\hline CHEMBL1308302 & 688128 & 4.4 & 4.5795 & TRN & \\
\hline CHEMBL1421979 & 688128 & 4.3 & 4.5981 & TRN & \\
\hline CHEMBL1460635 & 688128 & 4.3 & 4.9491 & TST & \\
\hline CHEMBL1578022 & 688128 & 4.35 & 4.4516 & TRN & \\
\hline CHEMBL1428977 & 688128 & 4.55 & 4.592 & TRN & \\
\hline CHEMBL1465987 & 688128 & 4.55 & 4.601 & TRN & \\
\hline CHEMBL1405194 & 688128 & 6.0 & 4.4196 & TRN & \\
\hline CHEMBL1347495 & 688128 & 4.4 & $4.5360 e$ & 00000000005 & TRN \\
\hline & & & & 16045 & \\
\hline
\end{tabular}




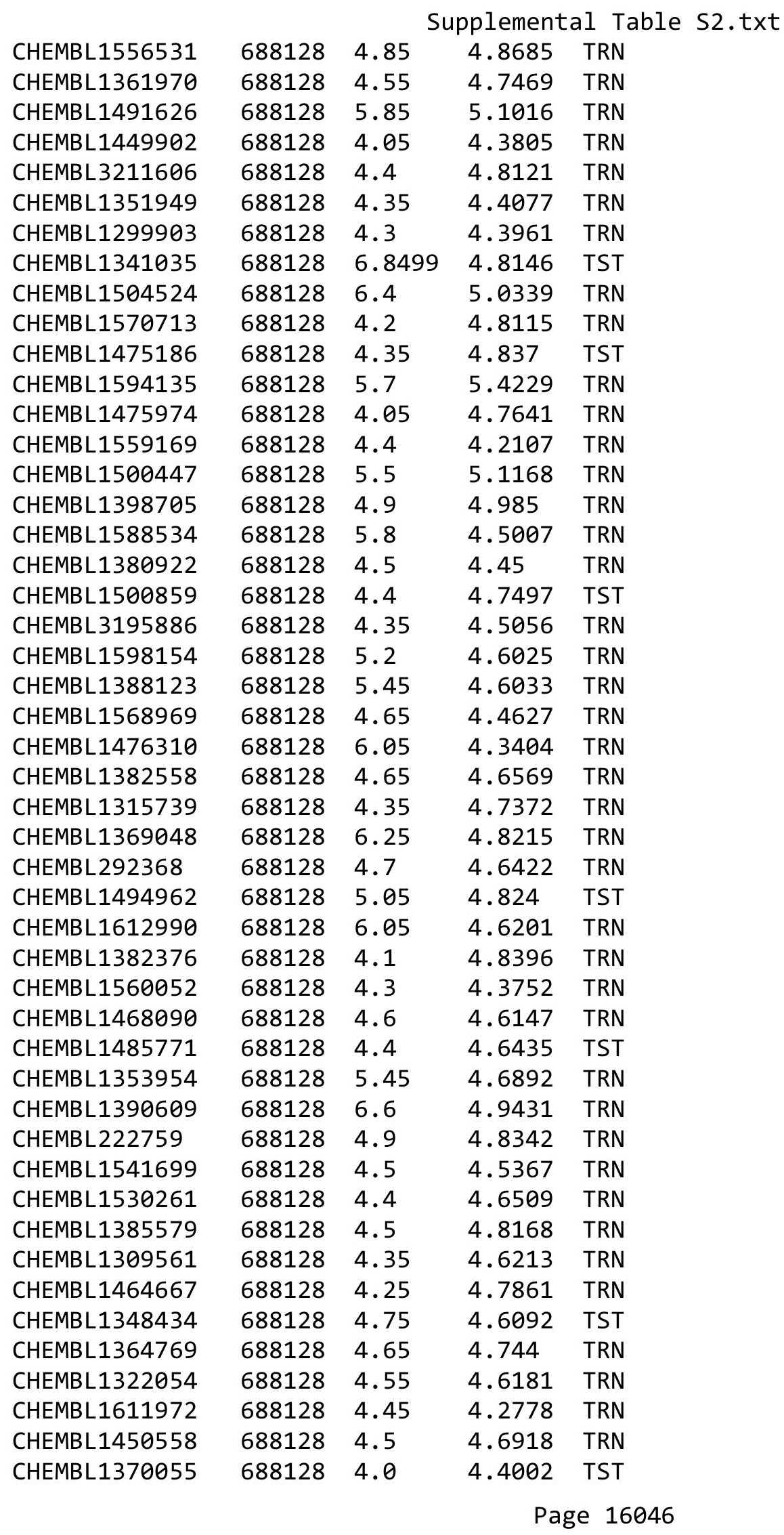




\begin{tabular}{|c|c|c|c|c|c|}
\hline \\
\hline CHEMBL1317757 & 688128 & 4.4 & 4.4669 & TRN & \\
\hline CHEMBL1537619 & 688128 & 4.7 & 4.3444 & TRN & \\
\hline CHEMBL1435257 & 688128 & 4.05 & 4.5821 & TST & \\
\hline CHEMBL1359869 & 688128 & 4.6 & 4.6811 & TRN & \\
\hline CHEMBL1506249 & 688128 & 5.3 & 4.6592 & TRN & \\
\hline CHEMBL1520020 & 688128 & 6.0 & 4.6208 & TRN & \\
\hline CHEMBL1526036 & 688128 & 5.55 & 4.7748 & TST & \\
\hline CHEMBL1483299 & 688128 & 4.4 & 4.739 & TRN & \\
\hline CHEMBL 2007077 & 688128 & 4.65 & 4.8092 & TRN & \\
\hline CHEMBL1540929 & 688128 & 6.3 & 5.1516 & TRN & \\
\hline CHEMBL1462159 & 688128 & 4.05 & 4.6521 & TRN & \\
\hline CHEMBL1511814 & 688128 & 4.45 & 4.3991 & TRN & \\
\hline CHEMBL1566738 & 688128 & 4.3 & 4.3749 & TRN & \\
\hline CHEMBL1406030 & 688128 & 4.4 & 4.5943 & TRN & \\
\hline CHEMBL1364766 & 688128 & 4.7 & 4.5504 & TRN & \\
\hline CHEMBL1342253 & 688128 & 4.05 & 4.5228 & TST & \\
\hline CHEMBL1332865 & 688128 & 4.4 & 4.4593 & TRN & \\
\hline CHEMBL1412489 & 688128 & 6.35 & 4.9451 & TST & \\
\hline CHEMBL1466228 & 688128 & 4.35 & 4.3923 & TRN & \\
\hline CHEMBL1485089 & 688128 & 4.3 & 4.6015 & TRN & \\
\hline CHEMBL 2004291 & 688128 & 5.15 & 4.6196 & TRN & \\
\hline CHEMBL1983549 & 688128 & 4.25 & 4.4445 & TRN & \\
\hline CHEMBL1979383 & 688128 & 4.35 & 4.5834 & TRN & \\
\hline CHEMBL1339090 & 688128 & 4.35 & 4.7938 & TRN & \\
\hline CHEMBL1305519 & 688128 & 4.65 & 4.3601 & TRN & \\
\hline CHEMBL1506327 & 688128 & 4.3 & 4.5891 & TRN & \\
\hline CHEMBL1480478 & 688128 & 5.3 & 4.671 & TRN & \\
\hline CHEMBL590186 & 688128 & 4.55 & 4.957 & TRN & \\
\hline CHEMBL1432404 & 688128 & 4.05 & 4.4422 & TRN & \\
\hline CHEMBL1480442 & 688128 & 4.65 & 4.7864 & TRN & \\
\hline CHEMBL1613045 & 688128 & 4.65 & 4.761 & TRN & \\
\hline CHEMBL1544390 & 688128 & 4.15 & 4.7701 & TST & \\
\hline CHEMBL1414725 & 688128 & 6.0 & 5.1942 & TRN & \\
\hline CHEMBL1352753 & 688128 & 4.3 & 4.6923 & TRN & \\
\hline CHEMBL1329875 & 688128 & 4.6 & 4.6191 & TRN & \\
\hline CHEMBL1382894 & 688128 & 4.3 & 4.3677 & TST & \\
\hline CHEMBL1441516 & 688128 & 5.35 & 4.9473 & TRN & \\
\hline CHEMBL1478277 & 688128 & 4.05 & 4.6265 & TRN & \\
\hline CHEMBL1464317 & 688128 & 4.5 & 4.5237 & TRN & \\
\hline CHEMBL1596205 & 688128 & 4.75 & 4.4809 & TRN & \\
\hline CHEMBL1546468 & 688128 & 4.4 & 4.76699 & 99999999995 & TRN \\
\hline CHEMBL1338495 & 688128 & 4.35 & 4.6842 & TRN & \\
\hline CHEMBL3193919 & 688128 & 4.35 & 4.8395 & TRN & \\
\hline CHEMBL1332012 & 688128 & 4.35 & 4.3915 & TST & \\
\hline CHEMBL1568801 & 688128 & 4.3 & 4.4533 & TRN & \\
\hline CHEMBL1455264 & 688128 & 4.65 & 4.6976 & TST & \\
\hline CHEMBL1531253 & 688128 & 5.75 & 4.3495 & TST & \\
\hline CHEMBL1299345 & 688128 & 4.65 & 4.5056 & TRN & \\
\hline & & & & 16 & \\
\hline
\end{tabular}




\begin{tabular}{|c|c|c|c|c|c|}
\hline & & \multicolumn{4}{|c|}{ Supplemental Table S2.txt } \\
\hline CHEMBL1364913 & 688128 & 4.95 & 4.3643 & TRN & \\
\hline CHEMBL1479824 & 688128 & 4.45 & 4.5609 & TRN & \\
\hline CHEMBL1519221 & 688128 & 4.3 & 4.5099 & TST & \\
\hline CHEMBL3212679 & 688128 & 4.3 & 4.5569 & TRN & \\
\hline CHEMBL1494130 & 688128 & 4.75 & 4.8336 & TRN & \\
\hline CHEMBL1611608 & 688128 & 4.25 & 4.9579 & TRN & \\
\hline CHEMBL1339135 & 688128 & 4.4 & 4.7423 & TRN & \\
\hline CHEMBL3209814 & 688128 & 4.3 & 4.6346 & TST & \\
\hline CHEMBL1580622 & 688128 & 4.35 & 4.9397 & TRN & \\
\hline CHEMBL1481730 & 688128 & 4.25 & 4.3289 & TRN & \\
\hline CHEMBL1569720 & 688128 & 4.3 & 4.5086 & TST & \\
\hline CHEMBL1355104 & 688128 & 4.7 & 4.7573 & TRN & \\
\hline CHEMBL1394762 & 688128 & 4.4 & 4.51 & TRN & \\
\hline CHEMBL1485750 & 688128 & 4.5 & 4.815 & TRN & \\
\hline CHEMBL1451859 & 688128 & 4.55 & 4.645 & TRN & \\
\hline CHEMBL1465188 & 688128 & 4.65 & 4.5505 & TRN & \\
\hline CHEMBL1344439 & 688128 & 4.75 & 4.5005 & TRN & \\
\hline CHEMBL1441462 & 688128 & 4.25 & 4.8046 & TRN & \\
\hline CHEMBL1360685 & 688128 & 4.3 & 4.4945 & TRN & \\
\hline CHEMBL1526629 & 688128 & 4.05 & 4.7354 & TRN & \\
\hline CHEMBL586031 & 688128 & 4.3 & 4.8552 & TRN & \\
\hline CHEMBL1498327 & 688128 & 5.0 & 4.9749 & TRN & \\
\hline CHEMBL1516063 & 688128 & 4.6 & 4.9621 & TRN & \\
\hline CHEMBL1367093 & 688128 & 4.4 & 4.6914 & TST & \\
\hline CHEMBL1306253 & 688128 & 4.35 & 4.7661 & TRN & \\
\hline CHEMBL1447511 & 688128 & 4.9 & 4.7343 & TST & \\
\hline CHEMBL3214002 & 688128 & 4.35 & 4.7083 & TST & \\
\hline CHEMBL1361317 & 688128 & 4.55 & 4.5976 & TRN & \\
\hline CHEMBL1338646 & 688128 & 4.7 & 4.6068 & TST & \\
\hline CHEMBL1497081 & 688128 & 4.1 & 4.5614 & TRN & \\
\hline CHEMBL1498210 & 688128 & 4.25 & 4.3516 & TRN & \\
\hline CHEMBL1402640 & 688128 & 4.8 & 4.7584 & TRN & \\
\hline CHEMBL1519239 & 688128 & 4.8 & 5.28799 & 9999999999 & TRN \\
\hline CHEMBL3191423 & 688128 & 4.45 & 4.6636 & TRN & \\
\hline CHEMBL1541148 & 688128 & 4.55 & 4.5316 & TRN & \\
\hline CHEMBL1607890 & 688128 & 4.25 & 4.9651 & TST & \\
\hline CHEMBL340416 & 688128 & 4.35 & 4.6081 & TRN & \\
\hline CHEMBL1464088 & 688128 & 4.3 & 4.8122 & TRN & \\
\hline CHEMBL1359361 & 688128 & 4.6 & 5.0343 & TRN & \\
\hline CHEMBL1320249 & 688128 & 5.3 & 4.5077 & TST & \\
\hline CHEMBL1588469 & 688128 & 4.5 & 4.7743 & TST & \\
\hline CHEMBL1554394 & 688128 & 4.3 & 4.8691 & TST & \\
\hline CHEMBL1387127 & 688128 & 4.4 & 4.596 & TRN & \\
\hline CHEMBL1381281 & 688128 & 4.45 & 4.5383 & TRN & \\
\hline CHEMBL1332375 & 688128 & 6.0 & 4.7823 & TRN & \\
\hline CHEMBL1454741 & 688128 & 4.35 & 4.5045 & TRN & \\
\hline CHEMBL1576064 & 688128 & 5.0 & 5.185 & TRN & \\
\hline CHEMBL1365472 & 688128 & 4.6 & 4.4071 & TRN & \\
\hline
\end{tabular}




\begin{tabular}{|c|c|c|c|c|c|}
\hline & & \multicolumn{4}{|c|}{ Supplemental Table S2.txt } \\
\hline CHEMBL1396295 & 688128 & 4.45 & 4.1895 & TRN & \\
\hline CHEMBL1604027 & 688128 & 4.35 & 4.8263 & TRN & \\
\hline CHEMBL1571759 & 688128 & 4.05 & 4.4983 & TST & \\
\hline CHEMBL1480088 & 688128 & 4.3 & 4.3627 & TRN & \\
\hline CHEMBL1565944 & 688128 & 4.95 & 4.6862 & TRN & \\
\hline CHEMBL1494714 & 688128 & 5.6 & 4.9685 & TRN & \\
\hline CHEMBL1443432 & 688128 & 4.65 & 4.3697 & TRN & \\
\hline CHEMBL1379402 & 688128 & 4.3 & 4.5769 & TRN & \\
\hline CHEMBL1396840 & 688128 & 4.35 & 4.82 & TRN & \\
\hline CHEMBL1524389 & 688128 & 4.5 & 4.4257 & TST & \\
\hline CHEMBL1380131 & 688128 & 4.25 & 4.5605 & TRN & \\
\hline CHEMBL1381764 & 688128 & 4.05 & 4.4779 & TST & \\
\hline CHEMBL1303479 & 688128 & 4.1 & 4.5481 & TST & \\
\hline CHEMBL1392885 & 688128 & 5.95 & 4.6867 & TST & \\
\hline CHEMBL1377876 & 688128 & 4.4 & 4.4995 & TRN & \\
\hline CHEMBL1586425 & 688128 & 6.5501 & 5.4992 & TRN & \\
\hline CHEMBL1355763 & 688128 & 4.4 & 4.5112 & TRN & \\
\hline CHEMBL1324817 & 688128 & 4.45 & 4.5505 & TRN & \\
\hline CHEMBL1325678 & 688128 & 4.35 & 4.5434 & TRN & \\
\hline CHEMBL1503387 & 688128 & 6.3 & 4.7303 & TRN & \\
\hline CHEMBL1408218 & 688128 & 4.8 & 4.6168 & TRN & \\
\hline CHEMBL1578869 & 688128 & 4.1 & 4.3999 & TST & \\
\hline CHEMBL1311580 & 688128 & 4.6 & 4.5026 & TST & \\
\hline CHEMBL1331611 & 688128 & 4.05 & 4.5751 & TRN & \\
\hline CHEMBL1408885 & 688128 & 5.15 & 4.7294 & TST & \\
\hline CHEMBL1379132 & 688128 & 4.25 & 4.3044 & TRN & \\
\hline CHEMBL1306962 & 688128 & 4.35 & 4.66 & TRN & \\
\hline CHEMBL1515775 & 688128 & 4.05 & 4.7587 & TST & \\
\hline CHEMBL1358353 & 688128 & 5.6 & 4.95100 & 00000000005 & TRN \\
\hline CHEMBL1424353 & 688128 & 4.9 & 4.9075 & TRN & \\
\hline CHEMBL1429939 & 688128 & 4.6 & 4.7054 & TRN & \\
\hline CHEMBL1359198 & 688128 & 4.8 & 4.3243 & TRN & \\
\hline CHEMBL1349219 & 688128 & 4.4 & 4.5114 & TST & \\
\hline CHEMBL1602733 & 688128 & 4.4 & 4.6615 & TST & \\
\hline CHEMBL1302358 & 688128 & 4.05 & 4.7292 & TST & \\
\hline CHEMBL1484811 & 688128 & 5.2 & 4.5454 & TRN & \\
\hline CHEMBL1430746 & 688128 & 4.05 & 4.6298 & TRN & \\
\hline CHEMBL3397112 & 688128 & 6.4 & 4.9116 & TRN & \\
\hline CHEMBL1344207 & 688128 & 4.65 & 4.8867 & TST & \\
\hline CHEMBL1359045 & 688128 & 4.4 & 4.4895 & TRN & \\
\hline CHEMBL1574519 & 688128 & 4.05 & 4.51699 & 99999999995 & TRN \\
\hline CHEMBL1345955 & 688128 & 4.3 & 4.5063 & TRN & \\
\hline CHEMBL1562019 & 688128 & 5.0 & 4.9833 & TRN & \\
\hline CHEMBL1353404 & 688128 & 4.5 & 4.6743 & TRN & \\
\hline CHEMBL1505939 & 688128 & 4.25 & 4.323 & TRN & \\
\hline CHEMBL1488898 & 688128 & 5.0 & 5.1533 & TRN & \\
\hline CHEMBL1370322 & 688128 & 4.05 & 4.9048 & TST & \\
\hline CHEMBL1367215 & 688128 & 4.6 & 4.7261 & TRN & \\
\hline
\end{tabular}




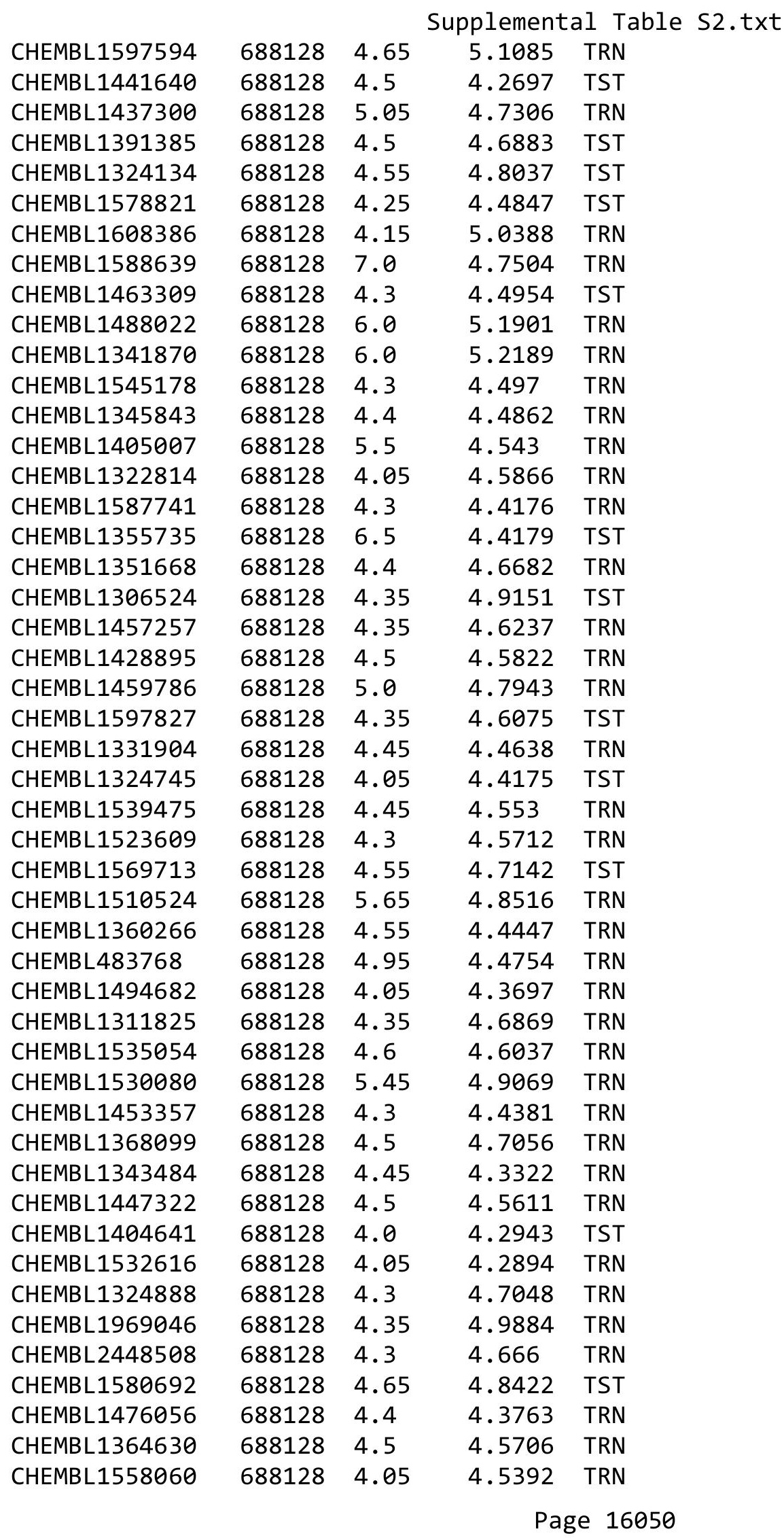




\begin{tabular}{|c|c|c|c|c|c|}
\hline \\
\hline CHEMBL1532477 & 688128 & 4.4 & 4.1201 & TRN & \\
\hline CHEMBL1497586 & 688128 & 4.5 & 4.7813 & TRN & \\
\hline CHEMBL1494223 & 688128 & 4.4 & 4.698 & TRN & \\
\hline CHEMBL1470292 & 688128 & 4.85 & 4.5487 & TRN & \\
\hline CHEMBL1371953 & 688128 & 5.4 & 4.6297 & TRN & \\
\hline CHEMBL1400168 & 688128 & 4.7 & 4.4842 & TRN & \\
\hline CHEMBL1574721 & 688128 & 4.1 & 4.603 & TRN & \\
\hline CHEMBL1491763 & 688128 & 4.25 & 4.5311 & TST & \\
\hline CHEMBL1445885 & 688128 & 4.25 & 4.5496 & TRN & \\
\hline CHEMBL1414469 & 688128 & 4.35 & 4.9189 & TRN & \\
\hline CHEMBL1510848 & 688128 & 5.45 & 4.7296 & TRN & \\
\hline CHEMBL1399366 & 688128 & 5.3 & 4.4604 & TRN & \\
\hline CHEMBL1518784 & 688128 & 4.35 & 4.4594 & TRN & \\
\hline CHEMBL3189237 & 688128 & 4.6 & 5.0064 & TRN & \\
\hline CHEMBL1458043 & 688128 & 4.4 & 4.909 & TST & \\
\hline CHEMBL1428507 & 688128 & 5.5 & $5.4670 e$ & 00000000005 & TRN \\
\hline CHEMBL1609957 & 688128 & 4.05 & 4.3627 & TRN & \\
\hline CHEMBL1326588 & 688128 & 4.6 & 4.7855 & TRN & \\
\hline CHEMBL1497295 & 688128 & 6.15 & 5.4219 & TRN & \\
\hline CHEMBL1457154 & 688128 & 4.3 & 4.3343 & TRN & \\
\hline CHEMBL1464457 & 688128 & 4.05 & 4.3995 & TRN & \\
\hline CHEMBL1447922 & 688128 & 5.2 & 4.773 & TRN & \\
\hline CHEMBL1521762 & 688128 & 4.4 & 4.5331 & TRN & \\
\hline CHEMBL1575657 & 688128 & 4.4 & 4.4727 & TRN & \\
\hline CHEMBL1368549 & 688128 & 4.4 & 4.6597 & TST & \\
\hline CHEMBL1561864 & 688128 & 4.35 & 4.6072 & TST & \\
\hline CHEMBL1311753 & 688128 & 4.3 & 4.4727 & TST & \\
\hline CHEMBL1489190 & 688128 & 4.05 & 4.769 & TRN & \\
\hline CHEMBL1420551 & 688128 & 4.05 & 4.8069 & TST & \\
\hline CHEMBL1351615 & 688128 & 4.55 & 4.6878 & TRN & \\
\hline CHEMBL1586278 & 688128 & 4.75 & 4.3544 & TST & \\
\hline CHEMBL1376469 & 688128 & 4.0 & 4.4542 & TRN & \\
\hline CHEMBL1356910 & 688128 & 4.3 & 4.6151 & TRN & \\
\hline CHEMBL1555229 & 688128 & 5.0 & 4.6745 & TST & \\
\hline CHEMBL1603829 & 688128 & 4.5 & 4.3717 & TRN & \\
\hline CHEMBL1430303 & 688128 & 4.35 & 4.4347 & TRN & \\
\hline CHEMBL1502711 & 688128 & 4.2 & 4.3421 & TRN & \\
\hline CHEMBL1447100 & 688128 & 4.05 & 4.4714 & TST & \\
\hline CHEMBL1547775 & 688128 & 4.5 & 4.4074 & TRN & \\
\hline CHEMBL1581827 & 688128 & 4.3 & 4.5836 & TRN & \\
\hline CHEMBL2369316 & 688128 & 4.25 & 4.8064 & TST & \\
\hline CHEMBL1474042 & 688128 & 5.05 & 4.6271 & TRN & \\
\hline CHEMBL1519057 & 688128 & 4.45 & 4.6082 & TRN & \\
\hline CHEMBL1341586 & 688128 & 5.8 & 5.3613 & TRN & \\
\hline CHEMBL1313446 & 688128 & 4.4 & 4.425 & TRN & \\
\hline CHEMBL1611524 & 688128 & 4.3 & 4.6337 & TRN & \\
\hline CHEMBL1446633 & 688128 & 6.0 & 4.5317 & TST & \\
\hline CHEMBL1575833 & 688128 & 4.35 & 4.6751 & TRN & \\
\hline
\end{tabular}




\begin{tabular}{|c|c|c|c|c|c|}
\hline \multicolumn{6}{|c|}{ Supplemental Table S2.txt } \\
\hline CHEMBL1992316 & 688128 & 6.5 & 4.5879 & TST & \\
\hline CHEMBL1312994 & 688128 & 4.55 & 5.0279 & TRN & \\
\hline CHEMBL1350557 & 688128 & 4.3 & 4.433 & TRN & \\
\hline CHEMBL1402117 & 688128 & 4.35 & $4.9110 e$ & 00000000005 & TST \\
\hline CHEMBL1532840 & 688128 & 4.3 & 4.5071 & TRN & \\
\hline CHEMBL1310375 & 688128 & 4.45 & 4.8072 & TRN & \\
\hline CHEMBL1356698 & 688128 & 4.3 & 4.7778 & TRN & \\
\hline CHEMBL1326464 & 688128 & 4.25 & 4.4561 & TST & \\
\hline CHEMBL1346840 & 688128 & 4.3 & 4.566 & TST & \\
\hline CHEMBL3198064 & 688128 & 4.2 & 4.4127 & TRN & \\
\hline CHEMBL1454156 & 688128 & 4.3 & 4.3354 & TRN & \\
\hline CHEMBL1538972 & 688128 & 6.05 & 4.6547 & TRN & \\
\hline CHEMBL1476357 & 688128 & 5.5 & 4.9541 & TRN & \\
\hline CHEMBL1347000 & 688128 & 4.3 & 4.7938 & TRN & \\
\hline CHEMBL1316822 & 688128 & 4.3 & 4.6317 & TST & \\
\hline CHEMBL1419972 & 688128 & 4.55 & 4.6014 & TRN & \\
\hline CHEMBL1582814 & 688128 & 4.5 & 4.8333 & TRN & \\
\hline CHEMBL1306104 & 688128 & 4.7 & 4.2914 & TST & \\
\hline CHEMBL1535202 & 688128 & 4.35 & 4.5985 & TST & \\
\hline CHEMBL1347575 & 688128 & 4.35 & 4.4782 & TST & \\
\hline CHEMBL1612802 & 688128 & 5.05 & 4.7356 & TRN & \\
\hline CHEMBL1522198 & 688128 & 5.55 & 5.0719 & TRN & \\
\hline CHEMBL1348754 & 688128 & 4.7 & 4.46 & TRN & \\
\hline CHEMBL1343905 & 688128 & 4.45 & 4.7046 & TRN & \\
\hline CHEMBL1506293 & 688128 & 4.3 & 4.0867 & TRN & \\
\hline CHEMBL1392226 & 688128 & 4.3 & 4.7915 & TRN & \\
\hline CHEMBL1537405 & 688128 & 4.9 & 4.9851 & TRN & \\
\hline CHEMBL1482877 & 688128 & 4.05 & 4.9201 & TST & \\
\hline CHEMBL3189366 & 688128 & 5.4 & 4.5675 & TST & \\
\hline CHEMBL1370313 & 688128 & 6.4 & 4.4939 & TST & \\
\hline CHEMBL1495485 & 688128 & 4.5 & 4.7175 & TST & \\
\hline CHEMBL1506505 & 688128 & 4.4 & 4.7286 & TRN & \\
\hline CHEMBL1430902 & 688128 & 4.7 & 4.811 & TRN & \\
\hline CHEMBL1311319 & 688128 & 4.4 & 4.9324 & TST & \\
\hline CHEMBL1319531 & 688128 & 4.25 & 4.2254 & TST & \\
\hline CHEMBL1353344 & 688128 & 4.3 & 4.6159 & TRN & \\
\hline CHEMBL1497717 & 688128 & 4.75 & 4.4898 & TRN & \\
\hline CHEMBL1563532 & 688128 & 4.1 & 4.8775 & TST & \\
\hline CHEMBL1482464 & 688128 & 4.2 & 4.5082 & TRN & \\
\hline CHEMBL1516408 & 688128 & 4.6 & 4.8797 & TRN & \\
\hline CHEMBL1605701 & 688128 & 4.35 & 4.6816 & TST & \\
\hline CHEMBL1533971 & 688128 & 4.4 & 4.7879 & TRN & \\
\hline CHEMBL3207384 & 688128 & 5.35 & 4.4064 & TRN & \\
\hline CHEMBL1468637 & 688128 & 4.45 & 4.355 & TST & \\
\hline CHEMBL1533984 & 688128 & 4.35 & 4.4109 & TRN & \\
\hline CHEMBL1442162 & 688128 & 4.35 & 4.5356 & TRN & \\
\hline CHEMBL1445890 & 688128 & 4.6 & 4.6298 & TST & \\
\hline CHEMBL1573038 & 688128 & 5.6 & 5.0276 & TRN & \\
\hline
\end{tabular}




\begin{tabular}{|c|c|c|c|c|c|}
\hline \multicolumn{6}{|c|}{ Supplemental Table S2.txt } \\
\hline CHEMBL1505036 & 688128 & 4.55 & 4.4489 & TRN & \\
\hline CHEMBL1516897 & 688128 & 4.6 & 4.5788 & TRN & \\
\hline CHEMBL1539637 & 688128 & 4.3 & 4.5926 & TRN & \\
\hline CHEMBL1439810 & 688128 & 4.6 & 4.6507 & TRN & \\
\hline CHEMBL1407415 & 688128 & 4.55 & 4.7693 & TRN & \\
\hline CHEMBL1389368 & 688128 & 4.5 & 4.5526 & TRN & \\
\hline CHEMBL1309278 & 688128 & 4.55 & 4.6686 & TRN & \\
\hline CHEMBL1525591 & 688128 & 4.35 & 4.5035 & TRN & \\
\hline CHEMBL1384773 & 688128 & 4.35 & 4.6978 & TRN & \\
\hline CHEMBL1300836 & 688128 & 4.45 & 4.7388 & TRN & \\
\hline CHEMBL1423854 & 688128 & 4.45 & 4.7692 & TST & \\
\hline CHEMBL1353907 & 688128 & 4.6 & 4.4787 & TRN & \\
\hline CHEMBL1427471 & 688128 & 4.35 & 4.6424 & TRN & \\
\hline CHEMBL1508933 & 688128 & 4.15 & 4.7826 & TST & \\
\hline CHEMBL1600475 & 688128 & 4.9 & 4.6845 & TRN & \\
\hline CHEMBL1351472 & 688128 & 4.25 & 4.5136 & TST & \\
\hline CHEMBL1417496 & 688128 & 4.4 & 4.6485 & TRN & \\
\hline CHEMBL3209902 & 688128 & 4.35 & 4.7227 & TRN & \\
\hline CHEMBL392515 & 688128 & 4.3 & 4.6406 & TRN & \\
\hline CHEMBL51931 & 688128 & 5.75 & 5.00899 & 99999999995 & TRN \\
\hline CHEMBL1337426 & 688128 & 4.35 & 4.5129 & TRN & \\
\hline CHEMBL1491569 & 688128 & 5.45 & 4.3901 & TST & \\
\hline CHEMBL1398421 & 688128 & 4.45 & 4.6231 & TRN & \\
\hline CHEMBL1516109 & 688128 & 4.3 & 4.3222 & TRN & \\
\hline CHEMBL1337271 & 688128 & 5.4 & 4.8215 & TST & \\
\hline CHEMBL3144899 & 688128 & 5.5 & 5.1817 & TRN & \\
\hline CHEMBL1543845 & 688128 & 4.85 & 4.6999 & TRN & \\
\hline CHEMBL1519810 & 688128 & 4.4 & 4.5021 & TRN & \\
\hline CHEMBL1305377 & 688128 & 5.5 & 4.7042 & TRN & \\
\hline CHEMBL1464752 & 688128 & 4.35 & 4.8081 & TRN & \\
\hline CHEMBL1523074 & 688128 & 4.35 & 4.6554 & TRN & \\
\hline CHEMBL1588250 & 688128 & 5.0 & 4.1847 & TRN & \\
\hline CHEMBL1379833 & 688128 & 4.95 & 5.1472 & TRN & \\
\hline CHEMBL1533420 & 688128 & 4.5 & 4.5019 & TRN & \\
\hline CHEMBL1463089 & 688128 & 4.4 & 4.5659 & TRN & \\
\hline CHEMBL1466584 & 688128 & 4.4 & 4.4219 & TRN & \\
\hline CHEMBL1530437 & 688128 & 5.75 & 4.8994 & TRN & \\
\hline CHEMBL1311127 & 688128 & 4.5 & 4.4987 & TRN & \\
\hline CHEMBL1556829 & 688128 & 4.05 & 4.3823 & TST & \\
\hline CHEMBL1424583 & 688128 & 4.55 & 4.4647 & TRN & \\
\hline CHEMBL1373203 & 688128 & 5.4 & 4.6395 & TRN & \\
\hline CHEMBL1401717 & 688128 & 4.4 & 4.7897 & TST & \\
\hline CHEMBL1462247 & 688128 & 4.35 & 4.9162 & TRN & \\
\hline CHEMBL1485957 & 688128 & 4.05 & 4.5024 & TST & \\
\hline CHEMBL1314954 & 688128 & 4.3 & 4.4859 & TRN & \\
\hline CHEMBL1517700 & 688128 & 5.3 & 4.6625 & TRN & \\
\hline CHEMBL1981103 & 688128 & 5.4 & 4.7482 & TST & \\
\hline CHEMBL1461482 & 688128 & 4.35 & 4.7596 & TRN & \\
\hline
\end{tabular}




\begin{tabular}{|c|c|c|c|c|}
\hline & & & upplement & $\mathrm{T}$ \\
\hline CHEMBL1509000 & 688128 & 4.15 & 4.8392 & TST \\
\hline CHEMBL1440774 & 688128 & 4.4 & 4.8261 & TRN \\
\hline CHEMBL1483809 & 688128 & 4.7 & 4.668 & TRN \\
\hline CHEMBL 2003964 & 688128 & 5.0 & 4.894 & TRN \\
\hline CHEMBL1539744 & 688128 & 4.05 & 4.6785 & TST \\
\hline CHEMBL1506928 & 688128 & 4.35 & 4.5373 & TRN \\
\hline CHEMBL1322139 & 688128 & 6.3 & 4.834 & TRN \\
\hline CHEMBL1548028 & 688128 & 5.05 & 4.4412 & TRN \\
\hline CHEMBL3211968 & 688128 & 4.5 & 4.2909 & TST \\
\hline CHEMBL1593702 & 688128 & 4.5 & 4.5913 & TRN \\
\hline CHEMBL1468638 & 688128 & 4.05 & 4.6872 & TRN \\
\hline CHEMBL1603516 & 688128 & 4.1 & 4.5781 & TRN \\
\hline CHEMBL1590501 & 688128 & 4.75 & 4.5666 & TRN \\
\hline CHEMBL1506672 & 688128 & 4.3 & 4.3781 & TRN \\
\hline CHEMBL1385948 & 688128 & 4.05 & 4.4137 & TST \\
\hline CHEMBL1328750 & 688128 & 4.25 & 4.6355 & TST \\
\hline CHEMBL1581640 & 688128 & 4.95 & 4.7822 & TST \\
\hline CHEMBL1429026 & 688128 & 4.05 & 4.7228 & TRN \\
\hline CHEMBL1378143 & 688128 & 4.4 & 4.6409 & TRN \\
\hline CHEMBL1566853 & 688128 & 5.6 & 5.3464 & TRN \\
\hline CHEMBL1451685 & 688128 & 4.85 & 4.666 & TRN \\
\hline CHEMBL1503837 & 688128 & 4.25 & 4.6056 & TRN \\
\hline CHEMBL1376596 & 688128 & 4.05 & 4.5424 & TST \\
\hline CHEMBL1431996 & 688128 & 5.05 & 4.3498 & TRN \\
\hline CHEMBL1429434 & 688128 & 4.5 & 4.9141 & TRN \\
\hline CHEMBL1418233 & 688128 & 4.5 & 4.6684 & TRN \\
\hline CHEMBL605747 & 688128 & 4.25 & 4.6169 & TRN \\
\hline CHEMBL1471335 & 688128 & 4.4 & 4.5485 & TRN \\
\hline CHEMBL3209536 & 688128 & 5.85 & 4.5899 & TST \\
\hline CHEMBL1492984 & 688128 & 4.3 & 4.4582 & TRN \\
\hline CHEMBL 274070 & 688128 & 4.3 & 4.9425 & TST \\
\hline CHEMBL1362107 & 688128 & 4.35 & 4.4702 & TRN \\
\hline CHEMBL1405189 & 688128 & 4.95 & 4.6277 & TRN \\
\hline CHEMBL1550554 & 688128 & 4.35 & 4.8736 & TRN \\
\hline CHEMBL1408370 & 688128 & 4.35 & 4.5257 & TRN \\
\hline CHEMBL1583980 & 688128 & 4.35 & 4.5623 & TRN \\
\hline CHEMBL1447412 & 688128 & 4.3 & 4.8841 & TRN \\
\hline CHEMBL1594896 & 688128 & 5.0 & 5.1329 & TRN \\
\hline CHEMBL1497767 & 688128 & 4.45 & 4.6245 & TRN \\
\hline CHEMBL1468387 & 688128 & 5.4 & 4.9585 & TRN \\
\hline CHEMBL1410188 & 688128 & 5.15 & 4.6776 & TST \\
\hline CHEMBL1300203 & 688128 & 5.0 & 4.3588 & TRN \\
\hline CHEMBL1587688 & 688128 & 4.45 & 4.9152 & TST \\
\hline CHEMBL1590618 & 688128 & 4.55 & 4.4817 & TRN \\
\hline CHEMBL3195354 & 688128 & 4.5 & 4.5251 & TST \\
\hline CHEMBL1303634 & 688128 & 4.0 & 4.3989 & TRN \\
\hline CHEMBL1537745 & 688128 & 4.4 & 4.327 & TRN \\
\hline CHEMBL1992255 & 688128 & 4.05 & 4.8087 & TST \\
\hline
\end{tabular}




\begin{tabular}{|c|c|c|c|c|c|}
\hline \\
\hline CHEMBL1376171 & 688128 & 5.2 & 4.5587 & TRN & \\
\hline CHEMBL1607271 & 688128 & 4.3 & 4.5968 & TRN & \\
\hline CHEMBL1522169 & 688128 & 4.5 & 4.5852 & TRN & \\
\hline CHEMBL1256727 & 688128 & 4.65 & 4.6591 & TRN & \\
\hline CHEMBL1542058 & 688128 & 4.05 & 4.9173 & TST & \\
\hline CHEMBL1318055 & 688128 & 5.05 & 5.1682 & TRN & \\
\hline CHEMBL1607238 & 688128 & 4.05 & 4.6298 & TRN & \\
\hline CHEMBL252417 & 688128 & 4.0 & 5.0379 & TST & \\
\hline CHEMBL1440432 & 688128 & 4.3 & 4.7513 & TST & \\
\hline CHEMBL1510594 & 688128 & 4.05 & 4.6263 & TST & \\
\hline CHEMBL1561474 & 688128 & 4.35 & 4.8451 & TST & \\
\hline CHEMBL1553713 & 688128 & 4.1 & 4.4807 & TRN & \\
\hline CHEMBL1330833 & 688128 & 4.8 & 4.7048 & TRN & \\
\hline CHEMBL1414905 & 688128 & 4.3 & 4.9367 & TST & \\
\hline CHEMBL1319062 & 688128 & 5.0 & 4.9212 & TRN & \\
\hline CHEMBL1496252 & 688128 & 4.85 & 4.53100 & 0000000001 & TRN \\
\hline CHEMBL1330042 & 688128 & 5.7 & 5.062 & TRN & \\
\hline CHEMBL1364109 & 688128 & 4.65 & 4.2863 & TRN & \\
\hline CHEMBL1578899 & 688128 & 5.0 & 4.8463 & TST & \\
\hline CHEMBL1352632 & 688128 & 4.55 & 4.677 & TST & \\
\hline CHEMBL1377824 & 688128 & 4.7 & 4.8992 & TRN & \\
\hline CHEMBL1355539 & 688128 & 4.6 & 4.67399 & 99999999995 & TRN \\
\hline CHEMBL1541526 & 688128 & 4.05 & 4.537 & TST & \\
\hline CHEMBL1458479 & 688128 & 5.25 & 4.9706 & TRN & \\
\hline CHEMBL1444937 & 688128 & 4.75 & 4.4752 & TST & \\
\hline CHEMBL1390493 & 688128 & 4.3 & 4.5055 & TST & \\
\hline CHEMBL1340188 & 688128 & 4.25 & 4.6198 & TRN & \\
\hline CHEMBL1566889 & 688128 & 4.45 & 4.7028 & TRN & \\
\hline CHEMBL1402444 & 688128 & 4.7 & 4.5873 & TRN & \\
\hline CHEMBL1329556 & 688128 & 4.4 & 4.7924 & TRN & \\
\hline CHEMBL1411075 & 688128 & 5.2 & 5.0012 & TRN & \\
\hline CHEMBL1388961 & 688128 & 4.0 & 4.7564 & TRN & \\
\hline CHEMBL1327680 & 688128 & 4.3 & 4.8656 & TRN & \\
\hline CHEMBL1304952 & 688128 & 4.45 & 4.768 & TRN & \\
\hline CHEMBL1327984 & 688128 & 4.15 & 4.8176 & TST & \\
\hline CHEMBL1311245 & 688128 & 4.45 & 4.5954 & TRN & \\
\hline CHEMBL1576012 & 688128 & 5.4 & 4.4447 & TST & \\
\hline CHEMBL3190834 & 688128 & 4.25 & 4.588 & TRN & \\
\hline CHEMBL1393442 & 688128 & 4.4 & 4.5968 & TRN & \\
\hline CHEMBL1477875 & 688128 & 4.3 & 4.5336 & TST & \\
\hline CHEMBL1612995 & 688128 & 4.05 & 4.7135 & TST & \\
\hline CHEMBL 3195484 & 688128 & 5.0 & 4.6984 & TST & \\
\hline CHEMBL1542145 & 688128 & 4.5 & 4.4018 & TRN & \\
\hline CHEMBL1604896 & 688128 & 4.4 & 4.737 & TRN & \\
\hline CHEMBL1346719 & 688128 & 4.6 & 4.6508 & TRN & \\
\hline CHEMBL1450648 & 688128 & 5.75 & 5.3201 & TRN & \\
\hline CHEMBL3199693 & 688128 & 4.45 & 4.50899 & 99999999995 & TRN \\
\hline CHEMBL 3214229 & 688128 & 4.35 & 4.6366 & TST & \\
\hline
\end{tabular}




\begin{tabular}{|c|c|c|c|c|c|}
\hline & & \multicolumn{4}{|c|}{ Supplemental Table s2.txt } \\
\hline CHEMBL1400573 & 688128 & 4.95 & 4.6019 & TRN & \\
\hline CHEMBL1325897 & 688128 & 4.35 & 4.5069 & TRN & \\
\hline CHEMBL1397166 & 688128 & 5.45 & 4.9788 & TRN & \\
\hline CHEMBL1539087 & 688128 & 4.05 & 5.0357 & TST & \\
\hline CHEMBL1461939 & 688128 & 4.4 & 4.4174 & TRN & \\
\hline CHEMBL1361533 & 688128 & 5.2 & 4.6762 & TST & \\
\hline CHEMBL1425754 & 688128 & 4.75 & 4.4847 & TRN & \\
\hline CHEMBL1602928 & 688128 & 4.35 & 4.6301 & TST & \\
\hline CHEMBL1350983 & 688128 & 5.85 & 4.7568 & TST & \\
\hline CHEMBL1484381 & 688128 & 5.75 & 4.6909 & TRN & \\
\hline CHEMBL1322906 & 688128 & 6.05 & 4.5954 & TST & \\
\hline CHEMBL1442964 & 688128 & 4.4 & 4.4119 & TRN & \\
\hline CHEMBL1319113 & 688128 & 5.5 & 5.0794 & TST & \\
\hline CHEMBL1447590 & 688128 & 4.45 & 4.5624 & TST & \\
\hline CHEMBL1329889 & 688128 & 4.35 & 4.593 & TST & \\
\hline CHEMBL1488859 & 688128 & 3.95 & 4.6585 & TRN & \\
\hline CHEMBL1490992 & 688128 & 4.5 & 4.7578 & TRN & \\
\hline CHEMBL1324272 & 688128 & 4.4 & 4.3567 & TRN & \\
\hline CHEMBL1570162 & 688128 & 4.05 & 4.5468 & TRN & \\
\hline CHEMBL1422567 & 688128 & 4.75 & 5.0023 & TRN & \\
\hline CHEMBL1342745 & 688128 & 4.3 & 4.4525 & TRN & \\
\hline CHEMBL1338730 & 688128 & 4.35 & 4.8406 & TRN & \\
\hline CHEMBL1359223 & 688128 & 4.25 & 4.8631 & TRN & \\
\hline CHEMBL1442683 & 688128 & 4.25 & 4.391 & TST & \\
\hline CHEMBL1554169 & 688128 & 6.25 & 4.6195 & TST & \\
\hline CHEMBL1560028 & 688128 & 4.6 & 4.7418 & TST & \\
\hline CHEMBL1517291 & 688128 & 4.5 & 4.613 & TRN & \\
\hline CHEMBL1572504 & 688128 & 4.55 & 4.4694 & TRN & \\
\hline CHEMBL1414180 & 688128 & 4.0 & 4.7669 & TST & \\
\hline CHEMBL3208977 & 688128 & 4.6 & 4.4364 & TRN & \\
\hline CHEMBL1378742 & 688128 & 4.35 & 4.8013 & TRN & \\
\hline CHEMBL1463534 & 688128 & 4.4 & 4.5832 & TRN & \\
\hline CHEMBL1337494 & 688128 & 6.0 & 4.82600 & 00000000005 & TRN \\
\hline CHEMBL1586021 & 688128 & 5.4 & 4.2745 & TRN & \\
\hline CHEMBL1606089 & 688128 & 4.6 & 4.4181 & TST & \\
\hline CHEMBL1503529 & 688128 & 4.3 & 4.4893 & TRN & \\
\hline CHEMBL1545559 & 688128 & 4.0 & 4.6158 & TST & \\
\hline CHEMBL3189373 & 688128 & 4.25 & 4.5676 & TST & \\
\hline CHEMBL1541383 & 688128 & 4.1 & 4.4725 & TRN & \\
\hline CHEMBL3212403 & 688128 & 4.4 & 4.765 & TST & \\
\hline CHEMBL1510191 & 688128 & 4.2 & 4.545 & TRN & \\
\hline CHEMBL1575033 & 688128 & 4.4 & 4.8569 & TST & \\
\hline CHEMBL1382876 & 688128 & 4.35 & 4.4169 & TRN & \\
\hline CHEMBL1587849 & 688128 & 4.05 & 4.8679 & TRN & \\
\hline CHEMBL1331231 & 688128 & 6.0 & 4.7936 & TRN & \\
\hline CHEMBL1316276 & 688128 & 5.4 & 5.013 & TRN & \\
\hline CHEMBL1549812 & 688128 & 5.65 & 5.3414 & TRN & \\
\hline CHEMBL1378421 & 688128 & 4.65 & 4.9606 & TRN & \\
\hline
\end{tabular}




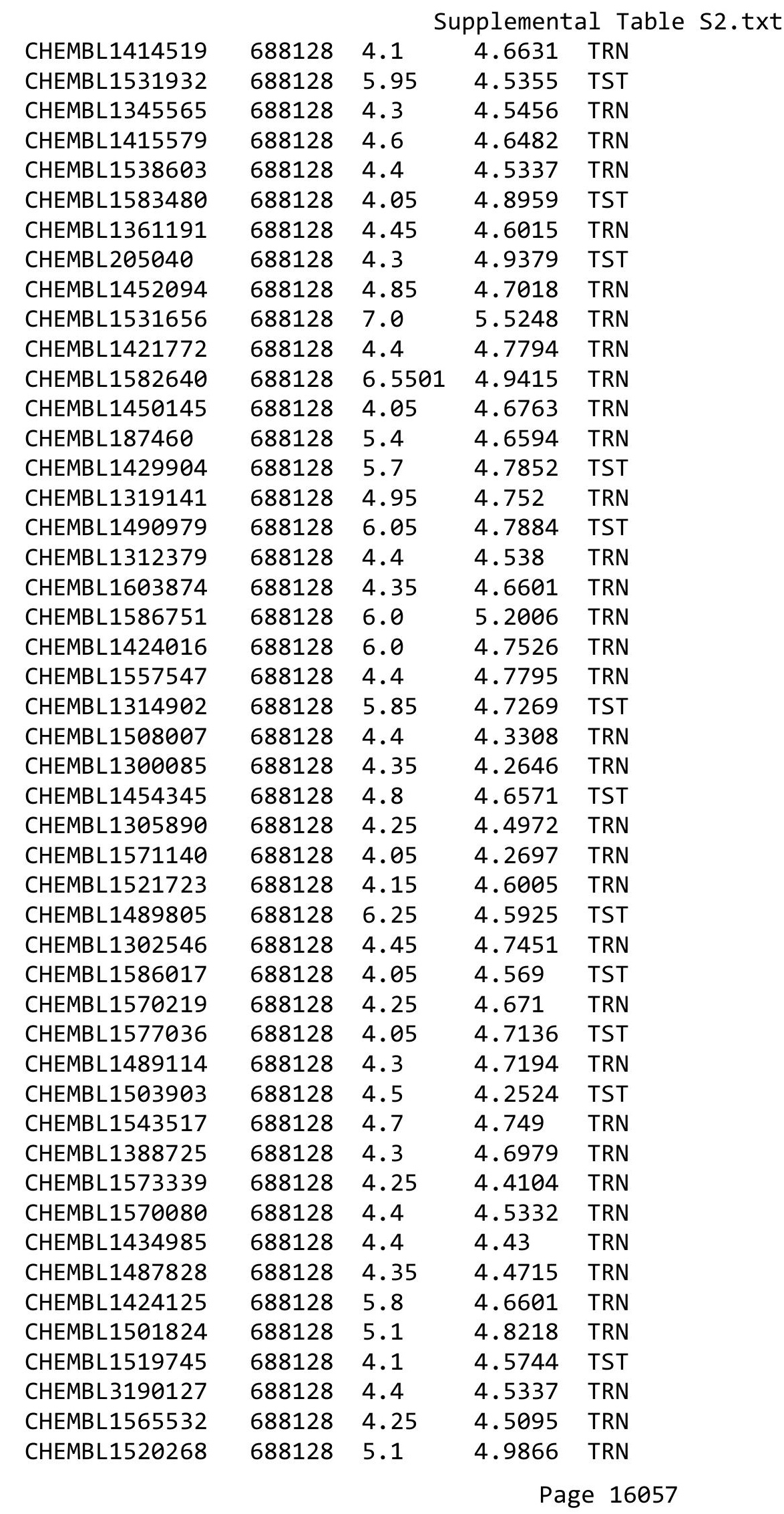




\begin{tabular}{|c|c|c|c|c|}
\hline \multicolumn{5}{|c|}{ Supplemental Table S2.txt } \\
\hline CHEMBL1323172 & 688128 & 4.3 & 4.4275 & TRN \\
\hline CHEMBL 3144873 & 688128 & 5.8 & 5.0252 & TRN \\
\hline CHEMBL1502485 & 688128 & 4.15 & 4.4645 & TRN \\
\hline CHEMBL1561293 & 688128 & 4.0 & 4.5659 & TRN \\
\hline CHEMBL1563313 & 688128 & 4.25 & 4.5164 & TST \\
\hline CHEMBL1346042 & 688128 & 4.05 & 4.6456 & TRN \\
\hline CHEMBL1465486 & 688128 & 4.45 & 4.5179 & TRN \\
\hline CHEMBL1463165 & 688128 & 4.25 & 4.4723 & TST \\
\hline CHEMBL1409823 & 688128 & 4.25 & 4.6659 & TRN \\
\hline CHEMBL1421882 & 688128 & 6.15 & 5.1013 & TRN \\
\hline CHEMBL1545457 & 688128 & 4.3 & 4.9438 & TRN \\
\hline CHEMBL1307207 & 688128 & 6.35 & 4.9608 & TST \\
\hline CHEMBL1613382 & 688128 & 5.7 & 4.9177 & TRN \\
\hline CHEMBL1603697 & 688128 & 4.4 & 4.532 & TRN \\
\hline CHEMBL1549687 & 688128 & 5.6 & 4.8424 & TRN \\
\hline CHEMBL1459217 & 688128 & 5.05 & 4.7392 & TRN \\
\hline CHEMBL1408556 & 688128 & 4.35 & 4.4131 & TRN \\
\hline CHEMBL1312305 & 688128 & 4.45 & 5.0157 & TRN \\
\hline CHEMBL1459896 & 688128 & 4.4 & 4.7731 & TRN \\
\hline CHEMBL1423675 & 688128 & 4.7 & 4.8865 & TRN \\
\hline CHEMBL1484695 & 688128 & 4.3 & 3.9934 & TRN \\
\hline CHEMBL1372555 & 688128 & 4.3 & 4.3426 & TRN \\
\hline CHEMBL1476394 & 688128 & 4.0 & 4.5549 & TST \\
\hline CHEMBL1492879 & 688128 & 6.05 & 4.5439 & TRN \\
\hline CHEMBL3192005 & 688128 & 4.05 & 4.6339 & TST \\
\hline CHEMBL1315215 & 688128 & 4.05 & 4.794 & TST \\
\hline CHEMBL1446381 & 688128 & 4.4 & 4.8343 & TRN \\
\hline CHEMBL1424594 & 688128 & 4.55 & 4.5209 & TRN \\
\hline CHEMBL1335254 & 688128 & 4.35 & 4.5098 & TRN \\
\hline CHEMBL1468425 & 688128 & 4.05 & 4.7326 & TST \\
\hline CHEMBL1503307 & 688128 & 4.9 & 4.7913 & TRN \\
\hline CHEMBL1305450 & 688128 & 5.45 & 5.1141 & TRN \\
\hline CHEMBL 1400510 & 688128 & 4.4 & 4.7411 & TRN \\
\hline CHEMBL599098 & 688128 & 4.95 & 4.6835 & TRN \\
\hline CHEMBL1340680 & 688128 & 4.8 & 5.1459 & TRN \\
\hline CHEMBL1451290 & 688128 & 4.35 & 4.7537 & TRN \\
\hline CHEMBL 2373620 & 688128 & 4.45 & 4.7501 & TRN \\
\hline CHEMBL1417623 & 688128 & 5.1 & 4.8222 & TST \\
\hline CHEMBL3212321 & 688128 & 4.05 & 4.5632 & TST \\
\hline CHEMBL1567666 & 688128 & 4.35 & 4.5868 & TRN \\
\hline CHEMBL1327134 & 688128 & 4.05 & 4.5073 & TRN \\
\hline CHEMBL1324738 & 688128 & 4.5 & 4.5862 & TRN \\
\hline CHEMBL1544376 & 688128 & 4.3 & 4.8311 & TRN \\
\hline CHEMBL 2006997 & 688128 & 4.3 & 4.9546 & TST \\
\hline CHEMBL1365956 & 688128 & 4.1 & 4.7647 & TRN \\
\hline CHEMBL1410369 & 688128 & 4.85 & 4.9228 & TRN \\
\hline CHEMBL1384033 & 688128 & 4.35 & 4.4288 & TRN \\
\hline CHEMBL1316411 & 688128 & 4.3 & 4.5073 & TRN \\
\hline
\end{tabular}




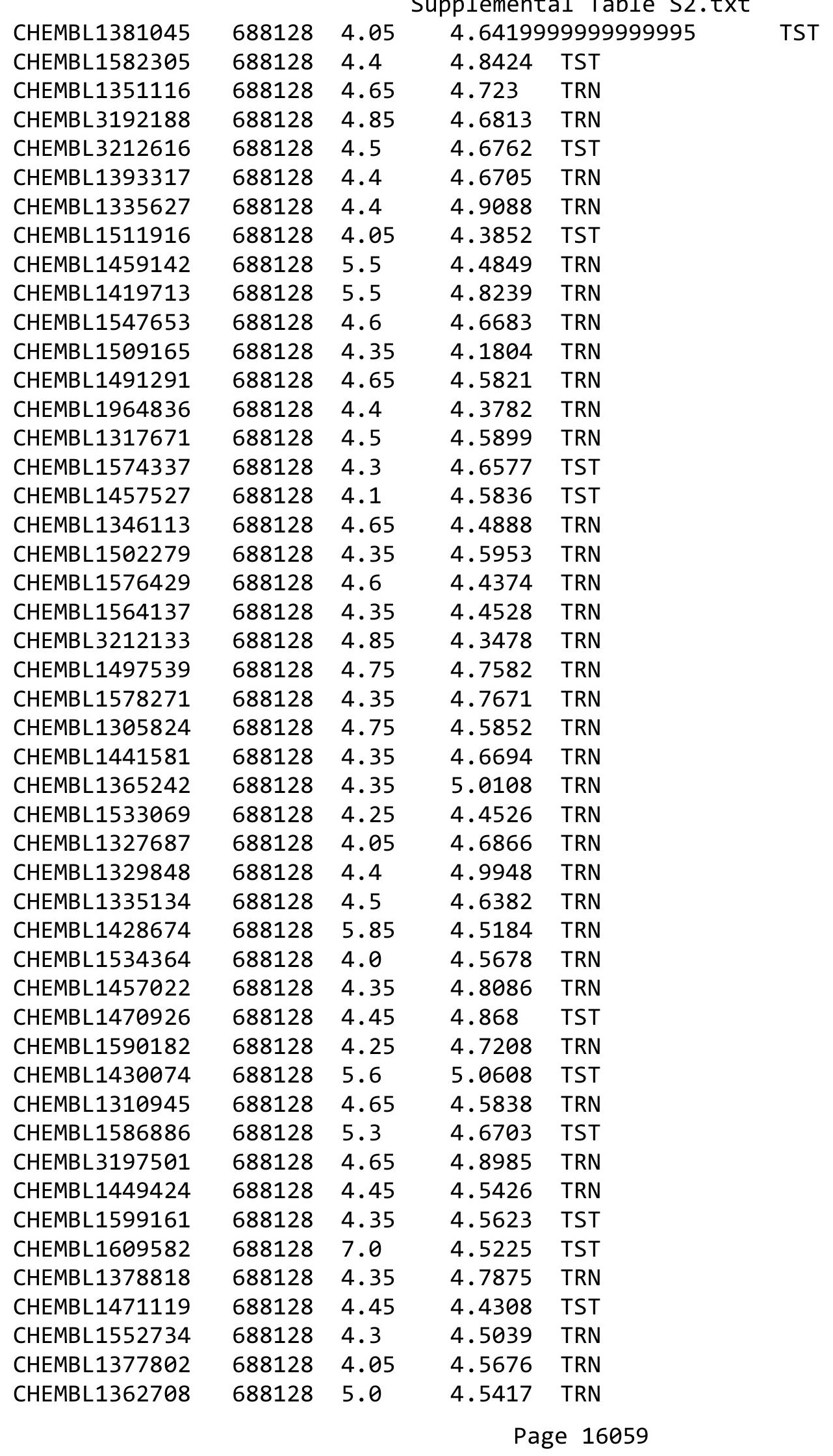




\begin{tabular}{|c|c|c|c|c|c|}
\hline \multicolumn{6}{|c|}{ Supplemental Table S2.txt } \\
\hline CHEMBL1391064 & 688128 & 5.8 & 4.6892 & TST & \\
\hline CHEMBL1405885 & 688128 & 4.05 & 4.6377 & TRN & \\
\hline CHEMBL1526761 & 688128 & 6.35 & 4.8508 & TST & \\
\hline CHEMBL1430083 & 688128 & 4.25 & 4.4742 & TRN & \\
\hline CHEMBL1468263 & 688128 & 4.35 & 4.6552 & TST & \\
\hline CHEMBL1428980 & 688128 & 4.3 & 4.7142 & TRN & \\
\hline CHEMBL1579664 & 688128 & 4.25 & 4.8184 & TRN & \\
\hline CHEMBL1433049 & 688128 & 4.35 & 4.5403 & TRN & \\
\hline CHEMBL3196616 & 688128 & 4.85 & 4.4697 & TRN & \\
\hline CHEMBL1328862 & 688128 & 4.4 & 4.508 & TST & \\
\hline CHEMBL1506316 & 688128 & 4.05 & 4.6286 & TRN & \\
\hline CHEMBL1600917 & 688128 & 4.95 & 4.73600 & 0000000001 & TRN \\
\hline CHEMBL1322274 & 688128 & 4.05 & 4.5923 & TST & \\
\hline CHEMBL1573167 & 688128 & 4.3 & 4.7313 & TST & \\
\hline CHEMBL1415740 & 688128 & 4.25 & 4.6819 & TRN & \\
\hline CHEMBL1584502 & 688128 & 4.45 & 4.8644 & TRN & \\
\hline CHEMBL1598864 & 688128 & 4.35 & 4.8622 & TRN & \\
\hline CHEMBL1434066 & 688128 & 4.3 & 4.6185 & TST & \\
\hline CHEMBL1438664 & 688128 & 4.65 & 4.8673 & TRN & \\
\hline CHEMBL1425789 & 688128 & 5.8 & 4.6852 & TRN & \\
\hline CHEMBL1334116 & 688128 & 5.1 & 5.2756 & TRN & \\
\hline CHEMBL1552018 & 688128 & 4.5 & 4.6582 & TRN & \\
\hline CHEMBL 3194086 & 688128 & 4.0 & 5.0657 & TRN & \\
\hline CHEMBL 1431872 & 688128 & 4.4 & 4.6491 & TST & \\
\hline CHEMBL1567688 & 688128 & 4.85 & 4.6733 & TRN & \\
\hline CHEMBL1600397 & 688128 & 6.4 & 5.1625 & TRN & \\
\hline CHEMBL1452409 & 688128 & 4.6 & 4.5649 & TRN & \\
\hline CHEMBL1581693 & 688128 & 4.4 & 4.6841 & TRN & \\
\hline CHEMBL1523497 & 688128 & 4.6 & 4.5445 & TST & \\
\hline CHEMBL1548329 & 688128 & 5.55 & 4.8661 & TST & \\
\hline CHEMBL1508219 & 688128 & 4.05 & 4.6945 & TST & \\
\hline CHEMBL3195078 & 688128 & 5.0 & 4.8856 & TRN & \\
\hline CHEMBL1369578 & 688128 & 4.3 & 4.58899 & 99999999995 & TRN \\
\hline CHEMBL1514273 & 688128 & 4.35 & 4.4599 & TRN & \\
\hline CHEMBL1611815 & 688128 & 5.1 & 4.5216 & TRN & \\
\hline CHEMBL1393134 & 688128 & 4.3 & 4.3518 & TRN & \\
\hline CHEMBL1450838 & 688128 & 4.95 & 4.7004 & TRN & \\
\hline CHEMBL1439796 & 688128 & 5.3 & 5.4164 & TRN & \\
\hline CHEMBL1548140 & 688128 & 5.0 & 4.8946 & TRN & \\
\hline CHEMBL1345786 & 688128 & 4.4 & 4.4 & TRN & \\
\hline CHEMBL1495241 & 688128 & 4.65 & 4.8192 & TRN & \\
\hline CHEMBL1519364 & 688128 & 4.4 & 4.6432 & TRN & \\
\hline CHEMBL1429979 & 688128 & 4.25 & 4.493 & TRN & \\
\hline CHEMBL1563954 & 688128 & 4.35 & 4.6866 & TRN & \\
\hline CHEMBL1511765 & 688128 & 5.1 & 4.346 & TST & \\
\hline CHEMBL3144965 & 688128 & 4.3 & 4.8377 & TST & \\
\hline CHEMBL1515661 & 688128 & 6.05 & 4.6592 & TRN & \\
\hline CHEMBL1344401 & 688128 & 4.3 & 4.5594 & TRN & \\
\hline
\end{tabular}




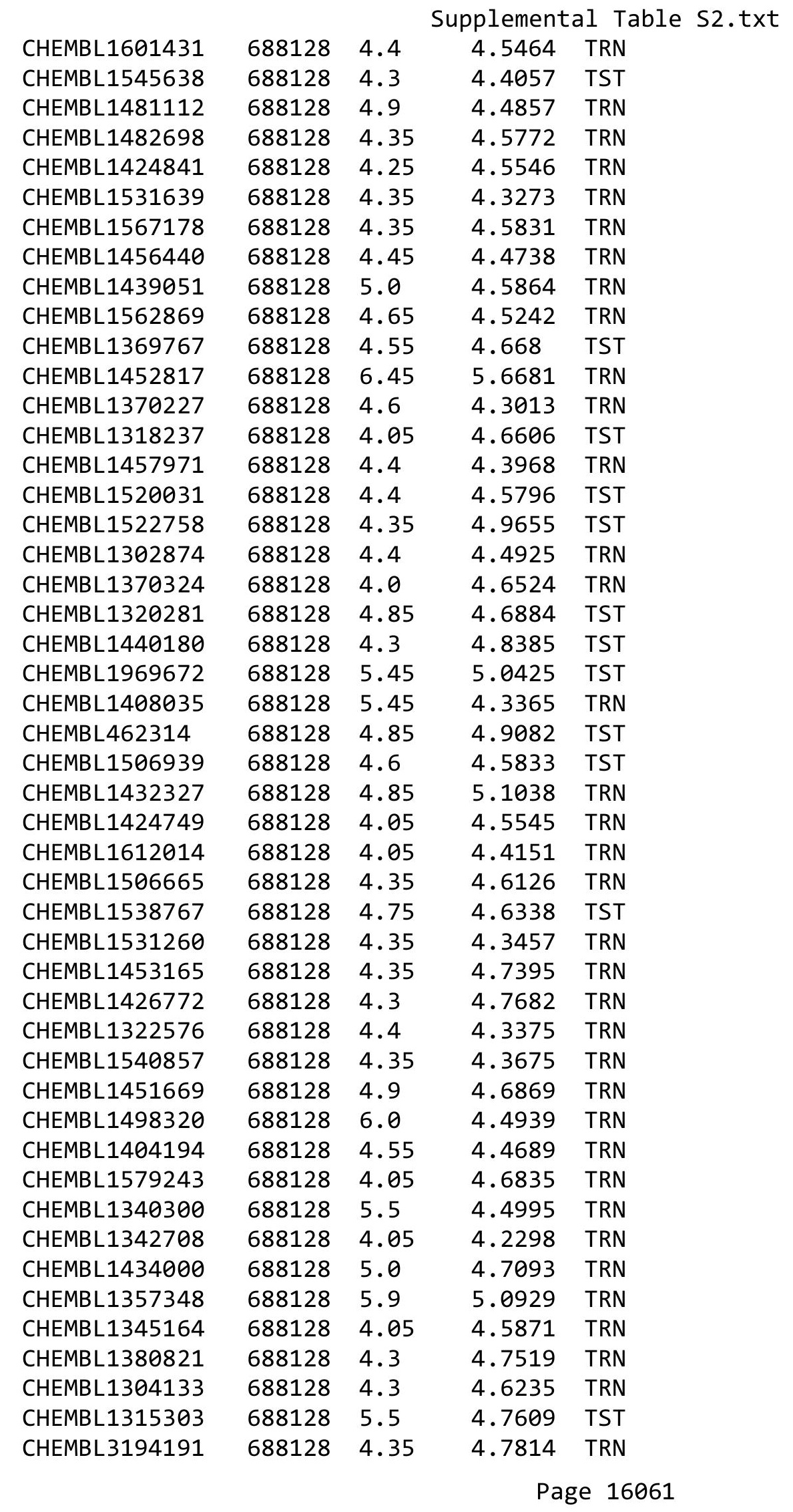




\begin{tabular}{|c|c|c|c|c|c|}
\hline \multicolumn{6}{|c|}{ Supplemental Table S2.txt } \\
\hline CHEMBL1305671 & 688128 & 4.05 & 4.3865 & TRN & \\
\hline CHEMBL1477050 & 688128 & 4.35 & 4.7222 & TRN & \\
\hline CHEMBL1332832 & 688128 & 4.55 & 4.8887 & TRN & \\
\hline CHEMBL1560580 & 688128 & 5.0 & 4.5262 & TRN & \\
\hline CHEMBL1530001 & 688128 & 4.1 & 4.7273 & TRN & \\
\hline CHEMBL1535711 & 688128 & 4.35 & 4.4735 & TRN & \\
\hline CHEMBL1491204 & 688128 & 4.05 & 4.4679 & TRN & \\
\hline CHEMBL1457910 & 688128 & 6.05 & 4.937 & TRN & \\
\hline CHEMBL1485369 & 688128 & 4.35 & 4.6785 & TST & \\
\hline CHEMBL1454886 & 688128 & 4.35 & 4.4125 & TRN & \\
\hline CHEMBL1463519 & 688128 & 4.65 & 4.5646 & TRN & \\
\hline CHEMBL1608438 & 688128 & 4.35 & 4.4705 & TRN & \\
\hline CHEMBL1310063 & 688128 & 4.0 & 4.6928 & TRN & \\
\hline CHEMBL1604319 & 688128 & 4.3 & 4.5076 & TRN & \\
\hline CHEMBL1471175 & 688128 & 4.25 & 4.3902 & TRN & \\
\hline CHEMBL1384534 & 688128 & 4.65 & 4.6991 & TST & \\
\hline CHEMBL1555654 & 688128 & 4.05 & 4.413 & TRN & \\
\hline CHEMBL1584415 & 688128 & 6.45 & 5.0699 & TRN & \\
\hline CHEMBL1433963 & 688128 & 5.0 & 5.0375 & TRN & \\
\hline CHEMBL1448807 & 688128 & 4.1 & 4.3058 & TRN & \\
\hline CHEMBL1525961 & 688128 & 4.25 & 4.5941 & TRN & \\
\hline CHEMBL1578435 & 688128 & 6.4 & 4.4758 & TST & \\
\hline CHEMBL1588047 & 688128 & 4.75 & 4.4372 & TST & \\
\hline CHEMBL1399081 & 688128 & 4.35 & 4.4544 & TRN & \\
\hline CHEMBL1424696 & 688128 & 4.6 & 4.6421 & TRN & \\
\hline CHEMBL1514731 & 688128 & 4.25 & 4.6633 & TRN & \\
\hline CHEMBL1393021 & 688128 & 4.35 & 4.7075 & TST & \\
\hline CHEMBL1306729 & 688128 & 5.95 & $4.7010 e$ & 00000000005 & TST \\
\hline CHEMBL1496638 & 688128 & 5.05 & 4.9061 & TRN & \\
\hline CHEMBL3198487 & 688128 & 4.7 & 4.734 & TRN & \\
\hline CHEMBL1328527 & 688128 & 4.25 & 4.6761 & TRN & \\
\hline CHEMBL1427610 & 688128 & 4.95 & 5.3851 & TRN & \\
\hline CHEMBL 3208004 & 688128 & 4.85 & 4.7399 & TRN & \\
\hline CHEMBL1424208 & 688128 & 4.75 & 4.8964 & TRN & \\
\hline CHEMBL163316 & 688128 & 4.55 & 4.8159 & TRN & \\
\hline CHEMBL1405376 & 688128 & 4.3 & 4.3788 & TRN & \\
\hline CHEMBL1569092 & 688128 & 4.4 & 4.4677 & TST & \\
\hline CHEMBL1577391 & 688128 & 4.0 & 4.6235 & TST & \\
\hline CHEMBL1370654 & 688128 & 4.35 & 4.5578 & TRN & \\
\hline CHEMBL1458409 & 688128 & 4.05 & 4.4883 & TRN & \\
\hline CHEMBL1404867 & 688128 & 4.05 & 4.2333 & TRN & \\
\hline CHEMBL1306227 & 688128 & 4.1 & 4.4646 & TST & \\
\hline CHEMBL1512713 & 688128 & 5.65 & 4.7123 & TST & \\
\hline CHEMBL1348432 & 688128 & 5.45 & 5.0019 & TRN & \\
\hline CHEMBL1568385 & 688128 & 4.3 & 4.75 & TRN & \\
\hline CHEMBL1509640 & 688128 & 5.4 & 4.8219 & TST & \\
\hline CHEMBL1459912 & 688128 & 4.35 & 4.475 & TRN & \\
\hline CHEMBL1411756 & 688128 & 4.4 & 4.3734 & TST & \\
\hline
\end{tabular}




\begin{tabular}{|c|c|c|c|c|c|}
\hline & & \multicolumn{4}{|c|}{ Supplemental Table S2.txt } \\
\hline CHEMBL1472434 & 688128 & 4.05 & 4.4726 & TST & \\
\hline CHEMBL3212541 & 688128 & 4.3 & 4.7006 & TST & \\
\hline CHEMBL1319613 & 688128 & 4.6 & 4.4508 & TRN & \\
\hline CHEMBL1331821 & 688128 & 4.65 & 4.6969 & TST & \\
\hline CHEMBL1610739 & 688128 & 5.8 & 5.2807 & TRN & \\
\hline CHEMBL1386676 & 688128 & 4.3 & 4.2161 & TRN & \\
\hline CHEMBL1387319 & 688128 & 4.7 & 4.6997 & TST & \\
\hline CHEMBL1307182 & 688128 & 4.3 & 4.7272 & TRN & \\
\hline CHEMBL1972249 & 688128 & 4.1 & 4.9243 & TRN & \\
\hline CHEMBL1584818 & 688128 & 4.5 & 4.5135 & TRN & \\
\hline CHEMBL1422369 & 688128 & 5.1 & 4.401 & TRN & \\
\hline CHEMBL1456288 & 688128 & 4.45 & 4.6528 & TRN & \\
\hline CHEMBL1502799 & 688128 & 4.3 & 4.6894 & TST & \\
\hline CHEMBL1319325 & 688128 & 4.4 & 4.5163 & TRN & \\
\hline CHEMBL1386552 & 688128 & 4.35 & 4.27800 & 00000000005 & TRN \\
\hline CHEMBL1559987 & 688128 & 5.0 & 4.7943 & TRN & \\
\hline CHEMBL1459218 & 688128 & 4.3 & 4.2267 & TRN & \\
\hline CHEMBL1581877 & 688128 & 4.35 & 4.8088 & TRN & \\
\hline CHEMBL1378409 & 688128 & 4.4 & 4.6736 & TST & \\
\hline CHEMBL1549466 & 688128 & 4.5 & 4.4806 & TRN & \\
\hline CHEMBL592111 & 688128 & 4.0 & 4.9914 & TRN & \\
\hline CHEMBL1498722 & 688128 & 4.05 & 4.593 & TRN & \\
\hline CHEMBL1332708 & 688128 & 4.45 & 4.5572 & TRN & \\
\hline CHEMBL1382266 & 688128 & 4.4 & 4.4204 & TRN & \\
\hline CHEMBL1551753 & 688128 & 4.55 & 4.7537 & TRN & \\
\hline CHEMBL1555262 & 688128 & 4.45 & 4.7916 & TRN & \\
\hline CHEMBL1351481 & 688128 & 4.45 & 4.6128 & TST & \\
\hline CHEMBL1373823 & 688128 & 4.1 & 4.4862 & TRN & \\
\hline CHEMBL1441302 & 688128 & 4.35 & 4.8094 & TRN & \\
\hline CHEMBL1401091 & 688128 & 4.55 & 4.7722 & TST & \\
\hline CHEMBL1456948 & 688128 & 4.55 & 4.6902 & TRN & \\
\hline CHEMBL1427957 & 688128 & 4.1 & 4.4951 & TRN & \\
\hline CHEMBL1372083 & 688128 & 5.4 & 4.7709 & TRN & \\
\hline CHEMBL1370879 & 688128 & 4.35 & 4.5803 & TRN & \\
\hline CHEMBL1556037 & 688128 & 4.4 & 4.4746 & TRN & \\
\hline CHEMBL1444239 & 688128 & 4.45 & 4.2016 & TRN & \\
\hline CHEMBL1585500 & 688128 & 4.45 & 4.5788 & TRN & \\
\hline CHEMBL1395894 & 688128 & 4.35 & 4.5734 & TRN & \\
\hline CHEMBL1367377 & 688128 & 4.05 & 4.5813 & TRN & \\
\hline CHEMBL1407758 & 688128 & 4.75 & 4.8737 & TRN & \\
\hline CHEMBL1521591 & 688128 & 4.4 & 4.6032 & TRN & \\
\hline CHEMBL1595627 & 688128 & 4.6 & 4.8019 & TRN & \\
\hline CHEMBL1324527 & 688128 & 4.45 & 4.7853 & TST & \\
\hline CHEMBL1570491 & 688128 & 4.4 & 4.3991 & TRN & \\
\hline CHEMBL1600931 & 688128 & 4.4 & 4.4943 & TRN & \\
\hline CHEMBL1598222 & 688128 & 4.05 & 4.2966 & TST & \\
\hline CHEMBL1586482 & 688128 & 4.6 & 4.5453 & TRN & \\
\hline CHEMBL1337515 & 688128 & 4.4 & 4.4039 & TRN & \\
\hline
\end{tabular}




\begin{tabular}{|c|c|c|c|c|c|}
\hline & & \multicolumn{4}{|c|}{ Supplemental Table s2.txt } \\
\hline CHEMBL1336449 & 688128 & 4.35 & 4.6523 & TRN & \\
\hline CHEMBL1475350 & 688128 & 5.3 & 4.3776 & TRN & \\
\hline CHEMBL3190825 & 688128 & 4.6 & 4.82600 & $\partial 0000000005$ & TRN \\
\hline CHEMBL1434554 & 688128 & 4.85 & 4.7231 & TRN & \\
\hline CHEMBL1524548 & 688128 & 4.25 & 4.5526 & TRN & \\
\hline CHEMBL1373091 & 688128 & 4.3 & 4.5805 & TRN & \\
\hline CHEMBL1470378 & 688128 & 4.55 & 4.5 & TRN & \\
\hline CHEMBL1479142 & 688128 & 4.7 & 4.6195 & TRN & \\
\hline CHEMBL1386432 & 688128 & 5.05 & 4.6703 & TRN & \\
\hline CHEMBL1318814 & 688128 & 4.7 & 4.6924 & TRN & \\
\hline CHEMBL1332519 & 688128 & 4.55 & 4.6581 & TST & \\
\hline CHEMBL1510514 & 688128 & 4.0 & 4.3674 & TRN & \\
\hline CHEMBL1578367 & 688128 & 4.85 & 4.6588 & TRN & \\
\hline CHEMBL1366215 & 688128 & 4.4 & 4.5615 & TRN & \\
\hline CHEMBL1309379 & 688128 & 5.35 & 4.7546 & TST & \\
\hline CHEMBL1404047 & 688128 & 4.05 & 4.6981 & TST & \\
\hline CHEMBL1395788 & 688128 & 4.45 & 4.6904 & TRN & \\
\hline CHEMBL1447402 & 688128 & 4.95 & 4.9538 & TRN & \\
\hline CHEMBL1419252 & 688128 & 5.25 & 5.0489 & TST & \\
\hline CHEMBL1507892 & 688128 & 4.3 & 4.5063 & TRN & \\
\hline CHEMBL1306788 & 688128 & 4.35 & 4.4031 & TRN & \\
\hline CHEMBL1585856 & 688128 & 4.5 & 4.2995 & TRN & \\
\hline CHEMBL1600963 & 688128 & 4.35 & 4.7736 & TRN & \\
\hline CHEMBL1540877 & 688128 & 5.45 & 4.8001 & TRN & \\
\hline CHEMBL1524136 & 688128 & 4.7 & 4.5308 & TRN & \\
\hline CHEMBL1606459 & 688128 & 5.95 & 4.5644 & TRN & \\
\hline CHEMBL1423986 & 688128 & 4.3 & 4.9925 & TRN & \\
\hline CHEMBL1311674 & 688128 & 4.4 & 4.2944 & TRN & \\
\hline CHEMBL1590532 & 688128 & 4.35 & 4.7081 & TRN & \\
\hline CHEMBL1443615 & 688128 & 4.6 & 4.738 & TRN & \\
\hline CHEMBL1499440 & 688128 & 6.15 & 4.8115 & TST & \\
\hline CHEMBL1555992 & 688128 & 5.6 & 4.9932 & TRN & \\
\hline CHEMBL1994148 & 688128 & 4.35 & 4.6958 & TRN & \\
\hline CHEMBL1493253 & 688128 & 4.65 & 4.7265 & TRN & \\
\hline CHEMBL1501903 & 688128 & 4.7 & 4.6763 & TRN & \\
\hline CHEMBL1564338 & 688128 & 4.35 & 4.6494 & TRN & \\
\hline CHEMBL1605099 & 688128 & 4.65 & 4.735 & TRN & \\
\hline CHEMBL1612892 & 688128 & 4.45 & 4.6238 & TRN & \\
\hline CHEMBL585651 & 688128 & 4.4 & 4.4098 & TRN & \\
\hline CHEMBL1426784 & 688128 & 4.4 & 4.4609 & TRN & \\
\hline CHEMBL3196960 & 688128 & 4.4 & 4.9859 & TRN & \\
\hline CHEMBL1560188 & 688128 & 5.6 & 4.9885 & TRN & \\
\hline CHEMBL1367142 & 688128 & 4.0 & 4.5227 & TRN & \\
\hline CHEMBL1479614 & 688128 & 4.25 & 4.5715 & TRN & \\
\hline CHEMBL1365331 & 688128 & 4.3 & 4.4408 & TRN & \\
\hline CHEMBL1524986 & 688128 & 4.55 & 4.6035 & TRN & \\
\hline CHEMBL1387167 & 688128 & 4.4 & 4.404 & TRN & \\
\hline CHEMBL1394879 & 688128 & 4.95 & 5.1804 & TRN & \\
\hline
\end{tabular}




\begin{tabular}{|c|c|c|c|c|}
\hline \multicolumn{5}{|c|}{ Supplemental Table S2.txt } \\
\hline CHEMBL1423507 & 688128 & 4.35 & 4.1401 & TRN \\
\hline CHEMBL3195780 & 688128 & 4.45 & 4.4882 & TRN \\
\hline CHEMBL1413495 & 688128 & 4.4 & 4.9069 & TRN \\
\hline CHEMBL1486698 & 688128 & 4.35 & 4.7105 & TRN \\
\hline CHEMBL1321664 & 688128 & 4.75 & 4.977 & TRN \\
\hline CHEMBL1527537 & 688128 & 4.65 & 5.3315 & TRN \\
\hline CHEMBL1412568 & 688128 & 4.4 & 5.0832 & TRN \\
\hline CHEMBL1519259 & 688128 & 4.4 & 4.5275 & TRN \\
\hline CHEMBL1326456 & 688128 & 4.35 & 4.373 & TRN \\
\hline CHEMBL1605903 & 688128 & 4.4 & 4.512 & TRN \\
\hline CHEMBL1547612 & 688128 & 4.4 & 4.7701 & TST \\
\hline CHEMBL1567327 & 688128 & 4.05 & 4.2172 & TRN \\
\hline CHEMBL1592366 & 688128 & 4.25 & 4.2786 & TRN \\
\hline CHEMBL1408131 & 688128 & 4.45 & 4.7923 & TRN \\
\hline CHEMBL1385384 & 688128 & 4.35 & 4.5281 & TRN \\
\hline CHEMBL1501526 & 688128 & 6.8499 & 4.5965 & TST \\
\hline CHEMBL1384810 & 688128 & 5.05 & 4.9452 & TRN \\
\hline CHEMBL1611655 & 688128 & 4.75 & 4.56 & TRN \\
\hline CHEMBL1345941 & 688128 & 4.85 & 4.8077 & TRN \\
\hline CHEMBL1539760 & 688128 & 4.4 & 4.5615 & TRN \\
\hline CHEMBL1339452 & 688128 & 4.6 & 4.4921 & TRN \\
\hline CHEMBL1601624 & 688128 & 4.8 & 4.8402 & TRN \\
\hline CHEMBL1463105 & 688128 & 4.3 & 4.6087 & TRN \\
\hline CHEMBL1428228 & 688128 & 5.45 & 5.1538 & TRN \\
\hline CHEMBL 2374093 & 688128 & 5.35 & 4.857 & TRN \\
\hline CHEMBL1336898 & 688128 & 4.05 & 4.6614 & TST \\
\hline CHEMBL1337005 & 688128 & 4.3 & 4.7543 & TRN \\
\hline CHEMBL1490488 & 688128 & 5.35 & 4.4548 & TST \\
\hline CHEMBL3199354 & 688128 & 4.85 & 4.7687 & TST \\
\hline CHEMBL1304416 & 688128 & 4.3 & 4.3688 & TRN \\
\hline CHEMBL1561792 & 688128 & 4.8 & 4.9273 & TRN \\
\hline CHEMBL1587884 & 688128 & 4.25 & 4.5417 & TRN \\
\hline CHEMBL1395346 & 688128 & 4.4 & 4.4973 & TRN \\
\hline CHEMBL1377983 & 688128 & 4.4 & 4.5453 & TRN \\
\hline CHEMBL1505176 & 688128 & 4.4 & 4.5961 & TRN \\
\hline CHEMBL1442136 & 688128 & 5.95 & 5.1241 & TRN \\
\hline CHEMBL1431389 & 688128 & 4.35 & 4.4593 & TRN \\
\hline CHEMBL1525386 & 688128 & 4.05 & 4.2376 & TRN \\
\hline CHEMBL1553301 & 688128 & 4.3 & 4.6666 & TST \\
\hline CHEMBL1545177 & 688128 & 4.35 & 4.8599 & TRN \\
\hline CHEMBL1393438 & 688128 & 4.75 & 4.6579 & TRN \\
\hline CHEMBL1388715 & 688128 & 4.5 & 4.4756 & TST \\
\hline CHEMBL1443052 & 688128 & 5.35 & 4.9707 & TRN \\
\hline CHEMBL1339936 & 688128 & 4.4 & 4.5636 & TRN \\
\hline CHEMBL1574831 & 688128 & 5.0 & 4.8961 & TRN \\
\hline CHEMBL1598785 & 688128 & 4.15 & 5.4771 & TRN \\
\hline CHEMBL1477528 & 688128 & 5.45 & 5.4071 & TRN \\
\hline CHEMBL1431979 & 688128 & 5.45 & 4.967 & TRN \\
\hline
\end{tabular}




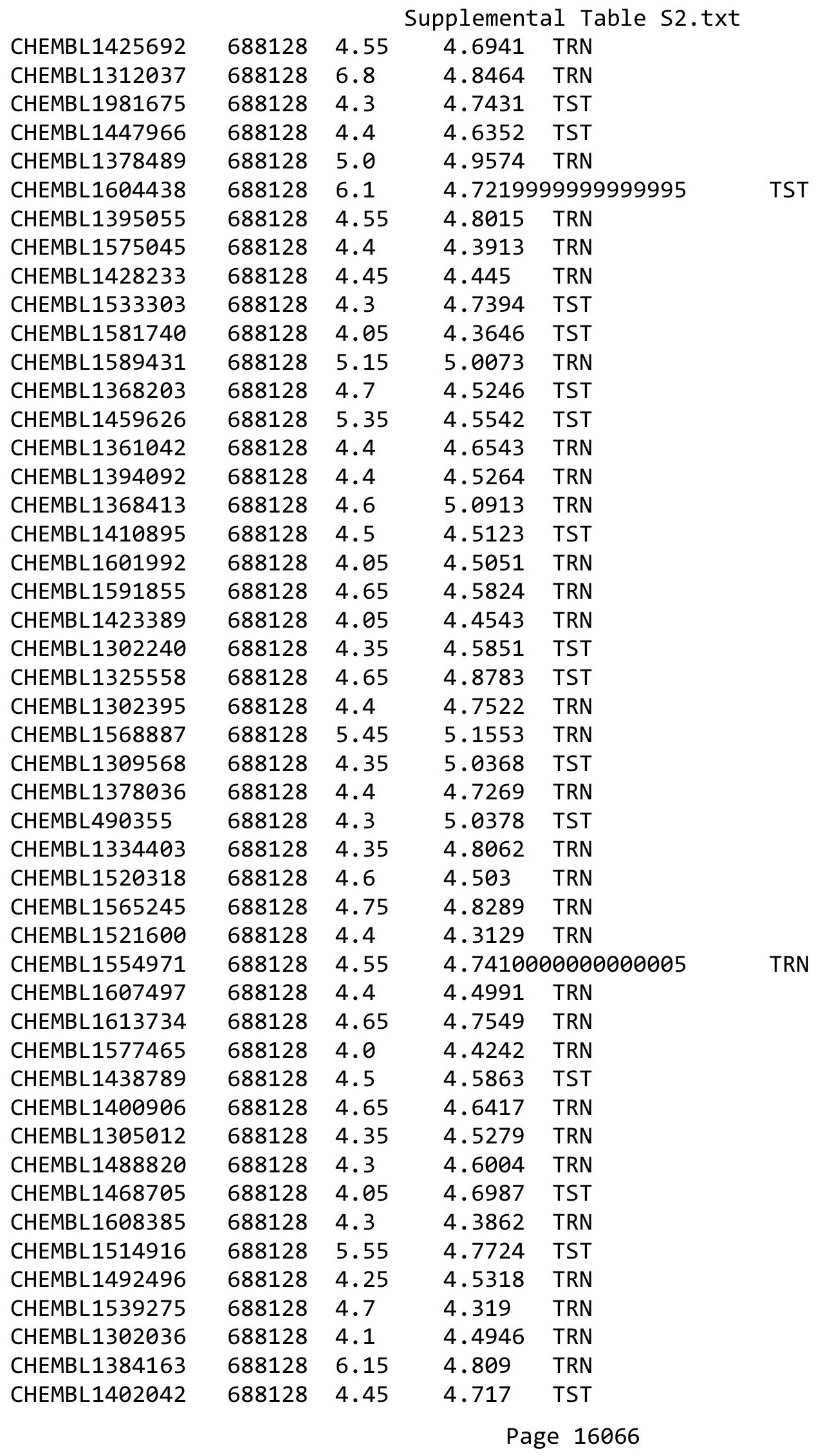




\begin{tabular}{|c|c|c|c|c|c|}
\hline \multicolumn{6}{|c|}{ Supplemental Table S2.txt } \\
\hline CHEMBL1407497 & 688128 & 4.35 & 4.8077 & TRN & \\
\hline CHEMBL1610472 & 688128 & 4.3 & 4.5736 & TRN & \\
\hline CHEMBL600908 & 688128 & 4.8 & 4.7617 & TRN & \\
\hline CHEMBL1509950 & 688128 & 4.85 & 4.4201 & TRN & \\
\hline CHEMBL1332619 & 688128 & 4.4 & 4.7235 & TRN & \\
\hline CHEMBL1376450 & 688128 & 4.3 & 4.4563 & TRN & \\
\hline CHEMBL1354063 & 688128 & 4.4 & 4.6566 & TST & \\
\hline CHEMBL3193187 & 688128 & 4.3 & 4.4501 & TRN & \\
\hline CHEMBL1389461 & 688128 & 4.5 & 5.2449 & TRN & \\
\hline CHEMBL1422020 & 688128 & 4.4 & 4.5841 & TST & \\
\hline CHEMBL1407714 & 688128 & 5.3 & 4.6262 & TRN & \\
\hline CHEMBL1521174 & 688128 & 4.0 & 4.8413 & TRN & \\
\hline CHEMBL1424206 & 688128 & 4.25 & 4.5725 & TST & \\
\hline CHEMBL1428999 & 688128 & 4.55 & 4.5414 & TST & \\
\hline CHEMBL1464210 & 688128 & 4.25 & 4.497 & TST & \\
\hline CHEMBL1399979 & 688128 & 5.45 & 4.8242 & TRN & \\
\hline CHEMBL1429260 & 688128 & 4.9 & 4.5191 & TST & \\
\hline CHEMBL1481479 & 688128 & 4.4 & 4.9106 & TRN & \\
\hline CHEMBL1384982 & 688128 & 4.05 & 4.5617 & TRN & \\
\hline CHEMBL1381926 & 688128 & 4.75 & 4.5074 & TRN & \\
\hline CHEMBL1411362 & 688128 & 4.0 & 4.5067 & TRN & \\
\hline CHEMBL1573278 & 688128 & 4.3 & 4.6053 & TRN & \\
\hline CHEMBL1331218 & 688128 & 4.35 & 4.7359 & TRN & \\
\hline CHEMBL1547321 & 688128 & 5.6 & 4.6173 & TRN & \\
\hline CHEMBL441473 & 688128 & 4.6 & 4.3113 & TRN & \\
\hline CHEMBL1486138 & 688128 & 5.05 & 4.8251 & TRN & \\
\hline CHEMBL1331025 & 688128 & 4.95 & 4.8955 & TRN & \\
\hline CHEMBL1392238 & 688128 & 5.9 & 4.63399 & 99999999995 & TST \\
\hline CHEMBL1213045 & 688128 & 4.45 & 4.9748 & TRN & \\
\hline CHEMBL1574820 & 688128 & 4.55 & 4.4021 & TST & \\
\hline CHEMBL1477054 & 688128 & 4.3 & 4.6936 & TST & \\
\hline CHEMBL1573166 & 688128 & 4.05 & 4.6216 & TRN & \\
\hline CHEMBL1328372 & 688128 & 4.65 & 4.4289 & TRN & \\
\hline CHEMBL1325921 & 688128 & 6.0 & 4.8894 & TRN & \\
\hline CHEMBL1463626 & 688128 & 4.35 & 4.664 & TRN & \\
\hline CHEMBL1581683 & 688128 & 4.3 & 5.0521 & TRN & \\
\hline CHEMBL 210208 & 688128 & 4.3 & 4.9856 & TST & \\
\hline CHEMBL1582698 & 688128 & 4.65 & 4.4092 & TRN & \\
\hline CHEMBL1355629 & 688128 & 4.3 & 4.8188 & TST & \\
\hline CHEMBL1549091 & 688128 & 4.3 & 4.6951 & TRN & \\
\hline CHEMBL1588284 & 688128 & 4.3 & 4.79 & TRN & \\
\hline CHEMBL1393889 & 688128 & 4.4 & 4.4371 & TRN & \\
\hline CHEMBL1528721 & 688128 & 4.4 & 4.7805 & TRN & \\
\hline CHEMBL1393178 & 688128 & 5.85 & 4.5454 & TRN & \\
\hline CHEMBL1563048 & 688128 & 5.25 & 4.7953 & TST & \\
\hline CHEMBL1364381 & 688128 & 4.3 & 4.4765 & TRN & \\
\hline CHEMBL1472238 & 688128 & 4.05 & 4.7282 & TST & \\
\hline CHEMBL1556634 & 688128 & 6.0 & 4.7988 & TRN & \\
\hline
\end{tabular}




\begin{tabular}{|c|c|c|c|c|}
\hline & & \multicolumn{3}{|c|}{ Supplemental Table S2.txt } \\
\hline CHEMBL1430122 & 688128 & 4.35 & 4.7259 & TRN \\
\hline CHEMBL 2374029 & 688128 & 5.45 & 4.9991 & TRN \\
\hline CHEMBL1387116 & 688128 & 4.4 & 4.7285 & TRN \\
\hline CHEMBL1363477 & 688128 & 5.35 & 4.7802 & TRN \\
\hline CHEMBL1349080 & 688128 & 4.85 & 4.7102 & TRN \\
\hline CHEMBL1322754 & 688128 & 5.15 & 5.0118 & TRN \\
\hline CHEMBL1546007 & 688128 & 4.05 & 4.9245 & TRN \\
\hline CHEMBL1575600 & 688128 & 4.8 & 4.6544 & TRN \\
\hline CHEMBL1322176 & 688128 & 4.35 & 4.7327 & TRN \\
\hline CHEMBL1393336 & 688128 & 4.5 & 4.3678 & TST \\
\hline CHEMBL1487299 & 688128 & 5.8 & 4.4176 & TRN \\
\hline CHEMBL1533687 & 688128 & 5.65 & 4.7692 & TST \\
\hline CHEMBL1330145 & 688128 & 4.55 & 4.4404 & TRN \\
\hline CHEMBL1403874 & 688128 & 4.0 & 4.3304 & TRN \\
\hline CHEMBL1579716 & 688128 & 4.05 & 4.6921 & TST \\
\hline CHEMBL1361481 & 688128 & 4.55 & 4.7025 & TST \\
\hline CHEMBL1504221 & 688128 & 4.75 & 5.2863 & TRN \\
\hline CHEMBL1545974 & 688128 & 5.05 & 4.2609 & TRN \\
\hline CHEMBL1302545 & 688128 & 4.4 & 4.7419 & TST \\
\hline CHEMBL1524117 & 688128 & 4.5 & 4.7359 & TST \\
\hline CHEMBL577589 & 688128 & 4.35 & 4.6251 & TRN \\
\hline CHEMBL1428862 & 688128 & 5.4 & 4.8688 & TRN \\
\hline CHEMBL1498537 & 688128 & 4.95 & 5.0402 & TRN \\
\hline CHEMBL1552033 & 688128 & 4.4 & 4.6351 & TST \\
\hline CHEMBL534244 & 688128 & 4.35 & 5.0061 & TST \\
\hline CHEMBL1416471 & 688128 & 5.15 & 4.6575 & TRN \\
\hline CHEMBL1380244 & 688128 & 4.6 & 4.6246 & TRN \\
\hline CHEMBL1445027 & 688128 & 4.35 & 4.5298 & TRN \\
\hline CHEMBL1568124 & 688128 & 4.75 & 4.7288 & TST \\
\hline CHEMBL1596008 & 688128 & 4.05 & 4.6342 & TRN \\
\hline CHEMBL1376068 & 688128 & 4.45 & 4.668 & TST \\
\hline CHEMBL1311000 & 688128 & 4.4 & 4.5635 & TRN \\
\hline CHEMBL1396482 & 688128 & 6.25 & 4.9399 & TRN \\
\hline CHEMBL1321033 & 688128 & 4.9 & 4.5468 & TST \\
\hline CHEMBL1444183 & 688128 & 4.25 & 4.9812 & TRN \\
\hline CHEMBL1401447 & 688128 & 4.4 & 4.577 & TRN \\
\hline CHEMBL1494502 & 688128 & 5.35 & 4.5283 & TRN \\
\hline CHEMBL1329587 & 688128 & 6.5 & 5.191 & TRN \\
\hline CHEMBL1353622 & 688128 & 4.6 & 4.5482 & TRN \\
\hline CHEMBL1315565 & 688128 & 5.4 & 4.6501 & TRN \\
\hline CHEMBL1581673 & 688128 & 4.3 & 4.5629 & TRN \\
\hline CHEMBL1310353 & 688128 & 6.0 & 5.3235 & TRN \\
\hline CHEMBL1304352 & 688128 & 4.45 & 4.324 & TRN \\
\hline CHEMBL1558485 & 688128 & 4.9 & 5.0968 & TRN \\
\hline CHEMBL3189443 & 688128 & 4.35 & 4.1929 & TST \\
\hline CHEMBL1440090 & 688128 & 4.05 & 4.5839 & TRN \\
\hline CHEMBL1470077 & 688128 & 4.75 & 4.4321 & TRN \\
\hline CHEMBL1485473 & 688128 & 5.2 & 4.7725 & TRN \\
\hline
\end{tabular}




\begin{tabular}{|c|c|c|c|c|c|}
\hline \multicolumn{6}{|c|}{ Supplemental Table s2.txt } \\
\hline CHEMBL3199942 & 688128 & 5.1 & 4.9236 & TRN & \\
\hline CHEMBL1441954 & 688128 & 4.4 & 4.3199 & TRN & \\
\hline CHEMBL1348156 & 688128 & 6.05 & 4.7581 & TST & \\
\hline CHEMBL1433661 & 688128 & 5.05 & 5.0252 & TRN & \\
\hline CHEMBL1537731 & 688128 & 4.6 & 4.8259 & TST & \\
\hline CHEMBL1453088 & 688128 & 4.0 & 4.2662 & TRN & \\
\hline CHEMBL1320499 & 688128 & 4.3 & 4.3979 & TRN & \\
\hline CHEMBL1373812 & 688128 & 4.3 & 4.5273 & TRN & \\
\hline CHEMBL1446102 & 688128 & 5.8 & 5.0587 & TRN & \\
\hline CHEMBL1443009 & 688128 & 4.85 & 4.8408 & TRN & \\
\hline CHEMBL1484104 & 688128 & 4.25 & 4.6577 & TRN & \\
\hline CHEMBL1392911 & 688128 & 4.4 & 4.4673 & TRN & \\
\hline CHEMBL1450497 & 688128 & 4.45 & 4.35 & TRN & \\
\hline CHEMBL525889 & 688128 & 4.05 & 4.6093 & TST & \\
\hline CHEMBL1596968 & 688128 & 4.1 & 4.6161 & TST & \\
\hline CHEMBL1608974 & 688128 & 4.3 & 4.6943 & TRN & \\
\hline CHEMBL1329486 & 688128 & 4.3 & 4.7082 & TRN & \\
\hline CHEMBL1453572 & 688128 & 4.4 & 5.0053 & TRN & \\
\hline CHEMBL1435205 & 688128 & 5.55 & 5.0054 & TRN & \\
\hline CHEMBL1425650 & 688128 & 5.5 & 4.5769 & TRN & \\
\hline CHEMBL1527788 & 688128 & 6.15 & 5.1937 & TRN & \\
\hline CHEMBL1442056 & 688128 & 5.2 & 4.9783 & TST & \\
\hline CHEMBL1337169 & 688128 & 4.35 & 4.4791 & TRN & \\
\hline CHEMBL1554258 & 688128 & 4.7 & 4.5709 & TST & \\
\hline CHEMBL1412630 & 688128 & 4.6 & 4.5183 & TRN & \\
\hline CHEMBL1571309 & 688128 & 4.4 & 4.7487 & TST & \\
\hline CHEMBL1607713 & 688128 & 6.0 & 4.54 & TST & \\
\hline CHEMBL1478006 & 688128 & 4.55 & 4.4864 & TRN & \\
\hline CHEMBL3190218 & 688128 & 4.3 & 4.3929 & TRN & \\
\hline CHEMBL1324735 & 688128 & 4.75 & 4.6018 & TST & \\
\hline CHEMBL1410260 & 688128 & 5.55 & 4.7032 & TRN & \\
\hline CHEMBL466179 & 688128 & 4.45 & 4.6391 & TST & \\
\hline CHEMBL1544548 & 688128 & 5.9 & 4.8138 & TST & \\
\hline CHEMBL1604119 & 688128 & 5.0 & 4.4295 & TRN & \\
\hline CHEMBL1370083 & 688128 & 6.05 & 4.7303 & TST & \\
\hline CHEMBL1471066 & 688128 & 4.05 & 4.6673 & TRN & \\
\hline CHEMBL3195553 & 688128 & 4.35 & 4.8003 & TST & \\
\hline CHEMBL1358004 & 688128 & 4.9 & 4.7269 & TRN & \\
\hline CHEMBL1528136 & 688128 & 4.35 & 4.4505 & TRN & \\
\hline CHEMBL1420612 & 688128 & 4.5 & 4.6377 & TRN & \\
\hline CHEMBL1309603 & 688128 & 4.5 & 4.485 & TRN & \\
\hline CHEMBL1409782 & 688128 & 4.35 & 4.6512 & TST & \\
\hline CHEMBL1381490 & 688128 & 5.45 & 4.89199 & 99999999995 & TRN \\
\hline CHEMBL1565221 & 688128 & 5.0 & 4.7273 & TRN & \\
\hline CHEMBL1393131 & 688128 & 6.15 & 5.1995 & TRN & \\
\hline CHEMBL1356574 & 688128 & 4.3 & 4.5639 & TST & \\
\hline CHEMBL1430795 & 688128 & 6.35 & 4.864 & TRN & \\
\hline CHEMBL1350219 & 688128 & 4.55 & 4.5543 & TRN & \\
\hline
\end{tabular}




\begin{tabular}{|c|c|c|c|c|c|}
\hline & & \multicolumn{4}{|c|}{ Supplemental Table S2.txt } \\
\hline CHEMBL560073 & 688128 & 5.45 & 4.6377 & TRN & \\
\hline CHEMBL1491595 & 688128 & 4.3 & 4.5524 & TST & \\
\hline CHEMBL3197211 & 688128 & 4.85 & 4.8008 & TRN & \\
\hline CHEMBL1597467 & 688128 & 4.35 & 4.7545 & TRN & \\
\hline CHEMBL1541860 & 688128 & 6.9 & 4.819 & TRN & \\
\hline CHEMBL1600751 & 688128 & 4.45 & 4.6148 & TRN & \\
\hline CHEMBL1458652 & 688128 & 4.75 & 4.8164 & TRN & \\
\hline CHEMBL1480776 & 688128 & 4.3 & 4.8645 & TRN & \\
\hline CHEMBL1437859 & 688128 & 6.0 & 4.8659 & TRN & \\
\hline CHEMBL1497139 & 688128 & 5.65 & 5.2174 & TRN & \\
\hline CHEMBL1561964 & 688128 & 4.35 & 4.7906 & TRN & \\
\hline CHEMBL1386252 & 688128 & 5.75 & 5.4599 & TRN & \\
\hline CHEMBL1373410 & 688128 & 4.35 & 4.4169 & TST & \\
\hline CHEMBL3191490 & 688128 & 4.35 & 4.6162 & TRN & \\
\hline CHEMBL1321230 & 688128 & 4.3 & 4.607 & TST & \\
\hline CHEMBL1312673 & 688128 & 5.6 & 4.9449 & TRN & \\
\hline CHEMBL1487965 & 688128 & 4.3 & 4.4555 & TRN & \\
\hline CHEMBL1550427 & 688128 & 5.4 & 4.6979 & TRN & \\
\hline CHEMBL3193248 & 688128 & 4.3 & 4.8062 & TST & \\
\hline CHEMBL1496328 & 688128 & 4.05 & 4.4402 & TRN & \\
\hline CHEMBL140425 & 688128 & 4.95 & 5.4153 & TRN & \\
\hline CHEMBL518292 & 688128 & 4.3 & 4.6782 & TST & \\
\hline CHEMBL1416524 & 688128 & 4.35 & 4.4362 & TST & \\
\hline CHEMBL1337469 & 688128 & 5.1 & 4.8507 & TRN & \\
\hline CHEMBL1404301 & 688128 & 5.45 & 5.0853 & TRN & \\
\hline CHEMBL1402862 & 688128 & 4.45 & 4.4927 & TRN & \\
\hline CHEMBL1510817 & 688128 & 4.3 & 4.4996 & TRN & \\
\hline CHEMBL1489583 & 688128 & 4.3 & 4.4488 & TRN & \\
\hline CHEMBL3189924 & 688128 & 4.35 & 4.6578 & TST & \\
\hline CHEMBL1320202 & 688128 & 4.45 & 4.58899 & 99999999995 & TRN \\
\hline CHEMBL1388742 & 688128 & 4.55 & 4.405 & TRN & \\
\hline CHEMBL1545218 & 688128 & 4.5 & 4.69300 & 00000000005 & TRN \\
\hline CHEMBL1340534 & 688128 & 4.4 & 4.4292 & TRN & \\
\hline CHEMBL1425241 & 688128 & 4.05 & 4.5203 & TRN & \\
\hline CHEMBL1434513 & 688128 & 5.75 & 4.9319 & TRN & \\
\hline CHEMBL1551852 & 688128 & 4.05 & 4.5098 & TRN & \\
\hline CHEMBL1320042 & 688128 & 4.4 & 4.7118 & TST & \\
\hline CHEMBL1522101 & 688128 & 4.3 & 4.4936 & TRN & \\
\hline CHEMBL1569908 & 688128 & 6.25 & 4.4787 & TRN & \\
\hline CHEMBL1537455 & 688128 & 5.5 & 4.6269 & TRN & \\
\hline CHEMBL1434661 & 688128 & 5.55 & 4.6432 & TRN & \\
\hline CHEMBL1316566 & 688128 & 4.9 & 4.5735 & TRN & \\
\hline CHEMBL1425363 & 688128 & 4.6 & 4.5972 & TST & \\
\hline CHEMBL1430645 & 688128 & 4.3 & 4.67399 & 99999999995 & TRN \\
\hline CHEMBL3207890 & 688128 & 4.45 & 4.6455 & TRN & \\
\hline CHEMBL1306140 & 688128 & 4.4 & 4.5876 & TST & \\
\hline CHEMBL1574268 & 688128 & 4.65 & 4.7084 & TRN & \\
\hline CHEMBL1539095 & 688128 & 4.0 & 4.6357 & TRN & \\
\hline
\end{tabular}




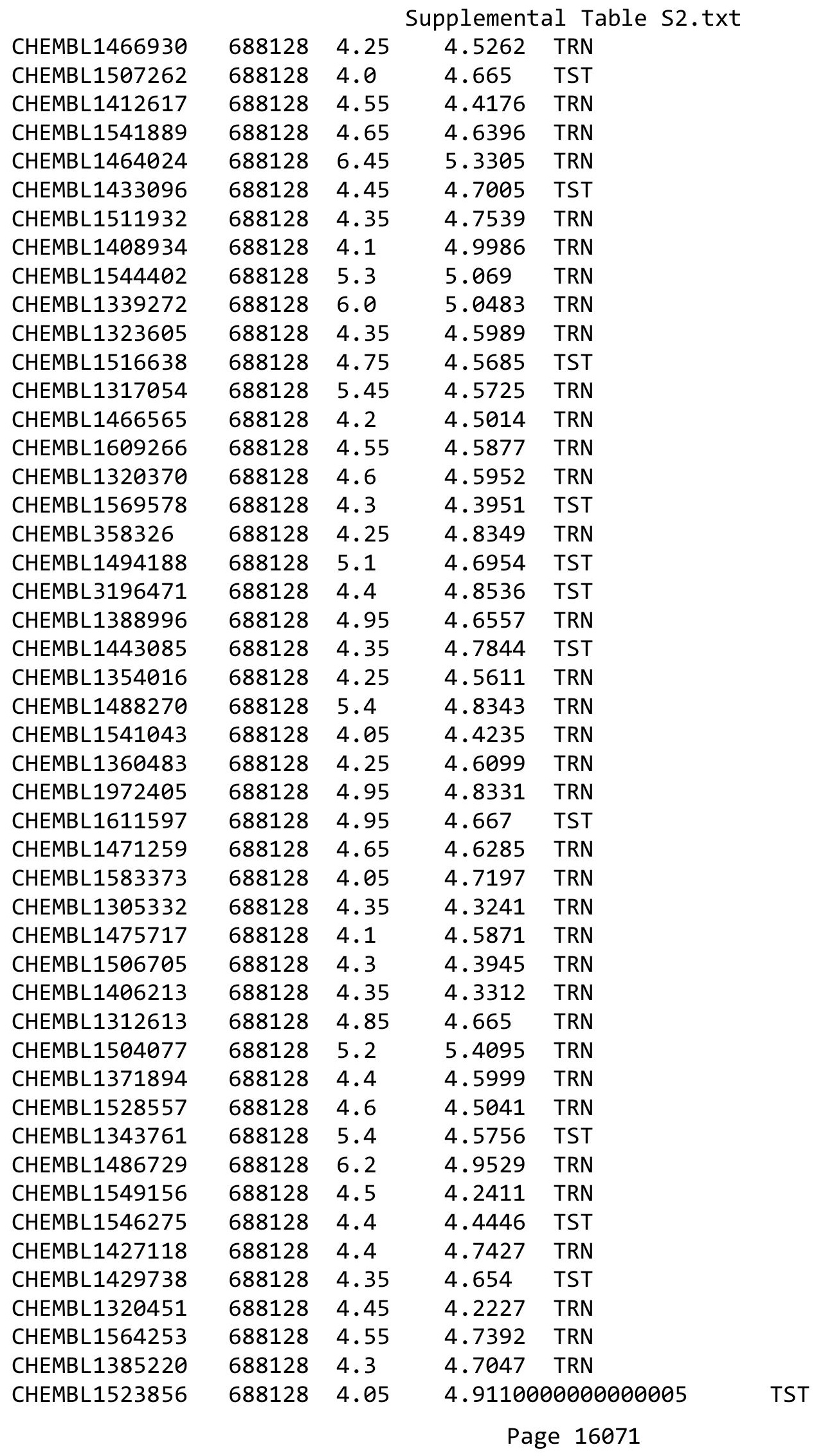




\begin{tabular}{|c|c|c|c|c|c|}
\hline \multicolumn{6}{|c|}{ Supplemental Table S2.txt } \\
\hline CHEMBL1491451 & 688128 & 4.3 & 4.7534 & TRN & \\
\hline CHEMBL1305107 & 688128 & 4.35 & 4.5559 & TRN & \\
\hline CHEMBL1324059 & 688128 & 4.45 & 4.3327 & TRN & \\
\hline CHEMBL1370836 & 688128 & 5.4 & 4.8802 & TRN & \\
\hline CHEMBL1504418 & 688128 & 4.55 & 4.8497 & TRN & \\
\hline CHEMBL1486690 & 688128 & 4.25 & 4.5168 & TST & \\
\hline CHEMBL1479041 & 688128 & 4.05 & 4.4858 & TRN & \\
\hline CHEMBL1437991 & 688128 & 4.95 & 4.8975 & TRN & \\
\hline CHEMBL1541269 & 688128 & 4.7 & 4.6711 & TRN & \\
\hline CHEMBL1467236 & 688128 & 4.7 & 4.365 & TRN & \\
\hline CHEMBL1453822 & 688128 & 4.25 & 4.6954 & TRN & \\
\hline CHEMBL1483351 & 688128 & 4.3 & 4.6335 & TST & \\
\hline CHEMBL1545348 & 688128 & 4.35 & 4.6318 & TRN & \\
\hline CHEMBL1308609 & 688128 & 4.3 & 4.5085 & TRN & \\
\hline CHEMBL1317359 & 688128 & 4.35 & 4.33899 & 99999999995 & TRN \\
\hline CHEMBL1544468 & 688128 & 6.1 & 4.9741 & TST & \\
\hline CHEMBL1500375 & 688128 & 4.3 & 4.7246 & TST & \\
\hline CHEMBL1455311 & 688128 & 4.3 & 4.6805 & TRN & \\
\hline CHEMBL1556537 & 688128 & 4.05 & 4.8166 & TRN & \\
\hline CHEMBL1453309 & 688128 & 4.75 & 4.6269 & TST & \\
\hline CHEMBL1569750 & 688128 & 4.4 & 4.5504 & TRN & \\
\hline CHEMBL1474454 & 688128 & 4.5 & 4.8501 & TRN & \\
\hline CHEMBL1301448 & 688128 & 4.4 & 4.4771 & TRN & \\
\hline CHEMBL1522545 & 688128 & 5.75 & 4.5746 & TST & \\
\hline CHEMBL1322665 & 688128 & 4.75 & 4.9133 & TRN & \\
\hline CHEMBL1527645 & 688128 & 4.5 & 4.5799 & TRN & \\
\hline CHEMBL1538620 & 688128 & 4.0 & 4.6547 & TRN & \\
\hline CHEMBL1494545 & 688128 & 4.35 & 4.6081 & TRN & \\
\hline CHEMBL1457261 & 688128 & 4.55 & 4.7294 & TRN & \\
\hline CHEMBL1412171 & 688128 & 5.4 & 4.9211 & TRN & \\
\hline CHEMBL1429338 & 688128 & 5.0 & 4.6275 & TRN & \\
\hline CHEMBL1480843 & 688128 & 4.35 & 4.4806 & TRN & \\
\hline CHEMBL1331628 & 688128 & 4.4 & 4.4711 & TRN & \\
\hline CHEMBL1492503 & 688128 & 5.0 & 4.6235 & TRN & \\
\hline CHEMBL1387343 & 688128 & 4.35 & 4.82100 & 3000000001 & TST \\
\hline CHEMBL1501899 & 688128 & 4.7 & 4.6316 & TRN & \\
\hline CHEMBL1442821 & 688128 & 4.3 & 4.3796 & TST & \\
\hline CHEMBL1339330 & 688128 & 4.35 & 4.4562 & TRN & \\
\hline CHEMBL1361112 & 688128 & 4.65 & 4.6154 & TRN & \\
\hline CHEMBL3211325 & 688128 & 5.2 & 4.5729 & TRN & \\
\hline CHEMBL1561115 & 688128 & 4.3 & 4.8542 & TRN & \\
\hline CHEMBL1526655 & 688128 & 4.6 & 4.5647 & TRN & \\
\hline CHEMBL1567917 & 688128 & 4.4 & 4.3117 & TST & \\
\hline CHEMBL1513313 & 688128 & 4.1 & 4.2871 & TST & \\
\hline CHEMBL1596821 & 688128 & 5.05 & 4.7017 & TRN & \\
\hline CHEMBL1401592 & 688128 & 4.4 & 4.5697 & TRN & \\
\hline CHEMBL1445268 & 688128 & 6.15 & 4.6662 & TRN & \\
\hline CHEMBL1528934 & 688128 & 6.8499 & 4.709 & TST & \\
\hline
\end{tabular}




\begin{tabular}{|c|c|c|c|c|}
\hline \multicolumn{5}{|c|}{ Supplemental Table S2.txt } \\
\hline CHEMBL1407483 & 688128 & 4.5 & 4.6908 & TST \\
\hline CHEMBL1328014 & 688128 & 4.3 & 4.8396 & TRN \\
\hline CHEMBL1336347 & 688128 & 4.45 & 4.3588 & TRN \\
\hline CHEMBL1537935 & 688128 & 4.25 & 4.6872 & TRN \\
\hline CHEMBL3208995 & 688128 & 4.6 & 4.5214 & TRN \\
\hline CHEMBL1577283 & 688128 & 4.9 & 4.9144 & TRN \\
\hline CHEMBL1371020 & 688128 & 4.15 & 4.7228 & TST \\
\hline CHEMBL1445902 & 688128 & 4.3 & 4.3627 & TRN \\
\hline CHEMBL3196877 & 688128 & 4.3 & 4.752 & TST \\
\hline CHEMBL1459258 & 688128 & 4.3 & 5.0895 & TRN \\
\hline CHEMBL1489063 & 688128 & 4.55 & 4.6308 & TRN \\
\hline CHEMBL1471377 & 688128 & 4.35 & 5.0752 & TRN \\
\hline CHEMBL1425606 & 688128 & 4.65 & 4.8037 & TRN \\
\hline CHEMBL1378993 & 688128 & 4.4 & 4.4594 & TRN \\
\hline CHEMBL1484636 & 688128 & 4.8 & 4.3658 & TRN \\
\hline CHEMBL1585997 & 688128 & 4.3 & 5.3106 & TRN \\
\hline CHEMBL1446414 & 688128 & 4.3 & 4.8085 & TRN \\
\hline CHEMBL1431606 & 688128 & 4.3 & 4.3745 & TRN \\
\hline CHEMBL1546827 & 688128 & 4.55 & 4.9712 & TRN \\
\hline CHEMBL1995862 & 688128 & 4.35 & 4.6684 & TRN \\
\hline CHEMBL1478728 & 688128 & 4.5 & 4.6434 & TST \\
\hline CHEMBL1557453 & 688128 & 4.05 & 4.7118 & TRN \\
\hline CHEMBL1312684 & 688128 & 4.8 & 4.5178 & TRN \\
\hline CHEMBL1613188 & 688128 & 4.4 & 4.7281 & TRN \\
\hline CHEMBL1519310 & 688128 & 4.3 & 4.6829 & TST \\
\hline CHEMBL1592961 & 688128 & 4.05 & 4.8206 & TRN \\
\hline CHEMBL1494303 & 688128 & 4.3 & 4.3664 & TRN \\
\hline CHEMBL1360781 & 688128 & 4.35 & 4.4281 & TRN \\
\hline CHEMBL3209324 & 688128 & 4.3 & 4.7456 & TRN \\
\hline CHEMBL1574878 & 688128 & 4.5 & 4.4418 & TRN \\
\hline CHEMBL562192 & 688128 & 4.6 & 4.3446 & TRN \\
\hline CHEMBL1404668 & 688128 & 4.1 & 4.4524 & TRN \\
\hline CHEMBL1354816 & 688128 & 4.2 & 4.6675 & TRN \\
\hline CHEMBL1310868 & 688128 & 4.3 & 4.4995 & TST \\
\hline CHEMBL1471666 & 688128 & 4.3 & 4.5769 & TRN \\
\hline CHEMBL1526767 & 688128 & 4.55 & 4.2724 & TRN \\
\hline CHEMBL1470357 & 688128 & 4.3 & 4.5196 & TRN \\
\hline CHEMBL1540463 & 688128 & 4.9 & 4.9027 & TST \\
\hline CHEMBL1482637 & 688128 & 4.3 & 4.5314 & TST \\
\hline CHEMBL1302207 & 688128 & 5.75 & 4.876 & TRN \\
\hline CHEMBL1573974 & 688128 & 4.25 & 4.4602 & TST \\
\hline CHEMBL 2110291 & 688128 & 5.05 & 4.8284 & TRN \\
\hline CHEMBL1522411 & 688128 & 4.5 & 4.5462 & TRN \\
\hline CHEMBL1487630 & 688128 & 4.45 & 4.5297 & TST \\
\hline CHEMBL1347570 & 688128 & 4.3 & 4.6985 & TRN \\
\hline CHEMBL1342084 & 688128 & 4.4 & 4.5561 & TRN \\
\hline CHEMBL1519611 & 688128 & 5.55 & 4.6268 & TST \\
\hline CHEMBL1338485 & 688128 & 5.4 & 4.7619 & TRN \\
\hline
\end{tabular}




\begin{tabular}{|c|c|c|c|c|}
\hline \multicolumn{5}{|c|}{ Supplemental Table S2.txt } \\
\hline CHEMBL1565440 & 688128 & 5.05 & 4.4627 & TRN \\
\hline CHEMBL1390468 & 688128 & 4.45 & 4.5699 & TRN \\
\hline CHEMBL1360250 & 688128 & 4.25 & 4.2593 & TRN \\
\hline CHEMBL1547597 & 688128 & 4.45 & 4.9338 & TST \\
\hline CHEMBL1419785 & 688128 & 4.4 & 4.7416 & TRN \\
\hline CHEMBL1559047 & 688128 & 4.3 & 4.5085 & TRN \\
\hline CHEMBL1330428 & 688128 & 4.6 & 4.5537 & TST \\
\hline CHEMBL1410449 & 688128 & 4.35 & 4.7141 & TRN \\
\hline CHEMBL1461617 & 688128 & 4.05 & 4.5243 & TRN \\
\hline CHEMBL1482856 & 688128 & 5.8 & 4.6818 & TRN \\
\hline CHEMBL3195770 & 688128 & 4.05 & 4.5898 & TRN \\
\hline CHEMBL 1607530 & 688128 & 4.35 & 4.4395 & TRN \\
\hline CHEMBL1392828 & 688128 & 4.6 & 4.6729 & TRN \\
\hline CHEMBL1352069 & 688128 & 4.3 & 4.796 & TRN \\
\hline CHEMBL1341017 & 688128 & 4.35 & 4.5128 & TRN \\
\hline CHEMBL1331856 & 688128 & 4.35 & 4.2441 & TRN \\
\hline CHEMBL1373776 & 688128 & 4.7 & 4.659 & TRN \\
\hline CHEMBL1498113 & 688128 & 4.4 & 4.5332 & TST \\
\hline CHEMBL1441037 & 688128 & 4.3 & 4.6942 & TRN \\
\hline CHEMBL1385000 & 688128 & 4.4 & 4.6835 & TRN \\
\hline CHEMBL377295 & 688128 & 5.05 & 4.6156 & TRN \\
\hline CHEMBL1347084 & 688128 & 5.15 & 5.1281 & TRN \\
\hline CHEMBL1481119 & 688128 & 4.1 & 4.5891 & TST \\
\hline CHEMBL1489890 & 688128 & 4.4 & 4.9254 & TRN \\
\hline CHEMBL1494943 & 688128 & 4.05 & 4.4513 & TST \\
\hline CHEMBL3191210 & 688128 & 4.65 & 4.5852 & TRN \\
\hline CHEMBL1310112 & 688128 & 4.6 & 4.6904 & TRN \\
\hline CHEMBL1509694 & 688128 & 4.35 & 4.7885 & TST \\
\hline CHEMBL1599933 & 688128 & 4.35 & 4.2332 & TRN \\
\hline CHEMBL1535680 & 688128 & 4.35 & 4.8448 & TRN \\
\hline CHEMBL1531585 & 688128 & 4.4 & 4.6218 & TRN \\
\hline CHEMBL1323536 & 688128 & 4.3 & 4.6511 & TRN \\
\hline CHEMBL1497752 & 688128 & 4.05 & 4.537 & TST \\
\hline CHEMBL1302300 & 688128 & 4.55 & 4.7106 & TRN \\
\hline CHEMBL1613362 & 688128 & 4.4 & 4.8291 & TRN \\
\hline CHEMBL1531365 & 688128 & 4.95 & 4.6289 & TRN \\
\hline CHEMBL1538731 & 688128 & 6.8499 & 4.6042 & TRN \\
\hline CHEMBL1482609 & 688128 & 4.55 & 4.3776 & TRN \\
\hline CHEMBL1389636 & 688128 & 4.4 & 4.6119 & TST \\
\hline CHEMBL238798 & 688128 & 4.55 & 4.6786 & TRN \\
\hline CHEMBL1505318 & 688128 & 5.85 & 4.6211 & TRN \\
\hline CHEMBL1466638 & 688128 & 4.25 & 4.6621 & TRN \\
\hline CHEMBL1414117 & 688128 & 4.25 & 4.738 & TRN \\
\hline CHEMBL1305787 & 688128 & 4.95 & 4.5546 & TRN \\
\hline CHEMBL3191108 & 688128 & 4.4 & 4.7615 & TRN \\
\hline CHEMBL1424114 & 688128 & 4.05 & 4.7758 & TRN \\
\hline CHEMBL1319484 & 688128 & 4.5 & 4.3114 & TRN \\
\hline CHEMBL3199577 & 688128 & 6.5501 & 5.034 & TRN \\
\hline
\end{tabular}




\begin{tabular}{|c|c|c|c|c|}
\hline & & & ipplemen & al $\mathrm{T}$ \\
\hline CHEMBL1543694 & 688128 & 4.6 & 4.4211 & TRN \\
\hline CHEMBL1485384 & 688128 & 4.5 & 4.628 & TRN \\
\hline CHEMBL1499318 & 688128 & 5.55 & 4.7777 & TRN \\
\hline CHEMBL1379716 & 688128 & 4.5 & 4.6948 & TRN \\
\hline CHEMBL1447605 & 688128 & 4.35 & 4.4541 & TRN \\
\hline CHEMBL1583565 & 688128 & 4.4 & 4.4636 & TRN \\
\hline CHEMBL1453050 & 688128 & 5.45 & 4.4693 & TRN \\
\hline CHEMBL1309416 & 688128 & 4.75 & 4.7959 & TRN \\
\hline CHEMBL1484134 & 688128 & 4.55 & 4.6603 & TRN \\
\hline CHEMBL 2000445 & 688128 & 4.3 & 4.7133 & TRN \\
\hline CHEMBL1339434 & 688128 & 4.25 & 4.5896 & TRN \\
\hline CHEMBL1378492 & 688128 & 4.55 & 4.7401 & TST \\
\hline CHEMBL1578561 & 688128 & 4.35 & 4.5379 & TRN \\
\hline CHEMBL 2003973 & 688128 & 5.45 & 4.83 & TST \\
\hline CHEMBL1458022 & 688128 & 6.1 & 4.829 & TST \\
\hline CHEMBL1343409 & 688128 & 4.4 & 4.3251 & TRN \\
\hline CHEMBL1432214 & 688128 & 4.25 & 5.1236 & TRN \\
\hline CHEMBL1491115 & 688128 & 4.55 & 4.5637 & TRN \\
\hline CHEMBL1499197 & 688128 & 4.3 & 4.7104 & TRN \\
\hline CHEMBL1350431 & 688128 & 4.3 & 4.3613 & TRN \\
\hline CHEMBL1518098 & 688128 & 5.2 & 4.9846 & TST \\
\hline CHEMBL1380628 & 688128 & 4.45 & 4.5729 & TRN \\
\hline CHEMBL1305192 & 688128 & 4.0 & 4.5406 & TRN \\
\hline CHEMBL1402473 & 688128 & 4.75 & 4.9276 & TRN \\
\hline CHEMBL1503949 & 688128 & 5.6 & 4.9581 & TRN \\
\hline CHEMBL1365977 & 688128 & 4.75 & 4.6308 & TRN \\
\hline CHEMBL1519226 & 688128 & 4.4 & 4.4952 & TST \\
\hline CHEMBL1451292 & 688128 & 4.05 & 4.7738 & TRN \\
\hline CHEMBL1486818 & 688128 & 5.35 & 4.5129 & TRN \\
\hline CHEMBL1529186 & 688128 & 6.0 & 4.6409 & TRN \\
\hline CHEMBL1377082 & 688128 & 4.2 & 4.7756 & TRN \\
\hline CHEMBL1384172 & 688128 & 6.15 & 5.1979 & TRN \\
\hline CHEMBL1581418 & 688128 & 4.45 & 5.0694 & TRN \\
\hline CHEMBL1600217 & 688128 & 4.1 & 4.4226 & TRN \\
\hline CHEMBL1333011 & 688128 & 4.3 & 4.7656 & TRN \\
\hline CHEMBL1360204 & 688128 & 4.9 & 4.5454 & TRN \\
\hline CHEMBL1370483 & 688128 & 4.55 & 4.5422 & TRN \\
\hline CHEMBL1396843 & 688128 & 4.4 & 4.7622 & TRN \\
\hline CHEMBL1403450 & 688128 & 4.3 & 4.5203 & TRN \\
\hline CHEMBL585591 & 688128 & 4.4 & 4.6125 & TST \\
\hline CHEMBL1604793 & 688128 & 6.0 & 5.0242 & TRN \\
\hline CHEMBL1418351 & 688128 & 4.1 & 4.6298 & TST \\
\hline CHEMBL1575680 & 688128 & 4.8 & 4.5696 & TRN \\
\hline CHEMBL1392720 & 688128 & 4.45 & 4.7355 & TRN \\
\hline CHEMBL1420962 & 688128 & 4.1 & 4.4435 & TRN \\
\hline CHEMBL1543127 & 688128 & 4.85 & 4.7583 & TRN \\
\hline CHEMBL1485796 & 688128 & 4.1 & 4.9794 & TST \\
\hline CHEMBL1299827 & 688128 & 4.3 & 4.4653 & TRN \\
\hline
\end{tabular}




\begin{tabular}{|c|c|c|c|c|}
\hline \multicolumn{5}{|c|}{ plemental T } \\
\hline CHEMBL1575022 & 688128 & 4.4 & 4.5778 & TRN \\
\hline CHEMBL1307453 & 688128 & 5.1 & 5.1739 & TRN \\
\hline CHEMBL1445654 & 688128 & 4.3 & 4.5495 & TRN \\
\hline CHEMBL1478193 & 688128 & 4.85 & 4.8054 & TRN \\
\hline CHEMBL1578354 & 688128 & 4.5 & 4.7829 & TRN \\
\hline CHEMBL1482635 & 688128 & 4.4 & 4.8798 & TRN \\
\hline CHEMBL1567974 & 688128 & 4.5 & 4.4412 & TRN \\
\hline CHEMBL1324611 & 688128 & 4.0 & 4.5398 & TRN \\
\hline CHEMBL 2006590 & 688128 & 5.8 & 4.7617 & TRN \\
\hline CHEMBL1601324 & 688128 & 4.35 & 4.5168 & TRN \\
\hline CHEMBL 1538147 & 688128 & 4.4 & 4.7591 & TRN \\
\hline CHEMBL1366635 & 688128 & 4.3 & 4.7615 & TST \\
\hline CHEMBL1354235 & 688128 & 4.3 & 5.0348 & TRN \\
\hline CHEMBL1366588 & 688128 & 4.95 & 5.0738 & TRN \\
\hline CHEMBL190880 & 688128 & 4.5 & 5.0906 & TRN \\
\hline CHEMBL3209542 & 688128 & 5.4 & 4.4372 & TST \\
\hline CHEMBL1410437 & 688128 & 4.05 & 4.7357 & TST \\
\hline CHEMBL1398990 & 688128 & 4.7 & 4.9014 & TRN \\
\hline CHEMBL1551448 & 688128 & 5.3 & 5.0588 & TRN \\
\hline CHEMBL1575737 & 688128 & 4.3 & 4.7345 & TST \\
\hline CHEMBL 1441844 & 688128 & 4.65 & 4.8531 & TRN \\
\hline CHEMBL1559739 & 688128 & 4.4 & 4.834 & TST \\
\hline CHEMBL1522306 & 688128 & 4.35 & 4.3252 & TRN \\
\hline CHEMBL1449681 & 688128 & 5.3 & 4.5409 & TRN \\
\hline CHEMBL1353644 & 688128 & 4.55 & 4.1858 & TRN \\
\hline CHEMBL1989917 & 688128 & 4.8 & 4.828 & TRN \\
\hline CHEMBL1457150 & 688128 & 4.05 & 4.7289 & TST \\
\hline CHEMBL1383769 & 688128 & 4.85 & 4.5841 & TRN \\
\hline CHEMBL1594846 & 688128 & 4.35 & 4.7475 & TRN \\
\hline CHEMBL1423257 & 688128 & 4.25 & 4.5989 & TRN \\
\hline CHEMBL1421967 & 688128 & 5.0 & 4.7417 & TST \\
\hline CHEMBL1524007 & 688128 & 4.3 & 4.5258 & TRN \\
\hline CHEMBL1527846 & 688128 & 4.55 & 4.8071 & TRN \\
\hline CHEMBL1341929 & 688128 & 4.45 & 4.8012 & TRN \\
\hline CHEMBL1395972 & 688128 & 4.1 & 4.8216 & TST \\
\hline CHEMBL1529772 & 688128 & 4.9 & 4.705 & TST \\
\hline CHEMBL1312239 & 688128 & 4.4 & 4.8908 & TST \\
\hline CHEMBL1519387 & 688128 & 4.3 & 4.4257 & TRN \\
\hline CHEMBL1457376 & 688128 & 4.3 & 4.7556 & TRN \\
\hline CHEMBL1358163 & 688128 & 5.8 & 4.9358 & TRN \\
\hline CHEMBL1569907 & 688128 & 4.45 & 4.3445 & TRN \\
\hline CHEMBL1575764 & 688128 & 4.65 & 4.5216 & TRN \\
\hline CHEMBL 1476273 & 688128 & 4.35 & 4.9227 & TST \\
\hline CHEMBL1433384 & 688128 & 4.3 & 4.5766 & TRN \\
\hline CHEMBL365327 & 688128 & 6.0 & 4.5786 & TRN \\
\hline CHEMBL1413394 & 688128 & 4.05 & 4.5613 & TRN \\
\hline CHEMBL1499996 & 688128 & 4.65 & 4.8032 & TRN \\
\hline CHEMBL1539447 & 688128 & 4.4 & 4.4274 & TST \\
\hline
\end{tabular}




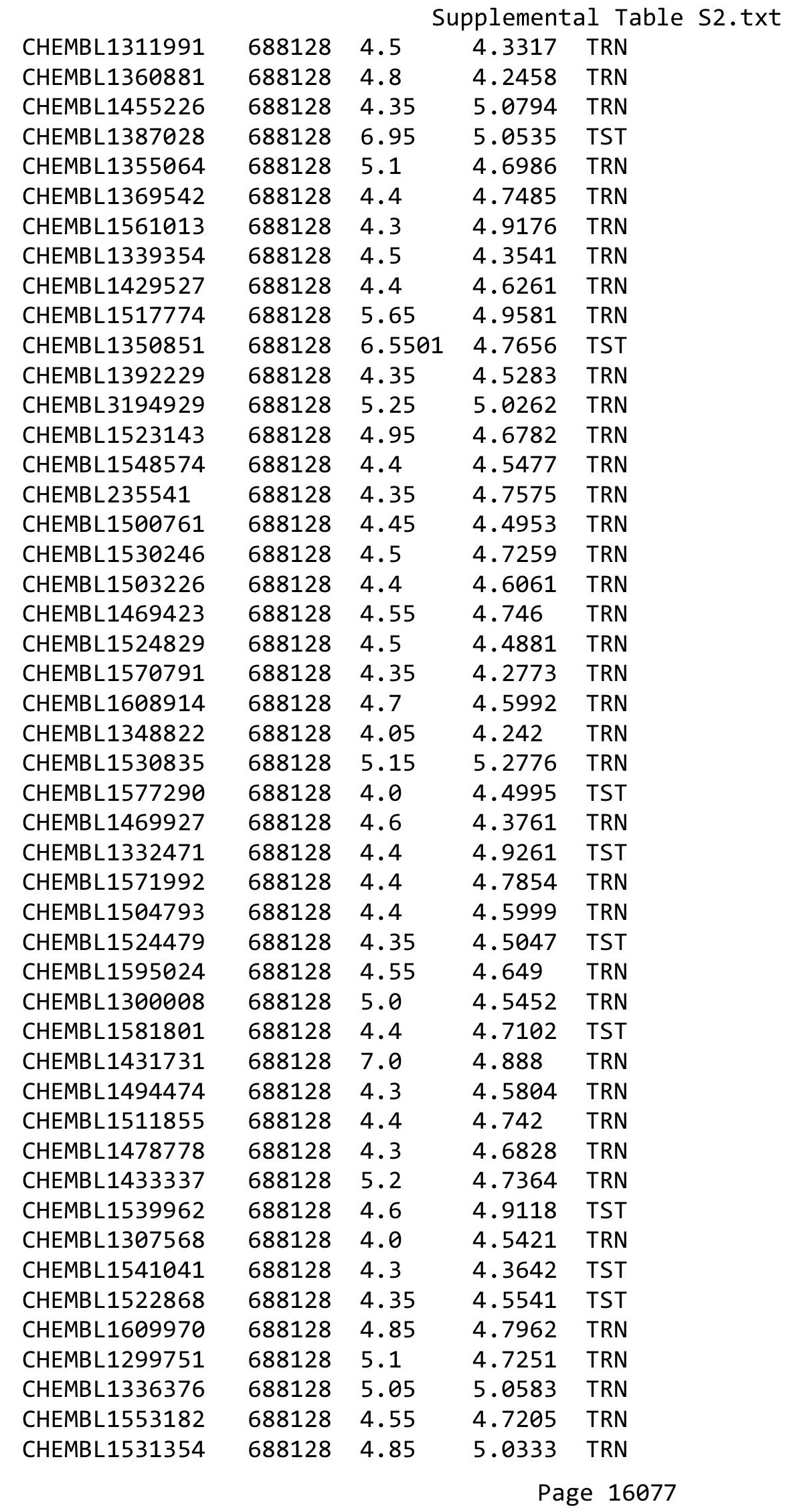




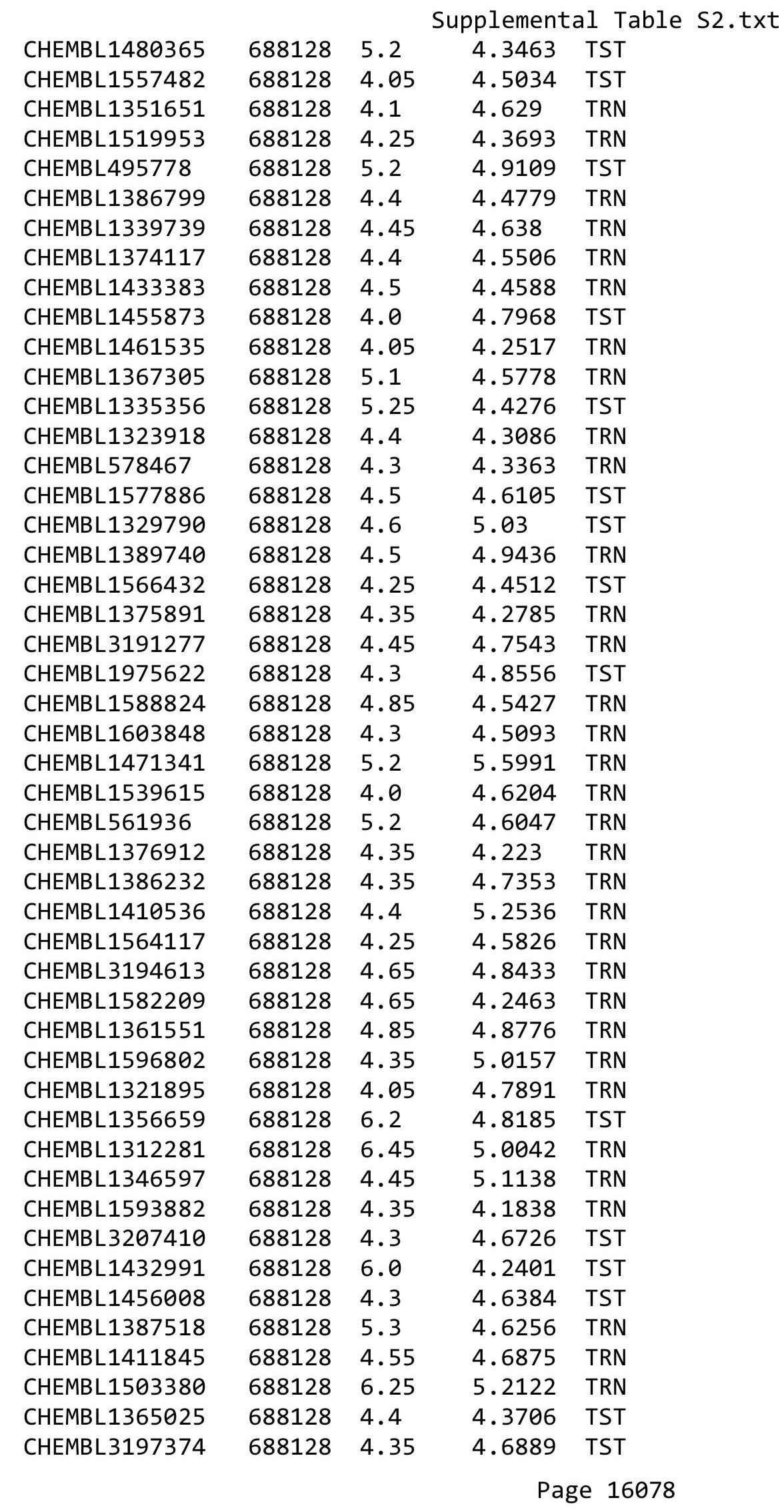




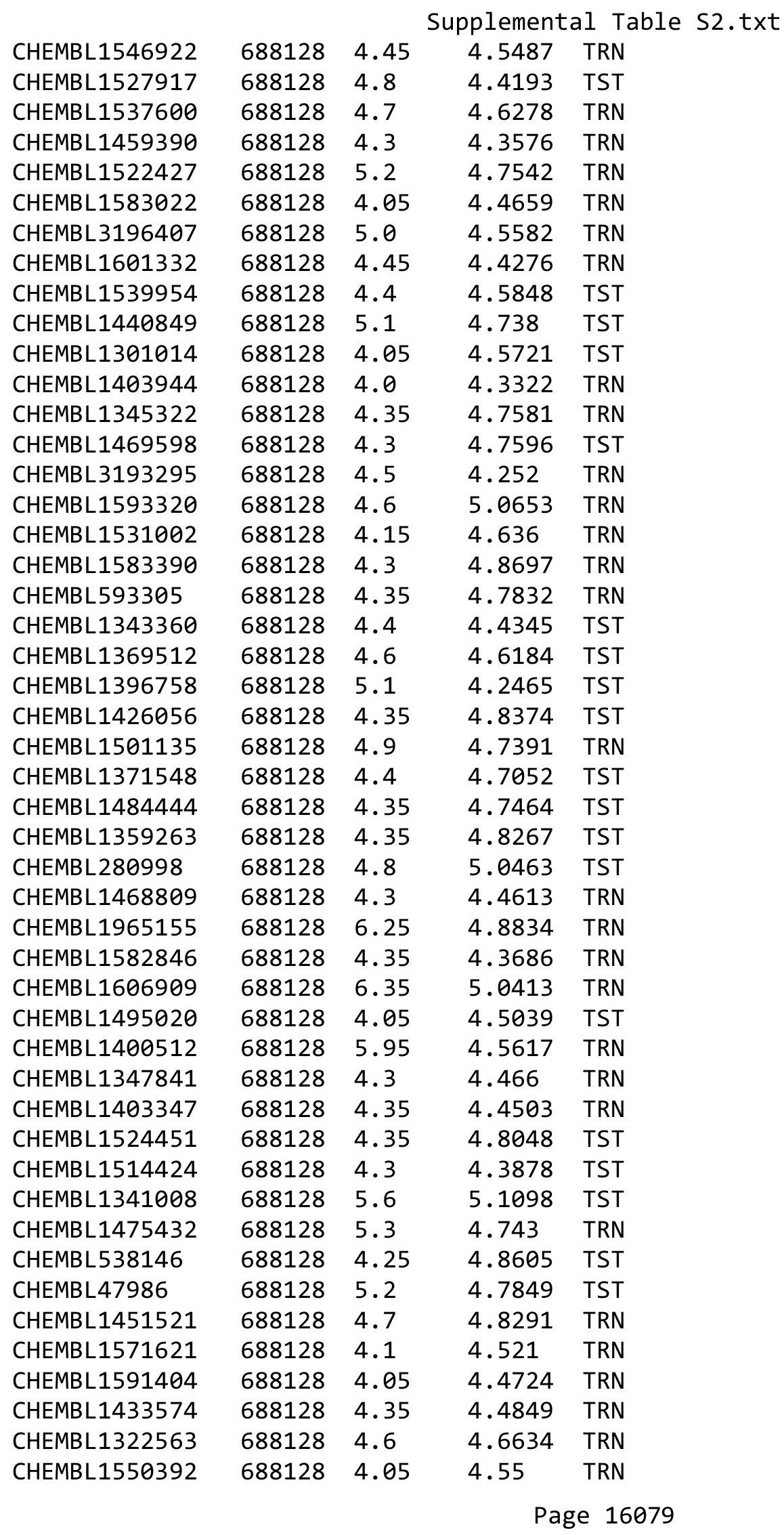




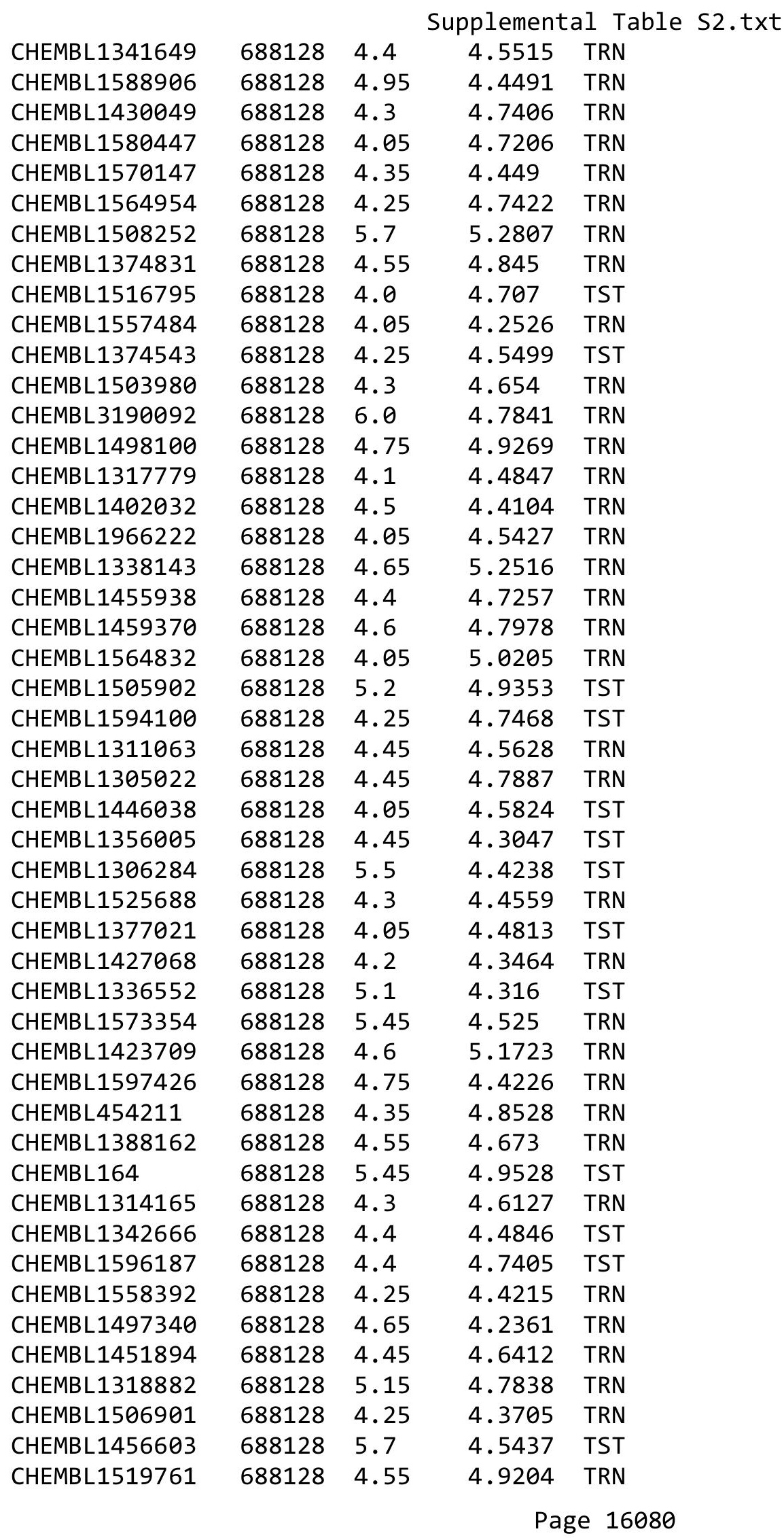




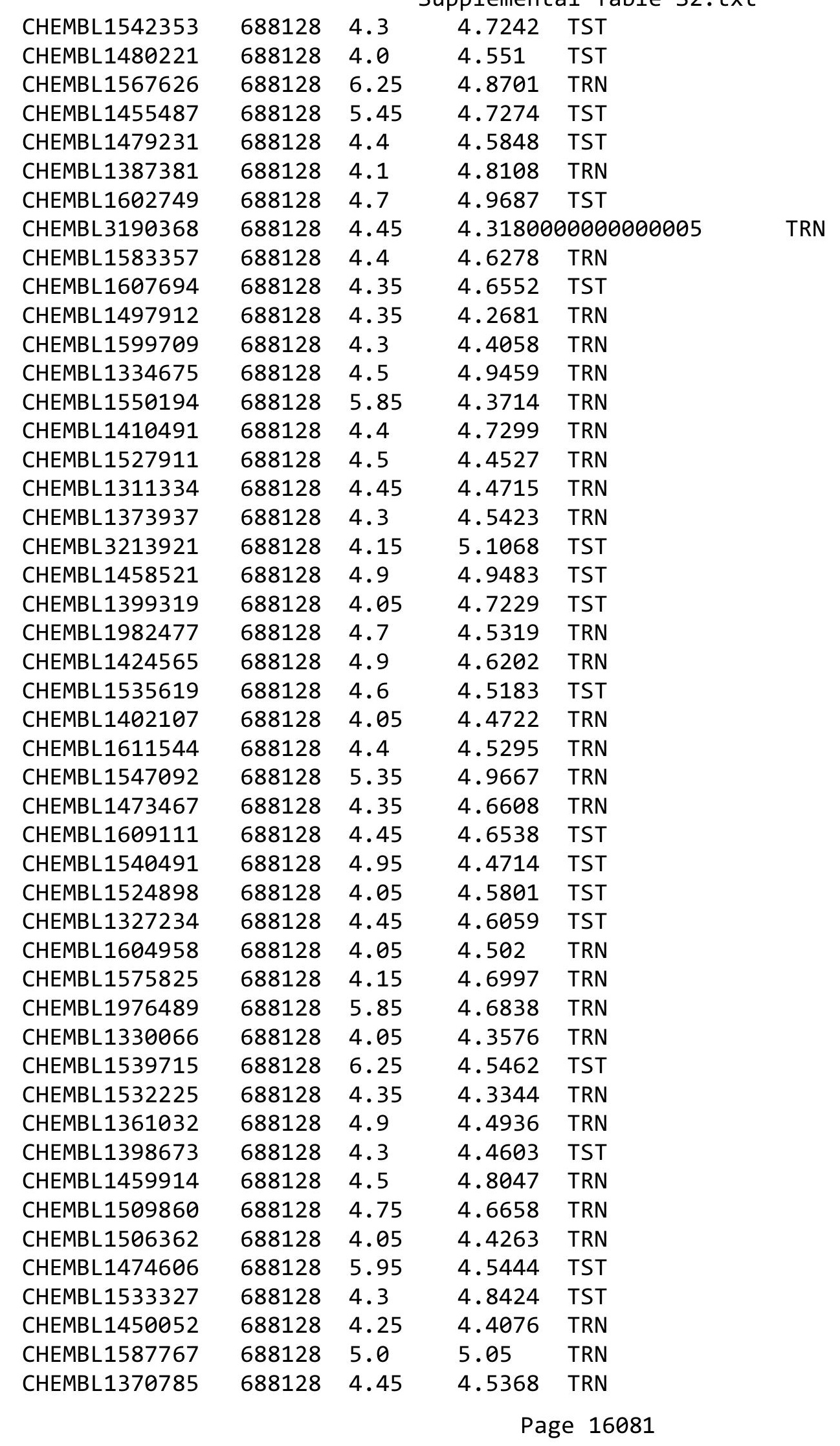




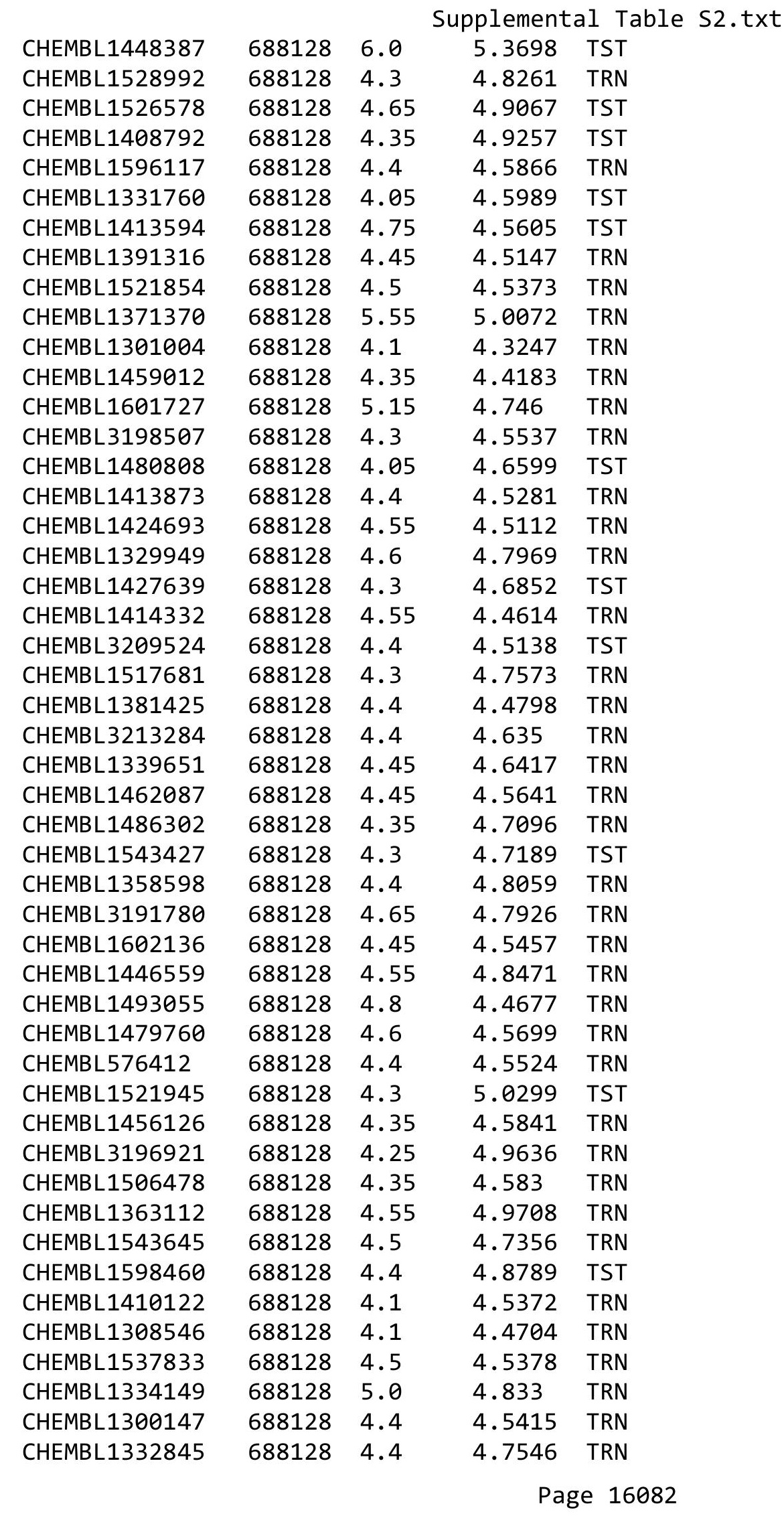




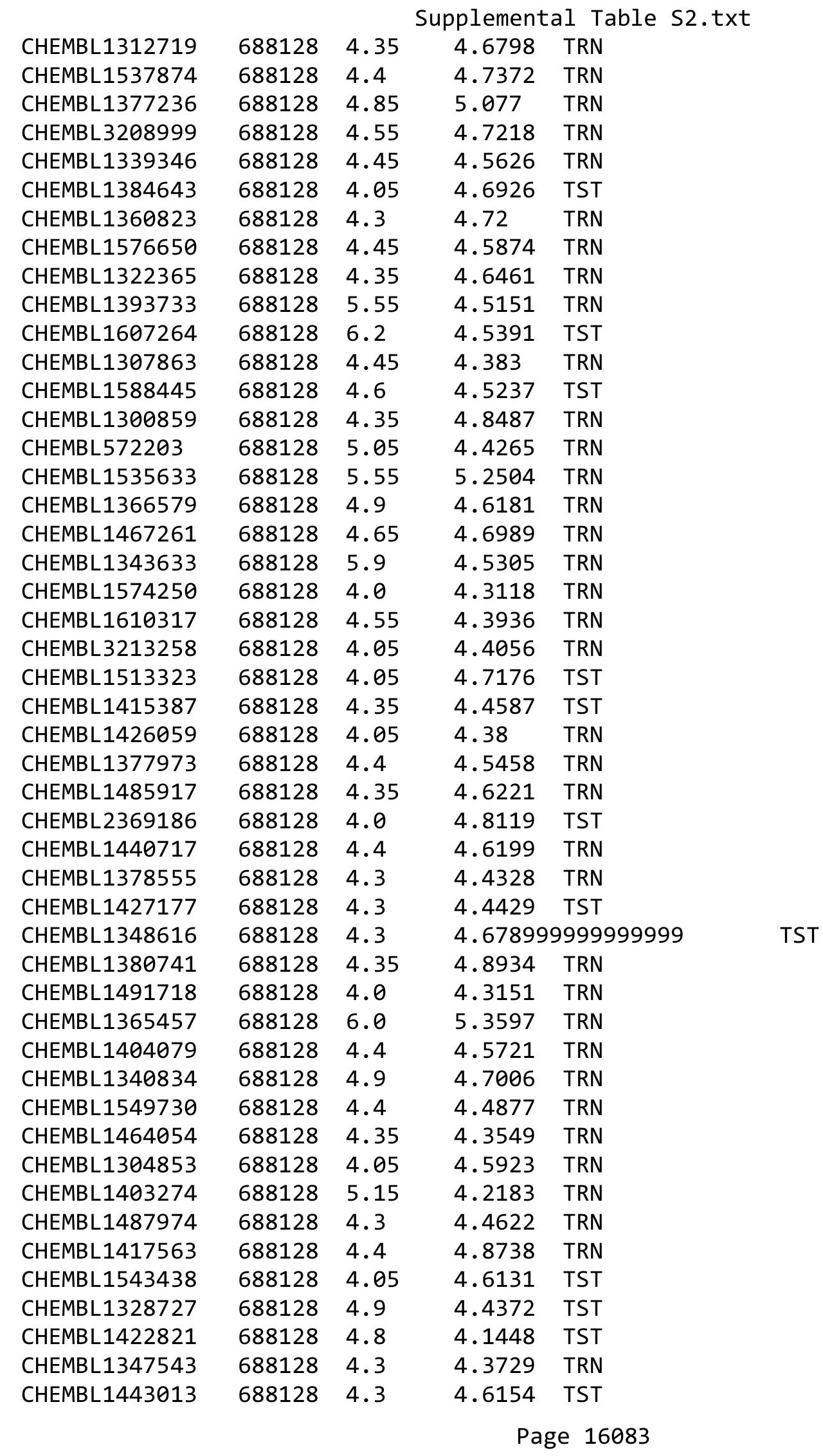




\begin{tabular}{|c|c|c|c|c|}
\hline & & & upplement & $\mathrm{Ta}$ \\
\hline CHEMBL1973156 & 688128 & 4.9 & 5.0749 & TRN \\
\hline CHEMBL1473776 & 688128 & 4.4 & 4.5806 & TRN \\
\hline CHEMBL1396050 & 688128 & 4.4 & 4.6186 & TRN \\
\hline CHEMBL1551258 & 688128 & 4.15 & 4.6422 & TRN \\
\hline CHEMBL1493518 & 688128 & 4.35 & 5.086 & TRN \\
\hline CHEMBL1449018 & 688128 & 5.05 & 4.6088 & TRN \\
\hline CHEMBL1514789 & 688128 & 5.95 & 4.651 & TRN \\
\hline CHEMBL1447834 & 688128 & 4.85 & 4.6919 & TRN \\
\hline CHEMBL1483840 & 688128 & 4.7 & 5.0171 & TST \\
\hline CHEMBL1332063 & 688128 & 4.3 & 4.2512 & TST \\
\hline CHEMBL1346331 & 688128 & 4.35 & 4.744 & TRN \\
\hline CHEMBL1363228 & 688128 & 4.1 & 4.7558 & TRN \\
\hline CHEMBL 3212376 & 688128 & 4.95 & 4.7937 & TRN \\
\hline CHEMBL1581079 & 688128 & 4.05 & 4.4576 & TRN \\
\hline CHEMBL1403911 & 688128 & 4.6 & 5.0161 & TRN \\
\hline CHEMBL1425541 & 688128 & 4.35 & 4.4607 & TRN \\
\hline CHEMBL1355324 & 688128 & 4.05 & 4.3852 & TRN \\
\hline CHEMBL1409202 & 688128 & 4.4 & 4.9102 & TRN \\
\hline CHEMBL1397983 & 688128 & 4.55 & 4.3621 & TRN \\
\hline CHEMBL1567146 & 688128 & 6.5 & 4.4089 & TST \\
\hline CHEMBL1403919 & 688128 & 5.25 & 4.6469 & TRN \\
\hline CHEMBL1372751 & 688128 & 4.45 & 4.9052 & TRN \\
\hline CHEMBL1427095 & 688128 & 4.25 & 4.6545 & TRN \\
\hline CHEMBL1323476 & 688128 & 4.75 & 4.6798 & TRN \\
\hline CHEMBL1338745 & 688128 & 4.55 & 4.6161 & TST \\
\hline CHEMBL1310901 & 688128 & 4.4 & 4.3813 & TRN \\
\hline CHEMBL1310988 & 688128 & 5.5 & 4.6356 & TRN \\
\hline CHEMBL1441847 & 688128 & 4.4 & 4.8187 & TRN \\
\hline CHEMBL1989853 & 688128 & 5.0 & 5.1069 & TST \\
\hline CHEMBL1374467 & 688128 & 5.0 & 4.5701 & TRN \\
\hline CHEMBL1609964 & 688128 & 4.4 & 4.7723 & TRN \\
\hline CHEMBL1484201 & 688128 & 4.4 & 4.545 & TRN \\
\hline CHEMBL3199715 & 688128 & 4.35 & 4.9199 & TRN \\
\hline CHEMBL1446489 & 688128 & 4.05 & 4.3476 & TRN \\
\hline CHEMBL1478186 & 688128 & 6.0 & 4.8415 & TRN \\
\hline CHEMBL1459605 & 688128 & 5.1 & 4.6673 & TRN \\
\hline CHEMBL1324389 & 688128 & 4.5 & 4.6929 & TRN \\
\hline CHEMBL3197422 & 688128 & 4.3 & 4.5292 & TST \\
\hline CHEMBL1557490 & 688128 & 4.75 & 4.7006 & TRN \\
\hline CHEMBL1581936 & 688128 & 4.4 & 5.055 & TRN \\
\hline CHEMBL1335437 & 688128 & 4.45 & 4.4221 & TRN \\
\hline CHEMBL1575594 & 688128 & 4.4 & 4.5753 & TRN \\
\hline CHEMBL1566964 & 688128 & 4.75 & 4.1294 & TRN \\
\hline CHEMBL1583507 & 688128 & 4.3 & 4.7376 & TRN \\
\hline CHEMBL1440003 & 688128 & 4.35 & 4.6586 & TRN \\
\hline CHEMBL1350275 & 688128 & 4.45 & 4.5108 & TRN \\
\hline CHEMBL1525192 & 688128 & 4.45 & 4.4789 & TST \\
\hline CHEMBL1609341 & 688128 & 4.75 & 4.7041 & TST \\
\hline
\end{tabular}




\begin{tabular}{|c|c|c|c|c|c|}
\hline & & & & & \\
\hline CHEMBL1322709 & 688128 & 5.5 & 5.3377 & TRN & \\
\hline CHEMBL1401494 & 688128 & 4.8 & 4.8559 & TST & \\
\hline CHEMBL 2374090 & 688128 & 5.15 & 5.2295 & TRN & \\
\hline CHEMBL1308931 & 688128 & 6.2 & 5.0114 & TRN & \\
\hline CHEMBL1535335 & 688128 & 4.95 & 4.6138 & TRN & \\
\hline CHEMBL1382119 & 688128 & 4.05 & 4.4776 & TST & \\
\hline CHEMBL1352586 & 688128 & 6.3 & 5.7575 & TRN & \\
\hline CHEMBL1612854 & 688128 & 4.1 & 4.3294 & TRN & \\
\hline CHEMBL1410738 & 688128 & 4.7 & 4.55699 & 99999999995 & TRN \\
\hline CHEMBL1571267 & 688128 & 4.3 & 4.8865 & TST & \\
\hline CHEMBL1449430 & 688128 & 4.95 & 4.2695 & TST & \\
\hline CHEMBL1300594 & 688128 & 4.3 & 4.7323 & TST & \\
\hline CHEMBL1416792 & 688128 & 4.6 & 4.3868 & TRN & \\
\hline CHEMBL1598747 & 688128 & 4.65 & 4.3987 & TRN & \\
\hline CHEMBL1450188 & 688128 & 4.35 & 4.4726 & TRN & \\
\hline CHEMBL1521043 & 688128 & 4.25 & 4.5461 & TST & \\
\hline CHEMBL1450851 & 688128 & 5.3 & 4.4642 & TRN & \\
\hline CHEMBL3207312 & 688128 & 4.3 & 4.1717 & TRN & \\
\hline CHEMBL1385667 & 688128 & 4.7 & 4.8039 & TRN & \\
\hline CHEMBL1427515 & 688128 & 4.0 & 4.2828 & TRN & \\
\hline CHEMBL1533679 & 688128 & 4.35 & 4.6343 & TST & \\
\hline CHEMBL1512098 & 688128 & 6.2 & 5.13 & TRN & \\
\hline CHEMBL1473474 & 688128 & 5.35 & 4.7243 & TRN & \\
\hline CHEMBL1341557 & 688128 & 4.4 & 4.601 & TRN & \\
\hline CHEMBL1525459 & 688128 & 4.4 & 4.3396 & TRN & \\
\hline CHEMBL1409464 & 688128 & 4.25 & 4.4275 & TST & \\
\hline CHEMBL1440405 & 688128 & 5.75 & 4.8689 & TST & \\
\hline CHEMBL1302305 & 688128 & 5.85 & 4.5458 & TST & \\
\hline CHEMBL1382025 & 688128 & 4.05 & 4.6051 & TRN & \\
\hline CHEMBL1415658 & 688128 & 5.15 & 4.7001 & TRN & \\
\hline CHEMBL1418103 & 688128 & 5.0 & 5.2722 & TRN & \\
\hline CHEMBL1408553 & 688128 & 4.45 & 4.8522 & TST & \\
\hline CHEMBL1343501 & 688128 & 4.35 & 4.9733 & TRN & \\
\hline CHEMBL1315964 & 688128 & 4.05 & 4.5332 & TRN & \\
\hline CHEMBL1528801 & 688128 & 4.35 & 4.7156 & TST & \\
\hline CHEMBL1421908 & 688128 & 4.85 & 4.3675 & TRN & \\
\hline CHEMBL1503694 & 688128 & 4.3 & 4.8363 & TST & \\
\hline CHEMBL1530238 & 688128 & 4.3 & 4.44606 & $\partial 000000001$ & TRN \\
\hline CHEMBL1446210 & 688128 & 4.35 & 4.3935 & TRN & \\
\hline CHEMBL1380929 & 688128 & 5.55 & 5.3565 & TRN & \\
\hline CHEMBL1492571 & 688128 & 6.4 & 5.2431 & TRN & \\
\hline CHEMBL1319791 & 688128 & 4.3 & 4.9006 & TRN & \\
\hline CHEMBL1346251 & 688128 & 4.4 & 4.6508 & TST & \\
\hline CHEMBL1500291 & 688128 & 4.7 & 4.5939 & 9999999999 & TST \\
\hline CHEMBL1502367 & 688128 & 4.65 & 4.8616 & TRN & \\
\hline CHEMBL1361188 & 688128 & 4.0 & 4.8488 & TRN & \\
\hline CHEMBL1564543 & 688128 & 5.6 & 5.0137 & TRN & \\
\hline CHEMBL1421346 & 688128 & 4.4 & 4.4228 & TRN & \\
\hline & & & & 16085 & \\
\hline
\end{tabular}




\begin{tabular}{|c|c|c|c|c|}
\hline \multicolumn{5}{|c|}{ Supplemental Table S2.txt } \\
\hline CHEMBL1425970 & 688128 & 4.45 & 4.5552 & TRN \\
\hline CHEMBL 2374041 & 688128 & 5.7 & 5.0419 & TRN \\
\hline CHEMBL1602269 & 688128 & 5.65 & 4.5826 & TRN \\
\hline CHEMBL1439384 & 688128 & 7.0 & 5.1673 & TRN \\
\hline CHEMBL1477979 & 688128 & 4.25 & 4.7633 & TRN \\
\hline CHEMBL1528924 & 688128 & 4.35 & 4.709 & TRN \\
\hline CHEMBL1502598 & 688128 & 4.3 & 4.6555 & TRN \\
\hline CHEMBL1480299 & 688128 & 5.3 & 4.4578 & TST \\
\hline CHEMBL1317153 & 688128 & 4.05 & 4.2584 & TRN \\
\hline CHEMBL1372329 & 688128 & 6.0 & 4.9779 & TRN \\
\hline CHEMBL1353130 & 688128 & 4.3 & 4.7503 & TRN \\
\hline CHEMBL1381495 & 688128 & 6.0 & 4.7495 & TRN \\
\hline CHEMBL1418539 & 688128 & 4.3 & 4.4517 & TST \\
\hline CHEMBL1495477 & 688128 & 5.1 & 4.3825 & TST \\
\hline CHEMBL1474769 & 688128 & 4.25 & 4.6026 & TRN \\
\hline CHEMBL1534469 & 688128 & 4.6 & 4.6684 & TST \\
\hline CHEMBL1385998 & 688128 & 4.8 & 4.6529 & TST \\
\hline CHEMBL3190787 & 688128 & 4.05 & 5.0635 & TST \\
\hline CHEMBL1544898 & 688128 & 4.35 & 4.8087 & TRN \\
\hline CHEMBL1372890 & 688128 & 4.05 & 4.5591 & TRN \\
\hline CHEMBL1333050 & 688128 & 4.7 & 4.8401 & TRN \\
\hline CHEMBL1556199 & 688128 & 4.4 & 4.7862 & TST \\
\hline CHEMBL1495335 & 688128 & 4.95 & 4.5364 & TST \\
\hline CHEMBL1420659 & 688128 & 4.0 & 4.5174 & TST \\
\hline CHEMBL1447276 & 688128 & 4.4 & 4.359 & TST \\
\hline CHEMBL1593496 & 688128 & 4.3 & 4.4761 & TRN \\
\hline CHEMBL1396810 & 688128 & 4.4 & 4.9425 & TRN \\
\hline CHEMBL3194770 & 688128 & 4.35 & 4.5606 & TRN \\
\hline CHEMBL 3208495 & 688128 & 4.3 & 4.8597 & TST \\
\hline CHEMBL1384108 & 688128 & 4.95 & 4.3872 & TRN \\
\hline CHEMBL1549691 & 688128 & 4.85 & 5.1755 & TRN \\
\hline CHEMBL1612725 & 688128 & 4.4 & 4.6137 & TRN \\
\hline CHEMBL1476204 & 688128 & 4.5 & 4.6908 & TST \\
\hline CHEMBL1318116 & 688128 & 4.6 & 4.8288 & TRN \\
\hline CHEMBL3211648 & 688128 & 4.35 & 4.5677 & TRN \\
\hline CHEMBL1994094 & 688128 & 4.55 & 4.9456 & TRN \\
\hline CHEMBL 1465236 & 688128 & 4.05 & 4.787 & TRN \\
\hline CHEMBL1611666 & 688128 & 4.35 & 4.4377 & TRN \\
\hline CHEMBL1463521 & 688128 & 4.35 & 4.5695 & TRN \\
\hline CHEMBL1491892 & 688128 & 4.7 & 4.575 & TST \\
\hline CHEMBL1491816 & 688128 & 5.6 & 4.2465 & TST \\
\hline CHEMBL1558197 & 688128 & 4.05 & 4.7649 & TRN \\
\hline CHEMBL1420037 & 688128 & 4.3 & 4.6258 & TRN \\
\hline CHEMBL1467797 & 688128 & 5.4 & 4.4668 & TST \\
\hline CHEMBL3213583 & 688128 & 4.4 & 4.5325 & TRN \\
\hline CHEMBL1529460 & 688128 & 5.85 & 4.7293 & TST \\
\hline CHEMBL1319900 & 688128 & 4.55 & 4.7469 & TRN \\
\hline CHEMBL1562098 & 688128 & 4.15 & 4.4229 & TRN \\
\hline
\end{tabular}




\begin{tabular}{|c|c|c|c|c|c|}
\hline & & \multicolumn{4}{|c|}{ Supplemental Table s2.txt } \\
\hline CHEMBL1356543 & 688128 & 4.35 & 5.1477 & TRN & \\
\hline CHEMBL1580494 & 688128 & 4.05 & 4.3115 & TRN & \\
\hline CHEMBL591126 & 688128 & 4.55 & 5.0653 & TRN & \\
\hline CHEMBL1998429 & 688128 & 4.3 & 4.7025 & TRN & \\
\hline CHEMBL1372319 & 688128 & 5.05 & 4.7205 & TRN & \\
\hline CHEMBL1556978 & 688128 & 5.45 & 4.7365 & TST & \\
\hline CHEMBL1468019 & 688128 & 4.1 & 4.6592 & TRN & \\
\hline CHEMBL1590690 & 688128 & 4.35 & 4.5971 & TRN & \\
\hline CHEMBL1310648 & 688128 & 4.4 & 4.6266 & TST & \\
\hline CHEMBL3192071 & 688128 & 5.65 & 4.7598 & TRN & \\
\hline CHEMBL1444164 & 688128 & 4.3 & 4.5961 & TRN & \\
\hline CHEMBL1596465 & 688128 & 4.35 & 4.9502 & TST & \\
\hline CHEMBL1411565 & 688128 & 4.95 & 4.7683 & TRN & \\
\hline CHEMBL1314125 & 688128 & 4.95 & 5.0799 & TRN & \\
\hline CHEMBL1342031 & 688128 & 4.4 & 4.5871 & TST & \\
\hline CHEMBL1587440 & 688128 & 4.6 & 4.6217 & TRN & \\
\hline CHEMBL1465338 & 688128 & 4.35 & 4.86100 & 0000000001 & TRN \\
\hline CHEMBL1309726 & 688128 & 4.3 & 4.6295 & TRN & \\
\hline CHEMBL1363338 & 688128 & 4.35 & 4.6051 & TST & \\
\hline CHEMBL1364009 & 688128 & 4.8 & 4.5978 & TRN & \\
\hline CHEMBL1403586 & 688128 & 5.15 & 4.7023 & TRN & \\
\hline CHEMBL1418370 & 688128 & 4.0 & 4.6267 & TRN & \\
\hline CHEMBL1370416 & 688128 & 4.25 & 4.4438 & TRN & \\
\hline CHEMBL1604692 & 688128 & 4.35 & 4.543 & TRN & \\
\hline CHEMBL1579334 & 688128 & 4.5 & 4.8495 & TRN & \\
\hline CHEMBL1405837 & 688128 & 4.65 & 4.67 & TRN & \\
\hline CHEMBL1508780 & 688128 & 4.55 & 4.5748 & TST & \\
\hline CHEMBL1366103 & 688128 & 4.65 & 4.6971 & TRN & \\
\hline CHEMBL309339 & 688128 & 6.9 & 4.7114 & TST & \\
\hline CHEMBL1365898 & 688128 & 4.15 & 4.3513 & TRN & \\
\hline CHEMBL1517129 & 688128 & 4.7 & 4.9209 & TRN & \\
\hline CHEMBL1351333 & 688128 & 4.4 & 4.5971 & TRN & \\
\hline CHEMBL1604595 & 688128 & 5.1 & 4.5174 & TRN & \\
\hline CHEMBL1407847 & 688128 & 4.7 & 4.5038 & TRN & \\
\hline CHEMBL1488248 & 688128 & 4.8 & 4.5431 & TRN & \\
\hline CHEMBL3194928 & 688128 & 4.45 & 4.8174 & TRN & \\
\hline CHEMBL1528391 & 688128 & 4.3 & 4.3965 & TRN & \\
\hline CHEMBL1609419 & 688128 & 6.5 & 5.8003 & TRN & \\
\hline CHEMBL1486710 & 688128 & 4.35 & 4.7631 & TST & \\
\hline CHEMBL1430160 & 688128 & 4.35 & 4.3741 & TRN & \\
\hline CHEMBL1492270 & 688128 & 4.1 & 4.5467 & TST & \\
\hline CHEMBL1530013 & 688128 & 4.3 & 4.6517 & TST & \\
\hline CHEMBL1567971 & 688128 & 4.3 & 4.4976 & TST & \\
\hline CHEMBL1309649 & 688128 & 4.3 & 4.6077 & TST & \\
\hline CHEMBL1402567 & 688128 & 4.4 & 4.934 & TRN & \\
\hline CHEMBL1469494 & 688128 & 4.3 & 4.49 & TST & \\
\hline CHEMBL1487713 & 688128 & 5.4 & 4.5982 & TRN & \\
\hline CHEMBL1401774 & 688128 & 5.5 & 4.48 & TRN & \\
\hline
\end{tabular}




\begin{tabular}{|c|c|c|c|c|c|}
\hline \multicolumn{6}{|c|}{ Supplemental Table S2.txt } \\
\hline CHEMBL1410528 & 688128 & 4.3 & 4.6957 & TRN & \\
\hline CHEMBL1395171 & 688128 & 4.25 & 4.5477 & TRN & \\
\hline CHEMBL3194970 & 688128 & 4.4 & 4.8397 & TST & \\
\hline CHEMBL1383302 & 688128 & 4.25 & 4.7356 & TRN & \\
\hline CHEMBL1489024 & 688128 & 6.15 & 5.256 & TRN & \\
\hline CHEMBL1442714 & 688128 & 6.2 & 4.9456 & TRN & \\
\hline CHEMBL1339803 & 688128 & 4.05 & 4.7356 & TST & \\
\hline CHEMBL1589017 & 688128 & 4.7 & 4.7722 & TST & \\
\hline CHEMBL1426418 & 688128 & 4.65 & 4.3732 & TRN & \\
\hline CHEMBL1321538 & 688128 & 5.7 & 5.0551 & TRN & \\
\hline CHEMBL1451598 & 688128 & 4.05 & 4.5468 & TRN & \\
\hline CHEMBL1574910 & 688128 & 4.3 & 4.7051 & TRN & \\
\hline CHEMBL1507615 & 688128 & 4.35 & 4.2966 & TRN & \\
\hline CHEMBL1444467 & 688128 & 4.05 & 4.7755 & TST & \\
\hline CHEMBL1398204 & 688128 & 4.8 & 4.6501 & TRN & \\
\hline CHEMBL1508235 & 688128 & 4.4 & 4.3929 & TRN & \\
\hline CHEMBL1501694 & 688128 & 4.3 & 4.3796 & TRN & \\
\hline CHEMBL1386240 & 688128 & 4.3 & $4.6160 e$ & 00000000005 & TRN \\
\hline CHEMBL1550522 & 688128 & 4.6 & 4.3608 & TRN & \\
\hline CHEMBL56897 & 688128 & 4.2 & 4.8928 & TST & \\
\hline CHEMBL1512885 & 688128 & 4.35 & 4.4534 & TRN & \\
\hline CHEMBL1401891 & 688128 & 4.05 & 4.8928 & TST & \\
\hline CHEMBL1478696 & 688128 & 4.3 & 4.5759 & TRN & \\
\hline CHEMBL1537426 & 688128 & 4.35 & 4.3918 & TRN & \\
\hline CHEMBL1530349 & 688128 & 4.3 & 4.3372 & TRN & \\
\hline CHEMBL1486165 & 688128 & 4.85 & 4.7908 & TRN & \\
\hline CHEMBL1552448 & 688128 & 4.3 & 4.5766 & TRN & \\
\hline CHEMBL3198477 & 688128 & 7.0 & 4.7896 & TRN & \\
\hline CHEMBL1301821 & 688128 & 4.3 & 4.5776 & TRN & \\
\hline CHEMBL1588578 & 688128 & 4.1 & 4.5171 & TRN & \\
\hline CHEMBL1370995 & 688128 & 4.7 & 4.6554 & TRN & \\
\hline CHEMBL1594336 & 688128 & 4.9 & 4.7001 & TRN & \\
\hline CHEMBL1985744 & 688128 & 4.8 & 4.5857 & TST & \\
\hline CHEMBL1506337 & 688128 & 4.35 & 4.6325 & TRN & \\
\hline CHEMBL1566161 & 688128 & 5.05 & 4.6164 & TST & \\
\hline CHEMBL1350087 & 688128 & 4.55 & 4.9546 & TRN & \\
\hline CHEMBL 1444672 & 688128 & 4.85 & 4.8516 & TRN & \\
\hline CHEMBL1589595 & 688128 & 4.35 & 4.6173 & TRN & \\
\hline CHEMBL1345764 & 688128 & 4.7 & 5.2164 & TRN & \\
\hline CHEMBL1496973 & 688128 & 4.45 & 4.5531 & TRN & \\
\hline CHEMBL1395940 & 688128 & 4.05 & 4.5808 & TRN & \\
\hline CHEMBL1437099 & 688128 & 4.7 & 4.3898 & TRN & \\
\hline CHEMBL1499523 & 688128 & 4.4 & 4.7996 & TRN & \\
\hline CHEMBL3207838 & 688128 & 4.5 & 4.8898 & TRN & \\
\hline CHEMBL1557983 & 688128 & 4.3 & 4.9218 & TST & \\
\hline CHEMBL1414696 & 688128 & 5.1 & 4.44 & TRN & \\
\hline CHEMBL1518320 & 688128 & 5.15 & 4.7755 & TRN & \\
\hline CHEMBL1572470 & 688128 & 5.0 & 5.1854 & TRN & \\
\hline
\end{tabular}




\begin{tabular}{|c|c|c|c|c|c|}
\hline \\
\hline CHEMBL1456730 & 688128 & 4.9 & 4.3578 & TRN & \\
\hline CHEMBL1407936 & 688128 & 4.4 & 4.7348 & TST & \\
\hline CHEMBL1492453 & 688128 & 4.9 & 4.7541 & TRN & \\
\hline CHEMBL1314812 & 688128 & 4.4 & 4.5658 & TST & \\
\hline CHEMBL504977 & 688128 & 4.65 & 4.794 & TST & \\
\hline CHEMBL1426029 & 688128 & 4.35 & 4.7172 & TRN & \\
\hline CHEMBL86966 & 688128 & 4.55 & 4.4498 & TST & \\
\hline CHEMBL1586190 & 688128 & 4.35 & 4.5438 & TST & \\
\hline CHEMBL1473473 & 688128 & 4.05 & 4.7718 & TRN & \\
\hline CHEMBL1534086 & 688128 & 4.25 & 4.6726 & TRN & \\
\hline CHEMBL1536411 & 688128 & 4.0 & 4.2299 & TST & \\
\hline CHEMBL 1461763 & 688128 & 4.7 & 4.76 & TRN & \\
\hline CHEMBL1439124 & 688128 & 4.45 & 5.3242 & TRN & \\
\hline CHEMBL1390983 & 688128 & 4.5 & 4.3274 & TRN & \\
\hline CHEMBL1604898 & 688128 & 4.6 & 4.4091 & TRN & \\
\hline CHEMBL1609031 & 688128 & 4.3 & 4.351 & TRN & \\
\hline CHEMBL1471075 & 688128 & 4.5 & 4.8962 & TST & \\
\hline CHEMBL1309951 & 688128 & 4.35 & 4.3675 & TRN & \\
\hline CHEMBL1315112 & 688128 & 4.3 & 4.57 & TST & \\
\hline CHEMBL1300041 & 688128 & 4.45 & 4.5743 & TST & \\
\hline CHEMBL1407081 & 688128 & 4.45 & 4.439 & TST & \\
\hline CHEMBL1545264 & 688128 & 4.5 & 5.1229 & TRN & \\
\hline CHEMBL1607036 & 688128 & 6.0 & 4.39199 & 99999999995 & TRN \\
\hline CHEMBL1544341 & 688128 & 4.05 & 4.4063 & TRN & \\
\hline CHEMBL1561303 & 688128 & 4.75 & 4.507 & TRN & \\
\hline CHEMBL1502340 & 688128 & 5.5 & 4.5565 & TRN & \\
\hline CHEMBL1369691 & 688128 & 6.0 & 5.0281 & TRN & \\
\hline CHEMBL1573697 & 688128 & 4.55 & 5.2931 & TRN & \\
\hline CHEMBL1517483 & 688128 & 4.7 & 4.5843 & TRN & \\
\hline CHEMBL1429641 & 688128 & 4.05 & 4.8382 & TST & \\
\hline CHEMBL1467340 & 688128 & 4.45 & 4.5269 & TST & \\
\hline CHEMBL1425623 & 688128 & 4.45 & 4.6198 & TRN & \\
\hline CHEMBL1509354 & 688128 & 4.5 & 4.6773 & TST & \\
\hline CHEMBL1327011 & 688128 & 4.45 & 4.649 & TRN & \\
\hline CHEMBL3194350 & 688128 & 4.4 & 4.5581 & TRN & \\
\hline CHEMBL1513972 & 688128 & 5.3 & 4.98600 & 2000000001 & TST \\
\hline CHEMBL1418460 & 688128 & 4.25 & 4.5763 & TST & \\
\hline CHEMBL3207666 & 688128 & 4.3 & 4.7503 & TRN & \\
\hline CHEMBL1429365 & 688128 & 4.95 & 4.4463 & TRN & \\
\hline CHEMBL1968824 & 688128 & 5.5 & 4.802 & TRN & \\
\hline CHEMBL1332065 & 688128 & 4.5 & 4.3224 & TST & \\
\hline CHEMBL1503940 & 688128 & 4.3 & 4.6078 & TST & \\
\hline CHEMBL1515535 & 688128 & 4.25 & 4.6439 & TST & \\
\hline CHEMBL1572806 & 688128 & 4.25 & 4.5822 & TRN & \\
\hline CHEMBL1390438 & 688128 & 4.15 & 4.4432 & TRN & \\
\hline CHEMBL1330969 & 688128 & 5.5 & 4.4901 & TST & \\
\hline CHEMBL1379311 & 688128 & 4.35 & 4.3629 & TRN & \\
\hline CHEMBL1611017 & 688128 & 4.4 & 4.6747 & TRN & \\
\hline
\end{tabular}




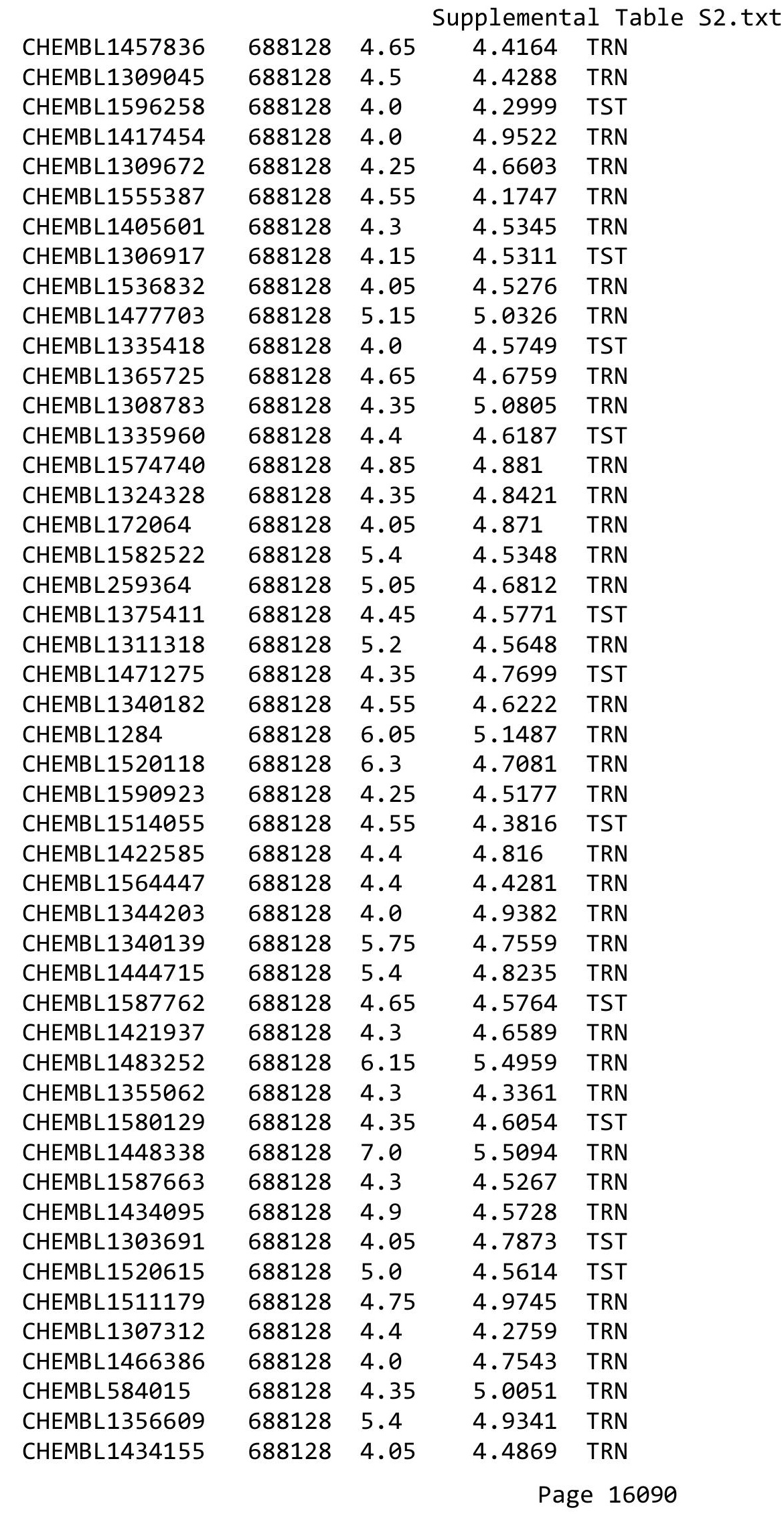




\begin{tabular}{|c|c|c|c|c|c|}
\hline & & \multicolumn{4}{|c|}{ Supplemental Table S2.txt } \\
\hline CHEMBL 3195740 & 688128 & 5.55 & 4.7052 & TRN & \\
\hline CHEMBL1584752 & 688128 & 5.35 & 5.1289 & TRN & \\
\hline CHEMBL1460265 & 688128 & 4.3 & 4.4488 & TRN & \\
\hline CHEMBL1422658 & 688128 & 4.5 & 4.6562 & TST & \\
\hline CHEMBL1318437 & 688128 & 4.05 & 4.5348 & TRN & \\
\hline CHEMBL1301906 & 688128 & 4.35 & 4.4703 & TRN & \\
\hline CHEMBL1367899 & 688128 & 4.3 & 4.5408 & TRN & \\
\hline CHEMBL1565644 & 688128 & 4.7 & 4.4355 & TRN & \\
\hline CHEMBL1582210 & 688128 & 5.4 & \multicolumn{2}{|c|}{4.843999999999999} & TRN \\
\hline CHEMBL1341981 & 688128 & 5.7 & 5.2704 & TRN & \\
\hline CHEMBL1519834 & 688128 & 4.1 & 4.6315 & TRN & \\
\hline CHEMBL1319850 & 688128 & 6.8499 & 4.7252 & TRN & \\
\hline CHEMBL1541976 & 688128 & 4.4 & 4.8604 & TRN & \\
\hline CHEMBL1338115 & 688128 & 4.35 & 4.5968 & TRN & \\
\hline CHEMBL1314278 & 688128 & 4.25 & 4.5559 & TRN & \\
\hline CHEMBL1530464 & 688128 & 6.5501 & 5.0844 & TRN & \\
\hline CHEMBL 2374051 & 688128 & 5.0 & 5.0986 & TRN & \\
\hline CHEMBL1454931 & 688128 & 4.45 & 4.9611 & TRN & \\
\hline CHEMBL1452848 & 688128 & 4.15 & 4.6875 & TST & \\
\hline CHEMBL1415648 & 688128 & 4.3 & 4.6199 & TRN & \\
\hline CHEMBL1431740 & 688128 & 4.65 & 4.6131 & TRN & \\
\hline CHEMBL1313828 & 688128 & 4.4 & 4.6424 & TRN & \\
\hline CHEMBL1362407 & 688128 & 4.45 & 4.7265 & TRN & \\
\hline CHEMBL 3198457 & 688128 & 4.3 & 4.4756 & TRN & \\
\hline CHEMBL1593662 & 688128 & 4.35 & 4.3903 & TRN & \\
\hline CHEMBL1323819 & 688128 & 4.3 & 4.7513 & TRN & \\
\hline CHEMBL1565514 & 688128 & 4.55 & \multicolumn{2}{|c|}{4.803999999999999} & TRN \\
\hline CHEMBL1428201 & 688128 & 4.45 & 4.5423 & TRN & \\
\hline CHEMBL1306196 & 688128 & 4.35 & 4.5644 & TRN & \\
\hline CHEMBL 1419383 & 688128 & 4.85 & 4.9278 & TRN & \\
\hline CHEMBL1537386 & 688128 & 4.3 & 4.3902 & TRN & \\
\hline CHEMBL1406590 & 688128 & 4.0 & 4.8084 & TST & \\
\hline CHEMBL1528462 & 688128 & 4.4 & 4.5231 & TRN & \\
\hline CHEMBL1412804 & 688128 & 4.65 & 4.74 & TRN & \\
\hline CHEMBL1310607 & 688128 & 4.25 & 4.6889 & TST & \\
\hline CHEMBL1374280 & 688128 & 4.3 & 4.95 & TRN & \\
\hline CHEMBL1404901 & 688128 & 4.05 & 4.4704 & TRN & \\
\hline CHEMBL1575658 & 688128 & 4.35 & 5.0393 & TRN & \\
\hline CHEMBL1441870 & 688128 & 4.35 & 4.6731 & TRN & \\
\hline CHEMBL1410038 & 688128 & 4.4 & 4.4226 & TRN & \\
\hline CHEMBL1406646 & 688128 & 4.35 & 4.593 & TRN & \\
\hline CHEMBL1361864 & 688128 & 4.4 & 4.6543 & TRN & \\
\hline CHEMBL1534763 & 688128 & 4.5 & 4.3581 & TRN & \\
\hline CHEMBL1493805 & 688128 & 4.45 & 4.5445 & TRN & \\
\hline CHEMBL1560634 & 688128 & 4.3 & 4.5794 & TRN & \\
\hline CHEMBL1549883 & 688128 & 5.05 & 4.5034 & TRN & \\
\hline CHEMBL1437787 & 688128 & 4.6 & 4.4364 & TRN & \\
\hline CHEMBL1499432 & 688128 & 4.5 & 4.5629 & TRN & \\
\hline
\end{tabular}




\begin{tabular}{|c|c|c|c|c|c|}
\hline \multicolumn{6}{|c|}{ Supplemental Table S2.txt } \\
\hline CHEMBL1332291 & 688128 & 4.65 & 4.4928 & TRN & \\
\hline CHEMBL1338698 & 688128 & 4.95 & 4.9285 & TRN & \\
\hline CHEMBL1305024 & 688128 & 4.05 & 4.5518 & TRN & \\
\hline CHEMBL1306397 & 688128 & 4.45 & 4.6792 & TRN & \\
\hline CHEMBL1526851 & 688128 & 4.35 & 4.7534 & TRN & \\
\hline CHEMBL1522077 & 688128 & 4.05 & 4.51699 & 99999999995 & TRN \\
\hline CHEMBL1545429 & 688128 & 6.0 & 5.2528 & TRN & \\
\hline CHEMBL1425669 & 688128 & 4.4 & 4.6102 & TRN & \\
\hline CHEMBL1350679 & 688128 & 4.65 & 4.5633 & TST & \\
\hline CHEMBL1419965 & 688128 & 4.3 & 4.9069 & TRN & \\
\hline CHEMBL1570505 & 688128 & 4.35 & 4.5584 & TRN & \\
\hline CHEMBL1511645 & 688128 & 4.35 & 4.6751 & TRN & \\
\hline CHEMBL1445726 & 688128 & 4.5 & 4.3679 & TRN & \\
\hline CHEMBL1553883 & 688128 & 4.3 & 4.546 & TRN & \\
\hline CHEMBL584905 & 688128 & 4.55 & 4.8463 & TST & \\
\hline CHEMBL1493759 & 688128 & 4.65 & 4.6849 & TRN & \\
\hline CHEMBL1553289 & 688128 & 5.05 & 4.3122 & TST & \\
\hline CHEMBL1308318 & 688128 & 5.6 & 4.8791 & TRN & \\
\hline CHEMBL1594948 & 688128 & 4.5 & 4.6561 & TRN & \\
\hline CHEMBL3199691 & 688128 & 4.35 & 4.9712 & TRN & \\
\hline CHEMBL1602068 & 688128 & 4.3 & 4.4278 & TST & \\
\hline CHEMBL3196410 & 688128 & 4.3 & 4.4162 & TST & \\
\hline CHEMBL1453853 & 688128 & 4.45 & 4.6727 & TRN & \\
\hline CHEMBL1300256 & 688128 & 4.85 & 4.3992 & TRN & \\
\hline CHEMBL1406220 & 688128 & 4.3 & 5.062 & TST & \\
\hline CHEMBL1315537 & 688128 & 4.75 & 4.655 & TRN & \\
\hline CHEMBL578915 & 688128 & 4.75 & 4.8054 & TRN & \\
\hline CHEMBL1519525 & 688128 & 4.05 & 4.5499 & TRN & \\
\hline CHEMBL1444939 & 688128 & 4.45 & 4.8882 & TRN & \\
\hline CHEMBL1587037 & 688128 & 5.9 & 4.6921 & TRN & \\
\hline CHEMBL1505360 & 688128 & 4.0 & 4.3417 & TST & \\
\hline CHEMBL1545013 & 688128 & 4.4 & 4.34699 & 99999999995 & TST \\
\hline CHEMBL1441571 & 688128 & 4.6 & 4.5542 & TRN & \\
\hline CHEMBL1329754 & 688128 & 4.35 & 4.7956 & TRN & \\
\hline CHEMBL1977611 & 688128 & 4.35 & 4.6599 & TST & \\
\hline CHEMBL1363871 & 688128 & 4.4 & 4.375 & TRN & \\
\hline CHEMBL1448241 & 688128 & 5.5 & 4.9461 & TRN & \\
\hline CHEMBL1584618 & 688128 & 4.35 & 4.6089 & TRN & \\
\hline CHEMBL1435722 & 688128 & 6.5501 & 4.6613 & TST & \\
\hline CHEMBL1533067 & 688128 & 5.75 & 4.9707 & TST & \\
\hline CHEMBL1578434 & 688128 & 4.55 & 4.5491 & TRN & \\
\hline CHEMBL1565513 & 688128 & 4.45 & 4.8925 & TRN & \\
\hline CHEMBL1422204 & 688128 & 4.3 & 4.5621 & TRN & \\
\hline CHEMBL1385437 & 688128 & 4.25 & 4.5844 & TRN & \\
\hline CHEMBL1409934 & 688128 & 6.3 & 5.0649 & TRN & \\
\hline CHEMBL1520166 & 688128 & 4.45 & 4.7074 & TRN & \\
\hline CHEMBL1508196 & 688128 & 5.0 & 4.7554 & TRN & \\
\hline CHEMBL1315955 & 688128 & 5.05 & 4.4769 & TRN & \\
\hline
\end{tabular}




\begin{tabular}{|c|c|c|c|c|}
\hline \multicolumn{5}{|c|}{ Supplemental Table S2.txt } \\
\hline CHEMBL1422527 & 688128 & 4.25 & 4.9939 & TST \\
\hline CHEMBL1399212 & 688128 & 4.45 & 4.7633 & TRN \\
\hline CHEMBL1459870 & 688128 & 4.35 & 4.6095 & TST \\
\hline CHEMBL1596437 & 688128 & 4.1 & 4.3697 & TRN \\
\hline CHEMBL1576024 & 688128 & 4.1 & 4.5435 & TRN \\
\hline CHEMBL1383283 & 688128 & 4.05 & 4.6708 & TST \\
\hline CHEMBL1522365 & 688128 & 4.3 & 4.5947 & TRN \\
\hline CHEMBL1557252 & 688128 & 5.0 & 4.9722 & TST \\
\hline CHEMBL1471198 & 688128 & 4.35 & 4.5701 & TRN \\
\hline CHEMBL1410083 & 688128 & 4.4 & 4.7047 & TRN \\
\hline CHEMBL1448250 & 688128 & 4.6 & 4.6035 & TST \\
\hline CHEMBL1565155 & 688128 & 4.05 & 4.7255 & TST \\
\hline CHEMBL1470108 & 688128 & 4.45 & 4.5678 & TST \\
\hline CHEMBL1558231 & 688128 & 4.45 & 4.5072 & TRN \\
\hline CHEMBL1453506 & 688128 & 4.3 & 4.5769 & TRN \\
\hline CHEMBL1490232 & 688128 & 4.4 & 4.7779 & TST \\
\hline CHEMBL1608667 & 688128 & 4.4 & 4.8513 & TRN \\
\hline CHEMBL1597240 & 688128 & 4.35 & 4.4868 & TST \\
\hline CHEMBL1536252 & 688128 & 4.2 & 4.9381 & TRN \\
\hline CHEMBL1560376 & 688128 & 4.3 & 4.6368 & TRN \\
\hline CHEMBL1384845 & 688128 & 4.4 & 4.6836 & TRN \\
\hline CHEMBL1548018 & 688128 & 4.05 & 5.1205 & TST \\
\hline CHEMBL1473132 & 688128 & 5.4 & 4.3163 & TRN \\
\hline CHEMBL1481136 & 688128 & 5.1 & 4.6555 & TST \\
\hline CHEMBL1488950 & 688128 & 4.4 & 4.4468 & TRN \\
\hline CHEMBL1548101 & 688128 & 4.35 & 4.5917 & TRN \\
\hline CHEMBL1581905 & 688128 & 4.3 & 4.4795 & TRN \\
\hline CHEMBL1327901 & 688128 & 4.3 & 4.3192 & TRN \\
\hline CHEMBL1350753 & 688128 & 4.0 & 4.4925 & TST \\
\hline CHEMBL1359872 & 688128 & 4.35 & 4.2872 & TRN \\
\hline CHEMBL1372271 & 688128 & 5.05 & 4.7122 & TRN \\
\hline CHEMBL1331581 & 688128 & 4.45 & 4.7254 & TRN \\
\hline CHEMBL1308404 & 688128 & 6.5 & 5.5302 & TRN \\
\hline CHEMBL1314866 & 688128 & 5.35 & 4.6923 & TST \\
\hline CHEMBL3190555 & 688128 & 4.3 & 4.7426 & TRN \\
\hline CHEMBL1433174 & 688128 & 4.35 & 4.5579 & TRN \\
\hline CHEMBL1327079 & 688128 & 4.1 & 4.2168 & TRN \\
\hline CHEMBL1508527 & 688128 & 4.25 & 4.4766 & TRN \\
\hline CHEMBL1516001 & 688128 & 5.35 & 4.4898 & TST \\
\hline CHEMBL1464204 & 688128 & 5.4 & 4.4856 & TRN \\
\hline CHEMBL1462239 & 688128 & 4.05 & 4.5253 & TRN \\
\hline CHEMBL1556754 & 688128 & 4.05 & 4.4618 & TRN \\
\hline CHEMBL1322180 & 688128 & 5.05 & 5.0156 & TST \\
\hline CHEMBL1502821 & 688128 & 4.35 & 4.3846 & TRN \\
\hline CHEMBL 3208880 & 688128 & 5.05 & 4.9238 & TRN \\
\hline CHEMBL1460841 & 688128 & 4.25 & 4.573 & TRN \\
\hline CHEMBL1531496 & 688128 & 7.0501 & 4.7283 & TRN \\
\hline CHEMBL1500779 & 688128 & 4.45 & 4.6436 & TRN \\
\hline
\end{tabular}




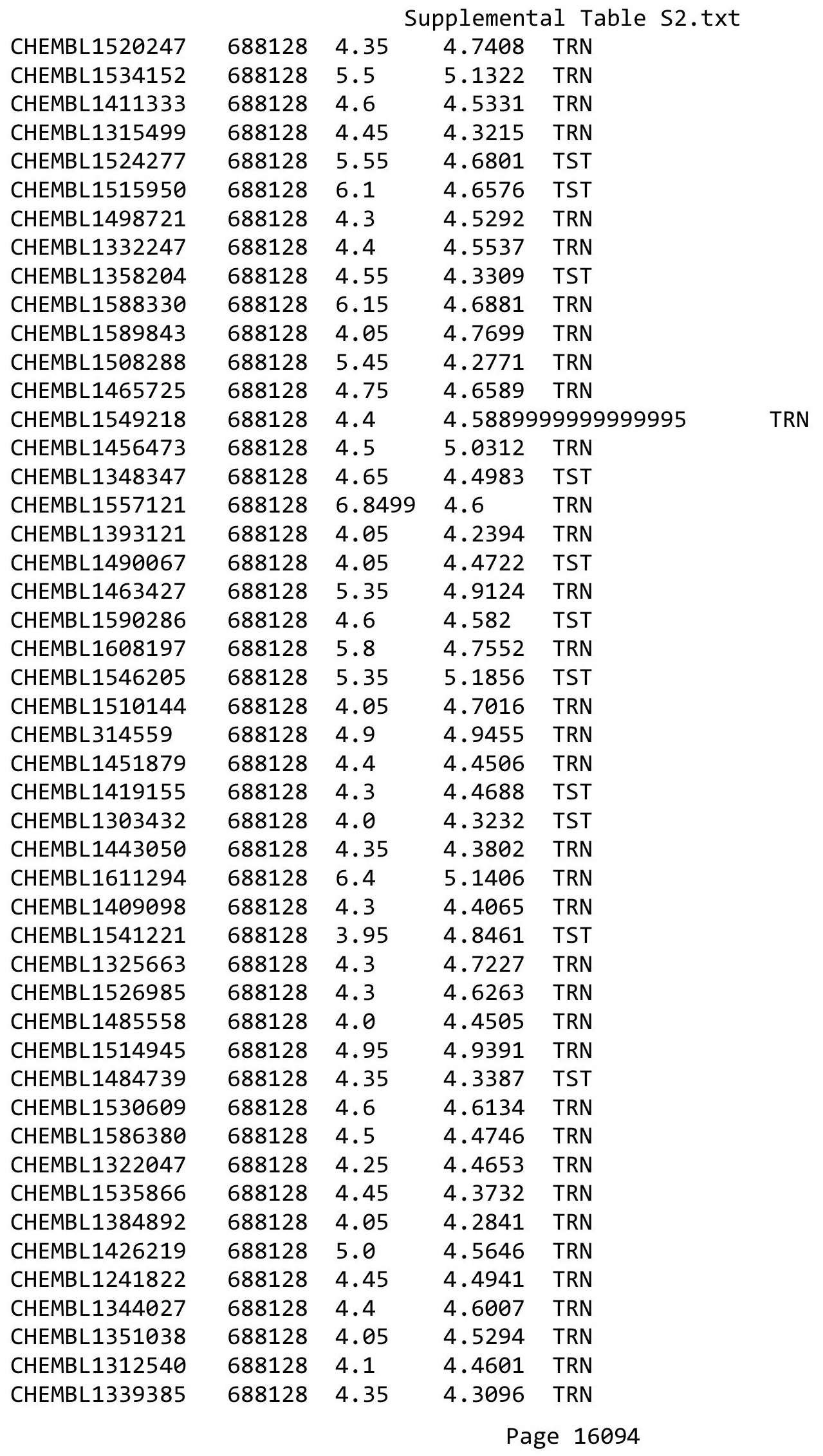




\begin{tabular}{|c|c|c|c|c|c|}
\hline \multicolumn{6}{|c|}{ Supplemental Table S2.txt } \\
\hline CHEMBL1393237 & 688128 & 4.7 & 4.7036 & TRN & \\
\hline CHEMBL3197201 & 688128 & 4.3 & 4.8147 & TRN & \\
\hline CHEMBL1299911 & 688128 & 4.4 & 4.6625 & TRN & \\
\hline CHEMBL1410802 & 688128 & 4.25 & 4.4371 & TRN & \\
\hline CHEMBL1366112 & 688128 & 4.4 & 4.7492 & TRN & \\
\hline CHEMBL3195906 & 688128 & 4.8 & 4.6955 & TST & \\
\hline CHEMBL1426411 & 688128 & 6.35 & 4.9948 & TRN & \\
\hline CHEMBL1382463 & 688128 & 4.75 & 4.7611 & TRN & \\
\hline CHEMBL1308689 & 688128 & 5.45 & 4.752 & TRN & \\
\hline CHEMBL1430852 & 688128 & 4.35 & 4.5672 & TST & \\
\hline CHEMBL1493410 & 688128 & 5.0 & 4.9178 & TRN & \\
\hline CHEMBL1435420 & 688128 & 4.4 & 4.7818 & TRN & \\
\hline CHEMBL1510168 & 688128 & 6.5 & 4.6952 & TRN & \\
\hline CHEMBL 3190778 & 688128 & 4.3 & 4.7514 & TST & \\
\hline CHEMBL1381637 & 688128 & 5.35 & 4.8281 & TST & \\
\hline CHEMBL1604303 & 688128 & 4.55 & 4.4857 & TST & \\
\hline CHEMBL1400467 & 688128 & 4.85 & 4.8203 & TRN & \\
\hline CHEMBL1343839 & 688128 & 4.4 & 4.6107 & TRN & \\
\hline CHEMBL1531500 & 688128 & 4.4 & 4.5361 & TRN & \\
\hline CHEMBL1548173 & 688128 & 4.3 & 4.7363 & TST & \\
\hline CHEMBL1390346 & 688128 & 4.8 & 4.7033 & TRN & \\
\hline CHEMBL1516325 & 688128 & 4.9 & 4.5297 & TRN & \\
\hline CHEMBL1300856 & 688128 & 5.3 & 4.6433 & TST & \\
\hline CHEMBL1495567 & 688128 & 4.35 & 4.6273 & TST & \\
\hline CHEMBL1611030 & 688128 & 4.45 & 4.7694 & TRN & \\
\hline CHEMBL1350994 & 688128 & 4.25 & 4.5025 & TRN & \\
\hline CHEMBL1513672 & 688128 & 4.3 & 4.5326 & TRN & \\
\hline CHEMBL1327425 & 688128 & 5.0 & 4.7106 & TRN & \\
\hline CHEMBL1302901 & 688128 & 4.4 & 4.6468 & TST & \\
\hline CHEMBL1460332 & 688128 & 4.35 & 4.7976 & TST & \\
\hline CHEMBL1459194 & 688128 & 4.95 & 5.0525 & TRN & \\
\hline CHEMBL1562042 & 688128 & 4.65 & 4.3826 & TRN & \\
\hline CHEMBL1313838 & 688128 & 4.45 & 4.3325 & TRN & \\
\hline CHEMBL1424285 & 688128 & 4.9 & 4.7806 & TST & \\
\hline CHEMBL580891 & 688128 & 4.4 & 4.6637 & TRN & \\
\hline CHEMBL1406351 & 688128 & 4.45 & 4.7256 & TRN & \\
\hline CHEMBL1499049 & 688128 & 4.05 & 4.6368 & TST & \\
\hline CHEMBL1435819 & 688128 & 4.9 & 4.6342 & TST & \\
\hline CHEMBL1939691 & 688128 & 4.7 & 4.8292 & TRN & \\
\hline CHEMBL317356 & 688128 & 5.15 & 4.9452 & TRN & \\
\hline CHEMBL1553115 & 688128 & 4.4 & 4.7425 & TRN & \\
\hline CHEMBL1362713 & 688128 & 4.9 & $4.9060 e$ & 0000000001 & TRN \\
\hline CHEMBL1978063 & 688128 & 5.95 & 4.7096 & TRN & \\
\hline CHEMBL1428293 & 688128 & 4.35 & 4.4478 & TRN & \\
\hline CHEMBL1564177 & 688128 & 4.35 & 4.7357 & TST & \\
\hline CHEMBL1568282 & 688128 & 5.5 & 4.6431 & TRN & \\
\hline CHEMBL3209529 & 688128 & 6.1 & 4.4802 & TRN & \\
\hline CHEMBL1563545 & 688128 & 4.05 & 4.5583 & TST & \\
\hline
\end{tabular}




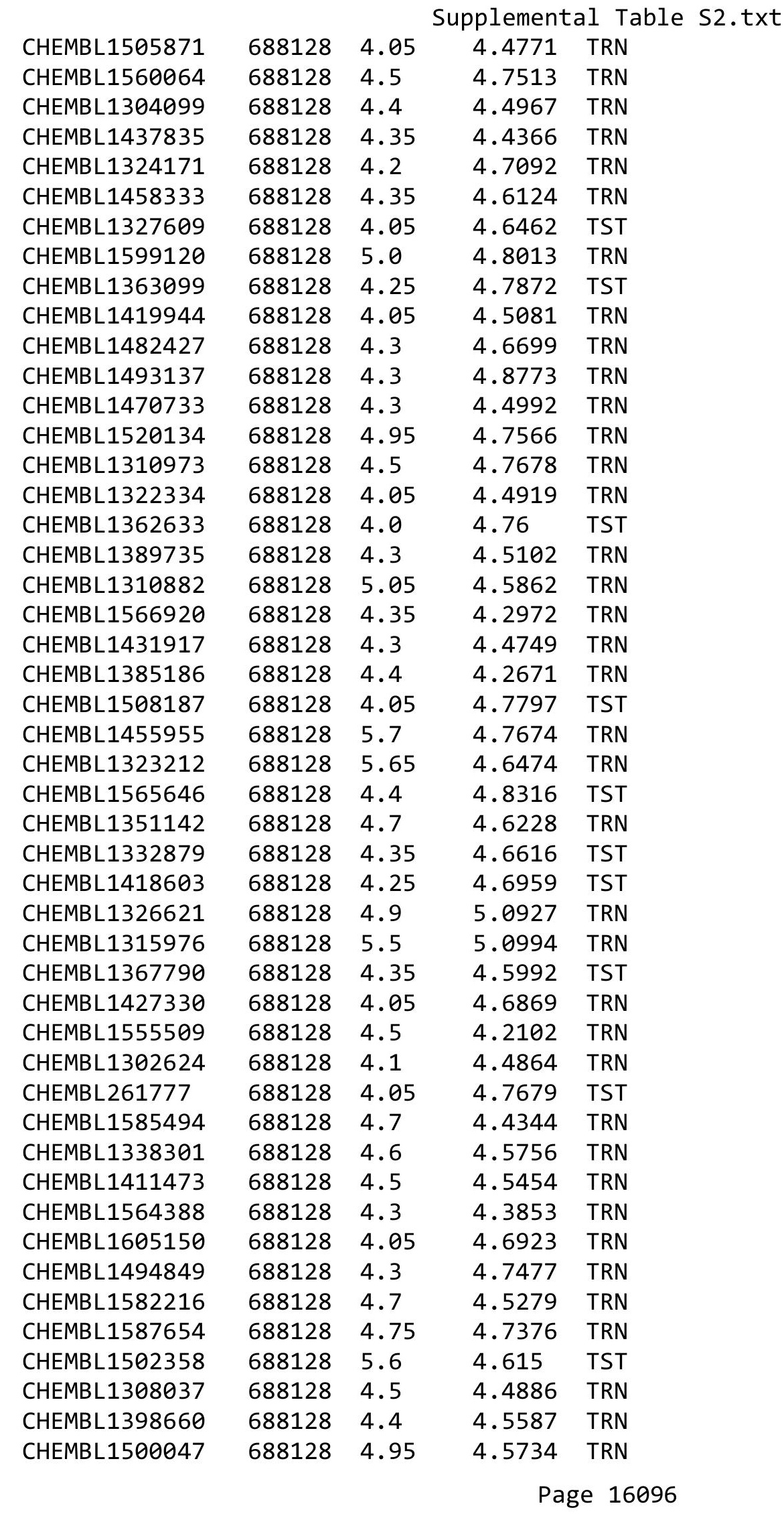




\begin{tabular}{|c|c|c|c|c|c|}
\hline & & \\
\hline CHEMBL1378702 & 688128 & 4.5 & 4.7158 & TRN & \\
\hline CHEMBL1359384 & 688128 & 6.0 & 4.8961 & TST & \\
\hline CHEMBL1534917 & 688128 & 5.05 & 5.0844 & TRN & \\
\hline CHEMBL1424455 & 688128 & 4.3 & 5.0164 & TRN & \\
\hline CHEMBL1491546 & 688128 & 4.45 & 4.9214 & TRN & \\
\hline CHEMBL1579636 & 688128 & 4.35 & 4.6967 & TST & \\
\hline CHEMBL1494884 & 688128 & 5.25 & 4.6925 & TRN & \\
\hline CHEMBL1392034 & 688128 & 5.1 & 4.5661 & TST & \\
\hline CHEMBL1580958 & 688128 & 5.35 & 4.5594 & TRN & \\
\hline CHEMBL1550174 & 688128 & 4.9 & 5.1128 & TRN & \\
\hline CHEMBL1453231 & 688128 & 4.55 & 4.3738 & TRN & \\
\hline CHEMBL1399038 & 688128 & 4.55 & 4.5725 & TRN & \\
\hline CHEMBL1441745 & 688128 & 4.45 & 4.4982 & TST & \\
\hline CHEMBL1438274 & 688128 & 6.0 & 4.6506 & TRN & \\
\hline CHEMBL1527900 & 688128 & 4.35 & 4.3082 & TRN & \\
\hline CHEMBL1525631 & 688128 & 4.9 & 4.8192 & TRN & \\
\hline CHEMBL1407473 & 688128 & 4.15 & 4.3253 & TRN & \\
\hline CHEMBL1488883 & 688128 & 4.0 & 4.4644 & TST & \\
\hline CHEMBL1433234 & 688128 & 5.5 & 4.8184 & TRN & \\
\hline CHEMBL1410832 & 688128 & 4.45 & 4.7112 & TRN & \\
\hline CHEMBL1460243 & 688128 & 4.05 & 4.4885 & TST & \\
\hline CHEMBL1465978 & 688128 & 4.35 & 4.3742 & TST & \\
\hline CHEMBL1319473 & 688128 & 4.65 & 4.6185 & TST & \\
\hline CHEMBL1523905 & 688128 & 4.25 & 4.6964 & TRN & \\
\hline CHEMBL1486834 & 688128 & 4.3 & 4.4305 & TRN & \\
\hline CHEMBL1424468 & 688128 & 4.4 & 4.3467 & TRN & \\
\hline CHEMBL1482010 & 688128 & 4.5 & 4.3987 & TRN & \\
\hline CHEMBL1401077 & 688128 & 4.4 & 4.4575 & TRN & \\
\hline CHEMBL1393010 & 688128 & 5.9 & $4.6080 e$ & 00000000005 & TST \\
\hline CHEMBL 3190970 & 688128 & 5.8 & 4.7313 & TRN & \\
\hline CHEMBL1612971 & 688128 & 4.85 & 4.3303 & TRN & \\
\hline CHEMBL1473137 & 688128 & 4.4 & 4.9016 & TST & \\
\hline CHEMBL1464539 & 688128 & 4.35 & 4.4936 & TRN & \\
\hline CHEMBL1564132 & 688128 & 4.3 & 5.038 & TRN & \\
\hline CHEMBL 3193038 & 688128 & 4.3 & 4.8352 & TST & \\
\hline CHEMBL489695 & 688128 & 4.55 & 4.4939 & TRN & \\
\hline CHEMBL1336400 & 688128 & 4.3 & $4.5280 €$ & 00000000005 & TRN \\
\hline CHEMBL1423650 & 688128 & 4.25 & 4.7677 & TST & \\
\hline CHEMBL1490194 & 688128 & 4.35 & 4.5276 & TRN & \\
\hline CHEMBL1519029 & 688128 & 4.3 & 4.4384 & TRN & \\
\hline CHEMBL1559599 & 688128 & 4.4 & 4.055 & TST & \\
\hline CHEMBL1341301 & 688128 & 4.3 & 4.6625 & TRN & \\
\hline CHEMBL1385446 & 688128 & 4.4 & 4.4104 & TRN & \\
\hline CHEMBL1518808 & 688128 & 4.35 & 4.4664 & TRN & \\
\hline CHEMBL1325619 & 688128 & 5.15 & 5.3307 & TRN & \\
\hline CHEMBL1469583 & 688128 & 4.45 & 4.6426 & TST & \\
\hline CHEMBL1354472 & 688128 & 4.4 & 4.662 & TRN & \\
\hline CHEMBL1500088 & 688128 & 5.55 & 4.9583 & TRN & \\
\hline & & & & וצבס & \\
\hline
\end{tabular}




\begin{tabular}{|c|c|c|c|c|c|}
\hline \multicolumn{6}{|c|}{ Supplemental Table S2.txt } \\
\hline CHEMBL1380484 & 688128 & 4.25 & 4.452 & TST & \\
\hline CHEMBL1303147 & 688128 & 4.55 & 4.7438 & TRN & \\
\hline CHEMBL3208376 & 688128 & 4.6 & 4.4075 & TRN & \\
\hline CHEMBL1395395 & 688128 & 4.3 & 4.3033 & TRN & \\
\hline CHEMBL1515108 & 688128 & 4.3 & 4.3047 & TRN & \\
\hline CHEMBL1360540 & 688128 & 4.25 & 4.6772 & TRN & \\
\hline CHEMBL1498602 & 688128 & 5.1 & 5.0304 & TST & \\
\hline CHEMBL1557190 & 688128 & 4.25 & 4.7872 & TST & \\
\hline CHEMBL1584766 & 688128 & 4.05 & 4.5938 & TRN & \\
\hline CHEMBL1450309 & 688128 & 4.25 & 4.5729 & TRN & \\
\hline CHEMBL1322821 & 688128 & 4.3 & 4.4438 & TRN & \\
\hline CHEMBL1576254 & 688128 & 5.15 & 4.6688 & TST & \\
\hline CHEMBL1329792 & 688128 & 4.75 & 4.5654 & TRN & \\
\hline CHEMBL1453495 & 688128 & 4.4 & 4.5376 & TRN & \\
\hline CHEMBL1442417 & 688128 & 4.3 & 4.9215 & TRN & \\
\hline CHEMBL1526375 & 688128 & 4.5 & 4.7441 & TST & \\
\hline CHEMBL1966952 & 688128 & 4.95 & 4.8484 & TST & \\
\hline CHEMBL1415914 & 688128 & 4.35 & 4.7129 & TST & \\
\hline CHEMBL1301169 & 688128 & 4.25 & 4.6607 & TRN & \\
\hline CHEMBL1418549 & 688128 & 4.35 & 4.5684 & TRN & \\
\hline CHEMBL1473591 & 688128 & 4.4 & 4.869 & TRN & \\
\hline CHEMBL1463460 & 688128 & 4.05 & 4.6664 & TST & \\
\hline CHEMBL1361996 & 688128 & 4.0 & 5.0085 & TST & \\
\hline CHEMBL1513630 & 688128 & 4.1 & 4.7682 & TST & \\
\hline CHEMBL1476423 & 688128 & 4.85 & 4.4484 & TST & \\
\hline CHEMBL1582521 & 688128 & 4.3 & 4.71899 & 9999999999 & TRN \\
\hline CHEMBL3191304 & 688128 & 4.8 & 4.7633 & TRN & \\
\hline CHEMBL1472810 & 688128 & 4.4 & 4.29899 & 99999999995 & TRN \\
\hline CHEMBL1558655 & 688128 & 4.35 & 4.1579 & TRN & \\
\hline CHEMBL1589807 & 688128 & 4.3 & 4.4396 & TRN & \\
\hline CHEMBL1423532 & 688128 & 4.3 & 4.5061 & TST & \\
\hline CHEMBL1523549 & 688128 & 4.6 & 4.7885 & TRN & \\
\hline CHEMBL1318817 & 688128 & 4.25 & 4.6483 & TRN & \\
\hline CHEMBL1464039 & 688128 & 4.85 & 4.8159 & TRN & \\
\hline CHEMBL1605720 & 688128 & 4.6 & 4.7206 & TST & \\
\hline CHEMBL1564176 & 688128 & 1.9 & 4.7134 & TRN & \\
\hline CHEMBL3198863 & 688128 & 4.05 & 4.9827 & TRN & \\
\hline CHEMBL1378682 & 688128 & 4.3 & 4.6947 & TST & \\
\hline CHEMBL1507575 & 688128 & 4.1 & 4.6158 & TST & \\
\hline CHEMBL1611365 & 688128 & 4.65 & 4.6555 & TRN & \\
\hline CHEMBL3194454 & 688128 & 4.4 & 4.94600 & 0000000001 & TST \\
\hline CHEMBL1300786 & 688128 & 4.4 & 4.9402 & TST & \\
\hline CHEMBL1327112 & 688128 & 4.35 & 4.6477 & TRN & \\
\hline CHEMBL1408375 & 688128 & 5.4 & 4.9898 & TRN & \\
\hline CHEMBL1547638 & 688128 & 4.3 & 4.9922 & TRN & \\
\hline CHEMBL1579145 & 688128 & 4.05 & 4.5782 & TST & \\
\hline CHEMBL1487300 & 688128 & 5.6 & 5.0051 & TRN & \\
\hline CHEMBL1580735 & 688128 & 4.45 & 4.7011 & TST & \\
\hline
\end{tabular}




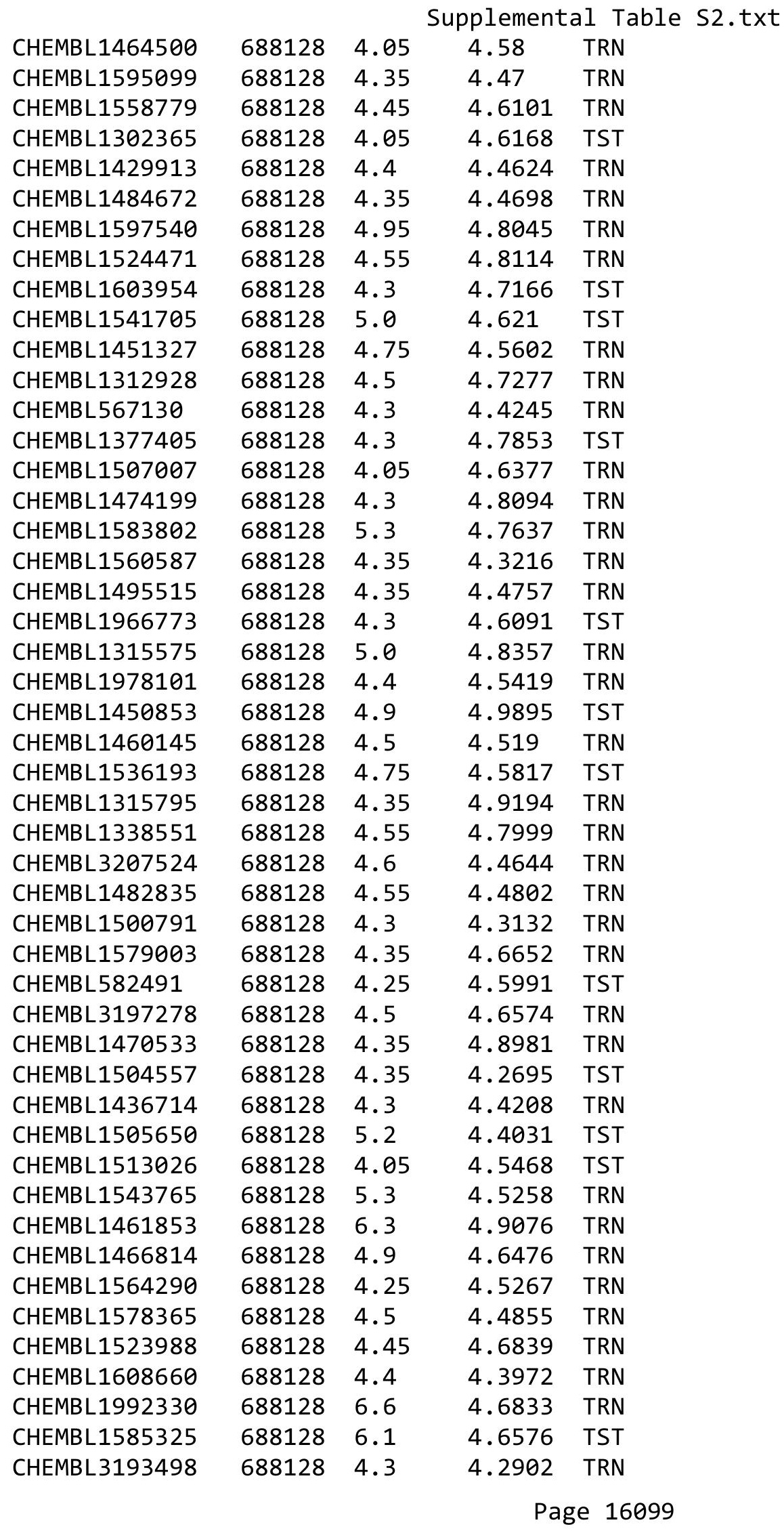




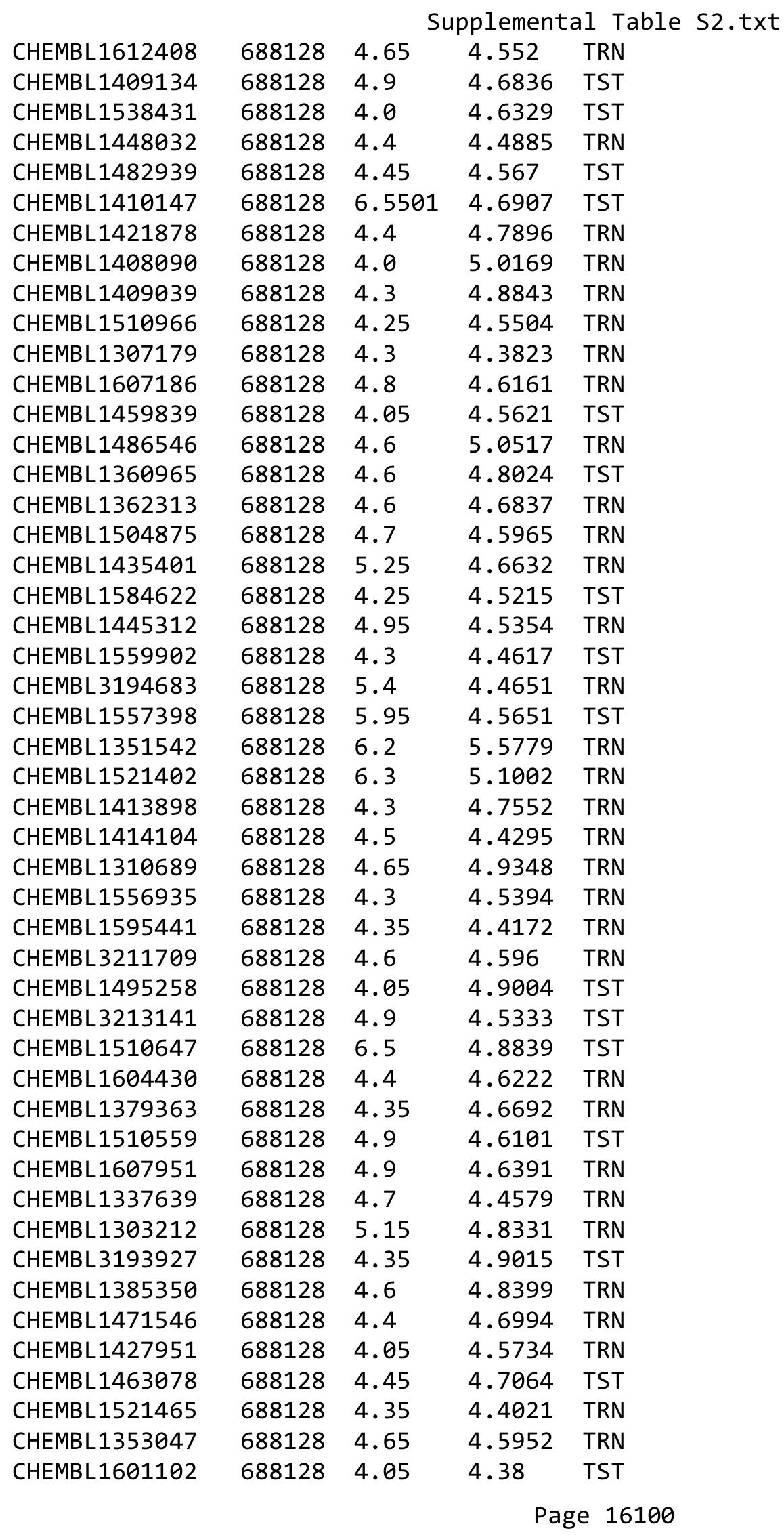




\begin{tabular}{|c|c|c|c|c|}
\hline \multicolumn{5}{|c|}{ Supplemental Table S2.txt } \\
\hline CHEMBL1376808 & 688128 & 4.7 & 4.5716 & TRN \\
\hline CHEMBL1424690 & 688128 & 4.9 & 4.4982 & TRN \\
\hline CHEMBL1301297 & 688128 & 4.35 & 4.8921 & TRN \\
\hline CHEMBL1408276 & 688128 & 4.8 & 4.9572 & TRN \\
\hline CHEMBL602126 & 688128 & 4.35 & 4.2833 & TRN \\
\hline CHEMBL1459421 & 688128 & 4.45 & 4.448 & TRN \\
\hline CHEMBL1548473 & 688128 & 4.25 & 5.0018 & TST \\
\hline CHEMBL1478224 & 688128 & 4.05 & 4.8267 & TRN \\
\hline CHEMBL1593094 & 688128 & 5.05 & 4.9896 & TRN \\
\hline CHEMBL1445214 & 688128 & 4.65 & 4.6857 & TRN \\
\hline CHEMBL1409368 & 688128 & 6.05 & 5.2203 & TRN \\
\hline CHEMBL1305121 & 688128 & 4.35 & 4.8227 & TST \\
\hline CHEMBL1304552 & 688128 & 4.45 & 4.532 & TRN \\
\hline CHEMBL1371459 & 688128 & 4.25 & 4.654 & TRN \\
\hline CHEMBL1416013 & 688128 & 4.7 & 4.6239 & TRN \\
\hline CHEMBL1403403 & 688128 & 4.25 & 4.5523 & TRN \\
\hline CHEMBL1441145 & 688128 & 4.4 & 4.6291 & TST \\
\hline CHEMBL1384410 & 688128 & 4.6 & 4.5363 & TRN \\
\hline CHEMBL1535849 & 688128 & 4.65 & 4.5319 & TRN \\
\hline CHEMBL1427464 & 688128 & 5.5 & 4.3472 & TST \\
\hline CHEMBL1572216 & 688128 & 5.15 & 4.7826 & TRN \\
\hline CHEMBL1561832 & 688128 & 6.3 & 5.3503 & TRN \\
\hline CHEMBL1511312 & 688128 & 4.45 & 4.5578 & TRN \\
\hline CHEMBL1463817 & 688128 & 4.55 & 4.575 & TST \\
\hline CHEMBL1573586 & 688128 & 4.4 & 4.7416 & TST \\
\hline CHEMBL1508849 & 688128 & 4.3 & 4.3054 & TST \\
\hline CHEMBL1489178 & 688128 & 6.0 & 4.3814 & TRN \\
\hline CHEMBL1416911 & 688128 & 4.3 & 4.7328 & TRN \\
\hline CHEMBL1608986 & 688128 & 4.2 & 4.7167 & TRN \\
\hline CHEMBL1348503 & 688128 & 4.4 & 4.8407 & TST \\
\hline CHEMBL1483090 & 688128 & 4.35 & 4.4274 & TRN \\
\hline CHEMBL1374374 & 688128 & 4.35 & 4.4581 & TRN \\
\hline CHEMBL1560059 & 688128 & 4.35 & 4.688 & TST \\
\hline CHEMBL1318330 & 688128 & 5.1 & 4.7339 & TRN \\
\hline CHEMBL1302919 & 688128 & 4.7 & 4.636 & TST \\
\hline CHEMBL7976 & 688128 & 4.55 & 4.7057 & TRN \\
\hline CHEMBL1306538 & 688128 & 4.25 & 4.6499 & TST \\
\hline CHEMBL1434097 & 688128 & 5.6 & 5.2056 & TRN \\
\hline CHEMBL1390903 & 688128 & 5.05 & 4.4627 & TRN \\
\hline CHEMBL1438281 & 688128 & 4.55 & 4.4686 & TRN \\
\hline CHEMBL1569695 & 688128 & 4.8 & 4.5385 & TRN \\
\hline CHEMBL1597369 & 688128 & 4.8 & 4.9603 & TRN \\
\hline CHEMBL1302173 & 688128 & 4.55 & 4.5698 & TST \\
\hline CHEMBL3189619 & 688128 & 4.15 & 4.3077 & TRN \\
\hline CHEMBL1566165 & 688128 & 6.15 & 5.2308 & TRN \\
\hline CHEMBL1328385 & 688128 & 4.05 & 4.4532 & TST \\
\hline CHEMBL1347676 & 688128 & 5.1 & 4.8289 & TRN \\
\hline CHEMBL1594861 & 688128 & 4.4 & 4.3339 & TRN \\
\hline
\end{tabular}




\begin{tabular}{|c|c|c|c|c|c|}
\hline \multicolumn{6}{|c|}{ Supplemental Table S2.txt } \\
\hline CHEMBL1602100 & 688128 & 4.0 & 4.4072 & TRN & \\
\hline CHEMBL1339538 & 688128 & 4.4 & 4.6282 & TST & \\
\hline CHEMBL1562215 & 688128 & 4.2 & 4.5717 & TRN & \\
\hline CHEMBL1343815 & 688128 & 4.9 & 4.4775 & TRN & \\
\hline CHEMBL1483848 & 688128 & 4.5 & 4.38399 & 99999999995 & TRN \\
\hline CHEMBL1560606 & 688128 & 4.4 & 4.4376 & TST & \\
\hline CHEMBL1477435 & 688128 & 4.05 & 4.6559 & TRN & \\
\hline CHEMBL1503882 & 688128 & 4.35 & 4.6591 & TRN & \\
\hline CHEMBL1408319 & 688128 & 4.35 & 4.6123 & TRN & \\
\hline CHEMBL1504264 & 688128 & 4.65 & 4.9029 & TST & \\
\hline CHEMBL1393171 & 688128 & 4.45 & 4.6993 & TRN & \\
\hline CHEMBL3192715 & 688128 & 6.05 & 4.8222 & TRN & \\
\hline CHEMBL1504043 & 688128 & 4.45 & 4.5188 & TRN & \\
\hline CHEMBL1495434 & 688128 & 4.55 & 4.6843 & TST & \\
\hline CHEMBL1579118 & 688128 & 4.95 & 4.7507 & TRN & \\
\hline CHEMBL1407928 & 688128 & 4.35 & 4.4085 & TST & \\
\hline CHEMBL1375645 & 688128 & 4.25 & 4.3992 & TRN & \\
\hline CHEMBL1434297 & 688128 & 4.35 & 4.5877 & TST & \\
\hline CHEMBL 397442 & 688128 & 4.3 & 4.614 & TRN & \\
\hline CHEMBL1979195 & 688128 & 4.8 & 4.6842 & TRN & \\
\hline CHEMBL1489368 & 688128 & 5.6 & 5.0054 & TRN & \\
\hline CHEMBL1328720 & 688128 & 4.05 & 4.5383 & TRN & \\
\hline CHEMBL1374462 & 688128 & 4.9 & 4.7278 & TRN & \\
\hline CHEMBL1379225 & 688128 & 4.4 & 4.7198 & TST & \\
\hline CHEMBL1417816 & 688128 & 4.35 & 4.4979 & TRN & \\
\hline CHEMBL1999959 & 688128 & 4.35 & 4.5147 & TRN & \\
\hline CHEMBL1480165 & 688128 & 4.65 & 4.6641 & TRN & \\
\hline CHEMBL1534754 & 688128 & 4.35 & 4.6193 & TRN & \\
\hline CHEMBL1454442 & 688128 & 4.25 & 4.5888 & TRN & \\
\hline CHEMBL1351890 & 688128 & 4.3 & 4.7243 & TST & \\
\hline CHEMBL1426184 & 688128 & 4.5 & 4.4874 & TRN & \\
\hline CHEMBL1516684 & 688128 & 4.85 & 4.3154 & TRN & \\
\hline CHEMBL1354075 & 688128 & 4.25 & 4.4206 & TST & \\
\hline CHEMBL1527144 & 688128 & 4.4 & 4.5578 & TRN & \\
\hline CHEMBL1437196 & 688128 & 5.65 & 4.7113 & TST & \\
\hline CHEMBL1456344 & 688128 & 4.4 & 4.698 & TRN & \\
\hline CHEMBL1570604 & 688128 & 4.25 & 4.6832 & TST & \\
\hline CHEMBL1360150 & 688128 & 4.3 & 4.8301 & TRN & \\
\hline CHEMBL3191551 & 688128 & 4.4 & 4.4649 & TRN & \\
\hline CHEMBL1410472 & 688128 & 4.25 & 4.6641 & TRN & \\
\hline CHEMBL1309397 & 688128 & 4.5 & 4.5547 & TST & \\
\hline CHEMBL1399968 & 688128 & 4.55 & 4.6993 & TRN & \\
\hline CHEMBL1326685 & 688128 & 5.45 & 4.4542 & TRN & \\
\hline CHEMBL1458252 & 688128 & 4.05 & 4.7892 & TRN & \\
\hline CHEMBL1330499 & 688128 & 4.3 & 4.2305 & TRN & \\
\hline CHEMBL1528736 & 688128 & 4.65 & 4.4717 & TRN & \\
\hline CHEMBL1510194 & 688128 & 5.0 & 4.3527 & TRN & \\
\hline CHEMBL1325759 & 688128 & 4.7 & 4.9541 & TST & \\
\hline
\end{tabular}




\begin{tabular}{|c|c|c|c|c|}
\hline \multicolumn{5}{|c|}{ Supplemental Table S2.txt } \\
\hline CHEMBL1327285 & 688128 & 4.35 & 4.4808 & TST \\
\hline CHEMBL1464451 & 688128 & 4.15 & 4.6372 & TST \\
\hline CHEMBL1523781 & 688128 & 4.3 & 4.4946 & TRN \\
\hline CHEMBL1324922 & 688128 & 4.7 & 4.9434 & TST \\
\hline CHEMBL1454588 & 688128 & 4.3 & 4.6722 & TRN \\
\hline CHEMBL1501645 & 688128 & 4.75 & 4.9701 & TRN \\
\hline CHEMBL1347178 & 688128 & 4.45 & 4.6474 & TRN \\
\hline CHEMBL1494907 & 688128 & 6.05 & 4.6003 & TST \\
\hline CHEMBL1549268 & 688128 & 4.25 & 4.6017 & TRN \\
\hline CHEMBL1369646 & 688128 & 4.4 & 4.6686 & TRN \\
\hline CHEMBL1423412 & 688128 & 4.05 & 4.8109 & TST \\
\hline CHEMBL1469035 & 688128 & 5.45 & 5.0503 & TRN \\
\hline CHEMBL1495989 & 688128 & 4.35 & 4.7191 & TST \\
\hline CHEMBL1517239 & 688128 & 4.65 & 4.2406 & TST \\
\hline CHEMBL1303953 & 688128 & 5.35 & 5.1771 & TRN \\
\hline CHEMBL1578220 & 688128 & 4.4 & 4.6285 & TRN \\
\hline CHEMBL1488779 & 688128 & 4.5 & 4.369 & TST \\
\hline CHEMBL1529871 & 688128 & 5.75 & 5.2603 & TRN \\
\hline CHEMBL1328670 & 688128 & 6.5501 & 4.6298 & TRN \\
\hline CHEMBL1377800 & 688128 & 4.2 & 4.5034 & TRN \\
\hline CHEMBL3198706 & 688128 & 4.3 & 4.5803 & TST \\
\hline CHEMBL1383321 & 688128 & 4.35 & 5.3122 & TRN \\
\hline CHEMBL1544440 & 688128 & 4.95 & 4.5114 & TRN \\
\hline CHEMBL1364099 & 688128 & 4.3 & 4.3728 & TRN \\
\hline CHEMBL233149 & 688128 & 4.05 & 4.5861 & TRN \\
\hline CHEMBL510132 & 688128 & 4.35 & 4.7079 & TRN \\
\hline CHEMBL1537686 & 688128 & 4.4 & 4.6042 & TRN \\
\hline CHEMBL1568126 & 688128 & 6.2 & 4.8347 & TRN \\
\hline CHEMBL1299313 & 688128 & 4.85 & 4.6081 & TRN \\
\hline CHEMBL 3210255 & 688128 & 4.55 & 4.9628 & TRN \\
\hline CHEMBL1333566 & 688128 & 4.35 & 4.5618 & TRN \\
\hline CHEMBL1496730 & 688128 & 4.4 & 4.5611 & TRN \\
\hline CHEMBL1391098 & 688128 & 4.6 & 4.5119 & TRN \\
\hline CHEMBL1599023 & 688128 & 5.1 & 4.8644 & TST \\
\hline CHEMBL1313052 & 688128 & 5.25 & 4.7978 & TRN \\
\hline CHEMBL1613231 & 688128 & 6.1 & 4.4984 & TRN \\
\hline CHEMBL 1485766 & 688128 & 4.75 & 4.8554 & TRN \\
\hline CHEMBL1465899 & 688128 & 4.55 & 4.971 & TRN \\
\hline CHEMBL1544696 & 688128 & 4.3 & 4.5608 & TRN \\
\hline CHEMBL1401908 & 688128 & 4.45 & 4.6937 & TRN \\
\hline CHEMBL1402907 & 688128 & 4.75 & 4.8688 & TRN \\
\hline CHEMBL1302252 & 688128 & 6.0 & 4.7112 & TRN \\
\hline CHEMBL1324367 & 688128 & 4.0 & 4.7849 & TST \\
\hline CHEMBL1310720 & 688128 & 5.5 & 4.8806 & TRN \\
\hline CHEMBL1493021 & 688128 & 4.5 & 4.7766 & TST \\
\hline CHEMBL1484602 & 688128 & 3.95 & 4.6292 & TST \\
\hline CHEMBL1508532 & 688128 & 4.55 & 4.3358 & TRN \\
\hline CHEMBL1465370 & 688128 & 4.85 & 4.6409 & TRN \\
\hline
\end{tabular}




\begin{tabular}{|c|c|c|c|c|c|}
\hline \multicolumn{6}{|c|}{ Supplemental Table S2.txt } \\
\hline CHEMBL1385082 & 688128 & 4.4 & 4.6782 & TST & \\
\hline CHEMBL1361744 & 688128 & 4.3 & 4.4404 & TRN & \\
\hline CHEMBL1369472 & 688128 & 4.45 & 4.559 & TRN & \\
\hline CHEMBL1309551 & 688128 & 4.35 & 4.5204 & TRN & \\
\hline CHEMBL1508083 & 688128 & 4.3 & 4.5154 & TRN & \\
\hline CHEMBL1589300 & 688128 & 4.5 & 4.8238 & TRN & \\
\hline CHEMBL1488522 & 688128 & 5.0 & 4.6099 & TRN & \\
\hline CHEMBL1596051 & 688128 & 4.2 & 4.3704 & TRN & \\
\hline CHEMBL1502701 & 688128 & 4.3 & 4.4517 & TRN & \\
\hline CHEMBL1546947 & 688128 & 5.25 & 4.3905 & TRN & \\
\hline CHEMBL1560947 & 688128 & 4.25 & 4.0275 & TRN & \\
\hline CHEMBL1429874 & 688128 & 4.75 & 4.5872 & TRN & \\
\hline CHEMBL1590238 & 688128 & 4.75 & 4.6117 & TST & \\
\hline CHEMBL1413430 & 688128 & 4.6 & 4.3763 & TRN & \\
\hline CHEMBL1427655 & 688128 & 6.1 & 4.4884 & TRN & \\
\hline CHEMBL180920 & 688128 & 4.25 & 4.7789 & TST & \\
\hline CHEMBL1413783 & 688128 & 4.35 & 4.8025 & TRN & \\
\hline CHEMBL1347911 & 688128 & 4.4 & 4.4498 & TST & \\
\hline CHEMBL1490258 & 688128 & 4.25 & 4.9408 & TRN & \\
\hline CHEMBL1346720 & 688128 & 4.35 & 4.4324 & TRN & \\
\hline CHEMBL1513718 & 688128 & 4.5 & $4.6160 e$ & 00000000005 & TRN \\
\hline CHEMBL1582226 & 688128 & 4.4 & 4.5932 & TRN & \\
\hline CHEMBL1502152 & 688128 & 4.35 & 4.4888 & TRN & \\
\hline CHEMBL1426159 & 688128 & 4.35 & 4.7487 & TRN & \\
\hline CHEMBL1424651 & 688128 & 5.4 & 4.5152 & TRN & \\
\hline CHEMBL1991157 & 688128 & 5.2 & 4.6054 & TRN & \\
\hline CHEMBL1360857 & 688128 & 6.0 & 4.6544 & TRN & \\
\hline CHEMBL1466241 & 688128 & 4.3 & 4.8325 & TRN & \\
\hline CHEMBL1587164 & 688128 & 5.7 & 4.5655 & TRN & \\
\hline CHEMBL1375963 & 688128 & 5.45 & 4.7978 & TRN & \\
\hline CHEMBL1541779 & 688128 & 4.35 & 4.3209 & TRN & \\
\hline CHEMBL1334719 & 688128 & 5.6 & 5.0526 & TRN & \\
\hline CHEMBL1417692 & 688128 & 5.6 & 5.07 & TRN & \\
\hline CHEMBL1471099 & 688128 & 4.4 & 4.4379 & TRN & \\
\hline CHEMBL1403820 & 688128 & 4.1 & 4.1899 & TRN & \\
\hline CHEMBL1315122 & 688128 & 5.25 & 5.0581 & TRN & \\
\hline CHEMBL1463492 & 688128 & 4.1 & 4.8236 & TST & \\
\hline CHEMBL3208988 & 688128 & 4.0 & 4.518 & TRN & \\
\hline CHEMBL1458804 & 688128 & 4.2 & 4.4507 & TRN & \\
\hline CHEMBL1345798 & 688128 & 4.85 & 4.4826 & TST & \\
\hline CHEMBL1580360 & 688128 & 4.3 & 4.7807 & TRN & \\
\hline CHEMBL1324805 & 688128 & 6.2 & 5.1608 & TRN & \\
\hline CHEMBL3209448 & 688128 & 4.0 & 4.7059 & TRN & \\
\hline CHEMBL1379882 & 688128 & 4.65 & 4.473 & TST & \\
\hline CHEMBL1584289 & 688128 & 4.35 & 4.4762 & TRN & \\
\hline CHEMBL1608118 & 688128 & 4.1 & 4.6594 & TST & \\
\hline CHEMBL1606225 & 688128 & 4.5 & 4.5968 & TST & \\
\hline CHEMBL1576474 & 688128 & 4.25 & 4.6233 & TST & \\
\hline
\end{tabular}




\begin{tabular}{|c|c|c|c|c|c|}
\hline & & \multicolumn{4}{|c|}{ Supplemental Table s2.txt } \\
\hline CHEMBL1425051 & 688128 & 4.05 & 4.9272 & TRN & \\
\hline CHEMBL1304956 & 688128 & 4.45 & 4.605 & TST & \\
\hline CHEMBL1510832 & 688128 & 4.2 & 4.4163 & TRN & \\
\hline CHEMBL1527896 & 688128 & 4.4 & 4.6474 & TRN & \\
\hline CHEMBL1597901 & 688128 & 4.3 & 4.5949 & TRN & \\
\hline CHEMBL1560366 & 688128 & 4.3 & 4.8607 & TST & \\
\hline CHEMBL1549318 & 688128 & 5.1 & 4.8749 & TRN & \\
\hline CHEMBL1463637 & 688128 & 4.05 & 4.8659 & TRN & \\
\hline CHEMBL1386968 & 688128 & 4.95 & 5.1202 & TRN & \\
\hline CHEMBL 1400846 & 688128 & 4.4 & 4.3703 & TST & \\
\hline CHEMBL 3187257 & 688128 & 4.25 & 4.5787 & TRN & \\
\hline CHEMBL1377255 & 688128 & 4.05 & 4.8375 & TRN & \\
\hline CHEMBL1327058 & 688128 & 4.05 & 4.8005 & TST & \\
\hline CHEMBL1301925 & 688128 & 4.4 & 4.6878 & TRN & \\
\hline CHEMBL1446502 & 688128 & 4.85 & 4.6296 & TRN & \\
\hline CHEMBL1300568 & 688128 & 4.4 & 4.5495 & TRN & \\
\hline CHEMBL1385669 & 688128 & 4.4 & 4.5756 & TRN & \\
\hline CHEMBL1410740 & 688128 & 4.35 & 4.7999 & TST & \\
\hline CHEMBL 3214123 & 688128 & 4.05 & 4.4732 & TST & \\
\hline CHEMBL1553272 & 688128 & 5.75 & 5.1414 & TRN & \\
\hline CHEMBL1421441 & 688128 & 4.7 & 5.4592 & TRN & \\
\hline CHEMBL1425725 & 688128 & 5.25 & 5.3179 & TRN & \\
\hline CHEMBL1552246 & 688128 & 4.4 & 4.3544 & TRN & \\
\hline CHEMBL1610098 & 688128 & 4.95 & 4.5442 & TRN & \\
\hline CHEMBL1315583 & 688128 & 4.3 & 4.7601 & TRN & \\
\hline CHEMBL1562846 & 688128 & 6.2 & 5.038 & TRN & \\
\hline CHEMBL1469388 & 688128 & 4.25 & 4.7228 & TST & \\
\hline CHEMBL1450389 & 688128 & 5.65 & 4.6042 & TRN & \\
\hline CHEMBL 3145021 & 688128 & 4.35 & 4.842 & TRN & \\
\hline CHEMBL 1390660 & 688128 & 4.25 & 4.4049 & TST & \\
\hline CHEMBL1546254 & 688128 & 4.3 & 4.9128 & TRN & \\
\hline CHEMBL1322235 & 688128 & 4.0 & 4.6706 & TST & \\
\hline CHEMBL1425602 & 688128 & 5.55 & 4.6782 & TRN & \\
\hline CHEMBL1566437 & 688128 & 4.7 & 4.5891 & TRN & \\
\hline CHEMBL1540993 & 688128 & 4.95 & 4.6766 & TRN & \\
\hline CHEMBL1372716 & 688128 & 4.7 & 4.7346 & TRN & \\
\hline CHEMBL1461942 & 688128 & 4.8 & 4.7681 & TST & \\
\hline CHEMBL1393306 & 688128 & 4.5 & 4.3289 & TRN & \\
\hline CHEMBL1461023 & 688128 & 6.25 & 4.9558 & TRN & \\
\hline CHEMBL1613327 & 688128 & 4.5 & 4.5963 & TST & \\
\hline CHEMBL1544163 & 688128 & 6.0 & 4.6097 & TRN & \\
\hline CHEMBL1483230 & 688128 & 4.8 & 4.7544 & TRN & \\
\hline CHEMBL1574875 & 688128 & 4.25 & 4.6366 & TRN & \\
\hline CHEMBL1556100 & 688128 & 4.9 & 4.6043 & TST & \\
\hline CHEMBL1329031 & 688128 & 5.7 & 5.0314 & TRN & \\
\hline CHEMBL1456636 & 688128 & 4.6 & 4.7339 & TRN & \\
\hline CHEMBL1555327 & 688128 & 4.3 & 4.47199 & 99999999995 & TRN \\
\hline CHEMBL1578797 & 688128 & 5.35 & 4.543 & TRN & \\
\hline
\end{tabular}




\begin{tabular}{|c|c|c|c|c|}
\hline \multicolumn{5}{|c|}{ Supplemental Table S2.txt } \\
\hline CHEMBL1345570 & 688128 & 4.3 & 4.6467 & TST \\
\hline CHEMBL1486510 & 688128 & 4.75 & 4.5928 & TRN \\
\hline CHEMBL1385155 & 688128 & 4.25 & 4.5722 & TRN \\
\hline CHEMBL1542667 & 688128 & 4.45 & 4.7055 & TRN \\
\hline CHEMBL1531711 & 688128 & 4.75 & 4.5123 & TRN \\
\hline CHEMBL1309615 & 688128 & 4.4 & 4.3751 & TRN \\
\hline CHEMBL1538402 & 688128 & 4.5 & 5.056 & TST \\
\hline CHEMBL1424555 & 688128 & 4.05 & 4.3068 & TRN \\
\hline CHEMBL 3212230 & 688128 & 4.8 & 4.5956 & TST \\
\hline CHEMBL1501076 & 688128 & 6.0 & 5.1519 & TRN \\
\hline CHEMBL1391009 & 688128 & 4.3 & 4.4713 & TRN \\
\hline CHEMBL1330977 & 688128 & 5.7 & 4.7156 & TRN \\
\hline CHEMBL1528294 & 688128 & 5.85 & 4.9635 & TRN \\
\hline CHEMBL1435147 & 688128 & 4.3 & 4.8652 & TST \\
\hline CHEMBL1596229 & 688128 & 4.05 & 4.5592 & TST \\
\hline CHEMBL1340933 & 688128 & 5.45 & 4.2422 & TRN \\
\hline CHEMBL1415985 & 688128 & 4.4 & 4.692 & TRN \\
\hline CHEMBL1577302 & 688128 & 4.4 & 4.9066 & TRN \\
\hline CHEMBL577894 & 688128 & 4.45 & 4.6485 & TRN \\
\hline CHEMBL1522403 & 688128 & 4.55 & 4.637 & TST \\
\hline CHEMBL1522249 & 688128 & 4.5 & 4.7913 & TRN \\
\hline CHEMBL1370141 & 688128 & 4.45 & 4.4746 & TRN \\
\hline CHEMBL1363965 & 688128 & 4.35 & 4.971 & TRN \\
\hline CHEMBL1555429 & 688128 & 4.5 & 4.6796 & TST \\
\hline CHEMBL1536589 & 688128 & 4.0 & 4.6264 & TRN \\
\hline CHEMBL1601794 & 688128 & 6.0 & 4.7121 & TST \\
\hline CHEMBL1335537 & 688128 & 5.5 & 5.1519 & TRN \\
\hline CHEMBL1452935 & 688128 & 4.3 & 4.7792 & TRN \\
\hline CHEMBL1479318 & 688128 & 4.25 & 4.2321 & TRN \\
\hline CHEMBL1336282 & 688128 & 4.8 & 4.9051 & TRN \\
\hline CHEMBL1373473 & 688128 & 4.4 & 4.6975 & TRN \\
\hline CHEMBL1606109 & 688128 & 4.25 & 4.4308 & TST \\
\hline CHEMBL1541973 & 688128 & 4.65 & 4.9218 & TRN \\
\hline CHEMBL1410862 & 688128 & 4.3 & 4.688 & TST \\
\hline CHEMBL1418530 & 688128 & 4.7 & 4.4092 & TRN \\
\hline CHEMBL1539188 & 688128 & 4.35 & 4.6909 & TST \\
\hline CHEMBL1602030 & 688128 & 5.45 & 4.6089 & TRN \\
\hline CHEMBL1501861 & 688128 & 4.35 & 4.5759 & TRN \\
\hline CHEMBL1381388 & 688128 & 4.05 & 4.6426 & TRN \\
\hline CHEMBL1392860 & 688128 & 4.05 & 4.3318 & TRN \\
\hline CHEMBL1574896 & 688128 & 4.5 & 4.7978 & TRN \\
\hline CHEMBL1555932 & 688128 & 4.5 & 4.6365 & TRN \\
\hline CHEMBL1346906 & 688128 & 4.35 & 4.9393 & TRN \\
\hline CHEMBL1578571 & 688128 & 6.25 & 4.9085 & TRN \\
\hline CHEMBL1603722 & 688128 & 4.4 & 4.5059 & TRN \\
\hline CHEMBL1540839 & 688128 & 4.45 & 4.4545 & TRN \\
\hline CHEMBL1491108 & 688128 & 4.4 & 4.4401 & TRN \\
\hline CHEMBL1322068 & 688128 & 4.7 & 4.5585 & TST \\
\hline
\end{tabular}




\begin{tabular}{|c|c|c|c|c|}
\hline \multicolumn{5}{|c|}{ Supplemental Table S2.txt } \\
\hline CHEMBL1495495 & 688128 & 4.45 & 4.5264 & TRN \\
\hline CHEMBL1572055 & 688128 & 4.25 & 4.3986 & TRN \\
\hline CHEMBL1383907 & 688128 & 4.05 & 4.4942 & TST \\
\hline CHEMBL1522047 & 688128 & 4.3 & 4.5462 & TRN \\
\hline CHEMBL1379601 & 688128 & 4.6 & 4.4596 & TRN \\
\hline CHEMBL8739 & 688128 & 4.45 & 4.8381 & TRN \\
\hline CHEMBL1543870 & 688128 & 4.7 & 5.0174 & TST \\
\hline CHEMBL1419381 & 688128 & 5.1 & 4.8803 & TST \\
\hline CHEMBL1471049 & 688128 & 4.3 & 4.9059 & TRN \\
\hline CHEMBL1467730 & 688128 & 4.3 & 4.4834 & TRN \\
\hline CHEMBL1538308 & 688128 & 4.5 & 4.8183 & TRN \\
\hline CHEMBL1398979 & 688128 & 4.3 & 4.625 & TRN \\
\hline CHEMBL1372692 & 688128 & 4.35 & 4.3155 & TST \\
\hline CHEMBL1481061 & 688128 & 5.0 & 4.822 & TST \\
\hline CHEMBL1539146 & 688128 & 4.3 & 4.2399 & TRN \\
\hline CHEMBL1610008 & 688128 & 4.35 & 4.7918 & TST \\
\hline CHEMBL1305162 & 688128 & 4.6 & 4.687 & TRN \\
\hline CHEMBL1339716 & 688128 & 5.1 & 4.3625 & TRN \\
\hline CHEMBL1428000 & 688128 & 4.95 & 4.5562 & TRN \\
\hline CHEMBL1482164 & 688128 & 4.5 & 4.4933 & TRN \\
\hline CHEMBL1462052 & 688128 & 4.4 & 4.5242 & TRN \\
\hline CHEMBL1358411 & 688128 & 5.5 & 4.4523 & TST \\
\hline CHEMBL1370523 & 688128 & 4.3 & 4.644 & TRN \\
\hline CHEMBL1403546 & 688128 & 4.35 & 4.8148 & TRN \\
\hline CHEMBL1504597 & 688128 & 4.05 & 4.6285 & TST \\
\hline CHEMBL1370725 & 688128 & 4.05 & 4.8656 & TRN \\
\hline CHEMBL1524454 & 688128 & 5.0 & 4.3925 & TRN \\
\hline CHEMBL1331156 & 688128 & 4.3 & 4.5002 & TRN \\
\hline CHEMBL1347149 & 688128 & 5.9 & 4.5408 & TRN \\
\hline CHEMBL1580468 & 688128 & 4.7 & 4.4923 & TST \\
\hline CHEMBL1319993 & 688128 & 4.35 & 4.7546 & TST \\
\hline CHEMBL1374223 & 688128 & 4.25 & 4.4516 & TRN \\
\hline CHEMBL1990866 & 688128 & 4.4 & 4.5679 & TST \\
\hline CHEMBL1523921 & 688128 & 5.5 & 4.6311 & TRN \\
\hline CHEMBL1372497 & 688128 & 4.1 & 4.669 & TRN \\
\hline CHEMBL209453 & 688128 & 4.75 & 4.8481 & TRN \\
\hline CHEMBL1434623 & 688128 & 4.85 & 4.52 & TRN \\
\hline CHEMBL1569054 & 688128 & 4.6 & 4.7716 & TRN \\
\hline CHEMBL1451336 & 688128 & 5.75 & 4.8439 & TRN \\
\hline CHEMBL1499345 & 688128 & 4.35 & 4.4418 & TRN \\
\hline CHEMBL584225 & 688128 & 4.05 & 4.7135 & TST \\
\hline CHEMBL1396113 & 688128 & 4.4 & 4.7894 & TRN \\
\hline CHEMBL1344135 & 688128 & 4.35 & 4.3556 & TRN \\
\hline CHEMBL1324487 & 688128 & 4.35 & 4.7745 & TRN \\
\hline CHEMBL1393259 & 688128 & 4.05 & 4.5543 & TRN \\
\hline CHEMBL1500208 & 688128 & 6.0 & 4.3994 & TRN \\
\hline CHEMBL1417652 & 688128 & 4.3 & 4.3631 & TRN \\
\hline CHEMBL1459140 & 688128 & 6.0 & 4.8007 & TRN \\
\hline
\end{tabular}




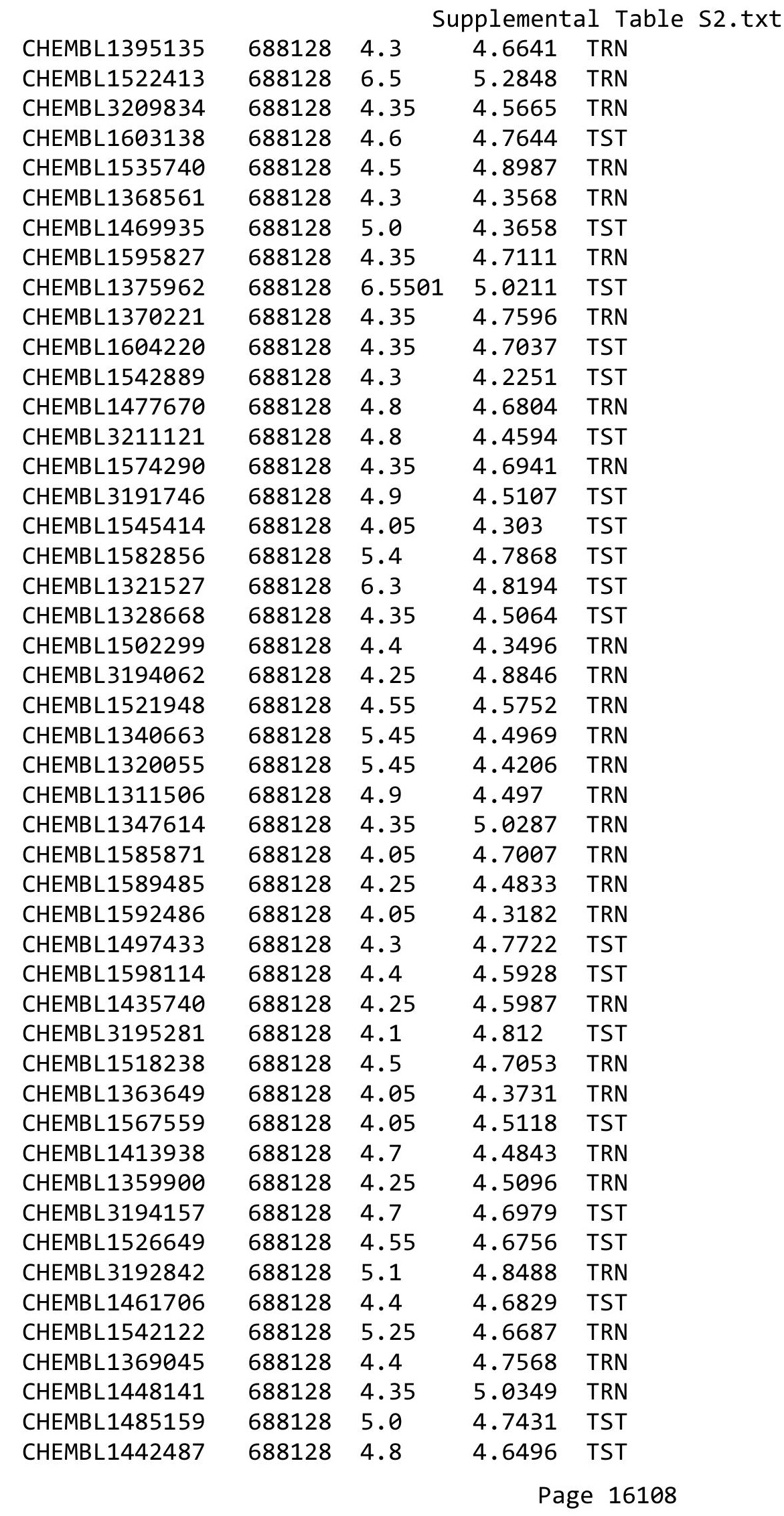




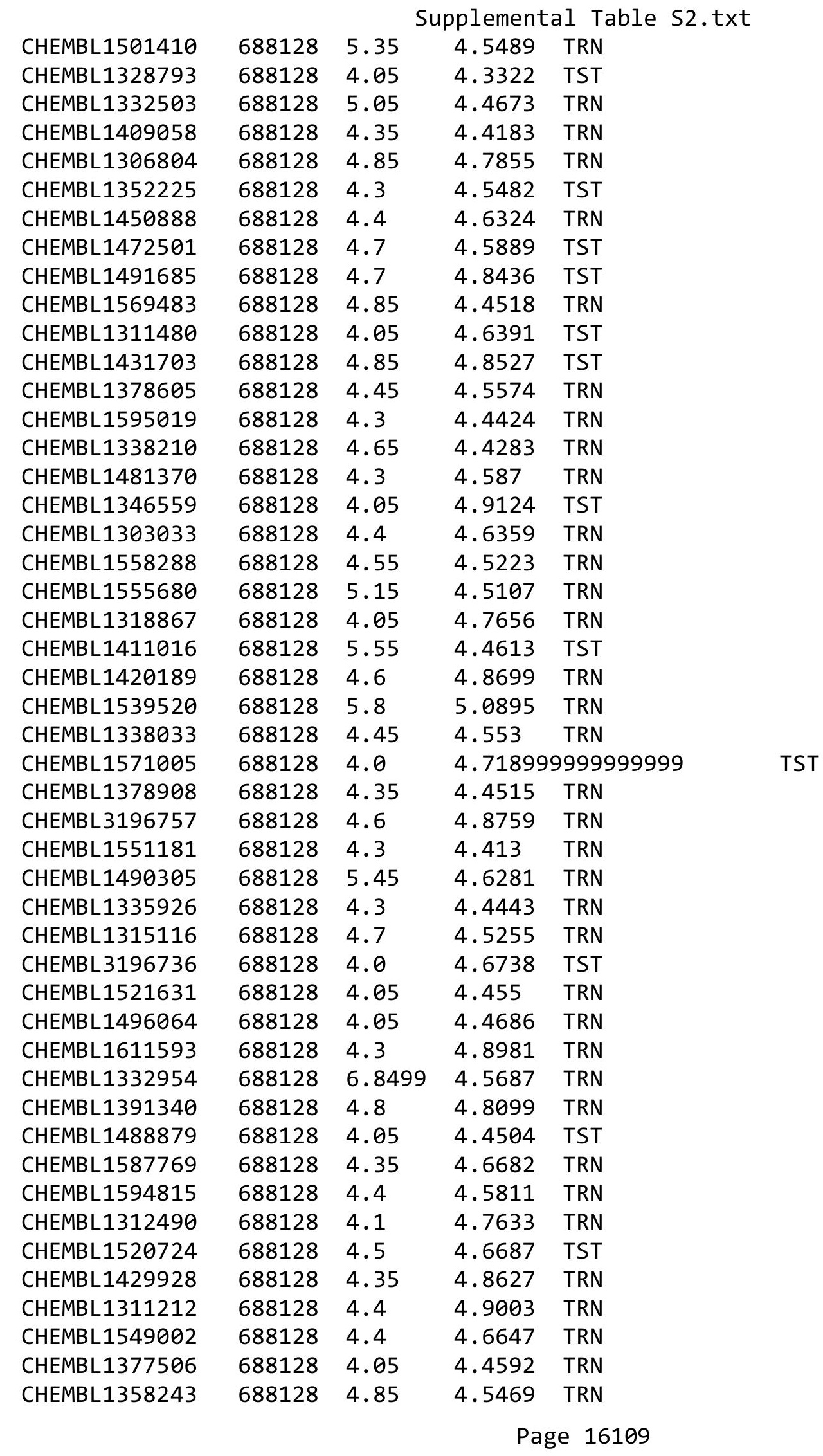




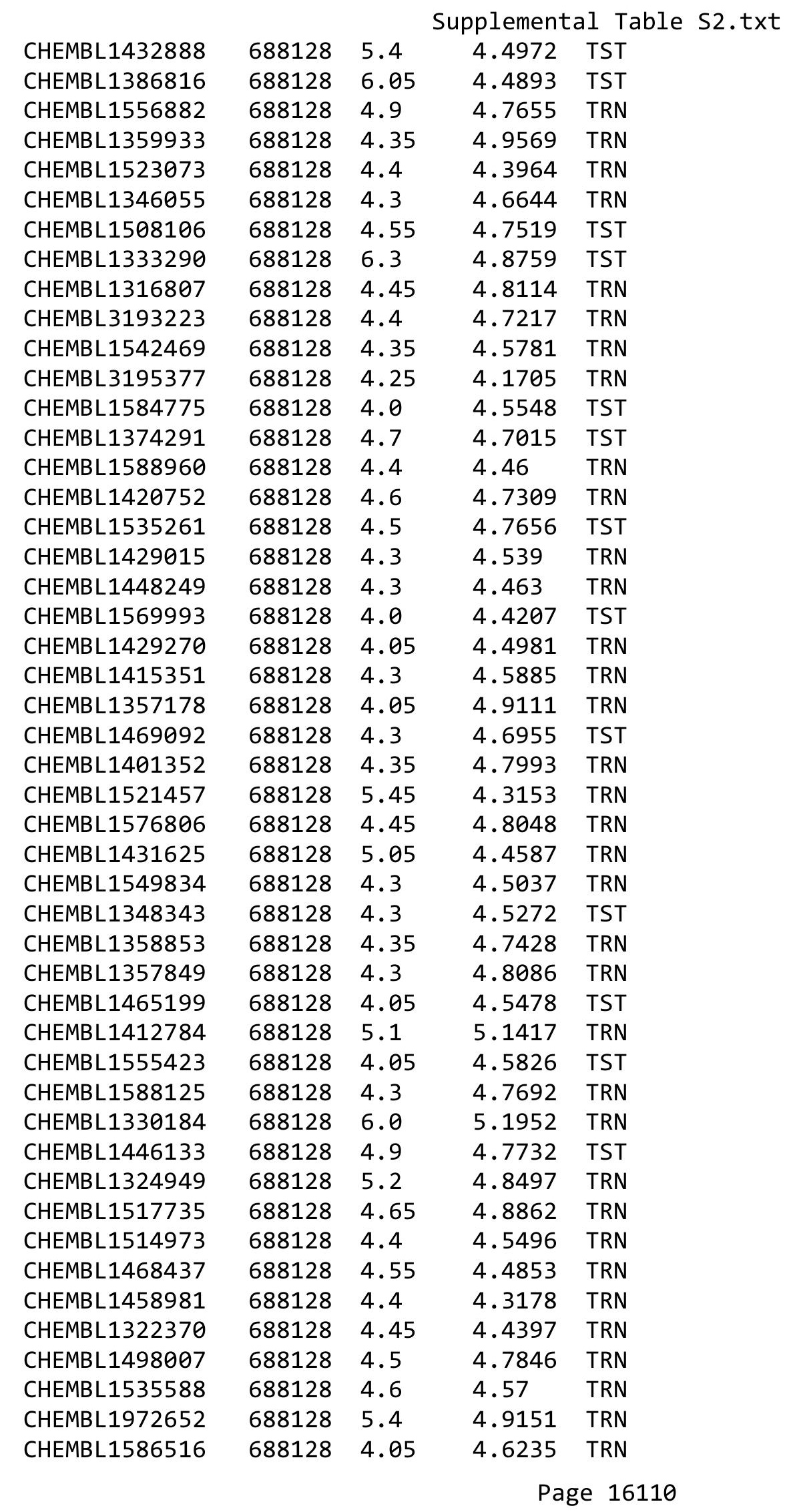




\begin{tabular}{|c|c|c|c|c|c|}
\hline \multicolumn{6}{|c|}{ Supplemental Table S2.txt } \\
\hline CHEMBL1301118 & 688128 & 4.35 & 4.3089 & TRN & \\
\hline CHEMBL1409344 & 688128 & 4.8 & 4.9837 & TRN & \\
\hline CHEMBL1546447 & 688128 & 4.1 & 4.6656 & TRN & \\
\hline CHEMBL1356839 & 688128 & 4.45 & 4.833 & TRN & \\
\hline CHEMBL1563284 & 688128 & 4.4 & 4.5993 & TRN & \\
\hline CHEMBL3192162 & 688128 & 4.0 & 4.6562 & TST & \\
\hline CHEMBL1370286 & 688128 & 4.45 & 4.5982 & TRN & \\
\hline CHEMBL1419507 & 688128 & 4.25 & 4.6909 & TRN & \\
\hline CHEMBL1332787 & 688128 & 4.3 & 4.5285 & TRN & \\
\hline CHEMBL3194763 & 688128 & 6.05 & 4.6328 & TRN & \\
\hline CHEMBL1356619 & 688128 & 4.75 & 4.6078 & TRN & \\
\hline CHEMBL1388963 & 688128 & 5.45 & 4.8227 & TRN & \\
\hline CHEMBL1447265 & 688128 & 5.2 & 5.1392 & TRN & \\
\hline CHEMBL1363793 & 688128 & 4.4 & 4.5161 & TRN & \\
\hline CHEMBL1537912 & 688128 & 4.55 & 4.471 & TRN & \\
\hline CHEMBL1471763 & 688128 & 4.4 & 4.2652 & TST & \\
\hline CHEMBL1406803 & 688128 & 4.6 & 4.6138 & TRN & \\
\hline CHEMBL1330652 & 688128 & 4.05 & 4.7358 & TRN & \\
\hline CHEMBL1326087 & 688128 & 6.0 & 4.4186 & TST & \\
\hline CHEMBL3189477 & 688128 & 4.4 & 4.7236 & TRN & \\
\hline CHEMBL1362990 & 688128 & 4.95 & 4.6671 & TRN & \\
\hline CHEMBL1477074 & 688128 & 4.25 & 4.5674 & TRN & \\
\hline CHEMBL1325651 & 688128 & 4.55 & 4.7357 & TRN & \\
\hline CHEMBL1555517 & 688128 & 5.6 & 4.6211 & TRN & \\
\hline CHEMBL1372060 & 688128 & 4.05 & 4.9607 & TRN & \\
\hline CHEMBL1408492 & 688128 & 6.05 & 4.6501 & TRN & \\
\hline CHEMBL1563633 & 688128 & 5.45 & 4.7702 & TRN & \\
\hline CHEMBL1443137 & 688128 & 4.4 & 4.5567 & TRN & \\
\hline CHEMBL1562353 & 688128 & 6.7001 & 4.51699 & 99999999995 & TRN \\
\hline CHEMBL1321725 & 688128 & 4.35 & 4.5994 & TST & \\
\hline CHEMBL1353782 & 688128 & 4.85 & 4.417 & TRN & \\
\hline CHEMBL1473417 & 688128 & 5.0 & 4.4169 & TRN & \\
\hline CHEMBL1567267 & 688128 & 4.55 & 4.8743 & TST & \\
\hline CHEMBL1372631 & 688128 & 5.85 & 4.6324 & TRN & \\
\hline CHEMBL1981612 & 688128 & 4.75 & 4.593 & TRN & \\
\hline CHEMBL1327233 & 688128 & 4.3 & 4.6758 & TRN & \\
\hline CHEMBL1381832 & 688128 & 4.3 & 4.6328 & TRN & \\
\hline CHEMBL1361234 & 688128 & 4.7 & 4.487 & TRN & \\
\hline CHEMBL1393836 & 688128 & 4.35 & 4.1863 & TRN & \\
\hline CHEMBL1312748 & 688128 & 4.4 & 4.3535 & TRN & \\
\hline CHEMBL1502275 & 688128 & 4.35 & 4.3032 & TRN & \\
\hline CHEMBL1430352 & 688128 & 4.9 & 4.5329 & TRN & \\
\hline CHEMBL1533752 & 688128 & 4.55 & 4.7194 & TRN & \\
\hline CHEMBL1308561 & 688128 & 4.05 & 4.6643 & TST & \\
\hline CHEMBL1379989 & 688128 & 4.9 & 5.0815 & TRN & \\
\hline CHEMBL1425999 & 688128 & 4.35 & 4.3633 & TRN & \\
\hline CHEMBL1466396 & 688128 & 4.25 & 4.5836 & TRN & \\
\hline CHEMBL1437985 & 688128 & 4.6 & 4.4931 & TST & \\
\hline
\end{tabular}




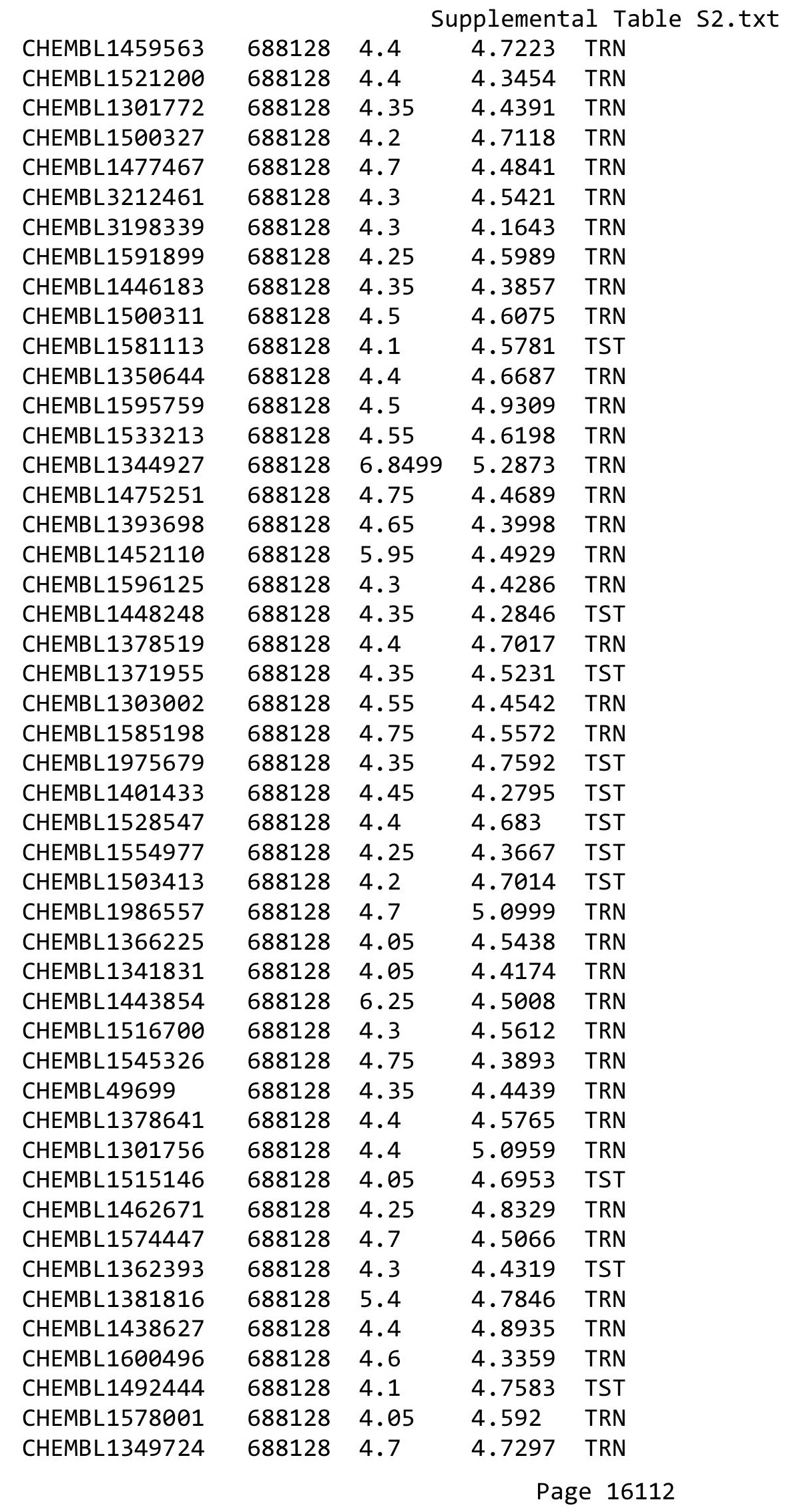




\begin{tabular}{|c|c|c|c|c|}
\hline \multicolumn{5}{|c|}{ Supplemental Tabl } \\
\hline CHEMBL1307539 & 688128 & 4.55 & 4.7858 & TRN \\
\hline CHEMBL1342145 & 688128 & 5.1 & 4.4656 & TRN \\
\hline CHEMBL1337909 & 688128 & 4.5 & 4.6888 & TRN \\
\hline CHEMBL1322784 & 688128 & 4.25 & 4.5739 & TRN \\
\hline CHEMBL1539671 & 688128 & 4.4 & 4.6586 & TRN \\
\hline CHEMBL1305803 & 688128 & 4.45 & 4.5335 & TRN \\
\hline CHEMBL1307387 & 688128 & 4.4 & 4.766 & TRN \\
\hline CHEMBL1352203 & 688128 & 5.4 & 5.1483 & TRN \\
\hline CHEMBL1300796 & 688128 & 4.35 & 4.2522 & TRN \\
\hline CHEMBL1578326 & 688128 & 5.9 & 4.5269 & TST \\
\hline CHEMBL1496769 & 688128 & 4.7 & 4.6427 & TST \\
\hline CHEMBL1488696 & 688128 & 4.25 & 4.4896 & TRN \\
\hline CHEMBL1420460 & 688128 & 4.25 & 4.7329 & TRN \\
\hline CHEMBL1528545 & 688128 & 4.55 & 4.6084 & TRN \\
\hline CHEMBL1340409 & 688128 & 4.25 & 4.7875 & TRN \\
\hline CHEMBL 2002062 & 688128 & 4.35 & 4.7256 & TRN \\
\hline CHEMBL1367645 & 688128 & 4.1 & 4.4717 & TRN \\
\hline CHEMBL1355573 & 688128 & 4.4 & 4.5439 & TRN \\
\hline CHEMBL1351734 & 688128 & 5.5 & 4.6785 & TRN \\
\hline CHEMBL1560706 & 688128 & 5.05 & 4.4719 & TRN \\
\hline CHEMBL1581429 & 688128 & 5.0 & 5.0104 & TRN \\
\hline CHEMBL1309633 & 688128 & 5.45 & 4.8252 & TST \\
\hline CHEMBL1505964 & 688128 & 4.4 & 4.7445 & TRN \\
\hline CHEMBL1610614 & 688128 & 4.3 & 5.0587 & TST \\
\hline CHEMBL1370800 & 688128 & 4.95 & 4.9015 & TST \\
\hline CHEMBL1452672 & 688128 & 4.05 & 4.4593 & TRN \\
\hline CHEMBL1377813 & 688128 & 4.05 & 4.723 & TST \\
\hline CHEMBL1360957 & 688128 & 4.35 & 4.8221 & TST \\
\hline CHEMBL1303067 & 688128 & 5.45 & 4.3688 & TRN \\
\hline CHEMBL1519658 & 688128 & 4.65 & 4.9393 & TST \\
\hline CHEMBL1338452 & 688128 & 4.9 & 4.7754 & TRN \\
\hline CHEMBL1456371 & 688128 & 4.6 & 4.7928 & TRN \\
\hline CHEMBL1504497 & 688128 & 4.9 & 4.7522 & TRN \\
\hline CHEMBL1388128 & 688128 & 4.4 & 4.49 & TRN \\
\hline CHEMBL1426792 & 688128 & 5.5 & 5.1215 & TRN \\
\hline CHEMBL1439948 & 688128 & 6.0 & 4.822 & TRN \\
\hline CHEMBL1571078 & 688128 & 4.05 & 4.7868 & TRN \\
\hline CHEMBL1375782 & 688128 & 4.65 & 4.4959 & TRN \\
\hline CHEMBL1093246 & 688128 & 4.65 & 4.694 & TRN \\
\hline CHEMBL1527699 & 688128 & 5.0 & 4.5685 & TRN \\
\hline CHEMBL3194139 & 688128 & 5.65 & 4.9746 & TRN \\
\hline CHEMBL3199775 & 688128 & 5.35 & 4.6538 & TST \\
\hline CHEMBL1590752 & 688128 & 4.35 & 4.4439 & TRN \\
\hline CHEMBL1525496 & 688128 & 4.7 & 4.5162 & TST \\
\hline CHEMBL1534412 & 688128 & 4.3 & 4.4545 & TRN \\
\hline CHEMBL1602941 & 688128 & 4.3 & 4.2247 & TRN \\
\hline CHEMBL1523907 & 688128 & 4.1 & 4.6987 & TST \\
\hline CHEMBL1443449 & 688128 & 4.25 & 4.2137 & TST \\
\hline
\end{tabular}




\begin{tabular}{|c|c|c|c|c|c|}
\hline & & \multicolumn{4}{|c|}{ Supplemental Table S2.txt } \\
\hline CHEMBL1525318 & 688128 & 4.7 & 4.8656 & TST & \\
\hline CHEMBL1439023 & 688128 & 4.7 & 4.462 & TRN & \\
\hline CHEMBL1571915 & 688128 & 4.4 & 4.7047 & TRN & \\
\hline CHEMBL1336719 & 688128 & 4.1 & 4.6843 & TRN & \\
\hline CHEMBL1416780 & 688128 & 4.45 & 4.5874 & TRN & \\
\hline CHEMBL1407470 & 688128 & 5.0 & 4.649 & TRN & \\
\hline CHEMBL1372912 & 688128 & 4.95 & 4.4844 & TRN & \\
\hline CHEMBL591618 & 688128 & 4.4 & 5.0383 & TRN & \\
\hline CHEMBL1407033 & 688128 & 4.3 & 4.6204 & TRN & \\
\hline CHEMBL1500378 & 688128 & 4.55 & 4.7931 & TRN & \\
\hline CHEMBL1386092 & 688128 & 4.25 & 4.46399 & 99999999995 & TRN \\
\hline CHEMBL1416538 & 688128 & 4.85 & 4.532 & TRN & \\
\hline CHEMBL1520179 & 688128 & 4.8 & 4.5029 & TRN & \\
\hline CHEMBL1356342 & 688128 & 4.3 & 4.6567 & TST & \\
\hline CHEMBL1443059 & 688128 & 4.35 & 4.5847 & TRN & \\
\hline CHEMBL1317253 & 688128 & 4.5 & 4.5823 & TRN & \\
\hline CHEMBL1518529 & 688128 & 4.35 & 4.5285 & TRN & \\
\hline CHEMBL1370492 & 688128 & 4.55 & 4.6293 & TRN & \\
\hline CHEMBL1513397 & 688128 & 4.05 & 4.6055 & TST & \\
\hline CHEMBL1359357 & 688128 & 4.05 & 4.7708 & TRN & \\
\hline CHEMBL1549124 & 688128 & 4.4 & 4.7152 & TRN & \\
\hline CHEMBL1538578 & 688128 & 4.6 & 4.7037 & TRN & \\
\hline CHEMBL1508958 & 688128 & 5.1 & 5.1987 & TRN & \\
\hline CHEMBL1378392 & 688128 & 4.5 & 4.8761 & TRN & \\
\hline CHEMBL1495054 & 688128 & 4.95 & 4.4833 & TRN & \\
\hline CHEMBL1497867 & 688128 & 4.4 & 4.7044 & TRN & \\
\hline CHEMBL1405462 & 688128 & 4.05 & 4.4859 & TRN & \\
\hline CHEMBL1368516 & 688128 & 4.3 & 4.4962 & TRN & \\
\hline CHEMBL1310325 & 688128 & 4.45 & 4.6199 & TST & \\
\hline CHEMBL1314232 & 688128 & 4.3 & 4.9344 & TST & \\
\hline CHEMBL1315824 & 688128 & 4.6 & 4.6813 & TRN & \\
\hline CHEMBL1362796 & 688128 & 6.0 & 4.9169 & TRN & \\
\hline CHEMBL1541286 & 688128 & 4.9 & 4.5964 & TRN & \\
\hline CHEMBL1349129 & 688128 & 4.45 & 4.4439 & TRN & \\
\hline CHEMBL1545900 & 688128 & 4.4 & 4.6453 & TST & \\
\hline CHEMBL1467317 & 688128 & 4.35 & 4.798 & TRN & \\
\hline CHEMBL3211475 & 688128 & 5.2 & 4.6265 & TRN & \\
\hline CHEMBL1326425 & 688128 & 4.3 & 4.2072 & TRN & \\
\hline CHEMBL1379831 & 688128 & 5.2 & 4.6728 & TRN & \\
\hline CHEMBL1456109 & 688128 & 4.55 & 4.3748 & TRN & \\
\hline CHEMBL1329850 & 688128 & 5.45 & 4.9405 & TRN & \\
\hline CHEMBL1319961 & 688128 & 4.35 & 4.1927 & TRN & \\
\hline CHEMBL1410284 & 688128 & 4.2 & 4.2974 & TRN & \\
\hline CHEMBL1591028 & 688128 & 5.4 & 4.827 & TRN & \\
\hline CHEMBL3195433 & 688128 & 5.0 & 4.7783 & TST & \\
\hline CHEMBL1411454 & 688128 & 6.35 & 4.8044 & TST & \\
\hline CHEMBL1467832 & 688128 & 4.45 & 4.8552 & TRN & \\
\hline CHEMBL1612557 & 688128 & 4.85 & 4.5633 & TRN & \\
\hline
\end{tabular}




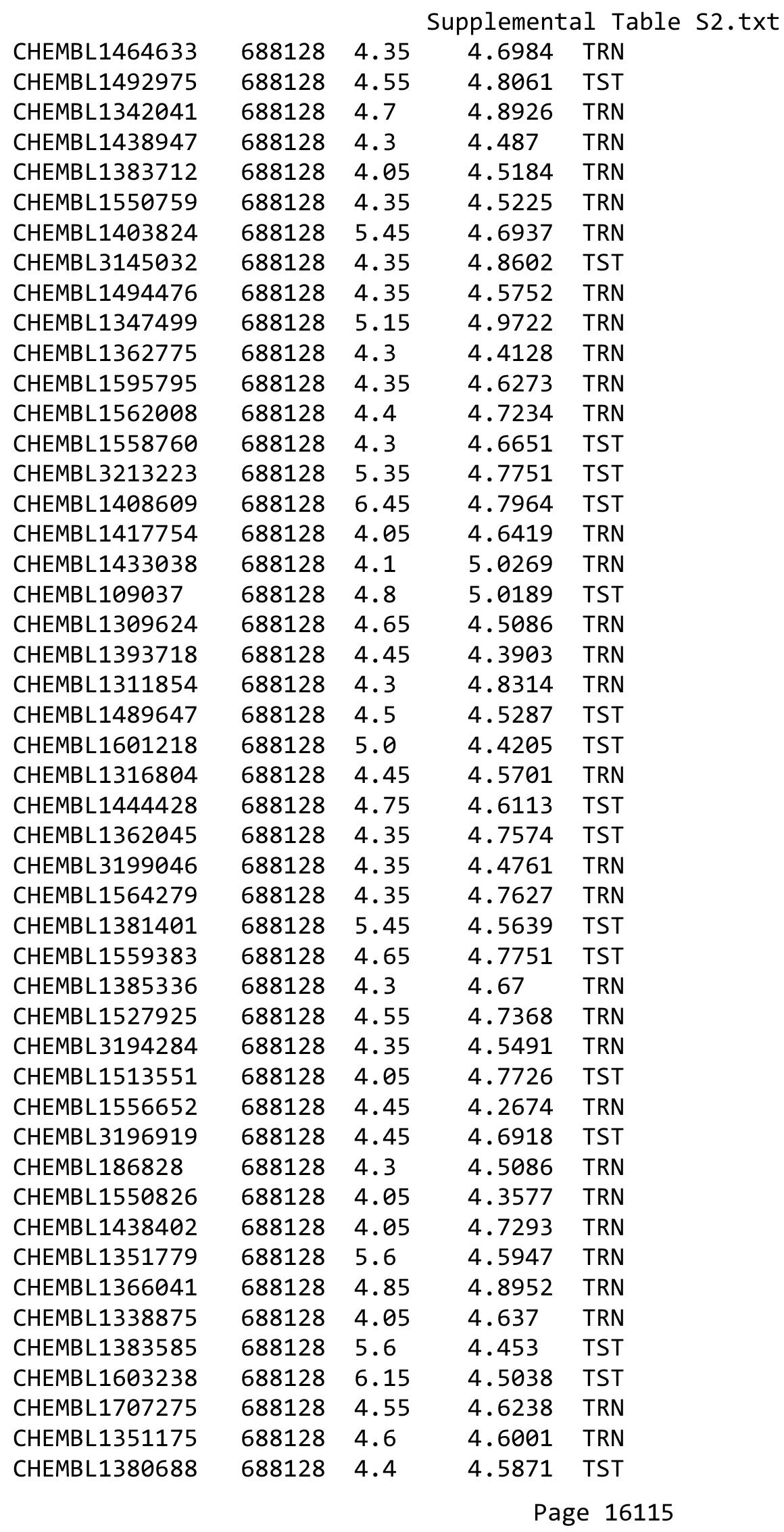




\begin{tabular}{|c|c|c|c|c|}
\hline \multicolumn{5}{|c|}{ Supplemental Table S2.txt } \\
\hline CHEMBL1430108 & 688128 & 5.6 & 4.7488 & TRN \\
\hline CHEMBL1520754 & 688128 & 4.1 & 4.5675 & TRN \\
\hline CHEMBL1494120 & 688128 & 7.0 & 5.3384 & TRN \\
\hline CHEMBL1299992 & 688128 & 4.4 & 4.4223 & TRN \\
\hline CHEMBL1475373 & 688128 & 4.0 & 4.7147 & TRN \\
\hline CHEMBL1366661 & 688128 & 4.35 & 4.6014 & TRN \\
\hline CHEMBL1464076 & 688128 & 4.45 & 4.5752 & TRN \\
\hline CHEMBL1472585 & 688128 & 4.5 & 4.6044 & TST \\
\hline CHEMBL1352539 & 688128 & 4.35 & 4.6825 & TRN \\
\hline CHEMBL1520893 & 688128 & 4.05 & 4.9966 & TST \\
\hline CHEMBL1440918 & 688128 & 4.25 & 4.6864 & TRN \\
\hline CHEMBL1465044 & 688128 & 4.45 & 4.3245 & TRN \\
\hline CHEMBL1610505 & 688128 & 4.25 & 4.6557 & TST \\
\hline CHEMBL1563419 & 688128 & 4.05 & 4.5662 & TST \\
\hline CHEMBL1485255 & 688128 & 4.6 & 4.4142 & TRN \\
\hline CHEMBL1447665 & 688128 & 4.3 & 4.5495 & TRN \\
\hline CHEMBL1453847 & 688128 & 5.0 & 4.4489 & TRN \\
\hline CHEMBL1352415 & 688128 & 6.5 & 4.4604 & TST \\
\hline CHEMBL1444802 & 688128 & 4.4 & 4.5654 & TRN \\
\hline CHEMBL1531905 & 688128 & 4.1 & 4.5158 & TST \\
\hline CHEMBL1367592 & 688128 & 4.4 & 4.6214 & TST \\
\hline CHEMBL1531631 & 688128 & 4.3 & 4.4941 & TRN \\
\hline CHEMBL1376265 & 688128 & 4.4 & 4.3174 & TRN \\
\hline CHEMBL1541226 & 688128 & 4.15 & 4.758 & TRN \\
\hline CHEMBL1552564 & 688128 & 4.95 & 4.4013 & TRN \\
\hline CHEMBL1299479 & 688128 & 4.4 & 4.5247 & TST \\
\hline CHEMBL1511982 & 688128 & 4.3 & 4.8727 & TRN \\
\hline CHEMBL1303879 & 688128 & 4.25 & 4.5704 & TRN \\
\hline CHEMBL1306765 & 688128 & 4.3 & 4.5846 & TRN \\
\hline CHEMBL1555974 & 688128 & 5.05 & 4.6708 & TRN \\
\hline CHEMBL1379112 & 688128 & 5.0 & 4.8037 & TRN \\
\hline CHEMBL1502157 & 688128 & 4.4 & 4.8076 & TRN \\
\hline CHEMBL1545260 & 688128 & 4.95 & 4.4009 & TRN \\
\hline CHEMBL1545047 & 688128 & 4.3 & 4.5071 & TRN \\
\hline CHEMBL1569780 & 688128 & 4.4 & 4.3829 & TRN \\
\hline CHEMBL1515715 & 688128 & 4.45 & 4.3875 & TRN \\
\hline CHEMBL1553273 & 688128 & 4.75 & 5.209 & TRN \\
\hline CHEMBL1423931 & 688128 & 4.4 & 4.7985 & TRN \\
\hline CHEMBL1471740 & 688128 & 4.9 & 5.0769 & TRN \\
\hline CHEMBL1543669 & 688128 & 4.45 & 4.567 & TRN \\
\hline CHEMBL1513729 & 688128 & 5.4 & 4.7237 & TRN \\
\hline CHEMBL3213153 & 688128 & 4.35 & 4.6875 & TRN \\
\hline CHEMBL1342299 & 688128 & 4.05 & 4.4862 & TRN \\
\hline CHEMBL1344595 & 688128 & 5.1 & 4.4294 & TRN \\
\hline CHEMBL3145018 & 688128 & 5.05 & 5.0359 & TRN \\
\hline CHEMBL1469636 & 688128 & 4.4 & 4.8381 & TRN \\
\hline CHEMBL1394406 & 688128 & 5.0 & 5.1364 & TRN \\
\hline CHEMBL1387499 & 688128 & 4.3 & 4.9995 & TRN \\
\hline
\end{tabular}




\begin{tabular}{|c|c|c|c|c|c|}
\hline \multicolumn{6}{|c|}{ Supplemental Table S2.txt } \\
\hline CHEMBL1348468 & 688128 & 4.85 & 4.9428 & TRN & \\
\hline CHEMBL1549868 & 688128 & 4.05 & 4.8032 & TST & \\
\hline CHEMBL1333136 & 688128 & 4.3 & 4.8318 & TRN & \\
\hline CHEMBL1412471 & 688128 & 5.7 & 4.4971 & TST & \\
\hline CHEMBL512261 & 688128 & 4.75 & 4.3658 & TRN & \\
\hline CHEMBL1353771 & 688128 & 4.3 & 4.905 & TRN & \\
\hline CHEMBL1528180 & 688128 & 5.1 & 4.9627 & TRN & \\
\hline CHEMBL1449527 & 688128 & 4.85 & 4.5248 & TRN & \\
\hline CHEMBL1331574 & 688128 & 5.35 & 4.7564 & TRN & \\
\hline CHEMBL1443135 & 688128 & 5.15 & 4.6227 & TST & \\
\hline CHEMBL1393955 & 688128 & 4.35 & 4.6807 & TRN & \\
\hline CHEMBL1369420 & 688128 & 4.4 & 4.7517 & TST & \\
\hline CHEMBL1538251 & 688128 & 4.5 & 4.6223 & TRN & \\
\hline CHEMBL1395315 & 688128 & 4.25 & 4.4655 & TRN & \\
\hline CHEMBL1538737 & 688128 & 4.6 & 4.73600 & 0000000001 & TST \\
\hline CHEMBL3192482 & 688128 & 4.4 & 4.7178 & TST & \\
\hline CHEMBL1381666 & 688128 & 4.3 & 4.3242 & TRN & \\
\hline CHEMBL1465584 & 688128 & 4.35 & 4.4521 & TRN & \\
\hline CHEMBL1606004 & 688128 & 4.35 & 4.6587 & TRN & \\
\hline CHEMBL1598711 & 688128 & 4.35 & 4.503 & TRN & \\
\hline CHEMBL1545263 & 688128 & 4.3 & 4.5305 & TST & \\
\hline CHEMBL1309211 & 688128 & 5.05 & 4.7619 & TRN & \\
\hline CHEMBL1334360 & 688128 & 4.4 & 4.806 & TRN & \\
\hline CHEMBL1364129 & 688128 & 4.3 & 4.5923 & TRN & \\
\hline CHEMBL1383909 & 688128 & 4.4 & 4.5855 & TRN & \\
\hline CHEMBL1545070 & 688128 & 4.8 & 4.5998 & TRN & \\
\hline CHEMBL1548809 & 688128 & 4.1 & 4.4371 & TRN & \\
\hline CHEMBL1399889 & 688128 & 4.35 & 4.7225 & TRN & \\
\hline CHEMBL1999049 & 688128 & 6.5 & 4.7676 & TST & \\
\hline CHEMBL1592730 & 688128 & 4.3 & 4.954 & TRN & \\
\hline CHEMBL1336273 & 688128 & 4.3 & 4.4528 & TRN & \\
\hline CHEMBL1593590 & 688128 & 5.4 & 4.5724 & TRN & \\
\hline CHEMBL1306197 & 688128 & 4.9 & 4.7348 & TST & \\
\hline CHEMBL1502263 & 688128 & 4.45 & 4.5525 & TRN & \\
\hline CHEMBL1549476 & 688128 & 4.3 & 4.6043 & TRN & \\
\hline CHEMBL1578693 & 688128 & 5.35 & 4.6995 & TRN & \\
\hline CHEMBL3212821 & 688128 & 4.3 & 4.7189 & TRN & \\
\hline CHEMBL1377784 & 688128 & 4.85 & 4.5355 & TRN & \\
\hline CHEMBL 3197404 & 688128 & 4.5 & 4.6087 & TST & \\
\hline CHEMBL1571978 & 688128 & 4.4 & 4.5683 & TRN & \\
\hline CHEMBL1437750 & 688128 & 5.6 & 4.5533 & TRN & \\
\hline CHEMBL1488944 & 688128 & 4.65 & 4.56 & TRN & \\
\hline CHEMBL1373297 & 688128 & 4.45 & 4.7899 & TRN & \\
\hline CHEMBL1416871 & 688128 & 4.35 & 4.8381 & TST & \\
\hline CHEMBL1353285 & 688128 & 4.25 & 4.4201 & TRN & \\
\hline CHEMBL1597336 & 688128 & 5.0 & 4.7743 & TRN & \\
\hline CHEMBL3214530 & 688128 & 5.45 & 4.9868 & TST & \\
\hline CHEMBL1493199 & 688128 & 5.35 & 5.027 & TST & \\
\hline
\end{tabular}




\begin{tabular}{|c|c|c|c|c|c|}
\hline & & \multicolumn{4}{|c|}{ Supplemental Table s2.txt } \\
\hline CHEMBL1488286 & 688128 & 4.05 & 4.5693 & TRN & \\
\hline CHEMBL1536550 & 688128 & 5.1 & 4.4774 & TRN & \\
\hline CHEMBL1612354 & 688128 & 4.55 & 4.6452 & TRN & \\
\hline CHEMBL1529034 & 688128 & 4.05 & 4.6667 & TRN & \\
\hline CHEMBL1986380 & 688128 & 4.4 & 4.5945 & TST & \\
\hline CHEMBL1380323 & 688128 & 4.9 & 4.6574 & TST & \\
\hline CHEMBL1361516 & 688128 & 4.35 & 4.6082 & TRN & \\
\hline CHEMBL1478492 & 688128 & 4.25 & 4.5978 & TST & \\
\hline CHEMBL1402554 & 688128 & 5.5 & 4.6078 & TRN & \\
\hline CHEMBL1612805 & 688128 & 6.35 & 5.1473 & TRN & \\
\hline CHEMBL1520961 & 688128 & 4.65 & 4.4755 & TST & \\
\hline CHEMBL1591391 & 688128 & 4.05 & 4.5339 & TRN & \\
\hline CHEMBL1598016 & 688128 & 4.05 & 4.3781 & TRN & \\
\hline CHEMBL1458649 & 688128 & 4.65 & 4.6637 & TST & \\
\hline CHEMBL1539955 & 688128 & 4.45 & 4.5414 & TRN & \\
\hline CHEMBL1512424 & 688128 & 5.35 & 4.2549 & TRN & \\
\hline CHEMBL3209890 & 688128 & 4.4 & 4.6616 & TST & \\
\hline CHEMBL1534450 & 688128 & 4.45 & 4.426 & TRN & \\
\hline CHEMBL1406168 & 688128 & 4.6 & 4.9328 & TRN & \\
\hline CHEMBL1518980 & 688128 & 4.95 & 4.9486 & TRN & \\
\hline CHEMBL1383184 & 688128 & 4.25 & 4.3877 & TRN & \\
\hline CHEMBL1520081 & 688128 & 4.4 & 4.6 & TRN & \\
\hline CHEMBL3199033 & 688128 & 4.95 & 4.7274 & TRN & \\
\hline CHEMBL1348679 & 688128 & 4.35 & 4.471 & TST & \\
\hline CHEMBL1382486 & 688128 & 4.3 & 4.6752 & TST & \\
\hline CHEMBL1349377 & 688128 & 6.2 & 4.7963 & TRN & \\
\hline CHEMBL1392651 & 688128 & 6.5501 & 4.9463 & TST & \\
\hline CHEMBL1423436 & 688128 & 3.95 & 4.3919 & 99999999995 & TRN \\
\hline CHEMBL1547253 & 688128 & 4.4 & 4.6427 & TRN & \\
\hline CHEMBL1548235 & 688128 & 4.35 & 4.6987 & TRN & \\
\hline CHEMBL1347994 & 688128 & 4.5 & 4.6051 & TRN & \\
\hline CHEMBL1602056 & 688128 & 4.3 & 4.8139 & TRN & \\
\hline CHEMBL3193108 & 688128 & 4.4 & 4.7243 & TST & \\
\hline CHEMBL1389511 & 688128 & 5.55 & 4.8817 & TST & \\
\hline CHEMBL1338466 & 688128 & 4.6 & 4.8157 & TRN & \\
\hline CHEMBL1343743 & 688128 & 4.75 & 4.9034 & TRN & \\
\hline CHEMBL 3214064 & 688128 & 4.0 & 4.4643 & TRN & \\
\hline CHEMBL1382719 & 688128 & 4.45 & 4.3745 & TRN & \\
\hline CHEMBL1559307 & 688128 & 4.45 & 4.4666 & TRN & \\
\hline CHEMBL1369527 & 688128 & 4.5 & 4.9439 & TRN & \\
\hline CHEMBL374569 & 688128 & 4.45 & 5.2656 & TRN & \\
\hline CHEMBL 2007438 & 688128 & 4.3 & 4.2241 & TRN & \\
\hline CHEMBL1508063 & 688128 & 4.55 & 4.1661 & TST & \\
\hline CHEMBL1595292 & 688128 & 4.65 & 4.4562 & TRN & \\
\hline CHEMBL1385375 & 688128 & 4.9 & 4.6335 & TRN & \\
\hline CHEMBL1390894 & 688128 & 4.65 & 4.5964 & TRN & \\
\hline CHEMBL1308400 & 688128 & 4.4 & 4.4038 & TRN & \\
\hline CHEMBL1585443 & 688128 & 4.95 & 4.9369 & TST & \\
\hline
\end{tabular}




\begin{tabular}{|c|c|c|c|c|c|}
\hline & & \multicolumn{4}{|c|}{ Supplemental Table s2.txt } \\
\hline CHEMBL1580036 & 688128 & 4.65 & 4.7294 & TRN & \\
\hline CHEMBL1517552 & 688128 & 4.25 & 4.9085 & TST & \\
\hline CHEMBL1381054 & 688128 & 5.8 & 4.6329 & TRN & \\
\hline CHEMBL1467111 & 688128 & 4.65 & 4.4603 & TRN & \\
\hline CHEMBL1312489 & 688128 & 4.35 & 4.4802 & TRN & \\
\hline CHEMBL1517389 & 688128 & 5.55 & 5.1684 & TRN & \\
\hline CHEMBL1562824 & 688128 & 4.45 & 5.1882 & TRN & \\
\hline CHEMBL1480568 & 688128 & 4.25 & 4.7338 & TST & \\
\hline CHEMBL1332002 & 688128 & 4.05 & 4.399 & TRN & \\
\hline CHEMBL1569314 & 688128 & 4.45 & 4.5703 & TRN & \\
\hline CHEMBL1384014 & 688128 & 4.3 & 4.3127 & TRN & \\
\hline CHEMBL3211664 & 688128 & 4.25 & 4.6704 & TST & \\
\hline CHEMBL1458829 & 688128 & 4.2 & 4.6818 & TRN & \\
\hline CHEMBL1373765 & 688128 & 4.35 & 4.6116 & TRN & \\
\hline CHEMBL1349837 & 688128 & 4.45 & 4.5965 & TRN & \\
\hline CHEMBL1356880 & 688128 & 6.1 & 4.4519 & TRN & \\
\hline CHEMBL1334158 & 688128 & 4.4 & 4.3837 & TRN & \\
\hline CHEMBL1455619 & 688128 & 4.05 & 4.7122 & TST & \\
\hline CHEMBL1569711 & 688128 & 4.35 & 4.6728 & TRN & \\
\hline CHEMBL1354690 & 688128 & 4.7 & 4.7192 & TRN & \\
\hline CHEMBL1557451 & 688128 & 4.35 & 4.4408 & TST & \\
\hline CHEMBL3194581 & 688128 & 4.05 & 4.6122 & TST & \\
\hline CHEMBL1385752 & 688128 & 4.4 & 4.4962 & TRN & \\
\hline CHEMBL1488942 & 688128 & 4.25 & 4.5132 & TST & \\
\hline CHEMBL1576291 & 688128 & 5.55 & 4.564 & TRN & \\
\hline CHEMBL1597672 & 688128 & 4.35 & 4.5842 & TRN & \\
\hline CHEMBL1437211 & 688128 & 4.4 & 4.6495 & TRN & \\
\hline CHEMBL1587454 & 688128 & 4.75 & 4.7337 & TRN & \\
\hline CHEMBL1399472 & 688128 & 4.05 & 4.5245 & TST & \\
\hline CHEMBL1348299 & 688128 & 4.5 & 4.8142 & TRN & \\
\hline CHEMBL1442463 & 688128 & 4.45 & 4.6723 & TRN & \\
\hline CHEMBL1443546 & 688128 & 4.35 & 4.8819 & TST & \\
\hline CHEMBL1546991 & 688128 & 4.6 & 4.4055 & TST & \\
\hline CHEMBL1450132 & 688128 & 4.75 & 4.7374 & TRN & \\
\hline CHEMBL1482071 & 688128 & 4.95 & 4.88399 & 99999999995 & TRN \\
\hline CHEMBL1998302 & 688128 & 4.7 & 4.8221 & TRN & \\
\hline CHEMBL482050 & 688128 & 5.1 & 5.2488 & TST & \\
\hline CHEMBL1438892 & 688128 & 4.3 & 4.3453 & TRN & \\
\hline CHEMBL1494615 & 688128 & 4.4 & 4.7441 & TST & \\
\hline CHEMBL1417858 & 688128 & 5.15 & 4.5333 & TRN & \\
\hline CHEMBL1487436 & 688128 & 5.9 & 5.0896 & TRN & \\
\hline CHEMBL1548150 & 688128 & 5.1 & 4.5004 & TRN & \\
\hline CHEMBL3190128 & 688128 & 4.55 & 4.5787 & TRN & \\
\hline CHEMBL1569476 & 688128 & 4.25 & 4.5467 & TRN & \\
\hline CHEMBL1311859 & 688128 & 4.35 & 4.485 & TRN & \\
\hline CHEMBL1351330 & 688128 & 4.05 & 4.3259 & TRN & \\
\hline CHEMBL1364077 & 688128 & 4.85 & 4.7715 & TRN & \\
\hline CHEMBL1437564 & 688128 & 4.0 & 4.352 & TRN & \\
\hline
\end{tabular}




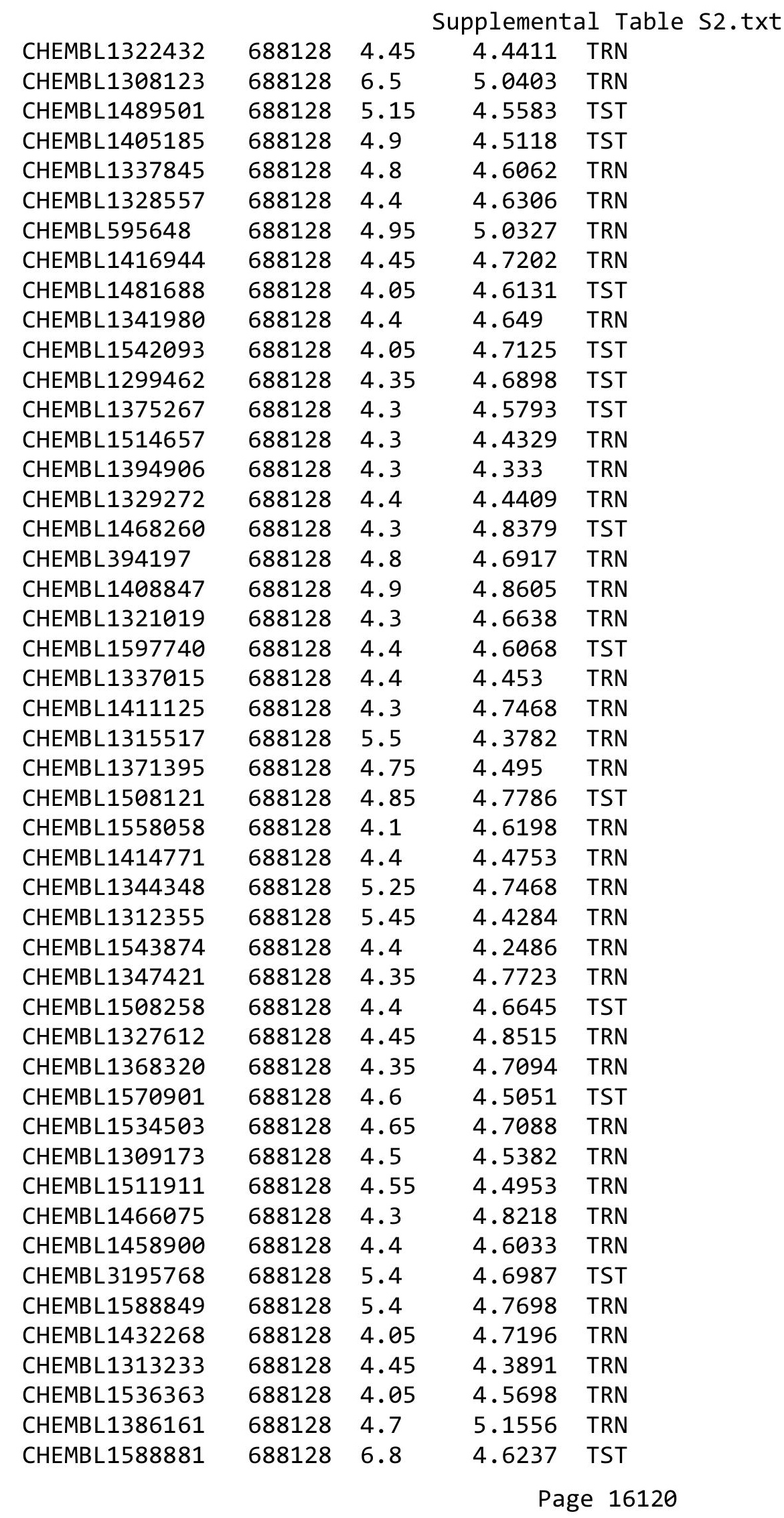




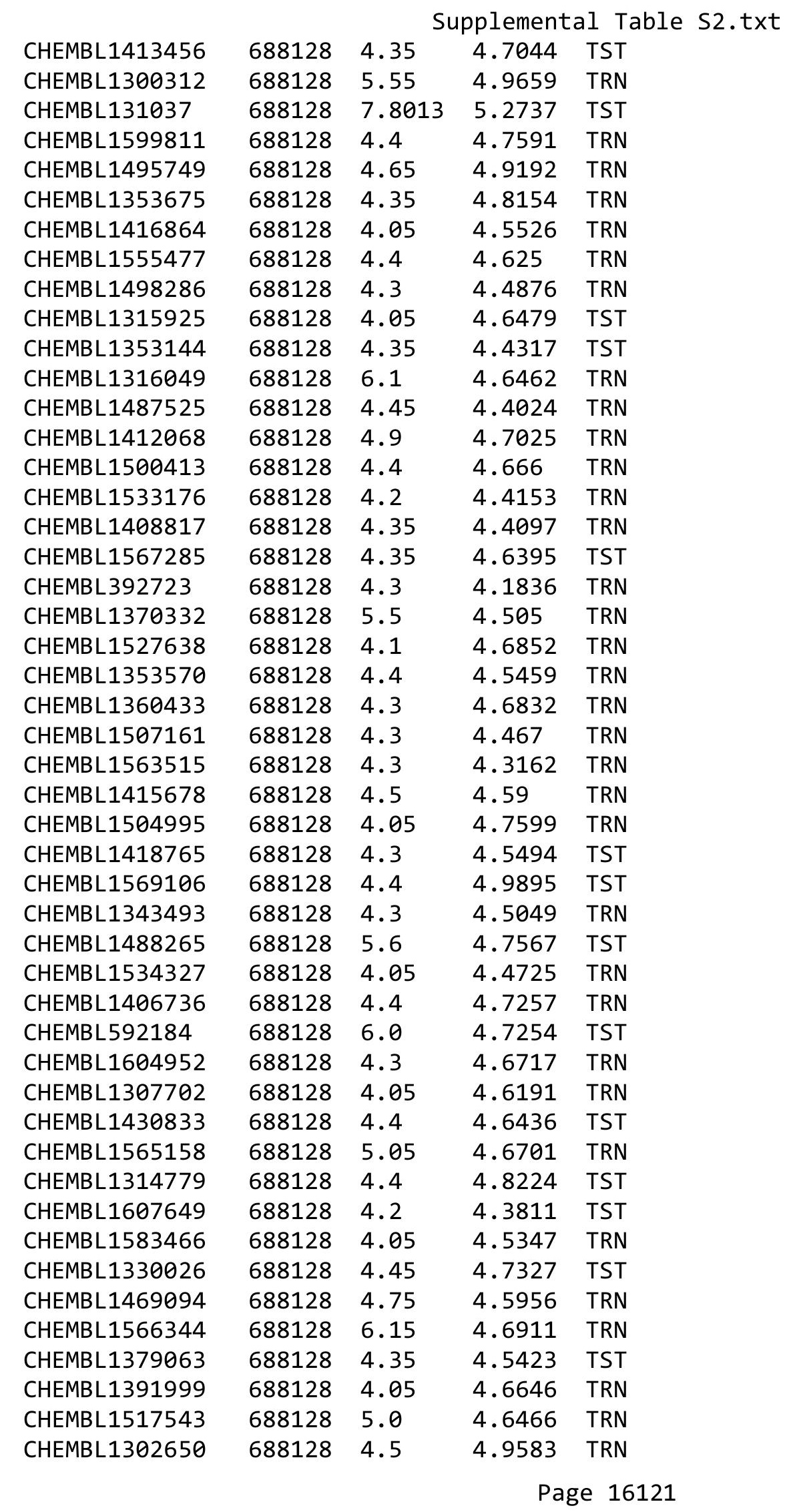




\begin{tabular}{|c|c|c|c|c|c|}
\hline \multicolumn{6}{|c|}{ Supplemental Table S2.txt } \\
\hline CHEMBL1392315 & 688128 & 4.1 & 4.797 & TRN & \\
\hline CHEMBL1598449 & 688128 & 4.1 & 4.3896 & TST & \\
\hline CHEMBL3208083 & 688128 & 4.05 & 4.8324 & TST & \\
\hline CHEMBL1389600 & 688128 & 4.25 & 4.4765 & TRN & \\
\hline CHEMBL1522821 & 688128 & 4.45 & 4.2868 & TRN & \\
\hline CHEMBL1431104 & 688128 & 5.3 & 4.5513 & TRN & \\
\hline CHEMBL1387020 & 688128 & 6.05 & 4.8038 & TST & \\
\hline CHEMBL1419154 & 688128 & 4.85 & 4.4329 & TST & \\
\hline CHEMBL1562449 & 688128 & 4.1 & 4.3426 & TST & \\
\hline CHEMBL1579104 & 688128 & 4.1 & 4.0484 & TST & \\
\hline CHEMBL1304003 & 688128 & 4.5 & 4.6242 & TRN & \\
\hline CHEMBL1306257 & 688128 & 4.65 & $4.3580 e$ & 00000000005 & TRN \\
\hline CHEMBL3199833 & 688128 & 4.45 & 4.632 & TRN & \\
\hline CHEMBL 3199741 & 688128 & 4.7 & 4.5259 & TRN & \\
\hline CHEMBL1539738 & 688128 & 4.05 & 4.5314 & TRN & \\
\hline CHEMBL1427859 & 688128 & 4.35 & 4.4279 & TRN & \\
\hline CHEMBL1572784 & 688128 & 4.4 & 4.4591 & TRN & \\
\hline CHEMBL1508200 & 688128 & 4.05 & 4.6785 & TST & \\
\hline CHEMBL1305813 & 688128 & 4.55 & 4.7089 & TRN & \\
\hline CHEMBL1493191 & 688128 & 5.35 & 4.9726 & TRN & \\
\hline CHEMBL1607688 & 688128 & 4.3 & 4.795 & TRN & \\
\hline CHEMBL1458505 & 688128 & 4.05 & $4.2360 e$ & 3000000001 & TRN \\
\hline CHEMBL1498525 & 688128 & 4.75 & 4.7178 & TRN & \\
\hline CHEMBL1610172 & 688128 & 4.45 & 4.3299 & TST & \\
\hline CHEMBL1481772 & 688128 & 4.35 & 4.7709 & TRN & \\
\hline CHEMBL1440421 & 688128 & 4.35 & 4.5288 & TRN & \\
\hline CHEMBL1502272 & 688128 & 4.05 & 4.5555 & TRN & \\
\hline CHEMBL3196033 & 688128 & 4.05 & 4.4201 & TRN & \\
\hline CHEMBL1464268 & 688128 & 4.45 & 4.5563 & TST & \\
\hline CHEMBL1441135 & 688128 & 5.15 & 4.6375 & TRN & \\
\hline CHEMBL1352563 & 688128 & 4.35 & 4.7066 & TRN & \\
\hline CHEMBL1502233 & 688128 & 4.25 & 4.2595 & TRN & \\
\hline CHEMBL1469416 & 688128 & 4.5 & 4.8158 & TRN & \\
\hline CHEMBL1331057 & 688128 & 4.05 & 4.4237 & TST & \\
\hline CHEMBL1440134 & 688128 & 4.3 & 4.4162 & TRN & \\
\hline CHEMBL1603625 & 688128 & 4.4 & 4.71899 & 9999999999 & TRN \\
\hline CHEMBL1373215 & 688128 & 4.05 & 4.6603 & TRN & \\
\hline CHEMBL1521587 & 688128 & 4.3 & 4.508 & TRN & \\
\hline CHEMBL1321218 & 688128 & 4.95 & 4.5974 & TRN & \\
\hline CHEMBL1325576 & 688128 & 4.55 & 4.4497 & TRN & \\
\hline CHEMBL1499082 & 688128 & 4.0 & 4.5016 & TRN & \\
\hline CHEMBL1385587 & 688128 & 4.75 & 4.9121 & TRN & \\
\hline CHEMBL3199156 & 688128 & 4.95 & 4.8406 & TRN & \\
\hline CHEMBL1544822 & 688128 & 4.8 & 4.3774 & TRN & \\
\hline CHEMBL1312377 & 688128 & 4.65 & 4.8996 & TST & \\
\hline CHEMBL1564072 & 688128 & 4.55 & 4.9658 & TRN & \\
\hline CHEMBL1378261 & 688128 & 4.0 & 4.5123 & TRN & \\
\hline CHEMBL1577428 & 688128 & 4.1 & 4.6676 & TST & \\
\hline
\end{tabular}




\begin{tabular}{|c|c|c|c|c|c|}
\hline & & \multicolumn{4}{|c|}{ Supplemental Table s2.txt } \\
\hline CHEMBL1606983 & 688128 & 4.05 & 4.5932 & TRN & \\
\hline CHEMBL1373605 & 688128 & 4.35 & 4.8224 & TST & \\
\hline CHEMBL3209951 & 688128 & 4.3 & 4.6863 & TRN & \\
\hline CHEMBL1338045 & 688128 & 6.6 & 5.0849 & TRN & \\
\hline CHEMBL1521351 & 688128 & 4.35 & 4.4251 & TRN & \\
\hline CHEMBL1514825 & 688128 & 4.45 & 4.3966 & TRN & \\
\hline CHEMBL1378054 & 688128 & 4.35 & 4.5794 & TRN & \\
\hline CHEMBL1416795 & 688128 & 4.4 & 4.5863 & TRN & \\
\hline CHEMBL1329127 & 688128 & 4.55 & 4.5182 & TST & \\
\hline CHEMBL1575155 & 688128 & 4.4 & 4.5321 & TRN & \\
\hline CHEMBL1320550 & 688128 & 4.4 & 4.2763 & TRN & \\
\hline CHEMBL1589093 & 688128 & 4.5 & 4.6438 & TST & \\
\hline CHEMBL1454835 & 688128 & 4.95 & 4.9024 & TRN & \\
\hline CHEMBL1429632 & 688128 & 4.95 & 4.9307 & TRN & \\
\hline CHEMBL1490600 & 688128 & 4.9 & 4.8855 & TRN & \\
\hline CHEMBL1529320 & 688128 & 4.05 & 4.5154 & TST & \\
\hline CHEMBL1477707 & 688128 & 4.25 & 4.5599 & TST & \\
\hline CHEMBL1403606 & 688128 & 4.4 & 4.8463 & TST & \\
\hline CHEMBL1516394 & 688128 & 4.3 & 4.414 & TRN & \\
\hline CHEMBL1363379 & 688128 & 5.45 & 4.6196 & TST & \\
\hline CHEMBL1378776 & 688128 & 4.3 & 4.8653 & TRN & \\
\hline CHEMBL1326892 & 688128 & 5.65 & 4.68 & TST & \\
\hline CHEMBL1584553 & 688128 & 4.6 & 4.7984 & TRN & \\
\hline CHEMBL1357165 & 688128 & 5.0 & 5.1899 & TRN & \\
\hline CHEMBL1313245 & 688128 & 5.4 & 4.9865 & TRN & \\
\hline CHEMBL1417556 & 688128 & 5.05 & 5.0272 & TRN & \\
\hline CHEMBL1545646 & 688128 & 4.55 & 4.5879 & TRN & \\
\hline CHEMBL3210106 & 688128 & 4.05 & 4.7886 & TRN & \\
\hline CHEMBL1559524 & 688128 & 4.0 & 4.3626 & TRN & \\
\hline CHEMBL3196495 & 688128 & 4.65 & 4.8466 & TRN & \\
\hline CHEMBL1506082 & 688128 & 6.0 & 5.09399 & 9999999999 & TRN \\
\hline CHEMBL1441628 & 688128 & 4.35 & 4.9715 & TRN & \\
\hline CHEMBL1377627 & 688128 & 4.4 & 4.7102 & TST & \\
\hline CHEMBL1508280 & 688128 & 4.65 & 4.5249 & TRN & \\
\hline CHEMBL1368312 & 688128 & 4.3 & 4.712 & TRN & \\
\hline CHEMBL1390516 & 688128 & 4.85 & 4.7798 & TRN & \\
\hline CHEMBL1450849 & 688128 & 5.45 & 4.7914 & TRN & \\
\hline CHEMBL1505262 & 688128 & 4.55 & 4.669 & TRN & \\
\hline CHEMBL1506100 & 688128 & 4.05 & 4.7981 & TST & \\
\hline CHEMBL1366283 & 688128 & 4.3 & 4.6443 & TRN & \\
\hline CHEMBL1586398 & 688128 & 4.3 & 4.4596 & TRN & \\
\hline CHEMBL1422636 & 688128 & 4.6 & 4.29899 & 99999999995 & TST \\
\hline CHEMBL1404959 & 688128 & 4.35 & 4.5654 & TRN & \\
\hline CHEMBL1599339 & 688128 & 4.25 & 4.4862 & TRN & \\
\hline CHEMBL1446745 & 688128 & 5.75 & 4.5624 & TRN & \\
\hline CHEMBL1405625 & 688128 & 4.6 & 4.5288 & TST & \\
\hline CHEMBL1330736 & 688128 & 4.75 & 4.5866 & TRN & \\
\hline CHEMBL1595612 & 688128 & 4.05 & 4.4774 & TST & \\
\hline
\end{tabular}




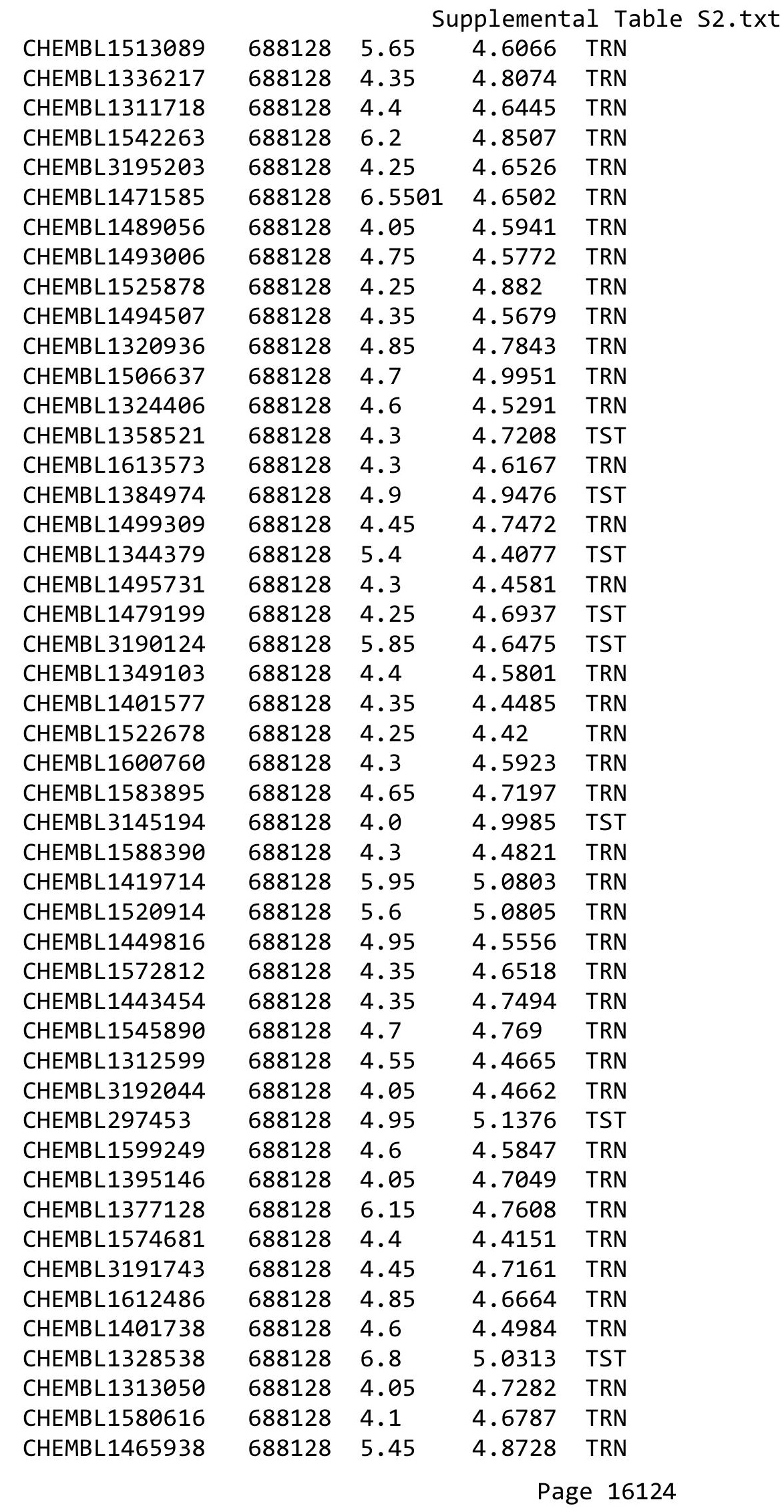




\begin{tabular}{|c|c|c|c|c|}
\hline \multicolumn{5}{|c|}{ Supplemental Table S2.txt } \\
\hline CHEMBL 3212446 & 688128 & 4.5 & 4.6806 & TRN \\
\hline CHEMBL1416763 & 688128 & 4.4 & 4.6617 & TRN \\
\hline CHEMBL1459807 & 688128 & 4.3 & 4.6279 & TST \\
\hline CHEMBL1299311 & 688128 & 4.4 & 4.3153 & TST \\
\hline CHEMBL1407361 & 688128 & 4.4 & 4.363 & TRN \\
\hline CHEMBL1345724 & 688128 & 5.15 & 4.9528 & TRN \\
\hline CHEMBL1602395 & 688128 & 4.4 & 4.3557 & TRN \\
\hline CHEMBL1334909 & 688128 & 4.35 & 4.5597 & TRN \\
\hline CHEMBL1383500 & 688128 & 5.5 & 5.1074 & TRN \\
\hline CHEMBL1450813 & 688128 & 4.25 & 4.4742 & TRN \\
\hline CHEMBL1559243 & 688128 & 4.25 & 4.4237 & TRN \\
\hline CHEMBL1484570 & 688128 & 5.15 & 4.7604 & TRN \\
\hline CHEMBL1507376 & 688128 & 5.3 & 4.45 & TRN \\
\hline CHEMBL1323575 & 688128 & 4.45 & 4.487 & TST \\
\hline CHEMBL89697 & 688128 & 4.6 & 5.099 & TRN \\
\hline CHEMBL1508916 & 688128 & 4.25 & 4.7871 & TRN \\
\hline CHEMBL1485192 & 688128 & 4.5 & 4.5258 & TRN \\
\hline CHEMBL1490337 & 688128 & 4.25 & 4.5999 & TRN \\
\hline CHEMBL1570733 & 688128 & 4.9 & 4.9154 & TST \\
\hline CHEMBL1610802 & 688128 & 4.35 & 4.7825 & TST \\
\hline CHEMBL1498368 & 688128 & 4.0 & 4.3054 & TRN \\
\hline CHEMBL3198456 & 688128 & 4.4 & 4.5789 & TRN \\
\hline CHEMBL1380780 & 688128 & 4.4 & 4.4954 & TRN \\
\hline CHEMBL1572564 & 688128 & 4.05 & 4.4952 & TRN \\
\hline CHEMBL1405993 & 688128 & 4.65 & 4.7375 & TRN \\
\hline CHEMBL1349239 & 688128 & 5.5 & 4.586 & TRN \\
\hline CHEMBL1977877 & 688128 & 4.1 & 4.3379 & TRN \\
\hline CHEMBL1551519 & 688128 & 4.4 & 4.6767 & TST \\
\hline CHEMBL1449795 & 688128 & 4.25 & 4.5439 & TST \\
\hline CHEMBL1466720 & 688128 & 4.05 & 4.5594 & TRN \\
\hline CHEMBL1363356 & 688128 & 4.4 & 4.5054 & TRN \\
\hline CHEMBL1413792 & 688128 & 4.1 & 4.2646 & TRN \\
\hline CHEMBL1506950 & 688128 & 4.4 & 4.4937 & TRN \\
\hline CHEMBL1313534 & 688128 & 4.45 & 4.3987 & TRN \\
\hline CHEMBL3193409 & 688128 & 4.05 & 4.5599 & TRN \\
\hline CHEMBL1350891 & 688128 & 4.7 & 4.6821 & TRN \\
\hline CHEMBL1429010 & 688128 & 4.4 & 4.7012 & TRN \\
\hline CHEMBL1431775 & 688128 & 4.3 & 4.4183 & TRN \\
\hline CHEMBL1377127 & 688128 & 4.55 & 4.4806 & TRN \\
\hline CHEMBL1588197 & 688128 & 4.6 & 4.5959 & TRN \\
\hline CHEMBL1612799 & 688128 & 4.6 & 4.8064 & TST \\
\hline CHEMBL1610971 & 688128 & 4.25 & 4.5053 & TRN \\
\hline CHEMBL1561575 & 688128 & 4.05 & 4.2432 & TST \\
\hline CHEMBL1572893 & 688128 & 4.3 & 4.4292 & TRN \\
\hline CHEMBL1503106 & 688128 & 4.95 & 4.8559 & TRN \\
\hline CHEMBL1389657 & 688128 & 4.05 & 4.4904 & TRN \\
\hline CHEMBL1342474 & 688128 & 4.55 & 4.3991 & TRN \\
\hline CHEMBL1362618 & 688128 & 4.5 & 4.3268 & TRN \\
\hline
\end{tabular}




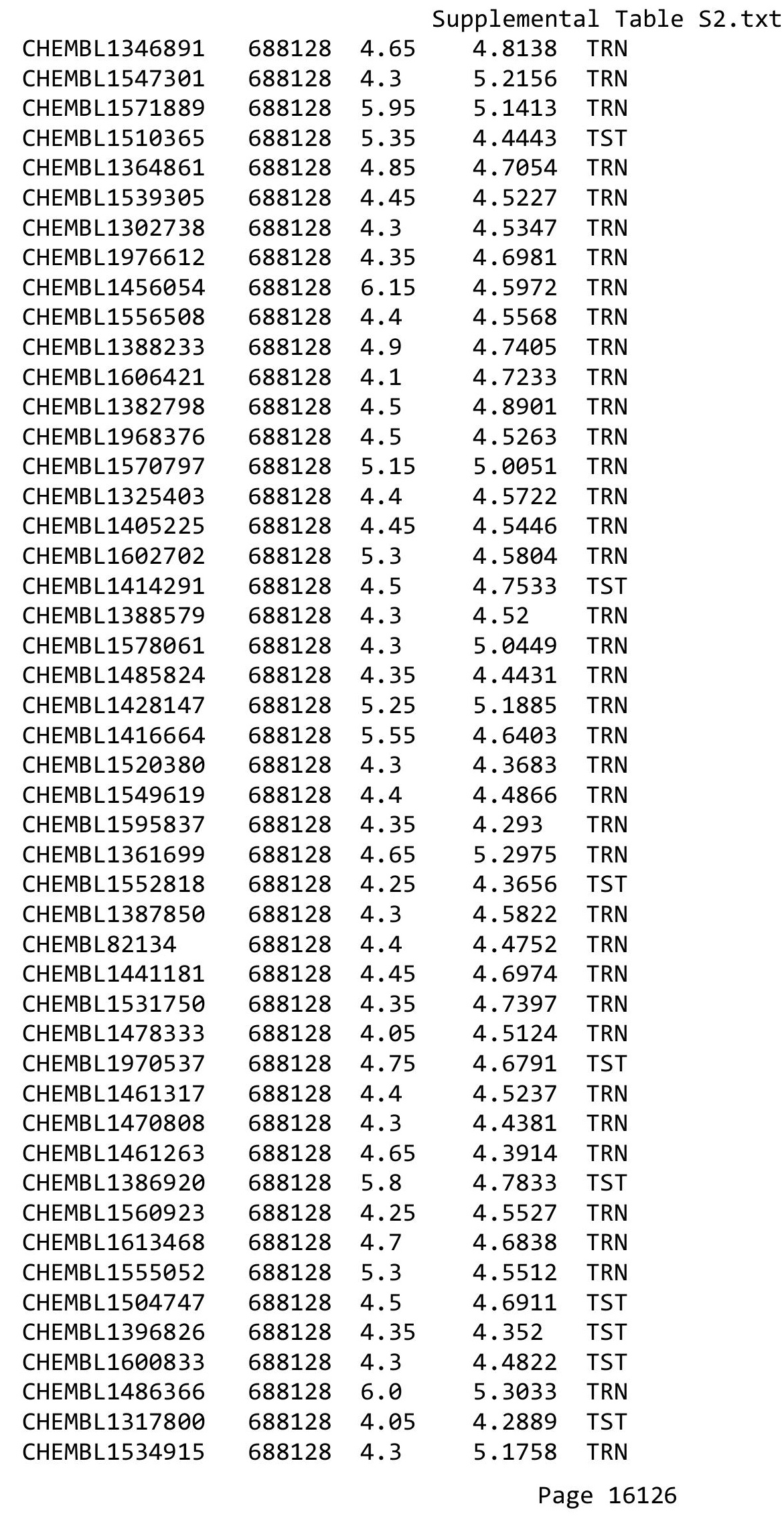




\begin{tabular}{|c|c|c|c|c|c|}
\hline \multirow{3}{*}{$\begin{array}{l}\text { CHEMBL1322963 } \\
\text { CHEMBL } 1976049\end{array}$} & \multirow{3}{*}{$\begin{array}{l}688128 \\
688128\end{array}$} & \multicolumn{4}{|c|}{ Supplemental Table s2.txt } \\
\hline & & 4.3 & 4.3610 & 0000000001 & TRN \\
\hline & & 5.45 & 4.8055 & TRN & \\
\hline CHEMBL1548033 & 688128 & 5.5 & 4.7901 & TRN & \\
\hline CHEMBL1529652 & 688128 & 4.75 & 4.7586 & TRN & \\
\hline CHEMBL1592214 & 688128 & 4.3 & 4.6659 & TRN & \\
\hline CHEMBL1488392 & 688128 & 4.35 & 4.6367 & TRN & \\
\hline CHEMBL1301644 & 688128 & 4.9 & 4.8098 & TRN & \\
\hline CHEMBL1432871 & 688128 & 4.05 & 4.4462 & TRN & \\
\hline CHEMBL1459101 & 688128 & 4.35 & 4.6812 & TRN & \\
\hline CHEMBL1455861 & 688128 & 4.45 & 4.6988 & TRN & \\
\hline CHEMBL3196988 & 688128 & 4.4 & 4.5457 & TRN & \\
\hline CHEMBL1456937 & 688128 & 4.25 & 4.9261 & TST & \\
\hline CHEMBL1562892 & 688128 & 5.75 & 4.7833 & TRN & \\
\hline CHEMBL1556069 & 688128 & 4.7 & 4.4032 & TRN & \\
\hline CHEMBL1485035 & 688128 & 4.45 & 4.5853 & TRN & \\
\hline CHEMBL1587027 & 688128 & 4.3 & 4.5629 & TST & \\
\hline CHEMBL1504338 & 688128 & 4.35 & 4.6153 & TST & \\
\hline CHEMBL1373449 & 688128 & 4.0 & 4.7655 & TRN & \\
\hline CHEMBL1376048 & 688128 & 4.05 & 4.7727 & TST & \\
\hline CHEMBL1586390 & 688128 & 4.9 & 4.5799 & TST & \\
\hline CHEMBL1383020 & 688128 & 4.9 & 4.62 & TST & \\
\hline CHEMBL1317194 & 688128 & 4.3 & 4.4504 & TRN & \\
\hline CHEMBL1487726 & 688128 & 6.25 & 4.6887 & TST & \\
\hline CHEMBL1501651 & 688128 & 4.1 & 4.5839 & TRN & \\
\hline CHEMBL1499006 & 688128 & 4.35 & 4.8015 & TRN & \\
\hline CHEMBL1310478 & 688128 & 4.3 & 4.6413 & TRN & \\
\hline CHEMBL1304584 & 688128 & 5.05 & 4.6744 & TRN & \\
\hline CHEMBL1526505 & 688128 & 4.95 & 4.508 & TRN & \\
\hline CHEMBL1542834 & 688128 & 4.4 & 4.7277 & TRN & \\
\hline CHEMBL1984001 & 688128 & 5.3 & 4.7746 & TRN & \\
\hline CHEMBL1611759 & 688128 & 4.35 & 4.7675 & TST & \\
\hline CHEMBL1446076 & 688128 & 4.35 & 4.6607 & TST & \\
\hline CHEMBL1371993 & 688128 & 4.05 & 4.5984 & TST & \\
\hline CHEMBL1522631 & 688128 & 5.8 & 4.71 & TRN & \\
\hline CHEMBL1348856 & 688128 & 4.35 & 4.632 & TRN & \\
\hline CHEMBL1421868 & 688128 & 4.25 & 4.8916 & TRN & \\
\hline CHEMBL1523257 & 688128 & 5.25 & 4.4561 & TST & \\
\hline CHEMBL1602827 & 688128 & 4.6 & 4.8471 & TRN & \\
\hline CHEMBL1537738 & 688128 & 4.95 & 4.3017 & TRN & \\
\hline CHEMBL1447587 & 688128 & 4.25 & 4.4199 & TRN & \\
\hline CHEMBL1521333 & 688128 & 4.7 & 4.6062 & TRN & \\
\hline CHEMBL1413418 & 688128 & 4.5 & 4.9156 & TRN & \\
\hline CHEMBL1335438 & 688128 & 4.05 & 4.6454 & TRN & \\
\hline CHEMBL1540425 & 688128 & 4.35 & 4.2287 & TRN & \\
\hline CHEMBL1611272 & 688128 & 5.55 & 4.4998 & TRN & \\
\hline CHEMBL1383576 & 688128 & 4.4 & 4.6915 & TST & \\
\hline CHEMBL1442482 & 688128 & 4.1 & 4.5392 & TST & \\
\hline CHEMBL1424275 & 688128 & 4.4 & 4.7274 & TRN & \\
\hline
\end{tabular}




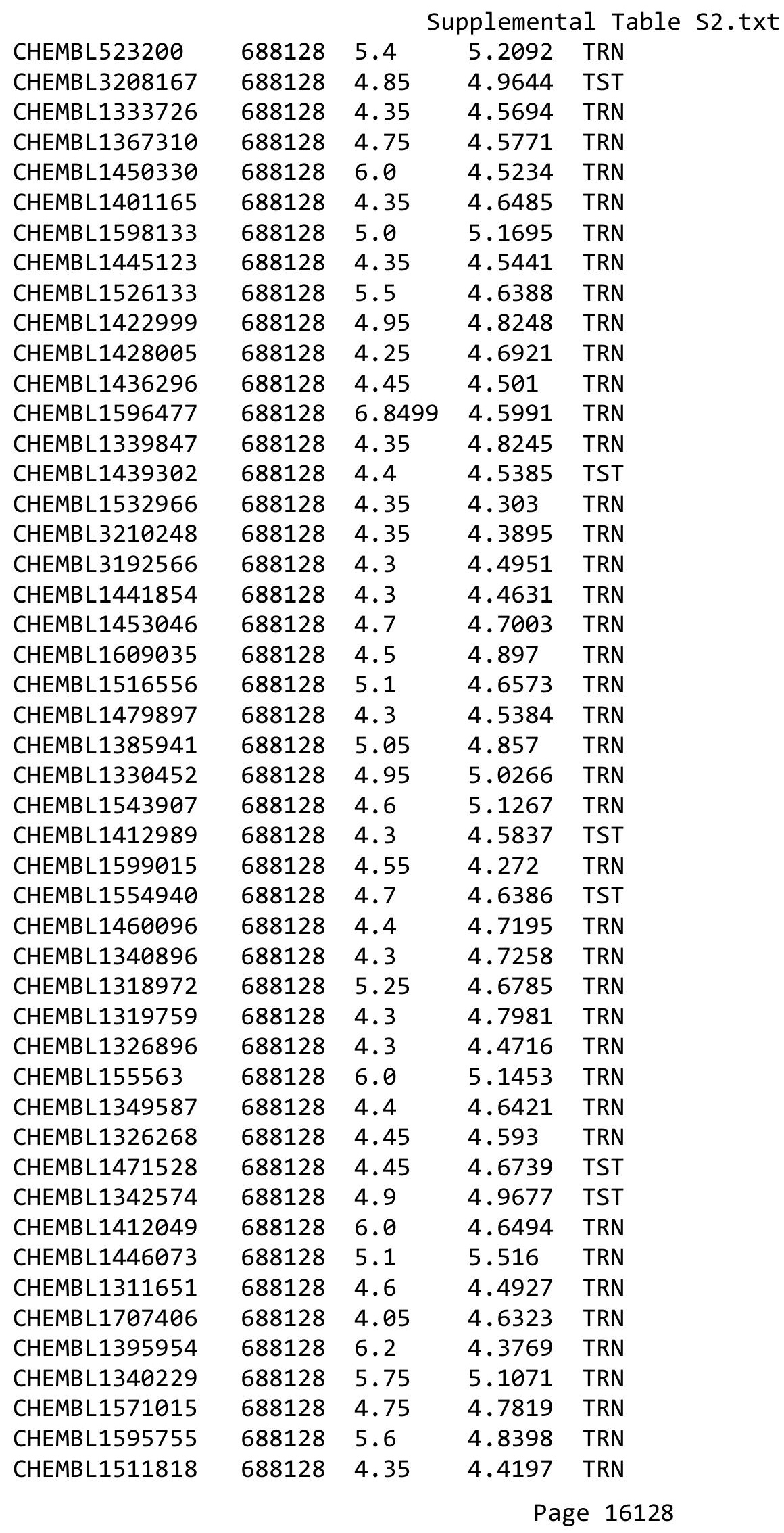




\begin{tabular}{|c|c|c|c|c|c|}
\hline \multicolumn{6}{|c|}{ Supplemental Table s2.txt } \\
\hline CHEMBL1402509 & 688128 & 4.4 & 4.5539 & TRN & \\
\hline CHEMBL1447732 & 688128 & 4.3 & 4.5334 & TRN & \\
\hline CHEMBL1442488 & 688128 & 4.3 & 4.5823 & TRN & \\
\hline CHEMBL1595491 & 688128 & 7.0 & 4.7956 & TST & \\
\hline CHEMBL1587781 & 688128 & 4.45 & 4.3555 & TRN & \\
\hline CHEMBL1492520 & 688128 & 4.65 & 4.2779 & TRN & \\
\hline CHEMBL585795 & 688128 & 6.45 & 4.7784 & TRN & \\
\hline CHEMBL1399535 & 688128 & 6.15 & 4.5934 & TRN & \\
\hline CHEMBL1613599 & 688128 & 4.95 & 4.7075 & TRN & \\
\hline CHEMBL1477221 & 688128 & 4.45 & 4.6609 & TRN & \\
\hline CHEMBL1418582 & 688128 & 4.85 & 4.6303 & TRN & \\
\hline CHEMBL1566081 & 688128 & 4.3 & 4.8095 & TST & \\
\hline CHEMBL3211095 & 688128 & 4.35 & 4.4615 & TRN & \\
\hline CHEMBL1360330 & 688128 & 4.35 & 4.6751 & TRN & \\
\hline CHEMBL1990184 & 688128 & 4.3 & 4.5708 & TRN & \\
\hline CHEMBL466004 & 688128 & 4.55 & 4.3067 & TRN & \\
\hline CHEMBL1383874 & 688128 & 4.3 & 4.7429 & TST & \\
\hline CHEMBL1368249 & 688128 & 4.35 & 4.3972 & TST & \\
\hline CHEMBL1345752 & 688128 & 4.35 & 4.3209 & TRN & \\
\hline CHEMBL1548006 & 688128 & 5.5 & 4.6614 & TRN & \\
\hline CHEMBL1484766 & 688128 & 4.35 & 4.7985 & TRN & \\
\hline CHEMBL1490629 & 688128 & 4.45 & 4.3645 & TRN & \\
\hline CHEMBL1302988 & 688128 & 4.75 & 4.5849 & TRN & \\
\hline CHEMBL1310702 & 688128 & 4.3 & 4.6075 & TRN & \\
\hline CHEMBL1521987 & 688128 & 6.25 & 5.0354 & TRN & \\
\hline CHEMBL1604713 & 688128 & 4.35 & 4.6225 & TRN & \\
\hline CHEMBL1352822 & 688128 & 4.05 & 4.4137 & TRN & \\
\hline CHEMBL1333710 & 688128 & 4.05 & 4.228 & TST & \\
\hline CHEMBL1531760 & 688128 & 4.35 & 4.8906 & TRN & \\
\hline CHEMBL1506469 & 688128 & 6.8 & 4.636 & TRN & \\
\hline CHEMBL567531 & 688128 & 5.05 & 4.9804 & TRN & \\
\hline CHEMBL1482373 & 688128 & 6.1 & 4.6731 & TST & \\
\hline CHEMBL1414419 & 688128 & 5.15 & 4.9385 & TST & \\
\hline CHEMBL1537393 & 688128 & 5.05 & 4.6127 & TRN & \\
\hline CHEMBL3196373 & 688128 & 4.3 & 4.7606 & TRN & \\
\hline CHEMBL1560673 & 688128 & 4.65 & 4.55699 & 99999999995 & TRN \\
\hline CHEMBL1578068 & 688128 & 4.3 & 4.316 & TRN & \\
\hline CHEMBL1994913 & 688128 & 6.15 & 4.503 & TRN & \\
\hline CHEMBL1452011 & 688128 & 4.85 & 4.655 & TRN & \\
\hline CHEMBL1578981 & 688128 & 5.3 & 4.7013 & TST & \\
\hline CHEMBL1542012 & 688128 & 4.45 & 4.1956 & TRN & \\
\hline CHEMBL1316454 & 688128 & 4.3 & 4.7505 & TST & \\
\hline CHEMBL1454944 & 688128 & 4.05 & 4.4777 & TRN & \\
\hline CHEMBL1377105 & 688128 & 4.05 & 4.6004 & TRN & \\
\hline CHEMBL1594162 & 688128 & 6.6 & 4.8306 & TRN & \\
\hline CHEMBL1372905 & 688128 & 4.35 & 4.7664 & TRN & \\
\hline CHEMBL3194832 & 688128 & 4.4 & 4.5957 & TRN & \\
\hline CHEMBL1393647 & 688128 & 4.6 & 4.6164 & TRN & \\
\hline
\end{tabular}




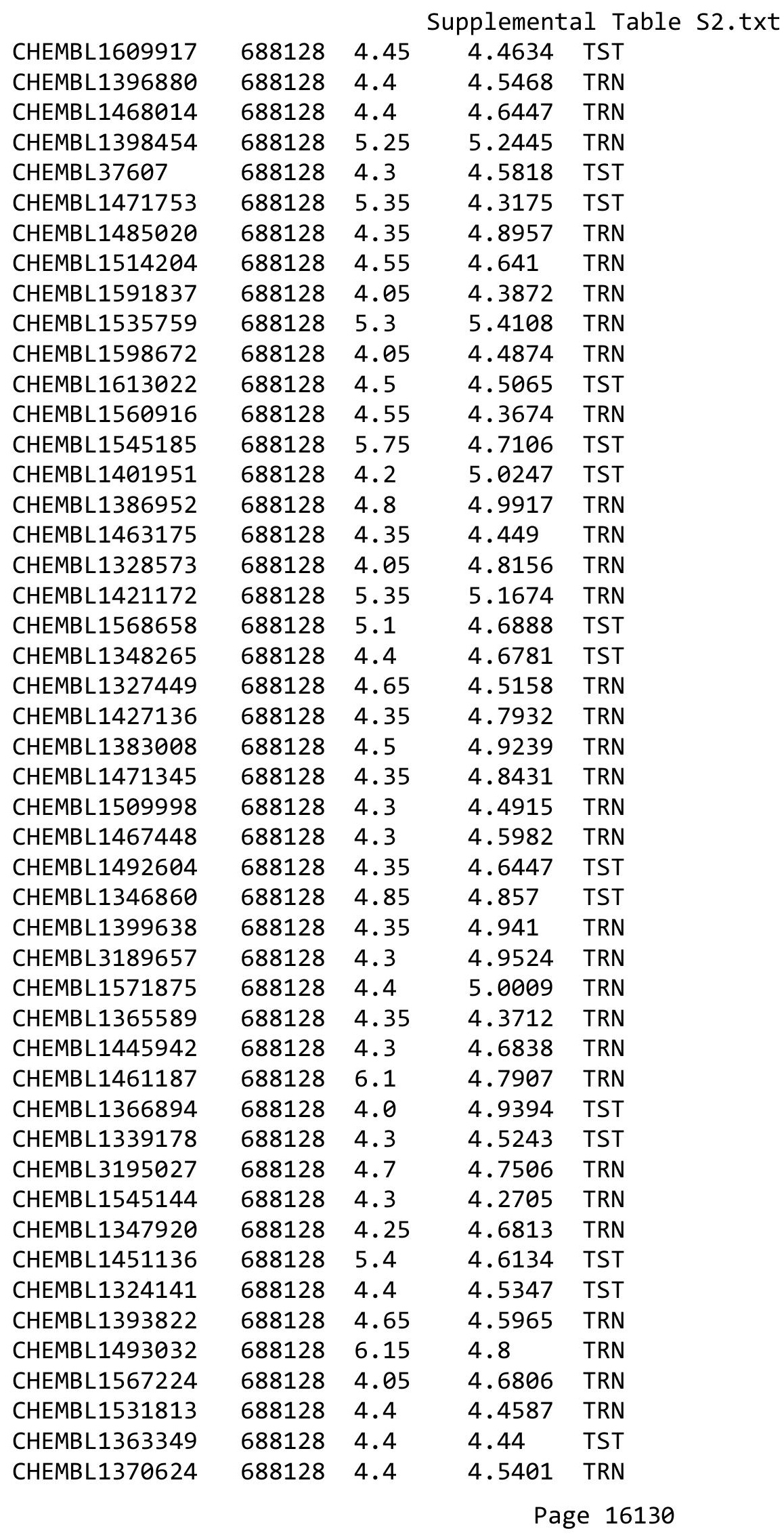




\begin{tabular}{|c|c|c|c|c|c|}
\hline CHEMBL1345931 & 688128 & 4.3 & 4.7417 & TRN & \\
\hline CHEMBL1560993 & 688128 & 4.3 & 4.59399 & 9999999999 & TRN \\
\hline CHEMBL1382859 & 688128 & 4.4 & 4.4428 & TRN & \\
\hline CHEMBL1419810 & 688128 & 4.4 & 4.7141 & TRN & \\
\hline CHEMBL1496094 & 688128 & 4.6 & 4.524 & TRN & \\
\hline CHEMBL1347567 & 688128 & 5.25 & 4.8839 & TST & \\
\hline CHEMBL1529684 & 688128 & 6.1 & 5.3266 & TRN & \\
\hline CHEMBL1502950 & 688128 & 5.05 & 5.189 & TRN & \\
\hline CHEMBL1597530 & 688128 & 4.25 & 4.2521 & TRN & \\
\hline CHEMBL1405965 & 688128 & 4.05 & 4.7284 & TST & \\
\hline CHEMBL1408348 & 688128 & 4.35 & 4.6878 & TRN & \\
\hline CHEMBL1518626 & 688128 & 4.6 & 4.6595 & TST & \\
\hline CHEMBL1311070 & 688128 & 4.35 & 4.629 & TRN & \\
\hline CHEMBL1387947 & 688128 & 4.35 & 4.7212 & TRN & \\
\hline CHEMBL3192651 & 688128 & 4.25 & 4.7186 & TRN & \\
\hline CHEMBL1320029 & 688128 & 4.35 & 4.6556 & TRN & \\
\hline CHEMBL1587016 & 688128 & 6.0 & 4.9012 & TRN & \\
\hline CHEMBL1604397 & 688128 & 4.3 & 4.6558 & TRN & \\
\hline CHEMBL1412370 & 688128 & 4.8 & 4.9867 & TRN & \\
\hline CHEMBL1350869 & 688128 & 4.35 & 4.6325 & TRN & \\
\hline CHEMBL1595805 & 688128 & 4.4 & 4.5673 & TRN & \\
\hline CHEMBL1562771 & 688128 & 5.35 & 4.7064 & TRN & \\
\hline CHEMBL1485684 & 688128 & 4.4 & 4.6986 & TRN & \\
\hline CHEMBL1433189 & 688128 & 4.4 & 4.6177 & TRN & \\
\hline CHEMBL1530812 & 688128 & 4.05 & 4.5896 & TST & \\
\hline CHEMBL1469807 & 688128 & 4.0 & 4.5218 & TST & \\
\hline CHEMBL1361920 & 688128 & 5.45 & 4.8355 & TRN & \\
\hline CHEMBL1478269 & 688128 & 5.2 & 4.4334 & TRN & \\
\hline CHEMBL1347668 & 688128 & 4.35 & 4.694 & TST & \\
\hline CHEMBL1417996 & 688128 & 4.35 & 4.5737 & TRN & \\
\hline CHEMBL1348868 & 688128 & 4.2 & 4.3017 & TRN & \\
\hline CHEMBL1364729 & 688128 & 4.85 & 4.4653 & TRN & \\
\hline CHEMBL1579857 & 688128 & 4.05 & 4.5323 & TRN & \\
\hline CHEMBL1447731 & 688128 & 4.4 & 4.5721 & TRN & \\
\hline CHEMBL1555753 & 688128 & 4.45 & 4.5998 & TST & \\
\hline CHEMBL1458840 & 688128 & 6.35 & 5.1903 & TRN & \\
\hline CHEMBL1481077 & 688128 & 4.4 & 4.9614 & TRN & \\
\hline CHEMBL1993944 & 688128 & 4.45 & 4.5952 & TST & \\
\hline CHEMBL1461619 & 688128 & 6.45 & 5.0828 & TRN & \\
\hline CHEMBL1590124 & 688128 & 4.85 & 4.5601 & TST & \\
\hline CHEMBL1584902 & 688128 & 4.15 & 4.6787 & TST & \\
\hline CHEMBL1333614 & 688128 & 4.55 & 4.5206 & TST & \\
\hline CHEMBL1378445 & 688128 & 4.4 & 4.4249 & TRN & \\
\hline CHEMBL1336232 & 688128 & 4.0 & 4.6132 & TRN & \\
\hline CHEMBL1392459 & 688128 & 4.1 & 4.772 & TST & \\
\hline CHEMBL1523938 & 688128 & 4.85 & 4.9661 & TST & \\
\hline CHEMBL1488705 & 688128 & 4.8 & 4.658 & TRN & \\
\hline CHEMBL1390916 & 688128 & 4.3 & 4.4651 & TRN & \\
\hline
\end{tabular}




\begin{tabular}{|c|c|c|c|c|c|}
\hline & & \multicolumn{4}{|c|}{ Supplemental Table s2.txt } \\
\hline CHEMBL1353832 & 688128 & 4.05 & 4.538 & TST & \\
\hline CHEMBL1348031 & 688128 & 4.35 & 4.4501 & TRN & \\
\hline CHEMBL1517695 & 688128 & 4.7 & 4.7855 & TRN & \\
\hline CHEMBL3194033 & 688128 & 4.3 & 4.562 & TST & \\
\hline CHEMBL1545899 & 688128 & 4.35 & 4.7479 & TRN & \\
\hline CHEMBL1309953 & 688128 & 5.05 & 5.2158 & TRN & \\
\hline CHEMBL1342292 & 688128 & 4.35 & 4.4841 & TST & \\
\hline CHEMBL1574327 & 688128 & 5.4 & 4.5682 & TRN & \\
\hline CHEMBL1531648 & 688128 & 4.35 & 4.3825 & TRN & \\
\hline CHEMBL1328900 & 688128 & 4.35 & 4.57600 & 00000000005 & TRN \\
\hline CHEMBL1509677 & 688128 & 4.3 & 4.5205 & TRN & \\
\hline CHEMBL1370425 & 688128 & 4.65 & 4.8459 & TRN & \\
\hline CHEMBL1382910 & 688128 & 4.95 & 4.6351 & TRN & \\
\hline CHEMBL603728 & 688128 & 4.05 & 4.3623 & TRN & \\
\hline CHEMBL1333543 & 688128 & 4.35 & 4.7364 & TRN & \\
\hline CHEMBL1544227 & 688128 & 4.6 & 4.4792 & TRN & \\
\hline CHEMBL1450637 & 688128 & 4.45 & 4.7924 & TRN & \\
\hline CHEMBL602218 & 688128 & 4.3 & 4.6251 & TRN & \\
\hline CHEMBL1409486 & 688128 & 4.7 & 4.7737 & TRN & \\
\hline CHEMBL1351563 & 688128 & 4.25 & 4.649 & TST & \\
\hline CHEMBL3190546 & 688128 & 4.05 & 5.0477 & TRN & \\
\hline CHEMBL1376353 & 688128 & 4.4 & 4.5755 & TST & \\
\hline CHEMBL485907 & 688128 & 4.25 & 4.7859 & TRN & \\
\hline CHEMBL1473045 & 688128 & 4.45 & 4.5531 & TRN & \\
\hline CHEMBL1412664 & 688128 & 5.1 & 4.8569 & TRN & \\
\hline CHEMBL1336399 & 688128 & 5.45 & 5.1487 & TRN & \\
\hline CHEMBL1550105 & 688128 & 4.4 & 4.4692 & TRN & \\
\hline CHEMBL1347811 & 688128 & 5.2 & 4.8019 & TRN & \\
\hline CHEMBL1344391 & 688128 & 5.9 & 4.6585 & TST & \\
\hline CHEMBL1508390 & 688128 & 4.2 & 4.542 & TRN & \\
\hline CHEMBL1398465 & 688128 & 4.25 & 4.6876 & TRN & \\
\hline CHEMBL1325021 & 688128 & 5.5 & 5.1587 & TRN & \\
\hline CHEMBL1435195 & 688128 & 4.05 & 4.5634 & TST & \\
\hline CHEMBL1402285 & 688128 & 5.1 & 4.6707 & TRN & \\
\hline CHEMBL1483075 & 688128 & 4.35 & 4.5176 & TRN & \\
\hline CHEMBL1527553 & 688128 & 4.4 & 4.7228 & TRN & \\
\hline CHEMBL1332544 & 688128 & 5.35 & 4.6793 & TRN & \\
\hline CHEMBL1379785 & 688128 & 4.3 & 4.6672 & TRN & \\
\hline CHEMBL1471270 & 688128 & 4.35 & 4.6163 & TRN & \\
\hline CHEMBL1480387 & 688128 & 4.25 & 4.797 & TRN & \\
\hline CHEMBL1408802 & 688128 & 4.75 & 4.6497 & TRN & \\
\hline CHEMBL1500814 & 688128 & 4.45 & 4.6666 & TRN & \\
\hline CHEMBL1487095 & 688128 & 4.05 & 4.3221 & TST & \\
\hline CHEMBL1534112 & 688128 & 6.9 & 4.5748 & TRN & \\
\hline CHEMBL1551251 & 688128 & 4.3 & 4.2909 & TRN & \\
\hline CHEMBL1524622 & 688128 & 4.25 & 4.6684 & TRN & \\
\hline CHEMBL1976046 & 688128 & 4.5 & 4.2199 & TRN & \\
\hline CHEMBL1452519 & 688128 & 4.4 & 4.4515 & TST & \\
\hline
\end{tabular}




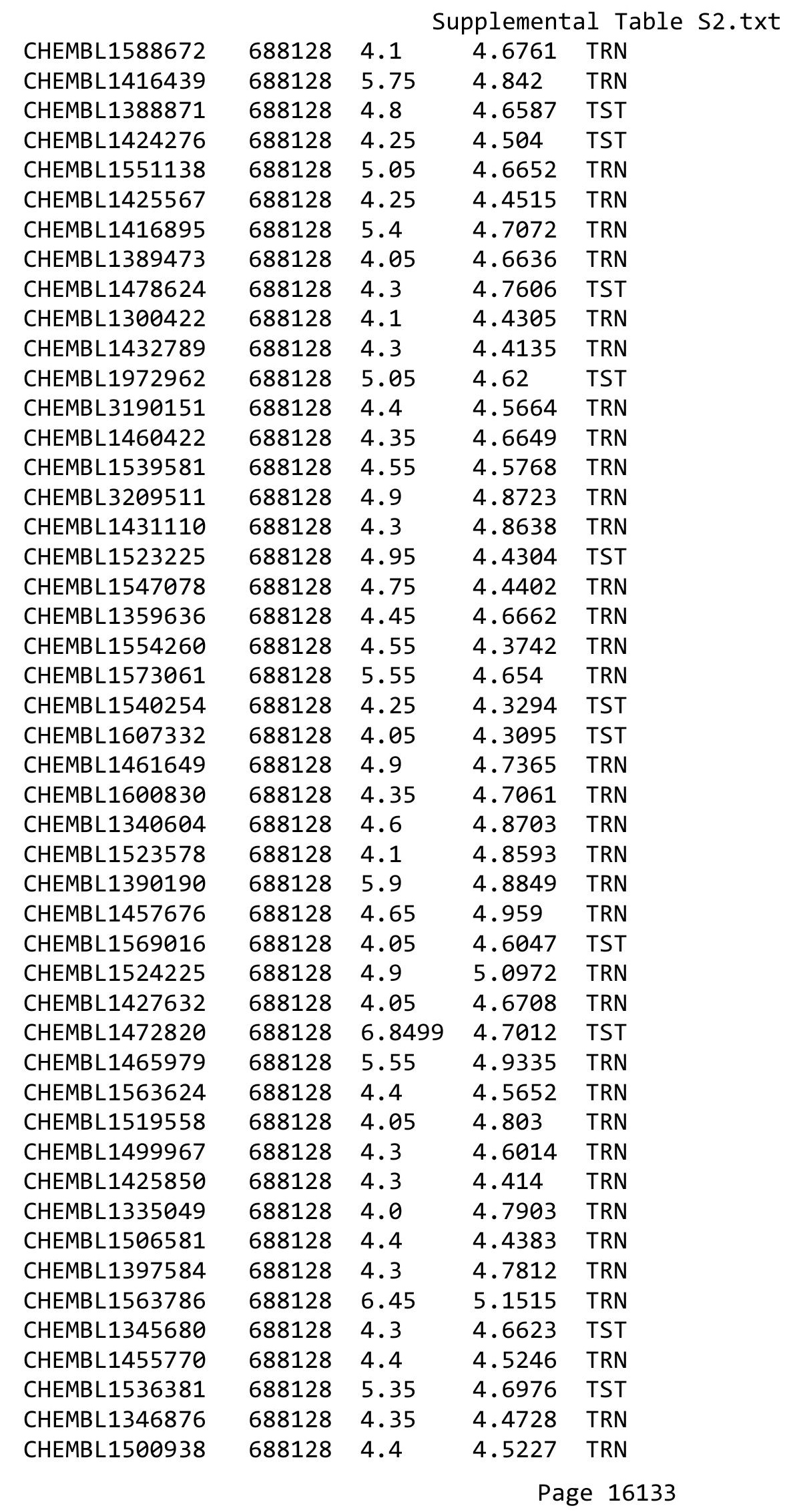




\begin{tabular}{|c|c|c|c|c|c|}
\hline \multicolumn{6}{|c|}{ Supplemental Table S2.txt } \\
\hline CHEMBL1411089 & 688128 & 6.05 & 4.9633 & TRN & \\
\hline CHEMBL1300216 & 688128 & 4.35 & 4.5821 & TST & \\
\hline CHEMBL1440195 & 688128 & 5.05 & 4.9429 & TST & \\
\hline CHEMBL1415510 & 688128 & 4.65 & 4.7936 & TRN & \\
\hline CHEMBL1572090 & 688128 & 4.05 & 4.80399 & 9999999999 & TRN \\
\hline CHEMBL1594352 & 688128 & 6.15 & 4.995 & TRN & \\
\hline CHEMBL1392999 & 688128 & 4.6 & 4.5732 & TRN & \\
\hline CHEMBL1512953 & 688128 & 4.8 & 4.3942 & TRN & \\
\hline CHEMBL1414961 & 688128 & 4.3 & 4.2935 & TRN & \\
\hline CHEMBL1560341 & 688128 & 4.55 & 4.6926 & TRN & \\
\hline CHEMBL1458071 & 688128 & 4.35 & 4.3862 & TRN & \\
\hline CHEMBL1391016 & 688128 & 4.35 & 4.7039 & TST & \\
\hline CHEMBL1567682 & 688128 & 4.3 & 4.2258 & TRN & \\
\hline CHEMBL1402524 & 688128 & 4.7 & 4.6891 & TST & \\
\hline CHEMBL1576758 & 688128 & 4.25 & 4.4258 & TRN & \\
\hline CHEMBL1608333 & 688128 & 5.35 & 4.8557 & TST & \\
\hline CHEMBL1581671 & 688128 & 4.45 & 4.3789 & TRN & \\
\hline CHEMBL1568978 & 688128 & 4.3 & 4.50899 & 99999999995 & TRN \\
\hline CHEMBL37514 & 688128 & 4.6 & 4.4755 & TRN & \\
\hline CHEMBL1333823 & 688128 & 4.95 & 4.7573 & TST & \\
\hline CHEMBL1612994 & 688128 & 4.35 & 4.6294 & TST & \\
\hline CHEMBL3192606 & 688128 & 5.3 & 4.5141 & TST & \\
\hline CHEMBL1345504 & 688128 & 4.5 & 4.4873 & TRN & \\
\hline CHEMBL1345035 & 688128 & 4.1 & 4.55699 & 99999999995 & TRN \\
\hline CHEMBL52682 & 688128 & 4.9 & 4.5555 & TRN & \\
\hline CHEMBL1341905 & 688128 & 4.4 & 4.8295 & TRN & \\
\hline CHEMBL1379904 & 688128 & 4.4 & 4.5326 & TST & \\
\hline CHEMBL1381145 & 688128 & 4.6 & 4.4278 & TST & \\
\hline CHEMBL1550817 & 688128 & 4.25 & 4.6169 & TRN & \\
\hline CHEMBL1505389 & 688128 & 4.35 & 4.5942 & TRN & \\
\hline CHEMBL1465515 & 688128 & 4.35 & 4.3717 & TRN & \\
\hline CHEMBL1405243 & 688128 & 4.4 & 4.5773 & TRN & \\
\hline CHEMBL1503194 & 688128 & 4.25 & 4.6923 & TST & \\
\hline CHEMBL1330519 & 688128 & 4.45 & 4.9091 & TRN & \\
\hline CHEMBL1376785 & 688128 & 4.35 & 4.4699 & TRN & \\
\hline CHEMBL1997990 & 688128 & 4.65 & 4.9584 & TRN & \\
\hline CHEMBL1546422 & 688128 & 4.7 & 4.5491 & TST & \\
\hline CHEMBL1376703 & 688128 & 4.4 & 4.7131 & TST & \\
\hline CHEMBL1577235 & 688128 & 5.85 & 4.5027 & TRN & \\
\hline CHEMBL1443448 & 688128 & 4.8 & 4.7952 & TRN & \\
\hline CHEMBL1539644 & 688128 & 4.3 & 4.4234 & TRN & \\
\hline CHEMBL1501372 & 688128 & 4.4 & 4.4831 & TST & \\
\hline CHEMBL1429117 & 688128 & 4.45 & 4.3875 & TRN & \\
\hline CHEMBL1372162 & 688128 & 4.45 & 4.3342 & TST & \\
\hline CHEMBL1432526 & 688128 & 4.3 & 4.6792 & TST & \\
\hline CHEMBL1328241 & 688128 & 4.35 & 4.8727 & TST & \\
\hline CHEMBL1533263 & 688128 & 5.05 & 4.7296 & TST & \\
\hline CHEMBL1452960 & 688128 & 4.3 & 4.5459 & TRN & \\
\hline
\end{tabular}




\begin{tabular}{|c|c|c|c|c|}
\hline \multicolumn{5}{|c|}{ plemental T } \\
\hline CHEMBL1508313 & 688128 & 4.3 & 4.9917 & TRN \\
\hline CHEMBL3207358 & 688128 & 4.3 & 4.6739 & TRN \\
\hline CHEMBL462376 & 688128 & 5.2 & 4.7795 & TRN \\
\hline CHEMBL1404348 & 688128 & 4.35 & 4.4238 & TRN \\
\hline CHEMBL1301900 & 688128 & 4.35 & 4.7244 & TRN \\
\hline CHEMBL1408285 & 688128 & 4.9 & 4.4674 & TRN \\
\hline CHEMBL1566503 & 688128 & 5.8 & 4.8322 & TRN \\
\hline CHEMBL1340651 & 688128 & 5.8 & 4.5618 & TRN \\
\hline CHEMBL1320821 & 688128 & 5.2 & 4.7271 & TRN \\
\hline CHEMBL1523285 & 688128 & 4.5 & 4.7432 & TRN \\
\hline CHEMBL1494597 & 688128 & 6.6 & 4.7156 & TST \\
\hline CHEMBL1558291 & 688128 & 6.8499 & 4.6183 & TRN \\
\hline CHEMBL1345825 & 688128 & 5.4 & 5.2031 & TRN \\
\hline CHEMBL1465071 & 688128 & 4.75 & 4.6892 & TRN \\
\hline CHEMBL1459053 & 688128 & 4.0 & 4.5135 & TRN \\
\hline CHEMBL1516488 & 688128 & 4.35 & 4.4457 & TRN \\
\hline CHEMBL1416995 & 688128 & 4.1 & 4.7593 & TRN \\
\hline CHEMBL1428327 & 688128 & 4.35 & 4.6871 & TST \\
\hline CHEMBL3194407 & 688128 & 4.45 & 4.6915 & TST \\
\hline CHEMBL3194643 & 688128 & 6.45 & 4.8216 & TRN \\
\hline CHEMBL1332522 & 688128 & 4.2 & 4.5162 & TRN \\
\hline CHEMBL1480996 & 688128 & 6.15 & 4.8349 & TST \\
\hline CHEMBL1307029 & 688128 & 4.25 & 4.6496 & TRN \\
\hline CHEMBL1322221 & 688128 & 4.35 & 4.7404 & TRN \\
\hline CHEMBL1600181 & 688128 & 6.15 & 4.6464 & TRN \\
\hline CHEMBL1369124 & 688128 & 4.6 & 4.721 & TRN \\
\hline CHEMBL1590085 & 688128 & 4.05 & 4.5756 & TRN \\
\hline CHEMBL1565267 & 688128 & 4.4 & 4.7713 & TST \\
\hline CHEMBL1502313 & 688128 & 4.55 & 4.9979 & TRN \\
\hline CHEMBL1447852 & 688128 & 4.4 & 4.7206 & TRN \\
\hline CHEMBL1429064 & 688128 & 4.65 & 4.3832 & TRN \\
\hline CHEMBL1514691 & 688128 & 5.25 & 4.6022 & TST \\
\hline CHEMBL1399767 & 688128 & 4.95 & 4.5396 & TRN \\
\hline CHEMBL1538460 & 688128 & 5.5 & 4.7787 & TRN \\
\hline CHEMBL1509904 & 688128 & 4.3 & 4.5869 & TRN \\
\hline CHEMBL1441303 & 688128 & 4.6 & 4.4774 & TST \\
\hline CHEMBL1506502 & 688128 & 4.45 & 4.6115 & TRN \\
\hline CHEMBL1416848 & 688128 & 4.3 & 4.8215 & TRN \\
\hline CHEMBL1593914 & 688128 & 4.3 & 4.3438 & TRN \\
\hline CHEMBL3189449 & 688128 & 5.1 & 4.8623 & TRN \\
\hline CHEMBL1330050 & 688128 & 4.75 & 4.7578 & TST \\
\hline CHEMBL1395379 & 688128 & 4.35 & 4.6701 & TRN \\
\hline CHEMBL1964317 & 688128 & 6.45 & 4.8527 & TRN \\
\hline CHEMBL1570274 & 688128 & 4.6 & 4.7302 & TST \\
\hline CHEMBL1355557 & 688128 & 4.75 & 5.3063 & TRN \\
\hline CHEMBL1411402 & 688128 & 4.65 & 4.9208 & TRN \\
\hline CHEMBL1434857 & 688128 & 4.4 & 4.6365 & TRN \\
\hline CHEMBL1441184 & 688128 & 4.05 & 4.7326 & TRN \\
\hline
\end{tabular}




\begin{tabular}{|c|c|c|c|c|c|}
\hline & & \multicolumn{4}{|c|}{ Supplemental Table S2.txt } \\
\hline CHEMBL1312190 & 688128 & 4.65 & 4.859 & TRN & \\
\hline CHEMBL1305640 & 688128 & 4.45 & 4.4543 & TRN & \\
\hline CHEMBL3195373 & 688128 & 4.85 & 4.6763 & TRN & \\
\hline CHEMBL1321604 & 688128 & 5.4 & 4.6278 & TRN & \\
\hline CHEMBL1387863 & 688128 & 4.4 & 4.7281 & TST & \\
\hline CHEMBL1365050 & 688128 & 4.3 & 4.6476 & TRN & \\
\hline CHEMBL1585751 & 688128 & 4.35 & 4.9817 & TRN & \\
\hline CHEMBL1526561 & 688128 & 4.4 & 5.0478 & TRN & \\
\hline CHEMBL1498347 & 688128 & 4.45 & 4.4492 & TRN & \\
\hline CHEMBL1369660 & 688128 & 4.2 & 4.6169 & TRN & \\
\hline CHEMBL1599086 & 688128 & 5.45 & 4.711 & TRN & \\
\hline CHEMBL1468155 & 688128 & 4.25 & 4.544 & TST & \\
\hline CHEMBL1447195 & 688128 & 4.3 & 4.4214 & TRN & \\
\hline CHEMBL1416162 & 688128 & 5.0 & 4.4528 & TST & \\
\hline CHEMBL1532699 & 688128 & 6.15 & 4.5272 & TRN & \\
\hline CHEMBL1603674 & 688128 & 6.5501 & 4.7311 & TRN & \\
\hline CHEMBL1374534 & 688128 & 4.05 & 4.6949 & TST & \\
\hline CHEMBL1329195 & 688128 & 4.55 & 4.5451 & TRN & \\
\hline CHEMBL1302352 & 688128 & 4.6 & 4.80399 & 7999999999 & TRN \\
\hline CHEMBL1450897 & 688128 & 4.3 & 4.7385 & TST & \\
\hline CHEMBL1572064 & 688128 & 4.35 & 4.678 & TST & \\
\hline CHEMBL1540573 & 688128 & 4.55 & 4.5042 & TRN & \\
\hline CHEMBL1459787 & 688128 & 4.6 & 4.8489 & TST & \\
\hline CHEMBL1979662 & 688128 & 4.75 & 4.9119 & TRN & \\
\hline CHEMBL1401154 & 688128 & 4.75 & 4.5867 & TRN & \\
\hline CHEMBL1525325 & 688128 & 4.1 & 4.5452 & TRN & \\
\hline CHEMBL1469257 & 688128 & 4.6 & 4.657 & TRN & \\
\hline CHEMBL1313824 & 688128 & 4.1 & 4.5388 & TRN & \\
\hline CHEMBL1613609 & 688128 & 4.35 & 4.56 & TRN & \\
\hline CHEMBL1359373 & 688128 & 4.05 & 4.7192 & TST & \\
\hline CHEMBL1442506 & 688128 & 4.35 & 4.5238 & TRN & \\
\hline CHEMBL1485879 & 688128 & 5.65 & 4.6899 & TST & \\
\hline CHEMBL1492237 & 688128 & 4.25 & 4.4643 & TRN & \\
\hline CHEMBL1407138 & 688128 & 4.25 & 4.5342 & TRN & \\
\hline CHEMBL1441315 & 688128 & 6.1 & 5.0562 & TRN & \\
\hline CHEMBL1303952 & 688128 & 5.4 & 4.8196 & TRN & \\
\hline CHEMBL1586422 & 688128 & 4.25 & 4.5445 & TST & \\
\hline CHEMBL1548297 & 688128 & 4.3 & 4.5598 & TRN & \\
\hline CHEMBL1556156 & 688128 & 4.65 & 4.6639 & TRN & \\
\hline CHEMBL1511261 & 688128 & 5.2 & 4.6552 & TRN & \\
\hline CHEMBL1429489 & 688128 & 3.95 & 4.6394 & TST & \\
\hline CHEMBL1602109 & 688128 & 4.05 & 4.8938 & TST & \\
\hline CHEMBL1533515 & 688128 & 4.3 & 4.5993 & TRN & \\
\hline CHEMBL1588198 & 688128 & 4.4 & 4.8156 & TST & \\
\hline CHEMBL1598839 & 688128 & 4.25 & 4.3905 & TST & \\
\hline CHEMBL1377125 & 688128 & 4.35 & 4.5256 & TRN & \\
\hline CHEMBL1305589 & 688128 & 5.6 & 4.4555 & TRN & \\
\hline CHEMBL3197420 & 688128 & 4.45 & 4.7543 & TRN & \\
\hline
\end{tabular}




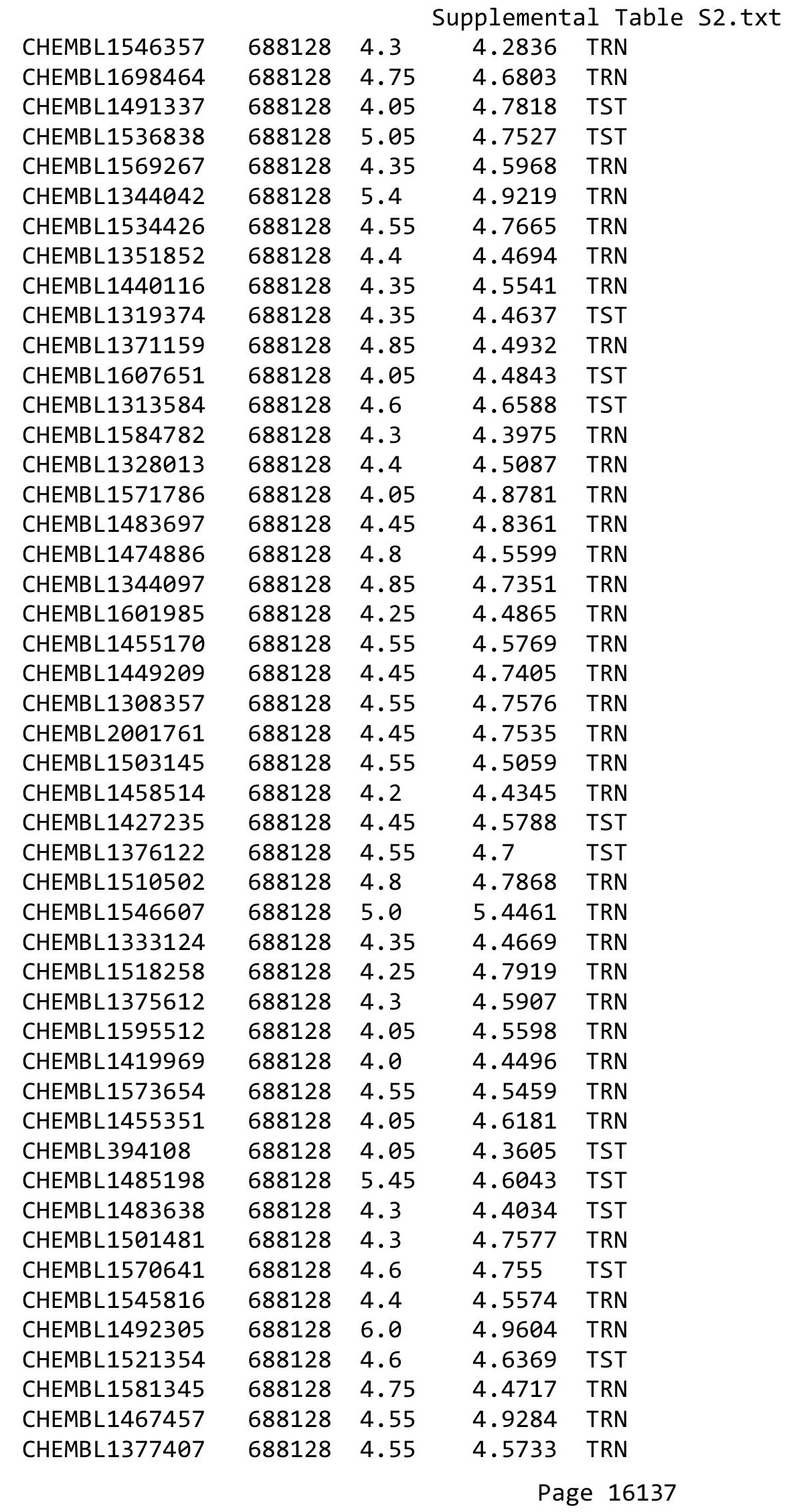




\begin{tabular}{|c|c|c|c|c|c|}
\hline \\
\hline CHEMBL1464548 & 688128 & 4.85 & 4.7911 & TST & \\
\hline CHEMBL1565214 & 688128 & 5.45 & 4.6545 & TRN & \\
\hline CHEMBL1477196 & 688128 & 4.4 & 4.7137 & TRN & \\
\hline CHEMBL1429438 & 688128 & 4.4 & 4.8107 & TRN & \\
\hline CHEMBL1516400 & 688128 & 4.35 & 4.4385 & TST & \\
\hline CHEMBL1510639 & 688128 & 6.0 & 4.5948 & TRN & \\
\hline CHEMBL1506234 & 688128 & 6.0 & 5.36 & TRN & \\
\hline CHEMBL1369359 & 688128 & 4.5 & 4.5121 & TRN & \\
\hline CHEMBL1522513 & 688128 & 4.3 & 4.408 & TRN & \\
\hline CHEMBL1570587 & 688128 & 7.0 & 4.9892 & TRN & \\
\hline CHEMBL3212729 & 688128 & 4.4 & 4.6141 & TRN & \\
\hline CHEMBL1413723 & 688128 & 5.45 & 4.4797 & TRN & \\
\hline CHEMBL1572831 & 688128 & 5.0 & 4.5515 & TRN & \\
\hline CHEMBL1439079 & 688128 & 6.6 & 4.5374 & TRN & \\
\hline CHEMBL1400274 & 688128 & 4.25 & 4.4326 & TRN & \\
\hline CHEMBL1967744 & 688128 & 4.55 & 4.9001 & TRN & \\
\hline CHEMBL1597351 & 688128 & 4.05 & 4.6325 & TRN & \\
\hline CHEMBL1459285 & 688128 & 4.55 & 4.7088 & TRN & \\
\hline CHEMBL1583825 & 688128 & 4.45 & 4.17399 & 99999999995 & TRN \\
\hline CHEMBL1597237 & 688128 & 5.8 & 5.3593 & TRN & \\
\hline CHEMBL1430826 & 688128 & 4.0 & 4.3605 & TRN & \\
\hline CHEMBL1438506 & 688128 & 4.25 & 4.2815 & TRN & \\
\hline CHEMBL1389842 & 688128 & 4.6 & 4.5079 & TST & \\
\hline CHEMBL1402456 & 688128 & 4.8 & 4.6549 & TRN & \\
\hline CHEMBL1508887 & 688128 & 4.0 & 4.725 & TRN & \\
\hline CHEMBL1403834 & 688128 & 4.4 & 4.524 & TRN & \\
\hline CHEMBL1382760 & 688128 & 5.05 & 5.0283 & TRN & \\
\hline CHEMBL1406990 & 688128 & 4.35 & 4.5207 & TRN & \\
\hline CHEMBL1361439 & 688128 & 4.05 & 4.6627 & TRN & \\
\hline CHEMBL3195731 & 688128 & 4.4 & 4.6346 & TST & \\
\hline CHEMBL1498820 & 688128 & 6.0 & 4.7258 & TRN & \\
\hline CHEMBL1345669 & 688128 & 4.3 & 4.4306 & TRN & \\
\hline CHEMBL1467670 & 688128 & 4.9 & 4.4438 & TRN & \\
\hline CHEMBL1327691 & 688128 & 4.3 & 4.5339 & TST & \\
\hline CHEMBL1335795 & 688128 & 4.0 & 4.7044 & TST & \\
\hline CHEMBL1428218 & 688128 & 5.1 & 4.6224 & TRN & \\
\hline CHEMBL1568547 & 688128 & 4.35 & 4.6299 & TRN & \\
\hline CHEMBL1389462 & 688128 & 4.4 & 4.2304 & TRN & \\
\hline CHEMBL1427070 & 688128 & 4.35 & 4.6498 & TRN & \\
\hline CHEMBL1385040 & 688128 & 4.6 & 4.5991 & TST & \\
\hline CHEMBL1319631 & 688128 & 4.35 & 4.6991 & TRN & \\
\hline CHEMBL1594751 & 688128 & 4.45 & 4.5455 & TRN & \\
\hline CHEMBL1301195 & 688128 & 4.3 & 4.6024 & TRN & \\
\hline CHEMBL1362232 & 688128 & 4.05 & 4.6186 & TRN & \\
\hline CHEMBL1431316 & 688128 & 4.05 & 4.5519 & TRN & \\
\hline CHEMBL1424352 & 688128 & 4.4 & 4.3184 & TRN & \\
\hline CHEMBL1593107 & 688128 & 4.7 & 4.5778 & TRN & \\
\hline CHEMBL1403132 & 688128 & 4.35 & 4.5622 & TRN & \\
\hline
\end{tabular}




\begin{tabular}{|c|c|c|c|c|c|}
\hline \multicolumn{6}{|c|}{ Supplemental Table s2.txt } \\
\hline CHEMBL1548577 & 688128 & 4.6 & 4.5917 & TRN & \\
\hline CHEMBL1606842 & 688128 & 4.25 & 4.7914 & TRN & \\
\hline CHEMBL1503470 & 688128 & 5.0 & 4.6671 & TRN & \\
\hline CHEMBL1421162 & 688128 & 4.3 & 4.8664 & TRN & \\
\hline CHEMBL1598493 & 688128 & 4.3 & 4.6174 & TRN & \\
\hline CHEMBL1434005 & 688128 & 4.4 & 4.6032 & TRN & \\
\hline CHEMBL1457986 & 688128 & 5.0 & 4.774 & TRN & \\
\hline CHEMBL1446275 & 688128 & 4.35 & 4.3977 & TRN & \\
\hline CHEMBL607553 & 688128 & 4.55 & 4.9419 & TRN & \\
\hline CHEMBL1435856 & 688128 & 4.3 & 4.6026 & TRN & \\
\hline CHEMBL1452831 & 688128 & 4.3 & 4.5033 & TST & \\
\hline CHEMBL1423210 & 688128 & 4.35 & 4.6695 & TRN & \\
\hline CHEMBL1319882 & 688128 & 4.6 & 4.3601 & TRN & \\
\hline CHEMBL1498729 & 688128 & 4.05 & 4.6279 & TST & \\
\hline CHEMBL1503787 & 688128 & 4.0 & 4.6451 & TRN & \\
\hline CHEMBL1319618 & 688128 & 5.2 & 5.1946 & TST & \\
\hline CHEMBL1606378 & 688128 & 4.25 & 4.5278 & TRN & \\
\hline CHEMBL1510361 & 688128 & 4.05 & 4.5398 & TRN & \\
\hline CHEMBL1382407 & 688128 & 4.55 & 4.4597 & TRN & \\
\hline CHEMBL1362867 & 688128 & 6.25 & 5.0025 & TRN & \\
\hline CHEMBL1327726 & 688128 & 4.1 & 4.636 & TST & \\
\hline CHEMBL1311754 & 688128 & 5.5 & 4.8141 & TRN & \\
\hline CHEMBL1372051 & 688128 & 4.85 & 4.8315 & TST & \\
\hline CHEMBL1379792 & 688128 & 4.2 & 4.5978 & TRN & \\
\hline CHEMBL1449855 & 688128 & 4.6 & 4.5712 & TRN & \\
\hline CHEMBL1521462 & 688128 & 4.3 & 4.5443 & TRN & \\
\hline CHEMBL1300245 & 688128 & 4.45 & 4.5566 & TST & \\
\hline CHEMBL1303353 & 688128 & 4.3 & 4.7719 & TRN & \\
\hline CHEMBL1470908 & 688128 & 4.7 & 4.5415 & TRN & \\
\hline CHEMBL1405495 & 688128 & 4.3 & 4.6045 & TST & \\
\hline CHEMBL1610905 & 688128 & 4.4 & 4.5343 & TST & \\
\hline CHEMBL1549026 & 688128 & 4.6 & 4.6483 & TRN & \\
\hline CHEMBL1471160 & 688128 & 5.05 & 4.6062 & TST & \\
\hline CHEMBL1565978 & 688128 & 4.3 & 4.6661 & TST & \\
\hline CHEMBL1448342 & 688128 & 4.7 & 4.3903 & TRN & \\
\hline CHEMBL1328412 & 688128 & 4.35 & 4.6516 & TST & \\
\hline CHEMBL1537509 & 688128 & 4.35 & 4.1181 & TST & \\
\hline CHEMBL1389480 & 688128 & 4.3 & 5.1425 & TRN & \\
\hline CHEMBL1429019 & 688128 & 4.4 & 4.7252 & TST & \\
\hline CHEMBL1309228 & 688128 & 5.85 & 5.1728 & TRN & \\
\hline CHEMBL1461421 & 688128 & 4.35 & 4.526 & TRN & \\
\hline CHEMBL1490133 & 688128 & 6.0 & 4.4241 & TRN & \\
\hline CHEMBL1387348 & 688128 & 4.4 & 4.743 & TST & \\
\hline CHEMBL1532552 & 688128 & 4.4 & 4.5426 & TST & \\
\hline CHEMBL1331405 & 688128 & 5.35 & 4.7158 & TRN & \\
\hline CHEMBL1479939 & 688128 & 5.5 & 4.5686 & TRN & \\
\hline CHEMBL1449794 & 688128 & 5.95 & 5.2841 & TRN & \\
\hline CHEMBL1496467 & 688128 & 6.0 & 4.65306 & 00000000005 & TRN \\
\hline & & & & 16139 & \\
\hline
\end{tabular}




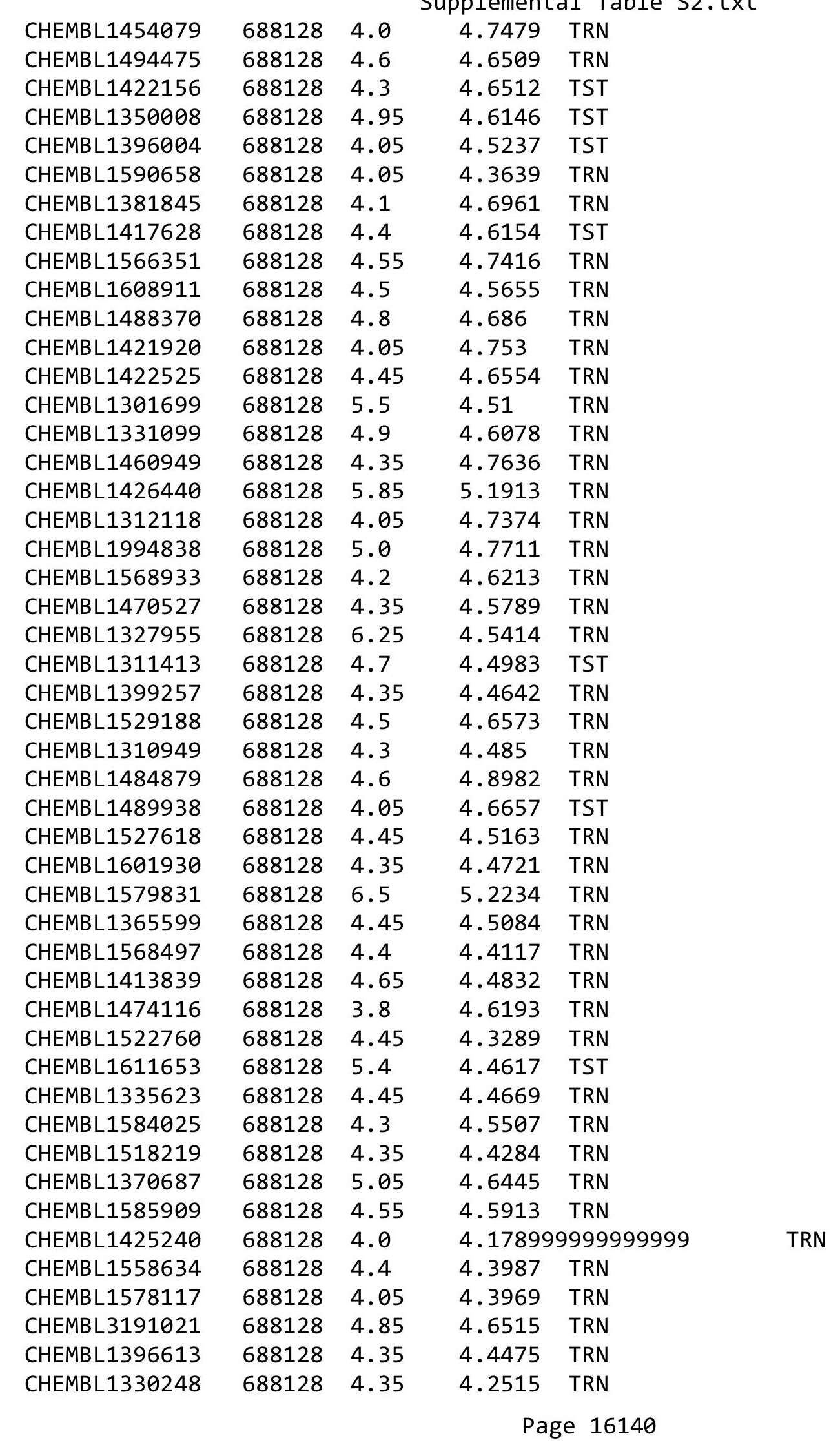




\begin{tabular}{|c|c|c|c|c|}
\hline \multicolumn{5}{|c|}{ Supplemental Table S2.txt } \\
\hline CHEMBL 3193380 & 688128 & 4.35 & 4.5533 & TST \\
\hline CHEMBL1597496 & 688128 & 4.45 & 4.7003 & TRN \\
\hline CHEMBL1440458 & 688128 & 4.05 & 4.3991 & TST \\
\hline CHEMBL1310960 & 688128 & 4.3 & 4.7244 & TRN \\
\hline CHEMBL1464418 & 688128 & 4.7 & 4.4756 & TRN \\
\hline CHEMBL1362470 & 688128 & 5.35 & 4.7136 & TRN \\
\hline CHEMBL1568022 & 688128 & 4.9 & 4.8778 & TRN \\
\hline CHEMBL1557745 & 688128 & 4.45 & 4.5019 & TRN \\
\hline CHEMBL 2373600 & 688128 & 4.95 & 4.8363 & TRN \\
\hline CHEMBL1374665 & 688128 & 4.4 & 4.8738 & TRN \\
\hline CHEMBL1511665 & 688128 & 4.7 & 4.6569 & TRN \\
\hline CHEMBL1451661 & 688128 & 4.65 & 4.6015 & TRN \\
\hline CHEMBL3208912 & 688128 & 6.05 & 4.7205 & TST \\
\hline CHEMBL 3194532 & 688128 & 4.4 & 4.7428 & TST \\
\hline CHEMBL1421843 & 688128 & 4.05 & 4.7214 & TST \\
\hline CHEMBL1462747 & 688128 & 4.25 & 4.3809 & TST \\
\hline CHEMBL1610250 & 688128 & 5.35 & 4.6784 & TST \\
\hline CHEMBL1521073 & 688128 & 4.85 & 4.6919 & TRN \\
\hline CHEMBL1530755 & 688128 & 4.65 & 4.6873 & TRN \\
\hline CHEMBL1497189 & 688128 & 4.0 & 4.7458 & TRN \\
\hline CHEMBL1358929 & 688128 & 4.4 & 4.2734 & TRN \\
\hline CHEMBL1575174 & 688128 & 5.15 & 4.5293 & TRN \\
\hline CHEMBL1410547 & 688128 & 4.55 & 4.4944 & TRN \\
\hline CHEMBL1485040 & 688128 & 4.45 & 4.6236 & TRN \\
\hline CHEMBL1578851 & 688128 & 4.5 & 4.3744 & TRN \\
\hline CHEMBL1442936 & 688128 & 4.3 & 4.6248 & TRN \\
\hline CHEMBL1537624 & 688128 & 4.35 & 4.625 & TRN \\
\hline CHEMBL1311354 & 688128 & 4.3 & 4.4558 & TRN \\
\hline CHEMBL1310941 & 688128 & 4.05 & 4.6821 & TRN \\
\hline CHEMBL1421775 & 688128 & 4.0 & 4.6848 & TST \\
\hline CHEMBL1306943 & 688128 & 5.7 & 4.8394 & TRN \\
\hline CHEMBL1333249 & 688128 & 5.05 & 4.954 & TRN \\
\hline CHEMBL1542194 & 688128 & 4.9 & 4.6759 & TRN \\
\hline CHEMBL1397001 & 688128 & 5.45 & 4.4113 & TRN \\
\hline CHEMBL1451897 & 688128 & 4.45 & 4.5813 & TRN \\
\hline CHEMBL1538020 & 688128 & 4.75 & 4.6294 & TRN \\
\hline CHEMBL1391614 & 688128 & 5.6 & 4.5081 & TST \\
\hline CHEMBL1406251 & 688128 & 4.1 & 4.6808 & TRN \\
\hline CHEMBL1454022 & 688128 & 4.75 & 4.6732 & TRN \\
\hline CHEMBL1443983 & 688128 & 4.75 & 4.4321 & TRN \\
\hline CHEMBL1362634 & 688128 & 4.3 & 4.5507 & TST \\
\hline CHEMBL1420823 & 688128 & 4.35 & 4.6207 & TRN \\
\hline CHEMBL1510317 & 688128 & 5.9 & 4.6526 & TST \\
\hline CHEMBL3190162 & 688128 & 4.4 & 4.5717 & TRN \\
\hline CHEMBL1369236 & 688128 & 6.15 & 4.9742 & TST \\
\hline CHEMBL1521853 & 688128 & 4.7 & 4.7362 & TST \\
\hline CHEMBL1413053 & 688128 & 5.2 & 4.8027 & TST \\
\hline CHEMBL1308988 & 688128 & 4.05 & 4.3609 & TST \\
\hline
\end{tabular}




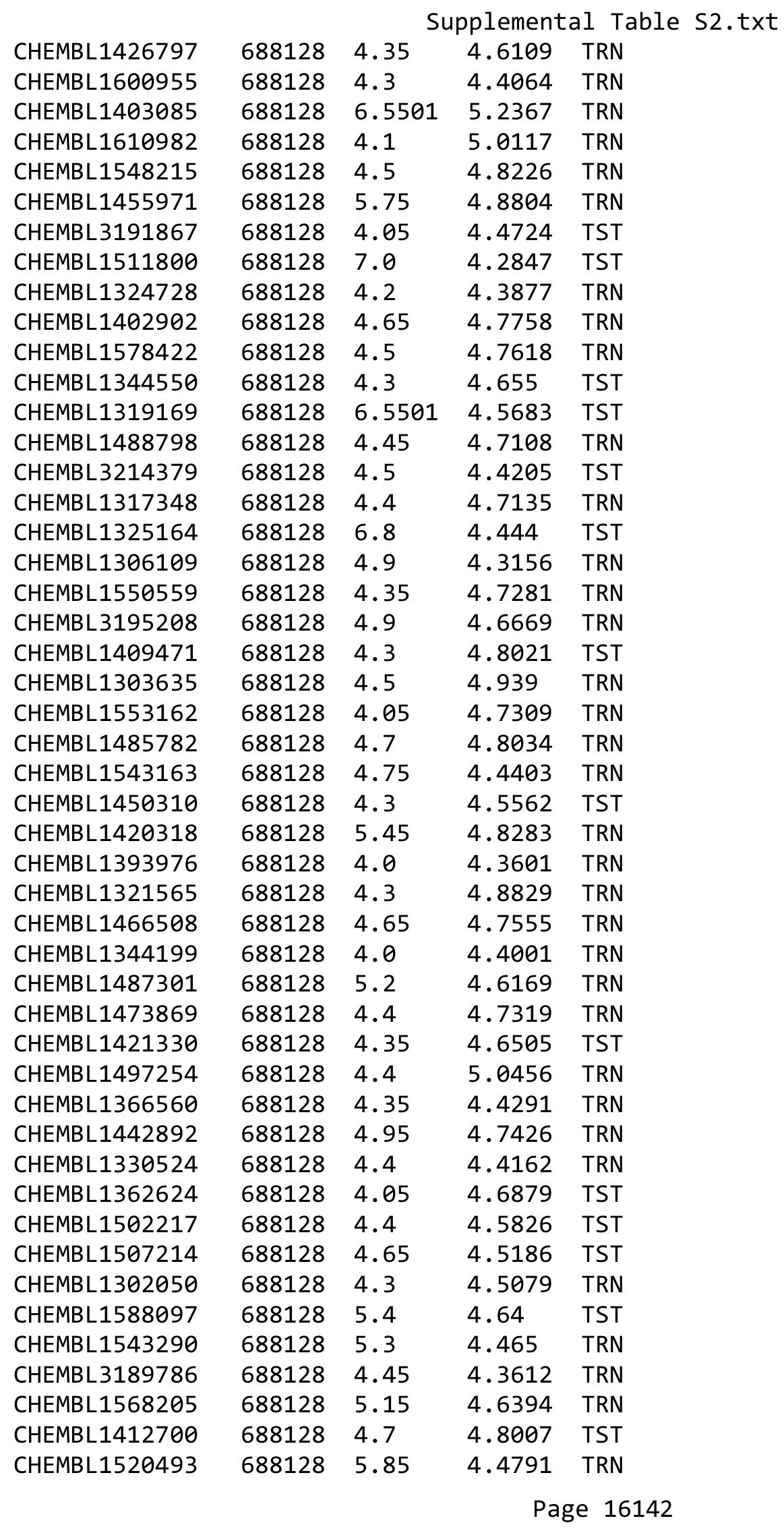




\begin{tabular}{|c|c|c|c|c|c|}
\hline \\
\hline CHEMBL1361769 & 688128 & 4.9 & 4.4437 & TST & \\
\hline CHEMBL1400912 & 688128 & 4.35 & 4.605 & TRN & \\
\hline CHEMBL1498759 & 688128 & 4.3 & 4.6001 & TRN & \\
\hline CHEMBL3190693 & 688128 & 4.05 & 4.7574 & TRN & \\
\hline CHEMBL1556391 & 688128 & 7.0 & 4.7142 & TST & \\
\hline CHEMBL1334378 & 688128 & 4.35 & 4.7888 & TST & \\
\hline CHEMBL1313485 & 688128 & 5.65 & 4.9261 & TRN & \\
\hline CHEMBL1329978 & 688128 & 4.05 & 4.5692 & TST & \\
\hline CHEMBL1559262 & 688128 & 4.35 & 4.5822 & TST & \\
\hline CHEMBL3211365 & 688128 & 4.35 & 4.703 & TRN & \\
\hline CHEMBL1330684 & 688128 & 5.6 & 4.7674 & TRN & \\
\hline CHEMBL1451978 & 688128 & 4.4 & 4.3469 & TRN & \\
\hline CHEMBL1584629 & 688128 & 4.75 & 4.30699 & 99999999995 & TRN \\
\hline CHEMBL1414794 & 688128 & 4.35 & 4.5614 & TRN & \\
\hline CHEMBL1481358 & 688128 & 4.3 & 4.6435 & TRN & \\
\hline CHEMBL3392041 & 688128 & 4.3 & 4.492 & TRN & \\
\hline CHEMBL1490935 & 688128 & 6.3 & 4.9497 & TRN & \\
\hline CHEMBL1565747 & 688128 & 4.95 & 4.7721 & TRN & \\
\hline CHEMBL1520241 & 688128 & 5.05 & 4.9141 & TST & \\
\hline CHEMBL1579189 & 688128 & 4.4 & 4.2484 & TST & \\
\hline CHEMBL1556744 & 688128 & 4.3 & 4.5323 & TRN & \\
\hline CHEMBL1315971 & 688128 & 4.35 & 4.6472 & TRN & \\
\hline CHEMBL1502229 & 688128 & 4.45 & 5.1144 & TST & \\
\hline CHEMBL1446317 & 688128 & 4.4 & 4.5708 & TRN & \\
\hline CHEMBL1429940 & 688128 & 4.85 & 4.4544 & TRN & \\
\hline CHEMBL1467324 & 688128 & 4.55 & 4.3471 & TRN & \\
\hline CHEMBL1372883 & 688128 & 4.45 & 4.6169 & TRN & \\
\hline CHEMBL1554339 & 688128 & 4.1 & 4.5267 & TRN & \\
\hline CHEMBL1986545 & 688128 & 4.35 & 4.9806 & TST & \\
\hline CHEMBL1573672 & 688128 & 6.0 & 4.7815 & TRN & \\
\hline CHEMBL1602314 & 688128 & 4.8 & 4.9572 & TRN & \\
\hline CHEMBL1542188 & 688128 & 4.4 & 4.8935 & TRN & \\
\hline CHEMBL1549122 & 688128 & 4.85 & 4.5386 & TST & \\
\hline CHEMBL1317338 & 688128 & 4.3 & 4.6094 & TRN & \\
\hline CHEMBL1511173 & 688128 & 6.4 & 4.7601 & TST & \\
\hline CHEMBL588804 & 688128 & 4.9 & 5.5896 & TRN & \\
\hline CHEMBL1545651 & 688128 & 4.4 & 4.5925 & TST & \\
\hline CHEMBL1476600 & 688128 & 4.1 & 4.3899 & TRN & \\
\hline CHEMBL1430284 & 688128 & 4.4 & 4.6018 & TST & \\
\hline CHEMBL1472210 & 688128 & 6.2 & 4.9103 & TRN & \\
\hline CHEMBL1451343 & 688128 & 4.25 & 4.374 & TST & \\
\hline CHEMBL1354201 & 688128 & 4.6 & 4.6234 & TST & \\
\hline CHEMBL1988918 & 688128 & 4.35 & 4.6099 & TRN & \\
\hline CHEMBL1527305 & 688128 & 4.25 & 4.7926 & TRN & \\
\hline CHEMBL1350506 & 688128 & 4.4 & 4.8283 & TRN & \\
\hline CHEMBL1318229 & 688128 & 4.4 & 4.5712 & TRN & \\
\hline CHEMBL1364365 & 688128 & 4.3 & 4.5701 & TRN & \\
\hline CHEMBL1490574 & 688128 & 4.4 & 4.9648 & TST & \\
\hline & & & & 614 & \\
\hline
\end{tabular}




\begin{tabular}{|c|c|c|c|c|}
\hline \multicolumn{5}{|c|}{ Supplemental Table S2.txt } \\
\hline CHEMBL1415456 & 688128 & 4.3 & 4.3957 & TRN \\
\hline CHEMBL437571 & 688128 & 4.5 & 5.1619 & TRN \\
\hline CHEMBL1360315 & 688128 & 4.45 & 4.4412 & TRN \\
\hline CHEMBL1338972 & 688128 & 4.3 & 4.8723 & TRN \\
\hline CHEMBL1475794 & 688128 & 4.25 & 4.5415 & TRN \\
\hline CHEMBL1544497 & 688128 & 4.05 & 4.6456 & TRN \\
\hline CHEMBL1509782 & 688128 & 4.4 & 4.6313 & TRN \\
\hline CHEMBL1597329 & 688128 & 5.1 & 4.8595 & TRN \\
\hline CHEMBL1401560 & 688128 & 4.3 & 4.3181 & TRN \\
\hline CHEMBL1529141 & 688128 & 6.1 & 4.7346 & TST \\
\hline CHEMBL1301399 & 688128 & 4.0 & 4.4933 & TST \\
\hline CHEMBL1513283 & 688128 & 4.25 & 4.4869 & TRN \\
\hline CHEMBL1597479 & 688128 & 4.65 & 4.5908 & TRN \\
\hline CHEMBL1512146 & 688128 & 4.3 & 4.5432 & TST \\
\hline CHEMBL 3210244 & 688128 & 4.35 & 4.863 & TRN \\
\hline CHEMBL1503962 & 688128 & 4.3 & 4.3796 & TST \\
\hline CHEMBL1583483 & 688128 & 5.4 & 4.5897 & TST \\
\hline CHEMBL1503331 & 688128 & 4.25 & 4.1812 & TRN \\
\hline CHEMBL1530883 & 688128 & 6.0 & 5.0881 & TRN \\
\hline CHEMBL3195949 & 688128 & 5.0 & 4.8835 & TRN \\
\hline CHEMBL1347863 & 688128 & 4.4 & 4.5883 & TRN \\
\hline CHEMBL1332126 & 688128 & 5.8 & 4.8722 & TST \\
\hline CHEMBL1480814 & 688128 & 4.4 & 4.6582 & TRN \\
\hline CHEMBL1506302 & 688128 & 4.35 & 4.3186 & TRN \\
\hline CHEMBL1569842 & 688128 & 4.85 & 4.9033 & TST \\
\hline CHEMBL1556227 & 688128 & 4.05 & 4.6318 & TRN \\
\hline CHEMBL1591318 & 688128 & 4.35 & 4.7727 & TST \\
\hline CHEMBL1418643 & 688128 & 5.0 & 5.2358 & TRN \\
\hline CHEMBL1398142 & 688128 & 6.2 & 4.8561 & TRN \\
\hline CHEMBL1557856 & 688128 & 5.2 & 4.7624 & TST \\
\hline CHEMBL1373451 & 688128 & 4.3 & 4.6815 & TRN \\
\hline CHEMBL45245 & 688128 & 4.65 & 4.8418 & TST \\
\hline CHEMBL1548620 & 688128 & 4.05 & 4.397 & TRN \\
\hline CHEMBL1502310 & 688128 & 4.5 & 4.6039 & TRN \\
\hline CHEMBL1563412 & 688128 & 4.6 & 4.3876 & TRN \\
\hline CHEMBL1480107 & 688128 & 4.3 & 4.7421 & TRN \\
\hline CHEMBL1993993 & 688128 & 4.05 & 5.0985 & TST \\
\hline CHEMBL1533767 & 688128 & 4.85 & 5.0502 & TRN \\
\hline CHEMBL1496857 & 688128 & 6.4 & 5.2464 & TRN \\
\hline CHEMBL1500316 & 688128 & 6.7001 & 5.0977 & TST \\
\hline CHEMBL1509133 & 688128 & 4.05 & 4.7809 & TRN \\
\hline CHEMBL1407704 & 688128 & 4.35 & 4.435 & TST \\
\hline CHEMBL1309118 & 688128 & 4.45 & 4.553 & TRN \\
\hline CHEMBL1379653 & 688128 & 4.55 & 4.6733 & TRN \\
\hline CHEMBL1487753 & 688128 & 4.05 & 4.5893 & TST \\
\hline CHEMBL3197532 & 688128 & 4.85 & 4.5043 & TRN \\
\hline CHEMBL1535119 & 688128 & 4.8 & 4.3495 & TRN \\
\hline CHEMBL1601144 & 688128 & 5.15 & 4.681 & TST \\
\hline
\end{tabular}




\begin{tabular}{|c|c|c|c|c|c|}
\hline & & \multicolumn{4}{|c|}{ Supplemental Table s2.txt } \\
\hline CHEMBL1365618 & 688128 & 4.25 & 4.7513 & TRN & \\
\hline CHEMBL1360568 & 688128 & 4.1 & 4.8301 & TST & \\
\hline CHEMBL1303009 & 688128 & 4.4 & 4.6715 & TST & \\
\hline CHEMBL1592421 & 688128 & 4.4 & 4.6544 & TST & \\
\hline CHEMBL1510325 & 688128 & 4.4 & 4.4632 & TRN & \\
\hline CHEMBL1480706 & 688128 & 4.45 & 4.7294 & TRN & \\
\hline CHEMBL1572734 & 688128 & 4.05 & 4.5171 & TRN & \\
\hline CHEMBL 3198510 & 688128 & 4.4 & 4.675 & TRN & \\
\hline CHEMBL1455769 & 688128 & 4.75 & 4.6221 & TRN & \\
\hline CHEMBL1610680 & 688128 & 4.2 & 4.6663 & TRN & \\
\hline CHEMBL1515977 & 688128 & 5.1 & 4.4256 & TRN & \\
\hline CHEMBL1382804 & 688128 & 4.65 & 4.7797 & TRN & \\
\hline CHEMBL1331441 & 688128 & 5.1 & 4.6623 & TRN & \\
\hline CHEMBL1513385 & 688128 & 4.05 & 4.6172 & TRN & \\
\hline CHEMBL1463892 & 688128 & 4.9 & 4.5387 & TST & \\
\hline CHEMBL1479442 & 688128 & 4.35 & 4.3174 & TRN & \\
\hline CHEMBL1571810 & 688128 & 4.0 & 4.6528 & TRN & \\
\hline CHEMBL1302241 & 688128 & 4.45 & 4.5533 & TST & \\
\hline CHEMBL1512430 & 688128 & 4.3 & 4.652 & TRN & \\
\hline CHEMBL1413287 & 688128 & 4.5 & 4.49100 & 00000000005 & TST \\
\hline CHEMBL1507710 & 688128 & 4.35 & 4.5275 & TRN & \\
\hline CHEMBL1375586 & 688128 & 4.05 & 4.6521 & TRN & \\
\hline CHEMBL1541230 & 688128 & 4.6 & 4.3782 & TRN & \\
\hline CHEMBL1389029 & 688128 & 4.3 & 4.4048 & TRN & \\
\hline CHEMBL1606756 & 688128 & 4.25 & 4.4283 & TRN & \\
\hline CHEMBL1302858 & 688128 & 4.35 & 4.6153 & TRN & \\
\hline CHEMBL1412013 & 688128 & 6.6 & 5.3687 & TRN & \\
\hline CHEMBL1502154 & 688128 & 4.05 & 4.8983 & TRN & \\
\hline CHEMBL1547391 & 688128 & 4.4 & 4.5432 & TRN & \\
\hline CHEMBL 1416087 & 688128 & 4.05 & 4.5652 & TST & \\
\hline CHEMBL1374550 & 688128 & 4.55 & 4.6894 & TRN & \\
\hline CHEMBL1429003 & 688128 & 4.3 & 4.8465 & TRN & \\
\hline CHEMBL1533269 & 688128 & 4.8 & 4.481 & TRN & \\
\hline CHEMBL1520174 & 688128 & 4.3 & 4.4554 & TRN & \\
\hline CHEMBL1487662 & 688128 & 4.5 & 4.7243 & TRN & \\
\hline CHEMBL1539100 & 688128 & 5.5 & 4.648 & TST & \\
\hline CHEMBL1585274 & 688128 & 4.05 & 4.7466 & TRN & \\
\hline CHEMBL465081 & 688128 & 4.8 & 4.1847 & TST & \\
\hline CHEMBL1335068 & 688128 & 4.55 & 4.694 & TRN & \\
\hline CHEMBL1578248 & 688128 & 4.05 & 4.4051 & TRN & \\
\hline CHEMBL1341086 & 688128 & 5.55 & 4.6827 & TST & \\
\hline CHEMBL1477288 & 688128 & 5.0 & 4.5167 & TST & \\
\hline CHEMBL1321634 & 688128 & 4.1 & 4.452 & TRN & \\
\hline CHEMBL1609609 & 688128 & 4.85 & 4.4837 & TRN & \\
\hline CHEMBL1438514 & 688128 & 4.85 & 4.5774 & TRN & \\
\hline CHEMBL1553074 & 688128 & 5.1 & 4.7693 & TST & \\
\hline CHEMBL1578703 & 688128 & 4.4 & 4.5645 & TST & \\
\hline CHEMBL1599480 & 688128 & 4.15 & 4.455 & TRN & \\
\hline
\end{tabular}




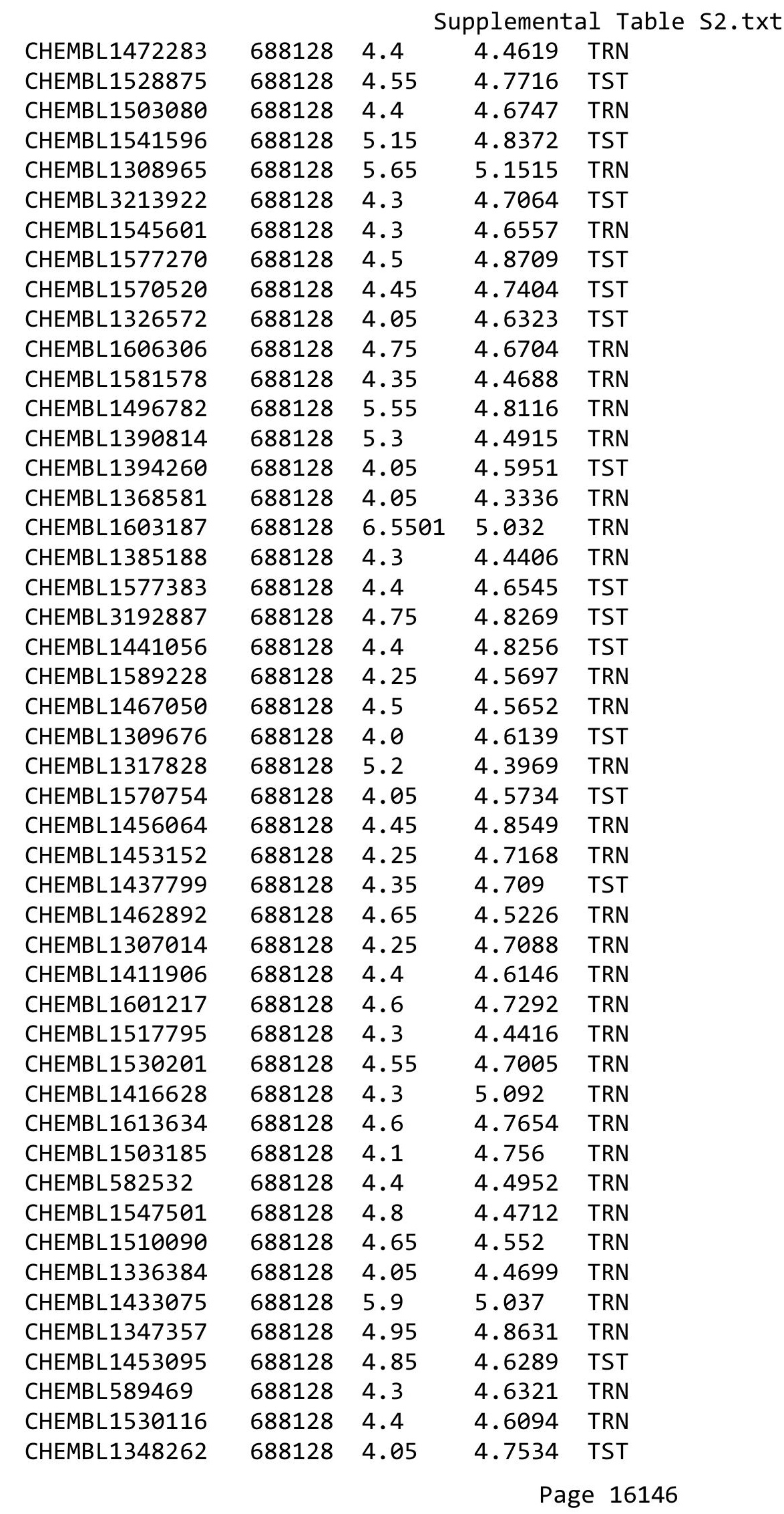




\begin{tabular}{|c|c|c|c|c|}
\hline \multicolumn{5}{|c|}{ Supplemental Table S2.txt } \\
\hline CHEMBL1564436 & 688128 & 4.45 & 4.4507 & TST \\
\hline CHEMBL1350353 & 688128 & 5.85 & 4.7412 & TRN \\
\hline CHEMBL1458687 & 688128 & 4.3 & 4.4559 & TRN \\
\hline CHEMBL1342094 & 688128 & 4.1 & 4.7007 & TST \\
\hline CHEMBL1479304 & 688128 & 4.4 & 4.9202 & TST \\
\hline CHEMBL1481627 & 688128 & 4.35 & 4.6682 & TST \\
\hline CHEMBL1602573 & 688128 & 5.0 & 4.5545 & TRN \\
\hline CHEMBL1475936 & 688128 & 6.1 & 4.4939 & TST \\
\hline CHEMBL1556793 & 688128 & 4.45 & 4.5839 & TRN \\
\hline CHEMBL1401342 & 688128 & 6.0 & 5.0887 & TST \\
\hline CHEMBL2374069 & 688128 & 5.15 & 5.0557 & TRN \\
\hline CHEMBL1466743 & 688128 & 4.35 & 4.4244 & TRN \\
\hline CHEMBL3191032 & 688128 & 4.6 & 4.6935 & TRN \\
\hline CHEMBL1319988 & 688128 & 4.1 & 4.1729 & TRN \\
\hline CHEMBL1416056 & 688128 & 4.3 & 4.9384 & TST \\
\hline CHEMBL1341098 & 688128 & 4.1 & 4.4068 & TRN \\
\hline CHEMBL1479288 & 688128 & 6.05 & 4.7263 & TRN \\
\hline CHEMBL1531400 & 688128 & 4.35 & 4.5499 & TRN \\
\hline CHEMBL1594820 & 688128 & 4.05 & 4.4031 & TST \\
\hline CHEMBL1493958 & 688128 & 4.95 & 4.3525 & TST \\
\hline CHEMBL1970641 & 688128 & 4.5 & 4.6888 & TRN \\
\hline CHEMBL1495378 & 688128 & 4.35 & 4.3941 & TRN \\
\hline CHEMBL1501890 & 688128 & 5.4 & 4.8477 & TRN \\
\hline CHEMBL 2002262 & 688128 & 4.75 & 4.4036 & TST \\
\hline CHEMBL1461418 & 688128 & 4.0 & 4.5221 & TRN \\
\hline CHEMBL1545810 & 688128 & 4.05 & 4.2807 & TRN \\
\hline CHEMBL1339600 & 688128 & 4.65 & 4.4475 & TST \\
\hline CHEMBL1348452 & 688128 & 4.3 & 4.8701 & TRN \\
\hline CHEMBL1447796 & 688128 & 6.05 & 4.748 & TST \\
\hline CHEMBL1538612 & 688128 & 4.3 & 4.3891 & TRN \\
\hline CHEMBL1577691 & 688128 & 4.35 & 4.629 & TRN \\
\hline CHEMBL1607585 & 688128 & 4.3 & 4.5869 & TRN \\
\hline CHEMBL1569989 & 688128 & 4.35 & 5.3012 & TRN \\
\hline CHEMBL3190664 & 688128 & 4.3 & 4.583 & TRN \\
\hline CHEMBL1388358 & 688128 & 4.85 & 4.9946 & TRN \\
\hline CHEMBL1502383 & 688128 & 4.05 & 4.4701 & TRN \\
\hline CHEMBL1472293 & 688128 & 4.35 & 4.7897 & TRN \\
\hline CHEMBL1603420 & 688128 & 4.4 & 4.5175 & TRN \\
\hline CHEMBL1333516 & 688128 & 6.2 & 5.1254 & TRN \\
\hline CHEMBL1610602 & 688128 & 4.35 & 5.0568 & TRN \\
\hline CHEMBL1559419 & 688128 & 4.3 & 4.5106 & TRN \\
\hline CHEMBL1968928 & 688128 & 6.25 & 4.9123 & TRN \\
\hline CHEMBL1334717 & 688128 & 4.55 & 4.8403 & TRN \\
\hline CHEMBL1605712 & 688128 & 4.3 & 4.4528 & TRN \\
\hline CHEMBL1436898 & 688128 & 5.05 & 4.8608 & TRN \\
\hline CHEMBL1503729 & 688128 & 5.45 & 5.3378 & TRN \\
\hline CHEMBL3198915 & 688128 & 4.3 & 4.6858 & TRN \\
\hline CHEMBL1486387 & 688128 & 4.3 & 4.5972 & TST \\
\hline
\end{tabular}




\begin{tabular}{|c|c|c|c|c|c|}
\hline & & \multicolumn{4}{|c|}{ Supplemental Table S2.txt } \\
\hline CHEMBL1496313 & 688128 & 5.55 & 4.8235 & TST & \\
\hline CHEMBL1344272 & 688128 & 5.6 & 4.4184 & TRN & \\
\hline CHEMBL1594490 & 688128 & 4.3 & 4.7737 & TST & \\
\hline CHEMBL1337197 & 688128 & 4.55 & 4.2927 & TRN & \\
\hline CHEMBL1524521 & 688128 & 4.45 & 4.4316 & TRN & \\
\hline CHEMBL1546902 & 688128 & 4.6 & 4.6396 & TRN & \\
\hline CHEMBL1421574 & 688128 & 5.05 & 4.7101 & TRN & \\
\hline CHEMBL1424266 & 688128 & 4.5 & 4.4213 & TST & \\
\hline CHEMBL1583803 & 688128 & 4.25 & 4.82100 & 0000000001 & TST \\
\hline CHEMBL1975975 & 688128 & 4.65 & 4.6413 & TRN & \\
\hline CHEMBL1611690 & 688128 & 5.35 & 4.8675 & TRN & \\
\hline CHEMBL1431490 & 688128 & 5.75 & 4.8474 & TRN & \\
\hline CHEMBL1504005 & 688128 & 4.65 & 4.6262 & TST & \\
\hline CHEMBL1583765 & 688128 & 4.4 & 4.5576 & TRN & \\
\hline CHEMBL1487546 & 688128 & 4.75 & 4.6802 & TRN & \\
\hline CHEMBL1518193 & 688128 & 4.05 & 4.7983 & TRN & \\
\hline CHEMBL1304072 & 688128 & 4.85 & 4.2539 & TRN & \\
\hline CHEMBL1478550 & 688128 & 4.3 & 4.7141 & TRN & \\
\hline CHEMBL1604917 & 688128 & 4.25 & 4.355 & TRN & \\
\hline CHEMBL1393529 & 688128 & 4.85 & 4.6061 & TRN & \\
\hline CHEMBL1543925 & 688128 & 4.6 & 4.3487 & TRN & \\
\hline CHEMBL1478700 & 688128 & 4.55 & 4.8772 & TRN & \\
\hline CHEMBL1329153 & 688128 & 4.45 & 4.18199 & 99999999995 & $1 \mathrm{kr}$ \\
\hline CHEMBL1333635 & 688128 & 4.25 & 4.8299 & TRN & \\
\hline CHEMBL1320393 & 688128 & 4.4 & 4.792 & TRN & \\
\hline CHEMBL1496387 & 688128 & 4.65 & 4.4946 & TRN & \\
\hline CHEMBL1367471 & 688128 & 4.05 & 4.5144 & TST & \\
\hline CHEMBL1572771 & 688128 & 4.35 & 4.5342 & TRN & \\
\hline CHEMBL 1446670 & 688128 & 4.4 & 4.5947 & TRN & \\
\hline CHEMBL1414033 & 688128 & 4.3 & 4.4975 & TRN & \\
\hline CHEMBL1499910 & 688128 & 4.95 & 4.8447 & TST & \\
\hline CHEMBL1332745 & 688128 & 5.85 & 4.9704 & TRN & \\
\hline CHEMBL1344264 & 688128 & 4.4 & 4.4331 & TRN & \\
\hline CHEMBL1359902 & 688128 & 5.9 & 5.1272 & TRN & \\
\hline CHEMBL1307625 & 688128 & 5.25 & 4.4374 & TRN & \\
\hline CHEMBL1518447 & 688128 & 4.3 & 4.5924 & TST & \\
\hline CHEMBL1405233 & 688128 & 6.0 & 4.8946 & TRN & \\
\hline CHEMBL1539010 & 688128 & 4.25 & 4.5585 & TRN & \\
\hline CHEMBL1546038 & 688128 & 4.55 & 4.7949 & TST & \\
\hline CHEMBL1381365 & 688128 & 4.35 & 4.3943 & TRN & \\
\hline CHEMBL1981008 & 688128 & 5.25 & 4.7351 & TRN & \\
\hline CHEMBL1444478 & 688128 & 4.0 & 4.5846 & TRN & \\
\hline CHEMBL3190570 & 688128 & 4.95 & 4.8038 & TRN & \\
\hline CHEMBL3208856 & 688128 & 4.25 & 4.6751 & TRN & \\
\hline CHEMBL3212424 & 688128 & 4.65 & 4.5661 & TST & \\
\hline CHEMBL1568118 & 688128 & 4.35 & 4.5025 & TRN & \\
\hline CHEMBL1310685 & 688128 & 4.6 & 4.5567 & TRN & \\
\hline CHEMBL1359949 & 688128 & 4.5 & 4.6967 & TRN & \\
\hline
\end{tabular}




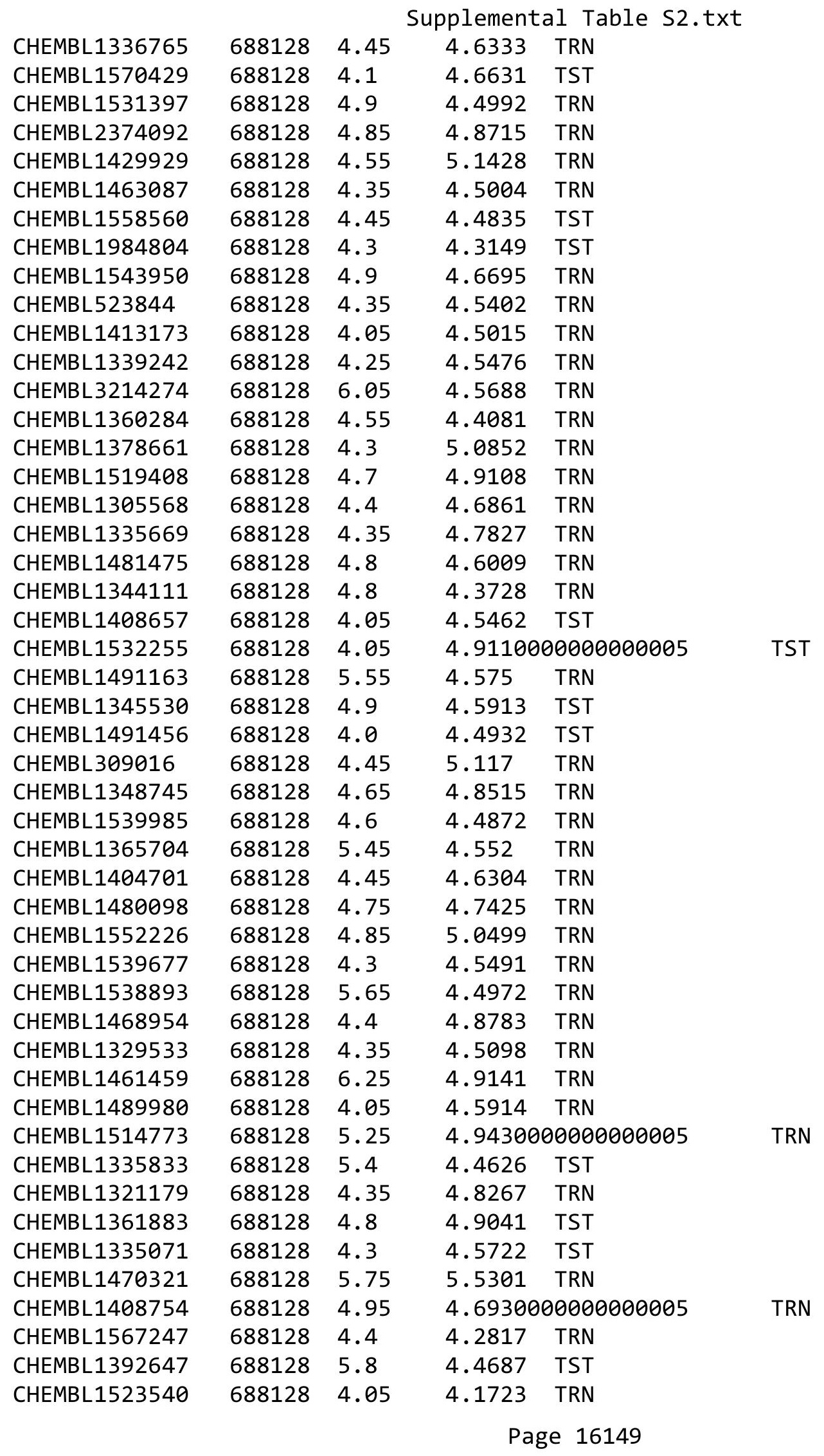




\begin{tabular}{|c|c|c|c|c|}
\hline \multicolumn{5}{|c|}{ Supplemental Table S2.txt } \\
\hline CHEMBL1601888 & 688128 & 5.65 & 4.8885 & TRN \\
\hline CHEMBL1540780 & 688128 & 4.75 & 4.7223 & TRN \\
\hline CHEMBL 3213748 & 688128 & 5.6 & 4.5382 & TST \\
\hline CHEMBL1383857 & 688128 & 4.65 & 4.5527 & TRN \\
\hline CHEMBL1393598 & 688128 & 4.95 & 4.8126 & TRN \\
\hline CHEMBL1544131 & 688128 & 5.2 & 5.1036 & TST \\
\hline CHEMBL1357297 & 688128 & 6.5 & 5.4396 & TRN \\
\hline CHEMBL1536991 & 688128 & 4.45 & 4.3532 & TRN \\
\hline CHEMBL1382392 & 688128 & 4.3 & 4.8244 & TRN \\
\hline CHEMBL1370269 & 688128 & 4.3 & 4.2871 & TRN \\
\hline CHEMBL1610182 & 688128 & 4.05 & 4.8976 & TRN \\
\hline CHEMBL1352112 & 688128 & 4.0 & 4.6712 & TRN \\
\hline CHEMBL1603683 & 688128 & 4.4 & 4.4695 & TRN \\
\hline CHEMBL 3208375 & 688128 & 4.4 & 4.6783 & TST \\
\hline CHEMBL1492663 & 688128 & 4.45 & 4.4137 & TRN \\
\hline CHEMBL1414811 & 688128 & 4.45 & 4.6925 & TRN \\
\hline CHEMBL1598963 & 688128 & 4.05 & 4.605 & TRN \\
\hline CHEMBL1375636 & 688128 & 4.3 & 4.8196 & TST \\
\hline CHEMBL1524618 & 688128 & 4.65 & 4.6134 & TRN \\
\hline CHEMBL1455144 & 688128 & 4.35 & 4.4757 & TST \\
\hline CHEMBL1379048 & 688128 & 4.25 & 4.7251 & TST \\
\hline CHEMBL1479976 & 688128 & 4.5 & 4.9168 & TRN \\
\hline CHEMBL1332698 & 688128 & 4.2 & 4.7616 & TRN \\
\hline CHEMBL1419333 & 688128 & 4.25 & 4.5941 & TRN \\
\hline CHEMBL1455245 & 688128 & 4.1 & 4.5285 & TRN \\
\hline CHEMBL1528674 & 688128 & 4.4 & 4.5526 & TRN \\
\hline CHEMBL1390268 & 688128 & 5.4 & 4.6178 & TST \\
\hline CHEMBL1370752 & 688128 & 4.35 & 4.7387 & TST \\
\hline CHEMBL1514478 & 688128 & 4.3 & 4.4262 & TRN \\
\hline CHEMBL1587156 & 688128 & 4.35 & 4.8756 & TRN \\
\hline CHEMBL1557079 & 688128 & 4.3 & 4.6555 & TRN \\
\hline CHEMBL1558151 & 688128 & 4.05 & 4.5803 & TRN \\
\hline CHEMBL1485655 & 688128 & 4.2 & 4.5142 & TRN \\
\hline CHEMBL1403339 & 688128 & 4.35 & 4.4832 & TRN \\
\hline CHEMBL1460699 & 688128 & 4.05 & 4.5674 & TST \\
\hline CHEMBL1444590 & 688128 & 4.3 & 4.6278 & TRN \\
\hline CHEMBL1515328 & 688128 & 4.05 & 4.5856 & TRN \\
\hline CHEMBL1552820 & 688128 & 5.45 & 4.4671 & TRN \\
\hline CHEMBL1870032 & 688128 & 5.4 & 4.5322 & TRN \\
\hline CHEMBL1441425 & 688128 & 4.35 & 4.5335 & TRN \\
\hline CHEMBL1548216 & 688128 & 4.5 & 4.6514 & TRN \\
\hline CHEMBL1380160 & 688128 & 4.55 & 4.3819 & TRN \\
\hline CHEMBL3211763 & 688128 & 4.4 & 4.5689 & TRN \\
\hline CHEMBL1456469 & 688128 & 4.4 & 4.5893 & TRN \\
\hline CHEMBL2095095 & 688128 & 4.3 & 5.4985 & TRN \\
\hline CHEMBL1304684 & 688128 & 4.6 & 5.0693 & TRN \\
\hline CHEMBL1392507 & 688128 & 4.3 & 4.5422 & TST \\
\hline CHEMBL1589914 & 688128 & 4.8 & 4.9382 & TST \\
\hline
\end{tabular}




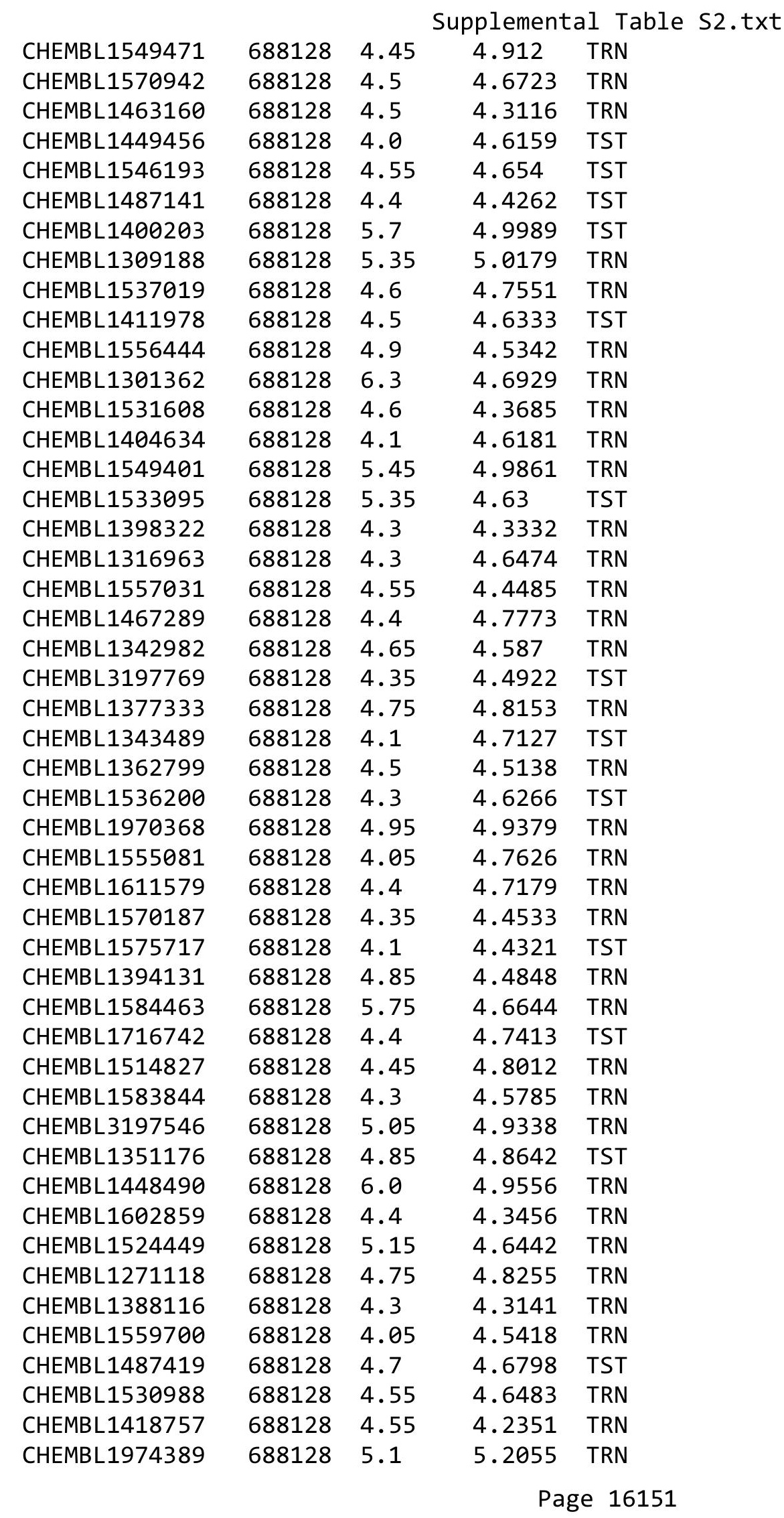




\begin{tabular}{|c|c|c|c|c|c|}
\hline & & \multicolumn{4}{|c|}{ Supplemental Table s2.txt } \\
\hline CHEMBL1305851 & 688128 & 4.05 & 4.4903 & TRN & \\
\hline CHEMBL1545206 & 688128 & 4.05 & 4.468 & TRN & \\
\hline CHEMBL1361964 & 688128 & 4.05 & 4.4841 & TRN & \\
\hline CHEMBL1329137 & 688128 & 4.4 & 4.6531 & TRN & \\
\hline CHEMBL1502599 & 688128 & 4.45 & 4.6182 & TRN & \\
\hline CHEMBL1324330 & 688128 & 4.3 & 4.3884 & TRN & \\
\hline CHEMBL1511625 & 688128 & 4.85 & 4.6556 & TST & \\
\hline CHEMBL1421256 & 688128 & 6.3 & 4.6836 & TRN & \\
\hline CHEMBL1580086 & 688128 & 4.05 & 4.6203 & TST & \\
\hline CHEMBL1557704 & 688128 & 4.35 & 4.9371 & TST & \\
\hline CHEMBL1443210 & 688128 & 5.1 & 4.8213 & TRN & \\
\hline CHEMBL 3199678 & 688128 & 4.05 & 4.7331 & TST & \\
\hline CHEMBL1382166 & 688128 & 5.4 & 4.6314 & TRN & \\
\hline CHEMBL1490449 & 688128 & 4.7 & 4.8578 & TRN & \\
\hline CHEMBL1584977 & 688128 & 4.65 & 5.0249 & TST & \\
\hline CHEMBL1333487 & 688128 & 5.05 & 4.8914 & TST & \\
\hline CHEMBL1546614 & 688128 & 4.05 & 4.5458 & TST & \\
\hline CHEMBL3197022 & 688128 & 4.5 & 4.6493 & TRN & \\
\hline CHEMBL1574207 & 688128 & 4.05 & 4.3984 & TRN & \\
\hline CHEMBL1575982 & 688128 & 4.35 & 4.4091 & TRN & \\
\hline CHEMBL1612519 & 688128 & 4.35 & 4.7486 & TST & \\
\hline CHEMBL1321078 & 688128 & 4.6 & 4.6735 & TST & \\
\hline CHEMBL1393061 & 688128 & 4.65 & 4.5152 & TST & \\
\hline CHEMBL602807 & 688128 & 5.25 & 4.9534 & TRN & \\
\hline CHEMBL1444119 & 688128 & 4.35 & 4.5297 & TST & \\
\hline CHEMBL1522563 & 688128 & 4.5 & 4.6553 & TST & \\
\hline CHEMBL1482975 & 688128 & 5.15 & 4.5949 & TRN & \\
\hline CHEMBL1303510 & 688128 & 6.0 & 4.4756 & TST & \\
\hline CHEMBL1564248 & 688128 & 4.4 & 4.4504 & TRN & \\
\hline CHEMBL1587831 & 688128 & 4.85 & 4.6083 & TST & \\
\hline CHEMBL1357964 & 688128 & 4.05 & 4.6317 & TST & \\
\hline CHEMBL1423558 & 688128 & 4.85 & 4.9563 & TRN & \\
\hline CHEMBL1470236 & 688128 & 4.3 & 4.635 & TRN & \\
\hline CHEMBL1546840 & 688128 & 4.3 & 4.5507 & TRN & \\
\hline CHEMBL1487808 & 688128 & 5.1 & 4.6957 & TST & \\
\hline CHEMBL1490563 & 688128 & 5.15 & 4.7838 & TRN & \\
\hline CHEMBL1531543 & 688128 & 4.55 & 4.70100 & 00000000005 & TST \\
\hline CHEMBL1590361 & 688128 & 4.3 & 4.5184 & TST & \\
\hline CHEMBL1474548 & 688128 & 4.5 & 4.6309 & TRN & \\
\hline CHEMBL1188078 & 688128 & 4.4 & 4.4313 & TST & \\
\hline CHEMBL1412196 & 688128 & 4.65 & 4.6807 & TRN & \\
\hline CHEMBL1534980 & 688128 & 4.4 & 4.59 & TRN & \\
\hline CHEMBL3196979 & 688128 & 4.3 & 4.5949 & TST & \\
\hline CHEMBL1549184 & 688128 & 4.6 & 4.4629 & TRN & \\
\hline CHEMBL1570865 & 688128 & 5.25 & 4.9825 & TRN & \\
\hline CHEMBL1554411 & 688128 & 5.4 & 4.7248 & TRN & \\
\hline CHEMBL3190849 & 688128 & 4.4 & 5.1508 & TRN & \\
\hline CHEMBL1570323 & 688128 & 4.85 & 4.4623 & TST & \\
\hline
\end{tabular}




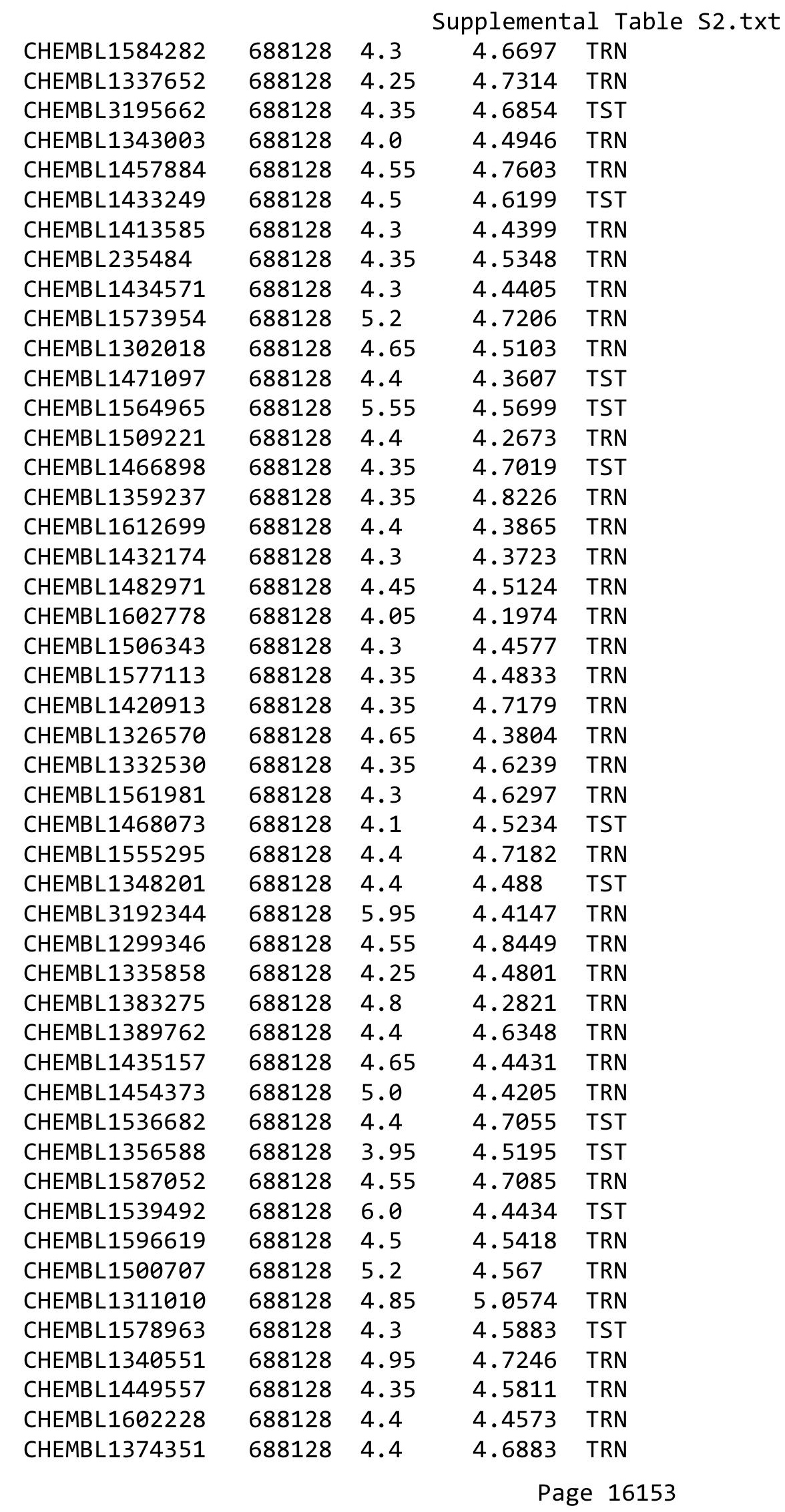




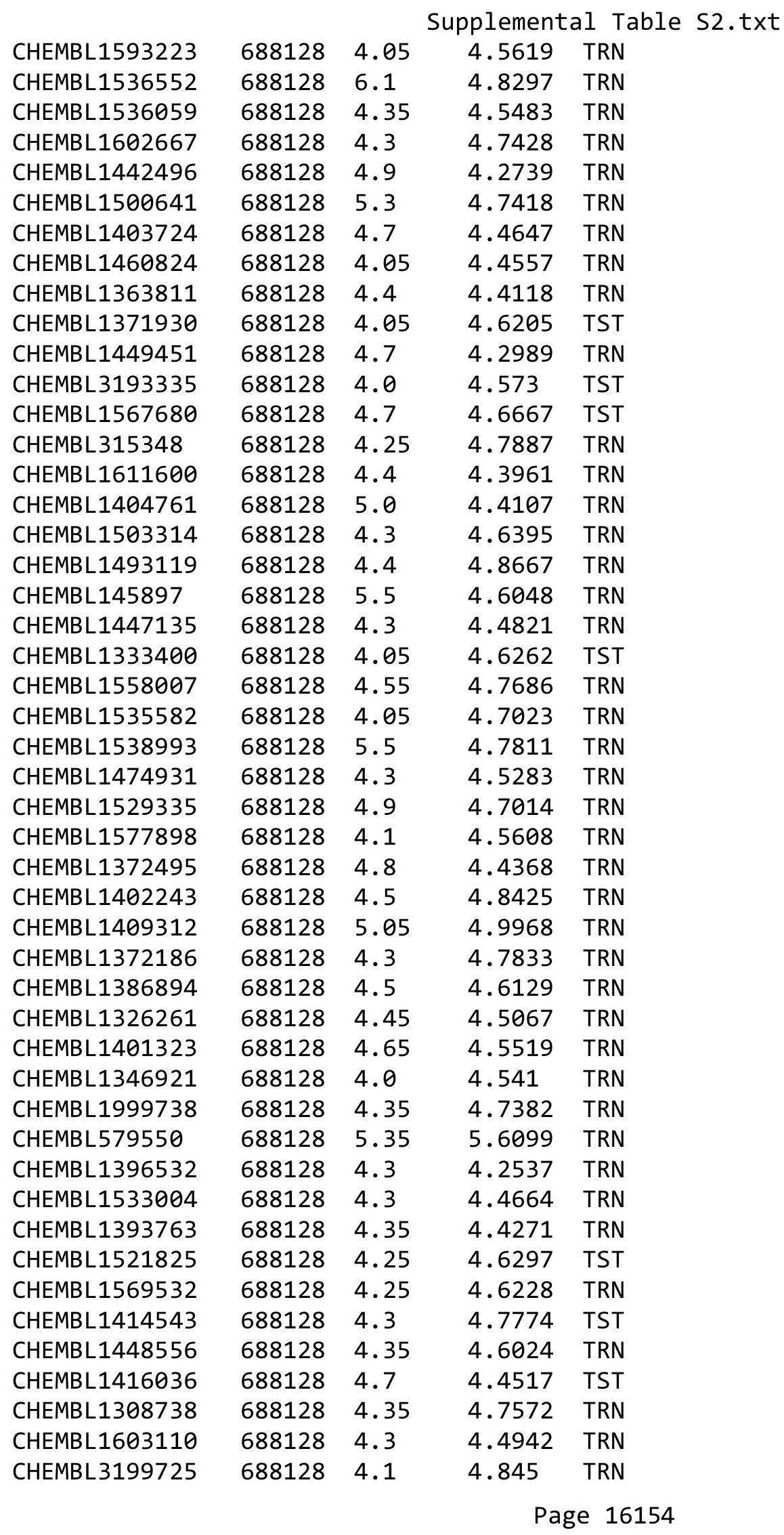




\begin{tabular}{|c|c|c|c|c|c|}
\hline & & \multicolumn{4}{|c|}{ Supplemental Table S2.txt } \\
\hline CHEMBL1419215 & 688128 & 4.4 & 4.7368 & TST & \\
\hline CHEMBL1562748 & 688128 & 4.8 & 4.9402 & TRN & \\
\hline CHEMBL1478653 & 688128 & 4.05 & 4.7913 & TST & \\
\hline CHEMBL1392812 & 688128 & 4.1 & 4.343 & TRN & \\
\hline CHEMBL1462615 & 688128 & 4.95 & 4.7399 & TRN & \\
\hline CHEMBL1328069 & 688128 & 4.3 & 4.6106 & TST & \\
\hline CHEMBL1377495 & 688128 & 4.4 & 4.3002 & TST & \\
\hline CHEMBL1394894 & 688128 & 5.4 & 4.6329 & TRN & \\
\hline CHEMBL1371747 & 688128 & 6.2 & 4.5945 & TST & \\
\hline CHEMBL1589834 & 688128 & 4.05 & 4.4086 & TST & \\
\hline CHEMBL1494500 & 688128 & 4.4 & 4.48300 & 00000000005 & TST \\
\hline CHEMBL1567659 & 688128 & 4.95 & 4.8859 & TST & \\
\hline CHEMBL1360941 & 688128 & 5.45 & 4.8022 & TRN & \\
\hline CHEMBL1362552 & 688128 & 5.6 & 5.0146 & TRN & \\
\hline CHEMBL1533103 & 688128 & 4.1 & 4.5184 & TRN & \\
\hline CHEMBL1613160 & 688128 & 4.45 & 4.7054 & TRN & \\
\hline CHEMBL1352875 & 688128 & 4.1 & 4.7294 & TST & \\
\hline CHEMBL1566610 & 688128 & 5.95 & 4.7968 & TRN & \\
\hline CHEMBL1473687 & 688128 & 4.45 & 4.3842 & TRN & \\
\hline CHEMBL1326943 & 688128 & 4.7 & 4.5435 & TRN & \\
\hline CHEMBL1506827 & 688128 & 4.4 & 4.7092 & TRN & \\
\hline CHEMBL1358847 & 688128 & 4.3 & 4.5112 & TRN & \\
\hline CHEMBL 2141452 & 688128 & 4.65 & 4.388 & TRN & \\
\hline CHEMBL1585796 & 688128 & 4.35 & 4.6232 & TST & \\
\hline CHEMBL1522492 & 688128 & 4.3 & 4.3636 & TRN & \\
\hline CHEMBL1449385 & 688128 & 4.4 & 4.603 & TRN & \\
\hline CHEMBL1534497 & 688128 & 4.35 & 4.8212 & TRN & \\
\hline CHEMBL1499557 & 688128 & 4.5 & 4.6804 & TRN & \\
\hline CHEMBL1369071 & 688128 & 4.4 & 4.8227 & TRN & \\
\hline CHEMBL1362206 & 688128 & 4.35 & 4.4079 & TRN & \\
\hline CHEMBL1505797 & 688128 & 4.3 & 4.3562 & TRN & \\
\hline CHEMBL1404090 & 688128 & 4.65 & 4.484 & TRN & \\
\hline CHEMBL1388398 & 688128 & 4.4 & 4.9355 & TRN & \\
\hline CHEMBL1378295 & 688128 & 5.55 & 4.8874 & TRN & \\
\hline CHEMBL3208216 & 688128 & 5.4 & 4.7392 & TRN & \\
\hline CHEMBL1477289 & 688128 & 4.55 & 4.6714 & TRN & \\
\hline CHEMBL1445697 & 688128 & 4.3 & 4.8312 & TST & \\
\hline CHEMBL1426881 & 688128 & 4.6 & 4.6782 & TRN & \\
\hline CHEMBL3197694 & 688128 & 5.75 & 4.7965 & TRN & \\
\hline CHEMBL1485466 & 688128 & 4.25 & 4.2599 & TRN & \\
\hline CHEMBL1447943 & 688128 & 4.1 & 4.843 & TRN & \\
\hline CHEMBL1392252 & 688128 & 4.3 & 4.6762 & TRN & \\
\hline CHEMBL1587011 & 688128 & 4.4 & 4.4403 & TRN & \\
\hline CHEMBL 2006431 & 688128 & 4.4 & 4.6215 & TRN & \\
\hline CHEMBL1484999 & 688128 & 4.05 & 4.4404 & TRN & \\
\hline CHEMBL1329521 & 688128 & 4.4 & 4.7064 & TRN & \\
\hline CHEMBL1338441 & 688128 & 5.1 & 4.433 & TST & \\
\hline CHEMBL1504373 & 688128 & 5.35 & 4.885 & TRN & \\
\hline
\end{tabular}




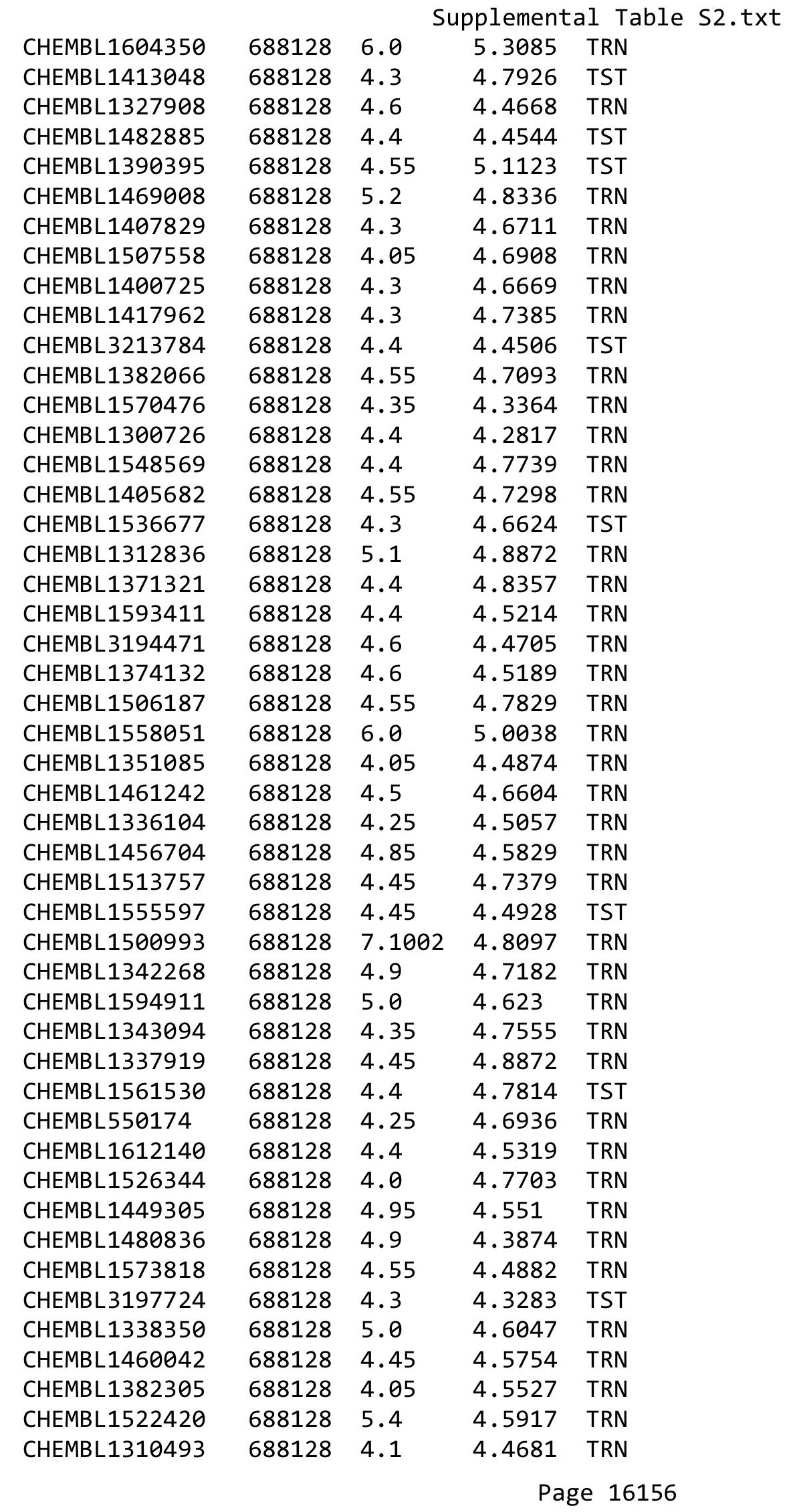




\begin{tabular}{|c|c|c|c|c|c|}
\hline \multicolumn{6}{|c|}{ Supplemental Table s2.txt } \\
\hline CHEMBL1316177 & 688128 & 4.4 & 4.6142 & TST & \\
\hline CHEMBL1381263 & 688128 & 4.35 & 4.4294 & TRN & \\
\hline CHEMBL1478753 & 688128 & 4.05 & 4.4842 & TRN & \\
\hline CHEMBL1481030 & 688128 & 4.95 & 4.8711 & TST & \\
\hline CHEMBL1453850 & 688128 & 4.3 & 4.6396 & TRN & \\
\hline CHEMBL1456026 & 688128 & 4.4 & 4.3749 & TRN & \\
\hline CHEMBL1494573 & 688128 & 4.7 & 4.2821 & TST & \\
\hline CHEMBL1412723 & 688128 & 4.5 & 4.5996 & TRN & \\
\hline CHEMBL1510249 & 688128 & 4.45 & 4.5331 & TST & \\
\hline CHEMBL1419341 & 688128 & 5.0 & 4.5616 & TRN & \\
\hline CHEMBL1371464 & 688128 & 4.55 & 4.9634 & TRN & \\
\hline CHEMBL1309382 & 688128 & 4.95 & $4.9910 e$ & 00000000005 & TRN \\
\hline CHEMBL1495692 & 688128 & 5.75 & 4.7893 & TRN & \\
\hline CHEMBL1453423 & 688128 & 4.35 & 4.5445 & TRN & \\
\hline CHEMBL572339 & 688128 & 4.0 & 4.8619 & TRN & \\
\hline CHEMBL1301096 & 688128 & 4.35 & 4.779 & TRN & \\
\hline CHEMBL1608152 & 688128 & 4.05 & 4.3705 & TRN & \\
\hline CHEMBL1361637 & 688128 & 4.3 & 4.5418 & TST & \\
\hline CHEMBL1589611 & 688128 & 4.5 & 4.5517 & TRN & \\
\hline CHEMBL1342141 & 688128 & 5.05 & 5.0774 & TST & \\
\hline CHEMBL1470562 & 688128 & 7.0 & 4.5464 & TST & \\
\hline CHEMBL1327479 & 688128 & 4.25 & 4.6985 & TRN & \\
\hline CHEMBL1305357 & 688128 & 4.25 & 4.7411 & TST & \\
\hline CHEMBL3197062 & 688128 & 4.0 & 4.51399 & 9999999999 & TRN \\
\hline CHEMBL1318099 & 688128 & 3.95 & 4.4344 & TRN & \\
\hline CHEMBL1335941 & 688128 & 4.35 & 4.8195 & TST & \\
\hline CHEMBL1458300 & 688128 & 4.35 & 4.2171 & TRN & \\
\hline CHEMBL3190330 & 688128 & 4.4 & 4.8252 & TRN & \\
\hline CHEMBL3191942 & 688128 & 6.0 & 4.7827 & TRN & \\
\hline CHEMBL1597039 & 688128 & 4.6 & 5.3362 & TRN & \\
\hline CHEMBL1575597 & 688128 & 5.05 & 4.7291 & TRN & \\
\hline CHEMBL3210583 & 688128 & 5.0 & 4.4898 & TRN & \\
\hline CHEMBL1464711 & 688128 & 4.25 & 4.9793 & TRN & \\
\hline CHEMBL1410534 & 688128 & 4.7 & 4.4428 & TRN & \\
\hline CHEMBL1589266 & 688128 & 4.5 & 4.5597 & TRN & \\
\hline CHEMBL1417287 & 688128 & 4.05 & 4.5269 & TRN & \\
\hline CHEMBL1410097 & 688128 & 4.65 & 4.5191 & TRN & \\
\hline CHEMBL1513322 & 688128 & 4.4 & 4.5423 & TRN & \\
\hline CHEMBL3211090 & 688128 & 6.05 & 4.7902 & TRN & \\
\hline CHEMBL1451903 & 688128 & 4.6 & 4.6285 & TST & \\
\hline CHEMBL1356901 & 688128 & 4.45 & 4.4869 & TRN & \\
\hline CHEMBL1999723 & 688128 & 5.75 & 4.9018 & TRN & \\
\hline CHEMBL1339921 & 688128 & 4.25 & 4.737 & TRN & \\
\hline CHEMBL1433358 & 688128 & 4.05 & 4.5765 & TRN & \\
\hline CHEMBL1413777 & 688128 & 4.25 & 4.5045 & TST & \\
\hline CHEMBL1492709 & 688128 & 6.1 & 4.7086 & TRN & \\
\hline CHEMBL1486475 & 688128 & 4.3 & 4.5341 & TRN & \\
\hline CHEMBL1498280 & 688128 & 4.4 & 4.4695 & TRN & \\
\hline
\end{tabular}




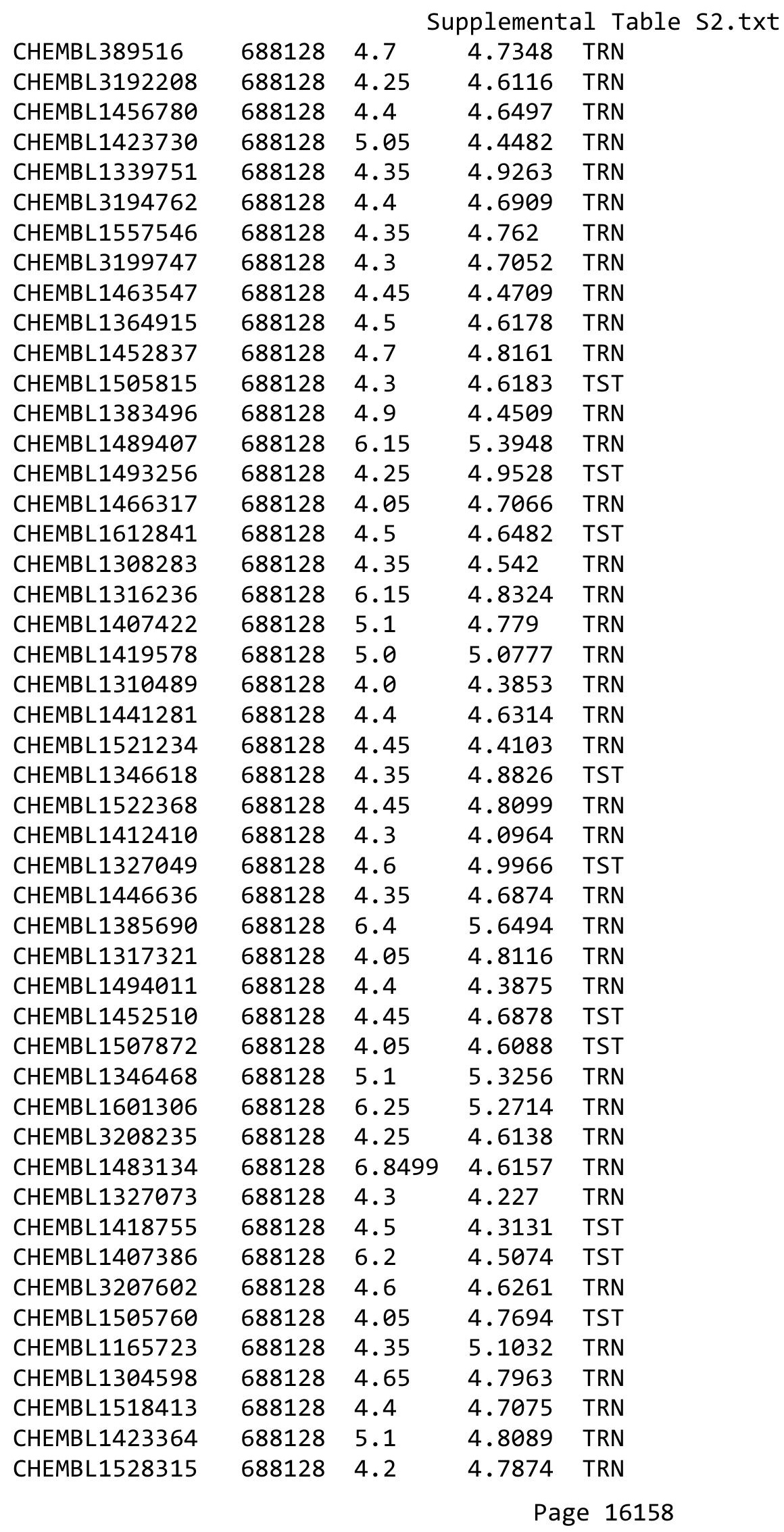




\begin{tabular}{|c|c|c|c|c|c|}
\hline & & \multicolumn{4}{|c|}{ Supplemental Table S2.txt } \\
\hline CHEMBL1430811 & 688128 & 5.3 & 4.768 & TRN & \\
\hline CHEMBL1420830 & 688128 & 4.5 & 4.7268 & TST & \\
\hline CHEMBL1548958 & 688128 & 4.0 & 4.9217 & TRN & \\
\hline CHEMBL1350063 & 688128 & 4.4 & 5.0138 & TRN & \\
\hline CHEMBL1478258 & 688128 & 4.65 & 4.617 & TRN & \\
\hline CHEMBL1409079 & 688128 & 6.0 & 5.0883 & TRN & \\
\hline CHEMBL1410091 & 688128 & 4.35 & 4.7626 & TRN & \\
\hline CHEMBL1526975 & 688128 & 4.3 & 4.5048 & TST & \\
\hline CHEMBL1504231 & 688128 & 4.4 & 4.8104 & TRN & \\
\hline CHEMBL1309899 & 688128 & 4.35 & 4.4416 & TST & \\
\hline CHEMBL1256674 & 688128 & 4.3 & 4.6835 & TST & \\
\hline CHEMBL1497608 & 688128 & 4.0 & 4.5341 & TST & \\
\hline CHEMBL1550509 & 688128 & 6.15 & 4.712 & TRN & \\
\hline CHEMBL229190 & 688128 & 5.25 & 4.7555 & TRN & \\
\hline CHEMBL1299822 & 688128 & 5.9 & 4.6917 & TRN & \\
\hline CHEMBL1543202 & 688128 & 4.4 & 4.4486 & TRN & \\
\hline CHEMBL1557520 & 688128 & 5.1 & 4.459 & TRN & \\
\hline CHEMBL90089 & 688128 & 5.55 & 5.1055 & TRN & \\
\hline CHEMBL1527410 & 688128 & 4.9 & 4.6319 & TRN & \\
\hline CHEMBL3190070 & 688128 & 4.4 & 4.5926 & TST & \\
\hline CHEMBL1331274 & 688128 & 5.75 & 4.6369 & TRN & \\
\hline CHEMBL1573495 & 688128 & 4.4 & 4.5807 & TST & \\
\hline CHEMBL1580464 & 688128 & 4.25 & 4.7974 & TRN & \\
\hline CHEMBL1471169 & 688128 & 4.3 & 4.8148 & TRN & \\
\hline CHEMBL1568850 & 688128 & 4.3 & 4.5525 & TRN & \\
\hline CHEMBL1575711 & 688128 & 4.25 & 4.7227 & TST & \\
\hline CHEMBL1334661 & 688128 & 4.05 & 4.5873 & TRN & \\
\hline CHEMBL1335787 & 688128 & 4.45 & 4.6144 & TRN & \\
\hline CHEMBL1520578 & 688128 & 4.3 & 4.3866 & TRN & \\
\hline CHEMBL1537542 & 688128 & 4.85 & $4.9910 e$ & 00000000005 & TRN \\
\hline CHEMBL1452473 & 688128 & 4.4 & 4.5755 & TST & \\
\hline CHEMBL1359862 & 688128 & 4.45 & 4.5346 & TRN & \\
\hline CHEMBL1570852 & 688128 & 4.4 & 4.7514 & TRN & \\
\hline CHEMBL1449349 & 688128 & 5.15 & 4.8278 & TST & \\
\hline CHEMBL1502461 & 688128 & 4.35 & 4.3806 & TRN & \\
\hline CHEMBL1390611 & 688128 & 4.25 & 4.3709 & TRN & \\
\hline CHEMBL1532515 & 688128 & 4.35 & 4.4065 & TRN & \\
\hline CHEMBL1379355 & 688128 & 4.6 & 4.6919 & TST & \\
\hline CHEMBL1978236 & 688128 & 4.5 & 5.0226 & TRN & \\
\hline CHEMBL1373619 & 688128 & 4.45 & 4.5273 & TRN & \\
\hline CHEMBL1485235 & 688128 & 4.0 & 4.9803 & TST & \\
\hline CHEMBL1354404 & 688128 & 4.9 & 4.7693 & TRN & \\
\hline CHEMBL1606605 & 688128 & 6.9 & 4.6645 & TST & \\
\hline CHEMBL2374091 & 688128 & 5.0 & 5.1931 & TRN & \\
\hline CHEMBL1490390 & 688128 & 4.35 & 4.4919 & TRN & \\
\hline CHEMBL1414512 & 688128 & 4.85 & 4.4516 & TRN & \\
\hline CHEMBL1392903 & 688128 & 5.4 & 4.4729 & TST & \\
\hline CHEMBL1342868 & 688128 & 5.5 & 4.7081 & TRN & \\
\hline
\end{tabular}




\begin{tabular}{|c|c|c|c|c|c|}
\hline & & \multicolumn{4}{|c|}{ Supplemental Table S2.txt } \\
\hline CHEMBL1539179 & 688128 & 6.15 & 4.7501 & TST & \\
\hline CHEMBL1308874 & 688128 & 4.25 & 4.7198 & TST & \\
\hline CHEMBL1526301 & 688128 & 4.3 & 4.3765 & TRN & \\
\hline CHEMBL1518362 & 688128 & 6.1 & 4.97199 & 99999999995 & TRN \\
\hline CHEMBL1452795 & 688128 & 4.55 & 4.9282 & TST & \\
\hline CHEMBL1563359 & 688128 & 4.6 & 4.6346 & TRN & \\
\hline CHEMBL1336127 & 688128 & 4.05 & 4.6417 & TRN & \\
\hline CHEMBL1407254 & 688128 & 5.6 & 4.7582 & TRN & \\
\hline CHEMBL1360917 & 688128 & 4.05 & 4.6069 & TRN & \\
\hline CHEMBL1342817 & 688128 & 4.35 & 4.7221 & TRN & \\
\hline CHEMBL1494093 & 688128 & 6.0 & 4.8623 & TRN & \\
\hline CHEMBL1419712 & 688128 & 4.7 & 4.8203 & TRN & \\
\hline CHEMBL1406708 & 688128 & 4.4 & 4.7635 & TST & \\
\hline CHEMBL1472252 & 688128 & 4.35 & 4.3559 & TRN & \\
\hline CHEMBL1504621 & 688128 & 4.65 & 4.855 & TST & \\
\hline CHEMBL1355363 & 688128 & 4.35 & 4.453 & TRN & \\
\hline CHEMBL1547820 & 688128 & 4.45 & 4.5678 & TRN & \\
\hline CHEMBL1450141 & 688128 & 4.35 & 4.4854 & TRN & \\
\hline CHEMBL1469135 & 688128 & 4.3 & 4.379 & TRN & \\
\hline CHEMBL1505705 & 688128 & 5.1 & 4.4464 & TRN & \\
\hline CHEMBL1504569 & 688128 & 6.5 & 5.4844 & TRN & \\
\hline CHEMBL1432825 & 688128 & 4.35 & 4.6361 & TRN & \\
\hline CHEMBL1377716 & 688128 & 4.35 & 4.7557 & TRN & \\
\hline CHEMBL1581608 & 688128 & 4.9 & 4.4003 & TRN & \\
\hline CHEMBL1542030 & 688128 & 5.25 & 4.5361 & TRN & \\
\hline CHEMBL3195802 & 688128 & 4.3 & 4.5499 & TRN & \\
\hline CHEMBL1440130 & 688128 & 4.35 & 4.5782 & TRN & \\
\hline CHEMBL1604931 & 688128 & 4.45 & 4.9437 & TRN & \\
\hline CHEMBL1530666 & 688128 & 4.3 & 4.6512 & TRN & \\
\hline CHEMBL3193247 & 688128 & 4.95 & 4.4352 & TST & \\
\hline CHEMBL1550069 & 688128 & 4.3 & 4.8457 & TRN & \\
\hline CHEMBL1434941 & 688128 & 4.7 & 4.5624 & TRN & \\
\hline CHEMBL1486227 & 688128 & 5.05 & 4.6335 & TST & \\
\hline CHEMBL1354807 & 688128 & 4.35 & 4.3721 & TRN & \\
\hline CHEMBL1435992 & 688128 & 4.05 & 4.1858 & TST & \\
\hline CHEMBL1327155 & 688128 & 4.3 & 4.5407 & TST & \\
\hline CHEMBL1586508 & 688128 & 4.25 & 4.7673 & TRN & \\
\hline CHEMBL1399622 & 688128 & 4.9 & 4.6456 & TRN & \\
\hline CHEMBL1970272 & 688128 & 4.55 & 4.7831 & TST & \\
\hline CHEMBL1364221 & 688128 & 6.5 & 5.30399 & 9999999999 & TRN \\
\hline CHEMBL1432915 & 688128 & 4.35 & 4.4869 & TRN & \\
\hline CHEMBL1299611 & 688128 & 4.15 & 4.4749 & TRN & \\
\hline CHEMBL1367414 & 688128 & 4.4 & 4.4457 & TRN & \\
\hline CHEMBL1300459 & 688128 & 4.6 & 5.1082 & TRN & \\
\hline CHEMBL1320433 & 688128 & 4.05 & 4.6173 & TST & \\
\hline CHEMBL1425414 & 688128 & 4.05 & 4.7104 & TST & \\
\hline CHEMBL1380050 & 688128 & 4.4 & 4.4898 & TRN & \\
\hline CHEMBL1587887 & 688128 & 4.6 & 4.6329 & TRN & \\
\hline
\end{tabular}




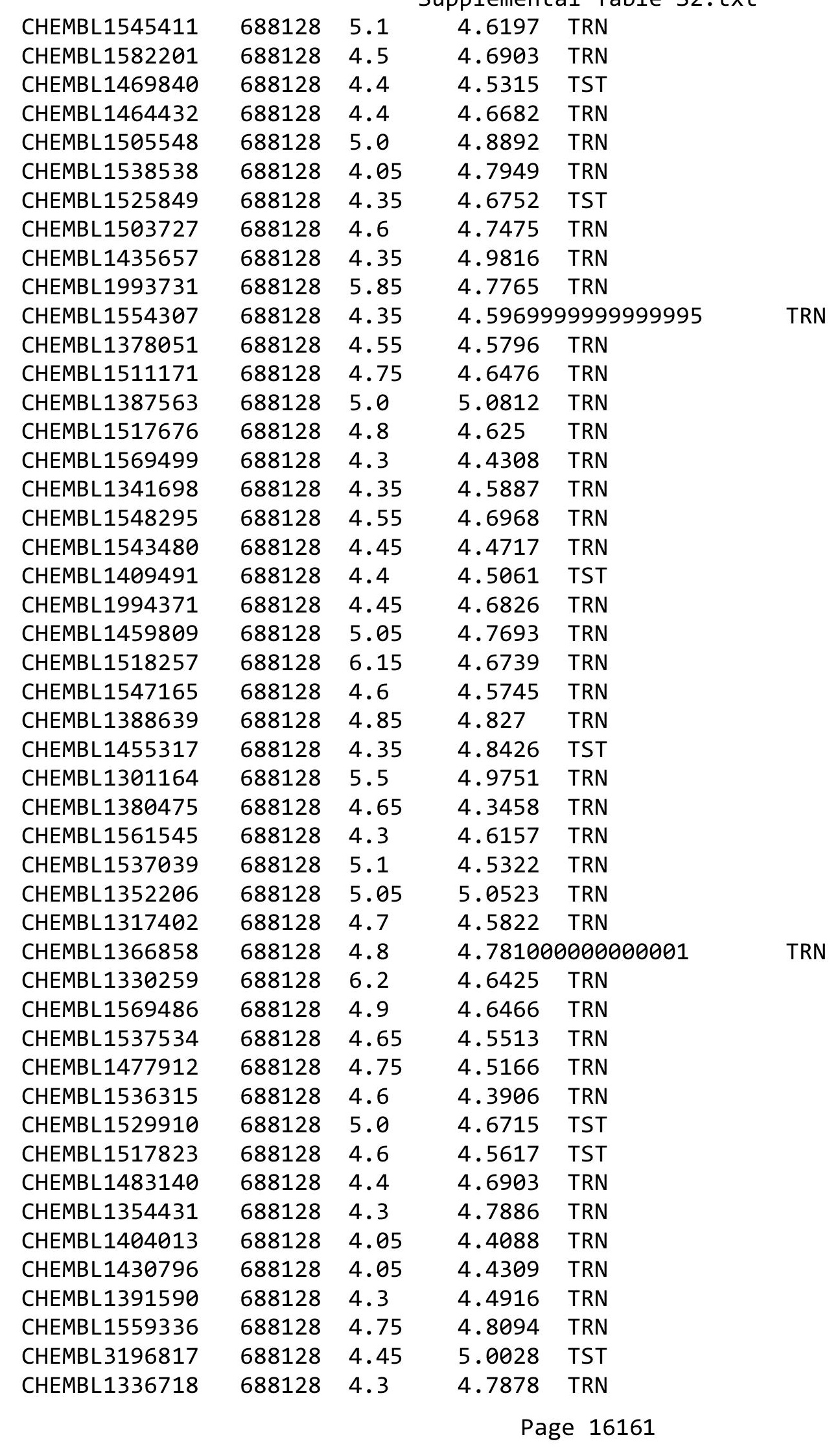




\begin{tabular}{|c|c|c|c|c|c|}
\hline & & \multicolumn{4}{|c|}{ Supplemental Table S2.txt } \\
\hline CHEMBL1580995 & 688128 & 4.35 & 4.6857 & TRN & \\
\hline CHEMBL1365360 & 688128 & 4.05 & 4.7991 & TST & \\
\hline CHEMBL1306126 & 688128 & 4.5 & 4.6505 & TST & \\
\hline CHEMBL1564329 & 688128 & 4.9 & 4.2431 & TRN & \\
\hline CHEMBL1332901 & 688128 & 4.45 & 4.5815 & TRN & \\
\hline CHEMBL1327494 & 688128 & 4.4 & 4.9976 & TRN & \\
\hline CHEMBL1576251 & 688128 & 4.3 & 4.3777 & TST & \\
\hline CHEMBL1466191 & 688128 & 4.65 & 4.7281 & TST & \\
\hline CHEMBL1319843 & 688128 & 4.35 & 4.4312 & TRN & \\
\hline CHEMBL1517745 & 688128 & 5.45 & 4.6124 & TST & \\
\hline CHEMBL1596795 & 688128 & 5.65 & 4.8313 & TRN & \\
\hline CHEMBL1511630 & 688128 & 4.45 & 4.8245 & TRN & \\
\hline CHEMBL1513220 & 688128 & 4.4 & 4.6836 & TST & \\
\hline CHEMBL1484525 & 688128 & 4.05 & 4.4054 & TRN & \\
\hline CHEMBL1436397 & 688128 & 4.85 & 4.58899 & 99999999995 & TRN \\
\hline CHEMBL1379471 & 688128 & 4.75 & 4.11 & TRN & \\
\hline CHEMBL1478304 & 688128 & 4.25 & 4.7012 & TRN & \\
\hline CHEMBL1403909 & 688128 & 4.0 & 4.4013 & TRN & \\
\hline CHEMBL1370205 & 688128 & 4.55 & 4.5736 & TRN & \\
\hline CHEMBL1327417 & 688128 & 6.2 & 4.8297 & TRN & \\
\hline CHEMBL1447495 & 688128 & 4.4 & 4.5689 & TST & \\
\hline CHEMBL1348688 & 688128 & 4.8 & 4.5749 & TRN & \\
\hline CHEMBL1337615 & 688128 & 4.25 & 4.5131 & TST & \\
\hline CHEMBL1529669 & 688128 & 4.3 & 4.4184 & TRN & \\
\hline CHEMBL490551 & 688128 & 5.5 & 4.727 & TRN & \\
\hline CHEMBL1456506 & 688128 & 4.05 & 4.6006 & TRN & \\
\hline CHEMBL1461220 & 688128 & 4.35 & 4.5475 & TRN & \\
\hline CHEMBL1489362 & 688128 & 5.15 & 4.6462 & TRN & \\
\hline CHEMBL1554461 & 688128 & 5.45 & 5.1485 & TRN & \\
\hline CHEMBL1523102 & 688128 & 4.6 & 4.5782 & TRN & \\
\hline CHEMBL1308710 & 688128 & 4.35 & 4.3569 & TRN & \\
\hline CHEMBL1356601 & 688128 & 4.3 & 4.3145 & TRN & \\
\hline CHEMBL1588411 & 688128 & 6.5 & 5.7987 & TRN & \\
\hline CHEMBL1448985 & 688128 & 5.9 & 5.0336 & TRN & \\
\hline CHEMBL1608791 & 688128 & 5.25 & 4.6281 & TRN & \\
\hline CHEMBL1536500 & 688128 & 4.4 & 4.8008 & TRN & \\
\hline CHEMBL1434651 & 688128 & 4.45 & 4.9627 & TRN & \\
\hline CHEMBL1388327 & 688128 & 4.9 & 4.6056 & TRN & \\
\hline CHEMBL1404677 & 688128 & 4.05 & 4.4607 & TRN & \\
\hline CHEMBL1507513 & 688128 & 4.3 & 4.6137 & TRN & \\
\hline CHEMBL1430895 & 688128 & 5.1 & 5.3316 & TRN & \\
\hline CHEMBL1351590 & 688128 & 4.4 & 4.3488 & TRN & \\
\hline CHEMBL1331429 & 688128 & 4.55 & 4.6286 & TRN & \\
\hline CHEMBL1444407 & 688128 & 4.65 & 4.6228 & TST & \\
\hline CHEMBL1506794 & 688128 & 4.05 & 4.7047 & TRN & \\
\hline CHEMBL1491243 & 688128 & 4.4 & 4.4671 & TST & \\
\hline CHEMBL1416210 & 688128 & 4.4 & 4.7549 & TST & \\
\hline CHEMBL3190263 & 688128 & 4.25 & 4.5066 & TRN & \\
\hline
\end{tabular}




\begin{tabular}{|c|c|c|c|c|c|}
\hline & & \multicolumn{4}{|c|}{ Supplemental Table S2.txt } \\
\hline CHEMBL1612743 & 688128 & 4.3 & 4.379 & TST & \\
\hline CHEMBL1427389 & 688128 & 4.7 & 4.564 & TRN & \\
\hline CHEMBL1326012 & 688128 & 4.35 & 4.9417 & TRN & \\
\hline CHEMBL1303456 & 688128 & 4.35 & 4.5743 & TRN & \\
\hline CHEMBL1472963 & 688128 & 5.4 & 4.814 & TRN & \\
\hline CHEMBL1430223 & 688128 & 3.95 & 4.6468 & TRN & \\
\hline CHEMBL1316496 & 688128 & 4.4 & 4.7045 & TST & \\
\hline CHEMBL 260148 & 688128 & 6.0 & 5.1751 & TRN & \\
\hline CHEMBL1511619 & 688128 & 4.25 & 4.4177 & TRN & \\
\hline CHEMBL1398190 & 688128 & 4.6 & 5.0722 & TRN & \\
\hline CHEMBL1541663 & 688128 & 4.1 & 4.6318 & TRN & \\
\hline CHEMBL1494034 & 688128 & 4.3 & 4.7975 & TRN & \\
\hline CHEMBL1389337 & 688128 & 4.0 & 4.5446 & TRN & \\
\hline CHEMBL1472082 & 688128 & 4.3 & 4.5469 & TRN & \\
\hline CHEMBL1609841 & 688128 & 6.15 & 5.0196 & TRN & \\
\hline CHEMBL1350071 & 688128 & 4.8 & 4.7798 & TRN & \\
\hline CHEMBL1509271 & 688128 & 5.0 & 4.50899 & 99999999995 & TST \\
\hline CHEMBL1508750 & 688128 & 4.35 & 4.8379 & TRN & \\
\hline CHEMBL1434399 & 688128 & 5.1 & 4.7956 & TRN & \\
\hline CHEMBL1584214 & 688128 & 4.45 & 4.7119 & TRN & \\
\hline CHEMBL1457535 & 688128 & 4.3 & 4.5546 & TRN & \\
\hline CHEMBL3199579 & 688128 & 4.35 & 4.4732 & TRN & \\
\hline CHEMBL1407849 & 688128 & 4.65 & 4.5203 & TST & \\
\hline CHEMBL1417686 & 688128 & 4.6 & 4.5769 & TRN & \\
\hline CHEMBL3211421 & 688128 & 4.3 & 4.7079 & TRN & \\
\hline CHEMBL1428889 & 688128 & 5.0 & 4.7394 & TRN & \\
\hline CHEMBL1424783 & 688128 & 4.55 & 4.8174 & TRN & \\
\hline CHEMBL1354860 & 688128 & 4.35 & 4.3505 & TRN & \\
\hline CHEMBL1537263 & 688128 & 6.0 & 4.9835 & TRN & \\
\hline CHEMBL3209226 & 688128 & 4.1 & 4.5703 & TRN & \\
\hline CHEMBL1369489 & 688128 & 4.3 & 4.4422 & TRN & \\
\hline CHEMBL1553583 & 688128 & 4.45 & 4.2656 & TRN & \\
\hline CHEMBL1389272 & 688128 & 4.35 & 4.58 & TRN & \\
\hline CHEMBL1532930 & 688128 & 4.35 & 4.705 & TRN & \\
\hline CHEMBL1429581 & 688128 & 5.2 & 4.5835 & TRN & \\
\hline CHEMBL1420038 & 688128 & 4.3 & 4.6646 & TST & \\
\hline CHEMBL1460614 & 688128 & 4.3 & 4.6825 & TRN & \\
\hline CHEMBL1392012 & 688128 & 4.3 & 4.5859 & TRN & \\
\hline CHEMBL1338527 & 688128 & 5.25 & 5.0854 & TRN & \\
\hline CHEMBL1595866 & 688128 & 4.9 & 4.6437 & TST & \\
\hline CHEMBL1322995 & 688128 & 4.5 & 5.2955 & TRN & \\
\hline CHEMBL1399683 & 688128 & 5.45 & 5.1872 & TRN & \\
\hline CHEMBL1533068 & 688128 & 4.3 & 4.4331 & TRN & \\
\hline CHEMBL1349230 & 688128 & 4.3 & 4.8994 & TRN & \\
\hline CHEMBL1449478 & 688128 & 4.45 & 4.3546 & TRN & \\
\hline CHEMBL1481914 & 688128 & 4.95 & 4.7487 & TRN & \\
\hline CHEMBL1517599 & 688128 & 5.1 & 4.789 & TRN & \\
\hline CHEMBL1414457 & 688128 & 4.95 & 4.8161 & TRN & \\
\hline
\end{tabular}




\begin{tabular}{|c|c|c|c|c|c|}
\hline \multirow{2}{*}{ CHEMBL1967540 } & \multirow{2}{*}{688128} & \\
\hline & & 4.35 & \multicolumn{2}{|c|}{4.531000000000001} & TRN \\
\hline CHEMBL1393648 & 688128 & 4.35 & 4.4767 & TRN & \\
\hline CHEMBL1369276 & 688128 & 4.25 & 4.596 & TRN & \\
\hline CHEMBL3194197 & 688128 & 4.75 & 4.8004 & TST & \\
\hline CHEMBL1543089 & 688128 & 4.4 & 4.7203 & TST & \\
\hline CHEMBL3197564 & 688128 & 4.25 & 4.74100 & 00000000005 & TRN \\
\hline CHEMBL 2373591 & 688128 & 4.3 & 4.7825 & TST & \\
\hline CHEMBL1517252 & 688128 & 4.3 & 4.4567 & TRN & \\
\hline CHEMBL1526671 & 688128 & 4.45 & 4.4183 & TRN & \\
\hline CHEMBL1611421 & 688128 & 4.05 & 4.4286 & TST & \\
\hline CHEMBL1510880 & 688128 & 4.45 & 4.4576 & TRN & \\
\hline CHEMBL1506427 & 688128 & 5.4 & 4.6755 & TST & \\
\hline CHEMBL1441795 & 688128 & 4.3 & 4.7474 & TRN & \\
\hline CHEMBL1335206 & 688128 & 4.6 & 4.9692 & TST & \\
\hline CHEMBL1404107 & 688128 & 5.3 & 4.4842 & TST & \\
\hline CHEMBL1394603 & 688128 & 4.35 & 4.391 & TRN & \\
\hline CHEMBL1472629 & 688128 & 5.4 & 4.6715 & TRN & \\
\hline CHEMBL1584006 & 688128 & 5.1 & 4.9366 & TRN & \\
\hline CHEMBL1334924 & 688128 & 4.3 & 4.6425 & TRN & \\
\hline CHEMBL1467825 & 688128 & 4.55 & 4.762 & TST & \\
\hline CHEMBL1495231 & 688128 & 4.1 & 4.5111 & TRN & \\
\hline CHEMBL1460642 & 688128 & 4.3 & 4.739 & TST & \\
\hline CHEMBL1367863 & 688128 & 4.3 & 4.47 & TST & \\
\hline CHEMBL1374108 & 688128 & 4.4 & 4.7479 & TRN & \\
\hline CHEMBL1463406 & 688128 & 4.8 & 4.8414 & TRN & \\
\hline CHEMBL1415735 & 688128 & 4.25 & 4.5121 & TST & \\
\hline CHEMBL1329903 & 688128 & 4.0 & 4.4304 & TRN & \\
\hline CHEMBL1498545 & 688128 & 4.55 & 4.6334 & TRN & \\
\hline CHEMBL1396691 & 688128 & 4.45 & 4.3421 & TRN & \\
\hline CHEMBL1450859 & 688128 & 5.05 & 4.5238 & TST & \\
\hline CHEMBL1602079 & 688128 & 6.8499 & 4.7255 & TRN & \\
\hline CHEMBL1547827 & 688128 & 4.1 & 4.4482 & TRN & \\
\hline CHEMBL1586171 & 688128 & 5.8 & 4.6631 & TRN & \\
\hline CHEMBL1994048 & 688128 & 4.3 & 4.5813 & TRN & \\
\hline CHEMBL1563800 & 688128 & 4.5 & 4.6325 & TRN & \\
\hline CHEMBL1303255 & 688128 & 4.3 & 4.7871 & TST & \\
\hline CHEMBL1305837 & 688128 & 4.4 & 4.5554 & TRN & \\
\hline CHEMBL1452637 & 688128 & 4.45 & 4.5984 & TST & \\
\hline CHEMBL1502209 & 688128 & 4.05 & 4.3772 & TRN & \\
\hline CHEMBL1425245 & 688128 & 4.35 & 5.0057 & TRN & \\
\hline CHEMBL1342716 & 688128 & 4.5 & 4.8116 & TRN & \\
\hline CHEMBL1573969 & 688128 & 4.8 & 4.7855 & TRN & \\
\hline CHEMBL1530589 & 688128 & 4.3 & 4.3569 & TRN & \\
\hline CHEMBL1561148 & 688128 & 4.3 & 4.6234 & TST & \\
\hline CHEMBL1592529 & 688128 & 5.4 & 5.0936 & TRN & \\
\hline CHEMBL3193790 & 688128 & 5.4 & 4.4707 & TST & \\
\hline CHEMBL1321934 & 688128 & 4.4 & 4.7323 & TRN & \\
\hline CHEMBL1385840 & 688128 & 5.1 & 4.8976 & TRN & \\
\hline
\end{tabular}




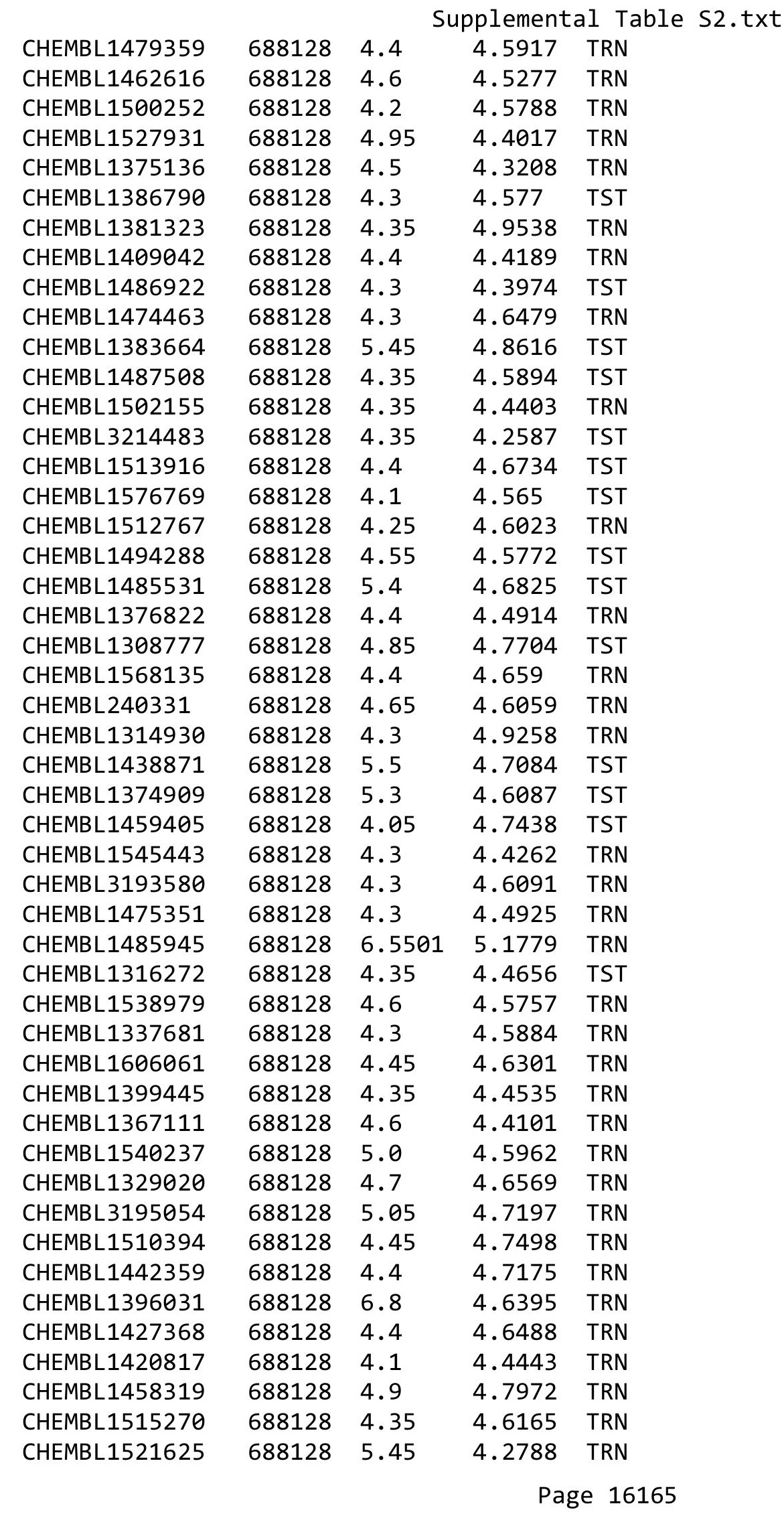




\begin{tabular}{|c|c|c|c|c|c|}
\hline \\
\hline CHEMBL1466622 & 688128 & 4.4 & 4.527 & TRN & \\
\hline CHEMBL1312438 & 688128 & 6.9 & 4.5834 & TRN & \\
\hline CHEMBL1414697 & 688128 & 4.35 & 4.4587 & TRN & \\
\hline CHEMBL1428299 & 688128 & 4.35 & 4.5229 & TRN & \\
\hline CHEMBL1985649 & 688128 & 5.0 & 4.6212 & TST & \\
\hline CHEMBL1587854 & 688128 & 4.3 & 4.7261 & TRN & \\
\hline CHEMBL1597146 & 688128 & 4.35 & 4.73600 & 0000000001 & TRN \\
\hline CHEMBL1510156 & 688128 & 4.4 & 5.1046 & TRN & \\
\hline CHEMBL1351159 & 688128 & 5.0 & 4.5897 & TRN & \\
\hline CHEMBL3191565 & 688128 & 4.35 & 4.6795 & TRN & \\
\hline CHEMBL1464944 & 688128 & 4.45 & 4.5527 & TRN & \\
\hline CHEMBL1411989 & 688128 & 4.05 & 4.6739 & TRN & \\
\hline CHEMBL1380575 & 688128 & 4.4 & 4.3251 & TRN & \\
\hline CHEMBL1329717 & 688128 & 4.45 & 4.5713 & TRN & \\
\hline CHEMBL1525045 & 688128 & 6.5501 & 4.6357 & TRN & \\
\hline CHEMBL1507813 & 688128 & 4.55 & 4.7847 & TRN & \\
\hline CHEMBL1460029 & 688128 & 5.35 & 4.7765 & TRN & \\
\hline CHEMBL1549102 & 688128 & 4.55 & 4.9791 & TRN & \\
\hline CHEMBL1370067 & 688128 & 4.4 & 4.8649 & TRN & \\
\hline CHEMBL1300889 & 688128 & 4.5 & 4.8199 & TST & \\
\hline CHEMBL1373785 & 688128 & 4.6 & 4.4471 & TST & \\
\hline CHEMBL1515647 & 688128 & 5.5 & 4.8125 & TRN & \\
\hline CHEMBL1545919 & 688128 & 4.5 & 4.5491 & TRN & \\
\hline CHEMBL1414095 & 688128 & 4.35 & 4.4597 & TST & \\
\hline CHEMBL1379963 & 688128 & 4.3 & 4.5855 & TRN & \\
\hline CHEMBL1515860 & 688128 & 5.55 & 4.6405 & TRN & \\
\hline CHEMBL1601543 & 688128 & 4.4 & 4.2909 & TRN & \\
\hline CHEMBL1504311 & 688128 & 4.1 & 4.82100 & 2000000001 & TRN \\
\hline CHEMBL1400332 & 688128 & 4.3 & 4.4811 & TST & \\
\hline CHEMBL1507963 & 688128 & 4.3 & 4.7519 & TRN & \\
\hline CHEMBL1602301 & 688128 & 4.05 & 4.6438 & TRN & \\
\hline CHEMBL1457388 & 688128 & 4.05 & 4.4927 & TRN & \\
\hline CHEMBL1498705 & 688128 & 4.3 & 4.5272 & TRN & \\
\hline CHEMBL1512228 & 688128 & 4.05 & 4.5493 & TRN & \\
\hline CHEMBL1540461 & 688128 & 4.55 & 4.67899 & 9999999999 & TRN \\
\hline CHEMBL1563703 & 688128 & 4.65 & 4.8176 & TRN & \\
\hline CHEMBL1550345 & 688128 & 4.65 & 4.6486 & TRN & \\
\hline CHEMBL1384612 & 688128 & 4.4 & 4.2646 & TST & \\
\hline CHEMBL1493207 & 688128 & 4.55 & 4.5891 & TRN & \\
\hline CHEMBL1325523 & 688128 & 4.65 & 4.6239 & TST & \\
\hline CHEMBL1504563 & 688128 & 4.35 & 4.6728 & TST & \\
\hline CHEMBL1451540 & 688128 & 4.4 & 4.7454 & TST & \\
\hline CHEMBL1345852 & 688128 & 4.35 & 4.7247 & TST & \\
\hline CHEMBL3197763 & 688128 & 4.05 & 4.6136 & TST & \\
\hline CHEMBL1598705 & 688128 & 4.4 & 4.4398 & TRN & \\
\hline CHEMBL1537752 & 688128 & 4.6 & 4.3069 & TRN & \\
\hline CHEMBL1536173 & 688128 & 5.2 & 4.7416 & TRN & \\
\hline CHEMBL1433158 & 688128 & 5.1 & 5.1448 & TRN & \\
\hline
\end{tabular}




\begin{tabular}{|c|c|c|c|c|c|}
\hline \\
\hline CHEMBL1445370 & 688128 & 4.3 & 4.5363 & TRN & \\
\hline CHEMBL1401456 & 688128 & 4.65 & 4.5837 & TRN & \\
\hline CHEMBL1458357 & 688128 & 5.0 & 4.75899 & 99999999995 & TRN \\
\hline CHEMBL1361801 & 688128 & 4.05 & 4.82100 & 0000000001 & TRN \\
\hline CHEMBL1401370 & 688128 & 4.35 & 4.8365 & TRN & \\
\hline CHEMBL1453258 & 688128 & 5.6 & 4.4326 & TST & \\
\hline CHEMBL1479465 & 688128 & 4.05 & 4.7497 & TST & \\
\hline CHEMBL1493672 & 688128 & 4.05 & 4.6902 & TRN & \\
\hline CHEMBL1540215 & 688128 & 4.4 & 4.6906 & TST & \\
\hline CHEMBL1417056 & 688128 & 5.1 & 5.1971 & TRN & \\
\hline CHEMBL1518185 & 688128 & 4.25 & 4.8011 & TRN & \\
\hline CHEMBL1386839 & 688128 & 4.8 & 4.5793 & TRN & \\
\hline CHEMBL1441835 & 688128 & 4.65 & 4.9337 & TRN & \\
\hline CHEMBL1340221 & 688128 & 5.2 & 4.9679 & TST & \\
\hline CHEMBL1451155 & 688128 & 4.35 & 4.7715 & TRN & \\
\hline CHEMBL1583696 & 688128 & 4.95 & 5.2216 & TRN & \\
\hline CHEMBL1389161 & 688128 & 4.05 & 4.4226 & TRN & \\
\hline CHEMBL1398841 & 688128 & 4.35 & 4.7764 & TRN & \\
\hline CHEMBL1343683 & 688128 & 4.4 & 4.3612 & TST & \\
\hline CHEMBL1586524 & 688128 & 4.7 & 4.4941 & TRN & \\
\hline CHEMBL3199025 & 688128 & 4.5 & 4.6704 & TRN & \\
\hline CHEMBL1498771 & 688128 & 4.5 & 4.4678 & TRN & \\
\hline CHEMBL1410019 & 688128 & 4.35 & 4.6566 & TRN & \\
\hline CHEMBL1488875 & 688128 & 5.45 & 4.8819 & TRN & \\
\hline CHEMBL1304744 & 688128 & 6.7001 & 4.52800 & 00000000005 & TST \\
\hline CHEMBL1520736 & 688128 & 6.25 & 4.5814 & TST & \\
\hline CHEMBL1422947 & 688128 & 4.35 & 4.8759 & TST & \\
\hline CHEMBL1311734 & 688128 & 4.4 & 4.4676 & TRN & \\
\hline CHEMBL1400078 & 688128 & 4.35 & 4.5767 & TST & \\
\hline CHEMBL1578236 & 688128 & 4.45 & 4.6387 & TST & \\
\hline CHEMBL1375824 & 688128 & 4.45 & 4.408 & TRN & \\
\hline CHEMBL3196143 & 688128 & 5.4 & 4.7716 & TRN & \\
\hline CHEMBL3191457 & 688128 & 4.05 & 4.3473 & TST & \\
\hline CHEMBL1330122 & 688128 & 4.7 & 4.7093 & TRN & \\
\hline CHEMBL1420785 & 688128 & 6.3 & 5.0324 & TRN & \\
\hline CHEMBL1520497 & 688128 & 4.3 & 4.7049 & TRN & \\
\hline CHEMBL1567475 & 688128 & 4.3 & 4.6689 & TRN & \\
\hline CHEMBL1576979 & 688128 & 4.95 & 4.53 & TRN & \\
\hline CHEMBL1328032 & 688128 & 4.1 & 4.4145 & TRN & \\
\hline CHEMBL1406859 & 688128 & 5.4 & 4.3599 & TST & \\
\hline CHEMBL1379914 & 688128 & 4.7 & 5.0937 & TST & \\
\hline CHEMBL1485919 & 688128 & 4.35 & 4.5878 & TRN & \\
\hline CHEMBL1504324 & 688128 & 5.1 & 4.7095 & TST & \\
\hline CHEMBL1376691 & 688128 & 4.55 & 4.5284 & TRN & \\
\hline CHEMBL1525546 & 688128 & 4.75 & 4.697 & TRN & \\
\hline CHEMBL1537553 & 688128 & 4.45 & 5.0835 & TST & \\
\hline CHEMBL1454294 & 688128 & 4.75 & 4.9553 & TST & \\
\hline CHEMBL1331358 & 688128 & 4.35 & 4.6756 & TRN & \\
\hline
\end{tabular}




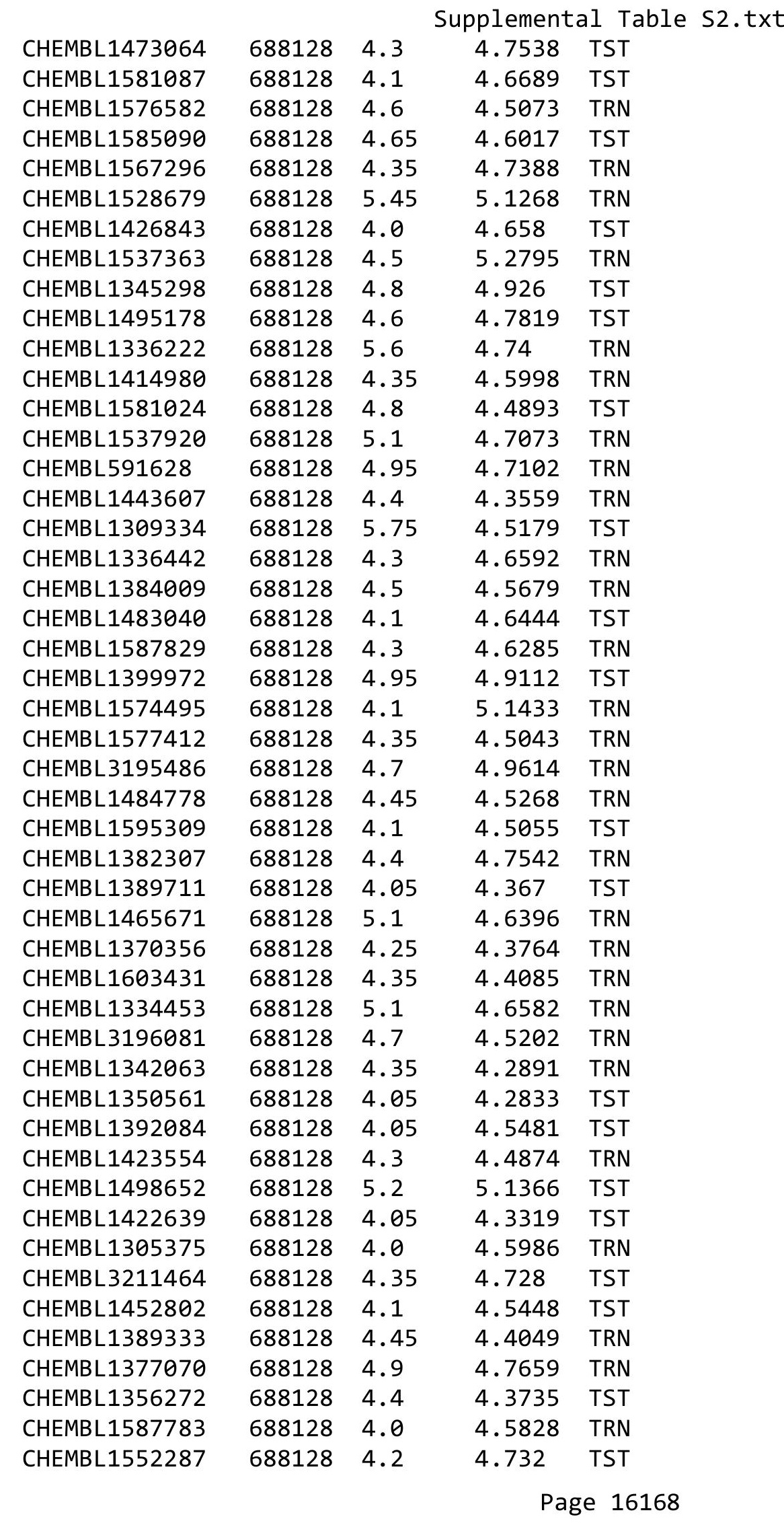




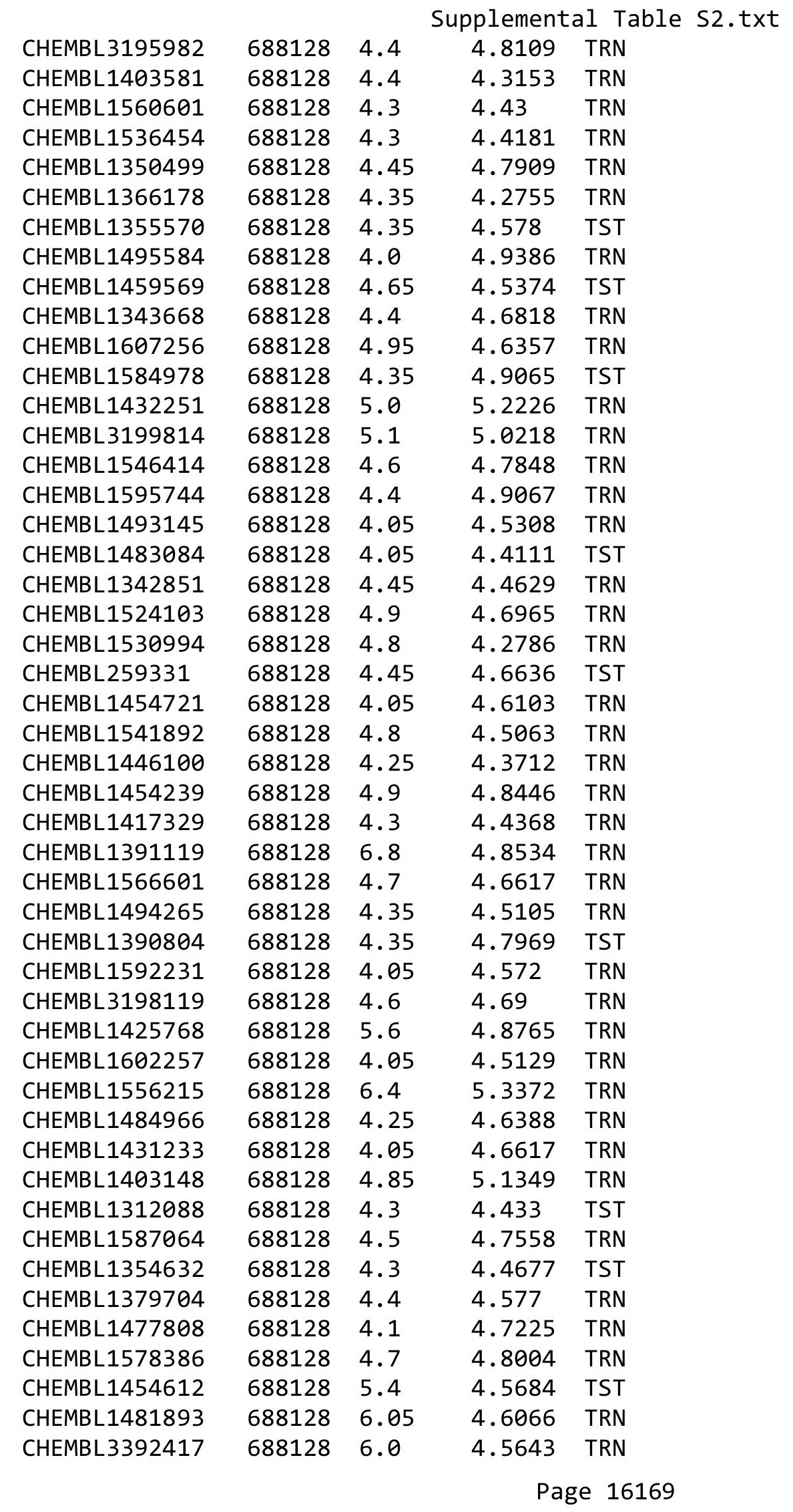




\begin{tabular}{|c|c|c|c|c|c|}
\hline & & \multicolumn{4}{|c|}{ Supplemental Table S2.txt } \\
\hline CHEMBL1566806 & 688128 & 4.85 & 4.4996 & TRN & \\
\hline CHEMBL1554891 & 688128 & 4.3 & 4.4922 & TRN & \\
\hline CHEMBL1460870 & 688128 & 4.3 & 4.6314 & TRN & \\
\hline CHEMBL1507875 & 688128 & 4.35 & 4.4777 & TRN & \\
\hline CHEMBL1459993 & 688128 & 4.6 & 4.997 & TRN & \\
\hline CHEMBL1343706 & 688128 & 5.55 & 4.53600 & 00000000005 & TRN \\
\hline CHEMBL1489162 & 688128 & 4.25 & 4.1613 & TRN & \\
\hline CHEMBL1368345 & 688128 & 4.45 & 4.4389 & TRN & \\
\hline CHEMBL1431036 & 688128 & 5.5 & 4.9319 & TST & \\
\hline CHEMBL1495266 & 688128 & 4.35 & 4.3797 & TRN & \\
\hline CHEMBL1425547 & 688128 & 4.05 & 5.063 & TRN & \\
\hline CHEMBL1368342 & 688128 & 4.3 & 4.7756 & TRN & \\
\hline CHEMBL1311109 & 688128 & 4.95 & 5.03100 & 3000000001 & TRN \\
\hline CHEMBL1486970 & 688128 & 4.4 & 4.6741 & TRN & \\
\hline CHEMBL 3198838 & 688128 & 4.4 & 4.671 & TRN & \\
\hline CHEMBL1596567 & 688128 & 4.3 & 4.51 & TST & \\
\hline CHEMBL1503703 & 688128 & 4.05 & 4.5593 & TRN & \\
\hline CHEMBL1419481 & 688128 & 4.4 & 5.0089 & TRN & \\
\hline CHEMBL1407694 & 688128 & 5.5 & 4.8293 & TRN & \\
\hline CHEMBL1467617 & 688128 & 4.05 & 4.511 & TRN & \\
\hline CHEMBL1444463 & 688128 & 4.1 & 4.7363 & TST & \\
\hline CHEMBL1343225 & 688128 & 4.1 & 4.8052 & TRN & \\
\hline CHEMBL1384261 & 688128 & 4.3 & 4.532 & TRN & \\
\hline CHEMBL1345144 & 688128 & 4.3 & 4.516 & TRN & \\
\hline CHEMBL 1470100 & 688128 & 5.2 & 4.3464 & TST & \\
\hline CHEMBL1508175 & 688128 & 5.1 & 4.4396 & TRN & \\
\hline CHEMBL1302468 & 688128 & 4.5 & 4.3832 & TRN & \\
\hline CHEMBL1480195 & 688128 & 4.45 & 4.6286 & TRN & \\
\hline CHEMBL1580904 & 688128 & 4.3 & 4.5948 & TST & \\
\hline CHEMBL1308724 & 688128 & 4.5 & 4.9615 & TRN & \\
\hline CHEMBL1426939 & 688128 & 4.3 & 4.7621 & TRN & \\
\hline CHEMBL1372743 & 688128 & 4.45 & 4.5301 & TRN & \\
\hline CHEMBL1323005 & 688128 & 4.85 & 4.601 & TRN & \\
\hline CHEMBL1455957 & 688128 & 4.8 & 5.155 & TST & \\
\hline CHEMBL1415851 & 688128 & 4.85 & 4.8221 & TRN & \\
\hline CHEMBL1546478 & 688128 & 4.05 & 4.2877 & TRN & \\
\hline CHEMBL1570908 & 688128 & 4.0 & 4.6853 & TST & \\
\hline CHEMBL1320510 & 688128 & 4.0 & 4.8195 & TRN & \\
\hline CHEMBL1440680 & 688128 & 4.9 & 4.695 & TST & \\
\hline CHEMBL1354674 & 688128 & 4.4 & 4.6902 & TST & \\
\hline CHEMBL1303970 & 688128 & 4.35 & 4.8161 & TRN & \\
\hline CHEMBL1408583 & 688128 & 4.6 & 4.6784 & TRN & \\
\hline CHEMBL1418901 & 688128 & 4.5 & 4.6502 & TST & \\
\hline CHEMBL1481501 & 688128 & 5.1 & 4.5673 & TRN & \\
\hline CHEMBL1472160 & 688128 & 4.6 & 4.8782 & TST & \\
\hline CHEMBL 1455030 & 688128 & 5.55 & 4.5506 & TST & \\
\hline CHEMBL1487604 & 688128 & 6.0 & 4.8962 & TRN & \\
\hline CHEMBL1328960 & 688128 & 4.35 & 4.6665 & TRN & \\
\hline
\end{tabular}




\begin{tabular}{|c|c|c|c|c|c|}
\hline & & \multicolumn{4}{|c|}{ Supplemental Table S2.txt } \\
\hline CHEMBL1401306 & 688128 & 4.55 & 4.756 & TRN & \\
\hline CHEMBL1392848 & 688128 & 4.95 & 4.5595 & TST & \\
\hline CHEMBL1537307 & 688128 & 4.2 & 4.5619 & TST & \\
\hline CHEMBL1462628 & 688128 & 6.15 & 5.2063 & TST & \\
\hline CHEMBL1594700 & 688128 & 4.5 & 4.6098 & TRN & \\
\hline CHEMBL1509317 & 688128 & 4.1 & 4.7752 & TST & \\
\hline CHEMBL1344409 & 688128 & 4.4 & 4.3097 & TST & \\
\hline CHEMBL1555302 & 688128 & 4.35 & 4.6255 & TST & \\
\hline CHEMBL1468300 & 688128 & 4.6 & 4.5962 & TRN & \\
\hline CHEMBL1501826 & 688128 & 4.35 & 4.5655 & TRN & \\
\hline CHEMBL1312293 & 688128 & 4.45 & 4.3404 & TRN & \\
\hline CHEMBL1447384 & 688128 & 4.6 & 4.6216 & TST & \\
\hline CHEMBL1411252 & 688128 & 4.95 & 4.8357 & TRN & \\
\hline CHEMBL1364521 & 688128 & 4.7 & 4.5666 & TRN & \\
\hline CHEMBL1408137 & 688128 & 4.3 & 4.2554 & TRN & \\
\hline CHEMBL1468358 & 688128 & 4.7 & 4.6922 & TRN & \\
\hline CHEMBL1413555 & 688128 & 5.5 & 4.4794 & TRN & \\
\hline CHEMBL483531 & 688128 & 6.8 & 4.7886 & TRN & \\
\hline CHEMBL1479816 & 688128 & 4.5 & 4.7659 & TRN & \\
\hline CHEMBL1461488 & 688128 & 4.35 & 4.5607 & TRN & \\
\hline CHEMBL1400638 & 688128 & 4.05 & 4.5905 & TRN & \\
\hline CHEMBL1570023 & 688128 & 4.05 & 4.4451 & TST & \\
\hline CHEMBL 2373684 & 688128 & 5.0 & 4.7661 & TRN & \\
\hline CHEMBL1601711 & 688128 & 5.45 & 4.6967 & TST & \\
\hline CHEMBL546580 & 688128 & 5.7 & 4.8146 & TST & \\
\hline CHEMBL1548667 & 688128 & 4.4 & 4.4305 & TRN & \\
\hline CHEMBL1388887 & 688128 & 4.5 & 4.8598 & TRN & \\
\hline CHEMBL1992492 & 688128 & 4.4 & 4.7784 & TRN & \\
\hline CHEMBL1559372 & 688128 & 5.05 & 4.5506 & TRN & \\
\hline CHEMBL1351878 & 688128 & 4.25 & 4.2821 & TRN & \\
\hline CHEMBL1340899 & 688128 & 4.4 & 4.6695 & TRN & \\
\hline CHEMBL3193888 & 688128 & 4.3 & 4.6065 & TRN & \\
\hline CHEMBL1526984 & 688128 & 4.0 & 4.377 & TST & \\
\hline CHEMBL1353503 & 688128 & 4.25 & 4.69 & TRN & \\
\hline CHEMBL1402185 & 688128 & 4.4 & 4.79899 & 99999999995 & TRN \\
\hline CHEMBL1474164 & 688128 & 4.75 & 4.6544 & TRN & \\
\hline CHEMBL3192675 & 688128 & 5.4 & 4.8632 & TRN & \\
\hline CHEMBL1579443 & 688128 & 6.0 & 4.5056 & TST & \\
\hline CHEMBL1409767 & 688128 & 4.0 & 4.6618 & TRN & \\
\hline CHEMBL1301101 & 688128 & 4.35 & 4.3449 & TST & \\
\hline CHEMBL1337270 & 688128 & 5.4 & 4.5101 & TRN & \\
\hline CHEMBL1442172 & 688128 & 4.4 & 4.3885 & TRN & \\
\hline CHEMBL1568987 & 688128 & 4.3 & 4.3895 & TRN & \\
\hline CHEMBL1414394 & 688128 & 4.5 & 4.6026 & TRN & \\
\hline CHEMBL1532546 & 688128 & 5.0 & 4.8124 & TRN & \\
\hline CHEMBL1306828 & 688128 & 5.3 & 4.3809 & TRN & \\
\hline CHEMBL1479207 & 688128 & 4.5 & 4.552 & TRN & \\
\hline CHEMBL1583229 & 688128 & 5.9 & 4.4929 & TRN & \\
\hline
\end{tabular}




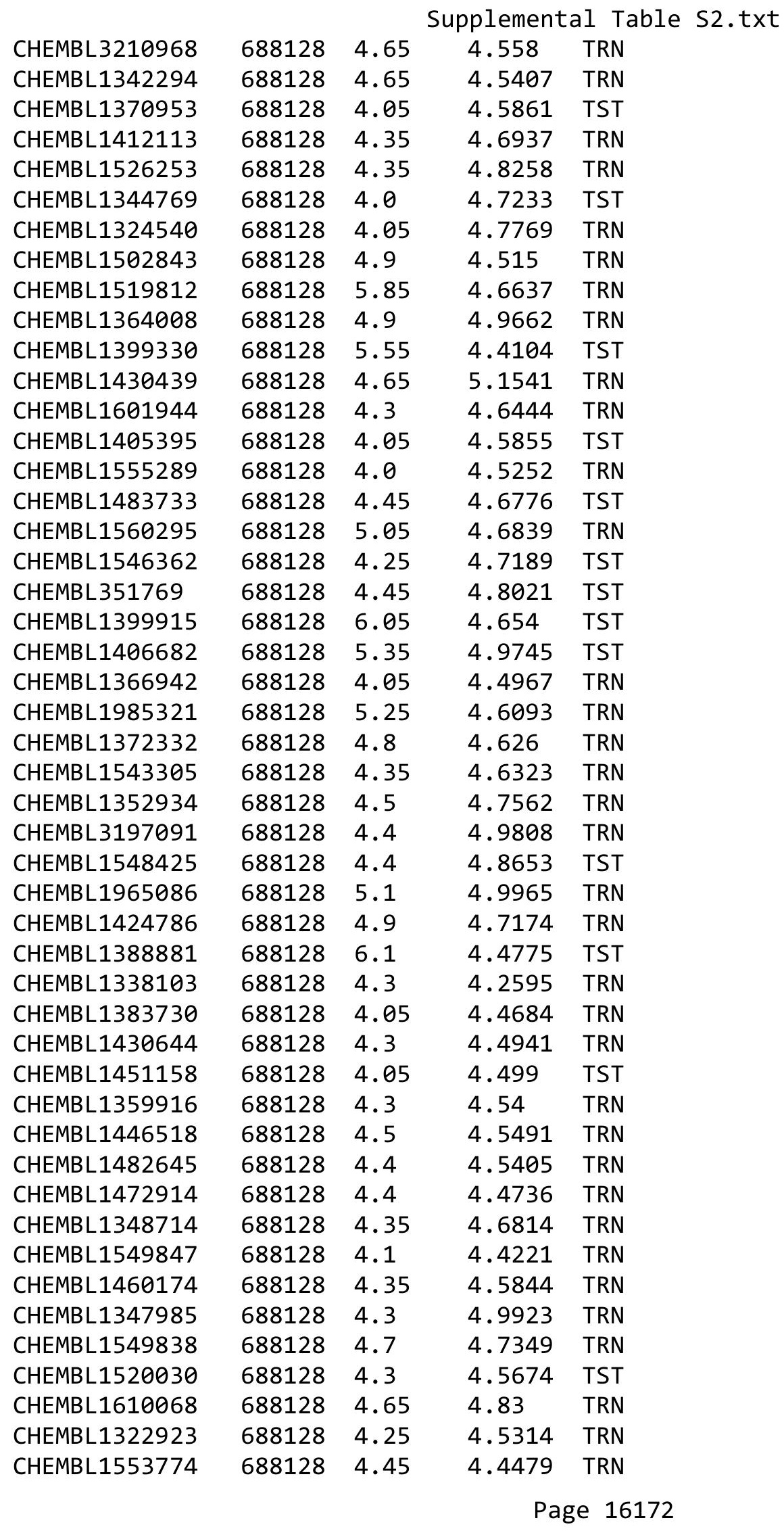




\begin{tabular}{|c|c|c|c|c|c|}
\hline \multicolumn{6}{|c|}{ Supplemental Table S2.txt } \\
\hline CHEMBL1352809 & 688128 & 4.0 & 4.6291 & TRN & \\
\hline CHEMBL1607110 & 688128 & 4.35 & 4.5458 & TST & \\
\hline CHEMBL1543175 & 688128 & 4.3 & 4.6544 & TST & \\
\hline CHEMBL1374785 & 688128 & 4.45 & 4.6065 & TRN & \\
\hline CHEMBL1459080 & 688128 & 4.4 & 4.7621 & TRN & \\
\hline CHEMBL3196491 & 688128 & 4.5 & 4.7822 & TRN & \\
\hline CHEMBL1353194 & 688128 & 4.6 & 4.876 & TRN & \\
\hline CHEMBL1485263 & 688128 & 4.35 & 4.4088 & TST & \\
\hline CHEMBL1569293 & 688128 & 4.4 & 4.3816 & TST & \\
\hline CHEMBL1328599 & 688128 & 4.3 & 4.4835 & TRN & \\
\hline CHEMBL1307820 & 688128 & 4.3 & 4.5479 & TRN & \\
\hline CHEMBL1379139 & 688128 & 6.5 & 5.0407 & TRN & \\
\hline CHEMBL1504251 & 688128 & 5.1 & 4.4076 & TRN & \\
\hline CHEMBL1407904 & 688128 & 4.05 & 4.4383 & TRN & \\
\hline CHEMBL1474319 & 688128 & 4.8 & 4.1448 & TRN & \\
\hline CHEMBL1566068 & 688128 & 4.05 & 4.6101 & TRN & \\
\hline CHEMBL1612983 & 688128 & 5.1 & 5.0823 & TRN & \\
\hline CHEMBL1424856 & 688128 & 5.05 & 5.0901 & TRN & \\
\hline CHEMBL1600447 & 688128 & 5.4 & 4.9424 & TST & \\
\hline CHEMBL1575513 & 688128 & 5.5 & 4.754 & TRN & \\
\hline CHEMBL1438884 & 688128 & 4.35 & 4.4914 & TRN & \\
\hline CHEMBL1306232 & 688128 & 4.45 & 4.6623 & TRN & \\
\hline CHEMBL1434083 & 688128 & 4.3 & 4.7549 & TST & \\
\hline CHEMBL1336687 & 688128 & 4.85 & 4.6531 & TRN & \\
\hline CHEMBL1352306 & 688128 & 4.55 & 4.6305 & TRN & \\
\hline CHEMBL1395551 & 688128 & 4.5 & 4.8028 & TRN & \\
\hline CHEMBL1418196 & 688128 & 4.4 & 4.6714 & TRN & \\
\hline CHEMBL1535361 & 688128 & 4.45 & 5.4859 & TRN & \\
\hline CHEMBL1332969 & 688128 & 6.0 & 4.6279 & TRN & \\
\hline CHEMBL1581821 & 688128 & 4.35 & 4.60800 & 00000000005 & TRN \\
\hline CHEMBL1448343 & 688128 & 4.3 & 4.637 & TST & \\
\hline CHEMBL1469766 & 688128 & 6.5 & 4.5628 & TRN & \\
\hline CHEMBL1338839 & 688128 & 4.35 & 4.6777 & TRN & \\
\hline CHEMBL1317174 & 688128 & 4.45 & 4.7125 & TST & \\
\hline CHEMBL1544741 & 688128 & 4.35 & 4.6108 & TRN & \\
\hline CHEMBL1597850 & 688128 & 5.0 & 4.7904 & TRN & \\
\hline CHEMBL1456601 & 688128 & 4.4 & 4.5686 & TRN & \\
\hline CHEMBL1431578 & 688128 & 4.4 & 4.51 & TST & \\
\hline CHEMBL1606184 & 688128 & 4.1 & 4.6476 & TRN & \\
\hline CHEMBL1448150 & 688128 & 5.0 & 4.4529 & TRN & \\
\hline CHEMBL3196310 & 688128 & 4.65 & 4.8253 & TRN & \\
\hline CHEMBL1442893 & 688128 & 6.0 & 5.3079 & TRN & \\
\hline CHEMBL1306260 & 688128 & 5.35 & 4.5985 & TRN & \\
\hline CHEMBL1335610 & 688128 & 4.35 & 4.8311 & TRN & \\
\hline CHEMBL3189877 & 688128 & 4.45 & 4.598 & TRN & \\
\hline CHEMBL1313636 & 688128 & 4.45 & 4.5993 & TRN & \\
\hline CHEMBL1500153 & 688128 & 4.5 & 4.6558 & TRN & \\
\hline CHEMBL1549499 & 688128 & 4.35 & 4.4183 & TRN & \\
\hline
\end{tabular}




\begin{tabular}{|c|c|c|c|c|}
\hline \multicolumn{5}{|c|}{ Supplemental Table S2.txt } \\
\hline CHEMBL1331437 & 688128 & 4.05 & 4.3015 & TRN \\
\hline CHEMBL1336065 & 688128 & 4.45 & 4.6294 & TRN \\
\hline CHEMBL1325510 & 688128 & 6.8499 & 4.4548 & TRN \\
\hline CHEMBL1559114 & 688128 & 4.7 & 4.7466 & TRN \\
\hline CHEMBL1526871 & 688128 & 4.35 & 4.7095 & TST \\
\hline CHEMBL1548680 & 688128 & 4.85 & 4.6479 & TRN \\
\hline CHEMBL1319261 & 688128 & 4.05 & 4.575 & TRN \\
\hline CHEMBL1572929 & 688128 & 4.4 & 4.4693 & TRN \\
\hline CHEMBL1416931 & 688128 & 4.5 & 4.525 & TRN \\
\hline CHEMBL1347052 & 688128 & 4.95 & 4.5891 & TRN \\
\hline CHEMBL1451030 & 688128 & 4.35 & 4.8072 & TST \\
\hline CHEMBL1424618 & 688128 & 4.5 & 4.5695 & TRN \\
\hline CHEMBL1410987 & 688128 & 4.65 & 4.4811 & TRN \\
\hline CHEMBL1464547 & 688128 & 5.2 & 4.7491 & TRN \\
\hline CHEMBL363535 & 688128 & 5.05 & 4.6566 & TRN \\
\hline CHEMBL1423711 & 688128 & 4.7 & 4.6179 & TST \\
\hline CHEMBL1498530 & 688128 & 5.2 & 4.81 & TRN \\
\hline CHEMBL1501161 & 688128 & 4.3 & 4.7524 & TRN \\
\hline CHEMBL1608816 & 688128 & 4.1 & 4.5901 & TRN \\
\hline CHEMBL1362459 & 688128 & 4.4 & 4.3911 & TRN \\
\hline CHEMBL1466741 & 688128 & 4.0 & 4.6743 & TRN \\
\hline CHEMBL1517197 & 688128 & 4.35 & 4.4338 & TRN \\
\hline CHEMBL1382279 & 688128 & 5.0 & 4.9953 & TRN \\
\hline CHEMBL1356374 & 688128 & 4.3 & 4.4349 & TST \\
\hline CHEMBL1444763 & 688128 & 4.5 & 4.5001 & TRN \\
\hline CHEMBL1603174 & 688128 & 4.35 & 4.5345 & TRN \\
\hline CHEMBL1561865 & 688128 & 4.05 & 4.3967 & TST \\
\hline CHEMBL1367676 & 688128 & 5.0 & 4.574 & TRN \\
\hline CHEMBL1372189 & 688128 & 4.45 & 4.5978 & TST \\
\hline CHEMBL1481375 & 688128 & 4.4 & 4.6059 & TRN \\
\hline CHEMBL1385439 & 688128 & 4.4 & 4.5742 & TST \\
\hline CHEMBL1375991 & 688128 & 4.35 & 4.4621 & TRN \\
\hline CHEMBL1350742 & 688128 & 6.45 & 4.5491 & TRN \\
\hline CHEMBL 1605746 & 688128 & 4.3 & 4.4818 & TRN \\
\hline CHEMBL1497659 & 688128 & 4.55 & 4.645 & TRN \\
\hline CHEMBL1449995 & 688128 & 5.15 & 4.6431 & TRN \\
\hline CHEMBL1577459 & 688128 & 4.3 & 4.4705 & TST \\
\hline CHEMBL1478395 & 688128 & 4.45 & 4.6234 & TST \\
\hline CHEMBL1576261 & 688128 & 5.4 & 4.5819 & TRN \\
\hline CHEMBL1348413 & 688128 & 5.1 & 4.981 & TRN \\
\hline CHEMBL1507718 & 688128 & 4.35 & 4.9011 & TST \\
\hline CHEMBL1566562 & 688128 & 4.35 & 4.6495 & TRN \\
\hline CHEMBL1567036 & 688128 & 4.5 & 4.4231 & TRN \\
\hline CHEMBL1369671 & 688128 & 4.75 & 4.9119 & TRN \\
\hline CHEMBL1359921 & 688128 & 5.6 & 4.6604 & TRN \\
\hline CHEMBL1613504 & 688128 & 4.05 & 4.5992 & TRN \\
\hline CHEMBL1557553 & 688128 & 4.4 & 4.5871 & TRN \\
\hline CHEMBL1536299 & 688128 & 4.05 & 4.5715 & TRN \\
\hline
\end{tabular}




\begin{tabular}{|c|c|c|c|c|c|}
\hline & & \multicolumn{4}{|c|}{ Supplemental Table S2.txt } \\
\hline CHEMBL1583264 & 688128 & 4.95 & 4.9119 & TST & \\
\hline CHEMBL1449181 & 688128 & 4.4 & 4.3866 & TRN & \\
\hline CHEMBL3199716 & 688128 & 4.45 & 4.5661 & TRN & \\
\hline CHEMBL1357935 & 688128 & 4.3 & 4.4948 & TRN & \\
\hline CHEMBL1338423 & 688128 & 5.15 & 4.8182 & TRN & \\
\hline CHEMBL1563712 & 688128 & 5.05 & 5.2442 & TRN & \\
\hline CHEMBL1476723 & 688128 & 4.7 & 4.7724 & TST & \\
\hline CHEMBL1342093 & 688128 & 6.2 & 4.6526 & TRN & \\
\hline CHEMBL1511498 & 688128 & 4.3 & 4.676 & TRN & \\
\hline CHEMBL1498800 & 688128 & 6.0 & 4.7023 & TRN & \\
\hline CHEMBL1608565 & 688128 & 4.05 & 4.4342 & TRN & \\
\hline CHEMBL1445524 & 688128 & 4.4 & 4.4583 & TRN & \\
\hline CHEMBL1463893 & 688128 & 7.0 & 4.5505 & TRN & \\
\hline CHEMBL1562004 & 688128 & 5.0 & \multicolumn{2}{|c|}{4.9510000000000005} & TRN \\
\hline CHEMBL1398707 & 688128 & 4.4 & 4.7798 & TRN & \\
\hline CHEMBL1320964 & 688128 & 4.8 & 4.9694 & TST & \\
\hline CHEMBL1369655 & 688128 & 5.0 & 5.4035 & TRN & \\
\hline CHEMBL1386190 & 688128 & 4.3 & 4.3381 & TRN & \\
\hline CHEMBL1504994 & 688128 & 4.3 & 4.8446 & TRN & \\
\hline CHEMBL1350229 & 688128 & 4.35 & 4.5844 & TRN & \\
\hline CHEMBL1428654 & 688128 & 4.35 & 4.5762 & TRN & \\
\hline CHEMBL3199171 & 688128 & 4.45 & \multicolumn{2}{|c|}{4.486000000000001} & TRN \\
\hline CHEMBL1456588 & 688128 & 5.6 & 4.5328 & TRN & \\
\hline CHEMBL1538456 & 688128 & 4.7 & 4.5435 & TST & \\
\hline CHEMBL1342944 & 688128 & 5.15 & 4.4116 & TST & \\
\hline CHEMBL1488526 & 688128 & 4.35 & 4.6565 & TRN & \\
\hline CHEMBL1390330 & 688128 & 4.3 & 4.5348 & TRN & \\
\hline CHEMBL1520647 & 688128 & 4.45 & 4.7179 & TRN & \\
\hline CHEMBL 3196447 & 688128 & 4.25 & 4.603 & TRN & \\
\hline CHEMBL1319191 & 688128 & 4.5 & 4.6134 & TRN & \\
\hline CHEMBL1346438 & 688128 & 4.3 & 4.5963 & TST & \\
\hline CHEMBL1360523 & 688128 & 4.4 & 4.4068 & TST & \\
\hline CHEMBL1334905 & 688128 & 4.0 & 4.5605 & TRN & \\
\hline CHEMBL1544126 & 688128 & 5.65 & 4.7123 & TRN & \\
\hline CHEMBL1430752 & 688128 & 4.35 & 4.3944 & TRN & \\
\hline CHEMBL1307861 & 688128 & 4.5 & 4.9295 & TRN & \\
\hline CHEMBL1573906 & 688128 & 4.9 & 4.9247 & TRN & \\
\hline CHEMBL1570831 & 688128 & 4.05 & 4.4122 & TST & \\
\hline CHEMBL1373979 & 688128 & 4.85 & 4.5749 & TST & \\
\hline CHEMBL1571432 & 688128 & 4.05 & 4.7585 & TST & \\
\hline CHEMBL1477136 & 688128 & 5.05 & 5.3167 & TRN & \\
\hline CHEMBL1307636 & 688128 & 4.75 & 4.7374 & TRN & \\
\hline CHEMBL1459432 & 688128 & 4.05 & 4.7038 & TRN & \\
\hline CHEMBL1338422 & 688128 & 4.65 & 4.9426 & TRN & \\
\hline CHEMBL1611363 & 688128 & 4.65 & 4.613 & TRN & \\
\hline CHEMBL1360899 & 688128 & 4.3 & 4.3039 & TRN & \\
\hline CHEMBL3192500 & 688128 & 4.55 & 4.713 & TRN & \\
\hline CHEMBL1419587 & 688128 & 5.15 & 4.5726 & TRN & \\
\hline
\end{tabular}




\begin{tabular}{|c|c|c|c|c|c|}
\hline \multicolumn{6}{|c|}{ Supplemental Table S2.txt } \\
\hline CHEMBL1388595 & 688128 & 4.65 & 4.6155 & TRN & \\
\hline CHEMBL458328 & 688128 & 4.7 & 4.5986 & TST & \\
\hline CHEMBL1435796 & 688128 & 4.3 & 4.6255 & TRN & \\
\hline CHEMBL1394280 & 688128 & 4.05 & 4.5672 & TRN & \\
\hline CHEMBL1414342 & 688128 & 4.95 & 4.82600 & 00000000005 & TRN \\
\hline CHEMBL1402838 & 688128 & 4.65 & 4.8175 & TRN & \\
\hline CHEMBL1458346 & 688128 & 4.4 & 4.6092 & TRN & \\
\hline CHEMBL1559965 & 688128 & 4.35 & 4.8027 & TRN & \\
\hline CHEMBL1411567 & 688128 & 6.8499 & 4.4979 & TRN & \\
\hline CHEMBL1604327 & 688128 & 4.45 & 4.4715 & TRN & \\
\hline CHEMBL3210653 & 688128 & 4.25 & 4.7997 & TST & \\
\hline CHEMBL1588749 & 688128 & 4.4 & 4.2575 & TST & \\
\hline CHEMBL1538248 & 688128 & 4.1 & 4.2734 & TRN & \\
\hline CHEMBL1428154 & 688128 & 4.65 & 4.805 & TRN & \\
\hline CHEMBL1592604 & 688128 & 4.25 & 4.5571 & TRN & \\
\hline CHEMBL1338797 & 688128 & 4.35 & 4.5962 & TRN & \\
\hline CHEMBL1580466 & 688128 & 4.3 & 4.3528 & TRN & \\
\hline CHEMBL1598610 & 688128 & 4.8 & 4.8861 & TRN & \\
\hline CHEMBL1389829 & 688128 & 4.6 & 4.6199 & TRN & \\
\hline CHEMBL1334870 & 688128 & 4.35 & 4.6219 & TRN & \\
\hline CHEMBL1421993 & 688128 & 4.45 & 4.6083 & TRN & \\
\hline CHEMBL1470845 & 688128 & 4.3 & 4.8306 & TST & \\
\hline CHEMBL1544812 & 688128 & 4.05 & 4.4591 & TRN & \\
\hline CHEMBL1556285 & 688128 & 4.75 & 4.7403 & TRN & \\
\hline CHEMBL1486643 & 688128 & 4.5 & 4.9943 & TST & \\
\hline CHEMBL1313013 & 688128 & 4.45 & 4.3282 & TRN & \\
\hline CHEMBL3196129 & 688128 & 4.4 & 4.4986 & TRN & \\
\hline CHEMBL1519698 & 688128 & 4.35 & 4.6483 & TST & \\
\hline CHEMBL1564423 & 688128 & 4.55 & 4.3121 & TRN & \\
\hline CHEMBL1523275 & 688128 & 4.45 & 4.7586 & TST & \\
\hline CHEMBL225903 & 688128 & 5.45 & 4.3779 & TRN & \\
\hline CHEMBL1390319 & 688128 & 4.6 & 4.4128 & TRN & \\
\hline CHEMBL1412109 & 688128 & 5.1 & 4.6856 & TRN & \\
\hline CHEMBL1511526 & 688128 & 5.15 & 5.1456 & TRN & \\
\hline CHEMBL1590542 & 688128 & 5.5 & 4.5483 & TRN & \\
\hline CHEMBL1363459 & 688128 & 4.35 & 4.5948 & TRN & \\
\hline CHEMBL1545924 & 688128 & 4.95 & 5.0336 & TRN & \\
\hline CHEMBL1514270 & 688128 & 4.4 & 4.2631 & TRN & \\
\hline CHEMBL1965872 & 688128 & 5.5 & 4.8989 & TST & \\
\hline CHEMBL1385641 & 688128 & 6.1 & 4.3565 & TRN & \\
\hline CHEMBL1341032 & 688128 & 5.8 & 4.8263 & TRN & \\
\hline CHEMBL1405513 & 688128 & 4.25 & 4.7472 & TRN & \\
\hline CHEMBL1603475 & 688128 & 4.7 & 4.5177 & TRN & \\
\hline CHEMBL1350863 & 688128 & 5.45 & 4.7788 & TST & \\
\hline CHEMBL1308063 & 688128 & 4.45 & 4.4798 & TRN & \\
\hline CHEMBL1551211 & 688128 & 4.25 & 4.6138 & TRN & \\
\hline CHEMBL1527982 & 688128 & 6.3 & 5.0174 & TRN & \\
\hline CHEMBL1398875 & 688128 & 4.3 & 4.6428 & TRN & \\
\hline
\end{tabular}




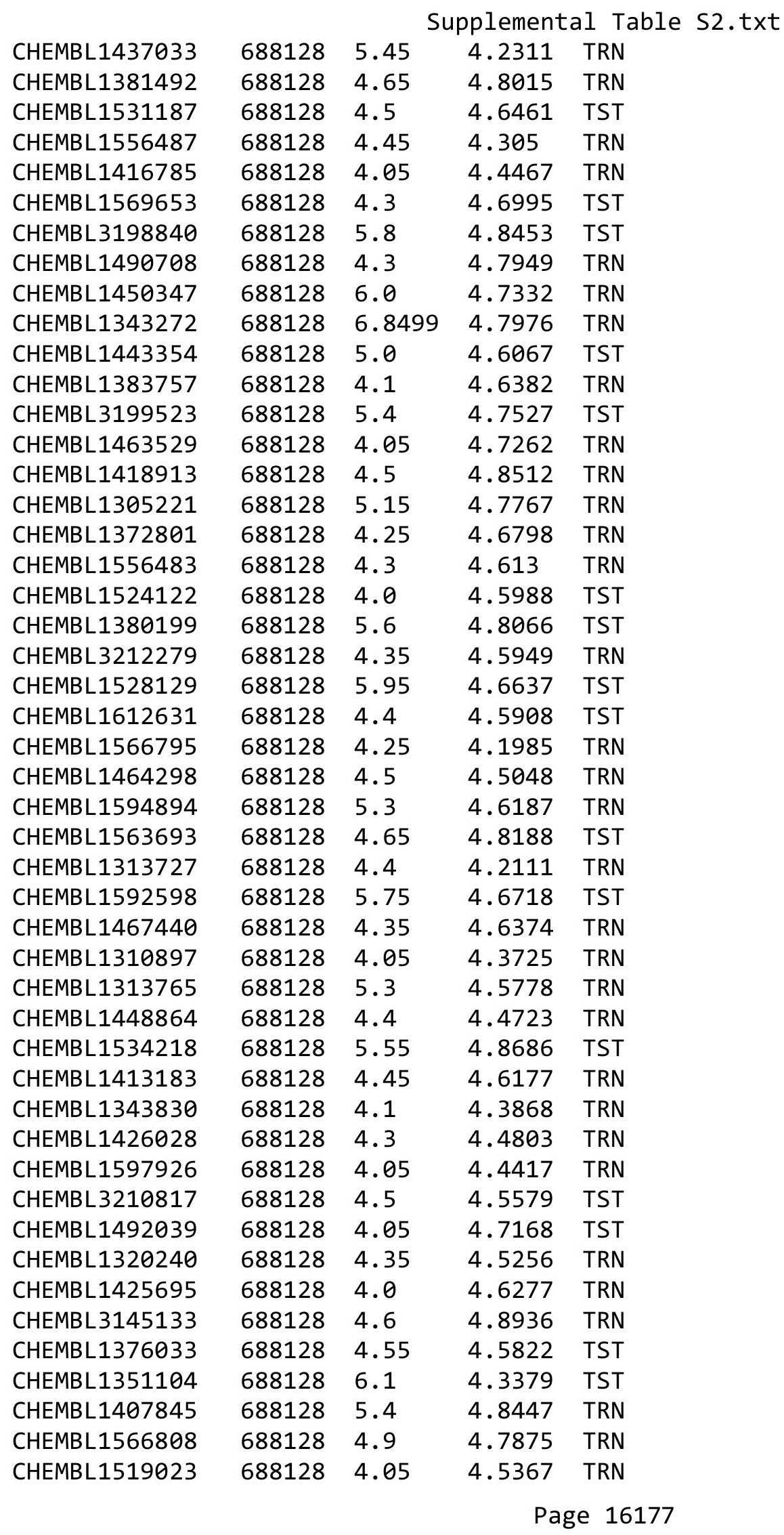




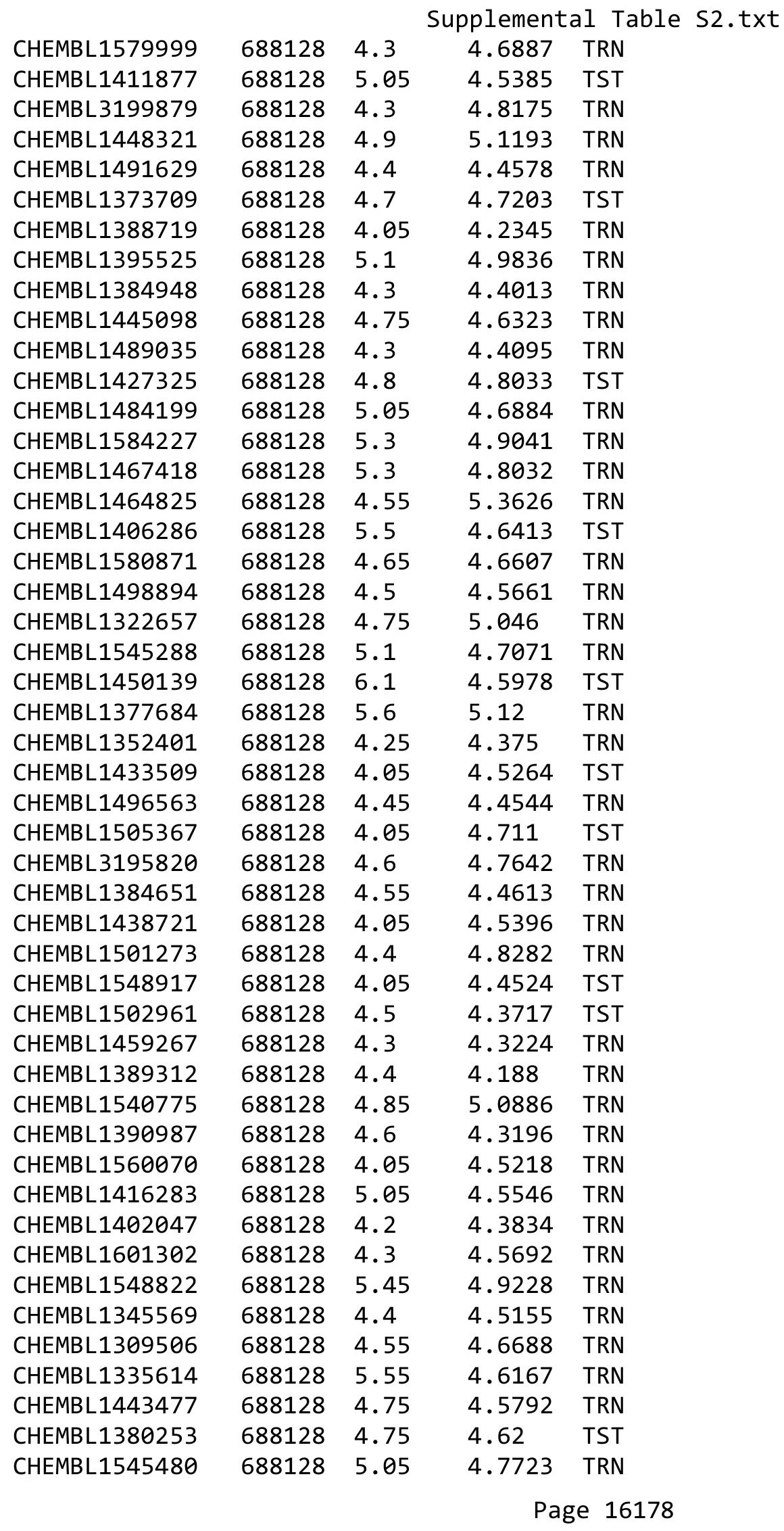




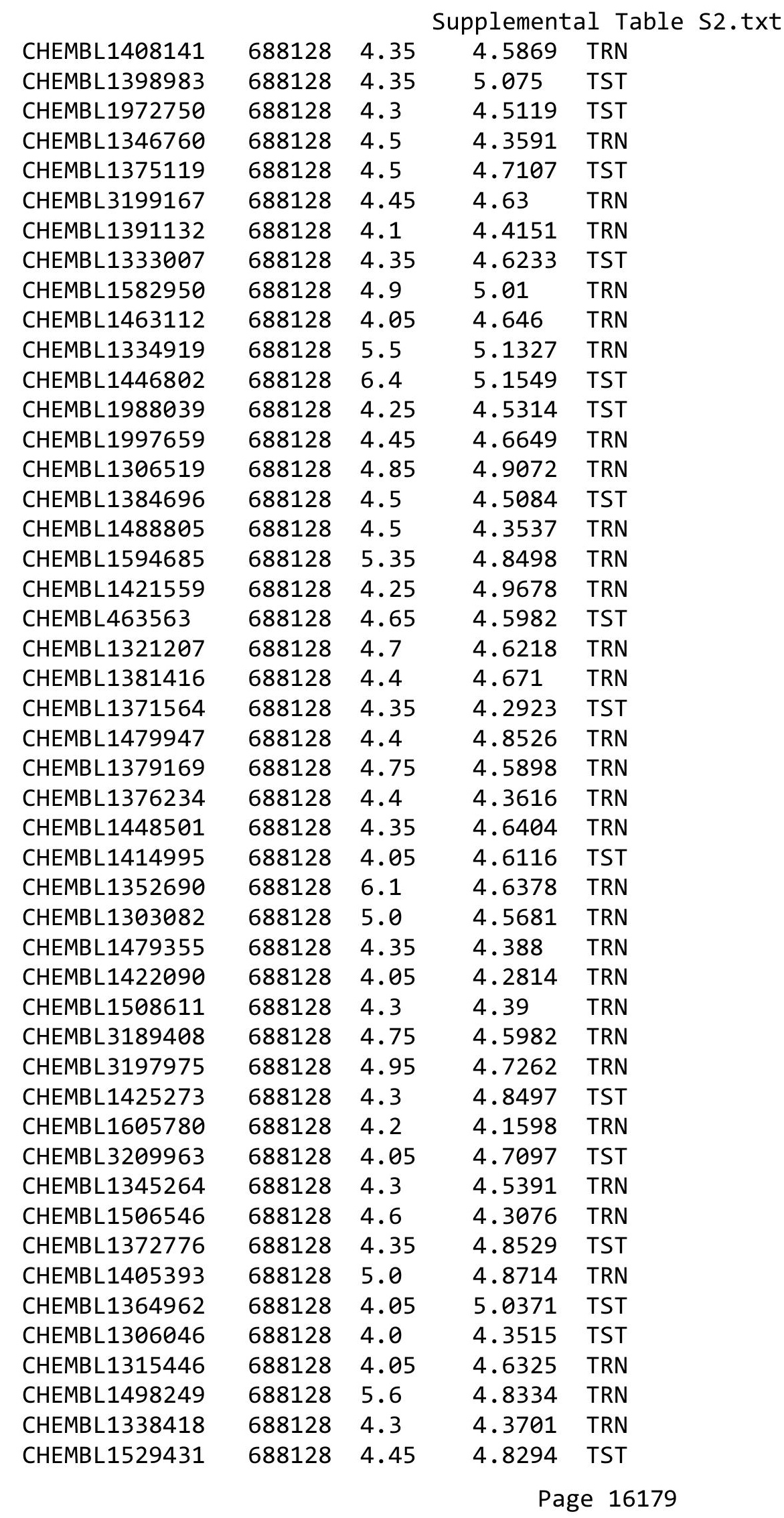




\begin{tabular}{|c|c|c|c|c|}
\hline \multicolumn{5}{|c|}{ Supplemental Table s2.txt } \\
\hline CHEMBL1384339 & 688128 & 4.4 & 4.7303 & TRN \\
\hline CHEMBL1563559 & 688128 & 4.3 & 4.5662 & TST \\
\hline CHEMBL3189244 & 688128 & 5.05 & 4.5371 & TST \\
\hline CHEMBL1384799 & 688128 & 4.6 & 4.4337 & TRN \\
\hline CHEMBL1337212 & 688128 & 4.3 & 4.4866 & TRN \\
\hline CHEMBL1326508 & 688128 & 5.4 & 4.8221 & TRN \\
\hline CHEMBL1512841 & 688128 & 4.3 & 4.659 & TRN \\
\hline CHEMBL1514676 & 688128 & 4.4 & 4.6884 & TRN \\
\hline CHEMBL1444045 & 688128 & 4.2 & 4.5943 & TST \\
\hline CHEMBL1600769 & 688128 & 4.05 & 4.9889 & TRN \\
\hline CHEMBL1341509 & 688128 & 4.65 & 4.4613 & TST \\
\hline CHEMBL1370183 & 688128 & 5.45 & 5.2012 & TRN \\
\hline CHEMBL1578056 & 688128 & 4.55 & 4.6243 & TST \\
\hline CHEMBL1404865 & 688128 & 4.6 & 4.5989 & TRN \\
\hline CHEMBL1528877 & 688128 & 4.3 & 4.6325 & TST \\
\hline CHEMBL1412785 & 688128 & 5.45 & 5.182 & TRN \\
\hline CHEMBL1301481 & 688128 & 5.7 & 4.9398 & TRN \\
\hline CHEMBL1359023 & 688128 & 4.35 & 4.502 & TRN \\
\hline CHEMBL1302591 & 688128 & 4.4 & 4.5265 & TRN \\
\hline CHEMBL1494462 & 688128 & 4.4 & 4.4292 & TST \\
\hline CHEMBL1580973 & 688128 & 4.9 & 4.5917 & TRN \\
\hline CHEMBL1364478 & 688128 & 6.1 & 4.5541 & TRN \\
\hline CHEMBL1521028 & 688128 & 4.95 & 4.4678 & TRN \\
\hline CHEMBL3196837 & 688128 & 4.85 & 4.9686 & TRN \\
\hline CHEMBL3211617 & 688128 & 4.3 & 4.4682 & TST \\
\hline CHEMBL1455753 & 688128 & 4.9 & 4.8363 & TRN \\
\hline CHEMBL1463619 & 688128 & 5.0 & 4.5753 & TRN \\
\hline CHEMBL1608338 & 688128 & 4.05 & 4.6624 & TST \\
\hline CHEMBL3191468 & 688128 & 4.4 & 4.6605 & TST \\
\hline CHEMBL1546649 & 688128 & 4.8 & 4.717 & TST \\
\hline CHEMBL1402412 & 688128 & 4.05 & 4.8649 & TST \\
\hline CHEMBL1527061 & 688128 & 4.3 & 4.6918 & TRN \\
\hline CHEMBL1378494 & 688128 & 5.15 & 5.0084 & TRN \\
\hline CHEMBL1608593 & 688128 & 4.3 & 4.467 & TRN \\
\hline CHEMBL1585020 & 688128 & 4.25 & 4.6959 & TRN \\
\hline CHEMBL1573909 & 688128 & 5.45 & 4.7532 & TRN \\
\hline CHEMBL1495810 & 688128 & 4.4 & 4.3006 & TRN \\
\hline CHEMBL1424400 & 688128 & 4.25 & 4.2552 & TST \\
\hline CHEMBL1310863 & 688128 & 4.35 & 4.3159 & TRN \\
\hline CHEMBL1359842 & 688128 & 4.35 & 4.6128 & TRN \\
\hline CHEMBL1482751 & 688128 & 4.6 & 4.7951 & TRN \\
\hline CHEMBL1531451 & 688128 & 4.4 & 4.6135 & TRN \\
\hline CHEMBL1353431 & 688128 & 6.05 & 4.5445 & TRN \\
\hline CHEMBL1305639 & 688128 & 4.4 & 4.5217 & TRN \\
\hline CHEMBL1547941 & 688128 & 4.05 & 4.6521 & TST \\
\hline CHEMBL1506097 & 688128 & 4.05 & 4.6781 & TST \\
\hline CHEMBL1502446 & 688128 & 4.45 & 4.57100 & 0000000001 \\
\hline CHEMBL1435321 & 688128 & 4.7 & 4.6006 & TRN \\
\hline
\end{tabular}




\begin{tabular}{|c|c|c|c|c|c|}
\hline \multicolumn{6}{|c|}{ Supplemental Table S2.txt } \\
\hline CHEMBL1302669 & 688128 & 4.05 & 4.5182 & TRN & \\
\hline CHEMBL1531635 & 688128 & 4.6 & 4.3412 & TRN & \\
\hline CHEMBL1542243 & 688128 & 4.65 & 4.6918 & TRN & \\
\hline CHEMBL1351046 & 688128 & 4.45 & 4.6102 & TST & \\
\hline CHEMBL1371556 & 688128 & 4.7 & 4.383 & TST & \\
\hline CHEMBL1438076 & 688128 & 4.15 & 4.9144 & TRN & \\
\hline CHEMBL1466164 & 688128 & 4.3 & 4.6213 & TRN & \\
\hline CHEMBL1546548 & 688128 & 4.35 & 4.2986 & TRN & \\
\hline CHEMBL1589514 & 688128 & 4.85 & 5.2454 & TRN & \\
\hline CHEMBL1346944 & 688128 & 4.05 & 4.3942 & TRN & \\
\hline CHEMBL1608727 & 688128 & 4.35 & 4.6927 & TST & \\
\hline CHEMBL1484572 & 688128 & 4.35 & 4.4828 & TST & \\
\hline CHEMBL1487345 & 688128 & 4.35 & 4.9588 & TRN & \\
\hline CHEMBL1503857 & 688128 & 4.05 & 4.5503 & TRN & \\
\hline CHEMBL1610388 & 688128 & 4.95 & 4.5317 & TRN & \\
\hline CHEMBL1548083 & 688128 & 5.55 & 4.7122 & TRN & \\
\hline CHEMBL1439324 & 688128 & 4.4 & 4.8662 & TST & \\
\hline CHEMBL1603415 & 688128 & 4.45 & 4.6796 & TRN & \\
\hline CHEMBL1444743 & 688128 & 4.3 & 4.3459 & TRN & \\
\hline CHEMBL1523923 & 688128 & 4.45 & 4.6679 & TRN & \\
\hline CHEMBL1331822 & 688128 & 6.1 & 4.9915 & TST & \\
\hline CHEMBL1541803 & 688128 & 4.35 & 4.609 & TRN & \\
\hline CHEMBL1583215 & 688128 & 4.3 & 4.4647 & TRN & \\
\hline CHEMBL1557536 & 688128 & 4.85 & 4.4029 & TRN & \\
\hline CHEMBL1974266 & 688128 & 4.55 & 4.8574 & TRN & \\
\hline CHEMBL1574510 & 688128 & 5.05 & $4.6160 e$ & 00000000005 & TRN \\
\hline CHEMBL1484163 & 688128 & 4.85 & 5.0494 & TRN & \\
\hline CHEMBL1564799 & 688128 & 4.7 & 4.5041 & TRN & \\
\hline CHEMBL1352793 & 688128 & 5.45 & 4.6348 & TRN & \\
\hline CHEMBL3191160 & 688128 & 5.95 & 4.7317 & TRN & \\
\hline CHEMBL3208135 & 688128 & 4.35 & 4.6708 & TST & \\
\hline CHEMBL1587620 & 688128 & 4.4 & 4.3836 & TRN & \\
\hline CHEMBL1452205 & 688128 & 4.4 & 4.6477 & TRN & \\
\hline CHEMBL3214039 & 688128 & 4.6 & 4.6719 & TRN & \\
\hline CHEMBL1457472 & 688128 & 4.5 & 4.7458 & TST & \\
\hline CHEMBL1509103 & 688128 & 4.0 & 4.6378 & TST & \\
\hline CHEMBL1481601 & 688128 & 4.3 & 4.6588 & TST & \\
\hline CHEMBL1456284 & 688128 & 4.3 & 4.4656 & TRN & \\
\hline CHEMBL1462570 & 688128 & 5.7 & 4.8788 & TST & \\
\hline CHEMBL1490237 & 688128 & 4.35 & 4.6876 & TRN & \\
\hline CHEMBL1531790 & 688128 & 4.35 & 4.6688 & TRN & \\
\hline CHEMBL1413540 & 688128 & 4.65 & 4.4842 & TRN & \\
\hline CHEMBL1576658 & 688128 & 5.45 & 4.9509 & TRN & \\
\hline CHEMBL1604505 & 688128 & 6.15 & 4.5778 & TST & \\
\hline CHEMBL1466442 & 688128 & 4.05 & 4.4453 & TST & \\
\hline CHEMBL1462302 & 688128 & 5.1 & 4.5922 & TRN & \\
\hline CHEMBL1577757 & 688128 & 6.05 & 4.7697 & TST & \\
\hline CHEMBL1556699 & 688128 & 4.4 & 4.5202 & TRN & \\
\hline
\end{tabular}




\begin{tabular}{|c|c|c|c|c|c|}
\hline \multicolumn{6}{|c|}{ Supplemental Table S2.txt } \\
\hline CHEMBL1337582 & 688128 & 4.15 & 4.5188 & TRN & \\
\hline CHEMBL1326955 & 688128 & 5.45 & 4.8902 & TRN & \\
\hline CHEMBL1499021 & 688128 & 4.3 & 4.2913 & TRN & \\
\hline CHEMBL1580506 & 688128 & 4.55 & 4.9642 & TST & \\
\hline CHEMBL1542647 & 688128 & 4.05 & 4.4541 & TRN & \\
\hline CHEMBL1415026 & 688128 & 4.05 & 4.7728 & TST & \\
\hline CHEMBL1406024 & 688128 & 4.3 & 4.3485 & TRN & \\
\hline CHEMBL1513773 & 688128 & 5.55 & 4.573 & TRN & \\
\hline CHEMBL1305312 & 688128 & 4.35 & 4.8416 & TST & \\
\hline CHEMBL1336205 & 688128 & 4.1 & 4.6369 & TST & \\
\hline CHEMBL1338594 & 688128 & 4.45 & 4.2979 & TRN & \\
\hline CHEMBL1517557 & 688128 & 4.7 & 4.4995 & TRN & \\
\hline CHEMBL1409417 & 688128 & 4.3 & 4.434 & TRN & \\
\hline CHEMBL1580242 & 688128 & 4.0 & 4.4231 & TRN & \\
\hline CHEMBL1510633 & 688128 & 6.5501 & 4.5182 & TRN & \\
\hline CHEMBL3190602 & 688128 & 4.4 & 4.7116 & TRN & \\
\hline CHEMBL1565096 & 688128 & 4.95 & 4.6134 & TST & \\
\hline CHEMBL1343844 & 688128 & 4.55 & 4.4847 & TRN & \\
\hline CHEMBL1323979 & 688128 & 4.25 & 4.3717 & TST & \\
\hline CHEMBL1299323 & 688128 & 4.25 & 4.8689 & TRN & \\
\hline CHEMBL1534574 & 688128 & 4.45 & 4.6364 & TRN & \\
\hline CHEMBL 366884 & 688128 & 4.5 & 4.6947 & TRN & \\
\hline CHEMBL1347416 & 688128 & 4.7 & 4.5424 & TRN & \\
\hline CHEMBL1456916 & 688128 & 4.8 & 4.5528 & TST & \\
\hline CHEMBL1457888 & 688128 & 4.7 & 4.6352 & TRN & \\
\hline CHEMBL1592540 & 688128 & 4.4 & 4.3635 & TRN & \\
\hline CHEMBL1451100 & 688128 & 4.3 & 4.6059 & TRN & \\
\hline CHEMBL1533511 & 688128 & 6.25 & 5.0067 & TRN & \\
\hline CHEMBL3192042 & 688128 & 5.4 & 4.886 & TST & \\
\hline CHEMBL1339082 & 688128 & 4.65 & 4.7144 & TRN & \\
\hline CHEMBL1569547 & 688128 & 5.0 & 5.0219 & TRN & \\
\hline CHEMBL1310693 & 688128 & 4.45 & 4.5347 & TRN & \\
\hline CHEMBL1445809 & 688128 & 4.3 & 4.6998 & TST & \\
\hline CHEMBL1610751 & 688128 & 4.0 & $4.2780 e$ & 00000000005 & TRN \\
\hline CHEMBL1532940 & 688128 & 4.2 & 4.6878 & TRN & \\
\hline CHEMBL1429837 & 688128 & 5.05 & 4.7278 & TRN & \\
\hline CHEMBL1586973 & 688128 & 5.5 & 5.0566 & TRN & \\
\hline CHEMBL1489471 & 688128 & 4.7 & 4.6126 & TRN & \\
\hline CHEMBL3193476 & 688128 & 5.0 & 5.0209 & TRN & \\
\hline CHEMBL1564211 & 688128 & 4.4 & 4.5374 & TRN & \\
\hline CHEMBL1564484 & 688128 & 4.7 & 4.5932 & TRN & \\
\hline CHEMBL1517116 & 688128 & 4.9 & 4.3526 & TRN & \\
\hline CHEMBL1415522 & 688128 & 4.85 & 5.0662 & TRN & \\
\hline CHEMBL1570322 & 688128 & 5.35 & 4.8811 & TRN & \\
\hline CHEMBL1557593 & 688128 & 4.35 & 4.6345 & TRN & \\
\hline CHEMBL1494430 & 688128 & 4.4 & 4.6981 & TST & \\
\hline CHEMBL1426763 & 688128 & 4.25 & 4.5751 & TRN & \\
\hline CHEMBL1510906 & 688128 & 4.4 & 4.5643 & TRN & \\
\hline
\end{tabular}




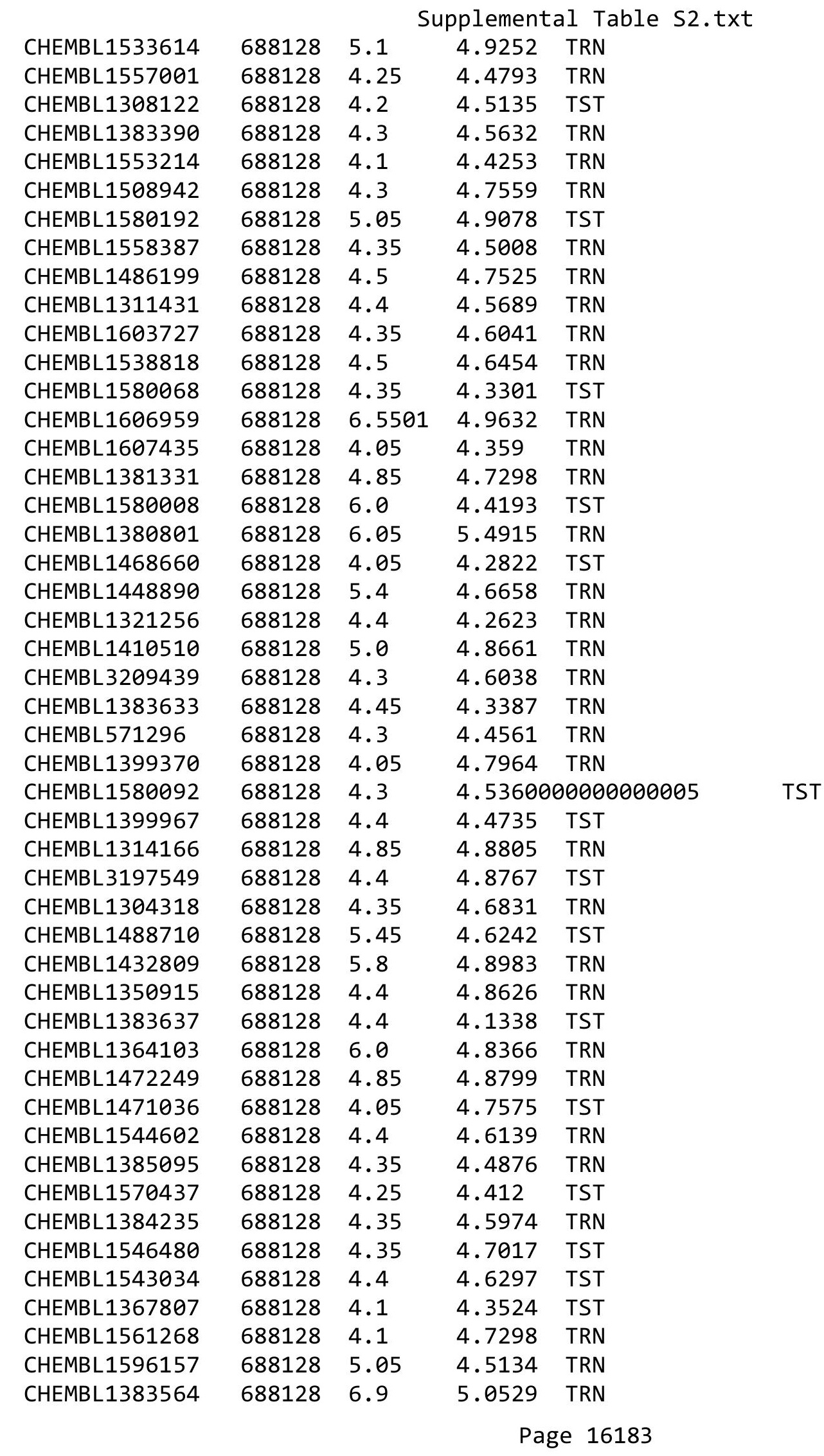




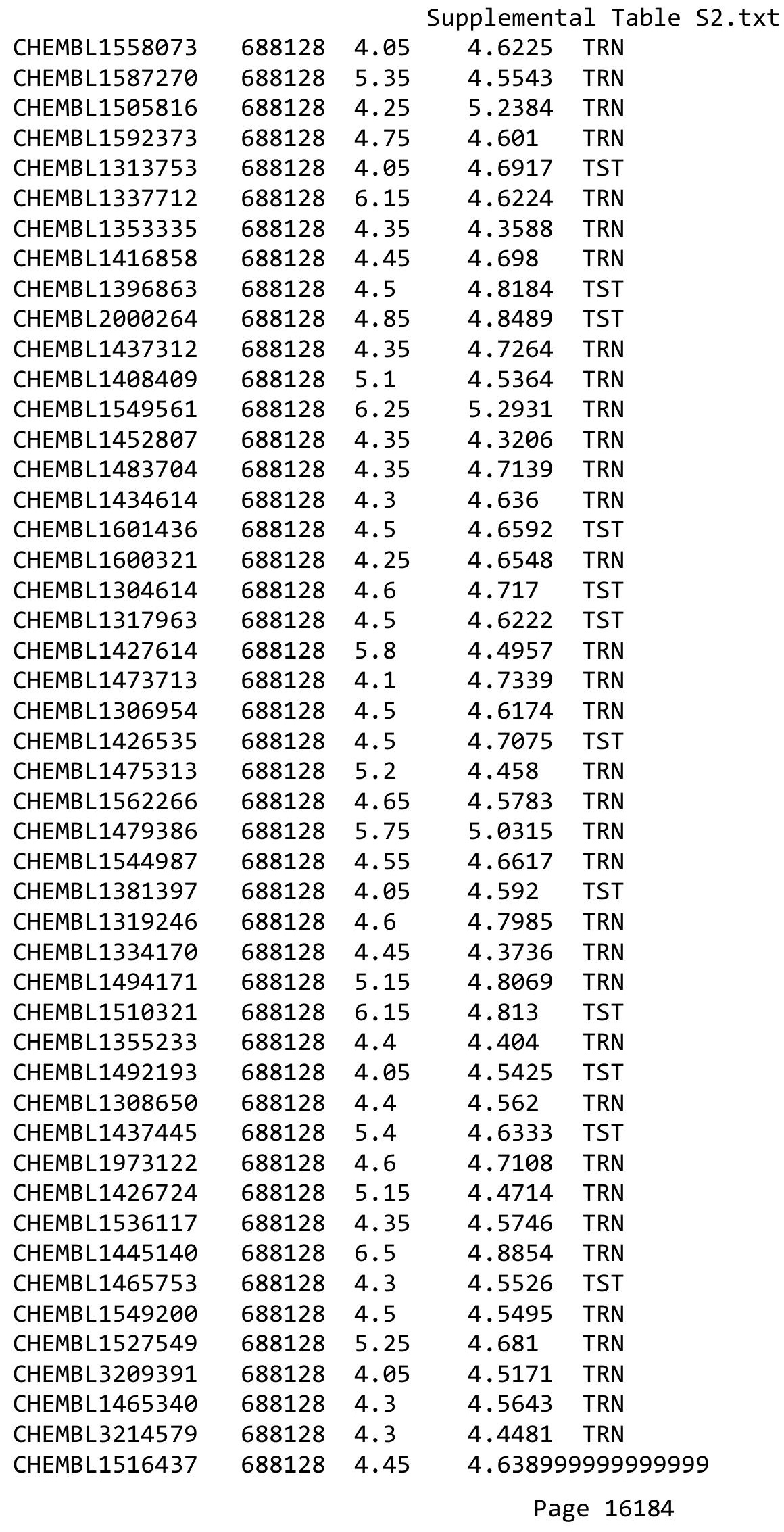

TRN 


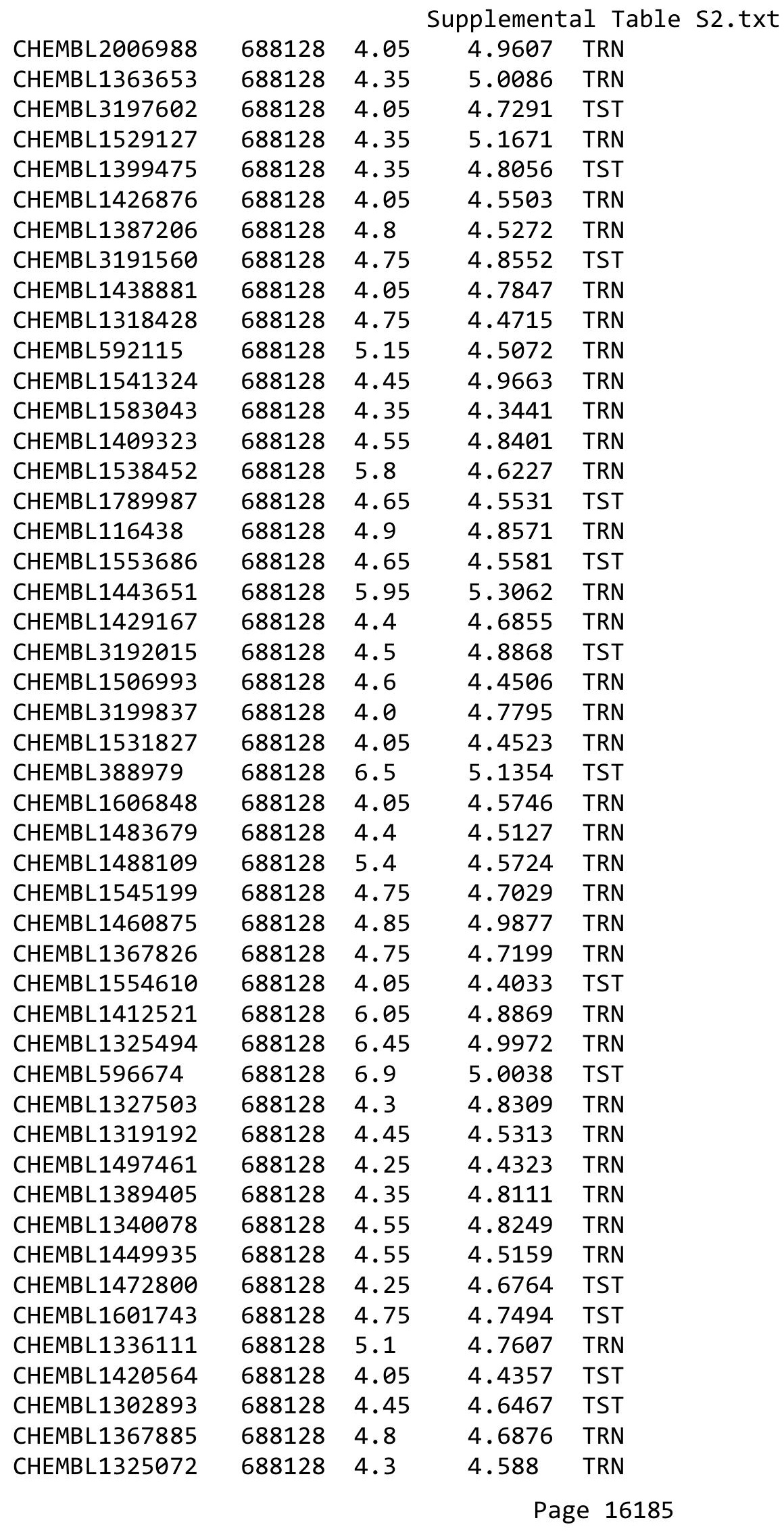




\begin{tabular}{|c|c|c|c|c|c|}
\hline \multicolumn{6}{|c|}{ Supplemental Table S2.txt } \\
\hline CHEMBL1343373 & 688128 & 4.4 & 4.6218 & TRN & \\
\hline CHEMBL1459812 & 688128 & 4.3 & 4.59 & TRN & \\
\hline CHEMBL1415971 & 688128 & 5.15 & 5.0099 & TRN & \\
\hline CHEMBL1454171 & 688128 & 4.8 & 4.6176 & TST & \\
\hline CHEMBL1609653 & 688128 & 4.4 & 4.5033 & TRN & \\
\hline CHEMBL1389625 & 688128 & 5.4 & 4.9259 & TRN & \\
\hline CHEMBL1529411 & 688128 & 5.15 & 4.4451 & TRN & \\
\hline CHEMBL1518908 & 688128 & 5.05 & 4.6076 & TST & \\
\hline CHEMBL1471601 & 688128 & 4.5 & 4.71399 & 99999999995 & TRN \\
\hline CHEMBL1540591 & 688128 & 4.3 & 4.5618 & TRN & \\
\hline CHEMBL1325945 & 688128 & 4.55 & 4.7585 & TRN & \\
\hline CHEMBL1419027 & 688128 & 4.35 & 4.5024 & TRN & \\
\hline CHEMBL1359729 & 688128 & 5.35 & 4.8471 & TST & \\
\hline CHEMBL1304665 & 688128 & 4.65 & 4.5672 & TRN & \\
\hline CHEMBL1407474 & 688128 & 4.5 & 4.8089 & TST & \\
\hline CHEMBL1382611 & 688128 & 4.25 & 4.4834 & TRN & \\
\hline CHEMBL1493381 & 688128 & 4.35 & 4.7665 & TRN & \\
\hline CHEMBL1981797 & 688128 & 4.6 & 4.9927 & TRN & \\
\hline CHEMBL1430739 & 688128 & 4.45 & 4.5835 & TRN & \\
\hline CHEMBL1469499 & 688128 & 4.65 & 4.5889 & TST & \\
\hline CHEMBL1320819 & 688128 & 7.0 & 4.5752 & TST & \\
\hline CHEMBL1579799 & 688128 & 4.45 & 4.8843 & TRN & \\
\hline CHEMBL1506915 & 688128 & 4.0 & 4.5732 & TST & \\
\hline CHEMBL1506895 & 688128 & 4.45 & 4.2928 & TST & \\
\hline CHEMBL1328132 & 688128 & 5.5 & 5.0551 & TRN & \\
\hline CHEMBL1473579 & 688128 & 4.95 & 5.0495 & TRN & \\
\hline CHEMBL1319458 & 688128 & 4.5 & 4.7586 & TRN & \\
\hline CHEMBL1560926 & 688128 & 4.25 & 4.5475 & TRN & \\
\hline CHEMBL1513489 & 688128 & 4.6 & 5.0072 & TRN & \\
\hline CHEMBL3197994 & 688128 & 3.95 & 4.6498 & TST & \\
\hline CHEMBL1433580 & 688128 & 4.4 & 4.3771 & TRN & \\
\hline CHEMBL1482493 & 688128 & 4.6 & 4.4521 & TRN & \\
\hline CHEMBL1367267 & 688128 & 4.65 & 4.7707 & TRN & \\
\hline CHEMBL1453175 & 688128 & 5.85 & 4.6519 & TRN & \\
\hline CHEMBL1468823 & 688128 & 4.05 & 4.4383 & TRN & \\
\hline CHEMBL1362803 & 688128 & 4.3 & 4.7237 & TST & \\
\hline CHEMBL1304659 & 688128 & 4.35 & 4.938 & TRN & \\
\hline CHEMBL1428424 & 688128 & 4.1 & 4.6517 & TRN & \\
\hline CHEMBL1511458 & 688128 & 4.95 & 4.8257 & TRN & \\
\hline CHEMBL1564286 & 688128 & 5.35 & 4.776 & TST & \\
\hline CHEMBL1319746 & 688128 & 4.45 & 4.7633 & TRN & \\
\hline CHEMBL1376549 & 688128 & 4.4 & 4.7098 & TRN & \\
\hline CHEMBL1476163 & 688128 & 4.35 & 4.4304 & TRN & \\
\hline CHEMBL1365691 & 688128 & 4.45 & 4.643 & TRN & \\
\hline CHEMBL602927 & 688128 & 5.45 & 5.4905 & TRN & \\
\hline CHEMBL1325106 & 688128 & 4.5 & 4.8432 & TRN & \\
\hline CHEMBL1565975 & 688128 & 4.1 & 4.7378 & TRN & \\
\hline CHEMBL1390406 & 688128 & 4.25 & 4.8907 & TST & \\
\hline
\end{tabular}




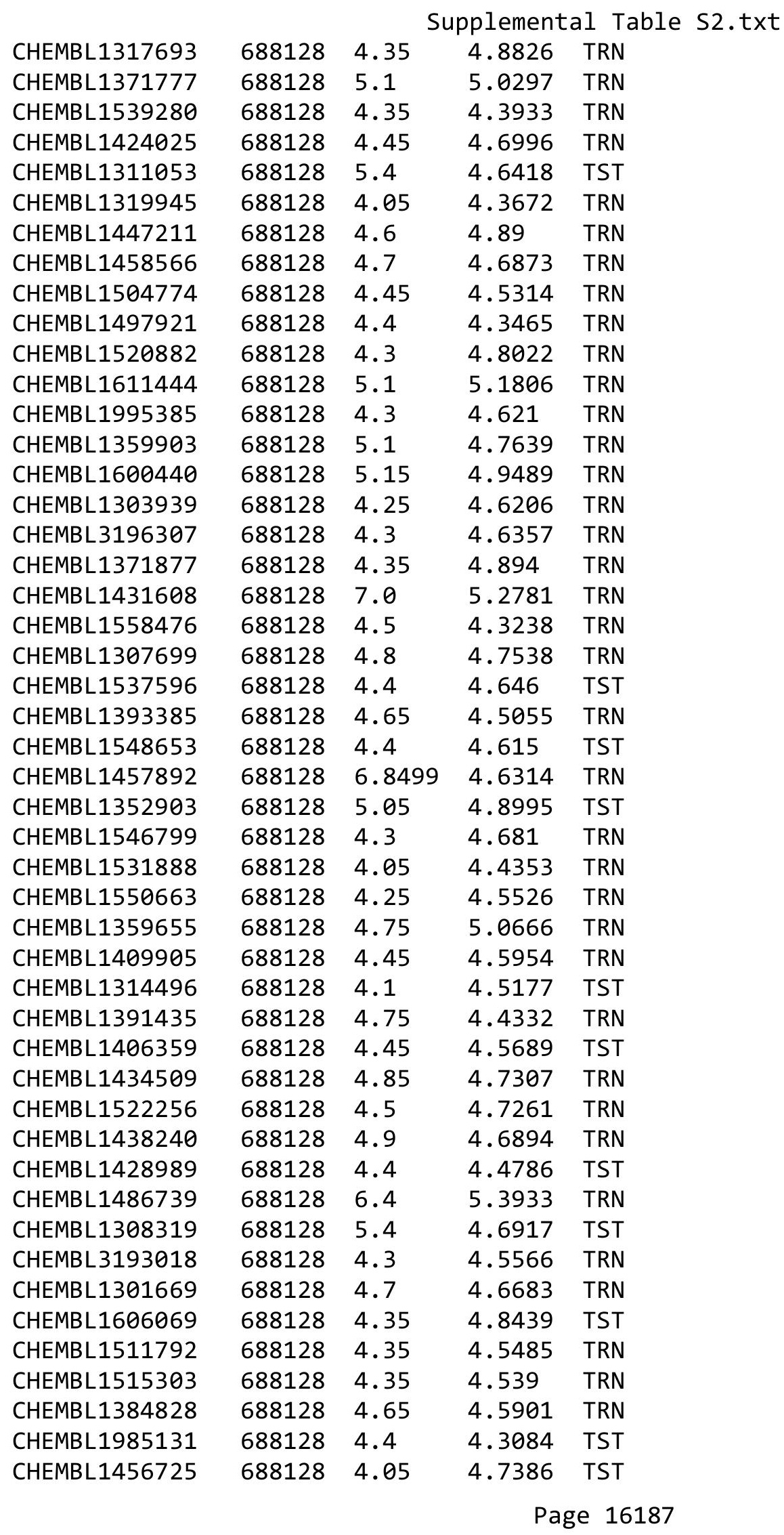




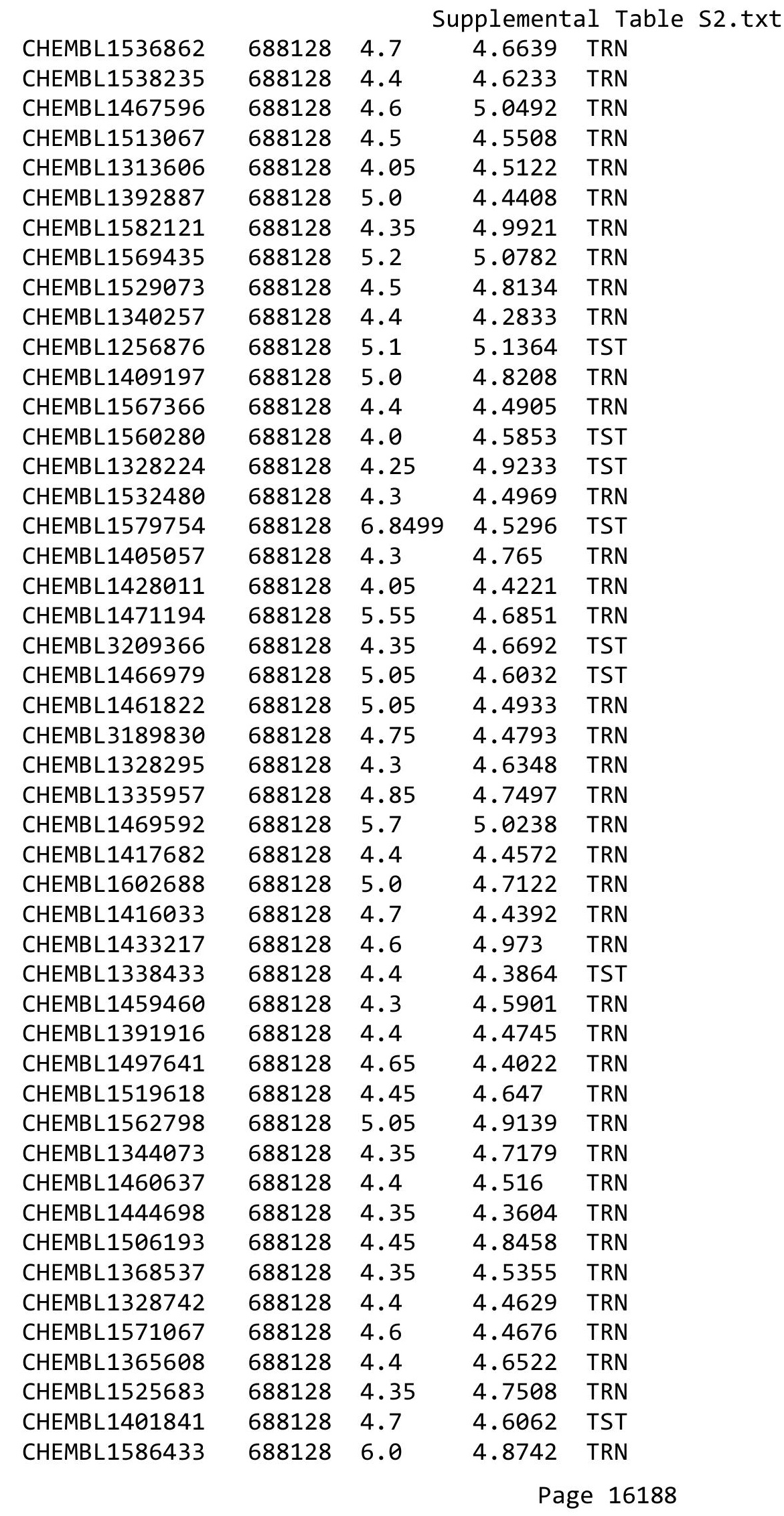




\begin{tabular}{|c|c|c|c|c|}
\hline \multicolumn{5}{|c|}{ Supplemental Table S2.txt } \\
\hline CHEMBL1304616 & 688128 & 4.7 & 4.7634 & TRN \\
\hline CHEMBL1372401 & 688128 & 4.9 & 4.6318 & TRN \\
\hline CHEMBL1510030 & 688128 & 5.4 & 4.7762 & TRN \\
\hline CHEMBL1437251 & 688128 & 4.3 & 4.9192 & TRN \\
\hline CHEMBL3198251 & 688128 & 4.5 & 4.8783 & TST \\
\hline CHEMBL1450625 & 688128 & 4.95 & 4.6427 & TRN \\
\hline CHEMBL 224032 & 688128 & 4.25 & 4.6748 & TRN \\
\hline CHEMBL1994460 & 688128 & 4.35 & 4.5272 & TRN \\
\hline CHEMBL1412972 & 688128 & 5.5 & 4.8861 & TRN \\
\hline CHEMBL1313744 & 688128 & 4.3 & 4.6143 & TRN \\
\hline CHEMBL1499916 & 688128 & 5.95 & 4.7045 & TST \\
\hline CHEMBL1346349 & 688128 & 6.7501 & 4.4551 & TST \\
\hline CHEMBL1347117 & 688128 & 4.55 & 4.6958 & TST \\
\hline CHEMBL1551103 & 688128 & 4.35 & 4.6066 & TST \\
\hline CHEMBL1512654 & 688128 & 4.25 & 4.5805 & TST \\
\hline CHEMBL1535770 & 688128 & 4.35 & 4.646 & TRN \\
\hline CHEMBL1421743 & 688128 & 4.3 & 4.7788 & TRN \\
\hline CHEMBL1385074 & 688128 & 4.6 & 4.5618 & TRN \\
\hline CHEMBL1584474 & 688128 & 4.3 & 4.4721 & TRN \\
\hline CHEMBL1550271 & 688128 & 5.4 & 4.5919 & TST \\
\hline CHEMBL1520666 & 688128 & 4.4 & 4.4923 & TRN \\
\hline CHEMBL1303725 & 688128 & 4.1 & 5.0049 & TRN \\
\hline CHEMBL1593006 & 688128 & 4.45 & 4.6861 & TRN \\
\hline CHEMBL1536716 & 688128 & 4.4 & 4.5696 & TRN \\
\hline CHEMBL1506783 & 688128 & 5.35 & 4.6235 & TST \\
\hline CHEMBL1509058 & 688128 & 4.35 & 4.5669 & TRN \\
\hline CHEMBL1496503 & 688128 & 5.5 & 4.9333 & TST \\
\hline CHEMBL1606693 & 688128 & 4.9 & 4.6359 & TRN \\
\hline CHEMBL1526566 & 688128 & 4.0 & 4.3689 & TRN \\
\hline CHEMBL1472278 & 688128 & 4.8 & 4.4082 & TRN \\
\hline CHEMBL1457462 & 688128 & 4.4 & 4.7925 & TRN \\
\hline CHEMBL1327616 & 688128 & 4.85 & 4.7138 & TRN \\
\hline CHEMBL1419124 & 688128 & 4.4 & 4.5832 & TRN \\
\hline CHEMBL1549969 & 688128 & 4.3 & 4.2963 & TRN \\
\hline CHEMBL1304055 & 688128 & 4.65 & 4.7035 & TST \\
\hline CHEMBL1442152 & 688128 & 4.4 & 4.3531 & TRN \\
\hline CHEMBL109866 & 688128 & 4.4 & 4.4463 & TST \\
\hline CHEMBL1327689 & 688128 & 5.05 & 4.6027 & TRN \\
\hline CHEMBL1411638 & 688128 & 4.55 & 4.7446 & TRN \\
\hline CHEMBL1396163 & 688128 & 4.45 & 4.8842 & TRN \\
\hline CHEMBL1592747 & 688128 & 4.4 & 4.458 & TST \\
\hline CHEMBL1342347 & 688128 & 4.4 & 4.3871 & TRN \\
\hline CHEMBL1403535 & 688128 & 4.65 & 4.7107 & TST \\
\hline CHEMBL3191892 & 688128 & 5.05 & 5.0651 & TRN \\
\hline CHEMBL1532407 & 688128 & 5.55 & 4.8293 & TRN \\
\hline CHEMBL1534509 & 688128 & 4.4 & 4.4753 & TST \\
\hline CHEMBL1455422 & 688128 & 4.5 & 4.7034 & TST \\
\hline CHEMBL1344392 & 688128 & 4.6 & 4.6041 & TRN \\
\hline
\end{tabular}




\begin{tabular}{|c|c|c|c|c|c|}
\hline \multicolumn{6}{|c|}{ Supplemental Table s2.txt } \\
\hline CHEMBL1542649 & 688128 & 4.3 & 4.3275 & TRN & \\
\hline CHEMBL3194633 & 688128 & 4.25 & 4.5168 & TST & \\
\hline CHEMBL1563370 & 688128 & 5.15 & 5.1576 & TRN & \\
\hline CHEMBL1385310 & 688128 & 4.35 & 4.5191 & TRN & \\
\hline CHEMBL1315447 & 688128 & 4.4 & 4.5257 & TST & \\
\hline CHEMBL1360057 & 688128 & 4.85 & 4.7321 & TRN & \\
\hline CHEMBL1417171 & 688128 & 4.3 & 4.5204 & TRN & \\
\hline CHEMBL1301409 & 688128 & 4.35 & 4.7164 & TST & \\
\hline CHEMBL1490036 & 688128 & 4.3 & 4.2565 & TRN & \\
\hline CHEMBL1600294 & 688128 & 4.65 & 4.4441 & TRN & \\
\hline CHEMBL3192863 & 688128 & 5.45 & 5.1729 & TRN & \\
\hline CHEMBL1431273 & 688128 & 4.05 & 4.4459 & TRN & \\
\hline CHEMBL1438541 & 688128 & 4.55 & 4.9394 & TRN & \\
\hline CHEMBL1554315 & 688128 & 4.4 & 4.4452 & TST & \\
\hline CHEMBL1347747 & 688128 & 4.0 & 4.6666 & TRN & \\
\hline CHEMBL1336404 & 688128 & 5.8 & 4.9632 & TRN & \\
\hline CHEMBL1411673 & 688128 & 6.35 & $5.1370 e$ & 00000000005 & TRN \\
\hline CHEMBL1360632 & 688128 & 4.6 & 4.4548 & TRN & \\
\hline CHEMBL1364300 & 688128 & 4.35 & 4.5507 & TRN & \\
\hline CHEMBL1600462 & 688128 & 5.55 & 4.5086 & TST & \\
\hline CHEMBL1361346 & 688128 & 5.0 & 4.4354 & TST & \\
\hline CHEMBL1555726 & 688128 & 6.0 & 4.7558 & TRN & \\
\hline CHEMBL1535452 & 688128 & 5.95 & 4.4929 & TRN & \\
\hline CHEMBL1338513 & 688128 & 4.05 & 4.758 & TST & \\
\hline CHEMBL1354974 & 688128 & 4.1 & 4.4873 & TRN & \\
\hline CHEMBL1572130 & 688128 & 4.45 & 4.9301 & TRN & \\
\hline CHEMBL 2001904 & 688128 & 6.0 & 4.9041 & TST & \\
\hline CHEMBL1382925 & 688128 & 4.3 & 4.5551 & TRN & \\
\hline CHEMBL1370948 & 688128 & 4.6 & 4.6237 & TST & \\
\hline CHEMBL1589086 & 688128 & 4.8 & 4.8899 & TRN & \\
\hline CHEMBL1432491 & 688128 & 4.05 & 4.6002 & TST & \\
\hline CHEMBL1565600 & 688128 & 4.4 & 4.6743 & TST & \\
\hline CHEMBL1307350 & 688128 & 4.05 & 4.6181 & TRN & \\
\hline CHEMBL1541103 & 688128 & 4.45 & 4.5779 & TRN & \\
\hline CHEMBL1521317 & 688128 & 4.5 & 4.9465 & TRN & \\
\hline CHEMBL1528195 & 688128 & 4.05 & 4.2823 & TRN & \\
\hline CHEMBL544115 & 688128 & 4.35 & 4.8947 & TST & \\
\hline CHEMBL1304801 & 688128 & 5.35 & 4.6142 & TRN & \\
\hline CHEMBL1459775 & 688128 & 4.55 & 4.7988 & TST & \\
\hline CHEMBL1304727 & 688128 & 4.25 & 4.515 & TST & \\
\hline CHEMBL1420111 & 688128 & 4.6 & 4.6343 & TRN & \\
\hline CHEMBL1422215 & 688128 & 5.4 & 4.6438 & TST & \\
\hline CHEMBL1355017 & 688128 & 4.35 & 4.9466 & TST & \\
\hline CHEMBL610198 & 688128 & 4.4 & 5.035 & TRN & \\
\hline CHEMBL1311732 & 688128 & 5.5 & 4.7719 & TRN & \\
\hline CHEMBL1580363 & 688128 & 4.05 & 4.5544 & TST & \\
\hline CHEMBL 373940 & 688128 & 4.4 & 4.4688 & TST & \\
\hline CHEMBL1515064 & 688128 & 4.1 & 4.55 & TRN & \\
\hline
\end{tabular}




\begin{tabular}{|c|c|c|c|c|}
\hline \multicolumn{5}{|c|}{ Supplemental Table S2.txt } \\
\hline CHEMBL1519374 & 688128 & 6.5 & 5.0797 & TRN \\
\hline CHEMBL1342831 & 688128 & 4.4 & 4.4747 & TRN \\
\hline CHEMBL1300512 & 688128 & 4.55 & 4.6293 & TST \\
\hline CHEMBL1579210 & 688128 & 6.0 & 4.5399 & TST \\
\hline CHEMBL1345085 & 688128 & 4.45 & 4.4343 & TST \\
\hline CHEMBL1309157 & 688128 & 5.05 & 4.7517 & TRN \\
\hline CHEMBL1314830 & 688128 & 4.3 & 4.6231 & TST \\
\hline CHEMBL1543513 & 688128 & 5.15 & 4.7197 & TRN \\
\hline CHEMBL1524365 & 688128 & 4.45 & 4.521 & TRN \\
\hline CHEMBL1580198 & 688128 & 4.4 & 4.5335 & TRN \\
\hline CHEMBL1343244 & 688128 & 5.45 & 4.5672 & TRN \\
\hline CHEMBL1997059 & 688128 & 4.35 & 4.6127 & TST \\
\hline CHEMBL1430473 & 688128 & 5.45 & 5.3479 & TRN \\
\hline CHEMBL1438379 & 688128 & 4.0 & 4.4937 & TRN \\
\hline CHEMBL1468393 & 688128 & 4.1 & 4.3601 & TST \\
\hline CHEMBL1453783 & 688128 & 5.45 & 4.5651 & TST \\
\hline CHEMBL1453346 & 688128 & 4.4 & 4.4586 & TRN \\
\hline CHEMBL1496587 & 688128 & 4.55 & 4.4885 & TRN \\
\hline CHEMBL1346853 & 688128 & 4.25 & 4.7487 & TRN \\
\hline CHEMBL1481063 & 688128 & 5.4 & 4.4459 & TST \\
\hline CHEMBL1433028 & 688128 & 6.0 & 4.8461 & TRN \\
\hline CHEMBL 290914 & 688128 & 4.4 & 5.0054 & TST \\
\hline CHEMBL1328431 & 688128 & 4.3 & 4.4825 & TST \\
\hline CHEMBL3392052 & 688128 & 4.35 & 4.81 & TRN \\
\hline CHEMBL1311253 & 688128 & 4.35 & 4.6799 & TRN \\
\hline CHEMBL1341046 & 688128 & 4.4 & 4.5728 & TRN \\
\hline CHEMBL1544774 & 688128 & 4.4 & 4.0918 & TRN \\
\hline CHEMBL1527114 & 688128 & 4.3 & 4.3789 & TRN \\
\hline CHEMBL1530039 & 688128 & 4.55 & 4.4699 & TRN \\
\hline CHEMBL3190886 & 688128 & 4.3 & 4.489 & TRN \\
\hline CHEMBL1303095 & 688128 & 5.4 & 4.6808 & TRN \\
\hline CHEMBL1570419 & 688128 & 4.05 & 4.6435 & TST \\
\hline CHEMBL1504516 & 688128 & 4.35 & 4.558 & TRN \\
\hline CHEMBL1358632 & 688128 & 4.4 & 4.6364 & TRN \\
\hline CHEMBL1523593 & 688128 & 4.45 & 4.6505 & TRN \\
\hline CHEMBL1545720 & 688128 & 4.7 & 4.3794 & TRN \\
\hline CHEMBL1371865 & 688128 & 4.4 & 4.99 & TRN \\
\hline CHEMBL1613703 & 688128 & 4.45 & 4.3846 & TRN \\
\hline CHEMBL1417173 & 688128 & 4.3 & 4.8284 & TRN \\
\hline CHEMBL1564646 & 688128 & 5.5 & 4.6594 & TRN \\
\hline CHEMBL1499053 & 688128 & 4.9 & 4.6247 & TRN \\
\hline CHEMBL1541752 & 688128 & 4.35 & 4.7256 & TST \\
\hline CHEMBL1400087 & 688128 & 4.25 & 4.4763 & TRN \\
\hline CHEMBL1471055 & 688128 & 5.1 & 4.3423 & TRN \\
\hline CHEMBL1481179 & 688128 & 4.0 & 4.421 & TST \\
\hline CHEMBL3211962 & 688128 & 4.3 & 4.618 & TRN \\
\hline CHEMBL 1345758 & 688128 & 4.4 & 4.5497 & TRN \\
\hline CHEMBL1307668 & 688128 & 4.1 & 4.8261 & TRN \\
\hline
\end{tabular}




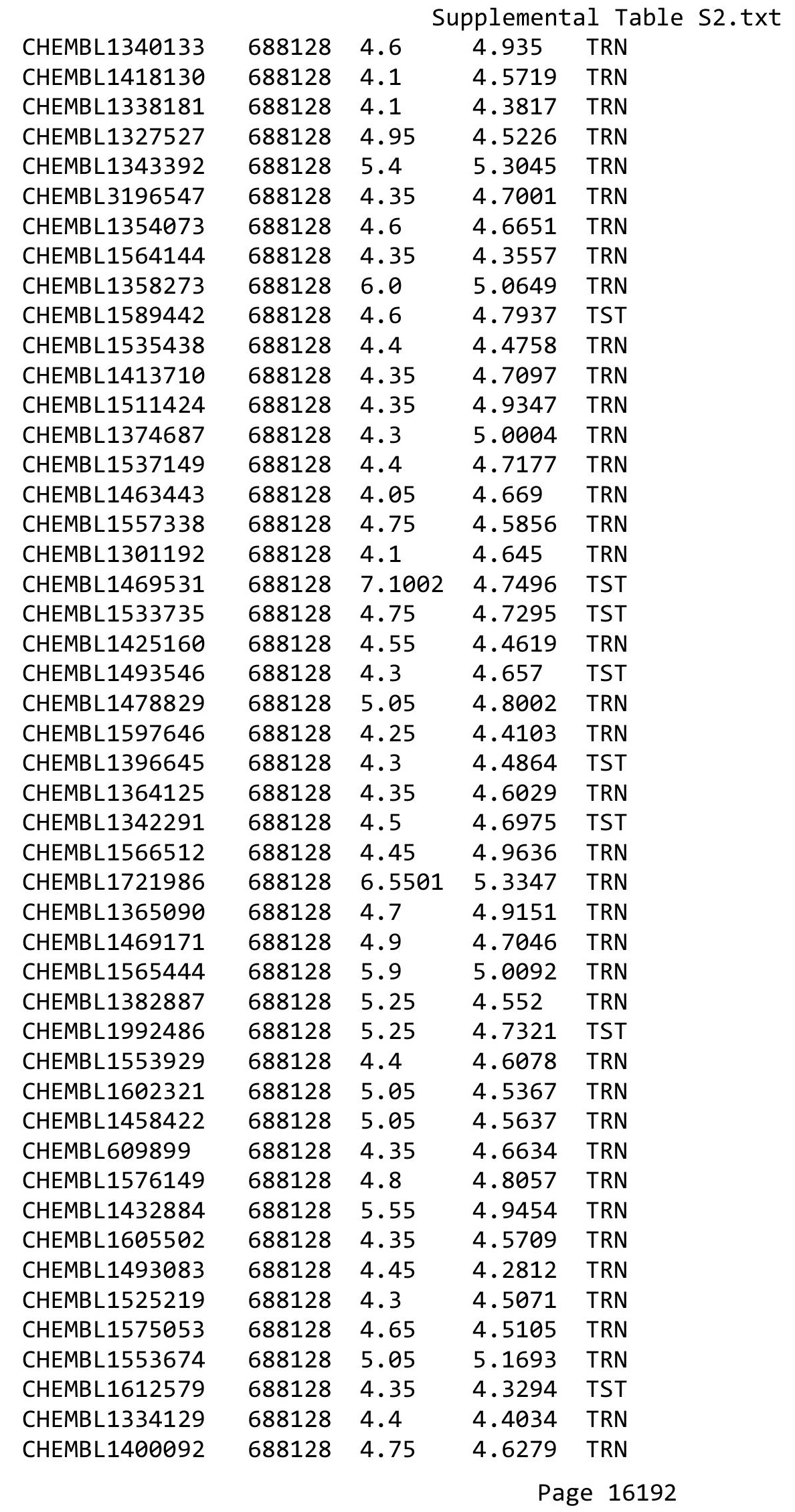




\begin{tabular}{|c|c|c|c|c|}
\hline \multicolumn{5}{|c|}{ Supplemental Table S2.txt } \\
\hline CHEMBL1378934 & 688128 & 4.4 & 4.4193 & TRN \\
\hline CHEMBL1581415 & 688128 & 4.3 & 4.7996 & TRN \\
\hline CHEMBL1569531 & 688128 & 5.0 & 4.4454 & TRN \\
\hline CHEMBL1449583 & 688128 & 4.7 & 4.7752 & TRN \\
\hline CHEMBL1399163 & 688128 & 4.7 & 4.502 & TRN \\
\hline CHEMBL1342946 & 688128 & 4.4 & 4.4186 & TRN \\
\hline CHEMBL1524140 & 688128 & 4.05 & 4.7193 & TST \\
\hline CHEMBL1585280 & 688128 & 5.55 & 4.6221 & TRN \\
\hline CHEMBL1582473 & 688128 & 4.55 & 4.7716 & TRN \\
\hline CHEMBL1431009 & 688128 & 4.6 & 4.485 & TRN \\
\hline CHEMBL1431707 & 688128 & 4.35 & 4.4049 & TST \\
\hline CHEMBL1402535 & 688128 & 4.5 & 4.5767 & TRN \\
\hline CHEMBL1556198 & 688128 & 4.35 & 4.8701 & TRN \\
\hline CHEMBL1493420 & 688128 & 4.35 & 4.4359 & TRN \\
\hline CHEMBL1578705 & 688128 & 4.75 & 4.4261 & TRN \\
\hline CHEMBL1437347 & 688128 & 4.1 & 4.4761 & TST \\
\hline CHEMBL3190418 & 688128 & 4.4 & 4.7405 & TRN \\
\hline CHEMBL1397382 & 688128 & 4.0 & 4.6019 & TRN \\
\hline CHEMBL1412821 & 688128 & 5.75 & 4.5624 & TRN \\
\hline CHEMBL1504227 & 688128 & 4.7 & 4.5356 & TRN \\
\hline CHEMBL3209440 & 688128 & 5.45 & 4.6103 & TRN \\
\hline CHEMBL1517551 & 688128 & 5.55 & 4.9595 & TRN \\
\hline CHEMBL1573202 & 688128 & 4.4 & 4.4132 & TRN \\
\hline CHEMBL1467714 & 688128 & 5.25 & 4.8122 & TRN \\
\hline CHEMBL3211208 & 688128 & 4.3 & 4.8428 & TRN \\
\hline CHEMBL1369958 & 688128 & 5.85 & 5.2043 & TRN \\
\hline CHEMBL1415844 & 688128 & 4.05 & 4.2565 & TST \\
\hline CHEMBL1398200 & 688128 & 4.35 & 4.6206 & TRN \\
\hline CHEMBL1499363 & 688128 & 4.3 & 4.8233 & TST \\
\hline CHEMBL1424109 & 688128 & 4.3 & 4.5473 & TST \\
\hline CHEMBL1385588 & 688128 & 4.25 & 4.5014 & TST \\
\hline CHEMBL1487112 & 688128 & 4.4 & 4.3591 & TRN \\
\hline CHEMBL1611754 & 688128 & 5.05 & 4.8566 & TRN \\
\hline CHEMBL1420342 & 688128 & 6.5501 & 4.7221 & TRN \\
\hline CHEMBL1443180 & 688128 & 5.55 & 4.888 & TRN \\
\hline CHEMBL1507676 & 688128 & 4.35 & 4.7585 & TST \\
\hline CHEMBL1529843 & 688128 & 4.05 & 4.5401 & TST \\
\hline CHEMBL1410049 & 688128 & 4.05 & 4.7412 & TST \\
\hline CHEMBL1392295 & 688128 & 4.95 & 4.7172 & TRN \\
\hline CHEMBL1352101 & 688128 & 6.9 & 4.5137 & TRN \\
\hline CHEMBL1398701 & 688128 & 4.3 & 4.6065 & TRN \\
\hline CHEMBL1519073 & 688128 & 4.15 & 4.4172 & TST \\
\hline CHEMBL1348043 & 688128 & 4.25 & 4.7454 & TRN \\
\hline CHEMBL1443980 & 688128 & 4.85 & 4.8342 & TRN \\
\hline CHEMBL1393222 & 688128 & 4.4 & 4.591 & TRN \\
\hline CHEMBL1606007 & 688128 & 4.35 & 4.9199 & TST \\
\hline CHEMBL1488455 & 688128 & 4.8 & 4.5532 & TRN \\
\hline CHEMBL1359988 & 688128 & 4.05 & 4.7027 & TST \\
\hline
\end{tabular}




\begin{tabular}{|c|c|c|c|c|c|}
\hline \multicolumn{6}{|c|}{ Supplemental Table S2.txt } \\
\hline CHEMBL1341590 & 688128 & 4.7 & 4.715 & TRN & \\
\hline CHEMBL1504280 & 688128 & 4.35 & 4.5577 & TRN & \\
\hline CHEMBL1549132 & 688128 & 4.05 & 4.5329 & TRN & \\
\hline CHEMBL 3145202 & 688128 & 4.4 & 4.5332 & TST & \\
\hline CHEMBL1551402 & 688128 & 4.35 & 4.4807 & TRN & \\
\hline CHEMBL1551456 & 688128 & 4.45 & 4.408 & TRN & \\
\hline CHEMBL1501173 & 688128 & 5.5 & 4.6617 & TST & \\
\hline CHEMBL1374511 & 688128 & 4.4 & 4.6721 & TRN & \\
\hline CHEMBL1561767 & 688128 & 4.4 & 4.8534 & TST & \\
\hline CHEMBL1498123 & 688128 & 4.35 & 5.0148 & TRN & \\
\hline CHEMBL489947 & 688128 & 4.45 & 4.8279 & TRN & \\
\hline CHEMBL 1445108 & 688128 & 4.35 & 4.4156 & TRN & \\
\hline CHEMBL1385954 & 688128 & 4.7 & 4.4078 & TRN & \\
\hline CHEMBL1532390 & 688128 & 5.45 & 4.8379 & TRN & \\
\hline CHEMBL1308747 & 688128 & 4.45 & 4.7318 & TST & \\
\hline CHEMBL1437357 & 688128 & 4.35 & 4.7844 & TRN & \\
\hline CHEMBL1452952 & 688128 & 4.65 & 4.5353 & TST & \\
\hline CHEMBL1427459 & 688128 & 4.65 & 4.6046 & TRN & \\
\hline CHEMBL1302746 & 688128 & 4.5 & 4.5874 & TRN & \\
\hline CHEMBL1311343 & 688128 & 4.3 & 4.51699 & 99999999995 & TST \\
\hline CHEMBL1572827 & 688128 & 4.25 & 4.5751 & TST & \\
\hline CHEMBL1562006 & 688128 & 4.5 & 4.591 & TRN & \\
\hline CHEMBL1407151 & 688128 & 4.0 & 4.4113 & TST & \\
\hline CHEMBL1425368 & 688128 & 4.45 & 4.3071 & TRN & \\
\hline CHEMBL1572689 & 688128 & 4.3 & 4.9027 & TRN & \\
\hline CHEMBL1370985 & 688128 & 4.8 & 5.1025 & TRN & \\
\hline CHEMBL1604403 & 688128 & 4.85 & 4.2964 & TRN & \\
\hline CHEMBL1530825 & 688128 & 5.55 & 4.4479 & TST & \\
\hline CHEMBL1496175 & 688128 & 4.35 & 4.4641 & TRN & \\
\hline CHEMBL1575931 & 688128 & 4.0 & 4.5156 & TRN & \\
\hline CHEMBL1522089 & 688128 & 4.05 & 4.596 & TRN & \\
\hline CHEMBL1608507 & 688128 & 4.35 & 4.8548 & TST & \\
\hline CHEMBL1547220 & 688128 & 6.5501 & 4.7233 & TST & \\
\hline CHEMBL 3199878 & 688128 & 4.35 & 4.6637 & TRN & \\
\hline CHEMBL3397117 & 688128 & 6.6 & 5.0502 & TRN & \\
\hline CHEMBL1548949 & 688128 & 4.85 & 4.7749 & TRN & \\
\hline CHEMBL3191085 & 688128 & 4.25 & 4.6126 & TST & \\
\hline CHEMBL1354689 & 688128 & 4.4 & 4.6071 & TRN & \\
\hline CHEMBL1382323 & 688128 & 4.2 & 4.4794 & TRN & \\
\hline CHEMBL1423447 & 688128 & 4.35 & 4.5889 & TRN & \\
\hline CHEMBL1611827 & 688128 & 4.3 & 4.3919 & TRN & \\
\hline CHEMBL1480358 & 688128 & 4.4 & 4.4567 & TRN & \\
\hline CHEMBL1523801 & 688128 & 4.3 & 4.5359 & TST & \\
\hline CHEMBL 3190558 & 688128 & 5.05 & 4.9228 & TST & \\
\hline CHEMBL1510049 & 688128 & 4.85 & 4.3828 & TRN & \\
\hline CHEMBL1578857 & 688128 & 4.45 & 4.9195 & TRN & \\
\hline CHEMBL1450314 & 688128 & 4.4 & 4.5364 & TRN & \\
\hline CHEMBL1606646 & 688128 & 4.25 & 4.7222 & TST & \\
\hline
\end{tabular}




\begin{tabular}{|c|c|c|c|c|}
\hline \multicolumn{5}{|c|}{ Supplemental Table S2.txt } \\
\hline CHEMBL1964978 & 688128 & 4.55 & 4.6404 & TRN \\
\hline CHEMBL1363755 & 688128 & 5.45 & 5.2852 & TRN \\
\hline CHEMBL1560571 & 688128 & 4.05 & 4.4028 & TST \\
\hline CHEMBL1458507 & 688128 & 4.05 & 4.8269 & TRN \\
\hline CHEMBL1505513 & 688128 & 4.05 & 4.5227 & TRN \\
\hline CHEMBL1409358 & 688128 & 6.3 & 5.1673 & TRN \\
\hline CHEMBL1597464 & 688128 & 4.0 & 4.4835 & TRN \\
\hline CHEMBL1305080 & 688128 & 4.35 & 4.7447 & TST \\
\hline CHEMBL1362244 & 688128 & 4.6 & 4.7458 & TRN \\
\hline CHEMBL1323196 & 688128 & 4.9 & 4.7627 & TRN \\
\hline CHEMBL1545397 & 688128 & 4.5 & 4.5706 & TST \\
\hline CHEMBL1376683 & 688128 & 6.45 & 5.0811 & TRN \\
\hline CHEMBL1519710 & 688128 & 4.4 & 4.5146 & TRN \\
\hline CHEMBL1456223 & 688128 & 4.4 & 4.5086 & TRN \\
\hline CHEMBL1582895 & 688128 & 4.65 & 4.8345 & TRN \\
\hline CHEMBL1507181 & 688128 & 4.6 & 4.7737 & TRN \\
\hline CHEMBL1439702 & 688128 & 4.6 & 4.5388 & TRN \\
\hline CHEMBL1613528 & 688128 & 4.85 & 4.363 & TRN \\
\hline CHEMBL1359104 & 688128 & 4.7 & 4.7362 & TRN \\
\hline CHEMBL1451917 & 688128 & 4.4 & 4.574 & TRN \\
\hline CHEMBL1486863 & 688128 & 4.35 & 4.6848 & TRN \\
\hline CHEMBL1491058 & 688128 & 4.05 & 4.5388 & TRN \\
\hline CHEMBL1349830 & 688128 & 5.75 & 4.5677 & TRN \\
\hline CHEMBL1430842 & 688128 & 6.8499 & 4.7554 & TRN \\
\hline CHEMBL1313997 & 688128 & 4.6 & 4.5714 & TRN \\
\hline CHEMBL1567071 & 688128 & 6.0 & 4.8661 & TRN \\
\hline CHEMBL1537892 & 688128 & 4.3 & 4.6502 & TRN \\
\hline CHEMBL264671 & 688128 & 6.2 & 4.6794 & TRN \\
\hline CHEMBL1518326 & 688128 & 4.95 & 4.7483 & TST \\
\hline CHEMBL1377709 & 688128 & 4.5 & 4.9112 & TRN \\
\hline CHEMBL1537016 & 688128 & 5.35 & 4.7601 & TRN \\
\hline CHEMBL1993708 & 688128 & 4.4 & 4.7877 & TST \\
\hline CHEMBL1610640 & 688128 & 4.4 & 4.5755 & TST \\
\hline CHEMBL1449732 & 688128 & 4.4 & 4.4251 & TRN \\
\hline CHEMBL1303396 & 688128 & 4.4 & 4.5189 & TRN \\
\hline CHEMBL1340331 & 688128 & 4.05 & 4.537 & TST \\
\hline CHEMBL1382779 & 688128 & 4.1 & 4.4511 & TRN \\
\hline CHEMBL1511700 & 688128 & 5.35 & 4.6141 & TRN \\
\hline CHEMBL1524564 & 688128 & 4.65 & 4.6135 & TRN \\
\hline CHEMBL1308764 & 688128 & 4.35 & 4.8306 & TRN \\
\hline CHEMBL1354729 & 688128 & 4.05 & 4.3768 & TST \\
\hline CHEMBL1312111 & 688128 & 4.05 & 4.4756 & TRN \\
\hline CHEMBL1601696 & 688128 & 4.0 & 4.6656 & TST \\
\hline CHEMBL1397381 & 688128 & 6.0 & 4.8422 & TRN \\
\hline CHEMBL1476988 & 688128 & 4.4 & 4.4612 & TRN \\
\hline CHEMBL1597780 & 688128 & 4.3 & 4.4062 & TRN \\
\hline CHEMBL1373770 & 688128 & 5.0 & 4.4175 & TRN \\
\hline CHEMBL1479414 & 688128 & 4.25 & 4.6019 & TRN \\
\hline
\end{tabular}




\begin{tabular}{|c|c|c|c|c|c|}
\hline \multicolumn{6}{|c|}{ Supplemental Table S2.txt } \\
\hline CHEMBL1330946 & 688128 & 4.4 & 4.447 & TRN & \\
\hline CHEMBL1422755 & 688128 & 4.3 & 4.8422 & TRN & \\
\hline CHEMBL1563799 & 688128 & 4.3 & 4.4829 & TRN & \\
\hline CHEMBL1495260 & 688128 & 5.2 & 4.7367 & TST & \\
\hline CHEMBL1477352 & 688128 & 4.55 & 4.9413 & TRN & \\
\hline CHEMBL1585137 & 688128 & 5.0 & 4.5115 & TRN & \\
\hline CHEMBL1550578 & 688128 & 4.45 & 4.6974 & TRN & \\
\hline CHEMBL 3209480 & 688128 & 4.65 & 5.0369 & TST & \\
\hline CHEMBL1466804 & 688128 & 4.6 & 4.9609 & TRN & \\
\hline CHEMBL1344865 & 688128 & 4.3 & 4.5549 & TRN & \\
\hline CHEMBL1409200 & 688128 & 5.15 & 4.7415 & TST & \\
\hline CHEMBL1562369 & 688128 & 4.95 & 4.7089 & TRN & \\
\hline CHEMBL1430488 & 688128 & 4.4 & 4.5427 & TRN & \\
\hline CHEMBL1360681 & 688128 & 4.8 & 4.6894 & TRN & \\
\hline CHEMBL1333283 & 688128 & 6.2 & 5.0321 & TRN & \\
\hline CHEMBL3199225 & 688128 & 4.45 & 4.6597 & TRN & \\
\hline CHEMBL1329284 & 688128 & 4.1 & 4.6435 & TST & \\
\hline CHEMBL1312865 & 688128 & 4.4 & 4.5466 & TRN & \\
\hline CHEMBL1509369 & 688128 & 5.0 & 4.9314 & TRN & \\
\hline CHEMBL1607778 & 688128 & 4.85 & 4.5533 & TRN & \\
\hline CHEMBL1483355 & 688128 & 4.6 & 4.5251 & TRN & \\
\hline CHEMBL1471512 & 688128 & 4.3 & 4.71399 & 99999999995 & TRN \\
\hline CHEMBL1386235 & 688128 & 4.9 & 4.9356 & TRN & \\
\hline CHEMBL461840 & 688128 & 4.35 & 4.5823 & TST & \\
\hline CHEMBL1589486 & 688128 & 4.35 & 4.7891 & TRN & \\
\hline CHEMBL1507866 & 688128 & 4.4 & 4.5546 & TRN & \\
\hline CHEMBL1408442 & 688128 & 6.25 & 5.1369 & TRN & \\
\hline CHEMBL1235157 & 688128 & 5.45 & 4.6476 & TST & \\
\hline CHEMBL1373339 & 688128 & 4.8 & 5.3113 & TRN & \\
\hline CHEMBL1495800 & 688128 & 4.4 & 4.5717 & TRN & \\
\hline CHEMBL1392629 & 688128 & 4.05 & 4.5347 & TRN & \\
\hline CHEMBL1502731 & 688128 & 4.75 & 5.1255 & TRN & \\
\hline CHEMBL1368402 & 688128 & 4.55 & 4.8879 & TRN & \\
\hline CHEMBL1547446 & 688128 & 6.4 & 5.3157 & TRN & \\
\hline CHEMBL1500202 & 688128 & 4.5 & 4.72 & TRN & \\
\hline CHEMBL1459212 & 688128 & 4.4 & 4.4515 & TRN & \\
\hline CHEMBL1981349 & 688128 & 4.25 & 4.603 & TRN & \\
\hline CHEMBL1496534 & 688128 & 5.05 & 4.9799 & TRN & \\
\hline CHEMBL1345617 & 688128 & 4.3 & 4.2997 & TRN & \\
\hline CHEMBL1508885 & 688128 & 4.55 & 4.47199 & 99999999995 & TST \\
\hline CHEMBL1327498 & 688128 & 6.0 & 4.6091 & TRN & \\
\hline CHEMBL1607319 & 688128 & 4.7 & 4.6183 & TRN & \\
\hline CHEMBL1538657 & 688128 & 4.5 & 4.4218 & TRN & \\
\hline CHEMBL1496867 & 688128 & 4.05 & 4.4606 & TST & \\
\hline CHEMBL1468179 & 688128 & 5.8 & 5.1399 & TRN & \\
\hline CHEMBL3212355 & 688128 & 4.8 & 4.6179 & TRN & \\
\hline CHEMBL1386013 & 688128 & 4.3 & 4.6049 & TRN & \\
\hline CHEMBL1378374 & 688128 & 4.35 & 4.5644 & TRN & \\
\hline
\end{tabular}




\begin{tabular}{|c|c|c|c|c|c|}
\hline \multicolumn{6}{|c|}{ Supplemental Table S2.txt } \\
\hline CHEMBL1317576 & 688128 & 4.35 & 4.7242 & TST & \\
\hline CHEMBL1455049 & 688128 & 4.35 & 4.4648 & TRN & \\
\hline CHEMBL1583176 & 688128 & 4.6 & 4.3502 & TRN & \\
\hline CHEMBL1489964 & 688128 & 4.55 & 4.8526 & TRN & \\
\hline CHEMBL1607016 & 688128 & 4.05 & 4.2972 & TRN & \\
\hline CHEMBL1541488 & 688128 & 4.5 & 4.7462 & TRN & \\
\hline CHEMBL1376446 & 688128 & 4.05 & 4.433 & TST & \\
\hline CHEMBL1351384 & 688128 & 4.65 & 4.4448 & TRN & \\
\hline CHEMBL1399637 & 688128 & 4.45 & 4.312 & TRN & \\
\hline CHEMBL1415254 & 688128 & 4.45 & 4.7349 & TRN & \\
\hline CHEMBL1449375 & 688128 & 4.6 & 4.7933 & TRN & \\
\hline CHEMBL1328267 & 688128 & 4.0 & 4.5548 & TRN & \\
\hline CHEMBL1422253 & 688128 & 4.65 & 4.713 & TRN & \\
\hline CHEMBL1393697 & 688128 & 4.4 & 4.4602 & TRN & \\
\hline CHEMBL1605034 & 688128 & 4.65 & 4.6884 & TRN & \\
\hline CHEMBL1352640 & 688128 & 4.25 & 4.5478 & TRN & \\
\hline CHEMBL1602080 & 688128 & 4.7 & 4.5729 & TRN & \\
\hline CHEMBL1430077 & 688128 & 4.65 & 4.409 & TST & \\
\hline CHEMBL3195110 & 688128 & 6.8499 & 4.6216 & TRN & \\
\hline CHEMBL1334432 & 688128 & 5.45 & 4.5609 & TST & \\
\hline CHEMBL1588446 & 688128 & 4.7 & 4.6682 & TRN & \\
\hline CHEMBL1315581 & 688128 & 4.9 & 4.9236 & TRN & \\
\hline CHEMBL1512177 & 688128 & 6.3 & 4.9365 & TRN & \\
\hline CHEMBL1506580 & 688128 & 7.0 & 5.564 & TRN & \\
\hline CHEMBL1368350 & 688128 & 4.3 & 4.6342 & TRN & \\
\hline CHEMBL3193485 & 688128 & 6.45 & 4.6224 & TST & \\
\hline CHEMBL1522144 & 688128 & 4.35 & 4.177 & TRN & \\
\hline CHEMBL1609402 & 688128 & 4.65 & 4.5415 & TRN & \\
\hline CHEMBL1368328 & 688128 & 4.3 & 4.5405 & TST & \\
\hline CHEMBL1372221 & 688128 & 4.4 & 4.4102 & TRN & \\
\hline CHEMBL1497102 & 688128 & 4.25 & 4.4912 & TST & \\
\hline CHEMBL1488181 & 688128 & 4.1 & 4.6367 & TST & \\
\hline CHEMBL1318761 & 688128 & 4.45 & 4.58 & TRN & \\
\hline CHEMBL1541523 & 688128 & 5.75 & 4.6764 & TRN & \\
\hline CHEMBL1611043 & 688128 & 4.5 & 4.46399 & 99999999995 & TRN \\
\hline CHEMBL1524118 & 688128 & 4.4 & 4.8613 & TRN & \\
\hline CHEMBL1434395 & 688128 & 5.8 & 4.9748 & TRN & \\
\hline CHEMBL1500231 & 688128 & 4.7 & 4.3315 & TRN & \\
\hline CHEMBL1371052 & 688128 & 4.05 & 4.5472 & TRN & \\
\hline CHEMBL1520245 & 688128 & 4.45 & 4.7426 & TRN & \\
\hline CHEMBL1327677 & 688128 & 4.3 & 4.6424 & TRN & \\
\hline CHEMBL1533401 & 688128 & 4.65 & 4.61600 & 00000000005 & TST \\
\hline CHEMBL3190730 & 688128 & 4.4 & 4.5513 & TRN & \\
\hline CHEMBL1504985 & 688128 & 4.4 & 4.6806 & TST & \\
\hline CHEMBL1481268 & 688128 & 4.55 & 4.9122 & TST & \\
\hline CHEMBL1509648 & 688128 & 4.65 & 4.9705 & TRN & \\
\hline CHEMBL1509768 & 688128 & 4.5 & 4.4159 & TST & \\
\hline CHEMBL1592249 & 688128 & 4.25 & 4.4751 & TRN & \\
\hline
\end{tabular}




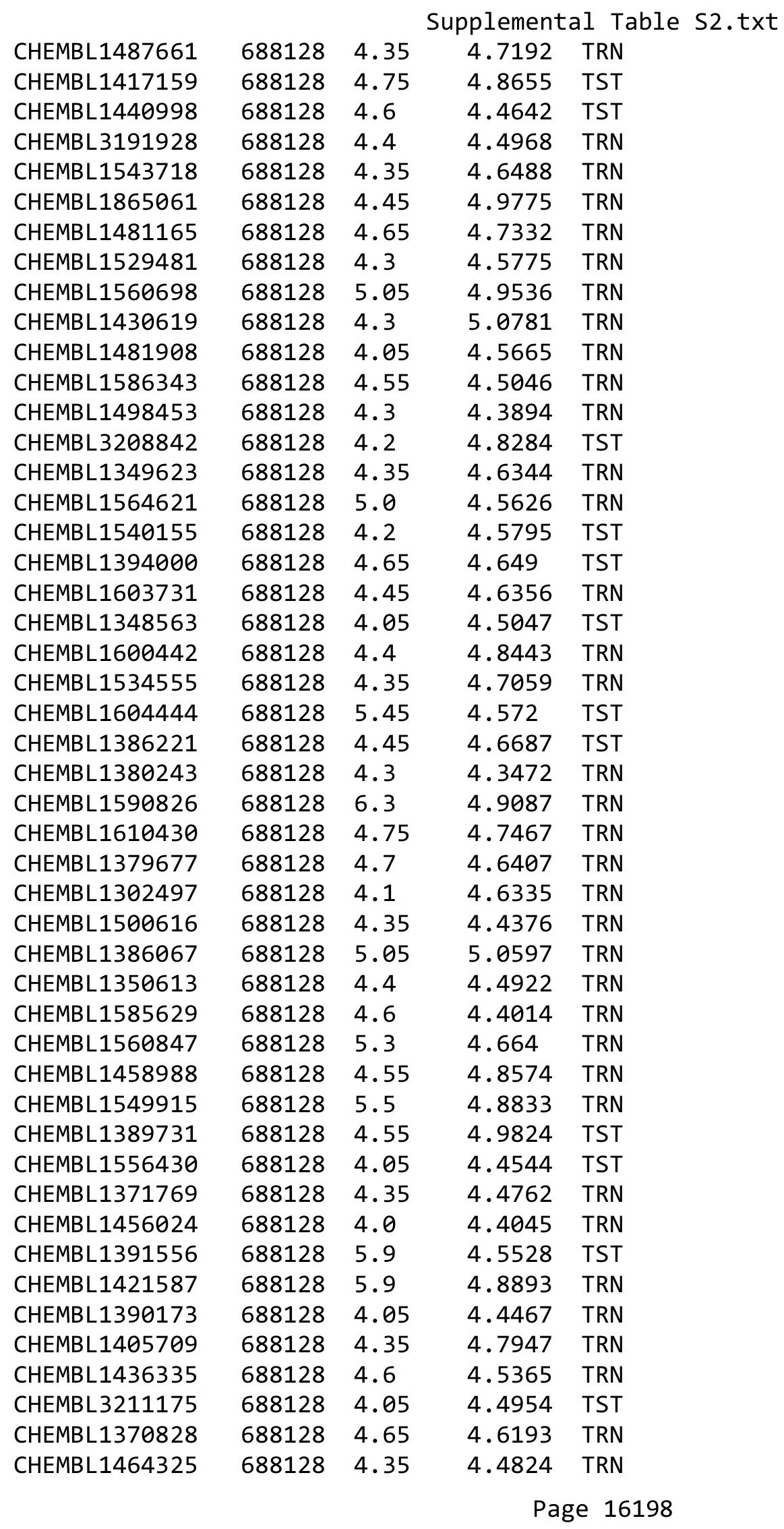




\begin{tabular}{|c|c|c|c|c|c|}
\hline \multicolumn{6}{|c|}{ Supplemental Table S2.txt } \\
\hline CHEMBL1361277 & 688128 & 4.25 & 4.4495 & TRN & \\
\hline CHEMBL1325597 & 688128 & 5.65 & 4.71 & TST & \\
\hline CHEMBL1608821 & 688128 & 4.95 & 4.5611 & TRN & \\
\hline CHEMBL1562937 & 688128 & 4.05 & 4.3869 & TST & \\
\hline CHEMBL1561737 & 688128 & 5.4 & 4.6998 & TST & \\
\hline CHEMBL1526305 & 688128 & 4.65 & 4.7293 & TRN & \\
\hline CHEMBL1498769 & 688128 & 4.35 & 4.6321 & TRN & \\
\hline CHEMBL1490903 & 688128 & 4.5 & 4.7465 & TRN & \\
\hline CHEMBL1331805 & 688128 & 5.3 & 4.6878 & TST & \\
\hline CHEMBL1503122 & 688128 & 6.2 & 4.6025 & TRN & \\
\hline CHEMBL1548733 & 688128 & 6.8 & 4.654 & TRN & \\
\hline CHEMBL1397959 & 688128 & 4.35 & 4.9141 & TRN & \\
\hline CHEMBL1501015 & 688128 & 5.35 & 4.8017 & TST & \\
\hline CHEMBL1571366 & 688128 & 4.6 & 4.6002 & TRN & \\
\hline CHEMBL1376972 & 688128 & 4.35 & 4.3589 & TRN & \\
\hline CHEMBL1487973 & 688128 & 4.1 & 4.5466 & TST & \\
\hline CHEMBL1454383 & 688128 & 4.3 & 4.8362 & TRN & \\
\hline CHEMBL1452217 & 688128 & 4.3 & 4.3927 & TRN & \\
\hline CHEMBL1408332 & 688128 & 5.4 & 4.9005 & TRN & \\
\hline CHEMBL1319716 & 688128 & 4.45 & 4.6044 & TST & \\
\hline CHEMBL1313529 & 688128 & 5.45 & 4.64199 & 99999999995 & TST \\
\hline CHEMBL1312974 & 688128 & 4.45 & 4.646 & TST & \\
\hline CHEMBL1432364 & 688128 & 5.05 & 5.0587 & TRN & \\
\hline CHEMBL3211815 & 688128 & 4.3 & 4.7241 & TRN & \\
\hline CHEMBL3194314 & 688128 & 4.2 & 4.5987 & TST & \\
\hline CHEMBL1501727 & 688128 & 4.05 & 4.4233 & TST & \\
\hline CHEMBL1300183 & 688128 & 4.05 & 4.7109 & TRN & \\
\hline CHEMBL1332695 & 688128 & 4.6 & 4.5299 & TRN & \\
\hline CHEMBL1384649 & 688128 & 4.75 & 4.4726 & TRN & \\
\hline CHEMBL1601581 & 688128 & 5.25 & 4.3842 & TRN & \\
\hline CHEMBL1360379 & 688128 & 6.5501 & 5.3838 & TRN & \\
\hline CHEMBL1483011 & 688128 & 4.05 & 4.6472 & TRN & \\
\hline CHEMBL 3192476 & 688128 & 4.3 & 4.6423 & TRN & \\
\hline CHEMBL1328353 & 688128 & 4.55 & 4.8148 & TST & \\
\hline CHEMBL1408563 & 688128 & 4.6 & 4.5229 & TRN & \\
\hline CHEMBL1410390 & 688128 & 4.1 & 4.562 & TRN & \\
\hline CHEMBL1329577 & 688128 & 4.3 & 4.5357 & TRN & \\
\hline CHEMBL1469213 & 688128 & 4.25 & 4.579 & TRN & \\
\hline CHEMBL1468412 & 688128 & 4.55 & 4.8086 & TRN & \\
\hline CHEMBL1549483 & 688128 & 4.4 & 4.7425 & TRN & \\
\hline CHEMBL1568073 & 688128 & 4.4 & 4.6905 & TRN & \\
\hline CHEMBL 273365 & 688128 & 4.8 & 4.595 & TRN & \\
\hline CHEMBL1310115 & 688128 & 4.4 & 4.6132 & TST & \\
\hline CHEMBL1316658 & 688128 & 4.05 & 4.659 & TRN & \\
\hline CHEMBL1565076 & 688128 & 4.1 & 4.4222 & TRN & \\
\hline CHEMBL1463793 & 688128 & 4.3 & 4.5631 & TRN & \\
\hline CHEMBL1533694 & 688128 & 4.6 & 4.3838 & TRN & \\
\hline CHEMBL1454699 & 688128 & 4.35 & 4.7615 & TST & \\
\hline
\end{tabular}




\begin{tabular}{|c|c|c|c|c|}
\hline \multicolumn{5}{|c|}{ Supplemental Table S2.txt } \\
\hline CHEMBL1447989 & 688128 & 4.7 & 4.6345 & TRN \\
\hline CHEMBL1556511 & 688128 & 4.45 & 4.4307 & TRN \\
\hline CHEMBL1299532 & 688128 & 4.3 & 4.4979 & TRN \\
\hline CHEMBL1422921 & 688128 & 4.15 & 4.3349 & TRN \\
\hline CHEMBL1520155 & 688128 & 4.4 & 4.407 & TRN \\
\hline CHEMBL1446832 & 688128 & 4.35 & 4.5367 & TRN \\
\hline CHEMBL1371820 & 688128 & 4.35 & 4.8792 & TRN \\
\hline CHEMBL1528258 & 688128 & 4.85 & 4.5433 & TRN \\
\hline CHEMBL1595260 & 688128 & 4.05 & 4.2873 & TST \\
\hline CHEMBL1571351 & 688128 & 4.4 & 4.6744 & TRN \\
\hline CHEMBL1582071 & 688128 & 4.4 & 4.7929 & TRN \\
\hline CHEMBL1412588 & 688128 & 4.4 & 5.0214 & TRN \\
\hline CHEMBL1466608 & 688128 & 4.6 & 4.7165 & TRN \\
\hline CHEMBL1350176 & 688128 & 4.45 & 4.4474 & TRN \\
\hline CHEMBL1706619 & 688128 & 4.35 & 4.3671 & TRN \\
\hline CHEMBL1544710 & 688128 & 6.5 & 4.6057 & TRN \\
\hline CHEMBL1563474 & 688128 & 4.05 & 4.6153 & TRN \\
\hline CHEMBL1375830 & 688128 & 4.4 & 4.6775 & TRN \\
\hline CHEMBL1968264 & 688128 & 5.45 & 4.8369 & TRN \\
\hline CHEMBL1499837 & 688128 & 3.95 & 4.5935 & TRN \\
\hline CHEMBL1368905 & 688128 & 4.05 & 4.3551 & TST \\
\hline CHEMBL157351 & 688128 & 4.1 & 4.7235 & TST \\
\hline CHEMBL1417547 & 688128 & 4.25 & 4.8051 & TRN \\
\hline CHEMBL1513653 & 688128 & 6.05 & 4.5042 & TRN \\
\hline CHEMBL1424671 & 688128 & 4.3 & 4.6907 & TST \\
\hline CHEMBL1526676 & 688128 & 4.35 & 4.7474 & TRN \\
\hline CHEMBL1362933 & 688128 & 4.3 & 4.8543 & TST \\
\hline CHEMBL1433814 & 688128 & 4.35 & 4.595 & TST \\
\hline CHEMBL1555587 & 688128 & 5.35 & 4.7306 & TRN \\
\hline CHEMBL1392292 & 688128 & 4.35 & 4.6215 & TST \\
\hline CHEMBL1464193 & 688128 & 4.3 & 4.942 & TST \\
\hline CHEMBL 2002162 & 688128 & 5.45 & 4.8374 & TST \\
\hline CHEMBL1374228 & 688128 & 4.35 & 4.4133 & TST \\
\hline CHEMBL1340477 & 688128 & 4.1 & 4.4914 & TRN \\
\hline CHEMBL1397989 & 688128 & 4.65 & 4.4724 & TRN \\
\hline CHEMBL1379391 & 688128 & 4.05 & 4.6187 & TRN \\
\hline CHEMBL1585190 & 688128 & 4.4 & 4.3376 & TRN \\
\hline CHEMBL1428590 & 688128 & 5.55 & 4.4011 & TRN \\
\hline CHEMBL1420031 & 688128 & 5.05 & 4.7914 & TRN \\
\hline CHEMBL1581447 & 688128 & 5.5 & 4.7598 & TRN \\
\hline CHEMBL1473052 & 688128 & 4.35 & 4.5905 & TRN \\
\hline CHEMBL1459476 & 688128 & 4.35 & 4.6032 & TST \\
\hline CHEMBL1999160 & 688128 & 4.75 & 4.9491 & TRN \\
\hline CHEMBL1388012 & 688128 & 4.25 & 4.6853 & TST \\
\hline CHEMBL1419684 & 688128 & 4.5 & 4.243 & TRN \\
\hline CHEMBL1604769 & 688128 & 4.05 & 4.5431 & TST \\
\hline CHEMBL3198269 & 688128 & 4.45 & 4.5728 & TRN \\
\hline CHEMBL3193997 & 688128 & 5.0 & 4.6282 & TST \\
\hline
\end{tabular}




\begin{tabular}{|c|c|c|c|c|c|}
\hline & & \multicolumn{4}{|c|}{ Supplemental Table S2.txt } \\
\hline CHEMBL1376835 & 688128 & 5.2 & 4.6455 & TST & \\
\hline CHEMBL1510195 & 688128 & 4.5 & 4.8324 & TRN & \\
\hline CHEMBL1512901 & 688128 & 5.45 & 4.5746 & TRN & \\
\hline CHEMBL1603959 & 688128 & 4.55 & 4.5812 & TRN & \\
\hline CHEMBL1437979 & 688128 & 4.45 & 4.4628 & TRN & \\
\hline CHEMBL1412354 & 688128 & 4.5 & 5.0114 & TST & \\
\hline CHEMBL1534959 & 688128 & 6.0 & 5.2999 & TRN & \\
\hline CHEMBL 3192665 & 688128 & 4.55 & 5.0135 & TST & \\
\hline CHEMBL1407812 & 688128 & 4.7 & 4.5693 & TRN & \\
\hline CHEMBL1503309 & 688128 & 4.35 & 4.793 & TRN & \\
\hline CHEMBL1426600 & 688128 & 4.6 & 4.4279 & TRN & \\
\hline CHEMBL1526753 & 688128 & 4.4 & 4.9206 & TRN & \\
\hline CHEMBL1499794 & 688128 & 4.5 & 4.3626 & TRN & \\
\hline CHEMBL1593753 & 688128 & 4.05 & 4.5186 & TST & \\
\hline CHEMBL1597081 & 688128 & 4.95 & 5.5027 & TRN & \\
\hline CHEMBL1460093 & 688128 & 4.4 & 4.9072 & TST & \\
\hline CHEMBL1542911 & 688128 & 5.6 & 4.72199 & 99999999995 & TST \\
\hline CHEMBL1405006 & 688128 & 4.65 & 4.4568 & TRN & \\
\hline CHEMBL1461843 & 688128 & 4.35 & 4.1989 & TRN & \\
\hline CHEMBL1590544 & 688128 & 4.4 & 4.6373 & TRN & \\
\hline CHEMBL1612236 & 688128 & 4.3 & 4.539 & TST & \\
\hline CHEMBL1390529 & 688128 & 4.35 & 4.471 & TRN & \\
\hline CHEMBL1473332 & 688128 & 4.35 & 4.3807 & TRN & \\
\hline CHEMBL1393087 & 688128 & 4.9 & 4.7889 & TRN & \\
\hline CHEMBL1529434 & 688128 & 4.35 & 4.3602 & TRN & \\
\hline CHEMBL1345795 & 688128 & 4.3 & 4.3534 & TRN & \\
\hline CHEMBL1567023 & 688128 & 5.55 & 4.6445 & TST & \\
\hline CHEMBL1471428 & 688128 & 4.0 & 4.7109 & TST & \\
\hline CHEMBL1364578 & 688128 & 4.45 & 4.6877 & TRN & \\
\hline CHEMBL1571002 & 688128 & 5.0 & 4.6361 & TRN & \\
\hline CHEMBL1436546 & 688128 & 4.5 & 4.6006 & TRN & \\
\hline CHEMBL1350080 & 688128 & 4.0 & 4.6013 & TST & \\
\hline CHEMBL1357506 & 688128 & 4.2 & 4.6851 & TRN & \\
\hline CHEMBL1308826 & 688128 & 4.4 & 4.6603 & TRN & \\
\hline CHEMBL1391020 & 688128 & 4.5 & 4.7412 & TRN & \\
\hline CHEMBL1459427 & 688128 & 4.5 & 4.689 & TRN & \\
\hline CHEMBL1309196 & 688128 & 4.3 & 4.5375 & TRN & \\
\hline CHEMBL1595473 & 688128 & 4.0 & 4.4203 & TST & \\
\hline CHEMBL1331573 & 688128 & 6.2 & 5.0977 & TRN & \\
\hline CHEMBL1390766 & 688128 & 5.85 & 4.5695 & TRN & \\
\hline CHEMBL1492656 & 688128 & 4.8 & 5.0699 & TRN & \\
\hline CHEMBL1489166 & 688128 & 4.9 & 4.5972 & TRN & \\
\hline CHEMBL1865547 & 688128 & 4.5 & 4.4087 & TST & \\
\hline CHEMBL1337628 & 688128 & 4.05 & 4.5806 & TRN & \\
\hline CHEMBL1537615 & 688128 & 5.6 & 5.0047 & TRN & \\
\hline CHEMBL1426916 & 688128 & 4.8 & 4.5425 & TRN & \\
\hline CHEMBL1474857 & 688128 & 4.1 & 4.4808 & TRN & \\
\hline CHEMBL1307846 & 688128 & 4.4 & 4.6688 & TRN & \\
\hline
\end{tabular}




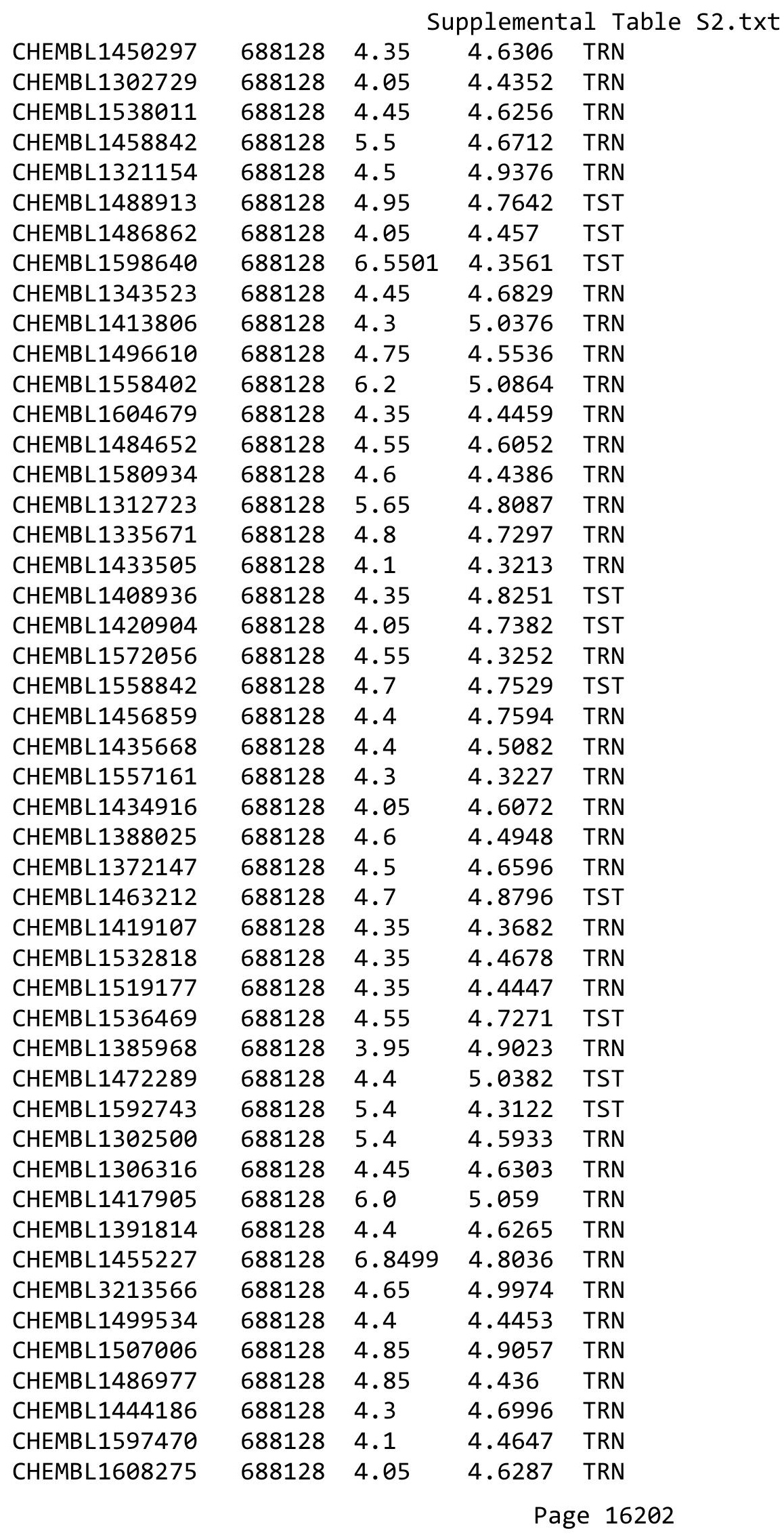




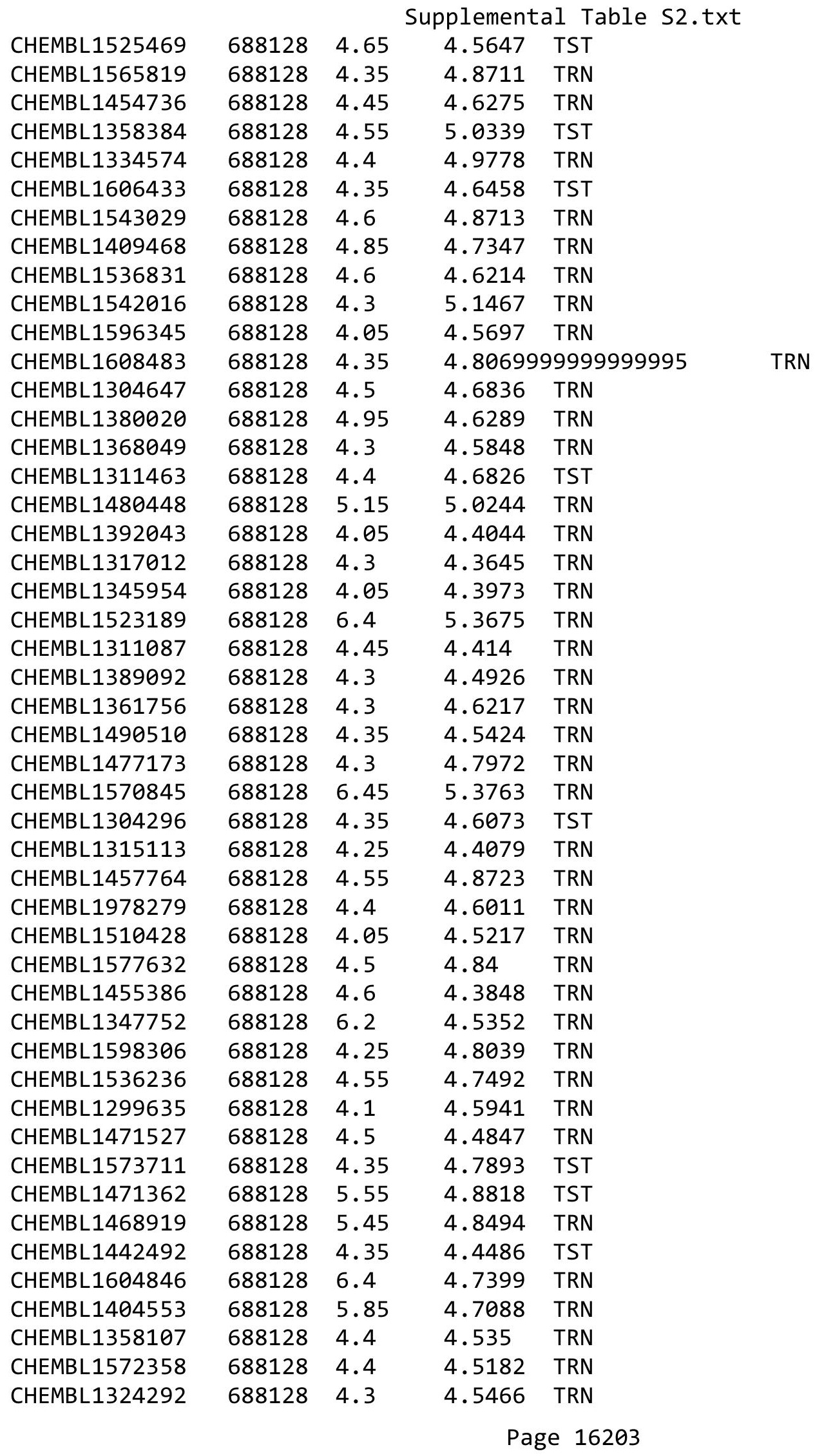




\begin{tabular}{|c|c|c|c|c|c|}
\hline \multicolumn{6}{|c|}{ Supplemental Table S2.txt } \\
\hline CHEMBL1531292 & 688128 & 4.3 & 4.7962 & TRN & \\
\hline CHEMBL1468488 & 688128 & 4.35 & 4.323 & TRN & \\
\hline CHEMBL1351379 & 688128 & 4.05 & 4.5775 & TRN & \\
\hline CHEMBL1529256 & 688128 & 4.35 & 4.7719 & TRN & \\
\hline CHEMBL1345903 & 688128 & 4.6 & 4.5752 & TRN & \\
\hline CHEMBL1445672 & 688128 & 4.9 & 4.6055 & TRN & \\
\hline CHEMBL1340344 & 688128 & 5.5 & 4.6964 & TRN & \\
\hline CHEMBL1447162 & 688128 & 4.25 & 4.4226 & TST & \\
\hline CHEMBL1572292 & 688128 & 4.45 & 4.5845 & TRN & \\
\hline CHEMBL1604863 & 688128 & 4.3 & 4.5917 & TRN & \\
\hline CHEMBL1330793 & 688128 & 4.3 & 4.7476 & TST & \\
\hline CHEMBL1549278 & 688128 & 4.5 & 4.7279 & TST & \\
\hline CHEMBL3196314 & 688128 & 4.3 & 4.8238 & TRN & \\
\hline CHEMBL1399893 & 688128 & 4.4 & 4.6704 & TRN & \\
\hline CHEMBL1346486 & 688128 & 4.6 & 4.9925 & TST & \\
\hline CHEMBL1444305 & 688128 & 5.15 & 4.8457 & TRN & \\
\hline CHEMBL1464975 & 688128 & 4.35 & 4.6673 & TRN & \\
\hline CHEMBL1399659 & 688128 & 4.05 & 4.591 & TST & \\
\hline CHEMBL1329104 & 688128 & 4.55 & 4.6972 & TRN & \\
\hline CHEMBL1489238 & 688128 & 4.55 & 4.4205 & TRN & \\
\hline CHEMBL1572692 & 688128 & 5.3 & 5.1331 & TRN & \\
\hline CHEMBL 213432 & 688128 & 5.05 & 4.8171 & TRN & \\
\hline CHEMBL1591501 & 688128 & 4.4 & 4.5735 & TRN & \\
\hline CHEMBL1475066 & 688128 & 4.05 & 4.5525 & TRN & \\
\hline CHEMBL1458775 & 688128 & 4.3 & 4.6261 & TRN & \\
\hline CHEMBL1402829 & 688128 & 4.4 & 4.5821 & TST & \\
\hline CHEMBL1573626 & 688128 & 4.3 & 4.637 & TST & \\
\hline CHEMBL1384295 & 688128 & 4.05 & 4.2313 & TRN & \\
\hline CHEMBL 252901 & 688128 & 4.3 & 4.3866 & TRN & \\
\hline CHEMBL1347979 & 688128 & 4.3 & 4.5749 & TRN & \\
\hline CHEMBL1560030 & 688128 & 4.05 & 4.7411 & TRN & \\
\hline CHEMBL1370188 & 688128 & 4.45 & 4.2954 & TRN & \\
\hline CHEMBL3189486 & 688128 & 4.85 & 4.6737 & TRN & \\
\hline CHEMBL1494038 & 688128 & 6.15 & 4.9573 & TRN & \\
\hline CHEMBL1571534 & 688128 & 4.05 & 4.421 & TRN & \\
\hline CHEMBL1423798 & 688128 & 4.35 & 4.3993 & TRN & \\
\hline CHEMBL1537921 & 688128 & 4.4 & 4.3973 & TST & \\
\hline CHEMBL1427429 & 688128 & 5.45 & 4.6178 & TRN & \\
\hline CHEMBL1441242 & 688128 & 4.75 & 4.7284 & TRN & \\
\hline CHEMBL1606962 & 688128 & 4.0 & 4.58899 & 99999999995 & TRN \\
\hline CHEMBL3189764 & 688128 & 4.6 & 4.4643 & TRN & \\
\hline CHEMBL1311666 & 688128 & 4.3 & 4.6801 & TRN & \\
\hline CHEMBL1514226 & 688128 & 4.35 & 4.4721 & TRN & \\
\hline CHEMBL3191983 & 688128 & 4.7 & 4.7837 & TRN & \\
\hline CHEMBL1538396 & 688128 & 4.3 & 4.8211 & TRN & \\
\hline CHEMBL1452838 & 688128 & 4.4 & 4.6898 & TRN & \\
\hline CHEMBL1588498 & 688128 & 5.7 & 4.4051 & TRN & \\
\hline CHEMBL1373739 & 688128 & 4.05 & 4.6064 & TST & \\
\hline
\end{tabular}




\begin{tabular}{|c|c|c|c|c|}
\hline \multicolumn{5}{|c|}{ Supplemental Table S2.txt } \\
\hline CHEMBL1451590 & 688128 & 6.2 & 4.7153 & TRN \\
\hline CHEMBL1451414 & 688128 & 4.95 & 4.4863 & TST \\
\hline CHEMBL1425772 & 688128 & 4.25 & 4.5855 & TRN \\
\hline CHEMBL1331544 & 688128 & 4.3 & 4.5305 & TRN \\
\hline CHEMBL1404985 & 688128 & 4.0 & 4.6722 & TST \\
\hline CHEMBL1515757 & 688128 & 5.0 & 4.5464 & TRN \\
\hline CHEMBL1303126 & 688128 & 4.35 & 4.4646 & TRN \\
\hline CHEMBL1483185 & 688128 & 5.4 & 4.4865 & TST \\
\hline CHEMBL1481937 & 688128 & 4.75 & 4.5217 & TRN \\
\hline CHEMBL1540638 & 688128 & 4.05 & 4.4736 & TST \\
\hline CHEMBL1528220 & 688128 & 4.85 & 4.4515 & TRN \\
\hline CHEMBL1569969 & 688128 & 4.05 & 4.4064 & TRN \\
\hline CHEMBL1574889 & 688128 & 4.3 & 4.9382 & TRN \\
\hline CHEMBL1520564 & 688128 & 4.3 & 4.5995 & TRN \\
\hline CHEMBL1490920 & 688128 & 4.25 & 4.2827 & TRN \\
\hline CHEMBL1482201 & 688128 & 4.5 & 4.4604 & TRN \\
\hline CHEMBL1527952 & 688128 & 4.75 & 4.6402 & TRN \\
\hline CHEMBL1432990 & 688128 & 4.4 & 4.4703 & TRN \\
\hline CHEMBL1305602 & 688128 & 4.7 & 4.5679 & TRN \\
\hline CHEMBL1391004 & 688128 & 4.45 & 4.8255 & TRN \\
\hline CHEMBL570468 & 688128 & 4.4 & 4.6392 & TST \\
\hline CHEMBL1405719 & 688128 & 4.4 & 4.5296 & TRN \\
\hline CHEMBL1584469 & 688128 & 5.85 & 4.5009 & TST \\
\hline CHEMBL1384875 & 688128 & 4.5 & 4.6883 & TRN \\
\hline CHEMBL1544470 & 688128 & 4.2 & 4.6895 & TRN \\
\hline CHEMBL1499059 & 688128 & 5.45 & 4.3456 & TRN \\
\hline CHEMBL1539790 & 688128 & 4.1 & 4.6813 & TRN \\
\hline CHEMBL1444859 & 688128 & 4.95 & 5.1548 & TRN \\
\hline CHEMBL1376077 & 688128 & 4.5 & 4.5043 & TRN \\
\hline CHEMBL1601980 & 688128 & 4.4 & 4.4396 & TRN \\
\hline CHEMBL1588231 & 688128 & 6.0 & 4.4842 & TRN \\
\hline CHEMBL1362157 & 688128 & 4.1 & 4.7908 & TRN \\
\hline CHEMBL1992540 & 688128 & 4.25 & 4.6181 & TRN \\
\hline CHEMBL1313109 & 688128 & 4.0 & 4.7916 & TST \\
\hline CHEMBL1385109 & 688128 & 4.0 & 4.7372 & TST \\
\hline CHEMBL1573690 & 688128 & 5.5 & 4.9861 & TRN \\
\hline CHEMBL95910 & 688128 & 5.5 & 4.6065 & TRN \\
\hline CHEMBL 3192944 & 688128 & 4.4 & 4.6909 & TRN \\
\hline CHEMBL1314903 & 688128 & 4.65 & 4.4916 & TRN \\
\hline CHEMBL1572006 & 688128 & 6.2 & 4.7785 & TST \\
\hline CHEMBL3191874 & 688128 & 4.4 & 4.7323 & TRN \\
\hline CHEMBL1544579 & 688128 & 4.9 & 4.538 & TRN \\
\hline CHEMBL3193982 & 688128 & 4.65 & 4.738 & TRN \\
\hline CHEMBL1524844 & 688128 & 6.0 & 4.5797 & TRN \\
\hline CHEMBL1463218 & 688128 & 4.05 & 4.5036 & TRN \\
\hline CHEMBL1393710 & 688128 & 4.75 & 4.6636 & TRN \\
\hline CHEMBL3196551 & 688128 & 4.4 & 4.4433 & TRN \\
\hline CHEMBL1538753 & 688128 & 5.0 & 4.7704 & TRN \\
\hline
\end{tabular}




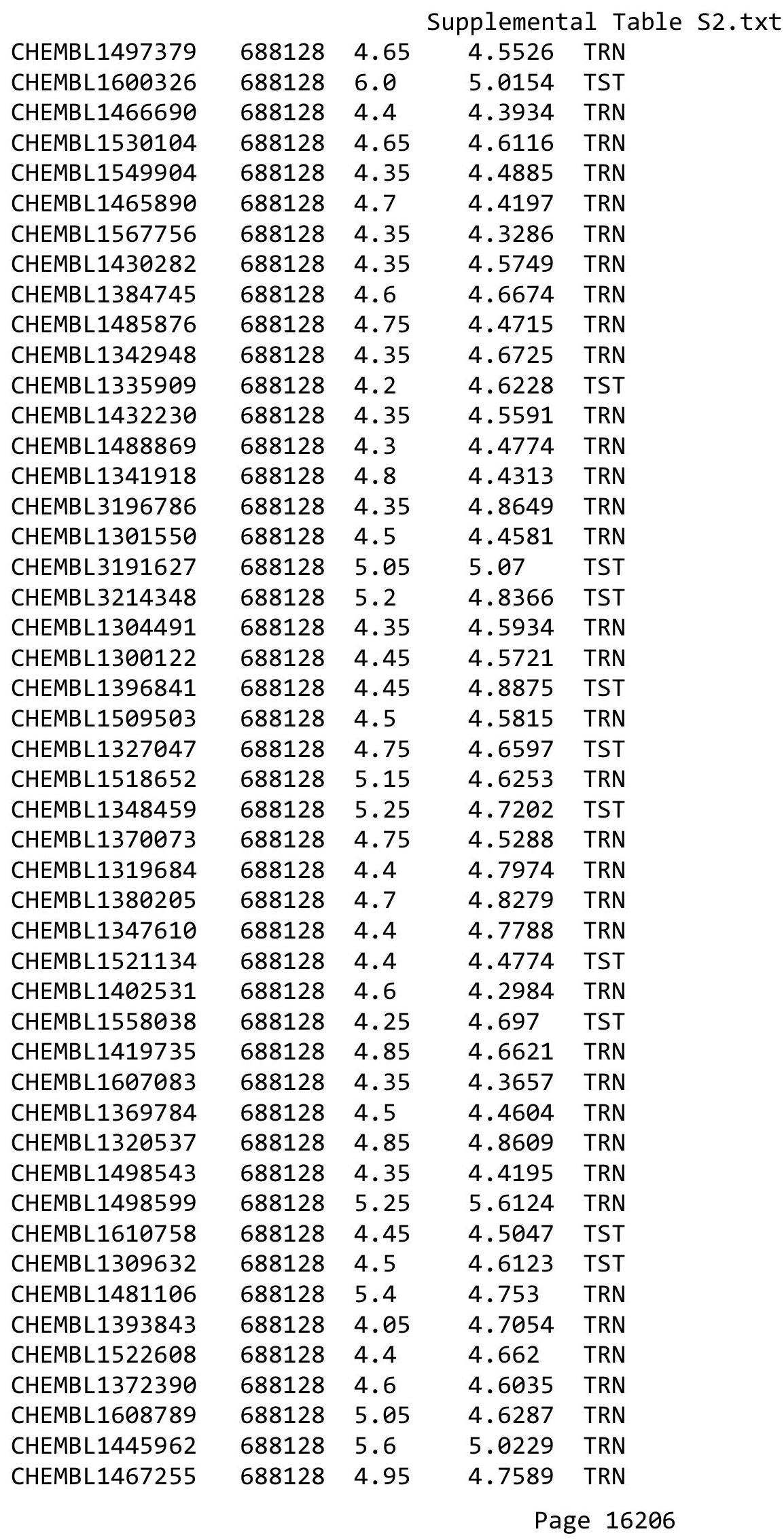




\begin{tabular}{|c|c|c|c|c|c|}
\hline & & \multicolumn{4}{|c|}{ Supplemental Table s2.txt } \\
\hline CHEMBL1305538 & 688128 & 4.4 & 4.6122 & TST & \\
\hline CHEMBL1461866 & 688128 & 5.85 & 4.5129 & TRN & \\
\hline CHEMBL1539359 & 688128 & 4.4 & 4.4236 & TST & \\
\hline CHEMBL1307903 & 688128 & 4.3 & 4.4595 & TRN & \\
\hline CHEMBL1507988 & 688128 & 4.35 & 4.3733 & TRN & \\
\hline CHEMBL1367108 & 688128 & 4.45 & 4.61 & TRN & \\
\hline CHEMBL3213214 & 688128 & 4.95 & 4.9225 & TRN & \\
\hline CHEMBL1418620 & 688128 & 4.4 & 4.6629 & TRN & \\
\hline CHEMBL1539086 & 688128 & 4.4 & 4.6144 & TRN & \\
\hline CHEMBL1407709 & 688128 & 4.4 & 4.5079 & TRN & \\
\hline CHEMBL1536101 & 688128 & 4.6 & 4.7151 & TRN & \\
\hline CHEMBL1457597 & 688128 & 5.05 & 4.6668 & TRN & \\
\hline CHEMBL1428816 & 688128 & 4.5 & 4.6354 & TRN & \\
\hline CHEMBL1472035 & 688128 & 5.05 & 4.591 & TRN & \\
\hline CHEMBL1603550 & 688128 & 4.4 & 4.3542 & TST & \\
\hline CHEMBL1311150 & 688128 & 4.05 & 4.5827 & TRN & \\
\hline CHEMBL1569108 & 688128 & 4.3 & 4.8098 & TST & \\
\hline CHEMBL1599037 & 688128 & 4.3 & 4.437 & TRN & \\
\hline CHEMBL1491977 & 688128 & 4.7 & 4.6583 & TRN & \\
\hline CHEMBL3210338 & 688128 & 4.3 & 4.7241 & TRN & \\
\hline CHEMBL1433650 & 688128 & 4.25 & 4.5038 & TST & \\
\hline CHEMBL1372399 & 688128 & 4.4 & 4.5367 & TRN & \\
\hline CHEMBL1320274 & 688128 & 4.9 & 4.9867 & TRN & \\
\hline CHEMBL1560510 & 688128 & 5.7 & 4.795 & TST & \\
\hline CHEMBL1606975 & 688128 & 4.05 & 4.4846 & TRN & \\
\hline CHEMBL1332807 & 688128 & 4.0 & 4.4874 & TRN & \\
\hline CHEMBL1457874 & 688128 & 4.3 & 4.2037 & TRN & \\
\hline CHEMBL1370349 & 688128 & 4.3 & 4.4925 & TRN & \\
\hline CHEMBL1554359 & 688128 & 4.05 & 4.8391 & TST & \\
\hline CHEMBL1589179 & 688128 & 4.05 & 4.5292 & TRN & \\
\hline CHEMBL1395465 & 688128 & 4.85 & 4.5284 & TRN & \\
\hline CHEMBL1304856 & 688128 & 4.3 & 4.4964 & TRN & \\
\hline CHEMBL1442858 & 688128 & 4.25 & 4.2895 & TRN & \\
\hline CHEMBL1409033 & 688128 & 6.0 & 4.7605 & TRN & \\
\hline CHEMBL1319488 & 688128 & 5.45 & $5.3670 e$ & 0000000001 & TRN \\
\hline CHEMBL1311315 & 688128 & 4.05 & 4.5764 & TRN & \\
\hline CHEMBL1423567 & 688128 & 5.75 & 4.8931 & TRN & \\
\hline CHEMBL1394149 & 688128 & 5.5 & 5.1299 & TRN & \\
\hline CHEMBL1482747 & 688128 & 4.65 & 4.8885 & TST & \\
\hline CHEMBL1457525 & 688128 & 4.05 & 4.6126 & TRN & \\
\hline CHEMBL1533658 & 688128 & 4.0 & 4.399 & TRN & \\
\hline CHEMBL1428746 & 688128 & 6.1 & 4.644 & TRN & \\
\hline CHEMBL1338987 & 688128 & 5.55 & 4.8831 & TRN & \\
\hline CHEMBL1498671 & 688128 & 4.4 & 4.7922 & TRN & \\
\hline CHEMBL1510877 & 688128 & 5.05 & 4.6223 & TRN & \\
\hline CHEMBL1414624 & 688128 & 4.7 & 4.7418 & TRN & \\
\hline CHEMBL1410073 & 688128 & 4.3 & 4.488 & TRN & \\
\hline CHEMBL1406934 & 688128 & 4.3 & 4.628 & TST & \\
\hline
\end{tabular}




\begin{tabular}{|c|c|c|c|c|c|}
\hline \multicolumn{6}{|c|}{ Supplemental Table S2.txt } \\
\hline CHEMBL1377576 & 688128 & 4.25 & 4.7256 & TRN & \\
\hline CHEMBL1469579 & 688128 & 4.5 & 4.7677 & TRN & \\
\hline CHEMBL1333997 & 688128 & 4.25 & 4.3528 & TRN & \\
\hline CHEMBL1397546 & 688128 & 4.3 & 4.5575 & TRN & \\
\hline CHEMBL1585901 & 688128 & 5.3 & 4.5243 & TRN & \\
\hline CHEMBL1370877 & 688128 & 4.35 & 4.6073 & TRN & \\
\hline CHEMBL1422752 & 688128 & 4.35 & 4.9261 & TST & \\
\hline CHEMBL1580455 & 688128 & 4.75 & 4.9047 & TRN & \\
\hline CHEMBL1516495 & 688128 & 4.5 & 4.8321 & TRN & \\
\hline CHEMBL1497928 & 688128 & 4.3 & 4.4931 & TRN & \\
\hline CHEMBL227881 & 688128 & 4.3 & 4.4248 & TRN & \\
\hline CHEMBL1465393 & 688128 & 6.8499 & 4.7833 & TRN & \\
\hline CHEMBL600309 & 688128 & 4.3 & 4.4617 & TST & \\
\hline CHEMBL1496542 & 688128 & 5.4 & 4.6515 & TRN & \\
\hline CHEMBL1338471 & 688128 & 4.3 & 4.7625 & TRN & \\
\hline CHEMBL1487010 & 688128 & 5.35 & 4.9079 & TRN & \\
\hline CHEMBL1473767 & 688128 & 5.45 & 4.6433 & TST & \\
\hline CHEMBL1588788 & 688128 & 4.6 & 4.3694 & TRN & \\
\hline CHEMBL1578121 & 688128 & 5.45 & 4.485 & TRN & \\
\hline CHEMBL1458726 & 688128 & 4.85 & 4.881 & TRN & \\
\hline CHEMBL1381310 & 688128 & 5.7 & 5.0416 & TRN & \\
\hline CHEMBL1342469 & 688128 & 4.65 & 4.747 & TRN & \\
\hline CHEMBL1492650 & 688128 & 4.75 & 4.7149 & TRN & \\
\hline CHEMBL1484258 & 688128 & 4.25 & 4.6913 & TST & \\
\hline CHEMBL1433182 & 688128 & 6.25 & 5.2907 & TRN & \\
\hline CHEMBL1401409 & 688128 & 4.1 & 4.4687 & TRN & \\
\hline CHEMBL1412342 & 688128 & 4.65 & 4.6548 & TRN & \\
\hline CHEMBL1542270 & 688128 & 4.05 & 4.6384 & TST & \\
\hline CHEMBL1994685 & 688128 & 4.85 & 5.0543 & TST & \\
\hline CHEMBL1587764 & 688128 & 5.55 & 5.0217 & TRN & \\
\hline CHEMBL1375508 & 688128 & 4.25 & 4.5567 & TRN & \\
\hline CHEMBL583555 & 688128 & 4.05 & 4.63399 & 99999999995 & TST \\
\hline CHEMBL3193772 & 688128 & 4.65 & 4.4391 & TST & \\
\hline CHEMBL1582004 & 688128 & 4.6 & 4.8099 & TRN & \\
\hline CHEMBL1350045 & 688128 & 4.7 & 4.5838 & TRN & \\
\hline CHEMBL3195319 & 688128 & 5.15 & 4.4459 & TST & \\
\hline CHEMBL1520873 & 688128 & 4.35 & 4.7941 & TST & \\
\hline CHEMBL1307923 & 688128 & 6.6 & 5.331 & TRN & \\
\hline CHEMBL1333016 & 688128 & 4.3 & 4.6315 & TST & \\
\hline CHEMBL1427101 & 688128 & 4.4 & 4.5803 & TRN & \\
\hline CHEMBL1391455 & 688128 & 6.15 & 4.83899 & 99999999995 & TRN \\
\hline CHEMBL1481015 & 688128 & 4.0 & 4.6498 & TST & \\
\hline CHEMBL1346537 & 688128 & 4.6 & 4.6622 & TRN & \\
\hline CHEMBL1493344 & 688128 & 4.45 & 4.8732 & TRN & \\
\hline CHEMBL1610708 & 688128 & 4.3 & 4.6272 & TRN & \\
\hline CHEMBL1527310 & 688128 & 5.7 & 5.0242 & TST & \\
\hline CHEMBL1489582 & 688128 & 4.25 & 4.5409 & TRN & \\
\hline CHEMBL3193319 & 688128 & 4.35 & 4.5161 & TRN & \\
\hline
\end{tabular}




\begin{tabular}{|c|c|c|c|c|c|}
\hline \multicolumn{6}{|c|}{ Supplemental Table S2.txt } \\
\hline CHEMBL187263 & 688128 & 4.35 & 4.7336 & TRN & \\
\hline CHEMBL1612693 & 688128 & 5.15 & 4.6666 & TRN & \\
\hline CHEMBL1444140 & 688128 & 6.15 & 4.4806 & TST & \\
\hline CHEMBL3212426 & 688128 & 4.35 & 4.6793 & TRN & \\
\hline CHEMBL1390901 & 688128 & 5.0 & 5.1483 & TRN & \\
\hline CHEMBL1507308 & 688128 & 4.8 & 4.902 & TRN & \\
\hline CHEMBL1445386 & 688128 & 4.9 & 4.9691 & TST & \\
\hline CHEMBL1501630 & 688128 & 4.3 & 4.7542 & TRN & \\
\hline CHEMBL1353353 & 688128 & 4.3 & 4.295 & TRN & \\
\hline CHEMBL1417125 & 688128 & 4.95 & 4.5781 & TST & \\
\hline CHEMBL1350904 & 688128 & 4.6 & 4.5934 & TRN & \\
\hline CHEMBL1439192 & 688128 & 4.95 & 4.9324 & TRN & \\
\hline CHEMBL1441714 & 688128 & 4.4 & 4.55699 & 99999999995 & TRN \\
\hline CHEMBL1506947 & 688128 & 4.4 & 4.7615 & TRN & \\
\hline CHEMBL1503248 & 688128 & 4.8 & 4.762 & TRN & \\
\hline CHEMBL1521536 & 688128 & 5.7 & 4.7944 & TRN & \\
\hline CHEMBL1455944 & 688128 & 4.05 & 4.8043 & TST & \\
\hline CHEMBL1443982 & 688128 & 5.5 & 4.756 & TRN & \\
\hline CHEMBL1481408 & 688128 & 4.45 & 4.4633 & TRN & \\
\hline CHEMBL3194780 & 688128 & 5.5 & 4.8313 & TRN & \\
\hline CHEMBL1388976 & 688128 & 4.35 & 4.5762 & TRN & \\
\hline CHEMBL1512513 & 688128 & 4.55 & 4.578 & TRN & \\
\hline CHEMBL1569534 & 688128 & 4.2 & 4.629 & TRN & \\
\hline CHEMBL1508989 & 688128 & 4.3 & 4.3809 & TRN & \\
\hline CHEMBL1430005 & 688128 & 4.3 & 4.6651 & TST & \\
\hline CHEMBL1412077 & 688128 & 5.0 & 4.9092 & TRN & \\
\hline CHEMBL1497721 & 688128 & 5.35 & 4.7665 & TRN & \\
\hline CHEMBL1581573 & 688128 & 4.4 & 4.5238 & TRN & \\
\hline CHEMBL1372115 & 688128 & 4.35 & 4.4693 & TRN & \\
\hline CHEMBL1544294 & 688128 & 4.4 & 4.8204 & TST & \\
\hline CHEMBL1460831 & 688128 & 5.6 & 4.783 & TRN & \\
\hline CHEMBL1538939 & 688128 & 4.05 & 4.4089 & TRN & \\
\hline CHEMBL1479317 & 688128 & 4.05 & 4.5968 & TRN & \\
\hline CHEMBL1391181 & 688128 & 5.8 & 4.544 & TST & \\
\hline CHEMBL1595839 & 688128 & 4.3 & 4.5802 & TRN & \\
\hline CHEMBL1586952 & 688128 & 4.65 & 4.4351 & TST & \\
\hline CHEMBL1529249 & 688128 & 4.35 & 4.5368 & TRN & \\
\hline CHEMBL1341507 & 688128 & 4.95 & 4.9111 & TRN & \\
\hline CHEMBL1459492 & 688128 & 4.5 & 4.6076 & TRN & \\
\hline CHEMBL1438012 & 688128 & 4.55 & 4.5261 & TST & \\
\hline CHEMBL3196785 & 688128 & 4.05 & 4.3762 & TRN & \\
\hline CHEMBL1560692 & 688128 & 4.3 & 4.4981 & TRN & \\
\hline CHEMBL1403177 & 688128 & 4.05 & 4.6527 & TST & \\
\hline CHEMBL1582281 & 688128 & 4.45 & 4.4269 & TRN & \\
\hline CHEMBL1464777 & 688128 & 4.75 & 4.6821 & TRN & \\
\hline CHEMBL1557263 & 688128 & 4.9 & 4.9363 & TST & \\
\hline CHEMBL1383611 & 688128 & 4.35 & 4.5346 & TST & \\
\hline CHEMBL1370314 & 688128 & 4.4 & 4.4996 & TRN & \\
\hline
\end{tabular}




\begin{tabular}{|c|c|c|c|c|c|}
\hline & & \multicolumn{4}{|c|}{ Supplemental Table S2.txt } \\
\hline CHEMBL1514395 & 688128 & 4.5 & 4.4354 & TRN & \\
\hline CHEMBL1492390 & 688128 & 4.35 & 4.5401 & TRN & \\
\hline CHEMBL1555488 & 688128 & 5.4 & 4.8476 & TRN & \\
\hline CHEMBL1507135 & 688128 & 4.1 & 4.7394 & TRN & \\
\hline CHEMBL1486520 & 688128 & 5.05 & 5.0281 & TRN & \\
\hline CHEMBL1514296 & 688128 & 5.2 & 5.1538 & TRN & \\
\hline CHEMBL1575046 & 688128 & 4.4 & 4.7236 & TRN & \\
\hline CHEMBL3213964 & 688128 & 4.95 & 4.5579 & TRN & \\
\hline CHEMBL1605318 & 688128 & 4.3 & 4.2791 & TRN & \\
\hline CHEMBL1556567 & 688128 & 4.25 & 4.6577 & TRN & \\
\hline CHEMBL1599546 & 688128 & 4.3 & 4.8617 & TRN & \\
\hline CHEMBL1601509 & 688128 & 5.35 & 4.7645 & TRN & \\
\hline CHEMBL1388509 & 688128 & 5.5 & 5.20700 & 0000000001 & TRN \\
\hline CHEMBL1530571 & 688128 & 4.05 & 4.4973 & TST & \\
\hline CHEMBL1371056 & 688128 & 4.9 & 4.4713 & TRN & \\
\hline CHEMBL1428776 & 688128 & 4.35 & 4.4114 & TRN & \\
\hline CHEMBL1470132 & 688128 & 4.55 & 4.5272 & TRN & \\
\hline CHEMBL1318296 & 688128 & 4.35 & 4.4572 & TST & \\
\hline CHEMBL1314116 & 688128 & 6.0 & 4.4602 & TRN & \\
\hline CHEMBL1442956 & 688128 & 4.5 & 4.6019 & TRN & \\
\hline CHEMBL1442848 & 688128 & 4.4 & 4.4962 & TRN & \\
\hline CHEMBL1327077 & 688128 & 4.7 & 4.3305 & TRN & \\
\hline CHEMBL1607381 & 688128 & 4.55 & 4.8316 & TRN & \\
\hline CHEMBL1571053 & 688128 & 4.25 & 4.54 & TRN & \\
\hline CHEMBL1410341 & 688128 & 4.65 & 4.5412 & TRN & \\
\hline CHEMBL1583315 & 688128 & 6.2 & 4.9316 & TRN & \\
\hline CHEMBL3190969 & 688128 & 5.4 & 4.3862 & TST & \\
\hline CHEMBL1456296 & 688128 & 4.6 & 4.7435 & TRN & \\
\hline CHEMBL1446008 & 688128 & 4.55 & 4.5432 & TRN & \\
\hline CHEMBL1324510 & 688128 & 4.45 & 4.6013 & TST & \\
\hline CHEMBL1377457 & 688128 & 4.4 & 4.3952 & TRN & \\
\hline CHEMBL1495030 & 688128 & 4.25 & 4.8466 & TST & \\
\hline CHEMBL1415289 & 688128 & 5.3 & 5.3248 & TRN & \\
\hline CHEMBL1311943 & 688128 & 5.7 & 4.6594 & TRN & \\
\hline CHEMBL1509734 & 688128 & 4.4 & 4.4316 & TRN & \\
\hline CHEMBL1574142 & 688128 & 4.3 & 4.3172 & TRN & \\
\hline CHEMBL1409762 & 688128 & 4.95 & 5.0593 & TRN & \\
\hline CHEMBL1331727 & 688128 & 4.9 & 4.8106 & TRN & \\
\hline CHEMBL3191603 & 688128 & 4.4 & 4.7184 & TST & \\
\hline CHEMBL1583569 & 688128 & 4.05 & 4.71899 & 9999999999 & TRN \\
\hline CHEMBL1485405 & 688128 & 5.0 & 5.3759 & TRN & \\
\hline CHEMBL1374465 & 688128 & 4.35 & 4.5609 & TRN & \\
\hline CHEMBL1347279 & 688128 & 4.3 & 4.7112 & TRN & \\
\hline CHEMBL1592091 & 688128 & 5.25 & 4.3712 & TRN & \\
\hline CHEMBL1543512 & 688128 & 6.95 & 4.6029 & TRN & \\
\hline CHEMBL1497385 & 688128 & 4.3 & 4.8106 & TST & \\
\hline CHEMBL1597387 & 688128 & 4.3 & 4.4734 & TRN & \\
\hline CHEMBL1347704 & 688128 & 5.4 & 4.688 & TRN & \\
\hline
\end{tabular}




\begin{tabular}{|c|c|c|c|c|}
\hline \multicolumn{5}{|c|}{ Supplemental Table S2.txt } \\
\hline CHEMBL1326485 & 688128 & 4.7 & 4.6541 & TRN \\
\hline CHEMBL1470784 & 688128 & 5.0 & 4.5842 & TST \\
\hline CHEMBL318727 & 688128 & 4.4 & 4.6306 & TST \\
\hline CHEMBL1405404 & 688128 & 4.4 & 4.4775 & TRN \\
\hline CHEMBL1420591 & 688128 & 4.3 & 4.5064 & TRN \\
\hline CHEMBL1400139 & 688128 & 4.0 & 4.8162 & TST \\
\hline CHEMBL1568293 & 688128 & 4.4 & 4.2116 & TRN \\
\hline CHEMBL3208936 & 688128 & 5.5 & 4.9693 & TST \\
\hline CHEMBL1490568 & 688128 & 4.35 & 4.4372 & TST \\
\hline CHEMBL1309043 & 688128 & 4.55 & 4.8079 & TRN \\
\hline CHEMBL1328188 & 688128 & 4.4 & 4.612 & TRN \\
\hline CHEMBL1408203 & 688128 & 4.7 & 4.6616 & TRN \\
\hline CHEMBL1436838 & 688128 & 5.4 & 4.5611 & TST \\
\hline CHEMBL1347015 & 688128 & 5.4 & 4.4553 & TST \\
\hline CHEMBL1396501 & 688128 & 4.05 & 4.3337 & TRN \\
\hline CHEMBL1331793 & 688128 & 4.4 & 4.4351 & TRN \\
\hline CHEMBL1529355 & 688128 & 4.3 & 4.6707 & TRN \\
\hline CHEMBL1416637 & 688128 & 4.3 & 4.6137 & TST \\
\hline CHEMBL1303279 & 688128 & 6.0 & 4.5984 & TRN \\
\hline CHEMBL1598141 & 688128 & 4.3 & 4.5995 & TST \\
\hline CHEMBL1550070 & 688128 & 4.3 & 4.6122 & TRN \\
\hline CHEMBL1393221 & 688128 & 4.05 & 4.6177 & TRN \\
\hline CHEMBL1524306 & 688128 & 4.05 & 4.9282 & TRN \\
\hline CHEMBL1422703 & 688128 & 4.4 & 4.6102 & TST \\
\hline CHEMBL1539670 & 688128 & 5.1 & 4.7253 & TRN \\
\hline CHEMBL1527226 & 688128 & 4.3 & 4.5263 & TRN \\
\hline CHEMBL1537004 & 688128 & 4.35 & 4.4735 & TRN \\
\hline CHEMBL1504918 & 688128 & 4.3 & 4.8987 & TRN \\
\hline CHEMBL1564326 & 688128 & 4.4 & 4.6549 & TRN \\
\hline CHEMBL3198096 & 688128 & 4.75 & 4.3826 & TST \\
\hline CHEMBL1361274 & 688128 & 4.05 & 4.6321 & TST \\
\hline CHEMBL1433918 & 688128 & 4.4 & 4.6102 & TRN \\
\hline CHEMBL1586300 & 688128 & 4.35 & 4.5879 & TRN \\
\hline CHEMBL1346362 & 688128 & 4.45 & 4.4411 & TRN \\
\hline CHEMBL1370430 & 688128 & 4.45 & 4.6787 & TST \\
\hline CHEMBL3195047 & 688128 & 4.9 & 4.8291 & TST \\
\hline CHEMBL1304147 & 688128 & 4.3 & 4.6922 & TRN \\
\hline CHEMBL1416103 & 688128 & 4.3 & 4.4936 & TST \\
\hline CHEMBL2005961 & 688128 & 4.35 & 4.6269 & TRN \\
\hline CHEMBL1471193 & 688128 & 4.45 & 4.6731 & TRN \\
\hline CHEMBL1312918 & 688128 & 5.05 & 4.7574 & TRN \\
\hline CHEMBL1586501 & 688128 & 4.0 & 4.8257 & TST \\
\hline CHEMBL1524885 & 688128 & 4.6 & 4.7528 & TST \\
\hline CHEMBL1330911 & 688128 & 4.25 & 4.5231 & TRN \\
\hline CHEMBL1524907 & 688128 & 4.55 & 4.6043 & TRN \\
\hline CHEMBL1398181 & 688128 & 5.0 & 4.5729 & TST \\
\hline CHEMBL1403597 & 688128 & 4.9 & 4.7855 & TRN \\
\hline CHEMBL3211998 & 688128 & 4.4 & 4.8296 & TST \\
\hline
\end{tabular}




\begin{tabular}{|c|c|c|c|c|c|}
\hline \multicolumn{6}{|c|}{ Supplemental Table S2.txt } \\
\hline CHEMBL1968732 & 688128 & 6.5 & 5.4029 & TRN & \\
\hline CHEMBL1333442 & 688128 & 4.05 & 4.6899 & TST & \\
\hline CHEMBL1372780 & 688128 & 4.45 & 4.6045 & TRN & \\
\hline CHEMBL1435143 & 688128 & 4.7 & 4.4972 & TRN & \\
\hline CHEMBL1520975 & 688128 & 4.35 & 4.8748 & TRN & \\
\hline CHEMBL1574150 & 688128 & 4.55 & 4.5063 & TRN & \\
\hline CHEMBL1513770 & 688128 & 6.05 & 4.2939 & TST & \\
\hline CHEMBL1431618 & 688128 & 4.05 & 4.8195 & TRN & \\
\hline CHEMBL1450779 & 688128 & 4.3 & 4.3307 & TRN & \\
\hline CHEMBL1371353 & 688128 & 5.05 & 4.9216 & TRN & \\
\hline CHEMBL3195833 & 688128 & 4.3 & 4.7967 & TST & \\
\hline CHEMBL1371845 & 688128 & 4.05 & 4.3323 & TRN & \\
\hline CHEMBL1462298 & 688128 & 5.4 & 4.6407 & TRN & \\
\hline CHEMBL1344946 & 688128 & 6.2 & 4.8039 & TST & \\
\hline CHEMBL1365079 & 688128 & 5.6 & 4.7991 & TRN & \\
\hline CHEMBL1387538 & 688128 & 4.45 & 4.7428 & TRN & \\
\hline CHEMBL 1305272 & 688128 & 4.3 & 4.4338 & TRN & \\
\hline CHEMBL1354506 & 688128 & 4.4 & 4.5718 & TRN & \\
\hline CHEMBL1521297 & 688128 & 4.25 & 4.9603 & TRN & \\
\hline CHEMBL1384843 & 688128 & 4.25 & 4.6848 & TST & \\
\hline CHEMBL1433447 & 688128 & 4.05 & 4.7985 & TRN & \\
\hline CHEMBL1332369 & 688128 & 4.05 & 4.3376 & TRN & \\
\hline CHEMBL1373982 & 688128 & 4.8 & 4.7777 & TRN & \\
\hline CHEMBL1385774 & 688128 & 4.3 & 4.5754 & TST & \\
\hline CHEMBL1603147 & 688128 & 4.3 & 4.6642 & TRN & \\
\hline CHEMBL1327397 & 688128 & 4.35 & 4.6925 & TRN & \\
\hline CHEMBL1611304 & 688128 & 4.35 & 4.4504 & TRN & \\
\hline CHEMBL1596321 & 688128 & 4.05 & 4.6388 & TST & \\
\hline CHEMBL1530239 & 688128 & 4.4 & 4.6929 & TRN & \\
\hline CHEMBL1368265 & 688128 & 5.05 & 4.9375 & TRN & \\
\hline CHEMBL1449526 & 688128 & 4.9 & 4.4911 & TRN & \\
\hline CHEMBL1416189 & 688128 & 4.4 & 4.5095 & TRN & \\
\hline CHEMBL1508651 & 688128 & 4.35 & 4.5992 & TRN & \\
\hline CHEMBL1421225 & 688128 & 4.3 & 4.4983 & TRN & \\
\hline CHEMBL 2005729 & 688128 & 4.35 & 4.5679 & TRN & \\
\hline CHEMBL1444721 & 688128 & 4.6 & 4.8703 & TRN & \\
\hline CHEMBL1382353 & 688128 & 4.05 & 4.6516 & TST & \\
\hline CHEMBL1456670 & 688128 & 4.8 & 4.4266 & TST & \\
\hline CHEMBL1600295 & 688128 & 4.4 & 4.5223 & TRN & \\
\hline CHEMBL1517511 & 688128 & 4.8 & 4.7401 & TRN & \\
\hline CHEMBL378104 & 688128 & 4.3 & 4.7701 & TRN & \\
\hline CHEMBL1427142 & 688128 & 4.75 & 4.6295 & TRN & \\
\hline CHEMBL1385516 & 688128 & 4.4 & 4.6058 & TRN & \\
\hline CHEMBL3196439 & 688128 & 5.0 & $5.1110 \ell$ & 0000000001 & TRN \\
\hline CHEMBL1490007 & 688128 & 4.3 & 4.4003 & TRN & \\
\hline CHEMBL1566198 & 688128 & 5.65 & 4.5063 & TST & \\
\hline CHEMBL1346176 & 688128 & 4.4 & 4.5503 & TRN & \\
\hline CHEMBL1459905 & 688128 & 4.4 & 4.6439 & TRN & \\
\hline
\end{tabular}




\begin{tabular}{|c|c|c|c|c|c|}
\hline \multicolumn{6}{|c|}{ Supplemental Table S2.txt } \\
\hline CHEMBL1483995 & 688128 & 5.4 & 4.7659 & TRN & \\
\hline CHEMBL1308472 & 688128 & 4.3 & 4.8917 & TRN & \\
\hline CHEMBL1476302 & 688128 & 4.55 & 4.6901 & TRN & \\
\hline CHEMBL3392067 & 688128 & 4.35 & 4.6811 & TRN & \\
\hline CHEMBL3210261 & 688128 & 4.05 & 4.3122 & TST & \\
\hline CHEMBL1476761 & 688128 & 4.5 & 4.8758 & TST & \\
\hline CHEMBL1307050 & 688128 & 5.2 & 5.4139 & TRN & \\
\hline CHEMBL1408577 & 688128 & 4.3 & 4.7196 & TRN & \\
\hline CHEMBL1553444 & 688128 & 4.3 & 4.6717 & TST & \\
\hline CHEMBL1362524 & 688128 & 4.7 & 4.926 & TRN & \\
\hline CHEMBL1393412 & 688128 & 5.35 & 4.5127 & TRN & \\
\hline CHEMBL1522528 & 688128 & 4.35 & 4.5945 & TRN & \\
\hline CHEMBL1573280 & 688128 & 5.55 & 5.027 & TRN & \\
\hline CHEMBL1552924 & 688128 & 4.3 & 4.6923 & TRN & \\
\hline CHEMBL1440806 & 688128 & 5.6 & 4.5164 & TRN & \\
\hline CHEMBL1597177 & 688128 & 4.25 & 4.9908 & TST & \\
\hline CHEMBL1357768 & 688128 & 4.3 & 4.5074 & TRN & \\
\hline CHEMBL1517018 & 688128 & 4.0 & 4.4081 & TRN & \\
\hline CHEMBL1512394 & 688128 & 4.05 & 4.4274 & TRN & \\
\hline CHEMBL1450406 & 688128 & 4.35 & 4.5152 & TST & \\
\hline CHEMBL1513759 & 688128 & 5.55 & 4.6328 & TRN & \\
\hline CHEMBL1417230 & 688128 & 4.35 & 4.5358 & TRN & \\
\hline CHEMBL1570840 & 688128 & 4.45 & 5.0449 & TRN & \\
\hline CHEMBL1340515 & 688128 & 4.35 & 4.8708 & TRN & \\
\hline CHEMBL1299960 & 688128 & 4.4 & 4.6557 & TRN & \\
\hline CHEMBL1504559 & 688128 & 6.2 & 4.50899 & 99999999995 & TRN \\
\hline CHEMBL1435602 & 688128 & 5.55 & 4.9594 & TRN & \\
\hline CHEMBL1489002 & 688128 & 4.4 & 4.4124 & TRN & \\
\hline CHEMBL1487921 & 688128 & 4.05 & 4.7258 & TRN & \\
\hline CHEMBL1441284 & 688128 & 4.05 & 4.6486 & TST & \\
\hline CHEMBL1532654 & 688128 & 4.45 & 4.4416 & TRN & \\
\hline CHEMBL1558809 & 688128 & 4.45 & 5.1806 & TRN & \\
\hline CHEMBL1460107 & 688128 & 5.3 & 4.8395 & TRN & \\
\hline CHEMBL1449722 & 688128 & 4.05 & 4.8736 & TST & \\
\hline CHEMBL460496 & 688128 & 4.95 & 4.6633 & TST & \\
\hline CHEMBL1383134 & 688128 & 5.15 & 4.5397 & TRN & \\
\hline CHEMBL1360824 & 688128 & 4.4 & 4.341 & TRN & \\
\hline CHEMBL1592564 & 688128 & 4.6 & 4.5106 & TRN & \\
\hline CHEMBL1445996 & 688128 & 4.05 & 4.5783 & TRN & \\
\hline CHEMBL1445548 & 688128 & 4.05 & 4.5945 & TRN & \\
\hline CHEMBL1969712 & 688128 & 4.4 & 4.9543 & TST & \\
\hline CHEMBL1494470 & 688128 & 4.35 & 4.8734 & TRN & \\
\hline CHEMBL1336776 & 688128 & 4.05 & 4.9456 & TST & \\
\hline CHEMBL1567678 & 688128 & 4.35 & 4.5113 & TRN & \\
\hline CHEMBL1309932 & 688128 & 4.3 & 4.3303 & TRN & \\
\hline CHEMBL1453217 & 688128 & 4.4 & 4.5593 & TRN & \\
\hline CHEMBL1388397 & 688128 & 4.35 & 4.7717 & TST & \\
\hline CHEMBL1357672 & 688128 & 4.0 & 4.5205 & TRN & \\
\hline
\end{tabular}




\begin{tabular}{|c|c|c|c|c|}
\hline \multicolumn{5}{|c|}{ Supplemental Table S2.txt } \\
\hline CHEMBL1528889 & 688128 & 4.3 & 5.1173 & TRN \\
\hline CHEMBL1428517 & 688128 & 4.35 & 4.44 & TRN \\
\hline CHEMBL1574018 & 688128 & 4.35 & 4.4125 & TRN \\
\hline CHEMBL1326863 & 688128 & 4.4 & 4.7306 & TRN \\
\hline CHEMBL1499168 & 688128 & 4.35 & 4.8111 & TRN \\
\hline CHEMBL1494991 & 688128 & 4.35 & 4.672 & TST \\
\hline CHEMBL1610587 & 688128 & 5.05 & 4.8337 & TST \\
\hline CHEMBL1476260 & 688128 & 4.05 & 4.388 & TRN \\
\hline CHEMBL1330228 & 688128 & 6.6499 & 4.5575 & TRN \\
\hline CHEMBL1469458 & 688128 & 4.35 & 4.6576 & TRN \\
\hline CHEMBL1524061 & 688128 & 4.5 & 4.4493 & TRN \\
\hline CHEMBL1494036 & 688128 & 4.1 & 4.5411 & TRN \\
\hline CHEMBL1407564 & 688128 & 4.0 & 4.6935 & TST \\
\hline CHEMBL3192978 & 688128 & 4.15 & 4.5566 & TRN \\
\hline CHEMBL1548788 & 688128 & 4.05 & 4.6653 & TRN \\
\hline CHEMBL1463023 & 688128 & 4.5 & 5.0308 & TRN \\
\hline CHEMBL1586286 & 688128 & 4.3 & 4.5463 & TRN \\
\hline CHEMBL1482462 & 688128 & 4.3 & 4.2782 & TRN \\
\hline CHEMBL1398590 & 688128 & 4.25 & 4.4741 & TRN \\
\hline CHEMBL1522849 & 688128 & 4.3 & 4.6958 & TST \\
\hline CHEMBL3213340 & 688128 & 4.85 & 4.7465 & TRN \\
\hline CHEMBL1333112 & 688128 & 4.35 & 4.5388 & TST \\
\hline CHEMBL1612237 & 688128 & 4.4 & 4.538 & TRN \\
\hline CHEMBL1388408 & 688128 & 4.3 & 4.7156 & TST \\
\hline CHEMBL1304433 & 688128 & 4.3 & 4.9504 & TRN \\
\hline CHEMBL1557230 & 688128 & 4.25 & 4.4816 & TRN \\
\hline CHEMBL1380078 & 688128 & 4.5 & 4.6923 & TRN \\
\hline CHEMBL1492920 & 688128 & 4.15 & 4.6463 & TST \\
\hline CHEMBL1591376 & 688128 & 4.55 & 4.461 & TRN \\
\hline CHEMBL1299823 & 688128 & 4.35 & 4.5589 & TRN \\
\hline CHEMBL1597427 & 688128 & 4.6 & 4.6201 & TRN \\
\hline CHEMBL3190165 & 688128 & 4.75 & 4.7466 & TRN \\
\hline CHEMBL1582247 & 688128 & 4.6 & 4.7474 & TRN \\
\hline CHEMBL3190400 & 688128 & 4.0 & 4.5555 & TRN \\
\hline CHEMBL1554898 & 688128 & 4.35 & 4.5382 & TRN \\
\hline CHEMBL1466165 & 688128 & 4.45 & 4.6404 & TST \\
\hline CHEMBL1437217 & 688128 & 4.1 & 4.6858 & TRN \\
\hline CHEMBL3198402 & 688128 & 4.25 & 4.6377 & TRN \\
\hline CHEMBL1374475 & 688128 & 5.05 & 4.7503 & TRN \\
\hline CHEMBL1490717 & 688128 & 4.55 & 4.6642 & TRN \\
\hline CHEMBL1306627 & 688128 & 5.5 & 4.6028 & TRN \\
\hline CHEMBL3210821 & 688128 & 4.05 & 4.5062 & TRN \\
\hline CHEMBL1300684 & 688128 & 4.45 & 4.5058 & TRN \\
\hline CHEMBL1323003 & 688128 & 5.9 & 4.8698 & TRN \\
\hline CHEMBL 3209835 & 688128 & 4.3 & 4.5833 & TST \\
\hline CHEMBL1302333 & 688128 & 4.25 & 4.5871 & TST \\
\hline CHEMBL1500227 & 688128 & 6.15 & 5.3677 & TRN \\
\hline CHEMBL1312627 & 688128 & 5.05 & 4.7374 & TRN \\
\hline
\end{tabular}




\begin{tabular}{|c|c|c|c|c|c|}
\hline & & \multicolumn{4}{|c|}{ Supplemental Table S2.txt } \\
\hline CHEMBL1534712 & 688128 & 4.25 & 4.6483 & TRN & \\
\hline CHEMBL1422665 & 688128 & 4.65 & 4.3301 & TRN & \\
\hline CHEMBL1396567 & 688128 & 4.4 & 4.6307 & TRN & \\
\hline CHEMBL1454783 & 688128 & 5.45 & 4.7643 & TRN & \\
\hline CHEMBL1553401 & 688128 & 4.3 & 4.3551 & TRN & \\
\hline CHEMBL1603776 & 688128 & 6.5501 & 5.2614 & TRN & \\
\hline CHEMBL1986541 & 688128 & 4.35 & 4.7595 & TRN & \\
\hline CHEMBL1605183 & 688128 & 5.0 & 4.4514 & TST & \\
\hline CHEMBL1562751 & 688128 & 4.35 & 4.7569 & TST & \\
\hline CHEMBL1586679 & 688128 & 4.5 & 4.5131 & TST & \\
\hline CHEMBL1377211 & 688128 & 4.35 & 4.5391 & TRN & \\
\hline CHEMBL1583964 & 688128 & 5.3 & 4.8136 & TST & \\
\hline CHEMBL1577015 & 688128 & 4.35 & 4.6256 & TRN & \\
\hline CHEMBL1543134 & 688128 & 5.15 & 4.9209 & TRN & \\
\hline CHEMBL1498770 & 688128 & 4.45 & 4.6411 & TRN & \\
\hline CHEMBL1402672 & 688128 & 4.85 & 4.4909 & TRN & \\
\hline CHEMBL1607817 & 688128 & 4.45 & 4.6557 & TRN & \\
\hline CHEMBL1387056 & 688128 & 4.3 & 4.6445 & TST & \\
\hline CHEMBL1307954 & 688128 & 5.2 & 4.5375 & TRN & \\
\hline CHEMBL1321251 & 688128 & 4.05 & 4.2516 & TRN & \\
\hline CHEMBL1318651 & 688128 & 4.85 & 5.2637 & TST & \\
\hline CHEMBL1346634 & 688128 & 4.05 & 4.5191 & TRN & \\
\hline CHEMBL1574006 & 688128 & 4.05 & 4.5212 & TRN & \\
\hline CHEMBL1575027 & 688128 & 4.35 & 4.2819 & TRN & \\
\hline CHEMBL1563414 & 688128 & 4.1 & 4.302 & TRN & \\
\hline CHEMBL1598489 & 688128 & 4.35 & 4.6526 & TST & \\
\hline CHEMBL1470976 & 688128 & 4.05 & 4.6095 & TRN & \\
\hline CHEMBL1495824 & 688128 & 4.5 & 4.6919 & TRN & \\
\hline CHEMBL1311845 & 688128 & 4.4 & 4.4312 & TRN & \\
\hline CHEMBL1513315 & 688128 & 5.4 & 4.5273 & TST & \\
\hline CHEMBL3192098 & 688128 & 4.3 & 4.6251 & TRN & \\
\hline CHEMBL1497117 & 688128 & 4.75 & 4.6174 & TRN & \\
\hline CHEMBL1556526 & 688128 & 7.0 & 4.80699 & 99999999995 & TRN \\
\hline CHEMBL1385638 & 688128 & 4.7 & 4.7448 & TRN & \\
\hline CHEMBL1376082 & 688128 & 4.3 & 4.4388 & TST & \\
\hline CHEMBL1550619 & 688128 & 4.25 & 4.5604 & TRN & \\
\hline CHEMBL1393059 & 688128 & 4.35 & 4.4075 & TST & \\
\hline CHEMBL1488518 & 688128 & 4.85 & 4.9153 & TRN & \\
\hline CHEMBL1587244 & 688128 & 5.1 & 4.7706 & TST & \\
\hline CHEMBL1597703 & 688128 & 4.45 & 4.7401 & TRN & \\
\hline CHEMBL1569941 & 688128 & 4.3 & 4.6887 & TRN & \\
\hline CHEMBL1472013 & 688128 & 5.35 & 4.7842 & TRN & \\
\hline CHEMBL1577232 & 688128 & 5.05 & 4.6919 & TRN & \\
\hline CHEMBL1532033 & 688128 & 4.6 & 4.6511 & TRN & \\
\hline CHEMBL1302444 & 688128 & 4.9 & 4.7507 & TRN & \\
\hline CHEMBL1606867 & 688128 & 6.0 & 4.6847 & TRN & \\
\hline CHEMBL1334651 & 688128 & 4.65 & 4.851 & TRN & \\
\hline CHEMBL1533312 & 688128 & 4.4 & 4.6213 & TST & \\
\hline
\end{tabular}




\begin{tabular}{|c|c|c|c|c|}
\hline \multicolumn{5}{|c|}{ lemental T } \\
\hline CHEMBL1469126 & 688128 & 4.4 & 4.9891 & TRN \\
\hline CHEMBL1418257 & 688128 & 4.4 & 4.5651 & TST \\
\hline CHEMBL1567615 & 688128 & 4.4 & 4.5346 & TRN \\
\hline CHEMBL1349094 & 688128 & 4.95 & 4.5326 & TRN \\
\hline CHEMBL1606104 & 688128 & 4.0 & 4.6004 & TRN \\
\hline CHEMBL1389930 & 688128 & 4.4 & 4.2997 & TRN \\
\hline CHEMBL1604992 & 688128 & 5.4 & 4.9152 & TST \\
\hline CHEMBL1302505 & 688128 & 4.35 & 4.4977 & TRN \\
\hline CHEMBL1528944 & 688128 & 4.0 & 4.6261 & TRN \\
\hline CHEMBL1567188 & 688128 & 4.65 & 4.4314 & TRN \\
\hline CHEMBL1575238 & 688128 & 4.65 & 4.5947 & TRN \\
\hline CHEMBL1390710 & 688128 & 5.2 & 4.9609 & TRN \\
\hline CHEMBL1580277 & 688128 & 4.3 & 4.6204 & TRN \\
\hline CHEMBL1500620 & 688128 & 4.05 & 4.4793 & TRN \\
\hline CHEMBL1551299 & 688128 & 4.1 & 4.5314 & TRN \\
\hline CHEMBL1461196 & 688128 & 4.4 & 4.7522 & TST \\
\hline CHEMBL1986284 & 688128 & 4.35 & 4.3349 & TRN \\
\hline CHEMBL1432588 & 688128 & 4.35 & 4.5223 & TRN \\
\hline CHEMBL1552937 & 688128 & 4.9 & 4.91 & TRN \\
\hline CHEMBL1560603 & 688128 & 4.3 & 4.6354 & TRN \\
\hline CHEMBL1582708 & 688128 & 4.9 & 5.0014 & TRN \\
\hline CHEMBL1397772 & 688128 & 5.1 & 4.6091 & TRN \\
\hline CHEMBL1323267 & 688128 & 5.6 & 4.5478 & TRN \\
\hline CHEMBL1498487 & 688128 & 4.95 & 4.6991 & TRN \\
\hline CHEMBL1416495 & 688128 & 4.35 & 4.6235 & TST \\
\hline CHEMBL1397158 & 688128 & 4.4 & 4.6511 & TRN \\
\hline CHEMBL1432505 & 688128 & 4.95 & 4.5887 & TRN \\
\hline CHEMBL1367716 & 688128 & 4.35 & 4.9483 & TST \\
\hline CHEMBL1463016 & 688128 & 4.05 & 4.373 & TST \\
\hline CHEMBL1376555 & 688128 & 5.05 & 5.2688 & TST \\
\hline CHEMBL1436778 & 688128 & 4.8 & 4.8846 & TST \\
\hline CHEMBL3194609 & 688128 & 4.05 & 4.9991 & TRN \\
\hline CHEMBL1459360 & 688128 & 4.4 & 4.6528 & TST \\
\hline CHEMBL1580209 & 688128 & 4.9 & 4.7034 & TRN \\
\hline CHEMBL1304129 & 688128 & 6.0 & 4.6946 & TRN \\
\hline CHEMBL1503941 & 688128 & 5.55 & 4.7406 & TRN \\
\hline CHEMBL1345331 & 688128 & 4.8 & 4.5574 & TRN \\
\hline CHEMBL1441838 & 688128 & 4.3 & 4.6221 & TRN \\
\hline CHEMBL1495878 & 688128 & 4.35 & 4.3373 & TRN \\
\hline CHEMBL1551315 & 688128 & 5.65 & 4.3369 & TST \\
\hline CHEMBL1315439 & 688128 & 4.6 & 4.5045 & TRN \\
\hline CHEMBL1456614 & 688128 & 4.6 & 4.6451 & TRN \\
\hline CHEMBL1486271 & 688128 & 4.0 & 4.6729 & TRN \\
\hline CHEMBL1338079 & 688128 & 4.35 & 4.6164 & TRN \\
\hline CHEMBL1320714 & 688128 & 4.35 & 4.7168 & TST \\
\hline CHEMBL1532697 & 688128 & 5.0 & 4.6424 & TST \\
\hline CHEMBL1410176 & 688128 & 4.3 & 4.3271 & TRN \\
\hline CHEMBL1376350 & 688128 & 4.35 & 4.4398 & TRN \\
\hline
\end{tabular}




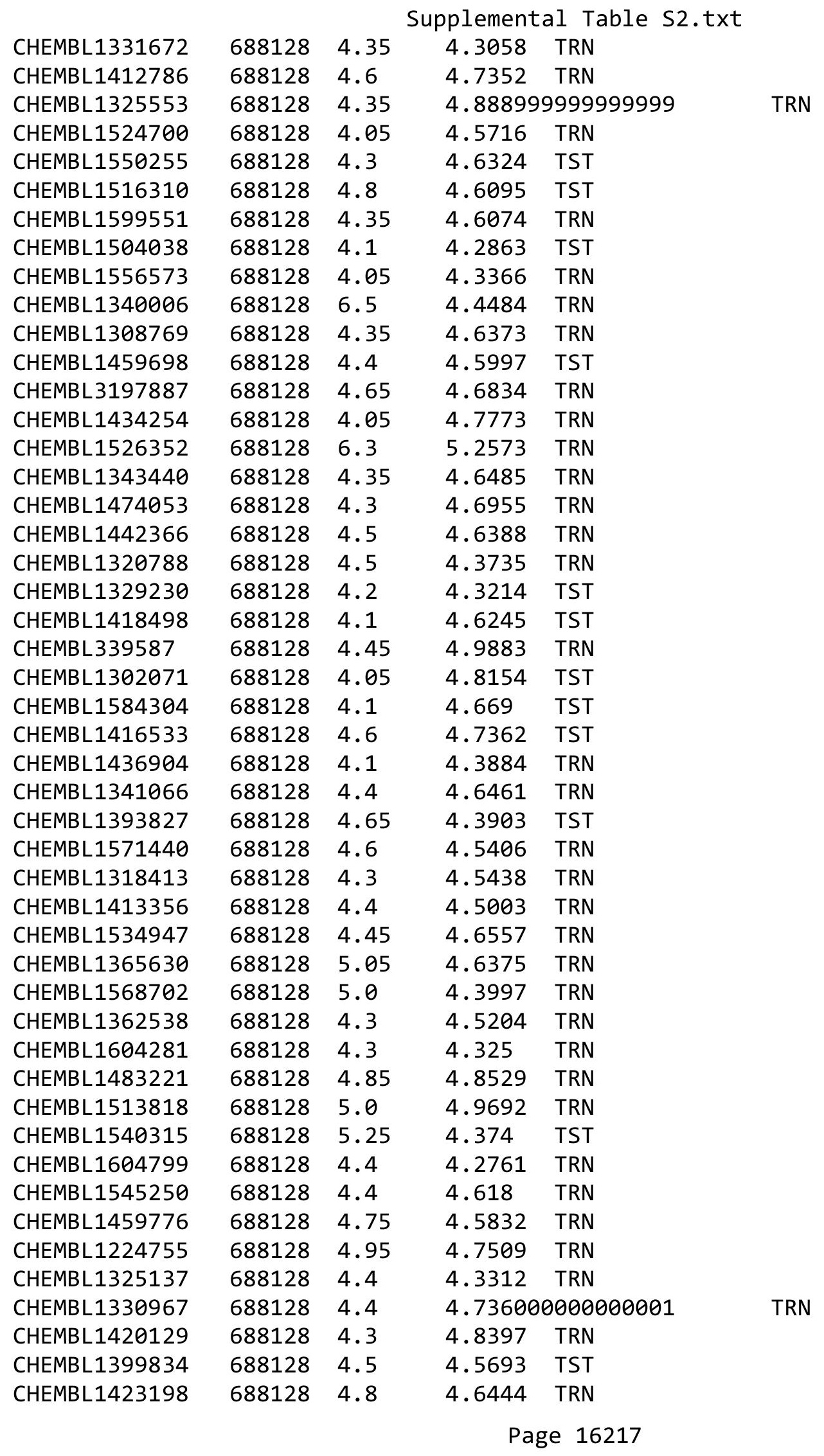




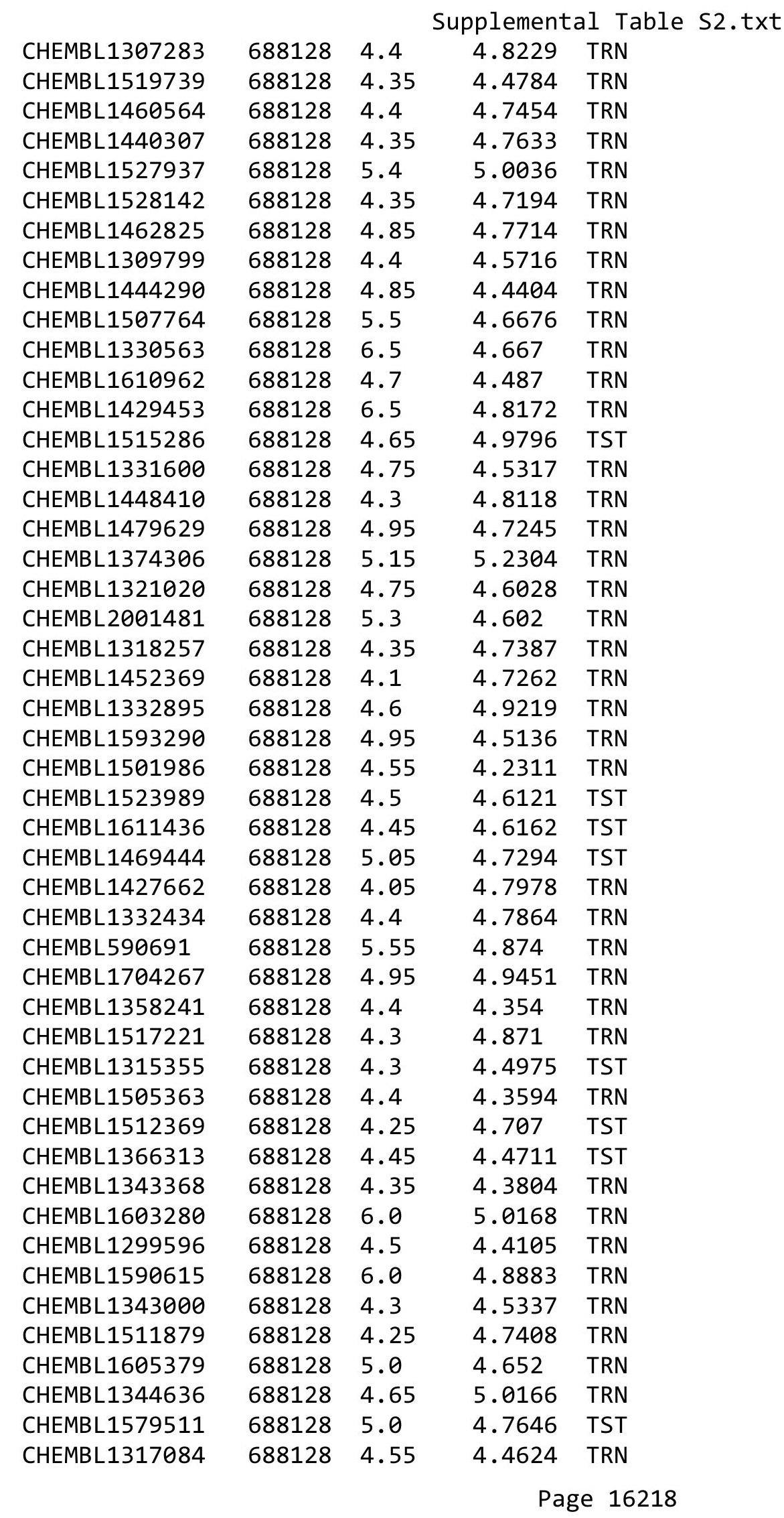




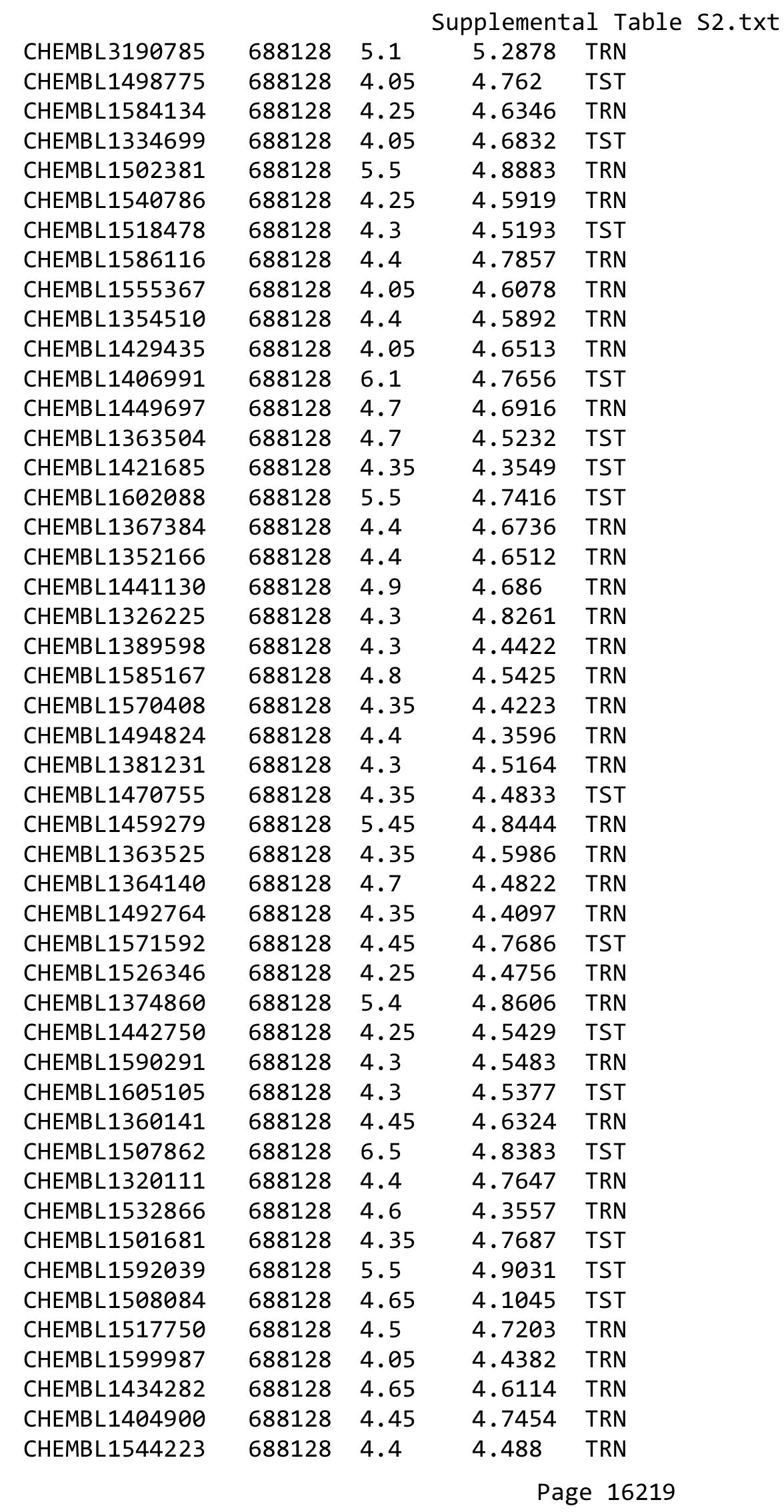




\begin{tabular}{|c|c|c|c|c|}
\hline \multicolumn{5}{|c|}{ Supplemental Tabl } \\
\hline CHEMBL1460957 & 688128 & 4.25 & 4.5651 & TRN \\
\hline CHEMBL1477942 & 688128 & 4.65 & 4.4115 & TRN \\
\hline CHEMBL600922 & 688128 & 4.4 & 4.7321 & TST \\
\hline CHEMBL1429537 & 688128 & 5.05 & 5.0573 & TST \\
\hline CHEMBL1607536 & 688128 & 4.35 & 4.8602 & TST \\
\hline CHEMBL3191504 & 688128 & 4.5 & 4.4026 & TRN \\
\hline CHEMBL1501253 & 688128 & 4.05 & 4.6438 & TRN \\
\hline CHEMBL1416726 & 688128 & 4.3 & 4.6385 & TRN \\
\hline CHEMBL1527635 & 688128 & 5.05 & 5.1739 & TRN \\
\hline CHEMBL1506325 & 688128 & 4.05 & 4.7003 & TST \\
\hline CHEMBL1449701 & 688128 & 4.05 & 4.106 & TST \\
\hline CHEMBL1439175 & 688128 & 4.75 & 4.6486 & TST \\
\hline CHEMBL3199011 & 688128 & 4.35 & 4.4843 & TRN \\
\hline CHEMBL1531265 & 688128 & 4.0 & 4.6585 & TRN \\
\hline CHEMBL1539013 & 688128 & 4.5 & 4.4458 & TRN \\
\hline CHEMBL3197154 & 688128 & 5.5 & 4.5739 & TRN \\
\hline CHEMBL1384532 & 688128 & 3.95 & 4.3711 & TST \\
\hline CHEMBL1362395 & 688128 & 4.4 & 4.4683 & TRN \\
\hline CHEMBL1585261 & 688128 & 4.25 & 4.5902 & TST \\
\hline CHEMBL1438230 & 688128 & 4.35 & 4.413 & TST \\
\hline CHEMBL1511086 & 688128 & 4.45 & 4.2256 & TST \\
\hline CHEMBL1512755 & 688128 & 5.85 & 4.7669 & TRN \\
\hline CHEMBL1789986 & 688128 & 4.3 & 4.8923 & TST \\
\hline CHEMBL1575435 & 688128 & 5.5 & 4.6879 & TRN \\
\hline CHEMBL1399109 & 688128 & 6.4 & 5.1298 & TRN \\
\hline CHEMBL1566197 & 688128 & 5.85 & 4.9802 & TRN \\
\hline CHEMBL1564836 & 688128 & 4.4 & 4.694 & TRN \\
\hline CHEMBL1331479 & 688128 & 6.0 & 4.5133 & TRN \\
\hline CHEMBL1518964 & 688128 & 4.45 & 4.5476 & TST \\
\hline CHEMBL1415610 & 688128 & 4.4 & 4.5105 & TRN \\
\hline CHEMBL1583782 & 688128 & 4.45 & 4.5624 & TST \\
\hline CHEMBL1515651 & 688128 & 4.35 & 4.9712 & TST \\
\hline CHEMBL1368847 & 688128 & 4.25 & 4.6791 & TRN \\
\hline CHEMBL1367704 & 688128 & 4.4 & 4.7032 & TST \\
\hline CHEMBL1432761 & 688128 & 4.05 & 4.5908 & TRN \\
\hline CHEMBL1349966 & 688128 & 4.25 & 4.5791 & TST \\
\hline CHEMBL1348141 & 688128 & 4.8 & 4.7811 & TRN \\
\hline CHEMBL1399139 & 688128 & 4.65 & 4.6946 & TRN \\
\hline CHEMBL1605640 & 688128 & 4.5 & 4.5107 & TST \\
\hline CHEMBL1484108 & 688128 & 4.45 & 4.5678 & TRN \\
\hline CHEMBL1442812 & 688128 & 5.0 & 4.5223 & TRN \\
\hline CHEMBL1427140 & 688128 & 4.35 & 5.0291 & TRN \\
\hline CHEMBL1608435 & 688128 & 4.3 & 4.8083 & TRN \\
\hline CHEMBL1550381 & 688128 & 4.3 & 4.5275 & TRN \\
\hline CHEMBL1557527 & 688128 & 4.65 & 4.6214 & TRN \\
\hline CHEMBL1413190 & 688128 & 4.4 & 4.6163 & TRN \\
\hline CHEMBL1400105 & 688128 & 4.05 & 4.5862 & TRN \\
\hline CHEMBL1353929 & 688128 & 4.75 & 4.746 & TRN \\
\hline
\end{tabular}




\begin{tabular}{|c|c|c|c|c|}
\hline \multicolumn{5}{|c|}{ Supplemental Table s2.txt } \\
\hline CHEMBL1362508 & 688128 & 4.4 & 4.6573 & TRN \\
\hline CHEMBL1559143 & 688128 & 4.45 & 4.4606 & TRN \\
\hline CHEMBL1573700 & 688128 & 4.5 & 4.956 & TRN \\
\hline CHEMBL1449550 & 688128 & 4.35 & 5.0988 & TRN \\
\hline CHEMBL1312739 & 688128 & 6.25 & 5.1941 & TRN \\
\hline CHEMBL1398297 & 688128 & 4.25 & 4.6036 & TRN \\
\hline CHEMBL1971185 & 688128 & 5.5 & 4.4695 & TRN \\
\hline CHEMBL1424999 & 688128 & 4.3 & 4.606 & TRN \\
\hline CHEMBL1318372 & 688128 & 4.05 & 4.305 & TRN \\
\hline CHEMBL1322000 & 688128 & 4.65 & 4.6849 & TRN \\
\hline CHEMBL1334062 & 688128 & 5.0 & 5.0515 & TRN \\
\hline CHEMBL1407181 & 688128 & 4.45 & 4.8884 & TST \\
\hline CHEMBL1312986 & 688128 & 4.3 & 4.625 & TRN \\
\hline CHEMBL1557951 & 688128 & 4.25 & 4.8198 & TRN \\
\hline CHEMBL1600119 & 688128 & 4.05 & 4.6623 & TRN \\
\hline CHEMBL1312784 & 688128 & 4.85 & 4.3843 & TRN \\
\hline CHEMBL1499409 & 688128 & 4.05 & 4.7136 & TST \\
\hline CHEMBL1305728 & 688128 & 4.6 & 4.7621 & TRN \\
\hline CHEMBL1339301 & 688128 & 4.55 & 4.5314 & TRN \\
\hline CHEMBL1518976 & 688128 & 4.7 & 4.7317 & TRN \\
\hline CHEMBL1505419 & 688128 & 4.3 & 4.6407 & TST \\
\hline CHEMBL1536811 & 688128 & 4.75 & 4.4335 & TRN \\
\hline CHEMBL1466991 & 688128 & 4.3 & 4.6869 & TRN \\
\hline CHEMBL1402563 & 688128 & 4.4 & 4.6619 & TRN \\
\hline CHEMBL1407632 & 688128 & 4.35 & 4.8989 & TRN \\
\hline CHEMBL1525010 & 688128 & 4.65 & 4.6116 & TRN \\
\hline CHEMBL1393811 & 688128 & 4.15 & 4.487 & TRN \\
\hline CHEMBL1381052 & 688128 & 4.6 & 4.8043 & TRN \\
\hline CHEMBL1331478 & 688128 & 4.35 & 4.7117 & TRN \\
\hline CHEMBL1459161 & 688128 & 4.35 & 4.3589 & TRN \\
\hline CHEMBL1476797 & 688128 & 4.45 & 5.0833 & TRN \\
\hline CHEMBL1516928 & 688128 & 4.35 & 4.5398 & TRN \\
\hline CHEMBL1400130 & 688128 & 6.45 & 4.8879 & TRN \\
\hline CHEMBL1509800 & 688128 & 4.0 & 4.4628 & TRN \\
\hline CHEMBL1424592 & 688128 & 4.9 & 4.5329 & TRN \\
\hline CHEMBL1503204 & 688128 & 4.6 & 4.4399 & TST \\
\hline CHEMBL1490154 & 688128 & 5.45 & 4.4753 & TST \\
\hline CHEMBL1406927 & 688128 & 4.5 & 4.7394 & TRN \\
\hline CHEMBL1428783 & 688128 & 4.25 & 4.8437 & TRN \\
\hline CHEMBL1379723 & 688128 & 4.0 & 4.569 & TRN \\
\hline CHEMBL1534783 & 688128 & 4.3 & 4.512 & TRN \\
\hline CHEMBL1464174 & 688128 & 4.3 & 4.7083 & TRN \\
\hline CHEMBL1568474 & 688128 & 4.5 & 5.0104 & TST \\
\hline CHEMBL1581503 & 688128 & 4.6 & 4.9687 & TRN \\
\hline CHEMBL1610511 & 688128 & 4.05 & 4.5961 & TRN \\
\hline CHEMBL1453722 & 688128 & 4.8 & 4.6326 & TST \\
\hline CHEMBL1379897 & 688128 & 4.35 & 4.468 & TRN \\
\hline CHEMBL3193862 & 688128 & 5.5 & 4.626 & TRN \\
\hline
\end{tabular}




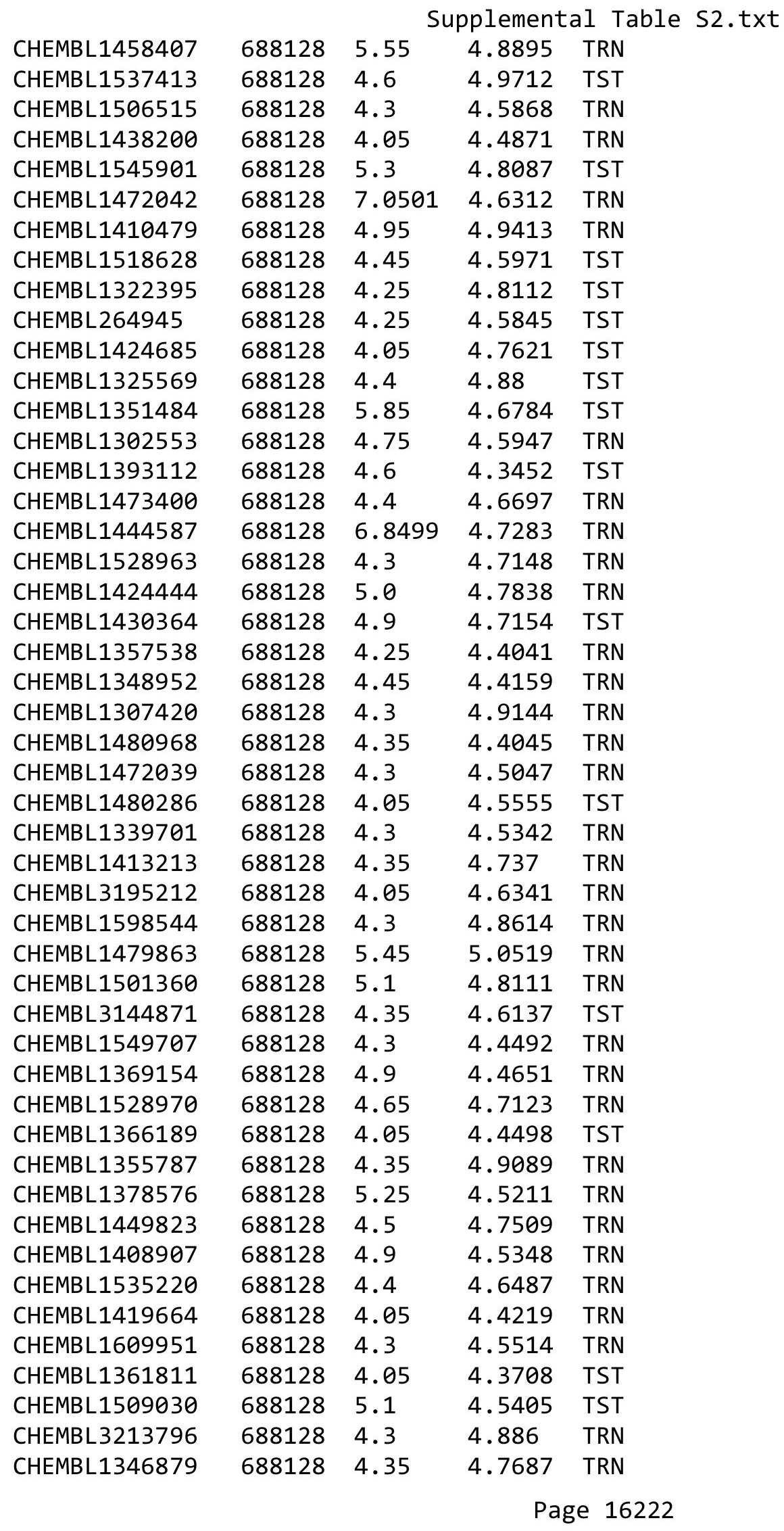




\begin{tabular}{|c|c|c|c|c|c|}
\hline & & \multicolumn{4}{|c|}{ Supplemental Table s2.txt } \\
\hline CHEMBL1520997 & 688128 & 4.3 & 4.3309 & TRN & \\
\hline CHEMBL1418799 & 688128 & 4.45 & 4.5187 & TST & \\
\hline CHEMBL1389925 & 688128 & 4.65 & 4.8628 & TST & \\
\hline CHEMBL1992641 & 688128 & 4.3 & 4.3701 & TST & \\
\hline CHEMBL1555735 & 688128 & 4.3 & 4.8347 & TRN & \\
\hline CHEMBL1462008 & 688128 & 4.4 & 5.1758 & TRN & \\
\hline CHEMBL1385787 & 688128 & 4.9 & 4.6571 & TRN & \\
\hline CHEMBL1603123 & 688128 & 4.45 & 4.6735 & TRN & \\
\hline CHEMBL1554318 & 688128 & 4.55 & 5.026 & TRN & \\
\hline CHEMBL1327753 & 688128 & 4.35 & 4.5369 & TRN & \\
\hline CHEMBL1337476 & 688128 & 4.35 & 4.449 & TRN & \\
\hline CHEMBL1497691 & 688128 & 4.05 & 4.664 & TRN & \\
\hline CHEMBL1369412 & 688128 & 6.2 & 4.796 & TST & \\
\hline CHEMBL1411115 & 688128 & 6.05 & 4.5348 & TRN & \\
\hline CHEMBL1549540 & 688128 & 4.5 & 5.2496 & TST & \\
\hline CHEMBL1446652 & 688128 & 4.4 & 4.5668 & TST & \\
\hline CHEMBL1532280 & 688128 & 4.4 & 4.71399 & 99999999995 & TRN \\
\hline CHEMBL1613515 & 688128 & 4.6 & 4.7829 & TST & \\
\hline CHEMBL1462734 & 688128 & 5.2 & 4.6308 & TST & \\
\hline CHEMBL1565090 & 688128 & 4.05 & 4.6989 & TST & \\
\hline CHEMBL1464472 & 688128 & 4.4 & 4.3664 & TST & \\
\hline CHEMBL1416045 & 688128 & 4.25 & 5.0322 & TST & \\
\hline CHEMBL1384666 & 688128 & 4.4 & 4.8812 & TRN & \\
\hline CHEMBL1425809 & 688128 & 5.05 & 4.809 & TRN & \\
\hline CHEMBL3192605 & 688128 & 4.7 & 4.7417 & TRN & \\
\hline CHEMBL1340633 & 688128 & 4.35 & 4.709 & TRN & \\
\hline CHEMBL1602150 & 688128 & 4.0 & 4.4407 & TRN & \\
\hline CHEMBL1525089 & 688128 & 4.35 & 4.4281 & TRN & \\
\hline CHEMBL1336617 & 688128 & 6.0 & 4.8266 & TRN & \\
\hline CHEMBL1594828 & 688128 & 4.45 & 4.5118 & TRN & \\
\hline CHEMBL1346710 & 688128 & 4.05 & 4.6232 & TRN & \\
\hline CHEMBL1968273 & 688128 & 4.7 & 4.7292 & TST & \\
\hline CHEMBL1587997 & 688128 & 4.3 & 4.7255 & TRN & \\
\hline CHEMBL1415513 & 688128 & 4.5 & 4.952 & TRN & \\
\hline CHEMBL1423060 & 688128 & 4.05 & 4.2674 & TRN & \\
\hline CHEMBL1588290 & 688128 & 4.25 & 4.4254 & TRN & \\
\hline CHEMBL1317847 & 688128 & 4.4 & 4.4932 & TRN & \\
\hline CHEMBL1572116 & 688128 & 4.65 & 4.8014 & TST & \\
\hline CHEMBL1557727 & 688128 & 4.55 & 4.6909 & TRN & \\
\hline CHEMBL1592429 & 688128 & 4.5 & 4.6454 & TRN & \\
\hline CHEMBL1414789 & 688128 & 5.4 & 4.5215 & TST & \\
\hline CHEMBL1613422 & 688128 & 4.3 & 4.413 & TRN & \\
\hline CHEMBL1406473 & 688128 & 6.1 & 4.2829 & TRN & \\
\hline CHEMBL1466583 & 688128 & 4.85 & 4.417 & TRN & \\
\hline CHEMBL1566082 & 688128 & 4.25 & 4.5425 & TST & \\
\hline CHEMBL1510526 & 688128 & 4.1 & 4.6738 & TRN & \\
\hline CHEMBL1448432 & 688128 & 4.05 & 4.4298 & TRN & \\
\hline CHEMBL1445728 & 688128 & 4.8 & 4.8641 & TRN & \\
\hline
\end{tabular}




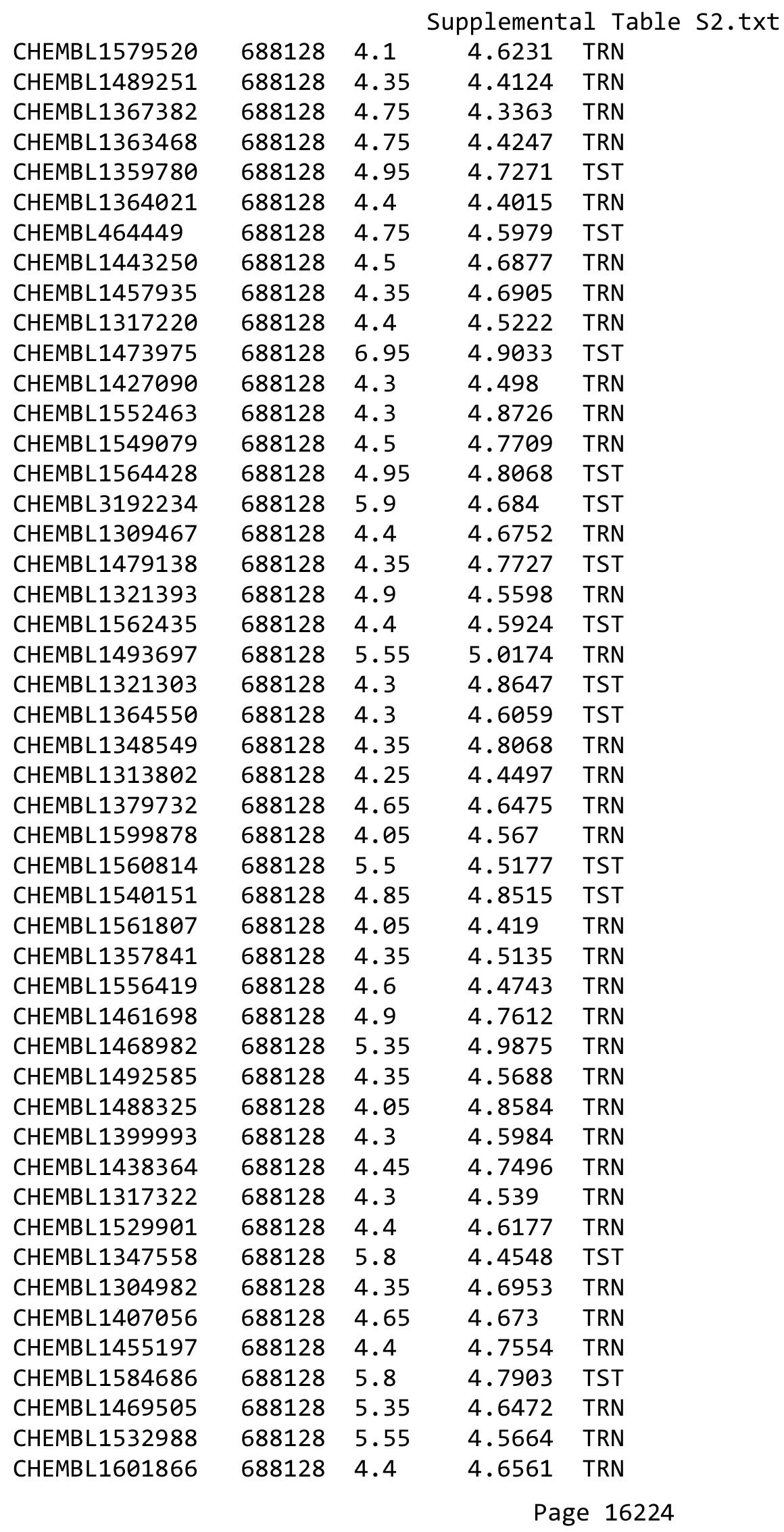




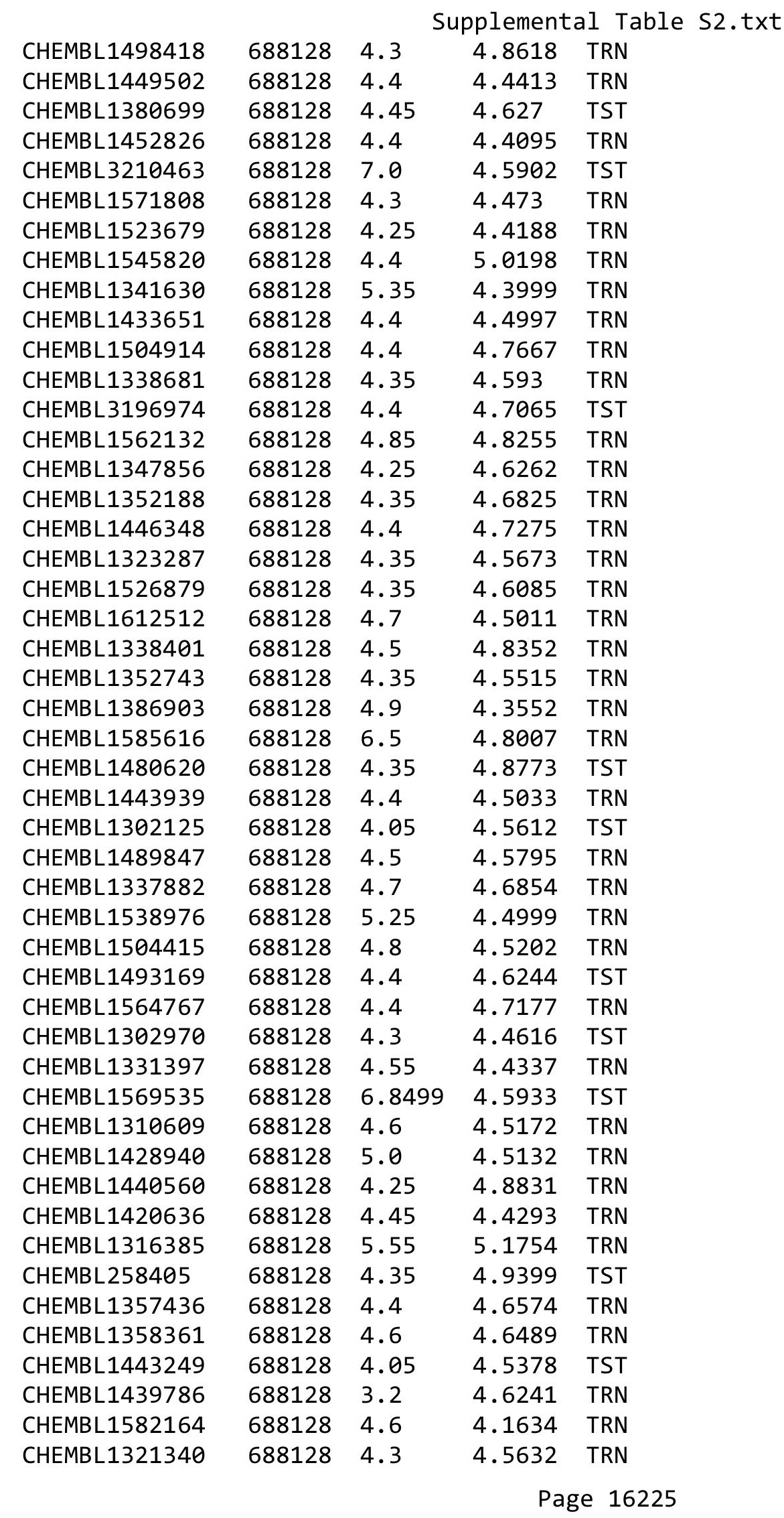




\begin{tabular}{|c|c|c|c|c|c|}
\hline \multicolumn{6}{|c|}{ Supplemental Table S2.txt } \\
\hline CHEMBL1442240 & 688128 & 4.25 & 4.4161 & TRN & \\
\hline CHEMBL1384321 & 688128 & 4.9 & 4.4575 & TRN & \\
\hline CHEMBL1520719 & 688128 & 4.55 & 4.6285 & TRN & \\
\hline CHEMBL1593384 & 688128 & 5.35 & 5.1684 & TRN & \\
\hline CHEMBL1387248 & 688128 & 6.15 & 5.0905 & TST & \\
\hline CHEMBL1419090 & 688128 & 4.05 & 4.8364 & TRN & \\
\hline CHEMBL1376439 & 688128 & 4.65 & 4.6017 & TST & \\
\hline CHEMBL1489771 & 688128 & 5.0 & 4.9245 & TRN & \\
\hline CHEMBL1393433 & 688128 & 4.5 & 4.426 & TRN & \\
\hline CHEMBL1322742 & 688128 & 5.0 & 4.7035 & TRN & \\
\hline CHEMBL1428073 & 688128 & 6.45 & 5.1008 & TRN & \\
\hline CHEMBL1530207 & 688128 & 6.8499 & 4.7737 & TRN & \\
\hline CHEMBL1344289 & 688128 & 4.6 & 4.5581 & TRN & \\
\hline CHEMBL1300799 & 688128 & 4.3 & 4.4622 & TRN & \\
\hline CHEMBL1583992 & 688128 & 4.05 & 4.8536 & TRN & \\
\hline CHEMBL1414172 & 688128 & 4.4 & 4.7418 & TST & \\
\hline CHEMBL1409713 & 688128 & 4.25 & 4.4935 & TST & \\
\hline CHEMBL1317722 & 688128 & 4.95 & 4.6417 & TRN & \\
\hline CHEMBL1458486 & 688128 & 4.6 & 4.6027 & TRN & \\
\hline CHEMBL 252744 & 688128 & 4.4 & 4.6412 & TST & \\
\hline CHEMBL1485889 & 688128 & 4.4 & 4.7066 & TRN & \\
\hline CHEMBL1545954 & 688128 & 5.1 & 5.0227 & TRN & \\
\hline CHEMBL1516569 & 688128 & 4.05 & 4.6915 & TST & \\
\hline CHEMBL1530932 & 688128 & 5.45 & 4.7369 & TRN & \\
\hline CHEMBL 269755 & 688128 & 5.15 & 4.79899 & 99999999995 & TST \\
\hline CHEMBL362941 & 688128 & 4.35 & 4.5924 & TRN & \\
\hline CHEMBL1401948 & 688128 & 4.45 & 4.9295 & TST & \\
\hline CHEMBL1419536 & 688128 & 4.9 & 4.9444 & TRN & \\
\hline CHEMBL1587328 & 688128 & 4.05 & 4.3967 & TST & \\
\hline CHEMBL1429234 & 688128 & 4.55 & 4.5889 & TRN & \\
\hline CHEMBL1472142 & 688128 & 4.45 & 4.3776 & TRN & \\
\hline CHEMBL1472974 & 688128 & 4.35 & 4.5939 & TRN & \\
\hline CHEMBL1467744 & 688128 & 4.55 & 4.4289 & 9999999999 & TRN \\
\hline CHEMBL1425479 & 688128 & 4.45 & 4.4301 & TRN & \\
\hline CHEMBL1546683 & 688128 & 4.65 & 4.7492 & TRN & \\
\hline CHEMBL1508456 & 688128 & 4.6 & 4.7081 & TRN & \\
\hline CHEMBL1550710 & 688128 & 5.1 & 4.833 & TST & \\
\hline CHEMBL1469355 & 688128 & 4.65 & 4.9221 & TST & \\
\hline CHEMBL1599293 & 688128 & 4.4 & 4.7181 & TRN & \\
\hline CHEMBL1380740 & 688128 & 4.4 & 4.9199 & TRN & \\
\hline CHEMBL1327579 & 688128 & 4.05 & 4.3505 & TRN & \\
\hline CHEMBL1463824 & 688128 & 5.15 & 4.6671 & TST & \\
\hline CHEMBL1324674 & 688128 & 4.6 & 4.718 & TRN & \\
\hline CHEMBL1550814 & 688128 & 4.25 & 4.6078 & TRN & \\
\hline CHEMBL1449006 & 688128 & 4.4 & 4.8711 & TST & \\
\hline CHEMBL1451772 & 688128 & 5.05 & 4.9535 & TRN & \\
\hline CHEMBL1360908 & 688128 & 4.35 & 4.5257 & TRN & \\
\hline CHEMBL1434809 & 688128 & 4.35 & 4.646 & TRN & \\
\hline
\end{tabular}




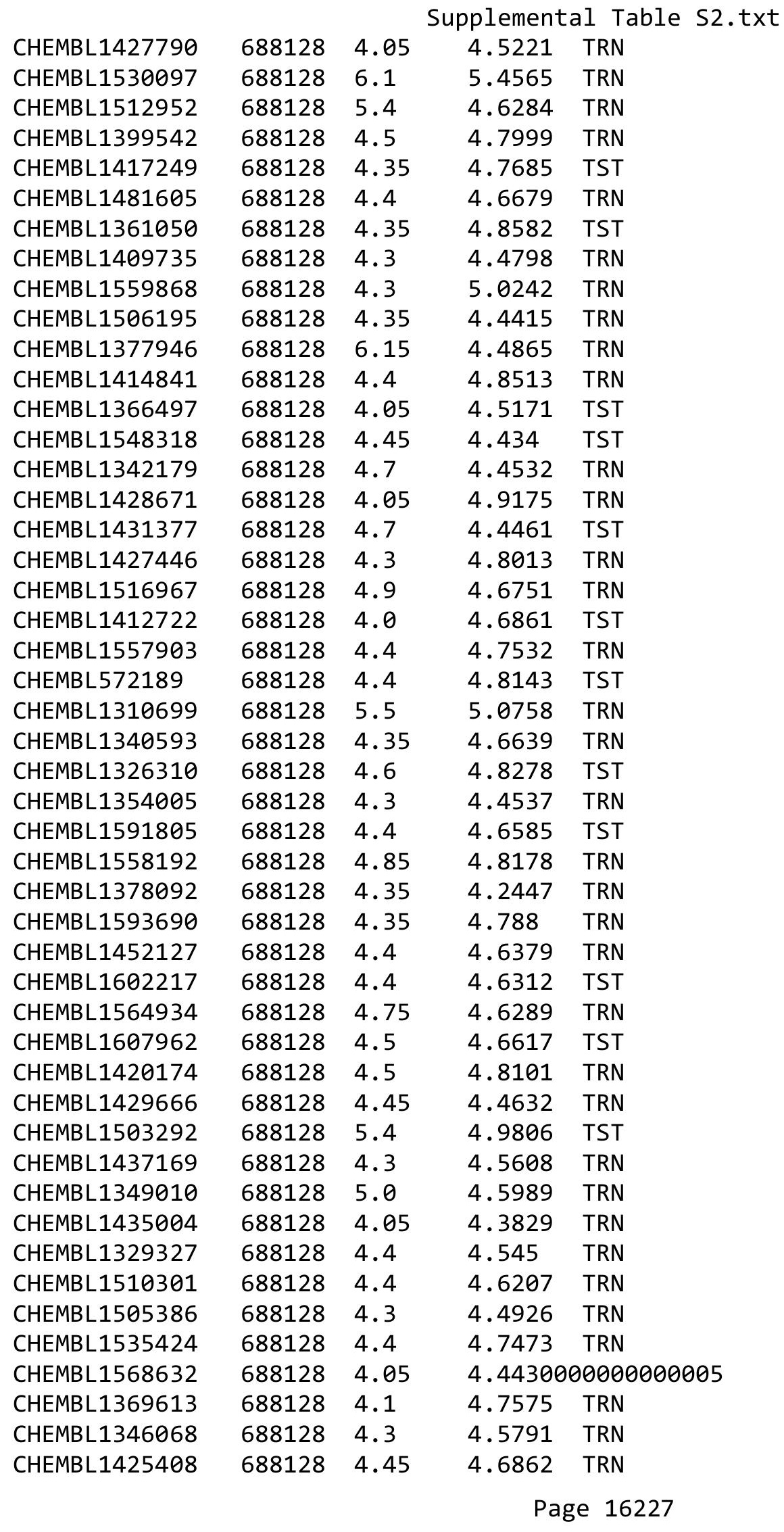




\begin{tabular}{|c|c|c|c|c|c|}
\hline CHEMBL1400687 & 688128 & 4.0 & 4.7324 & TRN & \\
\hline CHEMBL1511103 & 688128 & 6.1 & 4.5159 & TRN & \\
\hline CHEMBL1376926 & 688128 & 4.4 & 4.8406 & TST & \\
\hline CHEMBL1531359 & 688128 & 6.8499 & 4.6419 & TST & \\
\hline CHEMBL1351585 & 688128 & 5.1 & 4.4299 & TRN & \\
\hline CHEMBL1386846 & 688128 & 4.5 & 4.4547 & TRN & \\
\hline CHEMBL1545066 & 688128 & 4.4 & 5.0271 & TRN & \\
\hline CHEMBL1392620 & 688128 & 4.05 & 4.994 & TST & \\
\hline CHEMBL1606615 & 688128 & 4.25 & 4.7936 & TRN & \\
\hline CHEMBL1466463 & 688128 & 4.35 & 4.7427 & TRN & \\
\hline CHEMBL1317417 & 688128 & 4.05 & 4.7015 & TST & \\
\hline CHEMBL1578646 & 688128 & 5.0 & 4.6353 & TRN & \\
\hline CHEMBL1536472 & 688128 & 4.9 & 4.456 & TRN & \\
\hline CHEMBL1466548 & 688128 & 4.5 & 4.6154 & TRN & \\
\hline CHEMBL1495803 & 688128 & 5.45 & 4.9945 & TRN & \\
\hline CHEMBL1435484 & 688128 & 5.1 & 4.7539 & TRN & \\
\hline CHEMBL1487044 & 688128 & 6.2 & 4.6883 & TRN & \\
\hline CHEMBL1408127 & 688128 & 4.3 & 4.8853 & TRN & \\
\hline CHEMBL1483658 & 688128 & 4.4 & 4.6054 & TRN & \\
\hline CHEMBL1463618 & 688128 & 5.55 & 4.5643 & TST & \\
\hline CHEMBL1431209 & 688128 & 5.05 & 4.5232 & TST & \\
\hline CHEMBL1514459 & 688128 & 4.3 & 4.5755 & TRN & \\
\hline CHEMBL1416972 & 688128 & 4.35 & 4.5779 & TRN & \\
\hline CHEMBL1441411 & 688128 & 4.4 & 4.5665 & TRN & \\
\hline CHEMBL1387120 & 688128 & 4.65 & 4.8005 & TRN & \\
\hline CHEMBL1401222 & 688128 & 4.4 & 4.4385 & TRN & \\
\hline CHEMBL1309965 & 688128 & 4.3 & 4.5281 & TRN & \\
\hline CHEMBL1406625 & 688128 & 5.05 & 4.6256 & TST & \\
\hline CHEMBL1509989 & 688128 & 4.65 & 4.6808 & TRN & \\
\hline CHEMBL1372356 & 688128 & 5.4 & 4.6818 & TRN & \\
\hline CHEMBL1329827 & 688128 & 4.05 & 4.4396 & TST & \\
\hline CHEMBL1413623 & 688128 & 6.8499 & 4.4515 & TST & \\
\hline CHEMBL1526510 & 688128 & 4.05 & 4.4529 & TST & \\
\hline CHEMBL1377210 & 688128 & 4.45 & 4.3879 & TRN & \\
\hline CHEMBL1420641 & 688128 & 4.4 & 4.4689 & TRN & \\
\hline CHEMBL1489171 & 688128 & 4.3 & 4.3431 & TRN & \\
\hline CHEMBL1556789 & 688128 & 4.05 & 4.9428 & TRN & \\
\hline CHEMBL1454575 & 688128 & 4.5 & 4.7821 & TRN & \\
\hline CHEMBL1529016 & 688128 & 4.35 & 4.5094 & TRN & \\
\hline CHEMBL1499096 & 688128 & 5.05 & 4.8143 & TRN & \\
\hline CHEMBL1320727 & 688128 & 4.35 & 4.5185 & TST & \\
\hline CHEMBL1342053 & 688128 & 6.1 & 5.15799 & 99999999995 & TRN \\
\hline CHEMBL1999906 & 688128 & 4.75 & 4.7002 & TST & \\
\hline CHEMBL1486927 & 688128 & 4.4 & 4.6882 & TRN & \\
\hline CHEMBL1415505 & 688128 & 4.0 & 4.485 & TST & \\
\hline CHEMBL1415445 & 688128 & 4.25 & 4.72199 & 99999999995 & TRN \\
\hline CHEMBL1449826 & 688128 & 4.4 & 4.54 & TST & \\
\hline CHEMBL1328712 & 688128 & 5.55 & 4.5799 & TRN & \\
\hline
\end{tabular}




\begin{tabular}{|c|c|c|c|c|}
\hline \multicolumn{5}{|c|}{ Supplemental Table S2.txt } \\
\hline CHEMBL1301108 & 688128 & 5.2 & 5.1283 & TRN \\
\hline CHEMBL1341442 & 688128 & 4.05 & 4.5702 & TST \\
\hline CHEMBL1444899 & 688128 & 4.35 & 4.5468 & TRN \\
\hline CHEMBL1542160 & 688128 & 4.4 & 4.3113 & TRN \\
\hline CHEMBL1416511 & 688128 & 4.3 & 4.4717 & TST \\
\hline CHEMBL1538244 & 688128 & 6.0 & 5.0242 & TRN \\
\hline CHEMBL1417453 & 688128 & 4.1 & 4.5833 & TRN \\
\hline CHEMBL3192155 & 688128 & 4.05 & 4.423 & TRN \\
\hline CHEMBL1610886 & 688128 & 4.1 & 4.4033 & TRN \\
\hline CHEMBL1519711 & 688128 & 4.4 & 4.8739 & TST \\
\hline CHEMBL1590277 & 688128 & 6.9 & 4.6842 & TRN \\
\hline CHEMBL3194413 & 688128 & 5.65 & 4.5489 & TRN \\
\hline CHEMBL1455294 & 688128 & 4.05 & 4.5355 & TRN \\
\hline CHEMBL1505862 & 688128 & 5.6 & 4.7158 & TST \\
\hline CHEMBL1401415 & 688128 & 4.7 & 4.2073 & TRN \\
\hline CHEMBL1572534 & 688128 & 5.45 & 4.5532 & TRN \\
\hline CHEMBL1327157 & 688128 & 4.05 & 4.5666 & TRN \\
\hline CHEMBL1600411 & 688128 & 5.45 & 5.1864 & TRN \\
\hline CHEMBL1456429 & 688128 & 4.0 & 4.6153 & TST \\
\hline CHEMBL1385640 & 688128 & 4.05 & 4.5433 & TST \\
\hline CHEMBL1315495 & 688128 & 4.85 & 4.9101 & TRN \\
\hline CHEMBL1392093 & 688128 & 4.35 & 4.6979 & TST \\
\hline CHEMBL1537271 & 688128 & 4.95 & 4.8927 & TRN \\
\hline CHEMBL1321778 & 688128 & 4.35 & 4.6052 & TRN \\
\hline CHEMBL1426286 & 688128 & 5.35 & 4.7975 & TRN \\
\hline CHEMBL1410022 & 688128 & 5.0 & 4.4035 & TRN \\
\hline CHEMBL1560511 & 688128 & 4.4 & 4.5504 & TST \\
\hline CHEMBL1510117 & 688128 & 4.25 & 4.7326 & TRN \\
\hline CHEMBL1330161 & 688128 & 4.95 & 5.1711 & TRN \\
\hline CHEMBL1450604 & 688128 & 4.7 & 4.4097 & TRN \\
\hline CHEMBL1451628 & 688128 & 5.1 & 4.4828 & TRN \\
\hline CHEMBL1346478 & 688128 & 4.55 & 4.651 & TRN \\
\hline CHEMBL1596207 & 688128 & 5.05 & 4.5562 & TRN \\
\hline CHEMBL1473031 & 688128 & 4.45 & 4.3806 & TRN \\
\hline CHEMBL1449950 & 688128 & 4.45 & 4.6398 & TRN \\
\hline CHEMBL1577245 & 688128 & 5.65 & 4.9339 & TRN \\
\hline CHEMBL1593941 & 688128 & 4.55 & 4.5089 & TRN \\
\hline CHEMBL1430012 & 688128 & 4.3 & 4.6089 & TRN \\
\hline CHEMBL1368165 & 688128 & 4.35 & 4.7075 & TST \\
\hline CHEMBL1531144 & 688128 & 4.7 & 4.383 & TRN \\
\hline CHEMBL1330858 & 688128 & 4.55 & 4.65 & TST \\
\hline CHEMBL1516841 & 688128 & 5.35 & 4.896 & TST \\
\hline CHEMBL1608749 & 688128 & 4.05 & 4.4404 & TRN \\
\hline CHEMBL1372957 & 688128 & 5.45 & 4.7033 & TRN \\
\hline CHEMBL1307021 & 688128 & 4.2 & 4.0879 & TST \\
\hline CHEMBL1522218 & 688128 & 4.65 & 4.7344 & TRN \\
\hline CHEMBL1544697 & 688128 & 4.05 & 4.6654 & TST \\
\hline CHEMBL1399569 & 688128 & 4.4 & 4.6057 & TRN \\
\hline
\end{tabular}




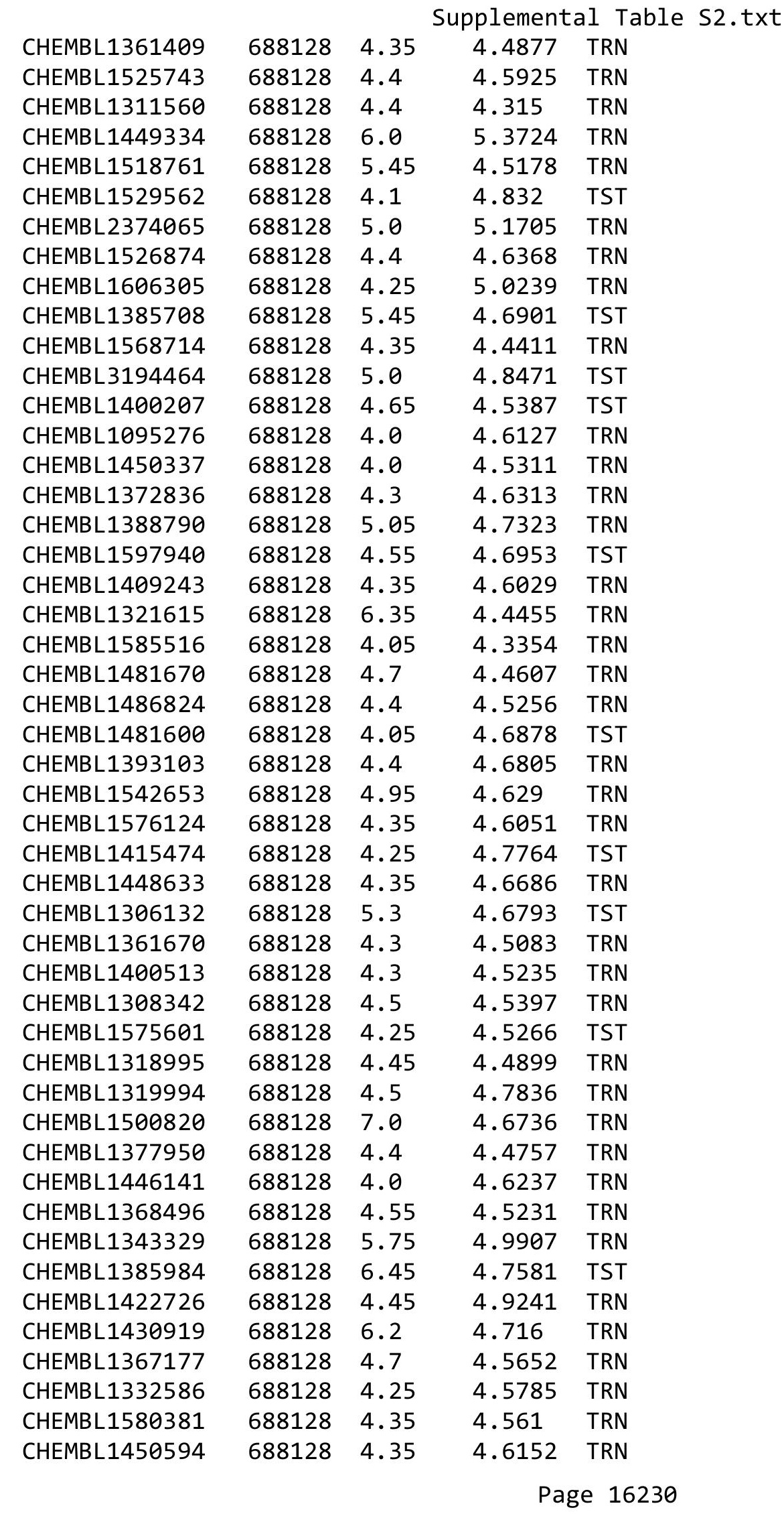




\begin{tabular}{|c|c|c|c|c|}
\hline \multicolumn{5}{|c|}{ lemental Table S } \\
\hline CHEMBL1375977 & 688128 & 4.6 & 4.4849 & TRN \\
\hline CHEMBL1307920 & 688128 & 6.1 & 4.7292 & TRN \\
\hline CHEMBL1479198 & 688128 & 4.45 & 4.4889 & TRN \\
\hline CHEMBL1564210 & 688128 & 6.05 & 4.6272 & TRN \\
\hline CHEMBL1417932 & 688128 & 5.4 & 4.9096 & TRN \\
\hline CHEMBL1575904 & 688128 & 4.25 & 4.7702 & TST \\
\hline CHEMBL1576074 & 688128 & 4.35 & 4.7728 & TRN \\
\hline CHEMBL1325293 & 688128 & 4.65 & 4.8381 & TRN \\
\hline CHEMBL1558093 & 688128 & 4.5 & 4.8049 & TRN \\
\hline CHEMBL1478207 & 688128 & 4.1 & 4.7381 & TRN \\
\hline CHEMBL 1418980 & 688128 & 4.65 & 4.9967 & TST \\
\hline CHEMBL1440507 & 688128 & 4.95 & 5.0738 & TRN \\
\hline CHEMBL1556805 & 688128 & 4.1 & 4.4371 & TRN \\
\hline CHEMBL1493867 & 688128 & 4.05 & 4.5727 & TRN \\
\hline CHEMBL1972037 & 688128 & 5.45 & 4.8058 & TST \\
\hline CHEMBL 1381126 & 688128 & 4.3 & 4.5187 & TST \\
\hline CHEMBL3193303 & 688128 & 4.5 & 4.2684 & TRN \\
\hline CHEMBL3196151 & 688128 & 4.45 & 4.4565 & TRN \\
\hline CHEMBL1511556 & 688128 & 4.9 & 5.1596 & TRN \\
\hline CHEMBL1586049 & 688128 & 4.5 & 4.5996 & TRN \\
\hline CHEMBL 1431650 & 688128 & 4.35 & 4.5378 & TRN \\
\hline CHEMBL1977683 & 688128 & 5.8 & 4.418 & TST \\
\hline CHEMBL1588862 & 688128 & 4.3 & 4.5309 & TST \\
\hline CHEMBL1349769 & 688128 & 4.65 & 4.6705 & TRN \\
\hline CHEMBL 364893 & 688128 & 4.7 & 4.6718 & TST \\
\hline CHEMBL1305446 & 688128 & 4.4 & 4.64199 & 99999999995 \\
\hline CHEMBL1452053 & 688128 & 4.3 & 4.22 & TRN \\
\hline CHEMBL1548840 & 688128 & 4.4 & 4.4867 & TRN \\
\hline CHEMBL1362626 & 688128 & 4.4 & 4.1258 & TRN \\
\hline CHEMBL1445307 & 688128 & 4.75 & 4.7017 & TRN \\
\hline CHEMBL1339149 & 688128 & 4.5 & 4.8118 & TRN \\
\hline CHEMBL1303567 & 688128 & 4.3 & 4.6481 & TST \\
\hline CHEMBL1526239 & 688128 & 4.3 & 4.4862 & TRN \\
\hline CHEMBL1339581 & 688128 & 4.5 & 4.9788 & TRN \\
\hline CHEMBL1499846 & 688128 & 4.35 & 4.607 & TRN \\
\hline CHEMBL1256396 & 688128 & 5.0 & 4.7367 & TST \\
\hline CHEMBL1326675 & 688128 & 4.7 & 5.1169 & TRN \\
\hline CHEMBL1338243 & 688128 & 4.5 & 4.6417 & TST \\
\hline CHEMBL 3213544 & 688128 & 4.05 & 4.3783 & TRN \\
\hline CHEMBL451748 & 688128 & 4.3 & 4.4182 & TRN \\
\hline CHEMBL1350117 & 688128 & 4.4 & 4.5572 & TRN \\
\hline CHEMBL1581932 & 688128 & 4.55 & 4.8563 & TST \\
\hline CHEMBL1373343 & 688128 & 4.35 & 4.8622 & TRN \\
\hline CHEMBL1460014 & 688128 & 4.25 & 4.4713 & TST \\
\hline CHEMBL1484702 & 688128 & 4.65 & 4.4498 & TST \\
\hline CHEMBL1611763 & 688128 & 4.05 & 4.4789 & TRN \\
\hline CHEMBL1363667 & 688128 & 4.05 & 4.6137 & TST \\
\hline CHEMBL1516766 & 688128 & 5.2 & 4.7557 & TRN \\
\hline
\end{tabular}




\begin{tabular}{|c|c|c|c|c|c|}
\hline & & & & & \\
\hline CHEMBL1466514 & 688128 & 4.4 & 4.718 & TST & \\
\hline CHEMBL1489080 & 688128 & 5.1 & 4.5397 & TRN & \\
\hline CHEMBL1535615 & 688128 & 4.35 & 4.3601 & TRN & \\
\hline CHEMBL1510028 & 688128 & 4.05 & 4.4814 & TST & \\
\hline CHEMBL1579137 & 688128 & 4.45 & 5.0021 & TRN & \\
\hline CHEMBL1433185 & 688128 & 4.55 & 4.5671 & TRN & \\
\hline CHEMBL1544870 & 688128 & 4.8 & 4.4479 & TRN & \\
\hline CHEMBL1319476 & 688128 & 4.9 & 5.0598 & TRN & \\
\hline CHEMBL1529085 & 688128 & 4.4 & $4.4110 e$ & 00000000005 & TRN \\
\hline CHEMBL1539333 & 688128 & 4.65 & 4.9897 & TRN & \\
\hline CHEMBL1491722 & 688128 & 5.85 & 4.5469 & TRN & \\
\hline CHEMBL1363533 & 688128 & 4.05 & 4.4893 & TRN & \\
\hline CHEMBL1518360 & 688128 & 4.05 & 4.7677 & TST & \\
\hline CHEMBL1520474 & 688128 & 4.05 & 4.7845 & TST & \\
\hline CHEMBL1519313 & 688128 & 4.3 & 4.4976 & TST & \\
\hline CHEMBL3196857 & 688128 & 4.4 & 4.5075 & TRN & \\
\hline CHEMBL1340704 & 688128 & 4.7 & 4.6998 & TRN & \\
\hline CHEMBL3194561 & 688128 & 6.0 & 4.6567 & TST & \\
\hline CHEMBL1590398 & 688128 & 4.85 & 4.5876 & TST & \\
\hline CHEMBL243652 & 688128 & 6.0 & 4.8508 & TRN & \\
\hline CHEMBL1329745 & 688128 & 4.4 & 4.7227 & TRN & \\
\hline CHEMBL1471696 & 688128 & 4.25 & 4.8931 & TST & \\
\hline CHEMBL1402262 & 688128 & 4.3 & 4.9269 & TRN & \\
\hline CHEMBL1442233 & 688128 & 6.2 & 4.4632 & TRN & \\
\hline CHEMBL1579691 & 688128 & 4.65 & 4.4043 & TRN & \\
\hline CHEMBL544348 & 688128 & 4.6 & 4.3261 & TRN & \\
\hline CHEMBL1333958 & 688128 & 4.05 & 4.5922 & TST & \\
\hline CHEMBL1405834 & 688128 & 5.9 & 5.1089 & TRN & \\
\hline CHEMBL1319413 & 688128 & 5.05 & 4.6632 & TST & \\
\hline CHEMBL1340005 & 688128 & 4.3 & 4.6803 & TRN & \\
\hline CHEMBL1588150 & 688128 & 4.4 & 4.4598 & TST & \\
\hline CHEMBL1410788 & 688128 & 4.85 & 4.5921 & TST & \\
\hline CHEMBL3196487 & 688128 & 4.35 & 4.6717 & TST & \\
\hline CHEMBL1299718 & 688128 & 4.8 & 4.7916 & TRN & \\
\hline CHEMBL1306093 & 688128 & 4.2 & 4.5689 & TST & \\
\hline CHEMBL1501515 & 688128 & 4.8 & 4.6375 & TRN & \\
\hline CHEMBL1420931 & 688128 & 5.0 & 4.5331 & TRN & \\
\hline CHEMBL1557559 & 688128 & 4.0 & 4.4752 & TST & \\
\hline CHEMBL1334863 & 688128 & 4.45 & $4.9860 €$ & 0000000001 & TST \\
\hline CHEMBL1388899 & 688128 & 5.6 & 4.8004 & TRN & \\
\hline CHEMBL1582464 & 688128 & 4.65 & 4.3058 & TRN & \\
\hline CHEMBL14282 & 688128 & 4.0 & 4.5477 & TRN & \\
\hline CHEMBL1365813 & 688128 & 5.05 & 4.7126 & TRN & \\
\hline CHEMBL1520364 & 688128 & 4.05 & 4.543 & TRN & \\
\hline CHEMBL1546703 & 688128 & 4.4 & 4.8589 & TRN & \\
\hline CHEMBL1389692 & 688128 & 4.3 & 4.4022 & TRN & \\
\hline CHEMBL1395884 & 688128 & 4.35 & 4.7195 & TRN & \\
\hline CHEMBL1522346 & 688128 & 4.1 & 4.3759 & TRN & \\
\hline & & & & 16232 & \\
\hline
\end{tabular}




\begin{tabular}{|c|c|c|c|c|c|}
\hline \multicolumn{6}{|c|}{ Supplemental Table S2.txt } \\
\hline CHEMBL1384198 & 688128 & 4.9 & 4.9549 & TRN & \\
\hline CHEMBL1447812 & 688128 & 6.0 & 5.2998 & TRN & \\
\hline CHEMBL1361991 & 688128 & 4.3 & 4.6617 & TRN & \\
\hline CHEMBL1399214 & 688128 & 4.0 & 4.7606 & TST & \\
\hline CHEMBL1351699 & 688128 & 4.25 & 4.7979 & TRN & \\
\hline CHEMBL1382942 & 688128 & 5.4 & 4.7448 & TST & \\
\hline CHEMBL585656 & 688128 & 5.4 & 5.1521 & TST & \\
\hline CHEMBL1542602 & 688128 & 4.3 & 4.5755 & TRN & \\
\hline CHEMBL1568254 & 688128 & 4.65 & 4.9352 & TRN & \\
\hline CHEMBL1432752 & 688128 & 4.6 & 4.636 & TRN & \\
\hline CHEMBL1350136 & 688128 & 4.25 & 4.6571 & TRN & \\
\hline CHEMBL1548898 & 688128 & 5.15 & 5.015 & TRN & \\
\hline CHEMBL3196071 & 688128 & 4.35 & 4.5623 & TST & \\
\hline CHEMBL1524047 & 688128 & 4.4 & 4.4783 & TST & \\
\hline CHEMBL1319266 & 688128 & 4.35 & 4.8236 & TRN & \\
\hline CHEMBL1439838 & 688128 & 4.35 & 4.5446 & TRN & \\
\hline CHEMBL1531101 & 688128 & 4.3 & 4.6099 & TST & \\
\hline CHEMBL1564073 & 688128 & 4.4 & 4.5333 & TRN & \\
\hline CHEMBL1466351 & 688128 & 4.6 & 4.5856 & TRN & \\
\hline CHEMBL1522131 & 688128 & 4.0 & 4.5541 & TRN & \\
\hline CHEMBL 2374067 & 688128 & 4.95 & 5.1905 & TRN & \\
\hline CHEMBL1386274 & 688128 & 4.4 & 4.4678 & TST & \\
\hline CHEMBL1461746 & 688128 & 4.55 & 4.749 & TST & \\
\hline CHEMBL1454646 & 688128 & 4.05 & 4.5739 & TRN & \\
\hline CHEMBL1524578 & 688128 & 4.1 & 4.5855 & TRN & \\
\hline CHEMBL1324855 & 688128 & 4.05 & 4.5717 & TRN & \\
\hline CHEMBL1580797 & 688128 & 4.9 & 4.8916 & TRN & \\
\hline CHEMBL1386995 & 688128 & 4.35 & 4.6827 & TRN & \\
\hline CHEMBL1526436 & 688128 & 5.35 & 4.7438 & TRN & \\
\hline CHEMBL1356969 & 688128 & 4.35 & 4.5088 & TRN & \\
\hline CHEMBL1542061 & 688128 & 4.45 & 5.0744 & TRN & \\
\hline CHEMBL1401604 & 688128 & 4.3 & 4.77800 & 00000000005 & TRN \\
\hline CHEMBL1607829 & 688128 & 5.3 & 4.6857 & TRN & \\
\hline CHEMBL1613666 & 688128 & 4.65 & 4.4435 & TRN & \\
\hline CHEMBL1373992 & 688128 & 5.55 & 5.2023 & TRN & \\
\hline CHEMBL1598059 & 688128 & 4.35 & 4.8094 & TRN & \\
\hline CHEMBL1512576 & 688128 & 4.4 & 4.3989 & TRN & \\
\hline CHEMBL1310746 & 688128 & 5.7 & 4.7412 & TRN & \\
\hline CHEMBL1311378 & 688128 & 4.3 & 4.6043 & TRN & \\
\hline CHEMBL1522117 & 688128 & 4.55 & 4.4667 & TRN & \\
\hline CHEMBL1343843 & 688128 & 4.6 & 4.7646 & TRN & \\
\hline CHEMBL1551263 & 688128 & 4.05 & 4.6072 & TRN & \\
\hline CHEMBL1346379 & 688128 & 4.4 & 4.9045 & TST & \\
\hline CHEMBL1992918 & 688128 & 4.3 & 4.7517 & TST & \\
\hline CHEMBL1495487 & 688128 & 4.35 & 4.7839 & TRN & \\
\hline CHEMBL1317367 & 688128 & 4.3 & 4.2621 & TRN & \\
\hline CHEMBL1544508 & 688128 & 5.05 & 4.9529 & TRN & \\
\hline CHEMBL1343621 & 688128 & 4.55 & 4.5194 & TRN & \\
\hline
\end{tabular}




\begin{tabular}{|c|c|c|c|c|c|}
\hline \multicolumn{6}{|c|}{ Supplemental Table S2.txt } \\
\hline CHEMBL1438186 & 688128 & 4.3 & 4.3892 & TRN & \\
\hline CHEMBL1541405 & 688128 & 4.95 & 4.9414 & TRN & \\
\hline CHEMBL1354897 & 688128 & 4.4 & 4.4895 & TRN & \\
\hline CHEMBL1528685 & 688128 & 4.6 & 5.0421 & TRN & \\
\hline CHEMBL1383774 & 688128 & 6.2 & 4.9095 & TRN & \\
\hline CHEMBL1344623 & 688128 & 4.4 & 4.437 & TRN & \\
\hline CHEMBL1455837 & 688128 & 5.55 & 5.1153 & TRN & \\
\hline CHEMBL1510408 & 688128 & 4.4 & 4.484 & TRN & \\
\hline CHEMBL1513628 & 688128 & 4.3 & 4.6334 & TRN & \\
\hline CHEMBL1398944 & 688128 & 4.55 & 5.0589 & TRN & \\
\hline CHEMBL1972346 & 688128 & 4.65 & 4.9168 & TRN & \\
\hline CHEMBL1393311 & 688128 & 4.65 & 4.9411 & TRN & \\
\hline CHEMBL1416180 & 688128 & 4.3 & 4.4966 & TST & \\
\hline CHEMBL1424118 & 688128 & 4.8 & 4.34399 & 9999999999 & TRN \\
\hline CHEMBL1403329 & 688128 & 6.15 & 5.6299 & TRN & \\
\hline CHEMBL1314867 & 688128 & 4.65 & 4.6389 & TRN & \\
\hline CHEMBL1412857 & 688128 & 4.3 & 4.4106 & TRN & \\
\hline CHEMBL1602787 & 688128 & 5.0 & 4.8588 & TRN & \\
\hline CHEMBL567175 & 688128 & 6.0 & 5.0645 & TRN & \\
\hline CHEMBL1377995 & 688128 & 4.75 & 4.5446 & TRN & \\
\hline CHEMBL1473401 & 688128 & 4.5 & 4.7698 & TRN & \\
\hline CHEMBL1987173 & 688128 & 4.35 & 4.9105 & TRN & \\
\hline CHEMBL1553210 & 688128 & 4.35 & 4.6677 & TST & \\
\hline CHEMBL1538676 & 688128 & 4.45 & 4.48 & TRN & \\
\hline CHEMBL1433620 & 688128 & 4.4 & 5.0277 & TRN & \\
\hline CHEMBL1491562 & 688128 & 6.35 & 5.1156 & TRN & \\
\hline CHEMBL1493998 & 688128 & 4.4 & 4.9355 & TRN & \\
\hline CHEMBL1521342 & 688128 & 4.6 & 4.6705 & TRN & \\
\hline CHEMBL1321649 & 688128 & 4.5 & 4.6434 & TRN & \\
\hline CHEMBL1603384 & 688128 & 5.2 & 4.4816 & TRN & \\
\hline CHEMBL1462635 & 688128 & 5.4 & 4.67399 & 99999999995 & TST \\
\hline CHEMBL1416434 & 688128 & 4.6 & 4.7519 & TRN & \\
\hline CHEMBL1359228 & 688128 & 4.45 & 4.5962 & TRN & \\
\hline CHEMBL1361565 & 688128 & 4.35 & 4.6784 & TST & \\
\hline CHEMBL1303425 & 688128 & 4.1 & 4.7503 & TRN & \\
\hline CHEMBL1530734 & 688128 & 4.35 & 4.6863 & TRN & \\
\hline CHEMBL1488257 & 688128 & 4.2 & 4.6579 & TRN & \\
\hline CHEMBL3214315 & 688128 & 4.5 & 4.5051 & TRN & \\
\hline CHEMBL1439857 & 688128 & 4.4 & 4.8028 & TST & \\
\hline CHEMBL1413185 & 688128 & 4.05 & 4.6674 & TST & \\
\hline CHEMBL1546006 & 688128 & 4.35 & 4.4258 & TST & \\
\hline CHEMBL1388225 & 688128 & 4.05 & 4.6553 & TST & \\
\hline CHEMBL1607712 & 688128 & 4.3 & 4.7057 & TRN & \\
\hline CHEMBL1579789 & 688128 & 4.3 & 4.6565 & TRN & \\
\hline CHEMBL1351570 & 688128 & 4.35 & 4.5872 & TRN & \\
\hline CHEMBL1476771 & 688128 & 4.4 & 4.7045 & TRN & \\
\hline CHEMBL1414448 & 688128 & 4.3 & 4.5252 & TST & \\
\hline CHEMBL1982662 & 688128 & 4.3 & 4.4801 & TRN & \\
\hline
\end{tabular}




\begin{tabular}{|c|c|c|c|c|}
\hline \multicolumn{5}{|c|}{ Supplemental Table S2.txt } \\
\hline CHEMBL1490188 & 688128 & 4.35 & 4.4594 & TRN \\
\hline CHEMBL1520036 & 688128 & 6.05 & 4.373 & TRN \\
\hline CHEMBL1582771 & 688128 & 5.4 & 5.01 & TST \\
\hline CHEMBL1499058 & 688128 & 4.35 & 4.5755 & TRN \\
\hline CHEMBL1587042 & 688128 & 4.3 & 4.6032 & TRN \\
\hline CHEMBL1563462 & 688128 & 4.35 & 4.8261 & TST \\
\hline CHEMBL1563093 & 688128 & 4.05 & 4.277 & TST \\
\hline CHEMBL1589235 & 688128 & 4.45 & 4.0689 & TRN \\
\hline CHEMBL1985310 & 688128 & 6.5 & 4.4952 & TST \\
\hline CHEMBL1392718 & 688128 & 4.4 & 4.5639 & TRN \\
\hline CHEMBL1974456 & 688128 & 4.55 & 4.5516 & TRN \\
\hline CHEMBL1392109 & 688128 & 4.1 & 4.5013 & TST \\
\hline CHEMBL1456912 & 688128 & 4.35 & 4.7184 & TRN \\
\hline CHEMBL1449204 & 688128 & 6.1 & 5.1697 & TRN \\
\hline CHEMBL1499971 & 688128 & 4.3 & 4.6237 & TRN \\
\hline CHEMBL1489531 & 688128 & 4.65 & 4.7415 & TRN \\
\hline CHEMBL1448619 & 688128 & 4.45 & 4.6557 & TRN \\
\hline CHEMBL1969543 & 688128 & 4.65 & 4.6157 & TRN \\
\hline CHEMBL1502286 & 688128 & 4.4 & 4.7906 & TRN \\
\hline CHEMBL1549128 & 688128 & 4.55 & 4.6262 & TST \\
\hline CHEMBL1300084 & 688128 & 5.0 & 4.5046 & TRN \\
\hline CHEMBL1438420 & 688128 & 4.05 & 4.8582 & TST \\
\hline CHEMBL1566333 & 688128 & 4.45 & 4.5293 & TRN \\
\hline CHEMBL1347720 & 688128 & 5.55 & 4.4438 & TRN \\
\hline CHEMBL1585358 & 688128 & 4.7 & 4.7669 & TST \\
\hline CHEMBL1422276 & 688128 & 4.5 & 4.6148 & TRN \\
\hline CHEMBL1420119 & 688128 & 4.35 & 4.5896 & TST \\
\hline CHEMBL1361512 & 688128 & 4.1 & 4.5097 & TRN \\
\hline CHEMBL1324833 & 688128 & 5.0 & 4.4107 & TRN \\
\hline CHEMBL1526009 & 688128 & 4.4 & 4.2406 & TRN \\
\hline CHEMBL1500520 & 688128 & 4.05 & 4.4189 & TRN \\
\hline CHEMBL1412859 & 688128 & 4.35 & 4.436 & TRN \\
\hline CHEMBL1547784 & 688128 & 5.45 & 4.8994 & TRN \\
\hline CHEMBL1322830 & 688128 & 4.4 & 4.5891 & TRN \\
\hline CHEMBL212827 & 688128 & 4.75 & 4.7218 & TRN \\
\hline CHEMBL1415853 & 688128 & 4.4 & 4.4895 & TRN \\
\hline CHEMBL1398180 & 688128 & 4.0 & 4.7602 & TST \\
\hline CHEMBL261185 & 688128 & 5.45 & 4.5339 & TRN \\
\hline CHEMBL1303140 & 688128 & 4.4 & 4.8281 & TRN \\
\hline CHEMBL1525629 & 688128 & 6.6499 & 4.9446 & TST \\
\hline CHEMBL1388615 & 688128 & 4.45 & 4.4516 & TRN \\
\hline CHEMBL1316535 & 688128 & 4.55 & 4.6818 & TRN \\
\hline CHEMBL1504779 & 688128 & 4.35 & 4.8261 & TRN \\
\hline CHEMBL1313550 & 688128 & 6.95 & 4.7564 & TRN \\
\hline CHEMBL1392563 & 688128 & 4.85 & 4.8692 & TRN \\
\hline CHEMBL1613385 & 688128 & 4.05 & 4.6406 & TST \\
\hline CHEMBL1528895 & 688128 & 4.4 & 4.9199 & TRN \\
\hline CHEMBL1589261 & 688128 & 4.45 & 4.4914 & TRN \\
\hline
\end{tabular}




\begin{tabular}{|c|c|c|c|c|c|}
\hline & & \multicolumn{4}{|c|}{ Supplemental Table S2.txt } \\
\hline CHEMBL1438511 & 688128 & 4.65 & 4.5891 & TRN & \\
\hline CHEMBL1530440 & 688128 & 4.4 & 4.942 & TRN & \\
\hline CHEMBL1438089 & 688128 & 4.5 & 4.7857 & TST & \\
\hline CHEMBL1563527 & 688128 & 4.65 & 4.8386 & TRN & \\
\hline CHEMBL1574225 & 688128 & 4.3 & 4.4431 & TRN & \\
\hline CHEMBL1325116 & 688128 & 4.95 & 4.8689 & TRN & \\
\hline CHEMBL1399079 & 688128 & 4.4 & 4.5536 & TRN & \\
\hline CHEMBL1388137 & 688128 & 6.3 & 5.33 & TRN & \\
\hline CHEMBL1481118 & 688128 & 4.3 & 4.3988 & TST & \\
\hline CHEMBL3199187 & 688128 & 4.3 & 4.6479 & TRN & \\
\hline CHEMBL1388178 & 688128 & 4.3 & 4.3612 & TRN & \\
\hline CHEMBL1381922 & 688128 & 4.5 & 4.313 & TRN & \\
\hline CHEMBL1387715 & 688128 & 5.45 & 4.7756 & TRN & \\
\hline CHEMBL1405988 & 688128 & 4.3 & 4.9966 & TRN & \\
\hline CHEMBL1419103 & 688128 & 4.4 & 4.6734 & TRN & \\
\hline CHEMBL1322796 & 688128 & 4.35 & 4.4518 & TST & \\
\hline CHEMBL 2000120 & 688128 & 4.6 & 4.9655 & TRN & \\
\hline CHEMBL1451027 & 688128 & 4.45 & 4.63899 & 7999999999 & TRN \\
\hline CHEMBL1518106 & 688128 & 4.25 & 4.4377 & TRN & \\
\hline CHEMBL1431957 & 688128 & 4.35 & 4.5112 & TRN & \\
\hline CHEMBL1984240 & 688128 & 4.9 & 4.909 & TRN & \\
\hline CHEMBL1441066 & 688128 & 4.95 & 4.525 & TRN & \\
\hline CHEMBL1439642 & 688128 & 4.1 & 4.5922 & TRN & \\
\hline CHEMBL1598490 & 688128 & 4.35 & 4.4201 & TST & \\
\hline CHEMBL1608602 & 688128 & 4.4 & 4.707 & TRN & \\
\hline CHEMBL1538310 & 688128 & 4.45 & 4.5689 & TRN & \\
\hline CHEMBL1307967 & 688128 & 4.5 & 4.5834 & TRN & \\
\hline CHEMBL1364451 & 688128 & 4.55 & 4.5037 & TRN & \\
\hline CHEMBL 3189545 & 688128 & 4.4 & 4.688 & TRN & \\
\hline CHEMBL1454218 & 688128 & 4.3 & 4.5899 & TRN & \\
\hline CHEMBL1424950 & 688128 & 4.4 & 4.6739 & TRN & \\
\hline CHEMBL1387437 & 688128 & 4.25 & 3.9832 & TRN & \\
\hline CHEMBL3211651 & 688128 & 4.6 & 4.9686 & TRN & \\
\hline CHEMBL1301261 & 688128 & 4.3 & 4.1562 & TRN & \\
\hline CHEMBL1382215 & 688128 & 5.85 & 4.9886 & TRN & \\
\hline CHEMBL1407267 & 688128 & 5.55 & 4.8059 & TRN & \\
\hline CHEMBL1606095 & 688128 & 4.4 & 4.4968 & TRN & \\
\hline CHEMBL1586830 & 688128 & 4.5 & 4.4129 & TRN & \\
\hline CHEMBL1327736 & 688128 & 4.25 & 4.495 & TRN & \\
\hline CHEMBL1599624 & 688128 & 4.0 & 4.372 & TST & \\
\hline CHEMBL1505994 & 688128 & 4.35 & 4.329 & TRN & \\
\hline CHEMBL1454871 & 688128 & 4.05 & 4.4574 & TRN & \\
\hline CHEMBL1397452 & 688128 & 4.4 & 4.7012 & TST & \\
\hline CHEMBL1578764 & 688128 & 4.3 & 4.7251 & TRN & \\
\hline CHEMBL1412065 & 688128 & 4.05 & 4.329 & TRN & \\
\hline CHEMBL120734 & 688128 & 4.3 & 4.3091 & TRN & \\
\hline CHEMBL1379270 & 688128 & 5.35 & 4.5794 & TRN & \\
\hline CHEMBL1484004 & 688128 & 4.35 & 4.5898 & TRN & \\
\hline
\end{tabular}




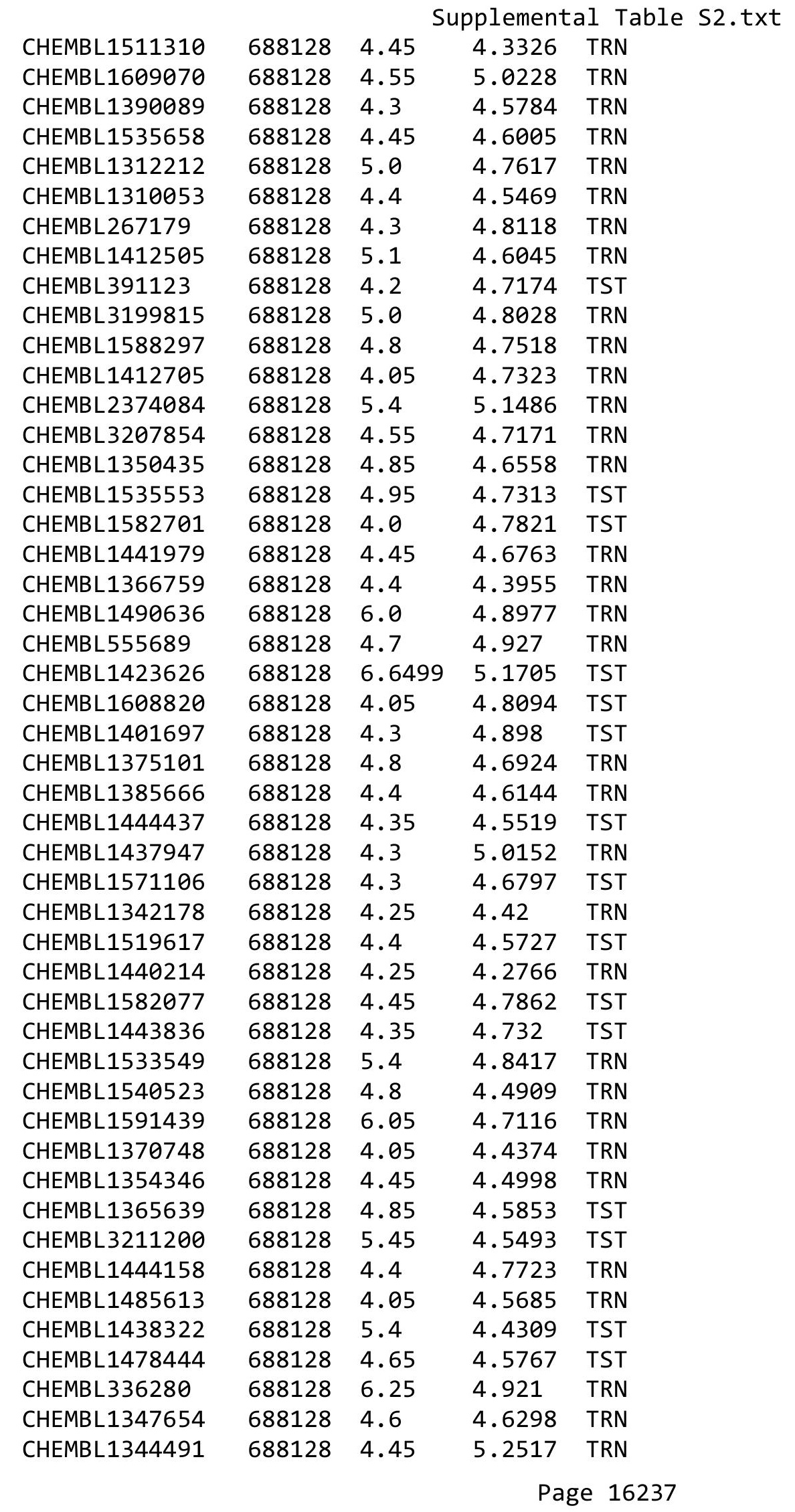




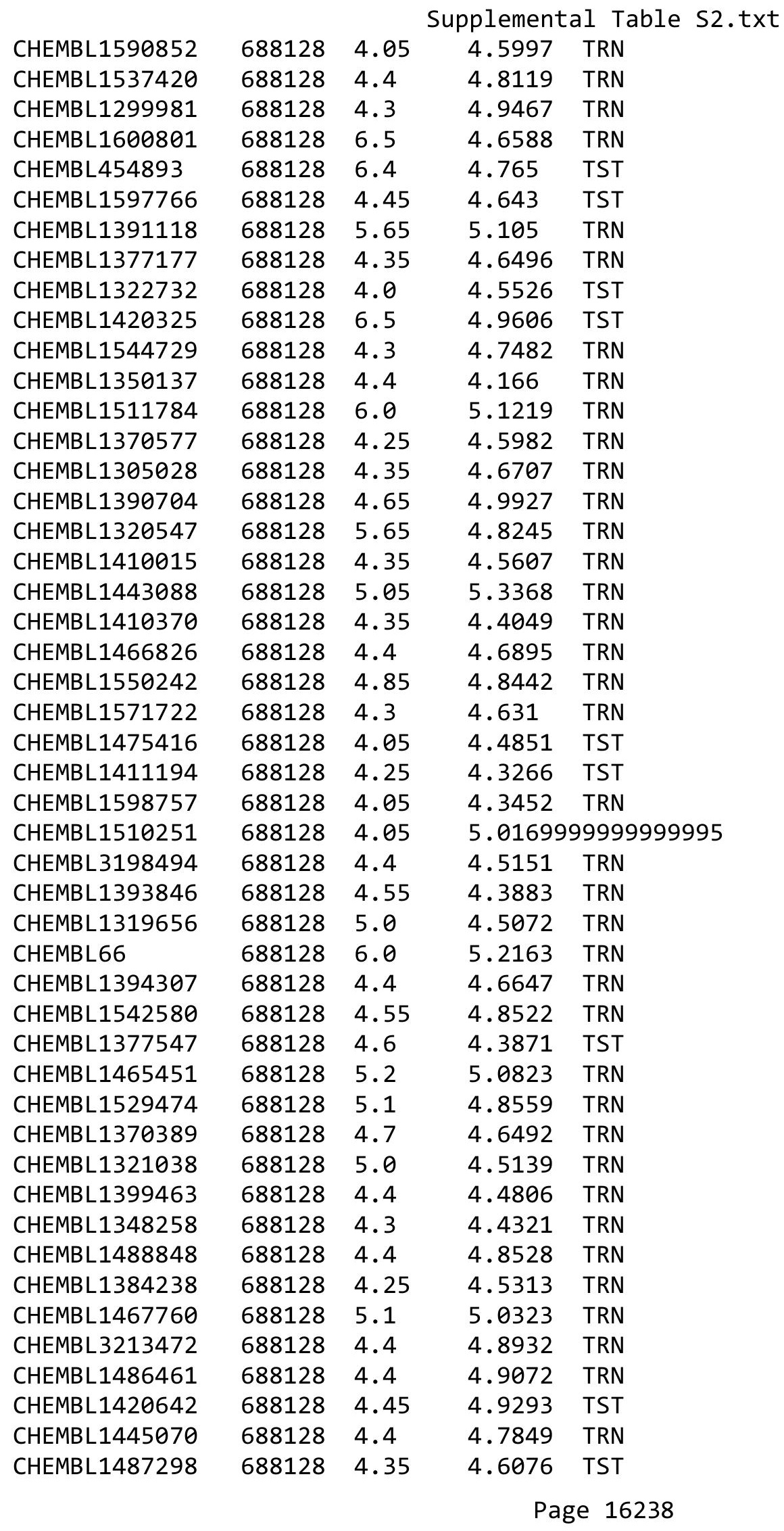




\begin{tabular}{|c|c|c|c|c|c|}
\hline \multicolumn{6}{|c|}{ Supplemental Table S2.txt } \\
\hline CHEMBL1470135 & 688128 & 4.7 & 4.9276 & TRN & \\
\hline CHEMBL1477200 & 688128 & 4.05 & 4.4922 & TST & \\
\hline CHEMBL1378655 & 688128 & 4.4 & 4.5851 & TRN & \\
\hline CHEMBL1486495 & 688128 & 4.3 & 4.4779 & TRN & \\
\hline CHEMBL1565212 & 688128 & 5.35 & 4.9152 & TRN & \\
\hline CHEMBL3191020 & 688128 & 6.35 & 4.5608 & TST & \\
\hline CHEMBL1461437 & 688128 & 4.35 & 4.7318 & TRN & \\
\hline CHEMBL1485010 & 688128 & 5.7 & 5.4193 & TRN & \\
\hline CHEMBL1400557 & 688128 & 4.5 & 4.3653 & TRN & \\
\hline CHEMBL1434437 & 688128 & 4.4 & 4.5297 & TRN & \\
\hline CHEMBL1389033 & 688128 & 4.45 & 4.7142 & TRN & \\
\hline CHEMBL1548148 & 688128 & 4.35 & 4.8439 & TRN & \\
\hline CHEMBL1595969 & 688128 & 4.3 & 4.5359 & TST & \\
\hline CHEMBL 3212627 & 688128 & 6.1 & 4.9097 & TST & \\
\hline CHEMBL1411308 & 688128 & 6.0 & 4.8436 & TRN & \\
\hline CHEMBL 2374035 & 688128 & 5.35 & 5.21899 & 9999999999 & TRN \\
\hline CHEMBL1344319 & 688128 & 4.05 & 4.1069 & TST & \\
\hline CHEMBL1374353 & 688128 & 4.7 & 4.6202 & TRN & \\
\hline CHEMBL1352178 & 688128 & 4.3 & 4.52 & TRN & \\
\hline CHEMBL1475555 & 688128 & 4.45 & 4.3217 & TRN & \\
\hline CHEMBL1467360 & 688128 & 4.3 & 4.4641 & TRN & \\
\hline CHEMBL1552002 & 688128 & 5.7 & 4.9574 & TRN & \\
\hline CHEMBL1433945 & 688128 & 4.3 & 4.6759 & TST & \\
\hline CHEMBL1450126 & 688128 & 6.0 & 4.6728 & TRN & \\
\hline CHEMBL1612807 & 688128 & 4.35 & 4.6513 & TRN & \\
\hline CHEMBL1449806 & 688128 & 5.8 & 4.9384 & TRN & \\
\hline CHEMBL1606948 & 688128 & 4.95 & 4.8568 & TRN & \\
\hline CHEMBL1383179 & 688128 & 4.0 & 4.218 & TRN & \\
\hline CHEMBL1347906 & 688128 & 4.5 & 4.6634 & TST & \\
\hline CHEMBL3196381 & 688128 & 4.05 & 4.5078 & TST & \\
\hline CHEMBL3193156 & 688128 & 4.7 & 4.5986 & TST & \\
\hline CHEMBL1312900 & 688128 & 4.5 & 4.4494 & TRN & \\
\hline CHEMBL1307896 & 688128 & 4.35 & 4.7081 & TRN & \\
\hline CHEMBL1391625 & 688128 & 4.3 & 4.5842 & TRN & \\
\hline CHEMBL1476358 & 688128 & 5.2 & 5.0272 & TRN & \\
\hline CHEMBL1418121 & 688128 & 4.7 & 4.6069 & TRN & \\
\hline CHEMBL1312828 & 688128 & 4.45 & 4.4281 & TRN & \\
\hline CHEMBL1344985 & 688128 & 4.55 & 4.7363 & TRN & \\
\hline CHEMBL1493065 & 688128 & 4.45 & 4.6629 & TRN & \\
\hline CHEMBL1416350 & 688128 & 6.3 & 5.0207 & TRN & \\
\hline CHEMBL1310393 & 688128 & 4.7 & 4.5851 & TRN & \\
\hline CHEMBL1432399 & 688128 & 5.1 & 4.8842 & TRN & \\
\hline CHEMBL1451719 & 688128 & 4.55 & 4.4009 & TRN & \\
\hline CHEMBL1594735 & 688128 & 4.65 & 4.6025 & TST & \\
\hline CHEMBL1559536 & 688128 & 4.5 & 4.562 & TRN & \\
\hline CHEMBL1301588 & 688128 & 5.15 & 4.4483 & TRN & \\
\hline CHEMBL 1448880 & 688128 & 4.1 & 4.362 & TRN & \\
\hline CHEMBL1346030 & 688128 & 4.5 & 5.2272 & TRN & \\
\hline
\end{tabular}




\begin{tabular}{|c|c|c|c|c|c|}
\hline \multicolumn{6}{|c|}{ Supplemental Table S2.txt } \\
\hline CHEMBL1608084 & 688128 & 4.2 & 4.4532 & TRN & \\
\hline CHEMBL1301407 & 688128 & 4.4 & 4.341 & TST & \\
\hline CHEMBL1464098 & 688128 & 4.3 & 4.8164 & TRN & \\
\hline CHEMBL1342007 & 688128 & 4.3 & 4.4007 & TRN & \\
\hline CHEMBL1408953 & 688128 & 4.45 & 4.7214 & TST & \\
\hline CHEMBL1400437 & 688128 & 4.55 & 4.5552 & TST & \\
\hline CHEMBL1535989 & 688128 & 4.8 & 4.8134 & TST & \\
\hline CHEMBL 3194002 & 688128 & 4.5 & 4.3525 & TRN & \\
\hline CHEMBL1483365 & 688128 & 4.35 & 4.5602 & TRN & \\
\hline CHEMBL1405468 & 688128 & 4.35 & 4.1541 & TRN & \\
\hline CHEMBL1417071 & 688128 & 4.05 & 4.9281 & TST & \\
\hline CHEMBL1369296 & 688128 & 4.65 & 5.0882 & TRN & \\
\hline CHEMBL1542712 & 688128 & 4.4 & 4.6166 & TRN & \\
\hline CHEMBL249914 & 688128 & 4.4 & 4.5526 & TRN & \\
\hline CHEMBL1571213 & 688128 & 4.35 & 4.6315 & TRN & \\
\hline CHEMBL1356665 & 688128 & 4.35 & 4.6861 & TRN & \\
\hline CHEMBL1314500 & 688128 & 4.35 & 4.4201 & TRN & \\
\hline CHEMBL1422035 & 688128 & 4.4 & 4.6119 & TRN & \\
\hline CHEMBL1381779 & 688128 & 4.35 & 4.6903 & TRN & \\
\hline CHEMBL1577744 & 688128 & 4.3 & 4.5632 & TRN & \\
\hline CHEMBL1574200 & 688128 & 4.85 & 4.5438 & TRN & \\
\hline CHEMBL1309857 & 688128 & 4.4 & 4.4173 & TRN & \\
\hline CHEMBL1359253 & 688128 & 4.3 & 4.3363 & TRN & \\
\hline CHEMBL1559748 & 688128 & 4.5 & 4.5547 & TRN & \\
\hline CHEMBL1321996 & 688128 & 4.05 & 4.6099 & TRN & \\
\hline CHEMBL1459961 & 688128 & 4.6 & 4.3844 & TRN & \\
\hline CHEMBL1339494 & 688128 & 4.5 & $4.9460 e$ & 0000000001 & TRN \\
\hline CHEMBL1589194 & 688128 & 4.7 & 4.6618 & TRN & \\
\hline CHEMBL1495451 & 688128 & 4.35 & 4.4741 & TST & \\
\hline CHEMBL1598811 & 688128 & 4.5 & 4.5058 & TRN & \\
\hline CHEMBL1326182 & 688128 & 4.65 & 4.7281 & TRN & \\
\hline CHEMBL1485193 & 688128 & 5.1 & 4.3897 & TRN & \\
\hline CHEMBL1459529 & 688128 & 4.35 & 4.5424 & TRN & \\
\hline CHEMBL1565473 & 688128 & 4.2 & 4.69 & TRN & \\
\hline CHEMBL1300672 & 688128 & 5.5 & 4.9183 & TRN & \\
\hline CHEMBL3213736 & 688128 & 5.35 & 4.6076 & TRN & \\
\hline CHEMBL1383340 & 688128 & 4.45 & 4.1546 & TST & \\
\hline CHEMBL1571874 & 688128 & 4.4 & 4.7908 & TST & \\
\hline CHEMBL3196863 & 688128 & 4.4 & 4.7217 & TRN & \\
\hline CHEMBL1448670 & 688128 & 5.2 & 4.9284 & TRN & \\
\hline CHEMBL1502681 & 688128 & 4.3 & 4.2773 & TRN & \\
\hline CHEMBL1489156 & 688128 & 5.45 & 4.5855 & TST & \\
\hline CHEMBL1450065 & 688128 & 4.3 & 4.205 & TRN & \\
\hline CHEMBL1309227 & 688128 & 4.5 & 4.6721 & TRN & \\
\hline CHEMBL 244649 & 688128 & 4.1 & 4.6978 & TRN & \\
\hline CHEMBL1555285 & 688128 & 4.05 & 4.6286 & TRN & \\
\hline CHEMBL1542039 & 688128 & 4.45 & 5.0787 & TRN & \\
\hline CHEMBL513349 & 688128 & 5.0 & 4.64 & TST & \\
\hline
\end{tabular}




\begin{tabular}{|c|c|c|c|c|c|}
\hline \multicolumn{6}{|c|}{ Supplemental Table S2.txt } \\
\hline CHEMBL1335288 & 688128 & 5.2 & 4.9121 & TST & \\
\hline CHEMBL1566098 & 688128 & 4.4 & 4.5532 & TRN & \\
\hline CHEMBL1575035 & 688128 & 4.05 & 4.6051 & TRN & \\
\hline CHEMBL1538187 & 688128 & 4.4 & 4.8587 & TST & \\
\hline CHEMBL1525254 & 688128 & 4.25 & 4.6674 & TRN & \\
\hline CHEMBL1521368 & 688128 & 4.3 & 4.8546 & TRN & \\
\hline CHEMBL1458749 & 688128 & 4.8 & 4.8861 & TST & \\
\hline CHEMBL1355254 & 688128 & 4.4 & 4.3362 & TRN & \\
\hline CHEMBL1412237 & 688128 & 4.8 & 4.6616 & TRN & \\
\hline CHEMBL1404086 & 688128 & 4.9 & 4.954 & TRN & \\
\hline CHEMBL1598919 & 688128 & 4.5 & 4.5415 & TRN & \\
\hline CHEMBL1352712 & 688128 & 5.8 & 5.2791 & TRN & \\
\hline CHEMBL1530797 & 688128 & 4.25 & 4.5362 & TST & \\
\hline CHEMBL1605956 & 688128 & 4.75 & 5.2883 & TRN & \\
\hline CHEMBL1312222 & 688128 & 4.6 & 4.3708 & TST & \\
\hline CHEMBL1381149 & 688128 & 4.35 & 4.8312 & TRN & \\
\hline CHEMBL1465903 & 688128 & 4.4 & 4.5346 & TRN & \\
\hline CHEMBL1351056 & 688128 & 4.7 & 4.7902 & TRN & \\
\hline CHEMBL1400005 & 688128 & 4.55 & 4.9553 & TRN & \\
\hline CHEMBL69612 & 688128 & 5.65 & $5.1770 e$ & 00000000005 & TST \\
\hline CHEMBL1539225 & 688128 & 4.35 & 4.9198 & TRN & \\
\hline CHEMBL3198550 & 688128 & 4.3 & 4.8541 & TST & \\
\hline CHEMBL1430425 & 688128 & 4.35 & 4.5003 & TRN & \\
\hline CHEMBL3195019 & 688128 & 4.4 & 4.7979 & TRN & \\
\hline CHEMBL1455865 & 688128 & 4.3 & 4.921 & TRN & \\
\hline CHEMBL1423479 & 688128 & 4.35 & 4.7089 & TRN & \\
\hline CHEMBL1504268 & 688128 & 4.95 & 4.4005 & TRN & \\
\hline CHEMBL1362934 & 688128 & 4.85 & 4.6029 & TRN & \\
\hline CHEMBL1416156 & 688128 & 4.4 & 4.5946 & TRN & \\
\hline CHEMBL1396329 & 688128 & 4.05 & 4.4048 & TST & \\
\hline CHEMBL1433304 & 688128 & 4.35 & 4.5879 & TRN & \\
\hline CHEMBL1351846 & 688128 & 4.3 & 4.8968 & TRN & \\
\hline CHEMBL1439491 & 688128 & 4.35 & 4.8175 & TRN & \\
\hline CHEMBL1359564 & 688128 & 5.55 & 4.7192 & TRN & \\
\hline CHEMBL1571541 & 688128 & 4.2 & 5.1225 & TRN & \\
\hline CHEMBL1576684 & 688128 & 4.3 & 4.4301 & TRN & \\
\hline CHEMBL1426102 & 688128 & 4.4 & 4.5427 & TRN & \\
\hline CHEMBL1523543 & 688128 & 4.4 & 4.6887 & TRN & \\
\hline CHEMBL1415645 & 688128 & 4.6 & 4.8121 & TRN & \\
\hline CHEMBL1453621 & 688128 & 4.4 & 4.5943 & TST & \\
\hline CHEMBL1493419 & 688128 & 4.85 & 4.7418 & TRN & \\
\hline CHEMBL1330862 & 688128 & 4.35 & 4.4498 & TRN & \\
\hline CHEMBL1594049 & 688128 & 5.15 & 5.1774 & TRN & \\
\hline CHEMBL1359123 & 688128 & 5.25 & 4.8496 & TRN & \\
\hline CHEMBL1469381 & 688128 & 4.7 & 4.4956 & TRN & \\
\hline CHEMBL1405791 & 688128 & 4.2 & 4.5315 & TRN & \\
\hline CHEMBL1454911 & 688128 & 4.05 & 4.6194 & TST & \\
\hline CHEMBL1395048 & 688128 & 4.1 & $4.6960 e$ & $\partial 000000001$ & TST \\
\hline & & & & 16241 & \\
\hline
\end{tabular}




\begin{tabular}{|c|c|c|c|c|c|}
\hline \\
\hline CHEMBL1559806 & 688128 & 4.9 & 4.4904 & TRN & \\
\hline CHEMBL1328902 & 688128 & 5.0 & 5.2898 & TRN & \\
\hline CHEMBL1407161 & 688128 & 5.3 & 5.2392 & TRN & \\
\hline CHEMBL1375120 & 688128 & 5.0 & 4.9931 & TST & \\
\hline CHEMBL1503432 & 688128 & 4.4 & 4.578 & TRN & \\
\hline CHEMBL1336632 & 688128 & 4.35 & 4.6749 & TST & \\
\hline CHEMBL1466739 & 688128 & 4.1 & 4.6792 & TRN & \\
\hline CHEMBL1444898 & 688128 & 4.35 & 4.327 & TRN & \\
\hline CHEMBL3212704 & 688128 & 4.7 & 4.9649 & TST & \\
\hline CHEMBL1397555 & 688128 & 4.4 & 4.6384 & TRN & \\
\hline CHEMBL1574197 & 688128 & 4.65 & 4.7234 & TRN & \\
\hline CHEMBL1537152 & 688128 & 4.0 & 4.461 & TRN & \\
\hline CHEMBL1598561 & 688128 & 5.05 & 5.2664 & TRN & \\
\hline CHEMBL1362273 & 688128 & 4.3 & 4.456 & TRN & \\
\hline CHEMBL1429855 & 688128 & 4.65 & 4.8365 & TST & \\
\hline CHEMBL1540004 & 688128 & 5.9 & 4.8696 & TST & \\
\hline CHEMBL1489331 & 688128 & 4.05 & 4.7433 & TRN & \\
\hline CHEMBL1315051 & 688128 & 4.05 & 4.4002 & TST & \\
\hline CHEMBL1336080 & 688128 & 4.55 & 4.38399 & 99999999995 & TRN \\
\hline CHEMBL1477835 & 688128 & 4.05 & 4.5577 & TRN & \\
\hline CHEMBL1394684 & 688128 & 4.35 & 4.5542 & TST & \\
\hline CHEMBL1600418 & 688128 & 4.35 & 4.9191 & TRN & \\
\hline CHEMBL1370649 & 688128 & 4.05 & 4.5368 & TRN & \\
\hline CHEMBL1395186 & 688128 & 6.15 & 4.8651 & TRN & \\
\hline CHEMBL1600463 & 688128 & 4.3 & 4.8383 & TRN & \\
\hline CHEMBL1555350 & 688128 & 4.25 & 4.542 & TRN & \\
\hline CHEMBL1404700 & 688128 & 4.45 & 4.7384 & TRN & \\
\hline CHEMBL1580674 & 688128 & 4.65 & 4.6154 & TRN & \\
\hline CHEMBL1406511 & 688128 & 4.25 & 4.5954 & TRN & \\
\hline CHEMBL1377882 & 688128 & 4.4 & 4.7348 & TRN & \\
\hline CHEMBL1456028 & 688128 & 6.8499 & 4.70100 & 00000000005 & TRN \\
\hline CHEMBL1609433 & 688128 & 4.05 & 4.4831 & TRN & \\
\hline CHEMBL1404218 & 688128 & 4.5 & 4.7058 & TRN & \\
\hline CHEMBL1395640 & 688128 & 4.1 & 4.6959 & TRN & \\
\hline CHEMBL313478 & 688128 & 4.1 & 4.1898 & TST & \\
\hline CHEMBL1444731 & 688128 & 5.45 & 4.574 & TRN & \\
\hline CHEMBL1474679 & 688128 & 4.3 & 4.7581 & TST & \\
\hline CHEMBL1387516 & 688128 & 4.3 & 4.7482 & TRN & \\
\hline CHEMBL1593033 & 688128 & 5.2 & 5.1347 & TRN & \\
\hline CHEMBL1373923 & 688128 & 4.35 & 4.8422 & TST & \\
\hline CHEMBL1302599 & 688128 & 4.65 & 4.7083 & TRN & \\
\hline CHEMBL1459814 & 688128 & 4.3 & 4.7294 & TST & \\
\hline CHEMBL1611870 & 688128 & 4.35 & 4.6254 & TRN & \\
\hline CHEMBL1347001 & 688128 & 4.05 & 4.771 & TRN & \\
\hline CHEMBL485012 & 688128 & 4.35 & 4.7386 & TRN & \\
\hline CHEMBL1585504 & 688128 & 4.4 & 4.5579 & TRN & \\
\hline CHEMBL1422996 & 688128 & 4.3 & 4.8514 & TRN & \\
\hline CHEMBL1417254 & 688128 & 4.3 & 4.4696 & TRN & \\
\hline & & & & 162 & \\
\hline
\end{tabular}




\begin{tabular}{|c|c|c|c|c|}
\hline \multicolumn{5}{|c|}{ Supplemental Table S2.txt } \\
\hline CHEMBL1399695 & 688128 & 4.6 & 4.7859 & TRN \\
\hline CHEMBL1603119 & 688128 & 6.3 & 4.8851 & TRN \\
\hline CHEMBL1361048 & 688128 & 6.0 & 4.4581 & TRN \\
\hline CHEMBL1535609 & 688128 & 4.55 & 4.6068 & TRN \\
\hline CHEMBL1300282 & 688128 & 4.35 & 4.7475 & TRN \\
\hline CHEMBL1463098 & 688128 & 4.5 & 4.5662 & TRN \\
\hline CHEMBL1411319 & 688128 & 4.4 & 4.7442 & TRN \\
\hline CHEMBL1495764 & 688128 & 5.05 & 4.6262 & TRN \\
\hline CHEMBL1344429 & 688128 & 6.6499 & 4.6622 & TST \\
\hline CHEMBL1460037 & 688128 & 4.95 & 5.2484 & TRN \\
\hline CHEMBL1550898 & 688128 & 4.3 & 4.7062 & TRN \\
\hline CHEMBL1555623 & 688128 & 4.4 & 4.523 & TRN \\
\hline CHEMBL1458332 & 688128 & 5.0 & 4.452 & TST \\
\hline CHEMBL1468099 & 688128 & 4.1 & 5.0572 & TST \\
\hline CHEMBL3212061 & 688128 & 5.1 & 5.0944 & TRN \\
\hline CHEMBL1593474 & 688128 & 5.45 & 4.5974 & TRN \\
\hline CHEMBL1449878 & 688128 & 4.5 & 4.8342 & TRN \\
\hline CHEMBL1439800 & 688128 & 4.35 & 4.7553 & TRN \\
\hline CHEMBL1427717 & 688128 & 4.5 & 4.6093 & TRN \\
\hline CHEMBL1310928 & 688128 & 4.75 & 4.7885 & TRN \\
\hline CHEMBL1443015 & 688128 & 5.1 & 4.654 & TRN \\
\hline CHEMBL1468811 & 688128 & 6.45 & 5.6796 & TRN \\
\hline CHEMBL3145071 & 688128 & 4.45 & 4.9899 & TRN \\
\hline CHEMBL1332732 & 688128 & 5.7 & 4.6793 & TRN \\
\hline CHEMBL1345047 & 688128 & 4.1 & 4.5746 & TRN \\
\hline CHEMBL1572795 & 688128 & 4.05 & 4.2991 & TST \\
\hline CHEMBL1606809 & 688128 & 4.4 & 4.9331 & TRN \\
\hline CHEMBL3199789 & 688128 & 4.4 & 4.4337 & TST \\
\hline CHEMBL1412043 & 688128 & 4.3 & 4.6851 & TRN \\
\hline CHEMBL1601594 & 688128 & 4.05 & 4.5239 & TST \\
\hline CHEMBL1414532 & 688128 & 4.4 & 4.5281 & TST \\
\hline CHEMBL1569343 & 688128 & 4.85 & 4.8732 & TRN \\
\hline CHEMBL1330844 & 688128 & 4.55 & 4.7816 & TRN \\
\hline CHEMBL1449374 & 688128 & 4.35 & 4.8931 & TST \\
\hline CHEMBL1426845 & 688128 & 5.55 & 4.7167 & TRN \\
\hline CHEMBL1438925 & 688128 & 4.05 & 4.3681 & TRN \\
\hline CHEMBL1447877 & 688128 & 5.05 & 4.6409 & TRN \\
\hline CHEMBL1389798 & 688128 & 5.95 & 4.7957 & TRN \\
\hline CHEMBL1534062 & 688128 & 5.0 & 4.5146 & TRN \\
\hline CHEMBL3192422 & 688128 & 4.4 & 4.8414 & TRN \\
\hline CHEMBL1445347 & 688128 & 4.05 & 4.4034 & TST \\
\hline CHEMBL1458709 & 688128 & 4.75 & 4.6368 & TST \\
\hline CHEMBL1444952 & 688128 & 4.3 & 4.619 & TRN \\
\hline CHEMBL1540182 & 688128 & 4.45 & 4.7793 & TRN \\
\hline CHEMBL3191460 & 688128 & 4.65 & 4.5285 & TST \\
\hline CHEMBL3193296 & 688128 & 4.35 & 4.9652 & TRN \\
\hline CHEMBL1579063 & 688128 & 4.35 & 4.8897 & TRN \\
\hline CHEMBL1609130 & 688128 & 4.35 & 4.5425 & TST \\
\hline
\end{tabular}




\begin{tabular}{|c|c|c|c|c|}
\hline \multicolumn{5}{|c|}{ Supplemental Table S2.txt } \\
\hline CHEMBL1502854 & 688128 & 6.3 & 4.9581 & TRN \\
\hline CHEMBL1538796 & 688128 & 4.75 & 5.1408 & TRN \\
\hline CHEMBL3191821 & 688128 & 5.0 & 4.912 & TRN \\
\hline CHEMBL1459491 & 688128 & 4.3 & 4.6449 & TRN \\
\hline CHEMBL1486338 & 688128 & 5.7 & 5.0811 & TRN \\
\hline CHEMBL3190233 & 688128 & 5.0 & 5.1681 & TRN \\
\hline CHEMBL1378309 & 688128 & 4.4 & 4.7839 & TRN \\
\hline CHEMBL1519437 & 688128 & 4.65 & 4.7584 & TRN \\
\hline CHEMBL1364944 & 688128 & 4.05 & 4.6672 & TRN \\
\hline CHEMBL1971234 & 688128 & 4.6 & 4.8179 & TST \\
\hline CHEMBL1482193 & 688128 & 5.2 & 4.7997 & TRN \\
\hline CHEMBL1427671 & 688128 & 4.4 & 4.7734 & TRN \\
\hline CHEMBL1583281 & 688128 & 4.4 & 4.5904 & TST \\
\hline CHEMBL1347401 & 688128 & 4.05 & 4.3784 & TRN \\
\hline CHEMBL1583342 & 688128 & 4.35 & 4.6653 & TRN \\
\hline CHEMBL1390698 & 688128 & 4.45 & 4.6329 & TRN \\
\hline CHEMBL1455761 & 688128 & 4.35 & 4.3865 & TRN \\
\hline CHEMBL1531473 & 688128 & 4.55 & 4.5877 & TRN \\
\hline CHEMBL1391926 & 688128 & 4.35 & 4.6188 & TST \\
\hline CHEMBL1414187 & 688128 & 4.0 & 4.5675 & TRN \\
\hline CHEMBL1476147 & 688128 & 4.35 & 4.5911 & TRN \\
\hline CHEMBL1583675 & 688128 & 4.45 & 4.6984 & TST \\
\hline CHEMBL1376946 & 688128 & 4.6 & 4.8733 & TST \\
\hline CHEMBL1368082 & 688128 & 4.3 & 4.6239 & TRN \\
\hline CHEMBL1537356 & 688128 & 4.45 & 4.7051 & TST \\
\hline CHEMBL1466149 & 688128 & 6.1 & 4.5871 & TRN \\
\hline CHEMBL1472352 & 688128 & 4.3 & 4.5486 & TRN \\
\hline CHEMBL1344160 & 688128 & 4.3 & 4.7953 & TRN \\
\hline CHEMBL1342450 & 688128 & 4.35 & 4.875 & TST \\
\hline CHEMBL1391790 & 688128 & 4.4 & 4.694 & TST \\
\hline CHEMBL1316035 & 688128 & 4.05 & 4.9319 & TRN \\
\hline CHEMBL1538150 & 688128 & 4.95 & 4.6044 & TRN \\
\hline CHEMBL1361861 & 688128 & 4.05 & 4.5012 & TST \\
\hline CHEMBL1406269 & 688128 & 4.25 & 4.4646 & TST \\
\hline CHEMBL1500855 & 688128 & 4.55 & 4.7725 & TRN \\
\hline CHEMBL1506543 & 688128 & 4.3 & 4.6287 & TST \\
\hline CHEMBL3210382 & 688128 & 4.05 & 4.6703 & TST \\
\hline CHEMBL1612419 & 688128 & 4.4 & 4.6253 & TRN \\
\hline CHEMBL1367964 & 688128 & 4.35 & 4.6149 & TRN \\
\hline CHEMBL1519874 & 688128 & 4.45 & 4.4932 & TRN \\
\hline CHEMBL1310837 & 688128 & 5.85 & 4.8882 & TRN \\
\hline CHEMBL1432842 & 688128 & 5.0 & 4.4875 & TST \\
\hline CHEMBL1467312 & 688128 & 4.3 & 4.5207 & TRN \\
\hline CHEMBL1326847 & 688128 & 4.3 & 4.2326 & TRN \\
\hline CHEMBL1311259 & 688128 & 4.3 & 4.4088 & TRN \\
\hline CHEMBL1587678 & 688128 & 4.25 & 4.7318 & TRN \\
\hline CHEMBL1498966 & 688128 & 4.45 & 4.4792 & TRN \\
\hline CHEMBL1607764 & 688128 & 4.05 & 4.8189 & TST \\
\hline
\end{tabular}




\begin{tabular}{|c|c|c|c|c|}
\hline \multicolumn{5}{|c|}{ Supplemental Table S2.txt } \\
\hline CHEMBL1488013 & 688128 & 4.8 & 4.6673 & TST \\
\hline CHEMBL1389172 & 688128 & 4.4 & 4.3263 & TRN \\
\hline CHEMBL3194553 & 688128 & 4.65 & 4.8335 & TRN \\
\hline CHEMBL1372717 & 688128 & 5.15 & 4.5894 & TST \\
\hline CHEMBL1595020 & 688128 & 4.4 & 4.6901 & TRN \\
\hline CHEMBL1304553 & 688128 & 4.85 & 4.9037 & TRN \\
\hline CHEMBL1373724 & 688128 & 4.3 & 4.5127 & TRN \\
\hline CHEMBL1420395 & 688128 & 4.65 & 4.8481 & TRN \\
\hline CHEMBL1393492 & 688128 & 4.3 & 4.555 & TRN \\
\hline CHEMBL1605220 & 688128 & 4.25 & 4.5258 & TRN \\
\hline CHEMBL1576722 & 688128 & 4.35 & 4.9368 & TRN \\
\hline CHEMBL1613311 & 688128 & 4.3 & 4.6425 & TRN \\
\hline CHEMBL1483781 & 688128 & 5.1 & 4.8268 & TRN \\
\hline CHEMBL1525677 & 688128 & 4.7 & 4.5017 & TRN \\
\hline CHEMBL1374416 & 688128 & 4.95 & 4.5746 & TRN \\
\hline CHEMBL1366091 & 688128 & 4.0 & 4.4151 & TRN \\
\hline CHEMBL1511186 & 688128 & 4.5 & 4.1943 & TRN \\
\hline CHEMBL1313132 & 688128 & 4.65 & 4.2814 & TRN \\
\hline CHEMBL3199115 & 688128 & 4.05 & 4.7112 & TRN \\
\hline CHEMBL1299954 & 688128 & 4.3 & 4.5846 & TRN \\
\hline CHEMBL1592329 & 688128 & 4.45 & 4.5789 & TRN \\
\hline CHEMBL1344963 & 688128 & 4.15 & 4.5265 & TRN \\
\hline CHEMBL1439692 & 688128 & 5.05 & 4.3912 & TST \\
\hline CHEMBL1529455 & 688128 & 5.45 & 4.6508 & TRN \\
\hline CHEMBL1306377 & 688128 & 5.2 & 4.7821 & TRN \\
\hline CHEMBL1559782 & 688128 & 4.7 & 4.5576 & TST \\
\hline CHEMBL1419429 & 688128 & 5.05 & 4.5439 & TRN \\
\hline CHEMBL1401518 & 688128 & 4.4 & 4.873 & TST \\
\hline CHEMBL1561426 & 688128 & 4.4 & 4.6769 & TRN \\
\hline CHEMBL3194411 & 688128 & 4.35 & 4.3397 & TRN \\
\hline CHEMBL1355098 & 688128 & 4.05 & 4.7392 & TST \\
\hline CHEMBL3189485 & 688128 & 4.6 & 4.5351 & TRN \\
\hline CHEMBL1306573 & 688128 & 4.85 & 4.8638 & TRN \\
\hline CHEMBL1465171 & 688128 & 4.55 & 4.6141 & TRN \\
\hline CHEMBL1553560 & 688128 & 6.1 & 4.49 & TRN \\
\hline CHEMBL1386924 & 688128 & 4.05 & 4.6293 & TST \\
\hline CHEMBL1475414 & 688128 & 5.0 & 4.3287 & TRN \\
\hline CHEMBL3208753 & 688128 & 4.05 & 4.3462 & TST \\
\hline CHEMBL1573441 & 688128 & 4.55 & 4.1854 & TRN \\
\hline CHEMBL1333943 & 688128 & 5.5 & 4.8621 & TRN \\
\hline CHEMBL1455209 & 688128 & 4.35 & 4.4336 & TST \\
\hline CHEMBL1996133 & 688128 & 4.35 & 4.3764 & TRN \\
\hline CHEMBL1551213 & 688128 & 4.35 & 4.481 & TRN \\
\hline CHEMBL1510274 & 688128 & 4.5 & 4.6445 & TRN \\
\hline CHEMBL1599257 & 688128 & 4.7 & 4.8683 & TRN \\
\hline CHEMBL1427579 & 688128 & 4.75 & 4.8103 & TST \\
\hline CHEMBL1430063 & 688128 & 4.3 & 4.7399 & TRN \\
\hline CHEMBL1527820 & 688128 & 5.95 & 5.0515 & TRN \\
\hline
\end{tabular}




\begin{tabular}{|c|c|c|c|c|c|}
\hline \multirow[b]{2}{*}{ CHEMBL1588844 } & \multirow[b]{2}{*}{688128} & \\
\hline & & 6.5 & 5.0583 & TRN & \\
\hline CHEMBL1320876 & 688128 & 4.4 & 4.4977 & TRN & \\
\hline CHEMBL1470580 & 688128 & 4.5 & 4.4867 & TRN & \\
\hline CHEMBL1420815 & 688128 & 6.0 & 5.1483 & TRN & \\
\hline CHEMBL3198223 & 688128 & 4.4 & 4.75899 & 99999999995 & TRN \\
\hline CHEMBL1598784 & 688128 & 4.4 & 4.8499 & TST & \\
\hline CHEMBL1411727 & 688128 & 5.05 & 4.5318 & TRN & \\
\hline CHEMBL1486265 & 688128 & 5.9 & 4.91100 & 00000000005 & TRN \\
\hline CHEMBL1594564 & 688128 & 4.4 & 4.6649 & TRN & \\
\hline CHEMBL3191664 & 688128 & 4.4 & 5.066 & TST & \\
\hline CHEMBL1304458 & 688128 & 4.35 & 4.6155 & TRN & \\
\hline CHEMBL1497121 & 688128 & 5.15 & 4.5108 & TRN & \\
\hline CHEMBL1311536 & 688128 & 4.3 & 4.5678 & TST & \\
\hline CHEMBL1328300 & 688128 & 4.3 & 4.51399 & 9999999999 & TRN \\
\hline CHEMBL1549704 & 688128 & 4.1 & 4.5995 & TRN & \\
\hline CHEMBL1299676 & 688128 & 5.35 & 4.6113 & TRN & \\
\hline CHEMBL1338738 & 688128 & 4.35 & 4.5762 & TRN & \\
\hline CHEMBL1507656 & 688128 & 4.05 & 4.7116 & TST & \\
\hline CHEMBL1581680 & 688128 & 4.3 & 4.6716 & TRN & \\
\hline CHEMBL1522559 & 688128 & 4.45 & 4.7482 & TRN & \\
\hline CHEMBL1485726 & 688128 & 4.35 & 4.2292 & TRN & \\
\hline CHEMBL1500368 & 688128 & 4.4 & 4.8078 & TRN & \\
\hline CHEMBL1470806 & 688128 & 4.35 & 4.6236 & TST & \\
\hline CHEMBL1601706 & 688128 & 4.4 & 4.4181 & TRN & \\
\hline CHEMBL1534381 & 688128 & 4.0 & 4.6615 & TRN & \\
\hline CHEMBL1606174 & 688128 & 4.35 & 4.3898 & TRN & \\
\hline CHEMBL605077 & 688128 & 4.95 & 4.7556 & TRN & \\
\hline CHEMBL1514336 & 688128 & 4.5 & 4.5617 & TST & \\
\hline CHEMBL1506026 & 688128 & 4.25 & 4.7226 & TRN & \\
\hline CHEMBL1402176 & 688128 & 4.35 & 4.7663 & TST & \\
\hline CHEMBL1557511 & 688128 & 4.45 & 4.5561 & TRN & \\
\hline CHEMBL1580089 & 688128 & 4.05 & 4.8053 & TRN & \\
\hline CHEMBL1479402 & 688128 & 4.65 & 4.84699 & 99999999995 & TRN \\
\hline CHEMBL1324923 & 688128 & 4.5 & 4.7891 & TRN & \\
\hline CHEMBL1310929 & 688128 & 4.35 & 4.8697 & TRN & \\
\hline CHEMBL1303779 & 688128 & 4.55 & 4.5761 & TRN & \\
\hline CHEMBL1429518 & 688128 & 4.4 & 4.6179 & TRN & \\
\hline CHEMBL1417460 & 688128 & 5.1 & 4.3563 & TRN & \\
\hline CHEMBL1597760 & 688128 & 4.3 & 4.4102 & TST & \\
\hline CHEMBL1580541 & 688128 & 4.25 & 4.4609 & TRN & \\
\hline CHEMBL1324001 & 688128 & 4.95 & 4.4712 & TRN & \\
\hline CHEMBL1405514 & 688128 & 4.3 & 4.4125 & TRN & \\
\hline CHEMBL275219 & 688128 & 5.4 & 4.612 & TRN & \\
\hline CHEMBL1541081 & 688128 & 4.3 & 4.2961 & TRN & \\
\hline CHEMBL1477983 & 688128 & 4.05 & 4.754 & TRN & \\
\hline CHEMBL1499797 & 688128 & 4.05 & 4.7411 & TST & \\
\hline CHEMBL1344068 & 688128 & 4.45 & 4.3696 & TRN & \\
\hline CHEMBL1448145 & 688128 & 5.4 & 4.8105 & TRN & \\
\hline & & & & 16246 & \\
\hline
\end{tabular}




\begin{tabular}{|c|c|c|c|c|c|}
\hline \multicolumn{6}{|c|}{ Supplemental Table S2.txt } \\
\hline CHEMBL1519079 & 688128 & 4.3 & 4.5604 & TRN & \\
\hline CHEMBL1998061 & 688128 & 4.0 & 4.5986 & TST & \\
\hline CHEMBL3210860 & 688128 & 6.9 & 4.6053 & TST & \\
\hline CHEMBL1500757 & 688128 & 4.35 & 4.3317 & TRN & \\
\hline CHEMBL1596077 & 688128 & 4.25 & 4.8373 & TST & \\
\hline CHEMBL1416494 & 688128 & 4.55 & 5.0963 & TST & \\
\hline CHEMBL3209984 & 688128 & 4.75 & 4.9293 & TRN & \\
\hline CHEMBL1598958 & 688128 & 4.3 & 4.511 & TRN & \\
\hline CHEMBL1389135 & 688128 & 4.6 & 4.5863 & TRN & \\
\hline CHEMBL1346343 & 688128 & 6.0 & 4.9189 & TRN & \\
\hline CHEMBL1522073 & 688128 & 4.4 & 4.6747 & TRN & \\
\hline CHEMBL1335901 & 688128 & 4.85 & 4.413 & TRN & \\
\hline CHEMBL1321103 & 688128 & 4.1 & 4.9289 & TRN & \\
\hline CHEMBL1365388 & 688128 & 4.05 & 4.5496 & TRN & \\
\hline CHEMBL1401029 & 688128 & 4.6 & 4.2919 & TRN & \\
\hline CHEMBL1455416 & 688128 & 4.35 & 4.6073 & TRN & \\
\hline CHEMBL1469910 & 688128 & 4.2 & 4.5788 & TST & \\
\hline CHEMBL1546181 & 688128 & 4.25 & 4.4932 & TRN & \\
\hline CHEMBL1469577 & 688128 & 4.4 & 4.6442 & TRN & \\
\hline CHEMBL1495570 & 688128 & 5.95 & 4.7891 & TST & \\
\hline CHEMBL1442416 & 688128 & 4.4 & 4.3131 & TRN & \\
\hline CHEMBL1322167 & 688128 & 4.3 & 4.7004 & TST & \\
\hline CHEMBL1442740 & 688128 & 4.05 & 4.9875 & TST & \\
\hline CHEMBL1426534 & 688128 & 4.45 & 4.447 & TRN & \\
\hline CHEMBL1097687 & 688128 & 6.7501 & 4.5324 & TRN & \\
\hline CHEMBL1333828 & 688128 & 4.65 & 4.6761 & TRN & \\
\hline CHEMBL1458821 & 688128 & 4.4 & 4.71899 & 9999999999 & TRN \\
\hline CHEMBL1499127 & 688128 & 4.95 & 5.1589 & TRN & \\
\hline CHEMBL1306687 & 688128 & 4.05 & 4.7049 & TST & \\
\hline CHEMBL1350297 & 688128 & 4.4 & 4.4986 & TRN & \\
\hline CHEMBL1582751 & 688128 & 4.45 & 4.4879 & TRN & \\
\hline CHEMBL1312320 & 688128 & 4.55 & 4.6546 & TRN & \\
\hline CHEMBL1457591 & 688128 & 4.35 & 4.7956 & TRN & \\
\hline CHEMBL1562617 & 688128 & 4.25 & 4.7408 & TRN & \\
\hline CHEMBL1324323 & 688128 & 5.0 & 4.6245 & TRN & \\
\hline CHEMBL1544660 & 688128 & 4.55 & 4.6371 & TST & \\
\hline CHEMBL1431413 & 688128 & 4.35 & 4.6659 & TST & \\
\hline CHEMBL1347900 & 688128 & 4.65 & 4.5648 & TRN & \\
\hline CHEMBL1407252 & 688128 & 6.8499 & 4.8576 & TRN & \\
\hline CHEMBL1329356 & 688128 & 4.4 & 4.7051 & TRN & \\
\hline CHEMBL1464886 & 688128 & 4.45 & 4.495 & TRN & \\
\hline CHEMBL1418235 & 688128 & 4.35 & 4.7527 & TRN & \\
\hline CHEMBL1521070 & 688128 & 5.65 & 5.1215 & TRN & \\
\hline CHEMBL1451112 & 688128 & 4.35 & 4.5777 & TST & \\
\hline CHEMBL1563714 & 688128 & 6.05 & 5.0403 & TRN & \\
\hline CHEMBL1578594 & 688128 & 5.4 & 4.8777 & TRN & \\
\hline CHEMBL1336633 & 688128 & 6.05 & 5.1179 & TST & \\
\hline CHEMBL1541460 & 688128 & 4.3 & 4.3434 & TRN & \\
\hline
\end{tabular}




\begin{tabular}{|c|c|c|c|c|}
\hline \multicolumn{5}{|c|}{ Supplemental Table S2.txt } \\
\hline CHEMBL1500121 & 688128 & 4.65 & 4.387 & TRN \\
\hline CHEMBL1491845 & 688128 & 4.25 & 4.6026 & TRN \\
\hline CHEMBL1472934 & 688128 & 5.35 & 4.3411 & TST \\
\hline CHEMBL1079297 & 688128 & 4.3 & 4.4829 & TRN \\
\hline CHEMBL1370914 & 688128 & 6.0 & 4.7437 & TRN \\
\hline CHEMBL1380356 & 688128 & 6.15 & 4.9567 & TRN \\
\hline CHEMBL1302504 & 688128 & 4.45 & 5.2882 & TRN \\
\hline CHEMBL1330951 & 688128 & 5.5 & 4.9812 & TST \\
\hline CHEMBL1408675 & 688128 & 4.35 & 4.7258 & TRN \\
\hline CHEMBL1440931 & 688128 & 4.35 & 4.6823 & TRN \\
\hline CHEMBL1534794 & 688128 & 4.6 & 4.7129 & TST \\
\hline CHEMBL1504076 & 688128 & 4.35 & 4.3638 & TRN \\
\hline CHEMBL1567318 & 688128 & 5.9 & 4.3213 & TRN \\
\hline CHEMBL1370107 & 688128 & 4.25 & 4.6725 & TST \\
\hline CHEMBL3208993 & 688128 & 4.6 & 4.572 & TRN \\
\hline CHEMBL1534787 & 688128 & 4.45 & 4.7961 & TRN \\
\hline CHEMBL1556332 & 688128 & 4.3 & 4.5367 & TRN \\
\hline CHEMBL1372207 & 688128 & 4.55 & 4.47 & TRN \\
\hline CHEMBL1436639 & 688128 & 4.4 & 4.6253 & TRN \\
\hline CHEMBL1440915 & 688128 & 4.05 & 4.4816 & TRN \\
\hline CHEMBL1611864 & 688128 & 4.3 & 4.3852 & TRN \\
\hline CHEMBL1379975 & 688128 & 4.0 & 4.5982 & TRN \\
\hline CHEMBL1368787 & 688128 & 4.3 & 4.5695 & TRN \\
\hline CHEMBL1468847 & 688128 & 5.2 & 5.3576 & TRN \\
\hline CHEMBL1542656 & 688128 & 4.65 & 4.6397 & TRN \\
\hline CHEMBL1349523 & 688128 & 4.45 & 4.8831 & TRN \\
\hline CHEMBL1334452 & 688128 & 5.75 & 5.0558 & TRN \\
\hline CHEMBL1410522 & 688128 & 4.0 & 4.5128 & TRN \\
\hline CHEMBL1509828 & 688128 & 4.25 & 4.7891 & TRN \\
\hline CHEMBL1466270 & 688128 & 4.35 & 4.4802 & TRN \\
\hline CHEMBL3195220 & 688128 & 4.95 & 5.0939 & TRN \\
\hline CHEMBL1601897 & 688128 & 5.2 & 4.8107 & TRN \\
\hline CHEMBL1597702 & 688128 & 4.4 & 4.3216 & TRN \\
\hline CHEMBL1905194 & 688128 & 4.4 & 4.3744 & TRN \\
\hline CHEMBL1557413 & 688128 & 4.65 & 4.4995 & TRN \\
\hline CHEMBL1581190 & 688128 & 4.6 & 4.8806 & TRN \\
\hline CHEMBL 1452340 & 688128 & 4.35 & 4.8235 & TRN \\
\hline CHEMBL1326331 & 688128 & 4.05 & 4.7028 & TRN \\
\hline CHEMBL1469425 & 688128 & 6.2 & 4.3909 & TRN \\
\hline CHEMBL1367156 & 688128 & 4.05 & 4.6704 & TRN \\
\hline CHEMBL1503671 & 688128 & 4.05 & 4.4671 & TRN \\
\hline CHEMBL1453092 & 688128 & 4.4 & 4.6592 & TST \\
\hline CHEMBL1539650 & 688128 & 4.05 & 4.5088 & TRN \\
\hline CHEMBL1426865 & 688128 & 4.3 & 4.1058 & TRN \\
\hline CHEMBL1412889 & 688128 & 4.4 & 4.6874 & TRN \\
\hline CHEMBL1434031 & 688128 & 4.65 & 4.9785 & TRN \\
\hline CHEMBL1535159 & 688128 & 4.9 & 4.7071 & TRN \\
\hline CHEMBL1351425 & 688128 & 4.8 & 4.5145 & TRN \\
\hline
\end{tabular}




\begin{tabular}{|c|c|c|c|c|}
\hline \multicolumn{5}{|c|}{ Supplemental Table } \\
\hline CHEMBL525098 & 688128 & 4.55 & 4.8299 & TST \\
\hline CHEMBL3189814 & 688128 & 4.2 & 4.4605 & TRN \\
\hline CHEMBL1342248 & 688128 & 4.65 & 4.935 & TRN \\
\hline CHEMBL1559280 & 688128 & 4.35 & 4.5923 & TRN \\
\hline CHEMBL3192657 & 688128 & 4.85 & 4.7266 & TRN \\
\hline CHEMBL1584263 & 688128 & 4.05 & 4.9893 & TRN \\
\hline CHEMBL3213781 & 688128 & 4.55 & 4.8772 & TST \\
\hline CHEMBL1475223 & 688128 & 4.35 & 4.6639 & TST \\
\hline CHEMBL1468247 & 688128 & 4.35 & 4.4195 & TST \\
\hline CHEMBL1392976 & 688128 & 5.6 & 4.9275 & TST \\
\hline CHEMBL1495622 & 688128 & 4.3 & 4.4866 & TRN \\
\hline CHEMBL1386830 & 688128 & 4.2 & 4.4516 & TRN \\
\hline CHEMBL1562312 & 688128 & 4.4 & 4.5791 & TRN \\
\hline CHEMBL 3210878 & 688128 & 4.05 & 4.5303 & TRN \\
\hline CHEMBL1372764 & 688128 & 4.05 & 4.5314 & TRN \\
\hline CHEMBL1399824 & 688128 & 5.25 & 4.521 & TRN \\
\hline CHEMBL1607746 & 688128 & 5.05 & 4.3519 & TRN \\
\hline CHEMBL1453409 & 688128 & 4.3 & 4.4851 & TRN \\
\hline CHEMBL1414480 & 688128 & 4.0 & 4.2603 & TRN \\
\hline CHEMBL1387989 & 688128 & 5.0 & 4.6346 & TRN \\
\hline CHEMBL3209773 & 688128 & 4.3 & 4.5545 & TRN \\
\hline CHEMBL1434420 & 688128 & 5.35 & 4.4049 & TRN \\
\hline CHEMBL1544150 & 688128 & 4.35 & 4.6955 & TRN \\
\hline CHEMBL1562133 & 688128 & 4.3 & 4.605 & TRN \\
\hline CHEMBL1346796 & 688128 & 4.55 & 4.6682 & TRN \\
\hline CHEMBL1339909 & 688128 & 6.45 & 5.3871 & TRN \\
\hline CHEMBL3195695 & 688128 & 4.55 & 4.5693 & TRN \\
\hline CHEMBL1466012 & 688128 & 4.35 & 4.5867 & TRN \\
\hline CHEMBL1332385 & 688128 & 4.7 & 4.5881 & TRN \\
\hline CHEMBL1459953 & 688128 & 4.4 & 4.3848 & TST \\
\hline CHEMBL1385448 & 688128 & 5.4 & 4.4899 & TRN \\
\hline CHEMBL1344330 & 688128 & 4.6 & 4.7725 & TST \\
\hline CHEMBL1574075 & 688128 & 5.15 & 4.676 & TRN \\
\hline CHEMBL1468239 & 688128 & 4.25 & 5.0267 & TRN \\
\hline CHEMBL1382484 & 688128 & 4.3 & 4.2641 & TRN \\
\hline CHEMBL1605451 & 688128 & 4.35 & 4.5952 & TRN \\
\hline CHEMBL3197231 & 688128 & 5.85 & 4.8627 & TRN \\
\hline CHEMBL1358564 & 688128 & 4.3 & 4.7076 & TST \\
\hline CHEMBL1509266 & 688128 & 4.9 & 4.7398 & TRN \\
\hline CHEMBL1375210 & 688128 & 4.3 & 4.5422 & TRN \\
\hline CHEMBL1418344 & 688128 & 4.4 & 5.0752 & TRN \\
\hline CHEMBL1389510 & 688128 & 4.4 & 4.7429 & TRN \\
\hline CHEMBL1570547 & 688128 & 4.45 & 4.4341 & TRN \\
\hline CHEMBL1580286 & 688128 & 5.2 & 4.575 & TRN \\
\hline CHEMBL1503806 & 688128 & 4.4 & 4.6385 & TST \\
\hline CHEMBL1413292 & 688128 & 5.45 & 4.7649 & TRN \\
\hline CHEMBL1545413 & 688128 & 4.55 & 4.7335 & TRN \\
\hline CHEMBL1395603 & 688128 & 5.7 & 4.6266 & TST \\
\hline
\end{tabular}




\begin{tabular}{|c|c|c|c|c|}
\hline \multicolumn{5}{|c|}{ Supplemental Table S2.txt } \\
\hline CHEMBL3194486 & 688128 & 4.5 & 4.758 & TST \\
\hline CHEMBL1413232 & 688128 & 4.3 & 4.4468 & TST \\
\hline CHEMBL1345933 & 688128 & 4.35 & 4.2372 & TRN \\
\hline CHEMBL1320229 & 688128 & 4.7 & 5.0093 & TRN \\
\hline CHEMBL1495478 & 688128 & 4.7 & 4.688 & TRN \\
\hline CHEMBL479330 & 688128 & 5.4 & 4.8455 & TRN \\
\hline CHEMBL1543232 & 688128 & 4.35 & 4.6274 & TST \\
\hline CHEMBL1549657 & 688128 & 5.6 & 4.8943 & TRN \\
\hline CHEMBL1432427 & 688128 & 4.35 & 5.0262 & TRN \\
\hline CHEMBL1373662 & 688128 & 4.35 & 4.482 & TRN \\
\hline CHEMBL1312412 & 688128 & 4.4 & 4.5345 & TRN \\
\hline CHEMBL1332066 & 688128 & 5.5 & 4.7347 & TRN \\
\hline CHEMBL1463405 & 688128 & 5.0 & 5.0265 & TRN \\
\hline CHEMBL1413946 & 688128 & 4.3 & 4.7096 & TST \\
\hline CHEMBL1557285 & 688128 & 5.4 & 4.9571 & TRN \\
\hline CHEMBL1346185 & 688128 & 4.2 & 4.346 & TRN \\
\hline CHEMBL1468542 & 688128 & 4.45 & 4.3193 & TST \\
\hline CHEMBL1518416 & 688128 & 5.35 & 4.6756 & TST \\
\hline CHEMBL1307250 & 688128 & 5.4 & 4.6732 & TRN \\
\hline CHEMBL1611382 & 688128 & 4.35 & 4.3489 & TRN \\
\hline CHEMBL3197470 & 688128 & 4.4 & 4.8355 & TRN \\
\hline CHEMBL1504164 & 688128 & 4.3 & 4.5155 & TRN \\
\hline CHEMBL1448671 & 688128 & 4.75 & 4.8926 & TRN \\
\hline CHEMBL1326599 & 688128 & 4.3 & 4.4826 & TRN \\
\hline CHEMBL1463810 & 688128 & 4.8 & 4.7942 & TRN \\
\hline CHEMBL1346145 & 688128 & 4.3 & 4.5359 & TRN \\
\hline CHEMBL1311760 & 688128 & 4.7 & 4.5488 & TRN \\
\hline CHEMBL1423718 & 688128 & 4.15 & 4.5113 & TRN \\
\hline CHEMBL1497883 & 688128 & 4.05 & 4.405 & TRN \\
\hline CHEMBL1528841 & 688128 & 4.05 & 4.4446 & TRN \\
\hline CHEMBL1408814 & 688128 & 4.7 & 4.4347 & TRN \\
\hline CHEMBL3190881 & 688128 & 4.6 & 4.74 & TST \\
\hline CHEMBL1309347 & 688128 & 4.55 & 4.6535 & TRN \\
\hline CHEMBL1562718 & 688128 & 5.2 & 4.975 & TRN \\
\hline CHEMBL1524064 & 688128 & 4.35 & 4.6702 & TRN \\
\hline CHEMBL1351229 & 688128 & 4.0 & 4.4561 & TST \\
\hline CHEMBL1350365 & 688128 & 5.6 & 4.6294 & TST \\
\hline CHEMBL1387653 & 688128 & 4.4 & 4.7013 & TRN \\
\hline CHEMBL1481742 & 688128 & 6.5 & 5.1532 & TRN \\
\hline CHEMBL1479670 & 688128 & 4.3 & 4.7708 & TRN \\
\hline CHEMBL1540419 & 688128 & 4.4 & 4.441 & TRN \\
\hline CHEMBL1421850 & 688128 & 4.65 & 4.4651 & TRN \\
\hline CHEMBL1369517 & 688128 & 5.15 & 4.5394 & TRN \\
\hline CHEMBL1541115 & 688128 & 4.5 & 4.436 & TRN \\
\hline CHEMBL3214416 & 688128 & 4.15 & 4.7958 & TST \\
\hline CHEMBL1498538 & 688128 & 5.65 & 4.657 & TRN \\
\hline CHEMBL1384653 & 688128 & 6.2 & 4.5861 & TST \\
\hline CHEMBL1588476 & 688128 & 5.1 & 5.0967 & TRN \\
\hline
\end{tabular}




\begin{tabular}{|c|c|c|c|c|}
\hline \multicolumn{5}{|c|}{ Supplemental Table S2.txt } \\
\hline CHEMBL1301648 & 688128 & 4.4 & 4.3847 & TST \\
\hline CHEMBL1436319 & 688128 & 4.05 & 4.8933 & TRN \\
\hline CHEMBL1594858 & 688128 & 4.35 & 4.7211 & TRN \\
\hline CHEMBL1495619 & 688128 & 4.45 & 4.3888 & TRN \\
\hline CHEMBL1425924 & 688128 & 4.7 & 4.9396 & TST \\
\hline CHEMBL1551641 & 688128 & 4.4 & 4.3447 & TRN \\
\hline CHEMBL567967 & 688128 & 4.4 & 4.7806 & TST \\
\hline CHEMBL1501956 & 688128 & 4.05 & 4.4811 & TRN \\
\hline CHEMBL1428792 & 688128 & 5.25 & 4.8404 & TRN \\
\hline CHEMBL1520237 & 688128 & 4.4 & 4.5776 & TRN \\
\hline CHEMBL1325946 & 688128 & 4.4 & 4.4453 & TRN \\
\hline CHEMBL1456510 & 688128 & 5.4 & 4.5195 & TRN \\
\hline CHEMBL1466256 & 688128 & 4.65 & 4.6294 & TRN \\
\hline CHEMBL1361394 & 688128 & 4.4 & 4.4708 & TRN \\
\hline CHEMBL1463326 & 688128 & 4.95 & 4.9548 & TRN \\
\hline CHEMBL1366310 & 688128 & 4.5 & 4.7371 & TST \\
\hline CHEMBL1377522 & 688128 & 4.95 & 4.5312 & TRN \\
\hline CHEMBL1442396 & 688128 & 4.6 & 4.6751 & TRN \\
\hline CHEMBL1474947 & 688128 & 4.35 & 4.9833 & TRN \\
\hline CHEMBL1565555 & 688128 & 4.25 & 4.8642 & TRN \\
\hline CHEMBL1326591 & 688128 & 4.05 & 4.7265 & TST \\
\hline CHEMBL1458614 & 688128 & 4.45 & 4.7407 & TST \\
\hline CHEMBL1527214 & 688128 & 4.35 & 4.6872 & TRN \\
\hline CHEMBL1361927 & 688128 & 4.8 & 5.0607 & TRN \\
\hline CHEMBL1465945 & 688128 & 4.8 & 4.814 & TRN \\
\hline CHEMBL1496932 & 688128 & 5.45 & 4.5073 & TST \\
\hline CHEMBL1559717 & 688128 & 6.0 & 4.5076 & TST \\
\hline CHEMBL1463873 & 688128 & 4.35 & 4.5803 & TRN \\
\hline CHEMBL1606533 & 688128 & 4.35 & 4.5763 & TRN \\
\hline CHEMBL1363529 & 688128 & 4.2 & 4.4637 & TRN \\
\hline CHEMBL1456612 & 688128 & 6.0 & 5.0187 & TRN \\
\hline CHEMBL3193909 & 688128 & 4.35 & 4.709 & TRN \\
\hline CHEMBL1547778 & 688128 & 5.45 & 4.6163 & TST \\
\hline CHEMBL1471206 & 688128 & 4.05 & 4.6762 & TRN \\
\hline CHEMBL1542165 & 688128 & 6.05 & 4.9419 & TRN \\
\hline CHEMBL1474091 & 688128 & 4.75 & 5.2158 & TRN \\
\hline CHEMBL1447835 & 688128 & 4.3 & 4.6262 & TRN \\
\hline CHEMBL1494965 & 688128 & 4.4 & 4.6101 & TRN \\
\hline CHEMBL1368188 & 688128 & 5.0 & 4.7982 & TRN \\
\hline CHEMBL1452479 & 688128 & 4.4 & 4.8355 & TRN \\
\hline CHEMBL1533012 & 688128 & 4.35 & 4.5814 & TRN \\
\hline CHEMBL1405629 & 688128 & 4.1 & 4.7777 & TST \\
\hline CHEMBL1385821 & 688128 & 4.8 & 4.6201 & TRN \\
\hline CHEMBL3193740 & 688128 & 5.45 & 4.5741 & TRN \\
\hline CHEMBL1439504 & 688128 & 4.35 & 4.4779 & TRN \\
\hline CHEMBL1410742 & 688128 & 4.35 & 4.6369 & TRN \\
\hline CHEMBL1589168 & 688128 & 5.35 & 4.8668 & TRN \\
\hline CHEMBL1346780 & 688128 & 6.35 & 5.1091 & TRN \\
\hline
\end{tabular}




\begin{tabular}{|c|c|c|c|c|}
\hline & & & & \\
\hline CHEMBL1372507 & 688128 & 4.3 & 4.543 & TRN \\
\hline CHEMBL1603441 & 688128 & 4.4 & 4.6997 & TRN \\
\hline CHEMBL1589140 & 688128 & 4.7 & 4.6621 & TRN \\
\hline CHEMBL1438143 & 688128 & 4.4 & 4.7232 & TRN \\
\hline CHEMBL1386593 & 688128 & 4.35 & 4.5602 & TST \\
\hline CHEMBL1506171 & 688128 & 4.55 & 4.6666 & TRN \\
\hline CHEMBL1344237 & 688128 & 4.65 & 4.5456 & TRN \\
\hline CHEMBL1374081 & 688128 & 4.45 & 4.4492 & TRN \\
\hline CHEMBL1572458 & 688128 & 4.65 & 4.5761 & TRN \\
\hline CHEMBL1365763 & 688128 & 4.05 & 4.5475 & TST \\
\hline CHEMBL1362565 & 688128 & 5.55 & 5.015 & TRN \\
\hline CHEMBL1480747 & 688128 & 4.45 & 4.7727 & TRN \\
\hline CHEMBL1964383 & 688128 & 6.6 & 4.6617 & TRN \\
\hline CHEMBL1351260 & 688128 & 4.1 & 4.2952 & TRN \\
\hline CHEMBL3199832 & 688128 & 4.25 & 4.3826 & TRN \\
\hline CHEMBL1558774 & 688128 & 4.4 & 4.6275 & TRN \\
\hline CHEMBL1350588 & 688128 & 4.35 & 4.6824 & TRN \\
\hline CHEMBL1543576 & 688128 & 4.1 & 4.6456 & TRN \\
\hline CHEMBL1549597 & 688128 & 4.35 & 4.7472 & TRN \\
\hline CHEMBL1532500 & 688128 & 4.3 & 4.6675 & TRN \\
\hline CHEMBL1381956 & 688128 & 4.35 & 4.5436 & TRN \\
\hline CHEMBL1437986 & 688128 & 4.4 & 4.3804 & TRN \\
\hline CHEMBL1543611 & 688128 & 4.35 & 4.7717 & TST \\
\hline CHEMBL1417620 & 688128 & 4.95 & 5.2115 & TST \\
\hline CHEMBL1450312 & 688128 & 4.1 & 4.695 & TRN \\
\hline CHEMBL1547363 & 688128 & 4.3 & 4.6786 & TRN \\
\hline CHEMBL1714415 & 688128 & 4.25 & 4.7377 & TRN \\
\hline CHEMBL1414397 & 688128 & 4.0 & 4.5331 & TRN \\
\hline CHEMBL1441585 & 688128 & 4.55 & 4.8214 & TRN \\
\hline CHEMBL1512469 & 688128 & 4.05 & 4.2918 & TST \\
\hline CHEMBL1379237 & 688128 & 4.35 & 4.6985 & TRN \\
\hline CHEMBL1435487 & 688128 & 4.85 & 5.0424 & TRN \\
\hline CHEMBL1597481 & 688128 & 4.45 & 4.6104 & TRN \\
\hline CHEMBL1316076 & 688128 & 4.25 & 4.7436 & TST \\
\hline CHEMBL1335445 & 688128 & 4.4 & 4.5534 & TST \\
\hline CHEMBL1350609 & 688128 & 6.8499 & 4.79 & TST \\
\hline CHEMBL1452930 & 688128 & 4.3 & 4.4607 & TRN \\
\hline CHEMBL1519796 & 688128 & 4.3 & 4.8464 & TRN \\
\hline CHEMBL1543295 & 688128 & 5.05 & 5.2077 & TRN \\
\hline CHEMBL1549683 & 688128 & 4.35 & 4.7227 & TST \\
\hline CHEMBL1527407 & 688128 & 4.45 & 4.7499 & TRN \\
\hline CHEMBL1566264 & 688128 & 4.3 & 4.7244 & TRN \\
\hline CHEMBL1406291 & 688128 & 4.95 & 4.8012 & TST \\
\hline CHEMBL1594401 & 688128 & 6.0 & 4.7675 & TRN \\
\hline CHEMBL1333429 & 688128 & 4.4 & 4.7543 & TRN \\
\hline CHEMBL1526775 & 688128 & 4.05 & 4.5378 & TST \\
\hline CHEMBL1561445 & 688128 & 4.05 & 4.4462 & TST \\
\hline CHEMBL1346911 & 688128 & 4.05 & 4.6727 & TST \\
\hline
\end{tabular}




\begin{tabular}{|c|c|c|c|c|}
\hline \multicolumn{5}{|c|}{ Supplemental Table S2.txt } \\
\hline CHEMBL1582927 & 688128 & 5.05 & 4.989 & TRN \\
\hline CHEMBL1322882 & 688128 & 5.5 & 4.5444 & TRN \\
\hline CHEMBL2132953 & 688128 & 4.3 & 4.5062 & TST \\
\hline CHEMBL 2374034 & 688128 & 5.0 & 5.0787 & TRN \\
\hline CHEMBL1425161 & 688128 & 4.25 & 4.5918 & TST \\
\hline CHEMBL1416276 & 688128 & 4.55 & 4.6292 & TRN \\
\hline CHEMBL1443658 & 688128 & 4.65 & 4.6587 & TST \\
\hline CHEMBL1548239 & 688128 & 6.15 & 4.8119 & TST \\
\hline CHEMBL1580018 & 688128 & 4.3 & 4.4734 & TRN \\
\hline CHEMBL1567968 & 688128 & 5.0 & 5.2649 & TRN \\
\hline CHEMBL1570948 & 688128 & 4.4 & 4.8087 & TRN \\
\hline CHEMBL1571049 & 688128 & 4.0 & 4.4919 & TRN \\
\hline CHEMBL1374672 & 688128 & 4.35 & 4.5664 & TRN \\
\hline CHEMBL1327407 & 688128 & 4.3 & 4.8446 & TST \\
\hline CHEMBL1361829 & 688128 & 4.95 & 4.6744 & TST \\
\hline CHEMBL1323388 & 688128 & 5.0 & 4.5193 & TST \\
\hline CHEMBL1338756 & 688128 & 4.3 & 4.7438 & TST \\
\hline CHEMBL1522025 & 688128 & 5.0 & 4.7427 & TRN \\
\hline CHEMBL1511082 & 688128 & 4.3 & 4.6373 & TST \\
\hline CHEMBL1487482 & 688128 & 4.3 & 4.7998 & TRN \\
\hline CHEMBL1556557 & 688128 & 4.65 & 4.6023 & TRN \\
\hline CHEMBL1396125 & 688128 & 4.05 & 4.7249 & TRN \\
\hline CHEMBL1422394 & 688128 & 4.35 & 4.4076 & TRN \\
\hline CHEMBL1429883 & 688128 & 4.25 & 4.4252 & TRN \\
\hline CHEMBL1452689 & 688128 & 4.25 & 4.2758 & TRN \\
\hline CHEMBL3212304 & 688128 & 4.3 & 4.5647 & TRN \\
\hline CHEMBL1357667 & 688128 & 4.6 & 4.5702 & TRN \\
\hline CHEMBL1505603 & 688128 & 4.4 & 4.4873 & TRN \\
\hline CHEMBL3191861 & 688128 & 4.5 & 4.7111 & TRN \\
\hline CHEMBL1398283 & 688128 & 4.6 & 4.5968 & TRN \\
\hline CHEMBL1538793 & 688128 & 4.4 & 4.2495 & TRN \\
\hline CHEMBL1569778 & 688128 & 4.05 & 4.4464 & TRN \\
\hline CHEMBL1256995 & 688128 & 4.35 & 4.7451 & TST \\
\hline CHEMBL1309012 & 688128 & 4.35 & 4.47 & TRN \\
\hline CHEMBL1414814 & 688128 & 4.65 & 4.6706 & TRN \\
\hline CHEMBL1546563 & 688128 & 4.3 & 4.6247 & TRN \\
\hline CHEMBL1499364 & 688128 & 4.9 & 4.7641 & TRN \\
\hline CHEMBL1347486 & 688128 & 4.3 & 4.6261 & TRN \\
\hline CHEMBL1491952 & 688128 & 4.4 & 4.6407 & TST \\
\hline CHEMBL1346172 & 688128 & 6.05 & 5.0094 & TRN \\
\hline CHEMBL1449023 & 688128 & 4.05 & 4.6325 & TRN \\
\hline CHEMBL1399498 & 688128 & 4.8 & 4.8077 & TRN \\
\hline CHEMBL1379537 & 688128 & 4.05 & 4.3101 & TRN \\
\hline CHEMBL1381386 & 688128 & 4.4 & 4.4713 & TRN \\
\hline CHEMBL1391609 & 688128 & 5.3 & 4.5951 & TST \\
\hline CHEMBL1441140 & 688128 & 4.3 & 4.3363 & TRN \\
\hline CHEMBL1413790 & 688128 & 4.05 & 4.6009 & TRN \\
\hline CHEMBL1572927 & 688128 & 5.5 & 4.7109 & TRN \\
\hline
\end{tabular}




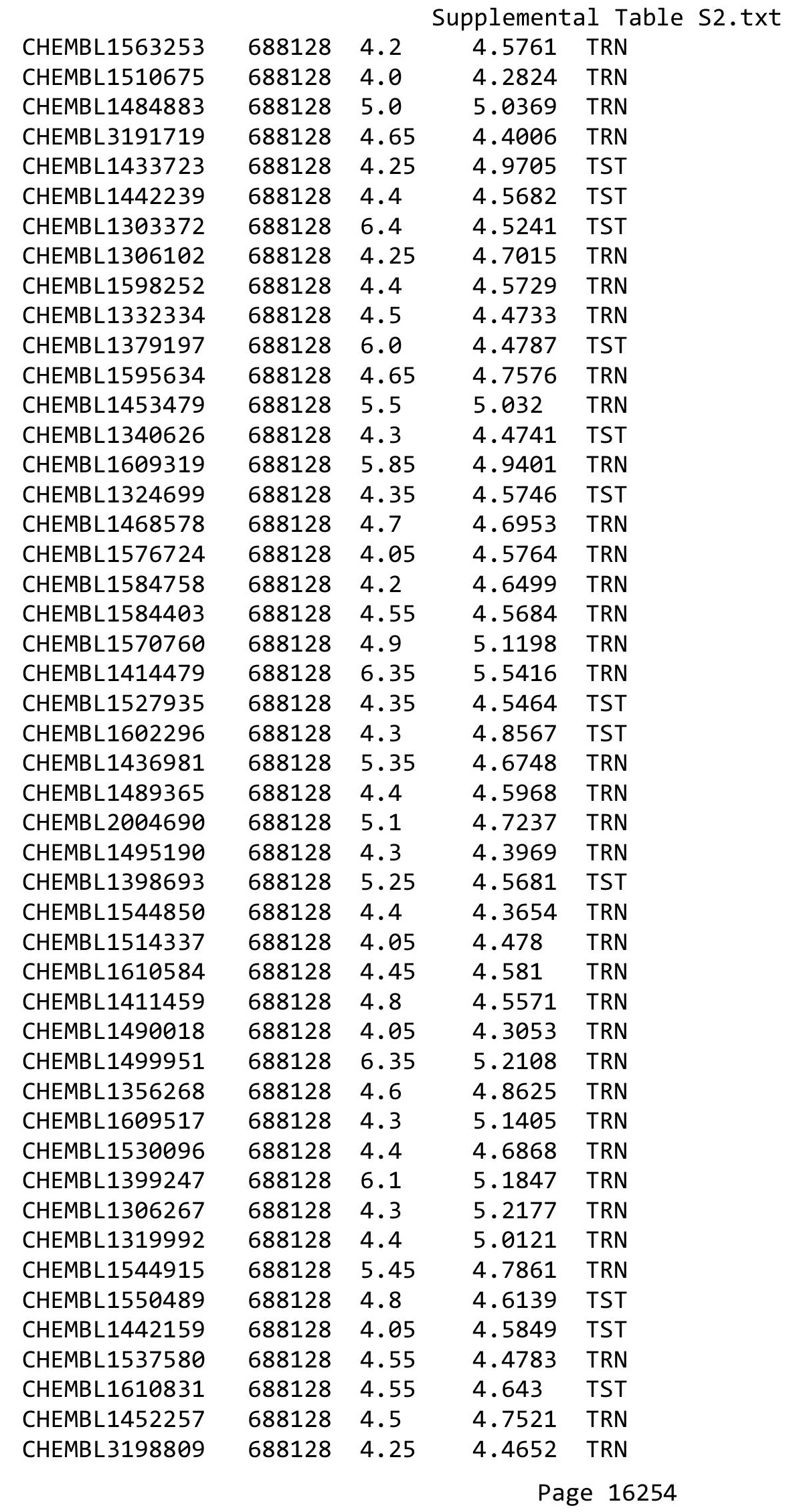




\begin{tabular}{|c|c|c|c|c|c|}
\hline & & \multicolumn{4}{|c|}{ Supplemental Table S2.txt } \\
\hline CHEMBL1445973 & 688128 & 4.35 & 4.4061 & TRN & \\
\hline CHEMBL1406745 & 688128 & 5.1 & 4.4747 & TRN & \\
\hline CHEMBL1411800 & 688128 & 4.55 & 4.728 & TRN & \\
\hline CHEMBL 3214098 & 688128 & 4.8 & 4.7501 & TST & \\
\hline CHEMBL1608455 & 688128 & 4.4 & 4.5059 & TRN & \\
\hline CHEMBL1555829 & 688128 & 4.6 & 4.2954 & TRN & \\
\hline CHEMBL1477386 & 688128 & 4.4 & 4.4847 & TST & \\
\hline CHEMBL1387974 & 688128 & 4.35 & 4.5124 & TRN & \\
\hline CHEMBL1518475 & 688128 & 6.5 & 4.9914 & TST & \\
\hline CHEMBL3196524 & 688128 & 4.35 & 4.479 & TRN & \\
\hline CHEMBL1582506 & 688128 & 5.15 & 4.56 & TRN & \\
\hline CHEMBL1399886 & 688128 & 4.1 & 4.3799 & TRN & \\
\hline CHEMBL1469647 & 688128 & 4.35 & 4.5126 & TRN & \\
\hline CHEMBL1466225 & 688128 & 4.35 & 4.7753 & TRN & \\
\hline CHEMBL1500573 & 688128 & 5.15 & 4.4474 & TRN & \\
\hline CHEMBL1539627 & 688128 & 4.45 & 4.6375 & TRN & \\
\hline CHEMBL1578304 & 688128 & 5.7 & 4.7041 & TRN & \\
\hline CHEMBL1561538 & 688128 & 4.4 & 4.851 & TRN & \\
\hline CHEMBL1330937 & 688128 & 4.45 & 4.58899 & 99999999995 & TRN \\
\hline CHEMBL1522451 & 688128 & 4.4 & 4.5289 & TRN & \\
\hline CHEMBL1370557 & 688128 & 6.0 & 4.5333 & TST & \\
\hline CHEMBL1563561 & 688128 & 4.45 & 4.9065 & TRN & \\
\hline CHEMBL3193775 & 688128 & 4.55 & 4.7086 & TST & \\
\hline CHEMBL 1426875 & 688128 & 4.35 & 4.343 & TRN & \\
\hline CHEMBL1566076 & 688128 & 4.35 & 4.5362 & TST & \\
\hline CHEMBL1514612 & 688128 & 6.5 & 5.0034 & TRN & \\
\hline CHEMBL1471970 & 688128 & 4.4 & 4.3624 & TRN & \\
\hline CHEMBL1330166 & 688128 & 4.35 & 4.6555 & TST & \\
\hline CHEMBL1589646 & 688128 & 4.05 & 4.6285 & TRN & \\
\hline CHEMBL1304351 & 688128 & 5.0 & 5.1534 & TRN & \\
\hline CHEMBL1442411 & 688128 & 4.1 & 4.5291 & TRN & \\
\hline CHEMBL1562965 & 688128 & 4.35 & 4.6061 & TRN & \\
\hline CHEMBL1528901 & 688128 & 5.85 & 4.8045 & TRN & \\
\hline CHEMBL1345086 & 688128 & 4.45 & 4.5296 & TST & \\
\hline CHEMBL1341732 & 688128 & 5.5 & 4.6949 & TRN & \\
\hline CHEMBL1547225 & 688128 & 4.3 & 4.3581 & TRN & \\
\hline CHEMBL1998940 & 688128 & 5.05 & 4.9244 & TST & \\
\hline CHEMBL1435438 & 688128 & 4.0 & 4.7645 & TRN & \\
\hline CHEMBL1581689 & 688128 & 4.75 & 4.4314 & TRN & \\
\hline CHEMBL1317266 & 688128 & 4.35 & 4.6034 & TRN & \\
\hline CHEMBL3197458 & 688128 & 4.3 & 4.5888 & TRN & \\
\hline CHEMBL1471387 & 688128 & 4.1 & 4.7686 & TRN & \\
\hline CHEMBL1566572 & 688128 & 5.45 & 4.6546 & TRN & \\
\hline CHEMBL1308019 & 688128 & 4.3 & 4.7198 & TRN & \\
\hline CHEMBL1319496 & 688128 & 4.35 & 4.5879 & TST & \\
\hline CHEMBL1594574 & 688128 & 4.95 & 4.4881 & TRN & \\
\hline CHEMBL1477212 & 688128 & 5.6 & 5.1136 & TRN & \\
\hline CHEMBL1522348 & 688128 & 4.35 & 4.5088 & TRN & \\
\hline
\end{tabular}




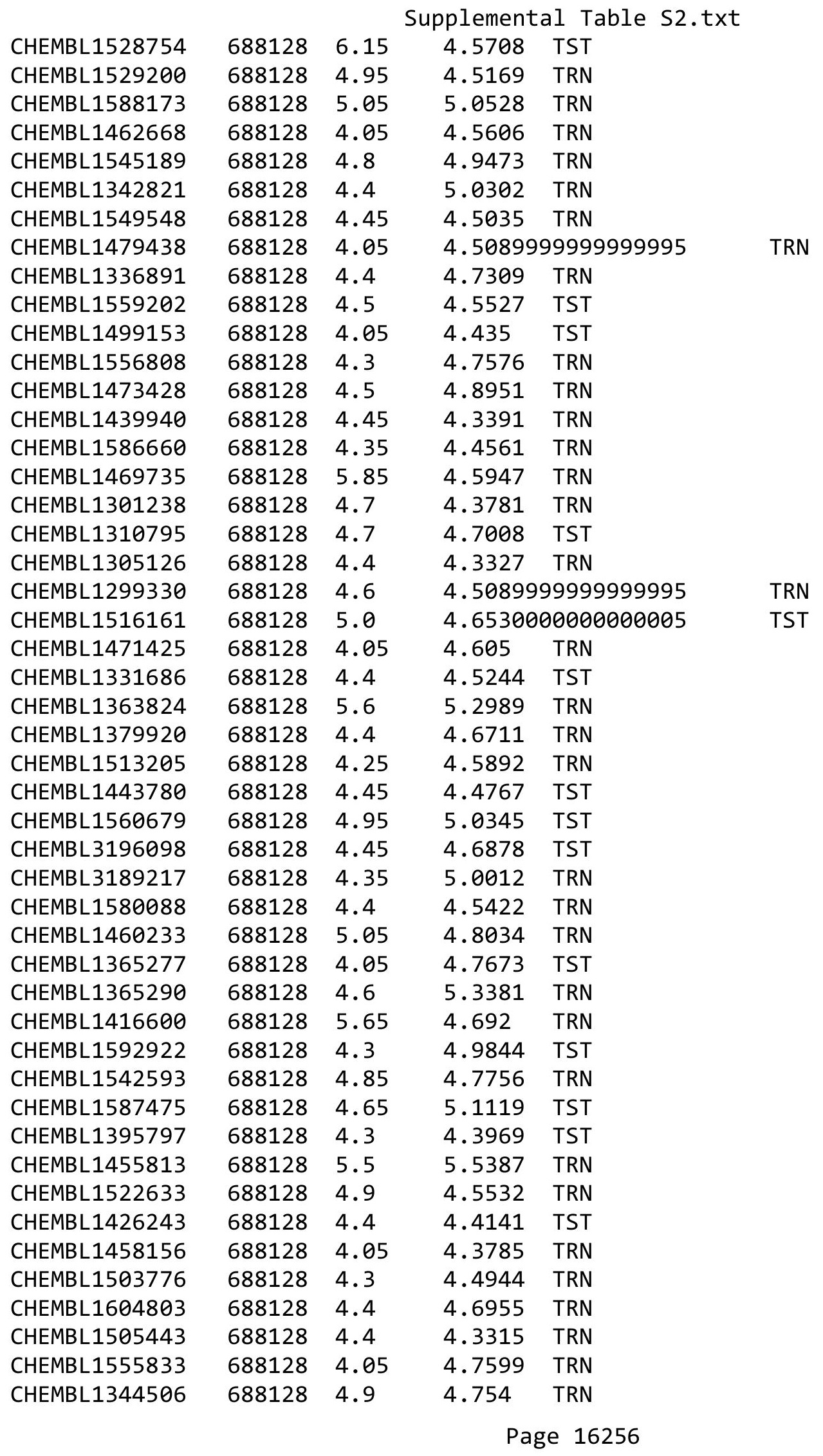




\begin{tabular}{|c|c|c|c|c|c|}
\hline CHEMBL1314042 & 688128 & 4.5 & \multicolumn{2}{|c|}{4.8260000000000005} & \multirow[t]{2}{*}{ TRN } \\
\hline CHEMBL1537618 & 688128 & 4.7 & 4.9525 & TRN & \\
\hline CHEMBL1315069 & 688128 & 4.35 & 4.7186 & TST & \\
\hline CHEMBL1410203 & 688128 & 4.35 & 4.6978 & TST & \\
\hline CHEMBL1338997 & 688128 & 4.1 & 4.3614 & TRN & \\
\hline CHEMBL1376216 & 688128 & 4.6 & 4.6452 & TRN & \\
\hline CHEMBL1343571 & 688128 & 4.45 & 4.6934 & TST & \\
\hline CHEMBL1396504 & 688128 & 6.1 & 4.8526 & TST & \\
\hline CHEMBL1516564 & 688128 & 4.05 & 4.3902 & TRN & \\
\hline CHEMBL467987 & 688128 & 5.25 & 5.0041 & TRN & \\
\hline CHEMBL1454987 & 688128 & 6.8499 & 4.6748 & TST & \\
\hline CHEMBL1379575 & 688128 & 4.4 & 4.4164 & TRN & \\
\hline CHEMBL1611938 & 688128 & 5.85 & 4.6659 & TRN & \\
\hline CHEMBL1399615 & 688128 & 4.3 & 4.7876 & TST & \\
\hline CHEMBL1488287 & 688128 & 4.95 & 4.7299 & TRN & \\
\hline CHEMBL1611283 & 688128 & 5.35 & 4.4461 & TRN & \\
\hline CHEMBL1519298 & 688128 & 6.3 & 5.2632 & TRN & \\
\hline CHEMBL1521901 & 688128 & 5.5 & 4.5816 & TRN & \\
\hline CHEMBL1547715 & 688128 & 4.65 & 4.8962 & TRN & \\
\hline CHEMBL1535042 & 688128 & 4.35 & 4.7337 & TRN & \\
\hline CHEMBL1374214 & 688128 & 4.4 & 4.2953 & TRN & \\
\hline CHEMBL1581951 & 688128 & 4.5 & 4.8646 & TST & \\
\hline CHEMBL1516808 & 688128 & 4.75 & 4.8373 & TRN & \\
\hline CHEMBL1307052 & 688128 & 5.15 & 4.6237 & TRN & \\
\hline CHEMBL1546756 & 688128 & 4.4 & 4.8244 & TST & \\
\hline CHEMBL1306461 & 688128 & 4.15 & 4.8575 & TRN & \\
\hline CHEMBL1611654 & 688128 & 4.55 & 4.6314 & TST & \\
\hline CHEMBL1411288 & 688128 & 4.55 & 4.4768 & TRN & \\
\hline CHEMBL1373732 & 688128 & 4.4 & 5.0698 & TRN & \\
\hline CHEMBL1310907 & 688128 & 4.3 & 4.5023 & TRN & \\
\hline CHEMBL1340843 & 688128 & 5.05 & 4.966 & TRN & \\
\hline CHEMBL1561215 & 688128 & 5.5 & 5.2826 & TRN & \\
\hline CHEMBL172439 & 688128 & 4.85 & 4.9373 & TST & \\
\hline CHEMBL1382121 & 688128 & 6.8499 & 4.7433 & TRN & \\
\hline CHEMBL1479517 & 688128 & 4.05 & 4.7711 & TST & \\
\hline CHEMBL1541295 & 688128 & 5.05 & 5.12799 & 9999999999 & TRN \\
\hline CHEMBL1426342 & 688128 & 4.45 & 4.356 & TRN & \\
\hline CHEMBL1516549 & 688128 & 4.65 & 4.6803 & TRN & \\
\hline CHEMBL1505563 & 688128 & 4.5 & 4.782 & TRN & \\
\hline CHEMBL3189971 & 688128 & 4.55 & 4.6235 & TST & \\
\hline CHEMBL1469285 & 688128 & 4.45 & 4.7457 & TRN & \\
\hline CHEMBL1423496 & 688128 & 4.5 & 4.9924 & TST & \\
\hline CHEMBL1595651 & 688128 & 4.35 & 4.4698 & TRN & \\
\hline CHEMBL1408033 & 688128 & 4.25 & 4.4607 & TRN & \\
\hline CHEMBL1986259 & 688128 & 4.35 & 4.9511 & TRN & \\
\hline CHEMBL1351716 & 688128 & 4.6 & 4.4676 & TRN & \\
\hline CHEMBL1379137 & 688128 & 4.65 & 4.7092 & TRN & \\
\hline CHEMBL1574530 & 688128 & 4.55 & 4.9994 & TRN & \\
\hline & & & & 16257 & \\
\hline
\end{tabular}




\begin{tabular}{|c|c|c|c|c|c|}
\hline \multicolumn{6}{|c|}{ Supplemental Table s2.txt } \\
\hline CHEMBL1392909 & 688128 & 4.7 & 4.6211 & TRN & \\
\hline CHEMBL1415540 & 688128 & 5.1 & 4.8502 & TST & \\
\hline CHEMBL1410403 & 688128 & 4.4 & 4.4362 & TRN & \\
\hline CHEMBL1338369 & 688128 & 5.7 & 4.5327 & TRN & \\
\hline CHEMBL1367913 & 688128 & 4.25 & 4.6336 & TRN & \\
\hline CHEMBL1368460 & 688128 & 4.7 & 4.6672 & TRN & \\
\hline CHEMBL1594321 & 688128 & 6.0 & 4.8944 & TRN & \\
\hline CHEMBL1592488 & 688128 & 4.05 & 4.7768 & TRN & \\
\hline CHEMBL1575101 & 688128 & 4.35 & 4.6812 & TRN & \\
\hline CHEMBL 1446450 & 688128 & 4.35 & 4.4853 & TST & \\
\hline CHEMBL1435546 & 688128 & 4.4 & 4.6481 & TRN & \\
\hline CHEMBL1396614 & 688128 & 5.6 & 4.5313 & TRN & \\
\hline CHEMBL1324227 & 688128 & 4.3 & 4.4034 & TRN & \\
\hline CHEMBL1584010 & 688128 & 4.4 & 4.7117 & TST & \\
\hline CHEMBL1496179 & 688128 & 4.3 & 4.6444 & TRN & \\
\hline CHEMBL1605817 & 688128 & 4.35 & 4.59699 & 99999999995 & TRN \\
\hline CHEMBL1421573 & 688128 & 6.5501 & 4.6247 & TRN & \\
\hline CHEMBL1503617 & 688128 & 4.3 & 4.4827 & TRN & \\
\hline CHEMBL1442031 & 688128 & 4.75 & 4.8289 & TRN & \\
\hline CHEMBL1447737 & 688128 & 5.1 & 4.8099 & TRN & \\
\hline CHEMBL1560176 & 688128 & 4.35 & 4.2366 & TRN & \\
\hline CHEMBL1460572 & 688128 & 4.45 & 4.8959 & TST & \\
\hline CHEMBL1970627 & 688128 & 4.55 & 4.7669 & TRN & \\
\hline CHEMBL 3194495 & 688128 & 4.3 & 4.5361 & TRN & \\
\hline CHEMBL1394467 & 688128 & 4.3 & 4.7789 & TST & \\
\hline CHEMBL1494255 & 688128 & 5.1 & 5.11100 & 0000000001 & TRN \\
\hline CHEMBL1542510 & 688128 & 4.7 & 4.9242 & TRN & \\
\hline CHEMBL1483646 & 688128 & 4.05 & 4.5699 & TRN & \\
\hline CHEMBL1557038 & 688128 & 4.3 & 4.5326 & TST & \\
\hline CHEMBL1542953 & 688128 & 4.3 & 4.2387 & TRN & \\
\hline CHEMBL1558086 & 688128 & 4.3 & 4.5389 & TRN & \\
\hline CHEMBL1500317 & 688128 & 4.5 & 4.4695 & TRN & \\
\hline CHEMBL1428232 & 688128 & 4.45 & 4.628 & TST & \\
\hline CHEMBL1394948 & 688128 & 5.5 & 4.6037 & TRN & \\
\hline CHEMBL1441909 & 688128 & 6.0 & 4.8639 & TRN & \\
\hline CHEMBL1520496 & 688128 & 4.35 & 4.6307 & TRN & \\
\hline CHEMBL 1357708 & 688128 & 4.45 & 4.7123 & TRN & \\
\hline CHEMBL1523496 & 688128 & 5.35 & 4.4897 & TST & \\
\hline CHEMBL1487945 & 688128 & 4.4 & 4.695 & TRN & \\
\hline CHEMBL1322241 & 688128 & 5.5 & 4.6371 & TRN & \\
\hline CHEMBL1325208 & 688128 & 6.1 & 4.6723 & TST & \\
\hline CHEMBL1499201 & 688128 & 4.25 & 4.5054 & TRN & \\
\hline CHEMBL1601688 & 688128 & 4.3 & 4.913 & TRN & \\
\hline CHEMBL212504 & 688128 & 6.1 & 4.9542 & TRN & \\
\hline CHEMBL1368835 & 688128 & 4.45 & 4.5971 & TRN & \\
\hline CHEMBL1321798 & 688128 & 4.05 & 4.3494 & TRN & \\
\hline CHEMBL1372732 & 688128 & 4.55 & 4.7275 & TST & \\
\hline CHEMBL1973773 & 688128 & 4.65 & 4.6707 & TST & \\
\hline
\end{tabular}




\begin{tabular}{|c|c|c|c|c|}
\hline \multicolumn{5}{|c|}{ Supplemental Table S2.txt } \\
\hline CHEMBL1354046 & 688128 & 5.15 & 4.912 & TRN \\
\hline CHEMBL3212973 & 688128 & 4.4 & 4.6714 & TST \\
\hline CHEMBL1307438 & 688128 & 4.05 & 4.3832 & TRN \\
\hline CHEMBL1407561 & 688128 & 4.9 & 4.5567 & TRN \\
\hline CHEMBL1531315 & 688128 & 4.45 & 4.7375 & TRN \\
\hline CHEMBL2373675 & 688128 & 4.95 & 4.9077 & TRN \\
\hline CHEMBL1342138 & 688128 & 4.1 & 4.4615 & TRN \\
\hline CHEMBL1530696 & 688128 & 3.95 & 4.7115 & TRN \\
\hline CHEMBL1572906 & 688128 & 4.1 & 4.5164 & TRN \\
\hline CHEMBL1611341 & 688128 & 4.35 & 4.5851 & TRN \\
\hline CHEMBL3189691 & 688128 & 4.4 & 4.6842 & TRN \\
\hline CHEMBL1593846 & 688128 & 4.9 & 4.7639 & TRN \\
\hline CHEMBL1310756 & 688128 & 4.4 & 4.4884 & TRN \\
\hline CHEMBL1984298 & 688128 & 4.35 & 5.0235 & TRN \\
\hline CHEMBL1446693 & 688128 & 5.0 & 4.5948 & TRN \\
\hline CHEMBL1609022 & 688128 & 4.05 & 4.5417 & TRN \\
\hline CHEMBL1557812 & 688128 & 5.7 & 4.9732 & TRN \\
\hline CHEMBL1485753 & 688128 & 6.15 & 4.7094 & TRN \\
\hline CHEMBL1456188 & 688128 & 4.4 & 4.6476 & TRN \\
\hline CHEMBL1522940 & 688128 & 4.3 & 4.7093 & TRN \\
\hline CHEMBL1555542 & 688128 & 4.65 & 4.4899 & TRN \\
\hline CHEMBL1570157 & 688128 & 4.25 & 4.9675 & TRN \\
\hline CHEMBL227432 & 688128 & 4.35 & 4.4409 & TRN \\
\hline CHEMBL1536461 & 688128 & 5.0 & 4.9008 & TRN \\
\hline CHEMBL1560328 & 688128 & 4.1 & 4.4514 & TST \\
\hline CHEMBL1524732 & 688128 & 4.35 & 4.6062 & TST \\
\hline CHEMBL1533875 & 688128 & 4.05 & 4.5352 & TRN \\
\hline CHEMBL1328575 & 688128 & 4.25 & 4.6317 & TRN \\
\hline CHEMBL1464481 & 688128 & 4.4 & 4.5436 & TRN \\
\hline CHEMBL1347821 & 688128 & 4.05 & 4.5632 & TRN \\
\hline CHEMBL1462228 & 688128 & 6.05 & 4.6725 & TST \\
\hline CHEMBL1547493 & 688128 & 4.75 & 4.2624 & TRN \\
\hline CHEMBL1610681 & 688128 & 4.45 & 4.6497 & TRN \\
\hline CHEMBL1578430 & 688128 & 5.35 & 4.5398 & TRN \\
\hline CHEMBL1398241 & 688128 & 4.4 & 4.5585 & TRN \\
\hline CHEMBL1373646 & 688128 & 5.65 & 4.7093 & TRN \\
\hline CHEMBL1318344 & 688128 & 4.3 & 4.5042 & TRN \\
\hline CHEMBL1609934 & 688128 & 4.3 & 4.4401 & TRN \\
\hline CHEMBL1314824 & 688128 & 4.25 & 4.6795 & TRN \\
\hline CHEMBL1579811 & 688128 & 5.1 & 4.8172 & TRN \\
\hline CHEMBL1423435 & 688128 & 4.7 & 4.803 & TRN \\
\hline CHEMBL3190086 & 688128 & 4.3 & 4.5698 & TST \\
\hline CHEMBL1372330 & 688128 & 4.5 & 4.7618 & TRN \\
\hline CHEMBL1354219 & 688128 & 4.9 & 4.7497 & TRN \\
\hline CHEMBL3190976 & 688128 & 5.55 & 4.9007 & TRN \\
\hline CHEMBL1546861 & 688128 & 4.4 & 4.4936 & TRN \\
\hline CHEMBL1506083 & 688128 & 4.4 & 4.2921 & TRN \\
\hline CHEMBL2369312 & 688128 & 5.15 & 4.9136 & TST \\
\hline
\end{tabular}




\begin{tabular}{|c|c|c|c|c|c|}
\hline \\
\hline CHEMBL1563623 & 688128 & 4.95 & 5.0338 & TRN & \\
\hline CHEMBL1301555 & 688128 & 5.15 & 4.765 & TST & \\
\hline CHEMBL1598899 & 688128 & 4.05 & 4.427 & TRN & \\
\hline CHEMBL1306755 & 688128 & 4.35 & 4.5337 & TRN & \\
\hline CHEMBL1602713 & 688128 & 4.35 & 4.4741 & TRN & \\
\hline CHEMBL1366936 & 688128 & 4.35 & 4.3136 & TRN & \\
\hline CHEMBL1458298 & 688128 & 4.05 & 4.5593 & TRN & \\
\hline CHEMBL1379958 & 688128 & 4.35 & 4.53100 & 3000000001 & TRN \\
\hline CHEMBL1578143 & 688128 & 4.4 & 4.479 & TRN & \\
\hline CHEMBL1497581 & 688128 & 4.55 & 4.5252 & TRN & \\
\hline CHEMBL1349862 & 688128 & 4.35 & 4.684 & TRN & \\
\hline CHEMBL1410496 & 688128 & 4.75 & 4.5095 & TRN & \\
\hline CHEMBL1343623 & 688128 & 5.45 & 4.7117 & TRN & \\
\hline CHEMBL1551899 & 688128 & 4.5 & 4.907 & TRN & \\
\hline CHEMBL1345692 & 688128 & 5.75 & 5.1252 & TRN & \\
\hline CHEMBL1491473 & 688128 & 4.25 & 4.6143 & TRN & \\
\hline CHEMBL1525111 & 688128 & 4.3 & 4.6742 & TRN & \\
\hline CHEMBL1488827 & 688128 & 4.75 & 4.6778 & TRN & \\
\hline CHEMBL1885024 & 688128 & 4.35 & 4.7651 & TST & \\
\hline CHEMBL3189778 & 688128 & 4.75 & 4.5068 & TST & \\
\hline CHEMBL1440303 & 688128 & 6.5 & 5.4061 & TRN & \\
\hline CHEMBL1501724 & 688128 & 4.4 & 4.8908 & TST & \\
\hline CHEMBL1424559 & 688128 & 6.8 & 4.92399 & 99999999995 & TRN \\
\hline CHEMBL1416201 & 688128 & 4.4 & 4.6043 & TST & \\
\hline CHEMBL1401109 & 688128 & 4.55 & 4.8071 & TRN & \\
\hline CHEMBL211969 & 688128 & 6.5501 & 4.9853 & TRN & \\
\hline CHEMBL1579037 & 688128 & 7.0 & 4.6726 & TRN & \\
\hline CHEMBL1452126 & 688128 & 4.35 & 4.6613 & TRN & \\
\hline CHEMBL1333035 & 688128 & 4.25 & 4.7109 & TST & \\
\hline CHEMBL1328137 & 688128 & 4.35 & 4.545 & TRN & \\
\hline CHEMBL1992234 & 688128 & 4.05 & 4.8469 & TST & \\
\hline CHEMBL1450872 & 688128 & 4.75 & 4.7519 & TRN & \\
\hline CHEMBL1542108 & 688128 & 4.0 & 4.5888 & TRN & \\
\hline CHEMBL3191275 & 688128 & 5.0 & 4.4818 & TRN & \\
\hline CHEMBL1488761 & 688128 & 4.4 & 4.6412 & TST & \\
\hline CHEMBL1567283 & 688128 & 4.3 & 4.6692 & TRN & \\
\hline CHEMBL1496635 & 688128 & 4.35 & 4.5966 & TST & \\
\hline CHEMBL1352441 & 688128 & 4.35 & 4.3922 & TRN & \\
\hline CHEMBL1481315 & 688128 & 4.2 & 4.5125 & TST & \\
\hline CHEMBL1327853 & 688128 & 4.75 & 4.7104 & TRN & \\
\hline CHEMBL1364206 & 688128 & 4.35 & 4.7235 & TRN & \\
\hline CHEMBL1509819 & 688128 & 4.5 & 4.7286 & TRN & \\
\hline CHEMBL1392809 & 688128 & 6.0 & 4.7651 & TRN & \\
\hline CHEMBL1416540 & 688128 & 4.4 & 4.4846 & TST & \\
\hline CHEMBL1458658 & 688128 & 4.6 & 4.5228 & TRN & \\
\hline CHEMBL1302637 & 688128 & 4.4 & 4.931 & TRN & \\
\hline CHEMBL1340285 & 688128 & 4.95 & 4.7901 & TRN & \\
\hline CHEMBL1550317 & 688128 & 4.95 & 4.5078 & TRN & \\
\hline
\end{tabular}




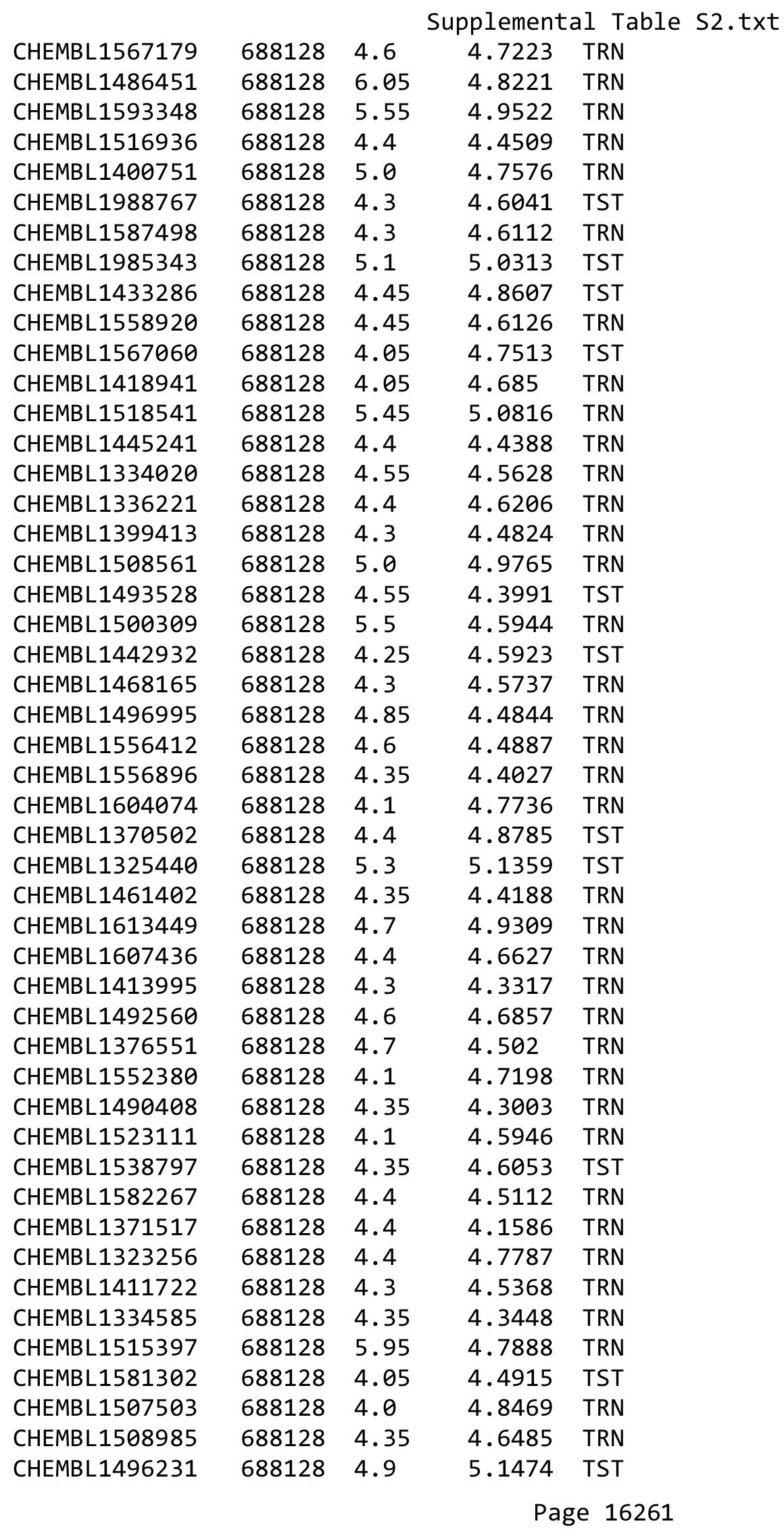




\begin{tabular}{|c|c|c|c|c|}
\hline \multicolumn{5}{|c|}{ Supplemental Table S2.txt } \\
\hline CHEMBL1563483 & 688128 & 5.65 & 4.9639 & TST \\
\hline CHEMBL1602872 & 688128 & 4.35 & 4.5468 & TRN \\
\hline CHEMBL1572766 & 688128 & 4.25 & 4.6176 & TRN \\
\hline CHEMBL1334573 & 688128 & 4.05 & 4.542 & TST \\
\hline CHEMBL1598331 & 688128 & 6.1 & 4.9746 & TRN \\
\hline CHEMBL1384091 & 688128 & 4.0 & 4.8012 & TRN \\
\hline CHEMBL1344293 & 688128 & 4.3 & 4.702 & TRN \\
\hline CHEMBL1554764 & 688128 & 4.3 & 4.5749 & TRN \\
\hline CHEMBL1413964 & 688128 & 4.85 & 4.3243 & TRN \\
\hline CHEMBL1496284 & 688128 & 4.65 & 4.5762 & TST \\
\hline CHEMBL1524516 & 688128 & 4.3 & 4.5475 & TRN \\
\hline CHEMBL1327199 & 688128 & 5.45 & 4.5179 & TRN \\
\hline CHEMBL1344968 & 688128 & 4.6 & 4.5981 & TRN \\
\hline CHEMBL1542495 & 688128 & 4.4 & 4.6879 & TRN \\
\hline CHEMBL1494486 & 688128 & 4.5 & 4.3625 & TRN \\
\hline CHEMBL1399894 & 688128 & 5.25 & 4.5443 & TRN \\
\hline CHEMBL1518826 & 688128 & 4.35 & 4.7662 & TRN \\
\hline CHEMBL1362569 & 688128 & 4.3 & 4.9273 & TRN \\
\hline CHEMBL1440993 & 688128 & 4.3 & 4.5988 & TRN \\
\hline CHEMBL1547684 & 688128 & 4.75 & 4.7387 & TST \\
\hline CHEMBL1479159 & 688128 & 4.5 & 4.4818 & TRN \\
\hline CHEMBL1379433 & 688128 & 4.65 & 4.6915 & TRN \\
\hline CHEMBL1334541 & 688128 & 4.85 & 4.6158 & TRN \\
\hline CHEMBL1462001 & 688128 & 5.0 & 5.0032 & TRN \\
\hline CHEMBL1514949 & 688128 & 4.2 & 4.2933 & TRN \\
\hline CHEMBL1604019 & 688128 & 5.0 & 4.4425 & TRN \\
\hline CHEMBL1326115 & 688128 & 5.65 & 4.7869 & TRN \\
\hline CHEMBL3190756 & 688128 & 4.75 & 4.6222 & TST \\
\hline CHEMBL3196134 & 688128 & 4.25 & 4.7959 & TRN \\
\hline CHEMBL1341790 & 688128 & 4.35 & 5.1747 & TRN \\
\hline CHEMBL1540782 & 688128 & 6.25 & 4.5769 & TRN \\
\hline CHEMBL1434886 & 688128 & 5.15 & 5.2043 & TRN \\
\hline CHEMBL3196933 & 688128 & 4.1 & 4.7858 & TRN \\
\hline CHEMBL1588482 & 688128 & 6.45 & 4.148 & TST \\
\hline CHEMBL3192999 & 688128 & 5.3 & 4.8737 & TRN \\
\hline CHEMBL1494685 & 688128 & 4.55 & 4.3466 & TRN \\
\hline CHEMBL1349858 & 688128 & 4.5 & 4.654 & TST \\
\hline CHEMBL1302773 & 688128 & 4.3 & 4.6899 & TRN \\
\hline CHEMBL1573195 & 688128 & 4.05 & 4.4324 & TRN \\
\hline CHEMBL1499314 & 688128 & 4.5 & 4.4358 & TRN \\
\hline CHEMBL 246957 & 688128 & 4.25 & 4.947 & TST \\
\hline CHEMBL1348385 & 688128 & 4.75 & 4.51 & TRN \\
\hline CHEMBL576607 & 688128 & 4.7 & 4.6595 & TRN \\
\hline CHEMBL1400696 & 688128 & 5.5 & 4.2831 & TRN \\
\hline CHEMBL1436178 & 688128 & 4.25 & 4.4796 & TST \\
\hline CHEMBL1398923 & 688128 & 4.35 & 4.5888 & TST \\
\hline CHEMBL1465778 & 688128 & 4.05 & 4.5942 & TST \\
\hline CHEMBL1329724 & 688128 & 4.95 & 4.6801 & TST \\
\hline
\end{tabular}




\begin{tabular}{|c|c|c|c|c|c|}
\hline \multicolumn{6}{|c|}{ supplemental Iable S2.tx } \\
\hline CHEMBL1597379 & 688128 & 4.25 & 4.6203 & TRN & \\
\hline CHEMBL1581396 & 688128 & 5.5 & 4.7879 & TRN & \\
\hline CHEMBL1316842 & 688128 & 4.4 & 4.4942 & TST & \\
\hline CHEMBL1480679 & 688128 & 4.3 & 4.6592 & TST & \\
\hline CHEMBL1542449 & 688128 & 4.4 & 5.05699 & 99999999995 & TRN \\
\hline CHEMBL1460141 & 688128 & 6.0 & 5.056 & TST & \\
\hline CHEMBL1368210 & 688128 & 4.35 & 4.6123 & TRN & \\
\hline CHEMBL1299727 & 688128 & 4.4 & 4.6401 & TRN & \\
\hline CHEMBL3196102 & 688128 & 5.9 & 4.4381 & TST & \\
\hline CHEMBL1368377 & 688128 & 4.4 & 4.3194 & TRN & \\
\hline CHEMBL1508694 & 688128 & 4.4 & 4.6277 & TST & \\
\hline CHEMBL1361071 & 688128 & 4.45 & 4.9225 & TST & \\
\hline CHEMBL1318742 & 688128 & 5.05 & 4.4383 & TRN & \\
\hline CHEMBL1304799 & 688128 & 4.6 & 4.916 & TST & \\
\hline CHEMBL1535279 & 688128 & 4.3 & 4.5982 & TRN & \\
\hline CHEMBL1423714 & 688128 & 4.45 & 4.5004 & TST & \\
\hline CHEMBL1299236 & 688128 & 4.55 & 4.6864 & TST & \\
\hline CHEMBL1448517 & 688128 & 4.05 & 4.5888 & TRN & \\
\hline CHEMBL1985598 & 688128 & 4.3 & 4.717 & TRN & \\
\hline CHEMBL1335509 & 688128 & 4.1 & 4.7421 & TRN & \\
\hline CHEMBL1527644 & 688128 & 4.15 & 4.7628 & TST & \\
\hline CHEMBL1400910 & 688128 & 4.3 & 4.6454 & TRN & \\
\hline CHEMBL1538057 & 688128 & 4.9 & 4.3743 & TST & \\
\hline CHEMBL1596272 & 688128 & 4.05 & 4.5879 & TRN & \\
\hline CHEMBL1610224 & 688128 & 5.0 & 5.1393 & TRN & \\
\hline CHEMBL1572533 & 688128 & 5.05 & 4.565 & TRN & \\
\hline CHEMBL1331291 & 688128 & 4.55 & 4.6001 & TRN & \\
\hline CHEMBL1345456 & 688128 & 4.4 & 4.6607 & TRN & \\
\hline CHEMBL1603507 & 688128 & 4.05 & 4.5228 & TRN & \\
\hline CHEMBL1365696 & 688128 & 5.7 & 5.2682 & TRN & \\
\hline CHEMBL1312956 & 688128 & 4.9 & 4.3687 & TRN & \\
\hline CHEMBL1445461 & 688128 & 5.5 & 4.8084 & TRN & \\
\hline CHEMBL1317972 & 688128 & 4.3 & 4.7925 & TRN & \\
\hline CHEMBL1596605 & 688128 & 4.45 & 4.4702 & TRN & \\
\hline CHEMBL1527013 & 688128 & 4.6 & 4.6086 & TRN & \\
\hline CHEMBL1311762 & 688128 & 4.6 & 4.5537 & TRN & \\
\hline CHEMBL1339808 & 688128 & 5.05 & 4.8203 & TRN & \\
\hline CHEMBL1374536 & 688128 & 5.2 & 4.9658 & TRN & \\
\hline CHEMBL1374212 & 688128 & 4.4 & 4.3489 & TRN & \\
\hline CHEMBL1319713 & 688128 & 4.4 & 4.4598 & TRN & \\
\hline CHEMBL1300209 & 688128 & 4.4 & 4.7782 & TST & \\
\hline CHEMBL1302851 & 688128 & 5.0 & 4.3089 & TRN & \\
\hline CHEMBL1455556 & 688128 & 5.5 & 4.9938 & TRN & \\
\hline CHEMBL1562504 & 688128 & 4.85 & 4.8149 & TRN & \\
\hline CHEMBL1407128 & 688128 & 4.85 & 4.8887 & TRN & \\
\hline CHEMBL1438801 & 688128 & 5.15 & 4.6711 & TRN & \\
\hline CHEMBL1450679 & 688128 & 4.95 & 4.7826 & TRN & \\
\hline CHEMBL1465511 & 688128 & 4.7 & 5.1767 & TRN & \\
\hline
\end{tabular}




\begin{tabular}{|c|c|c|c|c|}
\hline \multicolumn{5}{|c|}{ Supplemental Table S2.txt } \\
\hline CHEMBL1321073 & 688128 & 4.4 & 4.4954 & TRN \\
\hline CHEMBL1436692 & 688128 & 4.45 & 4.4427 & TRN \\
\hline CHEMBL1467629 & 688128 & 4.9 & 4.7878 & TRN \\
\hline CHEMBL1319385 & 688128 & 4.3 & 4.8485 & TST \\
\hline CHEMBL1308117 & 688128 & 4.0 & 4.4736 & TRN \\
\hline CHEMBL1370841 & 688128 & 4.4 & 4.5979 & TRN \\
\hline CHEMBL1422657 & 688128 & 4.4 & 4.6984 & TRN \\
\hline CHEMBL1472804 & 688128 & 4.4 & 4.7028 & TRN \\
\hline CHEMBL1463976 & 688128 & 6.4 & 4.4851 & TST \\
\hline CHEMBL1526938 & 688128 & 4.4 & 4.5231 & TRN \\
\hline CHEMBL1597945 & 688128 & 4.5 & 4.6238 & TST \\
\hline CHEMBL1405801 & 688128 & 4.5 & 4.9843 & TRN \\
\hline CHEMBL1341336 & 688128 & 4.3 & 4.6065 & TST \\
\hline CHEMBL1392431 & 688128 & 4.4 & 4.3958 & TRN \\
\hline CHEMBL1442518 & 688128 & 4.45 & 4.7012 & TRN \\
\hline CHEMBL3211461 & 688128 & 4.4 & 4.6658 & TST \\
\hline CHEMBL1523558 & 688128 & 4.05 & 4.6293 & TRN \\
\hline CHEMBL1466674 & 688128 & 4.4 & 4.6945 & TRN \\
\hline CHEMBL1608406 & 688128 & 4.3 & 4.5835 & TRN \\
\hline CHEMBL1299914 & 688128 & 4.55 & 4.785 & TRN \\
\hline CHEMBL1608853 & 688128 & 5.15 & 5.0257 & TST \\
\hline CHEMBL1307622 & 688128 & 5.55 & 4.7958 & TRN \\
\hline CHEMBL1395041 & 688128 & 4.1 & 4.604 & TRN \\
\hline CHEMBL1523984 & 688128 & 4.4 & 4.6007 & TRN \\
\hline CHEMBL1598710 & 688128 & 4.05 & 4.5683 & TRN \\
\hline CHEMBL1478582 & 688128 & 4.35 & 4.5118 & TRN \\
\hline CHEMBL450516 & 688128 & 4.05 & 4.7471 & TST \\
\hline CHEMBL1581211 & 688128 & 4.25 & 4.7446 & TST \\
\hline CHEMBL1342867 & 688128 & 4.35 & 4.8464 & TST \\
\hline CHEMBL3194594 & 688128 & 5.0 & 4.6138 & TRN \\
\hline CHEMBL1541373 & 688128 & 4.0 & 4.38 & TRN \\
\hline CHEMBL1421895 & 688128 & 4.5 & 4.6515 & TST \\
\hline CHEMBL1440508 & 688128 & 5.05 & 4.4614 & TRN \\
\hline CHEMBL1348074 & 688128 & 4.25 & 4.8303 & TRN \\
\hline CHEMBL1452137 & 688128 & 4.5 & 4.5679 & TRN \\
\hline CHEMBL3195786 & 688128 & 4.05 & 4.4936 & TST \\
\hline CHEMBL1324832 & 688128 & 4.3 & 4.7361 & TRN \\
\hline CHEMBL1518812 & 688128 & 4.35 & 4.3681 & TRN \\
\hline CHEMBL1373174 & 688128 & 4.25 & 4.6428 & TRN \\
\hline CHEMBL1536304 & 688128 & 5.2 & 4.9443 & TRN \\
\hline CHEMBL1557485 & 688128 & 4.05 & 4.9723 & TST \\
\hline CHEMBL1515772 & 688128 & 4.4 & 4.5525 & TRN \\
\hline CHEMBL1484309 & 688128 & 4.75 & 4.7281 & TRN \\
\hline CHEMBL1342396 & 688128 & 4.9 & 4.6093 & TRN \\
\hline CHEMBL1426107 & 688128 & 4.75 & 4.4113 & TRN \\
\hline CHEMBL1482264 & 688128 & 4.35 & 4.7196 & TST \\
\hline CHEMBL1575422 & 688128 & 5.75 & 4.7307 & TRN \\
\hline CHEMBL1543431 & 688128 & 5.0 & 4.6979 & TRN \\
\hline
\end{tabular}




\begin{tabular}{|c|c|c|c|c|c|}
\hline & & & & & \\
\hline CHEMBL1490683 & 688128 & 4.3 & 4.5506 & TRN & \\
\hline CHEMBL1535354 & 688128 & 4.9 & 4.7015 & TST & \\
\hline CHEMBL1303989 & 688128 & 4.5 & 4.3074 & TRN & \\
\hline CHEMBL1395700 & 688128 & 4.9 & 4.6656 & TRN & \\
\hline CHEMBL1364999 & 688128 & 4.9 & 4.5991 & TST & \\
\hline CHEMBL3198837 & 688128 & 4.9 & 4.8416 & TRN & \\
\hline CHEMBL1520783 & 688128 & 4.3 & 4.7336 & TST & \\
\hline CHEMBL1576150 & 688128 & 4.7 & 4.64199 & 99999999995 & TRN \\
\hline CHEMBL1388528 & 688128 & 4.35 & 4.6201 & TRN & \\
\hline CHEMBL1482344 & 688128 & 5.85 & 4.8582 & TRN & \\
\hline CHEMBL1602297 & 688128 & 5.25 & 4.5385 & TRN & \\
\hline CHEMBL1393229 & 688128 & 4.05 & 4.4324 & TRN & \\
\hline CHEMBL1567527 & 688128 & 4.45 & 4.9138 & TRN & \\
\hline CHEMBL1345117 & 688128 & 4.05 & 4.5056 & TRN & \\
\hline CHEMBL1570983 & 688128 & 4.25 & 4.734 & TST & \\
\hline CHEMBL1435505 & 688128 & 5.5 & 4.4988 & TRN & \\
\hline CHEMBL1336582 & 688128 & 4.05 & 4.6674 & TST & \\
\hline CHEMBL1517441 & 688128 & 4.25 & 4.5499 & TRN & \\
\hline CHEMBL1589201 & 688128 & 4.05 & 4.5823 & TRN & \\
\hline CHEMBL1450238 & 688128 & 5.55 & 4.6127 & TST & \\
\hline CHEMBL1543340 & 688128 & 5.6 & 4.7063 & TRN & \\
\hline CHEMBL3191858 & 688128 & 4.35 & 4.5536 & TRN & \\
\hline CHEMBL1561586 & 688128 & 4.35 & 4.3027 & TRN & \\
\hline CHEMBL1463050 & 688128 & 5.5 & 4.6883 & TST & \\
\hline CHEMBL1464837 & 688128 & 4.4 & 4.5608 & TRN & \\
\hline CHEMBL1496850 & 688128 & 4.05 & 4.7022 & TRN & \\
\hline CHEMBL1355854 & 688128 & 4.35 & 4.78600 & 20000000005 & TRN \\
\hline CHEMBL1552473 & 688128 & 4.6 & 4.7646 & TST & \\
\hline CHEMBL1353221 & 688128 & 5.65 & 4.7194 & TST & \\
\hline CHEMBL1362353 & 688128 & 4.35 & 4.5093 & TST & \\
\hline CHEMBL1569998 & 688128 & 4.05 & 4.4569 & TRN & \\
\hline CHEMBL1448474 & 688128 & 4.6 & 4.5618 & TRN & \\
\hline CHEMBL1338409 & 688128 & 4.35 & 4.657 & TRN & \\
\hline CHEMBL1423322 & 688128 & 4.35 & 4.4945 & TRN & \\
\hline CHEMBL1432936 & 688128 & 4.7 & 4.5498 & TST & \\
\hline CHEMBL1440527 & 688128 & 4.35 & 4.7661 & TRN & \\
\hline CHEMBL1398522 & 688128 & 4.4 & 4.8264 & TRN & \\
\hline CHEMBL1312513 & 688128 & 4.5 & 4.5075 & TRN & \\
\hline CHEMBL1566800 & 688128 & 4.5 & 4.604 & TRN & \\
\hline CHEMBL1536623 & 688128 & 4.3 & 4.8218 & TRN & \\
\hline CHEMBL1497692 & 688128 & 4.4 & 4.6108 & TRN & \\
\hline CHEMBL1441386 & 688128 & 4.45 & 4.4663 & TRN & \\
\hline CHEMBL1325690 & 688128 & 4.4 & 4.2886 & TRN & \\
\hline CHEMBL1457236 & 688128 & 5.15 & 4.5418 & TRN & \\
\hline CHEMBL1528385 & 688128 & 4.35 & 4.7618 & TST & \\
\hline CHEMBL1386854 & 688128 & 4.3 & 4.4074 & TRN & \\
\hline CHEMBL1520507 & 688128 & 6.45 & 4.8284 & TST & \\
\hline CHEMBL1379200 & 688128 & 4.35 & 4.631 & TRN & \\
\hline & & & & 16265 & \\
\hline
\end{tabular}




\begin{tabular}{|c|c|c|c|c|c|}
\hline & & \multicolumn{4}{|c|}{ Supplemental Table s2.txt } \\
\hline CHEMBL1418358 & 688128 & 4.95 & 4.7081 & TRN & \\
\hline CHEMBL1497604 & 688128 & 4.3 & 4.6088 & TRN & \\
\hline CHEMBL1354540 & 688128 & 4.1 & 4.99 & TRN & \\
\hline CHEMBL1567599 & 688128 & 4.9 & 4.4563 & TRN & \\
\hline CHEMBL1606039 & 688128 & 4.5 & 4.7295 & TRN & \\
\hline CHEMBL1548253 & 688128 & 5.45 & 4.7019 & TRN & \\
\hline CHEMBL1457293 & 688128 & 4.4 & 4.6072 & TRN & \\
\hline CHEMBL1430678 & 688128 & 4.9 & 4.6754 & TRN & \\
\hline CHEMBL1491255 & 688128 & 4.4 & 4.7918 & TRN & \\
\hline CHEMBL1501898 & 688128 & 5.5 & 5.0232 & TST & \\
\hline CHEMBL1518374 & 688128 & 5.3 & 4.67899 & 9999999999 & TRN \\
\hline CHEMBL1477399 & 688128 & 4.35 & 4.4125 & TRN & \\
\hline CHEMBL1612112 & 688128 & 4.9 & 4.7818 & TRN & \\
\hline CHEMBL1604259 & 688128 & 4.35 & 4.7979 & TRN & \\
\hline CHEMBL1613075 & 688128 & 4.15 & 4.5404 & TST & \\
\hline CHEMBL 240333 & 688128 & 4.55 & 5.0414 & TRN & \\
\hline CHEMBL1521358 & 688128 & 4.1 & 4.4369 & TRN & \\
\hline CHEMBL1507212 & 688128 & 4.8 & 4.4693 & TRN & \\
\hline CHEMBL1368358 & 688128 & 4.45 & 4.4791 & TRN & \\
\hline CHEMBL1571590 & 688128 & 5.35 & 4.6017 & TRN & \\
\hline CHEMBL1463022 & 688128 & 4.3 & 4.5189 & TRN & \\
\hline CHEMBL1310019 & 688128 & 4.0 & 4.456 & TRN & \\
\hline CHEMBL1448829 & 688128 & 4.4 & 4.4046 & TRN & \\
\hline CHEMBL1529214 & 688128 & 5.4 & 4.8336 & TRN & \\
\hline CHEMBL1561533 & 688128 & 4.45 & 4.3168 & TRN & \\
\hline CHEMBL1336666 & 688128 & 4.35 & 4.7841 & TRN & \\
\hline CHEMBL1309703 & 688128 & 4.2 & 4.3257 & TRN & \\
\hline CHEMBL1494667 & 688128 & 4.3 & 4.8828 & TRN & \\
\hline CHEMBL1584800 & 688128 & 4.3 & 4.4511 & TRN & \\
\hline CHEMBL1478401 & 688128 & 4.35 & 4.7227 & TRN & \\
\hline CHEMBL1543466 & 688128 & 4.25 & 4.5966 & TRN & \\
\hline CHEMBL1558021 & 688128 & 5.05 & 5.007 & TRN & \\
\hline CHEMBL1475636 & 688128 & 4.65 & 4.4456 & TRN & \\
\hline CHEMBL3192475 & 688128 & 4.85 & 4.8597 & TRN & \\
\hline CHEMBL1590537 & 688128 & 4.05 & 4.4396 & TST & \\
\hline CHEMBL1434521 & 688128 & 4.4 & 4.547 & TST & \\
\hline CHEMBL3211926 & 688128 & 4.4 & 4.5563 & TST & \\
\hline CHEMBL1421235 & 688128 & 4.5 & 4.6632 & TRN & \\
\hline CHEMBL3193048 & 688128 & 4.2 & 4.7443 & TRN & \\
\hline CHEMBL1347042 & 688128 & 4.4 & 4.992 & TRN & \\
\hline CHEMBL1372999 & 688128 & 4.3 & 4.7152 & TST & \\
\hline CHEMBL1504409 & 688128 & 4.4 & 4.6413 & TRN & \\
\hline CHEMBL1426242 & 688128 & 4.05 & 4.6286 & TRN & \\
\hline CHEMBL1485109 & 688128 & 4.5 & 4.6992 & TST & \\
\hline CHEMBL1607971 & 688128 & 4.1 & 4.5043 & TST & \\
\hline CHEMBL1970784 & 688128 & 4.45 & $4.6610 e$ & 00000000005 & TST \\
\hline CHEMBL1478589 & 688128 & 4.25 & 4.488 & TRN & \\
\hline CHEMBL1506095 & 688128 & 5.7 & 4.7314 & TST & \\
\hline
\end{tabular}




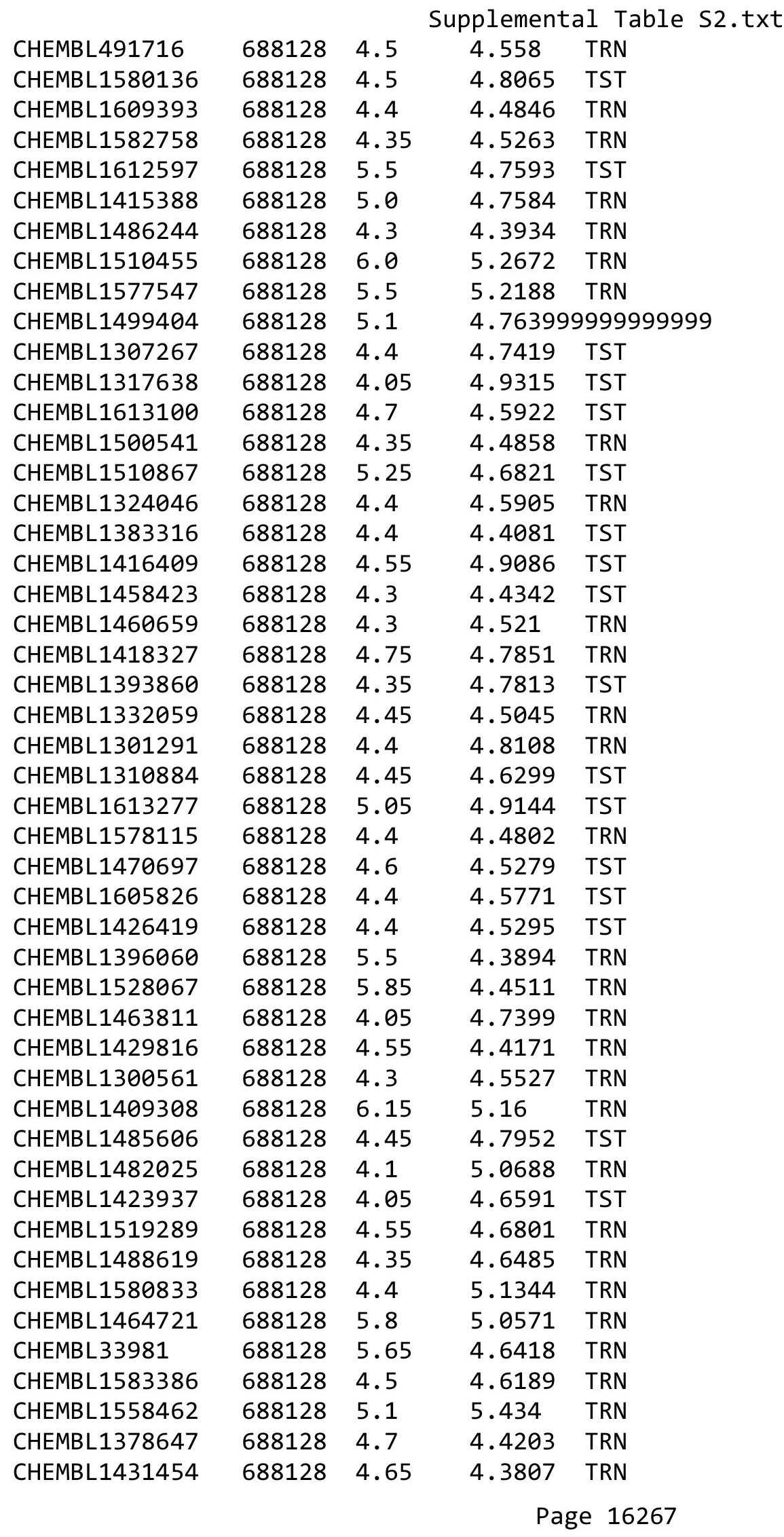




\begin{tabular}{|c|c|c|c|c|c|}
\hline & & \multicolumn{4}{|c|}{ Supplemental Table s2.txt } \\
\hline CHEMBL1569971 & 688128 & 4.45 & 4.6539 & TRN & \\
\hline CHEMBL1429781 & 688128 & 4.4 & 4.7565 & TRN & \\
\hline CHEMBL1431738 & 688128 & 4.7 & 4.7205 & TRN & \\
\hline CHEMBL1417107 & 688128 & 4.0 & 4.195 & TRN & \\
\hline CHEMBL1504333 & 688128 & 4.3 & 4.6923 & TRN & \\
\hline CHEMBL1323364 & 688128 & 5.5 & 5.1143 & TRN & \\
\hline CHEMBL1495219 & 688128 & 4.5 & 5.0034 & TRN & \\
\hline CHEMBL3189665 & 688128 & 4.25 & 4.7084 & TRN & \\
\hline CHEMBL1591489 & 688128 & 4.05 & 4.5817 & TRN & \\
\hline CHEMBL1398363 & 688128 & 4.15 & 4.5561 & TRN & \\
\hline CHEMBL1329772 & 688128 & 4.05 & 4.5537 & TST & \\
\hline CHEMBL1321852 & 688128 & 5.4 & 4.6611 & TRN & \\
\hline CHEMBL1430232 & 688128 & 4.7 & 5.3557 & TRN & \\
\hline CHEMBL1585311 & 688128 & 5.55 & 4.5277 & TST & \\
\hline CHEMBL1357214 & 688128 & 5.0 & 5.2254 & TRN & \\
\hline CHEMBL1395021 & 688128 & 4.8 & 4.8184 & TRN & \\
\hline CHEMBL1528096 & 688128 & 4.7 & 4.7515 & TRN & \\
\hline CHEMBL1483180 & 688128 & 4.45 & \multicolumn{2}{|c|}{4.8260000000000005} & TRN \\
\hline CHEMBL1554544 & 688128 & 4.3 & 4.5843 & TST & \\
\hline CHEMBL1299625 & 688128 & 4.3 & 4.5179 & TRN & \\
\hline CHEMBL1407838 & 688128 & 5.45 & 4.592 & TST & \\
\hline CHEMBL1431701 & 688128 & 4.4 & 4.5261 & TRN & \\
\hline CHEMBL1456019 & 688128 & 4.4 & 4.7282 & TRN & \\
\hline CHEMBL1481497 & 688128 & 5.5 & \multicolumn{2}{|c|}{4.8469999999999995} & TRN \\
\hline CHEMBL1474143 & 688128 & 4.3 & 4.6418 & TST & \\
\hline CHEMBL1383919 & 688128 & 5.75 & 4.7494 & TRN & \\
\hline CHEMBL1550917 & 688128 & 4.6 & 4.4512 & TRN & \\
\hline CHEMBL1419406 & 688128 & 4.4 & 4.4407 & TST & \\
\hline CHEMBL1517778 & 688128 & 4.85 & 4.8677 & TRN & \\
\hline CHEMBL1582866 & 688128 & 4.95 & 4.685 & TRN & \\
\hline CHEMBL1383530 & 688128 & 4.5 & 4.285 & TST & \\
\hline CHEMBL1378479 & 688128 & 5.85 & 4.8262 & TRN & \\
\hline CHEMBL1577002 & 688128 & 4.2 & 4.5176 & TRN & \\
\hline CHEMBL1314718 & 688128 & 4.3 & 4.8257 & TST & \\
\hline CHEMBL577938 & 688128 & 5.55 & 4.6197 & TRN & \\
\hline CHEMBL1464992 & 688128 & 4.85 & 4.5893 & TRN & \\
\hline CHEMBL1358669 & 688128 & 4.4 & 4.8371 & TRN & \\
\hline CHEMBL1307494 & 688128 & 4.55 & 4.5656 & TRN & \\
\hline CHEMBL1453530 & 688128 & 4.4 & 4.795 & TST & \\
\hline CHEMBL1403294 & 688128 & 4.65 & 4.7839 & TRN & \\
\hline CHEMBL1329056 & 688128 & 4.25 & 4.6108 & TRN & \\
\hline CHEMBL1387024 & 688128 & 4.05 & 4.7421 & TST & \\
\hline CHEMBL1368651 & 688128 & 4.4 & 4.813 & TRN & \\
\hline CHEMBL3194917 & 688128 & 5.2 & 4.8231 & TRN & \\
\hline CHEMBL1515271 & 688128 & 4.4 & 4.5134 & TRN & \\
\hline CHEMBL1405237 & 688128 & 5.05 & 4.6629 & TRN & \\
\hline CHEMBL1367306 & 688128 & 4.3 & 4.516 & TST & \\
\hline CHEMBL1509056 & 688128 & 4.05 & 4.3943 & TST & \\
\hline
\end{tabular}




\begin{tabular}{|c|c|c|c|c|}
\hline \multicolumn{5}{|c|}{ Supplemental Table s2.txt } \\
\hline CHEMBL1356781 & 688128 & 5.3 & 5.215 & TRN \\
\hline CHEMBL1542555 & 688128 & 4.35 & 4.4698 & TRN \\
\hline CHEMBL3194446 & 688128 & 4.3 & 4.6889 & TRN \\
\hline CHEMBL1316929 & 688128 & 4.35 & 4.8104 & TST \\
\hline CHEMBL1440962 & 688128 & 4.5 & 4.7329 & TRN \\
\hline CHEMBL1416753 & 688128 & 4.55 & 4.7583 & TRN \\
\hline CHEMBL1526294 & 688128 & 5.0 & 4.7751 & TST \\
\hline CHEMBL1559317 & 688128 & 5.0 & 4.7906 & TRN \\
\hline CHEMBL1438762 & 688128 & 4.75 & 4.7227 & TRN \\
\hline CHEMBL1477897 & 688128 & 4.2 & 4.851 & TST \\
\hline CHEMBL1359578 & 688128 & 4.3 & 4.5768 & TRN \\
\hline CHEMBL1540526 & 688128 & 4.4 & 4.177 & TRN \\
\hline CHEMBL1530044 & 688128 & 4.55 & 4.79 & TRN \\
\hline CHEMBL1430028 & 688128 & 4.5 & 4.3959 & TRN \\
\hline CHEMBL1305100 & 688128 & 4.35 & 4.471 & TRN \\
\hline CHEMBL1594617 & 688128 & 4.45 & 4.6445 & TRN \\
\hline CHEMBL1611841 & 688128 & 4.05 & 4.5851 & TST \\
\hline CHEMBL1328740 & 688128 & 5.1 & 4.7651 & TRN \\
\hline CHEMBL1327868 & 688128 & 5.5 & 4.6744 & TRN \\
\hline CHEMBL1305102 & 688128 & 4.45 & 4.4183 & TRN \\
\hline CHEMBL1399563 & 688128 & 5.15 & 5.0322 & TRN \\
\hline CHEMBL1969760 & 688128 & 5.1 & 4.8732 & TRN \\
\hline CHEMBL1329669 & 688128 & 4.45 & 4.7854 & TST \\
\hline CHEMBL1350132 & 688128 & 4.25 & 4.5372 & TRN \\
\hline CHEMBL1379416 & 688128 & 4.35 & 4.4538 & TRN \\
\hline CHEMBL1588356 & 688128 & 4.65 & 4.5175 & TRN \\
\hline CHEMBL1459044 & 688128 & 5.2 & 4.7199 & TRN \\
\hline CHEMBL1505331 & 688128 & 4.3 & 4.3215 & TRN \\
\hline CHEMBL3197674 & 688128 & 4.3 & 4.3909 & TRN \\
\hline CHEMBL1302924 & 688128 & 4.9 & 4.7792 & TST \\
\hline CHEMBL1362424 & 688128 & 6.15 & 4.4044 & TRN \\
\hline CHEMBL1386741 & 688128 & 5.25 & 4.6224 & TRN \\
\hline CHEMBL1545945 & 688128 & 4.25 & 4.7132 & TRN \\
\hline CHEMBL1353505 & 688128 & 4.7 & 4.7792 & TST \\
\hline CHEMBL1427393 & 688128 & 4.05 & 4.8412 & TRN \\
\hline CHEMBL1367044 & 688128 & 4.25 & 4.7105 & TST \\
\hline CHEMBL1609809 & 688128 & 4.95 & 4.3782 & TRN \\
\hline CHEMBL1492201 & 688128 & 4.45 & 4.2883 & TRN \\
\hline CHEMBL1497218 & 688128 & 4.05 & 4.7915 & TRN \\
\hline CHEMBL1411734 & 688128 & 4.7 & 4.3003 & TRN \\
\hline CHEMBL3198974 & 688128 & 4.5 & 4.6289 & TRN \\
\hline CHEMBL1340913 & 688128 & 4.8 & 4.4168 & TRN \\
\hline CHEMBL1319215 & 688128 & 4.5 & 4.3296 & TRN \\
\hline CHEMBL1308852 & 688128 & 4.05 & 4.4442 & TRN \\
\hline CHEMBL1474643 & 688128 & 4.3 & 4.8363 & TST \\
\hline CHEMBL1553791 & 688128 & 5.4 & 4.9365 & TRN \\
\hline CHEMBL1439505 & 688128 & 5.75 & 5.22 & TRN \\
\hline CHEMBL1359332 & 688128 & 6.1 & 4.6011 & TRN \\
\hline
\end{tabular}




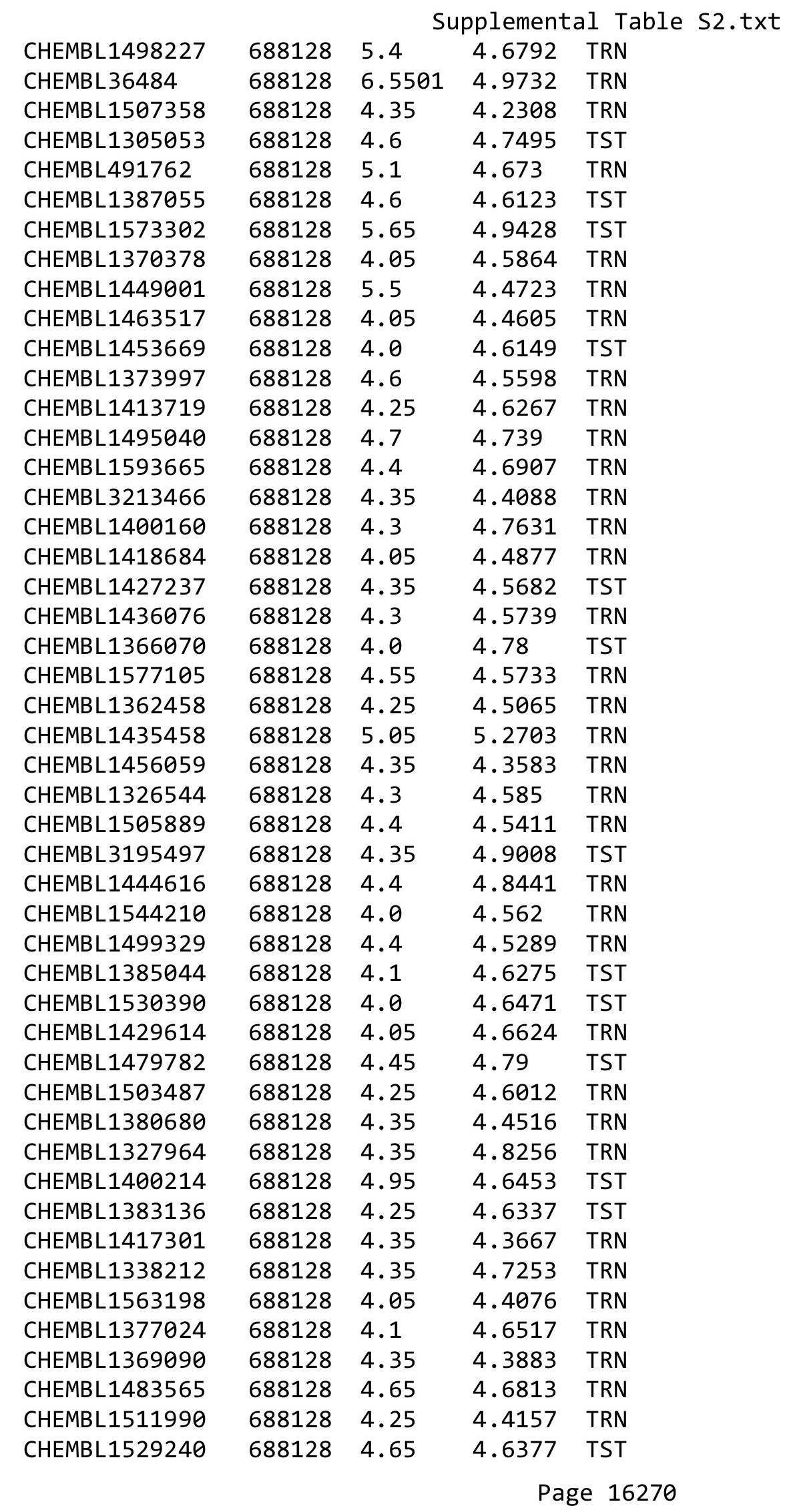




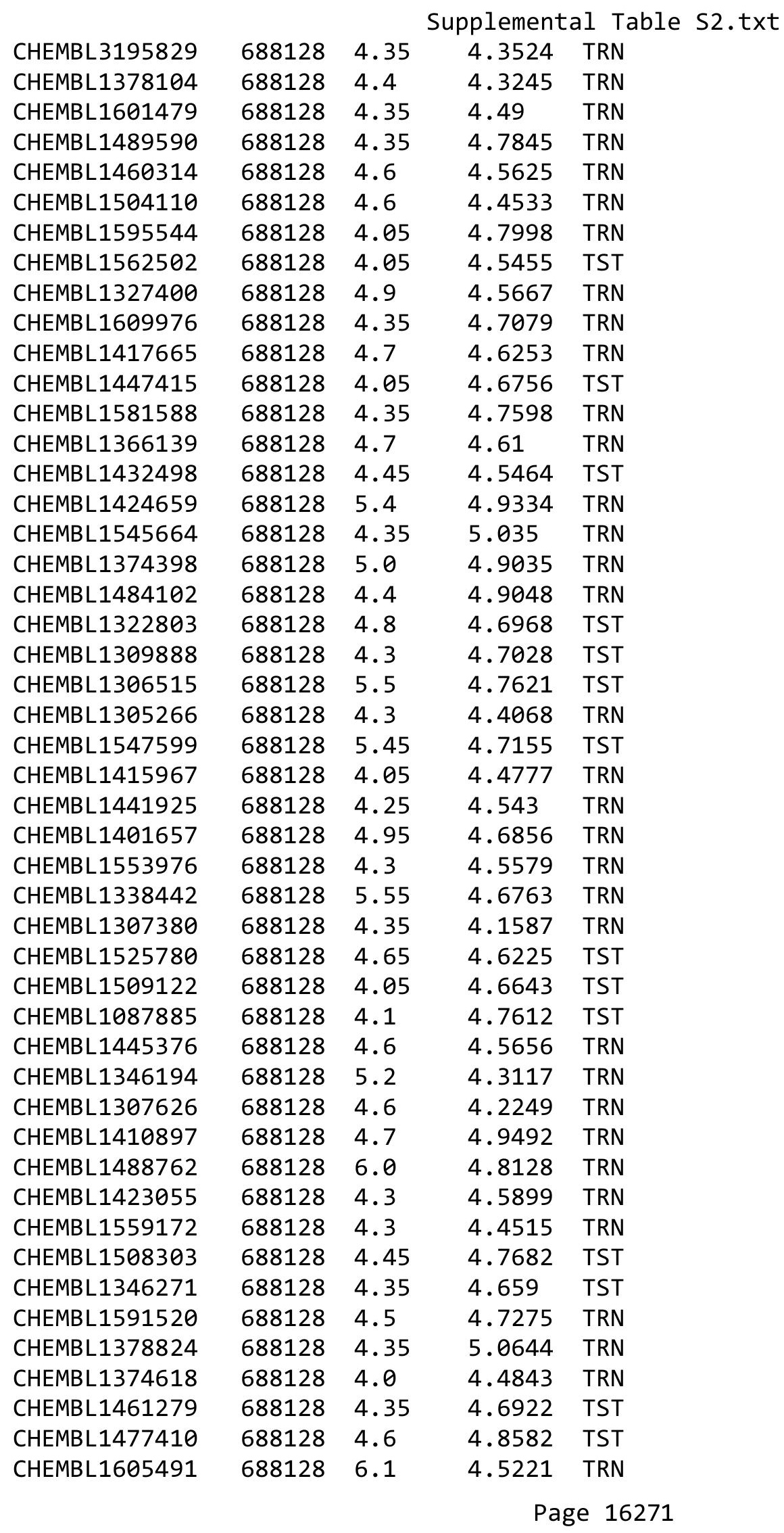




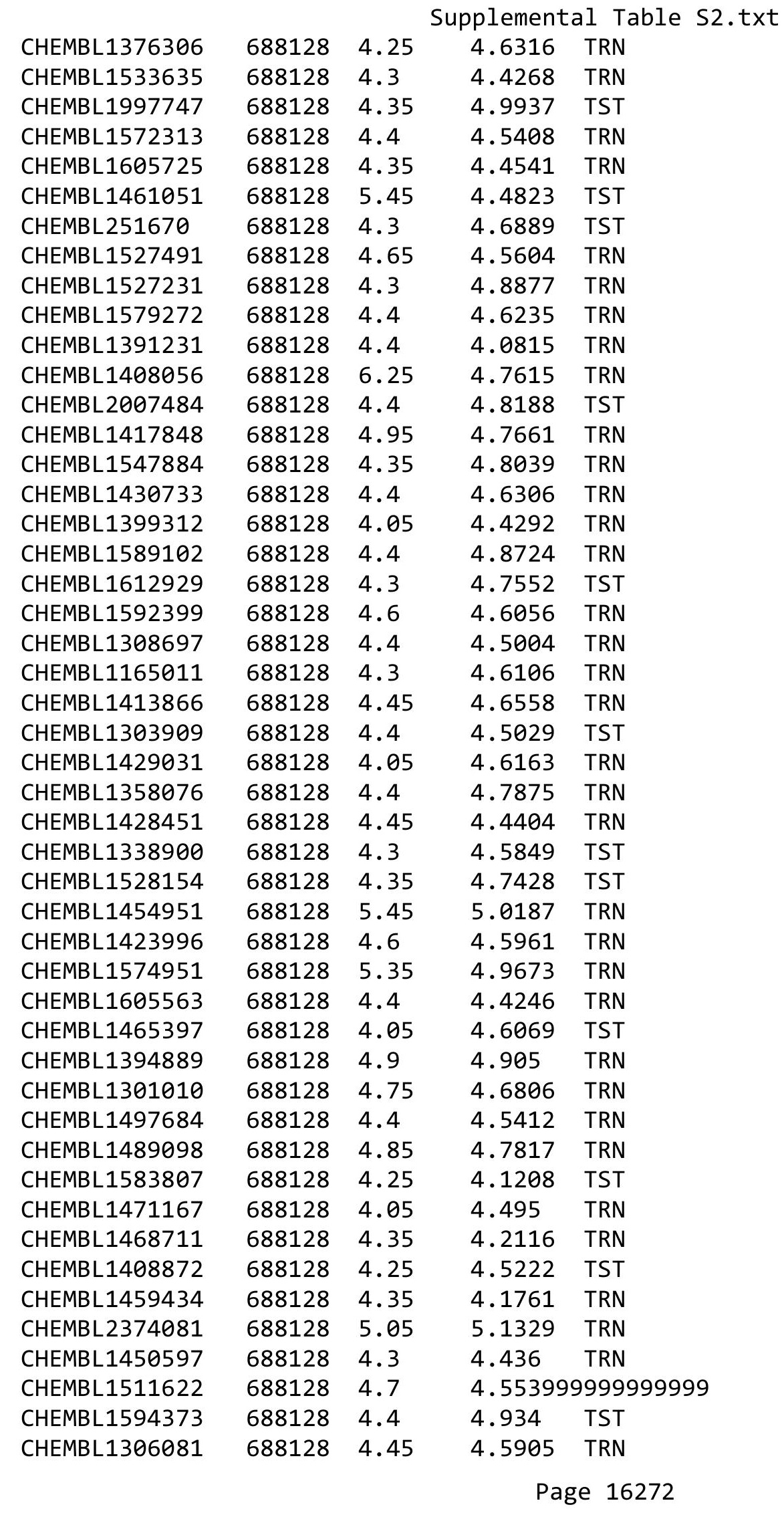

TRN 


\begin{tabular}{|c|c|c|c|c|c|}
\hline \multicolumn{6}{|c|}{ Supplemental Table S2.txt } \\
\hline CHEMBL1527429 & 688128 & 4.35 & 4.7337 & TRN & \\
\hline CHEMBL1576189 & 688128 & 4.3 & 4.4357 & TRN & \\
\hline CHEMBL1519503 & 688128 & 4.35 & 4.5249 & TRN & \\
\hline CHEMBL1424666 & 688128 & 5.2 & 4.3506 & TRN & \\
\hline CHEMBL1320509 & 688128 & 4.25 & 4.6497 & TRN & \\
\hline CHEMBL1392633 & 688128 & 4.05 & 4.8518 & TRN & \\
\hline CHEMBL1526675 & 688128 & 5.45 & 4.7919 & TRN & \\
\hline CHEMBL1595376 & 688128 & 5.1 & 4.5626 & TST & \\
\hline CHEMBL1579822 & 688128 & 4.0 & 4.6712 & TST & \\
\hline CHEMBL1321445 & 688128 & 4.4 & 4.6988 & TRN & \\
\hline CHEMBL1403616 & 688128 & 4.3 & 4.3843 & TRN & \\
\hline CHEMBL1789994 & 688128 & 5.25 & 4.8617 & TST & \\
\hline CHEMBL1369014 & 688128 & 5.55 & 4.8982 & TRN & \\
\hline CHEMBL1522147 & 688128 & 4.05 & 4.4932 & TRN & \\
\hline CHEMBL1592763 & 688128 & 5.3 & 4.5978 & TRN & \\
\hline CHEMBL1487779 & 688128 & 5.3 & 4.7635 & TRN & \\
\hline CHEMBL3211219 & 688128 & 4.05 & 4.4777 & TST & \\
\hline CHEMBL1353175 & 688128 & 4.3 & 4.272 & TRN & \\
\hline CHEMBL1370002 & 688128 & 4.7 & 4.6056 & TRN & \\
\hline CHEMBL1608489 & 688128 & 4.9 & 4.3094 & TRN & \\
\hline CHEMBL1424380 & 688128 & 4.8 & 4.8715 & TST & \\
\hline CHEMBL1404295 & 688128 & 4.4 & 4.5393 & TRN & \\
\hline CHEMBL1604989 & 688128 & 5.4 & $4.7410 e$ & 00000000005 & TST \\
\hline CHEMBL1458588 & 688128 & 4.4 & 4.8148 & TRN & \\
\hline CHEMBL1340418 & 688128 & 4.75 & 4.5715 & TST & \\
\hline CHEMBL1311294 & 688128 & 4.6 & 4.8267 & TRN & \\
\hline CHEMBL1535691 & 688128 & 4.65 & 4.4649 & TRN & \\
\hline CHEMBL1461169 & 688128 & 4.45 & 4.3819 & TRN & \\
\hline CHEMBL1414625 & 688128 & 4.35 & 4.7178 & TRN & \\
\hline CHEMBL1495013 & 688128 & 5.15 & 4.9029 & TST & \\
\hline CHEMBL1374324 & 688128 & 4.3 & 4.4102 & TST & \\
\hline CHEMBL1582601 & 688128 & 4.6 & 4.9896 & TRN & \\
\hline CHEMBL1324515 & 688128 & 4.35 & 4.562 & TRN & \\
\hline CHEMBL1373360 & 688128 & 5.15 & 4.6824 & TRN & \\
\hline CHEMBL1325923 & 688128 & 4.45 & 4.5695 & TST & \\
\hline CHEMBL1594681 & 688128 & 4.0 & 4.5878 & TST & \\
\hline CHEMBL1423410 & 688128 & 4.25 & 4.4997 & TRN & \\
\hline CHEMBL1359070 & 688128 & 6.05 & 5.0595 & TRN & \\
\hline CHEMBL1483101 & 688128 & 4.4 & 4.7645 & TRN & \\
\hline CHEMBL1354274 & 688128 & 4.45 & 4.6955 & TRN & \\
\hline CHEMBL1612425 & 688128 & 4.4 & 4.8145 & TRN & \\
\hline CHEMBL1529703 & 688128 & 4.4 & 4.7705 & TRN & \\
\hline CHEMBL1451702 & 688128 & 4.55 & 4.6376 & TST & \\
\hline CHEMBL1537709 & 688128 & 4.35 & 4.4193 & TRN & \\
\hline CHEMBL1536176 & 688128 & 5.75 & 4.872 & TRN & \\
\hline CHEMBL1488350 & 688128 & 4.25 & 4.5667 & TRN & \\
\hline CHEMBL1602950 & 688128 & 4.3 & 4.9545 & TST & \\
\hline CHEMBL1330733 & 688128 & 4.05 & 4.3331 & TRN & \\
\hline
\end{tabular}




\begin{tabular}{|c|c|c|c|c|c|}
\hline \multicolumn{6}{|c|}{ Supplemental Table S2.txt } \\
\hline CHEMBL1594741 & 688128 & 5.4 & 5.1195 & TST & \\
\hline CHEMBL1611877 & 688128 & 4.1 & 4.6395 & TRN & \\
\hline CHEMBL1308356 & 688128 & 4.7 & 4.587 & TRN & \\
\hline CHEMBL1598223 & 688128 & 4.65 & 4.5121 & TRN & \\
\hline CHEMBL1305833 & 688128 & 5.3 & 4.4572 & TRN & \\
\hline CHEMBL1312180 & 688128 & 4.55 & 5.0095 & TRN & \\
\hline CHEMBL1488249 & 688128 & 4.4 & 4.9252 & TRN & \\
\hline CHEMBL1497208 & 688128 & 4.05 & 4.8186 & TRN & \\
\hline CHEMBL1549198 & 688128 & 4.45 & 4.4951 & TRN & \\
\hline CHEMBL175193 & 688128 & 4.4 & 5.0303 & TRN & \\
\hline CHEMBL1563341 & 688128 & 4.9 & 4.8389 & TRN & \\
\hline CHEMBL1424640 & 688128 & 4.25 & 4.4415 & TST & \\
\hline CHEMBL1408170 & 688128 & 6.2 & 4.7358 & TRN & \\
\hline CHEMBL1500297 & 688128 & 4.6 & 4.4634 & TST & \\
\hline CHEMBL1502100 & 688128 & 4.45 & 4.5719 & TRN & \\
\hline CHEMBL1349599 & 688128 & 4.55 & 4.5477 & TST & \\
\hline CHEMBL1502325 & 688128 & 5.45 & 4.7299 & TST & \\
\hline CHEMBL1478578 & 688128 & 5.45 & 5.0416 & TRN & \\
\hline CHEMBL1353341 & 688128 & 5.0 & 4.8221 & TRN & \\
\hline CHEMBL1578508 & 688128 & 4.55 & 4.2742 & TRN & \\
\hline CHEMBL1539633 & 688128 & 4.4 & 4.4046 & TRN & \\
\hline CHEMBL1558993 & 688128 & 5.9 & 5.1309 & TRN & \\
\hline CHEMBL1417484 & 688128 & 4.05 & 4.9021 & TRN & \\
\hline CHEMBL1328959 & 688128 & 4.4 & 4.5237 & TRN & \\
\hline CHEMBL1531019 & 688128 & 4.3 & 4.9328 & TRN & \\
\hline CHEMBL1465859 & 688128 & 4.75 & 4.6193 & TRN & \\
\hline CHEMBL1404537 & 688128 & 4.7 & 4.6516 & TRN & \\
\hline CHEMBL1497049 & 688128 & 4.85 & 4.6493 & TST & \\
\hline CHEMBL1362388 & 688128 & 4.65 & 4.4232 & TRN & \\
\hline CHEMBL1599517 & 688128 & 4.4 & 4.5271 & TRN & \\
\hline CHEMBL1443990 & 688128 & 5.05 & 4.524 & TST & \\
\hline CHEMBL1324051 & 688128 & 5.6 & 5.4138 & TRN & \\
\hline CHEMBL1986086 & 688128 & 4.4 & 4.6388 & TRN & \\
\hline CHEMBL1560507 & 688128 & 4.35 & 4.5106 & TRN & \\
\hline CHEMBL1307185 & 688128 & 5.2 & 4.915 & TST & \\
\hline CHEMBL1501380 & 688128 & 4.35 & 4.8156 & TRN & \\
\hline CHEMBL1436630 & 688128 & 4.3 & 4.7658 & TRN & \\
\hline CHEMBL1547734 & 688128 & 4.4 & 4.3983 & TRN & \\
\hline CHEMBL1518588 & 688128 & 4.05 & 4.3979 & TRN & \\
\hline CHEMBL1528917 & 688128 & 5.75 & 4.7091 & TST & \\
\hline CHEMBL1442018 & 688128 & 4.65 & 4.6912 & TRN & \\
\hline CHEMBL1530704 & 688128 & 4.5 & $4.5710 e$ & 0000000001 & TRN \\
\hline CHEMBL1425475 & 688128 & 4.05 & 4.7803 & TRN & \\
\hline CHEMBL1360793 & 688128 & 4.55 & 4.762 & TRN & \\
\hline CHEMBL1452628 & 688128 & 4.3 & 4.7272 & TRN & \\
\hline CHEMBL1347107 & 688128 & 5.05 & 4.7821 & TRN & \\
\hline CHEMBL1419354 & 688128 & 4.05 & 4.7314 & TST & \\
\hline CHEMBL1322018 & 688128 & 4.05 & 4.4147 & TST & \\
\hline
\end{tabular}




\begin{tabular}{|c|c|c|c|c|c|}
\hline & & & & & \\
\hline CHEMBL1595769 & 688128 & 4.8 & 4.7527 & TRN & \\
\hline CHEMBL1349940 & 688128 & 4.4 & 4.3289 & TRN & \\
\hline CHEMBL1456437 & 688128 & 4.05 & 4.2506 & TRN & \\
\hline CHEMBL1372405 & 688128 & 4.45 & 4.6821 & TRN & \\
\hline CHEMBL1990418 & 688128 & 4.4 & 4.6675 & TRN & \\
\hline CHEMBL1478042 & 688128 & 4.6 & 4.5161 & TRN & \\
\hline CHEMBL1370375 & 688128 & 5.5 & 4.34699 & 99999999995 & TST \\
\hline CHEMBL1390139 & 688128 & 4.55 & 4.9243 & TRN & \\
\hline CHEMBL1309198 & 688128 & 4.95 & 5.1349 & TRN & \\
\hline CHEMBL1353992 & 688128 & 4.35 & 4.6292 & TRN & \\
\hline CHEMBL1473101 & 688128 & 5.65 & 4.6067 & TRN & \\
\hline CHEMBL1433128 & 688128 & 5.4 & 4.7167 & TST & \\
\hline CHEMBL1588419 & 688128 & 4.3 & 4.4556 & TRN & \\
\hline CHEMBL1320450 & 688128 & 5.25 & 4.9403 & TRN & \\
\hline CHEMBL1604622 & 688128 & 4.35 & 4.4075 & TRN & \\
\hline CHEMBL1377690 & 688128 & 4.65 & 4.4217 & TST & \\
\hline CHEMBL1982025 & 688128 & 4.35 & 4.7423 & TST & \\
\hline CHEMBL1526434 & 688128 & 4.95 & 4.8518 & TRN & \\
\hline CHEMBL1330628 & 688128 & 4.55 & 4.8258 & TRN & \\
\hline CHEMBL1355582 & 688128 & 4.6 & 4.44600 & 0000000001 & TRN \\
\hline CHEMBL1426288 & 688128 & 4.4 & 4.4227 & TRN & \\
\hline CHEMBL1533201 & 688128 & 4.5 & 4.3629 & TRN & \\
\hline CHEMBL1523492 & 688128 & 4.4 & 4.519 & TRN & \\
\hline CHEMBL1326356 & 688128 & 5.55 & 4.6764 & TRN & \\
\hline CHEMBL1550085 & 688128 & 4.75 & 4.6032 & TST & \\
\hline CHEMBL1437460 & 688128 & 4.05 & 4.7846 & TST & \\
\hline CHEMBL1329354 & 688128 & 4.95 & 4.3928 & TST & \\
\hline CHEMBL1597250 & 688128 & 5.05 & 4.794 & TRN & \\
\hline CHEMBL1332390 & 688128 & 4.55 & 4.5254 & TST & \\
\hline CHEMBL1515003 & 688128 & 4.35 & 4.4274 & TRN & \\
\hline CHEMBL1324935 & 688128 & 4.75 & 5.1175 & TRN & \\
\hline CHEMBL1343416 & 688128 & 5.35 & 4.6212 & TRN & \\
\hline CHEMBL1528923 & 688128 & 4.75 & 4.6948 & TRN & \\
\hline CHEMBL1608041 & 688128 & 4.45 & 5.0658 & TRN & \\
\hline CHEMBL1592472 & 688128 & 4.3 & 4.7429 & TRN & \\
\hline CHEMBL1412762 & 688128 & 5.4 & 4.7817 & TST & \\
\hline CHEMBL 1327282 & 688128 & 4.05 & 4.4988 & TRN & \\
\hline CHEMBL1610682 & 688128 & 4.05 & 4.5033 & TST & \\
\hline CHEMBL1375966 & 688128 & 4.45 & 4.8933 & TRN & \\
\hline CHEMBL1416417 & 688128 & 5.7 & 4.8229 & TRN & \\
\hline CHEMBL1976540 & 688128 & 4.3 & 4.6166 & TST & \\
\hline CHEMBL538104 & 688128 & 4.65 & 4.3515 & TST & \\
\hline CHEMBL1570916 & 688128 & 4.35 & 4.6322 & TRN & \\
\hline CHEMBL3214093 & 688128 & 4.85 & 4.6982 & TRN & \\
\hline CHEMBL1323035 & 688128 & 4.3 & 4.6006 & TRN & \\
\hline CHEMBL1387813 & 688128 & 4.05 & 4.5829 & TST & \\
\hline CHEMBL1379277 & 688128 & 4.75 & 4.8175 & TRN & \\
\hline CHEMBL1572845 & 688128 & 4.5 & 4.6272 & TRN & \\
\hline & & & & 16275 & \\
\hline
\end{tabular}




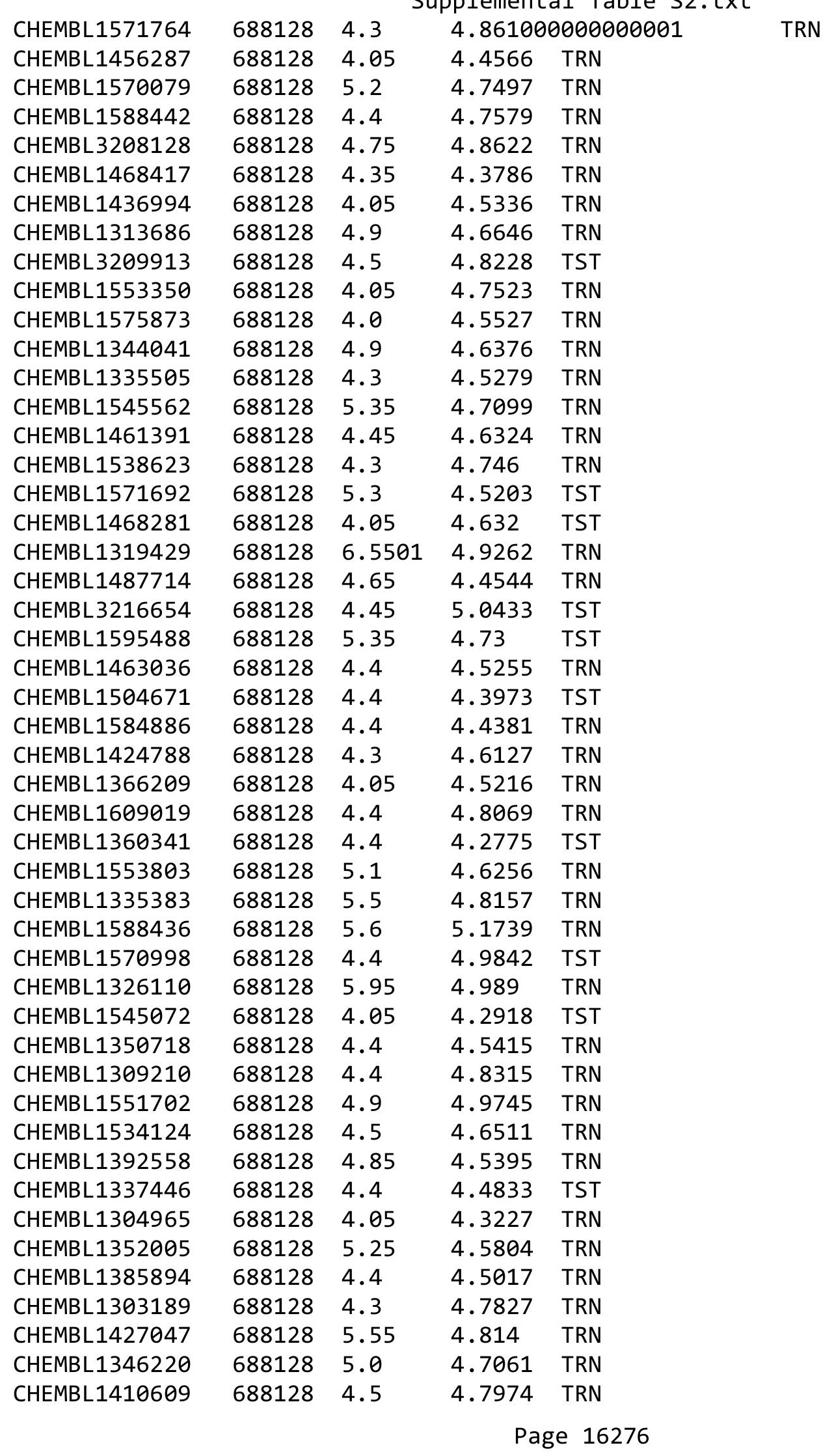




\begin{tabular}{|c|c|c|c|c|c|}
\hline \multicolumn{6}{|c|}{ Supplemental Table S2.txt } \\
\hline CHEMBL1508182 & 688128 & 6.2 & 5.4661 & TRN & \\
\hline CHEMBL1501715 & 688128 & 4.4 & 4.4697 & TST & \\
\hline CHEMBL1326716 & 688128 & 4.45 & 4.5324 & TRN & \\
\hline CHEMBL1403217 & 688128 & 4.3 & 4.8961 & TRN & \\
\hline CHEMBL1558995 & 688128 & 4.75 & 4.4895 & TST & \\
\hline CHEMBL1548516 & 688128 & 4.65 & 4.5415 & TST & \\
\hline CHEMBL1335881 & 688128 & 4.6 & 4.4724 & TST & \\
\hline CHEMBL1339308 & 688128 & 4.4 & 4.5567 & TST & \\
\hline CHEMBL1571513 & 688128 & 4.65 & 4.6134 & TRN & \\
\hline CHEMBL1336914 & 688128 & 4.3 & 4.4037 & TRN & \\
\hline CHEMBL1492155 & 688128 & 4.05 & 4.2465 & TRN & \\
\hline CHEMBL498373 & 688128 & 4.55 & 4.5972 & TRN & \\
\hline CHEMBL1307790 & 688128 & 4.05 & 4.4639 & TRN & \\
\hline CHEMBL1087042 & 688128 & 4.9 & 4.6847 & TRN & \\
\hline CHEMBL1527834 & 688128 & 4.5 & 4.5403 & TRN & \\
\hline CHEMBL1328254 & 688128 & 4.3 & 4.3318 & TRN & \\
\hline CHEMBL1390200 & 688128 & 4.05 & 4.467 & TRN & \\
\hline CHEMBL1317699 & 688128 & 4.6 & 4.8249 & TRN & \\
\hline CHEMBL3197600 & 688128 & 4.45 & 4.694 & TRN & \\
\hline CHEMBL1421600 & 688128 & 4.65 & 4.4081 & TRN & \\
\hline CHEMBL1530849 & 688128 & 4.75 & 4.3506 & TRN & \\
\hline CHEMBL1413413 & 688128 & 4.35 & 4.9801 & TST & \\
\hline CHEMBL 3210882 & 688128 & 4.0 & 4.6443 & TST & \\
\hline CHEMBL1353563 & 688128 & 4.0 & 4.6601 & TRN & \\
\hline CHEMBL1612543 & 688128 & 4.3 & 4.6157 & TRN & \\
\hline CHEMBL1467322 & 688128 & 4.2 & 4.6279 & TRN & \\
\hline CHEMBL1331751 & 688128 & 6.0 & 4.6488 & TRN & \\
\hline CHEMBL1520946 & 688128 & 4.6 & 4.49 & TRN & \\
\hline CHEMBL1486439 & 688128 & 4.45 & 4.6646 & TRN & \\
\hline CHEMBL1311500 & 688128 & 4.3 & 4.4336 & TST & \\
\hline CHEMBL1592176 & 688128 & 4.6 & 4.6538 & TRN & \\
\hline CHEMBL 254576 & 688128 & 4.3 & 5.0186 & TST & \\
\hline CHEMBL1606907 & 688128 & 6.0 & 4.8911 & TRN & \\
\hline CHEMBL1579434 & 688128 & 4.45 & 4.3938 & TRN & \\
\hline CHEMBL1446519 & 688128 & 4.5 & 4.1312 & TST & \\
\hline CHEMBL1307160 & 688128 & 4.25 & 4.4115 & TRN & \\
\hline CHEMBL1612916 & 688128 & 4.25 & 4.5236 & TST & \\
\hline CHEMBL1401850 & 688128 & 5.4 & 4.4933 & TST & \\
\hline CHEMBL1451970 & 688128 & 4.35 & 4.40300 & 00000000005 & TRN \\
\hline CHEMBL1464291 & 688128 & 4.0 & 4.5618 & TST & \\
\hline CHEMBL1524102 & 688128 & 4.05 & 4.4424 & TRN & \\
\hline CHEMBL1602510 & 688128 & 4.7 & 4.4946 & TRN & \\
\hline CHEMBL1580845 & 688128 & 6.0 & 5.2671 & TRN & \\
\hline CHEMBL3198431 & 688128 & 4.35 & 4.3757 & TRN & \\
\hline CHEMBL1589036 & 688128 & 5.0 & 4.5249 & TST & \\
\hline CHEMBL1503995 & 688128 & 4.7 & 5.0207 & TRN & \\
\hline CHEMBL1350286 & 688128 & 4.4 & 4.7481 & TRN & \\
\hline CHEMBL1477096 & 688128 & 4.65 & 4.7444 & TRN & \\
\hline
\end{tabular}




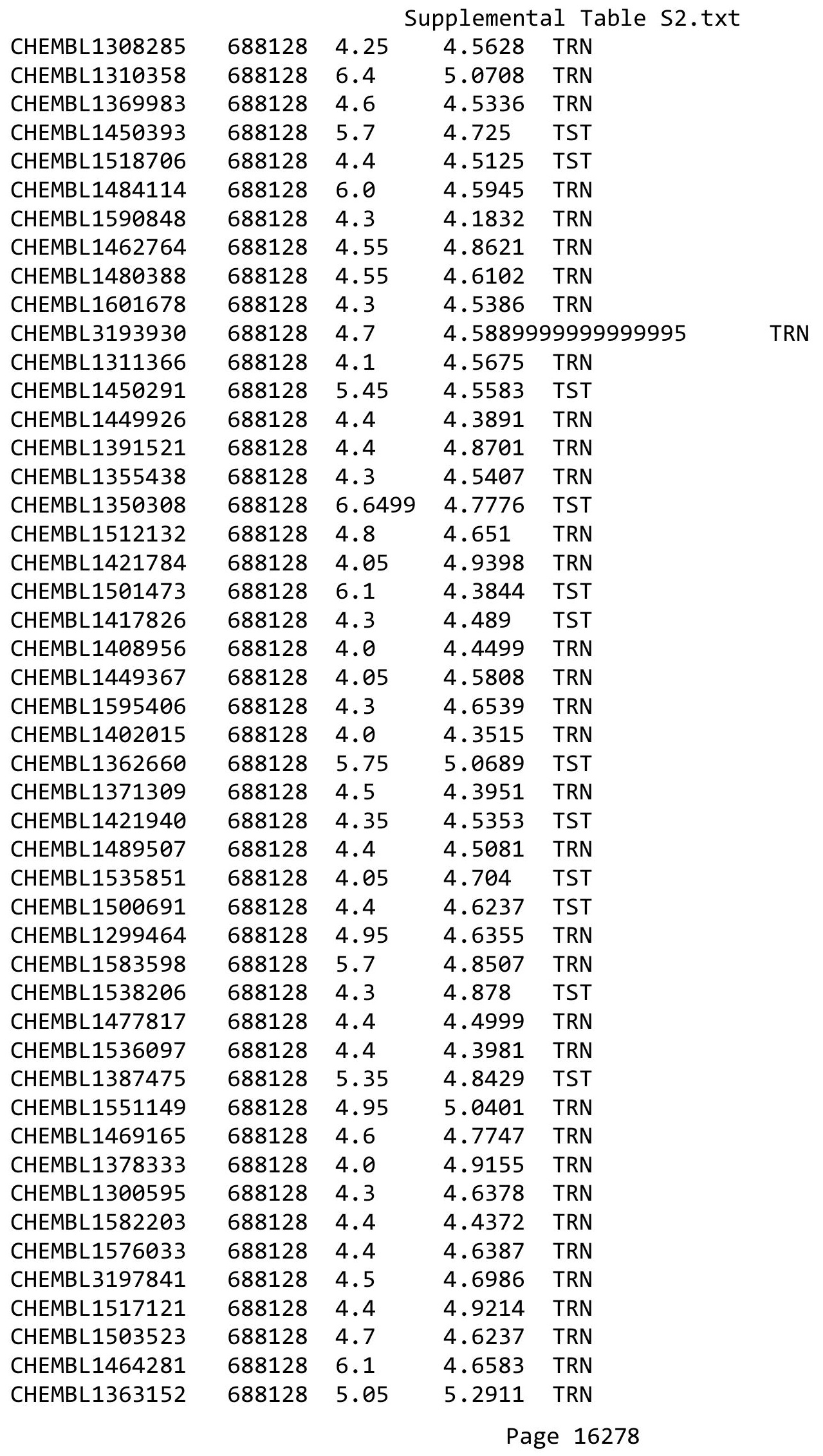




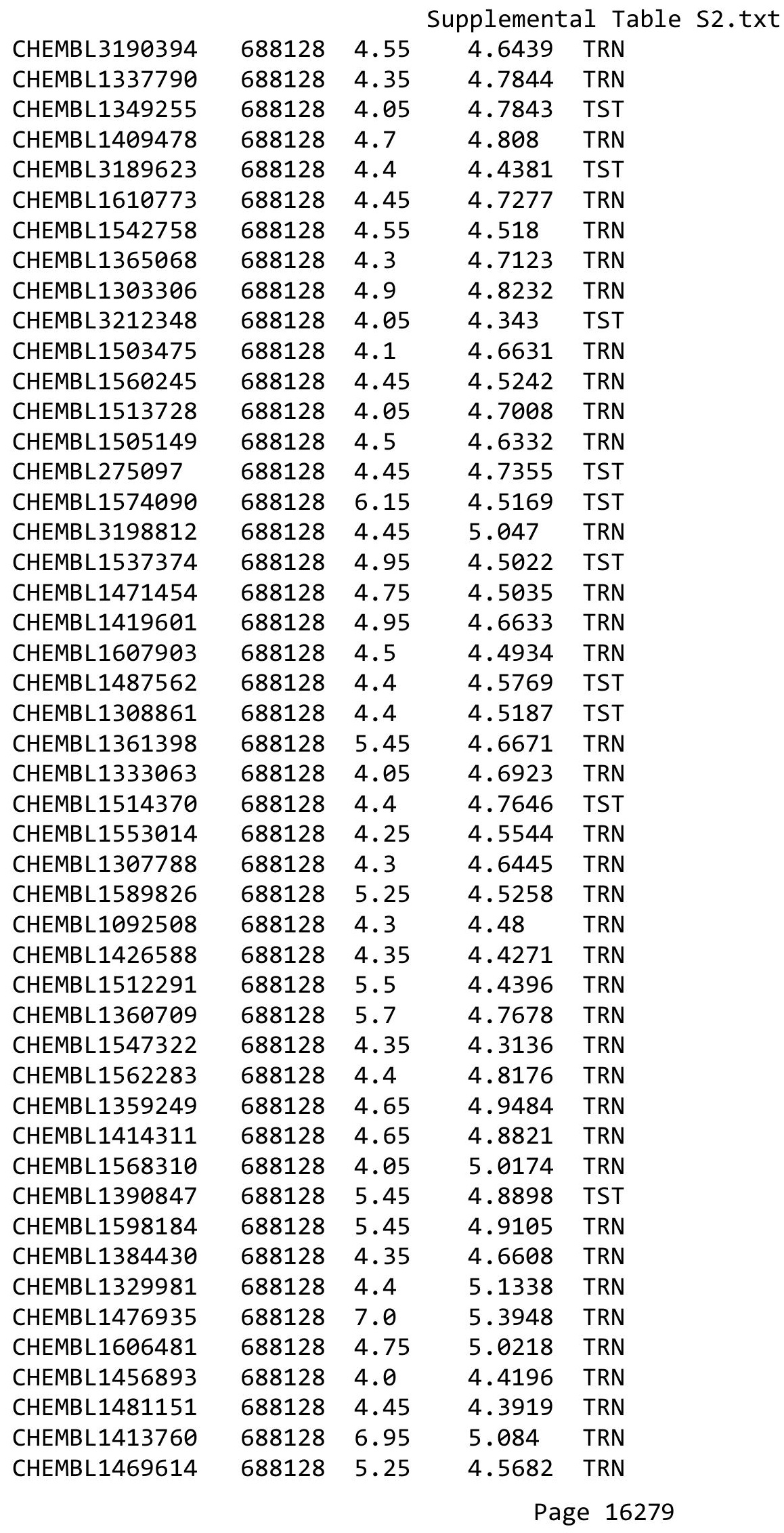




\begin{tabular}{|c|c|c|c|c|c|}
\hline & & \multicolumn{4}{|c|}{ Supplemental Table S2.txt } \\
\hline CHEMBL1306112 & 688128 & 4.55 & 4.6259 & TRN & \\
\hline CHEMBL1485413 & 688128 & 4.4 & 4.5275 & TRN & \\
\hline CHEMBL1454346 & 688128 & 4.3 & 4.7897 & TRN & \\
\hline CHEMBL1518357 & 688128 & 4.7 & 4.2611 & TRN & \\
\hline CHEMBL1380339 & 688128 & 5.2 & 4.5828 & TST & \\
\hline CHEMBL1326866 & 688128 & 6.1 & 4.4959 & TST & \\
\hline CHEMBL1453098 & 688128 & 4.35 & 4.6837 & TRN & \\
\hline CHEMBL1593130 & 688128 & 4.9 & 4.6336 & TRN & \\
\hline CHEMBL1371863 & 688128 & 5.45 & 4.4951 & TRN & \\
\hline CHEMBL1484164 & 688128 & 4.35 & 4.61100 & 0000000001 & TRN \\
\hline CHEMBL1553742 & 688128 & 4.4 & 4.4492 & TST & \\
\hline CHEMBL1582229 & 688128 & 4.55 & 4.982 & TRN & \\
\hline CHEMBL1429370 & 688128 & 4.3 & 4.4196 & TRN & \\
\hline CHEMBL3195294 & 688128 & 4.3 & 4.6104 & TST & \\
\hline CHEMBL1433546 & 688128 & 4.05 & 4.6482 & TRN & \\
\hline CHEMBL1536202 & 688128 & 4.9 & 4.603 & TRN & \\
\hline CHEMBL1388206 & 688128 & 4.4 & 4.5011 & TRN & \\
\hline CHEMBL3199209 & 688128 & 5.85 & 4.4142 & TST & \\
\hline CHEMBL1613653 & 688128 & 4.4 & 4.565 & TRN & \\
\hline CHEMBL1489999 & 688128 & 4.5 & 4.5561 & TST & \\
\hline CHEMBL1320784 & 688128 & 4.3 & 4.8007 & TST & \\
\hline CHEMBL1364657 & 688128 & 4.05 & 4.5335 & TRN & \\
\hline CHEMBL1501843 & 688128 & 5.5 & 4.7006 & TST & \\
\hline CHEMBL1556895 & 688128 & 4.05 & 4.6055 & TST & \\
\hline CHEMBL1515210 & 688128 & 4.25 & 4.542 & TRN & \\
\hline CHEMBL1595096 & 688128 & 4.85 & 4.5775 & TRN & \\
\hline CHEMBL1371173 & 688128 & 4.6 & 4.6407 & TST & \\
\hline CHEMBL1358365 & 688128 & 5.15 & 4.6271 & TRN & \\
\hline CHEMBL1445434 & 688128 & 4.45 & 4.3797 & TRN & \\
\hline CHEMBL1504429 & 688128 & 7.0 & 5.8101 & TRN & \\
\hline CHEMBL1481472 & 688128 & 4.4 & 4.6885 & TRN & \\
\hline CHEMBL1572715 & 688128 & 4.4 & 4.4242 & TRN & \\
\hline CHEMBL1521198 & 688128 & 4.95 & 4.7807 & TRN & \\
\hline CHEMBL3191602 & 688128 & 4.05 & 4.3335 & TRN & \\
\hline CHEMBL1585041 & 688128 & 4.3 & 4.3798 & TRN & \\
\hline CHEMBL1485869 & 688128 & 4.85 & 4.666 & TRN & \\
\hline CHEMBL1361892 & 688128 & 5.05 & 4.8005 & TRN & \\
\hline CHEMBL1506557 & 688128 & 4.5 & 5.0833 & TRN & \\
\hline CHEMBL1605931 & 688128 & 4.05 & 4.8151 & TST & \\
\hline CHEMBL255881 & 688128 & 5.15 & 4.947 & TRN & \\
\hline CHEMBL1439787 & 688128 & 6.05 & 4.6242 & TST & \\
\hline CHEMBL1509148 & 688128 & 4.7 & 4.5831 & TRN & \\
\hline CHEMBL1576566 & 688128 & 4.35 & 4.7865 & TST & \\
\hline CHEMBL1408899 & 688128 & 4.2 & 4.3276 & TST & \\
\hline CHEMBL1497522 & 688128 & 4.4 & 4.2122 & TST & \\
\hline CHEMBL1307342 & 688128 & 4.9 & 4.8736 & TRN & \\
\hline CHEMBL1523660 & 688128 & 4.55 & 4.5482 & TST & \\
\hline CHEMBL1331586 & 688128 & 4.1 & 4.7103 & TRN & \\
\hline
\end{tabular}




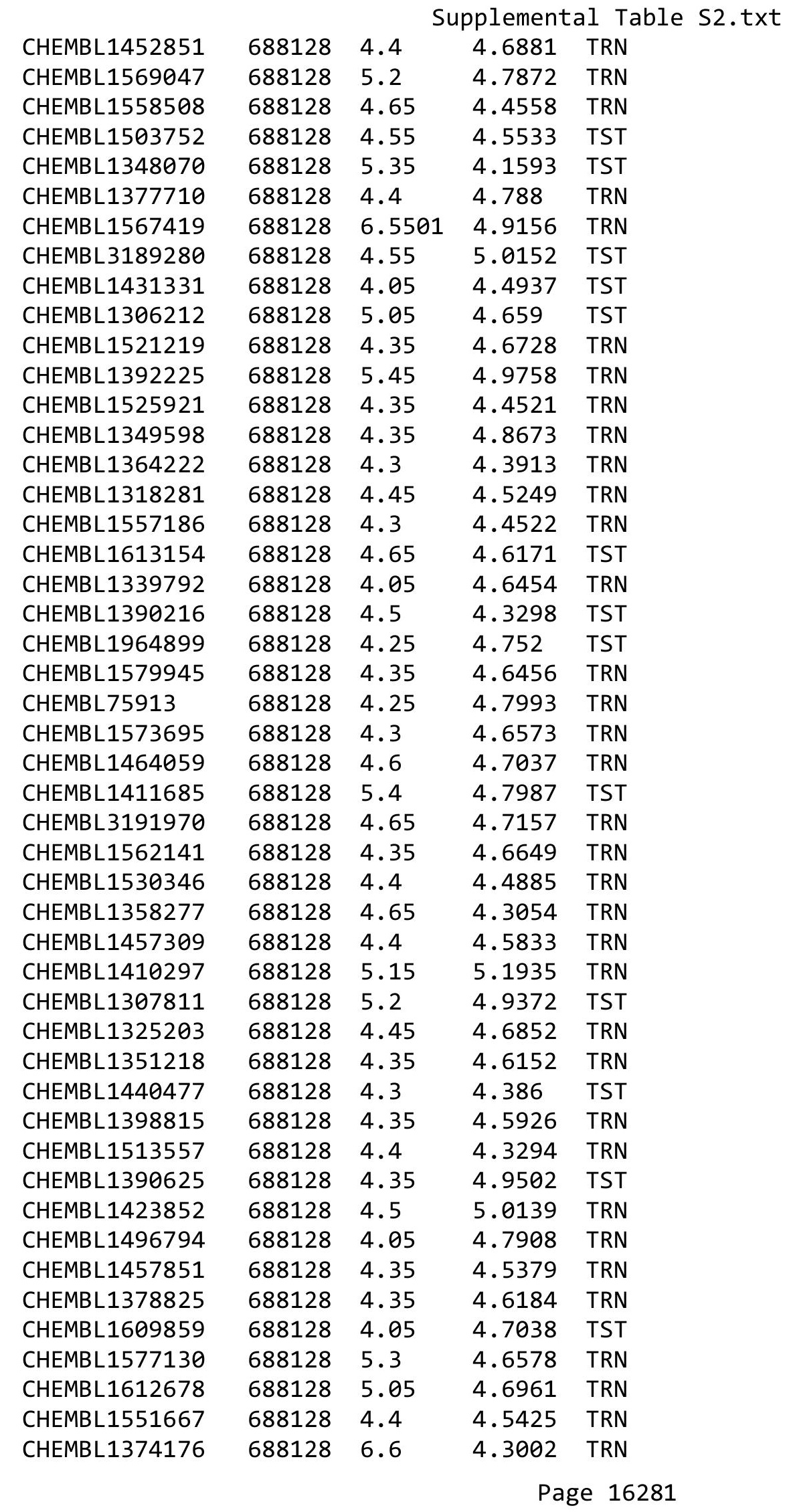




\begin{tabular}{|c|c|c|c|c|c|}
\hline \multirow[b]{2}{*}{ CHEMBL1421604 } & \multirow[b]{2}{*}{688128} & \\
\hline & & 4.3 & 5.0691 & TST & \\
\hline CHEMBL1594875 & 688128 & 5.1 & 4.7424 & TRN & \\
\hline CHEMBL 2001337 & 688128 & 4.65 & 4.5651 & TRN & \\
\hline CHEMBL1378159 & 688128 & 4.5 & 4.5485 & TRN & \\
\hline CHEMBL1438560 & 688128 & 6.0 & 4.5527 & TRN & \\
\hline CHEMBL1606403 & 688128 & 5.1 & 4.8023 & TRN & \\
\hline CHEMBL1516388 & 688128 & 6.0 & 4.9094 & TST & \\
\hline CHEMBL1335615 & 688128 & 4.25 & 4.6052 & TST & \\
\hline CHEMBL1305314 & 688128 & 4.45 & 4.4938 & TRN & \\
\hline CHEMBL1385760 & 688128 & 5.8 & 4.7532 & TRN & \\
\hline CHEMBL1465704 & 688128 & 5.5 & 4.4506 & TRN & \\
\hline CHEMBL1506619 & 688128 & 4.3 & 4.3833 & TST & \\
\hline CHEMBL1495188 & 688128 & 4.3 & 4.5145 & TST & \\
\hline CHEMBL1380496 & 688128 & 4.35 & 4.3723 & TST & \\
\hline CHEMBL1472308 & 688128 & 4.45 & 4.5731 & TST & \\
\hline CHEMBL1553480 & 688128 & 4.3 & 4.7108 & TST & \\
\hline CHEMBL1445126 & 688128 & 4.1 & 4.3309 & TRN & \\
\hline CHEMBL1429569 & 688128 & 4.35 & 4.4668 & TST & \\
\hline CHEMBL1388653 & 688128 & 5.85 & 4.7691 & TRN & \\
\hline CHEMBL1360765 & 688128 & 4.6 & 4.8154 & TST & \\
\hline CHEMBL1450031 & 688128 & 4.3 & 4.6275 & TRN & \\
\hline CHEMBL1525062 & 688128 & 4.35 & 4.5965 & TRN & \\
\hline CHEMBL1335799 & 688128 & 4.4 & 4.4958 & TRN & \\
\hline CHEMBL1486101 & 688128 & 4.35 & 4.6687 & TRN & \\
\hline CHEMBL1409017 & 688128 & 4.95 & 4.4555 & TRN & \\
\hline CHEMBL1448837 & 688128 & 4.3 & 4.6444 & TRN & \\
\hline CHEMBL1559870 & 688128 & 4.0 & 4.4702 & TST & \\
\hline CHEMBL3196856 & 688128 & 4.3 & 4.7246 & TRN & \\
\hline CHEMBL1325470 & 688128 & 5.05 & 4.5415 & TRN & \\
\hline CHEMBL 2002806 & 688128 & 4.65 & 4.54899 & 99999999995 & TRN \\
\hline CHEMBL1538389 & 688128 & 4.05 & 4.6102 & TRN & \\
\hline CHEMBL1568180 & 688128 & 4.35 & 4.4193 & TRN & \\
\hline CHEMBL1362520 & 688128 & 6.0 & 4.1714 & TST & \\
\hline CHEMBL1466645 & 688128 & 4.4 & 4.7639 & TST & \\
\hline CHEMBL1468611 & 688128 & 6.5 & 4.6925 & TRN & \\
\hline CHEMBL1445735 & 688128 & 5.4 & 4.3379 & TST & \\
\hline CHEMBL1442897 & 688128 & 4.3 & 4.4622 & TRN & \\
\hline CHEMBL1309785 & 688128 & 5.75 & 4.9434 & TRN & \\
\hline CHEMBL1527417 & 688128 & 4.3 & 4.5204 & TST & \\
\hline CHEMBL1596164 & 688128 & 4.45 & 4.8335 & TRN & \\
\hline CHEMBL1322912 & 688128 & 4.3 & 4.428 & TRN & \\
\hline CHEMBL1589471 & 688128 & 4.3 & 4.7448 & TRN & \\
\hline CHEMBL271958 & 688128 & 4.65 & 4.8742 & TST & \\
\hline CHEMBL1528008 & 688128 & 4.55 & 4.7352 & TRN & \\
\hline CHEMBL1482029 & 688128 & 4.75 & 4.9309 & TST & \\
\hline CHEMBL546257 & 688128 & 4.35 & 4.4068 & TST & \\
\hline CHEMBL1418847 & 688128 & 4.75 & 4.6325 & TRN & \\
\hline CHEMBL1505163 & 688128 & 4.25 & 4.4819 & TRN & \\
\hline & & & & 16282 & \\
\hline
\end{tabular}




\begin{tabular}{|c|c|c|c|c|}
\hline \multicolumn{5}{|c|}{ Supplemental Table S2.txt } \\
\hline CHEMBL1356866 & 688128 & 4.05 & 4.419 & TRN \\
\hline CHEMBL1346431 & 688128 & 5.15 & 4.56 & TRN \\
\hline CHEMBL1530999 & 688128 & 4.4 & 4.8564 & TRN \\
\hline CHEMBL1585690 & 688128 & 4.0 & 4.6284 & TRN \\
\hline CHEMBL1499939 & 688128 & 4.3 & 4.9406 & TRN \\
\hline CHEMBL1568397 & 688128 & 4.4 & 5.121 & TRN \\
\hline CHEMBL1346274 & 688128 & 4.05 & 4.9863 & TST \\
\hline CHEMBL1588242 & 688128 & 4.45 & 4.5721 & TRN \\
\hline CHEMBL1992601 & 688128 & 4.4 & 4.9076 & TST \\
\hline CHEMBL1487327 & 688128 & 4.7 & 4.542 & TRN \\
\hline CHEMBL1438907 & 688128 & 4.55 & 4.8384 & TST \\
\hline CHEMBL1412230 & 688128 & 4.4 & 4.8341 & TRN \\
\hline CHEMBL1306185 & 688128 & 4.25 & 4.5004 & TRN \\
\hline CHEMBL1604159 & 688128 & 4.35 & 4.6318 & TRN \\
\hline CHEMBL1301197 & 688128 & 5.4 & 4.4678 & TRN \\
\hline CHEMBL1365552 & 688128 & 4.4 & 4.8821 & TST \\
\hline CHEMBL1532540 & 688128 & 6.1 & 4.6726 & TST \\
\hline CHEMBL1409381 & 688128 & 4.35 & 4.9305 & TST \\
\hline CHEMBL1561489 & 688128 & 4.1 & 4.7718 & TRN \\
\hline CHEMBL1432885 & 688128 & 5.0 & 4.7346 & TRN \\
\hline CHEMBL1394822 & 688128 & 4.05 & 4.5157 & TRN \\
\hline CHEMBL1593885 & 688128 & 4.55 & 4.2437 & TRN \\
\hline CHEMBL1329403 & 688128 & 4.4 & 4.3722 & TRN \\
\hline CHEMBL1541304 & 688128 & 4.05 & 4.2737 & TRN \\
\hline CHEMBL1575492 & 688128 & 4.25 & 4.5871 & TRN \\
\hline CHEMBL1601725 & 688128 & 4.4 & 4.4786 & TRN \\
\hline CHEMBL1391283 & 688128 & 4.95 & 4.4609 & TRN \\
\hline CHEMBL1342737 & 688128 & 4.65 & 4.5446 & TRN \\
\hline CHEMBL1338917 & 688128 & 4.45 & 4.3124 & TRN \\
\hline CHEMBL1598721 & 688128 & 4.3 & 4.2367 & TRN \\
\hline CHEMBL1356444 & 688128 & 4.45 & 4.4168 & TRN \\
\hline CHEMBL1364228 & 688128 & 4.45 & 4.7501 & TST \\
\hline CHEMBL1569585 & 688128 & 5.0 & 4.6482 & TRN \\
\hline CHEMBL1389508 & 688128 & 5.45 & 4.6877 & TST \\
\hline CHEMBL1317718 & 688128 & 4.3 & 4.4948 & TRN \\
\hline CHEMBL1544072 & 688128 & 4.05 & 4.7191 & TRN \\
\hline CHEMBL 1612558 & 688128 & 4.3 & 4.6739 & TRN \\
\hline CHEMBL1507787 & 688128 & 4.05 & 4.6315 & TST \\
\hline CHEMBL1310003 & 688128 & 4.25 & 4.7351 & TRN \\
\hline CHEMBL3199179 & 688128 & 4.95 & 4.6915 & TRN \\
\hline CHEMBL1599462 & 688128 & 4.05 & 4.2596 & TRN \\
\hline CHEMBL1403791 & 688128 & 4.05 & 4.4166 & TST \\
\hline CHEMBL1408395 & 688128 & 5.5 & 5.1059 & TRN \\
\hline CHEMBL1412774 & 688128 & 4.45 & 4.5313 & TRN \\
\hline CHEMBL1341887 & 688128 & 4.35 & 4.5599 & TRN \\
\hline CHEMBL1428209 & 688128 & 4.3 & 5.043 & TRN \\
\hline CHEMBL1379674 & 688128 & 5.15 & 4.5504 & TRN \\
\hline CHEMBL1493667 & 688128 & 5.4 & 4.7542 & TST \\
\hline
\end{tabular}




\begin{tabular}{|c|c|c|c|c|c|}
\hline \multicolumn{6}{|c|}{ Supplemental Table s2.txt } \\
\hline CHEMBL1473486 & 688128 & 4.25 & 4.7566 & TST & \\
\hline CHEMBL1546584 & 688128 & 4.4 & 4.5978 & TRN & \\
\hline CHEMBL2369166 & 688128 & 4.55 & 4.975 & TST & \\
\hline CHEMBL1439679 & 688128 & 4.4 & 4.6077 & TRN & \\
\hline CHEMBL1387739 & 688128 & 4.7 & 4.9447 & TRN & \\
\hline CHEMBL1504694 & 688128 & 4.55 & 4.6726 & TRN & \\
\hline CHEMBL1418380 & 688128 & 4.3 & 4.5749 & TRN & \\
\hline CHEMBL1415557 & 688128 & 4.05 & 4.6287 & TST & \\
\hline CHEMBL1432130 & 688128 & 4.7 & 4.5599 & TST & \\
\hline CHEMBL1348308 & 688128 & 4.25 & 4.5154 & TRN & \\
\hline CHEMBL496729 & 688128 & 4.8 & 4.9764 & TRN & \\
\hline CHEMBL1312946 & 688128 & 4.4 & 4.519 & TRN & \\
\hline CHEMBL1601161 & 688128 & 4.75 & 4.6274 & TRN & \\
\hline CHEMBL1373551 & 688128 & 4.2 & 4.4863 & TRN & \\
\hline CHEMBL1482267 & 688128 & 4.05 & 4.6863 & TRN & \\
\hline CHEMBL1427326 & 688128 & 4.05 & 4.5596 & TRN & \\
\hline CHEMBL1520202 & 688128 & 4.35 & 4.6126 & TRN & \\
\hline CHEMBL1309232 & 688128 & 5.6 & 5.2875 & TRN & \\
\hline CHEMBL1509024 & 688128 & 6.6 & 4.4384 & TRN & \\
\hline CHEMBL1526171 & 688128 & 6.15 & 5.2017 & TRN & \\
\hline CHEMBL1422506 & 688128 & 4.3 & 4.5002 & TRN & \\
\hline CHEMBL3194327 & 688128 & 4.35 & 4.9036 & TST & \\
\hline CHEMBL1448738 & 688128 & 4.7 & 5.003 & TRN & \\
\hline CHEMBL1373332 & 688128 & 5.35 & $4.6110 e$ & 3000000001 & TRN \\
\hline CHEMBL1518358 & 688128 & 4.3 & 4.6151 & TRN & \\
\hline CHEMBL1308497 & 688128 & 4.4 & 4.5977 & TRN & \\
\hline CHEMBL1562670 & 688128 & 4.3 & 4.4475 & TRN & \\
\hline CHEMBL3211264 & 688128 & 4.3 & 4.6738 & TRN & \\
\hline CHEMBL1395617 & 688128 & 4.3 & 4.6036 & TRN & \\
\hline CHEMBL1367444 & 688128 & 5.35 & 4.7408 & TRN & \\
\hline CHEMBL1968316 & 688128 & 4.45 & 4.6584 & TST & \\
\hline CHEMBL1567274 & 688128 & 4.0 & 4.3369 & TRN & \\
\hline CHEMBL1503724 & 688128 & 4.65 & 4.6292 & TRN & \\
\hline CHEMBL1440151 & 688128 & 4.3 & 4.5798 & TST & \\
\hline CHEMBL1477548 & 688128 & 4.3 & 4.3997 & TRN & \\
\hline CHEMBL1490402 & 688128 & 4.35 & 4.3808 & TRN & \\
\hline CHEMBL 1445498 & 688128 & 4.65 & 4.7689 & TRN & \\
\hline CHEMBL1512280 & 688128 & 4.05 & 4.8815 & TST & \\
\hline CHEMBL1334040 & 688128 & 5.8 & 4.9838 & TST & \\
\hline CHEMBL1303211 & 688128 & 4.05 & 4.4568 & TRN & \\
\hline CHEMBL1472304 & 688128 & 4.35 & 4.5622 & TRN & \\
\hline CHEMBL1360960 & 688128 & 4.05 & 4.4746 & TRN & \\
\hline CHEMBL1332955 & 688128 & 4.4 & 4.982 & TRN & \\
\hline CHEMBL1434665 & 688128 & 4.4 & 4.8475 & TRN & \\
\hline CHEMBL1520850 & 688128 & 4.35 & 4.3088 & TST & \\
\hline CHEMBL1524627 & 688128 & 4.25 & 4.4373 & TRN & \\
\hline CHEMBL1445258 & 688128 & 4.35 & 4.5173 & TRN & \\
\hline CHEMBL1371148 & 688128 & 4.5 & 4.2697 & TRN & \\
\hline
\end{tabular}




\begin{tabular}{|c|c|c|c|c|c|}
\hline & & \multicolumn{4}{|c|}{ Supplemental Table S2.txt } \\
\hline CHEMBL1546507 & 688128 & 4.2 & 4.4512 & TRN & \\
\hline CHEMBL1461122 & 688128 & 4.0 & 4.523 & TRN & \\
\hline CHEMBL1340514 & 688128 & 5.7 & 4.8477 & TRN & \\
\hline CHEMBL1586614 & 688128 & 4.55 & 4.5049 & TRN & \\
\hline CHEMBL1506143 & 688128 & 4.05 & 4.5478 & TST & \\
\hline CHEMBL1467962 & 688128 & 4.5 & 4.5672 & TRN & \\
\hline CHEMBL1568318 & 688128 & 6.35 & 4.881 & TRN & \\
\hline CHEMBL1481446 & 688128 & 4.35 & 4.4443 & TRN & \\
\hline CHEMBL1515609 & 688128 & 4.9 & 4.4875 & TRN & \\
\hline CHEMBL1553580 & 688128 & 4.3 & 4.5848 & TST & \\
\hline CHEMBL1601679 & 688128 & 4.0 & 4.5935 & TRN & \\
\hline CHEMBL1373387 & 688128 & 4.2 & 4.6011 & TRN & \\
\hline CHEMBL1552980 & 688128 & 5.75 & 4.4552 & TST & \\
\hline CHEMBL1465409 & 688128 & 5.55 & 5.184 & TRN & \\
\hline CHEMBL1586082 & 688128 & 4.4 & 4.8817 & TRN & \\
\hline CHEMBL1522697 & 688128 & 4.85 & 4.7113 & TST & \\
\hline CHEMBL1531520 & 688128 & 4.4 & 4.6321 & TRN & \\
\hline CHEMBL1546502 & 688128 & 4.25 & 4.71399 & 99999999995 & TRN \\
\hline CHEMBL1533382 & 688128 & 4.4 & 4.8943 & TRN & \\
\hline CHEMBL1359537 & 688128 & 5.75 & 4.4275 & TRN & \\
\hline CHEMBL1528051 & 688128 & 5.05 & 4.8089 & TRN & \\
\hline CHEMBL1575363 & 688128 & 4.45 & 4.4907 & TRN & \\
\hline CHEMBL1363884 & 688128 & 4.4 & 4.6824 & TRN & \\
\hline CHEMBL1462716 & 688128 & 4.0 & 4.501 & TST & \\
\hline CHEMBL1438593 & 688128 & 4.35 & 4.6531 & TRN & \\
\hline CHEMBL1413896 & 688128 & 4.05 & 4.9288 & TST & \\
\hline CHEMBL1490148 & 688128 & 4.9 & 4.4899 & TRN & \\
\hline CHEMBL1430392 & 688128 & 4.3 & 4.5089 & TRN & \\
\hline CHEMBL1406750 & 688128 & 4.05 & 4.3324 & TRN & \\
\hline CHEMBL1474677 & 688128 & 4.6 & 4.6659 & TRN & \\
\hline CHEMBL1432777 & 688128 & 4.4 & 4.5995 & TRN & \\
\hline CHEMBL1426127 & 688128 & 5.1 & 4.8324 & TST & \\
\hline CHEMBL1483076 & 688128 & 4.35 & 4.763 & TRN & \\
\hline CHEMBL1558980 & 688128 & 5.4 & 4.5746 & TST & \\
\hline CHEMBL1380847 & 688128 & 4.55 & 4.5318 & TRN & \\
\hline CHEMBL1389158 & 688128 & 5.55 & 4.6036 & TRN & \\
\hline CHEMBL1311450 & 688128 & 4.1 & 4.9596 & TRN & \\
\hline CHEMBL1484210 & 688128 & 4.3 & 4.8595 & TST & \\
\hline CHEMBL1329179 & 688128 & 4.25 & 4.6429 & TRN & \\
\hline CHEMBL1568513 & 688128 & 4.25 & 4.5882 & TRN & \\
\hline CHEMBL1323998 & 688128 & 4.0 & 4.4347 & TST & \\
\hline CHEMBL1516913 & 688128 & 5.25 & 4.9249 & TRN & \\
\hline CHEMBL1375233 & 688128 & 4.05 & 4.7795 & TRN & \\
\hline CHEMBL1314834 & 688128 & 4.6 & 4.5638 & TRN & \\
\hline CHEMBL1551343 & 688128 & 4.25 & 4.5275 & TRN & \\
\hline CHEMBL1568173 & 688128 & 4.65 & 4.6147 & TRN & \\
\hline CHEMBL1436502 & 688128 & 4.05 & 4.2891 & TRN & \\
\hline CHEMBL1524288 & 688128 & 4.7 & 4.9143 & TRN & \\
\hline
\end{tabular}




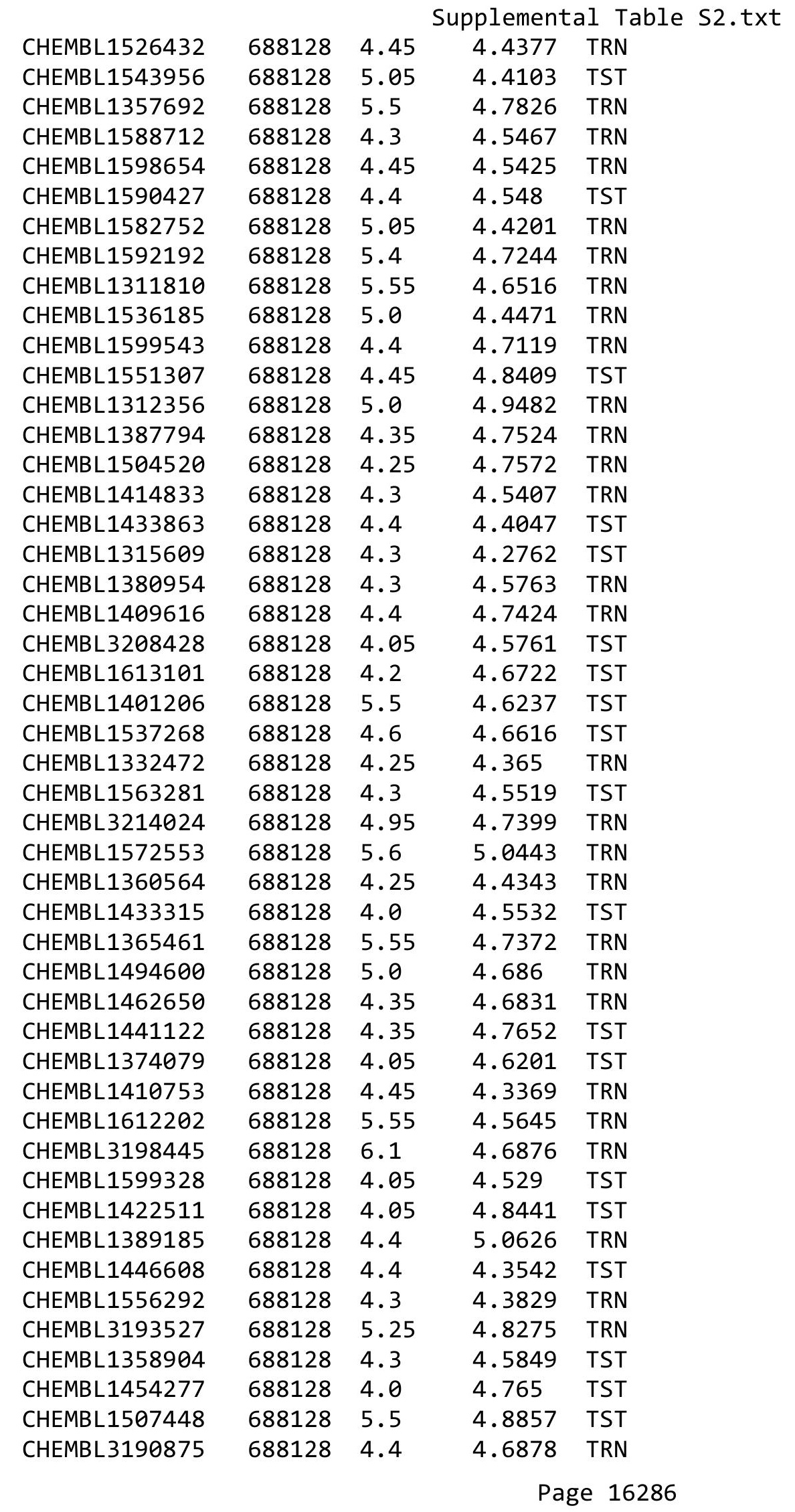




\begin{tabular}{|c|c|c|c|c|c|}
\hline & & & & & \\
\hline CHEMBL1392107 & 688128 & 4.4 & 4.5721 & TST & \\
\hline CHEMBL1485923 & 688128 & 5.95 & 5.1068 & TRN & \\
\hline CHEMBL1302044 & 688128 & 4.05 & 4.3536 & TRN & \\
\hline CHEMBL1513696 & 688128 & 4.3 & 4.7173 & TRN & \\
\hline CHEMBL1427258 & 688128 & 4.3 & 4.4021 & TRN & \\
\hline CHEMBL1528302 & 688128 & 4.4 & 4.4279 & TRN & \\
\hline CHEMBL1345875 & 688128 & 4.3 & 4.2544 & TRN & \\
\hline CHEMBL1417291 & 688128 & 4.9 & 4.6508 & TRN & \\
\hline CHEMBL1543490 & 688128 & 4.65 & 4.4734 & TRN & \\
\hline CHEMBL1547427 & 688128 & 4.75 & 4.55399 & 9999999999 & TRN \\
\hline CHEMBL1513621 & 688128 & 5.55 & 4.9955 & TRN & \\
\hline CHEMBL1459066 & 688128 & 4.45 & 5.29299 & 9999999999 & TRN \\
\hline CHEMBL1560117 & 688128 & 4.85 & 4.9605 & TRN & \\
\hline CHEMBL1434229 & 688128 & 5.2 & 4.6052 & TRN & \\
\hline CHEMBL3213855 & 688128 & 4.95 & 4.9488 & TRN & \\
\hline CHEMBL1332618 & 688128 & 4.5 & 4.5609 & TST & \\
\hline CHEMBL3189335 & 688128 & 4.35 & 4.6535 & TST & \\
\hline CHEMBL1532695 & 688128 & 5.35 & 4.8834 & TRN & \\
\hline CHEMBL1468650 & 688128 & 4.05 & 4.6025 & TRN & \\
\hline CHEMBL1517720 & 688128 & 4.55 & 4.6534 & TRN & \\
\hline CHEMBL1501814 & 688128 & 4.4 & 4.7242 & TST & \\
\hline CHEMBL1330255 & 688128 & 4.6 & 4.6658 & TRN & \\
\hline CHEMBL3210165 & 688128 & 4.5 & 4.5242 & TST & \\
\hline CHEMBL1383833 & 688128 & 4.05 & 4.4715 & TRN & \\
\hline CHEMBL1601318 & 688128 & 4.3 & 4.5502 & TRN & \\
\hline CHEMBL1507362 & 688128 & 4.35 & 4.8726 & TST & \\
\hline CHEMBL1381127 & 688128 & 4.3 & 4.1076 & TRN & \\
\hline CHEMBL1394867 & 688128 & 5.4 & 4.6335 & TRN & \\
\hline CHEMBL1393447 & 688128 & 4.85 & 4.7178 & TRN & \\
\hline CHEMBL1455064 & 688128 & 4.0 & 4.6969 & TST & \\
\hline CHEMBL1992432 & 688128 & 5.3 & 4.7966 & TRN & \\
\hline CHEMBL1317456 & 688128 & 5.05 & 5.087 & TRN & \\
\hline CHEMBL1574857 & 688128 & 5.75 & 5.0116 & TRN & \\
\hline CHEMBL1502603 & 688128 & 4.35 & 4.4332 & TRN & \\
\hline CHEMBL1417856 & 688128 & 5.45 & 4.7287 & TRN & \\
\hline CHEMBL1317442 & 688128 & 4.4 & 4.5973 & TST & \\
\hline CHEMBL1387950 & 688128 & 4.1 & 5.044 & TRN & \\
\hline CHEMBL1372057 & 688128 & 4.05 & 4.5345 & TST & \\
\hline CHEMBL1480946 & 688128 & 4.35 & 4.4349 & TRN & \\
\hline CHEMBL1973501 & 688128 & 5.45 & 4.5426 & TRN & \\
\hline CHEMBL1363507 & 688128 & 4.35 & 4.5321 & TRN & \\
\hline CHEMBL1404678 & 688128 & 4.4 & 4.5687 & TRN & \\
\hline CHEMBL1583865 & 688128 & 4.45 & 4.3871 & TRN & \\
\hline CHEMBL1580135 & 688128 & 4.3 & 4.9206 & TRN & \\
\hline CHEMBL1407135 & 688128 & 4.4 & 4.8662 & TRN & \\
\hline CHEMBL1474335 & 688128 & 4.05 & 4.648 & TST & \\
\hline CHEMBL1502008 & 688128 & 4.4 & 4.4639 & TRN & \\
\hline CHEMBL1534475 & 688128 & 4.3 & 4.4085 & TRN & \\
\hline
\end{tabular}




\begin{tabular}{|c|c|c|c|c|c|}
\hline \multicolumn{6}{|c|}{ Supplemental Table S2.txt } \\
\hline CHEMBL1369376 & 688128 & 4.3 & 4.7702 & TRN & \\
\hline CHEMBL1375324 & 688128 & 4.25 & 4.3892 & TRN & \\
\hline CHEMBL1513225 & 688128 & 4.05 & 4.422 & TRN & \\
\hline CHEMBL1352425 & 688128 & 6.8499 & 4.8306 & TRN & \\
\hline CHEMBL1376476 & 688128 & 4.3 & 4.3164 & TRN & \\
\hline CHEMBL1549450 & 688128 & 5.1 & 4.7949 & TST & \\
\hline CHEMBL1326652 & 688128 & 5.25 & 5.5212 & TRN & \\
\hline CHEMBL1514040 & 688128 & 4.4 & 4.7502 & TRN & \\
\hline CHEMBL1506772 & 688128 & 4.35 & 4.6649 & TRN & \\
\hline CHEMBL1478831 & 688128 & 5.0 & 4.6289 & TRN & \\
\hline CHEMBL1452290 & 688128 & 5.8 & 4.66100 & 00000000005 & TRN \\
\hline CHEMBL1594713 & 688128 & 4.25 & 4.8639 & TST & \\
\hline CHEMBL1318505 & 688128 & 4.25 & 4.5341 & TRN & \\
\hline CHEMBL1349494 & 688128 & 4.35 & 4.7983 & TRN & \\
\hline CHEMBL1485275 & 688128 & 4.3 & 5.2228 & TRN & \\
\hline CHEMBL1399942 & 688128 & 6.0 & 4.5464 & TST & \\
\hline CHEMBL1389990 & 688128 & 4.4 & 4.5691 & TRN & \\
\hline CHEMBL1368972 & 688128 & 5.4 & 4.6327 & TRN & \\
\hline CHEMBL1454881 & 688128 & 4.3 & 4.4468 & TRN & \\
\hline CHEMBL1429266 & 688128 & 4.4 & 4.6651 & TST & \\
\hline CHEMBL1351207 & 688128 & 4.4 & 4.7112 & TST & \\
\hline CHEMBL1319598 & 688128 & 4.05 & 4.7682 & TRN & \\
\hline CHEMBL1995041 & 688128 & 4.1 & 4.6738 & TRN & \\
\hline CHEMBL1470776 & 688128 & 4.0 & 4.7177 & TRN & \\
\hline CHEMBL1351519 & 688128 & 4.75 & 5.0596 & TST & \\
\hline CHEMBL1512549 & 688128 & 4.45 & 4.8025 & TST & \\
\hline CHEMBL1457824 & 688128 & 5.45 & 4.6289 & TRN & \\
\hline CHEMBL1370769 & 688128 & 4.35 & 4.6223 & TRN & \\
\hline CHEMBL1421723 & 688128 & 4.35 & 4.2484 & TRN & \\
\hline CHEMBL1529828 & 688128 & 4.45 & 4.5354 & TRN & \\
\hline CHEMBL1316924 & 688128 & 4.3 & 4.5707 & TRN & \\
\hline CHEMBL1379722 & 688128 & 4.7 & 4.3146 & TRN & \\
\hline CHEMBL1373467 & 688128 & 5.45 & 4.9877 & TST & \\
\hline CHEMBL1456007 & 688128 & 4.9 & 4.7357 & TRN & \\
\hline CHEMBL1582251 & 688128 & 5.35 & 4.5724 & TST & \\
\hline CHEMBL1478997 & 688128 & 4.95 & 4.5091 & TRN & \\
\hline CHEMBL1309643 & 688128 & 4.3 & 4.7352 & TST & \\
\hline CHEMBL1393593 & 688128 & 6.05 & 4.7361 & TRN & \\
\hline CHEMBL1400921 & 688128 & 4.4 & 4.3553 & TRN & \\
\hline CHEMBL1602244 & 688128 & 4.45 & 4.523 & TST & \\
\hline CHEMBL1446527 & 688128 & 4.4 & 4.8365 & TRN & \\
\hline CHEMBL1441827 & 688128 & 4.3 & 4.7181 & TRN & \\
\hline CHEMBL1358952 & 688128 & 4.65 & 4.455 & TRN & \\
\hline CHEMBL 3213300 & 688128 & 4.45 & 4.4361 & TRN & \\
\hline CHEMBL1607928 & 688128 & 4.05 & 4.6061 & TRN & \\
\hline CHEMBL1601898 & 688128 & 4.5 & 4.9152 & TRN & \\
\hline CHEMBL1605155 & 688128 & 5.35 & 4.4284 & TST & \\
\hline CHEMBL1451981 & 688128 & 4.45 & 4.7482 & TST & \\
\hline
\end{tabular}




\begin{tabular}{|c|c|c|c|c|c|}
\hline & & \multicolumn{4}{|c|}{ Supplemental Table S2.txt } \\
\hline CHEMBL1363865 & 688128 & 5.05 & 5.0961 & TRN & \\
\hline CHEMBL3196743 & 688128 & 4.4 & 4.7153 & TST & \\
\hline CHEMBL1478522 & 688128 & 4.0 & 4.75899 & 99999999995 & TRN \\
\hline CHEMBL1606669 & 688128 & 4.3 & 4.7378 & TRN & \\
\hline CHEMBL1454128 & 688128 & 4.7 & 5.0135 & TST & \\
\hline CHEMBL1549682 & 688128 & 5.55 & 4.9873 & TST & \\
\hline CHEMBL1524318 & 688128 & 4.6 & 4.4404 & TRN & \\
\hline CHEMBL3193558 & 688128 & 6.1 & 4.6678 & TST & \\
\hline CHEMBL1527611 & 688128 & 5.25 & 4.9208 & TRN & \\
\hline CHEMBL1381478 & 688128 & 4.0 & 4.7457 & TST & \\
\hline CHEMBL1466725 & 688128 & 4.25 & 4.437 & TRN & \\
\hline CHEMBL1594055 & 688128 & 4.75 & 5.1433 & TRN & \\
\hline CHEMBL1463442 & 688128 & 4.4 & 5.026 & TRN & \\
\hline CHEMBL1353018 & 688128 & 4.05 & 4.3653 & TRN & \\
\hline CHEMBL3210954 & 688128 & 4.25 & 4.445 & TST & \\
\hline CHEMBL1348623 & 688128 & 4.05 & 4.467 & TST & \\
\hline CHEMBL1311237 & 688128 & 4.35 & 4.4823 & TST & \\
\hline CHEMBL3199073 & 688128 & 4.35 & 4.4446 & TRN & \\
\hline CHEMBL1973159 & 688128 & 4.35 & 4.4306 & TRN & \\
\hline CHEMBL1304617 & 688128 & 4.55 & 4.7984 & TRN & \\
\hline CHEMBL1548793 & 688128 & 6.25 & 4.5768 & TRN & \\
\hline CHEMBL1603748 & 688128 & 4.5 & 4.9008 & TRN & \\
\hline CHEMBL1471539 & 688128 & 5.4 & 4.6553 & TST & \\
\hline CHEMBL1446236 & 688128 & 5.0 & 4.5643 & TRN & \\
\hline CHEMBL1541713 & 688128 & 4.45 & 4.5983 & TST & \\
\hline CHEMBL1586473 & 688128 & 4.3 & 4.5511 & TRN & \\
\hline CHEMBL1376608 & 688128 & 4.4 & 4.4442 & TST & \\
\hline CHEMBL 2094549 & 688128 & 4.3 & 4.6952 & TST & \\
\hline CHEMBL1527860 & 688128 & 4.9 & 4.5841 & TRN & \\
\hline CHEMBL520156 & 688128 & 4.55 & 4.703 & TST & \\
\hline CHEMBL1445564 & 688128 & 4.0 & 4.6411 & TRN & \\
\hline CHEMBL1556561 & 688128 & 5.1 & 4.7925 & TRN & \\
\hline CHEMBL1361119 & 688128 & 4.35 & 4.6455 & TRN & \\
\hline CHEMBL523375 & 688128 & 4.35 & 4.7058 & TRN & \\
\hline CHEMBL1581473 & 688128 & 4.7 & 4.629 & TRN & \\
\hline CHEMBL1409048 & 688128 & 4.05 & 4.5516 & TST & \\
\hline CHEMBL1998234 & 688128 & 4.85 & 4.4873 & TRN & \\
\hline CHEMBL1590166 & 688128 & 4.05 & 4.5264 & TRN & \\
\hline CHEMBL1378382 & 688128 & 4.35 & 4.6411 & TRN & \\
\hline CHEMBL1354746 & 688128 & 5.4 & 4.4641 & TST & \\
\hline CHEMBL1566160 & 688128 & 4.1 & 4.4589 & TST & \\
\hline CHEMBL1464498 & 688128 & 4.75 & 4.7253 & TRN & \\
\hline CHEMBL1613480 & 688128 & 4.95 & 4.4811 & TRN & \\
\hline CHEMBL1405054 & 688128 & 5.55 & 4.8177 & TRN & \\
\hline CHEMBL1407421 & 688128 & 4.0 & 4.5261 & TST & \\
\hline CHEMBL1407495 & 688128 & 4.65 & 4.5115 & TRN & \\
\hline CHEMBL1461386 & 688128 & 4.4 & 4.5622 & TRN & \\
\hline CHEMBL1313926 & 688128 & 6.3 & 4.9023 & TRN & \\
\hline
\end{tabular}




\begin{tabular}{|c|c|c|c|c|c|}
\hline \multicolumn{6}{|c|}{ Supplemental Table s2.txt } \\
\hline CHEMBL 3197521 & 688128 & 4.7 & 4.938 & TRN & \\
\hline CHEMBL1388967 & 688128 & 4.65 & 4.7657 & TST & \\
\hline CHEMBL591836 & 688128 & 4.55 & 4.2914 & TRN & \\
\hline CHEMBL1519009 & 688128 & 4.25 & 4.4294 & TRN & \\
\hline CHEMBL1340962 & 688128 & 4.75 & 4.8031 & TRN & \\
\hline CHEMBL1511693 & 688128 & 4.4 & 4.5633 & TRN & \\
\hline CHEMBL1308504 & 688128 & 4.35 & 4.7134 & TRN & \\
\hline CHEMBL1588908 & 688128 & 4.05 & 4.3932 & TRN & \\
\hline CHEMBL1585589 & 688128 & 5.35 & 4.4071 & TRN & \\
\hline CHEMBL1299824 & 688128 & 4.85 & 4.4766 & TRN & \\
\hline CHEMBL1502623 & 688128 & 4.05 & 4.7061 & TST & \\
\hline CHEMBL1355493 & 688128 & 4.45 & 4.4228 & TRN & \\
\hline CHEMBL1343041 & 688128 & 4.0 & 4.5287 & TRN & \\
\hline CHEMBL1384468 & 688128 & 6.5 & 4.9214 & TST & \\
\hline CHEMBL1538959 & 688128 & 4.4 & 4.5009 & TRN & \\
\hline CHEMBL 227423 & 688128 & 4.5 & 5.0317 & TRN & \\
\hline CHEMBL1376140 & 688128 & 6.2 & 4.9911 & TRN & \\
\hline CHEMBL1500355 & 688128 & 4.35 & 4.6114 & TRN & \\
\hline CHEMBL1449728 & 688128 & 5.25 & 5.1868 & TRN & \\
\hline CHEMBL1397400 & 688128 & 5.5 & 5.0079 & TRN & \\
\hline CHEMBL1542873 & 688128 & 4.25 & 4.7068 & TRN & \\
\hline CHEMBL1575357 & 688128 & 4.3 & 4.5383 & TRN & \\
\hline CHEMBL1305732 & 688128 & 4.35 & 4.5603 & TRN & \\
\hline CHEMBL1330186 & 688128 & 4.3 & 4.5903 & TST & \\
\hline CHEMBL1397411 & 688128 & 4.9 & 4.7333 & TST & \\
\hline CHEMBL1603563 & 688128 & 4.25 & 4.3671 & TRN & \\
\hline CHEMBL1333913 & 688128 & 4.05 & 4.5944 & TST & \\
\hline CHEMBL1366681 & 688128 & 4.55 & 4.7918 & TST & \\
\hline CHEMBL1326391 & 688128 & 4.55 & 4.3708 & TRN & \\
\hline CHEMBL1363360 & 688128 & 4.4 & 4.4765 & TRN & \\
\hline CHEMBL1351750 & 688128 & 5.2 & 4.9912 & TRN & \\
\hline CHEMBL1359172 & 688128 & 4.25 & 4.4767 & TRN & \\
\hline CHEMBL1328253 & 688128 & 4.05 & 4.7547 & TRN & \\
\hline CHEMBL1346461 & 688128 & 4.3 & 4.6363 & TRN & \\
\hline CHEMBL1330144 & 688128 & 4.2 & 4.525 & TRN & \\
\hline CHEMBL1588478 & 688128 & 4.0 & 4.7628 & TRN & \\
\hline CHEMBL1575230 & 688128 & 4.35 & 4.4997 & TRN & \\
\hline CHEMBL1405435 & 688128 & 4.65 & 4.7359 & TRN & \\
\hline CHEMBL 2002565 & 688128 & 4.1 & 4.6633 & TRN & \\
\hline CHEMBL1586643 & 688128 & 4.35 & 4.60800 & 00000000005 & \\
\hline CHEMBL1332881 & 688128 & 5.0 & 4.7489 & TRN & \\
\hline CHEMBL1609631 & 688128 & 4.15 & 4.2358 & TRN & \\
\hline CHEMBL1468465 & 688128 & 4.2 & 4.5066 & TRN & \\
\hline CHEMBL1493713 & 688128 & 4.2 & 4.4209 & TRN & \\
\hline CHEMBL1597716 & 688128 & 5.0 & 4.8397 & TRN & \\
\hline CHEMBL1420185 & 688128 & 4.05 & 4.6985 & TST & \\
\hline CHEMBL3189903 & 688128 & 4.5 & 4.734 & TRN & \\
\hline CHEMBL1495225 & 688128 & 4.7 & 4.5511 & TRN & \\
\hline
\end{tabular}




\begin{tabular}{|c|c|c|c|c|c|}
\hline \\
\hline CHEMBL1498989 & 688128 & 4.4 & 4.7495 & TRN & \\
\hline CHEMBL3195488 & 688128 & 4.7 & 4.934 & TRN & \\
\hline CHEMBL1523532 & 688128 & 4.45 & 4.48600 & 0000000001 & TRN \\
\hline CHEMBL1301700 & 688128 & 5.1 & 5.0398 & TRN & \\
\hline CHEMBL1386425 & 688128 & 5.55 & 4.6972 & TRN & \\
\hline CHEMBL1457239 & 688128 & 4.4 & 4.4032 & TRN & \\
\hline CHEMBL1471180 & 688128 & 5.0 & 4.621 & TST & \\
\hline CHEMBL1552222 & 688128 & 4.8 & 4.3354 & TRN & \\
\hline CHEMBL1577166 & 688128 & 4.75 & 4.5171 & TRN & \\
\hline CHEMBL1534669 & 688128 & 4.8 & 4.547 & TST & \\
\hline CHEMBL1323282 & 688128 & 4.55 & 4.7684 & TRN & \\
\hline CHEMBL1465012 & 688128 & 5.05 & 4.6629 & TRN & \\
\hline CHEMBL1307392 & 688128 & 4.05 & 4.2606 & TST & \\
\hline CHEMBL1324916 & 688128 & 4.3 & 4.6424 & TST & \\
\hline CHEMBL1594712 & 688128 & 4.55 & 4.5955 & TST & \\
\hline CHEMBL1594376 & 688128 & 4.75 & 4.9506 & TST & \\
\hline CHEMBL1428142 & 688128 & 4.6 & 4.3954 & TRN & \\
\hline CHEMBL1305026 & 688128 & 4.05 & 4.5107 & TST & \\
\hline CHEMBL1371835 & 688128 & 4.3 & 4.48600 & 0000000001 & TRN \\
\hline CHEMBL1549145 & 688128 & 5.55 & 4.5613 & TRN & \\
\hline CHEMBL1448919 & 688128 & 4.4 & 4.527 & TRN & \\
\hline CHEMBL1604782 & 688128 & 6.5 & 4.7002 & TRN & \\
\hline CHEMBL1330147 & 688128 & 4.05 & 4.64 & TRN & \\
\hline CHEMBL1578324 & 688128 & 5.7 & 5.3555 & TRN & \\
\hline CHEMBL1326107 & 688128 & 4.35 & 4.5689 & TRN & \\
\hline CHEMBL1343453 & 688128 & 4.6 & 4.8591 & TRN & \\
\hline CHEMBL1588381 & 688128 & 4.1 & 4.7448 & TRN & \\
\hline CHEMBL1422304 & 688128 & 4.95 & 5.0798 & TST & \\
\hline CHEMBL1572450 & 688128 & 4.05 & 4.6976 & TST & \\
\hline CHEMBL1401155 & 688128 & 4.55 & 4.4774 & TST & \\
\hline CHEMBL1318521 & 688128 & 4.4 & 4.8843 & TST & \\
\hline CHEMBL315687 & 688128 & 4.35 & 4.8659 & TST & \\
\hline CHEMBL1565831 & 688128 & 4.05 & 4.6096 & TRN & \\
\hline CHEMBL1469326 & 688128 & 5.45 & 4.5283 & TRN & \\
\hline CHEMBL1459185 & 688128 & 4.35 & 4.5869 & TST & \\
\hline CHEMBL1386698 & 688128 & 4.8 & 4.6273 & TRN & \\
\hline CHEMBL1459380 & 688128 & 4.35 & 4.4727 & TRN & \\
\hline CHEMBL1398535 & 688128 & 4.5 & 4.4582 & TST & \\
\hline CHEMBL3194820 & 688128 & 4.35 & 4.2188 & TRN & \\
\hline CHEMBL1452909 & 688128 & 5.0 & 4.783 & TRN & \\
\hline CHEMBL1385768 & 688128 & 4.25 & 4.5777 & TRN & \\
\hline CHEMBL1544879 & 688128 & 4.35 & 4.7276 & TRN & \\
\hline CHEMBL1591870 & 688128 & 5.1 & 4.4796 & TRN & \\
\hline CHEMBL1305525 & 688128 & 4.4 & 4.5795 & TRN & \\
\hline CHEMBL1348281 & 688128 & 5.75 & 4.9011 & TRN & \\
\hline CHEMBL1490682 & 688128 & 4.35 & 4.5587 & TRN & \\
\hline CHEMBL1582913 & 688128 & 5.0 & 4.7594 & TRN & \\
\hline CHEMBL1612118 & 688128 & 4.45 & 4.3212 & TRN & \\
\hline
\end{tabular}




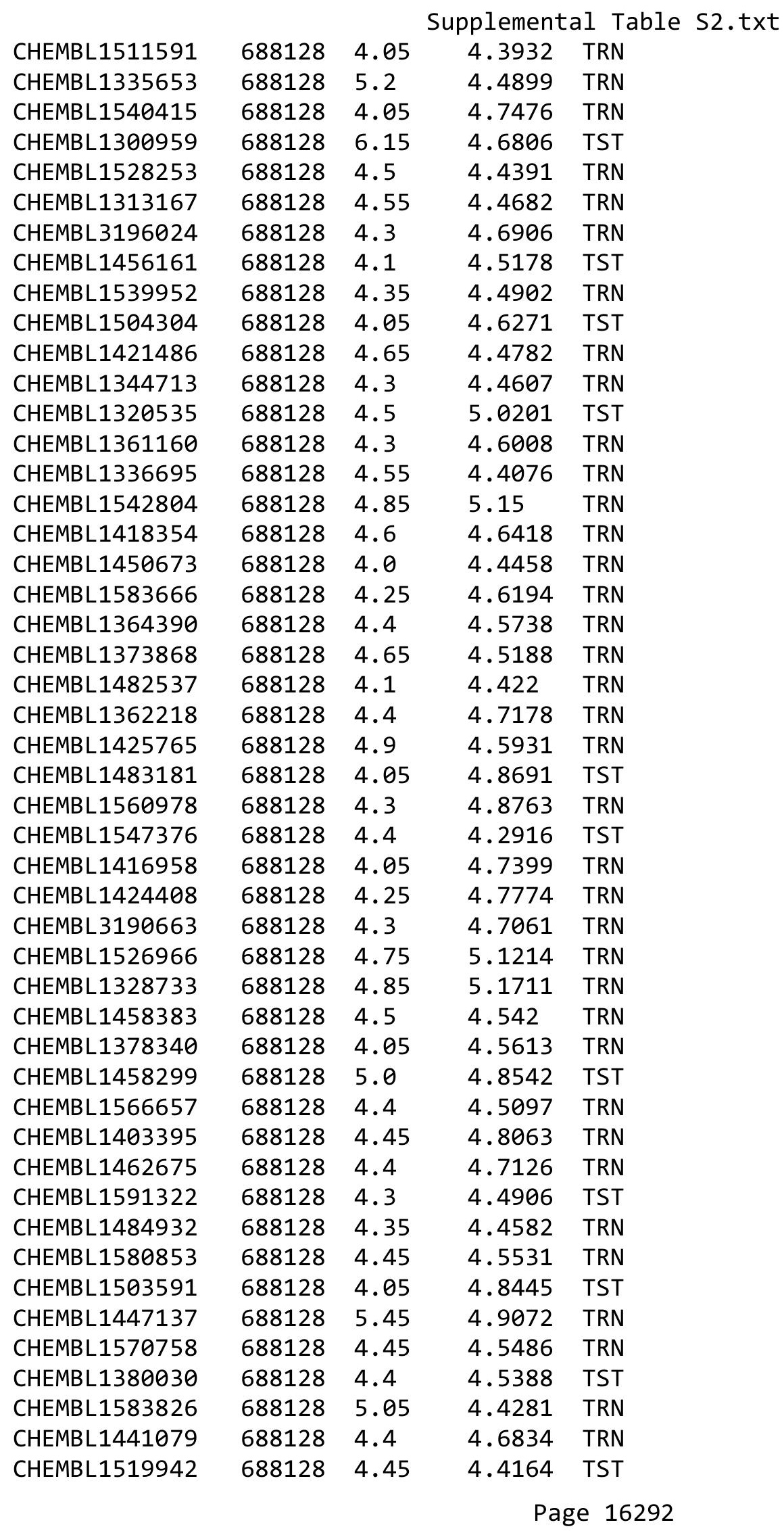




\begin{tabular}{|c|c|c|c|c|}
\hline \multicolumn{5}{|c|}{ Supplemental Tabl } \\
\hline CHEMBL1566530 & 688128 & 4.35 & 4.6815 & TRN \\
\hline CHEMBL1382848 & 688128 & 7.0 & 4.5157 & TRN \\
\hline CHEMBL1465305 & 688128 & 4.1 & 4.3656 & TRN \\
\hline CHEMBL1495026 & 688128 & 4.05 & 4.7406 & TST \\
\hline CHEMBL1314811 & 688128 & 4.05 & 4.476 & TRN \\
\hline CHEMBL1460959 & 688128 & 4.3 & 4.8964 & TRN \\
\hline CHEMBL1397377 & 688128 & 4.25 & 4.4915 & TRN \\
\hline CHEMBL1504377 & 688128 & 4.35 & 4.5627 & TRN \\
\hline CHEMBL1539606 & 688128 & 4.5 & 4.8039 & TRN \\
\hline CHEMBL1328202 & 688128 & 4.4 & 4.5457 & TRN \\
\hline CHEMBL1421335 & 688128 & 4.6 & 4.7924 & TRN \\
\hline CHEMBL1336270 & 688128 & 5.65 & 4.7501 & TRN \\
\hline CHEMBL1425749 & 688128 & 4.05 & 4.5887 & TST \\
\hline CHEMBL1508224 & 688128 & 4.3 & 4.8452 & TST \\
\hline CHEMBL1569528 & 688128 & 4.4 & 4.6558 & TRN \\
\hline CHEMBL1313834 & 688128 & 4.1 & 4.5226 & TST \\
\hline CHEMBL1401201 & 688128 & 4.35 & 4.3346 & TRN \\
\hline CHEMBL1491408 & 688128 & 4.05 & 4.7116 & TST \\
\hline CHEMBL1320230 & 688128 & 5.55 & 5.0471 & TRN \\
\hline CHEMBL1560508 & 688128 & 4.7 & 4.6986 & TRN \\
\hline CHEMBL1568152 & 688128 & 4.35 & 4.3912 & TRN \\
\hline CHEMBL1394114 & 688128 & 4.3 & 4.4651 & TRN \\
\hline CHEMBL1536691 & 688128 & 4.3 & 4.6887 & TST \\
\hline CHEMBL1399256 & 688128 & 4.35 & 4.4754 & TST \\
\hline CHEMBL1429437 & 688128 & 4.55 & 4.8928 & TRN \\
\hline CHEMBL1483125 & 688128 & 4.3 & 4.7764 & TST \\
\hline CHEMBL1521281 & 688128 & 4.35 & 4.352 & TRN \\
\hline CHEMBL1440260 & 688128 & 4.95 & 4.5656 & TRN \\
\hline CHEMBL1536603 & 688128 & 4.35 & 4.4375 & TRN \\
\hline CHEMBL1340383 & 688128 & 4.35 & 4.7298 & TRN \\
\hline CHEMBL1488432 & 688128 & 4.3 & 4.7342 & TRN \\
\hline CHEMBL1369122 & 688128 & 4.05 & 4.7176 & TRN \\
\hline CHEMBL1607341 & 688128 & 5.15 & 4.7156 & TRN \\
\hline CHEMBL1613051 & 688128 & 4.75 & 4.6699 & TST \\
\hline CHEMBL1313652 & 688128 & 4.15 & 4.6184 & TST \\
\hline CHEMBL1472988 & 688128 & 5.5 & 4.6949 & TRN \\
\hline CHEMBL1299254 & 688128 & 4.25 & 4.6967 & TRN \\
\hline CHEMBL1509436 & 688128 & 4.55 & 4.8448 & TST \\
\hline CHEMBL1518540 & 688128 & 5.05 & 4.9199 & TST \\
\hline CHEMBL1524109 & 688128 & 4.35 & 4.3613 & TRN \\
\hline CHEMBL1510549 & 688128 & 5.4 & 4.4538 & TRN \\
\hline CHEMBL1451515 & 688128 & 4.75 & 4.4578 & TRN \\
\hline CHEMBL1362964 & 688128 & 4.6 & 4.6762 & TRN \\
\hline CHEMBL1589621 & 688128 & 4.6 & 4.5322 & TRN \\
\hline CHEMBL1377484 & 688128 & 4.1 & 4.308 & TST \\
\hline CHEMBL1314293 & 688128 & 5.4 & 4.9071 & TRN \\
\hline CHEMBL1458899 & 688128 & 4.35 & 4.5466 & TRN \\
\hline CHEMBL1415045 & 688128 & 5.75 & 4.2686 & TST \\
\hline
\end{tabular}




\begin{tabular}{|c|c|c|c|c|c|}
\hline \multicolumn{6}{|c|}{ Supplemental Table S2.txt } \\
\hline CHEMBL1536268 & 688128 & 4.25 & 4.4797 & TRN & \\
\hline CHEMBL 2178107 & 688128 & 4.1 & 4.6161 & TRN & \\
\hline CHEMBL1538700 & 688128 & 4.45 & 4.5704 & TRN & \\
\hline CHEMBL1394560 & 688128 & 4.35 & 4.6585 & TRN & \\
\hline CHEMBL1458322 & 688128 & 5.15 & 4.2141 & TST & \\
\hline CHEMBL1455086 & 688128 & 4.05 & 4.7627 & TRN & \\
\hline CHEMBL1510655 & 688128 & 4.75 & 4.9354 & TST & \\
\hline CHEMBL1363457 & 688128 & 4.35 & 4.4396 & TRN & \\
\hline CHEMBL1519205 & 688128 & 4.15 & 4.8928 & TST & \\
\hline CHEMBL1363738 & 688128 & 4.05 & 4.4506 & TST & \\
\hline CHEMBL1980204 & 688128 & 4.85 & 4.7457 & TRN & \\
\hline CHEMBL1363790 & 688128 & 5.5 & 4.9875 & TRN & \\
\hline CHEMBL1351058 & 688128 & 4.3 & 4.5584 & TRN & \\
\hline CHEMBL1324737 & 688128 & 4.35 & 4.7586 & TST & \\
\hline CHEMBL1408586 & 688128 & 4.6 & 4.5588 & TRN & \\
\hline CHEMBL1609618 & 688128 & 5.1 & 4.7247 & TRN & \\
\hline CHEMBL1399519 & 688128 & 4.15 & 4.6116 & TRN & \\
\hline CHEMBL393296 & 688128 & 6.4 & 4.6906 & TRN & \\
\hline CHEMBL1414533 & 688128 & 6.3 & 4.4027 & TRN & \\
\hline CHEMBL1442630 & 688128 & 5.4 & 4.7013 & TRN & \\
\hline CHEMBL1603115 & 688128 & 4.4 & 4.38399 & 99999999995 & TRN \\
\hline CHEMBL 2448505 & 688128 & 6.0 & 4.7572 & TRN & \\
\hline CHEMBL1525007 & 688128 & 4.05 & 4.6744 & TST & \\
\hline CHEMBL1602471 & 688128 & 4.65 & 4.2429 & TRN & \\
\hline CHEMBL1581416 & 688128 & 4.7 & 4.812 & TRN & \\
\hline CHEMBL1428722 & 688128 & 4.0 & 4.4816 & TRN & \\
\hline CHEMBL1430490 & 688128 & 4.8 & 4.6464 & TRN & \\
\hline CHEMBL1565134 & 688128 & 4.05 & 4.5362 & TST & \\
\hline CHEMBL1301438 & 688128 & 4.35 & 4.4104 & TRN & \\
\hline CHEMBL1466530 & 688128 & 4.65 & 4.5602 & TRN & \\
\hline CHEMBL1490561 & 688128 & 4.95 & 4.3187 & TRN & \\
\hline CHEMBL1372767 & 688128 & 4.25 & 4.5055 & TRN & \\
\hline CHEMBL1305356 & 688128 & 4.35 & 4.4943 & TRN & \\
\hline CHEMBL1319630 & 688128 & 4.25 & 4.6645 & TRN & \\
\hline CHEMBL1412100 & 688128 & 4.3 & 4.7177 & TRN & \\
\hline CHEMBL1543630 & 688128 & 4.6 & 4.7825 & TRN & \\
\hline CHEMBL1611922 & 688128 & 5.15 & 4.8418 & TRN & \\
\hline CHEMBL1538505 & 688128 & 4.9 & 4.5397 & TRN & \\
\hline CHEMBL1600461 & 688128 & 5.4 & 4.5292 & TRN & \\
\hline CHEMBL1527498 & 688128 & 4.3 & 4.8308 & TRN & \\
\hline CHEMBL1417624 & 688128 & 4.4 & 4.4935 & TRN & \\
\hline CHEMBL1408292 & 688128 & 4.3 & 4.5238 & TRN & \\
\hline CHEMBL 240836 & 688128 & 4.65 & 4.7857 & TST & \\
\hline CHEMBL28319 & 688128 & 4.25 & 4.8123 & TST & \\
\hline CHEMBL1507857 & 688128 & 4.7 & 4.5158 & TRN & \\
\hline CHEMBL1338102 & 688128 & 4.25 & 4.6809 & TRN & \\
\hline CHEMBL3193980 & 688128 & 4.25 & 4.5537 & TRN & \\
\hline CHEMBL1350739 & 688128 & 4.05 & 4.4214 & TRN & \\
\hline
\end{tabular}




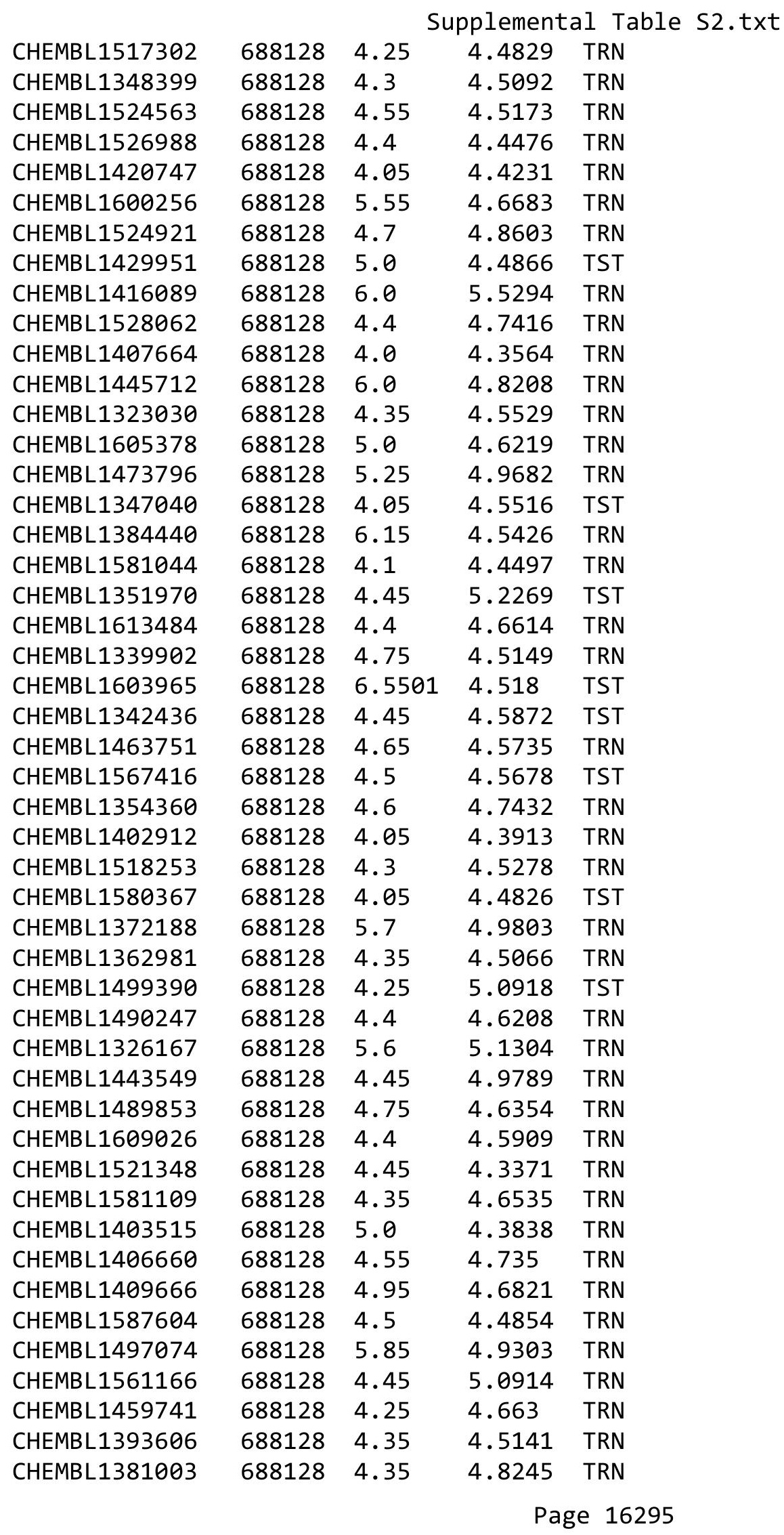




\begin{tabular}{|c|c|c|c|c|c|}
\hline \multirow[b]{2}{*}{ CHEMBL1465229 } & \multirow[b]{2}{*}{688128} & \multicolumn{4}{|c|}{ Supplemental Table s2.txt } \\
\hline & & 4.05 & 4.3889 & 9999999999 & TST \\
\hline CHEMBL1426956 & 688128 & 4.0 & 4.6048 & TST & \\
\hline CHEMBL1563607 & 688128 & 5.55 & 4.7721 & TRN & \\
\hline CHEMBL1503604 & 688128 & 4.3 & 4.7277 & TST & \\
\hline CHEMBL172840 & 688128 & 4.55 & 4.789 & TRN & \\
\hline CHEMBL1494155 & 688128 & 4.65 & 4.648 & TRN & \\
\hline CHEMBL1611106 & 688128 & 5.5 & 4.9078 & TRN & \\
\hline CHEMBL1550768 & 688128 & 4.3 & 4.243 & TRN & \\
\hline CHEMBL1532232 & 688128 & 5.15 & 4.9405 & TRN & \\
\hline CHEMBL1612895 & 688128 & 4.4 & 4.629 & TST & \\
\hline CHEMBL1354517 & 688128 & 5.0 & 4.6982 & TRN & \\
\hline CHEMBL1464447 & 688128 & 4.5 & 4.8207 & TRN & \\
\hline CHEMBL1421542 & 688128 & 4.4 & 4.5329 & TST & \\
\hline CHEMBL1440823 & 688128 & 4.5 & 4.2786 & TST & \\
\hline CHEMBL1447764 & 688128 & 5.45 & 4.8063 & TRN & \\
\hline CHEMBL1415033 & 688128 & 4.3 & 4.2196 & TRN & \\
\hline CHEMBL1429962 & 688128 & 5.85 & 4.856 & TRN & \\
\hline CHEMBL1337638 & 688128 & 4.3 & 4.4715 & TRN & \\
\hline CHEMBL1523006 & 688128 & 4.35 & 4.8417 & TRN & \\
\hline CHEMBL1416550 & 688128 & 4.35 & 4.3973 & TRN & \\
\hline CHEMBL1424848 & 688128 & 4.0 & 4.8146 & TST & \\
\hline CHEMBL1494393 & 688128 & 4.8 & 4.7604 & TRN & \\
\hline CHEMBL1449513 & 688128 & 4.45 & 4.4401 & TRN & \\
\hline CHEMBL 3198387 & 688128 & 4.3 & 4.5547 & TST & \\
\hline CHEMBL1341409 & 688128 & 5.0 & 4.5964 & TRN & \\
\hline CHEMBL1568657 & 688128 & 4.35 & 4.4868 & TRN & \\
\hline CHEMBL1391253 & 688128 & 4.35 & 4.3762 & TRN & \\
\hline CHEMBL1463703 & 688128 & 4.7 & 4.3379 & TRN & \\
\hline CHEMBL1425115 & 688128 & 4.05 & 4.5021 & TST & \\
\hline CHEMBL1533340 & 688128 & 6.1 & 4.7147 & TST & \\
\hline CHEMBL1343647 & 688128 & 4.75 & 5.0874 & TRN & \\
\hline CHEMBL1349924 & 688128 & 4.7 & 4.4893 & TRN & \\
\hline CHEMBL1420739 & 688128 & 4.5 & 5.1267 & TRN & \\
\hline CHEMBL1446176 & 688128 & 4.35 & 4.5829 & TST & \\
\hline CHEMBL1501155 & 688128 & 4.3 & 4.5942 & TRN & \\
\hline CHEMBL1501827 & 688128 & 4.3 & 4.2113 & TRN & \\
\hline CHEMBL1419385 & 688128 & 4.45 & 4.1972 & TRN & \\
\hline CHEMBL1444607 & 688128 & 4.65 & 4.6034 & TRN & \\
\hline CHEMBL3199438 & 688128 & 4.2 & 4.5716 & TRN & \\
\hline CHEMBL1611293 & 688128 & 4.6 & 4.7452 & TRN & \\
\hline CHEMBL1431144 & 688128 & 4.3 & 4.5045 & TRN & \\
\hline CHEMBL1410633 & 688128 & 4.3 & 4.6382 & TRN & \\
\hline CHEMBL 2003595 & 688128 & 4.65 & 4.633 & TST & \\
\hline CHEMBL1598828 & 688128 & 4.3 & 4.8035 & TRN & \\
\hline CHEMBL1380515 & 688128 & 5.4 & 4.5487 & TST & \\
\hline CHEMBL1437073 & 688128 & 4.1 & 4.2535 & TRN & \\
\hline CHEMBL1504211 & 688128 & 5.3 & 4.4163 & TST & \\
\hline CHEMBL1459226 & 688128 & 5.45 & 4.8137 & TRN & \\
\hline
\end{tabular}




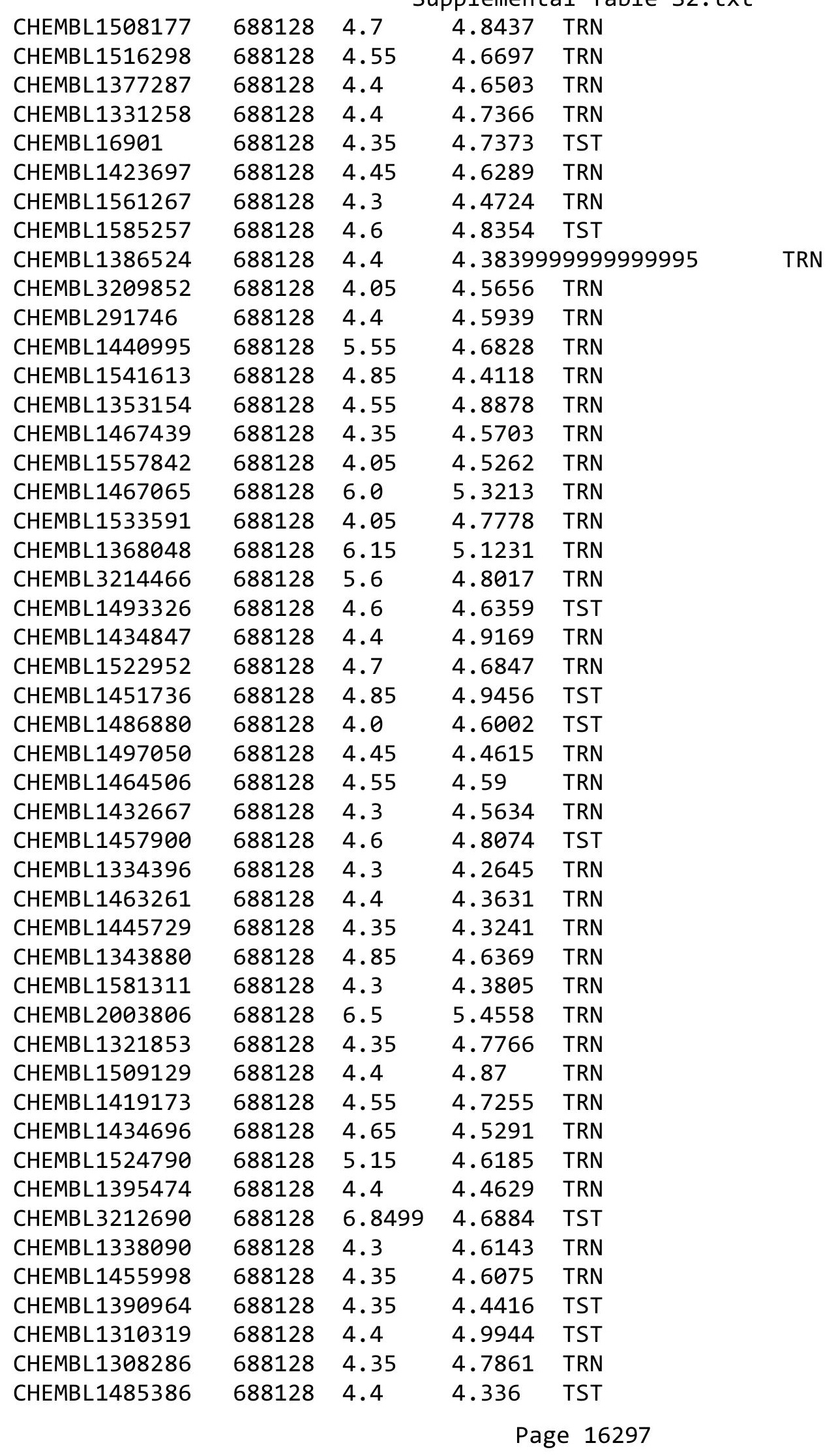




\begin{tabular}{|c|c|c|c|c|c|}
\hline \multicolumn{6}{|c|}{ Supplemental Table S2.txt } \\
\hline CHEMBL1388651 & 688128 & 4.0 & 5.0337 & TRN & \\
\hline CHEMBL1508086 & 688128 & 4.5 & 4.923 & TRN & \\
\hline CHEMBL1481595 & 688128 & 4.05 & 4.6654 & TRN & \\
\hline CHEMBL1337570 & 688128 & 5.2 & 4.3511 & TRN & \\
\hline CHEMBL1579228 & 688128 & 4.45 & 4.6331 & TRN & \\
\hline CHEMBL1336385 & 688128 & 4.75 & 4.3986 & TRN & \\
\hline CHEMBL1346249 & 688128 & 4.05 & 4.4007 & TRN & \\
\hline CHEMBL1406629 & 688128 & 4.05 & 4.5475 & TST & \\
\hline CHEMBL1571939 & 688128 & 4.05 & 4.6057 & TST & \\
\hline CHEMBL1545042 & 688128 & 4.35 & 4.63 & TRN & \\
\hline CHEMBL1510513 & 688128 & 6.2 & 4.8064 & TST & \\
\hline CHEMBL1359354 & 688128 & 4.9 & 4.5939 & TRN & \\
\hline CHEMBL1404277 & 688128 & 4.55 & 4.6993 & TRN & \\
\hline CHEMBL1374376 & 688128 & 4.25 & 4.5983 & TRN & \\
\hline CHEMBL1344475 & 688128 & 4.5 & 4.6367 & TRN & \\
\hline CHEMBL1352024 & 688128 & 4.05 & 4.539 & TRN & \\
\hline CHEMBL1521636 & 688128 & 4.4 & 4.5225 & TRN & \\
\hline CHEMBL1409123 & 688128 & 4.45 & 4.6094 & TRN & \\
\hline CHEMBL1389672 & 688128 & 6.0 & 4.7809 & TRN & \\
\hline CHEMBL1324033 & 688128 & 4.5 & 4.5362 & TRN & \\
\hline CHEMBL1417290 & 688128 & 4.45 & 4.5310 & 0000000001 & TRN \\
\hline CHEMBL3192568 & 688128 & 4.5 & 4.7006 & TRN & \\
\hline CHEMBL1359068 & 688128 & 4.4 & 4.738 & TST & \\
\hline CHEMBL1458261 & 688128 & 4.15 & 4.7789 & TRN & \\
\hline CHEMBL1529029 & 688128 & 6.0 & 4.346 & TRN & \\
\hline CHEMBL1505981 & 688128 & 4.3 & 4.5278 & TRN & \\
\hline CHEMBL1316212 & 688128 & 4.05 & 4.521 & TRN & \\
\hline CHEMBL1564268 & 688128 & 4.65 & 4.6315 & TRN & \\
\hline CHEMBL1518307 & 688128 & 4.05 & 4.8816 & TST & \\
\hline CHEMBL1488342 & 688128 & 4.7 & 4.4684 & TRN & \\
\hline CHEMBL171145 & 688128 & 4.3 & 4.5406 & TST & \\
\hline CHEMBL1537400 & 688128 & 4.15 & 4.3772 & TST & \\
\hline CHEMBL1531860 & 688128 & 4.35 & 4.7301 & TRN & \\
\hline CHEMBL1584216 & 688128 & 4.55 & 4.5122 & TRN & \\
\hline CHEMBL1337161 & 688128 & 6.6499 & 4.4421 & TRN & \\
\hline CHEMBL1430206 & 688128 & 4.4 & 4.4186 & TRN & \\
\hline CHEMBL1370450 & 688128 & 4.25 & 4.542 & TRN & \\
\hline CHEMBL3196575 & 688128 & 4.3 & 4.7817 & TST & \\
\hline CHEMBL1573927 & 688128 & 5.1 & 4.8113 & TRN & \\
\hline CHEMBL1382534 & 688128 & 5.7 & 4.5633 & TST & \\
\hline CHEMBL1524254 & 688128 & 4.8 & 4.9667 & TRN & \\
\hline CHEMBL1489397 & 688128 & 4.7 & 4.4371 & TRN & \\
\hline CHEMBL1327890 & 688128 & 4.45 & 4.5399 & TRN & \\
\hline CHEMBL1446655 & 688128 & 5.8 & 4.828 & TRN & \\
\hline CHEMBL1443321 & 688128 & 4.3 & 4.7791 & TRN & \\
\hline CHEMBL1524542 & 688128 & 6.0 & 4.8512 & TRN & \\
\hline CHEMBL1536818 & 688128 & 4.4 & 4.4353 & TRN & \\
\hline CHEMBL1475921 & 688128 & 4.55 & 4.5904 & TRN & \\
\hline
\end{tabular}




\begin{tabular}{|c|c|c|c|c|c|}
\hline \multicolumn{6}{|c|}{ Supplemental Table S2.txt } \\
\hline CHEMBL1326179 & 688128 & 4.4 & 4.5632 & TRN & \\
\hline CHEMBL1461293 & 688128 & 4.35 & 4.4874 & TST & \\
\hline CHEMBL1611822 & 688128 & 4.6 & 4.6654 & TRN & \\
\hline CHEMBL1449080 & 688128 & 4.95 & 4.6287 & TRN & \\
\hline CHEMBL1585527 & 688128 & 6.25 & 5.3547 & TRN & \\
\hline CHEMBL 3193322 & 688128 & 4.3 & 4.5474 & TRN & \\
\hline CHEMBL1508410 & 688128 & 4.05 & 4.477 & TRN & \\
\hline CHEMBL1379456 & 688128 & 4.0 & 4.2731 & TRN & \\
\hline CHEMBL1424304 & 688128 & 5.45 & 4.7978 & TST & \\
\hline CHEMBL1411000 & 688128 & 4.05 & 4.8993 & TRN & \\
\hline CHEMBL1363309 & 688128 & 4.4 & 4.7855 & TST & \\
\hline CHEMBL3198342 & 688128 & 6.0 & 4.6296 & TRN & \\
\hline CHEMBL 78257 & 688128 & 4.8 & 4.6742 & TRN & \\
\hline CHEMBL1305643 & 688128 & 4.4 & 4.5209 & TST & \\
\hline CHEMBL1425724 & 688128 & 4.25 & 4.635 & TRN & \\
\hline CHEMBL1564974 & 688128 & 4.7 & 4.7741 & TST & \\
\hline CHEMBL1383949 & 688128 & 4.25 & 4.7395 & TST & \\
\hline CHEMBL1578441 & 688128 & 4.5 & 4.5549 & TRN & \\
\hline CHEMBL1592134 & 688128 & 4.75 & 5.0883 & TRN & \\
\hline CHEMBL1482894 & 688128 & 4.1 & 4.5667 & TST & \\
\hline CHEMBL1437884 & 688128 & 4.35 & 4.3526 & TRN & \\
\hline CHEMBL1464841 & 688128 & 4.55 & 4.5802 & TST & \\
\hline CHEMBL1429810 & 688128 & 4.35 & $4.8660 e$ & 00000000005 & TRN \\
\hline CHEMBL1519846 & 688128 & 4.55 & 4.5831 & TRN & \\
\hline CHEMBL1408485 & 688128 & 4.4 & 4.5517 & TRN & \\
\hline CHEMBL1301615 & 688128 & 4.4 & 4.7247 & TRN & \\
\hline CHEMBL1591400 & 688128 & 4.05 & 4.4716 & TST & \\
\hline CHEMBL1423695 & 688128 & 4.4 & 4.7191 & TRN & \\
\hline CHEMBL1505320 & 688128 & 6.05 & 4.8719 & TST & \\
\hline CHEMBL1394519 & 688128 & 4.95 & 4.4846 & TRN & \\
\hline CHEMBL1606275 & 688128 & 4.3 & 4.538 & TRN & \\
\hline CHEMBL1377465 & 688128 & 4.85 & 4.7523 & TRN & \\
\hline CHEMBL1460855 & 688128 & 4.6 & 4.5574 & TRN & \\
\hline CHEMBL1312353 & 688128 & 4.55 & $4.8610 e$ & 0000000001 & TST \\
\hline CHEMBL1341532 & 688128 & 6.0 & 4.7768 & TRN & \\
\hline CHEMBL1460491 & 688128 & 4.4 & 4.6945 & TRN & \\
\hline CHEMBL1340142 & 688128 & 6.0 & 5.268 & TRN & \\
\hline CHEMBL1387744 & 688128 & 5.2 & 4.6464 & TRN & \\
\hline CHEMBL1441486 & 688128 & 4.3 & 4.5332 & TRN & \\
\hline CHEMBL1588493 & 688128 & 4.75 & 4.4482 & TRN & \\
\hline CHEMBL3212219 & 688128 & 4.35 & 4.2954 & TRN & \\
\hline CHEMBL1583835 & 688128 & 5.0 & 4.8626 & TST & \\
\hline CHEMBL1529080 & 688128 & 5.8 & 4.5882 & TST & \\
\hline CHEMBL1415174 & 688128 & 4.35 & 4.3361 & TST & \\
\hline CHEMBL1547922 & 688128 & 4.55 & 4.7587 & TRN & \\
\hline CHEMBL1412287 & 688128 & 4.4 & 4.467 & TST & \\
\hline CHEMBL1350258 & 688128 & 5.65 & 4.7998 & TST & \\
\hline CHEMBL1536515 & 688128 & 4.3 & 4.5058 & TRN & \\
\hline
\end{tabular}




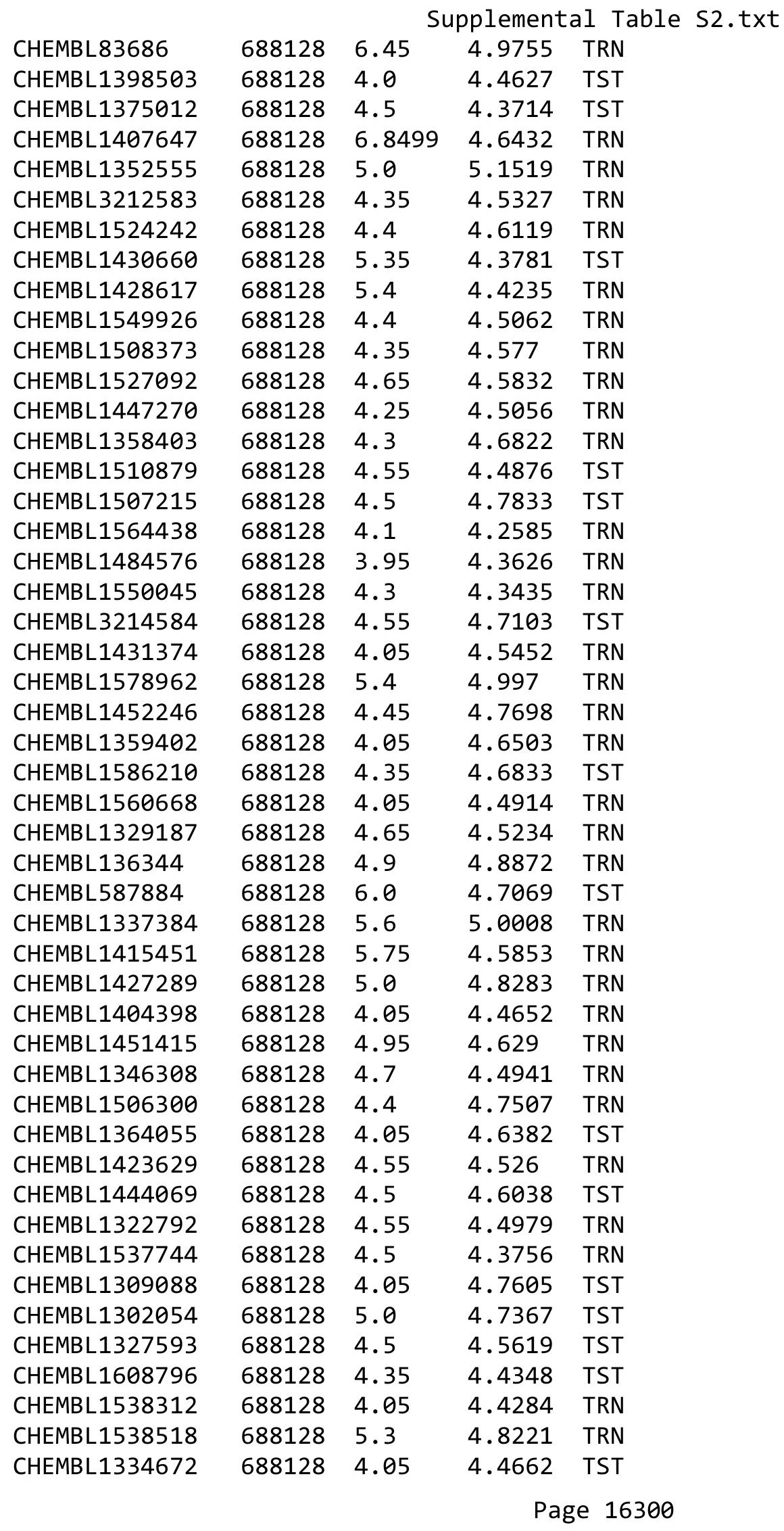




\begin{tabular}{|c|c|c|c|c|}
\hline \multicolumn{5}{|c|}{ Supplemental Table S2.txt } \\
\hline CHEMBL1369968 & 688128 & 4.4 & 4.5303 & TRN \\
\hline CHEMBL1447013 & 688128 & 4.95 & 4.7723 & TRN \\
\hline CHEMBL1437975 & 688128 & 4.75 & 4.6962 & TRN \\
\hline CHEMBL1269862 & 688128 & 6.3 & 5.153 & TRN \\
\hline CHEMBL1358119 & 688128 & 4.25 & 4.671 & TRN \\
\hline CHEMBL1320256 & 688128 & 4.05 & 4.51 & TRN \\
\hline CHEMBL1303900 & 688128 & 4.4 & 4.6028 & TST \\
\hline CHEMBL1361111 & 688128 & 4.35 & 4.5311 & TRN \\
\hline CHEMBL1378246 & 688128 & 4.5 & 4.4298 & TRN \\
\hline CHEMBL1379278 & 688128 & 5.5 & 4.4974 & TRN \\
\hline CHEMBL1509808 & 688128 & 4.3 & 4.5087 & TRN \\
\hline CHEMBL1457256 & 688128 & 4.35 & 4.631 & TRN \\
\hline CHEMBL1342410 & 688128 & 5.45 & 4.9048 & TRN \\
\hline CHEMBL1385793 & 688128 & 5.75 & 4.3724 & TST \\
\hline CHEMBL1438621 & 688128 & 4.6 & 4.5583 & TST \\
\hline CHEMBL1370951 & 688128 & 4.3 & 4.7287 & TST \\
\hline CHEMBL1367813 & 688128 & 4.25 & 4.1517 & TRN \\
\hline CHEMBL1349666 & 688128 & 4.45 & 4.6661 & TRN \\
\hline CHEMBL1337827 & 688128 & 4.4 & 4.8843 & TRN \\
\hline CHEMBL1409286 & 688128 & 4.4 & 4.5296 & TST \\
\hline CHEMBL1522927 & 688128 & 4.35 & 4.3282 & TRN \\
\hline CHEMBL1348437 & 688128 & 4.3 & 4.7837 & TRN \\
\hline CHEMBL1441760 & 688128 & 4.45 & 4.7085 & TRN \\
\hline CHEMBL1463790 & 688128 & 4.4 & 4.8126 & TRN \\
\hline CHEMBL1567228 & 688128 & 4.4 & 4.4974 & TRN \\
\hline CHEMBL1436025 & 688128 & 4.4 & 4.6698 & TST \\
\hline CHEMBL1405008 & 688128 & 4.05 & 4.6267 & TST \\
\hline CHEMBL1353319 & 688128 & 4.35 & 4.9376 & TST \\
\hline CHEMBL1341444 & 688128 & 4.45 & 4.9971 & TRN \\
\hline CHEMBL1555858 & 688128 & 4.35 & 4.356 & TRN \\
\hline CHEMBL1437334 & 688128 & 4.5 & 4.3595 & TRN \\
\hline CHEMBL1380309 & 688128 & 4.65 & 4.516 & TRN \\
\hline CHEMBL 3194794 & 688128 & 4.35 & 4.6548 & TST \\
\hline CHEMBL3193658 & 688128 & 6.15 & 4.7632 & TRN \\
\hline CHEMBL1481945 & 688128 & 4.4 & 4.705 & TRN \\
\hline CHEMBL1327122 & 688128 & 4.1 & 4.8049 & TST \\
\hline CHEMBL1321267 & 688128 & 4.35 & 4.7928 & TRN \\
\hline CHEMBL1552175 & 688128 & 5.25 & 4.993 & TRN \\
\hline CHEMBL1345696 & 688128 & 4.5 & 4.9202 & TRN \\
\hline CHEMBL1363225 & 688128 & 4.05 & 4.5576 & TST \\
\hline CHEMBL1585333 & 688128 & 5.5 & 4.7986 & TRN \\
\hline CHEMBL1496036 & 688128 & 4.45 & 4.7608 & TRN \\
\hline CHEMBL1342144 & 688128 & 4.4 & 4.5528 & TRN \\
\hline CHEMBL1368259 & 688128 & 4.4 & 4.5587 & TRN \\
\hline CHEMBL1369952 & 688128 & 5.45 & 4.6095 & TRN \\
\hline CHEMBL1503517 & 688128 & 4.65 & $4.9510 e$ & 00000000005 \\
\hline CHEMBL1577586 & 688128 & 4.3 & 4.6114 & TST \\
\hline CHEMBL1368690 & 688128 & 4.4 & 4.7982 & TST \\
\hline
\end{tabular}

TRN 


\begin{tabular}{|c|c|c|c|c|}
\hline \multicolumn{5}{|c|}{ Supplemental Table S2.txt } \\
\hline CHEMBL1332928 & 688128 & 4.25 & 4.3241 & TRN \\
\hline CHEMBL1322567 & 688128 & 4.3 & 4.9438 & TST \\
\hline CHEMBL1303438 & 688128 & 5.1 & 5.1493 & TRN \\
\hline CHEMBL1420623 & 688128 & 5.0 & 4.6731 & TRN \\
\hline CHEMBL1386906 & 688128 & 4.05 & 4.877 & TRN \\
\hline CHEMBL1424962 & 688128 & 4.3 & 4.6033 & TRN \\
\hline CHEMBL1459272 & 688128 & 5.4 & 4.6075 & TST \\
\hline CHEMBL1420345 & 688128 & 4.45 & 4.5346 & TRN \\
\hline CHEMBL1521055 & 688128 & 4.4 & 4.5382 & TRN \\
\hline CHEMBL1313001 & 688128 & 6.8499 & 4.8864 & TRN \\
\hline CHEMBL1317447 & 688128 & 4.3 & 4.7622 & TRN \\
\hline CHEMBL1597437 & 688128 & 4.05 & 4.5065 & TRN \\
\hline CHEMBL1470028 & 688128 & 4.25 & 4.6615 & TRN \\
\hline CHEMBL1438914 & 688128 & 5.35 & 4.5381 & TRN \\
\hline CHEMBL1353464 & 688128 & 4.35 & 4.4331 & TST \\
\hline CHEMBL 2374030 & 688128 & 5.05 & 5.1351 & TRN \\
\hline CHEMBL1579622 & 688128 & 4.6 & 4.8054 & TRN \\
\hline CHEMBL1550711 & 688128 & 4.4 & 4.4535 & TRN \\
\hline CHEMBL1424465 & 688128 & 4.65 & 4.1445 & TRN \\
\hline CHEMBL1367258 & 688128 & 4.3 & 4.1467 & TRN \\
\hline CHEMBL3189799 & 688128 & 4.4 & 4.9783 & TST \\
\hline CHEMBL1465508 & 688128 & 6.5 & 5.0461 & TRN \\
\hline CHEMBL1450204 & 688128 & 4.4 & 4.6806 & TST \\
\hline CHEMBL1504810 & 688128 & 4.4 & 4.5575 & TRN \\
\hline CHEMBL1440636 & 688128 & 4.4 & 4.9873 & TRN \\
\hline CHEMBL1412125 & 688128 & 4.45 & 4.5389 & TST \\
\hline CHEMBL1562574 & 688128 & 4.05 & 4.5075 & TST \\
\hline CHEMBL1405316 & 688128 & 4.4 & 4.9146 & TRN \\
\hline CHEMBL1356565 & 688128 & 4.45 & 4.261 & TRN \\
\hline CHEMBL1369507 & 688128 & 4.35 & 4.7278 & TRN \\
\hline CHEMBL1361034 & 688128 & 4.6 & 4.1043 & TST \\
\hline CHEMBL1391544 & 688128 & 6.5501 & 4.5872 & TRN \\
\hline CHEMBL1521641 & 688128 & 4.3 & 4.5648 & TRN \\
\hline CHEMBL1578249 & 688128 & 4.4 & 4.6684 & TRN \\
\hline CHEMBL1342486 & 688128 & 4.4 & 4.423 & TST \\
\hline CHEMBL151210 & 688128 & 4.65 & 4.8085 & TST \\
\hline CHEMBL1383263 & 688128 & 4.35 & 4.3503 & TST \\
\hline CHEMBL1412834 & 688128 & 4.3 & 4.4875 & TRN \\
\hline CHEMBL1542301 & 688128 & 4.7 & 4.6924 & TRN \\
\hline CHEMBL1567199 & 688128 & 4.45 & 4.4411 & TRN \\
\hline CHEMBL1348178 & 688128 & 4.35 & 4.6482 & TST \\
\hline CHEMBL1538768 & 688128 & 6.1 & 4.57606 & 00000000005 \\
\hline CHEMBL3191823 & 688128 & 4.55 & 4.4675 & TRN \\
\hline CHEMBL1430208 & 688128 & 4.0 & 4.9451 & TST \\
\hline CHEMBL1482460 & 688128 & 4.55 & 4.5741 & TRN \\
\hline CHEMBL1396465 & 688128 & 5.5 & 4.5815 & TRN \\
\hline CHEMBL1389843 & 688128 & 4.05 & 4.5523 & TST \\
\hline CHEMBL1460092 & 688128 & 4.3 & 4.8444 & TRN \\
\hline
\end{tabular}




\begin{tabular}{|c|c|c|c|c|}
\hline \multicolumn{5}{|c|}{ Supplemental Table S2.txt } \\
\hline CHEMBL1569384 & 688128 & 4.45 & 5.1041 & TRN \\
\hline CHEMBL1529670 & 688128 & 4.3 & 4.1958 & TRN \\
\hline CHEMBL1326162 & 688128 & 4.4 & 4.4643 & TRN \\
\hline CHEMBL1565328 & 688128 & 5.05 & 4.7884 & TRN \\
\hline CHEMBL1576056 & 688128 & 4.1 & 4.4153 & TRN \\
\hline CHEMBL1504113 & 688128 & 5.1 & 5.1099 & TRN \\
\hline CHEMBL1539317 & 688128 & 4.3 & 4.5725 & TRN \\
\hline CHEMBL1613190 & 688128 & 4.05 & 4.5911 & TST \\
\hline CHEMBL1490140 & 688128 & 4.55 & 4.4869 & TRN \\
\hline CHEMBL1308156 & 688128 & 4.45 & 4.6522 & TRN \\
\hline CHEMBL1422416 & 688128 & 5.3 & 4.712 & TRN \\
\hline CHEMBL437061 & 688128 & 4.6 & 4.7146 & TRN \\
\hline CHEMBL1993780 & 688128 & 4.35 & 5.0606 & TRN \\
\hline CHEMBL1546344 & 688128 & 4.05 & 4.6658 & TRN \\
\hline CHEMBL1343420 & 688128 & 4.4 & 4.5053 & TRN \\
\hline CHEMBL1431800 & 688128 & 4.3 & 4.9349 & TST \\
\hline CHEMBL1599449 & 688128 & 4.4 & 4.8906 & TRN \\
\hline CHEMBL1471187 & 688128 & 4.05 & 4.3783 & TRN \\
\hline CHEMBL1483245 & 688128 & 4.9 & 4.6066 & TRN \\
\hline CHEMBL40274 & 688128 & 4.65 & 4.7359 & TST \\
\hline CHEMBL1429535 & 688128 & 4.45 & 4.5444 & TST \\
\hline CHEMBL1489939 & 688128 & 4.35 & 4.6009 & TRN \\
\hline CHEMBL1411684 & 688128 & 4.75 & 4.5652 & TST \\
\hline CHEMBL1318963 & 688128 & 4.05 & 4.6121 & TRN \\
\hline CHEMBL1535552 & 688128 & 5.8 & 4.7862 & TST \\
\hline CHEMBL1522201 & 688128 & 4.0 & 4.4999 & TST \\
\hline CHEMBL1373443 & 688128 & 4.05 & 4.6829 & TRN \\
\hline CHEMBL1513112 & 688128 & 4.65 & 4.8306 & TST \\
\hline CHEMBL1372680 & 688128 & 4.3 & 4.5726 & TRN \\
\hline CHEMBL1532668 & 688128 & 5.85 & 5.3423 & TRN \\
\hline CHEMBL1581293 & 688128 & 4.0 & 4.648 & TST \\
\hline CHEMBL1554916 & 688128 & 4.35 & 4.6282 & TRN \\
\hline CHEMBL3198182 & 688128 & 4.3 & 4.5874 & TRN \\
\hline CHEMBL1345835 & 688128 & 5.55 & 4.9488 & TRN \\
\hline CHEMBL1516721 & 688128 & 4.4 & 4.2787 & TRN \\
\hline CHEMBL1342445 & 688128 & 4.05 & 4.6852 & TRN \\
\hline CHEMBL3190999 & 688128 & 4.4 & 4.8918 & TRN \\
\hline CHEMBL1447323 & 688128 & 4.35 & 4.4904 & TRN \\
\hline CHEMBL1790011 & 688128 & 4.4 & 4.3388 & TST \\
\hline CHEMBL234338 & 688128 & 5.4 & 4.6607 & TST \\
\hline CHEMBL1330899 & 688128 & 4.45 & 4.5316 & TRN \\
\hline CHEMBL1973042 & 688128 & 4.55 & 4.8282 & TRN \\
\hline CHEMBL1478938 & 688128 & 4.85 & 4.7189 & TRN \\
\hline CHEMBL1416298 & 688128 & 4.2 & 4.6426 & TST \\
\hline CHEMBL1589059 & 688128 & 4.5 & 4.5763 & TRN \\
\hline CHEMBL1540701 & 688128 & 5.75 & 4.7368 & TRN \\
\hline CHEMBL1391773 & 688128 & 4.45 & 4.846 & TST \\
\hline CHEMBL1342320 & 688128 & 4.0 & 4.7451 & TST \\
\hline
\end{tabular}




\begin{tabular}{|c|c|c|c|c|c|}
\hline \multicolumn{6}{|c|}{ Supplemental Table S2.txt } \\
\hline CHEMBL1444294 & 688128 & 5.05 & 4.9238 & TRN & \\
\hline CHEMBL1485583 & 688128 & 4.45 & 4.4058 & TRN & \\
\hline CHEMBL1549162 & 688128 & 4.4 & 4.3064 & TST & \\
\hline CHEMBL1482904 & 688128 & 4.35 & 4.6751 & TRN & \\
\hline CHEMBL1574497 & 688128 & 4.4 & 4.4830 & 00000000005 & TRN \\
\hline CHEMBL1476431 & 688128 & 4.35 & 4.6444 & TRN & \\
\hline CHEMBL1363963 & 688128 & 4.0 & 4.5757 & TRN & \\
\hline CHEMBL 2373596 & 688128 & 4.6 & 4.7 & TRN & \\
\hline CHEMBL1566949 & 688128 & 4.05 & 4.8568 & TRN & \\
\hline CHEMBL1584784 & 688128 & 4.95 & 4.6169 & TRN & \\
\hline CHEMBL1373296 & 688128 & 4.65 & 4.3939 & TRN & \\
\hline CHEMBL1329699 & 688128 & 4.35 & 4.4671 & TST & \\
\hline CHEMBL1596009 & 688128 & 4.25 & 4.7352 & TRN & \\
\hline CHEMBL1447391 & 688128 & 4.35 & 4.5051 & TST & \\
\hline CHEMBL1380406 & 688128 & 4.6 & 4.5915 & TRN & \\
\hline CHEMBL1543942 & 688128 & 4.35 & 4.2818 & TRN & \\
\hline CHEMBL1536956 & 688128 & 4.3 & 4.5085 & TRN & \\
\hline CHEMBL1389730 & 688128 & 5.55 & 4.7465 & TRN & \\
\hline CHEMBL1455396 & 688128 & 4.45 & 4.5752 & TRN & \\
\hline CHEMBL1415265 & 688128 & 4.45 & 4.4914 & TRN & \\
\hline CHEMBL1384483 & 688128 & 4.9 & 4.5503 & TRN & \\
\hline CHEMBL1354645 & 688128 & 4.05 & 4.191 & TRN & \\
\hline CHEMBL1436737 & 688128 & 4.05 & 4.3779 & TRN & \\
\hline CHEMBL1306105 & 688128 & 4.2 & 4.6015 & TRN & \\
\hline CHEMBL1611501 & 688128 & 5.05 & 4.4954 & TST & \\
\hline CHEMBL1607374 & 688128 & 4.3 & 4.3969 & TRN & \\
\hline CHEMBL1368726 & 688128 & 4.5 & 4.4398 & TST & \\
\hline CHEMBL1408107 & 688128 & 4.4 & 4.5098 & TRN & \\
\hline CHEMBL1580954 & 688128 & 4.6 & 4.7902 & TRN & \\
\hline CHEMBL162783 & 688128 & 4.5 & 5.3387 & TST & \\
\hline CHEMBL3212483 & 688128 & 4.5 & 4.5118 & TRN & \\
\hline CHEMBL1368603 & 688128 & 4.35 & 4.6722 & TRN & \\
\hline CHEMBL1502907 & 688128 & 4.45 & 4.4212 & TRN & \\
\hline CHEMBL1337894 & 688128 & 4.3 & 4.7387 & TRN & \\
\hline CHEMBL1498231 & 688128 & 4.05 & 4.5882 & TRN & \\
\hline CHEMBL1562512 & 688128 & 4.3 & 4.6127 & TRN & \\
\hline CHEMBL1513319 & 688128 & 4.3 & 4.5109 & TRN & \\
\hline CHEMBL1375430 & 688128 & 4.45 & 4.4544 & TRN & \\
\hline CHEMBL1382438 & 688128 & 7.0501 & 5.2782 & TRN & \\
\hline CHEMBL1385740 & 688128 & 5.6 & 5.4737 & TRN & \\
\hline CHEMBL1403668 & 688128 & 4.3 & 4.7345 & TRN & \\
\hline CHEMBL1325128 & 688128 & 4.45 & 4.4657 & TRN & \\
\hline CHEMBL1536745 & 688128 & 4.7 & 4.706 & TRN & \\
\hline CHEMBL1611270 & 688128 & 4.7 & 4.8979 & TRN & \\
\hline CHEMBL1460084 & 688128 & 4.6 & 4.725 & TRN & \\
\hline CHEMBL1527718 & 688128 & 4.1 & 4.8689 & TST & \\
\hline CHEMBL1522007 & 688128 & 6.3 & 5.1363 & TST & \\
\hline CHEMBL1494548 & 688128 & 4.3 & 4.4111 & TRN & \\
\hline
\end{tabular}




\begin{tabular}{|c|c|c|c|c|c|}
\hline & & \multicolumn{4}{|c|}{ Supplemental Table s2.txt } \\
\hline CHEMBL1311011 & 688128 & 4.35 & 4.7786 & TST & \\
\hline CHEMBL1451174 & 688128 & 5.4 & 4.6608 & TST & \\
\hline CHEMBL1395328 & 688128 & 4.1 & 4.7275 & TRN & \\
\hline CHEMBL1602489 & 688128 & 4.3 & 4.9114 & TRN & \\
\hline CHEMBL1414617 & 688128 & 5.05 & 4.9323 & TRN & \\
\hline CHEMBL1400363 & 688128 & 4.35 & 4.4879 & TRN & \\
\hline CHEMBL1321070 & 688128 & 5.35 & 4.8229 & TRN & \\
\hline CHEMBL1606221 & 688128 & 4.5 & 4.8532 & TRN & \\
\hline CHEMBL1367042 & 688128 & 4.25 & \multicolumn{2}{|c|}{4.486000000000001} & TRN \\
\hline CHEMBL1438989 & 688128 & 4.05 & 4.5966 & TRN & \\
\hline CHEMBL1591485 & 688128 & 4.3 & 4.7315 & TRN & \\
\hline CHEMBL1437811 & 688128 & 4.7 & 4.706 & TRN & \\
\hline CHEMBL1388300 & 688128 & 4.45 & 4.9304 & TRN & \\
\hline CHEMBL1422488 & 688128 & 4.35 & 4.5148 & TRN & \\
\hline CHEMBL1536053 & 688128 & 6.0 & 4.5951 & TRN & \\
\hline CHEMBL1486570 & 688128 & 4.45 & 4.5209 & TRN & \\
\hline CHEMBL 2003310 & 688128 & 4.35 & 4.8386 & TST & \\
\hline CHEMBL1539803 & 688128 & 4.3 & 4.5868 & TRN & \\
\hline CHEMBL1473552 & 688128 & 4.35 & 4.7178 & TRN & \\
\hline CHEMBL1416630 & 688128 & 6.05 & 4.6096 & TRN & \\
\hline CHEMBL1507647 & 688128 & 4.5 & 4.8344 & TRN & \\
\hline CHEMBL1403414 & 688128 & 6.0 & 5.2955 & TRN & \\
\hline CHEMBL1500401 & 688128 & 4.3 & 4.5808 & TRN & \\
\hline CHEMBL1328195 & 688128 & 4.6 & 5.0926 & TRN & \\
\hline CHEMBL3216873 & 688128 & 4.85 & 4.2714 & TST & \\
\hline CHEMBL1548872 & 688128 & 4.8 & 5.1724 & TRN & \\
\hline CHEMBL1981002 & 688128 & 5.45 & 4.7904 & TST & \\
\hline CHEMBL1300120 & 688128 & 6.0 & 4.7238 & TRN & \\
\hline CHEMBL1309820 & 688128 & 5.75 & 4.7529 & TRN & \\
\hline CHEMBL3198395 & 688128 & 4.45 & 4.8328 & TST & \\
\hline CHEMBL1519317 & 688128 & 4.05 & 4.4932 & TST & \\
\hline CHEMBL1549474 & 688128 & 4.3 & 4.4723 & TRN & \\
\hline CHEMBL1383151 & 688128 & 5.55 & 4.6151 & TRN & \\
\hline CHEMBL1414464 & 688128 & 4.45 & 4.6301 & TRN & \\
\hline CHEMBL1585702 & 688128 & 4.25 & 4.6966 & TST & \\
\hline CHEMBL1559596 & 688128 & 4.5 & 4.5273 & TRN & \\
\hline CHEMBL1451034 & 688128 & 4.05 & 4.6654 & TRN & \\
\hline CHEMBL1422950 & 688128 & 4.75 & 4.7839 & TRN & \\
\hline CHEMBL1612634 & 688128 & 4.3 & 4.8447 & TRN & \\
\hline CHEMBL1508505 & 688128 & 4.05 & 4.3727 & TRN & \\
\hline CHEMBL1378276 & 688128 & 6.05 & 4.599 & TRN & \\
\hline CHEMBL1463795 & 688128 & 4.35 & 4.3331 & TRN & \\
\hline CHEMBL1581413 & 688128 & 4.25 & 4.58899 & 99999999995 & TST \\
\hline CHEMBL1458339 & 688128 & 4.1 & 4.6774 & TST & \\
\hline CHEMBL1420714 & 688128 & 4.55 & 4.8888 & TST & \\
\hline CHEMBL1566275 & 688128 & 4.05 & 4.6769 & TRN & \\
\hline CHEMBL1543663 & 688128 & 4.3 & 4.4858 & TRN & \\
\hline CHEMBL3207315 & 688128 & 4.3 & 4.3078 & TRN & \\
\hline
\end{tabular}




\begin{tabular}{|c|c|c|c|c|}
\hline \multicolumn{5}{|c|}{ Supplemental Table S2.txt } \\
\hline CHEMBL1531029 & 688128 & 4.95 & 4.5335 & TRN \\
\hline CHEMBL1341145 & 688128 & 4.45 & 4.6002 & TRN \\
\hline CHEMBL1534037 & 688128 & 6.8499 & 4.4309 & TRN \\
\hline CHEMBL1494741 & 688128 & 5.1 & 4.4068 & TRN \\
\hline CHEMBL1520305 & 688128 & 4.0 & 4.4805 & TRN \\
\hline CHEMBL1345511 & 688128 & 4.35 & 4.5525 & TRN \\
\hline CHEMBL1595893 & 688128 & 4.65 & 4.4861 & TRN \\
\hline CHEMBL1331809 & 688128 & 5.35 & 4.8057 & TRN \\
\hline CHEMBL1387625 & 688128 & 4.05 & 4.877 & TST \\
\hline CHEMBL1317467 & 688128 & 4.65 & 4.6129 & TRN \\
\hline CHEMBL1985076 & 688128 & 5.05 & 4.426 & TST \\
\hline CHEMBL1573247 & 688128 & 4.5 & 4.8026 & TST \\
\hline CHEMBL1463399 & 688128 & 4.3 & 4.6767 & TRN \\
\hline CHEMBL1533864 & 688128 & 4.55 & 4.7703 & TRN \\
\hline CHEMBL3211285 & 688128 & 5.1 & 4.5789 & TRN \\
\hline CHEMBL1558504 & 688128 & 4.95 & 5.0701 & TRN \\
\hline CHEMBL1987108 & 688128 & 4.35 & 4.7811 & TRN \\
\hline CHEMBL1498206 & 688128 & 5.15 & 4.8105 & TRN \\
\hline CHEMBL1376537 & 688128 & 7.0 & 5.4821 & TRN \\
\hline CHEMBL1414808 & 688128 & 4.3 & 4.5816 & TRN \\
\hline CHEMBL1533683 & 688128 & 4.3 & 4.5344 & TRN \\
\hline CHEMBL594006 & 688128 & 4.4 & 4.5835 & TRN \\
\hline CHEMBL1464117 & 688128 & 4.5 & 4.4023 & TRN \\
\hline CHEMBL1429654 & 688128 & 4.35 & 4.574 & TRN \\
\hline CHEMBL3210187 & 688128 & 4.3 & 4.1454 & TRN \\
\hline CHEMBL1467234 & 688128 & 4.5 & 4.5137 & TRN \\
\hline CHEMBL1356384 & 688128 & 4.55 & 4.5716 & TRN \\
\hline CHEMBL3197525 & 688128 & 5.1 & 4.897 & TRN \\
\hline CHEMBL1493472 & 688128 & 6.05 & 4.5965 & TRN \\
\hline CHEMBL1424595 & 688128 & 4.8 & 4.9133 & TST \\
\hline CHEMBL1451040 & 688128 & 5.75 & 4.856 & TST \\
\hline CHEMBL1335969 & 688128 & 4.05 & 4.467 & TRN \\
\hline CHEMBL1360036 & 688128 & 4.55 & 4.5025 & TRN \\
\hline CHEMBL1601717 & 688128 & 4.05 & 5.0702 & TRN \\
\hline CHEMBL1436146 & 688128 & 4.35 & 4.7448 & TST \\
\hline CHEMBL1508337 & 688128 & 4.35 & 4.5056 & TRN \\
\hline CHEMBL1438385 & 688128 & 4.35 & 4.5755 & TRN \\
\hline CHEMBL1559309 & 688128 & 4.4 & 4.5182 & TRN \\
\hline CHEMBL1565528 & 688128 & 4.3 & 4.8213 & TRN \\
\hline CHEMBL1417945 & 688128 & 4.4 & 4.5219 & TRN \\
\hline CHEMBL1393568 & 688128 & 4.55 & 5.4493 & TRN \\
\hline CHEMBL1427939 & 688128 & 4.5 & 4.3356 & TST \\
\hline CHEMBL1562445 & 688128 & 5.55 & 4.3218 & TST \\
\hline CHEMBL1544438 & 688128 & 4.3 & 4.8039 & TST \\
\hline CHEMBL1604007 & 688128 & 5.65 & 4.8324 & TRN \\
\hline CHEMBL1408467 & 688128 & 6.25 & 4.8405 & TRN \\
\hline CHEMBL1312957 & 688128 & 4.0 & 4.966 & TST \\
\hline CHEMBL1431949 & 688128 & 5.45 & 4.6903 & TRN \\
\hline
\end{tabular}




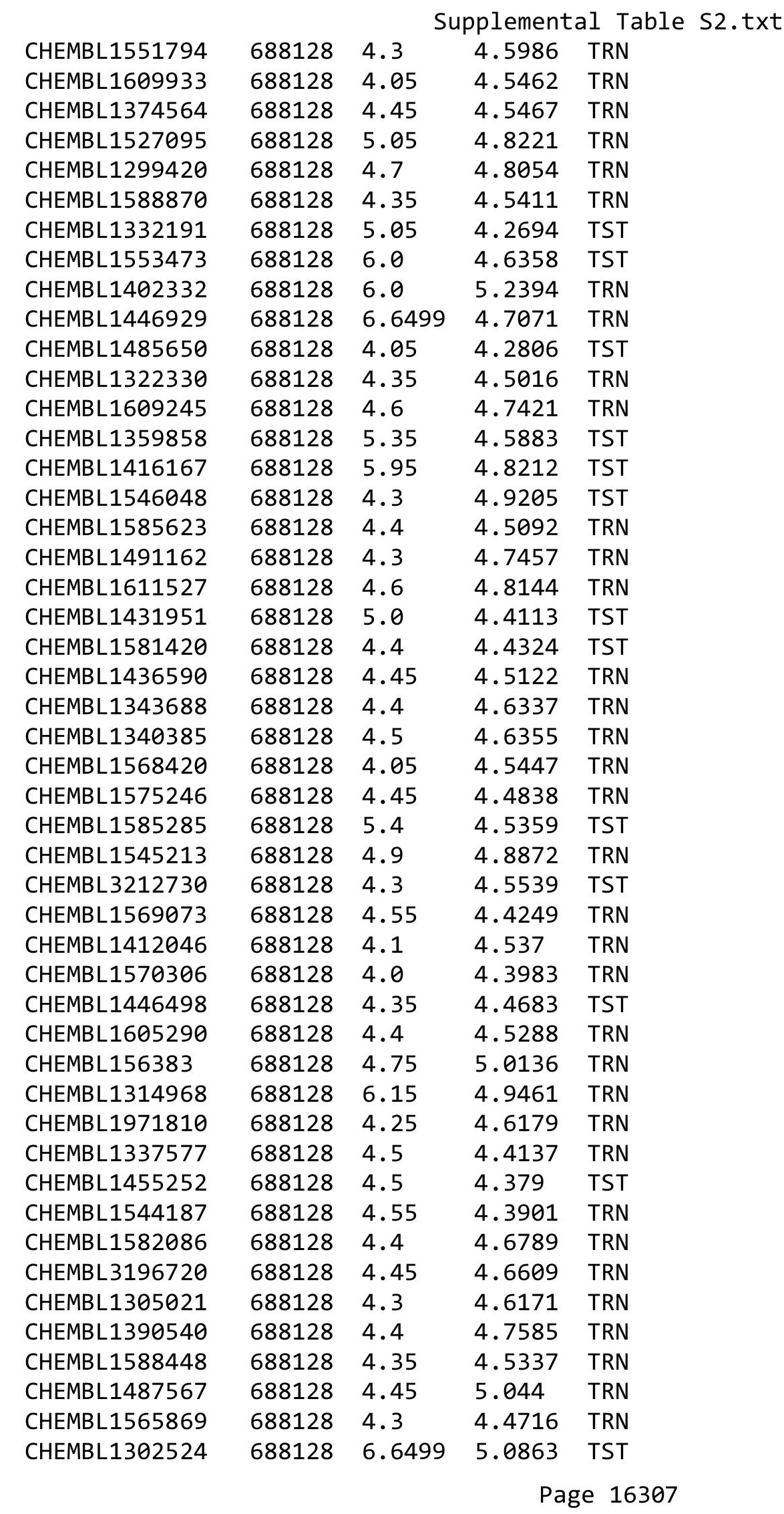




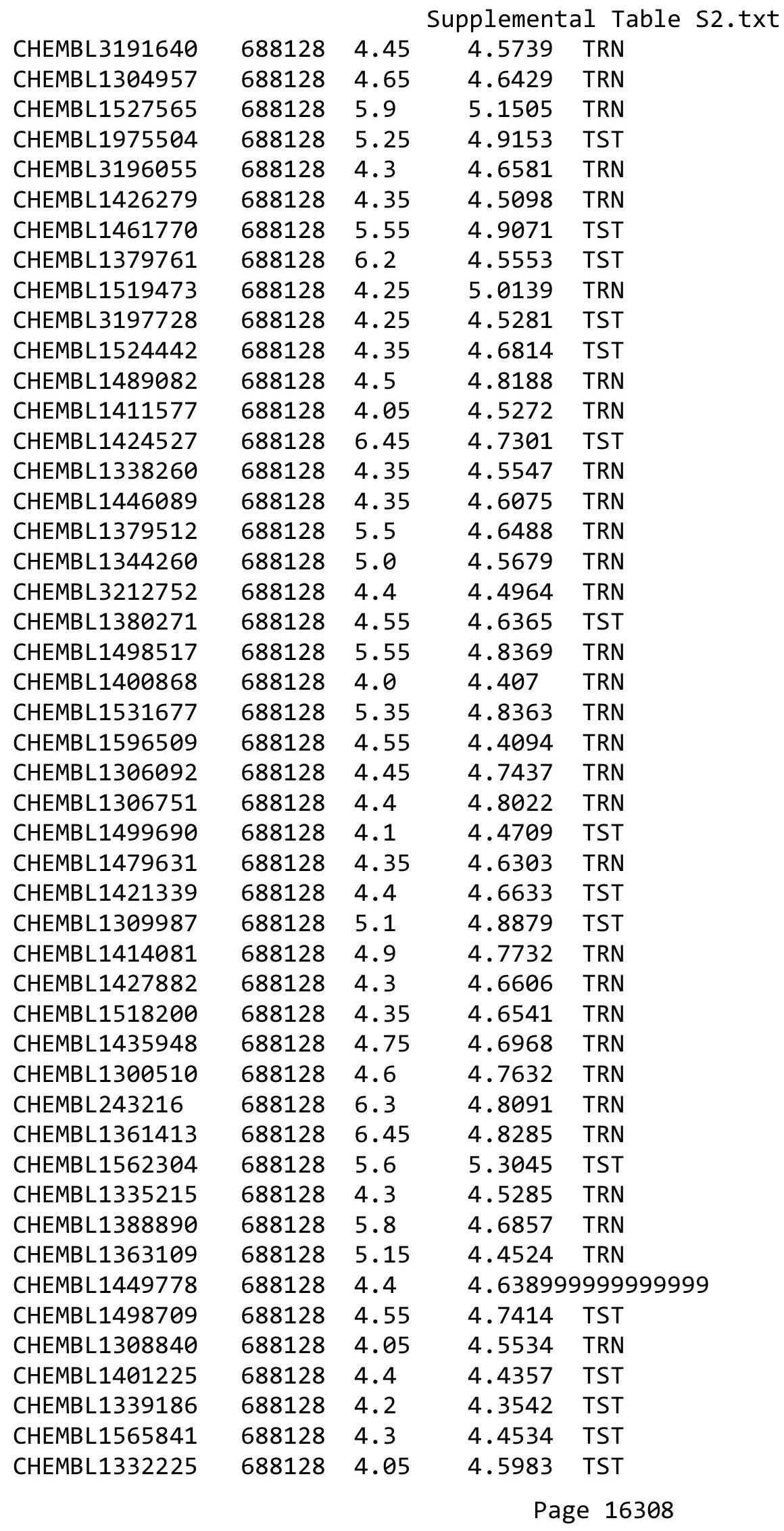

TRN 


\begin{tabular}{|c|c|c|c|c|}
\hline & & & ipplement & $d \perp$ \\
\hline CHEMBL1500022 & 688128 & 5.5 & 4.9507 & TRN \\
\hline CHEMBL1439270 & 688128 & 4.3 & 4.1925 & TRN \\
\hline CHEMBL1381169 & 688128 & 4.1 & 4.7161 & TRN \\
\hline CHEMBL1371028 & 688128 & 4.7 & 4.3936 & TST \\
\hline CHEMBL1439697 & 688128 & 4.1 & 5.0139 & TST \\
\hline CHEMBL1214404 & 688128 & 4.05 & 4.6934 & TRN \\
\hline CHEMBL1489599 & 688128 & 4.05 & 4.629 & TST \\
\hline CHEMBL1452630 & 688128 & 6.95 & 4.5053 & TST \\
\hline CHEMBL1384064 & 688128 & 4.4 & 4.5636 & TST \\
\hline CHEMBL1575123 & 688128 & 4.6 & 4.7463 & TRN \\
\hline CHEMBL1371103 & 688128 & 4.5 & 4.3131 & TRN \\
\hline CHEMBL3194769 & 688128 & 4.9 & 4.7452 & TST \\
\hline CHEMBL1611854 & 688128 & 4.7 & 4.8003 & TST \\
\hline CHEMBL1391901 & 688128 & 4.3 & 4.8212 & TRN \\
\hline CHEMBL1455760 & 688128 & 4.45 & 4.7313 & TRN \\
\hline CHEMBL3192197 & 688128 & 6.0 & 4.9817 & TRN \\
\hline CHEMBL1528521 & 688128 & 5.3 & 4.4282 & TST \\
\hline CHEMBL1426201 & 688128 & 4.35 & 4.4458 & TRN \\
\hline CHEMBL1382813 & 688128 & 4.3 & 4.7184 & TRN \\
\hline CHEMBL1487334 & 688128 & 4.95 & 4.5649 & TRN \\
\hline CHEMBL1443237 & 688128 & 6.15 & 4.9872 & TST \\
\hline CHEMBL 1343230 & 688128 & 4.6 & 4.7574 & TRN \\
\hline CHEMBL1347633 & 688128 & 4.3 & 4.9814 & TST \\
\hline CHEMBL1497954 & 688128 & 4.55 & 4.7764 & TRN \\
\hline CHEMBL1578270 & 688128 & 4.6 & 4.5055 & TRN \\
\hline CHEMBL1514498 & 688128 & 4.5 & 5.1242 & TRN \\
\hline CHEMBL1452351 & 688128 & 4.45 & 4.5262 & TRN \\
\hline CHEMBL1403533 & 688128 & 4.4 & 4.5053 & TRN \\
\hline CHEMBL1551368 & 688128 & 4.95 & 4.9414 & TRN \\
\hline CHEMBL1422151 & 688128 & 4.3 & 4.5236 & TRN \\
\hline CHEMBL1526786 & 688128 & 4.55 & 4.2343 & TRN \\
\hline CHEMBL1359413 & 688128 & 4.4 & 4.2769 & TRN \\
\hline CHEMBL1594951 & 688128 & 4.65 & 4.5416 & TRN \\
\hline CHEMBL1504414 & 688128 & 4.35 & 4.4768 & TRN \\
\hline CHEMBL1492761 & 688128 & 5.4 & 4.4919 & TRN \\
\hline CHEMBL1406943 & 688128 & 4.05 & 4.7374 & TRN \\
\hline CHEMBL1584897 & 688128 & 4.35 & 4.7848 & TRN \\
\hline CHEMBL1464132 & 688128 & 4.3 & 4.8839 & TST \\
\hline CHEMBL1344196 & 688128 & 4.4 & 4.3734 & TRN \\
\hline CHEMBL582674 & 688128 & 4.4 & 4.8013 & TRN \\
\hline CHEMBL1401426 & 688128 & 4.55 & 4.4066 & TRN \\
\hline CHEMBL3195065 & 688128 & 4.85 & 4.6538 & TRN \\
\hline CHEMBL1483268 & 688128 & 4.55 & 4.629 & TRN \\
\hline CHEMBL3191989 & 688128 & 4.9 & 4.8951 & TRN \\
\hline CHEMBL1465460 & 688128 & 4.45 & 4.4669 & TRN \\
\hline CHEMBL1506750 & 688128 & 4.4 & 4.8371 & TRN \\
\hline CHEMBL1393215 & 688128 & 4.45 & 4.9951 & TRN \\
\hline CHEMBL1368433 & 688128 & 5.7 & 4.9459 & TRN \\
\hline
\end{tabular}




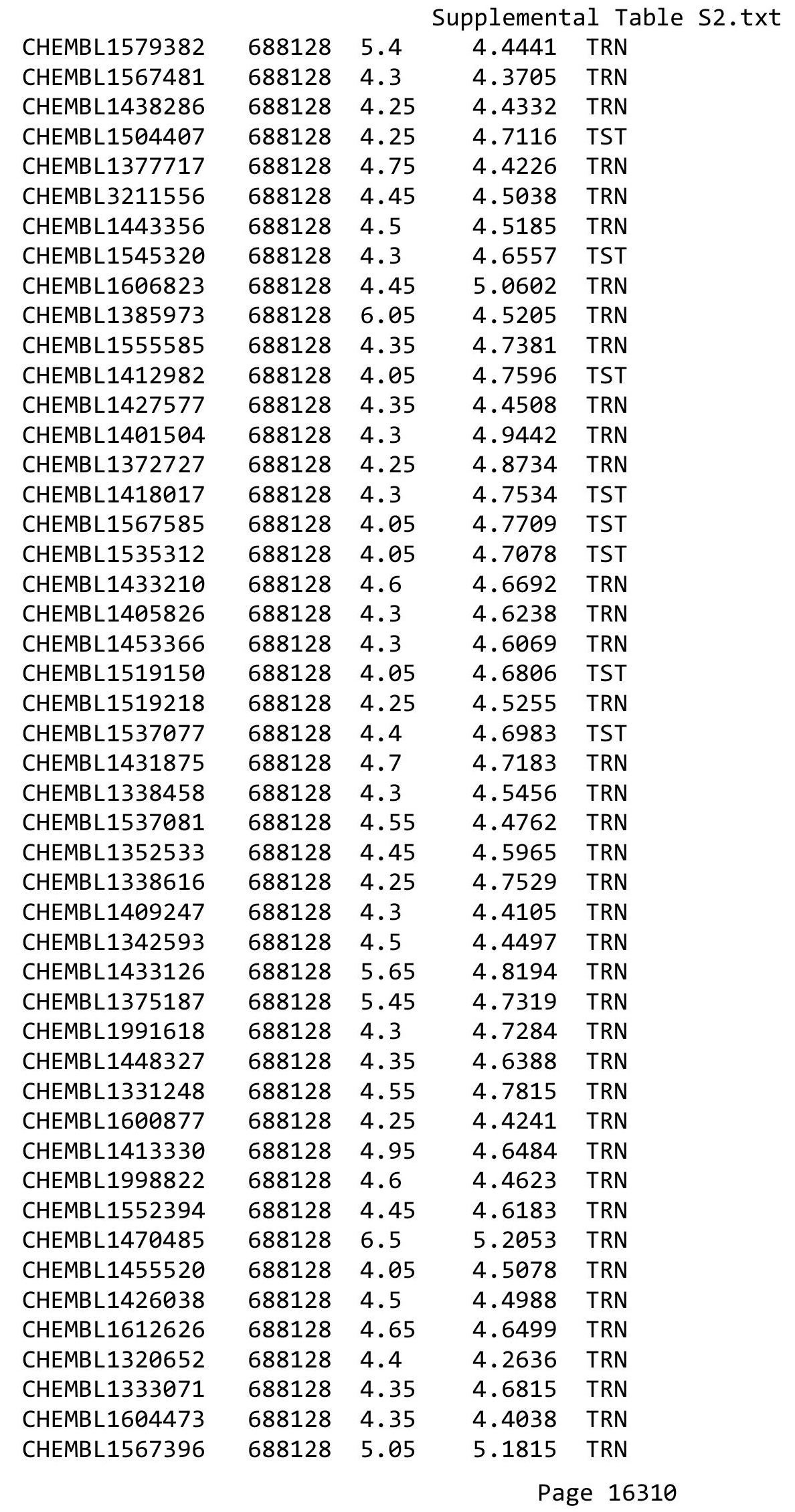




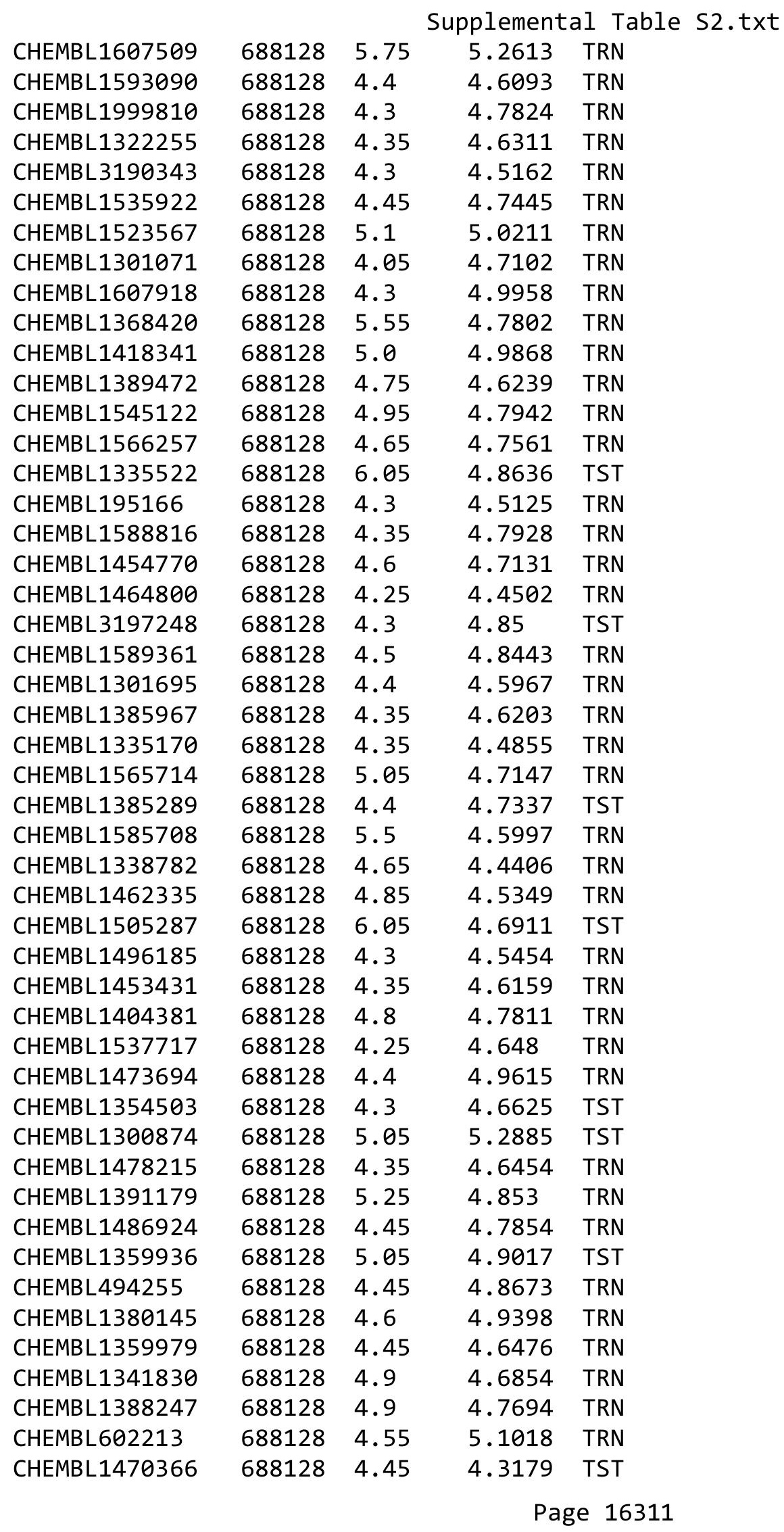




\begin{tabular}{|c|c|c|c|c|c|}
\hline \multirow[b]{2}{*}{ CHEMBL1411995 } & \multirow[b]{2}{*}{688128} & \multicolumn{4}{|c|}{ Supplemental Table s2.txt } \\
\hline & & 5.65 & 4.984 & TST & \\
\hline CHEMBL1574761 & 688128 & 4.5 & 4.4905 & TRN & \\
\hline CHEMBL1386264 & 688128 & 4.3 & 4.5388 & TRN & \\
\hline CHEMBL1476901 & 688128 & 4.25 & \multicolumn{2}{|c|}{4.6080000000000005} & TST \\
\hline CHEMBL1447215 & 688128 & 4.25 & 4.5621 & TRN & \\
\hline CHEMBL1475221 & 688128 & 4.3 & 4.4498 & TRN & \\
\hline CHEMBL1333510 & 688128 & 6.5 & 5.4637 & TRN & \\
\hline CHEMBL1566864 & 688128 & 4.8 & 4.8194 & TRN & \\
\hline CHEMBL1500335 & 688128 & 4.3 & 5.1557 & TRN & \\
\hline CHEMBL1370884 & 688128 & 5.65 & 5.3122 & TRN & \\
\hline CHEMBL1587477 & 688128 & 4.35 & 4.5847 & TRN & \\
\hline CHEMBL1420724 & 688128 & 4.35 & 4.3591 & TST & \\
\hline CHEMBL1511260 & 688128 & 4.25 & 4.2814 & TRN & \\
\hline CHEMBL1443226 & 688128 & 5.5 & 4.5242 & TRN & \\
\hline CHEMBL1583200 & 688128 & 4.6 & 4.5458 & TRN & \\
\hline CHEMBL1364873 & 688128 & 4.3 & 4.4112 & TRN & \\
\hline CHEMBL1362987 & 688128 & 4.55 & 4.591 & TRN & \\
\hline CHEMBL1596966 & 688128 & 4.65 & 4.7535 & TRN & \\
\hline CHEMBL1601463 & 688128 & 4.35 & 4.363 & TRN & \\
\hline CHEMBL1383606 & 688128 & 4.85 & 4.8185 & TRN & \\
\hline CHEMBL1322918 & 688128 & 4.35 & 4.4996 & TRN & \\
\hline CHEMBL1506252 & 688128 & 5.65 & 4.9977 & TRN & \\
\hline CHEMBL1327783 & 688128 & 5.6 & 5.3422 & TRN & \\
\hline CHEMBL 3210043 & 688128 & 4.65 & 4.6768 & TRN & \\
\hline CHEMBL1564325 & 688128 & 4.65 & 4.3693 & TRN & \\
\hline CHEMBL1457492 & 688128 & 4.7 & 4.5775 & TRN & \\
\hline CHEMBL1458941 & 688128 & 4.4 & 4.567 & TST & \\
\hline CHEMBL1580849 & 688128 & 4.45 & 4.4194 & TST & \\
\hline CHEMBL1498937 & 688128 & 4.05 & 4.4819 & TRN & \\
\hline CHEMBL1485960 & 688128 & 4.6 & 5.1102 & TRN & \\
\hline CHEMBL1481390 & 688128 & 6.95 & 5.4132 & TRN & \\
\hline CHEMBL1529636 & 688128 & 4.6 & 4.6824 & TST & \\
\hline CHEMBL3195771 & 688128 & 4.85 & 4.8484 & TRN & \\
\hline CHEMBL1442186 & 688128 & 4.75 & 4.6534 & TST & \\
\hline CHEMBL1492463 & 688128 & 4.25 & 4.541 & TRN & \\
\hline CHEMBL1998853 & 688128 & 4.5 & 4.7529 & TST & \\
\hline CHEMBL1314519 & 688128 & 4.05 & 4.5959 & TST & \\
\hline CHEMBL171637 & 688128 & 4.45 & 4.8312 & TST & \\
\hline CHEMBL1584764 & 688128 & 4.8 & 4.6855 & TRN & \\
\hline CHEMBL1562246 & 688128 & 5.15 & 4.4851 & TRN & \\
\hline CHEMBL1457765 & 688128 & 6.8 & 4.5033 & TRN & \\
\hline CHEMBL1558929 & 688128 & 4.0 & 4.4856 & TST & \\
\hline CHEMBL1577044 & 688128 & 4.95 & 4.871 & TRN & \\
\hline CHEMBL1321797 & 688128 & 4.4 & 4.7767 & TRN & \\
\hline CHEMBL1334926 & 688128 & 4.3 & 4.885 & TST & \\
\hline CHEMBL1328980 & 688128 & 4.4 & 4.565 & TRN & \\
\hline CHEMBL1575328 & 688128 & 6.0 & 5.3551 & TST & \\
\hline CHEMBL1581440 & 688128 & 4.3 & 4.58899 & 99999999995 & TRN \\
\hline & & & & 16312 & \\
\hline
\end{tabular}




\begin{tabular}{|c|c|c|c|c|}
\hline \multicolumn{5}{|c|}{ Supplemental Table S2.txt } \\
\hline CHEMBL1315827 & 688128 & 4.35 & 4.6842 & TRN \\
\hline CHEMBL1558533 & 688128 & 4.35 & 4.4431 & TRN \\
\hline CHEMBL1570511 & 688128 & 4.05 & 4.7461 & TST \\
\hline CHEMBL1534115 & 688128 & 4.3 & 4.3006 & TRN \\
\hline CHEMBL1591749 & 688128 & 4.3 & 4.2791 & TRN \\
\hline CHEMBL1455511 & 688128 & 4.35 & 4.7852 & TRN \\
\hline CHEMBL1595946 & 688128 & 4.25 & 4.6555 & TRN \\
\hline CHEMBL1468094 & 688128 & 6.45 & 5.1704 & TRN \\
\hline CHEMBL1350637 & 688128 & 6.0 & 4.8593 & TRN \\
\hline CHEMBL1484155 & 688128 & 4.9 & 4.7159 & TRN \\
\hline CHEMBL1381892 & 688128 & 4.3 & 4.4043 & TRN \\
\hline CHEMBL1575767 & 688128 & 5.2 & 5.0034 & TRN \\
\hline CHEMBL1506732 & 688128 & 5.85 & 4.4749 & TRN \\
\hline CHEMBL1545847 & 688128 & 4.35 & 4.3375 & TRN \\
\hline CHEMBL1323821 & 688128 & 4.95 & 4.7347 & TST \\
\hline CHEMBL1468710 & 688128 & 4.2 & 4.2368 & TRN \\
\hline CHEMBL1500987 & 688128 & 5.1 & 4.754 & TRN \\
\hline CHEMBL1350184 & 688128 & 4.25 & 4.8472 & TST \\
\hline CHEMBL1584155 & 688128 & 4.7 & 4.7075 & TRN \\
\hline CHEMBL1311139 & 688128 & 4.35 & 4.5502 & TRN \\
\hline CHEMBL1410187 & 688128 & 4.45 & 4.9607 & TRN \\
\hline CHEMBL1540903 & 688128 & 4.3 & 4.6968 & TST \\
\hline CHEMBL1304942 & 688128 & 4.7 & 4.8064 & TRN \\
\hline CHEMBL1505670 & 688128 & 4.2 & 4.5725 & TRN \\
\hline CHEMBL1376362 & 688128 & 4.05 & 4.6638 & TST \\
\hline CHEMBL1275611 & 688128 & 4.6 & 4.8011 & TRN \\
\hline CHEMBL1300013 & 688128 & 4.3 & 4.5624 & TRN \\
\hline CHEMBL1464700 & 688128 & 4.45 & 4.4617 & TRN \\
\hline CHEMBL1373099 & 688128 & 4.0 & 4.3767 & TRN \\
\hline CHEMBL1467732 & 688128 & 6.25 & 5.1128 & TRN \\
\hline CHEMBL3191696 & 688128 & 4.25 & 4.708 & TRN \\
\hline CHEMBL1393268 & 688128 & 4.25 & 4.6252 & TRN \\
\hline CHEMBL1371669 & 688128 & 4.35 & 4.5216 & TRN \\
\hline CHEMBL1546664 & 688128 & 4.3 & 4.5574 & TST \\
\hline CHEMBL1347351 & 688128 & 4.4 & 4.8231 & TRN \\
\hline CHEMBL1452986 & 688128 & 6.4 & 4.7499 & TRN \\
\hline CHEMBL1519952 & 688128 & 4.4 & 4.9406 & TRN \\
\hline CHEMBL1500845 & 688128 & 6.5501 & 4.8406 & TRN \\
\hline CHEMBL1325564 & 688128 & 4.3 & 4.3777 & TST \\
\hline CHEMBL1552024 & 688128 & 4.2 & 4.4278 & TRN \\
\hline CHEMBL3197962 & 688128 & 4.4 & 4.7556 & TRN \\
\hline CHEMBL3190305 & 688128 & 4.9 & 4.6451 & TRN \\
\hline CHEMBL1360482 & 688128 & 4.4 & 4.7743 & TRN \\
\hline CHEMBL1447173 & 688128 & 4.35 & 4.2605 & TRN \\
\hline CHEMBL1375254 & 688128 & 5.0 & 4.6678 & TRN \\
\hline CHEMBL1345810 & 688128 & 4.25 & 4.4859 & TRN \\
\hline CHEMBL1301505 & 688128 & 4.55 & 4.5433 & TRN \\
\hline CHEMBL1357976 & 688128 & 5.5 & 4.4774 & TRN \\
\hline
\end{tabular}




\begin{tabular}{|c|c|c|c|c|c|}
\hline \multicolumn{6}{|c|}{ Supplemental Table S2.txt } \\
\hline CHEMBL1411062 & 688128 & 5.0 & 4.5485 & TRN & \\
\hline CHEMBL1334367 & 688128 & 4.3 & 4.3435 & TST & \\
\hline CHEMBL1366410 & 688128 & 4.3 & 4.5097 & TRN & \\
\hline CHEMBL1440440 & 688128 & 4.3 & 4.8035 & TST & \\
\hline CHEMBL1586339 & 688128 & 4.4 & 4.4141 & TRN & \\
\hline CHEMBL1459670 & 688128 & 4.9 & 4.6377 & TRN & \\
\hline CHEMBL1311358 & 688128 & 4.25 & 4.4912 & TRN & \\
\hline CHEMBL1361855 & 688128 & 4.25 & 4.5251 & TST & \\
\hline CHEMBL1346740 & 688128 & 4.35 & 4.5366 & TRN & \\
\hline CHEMBL1601188 & 688128 & 4.4 & 4.622 & TRN & \\
\hline CHEMBL1432212 & 688128 & 5.45 & 4.7493 & TRN & \\
\hline CHEMBL1429397 & 688128 & 4.7 & 4.448 & TRN & \\
\hline CHEMBL 3190287 & 688128 & 4.45 & 4.5962 & TST & \\
\hline CHEMBL1495539 & 688128 & 4.75 & 4.7303 & TRN & \\
\hline CHEMBL1476281 & 688128 & 4.4 & 4.5193 & TRN & \\
\hline CHEMBL1605531 & 688128 & 5.15 & 5.226 & TRN & \\
\hline CHEMBL1372272 & 688128 & 5.25 & 4.8264 & TRN & \\
\hline CHEMBL1431653 & 688128 & 4.3 & 4.7598 & TRN & \\
\hline CHEMBL1504728 & 688128 & 6.1 & 4.7271 & TRN & \\
\hline CHEMBL1501373 & 688128 & 4.25 & 4.4375 & TRN & \\
\hline CHEMBL1481761 & 688128 & 4.3 & 4.388 & TRN & \\
\hline CHEMBL1340619 & 688128 & 4.3 & 5.1992 & TRN & \\
\hline CHEMBL1470498 & 688128 & 4.45 & 4.7883 & TRN & \\
\hline CHEMBL1460293 & 688128 & 4.35 & 4.6253 & TST & \\
\hline CHEMBL1463847 & 688128 & 5.85 & 4.97199 & 99999999995 & TRN \\
\hline CHEMBL1600658 & 688128 & 4.3 & 4.6113 & TRN & \\
\hline CHEMBL1581845 & 688128 & 4.7 & 4.8731 & TST & \\
\hline CHEMBL1322053 & 688128 & 4.45 & 4.8109 & TRN & \\
\hline CHEMBL3192597 & 688128 & 4.0 & 4.6239 & TST & \\
\hline CHEMBL1466925 & 688128 & 4.1 & 4.6619 & TRN & \\
\hline CHEMBL1612760 & 688128 & 4.4 & 4.5884 & TST & \\
\hline CHEMBL1392312 & 688128 & 4.0 & 5.0766 & TRN & \\
\hline CHEMBL1415013 & 688128 & 4.25 & 4.4528 & TST & \\
\hline CHEMBL3196177 & 688128 & 4.8 & 4.7946 & TRN & \\
\hline CHEMBL1478967 & 688128 & 4.05 & 4.63899 & 9999999999 & TST \\
\hline CHEMBL1604189 & 688128 & 5.55 & 4.7955 & TRN & \\
\hline CHEMBL1385987 & 688128 & 4.4 & 4.4888 & TRN & \\
\hline CHEMBL3199617 & 688128 & 4.25 & 4.4521 & TRN & \\
\hline CHEMBL1598952 & 688128 & 4.35 & 4.6297 & TST & \\
\hline CHEMBL1432127 & 688128 & 4.2 & 4.632 & TRN & \\
\hline CHEMBL1535231 & 688128 & 4.4 & 4.2058 & TRN & \\
\hline CHEMBL1446646 & 688128 & 4.4 & 4.6398 & TRN & \\
\hline CHEMBL1543835 & 688128 & 4.45 & 4.6391 & TRN & \\
\hline CHEMBL1319662 & 688128 & 4.75 & 4.7124 & TRN & \\
\hline CHEMBL1470243 & 688128 & 4.3 & 4.6938 & TRN & \\
\hline CHEMBL1586547 & 688128 & 4.4 & 4.3414 & TST & \\
\hline CHEMBL1310306 & 688128 & 4.4 & 4.8784 & TST & \\
\hline CHEMBL1595939 & 688128 & 4.9 & 4.6512 & TRN & \\
\hline
\end{tabular}




\begin{tabular}{|c|c|c|c|c|c|}
\hline \multicolumn{6}{|c|}{ Supplemental Table s2.txt } \\
\hline CHEMBL1338176 & 688128 & 4.1 & 4.8134 & TST & \\
\hline CHEMBL1367737 & 688128 & 6.45 & 5.0191 & TRN & \\
\hline CHEMBL1540264 & 688128 & 4.05 & 4.6924 & TST & \\
\hline CHEMBL1432483 & 688128 & 4.05 & 4.4283 & TRN & \\
\hline CHEMBL1311780 & 688128 & 4.35 & 4.4587 & TRN & \\
\hline CHEMBL1454571 & 688128 & 5.35 & 4.5594 & TRN & \\
\hline CHEMBL1344337 & 688128 & 4.35 & 4.5672 & TRN & \\
\hline CHEMBL1485823 & 688128 & 4.05 & 4.2476 & TRN & \\
\hline CHEMBL1451205 & 688128 & 4.05 & 4.6586 & TRN & \\
\hline CHEMBL1530848 & 688128 & 4.05 & 4.3941 & TRN & \\
\hline CHEMBL1375788 & 688128 & 4.4 & 4.6067 & TRN & \\
\hline CHEMBL1418299 & 688128 & 4.9 & 4.6245 & TRN & \\
\hline CHEMBL1419432 & 688128 & 4.65 & 4.6724 & TRN & \\
\hline CHEMBL1347822 & 688128 & 4.35 & 4.5678 & TRN & \\
\hline CHEMBL1326669 & 688128 & 4.3 & 4.2527 & TRN & \\
\hline CHEMBL1387355 & 688128 & 4.25 & 4.7147 & TRN & \\
\hline CHEMBL1338777 & 688128 & 4.3 & 4.5875 & TRN & \\
\hline CHEMBL1370675 & 688128 & 4.35 & 4.8348 & TRN & \\
\hline CHEMBL3191557 & 688128 & 6.95 & 4.7727 & TRN & \\
\hline CHEMBL1789993 & 688128 & 4.4 & 4.5617 & TST & \\
\hline CHEMBL1367092 & 688128 & 4.4 & 4.9619 & TRN & \\
\hline CHEMBL1515981 & 688128 & 4.4 & 4.5082 & TRN & \\
\hline CHEMBL1331498 & 688128 & 4.25 & 4.7717 & TRN & \\
\hline CHEMBL1496352 & 688128 & 4.3 & 4.3145 & TRN & \\
\hline CHEMBL1313871 & 688128 & 4.4 & 4.4985 & TRN & \\
\hline CHEMBL1455056 & 688128 & 6.35 & 5.0611 & TRN & \\
\hline CHEMBL1583243 & 688128 & 4.85 & 4.7731 & TRN & \\
\hline CHEMBL1462375 & 688128 & 5.7 & 5.1028 & TRN & \\
\hline CHEMBL1456285 & 688128 & 4.35 & 4.7987 & TRN & \\
\hline CHEMBL1530422 & 688128 & 4.05 & 4.5745 & TST & \\
\hline CHEMBL1544979 & 688128 & 4.3 & 4.5766 & TRN & \\
\hline CHEMBL1478804 & 688128 & 4.3 & 4.8613 & TRN & \\
\hline CHEMBL1605863 & 688128 & 4.3 & 4.5825 & TRN & \\
\hline CHEMBL1546417 & 688128 & 4.3 & 4.6595 & TRN & \\
\hline CHEMBL1600264 & 688128 & 5.45 & 4.9289 & TRN & \\
\hline CHEMBL1547756 & 688128 & 4.6 & 4.6082 & TRN & \\
\hline CHEMBL1481354 & 688128 & 4.25 & 4.83899 & 99999999995 & TST \\
\hline CHEMBL1585344 & 688128 & 4.55 & 4.7539 & TST & \\
\hline CHEMBL1535809 & 688128 & 4.6 & 4.8274 & TRN & \\
\hline CHEMBL1422677 & 688128 & 4.45 & 4.6543 & TST & \\
\hline CHEMBL1288936 & 688128 & 4.3 & 4.6772 & TST & \\
\hline CHEMBL1515822 & 688128 & 6.5 & 5.2057 & TRN & \\
\hline CHEMBL1611968 & 688128 & 4.05 & 4.8201 & TST & \\
\hline CHEMBL1517375 & 688128 & 4.3 & 4.5692 & TST & \\
\hline CHEMBL1335770 & 688128 & 4.4 & 4.6099 & TRN & \\
\hline CHEMBL1575074 & 688128 & 5.5 & 4.614 & TST & \\
\hline CHEMBL1360529 & 688128 & 4.35 & 4.5236 & TRN & \\
\hline CHEMBL1434708 & 688128 & 4.1 & 5.0459 & TRN & \\
\hline
\end{tabular}




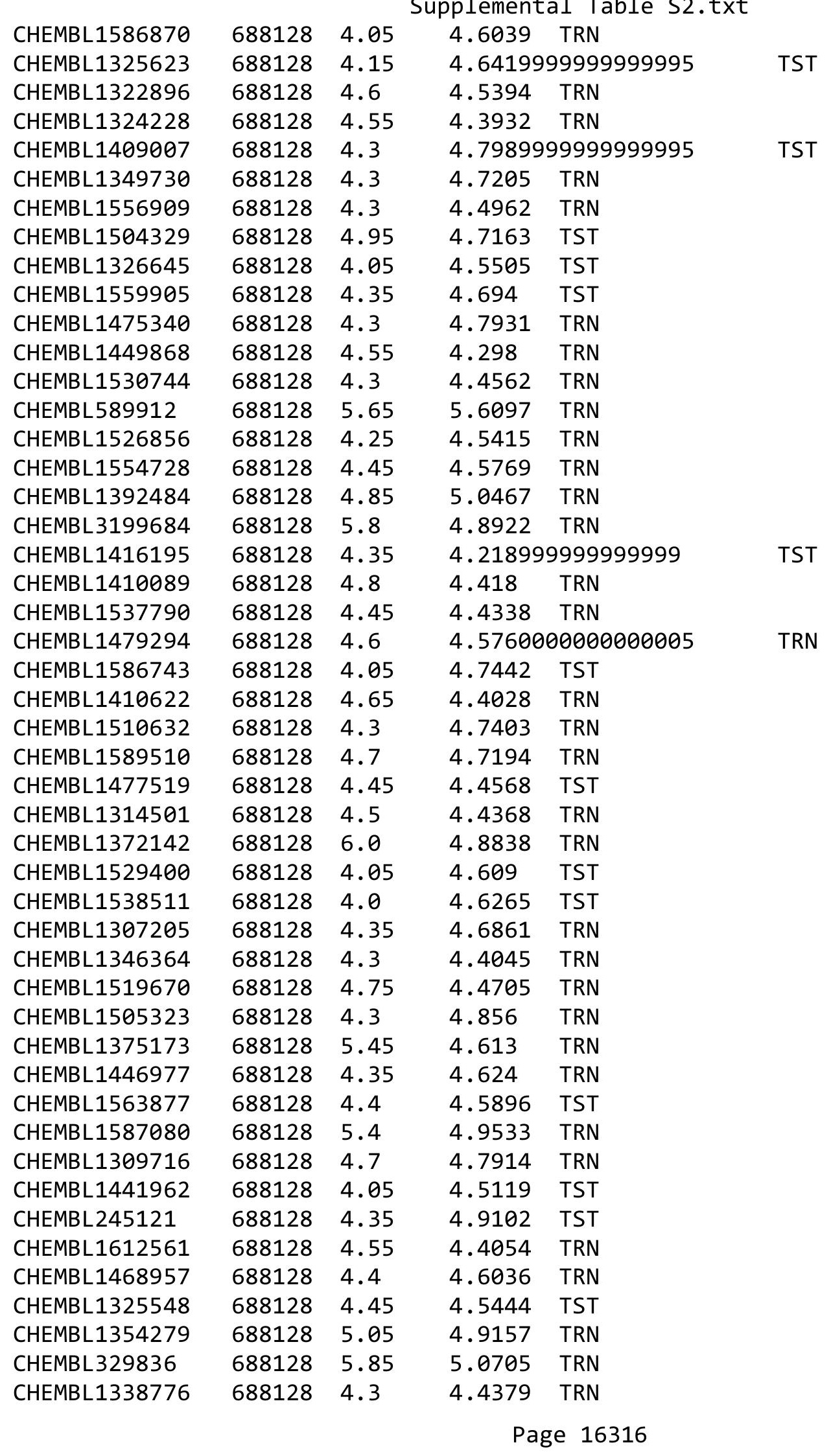




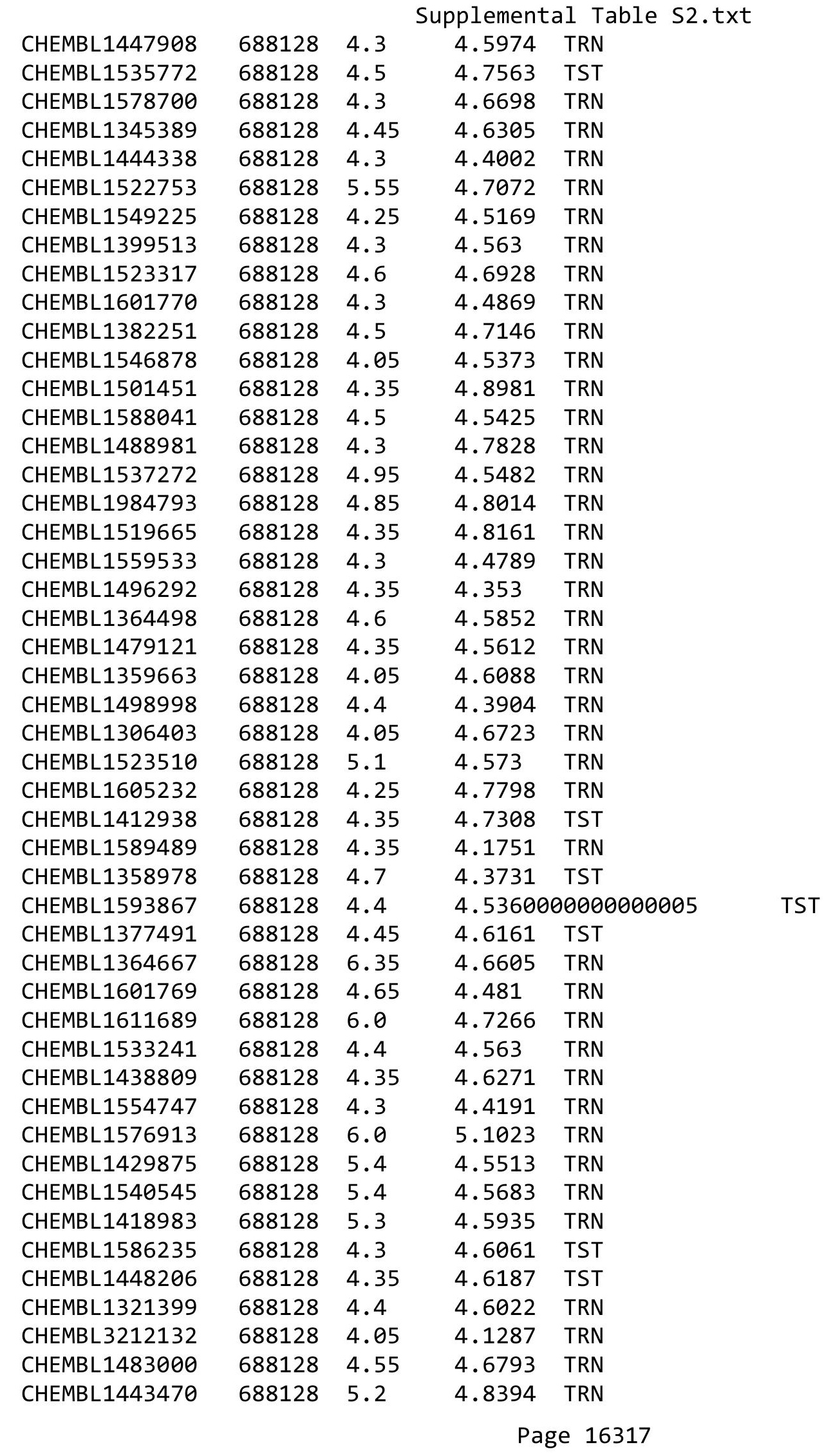




\begin{tabular}{|c|c|c|c|c|c|}
\hline \\
\hline CHEMBL1454601 & 688128 & 4.4 & 4.6496 & TST & \\
\hline CHEMBL1524392 & 688128 & 4.4 & 4.6025 & TRN & \\
\hline CHEMBL1382786 & 688128 & 5.5 & 4.76399 & 9999999999 & TRN \\
\hline CHEMBL1459472 & 688128 & 4.4 & 4.4265 & TST & \\
\hline CHEMBL1309579 & 688128 & 4.05 & 4.8793 & TST & \\
\hline CHEMBL1471625 & 688128 & 4.1 & 4.6528 & TRN & \\
\hline CHEMBL1301371 & 688128 & 5.45 & 5.3969 & TRN & \\
\hline CHEMBL1477755 & 688128 & 4.3 & 4.4835 & TRN & \\
\hline CHEMBL1565520 & 688128 & 5.45 & 5.1232 & TRN & \\
\hline CHEMBL1597655 & 688128 & 4.5 & 5.2652 & TRN & \\
\hline CHEMBL1582584 & 688128 & 4.7 & 4.5594 & TRN & \\
\hline CHEMBL1330039 & 688128 & 4.3 & 4.7897 & TST & \\
\hline CHEMBL1396119 & 688128 & 5.35 & 4.5116 & TST & \\
\hline CHEMBL1352732 & 688128 & 4.0 & 4.7656 & TST & \\
\hline CHEMBL1381589 & 688128 & 5.35 & 4.6485 & TRN & \\
\hline CHEMBL1556463 & 688128 & 5.05 & 4.9272 & TRN & \\
\hline CHEMBL1320628 & 688128 & 5.85 & 4.9816 & TRN & \\
\hline CHEMBL1502339 & 688128 & 4.35 & 4.6204 & TRN & \\
\hline CHEMBL3145062 & 688128 & 4.3 & 4.6702 & TST & \\
\hline CHEMBL1569206 & 688128 & 4.4 & 4.2344 & TST & \\
\hline CHEMBL1432704 & 688128 & 5.4 & 4.6884 & TST & \\
\hline CHEMBL1539755 & 688128 & 4.3 & 4.2134 & TRN & \\
\hline CHEMBL1535295 & 688128 & 4.35 & 4.698 & TST & \\
\hline CHEMBL1544436 & 688128 & 4.4 & 4.6255 & TRN & \\
\hline CHEMBL1564066 & 688128 & 5.55 & 4.9586 & TRN & \\
\hline CHEMBL1449004 & 688128 & 4.3 & 4.6043 & TRN & \\
\hline CHEMBL1399930 & 688128 & 4.95 & 4.7066 & TRN & \\
\hline CHEMBL1425530 & 688128 & 4.45 & 4.6303 & TRN & \\
\hline CHEMBL1580197 & 688128 & 4.05 & 4.7326 & TST & \\
\hline CHEMBL1576508 & 688128 & 5.15 & 4.39 & TRN & \\
\hline CHEMBL1513040 & 688128 & 5.0 & 5.0064 & TRN & \\
\hline CHEMBL1547422 & 688128 & 5.75 & 4.6248 & TST & \\
\hline CHEMBL1404903 & 688128 & 4.3 & 4.5819 & TRN & \\
\hline CHEMBL1507211 & 688128 & 4.05 & 4.6023 & TRN & \\
\hline CHEMBL3199561 & 688128 & 4.05 & 4.7555 & TRN & \\
\hline CHEMBL1364842 & 688128 & 4.6 & 4.6046 & TST & \\
\hline CHEMBL1392189 & 688128 & 4.7 & 4.4811 & TRN & \\
\hline CHEMBL1485340 & 688128 & 4.3 & 4.3907 & TST & \\
\hline CHEMBL1436148 & 688128 & 4.5 & 4.7649 & TRN & \\
\hline CHEMBL1504904 & 688128 & 4.45 & 4.53 & TRN & \\
\hline CHEMBL1359061 & 688128 & 5.85 & 4.9383 & TRN & \\
\hline CHEMBL1341321 & 688128 & 4.05 & 4.8679 & TST & \\
\hline CHEMBL1531167 & 688128 & 5.25 & 4.9512 & TRN & \\
\hline CHEMBL1400172 & 688128 & 6.1 & 4.5315 & TST & \\
\hline CHEMBL1550519 & 688128 & 4.75 & 4.6909 & TRN & \\
\hline CHEMBL1499282 & 688128 & 4.95 & 4.7967 & TRN & \\
\hline CHEMBL1568568 & 688128 & 4.4 & 4.3868 & TRN & \\
\hline CHEMBL1415412 & 688128 & 4.55 & 4.7007 & TRN & \\
\hline
\end{tabular}




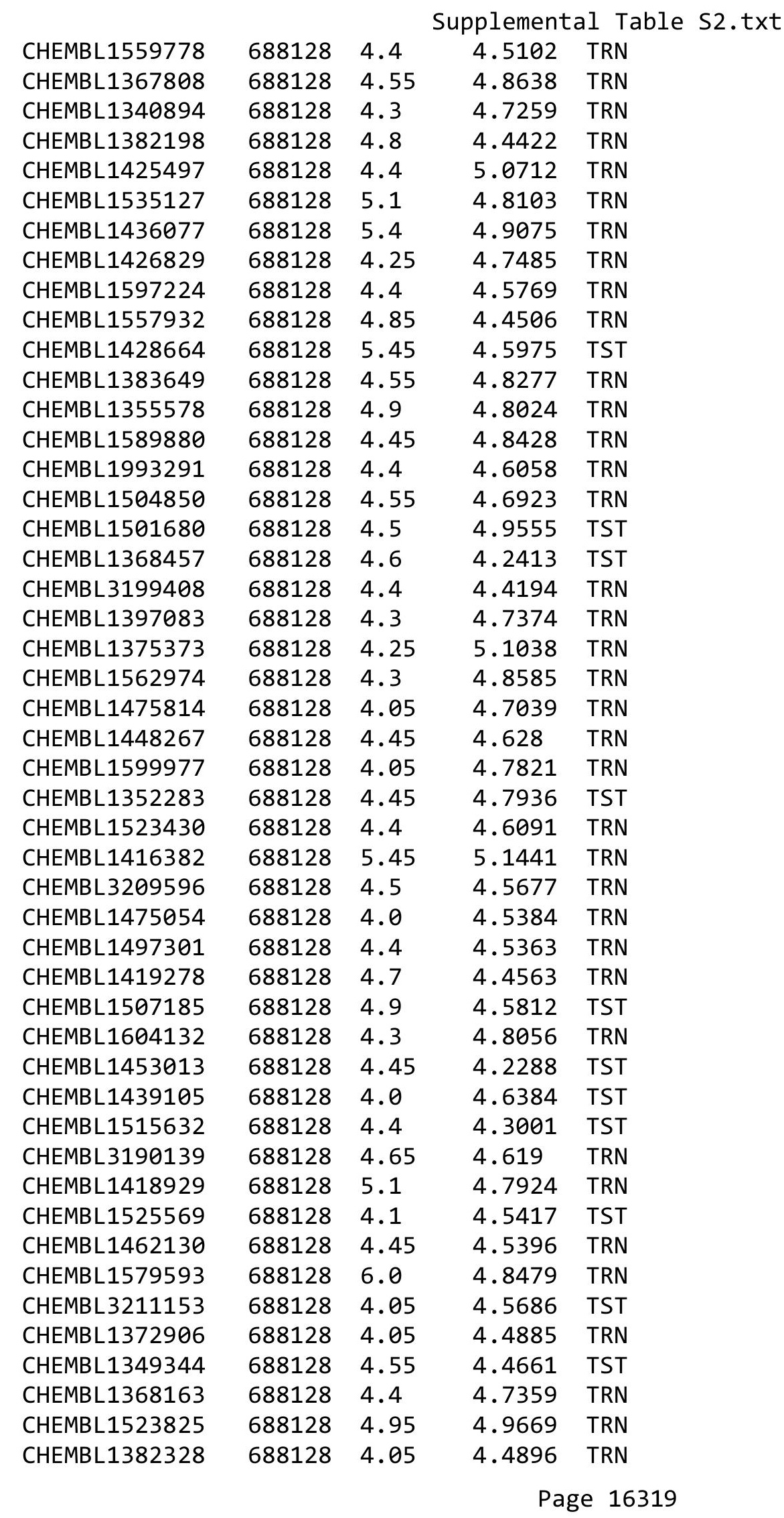




\begin{tabular}{|c|c|c|c|c|c|}
\hline \multicolumn{6}{|c|}{ Supplemental Table s2.txt } \\
\hline CHEMBL1374676 & 688128 & 4.3 & 4.6272 & TRN & \\
\hline CHEMBL1400414 & 688128 & 4.35 & 4.5137 & TRN & \\
\hline CHEMBL1342200 & 688128 & 4.45 & 4.556 & TST & \\
\hline CHEMBL1551627 & 688128 & 5.2 & 4.9097 & TRN & \\
\hline CHEMBL1429670 & 688128 & 4.4 & 4.482 & TRN & \\
\hline CHEMBL1334712 & 688128 & 4.5 & 4.5865 & TRN & \\
\hline CHEMBL1491632 & 688128 & 6.15 & 4.8114 & TRN & \\
\hline CHEMBL1360728 & 688128 & 4.35 & 4.3461 & TRN & \\
\hline CHEMBL 3211878 & 688128 & 4.65 & 4.5287 & TST & \\
\hline CHEMBL1310944 & 688128 & 4.3 & 4.5116 & TRN & \\
\hline CHEMBL1394096 & 688128 & 4.35 & 4.311 & TRN & \\
\hline CHEMBL1502020 & 688128 & 4.5 & 5.2645 & TRN & \\
\hline CHEMBL1480330 & 688128 & 4.25 & 4.5128 & TST & \\
\hline CHEMBL1547055 & 688128 & 4.3 & 4.5534 & TRN & \\
\hline CHEMBL1326740 & 688128 & 4.3 & 4.711 & TRN & \\
\hline CHEMBL1351976 & 688128 & 4.35 & 4.8171 & TRN & \\
\hline CHEMBL1546779 & 688128 & 4.5 & 4.7499 & TRN & \\
\hline CHEMBL1414213 & 688128 & 4.55 & 4.4972 & TRN & \\
\hline CHEMBL1370158 & 688128 & 4.05 & 4.6439 & TRN & \\
\hline CHEMBL1361254 & 688128 & 4.4 & 4.7369 & TRN & \\
\hline CHEMBL1309296 & 688128 & 6.05 & 4.5396 & TRN & \\
\hline CHEMBL1379950 & 688128 & 4.35 & 4.6212 & TRN & \\
\hline CHEMBL1312479 & 688128 & 4.3 & 4.7736 & TRN & \\
\hline CHEMBL1540682 & 688128 & 5.25 & 5.2501 & TRN & \\
\hline CHEMBL1442278 & 688128 & 4.55 & 4.5191 & TRN & \\
\hline CHEMBL1547901 & 688128 & 4.35 & 4.3132 & TRN & \\
\hline CHEMBL1502710 & 688128 & 4.4 & 4.8743 & TRN & \\
\hline CHEMBL1340292 & 688128 & 4.4 & 4.646 & TRN & \\
\hline CHEMBL1419887 & 688128 & 4.35 & 4.42399 & 99999999995 & TRN \\
\hline CHEMBL1547099 & 688128 & 4.6 & 4.6629 & TRN & \\
\hline CHEMBL568166 & 688128 & 5.05 & 4.3078 & TRN & \\
\hline CHEMBL 2000222 & 688128 & 4.5 & 4.4043 & TRN & \\
\hline CHEMBL1422690 & 688128 & 4.45 & 4.6282 & TST & \\
\hline CHEMBL1546136 & 688128 & 5.45 & 4.9046 & TRN & \\
\hline CHEMBL1305599 & 688128 & 4.4 & 4.6656 & TRN & \\
\hline CHEMBL3191485 & 688128 & 4.6 & 4.8354 & TRN & \\
\hline CHEMBL1343797 & 688128 & 4.3 & 4.6452 & TRN & \\
\hline CHEMBL1446180 & 688128 & 4.7 & 4.4815 & TST & \\
\hline CHEMBL1550311 & 688128 & 5.05 & 5.0866 & TRN & \\
\hline CHEMBL1497523 & 688128 & 4.3 & 4.8607 & TST & \\
\hline CHEMBL 2374079 & 688128 & 5.0 & 4.9591 & TRN & \\
\hline CHEMBL1593059 & 688128 & 4.3 & 4.3913 & TRN & \\
\hline CHEMBL1382306 & 688128 & 4.25 & 4.5262 & TST & \\
\hline CHEMBL1588322 & 688128 & 4.5 & 4.5855 & TRN & \\
\hline CHEMBL1535670 & 688128 & 4.25 & 4.8206 & TRN & \\
\hline CHEMBL1362572 & 688128 & 5.0 & 4.5336 & TST & \\
\hline CHEMBL1483022 & 688128 & 5.75 & 4.74 & TST & \\
\hline CHEMBL1470525 & 688128 & 4.3 & 4.5018 & TRN & \\
\hline
\end{tabular}




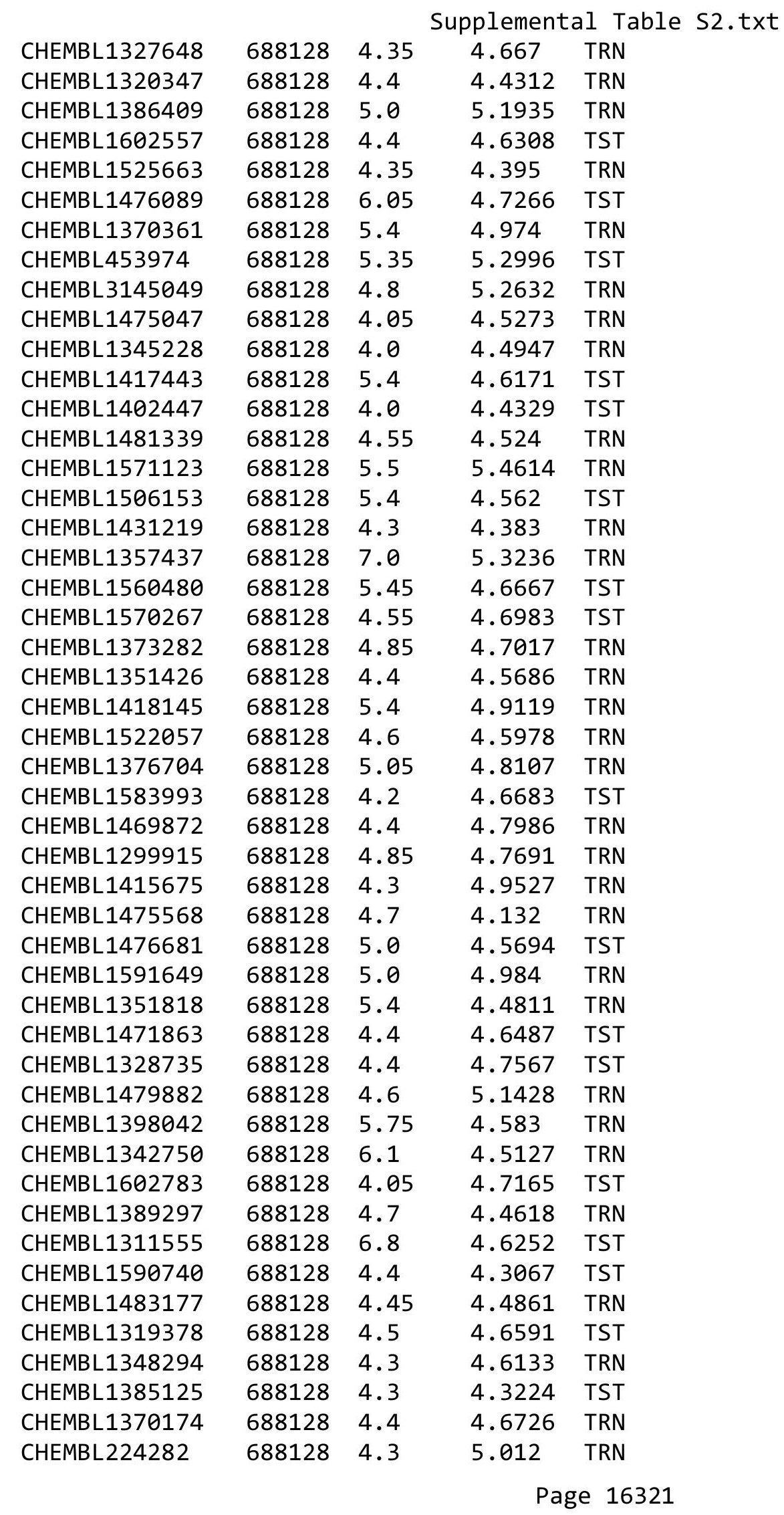




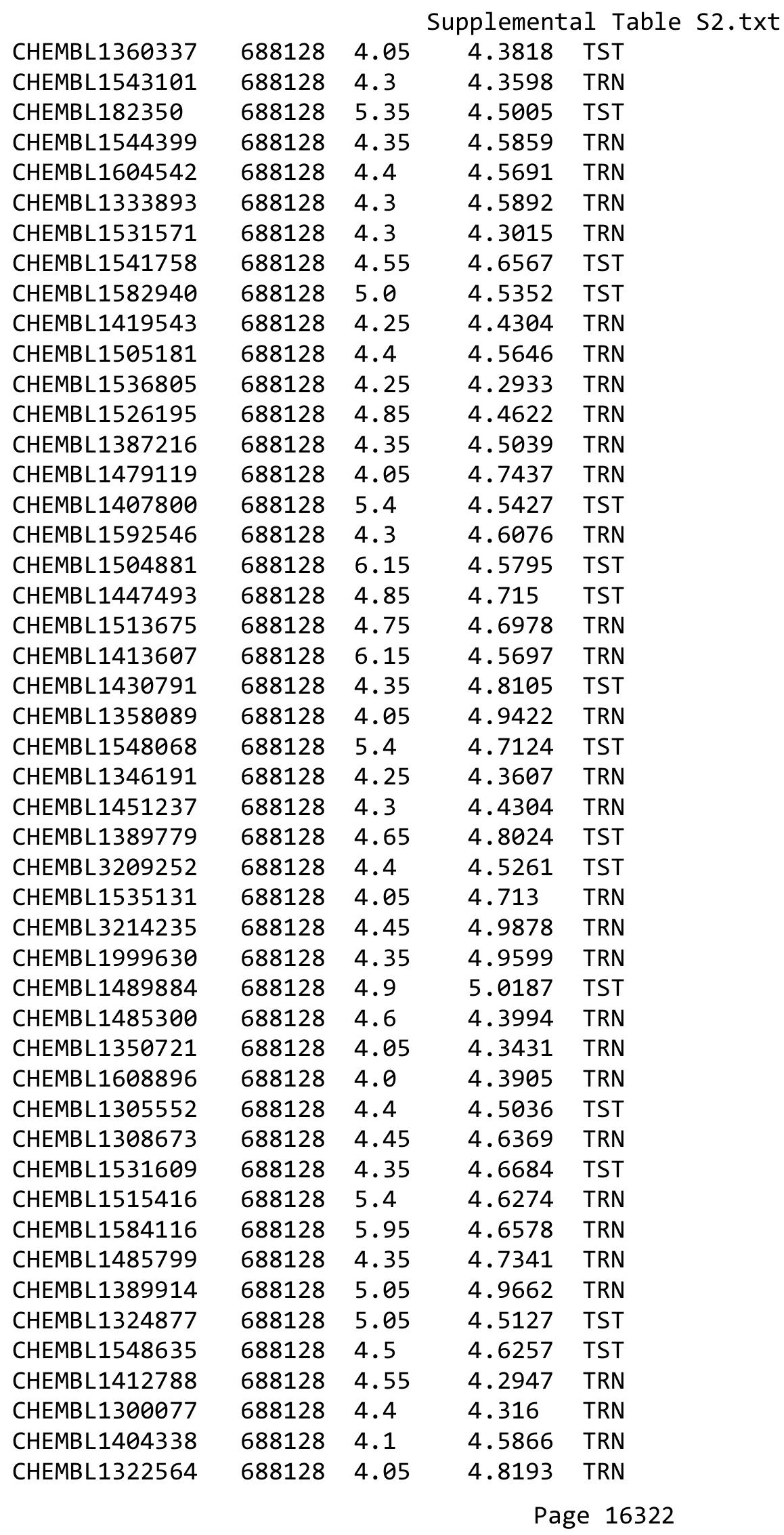




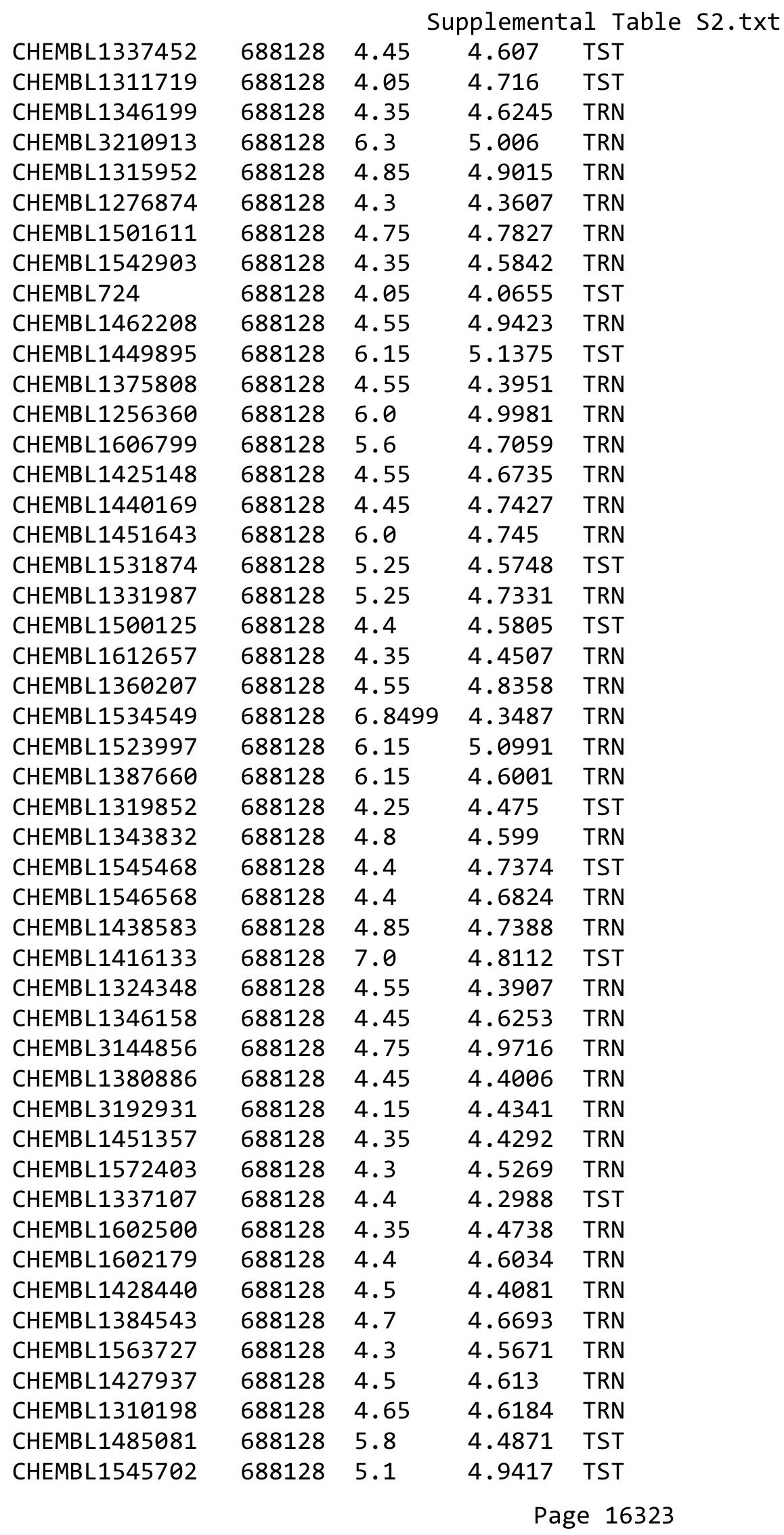




\begin{tabular}{|c|c|c|c|c|c|}
\hline & & \multicolumn{4}{|c|}{ Supplemental Table S2.txt } \\
\hline CHEMBL1553573 & 688128 & 4.3 & 4.6026 & TRN & \\
\hline CHEMBL1418545 & 688128 & 5.15 & 4.8541 & TST & \\
\hline CHEMBL266084 & 688128 & 4.35 & 4.5354 & TRN & \\
\hline CHEMBL1361853 & 688128 & 4.3 & 4.6481 & TRN & \\
\hline CHEMBL1306085 & 688128 & 5.55 & 4.9476 & TRN & \\
\hline CHEMBL3208513 & 688128 & 5.15 & 4.7802 & TST & \\
\hline CHEMBL 3212307 & 688128 & 4.3 & 4.6528 & TST & \\
\hline CHEMBL1556785 & 688128 & 4.0 & 4.4557 & TRN & \\
\hline CHEMBL1391089 & 688128 & 4.35 & 4.6072 & TRN & \\
\hline CHEMBL1468784 & 688128 & 4.5 & 4.7557 & TST & \\
\hline CHEMBL1375560 & 688128 & 4.95 & 4.5931 & TRN & \\
\hline CHEMBL1336593 & 688128 & 5.4 & 4.646 & TRN & \\
\hline CHEMBL1477642 & 688128 & 4.25 & 4.768 & TRN & \\
\hline CHEMBL1438598 & 688128 & 4.55 & 4.4592 & TRN & \\
\hline CHEMBL1469194 & 688128 & 4.05 & 4.6949 & TST & \\
\hline CHEMBL1602121 & 688128 & 4.5 & 4.8343 & TRN & \\
\hline CHEMBL1607257 & 688128 & 4.3 & 4.376 & TRN & \\
\hline CHEMBL1382174 & 688128 & 4.3 & 4.8825 & TST & \\
\hline CHEMBL1435022 & 688128 & 4.35 & 4.7581 & TRN & \\
\hline CHEMBL1539165 & 688128 & 5.5 & 4.7376 & TRN & \\
\hline CHEMBL1446143 & 688128 & 4.25 & 4.7903 & TST & \\
\hline CHEMBL1548646 & 688128 & 4.7 & 4.8485 & TST & \\
\hline CHEMBL1416047 & 688128 & 5.8 & 4.6671 & TRN & \\
\hline CHEMBL1550846 & 688128 & 4.1 & 4.5367 & TRN & \\
\hline CHEMBL1487605 & 688128 & 4.8 & 4.6284 & TRN & \\
\hline CHEMBL1492214 & 688128 & 4.2 & 4.8195 & TST & \\
\hline CHEMBL1971767 & 688128 & 4.3 & 4.9093 & TST & \\
\hline CHEMBL1466619 & 688128 & 4.5 & 4.7211 & TST & \\
\hline CHEMBL1516964 & 688128 & 4.8 & 4.5773 & TRN & \\
\hline CHEMBL1378996 & 688128 & 4.35 & 4.8395 & TRN & \\
\hline CHEMBL1379080 & 688128 & 4.5 & 4.7666 & TRN & \\
\hline CHEMBL135599 & 688128 & 5.35 & 4.7699 & TST & \\
\hline CHEMBL1343178 & 688128 & 5.0 & 4.3929 & TRN & \\
\hline CHEMBL1324931 & 688128 & 4.4 & 4.5248 & TRN & \\
\hline CHEMBL3199885 & 688128 & 5.05 & 4.8406 & TRN & \\
\hline CHEMBL1349959 & 688128 & 4.0 & 4.5384 & TST & \\
\hline CHEMBL1319442 & 688128 & 4.5 & 4.8707 & TST & \\
\hline CHEMBL1429876 & 688128 & 4.3 & 4.538 & TRN & \\
\hline CHEMBL1475887 & 688128 & 4.35 & 4.5269 & TRN & \\
\hline CHEMBL1384290 & 688128 & 4.4 & 4.7433 & TRN & \\
\hline CHEMBL3209222 & 688128 & 4.6 & 4.7296 & TRN & \\
\hline CHEMBL1447063 & 688128 & 4.55 & $4.1960 e$ & 0000000001 & TRN \\
\hline CHEMBL1561154 & 688128 & 4.8 & 4.7026 & TST & \\
\hline CHEMBL1409378 & 688128 & 4.35 & 4.61 & TRN & \\
\hline CHEMBL1386387 & 688128 & 4.2 & 4.8101 & TRN & \\
\hline CHEMBL1492677 & 688128 & 6.25 & 5.0237 & TRN & \\
\hline CHEMBL1410838 & 688128 & 4.05 & 4.6544 & TST & \\
\hline CHEMBL1373894 & 688128 & 4.5 & 4.6401 & TRN & \\
\hline
\end{tabular}




\begin{tabular}{|c|c|c|c|c|}
\hline \multicolumn{5}{|c|}{ Supplemental Table S2.txt } \\
\hline CHEMBL1467729 & 688128 & 6.1 & 4.466 & TST \\
\hline CHEMBL1402979 & 688128 & 4.35 & 4.8693 & TRN \\
\hline CHEMBL3198512 & 688128 & 5.5 & 4.8611 & TST \\
\hline CHEMBL1306165 & 688128 & 4.05 & 4.2828 & TRN \\
\hline CHEMBL1608078 & 688128 & 6.5 & 4.7885 & TRN \\
\hline CHEMBL3196633 & 688128 & 4.4 & 4.8572 & TST \\
\hline CHEMBL1589527 & 688128 & 4.35 & 4.6216 & TST \\
\hline CHEMBL1327947 & 688128 & 4.1 & 4.7006 & TRN \\
\hline CHEMBL1526690 & 688128 & 4.95 & 5.0046 & TRN \\
\hline CHEMBL1419797 & 688128 & 4.25 & 4.5746 & TRN \\
\hline CHEMBL1410714 & 688128 & 4.3 & 4.7205 & TRN \\
\hline CHEMBL1322297 & 688128 & 4.85 & 5.1564 & TRN \\
\hline CHEMBL3192533 & 688128 & 4.85 & 4.9085 & TRN \\
\hline CHEMBL1467515 & 688128 & 4.35 & 4.7834 & TST \\
\hline CHEMBL1509327 & 688128 & 4.4 & 4.6709 & TRN \\
\hline CHEMBL1544357 & 688128 & 4.05 & 4.2894 & TST \\
\hline CHEMBL1364492 & 688128 & 4.9 & 4.7048 & TRN \\
\hline CHEMBL1504425 & 688128 & 4.35 & 5.0746 & TRN \\
\hline CHEMBL1369383 & 688128 & 4.65 & 4.5281 & TRN \\
\hline CHEMBL1597735 & 688128 & 4.3 & 4.5202 & TRN \\
\hline CHEMBL1599429 & 688128 & 4.35 & 4.442 & TST \\
\hline CHEMBL1415813 & 688128 & 4.9 & 4.7725 & TRN \\
\hline CHEMBL1428634 & 688128 & 4.7 & 4.658 & TRN \\
\hline CHEMBL1540832 & 688128 & 5.4 & 4.5502 & TST \\
\hline CHEMBL1426812 & 688128 & 4.3 & 4.7947 & TRN \\
\hline CHEMBL1519182 & 688128 & 4.5 & 4.2495 & TRN \\
\hline CHEMBL1372908 & 688128 & 4.35 & 4.4056 & TRN \\
\hline CHEMBL1566604 & 688128 & 6.0 & 4.8944 & TRN \\
\hline CHEMBL1332890 & 688128 & 4.35 & 4.5321 & TRN \\
\hline CHEMBL1454866 & 688128 & 4.05 & 4.9037 & TRN \\
\hline CHEMBL1471951 & 688128 & 4.0 & 4.5722 & TRN \\
\hline CHEMBL1486958 & 688128 & 4.3 & 4.4701 & TRN \\
\hline CHEMBL1341049 & 688128 & 4.3 & 4.3976 & TRN \\
\hline CHEMBL1589209 & 688128 & 4.25 & 4.7514 & TRN \\
\hline CHEMBL1464127 & 688128 & 4.0 & 4.6844 & TRN \\
\hline CHEMBL1555216 & 688128 & 4.7 & 4.5226 & TRN \\
\hline CHEMBL1396024 & 688128 & 4.9 & 5.0215 & TRN \\
\hline CHEMBL1579277 & 688128 & 4.4 & 4.6705 & TST \\
\hline CHEMBL1338413 & 688128 & 4.85 & 4.4689 & TRN \\
\hline CHEMBL1580910 & 688128 & 4.95 & 4.9628 & TRN \\
\hline CHEMBL1503241 & 688128 & 6.45 & 4.6501 & TRN \\
\hline CHEMBL1484105 & 688128 & 4.35 & 4.4925 & TRN \\
\hline CHEMBL1490922 & 688128 & 4.4 & 4.6219 & TST \\
\hline CHEMBL1538027 & 688128 & 4.6 & 4.496 & TRN \\
\hline CHEMBL1356080 & 688128 & 4.3 & 4.827 & TRN \\
\hline CHEMBL1404772 & 688128 & 4.6 & 4.501 & TST \\
\hline CHEMBL1371701 & 688128 & 4.35 & 5.0075 & TRN \\
\hline CHEMBL1603643 & 688128 & 5.05 & 4.5878 & TRN \\
\hline
\end{tabular}




\begin{tabular}{|c|c|c|c|c|c|}
\hline & & \multicolumn{4}{|c|}{ Supplemental Table S2.txt } \\
\hline CHEMBL1560019 & 688128 & 4.55 & 4.7765 & TRN & \\
\hline CHEMBL1504051 & 688128 & 4.0 & 4.7283 & TST & \\
\hline CHEMBL1560906 & 688128 & 4.3 & 4.2941 & TRN & \\
\hline CHEMBL1525064 & 688128 & 5.25 & 5.0315 & TRN & \\
\hline CHEMBL1342816 & 688128 & 3.95 & 4.3986 & TST & \\
\hline CHEMBL1583903 & 688128 & 4.05 & 4.6878 & TST & \\
\hline CHEMBL1592339 & 688128 & 4.05 & 4.6192 & TST & \\
\hline CHEMBL1429071 & 688128 & 4.4 & 4.5606 & TRN & \\
\hline CHEMBL1448731 & 688128 & 4.35 & 4.8311 & TRN & \\
\hline CHEMBL1606520 & 688128 & 4.8 & 4.4857 & TRN & \\
\hline CHEMBL1418924 & 688128 & 4.85 & 4.4199 & TRN & \\
\hline CHEMBL1323344 & 688128 & 4.4 & 4.5465 & TRN & \\
\hline CHEMBL1986251 & 688128 & 6.4 & 4.9582 & TRN & \\
\hline CHEMBL1380875 & 688128 & 4.3 & 4.6112 & TRN & \\
\hline CHEMBL1496109 & 688128 & 4.3 & 4.4769 & TST & \\
\hline CHEMBL1423113 & 688128 & 5.4 & 4.5377 & TST & \\
\hline CHEMBL1413275 & 688128 & 5.0 & 4.765 & TST & \\
\hline CHEMBL1499947 & 688128 & 5.55 & 5.1239 & TRN & \\
\hline CHEMBL1558183 & 688128 & 4.35 & 4.872 & TST & \\
\hline CHEMBL1365769 & 688128 & 4.3 & 4.6293 & TRN & \\
\hline CHEMBL1373679 & 688128 & 4.35 & 4.5878 & TRN & \\
\hline CHEMBL1338680 & 688128 & 5.3 & 4.579 & TRN & \\
\hline CHEMBL1568498 & 688128 & 4.75 & 4.5427 & TRN & \\
\hline CHEMBL1370401 & 688128 & 4.05 & 4.5786 & TST & \\
\hline CHEMBL1458229 & 688128 & 4.65 & 4.4425 & TST & \\
\hline CHEMBL1455675 & 688128 & 4.05 & 4.7152 & TRN & \\
\hline CHEMBL1379556 & 688128 & 4.5 & 4.8276 & TRN & \\
\hline CHEMBL1327057 & 688128 & 4.35 & 4.5511 & TRN & \\
\hline CHEMBL3208955 & 688128 & 4.0 & 4.8262 & TST & \\
\hline CHEMBL1472041 & 688128 & 4.4 & 4.6229 & TST & \\
\hline CHEMBL1988686 & 688128 & 4.35 & 4.55399 & 9999999999 & TST \\
\hline CHEMBL1482554 & 688128 & 5.4 & 4.6469 & TST & \\
\hline CHEMBL1487333 & 688128 & 4.55 & 4.322 & TRN & \\
\hline CHEMBL1365204 & 688128 & 4.65 & 4.6579 & TRN & \\
\hline CHEMBL1395410 & 688128 & 4.35 & 4.3724 & TRN & \\
\hline CHEMBL1316976 & 688128 & 4.7 & 5.1993 & TRN & \\
\hline CHEMBL1549861 & 688128 & 4.45 & 4.5014 & TST & \\
\hline CHEMBL1577837 & 688128 & 6.0 & 4.6681 & TRN & \\
\hline CHEMBL1392539 & 688128 & 4.35 & 4.8669 & TST & \\
\hline CHEMBL3210536 & 688128 & 4.4 & 4.8327 & TST & \\
\hline CHEMBL1608578 & 688128 & 5.5 & 5.0515 & TRN & \\
\hline CHEMBL1527971 & 688128 & 4.6 & 4.5437 & TRN & \\
\hline CHEMBL1722566 & 688128 & 5.0 & 4.9426 & TRN & \\
\hline CHEMBL1527948 & 688128 & 5.15 & 4.2959 & TST & \\
\hline CHEMBL1512072 & 688128 & 4.45 & 4.6141 & TRN & \\
\hline CHEMBL1539845 & 688128 & 4.3 & 4.4482 & TST & \\
\hline CHEMBL1478144 & 688128 & 4.5 & 4.6959 & TRN & \\
\hline CHEMBL1572853 & 688128 & 4.3 & 4.8489 & TRN & \\
\hline
\end{tabular}




\begin{tabular}{|c|c|c|c|c|}
\hline \multicolumn{5}{|c|}{ Supplemental Table S2.txt } \\
\hline CHEMBL1507425 & 688128 & 4.35 & 4.5498 & TRN \\
\hline CHEMBL1404603 & 688128 & 4.9 & 4.7501 & TRN \\
\hline CHEMBL1487923 & 688128 & 4.65 & 4.6244 & TRN \\
\hline CHEMBL1502449 & 688128 & 5.45 & 4.5919 & TRN \\
\hline CHEMBL1983367 & 688128 & 4.4 & 4.5837 & TRN \\
\hline CHEMBL1317598 & 688128 & 5.15 & 4.9983 & TRN \\
\hline CHEMBL1487479 & 688128 & 4.1 & 4.6571 & TRN \\
\hline CHEMBL1360195 & 688128 & 4.35 & 4.4415 & TRN \\
\hline CHEMBL1589737 & 688128 & 4.55 & 4.6222 & TRN \\
\hline CHEMBL1329209 & 688128 & 4.25 & 4.4403 & TRN \\
\hline CHEMBL1488035 & 688128 & 4.4 & 4.926 & TRN \\
\hline CHEMBL1528722 & 688128 & 4.0 & 4.7645 & TST \\
\hline CHEMBL1322110 & 688128 & 5.0 & 4.8856 & TRN \\
\hline CHEMBL1507428 & 688128 & 4.3 & 4.893 & TST \\
\hline CHEMBL1517443 & 688128 & 4.35 & 4.273 & TRN \\
\hline CHEMBL530963 & 688128 & 4.4 & 4.6001 & TST \\
\hline CHEMBL1571925 & 688128 & 4.05 & 4.6042 & TRN \\
\hline CHEMBL1319053 & 688128 & 4.3 & 4.5051 & TRN \\
\hline CHEMBL1375959 & 688128 & 4.6 & 4.9872 & TRN \\
\hline CHEMBL1491439 & 688128 & 5.35 & 4.4473 & TRN \\
\hline CHEMBL1557738 & 688128 & 6.0 & 4.6574 & TRN \\
\hline CHEMBL1571997 & 688128 & 4.3 & 4.39 & TRN \\
\hline CHEMBL1424959 & 688128 & 4.3 & 4.6194 & TST \\
\hline CHEMBL1495691 & 688128 & 5.6 & 4.5571 & TST \\
\hline CHEMBL1549631 & 688128 & 4.3 & 4.4265 & TRN \\
\hline CHEMBL1563660 & 688128 & 6.1 & 4.8261 & TST \\
\hline CHEMBL1513326 & 688128 & 4.4 & 4.5173 & TRN \\
\hline CHEMBL1553022 & 688128 & 4.35 & 4.4289 & 9999999999 \\
\hline CHEMBL1599521 & 688128 & 4.25 & 4.2389 & TRN \\
\hline CHEMBL1312523 & 688128 & 4.25 & 4.8684 & TST \\
\hline CHEMBL1463312 & 688128 & 4.35 & 4.5053 & TRN \\
\hline CHEMBL1518503 & 688128 & 5.0 & 5.0709 & TRN \\
\hline CHEMBL1582232 & 688128 & 4.3 & 4.7486 & TRN \\
\hline CHEMBL1584677 & 688128 & 4.25 & 4.6101 & TRN \\
\hline CHEMBL1347163 & 688128 & 4.75 & 4.8054 & TST \\
\hline CHEMBL1422185 & 688128 & 4.6 & 4.8619 & TST \\
\hline CHEMBL1561708 & 688128 & 4.0 & 4.4294 & TRN \\
\hline CHEMBL1478152 & 688128 & 4.3 & 4.3183 & TST \\
\hline CHEMBL1444666 & 688128 & 4.7 & 4.6894 & TRN \\
\hline CHEMBL1592256 & 688128 & 4.5 & 4.5026 & TRN \\
\hline CHEMBL1343988 & 688128 & 5.85 & 4.9047 & TRN \\
\hline CHEMBL1597686 & 688128 & 4.65 & 4.533 & TRN \\
\hline CHEMBL1594572 & 688128 & 4.05 & 4.7321 & TRN \\
\hline CHEMBL1418998 & 688128 & 4.25 & 4.5811 & TRN \\
\hline CHEMBL1416218 & 688128 & 6.8499 & 5.2803 & TRN \\
\hline CHEMBL1464634 & 688128 & 4.0 & 4.8215 & TST \\
\hline CHEMBL1363661 & 688128 & 4.4 & 4.5545 & TRN \\
\hline CHEMBL1589656 & 688128 & 4.4 & 4.5509 & TST \\
\hline
\end{tabular}




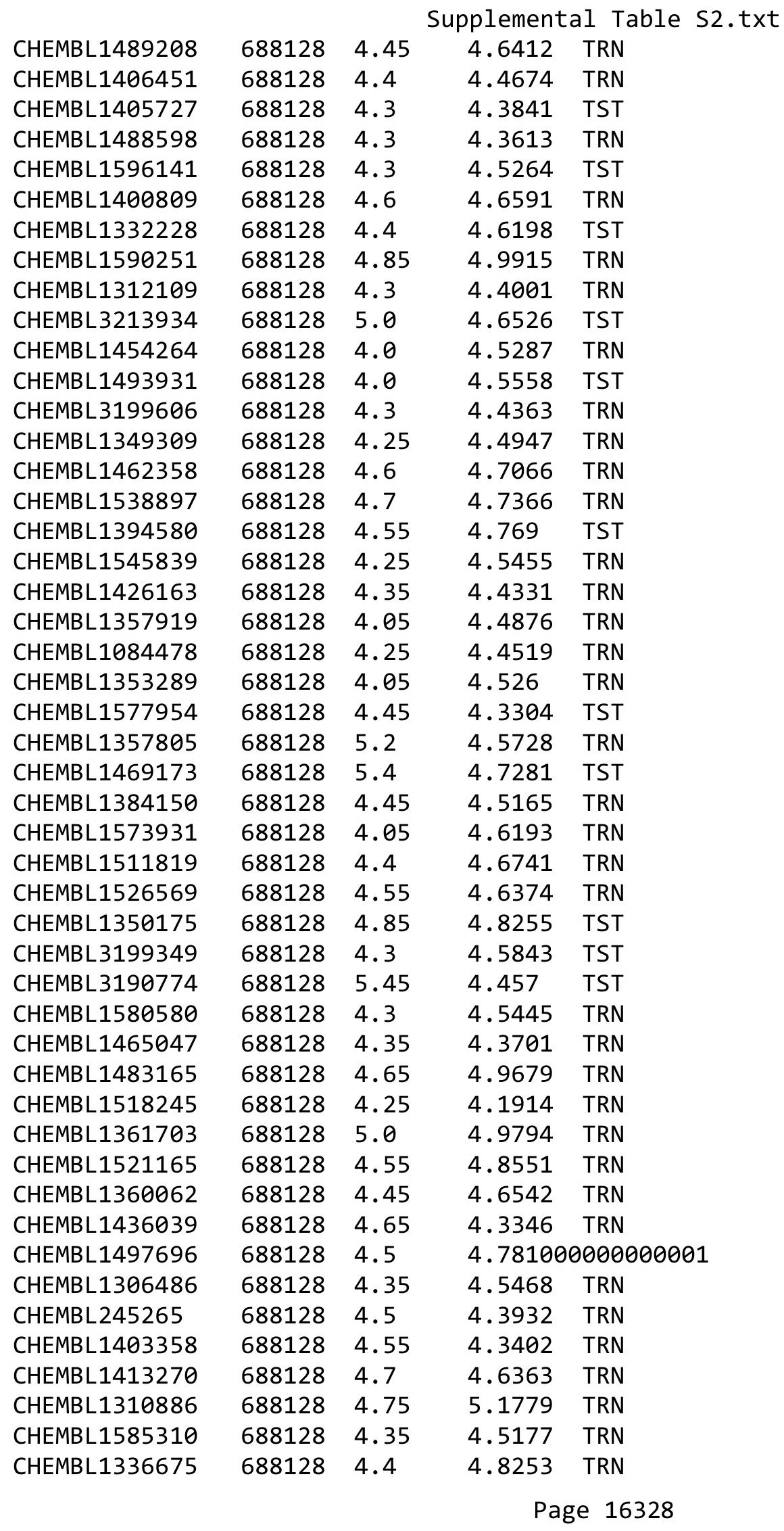




\begin{tabular}{|c|c|c|c|c|c|}
\hline & & \multicolumn{4}{|c|}{ Supplemental Table S2.txt } \\
\hline CHEMBL1483857 & 688128 & 4.35 & 4.3959 & TST & \\
\hline CHEMBL1458120 & 688128 & 4.35 & 4.4388 & TRN & \\
\hline CHEMBL1549645 & 688128 & 4.1 & 4.6074 & TRN & \\
\hline CHEMBL1412161 & 688128 & 5.85 & 4.6794 & TST & \\
\hline CHEMBL1316549 & 688128 & 5.35 & 4.4834 & TRN & \\
\hline CHEMBL1541374 & 688128 & 6.8499 & 4.72199 & 99999999995 & TRN \\
\hline CHEMBL1588492 & 688128 & 4.3 & 4.4621 & TRN & \\
\hline CHEMBL1391322 & 688128 & 4.85 & 5.0929 & TRN & \\
\hline CHEMBL1530253 & 688128 & 6.5501 & 4.4072 & TST & \\
\hline CHEMBL1304475 & 688128 & 4.6 & 4.585 & TRN & \\
\hline CHEMBL1600773 & 688128 & 4.3 & 4.4693 & TST & \\
\hline CHEMBL1334630 & 688128 & 6.8499 & 4.8777 & TST & \\
\hline CHEMBL1339939 & 688128 & 4.25 & 4.3384 & TRN & \\
\hline CHEMBL1576431 & 688128 & 4.9 & 4.7255 & TRN & \\
\hline CHEMBL1416496 & 688128 & 4.25 & 4.6521 & TRN & \\
\hline CHEMBL1483657 & 688128 & 4.35 & 4.8944 & TRN & \\
\hline CHEMBL1595909 & 688128 & 4.3 & 4.9876 & TRN & \\
\hline CHEMBL1333908 & 688128 & 5.05 & 4.8434 & TRN & \\
\hline CHEMBL1559406 & 688128 & 4.05 & 4.7331 & TST & \\
\hline CHEMBL1526459 & 688128 & 4.4 & 4.5063 & TRN & \\
\hline CHEMBL1400968 & 688128 & 4.05 & 4.6023 & TRN & \\
\hline CHEMBL1325864 & 688128 & 4.4 & 4.738 & TST & \\
\hline CHEMBL3211986 & 688128 & 4.75 & 4.5077 & TRN & \\
\hline CHEMBL1319415 & 688128 & 5.45 & 4.4498 & TST & \\
\hline CHEMBL1526120 & 688128 & 4.25 & 4.8128 & TST & \\
\hline CHEMBL1328213 & 688128 & 4.55 & 4.738 & TST & \\
\hline CHEMBL1594483 & 688128 & 4.3 & 4.3595 & TRN & \\
\hline CHEMBL1500979 & 688128 & 4.4 & 4.7798 & TST & \\
\hline CHEMBL1337322 & 688128 & 4.05 & 4.7915 & TRN & \\
\hline CHEMBL1404476 & 688128 & 4.55 & 4.8168 & TRN & \\
\hline CHEMBL1513426 & 688128 & 4.5 & 4.3265 & TRN & \\
\hline CHEMBL1447578 & 688128 & 4.3 & 4.4065 & TST & \\
\hline CHEMBL1378822 & 688128 & 4.35 & 4.6066 & TST & \\
\hline CHEMBL1428083 & 688128 & 4.3 & 4.5286 & TST & \\
\hline CHEMBL3198508 & 688128 & 5.0 & 4.7493 & TST & \\
\hline CHEMBL1358950 & 688128 & 4.4 & 4.4791 & TRN & \\
\hline CHEMBL1612567 & 688128 & 4.3 & 4.39 & TST & \\
\hline CHEMBL1608758 & 688128 & 5.3 & 4.9027 & TST & \\
\hline CHEMBL1328495 & 688128 & 4.05 & 4.845 & TST & \\
\hline CHEMBL1471012 & 688128 & 5.1 & 4.5783 & TST & \\
\hline CHEMBL1590948 & 688128 & 4.25 & 4.6676 & TRN & \\
\hline CHEMBL3190620 & 688128 & 4.6 & 4.628 & TST & \\
\hline CHEMBL1313909 & 688128 & 4.35 & 4.2649 & TRN & \\
\hline CHEMBL1365886 & 688128 & 4.3 & 4.7879 & TRN & \\
\hline CHEMBL1607603 & 688128 & 4.4 & 4.5855 & TRN & \\
\hline CHEMBL1608952 & 688128 & 4.4 & 4.5506 & TST & \\
\hline CHEMBL3193993 & 688128 & 4.0 & 4.5512 & TRN & \\
\hline CHEMBL1313583 & 688128 & 4.7 & 4.6396 & TRN & \\
\hline
\end{tabular}




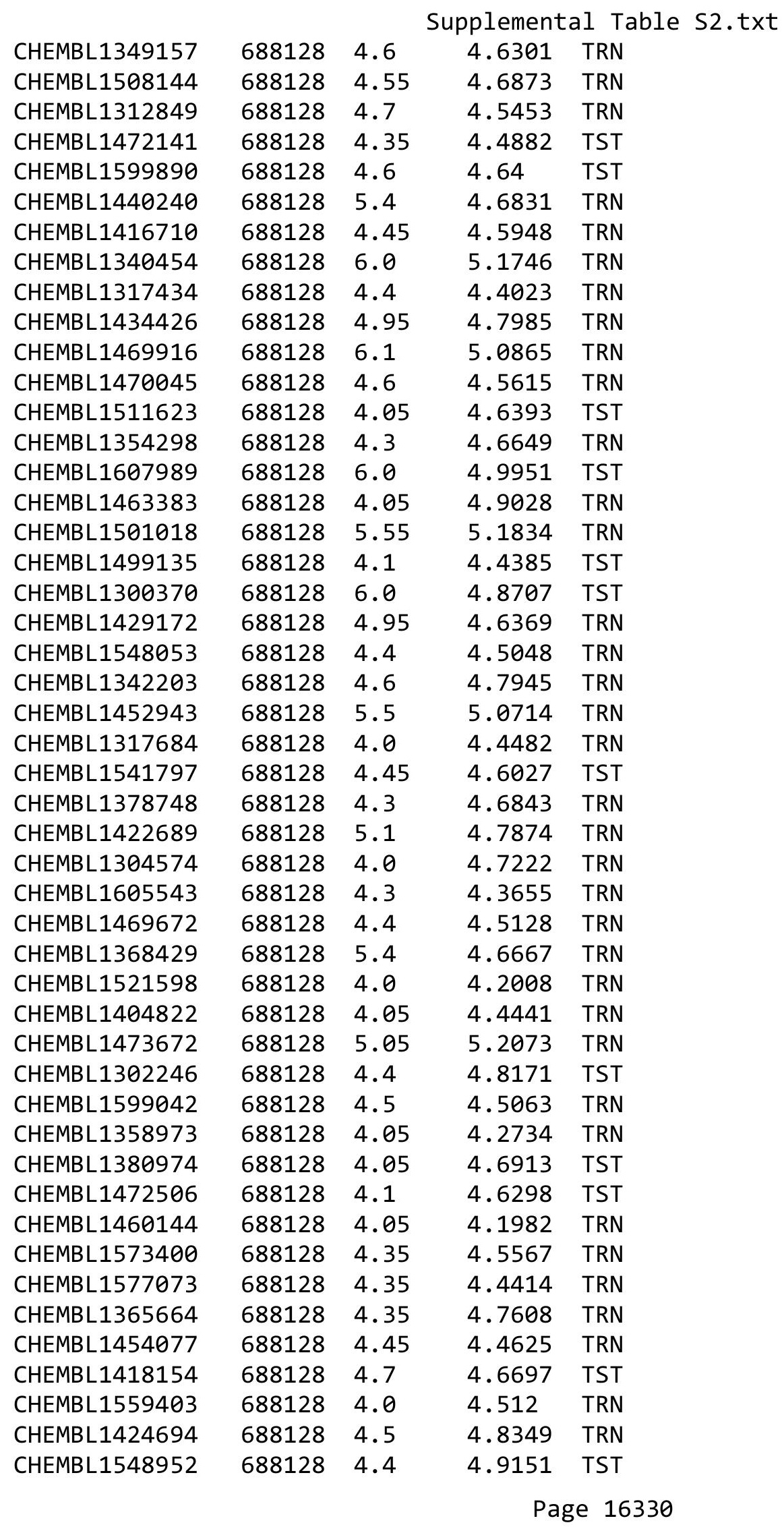




\begin{tabular}{|c|c|c|c|c|}
\hline \multicolumn{5}{|c|}{ Supplemental Tabl } \\
\hline CHEMBL 3196745 & 688128 & 4.05 & 4.4574 & TST \\
\hline CHEMBL1526698 & 688128 & 5.1 & 5.1041 & TRN \\
\hline CHEMBL1307322 & 688128 & 4.1 & 4.7751 & TRN \\
\hline CHEMBL1362499 & 688128 & 4.5 & 4.9012 & TST \\
\hline CHEMBL1382419 & 688128 & 5.1 & 4.5009 & TRN \\
\hline CHEMBL1428035 & 688128 & 4.05 & 4.7246 & TRN \\
\hline CHEMBL1569079 & 688128 & 4.25 & 4.3374 & TST \\
\hline CHEMBL 3198236 & 688128 & 4.25 & 4.6642 & TRN \\
\hline CHEMBL1470125 & 688128 & 5.4 & 4.4317 & TRN \\
\hline CHEMBL1506510 & 688128 & 7.0 & 5.3166 & TRN \\
\hline CHEMBL1415016 & 688128 & 4.75 & 4.3831 & TST \\
\hline CHEMBL1586263 & 688128 & 4.9 & 5.0431 & TRN \\
\hline CHEMBL1547403 & 688128 & 4.4 & 4.6059 & TST \\
\hline CHEMBL 3194412 & 688128 & 4.0 & 4.6952 & TRN \\
\hline CHEMBL1978327 & 688128 & 4.6 & 4.9738 & TRN \\
\hline CHEMBL1348760 & 688128 & 4.05 & 4.4235 & TRN \\
\hline CHEMBL1487695 & 688128 & 4.0 & 4.5047 & TST \\
\hline CHEMBL1427543 & 688128 & 4.35 & 4.8704 & TRN \\
\hline CHEMBL1385158 & 688128 & 5.05 & 4.9625 & TRN \\
\hline CHEMBL1440785 & 688128 & 5.7 & 4.4757 & TRN \\
\hline CHEMBL1433803 & 688128 & 4.05 & 4.5131 & TST \\
\hline CHEMBL 2004847 & 688128 & 4.4 & 4.7179 & TRN \\
\hline CHEMBL1545200 & 688128 & 4.25 & 4.4723 & TRN \\
\hline CHEMBL1477628 & 688128 & 4.35 & 5.2095 & TRN \\
\hline CHEMBL1558738 & 688128 & 4.4 & 4.7611 & TRN \\
\hline CHEMBL1510489 & 688128 & 4.7 & 4.5445 & TRN \\
\hline CHEMBL1368494 & 688128 & 5.0 & 4.395 & TRN \\
\hline CHEMBL1601965 & 688128 & 5.3 & 4.872 & TRN \\
\hline CHEMBL1378188 & 688128 & 4.05 & 4.4791 & TRN \\
\hline CHEMBL 3190334 & 688128 & 4.1 & 4.5415 & TRN \\
\hline CHEMBL3191795 & 688128 & 4.45 & 4.6382 & TRN \\
\hline CHEMBL1382452 & 688128 & 4.8 & 4.7855 & TRN \\
\hline CHEMBL1331475 & 688128 & 4.5 & 4.5735 & TRN \\
\hline CHEMBL1403096 & 688128 & 4.8 & 4.9639 & TRN \\
\hline CHEMBL1319290 & 688128 & 4.35 & 4.7511 & TRN \\
\hline CHEMBL1553549 & 688128 & 4.3 & 4.7357 & TRN \\
\hline CHEMBL1542944 & 688128 & 6.0 & 5.0021 & TRN \\
\hline CHEMBL1315571 & 688128 & 6.05 & 4.5745 & TRN \\
\hline CHEMBL1414940 & 688128 & 4.3 & 4.4906 & TST \\
\hline CHEMBL1374736 & 688128 & 6.0 & 4.5468 & TRN \\
\hline CHEMBL1342577 & 688128 & 4.8 & 4.3786 & TRN \\
\hline CHEMBL1314418 & 688128 & 4.3 & 4.8141 & TRN \\
\hline CHEMBL1456105 & 688128 & 4.95 & 4.4995 & TRN \\
\hline CHEMBL1498188 & 688128 & 4.25 & 4.4409 & TRN \\
\hline CHEMBL1487461 & 688128 & 4.3 & 4.5549 & TRN \\
\hline CHEMBL1502165 & 688128 & 4.75 & 4.435 & TRN \\
\hline CHEMBL1562705 & 688128 & 4.4 & 4.4458 & TRN \\
\hline CHEMBL1468319 & 688128 & 4.05 & 4.1771 & TST \\
\hline
\end{tabular}




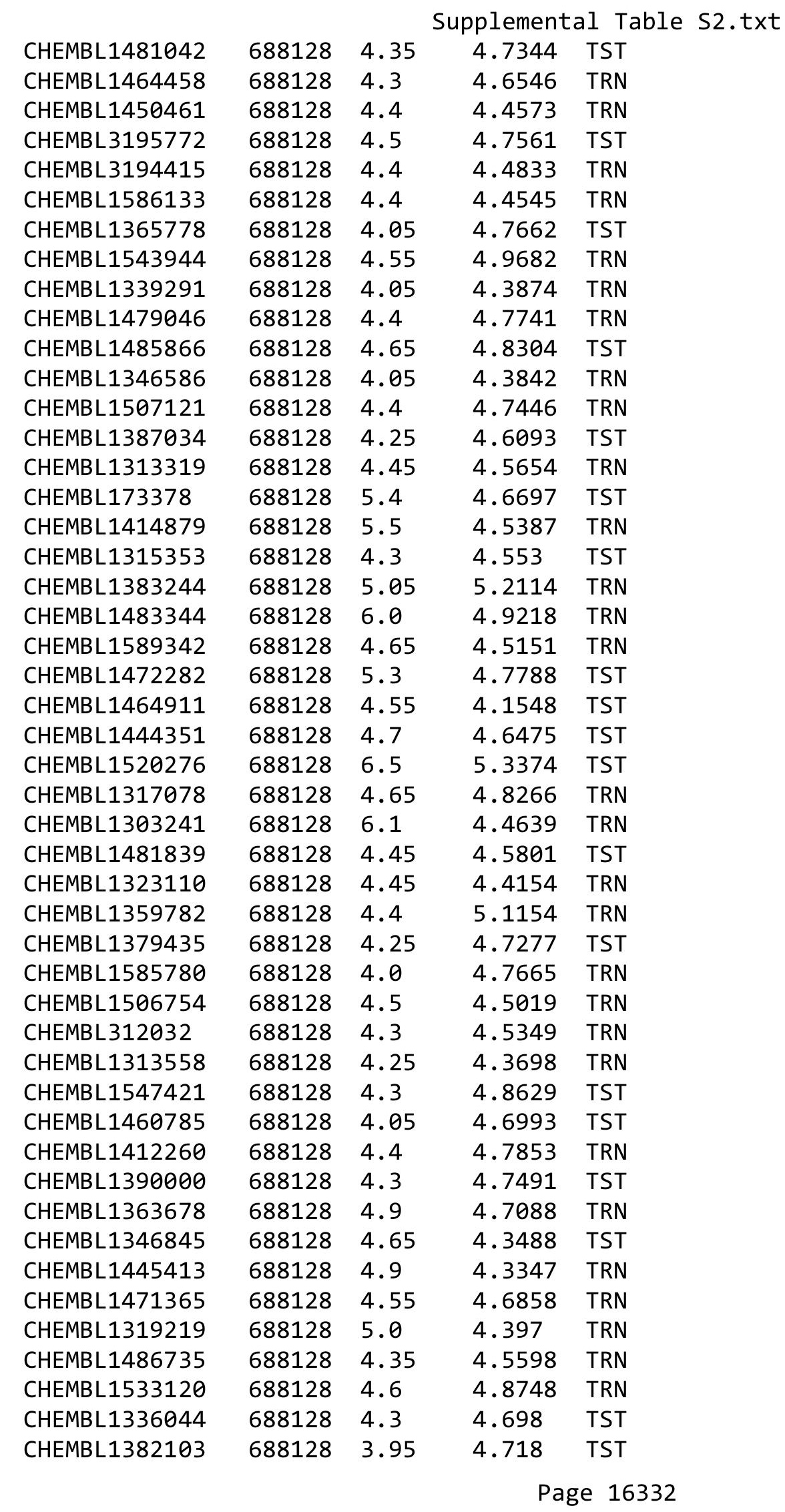




\begin{tabular}{|c|c|c|c|c|}
\hline \multicolumn{5}{|c|}{ Supplemental Table S2.txt } \\
\hline CHEMBL1524613 & 688128 & 4.4 & 4.6861 & TST \\
\hline CHEMBL1400404 & 688128 & 4.4 & 4.69 & TRN \\
\hline CHEMBL1372096 & 688128 & 4.4 & 4.7853 & TRN \\
\hline CHEMBL1382102 & 688128 & 4.5 & 4.532 & TRN \\
\hline CHEMBL1566986 & 688128 & 4.55 & 4.395 & TRN \\
\hline CHEMBL1609023 & 688128 & 4.85 & 4.3938 & TRN \\
\hline CHEMBL1317401 & 688128 & 4.4 & 4.5782 & TST \\
\hline CHEMBL1482441 & 688128 & 4.35 & 4.8772 & TST \\
\hline CHEMBL1558390 & 688128 & 5.4 & 4.4365 & TRN \\
\hline CHEMBL1428006 & 688128 & 5.75 & 4.8732 & TRN \\
\hline CHEMBL1492769 & 688128 & 4.0 & 4.5144 & TRN \\
\hline CHEMBL1441127 & 688128 & 5.35 & 4.6598 & TRN \\
\hline CHEMBL1468884 & 688128 & 4.4 & 4.5081 & TST \\
\hline CHEMBL1562953 & 688128 & 4.4 & 4.5348 & TST \\
\hline CHEMBL1335392 & 688128 & 4.35 & 4.7957 & TRN \\
\hline CHEMBL1574177 & 688128 & 5.05 & 4.5805 & TRN \\
\hline CHEMBL1599535 & 688128 & 4.35 & 4.9369 & TRN \\
\hline CHEMBL1605432 & 688128 & 5.9 & 5.1111 & TRN \\
\hline CHEMBL1496169 & 688128 & 5.4 & 4.8875 & TRN \\
\hline CHEMBL1542814 & 688128 & 4.8 & 4.7869 & TST \\
\hline CHEMBL1407487 & 688128 & 4.35 & 4.5693 & TRN \\
\hline CHEMBL1303773 & 688128 & 4.0 & 4.5476 & TRN \\
\hline CHEMBL1569615 & 688128 & 4.75 & 4.625 & TRN \\
\hline CHEMBL1329036 & 688128 & 4.35 & 4.5203 & TRN \\
\hline CHEMBL1445606 & 688128 & 5.1 & 4.5425 & TST \\
\hline CHEMBL1379815 & 688128 & 4.2 & 4.4434 & TRN \\
\hline CHEMBL1409186 & 688128 & 4.35 & 4.7956 & TRN \\
\hline CHEMBL1559828 & 688128 & 4.3 & 4.3093 & TRN \\
\hline CHEMBL1597948 & 688128 & 5.05 & 4.263 & TRN \\
\hline CHEMBL1463707 & 688128 & 5.35 & 4.7692 & TRN \\
\hline CHEMBL1432116 & 688128 & 4.55 & 4.8035 & TST \\
\hline CHEMBL1473964 & 688128 & 4.75 & 4.5884 & TRN \\
\hline CHEMBL1404331 & 688128 & 4.05 & 4.4813 & TST \\
\hline CHEMBL1336604 & 688128 & 4.35 & 4.4569 & TRN \\
\hline CHEMBL1340905 & 688128 & 5.15 & 4.7321 & TRN \\
\hline CHEMBL1362199 & 688128 & 4.05 & 4.9205 & TST \\
\hline CHEMBL1421228 & 688128 & 6.0 & 4.8525 & TRN \\
\hline CHEMBL1339008 & 688128 & 4.5 & 4.3283 & TRN \\
\hline CHEMBL1496840 & 688128 & 5.05 & 5.052 & TST \\
\hline CHEMBL1397716 & 688128 & 4.6 & 4.452 & TRN \\
\hline CHEMBL3199193 & 688128 & 4.7 & 4.6194 & TRN \\
\hline CHEMBL1434461 & 688128 & 4.35 & 4.7432 & TRN \\
\hline CHEMBL1600656 & 688128 & 4.0 & 4.3371 & TRN \\
\hline CHEMBL1414883 & 688128 & 4.4 & 4.5048 & TRN \\
\hline CHEMBL1471860 & 688128 & 4.4 & 4.6967 & TRN \\
\hline CHEMBL1478929 & 688128 & 4.4 & 4.5271 & TRN \\
\hline CHEMBL1345323 & 688128 & 4.55 & 4.6008 & TRN \\
\hline CHEMBL1471329 & 688128 & 4.35 & 4.3504 & TRN \\
\hline
\end{tabular}




\begin{tabular}{|c|c|c|c|c|c|}
\hline \multicolumn{6}{|c|}{ Supplemental Table s2.txt } \\
\hline CHEMBL1384490 & 688128 & 4.0 & 5.0494 & TRN & \\
\hline CHEMBL3197537 & 688128 & 4.45 & 4.7252 & TRN & \\
\hline CHEMBL1508987 & 688128 & 5.5 & 4.6 & TRN & \\
\hline CHEMBL1325188 & 688128 & 5.55 & 4.8645 & TRN & \\
\hline CHEMBL3213484 & 688128 & 4.75 & 4.8087 & TRN & \\
\hline CHEMBL1581318 & 688128 & 4.25 & 4.4166 & TRN & \\
\hline CHEMBL1520425 & 688128 & 6.5501 & 4.6146 & TRN & \\
\hline CHEMBL1313040 & 688128 & 4.55 & 4.5641 & TRN & \\
\hline CHEMBL1449165 & 688128 & 4.4 & 4.6981 & TRN & \\
\hline CHEMBL1349646 & 688128 & 4.65 & 5.0384 & TRN & \\
\hline CHEMBL1530810 & 688128 & 4.4 & 5.2049 & TRN & \\
\hline CHEMBL1412401 & 688128 & 4.0 & 4.9014 & TRN & \\
\hline CHEMBL1386742 & 688128 & 4.05 & 4.5834 & TST & \\
\hline CHEMBL1528409 & 688128 & 4.05 & 4.6477 & TST & \\
\hline CHEMBL1346640 & 688128 & 4.05 & 4.8672 & TRN & \\
\hline CHEMBL1474104 & 688128 & 4.55 & 4.808 & TRN & \\
\hline CHEMBL1736377 & 688128 & 4.35 & 4.7209 & TRN & \\
\hline CHEMBL1366236 & 688128 & 4.3 & 4.7537 & TRN & \\
\hline CHEMBL1311831 & 688128 & 6.0 & 4.739 & TRN & \\
\hline CHEMBL1469703 & 688128 & 4.1 & 4.3076 & TRN & \\
\hline CHEMBL1420617 & 688128 & 4.05 & 4.4047 & TST & \\
\hline CHEMBL1455292 & 688128 & 4.7 & 4.7005 & TST & \\
\hline CHEMBL1411307 & 688128 & 4.05 & 4.3267 & TST & \\
\hline CHEMBL1480916 & 688128 & 4.5 & 4.4030 & 00000000005 & TRN \\
\hline CHEMBL1438524 & 688128 & 5.2 & 4.4778 & TRN & \\
\hline CHEMBL1556152 & 688128 & 6.9 & 4.7259 & TST & \\
\hline CHEMBL1542572 & 688128 & 4.45 & 5.0277 & TRN & \\
\hline CHEMBL1406739 & 688128 & 4.5 & 4.5861 & TRN & \\
\hline CHEMBL581677 & 688128 & 4.7 & 5.0366 & TRN & \\
\hline CHEMBL1525537 & 688128 & 4.35 & 4.8527 & TRN & \\
\hline CHEMBL1458524 & 688128 & 4.45 & 4.9146 & TRN & \\
\hline CHEMBL 3210028 & 688128 & 4.6 & 4.6589 & TRN & \\
\hline CHEMBL1403747 & 688128 & 4.4 & 4.4695 & TRN & \\
\hline CHEMBL1313306 & 688128 & 4.45 & 4.3492 & TRN & \\
\hline CHEMBL1345125 & 688128 & 4.3 & 4.8282 & TST & \\
\hline CHEMBL1404112 & 688128 & 4.45 & 4.8836 & TRN & \\
\hline CHEMBL1456996 & 688128 & 6.0 & 5.1121 & TRN & \\
\hline CHEMBL1387313 & 688128 & 4.9 & 4.5294 & TRN & \\
\hline CHEMBL1500832 & 688128 & 4.65 & 4.7047 & TRN & \\
\hline CHEMBL1596577 & 688128 & 4.45 & 4.4976 & TRN & \\
\hline CHEMBL1514787 & 688128 & 5.5 & 4.5241 & TST & \\
\hline CHEMBL3189834 & 688128 & 4.05 & 4.388 & TRN & \\
\hline CHEMBL1521229 & 688128 & 4.0 & 4.5091 & TRN & \\
\hline CHEMBL1339022 & 688128 & 4.05 & 4.5247 & TRN & \\
\hline CHEMBL1585355 & 688128 & 5.0 & 4.6429 & TST & \\
\hline CHEMBL1529812 & 688128 & 4.3 & 4.6164 & TST & \\
\hline CHEMBL1322954 & 688128 & 4.5 & 4.5664 & TRN & \\
\hline CHEMBL1459452 & 688128 & 6.05 & 4.4228 & TST & \\
\hline
\end{tabular}




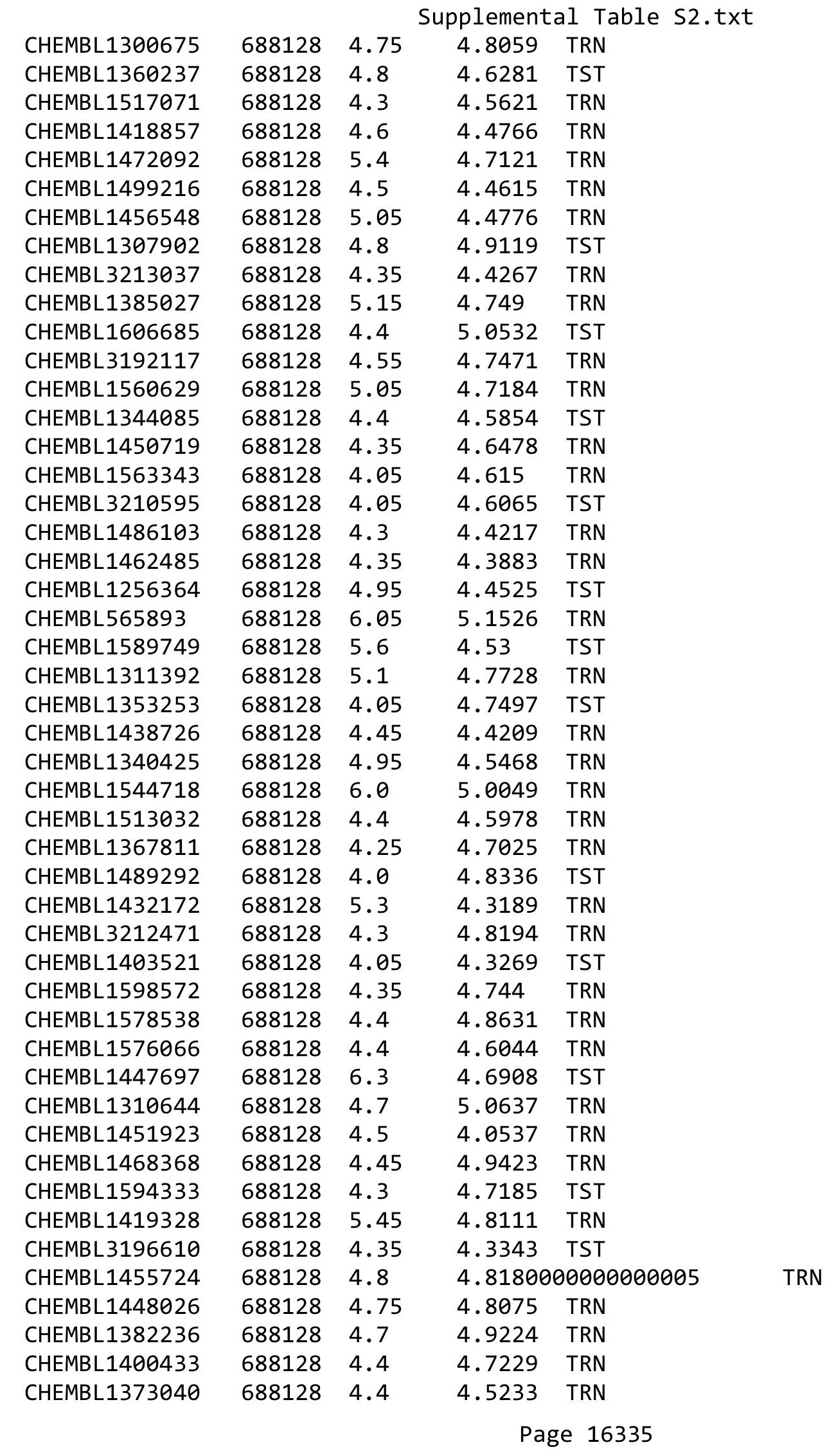




\begin{tabular}{|c|c|c|c|c|}
\hline \multicolumn{5}{|c|}{ Supplemental Table } \\
\hline CHEMBL1600305 & 688128 & 4.05 & 4.3558 & TRN \\
\hline CHEMBL1492032 & 688128 & 4.4 & 4.713 & TRN \\
\hline CHEMBL1399317 & 688128 & 4.05 & 4.5134 & TRN \\
\hline CHEMBL1403326 & 688128 & 4.0 & 4.4411 & TRN \\
\hline CHEMBL 1357682 & 688128 & 4.4 & 4.5594 & TRN \\
\hline CHEMBL1308799 & 688128 & 5.95 & 4.7885 & TST \\
\hline CHEMBL1529809 & 688128 & 4.3 & 4.871 & TRN \\
\hline CHEMBL1382429 & 688128 & 5.45 & 5.0306 & TRN \\
\hline CHEMBL1339946 & 688128 & 6.15 & 5.4016 & TRN \\
\hline CHEMBL1323218 & 688128 & 4.8 & 4.6759 & TRN \\
\hline CHEMBL1337773 & 688128 & 4.3 & 4.7559 & TRN \\
\hline CHEMBL1588951 & 688128 & 5.15 & 5.1305 & TRN \\
\hline CHEMBL1303600 & 688128 & 4.4 & 4.6196 & TRN \\
\hline CHEMBL1358185 & 688128 & 4.55 & 4.6162 & TST \\
\hline CHEMBL1402028 & 688128 & 4.35 & 4.4869 & TST \\
\hline CHEMBL1400988 & 688128 & 4.05 & 4.6644 & TRN \\
\hline CHEMBL1330672 & 688128 & 4.05 & 4.4519 & TST \\
\hline CHEMBL1545039 & 688128 & 6.1 & 4.805 & TST \\
\hline CHEMBL1546155 & 688128 & 4.05 & 4.921 & TST \\
\hline CHEMBL1320574 & 688128 & 4.35 & 4.5272 & TRN \\
\hline CHEMBL1491676 & 688128 & 4.95 & 4.5629 & TRN \\
\hline CHEMBL1454062 & 688128 & 4.65 & 4.5955 & TRN \\
\hline CHEMBL1415764 & 688128 & 4.25 & 4.5239 & TRN \\
\hline CHEMBL1439123 & 688128 & 5.2 & 4.7536 & TRN \\
\hline CHEMBL1601451 & 688128 & 4.0 & 4.3985 & TST \\
\hline CHEMBL1399806 & 688128 & 4.5 & 4.5477 & TRN \\
\hline CHEMBL1546748 & 688128 & 4.1 & 4.9732 & TST \\
\hline CHEMBL1514863 & 688128 & 4.3 & 4.7035 & TST \\
\hline CHEMBL1490970 & 688128 & 5.05 & 4.7526 & TST \\
\hline CHEMBL1409394 & 688128 & 4.8 & 4.8123 & TRN \\
\hline CHEMBL1348151 & 688128 & 5.7 & 4.5865 & TST \\
\hline CHEMBL1545882 & 688128 & 6.35 & 5.2584 & TRN \\
\hline CHEMBL1995910 & 688128 & 4.35 & 4.8899 & TRN \\
\hline CHEMBL1507586 & 688128 & 4.4 & 4.5993 & TRN \\
\hline CHEMBL2005973 & 688128 & 4.5 & 4.8943 & TRN \\
\hline CHEMBL1405652 & 688128 & 4.75 & 4.6399 & TRN \\
\hline CHEMBL 1495518 & 688128 & 4.55 & 5.0182 & TST \\
\hline CHEMBL1478748 & 688128 & 4.4 & 4.437 & TST \\
\hline CHEMBL1316279 & 688128 & 4.4 & 4.3517 & TRN \\
\hline CHEMBL1571350 & 688128 & 4.3 & 4.6692 & TRN \\
\hline CHEMBL1347893 & 688128 & 4.35 & 4.3182 & TRN \\
\hline CHEMBL1605376 & 688128 & 4.05 & 4.635 & TST \\
\hline CHEMBL1351276 & 688128 & 4.15 & 4.4593 & TRN \\
\hline CHEMBL1554452 & 688128 & 4.3 & 4.7711 & TST \\
\hline CHEMBL1443993 & 688128 & 4.35 & 4.3934 & TRN \\
\hline CHEMBL1330963 & 688128 & 5.45 & 4.9077 & TRN \\
\hline CHEMBL1318452 & 688128 & 4.55 & 4.5672 & TRN \\
\hline CHEMBL1545302 & 688128 & 4.75 & 4.3629 & TST \\
\hline
\end{tabular}




\begin{tabular}{|c|c|c|c|c|}
\hline \multicolumn{5}{|c|}{ Supplemental Table S2.txt } \\
\hline CHEMBL1563266 & 688128 & 4.6 & 4.3319 & TRN \\
\hline CHEMBL1371386 & 688128 & 4.35 & 4.1799 & TRN \\
\hline CHEMBL1508253 & 688128 & 4.3 & 4.5533 & TRN \\
\hline CHEMBL1384221 & 688128 & 4.4 & 4.4302 & TST \\
\hline CHEMBL1617452 & 688128 & 5.5 & 5.0707 & TRN \\
\hline CHEMBL1608362 & 688128 & 5.0 & 4.5817 & TRN \\
\hline CHEMBL1315969 & 688128 & 4.45 & 4.4642 & TRN \\
\hline CHEMBL1557358 & 688128 & 4.3 & 4.654 & TRN \\
\hline CHEMBL1469682 & 688128 & 4.4 & 4.5846 & TRN \\
\hline CHEMBL1452003 & 688128 & 4.8 & 4.6246 & TRN \\
\hline CHEMBL1455561 & 688128 & 4.3 & 4.4612 & TRN \\
\hline CHEMBL1425797 & 688128 & 4.35 & 4.3878 & TRN \\
\hline CHEMBL1555482 & 688128 & 4.4 & 4.6681 & TRN \\
\hline CHEMBL1598138 & 688128 & 4.0 & 4.6 & TRN \\
\hline CHEMBL1386941 & 688128 & 4.35 & 5.0238 & TRN \\
\hline CHEMBL1454918 & 688128 & 5.6 & 4.574 & TRN \\
\hline CHEMBL1344535 & 688128 & 4.65 & 4.6587 & TRN \\
\hline CHEMBL503470 & 688128 & 4.4 & 4.6988 & TRN \\
\hline CHEMBL1347122 & 688128 & 4.4 & 4.7629 & TRN \\
\hline CHEMBL1972370 & 688128 & 4.0 & 4.7167 & TRN \\
\hline CHEMBL1306571 & 688128 & 4.4 & 4.427 & TST \\
\hline CHEMBL1500636 & 688128 & 4.35 & 4.5745 & TST \\
\hline CHEMBL1487660 & 688128 & 5.8 & 4.9958 & TST \\
\hline CHEMBL1300689 & 688128 & 4.25 & 4.5344 & TRN \\
\hline CHEMBL1346708 & 688128 & 4.85 & 4.5432 & TRN \\
\hline CHEMBL1426076 & 688128 & 6.0 & 4.6946 & TST \\
\hline CHEMBL1359367 & 688128 & 4.45 & 4.7398 & TRN \\
\hline CHEMBL1972808 & 688128 & 4.05 & 4.7111 & TST \\
\hline CHEMBL1355304 & 688128 & 5.1 & 4.0959 & TST \\
\hline CHEMBL1350317 & 688128 & 4.35 & 4.6744 & TRN \\
\hline CHEMBL1398229 & 688128 & 4.35 & 4.7488 & TRN \\
\hline CHEMBL1408535 & 688128 & 4.9 & 5.0377 & TRN \\
\hline CHEMBL1322871 & 688128 & 4.4 & 4.8004 & TRN \\
\hline CHEMBL1329607 & 688128 & 4.3 & 4.4013 & TRN \\
\hline CHEMBL1589789 & 688128 & 4.4 & 4.3097 & TRN \\
\hline CHEMBL1576873 & 688128 & 4.25 & 4.6794 & TST \\
\hline CHEMBL1575188 & 688128 & 4.05 & 4.5903 & TST \\
\hline CHEMBL1256923 & 688128 & 4.3 & 4.5292 & TST \\
\hline CHEMBL3196770 & 688128 & 6.25 & 5.0466 & TRN \\
\hline CHEMBL1439357 & 688128 & 4.3 & 4.3513 & TRN \\
\hline CHEMBL1554008 & 688128 & 4.55 & 4.4926 & TRN \\
\hline CHEMBL1603997 & 688128 & 4.5 & 4.5362 & TST \\
\hline CHEMBL1565521 & 688128 & 4.55 & 4.8384 & TRN \\
\hline CHEMBL1312569 & 688128 & 4.25 & 4.6529 & TRN \\
\hline CHEMBL1429070 & 688128 & 5.0 & 4.9162 & TST \\
\hline CHEMBL1595054 & 688128 & 4.3 & 4.3937 & TST \\
\hline CHEMBL1606583 & 688128 & 4.35 & 4.9553 & TRN \\
\hline CHEMBL1410873 & 688128 & 5.55 & 4.7923 & TRN \\
\hline
\end{tabular}




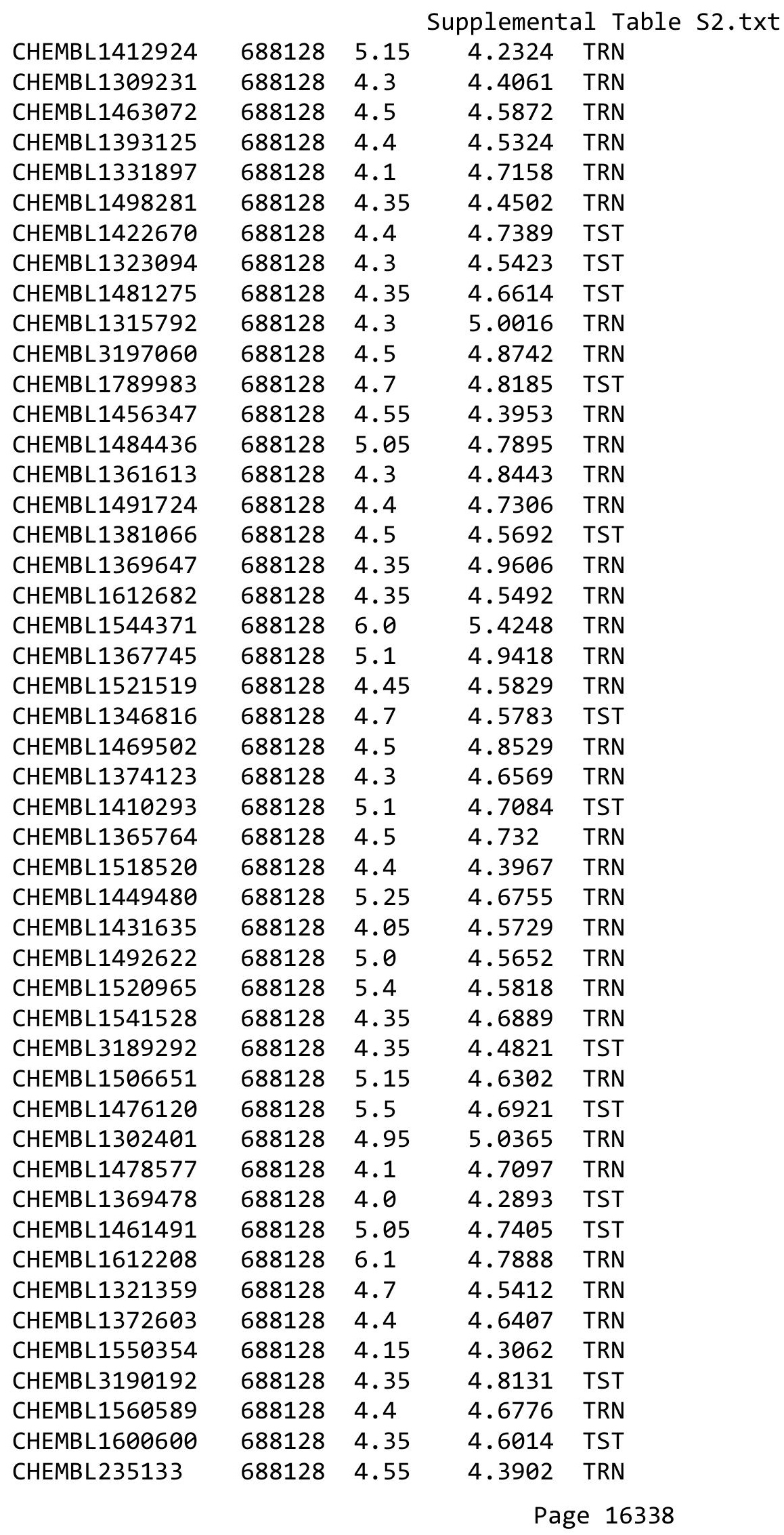




\begin{tabular}{|c|c|c|c|c|c|}
\hline & & \\
\hline CHEMBL3191399 & 688128 & 4.3 & 4.5787 & TRN & \\
\hline CHEMBL1524993 & 688128 & 5.1 & 4.4316 & TRN & \\
\hline CHEMBL1473239 & 688128 & 4.5 & 4.6158 & TRN & \\
\hline CHEMBL1400356 & 688128 & 5.4 & 4.5738 & TST & \\
\hline CHEMBL3210440 & 688128 & 4.4 & 4.5319 & TRN & \\
\hline CHEMBL1347189 & 688128 & 4.45 & 4.5592 & TST & \\
\hline CHEMBL1453134 & 688128 & 4.45 & 4.4085 & TRN & \\
\hline CHEMBL1392552 & 688128 & 5.55 & 4.6381 & TRN & \\
\hline CHEMBL1581733 & 688128 & 4.45 & 4.6247 & TST & \\
\hline CHEMBL1555995 & 688128 & 4.55 & 4.5742 & TRN & \\
\hline CHEMBL1513804 & 688128 & 4.35 & 4.2549 & TRN & \\
\hline CHEMBL1346583 & 688128 & 4.05 & 4.4592 & TST & \\
\hline CHEMBL1502645 & 688128 & 4.65 & 4.4835 & TST & \\
\hline CHEMBL1399551 & 688128 & 5.0 & 4.7164 & TRN & \\
\hline CHEMBL1604255 & 688128 & 4.4 & 4.6415 & TRN & \\
\hline CHEMBL1421203 & 688128 & 4.45 & 4.8186 & TRN & \\
\hline CHEMBL1464832 & 688128 & 5.75 & 4.7847 & TRN & \\
\hline CHEMBL1313507 & 688128 & 4.15 & 4.7085 & TST & \\
\hline CHEMBL1482205 & 688128 & 4.4 & 4.8006 & TST & \\
\hline CHEMBL1520351 & 688128 & 4.35 & 4.6393 & TRN & \\
\hline CHEMBL1319207 & 688128 & 4.35 & 4.4493 & TRN & \\
\hline CHEMBL1331401 & 688128 & 5.0 & 4.7148 & TRN & \\
\hline CHEMBL1496544 & 688128 & 4.6 & 4.2852 & TRN & \\
\hline CHEMBL1578687 & 688128 & 4.3 & 4.4666 & TRN & \\
\hline CHEMBL1534837 & 688128 & 4.35 & 4.4594 & TRN & \\
\hline CHEMBL3195310 & 688128 & 4.85 & 4.4457 & TRN & \\
\hline CHEMBL1304092 & 688128 & 4.95 & 4.8619 & TRN & \\
\hline CHEMBL598204 & 688128 & 4.45 & 4.1832 & TST & \\
\hline CHEMBL1300483 & 688128 & 4.45 & 4.543 & TRN & \\
\hline CHEMBL1526835 & 688128 & 4.05 & 4.6797 & TRN & \\
\hline CHEMBL1319165 & 688128 & 4.85 & 4.5272 & TST & \\
\hline CHEMBL1466124 & 688128 & 6.5501 & 5.0654 & TRN & \\
\hline CHEMBL1972638 & 688128 & 4.3 & 4.4739 & TRN & \\
\hline CHEMBL1322904 & 688128 & 5.15 & 4.6178 & TST & \\
\hline CHEMBL1506182 & 688128 & 4.4 & 4.4368 & TRN & \\
\hline CHEMBL1301723 & 688128 & 5.55 & 5.081 & TRN & \\
\hline CHEMBL1516772 & 688128 & 4.35 & 4.5385 & TRN & \\
\hline CHEMBL1455889 & 688128 & 4.3 & 4.3272 & TRN & \\
\hline CHEMBL1309463 & 688128 & 4.65 & 4.7841 & TRN & \\
\hline CHEMBL1536859 & 688128 & 4.0 & 4.252 & TRN & \\
\hline CHEMBL1438992 & 688128 & 4.05 & 4.3977 & TST & \\
\hline CHEMBL1300757 & 688128 & 4.05 & $4.6960 €$ & 0000000001 & TRN \\
\hline CHEMBL259018 & 688128 & 6.05 & 4.9266 & TST & \\
\hline CHEMBL1389585 & 688128 & 4.05 & 4.5106 & TRN & \\
\hline CHEMBL1384959 & 688128 & 5.0 & 4.5763 & TRN & \\
\hline CHEMBL591373 & 688128 & 4.35 & 4.8556 & TRN & \\
\hline CHEMBL1382734 & 688128 & 4.3 & 4.7509 & TRN & \\
\hline CHEMBL1577239 & 688128 & 4.05 & 4.5738 & TST & \\
\hline & & & & בנכ & \\
\hline
\end{tabular}




\begin{tabular}{|c|c|c|c|c|}
\hline \multicolumn{5}{|c|}{ Supplemental Table S2.txt } \\
\hline CHEMBL1538349 & 688128 & 4.4 & 4.7098 & TRN \\
\hline CHEMBL3192914 & 688128 & 4.45 & 4.6254 & TRN \\
\hline CHEMBL1977007 & 688128 & 5.65 & 4.6677 & TRN \\
\hline CHEMBL1486751 & 688128 & 4.45 & 4.3991 & TRN \\
\hline CHEMBL3193572 & 688128 & 5.55 & 4.6841 & TRN \\
\hline CHEMBL1500515 & 688128 & 4.3 & 4.6156 & TRN \\
\hline CHEMBL1314787 & 688128 & 4.8 & 4.752 & TRN \\
\hline CHEMBL1577797 & 688128 & 4.4 & 4.6072 & TST \\
\hline CHEMBL1326833 & 688128 & 4.35 & 4.8048 & TRN \\
\hline CHEMBL1364356 & 688128 & 4.35 & 4.4947 & TRN \\
\hline CHEMBL1503840 & 688128 & 5.5 & 5.2453 & TRN \\
\hline CHEMBL1363971 & 688128 & 4.25 & 4.5609 & TRN \\
\hline CHEMBL1381114 & 688128 & 4.4 & 4.5324 & TRN \\
\hline CHEMBL1319638 & 688128 & 4.55 & 4.4846 & TST \\
\hline CHEMBL1366154 & 688128 & 5.45 & 4.3874 & TST \\
\hline CHEMBL1596310 & 688128 & 4.05 & 4.5299 & TST \\
\hline CHEMBL1304161 & 688128 & 4.0 & 4.6498 & TST \\
\hline CHEMBL1493891 & 688128 & 5.5 & 4.7932 & TRN \\
\hline CHEMBL1972688 & 688128 & 4.05 & 4.6982 & TRN \\
\hline CHEMBL1560220 & 688128 & 4.0 & 4.2902 & TRN \\
\hline CHEMBL1532534 & 688128 & 4.45 & 4.5648 & TST \\
\hline CHEMBL3209064 & 688128 & 4.45 & 4.7331 & TRN \\
\hline CHEMBL1508805 & 688128 & 4.65 & 4.6765 & TRN \\
\hline CHEMBL1311591 & 688128 & 4.05 & 4.5854 & TRN \\
\hline CHEMBL1503231 & 688128 & 4.4 & 4.776 & TRN \\
\hline CHEMBL 244889 & 688128 & 4.8 & 4.8948 & TRN \\
\hline CHEMBL312815 & 688128 & 4.25 & 4.5953 & TRN \\
\hline CHEMBL1388953 & 688128 & 4.4 & 4.5739 & TRN \\
\hline CHEMBL1583083 & 688128 & 4.05 & 4.7593 & TRN \\
\hline CHEMBL1355094 & 688128 & 4.35 & 4.5695 & TRN \\
\hline CHEMBL1606596 & 688128 & 4.35 & 4.9066 & TRN \\
\hline CHEMBL1486500 & 688128 & 4.55 & 4.8172 & TRN \\
\hline CHEMBL1576702 & 688128 & 4.3 & 5.2097 & TST \\
\hline CHEMBL1375256 & 688128 & 4.25 & 4.6399 & TRN \\
\hline CHEMBL1497616 & 688128 & 4.3 & 4.6299 & TRN \\
\hline CHEMBL1361906 & 688128 & 4.45 & 4.1891 & TRN \\
\hline CHEMBL 2374038 & 688128 & 5.05 & 5.0379 & TRN \\
\hline CHEMBL1339461 & 688128 & 4.25 & 4.6956 & TST \\
\hline CHEMBL1490756 & 688128 & 4.55 & 4.6235 & TRN \\
\hline CHEMBL1499516 & 688128 & 4.35 & 4.4654 & TRN \\
\hline CHEMBL1608266 & 688128 & 4.85 & 4.6699 & TRN \\
\hline CHEMBL1482648 & 688128 & 4.9 & 4.8613 & TRN \\
\hline CHEMBL1502426 & 688128 & 4.4 & 4.4751 & TST \\
\hline CHEMBL1360804 & 688128 & 4.05 & 4.4266 & TRN \\
\hline CHEMBL1322268 & 688128 & 4.4 & 4.3649 & TRN \\
\hline CHEMBL1568038 & 688128 & 4.35 & 4.7119 & TRN \\
\hline CHEMBL1392296 & 688128 & 4.3 & 4.6384 & TRN \\
\hline CHEMBL1468515 & 688128 & 4.9 & 4.5518 & TST \\
\hline
\end{tabular}




\begin{tabular}{|c|c|c|c|c|}
\hline \multicolumn{5}{|c|}{ Supplemental Table S2.txt } \\
\hline CHEMBL1325580 & 688128 & 4.4 & 4.4874 & TRN \\
\hline CHEMBL1563864 & 688128 & 4.85 & 4.7202 & TST \\
\hline CHEMBL1311795 & 688128 & 4.1 & 4.7255 & TRN \\
\hline CHEMBL1413900 & 688128 & 4.6 & 4.7392 & TST \\
\hline CHEMBL1452226 & 688128 & 4.25 & 4.6045 & TST \\
\hline CHEMBL1531472 & 688128 & 5.05 & 4.8129 & TRN \\
\hline CHEMBL1303281 & 688128 & 6.5501 & 5.2854 & TRN \\
\hline CHEMBL1408818 & 688128 & 4.25 & 5.0141 & TRN \\
\hline CHEMBL449081 & 688128 & 5.65 & 5.0277 & TST \\
\hline CHEMBL1487230 & 688128 & 5.0 & 4.3947 & TRN \\
\hline CHEMBL1373994 & 688128 & 4.35 & 4.2042 & TRN \\
\hline CHEMBL1347694 & 688128 & 4.95 & 4.4695 & TRN \\
\hline CHEMBL1360438 & 688128 & 4.45 & 4.5791 & TRN \\
\hline CHEMBL1353780 & 688128 & 4.5 & 4.3781 & TRN \\
\hline CHEMBL1533697 & 688128 & 4.3 & 4.5846 & TRN \\
\hline CHEMBL3191142 & 688128 & 4.55 & 4.4947 & TRN \\
\hline CHEMBL1966328 & 688128 & 4.6 & 4.5443 & TRN \\
\hline CHEMBL1438567 & 688128 & 4.95 & 4.7999 & TRN \\
\hline CHEMBL1532900 & 688128 & 4.0 & 4.438 & TRN \\
\hline CHEMBL1517003 & 688128 & 6.0 & 4.9163 & TRN \\
\hline CHEMBL1974269 & 688128 & 4.3 & 4.5887 & TRN \\
\hline CHEMBL1345393 & 688128 & 4.4 & 4.7872 & TRN \\
\hline CHEMBL1388140 & 688128 & 6.4 & 5.2914 & TRN \\
\hline CHEMBL1310023 & 688128 & 4.3 & 4.4382 & TRN \\
\hline CHEMBL1572967 & 688128 & 5.15 & 5.3666 & TRN \\
\hline CHEMBL1475508 & 688128 & 4.4 & 4.8932 & TRN \\
\hline CHEMBL1459312 & 688128 & 5.5 & 5.1323 & TRN \\
\hline CHEMBL1391076 & 688128 & 4.3 & 4.4849 & TST \\
\hline CHEMBL1519976 & 688128 & 4.45 & 4.5352 & TRN \\
\hline CHEMBL1409795 & 688128 & 4.05 & 4.715 & TRN \\
\hline CHEMBL1445583 & 688128 & 5.6 & 5.1623 & TRN \\
\hline CHEMBL1301081 & 688128 & 4.35 & 4.522 & TRN \\
\hline CHEMBL1518799 & 688128 & 6.15 & 5.1037 & TRN \\
\hline CHEMBL3208579 & 688128 & 5.85 & 4.8887 & TRN \\
\hline CHEMBL1519284 & 688128 & 6.0 & 5.0335 & TRN \\
\hline CHEMBL1539802 & 688128 & 4.3 & 4.2478 & TRN \\
\hline CHEMBL1303333 & 688128 & 4.5 & 4.9411 & TRN \\
\hline CHEMBL1595511 & 688128 & 4.3 & 4.9482 & TRN \\
\hline CHEMBL1422568 & 688128 & 4.25 & 4.672 & TRN \\
\hline CHEMBL1423847 & 688128 & 4.35 & 4.5762 & TRN \\
\hline CHEMBL1326979 & 688128 & 4.3 & 4.513 & TST \\
\hline CHEMBL1305489 & 688128 & 4.05 & 5.0236 & TRN \\
\hline CHEMBL1478022 & 688128 & 4.25 & 4.6602 & TRN \\
\hline CHEMBL1477097 & 688128 & 4.35 & 4.2807 & TRN \\
\hline CHEMBL1310007 & 688128 & 4.35 & 4.4411 & TRN \\
\hline CHEMBL1484606 & 688128 & 4.05 & 4.1824 & TST \\
\hline CHEMBL1352475 & 688128 & 4.3 & 4.6677 & TRN \\
\hline CHEMBL1399910 & 688128 & 4.1 & 4.6215 & TRN \\
\hline
\end{tabular}




\begin{tabular}{|c|c|c|c|c|c|}
\hline \multirow[b]{2}{*}{ CHEMBL1421246 } & & \multicolumn{4}{|c|}{ Supplemental Table S2.txt } \\
\hline & 688128 & 4.75 & 4.6162 & TRN & \\
\hline CHEMBL1475273 & 688128 & 4.45 & 4.3278 & TRN & \\
\hline CHEMBL1423107 & 688128 & 4.4 & 4.49100 & 00000000005 & TRN \\
\hline CHEMBL1535421 & 688128 & 4.55 & 4.6395 & TRN & \\
\hline CHEMBL1351847 & 688128 & 4.5 & 4.6902 & TRN & \\
\hline CHEMBL1485547 & 688128 & 4.45 & 4.6391 & TRN & \\
\hline CHEMBL1361955 & 688128 & 4.7 & 4.4452 & TRN & \\
\hline CHEMBL1435562 & 688128 & 4.4 & 4.5283 & TRN & \\
\hline CHEMBL1988927 & 688128 & 4.05 & 4.6944 & TRN & \\
\hline CHEMBL93496 & 688128 & 3.1 & 4.7313 & TST & \\
\hline CHEMBL1603297 & 688128 & 4.35 & 4.6687 & TRN & \\
\hline CHEMBL1588023 & 688128 & 4.65 & 4.596 & TST & \\
\hline CHEMBL1471581 & 688128 & 6.2 & 4.3417 & TRN & \\
\hline CHEMBL1299967 & 688128 & 5.1 & 4.8745 & TRN & \\
\hline CHEMBL1339596 & 688128 & 4.3 & 4.5664 & TST & \\
\hline CHEMBL1406381 & 688128 & 4.55 & 4.8181 & TRN & \\
\hline CHEMBL3191843 & 688128 & 5.15 & 4.7253 & TRN & \\
\hline CHEMBL1378582 & 688128 & 4.05 & 4.5748 & TRN & \\
\hline CHEMBL1500542 & 688128 & 4.05 & 4.5473 & TRN & \\
\hline CHEMBL1371672 & 688128 & 4.3 & 4.377 & TRN & \\
\hline CHEMBL1542422 & 688128 & 4.85 & 4.4866 & TRN & \\
\hline CHEMBL1441967 & 688128 & 4.3 & 4.5966 & TST & \\
\hline CHEMBL1486963 & 688128 & 4.55 & 4.7842 & TRN & \\
\hline CHEMBL1464084 & 688128 & 4.05 & 4.6206 & TST & \\
\hline CHEMBL1309425 & 688128 & 5.35 & 4.7975 & TST & \\
\hline CHEMBL1597738 & 688128 & 4.55 & 4.7997 & TRN & \\
\hline CHEMBL1340023 & 688128 & 4.3 & 4.4392 & TRN & \\
\hline CHEMBL1397397 & 688128 & 4.25 & 4.6875 & TRN & \\
\hline CHEMBL1314809 & 688128 & 4.1 & 4.8271 & TST & \\
\hline CHEMBL1570245 & 688128 & 4.4 & 4.4388 & TRN & \\
\hline CHEMBL1452124 & 688128 & 4.05 & 4.7917 & TRN & \\
\hline CHEMBL1424662 & 688128 & 4.3 & 4.7204 & TST & \\
\hline CHEMBL1340299 & 688128 & 5.4 & 4.7249 & TRN & \\
\hline CHEMBL1431998 & 688128 & 4.35 & 4.6782 & TRN & \\
\hline CHEMBL3212921 & 688128 & 4.35 & 4.4832 & TST & \\
\hline CHEMBL1611333 & 688128 & 4.35 & 4.9546 & TRN & \\
\hline CHEMBL1366014 & 688128 & 4.3 & 4.4131 & TRN & \\
\hline CHEMBL1404973 & 688128 & 4.05 & 4.545 & TRN & \\
\hline CHEMBL1596811 & 688128 & 4.55 & 4.9519 & TRN & \\
\hline CHEMBL1506843 & 688128 & 4.0 & 4.7687 & TRN & \\
\hline CHEMBL1362349 & 688128 & 4.35 & 4.5292 & TRN & \\
\hline CHEMBL1311028 & 688128 & 4.05 & 4.4228 & TRN & \\
\hline CHEMBL1318888 & 688128 & 4.0 & 4.4124 & TST & \\
\hline CHEMBL 2374056 & 688128 & 5.35 & 5.2838 & TRN & \\
\hline CHEMBL383041 & 688128 & 4.7 & 4.5055 & TRN & \\
\hline CHEMBL1348685 & 688128 & 4.05 & 4.4654 & TRN & \\
\hline CHEMBL3191661 & 688128 & 4.5 & 4.6728 & TRN & \\
\hline CHEMBL1303586 & 688128 & 4.3 & 4.8475 & TST & \\
\hline
\end{tabular}




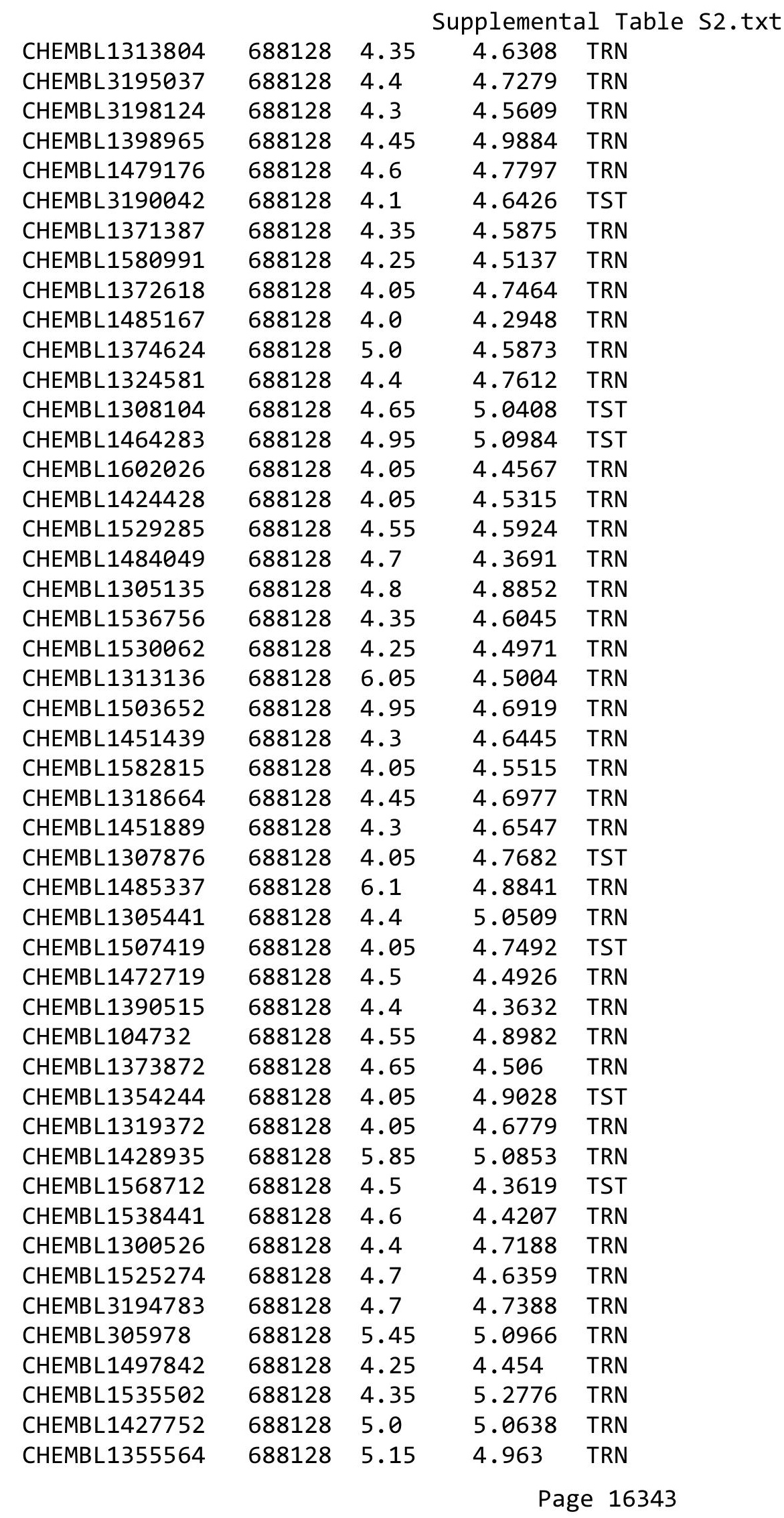




\begin{tabular}{|c|c|c|c|c|}
\hline & & & pplement & al $\mathrm{Ta}$ \\
\hline CHEMBL1576747 & 688128 & 5.7 & 4.6339 & TST \\
\hline CHEMBL1561796 & 688128 & 4.65 & 4.5705 & TRN \\
\hline CHEMBL1580218 & 688128 & 5.0 & 4.7555 & TRN \\
\hline CHEMBL1500377 & 688128 & 4.35 & 4.5531 & TRN \\
\hline CHEMBL1320799 & 688128 & 4.65 & 4.5262 & TRN \\
\hline CHEMBL1600576 & 688128 & 6.0 & 5.0395 & TRN \\
\hline CHEMBL1422753 & 688128 & 4.4 & 4.5202 & TRN \\
\hline CHEMBL1564307 & 688128 & 4.9 & 4.6758 & TST \\
\hline CHEMBL1986735 & 688128 & 5.25 & 4.6394 & TRN \\
\hline CHEMBL1303138 & 688128 & 4.45 & 4.6957 & TST \\
\hline CHEMBL1338221 & 688128 & 4.5 & 4.7353 & TRN \\
\hline CHEMBL1411874 & 688128 & 4.45 & 4.7778 & TRN \\
\hline CHEMBL1504942 & 688128 & 4.3 & 4.6329 & TST \\
\hline CHEMBL1437019 & 688128 & 4.05 & 4.4405 & TST \\
\hline CHEMBL1344647 & 688128 & 4.05 & 4.422 & TRN \\
\hline CHEMBL1401085 & 688128 & 4.45 & 4.6158 & TRN \\
\hline CHEMBL1439554 & 688128 & 4.0 & 4.471 & TST \\
\hline CHEMBL1495687 & 688128 & 6.05 & 4.919 & TST \\
\hline CHEMBL1549039 & 688128 & 4.25 & 4.6201 & TST \\
\hline CHEMBL1398419 & 688128 & 4.05 & 4.5825 & TRN \\
\hline CHEMBL1585905 & 688128 & 4.7 & 4.773 & TRN \\
\hline CHEMBL1576463 & 688128 & 4.4 & 4.3188 & TRN \\
\hline CHEMBL1414880 & 688128 & 4.2 & 4.7156 & TST \\
\hline CHEMBL1355290 & 688128 & 4.4 & 4.7052 & TRN \\
\hline CHEMBL1407199 & 688128 & 4.35 & 4.5237 & TRN \\
\hline CHEMBL1560802 & 688128 & 4.5 & 4.2805 & TRN \\
\hline CHEMBL1450271 & 688128 & 4.35 & 4.7333 & TRN \\
\hline CHEMBL3191815 & 688128 & 4.35 & 4.4961 & TRN \\
\hline CHEMBL1322518 & 688128 & 4.95 & 5.0095 & TST \\
\hline CHEMBL1355765 & 688128 & 4.7 & 4.7036 & TRN \\
\hline CHEMBL1500799 & 688128 & 5.1 & 4.6427 & TRN \\
\hline CHEMBL1580664 & 688128 & 4.9 & 4.4788 & TST \\
\hline CHEMBL1368314 & 688128 & 4.05 & 4.3185 & TRN \\
\hline CHEMBL1400358 & 688128 & 4.4 & 4.7184 & TRN \\
\hline CHEMBL3198493 & 688128 & 4.45 & 4.5013 & TRN \\
\hline CHEMBL1382931 & 688128 & 4.05 & 4.6849 & TRN \\
\hline CHEMBL1379372 & 688128 & 4.3 & 4.4039 & TRN \\
\hline CHEMBL1380498 & 688128 & 6.2 & 4.4136 & TST \\
\hline CHEMBL1546847 & 688128 & 5.05 & 4.5776 & TRN \\
\hline CHEMBL1332757 & 688128 & 4.05 & 4.4527 & TRN \\
\hline CHEMBL1303301 & 688128 & 4.65 & 4.5294 & TST \\
\hline CHEMBL1381468 & 688128 & 4.3 & 4.5567 & TRN \\
\hline CHEMBL1605588 & 688128 & 4.55 & 4.7389 & TRN \\
\hline CHEMBL1339312 & 688128 & 4.6 & 4.5363 & TRN \\
\hline CHEMBL1586371 & 688128 & 4.5 & 4.5412 & TRN \\
\hline CHEMBL1442861 & 688128 & 4.9 & 4.1436 & TRN \\
\hline CHEMBL1422967 & 688128 & 4.45 & 4.8332 & TRN \\
\hline CHEMBL1443589 & 688128 & 4.35 & 5.0048 & TST \\
\hline
\end{tabular}




\begin{tabular}{|c|c|c|c|c|}
\hline \multicolumn{5}{|c|}{ Supplemental Table S2.txt } \\
\hline CHEMBL1581080 & 688128 & 4.3 & 4.3937 & TRN \\
\hline CHEMBL1592331 & 688128 & 4.35 & 4.6075 & TRN \\
\hline CHEMBL1503064 & 688128 & 4.3 & 4.4723 & TRN \\
\hline CHEMBL1554305 & 688128 & 5.95 & 5.0471 & TRN \\
\hline CHEMBL23081 & 688128 & 4.25 & 4.762 & TST \\
\hline CHEMBL1595597 & 688128 & 4.65 & 4.547 & TRN \\
\hline CHEMBL1480886 & 688128 & 4.4 & 4.8593 & TRN \\
\hline CHEMBL1381091 & 688128 & 4.05 & 4.3149 & TRN \\
\hline CHEMBL1403660 & 688128 & 4.05 & 4.4805 & TST \\
\hline CHEMBL1522871 & 688128 & 4.35 & 4.6104 & TRN \\
\hline CHEMBL 1401740 & 688128 & 4.3 & 4.8276 & TRN \\
\hline CHEMBL1438743 & 688128 & 4.05 & 4.6988 & TST \\
\hline CHEMBL1602867 & 688128 & 4.35 & 4.6718 & TST \\
\hline CHEMBL3190383 & 688128 & 4.5 & 4.4855 & TST \\
\hline CHEMBL1367877 & 688128 & 4.5 & 4.8838 & TST \\
\hline CHEMBL1545163 & 688128 & 4.4 & 4.4912 & TRN \\
\hline CHEMBL1569472 & 688128 & 4.3 & 4.7993 & TRN \\
\hline CHEMBL1477573 & 688128 & 4.95 & 4.6099 & TRN \\
\hline CHEMBL1995681 & 688128 & 4.25 & 4.9096 & TRN \\
\hline CHEMBL1353488 & 688128 & 4.25 & 4.7785 & TST \\
\hline CHEMBL1536658 & 688128 & 5.45 & 4.8497 & TRN \\
\hline CHEMBL3193766 & 688128 & 4.65 & 4.8981 & TRN \\
\hline CHEMBL1577690 & 688128 & 6.05 & 4.3883 & TST \\
\hline CHEMBL1343462 & 688128 & 4.45 & 4.6888 & TRN \\
\hline CHEMBL1397852 & 688128 & 4.45 & 4.6292 & TRN \\
\hline CHEMBL1419908 & 688128 & 4.85 & 4.6266 & TRN \\
\hline CHEMBL1501377 & 688128 & 4.0 & 4.6777 & TRN \\
\hline CHEMBL1448695 & 688128 & 5.4 & 4.9669 & TRN \\
\hline CHEMBL1480392 & 688128 & 4.5 & 4.4444 & TRN \\
\hline CHEMBL1579190 & 688128 & 4.55 & 4.4686 & TRN \\
\hline CHEMBL1595877 & 688128 & 4.05 & 4.4316 & TRN \\
\hline CHEMBL1365059 & 688128 & 4.3 & 4.4025 & TRN \\
\hline CHEMBL1590257 & 688128 & 5.3 & 4.6454 & TRN \\
\hline CHEMBL1563171 & 688128 & 4.7 & 4.63 & TRN \\
\hline CHEMBL1446213 & 688128 & 4.5 & 4.4937 & TRN \\
\hline CHEMBL1445660 & 688128 & 4.4 & 4.3624 & TRN \\
\hline CHEMBL1527043 & 688128 & 5.3 & 4.5101 & TRN \\
\hline CHEMBL1537196 & 688128 & 4.85 & 4.6187 & TST \\
\hline CHEMBL3196200 & 688128 & 4.4 & 4.7112 & TRN \\
\hline CHEMBL1468448 & 688128 & 4.05 & 4.4705 & TRN \\
\hline CHEMBL1610594 & 688128 & 4.35 & 4.4187 & TRN \\
\hline CHEMBL1302944 & 688128 & 4.5 & 4.9386 & TRN \\
\hline CHEMBL1573221 & 688128 & 6.0 & 4.5574 & TRN \\
\hline CHEMBL1600137 & 688128 & 5.2 & 4.6975 & TRN \\
\hline CHEMBL1395951 & 688128 & 4.4 & 4.7603 & TRN \\
\hline CHEMBL1586326 & 688128 & 5.6 & 4.5554 & TRN \\
\hline CHEMBL 1580716 & 688128 & 4.05 & 4.6499 & TRN \\
\hline CHEMBL604116 & 688128 & 4.4 & 4.545 & TRN \\
\hline
\end{tabular}




\begin{tabular}{|c|c|c|c|c|c|}
\hline \multicolumn{6}{|c|}{ Supplemental Table S2.txt } \\
\hline CHEMBL1360098 & 688128 & 4.85 & 4.573 & TRN & \\
\hline CHEMBL1466905 & 688128 & 5.35 & 4.5726 & TRN & \\
\hline CHEMBL1358460 & 688128 & 4.5 & 4.5442 & TRN & \\
\hline CHEMBL1491258 & 688128 & 4.4 & 4.8236 & TST & \\
\hline CHEMBL1369567 & 688128 & 4.55 & 5.1486 & TST & \\
\hline CHEMBL1402717 & 688128 & 4.45 & 4.6524 & TST & \\
\hline CHEMBL1568102 & 688128 & 4.35 & 4.7261 & TRN & \\
\hline CHEMBL1439355 & 688128 & 4.45 & 4.6045 & TRN & \\
\hline CHEMBL1544049 & 688128 & 4.3 & 4.5605 & TRN & \\
\hline CHEMBL1516692 & 688128 & 4.05 & 4.3412 & TRN & \\
\hline CHEMBL1352844 & 688128 & 4.55 & 4.4954 & TRN & \\
\hline CHEMBL1316874 & 688128 & 4.4 & 4.5049 & TRN & \\
\hline CHEMBL1334647 & 688128 & 4.65 & 4.718 & TRN & \\
\hline CHEMBL1531921 & 688128 & 5.35 & 4.9201 & TRN & \\
\hline CHEMBL1439898 & 688128 & 4.35 & 4.8007 & TST & \\
\hline CHEMBL1543467 & 688128 & 4.25 & 4.5176 & TRN & \\
\hline CHEMBL1542562 & 688128 & 4.4 & 4.5937 & TRN & \\
\hline CHEMBL1314790 & 688128 & 5.0 & 5.1481 & TRN & \\
\hline CHEMBL1517240 & 688128 & 4.05 & 4.4935 & TRN & \\
\hline CHEMBL1402436 & 688128 & 5.45 & 5.2049 & TRN & \\
\hline CHEMBL1537227 & 688128 & 4.3 & 4.3757 & TRN & \\
\hline CHEMBL1410573 & 688128 & 4.3 & 4.6021 & TRN & \\
\hline CHEMBL1304740 & 688128 & 4.3 & 4.50899 & 99999999995 & TRN \\
\hline CHEMBL1607103 & 688128 & 4.05 & 4.5082 & TST & \\
\hline CHEMBL1400837 & 688128 & 4.55 & 4.3809 & TRN & \\
\hline CHEMBL1368248 & 688128 & 4.45 & 4.9825 & TRN & \\
\hline CHEMBL1339855 & 688128 & 4.65 & 4.2606 & TRN & \\
\hline CHEMBL3192107 & 688128 & 4.35 & 4.4609 & TRN & \\
\hline CHEMBL3392071 & 688128 & 5.0 & 4.6226 & TRN & \\
\hline CHEMBL1456886 & 688128 & 5.45 & 4.7508 & TRN & \\
\hline CHEMBL1459041 & 688128 & 4.35 & 4.7838 & TST & \\
\hline CHEMBL1350279 & 688128 & 4.8 & 4.5272 & TST & \\
\hline CHEMBL1299193 & 688128 & 6.0 & 4.2659 & TST & \\
\hline CHEMBL1542501 & 688128 & 4.4 & 4.9389 & TRN & \\
\hline CHEMBL1432336 & 688128 & 6.15 & 4.9688 & TRN & \\
\hline CHEMBL1418719 & 688128 & 6.5501 & 4.3126 & TRN & \\
\hline CHEMBL1373492 & 688128 & 4.45 & 4.6313 & TRN & \\
\hline CHEMBL1579955 & 688128 & 5.85 & 4.8147 & TRN & \\
\hline CHEMBL1969721 & 688128 & 4.45 & 4.6201 & TST & \\
\hline CHEMBL1299856 & 688128 & 4.2 & 4.7719 & TRN & \\
\hline CHEMBL1446222 & 688128 & 4.55 & 4.1928 & TRN & \\
\hline CHEMBL3198159 & 688128 & 4.85 & 4.7686 & TRN & \\
\hline CHEMBL1597333 & 688128 & 5.05 & 4.9439 & TRN & \\
\hline CHEMBL1591681 & 688128 & 4.6 & 4.6131 & TRN & \\
\hline CHEMBL1364151 & 688128 & 4.35 & 4.5965 & TRN & \\
\hline CHEMBL1461797 & 688128 & 4.35 & 4.3227 & TRN & \\
\hline CHEMBL1562376 & 688128 & 4.5 & 4.7733 & TRN & \\
\hline CHEMBL1513713 & 688128 & 5.0 & 4.9546 & TRN & \\
\hline
\end{tabular}




\begin{tabular}{|c|c|c|c|c|c|}
\hline & & \multicolumn{4}{|c|}{ Supplemental Table S2.txt } \\
\hline CHEMBL1467056 & 688128 & 4.35 & 4.5614 & TRN & \\
\hline CHEMBL1310450 & 688128 & 4.05 & 4.3416 & TST & \\
\hline CHEMBL1326192 & 688128 & 4.6 & 4.5025 & TRN & \\
\hline CHEMBL1525975 & 688128 & 4.5 & 4.6077 & TST & \\
\hline CHEMBL1342570 & 688128 & 4.85 & 4.5819 & TRN & \\
\hline CHEMBL1423849 & 688128 & 4.6 & 4.55399 & 9999999999 & TRN \\
\hline CHEMBL1350073 & 688128 & 4.35 & 4.6808 & TRN & \\
\hline CHEMBL1405269 & 688128 & 4.4 & 4.6675 & TRN & \\
\hline CHEMBL1533736 & 688128 & 4.3 & 4.4385 & TRN & \\
\hline CHEMBL3192095 & 688128 & 4.35 & 4.6475 & TRN & \\
\hline CHEMBL1455184 & 688128 & 4.35 & 4.7037 & TRN & \\
\hline CHEMBL1406361 & 688128 & 4.3 & 4.6548 & TRN & \\
\hline CHEMBL 3189307 & 688128 & 5.35 & 4.8789 & TRN & \\
\hline CHEMBL1552657 & 688128 & 4.05 & 4.4166 & TRN & \\
\hline CHEMBL1338649 & 688128 & 4.35 & 4.5023 & TRN & \\
\hline CHEMBL1340284 & 688128 & 4.6 & 4.6254 & TST & \\
\hline CHEMBL1979957 & 688128 & 4.4 & 5.0286 & TRN & \\
\hline CHEMBL1548757 & 688128 & 5.3 & 4.959 & TRN & \\
\hline CHEMBL1582400 & 688128 & 4.55 & 4.771 & TRN & \\
\hline CHEMBL1303354 & 688128 & 4.6 & 4.8118 & TST & \\
\hline CHEMBL1765369 & 688128 & 4.4 & 4.65 & TST & \\
\hline CHEMBL1575166 & 688128 & 4.05 & 4.4305 & TRN & \\
\hline CHEMBL1348547 & 688128 & 6.2 & 4.154 & TST & \\
\hline CHEMBL1569131 & 688128 & 4.4 & 4.3834 & TRN & \\
\hline CHEMBL1364011 & 688128 & 5.4 & 4.8155 & TRN & \\
\hline CHEMBL1397665 & 688128 & 4.3 & 4.8128 & TRN & \\
\hline CHEMBL1459591 & 688128 & 4.3 & 4.6447 & TRN & \\
\hline CHEMBL 3211487 & 688128 & 4.05 & 4.5068 & TRN & \\
\hline CHEMBL1543891 & 688128 & 4.8 & 4.4133 & TRN & \\
\hline CHEMBL1467157 & 688128 & 4.85 & 4.5184 & TRN & \\
\hline CHEMBL1369277 & 688128 & 4.35 & 4.67399 & 99999999995 & TST \\
\hline CHEMBL1547023 & 688128 & 4.35 & 4.5796 & TST & \\
\hline CHEMBL1987906 & 688128 & 4.3 & 4.4665 & TRN & \\
\hline CHEMBL1437745 & 688128 & 4.3 & 4.681 & TST & \\
\hline CHEMBL1349531 & 688128 & 6.05 & 4.4654 & TRN & \\
\hline CHEMBL1511718 & 688128 & 4.2 & 4.6419 & TRN & \\
\hline CHEMBL3199249 & 688128 & 4.05 & 4.258 & TST & \\
\hline CHEMBL1383517 & 688128 & 4.5 & 4.7224 & TRN & \\
\hline CHEMBL1597418 & 688128 & 5.15 & 4.6907 & TRN & \\
\hline CHEMBL1356622 & 688128 & 4.35 & 4.6796 & TRN & \\
\hline CHEMBL1375060 & 688128 & 4.05 & 4.4957 & TRN & \\
\hline CHEMBL1564367 & 688128 & 4.7 & 4.7737 & TRN & \\
\hline CHEMBL1467133 & 688128 & 4.9 & 4.6837 & TRN & \\
\hline CHEMBL1401847 & 688128 & 4.4 & 4.9174 & TST & \\
\hline CHEMBL1556708 & 688128 & 5.35 & 4.7682 & TRN & \\
\hline CHEMBL1502738 & 688128 & 5.55 & 4.8456 & TST & \\
\hline CHEMBL1488719 & 688128 & 4.4 & 4.4606 & TRN & \\
\hline CHEMBL1573447 & 688128 & 5.8 & 4.6126 & TST & \\
\hline
\end{tabular}




\begin{tabular}{|c|c|c|c|c|c|}
\hline \multirow[b]{2}{*}{ CHEMBL1320814 } & & \multicolumn{4}{|c|}{ Supplemental Table S2.txt } \\
\hline & 688128 & 4.05 & 4.6013 & TST & \\
\hline CHEMBL1479527 & 688128 & 4.05 & 4.5594 & TRN & \\
\hline CHEMBL1416516 & 688128 & 4.3 & 4.6447 & TRN & \\
\hline CHEMBL1330048 & 688128 & 4.4 & 4.6657 & TRN & \\
\hline CHEMBL1403219 & 688128 & 4.25 & 4.57100 & 2000000001 & TRN \\
\hline CHEMBL1546688 & 688128 & 4.7 & 4.63899 & 9999999999 & TRN \\
\hline CHEMBL1323000 & 688128 & 4.4 & 5.1818 & TRN & \\
\hline CHEMBL1566617 & 688128 & 4.85 & 5.0204 & TRN & \\
\hline CHEMBL1366662 & 688128 & 4.1 & 4.479 & TRN & \\
\hline CHEMBL1393484 & 688128 & 4.5 & 4.7584 & TST & \\
\hline CHEMBL1379593 & 688128 & 4.45 & 4.6364 & TRN & \\
\hline CHEMBL1374043 & 688128 & 4.15 & 4.5939 & TRN & \\
\hline CHEMBL1411412 & 688128 & 5.4 & 4.6872 & TRN & \\
\hline CHEMBL1531848 & 688128 & 4.55 & 4.8464 & TRN & \\
\hline CHEMBL1348969 & 688128 & 5.5 & 4.6117 & TRN & \\
\hline CHEMBL1415329 & 688128 & 4.4 & 4.7057 & TRN & \\
\hline CHEMBL1387012 & 688128 & 4.35 & 4.3141 & TRN & \\
\hline CHEMBL1502902 & 688128 & 4.4 & 4.622 & TRN & \\
\hline CHEMBL1455707 & 688128 & 4.6 & 5.1002 & TRN & \\
\hline CHEMBL1528537 & 688128 & 4.35 & 4.6406 & TRN & \\
\hline CHEMBL1599070 & 688128 & 5.0 & 4.6837 & TRN & \\
\hline CHEMBL1519189 & 688128 & 4.35 & 4.2766 & TST & \\
\hline CHEMBL1503454 & 688128 & 4.0 & 4.6353 & TST & \\
\hline CHEMBL1447203 & 688128 & 4.5 & 4.6407 & TST & \\
\hline CHEMBL1340760 & 688128 & 4.45 & 4.681 & TRN & \\
\hline CHEMBL1518073 & 688128 & 6.0 & 5.2306 & TRN & \\
\hline CHEMBL1384515 & 688128 & 4.35 & 4.9697 & TRN & \\
\hline CHEMBL1352328 & 688128 & 4.3 & 4.5516 & TRN & \\
\hline CHEMBL1488656 & 688128 & 4.85 & 4.4619 & TRN & \\
\hline CHEMBL1405483 & 688128 & 4.35 & 5.2264 & TRN & \\
\hline CHEMBL1452254 & 688128 & 4.5 & 5.3299 & TRN & \\
\hline CHEMBL1522237 & 688128 & 4.35 & 4.6876 & TRN & \\
\hline CHEMBL1561004 & 688128 & 4.5 & 4.2541 & TRN & \\
\hline CHEMBL1581419 & 688128 & 4.05 & 4.5094 & TST & \\
\hline CHEMBL1530601 & 688128 & 4.45 & 4.4583 & TRN & \\
\hline CHEMBL1374816 & 688128 & 4.4 & 4.6248 & TRN & \\
\hline CHEMBL1465863 & 688128 & 4.45 & 4.4049 & TRN & \\
\hline CHEMBL1438538 & 688128 & 4.4 & 4.6293 & TST & \\
\hline CHEMBL1507351 & 688128 & 4.65 & 4.5081 & TST & \\
\hline CHEMBL1440869 & 688128 & 4.4 & 4.783 & TRN & \\
\hline CHEMBL1388691 & 688128 & 4.9 & 4.8284 & TRN & \\
\hline CHEMBL1499344 & 688128 & 4.85 & 4.5008 & TRN & \\
\hline CHEMBL1338227 & 688128 & 4.6 & 4.8314 & TRN & \\
\hline CHEMBL1478327 & 688128 & 4.35 & 4.6214 & TRN & \\
\hline CHEMBL1454199 & 688128 & 4.05 & 4.6967 & TST & \\
\hline CHEMBL1541009 & 688128 & 5.4 & 4.4641 & TST & \\
\hline CHEMBL3207561 & 688128 & 4.45 & 4.6095 & TST & \\
\hline CHEMBL469424 & 688128 & 5.15 & 4.729 & TST & \\
\hline
\end{tabular}




\begin{tabular}{|c|c|c|c|c|c|}
\hline \multicolumn{6}{|c|}{ Supplemental Table S2.txt } \\
\hline CHEMBL1581129 & 688128 & 4.35 & 4.4585 & TRN & \\
\hline CHEMBL1605743 & 688128 & 5.05 & 4.7931 & TST & \\
\hline CHEMBL1533641 & 688128 & 5.15 & 4.9378 & TRN & \\
\hline CHEMBL1305678 & 688128 & 4.6 & 4.4492 & TRN & \\
\hline CHEMBL1548332 & 688128 & 4.05 & 4.7399 & TST & \\
\hline CHEMBL1470139 & 688128 & 4.55 & 4.6025 & TRN & \\
\hline CHEMBL1548122 & 688128 & 4.75 & 4.4794 & TRN & \\
\hline CHEMBL1312861 & 688128 & 4.55 & 4.7986 & TRN & \\
\hline CHEMBL1510628 & 688128 & 4.35 & 4.4921 & TST & \\
\hline CHEMBL1301358 & 688128 & 4.4 & 4.7229 & TRN & \\
\hline CHEMBL1564988 & 688128 & 4.3 & 4.5464 & TRN & \\
\hline CHEMBL1564979 & 688128 & 5.4 & 4.5937 & TST & \\
\hline CHEMBL1474227 & 688128 & 4.45 & 4.3323 & TST & \\
\hline CHEMBL1560702 & 688128 & 4.1 & 4.5592 & TRN & \\
\hline CHEMBL1482681 & 688128 & 4.3 & 4.6864 & TRN & \\
\hline CHEMBL1361137 & 688128 & 4.4 & 4.609 & TRN & \\
\hline CHEMBL1609173 & 688128 & 4.55 & 4.6715 & TRN & \\
\hline CHEMBL1350344 & 688128 & 4.6 & 4.6782 & TRN & \\
\hline CHEMBL1526342 & 688128 & 4.85 & 4.3764 & TRN & \\
\hline CHEMBL1582552 & 688128 & 6.6499 & 4.647 & TRN & \\
\hline CHEMBL3212382 & 688128 & 4.5 & 4.6801 & TRN & \\
\hline CHEMBL1351284 & 688128 & 4.25 & 4.5993 & TRN & \\
\hline CHEMBL1500640 & 688128 & 4.25 & 4.3967 & TRN & \\
\hline CHEMBL1504065 & 688128 & 4.45 & 4.53606 & 00000000005 & TRN \\
\hline CHEMBL3209765 & 688128 & 4.5 & 4.8615 & TRN & \\
\hline CHEMBL1479236 & 688128 & 4.65 & 4.5279 & TST & \\
\hline CHEMBL1333237 & 688128 & 4.4 & 4.6174 & TRN & \\
\hline CHEMBL1318922 & 688128 & 5.5 & 4.9231 & TRN & \\
\hline CHEMBL1532490 & 688128 & 4.35 & 4.6226 & TRN & \\
\hline CHEMBL1423813 & 688128 & 4.4 & 4.3702 & TRN & \\
\hline CHEMBL1316835 & 688128 & 4.3 & 4.6656 & TRN & \\
\hline CHEMBL3196327 & 688128 & 4.05 & 4.8688 & TST & \\
\hline CHEMBL1412396 & 688128 & 5.0 & 5.5051 & TRN & \\
\hline CHEMBL1477558 & 688128 & 4.6 & 4.2845 & TRN & \\
\hline CHEMBL1572023 & 688128 & 4.25 & 4.7574 & TRN & \\
\hline CHEMBL1359174 & 688128 & 4.35 & 4.3467 & TRN & \\
\hline CHEMBL1584949 & 688128 & 4.7 & 4.5042 & TRN & \\
\hline CHEMBL1439432 & 688128 & 4.25 & 4.8107 & TRN & \\
\hline CHEMBL1326083 & 688128 & 6.2 & 5.5886 & TRN & \\
\hline CHEMBL1457832 & 688128 & 4.3 & 4.5315 & TRN & \\
\hline CHEMBL1465977 & 688128 & 4.0 & 4.3073 & TRN & \\
\hline CHEMBL1551717 & 688128 & 4.3 & 4.543 & TRN & \\
\hline CHEMBL1406235 & 688128 & 6.5 & 4.94 & TRN & \\
\hline CHEMBL1343403 & 688128 & 4.3 & 4.6668 & TRN & \\
\hline CHEMBL1335702 & 688128 & 4.4 & 4.8636 & TST & \\
\hline CHEMBL1575751 & 688128 & 4.4 & 4.7494 & TRN & \\
\hline CHEMBL 1457179 & 688128 & 4.05 & 4.8504 & TST & \\
\hline CHEMBL1317890 & 688128 & 4.85 & 4.6978 & TRN & \\
\hline
\end{tabular}




\begin{tabular}{|c|c|c|c|c|}
\hline & & & \multicolumn{2}{|c|}{ Supplemental Table S2.txt } \\
\hline CHEMBL1531515 & 688128 & 4.45 & 4.6752 & TRN \\
\hline CHEMBL1490257 & 688128 & 4.3 & 4.3367 & TRN \\
\hline CHEMBL1551476 & 688128 & 4.5 & 4.2147 & TRN \\
\hline CHEMBL1602451 & 688128 & 4.4 & 4.4812 & TRN \\
\hline CHEMBL19980 & 688128 & 4.3 & 4.8797 & TST \\
\hline CHEMBL1400210 & 688128 & 5.35 & 4.4054 & TRN \\
\hline CHEMBL1328893 & 688128 & 4.4 & 4.7095 & TRN \\
\hline CHEMBL1461366 & 688128 & 4.35 & 4.3553 & TRN \\
\hline CHEMBL1372835 & 688128 & 5.6 & 4.3919 & TST \\
\hline CHEMBL1343776 & 688128 & 4.45 & 4.3809 & TRN \\
\hline CHEMBL1387768 & 688128 & 5.75 & 4.6531 & TRN \\
\hline CHEMBL1344686 & 688128 & 4.3 & 4.5104 & TRN \\
\hline CHEMBL1526126 & 688128 & 4.3 & 4.4204 & TRN \\
\hline CHEMBL1534403 & 688128 & 4.3 & 4.2122 & TRN \\
\hline CHEMBL1498198 & 688128 & 4.4 & 4.213 & TRN \\
\hline CHEMBL1471928 & 688128 & 4.45 & 5.1535 & TRN \\
\hline CHEMBL1403756 & 688128 & 5.0 & 4.4126 & TRN \\
\hline CHEMBL1552913 & 688128 & 4.45 & 5.2749 & TST \\
\hline CHEMBL1568922 & 688128 & 4.35 & 4.8167 & TST \\
\hline CHEMBL1508109 & 688128 & 4.4 & 4.3711 & TRN \\
\hline CHEMBL1468089 & 688128 & 4.25 & 4.6612 & TRN \\
\hline CHEMBL1338958 & 688128 & 5.55 & 5.0719 & TRN \\
\hline CHEMBL1334375 & 688128 & 4.3 & 4.9145 & TRN \\
\hline CHEMBL1329279 & 688128 & 5.4 & 4.7285 & TRN \\
\hline CHEMBL1520827 & 688128 & 5.05 & 5.2038 & TRN \\
\hline CHEMBL1509162 & 688128 & 4.3 & 4.4822 & TRN \\
\hline CHEMBL1577840 & 688128 & 6.2 & 4.9856 & TST \\
\hline CHEMBL1461399 & 688128 & 4.6 & 4.167 & TRN \\
\hline CHEMBL1469139 & 688128 & 5.35 & 4.4192 & TRN \\
\hline CHEMBL1455835 & 688128 & 4.0 & 4.6294 & TST \\
\hline CHEMBL1523714 & 688128 & 4.0 & 4.3746 & TRN \\
\hline CHEMBL1390786 & 688128 & 4.3 & 4.5616 & TRN \\
\hline CHEMBL1453052 & 688128 & 6.15 & 4.895 & TRN \\
\hline CHEMBL1432590 & 688128 & 6.45 & 5.3334 & TRN \\
\hline CHEMBL1593728 & 688128 & 4.05 & 4.7603 & TRN \\
\hline CHEMBL1452129 & 688128 & 4.35 & 4.718 & TST \\
\hline CHEMBL 1487558 & 688128 & 4.3 & 4.7179 & TST \\
\hline CHEMBL1374570 & 688128 & 4.65 & 4.7135 & TRN \\
\hline CHEMBL1428248 & 688128 & 4.4 & 4.5367 & TRN \\
\hline CHEMBL1583698 & 688128 & 4.65 & 4.9314 & TRN \\
\hline CHEMBL582764 & 688128 & 4.45 & 4.7976 & TRN \\
\hline CHEMBL1550000 & 688128 & 4.95 & 4.6419 & TRN \\
\hline CHEMBL1378988 & 688128 & 4.3 & 4.4989 & TRN \\
\hline CHEMBL1418010 & 688128 & 4.3 & 4.7726 & TRN \\
\hline CHEMBL3199127 & 688128 & 5.05 & 4.7498 & TRN \\
\hline CHEMBL1306782 & 688128 & 4.0 & 4.6571 & TST \\
\hline CHEMBL1347128 & 688128 & 4.35 & 4.3826 & TST \\
\hline CHEMBL3194886 & 688128 & 4.25 & 4.6433 & TRN \\
\hline
\end{tabular}




\begin{tabular}{|c|c|c|c|c|c|}
\hline \multicolumn{6}{|c|}{ Supplemental Table S2.txt } \\
\hline CHEMBL1451330 & 688128 & 4.75 & 4.6203 & TST & \\
\hline CHEMBL1436425 & 688128 & 4.3 & 4.0547 & TRN & \\
\hline CHEMBL1503265 & 688128 & 5.5 & 4.6504 & TST & \\
\hline CHEMBL1532342 & 688128 & 4.35 & 4.8132 & TRN & \\
\hline CHEMBL1333687 & 688128 & 4.85 & 4.9358 & TRN & \\
\hline CHEMBL1530170 & 688128 & 4.3 & 4.7589 & TRN & \\
\hline CHEMBL1464107 & 688128 & 4.8 & 4.6847 & TRN & \\
\hline CHEMBL 3214009 & 688128 & 4.05 & 4.7539 & TRN & \\
\hline CHEMBL1393998 & 688128 & 4.55 & 4.7236 & TRN & \\
\hline CHEMBL1605335 & 688128 & 4.35 & 4.5432 & TRN & \\
\hline CHEMBL1363221 & 688128 & 4.55 & 4.7796 & TST & \\
\hline CHEMBL1271881 & 688128 & 4.3 & 4.7006 & TRN & \\
\hline CHEMBL1587481 & 688128 & 5.45 & 4.7251 & TST & \\
\hline CHEMBL1573365 & 688128 & 5.3 & 4.5999 & TST & \\
\hline CHEMBL1529930 & 688128 & 5.0 & 4.8688 & TST & \\
\hline CHEMBL1574918 & 688128 & 4.8 & 4.6768 & TST & \\
\hline CHEMBL1300901 & 688128 & 4.7 & 4.6767 & TRN & \\
\hline CHEMBL1579827 & 688128 & 5.05 & 4.7504 & TRN & \\
\hline CHEMBL1512555 & 688128 & 4.45 & 4.5101 & TRN & \\
\hline CHEMBL1484743 & 688128 & 4.7 & 4.1987 & TRN & \\
\hline CHEMBL1310753 & 688128 & 4.35 & 4.7485 & TST & \\
\hline CHEMBL1336286 & 688128 & 4.35 & 4.9682 & TRN & \\
\hline CHEMBL1439587 & 688128 & 4.45 & 4.6381 & TRN & \\
\hline CHEMBL1393093 & 688128 & 4.55 & 4.2946 & TRN & \\
\hline CHEMBL3194601 & 688128 & 4.5 & 4.72 & TRN & \\
\hline CHEMBL1424688 & 688128 & 4.9 & 4.6104 & TRN & \\
\hline CHEMBL1338736 & 688128 & 4.05 & 4.7102 & TST & \\
\hline CHEMBL1371143 & 688128 & 4.25 & 4.5929 & TRN & \\
\hline CHEMBL1422746 & 688128 & 4.4 & 4.508 & TRN & \\
\hline CHEMBL1422059 & 688128 & 4.3 & 4.3633 & TRN & \\
\hline CHEMBL1449337 & 688128 & 4.65 & 4.5232 & TRN & \\
\hline CHEMBL1374473 & 688128 & 4.35 & 4.48600 & 0000000001 & TRN \\
\hline CHEMBL1503151 & 688128 & 5.0 & 4.3818 & TRN & \\
\hline CHEMBL1439912 & 688128 & 4.7 & 4.5405 & TRN & \\
\hline CHEMBL1501906 & 688128 & 4.6 & 4.4845 & TST & \\
\hline CHEMBL1341012 & 688128 & 4.1 & 4.4735 & TRN & \\
\hline CHEMBL1508472 & 688128 & 4.25 & 4.6717 & TRN & \\
\hline CHEMBL1332169 & 688128 & 4.45 & 4.4774 & TRN & \\
\hline CHEMBL1355796 & 688128 & 4.45 & 4.6711 & TRN & \\
\hline CHEMBL1566266 & 688128 & 5.45 & 4.904 & TRN & \\
\hline CHEMBL 3197223 & 688128 & 5.0 & 4.8018 & TRN & \\
\hline CHEMBL 1578953 & 688128 & 5.05 & 4.7625 & TRN & \\
\hline CHEMBL1300227 & 688128 & 4.25 & 4.7416 & TRN & \\
\hline CHEMBL1350283 & 688128 & 4.8 & 4.6947 & TRN & \\
\hline CHEMBL1487165 & 688128 & 4.5 & 4.5427 & TRN & \\
\hline CHEMBL1447668 & 688128 & 6.0 & 4.9574 & TRN & \\
\hline CHEMBL1360005 & 688128 & 4.25 & 4.5785 & TRN & \\
\hline CHEMBL1436788 & 688128 & 4.35 & 4.5892 & TRN & \\
\hline
\end{tabular}




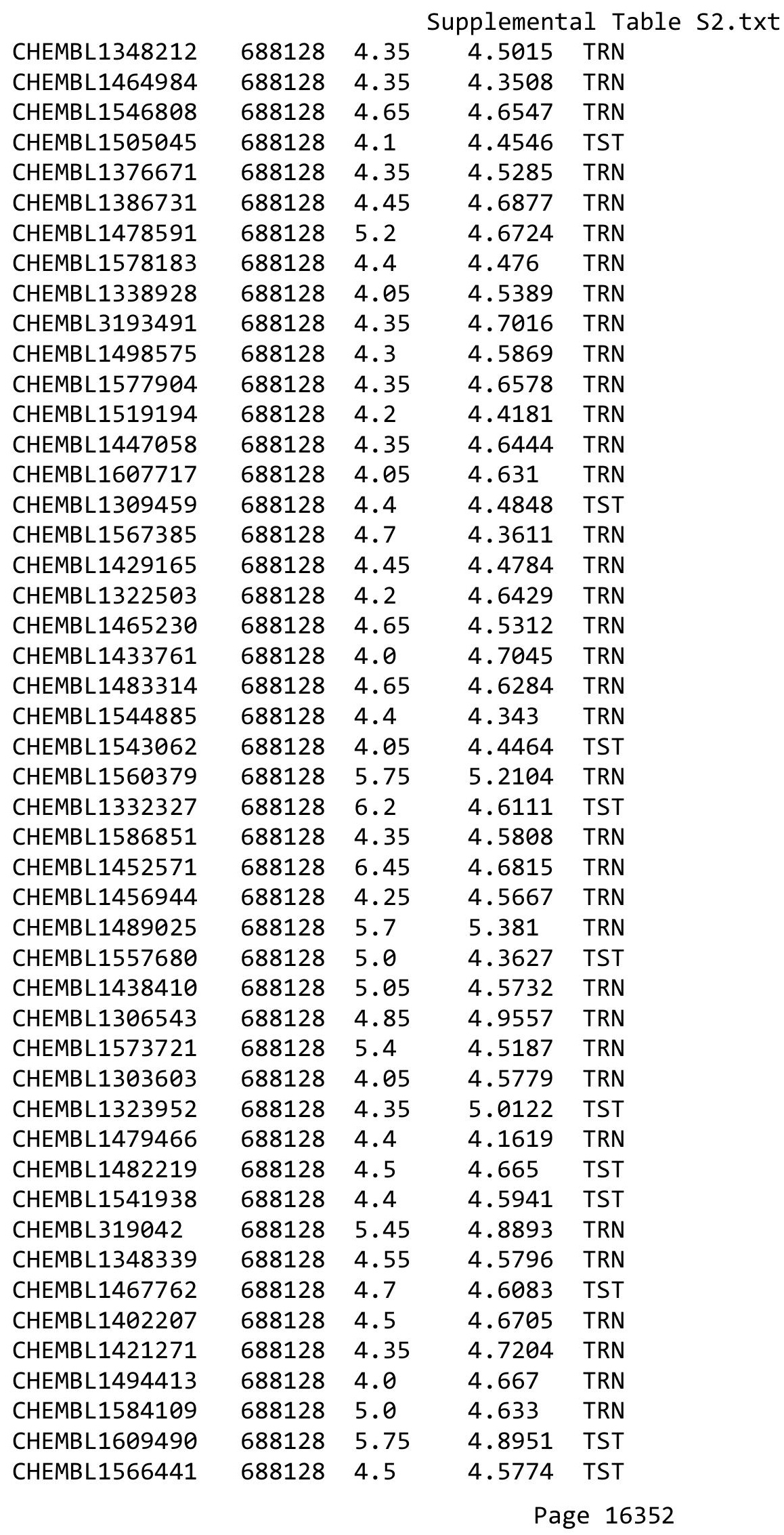




\begin{tabular}{|c|c|c|c|c|c|}
\hline \multicolumn{6}{|c|}{ Supplemental Table S2.txt } \\
\hline CHEMBL1437278 & 688128 & 4.4 & 4.5466 & TST & \\
\hline CHEMBL1491370 & 688128 & 4.75 & 4.7952 & TRN & \\
\hline CHEMBL1306511 & 688128 & 4.5 & 4.5055 & TRN & \\
\hline CHEMBL1478069 & 688128 & 4.95 & 5.0668 & TRN & \\
\hline CHEMBL1544586 & 688128 & 4.35 & 4.5086 & TRN & \\
\hline CHEMBL3198496 & 688128 & 4.55 & 5.1154 & TRN & \\
\hline CHEMBL1486522 & 688128 & 4.7 & 4.7028 & TRN & \\
\hline CHEMBL1330531 & 688128 & 4.25 & 4.493 & TRN & \\
\hline CHEMBL1307540 & 688128 & 4.35 & 4.363 & TRN & \\
\hline CHEMBL1359901 & 688128 & 4.4 & 4.4883 & TST & \\
\hline CHEMBL3199016 & 688128 & 5.35 & 4.508 & TRN & \\
\hline CHEMBL1547837 & 688128 & 4.6 & 4.5344 & TST & \\
\hline CHEMBL1391566 & 688128 & 4.4 & 4.6657 & TRN & \\
\hline CHEMBL1337478 & 688128 & 4.5 & 4.67399 & 99999999995 & TST \\
\hline CHEMBL1419650 & 688128 & 4.3 & 4.6099 & TRN & \\
\hline CHEMBL1406854 & 688128 & 4.05 & 4.5915 & TST & \\
\hline CHEMBL1612608 & 688128 & 4.3 & 4.9413 & TRN & \\
\hline CHEMBL1605629 & 688128 & 5.05 & 4.5691 & TST & \\
\hline CHEMBL1345135 & 688128 & 4.95 & 4.7112 & TRN & \\
\hline CHEMBL1414611 & 688128 & 4.95 & 4.4406 & TRN & \\
\hline CHEMBL1486574 & 688128 & 4.9 & 4.5536 & TST & \\
\hline CHEMBL1452397 & 688128 & 4.4 & 4.2592 & TRN & \\
\hline CHEMBL1326410 & 688128 & 5.6 & 4.7963 & TRN & \\
\hline CHEMBL1561391 & 688128 & 4.35 & 4.4771 & TRN & \\
\hline CHEMBL3208940 & 688128 & 4.4 & 4.5567 & TST & \\
\hline CHEMBL1403434 & 688128 & 4.45 & 4.8932 & TRN & \\
\hline CHEMBL1611755 & 688128 & 4.05 & 4.7794 & TRN & \\
\hline CHEMBL1446804 & 688128 & 4.45 & 4.9479 & TRN & \\
\hline CHEMBL1577575 & 688128 & 4.3 & 4.6981 & TRN & \\
\hline CHEMBL1302097 & 688128 & 4.35 & 4.3891 & TRN & \\
\hline CHEMBL1400852 & 688128 & 4.45 & 5.0803 & TRN & \\
\hline CHEMBL1566931 & 688128 & 5.4 & 4.6988 & TRN & \\
\hline CHEMBL1390930 & 688128 & 4.45 & 4.8435 & TRN & \\
\hline CHEMBL1541941 & 688128 & 4.3 & 4.8277 & TST & \\
\hline CHEMBL1429014 & 688128 & 4.1 & 4.6536 & TRN & \\
\hline CHEMBL1416072 & 688128 & 4.35 & 4.2356 & TRN & \\
\hline CHEMBL1403184 & 688128 & 5.4 & 4.6387 & TST & \\
\hline CHEMBL1462528 & 688128 & 4.15 & 4.6799 & TST & \\
\hline CHEMBL3196704 & 688128 & 4.3 & 4.723 & TRN & \\
\hline CHEMBL1341562 & 688128 & 4.95 & 4.3534 & TST & \\
\hline CHEMBL1426420 & 688128 & 4.45 & 4.5322 & TRN & \\
\hline CHEMBL1370057 & 688128 & 6.5 & 4.8802 & TST & \\
\hline CHEMBL1589285 & 688128 & 4.95 & 4.5024 & TRN & \\
\hline CHEMBL466401 & 688128 & 4.3 & 4.4589 & TRN & \\
\hline CHEMBL1609030 & 688128 & 4.45 & 4.5074 & TRN & \\
\hline CHEMBL1363244 & 688128 & 4.35 & 4.3685 & TRN & \\
\hline CHEMBL1501726 & 688128 & 6.15 & 5.0915 & TRN & \\
\hline CHEMBL1971614 & 688128 & 4.25 & 4.8977 & TST & \\
\hline
\end{tabular}




\begin{tabular}{|c|c|c|c|c|}
\hline \multicolumn{5}{|c|}{ Supplemental Table S2.txt } \\
\hline CHEMBL1346883 & 688128 & 5.8 & 4.8941 & TRN \\
\hline CHEMBL1341896 & 688128 & 4.5 & 4.381 & TRN \\
\hline CHEMBL1389034 & 688128 & 4.6 & 4.1366 & TRN \\
\hline CHEMBL1349105 & 688128 & 4.55 & 4.6435 & TST \\
\hline CHEMBL1559442 & 688128 & 4.25 & 4.516 & TRN \\
\hline CHEMBL1600528 & 688128 & 4.45 & 4.4947 & TRN \\
\hline CHEMBL3190912 & 688128 & 4.35 & 4.2313 & TRN \\
\hline CHEMBL1339695 & 688128 & 5.0 & 5.0471 & TRN \\
\hline CHEMBL1570634 & 688128 & 4.35 & 4.7986 & TST \\
\hline CHEMBL1527972 & 688128 & 4.85 & 4.5595 & TRN \\
\hline CHEMBL1386146 & 688128 & 6.0 & 4.5667 & TST \\
\hline CHEMBL1494202 & 688128 & 5.4 & 4.7523 & TST \\
\hline CHEMBL1470350 & 688128 & 4.05 & 4.6294 & TST \\
\hline CHEMBL46940 & 688128 & 4.4 & 4.8384 & TRN \\
\hline CHEMBL1504222 & 688128 & 4.4 & 4.901 & TRN \\
\hline CHEMBL1456143 & 688128 & 4.3 & 4.4204 & TRN \\
\hline CHEMBL1412131 & 688128 & 4.25 & 4.2227 & TRN \\
\hline CHEMBL1471444 & 688128 & 4.15 & 4.6165 & TRN \\
\hline CHEMBL1591026 & 688128 & 5.4 & 4.5167 & TST \\
\hline CHEMBL1610605 & 688128 & 4.3 & 4.5734 & TST \\
\hline CHEMBL1347224 & 688128 & 4.6 & 4.7319 & TRN \\
\hline CHEMBL1476476 & 688128 & 4.35 & 4.7244 & TRN \\
\hline CHEMBL1599525 & 688128 & 4.3 & 4.8464 & TRN \\
\hline CHEMBL1600836 & 688128 & 4.95 & 4.7201 & TRN \\
\hline CHEMBL1432028 & 688128 & 4.9 & 4.8444 & TRN \\
\hline CHEMBL1348590 & 688128 & 4.05 & 4.2356 & TRN \\
\hline CHEMBL1383424 & 688128 & 4.15 & 4.3161 & TST \\
\hline CHEMBL3392040 & 688128 & 4.5 & 4.7133 & TRN \\
\hline CHEMBL75412 & 688128 & 4.25 & 4.8143 & TRN \\
\hline CHEMBL1341762 & 688128 & 4.35 & 4.7214 & TRN \\
\hline CHEMBL1470071 & 688128 & 4.05 & 4.5794 & TRN \\
\hline CHEMBL1327123 & 688128 & 4.4 & 4.5862 & TRN \\
\hline CHEMBL1480815 & 688128 & 4.35 & 4.5393 & TRN \\
\hline CHEMBL1610748 & 688128 & 4.3 & 4.8055 & TRN \\
\hline CHEMBL1581139 & 688128 & 4.7 & 4.6138 & TRN \\
\hline CHEMBL1430866 & 688128 & 4.3 & 4.5541 & TRN \\
\hline CHEMBL1501512 & 688128 & 4.35 & 4.4987 & TRN \\
\hline CHEMBL1388084 & 688128 & 4.3 & 4.9047 & TRN \\
\hline CHEMBL1561089 & 688128 & 7.0 & 5.1577 & TST \\
\hline CHEMBL1316758 & 688128 & 4.05 & 4.5816 & TRN \\
\hline CHEMBL1383093 & 688128 & 4.35 & 4.5628 & TST \\
\hline CHEMBL1366590 & 688128 & 5.55 & 4.6717 & TST \\
\hline CHEMBL1612890 & 688128 & 4.4 & 4.4524 & TRN \\
\hline CHEMBL1422133 & 688128 & 4.2 & 4.5982 & TST \\
\hline CHEMBL1575738 & 688128 & 4.05 & 4.5215 & TST \\
\hline CHEMBL1539007 & 688128 & 4.4 & 4.6198 & TRN \\
\hline CHEMBL3199116 & 688128 & 5.45 & 4.6204 & TRN \\
\hline CHEMBL1469997 & 688128 & 4.4 & 4.3884 & TRN \\
\hline
\end{tabular}




\begin{tabular}{|c|c|c|c|c|c|}
\hline \multirow[b]{2}{*}{ CHEMBL1600280 } & \multirow[b]{2}{*}{688128} & \\
\hline & & 4.4 & 4.7283 & TRN & \\
\hline CHEMBL1513925 & 688128 & 4.35 & 4.4301 & TRN & \\
\hline CHEMBL1407042 & 688128 & 4.4 & 4.5743 & TRN & \\
\hline CHEMBL1352170 & 688128 & 5.55 & 4.8178 & TRN & \\
\hline CHEMBL1444502 & 688128 & 4.35 & 4.7314 & TRN & \\
\hline CHEMBL1448442 & 688128 & 4.5 & 4.6011 & TST & \\
\hline CHEMBL1412838 & 688128 & 4.4 & 4.3414 & TST & \\
\hline CHEMBL1588443 & 688128 & 4.3 & 4.5652 & TRN & \\
\hline CHEMBL1348034 & 688128 & 4.6 & 5.0345 & TRN & \\
\hline CHEMBL1375274 & 688128 & 4.3 & 4.4361 & TRN & \\
\hline CHEMBL1374460 & 688128 & 4.7 & 4.671 & TRN & \\
\hline CHEMBL1406316 & 688128 & 4.5 & 4.33899 & 99999999995 & TST \\
\hline CHEMBL1468895 & 688128 & 5.75 & 4.795 & TST & \\
\hline CHEMBL1447678 & 688128 & 4.95 & 4.3002 & TRN & \\
\hline CHEMBL1505948 & 688128 & 6.05 & 4.5859 & TRN & \\
\hline CHEMBL3189180 & 688128 & 4.3 & 4.5539 & TST & \\
\hline CHEMBL1384636 & 688128 & 4.4 & 4.4496 & TRN & \\
\hline CHEMBL1394345 & 688128 & 4.25 & 4.7474 & TRN & \\
\hline CHEMBL1496170 & 688128 & 4.35 & 4.5971 & TRN & \\
\hline CHEMBL1606671 & 688128 & 4.95 & 4.9185 & TRN & \\
\hline CHEMBL1392248 & 688128 & 4.6 & 4.544 & TRN & \\
\hline CHEMBL1572084 & 688128 & 5.9 & 4.98600 & 0000000001 & TRN \\
\hline CHEMBL1353481 & 688128 & 4.4 & 4.8308 & TST & \\
\hline CHEMBL1532626 & 688128 & 5.15 & 5.17299 & 9999999999 & TRN \\
\hline CHEMBL1300360 & 688128 & 4.25 & 4.9139 & TRN & \\
\hline CHEMBL1569364 & 688128 & 5.15 & 4.5468 & TRN & \\
\hline CHEMBL1457633 & 688128 & 4.6 & 4.5299 & TRN & \\
\hline CHEMBL1444901 & 688128 & 6.05 & 4.7853 & TRN & \\
\hline CHEMBL1480639 & 688128 & 5.8 & 4.6025 & TST & \\
\hline CHEMBL1425137 & 688128 & 4.65 & 4.6797 & TST & \\
\hline CHEMBL1367264 & 688128 & 4.05 & 4.6401 & TRN & \\
\hline CHEMBL1338774 & 688128 & 5.05 & 5.1352 & TRN & \\
\hline CHEMBL3196422 & 688128 & 5.6 & 4.8265 & TST & \\
\hline CHEMBL1478626 & 688128 & 6.05 & 4.45100 & 00000000005 & TRN \\
\hline CHEMBL1522129 & 688128 & 4.15 & 4.857 & TRN & \\
\hline CHEMBL1429955 & 688128 & 4.0 & 4.7004 & TST & \\
\hline CHEMBL1426559 & 688128 & 4.05 & 4.6195 & TST & \\
\hline CHEMBL1569705 & 688128 & 5.85 & 4.5349 & TST & \\
\hline CHEMBL1532278 & 688128 & 4.85 & 4.5984 & TRN & \\
\hline CHEMBL1433971 & 688128 & 4.35 & 4.6689 & TRN & \\
\hline CHEMBL1412830 & 688128 & 5.45 & 4.8664 & TST & \\
\hline CHEMBL1481495 & 688128 & 4.45 & 4.3478 & TRN & \\
\hline CHEMBL1613684 & 688128 & 4.05 & 4.7382 & TST & \\
\hline CHEMBL1414002 & 688128 & 4.25 & 4.3506 & TRN & \\
\hline CHEMBL1475904 & 688128 & 4.05 & 4.3927 & TST & \\
\hline CHEMBL1399504 & 688128 & 4.45 & 4.744 & TRN & \\
\hline CHEMBL1466518 & 688128 & 4.3 & 4.7637 & TRN & \\
\hline CHEMBL1567916 & 688128 & 4.25 & 4.5431 & TRN & \\
\hline & & & & 163 & \\
\hline
\end{tabular}




\begin{tabular}{|c|c|c|c|c|c|}
\hline \multicolumn{6}{|c|}{ Supplemental Table s2.txt } \\
\hline CHEMBL2374039 & 688128 & 5.4 & 5.0006 & TRN & \\
\hline CHEMBL1540795 & 688128 & 4.8 & 4.9235 & TST & \\
\hline CHEMBL1416615 & 688128 & 4.35 & 4.6992 & TRN & \\
\hline CHEMBL1324244 & 688128 & 4.6 & 4.8465 & TRN & \\
\hline CHEMBL1466366 & 688128 & 4.85 & 5.1592 & TRN & \\
\hline CHEMBL1591260 & 688128 & 5.0 & 4.949 & TRN & \\
\hline CHEMBL1575526 & 688128 & 4.25 & 4.5969 & TRN & \\
\hline CHEMBL1413887 & 688128 & 5.5 & 4.4483 & TRN & \\
\hline CHEMBL1579196 & 688128 & 6.8499 & 4.5748 & TRN & \\
\hline CHEMBL1374125 & 688128 & 5.25 & 4.7581 & TST & \\
\hline CHEMBL1446628 & 688128 & 4.05 & 4.442 & TRN & \\
\hline CHEMBL1569897 & 688128 & 4.3 & 4.428 & TST & \\
\hline CHEMBL1365967 & 688128 & 4.4 & 4.51699 & 99999999995 & TST \\
\hline CHEMBL1363611 & 688128 & 4.4 & 4.4457 & TRN & \\
\hline CHEMBL1600990 & 688128 & 5.2 & 4.5766 & TRN & \\
\hline CHEMBL1475937 & 688128 & 5.05 & 5.215 & TRN & \\
\hline CHEMBL1425034 & 688128 & 4.45 & 4.1691 & TRN & \\
\hline CHEMBL1382351 & 688128 & 4.7 & 4.4265 & TRN & \\
\hline CHEMBL1469955 & 688128 & 4.3 & 4.5021 & TRN & \\
\hline CHEMBL1584271 & 688128 & 5.05 & 4.707 & TST & \\
\hline CHEMBL1389146 & 688128 & 4.05 & 4.6604 & TRN & \\
\hline CHEMBL1506459 & 688128 & 4.7 & 4.5558 & TST & \\
\hline CHEMBL1366238 & 688128 & 4.3 & 4.7401 & TST & \\
\hline CHEMBL1434900 & 688128 & 4.25 & 4.7067 & TST & \\
\hline CHEMBL1515506 & 688128 & 5.7 & 5.0721 & TRN & \\
\hline CHEMBL1580914 & 688128 & 4.3 & 4.6073 & TRN & \\
\hline CHEMBL1484725 & 688128 & 4.35 & 4.726 & TST & \\
\hline CHEMBL3211777 & 688128 & 4.4 & 4.7458 & TRN & \\
\hline CHEMBL1347037 & 688128 & 4.05 & 4.7266 & TST & \\
\hline CHEMBL1589721 & 688128 & 4.65 & 4.2896 & TRN & \\
\hline CHEMBL1337130 & 688128 & 4.8 & 4.7083 & TST & \\
\hline CHEMBL1349269 & 688128 & 4.25 & 4.9501 & TRN & \\
\hline CHEMBL1587068 & 688128 & 4.05 & 4.4162 & TRN & \\
\hline CHEMBL1573750 & 688128 & 4.05 & 4.6706 & TST & \\
\hline CHEMBL1577734 & 688128 & 4.05 & 4.6418 & TST & \\
\hline CHEMBL1437722 & 688128 & 4.75 & 4.6403 & TRN & \\
\hline CHEMBL1549526 & 688128 & 4.55 & 4.7277 & TRN & \\
\hline CHEMBL584637 & 688128 & 4.25 & 4.8021 & TST & \\
\hline CHEMBL1425272 & 688128 & 4.55 & 4.4491 & TST & \\
\hline CHEMBL1422598 & 688128 & 4.9 & 4.5582 & TST & \\
\hline CHEMBL3207841 & 688128 & 4.3 & 4.283 & TRN & \\
\hline CHEMBL3195549 & 688128 & 4.35 & 4.6167 & TRN & \\
\hline CHEMBL1538533 & 688128 & 4.35 & 4.4124 & TRN & \\
\hline CHEMBL1548603 & 688128 & 5.5 & 4.9956 & TRN & \\
\hline CHEMBL1422089 & 688128 & 4.3 & 4.5829 & TST & \\
\hline CHEMBL1468909 & 688128 & 4.45 & 4.4957 & TRN & \\
\hline CHEMBL1391512 & 688128 & 4.75 & 4.401 & TRN & \\
\hline CHEMBL1356482 & 688128 & 5.45 & 4.6719 & TRN & \\
\hline
\end{tabular}




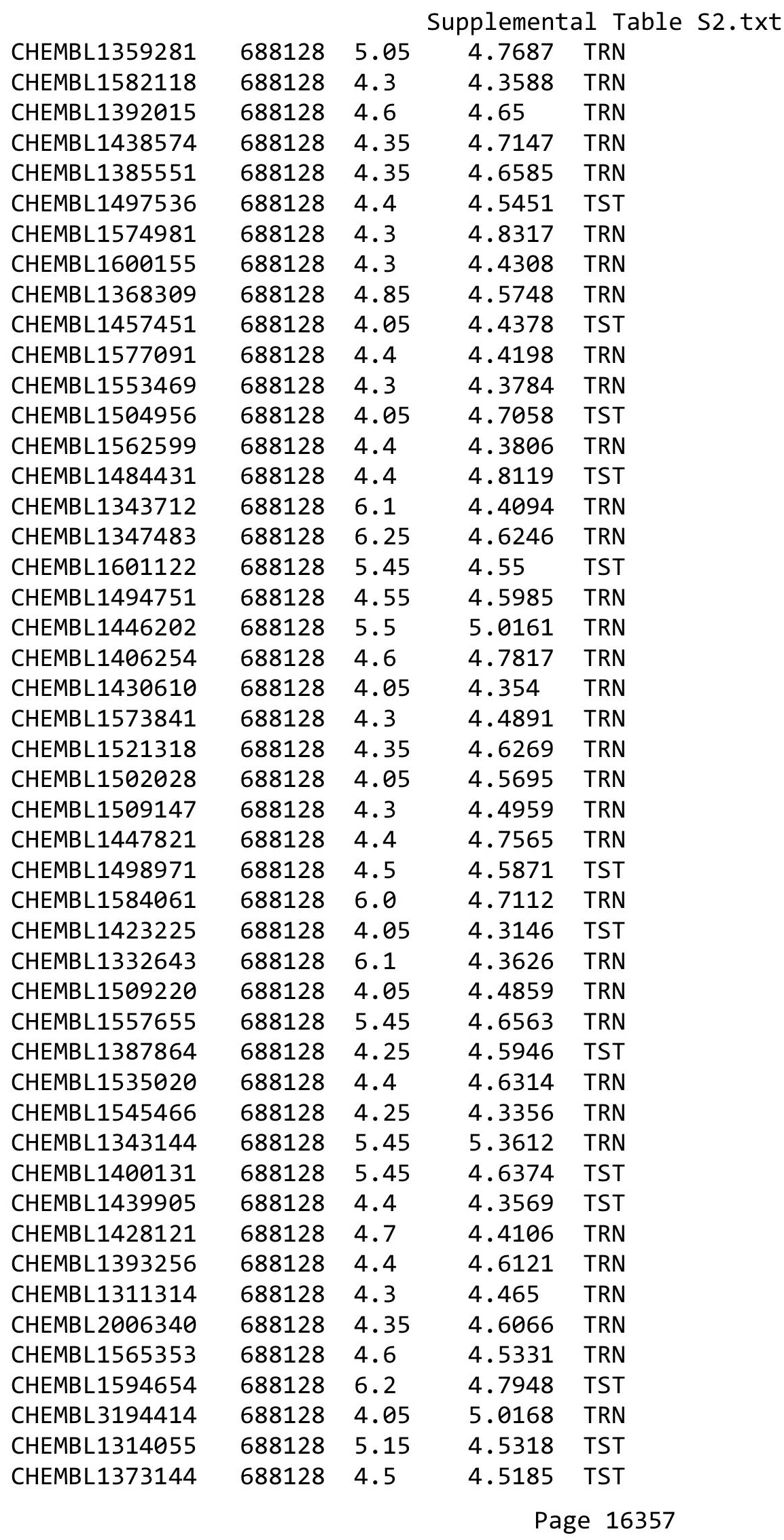




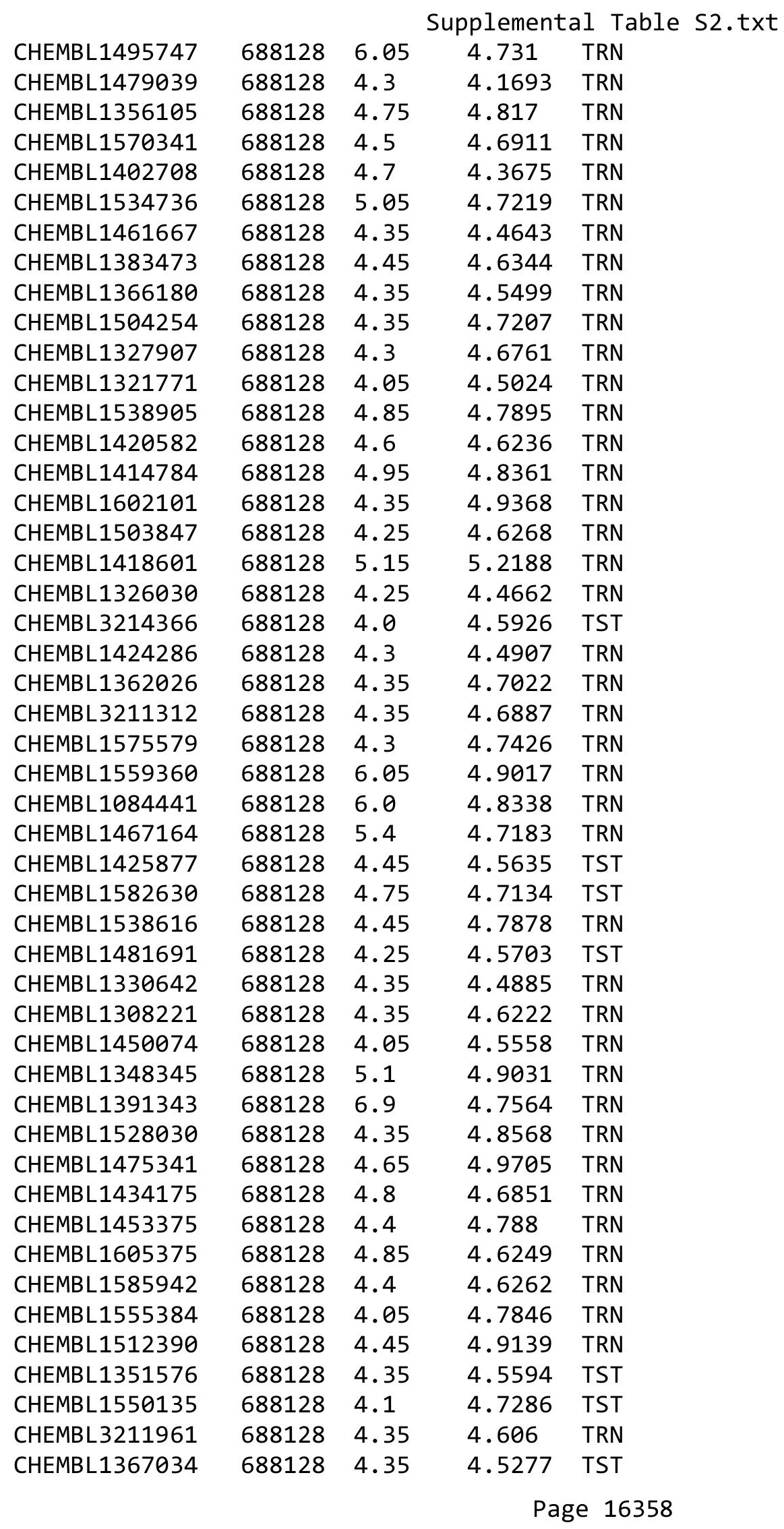




\begin{tabular}{|c|c|c|c|c|c|}
\hline & & \multicolumn{4}{|c|}{ Supplemental Table S2.txt } \\
\hline CHEMBL1597383 & 688128 & 4.95 & 4.4319 & TRN & \\
\hline CHEMBL1327179 & 688128 & 5.35 & 4.327 & TRN & \\
\hline CHEMBL1404153 & 688128 & 4.05 & 4.6784 & TST & \\
\hline CHEMBL1444950 & 688128 & 4.4 & 4.5755 & TRN & \\
\hline CHEMBL1448396 & 688128 & 4.05 & 4.6072 & TST & \\
\hline CHEMBL1495758 & 688128 & 4.3 & 4.64199 & 99999999995 & TRN \\
\hline CHEMBL3194751 & 688128 & 5.0 & 4.9565 & TRN & \\
\hline CHEMBL1350022 & 688128 & 4.85 & 4.5304 & TRN & \\
\hline CHEMBL1531439 & 688128 & 5.0 & 4.7158 & TRN & \\
\hline CHEMBL1427514 & 688128 & 4.55 & 4.7973 & TRN & \\
\hline CHEMBL1325456 & 688128 & 4.65 & 4.4041 & TRN & \\
\hline CHEMBL1355420 & 688128 & 4.4 & 4.5418 & TRN & \\
\hline CHEMBL1574571 & 688128 & 4.05 & 4.3943 & TST & \\
\hline CHEMBL1352863 & 688128 & 4.3 & 4.5587 & TRN & \\
\hline CHEMBL1433944 & 688128 & 4.4 & 4.7903 & TRN & \\
\hline CHEMBL1302731 & 688128 & 4.35 & 4.7022 & TRN & \\
\hline CHEMBL1568588 & 688128 & 4.05 & 4.5449 & TRN & \\
\hline CHEMBL1353727 & 688128 & 4.35 & 4.6765 & TRN & \\
\hline CHEMBL1345560 & 688128 & 4.4 & 4.6245 & TRN & \\
\hline CHEMBL1334903 & 688128 & 5.5 & 4.7335 & TRN & \\
\hline CHEMBL1534081 & 688128 & 4.05 & 4.6152 & TRN & \\
\hline CHEMBL1584444 & 688128 & 4.55 & 4.8434 & TRN & \\
\hline CHEMBL1327398 & 688128 & 4.05 & 4.2891 & TRN & \\
\hline CHEMBL1380804 & 688128 & 4.4 & 4.6689 & TRN & \\
\hline CHEMBL1414746 & 688128 & 6.05 & 4.7538 & TRN & \\
\hline CHEMBL1532364 & 688128 & 4.3 & 4.5742 & TRN & \\
\hline CHEMBL1354101 & 688128 & 5.45 & 4.3935 & TRN & \\
\hline CHEMBL1470463 & 688128 & 4.5 & 4.8256 & TRN & \\
\hline CHEMBL1532174 & 688128 & 4.55 & 4.5606 & TRN & \\
\hline CHEMBL1349705 & 688128 & 4.3 & 4.4603 & TRN & \\
\hline CHEMBL1365841 & 688128 & 4.25 & 4.9317 & TST & \\
\hline CHEMBL1515773 & 688128 & 4.05 & 4.4561 & TRN & \\
\hline CHEMBL1580040 & 688128 & 5.3 & 4.5706 & TRN & \\
\hline CHEMBL1303060 & 688128 & 4.05 & 4.5628 & TST & \\
\hline CHEMBL1557246 & 688128 & 4.4 & 4.575 & TRN & \\
\hline CHEMBL1558204 & 688128 & 4.35 & 5.0271 & TRN & \\
\hline CHEMBL1351407 & 688128 & 4.3 & 4.5146 & TRN & \\
\hline CHEMBL1342392 & 688128 & 4.7 & 4.5299 & TRN & \\
\hline CHEMBL1460154 & 688128 & 5.0 & 4.711 & TST & \\
\hline CHEMBL1995365 & 688128 & 4.3 & 4.6631 & TRN & \\
\hline CHEMBL1397528 & 688128 & 4.05 & 4.6185 & TST & \\
\hline CHEMBL1382390 & 688128 & 4.35 & 4.5249 & TRN & \\
\hline CHEMBL1438401 & 688128 & 4.9 & 4.4416 & TRN & \\
\hline CHEMBL1563009 & 688128 & 4.3 & 4.8468 & TRN & \\
\hline CHEMBL1309622 & 688128 & 4.5 & 4.6721 & TRN & \\
\hline CHEMBL1455390 & 688128 & 4.4 & 4.513 & TRN & \\
\hline CHEMBL1545142 & 688128 & 4.4 & 4.6917 & TRN & \\
\hline CHEMBL1582925 & 688128 & 4.45 & 4.5833 & TRN & \\
\hline
\end{tabular}




\begin{tabular}{|c|c|c|c|c|c|}
\hline & & \multicolumn{4}{|c|}{ Supplemental Table s2.txt } \\
\hline CHEMBL1517196 & 688128 & 4.1 & 4.6128 & TRN & \\
\hline CHEMBL1497133 & 688128 & 4.05 & 4.6719 & TST & \\
\hline CHEMBL1456381 & 688128 & 4.4 & 4.5881 & TRN & \\
\hline CHEMBL1555900 & 688128 & 5.4 & 4.7772 & TRN & \\
\hline CHEMBL3195363 & 688128 & 4.35 & 4.5144 & TST & \\
\hline CHEMBL1486605 & 688128 & 4.6 & 4.6879 & TRN & \\
\hline CHEMBL1521930 & 688128 & 5.0 & 4.7521 & TST & \\
\hline CHEMBL1509581 & 688128 & 4.9 & 4.6901 & TRN & \\
\hline CHEMBL1351081 & 688128 & 6.15 & 5.1831 & TRN & \\
\hline CHEMBL1555214 & 688128 & 5.0 & 4.9965 & TRN & \\
\hline CHEMBL1351212 & 688128 & 4.4 & 4.4484 & TRN & \\
\hline CHEMBL1430781 & 688128 & 4.3 & 4.4376 & TRN & \\
\hline CHEMBL1496390 & 688128 & 6.0 & 5.0018 & TRN & \\
\hline CHEMBL1467013 & 688128 & 4.35 & 4.2436 & TRN & \\
\hline CHEMBL1390636 & 688128 & 4.7 & 4.6888 & TRN & \\
\hline CHEMBL1435571 & 688128 & 6.1 & 4.676 & TST & \\
\hline CHEMBL1366123 & 688128 & 4.3 & 4.5991 & TRN & \\
\hline CHEMBL1391922 & 688128 & 4.55 & 4.6818 & TRN & \\
\hline CHEMBL1553673 & 688128 & 4.4 & 4.6499 & TST & \\
\hline CHEMBL1528435 & 688128 & 4.25 & 4.40600 & 0000000001 & TRN \\
\hline CHEMBL1471300 & 688128 & 4.05 & 4.3053 & TRN & \\
\hline CHEMBL1548782 & 688128 & 4.85 & 4.5829 & TST & \\
\hline CHEMBL1603699 & 688128 & 4.3 & 4.46899 & 9999999999 & TST \\
\hline CHEMBL1537678 & 688128 & 4.65 & 4.6161 & TRN & \\
\hline CHEMBL195705 & 688128 & 4.5 & 4.6567 & TRN & \\
\hline CHEMBL3199796 & 688128 & 4.45 & 4.7914 & TRN & \\
\hline CHEMBL1541557 & 688128 & 4.45 & 4.63 & TRN & \\
\hline CHEMBL1526323 & 688128 & 4.6 & 4.7965 & TRN & \\
\hline CHEMBL1419268 & 688128 & 4.55 & 4.6748 & TRN & \\
\hline CHEMBL1596744 & 688128 & 4.5 & 4.4947 & TST & \\
\hline CHEMBL1342054 & 688128 & 5.0 & 4.8574 & TRN & \\
\hline CHEMBL1325966 & 688128 & 4.5 & 4.6332 & TRN & \\
\hline CHEMBL1304408 & 688128 & 4.8 & 4.7108 & TRN & \\
\hline CHEMBL1487834 & 688128 & 5.35 & 5.0552 & TRN & \\
\hline CHEMBL1486979 & 688128 & 4.4 & 4.4461 & TRN & \\
\hline CHEMBL1460310 & 688128 & 4.3 & 4.9378 & TRN & \\
\hline CHEMBL1352514 & 688128 & 4.35 & 4.458 & TRN & \\
\hline CHEMBL1391180 & 688128 & 5.6 & 5.0953 & TRN & \\
\hline CHEMBL1337938 & 688128 & 4.5 & 4.6227 & TRN & \\
\hline CHEMBL1524376 & 688128 & 4.25 & 4.5893 & TRN & \\
\hline CHEMBL1508741 & 688128 & 4.55 & 4.2761 & TRN & \\
\hline CHEMBL1379136 & 688128 & 5.45 & 4.6619 & TRN & \\
\hline CHEMBL1574421 & 688128 & 4.45 & 4.2451 & TRN & \\
\hline CHEMBL1501629 & 688128 & 4.0 & 4.6972 & TST & \\
\hline CHEMBL1422324 & 688128 & 4.35 & 4.6758 & TRN & \\
\hline CHEMBL1383746 & 688128 & 5.8 & 5.0552 & TRN & \\
\hline CHEMBL1490141 & 688128 & 4.3 & 4.602 & TRN & \\
\hline CHEMBL1302721 & 688128 & 4.85 & 4.7629 & TRN & \\
\hline
\end{tabular}




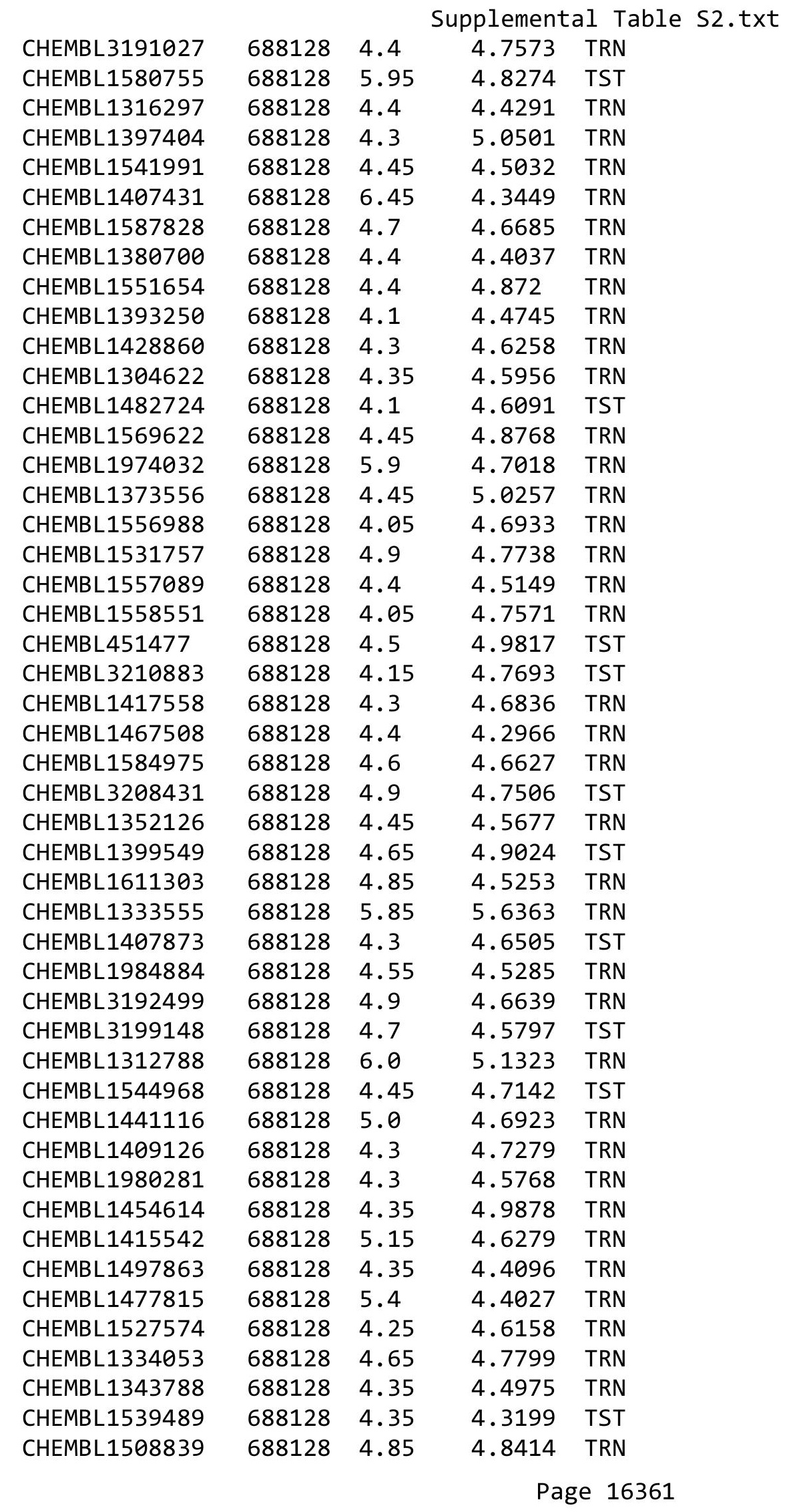




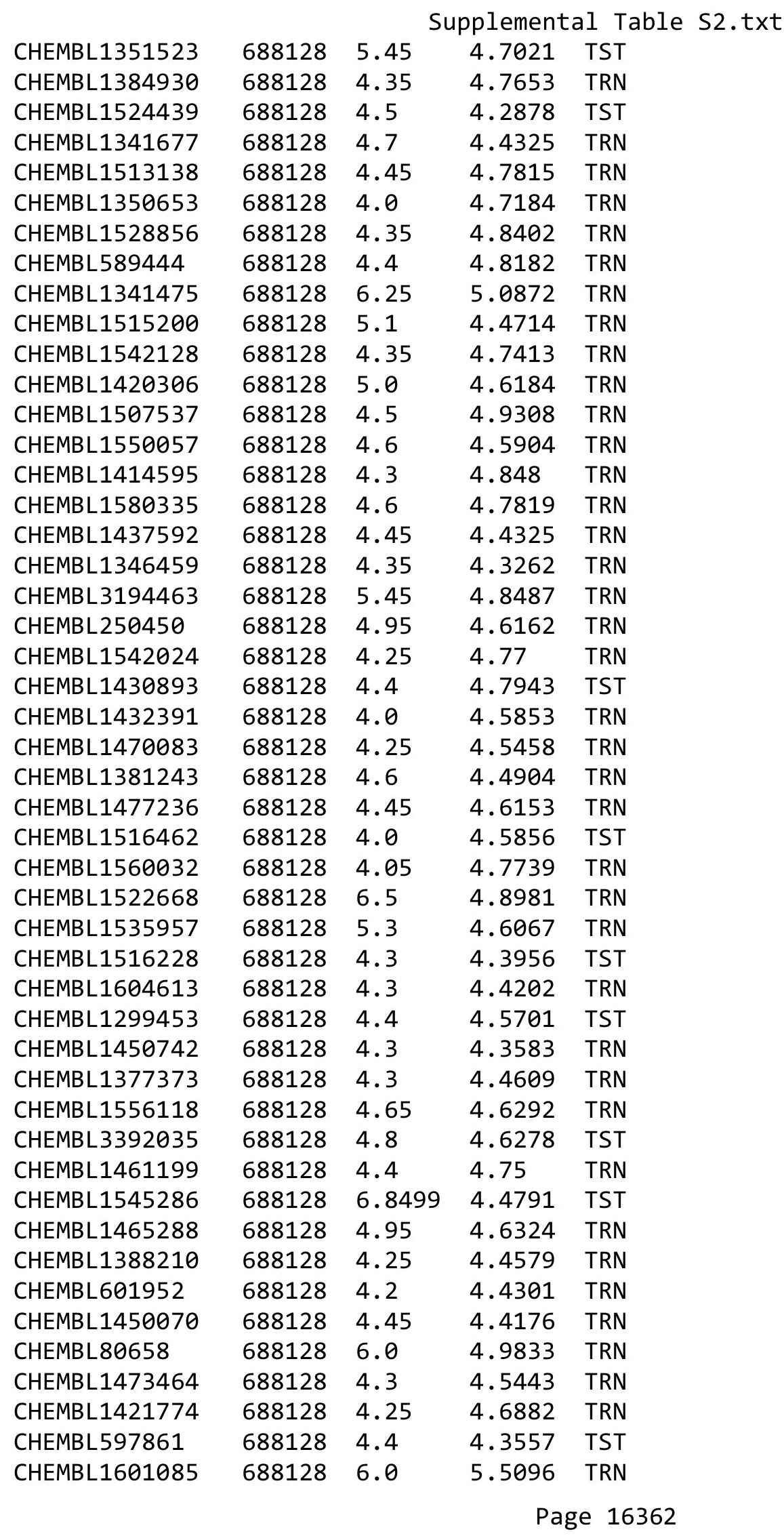




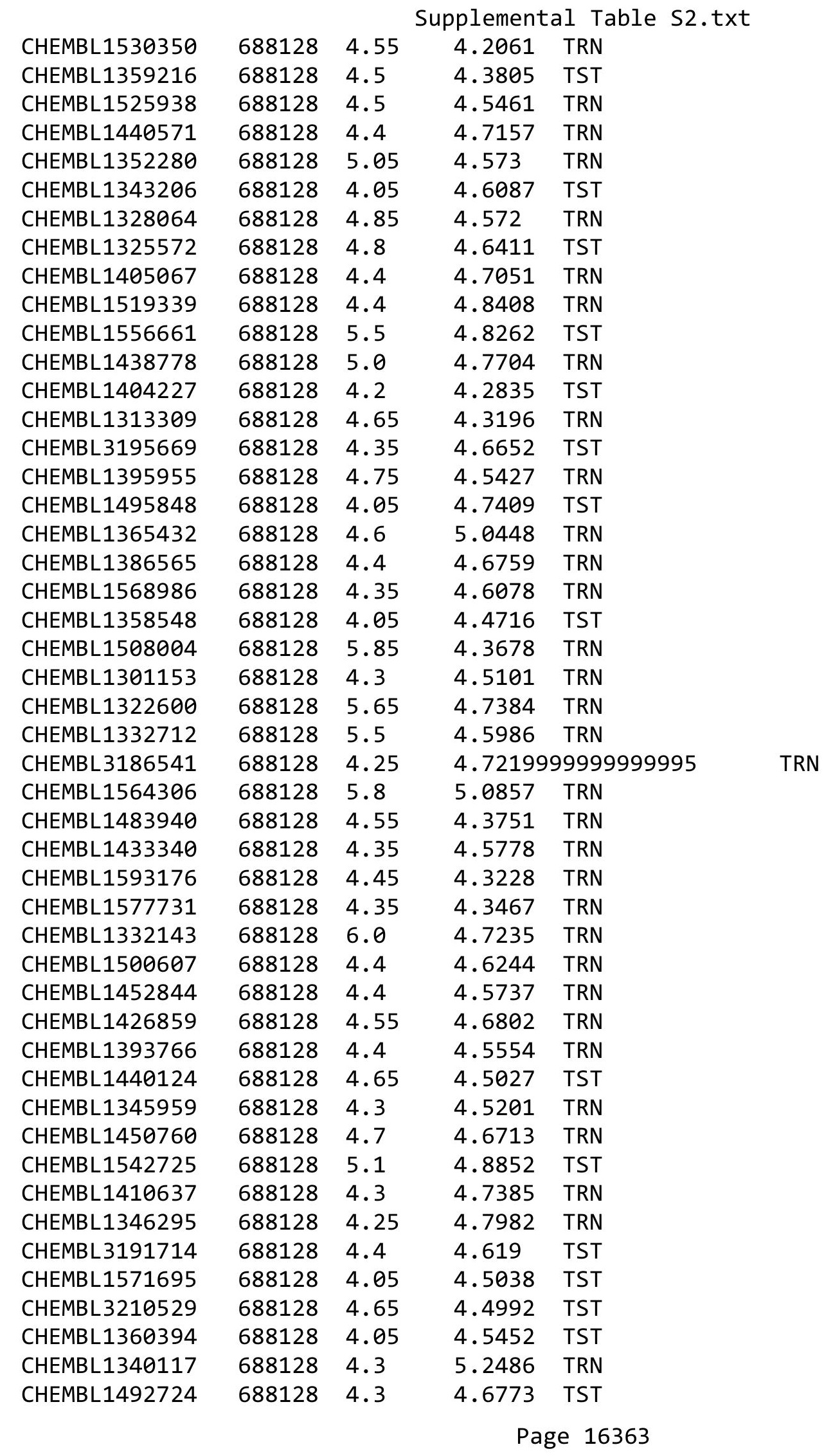




\begin{tabular}{|c|c|c|c|c|c|}
\hline & & \multicolumn{4}{|c|}{ Supplemental Table s2.txt } \\
\hline CHEMBL1325774 & 688128 & 4.65 & 4.4452 & TRN & \\
\hline CHEMBL1441236 & 688128 & 4.95 & 4.5167 & TRN & \\
\hline CHEMBL3211445 & 688128 & 4.35 & 4.4899 & TRN & \\
\hline CHEMBL1604232 & 688128 & 4.05 & 4.6856 & TRN & \\
\hline CHEMBL1410638 & 688128 & 4.75 & 4.6491 & TRN & \\
\hline CHEMBL1407750 & 688128 & 4.05 & 4.5508 & TST & \\
\hline CHEMBL1432148 & 688128 & 4.3 & 4.6811 & TST & \\
\hline CHEMBL1594915 & 688128 & 5.55 & 4.989 & TRN & \\
\hline CHEMBL1528271 & 688128 & 5.9 & 4.7515 & TST & \\
\hline CHEMBL3212812 & 688128 & 4.35 & 4.5339 & TRN & \\
\hline CHEMBL1329141 & 688128 & 4.5 & 5.2015 & TRN & \\
\hline CHEMBL1564535 & 688128 & 6.1 & 4.7023 & TRN & \\
\hline CHEMBL1355768 & 688128 & 4.05 & 4.3885 & TRN & \\
\hline CHEMBL1550384 & 688128 & 4.4 & 4.5014 & TST & \\
\hline CHEMBL1498073 & 688128 & 4.5 & 4.6522 & TRN & \\
\hline CHEMBL1411481 & 688128 & 4.5 & 4.5078 & TRN & \\
\hline CHEMBL1573538 & 688128 & 6.15 & 4.7976 & TRN & \\
\hline CHEMBL1381984 & 688128 & 4.4 & 4.6703 & TST & \\
\hline CHEMBL1385327 & 688128 & 5.15 & 5.1117 & TRN & \\
\hline CHEMBL1600284 & 688128 & 5.5 & 4.6005 & TST & \\
\hline CHEMBL1992689 & 688128 & 4.55 & 4.9997 & TRN & \\
\hline CHEMBL1355623 & 688128 & 4.25 & 4.628 & TST & \\
\hline CHEMBL1543719 & 688128 & 4.35 & 4.6927 & TRN & \\
\hline CHEMBL1339247 & 688128 & 5.55 & 4.7236 & TRN & \\
\hline CHEMBL1304121 & 688128 & 4.75 & 4.6023 & TST & \\
\hline CHEMBL1475347 & 688128 & 4.8 & 5.0548 & TRN & \\
\hline CHEMBL1467687 & 688128 & 4.55 & 4.6618 & TST & \\
\hline CHEMBL1577307 & 688128 & 4.55 & 4.8323 & TST & \\
\hline CHEMBL1602986 & 688128 & 4.55 & 4.4842 & TRN & \\
\hline CHEMBL1345401 & 688128 & 4.05 & 4.6163 & TRN & \\
\hline CHEMBL1574745 & 688128 & 4.05 & 4.5381 & TRN & \\
\hline CHEMBL1579591 & 688128 & 4.65 & 4.6013 & TST & \\
\hline CHEMBL1471900 & 688128 & 5.4 & 4.8169 & TRN & \\
\hline CHEMBL1602443 & 688128 & 4.25 & 5.0489 & TST & \\
\hline CHEMBL1365823 & 688128 & 5.7 & 4.9725 & TRN & \\
\hline CHEMBL1429122 & 688128 & 4.05 & 4.7888 & TST & \\
\hline CHEMBL1593691 & 688128 & 6.0 & 4.8672 & TRN & \\
\hline CHEMBL1422613 & 688128 & 5.3 & 5.016 & TRN & \\
\hline CHEMBL1568066 & 688128 & 4.2 & 4.5376 & TRN & \\
\hline CHEMBL1445232 & 688128 & 4.95 & 4.7827 & TRN & \\
\hline CHEMBL1379443 & 688128 & 5.15 & 4.4993 & TST & \\
\hline CHEMBL1590402 & 688128 & 5.75 & 4.9192 & TRN & \\
\hline CHEMBL1431684 & 688128 & 4.85 & 5.0086 & TRN & \\
\hline CHEMBL1477023 & 688128 & 4.4 & 4.6738 & TRN & \\
\hline CHEMBL1371078 & 688128 & 4.05 & 4.6583 & TST & \\
\hline CHEMBL1480659 & 688128 & 5.2 & 4.7633 & TRN & \\
\hline CHEMBL3189251 & 688128 & 4.55 & 4.9169 & TRN & \\
\hline CHEMBL1423623 & 688128 & 4.35 & 4.88899 & 9999999999 & TRN \\
\hline & & & & 16364 & \\
\hline
\end{tabular}




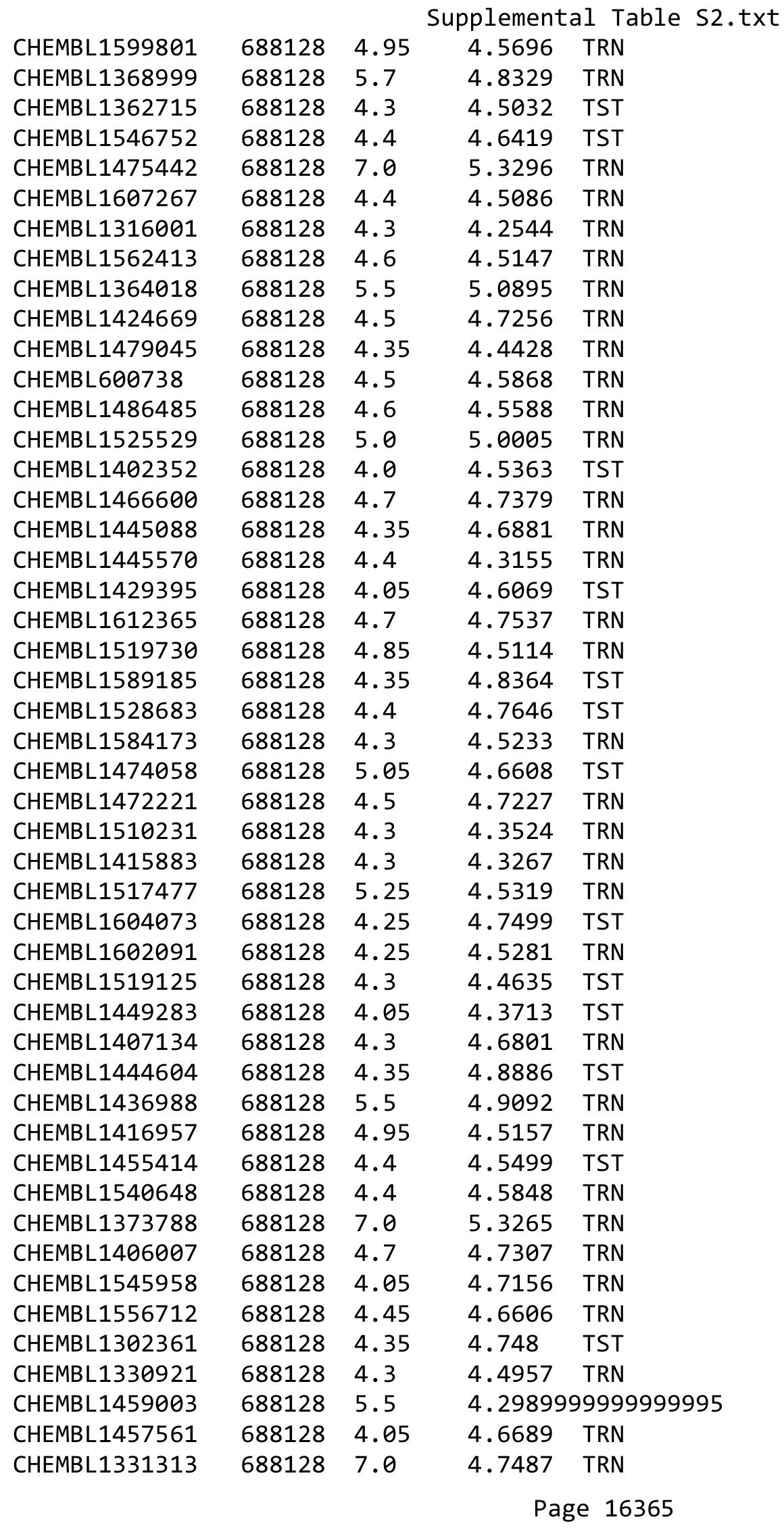

TRN 


\begin{tabular}{|c|c|c|c|c|c|}
\hline \\
\hline CHEMBL1324304 & 688128 & 4.35 & 4.4421 & TRN & \\
\hline CHEMBL1585654 & 688128 & 5.4 & 4.8541 & TRN & \\
\hline CHEMBL3198906 & 688128 & 5.4 & 4.6434 & TRN & \\
\hline CHEMBL1404480 & 688128 & 5.45 & 4.9933 & TRN & \\
\hline CHEMBL1409180 & 688128 & 4.5 & 4.7159 & TRN & \\
\hline CHEMBL1421887 & 688128 & 4.0 & 4.2688 & TRN & \\
\hline CHEMBL1475333 & 688128 & 4.4 & 4.5499 & TRN & \\
\hline CHEMBL1566671 & 688128 & 6.1 & 4.8062 & TRN & \\
\hline CHEMBL1515473 & 688128 & 4.8 & 4.6207 & TRN & \\
\hline CHEMBL1517789 & 688128 & 4.5 & 4.4681 & TRN & \\
\hline CHEMBL1555476 & 688128 & 4.95 & 4.9486 & TST & \\
\hline CHEMBL1306550 & 688128 & 5.85 & 4.59399 & 9999999999 & TRN \\
\hline CHEMBL1485829 & 688128 & 4.35 & 4.3915 & TRN & \\
\hline CHEMBL1348895 & 688128 & 5.0 & 4.5195 & TRN & \\
\hline CHEMBL1540979 & 688128 & 4.4 & 4.6124 & TST & \\
\hline CHEMBL1557133 & 688128 & 4.7 & 4.5888 & TRN & \\
\hline CHEMBL1418433 & 688128 & 4.1 & 4.6776 & TRN & \\
\hline CHEMBL1328911 & 688128 & 5.05 & 4.6403 & TRN & \\
\hline CHEMBL1447467 & 688128 & 5.0 & 4.7322 & TST & \\
\hline CHEMBL1352758 & 688128 & 4.3 & 4.7261 & TST & \\
\hline CHEMBL1450275 & 688128 & 4.9 & 4.5674 & TRN & \\
\hline CHEMBL591598 & 688128 & 4.0 & 4.2924 & TST & \\
\hline CHEMBL1552317 & 688128 & 4.05 & 4.3882 & TRN & \\
\hline CHEMBL1383387 & 688128 & 4.5 & 4.4709 & TRN & \\
\hline CHEMBL1473963 & 688128 & 4.55 & 4.5045 & TRN & \\
\hline CHEMBL1470712 & 688128 & 4.65 & 5.1706 & TRN & \\
\hline CHEMBL1367371 & 688128 & 4.05 & 4.4082 & TRN & \\
\hline CHEMBL1519014 & 688128 & 4.3 & 4.6379 & TST & \\
\hline CHEMBL1349697 & 688128 & 5.4 & 4.5285 & TRN & \\
\hline CHEMBL1411932 & 688128 & 4.05 & 4.55699 & 99999999995 & TRN \\
\hline CHEMBL1485934 & 688128 & 4.4 & 4.3224 & TRN & \\
\hline CHEMBL1375113 & 688128 & 4.05 & 4.1998 & TST & \\
\hline CHEMBL3191891 & 688128 & 4.35 & 4.7099 & TRN & \\
\hline CHEMBL1544515 & 688128 & 4.35 & 4.4276 & TRN & \\
\hline CHEMBL1531926 & 688128 & 4.3 & 4.3281 & TRN & \\
\hline CHEMBL1515898 & 688128 & 4.7 & 4.9836 & TRN & \\
\hline CHEMBL1529766 & 688128 & 4.75 & 4.5991 & TST & \\
\hline CHEMBL3194876 & 688128 & 5.0 & 4.8627 & TRN & \\
\hline CHEMBL1473915 & 688128 & 4.35 & 4.761 & TRN & \\
\hline CHEMBL3196620 & 688128 & 4.35 & 4.5805 & TRN & \\
\hline CHEMBL1321453 & 688128 & 6.8 & 4.6871 & TST & \\
\hline CHEMBL1412911 & 688128 & 4.75 & 4.7939 & TRN & \\
\hline CHEMBL1552401 & 688128 & 4.25 & 4.2262 & TRN & \\
\hline CHEMBL1557059 & 688128 & 4.4 & 4.6117 & TRN & \\
\hline CHEMBL1451497 & 688128 & 4.35 & 4.5366 & TRN & \\
\hline CHEMBL1365169 & 688128 & 4.55 & 4.395 & TRN & \\
\hline CHEMBL1559250 & 688128 & 4.35 & 4.9831 & TST & \\
\hline CHEMBL1494504 & 688128 & 4.35 & 4.5828 & TRN & \\
\hline
\end{tabular}




\begin{tabular}{|c|c|c|c|c|c|}
\hline \multirow{2}{*}{ CHEMBL1504009 } & \multirow{2}{*}{688128} & \\
\hline & & 5.9 & 4.9591 & TRN & \\
\hline CHEMBL1543652 & 688128 & 4.3 & 4.6214 & TRN & \\
\hline CHEMBL1508584 & 688128 & 4.9 & 4.4771 & TRN & \\
\hline CHEMBL1378616 & 688128 & 5.4 & 5.0531 & TRN & \\
\hline CHEMBL213580 & 688128 & 7.0 & 5.2465 & TST & \\
\hline CHEMBL1311638 & 688128 & 4.45 & 4.4149 & TRN & \\
\hline CHEMBL1547329 & 688128 & 4.35 & 4.2737 & TST & \\
\hline CHEMBL1564368 & 688128 & 4.55 & 4.3663 & TRN & \\
\hline CHEMBL1460263 & 688128 & 4.0 & 4.4124 & TRN & \\
\hline CHEMBL1367793 & 688128 & 4.85 & 4.3418 & TRN & \\
\hline CHEMBL1613405 & 688128 & 4.6 & 4.4903 & TST & \\
\hline CHEMBL1451639 & 688128 & 5.4 & 4.4529 & TRN & \\
\hline CHEMBL1561774 & 688128 & 4.05 & 4.6332 & TST & \\
\hline CHEMBL1388324 & 688128 & 4.0 & 4.7701 & TST & \\
\hline CHEMBL 3196834 & 688128 & 4.35 & 4.5102 & TRN & \\
\hline CHEMBL1400789 & 688128 & 4.4 & 4.5587 & TRN & \\
\hline CHEMBL1416391 & 688128 & 5.6 & 4.6237 & TRN & \\
\hline CHEMBL1530652 & 688128 & 4.3 & 4.6661 & TRN & \\
\hline CHEMBL1445237 & 688128 & 4.25 & 4.6205 & TRN & \\
\hline CHEMBL1486416 & 688128 & 4.3 & 4.5691 & TRN & \\
\hline CHEMBL1493712 & 688128 & 5.5 & 4.5121 & TRN & \\
\hline CHEMBL1526582 & 688128 & 4.3 & 4.4871 & TST & \\
\hline CHEMBL3198912 & 688128 & 4.8 & 4.5653 & TST & \\
\hline CHEMBL1430423 & 688128 & 4.45 & 4.9344 & TRN & \\
\hline CHEMBL1573701 & 688128 & 4.3 & 4.5543 & TRN & \\
\hline CHEMBL1391063 & 688128 & 4.8 & 5.0936 & TST & \\
\hline CHEMBL1602160 & 688128 & 6.0 & 4.9545 & TST & \\
\hline CHEMBL60718 & 688128 & 4.95 & 5.1293 & TRN & \\
\hline CHEMBL1558672 & 688128 & 5.85 & 4.5325 & TRN & \\
\hline CHEMBL1597789 & 688128 & 4.45 & 4.6427 & TRN & \\
\hline CHEMBL1369482 & 688128 & 4.4 & 4.7738 & TST & \\
\hline CHEMBL1613672 & 688128 & 4.65 & 4.515 & TRN & \\
\hline CHEMBL1481266 & 688128 & 4.3 & 4.6107 & TRN & \\
\hline CHEMBL1580646 & 688128 & 4.45 & 4.4219 & TRN & \\
\hline CHEMBL1308373 & 688128 & 4.5 & 4.399 & TRN & \\
\hline CHEMBL1507372 & 688128 & 5.55 & 4.915 & TRN & \\
\hline CHEMBL1522186 & 688128 & 5.25 & 4.9164 & TST & \\
\hline CHEMBL1468958 & 688128 & 4.3 & 4.5591 & TRN & \\
\hline CHEMBL1388329 & 688128 & 4.4 & 4.5604 & TRN & \\
\hline CHEMBL1363050 & 688128 & 5.95 & 4.8851 & TRN & \\
\hline CHEMBL1405245 & 688128 & 4.4 & 4.8256 & TRN & \\
\hline CHEMBL1528369 & 688128 & 5.4 & 4.5376 & TRN & \\
\hline CHEMBL1392234 & 688128 & 5.15 & 4.4499 & TST & \\
\hline CHEMBL1417892 & 688128 & 4.2 & 4.3759 & TRN & \\
\hline CHEMBL1436226 & 688128 & 4.05 & 4.6518 & TST & \\
\hline CHEMBL1383064 & 688128 & 4.5 & 4.5834 & TST & \\
\hline CHEMBL1357828 & 688128 & 4.4 & 4.5639 & TRN & \\
\hline CHEMBL 3189249 & 688128 & 7.5498 & 4.7010 & 00000000005 & TST \\
\hline & & & & 16367 & \\
\hline
\end{tabular}




\begin{tabular}{|c|c|c|c|c|c|}
\hline & & \multicolumn{4}{|c|}{ Supplemental Table s2.txt } \\
\hline CHEMBL1393216 & 688128 & 4.35 & 4.2286 & TRN & \\
\hline CHEMBL1396490 & 688128 & 5.05 & 5.0045 & TRN & \\
\hline CHEMBL1451271 & 688128 & 5.3 & 4.8462 & TST & \\
\hline CHEMBL1458434 & 688128 & 4.4 & 4.508 & TST & \\
\hline CHEMBL1445437 & 688128 & 4.55 & 4.6624 & TRN & \\
\hline CHEMBL1519069 & 688128 & 4.95 & 4.9675 & TST & \\
\hline CHEMBL1470711 & 688128 & 4.05 & 4.4712 & TRN & \\
\hline CHEMBL1351323 & 688128 & 4.3 & 4.3592 & TRN & \\
\hline CHEMBL1412144 & 688128 & 5.2 & 4.76 & TRN & \\
\hline CHEMBL1551363 & 688128 & 4.35 & 4.8229 & TST & \\
\hline CHEMBL1540427 & 688128 & 4.55 & 4.8762 & TST & \\
\hline CHEMBL1508154 & 688128 & 4.05 & 4.5009 & TRN & \\
\hline CHEMBL1533959 & 688128 & 4.85 & 4.862 & TRN & \\
\hline CHEMBL 3208475 & 688128 & 4.0 & 4.4171 & TRN & \\
\hline CHEMBL1610354 & 688128 & 4.4 & 4.4068 & TRN & \\
\hline CHEMBL1387212 & 688128 & 4.4 & 4.8317 & TRN & \\
\hline CHEMBL1608351 & 688128 & 4.05 & 4.7013 & TST & \\
\hline CHEMBL1602624 & 688128 & 4.6 & 4.6454 & TRN & \\
\hline CHEMBL1546777 & 688128 & 4.35 & 4.9049 & TRN & \\
\hline CHEMBL1421054 & 688128 & 4.05 & 4.3807 & TRN & \\
\hline CHEMBL1300903 & 688128 & 4.45 & 4.5653 & TRN & \\
\hline CHEMBL3199585 & 688128 & 4.5 & 4.578 & TRN & \\
\hline CHEMBL1605709 & 688128 & 4.4 & 4.7005 & TRN & \\
\hline CHEMBL1383925 & 688128 & 4.75 & 4.7006 & TRN & \\
\hline CHEMBL1517411 & 688128 & 4.95 & 4.7553 & TRN & \\
\hline CHEMBL1429804 & 688128 & 4.4 & 4.7188 & TRN & \\
\hline CHEMBL1397162 & 688128 & 4.0 & 4.8031 & TST & \\
\hline CHEMBL1612018 & 688128 & 4.95 & 4.6233 & TRN & \\
\hline CHEMBL1421428 & 688128 & 4.4 & 4.5204 & TRN & \\
\hline CHEMBL1376591 & 688128 & 6.1 & 4.6329 & TRN & \\
\hline CHEMBL1606243 & 688128 & 5.05 & 4.41 & TRN & \\
\hline CHEMBL1515505 & 688128 & 4.4 & 4.4391 & TST & \\
\hline CHEMBL1371773 & 688128 & 4.35 & 4.7406 & TRN & \\
\hline CHEMBL1535537 & 688128 & 4.4 & 4.6177 & TRN & \\
\hline CHEMBL1602181 & 688128 & 4.35 & 4.4894 & TRN & \\
\hline CHEMBL1397632 & 688128 & 4.35 & 4.56800 & 00000000005 & TRN \\
\hline CHEMBL1397031 & 688128 & 4.3 & 4.4851 & TRN & \\
\hline CHEMBL1336890 & 688128 & 5.9 & 4.6334 & TRN & \\
\hline CHEMBL1444578 & 688128 & 4.3 & 4.6412 & TRN & \\
\hline CHEMBL1421261 & 688128 & 4.6 & 4.5347 & TRN & \\
\hline CHEMBL1598152 & 688128 & 4.0 & 4.5198 & TRN & \\
\hline CHEMBL1505168 & 688128 & 4.35 & 4.3666 & TRN & \\
\hline CHEMBL1413557 & 688128 & 4.75 & 4.7177 & TRN & \\
\hline CHEMBL1462495 & 688128 & 5.0 & 4.7949 & TRN & \\
\hline CHEMBL1469127 & 688128 & 5.05 & 4.612 & TST & \\
\hline CHEMBL1310722 & 688128 & 4.8 & 4.5617 & TRN & \\
\hline CHEMBL46881 & 688128 & 4.05 & 4.4822 & TRN & \\
\hline CHEMBL1517255 & 688128 & 5.45 & 4.6318 & TRN & \\
\hline
\end{tabular}




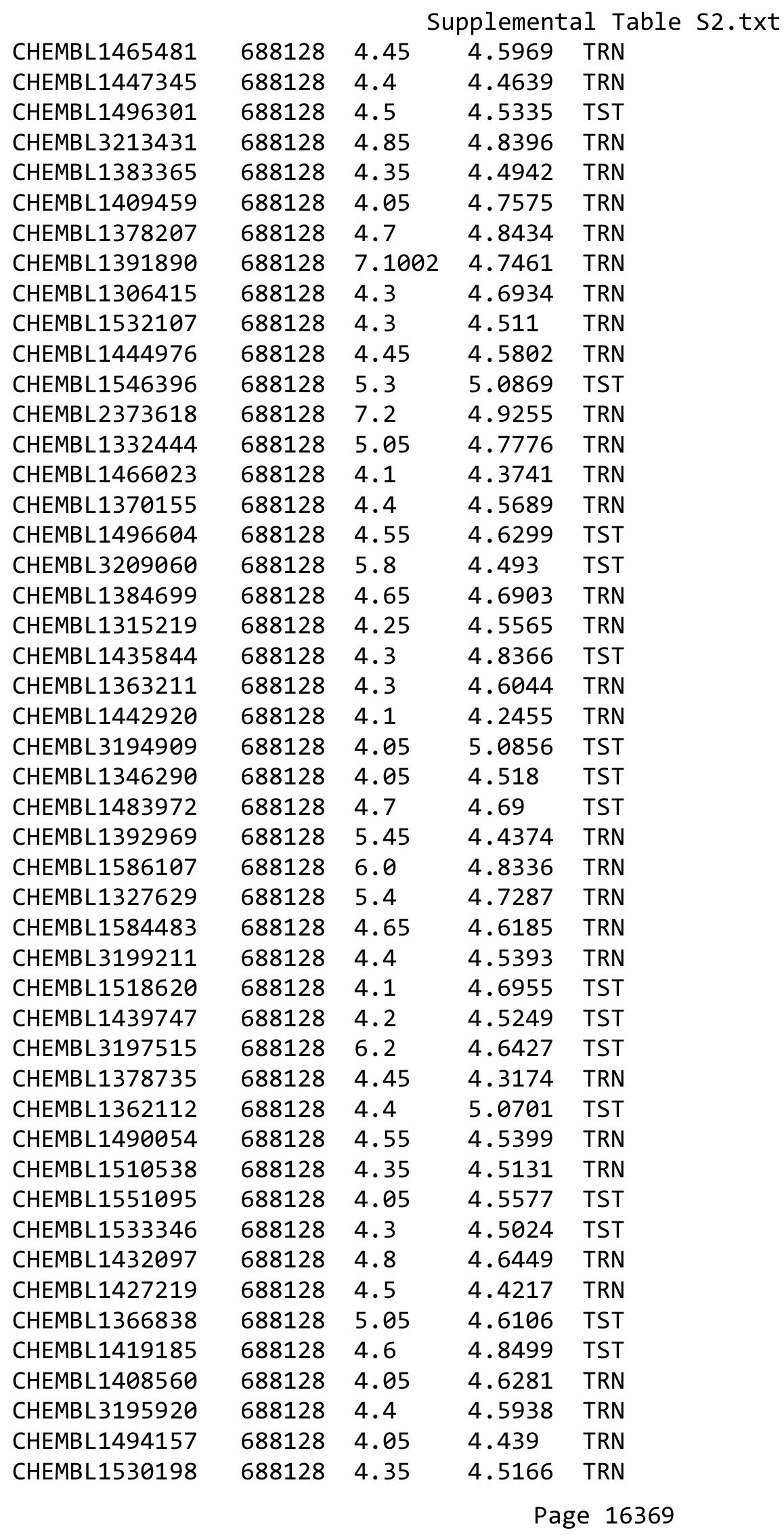




\begin{tabular}{|c|c|c|c|c|c|}
\hline \multicolumn{6}{|c|}{ Supplemental Table S2.txt } \\
\hline CHEMBL1346267 & 688128 & 4.4 & 4.7958 & TRN & \\
\hline CHEMBL1425609 & 688128 & 4.05 & 4.7327 & TRN & \\
\hline CHEMBL1576892 & 688128 & 6.05 & 4.995 & TRN & \\
\hline CHEMBL1600587 & 688128 & 5.0 & 5.3219 & TRN & \\
\hline CHEMBL1502814 & 688128 & 4.55 & 4.5706 & TRN & \\
\hline CHEMBL1604743 & 688128 & 4.9 & 4.5842 & TRN & \\
\hline CHEMBL1731995 & 688128 & 5.3 & 4.8206 & TRN & \\
\hline CHEMBL1334633 & 688128 & 5.1 & 5.1871 & TRN & \\
\hline CHEMBL1419338 & 688128 & 6.15 & 4.6564 & TRN & \\
\hline CHEMBL1582178 & 688128 & 4.5 & 4.3327 & TST & \\
\hline CHEMBL1314395 & 688128 & 5.1 & 4.6332 & TRN & \\
\hline CHEMBL 3198658 & 688128 & 4.4 & 4.5044 & TRN & \\
\hline CHEMBL1312744 & 688128 & 4.45 & 4.3841 & TRN & \\
\hline CHEMBL1342223 & 688128 & 4.45 & 4.4392 & TRN & \\
\hline CHEMBL1579470 & 688128 & 4.35 & 4.7971 & TST & \\
\hline CHEMBL1540888 & 688128 & 4.05 & 4.5015 & TST & \\
\hline CHEMBL1589526 & 688128 & 6.5501 & 5.2333 & TRN & \\
\hline CHEMBL1345639 & 688128 & 4.45 & 4.2223 & TRN & \\
\hline CHEMBL1441178 & 688128 & 4.95 & 4.4389 & TRN & \\
\hline CHEMBL1532228 & 688128 & 4.35 & 4.4925 & TRN & \\
\hline CHEMBL1371788 & 688128 & 4.05 & 4.3255 & TST & \\
\hline CHEMBL1563809 & 688128 & 5.0 & 4.6198 & TRN & \\
\hline CHEMBL1477122 & 688128 & 4.8 & 4.6734 & TRN & \\
\hline CHEMBL1339499 & 688128 & 4.35 & 4.57100 & 2000000001 & TRN \\
\hline CHEMBL3213560 & 688128 & 4.35 & 4.3424 & TRN & \\
\hline CHEMBL1566069 & 688128 & 4.3 & 4.4072 & TRN & \\
\hline CHEMBL1451311 & 688128 & 4.4 & 4.5859 & TST & \\
\hline CHEMBL1563200 & 688128 & 4.05 & 4.72199 & 99999999995 & TST \\
\hline CHEMBL1416754 & 688128 & 4.5 & 4.6201 & TRN & \\
\hline CHEMBL432044 & 688128 & 4.15 & 4.7854 & TRN & \\
\hline CHEMBL1300409 & 688128 & 4.25 & 4.5048 & TRN & \\
\hline CHEMBL1432717 & 688128 & 4.65 & 4.3922 & TRN & \\
\hline CHEMBL1393869 & 688128 & 4.05 & 4.7756 & TRN & \\
\hline CHEMBL3198758 & 688128 & 6.1 & 4.4694 & TST & \\
\hline CHEMBL1313733 & 688128 & 4.35 & 4.4543 & TST & \\
\hline CHEMBL1498952 & 688128 & 5.45 & 4.6871 & TRN & \\
\hline CHEMBL1319024 & 688128 & 4.35 & 4.8101 & TRN & \\
\hline CHEMBL1425000 & 688128 & 4.3 & 4.5426 & TRN & \\
\hline CHEMBL1370579 & 688128 & 5.45 & 4.936 & TRN & \\
\hline CHEMBL1475692 & 688128 & 4.4 & 4.7183 & TRN & \\
\hline CHEMBL1601748 & 688128 & 4.15 & 4.3384 & TST & \\
\hline CHEMBL1363283 & 688128 & 5.0 & 4.5091 & TRN & \\
\hline CHEMBL1978903 & 688128 & 4.25 & 4.5148 & TST & \\
\hline CHEMBL1457630 & 688128 & 5.05 & 4.9421 & TST & \\
\hline CHEMBL1522724 & 688128 & 4.6 & 4.6212 & TRN & \\
\hline CHEMBL1458750 & 688128 & 4.45 & 4.4 & TRN & \\
\hline CHEMBL1550927 & 688128 & 4.8 & 4.5935 & TRN & \\
\hline CHEMBL1312736 & 688128 & 4.35 & 4.6425 & TRN & \\
\hline
\end{tabular}




\begin{tabular}{|c|c|c|c|c|}
\hline \multicolumn{5}{|c|}{ Supplemental Table S2.txt } \\
\hline CHEMBL3208971 & 688128 & 4.4 & 4.7596 & TST \\
\hline CHEMBL1570574 & 688128 & 6.1 & 4.5341 & TST \\
\hline CHEMBL1609521 & 688128 & 4.05 & 4.6761 & TST \\
\hline CHEMBL1563021 & 688128 & 4.2 & 4.332 & TRN \\
\hline CHEMBL1344190 & 688128 & 4.55 & 4.6095 & TRN \\
\hline CHEMBL1534649 & 688128 & 4.4 & 4.8262 & TRN \\
\hline CHEMBL1523277 & 688128 & 5.2 & 4.5944 & TRN \\
\hline CHEMBL1980588 & 688128 & 4.95 & 4.7898 & TRN \\
\hline CHEMBL1597986 & 688128 & 4.0 & 4.3842 & TRN \\
\hline CHEMBL1588183 & 688128 & 4.6 & 4.37 & TRN \\
\hline CHEMBL 3194269 & 688128 & 4.35 & 4.6315 & TRN \\
\hline CHEMBL1530151 & 688128 & 4.4 & 4.6513 & TRN \\
\hline CHEMBL1414911 & 688128 & 4.55 & 4.6283 & TRN \\
\hline CHEMBL1515153 & 688128 & 4.25 & 4.4574 & TRN \\
\hline CHEMBL1443131 & 688128 & 4.05 & 4.698 & TST \\
\hline CHEMBL1386336 & 688128 & 4.3 & 4.3921 & TRN \\
\hline CHEMBL1349306 & 688128 & 4.6 & 4.8261 & TRN \\
\hline CHEMBL1397709 & 688128 & 4.55 & 4.5707 & TST \\
\hline CHEMBL3195709 & 688128 & 6.1 & 4.8647 & TST \\
\hline CHEMBL3213813 & 688128 & 4.1 & 4.4641 & TST \\
\hline CHEMBL1486966 & 688128 & 4.55 & 4.7549 & TRN \\
\hline CHEMBL1517812 & 688128 & 4.3 & 4.4393 & TRN \\
\hline CHEMBL1426115 & 688128 & 4.35 & 4.76 & TRN \\
\hline CHEMBL1363719 & 688128 & 5.8 & 5.3411 & TRN \\
\hline CHEMBL1353914 & 688128 & 4.55 & 4.4648 & TRN \\
\hline CHEMBL1426919 & 688128 & 4.05 & 4.5195 & TRN \\
\hline CHEMBL1382795 & 688128 & 4.25 & 4.6055 & TRN \\
\hline CHEMBL1386108 & 688128 & 4.5 & 4.3623 & TRN \\
\hline CHEMBL1336774 & 688128 & 4.65 & 4.6601 & TRN \\
\hline CHEMBL1466756 & 688128 & 4.55 & 4.5646 & TST \\
\hline CHEMBL1324682 & 688128 & 4.85 & 4.4382 & TRN \\
\hline CHEMBL1428001 & 688128 & 4.3 & 4.5172 & TST \\
\hline CHEMBL1368139 & 688128 & 4.55 & 4.4175 & TRN \\
\hline CHEMBL1470229 & 688128 & 4.4 & 4.7804 & TRN \\
\hline CHEMBL3194672 & 688128 & 4.35 & 4.4885 & TRN \\
\hline CHEMBL1341127 & 688128 & 5.8 & 4.3372 & TRN \\
\hline CHEMBL1406919 & 688128 & 5.4 & 4.9259 & TST \\
\hline CHEMBL1475731 & 688128 & 5.9 & 4.4737 & TRN \\
\hline CHEMBL1523732 & 688128 & 5.7 & 4.4058 & TRN \\
\hline CHEMBL1368041 & 688128 & 4.9 & 4.6703 & TRN \\
\hline CHEMBL1606468 & 688128 & 5.0 & 4.4268 & TRN \\
\hline CHEMBL1393193 & 688128 & 5.5 & 4.5934 & TRN \\
\hline CHEMBL1314737 & 688128 & 4.4 & 4.5223 & TRN \\
\hline CHEMBL1482069 & 688128 & 5.0 & 4.5419 & TRN \\
\hline CHEMBL1422954 & 688128 & 4.3 & 4.3015 & TRN \\
\hline CHEMBL1586531 & 688128 & 6.1 & 5.3944 & TRN \\
\hline CHEMBL1606400 & 688128 & 5.75 & 4.6763 & TRN \\
\hline CHEMBL 3208383 & 688128 & 4.95 & 4.9079 & TST \\
\hline
\end{tabular}




\begin{tabular}{|c|c|c|c|c|}
\hline \multicolumn{5}{|c|}{ Supplemental Tabl } \\
\hline CHEMBL1391267 & 688128 & 4.45 & 4.7403 & TRN \\
\hline CHEMBL1462156 & 688128 & 4.55 & 4.6566 & TRN \\
\hline CHEMBL1446372 & 688128 & 5.2 & 4.7542 & TRN \\
\hline CHEMBL1444958 & 688128 & 4.25 & 4.9283 & TRN \\
\hline CHEMBL1302056 & 688128 & 4.3 & 4.3986 & TRN \\
\hline CHEMBL1596993 & 688128 & 5.4 & 4.5932 & TRN \\
\hline CHEMBL1299746 & 688128 & 4.5 & 4.47 & TST \\
\hline CHEMBL1328987 & 688128 & 4.35 & 4.6485 & TRN \\
\hline CHEMBL1561357 & 688128 & 4.05 & 4.3961 & TRN \\
\hline CHEMBL 1487022 & 688128 & 4.35 & 4.4129 & TRN \\
\hline CHEMBL3191473 & 688128 & 4.6 & 4.8506 & TST \\
\hline CHEMBL1593562 & 688128 & 4.4 & 4.396 & TRN \\
\hline CHEMBL1401703 & 688128 & 4.35 & 4.3329 & TRN \\
\hline CHEMBL1416788 & 688128 & 4.55 & 4.6036 & TRN \\
\hline CHEMBL 2000670 & 688128 & 5.4 & 4.6491 & TST \\
\hline CHEMBL1543848 & 688128 & 4.4 & 4.512 & TRN \\
\hline CHEMBL1609327 & 688128 & 4.75 & 4.9223 & TST \\
\hline CHEMBL1426643 & 688128 & 4.4 & 4.6448 & TST \\
\hline CHEMBL1443216 & 688128 & 4.4 & 4.7454 & TRN \\
\hline CHEMBL3194508 & 688128 & 4.0 & 4.7537 & TST \\
\hline CHEMBL1557752 & 688128 & 5.15 & 4.8563 & TRN \\
\hline CHEMBL1579828 & 688128 & 4.05 & 4.6578 & TST \\
\hline CHEMBL1582205 & 688128 & 4.55 & 4.9028 & TRN \\
\hline CHEMBL1486131 & 688128 & 5.0 & 4.73 & TRN \\
\hline CHEMBL1442600 & 688128 & 4.45 & 4.4786 & TST \\
\hline CHEMBL1531126 & 688128 & 4.05 & 4.6583 & TST \\
\hline CHEMBL1541441 & 688128 & 5.55 & 5.267 & TRN \\
\hline CHEMBL1420319 & 688128 & 4.9 & 4.5324 & TRN \\
\hline CHEMBL1366669 & 688128 & 4.4 & 4.7367 & TRN \\
\hline CHEMBL1421972 & 688128 & 4.3 & 4.6005 & TRN \\
\hline CHEMBL1530611 & 688128 & 5.95 & 4.7384 & TRN \\
\hline CHEMBL1568818 & 688128 & 4.9 & 4.3479 & TST \\
\hline CHEMBL1369532 & 688128 & 4.05 & 4.6339 & TST \\
\hline CHEMBL1328990 & 688128 & 5.45 & 4.9109 & TRN \\
\hline CHEMBL1381744 & 688128 & 4.45 & 4.7275 & TRN \\
\hline CHEMBL1549014 & 688128 & 6.5 & 4.6892 & TRN \\
\hline CHEMBL1441170 & 688128 & 4.25 & 4.3461 & TST \\
\hline CHEMBL1576668 & 688128 & 4.75 & 4.7829 & TRN \\
\hline CHEMBL1419822 & 688128 & 5.75 & 4.9507 & TRN \\
\hline CHEMBL1305898 & 688128 & 5.4 & 4.5763 & TRN \\
\hline CHEMBL1567495 & 688128 & 4.3 & 4.4565 & TRN \\
\hline CHEMBL1504234 & 688128 & 4.35 & 4.4939 & TRN \\
\hline CHEMBL1458105 & 688128 & 4.3 & 4.7191 & TST \\
\hline CHEMBL1516345 & 688128 & 4.3 & 4.6389 & TRN \\
\hline CHEMBL1360155 & 688128 & 4.6 & 4.695 & TRN \\
\hline CHEMBL1398748 & 688128 & 4.5 & 4.8055 & TRN \\
\hline CHEMBL600841 & 688128 & 4.1 & 4.5756 & TRN \\
\hline CHEMBL1526564 & 688128 & 4.4 & 4.4799 & TST \\
\hline
\end{tabular}




\begin{tabular}{|c|c|c|c|c|c|}
\hline \multicolumn{6}{|c|}{ Supplemental Table S2.txt } \\
\hline CHEMBL1485455 & 688128 & 5.5 & 4.6032 & TRN & \\
\hline CHEMBL1367350 & 688128 & 4.35 & 4.3976 & TRN & \\
\hline CHEMBL1417149 & 688128 & 4.25 & 4.6614 & TST & \\
\hline CHEMBL1371391 & 688128 & 5.1 & 4.6338 & TRN & \\
\hline CHEMBL1409643 & 688128 & 4.45 & 4.8504 & TRN & \\
\hline CHEMBL1548821 & 688128 & 5.55 & 4.7654 & TST & \\
\hline CHEMBL1347524 & 688128 & 4.35 & 4.83 & TRN & \\
\hline CHEMBL1573563 & 688128 & 4.4 & 4.54899 & 99999999995 & TST \\
\hline CHEMBL1516907 & 688128 & 4.35 & 4.3056 & TRN & \\
\hline CHEMBL1572039 & 688128 & 4.35 & 4.613 & TST & \\
\hline CHEMBL1416126 & 688128 & 4.3 & 4.2272 & TRN & \\
\hline CHEMBL1491005 & 688128 & 4.3 & 4.4613 & TRN & \\
\hline CHEMBL1548368 & 688128 & 4.9 & 4.3555 & TST & \\
\hline CHEMBL1549804 & 688128 & 4.4 & 4.7854 & TST & \\
\hline CHEMBL1488395 & 688128 & 4.35 & 4.8152 & TRN & \\
\hline CHEMBL1486307 & 688128 & 4.75 & 4.5585 & TRN & \\
\hline CHEMBL1314343 & 688128 & 4.35 & 4.7787 & TRN & \\
\hline CHEMBL1570565 & 688128 & 4.3 & 4.8589 & TST & \\
\hline CHEMBL1544415 & 688128 & 4.35 & 4.4803 & TRN & \\
\hline CHEMBL1432520 & 688128 & 4.4 & 4.502 & TRN & \\
\hline CHEMBL1449573 & 688128 & 4.1 & 4.5223 & TRN & \\
\hline CHEMBL1563460 & 688128 & 4.4 & 4.4638 & TRN & \\
\hline CHEMBL1566013 & 688128 & 5.0 & 4.6674 & TRN & \\
\hline CHEMBL1476692 & 688128 & 4.05 & 4.613 & TST & \\
\hline CHEMBL1530778 & 688128 & 4.35 & 4.5936 & TRN & \\
\hline CHEMBL1489334 & 688128 & 4.0 & 4.3913 & TST & \\
\hline CHEMBL1502353 & 688128 & 4.6 & 4.7066 & TST & \\
\hline CHEMBL1608611 & 688128 & 4.25 & 4.6448 & TRN & \\
\hline CHEMBL1379235 & 688128 & 4.45 & 4.4695 & TST & \\
\hline CHEMBL1320777 & 688128 & 4.4 & 4.379 & TST & \\
\hline CHEMBL1494677 & 688128 & 4.35 & 4.5889 & TRN & \\
\hline CHEMBL1319350 & 688128 & 4.4 & 4.5163 & TRN & \\
\hline CHEMBL 3145382 & 688128 & 4.3 & 4.7306 & TST & \\
\hline CHEMBL1384557 & 688128 & 4.3 & 4.7177 & TRN & \\
\hline CHEMBL1462321 & 688128 & 4.4 & 4.6375 & TRN & \\
\hline CHEMBL1567504 & 688128 & 4.4 & 4.7813 & TRN & \\
\hline CHEMBL1333246 & 688128 & 4.05 & 4.5955 & TRN & \\
\hline CHEMBL1560574 & 688128 & 4.35 & 4.1825 & TRN & \\
\hline CHEMBL1977974 & 688128 & 4.55 & 4.6415 & TRN & \\
\hline CHEMBL1402465 & 688128 & 4.5 & 4.4439 & TRN & \\
\hline CHEMBL1582308 & 688128 & 4.65 & 4.7287 & TRN & \\
\hline CHEMBL1306399 & 688128 & 5.4 & 4.3995 & TST & \\
\hline CHEMBL1606036 & 688128 & 4.4 & $4.5680 e$ & 30000000005 & TST \\
\hline CHEMBL1451672 & 688128 & 4.5 & 4.4874 & TRN & \\
\hline CHEMBL1493396 & 688128 & 5.6 & 4.9027 & TRN & \\
\hline CHEMBL1482190 & 688128 & 4.05 & 4.4954 & TRN & \\
\hline CHEMBL1367587 & 688128 & 4.35 & 4.9265 & TRN & \\
\hline CHEMBL1435926 & 688128 & 4.4 & 5.0159 & TRN & \\
\hline
\end{tabular}




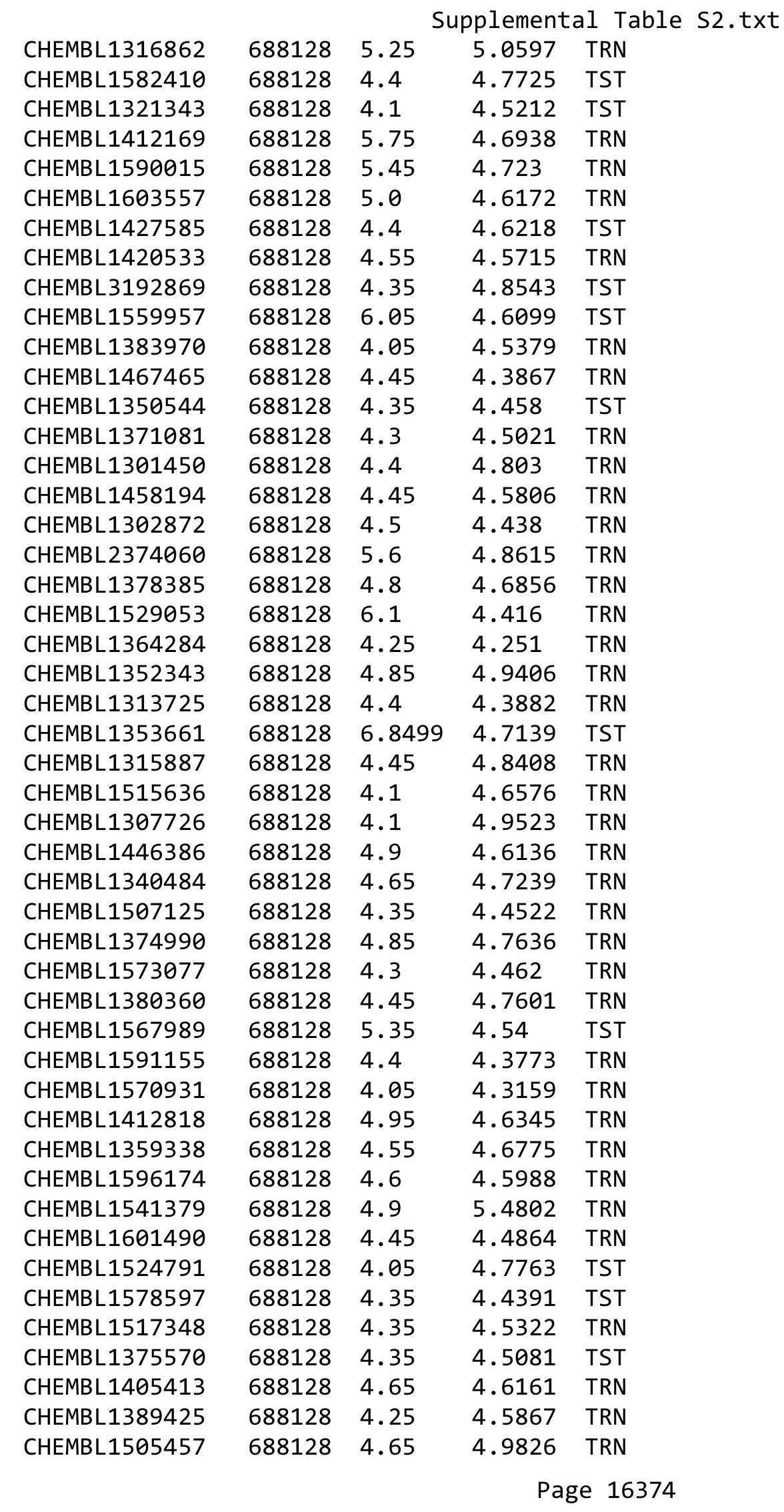




\begin{tabular}{|c|c|c|c|c|}
\hline \multicolumn{5}{|c|}{ Supplemental Tabl } \\
\hline CHEMBL1536650 & 688128 & 5.35 & 4.598 & TRN \\
\hline CHEMBL1543952 & 688128 & 4.3 & 4.5523 & TRN \\
\hline CHEMBL1471665 & 688128 & 5.05 & 4.8092 & TRN \\
\hline CHEMBL1592934 & 688128 & 4.4 & 4.2081 & TRN \\
\hline CHEMBL1468960 & 688128 & 4.15 & 4.5021 & TRN \\
\hline CHEMBL1580047 & 688128 & 4.45 & 4.7048 & TRN \\
\hline CHEMBL1529730 & 688128 & 4.05 & 4.7223 & TRN \\
\hline CHEMBL1594777 & 688128 & 5.0 & 4.6873 & TST \\
\hline CHEMBL1577365 & 688128 & 4.4 & 4.59 & TST \\
\hline CHEMBL1566032 & 688128 & 4.4 & 4.5459 & TRN \\
\hline CHEMBL1369680 & 688128 & 4.4 & 4.4233 & TST \\
\hline CHEMBL1574603 & 688128 & 4.35 & 4.896 & TST \\
\hline CHEMBL1339747 & 688128 & 4.8 & 4.5308 & TRN \\
\hline CHEMBL 2000592 & 688128 & 4.4 & 4.5496 & TRN \\
\hline CHEMBL1545995 & 688128 & 4.05 & 4.5325 & TST \\
\hline CHEMBL1448849 & 688128 & 4.25 & 4.6285 & TST \\
\hline CHEMBL1388857 & 688128 & 4.4 & 4.3853 & TRN \\
\hline CHEMBL1494656 & 688128 & 4.3 & 4.5437 & TRN \\
\hline CHEMBL1564250 & 688128 & 4.65 & 4.9158 & TST \\
\hline CHEMBL1344926 & 688128 & 5.1 & 4.6979 & TRN \\
\hline CHEMBL1365988 & 688128 & 4.55 & 5.0242 & TRN \\
\hline CHEMBL3192905 & 688128 & 4.05 & 4.5442 & TRN \\
\hline CHEMBL1385038 & 688128 & 5.4 & 4.9606 & TRN \\
\hline CHEMBL1390549 & 688128 & 4.45 & 4.5698 & TRN \\
\hline CHEMBL1568225 & 688128 & 4.3 & 4.3003 & TRN \\
\hline CHEMBL1323940 & 688128 & 4.4 & 4.8694 & TST \\
\hline CHEMBL1432157 & 688128 & 4.9 & 4.4986 & TRN \\
\hline CHEMBL 2000172 & 688128 & 5.0 & 4.8928 & TRN \\
\hline CHEMBL1497076 & 688128 & 4.3 & 4.6689 & TRN \\
\hline CHEMBL1473564 & 688128 & 4.05 & 4.6741 & TST \\
\hline CHEMBL1413217 & 688128 & 4.65 & 4.5127 & TST \\
\hline CHEMBL1468033 & 688128 & 4.65 & 4.4328 & TRN \\
\hline CHEMBL1461581 & 688128 & 4.4 & 4.5603 & TRN \\
\hline CHEMBL1407508 & 688128 & 4.05 & 4.6043 & TRN \\
\hline CHEMBL1452633 & 688128 & 4.4 & 4.7268 & TRN \\
\hline CHEMBL1411705 & 688128 & 4.05 & 4.6049 & TRN \\
\hline CHEMBL1331115 & 688128 & 4.5 & 4.601 & TRN \\
\hline CHEMBL1492777 & 688128 & 4.55 & 4.7056 & TRN \\
\hline CHEMBL1461015 & 688128 & 4.4 & 4.9807 & TRN \\
\hline CHEMBL1398964 & 688128 & 5.0 & 4.9816 & TST \\
\hline CHEMBL1592811 & 688128 & 7.0 & 5.2825 & TRN \\
\hline CHEMBL1591110 & 688128 & 4.4 & 4.548 & TST \\
\hline CHEMBL1419063 & 688128 & 4.35 & 4.6245 & TRN \\
\hline CHEMBL1476715 & 688128 & 4.35 & 4.6557 & TRN \\
\hline CHEMBL1563090 & 688128 & 4.35 & 4.4946 & TRN \\
\hline CHEMBL 210572 & 688128 & 4.05 & 4.4553 & TRN \\
\hline CHEMBL1555645 & 688128 & 4.55 & 5.1588 & TRN \\
\hline CHEMBL1473914 & 688128 & 5.75 & 5.4304 & TRN \\
\hline
\end{tabular}




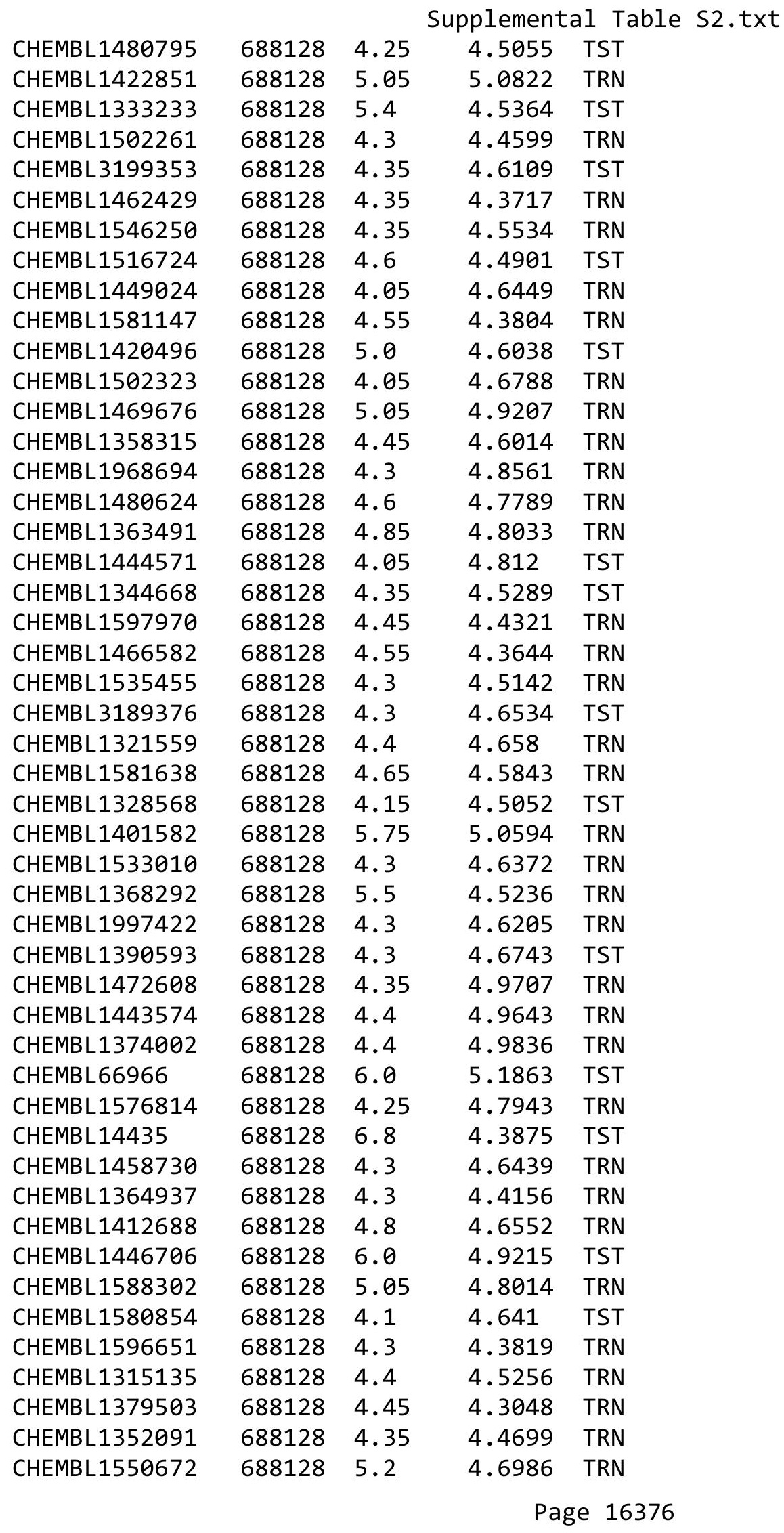




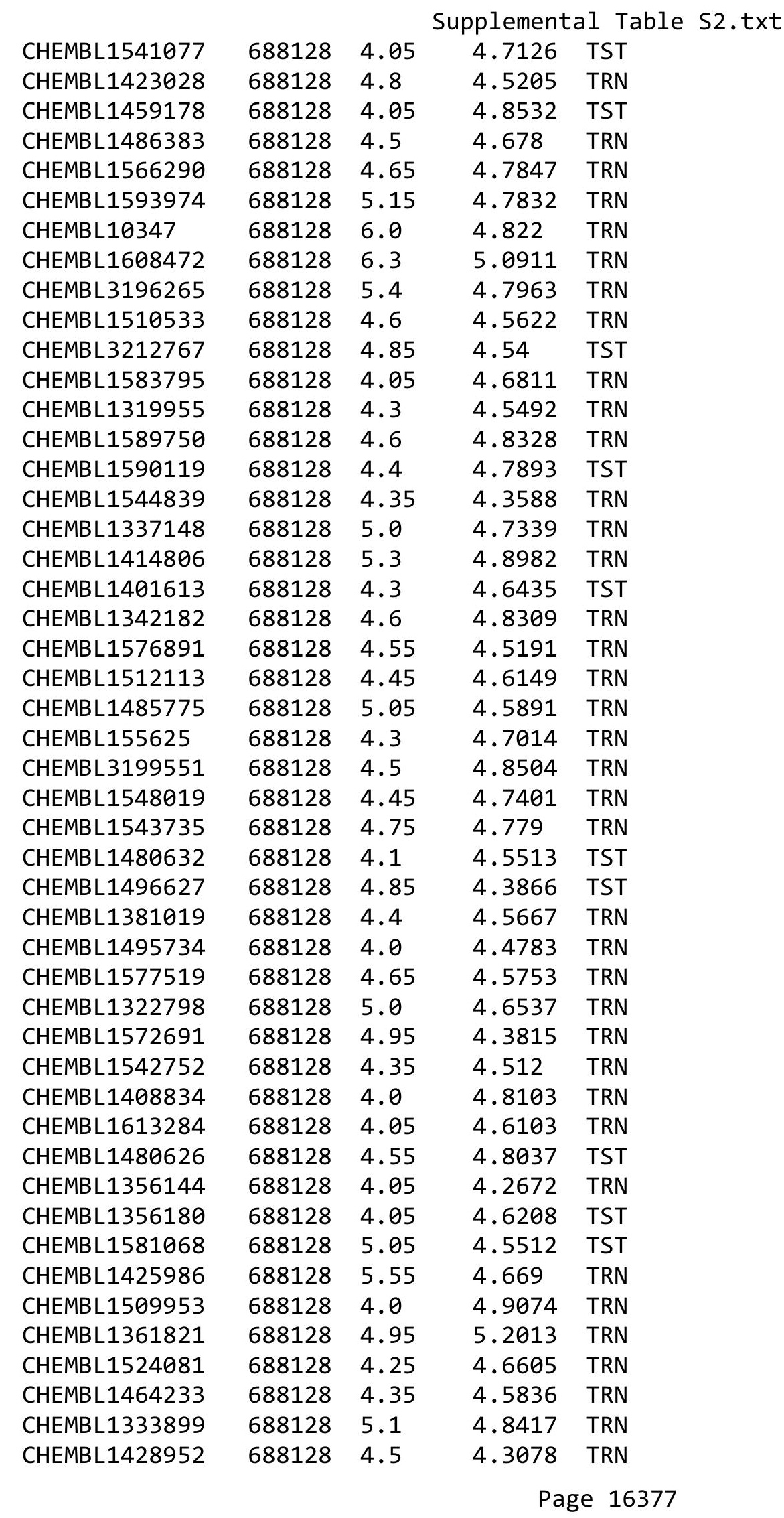




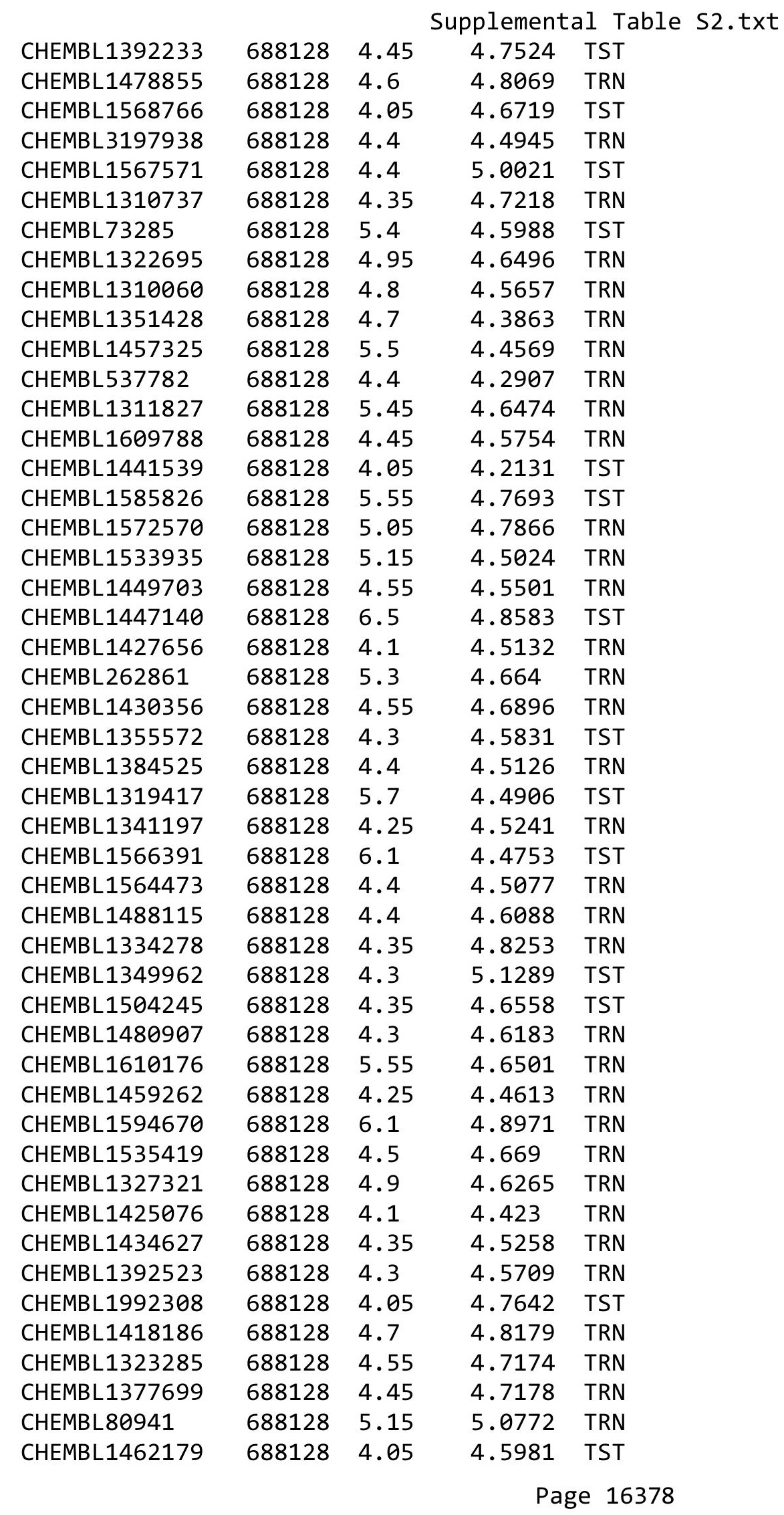




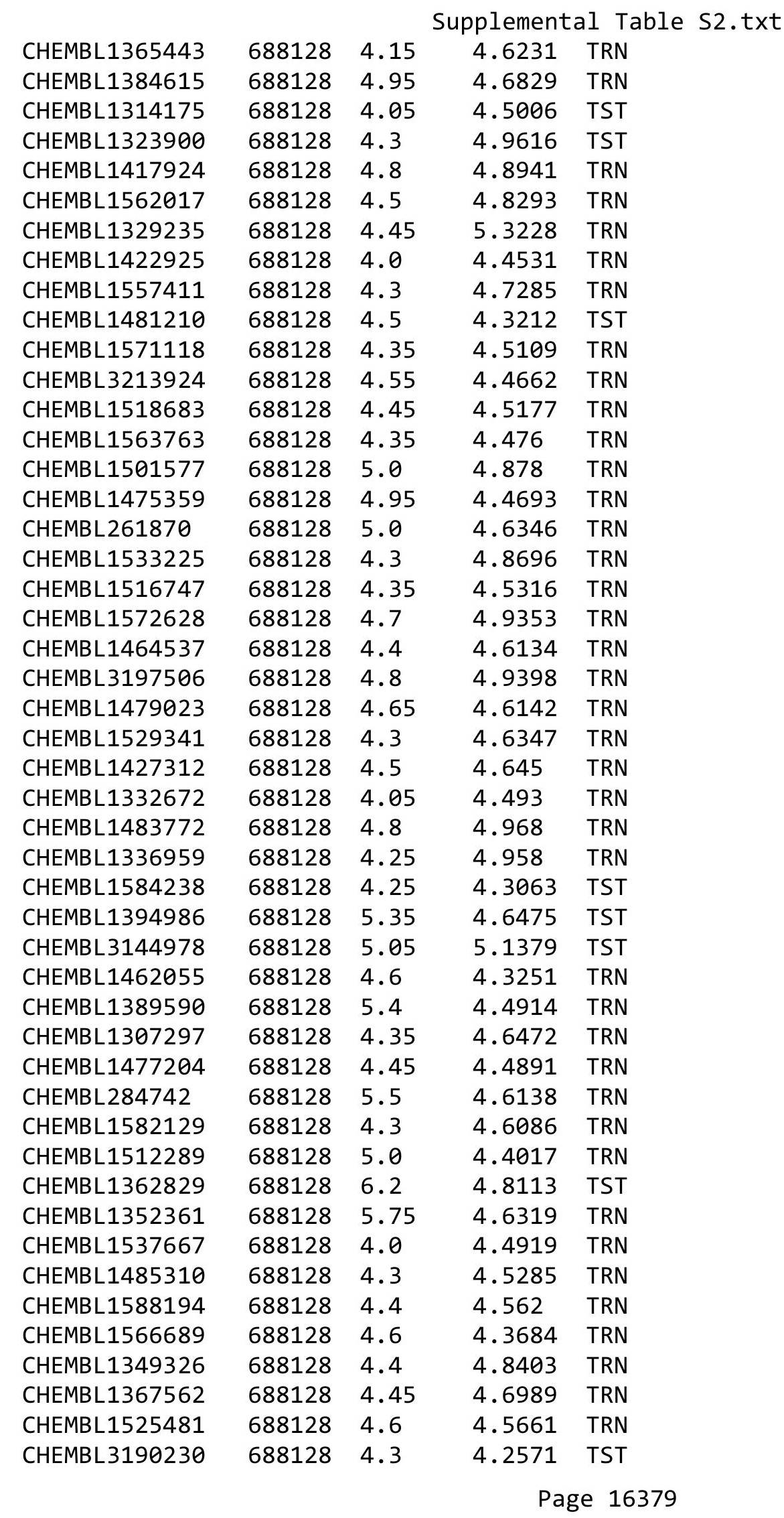




\begin{tabular}{|c|c|c|c|c|}
\hline \multicolumn{5}{|c|}{ Supplemental Table S2.txt } \\
\hline CHEMBL1304591 & 688128 & 4.7 & 4.604 & TST \\
\hline CHEMBL1449185 & 688128 & 4.65 & 4.6966 & TRN \\
\hline CHEMBL1407294 & 688128 & 4.15 & 4.9676 & TST \\
\hline CHEMBL1593031 & 688128 & 4.5 & 4.8053 & TRN \\
\hline CHEMBL1610947 & 688128 & 4.4 & 4.5591 & TRN \\
\hline CHEMBL1394610 & 688128 & 4.4 & 4.6573 & TRN \\
\hline CHEMBL1427277 & 688128 & 4.35 & 4.8008 & TRN \\
\hline CHEMBL3198029 & 688128 & 4.3 & 4.7116 & TRN \\
\hline CHEMBL1333348 & 688128 & 4.25 & 4.5563 & TRN \\
\hline CHEMBL1314094 & 688128 & 4.45 & 4.65 & TRN \\
\hline CHEMBL1378069 & 688128 & 4.4 & 4.685 & TRN \\
\hline CHEMBL1407501 & 688128 & 4.4 & 4.7051 & TRN \\
\hline CHEMBL1374635 & 688128 & 4.05 & 4.5938 & TRN \\
\hline CHEMBL1605695 & 688128 & 4.05 & 4.5364 & TRN \\
\hline CHEMBL1377737 & 688128 & 6.35 & 5.2675 & TRN \\
\hline CHEMBL1473556 & 688128 & 6.1 & 4.4029 & TST \\
\hline CHEMBL1407409 & 688128 & 4.3 & 4.8976 & TRN \\
\hline CHEMBL1456313 & 688128 & 4.55 & 4.7218 & TST \\
\hline CHEMBL1313135 & 688128 & 4.0 & 4.5731 & TRN \\
\hline CHEMBL1304357 & 688128 & 4.4 & 4.8419 & TST \\
\hline CHEMBL1573583 & 688128 & 4.65 & 4.6206 & TRN \\
\hline CHEMBL1370424 & 688128 & 4.75 & 4.4898 & TRN \\
\hline CHEMBL3213791 & 688128 & 5.5 & 4.8235 & TST \\
\hline CHEMBL1442773 & 688128 & 4.25 & 4.8511 & TRN \\
\hline CHEMBL1507533 & 688128 & 4.05 & 4.8055 & TST \\
\hline CHEMBL1435798 & 688128 & 5.0 & 4.3703 & TRN \\
\hline CHEMBL1307600 & 688128 & 4.75 & 4.6571 & TST \\
\hline CHEMBL1567083 & 688128 & 4.4 & 4.601 & TRN \\
\hline CHEMBL1542545 & 688128 & 4.05 & 4.8387 & TRN \\
\hline CHEMBL1366686 & 688128 & 4.4 & 4.8099 & TST \\
\hline CHEMBL1606503 & 688128 & 4.05 & 4.5744 & TRN \\
\hline CHEMBL1566330 & 688128 & 4.4 & 4.2971 & TRN \\
\hline CHEMBL1300980 & 688128 & 6.5501 & 4.7851 & TST \\
\hline CHEMBL1372076 & 688128 & 5.9 & 4.8385 & TRN \\
\hline CHEMBL1316002 & 688128 & 4.35 & 4.7311 & TRN \\
\hline CHEMBL1327237 & 688128 & 4.05 & 4.5882 & TRN \\
\hline CHEMBL1489039 & 688128 & 4.85 & 4.7193 & TRN \\
\hline CHEMBL448328 & 688128 & 4.3 & 4.8313 & TRN \\
\hline CHEMBL1584828 & 688128 & 5.0 & 4.9271 & TRN \\
\hline CHEMBL489696 & 688128 & 4.5 & 4.5749 & TRN \\
\hline CHEMBL1495438 & 688128 & 5.0 & 4.9371 & TRN \\
\hline CHEMBL1341241 & 688128 & 4.75 & 4.9026 & TRN \\
\hline CHEMBL3213987 & 688128 & 5.2 & 4.4246 & TST \\
\hline CHEMBL1349798 & 688128 & 5.0 & 4.5494 & TRN \\
\hline CHEMBL1316064 & 688128 & 4.3 & 4.5707 & TRN \\
\hline CHEMBL1596342 & 688128 & 6.3 & 4.9627 & TRN \\
\hline CHEMBL1590626 & 688128 & 4.3 & 4.3894 & TRN \\
\hline CHEMBL1545531 & 688128 & 4.3 & 4.9121 & TST \\
\hline
\end{tabular}




\begin{tabular}{|c|c|c|c|c|}
\hline \multicolumn{5}{|c|}{ Supplemental Table S2.txt } \\
\hline CHEMBL1376081 & 688128 & 4.4 & 4.73 & TST \\
\hline CHEMBL1470303 & 688128 & 4.4 & 4.6875 & TRN \\
\hline CHEMBL1489993 & 688128 & 5.1 & 4.4894 & TST \\
\hline CHEMBL1444832 & 688128 & 4.25 & 4.378 & TRN \\
\hline CHEMBL1497016 & 688128 & 4.35 & 4.5554 & TRN \\
\hline CHEMBL1504033 & 688128 & 4.3 & 4.7293 & TRN \\
\hline CHEMBL1341220 & 688128 & 6.15 & 4.4949 & TRN \\
\hline CHEMBL1563755 & 688128 & 4.85 & 4.6517 & TST \\
\hline CHEMBL1349686 & 688128 & 4.35 & 4.8256 & TRN \\
\hline CHEMBL1337716 & 688128 & 6.5 & 5.1394 & TRN \\
\hline CHEMBL1434852 & 688128 & 4.45 & 4.5825 & TST \\
\hline CHEMBL3198017 & 688128 & 4.4 & 4.7405 & TRN \\
\hline CHEMBL1601329 & 688128 & 5.15 & 4.6284 & TRN \\
\hline CHEMBL1398087 & 688128 & 4.05 & 4.7268 & TRN \\
\hline CHEMBL3209491 & 688128 & 4.4 & 4.845 & TRN \\
\hline CHEMBL1455402 & 688128 & 5.45 & 4.9851 & TRN \\
\hline CHEMBL1313564 & 688128 & 4.45 & 4.5127 & TST \\
\hline CHEMBL1331111 & 688128 & 4.3 & 4.5752 & TRN \\
\hline CHEMBL1569829 & 688128 & 4.3 & 4.322 & TRN \\
\hline CHEMBL1347369 & 688128 & 4.7 & 5.143 & TST \\
\hline CHEMBL1382825 & 688128 & 5.35 & 4.5722 & TST \\
\hline CHEMBL1429307 & 688128 & 4.45 & 4.6288 & TST \\
\hline CHEMBL1449387 & 688128 & 4.45 & 4.7981 & TRN \\
\hline CHEMBL1478054 & 688128 & 4.4 & 4.6154 & TRN \\
\hline CHEMBL1608042 & 688128 & 4.4 & 4.4131 & TRN \\
\hline CHEMBL1454101 & 688128 & 4.75 & 4.5277 & TRN \\
\hline CHEMBL1558210 & 688128 & 5.2 & 4.8514 & TRN \\
\hline CHEMBL1375347 & 688128 & 4.1 & 4.6844 & TRN \\
\hline CHEMBL1341995 & 688128 & 4.55 & 4.6749 & TRN \\
\hline CHEMBL1590666 & 688128 & 4.05 & 4.857 & TRN \\
\hline CHEMBL1554184 & 688128 & 4.4 & 4.3776 & TRN \\
\hline CHEMBL1353630 & 688128 & 4.35 & 4.3402 & TRN \\
\hline CHEMBL1439575 & 688128 & 4.0 & 4.6607 & TRN \\
\hline CHEMBL1307377 & 688128 & 4.7 & 4.4843 & TRN \\
\hline CHEMBL1352624 & 688128 & 5.4 & 4.7751 & TRN \\
\hline CHEMBL3210668 & 688128 & 4.4 & 4.8085 & TRN \\
\hline CHEMBL1414362 & 688128 & 4.45 & 4.5373 & TRN \\
\hline CHEMBL1588963 & 688128 & 4.3 & 4.3498 & TRN \\
\hline CHEMBL1395325 & 688128 & 4.8 & 4.5384 & TST \\
\hline CHEMBL1509074 & 688128 & 4.8 & 4.8385 & TRN \\
\hline CHEMBL1441665 & 688128 & 5.65 & 4.7396 & TRN \\
\hline CHEMBL1986183 & 688128 & 4.45 & 4.4928 & TRN \\
\hline CHEMBL1430398 & 688128 & 4.5 & 4.8145 & TRN \\
\hline CHEMBL3192558 & 688128 & 4.4 & 4.5362 & TRN \\
\hline CHEMBL1605439 & 688128 & 4.55 & 4.5062 & TST \\
\hline CHEMBL 2374088 & 688128 & 4.95 & 4.7749 & TRN \\
\hline CHEMBL1575442 & 688128 & 5.0 & 4.5398 & TRN \\
\hline CHEMBL1561874 & 688128 & 5.1 & 4.8735 & TRN \\
\hline
\end{tabular}




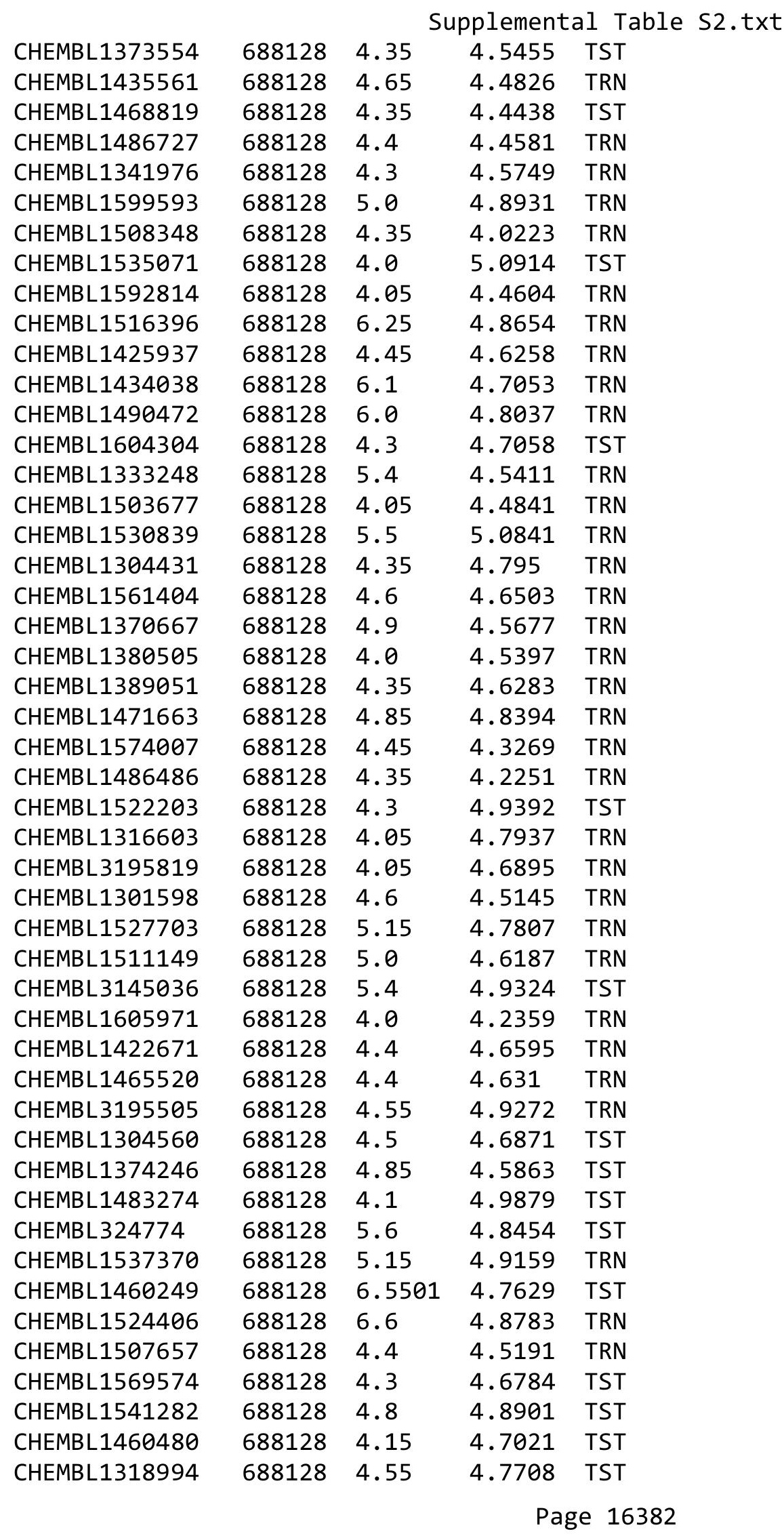




\begin{tabular}{|c|c|c|c|c|c|}
\hline & & \multicolumn{4}{|c|}{ Supplemental Table s2.txt } \\
\hline CHEMBL1338028 & 688128 & 4.35 & 4.5344 & TRN & \\
\hline CHEMBL1459705 & 688128 & 4.25 & 4.6027 & TST & \\
\hline CHEMBL1351776 & 688128 & 6.2 & 4.4386 & TST & \\
\hline CHEMBL1559272 & 688128 & 4.8 & 4.7374 & TRN & \\
\hline CHEMBL1419943 & 688128 & 4.3 & 4.5673 & TST & \\
\hline CHEMBL1543840 & 688128 & 5.0 & 4.9159 & TRN & \\
\hline CHEMBL1582074 & 688128 & 4.7 & 5.0014 & TRN & \\
\hline CHEMBL1372266 & 688128 & 4.25 & 4.5487 & TRN & \\
\hline CHEMBL1568926 & 688128 & 5.0 & 5.2564 & TRN & \\
\hline CHEMBL1975296 & 688128 & 4.05 & 4.5846 & TST & \\
\hline CHEMBL 3212537 & 688128 & 4.15 & 4.7172 & TRN & \\
\hline CHEMBL1497326 & 688128 & 5.8 & 4.7274 & TRN & \\
\hline CHEMBL3213640 & 688128 & 4.7 & 4.7416 & TST & \\
\hline CHEMBL1404113 & 688128 & 5.7 & 4.6833 & TRN & \\
\hline CHEMBL1586202 & 688128 & 4.55 & 4.425 & TRN & \\
\hline CHEMBL1582586 & 688128 & 4.05 & 4.6291 & TST & \\
\hline CHEMBL1375067 & 688128 & 4.35 & 4.4528 & TST & \\
\hline CHEMBL1406472 & 688128 & 4.3 & 4.7075 & TST & \\
\hline CHEMBL3190726 & 688128 & 4.25 & 4.4587 & TRN & \\
\hline CHEMBL1480159 & 688128 & 4.4 & 4.5134 & TRN & \\
\hline CHEMBL3208052 & 688128 & 4.35 & 4.9186 & TST & \\
\hline CHEMBL1524189 & 688128 & 4.5 & 4.4165 & TRN & \\
\hline CHEMBL1302945 & 688128 & 4.3 & 4.5723 & TRN & \\
\hline CHEMBL1581628 & 688128 & 4.45 & 4.3566 & TRN & \\
\hline CHEMBL1582637 & 688128 & 4.15 & 4.4529 & TRN & \\
\hline CHEMBL1574234 & 688128 & 4.45 & 4.431 & TRN & \\
\hline CHEMBL1379647 & 688128 & 4.35 & 4.7512 & TRN & \\
\hline CHEMBL1377249 & 688128 & 4.4 & 4.3589 & TRN & \\
\hline CHEMBL1579347 & 688128 & 4.55 & 4.4496 & TRN & \\
\hline CHEMBL1448292 & 688128 & 4.75 & 4.76699 & 99999999995 & TRN \\
\hline CHEMBL1460978 & 688128 & 4.45 & 4.5942 & TRN & \\
\hline CHEMBL1314263 & 688128 & 4.05 & 4.6584 & TST & \\
\hline CHEMBL1420917 & 688128 & 4.4 & 4.6036 & TRN & \\
\hline CHEMBL3210487 & 688128 & 5.75 & 4.8807 & TST & \\
\hline CHEMBL1373892 & 688128 & 4.35 & 4.6138 & TRN & \\
\hline CHEMBL3198614 & 688128 & 4.35 & 4.6662 & TRN & \\
\hline CHEMBL1590021 & 688128 & 4.3 & 4.5177 & TRN & \\
\hline CHEMBL1550726 & 688128 & 4.6 & 4.4461 & TRN & \\
\hline CHEMBL1606344 & 688128 & 5.4 & 4.4566 & TST & \\
\hline CHEMBL1499057 & 688128 & 4.8 & 4.71 & TRN & \\
\hline CHEMBL1496419 & 688128 & 4.75 & 4.8221 & TRN & \\
\hline CHEMBL1520113 & 688128 & 5.15 & 4.4741 & TRN & \\
\hline CHEMBL1419744 & 688128 & 5.45 & 4.8555 & TRN & \\
\hline CHEMBL1432081 & 688128 & 4.4 & 4.5954 & TRN & \\
\hline CHEMBL1567987 & 688128 & 5.45 & 4.8077 & TST & \\
\hline CHEMBL3211097 & 688128 & 4.55 & 4.8065 & TRN & \\
\hline CHEMBL1536935 & 688128 & 6.0 & 4.6347 & TRN & \\
\hline CHEMBL1464373 & 688128 & 4.95 & 4.3728 & TRN & \\
\hline
\end{tabular}




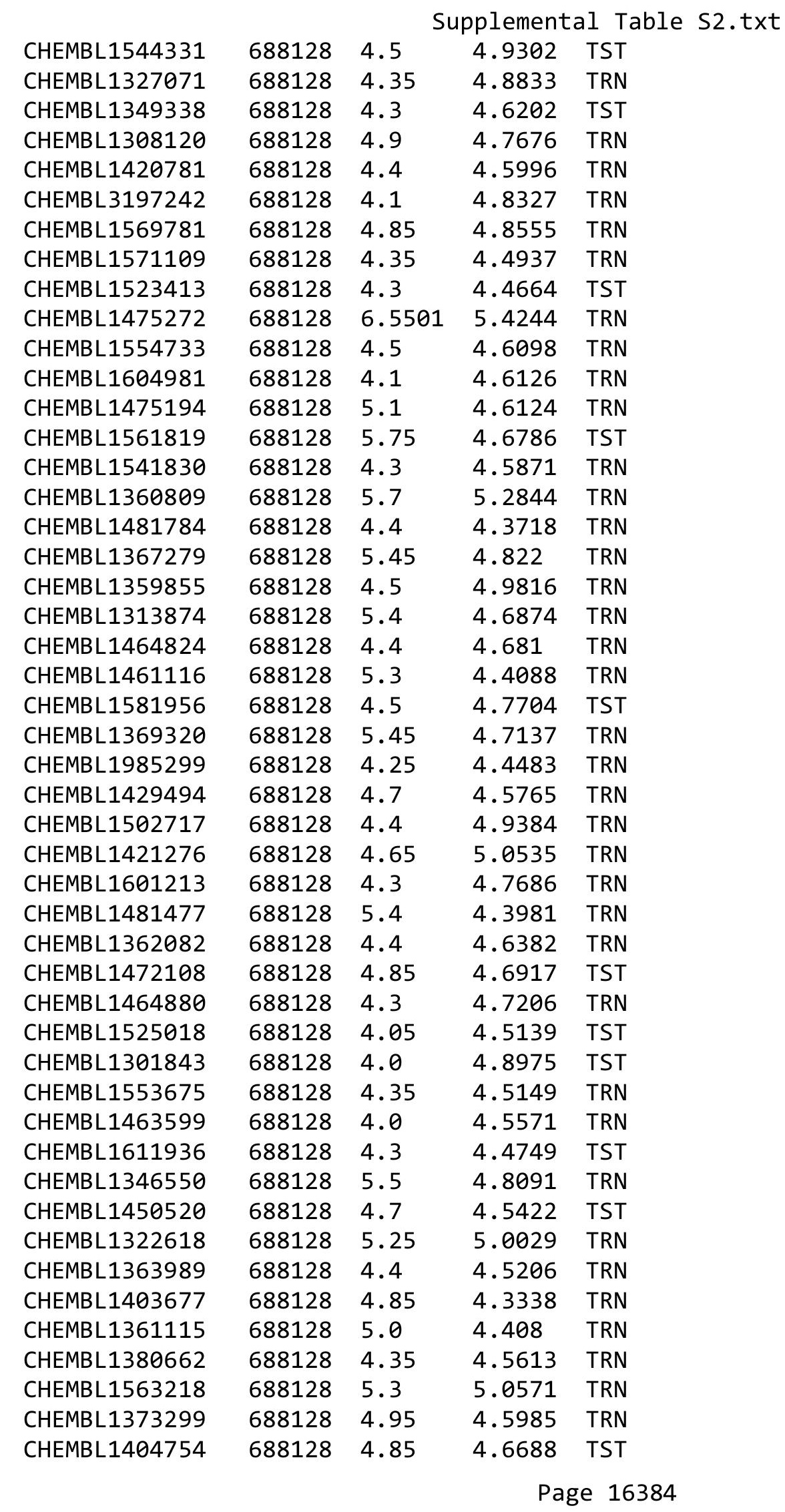




\begin{tabular}{|c|c|c|c|c|}
\hline \multicolumn{5}{|c|}{ Supplemental Table S2.txt } \\
\hline CHEMBL1500596 & 688128 & 4.3 & 4.4572 & TRN \\
\hline CHEMBL 1358074 & 688128 & 4.4 & 4.5643 & TST \\
\hline CHEMBL1474419 & 688128 & 4.35 & 4.3757 & TRN \\
\hline CHEMBL1330575 & 688128 & 4.4 & 4.9177 & TRN \\
\hline CHEMBL1472612 & 688128 & 4.35 & 4.791 & TRN \\
\hline CHEMBL1481359 & 688128 & 4.3 & 4.4523 & TRN \\
\hline CHEMBL1421193 & 688128 & 4.45 & 4.4863 & TRN \\
\hline CHEMBL1596943 & 688128 & 4.2 & 4.6313 & TRN \\
\hline CHEMBL1506613 & 688128 & 5.05 & 4.8168 & TRN \\
\hline CHEMBL1598156 & 688128 & 4.3 & 4.5742 & TRN \\
\hline CHEMBL1423383 & 688128 & 4.95 & 4.6476 & TRN \\
\hline CHEMBL1482147 & 688128 & 4.4 & 4.6857 & TRN \\
\hline CHEMBL1349208 & 688128 & 4.4 & 4.5921 & TRN \\
\hline CHEMBL1378004 & 688128 & 6.4 & 5.1802 & TRN \\
\hline CHEMBL1367792 & 688128 & 4.4 & 4.6938 & TRN \\
\hline CHEMBL1482087 & 688128 & 4.4 & 4.4353 & TRN \\
\hline CHEMBL1601362 & 688128 & 4.7 & 4.5522 & TRN \\
\hline CHEMBL1595351 & 688128 & 4.35 & 4.6129 & TRN \\
\hline CHEMBL1452551 & 688128 & 4.65 & 4.6115 & TRN \\
\hline CHEMBL1580572 & 688128 & 4.8 & 4.8751 & TRN \\
\hline CHEMBL1450829 & 688128 & 4.05 & 4.4272 & TRN \\
\hline CHEMBL1351634 & 688128 & 4.25 & 4.6391 & TRN \\
\hline CHEMBL1300802 & 688128 & 4.6 & 4.5485 & TRN \\
\hline CHEMBL1598738 & 688128 & 4.05 & 4.3815 & TRN \\
\hline CHEMBL1378653 & 688128 & 6.15 & 4.8322 & TST \\
\hline CHEMBL1534899 & 688128 & 4.3 & 4.4359 & TRN \\
\hline CHEMBL3195824 & 688128 & 4.55 & 4.7295 & TRN \\
\hline CHEMBL1381835 & 688128 & 4.1 & 4.3963 & TRN \\
\hline CHEMBL1304703 & 688128 & 4.1 & 4.503 & TRN \\
\hline CHEMBL1326859 & 688128 & 4.5 & 4.306 & TRN \\
\hline CHEMBL1577187 & 688128 & 4.05 & 4.4792 & TRN \\
\hline CHEMBL1598698 & 688128 & 4.95 & 4.8029 & TST \\
\hline CHEMBL1348604 & 688128 & 6.4 & 5.1241 & TRN \\
\hline CHEMBL458164 & 688128 & 4.85 & 4.6368 & TST \\
\hline CHEMBL1433119 & 688128 & 4.75 & 4.4866 & TRN \\
\hline CHEMBL1525115 & 688128 & 4.05 & 4.478 & TST \\
\hline CHEMBL 1385444 & 688128 & 4.05 & 4.2199 & TRN \\
\hline CHEMBL1391393 & 688128 & 5.85 & 4.6662 & TRN \\
\hline CHEMBL1410256 & 688128 & 4.8 & 4.5685 & TRN \\
\hline CHEMBL1321646 & 688128 & 4.4 & 4.4266 & TRN \\
\hline CHEMBL1573731 & 688128 & 4.65 & 4.9181 & TRN \\
\hline CHEMBL1306328 & 688128 & 4.4 & 4.5745 & TRN \\
\hline CHEMBL1613185 & 688128 & 4.8 & 4.7663 & TST \\
\hline CHEMBL1425644 & 688128 & 4.3 & 4.5466 & TRN \\
\hline CHEMBL1540372 & 688128 & 4.3 & 4.6856 & TRN \\
\hline CHEMBL3198938 & 688128 & 5.45 & 4.8333 & TST \\
\hline CHEMBL1609509 & 688128 & 5.75 & 4.4708 & TST \\
\hline CHEMBL1412685 & 688128 & 4.65 & 4.4804 & TRN \\
\hline
\end{tabular}




\begin{tabular}{|c|c|c|c|c|c|}
\hline \multicolumn{6}{|c|}{ Supplemental Table S2.txt } \\
\hline CHEMBL1986363 & 688128 & 5.1 & 4.4966 & TRN & \\
\hline CHEMBL1319469 & 688128 & 5.05 & 4.7786 & TST & \\
\hline CHEMBL1323252 & 688128 & 4.55 & 4.6596 & TRN & \\
\hline CHEMBL3195551 & 688128 & 4.3 & 4.814 & TRN & \\
\hline CHEMBL1373681 & 688128 & 4.25 & 4.423 & TST & \\
\hline CHEMBL1525220 & 688128 & 4.9 & 5.0033 & TRN & \\
\hline CHEMBL1549875 & 688128 & 4.35 & 5.024 & TRN & \\
\hline CHEMBL1388994 & 688128 & 4.65 & 4.5699 & TRN & \\
\hline CHEMBL3199299 & 688128 & 4.3 & 4.9219 & TST & \\
\hline CHEMBL1450618 & 688128 & 4.4 & 4.6238 & TRN & \\
\hline CHEMBL1319393 & 688128 & 4.05 & 4.2356 & TRN & \\
\hline CHEMBL1425509 & 688128 & 4.05 & 4.5961 & TST & \\
\hline CHEMBL1604325 & 688128 & 5.2 & 4.5396 & TST & \\
\hline CHEMBL1410659 & 688128 & 4.65 & 4.6582 & TRN & \\
\hline CHEMBL1511178 & 688128 & 5.35 & 4.2769 & TRN & \\
\hline CHEMBL1459687 & 688128 & 4.85 & 4.654 & TST & \\
\hline CHEMBL1304241 & 688128 & 4.25 & 4.8386 & TST & \\
\hline CHEMBL1503925 & 688128 & 4.35 & 4.6627 & TRN & \\
\hline CHEMBL1552169 & 688128 & 4.4 & 5.0685 & TRN & \\
\hline CHEMBL1565598 & 688128 & 4.35 & 4.5167 & TRN & \\
\hline CHEMBL1461684 & 688128 & 4.4 & 4.6497 & TRN & \\
\hline CHEMBL1425549 & 688128 & 4.5 & 4.6252 & TST & \\
\hline CHEMBL1365857 & 688128 & 4.55 & 4.8547 & TRN & \\
\hline CHEMBL1331203 & 688128 & 5.45 & 4.7733 & TRN & \\
\hline CHEMBL1481202 & 688128 & 4.35 & 4.6423 & TRN & \\
\hline CHEMBL1530393 & 688128 & 4.65 & 4.5599 & TRN & \\
\hline CHEMBL1328597 & 688128 & 4.4 & 4.58899 & 99999999995 & TRN \\
\hline CHEMBL1381058 & 688128 & 4.65 & 4.4692 & TRN & \\
\hline CHEMBL1583884 & 688128 & 4.05 & 4.2272 & TRN & \\
\hline CHEMBL1492654 & 688128 & 4.4 & 4.9798 & TRN & \\
\hline CHEMBL1398822 & 688128 & 4.05 & 4.537 & TRN & \\
\hline CHEMBL1504200 & 688128 & 4.4 & 4.4488 & TRN & \\
\hline CHEMBL1466563 & 688128 & 4.5 & 4.4967 & TST & \\
\hline CHEMBL1364193 & 688128 & 4.8 & 4.6152 & TRN & \\
\hline CHEMBL1360271 & 688128 & 4.05 & 4.6896 & TRN & \\
\hline CHEMBL1301935 & 688128 & 4.3 & 4.9554 & TRN & \\
\hline CHEMBL1557149 & 688128 & 4.4 & 4.7037 & TRN & \\
\hline CHEMBL1971965 & 688128 & 4.5 & 4.6711 & TRN & \\
\hline CHEMBL1497607 & 688128 & 4.25 & 4.6333 & TRN & \\
\hline CHEMBL1557256 & 688128 & 5.4 & 4.6326 & TST & \\
\hline CHEMBL1548224 & 688128 & 4.4 & 4.7623 & TST & \\
\hline CHEMBL1312012 & 688128 & 4.3 & 4.5474 & TST & \\
\hline CHEMBL1549777 & 688128 & 4.3 & 4.6786 & TRN & \\
\hline CHEMBL1372364 & 688128 & 4.4 & 4.5899 & TST & \\
\hline CHEMBL1318667 & 688128 & 6.0 & 4.8891 & TRN & \\
\hline CHEMBL1330264 & 688128 & 4.8 & 4.8506 & TRN & \\
\hline CHEMBL1460836 & 688128 & 4.4 & 4.9056 & TRN & \\
\hline CHEMBL1414027 & 688128 & 4.85 & 4.603 & TRN & \\
\hline
\end{tabular}




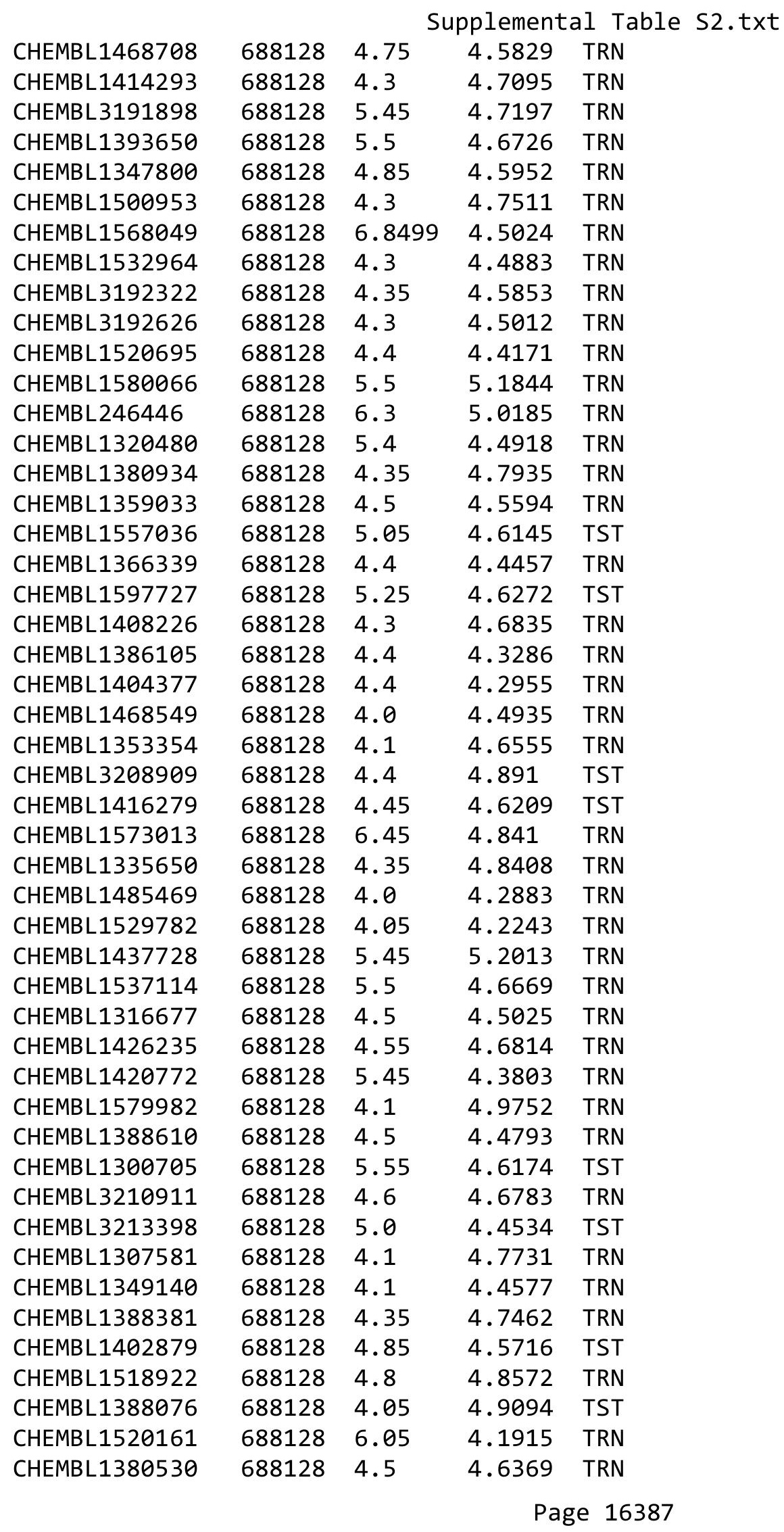




\begin{tabular}{|c|c|c|c|c|c|}
\hline CHEMBL1450029 & 688128 & 4.45 & $4.6560 e$ & al lable s & TST \\
\hline CHEMBL1364887 & 688128 & 4.45 & 4.6368 & TRN & \\
\hline CHEMBL1324525 & 688128 & 4.4 & 4.7346 & TRN & \\
\hline CHEMBL1529657 & 688128 & 4.4 & 4.3582 & TRN & \\
\hline CHEMBL1369748 & 688128 & 4.05 & 4.3704 & TRN & \\
\hline CHEMBL1392581 & 688128 & 5.4 & 4.5177 & TST & \\
\hline CHEMBL1612214 & 688128 & 4.05 & 4.5725 & TRN & \\
\hline CHEMBL1575306 & 688128 & 5.95 & 4.8411 & TST & \\
\hline CHEMBL1382614 & 688128 & 4.4 & 4.6458 & TRN & \\
\hline CHEMBL1339094 & 688128 & 4.85 & 4.965 & TRN & \\
\hline CHEMBL1439700 & 688128 & 4.3 & 4.5429 & TRN & \\
\hline CHEMBL1317062 & 688128 & 4.9 & 4.6871 & TRN & \\
\hline CHEMBL1504109 & 688128 & 4.3 & 4.4722 & TRN & \\
\hline CHEMBL1520726 & 688128 & 5.15 & 4.5473 & TRN & \\
\hline CHEMBL1321075 & 688128 & 4.35 & 4.751 & TRN & \\
\hline CHEMBL1378267 & 688128 & 4.5 & 4.5776 & TRN & \\
\hline CHEMBL1360525 & 688128 & 5.75 & 4.7978 & TRN & \\
\hline CHEMBL1346456 & 688128 & 4.35 & 5.03 & TST & \\
\hline CHEMBL1502040 & 688128 & 4.4 & 4.4928 & TRN & \\
\hline CHEMBL1398149 & 688128 & 4.6 & 4.6553 & TST & \\
\hline CHEMBL1353706 & 688128 & 4.4 & 4.7816 & TRN & \\
\hline CHEMBL1430078 & 688128 & 4.1 & 4.7507 & TST & \\
\hline CHEMBL1594675 & 688128 & 4.4 & 4.6655 & TST & \\
\hline CHEMBL1519958 & 688128 & 4.9 & 4.8737 & TST & \\
\hline CHEMBL1373092 & 688128 & 4.35 & 4.6882 & TRN & \\
\hline CHEMBL1434400 & 688128 & 4.45 & 4.6178 & TRN & \\
\hline CHEMBL1463869 & 688128 & 4.5 & 4.4625 & TRN & \\
\hline CHEMBL1541776 & 688128 & 4.1 & 4.7844 & TST & \\
\hline CHEMBL1493956 & 688128 & 5.55 & 4.7264 & TRN & \\
\hline CHEMBL1474940 & 688128 & 4.35 & 4.8095 & TRN & \\
\hline CHEMBL1362346 & 688128 & 5.0 & 4.5521 & TRN & \\
\hline CHEMBL1362935 & 688128 & 6.0 & 5.0029 & TST & \\
\hline CHEMBL1587892 & 688128 & 4.0 & 5.0335 & TRN & \\
\hline CHEMBL1387227 & 688128 & 4.4 & 4.6447 & TRN & \\
\hline CHEMBL1591369 & 688128 & 4.85 & 4.7698 & TRN & \\
\hline CHEMBL1584937 & 688128 & 4.5 & 4.7383 & TRN & \\
\hline CHEMBL1582790 & 688128 & 4.65 & 4.4638 & TST & \\
\hline CHEMBL1490480 & 688128 & 4.25 & 4.6772 & TST & \\
\hline CHEMBL1516910 & 688128 & 4.45 & 4.6271 & TRN & \\
\hline CHEMBL1397958 & 688128 & 4.25 & 4.5787 & TRN & \\
\hline CHEMBL1386479 & 688128 & 4.05 & 4.4697 & TST & \\
\hline CHEMBL1390755 & 688128 & 4.7 & 4.5733 & TRN & \\
\hline CHEMBL1518534 & 688128 & 5.0 & 4.6944 & TRN & \\
\hline CHEMBL1393638 & 688128 & 4.3 & 4.6671 & TRN & \\
\hline CHEMBL3210753 & 688128 & 4.4 & 4.5149 & TRN & \\
\hline CHEMBL1966283 & 688128 & 4.05 & 4.757 & TST & \\
\hline CHEMBL1300172 & 688128 & 4.4 & 4.7825 & TRN & \\
\hline CHEMBL1566506 & 688128 & 4.1 & 4.6537 & TST & \\
\hline
\end{tabular}




\begin{tabular}{|c|c|c|c|c|}
\hline & & & upplement & al $\mathrm{T}$ \\
\hline CHEMBL1485036 & 688128 & 4.05 & 4.7516 & TST \\
\hline CHEMBL1576193 & 688128 & 5.35 & 4.8815 & TRN \\
\hline CHEMBL1594898 & 688128 & 5.45 & 4.827 & TRN \\
\hline CHEMBL1406520 & 688128 & 4.35 & 4.563 & TST \\
\hline CHEMBL1579818 & 688128 & 4.45 & 4.6277 & TRN \\
\hline CHEMBL1305996 & 688128 & 4.3 & 4.842 & TST \\
\hline CHEMBL1304814 & 688128 & 5.5 & 4.4796 & TST \\
\hline CHEMBL1536062 & 688128 & 4.35 & 4.8062 & TRN \\
\hline CHEMBL1301755 & 688128 & 4.55 & 4.2636 & TRN \\
\hline CHEMBL1414559 & 688128 & 4.05 & 4.4993 & TRN \\
\hline CHEMBL1314668 & 688128 & 5.15 & 5.2539 & TRN \\
\hline CHEMBL1572902 & 688128 & 4.05 & 4.4582 & TRN \\
\hline CHEMBL1349005 & 688128 & 4.4 & 4.8263 & TRN \\
\hline CHEMBL1373462 & 688128 & 4.8 & 4.5576 & TST \\
\hline CHEMBL1372236 & 688128 & 4.1 & 4.501 & TRN \\
\hline CHEMBL1416948 & 688128 & 4.05 & 4.5564 & TST \\
\hline CHEMBL1492213 & 688128 & 4.4 & 4.6965 & TRN \\
\hline CHEMBL3194879 & 688128 & 4.45 & 4.7108 & TST \\
\hline CHEMBL1309538 & 688128 & 4.1 & 4.33 & TRN \\
\hline CHEMBL1515624 & 688128 & 4.3 & 4.5158 & TST \\
\hline CHEMBL1400828 & 688128 & 4.7 & 4.751 & TST \\
\hline CHEMBL1505787 & 688128 & 4.8 & 4.6008 & TST \\
\hline CHEMBL1339566 & 688128 & 4.45 & 4.591 & TRN \\
\hline CHEMBL1300635 & 688128 & 5.4 & 4.6795 & TRN \\
\hline CHEMBL1310508 & 688128 & 6.0 & 5.1734 & TRN \\
\hline CHEMBL1608377 & 688128 & 4.35 & 4.4471 & TRN \\
\hline CHEMBL1364967 & 688128 & 6.8 & 4.6289 & TRN \\
\hline CHEMBL1556911 & 688128 & 4.2 & 4.641 & TRN \\
\hline CHEMBL1583312 & 688128 & 4.3 & 4.4889 & TST \\
\hline CHEMBL1557391 & 688128 & 4.7 & 4.5442 & TRN \\
\hline CHEMBL1475408 & 688128 & 4.3 & 4.6547 & TRN \\
\hline CHEMBL1536331 & 688128 & 4.05 & 4.572 & TRN \\
\hline CHEMBL1570490 & 688128 & 5.5 & 4.7743 & TRN \\
\hline CHEMBL1368806 & 688128 & 4.05 & 4.6039 & TST \\
\hline CHEMBL1395763 & 688128 & 4.4 & 4.8077 & TRN \\
\hline CHEMBL3191952 & 688128 & 4.4 & 4.3713 & TST \\
\hline CHEMBL1364539 & 688128 & 4.35 & 4.6853 & TRN \\
\hline CHEMBL1508622 & 688128 & 5.1 & 4.8508 & TRN \\
\hline CHEMBL1319999 & 688128 & 4.6 & 4.4474 & TRN \\
\hline CHEMBL1353209 & 688128 & 4.3 & 4.606 & TRN \\
\hline CHEMBL1322559 & 688128 & 6.45 & 4.5652 & TST \\
\hline CHEMBL1524896 & 688128 & 4.05 & 4.9291 & TST \\
\hline CHEMBL1308094 & 688128 & 5.4 & 4.492 & TRN \\
\hline CHEMBL1573288 & 688128 & 4.3 & 4.2876 & TRN \\
\hline CHEMBL1575413 & 688128 & 4.6 & 4.6313 & TST \\
\hline CHEMBL1392520 & 688128 & 4.4 & 4.9181 & TRN \\
\hline CHEMBL1383544 & 688128 & 4.3 & 4.4388 & TRN \\
\hline CHEMBL3194392 & 688128 & 5.0 & 4.6441 & TRN \\
\hline
\end{tabular}




\begin{tabular}{|c|c|c|c|c|c|}
\hline \multicolumn{6}{|c|}{ Supplemental Table S2.txt } \\
\hline CHEMBL1572413 & 688128 & 4.3 & 4.5282 & TRN & \\
\hline CHEMBL1510385 & 688128 & 4.25 & 4.7756 & TRN & \\
\hline CHEMBL1592625 & 688128 & 4.45 & 4.4797 & TRN & \\
\hline CHEMBL1346587 & 688128 & 5.6 & 4.8065 & TST & \\
\hline CHEMBL1385771 & 688128 & 4.85 & 5.19799 & 99999999995 & TRN \\
\hline CHEMBL1595745 & 688128 & 5.45 & 4.6067 & TRN & \\
\hline CHEMBL1510233 & 688128 & 4.05 & 4.4472 & TST & \\
\hline CHEMBL1357238 & 688128 & 4.35 & 4.4901 & TRN & \\
\hline CHEMBL1360400 & 688128 & 4.8 & 4.8116 & TRN & \\
\hline CHEMBL1405098 & 688128 & 4.1 & 4.5648 & TRN & \\
\hline CHEMBL1352473 & 688128 & 4.25 & 4.9549 & TRN & \\
\hline CHEMBL1494992 & 688128 & 4.3 & 4.6991 & TRN & \\
\hline CHEMBL1560962 & 688128 & 4.3 & 4.8544 & TRN & \\
\hline CHEMBL1330935 & 688128 & 4.25 & 4.2747 & TRN & \\
\hline CHEMBL1337854 & 688128 & 4.05 & 4.6437 & TRN & \\
\hline CHEMBL1349755 & 688128 & 4.45 & 4.524 & TRN & \\
\hline CHEMBL1408581 & 688128 & 7.0 & 4.5968 & TRN & \\
\hline CHEMBL1575387 & 688128 & 4.35 & 4.8737 & TRN & \\
\hline CHEMBL1392894 & 688128 & 4.25 & 4.6891 & TST & \\
\hline CHEMBL1406831 & 688128 & 4.3 & 4.9051 & TRN & \\
\hline CHEMBL1387707 & 688128 & 4.1 & 4.901 & TST & \\
\hline CHEMBL1553520 & 688128 & 4.4 & 4.6508 & TRN & \\
\hline CHEMBL1363782 & 688128 & 4.3 & 4.5967 & TRN & \\
\hline CHEMBL1526005 & 688128 & 4.25 & 4.7194 & TRN & \\
\hline CHEMBL1361889 & 688128 & 4.55 & 4.3995 & TRN & \\
\hline CHEMBL1387058 & 688128 & 4.5 & 4.70100 & 00000000005 & TRN \\
\hline CHEMBL1597260 & 688128 & 5.4 & 4.6857 & TST & \\
\hline CHEMBL1378931 & 688128 & 4.85 & 4.8178 & TRN & \\
\hline CHEMBL1441686 & 688128 & 4.55 & 4.7862 & TST & \\
\hline CHEMBL1348980 & 688128 & 5.75 & 4.8524 & TST & \\
\hline CHEMBL3196440 & 688128 & 4.5 & 4.5732 & TRN & \\
\hline CHEMBL1367001 & 688128 & 4.4 & 4.4065 & TRN & \\
\hline CHEMBL1459369 & 688128 & 4.4 & 4.9527 & TST & \\
\hline CHEMBL1353228 & 688128 & 4.45 & 4.805 & TST & \\
\hline CHEMBL1599844 & 688128 & 4.4 & 4.5088 & TST & \\
\hline CHEMBL1384790 & 688128 & 4.95 & 4.4611 & TRN & \\
\hline CHEMBL1325349 & 688128 & 5.6 & 4.5956 & TRN & \\
\hline CHEMBL1476112 & 688128 & 4.4 & 4.5739 & TST & \\
\hline CHEMBL1344687 & 688128 & 5.6 & 5.2863 & TRN & \\
\hline CHEMBL1514471 & 688128 & 4.75 & 4.8995 & TRN & \\
\hline CHEMBL1332864 & 688128 & 6.0 & 4.6434 & TRN & \\
\hline CHEMBL1299965 & 688128 & 4.0 & 4.2026 & TST & \\
\hline CHEMBL1495174 & 688128 & 4.7 & 4.7704 & TRN & \\
\hline CHEMBL3213918 & 688128 & 4.3 & 4.5099 & TST & \\
\hline CHEMBL1304731 & 688128 & 4.4 & 4.2606 & TRN & \\
\hline CHEMBL1557539 & 688128 & 4.05 & 4.6294 & TRN & \\
\hline CHEMBL1350551 & 688128 & 4.45 & 4.5174 & TST & \\
\hline CHEMBL 2373607 & 688128 & 4.3 & 5.0555 & TST & \\
\hline
\end{tabular}




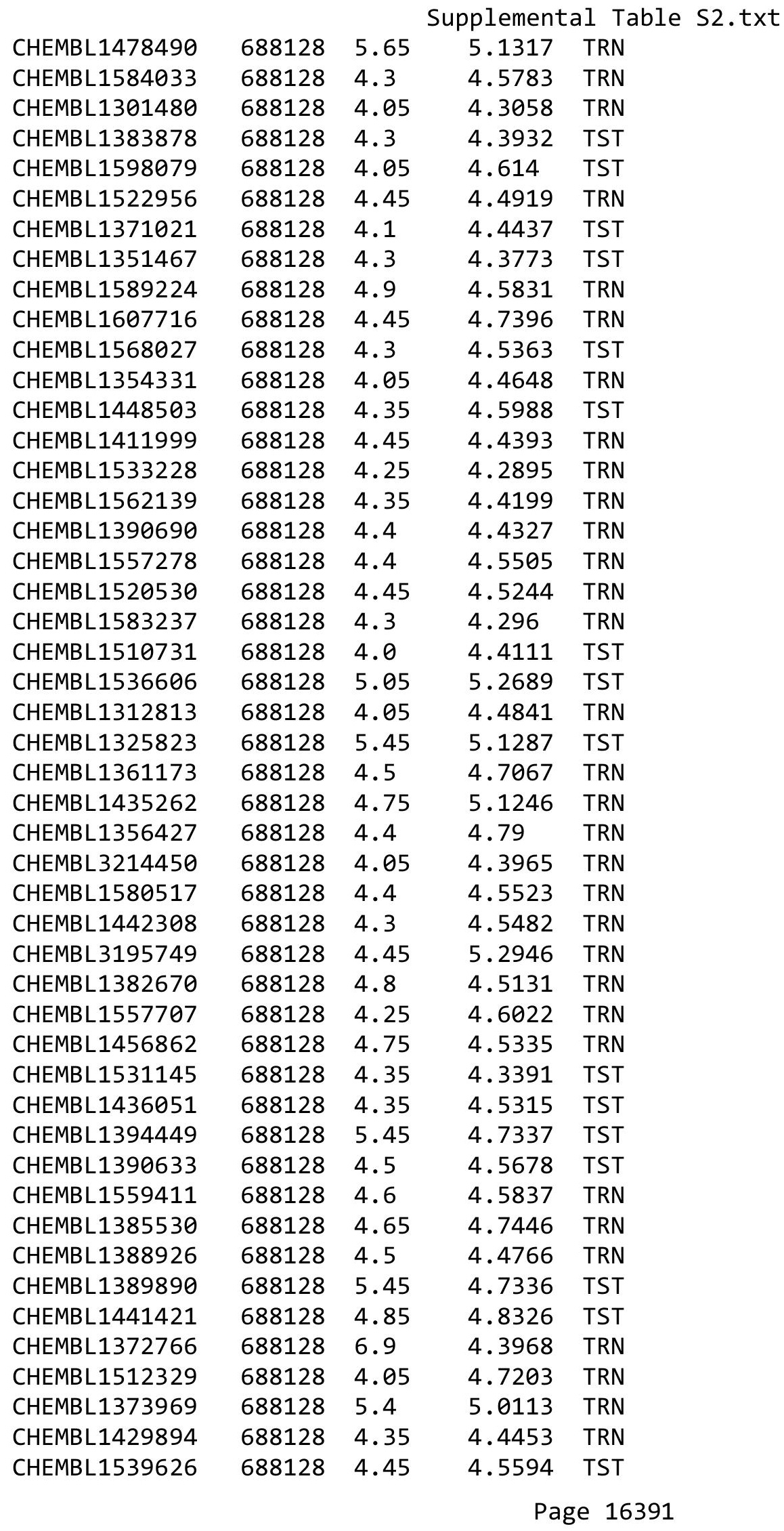




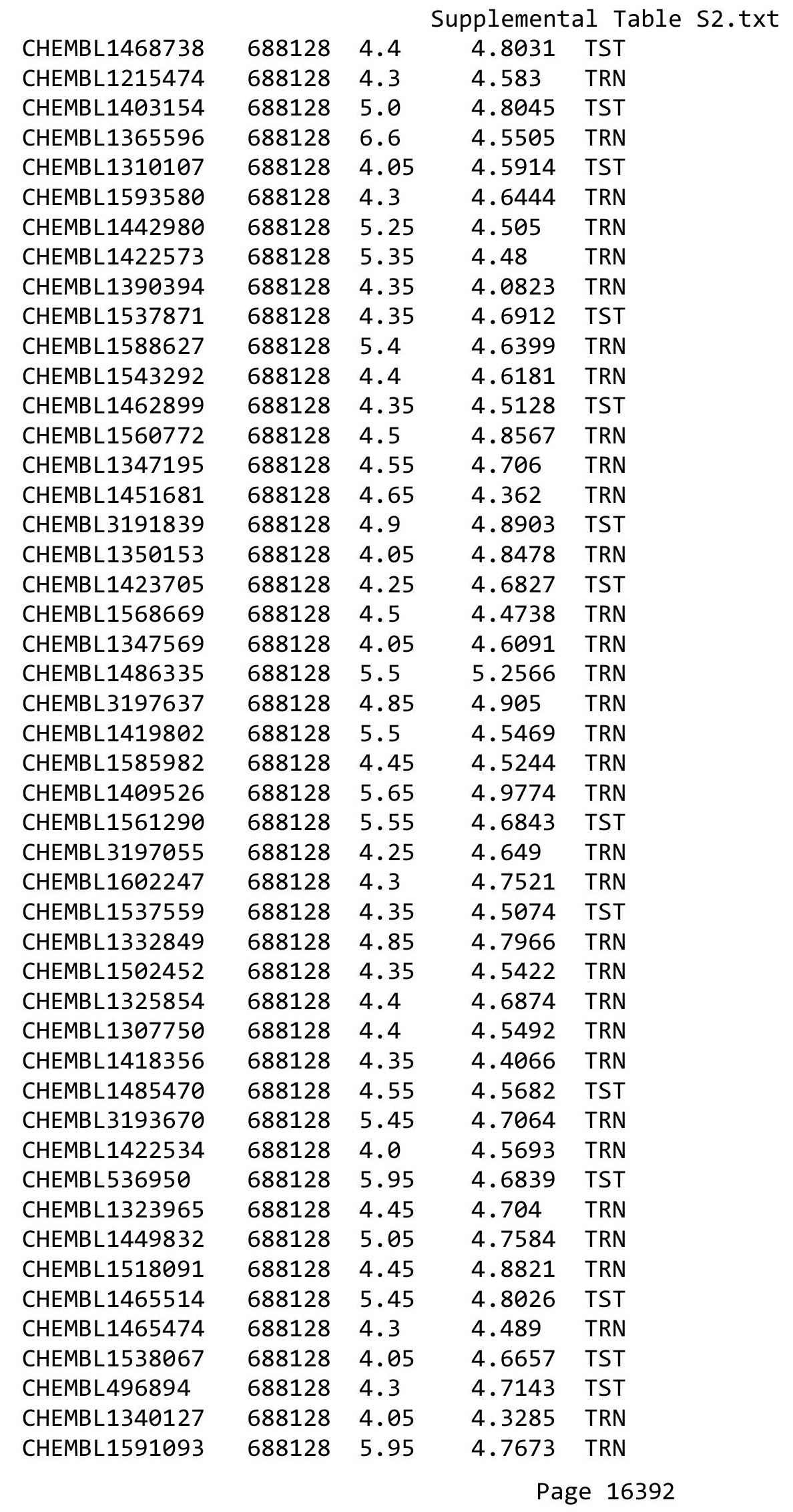




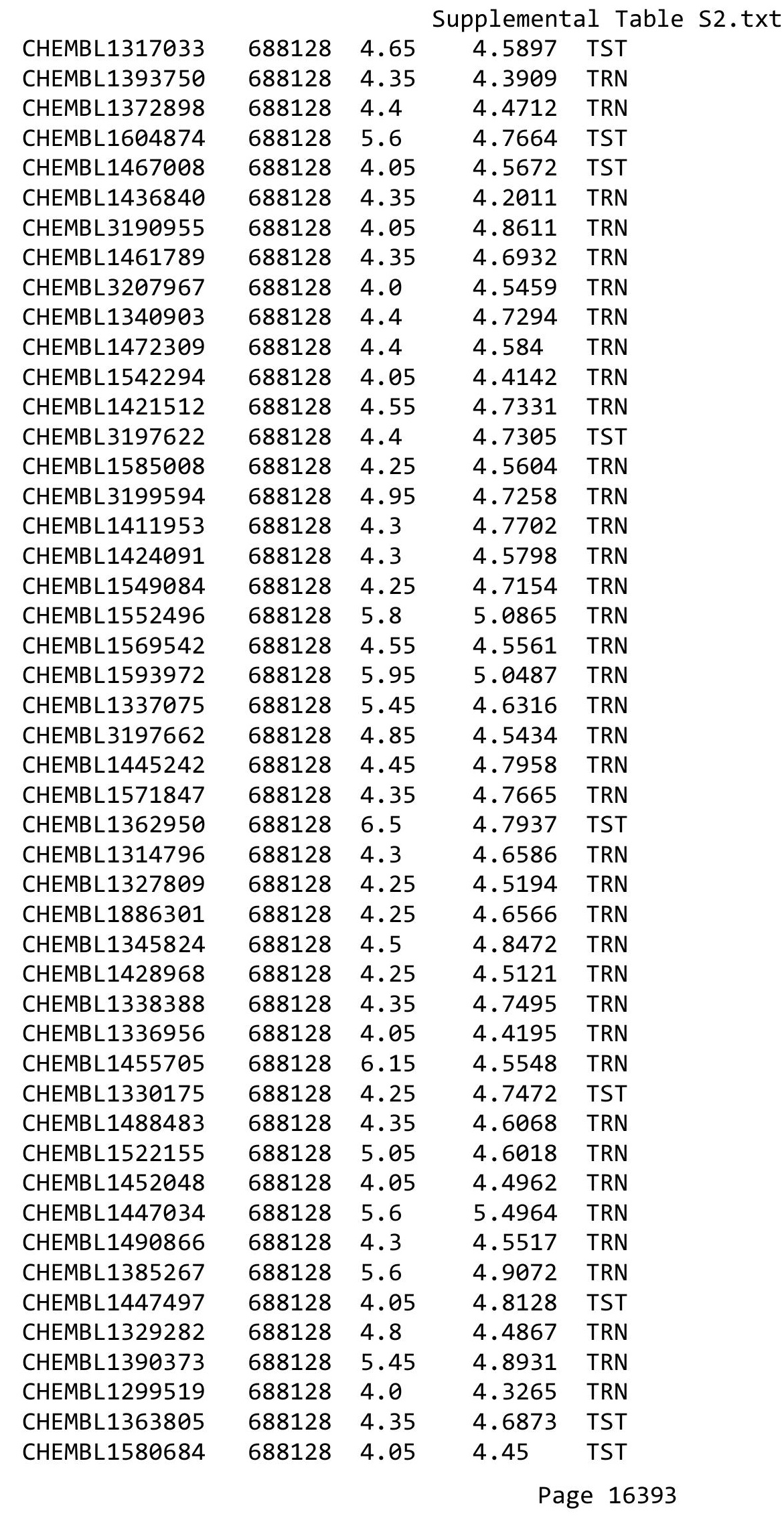




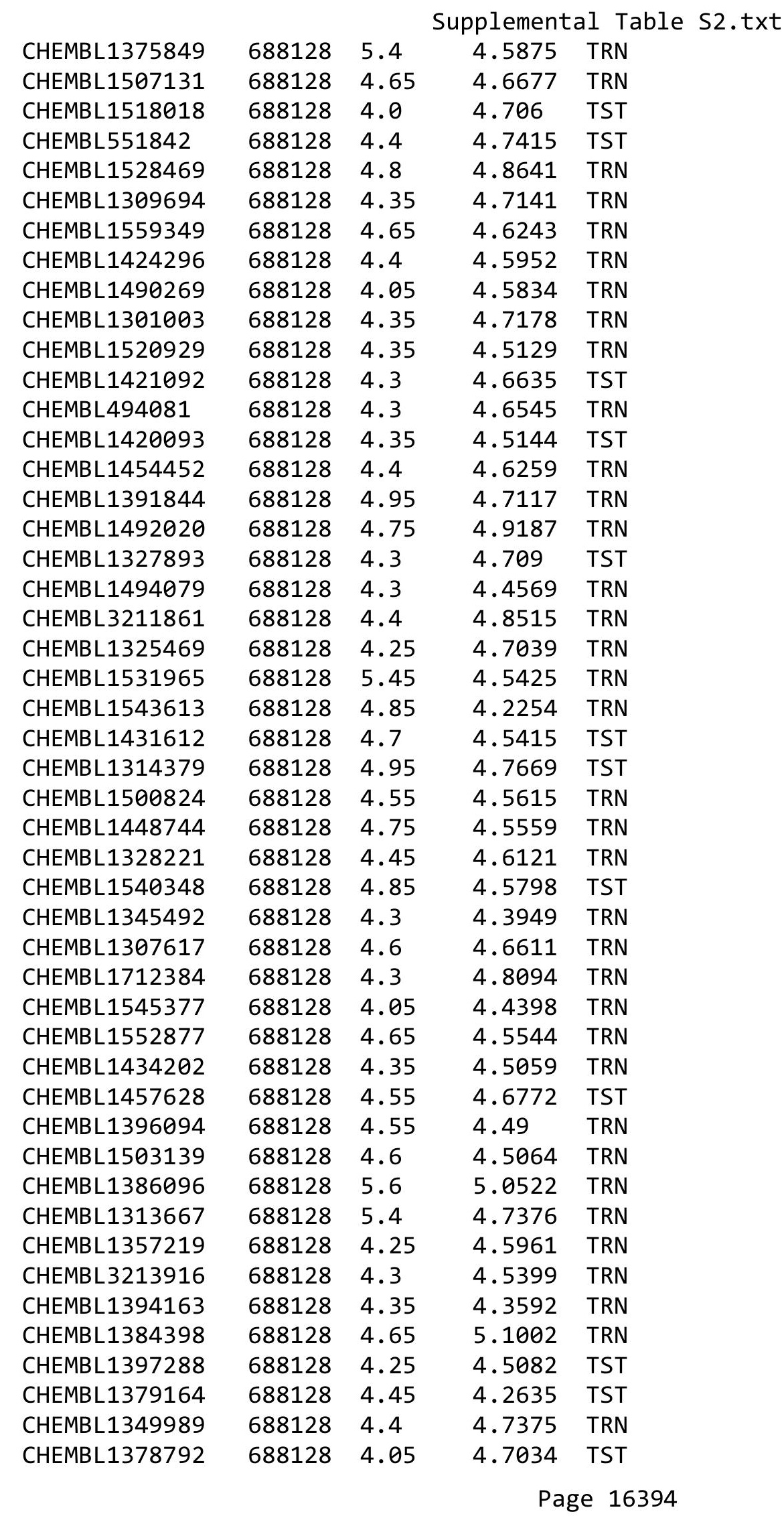




\begin{tabular}{|c|c|c|c|c|}
\hline \multicolumn{5}{|c|}{ Supplemental Table S2.txt } \\
\hline CHEMBL1317280 & 688128 & 4.25 & 4.6144 & TRN \\
\hline CHEMBL1574348 & 688128 & 4.05 & 4.6336 & TRN \\
\hline CHEMBL1462987 & 688128 & 4.5 & 4.5888 & TST \\
\hline CHEMBL1490677 & 688128 & 5.6 & 5.1437 & TST \\
\hline CHEMBL1504719 & 688128 & 6.1 & 4.4056 & TRN \\
\hline CHEMBL1369393 & 688128 & 4.5 & 4.5095 & TRN \\
\hline CHEMBL1389247 & 688128 & 4.6 & 4.9056 & TRN \\
\hline CHEMBL1380379 & 688128 & 4.6 & 4.4197 & TST \\
\hline CHEMBL48310 & 688128 & 4.05 & 4.9423 & TST \\
\hline CHEMBL1303930 & 688128 & 6.5 & 4.7367 & TST \\
\hline CHEMBL1466445 & 688128 & 4.7 & 5.0723 & TRN \\
\hline CHEMBL1447653 & 688128 & 5.45 & 4.705 & TRN \\
\hline CHEMBL1304811 & 688128 & 4.3 & 4.4674 & TRN \\
\hline CHEMBL1443827 & 688128 & 4.95 & 4.3417 & TRN \\
\hline CHEMBL1300310 & 688128 & 5.0 & 4.7498 & TRN \\
\hline CHEMBL1475399 & 688128 & 4.4 & 4.7154 & TRN \\
\hline CHEMBL1319092 & 688128 & 4.4 & 4.4067 & TRN \\
\hline CHEMBL1530402 & 688128 & 4.35 & 5.3325 & TRN \\
\hline CHEMBL1494579 & 688128 & 5.0 & 4.5805 & TRN \\
\hline CHEMBL1581282 & 688128 & 4.05 & 4.7734 & TST \\
\hline CHEMBL1436764 & 688128 & 4.4 & 4.9626 & TRN \\
\hline CHEMBL1255778 & 688128 & 6.5 & 4.8598 & TST \\
\hline CHEMBL1496473 & 688128 & 4.7 & 4.5385 & TST \\
\hline CHEMBL1579255 & 688128 & 4.0 & 4.7204 & TRN \\
\hline CHEMBL1370012 & 688128 & 6.0 & 4.5207 & TRN \\
\hline CHEMBL1499779 & 688128 & 4.45 & 4.6289 & TRN \\
\hline CHEMBL1607338 & 688128 & 4.35 & 4.6289 & TRN \\
\hline CHEMBL1570370 & 688128 & 4.35 & 4.334 & TRN \\
\hline CHEMBL1485603 & 688128 & 4.6 & 4.5321 & TRN \\
\hline CHEMBL1349824 & 688128 & 4.4 & 4.5501 & TRN \\
\hline CHEMBL1355284 & 688128 & 4.3 & 4.698 & TRN \\
\hline CHEMBL1603183 & 688128 & 4.3 & 4.3219 & TRN \\
\hline CHEMBL1507282 & 688128 & 5.05 & 4.8306 & TRN \\
\hline CHEMBL1493459 & 688128 & 4.85 & 4.9771 & TRN \\
\hline CHEMBL1519731 & 688128 & 5.1 & 4.6746 & TRN \\
\hline CHEMBL1376890 & 688128 & 4.65 & 4.5857 & TRN \\
\hline CHEMBL1512059 & 688128 & 5.5 & 5.3277 & TRN \\
\hline CHEMBL1563614 & 688128 & 4.8 & 4.7594 & TRN \\
\hline CHEMBL1330712 & 688128 & 4.35 & 4.7047 & TRN \\
\hline CHEMBL1451983 & 688128 & 4.4 & 4.5744 & TRN \\
\hline CHEMBL1427212 & 688128 & 4.4 & 4.8675 & TRN \\
\hline CHEMBL3392069 & 688128 & 5.35 & 4.7347 & TRN \\
\hline CHEMBL3213296 & 688128 & 6.15 & 4.5876 & TRN \\
\hline CHEMBL1439435 & 688128 & 4.05 & 4.6974 & TRN \\
\hline CHEMBL1984458 & 688128 & 6.8499 & 4.4873 & TST \\
\hline CHEMBL1313009 & 688128 & 4.7 & 4.5645 & TST \\
\hline CHEMBL3191734 & 688128 & 4.5 & 5.1952 & TST \\
\hline CHEMBL3195018 & 688128 & 5.0 & 4.6807 & TRN \\
\hline
\end{tabular}




\begin{tabular}{|c|c|c|c|c|c|}
\hline & & \multicolumn{4}{|c|}{ Supplemental Table S2.txt } \\
\hline CHEMBL582050 & 688128 & 5.4 & 4.7882 & TST & \\
\hline CHEMBL1503469 & 688128 & 5.1 & 4.4801 & TST & \\
\hline CHEMBL1557565 & 688128 & 4.6 & 4.7944 & TRN & \\
\hline CHEMBL1335802 & 688128 & 4.3 & 4.5401 & TRN & \\
\hline CHEMBL1602971 & 688128 & 4.3 & 4.3921 & TRN & \\
\hline CHEMBL1354664 & 688128 & 4.3 & 4.7496 & TRN & \\
\hline CHEMBL1467935 & 688128 & 4.4 & 4.4686 & TST & \\
\hline CHEMBL1488271 & 688128 & 4.35 & 4.4218 & TRN & \\
\hline CHEMBL 3190040 & 688128 & 4.15 & 4.6361 & TST & \\
\hline CHEMBL1516818 & 688128 & 4.4 & 4.3875 & TRN & \\
\hline CHEMBL 3211720 & 688128 & 4.45 & 4.859 & TRN & \\
\hline CHEMBL1500041 & 688128 & 4.35 & 4.0829 & TRN & \\
\hline CHEMBL 3210179 & 688128 & 4.0 & 5.0718 & TST & \\
\hline CHEMBL1546750 & 688128 & 4.5 & 4.4353 & TRN & \\
\hline CHEMBL1458478 & 688128 & 4.35 & 4.6559 & TST & \\
\hline CHEMBL1316943 & 688128 & 4.05 & 4.5896 & TST & \\
\hline CHEMBL1381771 & 688128 & 4.05 & 4.75899 & 99999999995 & TST \\
\hline CHEMBL1394168 & 688128 & 5.1 & 5.0808 & TRN & \\
\hline CHEMBL1453798 & 688128 & 5.05 & 4.9573 & TRN & \\
\hline CHEMBL1467905 & 688128 & 5.25 & 4.8145 & TRN & \\
\hline CHEMBL1514014 & 688128 & 4.4 & 4.4337 & TRN & \\
\hline CHEMBL1344269 & 688128 & 4.1 & 4.5815 & TRN & \\
\hline CHEMBL1495312 & 688128 & 6.1 & 5.1362 & TRN & \\
\hline CHEMBL1319792 & 688128 & 4.35 & 4.4786 & TRN & \\
\hline CHEMBL3392068 & 688128 & 4.55 & 4.6 & TRN & \\
\hline CHEMBL1433527 & 688128 & 4.35 & 4.6718 & TRN & \\
\hline CHEMBL1440298 & 688128 & 5.0 & 4.8864 & TRN & \\
\hline CHEMBL1504684 & 688128 & 4.6 & 4.5323 & TRN & \\
\hline CHEMBL527336 & 688128 & 4.9 & 4.7116 & TRN & \\
\hline CHEMBL1396772 & 688128 & 4.05 & 4.51399 & 9999999999 & TRN \\
\hline CHEMBL3208377 & 688128 & 4.0 & 4.5811 & TST & \\
\hline CHEMBL1564424 & 688128 & 4.3 & 4.7902 & TRN & \\
\hline CHEMBL1387447 & 688128 & 5.5 & 4.7982 & TRN & \\
\hline CHEMBL1336877 & 688128 & 4.1 & 4.4623 & TRN & \\
\hline CHEMBL1503168 & 688128 & 5.1 & 4.4558 & TRN & \\
\hline CHEMBL1408779 & 688128 & 4.7 & 4.4694 & TRN & \\
\hline CHEMBL1445731 & 688128 & 4.4 & 4.6839 & TST & \\
\hline CHEMBL1200462 & 688128 & 4.85 & 4.8257 & TST & \\
\hline CHEMBL1412819 & 688128 & 4.5 & 4.6498 & TRN & \\
\hline CHEMBL1490295 & 688128 & 6.1 & 4.3223 & TRN & \\
\hline CHEMBL1233274 & 688128 & 4.35 & 4.7639 & TRN & \\
\hline CHEMBL1457241 & 688128 & 4.4 & 4.364 & TRN & \\
\hline CHEMBL1471171 & 688128 & 4.3 & 4.5329 & TST & \\
\hline CHEMBL1600565 & 688128 & 4.35 & 4.6991 & TRN & \\
\hline CHEMBL1370741 & 688128 & 5.1 & 4.6914 & TRN & \\
\hline CHEMBL1520420 & 688128 & 6.15 & 4.6788 & TRN & \\
\hline CHEMBL1346575 & 688128 & 4.35 & 4.6243 & TST & \\
\hline CHEMBL1506994 & 688128 & 4.3 & 4.5735 & TRN & \\
\hline
\end{tabular}




\begin{tabular}{|c|c|c|c|c|c|}
\hline \multicolumn{6}{|c|}{ Supplemental Table S2.txt } \\
\hline CHEMBL1565618 & 688128 & 4.05 & 4.7021 & TST & \\
\hline CHEMBL1534998 & 688128 & 4.3 & 4.5268 & TRN & \\
\hline CHEMBL1326483 & 688128 & 5.45 & 4.80699 & 99999999995 & TST \\
\hline CHEMBL1524523 & 688128 & 4.05 & 4.7439 & TST & \\
\hline CHEMBL1412490 & 688128 & 4.45 & 4.5557 & TRN & \\
\hline CHEMBL1558950 & 688128 & 4.8 & 4.6803 & TRN & \\
\hline CHEMBL1515598 & 688128 & 4.45 & 4.9638 & TRN & \\
\hline CHEMBL1501862 & 688128 & 4.4 & 4.6462 & TRN & \\
\hline CHEMBL1612718 & 688128 & 4.9 & 4.7224 & TRN & \\
\hline CHEMBL1558610 & 688128 & 4.6 & 4.5915 & TRN & \\
\hline CHEMBL3144906 & 688128 & 4.6 & 5.029 & TRN & \\
\hline CHEMBL1403236 & 688128 & 6.5 & 4.5666 & TST & \\
\hline CHEMBL1349378 & 688128 & 4.85 & 4.9728 & TRN & \\
\hline CHEMBL1542630 & 688128 & 4.5 & 4.6312 & TRN & \\
\hline CHEMBL1382949 & 688128 & 5.75 & 4.9509 & TRN & \\
\hline CHEMBL1472970 & 688128 & 4.35 & 4.4347 & TRN & \\
\hline CHEMBL1572253 & 688128 & 4.45 & 4.4919 & TRN & \\
\hline CHEMBL1400568 & 688128 & 4.3 & 4.794 & TST & \\
\hline CHEMBL1448376 & 688128 & 5.85 & 4.55399 & 9999999999 & TRN \\
\hline CHEMBL1610295 & 688128 & 4.5 & 4.6847 & TST & \\
\hline CHEMBL1486651 & 688128 & 4.55 & 4.3714 & TRN & \\
\hline CHEMBL1548679 & 688128 & 4.25 & 4.6082 & TRN & \\
\hline CHEMBL1329250 & 688128 & 6.0 & 5.0438 & TRN & \\
\hline CHEMBL1469288 & 688128 & 5.85 & 5.3253 & TRN & \\
\hline CHEMBL1456777 & 688128 & 4.4 & 4.5196 & TRN & \\
\hline CHEMBL1472126 & 688128 & 5.0 & 5.1076 & TRN & \\
\hline CHEMBL1312922 & 688128 & 4.05 & 4.6805 & TST & \\
\hline CHEMBL1343236 & 688128 & 4.75 & 4.8063 & TST & \\
\hline CHEMBL1402280 & 688128 & 4.3 & 4.7643 & TST & \\
\hline CHEMBL1590681 & 688128 & 5.0 & 4.4665 & TRN & \\
\hline CHEMBL1603196 & 688128 & 4.5 & 5.0273 & TRN & \\
\hline CHEMBL1529184 & 688128 & 4.05 & 4.6653 & TRN & \\
\hline CHEMBL1531316 & 688128 & 4.3 & 4.8824 & TST & \\
\hline CHEMBL1358945 & 688128 & 5.75 & 4.6745 & TRN & \\
\hline CHEMBL1330827 & 688128 & 4.55 & 4.6068 & TRN & \\
\hline CHEMBL1453322 & 688128 & 5.2 & 4.5267 & TRN & \\
\hline CHEMBL261122 & 688128 & 6.0 & 4.6323 & TST & \\
\hline CHEMBL1421602 & 688128 & 5.3 & 4.5149 & TRN & \\
\hline CHEMBL3198782 & 688128 & 4.35 & 4.7698 & TST & \\
\hline CHEMBL1299559 & 688128 & 4.35 & 4.5689 & TRN & \\
\hline CHEMBL1563885 & 688128 & 4.4 & 4.6095 & TRN & \\
\hline CHEMBL1327489 & 688128 & 4.3 & 4.5678 & TRN & \\
\hline CHEMBL1541571 & 688128 & 4.35 & 4.6117 & TRN & \\
\hline CHEMBL1481872 & 688128 & 4.0 & 4.5274 & TST & \\
\hline CHEMBL1308396 & 688128 & 4.1 & 4.8397 & TST & \\
\hline CHEMBL1509250 & 688128 & 6.1 & 4.6857 & TRN & \\
\hline CHEMBL1336762 & 688128 & 6.0 & 4.7722 & TST & \\
\hline CHEMBL1402287 & 688128 & 4.05 & 4.7437 & TRN & \\
\hline
\end{tabular}




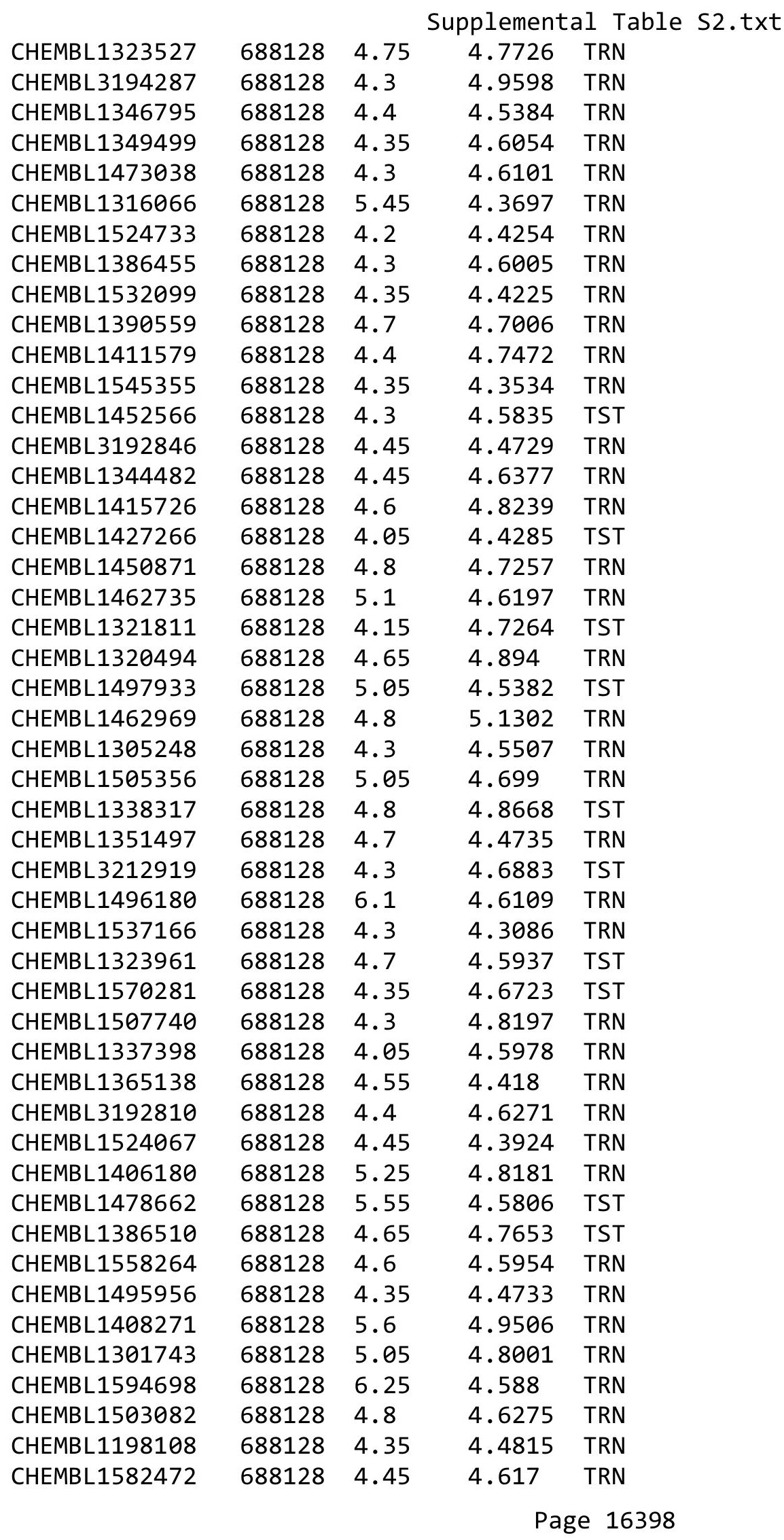




\begin{tabular}{|c|c|c|c|c|}
\hline \multicolumn{5}{|c|}{ Supplemental Table S2.txt } \\
\hline CHEMBL1441858 & 688128 & 4.35 & 4.5302 & TRN \\
\hline CHEMBL1567346 & 688128 & 4.9 & 4.4812 & TRN \\
\hline CHEMBL1381438 & 688128 & 4.35 & 4.7144 & TRN \\
\hline CHEMBL1344422 & 688128 & 5.65 & 4.7503 & TRN \\
\hline CHEMBL1426183 & 688128 & 4.25 & 4.525 & TRN \\
\hline CHEMBL1460349 & 688128 & 4.7 & 4.5371 & TST \\
\hline CHEMBL1393628 & 688128 & 4.95 & 4.3181 & TRN \\
\hline CHEMBL1517169 & 688128 & 4.4 & 4.4792 & TRN \\
\hline CHEMBL 307893 & 688128 & 4.4 & 5.2706 & TRN \\
\hline CHEMBL1557439 & 688128 & 4.4 & 4.5033 & TST \\
\hline CHEMBL1382111 & 688128 & 4.0 & 4.5166 & TRN \\
\hline CHEMBL1531159 & 688128 & 5.15 & 4.9819 & TRN \\
\hline CHEMBL1554207 & 688128 & 5.1 & 4.6427 & TRN \\
\hline CHEMBL1470115 & 688128 & 4.35 & 4.5303 & TST \\
\hline CHEMBL1549646 & 688128 & 4.45 & 4.7433 & TST \\
\hline CHEMBL1310969 & 688128 & 5.0 & 4.9915 & TRN \\
\hline CHEMBL1393343 & 688128 & 4.3 & 4.5724 & TST \\
\hline CHEMBL1529226 & 688128 & 4.45 & 4.6484 & TRN \\
\hline CHEMBL1494805 & 688128 & 4.7 & 4.8417 & TRN \\
\hline CHEMBL1587715 & 688128 & 5.6 & 5.1094 & TRN \\
\hline CHEMBL1435217 & 688128 & 4.05 & 4.5544 & TRN \\
\hline CHEMBL1526067 & 688128 & 5.45 & 4.553 & TRN \\
\hline CHEMBL1468067 & 688128 & 4.45 & 4.5607 & TRN \\
\hline CHEMBL1363711 & 688128 & 4.1 & 4.6494 & TRN \\
\hline CHEMBL1599536 & 688128 & 4.65 & 4.9303 & TRN \\
\hline CHEMBL1599601 & 688128 & 4.05 & 4.5506 & TRN \\
\hline CHEMBL3189381 & 688128 & 4.45 & 4.9596 & TRN \\
\hline CHEMBL1603402 & 688128 & 4.55 & 4.5354 & TRN \\
\hline CHEMBL1460547 & 688128 & 4.45 & 4.8586 & TRN \\
\hline CHEMBL1988416 & 688128 & 6.2 & 4.8685 & TST \\
\hline CHEMBL1319669 & 688128 & 4.05 & 4.6956 & TST \\
\hline CHEMBL1408758 & 688128 & 4.35 & 4.8806 & TRN \\
\hline CHEMBL1549120 & 688128 & 4.95 & 4.9625 & TRN \\
\hline CHEMBL1513060 & 688128 & 4.6 & 4.7317 & TST \\
\hline CHEMBL1605615 & 688128 & 4.3 & 4.7062 & TRN \\
\hline CHEMBL1534991 & 688128 & 4.35 & 4.5424 & TRN \\
\hline CHEMBL1433121 & 688128 & 4.4 & 4.4879 & TRN \\
\hline CHEMBL1464329 & 688128 & 4.25 & 4.477 & TRN \\
\hline CHEMBL1515766 & 688128 & 4.3 & 4.6216 & TRN \\
\hline CHEMBL1509785 & 688128 & 4.4 & 4.4947 & TRN \\
\hline CHEMBL1417070 & 688128 & 4.7 & 4.7324 & TRN \\
\hline CHEMBL1509773 & 688128 & 4.4 & 4.4182 & TRN \\
\hline CHEMBL1587184 & 688128 & 4.8 & 4.5384 & TRN \\
\hline CHEMBL1323018 & 688128 & 4.65 & 4.4244 & TST \\
\hline CHEMBL1428426 & 688128 & 4.25 & 4.9472 & TRN \\
\hline CHEMBL1551480 & 688128 & 4.4 & 4.4088 & TRN \\
\hline CHEMBL1300490 & 688128 & 4.5 & 4.6777 & TRN \\
\hline CHEMBL1528308 & 688128 & 4.7 & 4.7955 & TRN \\
\hline
\end{tabular}




\begin{tabular}{|c|c|c|c|c|c|}
\hline & & \multicolumn{4}{|c|}{ Supplemental Table S2.txt } \\
\hline CHEMBL1444977 & 688128 & 6.1 & 4.7615 & TRN & \\
\hline CHEMBL1309863 & 688128 & 4.05 & 4.537 & TST & \\
\hline CHEMBL1472403 & 688128 & 4.0 & 4.3941 & TRN & \\
\hline CHEMBL1506210 & 688128 & 4.75 & 5.2338 & TST & \\
\hline CHEMBL1543643 & 688128 & 4.4 & 4.5064 & TRN & \\
\hline CHEMBL1433878 & 688128 & 4.05 & 4.5487 & TRN & \\
\hline CHEMBL3196384 & 688128 & 5.15 & 4.9254 & TRN & \\
\hline CHEMBL1465371 & 688128 & 4.3 & 4.5811 & TRN & \\
\hline CHEMBL1512830 & 688128 & 4.5 & 4.3425 & TRN & \\
\hline CHEMBL1601184 & 688128 & 4.45 & 4.5986 & TRN & \\
\hline CHEMBL1317694 & 688128 & 4.3 & 4.7673 & TST & \\
\hline CHEMBL1528480 & 688128 & 6.2 & 5.2426 & TRN & \\
\hline CHEMBL1375613 & 688128 & 4.3 & 4.3833 & TST & \\
\hline CHEMBL1593847 & 688128 & 5.5 & 4.8322 & TST & \\
\hline CHEMBL1457377 & 688128 & 5.45 & 4.6312 & TRN & \\
\hline CHEMBL404140 & 688128 & 4.35 & 4.7981 & TST & \\
\hline CHEMBL1520874 & 688128 & 4.5 & 4.7191 & TRN & \\
\hline CHEMBL1606572 & 688128 & 5.4 & 5.1156 & TRN & \\
\hline CHEMBL1312998 & 688128 & 4.05 & 4.5303 & TRN & \\
\hline CHEMBL1429884 & 688128 & 5.2 & 4.7225 & TRN & \\
\hline CHEMBL3193457 & 688128 & 4.3 & 4.6149 & TRN & \\
\hline CHEMBL1329538 & 688128 & 4.4 & 4.4204 & TST & \\
\hline CHEMBL1603356 & 688128 & 4.35 & 4.5203 & TST & \\
\hline CHEMBL1303230 & 688128 & 4.25 & 4.6836 & TST & \\
\hline CHEMBL1316730 & 688128 & 5.45 & 5.2829 & TRN & \\
\hline CHEMBL1472836 & 688128 & 4.4 & 4.3697 & TST & \\
\hline CHEMBL1381085 & 688128 & 4.85 & 4.359 & TRN & \\
\hline CHEMBL1358194 & 688128 & 4.9 & 4.9284 & TRN & \\
\hline CHEMBL1569403 & 688128 & 4.25 & 4.7008 & TRN & \\
\hline CHEMBL1460185 & 688128 & 4.4 & 4.665 & TRN & \\
\hline CHEMBL1597161 & 688128 & 4.6 & 4.6576 & TST & \\
\hline CHEMBL1609864 & 688128 & 4.55 & 4.6262 & TRN & \\
\hline CHEMBL1549591 & 688128 & 4.4 & 4.6833 & TST & \\
\hline CHEMBL1304115 & 688128 & 4.35 & 4.2778 & TRN & \\
\hline CHEMBL 3210800 & 688128 & 4.3 & 4.5557 & TRN & \\
\hline CHEMBL1496655 & 688128 & 4.35 & 4.3709 & TST & \\
\hline CHEMBL1529056 & 688128 & 4.0 & 4.6029 & TRN & \\
\hline CHEMBL3197903 & 688128 & 4.35 & 4.8266 & TRN & \\
\hline CHEMBL1443569 & 688128 & 4.85 & 4.7731 & TRN & \\
\hline CHEMBL1604735 & 688128 & 4.55 & 4.6519 & TRN & \\
\hline CHEMBL1489145 & 688128 & 4.95 & 4.8464 & TRN & \\
\hline CHEMBL1561390 & 688128 & 4.7 & 4.54899 & 99999999995 & TRN \\
\hline CHEMBL1530766 & 688128 & 4.55 & 4.7498 & TRN & \\
\hline CHEMBL1549112 & 688128 & 4.25 & 5.007 & TRN & \\
\hline CHEMBL1469346 & 688128 & 4.3 & 4.4172 & TST & \\
\hline CHEMBL1360329 & 688128 & 4.25 & 4.2785 & TST & \\
\hline CHEMBL1386244 & 688128 & 4.65 & 4.8607 & TRN & \\
\hline CHEMBL1570386 & 688128 & 5.5 & 4.8935 & TRN & \\
\hline
\end{tabular}




\begin{tabular}{|c|c|c|c|c|c|}
\hline & & \multicolumn{4}{|c|}{ Supplemental Table S2.txt } \\
\hline CHEMBL1540492 & 688128 & 4.45 & 4.7378 & TRN & \\
\hline CHEMBL1514140 & 688128 & 4.8 & 4.4179 & TRN & \\
\hline CHEMBL1417618 & 688128 & 4.3 & 4.7852 & TRN & \\
\hline CHEMBL3191918 & 688128 & 4.6 & 4.8241 & TRN & \\
\hline CHEMBL1446781 & 688128 & 7.0 & 4.7492 & TRN & \\
\hline CHEMBL1507036 & 688128 & 4.45 & 4.8162 & TRN & \\
\hline CHEMBL1526426 & 688128 & 4.05 & 4.8243 & TRN & \\
\hline CHEMBL1354291 & 688128 & 5.0 & 4.487 & TRN & \\
\hline CHEMBL1375019 & 688128 & 4.9 & 4.8659 & TST & \\
\hline CHEMBL1388345 & 688128 & 4.95 & 4.6665 & TRN & \\
\hline CHEMBL1462382 & 688128 & 5.4 & 4.7058 & TST & \\
\hline CHEMBL 387762 & 688128 & 6.05 & 4.92399 & 99999999995 & TST \\
\hline CHEMBL1496566 & 688128 & 4.5 & 4.6188 & TST & \\
\hline CHEMBL1543241 & 688128 & 4.4 & 4.4546 & TRN & \\
\hline CHEMBL1533266 & 688128 & 4.05 & 4.4161 & TST & \\
\hline CHEMBL1538030 & 688128 & 4.55 & 5.0427 & TRN & \\
\hline CHEMBL1357410 & 688128 & 4.75 & 4.63 & TRN & \\
\hline CHEMBL1342135 & 688128 & 4.3 & 4.4374 & TRN & \\
\hline CHEMBL3199697 & 688128 & 4.7 & 4.6953 & TRN & \\
\hline CHEMBL1431988 & 688128 & 4.4 & 4.7177 & TRN & \\
\hline CHEMBL1355031 & 688128 & 4.05 & 4.5847 & TST & \\
\hline CHEMBL1473547 & 688128 & 4.4 & 4.5472 & TST & \\
\hline CHEMBL1535349 & 688128 & 4.4 & 4.5372 & TST & \\
\hline CHEMBL1344644 & 688128 & 4.05 & 4.6223 & TRN & \\
\hline CHEMBL1531718 & 688128 & 5.1 & 4.5434 & TRN & \\
\hline CHEMBL1444960 & 688128 & 4.85 & 4.7553 & TRN & \\
\hline CHEMBL1524909 & 688128 & 4.3 & 4.4318 & TST & \\
\hline CHEMBL1435161 & 688128 & 4.6 & 4.6804 & TRN & \\
\hline CHEMBL1600677 & 688128 & 4.35 & 4.3935 & TRN & \\
\hline CHEMBL1515193 & 688128 & 4.25 & 4.5968 & TRN & \\
\hline CHEMBL1477457 & 688128 & 4.1 & 4.7058 & TST & \\
\hline CHEMBL1442882 & 688128 & 4.9 & 4.8557 & TRN & \\
\hline CHEMBL3191107 & 688128 & 4.2 & 4.8612 & TST & \\
\hline CHEMBL1373066 & 688128 & 4.05 & 4.8174 & TRN & \\
\hline CHEMBL1304025 & 688128 & 4.4 & 4.3828 & TRN & \\
\hline CHEMBL1317044 & 688128 & 4.25 & 4.4173 & TST & \\
\hline CHEMBL1320891 & 688128 & 4.05 & 4.6707 & TRN & \\
\hline CHEMBL1357343 & 688128 & 4.35 & 4.7572 & TRN & \\
\hline CHEMBL1465480 & 688128 & 4.35 & 4.6743 & TST & \\
\hline CHEMBL1312201 & 688128 & 4.6 & 4.5744 & TRN & \\
\hline CHEMBL1358576 & 688128 & 4.65 & 4.5306 & TST & \\
\hline CHEMBL1593825 & 688128 & 4.4 & 4.6036 & TRN & \\
\hline CHEMBL1503530 & 688128 & 4.05 & 4.4541 & TRN & \\
\hline CHEMBL1318283 & 688128 & 6.1 & 4.7746 & TST & \\
\hline CHEMBL1489352 & 688128 & 4.3 & 4.431 & TRN & \\
\hline CHEMBL1981290 & 688128 & 5.3 & 4.6495 & TRN & \\
\hline CHEMBL1582196 & 688128 & 5.45 & 4.7612 & TST & \\
\hline CHEMBL1463829 & 688128 & 4.6 & 4.4808 & TRN & \\
\hline
\end{tabular}




\begin{tabular}{|c|c|c|c|c|c|}
\hline & & \multicolumn{4}{|c|}{ Supplemental Table S2.txt } \\
\hline CHEMBL1571356 & 688128 & 4.25 & 4.6934 & TRN & \\
\hline CHEMBL1547668 & 688128 & 4.25 & 4.2403 & TRN & \\
\hline CHEMBL1500685 & 688128 & 4.4 & 4.3014 & TRN & \\
\hline CHEMBL1535296 & 688128 & 4.45 & 4.676 & TST & \\
\hline CHEMBL1557073 & 688128 & 4.4 & 4.3568 & TST & \\
\hline CHEMBL1558315 & 688128 & 4.4 & 4.3731 & TRN & \\
\hline CHEMBL1326108 & 688128 & 4.45 & 4.3646 & TRN & \\
\hline CHEMBL1257003 & 688128 & 4.3 & 5.1245 & TST & \\
\hline CHEMBL1456412 & 688128 & 4.45 & 4.939 & TRN & \\
\hline CHEMBL1445346 & 688128 & 4.05 & 4.7431 & TRN & \\
\hline CHEMBL1565253 & 688128 & 4.75 & 4.6702 & TRN & \\
\hline CHEMBL1411896 & 688128 & 5.45 & 5.2579 & TRN & \\
\hline CHEMBL1583760 & 688128 & 4.9 & 4.7056 & TRN & \\
\hline CHEMBL1366298 & 688128 & 4.0 & 4.6935 & TST & \\
\hline CHEMBL1435777 & 688128 & 4.45 & 4.5857 & TRN & \\
\hline CHEMBL1460225 & 688128 & 4.25 & 4.493 & TRN & \\
\hline CHEMBL1604920 & 688128 & 5.0 & 4.4769 & TRN & \\
\hline CHEMBL1593346 & 688128 & 5.0 & 4.6062 & TRN & \\
\hline CHEMBL1585652 & 688128 & 4.35 & 4.7804 & TRN & \\
\hline CHEMBL1474103 & 688128 & 4.05 & 4.6853 & TST & \\
\hline CHEMBL1537106 & 688128 & 4.45 & 5.1778 & TRN & \\
\hline CHEMBL 3194341 & 688128 & 4.35 & 4.4994 & TRN & \\
\hline CHEMBL1349045 & 688128 & 4.6 & 4.4953 & TST & \\
\hline CHEMBL1501259 & 688128 & 4.35 & 4.7534 & TST & \\
\hline CHEMBL1429228 & 688128 & 4.4 & 4.6891 & TRN & \\
\hline CHEMBL1541005 & 688128 & 5.45 & 5.2647 & TRN & \\
\hline CHEMBL1595011 & 688128 & 5.25 & 4.88899 & & TRN \\
\hline CHEMBL1538752 & 688128 & 4.3 & 4.8967 & TRN & \\
\hline CHEMBL1594542 & 688128 & 5.5 & 4.7233 & TST & \\
\hline CHEMBL1564246 & 688128 & 4.05 & 4.7812 & TRN & \\
\hline CHEMBL1385865 & 688128 & 4.6 & 4.6021 & TRN & \\
\hline CHEMBL1413667 & 688128 & 4.3 & 4.6499 & TRN & \\
\hline CHEMBL1411883 & 688128 & 4.85 & 5.1655 & TRN & \\
\hline CHEMBL1372670 & 688128 & 4.6 & 4.3578 & TRN & \\
\hline CHEMBL1603842 & 688128 & 5.1 & 4.8969 & TRN & \\
\hline CHEMBL1504413 & 688128 & 4.35 & 4.6443 & TRN & \\
\hline CHEMBL1447031 & 688128 & 4.65 & 4.8789 & TST & \\
\hline CHEMBL1326401 & 688128 & 5.7 & 5.6821 & TRN & \\
\hline CHEMBL1602403 & 688128 & 4.6 & 4.2671 & TRN & \\
\hline CHEMBL1463360 & 688128 & 6.15 & 4.8592 & TRN & \\
\hline CHEMBL1544027 & 688128 & 4.9 & 4.7569 & TRN & \\
\hline CHEMBL1472025 & 688128 & 4.45 & 4.436 & TRN & \\
\hline CHEMBL1539685 & 688128 & 4.4 & 4.6889 & TRN & \\
\hline CHEMBL1500764 & 688128 & 4.5 & 4.6904 & TRN & \\
\hline CHEMBL1334570 & 688128 & 5.55 & 4.7848 & TRN & \\
\hline CHEMBL1302903 & 688128 & 4.5 & 4.5928 & TRN & \\
\hline CHEMBL1344991 & 688128 & 4.35 & 4.6757 & TRN & \\
\hline CHEMBL3208029 & 688128 & 4.1 & 4.7938 & TRN & \\
\hline
\end{tabular}




\begin{tabular}{|c|c|c|c|c|}
\hline \multicolumn{5}{|c|}{ Supplemental Table S2.txt } \\
\hline CHEMBL1607500 & 688128 & 5.0 & 4.6513 & TRN \\
\hline CHEMBL1474683 & 688128 & 4.4 & 4.5924 & TST \\
\hline CHEMBL1580019 & 688128 & 6.2 & 5.4348 & TRN \\
\hline CHEMBL1310925 & 688128 & 4.05 & 4.5586 & TST \\
\hline CHEMBL1391239 & 688128 & 5.35 & 4.7898 & TRN \\
\hline CHEMBL1322604 & 688128 & 4.35 & 4.7189 & TRN \\
\hline CHEMBL1596226 & 688128 & 4.6 & 4.6385 & TST \\
\hline CHEMBL1380303 & 688128 & 4.35 & 4.4015 & TST \\
\hline CHEMBL1529815 & 688128 & 4.25 & 4.3815 & TST \\
\hline CHEMBL1350188 & 688128 & 4.3 & 5.0207 & TST \\
\hline CHEMBL1544142 & 688128 & 4.3 & 4.6829 & TRN \\
\hline CHEMBL1607184 & 688128 & 4.55 & 4.5341 & TRN \\
\hline CHEMBL1509341 & 688128 & 4.4 & 4.5916 & TST \\
\hline CHEMBL1365694 & 688128 & 4.3 & 4.6509 & TRN \\
\hline CHEMBL1586256 & 688128 & 4.4 & 4.6519 & TRN \\
\hline CHEMBL1392913 & 688128 & 4.3 & 4.5599 & TST \\
\hline CHEMBL1516185 & 688128 & 4.35 & 5.0339 & TRN \\
\hline CHEMBL1591001 & 688128 & 4.35 & 4.3786 & TRN \\
\hline CHEMBL1515996 & 688128 & 5.1 & 5.0046 & TRN \\
\hline CHEMBL1308788 & 688128 & 4.4 & 4.6587 & TRN \\
\hline CHEMBL1566690 & 688128 & 4.35 & 4.7951 & TRN \\
\hline CHEMBL3191295 & 688128 & 4.45 & 4.8069 & TRN \\
\hline CHEMBL150924 & 688128 & 5.45 & 4.995 & TRN \\
\hline CHEMBL1497488 & 688128 & 4.4 & 4.69 & TRN \\
\hline CHEMBL495123 & 688128 & 5.05 & 5.0075 & TRN \\
\hline CHEMBL1534301 & 688128 & 4.5 & 4.3628 & TRN \\
\hline CHEMBL420385 & 688128 & 5.5 & 4.6745 & TRN \\
\hline CHEMBL1983700 & 688128 & 5.4 & 4.7291 & TRN \\
\hline CHEMBL 3192932 & 688128 & 4.05 & 4.7657 & TRN \\
\hline CHEMBL1561872 & 688128 & 4.4 & 4.5911 & TRN \\
\hline CHEMBL1554223 & 688128 & 4.25 & 4.1069 & TRN \\
\hline CHEMBL1365854 & 688128 & 4.35 & 4.6487 & TRN \\
\hline CHEMBL1549314 & 688128 & 4.3 & 4.6338 & TRN \\
\hline CHEMBL1362022 & 688128 & 4.45 & 4.6271 & TRN \\
\hline CHEMBL1597208 & 688128 & 4.35 & 4.5072 & TRN \\
\hline CHEMBL1440574 & 688128 & 4.8 & 4.5708 & TST \\
\hline CHEMBL3145155 & 688128 & 7.15 & 5.2387 & TST \\
\hline CHEMBL1558172 & 688128 & 5.4 & 4.4995 & TRN \\
\hline CHEMBL1401141 & 688128 & 4.35 & 4.71 & TST \\
\hline CHEMBL1439026 & 688128 & 4.35 & 4.5317 & TRN \\
\hline CHEMBL1602135 & 688128 & 4.4 & 4.4322 & TRN \\
\hline CHEMBL1465144 & 688128 & 5.55 & 4.6086 & TRN \\
\hline CHEMBL1404038 & 688128 & 4.75 & 5.2228 & TST \\
\hline CHEMBL1372098 & 688128 & 6.2 & 4.9761 & TRN \\
\hline CHEMBL1427505 & 688128 & 4.3 & 4.9516 & TRN \\
\hline CHEMBL1452984 & 688128 & 4.35 & 4.2272 & TRN \\
\hline CHEMBL1425379 & 688128 & 4.45 & 4.5574 & TRN \\
\hline CHEMBL1365471 & 688128 & 4.65 & 4.5907 & TRN \\
\hline
\end{tabular}




\begin{tabular}{|c|c|c|c|c|}
\hline \multicolumn{5}{|c|}{ Supplemental Table S2.txt } \\
\hline CHEMBL1601179 & 688128 & 4.6 & 4.4296 & TRN \\
\hline CHEMBL187866 & 688128 & 4.85 & 4.6689 & TRN \\
\hline CHEMBL1379712 & 688128 & 4.35 & 4.5554 & TST \\
\hline CHEMBL1560715 & 688128 & 4.9 & 4.5548 & TRN \\
\hline CHEMBL1527266 & 688128 & 6.5 & 5.117 & TRN \\
\hline CHEMBL1407086 & 688128 & 4.55 & 4.8972 & TRN \\
\hline CHEMBL1353328 & 688128 & 6.0 & 4.8325 & TRN \\
\hline CHEMBL1460466 & 688128 & 5.05 & 5.2165 & TRN \\
\hline CHEMBL1575228 & 688128 & 4.35 & 4.7445 & TRN \\
\hline CHEMBL3198604 & 688128 & 4.3 & 4.7017 & TRN \\
\hline CHEMBL1576670 & 688128 & 4.05 & 4.9231 & TST \\
\hline CHEMBL1431381 & 688128 & 4.3 & 4.3649 & TRN \\
\hline CHEMBL1360603 & 688128 & 4.65 & 4.4176 & TRN \\
\hline CHEMBL1478425 & 688128 & 4.05 & 4.4522 & TRN \\
\hline CHEMBL1550192 & 688128 & 4.5 & 4.5625 & TRN \\
\hline CHEMBL1372897 & 688128 & 4.05 & 4.7607 & TRN \\
\hline CHEMBL1492071 & 688128 & 6.0 & 4.6671 & TST \\
\hline CHEMBL1349892 & 688128 & 4.4 & 4.72 & TRN \\
\hline CHEMBL1448565 & 688128 & 4.85 & 4.5161 & TRN \\
\hline CHEMBL1496594 & 688128 & 4.5 & 4.78 & TST \\
\hline CHEMBL1317352 & 688128 & 4.5 & 4.8901 & TRN \\
\hline CHEMBL1580724 & 688128 & 4.9 & 4.5415 & TRN \\
\hline CHEMBL1550402 & 688128 & 4.05 & 4.6123 & TST \\
\hline CHEMBL1338316 & 688128 & 4.05 & 4.7168 & TST \\
\hline CHEMBL1505271 & 688128 & 4.25 & 4.4391 & TRN \\
\hline CHEMBL1310865 & 688128 & 5.15 & 4.9089 & TRN \\
\hline CHEMBL1340634 & 688128 & 4.3 & 4.6457 & TST \\
\hline CHEMBL1534293 & 688128 & 4.25 & 4.7737 & TST \\
\hline CHEMBL1494546 & 688128 & 4.35 & 4.5923 & TRN \\
\hline CHEMBL1432401 & 688128 & 4.35 & 4.5628 & TRN \\
\hline CHEMBL1521212 & 688128 & 4.35 & 4.6304 & TRN \\
\hline CHEMBL1418188 & 688128 & 4.55 & 4.6694 & TST \\
\hline CHEMBL1343100 & 688128 & 4.5 & 4.7555 & TST \\
\hline CHEMBL1573271 & 688128 & 4.3 & 4.4482 & TRN \\
\hline CHEMBL1399254 & 688128 & 4.3 & 4.6097 & TST \\
\hline CHEMBL1407925 & 688128 & 4.4 & 4.7019 & TST \\
\hline CHEMBL1429779 & 688128 & 4.35 & 4.6512 & TRN \\
\hline CHEMBL3210208 & 688128 & 4.05 & 4.7288 & TRN \\
\hline CHEMBL1537820 & 688128 & 4.5 & 4.4818 & TST \\
\hline CHEMBL1403320 & 688128 & 6.0 & 5.2235 & TRN \\
\hline CHEMBL1365568 & 688128 & 4.6 & 4.84 & TRN \\
\hline CHEMBL3211948 & 688128 & 4.4 & 4.4364 & TRN \\
\hline CHEMBL1587269 & 688128 & 4.6 & 4.6787 & TRN \\
\hline CHEMBL1451014 & 688128 & 4.25 & 4.8048 & TRN \\
\hline CHEMBL1555968 & 688128 & 4.95 & 4.7453 & TRN \\
\hline CHEMBL1596239 & 688128 & 4.3 & 4.3275 & TST \\
\hline CHEMBL1356230 & 688128 & 4.45 & 4.4852 & TRN \\
\hline CHEMBL1404529 & 688128 & 4.35 & 4.8228 & TRN \\
\hline
\end{tabular}




\begin{tabular}{|c|c|c|c|c|c|}
\hline \multicolumn{6}{|c|}{ Supplemental Table s2.txt } \\
\hline CHEMBL1532766 & 688128 & 4.45 & 4.4837 & TRN & \\
\hline CHEMBL1536667 & 688128 & 4.35 & 4.5734 & TRN & \\
\hline CHEMBL1382961 & 688128 & 4.6 & 4.6177 & TRN & \\
\hline CHEMBL 3194852 & 688128 & 4.35 & 4.6578 & TRN & \\
\hline CHEMBL1611511 & 688128 & 5.4 & 4.7122 & TST & \\
\hline CHEMBL1543322 & 688128 & 4.45 & 4.7061 & TRN & \\
\hline CHEMBL1322375 & 688128 & 4.35 & 4.6071 & TRN & \\
\hline CHEMBL1583509 & 688128 & 5.65 & 4.9694 & TRN & \\
\hline CHEMBL1498097 & 688128 & 5.0 & 4.8364 & TRN & \\
\hline CHEMBL3193649 & 688128 & 5.55 & 4.5609 & TST & \\
\hline CHEMBL1328619 & 688128 & 4.35 & 4.891 & TST & \\
\hline CHEMBL1575545 & 688128 & 4.35 & 4.3819 & TRN & \\
\hline CHEMBL1482505 & 688128 & 4.35 & 4.533 & TRN & \\
\hline CHEMBL1599560 & 688128 & 4.85 & 4.4883 & TST & \\
\hline CHEMBL1541863 & 688128 & 4.7 & 4.203 & TRN & \\
\hline CHEMBL1364254 & 688128 & 4.3 & 4.4898 & TRN & \\
\hline CHEMBL1345445 & 688128 & 4.3 & 4.7335 & TST & \\
\hline CHEMBL1528124 & 688128 & 4.7 & 4.433 & TRN & \\
\hline CHEMBL1386798 & 688128 & 4.05 & 4.836 & TST & \\
\hline CHEMBL1482776 & 688128 & 6.7001 & 5.2126 & TRN & \\
\hline CHEMBL1399548 & 688128 & 5.45 & 4.5235 & TST & \\
\hline CHEMBL1525487 & 688128 & 4.35 & 4.7921 & TRN & \\
\hline CHEMBL1452746 & 688128 & 4.45 & 4.7492 & TRN & \\
\hline CHEMBL1569046 & 688128 & 4.3 & 4.6721 & TRN & \\
\hline CHEMBL1451832 & 688128 & 4.4 & 4.38399 & 99999999995 & TST \\
\hline CHEMBL1270410 & 688128 & 6.1 & 4.5269 & TRN & \\
\hline CHEMBL1353137 & 688128 & 4.05 & 4.65600 & 0000000001 & TRN \\
\hline CHEMBL1573503 & 688128 & 4.3 & 4.5521 & TRN & \\
\hline CHEMBL1358874 & 688128 & 4.55 & 4.7743 & TRN & \\
\hline CHEMBL1441199 & 688128 & 4.65 & 4.4329 & TRN & \\
\hline CHEMBL1529813 & 688128 & 5.1 & 4.6853 & TRN & \\
\hline CHEMBL3196867 & 688128 & 4.35 & 4.3768 & TST & \\
\hline CHEMBL1564441 & 688128 & 5.45 & 4.6797 & TRN & \\
\hline CHEMBL1574795 & 688128 & 4.45 & 4.6482 & TRN & \\
\hline CHEMBL1335945 & 688128 & 5.55 & 4.3167 & TST & \\
\hline CHEMBL1372294 & 688128 & 4.35 & 4.7269 & TRN & \\
\hline CHEMBL1486225 & 688128 & 4.3 & 4.5459 & TRN & \\
\hline CHEMBL1584503 & 688128 & 4.3 & 4.63899 & 9999999999 & TRN \\
\hline CHEMBL1389153 & 688128 & 4.4 & 4.66100 & 00000000005 & TRN \\
\hline CHEMBL3193140 & 688128 & 4.15 & 4.5974 & TST & \\
\hline CHEMBL1372929 & 688128 & 5.0 & 4.6221 & TRN & \\
\hline CHEMBL1566539 & 688128 & 4.45 & 4.9599 & TRN & \\
\hline CHEMBL1454591 & 688128 & 4.1 & 4.5574 & TRN & \\
\hline CHEMBL1498795 & 688128 & 4.25 & 4.6406 & TST & \\
\hline CHEMBL1368329 & 688128 & 4.55 & 4.5067 & TRN & \\
\hline CHEMBL1334107 & 688128 & 4.05 & 4.4721 & TST & \\
\hline CHEMBL1299341 & 688128 & 4.85 & 4.9495 & TRN & \\
\hline CHEMBL1317184 & 688128 & 4.95 & 5.1175 & TRN & \\
\hline
\end{tabular}




\begin{tabular}{|c|c|c|c|c|}
\hline \multicolumn{5}{|c|}{ Supplemental Table S2.txt } \\
\hline CHEMBL1349866 & 688128 & 5.05 & 4.5013 & TRN \\
\hline CHEMBL1569011 & 688128 & 4.05 & 4.4482 & TST \\
\hline CHEMBL1351449 & 688128 & 4.3 & 4.4175 & TRN \\
\hline CHEMBL1508483 & 688128 & 4.4 & 4.4855 & TRN \\
\hline CHEMBL1357569 & 688128 & 4.5 & 4.9538 & TRN \\
\hline CHEMBL1364635 & 688128 & 4.75 & 4.7811 & TRN \\
\hline CHEMBL3208022 & 688128 & 4.4 & 4.4893 & TRN \\
\hline CHEMBL1387704 & 688128 & 5.95 & 5.3345 & TRN \\
\hline CHEMBL1464079 & 688128 & 6.8499 & 4.6681 & TST \\
\hline CHEMBL1511639 & 688128 & 4.5 & 4.7124 & TRN \\
\hline CHEMBL1499214 & 688128 & 4.95 & 4.6169 & TRN \\
\hline CHEMBL1586550 & 688128 & 4.0 & 4.7979 & TRN \\
\hline CHEMBL3187596 & 688128 & 4.6 & 4.8507 & TRN \\
\hline CHEMBL1430463 & 688128 & 5.55 & 4.7469 & TRN \\
\hline CHEMBL1368152 & 688128 & 4.45 & 4.3601 & TRN \\
\hline CHEMBL1517868 & 688128 & 4.3 & 4.5476 & TST \\
\hline CHEMBL1534924 & 688128 & 5.5 & 4.7309 & TRN \\
\hline CHEMBL1493471 & 688128 & 4.95 & 4.6 & TRN \\
\hline CHEMBL1989464 & 688128 & 4.55 & 4.4904 & TST \\
\hline CHEMBL1534533 & 688128 & 4.4 & 4.4388 & TST \\
\hline CHEMBL1340183 & 688128 & 4.6 & 4.5517 & TRN \\
\hline CHEMBL1493012 & 688128 & 5.45 & 4.6452 & TRN \\
\hline CHEMBL1491929 & 688128 & 4.35 & 4.7115 & TRN \\
\hline CHEMBL1458705 & 688128 & 4.05 & 4.5421 & TST \\
\hline CHEMBL1573416 & 688128 & 4.35 & 4.7166 & TRN \\
\hline CHEMBL1448309 & 688128 & 4.5 & 4.773 & TST \\
\hline CHEMBL1328948 & 688128 & 4.05 & 4.4245 & TRN \\
\hline CHEMBL1351063 & 688128 & 4.35 & 4.3937 & TRN \\
\hline CHEMBL1399082 & 688128 & 4.65 & 4.5121 & TRN \\
\hline CHEMBL1310172 & 688128 & 5.05 & 5.1196 & TRN \\
\hline CHEMBL1446690 & 688128 & 4.45 & 4.4411 & TRN \\
\hline CHEMBL1350238 & 688128 & 4.45 & 4.6106 & TRN \\
\hline CHEMBL1465319 & 688128 & 4.1 & 4.5918 & TRN \\
\hline CHEMBL1532656 & 688128 & 4.45 & 4.6011 & TRN \\
\hline CHEMBL1481400 & 688128 & 5.0 & 5.1097 & TRN \\
\hline CHEMBL1570923 & 688128 & 4.45 & 4.4533 & TRN \\
\hline CHEMBL1560017 & 688128 & 4.4 & 4.5005 & TST \\
\hline CHEMBL1329392 & 688128 & 4.1 & 4.7355 & TRN \\
\hline CHEMBL1546652 & 688128 & 4.35 & 4.6909 & TST \\
\hline CHEMBL1566150 & 688128 & 4.65 & 4.4887 & TRN \\
\hline CHEMBL1497235 & 688128 & 5.55 & 4.7247 & TRN \\
\hline CHEMBL1322245 & 688128 & 4.6 & 4.1629 & TRN \\
\hline CHEMBL170190 & 688128 & 4.25 & 4.6214 & TST \\
\hline CHEMBL1435092 & 688128 & 4.35 & 4.4591 & TRN \\
\hline CHEMBL1516127 & 688128 & 4.35 & 4.7829 & TRN \\
\hline CHEMBL1385418 & 688128 & 4.3 & 4.4805 & TRN \\
\hline CHEMBL1534689 & 688128 & 4.05 & 4.4038 & TST \\
\hline CHEMBL1454680 & 688128 & 5.0 & 4.8522 & TRN \\
\hline
\end{tabular}




\begin{tabular}{|c|c|c|c|c|c|}
\hline & & \multicolumn{4}{|c|}{ Supplemental Table S2.txt } \\
\hline CHEMBL3197026 & 688128 & 4.05 & 4.8408 & TRN & \\
\hline CHEMBL1583566 & 688128 & 4.1 & 4.5263 & TRN & \\
\hline CHEMBL1464853 & 688128 & 6.6 & 5.0223 & TST & \\
\hline CHEMBL1362221 & 688128 & 4.65 & 4.8402 & TRN & \\
\hline CHEMBL1558475 & 688128 & 4.4 & 4.6451 & TRN & \\
\hline CHEMBL1335472 & 688128 & 4.1 & 4.4496 & TRN & \\
\hline CHEMBL1384822 & 688128 & 4.3 & 4.5552 & TRN & \\
\hline CHEMBL1414766 & 688128 & 5.4 & 4.8858 & TRN & \\
\hline CHEMBL 1411480 & 688128 & 4.35 & 4.4649 & TRN & \\
\hline CHEMBL1318536 & 688128 & 4.4 & 4.497 & TST & \\
\hline CHEMBL1394624 & 688128 & 4.3 & 5.2535 & TST & \\
\hline CHEMBL1515900 & 688128 & 4.35 & 4.4851 & TRN & \\
\hline CHEMBL1431115 & 688128 & 4.4 & 4.6818 & TST & \\
\hline CHEMBL1549175 & 688128 & 6.4 & 5.5358 & TRN & \\
\hline CHEMBL1557778 & 688128 & 4.35 & 4.5585 & TRN & \\
\hline CHEMBL1546488 & 688128 & 4.4 & 4.4057 & TRN & \\
\hline CHEMBL1401215 & 688128 & 5.1 & 5.0637 & TRN & \\
\hline CHEMBL1567704 & 688128 & 5.0 & 4.6203 & TRN & \\
\hline CHEMBL 1967474 & 688128 & 5.0 & 4.6429 & TST & \\
\hline CHEMBL1334295 & 688128 & 4.4 & 4.6709 & TRN & \\
\hline CHEMBL1592514 & 688128 & 4.5 & 4.7411 & TRN & \\
\hline CHEMBL1570167 & 688128 & 4.4 & 4.5681 & TRN & \\
\hline CHEMBL1499762 & 688128 & 4.35 & 4.3164 & TRN & \\
\hline CHEMBL 1413680 & 688128 & 6.5 & 5.2131 & TST & \\
\hline CHEMBL1493959 & 688128 & 4.35 & 4.5555 & TRN & \\
\hline CHEMBL 2373661 & 688128 & 4.4 & 4.9597 & TST & \\
\hline CHEMBL1553285 & 688128 & 4.3 & 4.3659 & TRN & \\
\hline CHEMBL1497407 & 688128 & 4.4 & 4.4156 & TRN & \\
\hline CHEMBL3190152 & 688128 & 4.35 & 4.9427 & TRN & \\
\hline CHEMBL1365392 & 688128 & 4.4 & 4.6667 & TRN & \\
\hline CHEMBL1350220 & 688128 & 5.4 & 5.05399 & 9999999999 & TRN \\
\hline CHEMBL600526 & 688128 & 4.4 & 4.6678 & TRN & \\
\hline CHEMBL1999137 & 688128 & 4.45 & 4.5808 & TRN & \\
\hline CHEMBL1504470 & 688128 & 4.0 & 4.5887 & TRN & \\
\hline CHEMBL1482317 & 688128 & 5.05 & 4.802 & TRN & \\
\hline CHEMBL1563035 & 688128 & 4.35 & 4.4071 & TRN & \\
\hline CHEMBL1375429 & 688128 & 4.05 & 4.896 & TRN & \\
\hline CHEMBL1580403 & 688128 & 4.05 & 4.5785 & TRN & \\
\hline CHEMBL1589037 & 688128 & 4.3 & 4.3634 & TRN & \\
\hline CHEMBL1612340 & 688128 & 4.05 & 4.4178 & TST & \\
\hline CHEMBL3209533 & 688128 & 4.7 & 4.6596 & TRN & \\
\hline CHEMBL3193986 & 688128 & 4.35 & 4.6081 & TRN & \\
\hline CHEMBL3199006 & 688128 & 4.5 & 4.6567 & TRN & \\
\hline CHEMBL1347203 & 688128 & 4.05 & 4.4581 & TST & \\
\hline CHEMBL1484726 & 688128 & 5.2 & 4.2576 & TST & \\
\hline CHEMBL1414852 & 688128 & 4.05 & 4.4557 & TRN & \\
\hline CHEMBL1564663 & 688128 & 4.5 & 4.7872 & TRN & \\
\hline CHEMBL1414561 & 688128 & 4.05 & 4.6441 & TRN & \\
\hline
\end{tabular}




\begin{tabular}{|c|c|c|c|c|}
\hline \multicolumn{5}{|c|}{ Supplemental Table S2.txt } \\
\hline CHEMBL1418476 & 688128 & 4.4 & 4.583 & TRN \\
\hline CHEMBL1482836 & 688128 & 4.3 & 4.6799 & TRN \\
\hline CHEMBL1600683 & 688128 & 5.0 & 4.7505 & TST \\
\hline CHEMBL1490981 & 688128 & 4.25 & 4.5555 & TRN \\
\hline CHEMBL1597765 & 688128 & 4.3 & 4.3673 & TRN \\
\hline CHEMBL1418266 & 688128 & 5.5 & 4.5093 & TST \\
\hline CHEMBL1592285 & 688128 & 4.55 & 4.745 & TRN \\
\hline CHEMBL1443652 & 688128 & 4.35 & 4.521 & TRN \\
\hline CHEMBL1550798 & 688128 & 4.5 & 4.3929 & TRN \\
\hline CHEMBL1431865 & 688128 & 4.3 & 4.5108 & TRN \\
\hline CHEMBL1455722 & 688128 & 4.35 & 4.5983 & TRN \\
\hline CHEMBL1600809 & 688128 & 4.3 & 4.4089 & TRN \\
\hline CHEMBL1610436 & 688128 & 5.05 & 5.1292 & TRN \\
\hline CHEMBL1432084 & 688128 & 4.65 & 4.6147 & TRN \\
\hline CHEMBL1364155 & 688128 & 4.65 & 4.4997 & TRN \\
\hline CHEMBL1392013 & 688128 & 4.2 & 4.5276 & TRN \\
\hline CHEMBL1463582 & 688128 & 4.95 & 4.4381 & TRN \\
\hline CHEMBL527586 & 688128 & 4.7 & 4.4683 & TST \\
\hline CHEMBL 3197661 & 688128 & 4.55 & 4.7501 & TRN \\
\hline CHEMBL1452782 & 688128 & 4.35 & 4.61 & TRN \\
\hline CHEMBL1565851 & 688128 & 4.05 & 4.6796 & TRN \\
\hline CHEMBL1506574 & 688128 & 4.3 & 4.5822 & TRN \\
\hline CHEMBL1479483 & 688128 & 5.05 & 4.9654 & TRN \\
\hline CHEMBL1386239 & 688128 & 4.4 & 4.7384 & TRN \\
\hline CHEMBL1550485 & 688128 & 4.55 & 4.9669 & TRN \\
\hline CHEMBL1543818 & 688128 & 5.0 & 4.5301 & TST \\
\hline CHEMBL1589015 & 688128 & 5.0 & 4.9544 & TST \\
\hline CHEMBL1601735 & 688128 & 5.6 & 4.8963 & TRN \\
\hline CHEMBL1363838 & 688128 & 4.3 & 4.7574 & TST \\
\hline CHEMBL1421433 & 688128 & 4.95 & 4.6343 & TRN \\
\hline CHEMBL1303753 & 688128 & 4.3 & 4.1443 & TRN \\
\hline CHEMBL1447463 & 688128 & 4.3 & 4.6413 & TRN \\
\hline CHEMBL1599758 & 688128 & 4.3 & 4.6029 & TST \\
\hline CHEMBL1590246 & 688128 & 4.35 & 4.4127 & TST \\
\hline CHEMBL1625031 & 688128 & 6.4 & 5.1093 & TRN \\
\hline CHEMBL1582577 & 688128 & 5.75 & 4.4893 & TRN \\
\hline CHEMBL2006039 & 688128 & 4.85 & 4.6889 & TST \\
\hline CHEMBL1467202 & 688128 & 4.35 & 5.0599 & TST \\
\hline CHEMBL 3214589 & 688128 & 4.3 & 4.6143 & TRN \\
\hline CHEMBL1597459 & 688128 & 5.4 & 4.9582 & TST \\
\hline CHEMBL1414952 & 688128 & 4.95 & 4.6198 & TRN \\
\hline CHEMBL1429164 & 688128 & 4.85 & 4.9143 & TRN \\
\hline CHEMBL1326444 & 688128 & 4.4 & 4.5716 & TRN \\
\hline CHEMBL1593526 & 688128 & 4.35 & 4.6733 & TRN \\
\hline CHEMBL1468194 & 688128 & 4.95 & 4.7181 & TRN \\
\hline CHEMBL1498470 & 688128 & 4.05 & 4.49 & TRN \\
\hline CHEMBL1400671 & 688128 & 4.05 & 4.3684 & TRN \\
\hline CHEMBL1423193 & 688128 & 5.95 & 4.4541 & TRN \\
\hline
\end{tabular}




\begin{tabular}{|c|c|c|c|c|c|}
\hline & & \multicolumn{4}{|c|}{ Supplemental Table S2.txt } \\
\hline CHEMBL1465251 & 688128 & 4.45 & 4.5587 & TRN & \\
\hline CHEMBL1601413 & 688128 & 5.85 & 4.7835 & TST & \\
\hline CHEMBL1433187 & 688128 & 4.35 & 4.8546 & TRN & \\
\hline CHEMBL1337299 & 688128 & 4.4 & 4.5665 & TRN & \\
\hline CHEMBL1534982 & 688128 & 4.35 & 4.5785 & TRN & \\
\hline CHEMBL1498604 & 688128 & 4.85 & 4.6084 & TRN & \\
\hline CHEMBL1547738 & 688128 & 4.65 & 4.2698 & TRN & \\
\hline CHEMBL1518700 & 688128 & 4.35 & 4.7416 & TRN & \\
\hline CHEMBL1571430 & 688128 & 4.35 & 4.7861 & TRN & \\
\hline CHEMBL1463885 & 688128 & 7.0 & 5.0818 & TRN & \\
\hline CHEMBL1444021 & 688128 & 4.4 & 4.5292 & TRN & \\
\hline CHEMBL1466340 & 688128 & 5.1 & 5.2181 & TST & \\
\hline CHEMBL1342968 & 688128 & 4.05 & 4.6573 & TRN & \\
\hline CHEMBL1349991 & 688128 & 4.4 & 4.4744 & TRN & \\
\hline CHEMBL1309613 & 688128 & 4.35 & 4.2949 & TRN & \\
\hline CHEMBL1381697 & 688128 & 4.35 & 4.543 & TRN & \\
\hline CHEMBL1543567 & 688128 & 4.4 & 4.6222 & TRN & \\
\hline CHEMBL1531353 & 688128 & 4.05 & 4.6946 & TRN & \\
\hline CHEMBL1331083 & 688128 & 4.4 & 4.3256 & TST & \\
\hline CHEMBL1409414 & 688128 & 5.55 & 4.9873 & TRN & \\
\hline CHEMBL1579009 & 688128 & 4.05 & 4.1917 & TST & \\
\hline CHEMBL1320127 & 688128 & 4.4 & 4.658 & TRN & \\
\hline CHEMBL1998868 & 688128 & 6.2 & 4.6581 & TRN & \\
\hline CHEMBL1560745 & 688128 & 4.6 & 4.8139 & TRN & \\
\hline CHEMBL1492983 & 688128 & 4.0 & 4.3969 & TRN & \\
\hline CHEMBL1427295 & 688128 & 4.25 & 4.4559 & TRN & \\
\hline CHEMBL1489942 & 688128 & 4.95 & 4.6191 & TRN & \\
\hline CHEMBL1608902 & 688128 & 4.6 & 4.76699 & 99999999995 & TRN \\
\hline CHEMBL1598230 & 688128 & 4.05 & 4.6021 & TRN & \\
\hline CHEMBL1331524 & 688128 & 4.4 & 4.5037 & TRN & \\
\hline CHEMBL1487743 & 688128 & 5.35 & 4.399 & TST & \\
\hline CHEMBL1609231 & 688128 & 4.4 & 4.4505 & TRN & \\
\hline CHEMBL1305275 & 688128 & 5.05 & 4.5384 & TST & \\
\hline CHEMBL1489000 & 688128 & 4.35 & 4.5822 & TRN & \\
\hline CHEMBL1969470 & 688128 & 6.4 & 4.9259 & TST & \\
\hline CHEMBL1466126 & 688128 & 5.6 & 5.0514 & TRN & \\
\hline CHEMBL1374331 & 688128 & 4.4 & 4.327 & TRN & \\
\hline CHEMBL1489029 & 688128 & 6.05 & 4.5347 & TST & \\
\hline CHEMBL582722 & 688128 & 5.2 & 4.9567 & TRN & \\
\hline CHEMBL1319910 & 688128 & 4.7 & 4.6448 & TRN & \\
\hline CHEMBL1408400 & 688128 & 5.5 & 4.5034 & TRN & \\
\hline CHEMBL3199079 & 688128 & 4.3 & 4.5484 & TRN & \\
\hline CHEMBL1426599 & 688128 & 5.45 & 4.6929 & TRN & \\
\hline CHEMBL1459656 & 688128 & 4.5 & 4.4452 & TRN & \\
\hline CHEMBL1524927 & 688128 & 4.45 & 4.7494 & TRN & \\
\hline CHEMBL1489998 & 688128 & 4.6 & 4.6058 & TRN & \\
\hline CHEMBL1470626 & 688128 & 5.85 & 4.8257 & TRN & \\
\hline CHEMBL1377462 & 688128 & 5.8 & 4.7819 & TST & \\
\hline
\end{tabular}




\begin{tabular}{|c|c|c|c|c|c|}
\hline \multirow{2}{*}{ CHEMBL1526168 } & \multirow{2}{*}{688128} & \\
\hline & & 4.6 & 4.7104 & TRN & \\
\hline CHEMBL1361212 & 688128 & 4.7 & 4.2984 & TRN & \\
\hline CHEMBL1383041 & 688128 & 4.35 & 4.7435 & TRN & \\
\hline CHEMBL1965710 & 688128 & 4.55 & 4.552 & TRN & \\
\hline CHEMBL1449117 & 688128 & 4.4 & 4.7268 & TRN & \\
\hline CHEMBL1329817 & 688128 & 4.5 & 4.419 & TRN & \\
\hline CHEMBL1366037 & 688128 & 6.15 & 4.3873 & TRN & \\
\hline CHEMBL1514745 & 688128 & 5.4 & 4.5429 & TRN & \\
\hline CHEMBL1581007 & 688128 & 4.75 & 4.3461 & TRN & \\
\hline CHEMBL1541777 & 688128 & 4.35 & 5.0089 & 99999999995 & TST \\
\hline CHEMBL1494432 & 688128 & 4.4 & 5.3568 & TRN & \\
\hline CHEMBL1430324 & 688128 & 4.4 & 4.4167 & TRN & \\
\hline CHEMBL3210841 & 688128 & 4.0 & 4.3489 & TRN & \\
\hline CHEMBL1450178 & 688128 & 4.4 & 4.6517 & TST & \\
\hline CHEMBL1488531 & 688128 & 4.4 & 4.8647 & TRN & \\
\hline CHEMBL1480316 & 688128 & 4.85 & 4.9289 & 9999999999 & TST \\
\hline CHEMBL1484562 & 688128 & 4.6 & 4.6494 & TST & \\
\hline CHEMBL1357051 & 688128 & 4.45 & 4.4658 & TRN & \\
\hline CHEMBL1566869 & 688128 & 5.85 & 4.5821 & TST & \\
\hline CHEMBL1382984 & 688128 & 6.45 & 4.6041 & TRN & \\
\hline CHEMBL1489151 & 688128 & 4.9 & 4.5611 & TRN & \\
\hline CHEMBL1505170 & 688128 & 4.05 & 4.3751 & TST & \\
\hline CHEMBL 2004056 & 688128 & 4.45 & 4.7118 & TST & \\
\hline CHEMBL1538345 & 688128 & 4.35 & 4.3057 & TRN & \\
\hline CHEMBL1457139 & 688128 & 5.9 & 5.5428 & TRN & \\
\hline CHEMBL1588153 & 688128 & 4.35 & 4.5213 & TRN & \\
\hline CHEMBL1471745 & 688128 & 6.5 & $5.1320 €$ & 0000000001 & TRN \\
\hline CHEMBL1484846 & 688128 & 4.0 & 4.7189 & 9999999999 & TST \\
\hline CHEMBL1529438 & 688128 & 4.1 & 4.5904 & TST & \\
\hline CHEMBL1353220 & 688128 & 5.05 & 4.7953 & TST & \\
\hline CHEMBL1575580 & 688128 & 6.2 & 4.7638 & TRN & \\
\hline CHEMBL 3191087 & 688128 & 4.65 & 4.887 & TRN & \\
\hline CHEMBL1536531 & 688128 & 4.05 & 4.7795 & TRN & \\
\hline CHEMBL1365118 & 688128 & 4.3 & 4.793 & TRN & \\
\hline CHEMBL1336738 & 688128 & 6.0 & 4.4389 & TRN & \\
\hline CHEMBL1542608 & 688128 & 4.95 & 4.6516 & TRN & \\
\hline CHEMBL1603956 & 688128 & 4.0 & 4.3719 & TRN & \\
\hline CHEMBL1377830 & 688128 & 6.8499 & 4.4075 & TRN & \\
\hline CHEMBL1307419 & 688128 & 2.7 & 4.6864 & TST & \\
\hline CHEMBL1336119 & 688128 & 4.75 & 4.6863 & TRN & \\
\hline CHEMBL1549449 & 688128 & 5.4 & 4.4232 & TRN & \\
\hline CHEMBL1341272 & 688128 & 4.3 & 4.325 & TRN & \\
\hline CHEMBL1366824 & 688128 & 4.05 & 4.3533 & TRN & \\
\hline CHEMBL1588541 & 688128 & 4.55 & 4.6326 & TRN & \\
\hline CHEMBL1483039 & 688128 & 4.35 & 4.706 & TRN & \\
\hline CHEMBL1563443 & 688128 & 4.25 & 4.2201 & TRN & \\
\hline CHEMBL1520912 & 688128 & 4.65 & 4.4652 & TST & \\
\hline CHEMBL1319938 & 688128 & 4.3 & 4.6041 & TRN & \\
\hline
\end{tabular}




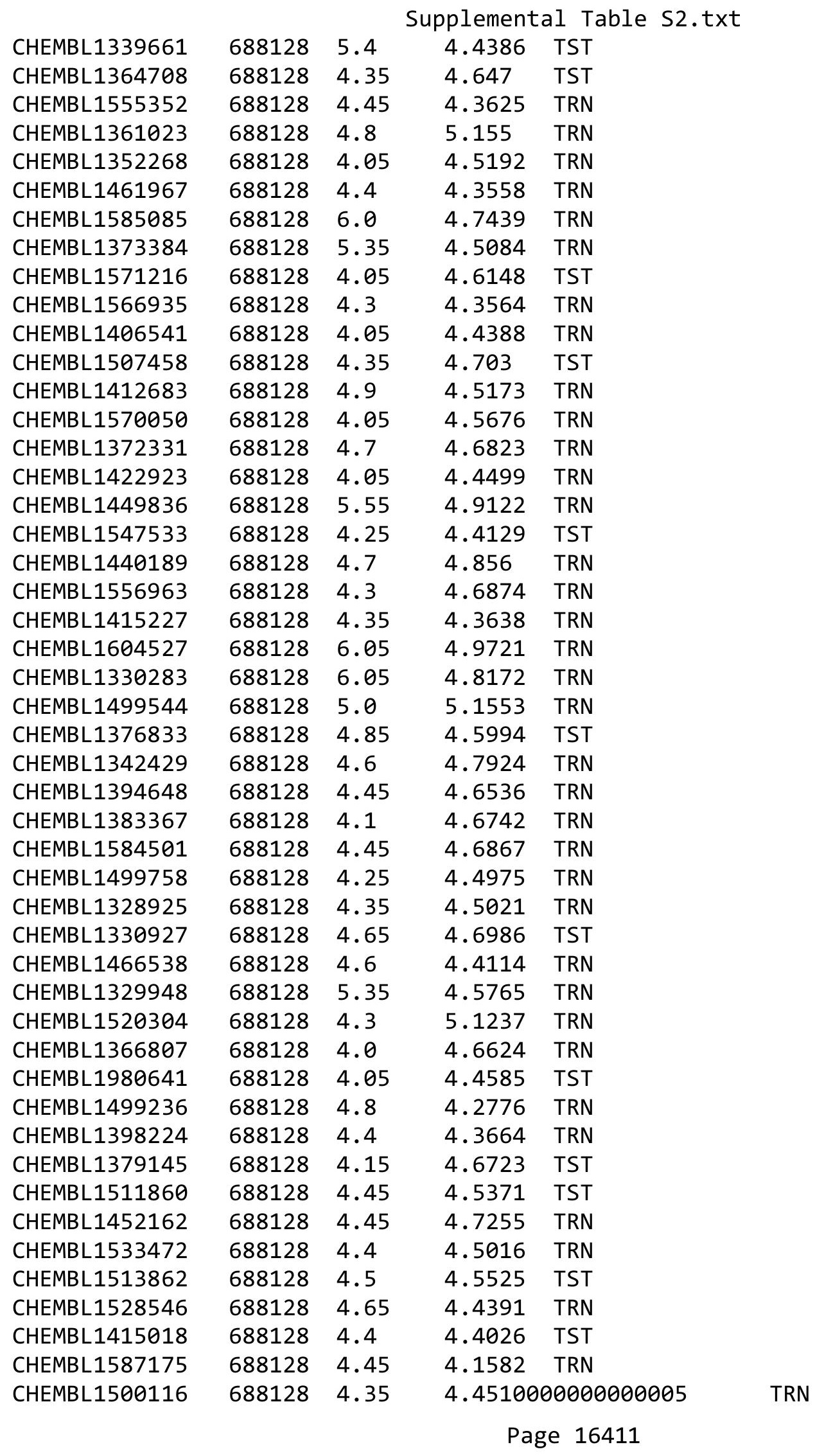




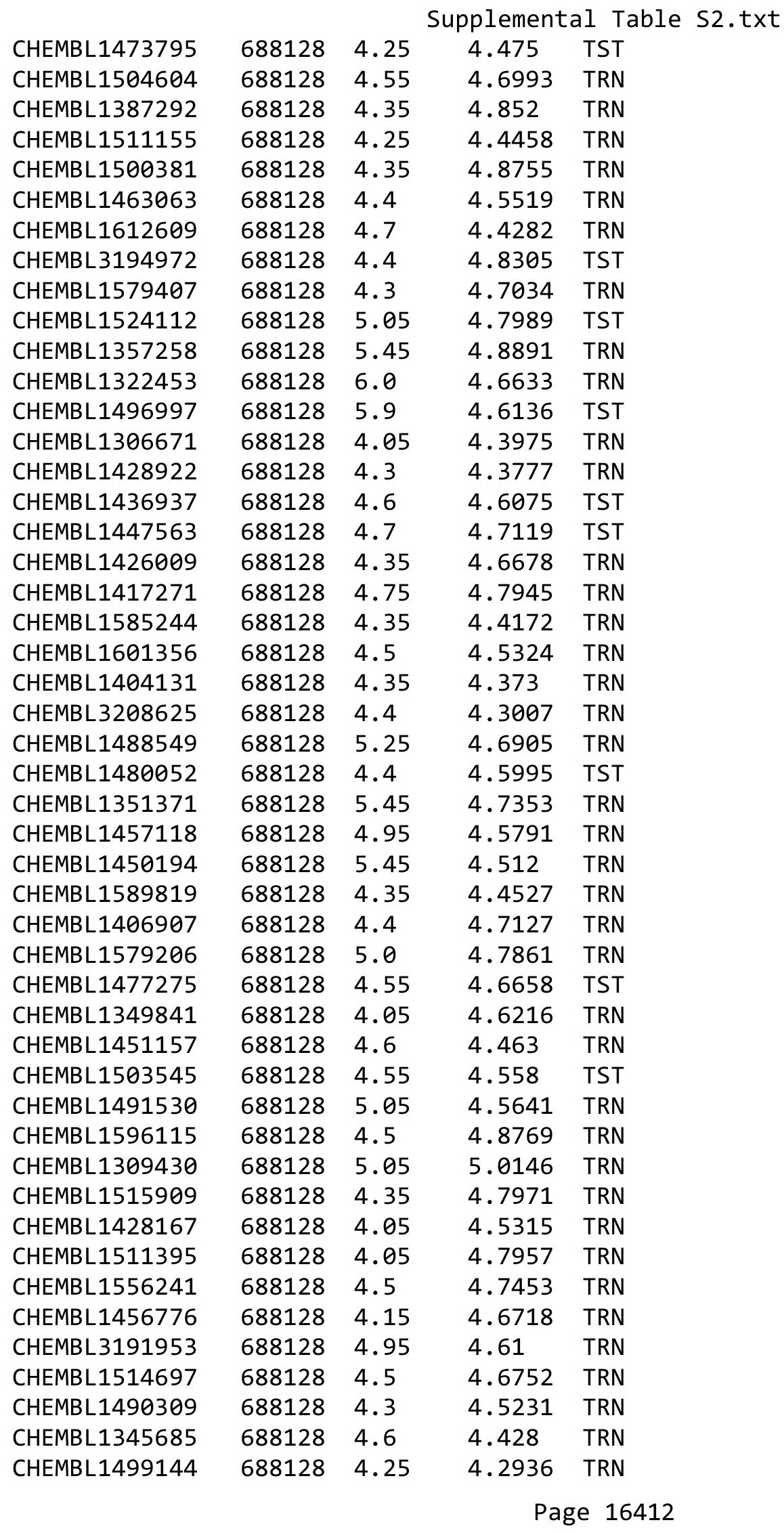




\begin{tabular}{|c|c|c|c|c|}
\hline & & & pplement & $\mathrm{Ta}$ \\
\hline CHEMBL1304283 & 688128 & 4.3 & 4.5841 & TRN \\
\hline CHEMBL1304184 & 688128 & 4.3 & 4.504 & TRN \\
\hline CHEMBL1442503 & 688128 & 4.4 & 4.7299 & TRN \\
\hline CHEMBL1309386 & 688128 & 4.05 & 4.291 & TRN \\
\hline CHEMBL1582568 & 688128 & 4.6 & 4.4744 & TRN \\
\hline CHEMBL1554337 & 688128 & 4.95 & 4.9172 & TRN \\
\hline CHEMBL1309269 & 688128 & 4.05 & 4.9647 & TST \\
\hline CHEMBL1556321 & 688128 & 4.6 & 4.6728 & TRN \\
\hline CHEMBL1550310 & 688128 & 4.35 & 4.7621 & TST \\
\hline CHEMBL3199709 & 688128 & 4.4 & 4.7474 & TST \\
\hline CHEMBL1601904 & 688128 & 4.05 & 4.6928 & TST \\
\hline CHEMBL1511851 & 688128 & 4.05 & 4.7058 & TST \\
\hline CHEMBL1578358 & 688128 & 4.35 & 4.6579 & TRN \\
\hline CHEMBL1320110 & 688128 & 4.45 & 4.4368 & TST \\
\hline CHEMBL1333580 & 688128 & 4.6 & 4.6564 & TRN \\
\hline CHEMBL1496277 & 688128 & 4.05 & 4.9029 & TST \\
\hline CHEMBL1608541 & 688128 & 5.55 & 4.7997 & TRN \\
\hline CHEMBL1510427 & 688128 & 5.0 & 4.8586 & TRN \\
\hline CHEMBL3192721 & 688128 & 5.55 & 4.9359 & TRN \\
\hline CHEMBL1371009 & 688128 & 5.4 & 4.7523 & TRN \\
\hline CHEMBL1436470 & 688128 & 4.1 & 4.5864 & TST \\
\hline CHEMBL1446816 & 688128 & 4.3 & 4.4867 & TRN \\
\hline CHEMBL1435247 & 688128 & 4.05 & 4.8465 & TST \\
\hline CHEMBL1411494 & 688128 & 4.8 & 4.3974 & TRN \\
\hline CHEMBL1366043 & 688128 & 4.45 & 4.6708 & TRN \\
\hline CHEMBL1349461 & 688128 & 4.35 & 4.5322 & TST \\
\hline CHEMBL1340552 & 688128 & 4.25 & 4.5549 & TRN \\
\hline CHEMBL2374059 & 688128 & 5.35 & 4.9828 & TRN \\
\hline CHEMBL1574935 & 688128 & 4.55 & 4.6039 & TRN \\
\hline CHEMBL1543488 & 688128 & 4.1 & 4.6652 & TST \\
\hline CHEMBL1531867 & 688128 & 4.4 & 4.334 & TRN \\
\hline CHEMBL3207413 & 688128 & 4.15 & 4.7399 & TST \\
\hline CHEMBL1548669 & 688128 & 4.4 & 4.8747 & TST \\
\hline CHEMBL1323332 & 688128 & 5.55 & 4.6622 & TRN \\
\hline CHEMBL3207423 & 688128 & 5.05 & 4.6925 & TRN \\
\hline CHEMBL1427028 & 688128 & 4.5 & 4.7718 & TRN \\
\hline CHEMBL1408877 & 688128 & 4.05 & 4.599 & TRN \\
\hline CHEMBL1373806 & 688128 & 4.4 & 4.8412 & TRN \\
\hline CHEMBL1548662 & 688128 & 4.45 & 4.6915 & TRN \\
\hline CHEMBL1402055 & 688128 & 4.4 & 4.5981 & TST \\
\hline CHEMBL1593241 & 688128 & 4.1 & 4.6987 & TST \\
\hline CHEMBL1594488 & 688128 & 5.55 & 4.7877 & TRN \\
\hline CHEMBL1595882 & 688128 & 6.0 & 4.7955 & TRN \\
\hline CHEMBL1327428 & 688128 & 4.35 & 4.5941 & TRN \\
\hline CHEMBL1517653 & 688128 & 4.4 & 4.5724 & TST \\
\hline CHEMBL1449632 & 688128 & 4.4 & 4.6332 & TRN \\
\hline CHEMBL1364052 & 688128 & 4.3 & 4.7283 & TRN \\
\hline CHEMBL1340783 & 688128 & 4.35 & 4.6601 & TST \\
\hline
\end{tabular}




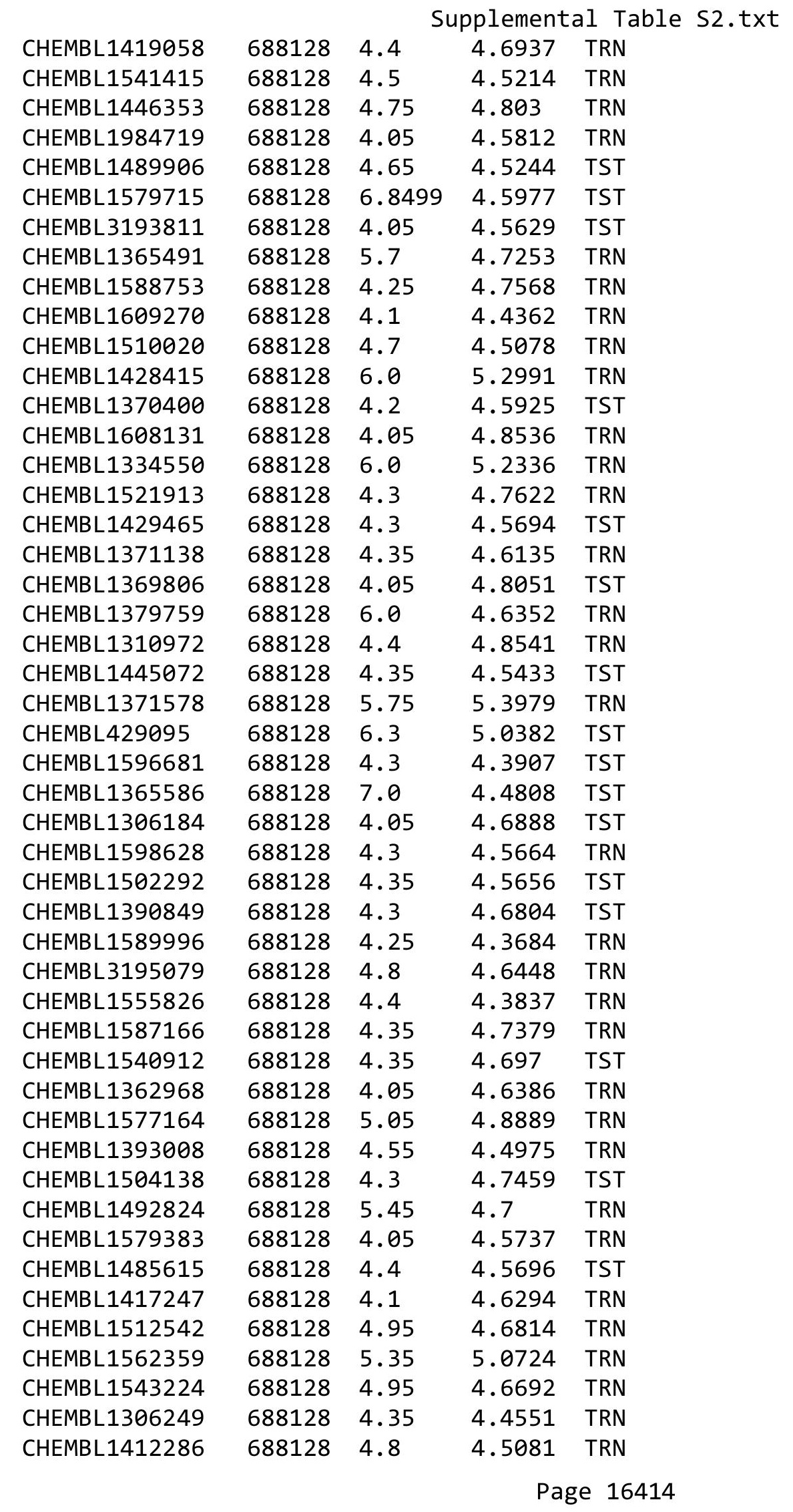




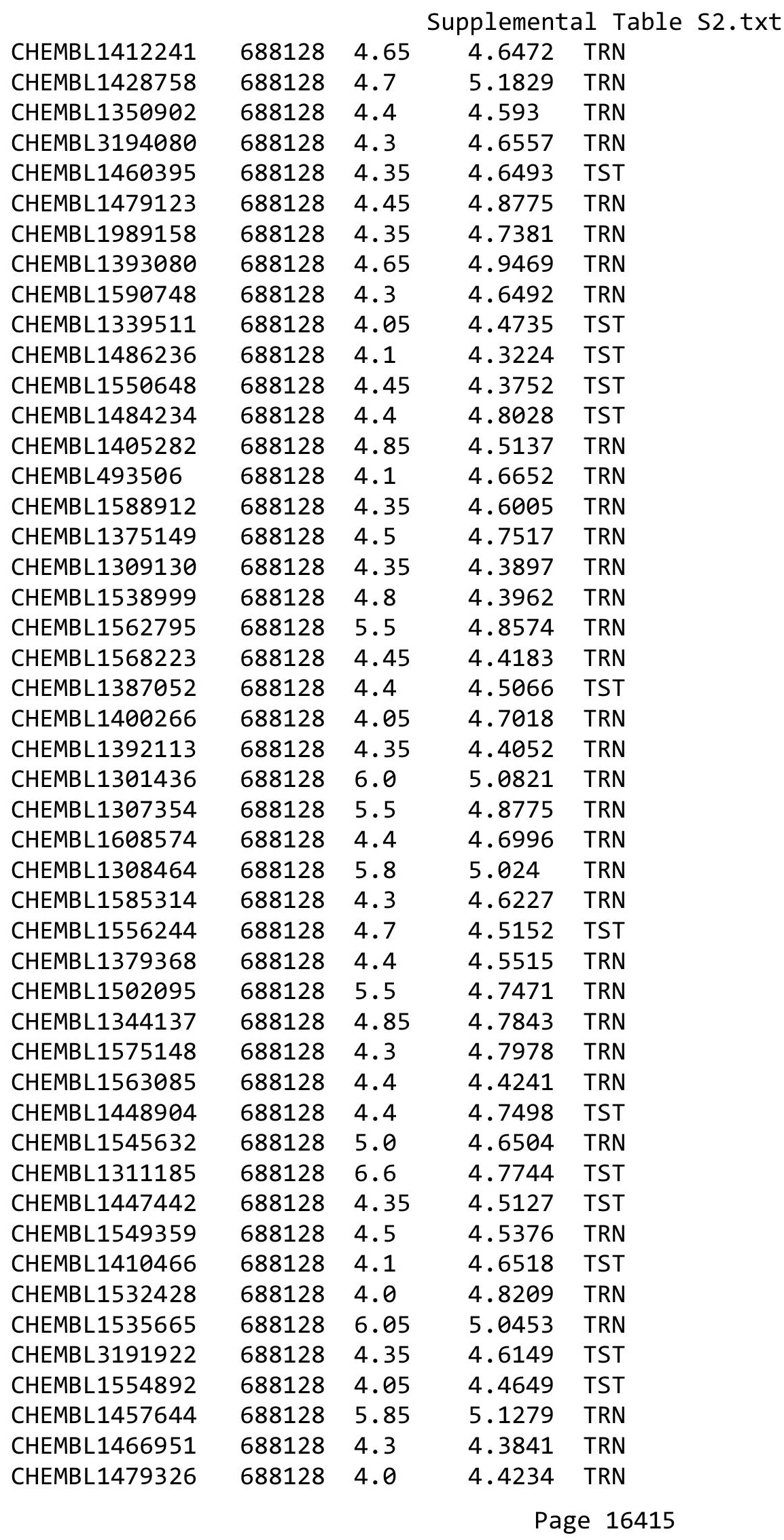




\begin{tabular}{|c|c|c|c|c|}
\hline \multicolumn{5}{|c|}{ Supplemental Table S2.txt } \\
\hline CHEMBL1407338 & 688128 & 5.7 & 4.75 & TRN \\
\hline CHEMBL1531850 & 688128 & 4.2 & 4.6397 & TRN \\
\hline CHEMBL1533499 & 688128 & 4.0 & 4.7874 & TRN \\
\hline CHEMBL1440686 & 688128 & 4.55 & 4.0883 & TRN \\
\hline CHEMBL1556991 & 688128 & 6.0 & 4.5184 & TRN \\
\hline CHEMBL1430505 & 688128 & 4.55 & 4.9415 & TST \\
\hline CHEMBL1470718 & 688128 & 4.45 & 4.4247 & TRN \\
\hline CHEMBL1366113 & 688128 & 4.05 & 4.63 & TST \\
\hline CHEMBL1384994 & 688128 & 4.6 & 4.5219 & TRN \\
\hline CHEMBL1373169 & 688128 & 4.3 & 4.4744 & TRN \\
\hline CHEMBL1572608 & 688128 & 4.4 & 4.5129 & TST \\
\hline CHEMBL1404559 & 688128 & 4.85 & 5.235 & TRN \\
\hline CHEMBL1567321 & 688128 & 5.45 & 4.7908 & TST \\
\hline CHEMBL1421080 & 688128 & 4.35 & 4.4309 & TRN \\
\hline CHEMBL3209134 & 688128 & 4.6 & 4.8774 & TRN \\
\hline CHEMBL1398019 & 688128 & 4.3 & 4.6585 & TST \\
\hline CHEMBL3191412 & 688128 & 4.5 & 4.7647 & TST \\
\hline CHEMBL1382399 & 688128 & 4.3 & 4.8044 & TRN \\
\hline CHEMBL1419176 & 688128 & 4.4 & 4.9473 & TRN \\
\hline CHEMBL1581891 & 688128 & 6.1 & 4.5069 & TST \\
\hline CHEMBL1313613 & 688128 & 4.0 & 4.3713 & TRN \\
\hline CHEMBL1425632 & 688128 & 5.3 & 4.5079 & TRN \\
\hline CHEMBL1595315 & 688128 & 4.7 & 4.59 & TRN \\
\hline CHEMBL1568811 & 688128 & 4.9 & 4.4837 & TRN \\
\hline CHEMBL1360096 & 688128 & 4.6 & 4.562 & TRN \\
\hline CHEMBL1366932 & 688128 & 4.4 & 4.7303 & TRN \\
\hline CHEMBL2374032 & 688128 & 5.2 & 5.2217 & TRN \\
\hline CHEMBL1548086 & 688128 & 5.75 & 4.7456 & TST \\
\hline CHEMBL1305427 & 688128 & 4.35 & 4.8231 & TST \\
\hline CHEMBL1305310 & 688128 & 4.35 & 4.6668 & TRN \\
\hline CHEMBL1549007 & 688128 & 6.8 & 4.493 & TST \\
\hline CHEMBL1469243 & 688128 & 4.35 & 4.6758 & TRN \\
\hline CHEMBL1256845 & 688128 & 4.35 & 4.6279 & TST \\
\hline CHEMBL1304816 & 688128 & 4.4 & 4.2028 & TRN \\
\hline CHEMBL1421414 & 688128 & 5.2 & 4.6665 & TRN \\
\hline CHEMBL3214329 & 688128 & 4.35 & 4.8189 & TST \\
\hline CHEMBL1528056 & 688128 & 4.3 & 4.6335 & TRN \\
\hline CHEMBL1331373 & 688128 & 4.4 & 4.4627 & TRN \\
\hline CHEMBL1320166 & 688128 & 4.3 & 4.7468 & TRN \\
\hline CHEMBL1365256 & 688128 & 4.25 & 4.4339 & TRN \\
\hline CHEMBL1365218 & 688128 & 5.15 & 4.753 & TST \\
\hline CHEMBL1382310 & 688128 & 6.9 & 4.7949 & TRN \\
\hline CHEMBL3210491 & 688128 & 4.05 & 4.812 & TST \\
\hline CHEMBL1483584 & 688128 & 4.7 & 4.6881 & TRN \\
\hline CHEMBL1364742 & 688128 & 4.45 & 4.6437 & TRN \\
\hline CHEMBL1344380 & 688128 & 4.4 & 4.8102 & TST \\
\hline CHEMBL1301453 & 688128 & 4.3 & 4.6734 & TST \\
\hline CHEMBL1387874 & 688128 & 4.35 & 4.3784 & TST \\
\hline
\end{tabular}




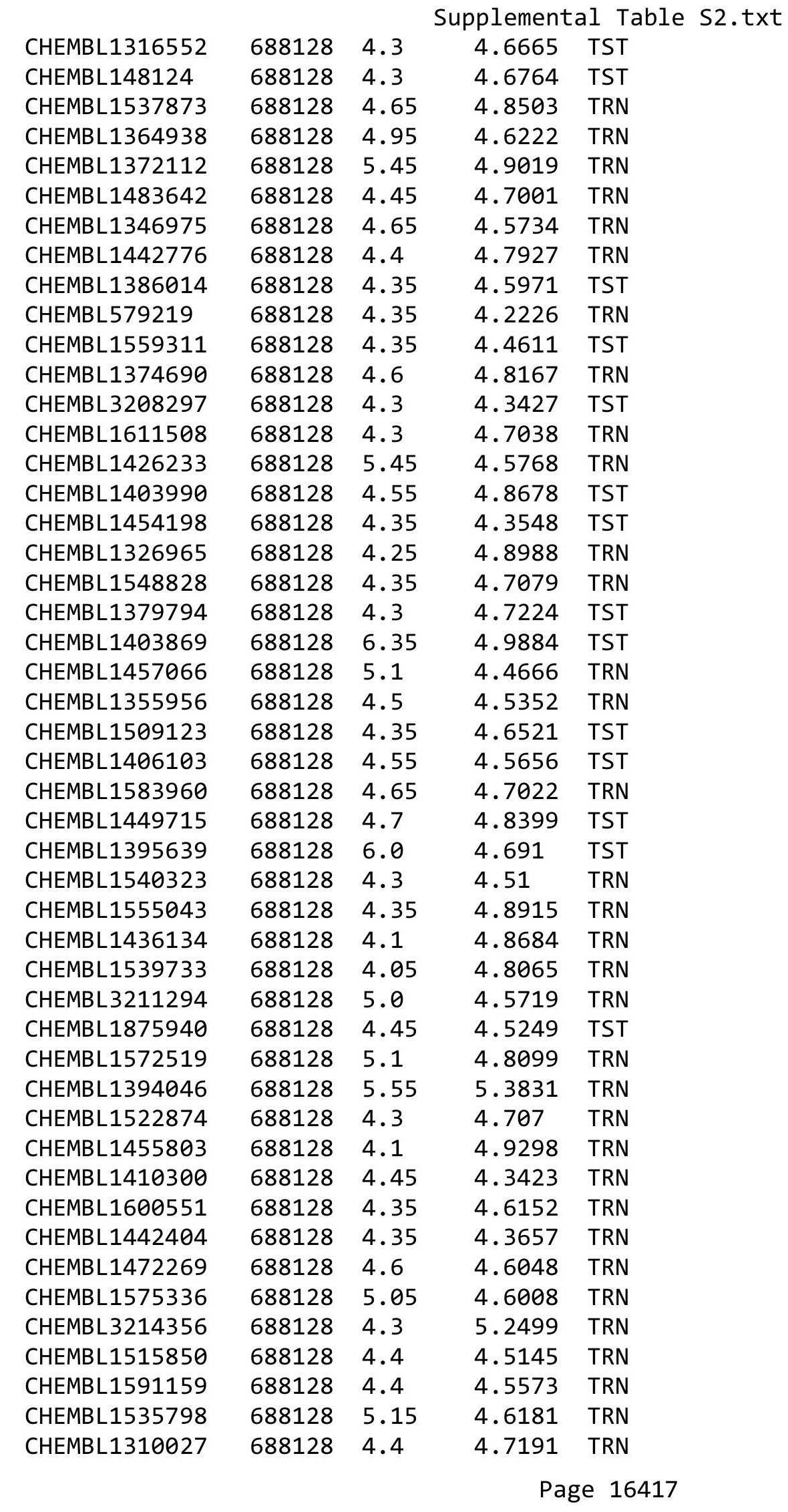




\begin{tabular}{|c|c|c|c|c|c|}
\hline \multicolumn{6}{|c|}{ Supplemental Table S2.txt } \\
\hline CHEMBL1605845 & 688128 & 4.95 & 4.5509 & TST & \\
\hline CHEMBL1413956 & 688128 & 5.45 & 4.9748 & TRN & \\
\hline CHEMBL1335029 & 688128 & 4.3 & 4.2696 & TRN & \\
\hline CHEMBL1450050 & 688128 & 4.6 & 4.6599 & TRN & \\
\hline CHEMBL1304902 & 688128 & 5.0 & 5.0617 & TRN & \\
\hline CHEMBL1212984 & 688128 & 5.0 & 4.6038 & TRN & \\
\hline CHEMBL3197693 & 688128 & 4.9 & 4.6233 & TST & \\
\hline CHEMBL1576563 & 688128 & 4.9 & 4.4982 & TRN & \\
\hline CHEMBL1600291 & 688128 & 4.1 & 4.5125 & TRN & \\
\hline CHEMBL3182828 & 688128 & 4.05 & 4.5246 & TST & \\
\hline CHEMBL1518875 & 688128 & 4.4 & 4.6174 & TRN & \\
\hline CHEMBL1574743 & 688128 & 4.4 & 4.65600 & 0000000001 & TRN \\
\hline CHEMBL1475529 & 688128 & 4.1 & 4.6604 & TRN & \\
\hline CHEMBL1436028 & 688128 & 5.5 & 4.7342 & TRN & \\
\hline CHEMBL1371153 & 688128 & 4.65 & 4.6996 & TRN & \\
\hline CHEMBL1336251 & 688128 & 4.05 & 4.6748 & TRN & \\
\hline CHEMBL1420534 & 688128 & 4.4 & 4.5401 & TRN & \\
\hline CHEMBL1326019 & 688128 & 4.05 & 4.5407 & TRN & \\
\hline CHEMBL1526580 & 688128 & 4.65 & 4.5202 & TRN & \\
\hline CHEMBL3193056 & 688128 & 4.45 & 4.5641 & TST & \\
\hline CHEMBL1578997 & 688128 & 6.8499 & 5.0246 & TRN & \\
\hline CHEMBL1580810 & 688128 & 4.05 & 4.535 & TRN & \\
\hline CHEMBL1583708 & 688128 & 6.1 & 5.1271 & TRN & \\
\hline CHEMBL1513587 & 688128 & 4.05 & 4.7131 & TST & \\
\hline CHEMBL1601783 & 688128 & 4.25 & 4.6545 & TST & \\
\hline CHEMBL1404962 & 688128 & 4.35 & 4.4355 & TRN & \\
\hline CHEMBL1497983 & 688128 & 4.35 & 4.388 & TRN & \\
\hline CHEMBL1435482 & 688128 & 4.35 & 4.4471 & TRN & \\
\hline CHEMBL1459833 & 688128 & 4.7 & 4.8274 & TST & \\
\hline CHEMBL1570331 & 688128 & 4.05 & 4.6393 & TST & \\
\hline CHEMBL1382415 & 688128 & 4.1 & 4.5277 & TRN & \\
\hline CHEMBL1612957 & 688128 & 4.4 & 4.3763 & TRN & \\
\hline CHEMBL1436209 & 688128 & 4.65 & 4.5738 & TRN & \\
\hline CHEMBL1573693 & 688128 & 5.65 & 4.7192 & TRN & \\
\hline CHEMBL3195480 & 688128 & 4.85 & 4.9844 & TST & \\
\hline CHEMBL1520327 & 688128 & 4.45 & 4.5591 & TRN & \\
\hline CHEMBL1467826 & 688128 & 4.5 & 4.641 & TRN & \\
\hline CHEMBL1391046 & 688128 & 4.05 & 4.5877 & TRN & \\
\hline CHEMBL1530295 & 688128 & 6.0 & 4.5886 & TRN & \\
\hline CHEMBL1396330 & 688128 & 4.55 & 4.3655 & TRN & \\
\hline CHEMBL1550178 & 688128 & 4.9 & 4.6291 & TRN & \\
\hline CHEMBL1505420 & 688128 & 4.4 & 4.8408 & TRN & \\
\hline CHEMBL1476259 & 688128 & 4.35 & 4.6784 & TRN & \\
\hline CHEMBL1508479 & 688128 & 4.05 & 4.3748 & TRN & \\
\hline CHEMBL1544797 & 688128 & 4.35 & 4.8267 & TST & \\
\hline CHEMBL1608141 & 688128 & 4.05 & 4.4012 & TST & \\
\hline CHEMBL1471043 & 688128 & 4.25 & 4.7305 & TRN & \\
\hline CHEMBL1570930 & 688128 & 4.3 & 4.3054 & TRN & \\
\hline
\end{tabular}




\begin{tabular}{|c|c|c|c|c|c|}
\hline & & \multicolumn{4}{|c|}{ Supplemental Table S2.txt } \\
\hline CHEMBL1384771 & 688128 & 4.5 & 4.5813 & TRN & \\
\hline CHEMBL1454054 & 688128 & 4.25 & 4.7112 & TRN & \\
\hline CHEMBL1370362 & 688128 & 4.4 & 4.5557 & TRN & \\
\hline CHEMBL1458243 & 688128 & 4.05 & 4.3453 & TST & \\
\hline CHEMBL1572918 & 688128 & 5.3 & 4.5805 & TST & \\
\hline CHEMBL1565964 & 688128 & 4.85 & 4.6414 & TST & \\
\hline CHEMBL1528581 & 688128 & 5.15 & 5.0404 & TRN & \\
\hline CHEMBL1382810 & 688128 & 4.55 & 4.591 & TRN & \\
\hline CHEMBL1472103 & 688128 & 4.5 & 4.813 & TST & \\
\hline CHEMBL1503595 & 688128 & 6.15 & 4.9435 & TST & \\
\hline CHEMBL1453524 & 688128 & 6.5501 & 4.4579 & TRN & \\
\hline CHEMBL1399362 & 688128 & 4.45 & 4.9475 & TRN & \\
\hline CHEMBL1436562 & 688128 & 4.4 & 4.51399 & 9999999999 & TRN \\
\hline CHEMBL1511410 & 688128 & 4.4 & 4.8146 & TRN & \\
\hline CHEMBL1324093 & 688128 & 5.45 & 5.0646 & TRN & \\
\hline CHEMBL1403130 & 688128 & 4.35 & 4.2116 & TRN & \\
\hline CHEMBL1475983 & 688128 & 4.4 & 4.7578 & TST & \\
\hline CHEMBL1569997 & 688128 & 4.35 & 4.8293 & TRN & \\
\hline CHEMBL 1465049 & 688128 & 6.0 & 4.9731 & TRN & \\
\hline CHEMBL1325743 & 688128 & 5.15 & 4.6481 & TRN & \\
\hline CHEMBL1586055 & 688128 & 4.3 & 4.5455 & TRN & \\
\hline CHEMBL1531686 & 688128 & 5.7 & 5.0897 & TRN & \\
\hline CHEMBL1375534 & 688128 & 4.35 & 4.3057 & TRN & \\
\hline CHEMBL1347805 & 688128 & 4.3 & 4.3265 & TRN & \\
\hline CHEMBL1515326 & 688128 & 4.05 & 4.6179 & TRN & \\
\hline CHEMBL1543251 & 688128 & 4.55 & 4.4123 & TRN & \\
\hline CHEMBL1398029 & 688128 & 4.05 & 4.3716 & TST & \\
\hline CHEMBL1381578 & 688128 & 4.45 & 4.4645 & TST & \\
\hline CHEMBL1342235 & 688128 & 4.5 & 4.7161 & TRN & \\
\hline CHEMBL1567635 & 688128 & 5.3 & 5.1071 & TRN & \\
\hline CHEMBL1392919 & 688128 & 4.7 & 4.7209 & TST & \\
\hline CHEMBL1438834 & 688128 & 4.05 & 4.397 & TST & \\
\hline CHEMBL1443242 & 688128 & 4.35 & 4.396 & TRN & \\
\hline CHEMBL1493917 & 688128 & 4.35 & 4.6361 & TRN & \\
\hline CHEMBL1490995 & 688128 & 4.5 & 4.6546 & TST & \\
\hline CHEMBL1495740 & 688128 & 4.3 & 4.6682 & TRN & \\
\hline CHEMBL1420486 & 688128 & 5.05 & 4.5954 & TRN & \\
\hline CHEMBL 3190283 & 688128 & 4.4 & 4.7155 & TRN & \\
\hline CHEMBL1340137 & 688128 & 4.85 & 4.8324 & TRN & \\
\hline CHEMBL1510344 & 688128 & 4.35 & 4.4821 & TRN & \\
\hline CHEMBL1498845 & 688128 & 4.45 & 4.7224 & TRN & \\
\hline CHEMBL1532829 & 688128 & 4.4 & 4.9282 & TST & \\
\hline CHEMBL1481591 & 688128 & 4.4 & 4.6046 & TRN & \\
\hline CHEMBL1442256 & 688128 & 4.3 & 4.4195 & TRN & \\
\hline CHEMBL1512403 & 688128 & 4.25 & 5.1317 & TRN & \\
\hline CHEMBL1499904 & 688128 & 4.3 & 4.0886 & TRN & \\
\hline CHEMBL1306292 & 688128 & 4.45 & 4.8342 & TRN & \\
\hline CHEMBL1443072 & 688128 & 7.15 & 4.4432 & TRN & \\
\hline
\end{tabular}




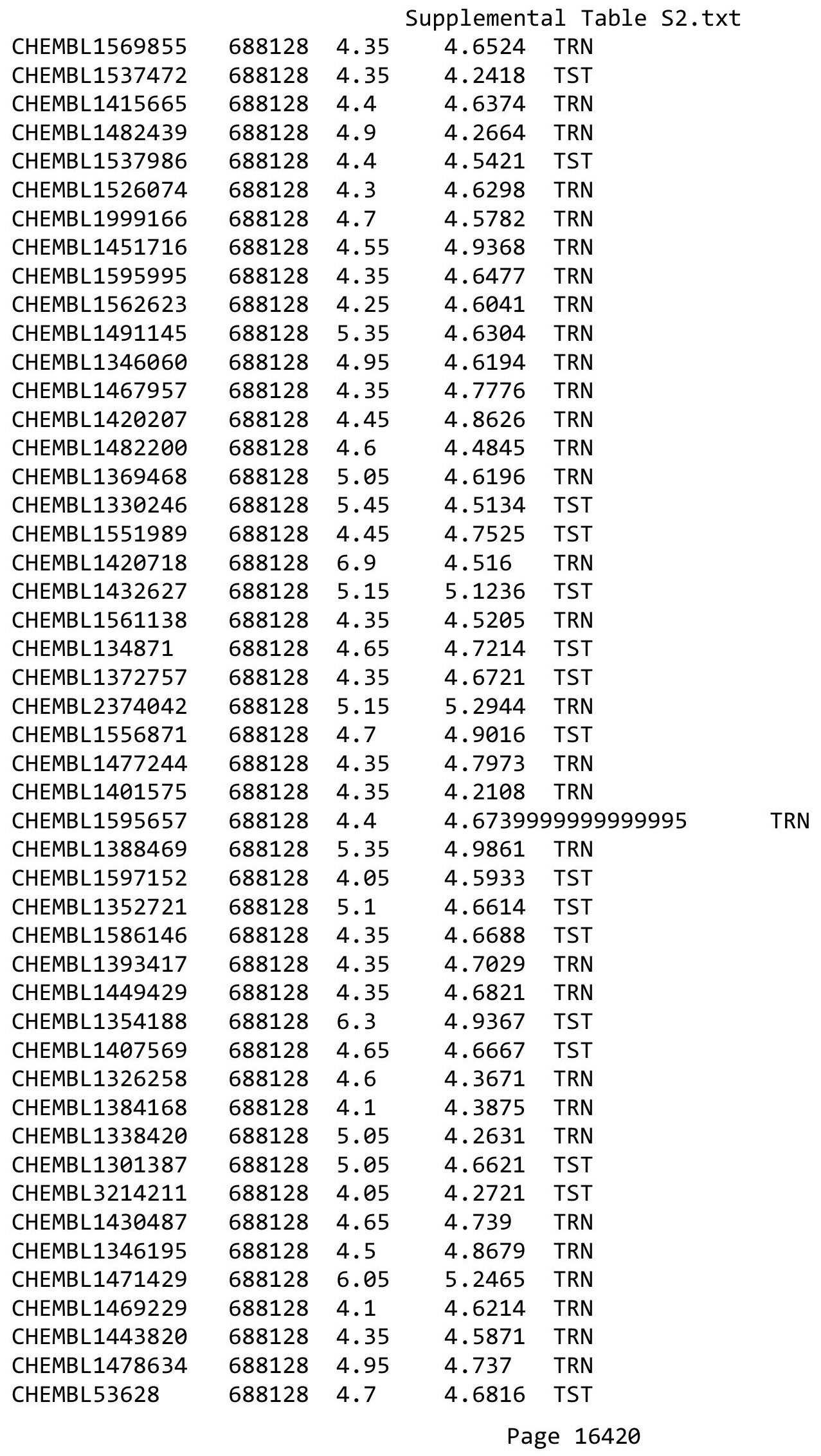




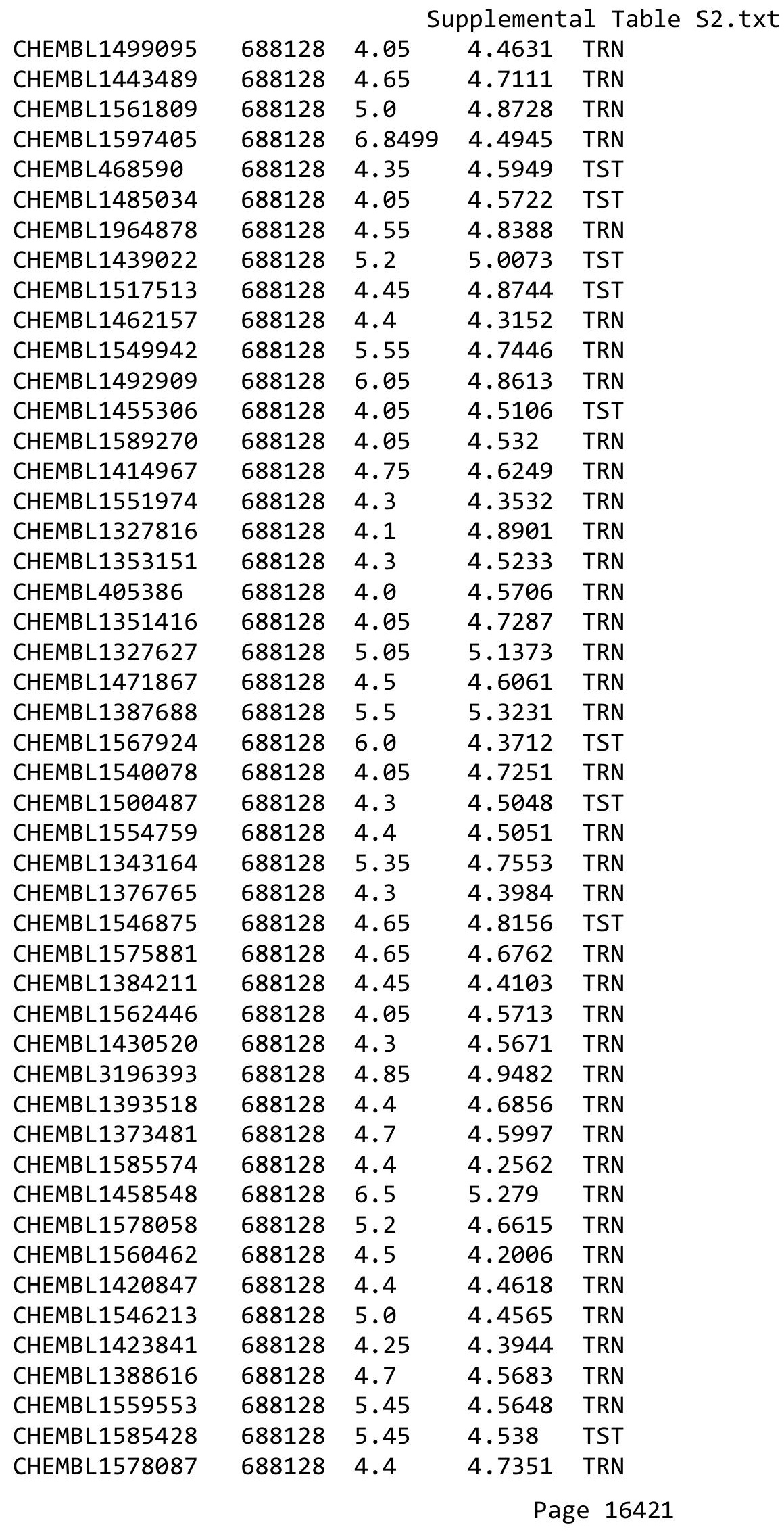




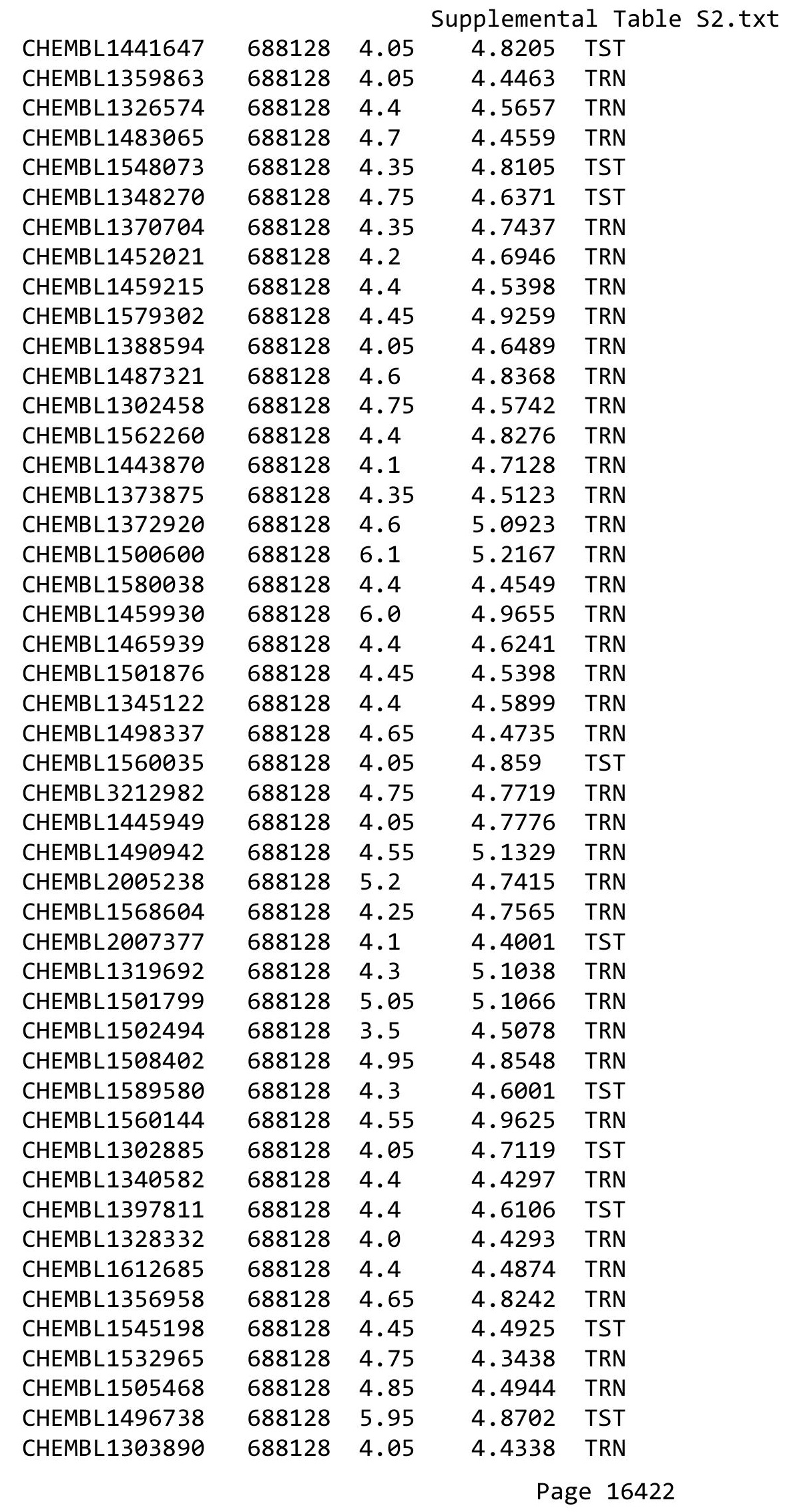




\begin{tabular}{|c|c|c|c|c|c|}
\hline & & \multicolumn{4}{|c|}{ Supplemental Table S2.txt } \\
\hline CHEMBL1530448 & 688128 & 4.35 & 4.3047 & TRN & \\
\hline CHEMBL1311453 & 688128 & 6.05 & 5.1255 & TRN & \\
\hline CHEMBL1609550 & 688128 & 4.85 & 4.827 & TRN & \\
\hline CHEMBL1490088 & 688128 & 4.65 & 4.5279 & TST & \\
\hline CHEMBL601616 & 688128 & 4.55 & 4.6584 & TRN & \\
\hline CHEMBL1312004 & 688128 & 4.1 & 4.7668 & TST & \\
\hline CHEMBL1342655 & 688128 & 4.5 & 4.6563 & TRN & \\
\hline CHEMBL1381159 & 688128 & 4.45 & 4.595 & TRN & \\
\hline CHEMBL1449015 & 688128 & 5.1 & 4.6716 & TRN & \\
\hline CHEMBL1474605 & 688128 & 4.25 & 4.5751 & TRN & \\
\hline CHEMBL1994837 & 688128 & 4.55 & 4.7123 & TRN & \\
\hline CHEMBL1387843 & 688128 & 4.4 & 4.5349 & TST & \\
\hline CHEMBL1340288 & 688128 & 4.65 & 4.5454 & TRN & \\
\hline CHEMBL474786 & 688128 & 4.65 & 4.5271 & TRN & \\
\hline CHEMBL1968986 & 688128 & 4.35 & 4.5744 & TRN & \\
\hline CHEMBL1395304 & 688128 & 4.3 & 4.8584 & TRN & \\
\hline CHEMBL1490273 & 688128 & 4.0 & 4.4038 & TRN & \\
\hline CHEMBL1488280 & 688128 & 4.5 & 4.4695 & TRN & \\
\hline CHEMBL1405452 & 688128 & 4.35 & 4.6508 & TRN & \\
\hline CHEMBL1381756 & 688128 & 4.3 & 4.2014 & TRN & \\
\hline CHEMBL1502403 & 688128 & 4.25 & 4.7469 & TRN & \\
\hline CHEMBL1339610 & 688128 & 4.45 & 4.7761 & TST & \\
\hline CHEMBL1562386 & 688128 & 4.35 & 4.2417 & TRN & \\
\hline CHEMBL1439367 & 688128 & 4.35 & 4.4554 & TRN & \\
\hline CHEMBL1454390 & 688128 & 4.75 & 4.6995 & TST & \\
\hline CHEMBL1571702 & 688128 & 6.1 & 4.5102 & TST & \\
\hline CHEMBL1361498 & 688128 & 4.35 & 4.5456 & TRN & \\
\hline CHEMBL1442635 & 688128 & 4.4 & 4.6646 & TRN & \\
\hline CHEMBL1506659 & 688128 & 4.25 & 4.5156 & TRN & \\
\hline CHEMBL3210349 & 688128 & 4.5 & 5.0252 & TRN & \\
\hline CHEMBL1497878 & 688128 & 4.2 & 4.3789 & TRN & \\
\hline CHEMBL1612171 & 688128 & 4.3 & 4.7596 & TRN & \\
\hline CHEMBL1465599 & 688128 & 4.15 & 4.654 & TST & \\
\hline CHEMBL1532712 & 688128 & 4.6 & 4.5166 & TST & \\
\hline CHEMBL1580688 & 688128 & 4.25 & 4.5589 & TST & \\
\hline CHEMBL1392892 & 688128 & 4.35 & 4.5351 & TRN & \\
\hline CHEMBL1430383 & 688128 & 5.2 & 5.0404 & TRN & \\
\hline CHEMBL3190047 & 688128 & 4.7 & 4.4881 & TRN & \\
\hline CHEMBL1322199 & 688128 & 4.1 & 4.6055 & TST & \\
\hline CHEMBL1613477 & 688128 & 6.0 & 4.5924 & TRN & \\
\hline CHEMBL1472780 & 688128 & 5.15 & 4.9415 & TRN & \\
\hline CHEMBL1305909 & 688128 & 4.2 & 4.8341 & TRN & \\
\hline CHEMBL1607270 & 688128 & 4.55 & 4.7321 & TRN & \\
\hline CHEMBL1531081 & 688128 & 4.6 & 4.2528 & TRN & \\
\hline CHEMBL1351822 & 688128 & 4.45 & 4.6313 & TRN & \\
\hline CHEMBL1494901 & 688128 & 4.05 & 4.2866 & TRN & \\
\hline CHEMBL1498500 & 688128 & 6.4 & 5.13899 & 9999999999 & TRN \\
\hline CHEMBL1331749 & 688128 & 4.05 & 4.9029 & TST & \\
\hline
\end{tabular}




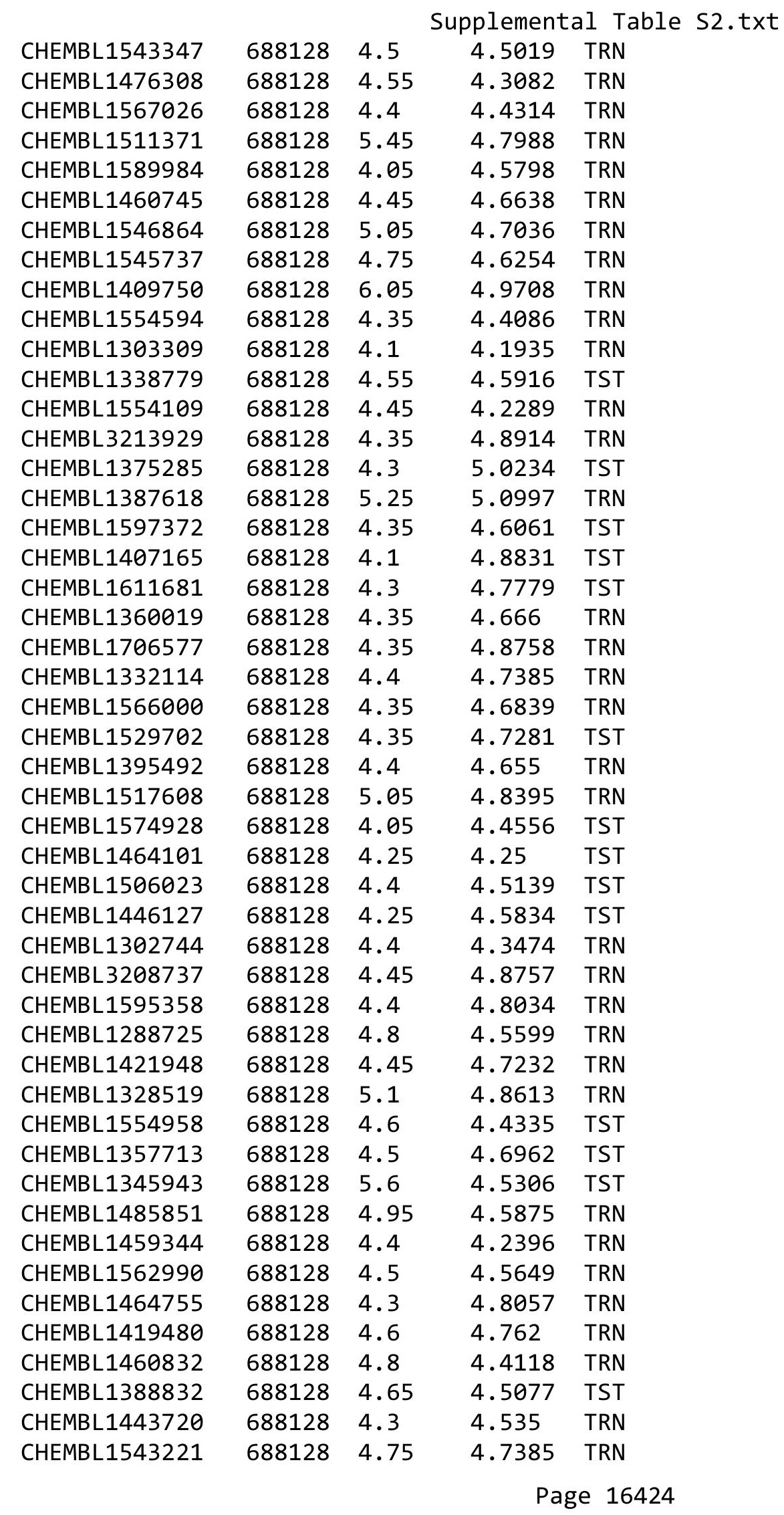




\begin{tabular}{|c|c|c|c|c|c|}
\hline \multicolumn{6}{|c|}{ Supplemental Table S2.txt } \\
\hline CHEMBL1402403 & 688128 & 5.0 & 4.6556 & TRN & \\
\hline CHEMBL3211394 & 688128 & 4.45 & 4.4503 & TST & \\
\hline CHEMBL1395483 & 688128 & 6.4 & 5.226 & TRN & \\
\hline CHEMBL1610826 & 688128 & 5.75 & 4.4177 & TRN & \\
\hline CHEMBL1543897 & 688128 & 4.3 & 4.5609 & TRN & \\
\hline CHEMBL1366265 & 688128 & 4.35 & 4.6786 & TRN & \\
\hline CHEMBL1570638 & 688128 & 4.35 & 4.6674 & TRN & \\
\hline CHEMBL1562151 & 688128 & 4.35 & 4.6126 & TRN & \\
\hline CHEMBL1407299 & 688128 & 4.5 & 4.7351 & TRN & \\
\hline CHEMBL1489430 & 688128 & 5.85 & 4.9027 & TRN & \\
\hline CHEMBL1525305 & 688128 & 5.1 & 4.8668 & TRN & \\
\hline CHEMBL1595787 & 688128 & 4.55 & 4.5362 & TRN & \\
\hline CHEMBL1351979 & 688128 & 4.35 & 4.823 & TRN & \\
\hline CHEMBL1561632 & 688128 & 4.25 & 4.3536 & TRN & \\
\hline CHEMBL1556071 & 688128 & 4.3 & 4.4627 & TRN & \\
\hline CHEMBL1406376 & 688128 & 4.8 & 4.8505 & TRN & \\
\hline CHEMBL1305452 & 688128 & 4.5 & 4.5269 & TST & \\
\hline CHEMBL1381033 & 688128 & 4.05 & 4.6189 & TST & \\
\hline CHEMBL1364821 & 688128 & 4.5 & 4.5909 & TRN & \\
\hline CHEMBL1492623 & 688128 & 5.85 & 5.2591 & TRN & \\
\hline CHEMBL1548955 & 688128 & 4.25 & 4.3589 & TRN & \\
\hline CHEMBL1315766 & 688128 & 4.1 & 4.5286 & TST & \\
\hline CHEMBL1411822 & 688128 & 4.05 & 4.529 & TRN & \\
\hline CHEMBL1379862 & 688128 & 4.6 & 4.2688 & TRN & \\
\hline CHEMBL1511128 & 688128 & 4.05 & 4.4229 & TRN & \\
\hline CHEMBL1351803 & 688128 & 4.85 & 4.6961 & TRN & \\
\hline CHEMBL1529914 & 688128 & 6.15 & 4.3359 & TRN & \\
\hline CHEMBL1565935 & 688128 & 4.15 & 4.477 & TST & \\
\hline CHEMBL1432040 & 688128 & 4.6 & 4.3803 & TRN & \\
\hline CHEMBL1543446 & 688128 & 4.3 & 4.7074 & TRN & \\
\hline CHEMBL1574110 & 688128 & 4.25 & 4.6642 & TST & \\
\hline CHEMBL1620590 & 688128 & 4.9 & 4.9261 & TRN & \\
\hline CHEMBL1424802 & 688128 & 4.0 & 4.4049 & TRN & \\
\hline CHEMBL1539278 & 688128 & 4.4 & 4.6689 & TST & \\
\hline CHEMBL1307859 & 688128 & 4.65 & 4.7555 & TST & \\
\hline CHEMBL1364427 & 688128 & 4.05 & 4.5347 & TRN & \\
\hline CHEMBL1461981 & 688128 & 4.3 & 4.926 & TRN & \\
\hline CHEMBL1407920 & 688128 & 4.3 & 4.4542 & TST & \\
\hline CHEMBL1475441 & 688128 & 4.55 & 4.3558 & TRN & \\
\hline CHEMBL1399858 & 688128 & 4.05 & 4.53600 & 00000000005 & \\
\hline CHEMBL1492106 & 688128 & 6.1 & 4.8194 & TRN & \\
\hline CHEMBL1598935 & 688128 & 4.4 & 4.8732 & TRN & \\
\hline CHEMBL1327056 & 688128 & 4.75 & 4.9922 & TRN & \\
\hline CHEMBL1578651 & 688128 & 4.05 & 4.7851 & TRN & \\
\hline CHEMBL1366170 & 688128 & 4.3 & 4.4612 & TRN & \\
\hline CHEMBL1445686 & 688128 & 4.45 & 4.5038 & TRN & \\
\hline CHEMBL1576458 & 688128 & 4.4 & 4.6984 & TRN & \\
\hline CHEMBL1320169 & 688128 & 5.45 & 4.6319 & TST & \\
\hline
\end{tabular}




\begin{tabular}{|c|c|c|c|c|c|}
\hline \multicolumn{6}{|c|}{ Supplemental Table S2.txt } \\
\hline CHEMBL1458444 & 688128 & 4.6 & 4.4418 & TRN & \\
\hline CHEMBL1382386 & 688128 & 4.65 & 4.654 & TRN & \\
\hline CHEMBL1346887 & 688128 & 5.45 & 4.9169 & TRN & \\
\hline CHEMBL1352080 & 688128 & 4.3 & 4.6206 & TRN & \\
\hline CHEMBL1486769 & 688128 & 4.45 & 4.4351 & TRN & \\
\hline CHEMBL1323502 & 688128 & 4.05 & 4.2947 & TRN & \\
\hline CHEMBL1533882 & 688128 & 5.5 & 4.6084 & TRN & \\
\hline CHEMBL1583097 & 688128 & 4.05 & 4.4255 & TRN & \\
\hline CHEMBL1362743 & 688128 & 4.4 & 4.5049 & TRN & \\
\hline CHEMBL3193342 & 688128 & 4.3 & 4.1961 & TRN & \\
\hline CHEMBL1364879 & 688128 & 4.7 & 4.7219 & TRN & \\
\hline CHEMBL1335806 & 688128 & 4.3 & 4.4517 & TRN & \\
\hline CHEMBL1525726 & 688128 & 4.7 & 4.5995 & TST & \\
\hline CHEMBL 2007329 & 688128 & 5.4 & 4.5382 & TST & \\
\hline CHEMBL1504023 & 688128 & 5.75 & 5.0667 & TRN & \\
\hline CHEMBL1339052 & 688128 & 6.8499 & 4.4033 & TST & \\
\hline CHEMBL1345977 & 688128 & 4.35 & 4.4478 & TRN & \\
\hline CHEMBL1371299 & 688128 & 4.4 & 4.5868 & TRN & \\
\hline CHEMBL1330168 & 688128 & 4.3 & 4.4569 & TST & \\
\hline CHEMBL1303576 & 688128 & 4.35 & 4.5415 & TRN & \\
\hline CHEMBL1430082 & 688128 & 4.3 & 4.8722 & TST & \\
\hline CHEMBL1352443 & 688128 & 6.1 & 4.7343 & TRN & \\
\hline CHEMBL1419087 & 688128 & 4.4 & 4.712 & TRN & \\
\hline CHEMBL1363630 & 688128 & 4.4 & 4.7404 & TRN & \\
\hline CHEMBL1376504 & 688128 & 5.0 & 4.7832 & TST & \\
\hline CHEMBL1606967 & 688128 & 4.3 & 4.5473 & TST & \\
\hline CHEMBL1603714 & 688128 & 4.4 & 4.4654 & TST & \\
\hline CHEMBL1580113 & 688128 & 5.4 & 4.3659 & TST & \\
\hline CHEMBL1430673 & 688128 & 5.35 & 5.1327 & TRN & \\
\hline CHEMBL1367421 & 688128 & 4.4 & 4.4511 & TST & \\
\hline CHEMBL1376182 & 688128 & 4.35 & 4.4573 & TRN & \\
\hline CHEMBL1301368 & 688128 & 4.3 & 4.8947 & TRN & \\
\hline CHEMBL1460436 & 688128 & 4.7 & 4.7741 & TRN & \\
\hline CHEMBL1600147 & 688128 & 4.25 & 4.4971 & TRN & \\
\hline CHEMBL1331134 & 688128 & 5.75 & 4.9868 & TRN & \\
\hline CHEMBL1538198 & 688128 & 5.15 & 4.7986 & TRN & \\
\hline CHEMBL1359180 & 688128 & 6.0 & 4.8801 & TRN & \\
\hline CHEMBL1540506 & 688128 & 4.3 & 4.6345 & TRN & \\
\hline CHEMBL3193110 & 688128 & 4.35 & 4.5362 & TRN & \\
\hline CHEMBL1302845 & 688128 & 4.35 & 4.7206 & TRN & \\
\hline CHEMBL1338152 & 688128 & 4.35 & 4.445 & TRN & \\
\hline CHEMBL1606030 & 688128 & 4.4 & 4.54899 & 99999999995 & TRN \\
\hline CHEMBL1439970 & 688128 & 4.95 & 4.666 & TST & \\
\hline CHEMBL1309497 & 688128 & 4.6 & 4.7395 & TRN & \\
\hline CHEMBL1351951 & 688128 & 4.55 & 4.5342 & TRN & \\
\hline CHEMBL1300478 & 688128 & 4.55 & 4.4183 & TRN & \\
\hline CHEMBL 2003214 & 688128 & 4.8 & 4.8317 & TRN & \\
\hline CHEMBL1504378 & 688128 & 4.6 & 4.9491 & TRN & \\
\hline
\end{tabular}




\begin{tabular}{|c|c|c|c|c|c|}
\hline \multicolumn{6}{|c|}{ Supplemental Table S2.txt } \\
\hline CHEMBL1446974 & 688128 & 4.35 & 4.5322 & TRN & \\
\hline CHEMBL1435324 & 688128 & 5.15 & 5.0431 & TRN & \\
\hline CHEMBL1491893 & 688128 & 4.5 & 4.561 & TRN & \\
\hline CHEMBL1422357 & 688128 & 4.3 & 4.5036 & TRN & \\
\hline CHEMBL1378966 & 688128 & 4.35 & 4.5365 & TST & \\
\hline CHEMBL1443616 & 688128 & 4.35 & 4.74 & TST & \\
\hline CHEMBL1560674 & 688128 & 4.4 & 4.4986 & TRN & \\
\hline CHEMBL1527103 & 688128 & 4.35 & 4.4226 & TRN & \\
\hline CHEMBL1345659 & 688128 & 4.45 & 4.3967 & TRN & \\
\hline CHEMBL1392502 & 688128 & 5.35 & 4.6885 & TRN & \\
\hline CHEMBL1369808 & 688128 & 4.6 & 4.8825 & TRN & \\
\hline CHEMBL1319300 & 688128 & 4.15 & 4.5004 & TRN & \\
\hline CHEMBL3212142 & 688128 & 4.4 & 4.7118 & TST & \\
\hline CHEMBL 3212227 & 688128 & 4.45 & 4.4055 & TST & \\
\hline CHEMBL1315232 & 688128 & 4.4 & 4.4402 & TRN & \\
\hline CHEMBL1508984 & 688128 & 4.35 & 4.8396 & TRN & \\
\hline CHEMBL1378645 & 688128 & 3.95 & 4.56800 & 00000000005 & TST \\
\hline CHEMBL1464144 & 688128 & 4.65 & 4.5371 & TRN & \\
\hline CHEMBL1417761 & 688128 & 4.35 & 4.593 & TRN & \\
\hline CHEMBL1601258 & 688128 & 4.5 & 4.28100 & 0000000001 & TRN \\
\hline CHEMBL1328531 & 688128 & 4.0 & 4.6222 & TST & \\
\hline CHEMBL1507310 & 688128 & 4.4 & 4.6432 & TRN & \\
\hline CHEMBL1315909 & 688128 & 4.05 & 4.8387 & TST & \\
\hline CHEMBL1504655 & 688128 & 4.4 & 4.8826 & TRN & \\
\hline CHEMBL1456911 & 688128 & 4.05 & 4.7298 & TRN & \\
\hline CHEMBL1456825 & 688128 & 4.85 & 4.4762 & TRN & \\
\hline CHEMBL1514275 & 688128 & 4.4 & 4.4497 & TST & \\
\hline CHEMBL1457038 & 688128 & 6.0 & 5.2168 & TRN & \\
\hline CHEMBL1376258 & 688128 & 4.4 & 4.1794 & TST & \\
\hline CHEMBL1375797 & 688128 & 4.35 & 4.5384 & TRN & \\
\hline CHEMBL1549465 & 688128 & 4.75 & 4.338 & TRN & \\
\hline CHEMBL1468534 & 688128 & 4.4 & 4.4935 & TRN & \\
\hline CHEMBL1467995 & 688128 & 4.4 & 4.4077 & TRN & \\
\hline CHEMBL1337058 & 688128 & 4.35 & 4.4592 & TRN & \\
\hline CHEMBL1513299 & 688128 & 4.05 & 4.5058 & TRN & \\
\hline CHEMBL3198848 & 688128 & 4.3 & 4.6343 & TST & \\
\hline CHEMBL1566994 & 688128 & 4.4 & 4.8342 & TRN & \\
\hline CHEMBL1335321 & 688128 & 6.05 & 5.2085 & TRN & \\
\hline CHEMBL1330054 & 688128 & 4.75 & 4.904 & TRN & \\
\hline CHEMBL1425429 & 688128 & 4.05 & 4.309 & TRN & \\
\hline CHEMBL1506499 & 688128 & 6.2 & 5.1288 & TRN & \\
\hline CHEMBL1406137 & 688128 & 4.75 & 4.5505 & TRN & \\
\hline CHEMBL3195904 & 688128 & 4.95 & 4.8616 & TRN & \\
\hline CHEMBL1361126 & 688128 & 4.3 & 4.322 & TRN & \\
\hline CHEMBL1577096 & 688128 & 4.35 & 4.3224 & TRN & \\
\hline CHEMBL1582237 & 688128 & 4.05 & 4.6015 & TST & \\
\hline CHEMBL1363679 & 688128 & 5.15 & 5.3757 & TRN & \\
\hline CHEMBL1599323 & 688128 & 4.3 & 4.2307 & TRN & \\
\hline
\end{tabular}




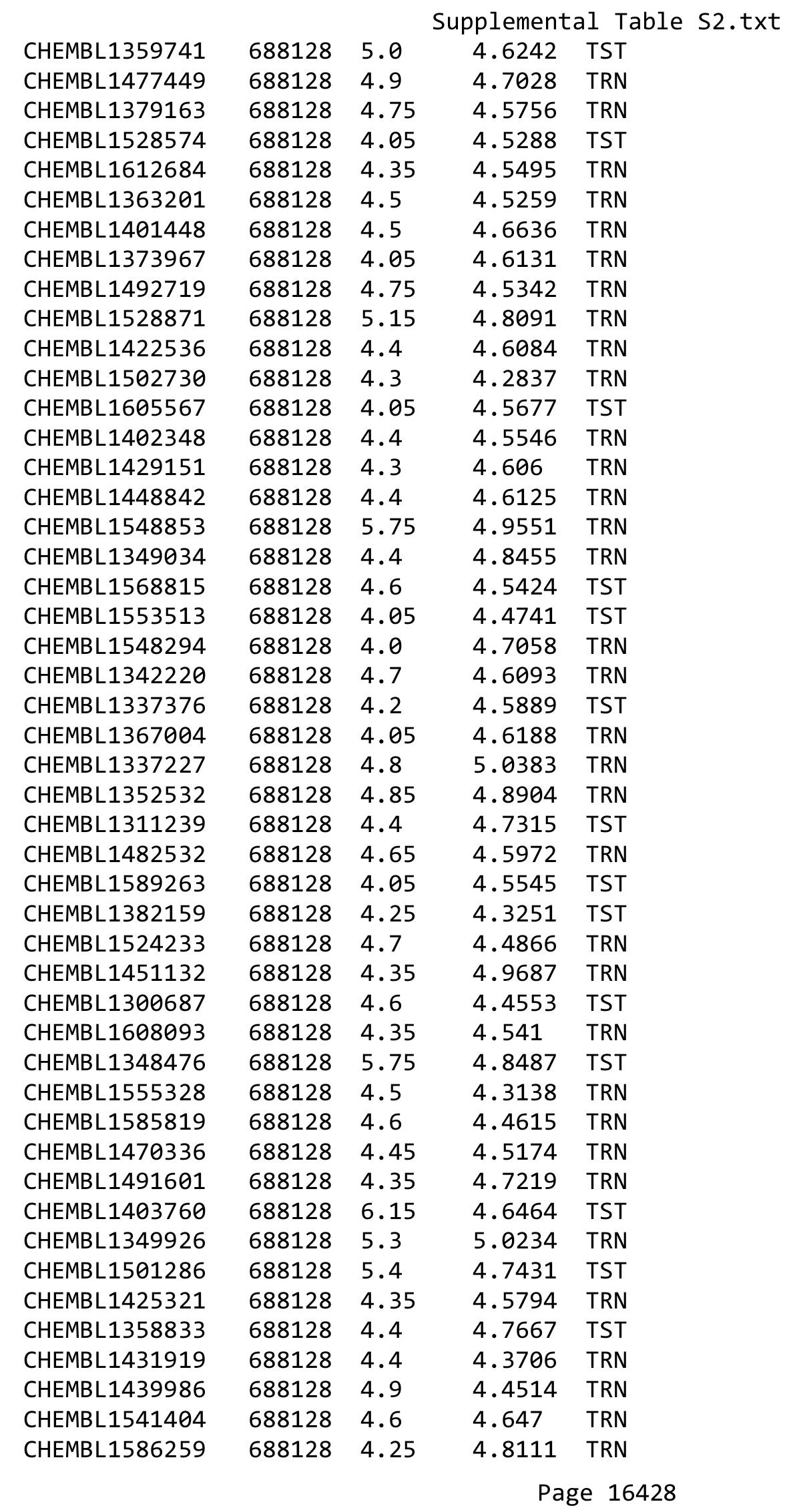




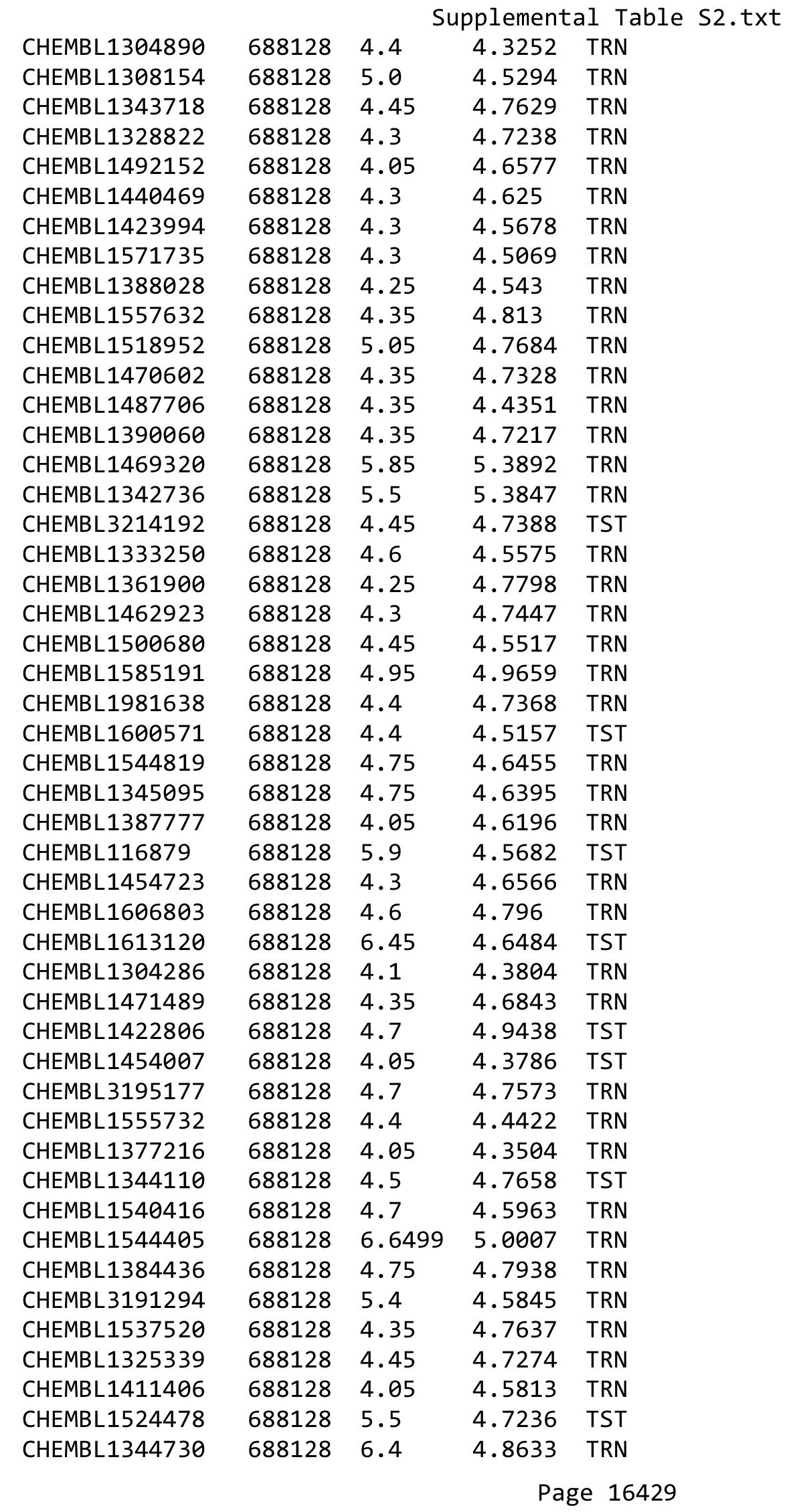




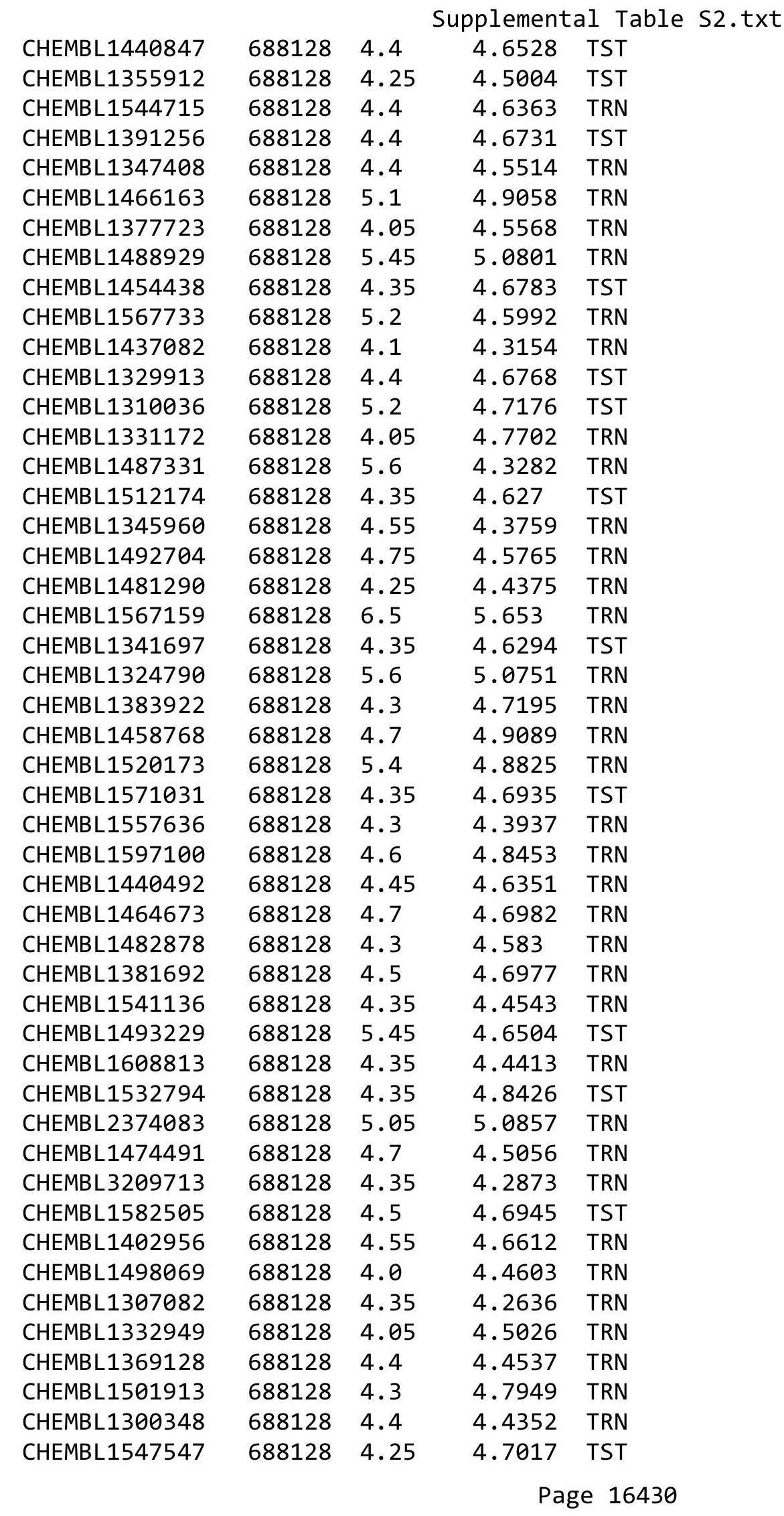




\begin{tabular}{|c|c|c|c|c|c|}
\hline \\
\hline CHEMBL1472028 & 688128 & 4.6 & 4.5577 & TRN & \\
\hline CHEMBL1516444 & 688128 & 4.05 & 4.4376 & TST & \\
\hline CHEMBL1557469 & 688128 & 4.4 & 4.5612 & TRN & \\
\hline CHEMBL1511342 & 688128 & 4.6 & 4.8889 & TRN & \\
\hline CHEMBL1356255 & 688128 & 4.4 & $4.5760 €$ & 00000000005 & TRN \\
\hline CHEMBL1445938 & 688128 & 5.2 & 4.5337 & TRN & \\
\hline CHEMBL1549343 & 688128 & 4.4 & 4.3241 & TST & \\
\hline CHEMBL1490014 & 688128 & 5.05 & 4.5789 & TRN & \\
\hline CHEMBL1335101 & 688128 & 4.05 & 4.7258 & TST & \\
\hline CHEMBL1573878 & 688128 & 4.35 & 4.4556 & TRN & \\
\hline CHEMBL1411869 & 688128 & 4.25 & 4.4762 & TST & \\
\hline CHEMBL1515541 & 688128 & 4.3 & 4.5658 & TRN & \\
\hline CHEMBL1370920 & 688128 & 4.3 & 4.2907 & TRN & \\
\hline CHEMBL1540195 & 688128 & 4.25 & 4.6543 & TRN & \\
\hline CHEMBL1455824 & 688128 & 4.05 & 4.6812 & TRN & \\
\hline CHEMBL1312771 & 688128 & 4.3 & 4.6506 & TRN & \\
\hline CHEMBL1477560 & 688128 & 4.05 & 4.396 & TRN & \\
\hline CHEMBL1453995 & 688128 & 4.3 & 4.5729 & TRN & \\
\hline CHEMBL1551269 & 688128 & 4.35 & 4.5205 & TRN & \\
\hline CHEMBL1446904 & 688128 & 5.8 & 4.901 & TRN & \\
\hline CHEMBL1565506 & 688128 & 4.9 & 4.9287 & TRN & \\
\hline CHEMBL1579456 & 688128 & 4.3 & 4.4766 & TRN & \\
\hline CHEMBL1441240 & 688128 & 4.4 & 4.7341 & TRN & \\
\hline CHEMBL1453921 & 688128 & 4.0 & 4.4655 & TST & \\
\hline CHEMBL1457931 & 688128 & 4.85 & 4.78606 & 20000000005 & TST \\
\hline CHEMBL1363166 & 688128 & 4.65 & 4.3752 & TST & \\
\hline CHEMBL1504405 & 688128 & 6.35 & 5.0768 & TRN & \\
\hline CHEMBL1433996 & 688128 & 5.55 & 4.5852 & TRN & \\
\hline CHEMBL1567111 & 688128 & 4.25 & 4.7254 & TRN & \\
\hline CHEMBL3193639 & 688128 & 4.9 & 5.0703 & TRN & \\
\hline CHEMBL1486827 & 688128 & 4.3 & 4.9998 & TRN & \\
\hline CHEMBL1407729 & 688128 & 4.05 & 4.9997 & TST & \\
\hline CHEMBL1476993 & 688128 & 4.45 & 4.5604 & TRN & \\
\hline CHEMBL1583910 & 688128 & 5.5 & 4.466 & TRN & \\
\hline CHEMBL1373412 & 688128 & 4.95 & 4.904 & TRN & \\
\hline CHEMBL1588243 & 688128 & 4.45 & 4.7565 & TRN & \\
\hline CHEMBL1573287 & 688128 & 4.45 & 4.8368 & TST & \\
\hline CHEMBL1331282 & 688128 & 4.3 & 4.6228 & TRN & \\
\hline CHEMBL1395815 & 688128 & 4.4 & 4.141 & TRN & \\
\hline CHEMBL1535271 & 688128 & 4.4 & 4.2897 & TRN & \\
\hline CHEMBL1345295 & 688128 & 4.8 & 5.1792 & TRN & \\
\hline CHEMBL 2374018 & 688128 & 5.45 & 5.0997 & TRN & \\
\hline CHEMBL1613512 & 688128 & 4.65 & 4.785 & TRN & \\
\hline CHEMBL1330919 & 688128 & 4.65 & 4.8796 & TRN & \\
\hline CHEMBL1412397 & 688128 & 4.7 & 4.7034 & TST & \\
\hline CHEMBL1370738 & 688128 & 4.4 & 4.1146 & TRN & \\
\hline CHEMBL1486754 & 688128 & 5.0 & 4.6966 & TRN & \\
\hline CHEMBL1304289 & 688128 & 4.65 & 4.5579 & TRN & \\
\hline & & & & 5431 & \\
\hline
\end{tabular}




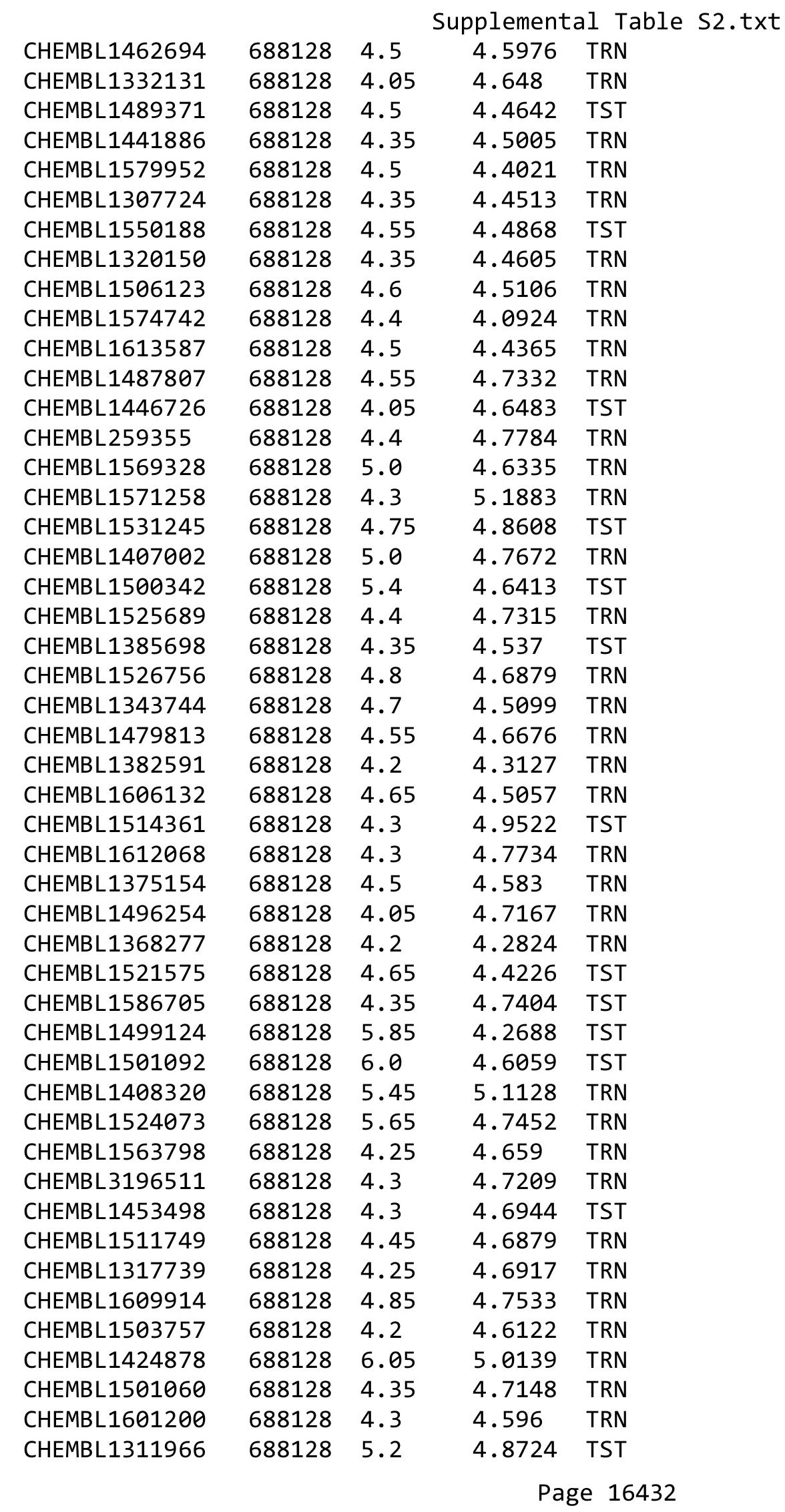




\begin{tabular}{|c|c|c|c|c|c|}
\hline \\
\hline CHEMBL1462419 & 688128 & 4.3 & 4.7731 & TST & \\
\hline CHEMBL1563692 & 688128 & 5.95 & 4.9151 & TRN & \\
\hline CHEMBL1504921 & 688128 & 4.4 & 4.9354 & TST & \\
\hline CHEMBL1485257 & 688128 & 4.45 & 4.3234 & TRN & \\
\hline CHEMBL3195591 & 688128 & 4.4 & 4.3886 & TRN & \\
\hline CHEMBL1576257 & 688128 & 4.3 & 4.4111 & TRN & \\
\hline CHEMBL1996179 & 688128 & 6.5 & 5.0193 & TST & \\
\hline CHEMBL66654 & 688128 & 4.3 & 4.6073 & TST & \\
\hline CHEMBL1485023 & 688128 & 4.3 & 4.5162 & TRN & \\
\hline CHEMBL3212687 & 688128 & 4.85 & 4.8363 & TRN & \\
\hline CHEMBL1381152 & 688128 & 4.65 & 4.9697 & TST & \\
\hline CHEMBL1488901 & 688128 & 4.35 & 4.3554 & TST & \\
\hline CHEMBL3194529 & 688128 & 5.8 & 4.5254 & TRN & \\
\hline CHEMBL1342923 & 688128 & 4.4 & 4.6259 & TRN & \\
\hline CHEMBL1436964 & 688128 & 4.4 & 4.68199 & 99999999995 & TRN \\
\hline CHEMBL1587906 & 688128 & 5.35 & 4.6967 & TRN & \\
\hline CHEMBL1464119 & 688128 & 4.3 & 4.6679 & TRN & \\
\hline CHEMBL1462204 & 688128 & 4.65 & 4.7183 & TST & \\
\hline CHEMBL1565397 & 688128 & 4.35 & 4.4514 & TRN & \\
\hline CHEMBL1304222 & 688128 & 4.65 & 4.746 & TRN & \\
\hline CHEMBL1413434 & 688128 & 4.05 & 4.7036 & TRN & \\
\hline CHEMBL1530141 & 688128 & 4.95 & 4.7337 & TRN & \\
\hline CHEMBL1528148 & 688128 & 4.35 & 4.4158 & TRN & \\
\hline CHEMBL1483548 & 688128 & 4.35 & 4.5346 & TRN & \\
\hline CHEMBL3193566 & 688128 & 4.3 & 4.3308 & TRN & \\
\hline CHEMBL1569698 & 688128 & 4.05 & 4.7552 & TRN & \\
\hline CHEMBL1428410 & 688128 & 5.35 & 4.5648 & TRN & \\
\hline CHEMBL1470874 & 688128 & 5.4 & 4.269 & TST & \\
\hline CHEMBL1385396 & 688128 & 4.4 & 4.7337 & TRN & \\
\hline CHEMBL1478025 & 688128 & 4.4 & 4.4373 & TST & \\
\hline CHEMBL1607597 & 688128 & 4.6 & 4.6329 & TRN & \\
\hline CHEMBL1452264 & 688128 & 4.35 & 4.575 & TRN & \\
\hline CHEMBL1561555 & 688128 & 6.8499 & 5.1242 & TRN & \\
\hline CHEMBL1372900 & 688128 & 4.45 & 4.761 & TRN & \\
\hline CHEMBL1398182 & 688128 & 6.05 & 4.9322 & TRN & \\
\hline CHEMBL1359304 & 688128 & 4.45 & 4.7274 & TST & \\
\hline CHEMBL1520455 & 688128 & 4.4 & 4.6713 & TST & \\
\hline CHEMBL1535382 & 688128 & 4.4 & 4.3171 & TRN & \\
\hline CHEMBL1327851 & 688128 & 4.25 & 4.3521 & TRN & \\
\hline CHEMBL1356425 & 688128 & 4.3 & 4.6287 & TRN & \\
\hline CHEMBL1484705 & 688128 & 4.95 & 4.7242 & TRN & \\
\hline CHEMBL1367906 & 688128 & 4.6 & 4.4442 & TRN & \\
\hline CHEMBL1516065 & 688128 & 4.45 & 4.6427 & TRN & \\
\hline CHEMBL1308941 & 688128 & 4.35 & 4.399 & TRN & \\
\hline CHEMBL1391624 & 688128 & 5.75 & 4.9841 & TRN & \\
\hline CHEMBL1590745 & 688128 & 4.25 & 5.0446 & TRN & \\
\hline CHEMBL1608218 & 688128 & 4.85 & 4.6214 & TRN & \\
\hline CHEMBL3191704 & 688128 & 4.35 & 4.6208 & TRN & \\
\hline
\end{tabular}




\begin{tabular}{|c|c|c|c|c|}
\hline \multicolumn{5}{|c|}{ Supplemental Tabl } \\
\hline CHEMBL1300426 & 688128 & 4.85 & 4.6376 & TRN \\
\hline CHEMBL1393672 & 688128 & 4.35 & 4.4036 & TRN \\
\hline CHEMBL1369837 & 688128 & 4.05 & 4.4458 & TRN \\
\hline CHEMBL1431848 & 688128 & 4.55 & 4.5113 & TRN \\
\hline CHEMBL1430389 & 688128 & 4.55 & 4.5382 & TST \\
\hline CHEMBL1533510 & 688128 & 4.85 & 4.7021 & TRN \\
\hline CHEMBL1367315 & 688128 & 4.05 & 4.5444 & TRN \\
\hline CHEMBL511953 & 688128 & 4.1 & 4.8045 & TST \\
\hline CHEMBL1499913 & 688128 & 4.55 & 4.5591 & TRN \\
\hline CHEMBL1398992 & 688128 & 4.0 & 4.73 & TST \\
\hline CHEMBL 3210078 & 688128 & 5.1 & 4.462 & TRN \\
\hline CHEMBL1469046 & 688128 & 4.25 & 4.2428 & TRN \\
\hline CHEMBL1361287 & 688128 & 4.3 & 4.6182 & TST \\
\hline CHEMBL1453997 & 688128 & 4.4 & 4.4324 & TRN \\
\hline CHEMBL1365159 & 688128 & 4.3 & 4.5213 & TRN \\
\hline CHEMBL1584272 & 688128 & 4.65 & 4.7324 & TRN \\
\hline CHEMBL1534185 & 688128 & 6.0 & 4.7584 & TST \\
\hline CHEMBL1559373 & 688128 & 4.05 & 4.5767 & TST \\
\hline CHEMBL1256971 & 688128 & 4.2 & 4.6048 & TST \\
\hline CHEMBL1469464 & 688128 & 4.9 & 4.3993 & TRN \\
\hline CHEMBL1596524 & 688128 & 4.55 & 4.4896 & TRN \\
\hline CHEMBL1609649 & 688128 & 4.35 & 4.8524 & TRN \\
\hline CHEMBL1383485 & 688128 & 6.5 & 4.5559 & TST \\
\hline CHEMBL1414637 & 688128 & 4.3 & 4.5431 & TST \\
\hline CHEMBL1451858 & 688128 & 4.95 & 5.0962 & TRN \\
\hline CHEMBL1477494 & 688128 & 4.45 & 4.7122 & TST \\
\hline CHEMBL1559558 & 688128 & 4.6 & 4.4313 & TRN \\
\hline CHEMBL1493194 & 688128 & 4.0 & 4.5076 & TST \\
\hline CHEMBL414890 & 688128 & 4.45 & 5.1908 & TST \\
\hline CHEMBL1458330 & 688128 & 4.85 & 4.7483 & TRN \\
\hline CHEMBL1561502 & 688128 & 4.45 & 4.4838 & TRN \\
\hline CHEMBL1560217 & 688128 & 5.6 & 4.9528 & TRN \\
\hline CHEMBL1364564 & 688128 & 4.3 & 4.7355 & TST \\
\hline CHEMBL1338653 & 688128 & 4.3 & 4.623 & TRN \\
\hline CHEMBL1347942 & 688128 & 4.85 & 4.746 & TST \\
\hline CHEMBL3212680 & 688128 & 4.35 & 4.5868 & TST \\
\hline CHEMBL1542862 & 688128 & 4.4 & 4.9911 & TRN \\
\hline CHEMBL1391295 & 688128 & 4.05 & 4.4954 & TRN \\
\hline CHEMBL1470488 & 688128 & 4.4 & 4.5445 & TRN \\
\hline CHEMBL1324375 & 688128 & 5.45 & 4.9288 & TRN \\
\hline CHEMBL1499242 & 688128 & 4.4 & 4.9933 & TRN \\
\hline CHEMBL1317571 & 688128 & 4.05 & 4.4335 & TRN \\
\hline CHEMBL1562433 & 688128 & 4.35 & 4.7812 & TRN \\
\hline CHEMBL1344948 & 688128 & 5.2 & 5.0106 & TRN \\
\hline CHEMBL1541382 & 688128 & 4.5 & 4.5628 & TST \\
\hline CHEMBL1383357 & 688128 & 5.7 & 4.465 & TRN \\
\hline CHEMBL1550203 & 688128 & 4.05 & 4.6241 & TRN \\
\hline CHEMBL1305755 & 688128 & 4.8 & 4.4995 & TST \\
\hline
\end{tabular}




\begin{tabular}{|c|c|c|c|c|c|}
\hline \multicolumn{6}{|c|}{ Supplemental Table s2.txt } \\
\hline CHEMBL1585934 & 688128 & 4.4 & 4.5275 & TRN & \\
\hline CHEMBL1471797 & 688128 & 4.65 & 4.8943 & TRN & \\
\hline CHEMBL1577212 & 688128 & 4.05 & 4.3822 & TRN & \\
\hline CHEMBL1367946 & 688128 & 4.9 & 4.5652 & TRN & \\
\hline CHEMBL1340799 & 688128 & 4.5 & 4.6392 & TRN & \\
\hline CHEMBL1492747 & 688128 & 4.55 & 4.7875 & TRN & \\
\hline CHEMBL1302871 & 688128 & 4.85 & 4.7377 & TRN & \\
\hline CHEMBL 3211037 & 688128 & 4.35 & 4.7548 & TST & \\
\hline CHEMBL1550675 & 688128 & 5.0 & 4.2842 & TRN & \\
\hline CHEMBL1368096 & 688128 & 4.95 & 4.8026 & TRN & \\
\hline CHEMBL1335247 & 688128 & 4.35 & 4.4927 & TRN & \\
\hline CHEMBL1605237 & 688128 & 4.45 & 4.5149 & TRN & \\
\hline CHEMBL1974319 & 688128 & 4.25 & 4.4364 & TRN & \\
\hline CHEMBL1544117 & 688128 & 4.4 & 4.5268 & TRN & \\
\hline CHEMBL333985 & 688128 & 4.3 & 4.5447 & TST & \\
\hline CHEMBL1450543 & 688128 & 4.6 & 4.1645 & TRN & \\
\hline CHEMBL1493700 & 688128 & 4.55 & 4.4926 & TRN & \\
\hline CHEMBL1459096 & 688128 & 4.95 & 4.7497 & TRN & \\
\hline CHEMBL1477307 & 688128 & 6.3 & 4.5133 & TRN & \\
\hline CHEMBL1514382 & 688128 & 5.4 & 5.1215 & TRN & \\
\hline CHEMBL1355888 & 688128 & 4.5 & 4.9012 & TRN & \\
\hline CHEMBL1420765 & 688128 & 4.8 & 4.7925 & TRN & \\
\hline CHEMBL1425699 & 688128 & 4.4 & $4.7780 e$ & 00000000005 & TRN \\
\hline CHEMBL1607100 & 688128 & 4.95 & 4.7621 & TRN & \\
\hline CHEMBL1610533 & 688128 & 4.55 & 4.5942 & TRN & \\
\hline CHEMBL1521721 & 688128 & 4.35 & 4.6716 & TST & \\
\hline CHEMBL1443435 & 688128 & 4.45 & 4.3589 & TST & \\
\hline CHEMBL1306273 & 688128 & 4.25 & 4.45 & TRN & \\
\hline CHEMBL1565668 & 688128 & 4.05 & 4.6185 & TST & \\
\hline CHEMBL1603676 & 688128 & 4.35 & 4.5598 & TRN & \\
\hline CHEMBL1319867 & 688128 & 6.2 & 5.7709 & TRN & \\
\hline CHEMBL1329998 & 688128 & 4.35 & 4.6125 & TRN & \\
\hline CHEMBL1579133 & 688128 & 5.85 & 4.5359 & TRN & \\
\hline CHEMBL1429858 & 688128 & 4.3 & 4.8004 & TRN & \\
\hline CHEMBL1300332 & 688128 & 4.4 & 4.5301 & TST & \\
\hline CHEMBL1314322 & 688128 & 5.3 & 4.6752 & TST & \\
\hline CHEMBL1582737 & 688128 & 4.6 & 4.9799 & TRN & \\
\hline CHEMBL1572197 & 688128 & 4.2 & 4.7987 & TRN & \\
\hline CHEMBL1359004 & 688128 & 4.35 & 4.5805 & TRN & \\
\hline CHEMBL3196320 & 688128 & 4.9 & 4.6295 & TST & \\
\hline CHEMBL1509256 & 688128 & 4.35 & 4.5749 & TRN & \\
\hline CHEMBL261055 & 688128 & 4.3 & 4.7563 & TRN & \\
\hline CHEMBL1529410 & 688128 & 4.75 & 4.41 & TRN & \\
\hline CHEMBL1568843 & 688128 & 4.9 & 4.7586 & TRN & \\
\hline CHEMBL1382902 & 688128 & 5.8 & 4.921 & TRN & \\
\hline CHEMBL1521626 & 688128 & 4.85 & 4.3683 & TRN & \\
\hline CHEMBL1545064 & 688128 & 4.65 & 4.7398 & TRN & \\
\hline CHEMBL1537348 & 688128 & 4.45 & 4.8549 & TRN & \\
\hline
\end{tabular}




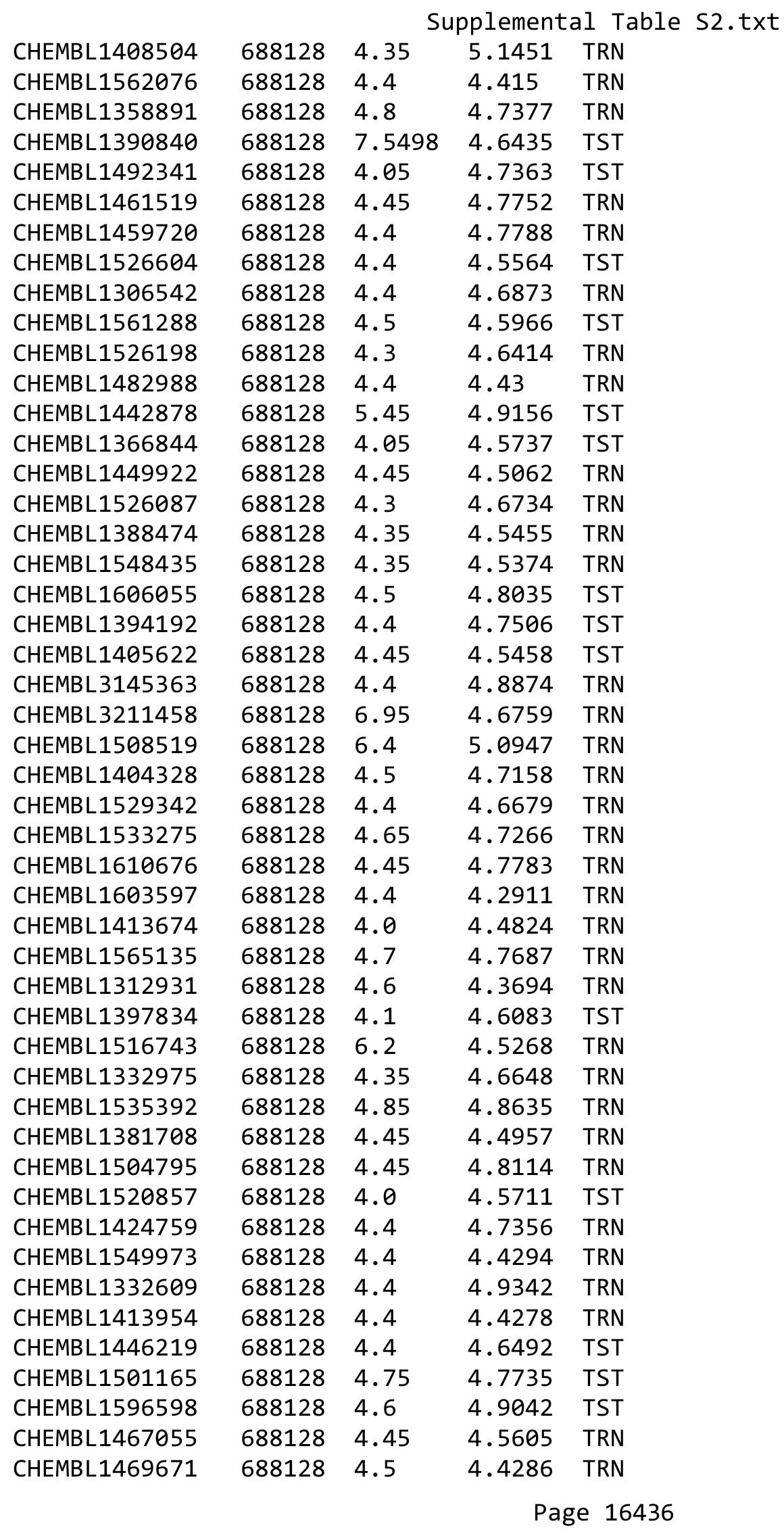




\begin{tabular}{|c|c|c|c|c|c|}
\hline \multicolumn{6}{|c|}{ Supplemental Table S2.txt } \\
\hline CHEMBL1393205 & 688128 & 5.1 & 4.3622 & TRN & \\
\hline CHEMBL1367498 & 688128 & 5.5 & 4.5516 & TRN & \\
\hline CHEMBL1373501 & 688128 & 4.05 & 4.7737 & TST & \\
\hline CHEMBL1360884 & 688128 & 4.65 & 4.6051 & TRN & \\
\hline CHEMBL1340103 & 688128 & 4.6 & 4.8654 & TRN & \\
\hline CHEMBL1411549 & 688128 & 4.95 & 4.3801 & TRN & \\
\hline CHEMBL1497580 & 688128 & 4.3 & 4.5819 & TRN & \\
\hline CHEMBL1416981 & 688128 & 4.7 & 4.5825 & TST & \\
\hline CHEMBL1467867 & 688128 & 4.4 & 5.0414 & TST & \\
\hline CHEMBL1423058 & 688128 & 4.05 & 4.7841 & TST & \\
\hline CHEMBL1407003 & 688128 & 5.7 & 4.9796 & TRN & \\
\hline CHEMBL1449606 & 688128 & 6.05 & 4.675 & TST & \\
\hline CHEMBL579045 & 688128 & 4.4 & 4.3134 & TST & \\
\hline CHEMBL1410478 & 688128 & 4.4 & 4.6462 & TRN & \\
\hline CHEMBL1452349 & 688128 & 4.4 & 4.7382 & TRN & \\
\hline CHEMBL1487916 & 688128 & 4.4 & 4.709 & TST & \\
\hline CHEMBL1536952 & 688128 & 4.65 & 4.4691 & TRN & \\
\hline CHEMBL1342024 & 688128 & 4.4 & 4.7766 & TRN & \\
\hline CHEMBL1392841 & 688128 & 4.35 & 4.3053 & TRN & \\
\hline CHEMBL1393833 & 688128 & 4.05 & 4.5394 & TRN & \\
\hline CHEMBL1441314 & 688128 & 5.25 & 4.3873 & TRN & \\
\hline CHEMBL1592020 & 688128 & 4.35 & 4.5036 & TST & \\
\hline CHEMBL1383250 & 688128 & 4.4 & $4.4860 e$ & 0000000001 & TRN \\
\hline CHEMBL1545416 & 688128 & 4.65 & 4.5114 & TST & \\
\hline CHEMBL1568727 & 688128 & 4.3 & 4.8235 & TRN & \\
\hline CHEMBL1334684 & 688128 & 5.5 & 5.0753 & TRN & \\
\hline CHEMBL1465917 & 688128 & 5.0 & 4.6825 & TRN & \\
\hline CHEMBL175916 & 688128 & 4.4 & 4.7793 & TRN & \\
\hline CHEMBL 3189264 & 688128 & 4.6 & 4.8371 & TRN & \\
\hline CHEMBL1569555 & 688128 & 4.35 & 4.7555 & TST & \\
\hline CHEMBL1348362 & 688128 & 4.4 & 4.5825 & TRN & \\
\hline CHEMBL1603433 & 688128 & 5.35 & 4.6309 & TRN & \\
\hline CHEMBL1520948 & 688128 & 4.4 & 4.4723 & TRN & \\
\hline CHEMBL1494871 & 688128 & 4.9 & 4.8936 & TRN & \\
\hline CHEMBL1466097 & 688128 & 4.4 & 4.4508 & TRN & \\
\hline CHEMBL1303019 & 688128 & 5.45 & 5.2016 & TRN & \\
\hline CHEMBL1526230 & 688128 & 4.25 & 4.4834 & TRN & \\
\hline CHEMBL1550196 & 688128 & 4.75 & 4.5855 & TRN & \\
\hline CHEMBL1410157 & 688128 & 5.75 & 4.7133 & TRN & \\
\hline CHEMBL1612047 & 688128 & 4.55 & 4.7213 & TRN & \\
\hline CHEMBL1440404 & 688128 & 5.1 & 4.8254 & TRN & \\
\hline CHEMBL1503852 & 688128 & 4.85 & 4.8822 & TRN & \\
\hline CHEMBL1508579 & 688128 & 4.0 & 4.2814 & TRN & \\
\hline CHEMBL402053 & 688128 & 4.35 & 4.9023 & TRN & \\
\hline CHEMBL1591131 & 688128 & 4.45 & 4.4328 & TRN & \\
\hline CHEMBL1547184 & 688128 & 4.3 & 4.5193 & TST & \\
\hline CHEMBL3195888 & 688128 & 4.45 & 4.5674 & TRN & \\
\hline CHEMBL1368727 & 688128 & 4.4 & 4.58899 & 99999999995 & TRN \\
\hline & & & & 16437 & \\
\hline
\end{tabular}




\begin{tabular}{|c|c|c|c|c|c|}
\hline \\
\hline CHEMBL1606720 & 688128 & 4.3 & 4.6082 & TRN & \\
\hline CHEMBL1402375 & 688128 & 5.35 & 4.5658 & TST & \\
\hline CHEMBL1531075 & 688128 & 4.6 & 4.8719 & TRN & \\
\hline CHEMBL1529081 & 688128 & 4.35 & 4.6952 & TRN & \\
\hline CHEMBL1545402 & 688128 & 4.9 & 4.5253 & TRN & \\
\hline CHEMBL1497053 & 688128 & 4.4 & 4.5148 & TST & \\
\hline CHEMBL1333617 & 688128 & 4.5 & 4.7043 & TST & \\
\hline CHEMBL1355569 & 688128 & 4.4 & 4.5687 & TRN & \\
\hline CHEMBL1583620 & 688128 & 6.5 & 4.6819 & TST & \\
\hline CHEMBL1329575 & 688128 & 4.8 & 4.6648 & TRN & \\
\hline CHEMBL3191291 & 688128 & 4.95 & 4.7862 & TRN & \\
\hline CHEMBL1308309 & 688128 & 4.35 & 4.4447 & TRN & \\
\hline CHEMBL157238 & 688128 & 4.05 & 4.5782 & TRN & \\
\hline CHEMBL1508914 & 688128 & 4.35 & 4.5074 & TRN & \\
\hline CHEMBL1351457 & 688128 & 4.3 & 4.6313 & TRN & \\
\hline CHEMBL1485079 & 688128 & 4.1 & 4.4987 & TRN & \\
\hline CHEMBL1457199 & 688128 & 4.65 & 4.47199 & 99999999995 & TRN \\
\hline CHEMBL1542037 & 688128 & 5.5 & 4.6279 & TRN & \\
\hline CHEMBL1595737 & 688128 & 4.3 & 4.50899 & 99999999995 & TST \\
\hline CHEMBL1610128 & 688128 & 4.2 & 4.7102 & TST & \\
\hline CHEMBL1560255 & 688128 & 4.0 & 4.293 & TRN & \\
\hline CHEMBL1462555 & 688128 & 4.4 & 4.3657 & TRN & \\
\hline CHEMBL1487184 & 688128 & 4.05 & 4.6297 & TRN & \\
\hline CHEMBL1543152 & 688128 & 4.15 & 4.8899 & TRN & \\
\hline CHEMBL1446599 & 688128 & 4.25 & 4.7427 & TRN & \\
\hline CHEMBL1463066 & 688128 & 5.65 & 4.9921 & TRN & \\
\hline CHEMBL1607313 & 688128 & 6.15 & 5.096 & TRN & \\
\hline CHEMBL1401295 & 688128 & 4.7 & 4.3846 & TRN & \\
\hline CHEMBL1444473 & 688128 & 4.8 & 4.9345 & TRN & \\
\hline CHEMBL1538303 & 688128 & 4.05 & 4.6474 & TST & \\
\hline CHEMBL1422209 & 688128 & 4.45 & 4.303 & TRN & \\
\hline CHEMBL 3214011 & 688128 & 4.1 & 4.4032 & TST & \\
\hline CHEMBL32011 & 688128 & 4.95 & 4.3988 & TRN & \\
\hline CHEMBL1351459 & 688128 & 4.4 & 4.6688 & TST & \\
\hline CHEMBL1483654 & 688128 & 6.15 & 5.2511 & TRN & \\
\hline CHEMBL1425218 & 688128 & 5.4 & 4.4248 & TST & \\
\hline CHEMBL1308796 & 688128 & 4.6 & 4.7489 & TST & \\
\hline CHEMBL1588325 & 688128 & 4.45 & 4.8102 & TRN & \\
\hline CHEMBL1559504 & 688128 & 4.4 & 4.3867 & TRN & \\
\hline CHEMBL1400966 & 688128 & 5.2 & 5.2284 & TRN & \\
\hline CHEMBL1342177 & 688128 & 4.65 & 4.5534 & TST & \\
\hline CHEMBL1368186 & 688128 & 6.05 & 4.5312 & TRN & \\
\hline CHEMBL1340573 & 688128 & 4.5 & 5.0081 & TST & \\
\hline CHEMBL3194498 & 688128 & 4.45 & 4.48 & TST & \\
\hline CHEMBL1548184 & 688128 & 4.45 & 4.667 & TST & \\
\hline CHEMBL1434126 & 688128 & 4.0 & 4.4253 & TRN & \\
\hline CHEMBL1417638 & 688128 & 4.55 & 4.4382 & TRN & \\
\hline CHEMBL1608296 & 688128 & 5.05 & 4.6935 & TRN & \\
\hline & & & & 54 & \\
\hline
\end{tabular}




\begin{tabular}{|c|c|c|c|c|c|}
\hline & & \multicolumn{4}{|c|}{ Supplemental Table S2.txt } \\
\hline CHEMBL1346310 & 688128 & 4.4 & 4.4886 & TRN & \\
\hline CHEMBL1321620 & 688128 & 4.95 & 4.8044 & TRN & \\
\hline CHEMBL1499013 & 688128 & 4.25 & 4.6746 & TRN & \\
\hline CHEMBL1468886 & 688128 & 4.75 & 4.5572 & TRN & \\
\hline CHEMBL1318983 & 688128 & 4.4 & 4.8401 & TRN & \\
\hline CHEMBL1572047 & 688128 & 4.4 & 4.4995 & TST & \\
\hline CHEMBL1421196 & 688128 & 5.05 & 4.7756 & TRN & \\
\hline CHEMBL1465380 & 688128 & 4.1 & 4.3764 & TRN & \\
\hline CHEMBL1522016 & 688128 & 4.05 & 4.4987 & TRN & \\
\hline CHEMBL1335988 & 688128 & 4.9 & 4.7714 & TRN & \\
\hline CHEMBL1309738 & 688128 & 4.35 & 4.8089 & TRN & \\
\hline CHEMBL1541339 & 688128 & 4.75 & 4.7157 & TST & \\
\hline CHEMBL3187659 & 688128 & 4.95 & 4.7692 & TRN & \\
\hline CHEMBL1481540 & 688128 & 4.55 & 4.6627 & TRN & \\
\hline CHEMBL1516420 & 688128 & 4.7 & 4.7154 & TRN & \\
\hline CHEMBL1475459 & 688128 & 4.5 & $4.7410 e$ & 00000000005 & TRN \\
\hline CHEMBL1605998 & 688128 & 4.25 & 4.605 & TRN & \\
\hline CHEMBL1578823 & 688128 & 4.35 & 4.846 & TST & \\
\hline CHEMBL1531073 & 688128 & 5.8 & 5.2629 & TRN & \\
\hline CHEMBL1591717 & 688128 & 4.3 & 4.5505 & TRN & \\
\hline CHEMBL1603474 & 688128 & 5.2 & 4.9799 & TRN & \\
\hline CHEMBL1516784 & 688128 & 4.3 & 4.7252 & TRN & \\
\hline CHEMBL1543775 & 688128 & 4.25 & 4.6139 & TRN & \\
\hline CHEMBL1364485 & 688128 & 4.35 & 4.6907 & TRN & \\
\hline CHEMBL1322610 & 688128 & 4.4 & 4.8488 & TRN & \\
\hline CHEMBL1382360 & 688128 & 4.55 & 4.4391 & TRN & \\
\hline CHEMBL1411140 & 688128 & 4.35 & 4.3716 & TRN & \\
\hline CHEMBL1348057 & 688128 & 4.7 & 4.669 & TRN & \\
\hline CHEMBL1573860 & 688128 & 4.95 & 4.675 & TRN & \\
\hline CHEMBL1543587 & 688128 & 4.5 & 4.3871 & TRN & \\
\hline CHEMBL1318103 & 688128 & 4.75 & 4.833 & TRN & \\
\hline CHEMBL1494382 & 688128 & 4.35 & 4.9701 & TRN & \\
\hline CHEMBL1559111 & 688128 & 4.35 & 4.6824 & TRN & \\
\hline CHEMBL1416674 & 688128 & 6.05 & 4.7361 & TST & \\
\hline CHEMBL1531565 & 688128 & 4.8 & 4.6721 & TRN & \\
\hline CHEMBL1417824 & 688128 & 4.65 & 4.7084 & TRN & \\
\hline CHEMBL1310526 & 688128 & 4.4 & 5.0945 & TRN & \\
\hline CHEMBL1331202 & 688128 & 4.55 & 5.004 & TRN & \\
\hline CHEMBL1509348 & 688128 & 4.35 & 4.3055 & TRN & \\
\hline CHEMBL1494688 & 688128 & 4.7 & 4.7166 & TRN & \\
\hline CHEMBL1604163 & 688128 & 5.1 & 4.5334 & TRN & \\
\hline CHEMBL1428384 & 688128 & 5.8 & 4.6735 & TST & \\
\hline CHEMBL1560656 & 688128 & 4.35 & 4.3518 & TRN & \\
\hline CHEMBL1330566 & 688128 & 5.0 & 4.822 & TRN & \\
\hline CHEMBL1455368 & 688128 & 5.05 & 4.8629 & TRN & \\
\hline CHEMBL1527312 & 688128 & 6.0 & 4.7721 & TRN & \\
\hline CHEMBL1379365 & 688128 & 4.85 & 4.7017 & TRN & \\
\hline CHEMBL1521637 & 688128 & 4.4 & 4.7849 & TRN & \\
\hline
\end{tabular}




\begin{tabular}{|c|c|c|c|c|c|}
\hline \multicolumn{6}{|c|}{ Supplemental Table S2.txt } \\
\hline CHEMBL1419245 & 688128 & 4.8 & 4.6496 & TRN & \\
\hline CHEMBL1438182 & 688128 & 5.35 & 5.0428 & TRN & \\
\hline CHEMBL1439733 & 688128 & 4.05 & 4.8229 & TRN & \\
\hline CHEMBL1345581 & 688128 & 4.3 & 4.3483 & TRN & \\
\hline CHEMBL1374016 & 688128 & 4.5 & 4.7413 & TRN & \\
\hline CHEMBL1502145 & 688128 & 4.45 & 4.9913 & TRN & \\
\hline CHEMBL1443315 & 688128 & 4.3 & 4.833 & TRN & \\
\hline CHEMBL1561285 & 688128 & 4.35 & 4.5842 & TRN & \\
\hline CHEMBL1479424 & 688128 & 4.55 & 4.5793 & TRN & \\
\hline CHEMBL1326062 & 688128 & 4.25 & 4.4142 & TRN & \\
\hline CHEMBL1343607 & 688128 & 4.25 & 4.3738 & TRN & \\
\hline CHEMBL1490262 & 688128 & 4.4 & 4.4693 & TRN & \\
\hline CHEMBL1319721 & 688128 & 4.5 & 4.6566 & TRN & \\
\hline CHEMBL1404578 & 688128 & 5.5 & 5.3499 & TRN & \\
\hline CHEMBL1437258 & 688128 & 4.65 & 4.5241 & TRN & \\
\hline CHEMBL1569791 & 688128 & 4.35 & 4.5156 & TRN & \\
\hline CHEMBL1345271 & 688128 & 4.4 & 4.402 & TRN & \\
\hline CHEMBL1473770 & 688128 & 4.4 & 4.4925 & TRN & \\
\hline CHEMBL3209725 & 688128 & 4.05 & 4.6815 & TST & \\
\hline CHEMBL1467793 & 688128 & 4.6 & 4.71899 & 9999999999 & TRN \\
\hline CHEMBL1550378 & 688128 & 4.4 & 4.7574 & TST & \\
\hline CHEMBL1412220 & 688128 & 4.85 & 4.7828 & TRN & \\
\hline CHEMBL1514552 & 688128 & 5.4 & 4.4959 & TRN & \\
\hline CHEMBL1609530 & 688128 & 4.55 & 4.6869 & TRN & \\
\hline CHEMBL1341619 & 688128 & 4.35 & 4.6412 & TRN & \\
\hline CHEMBL1339446 & 688128 & 4.75 & 4.8028 & TST & \\
\hline CHEMBL1516983 & 688128 & 4.8 & 4.5689 & TRN & \\
\hline CHEMBL1312203 & 688128 & 4.45 & 4.641 & TRN & \\
\hline CHEMBL1375358 & 688128 & 4.35 & 4.4909 & TRN & \\
\hline CHEMBL1609363 & 688128 & 4.4 & 4.7322 & TRN & \\
\hline CHEMBL1539567 & 688128 & 4.3 & 4.592 & TST & \\
\hline CHEMBL1327886 & 688128 & 4.45 & 4.6434 & TRN & \\
\hline CHEMBL1610772 & 688128 & 4.35 & 4.7903 & TRN & \\
\hline CHEMBL1378801 & 688128 & 4.6 & 4.3553 & TRN & \\
\hline CHEMBL1551376 & 688128 & 4.5 & 4.6818 & TRN & \\
\hline CHEMBL1590044 & 688128 & 6.5 & 4.9726 & TRN & \\
\hline CHEMBL1338013 & 688128 & 4.3 & 4.5874 & TST & \\
\hline CHEMBL1322028 & 688128 & 4.3 & 4.63399 & 99999999995 & TST \\
\hline CHEMBL1597606 & 688128 & 4.4 & 4.4668 & TRN & \\
\hline CHEMBL1491732 & 688128 & 5.5 & 4.8243 & TRN & \\
\hline CHEMBL1497606 & 688128 & 4.25 & 4.5605 & TST & \\
\hline CHEMBL3144970 & 688128 & 5.05 & 5.3502 & TRN & \\
\hline CHEMBL1516732 & 688128 & 4.45 & 4.4758 & TRN & \\
\hline CHEMBL1541205 & 688128 & 4.35 & 4.7038 & TRN & \\
\hline CHEMBL1492648 & 688128 & 5.0 & 5.27 & TRN & \\
\hline CHEMBL1382564 & 688128 & 4.75 & 4.7919 & TRN & \\
\hline CHEMBL1396258 & 688128 & 4.4 & 4.5695 & TRN & \\
\hline CHEMBL1476305 & 688128 & 4.5 & 4.5844 & TRN & \\
\hline
\end{tabular}




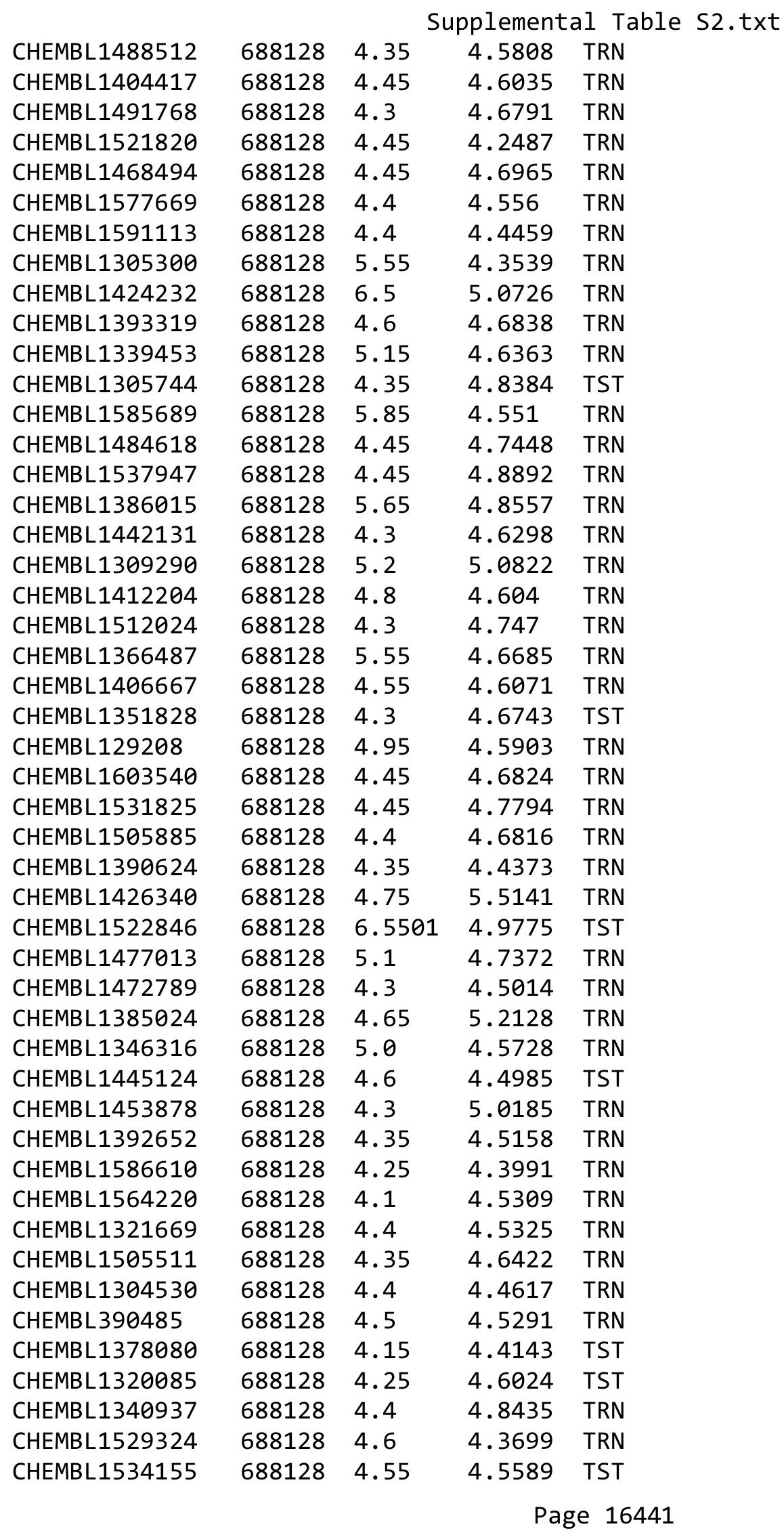




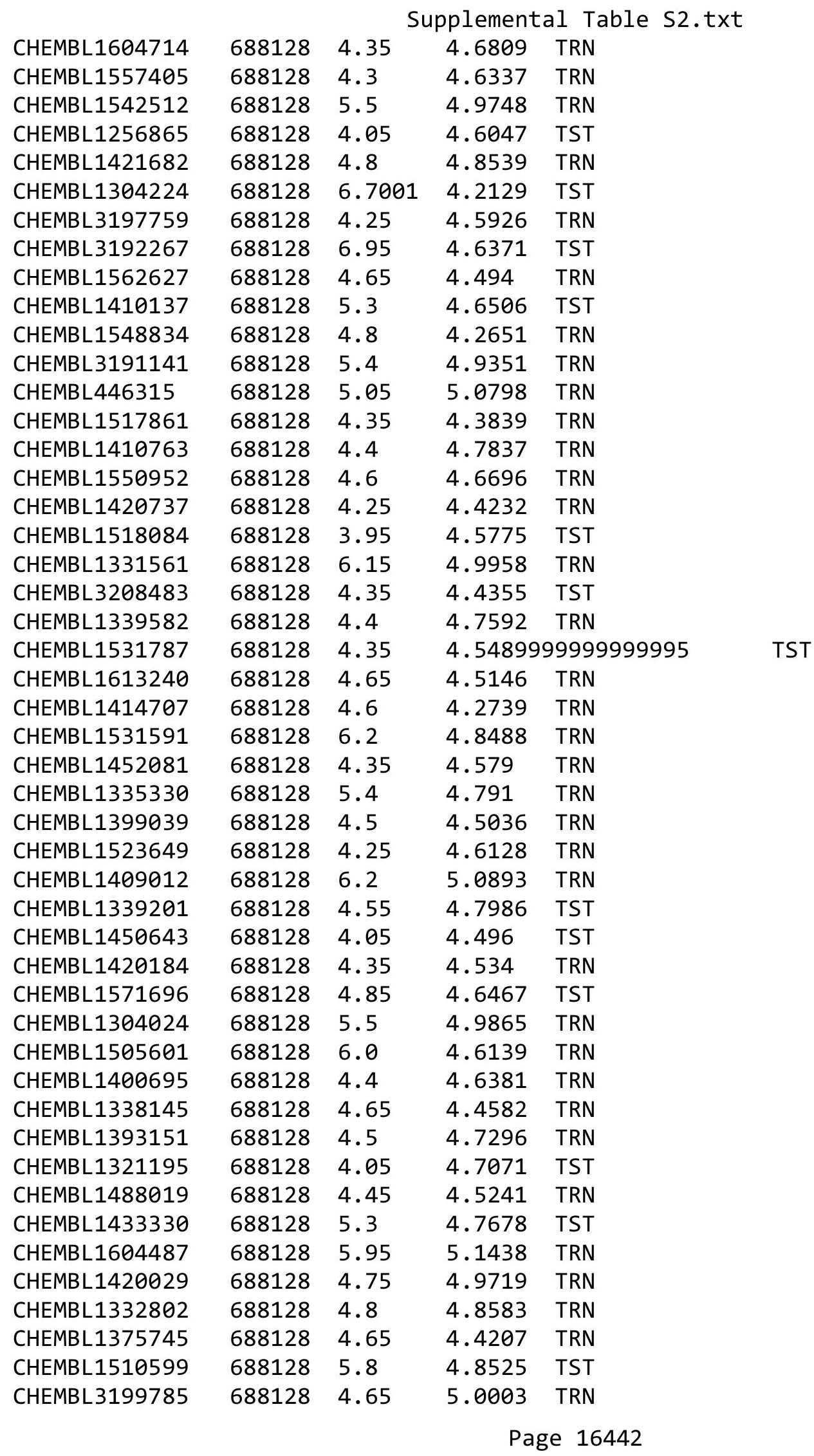




\begin{tabular}{|c|c|c|c|c|c|}
\hline \multicolumn{6}{|c|}{ Supplemental Table S2.txt } \\
\hline CHEMBL1577971 & 688128 & 4.9 & 4.2859 & TRN & \\
\hline CHEMBL1454487 & 688128 & 4.55 & 4.6589 & TRN & \\
\hline CHEMBL1511159 & 688128 & 4.05 & 4.3513 & TRN & \\
\hline CHEMBL1528328 & 688128 & 4.35 & 4.6838 & TRN & \\
\hline CHEMBL1524438 & 688128 & 5.05 & 4.9461 & TRN & \\
\hline CHEMBL1500797 & 688128 & 4.6 & 4.529 & TRN & \\
\hline CHEMBL1468055 & 688128 & 4.45 & 4.8641 & TRN & \\
\hline CHEMBL1471017 & 688128 & 4.45 & 4.4204 & TRN & \\
\hline CHEMBL1383009 & 688128 & 4.05 & 4.6232 & TST & \\
\hline CHEMBL1376098 & 688128 & 4.5 & 4.757 & TRN & \\
\hline CHEMBL1431362 & 688128 & 4.4 & 4.6563 & TRN & \\
\hline CHEMBL1352219 & 688128 & 4.4 & 4.6375 & TRN & \\
\hline CHEMBL1433353 & 688128 & 4.75 & 4.7288 & TRN & \\
\hline CHEMBL1374359 & 688128 & 4.3 & 4.645 & TRN & \\
\hline CHEMBL1430209 & 688128 & 4.3 & 4.4094 & TRN & \\
\hline CHEMBL1332460 & 688128 & 4.0 & 5.09 & TST & \\
\hline CHEMBL1355018 & 688128 & 4.05 & 4.5932 & TRN & \\
\hline CHEMBL1561862 & 688128 & 4.05 & 4.6598 & TST & \\
\hline CHEMBL522809 & 688128 & 4.35 & 4.6028 & TRN & \\
\hline CHEMBL1602864 & 688128 & 4.3 & 4.5083 & TRN & \\
\hline CHEMBL1358809 & 688128 & 4.35 & 4.5911 & TRN & \\
\hline CHEMBL3197651 & 688128 & 5.15 & 4.9938 & TRN & \\
\hline CHEMBL1380197 & 688128 & 4.4 & 4.9843 & TST & \\
\hline CHEMBL1583671 & 688128 & 4.5 & 4.7486 & TRN & \\
\hline CHEMBL1522941 & 688128 & 4.45 & 4.7204 & TRN & \\
\hline CHEMBL1525315 & 688128 & 5.05 & 5.0282 & TRN & \\
\hline CHEMBL1491779 & 688128 & 4.35 & 4.6659 & TRN & \\
\hline CHEMBL1348613 & 688128 & 4.35 & 4.3443 & TRN & \\
\hline CHEMBL3189336 & 688128 & 4.55 & 4.5939 & TRN & \\
\hline CHEMBL1611242 & 688128 & 4.85 & 4.9086 & TRN & \\
\hline CHEMBL1536713 & 688128 & 4.4 & 4.3275 & TRN & \\
\hline CHEMBL1335898 & 688128 & 4.6 & 4.5243 & TRN & \\
\hline CHEMBL1585552 & 688128 & 4.0 & 4.1153 & TRN & \\
\hline CHEMBL1447432 & 688128 & 4.95 & 4.9945 & TRN & \\
\hline CHEMBL1537602 & 688128 & 4.35 & 4.3638 & TRN & \\
\hline CHEMBL3145084 & 688128 & 4.8 & 4.54899 & 99999999995 & TST \\
\hline CHEMBL1524839 & 688128 & 4.35 & 4.7088 & TRN & \\
\hline CHEMBL1386129 & 688128 & 4.95 & 4.7893 & TST & \\
\hline CHEMBL1573330 & 688128 & 4.35 & 4.5494 & TRN & \\
\hline CHEMBL1421898 & 688128 & 4.85 & 4.5524 & TRN & \\
\hline CHEMBL1542702 & 688128 & 4.45 & 4.5299 & TRN & \\
\hline CHEMBL1302534 & 688128 & 4.45 & 4.2836 & TRN & \\
\hline CHEMBL1371245 & 688128 & 4.05 & 4.5568 & TST & \\
\hline CHEMBL1501005 & 688128 & 4.5 & 4.9554 & TRN & \\
\hline CHEMBL1589751 & 688128 & 5.35 & 4.7709 & TRN & \\
\hline CHEMBL1559481 & 688128 & 6.8 & 4.3299 & TRN & \\
\hline CHEMBL15594 & 688128 & 4.75 & 4.6395 & TRN & \\
\hline CHEMBL1585431 & 688128 & 4.15 & 4.3304 & TRN & \\
\hline
\end{tabular}




\begin{tabular}{|c|c|c|c|c|c|}
\hline \multirow[b]{2}{*}{ CHEMBL1368184 } & \multicolumn{5}{|c|}{ oplemental Table S2. } \\
\hline & 688128 & 4.05 & 4.6427 & TRN & \\
\hline CHEMBL1386214 & 688128 & 4.3 & $4.4910 e$ & 00000000005 & TRN \\
\hline CHEMBL1301017 & 688128 & 4.4 & 4.5295 & TRN & \\
\hline CHEMBL1530581 & 688128 & 4.35 & 4.9284 & TRN & \\
\hline CHEMBL1585912 & 688128 & 4.15 & 4.6564 & TRN & \\
\hline CHEMBL1326587 & 688128 & 5.05 & 4.7547 & TRN & \\
\hline CHEMBL 236268 & 688128 & 4.25 & 4.8068 & TST & \\
\hline CHEMBL1421265 & 688128 & 4.0 & 4.6916 & TST & \\
\hline CHEMBL1339387 & 688128 & 4.8 & 4.478 & TRN & \\
\hline CHEMBL1465856 & 688128 & 5.55 & 4.8605 & TRN & \\
\hline CHEMBL1332993 & 688128 & 4.35 & 4.5633 & TRN & \\
\hline CHEMBL1598944 & 688128 & 4.35 & 5.2925 & TRN & \\
\hline CHEMBL3192513 & 688128 & 4.45 & 4.3846 & TRN & \\
\hline CHEMBL1489743 & 688128 & 6.15 & 5.0748 & TRN & \\
\hline CHEMBL3196319 & 688128 & 4.5 & 4.7462 & TRN & \\
\hline CHEMBL1466413 & 688128 & 5.35 & 4.3001 & TRN & \\
\hline CHEMBL1358230 & 688128 & 4.25 & 4.5244 & TST & \\
\hline CHEMBL1589367 & 688128 & 4.25 & 4.7379 & TRN & \\
\hline CHEMBL1362200 & 688128 & 5.7 & 4.7877 & TRN & \\
\hline CHEMBL1504248 & 688128 & 4.3 & 4.4562 & TRN & \\
\hline CHEMBL1488172 & 688128 & 6.0 & 5.5776 & TRN & \\
\hline CHEMBL1600871 & 688128 & 4.15 & 4.6642 & TST & \\
\hline CHEMBL1302740 & 688128 & 4.25 & 4.5302 & TRN & \\
\hline CHEMBL1310268 & 688128 & 4.85 & 4.5022 & TRN & \\
\hline CHEMBL1379034 & 688128 & 4.7 & 4.5676 & TST & \\
\hline CHEMBL1320801 & 688128 & 4.4 & 4.3727 & TRN & \\
\hline CHEMBL1489800 & 688128 & 4.3 & 4.3675 & TRN & \\
\hline CHEMBL1312322 & 688128 & 4.45 & 4.3932 & TRN & \\
\hline CHEMBL1366536 & 688128 & 4.4 & 4.6732 & TRN & \\
\hline CHEMBL1569636 & 688128 & 5.45 & 4.8792 & TRN & \\
\hline CHEMBL1577656 & 688128 & 4.95 & 4.7592 & TRN & \\
\hline CHEMBL1559001 & 688128 & 4.65 & 4.9633 & TRN & \\
\hline CHEMBL1562636 & 688128 & 4.7 & 4.5248 & TRN & \\
\hline CHEMBL1468124 & 688128 & 4.25 & 4.6101 & TRN & \\
\hline CHEMBL1594031 & 688128 & 4.05 & 4.6139 & TRN & \\
\hline CHEMBL1440608 & 688128 & 6.0 & 4.9157 & TRN & \\
\hline CHEMBL1367692 & 688128 & 4.55 & 4.9894 & TRN & \\
\hline CHEMBL3197144 & 688128 & 5.4 & 4.7061 & TST & \\
\hline CHEMBL1486151 & 688128 & 5.6 & 4.92399 & 99999999995 & TRN \\
\hline CHEMBL3212641 & 688128 & 4.55 & 4.564 & TRN & \\
\hline CHEMBL1606994 & 688128 & 4.05 & 4.5238 & TST & \\
\hline CHEMBL1563722 & 688128 & 4.3 & 4.6523 & TRN & \\
\hline CHEMBL1486434 & 688128 & 4.35 & 4.8752 & TRN & \\
\hline CHEMBL1570823 & 688128 & 4.35 & 4.5207 & TRN & \\
\hline CHEMBL1400284 & 688128 & 4.8 & 4.6529 & TRN & \\
\hline CHEMBL1498488 & 688128 & 4.4 & 4.6454 & TRN & \\
\hline CHEMBL1391748 & 688128 & 4.5 & 4.6356 & TRN & \\
\hline CHEMBL1604142 & 688128 & 5.35 & 4.7479 & TRN & \\
\hline
\end{tabular}




\begin{tabular}{|c|c|c|c|c|c|}
\hline \\
\hline CHEMBL1353017 & 688128 & 4.3 & 4.5702 & TST & \\
\hline CHEMBL1437058 & 688128 & 4.55 & 4.4847 & TST & \\
\hline CHEMBL1526635 & 688128 & 5.2 & 5.154 & TRN & \\
\hline CHEMBL1518699 & 688128 & 4.65 & 4.6707 & TRN & \\
\hline CHEMBL1583534 & 688128 & 6.2 & 5.3826 & TRN & \\
\hline CHEMBL1546832 & 688128 & 4.85 & 4.717 & TST & \\
\hline CHEMBL1510990 & 688128 & 4.35 & 4.5551 & TST & \\
\hline CHEMBL1577858 & 688128 & 4.0 & 4.6226 & TRN & \\
\hline CHEMBL1327360 & 688128 & 4.3 & 4.6715 & TST & \\
\hline CHEMBL1337226 & 688128 & 5.55 & 4.9746 & TRN & \\
\hline CHEMBL1575546 & 688128 & 5.15 & 4.7205 & TST & \\
\hline CHEMBL1345657 & 688128 & 6.1 & 5.232 & TRN & \\
\hline CHEMBL1301992 & 688128 & 4.35 & 4.5806 & TRN & \\
\hline CHEMBL1559088 & 688128 & 4.7 & 4.8752 & TRN & \\
\hline CHEMBL1563307 & 688128 & 4.65 & 4.6693 & TRN & \\
\hline CHEMBL1539495 & 688128 & 5.15 & 4.6068 & TST & \\
\hline CHEMBL1434324 & 688128 & 4.0 & 4.2138 & TST & \\
\hline CHEMBL1334260 & 688128 & 4.9 & 5.2207 & TRN & \\
\hline CHEMBL1477595 & 688128 & 4.05 & 4.6229 & TST & \\
\hline CHEMBL1511391 & 688128 & 5.0 & 4.7812 & TRN & \\
\hline CHEMBL1311570 & 688128 & 4.4 & 4.5016 & TRN & \\
\hline CHEMBL1502540 & 688128 & 5.5 & 4.5415 & TRN & \\
\hline CHEMBL1526940 & 688128 & 4.35 & 4.4883 & TST & \\
\hline CHEMBL1442260 & 688128 & 5.15 & 4.743 & TRN & \\
\hline CHEMBL1572036 & 688128 & 4.45 & 4.5532 & TST & \\
\hline CHEMBL1425504 & 688128 & 5.95 & 5.2158 & TRN & \\
\hline CHEMBL1410773 & 688128 & 4.35 & 4.6722 & TRN & \\
\hline CHEMBL1468800 & 688128 & 6.4 & 5.2607 & TST & \\
\hline CHEMBL1455019 & 688128 & 4.3 & 4.69300 & 00000000005 & TRN \\
\hline CHEMBL1378842 & 688128 & 4.3 & 4.5476 & TST & \\
\hline CHEMBL1506792 & 688128 & 4.7 & 4.2533 & TRN & \\
\hline CHEMBL1456158 & 688128 & 4.3 & 4.567 & TRN & \\
\hline CHEMBL1493715 & 688128 & 4.3 & 4.4487 & TRN & \\
\hline CHEMBL591876 & 688128 & 4.1 & 5.6744 & TRN & \\
\hline CHEMBL1311228 & 688128 & 4.35 & 4.4469 & TRN & \\
\hline CHEMBL1531968 & 688128 & 4.9 & 4.6041 & TRN & \\
\hline CHEMBL1595885 & 688128 & 4.85 & 4.50899 & 99999999995 & TRN \\
\hline CHEMBL1494847 & 688128 & 4.4 & 4.4651 & TST & \\
\hline CHEMBL1386463 & 688128 & 4.3 & 4.7138 & TRN & \\
\hline CHEMBL1472373 & 688128 & 4.3 & 4.9369 & TRN & \\
\hline CHEMBL1513563 & 688128 & 4.3 & 4.695 & TRN & \\
\hline CHEMBL1473558 & 688128 & 4.35 & 4.3251 & TST & \\
\hline CHEMBL1607823 & 688128 & 6.1 & 4.9972 & TRN & \\
\hline CHEMBL1467399 & 688128 & 4.4 & 4.6052 & TRN & \\
\hline CHEMBL1322726 & 688128 & 4.25 & 4.728 & TST & \\
\hline CHEMBL1362604 & 688128 & 4.25 & 4.4464 & TRN & \\
\hline CHEMBL1973861 & 688128 & 4.65 & 4.4472 & TRN & \\
\hline CHEMBL1307832 & 688128 & 4.25 & 4.5875 & TST & \\
\hline
\end{tabular}




\begin{tabular}{|c|c|c|c|c|}
\hline \multicolumn{5}{|c|}{ Supplemental Table S2.txt } \\
\hline CHEMBL1464269 & 688128 & 4.5 & 4.4308 & TST \\
\hline CHEMBL1528348 & 688128 & 4.5 & 4.4439 & TRN \\
\hline CHEMBL1474368 & 688128 & 4.35 & 4.4864 & TST \\
\hline CHEMBL1384638 & 688128 & 4.3 & 4.3965 & TRN \\
\hline CHEMBL1449694 & 688128 & 4.45 & 4.7192 & TST \\
\hline CHEMBL1449928 & 688128 & 4.55 & 4.6664 & TRN \\
\hline CHEMBL1489575 & 688128 & 4.35 & 4.618 & TRN \\
\hline CHEMBL 3197080 & 688128 & 4.25 & 4.6941 & TRN \\
\hline CHEMBL1413265 & 688128 & 4.3 & 4.591 & TRN \\
\hline CHEMBL1489164 & 688128 & 4.05 & 4.2795 & TRN \\
\hline CHEMBL1490419 & 688128 & 4.4 & 4.6466 & TRN \\
\hline CHEMBL1495023 & 688128 & 4.3 & 4.6056 & TRN \\
\hline CHEMBL1607132 & 688128 & 5.4 & 4.4703 & TRN \\
\hline CHEMBL1493941 & 688128 & 4.3 & 4.8122 & TRN \\
\hline CHEMBL1356896 & 688128 & 4.85 & 4.6652 & TRN \\
\hline CHEMBL1307315 & 688128 & 4.05 & 4.6922 & TRN \\
\hline CHEMBL1520712 & 688128 & 4.1 & 4.5971 & TRN \\
\hline CHEMBL1350985 & 688128 & 4.1 & 4.8702 & TRN \\
\hline CHEMBL1464416 & 688128 & 4.4 & 4.4176 & TRN \\
\hline CHEMBL1364074 & 688128 & 4.4 & 4.7042 & TST \\
\hline CHEMBL1555222 & 688128 & 4.4 & 4.5434 & TRN \\
\hline CHEMBL1509853 & 688128 & 4.4 & 4.3869 & TRN \\
\hline CHEMBL1512627 & 688128 & 4.3 & 4.4281 & TRN \\
\hline CHEMBL1301688 & 688128 & 4.9 & 4.4673 & TRN \\
\hline CHEMBL1498232 & 688128 & 4.45 & 4.6558 & TRN \\
\hline CHEMBL1429668 & 688128 & 4.3 & 4.2072 & TRN \\
\hline CHEMBL1439606 & 688128 & 4.45 & 4.5879 & TRN \\
\hline CHEMBL1431845 & 688128 & 4.3 & 4.5019 & TRN \\
\hline CHEMBL1577300 & 688128 & 4.2 & 4.697 & TRN \\
\hline CHEMBL1565523 & 688128 & 4.55 & 4.7666 & TRN \\
\hline CHEMBL1373850 & 688128 & 6.0 & 4.5009 & TST \\
\hline CHEMBL1444711 & 688128 & 5.65 & 4.7877 & TST \\
\hline CHEMBL3196066 & 688128 & 4.05 & 4.6426 & TST \\
\hline CHEMBL1385750 & 688128 & 4.5 & 4.7985 & TST \\
\hline CHEMBL1579585 & 688128 & 4.7 & 4.7612 & TRN \\
\hline CHEMBL1506624 & 688128 & 4.9 & 4.4987 & TRN \\
\hline CHEMBL1396420 & 688128 & 4.35 & 4.5378 & TRN \\
\hline CHEMBL1389771 & 688128 & 4.45 & 4.38 & TRN \\
\hline CHEMBL1352876 & 688128 & 4.35 & 4.4153 & TRN \\
\hline CHEMBL1339384 & 688128 & 4.25 & 4.7561 & TRN \\
\hline CHEMBL1467000 & 688128 & 4.55 & 4.8416 & TST \\
\hline CHEMBL1432231 & 688128 & 4.4 & 4.535 & TST \\
\hline CHEMBL1404779 & 688128 & 4.4 & 4.6231 & TRN \\
\hline CHEMBL1532640 & 688128 & 4.6 & 4.5396 & TRN \\
\hline CHEMBL1544957 & 688128 & 4.6 & 4.5682 & TRN \\
\hline CHEMBL1326705 & 688128 & 4.05 & 4.647 & TST \\
\hline CHEMBL 1355560 & 688128 & 4.05 & 4.5279 & TST \\
\hline CHEMBL1583631 & 688128 & 4.3 & 4.5396 & TRN \\
\hline
\end{tabular}




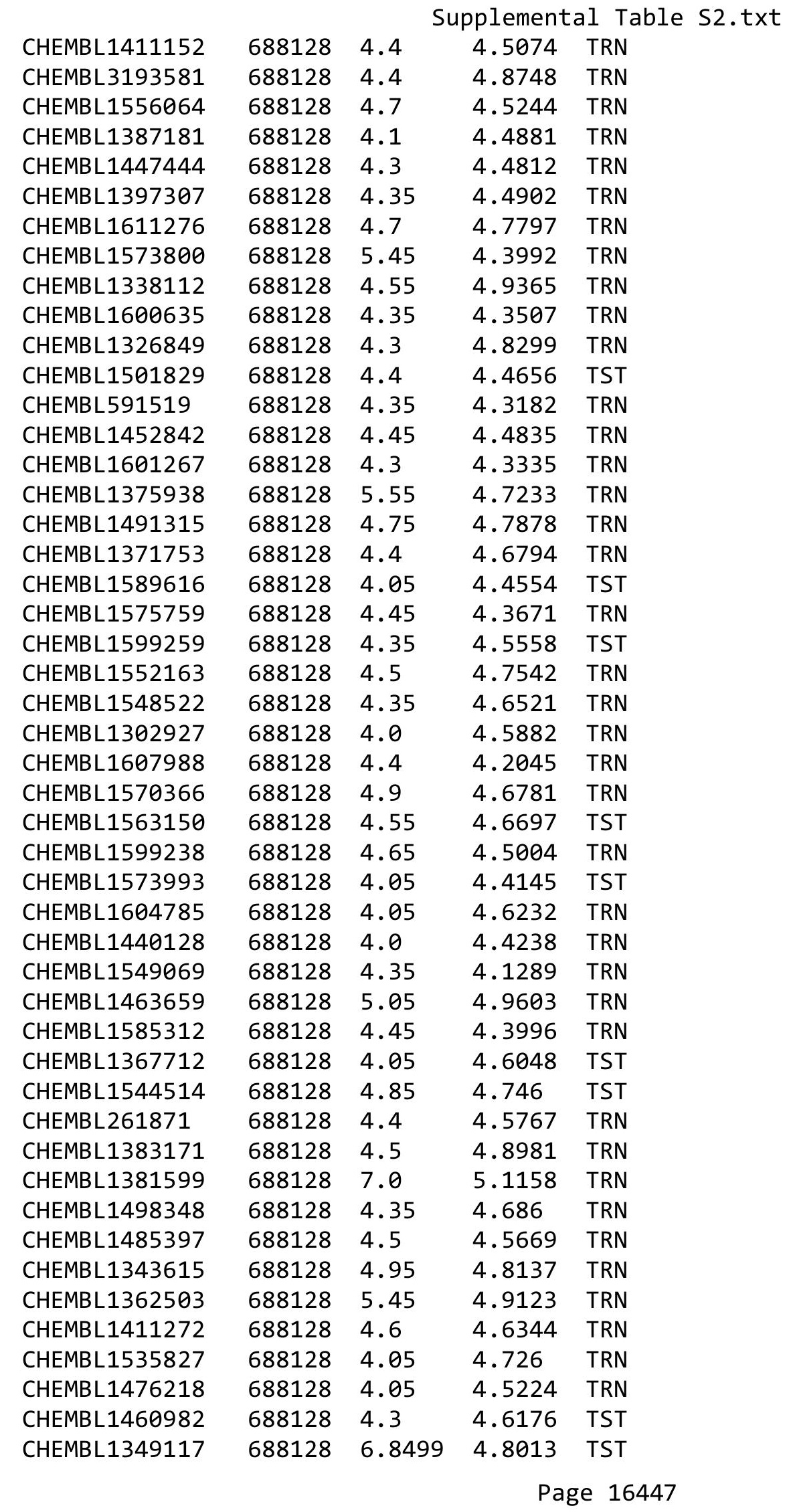




\begin{tabular}{|c|c|c|c|c|c|}
\hline \multicolumn{6}{|c|}{ Supplemental Table s2.txt } \\
\hline CHEMBL1372663 & 688128 & 4.0 & 4.4027 & TRN & \\
\hline CHEMBL1490243 & 688128 & 5.95 & 4.417 & TRN & \\
\hline CHEMBL297304 & 688128 & 4.05 & 4.9984 & TST & \\
\hline CHEMBL1576397 & 688128 & 4.8 & 4.7874 & TRN & \\
\hline CHEMBL1316919 & 688128 & 4.35 & 4.4971 & TRN & \\
\hline CHEMBL1450458 & 688128 & 4.85 & 4.7198 & TRN & \\
\hline CHEMBL1361003 & 688128 & 4.4 & 4.3631 & TRN & \\
\hline CHEMBL1986664 & 688128 & 4.4 & 4.8372 & TST & \\
\hline CHEMBL1609454 & 688128 & 5.65 & 5.0423 & TRN & \\
\hline CHEMBL3190706 & 688128 & 4.05 & 4.6032 & TRN & \\
\hline CHEMBL1362323 & 688128 & 4.3 & 4.4778 & TRN & \\
\hline CHEMBL1420544 & 688128 & 4.4 & 4.5122 & TRN & \\
\hline CHEMBL3209662 & 688128 & 4.35 & 4.6522 & TRN & \\
\hline CHEMBL1349475 & 688128 & 6.0 & 4.9426 & TRN & \\
\hline CHEMBL1523444 & 688128 & 4.9 & 4.6778 & TRN & \\
\hline CHEMBL1424930 & 688128 & 5.0 & 4.6819 & TST & \\
\hline CHEMBL1605419 & 688128 & 4.35 & 4.8295 & TRN & \\
\hline CHEMBL1324826 & 688128 & 4.35 & 4.6421 & TST & \\
\hline CHEMBL1315038 & 688128 & 4.4 & 4.216 & TRN & \\
\hline CHEMBL1301503 & 688128 & 4.35 & 4.4766 & TRN & \\
\hline CHEMBL3196288 & 688128 & 4.45 & 4.6888 & TRN & \\
\hline CHEMBL1326711 & 688128 & 4.25 & 4.8392 & TRN & \\
\hline CHEMBL1425117 & 688128 & 4.25 & 4.5356 & TRN & \\
\hline CHEMBL1475958 & 688128 & 4.4 & 4.5391 & TST & \\
\hline CHEMBL1362642 & 688128 & 4.35 & 4.4229 & TRN & \\
\hline CHEMBL1362839 & 688128 & 5.6 & 4.1123 & TST & \\
\hline CHEMBL1589197 & 688128 & 4.35 & 5.13399 & 99999999995 & TRN \\
\hline CHEMBL1473633 & 688128 & 4.35 & 4.6915 & TRN & \\
\hline CHEMBL1325319 & 688128 & 4.35 & 4.9488 & TRN & \\
\hline CHEMBL1342104 & 688128 & 4.7 & 4.7133 & TRN & \\
\hline CHEMBL3190579 & 688128 & 4.9 & 4.3659 & TST & \\
\hline CHEMBL1590543 & 688128 & 4.3 & 4.442 & TRN & \\
\hline CHEMBL1499122 & 688128 & 4.85 & 4.8235 & TRN & \\
\hline CHEMBL1561539 & 688128 & 6.8499 & 4.945 & TRN & \\
\hline CHEMBL1568897 & 688128 & 6.0 & 5.3042 & TRN & \\
\hline CHEMBL1509832 & 688128 & 5.55 & 5.4361 & TRN & \\
\hline CHEMBL1422341 & 688128 & 4.5 & 4.8782 & TRN & \\
\hline CHEMBL1300732 & 688128 & 4.1 & 4.8772 & TST & \\
\hline CHEMBL1468658 & 688128 & 4.8 & 4.6912 & TRN & \\
\hline CHEMBL1516834 & 688128 & 5.5 & 4.8815 & TRN & \\
\hline CHEMBL1332665 & 688128 & 4.55 & 4.6865 & TRN & \\
\hline CHEMBL1472183 & 688128 & 4.25 & 4.6327 & TST & \\
\hline CHEMBL1571662 & 688128 & 4.25 & 4.8837 & TRN & \\
\hline CHEMBL1332997 & 688128 & 4.8 & 4.3662 & TRN & \\
\hline CHEMBL3213318 & 688128 & 4.45 & 4.5833 & TST & \\
\hline CHEMBL1357537 & 688128 & 4.35 & 4.4615 & TRN & \\
\hline CHEMBL1570127 & 688128 & 4.25 & 4.5283 & TRN & \\
\hline CHEMBL1515145 & 688128 & 4.6 & 4.2785 & TRN & \\
\hline
\end{tabular}




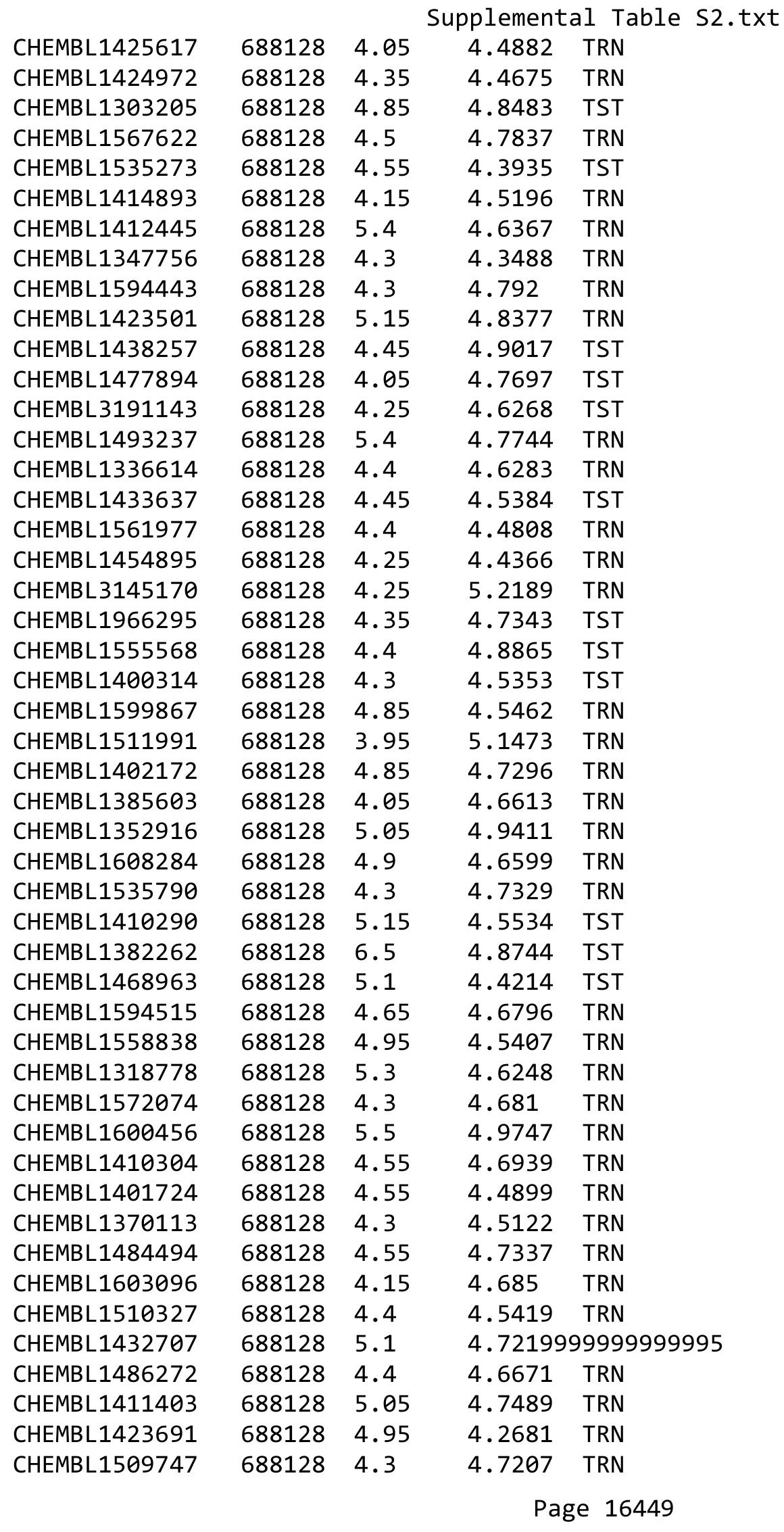




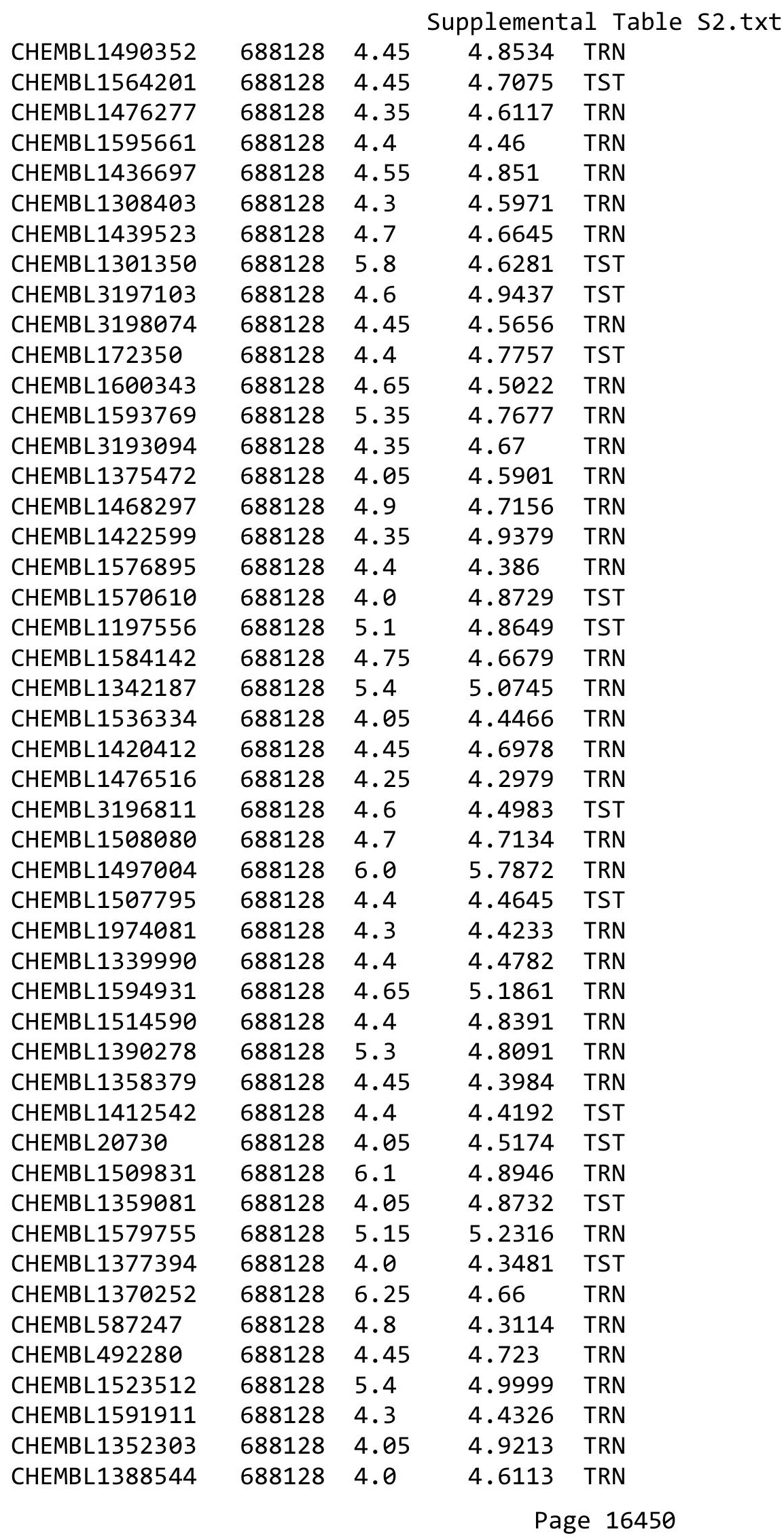




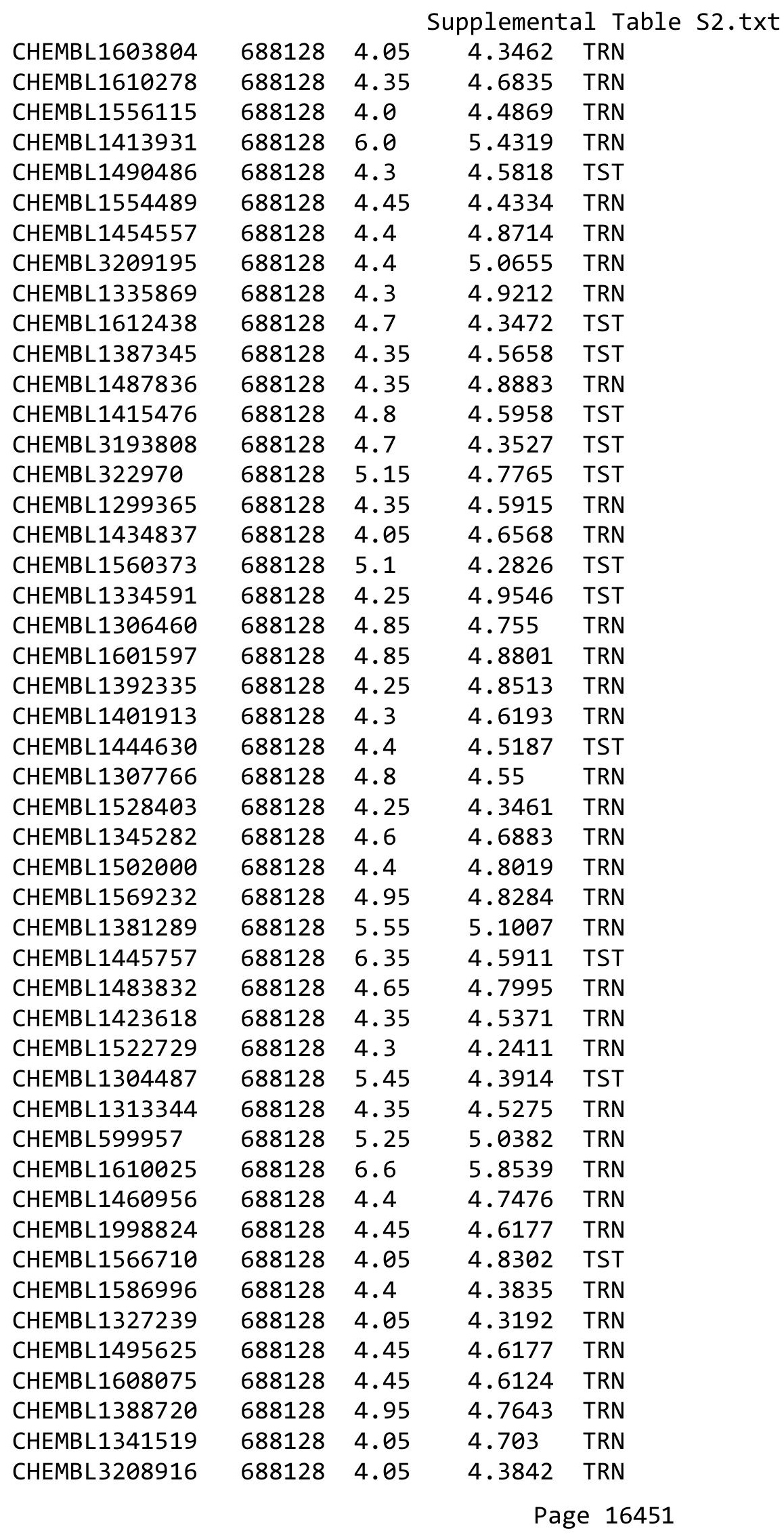




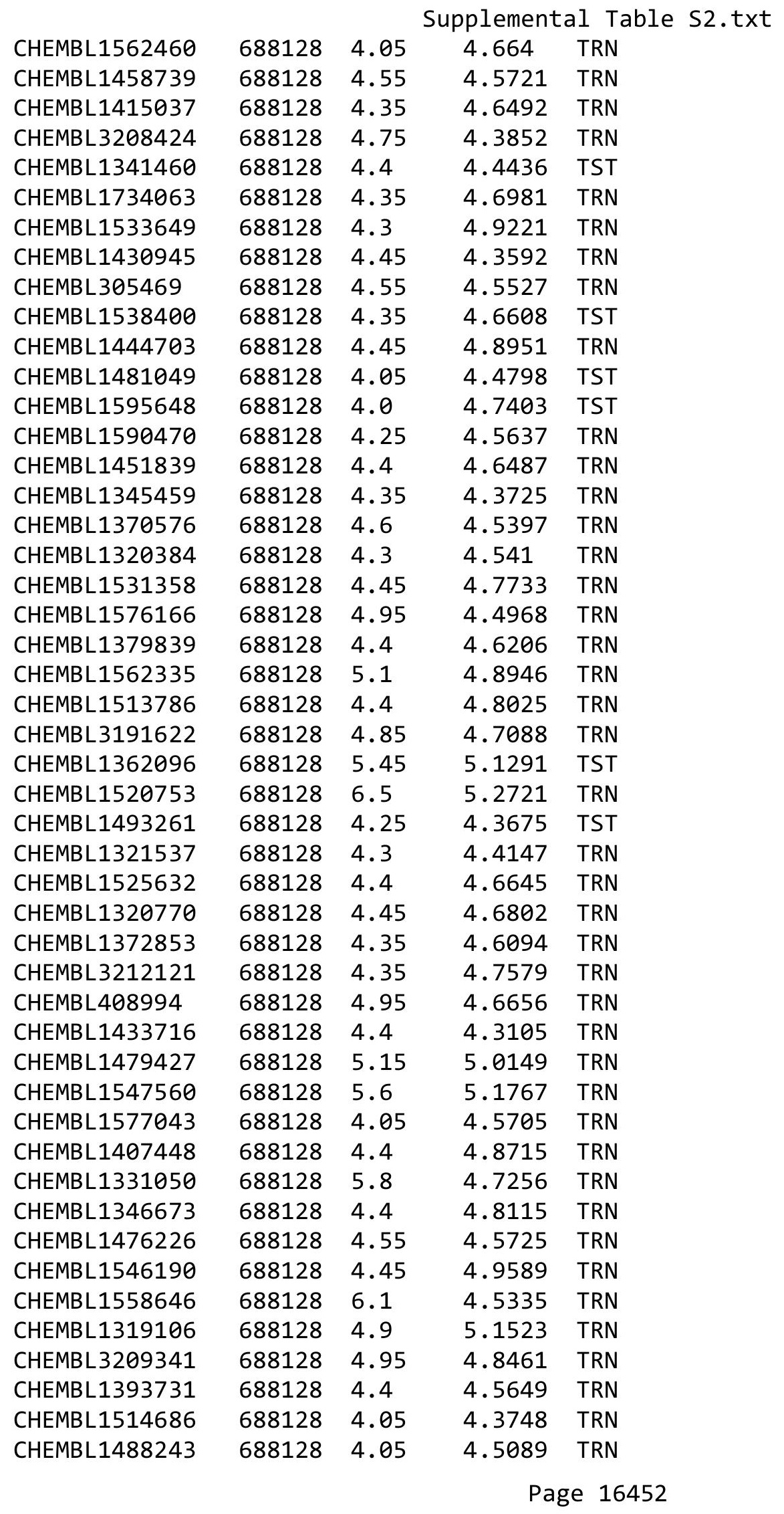




\begin{tabular}{|c|c|c|c|c|}
\hline \multicolumn{5}{|c|}{ Supplemental Table S2.txt } \\
\hline CHEMBL1437264 & 688128 & 4.4 & 4.5282 & TRN \\
\hline CHEMBL1320546 & 688128 & 4.3 & 4.6625 & TRN \\
\hline CHEMBL11475 & 688128 & 6.2 & 5.0774 & TST \\
\hline CHEMBL1481704 & 688128 & 4.4 & 4.2439 & TRN \\
\hline CHEMBL1447098 & 688128 & 4.4 & 4.6809 & TRN \\
\hline CHEMBL1612764 & 688128 & 5.55 & 4.6139 & TRN \\
\hline CHEMBL1347955 & 688128 & 4.45 & 4.5421 & TRN \\
\hline CHEMBL1367314 & 688128 & 6.25 & 4.8564 & TRN \\
\hline CHEMBL1339878 & 688128 & 4.5 & 4.3876 & TRN \\
\hline CHEMBL1320365 & 688128 & 4.35 & 4.6781 & TRN \\
\hline CHEMBL1588244 & 688128 & 5.6 & 4.5713 & TRN \\
\hline CHEMBL1409509 & 688128 & 4.0 & 4.5638 & TRN \\
\hline CHEMBL1313200 & 688128 & 4.3 & 4.452 & TRN \\
\hline CHEMBL1337942 & 688128 & 4.05 & 4.3651 & TRN \\
\hline CHEMBL1467004 & 688128 & 4.6 & 4.5512 & TRN \\
\hline CHEMBL1558099 & 688128 & 6.1 & 4.5673 & TRN \\
\hline CHEMBL1340829 & 688128 & 4.4 & 4.8108 & TRN \\
\hline CHEMBL1526664 & 688128 & 4.6 & 4.6297 & TRN \\
\hline CHEMBL1610999 & 688128 & 4.1 & 4.7558 & TST \\
\hline CHEMBL1566632 & 688128 & 4.0 & 4.5401 & TRN \\
\hline CHEMBL1509106 & 688128 & 4.35 & 4.5029 & TRN \\
\hline CHEMBL1379656 & 688128 & 4.3 & 4.8454 & TRN \\
\hline CHEMBL1492556 & 688128 & 4.5 & 4.8575 & TRN \\
\hline CHEMBL1492639 & 688128 & 4.7 & 4.8243 & TRN \\
\hline CHEMBL1507881 & 688128 & 4.85 & 5.1361 & TRN \\
\hline CHEMBL1423232 & 688128 & 5.05 & 4.6167 & TRN \\
\hline CHEMBL1563700 & 688128 & 4.35 & 4.4118 & TRN \\
\hline CHEMBL1495027 & 688128 & 4.35 & 4.7831 & TRN \\
\hline CHEMBL1526900 & 688128 & 4.05 & 4.5864 & TST \\
\hline CHEMBL1554253 & 688128 & 5.3 & 5.043 & TRN \\
\hline CHEMBL1339591 & 688128 & 4.65 & 4.7676 & TST \\
\hline CHEMBL1465227 & 688128 & 4.9 & 4.8762 & TRN \\
\hline CHEMBL465952 & 688128 & 6.7001 & 4.6283 & TRN \\
\hline CHEMBL1553539 & 688128 & 4.25 & 4.7917 & TST \\
\hline CHEMBL3196501 & 688128 & 6.5 & 4.703 & TRN \\
\hline CHEMBL1451849 & 688128 & 4.05 & 4.2793 & TRN \\
\hline CHEMBL1601843 & 688128 & 4.65 & 4.5529 & TRN \\
\hline CHEMBL1401360 & 688128 & 4.3 & 4.3941 & TRN \\
\hline CHEMBL1592311 & 688128 & 5.45 & 4.555 & TRN \\
\hline CHEMBL1408985 & 688128 & 4.25 & 4.4134 & TRN \\
\hline CHEMBL1372589 & 688128 & 5.25 & 4.5307 & TST \\
\hline CHEMBL1583681 & 688128 & 4.35 & 4.5164 & TRN \\
\hline CHEMBL3209080 & 688128 & 4.1 & 4.5014 & TST \\
\hline CHEMBL1475091 & 688128 & 4.45 & 4.7595 & TRN \\
\hline CHEMBL1462493 & 688128 & 4.7 & 4.4282 & TST \\
\hline CHEMBL1503697 & 688128 & 4.35 & 4.4628 & TRN \\
\hline CHEMBL1382888 & 688128 & 6.4 & 4.8501 & TRN \\
\hline CHEMBL1583512 & 688128 & 4.4 & 4.7895 & TRN \\
\hline
\end{tabular}




\begin{tabular}{|c|c|c|c|c|c|}
\hline \multicolumn{6}{|c|}{ Supplemental Table S2.txt } \\
\hline CHEMBL1345266 & 688128 & 4.4 & 4.6584 & TRN & \\
\hline CHEMBL1317443 & 688128 & 4.5 & 4.449 & TRN & \\
\hline CHEMBL1379077 & 688128 & 4.65 & 4.6039 & TRN & \\
\hline CHEMBL1389380 & 688128 & 4.3 & 4.62 & TRN & \\
\hline CHEMBL1469422 & 688128 & 4.25 & 4.5999 & TRN & \\
\hline CHEMBL1406107 & 688128 & 5.05 & 5.04899 & 99999999995 & TRN \\
\hline CHEMBL1324370 & 688128 & 4.9 & 4.6944 & TRN & \\
\hline CHEMBL1490735 & 688128 & 4.25 & 4.5013 & TST & \\
\hline CHEMBL1330802 & 688128 & 4.35 & 4.4838 & TST & \\
\hline CHEMBL1486840 & 688128 & 4.9 & 4.6166 & TRN & \\
\hline CHEMBL1359797 & 688128 & 4.9 & 4.6613 & TRN & \\
\hline CHEMBL1558313 & 688128 & 4.3 & 4.231 & TRN & \\
\hline CHEMBL1468761 & 688128 & 6.45 & 4.6613 & TRN & \\
\hline CHEMBL1311310 & 688128 & 4.7 & 4.7996 & TST & \\
\hline CHEMBL1428036 & 688128 & 4.45 & 4.4254 & TRN & \\
\hline CHEMBL1556677 & 688128 & 4.3 & 4.6809 & TRN & \\
\hline CHEMBL1318488 & 688128 & 4.35 & 4.4879 & TRN & \\
\hline CHEMBL1308112 & 688128 & 4.75 & 4.5778 & TRN & \\
\hline CHEMBL1332450 & 688128 & 4.4 & 5.0215 & TRN & \\
\hline CHEMBL1561567 & 688128 & 4.05 & 4.5272 & TRN & \\
\hline CHEMBL1576069 & 688128 & 5.2 & 4.961 & TRN & \\
\hline CHEMBL1382405 & 688128 & 4.65 & 5.0322 & TRN & \\
\hline CHEMBL1416817 & 688128 & 4.4 & 4.5481 & TRN & \\
\hline CHEMBL3198359 & 688128 & 4.8 & 4.4007 & TRN & \\
\hline CHEMBL1458665 & 688128 & 4.0 & 4.6818 & TST & \\
\hline CHEMBL1316764 & 688128 & 4.15 & 4.479 & TRN & \\
\hline CHEMBL1347047 & 688128 & 5.6 & 5.1688 & TRN & \\
\hline CHEMBL1309068 & 688128 & 4.45 & 4.8574 & TST & \\
\hline CHEMBL1537973 & 688128 & 4.3 & 4.6559 & TRN & \\
\hline CHEMBL1477147 & 688128 & 4.8 & 4.9107 & TRN & \\
\hline CHEMBL1494048 & 688128 & 4.4 & 4.5946 & TRN & \\
\hline CHEMBL1379259 & 688128 & 4.35 & 4.58 & TRN & \\
\hline CHEMBL1518898 & 688128 & 4.2 & 4.6288 & TRN & \\
\hline CHEMBL1443063 & 688128 & 4.3 & 4.7519 & TST & \\
\hline CHEMBL1470333 & 688128 & 4.8 & 4.6145 & TRN & \\
\hline CHEMBL1403129 & 688128 & 4.55 & 4.3562 & TRN & \\
\hline CHEMBL1521094 & 688128 & 4.0 & 4.5759 & TST & \\
\hline CHEMBL1584077 & 688128 & 4.45 & 4.6751 & TRN & \\
\hline CHEMBL1350894 & 688128 & 4.45 & 4.6582 & TRN & \\
\hline CHEMBL1307934 & 688128 & 4.7 & 4.529 & TRN & \\
\hline CHEMBL1339836 & 688128 & 4.4 & 4.6864 & TRN & \\
\hline CHEMBL3190247 & 688128 & 4.05 & 4.4917 & TRN & \\
\hline CHEMBL1500407 & 688128 & 4.3 & 4.4087 & TRN & \\
\hline CHEMBL1579034 & 688128 & 4.3 & 4.4943 & TRN & \\
\hline CHEMBL1601846 & 688128 & 4.9 & 4.9771 & TST & \\
\hline CHEMBL1299335 & 688128 & 5.2 & 5.1442 & TRN & \\
\hline CHEMBL1369525 & 688128 & 4.4 & 4.4685 & TRN & \\
\hline CHEMBL1440270 & 688128 & 4.35 & 4.5708 & TRN & \\
\hline
\end{tabular}




\begin{tabular}{|c|c|c|c|c|}
\hline \multicolumn{5}{|c|}{ Supplemental Table S2.txt } \\
\hline CHEMBL1508011 & 688128 & 4.5 & 4.7794 & TST \\
\hline CHEMBL1369463 & 688128 & 4.5 & 4.4795 & TRN \\
\hline CHEMBL1348278 & 688128 & 4.4 & 4.7995 & TST \\
\hline CHEMBL1399938 & 688128 & 4.85 & 5.2207 & TRN \\
\hline CHEMBL1566906 & 688128 & 4.35 & 4.6883 & TRN \\
\hline CHEMBL1367146 & 688128 & 4.05 & 4.5711 & TST \\
\hline CHEMBL1576079 & 688128 & 4.1 & 4.2775 & TRN \\
\hline CHEMBL1588058 & 688128 & 4.75 & 4.4973 & TRN \\
\hline CHEMBL1534260 & 688128 & 4.55 & 4.8453 & TST \\
\hline CHEMBL1459610 & 688128 & 4.05 & 4.4856 & TRN \\
\hline CHEMBL1980184 & 688128 & 4.55 & 4.8751 & TRN \\
\hline CHEMBL1377112 & 688128 & 4.4 & 4.6957 & TST \\
\hline CHEMBL1532519 & 688128 & 6.0 & 4.5956 & TRN \\
\hline CHEMBL1574618 & 688128 & 4.7 & 4.9191 & TST \\
\hline CHEMBL1608204 & 688128 & 4.35 & 4.8086 & TRN \\
\hline CHEMBL1590551 & 688128 & 4.05 & 4.8454 & TST \\
\hline CHEMBL1426339 & 688128 & 4.35 & 4.9699 & TRN \\
\hline CHEMBL1404932 & 688128 & 5.8 & 4.7811 & TRN \\
\hline CHEMBL1602613 & 688128 & 4.3 & 4.4827 & TRN \\
\hline CHEMBL1480043 & 688128 & 4.4 & 4.7101 & TRN \\
\hline CHEMBL1429775 & 688128 & 6.5501 & 5.01 & TRN \\
\hline CHEMBL1585965 & 688128 & 4.3 & 4.7178 & TRN \\
\hline CHEMBL1432953 & 688128 & 4.0 & 4.5798 & TRN \\
\hline CHEMBL1407220 & 688128 & 4.8 & 4.6663 & TST \\
\hline CHEMBL1313934 & 688128 & 4.35 & 4.3688 & TRN \\
\hline CHEMBL1465982 & 688128 & 5.2 & 4.8449 & TST \\
\hline CHEMBL1347624 & 688128 & 4.0 & 4.58899 & 99999999995 \\
\hline CHEMBL1351412 & 688128 & 4.4 & 4.9532 & TST \\
\hline CHEMBL1527642 & 688128 & 6.0 & 5.3511 & TRN \\
\hline CHEMBL1522686 & 688128 & 4.5 & 4.6501 & TRN \\
\hline CHEMBL1579212 & 688128 & 4.4 & 4.6778 & TRN \\
\hline CHEMBL1579620 & 688128 & 4.4 & 4.2672 & TRN \\
\hline CHEMBL1327965 & 688128 & 4.9 & 4.8612 & TRN \\
\hline CHEMBL1434611 & 688128 & 4.95 & 4.5931 & TST \\
\hline CHEMBL1331816 & 688128 & 4.55 & 4.737 & TRN \\
\hline CHEMBL1381913 & 688128 & 4.6 & 4.2921 & TRN \\
\hline CHEMBL1305454 & 688128 & 4.35 & 4.4692 & TRN \\
\hline CHEMBL 3189203 & 688128 & 4.25 & 4.2957 & TRN \\
\hline CHEMBL52347 & 688128 & 4.95 & 5.1339 & TST \\
\hline CHEMBL1396652 & 688128 & 4.3 & 4.6364 & TRN \\
\hline CHEMBL1347593 & 688128 & 4.45 & 4.5579 & TRN \\
\hline CHEMBL1605719 & 688128 & 4.4 & 4.4844 & TRN \\
\hline CHEMBL1486758 & 688128 & 6.1 & 4.633 & TST \\
\hline CHEMBL1439983 & 688128 & 4.4 & 4.7251 & TRN \\
\hline CHEMBL1448500 & 688128 & 4.35 & 4.5412 & TRN \\
\hline CHEMBL1323114 & 688128 & 4.4 & 4.676 & TRN \\
\hline CHEMBL1445776 & 688128 & 4.05 & 4.7792 & TRN \\
\hline CHEMBL1484665 & 688128 & 4.9 & 4.7022 & TRN \\
\hline
\end{tabular}




\begin{tabular}{|c|c|c|c|c|c|}
\hline \\
\hline CHEMBL1607367 & 688128 & 4.4 & 4.4968 & TST & \\
\hline CHEMBL3195205 & 688128 & 4.6 & 4.4307 & TST & \\
\hline CHEMBL1486822 & 688128 & 4.1 & 4.5785 & TRN & \\
\hline CHEMBL3192691 & 688128 & 4.5 & 4.5426 & TRN & \\
\hline CHEMBL1307678 & 688128 & 4.95 & 4.5553 & TST & \\
\hline CHEMBL1448533 & 688128 & 4.8 & 4.8891 & TRN & \\
\hline CHEMBL1544840 & 688128 & 4.5 & $4.5710 €$ & 0000000001 & TST \\
\hline CHEMBL1443643 & 688128 & 5.9 & $4.5760 e$ & 00000000005 & TRN \\
\hline CHEMBL1562319 & 688128 & 4.05 & 4.6554 & TRN & \\
\hline CHEMBL1327693 & 688128 & 4.6 & 4.5269 & TRN & \\
\hline CHEMBL1339882 & 688128 & 4.3 & 4.4152 & TRN & \\
\hline CHEMBL1084643 & 688128 & 4.4 & 4.7748 & TRN & \\
\hline CHEMBL1475231 & 688128 & 4.4 & 4.6193 & TRN & \\
\hline CHEMBL1339058 & 688128 & 5.3 & 4.6674 & TRN & \\
\hline CHEMBL1393881 & 688128 & 4.5 & 4.7832 & TST & \\
\hline CHEMBL1515630 & 688128 & 4.8 & 4.9203 & TST & \\
\hline CHEMBL1351799 & 688128 & 5.1 & 4.8129 & TRN & \\
\hline CHEMBL1492950 & 688128 & 4.45 & 4.4891 & TRN & \\
\hline CHEMBL1566454 & 688128 & 4.25 & 4.7715 & TRN & \\
\hline CHEMBL1510002 & 688128 & 4.45 & 4.5328 & TRN & \\
\hline CHEMBL1337508 & 688128 & 4.35 & 4.7374 & TST & \\
\hline CHEMBL1530416 & 688128 & 4.0 & 4.2849 & TRN & \\
\hline CHEMBL1311137 & 688128 & 4.95 & 4.8082 & TRN & \\
\hline CHEMBL1597359 & 688128 & 4.45 & 4.5218 & TST & \\
\hline CHEMBL1984648 & 688128 & 4.85 & 4.9761 & TRN & \\
\hline CHEMBL1351349 & 688128 & 4.3 & 4.7073 & TRN & \\
\hline CHEMBL1407596 & 688128 & 4.05 & 4.5785 & TRN & \\
\hline CHEMBL1372848 & 688128 & 5.5 & 5.0075 & TRN & \\
\hline CHEMBL1439825 & 688128 & 5.05 & 4.4877 & TRN & \\
\hline CHEMBL1467641 & 688128 & 4.35 & 4.5274 & TRN & \\
\hline CHEMBL1602766 & 688128 & 4.35 & 4.5037 & TRN & \\
\hline CHEMBL1363762 & 688128 & 5.5 & 4.5134 & TRN & \\
\hline CHEMBL1561382 & 688128 & 4.45 & 4.497 & TRN & \\
\hline CHEMBL1533381 & 688128 & 4.4 & 4.39 & TRN & \\
\hline CHEMBL1366971 & 688128 & 5.7 & 4.8146 & TRN & \\
\hline CHEMBL3198213 & 688128 & 4.3 & 4.9245 & TST & \\
\hline CHEMBL1426027 & 688128 & 4.35 & 4.843 & TRN & \\
\hline CHEMBL3209187 & 688128 & 4.3 & 4.7467 & TRN & \\
\hline CHEMBL1416243 & 688128 & 4.9 & 4.6968 & TRN & \\
\hline CHEMBL1376865 & 688128 & 4.3 & 4.618 & TRN & \\
\hline CHEMBL1484575 & 688128 & 4.6 & 4.5607 & TRN & \\
\hline CHEMBL1580932 & 688128 & 4.6 & 4.7114 & TRN & \\
\hline CHEMBL1470921 & 688128 & 4.45 & 4.6896 & TST & \\
\hline CHEMBL1375339 & 688128 & 4.4 & 4.7667 & TRN & \\
\hline CHEMBL1562870 & 688128 & 4.45 & 4.4624 & TRN & \\
\hline CHEMBL1406172 & 688128 & 4.05 & 4.6771 & TRN & \\
\hline CHEMBL1559132 & 688128 & 4.0 & 4.7109 & TRN & \\
\hline CHEMBL1563728 & 688128 & 4.4 & 4.3642 & TRN & \\
\hline
\end{tabular}




\begin{tabular}{|c|c|c|c|c|c|}
\hline \multicolumn{6}{|c|}{ Supplemental Table S2.txt } \\
\hline CHEMBL1582538 & 688128 & 5.5 & 4.891 & TRN & \\
\hline CHEMBL1393806 & 688128 & 5.4 & 4.4301 & TST & \\
\hline CHEMBL1562427 & 688128 & 4.4 & 4.402 & TRN & \\
\hline CHEMBL1406170 & 688128 & 4.65 & 4.5953 & TST & \\
\hline CHEMBL1511405 & 688128 & 4.3 & 4.7758 & TRN & \\
\hline CHEMBL1528832 & 688128 & 4.05 & 4.5915 & TRN & \\
\hline CHEMBL1339243 & 688128 & 4.8 & 4.5408 & TST & \\
\hline CHEMBL1396075 & 688128 & 5.45 & 4.9025 & TST & \\
\hline CHEMBL1471150 & 688128 & 4.3 & 4.5079 & TRN & \\
\hline CHEMBL1511596 & 688128 & 4.85 & 4.9199 & TRN & \\
\hline CHEMBL1393218 & 688128 & 4.35 & 4.6507 & TRN & \\
\hline CHEMBL1452498 & 688128 & 4.45 & 4.7994 & TRN & \\
\hline CHEMBL1574508 & 688128 & 4.85 & 4.6022 & TST & \\
\hline CHEMBL1355097 & 688128 & 4.05 & 4.7063 & TRN & \\
\hline CHEMBL1459659 & 688128 & 6.15 & 4.7034 & TRN & \\
\hline CHEMBL1571175 & 688128 & 4.05 & 4.4987 & TST & \\
\hline CHEMBL3191098 & 688128 & 4.6 & 4.8567 & TRN & \\
\hline CHEMBL1551756 & 688128 & 4.6 & 4.707 & TRN & \\
\hline CHEMBL1575158 & 688128 & 4.55 & 4.4852 & TRN & \\
\hline CHEMBL1411280 & 688128 & 4.95 & 4.8262 & TRN & \\
\hline CHEMBL1590761 & 688128 & 4.45 & 4.4436 & TRN & \\
\hline CHEMBL3199720 & 688128 & 4.05 & 4.5941 & TRN & \\
\hline CHEMBL1583232 & 688128 & 4.25 & $4.4910 e$ & 00000000005 & TRN \\
\hline CHEMBL1548781 & 688128 & 5.8 & 4.522 & TST & \\
\hline CHEMBL1336737 & 688128 & 4.4 & 4.3862 & TRN & \\
\hline CHEMBL1544793 & 688128 & 5.5 & 5.2534 & TRN & \\
\hline CHEMBL1300557 & 688128 & 5.55 & 4.6677 & TRN & \\
\hline CHEMBL1595177 & 688128 & 4.3 & 4.6084 & TRN & \\
\hline CHEMBL1462257 & 688128 & 4.55 & 4.9737 & TRN & \\
\hline CHEMBL1343752 & 688128 & 4.3 & 5.1163 & TRN & \\
\hline CHEMBL2374061 & 688128 & 4.85 & 4.7534 & TRN & \\
\hline CHEMBL1563552 & 688128 & 4.6 & 4.8625 & TRN & \\
\hline CHEMBL3196771 & 688128 & 4.7 & 4.7309 & TRN & \\
\hline CHEMBL1410261 & 688128 & 5.4 & 4.5962 & TST & \\
\hline CHEMBL1414234 & 688128 & 4.45 & 4.7203 & TRN & \\
\hline CHEMBL1299959 & 688128 & 4.4 & 4.6547 & TRN & \\
\hline CHEMBL1408777 & 688128 & 4.3 & 4.601 & TRN & \\
\hline CHEMBL1551812 & 688128 & 4.3 & 4.5293 & TRN & \\
\hline CHEMBL1344447 & 688128 & 4.35 & 4.3988 & TRN & \\
\hline CHEMBL1500072 & 688128 & 4.3 & 4.6645 & TRN & \\
\hline CHEMBL1487599 & 688128 & 4.05 & 4.624 & TRN & \\
\hline CHEMBL1515238 & 688128 & 4.05 & 4.4936 & TRN & \\
\hline CHEMBL1428267 & 688128 & 4.35 & 4.4892 & TRN & \\
\hline CHEMBL1453351 & 688128 & 4.2 & 4.6632 & TRN & \\
\hline CHEMBL1558353 & 688128 & 4.05 & 4.6674 & TRN & \\
\hline CHEMBL1606051 & 688128 & 4.25 & 4.4243 & TRN & \\
\hline CHEMBL1520019 & 688128 & 4.3 & 4.8694 & TST & \\
\hline CHEMBL1305934 & 688128 & 4.65 & 4.3245 & TRN & \\
\hline
\end{tabular}




\begin{tabular}{|c|c|c|c|c|}
\hline \multicolumn{5}{|c|}{ Supplemental Table S2.txt } \\
\hline CHEMBL1311377 & 688128 & 4.25 & 4.7695 & TRN \\
\hline CHEMBL1498566 & 688128 & 5.25 & 4.8343 & TRN \\
\hline CHEMBL1358573 & 688128 & 4.05 & 4.4044 & TST \\
\hline CHEMBL1587931 & 688128 & 4.3 & 4.7288 & TRN \\
\hline CHEMBL1348408 & 688128 & 5.45 & 4.8167 & TRN \\
\hline CHEMBL1605083 & 688128 & 4.35 & 4.7293 & TRN \\
\hline CHEMBL1418562 & 688128 & 4.6 & 4.2749 & TRN \\
\hline CHEMBL1343464 & 688128 & 4.35 & 4.1754 & TRN \\
\hline CHEMBL3199793 & 688128 & 4.35 & 4.7028 & TRN \\
\hline CHEMBL1580288 & 688128 & 4.3 & 4.8801 & TRN \\
\hline CHEMBL1315244 & 688128 & 4.45 & 4.9904 & TRN \\
\hline CHEMBL1336076 & 688128 & 4.4 & 4.3668 & TRN \\
\hline CHEMBL1547085 & 688128 & 4.45 & 4.5828 & TRN \\
\hline CHEMBL1506185 & 688128 & 4.9 & 4.9806 & TST \\
\hline CHEMBL1376564 & 688128 & 4.05 & 4.6356 & TST \\
\hline CHEMBL1349736 & 688128 & 4.4 & 4.7822 & TRN \\
\hline CHEMBL1535501 & 688128 & 4.45 & 4.3942 & TRN \\
\hline CHEMBL1518408 & 688128 & 4.05 & 4.5204 & TST \\
\hline CHEMBL1431784 & 688128 & 4.35 & 4.6176 & TRN \\
\hline CHEMBL1554948 & 688128 & 4.35 & 5.2134 & TRN \\
\hline CHEMBL1468974 & 688128 & 5.15 & 4.6163 & TRN \\
\hline CHEMBL1494352 & 688128 & 4.35 & 4.5773 & TST \\
\hline CHEMBL1428454 & 688128 & 4.55 & 4.6808 & TRN \\
\hline CHEMBL1310860 & 688128 & 4.85 & 4.8614 & TRN \\
\hline CHEMBL1488616 & 688128 & 4.05 & 4.7304 & TRN \\
\hline CHEMBL1426615 & 688128 & 5.0 & 4.427 & TRN \\
\hline CHEMBL1987928 & 688128 & 5.75 & 5.2531 & TRN \\
\hline CHEMBL1531013 & 688128 & 4.5 & 4.5665 & TST \\
\hline CHEMBL1606794 & 688128 & 4.05 & 4.4538 & TRN \\
\hline CHEMBL1447251 & 688128 & 5.0 & 4.4661 & TST \\
\hline CHEMBL1523971 & 688128 & 4.1 & 4.3823 & TST \\
\hline CHEMBL1544838 & 688128 & 6.5 & 4.4377 & TST \\
\hline CHEMBL1505451 & 688128 & 4.4 & 4.5724 & TRN \\
\hline CHEMBL1531521 & 688128 & 4.4 & 4.6533 & TRN \\
\hline CHEMBL1563308 & 688128 & 4.45 & 4.5928 & TRN \\
\hline CHEMBL1373183 & 688128 & 4.25 & 4.6417 & TRN \\
\hline CHEMBL 1412270 & 688128 & 4.7 & 4.688 & TRN \\
\hline CHEMBL1534203 & 688128 & 4.25 & 4.4042 & TRN \\
\hline CHEMBL1308336 & 688128 & 4.35 & 4.6881 & TRN \\
\hline CHEMBL1599411 & 688128 & 4.55 & 4.377 & TRN \\
\hline CHEMBL1468285 & 688128 & 4.25 & 4.5089 & TRN \\
\hline CHEMBL1453089 & 688128 & 5.0 & 5.0654 & TST \\
\hline CHEMBL1608636 & 688128 & 4.4 & 4.5788 & TST \\
\hline CHEMBL1331130 & 688128 & 4.35 & 4.3704 & TRN \\
\hline CHEMBL1508485 & 688128 & 4.3 & 4.1858 & TRN \\
\hline CHEMBL550890 & 688128 & 5.5 & 4.5425 & TRN \\
\hline CHEMBL1370261 & 688128 & 4.35 & 4.5895 & TST \\
\hline CHEMBL1466801 & 688128 & 4.35 & 4.7534 & TST \\
\hline
\end{tabular}




\begin{tabular}{|c|c|c|c|c|c|}
\hline & & & & & \\
\hline CHEMBL1444161 & 688128 & 4.9 & 4.501 & TST & \\
\hline CHEMBL1546656 & 688128 & 4.9 & 4.8018 & TRN & \\
\hline CHEMBL1424149 & 688128 & 4.4 & 4.7072 & TRN & \\
\hline CHEMBL1502137 & 688128 & 4.3 & 4.8895 & TRN & \\
\hline CHEMBL1332391 & 688128 & 4.05 & 4.6121 & TST & \\
\hline CHEMBL1352926 & 688128 & 4.3 & 4.3702 & TRN & \\
\hline CHEMBL1436328 & 688128 & 4.45 & 4.9157 & TRN & \\
\hline CHEMBL1344236 & 688128 & 4.05 & 4.8545 & TST & \\
\hline CHEMBL599255 & 688128 & 6.5 & 5.3991 & TRN & \\
\hline CHEMBL1587145 & 688128 & 4.55 & 4.7115 & TRN & \\
\hline CHEMBL1402785 & 688128 & 4.25 & 4.4651 & TRN & \\
\hline CHEMBL1442981 & 688128 & 4.05 & 4.8715 & TRN & \\
\hline CHEMBL1352633 & 688128 & 5.0 & 4.7281 & TRN & \\
\hline CHEMBL1326643 & 688128 & 4.9 & 4.8952 & TRN & \\
\hline CHEMBL1548074 & 688128 & 6.15 & 5.3185 & TRN & \\
\hline CHEMBL1473290 & 688128 & 4.4 & 4.4698 & TRN & \\
\hline CHEMBL3190629 & 688128 & 4.35 & 4.659 & TRN & \\
\hline CHEMBL1521400 & 688128 & 4.75 & 4.588 & TRN & \\
\hline CHEMBL1501664 & 688128 & 5.2 & 4.6202 & TST & \\
\hline CHEMBL3209592 & 688128 & 4.1 & 4.6591 & TRN & \\
\hline CHEMBL1359138 & 688128 & 4.05 & 4.8610 & 0000000001 & TST \\
\hline CHEMBL1533084 & 688128 & 4.0 & 4.3358 & TST & \\
\hline CHEMBL1453889 & 688128 & 4.65 & 4.5161 & TRN & \\
\hline CHEMBL1468095 & 688128 & 5.45 & 4.7078 & TRN & \\
\hline CHEMBL3210957 & 688128 & 4.4 & 4.6610 & 20000000005 & TST \\
\hline CHEMBL1515222 & 688128 & 4.8 & 4.6271 & TST & \\
\hline CHEMBL1346733 & 688128 & 5.9 & 4.8658 & TST & \\
\hline CHEMBL1313162 & 688128 & 4.1 & 4.7159 & TRN & \\
\hline CHEMBL1461776 & 688128 & 4.45 & 4.6855 & TRN & \\
\hline CHEMBL1426754 & 688128 & 4.35 & 4.9115 & TRN & \\
\hline CHEMBL1510227 & 688128 & 4.05 & 4.6437 & TRN & \\
\hline CHEMBL1397638 & 688128 & 4.65 & 4.9085 & TRN & \\
\hline CHEMBL1467749 & 688128 & 5.35 & 4.6648 & TRN & \\
\hline CHEMBL1321424 & 688128 & 4.35 & 4.3131 & TRN & \\
\hline CHEMBL1375883 & 688128 & 4.05 & 4.7551 & TST & \\
\hline CHEMBL1418174 & 688128 & 4.65 & 4.6114 & TRN & \\
\hline CHEMBL1559168 & 688128 & 4.05 & 4.351 & TRN & \\
\hline CHEMBL1597823 & 688128 & 4.35 & 4.4952 & TST & \\
\hline CHEMBL1373226 & 688128 & 4.35 & 4.5539 & 9999999999 & TRN \\
\hline CHEMBL1373896 & 688128 & 5.65 & 5.0213 & TST & \\
\hline CHEMBL1458073 & 688128 & 4.0 & 4.4311 & TST & \\
\hline CHEMBL1593604 & 688128 & 5.0 & 4.8004 & TRN & \\
\hline CHEMBL1404794 & 688128 & 4.6 & 4.5834 & TRN & \\
\hline CHEMBL3196993 & 688128 & 4.4 & 4.6114 & TST & \\
\hline CHEMBL1387580 & 688128 & 5.3 & 4.6789 & TRN & \\
\hline CHEMBL1467378 & 688128 & 4.65 & 4.4176 & TRN & \\
\hline CHEMBL1309134 & 688128 & 6.8499 & 4.8127 & TST & \\
\hline CHEMBL1485442 & 688128 & 4.45 & 5.001 & TST & \\
\hline
\end{tabular}




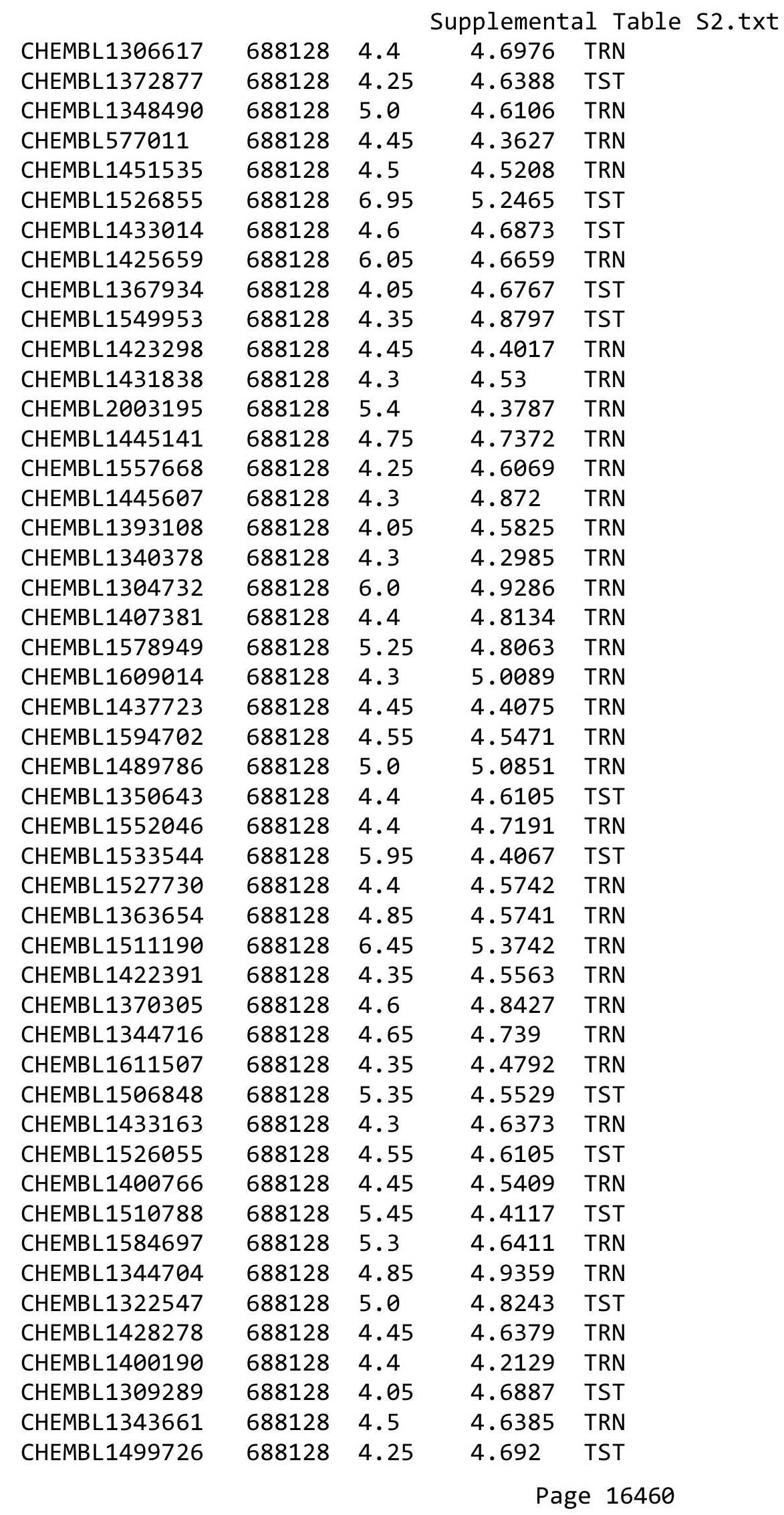




\begin{tabular}{|c|c|c|c|c|}
\hline & & & upplement & al Table S \\
\hline CHEMBL1398422 & 688128 & 4.0 & 4.2869 & TRN \\
\hline CHEMBL1401888 & 688128 & 4.3 & 4.3848 & TRN \\
\hline CHEMBL1410376 & 688128 & 5.3 & 4.6442 & TST \\
\hline CHEMBL1381634 & 688128 & 4.35 & 4.3292 & TST \\
\hline CHEMBL1541214 & 688128 & 4.4 & 4.7805 & TST \\
\hline CHEMBL1406091 & 688128 & 4.7 & 4.5885 & TRN \\
\hline CHEMBL1480510 & 688128 & 4.4 & 4.7547 & TST \\
\hline CHEMBL1495926 & 688128 & 5.4 & 4.4737 & TRN \\
\hline CHEMBL1426189 & 688128 & 5.1 & 4.6245 & TST \\
\hline CHEMBL1435367 & 688128 & 4.35 & 4.7263 & TST \\
\hline CHEMBL1424857 & 688128 & 4.4 & 4.6513 & TST \\
\hline CHEMBL3212706 & 688128 & 4.4 & 4.6731 & TRN \\
\hline CHEMBL1455370 & 688128 & 4.35 & 4.5558 & TRN \\
\hline CHEMBL1597109 & 688128 & 4.35 & 4.9454 & TRN \\
\hline CHEMBL1333013 & 688128 & 4.5 & 4.6385 & TRN \\
\hline CHEMBL1379538 & 688128 & 4.4 & 4.238 & TRN \\
\hline CHEMBL1409933 & 688128 & 3.95 & 4.4354 & TRN \\
\hline CHEMBL1515381 & 688128 & 6.5 & 5.2727 & TRN \\
\hline CHEMBL1524354 & 688128 & 4.3 & 4.6326 & TRN \\
\hline CHEMBL1372119 & 688128 & 4.75 & 4.6634 & TRN \\
\hline CHEMBL3392026 & 688128 & 4.85 & 4.8347 & TRN \\
\hline CHEMBL1546073 & 688128 & 4.4 & 4.4048 & TRN \\
\hline CHEMBL1451872 & 688128 & 4.85 & 4.4009 & TRN \\
\hline CHEMBL1453508 & 688128 & 4.4 & 4.8854 & TRN \\
\hline CHEMBL1333929 & 688128 & 6.0 & 5.2958 & TRN \\
\hline CHEMBL1376615 & 688128 & 4.3 & 3.9431 & TRN \\
\hline CHEMBL1361072 & 688128 & 4.45 & 4.6481 & TRN \\
\hline CHEMBL1322992 & 688128 & 4.5 & 4.8486 & TRN \\
\hline CHEMBL3214110 & 688128 & 5.5 & 4.6431 & TST \\
\hline CHEMBL1470467 & 688128 & 5.0 & 4.6211 & TST \\
\hline CHEMBL1578506 & 688128 & 4.8 & 4.6417 & TRN \\
\hline CHEMBL1981243 & 688128 & 4.8 & 4.9383 & TRN \\
\hline CHEMBL3209312 & 688128 & 4.4 & 4.4013 & TRN \\
\hline CHEMBL1585742 & 688128 & 5.5 & 5.1791 & TRN \\
\hline CHEMBL1472312 & 688128 & 4.0 & 4.4375 & TST \\
\hline CHEMBL1465496 & 688128 & 6.15 & 5.2501 & TRN \\
\hline CHEMBL1355626 & 688128 & 4.35 & 4.8384 & TRN \\
\hline CHEMBL1338897 & 688128 & 4.35 & 4.7452 & TRN \\
\hline CHEMBL1545681 & 688128 & 4.35 & 4.59399 & 9999999999 \\
\hline CHEMBL1553950 & 688128 & 4.35 & 4.4927 & TRN \\
\hline CHEMBL1429544 & 688128 & 4.05 & 4.4351 & TRN \\
\hline CHEMBL1506186 & 688128 & 4.4 & 4.3108 & TRN \\
\hline CHEMBL1383078 & 688128 & 4.55 & 4.7217 & TRN \\
\hline CHEMBL1358307 & 688128 & 5.35 & 4.675 & TST \\
\hline CHEMBL1531780 & 688128 & 4.3 & 4.7028 & TST \\
\hline CHEMBL1306908 & 688128 & 4.35 & 4.7718 & TRN \\
\hline CHEMBL401317 & 688128 & 4.3 & 4.5258 & TRN \\
\hline CHEMBL1374293 & 688128 & 5.15 & 4.6497 & TRN \\
\hline
\end{tabular}




\begin{tabular}{|c|c|c|c|c|}
\hline \multicolumn{5}{|c|}{ Supplemental Table s2.txt } \\
\hline CHEMBL1410473 & 688128 & 4.35 & 4.4562 & TRN \\
\hline CHEMBL269163 & 688128 & 4.35 & 4.8914 & TRN \\
\hline CHEMBL1597131 & 688128 & 4.4 & 4.4177 & TRN \\
\hline CHEMBL1573054 & 688128 & 4.35 & 4.7798 & TRN \\
\hline CHEMBL1507822 & 688128 & 4.35 & 4.8225 & TST \\
\hline CHEMBL1393169 & 688128 & 4.65 & 4.5035 & TRN \\
\hline CHEMBL1551544 & 688128 & 4.3 & 4.6486 & TST \\
\hline CHEMBL1508508 & 688128 & 4.4 & 4.7927 & TRN \\
\hline CHEMBL3193198 & 688128 & 4.4 & 4.7734 & TRN \\
\hline CHEMBL1362047 & 688128 & 4.55 & 4.8376 & TRN \\
\hline CHEMBL1543894 & 688128 & 4.45 & 4.5689 & TRN \\
\hline CHEMBL 7087 & 688128 & 4.05 & 4.5675 & TRN \\
\hline CHEMBL1546232 & 688128 & 4.6 & 4.9346 & TRN \\
\hline CHEMBL1385537 & 688128 & 4.5 & 4.5499 & TRN \\
\hline CHEMBL1307578 & 688128 & 4.35 & 4.6115 & TST \\
\hline CHEMBL1488131 & 688128 & 5.0 & 5.0135 & TST \\
\hline CHEMBL1389160 & 688128 & 4.4 & 4.5035 & TRN \\
\hline CHEMBL1459498 & 688128 & 4.7 & 4.6565 & TRN \\
\hline CHEMBL1587584 & 688128 & 4.7 & 4.7783 & TRN \\
\hline CHEMBL1385632 & 688128 & 4.45 & 4.8085 & TST \\
\hline CHEMBL1378096 & 688128 & 4.4 & 4.5884 & TRN \\
\hline CHEMBL1506192 & 688128 & 4.3 & 4.5941 & TRN \\
\hline CHEMBL1466699 & 688128 & 4.85 & 5.0336 & TRN \\
\hline CHEMBL1328778 & 688128 & 5.0 & 4.837 & TRN \\
\hline CHEMBL1424423 & 688128 & 5.5 & 4.7702 & TST \\
\hline CHEMBL1271013 & 688128 & 4.65 & 4.6557 & TRN \\
\hline CHEMBL1442664 & 688128 & 4.45 & 4.5741 & TRN \\
\hline CHEMBL1520400 & 688128 & 4.7 & 4.5777 & TRN \\
\hline CHEMBL1317565 & 688128 & 4.25 & 4.312 & TRN \\
\hline CHEMBL1521902 & 688128 & 4.05 & 4.5821 & TRN \\
\hline CHEMBL1526270 & 688128 & 4.4 & 5.0162 & TRN \\
\hline CHEMBL1552587 & 688128 & 4.4 & 4.4606 & TST \\
\hline CHEMBL1547938 & 688128 & 5.2 & 4.8797 & TRN \\
\hline CHEMBL1489926 & 688128 & 4.25 & 4.3 & TST \\
\hline CHEMBL1346653 & 688128 & 4.4 & 4.5144 & TRN \\
\hline CHEMBL3145366 & 688128 & 4.05 & 4.7578 & TST \\
\hline CHEMBL1611633 & 688128 & 4.6 & 4.5313 & TRN \\
\hline CHEMBL1447548 & 688128 & 4.4 & 4.7868 & TST \\
\hline CHEMBL1491141 & 688128 & 4.3 & 4.4116 & TST \\
\hline CHEMBL1465575 & 688128 & 4.05 & 4.5769 & TRN \\
\hline CHEMBL1600553 & 688128 & 4.4 & 4.46899 & 9999999999 \\
\hline CHEMBL1993020 & 688128 & 4.2 & 4.854 & TRN \\
\hline CHEMBL1455065 & 688128 & 4.35 & 4.6075 & TRN \\
\hline CHEMBL1405810 & 688128 & 4.85 & 4.6858 & TRN \\
\hline CHEMBL1420859 & 688128 & 4.4 & 4.2791 & TRN \\
\hline CHEMBL3191562 & 688128 & 4.5 & 4.9496 & TST \\
\hline CHEMBL1386571 & 688128 & 4.35 & 4.6013 & TRN \\
\hline CHEMBL1502682 & 688128 & 4.35 & 4.6103 & TRN \\
\hline
\end{tabular}




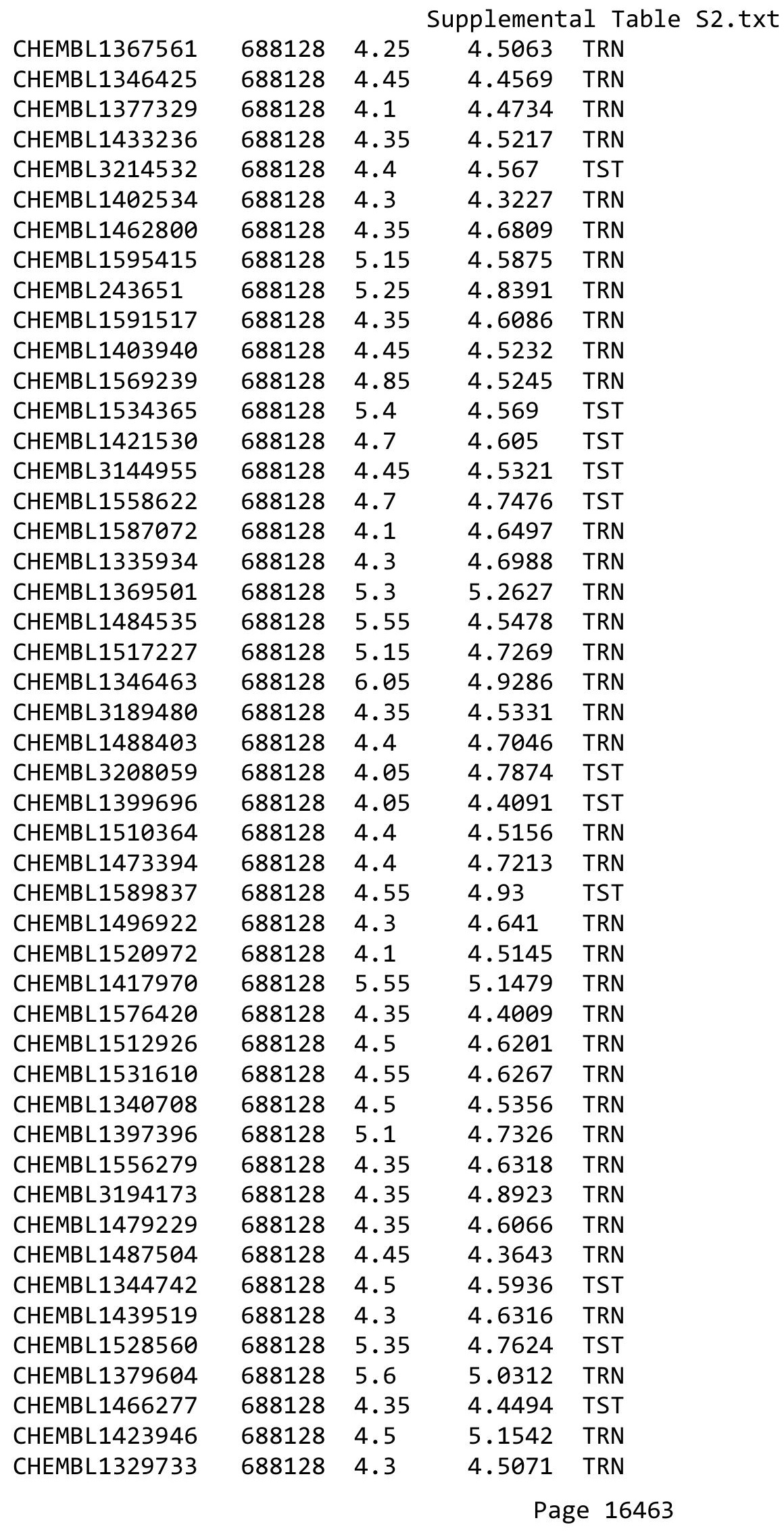




\begin{tabular}{|c|c|c|c|c|c|}
\hline \multicolumn{6}{|c|}{ Supplemental Table S2.txt } \\
\hline CHEMBL1587645 & 688128 & 4.45 & 4.7962 & TRN & \\
\hline CHEMBL1543402 & 688128 & 4.45 & 4.6278 & TRN & \\
\hline CHEMBL1498135 & 688128 & 4.3 & 4.3676 & TRN & \\
\hline CHEMBL1587947 & 688128 & 4.3 & 4.6823 & TST & \\
\hline CHEMBL1535340 & 688128 & 4.45 & 4.471 & TRN & \\
\hline CHEMBL1567222 & 688128 & 4.0 & 4.4032 & TRN & \\
\hline CHEMBL 3197573 & 688128 & 5.2 & 4.4871 & TRN & \\
\hline CHEMBL1454765 & 688128 & 5.5 & 4.6862 & TST & \\
\hline CHEMBL1489548 & 688128 & 4.3 & 4.6617 & TRN & \\
\hline CHEMBL1598225 & 688128 & 4.3 & 4.466 & TRN & \\
\hline CHEMBL1351118 & 688128 & 5.05 & 4.7558 & TRN & \\
\hline CHEMBL1473953 & 688128 & 4.4 & 4.7014 & TRN & \\
\hline CHEMBL1489748 & 688128 & 4.55 & 4.7502 & TRN & \\
\hline CHEMBL1342156 & 688128 & 4.45 & 4.6271 & TRN & \\
\hline CHEMBL1444211 & 688128 & 4.65 & 4.4325 & TRN & \\
\hline CHEMBL1476846 & 688128 & 4.8 & 4.8326 & TRN & \\
\hline CHEMBL1535744 & 688128 & 7.0 & 4.65 & TRN & \\
\hline CHEMBL1404591 & 688128 & 4.35 & 4.4563 & TRN & \\
\hline CHEMBL1516358 & 688128 & 4.05 & 4.7204 & TST & \\
\hline CHEMBL1497856 & 688128 & 4.3 & 4.5033 & TRN & \\
\hline CHEMBL1891759 & 688128 & 4.3 & 4.796 & TRN & \\
\hline CHEMBL1382639 & 688128 & 4.6 & 4.6714 & TRN & \\
\hline CHEMBL1312514 & 688128 & 4.45 & 4.7816 & TRN & \\
\hline CHEMBL1468933 & 688128 & 4.35 & 4.775 & TRN & \\
\hline CHEMBL1400983 & 688128 & 4.35 & 4.55699 & 99999999995 & TRN \\
\hline CHEMBL1483627 & 688128 & 4.4 & 5.0037 & TRN & \\
\hline CHEMBL1454251 & 688128 & 6.1 & 4.277 & TST & \\
\hline CHEMBL1503329 & 688128 & 7.6003 & 4.6863 & TRN & \\
\hline CHEMBL1322107 & 688128 & 4.5 & 4.5153 & TRN & \\
\hline CHEMBL1504336 & 688128 & 4.65 & 4.5375 & TRN & \\
\hline CHEMBL1439754 & 688128 & 4.05 & 4.5945 & TST & \\
\hline CHEMBL1490987 & 688128 & 6.0 & 5.1828 & TRN & \\
\hline CHEMBL1993627 & 688128 & 4.1 & 4.6477 & TRN & \\
\hline CHEMBL1521926 & 688128 & 4.55 & 4.428 & TRN & \\
\hline CHEMBL1491836 & 688128 & 4.3 & 4.6848 & TST & \\
\hline CHEMBL1540295 & 688128 & 4.6 & 4.8356 & TRN & \\
\hline CHEMBL1566495 & 688128 & 4.4 & 4.3953 & TRN & \\
\hline CHEMBL1512633 & 688128 & 5.55 & 5.277 & TRN & \\
\hline CHEMBL1578096 & 688128 & 4.3 & 4.67899 & & TRN \\
\hline CHEMBL1333602 & 688128 & 6.1 & 4.6922 & TRN & \\
\hline CHEMBL1512016 & 688128 & 4.45 & 4.7733 & TRN & \\
\hline CHEMBL1329076 & 688128 & 4.4 & 4.7208 & TRN & \\
\hline CHEMBL1301726 & 688128 & 4.35 & 4.4645 & TRN & \\
\hline CHEMBL1326881 & 688128 & 5.2 & 4.8945 & TRN & \\
\hline CHEMBL1306418 & 688128 & 4.55 & 4.7097 & TRN & \\
\hline CHEMBL1357920 & 688128 & 5.4 & 4.6691 & TST & \\
\hline CHEMBL1606731 & 688128 & 4.75 & 4.7711 & TST & \\
\hline CHEMBL1480798 & 688128 & 5.25 & 4.9625 & TRN & \\
\hline
\end{tabular}




\begin{tabular}{|c|c|c|c|c|c|}
\hline \multicolumn{6}{|c|}{ Supplemental Table S2.txt } \\
\hline CHEMBL1437932 & 688128 & 4.05 & 4.6001 & TST & \\
\hline CHEMBL1314599 & 688128 & 5.05 & 5.1602 & TRN & \\
\hline CHEMBL1497640 & 688128 & 4.4 & 4.7306 & TRN & \\
\hline CHEMBL1361103 & 688128 & 5.8 & 4.6037 & TST & \\
\hline CHEMBL1307824 & 688128 & 4.5 & 4.423 & TRN & \\
\hline CHEMBL1455013 & 688128 & 4.2 & 4.6601 & TST & \\
\hline CHEMBL1528775 & 688128 & 4.75 & 4.754 & TST & \\
\hline CHEMBL1364088 & 688128 & 4.35 & 4.6054 & TRN & \\
\hline CHEMBL1425392 & 688128 & 4.1 & 4.3872 & TRN & \\
\hline CHEMBL1422535 & 688128 & 4.95 & 4.4073 & TST & \\
\hline CHEMBL1533179 & 688128 & 4.05 & 4.5705 & TRN & \\
\hline CHEMBL1540542 & 688128 & 4.05 & 4.7895 & TRN & \\
\hline CHEMBL1307579 & 688128 & 5.15 & 4.6829 & TRN & \\
\hline CHEMBL1385928 & 688128 & 5.2 & 4.5308 & TRN & \\
\hline CHEMBL1433501 & 688128 & 7.0501 & 5.41799 & 9999999999 & TRN \\
\hline CHEMBL1578215 & 688128 & 4.4 & 4.7684 & TRN & \\
\hline CHEMBL1367908 & 688128 & 4.45 & 4.6287 & TST & \\
\hline CHEMBL1320650 & 688128 & 4.6 & 4.3301 & TRN & \\
\hline CHEMBL1442547 & 688128 & 4.25 & 4.6945 & TRN & \\
\hline CHEMBL1473091 & 688128 & 4.45 & 4.8229 & TST & \\
\hline CHEMBL1392938 & 688128 & 4.4 & 4.6319 & TST & \\
\hline CHEMBL1474348 & 688128 & 4.7 & 4.7513 & TST & \\
\hline CHEMBL1427607 & 688128 & 4.4 & 4.6612 & TRN & \\
\hline CHEMBL1491336 & 688128 & 4.45 & 4.4369 & TST & \\
\hline CHEMBL146710 & 688128 & 4.8 & 4.7707 & TST & \\
\hline CHEMBL1375927 & 688128 & 4.65 & 4.4594 & TRN & \\
\hline CHEMBL1978549 & 688128 & 4.05 & 4.6427 & TRN & \\
\hline CHEMBL1385145 & 688128 & 4.5 & 4.8782 & TRN & \\
\hline CHEMBL 3214073 & 688128 & 4.3 & 4.5637 & TRN & \\
\hline CHEMBL1347072 & 688128 & 4.4 & 4.337 & TRN & \\
\hline CHEMBL1379550 & 688128 & 4.3 & 4.6095 & TST & \\
\hline CHEMBL1580269 & 688128 & 4.45 & 4.6558 & TRN & \\
\hline CHEMBL1480668 & 688128 & 4.35 & 4.3212 & TRN & \\
\hline CHEMBL1342703 & 688128 & 4.6 & 4.9662 & TRN & \\
\hline CHEMBL1530205 & 688128 & 4.7 & 4.6125 & TST & \\
\hline CHEMBL1418124 & 688128 & 4.35 & 4.6394 & TRN & \\
\hline CHEMBL3190791 & 688128 & 4.45 & 4.7623 & TST & \\
\hline CHEMBL3392076 & 688128 & 5.55 & 4.699 & TRN & \\
\hline CHEMBL1508962 & 688128 & 4.05 & 4.671 & TRN & \\
\hline CHEMBL1492296 & 688128 & 4.4 & 4.8344 & TST & \\
\hline CHEMBL1509399 & 688128 & 4.9 & 4.78100 & 0000000001 & TST \\
\hline CHEMBL1586096 & 688128 & 5.6 & 4.8578 & TRN & \\
\hline CHEMBL1467836 & 688128 & 4.3 & 4.8191 & TRN & \\
\hline CHEMBL1454192 & 688128 & 4.35 & 4.7495 & TRN & \\
\hline CHEMBL1423318 & 688128 & 4.95 & 4.4818 & TRN & \\
\hline CHEMBL1572015 & 688128 & 4.5 & 4.4223 & TRN & \\
\hline CHEMBL1508009 & 688128 & 4.4 & 4.6106 & TST & \\
\hline CHEMBL1354027 & 688128 & 4.5 & 4.8189 & TRN & \\
\hline
\end{tabular}




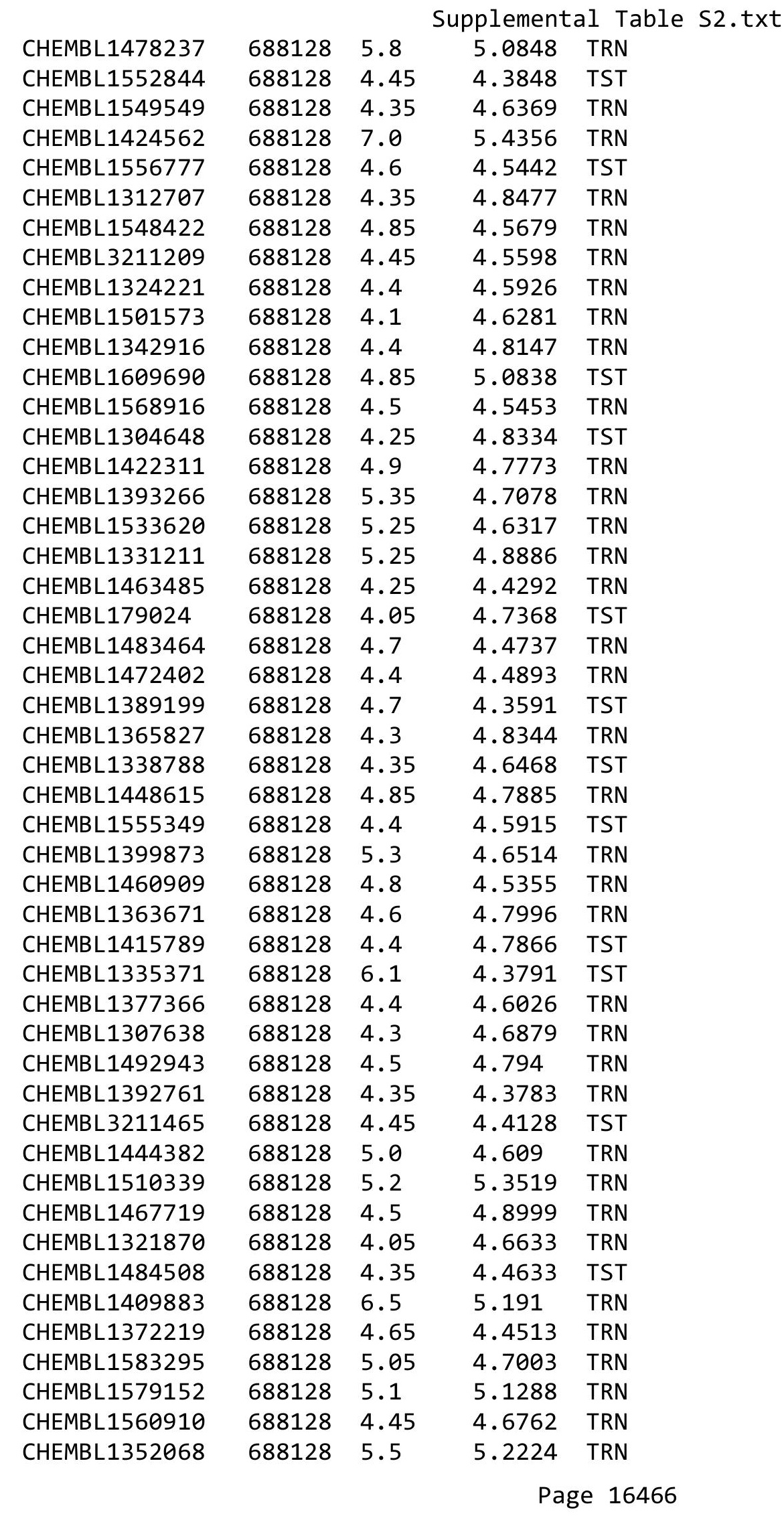




\begin{tabular}{|c|c|c|c|c|c|}
\hline \multicolumn{6}{|c|}{ Supplemental Table s2.txt } \\
\hline CHEMBL1334412 & 688128 & 6.2 & 5.2039 & TRN & \\
\hline CHEMBL1332521 & 688128 & 5.55 & 4.4211 & TRN & \\
\hline CHEMBL1612335 & 688128 & 6.8 & 4.4596 & TST & \\
\hline CHEMBL1299566 & 688128 & 4.5 & 4.8139 & TRN & \\
\hline CHEMBL1436756 & 688128 & 5.15 & 5.1061 & TRN & \\
\hline CHEMBL1572028 & 688128 & 4.7 & 4.775 & TRN & \\
\hline CHEMBL1559540 & 688128 & 4.05 & $4.1960 e$ & 3000000001 & TRN \\
\hline CHEMBL1540173 & 688128 & 4.3 & 4.4978 & TRN & \\
\hline CHEMBL1549058 & 688128 & 4.6 & 4.7816 & TRN & \\
\hline CHEMBL1404197 & 688128 & 4.35 & 4.6185 & TRN & \\
\hline CHEMBL1454429 & 688128 & 4.35 & 4.4836 & TRN & \\
\hline CHEMBL1500414 & 688128 & 5.35 & 4.7922 & TST & \\
\hline CHEMBL1381509 & 688128 & 4.3 & 4.6679 & TRN & \\
\hline CHEMBL1610977 & 688128 & 4.9 & 4.8527 & TRN & \\
\hline CHEMBL1541336 & 688128 & 4.5 & 4.8466 & TST & \\
\hline CHEMBL1363977 & 688128 & 4.45 & 4.4568 & TST & \\
\hline CHEMBL1486904 & 688128 & 4.4 & 4.6183 & TST & \\
\hline CHEMBL1481612 & 688128 & 4.05 & 4.5723 & TST & \\
\hline CHEMBL1506353 & 688128 & 4.6 & 4.9311 & TRN & \\
\hline CHEMBL1528951 & 688128 & 4.8 & 4.5947 & TRN & \\
\hline CHEMBL1406297 & 688128 & 4.35 & 4.4218 & TRN & \\
\hline CHEMBL1325427 & 688128 & 4.3 & 4.5181 & TRN & \\
\hline CHEMBL3196505 & 688128 & 4.4 & 4.574 & TRN & \\
\hline CHEMBL365161 & 688128 & 4.7 & 4.8312 & TST & \\
\hline CHEMBL1441874 & 688128 & 4.55 & 5.0716 & TRN & \\
\hline CHEMBL1514238 & 688128 & 6.05 & 5.1013 & TRN & \\
\hline CHEMBL1480257 & 688128 & 5.4 & 4.5639 & TRN & \\
\hline CHEMBL1315904 & 688128 & 4.5 & 4.7226 & TST & \\
\hline CHEMBL1326994 & 688128 & 4.05 & 4.7687 & TST & \\
\hline CHEMBL1420958 & 688128 & 4.1 & 4.6744 & TRN & \\
\hline CHEMBL1507247 & 688128 & 4.3 & 4.6536 & TRN & \\
\hline CHEMBL1514705 & 688128 & 5.0 & 4.9981 & TRN & \\
\hline CHEMBL1589643 & 688128 & 4.25 & 4.5003 & TST & \\
\hline CHEMBL1587482 & 688128 & 4.8 & 4.6703 & TRN & \\
\hline CHEMBL1608460 & 688128 & 4.7 & 4.2372 & TRN & \\
\hline CHEMBL1561121 & 688128 & 4.3 & 4.4705 & TRN & \\
\hline CHEMBL331938 & 688128 & 4.35 & 4.2858 & TST & \\
\hline CHEMBL1383085 & 688128 & 4.35 & 4.4447 & TRN & \\
\hline CHEMBL1484549 & 688128 & 4.35 & 4.6673 & TRN & \\
\hline CHEMBL1452778 & 688128 & 4.35 & 4.1158 & TRN & \\
\hline CHEMBL1429223 & 688128 & 4.35 & 4.7972 & TRN & \\
\hline CHEMBL1224757 & 688128 & 4.4 & 4.5951 & TRN & \\
\hline CHEMBL1584643 & 688128 & 4.4 & 4.6273 & TST & \\
\hline CHEMBL1473920 & 688128 & 5.4 & 4.5612 & TRN & \\
\hline CHEMBL1304002 & 688128 & 4.35 & 4.6534 & TRN & \\
\hline CHEMBL1605860 & 688128 & 4.8 & 4.2431 & TRN & \\
\hline CHEMBL1330307 & 688128 & 4.65 & 5.6555 & TRN & \\
\hline CHEMBL3197324 & 688128 & 4.4 & 4.703 & TST & \\
\hline
\end{tabular}




\begin{tabular}{|c|c|c|c|c|c|}
\hline \multicolumn{6}{|c|}{ Supplemental Table S2.txt } \\
\hline CHEMBL1531828 & 688128 & 5.05 & 4.9118 & TRN & \\
\hline CHEMBL1316769 & 688128 & 4.05 & 4.7087 & TRN & \\
\hline CHEMBL1509546 & 688128 & 4.3 & 4.5483 & TRN & \\
\hline CHEMBL1315490 & 688128 & 4.4 & 4.5184 & TST & \\
\hline CHEMBL1399383 & 688128 & 4.3 & 4.5572 & TST & \\
\hline CHEMBL1390809 & 688128 & 6.5501 & 5.0043 & TRN & \\
\hline CHEMBL1434392 & 688128 & 5.55 & 5.2987 & TRN & \\
\hline CHEMBL1428620 & 688128 & 5.45 & 4.8327 & TRN & \\
\hline CHEMBL1463953 & 688128 & 4.7 & 4.7073 & TRN & \\
\hline CHEMBL1503219 & 688128 & 4.95 & 5.1708 & TRN & \\
\hline CHEMBL1982078 & 688128 & 5.55 & 4.69 & TRN & \\
\hline CHEMBL1302764 & 688128 & 4.0 & 4.5758 & TST & \\
\hline CHEMBL1356638 & 688128 & 5.35 & 5.143 & TRN & \\
\hline CHEMBL1561937 & 688128 & 4.45 & 4.6546 & TST & \\
\hline CHEMBL1455241 & 688128 & 4.4 & 4.6572 & TRN & \\
\hline CHEMBL1347277 & 688128 & 4.85 & 5.1209 & TRN & \\
\hline CHEMBL1313832 & 688128 & 4.3 & 4.7155 & TRN & \\
\hline CHEMBL1578290 & 688128 & 4.55 & 4.7964 & TRN & \\
\hline CHEMBL1394653 & 688128 & 4.95 & 4.7005 & TRN & \\
\hline CHEMBL1456292 & 688128 & 4.05 & 4.4856 & TRN & \\
\hline CHEMBL1453331 & 688128 & 4.45 & 4.4555 & TRN & \\
\hline CHEMBL1497032 & 688128 & 4.3 & 4.5455 & TST & \\
\hline CHEMBL1300967 & 688128 & 4.65 & 4.6289 & TRN & \\
\hline CHEMBL1969246 & 688128 & 3.95 & 4.4354 & TRN & \\
\hline CHEMBL1494134 & 688128 & 4.4 & 4.8029 & TST & \\
\hline CHEMBL1608245 & 688128 & 4.3 & 5.0288 & TRN & \\
\hline CHEMBL1408628 & 688128 & 4.45 & 4.4985 & TRN & \\
\hline CHEMBL1464333 & 688128 & 4.3 & 4.6204 & TRN & \\
\hline CHEMBL578285 & 688128 & 4.5 & 4.8533 & TRN & \\
\hline CHEMBL1406025 & 688128 & 4.45 & 4.3768 & TRN & \\
\hline CHEMBL1397515 & 688128 & 4.3 & 4.5088 & TRN & \\
\hline CHEMBL1547079 & 688128 & 6.05 & 4.6559 & TST & \\
\hline CHEMBL1323985 & 688128 & 4.4 & 4.6395 & TRN & \\
\hline CHEMBL1543817 & 688128 & 4.35 & 4.4272 & TRN & \\
\hline CHEMBL1387349 & 688128 & 4.05 & 4.7868 & TRN & \\
\hline CHEMBL1541813 & 688128 & 4.9 & $4.8580 €$ & 00000000005 & TRN \\
\hline CHEMBL1422590 & 688128 & 5.3 & 4.92899 & 9999999999 & TRN \\
\hline CHEMBL1590407 & 688128 & 5.35 & 4.9407 & TRN & \\
\hline CHEMBL1322461 & 688128 & 4.4 & 4.6046 & TST & \\
\hline CHEMBL1538801 & 688128 & 4.7 & 4.5563 & TRN & \\
\hline CHEMBL1536685 & 688128 & 4.4 & 4.4167 & TRN & \\
\hline CHEMBL1316112 & 688128 & 4.05 & 4.6553 & TST & \\
\hline CHEMBL1484775 & 688128 & 4.1 & 4.6112 & TST & \\
\hline CHEMBL1419374 & 688128 & 4.4 & 4.5072 & TRN & \\
\hline CHEMBL1558607 & 688128 & 4.4 & 4.5979 & TRN & \\
\hline CHEMBL1490484 & 688128 & 4.95 & 4.5791 & TRN & \\
\hline CHEMBL1556214 & 688128 & 4.65 & 4.6936 & TRN & \\
\hline CHEMBL1565757 & 688128 & 4.6 & 4.4963 & TRN & \\
\hline
\end{tabular}




\begin{tabular}{|c|c|c|c|c|}
\hline \multicolumn{5}{|c|}{ Supplemental Table S2.txt } \\
\hline CHEMBL1373933 & 688128 & 4.3 & 4.8558 & TRN \\
\hline CHEMBL1400377 & 688128 & 4.6 & 4.1767 & TRN \\
\hline CHEMBL1502609 & 688128 & 4.85 & 4.8943 & TRN \\
\hline CHEMBL1373237 & 688128 & 5.05 & 4.8305 & TRN \\
\hline CHEMBL1427925 & 688128 & 4.5 & 4.6956 & TST \\
\hline CHEMBL1432712 & 688128 & 4.4 & 4.6461 & TRN \\
\hline CHEMBL1347531 & 688128 & 5.2 & 4.623 & TST \\
\hline CHEMBL1375756 & 688128 & 4.95 & 4.7022 & TRN \\
\hline CHEMBL1307124 & 688128 & 5.7 & 4.6754 & TRN \\
\hline CHEMBL1481759 & 688128 & 4.05 & 4.5859 & TRN \\
\hline CHEMBL1482221 & 688128 & 4.4 & 4.6489 & TRN \\
\hline CHEMBL1424093 & 688128 & 4.3 & 4.3524 & TRN \\
\hline CHEMBL1562821 & 688128 & 4.35 & 4.3707 & TRN \\
\hline CHEMBL1511169 & 688128 & 5.5 & 5.0788 & TRN \\
\hline CHEMBL1511562 & 688128 & 4.75 & 4.738 & TRN \\
\hline CHEMBL1543365 & 688128 & 4.45 & 4.713 & TRN \\
\hline CHEMBL1967862 & 688128 & 6.05 & 4.9716 & TRN \\
\hline CHEMBL1464512 & 688128 & 4.55 & 4.7127 & TST \\
\hline CHEMBL1427765 & 688128 & 4.6 & 4.1942 & TRN \\
\hline CHEMBL1320901 & 688128 & 4.35 & 4.507 & TST \\
\hline CHEMBL1382433 & 688128 & 6.5 & 4.9465 & TRN \\
\hline CHEMBL1609562 & 688128 & 5.45 & 4.463 & TRN \\
\hline CHEMBL1553128 & 688128 & 4.45 & 5.0033 & TST \\
\hline CHEMBL1374657 & 688128 & 4.45 & 4.2865 & TRN \\
\hline CHEMBL1557719 & 688128 & 4.35 & 4.6144 & TRN \\
\hline CHEMBL1548022 & 688128 & 5.7 & 5.0627 & TST \\
\hline CHEMBL1588076 & 688128 & 4.6 & 4.6356 & TRN \\
\hline CHEMBL1473319 & 688128 & 4.05 & 4.7154 & TRN \\
\hline CHEMBL1301879 & 688128 & 4.05 & 4.3792 & TRN \\
\hline CHEMBL3195792 & 688128 & 4.9 & 4.794 & TRN \\
\hline CHEMBL1613654 & 688128 & 4.2 & 4.6877 & TRN \\
\hline CHEMBL1613107 & 688128 & 4.4 & 4.598 & TRN \\
\hline CHEMBL1580147 & 688128 & 4.3 & 4.7999 & TRN \\
\hline CHEMBL1468411 & 688128 & 4.3 & 4.6281 & TRN \\
\hline CHEMBL1454493 & 688128 & 4.4 & 4.6455 & TST \\
\hline CHEMBL1546837 & 688128 & 5.55 & 4.7079 & TRN \\
\hline CHEMBL1612331 & 688128 & 4.3 & 4.6207 & TRN \\
\hline CHEMBL1476279 & 688128 & 4.35 & 5.012 & TRN \\
\hline CHEMBL83170 & 688128 & 4.75 & 4.5534 & TST \\
\hline CHEMBL1601013 & 688128 & 4.05 & 4.5051 & TRN \\
\hline CHEMBL1374603 & 688128 & 6.0 & 4.6926 & TRN \\
\hline CHEMBL1477380 & 688128 & 4.6 & 4.7319 & TRN \\
\hline CHEMBL1442001 & 688128 & 4.05 & 4.7351 & TST \\
\hline CHEMBL1391175 & 688128 & 5.0 & 4.7875 & TRN \\
\hline CHEMBL1501519 & 688128 & 4.3 & 4.8193 & TRN \\
\hline CHEMBL1451475 & 688128 & 4.1 & 4.6229 & TRN \\
\hline CHEMBL1560757 & 688128 & 5.4 & 5.1484 & TRN \\
\hline CHEMBL1443811 & 688128 & 4.1 & 4.4835 & TRN \\
\hline
\end{tabular}




\begin{tabular}{|c|c|c|c|c|}
\hline \multicolumn{5}{|c|}{ Supplemental Table S2.txt } \\
\hline CHEMBL1348286 & 688128 & 4.25 & 4.5585 & TRN \\
\hline CHEMBL1392832 & 688128 & 4.05 & 4.5027 & TRN \\
\hline CHEMBL1443718 & 688128 & 4.9 & 4.7815 & TRN \\
\hline CHEMBL1335165 & 688128 & 4.95 & 5.0361 & TST \\
\hline CHEMBL1572072 & 688128 & 4.5 & 5.107 & TRN \\
\hline CHEMBL1434442 & 688128 & 5.4 & 4.2945 & TST \\
\hline CHEMBL1353283 & 688128 & 4.35 & 4.5657 & TRN \\
\hline CHEMBL1331999 & 688128 & 4.35 & 4.7194 & TRN \\
\hline CHEMBL1502064 & 688128 & 4.05 & 4.6312 & TRN \\
\hline CHEMBL1409121 & 688128 & 4.4 & 4.6235 & TRN \\
\hline CHEMBL1609918 & 688128 & 5.15 & 4.9535 & TRN \\
\hline CHEMBL1410159 & 688128 & 4.3 & 4.6527 & TRN \\
\hline CHEMBL1601039 & 688128 & 4.5 & 4.4582 & TRN \\
\hline CHEMBL1523145 & 688128 & 4.35 & 4.4814 & TST \\
\hline CHEMBL1336576 & 688128 & 4.05 & 4.6938 & TST \\
\hline CHEMBL1414052 & 688128 & 4.3 & 4.4731 & TRN \\
\hline CHEMBL1603505 & 688128 & 4.05 & 4.4974 & TRN \\
\hline CHEMBL1300270 & 688128 & 4.6 & 4.4291 & TRN \\
\hline CHEMBL1563957 & 688128 & 4.35 & 4.4012 & TST \\
\hline CHEMBL1527778 & 688128 & 4.35 & 4.5103 & TRN \\
\hline CHEMBL1391662 & 688128 & 4.3 & 4.5809 & TRN \\
\hline CHEMBL3190938 & 688128 & 4.45 & 4.5558 & TRN \\
\hline CHEMBL1528814 & 688128 & 5.15 & 5.6786 & TRN \\
\hline CHEMBL1561059 & 688128 & 6.15 & 4.5704 & TRN \\
\hline CHEMBL1085065 & 688128 & 4.9 & 4.9779 & TRN \\
\hline CHEMBL1304041 & 688128 & 4.3 & 4.4232 & TRN \\
\hline CHEMBL1375370 & 688128 & 6.8499 & 4.5995 & TRN \\
\hline CHEMBL1606300 & 688128 & 4.25 & 4.3542 & TRN \\
\hline CHEMBL1340402 & 688128 & 4.35 & 4.3333 & TRN \\
\hline CHEMBL3213658 & 688128 & 4.75 & 4.2223 & TRN \\
\hline CHEMBL1382248 & 688128 & 4.05 & 4.5626 & TRN \\
\hline CHEMBL1482883 & 688128 & 4.3 & 4.9037 & TRN \\
\hline CHEMBL1361859 & 688128 & 5.0 & 4.5697 & TRN \\
\hline CHEMBL1523381 & 688128 & 4.75 & 4.7551 & TRN \\
\hline CHEMBL1376737 & 688128 & 4.35 & 4.8262 & TRN \\
\hline CHEMBL1442069 & 688128 & 4.3 & 4.2698 & TRN \\
\hline CHEMBL1468112 & 688128 & 4.85 & 4.6692 & TRN \\
\hline CHEMBL1325723 & 688128 & 4.5 & 4.853 & TST \\
\hline CHEMBL1477717 & 688128 & 4.55 & 4.3132 & TST \\
\hline CHEMBL1965791 & 688128 & 4.25 & 4.5999 & TRN \\
\hline CHEMBL1343791 & 688128 & 4.65 & 4.4222 & TRN \\
\hline CHEMBL1462736 & 688128 & 4.45 & 4.4251 & TRN \\
\hline CHEMBL1507273 & 688128 & 4.3 & 4.5722 & TST \\
\hline CHEMBL590168 & 688128 & 4.25 & 4.4789 & TRN \\
\hline CHEMBL1507118 & 688128 & 4.05 & 4.5278 & TRN \\
\hline CHEMBL1348645 & 688128 & 4.3 & 4.6332 & TST \\
\hline CHEMBL1373623 & 688128 & 4.3 & 4.3957 & TRN \\
\hline CHEMBL1542561 & 688128 & 6.0 & 4.5193 & TST \\
\hline
\end{tabular}




\begin{tabular}{|c|c|c|c|c|}
\hline \multicolumn{5}{|c|}{ Supplemental Table S2.txt } \\
\hline CHEMBL1486045 & 688128 & 4.4 & 4.5227 & TRN \\
\hline CHEMBL1422315 & 688128 & 4.5 & 4.5799 & TRN \\
\hline CHEMBL1380582 & 688128 & 4.5 & 4.7138 & TST \\
\hline CHEMBL1322433 & 688128 & 4.3 & 4.4932 & TRN \\
\hline CHEMBL1469421 & 688128 & 4.95 & 4.3862 & TRN \\
\hline CHEMBL1486263 & 688128 & 4.4 & 4.7685 & TRN \\
\hline CHEMBL1510085 & 688128 & 4.4 & 4.4941 & TRN \\
\hline CHEMBL1322196 & 688128 & 5.95 & 4.5399 & TRN \\
\hline CHEMBL1568957 & 688128 & 4.3 & 4.4352 & TRN \\
\hline CHEMBL1330572 & 688128 & 4.55 & 4.6835 & TRN \\
\hline CHEMBL1542043 & 688128 & 4.55 & 4.669 & TRN \\
\hline CHEMBL1380421 & 688128 & 5.4 & 4.6577 & TRN \\
\hline CHEMBL1423043 & 688128 & 4.85 & 4.6681 & TRN \\
\hline CHEMBL1425633 & 688128 & 4.05 & 4.7126 & TRN \\
\hline CHEMBL1594955 & 688128 & 4.5 & 4.6037 & TST \\
\hline CHEMBL1403881 & 688128 & 4.4 & 4.5741 & TRN \\
\hline CHEMBL1316047 & 688128 & 4.4 & 4.6653 & TRN \\
\hline CHEMBL1414988 & 688128 & 4.4 & 4.7585 & TRN \\
\hline CHEMBL 3193308 & 688128 & 4.35 & 4.9543 & TRN \\
\hline CHEMBL1348273 & 688128 & 4.3 & 4.3887 & TRN \\
\hline CHEMBL1437405 & 688128 & 4.3 & 4.2877 & TRN \\
\hline CHEMBL1583996 & 688128 & 4.05 & 4.3292 & TRN \\
\hline CHEMBL1382381 & 688128 & 4.9 & 4.7694 & TRN \\
\hline CHEMBL 3192872 & 688128 & 4.3 & 4.4931 & TRN \\
\hline CHEMBL1418334 & 688128 & 4.45 & 4.5548 & TRN \\
\hline CHEMBL1495778 & 688128 & 4.95 & 5.3135 & TST \\
\hline CHEMBL1445497 & 688128 & 5.35 & 4.7037 & TRN \\
\hline CHEMBL1528628 & 688128 & 5.15 & 4.613 & TRN \\
\hline CHEMBL1320715 & 688128 & 4.35 & 4.827 & TST \\
\hline CHEMBL1420284 & 688128 & 4.3 & 4.3485 & TRN \\
\hline CHEMBL1583847 & 688128 & 4.05 & 4.6221 & TST \\
\hline CHEMBL1538941 & 688128 & 4.25 & 4.721 & TRN \\
\hline CHEMBL1548186 & 688128 & 4.75 & 4.5399 & TRN \\
\hline CHEMBL1425036 & 688128 & 4.25 & 4.3936 & TRN \\
\hline CHEMBL1586866 & 688128 & 4.55 & 4.7318 & TRN \\
\hline CHEMBL1469501 & 688128 & 4.35 & 4.7053 & TST \\
\hline CHEMBL1327078 & 688128 & 4.45 & 4.4511 & TRN \\
\hline CHEMBL1596753 & 688128 & 5.0 & 4.6241 & TST \\
\hline CHEMBL1477285 & 688128 & 4.1 & 4.724 & TST \\
\hline CHEMBL1560226 & 688128 & 4.6 & 4.4763 & TRN \\
\hline CHEMBL1580035 & 688128 & 4.75 & 4.9068 & TRN \\
\hline CHEMBL1429479 & 688128 & 4.2 & 5.3965 & TRN \\
\hline CHEMBL1569249 & 688128 & 4.75 & 4.6865 & TRN \\
\hline CHEMBL1447573 & 688128 & 4.35 & 4.4549 & TST \\
\hline CHEMBL1433763 & 688128 & 5.45 & 4.7201 & TRN \\
\hline CHEMBL1432333 & 688128 & 4.9 & 4.5485 & TRN \\
\hline CHEMBL1441781 & 688128 & 4.45 & 4.2829 & TRN \\
\hline CHEMBL1577216 & 688128 & 4.3 & 4.5401 & TRN \\
\hline
\end{tabular}




\begin{tabular}{|c|c|c|c|c|}
\hline \multicolumn{5}{|c|}{ Supplemental Table S2.txt } \\
\hline CHEMBL1410993 & 688128 & 4.3 & 4.3921 & TST \\
\hline CHEMBL1455509 & 688128 & 4.3 & 4.3676 & TRN \\
\hline CHEMBL1495913 & 688128 & 4.5 & 4.5946 & TRN \\
\hline CHEMBL1509684 & 688128 & 4.0 & 4.5076 & TRN \\
\hline CHEMBL1421415 & 688128 & 4.35 & 4.5914 & TRN \\
\hline CHEMBL1396987 & 688128 & 4.4 & 4.3486 & TRN \\
\hline CHEMBL1496959 & 688128 & 4.45 & 5.0616 & TRN \\
\hline CHEMBL1312834 & 688128 & 4.4 & 4.6398 & TRN \\
\hline CHEMBL1513796 & 688128 & 4.1 & 4.6423 & TRN \\
\hline CHEMBL1344750 & 688128 & 4.3 & 4.7756 & TRN \\
\hline CHEMBL1463431 & 688128 & 4.4 & 4.9886 & TST \\
\hline CHEMBL1379088 & 688128 & 4.3 & 4.6934 & TRN \\
\hline CHEMBL3189977 & 688128 & 6.0 & 4.7313 & TRN \\
\hline CHEMBL1490302 & 688128 & 4.05 & 4.6147 & TRN \\
\hline CHEMBL1438397 & 688128 & 4.9 & 4.39 & TRN \\
\hline CHEMBL1387721 & 688128 & 4.45 & 4.7057 & TRN \\
\hline CHEMBL233549 & 688128 & 6.5501 & 4.9937 & TRN \\
\hline CHEMBL1456978 & 688128 & 5.05 & 4.5731 & TRN \\
\hline CHEMBL505670 & 688128 & 6.5501 & 5.0078 & TST \\
\hline CHEMBL1474826 & 688128 & 4.4 & 4.3595 & TRN \\
\hline CHEMBL1503175 & 688128 & 5.35 & 4.9788 & TRN \\
\hline CHEMBL1519860 & 688128 & 4.35 & 4.6344 & TST \\
\hline CHEMBL1564873 & 688128 & 4.5 & 4.5486 & TRN \\
\hline CHEMBL1612510 & 688128 & 4.05 & 4.5836 & TST \\
\hline CHEMBL1531305 & 688128 & 4.35 & 4.7833 & TST \\
\hline CHEMBL1350394 & 688128 & 4.45 & 4.3811 & TRN \\
\hline CHEMBL1381874 & 688128 & 4.05 & 4.6495 & TRN \\
\hline CHEMBL1365249 & 688128 & 5.9 & 5.1827 & TRN \\
\hline CHEMBL1551268 & 688128 & 4.85 & 4.9177 & TRN \\
\hline CHEMBL1329514 & 688128 & 5.4 & 4.7412 & TRN \\
\hline CHEMBL1410624 & 688128 & 4.25 & 4.5972 & TST \\
\hline CHEMBL1485698 & 688128 & 4.3 & 4.4926 & TRN \\
\hline CHEMBL1580894 & 688128 & 4.3 & 4.5849 & TRN \\
\hline CHEMBL1549133 & 688128 & 5.3 & 4.8396 & TRN \\
\hline CHEMBL1525223 & 688128 & 4.35 & 4.1969 & TRN \\
\hline CHEMBL1545279 & 688128 & 4.45 & 4.4526 & TRN \\
\hline CHEMBL1326457 & 688128 & 4.4 & 4.7264 & TRN \\
\hline CHEMBL1402830 & 688128 & 4.45 & 4.3938 & TRN \\
\hline CHEMBL1570534 & 688128 & 4.4 & 4.631 & TRN \\
\hline CHEMBL1573828 & 688128 & 4.4 & 4.6186 & TRN \\
\hline CHEMBL3208350 & 688128 & 4.2 & 4.4916 & TRN \\
\hline CHEMBL1610933 & 688128 & 6.6499 & 4.56 & TST \\
\hline CHEMBL1594404 & 688128 & 5.35 & 5.0519 & TST \\
\hline CHEMBL1334004 & 688128 & 4.65 & 4.649 & TRN \\
\hline CHEMBL1518056 & 688128 & 4.05 & 4.4521 & TST \\
\hline CHEMBL1534080 & 688128 & 4.4 & 4.6069 & TRN \\
\hline CHEMBL1562928 & 688128 & 4.3 & 4.6097 & TST \\
\hline CHEMBL1613650 & 688128 & 4.35 & 4.4202 & TRN \\
\hline
\end{tabular}




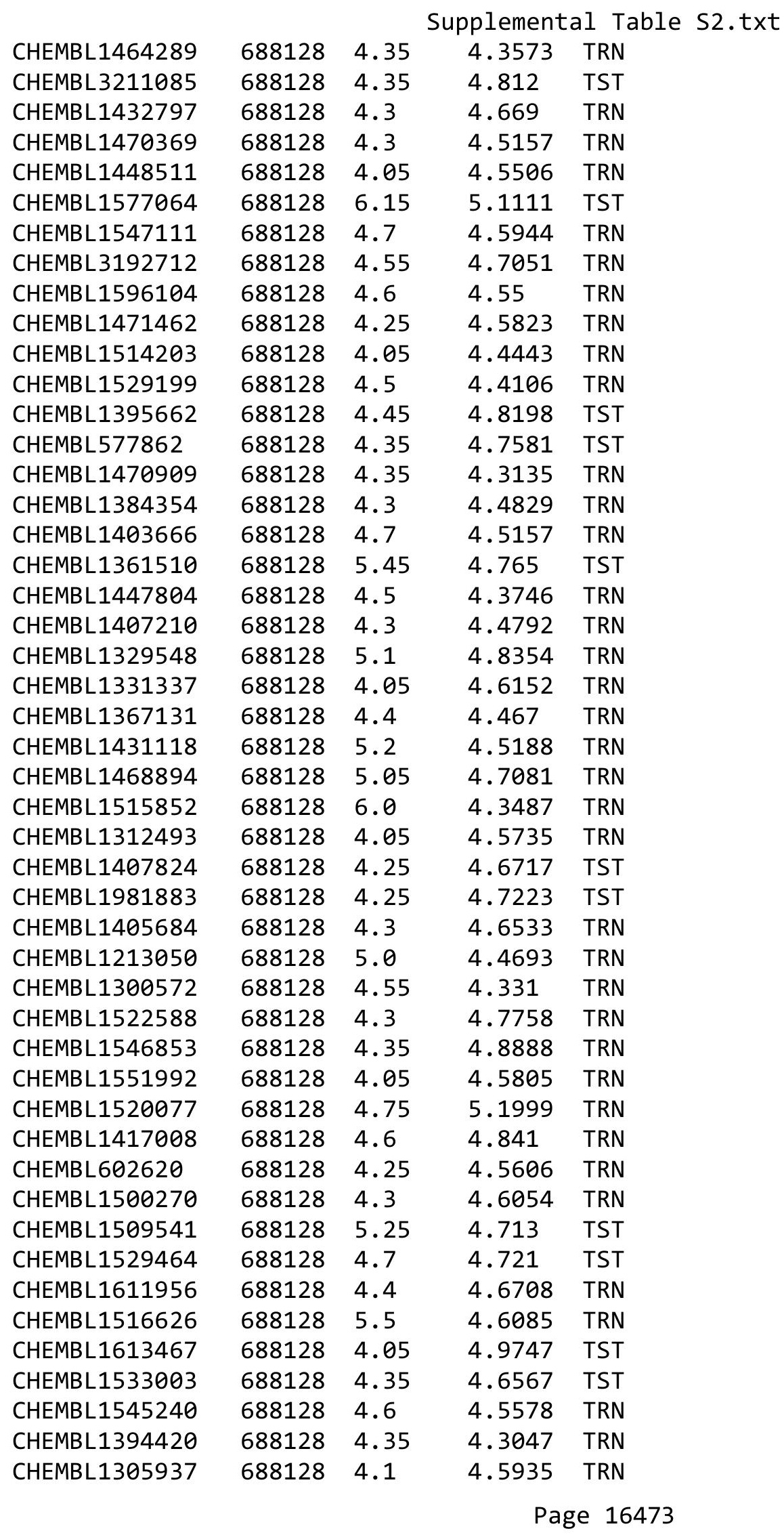




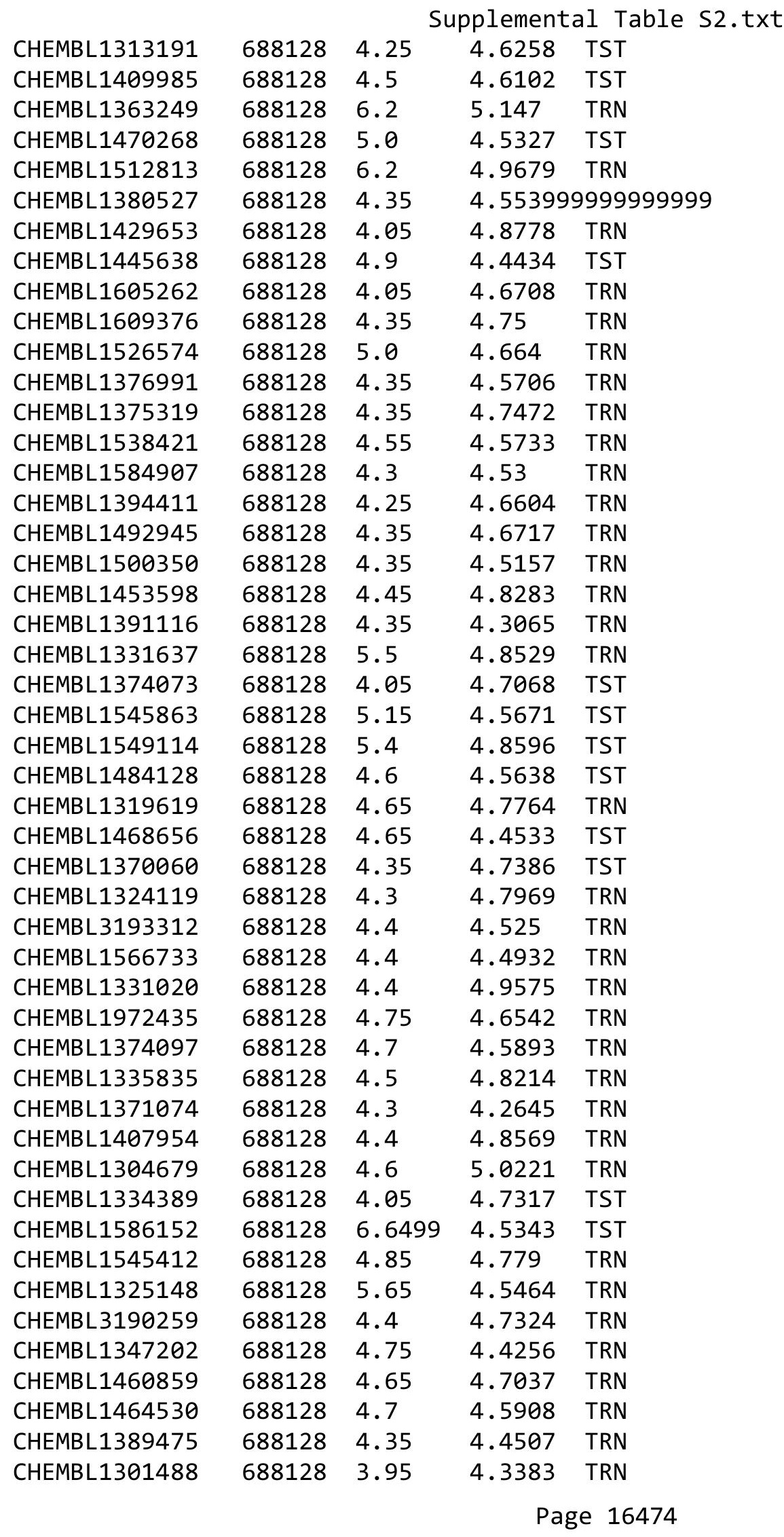




\begin{tabular}{|c|c|c|c|c|}
\hline \multicolumn{5}{|c|}{ Supplemental Table S2.txt } \\
\hline CHEMBL1543085 & 688128 & 5.45 & 4.5672 & TST \\
\hline CHEMBL1384580 & 688128 & 4.3 & 4.5747 & TRN \\
\hline CHEMBL2001831 & 688128 & 5.0 & 4.7764 & TRN \\
\hline CHEMBL1573961 & 688128 & 4.4 & 4.6035 & TRN \\
\hline CHEMBL1501895 & 688128 & 4.55 & 4.5214 & TRN \\
\hline CHEMBL1508183 & 688128 & 4.55 & 4.45 & TRN \\
\hline CHEMBL1601590 & 688128 & 4.4 & 4.5702 & TRN \\
\hline CHEMBL1326344 & 688128 & 4.4 & 4.9321 & TRN \\
\hline CHEMBL1540164 & 688128 & 5.15 & 4.7571 & TST \\
\hline CHEMBL1300090 & 688128 & 4.3 & 4.6622 & TRN \\
\hline CHEMBL1573452 & 688128 & 4.3 & 4.5707 & TRN \\
\hline CHEMBL1307162 & 688128 & 4.3 & 4.4806 & TRN \\
\hline CHEMBL1581825 & 688128 & 4.05 & 4.5582 & TST \\
\hline CHEMBL1332403 & 688128 & 4.9 & 4.8455 & TST \\
\hline CHEMBL1362550 & 688128 & 4.25 & 4.5342 & TRN \\
\hline CHEMBL1399221 & 688128 & 4.45 & 4.7426 & TST \\
\hline CHEMBL1364621 & 688128 & 4.85 & 5.0798 & TST \\
\hline CHEMBL1324238 & 688128 & 4.3 & 4.4944 & TRN \\
\hline CHEMBL1360431 & 688128 & 4.4 & 4.6452 & TST \\
\hline CHEMBL1418862 & 688128 & 4.3 & 4.2111 & TRN \\
\hline CHEMBL1368594 & 688128 & 5.5 & 4.6793 & TRN \\
\hline CHEMBL 2448498 & 688128 & 4.9 & 4.5815 & TRN \\
\hline CHEMBL1535901 & 688128 & 4.6 & 4.8545 & TRN \\
\hline CHEMBL1609465 & 688128 & 4.35 & 4.3047 & TRN \\
\hline CHEMBL1610328 & 688128 & 5.4 & 4.596 & TRN \\
\hline CHEMBL1372779 & 688128 & 4.05 & 4.4938 & TST \\
\hline CHEMBL1377275 & 688128 & 4.1 & 4.676 & TRN \\
\hline CHEMBL1998566 & 688128 & 4.85 & 4.9204 & TST \\
\hline CHEMBL1529155 & 688128 & 4.4 & 4.6547 & TRN \\
\hline CHEMBL1604819 & 688128 & 4.6 & 4.612 & TRN \\
\hline CHEMBL1508466 & 688128 & 4.75 & 4.6687 & TRN \\
\hline CHEMBL1370762 & 688128 & 4.05 & 4.6377 & TRN \\
\hline CHEMBL1362957 & 688128 & 4.35 & 4.6457 & TRN \\
\hline CHEMBL1325348 & 688128 & 6.15 & 5.2753 & TRN \\
\hline CHEMBL1441991 & 688128 & 4.4 & 4.7408 & TRN \\
\hline CHEMBL1404448 & 688128 & 4.5 & 4.4476 & TRN \\
\hline CHEMBL1533115 & 688128 & 4.3 & 4.2274 & TRN \\
\hline CHEMBL1452711 & 688128 & 4.55 & 5.4234 & TRN \\
\hline CHEMBL1420556 & 688128 & 4.25 & 4.7904 & TST \\
\hline CHEMBL1495868 & 688128 & 4.45 & 4.651 & TRN \\
\hline CHEMBL1558903 & 688128 & 4.05 & 4.2891 & TRN \\
\hline CHEMBL1358433 & 688128 & 5.6 & 5.4114 & TRN \\
\hline CHEMBL1331870 & 688128 & 4.4 & 4.4415 & TST \\
\hline CHEMBL1581353 & 688128 & 6.0 & 4.6952 & TRN \\
\hline CHEMBL1604330 & 688128 & 4.65 & 4.1874 & TRN \\
\hline CHEMBL1548250 & 688128 & 6.15 & 4.7741 & TRN \\
\hline CHEMBL1358698 & 688128 & 4.4 & 4.4564 & TRN \\
\hline CHEMBL3199278 & 688128 & 4.2 & 4.5712 & TRN \\
\hline
\end{tabular}




\begin{tabular}{|c|c|c|c|c|c|}
\hline \multicolumn{6}{|c|}{ Supplemental Table S2.txt } \\
\hline CHEMBL1581879 & 688128 & 4.55 & 4.5566 & TRN & \\
\hline CHEMBL1335384 & 688128 & 4.55 & 4.5426 & TST & \\
\hline CHEMBL1411496 & 688128 & 4.65 & 4.6291 & TRN & \\
\hline CHEMBL1527158 & 688128 & 4.0 & 4.7775 & TRN & \\
\hline CHEMBL1515921 & 688128 & 4.05 & 4.4975 & TRN & \\
\hline CHEMBL1440703 & 688128 & 5.05 & 4.7947 & TST & \\
\hline CHEMBL1433354 & 688128 & 4.05 & 4.6207 & TRN & \\
\hline CHEMBL1563172 & 688128 & 6.5 & 4.8966 & TST & \\
\hline CHEMBL1442431 & 688128 & 4.45 & 4.5489 & TRN & \\
\hline CHEMBL1503120 & 688128 & 4.45 & 4.8514 & TRN & \\
\hline CHEMBL1404883 & 688128 & 5.45 & 4.5528 & TRN & \\
\hline CHEMBL1400129 & 688128 & 4.35 & 4.3776 & TRN & \\
\hline CHEMBL1435882 & 688128 & 4.35 & 4.7513 & TRN & \\
\hline CHEMBL1611808 & 688128 & 4.35 & 4.56800 & 00000000005 & TRN \\
\hline CHEMBL1348830 & 688128 & 4.6 & 4.5122 & TST & \\
\hline CHEMBL1596453 & 688128 & 4.7 & 4.4095 & TRN & \\
\hline CHEMBL1416984 & 688128 & 4.6 & 4.5649 & TRN & \\
\hline CHEMBL1472014 & 688128 & 4.4 & 4.2819 & TRN & \\
\hline CHEMBL1431341 & 688128 & 4.1 & 4.978 & TST & \\
\hline CHEMBL1518803 & 688128 & 4.3 & 4.7621 & TRN & \\
\hline CHEMBL1965162 & 688128 & 6.0 & 4.5699 & TRN & \\
\hline CHEMBL1506936 & 688128 & 4.3 & 4.5192 & TRN & \\
\hline CHEMBL1452253 & 688128 & 5.2 & 4.4655 & TRN & \\
\hline CHEMBL1562148 & 688128 & 4.4 & 4.7347 & TRN & \\
\hline CHEMBL1403970 & 688128 & 4.8 & 4.6539 & TST & \\
\hline CHEMBL1506257 & 688128 & 4.3 & 4.4117 & TRN & \\
\hline CHEMBL582256 & 688128 & 5.85 & 4.599 & TRN & \\
\hline CHEMBL1345002 & 688128 & 4.5 & 4.9024 & TRN & \\
\hline CHEMBL1386596 & 688128 & 4.4 & 4.7473 & TRN & \\
\hline CHEMBL1385784 & 688128 & 6.5 & 5.4402 & TRN & \\
\hline CHEMBL1376201 & 688128 & 4.45 & 4.8382 & TST & \\
\hline CHEMBL1344910 & 688128 & 4.0 & 4.6319 & TST & \\
\hline CHEMBL1466765 & 688128 & 4.05 & 4.4751 & TRN & \\
\hline CHEMBL1982888 & 688128 & 4.55 & 4.9123 & TRN & \\
\hline CHEMBL1534864 & 688128 & 4.65 & 4.3443 & TRN & \\
\hline CHEMBL1402869 & 688128 & 5.45 & 4.90600 & 0000000001 & TRN \\
\hline CHEMBL581872 & 688128 & 4.0 & 4.6322 & TST & \\
\hline CHEMBL1562242 & 688128 & 5.45 & 4.4524 & TRN & \\
\hline CHEMBL1415156 & 688128 & 4.35 & 4.7002 & TST & \\
\hline CHEMBL1337366 & 688128 & 4.35 & 4.6434 & TRN & \\
\hline CHEMBL3190542 & 688128 & 4.3 & 4.6424 & TRN & \\
\hline CHEMBL1583313 & 688128 & 4.85 & 4.592 & TRN & \\
\hline CHEMBL1310473 & 688128 & 4.4 & 4.5241 & TRN & \\
\hline CHEMBL1344015 & 688128 & 4.6 & 4.5413 & TRN & \\
\hline CHEMBL1372701 & 688128 & 5.4 & 4.4329 & TST & \\
\hline CHEMBL1574144 & 688128 & 4.1 & 4.9138 & TST & \\
\hline CHEMBL1377892 & 688128 & 4.05 & 4.2921 & TRN & \\
\hline CHEMBL1322271 & 688128 & 4.85 & 4.8352 & TRN & \\
\hline
\end{tabular}




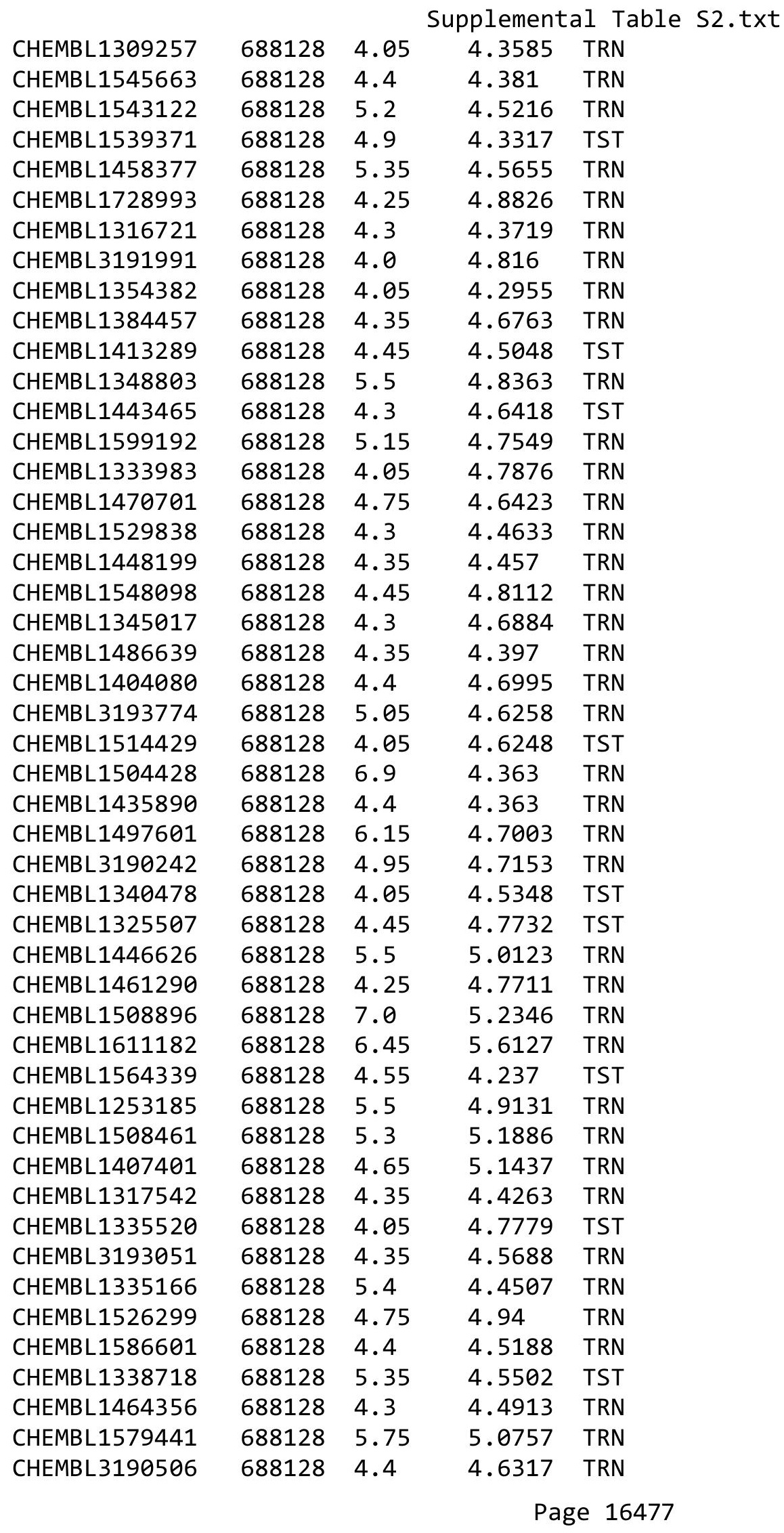




\begin{tabular}{|c|c|c|c|c|}
\hline \multicolumn{5}{|c|}{ Supplemental Table S2.txt } \\
\hline CHEMBL1532544 & 688128 & 4.8 & 4.8824 & TRN \\
\hline CHEMBL1468744 & 688128 & 4.75 & 4.76 & TST \\
\hline CHEMBL1433200 & 688128 & 4.35 & 4.7 & TRN \\
\hline CHEMBL1442356 & 688128 & 4.7 & 4.6092 & TRN \\
\hline CHEMBL1547634 & 688128 & 4.3 & 4.4649 & TST \\
\hline CHEMBL1336619 & 688128 & 6.2 & 4.7489 & TRN \\
\hline CHEMBL 2373575 & 688128 & 5.8 & 4.6446 & TRN \\
\hline CHEMBL1594367 & 688128 & 4.35 & 4.532 & TRN \\
\hline CHEMBL1565984 & 688128 & 4.05 & 4.5641 & TRN \\
\hline CHEMBL1412386 & 688128 & 5.05 & 4.7364 & TRN \\
\hline CHEMBL1541859 & 688128 & 5.4 & 4.8633 & TRN \\
\hline CHEMBL1332601 & 688128 & 5.3 & 4.6111 & TST \\
\hline CHEMBL1572001 & 688128 & 5.05 & 5.1119 & TRN \\
\hline CHEMBL1474782 & 688128 & 4.25 & 4.6147 & TRN \\
\hline CHEMBL1478033 & 688128 & 4.3 & 4.7536 & TRN \\
\hline CHEMBL1982945 & 688128 & 4.25 & 4.9137 & TST \\
\hline CHEMBL1312686 & 688128 & 5.4 & 4.5668 & TRN \\
\hline CHEMBL1359240 & 688128 & 4.65 & 4.6147 & TST \\
\hline CHEMBL1996625 & 688128 & 4.35 & 4.7527 & TRN \\
\hline CHEMBL173530 & 688128 & 4.7 & 4.6755 & TST \\
\hline CHEMBL1397507 & 688128 & 4.35 & 5.0334 & TST \\
\hline CHEMBL1318426 & 688128 & 4.75 & 4.7622 & TRN \\
\hline CHEMBL1427447 & 688128 & 4.65 & 4.7679 & TRN \\
\hline CHEMBL1366769 & 688128 & 5.25 & 5.1162 & TRN \\
\hline CHEMBL1384301 & 688128 & 4.05 & 4.8158 & TRN \\
\hline CHEMBL1604171 & 688128 & 4.35 & 4.4471 & TRN \\
\hline CHEMBL1430775 & 688128 & 4.85 & 4.7698 & TRN \\
\hline CHEMBL1213837 & 688128 & 4.6 & 4.5149 & TRN \\
\hline CHEMBL1540377 & 688128 & 4.65 & 5.0871 & TRN \\
\hline CHEMBL1450108 & 688128 & 4.3 & 5.1508 & TST \\
\hline CHEMBL1468558 & 688128 & 4.45 & 4.6147 & TRN \\
\hline CHEMBL1404943 & 688128 & 4.05 & 4.8258 & TRN \\
\hline CHEMBL1365851 & 688128 & 4.05 & 4.6149 & TRN \\
\hline CHEMBL1329360 & 688128 & 4.25 & 4.33 & TRN \\
\hline CHEMBL1469885 & 688128 & 4.7 & 4.8145 & TRN \\
\hline CHEMBL3199294 & 688128 & 4.45 & 4.5792 & TRN \\
\hline CHEMBL1432115 & 688128 & 4.6 & 4.7679 & TST \\
\hline CHEMBL1532547 & 688128 & 4.6 & 4.9303 & TRN \\
\hline CHEMBL1972491 & 688128 & 6.2 & 4.9307 & TRN \\
\hline CHEMBL1311816 & 688128 & 5.0 & 4.8435 & TST \\
\hline CHEMBL1311198 & 688128 & 4.4 & 5.0184 & TRN \\
\hline CHEMBL1504021 & 688128 & 4.5 & 4.4298 & TRN \\
\hline CHEMBL1454183 & 688128 & 5.6 & 4.7046 & TST \\
\hline CHEMBL1555808 & 688128 & 4.05 & 4.4793 & TRN \\
\hline CHEMBL1466017 & 688128 & 4.0 & 5.0445 & TRN \\
\hline CHEMBL1503347 & 688128 & 5.15 & 4.6483 & TRN \\
\hline CHEMBL1361582 & 688128 & 4.95 & 4.3585 & TST \\
\hline CHEMBL1395684 & 688128 & 4.35 & 4.6446 & TRN \\
\hline
\end{tabular}




\begin{tabular}{|c|c|c|c|c|c|}
\hline \multicolumn{6}{|c|}{ Supplemental Table s2.txt } \\
\hline CHEMBL1474547 & 688128 & 4.35 & 5.1834 & TRN & \\
\hline CHEMBL1370744 & 688128 & 4.75 & 4.5479 & TRN & \\
\hline CHEMBL3199315 & 688128 & 4.25 & 4.7777 & TRN & \\
\hline CHEMBL1557981 & 688128 & 4.55 & 4.596 & TRN & \\
\hline CHEMBL1468586 & 688128 & 4.95 & 4.8808 & TST & \\
\hline CHEMBL1511461 & 688128 & 4.35 & 4.583 & TRN & \\
\hline CHEMBL1402056 & 688128 & 4.8 & 4.8473 & TST & \\
\hline CHEMBL1462578 & 688128 & 5.85 & 5.0854 & TRN & \\
\hline CHEMBL1446194 & 688128 & 4.35 & 4.565 & TRN & \\
\hline CHEMBL292687 & 688128 & 5.65 & 4.8062 & TRN & \\
\hline CHEMBL1493163 & 688128 & 4.45 & 4.5325 & TRN & \\
\hline CHEMBL1380464 & 688128 & 4.35 & 4.5735 & TRN & \\
\hline CHEMBL1435980 & 688128 & 4.6 & 4.578 & TRN & \\
\hline CHEMBL1518267 & 688128 & 4.35 & 4.2735 & TRN & \\
\hline CHEMBL1596755 & 688128 & 4.9 & 4.6843 & TRN & \\
\hline CHEMBL76904 & 688128 & 5.85 & 5.1002 & TRN & \\
\hline CHEMBL1602243 & 688128 & 4.05 & 4.5574 & TRN & \\
\hline CHEMBL1558572 & 688128 & 6.6 & 4.7637 & TRN & \\
\hline CHEMBL1570659 & 688128 & 6.2 & 5.1209 & TRN & \\
\hline CHEMBL1484840 & 688128 & 4.05 & 4.78100 & 0000000001 & TST \\
\hline CHEMBL1442342 & 688128 & 4.3 & 4.8716 & TRN & \\
\hline CHEMBL1505770 & 688128 & 4.75 & 4.563 & TRN & \\
\hline CHEMBL1343035 & 688128 & 4.8 & 4.6009 & TRN & \\
\hline CHEMBL1345828 & 688128 & 4.35 & 4.6261 & TRN & \\
\hline CHEMBL1453926 & 688128 & 4.4 & 4.5403 & TRN & \\
\hline CHEMBL1449490 & 688128 & 4.25 & 4.7005 & TST & \\
\hline CHEMBL1325038 & 688128 & 5.1 & 4.835 & TRN & \\
\hline CHEMBL1503397 & 688128 & 4.35 & 4.3547 & TRN & \\
\hline CHEMBL1595870 & 688128 & 4.5 & 4.6439 & TST & \\
\hline CHEMBL1600146 & 688128 & 4.8 & 5.2817 & TRN & \\
\hline CHEMBL1332240 & 688128 & 4.75 & 4.6866 & TRN & \\
\hline CHEMBL1392265 & 688128 & 4.3 & 4.7151 & TST & \\
\hline CHEMBL1453738 & 688128 & 4.4 & 4.5045 & TRN & \\
\hline CHEMBL1606940 & 688128 & 4.9 & 4.9468 & TRN & \\
\hline CHEMBL1406232 & 688128 & 4.35 & 4.8108 & TRN & \\
\hline CHEMBL1388745 & 688128 & 4.05 & 4.4643 & TRN & \\
\hline CHEMBL1547146 & 688128 & 4.0 & 4.4892 & TRN & \\
\hline CHEMBL1537872 & 688128 & 4.3 & 4.8854 & TRN & \\
\hline CHEMBL1337858 & 688128 & 4.35 & 4.6598 & TRN & \\
\hline CHEMBL1399299 & 688128 & 4.3 & 4.7891 & TST & \\
\hline CHEMBL1588668 & 688128 & 4.4 & 4.5533 & TRN & \\
\hline CHEMBL1578461 & 688128 & 4.6 & 4.6937 & TRN & \\
\hline CHEMBL3208408 & 688128 & 5.15 & 4.8654 & TRN & \\
\hline CHEMBL1505060 & 688128 & 6.5501 & 5.1396 & TRN & \\
\hline CHEMBL1348222 & 688128 & 4.35 & 4.7685 & TST & \\
\hline CHEMBL1356924 & 688128 & 4.35 & 4.3286 & TST & \\
\hline CHEMBL1464266 & 688128 & 4.55 & 4.76699 & 99999999995 & TRN \\
\hline CHEMBL1591969 & 688128 & 4.4 & 4.6815 & TRN & \\
\hline
\end{tabular}




\begin{tabular}{|c|c|c|c|c|c|}
\hline \\
\hline CHEMBL1421787 & 688128 & 4.3 & 4.4576 & TRN & \\
\hline CHEMBL1425618 & 688128 & 4.4 & 4.6351 & TRN & \\
\hline CHEMBL1501722 & 688128 & 5.4 & 4.3566 & TRN & \\
\hline CHEMBL1414125 & 688128 & 4.4 & 4.5304 & TRN & \\
\hline CHEMBL1433108 & 688128 & 4.05 & 4.7719 & TRN & \\
\hline CHEMBL1509042 & 688128 & 4.95 & 4.8552 & TRN & \\
\hline CHEMBL1549700 & 688128 & 4.45 & 4.7763 & TRN & \\
\hline CHEMBL1478382 & 688128 & 5.0 & 4.8601 & TRN & \\
\hline CHEMBL1499529 & 688128 & 4.3 & 4.6383 & TST & \\
\hline CHEMBL1392332 & 688128 & 5.2 & 4.8691 & TST & \\
\hline CHEMBL1370195 & 688128 & 4.35 & 4.495 & TRN & \\
\hline CHEMBL1612604 & 688128 & 4.1 & 4.6165 & TRN & \\
\hline CHEMBL1347753 & 688128 & 5.6 & 4.98600 & 2000000001 & TRN \\
\hline CHEMBL1508980 & 688128 & 4.05 & 4.3284 & TRN & \\
\hline CHEMBL1536640 & 688128 & 5.35 & 4.6598 & TST & \\
\hline CHEMBL1426560 & 688128 & 5.45 & 4.6967 & TRN & \\
\hline CHEMBL1413569 & 688128 & 7.0 & 4.8569 & TST & \\
\hline CHEMBL521762 & 688128 & 5.0 & 4.893 & TRN & \\
\hline CHEMBL1483409 & 688128 & 5.3 & 4.5172 & TST & \\
\hline CHEMBL1310932 & 688128 & 4.05 & 4.6742 & TST & \\
\hline CHEMBL1332177 & 688128 & 4.35 & 4.6696 & TRN & \\
\hline CHEMBL3213179 & 688128 & 4.05 & 4.4228 & TST & \\
\hline CHEMBL1544450 & 688128 & 4.25 & 4.6237 & TRN & \\
\hline CHEMBL1606472 & 688128 & 4.8 & 4.6404 & TRN & \\
\hline CHEMBL1582546 & 688128 & 4.4 & 4.5112 & TRN & \\
\hline CHEMBL3213163 & 688128 & 4.45 & 4.3863 & TST & \\
\hline CHEMBL1606726 & 688128 & 6.0 & 4.9633 & TRN & \\
\hline CHEMBL1552935 & 688128 & 5.4 & 4.547 & TST & \\
\hline CHEMBL1381829 & 688128 & 6.5 & 4.8711 & TST & \\
\hline CHEMBL1391921 & 688128 & 5.0 & 5.272 & TRN & \\
\hline CHEMBL1438051 & 688128 & 4.25 & 4.7144 & TRN & \\
\hline CHEMBL1608156 & 688128 & 4.55 & 4.2234 & TRN & \\
\hline CHEMBL 2095128 & 688128 & 4.35 & 4.9597 & TST & \\
\hline CHEMBL1337561 & 688128 & 4.3 & 4.2722 & TRN & \\
\hline CHEMBL1607000 & 688128 & 5.6 & 4.5201 & TRN & \\
\hline CHEMBL1319585 & 688128 & 4.4 & 4.328 & TRN & \\
\hline CHEMBL1339743 & 688128 & 4.35 & 4.4461 & TRN & \\
\hline CHEMBL1400469 & 688128 & 6.25 & 4.9945 & TRN & \\
\hline CHEMBL1499583 & 688128 & 4.6 & 4.8819 & TRN & \\
\hline CHEMBL1344013 & 688128 & 4.65 & 4.7548 & TRN & \\
\hline CHEMBL1443795 & 688128 & 6.1 & 4.4543 & TRN & \\
\hline CHEMBL1336451 & 688128 & 4.1 & 4.3467 & TST & \\
\hline CHEMBL1581155 & 688128 & 4.25 & 4.5934 & TST & \\
\hline CHEMBL1583792 & 688128 & 4.2 & 4.5809 & TRN & \\
\hline CHEMBL1547022 & 688128 & 4.05 & 4.64199 & 99999999995 & TST \\
\hline CHEMBL1558147 & 688128 & 5.5 & 4.3354 & TRN & \\
\hline CHEMBL1326803 & 688128 & 4.3 & 4.3302 & TRN & \\
\hline CHEMBL1578801 & 688128 & 4.3 & 4.3083 & TST & \\
\hline
\end{tabular}




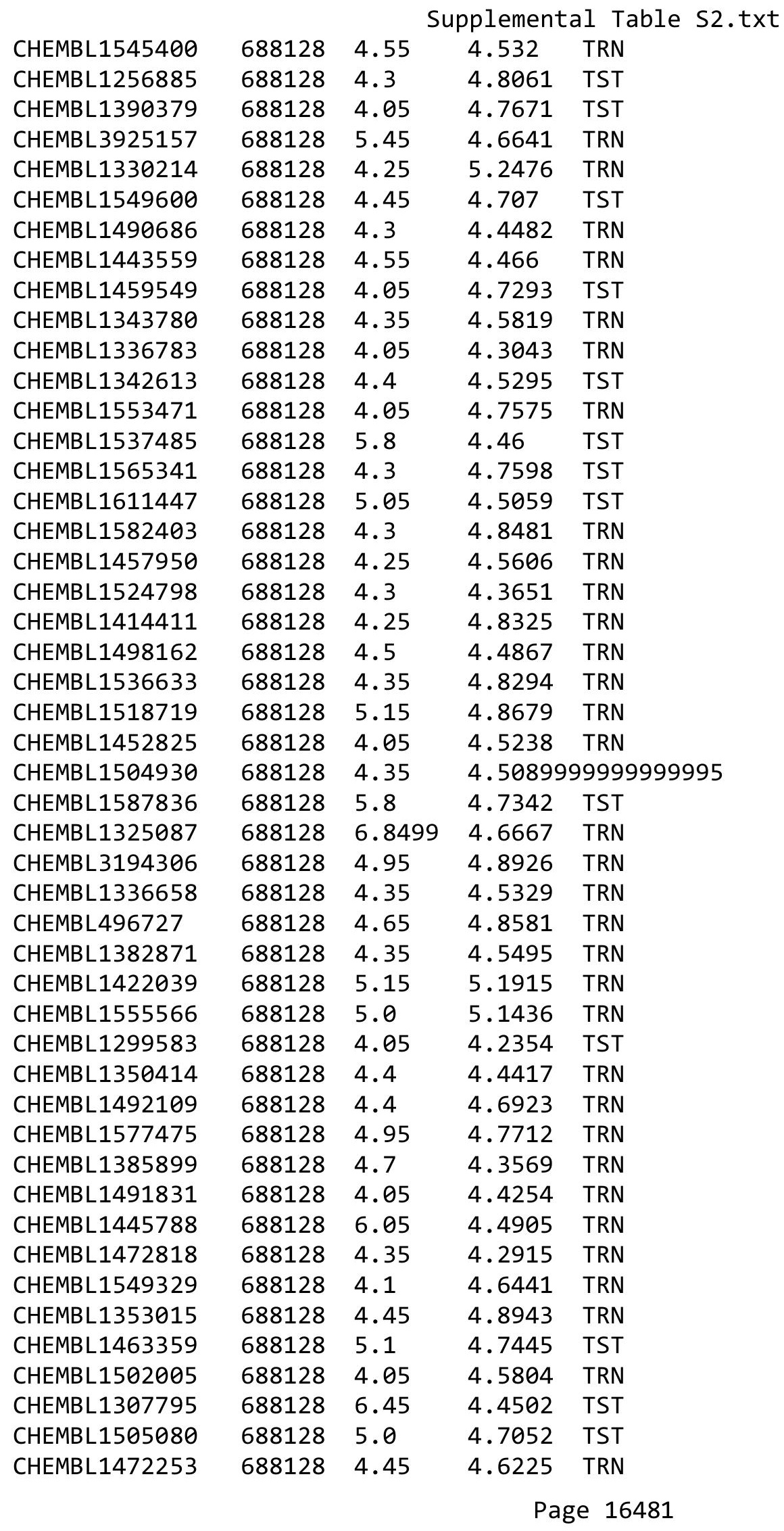




\begin{tabular}{|c|c|c|c|c|c|}
\hline \multicolumn{6}{|c|}{ Supplemental Table S2.txt } \\
\hline CHEMBL3196368 & 688128 & 6.0 & 4.6761 & TRN & \\
\hline CHEMBL1591550 & 688128 & 4.35 & 4.4876 & TRN & \\
\hline CHEMBL1591932 & 688128 & 4.05 & 4.5578 & TRN & \\
\hline CHEMBL1436946 & 688128 & 4.35 & 4.6452 & TST & \\
\hline CHEMBL3209973 & 688128 & 4.05 & 4.7443 & TST & \\
\hline CHEMBL1439052 & 688128 & 4.4 & 4.6495 & TRN & \\
\hline CHEMBL1480371 & 688128 & 4.05 & 4.7067 & TST & \\
\hline CHEMBL1530824 & 688128 & 4.35 & 4.7476 & TRN & \\
\hline CHEMBL1490015 & 688128 & 4.2 & 4.3737 & TRN & \\
\hline CHEMBL1465426 & 688128 & 4.05 & 4.6832 & TST & \\
\hline CHEMBL1494784 & 688128 & 4.3 & 4.6155 & TST & \\
\hline CHEMBL1557404 & 688128 & 4.95 & 4.7052 & TRN & \\
\hline CHEMBL1401798 & 688128 & 4.25 & 4.5658 & TRN & \\
\hline CHEMBL1502953 & 688128 & 4.7 & 4.6304 & TRN & \\
\hline CHEMBL551196 & 688128 & 4.05 & 5.1284 & TRN & \\
\hline CHEMBL1374573 & 688128 & 5.5 & 4.6191 & TRN & \\
\hline CHEMBL1328592 & 688128 & 4.05 & 4.6774 & TRN & \\
\hline CHEMBL1501928 & 688128 & 4.3 & 4.7829 & TRN & \\
\hline CHEMBL1524850 & 688128 & 4.55 & 4.76399 & 9999999999 & TRN \\
\hline CHEMBL1329802 & 688128 & 4.35 & 4.7233 & TRN & \\
\hline CHEMBL1543980 & 688128 & 4.0 & 4.5557 & TST & \\
\hline CHEMBL1507888 & 688128 & 4.35 & 4.4857 & TST & \\
\hline CHEMBL1419838 & 688128 & 4.3 & 4.547 & TRN & \\
\hline CHEMBL1418109 & 688128 & 4.4 & 4.6811 & TRN & \\
\hline CHEMBL1332263 & 688128 & 4.3 & 4.6138 & TRN & \\
\hline CHEMBL1437676 & 688128 & 4.95 & 4.6703 & TST & \\
\hline CHEMBL1300996 & 688128 & 6.0 & 4.4024 & TST & \\
\hline CHEMBL1474408 & 688128 & 4.65 & 4.2313 & TST & \\
\hline CHEMBL1470206 & 688128 & 4.3 & 4.7476 & TRN & \\
\hline CHEMBL1478101 & 688128 & 4.3 & 4.1764 & TRN & \\
\hline CHEMBL1990748 & 688128 & 5.65 & 4.6874 & TRN & \\
\hline CHEMBL1601288 & 688128 & 4.0 & 4.7434 & TST & \\
\hline CHEMBL1414511 & 688128 & 4.05 & 4.4808 & TST & \\
\hline CHEMBL1477375 & 688128 & 4.4 & 4.6344 & TST & \\
\hline CHEMBL1388713 & 688128 & 4.05 & 4.6239 & TRN & \\
\hline CHEMBL1462536 & 688128 & 4.05 & 4.4824 & TRN & \\
\hline CHEMBL201289 & 688128 & 6.05 & 5.3132 & TRN & \\
\hline CHEMBL1518806 & 688128 & 4.35 & 4.8262 & TRN & \\
\hline CHEMBL1548472 & 688128 & 4.3 & 4.7929 & TRN & \\
\hline CHEMBL1372761 & 688128 & 5.1 & 4.6562 & TST & \\
\hline CHEMBL1593022 & 688128 & 4.55 & 4.5523 & TRN & \\
\hline CHEMBL1365482 & 688128 & 4.2 & 4.7529 & TRN & \\
\hline CHEMBL1479289 & 688128 & 4.35 & 4.9433 & TRN & \\
\hline CHEMBL1351193 & 688128 & 5.4 & 4.6698 & TRN & \\
\hline CHEMBL1348840 & 688128 & 4.35 & 4.7193 & TRN & \\
\hline CHEMBL1451887 & 688128 & 4.65 & 4.277 & TRN & \\
\hline CHEMBL1490543 & 688128 & 4.2 & 4.4308 & TRN & \\
\hline CHEMBL1312407 & 688128 & 4.45 & 4.4672 & TRN & \\
\hline
\end{tabular}




\begin{tabular}{|c|c|c|c|c|}
\hline \multicolumn{5}{|c|}{ Supplemental Table S2.txt } \\
\hline CHEMBL1561738 & 688128 & 5.5 & 4.4767 & TRN \\
\hline CHEMBL1548374 & 688128 & 5.3 & 4.8209 & TRN \\
\hline CHEMBL1388316 & 688128 & 4.45 & 4.4448 & TST \\
\hline CHEMBL1410871 & 688128 & 4.3 & 4.7007 & TRN \\
\hline CHEMBL1560856 & 688128 & 4.35 & 4.4489 & TRN \\
\hline CHEMBL1370198 & 688128 & 4.35 & 4.665 & TRN \\
\hline CHEMBL1610334 & 688128 & 5.4 & 4.5244 & TRN \\
\hline CHEMBL1301512 & 688128 & 4.35 & 4.6337 & TRN \\
\hline CHEMBL1319267 & 688128 & 4.8 & 4.5813 & TRN \\
\hline CHEMBL1348654 & 688128 & 4.5 & 4.8015 & TRN \\
\hline CHEMBL1372557 & 688128 & 4.35 & 4.9257 & TRN \\
\hline CHEMBL1433131 & 688128 & 4.0 & $4.8210 \ell$ & 0000000001 \\
\hline CHEMBL1373527 & 688128 & 4.3 & 4.5245 & TRN \\
\hline CHEMBL1313416 & 688128 & 4.6 & 4.9577 & TST \\
\hline CHEMBL1415461 & 688128 & 5.45 & 4.3727 & TRN \\
\hline CHEMBL1508847 & 688128 & 5.3 & 5.0062 & TRN \\
\hline CHEMBL3210113 & 688128 & 6.0 & 4.7379 & TST \\
\hline CHEMBL1333876 & 688128 & 4.35 & 4.6404 & TST \\
\hline CHEMBL1566296 & 688128 & 5.45 & 4.5579 & TRN \\
\hline CHEMBL140 & 688128 & 4.4 & 4.8258 & TRN \\
\hline CHEMBL1318662 & 688128 & 4.35 & 4.4782 & TRN \\
\hline CHEMBL1533597 & 688128 & 4.4 & 4.6847 & TST \\
\hline CHEMBL1463031 & 688128 & 4.0 & 4.3872 & TRN \\
\hline CHEMBL1464308 & 688128 & 4.35 & 4.5983 & TST \\
\hline CHEMBL1321082 & 688128 & 4.0 & 4.7669 & TST \\
\hline CHEMBL1496770 & 688128 & 4.5 & 4.6894 & TRN \\
\hline CHEMBL1381732 & 688128 & 4.45 & 4.5005 & TRN \\
\hline CHEMBL1509561 & 688128 & 4.5 & 4.641 & TRN \\
\hline CHEMBL1377932 & 688128 & 6.0 & 4.9724 & TRN \\
\hline CHEMBL1314785 & 688128 & 4.25 & 4.5806 & TRN \\
\hline CHEMBL1992547 & 688128 & 4.3 & 4.5028 & TRN \\
\hline CHEMBL1536209 & 688128 & 4.4 & 4.4311 & TRN \\
\hline CHEMBL1411540 & 688128 & 6.5 & 5.2291 & TRN \\
\hline CHEMBL1503264 & 688128 & 4.3 & 4.5243 & TST \\
\hline CHEMBL1570066 & 688128 & 4.35 & 4.7227 & TRN \\
\hline CHEMBL1304259 & 688128 & 4.5 & 4.5924 & TRN \\
\hline CHEMBL1602069 & 688128 & 4.25 & 4.9005 & TST \\
\hline CHEMBL1594182 & 688128 & 5.65 & 5.008 & TRN \\
\hline CHEMBL 1377546 & 688128 & 5.2 & 4.4307 & TRN \\
\hline CHEMBL1373000 & 688128 & 6.15 & 4.877 & TRN \\
\hline CHEMBL1451297 & 688128 & 6.45 & 4.5765 & TST \\
\hline CHEMBL1407324 & 688128 & 5.05 & 4.9826 & TST \\
\hline CHEMBL1424532 & 688128 & 4.4 & 4.4619 & TRN \\
\hline CHEMBL1475144 & 688128 & 4.4 & 4.5647 & TRN \\
\hline CHEMBL1520740 & 688128 & 4.45 & 4.6763 & TRN \\
\hline CHEMBL3213329 & 688128 & 4.65 & 4.5554 & TRN \\
\hline CHEMBL1324773 & 688128 & 4.05 & 4.5622 & TST \\
\hline CHEMBL1342820 & 688128 & 4.35 & 4.5806 & TRN \\
\hline
\end{tabular}




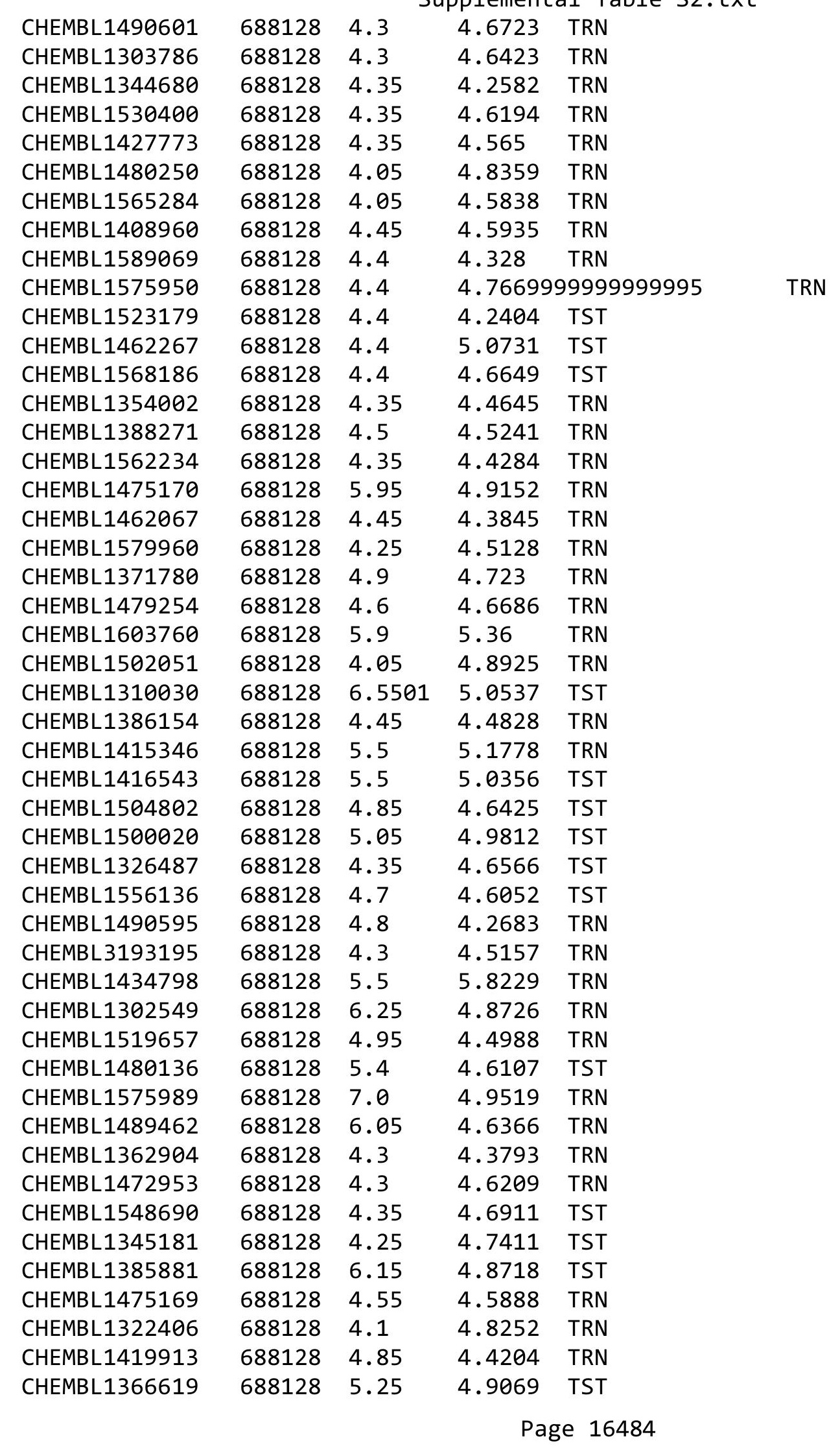




\begin{tabular}{|c|c|c|c|c|c|}
\hline \multicolumn{6}{|c|}{ Supplemental Table S2.txt } \\
\hline CHEMBL1567652 & 688128 & 4.05 & 4.4343 & TRN & \\
\hline CHEMBL1303616 & 688128 & 4.35 & 4.5076 & TRN & \\
\hline CHEMBL1575788 & 688128 & 4.45 & 4.7853 & TRN & \\
\hline CHEMBL 3192537 & 688128 & 4.7 & 4.7166 & TRN & \\
\hline CHEMBL1381761 & 688128 & 4.8 & 4.6667 & TRN & \\
\hline CHEMBL1432415 & 688128 & 4.6 & 4.6487 & TRN & \\
\hline CHEMBL1374689 & 688128 & 4.55 & 4.7983 & TRN & \\
\hline CHEMBL1421509 & 688128 & 5.8 & 4.8352 & TRN & \\
\hline CHEMBL1360205 & 688128 & 6.0 & 4.891 & TRN & \\
\hline CHEMBL1408495 & 688128 & 4.4 & 4.5543 & TRN & \\
\hline CHEMBL1331931 & 688128 & 4.65 & 4.5044 & TST & \\
\hline CHEMBL1425516 & 688128 & 4.35 & 4.5042 & TST & \\
\hline CHEMBL1479828 & 688128 & 5.6 & 4.7837 & TRN & \\
\hline CHEMBL1385763 & 688128 & 4.3 & 4.6848 & TRN & \\
\hline CHEMBL1410936 & 688128 & 4.3 & 4.5604 & TST & \\
\hline CHEMBL1978488 & 688128 & 4.4 & 4.5514 & TRN & \\
\hline CHEMBL1562523 & 688128 & 4.5 & 4.5998 & TRN & \\
\hline CHEMBL1599757 & 688128 & 4.95 & 4.9729 & TST & \\
\hline CHEMBL1485021 & 688128 & 4.5 & 4.5921 & TST & \\
\hline CHEMBL1343719 & 688128 & 4.3 & 4.5582 & TST & \\
\hline CHEMBL1472502 & 688128 & 4.95 & 4.3787 & TRN & \\
\hline CHEMBL1452727 & 688128 & 4.55 & 4.7692 & TRN & \\
\hline CHEMBL1602775 & 688128 & 4.9 & 4.5301 & TST & \\
\hline CHEMBL1353601 & 688128 & 4.45 & 4.5847 & TST & \\
\hline CHEMBL1371943 & 688128 & 4.35 & 4.6094 & TRN & \\
\hline CHEMBL1488661 & 688128 & 4.55 & 4.762 & TRN & \\
\hline CHEMBL1588972 & 688128 & 4.3 & 4.5149 & TST & \\
\hline CHEMBL1307165 & 688128 & 4.45 & 4.7876 & TRN & \\
\hline CHEMBL1600674 & 688128 & 4.65 & 4.482 & TRN & \\
\hline CHEMBL1336312 & 688128 & 4.65 & 4.5549 & TRN & \\
\hline CHEMBL1569773 & 688128 & 4.3 & 4.28600 & 00000000005 & TRN \\
\hline CHEMBL1533348 & 688128 & 4.05 & 4.5927 & TRN & \\
\hline CHEMBL1361777 & 688128 & 4.55 & 4.4142 & TRN & \\
\hline CHEMBL1329082 & 688128 & 4.7 & 4.4284 & TST & \\
\hline CHEMBL1362355 & 688128 & 4.25 & 4.4854 & TRN & \\
\hline CHEMBL1323245 & 688128 & 5.05 & 4.993 & TRN & \\
\hline CHEMBL1339791 & 688128 & 6.15 & 4.6871 & TST & \\
\hline CHEMBL1507732 & 688128 & 4.3 & 4.3585 & TRN & \\
\hline CHEMBL1516393 & 688128 & 4.3 & 4.4232 & TRN & \\
\hline CHEMBL1453222 & 688128 & 4.95 & 5.0 & TRN & \\
\hline CHEMBL1606328 & 688128 & 4.3 & 4.9752 & TRN & \\
\hline CHEMBL1599994 & 688128 & 4.85 & 4.6756 & TRN & \\
\hline CHEMBL1596427 & 688128 & 4.35 & 4.2939 & TRN & \\
\hline CHEMBL1464110 & 688128 & 4.55 & 4.7434 & TST & \\
\hline CHEMBL1577584 & 688128 & 4.25 & 4.5965 & TRN & \\
\hline CHEMBL1466348 & 688128 & 4.45 & 4.6442 & TRN & \\
\hline CHEMBL1367144 & 688128 & 4.4 & 5.0442 & TST & \\
\hline CHEMBL1331887 & 688128 & 4.3 & 4.7379 & TRN & \\
\hline
\end{tabular}




\begin{tabular}{|c|c|c|c|c|c|}
\hline \multicolumn{6}{|c|}{ Supplemental Table S2.txt } \\
\hline CHEMBL1351755 & 688128 & 5.8 & 5.2053 & TRN & \\
\hline CHEMBL1395706 & 688128 & 4.3 & 4.7759 & TST & \\
\hline CHEMBL1537473 & 688128 & 4.45 & 4.5091 & TRN & \\
\hline CHEMBL1399802 & 688128 & 6.6 & 5.1271 & TRN & \\
\hline CHEMBL1507449 & 688128 & 4.3 & 4.6353 & TRN & \\
\hline CHEMBL1454110 & 688128 & 4.3 & 4.8361 & TRN & \\
\hline CHEMBL1578720 & 688128 & 4.8 & 4.5296 & TRN & \\
\hline CHEMBL1582987 & 688128 & 4.65 & 4.5454 & TRN & \\
\hline CHEMBL1323764 & 688128 & 5.4 & 4.8474 & TRN & \\
\hline CHEMBL1409849 & 688128 & 6.6499 & 4.6637 & TST & \\
\hline CHEMBL1601446 & 688128 & 4.35 & 4.4914 & TRN & \\
\hline CHEMBL1315054 & 688128 & 5.05 & 4.6782 & TRN & \\
\hline CHEMBL1538652 & 688128 & 6.0 & 5.1526 & TRN & \\
\hline CHEMBL1400152 & 688128 & 4.25 & 4.5853 & TRN & \\
\hline CHEMBL1497012 & 688128 & 4.4 & 4.5841 & TRN & \\
\hline CHEMBL1442836 & 688128 & 4.35 & 4.399 & TRN & \\
\hline CHEMBL1373674 & 688128 & 4.35 & 4.57100 & 0000000001 & TRN \\
\hline CHEMBL1305194 & 688128 & 4.35 & 4.471 & TRN & \\
\hline CHEMBL1409120 & 688128 & 4.5 & 4.711 & TRN & \\
\hline CHEMBL1486219 & 688128 & 4.45 & 4.8804 & TST & \\
\hline CHEMBL1300206 & 688128 & 4.3 & 4.4759 & TRN & \\
\hline CHEMBL1307368 & 688128 & 4.0 & 4.2585 & TST & \\
\hline CHEMBL1584680 & 688128 & 4.65 & 4.4751 & TRN & \\
\hline CHEMBL1469246 & 688128 & 4.75 & 5.166 & TRN & \\
\hline CHEMBL1565744 & 688128 & 5.0 & 4.6655 & TRN & \\
\hline CHEMBL1538100 & 688128 & 4.5 & 4.8381 & TRN & \\
\hline CHEMBL1335646 & 688128 & 4.1 & 4.4068 & TST & \\
\hline CHEMBL1607594 & 688128 & 4.05 & 4.3143 & TST & \\
\hline CHEMBL1386017 & 688128 & 4.25 & 4.5848 & TST & \\
\hline CHEMBL1306380 & 688128 & 4.05 & 4.3785 & TRN & \\
\hline CHEMBL1440025 & 688128 & 4.05 & 4.7408 & TST & \\
\hline CHEMBL1395482 & 688128 & 5.4 & 4.6091 & TRN & \\
\hline CHEMBL1486675 & 688128 & 4.5 & 4.9067 & TRN & \\
\hline CHEMBL1349018 & 688128 & 4.35 & 4.6766 & TRN & \\
\hline CHEMBL3195139 & 688128 & 4.6 & 4.6821 & TST & \\
\hline CHEMBL1590381 & 688128 & 4.3 & 4.5349 & TST & \\
\hline CHEMBL1304911 & 688128 & 4.3 & 4.7428 & TST & \\
\hline CHEMBL1486352 & 688128 & 6.15 & 5.1533 & TRN & \\
\hline CHEMBL1539824 & 688128 & 4.55 & 4.7821 & TRN & \\
\hline CHEMBL1302103 & 688128 & 4.05 & 4.6947 & TST & \\
\hline CHEMBL1330359 & 688128 & 4.4 & 4.5802 & TRN & \\
\hline CHEMBL1304369 & 688128 & 4.75 & 4.7784 & TRN & \\
\hline CHEMBL1546239 & 688128 & 5.35 & 4.8023 & TRN & \\
\hline CHEMBL1305852 & 688128 & 4.35 & 4.6251 & TRN & \\
\hline CHEMBL1310502 & 688128 & 5.35 & 4.8373 & TRN & \\
\hline CHEMBL3197237 & 688128 & 4.65 & 4.7792 & TST & \\
\hline CHEMBL 2007180 & 688128 & 4.75 & 4.813 & TRN & \\
\hline CHEMBL1482176 & 688128 & 4.05 & 4.4484 & TST & \\
\hline
\end{tabular}




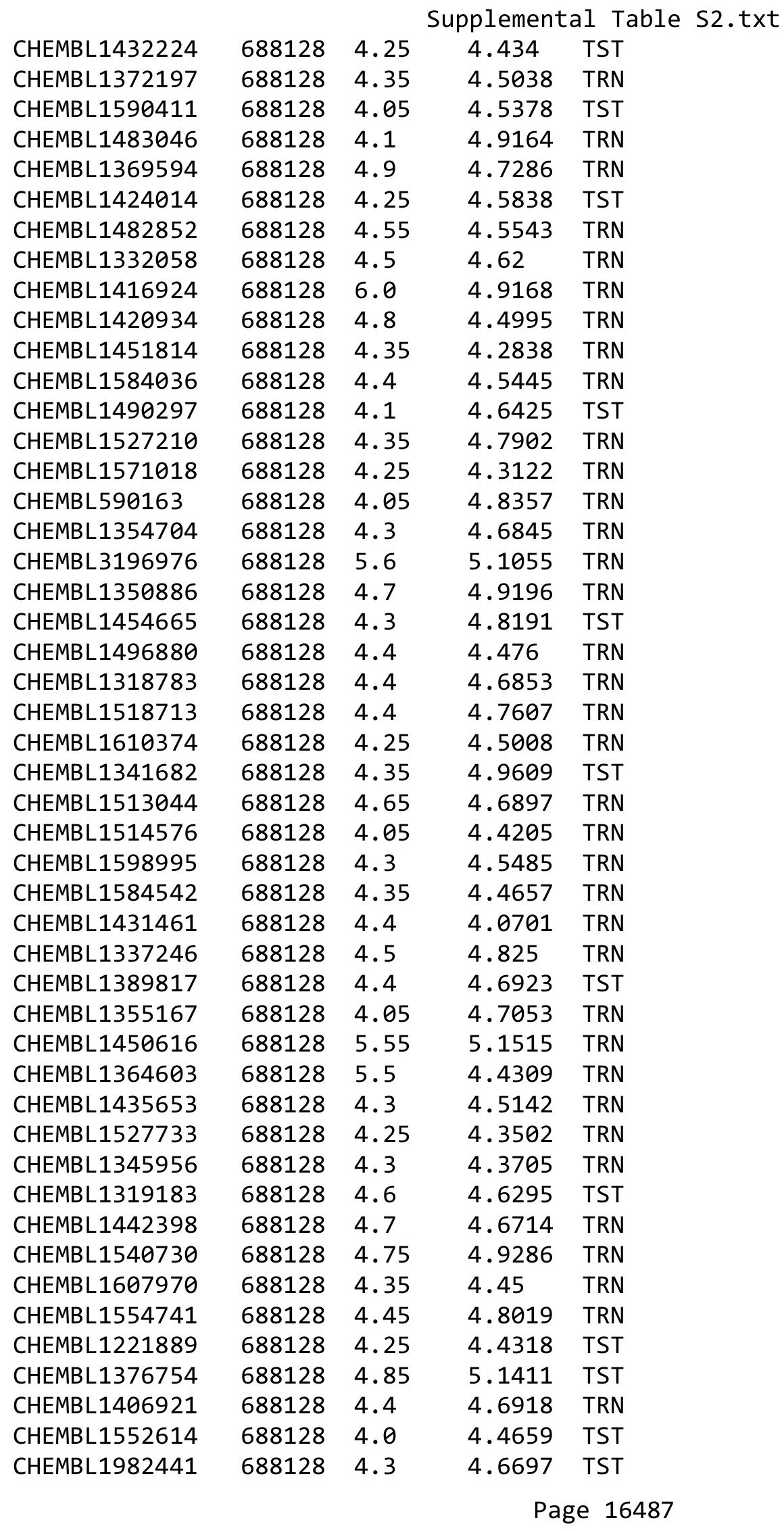




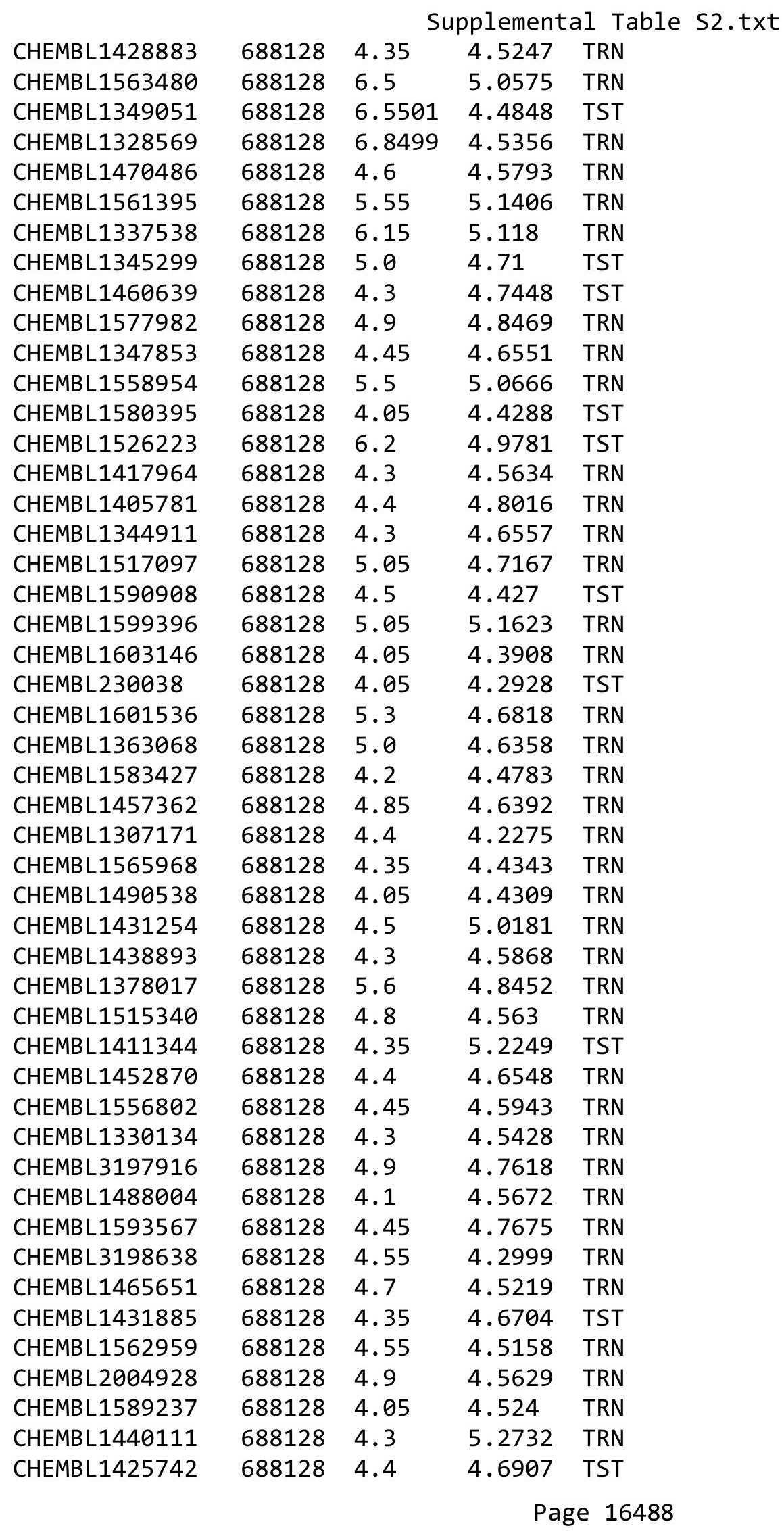




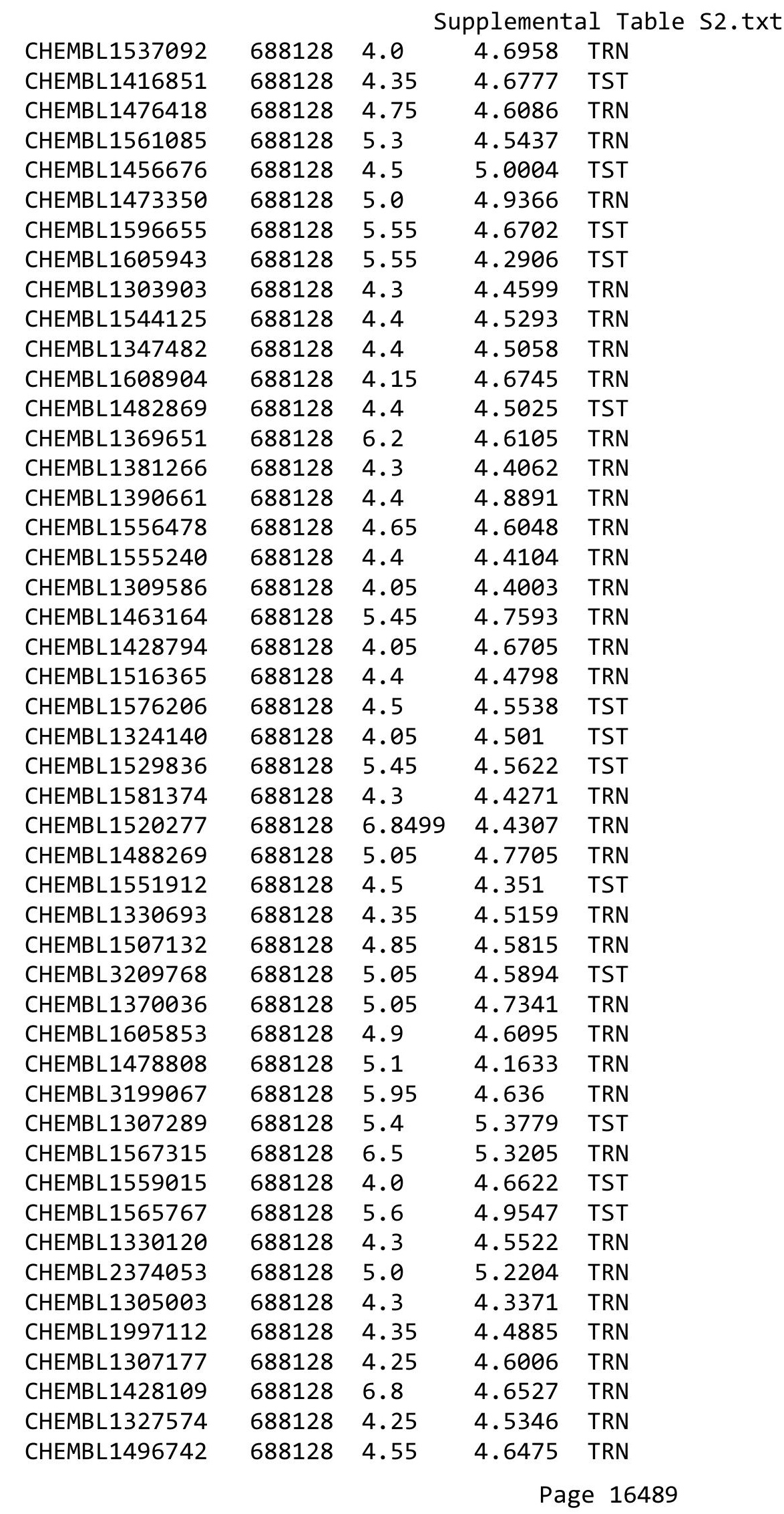




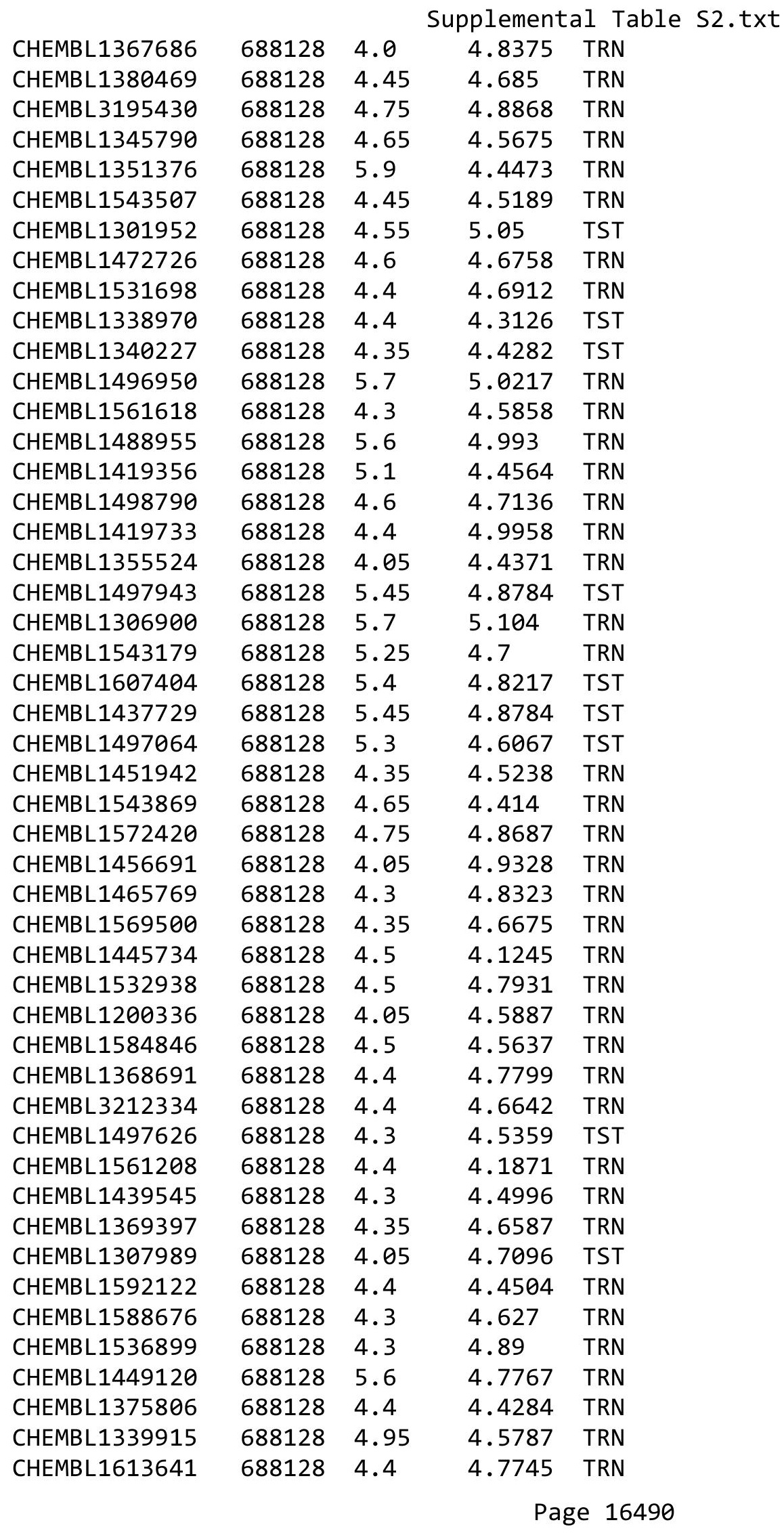




\begin{tabular}{|c|c|c|c|c|c|}
\hline \multicolumn{6}{|c|}{ Supplemental Table S2.txt } \\
\hline CHEMBL1566163 & 688128 & 4.3 & 4.6366 & TRN & \\
\hline CHEMBL1517406 & 688128 & 4.25 & 4.6026 & TRN & \\
\hline CHEMBL1451344 & 688128 & 4.85 & 4.7488 & TST & \\
\hline CHEMBL1419679 & 688128 & 4.35 & 4.5976 & TST & \\
\hline CHEMBL 2001408 & 688128 & 4.85 & 4.71399 & 99999999995 & TRN \\
\hline CHEMBL1479099 & 688128 & 5.0 & 4.5552 & TST & \\
\hline CHEMBL1355649 & 688128 & 4.05 & 4.3154 & TRN & \\
\hline CHEMBL1548238 & 688128 & 7.0 & 4.5732 & TST & \\
\hline CHEMBL1551340 & 688128 & 4.75 & 4.6718 & TST & \\
\hline CHEMBL1566215 & 688128 & 5.75 & 4.6699 & TRN & \\
\hline CHEMBL1579528 & 688128 & 4.5 & 5.0091 & TRN & \\
\hline CHEMBL1558692 & 688128 & 4.75 & 4.2202 & TST & \\
\hline CHEMBL 2136498 & 688128 & 4.4 & 4.5318 & TRN & \\
\hline CHEMBL1443752 & 688128 & 4.05 & 4.5666 & TST & \\
\hline CHEMBL3195522 & 688128 & 4.35 & 4.6448 & TRN & \\
\hline CHEMBL1601307 & 688128 & 4.45 & 4.6214 & TRN & \\
\hline CHEMBL1451060 & 688128 & 4.0 & 4.7086 & TRN & \\
\hline CHEMBL1533996 & 688128 & 4.4 & 4.6447 & TST & \\
\hline CHEMBL1497381 & 688128 & 6.05 & 4.9903 & TRN & \\
\hline CHEMBL3197464 & 688128 & 4.8 & 4.4638 & TRN & \\
\hline CHEMBL1336497 & 688128 & 4.55 & 4.52800 & 00000000005 & TRN \\
\hline CHEMBL1439426 & 688128 & 4.35 & 4.73300 & 00000000005 & TRN \\
\hline CHEMBL1522153 & 688128 & 4.4 & 4.5155 & TRN & \\
\hline CHEMBL1487205 & 688128 & 5.35 & 5.0854 & TRN & \\
\hline CHEMBL1444424 & 688128 & 4.4 & 4.4397 & TRN & \\
\hline CHEMBL1578617 & 688128 & 4.95 & 4.836 & TRN & \\
\hline CHEMBL1462900 & 688128 & 5.8 & 4.8591 & TST & \\
\hline CHEMBL1609950 & 688128 & 4.4 & 4.5248 & TRN & \\
\hline CHEMBL1588050 & 688128 & 5.0 & 4.7955 & TRN & \\
\hline CHEMBL1374841 & 688128 & 5.05 & 4.8774 & TRN & \\
\hline CHEMBL1370570 & 688128 & 4.05 & 4.6315 & TST & \\
\hline CHEMBL1551222 & 688128 & 6.5501 & 5.1579 & TRN & \\
\hline CHEMBL1549570 & 688128 & 4.05 & 4.4052 & TRN & \\
\hline CHEMBL1356102 & 688128 & 4.4 & 4.3443 & TST & \\
\hline CHEMBL1563406 & 688128 & 4.05 & 4.3666 & TST & \\
\hline CHEMBL1501424 & 688128 & 4.35 & 4.5884 & TRN & \\
\hline CHEMBL1587421 & 688128 & 4.4 & 4.4726 & TRN & \\
\hline CHEMBL1443803 & 688128 & 4.4 & 4.2828 & TRN & \\
\hline CHEMBL1463964 & 688128 & 4.35 & 4.8403 & TRN & \\
\hline CHEMBL1455042 & 688128 & 4.35 & 4.5994 & TST & \\
\hline CHEMBL1535145 & 688128 & 4.9 & 4.63 & TRN & \\
\hline CHEMBL1530802 & 688128 & 4.4 & 4.5917 & TRN & \\
\hline CHEMBL1443464 & 688128 & 4.35 & 4.8956 & TRN & \\
\hline CHEMBL1362557 & 688128 & 4.0 & 4.6277 & TST & \\
\hline CHEMBL1403685 & 688128 & 4.5 & 4.9549 & TST & \\
\hline CHEMBL1419030 & 688128 & 4.45 & 4.7192 & TST & \\
\hline CHEMBL1557855 & 688128 & 4.35 & 4.6567 & TRN & \\
\hline CHEMBL1565500 & 688128 & 5.6 & 5.2863 & TRN & \\
\hline
\end{tabular}




\begin{tabular}{|c|c|c|c|c|c|}
\hline \multicolumn{6}{|c|}{ Supplemental Table S2.txt } \\
\hline CHEMBL1445102 & 688128 & 4.6 & 4.4755 & TRN & \\
\hline CHEMBL1360939 & 688128 & 4.85 & 4.7009 & TRN & \\
\hline CHEMBL1424819 & 688128 & 5.4 & 4.9005 & TRN & \\
\hline CHEMBL1403674 & 688128 & 4.65 & 5.1156 & TRN & \\
\hline CHEMBL1459671 & 688128 & 4.25 & 4.6771 & TST & \\
\hline CHEMBL1447571 & 688128 & 5.4 & 4.5839 & TST & \\
\hline CHEMBL1523260 & 688128 & 4.65 & 4.61 & TRN & \\
\hline CHEMBL1436374 & 688128 & 4.1 & 4.30699 & 99999999995 & TRN \\
\hline CHEMBL1507483 & 688128 & 4.2 & 4.6385 & TRN & \\
\hline CHEMBL1558216 & 688128 & 5.6 & 4.8478 & TRN & \\
\hline CHEMBL1403201 & 688128 & 4.35 & 4.7461 & TRN & \\
\hline CHEMBL1301477 & 688128 & 4.9 & 4.6171 & TRN & \\
\hline CHEMBL1302323 & 688128 & 4.3 & 4.3531 & TRN & \\
\hline CHEMBL1384894 & 688128 & 4.5 & 4.5339 & TRN & \\
\hline CHEMBL365558 & 688128 & 4.55 & 4.54899 & 99999999995 & TRN \\
\hline CHEMBL1531337 & 688128 & 4.25 & 4.8046 & TRN & \\
\hline CHEMBL3195556 & 688128 & 4.3 & 4.439 & TRN & \\
\hline CHEMBL1382073 & 688128 & 4.05 & 4.5784 & TRN & \\
\hline CHEMBL1431930 & 688128 & 4.6 & 4.6884 & TST & \\
\hline CHEMBL1380403 & 688128 & 5.45 & 4.9427 & TRN & \\
\hline CHEMBL1528887 & 688128 & 4.25 & 4.8812 & TRN & \\
\hline CHEMBL1423923 & 688128 & 4.25 & 4.9155 & TRN & \\
\hline CHEMBL1325120 & 688128 & 6.15 & 4.5212 & TRN & \\
\hline CHEMBL3197017 & 688128 & 4.35 & 4.9689 & TST & \\
\hline CHEMBL1458191 & 688128 & 5.35 & 4.5823 & TRN & \\
\hline CHEMBL1559171 & 688128 & 4.3 & 4.5631 & TRN & \\
\hline CHEMBL1529392 & 688128 & 4.35 & 4.8555 & TRN & \\
\hline CHEMBL1321308 & 688128 & 4.8 & 4.5939 & TRN & \\
\hline CHEMBL1485878 & 688128 & 4.1 & 4.9708 & TST & \\
\hline CHEMBL1588505 & 688128 & 4.3 & 4.7577 & TRN & \\
\hline CHEMBL1508139 & 688128 & 4.4 & 4.8758 & TST & \\
\hline CHEMBL1593341 & 688128 & 5.3 & 4.5497 & TST & \\
\hline CHEMBL1443562 & 688128 & 4.45 & 4.9178 & TRN & \\
\hline CHEMBL1383525 & 688128 & 4.4 & 4.44600 & 3000000001 & TRN \\
\hline CHEMBL1605631 & 688128 & 4.4 & 4.4534 & TRN & \\
\hline CHEMBL1613066 & 688128 & 4.5 & 4.6352 & TRN & \\
\hline CHEMBL1442841 & 688128 & 4.55 & 4.7299 & TRN & \\
\hline CHEMBL1602334 & 688128 & 4.25 & 4.725 & TRN & \\
\hline CHEMBL1492069 & 688128 & 4.6 & 4.5638 & TRN & \\
\hline CHEMBL1570609 & 688128 & 4.1 & 4.7068 & TST & \\
\hline CHEMBL1482269 & 688128 & 5.05 & 5.0742 & TRN & \\
\hline CHEMBL1321535 & 688128 & 4.4 & 4.9133 & TRN & \\
\hline CHEMBL1435294 & 688128 & 4.45 & 4.541 & TST & \\
\hline CHEMBL1546954 & 688128 & 4.05 & 4.8451 & TST & \\
\hline CHEMBL1373849 & 688128 & 4.35 & 4.7431 & TRN & \\
\hline CHEMBL1413626 & 688128 & 5.8 & 4.8287 & TRN & \\
\hline CHEMBL1402836 & 688128 & 4.4 & 4.4288 & TRN & \\
\hline CHEMBL3192080 & 688128 & 4.4 & 4.7455 & TRN & \\
\hline
\end{tabular}




\begin{tabular}{|c|c|c|c|c|c|}
\hline & & \multicolumn{4}{|c|}{ Supplemental Table s2.txt } \\
\hline CHEMBL3196430 & 688128 & 4.7 & 4.8037 & TST & \\
\hline CHEMBL1422602 & 688128 & 4.6 & 4.4788 & TRN & \\
\hline CHEMBL1499070 & 688128 & 4.05 & 4.5335 & TRN & \\
\hline CHEMBL1586056 & 688128 & 4.75 & 4.5194 & TRN & \\
\hline CHEMBL1418166 & 688128 & 4.4 & 4.6792 & TRN & \\
\hline CHEMBL1522338 & 688128 & 4.4 & 4.6134 & TRN & \\
\hline CHEMBL1571638 & 688128 & 5.4 & 4.7564 & TST & \\
\hline CHEMBL1389360 & 688128 & 4.4 & 4.9131 & TRN & \\
\hline CHEMBL1392331 & 688128 & 5.45 & 4.5246 & TRN & \\
\hline CHEMBL1300239 & 688128 & 4.0 & 4.5321 & TRN & \\
\hline CHEMBL1365286 & 688128 & 4.35 & 4.4724 & TRN & \\
\hline CHEMBL1355538 & 688128 & 4.3 & 4.7168 & TST & \\
\hline CHEMBL1303633 & 688128 & 4.45 & 4.6468 & TRN & \\
\hline CHEMBL1471306 & 688128 & 5.6 & 5.1558 & TRN & \\
\hline CHEMBL1560724 & 688128 & 4.45 & 4.422 & TRN & \\
\hline CHEMBL455399 & 688128 & 4.8 & 4.8813 & TST & \\
\hline CHEMBL1602052 & 688128 & 4.85 & 4.6725 & TRN & \\
\hline CHEMBL1506668 & 688128 & 4.3 & 4.68199 & 99999999995 & TRN \\
\hline CHEMBL1427786 & 688128 & 4.4 & 4.7005 & TST & \\
\hline CHEMBL1414237 & 688128 & 4.05 & 4.4277 & TRN & \\
\hline CHEMBL 2374021 & 688128 & 4.95 & 4.7739 & TRN & \\
\hline CHEMBL1560485 & 688128 & 5.0 & 4.6346 & TRN & \\
\hline CHEMBL1404587 & 688128 & 4.4 & 4.6007 & TRN & \\
\hline CHEMBL1555856 & 688128 & 4.0 & 4.303 & TRN & \\
\hline CHEMBL1564865 & 688128 & 4.35 & 4.3931 & TRN & \\
\hline CHEMBL1401194 & 688128 & 6.9 & 4.7371 & TRN & \\
\hline CHEMBL1566203 & 688128 & 4.5 & 4.8186 & TRN & \\
\hline CHEMBL1429175 & 688128 & 4.35 & 4.6772 & TRN & \\
\hline CHEMBL1541006 & 688128 & 4.0 & 4.6515 & TST & \\
\hline CHEMBL1318717 & 688128 & 4.3 & 4.5067 & TRN & \\
\hline CHEMBL1611636 & 688128 & 4.45 & 4.6788 & TRN & \\
\hline CHEMBL3191236 & 688128 & 4.55 & 4.5273 & TRN & \\
\hline CHEMBL1612524 & 688128 & 4.6 & 4.4469 & TRN & \\
\hline CHEMBL1332545 & 688128 & 4.55 & 4.8121 & TRN & \\
\hline CHEMBL1548360 & 688128 & 4.3 & 4.7534 & TRN & \\
\hline CHEMBL1414010 & 688128 & 4.4 & 4.5932 & TRN & \\
\hline CHEMBL1495167 & 688128 & 4.35 & 4.4796 & TRN & \\
\hline CHEMBL1425318 & 688128 & 4.6 & 4.46 & TRN & \\
\hline CHEMBL1421468 & 688128 & 5.05 & 4.4386 & TRN & \\
\hline CHEMBL1599302 & 688128 & 4.3 & 4.5425 & TST & \\
\hline CHEMBL1506031 & 688128 & 4.35 & 4.5582 & TST & \\
\hline CHEMBL1548506 & 688128 & 5.35 & 4.5383 & TST & \\
\hline CHEMBL1579437 & 688128 & 4.35 & 4.6303 & TRN & \\
\hline CHEMBL1506534 & 688128 & 4.7 & 4.7286 & TRN & \\
\hline CHEMBL1542693 & 688128 & 4.35 & 5.0543 & TRN & \\
\hline CHEMBL3209703 & 688128 & 5.0 & 4.7093 & TRN & \\
\hline CHEMBL1493745 & 688128 & 6.05 & 4.521 & TRN & \\
\hline CHEMBL1388244 & 688128 & 4.4 & 4.3662 & TRN & \\
\hline
\end{tabular}




\begin{tabular}{|c|c|c|c|c|}
\hline \multicolumn{5}{|c|}{ Supplemental Table S2.txt } \\
\hline CHEMBL1324015 & 688128 & 5.1 & 4.7739 & TST \\
\hline CHEMBL1506621 & 688128 & 6.1 & 4.5882 & TST \\
\hline CHEMBL1373061 & 688128 & 4.9 & 4.52 & TRN \\
\hline CHEMBL1359202 & 688128 & 4.0 & 4.7364 & TST \\
\hline CHEMBL1981464 & 688128 & 4.75 & 4.5296 & TST \\
\hline CHEMBL1588953 & 688128 & 4.3 & 4.6995 & TRN \\
\hline CHEMBL1524877 & 688128 & 4.3 & 4.9677 & TRN \\
\hline CHEMBL1484332 & 688128 & 4.75 & 4.7349 & TRN \\
\hline CHEMBL1346739 & 688128 & 4.4 & 4.5222 & TST \\
\hline CHEMBL592124 & 688128 & 6.5 & 5.3314 & TRN \\
\hline CHEMBL1494449 & 688128 & 4.45 & 4.1925 & TRN \\
\hline CHEMBL1350232 & 688128 & 4.05 & 4.537 & TRN \\
\hline CHEMBL1543936 & 688128 & 4.4 & 4.5216 & TRN \\
\hline CHEMBL1392151 & 688128 & 4.4 & 4.4463 & TST \\
\hline CHEMBL1504629 & 688128 & 5.5 & 4.6736 & TRN \\
\hline CHEMBL1513980 & 688128 & 4.25 & 4.7073 & TRN \\
\hline CHEMBL1402153 & 688128 & 5.6 & 5.0842 & TRN \\
\hline CHEMBL1406445 & 688128 & 4.4 & 4.9037 & TST \\
\hline CHEMBL1371393 & 688128 & 5.35 & 4.7295 & TRN \\
\hline CHEMBL1537735 & 688128 & 4.9 & 4.9567 & TRN \\
\hline CHEMBL1536637 & 688128 & 4.25 & 4.4536 & TRN \\
\hline CHEMBL1466631 & 688128 & 4.4 & 4.5615 & TRN \\
\hline CHEMBL1379775 & 688128 & 4.05 & 4.5551 & TRN \\
\hline CHEMBL1578585 & 688128 & 4.05 & 4.7661 & TST \\
\hline CHEMBL1598192 & 688128 & 4.35 & 4.4663 & TRN \\
\hline CHEMBL1560880 & 688128 & 4.3 & 4.6855 & TRN \\
\hline CHEMBL1528235 & 688128 & 4.85 & 4.837 & TRN \\
\hline CHEMBL1314126 & 688128 & 4.25 & 4.5634 & TRN \\
\hline CHEMBL1306038 & 688128 & 4.6 & 4.5444 & TRN \\
\hline CHEMBL1609016 & 688128 & 4.3 & 4.4649 & TST \\
\hline CHEMBL3397111 & 688128 & 6.6 & 4.9901 & TRN \\
\hline CHEMBL1577177 & 688128 & 5.0 & 4.7576 & TRN \\
\hline CHEMBL1410702 & 688128 & 4.25 & 4.651 & TST \\
\hline CHEMBL1528598 & 688128 & 4.5 & 4.5647 & TST \\
\hline CHEMBL1415071 & 688128 & 4.05 & 4.6364 & TST \\
\hline CHEMBL1356747 & 688128 & 4.8 & 4.3337 & TRN \\
\hline CHEMBL1346253 & 688128 & 4.05 & 4.6397 & TRN \\
\hline CHEMBL1341865 & 688128 & 6.25 & 4.9173 & TRN \\
\hline CHEMBL1519288 & 688128 & 4.65 & 4.3767 & TST \\
\hline CHEMBL1517248 & 688128 & 4.05 & 4.6593 & TST \\
\hline CHEMBL1368746 & 688128 & 4.65 & 4.7713 & TRN \\
\hline CHEMBL1423137 & 688128 & 4.4 & 4.8378 & TRN \\
\hline CHEMBL1503967 & 688128 & 4.4 & 4.9562 & TRN \\
\hline CHEMBL1357908 & 688128 & 5.4 & 4.5159 & TRN \\
\hline CHEMBL1356903 & 688128 & 4.6 & 5.0401 & TRN \\
\hline CHEMBL1522199 & 688128 & 4.35 & 4.6291 & TRN \\
\hline CHEMBL1583174 & 688128 & 4.65 & 4.4635 & TRN \\
\hline CHEMBL1311841 & 688128 & 4.05 & 4.3533 & TRN \\
\hline
\end{tabular}




\begin{tabular}{|c|c|c|c|c|c|}
\hline \multicolumn{6}{|c|}{ Supplemental Table S2.txt } \\
\hline CHEMBL1323510 & 688128 & 4.4 & 4.7297 & TRN & \\
\hline CHEMBL1483312 & 688128 & 4.85 & 4.8792 & TRN & \\
\hline CHEMBL1300094 & 688128 & 4.05 & 4.4518 & TRN & \\
\hline CHEMBL1562478 & 688128 & 5.0 & 4.4613 & TRN & \\
\hline CHEMBL1403933 & 688128 & 5.5 & 4.6693 & TRN & \\
\hline CHEMBL1543626 & 688128 & 4.85 & 4.5423 & TRN & \\
\hline CHEMBL1564765 & 688128 & 4.55 & 4.627 & TRN & \\
\hline CHEMBL1441815 & 688128 & 4.25 & 4.3106 & TST & \\
\hline CHEMBL 3196438 & 688128 & 4.5 & 4.601 & TRN & \\
\hline CHEMBL1600052 & 688128 & 4.85 & 4.8356 & TRN & \\
\hline CHEMBL1440267 & 688128 & 4.0 & 4.5656 & TST & \\
\hline CHEMBL1326982 & 688128 & 5.4 & 4.8036 & TST & \\
\hline CHEMBL3198816 & 688128 & 4.4 & $4.6960 e$ & 0000000001 & TRN \\
\hline CHEMBL1461537 & 688128 & 4.45 & 4.7684 & TRN & \\
\hline CHEMBL1605885 & 688128 & 4.5 & 4.8663 & TRN & \\
\hline CHEMBL1535862 & 688128 & 5.0 & 4.7156 & TRN & \\
\hline CHEMBL1314609 & 688128 & 4.95 & 4.2763 & TRN & \\
\hline CHEMBL1425846 & 688128 & 4.85 & 4.8303 & TRN & \\
\hline CHEMBL1346066 & 688128 & 4.5 & 4.4406 & TRN & \\
\hline CHEMBL1421687 & 688128 & 4.35 & 4.3454 & TRN & \\
\hline CHEMBL1441366 & 688128 & 4.75 & 4.5811 & TRN & \\
\hline CHEMBL1384740 & 688128 & 5.0 & 4.8992 & TRN & \\
\hline CHEMBL1470783 & 688128 & 5.35 & $4.7360 e$ & 3000000001 & TRN \\
\hline CHEMBL1520795 & 688128 & 5.0 & 4.3426 & TRN & \\
\hline CHEMBL1374765 & 688128 & 4.4 & 4.4347 & TRN & \\
\hline CHEMBL1383355 & 688128 & 4.4 & 4.5778 & TRN & \\
\hline CHEMBL1468692 & 688128 & 4.65 & 4.6011 & TST & \\
\hline CHEMBL1519992 & 688128 & 4.95 & 4.8567 & TRN & \\
\hline CHEMBL1557595 & 688128 & 4.45 & 4.9253 & TRN & \\
\hline CHEMBL1579994 & 688128 & 4.85 & 4.4754 & TRN & \\
\hline CHEMBL1447927 & 688128 & 5.55 & 4.6683 & TRN & \\
\hline CHEMBL1466408 & 688128 & 7.0 & 4.6315 & TST & \\
\hline CHEMBL1441358 & 688128 & 5.45 & 4.7282 & TRN & \\
\hline CHEMBL1464727 & 688128 & 4.6 & 4.787 & TRN & \\
\hline CHEMBL1575827 & 688128 & 4.3 & 4.5594 & TRN & \\
\hline CHEMBL1312210 & 688128 & 4.3 & 4.6813 & TRN & \\
\hline CHEMBL 1458609 & 688128 & 4.55 & 4.7792 & TST & \\
\hline CHEMBL1383893 & 688128 & 4.8 & 4.7121 & TRN & \\
\hline CHEMBL1613137 & 688128 & 4.05 & 4.8331 & TST & \\
\hline CHEMBL1370240 & 688128 & 4.4 & 4.6628 & TRN & \\
\hline CHEMBL1440648 & 688128 & 4.6 & 4.453 & TRN & \\
\hline CHEMBL1401411 & 688128 & 4.05 & 4.485 & TST & \\
\hline CHEMBL1524420 & 688128 & 4.4 & 4.9512 & TRN & \\
\hline CHEMBL1555848 & 688128 & 4.75 & 4.5454 & TRN & \\
\hline CHEMBL1455674 & 688128 & 4.25 & 4.5887 & TST & \\
\hline CHEMBL1419622 & 688128 & 4.3 & 4.5205 & TRN & \\
\hline CHEMBL1359118 & 688128 & 4.6 & 4.6123 & TST & \\
\hline CHEMBL1564880 & 688128 & 4.3 & 4.6021 & TRN & \\
\hline
\end{tabular}




\begin{tabular}{|c|c|c|c|c|}
\hline \multicolumn{5}{|c|}{ Supplemental Table S2.txt } \\
\hline CHEMBL1305289 & 688128 & 4.65 & 4.6073 & TRN \\
\hline CHEMBL1340134 & 688128 & 4.3 & 4.6143 & TRN \\
\hline CHEMBL1519757 & 688128 & 4.0 & 4.6308 & TRN \\
\hline CHEMBL1537701 & 688128 & 4.05 & 4.3476 & TRN \\
\hline CHEMBL1390871 & 688128 & 4.35 & 4.4481 & TRN \\
\hline CHEMBL1604906 & 688128 & 4.9 & 5.0113 & TRN \\
\hline CHEMBL1504513 & 688128 & 4.65 & 4.5831 & TRN \\
\hline CHEMBL1480753 & 688128 & 4.3 & 4.3604 & TRN \\
\hline CHEMBL1371774 & 688128 & 4.5 & 5.2322 & TRN \\
\hline CHEMBL1412281 & 688128 & 6.0 & 4.7506 & TRN \\
\hline CHEMBL1431226 & 688128 & 4.05 & 4.6858 & TST \\
\hline CHEMBL1452735 & 688128 & 6.0 & 4.5874 & TST \\
\hline CHEMBL1351744 & 688128 & 4.05 & 4.7165 & TRN \\
\hline CHEMBL390559 & 688128 & 4.25 & 4.7781 & TRN \\
\hline CHEMBL215195 & 688128 & 4.05 & 4.5961 & TRN \\
\hline CHEMBL3189792 & 688128 & 5.05 & 4.9132 & TRN \\
\hline CHEMBL3212019 & 688128 & 4.25 & 4.5135 & TRN \\
\hline CHEMBL1556058 & 688128 & 4.4 & 4.7052 & TRN \\
\hline CHEMBL1401585 & 688128 & 4.35 & 4.7779 & TST \\
\hline CHEMBL1527404 & 688128 & 4.45 & 4.4567 & TST \\
\hline CHEMBL1392945 & 688128 & 4.45 & 4.3063 & TRN \\
\hline CHEMBL1386743 & 688128 & 4.75 & 4.6352 & TRN \\
\hline CHEMBL472437 & 688128 & 4.7 & 4.7476 & TST \\
\hline CHEMBL1490192 & 688128 & 4.05 & 4.5312 & TRN \\
\hline CHEMBL3192127 & 688128 & 4.05 & 4.5793 & TST \\
\hline CHEMBL1539334 & 688128 & 4.6 & 4.9253 & TRN \\
\hline CHEMBL1588563 & 688128 & 6.8 & 4.6802 & TST \\
\hline CHEMBL1514551 & 688128 & 4.4 & 4.5587 & TRN \\
\hline CHEMBL1345073 & 688128 & 4.0 & 4.5615 & TRN \\
\hline CHEMBL1358767 & 688128 & 4.25 & 4.4243 & TRN \\
\hline CHEMBL1510410 & 688128 & 5.55 & 4.4493 & TRN \\
\hline CHEMBL1564824 & 688128 & 4.25 & 4.9501 & TRN \\
\hline CHEMBL1500782 & 688128 & 4.65 & 4.5105 & TRN \\
\hline CHEMBL3192006 & 688128 & 4.1 & 4.5291 & TST \\
\hline CHEMBL1500477 & 688128 & 4.05 & 4.2738 & TRN \\
\hline CHEMBL1509116 & 688128 & 6.0 & 4.7052 & TST \\
\hline CHEMBL1302837 & 688128 & 4.65 & 4.8532 & TRN \\
\hline CHEMBL1486934 & 688128 & 5.25 & 5.0986 & TRN \\
\hline CHEMBL1558644 & 688128 & 4.4 & 4.8395 & TRN \\
\hline CHEMBL1538870 & 688128 & 6.35 & 5.0758 & TRN \\
\hline CHEMBL1554600 & 688128 & 5.45 & 4.5729 & TST \\
\hline CHEMBL1443882 & 688128 & 5.1 & $4.6080 e$ & 00000000005 \\
\hline CHEMBL3193269 & 688128 & 4.4 & 4.5926 & TRN \\
\hline CHEMBL1457369 & 688128 & 4.45 & 4.7639 & TRN \\
\hline CHEMBL1372866 & 688128 & 4.05 & 4.702 & TRN \\
\hline CHEMBL1607877 & 688128 & 4.5 & 4.7273 & TRN \\
\hline CHEMBL1380048 & 688128 & 4.55 & 4.5336 & TST \\
\hline CHEMBL3192859 & 688128 & 5.45 & 4.63 & TRN \\
\hline
\end{tabular}

TRN 


\begin{tabular}{|c|c|c|c|c|c|}
\hline \multicolumn{6}{|c|}{ Supplemental Table s2.txt } \\
\hline CHEMBL1400731 & 688128 & 4.5 & 5.3754 & TRN & \\
\hline CHEMBL1484934 & 688128 & 5.05 & 5.2216 & TRN & \\
\hline CHEMBL1516863 & 688128 & 4.4 & 4.552 & TRN & \\
\hline CHEMBL1341183 & 688128 & 4.65 & 4.4271 & TRN & \\
\hline CHEMBL1304200 & 688128 & 4.05 & 4.6491 & TRN & \\
\hline CHEMBL1584170 & 688128 & 4.4 & 4.9448 & TST & \\
\hline CHEMBL1467884 & 688128 & 4.2 & 4.7744 & TRN & \\
\hline CHEMBL3193521 & 688128 & 4.35 & 4.6769 & TRN & \\
\hline CHEMBL1446066 & 688128 & 4.55 & 4.5498 & TST & \\
\hline CHEMBL1407486 & 688128 & 4.3 & 4.6434 & TRN & \\
\hline CHEMBL1566054 & 688128 & 4.25 & 4.7361 & TRN & \\
\hline CHEMBL1482478 & 688128 & 4.9 & 4.8704 & TRN & \\
\hline CHEMBL3191961 & 688128 & 4.45 & 4.6924 & TST & \\
\hline CHEMBL3194898 & 688128 & 4.7 & 4.6699 & TST & \\
\hline CHEMBL1522133 & 688128 & 5.05 & 5.2233 & TRN & \\
\hline CHEMBL504791 & 688128 & 4.65 & 4.7213 & TST & \\
\hline CHEMBL1401747 & 688128 & 5.5 & 4.9417 & TRN & \\
\hline CHEMBL1391436 & 688128 & 4.15 & 4.8186 & TST & \\
\hline CHEMBL1452634 & 688128 & 4.05 & 4.5247 & TST & \\
\hline CHEMBL1421372 & 688128 & 4.0 & 4.6387 & TRN & \\
\hline CHEMBL1444998 & 688128 & 4.3 & 4.3853 & TRN & \\
\hline CHEMBL1360032 & 688128 & 4.35 & 4.5216 & TRN & \\
\hline CHEMBL1542957 & 688128 & 4.05 & 4.5882 & TRN & \\
\hline CHEMBL1530075 & 688128 & 4.3 & 4.9922 & TRN & \\
\hline CHEMBL1597235 & 688128 & 4.85 & 4.6293 & TRN & \\
\hline CHEMBL1336777 & 688128 & 4.35 & 4.6065 & TST & \\
\hline CHEMBL1452308 & 688128 & 4.4 & 4.7251 & TST & \\
\hline CHEMBL1448914 & 688128 & 4.4 & 4.394 & TRN & \\
\hline CHEMBL1445506 & 688128 & 4.25 & 4.5409 & TRN & \\
\hline CHEMBL602969 & 688128 & 4.45 & 4.4465 & TRN & \\
\hline CHEMBL1430712 & 688128 & 4.25 & 4.6624 & TST & \\
\hline CHEMBL 2001714 & 688128 & 4.65 & 4.7466 & TST & \\
\hline CHEMBL1368110 & 688128 & 4.05 & $4.3580 e$ & 00000000005 & TRN \\
\hline CHEMBL3198521 & 688128 & 4.9 & 5.0124 & TRN & \\
\hline CHEMBL1491246 & 688128 & 4.55 & 4.4899 & TRN & \\
\hline CHEMBL1397186 & 688128 & 4.4 & 4.5517 & TST & \\
\hline CHEMBL1535830 & 688128 & 4.0 & 4.6222 & TRN & \\
\hline CHEMBL1516338 & 688128 & 5.05 & 4.6182 & TRN & \\
\hline CHEMBL1532638 & 688128 & 5.5 & 4.6993 & TRN & \\
\hline CHEMBL1538237 & 688128 & 4.55 & 4.5007 & TST & \\
\hline CHEMBL1487918 & 688128 & 4.35 & 4.3732 & TRN & \\
\hline CHEMBL1427517 & 688128 & 4.3 & 4.7933 & TST & \\
\hline CHEMBL3197038 & 688128 & 4.3 & 4.2022 & TRN & \\
\hline CHEMBL1520273 & 688128 & 4.35 & 4.6388 & TRN & \\
\hline CHEMBL1563372 & 688128 & 4.5 & 4.4717 & TST & \\
\hline CHEMBL1328871 & 688128 & 4.3 & 5.0053 & TRN & \\
\hline CHEMBL1559986 & 688128 & 4.05 & 4.2748 & TRN & \\
\hline CHEMBL1462051 & 688128 & 4.4 & 4.8876 & TRN & \\
\hline
\end{tabular}




\begin{tabular}{|c|c|c|c|c|c|}
\hline \multirow{3}{*}{$\begin{array}{l}\text { CHEMBL } 1613510 \\
\text { CHEMBL1368435 }\end{array}$} & \multirow{3}{*}{$\begin{array}{l}688128 \\
688128\end{array}$} & \multicolumn{4}{|c|}{ Supplemental Table S2.txt } \\
\hline & & 4.55 & 4.9719 & 99999999995 & TRN \\
\hline & & 4.45 & 4.9278 & TRN & \\
\hline CHEMBL1307294 & 688128 & 4.05 & 4.6111 & TRN & \\
\hline CHEMBL 3191145 & 688128 & 4.95 & 4.5343 & TRN & \\
\hline CHEMBL1370838 & 688128 & 4.35 & 4.7659 & TST & \\
\hline CHEMBL1482353 & 688128 & 5.8 & 4.8784 & TRN & \\
\hline CHEMBL1325280 & 688128 & 4.05 & 4.4873 & TRN & \\
\hline CHEMBL1350914 & 688128 & 4.35 & 4.4837 & TRN & \\
\hline CHEMBL1334533 & 688128 & 4.5 & 4.7687 & TST & \\
\hline CHEMBL1593697 & 688128 & 6.0 & 5.2275 & TRN & \\
\hline CHEMBL1408790 & 688128 & 4.25 & 4.6074 & TRN & \\
\hline CHEMBL1459631 & 688128 & 5.35 & 4.5566 & TST & \\
\hline CHEMBL1604440 & 688128 & 5.0 & 4.5917 & TRN & \\
\hline CHEMBL1498871 & 688128 & 5.0 & 4.6235 & TRN & \\
\hline CHEMBL1408100 & 688128 & 4.9 & 4.7648 & TST & \\
\hline CHEMBL1501507 & 688128 & 4.85 & 4.9889 & TRN & \\
\hline CHEMBL1463595 & 688128 & 4.4 & 4.8187 & TRN & \\
\hline CHEMBL1392155 & 688128 & 4.7 & 4.7986 & TRN & \\
\hline CHEMBL3197516 & 688128 & 4.4 & 4.5317 & TST & \\
\hline CHEMBL1503558 & 688128 & 5.85 & 4.5219 & TRN & \\
\hline CHEMBL1523621 & 688128 & 5.5 & 5.0056 & TRN & \\
\hline CHEMBL1504809 & 688128 & 6.25 & 4.6373 & TST & \\
\hline CHEMBL1498156 & 688128 & 5.1 & 4.5338 & TRN & \\
\hline CHEMBL580816 & 688128 & 4.4 & 4.5571 & TST & \\
\hline CHEMBL1344084 & 688128 & 4.75 & 4.8035 & TRN & \\
\hline CHEMBL3191015 & 688128 & 5.65 & 4.8694 & TRN & \\
\hline CHEMBL1454388 & 688128 & 4.05 & 4.5687 & TST & \\
\hline CHEMBL1591816 & 688128 & 4.1 & 4.4412 & TST & \\
\hline CHEMBL1598468 & 688128 & 4.05 & 4.8905 & TST & \\
\hline CHEMBL1327833 & 688128 & 4.3 & 4.4906 & TRN & \\
\hline CHEMBL1481666 & 688128 & 4.25 & 4.747 & TRN & \\
\hline CHEMBL1303572 & 688128 & 4.0 & 4.6052 & TRN & \\
\hline CHEMBL1542055 & 688128 & 4.05 & 4.897 & TRN & \\
\hline CHEMBL1458563 & 688128 & 5.05 & 5.3336 & TRN & \\
\hline CHEMBL1995726 & 688128 & 4.45 & 4.6394 & TST & \\
\hline CHEMBL1435694 & 688128 & 4.85 & 4.7233 & TRN & \\
\hline CHEMBL3391711 & 688128 & 4.05 & 4.6221 & TST & \\
\hline CHEMBL1467244 & 688128 & 6.3 & 4.8052 & TRN & \\
\hline CHEMBL1305771 & 688128 & 5.75 & 5.2699 & TRN & \\
\hline CHEMBL1424661 & 688128 & 4.45 & 5.1208 & TST & \\
\hline CHEMBL1320275 & 688128 & 4.6 & 4.6769 & TRN & \\
\hline CHEMBL1372593 & 688128 & 4.3 & 4.5386 & TRN & \\
\hline CHEMBL1599312 & 688128 & 4.35 & 4.8831 & TRN & \\
\hline CHEMBL1359567 & 688128 & 4.45 & 4.5716 & TST & \\
\hline CHEMBL1510111 & 688128 & 5.2 & 4.6824 & TST & \\
\hline CHEMBL1545415 & 688128 & 4.7 & 4.5478 & TRN & \\
\hline CHEMBL1382741 & 688128 & 4.05 & 4.4785 & TRN & \\
\hline CHEMBL1587951 & 688128 & 4.45 & 4.3396 & TRN & \\
\hline
\end{tabular}




\begin{tabular}{|c|c|c|c|c|}
\hline \multicolumn{5}{|c|}{ Supplemental Table S2.txt } \\
\hline CHEMBL1427226 & 688128 & 4.4 & 4.5653 & TRN \\
\hline CHEMBL1411345 & 688128 & 4.35 & 4.3479 & TRN \\
\hline CHEMBL1594557 & 688128 & 4.35 & 4.3842 & TRN \\
\hline CHEMBL1571931 & 688128 & 4.05 & 4.313 & TRN \\
\hline CHEMBL1598558 & 688128 & 4.45 & 4.8093 & TRN \\
\hline CHEMBL1402570 & 688128 & 4.15 & 4.4914 & TRN \\
\hline CHEMBL 3192400 & 688128 & 4.25 & 4.8921 & TST \\
\hline CHEMBL1545921 & 688128 & 4.6 & 4.3577 & TRN \\
\hline CHEMBL1572577 & 688128 & 4.3 & 4.6027 & TST \\
\hline CHEMBL1471820 & 688128 & 4.35 & 4.5607 & TRN \\
\hline CHEMBL1351022 & 688128 & 4.75 & 4.5968 & TRN \\
\hline CHEMBL1380493 & 688128 & 4.4 & 4.6249 & TRN \\
\hline CHEMBL1373809 & 688128 & 4.4 & 4.5081 & TRN \\
\hline CHEMBL1331885 & 688128 & 4.5 & 4.8154 & TRN \\
\hline CHEMBL1343937 & 688128 & 4.3 & 4.4511 & TRN \\
\hline CHEMBL1443525 & 688128 & 4.4 & 4.5343 & TRN \\
\hline CHEMBL1459669 & 688128 & 4.45 & 4.5748 & TST \\
\hline CHEMBL1517429 & 688128 & 4.55 & 4.7262 & TRN \\
\hline CHEMBL1547774 & 688128 & 4.0 & 4.5515 & TRN \\
\hline CHEMBL1568444 & 688128 & 5.65 & 5.1812 & TRN \\
\hline CHEMBL1406218 & 688128 & 4.45 & 4.5525 & TRN \\
\hline CHEMBL1300043 & 688128 & 4.05 & 4.6987 & TRN \\
\hline CHEMBL1542659 & 688128 & 4.1 & 4.4715 & TRN \\
\hline CHEMBL1500438 & 688128 & 4.3 & 4.566 & TRN \\
\hline CHEMBL1503961 & 688128 & 4.05 & 4.4704 & TST \\
\hline CHEMBL1585739 & 688128 & 4.35 & 4.272 & TRN \\
\hline CHEMBL1549627 & 688128 & 4.55 & 4.7917 & TRN \\
\hline CHEMBL1462038 & 688128 & 4.25 & 4.5389 & TRN \\
\hline CHEMBL1579875 & 688128 & 4.4 & 4.473 & TRN \\
\hline CHEMBL1499679 & 688128 & 6.0 & 4.8547 & TRN \\
\hline CHEMBL1447816 & 688128 & 4.9 & 4.7607 & TRN \\
\hline CHEMBL1371536 & 688128 & 4.45 & 4.6193 & TRN \\
\hline CHEMBL1447615 & 688128 & 4.95 & 4.8592 & TRN \\
\hline CHEMBL1484139 & 688128 & 4.35 & 4.5165 & TRN \\
\hline CHEMBL1412988 & 688128 & 6.0 & 4.6665 & TRN \\
\hline CHEMBL1587933 & 688128 & 6.6 & 4.8474 & TRN \\
\hline CHEMBL1527520 & 688128 & 5.05 & 5.6507 & TRN \\
\hline CHEMBL1421547 & 688128 & 4.4 & 4.6161 & TRN \\
\hline CHEMBL1499638 & 688128 & 4.35 & 4.4375 & TRN \\
\hline CHEMBL1424715 & 688128 & 6.6 & 4.6708 & TST \\
\hline CHEMBL1495568 & 688128 & 4.5 & 4.992 & TST \\
\hline CHEMBL1384572 & 688128 & 4.25 & 4.5084 & TRN \\
\hline CHEMBL1396021 & 688128 & 4.3 & 4.7742 & TRN \\
\hline CHEMBL1569281 & 688128 & 4.6 & 4.6238 & TST \\
\hline CHEMBL1406101 & 688128 & 4.5 & 4.4229 & TRN \\
\hline CHEMBL1561129 & 688128 & 4.35 & 4.3172 & TRN \\
\hline CHEMBL1384154 & 688128 & 4.5 & 4.7788 & TRN \\
\hline CHEMBL1459367 & 688128 & 4.45 & 4.6352 & TRN \\
\hline
\end{tabular}




\begin{tabular}{|c|c|c|c|c|c|}
\hline \multicolumn{6}{|c|}{ Supplemental Table S2.txt } \\
\hline CHEMBL1520212 & 688128 & 6.5 & 5.0887 & TRN & \\
\hline CHEMBL1467692 & 688128 & 4.05 & 4.4662 & TRN & \\
\hline CHEMBL1495463 & 688128 & 4.05 & 4.5275 & TST & \\
\hline CHEMBL1455028 & 688128 & 4.65 & 4.7564 & TRN & \\
\hline CHEMBL1345399 & 688128 & 4.4 & 4.6447 & TST & \\
\hline CHEMBL1523490 & 688128 & 4.55 & 4.5836 & TRN & \\
\hline CHEMBL1401975 & 688128 & 4.45 & 4.7815 & TRN & \\
\hline CHEMBL1423359 & 688128 & 4.25 & 4.4425 & TRN & \\
\hline CHEMBL 3193505 & 688128 & 4.4 & 4.7382 & TRN & \\
\hline CHEMBL1443008 & 688128 & 4.2 & 4.4344 & TST & \\
\hline CHEMBL1547125 & 688128 & 5.45 & 4.6663 & TST & \\
\hline CHEMBL1547718 & 688128 & 4.25 & 4.6609 & TRN & \\
\hline CHEMBL1574335 & 688128 & 4.5 & 4.442 & TRN & \\
\hline CHEMBL1499410 & 688128 & 4.0 & 4.5642 & TRN & \\
\hline CHEMBL1569957 & 688128 & 5.45 & 4.6926 & TRN & \\
\hline CHEMBL1330251 & 688128 & 4.35 & 4.8199 & TRN & \\
\hline CHEMBL3190800 & 688128 & 4.55 & 4.5429 & TRN & \\
\hline CHEMBL1381032 & 688128 & 6.5501 & 4.6394 & TRN & \\
\hline CHEMBL1455110 & 688128 & 4.25 & 4.7525 & TRN & \\
\hline CHEMBL3198994 & 688128 & 5.75 & 5.2432 & TRN & \\
\hline CHEMBL1579509 & 688128 & 5.45 & 4.7962 & TRN & \\
\hline CHEMBL1399096 & 688128 & 6.3 & 5.1902 & TRN & \\
\hline CHEMBL 2374086 & 688128 & 4.95 & 5.1982 & TRN & \\
\hline CHEMBL 3144894 & 688128 & 4.4 & 4.7327 & TST & \\
\hline CHEMBL1611480 & 688128 & 4.0 & 4.5388 & TRN & \\
\hline CHEMBL1382702 & 688128 & 4.7 & 4.4296 & TRN & \\
\hline CHEMBL1361434 & 688128 & 4.9 & 4.7488 & TRN & \\
\hline CHEMBL1304053 & 688128 & 4.35 & 4.7077 & TRN & \\
\hline CHEMBL1392589 & 688128 & 4.45 & 4.7614 & TST & \\
\hline CHEMBL1400055 & 688128 & 5.7 & 5.3202 & TRN & \\
\hline CHEMBL1454893 & 688128 & 5.55 & 4.7656 & TRN & \\
\hline CHEMBL1366900 & 688128 & 4.05 & 4.7504 & TST & \\
\hline CHEMBL1394277 & 688128 & 4.05 & 4.7398 & TRN & \\
\hline CHEMBL1488358 & 688128 & 6.0 & 4.5708 & TRN & \\
\hline CHEMBL1607634 & 688128 & 4.05 & 4.769 & TRN & \\
\hline CHEMBL1502558 & 688128 & 4.5 & 4.8934 & TRN & \\
\hline CHEMBL1355161 & 688128 & 4.25 & 4.4353 & TRN & \\
\hline CHEMBL1598613 & 688128 & 4.4 & 4.7652 & TST & \\
\hline CHEMBL1509380 & 688128 & 4.05 & 4.8531 & TST & \\
\hline CHEMBL1501741 & 688128 & 4.55 & 4.39199 & 99999999995 & \\
\hline CHEMBL1536928 & 688128 & 4.05 & 4.5058 & TRN & \\
\hline CHEMBL1455548 & 688128 & 4.35 & 4.3686 & TRN & \\
\hline CHEMBL1371874 & 688128 & 4.3 & 4.9999 & TRN & \\
\hline CHEMBL1607176 & 688128 & 4.3 & 5.0491 & TST & \\
\hline CHEMBL1509004 & 688128 & 4.1 & 4.7418 & TST & \\
\hline CHEMBL1398061 & 688128 & 4.8 & 4.723 & TRN & \\
\hline CHEMBL1394972 & 688128 & 4.3 & 4.6808 & TRN & \\
\hline CHEMBL1608101 & 688128 & 4.5 & 4.5043 & TST & \\
\hline
\end{tabular}




\begin{tabular}{|c|c|c|c|c|}
\hline \multicolumn{5}{|c|}{ Supplemental Table S2.txt } \\
\hline CHEMBL1506589 & 688128 & 4.25 & 4.9418 & TRN \\
\hline CHEMBL1467766 & 688128 & 4.8 & 4.5947 & TST \\
\hline CHEMBL1405273 & 688128 & 4.4 & 4.6449 & TRN \\
\hline CHEMBL1347889 & 688128 & 6.45 & 4.5467 & TRN \\
\hline CHEMBL1310405 & 688128 & 4.35 & 4.6026 & TST \\
\hline CHEMBL1964407 & 688128 & 6.1 & 5.0456 & TST \\
\hline CHEMBL1309472 & 688128 & 4.25 & 4.8423 & TRN \\
\hline CHEMBL1535709 & 688128 & 4.4 & 4.4755 & TST \\
\hline CHEMBL1403541 & 688128 & 4.4 & 4.9081 & TRN \\
\hline CHEMBL1485143 & 688128 & 4.0 & 4.2379 & TRN \\
\hline CHEMBL1476542 & 688128 & 4.95 & 4.2987 & TST \\
\hline CHEMBL1494199 & 688128 & 4.05 & 4.6308 & TST \\
\hline CHEMBL1318472 & 688128 & 4.15 & 4.4149 & TRN \\
\hline CHEMBL1462074 & 688128 & 5.0 & 4.9519 & TST \\
\hline CHEMBL1546714 & 688128 & 4.35 & 4.5353 & TRN \\
\hline CHEMBL1342647 & 688128 & 4.3 & 4.8761 & TST \\
\hline CHEMBL1342289 & 688128 & 4.9 & 4.3017 & TRN \\
\hline CHEMBL1528757 & 688128 & 5.95 & 4.5223 & TST \\
\hline CHEMBL1312996 & 688128 & 4.3 & 4.4992 & TRN \\
\hline CHEMBL1408705 & 688128 & 5.1 & 4.9028 & TRN \\
\hline CHEMBL1409599 & 688128 & 4.0 & 4.4974 & TST \\
\hline CHEMBL1494674 & 688128 & 4.45 & 4.5653 & TRN \\
\hline CHEMBL1418558 & 688128 & 4.05 & 4.6093 & TRN \\
\hline CHEMBL1512299 & 688128 & 4.3 & 4.7128 & TST \\
\hline CHEMBL1360534 & 688128 & 4.5 & 4.7263 & TRN \\
\hline CHEMBL1363160 & 688128 & 6.15 & 4.7857 & TRN \\
\hline CHEMBL1969597 & 688128 & 5.1 & 4.4939 & TRN \\
\hline CHEMBL1307166 & 688128 & 4.4 & 4.5074 & TRN \\
\hline CHEMBL1560112 & 688128 & 4.35 & 4.6777 & TST \\
\hline CHEMBL1409332 & 688128 & 4.45 & 4.7694 & TRN \\
\hline CHEMBL1545432 & 688128 & 4.4 & 4.467 & TST \\
\hline CHEMBL1425954 & 688128 & 4.05 & 4.7288 & TRN \\
\hline CHEMBL1596209 & 688128 & 4.0 & 4.5551 & TST \\
\hline CHEMBL1390155 & 688128 & 4.35 & 4.7069 & TRN \\
\hline CHEMBL1487319 & 688128 & 4.25 & 4.8445 & TRN \\
\hline CHEMBL1507469 & 688128 & 4.5 & 4.3781 & TRN \\
\hline CHEMBL1362591 & 688128 & 5.8 & 4.6223 & TRN \\
\hline CHEMBL1441627 & 688128 & 4.45 & 4.421 & TST \\
\hline CHEMBL1397539 & 688128 & 4.7 & 4.8827 & TRN \\
\hline CHEMBL1364924 & 688128 & 5.05 & 4.681 & TRN \\
\hline CHEMBL1456635 & 688128 & 5.5 & 4.6669 & TRN \\
\hline CHEMBL1384567 & 688128 & 5.65 & 4.873 & TST \\
\hline CHEMBL1521995 & 688128 & 4.55 & 4.7184 & TRN \\
\hline CHEMBL1550406 & 688128 & 4.95 & 4.6106 & TRN \\
\hline CHEMBL1440675 & 688128 & 4.35 & 4.7236 & TRN \\
\hline CHEMBL1372290 & 688128 & 4.1 & 4.8322 & TST \\
\hline CHEMBL1385117 & 688128 & 4.85 & 4.8492 & TRN \\
\hline CHEMBL1451926 & 688128 & 4.05 & 4.438 & TRN \\
\hline
\end{tabular}




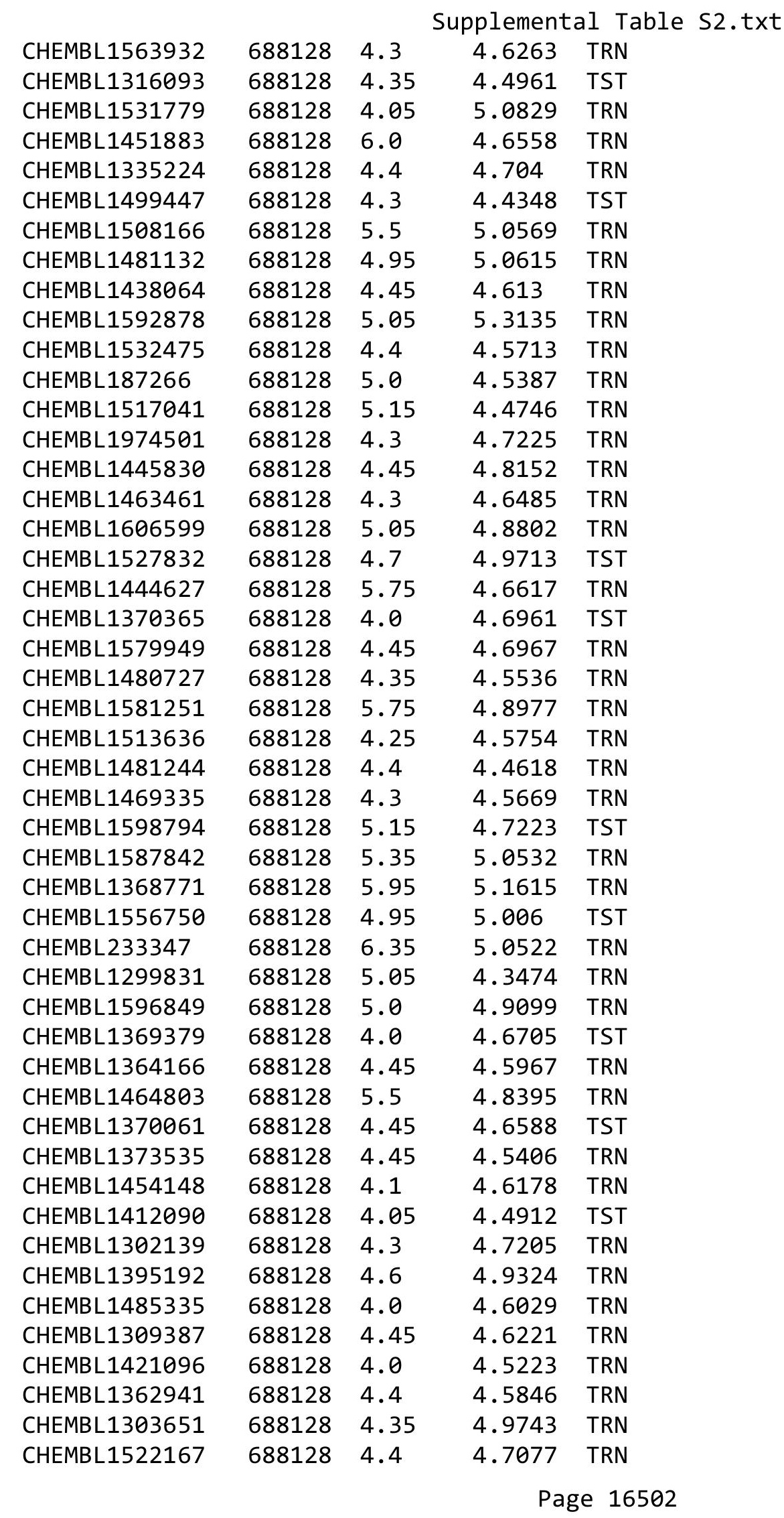




\begin{tabular}{|c|c|c|c|c|}
\hline \multicolumn{5}{|c|}{ Supplemental Table S2.txt } \\
\hline CHEMBL3199050 & 688128 & 5.65 & 4.9645 & TRN \\
\hline CHEMBL1469401 & 688128 & 4.45 & 4.6898 & TRN \\
\hline CHEMBL1317311 & 688128 & 5.15 & 4.8614 & TRN \\
\hline CHEMBL1528163 & 688128 & 4.05 & 4.6378 & TRN \\
\hline CHEMBL 1464086 & 688128 & 4.8 & 4.6792 & TRN \\
\hline CHEMBL1350122 & 688128 & 4.1 & 4.4919 & TRN \\
\hline CHEMBL1555150 & 688128 & 4.05 & 4.2822 & TRN \\
\hline CHEMBL1367262 & 688128 & 4.35 & 4.79 & TRN \\
\hline CHEMBL1307933 & 688128 & 4.4 & 4.6071 & TRN \\
\hline CHEMBL1360435 & 688128 & 4.85 & 4.5161 & TST \\
\hline CHEMBL1598199 & 688128 & 4.5 & 4.6142 & TRN \\
\hline CHEMBL1308774 & 688128 & 4.05 & 4.5646 & TRN \\
\hline CHEMBL1364072 & 688128 & 4.45 & 4.4714 & TRN \\
\hline CHEMBL1340173 & 688128 & 4.4 & 4.5046 & TRN \\
\hline CHEMBL1337837 & 688128 & 4.3 & 4.6234 & TRN \\
\hline CHEMBL1334456 & 688128 & 4.3 & 4.6996 & TST \\
\hline CHEMBL1502104 & 688128 & 5.1 & 5.0353 & TST \\
\hline CHEMBL1519734 & 688128 & 5.85 & 4.9517 & TRN \\
\hline CHEMBL1305805 & 688128 & 4.3 & 4.5562 & TST \\
\hline CHEMBL1521177 & 688128 & 4.15 & 4.3446 & TRN \\
\hline CHEMBL1503345 & 688128 & 5.85 & 4.5458 & TST \\
\hline CHEMBL1479654 & 688128 & 4.65 & 4.4949 & TST \\
\hline CHEMBL1448473 & 688128 & 4.35 & 4.6391 & TRN \\
\hline CHEMBL1562048 & 688128 & 4.8 & 4.6859 & TST \\
\hline CHEMBL1329465 & 688128 & 4.35 & 4.7639 & TRN \\
\hline CHEMBL1321994 & 688128 & 5.35 & 4.4786 & TRN \\
\hline CHEMBL1518197 & 688128 & 4.5 & 4.56 & TST \\
\hline CHEMBL1347857 & 688128 & 4.4 & 4.8241 & TST \\
\hline CHEMBL 3210787 & 688128 & 4.45 & 4.6072 & TRN \\
\hline CHEMBL1562577 & 688128 & 4.05 & 4.6505 & TRN \\
\hline CHEMBL1539253 & 688128 & 5.05 & 5.0861 & TRN \\
\hline CHEMBL1354880 & 688128 & 4.3 & 4.5995 & TRN \\
\hline CHEMBL1377464 & 688128 & 6.9 & 4.6612 & TRN \\
\hline CHEMBL1373267 & 688128 & 4.0 & 4.4656 & TST \\
\hline CHEMBL1465973 & 688128 & 4.4 & 4.4465 & TST \\
\hline CHEMBL1527833 & 688128 & 4.45 & 4.6056 & TRN \\
\hline CHEMBL1319364 & 688128 & 5.65 & 4.7524 & TRN \\
\hline CHEMBL1565446 & 688128 & 4.35 & 4.4126 & TRN \\
\hline CHEMBL1473652 & 688128 & 4.05 & 4.5023 & TRN \\
\hline CHEMBL1418892 & 688128 & 5.6 & 4.4158 & TRN \\
\hline CHEMBL1255656 & 688128 & 4.35 & 4.8541 & TST \\
\hline CHEMBL3196701 & 688128 & 4.8 & 4.7186 & TRN \\
\hline CHEMBL1431075 & 688128 & 4.6 & 5.2839 & TRN \\
\hline CHEMBL3210003 & 688128 & 4.35 & 4.6267 & TRN \\
\hline CHEMBL1486503 & 688128 & 5.45 & 4.7887 & TRN \\
\hline CHEMBL1325176 & 688128 & 4.6 & 4.555 & TRN \\
\hline CHEMBL1598032 & 688128 & 4.4 & 4.6715 & TRN \\
\hline CHEMBL1979558 & 688128 & 5.65 & 4.8946 & TRN \\
\hline
\end{tabular}




\begin{tabular}{|c|c|c|c|c|}
\hline \multicolumn{5}{|c|}{ Supplemental Table S2.txt } \\
\hline CHEMBL1579973 & 688128 & 4.4 & 4.4538 & TRN \\
\hline CHEMBL1597454 & 688128 & 5.05 & 5.4807 & TRN \\
\hline CHEMBL1310909 & 688128 & 4.95 & 5.2288 & TRN \\
\hline CHEMBL1374004 & 688128 & 4.3 & 4.4127 & TRN \\
\hline CHEMBL1479536 & 688128 & 4.25 & 4.4915 & TRN \\
\hline CHEMBL1366281 & 688128 & 4.4 & 4.5856 & TRN \\
\hline CHEMBL1436417 & 688128 & 4.3 & 4.6569 & TRN \\
\hline CHEMBL1533860 & 688128 & 4.35 & 4.5367 & TRN \\
\hline CHEMBL1397814 & 688128 & 4.4 & 4.3086 & TRN \\
\hline CHEMBL1468770 & 688128 & 4.05 & 4.5179 & TRN \\
\hline CHEMBL1555091 & 688128 & 4.75 & 5.0423 & TRN \\
\hline CHEMBL1967726 & 688128 & 4.35 & 4.3832 & TRN \\
\hline CHEMBL1376870 & 688128 & 6.15 & 5.1865 & TRN \\
\hline CHEMBL1601067 & 688128 & 4.25 & 4.6343 & TRN \\
\hline CHEMBL1302005 & 688128 & 4.35 & 4.38 & TRN \\
\hline CHEMBL1323001 & 688128 & 6.25 & 4.8265 & TRN \\
\hline CHEMBL1299506 & 688128 & 4.3 & 4.6533 & TRN \\
\hline CHEMBL1348235 & 688128 & 4.6 & 4.6561 & TST \\
\hline CHEMBL1536434 & 688128 & 5.95 & 5.1118 & TRN \\
\hline CHEMBL1472197 & 688128 & 5.5 & 4.4897 & TST \\
\hline CHEMBL1469844 & 688128 & 5.1 & 4.9589 & TRN \\
\hline CHEMBL1568920 & 688128 & 6.5501 & 4.9959 & TRN \\
\hline CHEMBL1494729 & 688128 & 4.4 & 4.9618 & TRN \\
\hline CHEMBL1518727 & 688128 & 4.35 & 4.5827 & TRN \\
\hline CHEMBL1439688 & 688128 & 4.9 & 4.4501 & TRN \\
\hline CHEMBL1373377 & 688128 & 4.35 & 4.731 & TST \\
\hline CHEMBL1503188 & 688128 & 5.45 & 4.9532 & TRN \\
\hline CHEMBL1387943 & 688128 & 4.3 & 4.9657 & TRN \\
\hline CHEMBL1429132 & 688128 & 4.35 & 4.3827 & TRN \\
\hline CHEMBL1504363 & 688128 & 4.35 & 4.5239 & TRN \\
\hline CHEMBL1566927 & 688128 & 4.45 & 4.7143 & TST \\
\hline CHEMBL1412832 & 688128 & 4.45 & 4.8071 & TRN \\
\hline CHEMBL1493726 & 688128 & 5.05 & 4.6117 & TRN \\
\hline CHEMBL1464021 & 688128 & 4.65 & 4.5451 & TRN \\
\hline CHEMBL1495447 & 688128 & 4.3 & 4.3664 & TRN \\
\hline CHEMBL1975120 & 688128 & 4.75 & 4.6803 & TST \\
\hline CHEMBL1347561 & 688128 & 4.25 & 4.7987 & TRN \\
\hline CHEMBL1467086 & 688128 & 4.5 & 4.5539 & TST \\
\hline CHEMBL1468536 & 688128 & 4.4 & 4.4427 & TRN \\
\hline CHEMBL1543242 & 688128 & 4.3 & 4.5705 & TRN \\
\hline CHEMBL1441707 & 688128 & 4.7 & 4.8393 & TRN \\
\hline CHEMBL 1455508 & 688128 & 4.05 & 4.8785 & TST \\
\hline CHEMBL1501151 & 688128 & 4.3 & 5.1119 & TRN \\
\hline CHEMBL1305960 & 688128 & 5.2 & 4.5284 & TST \\
\hline CHEMBL1388584 & 688128 & 4.35 & 4.7272 & TRN \\
\hline CHEMBL1371402 & 688128 & 4.35 & 4.6001 & TST \\
\hline CHEMBL1411621 & 688128 & 4.4 & 4.2503 & TRN \\
\hline CHEMBL567622 & 688128 & 6.15 & 5.2976 & TST \\
\hline
\end{tabular}




\begin{tabular}{|c|c|c|c|c|}
\hline \multicolumn{5}{|c|}{ Supplemental Table } \\
\hline CHEMBL1464486 & 688128 & 4.35 & 4.6024 & TRN \\
\hline CHEMBL1404231 & 688128 & 6.05 & 4.9012 & TRN \\
\hline CHEMBL1583000 & 688128 & 4.75 & 4.7129 & TST \\
\hline CHEMBL1581425 & 688128 & 5.45 & 4.899 & TRN \\
\hline CHEMBL1483117 & 688128 & 4.3 & 4.5039 & TRN \\
\hline CHEMBL1585604 & 688128 & 4.35 & 4.498 & TRN \\
\hline CHEMBL1470528 & 688128 & 4.15 & 4.6787 & TST \\
\hline CHEMBL1357575 & 688128 & 4.05 & 4.6184 & TRN \\
\hline CHEMBL1460100 & 688128 & 4.35 & 4.6785 & TRN \\
\hline CHEMBL1555080 & 688128 & 4.05 & 4.2921 & TST \\
\hline CHEMBL1304639 & 688128 & 4.3 & 4.2618 & TST \\
\hline CHEMBL1464949 & 688128 & 4.55 & 4.6526 & TRN \\
\hline CHEMBL1334123 & 688128 & 4.7 & 4.931 & TRN \\
\hline CHEMBL1511175 & 688128 & 4.3 & 4.8084 & TRN \\
\hline CHEMBL1550091 & 688128 & 4.3 & 4.4049 & TST \\
\hline CHEMBL1366420 & 688128 & 4.3 & 4.6118 & TRN \\
\hline CHEMBL3211512 & 688128 & 4.6 & 4.5589 & TRN \\
\hline CHEMBL1600689 & 688128 & 4.05 & 4.2436 & TRN \\
\hline CHEMBL1442096 & 688128 & 4.5 & 4.9575 & TRN \\
\hline CHEMBL1447404 & 688128 & 4.5 & 4.4576 & TRN \\
\hline CHEMBL1307247 & 688128 & 4.35 & 4.7379 & TRN \\
\hline CHEMBL1339889 & 688128 & 4.5 & 4.5998 & TRN \\
\hline CHEMBL1494713 & 688128 & 5.05 & 5.0347 & TRN \\
\hline CHEMBL1370290 & 688128 & 4.0 & 4.641 & TST \\
\hline CHEMBL3208878 & 688128 & 7.0501 & 4.526 & TRN \\
\hline CHEMBL3208106 & 688128 & 4.35 & 4.641 & TRN \\
\hline CHEMBL1326586 & 688128 & 4.3 & 4.7658 & TRN \\
\hline CHEMBL1439947 & 688128 & 4.3 & 4.8487 & TRN \\
\hline CHEMBL1560816 & 688128 & 4.6 & 4.5151 & TRN \\
\hline CHEMBL1409452 & 688128 & 4.4 & 4.3468 & TRN \\
\hline CHEMBL1435124 & 688128 & 4.3 & 4.601 & TRN \\
\hline CHEMBL1303921 & 688128 & 4.4 & 4.4912 & TRN \\
\hline CHEMBL1363426 & 688128 & 4.55 & 4.6064 & TRN \\
\hline CHEMBL1272150 & 688128 & 4.4 & 4.4147 & TRN \\
\hline CHEMBL1392820 & 688128 & 4.55 & 4.3904 & TRN \\
\hline CHEMBL1414721 & 688128 & 4.4 & 4.7902 & TST \\
\hline CHEMBL1341839 & 688128 & 4.55 & 4.7613 & TRN \\
\hline CHEMBL1397495 & 688128 & 4.3 & 4.4508 & TRN \\
\hline CHEMBL1574219 & 688128 & 6.25 & 4.9433 & TRN \\
\hline CHEMBL1467029 & 688128 & 4.4 & 4.8864 & TRN \\
\hline CHEMBL1529602 & 688128 & 4.05 & 4.4693 & TST \\
\hline CHEMBL512387 & 688128 & 4.35 & 4.5302 & TRN \\
\hline CHEMBL1481269 & 688128 & 4.4 & 4.1787 & TRN \\
\hline CHEMBL248564 & 688128 & 4.4 & 4.7978 & TST \\
\hline CHEMBL1356523 & 688128 & 4.4 & 4.6171 & TRN \\
\hline CHEMBL1308936 & 688128 & 5.0 & 4.4794 & TRN \\
\hline CHEMBL1457314 & 688128 & 4.8 & 4.5327 & TRN \\
\hline CHEMBL3209221 & 688128 & 4.5 & 4.7384 & TRN \\
\hline
\end{tabular}




\begin{tabular}{|c|c|c|c|c|}
\hline \multicolumn{5}{|c|}{ Supplemental Table S2.txt } \\
\hline CHEMBL1475855 & 688128 & 4.5 & 4.5005 & TRN \\
\hline CHEMBL1556121 & 688128 & 4.3 & 4.2712 & TRN \\
\hline CHEMBL1530593 & 688128 & 4.4 & 4.7601 & TRN \\
\hline CHEMBL1518903 & 688128 & 4.4 & 4.4202 & TST \\
\hline CHEMBL 78150 & 688128 & 5.3 & 4.8803 & TRN \\
\hline CHEMBL1537916 & 688128 & 4.8 & 4.6651 & TRN \\
\hline CHEMBL 2003651 & 688128 & 4.35 & 4.76 & TRN \\
\hline CHEMBL1400013 & 688128 & 4.3 & 4.6091 & TRN \\
\hline CHEMBL1422344 & 688128 & 4.6 & 4.5492 & TRN \\
\hline CHEMBL1505533 & 688128 & 4.4 & 4.1176 & TRN \\
\hline CHEMBL1448764 & 688128 & 4.4 & 4.703 & TST \\
\hline CHEMBL1574609 & 688128 & 4.45 & 4.5069 & TRN \\
\hline CHEMBL1545160 & 688128 & 4.25 & 4.6691 & TRN \\
\hline CHEMBL1415002 & 688128 & 4.6 & 4.5538 & TRN \\
\hline CHEMBL1313303 & 688128 & 5.45 & 4.1361 & TRN \\
\hline CHEMBL3210970 & 688128 & 4.3 & 4.5557 & TRN \\
\hline CHEMBL1403191 & 688128 & 4.95 & 4.5341 & TRN \\
\hline CHEMBL1438291 & 688128 & 4.2 & 4.5818 & TRN \\
\hline CHEMBL1418723 & 688128 & 4.05 & 4.6616 & TST \\
\hline CHEMBL1381181 & 688128 & 6.9 & 4.7032 & TST \\
\hline CHEMBL1340354 & 688128 & 4.45 & 4.6024 & TRN \\
\hline CHEMBL1351663 & 688128 & 5.2 & 4.7711 & TST \\
\hline CHEMBL1573534 & 688128 & 6.0 & 4.8392 & TRN \\
\hline CHEMBL1603362 & 688128 & 4.45 & 4.362 & TRN \\
\hline CHEMBL449392 & 688128 & 4.55 & 5.1053 & TST \\
\hline CHEMBL1326704 & 688128 & 4.3 & 4.4225 & TRN \\
\hline CHEMBL1442021 & 688128 & 4.05 & 4.3165 & TRN \\
\hline CHEMBL1584646 & 688128 & 4.75 & 4.6156 & TRN \\
\hline CHEMBL1569220 & 688128 & 4.85 & 4.4727 & TRN \\
\hline CHEMBL1312234 & 688128 & 4.5 & 4.5626 & TRN \\
\hline CHEMBL1593934 & 688128 & 4.3 & 4.3882 & TRN \\
\hline CHEMBL1546798 & 688128 & 4.4 & 4.352 & TRN \\
\hline CHEMBL1388640 & 688128 & 4.4 & 4.2751 & TRN \\
\hline CHEMBL1599935 & 688128 & 4.35 & 4.5262 & TRN \\
\hline CHEMBL1352065 & 688128 & 4.5 & 5.008 & TST \\
\hline CHEMBL1529201 & 688128 & 6.15 & 4.8334 & TST \\
\hline CHEMBL1339298 & 688128 & 4.4 & 4.707 & TST \\
\hline CHEMBL1584532 & 688128 & 6.1 & 4.5049 & TST \\
\hline CHEMBL1372365 & 688128 & 4.5 & 4.5584 & TRN \\
\hline CHEMBL1419309 & 688128 & 5.4 & 4.7063 & TST \\
\hline CHEMBL1360586 & 688128 & 4.3 & 4.56 & TRN \\
\hline CHEMBL 1447350 & 688128 & 6.25 & 4.9846 & TRN \\
\hline CHEMBL1300620 & 688128 & 5.15 & 4.7459 & TRN \\
\hline CHEMBL1608776 & 688128 & 6.5 & 4.9875 & TRN \\
\hline CHEMBL1334892 & 688128 & 4.05 & 4.4063 & TST \\
\hline CHEMBL1499491 & 688128 & 4.6 & 4.7252 & TRN \\
\hline CHEMBL1413851 & 688128 & 4.5 & 4.4499 & TST \\
\hline CHEMBL1447124 & 688128 & 6.1 & 4.9387 & TRN \\
\hline
\end{tabular}




\begin{tabular}{|c|c|c|c|c|}
\hline \multicolumn{5}{|c|}{ Supplemental Table S2.txt } \\
\hline CHEMBL1334018 & 688128 & 4.05 & 4.5777 & TRN \\
\hline CHEMBL499562 & 688128 & 4.05 & 4.7315 & TRN \\
\hline CHEMBL1484876 & 688128 & 4.4 & 4.5884 & TST \\
\hline CHEMBL1580176 & 688128 & 4.75 & 4.7346 & TRN \\
\hline CHEMBL1423471 & 688128 & 4.35 & 4.5485 & TRN \\
\hline CHEMBL1471108 & 688128 & 4.35 & 4.3459 & TST \\
\hline CHEMBL1572294 & 688128 & 4.3 & 4.4476 & TST \\
\hline CHEMBL88811 & 688128 & 4.25 & 4.7049 & TRN \\
\hline CHEMBL1408396 & 688128 & 4.4 & 4.3058 & TRN \\
\hline CHEMBL1991710 & 688128 & 4.4 & 4.8871 & TRN \\
\hline CHEMBL1428256 & 688128 & 4.4 & 4.5907 & TRN \\
\hline CHEMBL1340800 & 688128 & 4.65 & 5.0749 & TRN \\
\hline CHEMBL1514113 & 688128 & 4.5 & 4.437 & TRN \\
\hline CHEMBL1526076 & 688128 & 4.5 & 4.4713 & TRN \\
\hline CHEMBL1355838 & 688128 & 4.05 & 4.4556 & TRN \\
\hline CHEMBL1387109 & 688128 & 4.85 & 4.6465 & TRN \\
\hline CHEMBL1363614 & 688128 & 5.5 & 5.061 & TRN \\
\hline CHEMBL1432814 & 688128 & 4.85 & 5.1026 & TRN \\
\hline CHEMBL1469940 & 688128 & 4.4 & 4.8516 & TST \\
\hline CHEMBL1466158 & 688128 & 4.35 & 4.4506 & TRN \\
\hline CHEMBL1309683 & 688128 & 4.55 & 4.7568 & TRN \\
\hline CHEMBL1491412 & 688128 & 4.05 & 4.7418 & TST \\
\hline CHEMBL 3212020 & 688128 & 4.6 & 4.5141 & TRN \\
\hline CHEMBL1508776 & 688128 & 4.4 & 4.7019 & TRN \\
\hline CHEMBL1572807 & 688128 & 4.5 & 4.96 & TRN \\
\hline CHEMBL1411178 & 688128 & 4.25 & 4.4149 & TRN \\
\hline CHEMBL1338246 & 688128 & 5.05 & 4.6087 & TST \\
\hline CHEMBL1481783 & 688128 & 4.05 & 4.4284 & TRN \\
\hline CHEMBL1335488 & 688128 & 6.1 & 4.8721 & TRN \\
\hline CHEMBL1540999 & 688128 & 4.4 & 4.6205 & TRN \\
\hline CHEMBL1530467 & 688128 & 4.35 & 4.6548 & TRN \\
\hline CHEMBL1588645 & 688128 & 4.55 & 4.4129 & TRN \\
\hline CHEMBL1356578 & 688128 & 4.45 & 5.02 & TRN \\
\hline CHEMBL1328462 & 688128 & 6.0 & 4.8078 & TRN \\
\hline CHEMBL1335450 & 688128 & 4.3 & 4.5574 & TRN \\
\hline CHEMBL1465618 & 688128 & 4.35 & 4.4854 & TRN \\
\hline CHEMBL1486217 & 688128 & 4.05 & 4.1632 & TRN \\
\hline CHEMBL1445020 & 688128 & 4.25 & 4.7035 & TRN \\
\hline CHEMBL3197045 & 688128 & 4.25 & 4.5131 & TST \\
\hline CHEMBL1381325 & 688128 & 4.65 & 4.437 & TRN \\
\hline CHEMBL1536790 & 688128 & 4.9 & 4.2661 & TRN \\
\hline CHEMBL1456721 & 688128 & 4.45 & 4.2233 & TRN \\
\hline CHEMBL1398486 & 688128 & 4.4 & 4.5885 & TST \\
\hline CHEMBL1371060 & 688128 & 4.1 & 4.4558 & TST \\
\hline CHEMBL1375932 & 688128 & 4.5 & 4.6743 & TRN \\
\hline CHEMBL1347373 & 688128 & 4.5 & 4.9571 & TRN \\
\hline CHEMBL1425666 & 688128 & 4.05 & 4.1863 & TRN \\
\hline CHEMBL1438129 & 688128 & 4.55 & 4.6314 & TRN \\
\hline
\end{tabular}




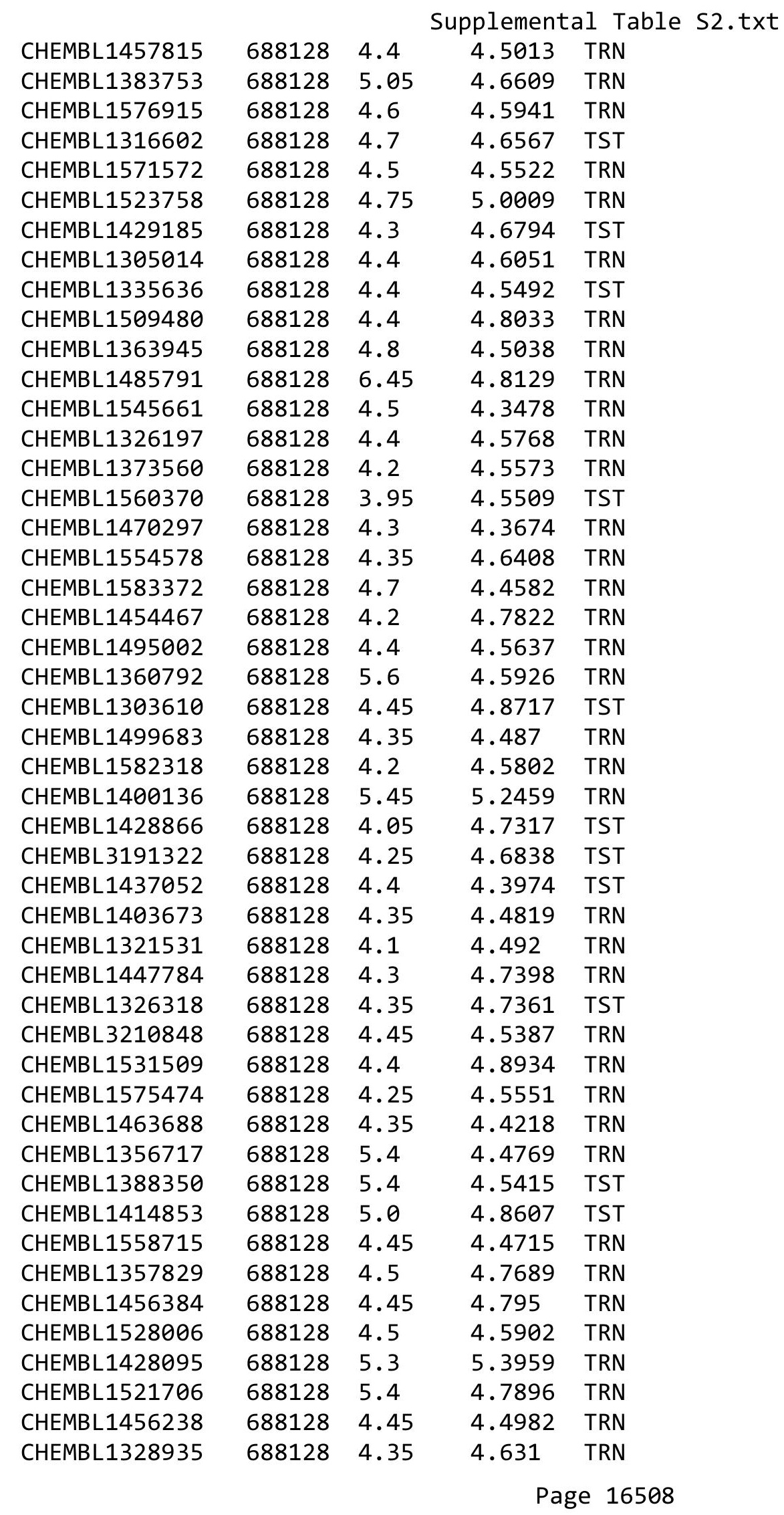




\begin{tabular}{|c|c|c|c|c|c|}
\hline \multicolumn{6}{|c|}{ Supplemental Table s2.txt } \\
\hline CHEMBL1314037 & 688128 & 4.35 & 4.6714 & TRN & \\
\hline CHEMBL1361993 & 688128 & 4.45 & 4.7714 & TST & \\
\hline CHEMBL 3195263 & 688128 & 4.45 & 4.4393 & TST & \\
\hline CHEMBL1415434 & 688128 & 4.4 & 4.9081 & TRN & \\
\hline CHEMBL1334420 & 688128 & 4.5 & 4.5686 & TRN & \\
\hline CHEMBL1365149 & 688128 & 4.3 & 4.6285 & TST & \\
\hline CHEMBL1341917 & 688128 & 4.3 & 4.6089 & TRN & \\
\hline CHEMBL1346824 & 688128 & 4.9 & 4.6778 & TST & \\
\hline CHEMBL1367084 & 688128 & 4.35 & 4.2538 & TRN & \\
\hline CHEMBL1394155 & 688128 & 4.35 & 4.4085 & TRN & \\
\hline CHEMBL1587254 & 688128 & 4.05 & 4.6025 & TRN & \\
\hline CHEMBL1372964 & 688128 & 6.0 & 5.0966 & TRN & \\
\hline CHEMBL1513582 & 688128 & 4.85 & 4.3737 & TRN & \\
\hline CHEMBL1565092 & 688128 & 4.45 & 4.4616 & TRN & \\
\hline CHEMBL 1497500 & 688128 & 4.65 & 4.5998 & TRN & \\
\hline CHEMBL1574739 & 688128 & 4.4 & 4.6001 & TST & \\
\hline CHEMBL1424470 & 688128 & 4.5 & 5.1073 & TST & \\
\hline CHEMBL1354448 & 688128 & 6.2 & 5.1249 & TST & \\
\hline CHEMBL1307219 & 688128 & 4.4 & 4.6108 & TRN & \\
\hline CHEMBL1512887 & 688128 & 4.4 & 4.538 & TRN & \\
\hline CHEMBL1344810 & 688128 & 5.15 & 4.5907 & TRN & \\
\hline CHEMBL1432601 & 688128 & 4.65 & 4.3443 & TRN & \\
\hline CHEMBL1321952 & 688128 & 4.4 & 4.7143 & TRN & \\
\hline CHEMBL548017 & 688128 & 5.4 & 4.6337 & TST & \\
\hline CHEMBL1328933 & 688128 & 4.9 & 4.5222 & TST & \\
\hline CHEMBL1536010 & 688128 & 5.5 & 4.80399 & 9999999999 & TRN \\
\hline CHEMBL1398004 & 688128 & 5.55 & 5.3651 & TRN & \\
\hline CHEMBL 3198265 & 688128 & 4.35 & 5.0257 & TRN & \\
\hline CHEMBL1582580 & 688128 & 4.7 & 4.8977 & TRN & \\
\hline CHEMBL1314925 & 688128 & 5.45 & 4.5488 & TRN & \\
\hline CHEMBL1327254 & 688128 & 4.4 & 4.9378 & TRN & \\
\hline CHEMBL1338024 & 688128 & 4.7 & 4.4138 & TRN & \\
\hline CHEMBL1475536 & 688128 & 4.35 & 4.5826 & TRN & \\
\hline CHEMBL1467516 & 688128 & 4.05 & 4.4887 & TRN & \\
\hline CHEMBL1544011 & 688128 & 4.25 & 4.8552 & TRN & \\
\hline CHEMBL1494982 & 688128 & 4.3 & 4.5769 & TST & \\
\hline CHEMBL1304527 & 688128 & 4.3 & 4.6046 & TST & \\
\hline CHEMBL1378118 & 688128 & 4.9 & 5.2637 & TRN & \\
\hline CHEMBL1352019 & 688128 & 5.6 & 4.7687 & TRN & \\
\hline CHEMBL1339359 & 688128 & 4.25 & 4.8035 & TRN & \\
\hline CHEMBL1568661 & 688128 & 4.65 & 4.813 & TST & \\
\hline CHEMBL1510479 & 688128 & 5.4 & 4.6454 & TRN & \\
\hline CHEMBL1446751 & 688128 & 5.3 & 4.4175 & TRN & \\
\hline CHEMBL1595141 & 688128 & 4.3 & 4.5256 & TST & \\
\hline CHEMBL1496624 & 688128 & 4.7 & 4.8411 & TRN & \\
\hline CHEMBL1373316 & 688128 & 7.0 & 5.1195 & TST & \\
\hline CHEMBL 1531742 & 688128 & 4.55 & 4.5 & TRN & \\
\hline CHEMBL1353378 & 688128 & 4.1 & 4.5181 & TRN & \\
\hline
\end{tabular}




\begin{tabular}{|c|c|c|c|c|}
\hline \multicolumn{5}{|c|}{ Supplemental Table S2.txt } \\
\hline CHEMBL1535216 & 688128 & 4.4 & 5.0822 & TRN \\
\hline CHEMBL1493792 & 688128 & 5.8 & 4.873 & TRN \\
\hline CHEMBL1509435 & 688128 & 5.35 & 4.3728 & TRN \\
\hline CHEMBL1422732 & 688128 & 5.55 & 4.9927 & TRN \\
\hline CHEMBL1300682 & 688128 & 4.3 & 4.603 & TRN \\
\hline CHEMBL1604538 & 688128 & 4.35 & 4.5918 & TRN \\
\hline CHEMBL1302838 & 688128 & 6.35 & 4.8772 & TST \\
\hline CHEMBL3191070 & 688128 & 4.3 & 4.5857 & TRN \\
\hline CHEMBL1455231 & 688128 & 4.5 & 4.4295 & TRN \\
\hline CHEMBL1507162 & 688128 & 4.7 & 4.938 & TRN \\
\hline CHEMBL1380513 & 688128 & 4.7 & 4.6722 & TRN \\
\hline CHEMBL1494865 & 688128 & 4.05 & 4.3426 & TST \\
\hline CHEMBL3193600 & 688128 & 4.05 & 4.4097 & TRN \\
\hline CHEMBL1368393 & 688128 & 4.1 & 4.5404 & TST \\
\hline CHEMBL1410890 & 688128 & 5.45 & 4.9604 & TST \\
\hline CHEMBL1388093 & 688128 & 4.4 & 4.6394 & TRN \\
\hline CHEMBL1495851 & 688128 & 4.65 & 4.6728 & TRN \\
\hline CHEMBL1324996 & 688128 & 4.95 & 4.5767 & TRN \\
\hline CHEMBL1397817 & 688128 & 4.05 & 4.5022 & TRN \\
\hline CHEMBL1378256 & 688128 & 4.45 & 4.3319 & TRN \\
\hline CHEMBL1393160 & 688128 & 4.35 & 4.5199 & TRN \\
\hline CHEMBL1545343 & 688128 & 4.1 & 4.6256 & TRN \\
\hline CHEMBL1328182 & 688128 & 4.8 & 4.762 & TRN \\
\hline CHEMBL 3195827 & 688128 & 5.4 & 4.7242 & TRN \\
\hline CHEMBL1565048 & 688128 & 4.45 & 4.5314 & TRN \\
\hline CHEMBL1348544 & 688128 & 4.5 & 4.4769 & TRN \\
\hline CHEMBL1556807 & 688128 & 4.25 & 4.5897 & TST \\
\hline CHEMBL1312677 & 688128 & 4.05 & 4.6031 & TRN \\
\hline CHEMBL1416030 & 688128 & 4.35 & 4.7103 & TRN \\
\hline CHEMBL1441324 & 688128 & 4.95 & 4.9211 & TRN \\
\hline CHEMBL1597423 & 688128 & 4.5 & 4.6028 & TRN \\
\hline CHEMBL1397597 & 688128 & 4.55 & 4.7549 & TST \\
\hline CHEMBL1427989 & 688128 & 4.05 & 4.462 & TRN \\
\hline CHEMBL1508463 & 688128 & 4.1 & 4.6812 & TRN \\
\hline CHEMBL1390825 & 688128 & 4.05 & 4.5507 & TRN \\
\hline CHEMBL1428578 & 688128 & 5.6 & 4.9742 & TRN \\
\hline CHEMBL1366252 & 688128 & 5.45 & 4.7166 & TST \\
\hline CHEMBL1601995 & 688128 & 4.3 & 4.6583 & TST \\
\hline CHEMBL1354479 & 688128 & 4.3 & 4.4937 & TRN \\
\hline CHEMBL1561877 & 688128 & 4.4 & 4.9066 & TRN \\
\hline CHEMBL 243644 & 688128 & 6.2 & 4.7698 & TRN \\
\hline CHEMBL1350426 & 688128 & 6.5 & 4.5364 & TRN \\
\hline CHEMBL1338630 & 688128 & 4.6 & 4.5458 & TRN \\
\hline CHEMBL1380414 & 688128 & 4.45 & 4.8363 & TRN \\
\hline CHEMBL1548102 & 688128 & 4.4 & 4.6729 & TRN \\
\hline CHEMBL1407693 & 688128 & 4.35 & 4.4732 & TRN \\
\hline CHEMBL1483714 & 688128 & 4.05 & 4.3398 & TRN \\
\hline CHEMBL1311950 & 688128 & 4.4 & 4.3481 & TRN \\
\hline
\end{tabular}




\begin{tabular}{|c|c|c|c|c|c|}
\hline \multicolumn{6}{|c|}{ Supplemental Table s2.txt } \\
\hline CHEMBL1386032 & 688128 & 4.6 & 4.6601 & TST & \\
\hline CHEMBL1359347 & 688128 & 4.4 & 4.5355 & TST & \\
\hline CHEMBL1489765 & 688128 & 4.7 & 4.5141 & TST & \\
\hline CHEMBL1418329 & 688128 & 4.25 & 4.4979 & TST & \\
\hline CHEMBL1343217 & 688128 & 4.05 & 4.5512 & TRN & \\
\hline CHEMBL1443946 & 688128 & 7.0 & 5.1598 & TRN & \\
\hline CHEMBL1502521 & 688128 & 4.3 & 4.6697 & TRN & \\
\hline CHEMBL1568465 & 688128 & 4.25 & 4.5423 & TRN & \\
\hline CHEMBL1406829 & 688128 & 4.3 & 4.2748 & TRN & \\
\hline CHEMBL1460137 & 688128 & 5.5 & 4.5706 & TRN & \\
\hline CHEMBL1454274 & 688128 & 4.45 & 4.5377 & TRN & \\
\hline CHEMBL1473698 & 688128 & 4.55 & 4.7098 & TST & \\
\hline CHEMBL1588642 & 688128 & 5.45 & 4.7406 & TRN & \\
\hline CHEMBL1524247 & 688128 & 4.5 & 4.6731 & TRN & \\
\hline CHEMBL1546505 & 688128 & 4.05 & 4.5628 & TST & \\
\hline CHEMBL1416358 & 688128 & 4.35 & 4.84399 & 9999999999 & TST \\
\hline CHEMBL1320113 & 688128 & 4.05 & 4.5008 & TST & \\
\hline CHEMBL1340987 & 688128 & 4.9 & 4.6837 & TST & \\
\hline CHEMBL1329953 & 688128 & 4.35 & 4.1508 & TST & \\
\hline CHEMBL1559308 & 688128 & 4.45 & 4.7079 & TRN & \\
\hline CHEMBL1584094 & 688128 & 4.4 & 4.7499 & TST & \\
\hline CHEMBL1478617 & 688128 & 4.6 & 4.6579 & TRN & \\
\hline CHEMBL3210772 & 688128 & 4.55 & 4.3856 & TRN & \\
\hline CHEMBL1322883 & 688128 & 4.2 & 4.5844 & TST & \\
\hline CHEMBL1571110 & 688128 & 4.2 & 4.6844 & TRN & \\
\hline CHEMBL3199152 & 688128 & 4.65 & 4.754 & TRN & \\
\hline CHEMBL1454863 & 688128 & 4.25 & 4.9066 & TRN & \\
\hline CHEMBL1413658 & 688128 & 4.0 & 4.5008 & TST & \\
\hline CHEMBL1403681 & 688128 & 4.25 & 4.3912 & TRN & \\
\hline CHEMBL1594981 & 688128 & 4.4 & 4.3444 & TST & \\
\hline CHEMBL1426925 & 688128 & 4.95 & 5.041 & TRN & \\
\hline CHEMBL1336284 & 688128 & 4.4 & 4.6421 & TST & \\
\hline CHEMBL1385121 & 688128 & 4.4 & 4.7526 & TRN & \\
\hline CHEMBL1401219 & 688128 & 4.3 & 4.6549 & TRN & \\
\hline CHEMBL1580733 & 688128 & 4.3 & 4.8385 & TRN & \\
\hline CHEMBL1505230 & 688128 & 4.3 & 4.7979 & TRN & \\
\hline CHEMBL1303733 & 688128 & 5.65 & 4.9719 & TRN & \\
\hline CHEMBL1606020 & 688128 & 4.4 & 4.4859 & TST & \\
\hline CHEMBL1505133 & 688128 & 4.4 & 4.3808 & TRN & \\
\hline CHEMBL1464823 & 688128 & 4.05 & 4.4538 & TST & \\
\hline CHEMBL1336764 & 688128 & 4.35 & 4.3646 & TRN & \\
\hline CHEMBL1569114 & 688128 & 5.6 & 4.4103 & TST & \\
\hline CHEMBL1507500 & 688128 & 4.4 & 4.6825 & TST & \\
\hline CHEMBL1505751 & 688128 & 4.4 & 4.3142 & TRN & \\
\hline CHEMBL1343353 & 688128 & 4.35 & 4.6527 & TRN & \\
\hline CHEMBL1329691 & 688128 & 4.6 & 4.6989 & TRN & \\
\hline CHEMBL1531225 & 688128 & 4.5 & 4.5353 & TST & \\
\hline CHEMBL1429406 & 688128 & 4.35 & 4.40300 & 00000000005 & TST \\
\hline & & & & 16511 & \\
\hline
\end{tabular}




\begin{tabular}{|c|c|c|c|c|c|}
\hline \multicolumn{6}{|c|}{ Supplemental Table s2.txt } \\
\hline CHEMBL1537608 & 688128 & 4.0 & 4.4115 & TRN & \\
\hline CHEMBL1460513 & 688128 & 4.35 & 4.3244 & TRN & \\
\hline CHEMBL1452026 & 688128 & 4.35 & 4.8438 & TRN & \\
\hline CHEMBL1300834 & 688128 & 4.35 & 4.9988 & TRN & \\
\hline CHEMBL1417344 & 688128 & 5.25 & 4.7104 & TRN & \\
\hline CHEMBL1304998 & 688128 & 4.35 & 4.8497 & TRN & \\
\hline CHEMBL1364974 & 688128 & 4.7 & 4.7998 & TRN & \\
\hline CHEMBL1549714 & 688128 & 4.4 & 4.5508 & TST & \\
\hline CHEMBL1404572 & 688128 & 4.75 & 4.6406 & TRN & \\
\hline CHEMBL345124 & 688128 & 4.4 & 4.5557 & TST & \\
\hline CHEMBL1349514 & 688128 & 4.35 & 4.5465 & TRN & \\
\hline CHEMBL1540453 & 688128 & 4.35 & 4.6794 & TRN & \\
\hline CHEMBL3194339 & 688128 & 4.05 & 4.6485 & TRN & \\
\hline CHEMBL1311537 & 688128 & 4.4 & 4.6556 & TRN & \\
\hline CHEMBL1457086 & 688128 & 4.3 & 4.5532 & TRN & \\
\hline CHEMBL567508 & 688128 & 4.9 & 4.6824 & TRN & \\
\hline CHEMBL1977063 & 688128 & 4.4 & 4.6009 & TRN & \\
\hline CHEMBL1479707 & 688128 & 4.25 & 4.4499 & TRN & \\
\hline CHEMBL1402302 & 688128 & 5.1 & 4.9096 & TRN & \\
\hline CHEMBL1313324 & 688128 & 4.3 & 4.97199 & 99999999995 & TRN \\
\hline CHEMBL1550974 & 688128 & 4.4 & 4.4087 & TRN & \\
\hline CHEMBL1337504 & 688128 & 4.4 & 4.7976 & TST & \\
\hline CHEMBL1363216 & 688128 & 4.05 & 4.5676 & TRN & \\
\hline CHEMBL1359285 & 688128 & 4.3 & 4.4908 & TST & \\
\hline CHEMBL1607665 & 688128 & 4.45 & 4.6832 & TRN & \\
\hline CHEMBL1564216 & 688128 & 4.3 & 4.7466 & TST & \\
\hline CHEMBL1976499 & 688128 & 5.05 & 4.7579 & TRN & \\
\hline CHEMBL1497311 & 688128 & 4.75 & 4.7212 & TRN & \\
\hline CHEMBL1550056 & 688128 & 4.05 & 4.6145 & TRN & \\
\hline CHEMBL3196477 & 688128 & 4.5 & 4.4299 & TST & \\
\hline CHEMBL1471629 & 688128 & 5.7 & 4.6128 & TRN & \\
\hline CHEMBL1357464 & 688128 & 5.6 & 5.1075 & TRN & \\
\hline CHEMBL1586719 & 688128 & 4.7 & 4.61 & TRN & \\
\hline CHEMBL3199587 & 688128 & 4.35 & 4.6099 & TRN & \\
\hline CHEMBL1460155 & 688128 & 6.5 & 5.3676 & TRN & \\
\hline CHEMBL1427221 & 688128 & 5.8 & 4.9684 & TRN & \\
\hline CHEMBL1420683 & 688128 & 4.3 & 4.5617 & TRN & \\
\hline CHEMBL1444601 & 688128 & 4.35 & 4.8598 & TRN & \\
\hline CHEMBL1459718 & 688128 & 4.3 & 4.7147 & TRN & \\
\hline CHEMBL1319354 & 688128 & 4.4 & 4.8737 & TRN & \\
\hline CHEMBL1576679 & 688128 & 4.4 & 4.5628 & TRN & \\
\hline CHEMBL1572881 & 688128 & 4.1 & 4.5455 & TST & \\
\hline CHEMBL1500339 & 688128 & 4.3 & 4.7 & TRN & \\
\hline CHEMBL1525518 & 688128 & 5.45 & 4.886 & TRN & \\
\hline CHEMBL1510164 & 688128 & 4.1 & 4.7897 & TST & \\
\hline CHEMBL1596855 & 688128 & 5.3 & 4.7148 & TRN & \\
\hline CHEMBL1360985 & 688128 & 5.05 & 4.6607 & TST & \\
\hline CHEMBL1489356 & 688128 & 4.35 & 4.6199 & TRN & \\
\hline
\end{tabular}




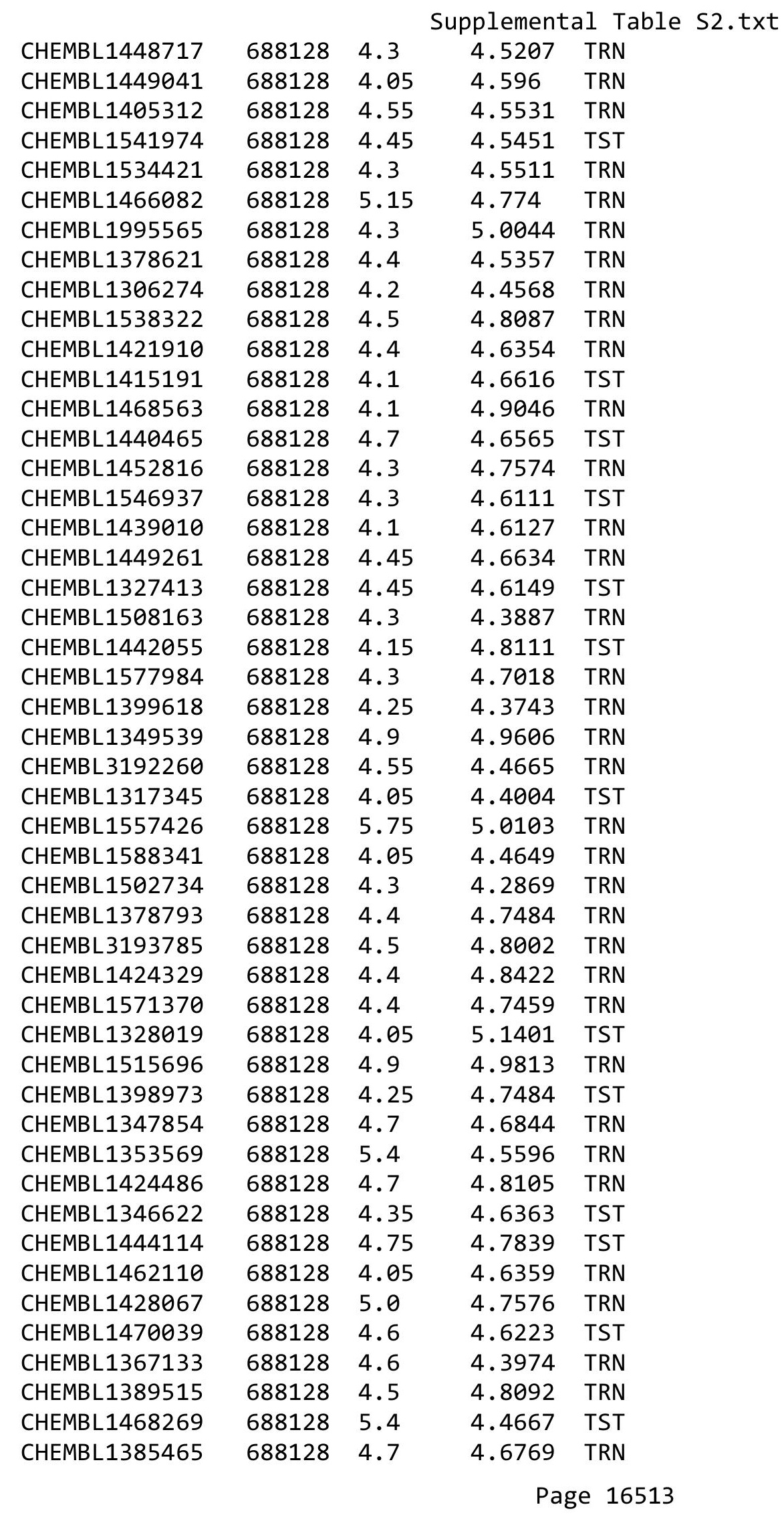




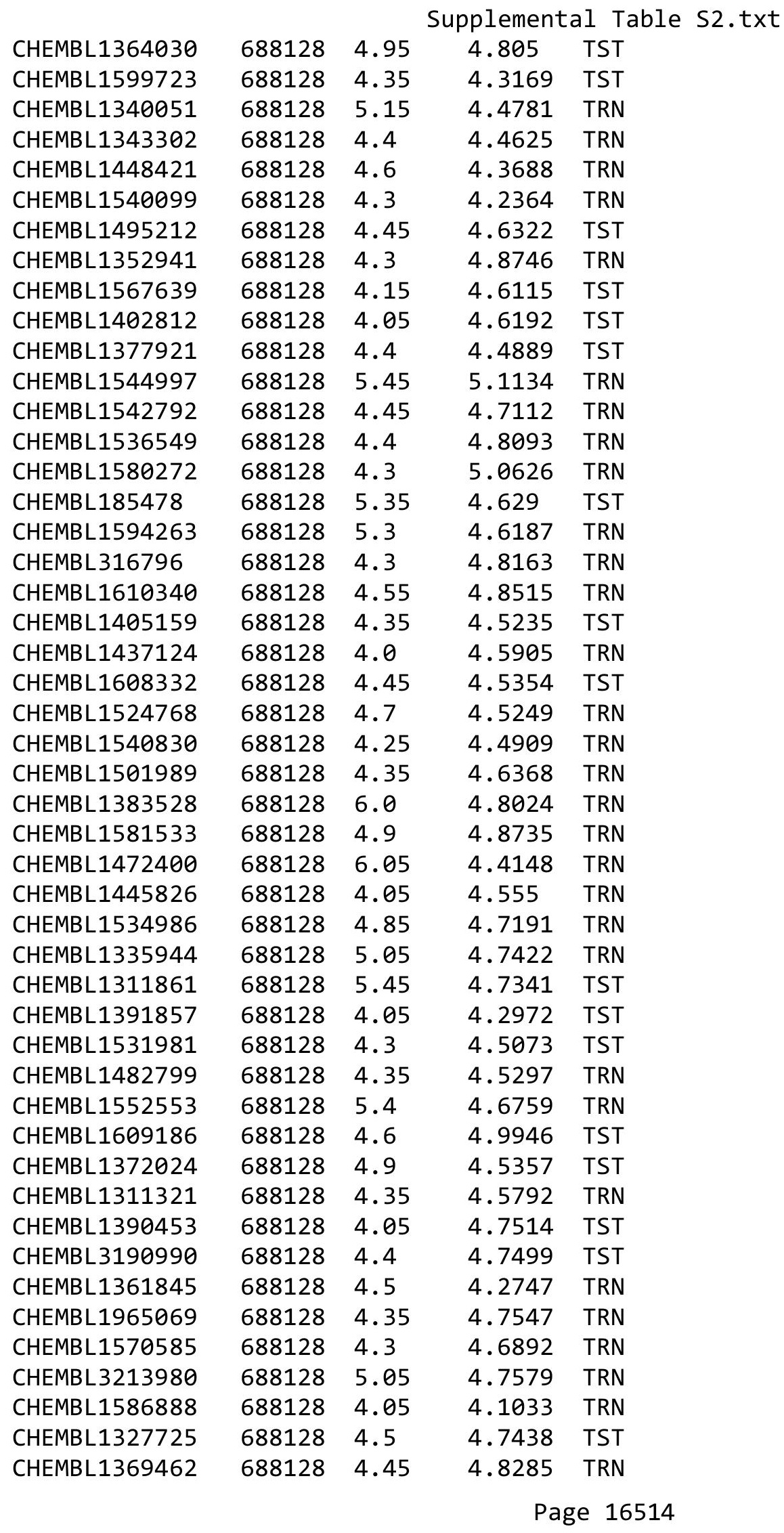




\begin{tabular}{|c|c|c|c|c|c|}
\hline \multicolumn{6}{|c|}{ Supplemental Table S2.txt } \\
\hline CHEMBL1558285 & 688128 & 4.05 & 4.7285 & TST & \\
\hline CHEMBL1470163 & 688128 & 4.45 & 4.5746 & TST & \\
\hline CHEMBL1311542 & 688128 & 4.3 & 4.7278 & TST & \\
\hline CHEMBL1505102 & 688128 & 4.45 & 4.478 & TRN & \\
\hline CHEMBL1485262 & 688128 & 4.45 & 4.3065 & TST & \\
\hline CHEMBL1432342 & 688128 & 4.35 & 4.5762 & TRN & \\
\hline CHEMBL1306557 & 688128 & 4.85 & 4.4383 & TRN & \\
\hline CHEMBL1393878 & 688128 & 5.0 & 4.6926 & TRN & \\
\hline CHEMBL1369936 & 688128 & 4.65 & 4.5842 & TRN & \\
\hline CHEMBL1980982 & 688128 & 4.85 & 4.7316 & TRN & \\
\hline CHEMBL1407118 & 688128 & 4.05 & 4.7948 & TST & \\
\hline CHEMBL1384310 & 688128 & 4.4 & 4.7552 & TRN & \\
\hline CHEMBL1426603 & 688128 & 4.35 & 4.6778 & TRN & \\
\hline CHEMBL1459251 & 688128 & 4.3 & 4.6967 & TRN & \\
\hline CHEMBL1405265 & 688128 & 4.6 & 4.4731 & TRN & \\
\hline CHEMBL1462274 & 688128 & 5.05 & 4.3382 & TRN & \\
\hline CHEMBL1383772 & 688128 & 4.35 & 4.38399 & 99999999995 & TRN \\
\hline CHEMBL1343849 & 688128 & 4.3 & 4.5377 & TRN & \\
\hline CHEMBL1539159 & 688128 & 5.3 & 4.82600 & 00000000005 & TRN \\
\hline CHEMBL1412712 & 688128 & 6.15 & 5.0384 & TRN & \\
\hline CHEMBL1405348 & 688128 & 4.05 & 4.5411 & TST & \\
\hline CHEMBL1558165 & 688128 & 6.2 & 4.6173 & TRN & \\
\hline CHEMBL1348736 & 688128 & 4.4 & 4.4646 & TRN & \\
\hline CHEMBL1397296 & 688128 & 4.75 & 4.4993 & TRN & \\
\hline CHEMBL 2000340 & 688128 & 4.35 & 4.8999 & TST & \\
\hline CHEMBL24983 & 688128 & 5.5 & 4.7511 & TST & \\
\hline CHEMBL1578916 & 688128 & 4.4 & 4.2876 & TRN & \\
\hline CHEMBL1363121 & 688128 & 4.5 & 4.3489 & TRN & \\
\hline CHEMBL1394235 & 688128 & 4.3 & 4.5937 & TST & \\
\hline CHEMBL1378223 & 688128 & 5.45 & 4.6837 & TST & \\
\hline CHEMBL1525730 & 688128 & 4.05 & 4.6109 & TRN & \\
\hline CHEMBL1576666 & 688128 & 4.1 & 4.7116 & TRN & \\
\hline CHEMBL1433240 & 688128 & 4.8 & 4.636 & TRN & \\
\hline CHEMBL1580438 & 688128 & 4.3 & 4.4179 & TRN & \\
\hline CHEMBL1369377 & 688128 & 4.3 & 4.1042 & TRN & \\
\hline CHEMBL3189191 & 688128 & 4.8 & 4.7919 & TRN & \\
\hline CHEMBL1519634 & 688128 & 4.3 & 4.7325 & TST & \\
\hline CHEMBL1425998 & 688128 & 4.8 & 4.54 & TRN & \\
\hline CHEMBL1377763 & 688128 & 4.4 & 4.5696 & TST & \\
\hline CHEMBL1590345 & 688128 & 4.6 & 4.6416 & TRN & \\
\hline CHEMBL1333605 & 688128 & 4.35 & 4.2973 & TST & \\
\hline CHEMBL1423713 & 688128 & 4.45 & 4.6882 & TST & \\
\hline CHEMBL1320277 & 688128 & 4.3 & 4.9285 & TRN & \\
\hline CHEMBL1528603 & 688128 & 5.0 & 4.4861 & TRN & \\
\hline CHEMBL1387770 & 688128 & 4.25 & 4.5941 & TRN & \\
\hline CHEMBL1457174 & 688128 & 4.65 & 5.1316 & TRN & \\
\hline CHEMBL3209697 & 688128 & 4.3 & 4.4954 & TST & \\
\hline CHEMBL1384891 & 688128 & 4.35 & 4.6341 & TRN & \\
\hline
\end{tabular}




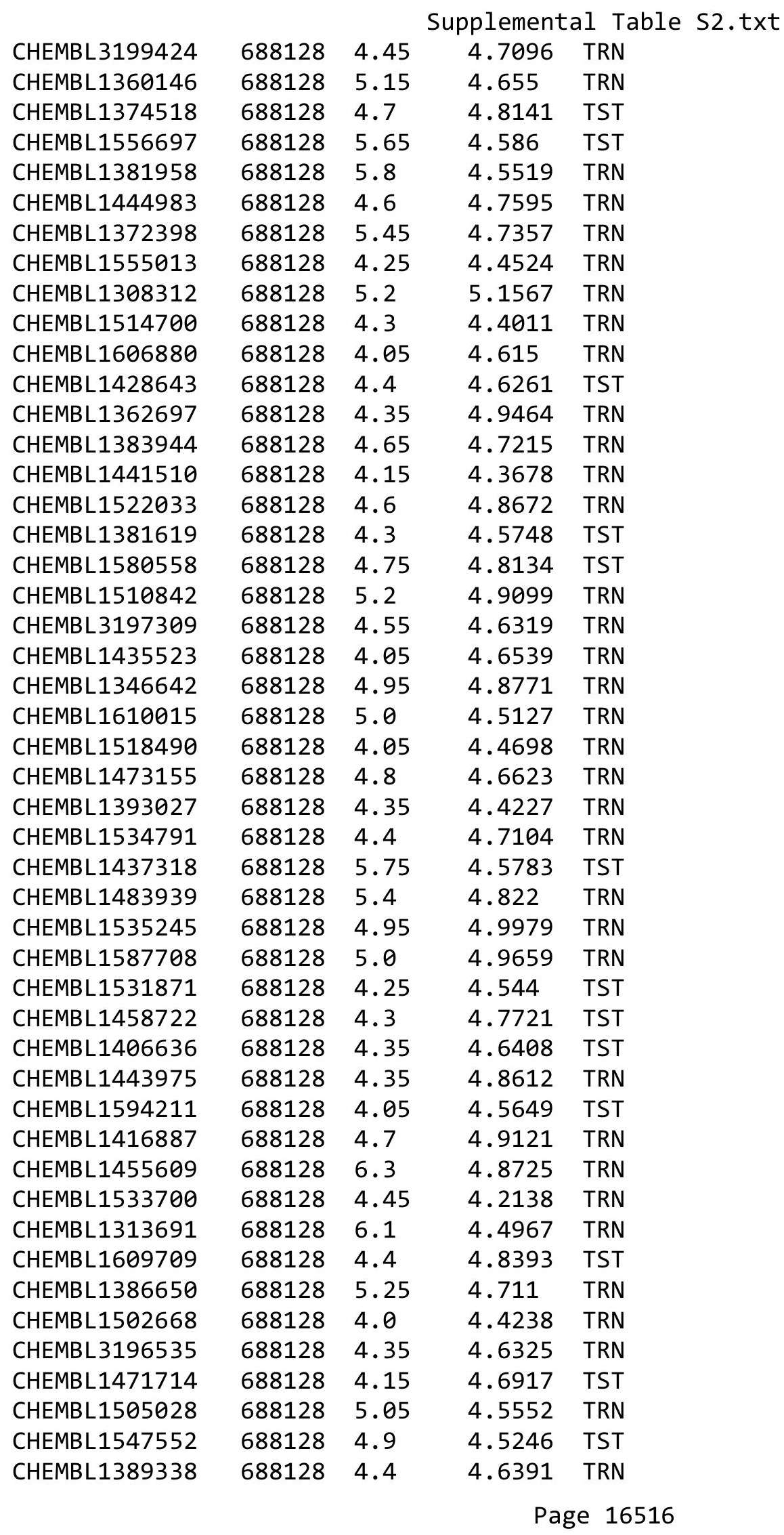




\begin{tabular}{|c|c|c|c|c|}
\hline \multicolumn{5}{|c|}{ Supplemental Table S2.txt } \\
\hline CHEMBL1483302 & 688128 & 4.05 & 4.2499 & TRN \\
\hline CHEMBL1560541 & 688128 & 5.55 & 4.6198 & TST \\
\hline CHEMBL1308226 & 688128 & 4.1 & 4.7131 & TRN \\
\hline CHEMBL1592624 & 688128 & 4.25 & 4.7365 & TRN \\
\hline CHEMBL 1450298 & 688128 & 4.85 & 4.6352 & TRN \\
\hline CHEMBL1487052 & 688128 & 4.95 & 4.7176 & TRN \\
\hline CHEMBL1539384 & 688128 & 4.45 & 4.8204 & TRN \\
\hline CHEMBL1339717 & 688128 & 6.8 & 4.4616 & TST \\
\hline CHEMBL1316640 & 688128 & 4.8 & 4.8987 & TRN \\
\hline CHEMBL1607070 & 688128 & 4.65 & 4.5902 & TRN \\
\hline CHEMBL1557115 & 688128 & 4.3 & 4.5475 & TRN \\
\hline CHEMBL1502559 & 688128 & 4.35 & 4.6734 & TST \\
\hline CHEMBL1582080 & 688128 & 5.55 & 4.9001 & TST \\
\hline CHEMBL1579081 & 688128 & 4.35 & 4.6727 & TRN \\
\hline CHEMBL1372009 & 688128 & 6.15 & 4.5021 & TRN \\
\hline CHEMBL1447156 & 688128 & 4.0 & 4.2232 & TRN \\
\hline CHEMBL1318438 & 688128 & 4.4 & 4.4692 & TST \\
\hline CHEMBL1413017 & 688128 & 5.4 & 4.7677 & TRN \\
\hline CHEMBL1309415 & 688128 & 5.0 & 4.8628 & TST \\
\hline CHEMBL1435767 & 688128 & 4.15 & 4.4359 & TRN \\
\hline CHEMBL1544632 & 688128 & 4.35 & 4.6224 & TRN \\
\hline CHEMBL1572585 & 688128 & 5.2 & 5.4153 & TRN \\
\hline CHEMBL1573101 & 688128 & 4.3 & 4.7772 & TRN \\
\hline CHEMBL1495522 & 688128 & 4.25 & 4.5493 & TST \\
\hline CHEMBL1435633 & 688128 & 4.7 & 4.8258 & TRN \\
\hline CHEMBL1421554 & 688128 & 4.05 & 4.7039 & TRN \\
\hline CHEMBL1588592 & 688128 & 4.4 & 4.6304 & TRN \\
\hline CHEMBL1426709 & 688128 & 4.6 & 4.5027 & TST \\
\hline CHEMBL1328018 & 688128 & 4.4 & 4.6383 & TRN \\
\hline CHEMBL1484620 & 688128 & 4.35 & 4.6749 & TRN \\
\hline CHEMBL1574469 & 688128 & 4.45 & 4.8306 & TRN \\
\hline CHEMBL1522293 & 688128 & 4.05 & 4.6151 & TRN \\
\hline CHEMBL1526861 & 688128 & 4.55 & 4.5018 & TRN \\
\hline CHEMBL1361463 & 688128 & 5.5 & 4.3762 & TRN \\
\hline CHEMBL1462433 & 688128 & 4.85 & 4.6458 & TST \\
\hline CHEMBL1470572 & 688128 & 4.25 & 4.6644 & TRN \\
\hline CHEMBL1359753 & 688128 & 4.95 & 5.0184 & TRN \\
\hline CHEMBL1552208 & 688128 & 5.0 & 4.9767 & TRN \\
\hline CHEMBL1452574 & 688128 & 4.85 & 4.5247 & TRN \\
\hline CHEMBL1604554 & 688128 & 4.1 & 4.1429 & TST \\
\hline CHEMBL1562005 & 688128 & 4.25 & 4.6049 & TRN \\
\hline CHEMBL1457908 & 688128 & 4.6 & 4.4146 & TRN \\
\hline CHEMBL1559493 & 688128 & 4.3 & 4.6828 & TRN \\
\hline CHEMBL1340319 & 688128 & 4.4 & 4.8004 & TST \\
\hline CHEMBL1377279 & 688128 & 4.45 & 4.6855 & TRN \\
\hline CHEMBL1531003 & 688128 & 4.4 & 4.9951 & TST \\
\hline CHEMBL1521758 & 688128 & 4.65 & 4.8496 & TRN \\
\hline CHEMBL1558780 & 688128 & 4.45 & 4.6661 & TRN \\
\hline
\end{tabular}




\begin{tabular}{|c|c|c|c|c|c|}
\hline & & \multicolumn{4}{|c|}{ Supplemental Table S2.txt } \\
\hline CHEMBL1585213 & 688128 & 4.4 & 4.7212 & TST & \\
\hline CHEMBL1399218 & 688128 & 4.3 & 4.744 & TRN & \\
\hline CHEMBL1351217 & 688128 & 4.65 & 5.0165 & TRN & \\
\hline CHEMBL1495752 & 688128 & 4.25 & 4.5731 & TST & \\
\hline CHEMBL1501485 & 688128 & 4.4 & 4.6126 & TRN & \\
\hline CHEMBL1579680 & 688128 & 4.25 & 4.7267 & TST & \\
\hline CHEMBL1360658 & 688128 & 4.5 & 4.3268 & TRN & \\
\hline CHEMBL1350543 & 688128 & 5.4 & $4.9910 e$ & 00000000005 & TRN \\
\hline CHEMBL1523645 & 688128 & 5.4 & 4.7608 & TST & \\
\hline CHEMBL1347667 & 688128 & 4.3 & 4.262 & TRN & \\
\hline CHEMBL1307137 & 688128 & 4.45 & 4.6225 & TRN & \\
\hline CHEMBL1548906 & 688128 & 4.9 & 4.5319 & TRN & \\
\hline CHEMBL1599552 & 688128 & 4.0 & 4.6925 & TRN & \\
\hline CHEMBL1432200 & 688128 & 4.75 & 4.689 & TRN & \\
\hline CHEMBL1411652 & 688128 & 5.45 & 4.4879 & TST & \\
\hline CHEMBL224916 & 688128 & 4.2 & 4.9627 & TRN & \\
\hline CHEMBL1419484 & 688128 & 5.65 & 5.0965 & TST & \\
\hline CHEMBL1549250 & 688128 & 4.0 & 4.6102 & TRN & \\
\hline CHEMBL1473988 & 688128 & 4.6 & 4.622 & TRN & \\
\hline CHEMBL1571492 & 688128 & 5.5 & 4.63399 & 99999999995 & TRN \\
\hline CHEMBL1443007 & 688128 & 4.4 & 4.6284 & TRN & \\
\hline CHEMBL1481856 & 688128 & 4.4 & 4.5928 & TRN & \\
\hline CHEMBL1496269 & 688128 & 4.3 & 4.8445 & TRN & \\
\hline CHEMBL1489117 & 688128 & 5.45 & 4.5959 & TST & \\
\hline CHEMBL1457328 & 688128 & 4.35 & 4.3011 & TRN & \\
\hline CHEMBL1306564 & 688128 & 5.15 & 4.8495 & TRN & \\
\hline CHEMBL1499843 & 688128 & 5.25 & 4.4296 & TRN & \\
\hline CHEMBL1524234 & 688128 & 4.3 & 4.5153 & TRN & \\
\hline CHEMBL3190225 & 688128 & 4.35 & 4.5469 & TST & \\
\hline CHEMBL1513600 & 688128 & 5.45 & 4.572 & TST & \\
\hline CHEMBL1566960 & 688128 & 4.4 & 4.8601 & TST & \\
\hline CHEMBL1585393 & 688128 & 4.3 & 4.6474 & TRN & \\
\hline CHEMBL1520210 & 688128 & 4.3 & 4.6881 & TRN & \\
\hline CHEMBL1393503 & 688128 & 4.35 & 4.6397 & TRN & \\
\hline CHEMBL1581179 & 688128 & 5.7 & 4.68 & TST & \\
\hline CHEMBL1535664 & 688128 & 4.3 & 4.5914 & TRN & \\
\hline CHEMBL1603579 & 688128 & 4.3 & 4.4267 & TRN & \\
\hline CHEMBL1336405 & 688128 & 4.55 & 4.6657 & TRN & \\
\hline CHEMBL1468929 & 688128 & 4.4 & 4.6836 & TST & \\
\hline CHEMBL1429556 & 688128 & 4.35 & 5.0509 & TRN & \\
\hline CHEMBL1373277 & 688128 & 4.7 & 4.6413 & TST & \\
\hline CHEMBL1539907 & 688128 & 4.4 & 4.506 & TST & \\
\hline CHEMBL1319008 & 688128 & 5.7 & 4.4611 & TRN & \\
\hline CHEMBL1442682 & 688128 & 4.4 & 4.4936 & TRN & \\
\hline CHEMBL1584649 & 688128 & 3.95 & 4.5441 & TRN & \\
\hline CHEMBL1408102 & 688128 & 4.4 & 4.5916 & TRN & \\
\hline CHEMBL3195169 & 688128 & 4.55 & 4.8482 & TST & \\
\hline CHEMBL1611773 & 688128 & 4.4 & 4.7349 & TST & \\
\hline
\end{tabular}




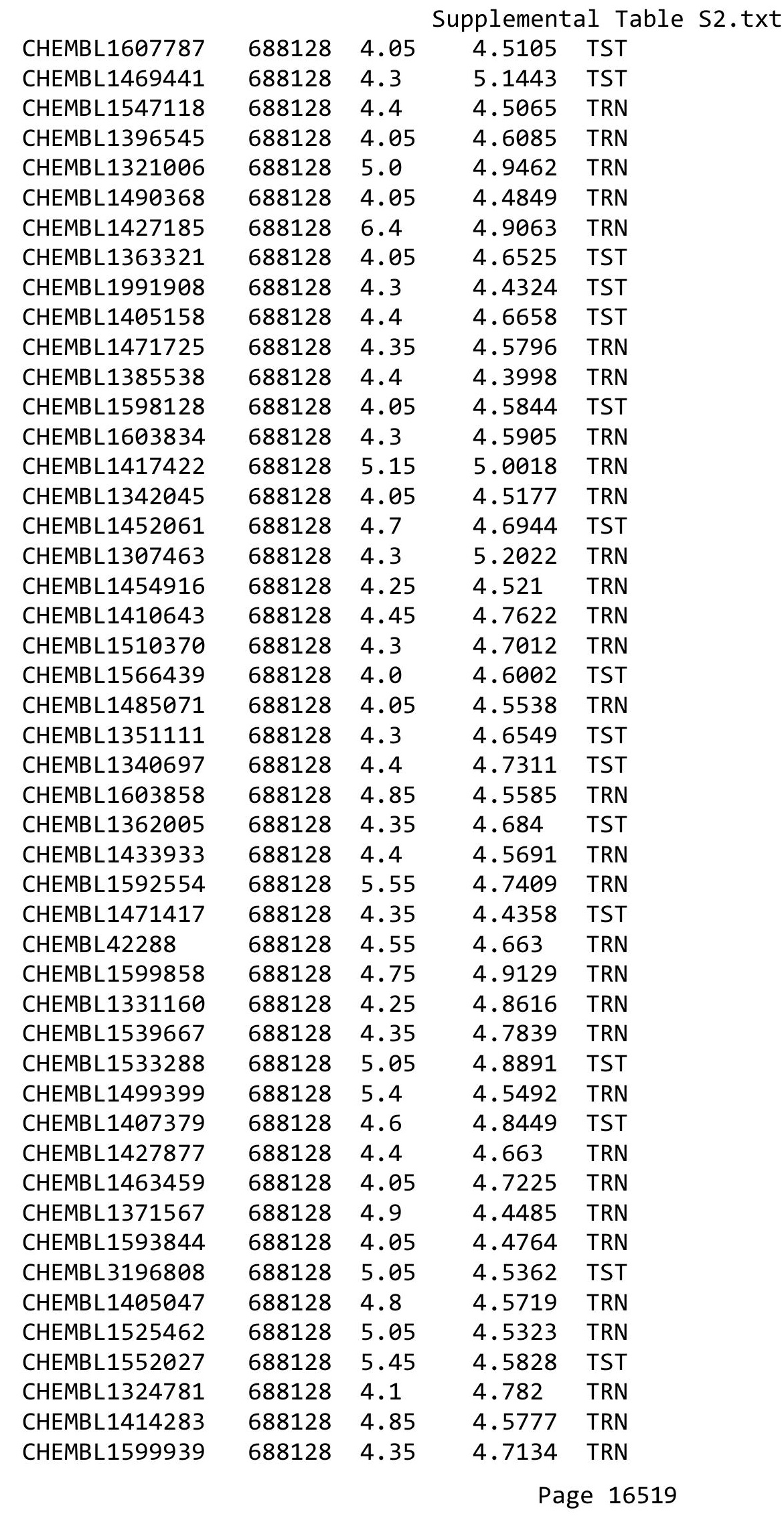




\begin{tabular}{|c|c|c|c|c|c|}
\hline \\
\hline CHEMBL1519080 & 688128 & 4.7 & 4.47 & TRN & \\
\hline CHEMBL1443266 & 688128 & 4.4 & 5.0118 & TRN & \\
\hline CHEMBL1388902 & 688128 & 4.4 & 4.4316 & TRN & \\
\hline CHEMBL 3192684 & 688128 & 4.1 & 4.6961 & TST & \\
\hline CHEMBL1307692 & 688128 & 5.1 & 5.3325 & TRN & \\
\hline CHEMBL1390461 & 688128 & 4.4 & 4.4495 & TRN & \\
\hline CHEMBL 3195347 & 688128 & 4.05 & 5.0164 & TST & \\
\hline CHEMBL1561094 & 688128 & 4.35 & 4.6206 & TRN & \\
\hline CHEMBL1385071 & 688128 & 4.05 & 4.5425 & TST & \\
\hline CHEMBL1509645 & 688128 & 4.25 & 4.4987 & TRN & \\
\hline CHEMBL1568867 & 688128 & 4.25 & 4.7066 & TRN & \\
\hline CHEMBL1540031 & 688128 & 6.6499 & 4.7241 & TRN & \\
\hline CHEMBL3199621 & 688128 & 4.35 & 4.315 & TST & \\
\hline CHEMBL1377117 & 688128 & 6.5 & 5.1342 & TRN & \\
\hline CHEMBL1487037 & 688128 & 5.65 & 4.5427 & TRN & \\
\hline CHEMBL1345263 & 688128 & 4.3 & 4.6733 & TST & \\
\hline CHEMBL1564026 & 688128 & 4.4 & 4.3868 & TRN & \\
\hline CHEMBL1508433 & 688128 & 6.0 & 5.348 & TRN & \\
\hline CHEMBL1435581 & 688128 & 5.15 & 4.8112 & TRN & \\
\hline CHEMBL1464102 & 688128 & 4.4 & 4.777 & TRN & \\
\hline CHEMBL3193859 & 688128 & 6.0 & 4.4149 & TRN & \\
\hline CHEMBL1528158 & 688128 & 4.3 & 4.5511 & TRN & \\
\hline CHEMBL369996 & 688128 & 4.3 & 4.5225 & TRN & \\
\hline CHEMBL1464666 & 688128 & 4.05 & 4.7226 & TST & \\
\hline CHEMBL1339830 & 688128 & 4.45 & $4.7410 e$ & 00000000005 & TRN \\
\hline CHEMBL1445546 & 688128 & 4.55 & 4.6067 & TRN & \\
\hline CHEMBL1421237 & 688128 & 4.9 & 4.7169 & TST & \\
\hline CHEMBL1529446 & 688128 & 4.25 & 4.4591 & TRN & \\
\hline CHEMBL1444055 & 688128 & 4.45 & 4.4002 & TRN & \\
\hline CHEMBL1474564 & 688128 & 4.35 & 4.742 & TRN & \\
\hline CHEMBL1554850 & 688128 & 4.05 & 4.4986 & TRN & \\
\hline CHEMBL1469628 & 688128 & 4.4 & 4.5162 & TRN & \\
\hline CHEMBL1457396 & 688128 & 4.95 & 4.8358 & TRN & \\
\hline CHEMBL1312926 & 688128 & 4.35 & 4.2705 & TRN & \\
\hline CHEMBL1494580 & 688128 & 4.05 & 4.5436 & TRN & \\
\hline CHEMBL1503424 & 688128 & 5.15 & 4.7862 & TST & \\
\hline CHEMBL1458488 & 688128 & 4.05 & 4.5807 & TST & \\
\hline CHEMBL1450243 & 688128 & 4.65 & 4.6608 & TRN & \\
\hline CHEMBL1402920 & 688128 & 4.35 & 4.5919 & TRN & \\
\hline CHEMBL1602542 & 688128 & 6.05 & 4.5789 & TRN & \\
\hline CHEMBL1440723 & 688128 & 4.4 & 4.5657 & TST & \\
\hline CHEMBL1574377 & 688128 & 4.55 & 4.47 & TRN & \\
\hline CHEMBL3208680 & 688128 & 5.45 & 4.4733 & TST & \\
\hline CHEMBL1612490 & 688128 & 4.8 & 4.5849 & TRN & \\
\hline CHEMBL1501564 & 688128 & 4.5 & 4.6922 & TRN & \\
\hline CHEMBL1488108 & 688128 & 4.3 & 4.6126 & TRN & \\
\hline CHEMBL1318213 & 688128 & 4.9 & 4.7557 & TRN & \\
\hline CHEMBL1319086 & 688128 & 4.5 & 4.6216 & TRN & \\
\hline
\end{tabular}




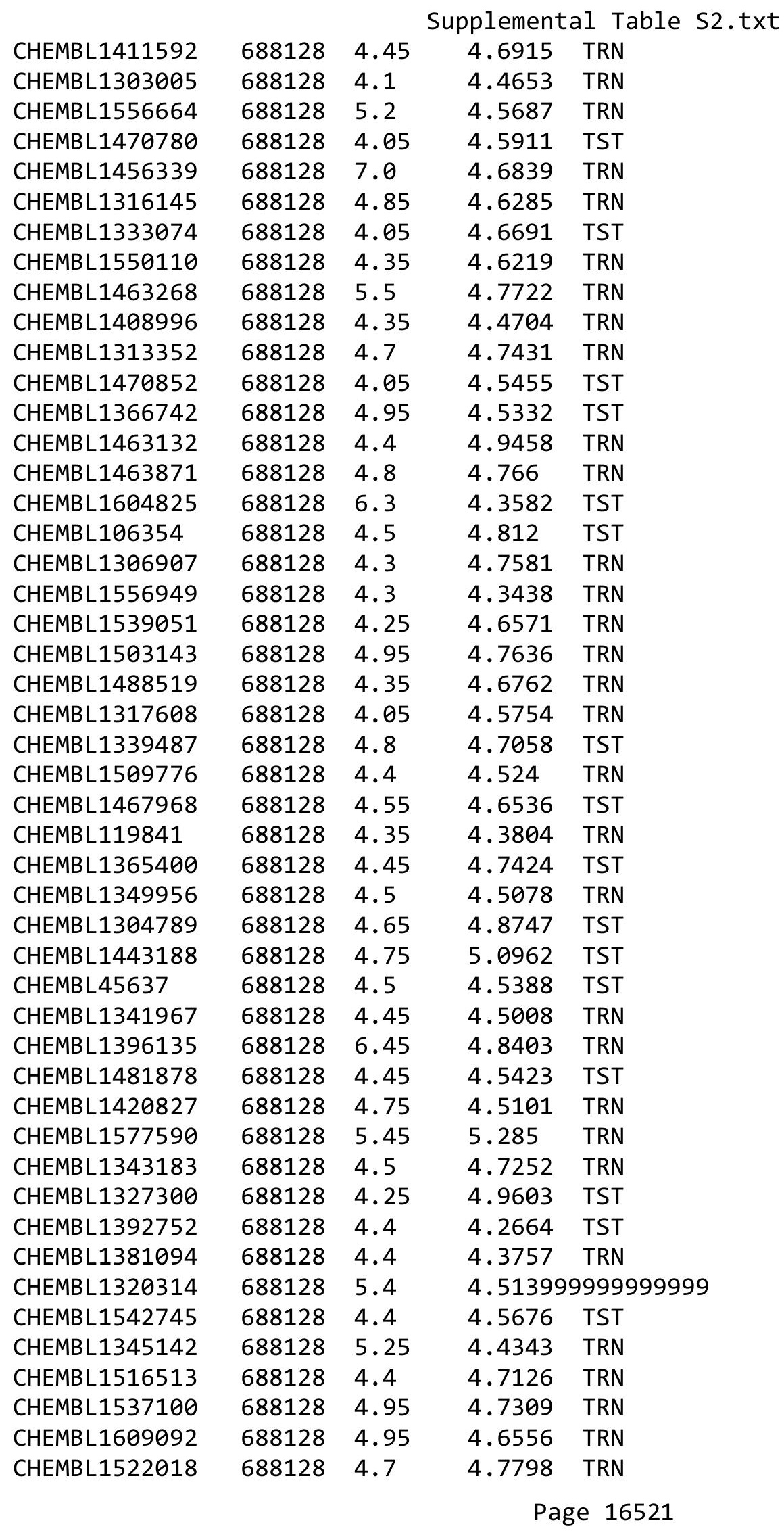

TRN 


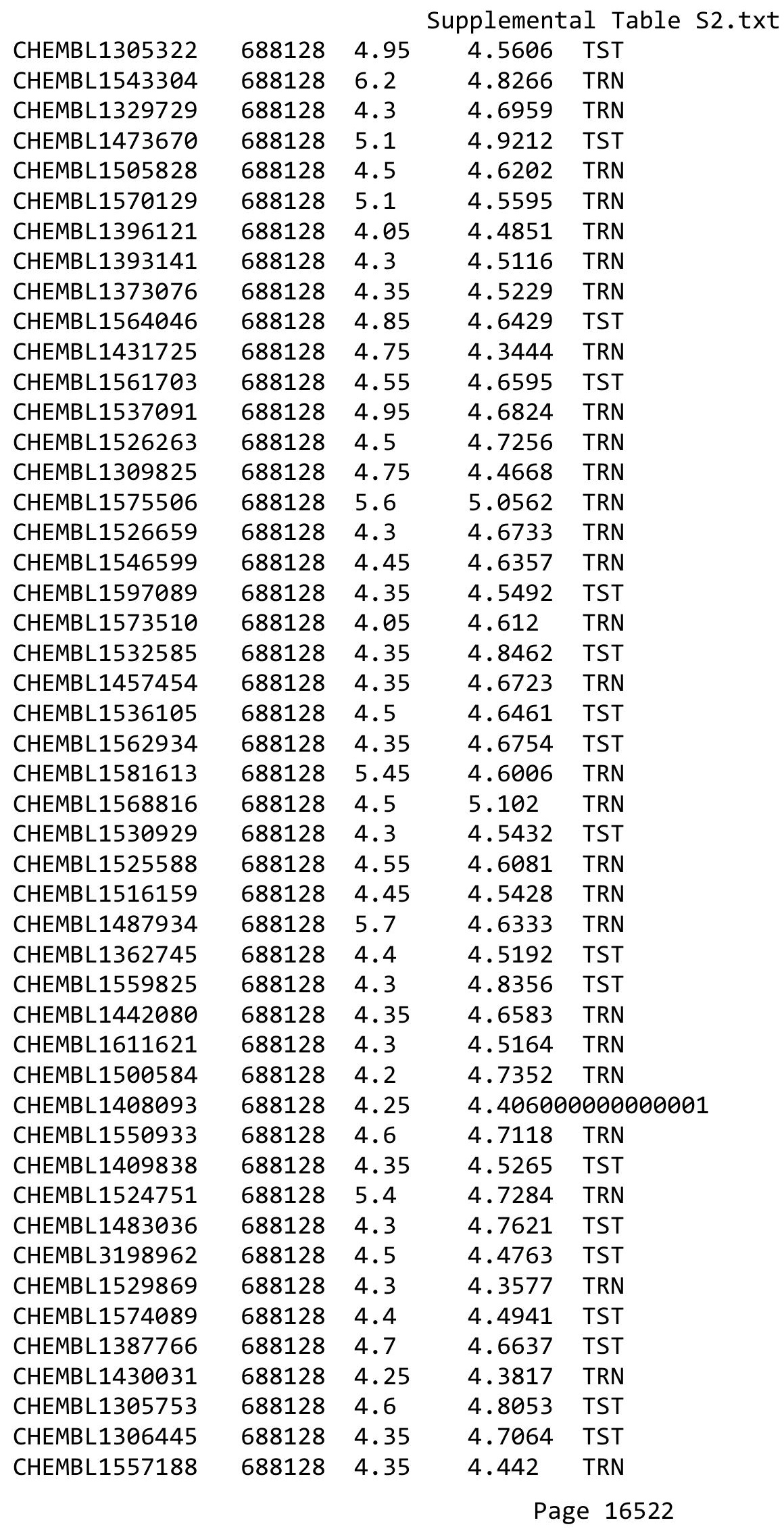




\begin{tabular}{|c|c|c|c|c|c|}
\hline \multicolumn{6}{|c|}{ Supplemental Table s2.txt } \\
\hline CHEMBL1426039 & 688128 & 4.8 & 4.8488 & TRN & \\
\hline CHEMBL1392078 & 688128 & 4.35 & 4.6152 & TRN & \\
\hline CHEMBL1499755 & 688128 & 4.5 & 4.4347 & TST & \\
\hline CHEMBL1317836 & 688128 & 6.15 & 4.6394 & TRN & \\
\hline CHEMBL1596877 & 688128 & 4.45 & 4.362 & TRN & \\
\hline CHEMBL1595012 & 688128 & 4.05 & 4.8121 & TST & \\
\hline CHEMBL1368941 & 688128 & 4.4 & 4.57100 & 0000000001 & TRN \\
\hline CHEMBL1505696 & 688128 & 4.3 & 4.7773 & TRN & \\
\hline CHEMBL1310629 & 688128 & 4.5 & 4.777 & TRN & \\
\hline CHEMBL1599947 & 688128 & 5.4 & 4.4631 & TST & \\
\hline CHEMBL1347838 & 688128 & 4.95 & 4.5639 & TST & \\
\hline CHEMBL1564442 & 688128 & 4.3 & 4.8062 & TRN & \\
\hline CHEMBL 2000499 & 688128 & 4.55 & 4.5943 & TRN & \\
\hline CHEMBL1379922 & 688128 & 4.35 & 4.7151 & TRN & \\
\hline CHEMBL1971698 & 688128 & 5.5 & 4.6828 & TRN & \\
\hline CHEMBL1419637 & 688128 & 4.3 & 4.7333 & TRN & \\
\hline CHEMBL1585241 & 688128 & 4.3 & 4.7021 & TST & \\
\hline CHEMBL1580784 & 688128 & 4.1 & 4.2488 & TRN & \\
\hline CHEMBL 1444343 & 688128 & 4.45 & 4.5551 & TST & \\
\hline CHEMBL1570389 & 688128 & 5.0 & 4.5105 & TRN & \\
\hline CHEMBL1383036 & 688128 & 4.65 & 4.7782 & TST & \\
\hline CHEMBL1582627 & 688128 & 4.3 & 4.3605 & TRN & \\
\hline CHEMBL1391097 & 688128 & 4.95 & 5.0268 & TRN & \\
\hline CHEMBL1505079 & 688128 & 4.05 & 4.6765 & TRN & \\
\hline CHEMBL3198896 & 688128 & 4.05 & 4.4064 & TRN & \\
\hline CHEMBL1371754 & 688128 & 6.25 & 4.7819 & TRN & \\
\hline CHEMBL1405867 & 688128 & 5.45 & 4.4638 & TRN & \\
\hline CHEMBL1605029 & 688128 & 4.3 & 4.816 & TST & \\
\hline CHEMBL1350059 & 688128 & 4.45 & 4.8168 & TRN & \\
\hline CHEMBL1560665 & 688128 & 4.4 & 4.6031 & TRN & \\
\hline CHEMBL1496732 & 688128 & 4.65 & 4.7302 & TRN & \\
\hline CHEMBL1542310 & 688128 & 4.25 & 4.6366 & TST & \\
\hline CHEMBL1521075 & 688128 & 4.5 & 4.8451 & TST & \\
\hline CHEMBL1358480 & 688128 & 4.05 & 4.5364 & TRN & \\
\hline CHEMBL1447022 & 688128 & 4.4 & 4.6567 & TRN & \\
\hline CHEMBL1498323 & 688128 & 4.35 & 4.7137 & TRN & \\
\hline CHEMBL1509975 & 688128 & 6.5 & 5.0599 & TRN & \\
\hline CHEMBL1488570 & 688128 & 5.55 & 4.8298 & TRN & \\
\hline CHEMBL1567523 & 688128 & 4.4 & 4.643 & TST & \\
\hline CHEMBL1347113 & 688128 & 4.35 & 4.7877 & TST & \\
\hline CHEMBL1581596 & 688128 & 4.75 & 4.7542 & TRN & \\
\hline CHEMBL3209202 & 688128 & 4.35 & 4.6576 & TST & \\
\hline CHEMBL1536255 & 688128 & 4.3 & 4.4763 & TST & \\
\hline CHEMBL 1450242 & 688128 & 6.0 & 5.3652 & TRN & \\
\hline CHEMBL1480010 & 688128 & 4.5 & 4.5072 & TRN & \\
\hline CHEMBL1587571 & 688128 & 4.3 & 4.3856 & TST & \\
\hline CHEMBL1519505 & 688128 & 4.45 & 4.1555 & TRN & \\
\hline CHEMBL1331302 & 688128 & 4.35 & 4.5118 & TST & \\
\hline
\end{tabular}




\begin{tabular}{|c|c|c|c|c|}
\hline & & & pplement & al $\mathrm{T}$ \\
\hline CHEMBL1526860 & 688128 & 4.5 & 4.4265 & TRN \\
\hline CHEMBL1550476 & 688128 & 4.35 & 4.5059 & TRN \\
\hline CHEMBL1325366 & 688128 & 4.4 & 4.6283 & TRN \\
\hline CHEMBL1465510 & 688128 & 6.0 & 4.7722 & TST \\
\hline CHEMBL1995112 & 688128 & 4.4 & 4.7407 & TRN \\
\hline CHEMBL1498042 & 688128 & 4.05 & 4.6515 & TRN \\
\hline CHEMBL1964615 & 688128 & 4.35 & 4.8024 & TRN \\
\hline CHEMBL1507788 & 688128 & 4.65 & 4.5308 & TRN \\
\hline CHEMBL1536196 & 688128 & 4.65 & 5.1296 & TST \\
\hline CHEMBL1518291 & 688128 & 4.9 & 4.9161 & TST \\
\hline CHEMBL541847 & 688128 & 4.4 & 4.2996 & TRN \\
\hline CHEMBL1501783 & 688128 & 4.05 & 4.493 & TST \\
\hline CHEMBL1374225 & 688128 & 4.25 & 4.6657 & TRN \\
\hline CHEMBL1370681 & 688128 & 5.05 & 5.2011 & TRN \\
\hline CHEMBL 1485074 & 688128 & 6.8499 & 4.8737 & TRN \\
\hline CHEMBL1432901 & 688128 & 4.55 & 4.8038 & TRN \\
\hline CHEMBL1587427 & 688128 & 4.25 & 4.4931 & TST \\
\hline CHEMBL1602151 & 688128 & 4.4 & 4.6732 & TRN \\
\hline CHEMBL1992211 & 688128 & 7.0501 & 4.4541 & TST \\
\hline CHEMBL1412810 & 688128 & 4.25 & 4.5196 & TRN \\
\hline CHEMBL1592608 & 688128 & 4.05 & 4.5647 & TRN \\
\hline CHEMBL1547432 & 688128 & 4.05 & 4.5985 & TST \\
\hline CHEMBL1555752 & 688128 & 5.5 & 5.0163 & TRN \\
\hline CHEMBL1485691 & 688128 & 4.25 & 4.4474 & TRN \\
\hline CHEMBL1985165 & 688128 & 4.3 & 4.6294 & TRN \\
\hline CHEMBL1300493 & 688128 & 4.3 & 4.3695 & TRN \\
\hline CHEMBL1610049 & 688128 & 5.75 & 4.947 & TST \\
\hline CHEMBL1540474 & 688128 & 6.5 & 4.8054 & TRN \\
\hline CHEMBL1558399 & 688128 & 4.4 & 4.5976 & TRN \\
\hline CHEMBL1488823 & 688128 & 4.05 & 4.3461 & TRN \\
\hline CHEMBL1336118 & 688128 & 4.35 & 4.1201 & TST \\
\hline CHEMBL1531884 & 688128 & 4.3 & 4.7213 & TST \\
\hline CHEMBL1544901 & 688128 & 4.6 & 4.7681 & TRN \\
\hline CHEMBL1466407 & 688128 & 4.4 & 4.8198 & TRN \\
\hline CHEMBL1315228 & 688128 & 4.7 & 4.8003 & TRN \\
\hline CHEMBL1479845 & 688128 & 4.5 & 4.6681 & TRN \\
\hline CHEMBL1582971 & 688128 & 4.05 & 4.4612 & TST \\
\hline CHEMBL1543986 & 688128 & 4.35 & 4.4979 & TRN \\
\hline CHEMBL1586101 & 688128 & 4.55 & 4.4428 & TRN \\
\hline CHEMBL 3196328 & 688128 & 4.35 & 4.3841 & TRN \\
\hline CHEMBL1309562 & 688128 & 5.15 & 4.6947 & TST \\
\hline CHEMBL1309097 & 688128 & 4.3 & 4.4386 & TRN \\
\hline CHEMBL1382182 & 688128 & 4.3 & 4.7522 & TST \\
\hline CHEMBL1475152 & 688128 & 4.05 & 4.7865 & TRN \\
\hline CHEMBL1526514 & 688128 & 4.7 & 4.4783 & TRN \\
\hline CHEMBL1594865 & 688128 & 6.2 & 4.7566 & TRN \\
\hline CHEMBL1389179 & 688128 & 5.15 & 4.7972 & TRN \\
\hline CHEMBL1427735 & 688128 & 4.45 & 4.1928 & TRN \\
\hline
\end{tabular}




\begin{tabular}{|c|c|c|c|c|c|}
\hline & & \multicolumn{4}{|c|}{ Supplemental Table s2.txt } \\
\hline CHEMBL 2374024 & 688128 & 5.15 & 5.2358 & TRN & \\
\hline CHEMBL1347510 & 688128 & 4.0 & 4.5753 & TRN & \\
\hline CHEMBL1583482 & 688128 & 4.4 & 4.7242 & TRN & \\
\hline CHEMBL1603809 & 688128 & 5.05 & 4.7184 & TRN & \\
\hline CHEMBL3189151 & 688128 & 4.3 & 4.864 & TST & \\
\hline CHEMBL3199323 & 688128 & 4.35 & 4.8265 & TRN & \\
\hline CHEMBL1392164 & 688128 & 4.8 & 4.8466 & TRN & \\
\hline CHEMBL1345041 & 688128 & 4.45 & 4.6568 & TRN & \\
\hline CHEMBL1317632 & 688128 & 4.05 & 4.4675 & TRN & \\
\hline CHEMBL1315664 & 688128 & 5.4 & 4.363 & TRN & \\
\hline CHEMBL1419161 & 688128 & 4.5 & 4.4698 & TRN & \\
\hline CHEMBL1368927 & 688128 & 4.25 & 4.6857 & TST & \\
\hline CHEMBL1454878 & 688128 & 4.85 & 4.672 & TRN & \\
\hline CHEMBL1341878 & 688128 & 4.75 & 4.5764 & TRN & \\
\hline CHEMBL1422785 & 688128 & 4.25 & 4.7452 & TST & \\
\hline CHEMBL1536910 & 688128 & 6.3 & 5.0158 & TRN & \\
\hline CHEMBL1308468 & 688128 & 5.45 & 4.6949 & TRN & \\
\hline CHEMBL1558677 & 688128 & 4.45 & 4.4146 & TRN & \\
\hline CHEMBL1527599 & 688128 & 4.05 & \multicolumn{2}{|c|}{ 4.5489999999999995 } & TST \\
\hline CHEMBL1584199 & 688128 & 5.4 & 4.3943 & TRN & \\
\hline CHEMBL1399331 & 688128 & 4.35 & 5.1247 & TRN & \\
\hline CHEMBL179611 & 688128 & 4.3 & 4.763 & TST & \\
\hline CHEMBL1421664 & 688128 & 4.0 & 4.6469 & TRN & \\
\hline CHEMBL1496618 & 688128 & 5.8 & 4.8025 & TST & \\
\hline CHEMBL1561948 & 688128 & 4.5 & 4.7018 & TRN & \\
\hline CHEMBL1377288 & 688128 & 4.4 & 4.8984 & TRN & \\
\hline CHEMBL1565536 & 688128 & 4.4 & 4.8183 & TRN & \\
\hline CHEMBL1343474 & 688128 & 4.0 & 4.6255 & TST & \\
\hline CHEMBL1403497 & 688128 & 6.25 & 4.9069 & TRN & \\
\hline CHEMBL1609915 & 688128 & 4.5 & 4.7828 & TST & \\
\hline CHEMBL1418209 & 688128 & 5.25 & 4.7673 & TRN & \\
\hline CHEMBL1327120 & 688128 & 5.0 & 4.7137 & TRN & \\
\hline CHEMBL1527000 & 688128 & 4.3 & 4.5562 & TRN & \\
\hline CHEMBL1373490 & 688128 & 6.05 & 4.5002 & TST & \\
\hline CHEMBL1554329 & 688128 & 6.25 & 4.5036 & TRN & \\
\hline CHEMBL1338565 & 688128 & 4.3 & 4.5946 & TRN & \\
\hline CHEMBL1447918 & 688128 & 5.5 & 4.8093 & TRN & \\
\hline CHEMBL1410178 & 688128 & 4.4 & 4.4416 & TRN & \\
\hline CHEMBL1363342 & 688128 & 4.4 & 4.4935 & TRN & \\
\hline CHEMBL1455183 & 688128 & 4.1 & \multicolumn{2}{|c|}{4.4910000000000005} & TST \\
\hline CHEMBL1591289 & 688128 & 4.25 & 4.4506 & TRN & \\
\hline CHEMBL1552189 & 688128 & 4.35 & 4.7794 & TRN & \\
\hline CHEMBL1468593 & 688128 & 4.9 & 4.8519 & TRN & \\
\hline CHEMBL1365532 & 688128 & 4.45 & 4.5282 & TRN & \\
\hline CHEMBL1609394 & 688128 & 4.7 & 4.6077 & TRN & \\
\hline CHEMBL1362489 & 688128 & 5.35 & 5.1239 & TRN & \\
\hline CHEMBL3194281 & 688128 & 4.4 & 4.7282 & TST & \\
\hline CHEMBL1594580 & 688128 & 4.65 & 4.6292 & TST & \\
\hline
\end{tabular}




\begin{tabular}{|c|c|c|c|c|}
\hline \multicolumn{5}{|c|}{ Supplemental Table s2.txt } \\
\hline CHEMBL1481212 & 688128 & 4.4 & 4.7865 & TRN \\
\hline CHEMBL1446736 & 688128 & 4.25 & 4.4284 & TRN \\
\hline CHEMBL1468908 & 688128 & 4.4 & 5.0216 & TST \\
\hline CHEMBL1469983 & 688128 & 4.8 & 4.5541 & TRN \\
\hline CHEMBL1374242 & 688128 & 6.5501 & 5.1236 & TRN \\
\hline CHEMBL 3210947 & 688128 & 4.25 & 4.4952 & TST \\
\hline CHEMBL1380684 & 688128 & 6.0 & 4.8958 & TST \\
\hline CHEMBL23150 & 688128 & 4.35 & 4.953 & TST \\
\hline CHEMBL3190376 & 688128 & 4.4 & 4.8663 & TRN \\
\hline CHEMBL1520262 & 688128 & 4.05 & 4.3947 & TRN \\
\hline CHEMBL1324206 & 688128 & 6.15 & 4.9108 & TRN \\
\hline CHEMBL3210236 & 688128 & 4.85 & 4.6306 & TRN \\
\hline CHEMBL1310055 & 688128 & 4.75 & 4.6883 & TRN \\
\hline CHEMBL1428362 & 688128 & 4.4 & 4.6579 & TST \\
\hline CHEMBL1458536 & 688128 & 4.5 & 4.5785 & TRN \\
\hline CHEMBL1315099 & 688128 & 4.8 & 4.9837 & TRN \\
\hline CHEMBL1587473 & 688128 & 5.2 & 5.154 & TRN \\
\hline CHEMBL1596975 & 688128 & 4.45 & 4.4888 & TRN \\
\hline CHEMBL3193399 & 688128 & 4.0 & 4.4449 & TRN \\
\hline CHEMBL1600684 & 688128 & 5.0 & 4.7777 & TRN \\
\hline CHEMBL1584702 & 688128 & 5.15 & 4.872 & TRN \\
\hline CHEMBL1455639 & 688128 & 4.9 & 4.792 & TST \\
\hline CHEMBL1587260 & 688128 & 4.4 & 4.4349 & TRN \\
\hline CHEMBL1366423 & 688128 & 5.9 & 5.0674 & TRN \\
\hline CHEMBL1549992 & 688128 & 4.6 & 4.3953 & TRN \\
\hline CHEMBL1573965 & 688128 & 4.05 & 4.5906 & TRN \\
\hline CHEMBL1514628 & 688128 & 4.0 & 4.4398 & TST \\
\hline CHEMBL1485858 & 688128 & 4.05 & 5.0178 & TST \\
\hline CHEMBL1563599 & 688128 & 4.65 & 4.4767 & TRN \\
\hline CHEMBL1366492 & 688128 & 4.05 & 4.4415 & TRN \\
\hline CHEMBL1533671 & 688128 & 4.25 & 4.4658 & TRN \\
\hline CHEMBL1587827 & 688128 & 6.0 & 5.2212 & TRN \\
\hline CHEMBL1397072 & 688128 & 4.3 & 4.5245 & TRN \\
\hline CHEMBL1573675 & 688128 & 4.45 & 4.6863 & TRN \\
\hline CHEMBL1466127 & 688128 & 4.7 & 4.6673 & TRN \\
\hline CHEMBL1611137 & 688128 & 4.45 & 4.5787 & TRN \\
\hline CHEMBL1527009 & 688128 & 4.4 & 4.606 & TRN \\
\hline CHEMBL1498861 & 688128 & 4.05 & 4.2675 & TRN \\
\hline CHEMBL1518934 & 688128 & 4.55 & 4.5996 & TRN \\
\hline CHEMBL1378010 & 688128 & 4.5 & 4.3572 & TST \\
\hline CHEMBL1386826 & 688128 & 5.5 & 4.478 & TRN \\
\hline CHEMBL1527395 & 688128 & 4.8 & 4.6629 & TRN \\
\hline CHEMBL3199772 & 688128 & 4.3 & 4.7386 & TST \\
\hline CHEMBL1367499 & 688128 & 4.05 & 4.4598 & TST \\
\hline CHEMBL1324025 & 688128 & 4.05 & 4.6362 & TST \\
\hline CHEMBL1401046 & 688128 & 4.25 & 4.9309 & TRN \\
\hline CHEMBL1384293 & 688128 & 4.6 & 4.7518 & TRN \\
\hline CHEMBL1389775 & 688128 & 4.35 & 4.7152 & TRN \\
\hline
\end{tabular}




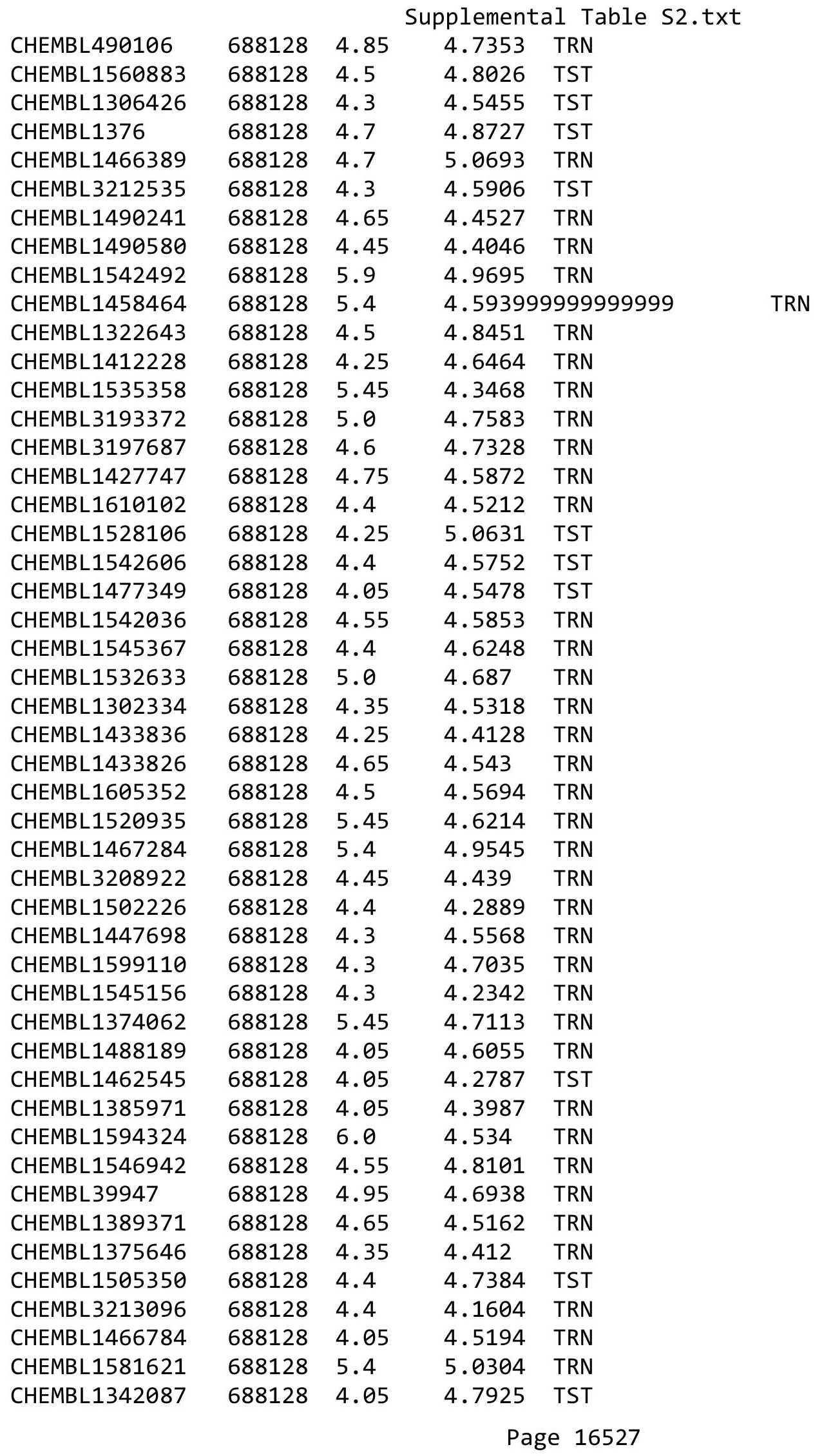




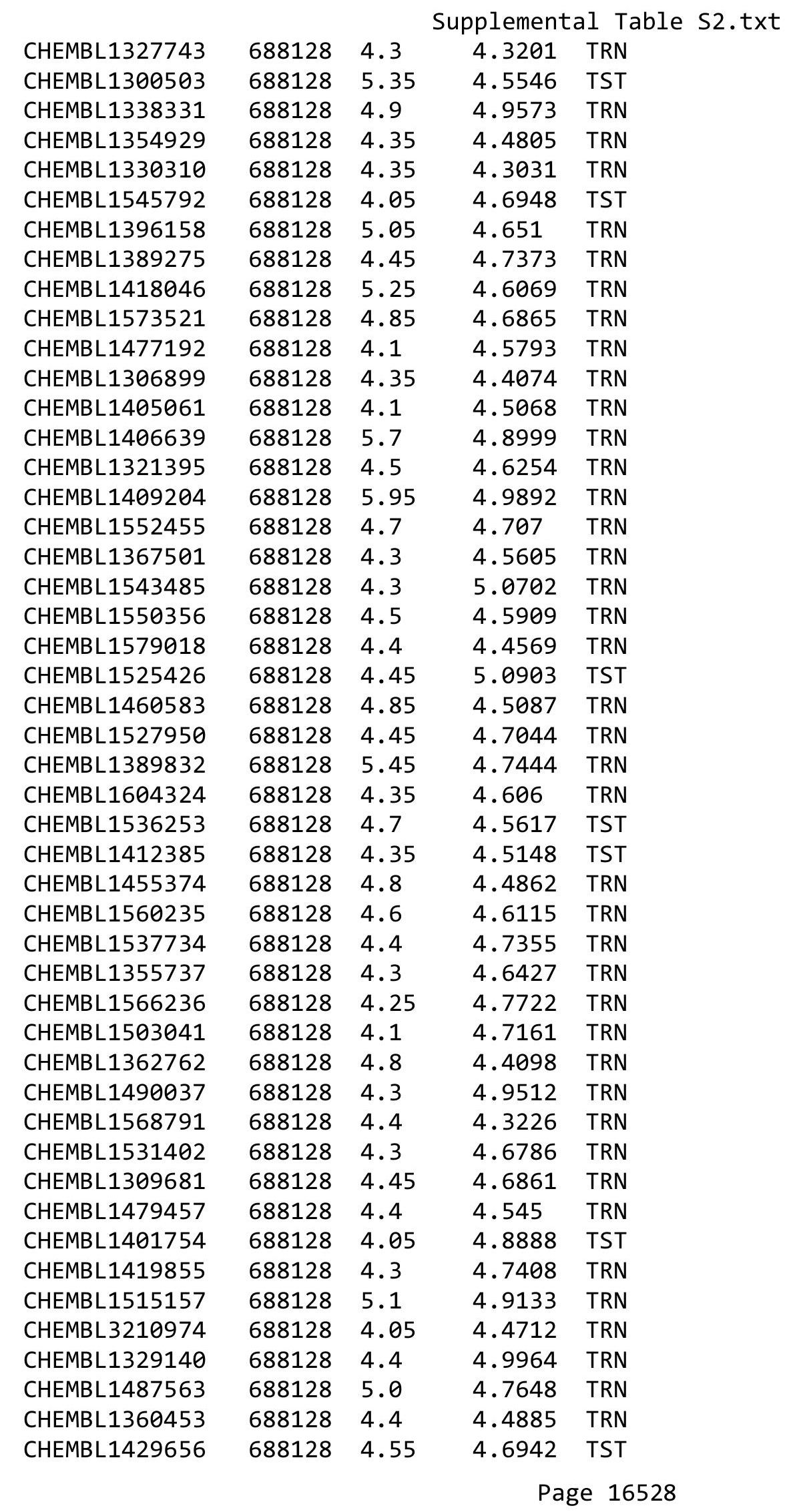




\begin{tabular}{|c|c|c|c|c|c|}
\hline & & \multicolumn{4}{|c|}{ Supplemental Table S2.txt } \\
\hline CHEMBL1378612 & 688128 & 4.65 & 4.6522 & TRN & \\
\hline CHEMBL1476458 & 688128 & 4.35 & 4.8037 & TRN & \\
\hline CHEMBL3195721 & 688128 & 5.75 & 4.3832 & TST & \\
\hline CHEMBL1383034 & 688128 & 5.7 & 4.4972 & TRN & \\
\hline CHEMBL1382177 & 688128 & 4.35 & 4.4335 & TRN & \\
\hline CHEMBL1585364 & 688128 & 5.15 & 4.8991 & TST & \\
\hline CHEMBL1505496 & 688128 & 6.1 & 4.8302 & TST & \\
\hline CHEMBL1447546 & 688128 & 4.95 & 4.4757 & TRN & \\
\hline CHEMBL1503233 & 688128 & 6.05 & 4.6889 & TRN & \\
\hline CHEMBL1597601 & 688128 & 4.4 & 4.7664 & TRN & \\
\hline CHEMBL1532419 & 688128 & 5.45 & 4.3816 & TRN & \\
\hline CHEMBL1552387 & 688128 & 5.45 & 4.6827 & TRN & \\
\hline CHEMBL1549566 & 688128 & 5.8 & 5.0193 & TRN & \\
\hline CHEMBL1487257 & 688128 & 4.6 & 4.4263 & TRN & \\
\hline CHEMBL1373655 & 688128 & 4.45 & 5.0211 & TRN & \\
\hline CHEMBL1564699 & 688128 & 5.15 & 4.8359 & TRN & \\
\hline CHEMBL1311373 & 688128 & 4.45 & 4.4483 & TRN & \\
\hline CHEMBL1440883 & 688128 & 4.4 & 4.3761 & TRN & \\
\hline CHEMBL1987136 & 688128 & 5.15 & 4.7699 & TRN & \\
\hline CHEMBL1436513 & 688128 & 4.3 & 4.4218 & TRN & \\
\hline CHEMBL1509126 & 688128 & 4.7 & 4.6676 & TST & \\
\hline CHEMBL1447783 & 688128 & 6.4 & 4.9506 & TRN & \\
\hline CHEMBL1440473 & 688128 & 4.45 & 4.7343 & TST & \\
\hline CHEMBL1492949 & 688128 & 4.95 & 4.8625 & TRN & \\
\hline CHEMBL1502860 & 688128 & 5.6 & 4.79899 & 99999999995 & TRN \\
\hline CHEMBL1335938 & 688128 & 4.1 & 4.5033 & TRN & \\
\hline CHEMBL1609959 & 688128 & 4.05 & 4.5286 & TST & \\
\hline CHEMBL1524838 & 688128 & 5.0 & 4.5991 & TRN & \\
\hline CHEMBL1332454 & 688128 & 6.0 & 5.3425 & TRN & \\
\hline CHEMBL1491360 & 688128 & 4.8 & 4.6721 & TRN & \\
\hline CHEMBL1364131 & 688128 & 4.05 & 4.4696 & TST & \\
\hline CHEMBL1366072 & 688128 & 5.2 & 4.5871 & TST & \\
\hline CHEMBL1542894 & 688128 & 4.4 & 4.2525 & TRN & \\
\hline CHEMBL1546805 & 688128 & 4.45 & 4.9378 & TRN & \\
\hline CHEMBL1965204 & 688128 & 4.4 & 4.4663 & TRN & \\
\hline CHEMBL1384554 & 688128 & 4.6 & 4.4224 & TRN & \\
\hline CHEMBL1538716 & 688128 & 4.45 & 4.356 & TRN & \\
\hline CHEMBL1468433 & 688128 & 4.45 & 4.6005 & TST & \\
\hline CHEMBL1350231 & 688128 & 4.85 & 4.8659 & TST & \\
\hline CHEMBL1347786 & 688128 & 5.35 & 4.3456 & TRN & \\
\hline CHEMBL1576140 & 688128 & 4.25 & 4.5871 & TRN & \\
\hline CHEMBL1583872 & 688128 & 4.25 & 4.4602 & TRN & \\
\hline CHEMBL1344426 & 688128 & 5.15 & 5.0817 & TRN & \\
\hline CHEMBL1395688 & 688128 & 4.4 & 4.2767 & TRN & \\
\hline CHEMBL1336816 & 688128 & 4.8 & 4.8225 & TRN & \\
\hline CHEMBL1307872 & 688128 & 4.4 & 4.6433 & TRN & \\
\hline CHEMBL1458026 & 688128 & 4.25 & 4.4615 & TRN & \\
\hline CHEMBL1345021 & 688128 & 4.3 & 4.5728 & TRN & \\
\hline
\end{tabular}




\begin{tabular}{|c|c|c|c|c|}
\hline \multicolumn{5}{|c|}{ Supplemental Table S2.txt } \\
\hline CHEMBL1318035 & 688128 & 4.05 & 4.4493 & TRN \\
\hline CHEMBL 3190292 & 688128 & 6.05 & 4.5361 & TST \\
\hline CHEMBL1504134 & 688128 & 4.9 & 4.8007 & TRN \\
\hline CHEMBL1344115 & 688128 & 6.15 & 4.6614 & TRN \\
\hline CHEMBL1327531 & 688128 & 5.7 & 5.0245 & TRN \\
\hline CHEMBL1375576 & 688128 & 4.45 & 4.7122 & TRN \\
\hline CHEMBL1369901 & 688128 & 4.7 & 4.694 & TST \\
\hline CHEMBL1336918 & 688128 & 4.45 & 4.5904 & TRN \\
\hline CHEMBL1366195 & 688128 & 4.35 & 4.712 & TRN \\
\hline CHEMBL1363892 & 688128 & 4.1 & 4.6283 & TRN \\
\hline CHEMBL1432963 & 688128 & 5.3 & 4.6983 & TRN \\
\hline CHEMBL1473289 & 688128 & 4.4 & 4.1772 & TST \\
\hline CHEMBL1484673 & 688128 & 4.45 & 4.8048 & TRN \\
\hline CHEMBL1443231 & 688128 & 4.0 & 4.7795 & TRN \\
\hline CHEMBL1543037 & 688128 & 4.05 & 4.5864 & TST \\
\hline CHEMBL1588513 & 688128 & 4.3 & 5.268 & TST \\
\hline CHEMBL1536283 & 688128 & 4.05 & 4.6374 & TST \\
\hline CHEMBL1385240 & 688128 & 4.55 & 4.7218 & TRN \\
\hline CHEMBL1326933 & 688128 & 4.75 & 4.9288 & TRN \\
\hline CHEMBL521653 & 688128 & 4.45 & 4.825 & TRN \\
\hline CHEMBL1359684 & 688128 & 4.3 & 4.5157 & TRN \\
\hline CHEMBL1499893 & 688128 & 5.25 & 5.0788 & TRN \\
\hline CHEMBL1300045 & 688128 & 5.95 & 4.6281 & TRN \\
\hline CHEMBL1555787 & 688128 & 5.55 & 5.3645 & TRN \\
\hline CHEMBL1368092 & 688128 & 4.85 & 4.6674 & TRN \\
\hline CHEMBL3195012 & 688128 & 5.0 & 4.9098 & TRN \\
\hline CHEMBL1374828 & 688128 & 4.1 & 4.5209 & TRN \\
\hline CHEMBL1373522 & 688128 & 4.4 & 4.5029 & TRN \\
\hline CHEMBL1579998 & 688128 & 4.35 & 4.5907 & TRN \\
\hline CHEMBL1345716 & 688128 & 4.65 & 4.6291 & TST \\
\hline CHEMBL1562521 & 688128 & 4.45 & 4.4341 & TRN \\
\hline CHEMBL1412219 & 688128 & 4.5 & 4.8487 & TRN \\
\hline CHEMBL1332566 & 688128 & 5.45 & 4.9099 & TRN \\
\hline CHEMBL1553454 & 688128 & 4.25 & 4.6639 & TST \\
\hline CHEMBL1331287 & 688128 & 4.35 & 4.4121 & TRN \\
\hline CHEMBL1471775 & 688128 & 4.2 & 4.6505 & TRN \\
\hline CHEMBL1520952 & 688128 & 5.05 & 4.4569 & TRN \\
\hline CHEMBL1974521 & 688128 & 6.0 & 5.1523 & TRN \\
\hline CHEMBL1542591 & 688128 & 5.05 & 4.7584 & TRN \\
\hline CHEMBL1452517 & 688128 & 4.35 & 4.8989 & TRN \\
\hline CHEMBL1477758 & 688128 & 4.25 & 4.5506 & TRN \\
\hline CHEMBL1547930 & 688128 & 4.45 & 4.5568 & TRN \\
\hline CHEMBL1579781 & 688128 & 4.4 & 4.7945 & TST \\
\hline CHEMBL1995720 & 688128 & 4.3 & 4.5083 & TRN \\
\hline CHEMBL1348677 & 688128 & 4.5 & 4.6311 & TRN \\
\hline CHEMBL1338027 & 688128 & 5.15 & 4.8623 & TRN \\
\hline CHEMBL1469364 & 688128 & 5.45 & 4.6369 & TST \\
\hline CHEMBL1607423 & 688128 & 4.05 & 4.4686 & TRN \\
\hline
\end{tabular}




\begin{tabular}{|c|c|c|c|c|}
\hline \multicolumn{5}{|c|}{ Supplemental Table s2.txt } \\
\hline CHEMBL 3198225 & 688128 & 4.65 & 4.4846 & TRN \\
\hline CHEMBL1606812 & 688128 & 4.85 & 5.0481 & TRN \\
\hline CHEMBL1549143 & 688128 & 4.9 & 4.615 & TRN \\
\hline CHEMBL1521123 & 688128 & 4.3 & 4.4502 & TRN \\
\hline CHEMBL1549818 & 688128 & 5.05 & 4.5801 & TST \\
\hline CHEMBL3199590 & 688128 & 6.0 & 4.8748 & TRN \\
\hline CHEMBL1429471 & 688128 & 5.2 & 4.753 & TRN \\
\hline CHEMBL1306457 & 688128 & 6.35 & 4.873 & TRN \\
\hline CHEMBL1301166 & 688128 & 4.7 & 4.8217 & TRN \\
\hline CHEMBL1333881 & 688128 & 4.3 & 4.7517 & TST \\
\hline CHEMBL1308083 & 688128 & 4.8 & 4.3543 & TRN \\
\hline CHEMBL1560948 & 688128 & 4.55 & 4.7332 & TRN \\
\hline CHEMBL1581960 & 688128 & 4.4 & 4.8394 & TST \\
\hline CHEMBL1520432 & 688128 & 4.4 & 4.756 & TRN \\
\hline CHEMBL1481881 & 688128 & 4.4 & 4.4577 & TRN \\
\hline CHEMBL1515304 & 688128 & 4.4 & 4.6693 & TRN \\
\hline CHEMBL338474 & 688128 & 4.6 & 4.6555 & TRN \\
\hline CHEMBL1496320 & 688128 & 4.55 & 4.0342 & TRN \\
\hline CHEMBL1313209 & 688128 & 4.9 & 4.8414 & TRN \\
\hline CHEMBL1169821 & 688128 & 4.5 & 4.7846 & TRN \\
\hline CHEMBL1509614 & 688128 & 4.05 & 4.7473 & TST \\
\hline CHEMBL1499696 & 688128 & 4.4 & 4.6924 & TST \\
\hline CHEMBL1563101 & 688128 & 4.4 & 4.5442 & TRN \\
\hline CHEMBL1494896 & 688128 & 4.4 & 4.5071 & TRN \\
\hline CHEMBL1328094 & 688128 & 5.2 & 4.563 & TRN \\
\hline CHEMBL3191969 & 688128 & 4.3 & 4.7653 & TRN \\
\hline CHEMBL1395637 & 688128 & 4.4 & 4.6351 & TST \\
\hline CHEMBL1586047 & 688128 & 5.5 & 4.9043 & TRN \\
\hline CHEMBL1424378 & 688128 & 4.35 & 4.5645 & TRN \\
\hline CHEMBL1401748 & 688128 & 5.05 & 4.4545 & TRN \\
\hline CHEMBL1301842 & 688128 & 4.75 & 4.9171 & TRN \\
\hline CHEMBL1494850 & 688128 & 4.3 & 4.7799 & TRN \\
\hline CHEMBL1490070 & 688128 & 4.3 & 4.6866 & TRN \\
\hline CHEMBL1323384 & 688128 & 4.35 & 4.7801 & TRN \\
\hline CHEMBL1488625 & 688128 & 4.35 & 4.7164 & TRN \\
\hline CHEMBL3196475 & 688128 & 4.4 & 4.6476 & TST \\
\hline CHEMBL1336101 & 688128 & 4.4 & 4.6785 & TRN \\
\hline CHEMBL1429570 & 688128 & 4.45 & 4.7764 & TRN \\
\hline CHEMBL1571290 & 688128 & 6.0 & 4.6777 & TRN \\
\hline CHEMBL1374719 & 688128 & 5.0 & 4.8171 & TRN \\
\hline CHEMBL3190646 & 688128 & 4.3 & 4.6153 & TST \\
\hline CHEMBL1400218 & 688128 & 5.0 & 4.3624 & TRN \\
\hline CHEMBL1338966 & 688128 & 4.0 & 4.5672 & TST \\
\hline CHEMBL1602972 & 688128 & 4.05 & 4.327 & TRN \\
\hline CHEMBL1466059 & 688128 & 5.0 & 4.7921 & TST \\
\hline CHEMBL1612316 & 688128 & 4.4 & 4.6854 & TRN \\
\hline CHEMBL1364513 & 688128 & 4.35 & 4.6562 & TRN \\
\hline CHEMBL1375582 & 688128 & 4.05 & 4.3027 & TST \\
\hline
\end{tabular}




\begin{tabular}{|c|c|c|c|c|}
\hline & & & pplement & dI \\
\hline CHEMBL1385808 & 688128 & 4.5 & 5.2279 & TST \\
\hline CHEMBL1566255 & 688128 & 4.35 & 4.3784 & TST \\
\hline CHEMBL1451973 & 688128 & 4.4 & 4.7071 & TRN \\
\hline CHEMBL1528262 & 688128 & 4.05 & 4.5169 & TRN \\
\hline CHEMBL1576918 & 688128 & 5.8 & 4.5517 & TRN \\
\hline CHEMBL1584805 & 688128 & 4.65 & 4.5424 & TRN \\
\hline CHEMBL1307526 & 688128 & 5.15 & 4.7984 & TRN \\
\hline CHEMBL1564402 & 688128 & 4.45 & 4.7623 & TST \\
\hline CHEMBL3213183 & 688128 & 4.1 & 4.3925 & TRN \\
\hline CHEMBL 2005657 & 688128 & 4.4 & 4.7241 & TRN \\
\hline CHEMBL1612283 & 688128 & 5.4 & 4.5674 & TST \\
\hline CHEMBL1390452 & 688128 & 5.05 & 4.7303 & TST \\
\hline CHEMBL1333043 & 688128 & 4.7 & 4.8715 & TRN \\
\hline CHEMBL 252978 & 688128 & 4.3 & 4.5548 & TRN \\
\hline CHEMBL1502982 & 688128 & 4.35 & 4.54 & TRN \\
\hline CHEMBL1492433 & 688128 & 4.05 & 4.5685 & TST \\
\hline CHEMBL1525795 & 688128 & 4.25 & 4.5358 & TRN \\
\hline CHEMBL1419054 & 688128 & 4.35 & 4.4081 & TRN \\
\hline CHEMBL1423001 & 688128 & 4.55 & 4.9988 & TST \\
\hline CHEMBL1457320 & 688128 & 5.3 & 4.6872 & TRN \\
\hline CHEMBL1574253 & 688128 & 4.45 & 4.6375 & TRN \\
\hline CHEMBL1573671 & 688128 & 5.5 & 4.9561 & TRN \\
\hline CHEMBL1548211 & 688128 & 4.95 & 4.5035 & TRN \\
\hline CHEMBL1415479 & 688128 & 4.75 & 4.6287 & TRN \\
\hline CHEMBL 3191725 & 688128 & 4.4 & 4.5477 & TRN \\
\hline CHEMBL1467543 & 688128 & 4.65 & 4.6991 & TRN \\
\hline CHEMBL1556369 & 688128 & 5.55 & 4.5897 & TST \\
\hline CHEMBL1547895 & 688128 & 5.4 & 4.8705 & TRN \\
\hline CHEMBL1518788 & 688128 & 4.25 & 4.404 & TRN \\
\hline CHEMBL1361740 & 688128 & 6.5501 & 5.1268 & TST \\
\hline CHEMBL1425723 & 688128 & 6.3 & 5.0705 & TRN \\
\hline CHEMBL1463510 & 688128 & 4.4 & 4.3058 & TRN \\
\hline CHEMBL1550853 & 688128 & 4.35 & 4.2972 & TRN \\
\hline CHEMBL1458553 & 688128 & 4.45 & 4.4811 & TRN \\
\hline CHEMBL1506872 & 688128 & 4.05 & 4.6774 & TST \\
\hline CHEMBL1463894 & 688128 & 4.5 & 4.5809 & TST \\
\hline CHEMBL1439573 & 688128 & 4.25 & 4.5424 & TST \\
\hline CHEMBL1518758 & 688128 & 6.15 & 4.6016 & TRN \\
\hline CHEMBL1442679 & 688128 & 4.3 & 4.5259 & TRN \\
\hline CHEMBL1552901 & 688128 & 5.05 & 4.9679 & TRN \\
\hline CHEMBL1405440 & 688128 & 4.4 & 4.5942 & TRN \\
\hline CHEMBL1434215 & 688128 & 4.75 & 4.9544 & TRN \\
\hline CHEMBL1437741 & 688128 & 6.35 & 4.8065 & TRN \\
\hline CHEMBL1393177 & 688128 & 4.4 & 4.3055 & TRN \\
\hline CHEMBL3196899 & 688128 & 4.35 & 4.8421 & TRN \\
\hline CHEMBL1575990 & 688128 & 4.4 & 4.5085 & TRN \\
\hline CHEMBL1493503 & 688128 & 4.05 & 4.5353 & TST \\
\hline CHEMBL1600893 & 688128 & 4.1 & 4.8061 & TRN \\
\hline
\end{tabular}




\begin{tabular}{|c|c|c|c|c|}
\hline & & & pplemen & 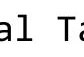 \\
\hline CHEMBL1429726 & 688128 & 4.95 & 4.537 & TRN \\
\hline CHEMBL1490436 & 688128 & 4.6 & 4.8537 & TRN \\
\hline CHEMBL1429203 & 688128 & 4.65 & 4.8602 & TRN \\
\hline CHEMBL1965174 & 688128 & 4.55 & 4.5765 & TST \\
\hline CHEMBL1407371 & 688128 & 4.05 & 4.7203 & TRN \\
\hline CHEMBL1567237 & 688128 & 4.05 & 4.457 & TST \\
\hline CHEMBL1610429 & 688128 & 4.35 & 4.6158 & TST \\
\hline CHEMBL1410833 & 688128 & 5.3 & 5.2069 & TRN \\
\hline CHEMBL1469911 & 688128 & 5.3 & 4.5794 & TRN \\
\hline CHEMBL3196589 & 688128 & 4.3 & 4.6734 & TRN \\
\hline CHEMBL1592705 & 688128 & 4.35 & 4.7091 & TST \\
\hline CHEMBL1323503 & 688128 & 4.35 & 4.7065 & TRN \\
\hline CHEMBL 2448512 & 688128 & 4.3 & 4.5551 & TRN \\
\hline CHEMBL1370669 & 688128 & 5.1 & 4.8085 & TRN \\
\hline CHEMBL1578521 & 688128 & 4.95 & 4.9486 & TST \\
\hline CHEMBL 2001792 & 688128 & 4.3 & 4.5548 & TST \\
\hline CHEMBL3190654 & 688128 & 5.05 & 4.6392 & TRN \\
\hline CHEMBL1341931 & 688128 & 4.7 & 4.5589 & TRN \\
\hline CHEMBL 1318060 & 688128 & 4.7 & 4.1971 & TRN \\
\hline CHEMBL1500082 & 688128 & 4.4 & 4.5137 & TST \\
\hline CHEMBL1336927 & 688128 & 5.05 & 4.5337 & TRN \\
\hline CHEMBL1544524 & 688128 & 4.55 & 4.5754 & TRN \\
\hline CHEMBL1345012 & 688128 & 4.6 & 4.7623 & TRN \\
\hline CHEMBL1440974 & 688128 & 4.4 & 4.7399 & TRN \\
\hline CHEMBL1383455 & 688128 & 4.85 & 5.0176 & TRN \\
\hline CHEMBL1483522 & 688128 & 4.35 & 4.3607 & TRN \\
\hline CHEMBL1427701 & 688128 & 4.0 & 4.3455 & TRN \\
\hline CHEMBL1562417 & 688128 & 4.8 & 4.2176 & TRN \\
\hline CHEMBL1600617 & 688128 & 4.35 & 4.5872 & TST \\
\hline CHEMBL1610796 & 688128 & 4.3 & 4.4774 & TRN \\
\hline CHEMBL1543861 & 688128 & 4.3 & 4.5953 & TRN \\
\hline CHEMBL1500612 & 688128 & 4.4 & 4.573 & TRN \\
\hline CHEMBL1582142 & 688128 & 4.3 & 4.8695 & TRN \\
\hline CHEMBL1470476 & 688128 & 6.05 & 5.2004 & TRN \\
\hline CHEMBL1561710 & 688128 & 4.3 & 4.6947 & TRN \\
\hline CHEMBL1336643 & 688128 & 4.95 & 4.7218 & TRN \\
\hline CHEMBL1349386 & 688128 & 4.6 & 4.6403 & TRN \\
\hline CHEMBL1612008 & 688128 & 4.4 & 4.81 & TST \\
\hline CHEMBL1381067 & 688128 & 4.4 & 4.7648 & TRN \\
\hline CHEMBL1492315 & 688128 & 4.3 & 4.5563 & TRN \\
\hline CHEMBL1378205 & 688128 & 4.05 & 4.8299 & TRN \\
\hline CHEMBL1577004 & 688128 & 5.05 & 4.8085 & TST \\
\hline CHEMBL1324111 & 688128 & 5.55 & 4.8385 & TST \\
\hline CHEMBL 1445862 & 688128 & 4.05 & 4.7381 & TST \\
\hline CHEMBL1391248 & 688128 & 4.7 & 4.732 & TRN \\
\hline CHEMBL1519624 & 688128 & 5.35 & 4.5482 & TRN \\
\hline CHEMBL1327591 & 688128 & 5.35 & 4.7775 & TRN \\
\hline CHEMBL1516341 & 688128 & 4.05 & 4.6534 & TRN \\
\hline
\end{tabular}




\begin{tabular}{|c|c|c|c|c|}
\hline \multicolumn{5}{|c|}{ Supplemental Table S2.txt } \\
\hline CHEMBL1566177 & 688128 & 4.35 & 4.546 & TRN \\
\hline CHEMBL1352612 & 688128 & 4.25 & 4.5861 & TRN \\
\hline CHEMBL1337159 & 688128 & 4.45 & 4.5794 & TRN \\
\hline CHEMBL1583062 & 688128 & 4.3 & 4.4127 & TRN \\
\hline CHEMBL1317783 & 688128 & 4.5 & 4.5574 & TRN \\
\hline CHEMBL 1494400 & 688128 & 4.7 & 4.8262 & TRN \\
\hline CHEMBL1355173 & 688128 & 4.65 & 4.8319 & TST \\
\hline CHEMBL1400278 & 688128 & 6.0 & 4.9476 & TRN \\
\hline CHEMBL1545577 & 688128 & 4.05 & 4.5597 & TRN \\
\hline CHEMBL1461631 & 688128 & 6.4 & 4.6585 & TRN \\
\hline CHEMBL1352952 & 688128 & 4.05 & 4.7564 & TRN \\
\hline CHEMBL1561826 & 688128 & 4.25 & 4.6216 & TRN \\
\hline CHEMBL1586934 & 688128 & 4.4 & 4.4432 & TRN \\
\hline CHEMBL1541411 & 688128 & 4.3 & 4.8401 & TRN \\
\hline CHEMBL1518888 & 688128 & 5.15 & 4.8266 & TRN \\
\hline CHEMBL1495132 & 688128 & 4.3 & 4.7616 & TST \\
\hline CHEMBL1459855 & 688128 & 4.05 & 4.6903 & TRN \\
\hline CHEMBL1445662 & 688128 & 4.3 & 4.4256 & TRN \\
\hline CHEMBL1474308 & 688128 & 4.8 & 4.2293 & TRN \\
\hline CHEMBL1354610 & 688128 & 4.4 & 4.8077 & TST \\
\hline CHEMBL1482811 & 688128 & 4.3 & 4.4702 & TRN \\
\hline CHEMBL1544239 & 688128 & 4.9 & 4.5868 & TRN \\
\hline CHEMBL1589411 & 688128 & 4.5 & 4.3328 & TRN \\
\hline CHEMBL1307339 & 688128 & 4.1 & 4.3387 & TRN \\
\hline CHEMBL1506720 & 688128 & 4.35 & 4.5815 & TRN \\
\hline CHEMBL1331135 & 688128 & 5.15 & 4.7643 & TRN \\
\hline CHEMBL1465475 & 688128 & 4.6 & 4.6101 & TRN \\
\hline CHEMBL1606452 & 688128 & 4.3 & 4.8418 & TST \\
\hline CHEMBL1392444 & 688128 & 4.4 & 4.5515 & TRN \\
\hline CHEMBL1303376 & 688128 & 4.65 & 4.5247 & TRN \\
\hline CHEMBL1309609 & 688128 & 4.1 & 4.5649 & TRN \\
\hline CHEMBL1538875 & 688128 & 4.1 & 4.51 & TRN \\
\hline CHEMBL1452104 & 688128 & 4.3 & 4.5833 & TRN \\
\hline CHEMBL 220845 & 688128 & 5.95 & 5.2239 & TST \\
\hline CHEMBL1371766 & 688128 & 4.95 & 4.8165 & TRN \\
\hline CHEMBL1598774 & 688128 & 5.3 & 4.8491 & TRN \\
\hline CHEMBL1450698 & 688128 & 4.4 & 4.8073 & TRN \\
\hline CHEMBL1571478 & 688128 & 4.8 & 4.4376 & TRN \\
\hline CHEMBL1401040 & 688128 & 5.05 & 4.9757 & TRN \\
\hline CHEMBL 3198688 & 688128 & 4.6 & 4.5887 & TST \\
\hline CHEMBL1374020 & 688128 & 4.3 & 4.3514 & TRN \\
\hline CHEMBL1572007 & 688128 & 6.5 & 4.4793 & TST \\
\hline CHEMBL1543429 & 688128 & 4.05 & 4.8911 & TRN \\
\hline CHEMBL1347328 & 688128 & 4.35 & 4.5746 & TRN \\
\hline CHEMBL1491169 & 688128 & 4.6 & 4.6601 & TRN \\
\hline CHEMBL1586946 & 688128 & 4.05 & 4.4191 & TST \\
\hline CHEMBL1520792 & 688128 & 5.3 & 4.6514 & TRN \\
\hline CHEMBL1481999 & 688128 & 4.0 & 4.6122 & TRN \\
\hline
\end{tabular}




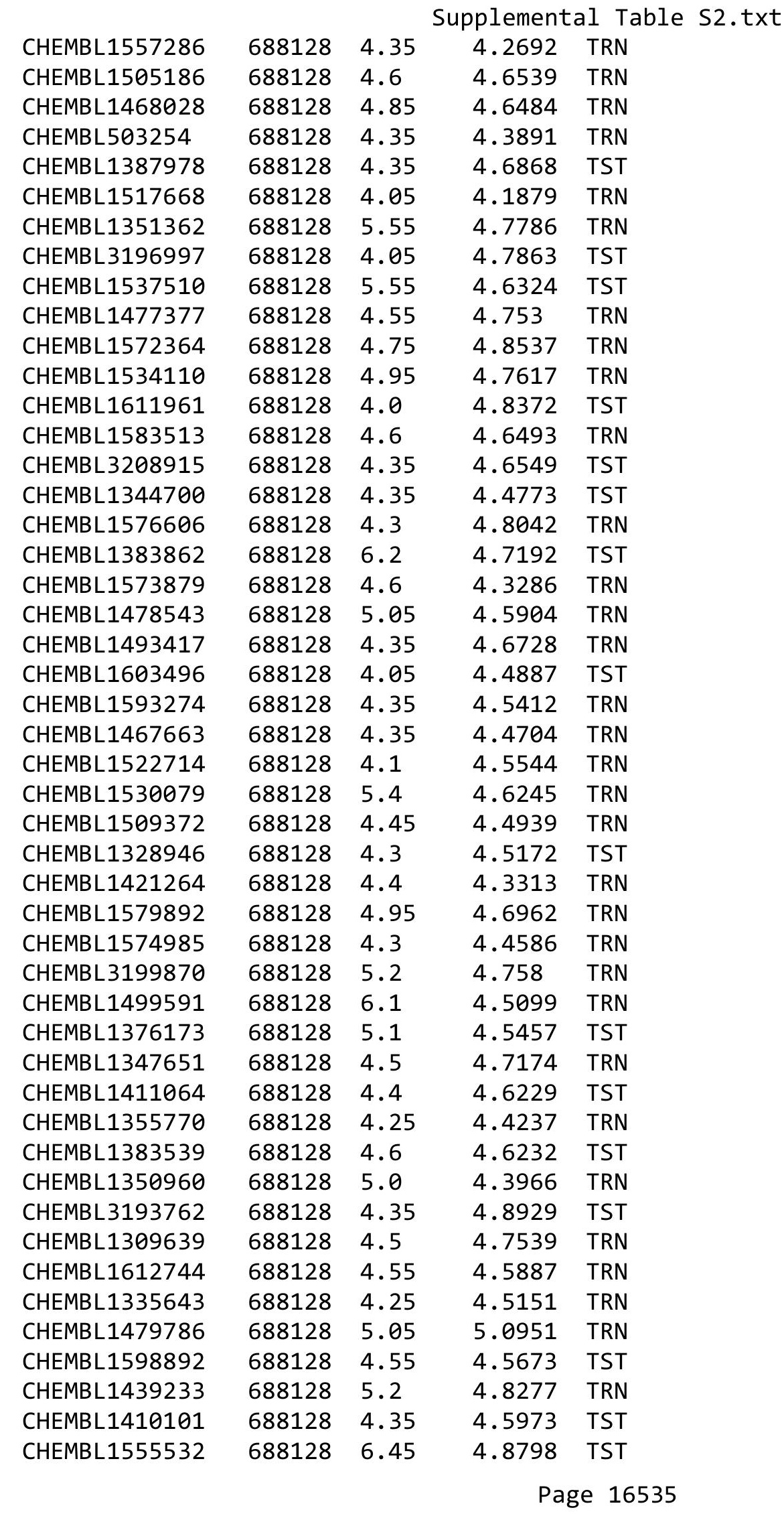




\begin{tabular}{|c|c|c|c|c|c|}
\hline & & \multicolumn{4}{|c|}{ Supplemental Table S2.txt } \\
\hline CHEMBL1419870 & 688128 & 4.65 & 4.9803 & TRN & \\
\hline CHEMBL1481278 & 688128 & 5.5 & 4.6948 & TRN & \\
\hline CHEMBL 2448510 & 688128 & 4.25 & 4.768 & TRN & \\
\hline CHEMBL1414156 & 688128 & 4.2 & 4.7659 & TRN & \\
\hline CHEMBL1381824 & 688128 & 4.75 & 4.6126 & TRN & \\
\hline CHEMBL1561647 & 688128 & 4.35 & 4.2615 & TRN & \\
\hline CHEMBL1406134 & 688128 & 4.05 & 4.8693 & TST & \\
\hline CHEMBL1403448 & 688128 & 5.25 & 4.8157 & TRN & \\
\hline CHEMBL1453690 & 688128 & 5.4 & 4.3539 & TRN & \\
\hline CHEMBL1351226 & 688128 & 4.5 & 4.5934 & TST & \\
\hline CHEMBL1425113 & 688128 & 4.6 & 4.5607 & TRN & \\
\hline CHEMBL1606613 & 688128 & 4.55 & 5.0298 & TRN & \\
\hline CHEMBL1358910 & 688128 & 4.0 & 4.5589 & TRN & \\
\hline CHEMBL1440817 & 688128 & 4.75 & 4.9755 & TRN & \\
\hline CHEMBL1573096 & 688128 & 4.2 & 4.6304 & TRN & \\
\hline CHEMBL1814509 & 688128 & 5.45 & 4.823 & TRN & \\
\hline CHEMBL1370253 & 688128 & 5.95 & 4.5164 & TRN & \\
\hline CHEMBL1419247 & 688128 & 4.25 & 5.0124 & TRN & \\
\hline CHEMBL1495072 & 688128 & 6.0 & 5.2835 & TRN & \\
\hline CHEMBL1308717 & 688128 & 4.05 & 4.8401 & TRN & \\
\hline CHEMBL1476972 & 688128 & 4.3 & 4.5157 & TRN & \\
\hline CHEMBL1596063 & 688128 & 4.3 & 4.5311 & TRN & \\
\hline CHEMBL1595459 & 688128 & 4.5 & 4.3325 & TRN & \\
\hline CHEMBL1414580 & 688128 & 4.85 & 4.6829 & TST & \\
\hline CHEMBL1445450 & 688128 & 4.7 & 4.1556 & TRN & \\
\hline CHEMBL1564366 & 688128 & 4.4 & 4.4706 & TRN & \\
\hline CHEMBL1463774 & 688128 & 4.9 & 4.6164 & TST & \\
\hline CHEMBL1518901 & 688128 & 4.25 & 4.6211 & TRN & \\
\hline CHEMBL1573007 & 688128 & 5.7 & 4.8682 & TST & \\
\hline CHEMBL1536701 & 688128 & 5.0 & 4.8854 & TRN & \\
\hline CHEMBL1483200 & 688128 & 4.35 & 4.4928 & TRN & \\
\hline CHEMBL1580472 & 688128 & 5.2 & 4.8125 & TRN & \\
\hline CHEMBL1367346 & 688128 & 4.05 & 4.42399 & 99999999995 & TRN \\
\hline CHEMBL1485807 & 688128 & 4.25 & 4.9042 & TRN & \\
\hline CHEMBL1582188 & 688128 & 4.1 & 4.4835 & TRN & \\
\hline CHEMBL66953 & 688128 & 5.05 & 5.2973 & TST & \\
\hline CHEMBL3195969 & 688128 & 4.35 & 4.5134 & TRN & \\
\hline CHEMBL1312235 & 688128 & 6.0 & 4.6915 & TST & \\
\hline CHEMBL1486270 & 688128 & 4.6 & 4.3993 & TRN & \\
\hline CHEMBL1511621 & 688128 & 6.4 & 4.5484 & TST & \\
\hline CHEMBL 2007212 & 688128 & 6.25 & 4.6865 & TST & \\
\hline CHEMBL1592919 & 688128 & 5.45 & 4.7106 & TRN & \\
\hline CHEMBL3194422 & 688128 & 4.05 & 4.7244 & TRN & \\
\hline CHEMBL1489374 & 688128 & 4.3 & 4.2111 & TRN & \\
\hline CHEMBL1301323 & 688128 & 4.95 & 4.8786 & TRN & \\
\hline CHEMBL1522208 & 688128 & 4.0 & 4.9433 & TRN & \\
\hline CHEMBL1572477 & 688128 & 5.4 & 4.511 & TST & \\
\hline CHEMBL1545768 & 688128 & 4.45 & 4.6079 & TRN & \\
\hline
\end{tabular}




\begin{tabular}{|c|c|c|c|c|c|}
\hline \multicolumn{6}{|c|}{ Supplemental Table S2.txt } \\
\hline CHEMBL1426351 & 688128 & 4.9 & 4.6949 & TRN & \\
\hline CHEMBL1400464 & 688128 & 4.95 & 4.8761 & TRN & \\
\hline CHEMBL1578527 & 688128 & 4.4 & 4.6658 & TRN & \\
\hline CHEMBL1561878 & 688128 & 6.25 & 4.3204 & TRN & \\
\hline CHEMBL1422477 & 688128 & 5.6 & 4.9927 & TRN & \\
\hline CHEMBL1339881 & 688128 & 4.55 & 4.6453 & TST & \\
\hline CHEMBL1469330 & 688128 & 6.0 & \multicolumn{2}{|c|}{4.531000000000001} & TRN \\
\hline CHEMBL1438591 & 688128 & 4.45 & 4.684 & TRN & \\
\hline CHEMBL1475836 & 688128 & 4.3 & 4.6952 & TST & \\
\hline CHEMBL1519984 & 688128 & 4.55 & 4.4835 & TST & \\
\hline CHEMBL1344503 & 688128 & 6.5501 & 4.7261 & TST & \\
\hline CHEMBL1465489 & 688128 & 4.4 & 4.5887 & TST & \\
\hline CHEMBL1733454 & 688128 & 4.4 & 4.5813 & TRN & \\
\hline CHEMBL1408017 & 688128 & 5.2 & 4.82 & TRN & \\
\hline CHEMBL1416651 & 688128 & 4.0 & 4.7467 & TRN & \\
\hline CHEMBL1464479 & 688128 & 4.35 & 4.3497 & TRN & \\
\hline CHEMBL3196187 & 688128 & 4.25 & \multicolumn{2}{|c|}{4.428999999999999} & TRN \\
\hline CHEMBL 3212731 & 688128 & 4.65 & 4.9077 & TST & \\
\hline CHEMBL 1350840 & 688128 & 4.7 & 4.6975 & TRN & \\
\hline CHEMBL1369711 & 688128 & 6.25 & 5.3346 & TRN & \\
\hline CHEMBL1462362 & 688128 & 5.45 & 4.6471 & TRN & \\
\hline CHEMBL1539621 & 688128 & 5.05 & 4.6232 & TRN & \\
\hline CHEMBL1494156 & 688128 & 4.6 & 4.4058 & TRN & \\
\hline CHEMBL1440373 & 688128 & 4.35 & 4.4345 & TRN & \\
\hline CHEMBL1309066 & 688128 & 4.3 & 4.6661 & TRN & \\
\hline CHEMBL1517369 & 688128 & 4.95 & 4.4813 & TRN & \\
\hline CHEMBL1342415 & 688128 & 4.05 & \multicolumn{2}{|c|}{4.4239999999999995} & TRN \\
\hline CHEMBL1301336 & 688128 & 4.9 & 4.5698 & TRN & \\
\hline CHEMBL1593695 & 688128 & 4.1 & 4.6724 & TRN & \\
\hline CHEMBL1335042 & 688128 & 6.5501 & 5.1125 & TRN & \\
\hline CHEMBL1585498 & 688128 & 4.4 & 4.4775 & TRN & \\
\hline CHEMBL1494893 & 688128 & 5.4 & 4.5774 & TRN & \\
\hline CHEMBL1554715 & 688128 & 4.5 & 4.5206 & TRN & \\
\hline CHEMBL1541950 & 688128 & 4.25 & 4.9003 & TRN & \\
\hline CHEMBL1466650 & 688128 & 4.6 & 4.5452 & TRN & \\
\hline CHEMBL1528123 & 688128 & 4.6 & 4.4301 & TRN & \\
\hline CHEMBL1394238 & 688128 & 4.95 & 4.6709 & TRN & \\
\hline CHEMBL1544782 & 688128 & 4.65 & 4.7768 & TRN & \\
\hline CHEMBL1543495 & 688128 & 4.35 & 4.7323 & TRN & \\
\hline CHEMBL1534459 & 688128 & 4.6 & 4.6552 & TST & \\
\hline CHEMBL1510087 & 688128 & 5.05 & 4.6644 & TRN & \\
\hline CHEMBL1499567 & 688128 & 4.35 & 4.8753 & TRN & \\
\hline CHEMBL1524508 & 688128 & 4.3 & 4.4285 & TRN & \\
\hline CHEMBL3212917 & 688128 & 5.85 & 4.4831 & TRN & \\
\hline CHEMBL1458441 & 688128 & 5.85 & 4.7035 & TRN & \\
\hline CHEMBL1363218 & 688128 & 4.0 & 4.649 & TST & \\
\hline CHEMBL1314567 & 688128 & 4.05 & 4.6347 & TRN & \\
\hline CHEMBL1515949 & 688128 & 4.05 & 4.5679 & TRN & \\
\hline
\end{tabular}




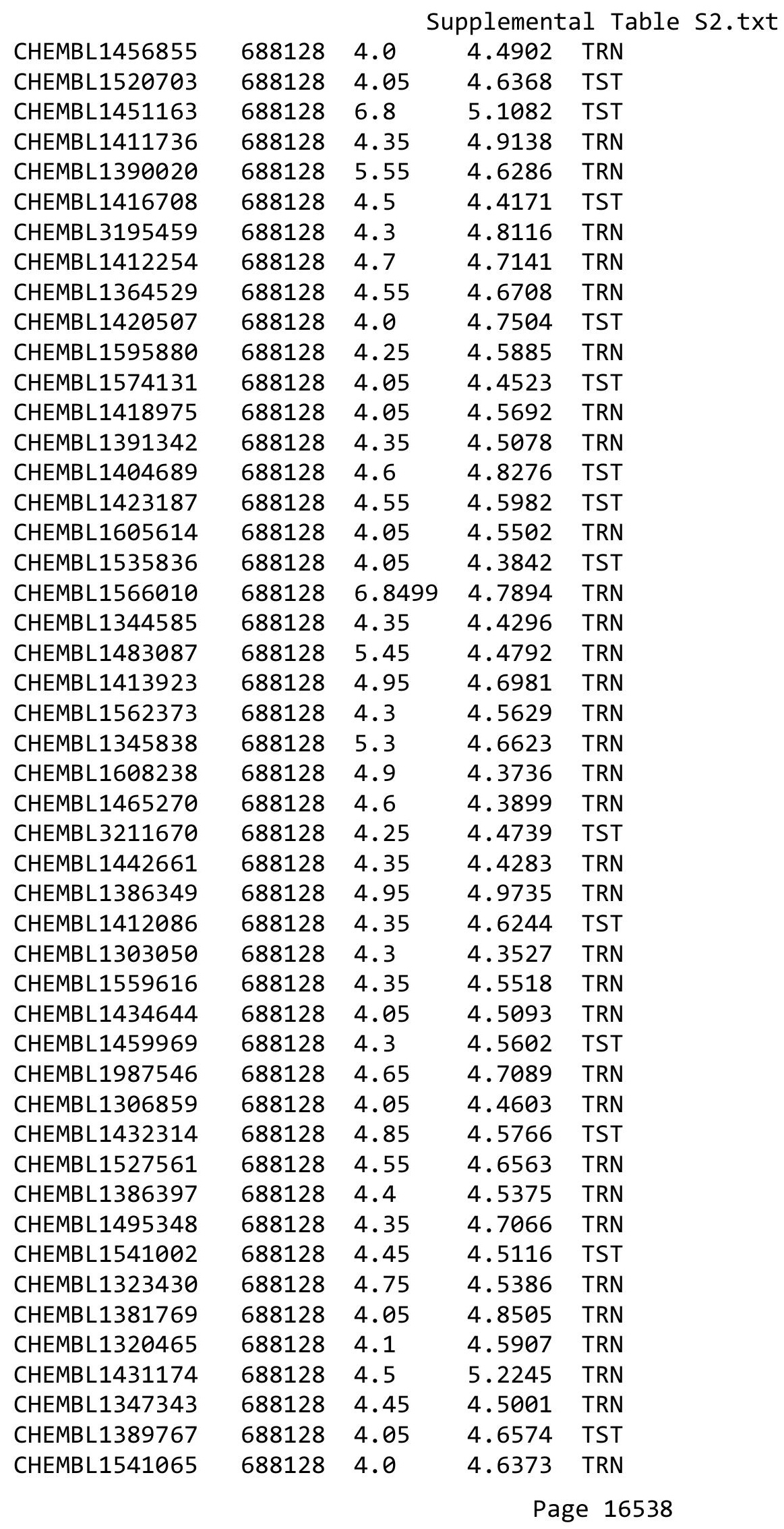




\begin{tabular}{|c|c|c|c|c|c|}
\hline \multicolumn{6}{|c|}{ Supplemental Table S2.txt } \\
\hline CHEMBL1338521 & 688128 & 4.35 & 4.34 & TRN & \\
\hline CHEMBL1400481 & 688128 & 6.5 & 5.0399 & TST & \\
\hline CHEMBL1556881 & 688128 & 6.95 & 4.7549 & TRN & \\
\hline CHEMBL1531307 & 688128 & 4.25 & 4.7243 & TRN & \\
\hline CHEMBL1561314 & 688128 & 5.4 & 4.9588 & TST & \\
\hline CHEMBL1507971 & 688128 & 5.45 & 4.7725 & TRN & \\
\hline CHEMBL1445047 & 688128 & 4.55 & 4.601 & TST & \\
\hline CHEMBL1352778 & 688128 & 4.3 & 4.5462 & TST & \\
\hline CHEMBL1492998 & 688128 & 4.1 & 4.5954 & TST & \\
\hline CHEMBL1366868 & 688128 & 4.35 & 4.8475 & TST & \\
\hline CHEMBL1429852 & 688128 & 4.25 & 4.65 & TRN & \\
\hline CHEMBL1531987 & 688128 & 4.4 & 4.9142 & TRN & \\
\hline CHEMBL1431094 & 688128 & 4.15 & 4.3272 & TRN & \\
\hline CHEMBL1456368 & 688128 & 4.4 & 4.5788 & TST & \\
\hline CHEMBL1553603 & 688128 & 4.45 & 4.3731 & TST & \\
\hline CHEMBL1540882 & 688128 & 4.3 & 4.4869 & TRN & \\
\hline CHEMBL1406337 & 688128 & 4.4 & 4.604 & TRN & \\
\hline CHEMBL1608717 & 688128 & 4.4 & 4.4786 & TRN & \\
\hline CHEMBL1360372 & 688128 & 4.9 & 4.6871 & TRN & \\
\hline CHEMBL1546523 & 688128 & 4.25 & 4.593 & TRN & \\
\hline CHEMBL1565039 & 688128 & 4.05 & 4.5006 & TST & \\
\hline CHEMBL1432113 & 688128 & 4.35 & 4.41100 & 00000000005 & TRN \\
\hline CHEMBL1504853 & 688128 & 4.65 & 4.5508 & TRN & \\
\hline CHEMBL3214391 & 688128 & 5.4 & 4.3517 & TRN & \\
\hline CHEMBL1318284 & 688128 & 4.4 & 4.6856 & TST & \\
\hline CHEMBL1396283 & 688128 & 4.05 & 4.8097 & TRN & \\
\hline CHEMBL1527328 & 688128 & 4.7 & 4.4365 & TRN & \\
\hline CHEMBL1369813 & 688128 & 5.4 & 4.841 & TRN & \\
\hline CHEMBL1612079 & 688128 & 6.0 & 5.2392 & TRN & \\
\hline CHEMBL1328836 & 688128 & 5.05 & 4.58 & TRN & \\
\hline CHEMBL1527623 & 688128 & 4.05 & 4.7075 & TST & \\
\hline CHEMBL1403697 & 688128 & 4.3 & 4.7707 & TRN & \\
\hline CHEMBL1545615 & 688128 & 4.35 & 4.6385 & TRN & \\
\hline CHEMBL1462131 & 688128 & 4.5 & 4.6767 & TRN & \\
\hline CHEMBL1406312 & 688128 & 4.55 & 4.8051 & TST & \\
\hline CHEMBL1510242 & 688128 & 4.25 & 4.7333 & TRN & \\
\hline CHEMBL1587984 & 688128 & 5.4 & 4.6838 & TRN & \\
\hline CHEMBL1429973 & 688128 & 4.35 & 4.5555 & TRN & \\
\hline CHEMBL3897228 & 1618862 & 5.7852 & 6.8453 & TRN & \\
\hline CHEMBL3985610 & 1618862 & 6.7055 & 6.1403 & TST & \\
\hline CHEMBL 3943573 & 1618862 & 7.0315 & 7.0099 & TRN & \\
\hline CHEMBL3929014 & 1618862 & 6.2676 & 6.348 & TRN & \\
\hline CHEMBL 3948291 & 1618862 & 5.6126 & 5.9939 & TST & \\
\hline CHEMBL3892592 & 1618862 & 6.3585 & 5.7802 & TRN & \\
\hline CHEMBL3967635 & 1618862 & 8.699 & 7.845 & TRN & \\
\hline CHEMBL 3938033 & 1618862 & 7.6383 & 7.95700 & 3000000001 & TRN \\
\hline CHEMBL3895884 & 1618862 & 7.699 & 6.965 & TST & \\
\hline CHEMBL 3895777 & 1618862 & 5.767 & 6.0263 & TST & \\
\hline
\end{tabular}


Supplemental Table S2.txt

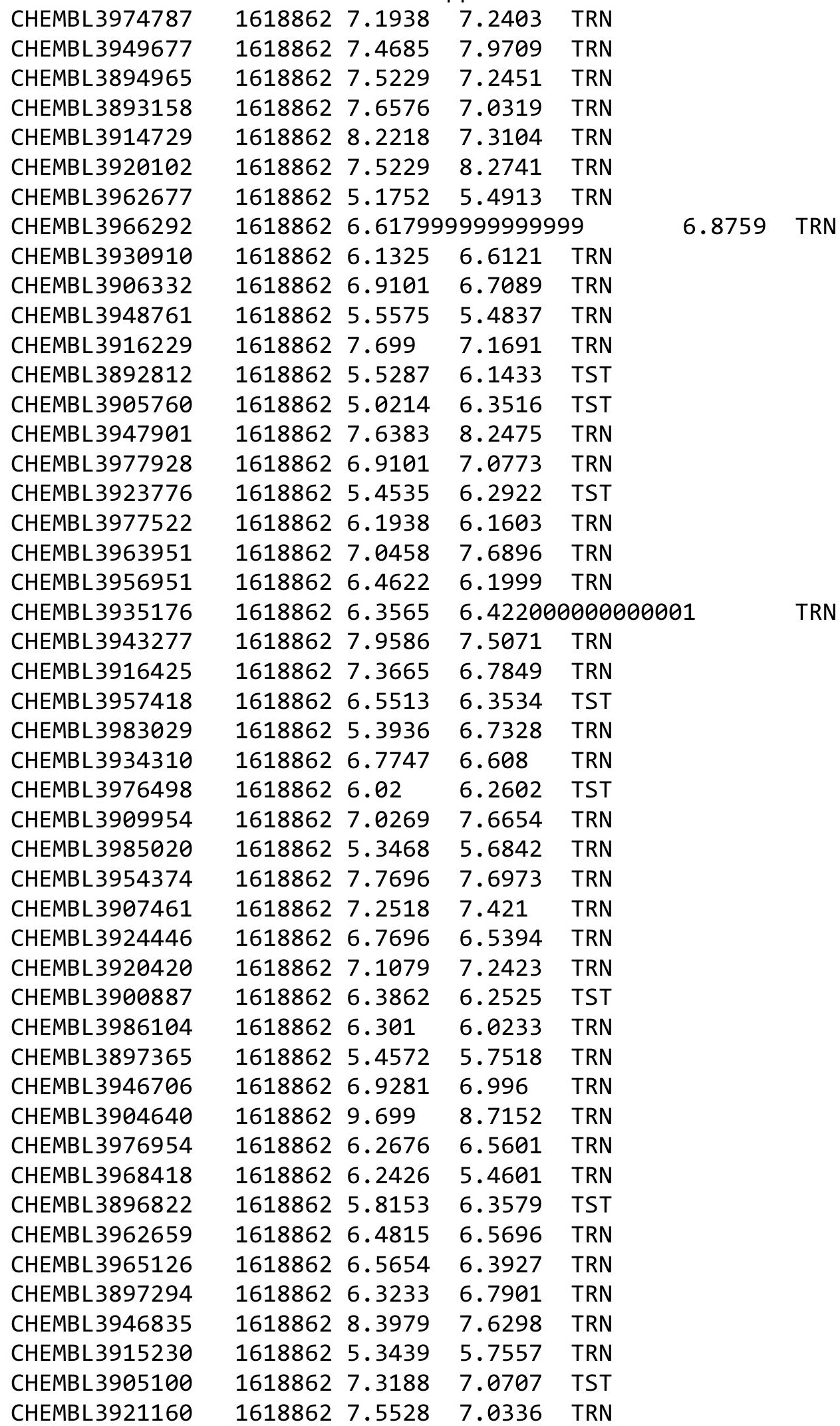

Page 16540 
Supplemental Table S2.txt

\begin{tabular}{|c|c|c|c|c|}
\hline CHEMBL3925415 & 1618862 & 6.8697 & 6.7062 & TRN \\
\hline CHEMBL3967976 & 1618862 & 5.684 & 5.9325 & TST \\
\hline CHEMBL3978001 & 1618862 & 8.3979 & 7.3717 & TST \\
\hline CHEMBL3961582 & 1618862 & 6.1871 & 7.5629 & TST \\
\hline CHEMBL3986186 & 1618862 & 5.2179 & 6.7733 & TST \\
\hline CHEMBL1684841 & 727292 & 8.1024 & 8.2306 & TRN \\
\hline CHEMBL1685017 & 727292 & 8.5528 & 9.0985 & TRN \\
\hline CHEMBL1684840 & 727292 & 6.585 & 6.9565 & TRN \\
\hline CHEMBL1684844 & 727292 & 4.6778 & 5.8664 & TST \\
\hline CHEMBL1685015 & 727292 & 5.2218 & 5.4628 & TRN \\
\hline CHEMBL1684827 & 727292 & 6.8861 & 6.2167 & TRN \\
\hline CHEMBL1685013 & 727292 & 5.2218 & 5.2165 & TRN \\
\hline CHEMBL1684834 & 727292 & 6.3872 & 6.4286 & TRN \\
\hline CHEMBL1684824 & 727292 & 5.7696 & 7.5799 & TST \\
\hline CHEMBL1685028 & 727292 & 8.699 & 8.7271 & TRN \\
\hline CHEMBL1684837 & 727292 & 8.6383 & 8.5197 & TRN \\
\hline CHEMBL1684833 & 727292 & 8.7959 & 9.2333 & TRN \\
\hline CHEMBL1684995 & 727292 & 5.2218 & 6.0992 & TRN \\
\hline CHEMBL1685011 & 727292 & 7.7696 & 7.8908 & TRN \\
\hline CHEMBL1684828 & 727292 & 7.0132 & 6.9016 & TRN \\
\hline CHEMBL1685010 & 727292 & 5.7696 & 6.6023 & TRN \\
\hline CHEMBL1685016 & 727292 & 5.2218 & 5.3216 & TRN \\
\hline CHEMBL1685003 & 727292 & 5.2218 & 6.2443 & TRN \\
\hline CHEMBL1685027 & 727292 & 5.2218 & 4.9772 & TRN \\
\hline CHEMBL1685006 & 727292 & 5.2218 & 5.8651 & TRN \\
\hline CHEMBL1684829 & 727292 & 8.8861 & 8.6059 & TRN \\
\hline CHEMBL1685009 & 727292 & 7.8861 & 7.0663 & TST \\
\hline CHEMBL1685002 & 727292 & 7.5528 & 8.0189 & TRN \\
\hline CHEMBL1684997 & 727292 & 6.6778 & 6.4215 & TRN \\
\hline CHEMBL1684826 & 727292 & 9.0706 & 7.0393 & TRN \\
\hline CHEMBL1684838 & 727292 & 8.9586 & 9.1722 & TRN \\
\hline CHEMBL1684830 & 727292 & 6.5528 & 7.1971 & TRN \\
\hline CHEMBL1684836 & 727292 & 6.6576 & 7.8004 & TST \\
\hline CHEMBL1684846 & 727292 & 6.1871 & 7.1107 & TST \\
\hline CHEMBL1684839 & 727292 & 5.6778 & 6.5583 & TRN \\
\hline CHEMBL1685005 & 727292 & 8.585 & 8.0509 & TRN \\
\hline CHEMBL1685014 & 727292 & 8.7696 & 7.7747 & TRN \\
\hline CHEMBL1684994 & 727292 & 8.699 & 6.94 & TRN \\
\hline CHEMBL1684848 & 727292 & 6.1135 & 6.1077 & TRN \\
\hline CHEMBL1684842 & 727292 & 4.2218 & 6.1432 & TRN \\
\hline CHEMBL1685012 & 727292 & 5.2218 & 6.0644 & TRN \\
\hline CHEMBL1684831 & 727292 & 8.6198 & 8.6003 & TRN \\
\hline CHEMBL1685023 & 727292 & 6.7212 & 5.7331 & TRN \\
\hline CHEMBL1685024 & 727292 & 5.2218 & 4.8903 & TRN \\
\hline CHEMBL1684835 & 727292 & 7.699 & 5.9026 & TRN \\
\hline CHEMBL1684849 & 727292 & 9.3468 & 7.4696 & TRN \\
\hline CHEMBL1684998 & 727292 & 6.3872 & 6.1409 & TRN \\
\hline CHEMBL1685018 & 727292 & 8.1549 & 6.8323 & TST \\
\hline
\end{tabular}




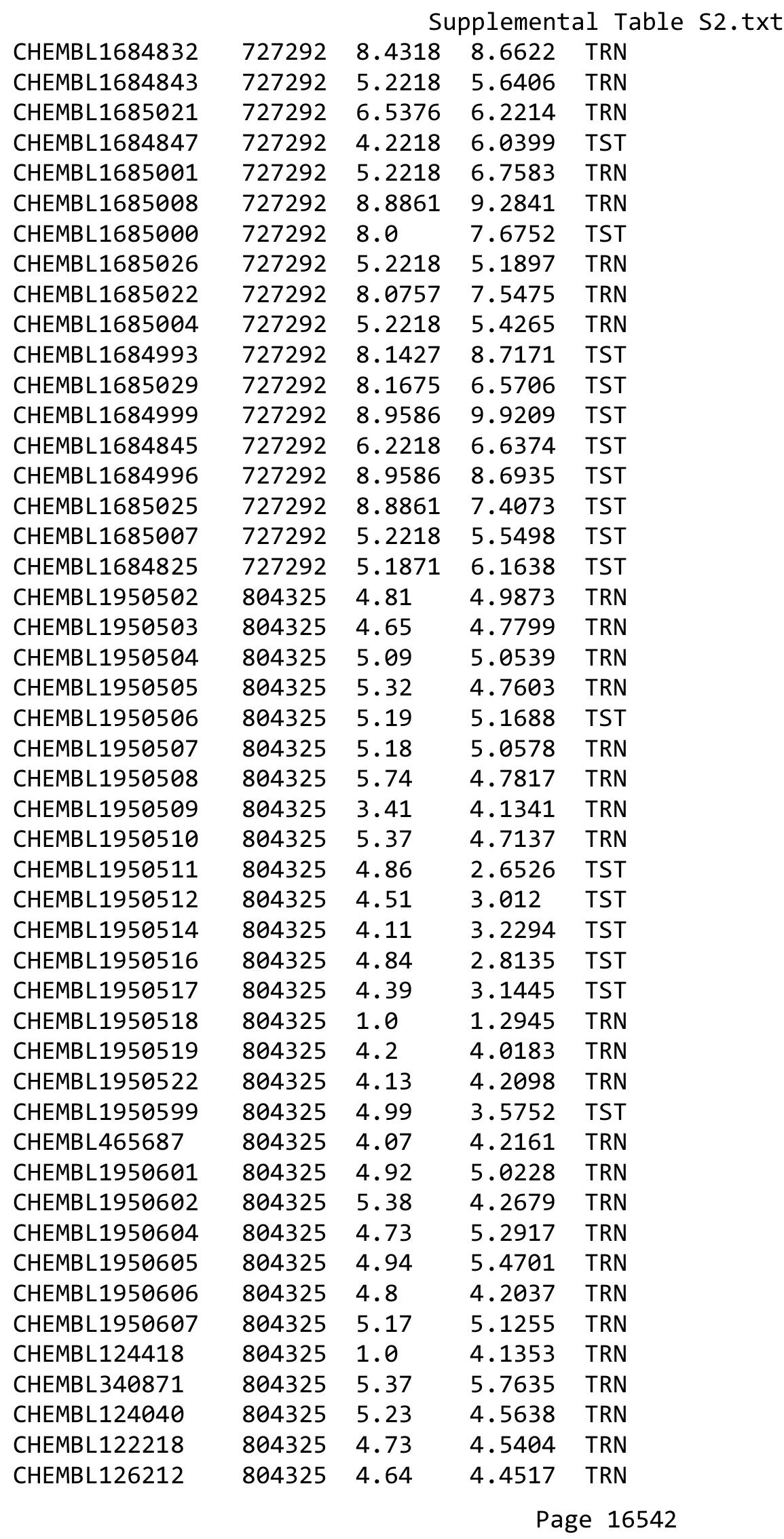




\begin{tabular}{|c|c|c|c|c|}
\hline \multicolumn{5}{|c|}{ Supplemental Table S2.txt } \\
\hline CHEMBL431671 & 804325 & 4.92 & 4.7415 & TRN \\
\hline CHEMBL124481 & 804325 & 5.26 & 4.6837 & TRN \\
\hline CHEMBL1950608 & 804325 & 4.57 & 4.9852 & TRN \\
\hline CHEMBL123313 & 804325 & 5.3 & 4.519 & TRN \\
\hline CHEMBL1950612 & 804325 & 4.13 & 4.8972 & TRN \\
\hline CHEMBL1950613 & 804325 & 5.04 & 4.8746 & TRN \\
\hline CHEMBL1950615 & 804325 & 4.84 & 4.4712 & TRN \\
\hline CHEMBL1950616 & 804325 & 4.48 & 4.4148 & TRN \\
\hline CHEMBL1950618 & 804325 & 2.7 & 3.8913 & TRN \\
\hline CHEMBL1950620 & 804325 & 4.38 & 4.7899 & TRN \\
\hline CHEMBL1950621 & 804325 & 4.54 & 4.5223 & TRN \\
\hline CHEMBL1949684 & 804325 & 4.93 & 5.2039 & TRN \\
\hline CHEMBL1950622 & 804325 & 4.93 & 4.1073 & TRN \\
\hline CHEMBL1950623 & 804325 & 5.43 & 4.6721 & TST \\
\hline CHEMBL1950624 & 804325 & 4.81 & 3.7643 & TRN \\
\hline CHEMBL1950625 & 804325 & 4.98 & 4.2156 & TST \\
\hline CHEMBL1950626 & 804325 & 5.14 & 3.2114 & TST \\
\hline CHEMBL1950627 & 804325 & 4.97 & 4.9066 & TST \\
\hline CHEMBL1950628 & 804325 & 4.76 & 5.1098 & TST \\
\hline CHEMBL1950636 & 804325 & 3.48 & 4.1167 & TST \\
\hline CHEMBL3683184 & 1535247 & 4.4377 & 4.4317 & TRN \\
\hline CHEMBL3954004 & 1535247 & 4.7481 & 4.7587 & TRN \\
\hline CHEMBL3970096 & 1535247 & 5.2211 & 5.2187 & TRN \\
\hline CHEMBL3683182 & 1535247 & 5.8665 & 5.8749 & TRN \\
\hline CHEMBL3683165 & 1535247 & 4.604 & 4.6575 & TRN \\
\hline CHEMBL3683158 & 1535247 & 4.643 & 5.2711 & TST \\
\hline CHEMBL3947307 & 1535247 & 4.1708 & 4.1873 & TRN \\
\hline CHEMBL3925840 & 1535247 & 4.5367 & 4.5223 & TRN \\
\hline CHEMBL3683124 & 1535247 & 5.0899 & 4.5929 & TST \\
\hline CHEMBL3942639 & 1535247 & 4.4844 & 4.501 & TRN \\
\hline CHEMBL3891884 & 1535247 & 4.1114 & 4.1083 & TRN \\
\hline CHEMBL3925994 & 1535247 & 5.6383 & 5.6341 & TRN \\
\hline CHEMBL3966566 & 1535247 & 4.758 & 4.7481 & TRN \\
\hline CHEMBL3683169 & 1535247 & 4.9031 & 4.8932 & TRN \\
\hline CHEMBL3927502 & 1535247 & 4.3807 & 4.3628 & TRN \\
\hline CHEMBL3898785 & 1535247 & 4.2912 & 4.2872 & TRN \\
\hline CHEMBL3683117 & 1535247 & 4.3799 & 4.3802 & TRN \\
\hline CHEMBL3683166 & 1535247 & 5.0458 & 4.5744 & TST \\
\hline CHEMBL3601398 & 1535247 & 5.6778 & 5.7042 & TRN \\
\hline CHEMBL3920413 & 1535247 & 4.6107 & 4.6091 & TRN \\
\hline CHEMBL3683157 & 1535247 & 5.0057 & 5.0154 & TRN \\
\hline CHEMBL3953475 & 1535247 & 4.5213 & 4.5228 & TRN \\
\hline CHEMBL3683120 & 1535247 & 4.2208 & 4.3384 & TST \\
\hline CHEMBL3683111 & 1535247 & 4.3383 & 4.1565 & TST \\
\hline CHEMBL3683170 & 1535247 & 4.4627 & 4.4613 & TRN \\
\hline CHEMBL3601401 & 1535247 & 5.7878 & 5.7925 & TRN \\
\hline CHEMBL3913081 & 1535247 & 4.7768 & 4.8101 & TRN \\
\hline CHEMBL3924672 & 1535247 & 4.5116 & 4.4971 & TRN \\
\hline
\end{tabular}


Supplemental Table S2.txt

\begin{tabular}{|c|c|c|c|c|c|c|}
\hline CHEMBL 3953507 & 1535247 & 4.086 & 4.2166 & TST & & \\
\hline CHEMBL 3683160 & 1535247 & 5.6364 & 5.6093 & TRN & & \\
\hline CHEMBL 3683180 & 1535247 & 5.0665 & 5.0653 & TRN & & \\
\hline CHEMBL 3601402 & 1535247 & 5.0904 & 5.0788 & TRN & & \\
\hline CHEMBL 3683162 & 1535247 & 5.5214 & 5.5214 & TRN & & \\
\hline CHEMBL 3683173 & 1535247 & \multicolumn{3}{|c|}{5.7620000000000005} & 5.7536 & TRN \\
\hline CHEMBL3936602 & 1535247 & 4.0363 & 4.0545 & TRN & & \\
\hline CHEMBL 3683164 & 1535247 & 4.5544 & 4.5489 & TRN & & \\
\hline CHEMBL3683159 & 1535247 & 5.5528 & 5.546 & TRN & & \\
\hline CHEMBL3683171 & 1535247 & 5.7696 & 5.7675 & TRN & & \\
\hline CHEMBL 3683108 & 1535247 & 4.2172 & 4.4907 & TST & & \\
\hline CHEMBL3914742 & 1535247 & 5.1656 & 5.1766 & TRN & & \\
\hline CHEMBL 3683172 & 1535247 & 5.6925 & 5.6718 & TRN & & \\
\hline CHEMBL 3928800 & 1535247 & 4.3833 & 4.3848 & TRN & & \\
\hline CHEMBL 3639820 & 1535247 & 4.4198 & 4.5376 & TST & & \\
\hline CHEMBL 3907926 & 1535247 & 5.0964 & 5.1187 & TRN & & \\
\hline CHEMBL3948320 & 1535247 & 5.3936 & 5.3932 & TRN & & \\
\hline CHEMBL 3963303 & 1535247 & \multicolumn{3}{|c|}{ 4.71399999999999995 } & 4.7104 & TRN \\
\hline CHEMBL 3683183 & 1535247 & 5.8069 & 5.8145 & TRN & & \\
\hline CHEMBL3919162 & 1535247 & 4.5728 & 4.5665 & TRN & & \\
\hline CHEMBL 3683122 & 1535247 & 4.6249 & 4.2485 & TST & & \\
\hline CHEMBL 3683161 & 1535247 & 5.1518 & 5.1586 & TRN & & \\
\hline CHEMBL 3960970 & 1535247 & 4.1958 & 4.1876 & TRN & & \\
\hline CHEMBL 3981474 & 1535247 & 5.3915 & 5.3917 & TRN & & \\
\hline CHEMBL 3933510 & 1535247 & 5.3429 & 5.3352 & TRN & & \\
\hline CHEMBL3982236 & 1535247 & 4.1912 & 4.1798 & TRN & & \\
\hline CHEMBL 3683174 & 1535247 & 5.0788 & 5.0897 & TRN & & \\
\hline CHEMBL 3601403 & 1535247 & 5.426 & 5.391 & TRN & & \\
\hline CHEMBL 3903023 & 1535247 & 4.7411 & 4.7497 & TRN & & \\
\hline CHEMBL 3683123 & 1535247 & 4.9439 & 4.3196 & TST & & \\
\hline CHEMBL 3683177 & 1535247 & 5.2933 & 5.2917 & TRN & & \\
\hline CHEMBL 3683163 & 1535247 & 5.7352 & 5.7436 & TRN & & \\
\hline CHEMBL 3898896 & 1535247 & \multicolumn{3}{|c|}{4.9830000000000005} & 4.9882 & 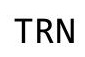 \\
\hline CHEMBL3890507 & 1535247 & 4.9504 & 4.9114 & TRN & & \\
\hline CHEMBL3683119 & 1535247 & 4.2034 & 4.189 & TRN & & \\
\hline CHEMBL3683179 & 1535247 & \multicolumn{3}{|c|}{5.3839999999999995} & 5.402 & 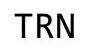 \\
\hline CHEMBL3601323 & 1535247 & 5.6498 & 5.5451 & TST & & \\
\hline CHEMBL 3683178 & 1535247 & 5.6676 & 5.0924 & TST & & \\
\hline CHEMBL 3604660 & 1535247 & 4.1826 & 4.3632 & TST & & \\
\hline CHEMBL3683121 & 1535247 & 4.4158 & 4.4448 & TST & & \\
\hline CHEMBL3601397 & 1535247 & 5.7799 & 5.79700 & 0000000001 & & U. \\
\hline CHEMBL3974583 & 1535247 & 4.2386 & 3.6641 & TST & & \\
\hline CHEMBL3950607 & 1535247 & 4.3599 & 4.2415 & TST & & \\
\hline CHEMBL 3950021 & 1535247 & 4.0449 & 4.2632 & TST & & \\
\hline CHEMBL3683156 & 1535247 & 5.5391 & 5.4551 & TST & & \\
\hline CHEMBL3923132 & 1528252 & 6.0 & 7.5448 & TRN & & \\
\hline CHEMBL 2152918 & 1528252 & 8.7959 & 7.9625 & TRN & & \\
\hline CHEMBL3657419 & 1528252 & 8.2757 & 6.8035 & TRN & & \\
\hline
\end{tabular}


Supplemental Table S2.txt

\begin{tabular}{|c|c|c|c|c|c|c|}
\hline CHEMBL3907727 & 1528252 & 6.0 & 7.1212 & TRN & & \\
\hline CHEMBL 2152920 & 1528252 & 8.6383 & 7.7962 & TRN & & \\
\hline CHEMBL3916726 & 1528252 & 8.4815 & 8.926 & TRN & & \\
\hline CHEMBL 3653724 & 1528252 & 7.6778 & 6.5276 & TRN & & \\
\hline CHEMBL 3974225 & 1528252 & 9.1427 & 7.8578 & TRN & & \\
\hline CHEMBL 3922553 & 1528252 & 7.7696 & 7.5167 & TST & & \\
\hline CHEMBL 3894452 & 1528252 & 8.4815 & 7.5945 & TRN & & \\
\hline CHEMBL3895159 & 1528252 & 8.585 & 7.2429 & TRN & & \\
\hline CHEMBL 3653698 & 1528252 & 8.28399 & 999999999 & & 8.4041 & TRN \\
\hline CHEMBL 3928162 & 1528252 & 7.8861 & 7.8847 & TRN & & \\
\hline CHEMBL 3985518 & 1528252 & 8.8239 & 8.5661 & TRN & & \\
\hline CHEMBL 3653663 & 1528252 & 7.6576 & 7.4592 & TST & & \\
\hline CHEMBL 3653730 & 1528252 & 6.9957 & 7.3664 & TRN & & \\
\hline CHEMBL 2152916 & 1528252 & 6.0 & 6.9841 & TRN & & \\
\hline CHEMBL 3653695 & 1528252 & 8.1367 & 8.4106 & TRN & & \\
\hline CHEMBL 3929159 & 1528252 & 8.6576 & 8.0476 & TRN & & \\
\hline CHEMBL3639562 & 1528252 & 8.8861 & 7.9965 & TRN & & \\
\hline CHEMBL 3925456 & 1528252 & 7.699 & 7.5555 & TST & & \\
\hline CHEMBL 3970341 & 1528252 & 7.2757 & 7.1187 & TRN & & \\
\hline CHEMBL 3653732 & 1528252 & 7.6576 & 7.6107 & TRN & & \\
\hline CHEMBL3936953 & 1528252 & 6.0 & 6.9304 & TRN & & \\
\hline CHEMBL 3653702 & 1528252 & 6.0 & 8.604 & TST & & \\
\hline CHEMBL 3922674 & 1528252 & 7.7447 & 7.511 & TST & & \\
\hline CHEMBL3939422 & 1528252 & 8.3098 & 7.8762 & TRN & & \\
\hline CHEMBL 3972170 & 1528252 & 8.28399 & 999999999 & & 7.0614 & $T_{0}$ \\
\hline CHEMBL2152914 & 1528252 & 6.0 & 7.8761 & TRN & & \\
\hline CHEMBL 2152919 & 1528252 & 8.8539 & 8.2096 & TRN & & \\
\hline CHEMBL 3937468 & 1528252 & 8.2596 & 8.575 & TRN & & \\
\hline CHEMBL3928450 & 1528252 & 6.0 & 7.6613 & TRN & & \\
\hline CHEMBL 3971150 & 1528252 & 8.5086 & 8.0267 & TRN & & \\
\hline CHEMBL 3653708 & 1528252 & 8.301 & 8.6003 & TST & & \\
\hline CHEMBL 3653723 & 1528252 & 6.0 & 7.0998 & TRN & & \\
\hline CHEMBL 3939410 & 1528252 & 8.6778 & 9.0815 & TRN & & \\
\hline CHEMBL3653726 & 1528252 & 8.8861 & 8.0973 & TRN & & \\
\hline CHEMBL 3903281 & 1528252 & 8.4089 & 8.6655 & TRN & & \\
\hline CHEMBL3653722 & 1528252 & 6.0 & 7.234 & TRN & & \\
\hline CHEMBL 3657429 & 1528252 & 9.0 & 7.9227 & TRN & & \\
\hline CHEMBL 3653725 & 1528252 & 6.0 & 6.2578 & TRN & & \\
\hline CHEMBL 3653714 & 1528252 & 7.7212 & 8.0348 & TRN & & \\
\hline CHEMBL2151058 & 1528252 & 8.8539 & 7.8049 & TRN & & \\
\hline CHEMBL3951608 & 1528252 & 7.8239 & 7.361000 & 000000001 & & N \\
\hline CHEMBL 3980368 & 1528252 & 6.0 & 7.9548 & TRN & & \\
\hline CHEMBL 3657420 & 1528252 & 6.0 & 6.7718 & TRN & & \\
\hline CHEMBL 3898686 & 1528252 & 7.5528 & 7.4064 & TST & & \\
\hline CHEMBL3953357 & 1528252 & 8.5528 & 8.3393 & TST & & \\
\hline CHEMBL3653697 & 1528252 & 8.2757 & 8.2962 & TST & & \\
\hline CHEMBL 3901045 & 1528252 & 8.6383 & 7.805 & TST & & \\
\hline CHEMBL 3983379 & 1528252 & 7.4685 & 8.4199 & TST & & \\
\hline
\end{tabular}


Supplemental Table S2.txt

\begin{tabular}{|c|c|c|c|c|}
\hline CHEMBL3955716 & 1528252 & 8.8239 & 7.6861 & TST \\
\hline CHEMBL 2152917 & 1528252 & 9.0506 & 7.652 & TST \\
\hline CHEMBL3909571 & 1528252 & 7.7212 & 8.133 & TST \\
\hline CHEMBL3394164 & 1641656 & 9.1175 & 8.9683 & TRN \\
\hline CHEMBL 3984463 & 1641656 & 6.2677 & 6.6709 & TRN \\
\hline CHEMBL3937821 & 1641656 & 7.2018 & 6.9256 & TRN \\
\hline CHEMBL3891490 & 1641656 & 7.2671 & 7.1795 & TRN \\
\hline CHEMBL3984537 & 1641656 & 6.8549 & 7.5363 & TRN \\
\hline CHEMBL3945136 & 1641656 & 7.9104 & 7.8378 & TRN \\
\hline CHEMBL3893588 & 1641656 & 9.0009 & 8.9298 & TRN \\
\hline CHEMBL 3986966 & 1641656 & 6.7686 & 6.86 & TRN \\
\hline CHEMBL3394062 & 1641656 & 6.7423 & 6.9008 & TST \\
\hline CHEMBL 3975552 & 1641656 & 7.765 & 8.1147 & TRN \\
\hline CHEMBL3394069 & 1641656 & 8.2952 & 8.2972 & TRN \\
\hline CHEMBL3394172 & 1641656 & 7.9722 & 8.2863 & TRN \\
\hline CHEMBL3918394 & 1641656 & 7.7051 & 7.9896 & TRN \\
\hline CHEMBL3925503 & 1641656 & 7.8636 & 7.4488 & TRN \\
\hline CHEMBL 3932201 & 1641656 & 9.3028 & 8.7218 & TRN \\
\hline CHEMBL3394167 & 1641656 & 8.8016 & 8.4002 & TRN \\
\hline CHEMBL 3942045 & 1641656 & 6.4511 & 6.0059 & TRN \\
\hline CHEMBL 3975438 & 1641656 & 6.2822 & 6.2811 & TRN \\
\hline CHEMBL3971473 & 1641656 & 8.9144 & 8.9235 & TRN \\
\hline CHEMBL3974432 & 1641656 & 7.0694 & 6.8835 & TRN \\
\hline CHEMBL3902931 & 1641656 & 6.0996 & 6.1293 & TST \\
\hline CHEMBL3916074 & 1641656 & 7.9442 & 7.9135 & TRN \\
\hline CHEMBL3965218 & 1641656 & 8.60799 & 999999999 & 8.5027 \\
\hline CHEMBL3985653 & 1641656 & 7.0766 & 7.2475 & TST \\
\hline CHEMBL3904737 & 1641656 & 8.3039 & 8.4574 & TRN \\
\hline CHEMBL3918311 & 1641656 & 6.5102 & 7.0544 & TST \\
\hline CHEMBL3986124 & 1641656 & 8.4693 & 8.648 & TRN \\
\hline CHEMBL3918784 & 1641656 & 6.6907 & 6.7422 & TRN \\
\hline CHEMBL3915618 & 1641656 & 8.0049 & 7.7665 & TST \\
\hline CHEMBL 3985673 & 1641656 & 6.2932 & 6.7345 & TRN \\
\hline CHEMBL3896735 & 1641656 & 8.2729 & 7.9991 & TRN \\
\hline CHEMBL3901582 & 1641656 & 9.3716 & 8.6893 & TRN \\
\hline CHEMBL3943596 & 1641656 & 6.7739 & 6.6532 & TRN \\
\hline CHEMBL3927004 & 1641656 & 8.1484 & 8.3161 & TRN \\
\hline CHEMBL3958260 & 1641656 & 6.388 & 6.6575 & TST \\
\hline CHEMBL3394171 & 1641656 & 6.0 & 7.1448 & TRN \\
\hline CHEMBL3933697 & 1641656 & 8.2418 & 8.1399 & TRN \\
\hline CHEMBL3903410 & 1641656 & 7.1665 & 7.4399 & TRN \\
\hline CHEMBL3901647 & 1641656 & 6.0 & 7.1236 & TST \\
\hline CHEMBL3939836 & 1641656 & 7.8567 & 7.7241 & TST \\
\hline CHEMBL3953669 & 1641656 & 6.2956 & 6.7916 & TRN \\
\hline CHEMBL3394061 & 1641656 & 6.7478 & 7.028 & TST \\
\hline CHEMBL 3889658 & 1641656 & 6.8338 & 7.3813 & TST \\
\hline CHEMBL3974156 & 1641656 & 7.0873 & 7.218999 & 9999999999 \\
\hline CHEMBL3965031 & 1641656 & 8.6203 & 8.5984 & TRN \\
\hline
\end{tabular}


Supplemental Table S2.txt

\begin{tabular}{|c|c|c|c|c|c|}
\hline CHEMBL 3892029 & 1641656 & 8.8395 & 8.5328 & TRN & \\
\hline CHEMBL3921252 & 1641656 & 7.4852 & 7.9227 & TRN & \\
\hline CHEMBL3912306 & 1641656 & 7.0445 & 7.3637 & TRN & \\
\hline CHEMBL3981772 & 1641656 & 8.3838 & 8.3717 & TRN & \\
\hline CHEMBL 3908000 & 1641656 & 8.7762 & 8.6287 & TST & \\
\hline CHEMBL 3965804 & 1641656 & 7.5844 & 7.5166 & TRN & \\
\hline CHEMBL3891145 & 1641656 & 6.8411 & 7.0086 & TRN & \\
\hline CHEMBL3965029 & 1641656 & 8.0687 & 8.2768 & TRN & \\
\hline CHEMBL3977572 & 1641656 & \multicolumn{2}{|c|}{6.037000000000001} & 6.5049 & TRN \\
\hline CHEMBL 3892287 & 1641656 & 8.2563 & 8.1523 & TRN & \\
\hline CHEMBL3909365 & 1641656 & 7.9197 & 8.0492 & TRN & \\
\hline CHEMBL3980995 & 1641656 & 7.2509 & 7.3994 & TST & \\
\hline CHEMBL 3894736 & 1641656 & 7.8867 & 7.3733 & TRN & \\
\hline CHEMBL3939931 & 1641656 & 5.8313 & 5.9616 & TRN & \\
\hline CHEMBL 3948227 & 1641656 & 8.198 & 7.9614 & TST & \\
\hline CHEMBL3912741 & 1641656 & 9.0453 & 8.8893 & TRN & \\
\hline CHEMBL 3890347 & 1641656 & 8.2409 & 8.4314 & TRN & \\
\hline CHEMBL 3943843 & 1641656 & 7.8041 & 8.321 & TRN & \\
\hline CHEMBL 3942435 & 1641656 & 8.7948 & 8.8778 & TRN & \\
\hline CHEMBL 3932794 & 1641656 & 9.0114 & 8.9361 & TRN & \\
\hline CHEMBL 3892162 & 1641656 & 5.8969 & 6.0356 & TRN & \\
\hline CHEMBL3952167 & 1641656 & 7.3606 & 7.44600 & 0000000001 & TST \\
\hline CHEMBL 3932720 & 1641656 & 7.7854 & 7.7215 & TRN & \\
\hline CHEMBL 3394060 & 1641656 & 6.5735 & 6.859 & TST & \\
\hline CHEMBL 3924622 & 1641656 & 6.5108 & 6.6807 & TRN & \\
\hline CHEMBL 3892732 & 1641656 & 8.7404 & 8.8296 & TRN & \\
\hline CHEMBL3972180 & 1641656 & 7.6269 & 7.91100 & 00000000005 & . \\
\hline CHEMBL3394170 & 1641656 & 8.1077 & 8.1067 & TRN & \\
\hline CHEMBL3922724 & 1641656 & 8.1537 & 8.1925 & TRN & \\
\hline CHEMBL 3890422 & 1641656 & 7.7886 & 7.6842 & TRN & \\
\hline CHEMBL3981553 & 1641656 & 8.2925 & 8.5799 & TRN & \\
\hline CHEMBL3965530 & 1641656 & 7.0385 & 6.7996 & TST & \\
\hline CHEMBL 3898134 & 1641656 & 6.407 & 6.6909 & TRN & \\
\hline CHEMBL 3394073 & 1641656 & 8.3582 & 8.2656 & TRN & \\
\hline CHEMBL 3905618 & 1641656 & 9.4609 & 9.186 & TRN & \\
\hline CHEMBL3942496 & 1641656 & 7.5745 & 7.8616 & TRN & \\
\hline CHEMBL 3981152 & 1641656 & 7.6878 & 7.89 & TRN & \\
\hline CHEMBL 3982628 & 1641656 & 7.534 & 7.6339 & TRN & \\
\hline CHEMBL 3948403 & 1641656 & 6.8026 & 6.5215 & TRN & \\
\hline CHEMBL 3942256 & 1641656 & 8.6467 & 8.299 & TRN & \\
\hline CHEMBL 3394165 & 1641656 & 8.7016 & 8.8116 & TRN & \\
\hline CHEMBL 3394067 & 1641656 & 6.0 & 6.9285 & TRN & \\
\hline CHEMBL3914961 & 1641656 & 8.169 & 8.1063 & TRN & \\
\hline CHEMBL 3964167 & 1641656 & 7.7533 & 7.9086 & TRN & \\
\hline CHEMBL 3973417 & 1641656 & 8.4268 & 8.7055 & TRN & \\
\hline CHEMBL3911670 & 1641656 & 6.5618 & 6.6358 & TRN & \\
\hline CHEMBL 3962369 & 1641656 & 7.3945 & 7.4923 & TST & \\
\hline CHEMBL 3919337 & 1641656 & 9.3615 & 7.1752 & TRN & \\
\hline
\end{tabular}

Page 16547 
Supplemental Table S2.txt

\begin{tabular}{|c|c|c|c|c|c|}
\hline CHEMBL 3957078 & 1641656 & 6.5159 & 6.4484 & TRN & \\
\hline CHEMBL 3951570 & 1641656 & 8.245 & 8.4518 & TRN & \\
\hline CHEMBL3910525 & 1641656 & 7.0238 & 7.3375 & TST & \\
\hline CHEMBL 3394068 & 1641656 & 8.2661 & 8.2853 & TRN & \\
\hline CHEMBL 3917311 & 1641656 & 9.2321 & 9.2197 & TRN & \\
\hline CHEMBL 3961142 & 1641656 & 6.1982 & 6.1262 & TRN & \\
\hline CHEMBL3952591 & 1641656 & 8.3739 & 8.3697 & TRN & \\
\hline CHEMBL 3899404 & 1641656 & 8.6849 & 8.624 & TST & \\
\hline CHEMBL 3972727 & 1641656 & 7.8649 & 7.8722 & TRN & \\
\hline CHEMBL3959112 & 1641656 & 8.398 & 8.1521 & TRN & \\
\hline CHEMBL 3982237 & 1641656 & 7.7357 & 7.587006 & 0000000001 & TST \\
\hline CHEMBL 3916044 & 1641656 & 6.3809 & 5.9276 & TRN & \\
\hline CHEMBL 3938446 & 1641656 & 8.1071 & 8.2107 & TRN & \\
\hline CHEMBL 3927342 & 1641656 & 6.7549 & 6.9649 & TST & \\
\hline CHEMBL 3984864 & 1641656 & 7.3172 & 7.5681 & TRN & \\
\hline CHEMBL 3934994 & 1641656 & 7.8788 & 8.0106 & TRN & \\
\hline CHEMBL 3900578 & 1641656 & 6.0 & 7.195 & TST & \\
\hline CHEMBL 3890140 & 1641656 & 9.1752 & 9.0463 & TRN & \\
\hline CHEMBL 3967959 & 1641656 & 8.5552 & 8.6053 & TRN & \\
\hline CHEMBL 3904314 & 1641656 & 8.6645 & 8.1591 & TST & \\
\hline CHEMBL 3957552 & 1641656 & 8.8245 & 8.3005 & TRN & \\
\hline CHEMBL 3930502 & 1641656 & 7.1356 & 6.8137 & TRN & \\
\hline CHEMBL 3967448 & 1641656 & 6.942 & 7.3475 & TRN & \\
\hline CHEMBL3952291 & 1641656 & 7.7335 & 7.6112 & TRN & \\
\hline CHEMBL 3921475 & 1641656 & 7.6174 & 7.7931 & TRN & \\
\hline CHEMBL 3922191 & 1641656 & 6.1923 & 6.8901 & TST & \\
\hline CHEMBL 3963322 & 1641656 & 6.5745 & 6.6063 & TRN & \\
\hline CHEMBL 3394168 & 1641656 & 8.3392 & 8.186 & TRN & \\
\hline CHEMBL3921086 & 1641656 & 7.5522 & 7.3962 & TRN & \\
\hline CHEMBL 3962494 & 1641656 & 7.9115 & 8.1053 & TRN & \\
\hline CHEMBL 3898847 & 1641656 & 7.9547 & 7.8271 & TST & \\
\hline CHEMBL3394166 & 1641656 & 8.4878 & 8.3252 & TRN & \\
\hline CHEMBL 3394070 & 1641656 & 7.6664 & 7.8405 & TRN & \\
\hline CHEMBL3972469 & 1641656 & 7.3284 & 7.6537 & TRN & \\
\hline CHEMBL 3910677 & 1641656 & 8.6014 & 8.2522 & TRN & \\
\hline CHEMBL3394169 & 1641656 & 7.7501 & 8.0046 & TRN & \\
\hline CHEMBL 3933275 & 1641656 & 7.7022 & 7.5676 & TRN & \\
\hline CHEMBL 3923772 & 1641656 & 8.1145 & 7.6484 & TRN & \\
\hline CHEMBL 3911843 & 1641656 & 8.0237 & 7.8767 & TRN & \\
\hline CHEMBL3927492 & 1641656 & 7.5694 & 7.5868 & TRN & \\
\hline CHEMBL 3946988 & 1641656 & 6.7867 & 6.9447 & TST & \\
\hline CHEMBL 3955578 & 1641656 & 6.6842 & \multicolumn{2}{|c|}{5.9910000000000005} & TRN \\
\hline CHEMBL 3893572 & 1641656 & 7.907999 & 99999999 & 8.6198 & TST \\
\hline CHEMBL 3940277 & 1641656 & 7.9965 & 7.8074 & TRN & \\
\hline CHEMBL 3936230 & 1641656 & 7.9278 & 8.0614 & TRN & \\
\hline CHEMBL3911316 & 1641656 & 9.5129 & 8.6641 & TRN & \\
\hline CHEMBL 3903651 & 1641656 & 6.9348 & 6.7885 & TRN & \\
\hline CHEMBL 3394071 & 1641656 & 7.5421 & 7.5441 & TRN & \\
\hline
\end{tabular}

Page 16548 
Supplemental Table S2.txt

\begin{tabular}{|c|c|c|c|c|c|}
\hline CHEMBL3969190 & 1641656 & 6.6437 & 6.7525 & TRN & \\
\hline CHEMBL3896794 & 1641656 & 8.7994 & 8.6846 & TRN & \\
\hline CHEMBL3919198 & 1641656 & 7.0733 & 6.8329 & TRN & \\
\hline CHEMBL3951087 & 1641656 & 7.0903 & 7.2184 & TST & \\
\hline CHEMBL3958501 & 1641656 & 6.3986 & 6.2364 & TRN & \\
\hline CHEMBL3958986 & 1641656 & 7.3168 & 7.9026 & TRN & \\
\hline CHEMBL 3904783 & 1641656 & 8.9654 & 8.9732 & TRN & \\
\hline CHEMBL3946212 & 1641656 & 9.1343 & 8.8341 & TRN & \\
\hline CHEMBL3960298 & 1641656 & 8.5952 & 8.6928 & TRN & \\
\hline CHEMBL3906121 & 1641656 & 6.9097 & 6.8444 & TRN & \\
\hline CHEMBL3920604 & 1641656 & 6.5713 & 6.6046 & TRN & \\
\hline CHEMBL 3960832 & 1641656 & 7.17299 & 99999999 & 7.5852 & $T c$ \\
\hline CHEMBL3959316 & 1641656 & 8.1002 & 8.0629 & TRN & \\
\hline CHEMBL3962189 & 1641656 & 5.624 & 6.5855 & TST & \\
\hline CHEMBL3944661 & 1641656 & 7.8726 & 7.294 & TST & \\
\hline CHEMBL 3975848 & 1641656 & 7.4241 & 7.778 & TRN & \\
\hline CHEMBL3394074 & 1641656 & 8.9382 & 8.6867 & TRN & \\
\hline CHEMBL3930916 & 1641656 & 8.5194 & 8.1668 & TRN & \\
\hline CHEMBL3950062 & 1641656 & 6.8259 & 7.1068 & TRN & \\
\hline CHEMBL3912927 & 1641656 & 7.6478 & 7.5399 & TRN & \\
\hline CHEMBL3915900 & 1641656 & 6.9003 & 6.914 & TRN & \\
\hline CHEMBL3957081 & 1641656 & 6.4543 & 6.3026 & TRN & \\
\hline CHEMBL3952561 & 1641656 & 8.9179 & 8.8366 & TRN & \\
\hline CHEMBL3981095 & 1641656 & 6.8603 & 6.6678 & TRN & \\
\hline CHEMBL 3900255 & 1641656 & 7.2651 & 7.5661 & TRN & \\
\hline CHEMBL3894390 & 1641656 & 7.4414 & 7.5132 & TRN & \\
\hline CHEMBL3970964 & 1641656 & 6.9137 & 7.1676 & TST & \\
\hline CHEMBL3899208 & 1641656 & 8.1143 & 8.2819 & TRN & \\
\hline CHEMBL3964669 & 1641656 & 8.1901 & 8.5091 & TRN & \\
\hline CHEMBL3895619 & 1641656 & 7.9104 & 8.0086 & TRN & \\
\hline CHEMBL3956673 & 1641656 & 7.8428 & 7.6559 & TRN & \\
\hline CHEMBL3942495 & 1641656 & 8.1721 & 7.7508 & TRN & \\
\hline CHEMBL 3901121 & 1641656 & 6.0451 & 6.0079 & TRN & \\
\hline CHEMBL3910838 & 1641656 & 8.0 & 7.9565 & TRN & \\
\hline CHEMBL3939297 & 1641656 & 7.3046 & \multicolumn{2}{|c|}{7.422000000000001} & TRN \\
\hline CHEMBL3968565 & 1641656 & 8.1468 & 7.8572 & TRN & \\
\hline CHEMBL3980131 & 1641656 & 8.9743 & 9.1611 & TRN & \\
\hline CHEMBL3967996 & 1641656 & 8.2711 & 8.2757 & TRN & \\
\hline CHEMBL3394065 & 1641656 & 6.7314 & 7.2124 & TRN & \\
\hline CHEMBL3896741 & 1641656 & 7.5093 & 7.5962 & TRN & \\
\hline CHEMBL3981344 & 1641656 & 8.6686 & 8.4337 & TRN & \\
\hline CHEMBL3977709 & 1641656 & 7.5397 & 7.1138 & TRN & \\
\hline CHEMBL3930832 & 1641656 & 8.7373 & 8.8811 & TRN & \\
\hline CHEMBL3981312 & 1641656 & 7.7567 & 7.4323 & TST & \\
\hline CHEMBL3394064 & 1641656 & 7.0148 & 7.2009 & TST & \\
\hline CHEMBL3913009 & 1641656 & 7.8586 & 8.0175 & TRN & \\
\hline CHEMBL3919558 & 1641656 & 7.5161 & 7.7173 & TRN & \\
\hline CHEMBL 3937011 & 1641656 & 8.6554 & 9.0452 & TRN & \\
\hline
\end{tabular}

Page 16549 
Supplemental Table S2.txt

\begin{tabular}{|c|c|c|c|c|c|}
\hline CHEMBL 3925863 & 1641656 & 8.7757 & 8.7301 & TRN & \\
\hline CHEMBL3922231 & 1641656 & 8.4134 & 8.3138 & TRN & \\
\hline CHEMBL3915388 & 1641656 & 6.8663 & 6.5863 & TRN & \\
\hline CHEMBL 3907899 & 1641656 & 7.8271 & 8.075 & TRN & \\
\hline CHEMBL 3914520 & 1641656 & 8.5252 & 8.2776 & TST & \\
\hline CHEMBL 3930311 & 1641656 & 7.2253 & 6.902 & TST & \\
\hline CHEMBL3963493 & 1641656 & 6.909 & 7.2263 & TST & \\
\hline CHEMBL3976511 & 1641656 & 7.6607 & 8.0672 & TST & \\
\hline CHEMBL 3918913 & 1641656 & 7.7387 & 7.8967 & TST & \\
\hline CHEMBL 3935173 & 1641656 & 8.3073 & 7.8888 & TST & \\
\hline CHEMBL 3960208 & 1641656 & 8.4 & 8.1642 & TST & \\
\hline CHEMBL 3945003 & 1641656 & 7.8202 & 7.8803 & TST & \\
\hline CHEMBL 3963678 & 1641656 & 6.0777 & 6.4582 & TST & \\
\hline CHEMBL3962808 & 1641656 & 9.2041 & 8.6031 & TST & \\
\hline CHEMBL 3954897 & 1641656 & 7.0719 & 7.2288 & TST & \\
\hline CHEMBL 3930004 & 1641656 & 8.8477 & 8.2628 & TST & \\
\hline CHEMBL3970168 & 1641656 & 8.7484 & 8.7552 & TST & \\
\hline CHEMBL 3901441 & 1641656 & 8.9531 & 8.5584 & TST & \\
\hline CHEMBL3951344 & 1641656 & 7.0665 & 7.3468 & TST & \\
\hline CHEMBL 3941886 & 1641656 & 6.7829 & 7.085 & TST & \\
\hline CHEMBL 3957441 & 1641656 & 8.1304 & 8.1903 & TST & \\
\hline CHEMBL 3982420 & 1641656 & 6.3833 & 5.9785 & TST & \\
\hline CHEMBL 3947592 & 1641656 & 6.7052 & 7.002006 & 0000000001 & TST \\
\hline CHEMBL 2094979 & 842698 & 3.9821 & 4.8849 & TRN & \\
\hline CHEMBL 2094748 & 842698 & 3.9821 & 4.9577 & TRN & \\
\hline CHEMBL428064 & 842698 & 5.5421 & 5.0454 & TRN & \\
\hline CHEMBL 2094880 & 842698 & 3.9821 & 4.6797 & TRN & \\
\hline CHEMBL 2094698 & 842698 & 5.5045 & 4.7596 & TRN & \\
\hline CHEMBL1449179 & 842698 & 5.2708 & 4.752 & TRN & \\
\hline CHEMBL 2094923 & 842698 & 3.9821 & 4.9047 & TST & \\
\hline CHEMBL 2095093 & 842698 & 5.2832 & 5.5409 & TST & \\
\hline CHEMBL 2095104 & 842698 & 5.4868 & 5.0388 & TRN & \\
\hline CHEMBL1460809 & 842698 & 5.3279 & 5.0206 & TRN & \\
\hline CHEMBL 2094729 & 842698 & 5.4353 & 5.4149 & TRN & \\
\hline CHEMBL116649 & 842698 & 5.3261 & 4.82100 & 0000000001 & TRN \\
\hline CHEMBL2094361 & 842698 & 5.8827 & 4.6993 & TRN & \\
\hline CHEMBL 2094953 & 842698 & 3.9821 & 5.2187 & TRN & \\
\hline CHEMBL2094482 & 842698 & $5.7570 e$ & j00000006 & 4.6265 & TRN \\
\hline CHEMBL487356 & 842698 & 3.9821 & 4.5709 & TRN & \\
\hline CHEMBL 2094972 & 842698 & 3.9821 & 4.9788 & TRN & \\
\hline CHEMBL 2094609 & 842698 & 5.5302 & 4.9858 & TRN & \\
\hline CHEMBL 2094867 & 842698 & 5.2573 & 5.1023 & TRN & \\
\hline CHEMBL 2094885 & 842698 & 3.9821 & 4.7303 & TRN & \\
\hline CHEMBL 2094287 & 842698 & 9.3979 & 6.3755 & TRN & \\
\hline CHEMBL 2095071 & 842698 & 3.9821 & 4.5671 & TST & \\
\hline CHEMBL 2094554 & 842698 & 5.2749 & 5.1308 & TST & \\
\hline CHEMBL 2094622 & 842698 & 3.9821 & 4.8728 & TRN & \\
\hline CHEMBL2094525 & 842698 & 3.9821 & 4.7686 & TRN & \\
\hline
\end{tabular}




\begin{tabular}{|c|c|c|c|c|c|}
\hline \multicolumn{6}{|c|}{ Supplemental Table s2.txt } \\
\hline CHEMBL1333600 & 842698 & 6.0 & 6.0701 & TST & \\
\hline CHEMBL1981680 & 842698 & 3.9821 & 5.0661 & TRN & \\
\hline CHEMBL381688 & 842698 & 6.0 & 5.0214 & TRN & \\
\hline CHEMBL 2094354 & 842698 & 6.011 & 4.7939 & TRN & \\
\hline CHEMBL2094611 & 842698 & 5.2676 & 4.8158 & TRN & \\
\hline CHEMBL 2094789 & 842698 & 3.9821 & 4.7854 & TST & \\
\hline CHEMBL 2094389 & 842698 & 5.2097 & 4.9331 & TRN & \\
\hline CHEMBL2094991 & 842698 & 3.9821 & 4.5957 & TRN & \\
\hline CHEMBL 2094508 & 842698 & 7.5528 & 5.8292 & TRN & \\
\hline CHEMBL2094475 & 842698 & 5.2636 & 4.9596 & TRN & \\
\hline CHEMBL 2008026 & 842698 & 3.9821 & 5.1901 & TRN & \\
\hline CHEMBL 2094420 & 842698 & 6.041 & 5.2258 & TRN & \\
\hline CHEMBL1459280 & 842698 & 3.9821 & 4.7086 & TRN & \\
\hline CHEMBL 339050 & 842698 & 5.2204 & 5.0261 & TRN & \\
\hline CHEMBL2095129 & 842698 & 3.9821 & 4.6345 & TRN & \\
\hline CHEMBL1462710 & 842698 & 6.4711 & 4.6202 & TRN & \\
\hline CHEMBL2094790 & 842698 & 5.2684 & 5.2796 & TRN & \\
\hline CHEMBL2095132 & 842698 & 3.9821 & 4.795 & TRN & \\
\hline CHEMBL2094915 & 842698 & 6.0726 & 4.9115 & TRN & \\
\hline CHEMBL2094642 & 842698 & 5.3152 & 5.4959 & TRN & \\
\hline CHEMBL 2094404 & 842698 & 3.9821 & 4.5069 & TST & \\
\hline CHEMBL2094697 & 842698 & 6.0 & 4.9978 & TRN & \\
\hline CHEMBL 2094957 & 842698 & 3.9821 & 5.3275 & TRN & \\
\hline CHEMBL 2094891 & 842698 & 6.3143 & 5.1978 & TRN & \\
\hline CHEMBL601137 & 842698 & 6.3215 & 5.9138 & TRN & \\
\hline CHEMBL1224755 & 842698 & 7.5229 & 4.9286 & TRN & \\
\hline CHEMBL1330143 & 842698 & 5.9245 & 4.5377 & TRN & \\
\hline CHEMBL 2094396 & 842698 & 3.9821 & 4.5465 & TRN & \\
\hline CHEMBL1865517 & 842698 & 3.9821 & 4.6934 & TRN & \\
\hline CHEMBL2094284 & 842698 & 5.2503 & 4.6381 & TRN & \\
\hline CHEMBL 372023 & 842698 & 6.8827 & 5.63700 & 00000000005 & TRN \\
\hline CHEMBL2094509 & 842698 & 3.9821 & 5.0061 & TRN & \\
\hline CHEMBL 2094416 & 842698 & 6.3615 & 4.9614 & TRN & \\
\hline CHEMBL1420457 & 842698 & 5.4672 & 5.1259 & TRN & \\
\hline CHEMBL2094983 & 842698 & 3.9821 & 4.7368 & TRN & \\
\hline CHEMBL1401091 & 842698 & 3.9821 & 4.8415 & TST & \\
\hline CHEMBL2094783 & 842698 & 3.9821 & 4.6988 & TST & \\
\hline CHEMBL 2094286 & 842698 & 5.3726 & 5.0171 & TST & \\
\hline CHEMBL2094278 & 842698 & 3.9821 & 4.7262 & TST & \\
\hline CHEMBL 2094803 & 842698 & 5.6576 & 4.8739 & TRN & \\
\hline CHEMBL 2094279 & 842698 & 5.7011 & 5.0294 & TST & \\
\hline CHEMBL2094708 & 842698 & 5.2534 & 5.0973 & TRN & \\
\hline CHEMBL 2094884 & 842698 & 3.9821 & 5.24700 & 0000000001 & TRN \\
\hline CHEMBL 2095008 & 842698 & 3.9821 & 4.695 & TRN & \\
\hline CHEMBL2094588 & 842698 & 3.9821 & 4.7694 & TRN & \\
\hline CHEMBL592608 & 842698 & 5.3958 & 5.2238 & TRN & \\
\hline CHEMBL2094692 & 842698 & 6.0 & 4.6524 & TRN & \\
\hline CHEMBL2094779 & 842698 & 5.2684 & 5.0547 & TRN & \\
\hline
\end{tabular}




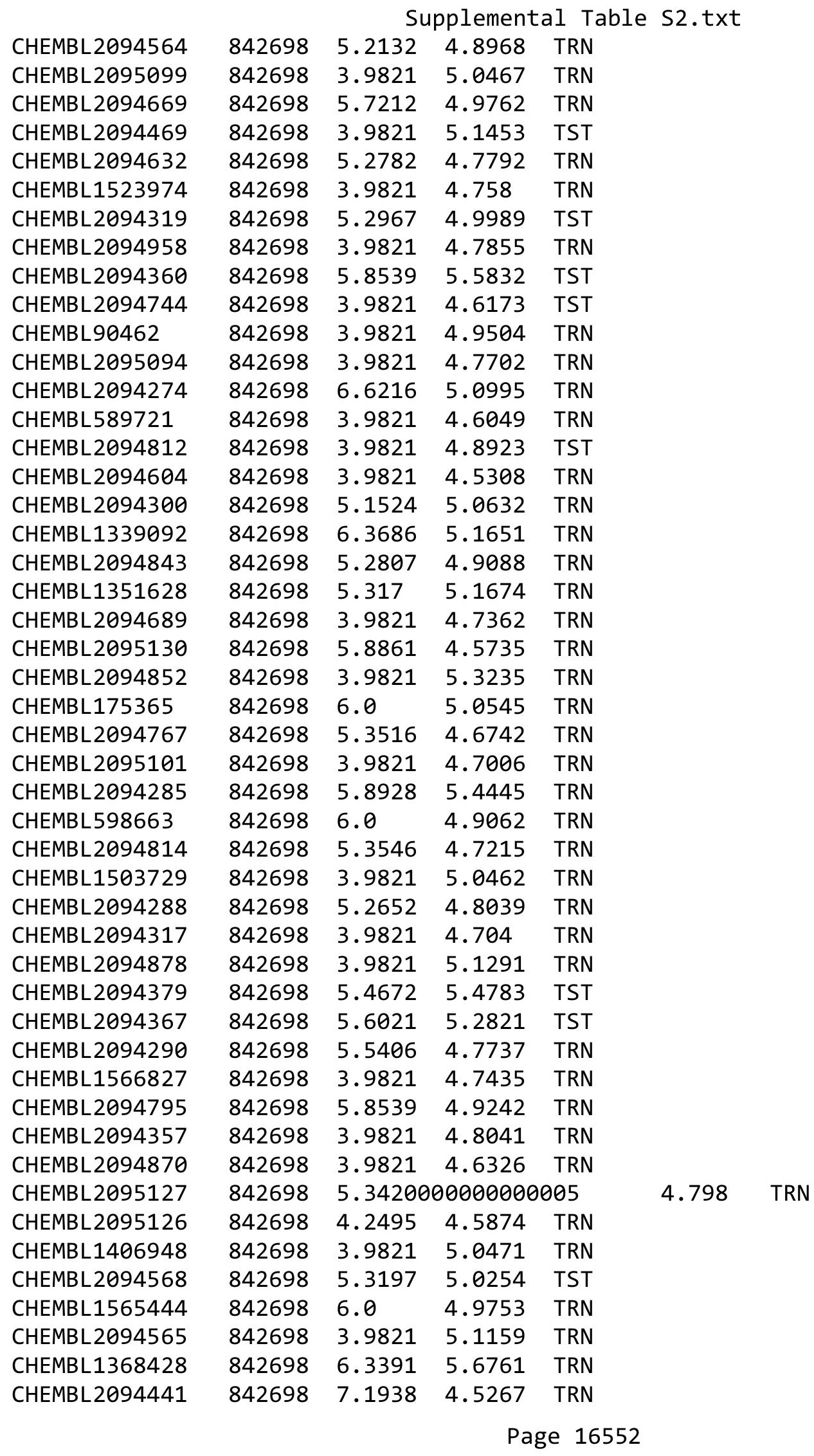




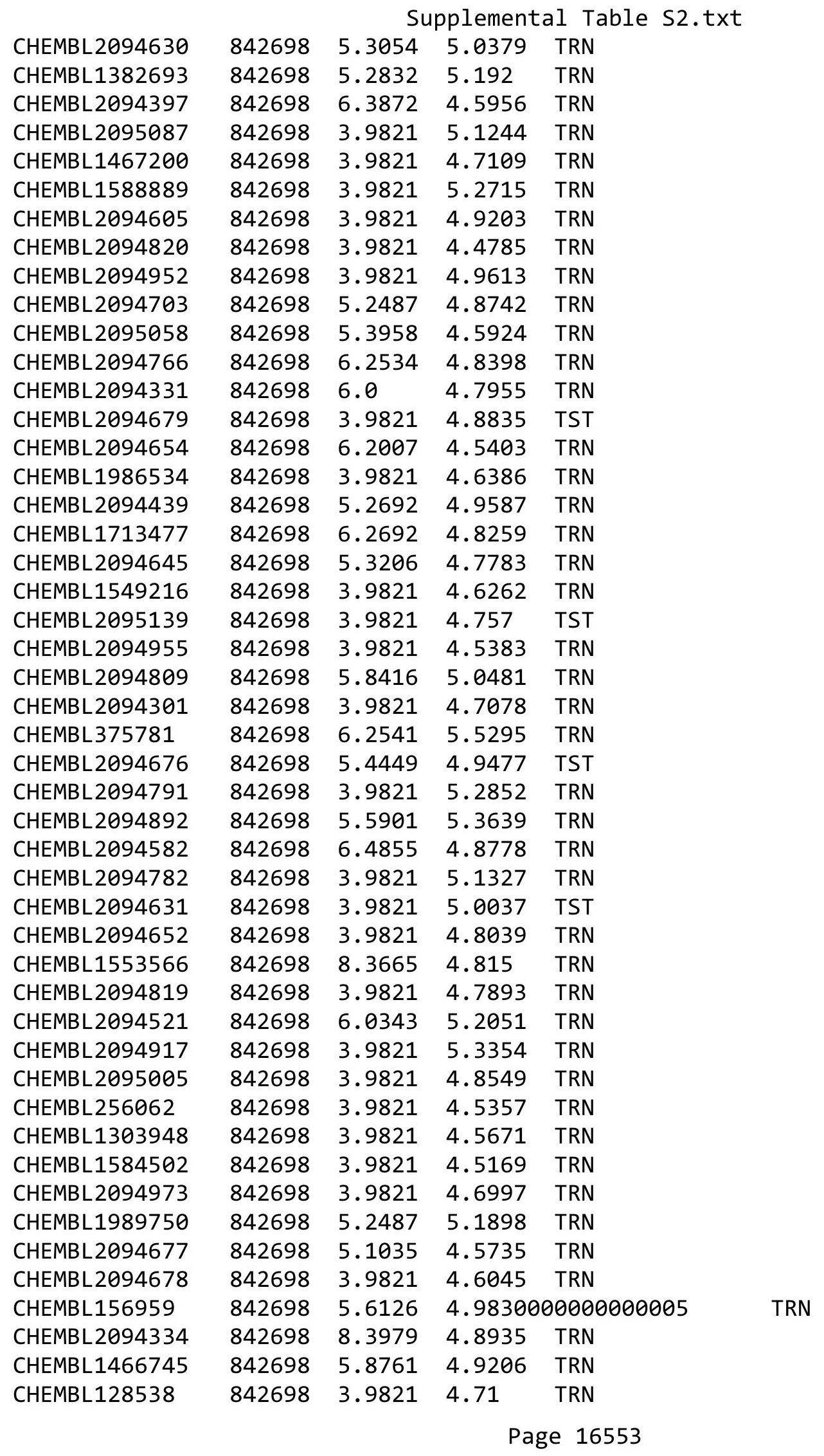


Supplemental Table S2.txt

\begin{tabular}{|c|c|c|c|c|c|}
\hline CHEMBL 2094742 & 842698 & 5.3372 & 4.9829 & TRN & \\
\hline CHEMBL 2094550 & 842698 & 5.1669 & 5.1913 & TRN & \\
\hline CHEMBL3211612 & 842698 & 3.9821 & 4.9853 & TST & \\
\hline CHEMBL 2094683 & 842698 & 5.7144 & 4.6529 & TRN & \\
\hline CHEMBL2094280 & 842698 & 3.9821 & 4.8671 & TRN & \\
\hline CHEMBL 2002849 & 842698 & 6.0 & 4.9099 & TRN & \\
\hline CHEMBL 2094293 & 842698 & 5.3716 & 4.834 & TST & \\
\hline CHEMBL1303587 & 842698 & 5.2993 & 4.8346 & TRN & \\
\hline CHEMBL2094904 & 842698 & 3.9821 & 4.9396 & TRN & \\
\hline CHEMBL1318284 & 842698 & 5.3242 & 5.3186 & TRN & \\
\hline CHEMBL 2094670 & 842698 & 7.1135 & 5.9523 & TRN & \\
\hline CHEMBL 2094386 & 842698 & 5.1512 & 5.0198 & TRN & \\
\hline CHEMBL2094377 & 842698 & 6.3716 & 5.2304 & TRN & \\
\hline CHEMBL2094731 & 842698 & 3.9821 & 4.9566 & TRN & \\
\hline CHEMBL2095113 & 842698 & 3.9821 & 4.5196 & TRN & \\
\hline CHEMBL 2094999 & 842698 & 3.9821 & 4.928 & TRN & \\
\hline CHEMBL2094617 & 842698 & 3.9821 & 4.8812 & TRN & \\
\hline CHEMBL1576659 & 842698 & 5.4461 & 4.7159 & TRN & \\
\hline CHEMBL 2095006 & 842698 & 6.9666 & 4.6981 & TRN & \\
\hline CHEMBL2094398 & 842698 & 6.0443 & 5.07 & TRN & \\
\hline CHEMBL 2094464 & 842698 & 3.9821 & 4.444 & TRN & \\
\hline CHEMBL2094932 & 842698 & 5.2373 & 4.6561 & TRN & \\
\hline CHEMBL1413146 & 842698 & 3.9821 & 5.20799 & 9999999999 & TRN \\
\hline CHEMBL2095100 & 842698 & 5.2441 & 4.8745 & TRN & \\
\hline CHEMBL2094555 & 842698 & 5.2907 & 5.0821 & TRN & \\
\hline CHEMBL 2094798 & 842698 & 6.0 & 4.6452 & TRN & \\
\hline CHEMBL1728864 & 842698 & 5.7932 & 4.7824 & TRN & \\
\hline CHEMBL 2094735 & 842698 & 6.5406 & 4.9693 & TRN & \\
\hline CHEMBL1990043 & 842698 & 3.9821 & 4.8901 & TRN & \\
\hline CHEMBL2094772 & 842698 & 3.9821 & 4.7312 & TRN & \\
\hline CHEMBL 2094312 & 842698 & 3.9821 & 5.078 & TRN & \\
\hline CHEMBL 2094883 & 842698 & 3.9821 & 5.1859 & TRN & \\
\hline CHEMBL 2094971 & 842698 & 3.9821 & 5.0627 & TRN & \\
\hline CHEMBL530067 & 842698 & 5.3893 & 5.685 & TRN & \\
\hline CHEMBL1530911 & 842698 & 3.9821 & 5.0968 & TRN & \\
\hline CHEMBL 2094355 & 842698 & 5.9957 & 4.7304 & TST & \\
\hline CHEMBL2095095 & 842698 & 3.9821 & 5.2543 & TRN & \\
\hline CHEMBL2094430 & 842698 & 6.3625 & 5.3487 & TRN & \\
\hline CHEMBL1585652 & 842698 & 3.9821 & 5.5364 & TRN & \\
\hline CHEMBL2094337 & 842698 & 5.4248 & 4.9423 & TRN & \\
\hline CHEMBL 2094723 & 842698 & 5.3251 & 4.9722 & TRN & \\
\hline CHEMBL2094959 & 842698 & 3.9821 & 5.2308 & TRN & \\
\hline CHEMBL2094745 & 842698 & 6.4365 & 5.0681 & TRN & \\
\hline CHEMBL2094625 & 842698 & 3.9821 & 5.1622 & TRN & \\
\hline CHEMBL2094311 & 842698 & 3.9821 & 5.1805 & TST & \\
\hline CHEMBL 2094720 & 842698 & 3.9821 & 4.6855 & TRN & \\
\hline CHEMBL2095043 & 842698 & 5.3134 & 4.5738 & TRN & \\
\hline CHEMBL1368987 & 842698 & 5.3028 & 4.882 & TRN & \\
\hline
\end{tabular}




\begin{tabular}{|c|c|c|c|c|c|}
\hline & & \multicolumn{4}{|c|}{ Supplemental Table s2.txt } \\
\hline CHEMBL1603850 & 842698 & 3.9821 & 5.0837 & TRN & \\
\hline CHEMBL2094309 & 842698 & 5.2495 & 4.9999 & TST & \\
\hline CHEMBL2094512 & 842698 & 3.9821 & 5.1499 & TST & \\
\hline CHEMBL 2094385 & 842698 & 3.9821 & 4.43199 & 99999999995 & TRN \\
\hline CHEMBL 2094650 & 842698 & 3.9821 & 4.8608 & TST & \\
\hline CHEMBL2094297 & 842698 & 6.0311 & 4.8497 & TRN & \\
\hline CHEMBL2094995 & 842698 & 5.3242 & 5.0453 & TRN & \\
\hline CHEMBL1402376 & 842698 & 3.9821 & 5.0138 & TRN & \\
\hline CHEMBL603013 & 842698 & 5.1938 & 5.5731 & TST & \\
\hline CHEMBL1608056 & 842698 & 3.9821 & 5.2384 & TRN & \\
\hline CHEMBL 2094910 & 842698 & 6.4353 & 5.4979 & TRN & \\
\hline CHEMBL1449731 & 842698 & 5.2588 & 4.7477 & TRN & \\
\hline CHEMBL2094597 & 842698 & 5.2848 & 5.1551 & TRN & \\
\hline CHEMBL 2094840 & 842698 & 6.0 & 5.2502 & TRN & \\
\hline CHEMBL1163998 & 842698 & 6.2984 & 4.9071 & TRN & \\
\hline CHEMBL 2095027 & 842698 & 5.9825 & 4.8741 & TRN & \\
\hline CHEMBL2095065 & 842698 & 3.9821 & 4.7381 & TST & \\
\hline CHEMBL2094327 & 842698 & 5.4815 & 4.8289 & TST & \\
\hline CHEMBL 2095118 & 842698 & 3.9821 & 5.16700 & 0000000001 & TRN \\
\hline CHEMBL 2094943 & 842698 & 3.9821 & 5.1132 & TST & \\
\hline CHEMBL 2094988 & 842698 & 6.1669 & 4.8121 & TRN & \\
\hline CHEMBL1613096 & 842698 & 3.9821 & 4.9621 & TRN & \\
\hline CHEMBL 2094785 & 842698 & 3.9821 & 4.9794 & TST & \\
\hline CHEMBL 2094876 & 842698 & 3.9821 & 4.836 & TRN & \\
\hline CHEMBL2094514 & 842698 & 6.0223 & 4.8871 & TRN & \\
\hline CHEMBL 2094881 & 842698 & 3.9821 & 4.9351 & TRN & \\
\hline CHEMBL2094615 & 842698 & 3.9821 & 4.9501 & TRN & \\
\hline CHEMBL2094573 & 842698 & 3.9821 & 5.0671 & TRN & \\
\hline CHEMBL1526562 & 842698 & 3.9821 & 4.8142 & TRN & \\
\hline CHEMBL2094886 & 842698 & 5.4214 & 5.25899 & 99999999995 & TRN \\
\hline CHEMBL2095106 & 842698 & 5.3809 & 4.4709 & TRN & \\
\hline CHEMBL2094866 & 842698 & 3.9821 & 4.8307 & TRN & \\
\hline CHEMBL2094349 & 842698 & 6.0357 & 4.4453 & TRN & \\
\hline CHEMBL2094914 & 842698 & 5.9914 & 5.0177 & TRN & \\
\hline CHEMBL2094476 & 842698 & 3.9821 & 4.8367 & TRN & \\
\hline CHEMBL1537417 & 842698 & 5.2596 & 4.70100 & 00000000005 & TRN \\
\hline CHEMBL1375373 & 842698 & 5.308 & 5.1079 & TRN & \\
\hline CHEMBL2094899 & 842698 & 6.0 & 4.8416 & TRN & \\
\hline CHEMBL2094639 & 842698 & 6.6271 & 4.8622 & TRN & \\
\hline CHEMBL2094762 & 842698 & 5.8601 & 5.0442 & TRN & \\
\hline CHEMBL1562165 & 842698 & 3.9821 & 4.6247 & TRN & \\
\hline CHEMBL2094306 & 842698 & 3.9821 & 5.1325 & TRN & \\
\hline CHEMBL 2094718 & 842698 & 8.3979 & 4.9831 & TRN & \\
\hline CHEMBL582264 & 842698 & 5.3737 & 5.4871 & TRN & \\
\hline CHEMBL1520282 & 842698 & 5.8327 & 5.2925 & TRN & \\
\hline CHEMBL1563889 & 842698 & 3.9821 & 4.965 & TRN & \\
\hline CHEMBL2094351 & 842698 & 3.9821 & 5.1395 & TRN & \\
\hline CHEMBL2094811 & 842698 & 5.556 & 5.1261 & TRN & \\
\hline
\end{tabular}




\begin{tabular}{|c|c|c|c|c|}
\hline & & & pplement & al $\mathrm{Tc}$ \\
\hline CHEMBL 2094857 & 842698 & 5.284 & 5.0519 & TRN \\
\hline CHEMBL 2094324 & 842698 & 5.9208 & 4.7374 & TRN \\
\hline CHEMBL2094613 & 842698 & 5.8125 & 5.0141 & TRN \\
\hline CHEMBL 2094307 & 842698 & 3.9821 & 5.1782 & TRN \\
\hline CHEMBL2094658 & 842698 & 5.5229 & 5.3719 & TRN \\
\hline CHEMBL 2094373 & 842698 & 3.9821 & 5.0171 & TRN \\
\hline CHEMBL 2094559 & 842698 & 6.3556 & 4.7481 & TRN \\
\hline CHEMBL 2094600 & 842698 & 5.27 & 4.6267 & TRN \\
\hline CHEMBL 2094871 & 842698 & 3.9821 & 4.9179 & TRN \\
\hline CHEMBL2095026 & 842698 & 3.9821 & 4.9538 & TRN \\
\hline CHEMBL 2094733 & 842698 & 5.2733 & 4.7556 & TRN \\
\hline CHEMBL 2094330 & 842698 & 5.8477 & 4.898 & TRN \\
\hline CHEMBL 2094595 & 842698 & 3.9821 & 4.7597 & TST \\
\hline CHEMBL1334191 & 842698 & 3.9821 & 4.9345 & TRN \\
\hline CHEMBL2094489 & 842698 & 3.9821 & 5.0904 & TST \\
\hline CHEMBL 2094458 & 842698 & 4.963 & 4.9911 & TRN \\
\hline CHEMBL 2094741 & 842698 & 5.466 & 5.0621 & TRN \\
\hline CHEMBL 2094340 & 842698 & 5.2581 & 4.738 & TRN \\
\hline CHEMBL 2094998 & 842698 & 5.2967 & 5.0199 & TST \\
\hline CHEMBL 2094310 & 842698 & 6.5784 & 4.6601 & TRN \\
\hline CHEMBL 2094387 & 842698 & 5.2557 & 4.8295 & TRN \\
\hline CHEMBL1429899 & 842698 & 5.3288 & 5.0519 & TST \\
\hline CHEMBL 2094460 & 842698 & 5.2832 & 4.9376 & TST \\
\hline CHEMBL 2095046 & 842698 & 5.3063 & 4.6637 & TRN \\
\hline CHEMBL2094743 & 842698 & 5.2933 & 4.9626 & TRN \\
\hline CHEMBL 2094526 & 842698 & 5.9208 & 4.9954 & TRN \\
\hline CHEMBL 2094657 & 842698 & 5.2487 & 5.2044 & TRN \\
\hline CHEMBL 2094371 & 842698 & 3.9821 & 4.708 & TRN \\
\hline CHEMBL2094722 & 842698 & 5.3851 & 4.5315 & TST \\
\hline CHEMBL 2094530 & 842698 & 3.9821 & 5.2189 & TRN \\
\hline CHEMBL 2094719 & 842698 & 3.9821 & 4.7494 & TRN \\
\hline CHEMBL 2094856 & 842698 & 3.9821 & 4.8407 & TRN \\
\hline CHEMBL 2094518 & 842698 & 3.9821 & 4.8009 & TRN \\
\hline CHEMBL2094335 & 842698 & 5.4342 & 4.982 & TST \\
\hline CHEMBL 2095066 & 842698 & 5.2807 & 4.9564 & TRN \\
\hline CHEMBL 2094668 & 842698 & 3.9821 & 5.0642 & TRN \\
\hline CHEMBL 2094909 & 842698 & 3.9821 & 4.6657 & TRN \\
\hline CHEMBL 2094419 & 842698 & 3.9821 & 4.8049 & TRN \\
\hline CHEMBL1407401 & 842698 & 5.644 & 4.9675 & TST \\
\hline CHEMBL1731432 & 842698 & 5.5702 & 4.743 & TRN \\
\hline CHEMBL 2094315 & 842698 & 5.3575 & 5.1547 & TST \\
\hline CHEMBL 2095054 & 842698 & 3.9821 & 4.8426 & TRN \\
\hline CHEMBL 2094848 & 842698 & 5.2907 & 5.0697 & TRN \\
\hline CHEMBL1446211 & 842698 & 3.9821 & 4.936 & TRN \\
\hline CHEMBL 2094960 & 842698 & 3.9821 & 5.3402 & TRN \\
\hline CHEMBL 2094425 & 842698 & 3.9821 & 5.1588 & TRN \\
\hline CHEMBL 2095121 & 842698 & 3.9821 & 4.8067 & TRN \\
\hline CHEMBL2095131 & 842698 & 5.2958 & 4.5008 & TRN \\
\hline
\end{tabular}


Supplemental Table S2.txt

\begin{tabular}{|c|c|c|c|c|c|}
\hline CHEMBL2095137 & 842698 & 5.5229 & 5.1643 & TRN & \\
\hline CHEMBL 2094662 & 842698 & 5.2373 & 4.7671 & TRN & \\
\hline CHEMBL 2094567 & 842698 & 5.2874 & 5.635 & TRN & \\
\hline CHEMBL 2094501 & 842698 & 5.1805 & 5.5135 & TRN & \\
\hline CHEMBL 2094948 & 842698 & 3.9821 & 4.7494 & TRN & \\
\hline CHEMBL269850 & 842698 & 3.9821 & 4.6455 & TRN & \\
\hline CHEMBL1541861 & 842698 & 6.5317 & 5.8089 & TRN & \\
\hline CHEMBL 2094916 & 842698 & 3.9821 & 4.694 & TRN & \\
\hline CHEMBL1522907 & 842698 & 6.0 & 5.1381 & TRN & \\
\hline CHEMBL602633 & 842698 & 5.4535 & 5.1203 & TRN & \\
\hline CHEMBL 2094764 & 842698 & 3.9821 & 4.6443 & TRN & \\
\hline CHEMBL 2094684 & 842698 & 5.3526 & 4.7071 & TRN & \\
\hline CHEMBL280333 & 842698 & 3.9821 & 4.785 & TRN & \\
\hline CHEMBL 3145326 & 842698 & 3.9821 & 4.7594 & TRN & \\
\hline CHEMBL 3145327 & 842698 & 6.0482 & 5.0266 & TRN & \\
\hline CHEMBL346910 & 842698 & 5.279 & 5.1264 & TRN & \\
\hline CHEMBL 2094827 & 842698 & 3.9821 & 4.716 & TRN & \\
\hline CHEMBL 2095109 & 842698 & 6.0 & 4.9043 & TRN & \\
\hline CHEMBL 2094313 & 842698 & 6.1891 & 5.3414 & TRN & \\
\hline CHEMBL2094701 & 842698 & 5.3089 & 4.9963 & TRN & \\
\hline CHEMBL 2094954 & 842698 & 5.2557 & 4.6934 & TRN & \\
\hline CHEMBL 2094939 & 842698 & 3.9821 & 5.1149 & TRN & \\
\hline CHEMBL 2094898 & 842698 & 5.3251 & 4.9961 & TRN & \\
\hline CHEMBL598287 & 842698 & 6.4045 & 5.4971 & TRN & \\
\hline CHEMBL2094739 & 842698 & 5.1506 & 5.3918 & TRN & \\
\hline CHEMBL 2095091 & 842698 & 5.7122 & 5.1246 & TRN & \\
\hline CHEMBL582727 & 842698 & 5.6003 & 5.4702 & TRN & \\
\hline CHEMBL1549738 & 842698 & 6.0915 & 4.8556 & TST & \\
\hline CHEMBL2095075 & 842698 & 3.9821 & 5.13200 & 0000000001 & TRN \\
\hline CHEMBL2095059 & 842698 & 3.9821 & 4.7002 & TRN & \\
\hline CHEMBL585655 & 842698 & 6.0 & 5.4714 & TRN & \\
\hline CHEMBL 2094982 & 842698 & 5.2411 & 4.874 & TRN & \\
\hline CHEMBL 2094822 & 842698 & 5.3072 & 5.1352 & TRN & \\
\hline CHEMBL330372 & 842698 & 5.71 & 4.8637 & TRN & \\
\hline CHEMBL 2094403 & 842698 & 5.3335 & 5.1275 & TRN & \\
\hline CHEMBL 2094388 & 842698 & 3.9821 & 5.0958 & TRN & \\
\hline CHEMBL 2094451 & 842698 & 3.9821 & 4.7337 & TST & \\
\hline CHEMBL 2094717 & 842698 & \multicolumn{3}{|c|}{5.821000000000001} & TRN \\
\hline CHEMBL1522909 & 842698 & 5.2865 & 5.2337 & TRN & \\
\hline CHEMBL 2094384 & 842698 & 5.067 & 5.1007 & TRN & \\
\hline CHEMBL 2094763 & 842698 & 5.7055 & 5.4849 & TRN & \\
\hline CHEMBL 2094299 & 842698 & 3.9821 & 4.7983 & TRN & \\
\hline CHEMBL 2094376 & 842698 & 3.9821 & 4.9442 & TRN & \\
\hline CHEMBL 2094813 & 842698 & 5.8153 & 4.8703 & TRN & \\
\hline CHEMBL1439833 & 842698 & 3.9821 & 5.0361 & TRN & \\
\hline CHEMBL 2094702 & 842698 & 6.0799 & 5.0581 & TST & \\
\hline CHEMBL2095051 & 842698 & 4.9642 & 5.0412 & TRN & \\
\hline CHEMBL1307453 & 842698 & 3.9821 & 4.9766 & TRN & \\
\hline
\end{tabular}

Page 16557 


\begin{tabular}{|c|c|c|c|c|c|c|}
\hline & & \multicolumn{5}{|c|}{ Supplemental Table S2.txt } \\
\hline CHEMBL 2094694 & 842698 & 5.6655 & 4.8347 & TST & & \\
\hline CHEMBL 2094896 & 842698 & 3.9821 & 4.8345 & TRN & & \\
\hline CHEMBL2094390 & 842698 & 3.9821 & 4.815 & TRN & & \\
\hline CHEMBL 2094507 & 842698 & 3.9821 & 5.4573 & TRN & & \\
\hline CHEMBL 2094494 & 842698 & 3.9821 & 4.8821 & TRN & & \\
\hline CHEMBL 2094544 & 842698 & 5.3507 & 5.2393 & TRN & & \\
\hline CHEMBL 2094484 & 842698 & 5.6308 & 4.7877 & TRN & & \\
\hline CHEMBL2086889 & 842698 & 3.9821 & 4.5591 & TRN & & \\
\hline CHEMBL 2094487 & 842698 & 3.9821 & 5.1818 & TRN & & \\
\hline CHEMBL1431017 & 842698 & 5.3969 & 4.8678 & TRN & & \\
\hline CHEMBL1343568 & 842698 & 3.9821 & 5.0371 & TRN & & \\
\hline CHEMBL1310701 & 842698 & 5.3152 & 5.0147 & TRN & & \\
\hline CHEMBL1606743 & 842698 & 5.279 & 5.1932 & TRN & & \\
\hline CHEMBL 2094787 & 842698 & 5.7471 & 4.959 & TRN & & \\
\hline CHEMBL600718 & 842698 & 6.2807 & 4.6314 & TST & & \\
\hline CHEMBL 2094408 & 842698 & 3.9821 & 4.8402 & TRN & & \\
\hline CHEMBL1320798 & 842698 & 6.38299 & 99999999 & 99 & 4.8345 & TRN \\
\hline CHEMBL 2094986 & 842698 & 3.9821 & 4.9598 & TRN & & \\
\hline CHEMBL 2094456 & 842698 & 3.9821 & 5.007 & TRN & & \\
\hline CHEMBL1415851 & 842698 & 5.2418 & 4.8153 & TST & & \\
\hline CHEMBL 2094700 & 842698 & 5.6421 & 4.9912 & TRN & & \\
\hline CHEMBL1478755 & 842698 & 7.4202 & 6.1412 & TRN & & \\
\hline CHEMBL 314083 & 842698 & 3.9821 & 5.2845 & TRN & & \\
\hline CHEMBL 2094990 & 842698 & 3.9821 & 4.823 & TRN & & \\
\hline CHEMBL 2094926 & 842698 & 5.3372 & 4.7043 & TRN & & \\
\hline CHEMBL 2095134 & 842698 & 5.2765 & 4.6863 & TRN & & \\
\hline CHEMBL 2095009 & 842698 & 3.9821 & 4.9399 & TRN & & \\
\hline CHEMBL 2094808 & 842698 & 3.9821 & 4.6556 & TST & & \\
\hline CHEMBL 2094970 & 842698 & 5.5751 & 5.0434 & TST & & \\
\hline CHEMBL1330352 & 842698 & 5.5918 & 4.4908 & TRN & & \\
\hline CHEMBL2094769 & 842698 & 6.4089 & 4.6633 & TST & & \\
\hline CHEMBL 2094656 & 842698 & 5.3045 & 5.0537 & TRN & & \\
\hline CHEMBL 2094666 & 842698 & 5.8125 & 4.9961 & TRN & & \\
\hline CHEMBL 2094341 & 842698 & 5.6882 & 4.7469 & TRN & & \\
\hline CHEMBL 2094846 & 842698 & 3.9821 & 4.3577 & TRN & & \\
\hline CHEMBL 2094784 & 842698 & 5.5171 & 4.7906 & TRN & & \\
\hline CHEMBL 2095138 & 842698 & 5.3197 & 4.912 & TRN & & \\
\hline CHEMBL 2094978 & 842698 & 3.9821 & 4.4551 & TRN & & \\
\hline CHEMBL148401 & 842698 & 6.6108 & 4.988 & TRN & & \\
\hline CHEMBL600977 & 842698 & 6.284 & 5.2613 & TRN & & \\
\hline CHEMBL593211 & 842698 & 5.4225 & 5.0968 & TRN & & \\
\hline CHEMBL 2094655 & 842698 & 3.9821 & 4.7228 & TRN & & \\
\hline CHEMBL 2094946 & 842698 & 5.2644 & 4.9223 & TST & & \\
\hline CHEMBL 2094667 & 842698 & 5.4353 & 4.6384 & TRN & & \\
\hline CHEMBL1417823 & 842698 & 5.3125 & 5.558 & TRN & & \\
\hline CHEMBL1333987 & 842698 & 3.9821 & 5.1792 & TRN & & \\
\hline CHEMBL1503254 & 842698 & 5.2933 & 5.4363 & TRN & & \\
\hline CHEMBL2094713 & 842698 & 3.9821 & 4.7299 & TRN & & \\
\hline
\end{tabular}




\begin{tabular}{|c|c|c|c|c|c|}
\hline \multicolumn{6}{|c|}{ Supplemental Table S2.txt } \\
\hline CHEMBL 2094412 & 842698 & 5.2418 & 5.2281 & TRN & \\
\hline CHEMBL 2094680 & 842698 & 3.9821 & 4.8896 & TRN & \\
\hline CHEMBL 2094751 & 842698 & 3.9821 & 4.8622 & TST & \\
\hline CHEMBL 2094976 & 842698 & 3.9821 & 4.2048 & TRN & \\
\hline CHEMBL1389794 & 842698 & 3.9821 & 4.622 & TRN & \\
\hline CHEMBL 2094643 & 842698 & 3.9821 & 5.0819 & TRN & \\
\hline CHEMBL 2094908 & 842698 & 3.9821 & 4.8169 & TRN & \\
\hline CHEMBL 2094453 & 842698 & 5.4377 & 5.4221 & TRN & \\
\hline CHEMBL599494 & 842698 & 3.9821 & 5.4052 & TRN & \\
\hline CHEMBL 1608375 & 842698 & 5.8268 & 4.8448 & TST & \\
\hline CHEMBL489770 & 842698 & 6.1439 & 5.7237 & TRN & \\
\hline CHEMBL395209 & 842698 & 5.9706 & 5.7924 & TRN & \\
\hline CHEMBL 2094548 & 842698 & 5.9172 & 4.9093 & TRN & \\
\hline CHEMBL 2094806 & 842698 & 6.4547 & 4.92899 & 9999999999 & TRN \\
\hline CHEMBL 2094610 & 842698 & 5.3072 & 5.0813 & TRN & \\
\hline CHEMBL 2094865 & 842698 & 6.3028 & 4.569 & TRN & \\
\hline CHEMBL 2094477 & 842698 & 3.9821 & 4.7532 & TRN & \\
\hline CHEMBL 2094586 & 842698 & 5.4023 & 4.9085 & TRN & \\
\hline CHEMBL 2094937 & 842698 & 5.3391 & 5.0351 & TRN & \\
\hline CHEMBL 2095053 & 842698 & 6.3546 & 4.768 & TRN & \\
\hline CHEMBL 2094516 & 842698 & 5.3116 & 5.03100 & 0000000001 & TRN \\
\hline CHEMBL 2095035 & 842698 & 5.3019 & 5.0038 & TRN & \\
\hline CHEMBL 2094638 & 842698 & 3.9821 & 4.7452 & TRN & \\
\hline CHEMBL 2094765 & 842698 & 5.2815 & 6.2222 & TRN & \\
\hline CHEMBL 2095070 & 842698 & 3.9821 & 4.8287 & TRN & \\
\hline CHEMBL 2094889 & 842698 & 3.9821 & 4.7326 & TRN & \\
\hline CHEMBL 2094490 & 842698 & 6.5072 & 5.5965 & TRN & \\
\hline CHEMBL 2095049 & 842698 & 3.9821 & 4.6184 & TRN & \\
\hline CHEMBL 97706 & 842698 & 6.0 & 4.9126 & TRN & \\
\hline CHEMBL 2094829 & 842698 & 3.9821 & 5.1821 & TRN & \\
\hline CHEMBL564874 & 842698 & 5.2132 & 5.2469 & TRN & \\
\hline CHEMBL559862 & 842698 & 5.3089 & 5.1621 & TRN & \\
\hline CHEMBL 2095041 & 842698 & 3.9821 & 4.9466 & TRN & \\
\hline CHEMBL 2094828 & 842698 & 3.9821 & 4.586 & TRN & \\
\hline CHEMBL 2095000 & 842698 & 3.9821 & 4.8278 & TST & \\
\hline CHEMBL1504762 & 842698 & 3.9821 & 4.5662 & TRN & \\
\hline CHEMBL 2094463 & 842698 & 5.251 & 5.0817 & TRN & \\
\hline CHEMBL 2094472 & 842698 & 6.0 & 5.0174 & TRN & \\
\hline CHEMBL 2095064 & 842698 & 3.9821 & 4.6812 & TRN & \\
\hline CHEMBL 2094653 & 842698 & 5.9586 & 4.9757 & TRN & \\
\hline CHEMBL 2094571 & 842698 & 3.9821 & 4.8284 & TRN & \\
\hline CHEMBL 2095028 & 842698 & 3.9821 & 4.6192 & TRN & \\
\hline CHEMBL 2094329 & 842698 & 6.0 & 5.1122 & TRN & \\
\hline CHEMBL 2094940 & 842698 & 3.9821 & 4.985 & TRN & \\
\hline CHEMBL 2094328 & 842698 & 5.3883 & 5.0976 & TRN & \\
\hline CHEMBL1190605 & 842698 & 5.3468 & 4.9168 & TRN & \\
\hline CHEMBL1564893 & 842698 & 3.9821 & 4.7201 & TST & \\
\hline CHEMBL 2094715 & 842698 & 6.4295 & 4.8108 & TRN & \\
\hline
\end{tabular}




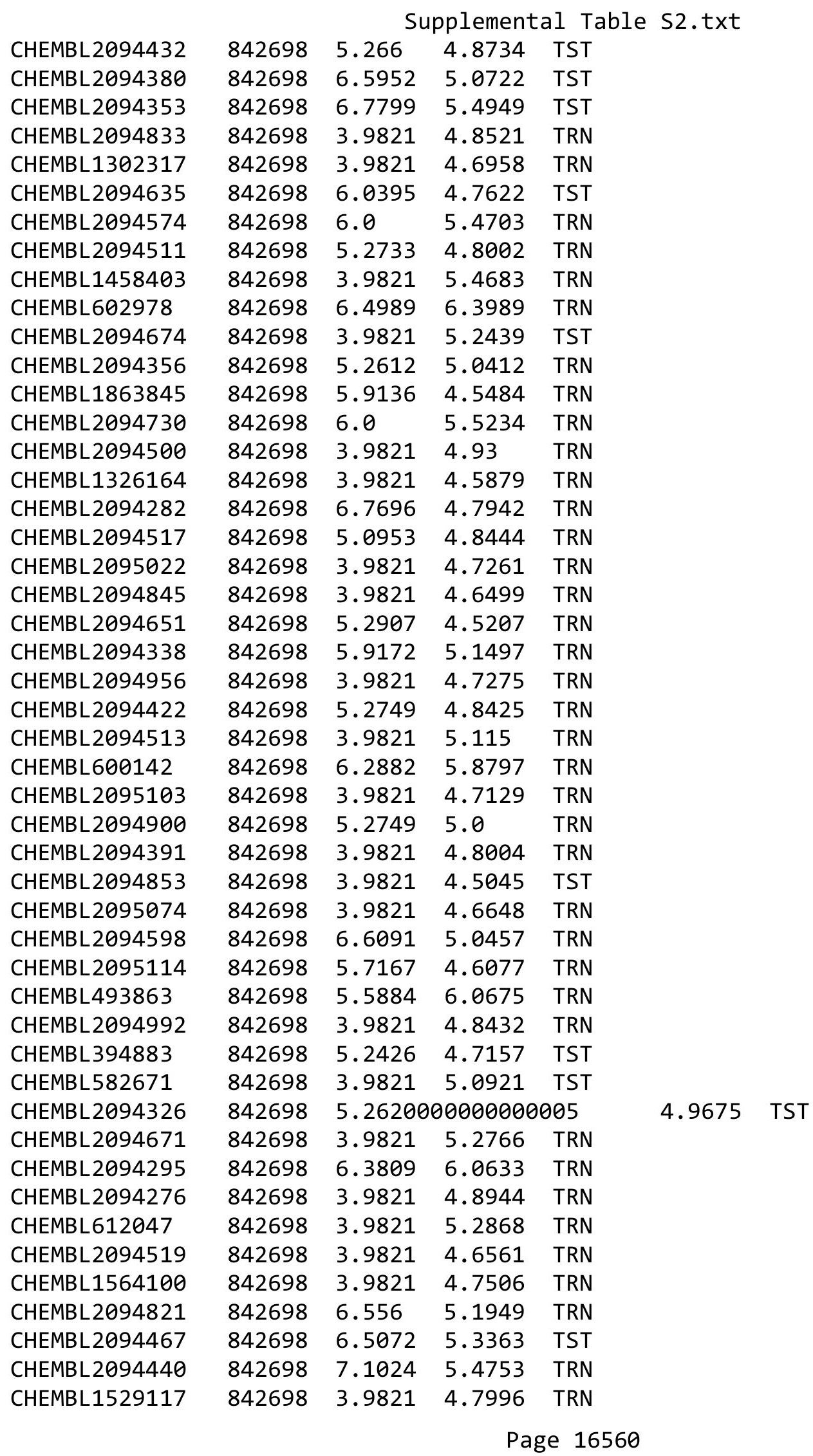




\begin{tabular}{|c|c|c|c|c|c|}
\hline & & \multicolumn{4}{|c|}{ Supplemental Table S2.txt } \\
\hline CHEMBL2094532 & 842698 & 6.2832 & 4.6213 & TRN & \\
\hline CHEMBL 2094468 & 842698 & 5.5406 & 5.2505 & TST & \\
\hline CHEMBL 2094640 & 842698 & 5.2503 & 5.1429 & TRN & \\
\hline CHEMBL3193662 & 842698 & 5.71 & 5.2073 & TRN & \\
\hline CHEMBL 2094540 & 842698 & 3.9821 & 4.8917 & TRN & \\
\hline CHEMBL 2094894 & 842698 & 3.9821 & 4.9923 & TRN & \\
\hline CHEMBL1335833 & 842698 & 3.9821 & 5.1165 & TRN & \\
\hline CHEMBL 2094366 & 842698 & 5.3354 & 5.1807 & TST & \\
\hline CHEMBL 2094450 & 842698 & 5.4413 & 5.2091 & TRN & \\
\hline CHEMBL 2094325 & 842698 & 5.2708 & 5.2498 & TRN & \\
\hline CHEMBL 2095098 & 842698 & 3.9821 & 4.9641 & TRN & \\
\hline CHEMBL 2094423 & 842698 & 6.3706 & 4.8404 & TRN & \\
\hline CHEMBL 2094583 & 842698 & 3.9821 & 5.2295 & TRN & \\
\hline CHEMBL 2094709 & 842698 & 7.0088 & 4.8202 & TRN & \\
\hline CHEMBL 2094873 & 842698 & 3.9821 & 4.4403 & TRN & \\
\hline CHEMBL 2094342 & 842698 & 6.2 & 5.12700 & 0000000001 & TRN \\
\hline CHEMBL1380650 & 842698 & 5.3089 & 5.1355 & TRN & \\
\hline CHEMBL1503190 & 842698 & 5.3904 & 4.9558 & TRN & \\
\hline CHEMBL592116 & 842698 & 5.8013 & 5.2356 & TRN & \\
\hline CHEMBL191140 & 842698 & 3.9821 & 5.727 & TRN & \\
\hline CHEMBL 2094707 & 842698 & 5.2798 & 4.9377 & TRN & \\
\hline CHEMBL494669 & 842698 & 5.6144 & 5.86 & TRN & \\
\hline CHEMBL 2094912 & 842698 & 5.2733 & 5.6047 & TRN & \\
\hline CHEMBL 2094675 & 842698 & 5.4962 & 4.7585 & TRN & \\
\hline CHEMBL 2095133 & 842698 & 5.06 & 5.4116 & TRN & \\
\hline CHEMBL 2094985 & 842698 & 6.0 & 5.0569 & TRN & \\
\hline CHEMBL 2094897 & 842698 & 3.9821 & 4.5236 & TRN & \\
\hline CHEMBL 2094455 & 842698 & 5.5719 & 4.9123 & TRN & \\
\hline CHEMBL 2094835 & 842698 & 3.9821 & 4.974 & TRN & \\
\hline CHEMBL 2094749 & 842698 & 5.2321 & 4.9347 & TRN & \\
\hline CHEMBL 2094770 & 842698 & 5.5834 & 5.0409 & TRN & \\
\hline CHEMBL 2094863 & 842698 & 6.8386 & 5.5612 & TRN & \\
\hline CHEMBL 2094996 & 842698 & 6.0 & 5.0639 & TST & \\
\hline CHEMBL1596972 & 842698 & 3.9821 & 4.8566 & TRN & \\
\hline CHEMBL1603313 & 842698 & 3.9821 & 4.8085 & TRN & \\
\hline CHEMBL 2094350 & 842698 & 3.9821 & 5.0679 & TRN & \\
\hline CHEMBL 2094928 & 842698 & 3.9821 & 4.7732 & TRN & \\
\hline CHEMBL 2095039 & 842698 & 6.2097 & 4.962 & TRN & \\
\hline CHEMBL 2094618 & 842698 & 5.4473 & 5.0205 & TRN & \\
\hline CHEMBL 2094375 & 842698 & 6.1385 & 4.8632 & TRN & \\
\hline CHEMBL 2095048 & 842698 & 3.9821 & 4.7391 & TRN & \\
\hline CHEMBL 2095040 & 842698 & 5.3019 & 4.9608 & TRN & \\
\hline CHEMBL 2095092 & 842698 & 3.9821 & 4.5692 & TRN & \\
\hline CHEMBL1346426 & 842698 & 3.9821 & 4.82100 & 2000000001 & TRN \\
\hline CHEMBL 2094895 & 842698 & 5.5086 & 4.98300 & 00000000005 & TST \\
\hline CHEMBL 2094911 & 842698 & 5.2958 & 4.9498 & TST & \\
\hline CHEMBL 2094591 & 842698 & 5.7959 & 4.9191 & TRN & \\
\hline CHEMBL 2094753 & 842698 & 3.9821 & 4.8964 & TRN & \\
\hline
\end{tabular}




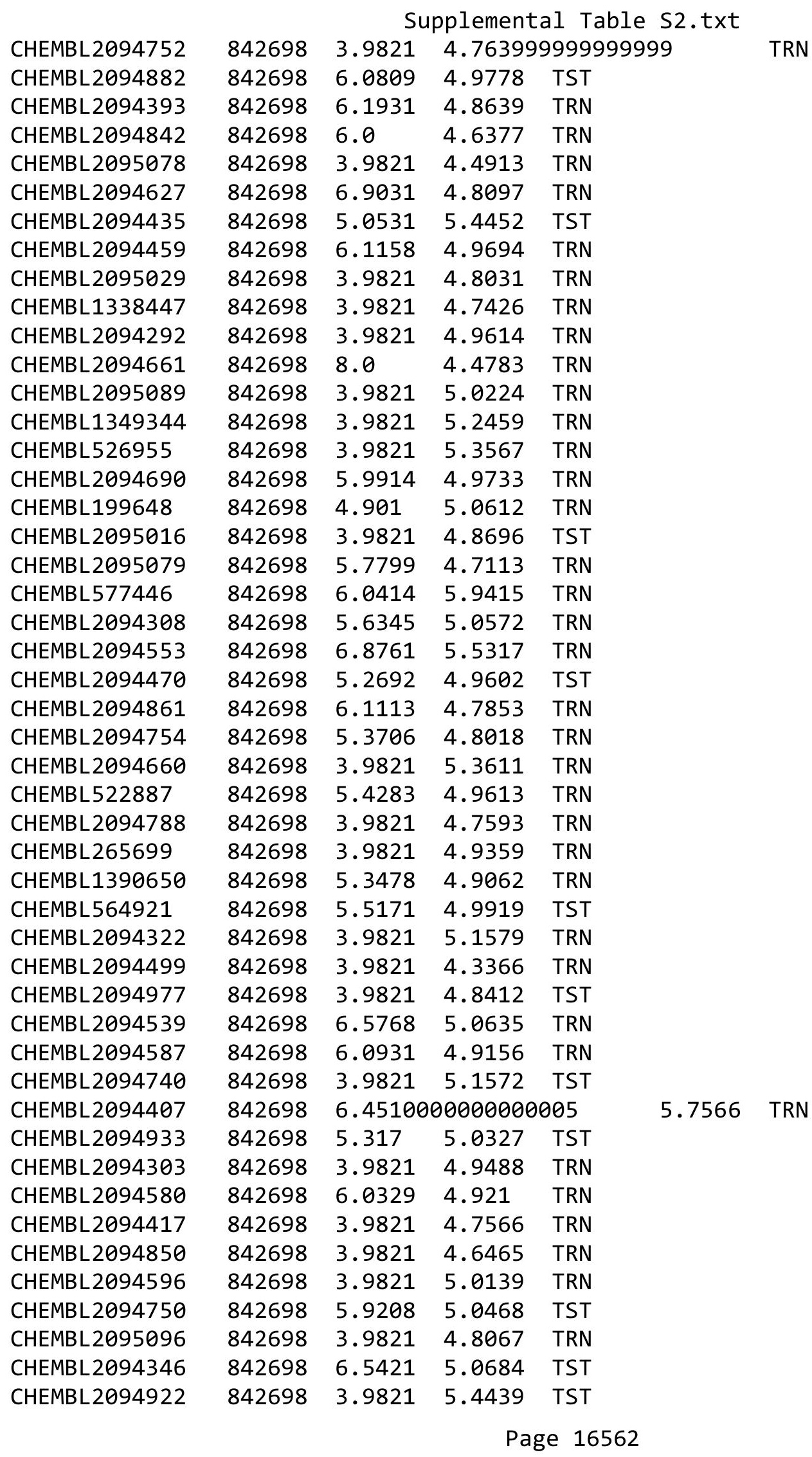




\begin{tabular}{|c|c|c|c|c|c|}
\hline \multicolumn{6}{|c|}{ Supplemental Table S2.txt } \\
\hline CHEMBL 2094560 & 842698 & 5.8447 & 4.9194 & TRN & \\
\hline CHEMBL 2095097 & 842698 & 3.9821 & 4.7991 & TRN & \\
\hline CHEMBL 2094830 & 842698 & 6.0825 & 4.6797 & TRN & \\
\hline CHEMBL1372629 & 842698 & 6.1261 & 4.5314 & TRN & \\
\hline CHEMBL 2094839 & 842698 & 6.3893 & 5.5071 & TRN & \\
\hline CHEMBL 2094877 & 842698 & 5.266 & 4.5139 & TST & \\
\hline CHEMBL 2094921 & 842698 & 3.9821 & 4.6404 & TRN & \\
\hline CHEMBL 2095018 & 842698 & 3.9821 & 5.3333 & TRN & \\
\hline CHEMBL 2094359 & 842698 & 5.4597 & 5.2186 & TRN & \\
\hline CHEMBL 2094599 & 842698 & 6.21899 & 99999999 & 4.9601 & TRN \\
\hline CHEMBL 2095082 & 842698 & 3.9821 & 4.893 & TRN & \\
\hline CHEMBL 2094781 & 842698 & 3.9821 & 4.8809 & TRN & \\
\hline CHEMBL 2094629 & 842698 & 5.4962 & 5.01399 & 9999999999 & TRN \\
\hline CHEMBL 2094974 & 842698 & 3.9821 & 5.1425 & TST & \\
\hline CHEMBL 2095076 & 842698 & 6.0 & 5.1711 & TRN & \\
\hline CHEMBL 2094314 & 842698 & 5.341 & 4.6836 & TRN & \\
\hline CHEMBL 2094817 & 842698 & 5.9393 & 4.695 & TRN & \\
\hline CHEMBL601957 & 842698 & $5.3420 e$ & 00000000 & 5.8618 & TRN \\
\hline CHEMBL 2094941 & 842698 & 3.9821 & 4.9283 & TRN & \\
\hline CHEMBL 2094462 & 842698 & 3.9821 & 5.01699 & 99999999995 & TRN \\
\hline CHEMBL 2094950 & 842698 & 6.0 & 4.9893 & TRN & \\
\hline CHEMBL 2095124 & 842698 & 5.1637 & 4.8702 & TRN & \\
\hline CHEMBL 2094980 & 842698 & 3.9821 & 4.8467 & TRN & \\
\hline CHEMBL579905 & 842698 & 6.5607 & 6.4189 & TRN & \\
\hline CHEMBL 2094485 & 842698 & 3.9821 & 4.8526 & TST & \\
\hline CHEMBL1486366 & 842698 & 3.9821 & 4.8319 & TRN & \\
\hline CHEMBL1567571 & 842698 & 3.9821 & 4.8705 & TRN & \\
\hline CHEMBL 2095107 & 842698 & 3.9821 & 4.8395 & TRN & \\
\hline CHEMBL2094768 & 842698 & 3.9821 & 5.1188 & TRN & \\
\hline CHEMBL1308677 & 842698 & 3.9821 & 4.7113 & TRN & \\
\hline CHEMBL 2094931 & 842698 & 3.9821 & 4.6903 & TRN & \\
\hline CHEMBL1320453 & 842698 & 3.9821 & 4.8644 & TRN & \\
\hline CHEMBL577374 & 842698 & 6.4473 & 5.9168 & TRN & \\
\hline CHEMBL 2094289 & 842698 & 3.9821 & 4.3726 & TRN & \\
\hline CHEMBL 2094688 & 842698 & 5.9586 & 5.2092 & TRN & \\
\hline CHEMBL 2095102 & 842698 & 3.9821 & 5.3025 & TRN & \\
\hline CHEMBL 2095060 & 842698 & 3.9821 & 4.7873 & TRN & \\
\hline CHEMBL1438389 & 842698 & 3.9821 & 4.6638 & TRN & \\
\hline CHEMBL1528359 & 842698 & 3.9821 & 4.9554 & TRN & \\
\hline CHEMBL 2094681 & 842698 & 5.2798 & 5.0559 & TRN & \\
\hline CHEMBL1341830 & 842698 & 3.9821 & 5.0563 & TST & \\
\hline CHEMBL529594 & 842698 & 5.3298 & 5.1902 & TRN & \\
\hline CHEMBL 2094414 & 842698 & 3.9821 & 4.9497 & TRN & \\
\hline CHEMBL 2094984 & 842698 & 3.9821 & 4.4879 & TRN & \\
\hline CHEMBL577632 & 842698 & 6.0 & 5.0394 & TRN & \\
\hline CHEMBL 2094903 & 842698 & 3.9821 & 5.3791 & TRN & \\
\hline CHEMBL 2094624 & 842698 & 3.9821 & 4.6335 & TRN & \\
\hline CHEMBL2094691 & 842698 & 5.3298 & 5.5784 & TRN & \\
\hline
\end{tabular}




\begin{tabular}{|c|c|c|c|c|c|c|}
\hline & & \multicolumn{5}{|c|}{ Supplemental Table s2.txt } \\
\hline CHEMBL 2094581 & 842698 & 3.9821 & 4.5396 & TRN & & \\
\hline CHEMBL 2094524 & 842698 & 5.279 & 4.7146 & TRN & & \\
\hline CHEMBL1442783 & 842698 & 5.2823 & 5.7267 & TST & & \\
\hline CHEMBL 2095021 & 842698 & 3.9821 & 4.9467 & TST & & \\
\hline CHEMBL 2095068 & 842698 & 3.9821 & 4.7598 & TRN & & \\
\hline CHEMBL 2094938 & 842698 & 5.5272 & 5.0639 & TRN & & \\
\hline CHEMBL 2094563 & 842698 & 6.3605 & 5.3775 & TRN & & \\
\hline CHEMBL 2094358 & 842698 & 5.2857 & 4.5063 & TRN & & \\
\hline CHEMBL 2095004 & 842698 & 3.9821 & 4.7659 & TRN & & \\
\hline CHEMBL 2094836 & 842698 & 3.9821 & 5.4051 & TRN & & \\
\hline CHEMBL 2095017 & 842698 & 5.6576 & 5.1092 & TRN & & \\
\hline CHEMBL 2095030 & 842698 & 3.9821 & 4.9429 & TRN & & \\
\hline CHEMBL 2094918 & 842698 & 6.0804 & 5.9044 & TRN & & \\
\hline CHEMBL 2094841 & 842698 & \multicolumn{3}{|c|}{5.3420000000000005} & 5.3411 & TST \\
\hline CHEMBL 2094888 & 842698 & 5.3429 & 4.8065 & TRN & & \\
\hline CHEMBL 2095067 & 842698 & 5.2581 & 4.6511 & TRN & & \\
\hline CHEMBL 2095083 & 842698 & 6.2874 & 4.6381 & TRN & & \\
\hline CHEMBL 2094761 & 842698 & 5.2628 & 4.8585 & TRN & & \\
\hline CHEMBL 1326758 & 842698 & 3.9821 & 4.9755 & TRN & & \\
\hline CHEMBL 2094776 & 842698 & 3.9821 & 4.8054 & TST & & \\
\hline CHEMBL1442500 & 842698 & 5.3206 & 4.7938 & TRN & & \\
\hline CHEMBL1453126 & 842698 & 6.4559 & 5.2309 & TRN & & \\
\hline CHEMBL 2094411 & 842698 & 5.4711 & 4.6748 & TST & & \\
\hline CHEMBL 2094699 & 842698 & 3.9821 & 4.8443 & TST & & \\
\hline CHEMBL 2094774 & 842698 & 3.9821 & 4.7245 & TRN & & \\
\hline CHEMBL 2095010 & 842698 & 5.2457 & 5.1802 & TRN & & \\
\hline CHEMBL 2095002 & 842698 & 3.9821 & 5.3316 & TRN & & \\
\hline CHEMBL 2094929 & 842698 & 5.5406 & 4.5303 & TRN & & \\
\hline CHEMBL 2095080 & 842698 & 3.9821 & 4.9904 & TRN & & \\
\hline CHEMBL589674 & 842698 & 5.3152 & 5.0607 & TRN & & \\
\hline CHEMBL 2094834 & 842698 & 5.6144 & 5.16 & TRN & & \\
\hline CHEMBL1492017 & 842698 & 5.2874 & 4.8141 & TRN & & \\
\hline CHEMBL1454397 & 842698 & 5.3002 & 4.8697 & TRN & & \\
\hline CHEMBL 2094989 & 842698 & 6.1675 & 5.7872 & TRN & & \\
\hline CHEMBL 2094535 & 842698 & 3.9821 & 4.8859 & TRN & & \\
\hline CHEMBL 2094920 & 842698 & 3.9821 & 4.7533 & TRN & & \\
\hline CHEMBL 2094724 & 842698 & 3.9821 & 4.893 & TRN & & \\
\hline CHEMBL 2094637 & 842698 & 3.9821 & 4.9801 & TRN & & \\
\hline CHEMBL1526692 & 842698 & 5.1972 & 4.9125 & TST & & \\
\hline CHEMBL 2094552 & 842698 & 5.2573 & 5.0646 & TRN & & \\
\hline CHEMBL 2094686 & 842698 & 5.4413 & 4.7947 & TRN & & \\
\hline CHEMBL 2094347 & 842698 & 5.2832 & 5.0285 & TRN & & \\
\hline CHEMBL1490332 & 842698 & 5.8013 & 4.8603 & TRN & & \\
\hline CHEMBL577232 & 842698 & 3.9821 & 5.6515 & TRN & & \\
\hline CHEMBL 2095014 & 842698 & 3.9821 & 4.7786 & TRN & & \\
\hline CHEMBL 2094381 & 842698 & 3.9821 & 4.8264 & TRN & & \\
\hline CHEMBL599708 & 842698 & 6.5969 & 5.4008 & TRN & & \\
\hline CHEMBL 2094298 & 842698 & 3.9821 & 4.6729 & TST & & \\
\hline
\end{tabular}




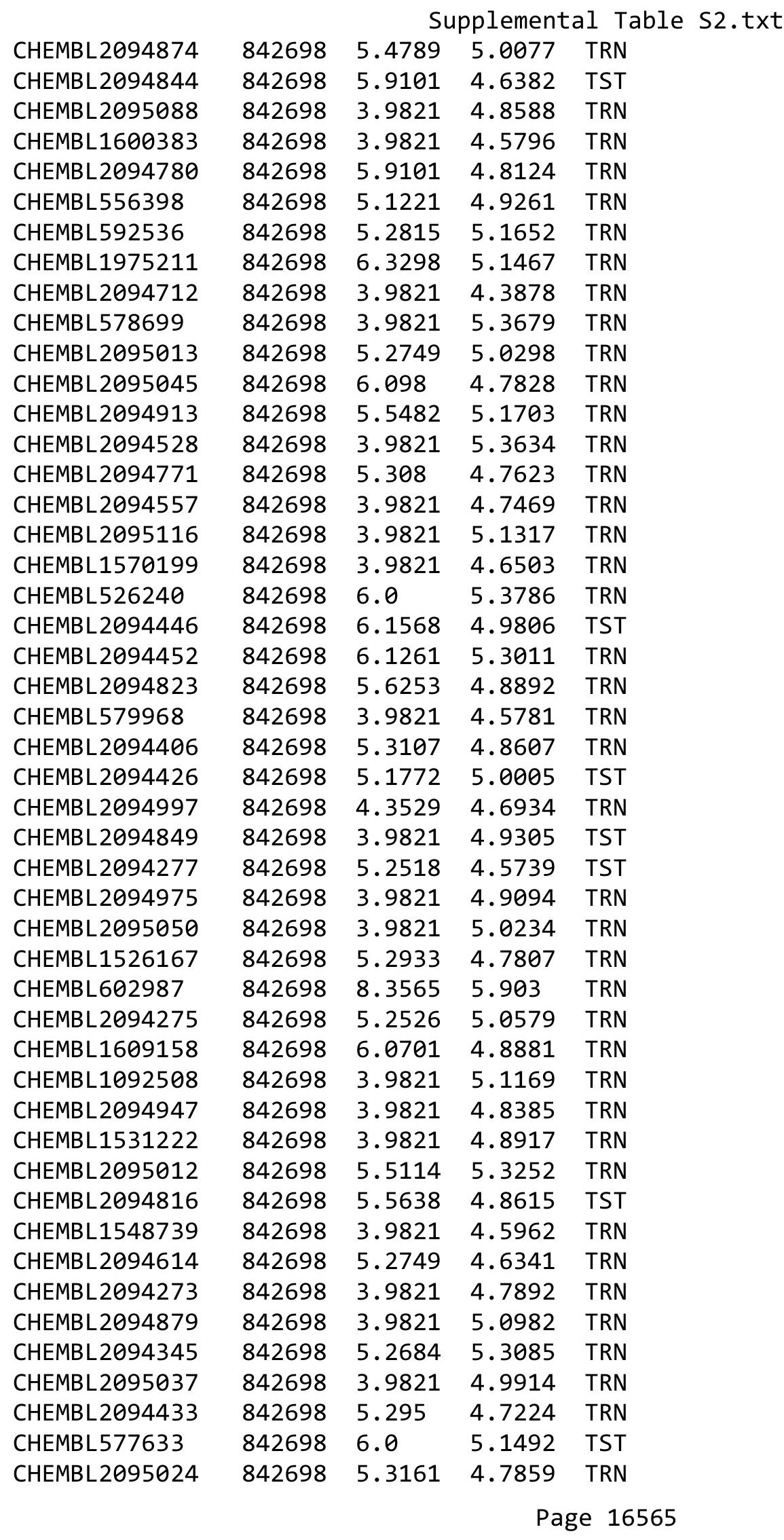




\begin{tabular}{|c|c|c|c|c|}
\hline & & & oplement & al $\mathrm{Tc}$ \\
\hline CHEMBL 2094492 & 842698 & 3.9821 & 4.6196 & TRN \\
\hline CHEMBL 2094418 & 842698 & 3.9821 & 5.1572 & TRN \\
\hline CHEMBL548540 & 842698 & 6.1765 & 4.9728 & TRN \\
\hline CHEMBL354714 & 842698 & 5.2941 & 5.0099 & TST \\
\hline CHEMBL1588679 & 842698 & 3.9821 & 4.9937 & TRN \\
\hline CHEMBL2094714 & 842698 & 3.9821 & 4.5769 & TRN \\
\hline CHEMBL1379900 & 842698 & 3.9821 & 4.7889 & TRN \\
\hline CHEMBL2094438 & 842698 & 3.9821 & 4.8932 & TRN \\
\hline CHEMBL 2094721 & 842698 & 6.5317 & 5.8126 & TRN \\
\hline CHEMBL 2094664 & 842698 & 5.1343 & 4.8214 & TRN \\
\hline CHEMBL2094737 & 842698 & 6.1427 & 5.0848 & TRN \\
\hline CHEMBL 2095110 & 842698 & 5.3072 & 4.8089 & TST \\
\hline CHEMBL2094906 & 842698 & 5.3054 & 5.239 & TRN \\
\hline CHEMBL 2094493 & 842698 & 3.9821 & 5.3456 & TRN \\
\hline CHEMBL 2094365 & 842698 & 5.3288 & 5.3061 & TRN \\
\hline CHEMBL577668 & 842698 & 7.0655 & 6.1106 & TRN \\
\hline CHEMBL 2094421 & 842698 & 5.3125 & 4.6456 & TRN \\
\hline CHEMBL 2094296 & 842698 & 3.9821 & 4.9519 & TRN \\
\hline CHEMBL1972216 & 842698 & 5.7545 & 4.9653 & TRN \\
\hline CHEMBL 2094704 & 842698 & 6.0926 & 4.5948 & TRN \\
\hline CHEMBL1390716 & 842698 & 5.6676 & 4.9316 & TST \\
\hline CHEMBL 2094875 & 842698 & 5.0325 & 5.1231 & TRN \\
\hline CHEMBL1546223 & 842698 & 3.9821 & 5.0079 & TRN \\
\hline CHEMBL 2094474 & 842698 & 5.9355 & 4.7908 & TRN \\
\hline CHEMBL599786 & 842698 & 3.9821 & 5.1301 & TST \\
\hline CHEMBL 2094496 & 842698 & 3.9821 & 4.9881 & TRN \\
\hline CHEMBL 2094759 & 842698 & 3.9821 & 5.019 & TST \\
\hline CHEMBL 2094682 & 842698 & 6.3279 & 5.0346 & TST \\
\hline CHEMBL2095112 & 842698 & 3.9821 & 4.9313 & TRN \\
\hline CHEMBL 2094320 & 842698 & 6.1549 & 4.9595 & TST \\
\hline CHEMBL1427413 & 842698 & 5.2798 & 5.2909 & TRN \\
\hline CHEMBL 2094777 & 842698 & 3.9821 & 4.7416 & TRN \\
\hline CHEMBL 2094437 & 842698 & 5.8097 & 4.9526 & TRN \\
\hline CHEMBL1445650 & 842698 & 3.9821 & 4.8033 & TRN \\
\hline CHEMBL 2094506 & 842698 & 5.6038 & 5.3636 & TRN \\
\hline CHEMBL 2094546 & 842698 & 5.065 & 5.0528 & TRN \\
\hline CHEMBL1420370 & 842698 & 3.9821 & 5.1417 & TRN \\
\hline CHEMBL 2094538 & 842698 & 6.8761 & 4.8832 & TRN \\
\hline CHEMBL 2094374 & 842698 & 6.0 & 5.4911 & TST \\
\hline CHEMBL 2094706 & 842698 & 5.2765 & 4.8365 & TST \\
\hline CHEMBL 2094854 & 842698 & 3.9821 & 4.8662 & TST \\
\hline CHEMBL 2094585 & 842698 & 3.9821 & 5.0575 & TST \\
\hline CHEMBL2094859 & 842698 & 5.3307 & 5.6059 & TRN \\
\hline CHEMBL1362503 & 842698 & 3.9821 & 4.8082 & TRN \\
\hline CHEMBL2094711 & 842698 & 6.0 & 4.7609 & TRN \\
\hline CHEMBL1431115 & 842698 & 6.1146 & 4.8891 & TRN \\
\hline CHEMBL 2094405 & 842698 & 3.9821 & 5.1742 & TST \\
\hline CHEMBL1739979 & 842698 & 3.9821 & 5.3106 & TRN \\
\hline
\end{tabular}




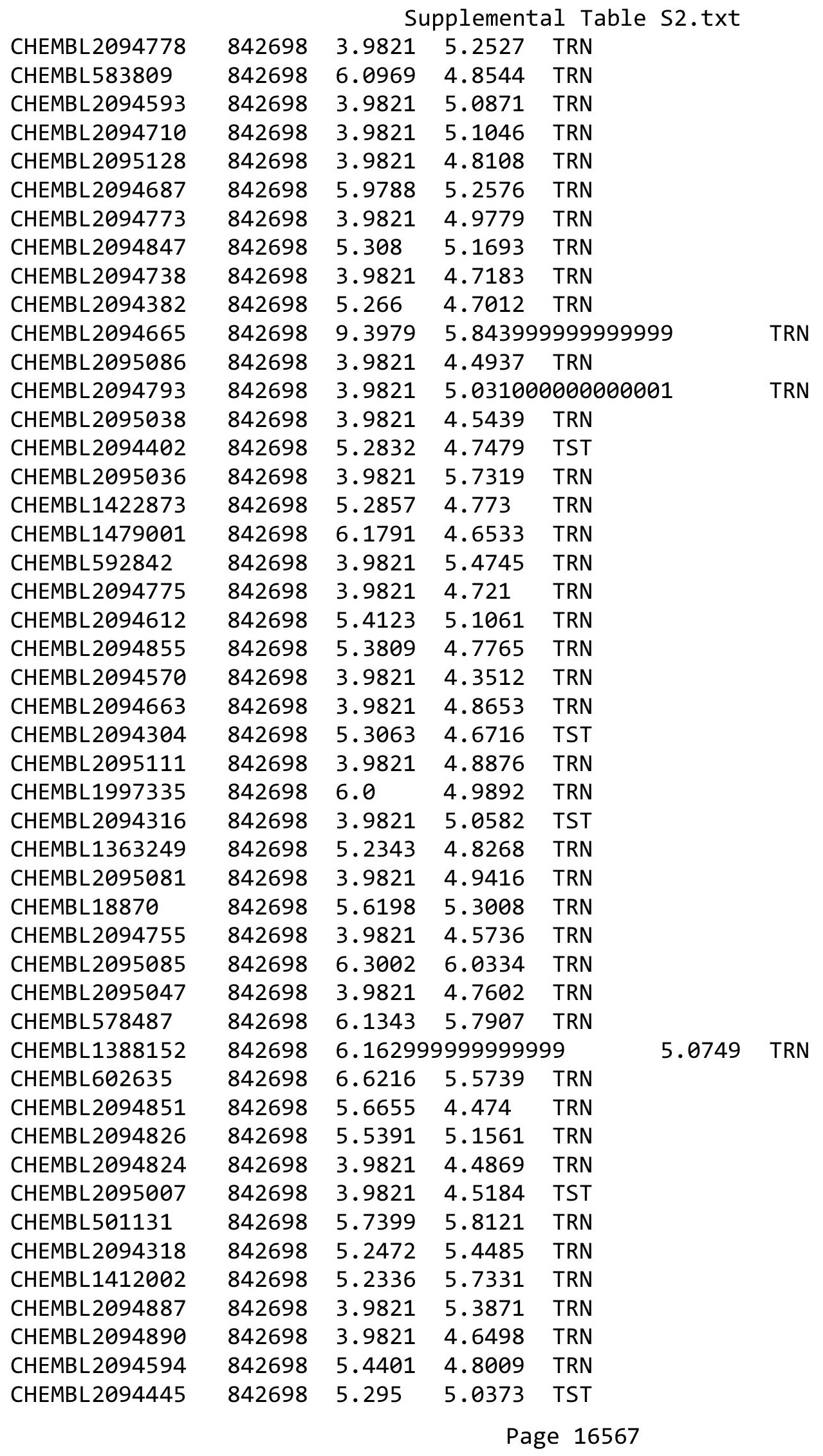




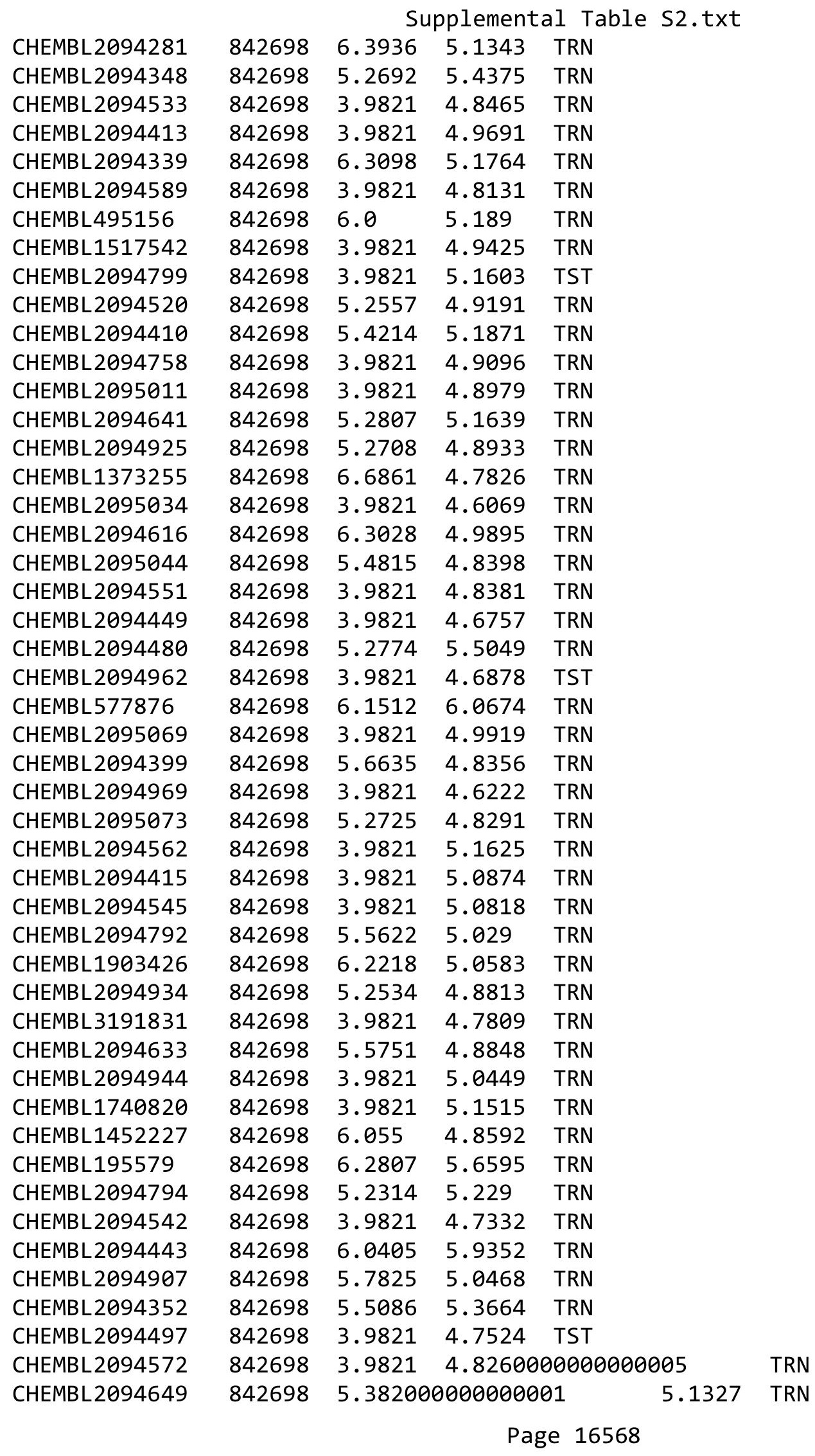




\begin{tabular}{|c|c|c|c|c|c|}
\hline & & \multicolumn{4}{|c|}{ Supplemental Table S2.txt } \\
\hline CHEMBL2094272 & 842698 & 5.8386 & 5.1515 & TRN & \\
\hline CHEMBL 2095003 & 842698 & 4.9731 & 4.84399 & 9999999999 & TRN \\
\hline CHEMBL2094394 & 842698 & 5.301 & 4.9876 & TST & \\
\hline CHEMBL 2094534 & 842698 & 6.3615 & 4.6193 & TRN & \\
\hline CHEMBL 2094967 & 842698 & 5.1785 & 5.144 & TRN & \\
\hline CHEMBL 2094705 & 842698 & 3.9821 & 5.1537 & TRN & \\
\hline CHEMBL 2095052 & 842698 & 3.9821 & 4.7955 & TRN & \\
\hline CHEMBL1990783 & 842698 & 3.9821 & 5.0309 & TRN & \\
\hline CHEMBL1537070 & 842698 & 3.9821 & 4.993 & TST & \\
\hline CHEMBL2095062 & 842698 & 3.9821 & 4.8385 & TRN & \\
\hline CHEMBL1533937 & 842698 & 3.9821 & 5.2216 & TRN & \\
\hline CHEMBL 2094901 & 842698 & 6.2588 & 4.6943 & TRN & \\
\hline CHEMBL 2094483 & 842698 & 3.9821 & 5.0119 & TRN & \\
\hline CHEMBL 2094869 & 842698 & 3.9821 & 4.8411 & TRN & \\
\hline CHEMBL 2094344 & 842698 & 3.9821 & 4.7531 & TRN & \\
\hline CHEMBL 2094531 & 842698 & 3.9821 & 4.7064 & TRN & \\
\hline CHEMBL 2094601 & 842698 & 5.2628 & 5.2398 & TRN & \\
\hline CHEMBL 2094728 & 842698 & 5.7878 & 4.9464 & TRN & \\
\hline CHEMBL 2094447 & 842698 & 6.067 & 4.7308 & TRN & \\
\hline CHEMBL 2094608 & 842698 & 5.2588 & 4.7822 & TRN & \\
\hline CHEMBL 2094862 & 842698 & 3.9821 & 4.6165 & TRN & \\
\hline CHEMBL 2095023 & 842698 & 6.0 & 4.6005 & TRN & \\
\hline CHEMBL 2094993 & 842698 & 3.9821 & 4.5456 & TRN & \\
\hline CHEMBL1197848 & 842698 & 7.2518 & 5.2683 & TRN & \\
\hline CHEMBL2094291 & 842698 & 5.2604 & 4.4448 & TST & \\
\hline CHEMBL 2094945 & 842698 & 5.2472 & 4.8708 & TST & \\
\hline CHEMBL2094673 & 842698 & 3.9821 & 4.8996 & TRN & \\
\hline CHEMBL 2094547 & 842698 & 5.4123 & 4.9819 & TRN & \\
\hline CHEMBL2094561 & 842698 & 6.0 & 4.8913 & TRN & \\
\hline CHEMBL1703458 & 842698 & 3.9821 & 4.6958 & TRN & \\
\hline CHEMBL 2094603 & 842698 & 3.9821 & 5.3909 & TRN & \\
\hline CHEMBL2094323 & 842698 & 5.2815 & 5.0819 & TST & \\
\hline CHEMBL586013 & 842698 & 6.2692 & 6.2496 & TRN & \\
\hline CHEMBL1344912 & 842698 & 5.4271 & 5.693 & TRN & \\
\hline CHEMBL 2094481 & 842698 & 3.9821 & 4.6359 & TRN & \\
\hline CHEMBL537718 & 842698 & 5.2733 & 4.7843 & TRN & \\
\hline CHEMBL1522984 & 842698 & 5.7352 & 4.7438 & TRN & \\
\hline CHEMBL 2094536 & 842698 & 5.2899 & 4.7775 & TST & \\
\hline CHEMBL 2094620 & 842698 & 8.3979 & 5.1828 & TRN & \\
\hline CHEMBL 2094837 & 842698 & 3.9821 & 4.669 & TRN & \\
\hline CHEMBL 2094270 & 842698 & 6.1805 & 4.7896 & TRN & \\
\hline CHEMBL1311879 & 842698 & 6.1439 & 5.1503 & TRN & \\
\hline CHEMBL2094930 & 842698 & 6.0 & 4.8503 & TRN & \\
\hline CHEMBL1621012 & 842698 & 5.2526 & 4.9731 & TRN & \\
\hline CHEMBL1498652 & 842698 & 3.9821 & 5.0457 & TRN & \\
\hline CHEMBL 2094471 & 842698 & 3.9821 & 4.7542 & TRN & \\
\hline CHEMBL1327172 & 842698 & 3.9821 & 4.9143 & TRN & \\
\hline CHEMBL2094473 & 842698 & 3.9821 & 5.2833 & TST & \\
\hline
\end{tabular}


Supplemental Table S2.txt

\begin{tabular}{|c|c|c|c|c|}
\hline CHEMBL 2094961 & 842698 & 3.9821 & 4.7585 & TRN \\
\hline CHEMBL 2094634 & 842698 & 5.2733 & 5.2712 & TRN \\
\hline CHEMBL2095015 & 842698 & 5.4237 & 4.7786 & TRN \\
\hline CHEMBL 2094332 & 842698 & 5.4935 & 5.2674 & TST \\
\hline CHEMBL527775 & 842698 & 5.3251 & 5.5045 & TST \\
\hline CHEMBL 2094305 & 842698 & 3.9821 & 5.26 & TRN \\
\hline CHEMBL 2094987 & 842698 & 3.9821 & 4.5845 & TRN \\
\hline CHEMBL 2094510 & 842698 & 6.4584 & 5.0243 & TST \\
\hline CHEMBL601608 & 842698 & 5.2668 & 5.5719 & TRN \\
\hline CHEMBL 2094966 & 842698 & 3.9821 & 4.8054 & TRN \\
\hline CHEMBL2094502 & 842698 & 5.2684 & 4.6588 & TRN \\
\hline CHEMBL 2094395 & 842698 & 5.2604 & 5.2311 & TRN \\
\hline CHEMBL590424 & 842698 & 5.6364 & 4.9745 & TRN \\
\hline CHEMBL 2094392 & 842698 & 5.7167 & 5.0718 & TRN \\
\hline CHEMBL 2094942 & 842698 & 5.6946 & 5.0076 & TRN \\
\hline CHEMBL 2094529 & 842698 & 6.0 & 5.2353 & TRN \\
\hline CHEMBL 2095042 & 842698 & 3.9821 & 4.6336 & TRN \\
\hline CHEMBL 2094428 & 842698 & 5.2865 & 4.7902 & TRN \\
\hline CHEMBL 2094427 & 842698 & 3.9821 & 4.834 & TRN \\
\hline CHEMBL204914 & 842698 & 5.2916 & 5.1279 & TRN \\
\hline CHEMBL578928 & 842698 & 5.3478 & 5.2364 & TRN \\
\hline CHEMBL1481509 & 842698 & 3.9821 & 4.8706 & TST \\
\hline CHEMBL 2094606 & 842698 & 5.279 & 5.1694 & TRN \\
\hline CHEMBL 2095032 & 842698 & 5.1186 & \multicolumn{2}{|c|}{5.571000000000001} \\
\hline CHEMBL 2094378 & 842698 & 3.9821 & 4.8636 & TRN \\
\hline CHEMBL2094804 & 842698 & 3.9821 & 4.8981 & TRN \\
\hline CHEMBL 2094523 & 842698 & 3.9821 & 4.644 & TRN \\
\hline CHEMBL193528 & 842698 & 7.3098 & 5.5959 & TRN \\
\hline CHEMBL200628 & 842698 & 5.301 & 4.7616 & TRN \\
\hline CHEMBL 2095025 & 842698 & 6.0991 & 4.6383 & TRN \\
\hline CHEMBL2094802 & 842698 & 5.2933 & 5.4742 & TRN \\
\hline CHEMBL 2094868 & 842698 & 3.9821 & 4.5213 & TRN \\
\hline CHEMBL2094800 & 842698 & 3.9821 & 5.6001 & TRN \\
\hline CHEMBL1346025 & 842698 & 3.9821 & 4.8804 & TRN \\
\hline CHEMBL1572415 & 842698 & 5.2588 & 4.7043 & TRN \\
\hline CHEMBL1385558 & 842698 & 3.9821 & 4.6869 & TRN \\
\hline CHEMBL1652416 & 842698 & 3.9821 & 4.7327 & TST \\
\hline CHEMBL2094924 & 842698 & 6.3279 & 4.729 & TRN \\
\hline CHEMBL 2095019 & 842698 & 3.9821 & 5.1692 & TRN \\
\hline CHEMBL 2094434 & 842698 & 5.5638 & 5.4169 & TRN \\
\hline CHEMBL1197837 & 842698 & 5.062 & 5.3062 & TRN \\
\hline CHEMBL 2094732 & 842698 & 5.295 & 5.2042 & TRN \\
\hline CHEMBL2094362 & 842698 & 6.0 & 5.002 & TRN \\
\hline CHEMBL 2094592 & 842698 & 3.9821 & 4.598 & TRN \\
\hline CHEMBL2094725 & 842698 & 6.0119 & 5.0946 & TRN \\
\hline CHEMBL 2094648 & 842698 & 5.1337 & 4.7111 & TRN \\
\hline CHEMBL 2094429 & 842698 & 5.6615 & 4.7589 & TRN \\
\hline CHEMBL 2094577 & 842698 & 5.5258 & 4.6693 & TRN \\
\hline
\end{tabular}




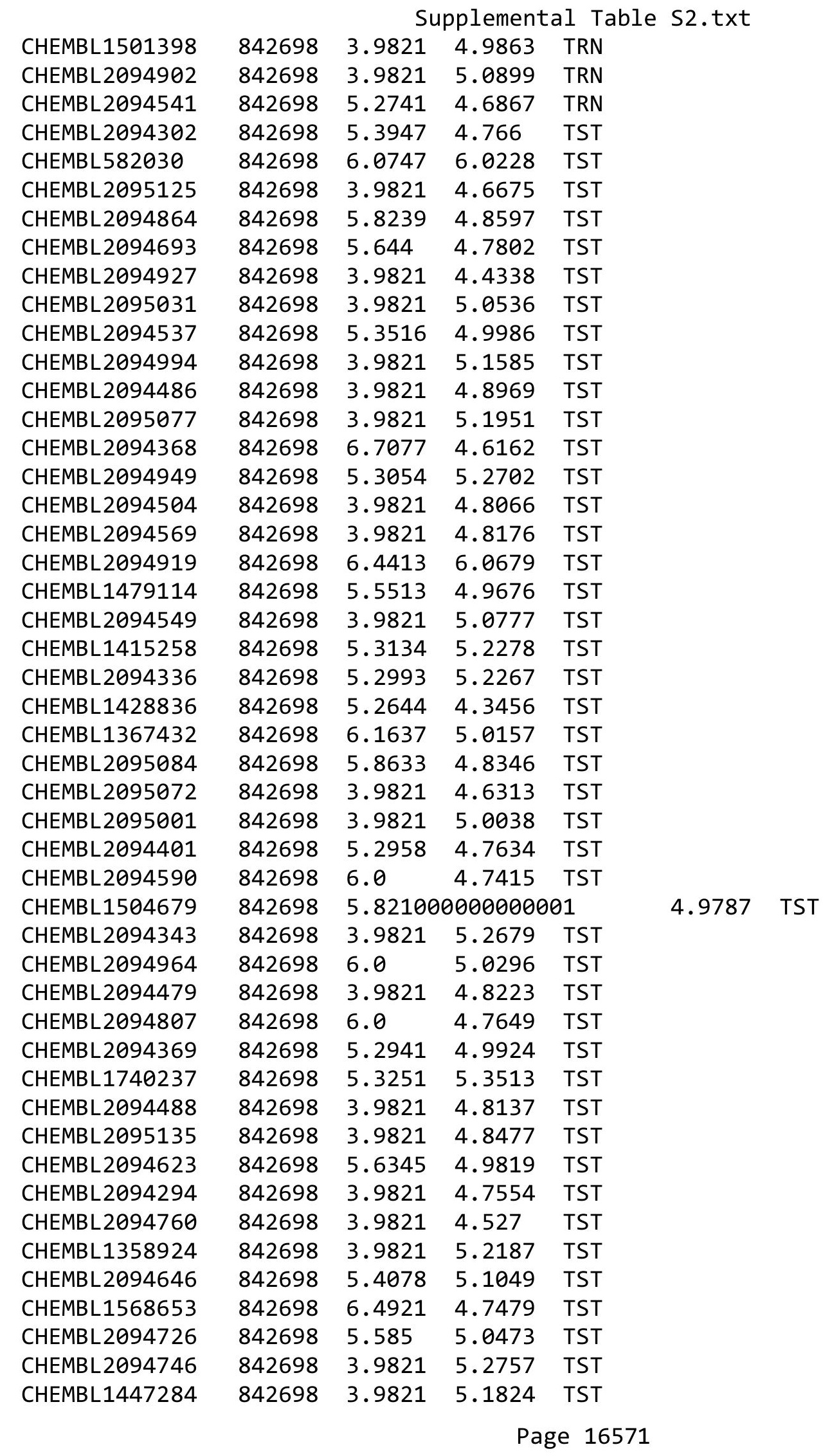




\begin{tabular}{|c|c|c|c|c|}
\hline \multicolumn{5}{|c|}{ Supplemental Table S2.txt } \\
\hline CHEMBL 2094602 & 842698 & 5.2328 & 4.649 & TST \\
\hline CHEMBL1994034 & 842698 & 3.9821 & 4.8798 & TST \\
\hline CHEMBL 2094503 & 842698 & 5.5003 & 5.1198 & TST \\
\hline CHEMBL 2094478 & 842698 & 3.9821 & 4.7975 & TST \\
\hline CHEMBL 2095105 & 842698 & 3.9821 & 4.9132 & TST \\
\hline CHEMBL 2094696 & 842698 & 3.9821 & 5.0087 & TST \\
\hline CHEMBL 2094454 & 842698 & 3.9821 & 4.665 & TST \\
\hline CHEMBL 2095115 & 842698 & 5.3979 & 5.50200 & 0000000001 \\
\hline CHEMBL 2094576 & 842698 & 3.9821 & 4.8439 & TST \\
\hline CHEMBL 2095055 & 842698 & 3.9821 & 4.4863 & TST \\
\hline CHEMBL 2094466 & 842698 & 5.6055 & 4.9803 & TST \\
\hline CHEMBL 2094965 & 842698 & 3.9821 & 4.6967 & TST \\
\hline CHEMBL 2094283 & 842698 & 5.5817 & 5.1659 & TST \\
\hline CHEMBL 2094370 & 842698 & 6.0048 & 4.9857 & TST \\
\hline CHEMBL532124 & 842698 & 3.9821 & 4.8059 & TST \\
\hline CHEMBL1604852 & 842698 & 5.2604 & 5.2709 & TST \\
\hline CHEMBL 2094860 & 842698 & 5.644 & 4.7401 & TST \\
\hline CHEMBL 2094626 & 842698 & 3.9821 & 5.0328 & TST \\
\hline CHEMBL 2095057 & 842698 & 3.9821 & 4.9123 & TST \\
\hline CHEMBL 2094621 & 842698 & 3.9821 & 5.3163 & TST \\
\hline CHEMBL590199 & 842698 & 5.2916 & 6.1665 & TST \\
\hline CHEMBL 2094831 & 842698 & 5.3665 & 4.6658 & TST \\
\hline CHEMBL1446254 & 842698 & 6.3161 & 4.9596 & TST \\
\hline CHEMBL 2094465 & 842698 & 5.3089 & 4.916 & TST \\
\hline CHEMBL 2094736 & 842698 & 6.3063 & 4.7292 & TST \\
\hline CHEMBL 2094363 & 842698 & 5.2526 & 5.1637 & TST \\
\hline CHEMBL 2095122 & 842698 & 3.9821 & 5.0825 & TST \\
\hline CHEMBL 2094936 & 842698 & 3.9821 & 4.6271 & TST \\
\hline CHEMBL 2095063 & 842698 & 3.9821 & 4.8484 & TST \\
\hline CHEMBL195710 & 842698 & 9.3979 & 5.9106 & TST \\
\hline CHEMBL 2095117 & 842698 & 5.5229 & 4.5265 & TST \\
\hline CHEMBL1905963 & 842698 & 3.9821 & 5.1058 & TST \\
\hline CHEMBL 2095020 & 842698 & 3.9821 & 4.9695 & TST \\
\hline CHEMBL 2095108 & 842698 & 5.2823 & 4.638 & TST \\
\hline CHEMBL 2094805 & 842698 & 3.9821 & 4.5317 & TST \\
\hline CHEMBL 2094409 & 842698 & 3.9821 & 4.9514 & TST \\
\hline CHEMBL 2094607 & 842698 & 5.7852 & 5.2627 & TST \\
\hline CHEMBL1402404 & 842698 & 3.9821 & 5.1798 & TST \\
\hline CHEMBL 2094838 & 842698 & 3.9821 & 4.5933 & TST \\
\hline CHEMBL 2094981 & 842698 & 3.9821 & 5.3963 & TST \\
\hline CHEMBL 2094505 & 842698 & 3.9821 & 4.9204 & TST \\
\hline CHEMBL 2094495 & 842698 & 3.9821 & 4.6174 & TST \\
\hline CHEMBL592067 & 842698 & 3.9821 & 4.6848 & TST \\
\hline CHEMBL 2094527 & 842698 & 3.9821 & 4.9257 & TST \\
\hline CHEMBL 2094321 & 842698 & 5.3152 & 4.97 & TST \\
\hline CHEMBL 2094333 & 842698 & 5.71 & 5.4405 & TST \\
\hline CHEMBL 2094491 & 842698 & 3.9821 & 4.7213 & TST \\
\hline CHEMBL 2094515 & 842698 & 5.1192 & 5.3675 & TST \\
\hline
\end{tabular}


Supplemental Table S2.txt

\begin{tabular}{|c|c|c|c|c|}
\hline CHEMBL1905744 & 842698 & 5.3206 & 4.6561 & TST \\
\hline CHEMBL602579 & 842698 & 5.1733 & 5.2442 & TST \\
\hline CHEMBL 2094756 & 842698 & 3.9821 & 4.7729 & TST \\
\hline CHEMBL 2094457 & 842698 & 6.5702 & 5.0194 & TST \\
\hline CHEMBL241441 & 842698 & 7.2757 & 4.9467 & TST \\
\hline CHEMBL 2094951 & 842698 & 5.9788 & 5.1621 & TST \\
\hline CHEMBL1333049 & 842698 & 5.433 & 4.6295 & TST \\
\hline CHEMBL1472891 & 842698 & 6.1343 & 4.8699 & TST \\
\hline CHEMBL1386434 & 842698 & 3.9821 & 5.1228 & TST \\
\hline CHEMBL 2095119 & 842698 & 5.2684 & 4.6816 & TST \\
\hline CHEMBL365538 & 842698 & 6.3947 & 5.6425 & TST \\
\hline CHEMBL 2094636 & 842698 & 6.0 & 4.8356 & TST \\
\hline CHEMBL 2094566 & 842698 & 5.3382 & 4.9515 & TST \\
\hline CHEMBL 2095056 & 842698 & 6.0 & 4.574 & TST \\
\hline CHEMBL1481721 & 842698 & 3.9821 & 4.6052 & TST \\
\hline CHEMBL 2094647 & 842698 & 6.71 & 5.1969 & TST \\
\hline CHEMBL 2094858 & 842698 & 5.301 & 5.2442 & TST \\
\hline CHEMBL 2095123 & 842698 & 5.2774 & 4.6953 & TST \\
\hline CHEMBL 2094400 & 842698 & 5.3645 & 5.051 & TST \\
\hline CHEMBL 2095033 & 842698 & 3.9821 & 4.7772 & TST \\
\hline CHEMBL 2095090 & 842698 & 5.3655 & 4.4847 & TST \\
\hline CHEMBL 2094727 & 842698 & 3.9821 & 4.774 & TST \\
\hline CHEMBL 2094644 & 842698 & 5.7595 & 4.5708 & TST \\
\hline CHEMBL 2094558 & 842698 & 6.1838 & 5.3857 & TST \\
\hline CHEMBL 2094963 & 842698 & 6.1018 & 4.6478 & TST \\
\hline CHEMBL 2094832 & 842698 & 5.2976 & 5.1982 & TST \\
\hline CHEMBL 2095120 & 842698 & 5.6421 & 4.6612 & TST \\
\hline CHEMBL 2094695 & 842698 & 3.9821 & 4.9301 & TST \\
\hline CHEMBL 2094810 & 842698 & 3.9821 & 5.0153 & TST \\
\hline CHEMBL 2094825 & 842698 & 3.9821 & 4.6244 & TST \\
\hline CHEMBL 2094905 & 842698 & 5.2984 & 4.6884 & TST \\
\hline CHEMBL 2094498 & 842698 & 5.9825 & 5.0541 & TST \\
\hline CHEMBL 2094672 & 842698 & 5.4547 & 5.3254 & TST \\
\hline CHEMBL 2094578 & 842698 & 5.5952 & 5.1671 & TST \\
\hline CHEMBL 7571 & 842698 & 6.4737 & 5.225 & TST \\
\hline CHEMBL591646 & 842698 & 3.9821 & 5.0983 & TST \\
\hline CHEMBL1319708 & 842698 & 5.3316 & 4.7404 & TST \\
\hline CHEMBL 2094716 & 842698 & 5.3507 & 4.9749 & TST \\
\hline CHEMBL 2094734 & 842698 & 5.6253 & 5.2901 & TST \\
\hline CHEMBL 2094872 & 842698 & 5.3799 & 4.9969 & TST \\
\hline CHEMBL 2094628 & 842698 & 6.2708 & 5.7453 & TST \\
\hline CHEMBL 2094575 & 842698 & 3.9821 & 4.5994 & TST \\
\hline CHEMBL1392244 & 842698 & 4.9927 & 5.1554 & TST \\
\hline CHEMBL 2094584 & 842698 & 6.0 & 5.15 & TST \\
\hline CHEMBL 2094801 & 842698 & 6.983 & \multicolumn{2}{|c|}{4.906000000000001} \\
\hline CHEMBL1233867 & 842698 & 3.9821 & 4.8068 & TST \\
\hline CHEMBL 2094815 & 842698 & 5.3233 & 5.2746 & TST \\
\hline CHEMBL1511179 & 842698 & 3.9821 & 5.0925 & TST \\
\hline
\end{tabular}




\begin{tabular}{|c|c|c|c|c|c|}
\hline & & \multicolumn{4}{|c|}{ Supplemental Table S2.txt } \\
\hline CHEMBL1587430 & 842698 & 3.9821 & 4.9832 & TST & \\
\hline CHEMBL 2094935 & 842698 & 3.9821 & 4.5328 & TST & \\
\hline CHEMBL146976 & 842698 & 5.8928 & 5.1431 & TST & \\
\hline CHEMBL1417180 & 842698 & 5.58 & 5.1511 & TST & \\
\hline CHEMBL1346468 & 842698 & 5.2411 & 4.8777 & TST & \\
\hline CHEMBL 2094444 & 842698 & 3.9821 & 4.5586 & TST & \\
\hline CHEMBL 3714771 & 1536808 & 8.0 & 7.6966 & TRN & \\
\hline CHEMBL3716892 & 1536808 & 6.699 & 6.4091 & TRN & \\
\hline CHEMBL 3716447 & 1536808 & 8.0 & 7.0999 & TRN & \\
\hline CHEMBL3717942 & 1536808 & 8.0 & 7.9986 & TRN & \\
\hline CHEMBL3717691 & 1536808 & 8.0 & 7.0099 & TST & \\
\hline CHEMBL 3717170 & 1536808 & 8.0 & 8.0033 & TRN & \\
\hline CHEMBL3715109 & 1536808 & 8.0 & 8.1618 & TRN & \\
\hline CHEMBL 3717995 & 1536808 & 6.5229 & 6.4829 & TRN & \\
\hline CHEMBL 3718984 & 1536808 & 8.0 & 8.1043 & TRN & \\
\hline CHEMBL3715802 & 1536808 & 8.0 & 8.1002 & TRN & \\
\hline CHEMBL3718679 & 1536808 & 8.0 & 8.1582 & TRN & \\
\hline CHEMBL 3718389 & 1536808 & 8.0 & 7.7434 & TRN & \\
\hline CHEMBL 3715481 & 1536808 & 8.0 & 8.0955 & TRN & \\
\hline CHEMBL3718205 & 1536808 & 7.0 & 8.0737 & TST & \\
\hline CHEMBL 3715447 & 1536808 & 6.5229 & 7.1565 & TST & \\
\hline CHEMBL 3719041 & 1536808 & 8.0 & 7.8037 & TRN & \\
\hline CHEMBL 3719082 & 1536808 & 6.699 & 7.1161 & TRN & \\
\hline CHEMBL 3716137 & 1536808 & 8.0 & 7.7695 & TST & \\
\hline CHEMBL3718553 & 1536808 & 8.0 & 7.9523 & TRN & \\
\hline CHEMBL 3716347 & 1536808 & 8.0 & 8.2885 & TRN & \\
\hline CHEMBL3717989 & 1536808 & 8.0 & 8.6131 & TST & \\
\hline CHEMBL 3716782 & 1536808 & 6.699 & 7.1493 & TRN & \\
\hline CHEMBL 3718495 & 1536808 & 8.0 & 8.2812 & TRN & \\
\hline CHEMBL3716440 & 1536808 & 6.3979 & 6.6206 & TRN & \\
\hline CHEMBL3717019 & 1536808 & 6.5229 & 6.5809 & TRN & \\
\hline CHEMBL 3717290 & 1536808 & 6.5229 & 7.0207 & TST & \\
\hline CHEMBL 3716102 & 1536808 & 6.5229 & 6.8387 & TRN & \\
\hline CHEMBL3719091 & 1536808 & 7.0 & 7.5181 & TRN & \\
\hline CHEMBL 3717843 & 1536808 & 6.301 & 8.0191 & TST & \\
\hline CHEMBL3719096 & 1536808 & 6.5229 & 6.8499 & TRN & \\
\hline CHEMBL3716951 & 1536808 & 8.0 & 8.0182 & TRN & \\
\hline CHEMBL3719319 & 1536808 & 8.0 & 7.8419 & TRN & \\
\hline CHEMBL 3717619 & 1536808 & 8.0 & 8.1062 & TST & \\
\hline CHEMBL3719054 & 1536808 & 7.0 & 6.845 & TRN & \\
\hline CHEMBL3716547 & 1536808 & 8.0 & 7.38299 & 9999999999 & TRN \\
\hline CHEMBL3716346 & 1536808 & 8.0 & 7.8556 & TRN & \\
\hline CHEMBL3715386 & 1536808 & 8.0 & 8.1232 & TST & \\
\hline CHEMBL3716298 & 1536808 & 8.0 & 7.8487 & TRN & \\
\hline CHEMBL3716385 & 1536808 & 6.5229 & 7.2651 & TRN & \\
\hline CHEMBL 3717261 & 1536808 & 7.0 & 7.5586 & TRN & \\
\hline CHEMBL3716970 & 1536808 & 6.5229 & 7.3491 & TST & \\
\hline CHEMBL3715951 & 1536808 & 8.0 & 8.2564 & TRN & \\
\hline
\end{tabular}




\begin{tabular}{|c|c|c|c|c|c|}
\hline \multirow{2}{*}{ CHEMBL3718067 } & \multirow{2}{*}{1536808} & \\
\hline & & 8.0 & 7.9434 & TST & \\
\hline CHEMBL 3716850 & 1536808 & 8.0 & 7.3089 & TRN & \\
\hline CHEMBL3714916 & 1536808 & 8.0 & 7.8596 & TST & \\
\hline CHEMBL3718954 & 1536808 & 8.0 & 7.4877 & TRN & \\
\hline CHEMBL 3716279 & 1536808 & 8.0 & 7.6515 & TRN & \\
\hline CHEMBL3716959 & 1536808 & 7.0 & 7.3497 & TRN & \\
\hline CHEMBL3718650 & 1536808 & 8.0 & 8.1188 & TRN & \\
\hline CHEMBL 3715132 & 1536808 & 8.0 & 8.0754 & TRN & \\
\hline CHEMBL 3719342 & 1536808 & 8.0 & 7.2886 & TRN & \\
\hline CHEMBL3716615 & 1536808 & 8.0 & 8.0286 & TRN & \\
\hline CHEMBL 3718465 & 1536808 & 6.699 & \multicolumn{2}{|c|}{8.107000000000001} & TST \\
\hline CHEMBL 3714770 & 1536808 & 6.699 & 7.0428 & TRN & \\
\hline CHEMBL3718849 & 1536808 & 8.0 & 7.4975 & TRN & \\
\hline CHEMBL 3715431 & 1536808 & 6.5229 & \multicolumn{2}{|c|}{6.667000000000001} & TRN \\
\hline CHEMBL3715796 & 1536808 & 8.0 & \multicolumn{2}{|c|}{8.277999999999999} & TST \\
\hline CHEMBL3716177 & 1536808 & 8.0 & 7.794 & TRN & \\
\hline CHEMBL3719183 & 1536808 & 8.0 & 8.1045 & TST & \\
\hline CHEMBL 3716845 & 1536808 & 7.0 & 7.0382 & TST & \\
\hline CHEMBL 3717041 & 1536808 & 8.0 & 7.7779 & TRN & \\
\hline CHEMBL3715830 & 1536808 & 7.0 & 7.1779 & TRN & \\
\hline CHEMBL3715310 & 1536808 & 8.0 & 7.3798 & TST & \\
\hline CHEMBL3716840 & 1536808 & 6.699 & 7.1154 & TRN & \\
\hline CHEMBL3716786 & 1536808 & 8.0 & 7.5883 & TRN & \\
\hline CHEMBL3716977 & 1536808 & 8.0 & 7.8484 & TRN & \\
\hline CHEMBL 3719241 & 1536808 & 7.0 & \multicolumn{2}{|c|}{7.2860000000000005} & TRN \\
\hline CHEMBL 2165021 & 860488 & 6.9208 & 6.9435 & TRN & \\
\hline CHEMBL 2165029 & 860488 & 7.6576 & 7.6363 & TRN & \\
\hline CHEMBL 2165018 & 860488 & 7.7696 & 7.7213 & TRN & \\
\hline CHEMBL 2165270 & 860488 & 7.5528 & 7.3143 & TST & \\
\hline CHEMBL 2165271 & 860488 & 6.8239 & 6.6803 & TRN & \\
\hline CHEMBL 2165041 & 860488 & 5.0809 & 5.4276 & TST & \\
\hline CHEMBL 2165027 & 860488 & 7.3098 & 7.1882 & TRN & \\
\hline CHEMBL 2165008 & 860488 & 6.5686 & 6.6146 & TRN & \\
\hline CHEMBL 2165042 & 860488 & 5.7696 & 5.8869 & TRN & \\
\hline CHEMBL 2165048 & 860488 & 5.8861 & 6.1085 & TRN & \\
\hline CHEMBL2165019 & 860488 & 7.6576 & 7.8112 & TRN & \\
\hline CHEMBL1762782 & 860488 & 7.7959 & 7.2065 & TST & \\
\hline CHEMBL 2165038 & 860488 & 6.7212 & 6.7024 & TRN & \\
\hline CHEMBL2165013 & 860488 & 7.2147 & 7.0389 & TRN & \\
\hline CHEMBL 2165024 & 860488 & 6.6198 & 6.7016 & TRN & \\
\hline CHEMBL 2165011 & 860488 & 6.699 & 6.6245 & TRN & \\
\hline CHEMBL 2165022 & 860488 & 6.5376 & 6.5981 & TRN & \\
\hline CHEMBL 2165007 & 860488 & 8.5229 & 8.578 & TRN & \\
\hline CHEMBL2165039 & 860488 & 7.1739 & 7.0843 & TST & \\
\hline CHEMBL2165030 & 860488 & 8.301 & 8.3708 & TRN & \\
\hline CHEMBL 2165026 & 860488 & 7.2007 & 7.0133 & TRN & \\
\hline CHEMBL 2165036 & 860488 & 5.4949 & 5.3842 & TRN & \\
\hline CHEMBL 2165052 & 860488 & 7.9208 & 7.4081 & TST & \\
\hline & & & & 16575 & \\
\hline
\end{tabular}




\begin{tabular}{|c|c|c|c|c|}
\hline & & & oplement & al $\mathrm{T}$ \\
\hline CHEMBL2165269 & 860488 & 6.9586 & 7.0009 & TRN \\
\hline CHEMBL 2165009 & 860488 & 6.8239 & 6.7889 & TRN \\
\hline CHEMBL2165033 & 860488 & 8.0969 & 8.1614 & TRN \\
\hline CHEMBL2165053 & 860488 & 7.0362 & 6.7699 & TST \\
\hline CHEMBL2165010 & 860488 & 7.0 & 7.1863 & TRN \\
\hline CHEMBL2165025 & 860488 & 7.2596 & 7.2049 & TRN \\
\hline CHEMBL 2165037 & 860488 & 7.4089 & 6.7811 & TST \\
\hline CHEMBL 2165045 & 860488 & 5.3098 & 6.068 & TST \\
\hline CHEMBL 2165020 & 860488 & 8.0458 & 7.9593 & TRN \\
\hline CHEMBL 2165023 & 860488 & 6.6021 & 6.5038 & TRN \\
\hline CHEMBL2165012 & 860488 & 6.5528 & 6.5904 & TRN \\
\hline CHEMBL 2165003 & 860488 & 7.4815 & 7.5796 & TRN \\
\hline CHEMBL2165015 & 860488 & 7.0269 & 7.0529 & TRN \\
\hline CHEMBL 2165040 & 860488 & 4.0 & 4.8652 & TST \\
\hline CHEMBL 2165047 & 860488 & 6.2076 & 6.1991 & TRN \\
\hline CHEMBL2165046 & 860488 & 6.1938 & 6.2352 & TRN \\
\hline CHEMBL 2165034 & 860488 & 6.7959 & 6.6704 & TRN \\
\hline CHEMBL2165044 & 860488 & 4.0 & 5.6369 & TST \\
\hline CHEMBL2165049 & 860488 & 6.9208 & 6.9219 & TRN \\
\hline CHEMBL 2165035 & 860488 & 6.0315 & 6.1387 & TST \\
\hline CHEMBL 2165017 & 860488 & 8.0458 & 7.9278 & TRN \\
\hline CHEMBL 2165028 & 860488 & 6.5528 & 6.6035 & TRN \\
\hline CHEMBL 2165016 & 860488 & 7.0757 & 7.08 & TRN \\
\hline CHEMBL 2165005 & 860488 & 7.1367 & 7.0671 & TRN \\
\hline CHEMBL2165014 & 860488 & 6.585 & 6.7422 & TRN \\
\hline CHEMBL 2165004 & 860488 & 7.7959 & 7.8413 & TRN \\
\hline CHEMBL 2165268 & 860488 & 6.699 & 6.8714 & TST \\
\hline CHEMBL 2165006 & 860488 & 7.2291 & 7.2564 & TRN \\
\hline CHEMBL 2165043 & 860488 & 4.0 & 5.3564 & TST \\
\hline CHEMBL 2165051 & 860488 & 8.699 & 7.2813 & TST \\
\hline CHEMBL 2165032 & 860488 & 8.0969 & 8.0438 & TRN \\
\hline CHEMBL1615182 & 860488 & 6.4559 & 6.6871 & TST \\
\hline CHEMBL 2165031 & 860488 & 7.4089 & 7.3349 & TRN \\
\hline CHEMBL 2165050 & 860488 & 6.284 & 6.2979 & TRN \\
\hline CHEMBL1720380 & 954352 & 7.585 & 4.9471 & TST \\
\hline CHEMBL1458178 & 954352 & 5.5751 & 5.1391 & TST \\
\hline CHEMBL3199673 & 954352 & 6.1972 & 5.6395 & TRN \\
\hline CHEMBL577635 & 954352 & 5.7258 & 5.6252 & TST \\
\hline CHEMBL1602637 & 954352 & 5.7932 & 6.2689 & TRN \\
\hline CHEMBL2360567 & 954352 & 5.1427 & 5.2187 & TST \\
\hline CHEMBL2354530 & 954352 & 6.0 & 5.6284 & TRN \\
\hline CHEMBL1352290 & 954352 & 4.9462 & 4.9973 & TRN \\
\hline CHEMBL2355359 & 954352 & 4.9759 & 5.2447 & TRN \\
\hline CHEMBL 225903 & 954352 & 5.1746 & 4.9626 & TRN \\
\hline CHEMBL3193058 & 954352 & 5.7852 & 5.5017 & TST \\
\hline CHEMBL 2359541 & 954352 & 6.0 & 5.9046 & TRN \\
\hline CHEMBL1402055 & 954352 & 5.0434 & 5.5741 & TST \\
\hline CHEMBL1459468 & 954352 & 5.6904 & 5.5502 & TRN \\
\hline
\end{tabular}




\begin{tabular}{|c|c|c|c|c|}
\hline & & & oplement & al $\mathrm{T}$ \\
\hline CHEMBL1876267 & 954352 & 5.8539 & 5.3686 & TRN \\
\hline CHEMBL 2357983 & 954352 & 4.9115 & 4.6005 & TRN \\
\hline CHEMBL16288 & 954352 & 7.585 & 6.0061 & TST \\
\hline CHEMBL567340 & 954352 & 5.3002 & 4.8866 & TST \\
\hline CHEMBL1303426 & 954352 & 5.0472 & 4.9019 & TRN \\
\hline CHEMBL2360506 & 954352 & 4.7794 & 4.9374 & TRN \\
\hline CHEMBL 2355076 & 954352 & 4.6302 & 4.872 & TRN \\
\hline CHEMBL1466305 & 954352 & 5.7305 & 5.7214 & TRN \\
\hline CHEMBL 2354788 & 954352 & 5.1918 & 5.1457 & TRN \\
\hline CHEMBL2355498 & 954352 & 5.1864 & 5.2922 & TRN \\
\hline CHEMBL1388595 & 954352 & 5.6055 & 5.1673 & TRN \\
\hline CHEMBL1548488 & 954352 & 4.4791 & 4.8662 & TRN \\
\hline CHEMBL2355724 & 954352 & 6.0 & 5.8678 & TRN \\
\hline CHEMBL 2143950 & 954352 & 4.4496 & 5.3397 & TRN \\
\hline CHEMBL1625031 & 954352 & 5.1445 & 5.2035 & TRN \\
\hline CHEMBL1403148 & 954352 & 5.8861 & 6.1194 & TRN \\
\hline CHEMBL 2355378 & 954352 & 4.8116 & 5.1941 & TRN \\
\hline CHEMBL2361881 & 954352 & 4.7647 & 5.2865 & TRN \\
\hline CHEMBL1428437 & 954352 & 5.3556 & 4.7694 & TST \\
\hline CHEMBL2359649 & 954352 & 4.6676 & 5.1773 & TRN \\
\hline CHEMBL 2004157 & 954352 & 5.4559 & 5.9711 & TRN \\
\hline CHEMBL1518421 & 954352 & 4.3618 & 4.9013 & TRN \\
\hline CHEMBL2359974 & 954352 & 6.0 & 5.3853 & TRN \\
\hline CHEMBL2359612 & 954352 & 6.0 & 5.7809 & TRN \\
\hline CHEMBL1551808 & 954352 & 5.6925 & 5.5558 & TRN \\
\hline CHEMBL3189080 & 954352 & 5.4425 & 5.2359 & TRN \\
\hline CHEMBL 2132942 & 954352 & 4.7089 & 5.1175 & TRN \\
\hline CHEMBL1720734 & 954352 & 5.7399 & 5.8687 & TRN \\
\hline CHEMBL1886514 & 954352 & 5.2596 & 5.1829 & TRN \\
\hline CHEMBL1521433 & 954352 & 5.4647 & 5.4675 & TRN \\
\hline CHEMBL1439938 & 954352 & 5.8069 & 5.5214 & TRN \\
\hline CHEMBL2361967 & 954352 & 4.6536 & 5.2292 & TRN \\
\hline CHEMBL1359120 & 954352 & 6.1267 & 4.864 & TST \\
\hline CHEMBL1871451 & 954352 & 5.5544 & 5.2149 & TRN \\
\hline CHEMBL1727997 & 954352 & 4.8529 & 5.1229 & TRN \\
\hline CHEMBL2360114 & 954352 & 4.9727 & 5.1766 & TRN \\
\hline CHEMBL 2362273 & 954352 & 6.0 & 5.4921 & TRN \\
\hline CHEMBL3188935 & 954352 & 4.9516 & 5.7054 & TRN \\
\hline CHEMBL1471341 & 954352 & 4.7652 & 5.0565 & TRN \\
\hline CHEMBL1570958 & 954352 & 5.1232 & 5.0006 & TST \\
\hline CHEMBL 2362144 & 954352 & 5.9031 & 5.7655 & TRN \\
\hline CHEMBL1457068 & 954352 & 5.7721 & 5.6158 & TRN \\
\hline CHEMBL171699 & 954352 & 6.5317 & 6.2721 & TST \\
\hline CHEMBL2359989 & 954352 & 4.9458 & 5.3186 & TRN \\
\hline CHEMBL1544186 & 954352 & 5.2262 & 5.1617 & TRN \\
\hline CHEMBL1520774 & 954352 & 4.9169 & 5.2465 & TRN \\
\hline CHEMBL2361049 & 954352 & 6.0 & 5.6402 & TRN \\
\hline CHEMBL1472126 & 954352 & 5.6126 & 5.9599 & TRN \\
\hline
\end{tabular}




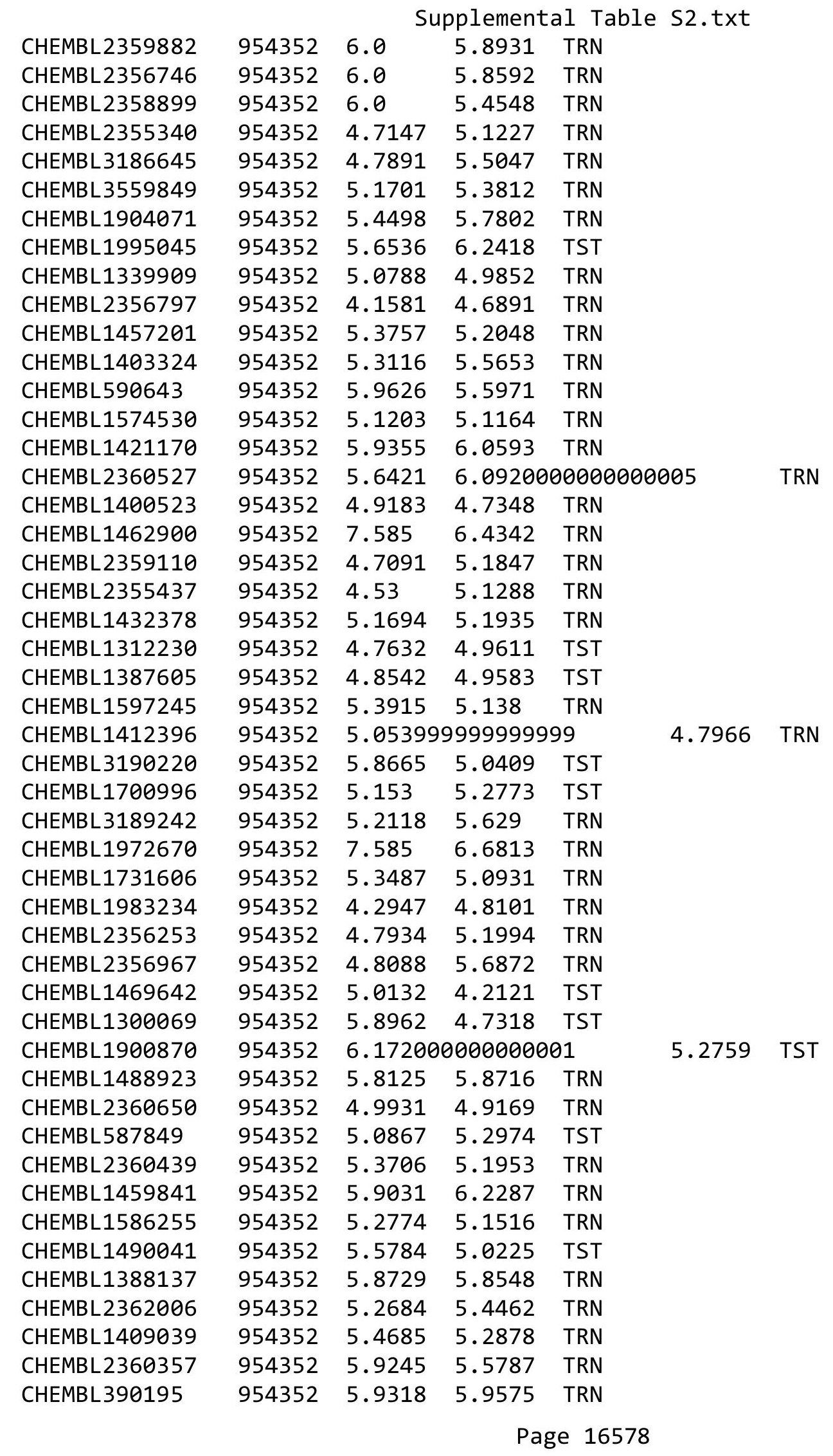


Supplemental Table S2.txt

\begin{tabular}{|c|c|c|c|c|c|}
\hline CHEMBL1734083 & 954352 & 5.8327 & 5.3472 & TST & \\
\hline CHEMBL1452421 & 954352 & 5.6126 & 5.4916 & TRN & \\
\hline CHEMBL 2359040 & 954352 & 6.0 & 5.6611 & TRN & \\
\hline CHEMBL1512775 & 954352 & 5.0516 & 5.0321 & TST & \\
\hline CHEMBL1436736 & 954352 & 5.9666 & 5.379 & TST & \\
\hline CHEMBL1596638 & 954352 & 4.2275 & \multicolumn{2}{|c|}{5.0489999999999995} & TRN \\
\hline CHEMBL 3560974 & 954352 & 4.7817 & 5.6241 & TRN & \\
\hline CHEMBL1711200 & 954352 & 5.1824 & 5.1838 & TRN & \\
\hline CHEMBL1971018 & 954352 & 5.2291 & 5.89 & TST & \\
\hline CHEMBL 2359667 & 954352 & 5.091 & 5.255 & TRN & \\
\hline CHEMBL1543417 & 954352 & 5.4191 & 5.425 & TRN & \\
\hline CHEMBL 2357075 & 954352 & 5.1278 & 4.788 & TRN & \\
\hline CHEMBL 2361755 & 954352 & 6.0 & 5.5767 & TRN & \\
\hline CHEMBL 2360741 & 954352 & 6.0 & 5.0754 & TRN & \\
\hline CHEMBL1299769 & 954352 & 5.0878 & 5.1683 & TRN & \\
\hline CHEMBL1597090 & 954352 & 4.8094 & 4.9083 & TRN & \\
\hline CHEMBL 2362650 & 954352 & 5.6073 & 5.7038 & TRN & \\
\hline CHEMBL1710184 & 954352 & 5.3665 & 5.4023 & TRN & \\
\hline CHEMBL 2358870 & 954352 & 5.2449 & 5.1692 & TRN & \\
\hline CHEMBL1515610 & 954352 & 5.063 & 4.9122 & TRN & \\
\hline CHEMBL1486329 & 954352 & 5.308 & 4.7044 & TST & \\
\hline CHEMBL 2355250 & 954352 & 5.1024 & 5.0957 & TRN & \\
\hline CHEMBL 2357399 & 954352 & 5.5143 & 5.6256 & TRN & \\
\hline CHEMBL1416856 & 954352 & 5.3595 & 5.5068 & TST & \\
\hline CHEMBL1901000 & 954352 & 6.2692 & 5.6039 & TRN & \\
\hline CHEMBL1584985 & 954352 & 5.7595 & 5.6515 & TRN & \\
\hline CHEMBL 2357916 & 954352 & 6.0 & 5.4356 & TRN & \\
\hline CHEMBL1967856 & 954352 & 5.1752 & 4.97 & TRN & \\
\hline CHEMBL1452669 & 954352 & 4.3723 & 4.9959 & TST & \\
\hline CHEMBL 2357706 & 954352 & 4.9594 & 4.453 & TRN & \\
\hline CHEMBL1327129 & 954352 & 5.0079 & 4.7824 & TRN & \\
\hline CHEMBL1362660 & 954352 & 5.5751 & 5.777 & TRN & \\
\hline CHEMBL1591205 & 954352 & 6.0 & 6.0231 & TST & \\
\hline CHEMBL1884473 & 954352 & 5.3054 & 5.7126 & TST & \\
\hline CHEMBL1521172 & 954352 & 7.585 & 6.1547 & TRN & \\
\hline CHEMBL1442136 & 954352 & 5.5467 & 6.0037 & TRN & \\
\hline CHEMBL1720547 & 954352 & 5.9508 & 5.999 & TST & \\
\hline CHEMBL 2355859 & 954352 & 6.0 & 5.6429 & TRN & \\
\hline CHEMBL 2360680 & 954352 & 6.0 & 5.3787 & TRN & \\
\hline CHEMBL1587473 & 954352 & 5.0872 & 5.4918 & TRN & \\
\hline CHEMBL1985082 & 954352 & 5.8633 & 5.0429 & TRN & \\
\hline CHEMBL1437083 & 954352 & 5.5607 & 5.0883 & TST & \\
\hline CHEMBL1337592 & 954352 & 7.301 & 6.3673 & TRN & \\
\hline CHEMBL1399757 & 954352 & 5.1733 & 5.2319 & TST & \\
\hline CHEMBL1321538 & 954352 & 5.4962 & 5.5757 & TRN & \\
\hline CHEMBL517986 & 954352 & 4.67899 & 999999999 & 5.3774 & TST \\
\hline CHEMBL1435955 & 954352 & 4.7399 & 4.6956 & TRN & \\
\hline CHEMBL 3182635 & 954352 & 4.6463 & 4.5903 & TRN & \\
\hline
\end{tabular}

Page 16579 
Supplemental Table S2.txt

\begin{tabular}{|c|c|c|c|c|}
\hline 248 & 54352 & .0273 & 5727 & TP \\
\hline HFMRI 2354757 & & 6.0 & 5.6934 & \\
\hline JFA & & & & \\
\hline HEMBL1 & & 6383 & 9055 & 2N1 \\
\hline AEMBL2354318 & 52 & 21 & 1734 & \\
\hline HEMBL 568092 & 54352 & 5.4271 & .2218 & \\
\hline HEMBL1 & & 331 & 5695 & \\
\hline AEMBL 235 & & & & \\
\hline HEMBL160 & & & .7085 & \\
\hline HEMBL148: & 52 & 67 & .104 & \\
\hline HEMBL3185154 & 2 & . 6914 & .2082 & \\
\hline AEMBL 235 & & 14 & .4135 & \\
\hline AEMBL14 & & & .6293 & RN \\
\hline HEMBL1362612 & & .4881 & 5.4452 & \\
\hline AEMBL 49 & 2 & 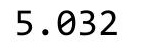 & 3955 & \\
\hline AEMBL21 & 2 & 6 & 7312 & \\
\hline HEMBL1 & & & 435 & m \\
\hline HEMBL1: & & & 5357 & \\
\hline HEMBL173 & & 7 & 6.0179 & \\
\hline AEMBL14 & & & & \\
\hline AEMBL23 & 2 & & 3162 & Trv \\
\hline AEMBL3 & & & & ST \\
\hline HEMBLI & & & 58 & \\
\hline HEMBL137 & & & 5.2293 & \\
\hline HEMBL 235 & & & & $\Gamma \mathrm{RN}$ \\
\hline HEMBL1 & & -0 & 1017 & KIV \\
\hline HEMBL2 & & & 322 & RN \\
\hline HFMBI 12 & & & 345 & \\
\hline HEMBL236 & & & & $\ln$ \\
\hline HEMBL 1383 & & & & 15 \\
\hline HEMBL 318 & & & 906 & RN \\
\hline HEMBL2 & & & 41 & RN \\
\hline HEMBL1 & & 2 & 31 & \\
\hline HEMBL1384292 & & & 5288 & $\mathrm{IR}$ \\
\hline HEMBL1865393 & & +9 & 5.6867 & TRN \\
\hline HEMBL187 & & & 635 & RN \\
\hline HEMRI 1 & & 2 & 91 & $\Gamma \mathrm{RN}$ \\
\hline HEMBL186 & & 8 & 259 & ГRN \\
\hline HEMBL1980982 & & $5.8 \varepsilon$ & 5.7812 & TST \\
\hline AEMBL28 & & & 6.0073 & TST \\
\hline HEMBL1S & & 97 & 4.9819 & PNA \\
\hline CHEMBL 23 & & & & TRN \\
\hline HEMBL1590547 & & & 4.9243 & TRN \\
\hline HEMBL1394653 & 52 & 37 & 4.9154 & TS \\
\hline MBL2: & & & 5.22 & IRN \\
\hline HEMBL 23 & & & 5.6362 & \\
\hline CHEMBL2361970 & & .5143 & 5.6125 & \\
\hline CHEMBL1990866 & 954352 & 5.7959 & 5.4551 & - \\
\hline
\end{tabular}

Page 16580 


\begin{tabular}{|c|c|c|c|c|c|c|}
\hline \multirow[b]{2}{*}{ CHEMBL1603615 } & & \multicolumn{5}{|c|}{ Supplemental Table S2.txt } \\
\hline & 954352 & 5.1593 & 4.94600 & 0000000001 & & TRN \\
\hline CHEMBL1404301 & 954352 & 4.9834 & 5.0371 & TRN & & \\
\hline CHEMBL 2362783 & 954352 & 6.0 & 5.038 & TRN & & \\
\hline CHEMBL2360055 & 954352 & 6.0 & 5.956 & TRN & & \\
\hline CHEMBL 3188673 & 954352 & 6.0 & 5.3609 & TRN & & \\
\hline CHEMBL2357026 & 954352 & 6.0 & 5.4892 & TRN & & \\
\hline CHEMBL3196760 & 954352 & 6.1379 & 6.0755 & TRN & & \\
\hline CHEMBL1427059 & 954352 & 5.2418 & 5.4844 & TRN & & \\
\hline CHEMBL1489779 & 954352 & 5.7011 & 5.9567 & TRN & & \\
\hline CHEMBL2356372 & 954352 & 4.8827 & 5.0211 & TRN & & \\
\hline CHEMBL2357993 & 954352 & 5.0443 & 5.011 & TRN & & \\
\hline CHEMBL1464024 & 954352 & 5.2725 & 5.6429 & TRN & & \\
\hline CHEMBL1589168 & 954352 & 5.1512 & 5.2668 & TST & & \\
\hline CHEMBL2356528 & 954352 & 6.0 & 6.0786 & TRN & & \\
\hline CHEMBL2359013 & 954352 & 5.1952 & 5.4478 & TRN & & \\
\hline CHEMBL3182010 & 954352 & 4.4652 & 4.9737 & TRN & & \\
\hline CHEMBL1894888 & 954352 & 5.21399 & 79999999 & 995 & 5.5507 & TRN \\
\hline CHEMBL1904111 & 954352 & 5.0052 & 5.1492 & TRN & & \\
\hline CHEMBL1985044 & 954352 & 4.8847 & 4.8422 & TRN & & \\
\hline CHEMBL 2142401 & 954352 & 4.9805 & 4.7621 & TRN & & \\
\hline CHEMBL1353013 & 954352 & 5.1487 & 4.7043 & TRN & & \\
\hline CHEMBL536166 & 954352 & 6.1694 & 6.0861 & TRN & & \\
\hline CHEMBL1536108 & 954352 & 5.2299 & 4.9765 & TRN & & \\
\hline CHEMBL1992486 & 954352 & 5.3947 & 5.7624 & TST & & \\
\hline CHEMBL1420472 & 954352 & 5.0645 & 5.4897 & TRN & & \\
\hline CHEMBL 2354745 & 954352 & 4.5552 & 5.185 & TRN & & \\
\hline CHEMBL 210868 & 954352 & 5.055 & 4.8076 & TST & & \\
\hline CHEMBL1573994 & 954352 & 6.5735 & 7.2961 & TRN & & \\
\hline CHEMBL1500335 & 954352 & 5.4473 & 5.4487 & TRN & & \\
\hline CHEMBL1347023 & 954352 & 6.1349 & 5.3311 & TRN & & \\
\hline CHEMBL 2142762 & 954352 & 4.9872 & 5.2204 & TRN & & \\
\hline CHEMBL2356076 & 954352 & 4.9547 & 4.7633 & TRN & & \\
\hline CHEMBL1574179 & 954352 & 5.2725 & 5.6273 & TST & & \\
\hline CHEMBL1475514 & 954352 & 5.5918 & 4.842 & TST & & \\
\hline CHEMBL1503359 & 954352 & 5.2426 & 5.46 & TRN & & \\
\hline CHEMBL2360631 & 954352 & 6.0 & 5.6902 & TRN & & \\
\hline CHEMBL 2357556 & 954352 & 5.2549 & 5.0234 & TRN & & \\
\hline CHEMBL1732845 & 954352 & 4.1778 & 4.6365 & TRN & & \\
\hline CHEMBL1867894 & 954352 & 5.7496 & 5.6221 & TRN & & \\
\hline CHEMBL2359997 & 954352 & 5.3883 & 5.36100 & 0000000001 & & TRN \\
\hline CHEMBL2360303 & 954352 & 6.0 & 5.5617 & TRN & & \\
\hline CHEMBL1704218 & 954352 & 4.3805 & 4.3936 & TRN & & \\
\hline CHEMBL1505552 & 954352 & 5.2284 & 5.6911 & TRN & & \\
\hline CHEMBL1445297 & 954352 & 6.1343 & 6.2489 & TRN & & \\
\hline CHEMBL 2356002 & 954352 & 6.0 & 5.7174 & TRN & & \\
\hline CHEMBL562051 & 954352 & 5.567 & 5.8151 & TRN & & \\
\hline CHEMBL 2356174 & 954352 & 6.0 & 5.8997 & TRN & & \\
\hline CHEMBL1359655 & 954352 & 5.5214 & 5.7622 & TRN & & \\
\hline
\end{tabular}




\begin{tabular}{|c|c|c|c|c|}
\hline \multicolumn{5}{|c|}{ Supplemental Table S2.txt } \\
\hline CHEMBL 2359046 & 954352 & 5.2449 & 4.8227 & TRN \\
\hline CHEMBL1443084 & 954352 & 4.8465 & 4.9219 & TST \\
\hline CHEMBL3183232 & 954352 & 5.4437 & 5.2181 & TRN \\
\hline CHEMBL 2138317 & 954352 & 5.5058 & 5.7167 & TRN \\
\hline CHEMBL1350970 & 954352 & 4.3823 & 4.4536 & TRN \\
\hline CHEMBL1728514 & 954352 & 6.4881 & 5.6034 & TST \\
\hline CHEMBL1473985 & 954352 & 5.5086 & 5.191 & TST \\
\hline CHEMBL1895200 & 954352 & 5.0128 & 5.1764 & TST \\
\hline CHEMBL1392527 & 954352 & 5.9136 & 5.8982 & TRN \\
\hline CHEMBL1506210 & 954352 & 5.2958 & 5.1312 & TST \\
\hline CHEMBL1546172 & 954352 & 5.317 & 5.391 & TST \\
\hline CHEMBL188423 & 954352 & 5.3575 & 5.2845 & TRN \\
\hline CHEMBL1531308 & 954352 & 5.0173 & 5.4833 & TRN \\
\hline CHEMBL 2355635 & 954352 & 5.3585 & 5.5044 & TRN \\
\hline CHEMBL1368103 & 954352 & 6.1494 & 5.9727 & TRN \\
\hline CHEMBL 3182148 & 954352 & 5.1433 & 5.1842 & TRN \\
\hline CHEMBL 2143863 & 954352 & 6.0 & 5.5629 & TRN \\
\hline CHEMBL3185444 & 954352 & 4.8732 & 5.1543 & TRN \\
\hline CHEMBL3561049 & 954352 & 5.1798 & 5.2636 & TRN \\
\hline CHEMBL1560870 & 954352 & 4.9851 & 5.0459 & TRN \\
\hline CHEMBL 2359438 & 954352 & 6.0 & 5.4172 & TRN \\
\hline CHEMBL 2359372 & 954352 & 6.0 & 5.3394 & TRN \\
\hline CHEMBL1583292 & 954352 & 5.8097 & 5.9015 & TST \\
\hline CHEMBL 2361365 & 954352 & 5.0942 & 5.1813 & TRN \\
\hline CHEMBL1904974 & 954352 & 6.015 & 5.5918 & TRN \\
\hline CHEMBL 2355506 & 954352 & 6.0 & 5.7233 & TRN \\
\hline CHEMBL1503659 & 954352 & 5.4724 & 5.9241 & TRN \\
\hline CHEMBL 2355203 & 954352 & 4.8589 & 5.0392 & TRN \\
\hline CHEMBL 2362010 & 954352 & 6.0 & 5.479 & TRN \\
\hline CHEMBL1998716 & 954352 & 5.6778 & 5.334 & TRN \\
\hline CHEMBL1879116 & 954352 & 5.007 & 4.6617 & TRN \\
\hline CHEMBL 2355845 & 954352 & 5.279 & 5.4116 & TRN \\
\hline CHEMBL 2357640 & 954352 & 6.0 & 5.3581 & TRN \\
\hline CHEMBL 2362772 & 954352 & 6.0 & 5.4346 & TRN \\
\hline CHEMBL1299526 & 954352 & 5.3354 & 5.2386 & TRN \\
\hline CHEMBL 2356683 & 954352 & 4.671 & 5.3549 & TRN \\
\hline CHEMBL1864760 & 954352 & 5.2581 & 5.2745 & TRN \\
\hline CHEMBL 2359622 & 954352 & 6.0 & 5.4135 & TRN \\
\hline CHEMBL3184535 & 954352 & 4.8788 & 4.2227 & TRN \\
\hline CHEMBL1559813 & 954352 & 5.0926 & 5.3985 & TRN \\
\hline CHEMBL1553368 & 954352 & 5.8508 & 5.3331 & TST \\
\hline CHEMBL1387923 & 954352 & 5.5272 & 5.415 & TRN \\
\hline CHEMBL1706082 & 954352 & 7.585 & 6.9079 & TRN \\
\hline CHEMBL 2361274 & 954352 & 5.4949 & 5.5389 & TRN \\
\hline CHEMBL 2356442 & 954352 & 6.0 & 5.5956 & TRN \\
\hline CHEMBL1698464 & 954352 & 5.5498 & 5.4623 & TRN \\
\hline CHEMBL 248564 & 954352 & 5.2652 & 5.9553 & TST \\
\hline CHEMBL1466117 & 954352 & 5.1062 & 5.2856 & TRN \\
\hline
\end{tabular}




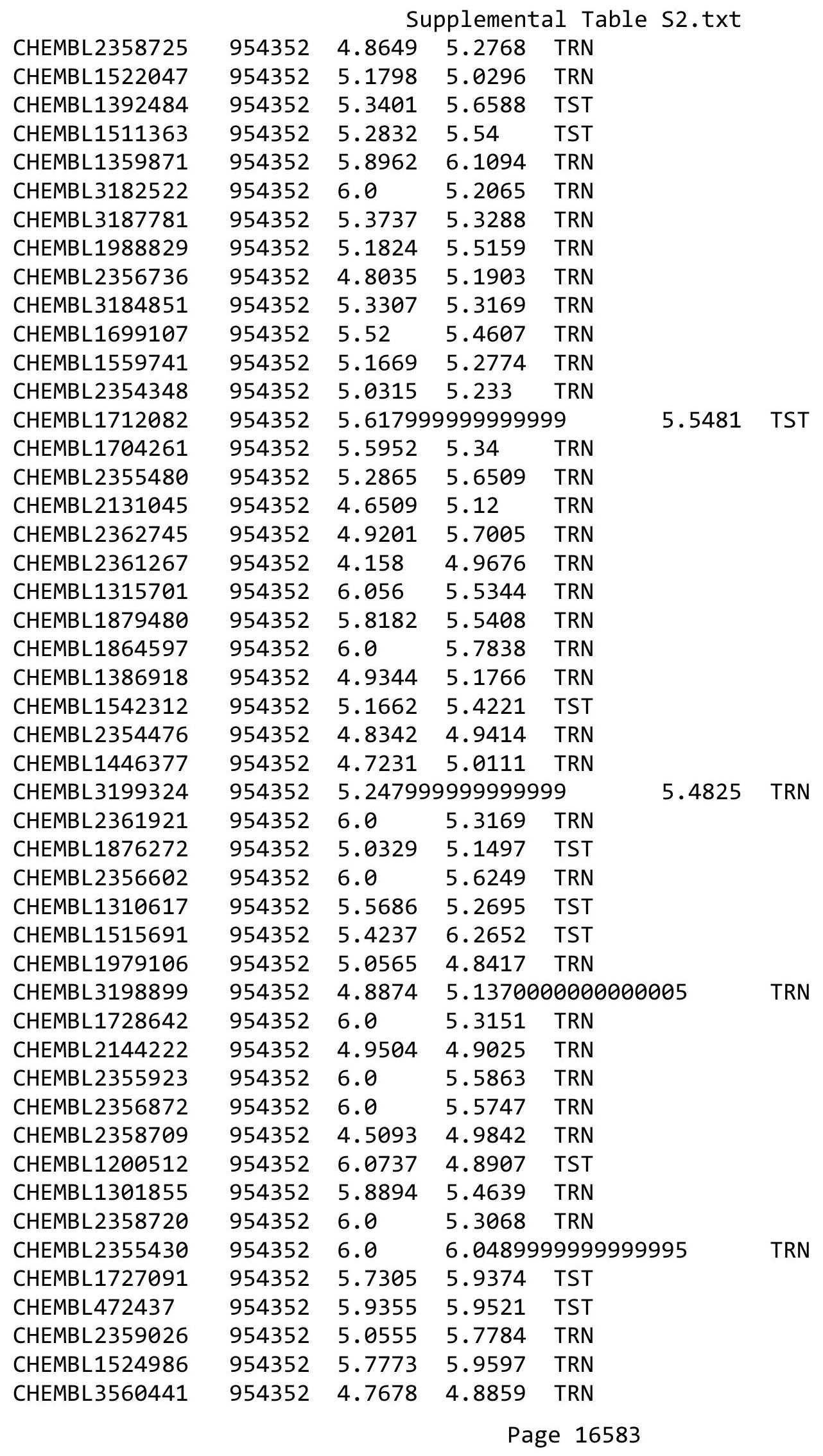




\begin{tabular}{|c|c|c|c|c|c|}
\hline \multirow[b]{2}{*}{ CHEMBL1709094 } & \multicolumn{5}{|c|}{ Supplemental Table S2.txt } \\
\hline & 954352 & 5.0061 & 5.1497 & TST & \\
\hline CHEMBL1735961 & 954352 & 4.8128 & 4.8437 & TRN & \\
\hline CHEMBL1893210 & 954352 & 5.2933 & 5.3779 & TRN & \\
\hline CHEMBL 2357597 & 954352 & 6.0 & 5.1623 & TRN & \\
\hline CHEMBL1349063 & 954352 & 6.06 & 6.3521 & TRN & \\
\hline CHEMBL 2360428 & 954352 & 6.0 & 5.4689 & TRN & \\
\hline CHEMBL 2357729 & 954352 & 4.5426 & 5.1126 & TRN & \\
\hline CHEMBL1709364 & 954352 & 7.585 & 6.7152 & TRN & \\
\hline CHEMBL1367776 & 954352 & 5.6778 & 5.5511 & TRN & \\
\hline CHEMBL1319866 & 954352 & 5.4101 & 5.0685 & TST & \\
\hline CHEMBL1877382 & 954352 & 5.1331 & 5.0044 & TST & \\
\hline CHEMBL1889303 & 954352 & 5.4413 & 5.9955 & TST & \\
\hline CHEMBL1866791 & 954352 & 5.1163 & 5.38399 & 99999999995 & TRN \\
\hline CHEMBL580918 & 954352 & 5.6271 & 6.0861 & TRN & \\
\hline CHEMBL1428368 & 954352 & 4.8716 & 4.6362 & TST & \\
\hline CHEMBL 2359335 & 954352 & 4.1797 & 4.9523 & TRN & \\
\hline CHEMBL 2357429 & 954352 & 4.9329 & 5.5742 & TRN & \\
\hline CHEMBL1905379 & 954352 & 5.5171 & 5.0938 & TST & \\
\hline CHEMBL235504 & 954352 & 5.4789 & 5.2567 & TRN & \\
\hline CHEMBL 2360750 & 954352 & 5.2306 & 5.1798 & TRN & \\
\hline CHEMBL 2358011 & 954352 & 4.8242 & 5.1987 & TRN & \\
\hline CHEMBL3391721 & 954352 & 5.7033 & 6.126 & TST & \\
\hline CHEMBL1574585 & 954352 & 4.8413 & 4.4865 & TRN & \\
\hline CHEMBL607553 & 954352 & 5.2916 & 5.3141 & TRN & \\
\hline CHEMBL1440293 & 954352 & 5.8182 & 4.7274 & TST & \\
\hline CHEMBL 2135933 & 954352 & 4.6576 & 5.0494 & TRN & \\
\hline CHEMBL 2355745 & 954352 & 6.0 & 5.8459 & TRN & \\
\hline CHEMBL26260 & 954352 & 5.2291 & 5.0825 & TST & \\
\hline CHEMBL1390112 & 954352 & 5.5214 & 5.6734 & TRN & \\
\hline CHEMBL1883309 & 954352 & 5.1878 & 5.8597 & TST & \\
\hline CHEMBL 2356728 & 954352 & 5.5017 & 5.7694 & TRN & \\
\hline CHEMBL 2355572 & 954352 & 4.9097 & 4.7714 & TRN & \\
\hline CHEMBL3391717 & 954352 & 6.4622 & 6.1855 & TST & \\
\hline CHEMBL3187662 & 954352 & 6.0 & 5.4545 & TRN & \\
\hline CHEMBL1715216 & 954352 & 4.228 & 5.0039 & TRN & \\
\hline CHEMBL330320 & 954352 & 7.585 & 6.2269 & TST & \\
\hline CHEMBL1333987 & 954352 & $5.3820 e$ & 00000000 & 5.7888 & $T E$ \\
\hline CHEMBL1500469 & 954352 & 5.644 & 5.8098 & TRN & \\
\hline CHEMBL 2354505 & 954352 & 5.2588 & 5.1462 & TRN & \\
\hline CHEMBL 2361778 & 954352 & 6.0 & 5.58299 & 9999999999 & 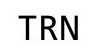 \\
\hline CHEMBL 2357924 & 954352 & 5.5258 & 5.5043 & TRN & \\
\hline CHEMBL 2362522 & 954352 & 5.1361 & 5.5275 & TRN & \\
\hline CHEMBL1712850 & 954352 & 5.5452 & 5.5828 & TRN & \\
\hline CHEMBL 2361513 & 954352 & 6.0 & 5.6223 & TRN & \\
\hline CHEMBL1485626 & 954352 & 4.9957 & 5.3132 & TRN & \\
\hline CHEMBL 2356524 & 954352 & 5.5031 & 5.8454 & TRN & \\
\hline CHEMBL 2359950 & 954352 & 6.0 & 5.8228 & TRN & \\
\hline CHEMBL1888815 & 954352 & 4.9311 & 5.8141 & TST & \\
\hline
\end{tabular}


Supplemental Table S2.txt

\begin{tabular}{|c|c|c|c|c|}
\hline CHEMBL1970422 & 954352 & 5.6596 & 6.325 & TST \\
\hline CHEMBL2357176 & 954352 & 6.0 & 5.956 & TRN \\
\hline CHEMBL1729132 & 954352 & 5.4672 & 5.7531 & TST \\
\hline CHEMBL1319018 & 954352 & 4.8989 & 5.0293 & TRN \\
\hline CHEMBL2356893 & 954352 & 5.0088 & 5.2095 & TRN \\
\hline CHEMBL1357675 & 954352 & 5.4789 & 5.4015 & TST \\
\hline CHEMBL1884966 & 954352 & 5.0535 & 5.1678 & TST \\
\hline CHEMBL 2359525 & 954352 & 4.6546 & 5.8246 & TRN \\
\hline CHEMBL257286 & 954352 & 5.1898 & 4.9194 & TRN \\
\hline CHEMBL1580784 & 954352 & 5.8013 & 5.3113 & TRN \\
\hline CHEMBL2354497 & 954352 & 6.0 & 5.7636 & TRN \\
\hline CHEMBL1588275 & 954352 & 5.0467 & 4.9108 & TRN \\
\hline CHEMBL1343490 & 954352 & 6.0429 & 5.4911 & TST \\
\hline CHEMBL3195026 & 954352 & 4.4458 & 5.1794 & TRN \\
\hline CHEMBL3192873 & 954352 & 5.2373 & 5.2754 & TRN \\
\hline CHEMBL2361773 & 954352 & 4.9446 & 5.3889 & TRN \\
\hline CHEMBL1373096 & 954352 & 5.7235 & 5.9683 & TRN \\
\hline CHEMBL3198763 & 954352 & 5.2848 & 6.2117 & TST \\
\hline CHEMBL 2358729 & 954352 & 5.4597 & 5.4859 & TRN \\
\hline CHEMBL1544836 & 954352 & 4.8383 & 4.9514 & TRN \\
\hline CHEMBL1341816 & 954352 & 5.0516 & 5.2531 & TRN \\
\hline CHEMBL 270297 & 954352 & 6.1296 & 6.3121 & TST \\
\hline CHEMBL1384845 & 954352 & 5.1445 & 4.9923 & TRN \\
\hline CHEMBL1966222 & 954352 & 5.2013 & 5.0203 & TRN \\
\hline CHEMBL1440503 & 954352 & 5.15 & 4.8556 & TST \\
\hline CHEMBL1355541 & 954352 & 7.585 & 5.8732 & TST \\
\hline CHEMBL1585185 & 954352 & 5.7077 & 4.9983 & TRN \\
\hline CHEMBL1719994 & 954352 & 5.5768 & 5.735 & TRN \\
\hline CHEMBL1489769 & 954352 & 5.4535 & 5.1296 & TST \\
\hline CHEMBL1898535 & 954352 & 5.5331 & 5.2141 & TRN \\
\hline CHEMBL2359185 & 954352 & 6.0 & 5.8165 & TRN \\
\hline CHEMBL2354622 & 954352 & 4.9901 & 4.7595 & TRN \\
\hline CHEMBL2354800 & 954352 & 5.1931 & 5.1857 & TRN \\
\hline CHEMBL1505058 & 954352 & 4.3169 & 4.8523 & TST \\
\hline CHEMBL1981797 & 954352 & 5.1568 & 5.1739 & TST \\
\hline CHEMBL1330459 & 954352 & 6.2628 & 5.9734 & TST \\
\hline CHEMBL2360307 & 954352 & 6.0 & 5.4661 & TRN \\
\hline CHEMBL2005533 & 954352 & 6.5436 & 6.0025 & TRN \\
\hline CHEMBL 2139793 & 954352 & 5.8761 & 5.9661 & TRN \\
\hline CHEMBL2360134 & 954352 & 4.8697 & 5.1084 & TRN \\
\hline CHEMBL2360326 & 954352 & 4.6726 & 5.4915 & TST \\
\hline CHEMBL1514790 & 954352 & 4.9234 & 4.66 & TRN \\
\hline CHEMBL1555935 & 954352 & 7.585 & 7.3117 & TRN \\
\hline CHEMBL3183087 & 954352 & 5.3188 & 5.5954 & TRN \\
\hline CHEMBL2136684 & 954352 & 4.8395 & 5.3316 & TRN \\
\hline CHEMBL2355890 & 954352 & 6.0 & 5.4623 & TRN \\
\hline CHEMBL2358200 & 954352 & 5.0867 & 5.7878 & TRN \\
\hline CHEMBL2356010 & 954352 & 6.0 & 5.8419 & TRN \\
\hline
\end{tabular}


Supplemental Table S2.txt

\begin{tabular}{|c|c|c|c|c|c|}
\hline CHEMBL1325021 & 954352 & 5.8069 & 5.8704 & TRN & \\
\hline CHEMBL 3189212 & 954352 & 4.5701 & 4.8684 & TRN & \\
\hline CHEMBL1904760 & 954352 & 5.8125 & 5.5559 & TRN & \\
\hline CHEMBL1971760 & 954352 & 7.585 & 5.9885 & TST & \\
\hline CHEMBL1721451 & 954352 & 5.6576 & 5.1128 & TST & \\
\hline CHEMBL 3183033 & 954352 & 4.8389 & 5.0736 & TRN & \\
\hline CHEMBL1900730 & 954352 & 5.5186 & 5.434 & TRN & \\
\hline CHEMBL2359037 & 954352 & 5.3546 & 4.9039 & TRN & \\
\hline CHEMBL1479393 & 954352 & 5.0501 & 5.0689 & TRN & \\
\hline CHEMBL 78765 & 954352 & 4.9508 & 4.9759 & TST & \\
\hline CHEMBL1419952 & 954352 & 5.2741 & 4.9355 & TST & \\
\hline CHEMBL1973122 & 954352 & 6.2426 & 5.4494 & TST & \\
\hline CHEMBL2355402 & 954352 & 6.0 & 5.2759 & TRN & \\
\hline CHEMBL1703122 & 954352 & 4.914 & 4.9593 & TRN & \\
\hline CHEMBL 2355817 & 954352 & 4.6153 & 5.2596 & TRN & \\
\hline CHEMBL509617 & 954352 & 7.585 & 6.2157 & TST & \\
\hline CHEMBL461193 & 954352 & 4.7199 & 4.6734 & TST & \\
\hline CHEMBL1430096 & 954352 & 7.585 & 7.0285 & TRN & \\
\hline CHEMBL1350915 & 954352 & 5.2798 & 4.9983 & TRN & \\
\hline CHEMBL 2355497 & 954352 & 5.1249 & 5.5141 & TRN & \\
\hline CHEMBL1698492 & 954352 & 5.0405 & 4.5314 & TRN & \\
\hline CHEMBL 2357342 & 954352 & 5.6126 & 6.0229 & TRN & \\
\hline CHEMBL1904243 & 954352 & 5.1851 & 5.7858 & TRN & \\
\hline CHEMBL2358156 & 954352 & 5.1959 & 5.38399 & 99999999995 & TRN \\
\hline CHEMBL 2360122 & 954352 & 5.3546 & 5.1982 & TRN & \\
\hline CHEMBL1864744 & 954352 & 5.6696 & 5.7967 & TRN & \\
\hline CHEMBL1728992 & 954352 & 6.3706 & 5.5695 & TST & \\
\hline CHEMBL 2359879 & 954352 & 6.0 & 5.5726 & TRN & \\
\hline CHEMBL2354341 & 954352 & 6.0 & 5.4992 & TRN & \\
\hline CHEMBL1448282 & 954352 & 5.7423 & 5.62 & TRN & \\
\hline CHEMBL1379447 & 954352 & 5.3401 & 5.2837 & TRN & \\
\hline CHEMBL 2360968 & 954352 & 5.0017 & 5.4141 & TRN & \\
\hline CHEMBL 3188797 & 954352 & 5.0311 & 5.0769 & TRN & \\
\hline CHEMBL1350432 & 954352 & 5.1238 & 4.9944 & TST & \\
\hline CHEMBL 2359785 & 954352 & 6.0 & 5.5915 & TRN & \\
\hline CHEMBL1991187 & 954352 & 4.2861 & 5.2286 & TRN & \\
\hline CHEMBL455284 & 954352 & 7.585 & 7.0856 & TRN & \\
\hline CHEMBL1321754 & 954352 & 5.2411 & 5.0201 & TRN & \\
\hline CHEMBL1904209 & 954352 & 5.8239 & 5.09699 & 99999999995 & TST \\
\hline CHEMBL1473633 & 954352 & 5.4498 & 5.1533 & TRN & \\
\hline CHEMBL2373582 & 954352 & 7.585 & 5.8467 & TST & \\
\hline CHEMBL507237 & 954352 & 7.585 & 5.7176 & TST & \\
\hline CHEMBL2361979 & 954352 & 4.7284 & 5.4465 & TRN & \\
\hline CHEMBL1520312 & 954352 & 5.9245 & 6.0099 & TRN & \\
\hline CHEMBL1971727 & 954352 & 5.0419 & 4.9773 & TRN & \\
\hline CHEMBL1481061 & 954352 & 5.4724 & 6.0192 & TST & \\
\hline CHEMBL1438210 & 954352 & 5.2534 & 5.3854 & TST & \\
\hline CHEMBL1550791 & 954352 & 4.595 & 4.8333 & TRN & \\
\hline
\end{tabular}


Supplemental Table S2.txt

\begin{tabular}{|c|c|c|c|c|c|}
\hline CHEMBL1540377 & 954352 & 5.6003 & 5.6064 & TRN & \\
\hline CHEMBL1361319 & 954352 & 5.2865 & 5.5911 & TRN & \\
\hline CHEMBL1880905 & 954352 & 5.3747 & 5.6044 & TRN & \\
\hline CHEMBL3196977 & 954352 & 5.4881 & 5.3577 & TST & \\
\hline CHEMBL 2356021 & 954352 & 5.2503 & 5.2901 & TRN & \\
\hline CHEMBL1306900 & 954352 & 5.1524 & 5.2619 & TRN & \\
\hline CHEMBL 2362397 & 954352 & 4.9743 & 4.935 & TRN & \\
\hline CHEMBL1719544 & 954352 & 5.0477 & 5.081 & TRN & \\
\hline CHEMBL 2357340 & 954352 & 5.6655 & 5.4822 & TRN & \\
\hline CHEMBL1436569 & 954352 & 5.4855 & 5.4136 & TRN & \\
\hline CHEMBL1902074 & 954352 & 5.3904 & 6.0982 & TST & \\
\hline CHEMBL 2356019 & 954352 & 5.1993 & 5.2997 & TRN & \\
\hline CHEMBL1375884 & 954352 & 5.0325 & 5.2315 & TRN & \\
\hline CHEMBL 2356820 & 954352 & 6.0 & 5.3645 & TRN & \\
\hline CHEMBL 2356752 & 954352 & 5.7423 & 5.9666 & TRN & \\
\hline CHEMBL1331598 & 954352 & 4.8041 & 4.7451 & TST & \\
\hline CHEMBL1319618 & 954352 & 5.1175 & 5.1204 & TRN & \\
\hline CHEMBL 2361179 & 954352 & 6.0 & 5.2796 & TRN & \\
\hline CHEMBL 2131973 & 954352 & 4.99100 & 00000006 & 05 & 5.5557 \\
\hline CHEMBL1304647 & 954352 & 5.3872 & 5.5132 & TRN & \\
\hline CHEMBL 2354739 & 954352 & 6.0 & 5.6257 & TRN & \\
\hline CHEMBL 2358020 & 954352 & 4.9834 & 5.4326 & TRN & \\
\hline CHEMBL1544268 & 954352 & 5.0888 & 5.0272 & TRN & \\
\hline CHEMBL1531245 & 954352 & 5.1752 & 5.4393 & TRN & \\
\hline CHEMBL1871279 & 954352 & 6.0 & 5.2124 & TRN & \\
\hline CHEMBL 2356120 & 954352 & 5.4949 & 5.5268 & TRN & \\
\hline CHEMBL 2130861 & 954352 & 5.1688 & 5.6972 & TST & \\
\hline CHEMBL1418341 & 954352 & 5.209 & 5.2531 & TRN & \\
\hline CHEMBL1424729 & 954352 & 4.6396 & 5.4991 & TST & \\
\hline CHEMBL 2354815 & 954352 & 6.0 & 5.4988 & TRN & \\
\hline CHEMBL3191855 & 954352 & 5.7305 & 5.641 & TRN & \\
\hline CHEMBL1722325 & 954352 & 5.3261 & 6.4341 & TST & \\
\hline CHEMBL1700268 & 954352 & 6.0794 & 6.1126 & TST & \\
\hline CHEMBL2358604 & 954352 & 4.5602 & 4.6478 & TRN & \\
\hline CHEMBL 2359502 & 954352 & 6.0 & 5.5956 & TRN & \\
\hline CHEMBL1491792 & 954352 & 4.1859 & 5.0745 & TRN & \\
\hline CHEMBL1704298 & 954352 & 5.1124 & 5.4316 & TRN & \\
\hline CHEMBL1438038 & 954352 & 4.8674 & 5.3496 & TRN & \\
\hline CHEMBL1504077 & 954352 & 4.9842 & 4.9289 & TRN & \\
\hline CHEMBL 2361240 & 954352 & 6.0 & 5.4689 & TRN & \\
\hline CHEMBL 2361658 & 954352 & 6.3325 & 5.8313 & TRN & \\
\hline CHEMBL1524431 & 954352 & 5.224 & 5.6632 & TRN & \\
\hline CHEMBL 2356523 & 954352 & 5.5129 & 5.8459 & TRN & \\
\hline CHEMBL1376166 & 954352 & 5.4248 & 6.0161 & TRN & \\
\hline CHEMBL1472681 & 954352 & 5.5331 & 5.6843 & TRN & \\
\hline CHEMBL 2132817 & 954352 & 5.0482 & 5.1258 & TRN & \\
\hline CHEMBL1499914 & 954352 & 5.6289 & 5.0756 & TRN & \\
\hline CHEMBL 2360927 & 954352 & 6.0 & 5.8539 & TRN & \\
\hline
\end{tabular}


Supplemental Table S2.txt

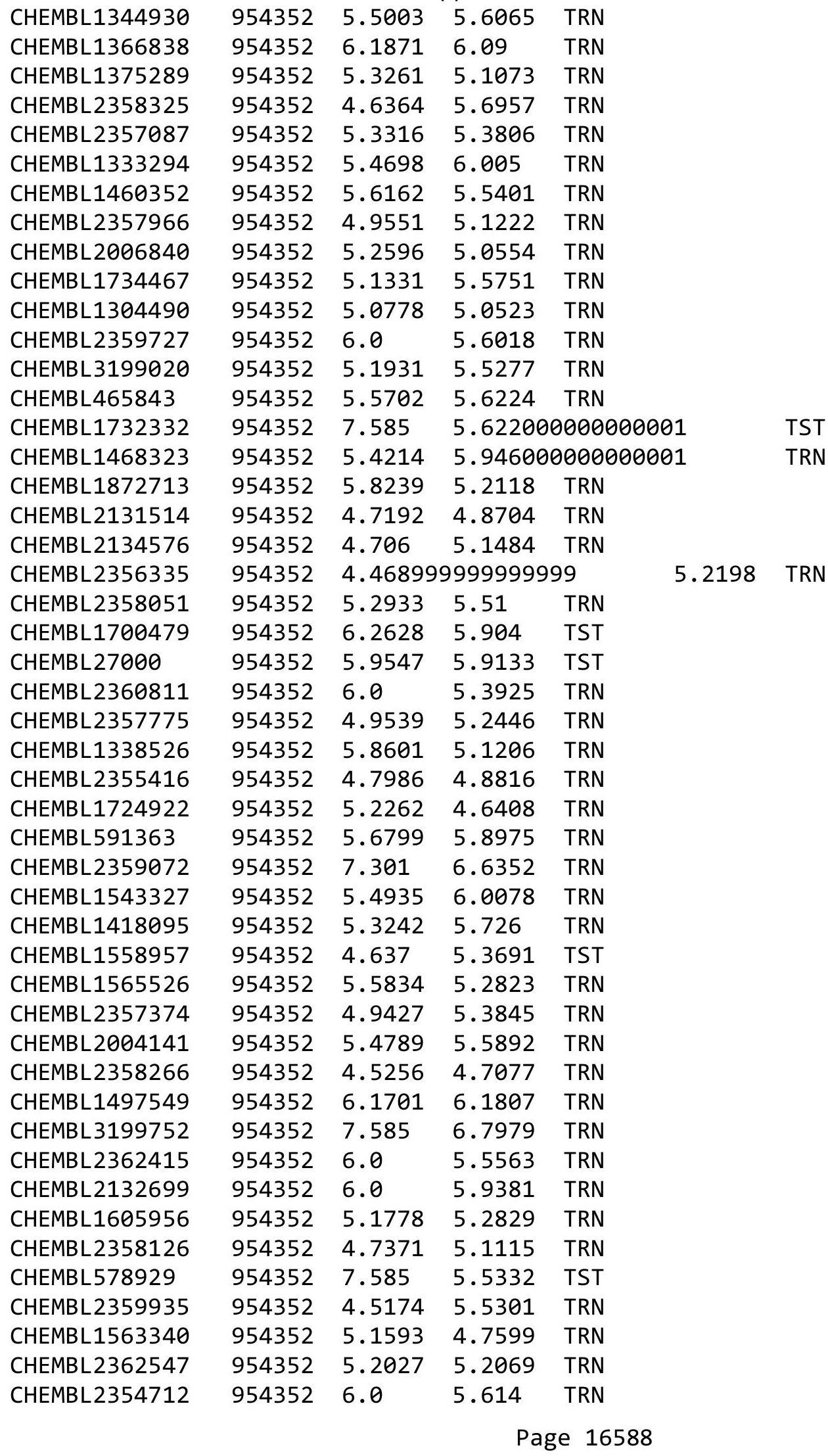




\begin{tabular}{|c|c|c|c|c|c|}
\hline \multirow[b]{2}{*}{ CHEMBL1622981 } & \multicolumn{5}{|c|}{ Supplemental Table S2.txt } \\
\hline & 954352 & 5.0526 & 5.479 & TRN & \\
\hline CHEMBL 2362032 & 954352 & 4.23 & 4.9114 & TRN & \\
\hline CHEMBL2359591 & 954352 & 6.0 & 5.4792 & TRN & \\
\hline CHEMBL2356947 & 954352 & 6.0 & 5.7113 & TRN & \\
\hline CHEMBL1490308 & 954352 & 5.2118 & 5.1177 & TST & \\
\hline CHEMBL1379675 & 954352 & 5.4202 & 5.3331 & TRN & \\
\hline CHEMBL1339433 & 954352 & 4.828 & 5.0653 & TRN & \\
\hline CHEMBL1560774 & 954352 & 5.3595 & 5.2275 & TRN & \\
\hline CHEMBL1897145 & 954352 & 5.7747 & 5.3438 & TRN & \\
\hline CHEMBL1332565 & 954352 & 6.032 & 5.8952 & TRN & \\
\hline CHEMBL1903021 & 954352 & 5.2 & 5.1248 & TRN & \\
\hline CHEMBL1501466 & 954352 & 5.2733 & 4.5428 & TRN & \\
\hline CHEMBL1592124 & 954352 & 6.2083 & 6.0956 & TRN & \\
\hline CHEMBL 2359448 & 954352 & 4.7655 & 4.6823 & TRN & \\
\hline CHEMBL1412039 & 954352 & 5.1931 & 5.0801 & TRN & \\
\hline CHEMBL2355758 & 954352 & 6.0 & 5.6541 & TRN & \\
\hline CHEMBL 2358486 & 954352 & 4.9314 & 5.3734 & TRN & \\
\hline CHEMBL2358447 & 954352 & 4.7673 & 5.62 & TRN & \\
\hline CHEMBL2360282 & 954352 & 5.1878 & 5.4621 & TRN & \\
\hline CHEMBL1730515 & 954352 & 5.4045 & 5.24799 & 9999999999 & TRN \\
\hline CHEMBL2356186 & 954352 & 5.9355 & 5.5662 & TRN & \\
\hline CHEMBL1898104 & 954352 & 5.5346 & 5.1302 & TRN & \\
\hline CHEMBL 2357404 & 954352 & 6.0 & 6.1818 & TRN & \\
\hline CHEMBL1565895 & 954352 & 4.9813 & 5.1889 & TRN & \\
\hline CHEMBL2357811 & 954352 & 6.0 & 5.7725 & TRN & \\
\hline CHEMBL1598445 & 954352 & 5.38299 & 79999999 & 5.2683 & TRN \\
\hline CHEMBL 2359728 & 954352 & 5.2557 & 5.3109 & TRN & \\
\hline CHEMBL1542823 & 954352 & 4.3912 & 5.1815 & TST & \\
\hline CHEMBL2359952 & 954352 & 6.0 & 5.2453 & TRN & \\
\hline CHEMBL 21677 & 954352 & 5.2426 & 4.9545 & TST & \\
\hline CHEMBL1316831 & 954352 & 5.5467 & 6.4837 & TST & \\
\hline CHEMBL 2139743 & 954352 & 6.0 & 5.0192 & TRN & \\
\hline CHEMBL 2140121 & 954352 & 4.6033 & 4.6292 & TST & \\
\hline CHEMBL2360805 & 954352 & 5.2457 & 5.0109 & TRN & \\
\hline CHEMBL 2356860 & 954352 & 5.2388 & 5.4226 & TRN & \\
\hline CHEMBL1493437 & 954352 & 4.8202 & 4.6169 & TRN & \\
\hline CHEMBL 2357765 & 954352 & 6.0 & 5.3362 & TRN & \\
\hline CHEMBL1903878 & 954352 & 5.0424 & 5.0348 & TRN & \\
\hline CHEMBL3194269 & 954352 & 5.5436 & 6.0559 & TST & \\
\hline CHEMBL1543215 & 954352 & 5.4522 & 5.4264 & TRN & \\
\hline CHEMBL1559529 & 954352 & 5.2899 & 5.0967 & TRN & \\
\hline CHEMBL1589062 & 954352 & 4.8901 & 5.1039 & TST & \\
\hline CHEMBL404613 & 954352 & 7.585 & 5.7608 & TST & \\
\hline CHEMBL1487345 & 954352 & 5.2182 & 5.3684 & TRN & \\
\hline CHEMBL1898569 & 954352 & 5.0292 & 5.313 & TST & \\
\hline CHEMBL1350192 & 954352 & 5.7471 & 5.7132 & TRN & \\
\hline CHEMBL1720389 & 954352 & 4.8857 & 4.9003 & TRN & \\
\hline CHEMBL1714885 & 954352 & 5.1911 & 5.2713 & TST & \\
\hline
\end{tabular}




\begin{tabular}{|c|c|c|c|c|}
\hline & & & oplement & al $\mathrm{T}$ \\
\hline CHEMBL 2362170 & 954352 & 4.9255 & 5.3691 & TRN \\
\hline CHEMBL 2357149 & 954352 & 4.6782 & 5.2738 & TRN \\
\hline CHEMBL1416026 & 954352 & 4.5669 & 5.6311 & TST \\
\hline CHEMBL1966062 & 954352 & 7.585 & 5.8435 & TST \\
\hline CHEMBL18936 & 954352 & 7.585 & 5.6746 & TST \\
\hline CHEMBL3392492 & 954352 & 5.2306 & 5.1056 & TRN \\
\hline CHEMBL1965758 & 954352 & 5.5391 & 5.4545 & TRN \\
\hline CHEMBL2358913 & 954352 & 6.0 & 5.1519 & TRN \\
\hline CHEMBL1477197 & 954352 & 5.2692 & 5.4744 & TRN \\
\hline CHEMBL1878940 & 954352 & 4.9923 & 5.2857 & TST \\
\hline CHEMBL1590402 & 954352 & 5.4056 & 5.2585 & TRN \\
\hline CHEMBL1561133 & 954352 & 4.7585 & 4.6001 & TST \\
\hline CHEMBL1553183 & 954352 & 5.4486 & 4.827 & TST \\
\hline CHEMBL2355205 & 954352 & 6.0 & 5.4896 & TRN \\
\hline CHEMBL1450797 & 954352 & 5.129 & 5.1536 & TRN \\
\hline CHEMBL1534838 & 954352 & 4.7857 & 5.0842 & TRN \\
\hline CHEMBL 2359840 & 954352 & 6.0 & 5.4562 & TRN \\
\hline CHEMBL3190095 & 954352 & 5.4157 & 5.0298 & TST \\
\hline CHEMBL1607801 & 954352 & 5.7852 & 6.4204 & TRN \\
\hline CHEMBL1301164 & 954352 & 5.1062 & 5.1367 & TRN \\
\hline CHEMBL 2358823 & 954352 & 6.0 & 5.9442 & TRN \\
\hline CHEMBL1873627 & 954352 & 4.6558 & 5.1409 & TRN \\
\hline CHEMBL1617452 & 954352 & 5.3215 & 5.221 & TRN \\
\hline CHEMBL3188780 & 954352 & 4.967 & 5.5533 & TRN \\
\hline CHEMBL1723226 & 954352 & 4.9851 & 5.5968 & TRN \\
\hline CHEMBL2359007 & 954352 & 4.575 & 5.1721 & TRN \\
\hline CHEMBL 2361216 & 954352 & 6.0 & 5.5774 & TRN \\
\hline CHEMBL 2354903 & 954352 & 4.6635 & 5.1336 & TRN \\
\hline CHEMBL1698715 & 954352 & 5.4353 & 5.2648 & TST \\
\hline CHEMBL1719004 & 954352 & 5.8182 & 6.3787 & TST \\
\hline CHEMBL1513608 & 954352 & 5.0894 & 4.9605 & TST \\
\hline CHEMBL1480031 & 954352 & 5.1073 & 5.3397 & TRN \\
\hline CHEMBL 2137915 & 954352 & 5.7986 & 5.8068 & TRN \\
\hline CHEMBL1499998 & 954352 & 4.7097 & 4.8527 & TRN \\
\hline CHEMBL 2356480 & 954352 & 6.0 & 5.6981 & TRN \\
\hline CHEMBL1362287 & 954352 & 5.4214 & 6.0271 & TST \\
\hline CHEMBL1557727 & 954352 & 5.2749 & 5.7072 & TRN \\
\hline CHEMBL1338085 & 954352 & 5.2269 & 5.1483 & TRN \\
\hline CHEMBL1496788 & 954352 & 5.4672 & 5.0522 & TST \\
\hline CHEMBL1889001 & 954352 & 5.1605 & 5.4529 & TRN \\
\hline CHEMBL2356345 & 954352 & 6.0 & 5.5481 & TRN \\
\hline CHEMBL2358863 & 954352 & 4.7627 & 4.7377 & TRN \\
\hline CHEMBL2357977 & 954352 & 6.0 & 5.5735 & TRN \\
\hline CHEMBL1487099 & 954352 & 5.5376 & 5.9069 & TST \\
\hline CHEMBL1301748 & 954352 & 4.5795 & 4.8807 & TRN \\
\hline CHEMBL1379604 & 954352 & 5.2034 & 5.2784 & TRN \\
\hline CHEMBL1451348 & 954352 & 5.1361 & 5.3363 & TRN \\
\hline CHEMBL1706279 & 954352 & 7.585 & 5.8875 & TST \\
\hline
\end{tabular}


Supplemental Table S2.txt

\begin{tabular}{|c|c|c|c|c|c|}
\hline CHEMBL1528275 & 954352 & 5.0329 & 4.6863 & TRN & \\
\hline CHEMBL1579170 & 954352 & 5.1898 & 4.898 & TRN & \\
\hline CHEMBL2355530 & 954352 & 6.0 & 4.829 & TRN & \\
\hline CHEMBL1884846 & 954352 & 5.5406 & 5.6207 & TRN & \\
\hline CHEMBL156174 & 954352 & 4.9784 & 4.9642 & TRN & \\
\hline CHEMBL 2358544 & 954352 & 4.2964 & 4.3763 & TRN & \\
\hline CHEMBL1335110 & 954352 & 5.556 & 4.9518 & TST & \\
\hline CHEMBL2360990 & 954352 & 5.644 & 5.8517 & TRN & \\
\hline CHEMBL2354647 & 954352 & 6.0 & 5.7636 & TRN & \\
\hline CHEMBL2358923 & 954352 & 4.7846 & 5.0322 & TRN & \\
\hline CHEMBL1314191 & 954352 & 5.3279 & 5.3111 & TRN & \\
\hline CHEMBL1558065 & 954352 & 5.7399 & 5.3631 & TRN & \\
\hline CHEMBL1360862 & 954352 & 5.1605 & 5.0155 & TRN & \\
\hline CHEMBL2359257 & 954352 & 5.295 & 5.2592 & TRN & \\
\hline CHEMBL1444103 & 954352 & 5.2255 & 5.58 & TST & \\
\hline CHEMBL1427279 & 954352 & 5.4473 & 5.1278 & TRN & \\
\hline CHEMBL1305372 & 954352 & 5.2976 & 5.19799 & 99999999995 & TRN \\
\hline CHEMBL2359846 & 954352 & 5.2111 & 4.9362 & TRN & \\
\hline CHEMBL2361605 & 954352 & 5.426 & 5.4764 & TRN & \\
\hline CHEMBL2361002 & 954352 & 6.0 & 5.6347 & TRN & \\
\hline CHEMBL 2359250 & 954352 & 6.0 & 5.9592 & TRN & \\
\hline CHEMBL1731329 & 954352 & 5.1605 & 4.8037 & TRN & \\
\hline CHEMBL 2362454 & 954352 & 5.3788 & 5.7256 & TRN & \\
\hline CHEMBL1899873 & 954352 & 5.4572 & 5.2743 & TRN & \\
\hline CHEMBL2362628 & 954352 & 5.8041 & 5.4251 & TRN & \\
\hline CHEMBL 2355771 & 954352 & 5.3125 & 5.445 & TRN & \\
\hline CHEMBL2355664 & 954352 & 6.0 & 5.8497 & TRN & \\
\hline CHEMBL1891222 & 954352 & 5.3134 & 5.2705 & TRN & \\
\hline CHEMBL 2136180 & 954352 & 6.0 & 5.9757 & TRN & \\
\hline CHEMBL2362817 & 954352 & 4.8492 & 4.9805 & TRN & \\
\hline CHEMBL1413839 & 954352 & 5.1694 & 5.2202 & TRN & \\
\hline CHEMBL2361273 & 954352 & 5.1759 & 4.9656 & TRN & \\
\hline CHEMBL2362904 & 954352 & 6.0 & 6.0359 & TRN & \\
\hline CHEMBL2358940 & 954352 & 6.0 & 5.8923 & TRN & \\
\hline CHEMBL2354680 & 954352 & 4.2054 & 4.8753 & TRN & \\
\hline CHEMBL1897634 & 954352 & 5.767 & 6.1659 & TST & \\
\hline CHEMBL1867000 & 954352 & 6.1051 & 5.9243 & TST & \\
\hline CHEMBL56897 & 954352 & 5.5017 & 5.9005 & TST & \\
\hline CHEMBL2357390 & 954352 & 5.4672 & 5.3991 & TRN & \\
\hline CHEMBL1519285 & 954352 & 5.6271 & 5.534 & TRN & \\
\hline CHEMBL 2361677 & 954352 & 4.7385 & 4.6152 & TRN & \\
\hline CHEMBL1990598 & 954352 & 6.0696 & 5.4359 & TST & \\
\hline CHEMBL2360276 & 954352 & 4.8356 & 5.4798 & TRN & \\
\hline CHEMBL1901984 & 954352 & \multicolumn{3}{|c|}{5.752000000000001} & TST \\
\hline CHEMBL1723395 & 954352 & 5.061 & 5.1854 & TRN & \\
\hline CHEMBL 2357163 & 954352 & 6.0 & 5.9043 & TRN & \\
\hline CHEMBL2356655 & 954352 & 4.8639 & 5.4559 & TRN & \\
\hline CHEMBL2359515 & 954352 & 6.0 & 5.2857 & TRN & \\
\hline
\end{tabular}




\begin{tabular}{|c|c|c|c|c|}
\hline & & \multicolumn{3}{|c|}{ Supplemental Table s2.txt } \\
\hline CHEMBL1305642 & 954352 & 5.2882 & 5.1747 & TRN \\
\hline CHEMBL2354467 & 954352 & 5.0991 & 5.2018 & TRN \\
\hline CHEMBL1873644 & 954352 & 7.585 & 5.5226 & TST \\
\hline CHEMBL2358490 & 954352 & 6.0 & 6.1686 & TRN \\
\hline CHEMBL3392476 & 954352 & 5.0931 & 5.1871 & TRN \\
\hline CHEMBL1901008 & 954352 & 5.4202 & 5.5456 & TRN \\
\hline CHEMBL1499306 & 954352 & 5.5003 & 5.025 & TRN \\
\hline CHEMBL1350867 & 954352 & 4.1919 & 4.9146 & TRN \\
\hline CHEMBL2361591 & 954352 & 6.0 & 5.4733 & TRN \\
\hline CHEMBL1502512 & 954352 & 5.301 & 5.1517 & TST \\
\hline CHEMBL1524929 & 954352 & 5.433 & 5.4658 & TRN \\
\hline CHEMBL1478228 & 954352 & 4.202 & 5.3833 & TST \\
\hline CHEMBL1602800 & 954352 & 5.2941 & 5.2509 & TRN \\
\hline CHEMBL1881977 & 954352 & 5.6819 & 5.8217 & TRN \\
\hline CHEMBL1461730 & 954352 & 5.8996 & 6.0165 & TRN \\
\hline CHEMBL1893035 & 954352 & 4.2668 & 5.0839 & TST \\
\hline CHEMBL3194248 & 954352 & 5.3556 & 5.7039 & TRN \\
\hline CHEMBL2356215 & 954352 & 4.9727 & 5.4314 & TRN \\
\hline CHEMBL2358498 & 954352 & 6.0 & 5.2451 & TRN \\
\hline CHEMBL1552018 & 954352 & 5.266 & 5.1775 & TRN \\
\hline CHEMBL1352668 & 954352 & 4.8108 & 5.0103 & TRN \\
\hline CHEMBL1428095 & 954352 & 5.0061 & 5.1891 & TRN \\
\hline CHEMBL 2356397 & 954352 & 6.0 & 5.8657 & TRN \\
\hline CHEMBL1902079 & 954352 & 4.691 & 4.8294 & TRN \\
\hline CHEMBL2360358 & 954352 & 5.0467 & 5.3083 & TRN \\
\hline CHEMBL1499804 & 954352 & 5.1931 & 5.192 & TRN \\
\hline CHEMBL1414311 & 954352 & 5.1726 & 5.2267 & TRN \\
\hline CHEMBL102714 & 954352 & 5.3363 & 5.6383 & TRN \\
\hline CHEMBL3561089 & 954352 & 4.6826 & 5.5103 & TRN \\
\hline CHEMBL2356813 & 954352 & 5.2882 & 5.13899 & 9999999999 \\
\hline CHEMBL3183001 & 954352 & 6.0 & 5.4461 & TRN \\
\hline CHEMBL2361222 & 954352 & 6.0 & 5.5684 & TRN \\
\hline CHEMBL1418818 & 954352 & 5.1952 & 5.2448 & TRN \\
\hline CHEMBL1874983 & 954352 & 5.4225 & 5.3548 & TRN \\
\hline CHEMBL 2360720 & 954352 & 6.0 & 5.5544 & TRN \\
\hline CHEMBL1407961 & 954352 & 5.2464 & 5.5905 & TRN \\
\hline CHEMBL 2354922 & 954352 & 6.0 & 5.4041 & TRN \\
\hline CHEMBL3198633 & 954352 & 7.585 & 5.9125 & TST \\
\hline CHEMBL2132750 & 954352 & 5.224 & 5.3137 & TRN \\
\hline CHEMBL535307 & 954352 & 7.585 & 6.4289 & TST \\
\hline CHEMBL1611182 & 954352 & 5.1403 & 5.0085 & TRN \\
\hline CHEMBL 2358308 & 954352 & 6.0 & 5.6084 & TRN \\
\hline CHEMBL1581949 & 954352 & 5.5784 & 5.4335 & TRN \\
\hline CHEMBL1733422 & 954352 & 5.7033 & 5.5277 & TRN \\
\hline CHEMBL2355936 & 954352 & 4.2428 & 5.1151 & TRN \\
\hline CHEMBL2361342 & 954352 & 6.0 & 5.2547 & TRN \\
\hline CHEMBL2361796 & 954352 & 6.0 & 5.7822 & TRN \\
\hline CHEMBL1873119 & 954352 & 5.7595 & 5.4572 & TST \\
\hline
\end{tabular}


Supplemental Table S2.txt

\begin{tabular}{|c|c|c|c|c|c|}
\hline CHEMBL1321427 & 954352 & 6.0357 & 6.4732 & TRN & \\
\hline CHEMBL1361509 & 954352 & 5.5751 & 5.1947 & TRN & \\
\hline CHEMBL1704382 & 954352 & 4.7742 & 5.0306 & TST & \\
\hline CHEMBL1481390 & 954352 & 4.8225 & 4.9435 & TRN & \\
\hline CHEMBL 2358998 & 954352 & 4.6459 & 5.1743 & TRN & \\
\hline CHEMBL 2361680 & 954352 & 5.1308 & 5.5949 & TRN & \\
\hline CHEMBL 2356549 & 954352 & 5.0516 & 4.9731 & TRN & \\
\hline CHEMBL 3186447 & 954352 & 6.0 & 5.5689 & TRN & \\
\hline CHEMBL 2354376 & 954352 & 4.9281 & 5.056999 & 9999999995 & TRN \\
\hline CHEMBL1402767 & 954352 & 4.4578 & 5.4858 & TST & \\
\hline CHEMBL1875746 & 954352 & 5.3788 & 5.1626 & TRN & \\
\hline CHEMBL1423192 & 954352 & 5.301 & 5.5966 & TRN & \\
\hline CHEMBL 2356611 & 954352 & 4.9996 & 5.4874 & TRN & \\
\hline CHEMBL3191107 & 954352 & 6.1593 & 5.8322 & TRN & \\
\hline CHEMBL213580 & 954352 & 5.0872 & 4.7912 & TRN & \\
\hline CHEMBL1352995 & 954352 & 4.8459 & 5.0097 & TRN & \\
\hline CHEMBL1864580 & 954352 & 5.2168 & 5.1109 & TST & \\
\hline CHEMBL 2357642 & 954352 & 6.0 & 5.3401 & TRN & \\
\hline CHEMBL1727847 & 954352 & 7.585 & 5.718 & TST & \\
\hline CHEMBL1481849 & 954352 & 5.0031 & 4.9806 & TRN & \\
\hline CHEMBL 2359710 & 954352 & 4.71 & 5.3227 & TRN & \\
\hline CHEMBL1312935 & 954352 & 6.2573 & 5.2327 & TST & \\
\hline CHEMBL1716326 & 954352 & 5.2549 & 5.0955 & TST & \\
\hline CHEMBL1537190 & 954352 & 5.0878 & 5.0559 & TRN & \\
\hline CHEMBL1337726 & 954352 & 5.1175 & 5.6362 & TRN & \\
\hline CHEMBL 2132745 & 954352 & 4.9151 & 4.6719 & TRN & \\
\hline CHEMBL1400861 & 954352 & 4.637 & 4.8399 & TST & \\
\hline CHEMBL1413931 & 954352 & 5.1129 & 4.7537 & TRN & \\
\hline CHEMBL1725454 & 954352 & 7.585 & 6.0479 & TST & \\
\hline CHEMBL1731294 & 954352 & 5.1278 & 5.21 & TRN & \\
\hline CHEMBL 2355313 & 954352 & 6.0 & 5.4617 & TRN & \\
\hline CHEMBL3190804 & 954352 & 5.5686 & 5.3343 & TRN & \\
\hline CHEMBL 2360167 & 954352 & 5.2306 & 5.4198 & TRN & \\
\hline CHEMBL 2360341 & 954352 & 6.0 & 6.0212 & TRN & \\
\hline CHEMBL 2360842 & 954352 & 6.0 & 5.8938 & TRN & \\
\hline CHEMBL1560933 & 954352 & 5.1215 & 4.7492 & TRN & \\
\hline CHEMBL1511179 & 954352 & 5.5346 & 5.3455 & TRN & \\
\hline CHEMBL1378851 & 954352 & 5.382006 & 000000000 & 4.7616 & וSI \\
\hline CHEMBL1613147 & 954352 & 5.4145 & 5.6353 & TRN & \\
\hline CHEMBL551783 & 954352 & 5.4572 & 5.7343 & TRN & \\
\hline CHEMBL 2360462 & 954352 & 4.9834 & 5.2677 & TRN & \\
\hline CHEMBL585827 & 954352 & 5.4895 & 5.5066 & TRN & \\
\hline CHEMBL1499951 & 954352 & 5.1772 & 5.3205 & TRN & \\
\hline CHEMBL1320274 & 954352 & 5.0022 & 5.2392 & TRN & \\
\hline CHEMBL 2357864 & 954352 & 4.6194 & 5.5345 & TST & \\
\hline CHEMBL 2357535 & 954352 & 6.0 & 5.6823 & TRN & \\
\hline CHEMBL 2360228 & 954352 & 4.7657 & 5.1479 & TRN & \\
\hline CHEMBL 2357369 & 954352 & 6.0 & 5.6632 & TRN & \\
\hline
\end{tabular}




\begin{tabular}{|c|c|c|c|c|c|}
\hline \multirow[b]{2}{*}{ CHEMBL1728866 } & \multicolumn{5}{|c|}{ Supplemental Table S2.txt } \\
\hline & 954352 & 7.585 & 6.5384 & TRN & \\
\hline CHEMBL 2358546 & 954352 & 6.0 & 5.8853 & TRN & \\
\hline CHEMBL1882616 & 954352 & 7.585 & 5.9364 & TST & \\
\hline CHEMBL2362598 & 954352 & 5.4365 & 5.3936 & TRN & \\
\hline CHEMBL 2137170 & 954352 & 5.399 & 5.6074 & TRN & \\
\hline CHEMBL3208866 & 954352 & $4.4430 €$ & 00000000 & 205 & TST \\
\hline CHEMBL1582221 & 954352 & 5.3372 & 5.4259 & TRN & \\
\hline CHEMBL2360426 & 954352 & 6.0 & 5.5522 & TRN & \\
\hline CHEMBL3188924 & 954352 & 4.6629 & 5.3541 & TRN & \\
\hline CHEMBL 2357876 & 954352 & 4.4969 & 4.8706 & TRN & \\
\hline CHEMBL 2141584 & 954352 & 4.6639 & 4.9165 & TRN & \\
\hline CHEMBL 2361807 & 954352 & 6.0 & 5.6066 & TRN & \\
\hline CHEMBL2356837 & 954352 & 4.9087 & 5.0838 & TRN & \\
\hline CHEMBL 2360345 & 954352 & 4.6358 & 5.3281 & TRN & \\
\hline CHEMBL2355931 & 954352 & 4.6659 & 4.8868 & TRN & \\
\hline CHEMBL1889837 & 954352 & 5.1101 & 4.7741 & TRN & \\
\hline CHEMBL1427180 & 954352 & 4.43 & 5.2721 & TST & \\
\hline CHEMBL1325823 & 954352 & 5.6459 & 5.01699 & 99999999995 & TST \\
\hline CHEMBL1443454 & 954352 & 5.3116 & 4.9804 & TRN & \\
\hline CHEMBL2356106 & 954352 & 6.0 & 5.3248 & TRN & \\
\hline CHEMBL486504 & 954352 & 6.4318 & 6.0197 & TST & \\
\hline CHEMBL1321622 & 954352 & 5.1439 & 5.3212 & TRN & \\
\hline CHEMBL 2359934 & 954352 & 4.3778 & 5.0788 & TRN & \\
\hline CHEMBL1532920 & 954352 & 4.7428 & 4.8852 & TRN & \\
\hline CHEMBL2361127 & 954352 & 5.1051 & 5.3031 & TRN & \\
\hline CHEMBL1612044 & 954352 & 5.7825 & 5.5198 & TRN & \\
\hline CHEMBL2355186 & 954352 & 4.8798 & 5.2151 & TRN & \\
\hline CHEMBL1396619 & 954352 & 5.4572 & 5.621 & TRN & \\
\hline CHEMBL2359861 & 954352 & 4.473 & 4.9844 & TRN & \\
\hline CHEMBL2357173 & 954352 & 6.0 & 6.1117 & TRN & \\
\hline CHEMBL1382414 & 954352 & 4.3197 & 4.5066 & TRN & \\
\hline CHEMBL1400196 & 954352 & 5.71 & 4.9663 & TST & \\
\hline CHEMBL 2140530 & 954352 & 5.1524 & 4.9201 & TRN & \\
\hline CHEMBL1312037 & 954352 & 5.4034 & 5.2501 & TRN & \\
\hline CHEMBL1459394 & 954352 & 6.0 & 5.8428 & TRN & \\
\hline CHEMBL1711326 & 954352 & 4.961 & 4.881 & TRN & \\
\hline CHEMBL3210608 & 954352 & 4.6216 & 5.0301 & TRN & \\
\hline CHEMBL1399938 & 954352 & 5.4609 & 5.74700 & 2000000001 & TRN \\
\hline CHEMBL1333449 & 954352 & 5.5638 & 6.1258 & TRN & \\
\hline CHEMBL1465040 & 954352 & 5.083 & 5.5181 & TRN & \\
\hline CHEMBL1570857 & 954352 & 5.0381 & 4.9391 & TRN & \\
\hline CHEMBL1448905 & 954352 & 5.1035 & 5.29 & TRN & \\
\hline CHEMBL493863 & 954352 & 5.1524 & 4.9075 & TST & \\
\hline CHEMBL 2358640 & 954352 & 5.007 & 4.9955 & TRN & \\
\hline CHEMBL2360368 & 954352 & 4.9974 & 5.17399 & 99999999995 & TRN \\
\hline CHEMBL1313685 & 954352 & 4.4466 & 4.8595 & TST & \\
\hline CHEMBL 2360390 & 954352 & 4.8765 & 5.2163 & TRN & \\
\hline CHEMBL1882125 & 954352 & 4.9759 & 4.4994 & TRN & \\
\hline
\end{tabular}




\begin{tabular}{|c|c|c|c|c|c|c|}
\hline & & \multicolumn{5}{|c|}{ Supplemental Table S2.txt } \\
\hline CHEMBL1728280 & 954352 & 5.9747 & 5.2341 & TST & & \\
\hline CHEMBL1539180 & 954352 & 5.2899 & 5.1035 & TRN & & \\
\hline CHEMBL1468011 & 954352 & 5.585 & 5.4976 & TRN & & \\
\hline CHEMBL1561102 & 954352 & 5.3862 & 5.3072 & TST & & \\
\hline CHEMBL1883124 & 954352 & 5.3625 & 6.0303 & TST & & \\
\hline CHEMBL1255733 & 954352 & 5.2692 & 5.7442 & TST & & \\
\hline CHEMBL1499127 & 954352 & 5.2182 & 5.5547 & TRN & & \\
\hline CHEMBL1708714 & 954352 & \multicolumn{3}{|c|}{5.3420000000000005} & 5.1696 & TST \\
\hline CHEMBL1727019 & 954352 & 7.585 & 5.2376 & TST & & \\
\hline CHEMBL2359895 & 954352 & 5.6757 & 5.4356 & TRN & & \\
\hline CHEMBL2361252 & 954352 & 5.1457 & 5.0796 & TRN & & \\
\hline CHEMBL1870939 & 954352 & 5.4078 & 5.3738 & TRN & & \\
\hline CHEMBL1384771 & 954352 & 5.4634 & 5.2926 & TST & & \\
\hline CHEMBL3559925 & 954352 & 4.7247 & 5.3707 & TRN & & \\
\hline CHEMBL2354913 & 954352 & 4.7755 & 5.2168 & TRN & & \\
\hline CHEMBL1700729 & 954352 & 5.2291 & 5.2038 & TST & & \\
\hline CHEMBL1885024 & 954352 & 5.556 & 4.6967 & TST & & \\
\hline CHEMBL1392570 & 954352 & 5.1244 & 5.4961 & TRN & & \\
\hline CHEMBL1333830 & 954352 & 5.4413 & 4.8204 & TST & & \\
\hline CHEMBL2361832 & 954352 & 4.9735 & 5.4249 & TRN & & \\
\hline CHEMBL2361099 & 954352 & 4.9393 & 4.7293 & TRN & & \\
\hline CHEMBL515505 & 954352 & 5.6635 & 5.3286 & TST & & \\
\hline CHEMBL1537997 & 954352 & 4.2912 & 5.2739 & TRN & & \\
\hline CHEMBL 2356271 & 954352 & 6.0 & 5.3532 & TRN & & \\
\hline CHEMBL2360971 & 954352 & 6.0 & 5.5247 & TRN & & \\
\hline CHEMBL 2356340 & 954352 & 5.317 & 5.3639 & TRN & & \\
\hline CHEMBL1575394 & 954352 & 4.3415 & 4.6667 & TRN & & \\
\hline CHEMBL1599994 & 954352 & 5.3936 & 5.4162 & TRN & & \\
\hline CHEMBL1967497 & 954352 & 4.919 & 4.7055 & TRN & & \\
\hline CHEMBL1444020 & 954352 & 6.2733 & 6.0093 & TRN & & \\
\hline CHEMBL1736766 & 954352 & 7.585 & 5.6981 & TST & & \\
\hline CHEMBL1361883 & 954352 & 5.3696 & 5.1417 & TRN & & \\
\hline CHEMBL2359466 & 954352 & 6.0 & 5.9699 & TRN & & \\
\hline CHEMBL1408708 & 954352 & 5.5157 & 5.4948 & TRN & & \\
\hline CHEMBL1305849 & 954352 & 4.9311 & 5.593 & TRN & & \\
\hline CHEMBL3185199 & 954352 & 4.5974 & 5.4808 & TRN & & \\
\hline CHEMBL1478578 & 954352 & 5.3401 & 5.1644 & TRN & & \\
\hline CHEMBL1351908 & 954352 & 5.2749 & 5.3564 & TRN & & \\
\hline CHEMBL1868105 & 954352 & 4.9397 & 5.0781 & TST & & \\
\hline CHEMBL2361968 & 954352 & 5.1439 & 5.29200 & 0000000001 & & TRN \\
\hline CHEMBL1530314 & 954352 & 7.585 & 5.7357 & TST & & \\
\hline CHEMBL1235676 & 954352 & 7.585 & 5.4282 & TST & & \\
\hline CHEMBL3391720 & 954352 & 6.0921 & 5.8929 & TST & & \\
\hline CHEMBL1301042 & 954352 & 6.4214 & 6.0406 & TRN & & \\
\hline CHEMBL188 & 954352 & 5.05699 & و9999999 & 995 & 5.6819 & TST \\
\hline CHEMBL1560962 & 954352 & 4.8441 & 4.9077 & TRN & & \\
\hline CHEMBL 2358509 & 954352 & 4.5969 & 5.1773 & TRN & & \\
\hline CHEMBL 2354572 & 954352 & 4.7501 & 5.2787 & TRN & & \\
\hline
\end{tabular}




\begin{tabular}{|c|c|c|c|c|c|}
\hline \multicolumn{6}{|c|}{ Supplemental Table S2.txt } \\
\hline CHEMBL 2362816 & 954352 & 5.0991 & 5.0032 & TRN & \\
\hline CHEMBL 2357518 & 954352 & 6.0 & 5.5118 & TRN & \\
\hline CHEMBL1417929 & 954352 & 5.1938 & 5.1777 & TRN & \\
\hline CHEMBL1366140 & 954352 & 5.0376 & 5.46399 & 99999999995 & TST \\
\hline CHEMBL1378232 & 954352 & 5.6234 & 6.0306 & TRN & \\
\hline CHEMBL 2131792 & 954352 & 7.585 & 6.0101 & TRN & \\
\hline CHEMBL 2359003 & 954352 & 6.0 & 5.9202 & TRN & \\
\hline CHEMBL 2355418 & 954352 & 5.0255 & 5.1671 & TRN & \\
\hline CHEMBL1403024 & 954352 & 4.8088 & 5.0071 & TRN & \\
\hline CHEMBL1698341 & 954352 & 6.1198 & 5.3425 & TST & \\
\hline CHEMBL1393529 & 954352 & 5.284 & 5.2331 & TRN & \\
\hline CHEMBL1707775 & 954352 & 7.585 & 5.8715 & TST & \\
\hline CHEMBL1352850 & 954352 & 5.8996 & 5.7111 & TRN & \\
\hline CHEMBL18115 & 954352 & 6.0 & 5.3738 & TST & \\
\hline CHEMBL1505902 & 954352 & 5.0516 & 5.1514 & TST & \\
\hline CHEMBL1419822 & 954352 & 5.4191 & 4.872 & TRN & \\
\hline CHEMBL 2359385 & 954352 & 4.317 & 4.7669 & TRN & \\
\hline CHEMBL 2354657 & 954352 & 4.7481 & 5.86600 & 00000000005 & TRN \\
\hline CHEMBL1342336 & 954352 & 6.4989 & 6.2363 & TRN & \\
\hline CHEMBL1519289 & 954352 & 5.3851 & 5.7087 & TRN & \\
\hline CHEMBL 2360144 & 954352 & 5.6038 & 4.816 & TRN & \\
\hline CHEMBL1402010 & 954352 & 5.6696 & 6.2524 & TRN & \\
\hline CHEMBL1307919 & 954352 & 5.5346 & 5.6454 & TRN & \\
\hline CHEMBL 1445386 & 954352 & 5.9547 & 4.8089 & TST & \\
\hline CHEMBL 2355230 & 954352 & 4.9884 & 5.6251 & TRN & \\
\hline CHEMBL1451470 & 954352 & 5.3316 & 5.0803 & TRN & \\
\hline CHEMBL1561089 & 954352 & 5.3382 & 5.4881 & TST & \\
\hline CHEMBL1720005 & 954352 & 4.9266 & 6.1821 & TST & \\
\hline CHEMBL1732967 & 954352 & 5.7011 & 5.3993 & TRN & \\
\hline CHEMBL1507537 & 954352 & 5.2503 & 5.4726 & TRN & \\
\hline CHEMBL1863734 & 954352 & 5.767 & 5.1232 & TRN & \\
\hline CHEMBL 2358424 & 954352 & 6.0 & 5.63399 & 99999999995 & TRN \\
\hline CHEMBL1437139 & 954352 & 6.0 & 5.9712 & TST & \\
\hline CHEMBL 2362033 & 954352 & 4.5123 & 5.0488 & TRN & \\
\hline CHEMBL 2355651 & 954352 & 4.9931 & 4.7027 & TRN & \\
\hline CHEMBL1488060 & 954352 & 5.2255 & 5.2143 & TST & \\
\hline CHEMBL1474947 & 954352 & 5.3904 & 5.2945 & TRN & \\
\hline CHEMBL 2359109 & 954352 & 6.0 & 5.3325 & TRN & \\
\hline CHEMBL 2360277 & 954352 & 5.1101 & 5.199 & TRN & \\
\hline CHEMBL1530866 & 954352 & 5.1543 & 5.2429 & TRN & \\
\hline CHEMBL1497597 & 954352 & 4.7642 & 4.6802 & TST & \\
\hline CHEMBL1440422 & 954352 & 5.4609 & 4.8515 & TST & \\
\hline CHEMBL1597459 & 954352 & 5.3391 & 4.814 & TST & \\
\hline CHEMBL610198 & 954352 & 5.2147 & 5.1923 & TRN & \\
\hline CHEMBL 2354354 & 954352 & 4.5589 & 5.4402 & TRN & \\
\hline CHEMBL1456324 & 954352 & 5.0311 & 5.7337 & TST & \\
\hline CHEMBL 2359470 & 954352 & 6.0 & 5.4707 & TRN & \\
\hline CHEMBL1717890 & 954352 & 5.3536 & 4.8039 & TRN & \\
\hline
\end{tabular}


Supplemental Table S2.txt

\begin{tabular}{|c|c|c|c|c|}
\hline CHEMBL1537604 & 954352 & 5.1192 & 4.8024 & TST \\
\hline CHEMBL 2361503 & 954352 & 4.4573 & 4.6117 & TRN \\
\hline CHEMBL 2357329 & 954352 & 5.1221 & 5.1618 & TRN \\
\hline CHEMBL 2137367 & 954352 & 4.9586 & 5.0468 & TRN \\
\hline CHEMBL 2359406 & 954352 & 5.5391 & 5.3351 & TRN \\
\hline CHEMBL 2362001 & 954352 & 5.4134 & 5.4649 & TRN \\
\hline CHEMBL1441619 & 954352 & 5.1561 & 5.06 & TRN \\
\hline CHEMBL1398260 & 954352 & 5.6289 & 5.8278 & TST \\
\hline CHEMBL1435754 & 954352 & 7.585 & 5.4697 & TST \\
\hline CHEMBL 2360775 & 954352 & 6.0 & 5.1451 & TRN \\
\hline CHEMBL1382558 & 954352 & 5.4067 & 5.1586 & TRN \\
\hline CHEMBL 2355487 & 954352 & 5.2636 & 5.1046 & TRN \\
\hline CHEMBL1701527 & 954352 & 4.8245 & 5.0665 & TRN \\
\hline CHEMBL1735482 & 954352 & 5.9136 & 5.1755 & TRN \\
\hline CHEMBL 2354720 & 954352 & 4.7129 & 5.2788 & TRN \\
\hline CHEMBL2361299 & 954352 & 4.8668 & 5.2064 & TRN \\
\hline CHEMBL1463884 & 954352 & 5.1403 & 5.0421 & TRN \\
\hline CHEMBL598263 & 954352 & 7.585 & 7.4539 & TRN \\
\hline CHEMBL1879111 & 954352 & 5.3449 & 5.4896 & TRN \\
\hline CHEMBL 2361242 & 954352 & 4.4748 & 5.2383 & TRN \\
\hline CHEMBL 2359429 & 954352 & 4.1575 & 5.0722 & TRN \\
\hline CHEMBL 2357224 & 954352 & 4.8871 & 5.3247 & TRN \\
\hline CHEMBL1308009 & 954352 & 4.8011 & 4.8955 & TRN \\
\hline CHEMBL 2360588 & 954352 & 4.572 & 4.707 & TRN \\
\hline CHEMBL1317135 & 954352 & 7.585 & 5.7944 & TST \\
\hline CHEMBL 2359675 & 954352 & 6.0 & 5.75 & TRN \\
\hline CHEMBL1982945 & 954352 & 5.3478 & 5.2971 & TRN \\
\hline CHEMBL1405749 & 954352 & 5.7595 & 6.0884 & TRN \\
\hline CHEMBL 2133790 & 954352 & 5.7878 & 5.7883 & TRN \\
\hline CHEMBL1499544 & 954352 & 6.4908 & 6.0223 & TRN \\
\hline CHEMBL1898843 & 954352 & 5.4737 & 5.3966 & TRN \\
\hline CHEMBL1720745 & 954352 & 4.7975 & 4.9196 & TRN \\
\hline CHEMBL1405453 & 954352 & 7.585 & 6.2182 & TRN \\
\hline CHEMBL 2360633 & 954352 & 4.8996 & 5.1855 & TRN \\
\hline CHEMBL1299925 & 954352 & 4.7711 & 5.1423 & TRN \\
\hline CHEMBL1720852 & 954352 & 5.2716 & 5.2713 & TST \\
\hline CHEMBL3187852 & 954352 & 5.3706 & 5.6741 & TRN \\
\hline CHEMBL 2361631 & 954352 & 4.8496 & 5.3689 & TRN \\
\hline CHEMBL1699228 & 954352 & 5.8447 & 6.17399 & 99999999995 \\
\hline CHEMBL 2357424 & 954352 & 5.0762 & 5.2465 & TRN \\
\hline CHEMBL2359969 & 954352 & 5.0825 & 5.2778 & TRN \\
\hline CHEMBL 2361971 & 954352 & 4.3693 & 4.716 & TRN \\
\hline CHEMBL1484139 & 954352 & 5.0269 & 4.8835 & TST \\
\hline CHEMBL 2362639 & 954352 & 6.0 & 5.5625 & TRN \\
\hline CHEMBL1576251 & 954352 & 5.6615 & 5.7487 & TRN \\
\hline CHEMBL2355103 & 954352 & 5.3098 & 5.2486 & TRN \\
\hline CHEMBL 2355634 & 954352 & 5.1707 & 5.0703 & TRN \\
\hline CHEMBL3560275 & 954352 & 4.6031 & 5.0596 & TRN \\
\hline
\end{tabular}




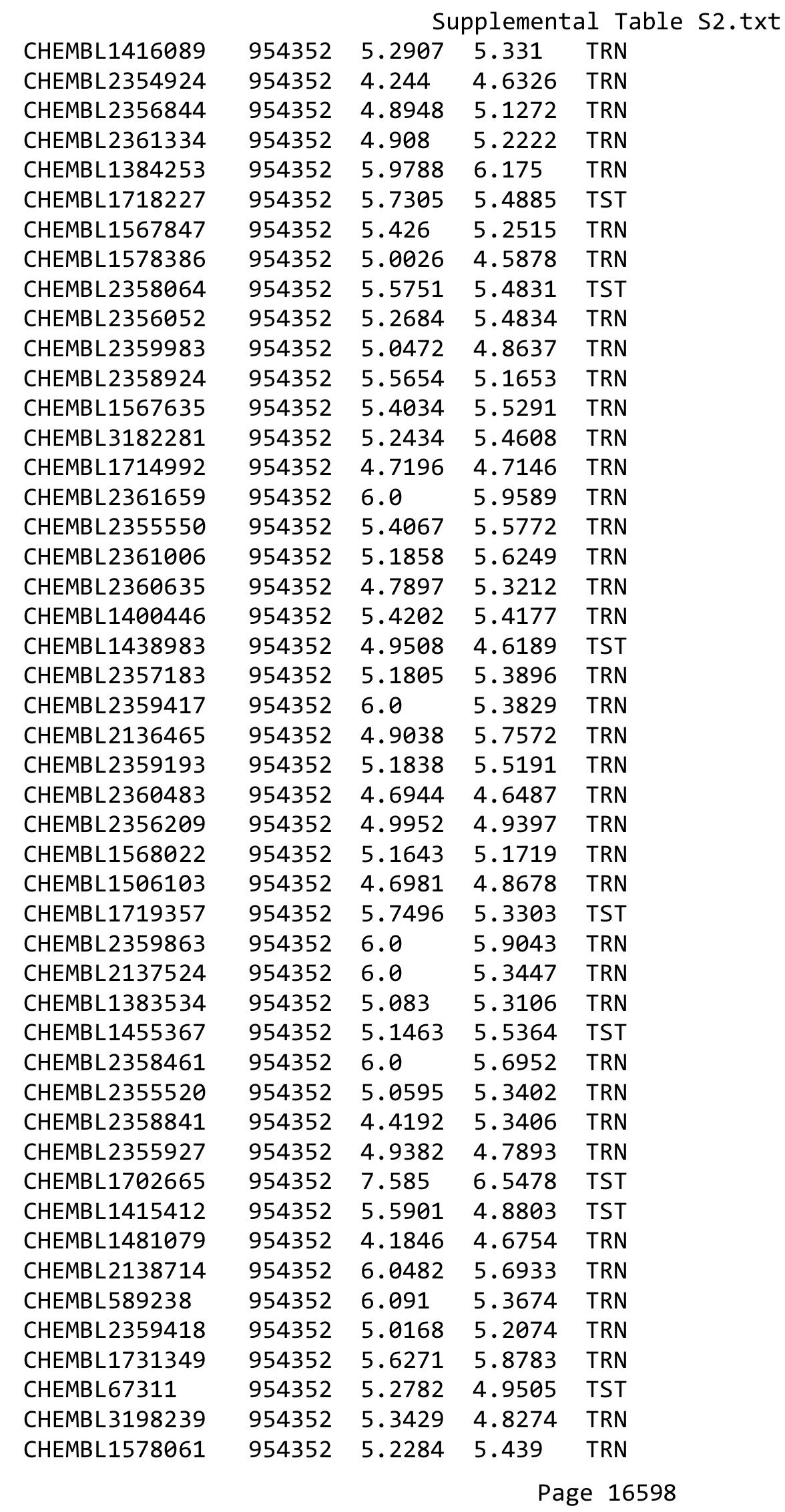




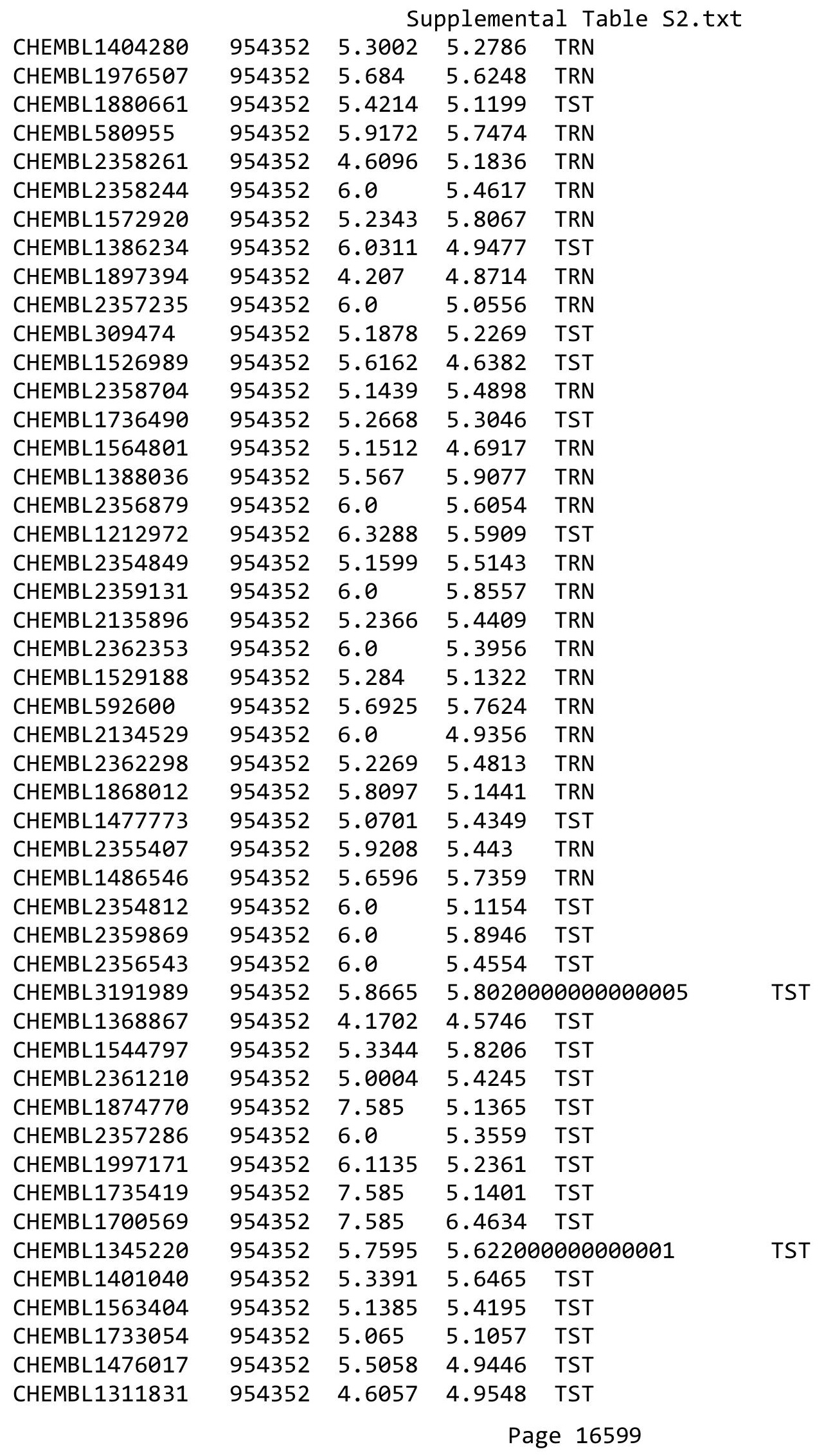




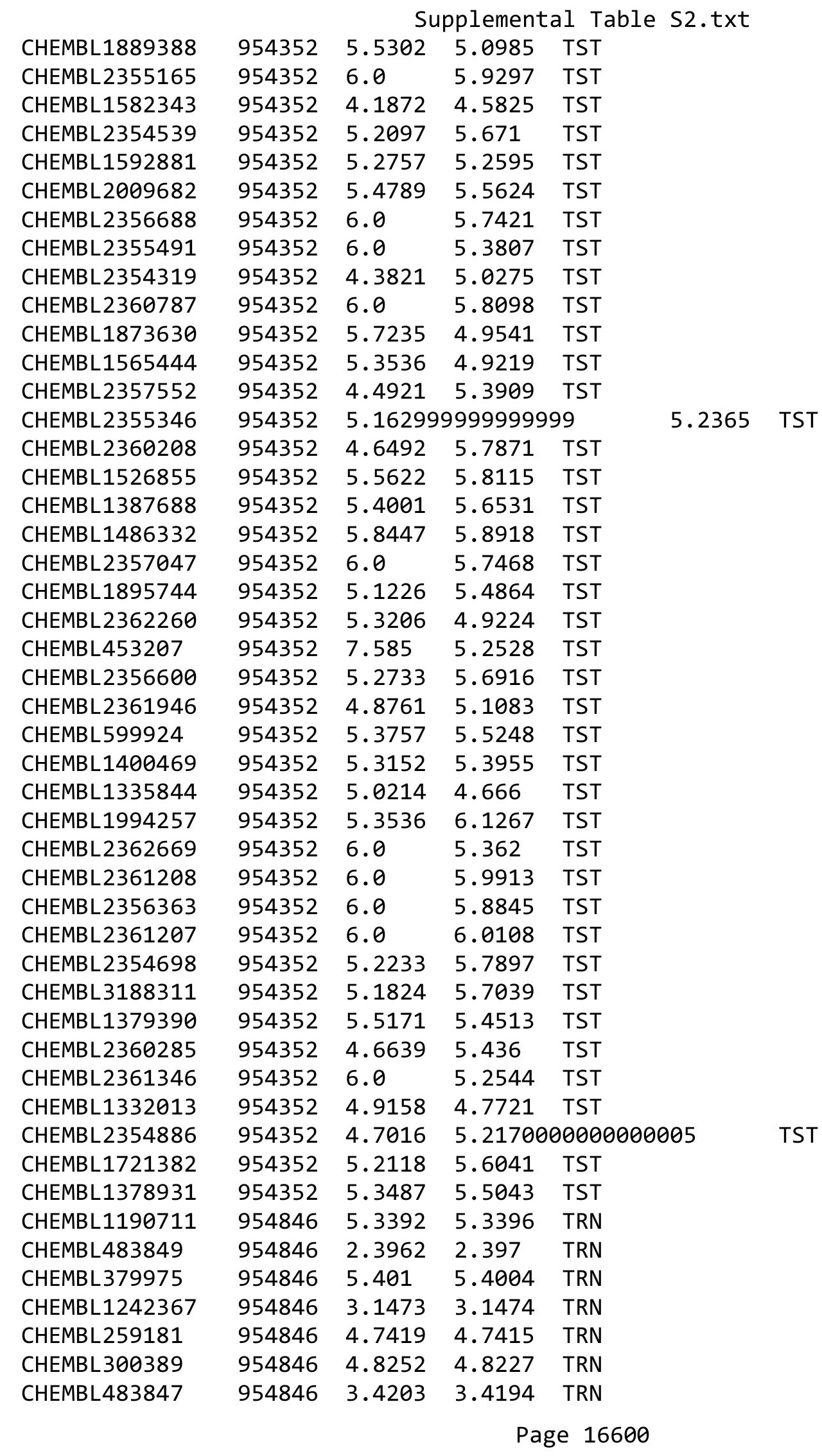




\begin{tabular}{|c|c|c|c|c|c|c|}
\hline & & \multicolumn{5}{|c|}{ Supplemental Table S2.txt } \\
\hline CHEMBL558642 & 954846 & 4.091 & 4.0914 & TRN & & \\
\hline CHEMBL258844 & 954846 & 4.6923 & 4.6938 & TRN & & \\
\hline CHEMBL9470 & 954846 & 6.2769 & 5.7092 & TST & & \\
\hline CHEMBL220241 & 954846 & 4.864 & 4.8623 & TRN & & \\
\hline CHEMBL3392440 & 954846 & \multicolumn{3}{|c|}{ 4. 388999999999999} & 4.3907 & TRN \\
\hline CHEMBL189584 & 954846 & 4.5461 & 4.5459 & TRN & & \\
\hline CHEMBL102714 & 954846 & 3.4246 & 3.4323 & TRN & & \\
\hline CHEMBL 209148 & 954846 & 3.1303 & 3.1305 & TRN & & \\
\hline CHEMBL65 & 954846 & 6.8237 & 6.8235 & TRN & & \\
\hline CHEMBL373751 & 954846 & 3.199 & 3.2006 & TRN & & \\
\hline CHEMBL 3199475 & 954846 & 4.2439 & 4.2408 & TRN & & \\
\hline CHEMBL573107 & 954846 & 6.2061 & 6.2089 & TRN & & \\
\hline CHEMBL 379300 & 954846 & 3.6867 & 3.6915 & TRN & & \\
\hline CHEMBL412142 & 954846 & 3.6762 & 3.6702 & TRN & & \\
\hline CHEMBL213100 & 954846 & 2.8263 & 2.8272 & TRN & & \\
\hline CHEMBL1230020 & 954846 & 4.4698 & 4.4695 & TRN & & \\
\hline CHEMBL3186408 & 954846 & 4.0868 & 4.1642 & TST & & \\
\hline CHEMBL585951 & 954846 & 6.067 & 6.0692 & TRN & & \\
\hline CHEMBL1970879 & 954846 & 3.5287 & 3.5272 & TRN & & \\
\hline CHEMBL3349342 & 954846 & 5.5582 & 5.5579 & TRN & & \\
\hline CHEMBL1788116 & 954846 & 4.7299 & 4.7287 & TRN & & \\
\hline CHEMBL1256459 & 954846 & 3.7202 & 3.7192 & TRN & & \\
\hline CHEMBL191334 & 954846 & 3.5102 & 3.5099 & TRN & & \\
\hline CHEMBL135561 & 954846 & 4.8547 & 4.8552 & TRN & & \\
\hline CHEMBL92309 & 954846 & 2.8219 & 3.5744 & TST & & \\
\hline CHEMBL 2144069 & 954846 & 4.9132 & 4.9155 & TRN & & \\
\hline CHEMBL192566 & 954846 & 8.6753 & 6.7293 & TST & & \\
\hline CHEMBL509032 & 954846 & 4.5876 & 4.5858 & TRN & & \\
\hline CHEMBL472940 & 954846 & 4.2061 & 4.2043 & TRN & & \\
\hline CHEMBL449158 & 954846 & 6.2654 & 5.88899 & 9999999999 & & TST \\
\hline CHEMBL1516890 & 954846 & 3.9709 & 3.9658 & TRN & & \\
\hline CHEMBL180127 & 954846 & 3.5746 & 3.5741 & TRN & & \\
\hline CHEMBL1909414 & 954846 & 4.2908 & 4.293 & TRN & & \\
\hline CHEMBL1404918 & 954846 & 3.2339 & 3.2343 & TRN & & \\
\hline CHEMBL393929 & 954846 & 3.5423 & 3.5407 & TRN & & \\
\hline CHEMBL1590308 & 954846 & 3.2539 & 3.3757 & TST & & \\
\hline CHEMBL 202721 & 954846 & 4.5301 & 4.5308 & TRN & & \\
\hline CHEMBL515416 & 954846 & 4.1423 & 4.1445 & TRN & & \\
\hline CHEMBL 2005886 & 954846 & 4.0298 & 4.0304 & TRN & & \\
\hline CHEMBL2363137 & 954846 & 5.0187 & 5.016 & TRN & & \\
\hline CHEMBL 210618 & 954846 & 3.6944 & 3.694 & TRN & & \\
\hline CHEMBL1643959 & 954846 & 2.7934 & 3.6902 & TST & & \\
\hline CHEMBL1673039 & 954846 & 2.761 & 3.9869 & TST & & \\
\hline CHEMBL221137 & 954846 & 4.9784 & 5.0609 & TST & & \\
\hline CHEMBL1357247 & 954846 & 3.0175 & 4.0007 & TST & & \\
\hline CHEMBL392695 & 954846 & 2.8649 & 4.0949 & TST & & \\
\hline CHEMBL514499 & 954846 & 4.1879 & 4.3233 & TST & & \\
\hline CHEMBL512504 & 954846 & 6.3458 & 5.316 & TST & & \\
\hline
\end{tabular}




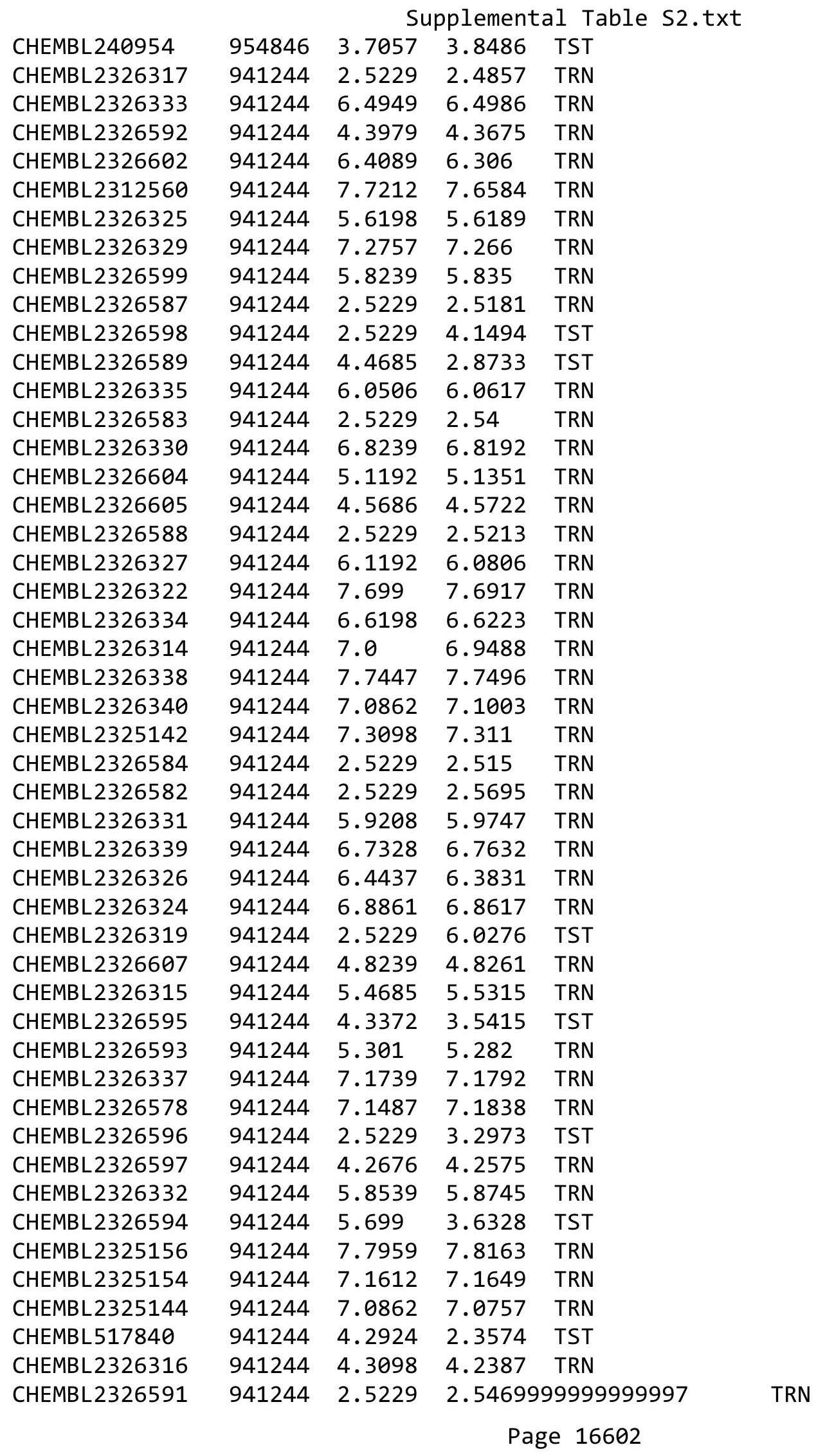




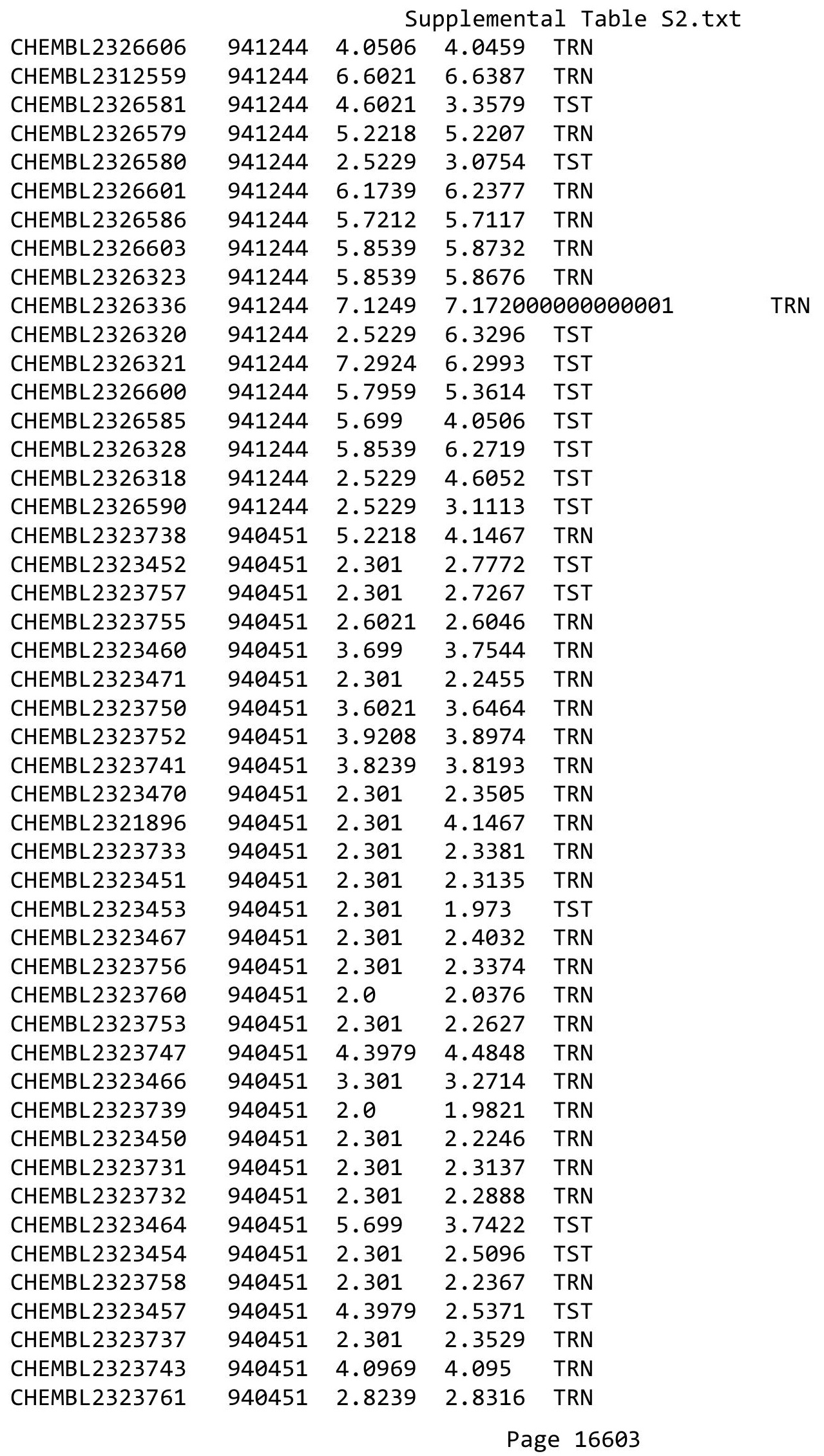




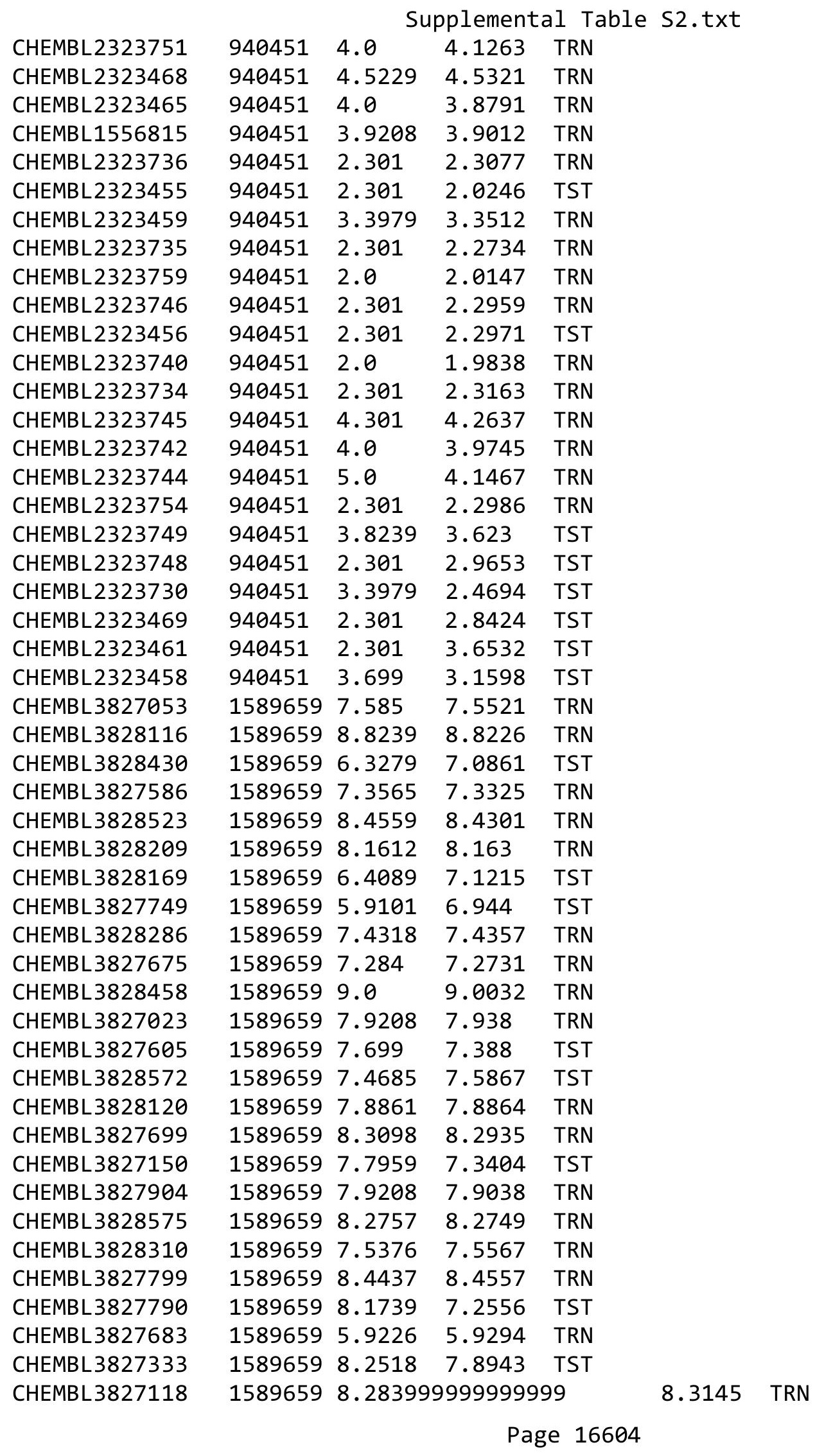


Supplemental Table S2.txt

\begin{tabular}{|c|c|c|c|c|c|}
\hline CHEMBL 3827874 & 1589659 & 7.4815 & 7.4951 & TRN & \\
\hline CHEMBL3828472 & 1589659 & 7.0 & 6.9895 & TRN & \\
\hline CHEMBL3827758 & 1589659 & 7.9208 & 7.9516 & TRN & \\
\hline CHEMBL3827673 & 1589659 & 7.6021 & 7.6129 & TRN & \\
\hline CHEMBL 3827983 & 1589659 & 8.4437 & 8.44700 & 0000000001 & TRN \\
\hline CHEMBL 3827482 & 1589659 & 8.3279 & 8.3244 & TRN & \\
\hline CHEMBL3827666 & 1589659 & 6.0883 & 6.0802 & TRN & \\
\hline CHEMBL 3827678 & 1589659 & 8.2518 & 7.9818 & TST & \\
\hline CHEMBL3828266 & 1589659 & 7.5528 & 7.5948 & TRN & \\
\hline CHEMBL 3828553 & 1589659 & 8.9586 & 8.9209 & TRN & \\
\hline CHEMBL 3828503 & 1589659 & 8.3372 & 8.2425 & TST & \\
\hline CHEMBL 3828003 & 1589659 & 8.3468 & 8.3481 & TRN & \\
\hline CHEMBL3828129 & 1589659 & 6.7959 & 7.4251 & TST & \\
\hline CHEMBL3828470 & 1589659 & 7.4437 & 7.4116 & TRN & \\
\hline CHEMBL 3828637 & 1589659 & 9.0458 & 9.0455 & TRN & \\
\hline CHEMBL 3827944 & 1589659 & 8.7447 & 8.7414 & TRN & \\
\hline CHEMBL3828689 & 1589659 & 8.2076 & 8.254 & TRN & \\
\hline CHEMBL 3827327 & 1589659 & 8.6778 & 8.6684 & TRN & \\
\hline CHEMBL3828221 & 1589659 & 9.1487 & 7.7743 & TST & \\
\hline CHEMBL 3828084 & 1589659 & 7.6778 & 7.6873 & TRN & \\
\hline CHEMBL3828071 & 1589659 & 7.7696 & 7.7626 & TRN & \\
\hline CHEMBL 3827470 & 1589659 & 8.6198 & 8.62 & TRN & \\
\hline CHEMBL 3828370 & 1589659 & 7.9586 & 7.9463 & TRN & \\
\hline CHEMBL3827774 & 1589659 & 8.2676 & 8.2683 & TRN & \\
\hline CHEMBL 3827664 & 1589659 & 8.041 & 7.8967 & TST & \\
\hline CHEMBL 2086529 & 841030 & 7.2596 & 7.1048 & TRN & \\
\hline CHEMBL2086519 & 841030 & 7.3565 & \multicolumn{2}{|c|}{7.462000000000001} & TRN \\
\hline CHEMBL 2089385 & 841030 & 6.699 & 2.6713 & TST & \\
\hline CHEMBL 2086536 & 841030 & 6.4202 & 6.3517 & TRN & \\
\hline CHEMBL 2086507 & 841030 & 7.2676 & 7.3184 & TRN & \\
\hline CHEMBL 2086495 & 841030 & 3.0969 & 3.2989 & TRN & \\
\hline CHEMBL2086539 & 841030 & 7.1079 & 7.0223 & TRN & \\
\hline CHEMBL 2086545 & 841030 & 5.3468 & 5.3026 & TRN & \\
\hline CHEMBL 2089397 & 841030 & 6.4202 & 6.6594 & TRN & \\
\hline CHEMBL 2086504 & 841030 & 6.041 & 6.1867 & TRN & \\
\hline CHEMBL 2086526 & 841030 & 7.3872 & 7.38 & TRN & \\
\hline CHEMBL 2086542 & 841030 & 7.585 & 7.3818 & TRN & \\
\hline CHEMBL 2086535 & 841030 & 6.7212 & 6.3039 & TRN & \\
\hline CHEMBL2367730 & 841030 & 7.4685 & 7.5103 & TRN & \\
\hline CHEMBL 2086489 & 841030 & 6.0 & 5.4462 & TRN & \\
\hline CHEMBL2089393 & 841030 & 6.8539 & 6.4623 & TRN & \\
\hline CHEMBL 2086480 & 841030 & 7.4949 & 7.3142 & TRN & \\
\hline CHEMBL2086538 & 841030 & 7.0132 & 7.3057 & TRN & \\
\hline CHEMBL2086516 & 841030 & 7.2218 & 7.3594 & TRN & \\
\hline CHEMBL2086505 & 841030 & 6.7447 & 6.3987 & TRN & \\
\hline CHEMBL 2086532 & 841030 & 7.284 & 6.9862 & TRN & \\
\hline CHEMBL 2086501 & 841030 & 4.1192 & 4.2132 & TRN & \\
\hline CHEMBL 2086476 & 841030 & 5.4202 & 4.7479 & TST & \\
\hline
\end{tabular}




\begin{tabular}{|c|c|c|c|c|c|}
\hline \multicolumn{6}{|c|}{ Supplemental Table S2.txt } \\
\hline CHEMBL2086888 & 841030 & 5.0506 & 3.341 & TST & \\
\hline CHEMBL 2086508 & 841030 & 7.1549 & 7.296 & TRN & \\
\hline CHEMBL 2086470 & 841030 & 5.5229 & 5.1047 & TST & \\
\hline CHEMBL2086469 & 841030 & 4.3665 & 4.5066 & TST & \\
\hline CHEMBL 2086531 & 841030 & 7.4559 & 6.8509 & TRN & \\
\hline CHEMBL 2086524 & 841030 & 7.585 & 7.7113 & TRN & \\
\hline CHEMBL 2086503 & 841030 & 5.6021 & 5.647 & TRN & \\
\hline CHEMBL 2086487 & 841030 & 4.0 & 4.7929 & TRN & \\
\hline CHEMBL 2086544 & 841030 & 7.8539 & 8.1401 & TRN & \\
\hline CHEMBL2086466 & 841030 & 5.8539 & 4.9133 & TRN & \\
\hline CHEMBL 2089383 & 841030 & 4.2366 & 4.977 & TST & \\
\hline CHEMBL2089399 & 841030 & 6.3468 & 6.5707 & TRN & \\
\hline CHEMBL 2086497 & 841030 & 3.0969 & 3.3025 & TRN & \\
\hline CHEMBL 2086479 & 841030 & 6.4559 & 6.3876 & TRN & \\
\hline CHEMBL2089394 & 841030 & 5.8239 & $5.4520 e$ & 2000000001 & TST \\
\hline CHEMBL 2086472 & 841030 & 4.5376 & 5.3177 & TST & \\
\hline CHEMBL 2086492 & 841030 & 3.0969 & 3.3262 & TRN & \\
\hline CHEMBL 2086890 & 841030 & 6.7212 & 6.6865 & TRN & \\
\hline CHEMBL 2086891 & 841030 & 6.9586 & 6.9337 & TRN & \\
\hline CHEMBL 2086491 & 841030 & 3.0969 & 3.5635 & TRN & \\
\hline CHEMBL 2089388 & 841030 & 6.9208 & 6.9521 & TRN & \\
\hline CHEMBL 2086540 & 841030 & 6.7447 & 7.1862 & TRN & \\
\hline CHEMBL 2086522 & 841030 & 6.9586 & 7.0855 & TRN & \\
\hline CHEMBL 2086889 & 841030 & 7.6021 & 3.2034 & TST & \\
\hline CHEMBL 2086527 & 841030 & 7.2441 & 6.9608 & TRN & \\
\hline CHEMBL 2086499 & 841030 & 5.3979 & 4.8486 & TRN & \\
\hline CHEMBL 2086543 & 841030 & 7.1612 & 6.5317 & TRN & \\
\hline CHEMBL 2086518 & 841030 & 7.1427 & 6.8688 & TRN & \\
\hline CHEMBL 2086481 & 841030 & 4.5528 & 4.4817 & TRN & \\
\hline CHEMBL 2086468 & 841030 & 3.0969 & 2.2834 & TST & \\
\hline CHEMBL 2086512 & 841030 & 7.1549 & 7.1191 & TRN & \\
\hline CHEMBL 2089382 & 841030 & 4.585 & 5.5785 & TST & \\
\hline CHEMBL 2086523 & 841030 & 7.699 & 7.4871 & TRN & \\
\hline CHEMBL 2089400 & 841030 & 6.3372 & 6.8391 & TRN & \\
\hline CHEMBL2086515 & 841030 & 7.2676 & 7.1839 & TRN & \\
\hline CHEMBL2086533 & 841030 & 7.1192 & 7.0342 & TRN & \\
\hline CHEMBL 2086510 & 841030 & 6.9586 & 7.0155 & TRN & \\
\hline CHEMBL2089398 & 841030 & 6.6576 & 6.8204 & TRN & \\
\hline CHEMBL 2086513 & 841030 & 7.0862 & 7.33799 & 9999999999 & TRN \\
\hline CHEMBL 2086474 & 841030 & 5.301 & 5.3998 & TST & \\
\hline CHEMBL1605548 & 841030 & 5.4815 & 5.215 & TST & \\
\hline CHEMBL 2086498 & 841030 & 4.041 & 4.0715 & TRN & \\
\hline CHEMBL 2086520 & 841030 & 6.7959 & 6.7172 & TRN & \\
\hline CHEMBL 2086478 & 841030 & 4.3468 & 5.1002 & TST & \\
\hline CHEMBL2086486 & 841030 & 3.0969 & 3.2341 & TRN & \\
\hline CHEMBL 2086506 & 841030 & 7.3372 & 7.8399 & TRN & \\
\hline CHEMBL 2086514 & 841030 & 6.6576 & 7.045 & TRN & \\
\hline CHEMBL 2086530 & 841030 & 7.6021 & 7.1707 & TRN & \\
\hline
\end{tabular}




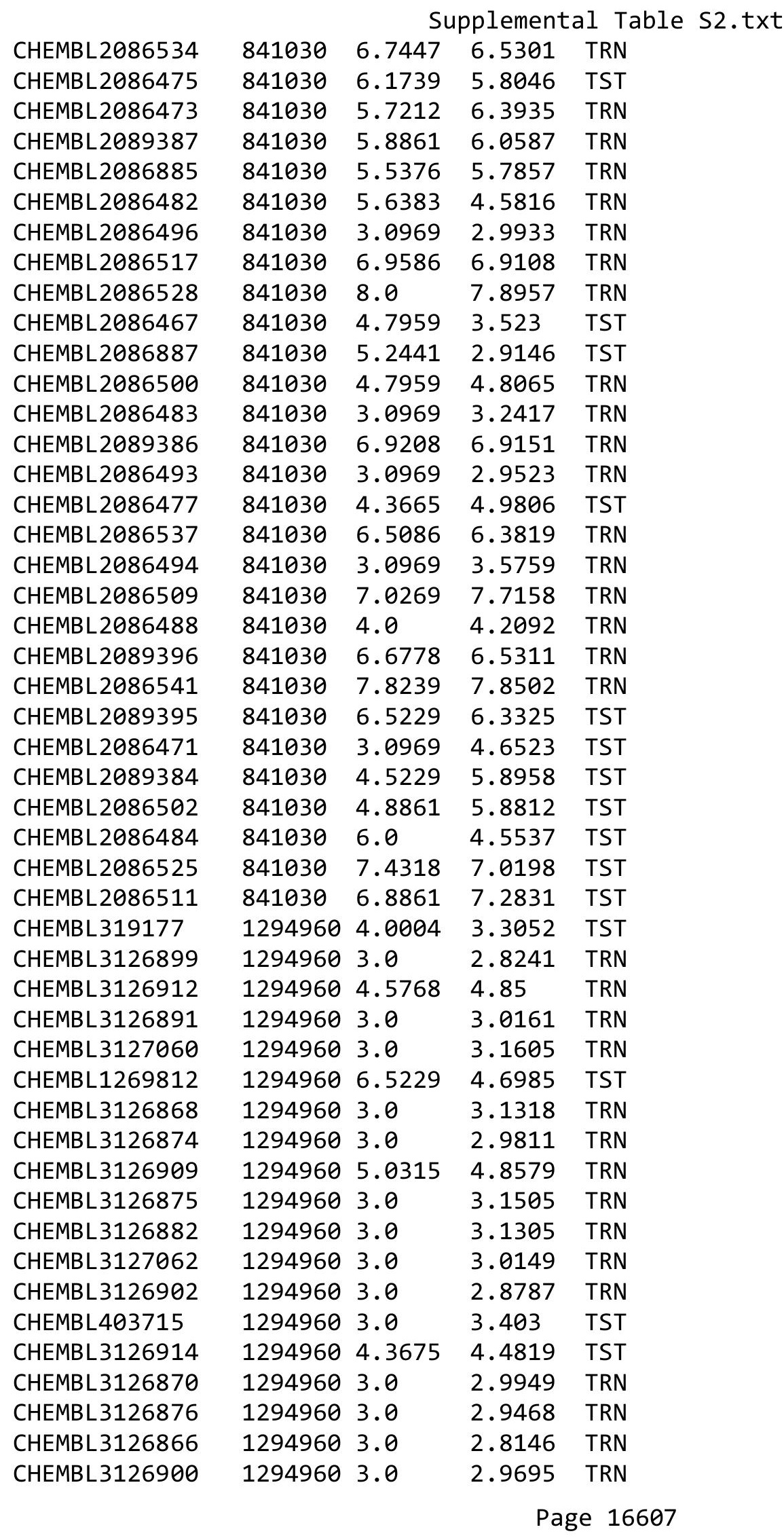


Supplemental Table S2.txt

\begin{tabular}{|c|c|c|c|c|c|}
\hline CHEMBL 3127049 & 1294960 & 3.0 & 2.9823 & TRN & \\
\hline CHEMBL 3126894 & 1294960 & 3.0 & 3.0438 & TRN & \\
\hline CHEMBL3126869 & 1294960 & 3.0 & 2.7661 & TRN & \\
\hline CHEMBL3126907 & 1294960 & 3.0 & 3.18 & TST & \\
\hline CHEMBL 3126897 & 1294960 & 3.0 & 3.1546 & TST & \\
\hline CHEMBL 3127044 & 1294960 & 4.6819 & 4.9285 & TST & \\
\hline CHEMBL 3127048 & 1294960 & 3.0 & 3.3292 & TST & \\
\hline CHEMBL3126901 & 1294960 & 3.0 & 3.1024 & TRN & \\
\hline CHEMBL3126889 & 1294960 & 4.6091 & 4.697 & TRN & \\
\hline CHEMBL3126915 & 1294960 & 4.289 & 4.8078 & TST & \\
\hline CHEMBL 3127054 & 1294960 & 3.0 & 3.4102 & TRN & \\
\hline CHEMBL 3127045 & 1294960 & 3.0 & 3.1142 & TRN & \\
\hline CHEMBL 3127063 & 1294960 & 3.0 & 3.29699 & 99999999997 & TRN \\
\hline CHEMBL 3124960 & 1294960 & 3.0 & 3.0881 & TRN & \\
\hline CHEMBL 3127068 & 1294960 & 3.0 & 2.9478 & TRN & \\
\hline CHEMBL 3126877 & 1294960 & 3.0 & 3.1473 & TRN & \\
\hline CHEMBL 3126873 & 1294960 & 3.0 & 2.8984 & TRN & \\
\hline CHEMBL1814767 & 1294960 & 4.7595 & 4.8841 & TRN & \\
\hline CHEMBL 3126910 & 1294960 & 4.8539 & 4.9646 & TRN & \\
\hline CHEMBL 3126887 & 1294960 & 3.0 & 4.2366 & TRN & \\
\hline CHEMBL 3126879 & 1294960 & 3.0 & 2.8731 & TRN & \\
\hline CHEMBL3126906 & 1294960 & 3.0 & 3.0549 & TST & \\
\hline CHEMBL 3126903 & 1294960 & 3.0 & 2.969 & TRN & \\
\hline CHEMBL3126896 & 1294960 & 3.0 & 2.8452 & TST & \\
\hline CHEMBL 3127053 & 1294960 & 3.0 & 3.1243 & TRN & \\
\hline CHEMBL 3126881 & 1294960 & 3.0 & 2.9664 & TRN & \\
\hline CHEMBL 3126913 & 1294960 & 5.6778 & 5.1285 & TRN & \\
\hline CHEMBL 3126872 & 1294960 & 3.0 & 2.9727 & TST & \\
\hline CHEMBL 3127067 & 1294960 & 3.0 & 3.1798 & TRN & \\
\hline CHEMBL3127061 & 1294960 & 3.0 & 2.9387 & TRN & \\
\hline CHEMBL 3127057 & 1294960 & 4.06 & 3.4587 & TST & \\
\hline CHEMBL 3126867 & 1294960 & 3.0 & 2.8907 & TRN & \\
\hline CHEMBL 3126911 & 1294960 & 4.7328 & 4.7268 & TRN & \\
\hline CHEMBL 3126898 & 1294960 & 4.06 & 3.2953 & TST & \\
\hline CHEMBL3126871 & 1294960 & 3.0 & 3.2698 & TRN & \\
\hline CHEMBL3127056 & 1294960 & 4.0141 & 3.5796 & TST & \\
\hline CHEMBL 3126893 & 1294960 & 3.0 & 2.9536 & TRN & \\
\hline CHEMBL3127059 & 1294960 & 3.0 & 3.0115 & TRN & \\
\hline CHEMBL 3126884 & 1294960 & 4.0757 & 4.3131 & TRN & \\
\hline CHEMBL3126880 & 1294960 & 3.0 & 2.9866 & TRN & \\
\hline CHEMBL 3127052 & 1294960 & 4.0061 & 3.0612 & TRN & \\
\hline CHEMBL 3126865 & 1294960 & 3.0 & 3.173 & TST & \\
\hline CHEMBL 3127050 & 1294960 & 3.0 & 3.1464 & TRN & \\
\hline CHEMBL 3127058 & 1294960 & 3.0 & 2.9457 & TRN & \\
\hline CHEMBL 3126904 & 1294960 & 3.0 & 3.2961 & TRN & \\
\hline CHEMBL 3126890 & 1294960 & 3.0 & 2.9854 & TRN & \\
\hline CHEMBL 3127064 & 1294960 & 3.0 & 3.0104 & TST & \\
\hline CHEMBL3127046 & 1294960 & 4.1337 & 3.4548 & TRN & \\
\hline
\end{tabular}

Page 16608 


\begin{tabular}{|c|c|c|c|c|c|}
\hline \multicolumn{6}{|c|}{ Supplemental Table S2.txt } \\
\hline CHEMBL 3126895 & 1294960 & 3.0 & 3.3039 & TRN & \\
\hline CHEMBL 3126878 & 1294960 & 3.0 & 3.2388 & TRN & \\
\hline CHEMBL1814768 & 1294960 & 5.3251 & 5.2394 & TRN & \\
\hline CHEMBL 3127051 & 1294960 & 3.0 & 3.2227 & TRN & \\
\hline CHEMBL3126886 & 1294960 & 5.6126 & 4.7199 & TRN & \\
\hline CHEMBL 3127047 & 1294960 & 3.0 & 3.06 & TST & \\
\hline CHEMBL 3126885 & 1294960 & 4.1457 & 4.3577 & TRN & \\
\hline CHEMBL3127055 & 1294960 & 3.0 & 3.1215 & TST & \\
\hline CHEMBL3126908 & 1294960 & 4.4101 & 4.7033 & TRN & \\
\hline CHEMBL3126888 & 1294960 & 5.0691 & 4.4394 & TRN & \\
\hline CHEMBL 3127066 & 1294960 & 3.0 & 3.0711 & TRN & \\
\hline CHEMBL 3127065 & 1294960 & 3.0 & 2.926 & TRN & \\
\hline CHEMBL3126892 & 1294960 & 4.0825 & 3.3563 & TRN & \\
\hline CHEMBL3126883 & 1294960 & 3.0 & 3.2938 & TST & \\
\hline CHEMBL3126905 & 1294960 & 3.0 & 2.8643 & TST & \\
\hline CHEMBL65014 & 371466 & 8.51 & 8.5004 & TRN & \\
\hline CHEMBL62731 & 371466 & 7.35 & 7.3212 & TRN & \\
\hline CHEMBL62700 & 371466 & 8.68 & 8.6917 & TRN & \\
\hline CHEMBL64913 & 371466 & 8.21 & 8.2054 & TRN & \\
\hline CHEMBL66650 & 371466 & 6.54 & 6.5288 & TRN & \\
\hline CHEMBL 294265 & 371466 & 6.32 & 6.2929 & TRN & \\
\hline CHEMBL62798 & 371466 & 6.69 & 6.6901 & TRN & \\
\hline CHEMBL62227 & 371466 & 8.35 & 8.3067 & TRN & \\
\hline CHEMBL62761 & 371466 & 7.91 & 7.8794 & TRN & \\
\hline CHEMBL65743 & 371466 & 8.25 & 8.2756 & TRN & \\
\hline CHEMBL418684 & 371466 & 7.87 & 7.8859 & TRN & \\
\hline CHEMBL 303293 & 371466 & 6.45 & 6.4425 & TRN & \\
\hline CHEMBL64294 & 371466 & 8.17 & 8.1693 & TRN & \\
\hline CHEMBL65522 & 371466 & 7.07 & 7.1055 & TRN & \\
\hline CHEMBL294116 & 371466 & 7.35 & 7.3194 & TRN & \\
\hline CHEMBL62714 & 371466 & 6.56 & 6.58799 & 9999999999 & TRN \\
\hline CHEMBL63610 & 371466 & 6.61 & 6.6035 & TRN & \\
\hline CHEMBL63870 & 371466 & 7.82 & 7.8533 & TRN & \\
\hline CHEMBL64123 & 371466 & 7.89 & 7.8717 & TRN & \\
\hline CHEMBL65079 & 371466 & 7.71 & 7.7398 & TRN & \\
\hline CHEMBL67362 & 371466 & 7.08 & 7.0818 & TRN & \\
\hline CHEMBL132889 & 371466 & 8.41 & 7.8527 & TST & \\
\hline CHEMBL131681 & 371466 & 7.91 & 8.1618 & TST & \\
\hline CHEMBL131855 & 371466 & 7.59 & 7.6137 & TRN & \\
\hline CHEMBL132950 & 371466 & 6.6 & 6.6316 & TRN & \\
\hline CHEMBL132192 & 371466 & 6.36 & 6.3447 & TRN & \\
\hline CHEMBL132193 & 371466 & 7.26 & 7.2696 & TRN & \\
\hline CHEMBL133656 & 371466 & 8.59 & 8.6048 & TRN & \\
\hline CHEMBL134786 & 371466 & 7.1 & 7.07600 & 00000000005 & TRN \\
\hline CHEMBL339399 & 371466 & 7.51 & 7.5166 & TRN & \\
\hline CHEMBL133661 & 371466 & 7.92 & 7.8955 & TRN & \\
\hline CHEMBL538158 & 371466 & 7.49 & 7.4911 & TRN & \\
\hline CHEMBL133794 & 371466 & 7.6 & 7.6024 & TRN & \\
\hline
\end{tabular}




\begin{tabular}{|c|c|c|c|c|c|}
\hline \multirow[b]{2}{*}{ CHEMBL337199 } & \multicolumn{5}{|c|}{ Supplemental Table S2.txt } \\
\hline & 371466 & 6.63 & 6.6147 & TRN & \\
\hline CHEMBL334890 & 371466 & 7.44 & 7.4179 & 9999999999 & TRN \\
\hline CHEMBL132195 & 371466 & 7.51 & 7.5374 & TRN & \\
\hline CHEMBL335992 & 371466 & 8.46 & 7.8504 & TST & \\
\hline CHEMBL337885 & 371466 & 7.43 & 7.5922 & TST & \\
\hline CHEMBL117308 & 371466 & 8.3 & 9.3015 & TST & \\
\hline CHEMBL 93027 & 371466 & 7.7 & 8.7564 & TST & \\
\hline CHEMBL117465 & 371466 & 8.0 & 9.0453 & TST & \\
\hline CHEMBL115904 & 371466 & 7.72 & 8.1982 & TST & \\
\hline CHEMBL117586 & 371466 & 8.0 & 9.0283 & TST & \\
\hline CHEMBL117585 & 371466 & 6.74 & 8.7248 & TST & \\
\hline CHEMBL 93463 & 371466 & 6.88 & 8.4705 & TST & \\
\hline CHEMBL330726 & 371466 & 7.11 & 7.6986 & TST & \\
\hline CHEMBL91858 & 371466 & 6.77 & 7.2927 & TST & \\
\hline CHEMBL327551 & 371466 & 7.11 & 8.0726 & TST & \\
\hline CHEMBL431280 & 371466 & 7.68 & 7.6835 & TRN & \\
\hline CHEMBL 328804 & 371466 & 7.01 & 6.9918 & TRN & \\
\hline CHEMBL 91927 & 371466 & 7.81 & 7.8699 & TRN & \\
\hline CHEMBL446160 & 371466 & 6.7 & 6.74 & TRN & \\
\hline CHEMBL330235 & 371466 & 7.24 & 7.3114 & TRN & \\
\hline CHEMBL92730 & 371466 & 7.89 & 7.8335 & TRN & \\
\hline CHEMBL90766 & 371466 & 7.54 & 8.633 & TST & \\
\hline CHEMBL 94286 & 371466 & 5.45 & 8.4835 & TST & \\
\hline CHEMBL329339 & 371466 & 6.95 & 8.4273 & TST & \\
\hline CHEMBL328058 & 371466 & 6.74 & 8.174 & TST & \\
\hline CHEMBL433403 & 371466 & 8.82 & 8.7984 & TRN & \\
\hline CHEMBL330527 & 371466 & 8.72 & 8.7627 & TRN & \\
\hline CHEMBL327847 & 371466 & 8.51 & 8.5217 & TRN & \\
\hline CHEMBL313418 & 371466 & 7.95 & 7.9669 & TRN & \\
\hline CHEMBL 93690 & 371466 & 8.64 & 8.581 & TRN & \\
\hline CHEMBL 92750 & 371466 & 8.46 & 8.4977 & TRN & \\
\hline CHEMBL328523 & 371466 & 7.54 & 7.5281 & TRN & \\
\hline CHEMBL446418 & 371466 & 7.62 & 7.6048 & TRN & \\
\hline CHEMBL328506 & 371466 & 8.44 & 8.356 & TRN & \\
\hline CHEMBL93345 & 371466 & 6.75 & 6.7217 & TRN & \\
\hline CHEMBL 92089 & 371466 & 7.91 & 7.853 & TRN & \\
\hline CHEMBL329198 & 371466 & 7.85 & 7.939 & TRN & \\
\hline CHEMBL1485551 & 752585 & 4.7311 & 4.5509 & TRN & \\
\hline CHEMBL 3190786 & 752585 & 4.2818 & 4.2574 & TRN & \\
\hline CHEMBL1496396 & 752585 & 4.5699 & 4.1902 & TST & \\
\hline CHEMBL1314125 & 752585 & 4.3696 & 3.8884 & TRN & \\
\hline CHEMBL3196351 & 752585 & 4.5408 & 4.0978 & TRN & \\
\hline CHEMBL1443454 & 752585 & 4.5988 & 3.8946 & TRN & \\
\hline CHEMBL1338805 & 752585 & 4.5439 & 4.285 & TRN & \\
\hline CHEMBL1418980 & 752585 & 4.5573 & 4.4594 & TRN & \\
\hline CHEMBL1345067 & 752585 & 3.9586 & 3.7526 & TRN & \\
\hline CHEMBL1442783 & 752585 & 4.6835 & 4.9427 & TRN & \\
\hline CHEMBL1424665 & 752585 & 4.3065 & 4.2637 & TRN & \\
\hline
\end{tabular}




\begin{tabular}{|c|c|c|c|c|c|}
\hline & & \multicolumn{4}{|c|}{ Supplemental Table S2.txt } \\
\hline CHEMBL1531245 & 752585 & 4.5386 & 4.75 & TRN & \\
\hline CHEMBL1559811 & 752585 & 3.4559 & 3.8238 & TRN & \\
\hline CHEMBL1715042 & 752585 & 3.4559 & 4.1295 & TST & \\
\hline CHEMBL1589637 & 752585 & 4.5873 & 4.3444 & TRN & \\
\hline CHEMBL3199673 & 752585 & 4.5246 & 4.2915 & TRN & \\
\hline CHEMBL1491532 & 752585 & 3.4559 & 3.8333 & TRN & \\
\hline CHEMBL1571852 & 752585 & 3.4559 & 4.2121 & TRN & \\
\hline CHEMBL1512375 & 752585 & 4.6891 & 4.3149 & TRN & \\
\hline CHEMBL1339694 & 752585 & 3.4559 & 3.3171 & TRN & \\
\hline CHEMBL602718 & 752585 & 4.4562 & 4.5199 & TRN & \\
\hline CHEMBL3207960 & 752585 & 3.4559 & 4.0317 & TRN & \\
\hline CHEMBL3191116 & 752585 & 4.7582 & 4.3912 & TRN & \\
\hline CHEMBL1383386 & 752585 & 4.6766 & 4.2765 & TRN & \\
\hline CHEMBL1462611 & 752585 & 3.4559 & 3.5635 & TRN & \\
\hline CHEMBL1706149 & 752585 & 3.4559 & 3.605 & TRN & \\
\hline CHEMBL1455963 & 752585 & 3.4559 & 4.1446 & TRN & \\
\hline CHEMBL1386881 & 752585 & 4.7884 & 4.34699 & 99999999995 & TRN \\
\hline CHEMBL1369593 & 752585 & 4.7378 & 4.1906 & TRN & \\
\hline CHEMBL1450335 & 752585 & 3.4559 & 3.9591 & TRN & \\
\hline CHEMBL1450527 & 752585 & 4.319 & 3.8235 & TRN & \\
\hline CHEMBL1981103 & 752585 & 4.9821 & 4.9295 & TST & \\
\hline CHEMBL1509812 & 752585 & 4.3644 & 4.3917 & TRN & \\
\hline CHEMBL1979784 & 752585 & $4.3260 e$ & 00000000 & 4.1938 & TRN \\
\hline CHEMBL3208179 & 752585 & 4.7445 & 4.4396 & TRN & \\
\hline CHEMBL3196181 & 752585 & 4.3341 & 4.4549 & TRN & \\
\hline CHEMBL1538410 & 752585 & 4.4314 & 4.5689 & TRN & \\
\hline CHEMBL1711546 & 752585 & 3.4559 & 3.8745 & TST & \\
\hline CHEMBL1424746 & 752585 & 4.665 & 4.2236 & TST & \\
\hline CHEMBL1513566 & 752585 & 3.4559 & 3.9976 & TRN & \\
\hline CHEMBL1433859 & 752585 & 4.5206 & 4.203 & TRN & \\
\hline CHEMBL1547092 & 752585 & 4.0401 & 4.0862 & TRN & \\
\hline CHEMBL1411646 & 752585 & 4.5797 & 4.7385 & TRN & \\
\hline CHEMBL1453723 & 752585 & 4.3241 & 3.9793 & TRN & \\
\hline CHEMBL1562684 & 752585 & 4.3689 & 4.0988 & TRN & \\
\hline CHEMBL1456979 & 752585 & 4.5208 & 4.0088 & TRN & \\
\hline CHEMBL1336277 & 752585 & 4.5595 & 4.3267 & TRN & \\
\hline CHEMBL1321427 & 752585 & 3.4559 & 3.582 & TRN & \\
\hline CHEMBL1481192 & 752585 & 4.5459 & 4.1806 & TST & \\
\hline CHEMBL1601310 & 752585 & 4.742 & 4.7465 & TRN & \\
\hline CHEMBL1404138 & 752585 & 4.6941 & 4.8539 & TST & \\
\hline CHEMBL1379675 & 752585 & 4.4795 & 4.3414 & TRN & \\
\hline CHEMBL1303653 & 752585 & 3.4559 & 3.6973 & TRN & \\
\hline CHEMBL1406465 & 752585 & 3.9586 & 4.3142 & TRN & \\
\hline CHEMBL1387181 & 752585 & 4.074 & 4.6029 & TST & \\
\hline CHEMBL1334040 & 752585 & 4.808 & 4.6275 & TRN & \\
\hline CHEMBL1545556 & 752585 & 4.7356 & 4.1102 & TRN & \\
\hline CHEMBL602990 & 752585 & 4.3778 & 4.1709 & TRN & \\
\hline CHEMBL1308547 & 752585 & 4.6118 & 4.5209 & TRN & \\
\hline
\end{tabular}




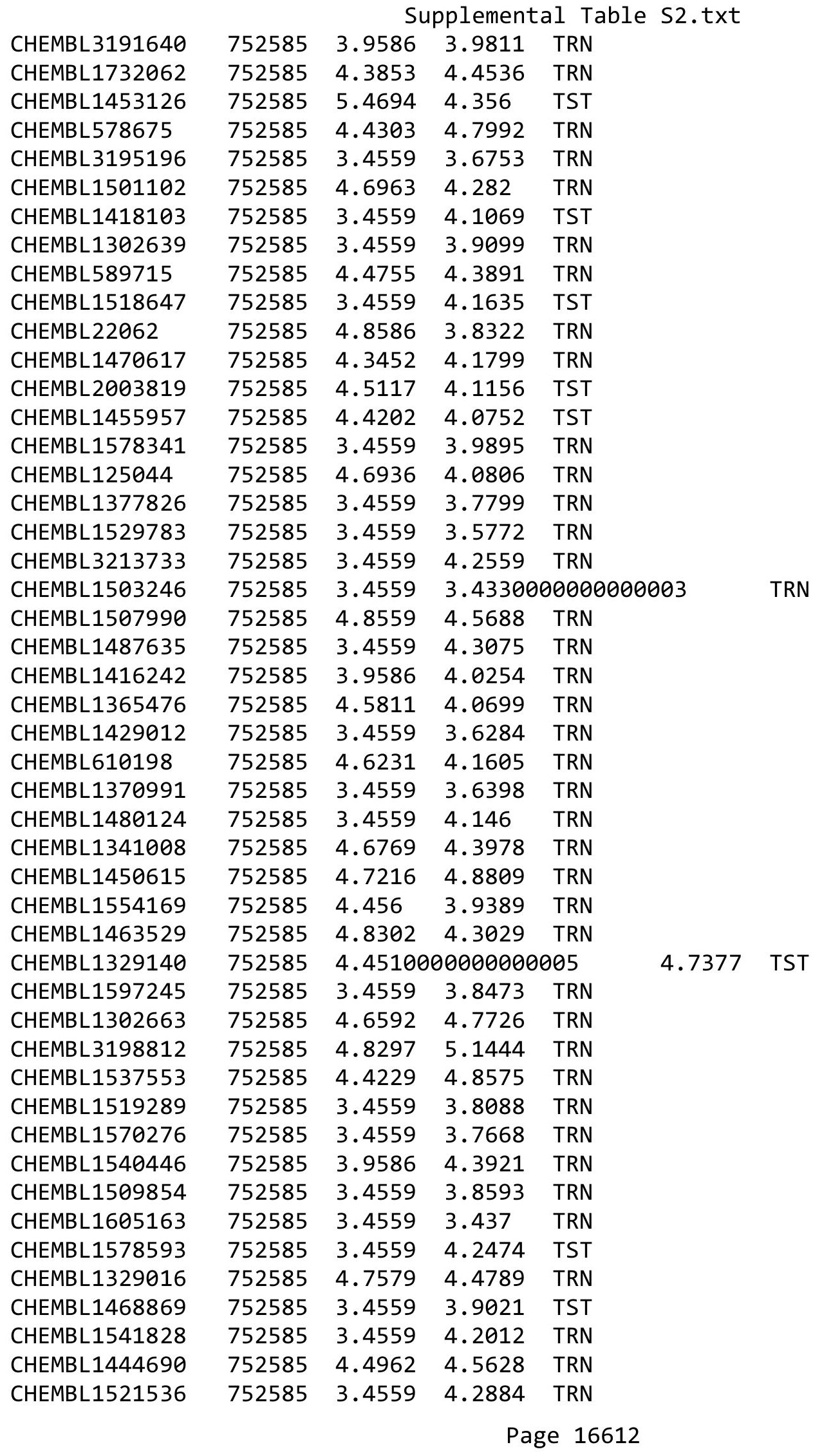




\begin{tabular}{|c|c|c|c|c|c|c|}
\hline & & \multicolumn{5}{|c|}{ Supplemental Table S2.txt } \\
\hline CHEMBL1698608 & 752585 & 4.4598 & 3.9416 & TRN & & \\
\hline CHEMBL3189325 & 752585 & 4.3919 & 4.6576 & TRN & & \\
\hline CHEMBL1320886 & 752585 & 3.4559 & 3.6179 & TRN & & \\
\hline CHEMBL1463626 & 752585 & 4.6671 & 4.0784 & TST & & \\
\hline CHEMBL1586895 & 752585 & 4.3385 & 4.0904 & TRN & & \\
\hline CHEMBL1586034 & 752585 & 3.4559 & 3.6412 & TRN & & \\
\hline CHEMBL1489428 & 752585 & 3.4559 & 3.4729 & TRN & & \\
\hline CHEMBL1992138 & 752585 & 3.4559 & 3.8299 & TRN & & \\
\hline CHEMBL1452555 & 752585 & 3.9586 & 4.2293 & TRN & & \\
\hline CHEMBL1306583 & 752585 & 4.5189 & 4.612 & TRN & & \\
\hline CHEMBL1377750 & 752585 & 4.7001 & 4.7154 & TRN & & \\
\hline CHEMBL1573994 & 752585 & 4.5903 & 4.3864 & TRN & & \\
\hline CHEMBL1518326 & 752585 & 4.8149 & 4.412 & TRN & & \\
\hline CHEMBL1485890 & 752585 & 5.1146 & 4.7349 & TRN & & \\
\hline CHEMBL1538643 & 752585 & 4.3886 & 4.8885 & TRN & & \\
\hline CHEMBL1382429 & 752585 & 4.9013 & 4.7359 & TRN & & \\
\hline CHEMBL1970597 & 752585 & 3.9586 & 4.3078 & TRN & & \\
\hline CHEMBL1359715 & 752585 & 3.4559 & 3.2856 & TRN & & \\
\hline CHEMBL1488909 & 752585 & 3.4559 & 3.907 & TRN & & \\
\hline CHEMBL1405281 & 752585 & 4.7241 & 4.6453 & TRN & & \\
\hline CHEMBL1560590 & 752585 & 4.4061 & 4.2845 & TRN & & \\
\hline CHEMBL1354020 & 752585 & 4.5269 & 4.334 & TRN & & \\
\hline CHEMBL1572028 & 752585 & 3.9586 & 4.4841 & TRN & & \\
\hline CHEMBL1572924 & 752585 & 4.4688 & 4.5293 & TRN & & \\
\hline CHEMBL1724238 & 752585 & 3.4559 & 4.5636 & TST & & \\
\hline CHEMBL1456821 & 752585 & 4.5933 & 4.7105 & TST & & \\
\hline CHEMBL1414808 & 752585 & 4.4653 & 4.5499 & TRN & & \\
\hline CHEMBL1441491 & 752585 & 3.4559 & 3.7749 & TRN & & \\
\hline CHEMBL1966869 & 752585 & 4.5277 & 3.8296 & TRN & & \\
\hline CHEMBL1447872 & 752585 & 3.4559 & 3.8584 & TRN & & \\
\hline CHEMBL3198933 & 752585 & 4.6175 & 4.4097 & TRN & & \\
\hline CHEMBL1504139 & 752585 & 4.662 & 4.4358 & TRN & & \\
\hline CHEMBL3196173 & 752585 & 3.4559 & 4.3418 & TRN & & \\
\hline CHEMBL1328118 & 752585 & 4.7569 & 4.9841 & TRN & & \\
\hline CHEMBL1451348 & 752585 & 5.17899 & 99999999 & 99 & 4.6747 & TRN \\
\hline CHEMBL1384006 & 752585 & 3.4559 & 3.7136 & TRN & & \\
\hline CHEMBL1336446 & 752585 & 4.4808 & 4.1492 & TRN & & \\
\hline CHEMBL1438983 & 752585 & 4.8296 & 5.1184 & TST & & \\
\hline CHEMBL1585764 & 752585 & 3.9586 & 4.4073 & TRN & & \\
\hline CHEMBL1480031 & 752585 & 3.4559 & 3.7726 & TRN & & \\
\hline CHEMBL1417704 & 752585 & 3.4559 & 3.668 & TRN & & \\
\hline CHEMBL3190217 & 752585 & 3.4559 & 4.3653 & TRN & & \\
\hline CHEMBL1543238 & 752585 & 4.3869 & 3.9032 & TRN & & \\
\hline CHEMBL1347156 & 752585 & 4.3928 & 3.79 & TRN & & \\
\hline CHEMBL1416329 & 752585 & 4.7178 & 4.8599 & TRN & & \\
\hline CHEMBL1565526 & 752585 & 4.2541 & 4.2404 & TRN & & \\
\hline CHEMBL1569824 & 752585 & 4.7014 & 4.6569 & TRN & & \\
\hline CHEMBL95704 & 752585 & 4.3368 & 4.4731 & TST & & \\
\hline
\end{tabular}


Supplemental Table S2.txt

\begin{tabular}{|c|c|c|c|c|}
\hline CHEMBL1427087 & 752585 & 4.5163 & 4.2766 & TRN \\
\hline CHEMBL1352326 & 752585 & 3.4559 & 3.3682 & TRN \\
\hline CHEMBL1489022 & 752585 & 3.9586 & 4.3781 & TRN \\
\hline CHEMBL1337227 & 752585 & 3.4559 & 3.9195 & TRN \\
\hline CHEMBL1534959 & 752585 & 4.5141 & 4.2206 & TST \\
\hline CHEMBL1459312 & 752585 & 3.4559 & 3.81 & TRN \\
\hline CHEMBL1558863 & 752585 & 4.4699 & 4.1803 & TRN \\
\hline CHEMBL1610029 & 752585 & 4.6147 & 4.4374 & TST \\
\hline CHEMBL1387688 & 752585 & 5.1229 & 4.4918 & TRN \\
\hline CHEMBL1321756 & 752585 & 4.3844 & 4.2258 & TRN \\
\hline CHEMBL1430520 & 752585 & 4.4364 & 4.6083 & TRN \\
\hline CHEMBL1485562 & 752585 & 4.4253 & 4.3326 & TST \\
\hline CHEMBL1430071 & 752585 & 4.7295 & 4.7181 & TRN \\
\hline CHEMBL533082 & 752585 & 4.6738 & 4.0057 & TRN \\
\hline CHEMBL1407228 & 752585 & 4.7514 & 4.6761 & TRN \\
\hline CHEMBL1428758 & 752585 & 4.5109 & 4.289 & TRN \\
\hline CHEMBL1454102 & 752585 & 3.4559 & 4.2309 & TRN \\
\hline CHEMBL1378837 & 752585 & 3.4559 & 4.2191 & TST \\
\hline CHEMBL1413039 & 752585 & 3.9586 & 4.2996 & TRN \\
\hline CHEMBL 373137 & 752585 & 3.4559 & 4.4497 & TST \\
\hline CHEMBL3208387 & 752585 & 3.4559 & 3.5988 & TRN \\
\hline CHEMBL1584006 & 752585 & 4.5675 & 4.1796 & TRN \\
\hline CHEMBL1321668 & 752585 & 3.4559 & 3.2692 & TRN \\
\hline CHEMBL1338690 & 752585 & 3.4559 & 4.0023 & TRN \\
\hline CHEMBL1455230 & 752585 & 4.3104 & 4.1331 & TRN \\
\hline CHEMBL1727052 & 752585 & 4.5889 & 4.5176 & TRN \\
\hline CHEMBL1400379 & 752585 & 3.4559 & 3.4486 & TRN \\
\hline CHEMBL1487952 & 752585 & 4.4364 & 4.1469 & TRN \\
\hline CHEMBL1423040 & 752585 & 4.4585 & 4.5121 & TST \\
\hline CHEMBL1605224 & 752585 & 4.7373 & 4.6372 & TRN \\
\hline CHEMBL1716759 & 752585 & 4.5435 & 4.2601 & TRN \\
\hline CHEMBL1301197 & 752585 & 3.9586 & 4.324 & TRN \\
\hline CHEMBL1304623 & 752585 & 3.4559 & 3.9075 & TRN \\
\hline CHEMBL1710184 & 752585 & 4.6248 & 4.482 & TRN \\
\hline CHEMBL1430757 & 752585 & 4.3262 & 4.632 & TRN \\
\hline CHEMBL1583552 & 752585 & 4.6534 & 4.5292 & TRN \\
\hline CHEMBL1346027 & 752585 & 3.4559 & 3.5113 & TRN \\
\hline CHEMBL1373255 & 752585 & 4.6949 & 3.9512 & TRN \\
\hline CHEMBL1385384 & 752585 & 4.4651 & 4.3702 & TRN \\
\hline CHEMBL1517511 & 752585 & 4.2951 & 4.3732 & TST \\
\hline CHEMBL1377376 & 752585 & 3.4559 & 4.3327 & TST \\
\hline CHEMBL1403131 & 752585 & 4.7617 & 4.5776 & TRN \\
\hline CHEMBL1333929 & 752585 & 3.4559 & 4.6035 & TST \\
\hline CHEMBL1323821 & 752585 & 3.9586 & 4.0335 & TRN \\
\hline CHEMBL1420393 & 752585 & 4.5496 & 4.14199 & 99999999995 \\
\hline CHEMBL1502980 & 752585 & 4.8586 & 4.5174 & TRN \\
\hline CHEMBL1326819 & 752585 & 3.9586 & 4.3421 & TRN \\
\hline CHEMBL1559741 & 752585 & 3.4559 & 3.9714 & TRN \\
\hline
\end{tabular}




\begin{tabular}{|c|c|c|c|c|c|c|}
\hline & & \multicolumn{5}{|c|}{ Supplemental Table S2.txt } \\
\hline CHEMBL601146 & 752585 & 4.3843 & 4.558 & TRN & & \\
\hline CHEMBL1714133 & 752585 & 4.7691 & 4.4917 & TRN & & \\
\hline CHEMBL1378851 & 752585 & 3.4559 & 4.3129 & TST & & \\
\hline CHEMBL1329235 & 752585 & 4.87 & 4.1944 & TRN & & \\
\hline CHEMBL1729277 & 752585 & 4.3786 & 4.3378 & TRN & & \\
\hline CHEMBL1576310 & 752585 & 4.5578 & 4.3744 & TRN & & \\
\hline CHEMBL1989225 & 752585 & 4.3144 & 4.183 & TRN & & \\
\hline CHEMBL1315054 & 752585 & 4.4762 & 4.7816 & TRN & & \\
\hline CHEMBL1536628 & 752585 & 4.6348 & 4.3457 & TRN & & \\
\hline CHEMBL1601288 & 752585 & 3.9586 & 3.6589 & TRN & & \\
\hline CHEMBL582722 & 752585 & 4.3693 & 4.3023 & TRN & & \\
\hline CHEMBL1550485 & 752585 & 4.4738 & 4.1249 & TST & & \\
\hline CHEMBL3191413 & 752585 & 3.4559 & 3.8942 & TRN & & \\
\hline CHEMBL1447697 & 752585 & 3.4559 & 3.9441 & TRN & & \\
\hline CHEMBL1426177 & 752585 & 4.7257 & 4.6167 & TRN & & \\
\hline CHEMBL1550490 & 752585 & $5.1770 e$ & 00000000 & 205 & 4.6579 & TRN \\
\hline CHEMBL1587205 & 752585 & 4.7065 & 4.3522 & TRN & & \\
\hline CHEMBL1361227 & 752585 & 4.4413 & 4.7665 & TRN & & \\
\hline CHEMBL1458479 & 752585 & 5.2278 & 4.9241 & TRN & & \\
\hline CHEMBL1611269 & 752585 & 3.4559 & 3.2512 & TST & & \\
\hline CHEMBL1562186 & 752585 & 4.6677 & 4.448 & TRN & & \\
\hline CHEMBL1419104 & 752585 & 4.4562 & 4.3459 & TRN & & \\
\hline CHEMBL1377682 & 752585 & 4.4835 & 4.1963 & TRN & & \\
\hline CHEMBL1531003 & 752585 & 4.423 & 4.4948 & TRN & & \\
\hline CHEMBL1507162 & 752585 & 4.4806 & 4.3217 & TRN & & \\
\hline CHEMBL601351 & 752585 & 4.5254 & 5.022 & TST & & \\
\hline CHEMBL1514238 & 752585 & 4.5244 & 3.9234 & TRN & & \\
\hline CHEMBL1387011 & 752585 & 3.4559 & 3.9252 & TRN & & \\
\hline CHEMBL1305475 & 752585 & 4.6852 & 4.7109 & TRN & & \\
\hline CHEMBL1302028 & 752585 & 3.4559 & 3.7219 & TST & & \\
\hline CHEMBL1335687 & 752585 & 4.5737 & 4.2594 & TST & & \\
\hline CHEMBL1527537 & 752585 & 4.4852 & 4.149 & TST & & \\
\hline CHEMBL1331514 & 752585 & 4.4719 & 3.4602 & TST & & \\
\hline CHEMBL3189770 & 752585 & 4.7345 & 4.3851 & TST & & \\
\hline CHEMBL1398224 & 752585 & 4.7021 & 4.5334 & TST & & \\
\hline CHEMBL1701600 & 752585 & 4.6293 & 4.5002 & TST & & \\
\hline CHEMBL1416660 & 752585 & 4.4674 & 4.6134 & TST & & \\
\hline CHEMBL1501466 & 752585 & 4.6069 & 4.584 & TST & & \\
\hline CHEMBL1373823 & 752585 & 3.4559 & 3.935 & TST & & \\
\hline CHEMBL 2369158 & 752585 & 3.4559 & 3.8883 & TST & & \\
\hline CHEMBL591370 & 752585 & 4.419 & 4.4742 & TST & & \\
\hline CHEMBL1385190 & 752585 & 4.4342 & 4.1316 & TST & & \\
\hline CHEMBL1447782 & 752585 & 4.7048 & 4.3332 & TST & & \\
\hline CHEMBL1423463 & 752585 & 4.6398 & 4.7684 & TST & & \\
\hline CHEMBL1504077 & 752585 & 3.9586 & 4.0459 & TST & & \\
\hline CHEMBL1561133 & 752585 & 4.751 & 4.5882 & TST & & \\
\hline CHEMBL1494202 & 752585 & 3.4559 & 3.8036 & TST & & \\
\hline CHEMBL1350245 & 752585 & 4.434 & 4.7942 & TST & & \\
\hline
\end{tabular}


Supplemental Table S2.txt

\begin{tabular}{|c|c|c|c|c|c|}
\hline CHEMBL155563 & 752585 & 5.3797 & 4.7927 & TST & \\
\hline CHEMBL1585409 & 752585 & 3.4559 & 3.8652 & TST & \\
\hline CHEMBL1573697 & 752585 & 4.3917 & 4.3861 & TST & \\
\hline CHEMBL1556118 & 752585 & 4.6261 & 4.0104 & TST & \\
\hline CHEMBL1970537 & 752585 & 3.4559 & 4.0391 & TST & \\
\hline CHEMBL1363130 & 752585 & 3.9586 & 4.1377 & TST & \\
\hline CHEMBL1487205 & 752585 & 3.4559 & 4.2693 & TST & \\
\hline CHEMBL1472327 & 752585 & 4.452 & 4.3983 & TST & \\
\hline CHEMBL1573916 & 752585 & 3.4559 & 4.0248 & TST & \\
\hline CHEMBL1493902 & 752585 & 3.4559 & 4.2742 & TST & \\
\hline CHEMBL1462821 & 752585 & 3.4559 & 3.8783 & TST & \\
\hline CHEMBL1458483 & 752585 & 4.67399 & 99999999 & 995 & 4.5439 \\
\hline CHEMBL1413633 & 752585 & 3.4559 & 4.1423 & TST & \\
\hline CHEMBL1410873 & 752585 & 4.55 & 4.3589 & TST & \\
\hline CHEMBL 2387745 & 963381 & 4.0 & 3.9283 & TRN & \\
\hline CHEMBL516339 & 963381 & 5.0 & 5.2394 & TRN & \\
\hline CHEMBL 2181551 & 963381 & 5.399 & 5.3064 & TRN & \\
\hline CHEMBL 2177255 & 963381 & 4.0 & 4.5909 & TRN & \\
\hline CHEMBL 2177252 & 963381 & 4.0 & 4.553 & TRN & \\
\hline CHEMBL513763 & 963381 & 5.5513 & 4.1895 & TRN & \\
\hline CHEMBL 2177251 & 963381 & 4.0 & 4.4106 & TRN & \\
\hline CHEMBL 2387535 & 963381 & 5.0306 & 4.695 & TRN & \\
\hline CHEMBL 2177262 & 963381 & 4.0 & 4.8377 & TRN & \\
\hline CHEMBL506746 & 963381 & 5.4622 & 5.7928 & TRN & \\
\hline CHEMBL455557 & 963381 & 4.0 & 4.8558 & TST & \\
\hline CHEMBL 2387534 & 963381 & 4.8928 & 4.7856 & TRN & \\
\hline CHEMBL470019 & 963381 & 4.0 & 4.5363 & TRN & \\
\hline CHEMBL 2177264 & 963381 & 6.4461 & 5.4597 & TRN & \\
\hline CHEMBL447225 & 963381 & 4.0 & 4.3617 & TST & \\
\hline CHEMBL 2181544 & 963381 & 6.0685 & 5.2085 & TRN & \\
\hline CHEMBL 2387540 & 963381 & 4.0 & 4.4625 & TRN & \\
\hline CHEMBL 2177257 & 963381 & 5.1972 & 4.6553 & TRN & \\
\hline CHEMBL472634 & 963381 & 4.0 & 4.6644 & TST & \\
\hline CHEMBL 2177259 & 963381 & 5.0458 & 4.5612 & TRN & \\
\hline CHEMBL 2181548 & 963381 & 4.0 & 4.4282 & TRN & \\
\hline CHEMBL 2387536 & 963381 & 4.8697 & 4.7789 & TRN & \\
\hline CHEMBL 2387530 & 963381 & 5.4828 & 4.5713 & TRN & \\
\hline CHEMBL 2387743 & 963381 & 5.1463 & 4.6309 & TRN & \\
\hline CHEMBL472493 & 963381 & 4.0 & 4.263 & TRN & \\
\hline CHEMBL511303 & 963381 & 5.0 & 5.0923 & TRN & \\
\hline CHEMBL 2387539 & 963381 & 5.2874 & 4.8324 & TRN & \\
\hline CHEMBL471247 & 963381 & 4.0 & 3.68 & TRN & \\
\hline CHEMBL 2387538 & 963381 & 5.1141 & 4.9316 & TRN & \\
\hline CHEMBL470198 & 963381 & 4.0 & 4.8365 & TST & \\
\hline CHEMBL470199 & 963381 & 5.1713 & 4.0817 & TRN & \\
\hline CHEMBL 2387537 & 963381 & 4.9872 & 4.8698 & TRN & \\
\hline CHEMBL 2181542 & 963381 & 6.9469 & 5.7655 & TRN & \\
\hline CHEMBL 2181547 & 963381 & 4.0 & 4.5263 & TRN & \\
\hline
\end{tabular}




\begin{tabular}{|c|c|c|c|c|c|c|}
\hline & & \multicolumn{5}{|c|}{ Supplemental Table S2.txt } \\
\hline CHEMBL470224 & 963381 & 5.2733 & 5.1846 & TRN & & \\
\hline CHEMBL 2181545 & 963381 & 4.0 & 4.7386 & TRN & & \\
\hline CHEMBL 2177261 & 963381 & 4.0 & 4.6717 & TRN & & \\
\hline CHEMBL 2181546 & 963381 & 6.0173 & 5.1392 & TRN & & \\
\hline CHEMBL443168 & 963381 & 4.0 & 4.5345 & TRN & & \\
\hline CHEMBL 2387532 & 963381 & 5.4248 & 4.7594 & TRN & & \\
\hline CHEMBL 2387744 & 963381 & 5.2441 & 5.5087 & TRN & & \\
\hline CHEMBL508042 & 963381 & 4.0 & 5.4606 & TST & & \\
\hline CHEMBL 2177250 & 963381 & 4.9747 & 4.9199 & TRN & & \\
\hline CHEMBL 2181697 & 963381 & 4.0 & 5.2242 & TRN & & \\
\hline CHEMBL 2387533 & 963381 & 6.0083 & 4.9845 & TRN & & \\
\hline CHEMBL 2181550 & 963381 & 5.0 & 4.846 & TRN & & \\
\hline CHEMBL 2177258 & 963381 & 4.0 & 4.7734 & TRN & & \\
\hline CHEMBL472067 & 963381 & 4.0 & 4.6773 & TST & & \\
\hline CHEMBL 2177256 & 963381 & 4.0 & 4.7199 & TRN & & \\
\hline CHEMBL470197 & 963381 & 4.0 & 5.6303 & TST & & \\
\hline CHEMBL 2181539 & 963381 & 4.0 & 5.0287 & TRN & & \\
\hline CHEMBL 2387531 & 963381 & 5.0 & 4.5954 & TRN & & \\
\hline CHEMBL 2181541 & 963381 & 4.0 & 5.0287 & TRN & & \\
\hline CHEMBL469519 & 963381 & 4.0 & 4.7197 & TRN & & \\
\hline CHEMBL 2177260 & 963381 & 4.0 & 4.8469 & TST & & \\
\hline CHEMBL2181540 & 963381 & 6.5834 & 5.7655 & TST & & \\
\hline CHEMBL 2177253 & 963381 & 5.2941 & 4.6236 & TST & & \\
\hline CHEMBL 2177263 & 963381 & 5.0 & 4.5997 & TST & & \\
\hline CHEMBL 2181543 & 963381 & 4.0 & 4.8192 & TST & & \\
\hline CHEMBL 2181552 & 963381 & 4.0 & 5.18 & TST & & \\
\hline CHEMBL 2177249 & 963381 & 5.4908 & 5.3702 & TST & & \\
\hline CHEMBL 2177254 & 963381 & 4.0 & 4.8328 & TST & & \\
\hline CHEMBL 2181549 & 963381 & 5.7520 & 00000000 & $\partial 1$ & 5.3148 & TST \\
\hline CHEMBL529716 & 1592859 & 6.2218 & 6.3187 & TRN & & \\
\hline CHEMBL524204 & 1592859 & 6.5528 & 6.4925 & TRN & & \\
\hline CHEMBL546400 & 1592859 & 6.2366 & 6.2418 & TRN & & \\
\hline CHEMBL532369 & 1592859 & 5.9666 & 6.0787 & TRN & & \\
\hline CHEMBL3637877 & 1592859 & 4.699 & 5.3377 & TRN & & \\
\hline CHEMBL588781 & 1592859 & 5.9788 & 5.2069 & TRN & & \\
\hline CHEMBL531393 & 1592859 & 6.0809 & 6.1905 & TRN & & \\
\hline CHEMBL526418 & 1592859 & 6.0088 & 6.0343 & TRN & & \\
\hline CHEMBL601337 & 1592859 & 5.7055 & 6.004 & TRN & & \\
\hline CHEMBL548417 & 1592859 & 6.0177 & 5.8735 & TRN & & \\
\hline CHEMBL586794 & 1592859 & 5.8962 & 5.8599 & TRN & & \\
\hline CHEMBL3637899 & 1592859 & 6.5229 & 6.0967 & TRN & & \\
\hline CHEMBL536678 & 1592859 & 6.0969 & 6.0939 & TST & & \\
\hline CHEMBL528061 & 1592859 & 5.8894 & 5.9326 & TRN & & \\
\hline CHEMBL529986 & 1592859 & 6.0458 & 6.0395 & TRN & & \\
\hline CHEMBL528922 & 1592859 & 6.9208 & 6.723 & TRN & & \\
\hline CHEMBL586311 & 1592859 & 5.9872 & 6.0054 & TRN & & \\
\hline CHEMBL587139 & 1592859 & 6.0269 & 6.2223 & TST & & \\
\hline CHEMBL601821 & 1592859 & 6.1938 & 6.2732 & TRN & & \\
\hline
\end{tabular}


Supplemental Table S2.txt

\begin{tabular}{|c|c|c|c|c|c|}
\hline CHEMBL527297 & 1592859 & 5.9208 & 5.8466 & TRN & \\
\hline CHEMBL598494 & 1592859 & 7.0 & 6.8671 & TRN & \\
\hline CHEMBL532350 & 1592859 & 5.9547 & 6.2068 & TRN & \\
\hline CHEMBL582027 & 1592859 & 6.0862 & 6.0625 & TRN & \\
\hline CHEMBL1588046 & 1592859 & 4.699 & 5.9601 & TRN & \\
\hline CHEMBL 3637887 & 1592859 & 4.699 & 5.1313 & TRN & \\
\hline CHEMBL534797 & 1592859 & 6.1079 & 6.1399 & TRN & \\
\hline CHEMBL1404608 & 1592859 & 6.3768 & 6.3872 & TRN & \\
\hline CHEMBL587947 & 1592859 & 6.6576 & 6.7026 & TRN & \\
\hline CHEMBL 3637875 & 1592859 & 5.8356 & 5.9798 & TRN & \\
\hline CHEMBL535286 & 1592859 & 5.7799 & 5.8993 & TST & \\
\hline CHEMBL 267274 & 1592859 & 6.3188 & 6.3862 & TRN & \\
\hline CHEMBL1197790 & 1592859 & 6.2924 & 6.4958 & TST & \\
\hline CHEMBL525702 & 1592859 & 6.6198 & 6.5962 & TRN & \\
\hline CHEMBL524742 & 1592859 & 5.983 & 6.0895 & TRN & \\
\hline CHEMBL531326 & 1592859 & 7.0458 & 6.8854 & TRN & \\
\hline CHEMBL567341 & 1592859 & 6.0458 & 6.2738 & TST & \\
\hline CHEMBL537372 & 1592859 & 6.1549 & 6.4347 & TRN & \\
\hline CHEMBL1324287 & 1592859 & 6.5376 & 6.6288 & TST & \\
\hline CHEMBL 3637883 & 1592859 & 4.699 & 5.21399 & 99999999995 & TST \\
\hline CHEMBL600894 & 1592859 & 5.9747 & 5.3065 & TST & \\
\hline CHEMBL534395 & 1592859 & 6.2007 & 6.2728 & TRN & \\
\hline CHEMBL 2172226 & 1592859 & 6.4202 & 6.2234 & TRN & \\
\hline CHEMBL 3637888 & 1592859 & 7.0 & 6.1516 & TRN & \\
\hline CHEMBL530887 & 1592859 & 5.9469 & 5.9608 & TST & \\
\hline CHEMBL 3637880 & 1592859 & 6.1805 & 5.9528 & TRN & \\
\hline CHEMBL 3637889 & 1592859 & 7.0 & 6.2438 & TRN & \\
\hline CHEMBL582507 & 1592859 & 6.2676 & 5.9574 & TRN & \\
\hline CHEMBL2375614 & 1592859 & 4.699 & 5.2864 & TRN & \\
\hline CHEMBL580794 & 1592859 & 5.9626 & 6.2505 & TRN & \\
\hline CHEMBL545949 & 1592859 & 5.6778 & 5.6615 & TRN & \\
\hline CHEMBL 3637884 & 1592859 & 4.699 & 5.1565 & TRN & \\
\hline CHEMBL586872 & 1592859 & 6.1427 & 6.2918 & TRN & \\
\hline CHEMBL535002 & 1592859 & 6.4559 & 5.7377 & TRN & \\
\hline CHEMBL534391 & 1592859 & 6.7212 & 6.1661 & TRN & \\
\hline CHEMBL602226 & 1592859 & 5.6861 & 5.9001 & TRN & \\
\hline CHEMBL531095 & 1592859 & 6.1487 & 6.1727 & TRN & \\
\hline CHEMBL587715 & 1592859 & 6.301 & 6.3216 & TRN & \\
\hline CHEMBL587610 & 1592859 & 7.5229 & 7.6248 & TRN & \\
\hline CHEMBL525112 & 1592859 & 5.9666 & 6.1268 & TRN & \\
\hline CHEMBL604099 & 1592859 & 6.4437 & 6.5998 & TRN & \\
\hline CHEMBL600161 & 1592859 & 4.699 & 6.1353 & TRN & \\
\hline CHEMBL139814 & 1592859 & 6.2218 & 6.1058 & TRN & \\
\hline CHEMBL580816 & 1592859 & 6.284 & 6.2105 & TRN & \\
\hline CHEMBL546607 & 1592859 & 5.8539 & 6.0529 & TRN & \\
\hline CHEMBL578464 & 1592859 & 5.9355 & 6.1567 & TRN & \\
\hline CHEMBL529068 & 1592859 & 6.3872 & 6.6711 & TST & \\
\hline CHEMBL526813 & 1592859 & 6.2441 & 6.1131 & TRN & \\
\hline
\end{tabular}


Supplemental Table S2.txt

\begin{tabular}{|c|c|c|}
\hline CHEMBL581767 & 592859 & \\
\hline CHEMBL525292 & 1592859 & \\
\hline CHEMBL530160 & 592859 & \\
\hline CHEMBL601970 & 1592859 & \\
\hline CHEMBL529152 & 1592859 & \\
\hline CHEMBL529610 & 1592859 & \\
\hline CHEMBL3637890 & 1592859 & 8.0 \\
\hline CHEMBL3637886 & 1592859 & 4.6 \\
\hline HEMBL581128 & 1592859 & \\
\hline CHEMBL596639 & 1592859 & \\
\hline CHEMBL598495 & 1592859 & \\
\hline CHEMBL580443 & 1592859 & \\
\hline CHEMBL230001 & 1592859 & 7.3 \\
\hline CHEMBL3637881 & 1592859 & \\
\hline CHEMBL3637879 & 1592859 & \\
\hline CHEMBL545853 & 1592859 & \\
\hline CHEMBL 270317 & 1592859 & \\
\hline CHEMBL536806 & 1592859 & \\
\hline CHEMBL585651 & 159 & \\
\hline CHEMBL3637874 & 159 & \\
\hline CHEMBL581971 & 1592859 & \\
\hline CHEMBL 3637842 & 1592859 & \\
\hline CHEMBL536144 & 1592 & \\
\hline CHEMBL3637882 & 159 & 4.65 \\
\hline CHEMBL597266 & 159 & 6.23 \\
\hline CHEMBL530228 & 1592859 & \\
\hline CHEMBL586864 & 1592859 & \\
\hline CHEMBL546398 & 159 & \\
\hline CHEMBL533421 & 15 & 6. \\
\hline CHEMBL 3637872 & 1592859 & \\
\hline CHEMBL531591 & 1592859 & \\
\hline CHEMBL531497 & 1592859 & \\
\hline CHEMBL586583 & 159 & \\
\hline CHEMBL535295 & $15 c$ & \\
\hline CHEMBL582371 & 1592859 & \\
\hline CHEMBL528507 & 1592859 & \\
\hline CHEMBL1552197 & 1592859 & \\
\hline CHEMBL611077 & 159 & \\
\hline CHEMBL 3637873 & 159 & \\
\hline CHEMBL587161 & 1592859 & 6.4 \\
\hline CHEMBL579902 & 1592859 & 6.0 \\
\hline CHEMBL580352 & 1592859 & \\
\hline CHEMBL528966 & 1592859 & 7.0 \\
\hline CHEMBL580702 & 1592859 & 6.5 \\
\hline CHEMBL 3637885 & 1592859 & 4.6 \\
\hline CHEMBL3637891 & 1592859 & $5 . \varepsilon$ \\
\hline CHEMBL3637876 & 1592859 & \\
\hline CHEMBL532242 & 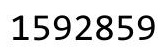 & \\
\hline
\end{tabular}

\begin{tabular}{ll}
6.0119 & TRN \\
6.2748 & TRN \\
6.099 & TST \\
6.6331 & TRN \\
6.4053 & TST \\
6.1098 & TST \\
6.1275 & TRN \\
5.2024 & TRN \\
6.1011 & TRN \\
6.2351 & TRN \\
5.3148 & TRN \\
6.1368 & TRN \\
6.9375 & TRN \\
6.5893 & TRN \\
6.1587 & TRN \\
6.0261 & TRN \\
6.0811 & TRN \\
6.6779 & TST \\
5.2861 & TRN \\
6.115 & TRN \\
6.0764 & TRN \\
5.9471 & TRN \\
6.3324 & TRN \\
5.4244 & TST \\
5.9281 & TRN \\
6.4103 & TRN \\
5.9315 & TRN \\
5.9721 & TRN \\
6.1561 & TRN \\
6.2313 & TRN \\
5.8222 & TRN \\
6.2505 & TRN \\
5.83 & TRN \\
6.0198 & TRN \\
5.7666 & TRN \\
6.3364 & TRN \\
5.3063 & TRN \\
6.1839 & TRN \\
6.2588 & TRN \\
6.4874 & TRN \\
6.1547 & TST \\
6.0191 & TST \\
6.9046 & TST \\
6.7264 & TST \\
5.1991 & TST \\
6.0626 & TST \\
6.9294 & TST \\
\hline & TST
\end{tabular}

Page 16619 


$$
\text { Supplemental Table S2.txt }
$$

\begin{tabular}{|c|c|c|c|c|c|}
\hline CHEMBL602219 & 1592859 & 5.7258 & 5.3836 & TST & \\
\hline CHEMBL599305 & 1592859 & 6.1079 & 5.8914 & TST & \\
\hline CHEMBL526214 & 1592859 & 6.5229 & 6.1209 & TST & \\
\hline CHEMBL597856 & 1592859 & 4.699 & 6.0222 & TST & \\
\hline CHEMBL586383 & 1592859 & 6.1487 & 6.0902 & TST & \\
\hline CHEMBL587398 & 1592859 & 6.0655 & 5.9976 & TST & \\
\hline CHEMBL546977 & 1592859 & 6.301 & 6.4212 & TST & \\
\hline CHEMBL546835 & 1592859 & 6.0315 & 5.9006 & TST & \\
\hline CHEMBL3929286 & 1640000 & 8.0 & 7.9125 & TST & \\
\hline CHEMBL3896457 & 1640000 & 8.0 & \multicolumn{2}{|c|}{8.072000000000001} & TRN \\
\hline CHEMBL3943723 & 1640000 & 7.0 & 7.0637 & TRN & \\
\hline CHEMBL3918799 & 1640000 & 8.0 & 7.9899 & TRN & \\
\hline CHEMBL3944834 & 1640000 & 7.0 & 6.8426 & TRN & \\
\hline CHEMBL3894025 & 1640000 & 8.0 & 7.9619 & TRN & \\
\hline CHEMBL3903968 & 1640000 & 6.0 & 6.2041 & TRN & \\
\hline CHEMBL3928537 & 1640000 & 8.0 & 7.7452 & TRN & \\
\hline CHEMBL3895329 & 1640000 & 8.0 & 7.9814 & TRN & \\
\hline CHEMBL3985164 & 1640000 & 8.0 & 7.9445 & TRN & \\
\hline CHEMBL3915612 & 1640000 & 8.0 & 7.8111 & TRN & \\
\hline CHEMBL3907167 & 1640000 & 8.0 & 7.721 & TRN & \\
\hline CHEMBL3913111 & 1640000 & 8.0 & 8.1546 & TRN & \\
\hline CHEMBL 3980780 & 1640000 & 7.0 & 6.8242 & TRN & \\
\hline CHEMBL3937967 & 1640000 & 8.0 & 7.9372 & TRN & \\
\hline CHEMBL3973795 & 1640000 & 8.0 & 7.8597 & TRN & \\
\hline CHEMBL3935926 & 1640000 & 8.0 & 7.8091 & TRN & \\
\hline CHEMBL3909114 & 1640000 & 6.0 & 6.2032 & TRN & \\
\hline CHEMBL3909984 & 1640000 & 8.0 & 7.9551 & TRN & \\
\hline CHEMBL3977083 & 1640000 & 7.0 & 6.0575 & TRN & \\
\hline CHEMBL3895867 & 1640000 & 8.0 & 7.7742 & TRN & \\
\hline CHEMBL3905944 & 1640000 & 8.0 & 7.8741 & TST & \\
\hline CHEMBL3898105 & 1640000 & 8.0 & 8.1728 & TRN & \\
\hline CHEMBL3970597 & 1640000 & 8.0 & 8.0476 & TRN & \\
\hline CHEMBL 3898644 & 1640000 & 8.0 & 7.4271 & TRN & \\
\hline CHEMBL3964369 & 1640000 & 8.0 & 8.1974 & TRN & \\
\hline CHEMBL3935700 & 1640000 & 8.0 & 8.1184 & TRN & \\
\hline CHEMBL3969421 & 1640000 & 8.0 & 8.0704 & TRN & \\
\hline CHEMBL3897556 & 1640000 & 7.0 & 5.8248 & TRN & \\
\hline CHEMBL3966875 & 1640000 & 8.0 & 7.7978 & TRN & \\
\hline CHEMBL3929784 & 1640000 & 8.0 & 8.0075 & TRN & \\
\hline CHEMBL3921633 & 1640000 & 8.0 & 8.041 & TRN & \\
\hline CHEMBL3959716 & 1640000 & 6.0 & 6.434 & TRN & \\
\hline CHEMBL3895663 & 1640000 & 8.0 & 7.9346 & TRN & \\
\hline CHEMBL3919095 & 1640000 & 8.0 & 8.0892 & TRN & \\
\hline CHEMBL3916768 & 1640000 & 8.0 & 8.1956 & TST & \\
\hline CHEMBL 3941495 & 1640000 & 8.0 & 7.6998 & TRN & \\
\hline CHEMBL3955234 & 1640000 & 7.0 & 6.9726 & TRN & \\
\hline CHEMBL3953942 & 1640000 & 7.0 & 7.0631 & TRN & \\
\hline CHEMBL3967155 & 1640000 & 8.0 & 8.0014 & TRN & \\
\hline
\end{tabular}




\begin{tabular}{|c|c|c|c|c|}
\hline & & & & $a \perp 1$ \\
\hline CHEMBL3962041 & 1640000 & 7.0 & 6.676 & TRN \\
\hline CHEMBL3976175 & 1640000 & 6.0 & 6.1149 & TRN \\
\hline CHEMBL3938488 & 1640000 & 7.0 & 7.2205 & TRN \\
\hline CHEMBL3971958 & 1640000 & 4.0 & 3.9331 & TST \\
\hline CHEMBL3922054 & 1640000 & 8.0 & 7.9711 & TRN \\
\hline CHEMBL3943347 & 1640000 & 4.0 & 3.4183 & TRN \\
\hline CHEMBL3953994 & 1640000 & 8.0 & 8.043 & TRN \\
\hline CHEMBL3920728 & 1640000 & 8.0 & 8.0003 & TRN \\
\hline CHEMBL3926623 & 1640000 & 8.0 & 7.8854 & TST \\
\hline CHEMBL3890661 & 1640000 & 4.0 & 3.5964 & TST \\
\hline CHEMBL3947160 & 1640000 & 4.0 & 3.5679 & TST \\
\hline CHEMBL 3987021 & 1640000 & 8.0 & 7.5829 & TST \\
\hline CHEMBL3911090 & 1640000 & 8.0 & 7.7931 & TRN \\
\hline CHEMBL3949703 & 1640000 & 8.0 & 7.95700 & 0000000001 \\
\hline CHEMBL3918000 & 1640000 & 7.0 & 6.9448 & TRN \\
\hline CHEMBL3893461 & 1640000 & 8.0 & 7.7635 & TST \\
\hline CHEMBL3958330 & 1640000 & 7.0 & 7.769 & TST \\
\hline CHEMBL3925259 & 1640000 & 4.0 & 3.4159 & TST \\
\hline CHEMBL3906845 & 1640000 & 8.0 & 8.0448 & TRN \\
\hline CHEMBL3945115 & 1640000 & 6.0 & 5.7133 & TRN \\
\hline CHEMBL 3970324 & 1640000 & 8.0 & 7.9285 & TRN \\
\hline CHEMBL 3964601 & 1640000 & 8.0 & 7.8086 & TST \\
\hline CHEMBL3984827 & 1640000 & 8.0 & 7.8765 & TST \\
\hline CHEMBL3936983 & 1640000 & 7.0 & 7.8555 & TRN \\
\hline CHEMBL3976035 & 1640000 & 8.0 & 7.8915 & TST \\
\hline CHEMBL 3917411 & 1640000 & 8.0 & 7.8356 & TST \\
\hline CHEMBL3910964 & 1640000 & 7.0 & 6.2486 & TRN \\
\hline CHEMBL3927073 & 1640000 & 8.0 & 8.13 & TRN \\
\hline CHEMBL3907117 & 1640000 & 8.0 & 7.9704 & TRN \\
\hline CHEMBL 3905527 & 1640000 & 8.0 & 7.895 & TRN \\
\hline CHEMBL3930091 & 1640000 & 6.0 & 6.4845 & TRN \\
\hline CHEMBL 3928989 & 1640000 & 8.0 & 7.9091 & TRN \\
\hline CHEMBL3893012 & 1640000 & 8.0 & 6.9587 & TRN \\
\hline CHEMBL3964152 & 1640000 & 8.0 & 7.9802 & TRN \\
\hline CHEMBL3966310 & 1640000 & 8.0 & 7.9219 & TRN \\
\hline CHEMBL3917344 & 1640000 & 7.0 & 6.0871 & TRN \\
\hline CHEMBL 3947386 & 1640000 & 8.0 & 7.9152 & TRN \\
\hline CHEMBL3970927 & 1640000 & 4.0 & 3.7654 & TST \\
\hline CHEMBL3949483 & 1640000 & 8.0 & 8.2183 & TRN \\
\hline CHEMBL3966949 & 1640000 & 8.0 & 7.9024 & TRN \\
\hline CHEMBL 3978077 & 1640000 & 6.0 & 6.1971 & TRN \\
\hline CHEMBL 3955737 & 1640000 & 8.0 & 7.9533 & TRN \\
\hline CHEMBL3946558 & 1640000 & 6.0 & 5.563 & TST \\
\hline CHEMBL3983778 & 1640000 & 6.0 & 6.2381 & TST \\
\hline CHEMBL 3918142 & 1640000 & 8.0 & 7.8534 & TRN \\
\hline CHEMBL 3910376 & 1640000 & 8.0 & 8.0196 & TRN \\
\hline CHEMBL3959066 & 1640000 & 8.0 & 7.9668 & TRN \\
\hline CHEMBL3983221 & 1640000 & 7.0 & 6.8536 & TRN \\
\hline
\end{tabular}

TRN 


\begin{tabular}{|c|c|c|c|c|}
\hline & & & ient & $a \perp 1 a$ \\
\hline CHEMBL 3930663 & 1640000 & 6.0 & 6.0675 & TRN \\
\hline CHEMBL3912249 & 1640000 & 8.0 & 7.9903 & TRN \\
\hline CHEMBL3964285 & 1640000 & 4.0 & 4.0714 & TST \\
\hline CHEMBL 3922085 & 1640000 & 6.0 & 6.2928 & TRN \\
\hline CHEMBL3924015 & 1640000 & 6.0 & 6.0287 & TST \\
\hline CHEMBL3976013 & 1640000 & 6.0 & 6.0551 & TST \\
\hline CHEMBL3899555 & 1640000 & 8.0 & 7.8284 & TRN \\
\hline CHEMBL3931903 & 1640000 & 8.0 & 7.9708 & TRN \\
\hline CHEMBL3935921 & 1640000 & 8.0 & 7.8976 & TRN \\
\hline CHEMBL3940197 & 1640000 & 4.0 & 3.5036 & TST \\
\hline CHEMBL3950764 & 1640000 & 7.0 & 6.3079 & TRN \\
\hline CHEMBL3891119 & 1640000 & 8.0 & 7.9711 & TRN \\
\hline CHEMBL3929763 & 1640000 & 4.0 & 4.2735 & TST \\
\hline CHEMBL 3984321 & 1640000 & 8.0 & 7.97 & TRN \\
\hline CHEMBL3977694 & 1640000 & 7.0 & 6.3799 & TRN \\
\hline CHEMBL3901474 & 1640000 & 8.0 & 7.9024 & TST \\
\hline CHEMBL3981991 & 1640000 & 8.0 & 8.0645 & TST \\
\hline CHEMBL3942857 & 1640000 & 7.0 & 6.9705 & TRN \\
\hline CHEMBL3916734 & 1640000 & 8.0 & 7.9579 & TRN \\
\hline CHEMBL3908184 & 1640000 & 7.0 & 6.5403 & TRN \\
\hline CHEMBL 3968487 & 1640000 & 7.0 & 6.4644 & TRN \\
\hline CHEMBL3980197 & 1640000 & 4.0 & 4.9356 & TRN \\
\hline CHEMBL3900426 & 1640000 & 6.0 & 3.7526 & TST \\
\hline CHEMBL3951234 & 1640000 & 6.0 & 6.1772 & TRN \\
\hline CHEMBL3941667 & 1640000 & 8.0 & 8.0714 & TRN \\
\hline CHEMBL 3897055 & 1640000 & 4.0 & 4.2026 & TRN \\
\hline CHEMBL3952140 & 1640000 & 8.0 & 7.9186 & TRN \\
\hline CHEMBL3984514 & 1640000 & 8.0 & 7.9644 & TRN \\
\hline CHEMBL3981032 & 1640000 & 8.0 & 7.8089 & TST \\
\hline CHEMBL 3928629 & 1640000 & 4.0 & 3.7747 & TST \\
\hline CHEMBL3961946 & 1640000 & 8.0 & 7.9964 & TRN \\
\hline CHEMBL3968884 & 1640000 & 8.0 & 7.9278 & TRN \\
\hline CHEMBL3934876 & 1640000 & 8.0 & 7.9503 & TRN \\
\hline CHEMBL 3980228 & 1640000 & 8.0 & 7.7782 & TST \\
\hline CHEMBL3952670 & 1640000 & 7.0 & 8.0873 & TRN \\
\hline CHEMBL3923498 & 1640000 & 8.0 & 7.9632 & TRN \\
\hline CHEMBL3927298 & 1640000 & 8.0 & 7.956 & TRN \\
\hline CHEMBL3892620 & 1640000 & 6.0 & 6.0067 & TRN \\
\hline CHEMBL 3889881 & 1640000 & 4.0 & 4.7999 & TRN \\
\hline CHEMBL3912868 & 1640000 & 8.0 & 7.9637 & TRN \\
\hline CHEMBL 3937421 & 1640000 & 4.0 & 3.8945 & TST \\
\hline CHEMBL 3974840 & 1640000 & 8.0 & 7.8781 & TST \\
\hline CHEMBL3957403 & 1640000 & 8.0 & 8.1444 & TRN \\
\hline CHEMBL 3899554 & 1640000 & 8.0 & 8.1721 & TRN \\
\hline CHEMBL3926363 & 1640000 & 8.0 & 7.9953 & TRN \\
\hline CHEMBL 3932888 & 1640000 & 6.0 & 6.0182 & TRN \\
\hline CHEMBL3984031 & 1640000 & 8.0 & 7.9336 & TRN \\
\hline CHEMBL3973546 & 1640000 & 8.0 & 7.829 & TRN \\
\hline
\end{tabular}




\begin{tabular}{|c|c|c|c|c|c|}
\hline CHEMBL 3949857 & 1640000 & 6.0 & \multicolumn{2}{|c|}{5.6610000000000005} & TST \\
\hline CHEMBL 3895695 & 1640000 & 8.0 & 7.8559 & TST & \\
\hline CHEMBL3967006 & 1640000 & 4.0 & 3.8292 & TST & \\
\hline CHEMBL3894038 & 1640000 & 8.0 & 7.8571 & TRN & \\
\hline CHEMBL3960192 & 1640000 & 8.0 & 7.9121 & TRN & \\
\hline CHEMBL3909916 & 1640000 & 6.0 & 6.1404 & TRN & \\
\hline CHEMBL3936915 & 1640000 & 4.0 & 4.2103 & TST & \\
\hline CHEMBL 3904708 & 1640000 & 7.0 & 7.1429 & TRN & \\
\hline CHEMBL3958711 & 1640000 & 6.0 & 6.1196 & TRN & \\
\hline CHEMBL3954219 & 1640000 & 7.0 & 7.0523 & TRN & \\
\hline CHEMBL3969503 & 1640000 & 8.0 & 8.0411 & TRN & \\
\hline CHEMBL3903124 & 1640000 & 6.0 & \multicolumn{2}{|c|}{5.712999999999999} & TST \\
\hline CHEMBL 3950389 & 1640000 & 7.0 & 7.7896 & TRN & \\
\hline CHEMBL3906156 & 1640000 & 6.0 & 5.8429 & TRN & \\
\hline CHEMBL3933037 & 1640000 & 8.0 & 8.0337 & TST & \\
\hline CHEMBL3893926 & 1640000 & 6.0 & 6.3581 & TRN & \\
\hline CHEMBL3967373 & 1640000 & 8.0 & 8.1748 & TRN & \\
\hline CHEMBL3933953 & 1640000 & 7.0 & 6.2971 & TRN & \\
\hline CHEMBL3921128 & 1640000 & 8.0 & 7.3935 & TST & \\
\hline CHEMBL3952219 & 1640000 & 8.0 & 7.1944 & TRN & \\
\hline CHEMBL3915517 & 1640000 & 4.0 & 3.2094 & TST & \\
\hline CHEMBL3913796 & 1640000 & 6.0 & 4.4669 & TRN & \\
\hline CHEMBL 3977336 & 1640000 & 8.0 & 8.1956 & TRN & \\
\hline CHEMBL3899373 & 1640000 & 8.0 & 8.1631 & TRN & \\
\hline CHEMBL 3919386 & 1640000 & 8.0 & 8.0662 & TRN & \\
\hline CHEMBL 3948783 & 1640000 & 8.0 & 6.9407 & TRN & \\
\hline CHEMBL3979227 & 1640000 & 6.0 & 6.8161 & TRN & \\
\hline CHEMBL 3984011 & 1640000 & 7.0 & 6.9815 & TRN & \\
\hline CHEMBL3970673 & 1640000 & 7.0 & 7.9695 & TRN & \\
\hline CHEMBL 3892962 & 1640000 & 8.0 & 7.782 & TRN & \\
\hline CHEMBL3944333 & 1640000 & 4.0 & 4.3652 & TRN & \\
\hline CHEMBL3932536 & 1640000 & 8.0 & 8.1541 & TRN & \\
\hline CHEMBL 3913502 & 1640000 & 4.0 & 3.6733 & TST & \\
\hline CHEMBL3970988 & 1640000 & 8.0 & 7.67 & TRN & \\
\hline CHEMBL 3927893 & 1640000 & 6.0 & 6.3555 & TRN & \\
\hline CHEMBL3976828 & 1640000 & 4.0 & 3.9084 & TST & \\
\hline CHEMBL3902602 & 1640000 & 8.0 & 7.9324 & TRN & \\
\hline CHEMBL 3946440 & 1640000 & 7.0 & 6.9818 & TRN & \\
\hline CHEMBL3900361 & 1640000 & 4.0 & 4.6284 & TRN & \\
\hline CHEMBL 3940480 & 1640000 & 6.0 & 5.4446 & TST & \\
\hline CHEMBL3954791 & 1640000 & 8.0 & 7.9409 & TST & \\
\hline CHEMBL3902307 & 1640000 & 8.0 & 7.9757 & TRN & \\
\hline CHEMBL3909653 & 1640000 & 6.0 & 6.0898 & TST & \\
\hline CHEMBL3890638 & 1640000 & 8.0 & 8.0452 & TRN & \\
\hline CHEMBL3986191 & 1640000 & 8.0 & 8.0408 & TRN & \\
\hline CHEMBL3944905 & 1640000 & 4.0 & 3.7272 & TST & \\
\hline CHEMBL3920214 & 1640000 & 7.0 & 7.1931 & TRN & \\
\hline CHEMBL3891883 & 1640000 & 4.0 & 3.6955 & TST & \\
\hline & & & & 6623 & \\
\hline
\end{tabular}




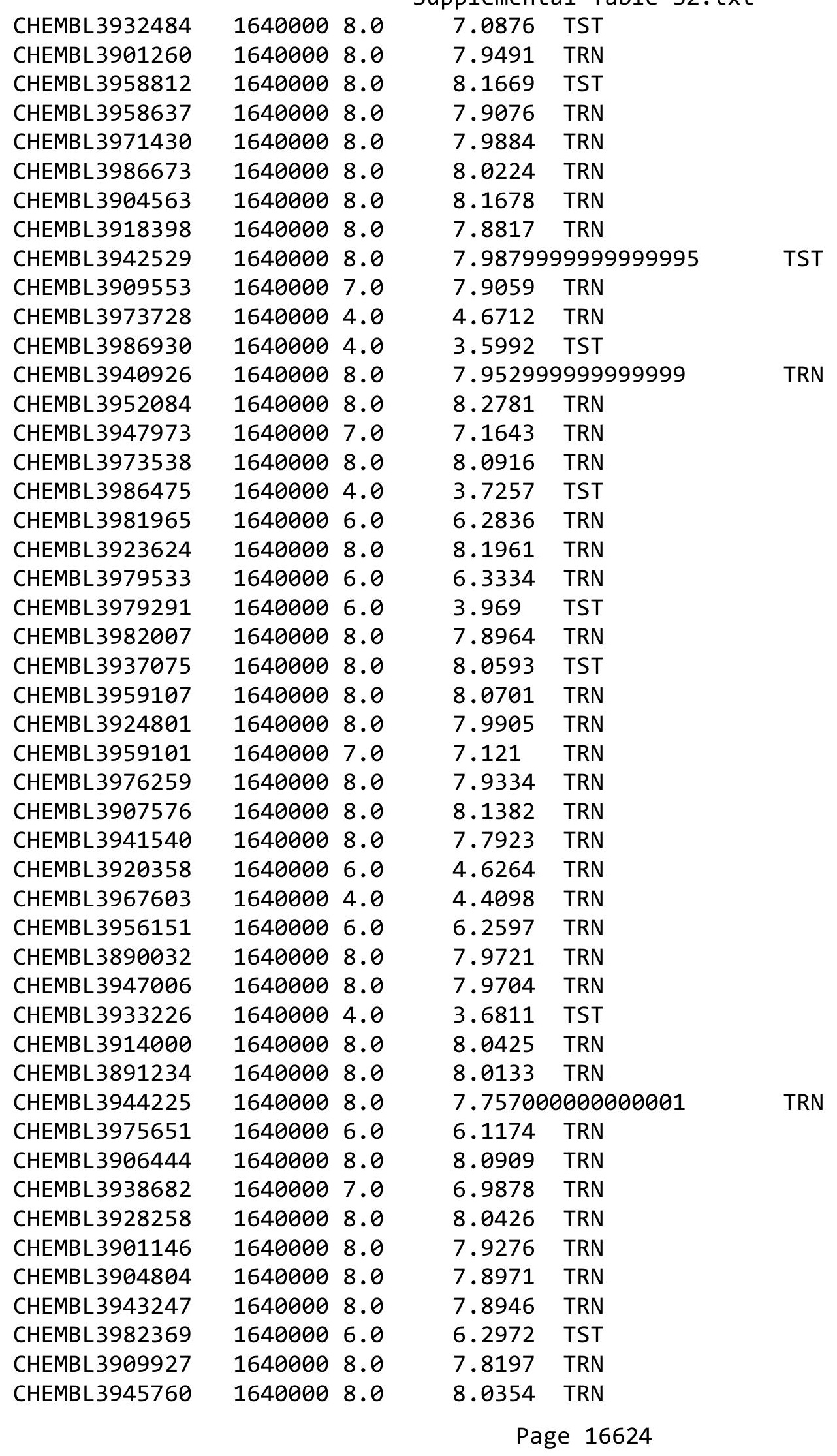




\begin{tabular}{|c|c|c|c|c|}
\hline & & & & \\
\hline CHEMBL3919040 & 1640000 & 8.0 & 7.9178 & TRN \\
\hline CHEMBL3947518 & 1640000 & 4.0 & 3.926 & TST \\
\hline CHEMBL3908455 & 1640000 & 8.0 & 8.1787 & TRN \\
\hline CHEMBL3945323 & 1640000 & 8.0 & 7.8155 & TRN \\
\hline CHEMBL3980367 & 1640000 & 4.0 & 4.4615 & TRN \\
\hline CHEMBL3912932 & 1640000 & 8.0 & 8.0458 & TRN \\
\hline CHEMBL3922513 & 1640000 & 4.0 & 3.6642 & TST \\
\hline CHEMBL3944184 & 1640000 & 6.0 & 6.4327 & TRN \\
\hline CHEMBL3966934 & 1640000 & 7.0 & 7.0555 & TRN \\
\hline CHEMBL3970715 & 1640000 & 4.0 & 4.2043 & TST \\
\hline CHEMBL3981288 & 1640000 & 7.0 & 6.5984 & TST \\
\hline CHEMBL3978172 & 1640000 & 4.0 & 4.3108 & TRN \\
\hline CHEMBL3962432 & 1640000 & 4.0 & 4.9009 & TST \\
\hline CHEMBL3924770 & 1640000 & 8.0 & 7.9728 & TRN \\
\hline CHEMBL3922711 & 1640000 & 8.0 & 8.0126 & TRN \\
\hline CHEMBL3953302 & 1640000 & 8.0 & 8.0798 & TRN \\
\hline CHEMBL3938119 & 1640000 & 6.0 & 5.2373 & TST \\
\hline CHEMBL3909298 & 1640000 & 8.0 & 8.0346 & TRN \\
\hline CHEMBL3975749 & 1640000 & 4.0 & 4.3934 & TRN \\
\hline CHEMBL3905653 & 1640000 & 7.0 & 7.0709 & TRN \\
\hline CHEMBL3957627 & 1640000 & 8.0 & 7.8373 & TST \\
\hline CHEMBL 3976273 & 1640000 & 8.0 & 8.1091 & TST \\
\hline CHEMBL3919431 & 1640000 & 6.0 & 6.1111 & TRN \\
\hline CHEMBL 3957394 & 1640000 & 8.0 & 8.0287 & TRN \\
\hline CHEMBL3914011 & 1640000 & 8.0 & 8.1587 & TRN \\
\hline CHEMBL3912984 & 1640000 & 4.0 & 3.4659 & TST \\
\hline CHEMBL3922123 & 1640000 & 8.0 & 7.9338 & TRN \\
\hline CHEMBL3902344 & 1640000 & 8.0 & 6.9534 & TRN \\
\hline CHEMBL3965301 & 1640000 & 8.0 & 8.1274 & TRN \\
\hline CHEMBL 3960908 & 1640000 & 8.0 & 7.97 & TRN \\
\hline CHEMBL3907433 & 1640000 & 8.0 & 7.4009 & TRN \\
\hline CHEMBL 3906753 & 1640000 & 6.0 & 5.5802 & TST \\
\hline CHEMBL3927071 & 1640000 & 7.0 & 5.8557 & TST \\
\hline CHEMBL3946129 & 1640000 & 8.0 & 7.0454 & TRN \\
\hline CHEMBL3905869 & 1640000 & 7.0 & 7.1801 & TRN \\
\hline CHEMBL3905034 & 1640000 & 8.0 & 7.6405 & TST \\
\hline CHEMBL 3936484 & 1640000 & 6.0 & 6.4419 & TRN \\
\hline CHEMBL3891219 & 1640000 & 6.0 & 6.4473 & TST \\
\hline CHEMBL3959318 & 1640000 & 6.0 & 6.0643 & TRN \\
\hline CHEMBL3916640 & 1640000 & 8.0 & 8.0344 & TRN \\
\hline CHEMBL3967991 & 1640000 & 4.0 & 3.7061 & TST \\
\hline CHEMBL 3979587 & 1640000 & 7.0 & 7.0632 & TRN \\
\hline CHEMBL3966007 & 1640000 & 8.0 & 8.0513 & TRN \\
\hline CHEMBL3926152 & 1640000 & 6.0 & 6.1527 & TRN \\
\hline CHEMBL 3982585 & 1640000 & 8.0 & 8.0928 & TRN \\
\hline CHEMBL 3957501 & 1640000 & 8.0 & 8.0237 & TRN \\
\hline CHEMBL 3901717 & 1640000 & 8.0 & 7.9916 & TRN \\
\hline CHEMBL3970569 & 1640000 & 6.0 & 6.4572 & TRN \\
\hline
\end{tabular}




\begin{tabular}{|c|c|c|c|c|c|}
\hline \\
\hline CHEMBL3905522 & 1640000 & 8.0 & 8.0176 & TST & \\
\hline CHEMBL3928812 & 1640000 & 7.0 & 6.2823 & TRN & \\
\hline CHEMBL3903202 & 1640000 & 8.0 & 8.1494 & TRN & \\
\hline CHEMBL 3959362 & 1640000 & 8.0 & 7.6051 & TRN & \\
\hline CHEMBL3908146 & 1640000 & 8.0 & 7.9289 & TRN & \\
\hline CHEMBL3984324 & 1640000 & 8.0 & 7.8579 & TST & \\
\hline CHEMBL3930538 & 1640000 & 4.0 & 3.8657 & TST & \\
\hline CHEMBL3969244 & 1640000 & 4.0 & 3.4677 & TST & \\
\hline CHEMBL3924550 & 1640000 & 8.0 & 8.0456 & TRN & \\
\hline CHEMBL3966378 & 1640000 & 7.0 & 7.2068 & TRN & \\
\hline CHEMBL3904626 & 1640000 & 7.0 & 7.1512 & TRN & \\
\hline CHEMBL3980198 & 1640000 & 7.0 & 7.1324 & TRN & \\
\hline CHEMBL3959600 & 1640000 & 7.0 & 7.8809 & TRN & \\
\hline CHEMBL3960991 & 1640000 & 8.0 & 7.9672 & TRN & \\
\hline CHEMBL 3900630 & 1640000 & 6.0 & 6.2119 & TRN & \\
\hline CHEMBL3930184 & 1640000 & 8.0 & 7.994 & TRN & \\
\hline CHEMBL3960844 & 1640000 & 7.0 & 7.2051 & TRN & \\
\hline CHEMBL3924322 & 1640000 & 6.0 & 6.15 & TRN & \\
\hline CHEMBL3924269 & 1640000 & 6.0 & 6.0167 & TST & \\
\hline CHEMBL3926056 & 1640000 & 4.0 & 3.8193 & TST & \\
\hline CHEMBL3952619 & 1640000 & 4.0 & 3.7483 & TST & \\
\hline CHEMBL3920753 & 1640000 & 8.0 & 7.9728 & TRN & \\
\hline CHEMBL3920152 & 1640000 & 8.0 & 7.9916 & TRN & \\
\hline CHEMBL3962184 & 1640000 & 8.0 & 8.0052 & TRN & \\
\hline CHEMBL 3935089 & 1640000 & 8.0 & 7.5703 & TRN & \\
\hline CHEMBL3941642 & 1640000 & 6.0 & 6.1254 & TRN & \\
\hline CHEMBL3915300 & 1640000 & 8.0 & 7.9438 & TRN & \\
\hline CHEMBL3935169 & 1640000 & 8.0 & 7.94799 & 99999999995 & TRN \\
\hline CHEMBL3904666 & 1640000 & 7.0 & 7.6761 & TRN & \\
\hline CHEMBL3969603 & 1640000 & 4.0 & 4.5284 & TRN & \\
\hline CHEMBL3955283 & 1640000 & 7.0 & 7.1349 & TRN & \\
\hline CHEMBL3901021 & 1640000 & 6.0 & 6.0651 & TRN & \\
\hline CHEMBL3912623 & 1640000 & 8.0 & 7.9666 & TRN & \\
\hline CHEMBL3950894 & 1640000 & 7.0 & 7.2789 & TRN & \\
\hline CHEMBL3970918 & 1640000 & 8.0 & 7.9715 & TRN & \\
\hline CHEMBL3939435 & 1640000 & 8.0 & 7.7751 & TST & \\
\hline CHEMBL 3897867 & 1640000 & 8.0 & 6.9612 & TRN & \\
\hline CHEMBL 3982784 & 1640000 & 6.0 & 6.1296 & TRN & \\
\hline CHEMBL3950051 & 1640000 & 8.0 & 7.1958 & TRN & \\
\hline CHEMBL 3900407 & 1640000 & 6.0 & 5.2084 & TST & \\
\hline CHEMBL3931030 & 1640000 & 7.0 & 7.0681 & TRN & \\
\hline CHEMBL3901924 & 1640000 & 8.0 & 8.0139 & TRN & \\
\hline CHEMBL 3942608 & 1640000 & 8.0 & 8.0895 & TST & \\
\hline CHEMBL3970625 & 1640000 & 8.0 & 8.0954 & TST & \\
\hline CHEMBL 3949534 & 1640000 & 8.0 & 8.0674 & TRN & \\
\hline CHEMBL3986250 & 1640000 & 7.0 & 7.7495 & TRN & \\
\hline CHEMBL3910459 & 1640000 & 8.0 & 8.11 & TRN & \\
\hline CHEMBL 3974428 & 1640000 & 8.0 & 8.0122 & TRN & \\
\hline
\end{tabular}




\begin{tabular}{|c|c|c|c|c|c|}
\hline CHEMBL 3897377 & 1640000 & 7.0 & 7.2282 & TRN & \\
\hline CHEMBL3935093 & 1640000 & 4.0 & 3.722 & TST & \\
\hline CHEMBL3895242 & 1640000 & 6.0 & 5.6545 & TST & \\
\hline CHEMBL3972982 & 1640000 & 8.0 & 8.1009 & TRN & \\
\hline CHEMBL3918099 & 1640000 & 8.0 & 7.9712 & TRN & \\
\hline CHEMBL3915568 & 1640000 & 8.0 & 7.812 & TRN & \\
\hline CHEMBL3933706 & 1640000 & 8.0 & 7.8891 & TRN & \\
\hline CHEMBL3930992 & 1640000 & 8.0 & 8.1369 & TST & \\
\hline CHEMBL3919540 & 1640000 & 8.0 & 7.8597 & TRN & \\
\hline CHEMBL 3984062 & 1640000 & 8.0 & 8.0512 & TRN & \\
\hline CHEMBL3980773 & 1640000 & 7.0 & 6.6983 & TRN & \\
\hline CHEMBL 3939858 & 1640000 & 8.0 & 8.0176 & TRN & \\
\hline CHEMBL3935590 & 1640000 & 7.0 & 7.0207 & TRN & \\
\hline CHEMBL3912908 & 1640000 & 8.0 & 7.83200 & 0000000001 & TRN \\
\hline CHEMBL 3948255 & 1640000 & 8.0 & 8.0186 & TRN & \\
\hline CHEMBL3977852 & 1640000 & 8.0 & 8.1267 & TST & \\
\hline CHEMBL3958798 & 1640000 & 7.0 & 5.99700 & 0000000001 & TRN \\
\hline CHEMBL3929028 & 1640000 & 8.0 & 7.9854 & TRN & \\
\hline CHEMBL 3927054 & 1640000 & 8.0 & 7.8977 & TRN & \\
\hline CHEMBL 3916234 & 1640000 & 6.0 & 6.3067 & TRN & \\
\hline CHEMBL3952387 & 1640000 & 8.0 & 8.1053 & TST & \\
\hline CHEMBL 3943118 & 1640000 & 4.0 & 4.9201 & TST & \\
\hline CHEMBL3936719 & 1640000 & 8.0 & 7.9825 & TRN & \\
\hline CHEMBL3983280 & 1640000 & 7.0 & 6.8012 & TRN & \\
\hline CHEMBL 3965978 & 1640000 & 7.0 & 6.3604 & TRN & \\
\hline CHEMBL3938777 & 1640000 & 8.0 & 8.0125 & TRN & \\
\hline CHEMBL 3912822 & 1640000 & 4.0 & 3.2772 & TST & \\
\hline CHEMBL 3929729 & 1640000 & 6.0 & 6.3698 & TRN & \\
\hline CHEMBL3948502 & 1640000 & 4.0 & 3.7219 & TST & \\
\hline CHEMBL3921838 & 1640000 & 8.0 & 7.8891 & TRN & \\
\hline CHEMBL3910201 & 1640000 & 7.0 & 6.9588 & TRN & \\
\hline CHEMBL3899779 & 1640000 & 6.0 & 5.8969 & TRN & \\
\hline CHEMBL 3954403 & 1640000 & 8.0 & 7.9735 & TRN & \\
\hline CHEMBL3928712 & 1640000 & 6.0 & 5.664 & TST & \\
\hline CHEMBL 3899830 & 1640000 & 8.0 & 7.9411 & TRN & \\
\hline CHEMBL3932042 & 1640000 & 8.0 & 8.1821 & TRN & \\
\hline CHEMBL 3961262 & 1640000 & 8.0 & 7.8465 & TST & \\
\hline CHEMBL3977911 & 1640000 & 8.0 & 7.9791 & TST & \\
\hline CHEMBL3898336 & 1640000 & 8.0 & 8.0922 & TRN & \\
\hline CHEMBL3977957 & 1640000 & 8.0 & 8.1409 & TRN & \\
\hline CHEMBL3922597 & 1640000 & 6.0 & 5.9788 & TRN & \\
\hline CHEMBL 3976834 & 1640000 & 8.0 & 8.0072 & TRN & \\
\hline CHEMBL 3902864 & 1640000 & 8.0 & 7.57600 & 00000000005 & TRN \\
\hline CHEMBL3945970 & 1640000 & 8.0 & 8.1225 & TST & \\
\hline CHEMBL3972019 & 1640000 & 4.0 & 4.0138 & TST & \\
\hline CHEMBL 3916543 & 1640000 & 4.0 & 6.1462 & TRN & \\
\hline CHEMBL3892934 & 1640000 & 7.0 & 7.0468 & TRN & \\
\hline \multirow[t]{2}{*}{ CHEMBL3917582 } & 1640000 & 6.0 & 3.8215 & TST & \\
\hline & & \multicolumn{4}{|c|}{ Page 16627} \\
\hline
\end{tabular}




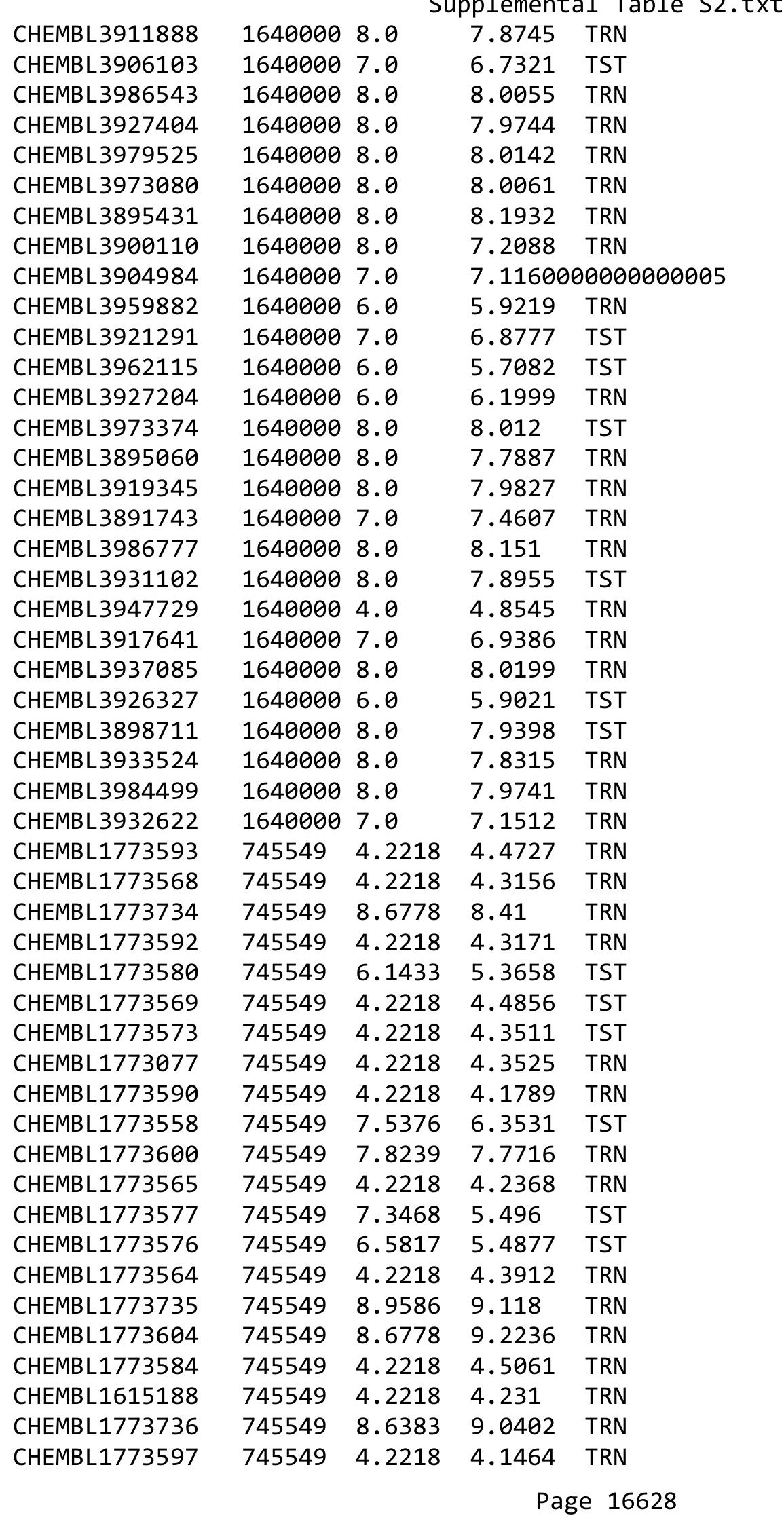

TRN 


\begin{tabular}{|c|c|c|c|c|c|}
\hline \multirow[b]{2}{*}{ CHEMBL1773595 } & \multicolumn{5}{|c|}{ Supplemental Table S2.txt } \\
\hline & 745549 & 4.2218 & 4.2316 & TRN & \\
\hline CHEMBL1773582 & 745549 & 6.5702 & 5.8348 & TST & \\
\hline CHEMBL1773563 & 745549 & 4.2218 & 4.1742 & TRN & \\
\hline CHEMBL1773587 & 745549 & 4.2218 & 4.3386 & TRN & \\
\hline CHEMBL1773733 & 745549 & 8.6778 & 8.8926 & TRN & \\
\hline CHEMBL1773594 & 745549 & 4.2218 & 4.1657 & TRN & \\
\hline CHEMBL1773581 & 745549 & 7.1871 & 5.598 & TST & \\
\hline CHEMBL1773559 & 745549 & 5.5214 & 4.9566 & TRN & \\
\hline CHEMBL1773602 & 745549 & 8.7959 & 8.7511 & TRN & \\
\hline CHEMBL1773560 & 745549 & 4.2218 & 4.1155 & TRN & \\
\hline CHEMBL1773591 & 745549 & 4.2218 & 4.1398 & TRN & \\
\hline CHEMBL1773598 & 745549 & 4.2218 & 4.6827 & TST & \\
\hline CHEMBL1773578 & 745549 & 4.2218 & 5.6547 & TST & \\
\hline CHEMBL1773574 & 745549 & 7.2441 & 5.7995 & TST & \\
\hline CHEMBL1773561 & 745549 & 4.2218 & 4.0986 & TRN & \\
\hline CHEMBL1773729 & 745549 & 8.7959 & 8.9561 & TRN & \\
\hline CHEMBL1773586 & 745549 & 4.2218 & 4.2799 & TRN & \\
\hline CHEMBL1773583 & 745549 & 4.2218 & 4.5947 & TST & \\
\hline CHEMBL1773566 & 745549 & 4.2218 & 4.2284 & TRN & \\
\hline CHEMBL1773728 & 745549 & 10.0 & 9.6019 & TRN & \\
\hline CHEMBL1773603 & 745549 & 8.2218 & 8.174 & TRN & \\
\hline CHEMBL1773589 & 745549 & 4.2218 & 4.3557 & TRN & \\
\hline CHEMBL1773596 & 745549 & 4.2218 & 4.5831 & TST & \\
\hline CHEMBL1773575 & 745549 & 6.5452 & 6.0213 & TST & \\
\hline CHEMBL1773572 & 745549 & 4.2218 & 4.1007 & TRN & \\
\hline CHEMBL1773585 & 745549 & 4.2218 & 4.3566 & TRN & \\
\hline CHEMBL1773599 & 745549 & 7.9586 & 7.9999 & TRN & \\
\hline CHEMBL1773731 & 745549 & 10.0 & 10.1105 & TRN & \\
\hline CHEMBL1773606 & 745549 & 10.0 & 9.9826 & TRN & \\
\hline CHEMBL1615189 & 745549 & 8.699 & 8.8851 & TRN & \\
\hline CHEMBL1773579 & 745549 & 7.3279 & 5.6816 & TST & \\
\hline CHEMBL1773605 & 745549 & 10.0 & 9.5898 & TRN & \\
\hline CHEMBL1773567 & 745549 & 6.0395 & 6.0303 & TRN & \\
\hline CHEMBL1773732 & 745549 & 10.0 & 9.7346 & TRN & \\
\hline CHEMBL1773601 & 745549 & 5.8239 & 5.6949 & TRN & \\
\hline CHEMBL1773562 & 745549 & 4.2218 & 4.0364 & TRN & \\
\hline CHEMBL1773730 & 745549 & 10.0 & 9.8175 & TRN & \\
\hline CHEMBL1773588 & 745549 & 4.2218 & 4.1239 & TRN & \\
\hline CHEMBL120539 & 139388 & 5.3799 & 5.5678 & TRN & \\
\hline CHEMBL123099 & 139388 & 6.0625 & 5.8726 & TRN & \\
\hline CHEMBL121059 & 139388 & 7.0685 & 6.9056 & TRN & \\
\hline CHEMBL120109 & 139388 & 6.01 & 5.593999 & 9999999999 & TRN \\
\hline CHEMBL121298 & 139388 & 5.301 & 5.6442 & TRN & \\
\hline CHEMBL120963 & 139388 & 5.5074 & 5.3993 & TRN & \\
\hline CHEMBL122353 & 139388 & 5.9477 & 6.0949 & TRN & \\
\hline CHEMBL332405 & 139388 & 5.6829 & 5.3443 & TST & \\
\hline CHEMBL324712 & 139388 & 6.5936 & 6.6228 & TRN & \\
\hline CHEMBL120599 & 139388 & 6.7981 & 6.3541 & TRN & \\
\hline
\end{tabular}




\begin{tabular}{|c|c|c|c|c|c|}
\hline \\
\hline CHEMBL120135 & 139388 & 6.0 & 6.3903 & TST & \\
\hline CHEMBL120329 & 139388 & 6.2198 & 6.3509 & TRN & \\
\hline CHEMBL332335 & 139388 & 5.8758 & 5.9715 & TRN & \\
\hline CHEMBL332181 & 139388 & 6.5772 & 6.57600 & 00000000005 & TRN \\
\hline CHEMBL332645 & 139388 & 4.5078 & 4.6657 & TRN & \\
\hline CHEMBL262198 & 139388 & 7.1073 & 7.331 & TRN & \\
\hline CHEMBL340561 & 139388 & 6.4661 & 6.7172 & TRN & \\
\hline CHEMBL332320 & 139388 & 6.6278 & 6.9056 & TRN & \\
\hline CHEMBL431688 & 139388 & 5.8335 & 5.5902 & TST & \\
\hline CHEMBL540316 & 139388 & 6.5921 & 6.3517 & TRN & \\
\hline CHEMBL541584 & 139388 & 7.3716 & 7.1155 & TRN & \\
\hline CHEMBL122354 & 139388 & 6.8573 & 6.9056 & TRN & \\
\hline CHEMBL543177 & 139388 & 6.5642 & 6.7807 & TRN & \\
\hline CHEMBL116601 & 139388 & 6.4271 & 6.4339 & TRN & \\
\hline CHEMBL121476 & 139388 & 6.2698 & 6.3453 & TRN & \\
\hline CHEMBL 334093 & 139388 & 5.8047 & 5.7667 & TRN & \\
\hline CHEMBL 340780 & 139388 & 6.6535 & 6.6728 & TST & \\
\hline CHEMBL324936 & 139388 & 7.2007 & 7.0006 & TRN & \\
\hline CHEMBL332980 & 139388 & 7.2668 & 7.1965 & TRN & \\
\hline CHEMBL121385 & 139388 & 5.8995 & 6.0682 & TRN & \\
\hline CHEMBL543890 & 139388 & 6.3193 & 6.4967 & TRN & \\
\hline CHEMBL121299 & 139388 & 6.3013 & 6.4181 & TRN & \\
\hline CHEMBL330999 & 139388 & 6.6686 & 6.6533 & TRN & \\
\hline CHEMBL333125 & 139388 & 6.0747 & 6.3783 & TRN & \\
\hline CHEMBL120472 & 139388 & 7.2503 & 6.88 & TRN & \\
\hline CHEMBL 330892 & 139388 & 6.4803 & 6.3621 & TST & \\
\hline CHEMBL123198 & 139388 & 5.4478 & 5.4993 & TST & \\
\hline CHEMBL333940 & 139388 & 5.9528 & 6.3453 & TST & \\
\hline CHEMBL121552 & 139388 & 6.2527 & 6.2467 & TST & \\
\hline CHEMBL120119 & 139388 & 7.6055 & 7.64 & TRN & \\
\hline CHEMBL120972 & 139388 & 6.4833 & 6.3453 & TST & \\
\hline CHEMBL338280 & 139388 & 5.8045 & 5.4833 & TRN & \\
\hline CHEMBL120080 & 139388 & 7.2373 & 6.9056 & TRN & \\
\hline CHEMBL120581 & 139388 & 6.3901 & 6.4033 & TRN & \\
\hline CHEMBL330885 & 139388 & 4.7721 & 4.8701 & TST & \\
\hline CHEMBL331516 & 139388 & 6.3259 & 6.2402 & TRN & \\
\hline CHEMBL118241 & 139388 & 6.3973 & 6.3453 & TST & \\
\hline CHEMBL124173 & 139388 & 6.7206 & 6.7823 & TST & \\
\hline CHEMBL118553 & 139388 & 4.9598 & 5.5363 & TST & \\
\hline CHEMBL121520 & 139388 & 6.9378 & 6.9888 & TRN & \\
\hline CHEMBL 334245 & 139388 & 6.7118 & 6.9056 & TRN & \\
\hline CHEMBL1373194 & 1301727 & 4.5207 & 4.2982 & TRN & \\
\hline CHEMBL1329726 & 1301727 & 3.284 & 4.4433 & TST & \\
\hline CHEMBL 3187578 & 1301727 & 3.284 & 3.8704 & TRN & \\
\hline CHEMBL1500923 & 1301727 & 3.284 & 3.36899 & 99999999998 & TRN \\
\hline CHEMBL1506503 & 1301727 & 3.284 & 3.8772 & TRN & \\
\hline CHEMBL1380459 & 1301727 & 4.971 & 4.3226 & TRN & \\
\hline CHEMBL1317312 & 1301727 & 3.284 & 3.7959 & TRN & \\
\hline
\end{tabular}


Supplemental Table S2.txt

\begin{tabular}{|c|c|c|c|c|}
\hline CHEMBL1468011 & 1301727 & 4.3136 & 3.4644 & TRN \\
\hline CHEMBL1505604 & 1301727 & 4.9646 & 5.2365 & TRN \\
\hline CHEMBL1544685 & 1301727 & 4.3258 & 3.4648 & TRN \\
\hline CHEMBL1486726 & 1301727 & 4.5637 & 4.2226 & TRN \\
\hline CHEMBL1981570 & 1301727 & 5.1232 & 5.1941 & TRN \\
\hline CHEMBL1589837 & 1301727 & 4.5173 & 4.5123 & TRN \\
\hline CHEMBL1499127 & 1301727 & 4.8164 & 4.5622 & TRN \\
\hline CHEMBL1481861 & 1301727 & 3.284 & 4.2695 & TRN \\
\hline CHEMBL252403 & 1301727 & 4.4297 & 4.3315 & TRN \\
\hline CHEMBL1900256 & 1301727 & 4.4467 & 4.3985 & TRN \\
\hline CHEMBL1561956 & 1301727 & 3.284 & 3.9083 & TRN \\
\hline CHEMBL598885 & 1301727 & 3.284 & 4.2169 & TRN \\
\hline CHEMBL1877015 & 1301727 & 4.7418 & 4.3162 & TRN \\
\hline CHEMBL3185466 & 1301727 & 4.7496 & 4.8388 & TRN \\
\hline CHEMBL1329650 & 1301727 & 3.284 & 3.8995 & TRN \\
\hline CHEMBL1387720 & 1301727 & 4.8636 & 4.4199 & TRN \\
\hline CHEMBL1516047 & 1301727 & 4.2842 & 3.9087 & TRN \\
\hline CHEMBL1342147 & 1301727 & 4.7557 & 4.3162 & TRN \\
\hline CHEMBL1412573 & 1301727 & 3.284 & 4.5266 & TST \\
\hline CHEMBL1474280 & 1301727 & 4.5056 & 3.5141 & TRN \\
\hline CHEMBL1893675 & 1301727 & 5.1361 & 4.8732 & TST \\
\hline CHEMBL1553183 & 1301727 & 4.9523 & 5.024 & TRN \\
\hline CHEMBL234378 & 1301727 & 3.284 & 4.0164 & TRN \\
\hline CHEMBL1563176 & 1301727 & 4.9296 & 4.8312 & TST \\
\hline CHEMBL1301042 & 1301727 & 4.3323 & 3.7401 & TRN \\
\hline CHEMBL1597627 & 1301727 & 4.8539 & 4.8701 & TRN \\
\hline CHEMBL1428820 & 1301727 & 3.284 & 3.6362 & TRN \\
\hline CHEMBL607553 & 1301727 & 5.1331 & 4.8883 & TRN \\
\hline CHEMBL1475514 & 1301727 & 5.0146 & 4.926 & TRN \\
\hline CHEMBL1453723 & 1301727 & 4.6036 & 4.36100 & 0000000001 \\
\hline CHEMBL125044 & 1301727 & 4.6315 & 4.5036 & TRN \\
\hline CHEMBL1488948 & 1301727 & 4.5948 & 3.8684 & TRN \\
\hline CHEMBL1427736 & 1301727 & 3.284 & 3.8644 & TRN \\
\hline CHEMBL1584960 & 1301727 & 5.3883 & 4.1925 & TRN \\
\hline CHEMBL1530972 & 1301727 & 3.284 & 4.1175 & TRN \\
\hline CHEMBL3185012 & 1301727 & 4.7788 & 4.8994 & TRN \\
\hline CHEMBL 2136235 & 1301727 & 4.7622 & 4.4957 & TRN \\
\hline CHEMBL1556786 & 1301727 & 4.4477 & 3.5691 & TRN \\
\hline CHEMBL1453108 & 1301727 & 5.2534 & 4.6986 & TST \\
\hline CHEMBL1317322 & 1301727 & 4.66 & 4.5188 & TRN \\
\hline CHEMBL1493204 & 1301727 & 3.284 & 3.92100 & 00000000003 \\
\hline CHEMBL1361072 & 1301727 & 5.2154 & 4.5572 & TST \\
\hline CHEMBL1511219 & 1301727 & 5.475 & 4.9582 & TRN \\
\hline CHEMBL1995726 & 1301727 & 4.9582 & 4.7036 & TRN \\
\hline CHEMBL1349863 & 1301727 & 3.284 & 4.5302 & TRN \\
\hline CHEMBL1579902 & 1301727 & 3.284 & 3.593 & TRN \\
\hline CHEMBL1444050 & 1301727 & 3.284 & 3.8325 & TRN \\
\hline CHEMBL1899738 & 1301727 & 4.7768 & 4.167 & TST \\
\hline
\end{tabular}


Supplemental Table S2.txt

\begin{tabular}{|c|c|c|c|c|c|}
\hline CHEMBL1895747 & 1301727 & 3.284 & 4.5018 & TRN & \\
\hline CHEMBL1425919 & 1301727 & 4.4435 & 3.4851 & TRN & \\
\hline CHEMBL1360928 & 1301727 & 4.5464 & 4.3361 & TRN & \\
\hline CHEMBL1548433 & 1301727 & 5.5751 & 4.5171 & TRN & \\
\hline CHEMBL1558021 & 1301727 & 5.1226 & 4.687 & TRN & \\
\hline CHEMBL1608301 & 1301727 & 4.5694 & 4.1769 & TRN & \\
\hline CHEMBL1542560 & 1301727 & 4.8077 & 4.7266 & TST & \\
\hline CHEMBL1302266 & 1301727 & 4.7983 & 4.4229 & TRN & \\
\hline CHEMBL1458112 & 1301727 & 3.284 & 3.7694 & TRN & \\
\hline CHEMBL1441042 & 1301727 & 4.5114 & 4.4493 & TRN & \\
\hline CHEMBL1601310 & 1301727 & 5.0904 & 4.9735 & TRN & \\
\hline CHEMBL1435056 & 1301727 & 3.284 & 3.569 & TST & \\
\hline CHEMBL1415412 & 1301727 & 5.1884 & 5.0172 & TRN & \\
\hline CHEMBL 2359013 & 1301727 & 4.5521 & 5.033 & TRN & \\
\hline CHEMBL 2361605 & 1301727 & 4.6893 & 4.9064 & TRN & \\
\hline CHEMBL1546205 & 1301727 & 5.0883 & 4.8766 & TRN & \\
\hline CHEMBL1525789 & 1301727 & 3.284 & 4.1523 & TRN & \\
\hline CHEMBL1488923 & 1301727 & 5.6326 & 4.9882 & TRN & \\
\hline CHEMBL 2144728 & 1301727 & 5.71 & 5.3661 & TRN & \\
\hline CHEMBL405317 & 1301727 & 5.2062 & 5.0575 & TRN & \\
\hline CHEMBL1332533 & 1301727 & 5.1824 & 3.738 & TRN & \\
\hline CHEMBL1451470 & 1301727 & 5.0701 & 4.8647 & TST & \\
\hline CHEMBL 3186711 & 1301727 & 3.284 & 4.0148 & TST & \\
\hline CHEMBL1734467 & 1301727 & 5.1469 & 4.508 & TRN & \\
\hline CHEMBL1256656 & 1301727 & 4.8377 & 4.6641 & TRN & \\
\hline CHEMBL1402010 & 1301727 & 5.3904 & 4.8827 & TRN & \\
\hline CHEMBL1610597 & 1301727 & 4.5394 & 3.9723 & TST & \\
\hline CHEMBL523200 & 1301727 & 5.0711 & 4.8846 & TRN & \\
\hline CHEMBL1369200 & 1301727 & 5.4698 & 4.6705 & TRN & \\
\hline CHEMBL1440303 & 1301727 & 4.9208 & 4.8888 & TRN & \\
\hline CHEMBL509617 & 1301727 & 6.1209 & 5.4506 & TST & \\
\hline CHEMBL1303404 & 1301727 & 3.284 & 3.8493 & TRN & \\
\hline CHEMBL1455137 & 1301727 & 5.3809 & 4.9375 & TST & \\
\hline CHEMBL 3189080 & 1301727 & 4.7675 & 4.4746 & TRN & \\
\hline CHEMBL1421255 & 1301727 & 3.284 & 3.6413 & TRN & \\
\hline CHEMBL1437083 & 1301727 & 4.9531 & 4.9392 & TRN & \\
\hline CHEMBL1564490 & 1301727 & 3.284 & 4.0655 & TRN & \\
\hline CHEMBL1579644 & 1301727 & 5.5003 & 4.9298 & TST & \\
\hline CHEMBL1588716 & 1301727 & 3.284 & 4.157 & TRN & \\
\hline CHEMBL1310837 & 1301727 & 4.4987 & 4.0266 & TRN & \\
\hline CHEMBL1468355 & 1301727 & 4.8677 & 4.338999 & 99999999995 & TRN \\
\hline CHEMBL 261693 & 1301727 & 4.7373 & 4.428 & TRN & \\
\hline CHEMBL1878853 & 1301727 & 4.8047 & 4.8226 & TRN & \\
\hline CHEMBL1423927 & 1301727 & 4.4599 & 3.5216 & TRN & \\
\hline CHEMBL1476017 & 1301727 & 5.1068 & 4.9593 & TRN & \\
\hline CHEMBL1877321 & 1301727 & 3.284 & 3.8642 & TRN & \\
\hline CHEMBL1299526 & 1301727 & 5.20200 & 000000000 & 4.8651 & TRN \\
\hline CHEMBL 2355635 & 1301727 & 3.284 & 4.6961 & TRN & \\
\hline
\end{tabular}


Supplemental Table S2.txt

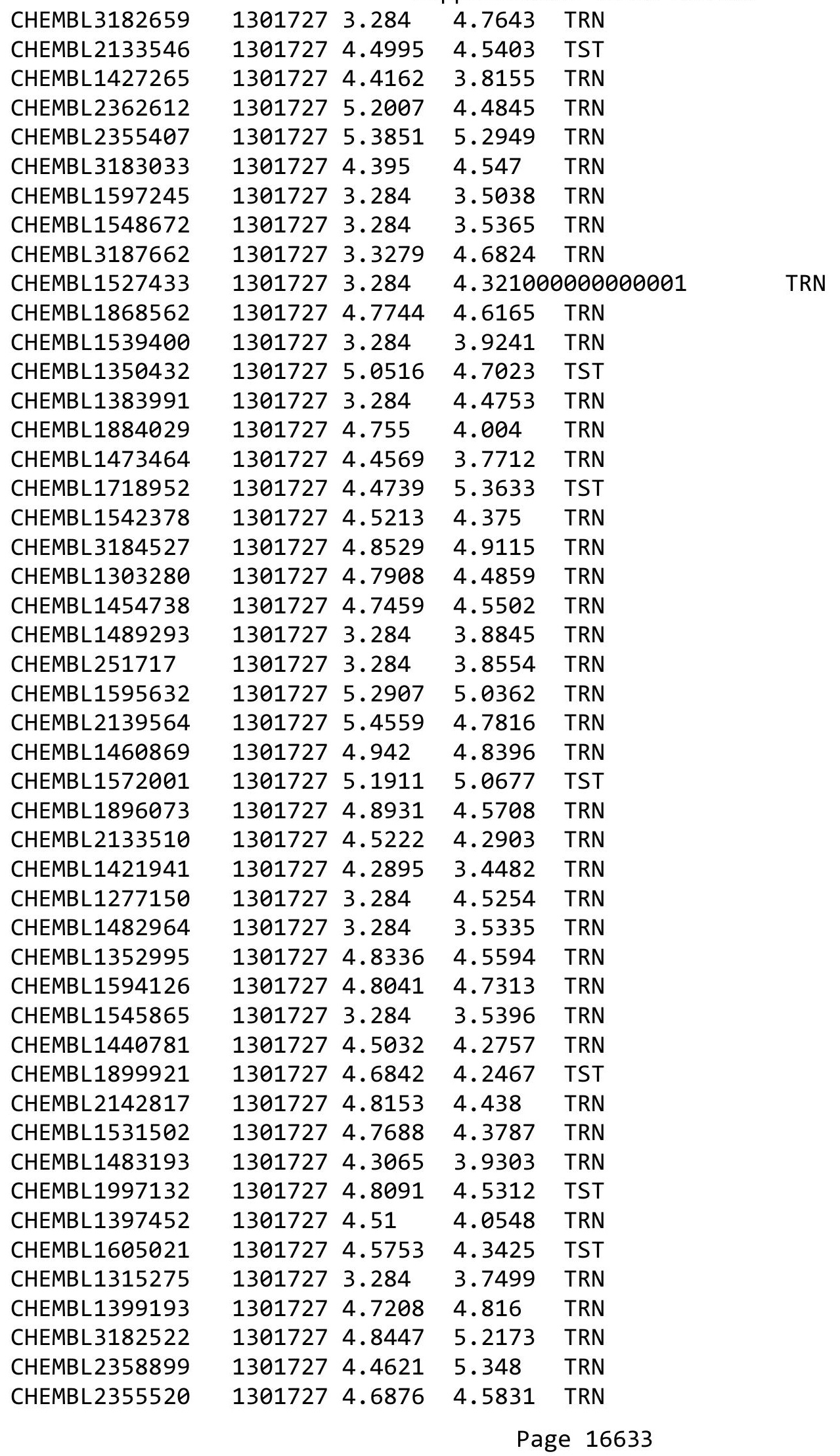


Supplemental Table S2.txt

$\begin{array}{lllll}\text { CHEMBL1396351 } & 1301727 & 4.8579 & 4.9469 & \text { TRN } \\ \text { CHEMBL1463529 } & 1301727 & 4.7667 & 4.6142 & \text { TRN } \\ \text { CHEMBL595825 } & 1301727 & 4.3606 & 3.8851 & \text { TRN } \\ \text { CHEMBL1311094 } & 1301727 & 4.5067 & 4.2688 & \text { TRN } \\ \text { CHEMBL1458038 } & 1301727 & 4.6861 & 4.2147 & \text { TRN } \\ \text { CHEMBL2357924 } & 1301727 & 4.6107 & 5.0617 & \text { TRN } \\ \text { CHEMBL3187852 } & 1301727 & 4.7066 & 4.8263 & \text { TRN } \\ \text { CHEMBL1446234 } & 1301727 & 4.5286 & 4.6999 & \text { TST } \\ \text { CHEMBL1499752 } & 1301727 & 4.3735 & 4.0505 & \text { TRN } \\ \text { CHEMBL1576166 } & 1301727 & 4.4917 & 3.9494 & \text { TRN } \\ \text { CHEMBL1602085 } & 1301727 & 3.284 & 3.5577 & \text { TRN } \\ \text { CHEMBL1325451 } & 1301727 & 4.8614 & 4.5495 & \text { TRN } \\ \text { CHEMBL1604245 } & 1301727 & 3.284 & 3.9871 & \text { TRN } \\ \text { CHEMBL1490336 } & 1301727 & 5.0696 & 4.8968 & \text { TRN } \\ \text { CHEMBL1436077 } & 1301727 & 4.5538 & 4.8054 & \text { TRN } \\ \text { CHEMBL1409423 } & 1301727 & 4.7989 & 4.4894 & \text { TRN } \\ \text { CHEMBL1577174 } & 1301727 & 4.4637 & 4.4312 & \text { TRN } \\ \text { CHEMBL2356186 } & 1301727 & 5.7696 & 5.5548 & \text { TRN } \\ \text { CHEMBL1407659 } & 1301727 & 4.8428 & 3.9631 & \text { TRN } \\ \text { CHEMBL1488020 } & 1301727 & 4.6562 & 4.2229 & \text { TRN } \\ \text { CHEMBL1325945 } & 1301727 & 4.5667 & 4.9693 & \text { TRN } \\ \text { CHEMBL1895744 } & 1301727 & 4.9957 & 4.1244 & \text { TRN } \\ \text { CHEMBL3185370 } & 1301727 & 4.7711 & 4.8584 & \text { TRN } \\ \text { CHEMBL1710184 } & 1301727 & 5.1232 & 4.7699 & \text { TRN } \\ \text { CHEMBL3183087 } & 1301727 & 4.5456 & 4.3174 & \text { TRN } \\ \text { CHEMBL1595274 } & 1301727 & 3.284 & 3.5249 & \text { TRN } \\ \text { CHEMBL1549208 } & 1301727 & 3.284 & 3.4229 & \text { TRN } \\ \text { CHEMBL1551577 } & 1301727 & 3.284 & 4.0116 & \text { TRN } \\ \text { CHEMBL1352521 } & 1301727 & 4.7113 & 4.599 & \text { TRN } \\ \text { CHEMBL2354532 } & 1301727 & 4.8548 & 4.912 & \text { TRN } \\ \text { CHEMBEML1594369 } & 1301727 & 4.643 & 4.6447 & \text { TST } \\ \text { CHEMBL1392611 } & 1301727 & 4.3122 & 4.3447 & \text { TRN } \\ \text { CHEMBL1597726 } & 1301727 & 3.284 & 4.0033 & \text { TST } \\ \text { CHEMBEM } & & & & \end{array}$

Page 16634 


\begin{tabular}{|c|c|c|c|c|c|}
\hline \multicolumn{6}{|c|}{ Supplemental Table S2.txt } \\
\hline CHEMBL414890 & 1301727 & 5.2899 & 4.9152 & TST & \\
\hline CHEMBL1545203 & 1301727 & 3.284 & 3.9538 & TRN & \\
\hline CHEMBL1522279 & 1301727 & 5.1079 & 4.0932 & TRN & \\
\hline CHEMBL1553265 & 1301727 & 3.284 & 3.4958 & TRN & \\
\hline CHEMBL1313954 & 1301727 & 3.284 & 3.8206 & TRN & \\
\hline CHEMBL1428752 & 1301727 & 4.4521 & 3.9181 & TST & \\
\hline CHEMBL1356587 & 1301727 & 3.284 & 3.98199 & 99999999998 & TRN \\
\hline CHEMBL1866836 & 1301727 & 4.3336 & 3.8078 & TRN & \\
\hline CHEMBL 2359304 & 1301727 & 3.284 & 4.482 & TST & \\
\hline CHEMBL1363219 & 1301727 & 5.7825 & 5.2636 & TRN & \\
\hline CHEMBL1408307 & 1301727 & 4.4037 & 4.3475 & TRN & \\
\hline CHEMBL1418175 & 1301727 & 4.9179 & 4.6027 & TRN & \\
\hline CHEMBL1510327 & 1301727 & 3.284 & 3.8271 & TST & \\
\hline CHEMBL 2132815 & 1301727 & 4.5379 & 4.6009 & TST & \\
\hline CHEMBL1607801 & 1301727 & 3.284 & 3.8618 & TRN & \\
\hline CHEMBL3186317 & 1301727 & 4.8564 & 4.8526 & TRN & \\
\hline CHEMBL3187125 & 1301727 & 3.284 & 3.8236 & TRN & \\
\hline CHEMBL1406361 & 1301727 & 3.284 & 3.6018 & TRN & \\
\hline CHEMBL1390421 & 1301727 & 4.6853 & 3.44100 & 00000000003 & TRN \\
\hline CHEMBL3186645 & 1301727 & 4.8047 & 4.7618 & TRN & \\
\hline CHEMBL1705423 & 1301727 & 4.8459 & 4.8324 & TST & \\
\hline CHEMBL1877386 & 1301727 & 5.3045 & 5.1298 & TRN & \\
\hline CHEMBL1521051 & 1301727 & 3.284 & 3.5301 & TRN & \\
\hline CHEMBL1323174 & 1301727 & 3.284 & 4.0166 & TRN & \\
\hline CHEMBL1520753 & 1301727 & 5.0878 & 4.8716 & TRN & \\
\hline CHEMBL1484344 & 1301727 & 3.284 & 3.9709 & TRN & \\
\hline CHEMBL1978643 & 1301727 & 4.7846 & 4.8351 & TRN & \\
\hline CHEMBL1698291 & 1301727 & 4.522 & 4.0804 & TST & \\
\hline CHEMBL 3188022 & 1301727 & 3.284 & 5.0398 & TRN & \\
\hline CHEMBL1470676 & 1301727 & 3.284 & 3.6346 & TRN & \\
\hline CHEMBL1444124 & 1301727 & 3.284 & 4.0375 & TRN & \\
\hline CHEMBL1713163 & 1301727 & 5.3224 & 4.5046 & TST & \\
\hline CHEMBL1902024 & 1301727 & 5.0814 & 4.6005 & TRN & \\
\hline CHEMBL3187421 & 1301727 & 3.284 & 4.4951 & TRN & \\
\hline CHEMBL1608430 & 1301727 & 4.678 & 4.377 & TRN & \\
\hline CHEMBL1438983 & 1301727 & 4.848 & 4.766 & TST & \\
\hline CHEMBL2355651 & 1301727 & 5.0164 & 4.9549 & TRN & \\
\hline CHEMBL3183439 & 1301727 & 3.3279 & 4.2055 & TRN & \\
\hline CHEMBL1340855 & 1301727 & 3.284 & 3.6482 & TRN & \\
\hline CHEMBL367376 & 1301727 & 6.7773 & 6.1131 & TST & \\
\hline CHEMBL1573331 & 1301727 & 4.6029 & 4.1942 & TRN & \\
\hline CHEMBL1466997 & 1301727 & 4.9551 & 4.0389 & TRN & \\
\hline CHEMBL1485101 & 1301727 & 4.5592 & 4.4528 & TRN & \\
\hline CHEMBL1496788 & 1301727 & 5.0419 & 4.8639 & TRN & \\
\hline CHEMBL1535919 & 1301727 & 4.6749 & 4.4861 & TRN & \\
\hline CHEMBL1591445 & 1301727 & 4.529 & 4.47 & TST & \\
\hline CHEMBL3186502 & 1301727 & 3.284 & 4.151 & TRN & \\
\hline CHEMBL1468055 & 1301727 & 3.284 & 4.3385 & TRN & \\
\hline
\end{tabular}


Supplemental Table S2.txt

\begin{tabular}{|c|c|c|c|c|c|}
\hline CHEMBL1429164 & 1301727 & 4.9041 & 4.6563 & TRN & \\
\hline CHEMBL 213580 & 1301727 & 5.0937 & 4.8787 & TRN & \\
\hline CHEMBL1613147 & 1301727 & 4.3933 & 3.7825 & TRN & \\
\hline CHEMBL1462900 & 1301727 & 5.7282 & 5.1832 & TRN & \\
\hline CHEMBL1301480 & 1301727 & 4.7937 & 4.6749 & TRN & \\
\hline CHEMBL1995375 & 1301727 & 4.5438 & 3.9378 & TRN & \\
\hline CHEMBL1488712 & 1301727 & 5.3737 & 4.5786 & TRN & \\
\hline CHEMBL1329974 & 1301727 & 4.6726 & 4.7622 & TRN & \\
\hline CHEMBL1897363 & 1301727 & 4.7535 & 4.4201 & TRN & \\
\hline CHEMBL1527400 & 1301727 & 5.1361 & 4.9376 & TRN & \\
\hline CHEMBL1438614 & 1301727 & 4.5013 & 4.5353 & TST & \\
\hline CHEMBL1378392 & 1301727 & 4.5887 & 4.8109 & TRN & \\
\hline CHEMBL1531169 & 1301727 & 5.1062 & 4.6707 & TRN & \\
\hline CHEMBL1517072 & 1301727 & 4.3705 & 3.924 & TRN & \\
\hline CHEMBL1336419 & 1301727 & 3.284 & 4.0142 & TST & \\
\hline CHEMBL1581094 & 1301727 & 4.7781 & 3.5269 & TST & \\
\hline CHEMBL 2132785 & 1301727 & 3.284 & 3.5904 & TST & \\
\hline CHEMBL1872338 & 1301727 & 4.5259 & 4.5409 & TRN & \\
\hline CHEMBL1612044 & 1301727 & 5.6517 & 4.9782 & TRN & \\
\hline CHEMBL530609 & 1301727 & 4.8791 & 4.708 & TRN & \\
\hline CHEMBL1567944 & 1301727 & 7.1361 & 6.4178 & TST & \\
\hline CHEMBL3184207 & 1301727 & 6.0 & 5.1193 & TRN & \\
\hline CHEMBL1570216 & 1301727 & 3.284 & 3.4501 & TRN & \\
\hline CHEMBL1427072 & 1301727 & 4.534 & 3.8908 & TRN & \\
\hline CHEMBL1590615 & 1301727 & 4.3092 & 4.4254 & TST & \\
\hline CHEMBL490083 & 1301727 & 3.284 & 3.83699 & 99999999997 & TRN \\
\hline CHEMBL1550664 & 1301727 & 4.5016 & 3.4211 & TRN & \\
\hline CHEMBL1871360 & 1301727 & 3.284 & 4.2668 & TST & \\
\hline CHEMBL1351908 & 1301727 & 4.46899 & 99999999 & 3.9954 & TRN \\
\hline CHEMBL1732834 & 1301727 & 4.5518 & 4.7124 & TRN & \\
\hline CHEMBL2357026 & 1301727 & 4.5542 & 4.6332 & TRN & \\
\hline CHEMBL1602614 & 1301727 & 3.284 & 4.3256 & TRN & \\
\hline CHEMBL1494038 & 1301727 & 5.1675 & 4.6568 & TRN & \\
\hline CHEMBL1373146 & 1301727 & 3.284 & 3.9362 & TST & \\
\hline CHEMBL1521187 & 1301727 & 3.284 & 4.1865 & TRN & \\
\hline CHEMBL2135896 & 1301727 & 4.8099 & 4.602 & TRN & \\
\hline CHEMBL1451293 & 1301727 & 3.284 & 3.6476 & TRN & \\
\hline CHEMBL1383534 & 1301727 & 4.5336 & 4.3873 & TRN & \\
\hline CHEMBL1352223 & 1301727 & 4.6212 & 5.149 & TST & \\
\hline CHEMBL1988859 & 1301727 & 3.284 & 4.5343 & TRN & \\
\hline CHEMBL1404547 & 1301727 & 5.0595 & 4.7109 & TRN & \\
\hline CHEMBL1468323 & 1301727 & 3.284 & 3.7699 & TRN & \\
\hline CHEMBL1902247 & 1301727 & 4.8508 & 4.6188 & TRN & \\
\hline CHEMBL 2131028 & 1301727 & 4.3831 & 4.5608 & TRN & \\
\hline CHEMBL1899585 & 1301727 & 5.2132 & 4.8603 & TRN & \\
\hline CHEMBL1586425 & 1301727 & 5.1249 & 4.8461 & TRN & \\
\hline CHEMBL1387923 & 1301727 & 4.8097 & 4.7536 & TRN & \\
\hline CHEMBL1575124 & 1301727 & 4.6043 & 4.501 & TRN & \\
\hline
\end{tabular}




\begin{tabular}{|c|c|c|c|c|c|}
\hline \multicolumn{6}{|c|}{ Supplemental Table s2.txt } \\
\hline CHEMBL460508 & 1301727 & 3.284 & 3.7886 & TRN & \\
\hline CHEMBL1494214 & 1301727 & 4.6105 & 4.896 & TRN & \\
\hline CHEMBL1376674 & 1301727 & 3.284 & 3.6815 & TRN & \\
\hline CHEMBL1539359 & 1301727 & 4.6112 & 4.5815 & TRN & \\
\hline CHEMBL1309573 & 1301727 & 5.0862 & 5.0378 & TRN & \\
\hline CHEMBL1488371 & 1301727 & 5.5258 & 4.808 & TRN & \\
\hline CHEMBL1866397 & 1301727 & 4.8969 & 4.1745 & TST & \\
\hline CHEMBL1465893 & 1301727 & 5.2644 & 3.9944 & TST & \\
\hline CHEMBL1726559 & 1301727 & 4.7757 & 4.5844 & TRN & \\
\hline CHEMBL1559713 & 1301727 & 4.2977 & 4.2789 & TRN & \\
\hline CHEMBL1459468 & 1301727 & 5.6326 & 5.0359 & TRN & \\
\hline CHEMBL1450748 & 1301727 & 5.6556 & 5.0223 & TRN & \\
\hline CHEMBL1419031 & 1301727 & 4.2908 & 4.6507 & TRN & \\
\hline CHEMBL 2148124 & 1301727 & 5.0605 & 4.9285 & TRN & \\
\hline CHEMBL1382215 & 1301727 & 5.3429 & 4.4158 & TRN & \\
\hline CHEMBL1409101 & 1301727 & 3.284 & 3.8757 & TRN & \\
\hline CHEMBL1359120 & 1301727 & 4.5408 & 4.6503 & TRN & \\
\hline CHEMBL1355823 & 1301727 & 4.5896 & 5.0277 & TRN & \\
\hline CHEMBL1553553 & 1301727 & 3.284 & 3.8098 & TST & \\
\hline CHEMBL1481849 & 1301727 & 5.1073 & 4.9899 & TST & \\
\hline CHEMBL3182996 & 1301727 & 3.284 & 3.9828 & TRN & \\
\hline CHEMBL1336447 & 1301727 & 4.4777 & 4.2034 & TRN & \\
\hline CHEMBL1490041 & 1301727 & 5.2034 & 4.9922 & TRN & \\
\hline CHEMBL 3185444 & 1301727 & 4.2935 & 4.6462 & TRN & \\
\hline CHEMBL1396619 & 1301727 & 4.5035 & 4.4124 & TRN & \\
\hline CHEMBL1386609 & 1301727 & 4.4302 & 3.8915 & TST & \\
\hline CHEMBL1540839 & 1301727 & 4.4702 & 4.4667 & TRN & \\
\hline CHEMBL1876725 & 1301727 & 4.7953 & 4.819 & TRN & \\
\hline CHEMBL1430096 & 1301727 & 4.5352 & 4.5131 & TRN & \\
\hline CHEMBL1712850 & 1301727 & 5.1029 & 4.8825 & TRN & \\
\hline CHEMBL1736766 & 1301727 & 6.4935 & 5.92899 & 9999999999 & TST \\
\hline CHEMBL1891068 & 1301727 & 4.8024 & 4.5457 & TST & \\
\hline CHEMBL 2362144 & 1301727 & 4.8834 & 5.3383 & TRN & \\
\hline CHEMBL1903021 & 1301727 & 4.8333 & 4.7116 & TRN & \\
\hline CHEMBL1486546 & 1301727 & 5.066 & 4.6845 & TRN & \\
\hline CHEMBL3183907 & 1301727 & 4.3298 & 4.3991 & TRN & \\
\hline CHEMBL1309228 & 1301727 & 4.9183 & 4.723 & TRN & \\
\hline CHEMBL 2137423 & 1301727 & 4.6492 & 4.637 & TRN & \\
\hline CHEMBL1507537 & 1301727 & 5.1035 & 4.8328 & TRN & \\
\hline CHEMBL1455421 & 1301727 & 4.9935 & 4.6041 & TRN & \\
\hline CHEMBL1607086 & 1301727 & 3.284 & 4.0083 & TRN & \\
\hline CHEMBL1588387 & 1301727 & 3.284 & 4.0334 & TRN & \\
\hline CHEMBL1489344 & 1301727 & 3.284 & 4.3983 & TRN & \\
\hline CHEMBL1384167 & 1301727 & 5.3516 & 5.1806 & TRN & \\
\hline CHEMBL3188377 & 1301727 & 4.5284 & 4.7532 & TRN & \\
\hline CHEMBL1573994 & 1301727 & 4.838 & 4.925 & TRN & \\
\hline CHEMBL1421442 & 1301727 & 4.7757 & 4.5183 & TRN & \\
\hline CHEMBL1707441 & 1301727 & 4.7794 & 4.7543 & TST & \\
\hline
\end{tabular}




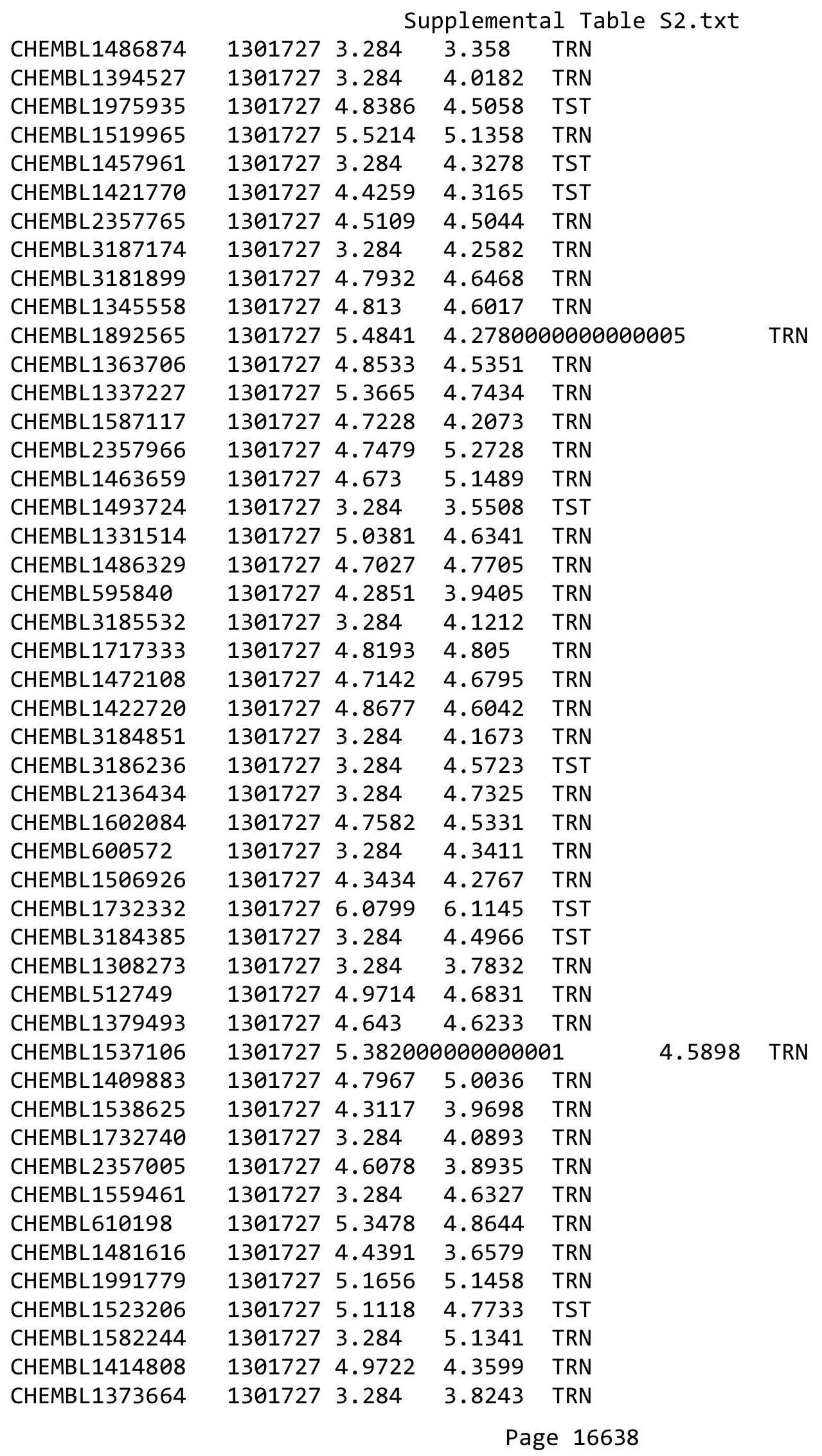


Supplemental Table S2.txt

\begin{tabular}{|c|c|c|c|c|c|c|}
\hline CHEMBL473735 & 1301727 & 4.4959 & 4.247 & TRN & & \\
\hline CHEMBL1484208 & 1301727 & 4.963 & 5.0118 & TRN & & \\
\hline CHEMBL1438758 & 1301727 & 3.284 & 3.9155 & TRN & & \\
\hline CHEMBL1377992 & 1301727 & 4.474 & 3.8984 & TRN & & \\
\hline CHEMBL267099 & 1301727 & 5.7959 & 5.9329 & TST & & \\
\hline CHEMBL2359438 & 1301727 & 4.6521 & 4.5277 & TST & & \\
\hline CHEMBL1365689 & 1301727 & 3.284 & 3.6383 & TST & & \\
\hline CHEMBL1392228 & 1301727 & 4.9535 & 4.4513 & TST & & \\
\hline CHEMBL1534441 & 1301727 & 3.284 & 4.3059 & TST & & \\
\hline CHEMBL3187821 & 1301727 & \multicolumn{3}{|c|}{5.0569999999999995} & 5.2017 & TST \\
\hline CHEMBL1361922 & 1301727 & 4.3956 & 3.8259 & TST & & \\
\hline CHEMBL1513654 & 1301727 & 4.857 & 4.8584 & TST & & \\
\hline CHEMBL1524929 & 1301727 & 5.4425 & 4.9795 & TST & & \\
\hline CHEMBL1528342 & 1301727 & 3.284 & \multicolumn{3}{|c|}{4.4510000000000005} & TST \\
\hline CHEMBL1521269 & 1301727 & 4.9694 & 4.3311 & TST & & \\
\hline CHEMBL1720155 & 1301727 & 4.6423 & 4.2051 & TST & & \\
\hline CHEMBL1304031 & 1301727 & 3.284 & 4.1836 & TST & & \\
\hline CHEMBL3188935 & 1301727 & 4.8027 & 4.9127 & TST & & \\
\hline CHEMBL1978733 & 1301727 & 5.0074 & 5.0747 & TST & & \\
\hline CHEMBL1375966 & 1301727 & 4.4793 & 3.9365 & TST & & \\
\hline CHEMBL261123 & 1301727 & 4.4008 & 3.5174 & TST & & \\
\hline CHEMBL535307 & 1301727 & 6.8153 & 6.2038 & TST & & \\
\hline CHEMBL1439384 & 1301727 & 4.9996 & 4.8811 & TST & & \\
\hline CHEMBL1530216 & 1301727 & 4.667 & 4.293 & TST & & \\
\hline CHEMBL1436748 & 1301727 & 4.6755 & 4.5982 & TST & & \\
\hline CHEMBL1328462 & 1301727 & 4.9788 & 4.5751 & TST & & \\
\hline CHEMBL1479010 & 1301727 & 5.3778 & 4.8902 & TST & & \\
\hline CHEMBL1898104 & 1301727 & 4.769 & 4.4183 & TST & & \\
\hline CHEMBL1489148 & 1301727 & 3.284 & 4.3094 & TST & & \\
\hline CHEMBL1734568 & 1301727 & 4.3204 & 4.0098 & TST & & \\
\hline CHEMBL1878940 & 1301727 & 5.1871 & 4.6705 & TST & & \\
\hline CHEMBL1555066 & 1301727 & 5.1918 & 4.6719 & TST & & \\
\hline CHEMBL1900154 & 1301727 & 4.293 & 4.6504 & TST & & \\
\hline CHEMBL2360439 & 1301727 & 3.284 & 4.7139 & TST & & \\
\hline CHEMBL1348884 & 1301727 & 3.284 & 3.3693 & TST & & \\
\hline CHEMBL1328504 & 1301727 & \multicolumn{3}{|c|}{5.202000000000001} & 4.6734 & TST \\
\hline CHEMBL3183714 & 1301727 & \multicolumn{3}{|c|}{4.5360000000000005} & 4.0512 & TST \\
\hline CHEMBL2004141 & 1301727 & 5.4295 & 5.2567 & TST & & \\
\hline CHEMBL1483331 & 1301727 & 4.7256 & 4.599 & TST & & \\
\hline CHEMBL2359997 & 1301727 & 4.8153 & 4.6999 & TST & & \\
\hline CHEMBL1535021 & 1301727 & 3.284 & 4.0417 & TST & & \\
\hline CHEMBL1488730 & 1301727 & 3.284 & 3.5901 & TST & & \\
\hline CHEMBL1315789 & 1301727 & 5.0926 & 4.9696 & TST & & \\
\hline CHEMBL1385499 & 1301727 & 5.0575 & 3.9471 & TST & & \\
\hline CHEMBL1415374 & 1301727 & 3.284 & 3.8865 & TST & & \\
\hline CHEMBL1315401 & 1301727 & 4.614 & 4.3057 & TST & & \\
\hline CHEMBL1547570 & 1301727 & 3.284 & 3.9951 & TST & & \\
\hline CHEMBL1547229 & 1301727 & 4.3006 & 4.0593 & TST & & \\
\hline
\end{tabular}


Supplemental Table S2.txt

\begin{tabular}{|c|c|c|c|c|c|}
\hline CHEMBL1611128 & 1301727 & 3.284 & 3.3738 & TST & \\
\hline CHEMBL515416 & 954411 & 3.0136 & 3.0139 & TRN & \\
\hline CHEMBL180127 & 954411 & 4.4986 & 4.5495 & TRN & \\
\hline CHEMBL92309 & 954411 & 2.9488 & 2.703999 & 99999999997 & TST \\
\hline CHEMBL 3392440 & 954411 & 3.4557 & 3.4434 & TRN & \\
\hline CHEMBL392695 & 954411 & 5.3231 & 5.2872 & TRN & \\
\hline CHEMBL379975 & 954411 & 6.2505 & 6.2408 & TRN & \\
\hline CHEMBL472940 & 954411 & 2.661 & 2.6773 & TRN & \\
\hline CHEMBL1404918 & 954411 & 3.49 & 3.4655 & TRN & \\
\hline CHEMBL1788116 & 954411 & 4.1381 & 4.1519 & TRN & \\
\hline CHEMBL 3199475 & 954411 & 5.0636 & 5.0602 & TRN & \\
\hline CHEMBL65 & 954411 & 10.3149 & 10.3092 & TRN & \\
\hline CHEMBL 379300 & 954411 & 6.6084 & 6.6475 & TRN & \\
\hline CHEMBL412142 & 954411 & 3.6449 & 3.6236 & TRN & \\
\hline CHEMBL1357247 & 954411 & 2.8591 & 2.8786 & TRN & \\
\hline CHEMBL483849 & 954411 & 2.4921 & 2.5241 & TRN & \\
\hline CHEMBL1909414 & 954411 & 4.4501 & 4.4642 & TRN & \\
\hline CHEMBL 2363137 & 954411 & 4.1423 & 4.1223 & TRN & \\
\hline CHEMBL213100 & 954411 & 3.0929 & 3.0986 & TRN & \\
\hline CHEMBL209148 & 954411 & 3.7562 & 3.7675 & TRN & \\
\hline CHEMBL573107 & 954411 & 6.1145 & 6.077000 & 0000000001 & TRN \\
\hline CHEMBL 9470 & 954411 & 4.9098 & 5.4511 & TST & \\
\hline CHEMBL483847 & 954411 & 4.6567 & 4.6563 & TRN & \\
\hline CHEMBL1590308 & 954411 & 2.8911 & 3.1505 & TST & \\
\hline CHEMBL191334 & 954411 & 3.7141 & 3.69 & TRN & \\
\hline CHEMBL 3186408 & 954411 & 2.9981 & 3.4371 & TST & \\
\hline CHEMBL585951 & 954411 & 5.899 & 5.9223 & TRN & \\
\hline CHEMBL1230020 & 954411 & 5.7936 & 5.7851 & TRN & \\
\hline CHEMBL102714 & 954411 & 3.6198 & 3.6021 & TRN & \\
\hline CHEMBL1256459 & 954411 & \multicolumn{3}{|c|}{6.638999999999999} & 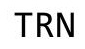 \\
\hline CHEMBL558642 & 954411 & 4.1798 & 4.2 & TRN & \\
\hline CHEMBL 2005886 & 954411 & 3.0475 & 3.0148 & TRN & \\
\hline CHEMBL2144069 & 954411 & 3.9904 & 3.9725 & TRN & \\
\hline CHEMBL189584 & 954411 & 5.3389 & 5.3264 & TRN & \\
\hline CHEMBL1970879 & 954411 & 3.1454 & 3.1595 & TRN & \\
\hline CHEMBL1242367 & 954411 & 4.2339 & 4.2038 & TRN & \\
\hline CHEMBL300389 & 954411 & 6.87 & 6.854 & TRN & \\
\hline CHEMBL509032 & 954411 & 5.0635 & 5.0719 & TRN & \\
\hline CHEMBL258844 & 954411 & 3.8048 & 3.8182 & TRN & \\
\hline CHEMBL373751 & 954411 & 3.5174 & 3.5243 & TRN & \\
\hline CHEMBL192566 & 954411 & 7.7423 & 7.9377 & TST & \\
\hline CHEMBL 202721 & 954411 & 5.9333 & 5.9557 & TRN & \\
\hline CHEMBL221137 & 954411 & 4.4816 & 4.4486 & TST & \\
\hline CHEMBL1190711 & 954411 & 5.0089 & 4.9982 & TRN & \\
\hline CHEMBL220241 & 954411 & 4.6454 & 4.6483 & TRN & \\
\hline CHEMBL514499 & 954411 & 6.6487 & 6.6798 & TRN & \\
\hline CHEMBL1673039 & 954411 & 4.7562 & 4.7241 & TRN & \\
\hline CHEMBL1516890 & 954411 & 3.8705 & 3.8846 & TRN & \\
\hline
\end{tabular}

Page 16640 


\begin{tabular}{|c|c|c|c|c|c|c|}
\hline \multirow[b]{2}{*}{ CHEMBL512504 } & & \multicolumn{5}{|c|}{ Supplemental Table S2.txt } \\
\hline & 954411 & 5.4446 & 5.4556 & TRN & & \\
\hline CHEMBL393929 & 954411 & 3.6446 & 4.4397 & TST & & \\
\hline CHEMBL135561 & 954411 & \multicolumn{3}{|c|}{3.7880000000000003} & 4.5229 & TST \\
\hline CHEMBL1643959 & 954411 & 3.7901 & 3.4995 & TST & & \\
\hline CHEMBL259181 & 954411 & 3.3146 & 4.3039 & TST & & \\
\hline CHEMBL3349342 & 954411 & 4.1001 & 4.8514 & TST & & \\
\hline CHEMBL 210618 & 954411 & 3.5709 & 3.5708 & TST & & \\
\hline CHEMBL449158 & 954411 & 6.6349 & 7.1762 & TST & & \\
\hline CHEMBL 240954 & 954411 & 3.7154 & 4.12 & TST & & \\
\hline CHEMBL540483 & 864365 & 5.0362 & 4.6523 & TRN & & \\
\hline CHEMBL 2172425 & 864365 & 4.6904 & 5.3734 & TRN & & \\
\hline CHEMBL 2172398 & 864365 & 5.0757 & 4.6596 & TRN & & \\
\hline CHEMBL539148 & 864365 & 5.3279 & 4.6163 & TRN & & \\
\hline CHEMBL 2172534 & 864365 & 5.585 & 4.5295 & TRN & & \\
\hline CHEMBL541677 & 864365 & 5.1739 & 4.6133 & TRN & & \\
\hline CHEMBL 2172404 & 864365 & 6.1249 & 4.8795 & TRN & & \\
\hline CHEMBL538668 & 864365 & 3.6198 & 4.6523 & TRN & & \\
\hline CHEMBL1173475 & 864365 & 3.9876 & 4.5575 & TST & & \\
\hline CHEMBL539149 & 864365 & 5.5086 & 4.6163 & TRN & & \\
\hline CHEMBL 2172418 & 864365 & 6.0088 & 6.4323 & TST & & \\
\hline CHEMBL 2172402 & 864365 & 5.301 & 5.5767 & TRN & & \\
\hline CHEMBL 2172424 & 864365 & 6.3565 & 6.4403 & TRN & & \\
\hline CHEMBL151 & 864365 & \multicolumn{3}{|c|}{3.9419999999999997} & 4.7675 & TST \\
\hline CHEMBL 2172410 & 864365 & 3.0 & 4.1766 & TRN & & \\
\hline CHEMBL 2172536 & 864365 & 5.4949 & 4.8287 & TRN & & \\
\hline CHEMBL539147 & 864365 & 3.6198 & 4.6523 & TRN & & \\
\hline CHEMBL 2172399 & 864365 & 3.0 & 4.4049 & TRN & & \\
\hline CHEMBL 2172532 & 864365 & 5.2757 & 4.6523 & TRN & & \\
\hline CHEMBL 2172413 & 864365 & 5.8539 & 6.3356 & TRN & & \\
\hline CHEMBL 2172414 & 864365 & 6.7212 & 6.5394 & TRN & & \\
\hline CHEMBL558734 & 864365 & 5.0269 & 4.6523 & TRN & & \\
\hline CHEMBL558735 & 864365 & 3.6198 & 4.6163 & TRN & & \\
\hline CHEMBL 2172396 & 864365 & 5.4949 & 4.7769 & TRN & & \\
\hline CHEMBL 2172420 & 864365 & 6.2518 & 6.3937 & TRN & & \\
\hline CHEMBL555600 & 864365 & 5.2076 & 4.6523 & TRN & & \\
\hline CHEMBL 2172535 & 864365 & 5.4815 & 4.7618 & TRN & & \\
\hline CHEMBL 2172403 & 864365 & 3.0 & 4.623 & TST & & \\
\hline CHEMBL 2172400 & 864365 & 3.0 & 4.3123 & TRN & & \\
\hline CHEMBL2172406 & 864365 & 5.0506 & 4.7246 & TRN & & \\
\hline CHEMBL 2172397 & 864365 & 5.4949 & 4.6945 & TST & & \\
\hline CHEMBL532047 & 864365 & 5.3188 & 4.6038 & TST & & \\
\hline CHEMBL 2172422 & 864365 & 5.9586 & 5.3105 & TRN & & \\
\hline CHEMBL2172407 & 864365 & 3.0 & 4.3268 & TRN & & \\
\hline CHEMBL 2169912 & 864365 & 5.4202 & 4.875 & TRN & & \\
\hline CHEMBL539987 & 864365 & 3.6198 & 4.6053 & TRN & & \\
\hline CHEMBL 2172415 & 864365 & 5.6383 & 6.5717 & TRN & & \\
\hline CHEMBL558751 & 864365 & 5.7212 & 4.6038 & TST & & \\
\hline CHEMBL2172533 & 864365 & 5.1612 & 4.6038 & TST & & \\
\hline
\end{tabular}




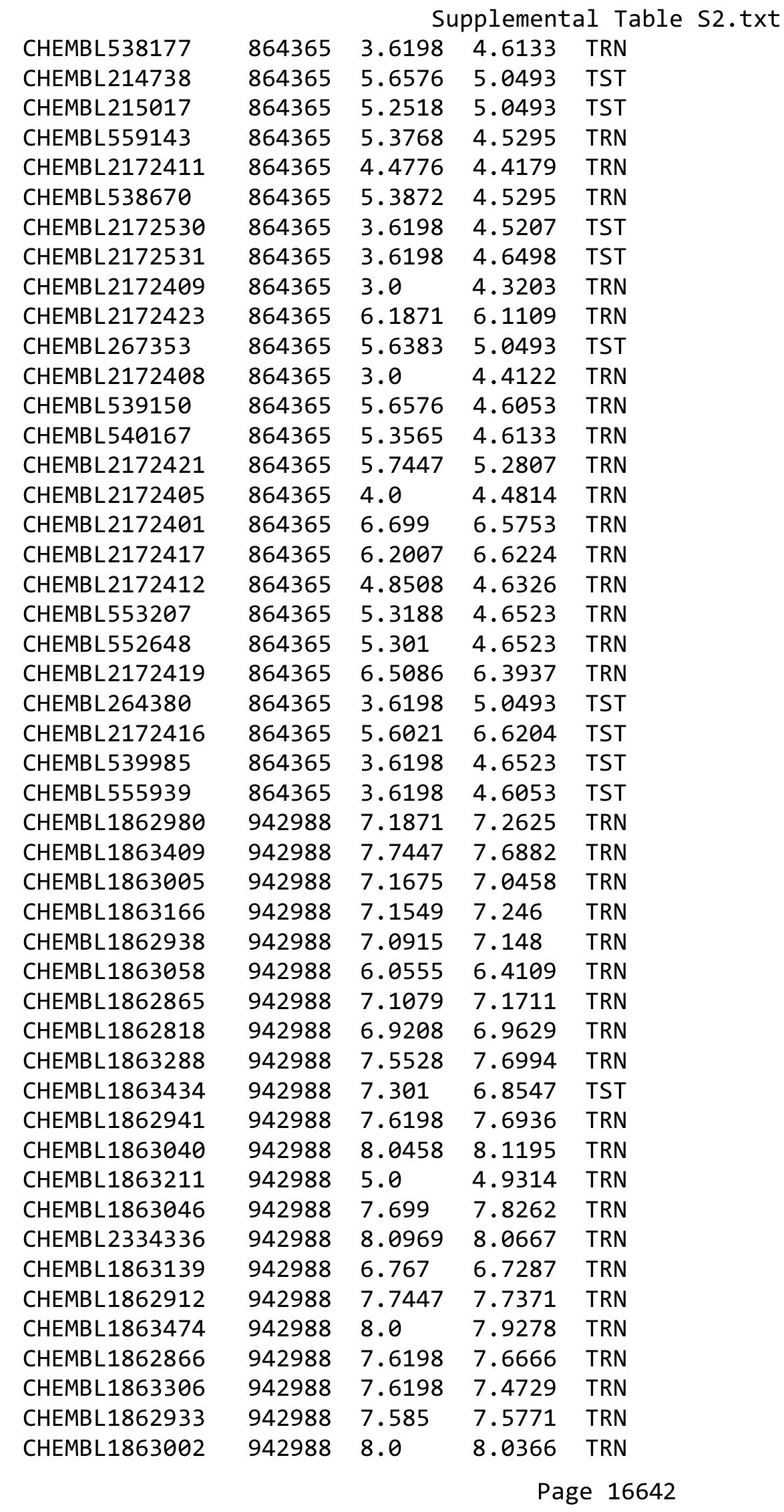




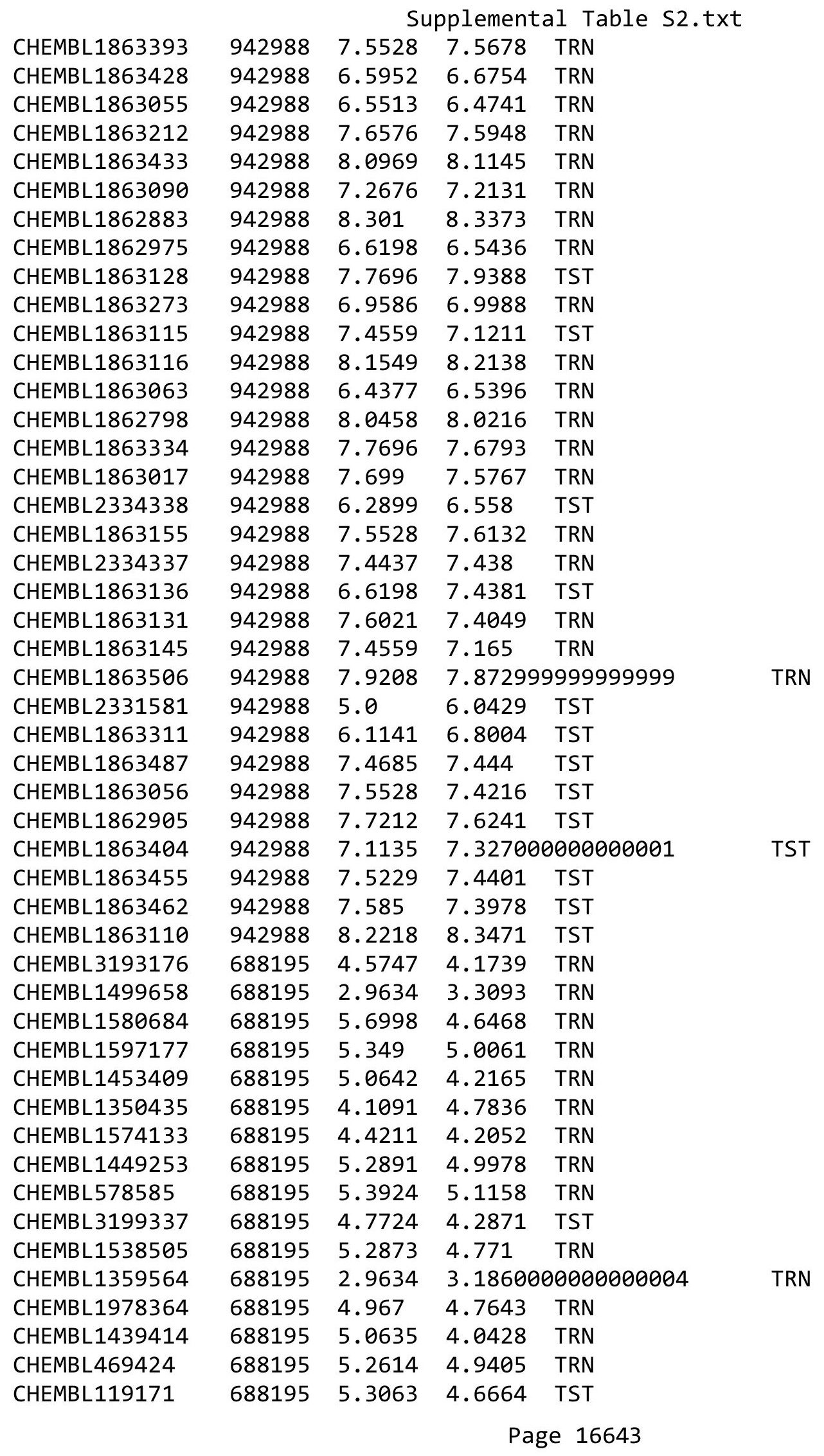


Supplemental Table S2.txt

\begin{tabular}{|c|c|c|c|c|c|c|}
\hline CHEMBL1373095 & 688195 & 5.3705 & 4.7637 & TRN & & \\
\hline CHEMBL1318277 & 688195 & 4.8227 & 4.4935 & TRN & & \\
\hline CHEMBL1449836 & 688195 & 5.5352 & 5.2704 & TRN & & \\
\hline CHEMBL1307648 & 688195 & 4.9325 & 4.2358 & TRN & & \\
\hline CHEMBL3192179 & 688195 & 5.6321 & 5.8631 & TRN & & \\
\hline CHEMBL1449334 & 688195 & 4.878 & 5.0425 & TRN & & \\
\hline CHEMBL1595621 & 688195 & 4.5289 & 4.6742 & TRN & & \\
\hline CHEMBL1515153 & 688195 & 4.54 & 4.1471 & TRN & & \\
\hline CHEMBL 1467730 & 688195 & 4.9555 & 4.4532 & TRN & & \\
\hline CHEMBL1416189 & 688195 & 3.9176 & 3.8262 & TRN & & \\
\hline CHEMBL1966952 & 688195 & 5.0395 & 5.0418 & TRN & & \\
\hline CHEMBL1419305 & 688195 & 2.9634 & 3.6562 & TRN & & \\
\hline CHEMBL1459125 & 688195 & 4.3964 & 4.718 & TRN & & \\
\hline CHEMBL1397359 & 688195 & 2.9634 & 4.1428 & TRN & & \\
\hline CHEMBL1348273 & 688195 & 4.7418 & 4.5606 & TRN & & \\
\hline CHEMBL1512376 & 688195 & 4.9607 & 4.4819 & TRN & & \\
\hline CHEMBL1981150 & 688195 & 2.9634 & 3.8183 & TRN & & \\
\hline CHEMBL1520254 & 688195 & 4.7746 & 4.1684 & TST & & \\
\hline CHEMBL1558195 & 688195 & 4.3947 & 4.7574 & TRN & & \\
\hline CHEMBL1342429 & 688195 & 2.9634 & 3.4066 & TST & & \\
\hline CHEMBL458328 & 688195 & 6.3551 & 4.3089 & TST & & \\
\hline CHEMBL1312353 & 688195 & 4.9318 & 4.8564 & TRN & & \\
\hline CHEMBL1468800 & 688195 & 5.75899 & 99999999 & 995 & 5.4505 & TRN \\
\hline CHEMBL3192011 & 688195 & 2.9634 & 2.9559 & TRN & & \\
\hline CHEMBL3199065 & 688195 & 4.6373 & 3.9387 & TRN & & \\
\hline CHEMBL1510117 & 688195 & 4.7718 & 4.343 & TRN & & \\
\hline CHEMBL1606013 & 688195 & 3.9176 & 3.9894 & TRN & & \\
\hline CHEMBL1476707 & 688195 & 4.2996 & 4.1985 & TRN & & \\
\hline CHEMBL11875 & 688195 & 2.9634 & 3.8254 & TRN & & \\
\hline CHEMBL1401406 & 688195 & \multicolumn{3}{|c|}{5.1979999999999995} & 3.8796 & TST \\
\hline CHEMBL1990772 & 688195 & 2.9634 & 3.9634 & TRN & & \\
\hline CHEMBL1579209 & 688195 & 4.8508 & 4.6091 & TRN & & \\
\hline CHEMBL1435948 & 688195 & 5.4541 & 4.9932 & TRN & & \\
\hline CHEMBL1592276 & 688195 & 5.4616 & 4.1867 & TST & & \\
\hline CHEMBL 1384172 & 688195 & 4.8719 & 5.3225 & TRN & & \\
\hline CHEMBL234338 & 688195 & 4.727 & 5.2142 & TRN & & \\
\hline CHEMBL1981243 & 688195 & 2.9634 & 4.5605 & TRN & & \\
\hline CHEMBL1387693 & 688195 & 5.3067 & 4.9694 & TRN & & \\
\hline CHEMBL3193581 & 688195 & 4.2285 & 4.3007 & TRN & & \\
\hline CHEMBL1964442 & 688195 & 4.9993 & 4.5947 & TRN & & \\
\hline CHEMBL1576140 & 688195 & 5.0281 & 5.3881 & TRN & & \\
\hline CHEMBL1299990 & 688195 & 4.3947 & 4.1024 & TRN & & \\
\hline CHEMBL1451039 & 688195 & 5.0641 & 4.4623 & TST & & \\
\hline CHEMBL1488981 & 688195 & 2.9634 & 4.0232 & TST & & \\
\hline CHEMBL1377223 & 688195 & 4.8758 & 5.2347 & TRN & & \\
\hline CHEMBL1200938 & 688195 & 4.6909 & 3.8634 & TST & & \\
\hline CHEMBL1310309 & 688195 & 4.4275 & 4.8917 & TRN & & \\
\hline CHEMBL1301692 & 688195 & 2.9634 & 4.1366 & TRN & & \\
\hline
\end{tabular}


Supplemental Table S2.txt

\begin{tabular}{|c|c|c|c|c|}
\hline & & & & \\
\hline 70 & 8195 & 2026 & & \\
\hline IEMBL1482959 & 8195 & 5238 & 0947 & \\
\hline HEMBL1360150 & 195 & 558 & 7219 & \\
\hline & 195 & & & \\
\hline IEMBL 20 & 195 & 34 & & \\
\hline AEMBL1344422 & 88195 & 3.9176 & 3904 & \\
\hline AEMBL1519408 & 88195 & 634 & .9166 & \\
\hline AEMBL142 & 195 & 182 & & \\
\hline IEMBL16 & 195 & & & \\
\hline AEMBL1330042 & 195 & & & \\
\hline AEMBL3197557 & 588195 & 847 & & \\
\hline AEMBL3195986 & 195 & 85 & & ות \\
\hline IEMBL160 & 195 & 4. & 43 & \\
\hline EMBL14S & & & & \\
\hline AEMBL 145 & & & & \\
\hline AEMBL1571442 & 195 & & & \\
\hline AEMBL141 & 195 & $\partial 1$ & & \\
\hline IEMBL31 & 5 & & 59 & \\
\hline EMBL13 & & & & \\
\hline AEMBL20 & 95 & & & \\
\hline AEMBL1337575 & 195 & & & \\
\hline IEMBL1308606 & & & & \\
\hline IEMBL17 & & & & RI \\
\hline IEMBL19 & & & & (3) \\
\hline AFMRI 14 & 95 & 4. & & RN \\
\hline L150 & & & & ST \\
\hline HEMBL 144 & & & & $\mathrm{RI}$ \\
\hline AEMBL318 & 95 & & & RI \\
\hline-13 & 95 & & & 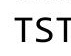 \\
\hline 384 & & & & -8 \\
\hline HEMBL1514693 & & & & ST \\
\hline AEMBL1410381 & & & & RI \\
\hline IEMBL14 & 95 & & & RI \\
\hline 397 & 95 & & 51 & . \\
\hline 38 & & & & ST \\
\hline AEMBL1359782 & & & & RN \\
\hline AEMBL1316816 & & & & RI \\
\hline EMBL134 & & & & RI \\
\hline זבים וחוזו & & & & \\
\hline & & & & ST \\
\hline HEMBL1699206 & 195 & 47 & 42 & $\mathrm{R}$ \\
\hline IEMBL1345135 & & & & \\
\hline HEMBL13: & & & & \\
\hline HEMBL141 & & & & ST \\
\hline CHEMBL198 & & & 98 & $\mathrm{RN}$ \\
\hline AEMBL1454531 & 8195 & 5.0569 & 4.3954 & $T R$ \\
\hline HFMBI 3191557 & 688195 & 3.4405 & 4.8179 & \\
\hline
\end{tabular}

Page 16645 


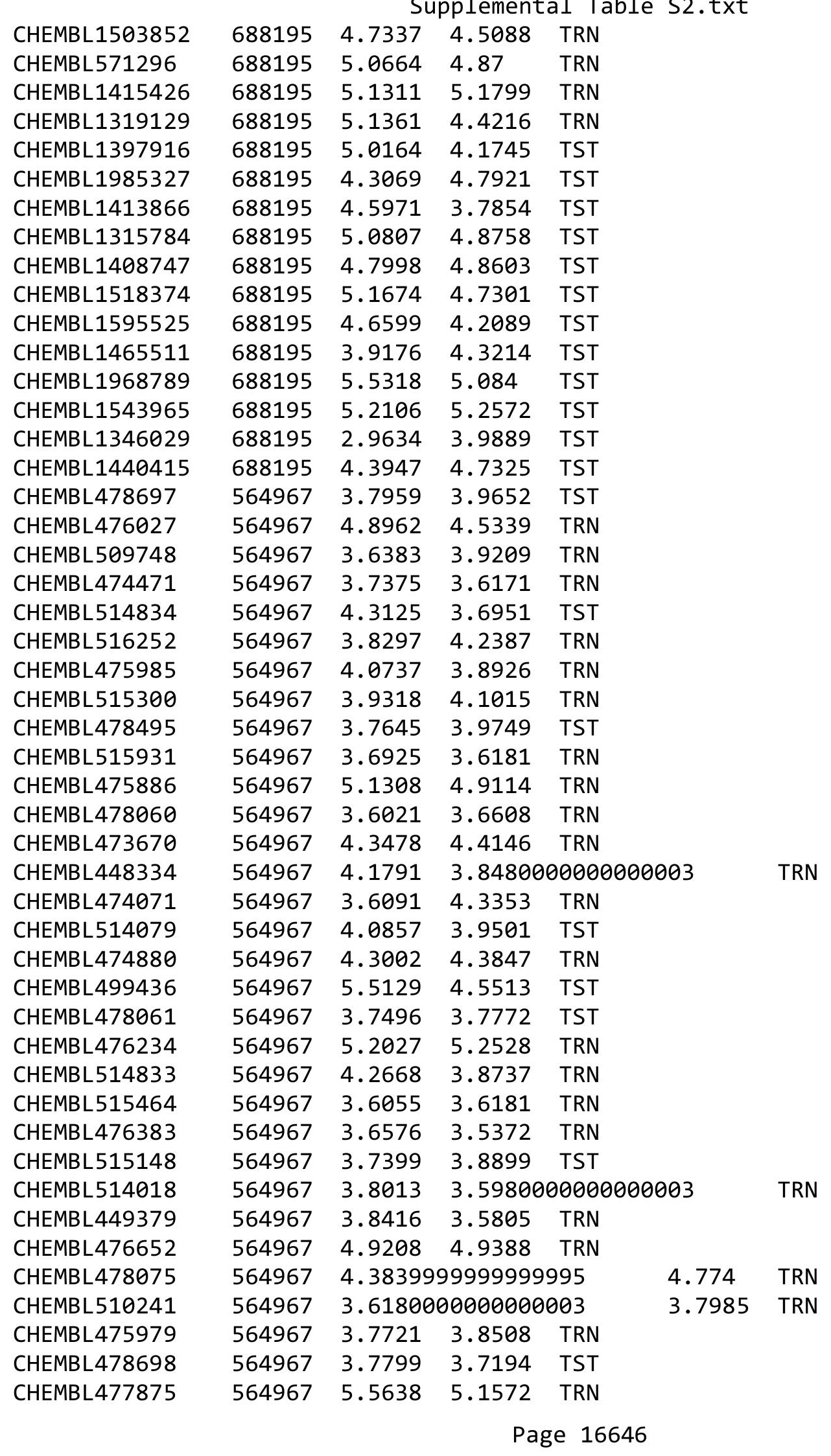




\begin{tabular}{|c|c|c|c|c|c|}
\hline \\
\hline CHEMBL476653 & 564967 & 4.7352 & 4.7627 & TRN & \\
\hline CHEMBL476068 & 564967 & 5.9318 & 4.6901 & TST & \\
\hline CHEMBL476654 & 564967 & 3.7905 & 4.0936 & TRN & \\
\hline CHEMBL478325 & 564967 & 5.0164 & 4.3014 & TST & \\
\hline CHEMBL475978 & 564967 & 4.9914 & 4.8669 & TRN & \\
\hline CHEMBL476013 & 564967 & 3.7305 & 3.9062 & TRN & \\
\hline CHEMBL515961 & 564967 & 3.7799 & 3.7137 & TRN & \\
\hline CHEMBL478128 & 564967 & 5.1249 & 4.774 & TRN & \\
\hline CHEMBL478515 & 564967 & 4.9393 & 4.9226 & TRN & \\
\hline CHEMBL478494 & 564967 & 3.7905 & 3.9392 & TST & \\
\hline CHEMBL473051 & 564967 & 3.7167 & 3.7399 & TRN & \\
\hline CHEMBL507262 & 564967 & 4.0255 & 4.1274 & TRN & \\
\hline CHEMBL449068 & 564967 & 4.342 & 4.6732 & TRN & \\
\hline CHEMBL470445 & 564967 & 3.7852 & 3.8632 & TRN & \\
\hline CHEMBL476012 & 564967 & 3.9393 & 3.9152 & TRN & \\
\hline CHEMBL476390 & 564967 & 3.7167 & 3.7847 & TRN & \\
\hline CHEMBL514531 & 564967 & 3.8297 & 3.9877 & TRN & \\
\hline CHEMBL450904 & 564967 & 3.9508 & 3.8775 & TRN & \\
\hline CHEMBL449459 & 564967 & 4.7282 & 4.7068 & TRN & \\
\hline CHEMBL477869 & 564967 & 3.7212 & 3.6672 & TST & \\
\hline CHEMBL514628 & 564967 & 4.279 & 4.0219 & TST & \\
\hline CHEMBL506941 & 564967 & 3.7399 & 3.6472 & TST & \\
\hline CHEMBL476061 & 564967 & 4.757 & 4.5711 & TRN & \\
\hline CHEMBL514996 & 564967 & 4.3788 & 4.121 & TRN & \\
\hline CHEMBL3965495 & 1640412 & 8.3979 & 7.5694 & TRN & \\
\hline CHEMBL 3893264 & 1640412 & 6.0 & 6.8821 & TRN & \\
\hline CHEMBL3937269 & 1640412 & 8.3768 & 8.2031 & TST & \\
\hline CHEMBL3980841 & 1640412 & 8.4318 & 6.9809 & TRN & \\
\hline CHEMBL 3922858 & 1640412 & 6.0 & 7.1086 & TRN & \\
\hline CHEMBL3921642 & 1640412 & 8.699 & 7.3353 & TST & \\
\hline CHEMBL3900169 & 1640412 & 6.0 & 7.3212 & TRN & \\
\hline CHEMBL3966763 & 1640412 & 8.0 & 6.8128 & TRN & \\
\hline CHEMBL3925298 & 1640412 & 6.0 & 7.2742 & TRN & \\
\hline CHEMBL3974518 & 1640412 & 8.699 & 8.1384 & TRN & \\
\hline CHEMBL3903940 & 1640412 & 8.1549 & 8.1864 & TRN & \\
\hline CHEMBL3927976 & 1640412 & 9.0 & 8.0127 & TRN & \\
\hline CHEMBL3921503 & 1640412 & 6.0 & 6.4956 & TRN & \\
\hline CHEMBL3918201 & 1640412 & 6.0 & 6.5941 & TRN & \\
\hline CHEMBL3933092 & 1640412 & 6.0 & 6.6308 & TRN & \\
\hline CHEMBL3891008 & 1640412 & 6.0088 & 6.5895 & TRN & \\
\hline CHEMBL3897255 & 1640412 & 8.1549 & 7.004 & TST & \\
\hline CHEMBL3919068 & 1640412 & 6.0 & 7.3295 & TRN & \\
\hline CHEMBL3981724 & 1640412 & 7.699 & 7.9622 & TRN & \\
\hline CHEMBL3979872 & 1640412 & 8.301 & 7.3003 & TST & \\
\hline CHEMBL3892680 & 1640412 & 6.0 & 6.86100 & 0000000001 & TRN \\
\hline CHEMBL3905316 & 1640412 & 7.9586 & 7.2189 & TRN & \\
\hline CHEMBL 3900330 & 1640412 & 7.5376 & 6.9757 & TRN & \\
\hline CHEMBL3934483 & 1640412 & 8.1549 & 8.0146 & TRN & \\
\hline
\end{tabular}




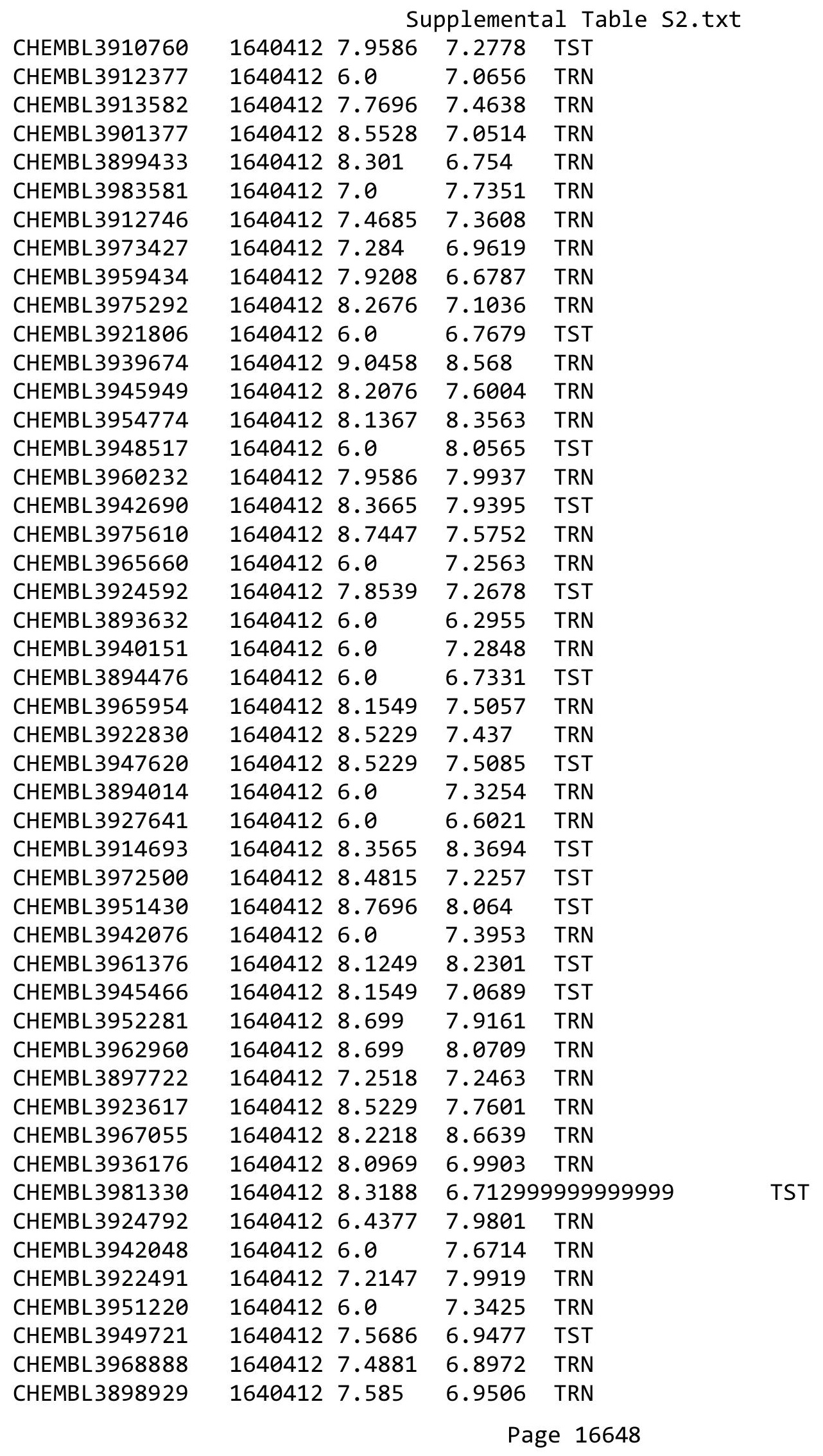


Supplemental Table S2.txt

\begin{tabular}{|c|c|c|c|c|c|c|}
\hline CHEMBL3984974 & 1640412 & 8.4949 & 7.2381 & TRN & & \\
\hline CHEMBL3904403 & 1640412 & 6.0 & 7.2971 & TST & & \\
\hline CHEMBL3927127 & 1640412 & 8.699 & 7.7399 & TRN & & \\
\hline CHEMBL328895 & 32001 & 6.5376 & 6.5407 & TRN & & \\
\hline CHEMBL89797 & 32001 & 6.295 & 6.2761 & TRN & & \\
\hline CHEMBL90282 & 32001 & \multicolumn{3}{|c|}{7.1579999999999995} & 7.1501 & TRN \\
\hline CHEMBL89093 & 32001 & 6.2518 & 3.5937 & TST & & \\
\hline CHEMBL86829 & 32001 & 6.3536 & 6.3566 & TRN & & \\
\hline CHEMBL90160 & 32001 & 6.5031 & 6.5051 & TRN & & \\
\hline CHEMBL315897 & 32001 & 5.2549 & 5.2459 & TRN & & \\
\hline CHEMBL89362 & 32001 & 6.6576 & 6.6823 & TRN & & \\
\hline CHEMBL313459 & 32001 & \multicolumn{3}{|c|}{7.752000000000001} & 7.7425 & TRN \\
\hline CHEMBL330696 & 32001 & 6.7721 & 6.7454 & TRN & & \\
\hline CHEMBL86692 & 32001 & 5.7645 & 5.769 & TRN & & \\
\hline CHEMBL442752 & 32001 & 7.4271 & 7.4368 & TRN & & \\
\hline CHEMBL89391 & 32001 & 3.7696 & 6.8741 & TST & & \\
\hline CHEMBL85130 & 32001 & 4.9626 & 5.1224 & TST & & \\
\hline CHEMBL314071 & 32001 & 5.767 & 5.7528 & TRN & & \\
\hline CHEMBL89343 & 32001 & 5.644 & 6.6955 & TST & & \\
\hline CHEMBL85410 & 32001 & 6.5287 & 6.5295 & TRN & & \\
\hline CHEMBL89472 & 32001 & 7.7447 & 4.8288 & TST & & \\
\hline CHEMBL265096 & 32001 & 8.5702 & 8.5655 & TRN & & \\
\hline CHEMBL405982 & 32001 & 7.4437 & 7.4511 & TRN & & \\
\hline CHEMBL89803 & 32001 & 6.8356 & 6.8409 & TRN & & \\
\hline CHEMBL89494 & 32001 & 5.983 & 6.0007 & TRN & & \\
\hline CHEMBL 88688 & 32001 & 5.5884 & 5.5929 & TRN & & \\
\hline CHEMBL88147 & 32001 & 9.1871 & 2.7823 & TST & & \\
\hline CHEMBL 89575 & 32001 & 4.7167 & 4.7229 & TRN & & \\
\hline CHEMBL89264 & 32001 & 7.2248 & 7.2294 & TRN & & \\
\hline CHEMBL315458 & 32001 & 7.1158 & 7.0784 & TRN & & \\
\hline CHEMBL 276854 & 32001 & 5.0804 & 5.084 & TRN & & \\
\hline CHEMBL89852 & 32001 & 7.5031 & 7.5578 & TRN & & \\
\hline CHEMBL 329342 & 32001 & 8.0665 & 8.0545 & TRN & & \\
\hline CHEMBL89844 & 32001 & 7.1662 & 7.1515 & TRN & & \\
\hline CHEMBL 86588 & 32001 & 7.2807 & 7.2724 & TRN & & \\
\hline CHEMBL86647 & 32001 & 7.0283 & 7.0369 & TRN & & \\
\hline CHEMBL312989 & 32001 & 5.301 & 5.2876 & TRN & & \\
\hline CHEMBL 2063640 & 32001 & 4.9208 & 5.6634 & TST & & \\
\hline CHEMBL315720 & 32001 & 5.983 & 5.9728 & TRN & & \\
\hline CHEMBL86377 & 32001 & 6.9586 & 6.9654 & TRN & & \\
\hline CHEMBL90733 & 32001 & 3.0 & 5.8894 & TST & & \\
\hline CHEMBL 89874 & 32001 & 4.9136 & 4.9261 & TRN & & \\
\hline CHEMBL327554 & 32001 & 7.1209 & 7.1254 & TRN & & \\
\hline CHEMBL86968 & 32001 & 5.8013 & 5.8058 & TRN & & \\
\hline CHEMBL 89358 & 32001 & 5.6126 & 5.4856 & TST & & \\
\hline CHEMBL311542 & 32001 & 5.0675 & 5.0759 & TRN & & \\
\hline CHEMBL419306 & 32001 & 6.7033 & 6.7218 & TRN & & \\
\hline CHEMBL84583 & 32001 & 6.2464 & 6.2414 & TRN & & \\
\hline
\end{tabular}




\begin{tabular}{|c|c|c|c|c|c|}
\hline \multicolumn{6}{|c|}{ Supplemental Table S2.txt } \\
\hline CHEMBL315984 & 32001 & 6.9666 & 6.9571 & TRN & \\
\hline CHEMBL 2112340 & 32001 & 6.0269 & 6.3798 & TST & \\
\hline CHEMBL52735 & 32001 & 7.8861 & 3.8964 & TST & \\
\hline CHEMBL85172 & 32001 & 5.5086 & 5.4946 & TRN & \\
\hline CHEMBL87053 & 32001 & 6.9508 & 7.1686 & TST & \\
\hline CHEMBL315168 & 32001 & 7.2328 & 6.8327 & TST & \\
\hline CHEMBL433379 & 304008 & 8.11 & 8.0949 & TRN & \\
\hline CHEMBL188823 & 304008 & 8.24 & 8.3075 & TRN & \\
\hline CHEMBL 94186 & 304008 & 8.14 & 8.1085 & TRN & \\
\hline CHEMBL93619 & 304008 & 8.15 & 7.9382 & TRN & \\
\hline CHEMBL92736 & 304008 & 8.55 & 8.4937 & TRN & \\
\hline CHEMBL92955 & 304008 & 7.85 & 8.0802 & TRN & \\
\hline CHEMBL93936 & 304008 & 9.1 & 8.8197 & TRN & \\
\hline CHEMBL420625 & 304008 & 7.7 & 7.6729 & TRN & \\
\hline CHEMBL330004 & 304008 & 7.3 & 7.28600 & 00000000005 & TRN \\
\hline CHEMBL92775 & 304008 & 7.0 & 7.1964 & TRN & \\
\hline CHEMBL92663 & 304008 & 8.06 & 8.032 & TRN & \\
\hline CHEMBL93241 & 304008 & 6.05 & 6.8937 & TRN & \\
\hline CHEMBL94059 & 304008 & 5.59 & 5.4539 & TRN & \\
\hline CHEMBL92629 & 304008 & 6.49 & 5.824 & TRN & \\
\hline CHEMBL328102 & 304008 & 7.0 & 6.4454 & TRN & \\
\hline CHEMBL92142 & 304008 & 6.66 & 6.1555 & TRN & \\
\hline CHEMBL92958 & 304008 & 6.92 & 6.4572 & TRN & \\
\hline CHEMBL 329231 & 304008 & 9.24 & 9.3863 & TRN & \\
\hline CHEMBL328468 & 304008 & 9.02 & 9.2305 & TRN & \\
\hline CHEMBL426441 & 304008 & 9.32 & 9.4215 & TRN & \\
\hline CHEMBL 95020 & 304008 & 8.44 & 8.5216 & TRN & \\
\hline CHEMBL185799 & 304008 & 6.6 & 6.5795 & TST & \\
\hline CHEMBL186144 & 304008 & 8.1 & 7.3954 & TRN & \\
\hline CHEMBL 361869 & 304008 & 7.37 & 6.9781 & TRN & \\
\hline CHEMBL189283 & 304008 & 6.42 & 6.5068 & TRN & \\
\hline CHEMBL362711 & 304008 & 6.96 & 6.7995 & TRN & \\
\hline CHEMBL185976 & 304008 & 6.92 & 6.9136 & TRN & \\
\hline CHEMBL 188325 & 304008 & 6.28 & 6.3062 & TRN & \\
\hline CHEMBL187812 & 304008 & 4.71 & 5.5409 & TRN & \\
\hline CHEMBL191729 & 304008 & 5.57 & 5.7691 & TRN & \\
\hline CHEMBL364125 & 304008 & 7.28 & 7.1282 & TRN & \\
\hline CHEMBL610243 & 304008 & 7.49 & 7.535 & TRN & \\
\hline CHEMBL 372491 & 304008 & 7.55 & 7.4976 & TRN & \\
\hline CHEMBL364585 & 304008 & 7.1 & 7.1533 & TRN & \\
\hline CHEMBL188917 & 304008 & 6.41 & 6.6886 & TRN & \\
\hline CHEMBL188338 & 304008 & 6.0 & 6.5591 & TRN & \\
\hline CHEMBL366114 & 304008 & 6.05 & 6.4927 & TRN & \\
\hline CHEMBL 188753 & 304008 & 6.55 & 6.8232 & TRN & \\
\hline CHEMBL189122 & 304008 & 6.66 & 7.654 & TRN & \\
\hline CHEMBL189517 & 304008 & 6.96 & 7.0647 & TRN & \\
\hline CHEMBL365904 & 304008 & 7.4 & 7.221 & TRN & \\
\hline CHEMBL186264 & 304008 & 8.15 & 7.5264 & TRN & \\
\hline
\end{tabular}




\begin{tabular}{|c|c|c|c|c|c|c|}
\hline & & \multicolumn{5}{|c|}{ Supplemental Table S2.txt } \\
\hline CHEMBL187818 & 304008 & 8.59 & 8.0126 & TRN & & \\
\hline CHEMBL188011 & 304008 & 6.0 & 6.7747 & TRN & & \\
\hline CHEMBL362752 & 304008 & 8.22 & 7.8701 & TRN & & \\
\hline CHEMBL610242 & 304008 & 8.35 & 7.9788 & TRN & & \\
\hline CHEMBL86031 & 304008 & 7.0 & 7.0056 & TST & & \\
\hline CHEMBL313231 & 304008 & 7.38 & 7.1177 & TST & & \\
\hline CHEMBL313582 & 304008 & 6.86 & 6.9917 & TST & & \\
\hline CHEMBL87823 & 304008 & 7.3 & 6.9393 & TST & & \\
\hline CHEMBL432376 & 304008 & 6.92 & 6.9987 & TST & & \\
\hline CHEMBL87014 & 304008 & 7.66 & 7.3176 & TST & & \\
\hline CHEMBL418955 & 304008 & 8.08 & 8.0475 & TRN & & \\
\hline CHEMBL93123 & 304008 & 8.03 & 8.2561 & TRN & & \\
\hline CHEMBL92463 & 304008 & 7.59 & 7.8096 & TRN & & \\
\hline CHEMBL328715 & 304008 & 6.09 & 5.6877 & TRN & & \\
\hline CHEMBL362350 & 304008 & 6.47 & 6.3188 & TST & & \\
\hline CHEMBL187603 & 304008 & 6.72 & 6.8091 & TST & & \\
\hline CHEMBL360832 & 304008 & 7.05 & 6.8939 & TST & & \\
\hline CHEMBL186090 & 304008 & 6.12 & 6.4934 & TST & & \\
\hline CHEMBL187591 & 304008 & 4.52 & 5.3726 & TST & & \\
\hline CHEMBL188714 & 304008 & 7.27 & 7.2515 & TST & & \\
\hline CHEMBL187330 & 304008 & 5.59 & 6.5143 & TST & & \\
\hline CHEMBL189774 & 304008 & 7.52 & 7.3016 & TST & & \\
\hline CHEMBL186042 & 304008 & 8.34 & 7.6156 & TST & & \\
\hline CHEMBL363455 & 304008 & 6.62 & 6.7454 & TST & & \\
\hline CHEMBL191739 & 303291 & 3.0 & 2.5543 & TRN & & \\
\hline CHEMBL90039 & 303291 & 3.0 & 3.4898 & TRN & & \\
\hline CHEMBL362996 & 303291 & 8.0969 & 7.0938 & TRN & & \\
\hline CHEMBL365517 & 303291 & 3.0 & 4.6639 & TRN & & \\
\hline CHEMBL192595 & 303291 & 3.0 & 2.5 & TRN & & \\
\hline CHEMBL191688 & 303291 & 3.0 & 2.2945 & TST & & \\
\hline CHEMBL193229 & 303291 & 7.1337 & 7.0071 & TRN & & \\
\hline CHEMBL190613 & 303291 & 3.0 & 2.3498 & TST & & \\
\hline CHEMBL191513 & 303291 & 5.4672 & 5.6801 & TRN & & \\
\hline CHEMBL192648 & 303291 & 3.0 & 3.2192 & TRN & & \\
\hline CHEMBL370059 & 303291 & 6.2807 & 6.335 & TRN & & \\
\hline CHEMBL371858 & 303291 & 6.9031 & 7.1205 & TRN & & \\
\hline CHEMBL365392 & 303291 & 5.7825 & 5.3401 & TRN & & \\
\hline CHEMBL192474 & 303291 & $6.7570 e$ & 20000000 & $\partial 1$ & 6.9975 & TRN \\
\hline CHEMBL191796 & 303291 & 4.7423 & 5.0304 & TRN & & \\
\hline CHEMBL193180 & 303291 & 6.4295 & 6.441 & TRN & & \\
\hline CHEMBL365161 & 303291 & 7.0526 & 3.9258 & TST & & \\
\hline CHEMBL370299 & 303291 & 3.0 & 3.5183 & TRN & & \\
\hline CHEMBL193228 & 303291 & 3.0 & 3.406 & TRN & & \\
\hline CHEMBL191676 & 303291 & 3.0 & 3.0094 & TRN & & \\
\hline CHEMBL363919 & 303291 & 3.0 & 2.7044 & TST & & \\
\hline CHEMBL192809 & 303291 & 3.0 & 3.2176 & TRN & & \\
\hline CHEMBL192180 & 303291 & 7.3242 & 7.1744 & TRN & & \\
\hline CHEMBL365982 & 303291 & 3.0 & 3.0168 & TRN & & \\
\hline
\end{tabular}




\begin{tabular}{|c|c|c|c|c|c|}
\hline & & \multicolumn{4}{|c|}{ Supplemental Table S2.txt } \\
\hline CHEMBL193140 & 303291 & 7.0039 & 7.4736 & TRN & \\
\hline CHEMBL192252 & 303291 & 6.7959 & 6.6983 & TRN & \\
\hline CHEMBL 8320 & 303291 & 3.0 & 2.6945 & TST & \\
\hline CHEMBL192625 & 303291 & 6.2741 & 6.1598 & TRN & \\
\hline CHEMBL425192 & 303291 & 3.0 & 4.0052 & TRN & \\
\hline CHEMBL195713 & 303291 & 5.7721 & 5.8323 & TRN & \\
\hline CHEMBL192627 & 303291 & 7.0762 & 5.0848 & TST & \\
\hline CHEMBL365129 & 303291 & 3.0 & 3.1826 & TRN & \\
\hline CHEMBL371523 & 303291 & 4.585 & 4.4968 & TRN & \\
\hline CHEMBL371371 & 303291 & 3.0 & 2.5565 & TST & \\
\hline CHEMBL192657 & 303291 & 3.0 & 2.0329 & TRN & \\
\hline CHEMBL372856 & 303291 & 3.0 & 2.8303 & TRN & \\
\hline CHEMBL192258 & 303291 & 5.2782 & 5.7275 & TRN & \\
\hline CHEMBL192039 & 303291 & 3.0 & 2.072 & TRN & \\
\hline CHEMBL364729 & 303291 & 5.2644 & 4.7609 & TST & \\
\hline CHEMBL363186 & 303291 & 3.0 & 2.4951 & TST & \\
\hline CHEMBL192712 & 303291 & 3.0 & 2.7363 & TST & \\
\hline CHEMBL190496 & 303291 & 3.0 & 3.2263 & TRN & \\
\hline CHEMBL 363855 & 303291 & 3.0 & 3.6432 & TRN & \\
\hline CHEMBL191822 & 303291 & 5.4815 & 5.8696 & TRN & \\
\hline CHEMBL 284028 & 303291 & 3.0 & 2.6456 & TST & \\
\hline CHEMBL 364588 & 303291 & 4.7721 & 4.2143 & TRN & \\
\hline CHEMBL189886 & 303291 & 7.3458 & 6.7769 & TRN & \\
\hline CHEMBL189727 & 303291 & 3.0 & 2.4985 & TST & \\
\hline CHEMBL192410 & 303291 & 6.6364 & 6.409 & TRN & \\
\hline CHEMBL435109 & 303291 & 5.8125 & 6.1188 & TRN & \\
\hline CHEMBL192241 & 303291 & 7.1101 & 6.67299 & 9999999999 & TRN \\
\hline CHEMBL 365809 & 303291 & 3.0 & 3.2196 & TRN & \\
\hline CHEMBL189988 & 303291 & 3.0 & 2.9774 & TRN & \\
\hline CHEMBL191800 & 303291 & 3.0 & 2.9171 & TST & \\
\hline CHEMBL192139 & 303291 & 6.7399 & 6.0974 & TRN & \\
\hline CHEMBL364734 & 303291 & 4.8153 & 4.1214 & TRN & \\
\hline CHEMBL192589 & 303291 & 6.6676 & 6.26399 & 9999999999 & TRN \\
\hline CHEMBL191847 & 303291 & 6.5302 & 6.6002 & TRN & \\
\hline CHEMBL191625 & 303291 & 3.0 & 3.1731 & TST & \\
\hline CHEMBL366205 & 303291 & 3.0 & 2.7598 & TST & \\
\hline CHEMBL 2113942 & 844788 & 7.9208 & 7.9715 & TRN & \\
\hline CHEMBL 2113947 & 844788 & 7.2676 & 7.2469 & TRN & \\
\hline CHEMBL 2113927 & 844788 & 6.7545 & 7.4682 & TRN & \\
\hline CHEMBL35228 & 844788 & 8.4949 & 4.19 & TST & \\
\hline CHEMBL 2113946 & 844788 & 6.5129 & 6.7538 & TRN & \\
\hline CHEMBL 2113979 & 844788 & 3.3979 & 3.3318 & TRN & \\
\hline CHEMBL 2113954 & 844788 & 3.3979 & 3.4623 & TRN & \\
\hline CHEMBL 2113970 & 844788 & 3.3979 & 3.3973 & TRN & \\
\hline CHEMBL 2113939 & 844788 & 9.0 & 8.6982 & TRN & \\
\hline CHEMBL 2113961 & 844788 & 6.3585 & 2.6698 & TST & \\
\hline CHEMBL 2113966 & 844788 & 3.3979 & 3.8759 & TST & \\
\hline CHEMBL 2113984 & 844788 & 4.9469 & 5.2102 & TRN & \\
\hline
\end{tabular}


Supplemental Table S2.txt

\begin{tabular}{|c|c|c|c|c|}
\hline HEM & 44788 & 6.4776 & 3.207 & m \\
\hline & & 3.3979 & 3.4965 & \\
\hline HFMRI $211=$ & & & & \\
\hline IEMBL2 & & & 1 & \\
\hline AEMBL599702 & 44788 & & 5929 & \\
\hline HEMBL2113996 & 38 & 79 & .0683 & \\
\hline HEMBL2113948 & & & 4625 & \\
\hline AEMBL2113967 & & & & \\
\hline HEMBL2113972 & & 979 & 4.31 & \\
\hline HEMBL2113960 & & & 3218 & \\
\hline HEMBL2113965 & & & 8586 & \\
\hline 3985 & & & 681 & \\
\hline AEMBL 2113986 & & & & \\
\hline HEMBL2113998 & & & .1922 & \\
\hline HEMBL2113955 & & & & \\
\hline AEMBL2113989 & & & 1598 & \\
\hline AEMBL2113982 & & & 687 & \\
\hline AEMBL 2113973 & & & 629 & \\
\hline HEMBL2113938 & & & & \\
\hline HEMBL 2113944 & & & & I KIV \\
\hline AEMBL 2 & & & 17 & RIN \\
\hline 3269 & & & 272 & \\
\hline 13997 & & & 3564 & \\
\hline AFMPI 21120 & & & & \\
\hline AEMBL 2113981 & & & 611 & RN \\
\hline HEMBL 211398 & & & 807 & RN \\
\hline HFM & & & 45 & ונס \\
\hline 0 & & & 34 & \\
\hline AEMBL 211396 & & & & |S| \\
\hline AEMBL 2113953 & & & 509 & TRN \\
\hline HEMBL 2113922 & & & 471 & RN \\
\hline 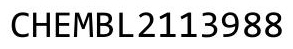 & & & & $\mathrm{RN}$ \\
\hline 13012 & & & & $\mathrm{RN}$ \\
\hline HEMBL2113975 & & & 278 & 「RN \\
\hline AEMBL 2113932 & & & 952 & RN \\
\hline AEMBL21139 & & & 24 & TRN \\
\hline 12 & & & & ГRN \\
\hline HEMBL 211399 & & & 3.1854 & TRN \\
\hline HEMBL 211392 & & & & R \\
\hline$T$ & & & & IST \\
\hline HEMBL2113945 & & & 592 & TRN \\
\hline HEMBL2113956 & & & 3.4653 & 「RN \\
\hline HEMBL 207990 & & & 2.722 & TST \\
\hline HEMBL2113958 & & & 39 & TR \\
\hline 50 & & & & \\
\hline HEMBL 211393 & & & .6269 & \\
\hline HEMBL549220 & & 6.3936 & 5.1414 & \\
\hline HEMBL 211395 & 844788 & 3.3979 & 3.9488 & \\
\hline
\end{tabular}

Page 16653 
Supplemental Table S2.txt

\begin{tabular}{|c|c|c|c|c|}
\hline CHEMBL 2113926 & 844788 & 7.3279 & 7.1191 & TRN \\
\hline CHEMBL 2113952 & 844788 & 3.3979 & 4.07 & TRN \\
\hline CHEMBL 2113992 & 844788 & 3.3979 & 3.4865 & TRN \\
\hline CHEMBL 2113963 & 844788 & 3.3979 & 2.9287 & TST \\
\hline CHEMBL 2113964 & 844788 & 5.0269 & 3.1638 & TST \\
\hline CHEMBL 2113941 & 844788 & 5.5058 & 5.4217 & TRN \\
\hline CHEMBL3746912 & 1545548 & 6.0888 & 5.9858 & TRN \\
\hline CHEMBL3746701 & 1545548 & 4.301 & 4.2838 & TRN \\
\hline CHEMBL3746787 & 1545548 & 6.6055 & \multicolumn{2}{|c|}{6.332000000000001} \\
\hline CHEMBL3747075 & 1545548 & 6.8268 & 7.0342 & TST \\
\hline CHEMBL3747552 & 1545548 & 5.0502 & 5.149 & TRN \\
\hline CHEMBL3745800 & 1545548 & 4.301 & 4.3081 & TRN \\
\hline CHEMBL 3696878 & 1545548 & 6.6326 & 6.5782 & TRN \\
\hline CHEMBL3696879 & 1545548 & 6.644 & 6.3444 & TRN \\
\hline CHEMBL3747498 & 1545548 & 7.0088 & 7.1415 & TRN \\
\hline CHEMBL3747097 & 1545548 & 5.4134 & 5.2471 & TRN \\
\hline CHEMBL 3746037 & 1545548 & 6.3716 & 6.1377 & TRN \\
\hline CHEMBL 3745860 & 1545548 & 4.301 & 3.7612 & TRN \\
\hline CHEMBL3746000 & 1545548 & 6.8416 & 6.43 & TRN \\
\hline CHEMBL3746353 & 1545548 & 7.1192 & 7.0639 & TRN \\
\hline CHEMBL3747091 & 1545548 & 4.301 & 4.8855 & TRN \\
\hline CHEMBL 3747049 & 1545548 & 7.6383 & 7.6542 & TRN \\
\hline CHEMBL3745805 & 1545548 & 6.466 & 6.381 & TRN \\
\hline CHEMBL3696863 & 1545548 & 6.8386 & 6.8831 & TRN \\
\hline CHEMBL3747600 & 1545548 & 5.4076 & 5.2737 & TRN \\
\hline CHEMBL3747272 & 1545548 & 4.301 & 4.4128 & TRN \\
\hline CHEMBL3746827 & 1545548 & 4.301 & 4.7832 & TRN \\
\hline CHEMBL3696895 & 1545548 & 5.5039 & 5.3119 & TRN \\
\hline CHEMBL3745859 & 1545548 & 4.301 & 4.4716 & TRN \\
\hline CHEMBL3745888 & 1545548 & 7.1487 & 7.1589 & TRN \\
\hline CHEMBL3747639 & 1545548 & 6.6676 & 6.0272 & TRN \\
\hline CHEMBL3747448 & 1545548 & 8.2218 & 8.1935 & TRN \\
\hline CHEMBL3696916 & 1545548 & 6.3516 & 7.0607 & TRN \\
\hline CHEMBL3696925 & 1545548 & 7.1675 & 7.0733 & TRN \\
\hline CHEMBL3747511 & 1545548 & 5.5229 & 5.6138 & TST \\
\hline CHEMBL3696867 & 1545548 & 6.0424 & 5.6561 & TRN \\
\hline CHEMBL3747194 & 1545548 & 5.683 & 5.8566 & TRN \\
\hline CHEMBL3746879 & 1545548 & 4.301 & 5.0473 & TRN \\
\hline CHEMBL 3747081 & 1545548 & 4.301 & 5.3699 & TRN \\
\hline CHEMBL3696861 & 1545548 & 6.8182 & 6.7017 & TRN \\
\hline CHEMBL3747647 & 1545548 & 7.3979 & 6.6647 & TRN \\
\hline CHEMBL3696896 & 1545548 & 6.7167 & 5.6239 & TRN \\
\hline CHEMBL3696924 & 1545548 & 7.3665 & 7.1311 & TRN \\
\hline CHEMBL 3747138 & 1545548 & 6.1864 & 6.51399 & 9999999999 \\
\hline CHEMBL3747449 & 1545548 & 4.301 & 3.5975 & TRN \\
\hline CHEMBL3746469 & 1545548 & 4.301 & 4.2019 & TRN \\
\hline CHEMBL3696917 & 1545548 & 6.8153 & 6.89 & TRN \\
\hline CHEMBL3696862 & 1545548 & 4.301 & 5.5235 & TRN \\
\hline
\end{tabular}


Supplemental Table S2.txt

\begin{tabular}{|c|c|c|c|c|c|}
\hline CHEMBL3696887 & 1545548 & 5.9714 & 6.3416 & TRN & \\
\hline CHEMBL3746907 & 1545548 & 4.301 & 6.1887 & TST & \\
\hline CHEMBL3696926 & 1545548 & 6.0996 & 6.7764 & TRN & \\
\hline CHEMBL3746179 & 1545548 & 7.8239 & \multicolumn{2}{|c|}{7.5120000000000005} & TRN \\
\hline CHEMBL3747371 & 1545548 & 6.1884 & \multicolumn{2}{|c|}{6.3420000000000005} & TRN \\
\hline CHEMBL 3747425 & 1545548 & 4.301 & 4.3002 & TST & \\
\hline CHEMBL3696920 & 1545548 & 6.4318 & 6.6073 & TST & \\
\hline CHEMBL3745761 & 1545548 & 4.301 & 5.7575 & TST & \\
\hline CHEMBL3747513 & 1545548 & 7.9586 & 7.8369 & TRN & \\
\hline CHEMBL3746833 & 1545548 & 6.4353 & 6.1766 & TST & \\
\hline CHEMBL3696923 & 1545548 & 4.301 & 6.5223 & TST & \\
\hline CHEMBL 3747464 & 1545548 & 4.301 & 5.9007 & TST & \\
\hline CHEMBL3746650 & 1545548 & 7.0223 & 6.3519 & TRN & \\
\hline CHEMBL 3747140 & 1545548 & 6.1993 & 6.4824 & TRN & \\
\hline CHEMBL3746850 & 1545548 & 4.301 & 5.3021 & TST & \\
\hline CHEMBL3696873 & 1545548 & 6.7447 & 5.9086 & TST & \\
\hline CHEMBL3746009 & 1545548 & 4.301 & 6.6181 & TST & \\
\hline CHEMBL3746410 & 1545548 & 4.301 & 4.2883 & TST & \\
\hline CHEMBL3696880 & 1545548 & 4.301 & 6.221 & TST & \\
\hline CHEMBL3696915 & 1545548 & 7.3279 & 7.3881 & TRN & \\
\hline CHEMBL3746629 & 1545548 & 5.3159 & 5.317 & TRN & \\
\hline CHEMBL3746988 & 1545548 & 6.5171 & 6.5604 & TST & \\
\hline CHEMBL87338 & 92156 & 6.8861 & 6.6251 & TRN & \\
\hline CHEMBL87976 & 92156 & 5.4089 & 5.6275 & TRN & \\
\hline CHEMBL87457 & 92156 & 6.3872 & 6.0207 & TRN & \\
\hline CHEMBL85822 & 92156 & 7.4559 & 6.9031 & TRN & \\
\hline CHEMBL419856 & 92156 & 6.3468 & 6.1055 & TRN & \\
\hline CHEMBL315851 & 92156 & 5.1135 & 5.0036 & TRN & \\
\hline CHEMBL 315335 & 92156 & 5.0 & 5.7519 & TST & \\
\hline CHEMBL312978 & 92156 & 6.8539 & 6.9845 & TRN & \\
\hline CHEMBL316427 & 92156 & 6.0969 & 6.2702 & TRN & \\
\hline CHEMBL83026 & 92156 & 6.3979 & 6.5369 & TRN & \\
\hline CHEMBL315069 & 92156 & 6.699 & 6.4626 & TRN & \\
\hline CHEMBL315336 & 92156 & 6.4559 & 6.7642 & TRN & \\
\hline CHEMBL87274 & 92156 & 6.6778 & 6.1133 & TRN & \\
\hline CHEMBL314362 & 92156 & 5.0 & 5.559 & TST & \\
\hline CHEMBL85970 & 92156 & 5.3098 & 5.7312 & TRN & \\
\hline CHEMBL84791 & 92156 & 7.301 & 7.4969 & TRN & \\
\hline CHEMBL 88100 & 92156 & 5.3565 & 4.9122 & TRN & \\
\hline CHEMBL315145 & 92156 & 6.2291 & 6.2743 & TRN & \\
\hline CHEMBL315362 & 92156 & 4.5229 & 5.9252 & TST & \\
\hline CHEMBL314158 & 92156 & 6.3468 & 5.8707 & TRN & \\
\hline CHEMBL87359 & 92156 & 5.7959 & 5.7198 & TRN & \\
\hline CHEMBL 315130 & 92156 & 4.5229 & 4.8647 & TRN & \\
\hline CHEMBL87269 & 92156 & 5.8239 & 6.1209 & TRN & \\
\hline CHEMBL86615 & 92156 & 7.3468 & 6.5036 & TRN & \\
\hline CHEMBL314316 & 92156 & 6.0809 & 5.7776 & TST & \\
\hline CHEMBL316150 & 92156 & 5.4318 & 5.9563 & TRN & \\
\hline
\end{tabular}




\begin{tabular}{|c|c|c|c|c|c|}
\hline \multirow[b]{2}{*}{ CHEMBL316224 } & \multicolumn{5}{|c|}{ Supplemental Table S2.txt } \\
\hline & 92156 & 4.5229 & 4.9865 & TRN & \\
\hline CHEMBL 85810 & 92156 & 5.0 & 5.7411 & TST & \\
\hline CHEMBL423679 & 92156 & 6.3872 & 6.8722 & TRN & \\
\hline CHEMBL86678 & 92156 & 5.1938 & 5.0362 & TST & \\
\hline CHEMBL87789 & 92156 & 6.0 & 6.2265 & TRN & \\
\hline CHEMBL84869 & 92156 & 5.5528 & 6.0898 & TST & \\
\hline CHEMBL87572 & 92156 & 5.699 & 5.8262 & TRN & \\
\hline CHEMBL87795 & 92156 & 5.9586 & 5.46 & TRN & \\
\hline CHEMBL315941 & 92156 & 6.284 & 6.5301 & TRN & \\
\hline CHEMBL83024 & 92156 & 6.1871 & 6.3928 & TRN & \\
\hline CHEMBL418938 & 92156 & 6.1192 & 6.395 & TST & \\
\hline CHEMBL432946 & 92156 & 6.0809 & 6.1818 & TRN & \\
\hline CHEMBL315804 & 92156 & 7.0088 & 5.8838 & TRN & \\
\hline CHEMBL82972 & 92156 & 6.699 & 6.1318 & TRN & \\
\hline CHEMBL87433 & 92156 & 6.5229 & 6.301 & TRN & \\
\hline CHEMBL86834 & 92156 & 4.5229 & 4.6329 & TRN & \\
\hline CHEMBL87877 & 92156 & 6.3665 & 6.3234 & TRN & \\
\hline CHEMBL82800 & 92156 & 4.8861 & 5.54200 & 0000000001 & TRN \\
\hline CHEMBL87744 & 92156 & 5.6576 & 6.0333 & TRN & \\
\hline CHEMBL85553 & 92156 & 6.9208 & 7.1544 & TRN & \\
\hline CHEMBL85285 & 92156 & 5.9208 & 6.0756 & TRN & \\
\hline CHEMBL85293 & 92156 & 6.4202 & 6.1131 & TRN & \\
\hline CHEMBL86332 & 92156 & 6.2007 & 6.6621 & TST & \\
\hline CHEMBL87467 & 92156 & 5.4202 & 6.1744 & TRN & \\
\hline CHEMBL 87876 & 92156 & 7.0269 & 7.4084 & TST & \\
\hline CHEMBL313824 & 92156 & 5.7696 & 6.5321 & TST & \\
\hline CHEMBL87043 & 92156 & 5.2218 & 6.2913 & TST & \\
\hline CHEMBL315919 & 92156 & 5.7212 & 5.9699 & TST & \\
\hline CHEMBL85908 & 92156 & 6.9208 & 6.7861 & TST & \\
\hline CHEMBL9470 & 954578 & 4.6033 & 5.8151 & TST & \\
\hline CHEMBL472940 & 954578 & 3.0168 & 3.7017 & TRN & \\
\hline CHEMBL1357247 & 954578 & 3.5186 & 3.2235 & TRN & \\
\hline CHEMBL 258844 & 954578 & 4.6523 & 4.4245 & TRN & \\
\hline CHEMBL2137530 & 954578 & 5.221 & 4.8226 & TRN & \\
\hline CHEMBL151176 & 954578 & 6.1503 & 4.7331 & TRN & \\
\hline CHEMBL577784 & 954578 & 4.4085 & 5.249 & TRN & \\
\hline CHEMBL573107 & 954578 & 5.4697 & 5.1584 & TRN & \\
\hline CHEMBL135561 & 954578 & 3.9185 & 4.5208 & TRN & \\
\hline CHEMBL191334 & 954578 & 4.3819 & 4.2639 & TRN & \\
\hline CHEMBL188678 & 954578 & 4.3488 & 4.4142 & TRN & \\
\hline CHEMBL259181 & 954578 & 4.0596 & 4.5831 & TRN & \\
\hline CHEMBL209148 & 954578 & 5.3332 & 4.6914 & TRN & \\
\hline CHEMBL2005886 & 954578 & 5.5667 & 5.5819 & TRN & \\
\hline CHEMBL2134202 & 954578 & 4.3601 & 4.3782 & TRN & \\
\hline CHEMBL 202721 & 954578 & 3.7572 & 4.9899 & TRN & \\
\hline CHEMBL210618 & 954578 & 4.2305 & 3.4879 & TRN & \\
\hline CHEMBL65 & 954578 & 7.4512 & 7.9308 & TRN & \\
\hline CHEMBL221137 & 954578 & 3.8941 & 4.7607 & TST & \\
\hline
\end{tabular}




\begin{tabular}{|c|c|c|c|c|c|c|c|}
\hline \multicolumn{8}{|c|}{ Supplemental Table S2.txt } \\
\hline CHEMBL1788116 & 954578 & 5.1054 & 4.487 & TRN & & & \\
\hline CHEMBL1909414 & 954578 & 3.5073 & 3.9958 & TRN & & & \\
\hline CHEMBL 217354 & 954578 & 6.5895 & 6.0937 & TRN & & & \\
\hline CHEMBL1190711 & 954578 & 5.7354 & 5.107 & TRN & & & \\
\hline CHEMBL2363137 & 954578 & 5.36799 & 99999999 & & 4.8611 & TRN & \\
\hline CHEMBL1643959 & 954578 & 4.7706 & 3.8971 & TRN & & & \\
\hline CHEMBL102714 & 954578 & 3.23199 & 99999999 & 998 & 3.55800 & 00000000003 & TRN \\
\hline CHEMBL 213100 & 954578 & 4.688 & 5.1093 & TRN & & & \\
\hline CHEMBL240954 & 954578 & 3.5017 & 3.742 & TST & & & \\
\hline CHEMBL412142 & 954578 & 3.9787 & 4.0793 & TRN & & & \\
\hline CHEMBL392695 & 954578 & 5.8925 & 5.3064 & TRN & & & \\
\hline CHEMBL192566 & 954578 & 7.9055 & 8.1338 & TST & & & \\
\hline CHEMBL1186585 & 954578 & 4.5392 & 4.4142 & TRN & & & \\
\hline CHEMBL3349342 & 954578 & 5.1035 & 5.1874 & TRN & & & \\
\hline CHEMBL1516890 & 954578 & 4.4608 & 4.0884 & TRN & & & \\
\hline CHEMBL222102 & 954578 & 3.6727 & 3.80899 & 999999999s & 97 & TRN & \\
\hline CHEMBL189584 & 954578 & 4.0215 & 4.635 & TRN & & & \\
\hline CHEMBL483847 & 954578 & 4.0762 & 4.3038 & TRN & & & \\
\hline CHEMBL 393929 & 954578 & 3.3783 & 3.9552 & TRN & & & \\
\hline CHEMBL3199475 & 954578 & 3.858 & 4.4387 & TRN & & & \\
\hline CHEMBL92309 & 954578 & 2.1344 & 3.0697 & TST & & & \\
\hline CHEMBL515416 & 954578 & 4.7782 & 4.6398 & TRN & & & \\
\hline CHEMBL449158 & 954578 & 6.9778 & 6.8246 & TST & & & \\
\hline CHEMBL 379975 & 954578 & 5.2117 & 5.0013 & TRN & & & \\
\hline CHEMBL 379300 & 954578 & 6.5372 & 6.5374 & TRN & & & \\
\hline CHEMBL1256459 & 954578 & 6.6141 & 7.2651 & TRN & & & \\
\hline CHEMBL 255342 & 954578 & 3.6366 & 3.6611 & TRN & & & \\
\hline CHEMBL512504 & 954578 & 4.146 & 4.7953 & TRN & & & \\
\hline CHEMBL1404918 & 954578 & 2.7245 & 2.9654 & TRN & & & \\
\hline CHEMBL509032 & 954578 & 5.6918 & 5.7646 & TRN & & & \\
\hline CHEMBL514499 & 954578 & 8.1231 & 7.1749 & TRN & & & \\
\hline CHEMBL 300389 & 954578 & 6.9831 & 6.8747 & TST & & & \\
\hline CHEMBL1242367 & 954578 & 4.0738 & 4.3451 & TST & & & \\
\hline CHEMBL483849 & 954578 & 2.638 & 2.3387 & TST & & & \\
\hline CHEMBL1970879 & 954578 & 4.9143 & 4.8783 & TST & & & \\
\hline CHEMBL558642 & 954578 & 3.9148 & 4.2666 & TST & & & \\
\hline CHEMBL1230020 & 954578 & 3.4799 & 4.0718 & TST & & & \\
\hline CHEMBL 399530 & 954578 & 4.4291 & 4.605 & TST & & & \\
\hline CHEMBL3392440 & 954578 & 3.7118 & 3.9763 & TST & & & \\
\hline CHEMBL585951 & 954578 & 6.1957 & 6.1436 & TST & & & \\
\hline CHEMBL3093999 & 1440356 & 6.39 & 6.4379 & TRN & & & \\
\hline CHEMBL3093998 & 1440356 & 6.24 & 5.6 & TRN & & & \\
\hline CHEMBL3093997 & 1440356 & 6.9 & 6.7522 & TRN & & & \\
\hline CHEMBL3093996 & 1440356 & 6.94 & 6.7301 & TRN & & & \\
\hline CHEMBL3093995 & 1440356 & 6.58 & 6.3718 & TRN & & & \\
\hline CHEMBL 3093994 & 1440356 & 6.12 & 5.501 & TRN & & & \\
\hline CHEMBL3093993 & 1440356 & 8.24 & 8.2062 & TRN & & & \\
\hline CHEMBL3093992 & 1440356 & 8.11 & 8.1727 & TRN & & & \\
\hline
\end{tabular}




\begin{tabular}{|c|c|c|c|c|}
\hline & & & pplement & al $\mathrm{Ta}$ \\
\hline CHEMBL3093991 & 1440356 & 7.44 & 7.7481 & TRN \\
\hline CHEMBL3093990 & 1440356 & 7.0 & 6.8973 & TRN \\
\hline CHEMBL3093989 & 1440356 & 5.64 & 5.7806 & TRN \\
\hline CHEMBL 3094134 & 1440356 & 5.77 & 5.767 & TRN \\
\hline CHEMBL574860 & 1440356 & 5.95 & 7.2937 & TRN \\
\hline CHEMBL3094133 & 1440356 & 6.35 & 6.2076 & TRN \\
\hline CHEMBL 3094132 & 1440356 & 6.69 & 6.5897 & TRN \\
\hline CHEMBL 3094131 & 1440356 & 7.96 & 7.8221 & TRN \\
\hline CHEMBL 239507 & 1440356 & 7.89 & 7.7612 & TRN \\
\hline CHEMBL572534 & 1440356 & 7.82 & 8.2245 & TRN \\
\hline CHEMBL577616 & 1440356 & 7.4 & 6.7861 & TRN \\
\hline CHEMBL575931 & 1440356 & 7.62 & 7.3081 & TRN \\
\hline CHEMBL575738 & 1440356 & 7.52 & 7.6397 & TRN \\
\hline CHEMBL575093 & 1440356 & 7.8 & 7.6252 & TRN \\
\hline CHEMBL3094039 & 1440356 & 7.11 & 7.3282 & TST \\
\hline CHEMBL 3094038 & 1440356 & 7.85 & 8.1084 & TRN \\
\hline CHEMBL 3094037 & 1440356 & 8.28 & 8.032 & TRN \\
\hline CHEMBL3094036 & 1440356 & 6.66 & 7.1654 & TRN \\
\hline CHEMBL 3094035 & 1440356 & 6.99 & 7.7093 & TST \\
\hline CHEMBL 3094034 & 1440356 & 6.63 & 7.0261 & TRN \\
\hline CHEMBL3094033 & 1440356 & 6.38 & 6.1053 & TRN \\
\hline CHEMBL3094032 & 1440356 & 4.0 & 4.4413 & TRN \\
\hline CHEMBL 3094031 & 1440356 & 7.4 & 6.7409 & TRN \\
\hline CHEMBL239508 & 1440356 & 7.28 & 7.2335 & TRN \\
\hline CHEMBL 3094030 & 1440356 & 7.32 & 7.7038 & TRN \\
\hline CHEMBL 3094029 & 1440356 & 6.31 & 6.785 & TRN \\
\hline CHEMBL 3094028 & 1440356 & 6.32 & 6.6664 & TRN \\
\hline CHEMBL 3094027 & 1440356 & 5.68 & 6.2986 & TST \\
\hline CHEMBL141326 & 1440356 & 5.04 & 5.4185 & TST \\
\hline CHEMBL 3094026 & 1440356 & 6.68 & 7.6632 & TRN \\
\hline CHEMBL 3094025 & 1440356 & 7.36 & 7.5916 & TRN \\
\hline CHEMBL 3094024 & 1440356 & 7.68 & 7.4918 & TRN \\
\hline CHEMBL 3094023 & 1440356 & 6.06 & 6.9055 & TST \\
\hline CHEMBL 3094022 & 1440356 & 7.54 & 7.1093 & TRN \\
\hline CHEMBL575934 & 1440356 & 8.13 & 7.5276 & TRN \\
\hline CHEMBL3094021 & 1440356 & 7.77 & 7.5344 & TST \\
\hline CHEMBL3359951 & 1440356 & 6.4 & 6.0944 & TRN \\
\hline CHEMBL3359950 & 1440356 & 7.31 & 6.7305 & TST \\
\hline CHEMBL3359949 & 1440356 & 7.54 & 7.8049 & TRN \\
\hline CHEMBL3359948 & 1440356 & 7.82 & 7.3985 & TRN \\
\hline CHEMBL3359947 & 1440356 & 5.92 & 5.9758 & TRN \\
\hline CHEMBL3359946 & 1440356 & 5.42 & 5.3876 & TRN \\
\hline CHEMBL3359945 & 1440356 & 7.49 & 7.69 & TRN \\
\hline CHEMBL 3359944 & 1440356 & 7.89 & 7.6762 & TRN \\
\hline CHEMBL3359943 & 1440356 & 8.13 & 7.9825 & TRN \\
\hline CHEMBL3093988 & 1440356 & 4.89 & 5.6827 & TST \\
\hline CHEMBL 3094020 & 1440356 & 4.41 & 5.6098 & TST \\
\hline CHEMBL 3094019 & 1440356 & 6.3 & 6.756 & TRN \\
\hline
\end{tabular}





\begin{tabular}{|c|c|c|c|c|c|}
\hline \multicolumn{6}{|c|}{ Supplemental Table S2.txt } \\
\hline CHEMBL3221199 & 1330005 & 4.0 & 4.0062 & TRN & \\
\hline CHEMBL 3221207 & 1330005 & 4.0 & 4.0037 & TRN & \\
\hline CHEMBL 3221204 & 1330005 & 4.0 & 3.6833 & TST & \\
\hline CHEMBL 3221201 & 1330005 & 5.7825 & 5.7866 & TRN & \\
\hline CHEMBL 3220955 & 1330005 & 4.0 & 4.0026 & TRN & \\
\hline CHEMBL 3221194 & 1330005 & 4.0 & 3.9992 & TRN & \\
\hline CHEMBL 3220959 & 1330005 & 4.0 & 3.9962 & TRN & \\
\hline CHEMBL 3221197 & 1330005 & 5.7423 & 5.7844 & TRN & \\
\hline CHEMBL 3220945 & 1330005 & 4.0 & 3.5338 & TST & \\
\hline CHEMBL3221195 & 1330005 & 5.2652 & 5.2632 & TRN & \\
\hline CHEMBL 3220944 & 1330005 & 4.0 & 3.6456 & TST & \\
\hline CHEMBL 3220957 & 1330005 & 4.0 & 3.9939 & TRN & \\
\hline CHEMBL3221185 & 1330005 & 4.7799 & 4.7838 & TRN & \\
\hline CHEMBL 3221188 & 1330005 & 5.3947 & 5.4145 & TRN & \\
\hline CHEMBL3221203 & 1330005 & 4.0 & 3.9998 & TRN & \\
\hline CHEMBL3221180 & 1330005 & 4.0 & 4.0014 & TRN & \\
\hline CHEMBL 3221181 & 1330005 & 4.0 & 4.0042 & TRN & \\
\hline CHEMBL3221190 & 1330005 & 6.0223 & 6.0111 & TRN & \\
\hline CHEMBL 3220951 & 1330005 & 4.0 & 3.4426 & TST & \\
\hline CHEMBL 3221210 & 1330005 & 4.0 & 3.9973 & TRN & \\
\hline CHEMBL3221182 & 1330005 & 4.0 & 4.0007 & TRN & \\
\hline CHEMBL 3221189 & 1330005 & 4.0 & 6.0971 & TST & \\
\hline CHEMBL3220958 & 1330005 & 4.0 & 4.2525 & TST & \\
\hline CHEMBL 3668458 & 1528775 & 7.1739 & 6.9935 & TST & \\
\hline CHEMBL 3668490 & 1528775 & 7.2757 & 7.0746 & TST & \\
\hline CHEMBL 3663765 & 1528775 & 7.1135 & 7.0877 & TRN & \\
\hline CHEMBL3668401 & 1528775 & 7.8539 & 7.4286 & TRN & \\
\hline CHEMBL 3668517 & 1528775 & 7.3279 & 6.8739 & TST & \\
\hline CHEMBL 3668426 & 1528775 & 7.2924 & 7.4928 & TRN & \\
\hline CHEMBL 3668542 & 1528775 & 7.0605 & 6.78100 & 0000000001 & TRN \\
\hline CHEMBL 3673540 & 1528775 & 8.699 & 8.3384 & TRN & \\
\hline CHEMBL 3673490 & 1528775 & 7.0809 & 7.3522 & TRN & \\
\hline CHEMBL3663807 & 1528775 & 7.4318 & 7.229 & TRN & \\
\hline CHEMBL 3668427 & 1528775 & 7.8239 & 7.465 & TRN & \\
\hline CHEMBL 3673516 & 1528775 & 5.585 & 7.5587 & TST & \\
\hline CHEMBL 3663800 & 1528775 & 7.6021 & 7.5369 & TRN & \\
\hline CHEMBL 3668356 & 1528775 & 6.7447 & 6.6886 & TRN & \\
\hline CHEMBL3668547 & 1528775 & 6.9318 & 6.61600 & 00000000005 & TRN \\
\hline CHEMBL 3924904 & 1528775 & 7.1549 & 7.06 & TRN & \\
\hline CHEMBL 3668387 & 1528775 & 7.4437 & 7.1981 & TRN & \\
\hline CHEMBL 3673521 & 1528775 & 7.8239 & 7.6424 & TST & \\
\hline CHEMBL 3663803 & 1528775 & 7.6576 & 7.3611 & TRN & \\
\hline CHEMBL3668509 & 1528775 & 7.1549 & 6.5453 & TST & \\
\hline CHEMBL 3668361 & 1528775 & 8.0 & 7.5864 & TST & \\
\hline CHEMBL 3668515 & 1528775 & 7.6383 & 7.5143 & TRN & \\
\hline CHEMBL 3668439 & 1528775 & 6.7959 & 6.6659 & TRN & \\
\hline CHEMBL 3663794 & 1528775 & 7.7212 & 7.5679 & TRN & \\
\hline CHEMBL3668476 & 1528775 & 7.9586 & 7.5272 & TRN & \\
\hline
\end{tabular}


Supplemental Table S2.txt

\begin{tabular}{|c|c|c|c|c|c|}
\hline CHEMBL3673552 & 1528775 & 7.3565 & 7.4644 & TST & \\
\hline CHEMBL3668475 & 1528775 & 7.6383 & 7.5502 & TRN & \\
\hline CHEMBL3668499 & 1528775 & 7.3468 & 7.1003 & TRN & \\
\hline CHEMBL 3668436 & 1528775 & 6.3468 & 7.0846 & TRN & \\
\hline CHEMBL3668385 & 1528775 & 7.8539 & 7.593 & TRN & \\
\hline CHEMBL 3663756 & 1528775 & 6.3098 & 6.4321 & TRN & \\
\hline CHEMBL 3668502 & 1528775 & 7.4202 & 7.3035 & TRN & \\
\hline CHEMBL 3673491 & 1528775 & 6.9393 & 6.6347 & TRN & \\
\hline CHEMBL 3668412 & 1528775 & 7.699 & 7.5703 & TRN & \\
\hline CHEMBL3668521 & 1528775 & 7.0458 & 7.1293 & TRN & \\
\hline CHEMBL 3668469 & 1528775 & 7.5376 & 7.2885 & TRN & \\
\hline CHEMBL 3668537 & 1528775 & 6.9136 & 7.4535 & TST & \\
\hline CHEMBL3663791 & 1528775 & 7.3098 & 7.8724 & TRN & \\
\hline CHEMBL 3668390 & 1528775 & 7.2147 & 7.4188 & TRN & \\
\hline CHEMBL3663764 & 1528775 & 7.9208 & 7.3 & TRN & \\
\hline CHEMBL 3663758 & 1528775 & 6.1135 & 6.5459 & TRN & \\
\hline CHEMBL3668556 & 1528775 & 7.0315 & 6.78700 & 0000000001 & TRN \\
\hline CHEMBL3663779 & 1528775 & 7.4815 & 7.526 & TRN & \\
\hline CHEMBL 3668506 & 1528775 & 7.2757 & 7.1461 & TRN & \\
\hline CHEMBL3668391 & 1528775 & 7.3665 & 7.5756 & TRN & \\
\hline CHEMBL 3673543 & 1528775 & 6.9586 & 8.1181 & TST & \\
\hline CHEMBL3668350 & 1528775 & 7.7696 & 7.7526 & TST & \\
\hline CHEMBL3668486 & 1528775 & 7.5229 & 7.4066 & TRN & \\
\hline CHEMBL3663792 & 1528775 & 7.8539 & 7.8184 & TRN & \\
\hline CHEMBL 3668386 & 1528775 & 7.6383 & 7.6552 & TRN & \\
\hline CHEMBL 3668400 & 1528775 & 7.6778 & 7.1989 & TRN & \\
\hline CHEMBL 3668460 & 1528775 & 7.6383 & 7.749 & TST & \\
\hline CHEMBL3668540 & 1528775 & 7.0458 & 7.3317 & TRN & \\
\hline CHEMBL 3663752 & 1528775 & 6.4949 & 6.4664 & TRN & \\
\hline CHEMBL 3673539 & 1528775 & 8.0969 & 7.5774 & TST & \\
\hline CHEMBL 3673514 & 1528775 & 7.5528 & 7.8136 & TRN & \\
\hline CHEMBL3928559 & 1528775 & 7.6576 & 7.193 & TST & \\
\hline CHEMBL 3673508 & 1528775 & 7.5086 & 7.8621 & TRN & \\
\hline CHEMBL 3668392 & 1528775 & 7.4318 & 7.4282 & TRN & \\
\hline CHEMBL3668419 & 1528775 & 7.5086 & 7.5864 & TRN & \\
\hline CHEMBL3668433 & 1528775 & 7.5528 & 7.3839 & TRN & \\
\hline CHEMBL3668352 & 1528775 & 7.2007 & 7.3275 & TST & \\
\hline CHEMBL3918885 & 1528775 & 6.9431 & 6.9571 & TRN & \\
\hline CHEMBL 3668551 & 1528775 & 6.6968 & 6.6606 & TRN & \\
\hline CHEMBL3668343 & 1528775 & 6.6021 & 7.0575 & TRN & \\
\hline CHEMBL3663766 & 1528775 & 7.1675 & 6.9278 & TRN & \\
\hline CHEMBL3663774 & 1528775 & 7.8239 & 7.9267 & TRN & \\
\hline CHEMBL3663798 & 1528775 & 7.6198 & 7.2661 & TRN & \\
\hline CHEMBL3668414 & 1528775 & 7.1612 & \multicolumn{2}{|c|}{7.0089999999999995} & TRN \\
\hline CHEMBL3663782 & 1528775 & 6.2596 & 7.0136 & TRN & \\
\hline CHEMBL3668459 & 1528775 & 7.3372 & 7.4571 & TRN & \\
\hline CHEMBL3668472 & 1528775 & 7.699 & 7.8023 & TRN & \\
\hline CHEMBL3663762 & 1528775 & 7.5086 & 7.045 & TRN & \\
\hline
\end{tabular}


Supplemental Table S2.txt

\begin{tabular}{|c|c|c|c|c|}
\hline AEMBL 3668514 & 528775 & & & \\
\hline & 528775 & 7.9586 & 7.7932 & \\
\hline & 8775 & & & \\
\hline EMBL: & 528775 & 0655 & & \\
\hline AEMBL & 528775 & 8.0 & 638 & \\
\hline AEMBL3668346 & 528775 & 6.4437 & 1684 & \\
\hline IEMB & 775 & & 873 & \\
\hline EMB & 775 & & & \\
\hline IEMBL3949793 & 528775 & 7.3979 & & \\
\hline AEMBL3668493 & 528775 & 7.4089 & .4204 & \\
\hline AEMBL 3668496 & 528775 & 7.5528 & & \\
\hline IEMBL & 775 & 279 & 865 & \\
\hline EMBL & 775 & & & \\
\hline 8562 & 775 & .0809 & 963 & \\
\hline IEMBL & 775 & 2218 & 2541 & \\
\hline IEMBL3673534 & 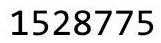 & 3872 & 87 & \\
\hline IEMBL & 3 & 8996 & 21 & \\
\hline IEMBL & 75 & & & \\
\hline IEMBL & 775 & .5686 & 4219 & \\
\hline IEMBL & 75 & & & \\
\hline IEMBL & 75 & 79 & 79 & \\
\hline 25 & 3 & 6 & $\partial 1$ & \\
\hline EMB & 75 & & & \\
\hline 511 & 775 & 6.2076 & & \\
\hline IEMBL 3663787 & & & & 1 \\
\hline IEMBL & 5 & 6 & $\partial 68$ & ST \\
\hline EMB & 5 & & 58 & \\
\hline EMB & 75 & 86 & 96 & TIV \\
\hline IEMBL & 75 & & & \\
\hline IEMBL 3668447 & 5 & & & RN \\
\hline IEMBL: & 75 & & 61 & RI \\
\hline$M$ & 5 & & & 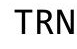 \\
\hline & 5 & 12 & 96 & RN \\
\hline IEMBL3673532 & 75 & & 57 & ST \\
\hline IEMBL3668417 & 528 & 7.5376 & & 5 \\
\hline IEMBL & & & 27 & $S$ \\
\hline 2 & & & & 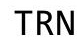 \\
\hline & & & & ST \\
\hline IEMBL3668418 & 75 & 7.9208 & 387 & $\mathrm{RI}$ \\
\hline EMBL & 15 & 7.7447 & 502 & $\mathrm{RI}$ \\
\hline HEMBL & 13 & 7.6778 & 819 & \\
\hline 68370 & & & & 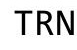 \\
\hline HEMBL & & 6.2366 & & $\mathrm{RI}$ \\
\hline IEMBL3663784 & 28775 & 5.2924 & 854 & S \\
\hline$M B L$ & $328 / 15$ & 6.76 & & \\
\hline CHEMBL3668452 & 528775 & 7.7212 & 7.6243 & \\
\hline CHEMBL366844 & 528775 & 1079 & 7.1713 & \\
\hline CHEMBL3668437 & 1528775 & 6.5686 & 7.3717 & $S$ \\
\hline
\end{tabular}

Page 16662 
Supplemental Table S2.txt

\begin{tabular}{|c|c|c|c|}
\hline HEMBL3668404 & 1528775 & 6.8861 & 6.5846 \\
\hline CHEMBL 3673517 & 1528775 & 7.9208 & 7.8183 \\
\hline HEMBL3974193 & 528775 & 7.4559 & \\
\hline HEMBL3668504 & 528775 & 6.8861 & \\
\hline HEMBL3673526 & 528775 & 7.7212 & 7482 \\
\hline HEMBL3663754 & .528775 & 7.0315 & 6.9675 \\
\hline HEMBL3668379 & 528775 & 6.7447 & 82 \\
\hline AEMBL3668428 & L528775 & 7.3098 & \\
\hline HEMBL3668443 & 1528775 & 7.1192 & \\
\hline HEMBL3673548 & 1528775 & 7.3565 & 7.5311 \\
\hline HEMBL3668541 & 1528775 & 7.1805 & 59 \\
\hline HEMBL3668555 & 1528775 & 7.1079 & 357 \\
\hline HEMBL3668487 & 1528775 & 7.2518 & \\
\hline HEMBL3668357 & 1528775 & 5.8861 & 6.3058 \\
\hline HEMBL3668380 & 1528775 & 7.4437 & 411 \\
\hline HEMBL3668353 & 1528775 & 6.0757 & 6. \\
\hline HEMBL3668558 & 1528775 & 7.1549 & 6. \\
\hline HEMBL3673497 & 1528775 & 6.7696 & \\
\hline HEMBL3668463 & 1528775 & 6.0915 & 835 \\
\hline HEMBL3668359 & 1528775 & 7.0 & \\
\hline HEMBL3668434 & 1528775 & 6.9586 & 53 \\
\hline AEMBL3673515 & 1528775 & 7.8239 & 7. \\
\hline HEMBL3673512 & 1528775 & 8.0 & 15 \\
\hline AEMBL3668364 & 1528775 & 7.5376 & \\
\hline HEMBL3668415 & 775 & 6.4949 & \\
\hline CHEMBL3668389 & 1528775 & 7 . & 22 \\
\hline 68498 & 1528775 & 6.9957 & 96 \\
\hline HEMBL3668500 & 1528775 & 7.6383 & 86 \\
\hline AEMBL3668348 & 1528775 & 7.6198 & 219 \\
\hline HEMBL3673506 & 1528775 & 7.4437 & 7.5 \\
\hline CHEMBL3639672 & 1528775 & 7.6778 & \\
\hline HEMBL 3 & 1528775 & 7.8239 & 24 \\
\hline CHEMBL 3668438 & 1528775 & 7.1367 & 746 \\
\hline CHEMBL 3668383 & 1528775 & 7.3565 & 7.6 \\
\hline HEMBL3668369 & 1528775 & 7.301 & 6.9449 \\
\hline HEMBL3668384 & 1528775 & 7.4202 & 732 \\
\hline CHEMBL 3663743 & 1528775 & 6.0 & 01 \\
\hline CHEMBL3668351 & 1528775 & 7.6021 & 7.3617 \\
\hline CHEMBL 3668431 & 1528775 & 7.3872 & 7.6775 \\
\hline CHEMBL 3668372 & 1528775 & 5.8861 & 6.5018 \\
\hline CHEMBL3673498 & 1528775 & 6.3098 & 7.4961 \\
\hline CHEMBL3668405 & 1528775 & 5.8239 & 6.1837 \\
\hline CHEMBL3668441 & 1528775 & 6.5376 & 7.3155 \\
\hline CHEMBL 3668451 & 1528775 & 7.6383 & 7.2751 \\
\hline CHEMBL 3668489 & 1528775 & 7.2076 & 7.0489 \\
\hline CHEMBL 3668411 & 1528775 & 6.9208 & 7.1343 \\
\hline CHEMBL3663753 & 1528775 & 7.4815 & 7.1964 \\
\hline CHEMBL3668410 & 1528775 & 7.4815 & 7.5558 \\
\hline
\end{tabular}

Page 16663 
Supplemental Table S2.txt

\begin{tabular}{|c|c|c|c|c|}
\hline CHEMBL3668397 & 1528775 & 7.3372 & 7.2297 & TRN \\
\hline CHEMBL3668381 & 1528775 & 7.1308 & 6.7304 & TRN \\
\hline CHEMBL3668377 & 1528775 & 7.3565 & 7.0675 & TST \\
\hline CHEMBL3663761 & 1528775 & 7.7212 & 7.4972 & TRN \\
\hline CHEMBL3673538 & 1528775 & 8.0458 & 7.8447 & TST \\
\hline CHEMBL3668413 & 1528775 & 7.6198 & 7.6172 & TRN \\
\hline CHEMBL3673545 & 1528775 & 8.2218 & 8.0647 & TRN \\
\hline CHEMBL3663770 & 1528775 & 7.6383 & 7.6343 & TRN \\
\hline CHEMBL3673536 & 1528775 & 7.0915 & 7.3003 & TRN \\
\hline CHEMBL3673495 & 1528775 & 6.6198 & 7.4583 & TST \\
\hline CHEMBL3668409 & 1528775 & 7.4089 & 6.7366 & TRN \\
\hline CHEMBL3668444 & 1528775 & 7.1249 & 6.8091 & TRN \\
\hline CHEMBL 3668407 & 1528775 & 7.3565 & 7.1859 & TRN \\
\hline CHEMBL3663790 & 1528775 & 6.2441 & 6.5401 & TST \\
\hline CHEMBL3663789 & 1528775 & 7.0605 & 6.7398 & TRN \\
\hline CHEMBL3663755 & 1528775 & 6.8861 & 7.0584 & TRN \\
\hline CHEMBL3668450 & 1528775 & 7.284 & 7.4885 & TST \\
\hline CHEMBL 3668533 & 1528775 & 6.8268 & 7.041 & TRN \\
\hline CHEMBL3668491 & 1528775 & 7.6778 & 7.6271 & TRN \\
\hline CHEMBL3663768 & 1528775 & 7.5686 & 7.1103 & TRN \\
\hline CHEMBL3668478 & 1528775 & 7.3665 & 7.0003 & TRN \\
\hline CHEMBL 3668473 & 1528775 & 8.0969 & 7.5728 & TRN \\
\hline CHEMBL3663750 & 1528775 & 7.3098 & 7.0392 & TRN \\
\hline CHEMBL3673549 & 1528775 & 7.7447 & 7.2881 & TST \\
\hline CHEMBL 3668520 & 1528775 & 7.0223 & 6.8008 & TST \\
\hline CHEMBL3668495 & 1528775 & 7.4815 & 7.5886 & TRN \\
\hline CHEMBL 3668525 & 1528775 & 6.9914 & 7.1856 & TRN \\
\hline CHEMBL3668416 & 1528775 & 6.4318 & 6.3361 & TRN \\
\hline CHEMBL3668513 & 1528775 & 7.4089 & 7.4856 & TRN \\
\hline CHEMBL3668453 & 1528775 & 7.6576 & 7.471 & TRN \\
\hline CHEMBL3943237 & 1528775 & 6.9208 & 6.8689 & TRN \\
\hline CHEMBL3668479 & 1528775 & 7.0969 & 6.9258 & TRN \\
\hline CHEMBL3673529 & 1528775 & 7.3468 & 7.5006 & TRN \\
\hline CHEMBL3668462 & 1528775 & 7.6021 & 7.7755 & TST \\
\hline CHEMBL3668374 & 1528775 & 7.4437 & 7.5202 & TRN \\
\hline CHEMBL3673528 & 1528775 & 7.6198 & 7.277 & TRN \\
\hline CHEMBL3673499 & 1528775 & 6.585 & 7.0737 & TST \\
\hline CHEMBL 3668445 & 1528775 & 7.6021 & 7.0863 & TRN \\
\hline CHEMBL3668430 & 1528775 & 7.0655 & 7.6656 & TRN \\
\hline CHEMBL 3668344 & 1528775 & 7.1871 & 7.1911 & TRN \\
\hline CHEMBL 3673494 & 1528775 & 8.0458 & 7.66299 & 9999999999 \\
\hline CHEMBL3673507 & 1528775 & 8.0458 & 8.2926 & TRN \\
\hline CHEMBL 3668560 & 1528775 & 6.9245 & 7.0583 & TRN \\
\hline CHEMBL3668559 & 1528775 & 7.3768 & 7.0729 & TRN \\
\hline CHEMBL3663786 & 1528775 & 7.6778 & 6.9352 & TST \\
\hline CHEMBL3668403 & 1528775 & 7.1938 & 7.4487 & TST \\
\hline CHEMBL3668376 & 1528775 & 6.3665 & 7.0697 & TRN \\
\hline CHEMBL3663772 & 1528775 & 5.585 & 6.5621 & TRN \\
\hline
\end{tabular}


Supplemental Table S2.txt

\begin{tabular}{|c|c|c|c|c|}
\hline HEMB I & 528775 & 7.6778 & 6966 & \\
\hline & 528775 & 7.1487 & .0297 & \\
\hline & 28775 & & 9886 & \\
\hline AEMBL & & 33 & & \\
\hline AEMBL & 528775 & 05 & 7563 & \\
\hline HEMBL3663777 & 528775 & 7.7696 & 1962 & \\
\hline & 775 & & & \\
\hline |FMRI & & & & \\
\hline 73527 & 775 & 2218 & .4362 & \\
\hline HEMBL3663751 & 528775 & & . 9723 & \\
\hline AEMBL3668548 & 5287 & & .0539 & \\
\hline AEMBL3 & 3 & & 561 & \\
\hline HEMBL; & & & & \\
\hline HEMBL3 & 75 & & & \\
\hline AEMBL3 & 3 & & & \\
\hline AEMBL3668 & 22 & 24 & 2208 & \\
\hline AEMBL & 2 & & 734 & \\
\hline HEMBL; & & & 102 & \\
\hline HEMBL3 & 75 & 21 & 5452 & \\
\hline AEMBL3 & 75 & & & \\
\hline AEMIBL & 15 & & 87 & - \\
\hline AEMBL & & & 37 & 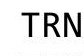 \\
\hline AEMBL & & & 38 & \\
\hline 28 & & & & \\
\hline AEMBL3 & & & & N \\
\hline HEMBL & 52 & 8 & 901 & 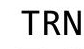 \\
\hline HEMBL & & & 47 & RN \\
\hline HFMBL & 75 & & 71 & \\
\hline HEMBL3 & & & 862 & RIV \\
\hline HEMBL 3668 & & & & I RIV \\
\hline HEMBL3 & 5 & & 264 & RN \\
\hline HEMBL & 5 & & 25 & RN \\
\hline HEMBL & 75 & & & RN \\
\hline HEMBL3668395 & & & 36 & IRN \\
\hline HEMBL3668456 & 5287 & & 7.0293 & TRN \\
\hline HEMBL3 & 52 & & 7.0428 & TRN \\
\hline HEMRI & & & 45 & ST \\
\hline HEMBL & & & 381 & RN \\
\hline HEMBL3668497 & 528775 & 7.72 & 7.291 & TRN \\
\hline AEMBL3 & -0 & & 224 & TRN \\
\hline HEMBL3 & J & 35 & 7.1708 & \\
\hline CHEMBL3 & 1528775 & 6. & & ו \\
\hline HEMBL3 & 775 & & 7.8122 & RN \\
\hline HEMBL3668516 & 528775 & 7.5528 & 7.4507 & TRN \\
\hline MPI. & & & 6.4738 & $\mathrm{~N}$ \\
\hline HEMBL3 & & & 7.2176 & \\
\hline CHEMBL3668455 & & 7.5229 & 7.3386 & \\
\hline HEMBL3673523 & 1528775 & 7.9586 & 7.9403 & \\
\hline
\end{tabular}

Page 16665 
Supplemental Table S2.txt

\begin{tabular}{|c|c|c|c|c|c|}
\hline CHEMBL3663767 & 1528775 & 7.1135 & 6.567 & TRN & \\
\hline CHEMBL3663759 & 1528775 & 7.9586 & 7.5848 & TRN & \\
\hline CHEMBL3668511 & 1528775 & 6.9281 & 7.1396 & TRN & \\
\hline CHEMBL3668402 & 1528775 & 7.301 & 7.2309 & TRN & \\
\hline CHEMBL3668446 & 1528775 & 7.0 & 7.081 & TRN & \\
\hline CHEMBL 3668388 & 1528775 & 7.5376 & 7.4255 & TRN & \\
\hline CHEMBL3668398 & 1528775 & 7.1249 & 7.4221 & TST & \\
\hline CHEMBL3668378 & 1528775 & 7.8861 & 7.6173 & TRN & \\
\hline CHEMBL3668466 & 1528775 & 6.041 & 6.7626 & TRN & \\
\hline CHEMBL3668467 & 1528775 & 6.1367 & 7.4554 & TST & \\
\hline CHEMBL 3668470 & 1528775 & 7.2596 & 6.6657 & TST & \\
\hline CHEMBL3673496 & 1528775 & 6.6021 & 7.2614 & TST & \\
\hline CHEMBL3668362 & 1528775 & 7.5229 & 7.1872 & TRN & \\
\hline CHEMBL3673551 & 1528775 & 7.0605 & 7.2686 & TST & \\
\hline CHEMBL3663788 & 1528775 & 7.0915 & 6.8628 & TRN & \\
\hline CHEMBL 3668527 & 1528775 & 6.0 & 7.2277 & TST & \\
\hline CHEMBL3668468 & 1528775 & 6.7959 & 6.6174 & TRN & \\
\hline CHEMBL3919070 & 1528775 & 7.2218 & 7.2308 & TST & \\
\hline CHEMBL 3668518 & 1528775 & 7.2518 & 7.3454 & TRN & \\
\hline CHEMBL3673531 & 1528775 & 7.8539 & 8.193 & TST & \\
\hline CHEMBL3668529 & 1528775 & 6.9957 & 7.227 & TRN & \\
\hline CHEMBL3673522 & 1528775 & 7.5686 & 7.5386 & TRN & \\
\hline CHEMBL 3673535 & 1528775 & 7.3665 & 7.7112 & TRN & \\
\hline CHEMBL3668492 & 1528775 & 7.0757 & 7.0364 & TRN & \\
\hline CHEMBL3668454 & 1528775 & 7.6576 & 7.7071 & TRN & \\
\hline CHEMBL 3663804 & 1528775 & 7.6021 & 7.4454 & TRN & \\
\hline CHEMBL 3663780 & 1528775 & 7.7212 & 8.1894 & TRN & \\
\hline CHEMBL3668461 & 1528775 & 8.0969 & 7.9607 & TST & \\
\hline CHEMBL3668501 & 1528775 & 7.3279 & 7.0837 & TRN & \\
\hline CHEMBL3673550 & 1528775 & 7.0757 & 7.3012 & TST & \\
\hline CHEMBL3663769 & 1528775 & 7.7696 & 7.5926 & TRN & \\
\hline CHEMBL3668366 & 1528775 & 7.4685 & 7.3012 & TRN & \\
\hline CHEMBL 3663747 & 1528775 & 5.1612 & 5.4264 & TRN & \\
\hline CHEMBL3668420 & 1528775 & 7.6778 & 7.9326 & TRN & \\
\hline CHEMBL3668532 & 1528775 & 6.8697 & 7.24799 & & TRN \\
\hline CHEMBL 3668440 & 1528775 & 7.4685 & 7.7355 & TRN & \\
\hline CHEMBL3668464 & 1528775 & 7.4815 & 7.2023 & TRN & \\
\hline CHEMBL 3668345 & 1528775 & 7.2007 & 7.0617 & TST & \\
\hline CHEMBL3668508 & 1528775 & 7.0969 & 6.887006 & 00000000005 & TST \\
\hline CHEMBL3668422 & 1528775 & 6.4685 & 6.6822 & TRN & \\
\hline CHEMBL3668429 & 1528775 & 7.041 & 7.3203 & TRN & \\
\hline CHEMBL3668373 & 1528775 & 7.4815 & 7.1423 & TRN & \\
\hline CHEMBL3668544 & 1528775 & 6.9066 & 6.7858 & TST & \\
\hline CHEMBL3673502 & 1528775 & 7.5086 & 7.1663 & TRN & \\
\hline CHEMBL3668393 & 1528775 & 7.6576 & 7.3625 & TST & \\
\hline CHEMBL 3673554 & 1528775 & 6.2441 & 7.3283 & TRN & \\
\hline CHEMBL3668394 & 1528775 & 7.4685 & 7.2184 & TST & \\
\hline \multirow[t]{2}{*}{ CHEMBL3668368 } & 1528775 & 6.8239 & 6.96399 & 99999999995 & TRN \\
\hline & & \multicolumn{4}{|c|}{ Page 16666} \\
\hline
\end{tabular}


Supplemental Table S2.txt

\begin{tabular}{|c|c|c|c|c|}
\hline CHEMBL3902691 & 1528775 & 6.8827 & 6.8559 & TST \\
\hline CHEMBL3668425 & 1528775 & 6.8239 & 6.7088 & TRN \\
\hline CHEMBL3673519 & 1528775 & 7.6778 & 7.5479 & TRN \\
\hline CHEMBL 3668526 & 1528775 & 6.0 & 7.2669 & TST \\
\hline CHEMBL3673524 & 1528775 & 7.8539 & \multicolumn{2}{|c|}{7.537999999999999} \\
\hline CHEMBL 3663773 & 1528775 & 7.6778 & 7.5026 & TRN \\
\hline CHEMBL 3673493 & 1528775 & 7.8239 & 8.198 & TRN \\
\hline CHEMBL 3668424 & 1528775 & 7.3279 & 7.6838 & TRN \\
\hline CHEMBL 3673541 & 1528775 & 8.699 & 7.4984 & TST \\
\hline CHEMBL3668355 & 1528775 & 6.1938 & 6.3476 & TRN \\
\hline CHEMBL 3639626 & 1528775 & 6.5229 & 6.8889 & TRN \\
\hline CHEMBL 3663771 & 1528775 & 6.9208 & 6.9427 & TRN \\
\hline CHEMBL3668552 & 1528775 & 6.983 & 6.7755 & TRN \\
\hline CHEMBL 3668482 & 1528775 & 7.6778 & 7.9391 & TRN \\
\hline CHEMBL3668406 & 1528775 & 6.9208 & 6.9189 & TST \\
\hline CHEMBL 3668435 & 1528775 & 7.5229 & 7.3747 & TST \\
\hline CHEMBL3673500 & 1528775 & 7.8239 & 7.3119 & TST \\
\hline CHEMBL3668519 & 1528775 & 7.1135 & 7.3449 & TRN \\
\hline CHEMBL 3673530 & 1528775 & 8.0458 & 8.0346 & TST \\
\hline CHEMBL3668442 & 1528775 & 7.0458 & 7.5647 & TRN \\
\hline CHEMBL 3673547 & 1528775 & 7.9586 & 7.1186 & TST \\
\hline CHEMBL 3673537 & 1528775 & 7.1805 & 7.2983 & TST \\
\hline CHEMBL3673501 & 1528775 & 8.301 & 7.6438 & TST \\
\hline CHEMBL 3668354 & 1528775 & 7.4089 & 6.9991 & TST \\
\hline CHEMBL 3673492 & 1528775 & 6.8601 & 6.8212 & TRN \\
\hline CHEMBL 3668536 & 1528775 & 6.983 & 7.3021 & TST \\
\hline CHEMBL 3668524 & 1528775 & 7.0706 & \multicolumn{2}{|c|}{7.196000000000001} \\
\hline CHEMBL3673518 & 1528775 & 7.8539 & 7.9439 & TST \\
\hline CHEMBL 3668448 & 1528775 & 7.2596 & 6.8884 & TST \\
\hline CHEMBL 3663808 & 1528775 & 6.2924 & 7.1044 & TRN \\
\hline CHEMBL 3663760 & 1528775 & 7.7212 & 7.6559 & TRN \\
\hline CHEMBL 3986015 & 1528775 & 7.6383 & 7.4421 & TST \\
\hline CHEMBL 3668457 & 1528775 & 8.3979 & 7.8971 & TRN \\
\hline CHEMBL 3668399 & 1528775 & 7.6383 & 7.1452 & TST \\
\hline CHEMBL 3668347 & 1528775 & 6.9208 & 7.0172 & TST \\
\hline CHEMBL3668423 & 1528775 & 7.0177 & 7.1022 & TST \\
\hline CHEMBL 3673503 & 1528775 & 8.301 & 8.0923 & TST \\
\hline CHEMBL 3673520 & 1528775 & 7.8861 & 7.7193 & TST \\
\hline CHEMBL 3673513 & 1528775 & 7.5229 & 7.2308 & TST \\
\hline CHEMBL3663776 & 1528775 & 7.6778 & 7.9367 & TST \\
\hline CHEMBL 3663744 & 1528775 & 7.6576 & 7.2389 & TRN \\
\hline CHEMBL3668488 & 1528775 & 7.1938 & 7.0564 & TRN \\
\hline CHEMBL3668538 & 1528775 & 7.0915 & 7.6301 & TRN \\
\hline CHEMBL3663806 & 1528775 & 7.3768 & \multicolumn{2}{|c|}{7.3020000000000005} \\
\hline CHEMBL3668396 & 1528775 & 7.4089 & 7.7824 & TRN \\
\hline CHEMBL376417 & 428054 & 8.0969 & 8.2298 & TRN \\
\hline CHEMBL220555 & 428054 & 8.5229 & 8.3507 & TRN \\
\hline CHEMBL220687 & 428054 & 7.9208 & 7.7658 & TST \\
\hline
\end{tabular}




\begin{tabular}{|c|c|c|c|c|}
\hline & & & oplement & al Ta \\
\hline CHEMBL219932 & 428054 & 7.8239 & 7.8608 & TRN \\
\hline CHEMBL173992 & 428054 & 7.0969 & 7.2681 & TRN \\
\hline CHEMBL220571 & 428054 & 8.0 & 7.6891 & TRN \\
\hline CHEMBL220770 & 428054 & 9.3979 & 8.4833 & TRN \\
\hline CHEMBL220612 & 428054 & 6.8861 & 7.3384 & TRN \\
\hline CHEMBL220326 & 428054 & 7.1871 & 7.3294 & TRN \\
\hline CHEMBL219954 & 428054 & 7.6021 & 8.2135 & TRN \\
\hline CHEMBL223694 & 428054 & 6.3979 & 6.3845 & TRN \\
\hline CHEMBL220312 & 428054 & 8.5229 & 8.2566 & TRN \\
\hline CHEMBL220731 & 428054 & 6.4559 & 7.1595 & TST \\
\hline CHEMBL220944 & 428054 & 5.8239 & 6.4757 & TRN \\
\hline CHEMBL374895 & 428054 & 8.699 & 8.0644 & TRN \\
\hline CHEMBL220892 & 428054 & 7.301 & 8.2847 & TRN \\
\hline CHEMBL219615 & 428054 & 4.6021 & 8.4349 & TST \\
\hline CHEMBL219871 & 428054 & 8.1549 & 8.4101 & TRN \\
\hline CHEMBL220429 & 428054 & 8.0 & 8.2476 & TRN \\
\hline CHEMBL220376 & 428054 & 7.3979 & 7.5561 & TRN \\
\hline CHEMBL424762 & 428054 & 4.3468 & 8.1671 & TST \\
\hline CHEMBL220379 & 428054 & 8.8861 & 8.9277 & TRN \\
\hline CHEMBL276233 & 428054 & 6.5229 & 6.1417 & TRN \\
\hline CHEMBL220449 & 428054 & 8.301 & 8.2505 & TST \\
\hline CHEMBL220783 & 428054 & 8.4815 & 8.2425 & TRN \\
\hline CHEMBL220572 & 428054 & 5.3768 & 8.6832 & TST \\
\hline CHEMBL373606 & 428054 & 9.0969 & 8.3227 & TRN \\
\hline CHEMBL374235 & 428054 & 8.4949 & 8.6031 & TRN \\
\hline CHEMBL220556 & 428054 & 8.4559 & 8.6564 & TRN \\
\hline CHEMBL441556 & 428054 & 8.301 & 7.6251 & TRN \\
\hline CHEMBL177922 & 428054 & 8.6383 & 8.1702 & TRN \\
\hline CHEMBL220447 & 428054 & 5.6778 & 8.4081 & TST \\
\hline CHEMBL 373644 & 428054 & 7.9586 & 7.9821 & TRN \\
\hline CHEMBL177577 & 428054 & 8.3279 & 8.2134 & TRN \\
\hline CHEMBL385097 & 428054 & 8.0 & 7.6482 & TRN \\
\hline CHEMBL374708 & 428054 & 8.4559 & 8.8149 & TRN \\
\hline CHEMBL220730 & 428054 & 7.2007 & 7.5256 & TRN \\
\hline CHEMBL368284 & 428054 & 8.2757 & 7.8552 & TRN \\
\hline CHEMBL376536 & 428054 & 5.4559 & 7.6372 & TRN \\
\hline CHEMBL220991 & 428054 & 5.6021 & 7.8457 & TST \\
\hline CHEMBL220729 & 428054 & 7.5229 & 8.0543 & TRN \\
\hline CHEMBL220629 & 428054 & 9.0969 & 8.5449 & TRN \\
\hline CHEMBL219955 & 428054 & 7.0458 & 7.0135 & TRN \\
\hline CHEMBL219942 & 428054 & 7.699 & 7.9272 & TRN \\
\hline CHEMBL219675 & 428054 & 8.301 & 8.3943 & TRN \\
\hline CHEMBL375573 & 428054 & 6.8861 & 6.6434 & TRN \\
\hline CHEMBL220727 & 428054 & 8.2218 & 8.0614 & TRN \\
\hline CHEMBL219632 & 428054 & 7.8239 & 7.6387 & TRN \\
\hline CHEMBL220067 & 428054 & 5.5229 & 8.5919 & TST \\
\hline CHEMBL177356 & 428054 & 7.9208 & 7.841 & TRN \\
\hline CHEMBL219616 & 428054 & 4.7959 & 8.8336 & TST \\
\hline
\end{tabular}


Supplemental Table S2.txt

\begin{tabular}{|c|c|c|c|c|c|}
\hline CHEMBL375804 & 428054 & 5.699 & 8.6784 & TST & \\
\hline CHEMBL374117 & 428054 & 7.7959 & 7.8264 & TRN & \\
\hline CHEMBL220938 & 428054 & 7.0969 & 8.208 & TRN & \\
\hline CHEMBL220615 & 428054 & 8.2596 & 8.1439 & TRN & \\
\hline CHEMBL220844 & 428054 & 6.1249 & 6.3903 & TRN & \\
\hline CHEMBL220377 & 428054 & 8.5528 & 8.49 & TRN & \\
\hline CHEMBL222415 & 428054 & 6.7696 & 6.0969 & TRN & \\
\hline CHEMBL 375746 & 428054 & 7.6198 & 8.0638 & TRN & \\
\hline CHEMBL220613 & 428054 & 8.301 & 8.1306 & TRN & \\
\hline CHEMBL220614 & 428054 & 9.0 & 8.3511 & TRN & \\
\hline CHEMBL219681 & 428054 & 8.1549 & 8.398 & TRN & \\
\hline CHEMBL375303 & 428054 & 7.7212 & 7.4257 & TRN & \\
\hline CHEMBL175761 & 428054 & 7.6576 & 7.4893 & TRN & \\
\hline CHEMBL268184 & 428054 & 5.6383 & 8.4688 & TST & \\
\hline CHEMBL220309 & 428054 & 7.0 & 7.2025 & TRN & \\
\hline CHEMBL219818 & 428054 & 7.8239 & 7.5815 & TRN & \\
\hline CHEMBL220378 & 428054 & 8.3979 & 8.0472 & TRN & \\
\hline CHEMBL223302 & 428054 & 7.9208 & 8.2457 & TRN & \\
\hline CHEMBL220784 & 428054 & 9.0458 & 8.6395 & TRN & \\
\hline CHEMBL219674 & 428054 & 7.5528 & 7.7811 & TRN & \\
\hline CHEMBL220686 & 428054 & 7.6021 & 8.2823 & TRN & \\
\hline CHEMBL222463 & 428054 & 7.301 & 7.2517 & TRN & \\
\hline CHEMBL222614 & 428054 & 7.2076 & 7.0483 & TRN & \\
\hline CHEMBL220679 & 428054 & 8.699 & 8.3409 & TRN & \\
\hline CHEMBL347894 & 428054 & 6.0969 & 8.6967 & TST & \\
\hline CHEMBL220012 & 428054 & 5.301 & 5.9539 & TRN & \\
\hline CHEMBL219659 & 428054 & 8.699 & 8.7677 & TRN & \\
\hline CHEMBL219740 & 428054 & 4.0 & 8.8197 & TST & \\
\hline CHEMBL373906 & 428054 & 7.5229 & 8.0797 & TRN & \\
\hline CHEMBL223693 & 428054 & 6.9586 & 6.3132 & TRN & \\
\hline CHEMBL387376 & 428054 & 7.301 & 7.4374 & TRN & \\
\hline CHEMBL219741 & 428054 & 4.0 & 8.0315 & TST & \\
\hline CHEMBL219943 & 428054 & 8.9208 & 8.5892 & TRN & \\
\hline CHEMBL220728 & 428054 & 6.8861 & 6.7413 & TRN & \\
\hline CHEMBL376201 & 428054 & 7.585 & \multicolumn{2}{|c|}{7.122000000000001} & TST \\
\hline CHEMBL219658 & 428054 & 9.2218 & 8.6517 & TRN & \\
\hline CHEMBL219931 & 428054 & 6.301 & 6.775 & TRN & \\
\hline CHEMBL220518 & 428054 & 7.3979 & 7.6061 & TRN & \\
\hline CHEMBL373555 & 428054 & 8.5229 & 8.2672 & TRN & \\
\hline CHEMBL220125 & 428054 & 7.3188 & 8.0952 & TST & \\
\hline CHEMBL178071 & 428054 & 7.2596 & 7.5416 & TRN & \\
\hline CHEMBL223435 & 428054 & 7.2218 & 6.34399 & 7999999999 & TRN \\
\hline CHEMBL219633 & 428054 & 8.9586 & 8.7193 & TRN & \\
\hline CHEMBL222613 & 428054 & 7.2218 & 7.1533 & TRN & \\
\hline CHEMBL219953 & 428054 & 8.1549 & 8.1343 & TRN & \\
\hline CHEMBL220005 & 428054 & 7.3979 & 7.8152 & TST & \\
\hline CHEMBL223406 & 428054 & 8.2218 & 8.1401 & TST & \\
\hline CHEMBL373814 & 428054 & 7.301 & 7.5964 & TST & \\
\hline
\end{tabular}




\begin{tabular}{|c|c|c|c|c|c|c|}
\hline \multirow[b]{2}{*}{ CHEMBL373961 } & & \multicolumn{5}{|c|}{ Supplemental Table S2.txt } \\
\hline & 428054 & 5.2218 & 5.7969 & TST & & \\
\hline CHEMBL220066 & 428054 & 6.8539 & 6.9595 & TST & & \\
\hline CHEMBL219880 & 428054 & 8.0969 & 8.3789 & TST & & \\
\hline CHEMBL220680 & 428054 & 7.0969 & 7.782 & TST & & \\
\hline CHEMBL91417 & 428054 & 7.6021 & 8.1159 & TST & & \\
\hline CHEMBL219660 & 428054 & 8.699 & 8.3033 & TST & & \\
\hline CHEMBL220094 & 428054 & 5.6383 & 8.4433 & TST & & \\
\hline CHEMBL 3698337 & 1528294 & 6.9547 & 6.4129 & TRN & & \\
\hline CHEMBL 3701641 & 1528294 & 8.025 & 8.0008 & TRN & & \\
\hline CHEMBL3701663 & 1528294 & 7.8729 & 7.7135 & TRN & & \\
\hline CHEMBL3701672 & 1528294 & 8.6383 & 8.464 & TRN & & \\
\hline CHEMBL3698364 & 1528294 & 8.3799 & 8.5836 & TRN & & \\
\hline CHEMBL3698359 & 1528294 & 8.1891 & 7.0173 & TST & & \\
\hline CHEMBL3698367 & 1528294 & $7.7620 e$ & 00000000 & 205 & 6.0674 & TST \\
\hline CHEMBL3698320 & 1528294 & 5.0208 & 4.8852 & TST & & \\
\hline CHEMBL3698340 & 1528294 & 7.3565 & 6.9943 & TRN & & \\
\hline CHEMBL3701667 & 1528294 & 8.8268 & 9.0157 & TRN & & \\
\hline CHEMBL 3698354 & 1528294 & 8.5581 & 8.242 & TRN & & \\
\hline CHEMBL3701682 & 1528294 & 7.4776 & 6.9371 & TRN & & \\
\hline CHEMBL 2171932 & 1528294 & 6.4413 & 6.6253 & TRN & & \\
\hline CHEMBL3701639 & 1528294 & 8.0545 & 8.4895 & TRN & & \\
\hline CHEMBL3698352 & 1528294 & 6.6383 & 7.2145 & TRN & & \\
\hline CHEMBL3698286 & 1528294 & 7.0284 & 7.5731 & TRN & & \\
\hline CHEMBL3701688 & 1528294 & 7.2757 & 7.692 & TRN & & \\
\hline CHEMBL3698287 & 1528294 & 6.6308 & 6.8369 & TRN & & \\
\hline CHEMBL 2171927 & 1528294 & 8.0099 & 7.5317 & TRN & & \\
\hline CHEMBL 2171925 & 1528294 & 7.0942 & 7.4826 & TRN & & \\
\hline CHEMBL3701653 & 1528294 & 8.8182 & 8.4841 & TRN & & \\
\hline CHEMBL 3701684 & 1528294 & 8.5003 & 8.4214 & TRN & & \\
\hline CHEMBL3698327 & 1528294 & 6.0066 & 5.654 & TRN & & \\
\hline CHEMBL3698317 & 1528294 & 5.4977 & 6.0649 & TRN & & \\
\hline CHEMBL3698342 & 1528294 & 6.2874 & 6.2093 & TRN & & \\
\hline CHEMBL3698316 & 1528294 & 6.2062 & 6.3692 & TRN & & \\
\hline CHEMBL3698299 & 1528294 & 8.3532 & 7.6365 & TRN & & \\
\hline CHEMBL3698297 & 1528294 & 5.8456 & 5.8311 & TRN & & \\
\hline CHEMBL3701659 & 1528294 & 6.05399 & 99999999 & 99 & 5.7759 & TRN \\
\hline CHEMBL 2216891 & 1528294 & 8.9788 & 8.4221 & TRN & & \\
\hline CHEMBL3698304 & 1528294 & 7.1622 & 7.2988 & TRN & & \\
\hline CHEMBL3639971 & 1528294 & 5.4013 & 5.7238 & TRN & & \\
\hline CHEMBL3698324 & 1528294 & 5.3862 & 4.5411 & TST & & \\
\hline CHEMBL3698322 & 1528294 & 5.8419 & 3.5311 & TST & & \\
\hline CHEMBL3701669 & 1528294 & 7.9066 & 8.103 & TRN & & \\
\hline CHEMBL3701642 & 1528294 & 8.1884 & 7.8958 & TRN & & \\
\hline CHEMBL3701638 & 1528294 & 8.8125 & 8.6687 & TRN & & \\
\hline CHEMBL3698325 & 1528294 & 5.8294 & 2.872 & TST & & \\
\hline CHEMBL3701649 & 1528294 & 7.9172 & 7.5954 & TRN & & \\
\hline CHEMBL3698326 & 1528294 & 5.9654 & 3.6201 & TST & & \\
\hline CHEMBL3701660 & 1528294 & 7.9031 & 7.642 & TRN & & \\
\hline
\end{tabular}


Supplemental Table S2.txt

\begin{tabular}{|c|c|c|c|c|c|c|}
\hline CHEMBL 3701648 & 1528294 & 8.7905 & 8.6464 & TRN & & \\
\hline CHEMBL3701650 & 1528294 & 8.2848 & 8.4863 & TRN & & \\
\hline CHEMBL3701687 & 1528294 & 8.6498 & 8.478 & TRN & & \\
\hline CHEMBL 3698363 & 1528294 & 7.6615 & 7.9187 & TST & & \\
\hline CHEMBL 2171930 & 1528294 & 8.4785 & 8.2907 & TRN & & \\
\hline CHEMBL 2171929 & 1528294 & 8.1701 & 8.1174 & TRN & & \\
\hline CHEMBL3698295 & 1528294 & 6.3056 & 6.1216 & TRN & & \\
\hline CHEMBL 3698365 & 1528294 & 8.5031 & 8.8934 & TRN & & \\
\hline CHEMBL 3698330 & 1528294 & 7.1367 & 6.7485 & TRN & & \\
\hline CHEMBL3701670 & 1528294 & 8.8633 & 8.5751 & TRN & & \\
\hline CHEMBL 3698329 & 1528294 & 6.8153 & 5.052 & TST & & \\
\hline CHEMBL 3698308 & 1528294 & 7.6925 & 7.3693 & TRN & & \\
\hline CHEMBL3698368 & 1528294 & 7.7352 & 8.5844 & TRN & & \\
\hline CHEMBL3698294 & 1528294 & 7.5375 & 7.3809 & TST & & \\
\hline CHEMBL3698360 & 1528294 & 7.05399 & 99999999 & 99 & 7.8588 & TST \\
\hline CHEMBL3701665 & 1528294 & 8.0 & 8.1668 & TRN & & \\
\hline CHEMBL3701666 & 1528294 & 8.5072 & 8.2893 & TRN & & \\
\hline CHEMBL3698370 & 1528294 & 8.5229 & 7.9747 & TRN & & \\
\hline CHEMBL 3701644 & 1528294 & 8.3458 & 8.0504 & TRN & & \\
\hline CHEMBL3701674 & 1528294 & 7.556 & 7.8914 & TRN & & \\
\hline CHEMBL3701671 & 1528294 & 7.1911 & 7.6575 & TRN & & \\
\hline CHEMBL3701689 & 1528294 & 8.27 & 8.1567 & TRN & & \\
\hline CHEMBL3701646 & 1528294 & 8.5719 & 7.1662 & TST & & \\
\hline CHEMBL3698293 & 1528294 & 7.0215 & 6.609 & TRN & & \\
\hline CHEMBL 3698356 & 1528294 & 8.0904 & 7.1109 & TST & & \\
\hline CHEMBL 2171935 & 1528294 & 7.3279 & 6.9126 & TRN & & \\
\hline CHEMBL 3698315 & 1528294 & 6.7077 & 6.1866 & TRN & & \\
\hline CHEMBL3701678 & 1528294 & 6.6596 & 7.2888 & TRN & & \\
\hline CHEMBL 3698303 & 1528294 & 7.8315 & 7.7574 & TRN & & \\
\hline CHEMBL 3698328 & 1528294 & 5.4306 & 5.7225 & TST & & \\
\hline CHEMBL 3698318 & 1528294 & 5.2547 & 6.1347 & TST & & \\
\hline CHEMBL 2171933 & 1528294 & 6.2034 & 6.6128 & TRN & & \\
\hline CHEMBL3701652 & 1528294 & 8.2676 & 8.4719 & TRN & & \\
\hline CHEMBL 3698366 & 1528294 & 8.6308 & 6.9905 & TST & & \\
\hline CHEMBL3701643 & 1528294 & 6.4949 & 6.9232 & TRN & & \\
\hline CHEMBL3698348 & 1528294 & 6.2441 & 6.4876 & TRN & & \\
\hline CHEMBL3698335 & 1528294 & 6.1124 & 6.1185 & TRN & & \\
\hline CHEMBL 3698332 & 1528294 & 5.1249 & 4.1015 & TST & & \\
\hline CHEMBL 3698351 & 1528294 & 8.5376 & 7.6708 & TST & & \\
\hline CHEMBL3701657 & 1528294 & 7.1811 & 7.5702 & TRN & & \\
\hline CHEMBL3698355 & 1528294 & 8.5415 & 7.5132 & TST & & \\
\hline CHEMBL3698309 & 1528294 & 5.5117 & 5.6793 & TRN & & \\
\hline CHEMBL3701683 & 1528294 & 7.3054 & 7.3088 & TRN & & \\
\hline CHEMBL 2171922 & 1528294 & 7.0396 & 6.9964 & TRN & & \\
\hline CHEMBL3701690 & 1528294 & 6.8125 & 6.8114 & TRN & & \\
\hline CHEMBL3698331 & 1528294 & 6.2434 & 5.0994 & TST & & \\
\hline CHEMBL3701686 & 1528294 & 8.6383 & 8.7729 & TST & & \\
\hline CHEMBL 3698291 & 1528294 & 8.3903 & 8.3002 & TRN & & \\
\hline
\end{tabular}

Page 16671 
Supplemental Table S2.txt

\begin{tabular}{|c|c|c|c|c|}
\hline CHEMBL3701662 & 1528294 & 7.5498 & 7.5866 & TRN \\
\hline CHEMBL3698369 & 1528294 & 8.2832 & 8.3475 & TRN \\
\hline CHEMBL 3701685 & 1528294 & 8.8962 & 8.8174 & TST \\
\hline CHEMBL 3698349 & 1528294 & 6.7056 & 7.0595 & TRN \\
\hline CHEMBL 3701673 & 1528294 & 8.2692 & 8.3359 & TRN \\
\hline CHEMBL 3698338 & 1528294 & 6.1842 & 6.2413 & TRN \\
\hline CHEMBL 2171934 & 1528294 & 7.0687 & 6.8313 & TRN \\
\hline CHEMBL 3701668 & 1528294 & 8.5686 & 8.1721 & TST \\
\hline CHEMBL 3698290 & 1528294 & 7.83799 & 99999999 & 7.9759 \\
\hline CHEMBL 3701664 & 1528294 & 8.6271 & 8.1537 & TRN \\
\hline CHEMBL 3698339 & 1528294 & 6.209 & 6.3249 & TRN \\
\hline CHEMBL 3701676 & 1528294 & 7.6459 & 7.6437 & TRN \\
\hline CHEMBL 3698298 & 1528294 & 7.9905 & 7.7353 & TRN \\
\hline CHEMBL 3701661 & 1528294 & 7.5129 & 7.2473 & TRN \\
\hline CHEMBL 3698361 & 1528294 & 7.767 & 8.2472 & TST \\
\hline CHEMBL 3701651 & 1528294 & 8.1618 & 8.0124 & TRN \\
\hline CHEMBL 2171931 & 1528294 & 8.0054 & 7.9774 & TRN \\
\hline CHEMBL 3698344 & 1528294 & 5.9454 & 6.1342 & TRN \\
\hline CHEMBL 3698289 & 1528294 & 8.2315 & 8.0829 & TRN \\
\hline CHEMBL 3698312 & 1528294 & 8.3902 & 8.3652 & TRN \\
\hline CHEMBL 3701637 & 1528294 & 7.7773 & 7.6373 & TRN \\
\hline CHEMBL 3698300 & 1528294 & 8.6131 & 8.6581 & TRN \\
\hline CHEMBL 3698288 & 1528294 & 7.3233 & 7.8436 & TRN \\
\hline CHEMBL 3701655 & 1528294 & 8.6536 & 7.0821 & TST \\
\hline CHEMBL 2171920 & 1528294 & 7.5717 & 7.7219 & TRN \\
\hline CHEMBL 3698314 & 1528294 & 7.1325 & 7.5804 & TST \\
\hline CHEMBL 3698353 & 1528294 & 6.7104 & 7.1279 & TRN \\
\hline CHEMBL 3698302 & 1528294 & 8.1079 & 8.2048 & TRN \\
\hline CHEMBL 2171919 & 1528294 & 6.8072 & 7.5448 & TRN \\
\hline CHEMBL 3698323 & 1528294 & 5.6874 & 4.3964 & TST \\
\hline CHEMBL 3698321 & 1528294 & 5.9003 & 5.3771 & TST \\
\hline CHEMBL 2171926 & 1528294 & 5.2985 & 5.1898 & TRN \\
\hline CHEMBL 2171921 & 1528294 & 6.3468 & 6.7443 & TRN \\
\hline CHEMBL 2171923 & 1528294 & 7.739 & 7.7891 & TRN \\
\hline CHEMBL 3698305 & 1528294 & 6.8957 & 6.8421 & TRN \\
\hline CHEMBL 3698285 & 1528294 & 6.8121 & 6.5181 & TRN \\
\hline CHEMBL 2171918 & 1528294 & 7.5204 & 7.6824 & TRN \\
\hline CHEMBL 3698341 & 1528294 & 7.301 & 6.4023 & TRN \\
\hline CHEMBL 3698358 & 1528294 & 6.4547 & 6.3759 & TRN \\
\hline CHEMBL 3698346 & 1528294 & 7.6295 & 6.5246 & TST \\
\hline CHEMBL 3698306 & 1528294 & 7.6759 & 7.7926 & TRN \\
\hline CHEMBL 3698301 & 1528294 & 6.8088 & 7.2147 & TRN \\
\hline CHEMBL 3701691 & 1528294 & 7.4949 & 8.0143 & TRN \\
\hline CHEMBL 3701679 & 1528294 & 7.5376 & 7.6468 & TRN \\
\hline CHEMBL 3701656 & 1528294 & 8.7077 & 7.5625 & TST \\
\hline CHEMBL 3698313 & 1528294 & 6.3594 & 6.911006 & 30000000005 \\
\hline CHEMBL 3701675 & 1528294 & 8.3605 & 7.809 & TRN \\
\hline CHEMBL 3701658 & 1528294 & 8.1169 & 8.4411 & TST \\
\hline
\end{tabular}


Supplemental Table S2.txt

\begin{tabular}{|c|c|c|c|c|c|}
\hline CHEMBL3701677 & 1528294 & 7.3809 & 6.8511 & TRN & \\
\hline CHEMBL3701654 & 1528294 & 8.821 & 8.3396 & TRN & \\
\hline CHEMBL3701640 & 1528294 & 8.2588 & 8.7911 & TST & \\
\hline CHEMBL3701647 & 1528294 & 8.6271 & 8.5727 & TST & \\
\hline CHEMBL3701680 & 1528294 & 7.0264 & 7.2031 & TRN & \\
\hline CHEMBL3698357 & 1528294 & 8.5725 & 6.5949 & TST & \\
\hline CHEMBL 2171924 & 1528294 & 8.1107 & 8.3592 & TRN & \\
\hline CHEMBL3701681 & 1528294 & 7.8761 & 7.7478 & TRN & \\
\hline CHEMBL3698292 & 1528294 & 7.2531 & 5.879 & TST & \\
\hline CHEMBL3698350 & 1528294 & 8.4949 & 7.38 & TST & \\
\hline CHEMBL3698307 & 1528294 & 8.4779 & 8.0014 & TRN & \\
\hline CHEMBL3698347 & 1528294 & 7.5955 & 7.1785 & TRN & \\
\hline CHEMBL3698336 & 1528294 & 5.581 & 6.1062 & TRN & \\
\hline CHEMBL3701645 & 1528294 & 8.3335 & 7.5078 & TST & \\
\hline CHEMBL 3698334 & 1528294 & 5.4022 & 5.4322 & TRN & \\
\hline CHEMBL3698296 & 1528294 & 7.8058 & 7.6924 & TRN & \\
\hline CHEMBL3698311 & 1528294 & 6.0504 & 6.3391 & TRN & \\
\hline CHEMBL3698343 & 1528294 & 5.6757 & 3.2417 & TST & \\
\hline CHEMBL3698310 & 1528294 & 5.4226 & 5.4334 & TRN & \\
\hline CHEMBL 3698345 & 1528294 & 7.5528 & 5.8969 & TST & \\
\hline CHEMBL 2171928 & 1528294 & 6.3476 & 6.3728 & TRN & \\
\hline CHEMBL3640005 & 1528294 & 7.16299 & \multirow{2}{*}{\multicolumn{2}{|c|}{99}} & TRN \\
\hline CHEMBL3698362 & 1528294 & 7.8894 & & & TST \\
\hline CHEMBL3698319 & 1528294 & 5.7688 & 4.2306 & TST & \\
\hline CHEMBL3698333 & 1528294 & 6.9172 & 7.117000 & 0000000001 & TRN \\
\hline CHEMBL 2335564 & 945360 & 5.6198 & 4.8711 & TRN & \\
\hline CHEMBL 2335546 & 945360 & 4.4793 & 4.5021 & TRN & \\
\hline CHEMBL 2335531 & 945360 & 5.5498 & 5.5496 & TRN & \\
\hline CHEMBL 2335559 & 945360 & 4.7825 & 4.8711 & TRN & \\
\hline CHEMBL 2335522 & 945360 & 4.2041 & 4.9003 & TRN & \\
\hline CHEMBL2335565 & 945360 & 4.8633 & 4.8711 & TRN & \\
\hline CHEMBL 2335551 & 945360 & 5.26200 & 000000000 & 4.3899 & 1. \\
\hline CHEMBL 2335550 & 945360 & 4.3362 & 4.3899 & TRN & \\
\hline CHEMBL 2335515 & 945360 & 4.3823 & 4.3899 & TRN & \\
\hline CHEMBL 2335543 & 945360 & 5.2472 & 5.2501 & TRN & \\
\hline CHEMBL 2335524 & 945360 & 4.3152 & 4.9003 & TRN & \\
\hline CHEMBL 2335555 & 945360 & 4.2588 & 4.2643 & TRN & \\
\hline CHEMBL 2335534 & 945360 & 5.0867 & 4.7171 & TST & \\
\hline CHEMBL2335536 & 945360 & 4.997 & 4.5356 & TST & \\
\hline CHEMBL 257943 & 945360 & 5.4318 & 5.7233 & TST & \\
\hline CHEMBL 2335552 & 945360 & 4.1003 & 4.3899 & TRN & \\
\hline CHEMBL 2335525 & 945360 & 4.6615 & 4.9003 & TRN & \\
\hline CHEMBL2335535 & 945360 & 4.9389 & 4.9387 & TRN & \\
\hline CHEMBL 2335532 & 945360 & 5.2941 & 4.5143 & TST & \\
\hline CHEMBL 2335554 & 945360 & 4.0799 & 4.0867 & TRN & \\
\hline CHEMBL 2335520 & 945360 & 4.3468 & 4.3517 & TRN & \\
\hline CHEMBL2335513 & 945360 & 4.6424 & 4.7492 & TST & \\
\hline CHEMBL 2335540 & 945360 & 5.7799 & 4.5356 & TST & \\
\hline
\end{tabular}




\begin{tabular}{|c|c|c|c|c|c|c|}
\hline & & \multicolumn{5}{|c|}{ Supplemental Table S2.txt } \\
\hline CHEMBL2335521 & 945360 & 4.5421 & 4.5478 & TRN & & \\
\hline CHEMBL2335558 & 945360 & 4.6882 & 4.8711 & TRN & & \\
\hline CHEMBL2335523 & 945360 & 4.2716 & 4.9003 & TRN & & \\
\hline CHEMBL2335539 & 945360 & 6.2218 & 4.5356 & TST & & \\
\hline CHEMBL2335547 & 945360 & 4.5661 & 4.5578 & TRN & & \\
\hline CHEMBL2335519 & 945360 & 3.0 & 2.9991 & TRN & & \\
\hline CHEMBL 243796 & 945360 & 4.9626 & 6.5625 & TST & & \\
\hline CHEMBL2335557 & 945360 & 4.6073 & 4.6079 & TRN & & \\
\hline CHEMBL2335549 & 945360 & 4.3501 & 4.3899 & TRN & & \\
\hline CHEMBL2335556 & 945360 & 4.6326 & 4.607 & TRN & & \\
\hline CHEMBL2335563 & 945360 & 5.9586 & 4.8711 & TRN & & \\
\hline CHEMBL 2335538 & 945360 & 5.7878 & 4.5356 & TST & & \\
\hline CHEMBL2335541 & 945360 & \multicolumn{3}{|c|}{5.3839999999999995} & 4.5356 & TST \\
\hline CHEMBL2335560 & 945360 & 4.8508 & 4.8711 & TRN & & \\
\hline CHEMBL2335566 & 945360 & 3.0 & 4.8711 & TRN & & \\
\hline CHEMBL2335527 & 945360 & 5.4685 & 4.9003 & TRN & & \\
\hline CHEMBL2335561 & 945360 & 4.9872 & 4.8711 & TRN & & \\
\hline CHEMBL2335516 & 945360 & 4.247 & 4.3899 & TRN & & \\
\hline CHEMBL2335553 & 945360 & 3.0 & 2.9977 & TRN & & \\
\hline CHEMBL2335530 & 945360 & 4.8894 & 4.9003 & TRN & & \\
\hline CHEMBL2335545 & 945360 & 4.5599 & 4.5554 & TRN & & \\
\hline CHEMBL2335533 & 945360 & 5.104 & 4.753 & TST & & \\
\hline CHEMBL2335544 & 945360 & 4.7493 & 4.7417 & TRN & & \\
\hline CHEMBL2335529 & 945360 & 5.2366 & 4.9003 & TRN & & \\
\hline CHEMBL2335537 & 945360 & 5.2218 & 4.5356 & TST & & \\
\hline CHEMBL2335514 & 945360 & 4.0639 & 4.3899 & TRN & & \\
\hline CHEMBL2335528 & 945360 & 6.3565 & 4.9003 & TRN & & \\
\hline CHEMBL531383 & 945360 & 5.1244 & 4.4789 & TST & & \\
\hline CHEMBL2335562 & 945360 & 5.0757 & 4.8711 & TRN & & \\
\hline CHEMBL2331597 & 945360 & 5.062 & 4.5356 & TST & & \\
\hline CHEMBL2335548 & 945360 & 4.3823 & 4.3899 & TRN & & \\
\hline CHEMBL2335526 & 945360 & 4.7077 & 4.9003 & TRN & & \\
\hline CHEMBL2335567 & 945360 & 3.0 & 2.9998 & TRN & & \\
\hline CHEMBL2335518 & 945360 & 3.0 & 2.9997 & TRN & & \\
\hline CHEMBL2335542 & 945360 & 5.8386 & 4.5356 & TST & & \\
\hline CHEMBL590751 & 613982 & \multicolumn{3}{|c|}{7.752000000000001} & 7.8026 & TRN \\
\hline CHEMBL606689 & 613982 & 6.9872 & 7.1005 & TRN & & \\
\hline CHEMBL601510 & 613982 & 8.4547 & 8.3721 & TRN & & \\
\hline CHEMBL591714 & 613982 & 6.4214 & \multicolumn{3}{|c|}{6.497999999999999} & Thiv \\
\hline CHEMBL591485 & 613982 & \multicolumn{3}{|c|}{6.117999999999999} & 6.1338 & TRN \\
\hline CHEMBL592667 & 613982 & 4.0 & 4.0336 & TRN & & \\
\hline CHEMBL590272 & 613982 & 7.1391 & 7.2061 & TRN & & \\
\hline CHEMBL590752 & 613982 & 6.9747 & 6.9708 & TRN & & \\
\hline CHEMBL590299 & 613982 & 6.5901 & 6.6334 & TRN & & \\
\hline CHEMBL589079 & 613982 & 4.0 & 3.9404 & TRN & & \\
\hline CHEMBL592189 & 613982 & 4.0 & 4.585 & TST & & \\
\hline CHEMBL591949 & 613982 & 8.3915 & 8.4128 & TRN & & \\
\hline CHEMBL602721 & 613982 & 6.6038 & 6.5926 & TRN & & \\
\hline
\end{tabular}




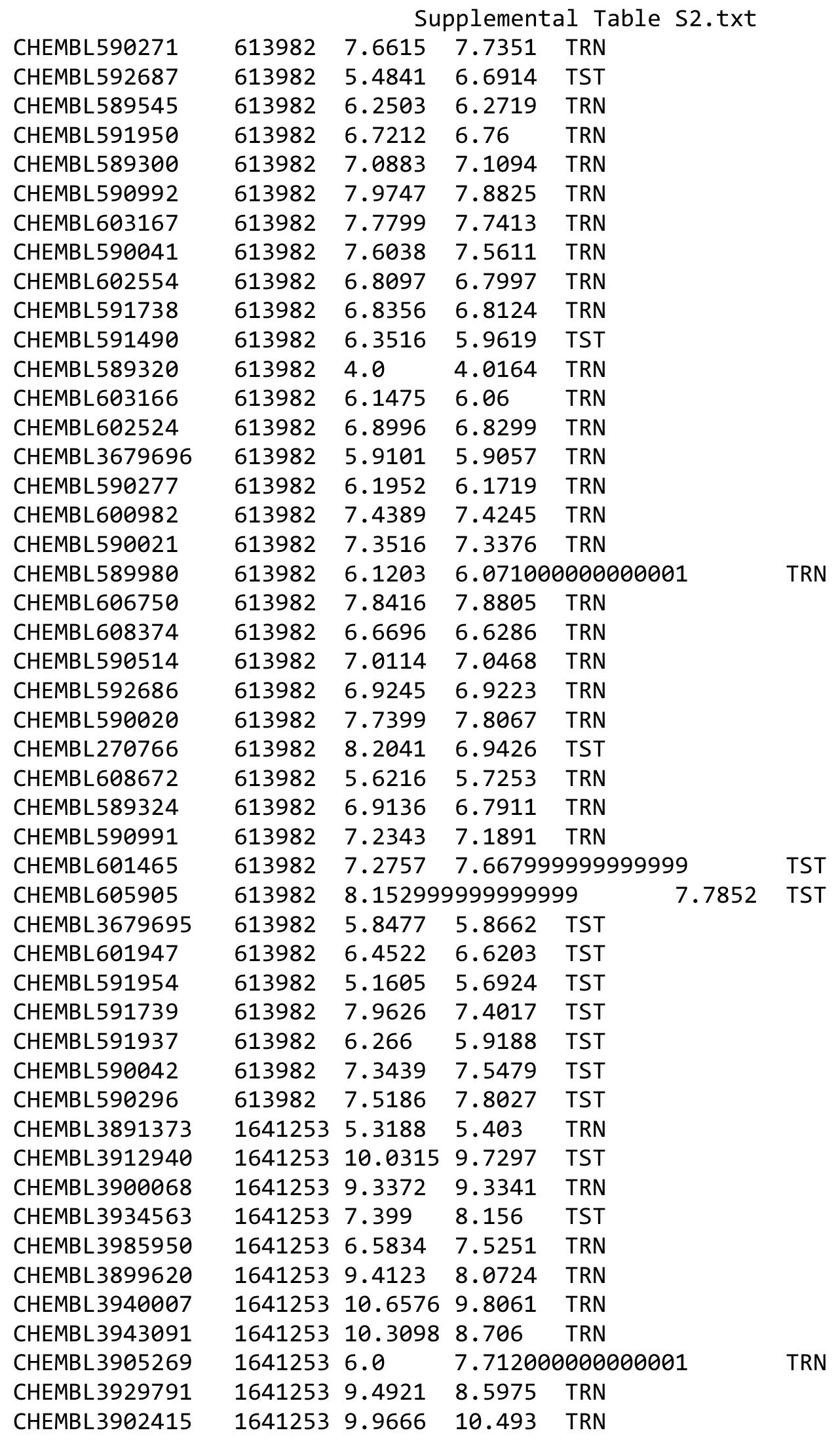

Page 16675 
Supplemental Table S2.txt

\begin{tabular}{|c|c|c|c|c|c|c|}
\hline CHEMBL3927435 & 1641253 & 10.5229 & \multicolumn{3}{|c|}{9.652999999999999} & TRN \\
\hline CHEMBL 3967003 & 1641253 & 8.6364 & 7.9769 & TRN & & \\
\hline CHEMBL3972403 & 1641253 & 10.69900 & 900000000 & 02 & 9.3484 & TRN \\
\hline CHEMBL 3919442 & 1641253 & 6.0 & 9.1533 & TRN & & \\
\hline CHEMBL3902878 & 1641253 & 6.0 & 7.8972 & TRN & & \\
\hline CHEMBL3891378 & 1641253 & 7.3665 & 8.0831 & TST & & \\
\hline CHEMBL3910663 & 1641253 & 9.8861 & 10.4067 & TRN & & \\
\hline CHEMBL3634783 & 1641253 & 11.0 & 9.7803 & TRN & & \\
\hline CHEMBL3928058 & 1641253 & 7.9469 & 8.7442 & TRN & & \\
\hline CHEMBL3922627 & 1641253 & 8.1599 & 7.6621 & TRN & & \\
\hline CHEMBL3895153 & 1641253 & 8.618 & 7.5204 & TRN & & \\
\hline CHEMBL3954672 & 1641253 & 5.2596 & 5.0267 & TRN & & \\
\hline CHEMBL3915064 & 1641253 & 9.2358 & 9.0457 & TRN & & \\
\hline CHEMBL3957858 & 1641253 & 9.5072 & 9.3778 & TRN & & \\
\hline CHEMBL3911749 & 1641253 & 9.466000 & 000000000 & & 6.9377 & TST \\
\hline CHEMBL3915842 & 1641253 & 8.8508 & 7.769 & TST & & \\
\hline CHEMBL3950124 & 1641253 & 9.3936 & 8.831 & TRN & & \\
\hline CHEMBL3960318 & 1641253 & 8.8827 & 8.552999 & 999999999 & & TRN \\
\hline CHEMBL3916333 & 1641253 & 6.0 & 5.2683 & TRN & & \\
\hline CHEMBL3966702 & 1641253 & 8.767000 & 000000000 & & 9.0373 & TRN \\
\hline CHEMBL3915381 & 1641253 & 9.7423 & 10.14 & TRN & & \\
\hline CHEMBL3634778 & 1641253 & 8.2366 & 7.4257 & TRN & & \\
\hline CHEMBL3891239 & 1641253 & 9.8794 & 10.3082 & TRN & & \\
\hline CHEMBL3949010 & 1641253 & 9.5045 & 8.4017 & TST & & \\
\hline CHEMBL3906142 & 1641253 & 8.2774 & 9.6187 & TST & & \\
\hline CHEMBL3891654 & 1641253 & 6.0 & 8.581 & TRN & & \\
\hline CHEMBL3946733 & 1641253 & 6.0 & 8.7952 & TRN & & \\
\hline CHEMBL3962063 & 1641253 & 8.0114 & 8.7693 & TST & & \\
\hline CHEMBL3971764 & 1641253 & 7.7545 & 9.4235 & TST & & \\
\hline CHEMBL3913561 & 1641253 & 8.5302 & 8.0611 & TRN & & \\
\hline CHEMBL3634792 & 1641253 & 6.0 & 5.5784 & TRN & & \\
\hline CHEMBL3901903 & 1641253 & 6.0 & 6.7178 & TRN & & \\
\hline CHEMBL3895582 & 1641253 & 10.69900 & 000000000 & 02 & 10.2325 & TRN \\
\hline CHEMBL3984117 & 1641253 & 6.0362 & 6.0305 & TST & & \\
\hline CHEMBL3968244 & 1641253 & 8.5058 & 6.6727 & TST & & \\
\hline CHEMBL3919155 & 1641253 & 6.0 & 7.6573 & TRN & & \\
\hline CHEMBL3908523 & 1641253 & 9.4248 & 9.7956 & TRN & & \\
\hline CHEMBL3941916 & 1641253 & 9.4101 & 8.7555 & TRN & & \\
\hline CHEMBL3980792 & 1641253 & 10.0655 & 9.6158 & TRN & & \\
\hline CHEMBL3940311 & 1641253 & 8.0716 & 8.4425 & TRN & & \\
\hline CHEMBL3943830 & 1641253 & 10.3372 & 9.4172 & TRN & & \\
\hline CHEMBL3976039 & 1641253 & 7.1494 & 6.7483 & TST & & \\
\hline CHEMBL3909163 & 1641253 & 10.2269 & 9.3729 & TRN & & \\
\hline CHEMBL3980748 & 1641253 & 7.7645 & 7.9288 & TRN & & \\
\hline CHEMBL3921180 & 1641253 & 9.8996 & 8.4541 & TRN & & \\
\hline CHEMBL3969982 & 1641253 & 5.8239 & 6.0109 & TRN & & \\
\hline CHEMBL3928385 & 1641253 & 5.4202 & 9.0453 & TST & & \\
\hline CHEMBL3942159 & 1641253 & 6.5228 & 9.023 & TST & & \\
\hline
\end{tabular}




\begin{tabular}{|c|c|c|c|c|c|}
\hline \multicolumn{6}{|c|}{ Supplemental Table S2.txt } \\
\hline CHEMBL3900009 & 1641253 & 6.0 & 8.6548 & TRN & \\
\hline CHEMBL 3634781 & 1641253 & 10.4318 & 9.8953 & TRN & \\
\hline CHEMBL 3903449 & 1641253 & 6.0 & 8.5426 & TRN & \\
\hline CHEMBL3985827 & 1641253 & 7.2668 & 8.1097 & TRN & \\
\hline CHEMBL 3925624 & 1641253 & 7.7986 & 7.8127 & TRN & \\
\hline CHEMBL3918444 & 1641253 & 9.6716 & 10.4341 & TRN & \\
\hline CHEMBL3933509 & 1641253 & 10.5528 & 10.4678 & TRN & \\
\hline CHEMBL 3944164 & 1641253 & 5.8539 & 8.1181 & TST & \\
\hline CHEMBL 3634758 & 1641253 & 6.0 & 7.7735 & TRN & \\
\hline CHEMBL3967523 & 1641253 & 10.8239 & 9.7769 & TRN & \\
\hline CHEMBL3986201 & 1641253 & 6.617999 & 999999999 & 5.3278 & TST \\
\hline CHEMBL3956461 & 1641253 & 9.5719 & 9.6005 & TRN & \\
\hline CHEMBL3955711 & 1641253 & 7.6108 & 7.2673 & TRN & \\
\hline CHEMBL 3925376 & 1641253 & 8.2161 & 7.4288 & TRN & \\
\hline CHEMBL3918383 & 1641253 & 7.9747 & 8.1916 & TRN & \\
\hline CHEMBL3982705 & 1641253 & 6.0 & 8.3826 & TRN & \\
\hline CHEMBL3977619 & 1641253 & 10.0177 & 9.8682 & TRN & \\
\hline CHEMBL3634782 & 1641253 & 10.3872 & 10.4641 & TRN & \\
\hline CHEMBL 3922007 & 1641253 & 9.8268 & 8.7574 & TRN & \\
\hline CHEMBL3933966 & 1641253 & 6.0 & 6.1663 & TRN & \\
\hline CHEMBL3956027 & 1641253 & 10.1549 & 8.8158 & TRN & \\
\hline CHEMBL 3973141 & 1641253 & 9.7852 & 9.9655 & TRN & \\
\hline CHEMBL 3634774 & 1641253 & 6.767 & 8.7077 & TST & \\
\hline CHEMBL 3950347 & 1641253 & 5.4559 & 6.1729 & TRN & \\
\hline CHEMBL3902989 & 1641253 & 6.0 & 8.7966 & TRN & \\
\hline CHEMBL3934472 & 1641253 & 9.9747 & 10.5092 & TRN & \\
\hline CHEMBL3957328 & 1641253 & 10.3098 & 9.6078 & TRN & \\
\hline CHEMBL3959285 & 1641253 & 9.8601 & 10.1027 & TRN & \\
\hline CHEMBL 3634770 & 1641253 & 10.4437 & 10.5267 & TRN & \\
\hline CHEMBL 3965567 & 1641253 & 10.0757 & 8.7394 & TRN & \\
\hline CHEMBL3898949 & 1641253 & 10.1549 & 9.8895 & TRN & \\
\hline CHEMBL 3952046 & 1641253 & 9.2993 & 8.8077 & TRN & \\
\hline CHEMBL3891613 & 1641253 & 6.6799 & 7.032999 & 99999999995 & TRN \\
\hline CHEMBL 3634771 & 1641253 & 10.6576 & 10.5551 & TRN & \\
\hline CHEMBL3905211 & 1641253 & 6.0 & 8.3814 & TRN & \\
\hline CHEMBL 3948473 & 1641253 & 10.0762 & 8.9057 & TRN & \\
\hline CHEMBL3962485 & 1641253 & 10.6576 & 10.2936 & TRN & \\
\hline CHEMBL3890794 & 1641253 & 10.4559 & 10.0367 & TRN & \\
\hline CHEMBL3941606 & 1641253 & 9.382 & 8.812999 & 9999999999 & TRN \\
\hline CHEMBL 3894135 & 1641253 & 6.0 & 7.1242 & TST & \\
\hline CHEMBL3923994 & 1641253 & 6.0 & 6.3416 & TRN & \\
\hline CHEMBL 3902873 & 1641253 & 6.0 & 7.0513 & TRN & \\
\hline CHEMBL3937388 & 1641253 & 5.4949 & 8.7527 & TST & \\
\hline CHEMBL 3903439 & 1641253 & 5.8861 & 5.7279 & TST & \\
\hline CHEMBL3895408 & 1641253 & 9.2411 & 8.3305 & TRN & \\
\hline CHEMBL3949697 & 1641253 & 9.5901 & 9.7195 & TRN & \\
\hline CHEMBL3931505 & 1641253 & 9.9508 & 7.2599 & TRN & \\
\hline CHEMBL3943032 & 1641253 & 10.1308 & 9.3641 & TRN & \\
\hline
\end{tabular}


Supplemental Table S2.txt

\begin{tabular}{|c|c|c|c|c|}
\hline & 253 & & & \\
\hline 218 & 641253 & 10.7959 & 9.6253 & \\
\hline & & & & \\
\hline 227 & 253 & & & \\
\hline 90025 & 641253 & 6.0 & & \\
\hline IEMBL 3921929 & 641253 & 7.1831 & 1386 & \\
\hline 776 & 253 & 367 & 524 & \\
\hline 723 & 53 & & 32 & \\
\hline IEMBL & 253 & 157 & & \\
\hline IEMBL 3924840 & 253 & 8.4248 & 262 & \\
\hline IEMBL 3920195 & 253 & 9.1778 & & \\
\hline 346 & 253 & 8.58 & & \\
\hline & & & & \\
\hline 761 & 53 & 10.1367 & 773 & \\
\hline 9770 & 253 & 6.0 & 7.0783 & \\
\hline 249 & 164 & 6.5 & & \\
\hline 766 & 3 & 8. & & \\
\hline & & 86 & & \\
\hline 779 & 53 & 9.5 & & \\
\hline 899 & 53 & 6.0 & & \\
\hline 979 & 53 & 7.7825 & 27 & \\
\hline 682 & 33 & 10 . & 505 & \\
\hline 604 & & 6.0 & & \\
\hline 717 & 53 & 6.0 & & \\
\hline 031 & & 7. & & \\
\hline 377 & 3 & 9.7 & & \\
\hline 946 & & 9.5 & & \\
\hline 1 & & & & \\
\hline & & 11 & & \\
\hline 179 & 3 & 7.5 & & \\
\hline & & 9.4 & & \\
\hline 36 & 3 & 10.2441 & & \\
\hline & 16 & 6.0 & & \\
\hline & & 9.21 & & \\
\hline 548 & 164 & 7.0921 & & \\
\hline & & 14 & & \\
\hline & & & & \\
\hline & 164 & 7.2916 & & \\
\hline 2557 & 164 & 6.0 & 575 & \\
\hline & 53 & 8.721 & & \\
\hline 02 & 164 & 10.3098 & 38 & \\
\hline & & & & \\
\hline 7020 & 164 & 7.3605 & 8.0595 & $\mathrm{n}$ \\
\hline 2110 & 164 & 11.0 & 149 & $\mathrm{n}$ \\
\hline & 3 & 11 & & \\
\hline . & & 7.8508 & 053 & \\
\hline 549 & & 0.2924 & 8.2089 & \\
\hline CHEMBL3919615 & 1641253 & 10.1427 & 8.68 & \\
\hline
\end{tabular}

Page 16678 


\begin{tabular}{|c|c|c|c|c|c|c|}
\hline \multicolumn{7}{|c|}{ Supplemental Table S2.txt } \\
\hline CHEMBL 3903586 & 1641253 & 6.0 & 6.5887 & TRN & & \\
\hline CHEMBL 3980904 & 1641253 & 6.0 & 7.6488 & TRN & & \\
\hline CHEMBL 3900279 & 1641253 & 6.0 & 7.4083 & TRN & & \\
\hline CHEMBL 3901840 & 1641253 & 10.1791 & 7.8914 & TRN & & \\
\hline CHEMBL 3634786 & 1641253 & 6.7212 & 6.6787 & TRN & & \\
\hline CHEMBL3923702 & 1641253 & 6.0 & 7.2292 & TST & & \\
\hline CHEMBL3897509 & 1641253 & 10.6576 & 10.417 & TRN & & \\
\hline CHEMBL 3906211 & 1641253 & 10.0362 & 10.648 & TRN & & \\
\hline CHEMBL3924181 & 1641253 & 6.4895 & 6.822 & TST & & \\
\hline CHEMBL3965036 & 1641253 & 9.0264 & 8.485 & TRN & & \\
\hline CHEMBL3964593 & 1641253 & 8.7959 & 8.8547 & TRN & & \\
\hline CHEMBL 3956349 & 1641253 & 6.0 & 7.4479 & TRN & & \\
\hline CHEMBL 3950271 & 1641253 & 8.7167 & 7.7909 & TRN & & \\
\hline CHEMBL 3905023 & 1641253 & 10.6778 & 10.8395 & TRN & & \\
\hline CHEMBL 3895900 & 1641253 & 9.5287 & 8.7875 & TRN & & \\
\hline CHEMBL3956156 & 1641253 & 9.8665 & 7.6359 & TRN & & \\
\hline CHEMBL3911463 & 1641253 & 6.9747 & 7.296 & TST & & \\
\hline CHEMBL 3918297 & 1641253 & 7.4145 & 7.5638 & TRN & & \\
\hline CHEMBL3938860 & 1641253 & 9.6635 & 9.1397 & TRN & & \\
\hline CHEMBL 3634788 & 1641253 & 6.52 & 6.4047 & TST & & \\
\hline CHEMBL3936599 & 1641253 & 8.8041 & 8.1536 & TRN & & \\
\hline CHEMBL3939866 & 1641253 & 10.0655 & 8.6111 & TRN & & \\
\hline CHEMBL3912777 & 1641253 & 6.5129 & 7.8478 & TRN & & \\
\hline CHEMBL3910119 & 1641253 & 6.0 & 8.4086 & TRN & & \\
\hline CHEMBL 3898059 & 1641253 & 7.5735 & 6.3046 & TST & & \\
\hline CHEMBL3898594 & 1641253 & 6.2343 & 7.7641 & TST & & \\
\hline CHEMBL 3983008 & 1641253 & 7.644 & 7.9907 & TST & & \\
\hline CHEMBL 3981452 & 1641253 & 7.75200 & 000000000 & 01 & 8.7383 & TST \\
\hline CHEMBL 3955073 & 1641253 & 6.4123 & 7.7937 & TST & & \\
\hline CHEMBL 3972871 & 1641253 & 11.0458 & 9.3266 & TRN & & \\
\hline CHEMBL3910790 & 1641253 & 6.0 & 7.9885 & TRN & & \\
\hline CHEMBL 3971052 & 1641253 & 9.9469 & 10.0246 & TRN & & \\
\hline CHEMBL3932937 & 1641253 & 10.5376 & 10.1499 & TRN & & \\
\hline CHEMBL 3941538 & 1641253 & 10.3979 & 10.3095 & TRN & & \\
\hline CHEMBL3966119 & 1641253 & 9.9281 & 8.6188 & TRN & & \\
\hline CHEMBL3900915 & 1641253 & 9.5735 & 7.9964 & TST & & \\
\hline CHEMBL3937913 & 1641253 & 6.0 & 9.2821 & TRN & & \\
\hline CHEMBL3898418 & 1641253 & 9.4342 & 9.5035 & TRN & & \\
\hline CHEMBL 3910227 & 1641253 & 10.1549 & 9.3635 & TRN & & \\
\hline CHEMBL3908352 & 1641253 & 6.0 & 8.4395 & TRN & & \\
\hline CHEMBL3930783 & 1641253 & 9.4101 & 7.4357 & TRN & & \\
\hline CHEMBL 3634780 & 1641253 & 9.5058 & 9.2634 & TST & & \\
\hline CHEMBL3891729 & 1641253 & 6.0 & 8.04 & TRN & & \\
\hline CHEMBL 3634763 & 1641253 & 8.4023 & 8.5789 & TRN & & \\
\hline CHEMBL3898497 & 1641253 & 9.2434 & 9.3748 & TRN & & \\
\hline CHEMBL3929385 & 1641253 & 9.8861 & 8.1855 & TRN & & \\
\hline CHEMBL 3634772 & 1641253 & 10.6778 & 9.7469 & TRN & & \\
\hline CHEMBL 3974500 & 1641253 & 10.0458 & 9.9955 & TRN & & \\
\hline
\end{tabular}

Page 16679 
Supplemental Table S2.txt

CHEMBL3944261

CHEMBL3959473

CHEMBL 3938145

CHEMBL 3939792

CHEMBL 3975801

CHEMBL 3972080

CHEMBL 3957883

CHEMBL 3945643

CHEMBL 3942480

CHEMBL3941039

CHEMBL3972654

CHEMBL 3954635

CHEMBL 3902734

CHEMBL 3904083

CHEMBL 3957313

CHEMBL3947993

CHEMBL 3984278

CHEMBL 3634790

CHEMBL3967263

CHEMBL 3984500

CHEMBL 3973045

CHEMBL 3985731

CHEMBL3936994

CHEMBL3947454

CHEMBL3915245

CHEMBL 3962397

CHEMBL3898951

CHEMBL 3963658

CHEMBL 3901155

CHEMBL 3987002

CHEMBL3962879

CHEMBL3930859

CHEMBL 3910899

CHEMBL 3913040

CHEMBL3964935

CHEMBL3898821

CHEMBL3975794

CHEMBL 3907357

CHEMBL3900487

CHEMBL3895332

CHEMBL3966229

CHEMBL 3944848

CHEMBL3983797

CHEMBL 3977172

CHEMBL3634764

CHEMBL3969949

CHEMBL 3918702

CHEMBL 3915982

\begin{tabular}{|c|c|c|c|c|}
\hline & & pplementa & al Table S & \\
\hline 1641253 & 10.4089 & 10.308 & TRN & \\
\hline 1641253 & 8.1051 & 7.6386 & TRN & \\
\hline 1641253 & 8.3215 & 7.9701 & TST & \\
\hline 1641253 & 10.2218 & 9.3466 & TRN & \\
\hline 1641253 & 10.0506 & 7.5949 & TRN & \\
\hline 1641253 & 6.2076 & 5.6988 & TST & \\
\hline 1641253 & 9.3706 & 10.5469 & TRN & \\
\hline 1641253 & 7.3809 & 6.9621 & TST & \\
\hline 1641253 & 10.4437 & 10.7757 & TRN & \\
\hline 1641253 & 7.8827 & 8.3286 & TST & \\
\hline 1641253 & 8.5482 & 8.1987 & TST & \\
\hline 1641253 & 6.0 & 6.8894 & TRN & \\
\hline 1641253 & 6.3851 & 6.4817 & TRN & \\
\hline 1641253 & 6.0 & 8.488999 & 9999999999 & TRN \\
\hline 1641253 & 9.0991 & 9.2906 & TRN & \\
\hline 1641253 & 10.1549 & 7.9806 & TRN & \\
\hline 1641253 & 8.6162 & 9.0062 & TST & \\
\hline 1641253 & 8.0155 & 7.1433 & TST & \\
\hline 1641253 & 7.8633 & 6.4608 & TRN & \\
\hline 1641253 & 8.0 & 7.7536 & TST & \\
\hline 1641253 & 9.7747 & 9.0533 & TRN & \\
\hline 1641253 & 7.475 & 6.3259 & TST & \\
\hline 1641253 & 8.3862 & 8.5363 & TST & \\
\hline 1641253 & 9.5686 & 9.4545 & TST & \\
\hline 1641253 & 10.0315 & 10.6653 & TRN & \\
\hline 1641253 & 6.5935 & 6.388 & TRN & \\
\hline 1641253 & 9.9788 & 9.2665 & TST & \\
\hline 1641253 & 6.1421 & 6.8749 & TRN & \\
\hline 1641253 & 9.4547 & 9.0449 & TRN & \\
\hline 1641253 & 8.2218 & 7.696000 & 0000000001 & TST \\
\hline 1641253 & 10.0862 & 6.7557 & TRN & \\
\hline 1641253 & 9.5817 & 8.9018 & TRN & \\
\hline 1641253 & 8.057 & 7.2185 & TST & \\
\hline 1641253 & 6.8861 & 7.5974 & TST & \\
\hline 1641253 & 9.7423 & 8.9463 & TRN & \\
\hline 1641253 & 5.6576 & 6.3625 & TST & \\
\hline 1641253 & 8.9136 & 8.3328 & TRN & \\
\hline 1641253 & 9.0132 & 8.3553 & TRN & \\
\hline 1641253 & 9.5272 & 10.7511 & TRN & \\
\hline 1641253 & 10.4949 & 9.2103 & TRN & \\
\hline 1641253 & 8.2541 & 7.8757 & TRN & \\
\hline 1641253 & 6.0 & 7.9917 & TRN & \\
\hline 1641253 & 8.3363 & 6.8537 & TST & \\
\hline 1641253 & 10.5229 & 8.7829 & TRN & \\
\hline 1641253 & 7.8996 & 7.1497 & TRN & \\
\hline 1641253 & 9.2464 & 6.9464 & TST & \\
\hline 1641253 & 6.0 & 7.9422 & TRN & \\
\hline 1641253 & 9.4214 & 7.6721 & TST & \\
\hline
\end{tabular}


Supplemental Table S2.txt

\begin{tabular}{|c|c|c|c|c|c|}
\hline CHEMBL3938434 & 1641253 & 6.1805 & 5.4868 & TRN & \\
\hline CHEMBL3918515 & 1641253 & 5.8239 & 6.5905 & TRN & \\
\hline CHEMBL3948781 & 1641253 & 10.5686 & 11.6008 & TRN & \\
\hline CHEMBL3894842 & 1641253 & 8.6778 & 8.9156 & TRN & \\
\hline CHEMBL3905806 & 1641253 & 6.0737 & 7.2573 & TST & \\
\hline CHEMBL3893806 & 1641253 & 8.7986 & 9.9068 & TRN & \\
\hline CHEMBL3918765 & 1641253 & 6.0 & 6.6213 & TRN & \\
\hline CHEMBL3923325 & 1641253 & 6.0 & 7.7098 & TRN & \\
\hline CHEMBL3925349 & 1641253 & 6.0 & 8.4586 & TRN & \\
\hline CHEMBL3915324 & 1641253 & 6.0 & 8.1168 & TRN & \\
\hline CHEMBL3916440 & 1641253 & 6.0 & 6.3877 & TRN & \\
\hline CHEMBL3890600 & 1641253 & 10.6383 & 10.0291 & TRN & \\
\hline CHEMBL3922596 & 1641253 & 10.8539 & 10.2202 & TRN & \\
\hline CHEMBL3942966 & 1641253 & 7.5719 & 6.5755 & TST & \\
\hline CHEMBL3981863 & 1641253 & 6.3161 & 6.1274 & TRN & \\
\hline CHEMBL3900358 & 1641253 & 9.9706 & 9.5436 & TRN & \\
\hline CHEMBL3919728 & 1641253 & 8.4134 & 8.997 & TST & \\
\hline CHEMBL3935203 & 1641253 & 9.9318 & 9.8158 & TRN & \\
\hline CHEMBL3634773 & 1641253 & 8.7399 & 8.6056 & TRN & \\
\hline CHEMBL3925594 & 1641253 & 10.8539 & 10.7615 & TRN & \\
\hline CHEMBL3634775 & 1641253 & 8.7077 & 8.1227 & TST & \\
\hline CHEMBL3942799 & 1641253 & 10.1938 & 10.4033 & TRN & \\
\hline CHEMBL3929377 & 1641253 & 6.983 & 7.0621 & TRN & \\
\hline CHEMBL3925846 & 1641253 & 6.0 & \multicolumn{2}{|c|}{8.687000000000001} & TRN \\
\hline CHEMBL3937591 & 1641253 & 6.6596 & 6.7353 & TRN & \\
\hline CHEMBL3910463 & 1641253 & 7.8041 & 8.1594 & TRN & \\
\hline CHEMBL3923115 & 1641253 & 10.2924 & 8.727 & TRN & \\
\hline CHEMBL3634760 & 1641253 & 10.8861 & 9.1489 & TRN & \\
\hline CHEMBL3923697 & 1641253 & 10.0 & 9.23 & TRN & \\
\hline CHEMBL 3918555 & 1641253 & 6.0 & 8.4031 & TRN & \\
\hline CHEMBL3974781 & 1641253 & 7.0092 & 8.7636 & TST & \\
\hline CHEMBL3899964 & 1641253 & 10.6778 & 9.5419 & TRN & \\
\hline CHEMBL3955565 & 1641253 & 9.0066 & 9.3395 & TRN & \\
\hline CHEMBL 3634793 & 1641253 & 6.0 & 6.1906 & TRN & \\
\hline CHEMBL3973525 & 1641253 & 10.3979 & 8.6232 & TRN & \\
\hline CHEMBL3943201 & 1641253 & 9.5229 & 9.3428 & TST & \\
\hline CHEMBL3921516 & 1641253 & 6.0 & 7.68 & TRN & \\
\hline CHEMBL3967318 & 1641253 & 6.0921 & 4.8927 & TST & \\
\hline CHEMBL3890885 & 1641253 & 9.9706 & 10.1134 & TRN & \\
\hline CHEMBL3934124 & 1641253 & 10.0177 & 9.5867 & TRN & \\
\hline CHEMBL3634769 & 1641253 & 10.8239 & 8.972000 & 0000000001 & TST \\
\hline CHEMBL3937665 & 1641253 & 9.585 & 9.8159 & TRN & \\
\hline CHEMBL3941449 & 1641253 & 7.7328 & 7.3282 & TST & \\
\hline CHEMBL3978766 & 1641253 & 10.7212 & 10.0017 & TRN & \\
\hline CHEMBL3926542 & 1641253 & 10.5376 & 9.7135 & TRN & \\
\hline CHEMBL3985979 & 1641253 & 6.0 & 7.3491 & TRN & \\
\hline CHEMBL3957209 & 1641253 & 9.5784 & 7.9442 & TRN & \\
\hline CHEMBL3971047 & 1641253 & 6.0 & 8.1114 & TRN & \\
\hline
\end{tabular}


Supplemental Table S2.txt

\begin{tabular}{|c|c|c|c|c|c|}
\hline CHEMBL3949620 & 1641253 & 10.8861 & 9.2416 & TRN & \\
\hline CHEMBL3953052 & 1641253 & 6.0 & 7.7293 & TRN & \\
\hline CHEMBL3893927 & 1641253 & 6.0 & 9.3427 & TRN & \\
\hline CHEMBL3634765 & 1641253 & 8.4828 & 7.8577 & TRN & \\
\hline CHEMBL3901069 & 1641253 & 10.2518 & 9.0886 & TRN & \\
\hline CHEMBL3951910 & 1641253 & 5.8239 & 6.4199 & TRN & \\
\hline CHEMBL3922340 & 1641253 & 8.061 & 6.6636 & TST & \\
\hline CHEMBL3935240 & 1641253 & 6.1325 & 6.4225 & TST & \\
\hline CHEMBL3909060 & 1641253 & 9.2549 & 8.3294 & TRN & \\
\hline CHEMBL3920391 & 1641253 & 7.4815 & 7.2179 & TST & \\
\hline CHEMBL3634768 & 1641253 & 9.6498 & 9.4936 & TRN & \\
\hline CHEMBL3976240 & 1641253 & 9.209 & 9.9145 & TRN & \\
\hline CHEMBL3924978 & 1641253 & 7.51 & 6.6477 & TST & \\
\hline CHEMBL3895992 & 1641253 & 10.5376 & 9.6759 & TRN & \\
\hline CHEMBL3961362 & 1641253 & 10.0706 & 9.7763 & TRN & \\
\hline CHEMBL3973653 & 1641253 & 10.2218 & 10.0336 & TRN & \\
\hline CHEMBL3899646 & 1641253 & 6.082999 & 799999999 & 99 & 7.5583 \\
\hline CHEMBL3980997 & 1641253 & 5.9586 & 7.3502 & TST & \\
\hline CHEMBL3889536 & 1641253 & 9.3883 & 8.5828 & TST & \\
\hline CHEMBL3948867 & 1641253 & 10.2596 & 10.1887 & TRN & \\
\hline CHEMBL3926312 & 1641253 & 8.8894 & 8.1237 & TST & \\
\hline CHEMBL3921569 & 1641253 & 9.7959 & 9.3733 & TRN & \\
\hline CHEMBL3954344 & 1641253 & 9.5467 & 10.1631 & TRN & \\
\hline CHEMBL3955675 & 1641253 & 10.2924 & 10.1351 & TRN & \\
\hline CHEMBL3933778 & 1641253 & 8.556000 & 00000000 & 91 & 8.4614 \\
\hline CHEMBL3919641 & 1641253 & 10.1024 & 10.3627 & TRN & \\
\hline CHEMBL3974232 & 1641253 & 8.4089 & 8.4927 & TST & \\
\hline CHEMBL3921989 & 1641253 & 7.5406 & 8.0524 & TST & \\
\hline CHEMBL3922631 & 1641253 & 6.9136 & 7.0791 & TST & \\
\hline CHEMBL3634791 & 1641253 & 7.9355 & 7.6846 & TST & \\
\hline CHEMBL3897205 & 1641253 & 10.5229 & 9.3849 & TRN & \\
\hline CHEMBL3914022 & 1641253 & 11.3979 & 10.7381 & TRN & \\
\hline CHEMBL3967325 & 1641253 & 10.2596 & 9.7587 & TRN & \\
\hline CHEMBL3962686 & 1641253 & 9.8827 & 8.3995 & TRN & \\
\hline CHEMBL3950139 & 1641253 & 9.1445 & 9.248 & TST & \\
\hline CHEMBL3634776 & 1641253 & 7.5072 & 7.0534 & TRN & \\
\hline CHEMBL3914452 & 1641253 & 9.3536 & 9.4046 & TST & \\
\hline CHEMBL3972762 & 1641253 & 8.1898 & 7.2247 & TST & \\
\hline CHEMBL3945080 & 1641253 & 9.2782 & 10.2203 & TRN & \\
\hline CHEMBL3972194 & 1641253 & 7.9747 & 7.9723 & TRN & \\
\hline CHEMBL3915485 & 1641253 & 10.1192 & 8.41 & TRN & \\
\hline CHEMBL3951436 & 1641253 & 8.1451 & 7.4727 & TST & \\
\hline CHEMBL3929444 & 1641253 & 8.8697 & 8.62 & TRN & \\
\hline CHEMBL573107 & 954957 & 4.2336 & 4.2057 & TRN & \\
\hline CHEMBL65 & 954957 & 6.3856 & 6.3997 & TRN & \\
\hline CHEMBL483849 & 954957 & 0.7662 & 2.5878 & TST & \\
\hline CHEMBL412142 & 954957 & 4.5645 & 4.4707 & TRN & \\
\hline CHEMBL221137 & 954957 & 4.6196 & 4.6984 & TST & \\
\hline
\end{tabular}




\begin{tabular}{|c|c|c|c|c|c|}
\hline & & & & & \\
\hline CHEMBL379975 & 954957 & 4.4856 & 4.5919 & TRN & \\
\hline CHEMBL512504 & 954957 & 4.2861 & 4.3305 & TRN & \\
\hline CHEMBL188678 & 954957 & 4.1928 & 4.2676 & TRN & \\
\hline CHEMBL 9470 & 954957 & 6.1645 & 5.2955 & TST & \\
\hline CHEMBL1404918 & 954957 & 2.9062 & 2.9078 & TRN & \\
\hline CHEMBL300389 & 954957 & 7.2546 & 7.1669 & TRN & \\
\hline CHEMBL515416 & 954957 & 4.4116 & 4.6761 & TRN & \\
\hline CHEMBL449158 & 954957 & 5.99 & 6.1381 & TST & \\
\hline CHEMBL1516890 & 954957 & 4.4156 & 4.4023 & TRN & \\
\hline CHEMBL151176 & 954957 & 6.5044 & 5.7584 & TRN & \\
\hline CHEMBL191334 & 954957 & 3.1993 & 3.1071 & TRN & \\
\hline CHEMBL577784 & 954957 & 3.967 & 4.0121 & TRN & \\
\hline CHEMBL3199475 & 954957 & 4.7603 & 4.8367 & TRN & \\
\hline CHEMBL 222102 & 954957 & 3.7703 & 3.8403 & TRN & \\
\hline CHEMBL135561 & 954957 & 4.5614 & 4.6927 & TRN & \\
\hline CHEMBL 2137530 & 954957 & 4.4566 & 4.9985 & TRN & \\
\hline CHEMBL102714 & 954957 & 3.3986 & 3.7211 & TRN & \\
\hline CHEMBL258844 & 954957 & 5.5273 & 5.2206 & TRN & \\
\hline CHEMBL558642 & 954957 & 3.9239 & 3.9791 & TRN & \\
\hline CHEMBL509032 & 954957 & 4.6127 & 4.3655 & TRN & \\
\hline CHEMBL259181 & 954957 & 3.4216 & 3.8751 & TRN & \\
\hline CHEMBL255342 & 954957 & 3.3234 & 3.4974 & TRN & \\
\hline CHEMBL1357247 & 954957 & 3.3365 & 3.5022 & TRN & \\
\hline CHEMBL 2005886 & 954957 & 5.4413 & 5.3816 & TRN & \\
\hline CHEMBL 399530 & 954957 & 3.945 & 4.0966 & TRN & \\
\hline CHEMBL209148 & 954957 & 3.6813 & 3.7574 & TRN & \\
\hline CHEMBL514499 & 954957 & 6.671 & 6.7717 & TRN & \\
\hline CHEMBL392695 & 954957 & 5.266 & 5.7828 & TRN & \\
\hline CHEMBL92309 & 954957 & 2.8002 & 3.2051 & TST & \\
\hline CHEMBL 2134202 & 954957 & 4.4758 & 4.371 & TRN & \\
\hline CHEMBL1256459 & 954957 & 7.1815 & 7.227 & TRN & \\
\hline CHEMBL3392440 & 954957 & 4.0966 & 3.9149 & TRN & \\
\hline CHEMBL3349342 & 954957 & 4.7841 & 4.5827 & TRN & \\
\hline CHEMBL1242367 & 954957 & 4.8563 & 4.7944 & TRN & \\
\hline CHEMBL189584 & 954957 & 3.8055 & 3.4528 & TRN & \\
\hline CHEMBL1970879 & 954957 & 5.6026 & 5.3585 & TRN & \\
\hline CHEMBL210618 & 954957 & 3.3556 & 3.0668 & TRN & \\
\hline CHEMBL472940 & 954957 & 3.7182 & 3.8181 & TRN & \\
\hline CHEMBL1230020 & 954957 & 3.6058 & 3.5551 & TRN & \\
\hline CHEMBL1643959 & 954957 & 4.2871 & 4.0118 & TRN & \\
\hline CHEMBL1909414 & 954957 & 3.3143 & 3.45399 & 99999999997 & TST \\
\hline CHEMBL585951 & 954957 & 5.7425 & 5.979 & TRN & \\
\hline CHEMBL217354 & 954957 & 5.7112 & 5.5876 & TRN & \\
\hline CHEMBL1186585 & 954957 & 4.4335 & 4.2717 & TRN & \\
\hline CHEMBL213100 & 954957 & 5.7299 & 5.6826 & TRN & \\
\hline CHEMBL202721 & 954957 & 4.2425 & $4.4860 e$ & 0000000001 & TS \\
\hline CHEMBL2363137 & 954957 & 5.1811 & 4.4408 & TST & \\
\hline CHEMBL1788116 & 954957 & 4.6989 & 4.8586 & TST & \\
\hline
\end{tabular}




\begin{tabular}{|c|c|c|c|c|c|}
\hline \multicolumn{6}{|c|}{ Supplemental Table S2.txt } \\
\hline CHEMBL192566 & 954957 & 7.1534 & 7.0376 & TST & \\
\hline CHEMBL483847 & 954957 & 4.1097 & 4.5902 & TST & \\
\hline CHEMBL1190711 & 954957 & 4.3086 & 4.4087 & TST & \\
\hline CHEMBL240954 & 954957 & 3.0483 & 3.5504 & TST & \\
\hline CHEMBL379300 & 954957 & 6.6458 & 6.1238 & TST & \\
\hline CHEMBL393929 & 954957 & 3.7647 & 3.6907 & TST & \\
\hline CHEMBL1271244 & 674717 & 8.0 & 7.2952 & TST & \\
\hline CHEMBL1270935 & 674717 & 7.3979 & 7.3926 & TRN & \\
\hline CHEMBL582044 & 674717 & 4.4202 & 5.5973 & TST & \\
\hline CHEMBL1271344 & 674717 & 7.5229 & 6.9991 & TST & \\
\hline CHEMBL1270337 & 674717 & 7.3979 & 7.2906 & TRN & \\
\hline CHEMBL1270629 & 674717 & 7.699 & 7.58200 & 0000000001 & TRN \\
\hline CHEMBL1270934 & 674717 & 6.0 & 6.9075 & TRN & \\
\hline CHEMBL1271037 & 674717 & 8.0 & 7.5877 & TRN & \\
\hline CHEMBL1270527 & 674717 & 6.0 & 7.0166 & TST & \\
\hline CHEMBL1270240 & 674717 & 7.699 & 6.9727 & TRN & \\
\hline CHEMBL1270529 & 674717 & 7.5229 & 7.5963 & TRN & \\
\hline CHEMBL1270239 & 674717 & 7.0969 & 7.545 & TRN & \\
\hline CHEMBL1270530 & 674717 & 7.1549 & 7.0816 & TRN & \\
\hline CHEMBL1270338 & 674717 & 7.5229 & 7.3931 & TRN & \\
\hline CHEMBL1270029 & 674717 & 8.0 & 7.4016 & TRN & \\
\hline CHEMBL1270631 & 674717 & 7.699 & 7.0166 & TRN & \\
\hline CHEMBL1270936 & 674717 & 7.3872 & 6.8606 & TRN & \\
\hline CHEMBL1270833 & 674717 & 6.585 & 6.9344 & TRN & \\
\hline CHEMBL1270526 & 674717 & 7.9208 & 7.2022 & TRN & \\
\hline CHEMBL1269920 & 674717 & 7.699 & 7.3694 & TRN & \\
\hline CHEMBL1270628 & 674717 & 7.699 & 7.3442 & TST & \\
\hline CHEMBL1271346 & 674717 & 7.699 & 7.5686 & TRN & \\
\hline CHEMBL1269919 & 674717 & 6.0458 & 6.91100 & 00000000005 & TRN \\
\hline CHEMBL1270834 & 674717 & 6.0 & 7.1048 & TRN & \\
\hline CHEMBL1271343 & 674717 & 6.7696 & 6.3206 & TRN & \\
\hline CHEMBL1270435 & 674717 & 8.0 & 7.3827 & TRN & \\
\hline CHEMBL1270431 & 674717 & 7.0969 & 6.355 & TRN & \\
\hline CHEMBL1271245 & 674717 & 7.699 & 6.9632 & TRN & \\
\hline CHEMBL1270339 & 674717 & 7.1549 & 7.3097 & TRN & \\
\hline CHEMBL1271450 & 674717 & 7.5229 & 7.3411 & TST & \\
\hline CHEMBL1270134 & 674717 & 7.2218 & 7.3072 & TRN & \\
\hline CHEMBL1269921 & 674717 & 8.0 & 7.9795 & TRN & \\
\hline CHEMBL1271036 & 674717 & 7.5229 & 7.6751 & TRN & \\
\hline CHEMBL1270238 & 674717 & 7.301 & 7.136 & TRN & \\
\hline CHEMBL1271141 & 674717 & 8.0 & 7.6103 & TRN & \\
\hline CHEMBL1270433 & 674717 & 7.5229 & 7.3461 & TST & \\
\hline CHEMBL1270026 & 674717 & 7.0458 & 7.1406 & TRN & \\
\hline CHEMBL1270832 & 674717 & 7.3979 & 7.6276 & TST & \\
\hline CHEMBL1270630 & 674717 & 6.0 & 6.5955 & TRN & \\
\hline CHEMBL1271451 & 674717 & 5.8477 & 5.8033 & TRN & \\
\hline CHEMBL1270027 & 674717 & 7.0458 & 7.4108 & TRN & \\
\hline CHEMBL 291784 & 674717 & 5.4634 & 5.4616 & TRN & \\
\hline
\end{tabular}




\begin{tabular}{|c|c|c|c|c|c|}
\hline \multicolumn{6}{|c|}{ Supplemental Table S2.txt } \\
\hline CHEMBL1270334 & 674717 & 7.8861 & 7.0015 & TRN & \\
\hline CHEMBL1271246 & 674717 & 6.0 & 6.7947 & TRN & \\
\hline CHEMBL1270729 & 674717 & 7.301 & 7.5093 & TST & \\
\hline CHEMBL1270241 & 674717 & 6.699 & 6.7715 & TRN & \\
\hline CHEMBL568115 & 674717 & 7.699 & 6.7394 & TST & \\
\hline CHEMBL1270336 & 674717 & 7.0969 & 7.1727 & TST & \\
\hline CHEMBL1270028 & 674717 & 6.9208 & 7.4027 & TRN & \\
\hline CHEMBL584695 & 674717 & 8.0 & 7.0976 & TST & \\
\hline CHEMBL1271452 & 674717 & 7.699 & 7.87299 & 9999999999 & TRN \\
\hline CHEMBL1271140 & 674717 & 7.2218 & 6.8273 & TST & \\
\hline CHEMBL1271345 & 674717 & 6.4815 & 6.7212 & TRN & \\
\hline CHEMBL1270432 & 674717 & 6.0 & 6.4852 & TRN & \\
\hline CHEMBL1271142 & 674717 & 7.3979 & 7.7179 & TRN & \\
\hline CHEMBL1270135 & 674717 & 7.0 & 7.4079 & TRN & \\
\hline CHEMBL1270434 & 674717 & 7.0458 & 7.0086 & TST & \\
\hline CHEMBL1269918 & 674717 & 5.9066 & 6.396 & TST & \\
\hline CHEMBL1271453 & 674717 & 8.0 & 7.7805 & TRN & \\
\hline CHEMBL1270133 & 674717 & 6.9586 & 7.176 & TRN & \\
\hline CHEMBL1270727 & 674717 & 7.5229 & 7.3514 & TRN & \\
\hline CHEMBL1270436 & 674717 & 7.5229 & 7.5436 & TRN & \\
\hline CHEMBL1270730 & 674717 & 7.301 & 7.4776 & TST & \\
\hline CHEMBL1270136 & 674717 & 6.699 & 7.2867 & TRN & \\
\hline CHEMBL3700974 & 1528827 & 8.4437 & 8.6232 & TRN & \\
\hline CHEMBL3700941 & 1528827 & 8.0605 & 8.7468 & TST & \\
\hline CHEMBL3978629 & 1528827 & 8.1675 & 8.4788 & TRN & \\
\hline CHEMBL3704376 & 1528827 & 8.1549 & 8.3576 & TRN & \\
\hline CHEMBL3907198 & 1528827 & 9.1549 & 8.7294 & TRN & \\
\hline CHEMBL3700982 & 1528827 & 8.1675 & 8.1549 & TRN & \\
\hline CHEMBL3948732 & 1528827 & 8.2366 & 7.824 & TRN & \\
\hline CHEMBL3700980 & 1528827 & 8.5376 & 8.3709 & TRN & \\
\hline CHEMBL3972351 & 1528827 & 7.6383 & 8.794 & TST & \\
\hline CHEMBL3700958 & 1528827 & 8.7696 & 8.6012 & TRN & \\
\hline CHEMBL3700977 & 1528827 & 8.7212 & 8.8031 & TRN & \\
\hline CHEMBL3700978 & 1528827 & 8.4437 & 8.7955 & TRN & \\
\hline CHEMBL3700966 & 1528827 & 8.8861 & 8.5557 & TRN & \\
\hline CHEMBL3704383 & 1528827 & 8.3098 & 8.3477 & TRN & \\
\hline CHEMBL3700907 & 1528827 & 8.6576 & 9.3408 & TST & \\
\hline CHEMBL3933149 & 1528827 & 8.3979 & 7.9788 & TRN & \\
\hline CHEMBL 3704374 & 1528827 & 8.0809 & 8.1793 & TRN & \\
\hline CHEMBL 3950274 & 1528827 & 9.0 & 8.8076 & TRN & \\
\hline CHEMBL3700924 & 1528827 & 9.0969 & 9.4065 & TRN & \\
\hline CHEMBL3893546 & 1528827 & 7.9208 & 8.3548 & TRN & \\
\hline CHEMBL3700968 & 1528827 & 8.699 & 8.5678 & TRN & \\
\hline CHEMBL3704388 & 1528827 & 7.4949 & 9.1937 & TST & \\
\hline CHEMBL3924212 & 1528827 & 9.5229 & 8.65299 & 9999999999 & TRN \\
\hline CHEMBL 3969002 & 1528827 & 8.1308 & 8.1247 & TRN & \\
\hline CHEMBL3700917 & 1528827 & 9.4089 & 9.3744 & TRN & \\
\hline CHEMBL3958978 & 1528827 & 7.7959 & 7.858 & TRN & \\
\hline
\end{tabular}


Supplemental Table S2.txt

\begin{tabular}{|c|c|c|c|c|}
\hline CHEMBL3900186 & 1528827 & 7.9586 & 8.0787 & TRN \\
\hline CHEMBL3704375 & 1528827 & 8.1739 & 8.5625 & TRN \\
\hline CHEMBL3704382 & 1528827 & 8.3768 & 8.2542 & TRN \\
\hline CHEMBL3700983 & 1528827 & 8.1024 & 8.1388 & TRN \\
\hline CHEMBL 3704377 & 1528827 & 7.5376 & 8.0076 & TRN \\
\hline CHEMBL3912452 & 1528827 & 8.6778 & 8.0975 & TRN \\
\hline CHEMBL3700932 & 1528827 & 9.5229 & 9.4755 & TRN \\
\hline CHEMBL3937444 & 1528827 & 7.5376 & 7.8081 & TRN \\
\hline CHEMBL3945005 & 1528827 & 7.8861 & 7.8422 & TRN \\
\hline CHEMBL3939691 & 1528827 & 8.2366 & 8.0315 & TRN \\
\hline CHEMBL 3704370 & 1528827 & 8.0132 & 8.057 & TRN \\
\hline CHEMBL3939271 & 1528827 & 9.301 & 8.6147 & TST \\
\hline CHEMBL3942021 & 1528827 & 7.3565 & 8.1081 & TST \\
\hline CHEMBL 3704380 & 1528827 & 7.5229 & 8.3386 & TST \\
\hline CHEMBL 3704378 & 1528827 & 8.2007 & 8.2655 & TRN \\
\hline CHEMBL3700934 & 1528827 & 9.2218 & 9.0103 & TRN \\
\hline CHEMBL3700909 & 1528827 & 7.9586 & 9.2186 & TST \\
\hline CHEMBL3973447 & 1528827 & 7.7212 & 8.9912 & TST \\
\hline CHEMBL3951470 & 1528827 & 9.3979 & 8.3921 & TST \\
\hline CHEMBL3704395 & 1528827 & 7.4815 & 8.9146 & TST \\
\hline CHEMBL3965865 & 1528827 & 7.8861 & 8.0127 & TST \\
\hline CHEMBL3704373 & 1528827 & 8.1024 & 8.1093 & TRN \\
\hline CHEMBL3704397 & 1528827 & 7.5086 & 9.3248 & TST \\
\hline CHEMBL3704393 & 1528827 & 7.6198 & 8.997 & TST \\
\hline CHEMBL 3890594 & 1528827 & 8.3872 & 8.0024 & TRN \\
\hline CHEMBL 3700975 & 1528827 & 8.7696 & 9.0175 & TRN \\
\hline CHEMBL3700965 & 1528827 & 8.6778 & 8.582 & TRN \\
\hline CHEMBL3700940 & 1528827 & 8.0 & 8.4689 & TRN \\
\hline CHEMBL3700920 & 1528827 & 9.0969 & 8.5685 & TST \\
\hline CHEMBL3704385 & 1528827 & 7.5686 & 9.167 & TST \\
\hline CHEMBL3700972 & 1528827 & 8.699 & 8.6821 & TRN \\
\hline CHEMBL3700963 & 1528827 & 8.4202 & 8.5156 & TRN \\
\hline CHEMBL3968228 & 1528827 & 7.9508 & 7.9136 & TRN \\
\hline CHEMBL3704372 & 1528827 & 8.1612 & 8.165 & TRN \\
\hline CHEMBL3704381 & 1528827 & 8.1612 & 8.1113 & TRN \\
\hline CHEMBL3700969 & 1528827 & 9.0969 & 8.6997 & TRN \\
\hline CHEMBL3903222 & 1528827 & 7.3516 & 8.138 & TRN \\
\hline CHEMBL3704379 & 1528827 & 7.7696 & 8.0587 & TRN \\
\hline CHEMBL3700911 & 1528827 & 8.0706 & 8.8244 & TST \\
\hline CHEMBL3335175 & 1433007 & 3.301 & 3.3105 & TRN \\
\hline CHEMBL3335142 & 1433007 & 3.301 & 3.2923 & TRN \\
\hline CHEMBL3335167 & 1433007 & 3.301 & 3.3467 & TRN \\
\hline CHEMBL3335159 & 1433007 & 3.301 & \multicolumn{2}{|c|}{3.2289999999999996} \\
\hline CHEMBL3335141 & 1433007 & 4.5086 & \multicolumn{2}{|c|}{4.4719999999999995} \\
\hline CHEMBL3335120 & 1433007 & 3.301 & 4.0852 & TST \\
\hline CHEMBL3335129 & 1433007 & 4.4559 & 4.4087 & TRN \\
\hline CHEMBL3335149 & 1433007 & 6.0969 & 6.1704 & TRN \\
\hline CHEMBL3335170 & 1433007 & 4.4202 & 4.0879 & TST \\
\hline
\end{tabular}


Supplemental Table S2.txt

\begin{tabular}{|c|c|c|c|c|}
\hline CHEMBL3335124 & 1433007 & 6.0969 & 6.0873 & TRN \\
\hline CHEMBL3335153 & 1433007 & 7.0 & 6.9591 & TRN \\
\hline CHEMBL3335152 & 1433007 & 4.4685 & 5.0104 & TST \\
\hline CHEMBL3334507 & 1433007 & 4.3468 & 4.215 & TRN \\
\hline CHEMBL3335160 & 1433007 & 3.301 & 3.2918 & TRN \\
\hline CHEMBL3335173 & 1433007 & 3.301 & \multicolumn{2}{|c|}{3.2560000000000002} \\
\hline CHEMBL3335146 & 1433007 & 5.6021 & 5.5722 & TRN \\
\hline CHEMBL3335121 & 1433007 & 3.301 & 3.366 & TRN \\
\hline CHEMBL3335158 & 1433007 & 4.3768 & 4.4261 & TRN \\
\hline CHEMBL3335156 & 1433007 & 3.301 & 3.2985 & TRN \\
\hline CHEMBL3335178 & 1433007 & 3.301 & 3.2462 & TRN \\
\hline CHEMBL3335154 & 1433007 & 4.5528 & 4.5619 & TRN \\
\hline CHEMBL3335127 & 1433007 & 5.4685 & 5.4937 & TRN \\
\hline CHEMBL3335123 & 1433007 & 5.5086 & 5.5959 & TRN \\
\hline CHEMBL3335145 & 1433007 & 4.8861 & 4.8415 & TRN \\
\hline CHEMBL3335126 & 1433007 & 5.4815 & 5.455 & TRN \\
\hline CHEMBL3335176 & 1433007 & 3.301 & 3.2767 & TRN \\
\hline CHEMBL3335144 & 1433007 & 6.2218 & 6.3063 & TRN \\
\hline CHEMBL3335119 & 1433007 & 3.301 & 4.224 & TST \\
\hline CHEMBL3335128 & 1433007 & 5.8239 & 5.8621 & TRN \\
\hline CHEMBL3335150 & 1433007 & 6.0 & 5.4698 & TST \\
\hline CHEMBL3335157 & 1433007 & 4.4559 & 4.4261 & TRN \\
\hline CHEMBL3335155 & 1433007 & 3.301 & 3.528 & TRN \\
\hline CHEMBL3335164 & 1433007 & 3.301 & 3.3236 & TRN \\
\hline CHEMBL3335165 & 1433007 & 3.301 & 3.3514 & TRN \\
\hline CHEMBL3335162 & 1433007 & 3.301 & 3.3118 & TRN \\
\hline CHEMBL3335148 & 1433007 & 4.699 & 4.7272 & TRN \\
\hline CHEMBL3335140 & 1433007 & 4.7959 & 4.7891 & TRN \\
\hline CHEMBL3335168 & 1433007 & 4.4685 & 4.4393 & TRN \\
\hline CHEMBL 3335174 & 1433007 & 3.301 & 3.3221 & TST \\
\hline CHEMBL3335161 & 1433007 & 4.301 & 3.091 & TST \\
\hline CHEMBL3335172 & 1433007 & 3.301 & 4.1586 & TST \\
\hline CHEMBL3335151 & 1433007 & 5.2291 & 5.1699 & TST \\
\hline CHEMBL3335169 & 1433007 & 3.301 & 3.3112 & TRN \\
\hline CHEMBL3335171 & 1433007 & 3.301 & 3.0009 & TST \\
\hline CHEMBL3335122 & 1433007 & 4.3979 & 4.3463 & TRN \\
\hline CHEMBL3335166 & 1433007 & 3.301 & 3.755 & TST \\
\hline CHEMBL3335163 & 1433007 & 3.301 & 2.6598 & TST \\
\hline CHEMBL3335143 & 1433007 & 4.9586 & 4.9325 & TRN \\
\hline CHEMBL3335147 & 1433007 & 3.301 & 3.2836 & TRN \\
\hline CHEMBL3335177 & 1433007 & 3.301 & 2.7473 & TST \\
\hline CHEMBL3335125 & 1433007 & 6.0 & 5.9085 & TRN \\
\hline CHEMBL283162 & 56498 & 9.0 & 8.4211 & TRN \\
\hline CHEMBL20344 & 56498 & 6.8861 & 7.5199 & TRN \\
\hline CHEMBL435756 & 56498 & 8.2218 & 8.4062 & TRN \\
\hline CHEMBL20927 & 56498 & 7.1549 & 7.7801 & TRN \\
\hline CHEMBL 20701 & 56498 & 6.9208 & 8.0869 & TRN \\
\hline CHEMBL20178 & 56498 & 6.6021 & 7.6071 & TRN \\
\hline
\end{tabular}




\begin{tabular}{|c|c|c|c|c|c|}
\hline \multicolumn{6}{|c|}{ Supplemental Table S2.txt } \\
\hline CHEMBL 20003 & 56498 & 8.1549 & 8.4113 & TRN & \\
\hline CHEMBL 281780 & 56498 & 7.0969 & 8.032 & TRN & \\
\hline CHEMBL 20267 & 56498 & 8.3979 & 8.2518 & TRN & \\
\hline CHEMBL 20194 & 56498 & 8.301 & 6.7304 & TRN & \\
\hline CHEMBL282666 & 56498 & 6.301 & 6.8509 & TST & \\
\hline CHEMBL 20163 & 56498 & 8.5229 & 8.4295 & TRN & \\
\hline CHEMBL 277678 & 56498 & 7.8239 & 8.3138 & TRN & \\
\hline CHEMBL 20359 & 56498 & 6.4318 & 8.4163 & TST & \\
\hline CHEMBL429066 & 56498 & 8.5229 & 8.3391 & TRN & \\
\hline CHEMBL 283790 & 56498 & 7.2924 & 8.1289 & TRN & \\
\hline CHEMBL19640 & 56498 & 9.2218 & 8.2266 & TRN & \\
\hline CHEMBL 279665 & 56498 & 8.699 & 8.441 & TRN & \\
\hline CHEMBL 21224 & 56498 & 8.2218 & 8.1801 & TRN & \\
\hline CHEMBL19747 & 56498 & 9.1549 & 8.3071 & TRN & \\
\hline CHEMBL 283365 & 56498 & 6.0 & 6.5058 & TRN & \\
\hline CHEMBL 20196 & 56498 & 6.5229 & 7.3155 & TST & \\
\hline CHEMBL20019 & 56498 & 9.1549 & 8.5892 & TRN & \\
\hline CHEMBL282495 & 56498 & 7.6021 & 7.581 & TRN & \\
\hline CHEMBL418370 & 56498 & 6.0 & 7.6064 & TST & \\
\hline CHEMBL 20877 & 56498 & 8.301 & 8.0583 & TRN & \\
\hline CHEMBL 283113 & 56498 & 6.9208 & 8.0531 & TST & \\
\hline CHEMBL418556 & 56498 & 7.8239 & 7.6372 & TRN & \\
\hline CHEMBL20591 & 56498 & 7.0 & 7.11700 & 0000000001 & TRN \\
\hline CHEMBL19917 & 56498 & 7.1249 & 7.7443 & TRN & \\
\hline CHEMBL 20418 & 56498 & 8.3979 & 8.094 & TRN & \\
\hline CHEMBL19721 & 56498 & 6.8239 & 8.1144 & TRN & \\
\hline CHEMBL 283339 & 56498 & 8.3979 & 8.283 & TRN & \\
\hline CHEMBL281139 & 56498 & 6.9586 & 7.1742 & TST & \\
\hline CHEMBL20323 & 56498 & 8.1549 & 8.2151 & TRN & \\
\hline CHEMBL430333 & 56498 & 7.8239 & 7.7164 & TRN & \\
\hline CHEMBL 280210 & 56498 & 8.3979 & 8.4138 & TRN & \\
\hline CHEMBL 278635 & 56498 & 7.6021 & 8.2656 & TRN & \\
\hline CHEMBL 277618 & 56498 & 8.1549 & 7.4467 & TRN & \\
\hline CHEMBL 281779 & 56498 & 9.0 & 8.3262 & TRN & \\
\hline CHEMBL 282883 & 56498 & 9.0 & 8.3374 & TRN & \\
\hline CHEMBL283152 & 56498 & 7.0 & 7.1243 & TRN & \\
\hline CHEMBL 277701 & 56498 & 9.699 & 8.3985 & TRN & \\
\hline CHEMBL282905 & 56498 & 8.2218 & 8.1919 & TRN & \\
\hline CHEMBL 20577 & 56498 & 6.0 & 7.7721 & TST & \\
\hline CHEMBL417275 & 56498 & 7.9208 & 8.2224 & TRN & \\
\hline CHEMBL 20690 & 56498 & 7.0458 & 7.8194 & TRN & \\
\hline CHEMBL 279476 & 56498 & 6.2518 & 7.7803 & TST & \\
\hline CHEMBL 277650 & 56498 & 7.8861 & 7.9743 & TRN & \\
\hline CHEMBL 20808 & 56498 & 6.4437 & 7.9938 & TST & \\
\hline CHEMBL 280683 & 56498 & 8.301 & 8.3385 & TRN & \\
\hline CHEMBL 20691 & 56498 & 7.6021 & 8.1129 & TRN & \\
\hline CHEMBL 279021 & 56498 & 7.301 & 7.004 & TRN & \\
\hline CHEMBL 277029 & 56498 & 8.301 & 8.2459 & TRN & \\
\hline
\end{tabular}




\begin{tabular}{|c|c|c|c|c|c|}
\hline & & \multicolumn{4}{|c|}{ Supplemental Table S2.txt } \\
\hline CHEMBL 279084 & 56498 & 6.699 & 6.7935 & TRN & \\
\hline CHEMBL20195 & 56498 & 9.5229 & 8.395 & TRN & \\
\hline CHEMBL 279893 & 56498 & 7.5229 & 7.7518 & TRN & \\
\hline CHEMBL 20208 & 56498 & 8.301 & 8.4373 & TRN & \\
\hline CHEMBL279664 & 56498 & 7.699 & 7.3386 & TRN & \\
\hline CHEMBL 20343 & 56498 & 8.0458 & 8.2741 & TRN & \\
\hline CHEMBL19801 & 56498 & 8.0 & 7.2835 & TRN & \\
\hline CHEMBL 20033 & 56498 & 7.699 & 7.5426 & TRN & \\
\hline CHEMBL 20914 & 56498 & 6.0 & 8.0428 & TST & \\
\hline CHEMBL 278072 & 56498 & 8.1549 & 8.021 & TRN & \\
\hline CHEMBL 20141 & 56498 & 7.0 & 6.9735 & TRN & \\
\hline CHEMBL280401 & 56498 & 7.9208 & 8.4986 & TRN & \\
\hline CHEMBL20325 & 56498 & 6.0 & 7.1264 & TST & \\
\hline CHEMBL 20644 & 56498 & 7.8239 & 7.9802 & TST & \\
\hline CHEMBL 277245 & 56498 & 7.3979 & 7.49100 & 00000000005 & TST \\
\hline CHEMBL 21026 & 56498 & 7.1249 & 7.9965 & TST & \\
\hline CHEMBL20293 & 56498 & 7.5229 & 8.3403 & TST & \\
\hline CHEMBL 279234 & 56498 & 8.0458 & 8.3381 & TST & \\
\hline CHEMBL 283525 & 56498 & 7.9208 & 8.4141 & TST & \\
\hline CHEMBL19991 & 56498 & 7.3468 & 7.2988 & TST & \\
\hline CHEMBL19947 & 56498 & 8.301 & 7.3124 & TST & \\
\hline CHEMBL1824938 & 767700 & 6.0273 & 6.3195 & TRN & \\
\hline CHEMBL1824945 & 767700 & 7.0969 & 6.8236 & TRN & \\
\hline CHEMBL1824954 & 767700 & 6.5452 & 6.5263 & TRN & \\
\hline CHEMBL1825182 & 767700 & 6.1186 & 6.8258 & TST & \\
\hline CHEMBL1824953 & 767700 & 5.567 & 6.3976 & TRN & \\
\hline CHEMBL1824952 & 767700 & 5.9281 & 6.2779 & TRN & \\
\hline CHEMBL1824961 & 767700 & 8.5229 & 8.2108 & TRN & \\
\hline CHEMBL1824943 & 767700 & 7.9208 & 6.9497 & TST & \\
\hline CHEMBL1825189 & 767700 & 8.301 & 7.3896 & TST & \\
\hline CHEMBL1825177 & 767700 & 5.7959 & 5.2926 & TST & \\
\hline CHEMBL1824939 & 767700 & 6.0 & 5.5846 & TST & \\
\hline CHEMBL1824931 & 767700 & 7.6198 & 6.9244 & TRN & \\
\hline CHEMBL1824963 & 767700 & 6.9586 & 7.5128 & TRN & \\
\hline CHEMBL1824958 & 767700 & 5.1785 & 5.1252 & TRN & \\
\hline CHEMBL1824933 & 767700 & 6.4921 & 6.5416 & TRN & \\
\hline CHEMBL1825184 & 767700 & 6.0706 & 6.8838 & TST & \\
\hline CHEMBL1824925 & 767700 & 6.1599 & 6.2882 & TRN & \\
\hline CHEMBL1824934 & 767700 & 6.9706 & 6.8919 & TRN & \\
\hline CHEMBL1824936 & 767700 & 8.8861 & 8.8544 & TRN & \\
\hline CHEMBL1825188 & 767700 & 6.2865 & 6.9812 & TRN & \\
\hline CHEMBL1825186 & 767700 & 6.3737 & 6.9839 & TRN & \\
\hline CHEMBL1824926 & 767700 & 6.2899 & 6.8112 & TRN & \\
\hline CHEMBL1825183 & 767700 & 7.8539 & 7.5263 & TST & \\
\hline CHEMBL1825180 & 767700 & 6.9508 & 7.2861 & TRN & \\
\hline CHEMBL1824937 & 767700 & 7.2147 & 6.0858 & TST & \\
\hline CHEMBL1824959 & 767700 & 4.301 & 5.1603 & TRN & \\
\hline CHEMBL1824942 & 767700 & 6.6091 & 6.7794 & TST & \\
\hline
\end{tabular}




\begin{tabular}{|c|c|c|c|c|c|}
\hline \multirow[b]{2}{*}{ CHEMBL1825187 } & \multicolumn{5}{|c|}{ Supplemental Table S2.txt } \\
\hline & 767700 & 8.5229 & 8.0283 & TRN & \\
\hline CHEMBL1824928 & 767700 & 6.6946 & 6.8883 & TRN & \\
\hline CHEMBL1825181 & 767700 & 8.699 & 8.8592 & TRN & \\
\hline CHEMBL1825185 & 767700 & 6.4949 & 6.7961 & TRN & \\
\hline CHEMBL1824940 & 767700 & 6.9208 & 5.82600 & 00000000005 & TST \\
\hline CHEMBL1824951 & 767700 & 6.34200 & 00000000 & 6.4282 & TRN \\
\hline CHEMBL1824949 & 767700 & 6.1586 & 6.1175 & TRN & \\
\hline CHEMBL1824956 & 767700 & 7.1549 & 6.5308 & TRN & \\
\hline CHEMBL1824929 & 767700 & 7.1308 & 8.1272 & TRN & \\
\hline CHEMBL1824948 & 767700 & 6.8447 & 6.54799 & 9999999999 & TRN \\
\hline CHEMBL1825179 & 767700 & 7.5686 & 6.9828 & TRN & \\
\hline CHEMBL1824955 & 767700 & 7.2441 & 6.3941 & TRN & \\
\hline CHEMBL1824964 & 767700 & 8.0458 & 7.2294 & TST & \\
\hline CHEMBL1825178 & 767700 & 6.3063 & 6.3072 & TRN & \\
\hline CHEMBL1824935 & 767700 & 7.8539 & 7.3627 & TRN & \\
\hline CHEMBL1824944 & 767700 & 8.3979 & 7.4931 & TRN & \\
\hline CHEMBL1824962 & 767700 & 7.0969 & 7.6345 & TRN & \\
\hline CHEMBL1824957 & 767700 & 6.8182 & 7.5047 & TST & \\
\hline CHEMBL1824924 & 767700 & 6.6021 & 6.2188 & TRN & \\
\hline CHEMBL1824950 & 767700 & 6.5376 & 6.0046 & TRN & \\
\hline CHEMBL1824927 & 767700 & 6.5086 & 6.8291 & TRN & \\
\hline CHEMBL1824946 & 767700 & 7.2218 & 6.5308 & TRN & \\
\hline CHEMBL1824932 & 767700 & 7.2596 & 6.9017 & TRN & \\
\hline CHEMBL1824960 & 767700 & 7.8539 & 7.1332 & TRN & \\
\hline CHEMBL1824947 & 767700 & 6.4089 & 6.7158 & TRN & \\
\hline CHEMBL1824930 & 767700 & 7.2441 & 7.5525 & TRN & \\
\hline CHEMBL1824941 & 767700 & 5.8356 & 6.7058 & TST & \\
\hline CHEMBL1824965 & 767700 & 6.2291 & 5.2463 & TST & \\
\hline CHEMBL3978353 & 1642024 & 3.2612 & 4.2164 & TRN & \\
\hline CHEMBL3970703 & 1642024 & 4.7187 & 4.6228 & TRN & \\
\hline CHEMBL3930947 & 1642024 & 4.2612 & 4.3734 & TRN & \\
\hline CHEMBL 3040818 & 1642024 & 3.2612 & 3.8904 & TRN & \\
\hline CHEMBL 3896568 & 1642024 & 4.8827 & 4.6709 & TRN & \\
\hline CHEMBL3896598 & 1642024 & 4.4302 & 3.8438 & TST & \\
\hline CHEMBL3957743 & 1642024 & 4.63 & 4.751 & TRN & \\
\hline CHEMBL3898307 & 1642024 & 3.2612 & 3.0733 & TRN & \\
\hline CHEMBL3946301 & 1642024 & 3.2612 & 3.1705 & TRN & \\
\hline CHEMBL3952813 & 1642024 & 4.5659 & 4.2405 & TRN & \\
\hline CHEMBL3926570 & 1642024 & 4.3815 & 4.5619 & TRN & \\
\hline CHEMBL3924128 & 1642024 & 3.2612 & 3.4227 & TRN & \\
\hline CHEMBL3962581 & 1642024 & 4.3788 & 4.1468 & TRN & \\
\hline CHEMBL3927629 & 1642024 & 4.2612 & 4.5328 & TRN & \\
\hline CHEMBL3934042 & 1642024 & 3.2612 & 3.8468 & TST & \\
\hline CHEMBL3923724 & 1642024 & 4.8867 & 3.8586 & TRN & \\
\hline CHEMBL3943405 & 1642024 & 6.0 & 4.9878 & TRN & \\
\hline CHEMBL 3906624 & 1642024 & 3.2612 & 3.175 & TRN & \\
\hline CHEMBL 3908665 & 1642024 & 3.2612 & 3.6667 & TST & \\
\hline CHEMBL 3948318 & 1642024 & 3.2612 & 2.9991 & TRN & \\
\hline
\end{tabular}

Page 16690 
Supplemental Table S2.txt

\begin{tabular}{|c|c|c|c|c|}
\hline & & & & \\
\hline CHEMBL 3928416 & 542024 & 4.4299 & $\partial 861$ & \\
\hline HEMBL3905369 & 242024 & 509 & & \\
\hline 3097 & 542024 & & & \\
\hline EMBL3C & 542024 & 3.2612 & & \\
\hline AEMBL3933732 & 642024 & 3.2612 & 033 & \\
\hline AEMBL3905534 & 642024 & 3.2612 & 438 & \\
\hline AEMBL 39 & 024 & 3.2612 & & \\
\hline EMBL3 & 642024 & 3.2612 & & \\
\hline IEMBL3 & 642024 & 4.4314 & & \\
\hline AEMBL3917680 & 642024 & 3.301 & 651 & \\
\hline HEMBL3899943 & 642024 & 3.2612 & & \\
\hline HEMBL3972444 & 024 & 2612 & & \\
\hline AEMBL & 024 & 3.2612 & & \\
\hline HEMBL & 024 & 3.2612 & & \\
\hline IEMBL 3977386 & 642024 & 4.2612 & 564 & \\
\hline AEMBL 3890934 & 024 & 4.4159 & & \\
\hline HEMBL 391 & 164 & 2 & & \\
\hline HEMBL 39 & 24 & 12 & & \\
\hline 5190 & 024 & 3.2612 & & \\
\hline IEMBL 3922153 & 024 & 4.4811 & & \\
\hline IEMBL 3944732 & 24 & 2 & & \\
\hline HEMBL 394 & 164 & 2 & & \\
\hline HEMBL; & 24 & 12 & & \\
\hline AEMB & $\partial 24$ & 744 & & RN \\
\hline IEMBL3 & $\partial 24$ & 612 & & \\
\hline AEMBL 3040828 & 24 & & & \\
\hline AEMBL 3889914 & 324 & 2 & & \\
\hline IEMB & 24 & & & \\
\hline 81 & 24 & 12 & & r \\
\hline IEMBL 3903864 & 324 & 2 & & \\
\hline AEMBL 3933545 & 024 & 3.2612 & & \\
\hline EMBL & 24 & 12 & & \\
\hline 8 & 24 & 12 & & \\
\hline 61 & 24 & 12 & & \\
\hline AEMBL3933859 & 024 & 4.7647 & & \\
\hline AEMBL3910969 & 024 & 3.2612 & & \\
\hline 93 & & & & $\mathrm{RI}$ \\
\hline וסMינזו & 24 & 2 & 84 & \\
\hline AEMBL: & 24 & & & \\
\hline IEMBL 3983818 & 024 & & 35 & ST \\
\hline IEMBL 39 & 024 & 729 & & RI \\
\hline 49 & & & & \\
\hline CHEMBL 3932143 & 024 & 4.4959 & 508 & \\
\hline CHEMBL3940874 & 1642024 & 3.2612 & 851 & RD \\
\hline AEMBL3893188 & 642024 & 2612 & 024 & \\
\hline HEMBL3942830 & & & & \\
\hline CHEMBL389112 & & & 3.7123 & \\
\hline
\end{tabular}

Page 16691 
Supplemental Table S2.txt

\begin{tabular}{|c|c|c|c|c|c|}
\hline CHEMBL3914731 & 1642024 & 4.8598 & 4.1319 & TRN & \\
\hline CHEMBL3967129 & 1642024 & 3.2612 & 3.7621 & TRN & \\
\hline CHEMBL3902270 & 1642024 & 3.2612 & 3.4853 & TST & \\
\hline CHEMBL3948021 & 1642024 & 4.4893 & 4.0789 & TRN & \\
\hline CHEMBL3948518 & 1642024 & 3.2612 & 3.2095 & TRN & \\
\hline CHEMBL3891098 & 1642024 & 3.2612 & 2.9826 & TRN & \\
\hline CHEMBL3977955 & 1642024 & 4.3646 & 3.8202 & TRN & \\
\hline CHEMBL3899602 & 1642024 & 6.0 & 5.4195 & TRN & \\
\hline CHEMBL3944600 & 1642024 & 4.4281 & 4.4634 & TRN & \\
\hline CHEMBL3987110 & 1642024 & 4.4552 & 4.3652 & TST & \\
\hline CHEMBL 3956041 & 1642024 & 4.4242 & 3.3896 & TRN & \\
\hline CHEMBL3935639 & 1642024 & 4.2612 & 4.8157 & TRN & \\
\hline CHEMBL3915435 & 1642024 & 4.3366 & 4.7134 & TRN & \\
\hline CHEMBL3919168 & 1642024 & 4.8182 & 4.6017 & TST & \\
\hline CHEMBL3948020 & 1642024 & 3.2612 & 3.36899 & 99999999998 & TRN \\
\hline CHEMBL3926445 & 1642024 & 3.2612 & 3.5899 & TRN & \\
\hline CHEMBL3939245 & 1642024 & 4.8655 & 4.2832 & TRN & \\
\hline CHEMBL3979396 & 1642024 & 4.274 & 4.3456 & TRN & \\
\hline CHEMBL3937541 & 1642024 & 3.266 & 3.53899 & 99999999997 & TST \\
\hline CHEMBL3928090 & 1642024 & 4.848 & 3.8733 & TST & \\
\hline CHEMBL3940451 & 1642024 & 3.2612 & 3.5819 & TST & \\
\hline CHEMBL3911286 & 1642024 & 3.2612 & 3.3409 & TRN & \\
\hline CHEMBL3954504 & 1642024 & 4.4901 & 4.3262 & TRN & \\
\hline CHEMBL3935669 & 1642024 & 4.4438 & 4.4782 & TRN & \\
\hline CHEMBL3911797 & 1642024 & 3.2612 & 3.2478 & TRN & \\
\hline CHEMBL3913148 & 1642024 & 6.0 & 4.7085 & TRN & \\
\hline CHEMBL3900675 & 1642024 & 3.266 & 3.3287 & TST & \\
\hline CHEMBL3958572 & 1642024 & 3.2612 & 3.877 & TRN & \\
\hline CHEMBL3950374 & 1642024 & 3.2612 & 3.7395 & TST & \\
\hline CHEMBL3965099 & 1642024 & 3.2612 & 3.3357 & TRN & \\
\hline CHEMBL3955727 & 1642024 & 3.2612 & 3.5184 & TRN & \\
\hline CHEMBL3040866 & 1642024 & 4.6451 & 4.0024 & TRN & \\
\hline CHEMBL3912876 & 1642024 & 3.2612 & 3.6361 & TRN & \\
\hline CHEMBL3921114 & 1642024 & 4.2612 & 4.5521 & TRN & \\
\hline CHEMBL3906278 & 1642024 & 3.2749 & 4.1897 & TRN & \\
\hline CHEMBL3917199 & 1642024 & 3.2612 & 3.0085 & TRN & \\
\hline CHEMBL3970775 & 1642024 & 4.3132 & 4.3963 & TST & \\
\hline CHEMBL3959655 & 1642024 & 4.5188 & 4.5468 & TRN & \\
\hline CHEMBL3929820 & 1642024 & 4.8273 & 3.6294 & TST & \\
\hline CHEMBL3906466 & 1642024 & 4.593 & 4.418 & TRN & \\
\hline CHEMBL3909777 & 1642024 & 3.2612 & 3.6622 & TST & \\
\hline CHEMBL3912532 & 1642024 & 4.7817 & 3.78800 & 00000000003 & TRN \\
\hline CHEMBL3933065 & 1642024 & 3.2612 & 3.6337 & TRN & \\
\hline CHEMBL3955541 & 1642024 & 3.2612 & 3.3855 & TRN & \\
\hline CHEMBL 3040405 & 1642024 & 4.6428 & 4.0205 & TRN & \\
\hline CHEMBL1418271 & 688249 & 3.0 & 2.3057 & TRN & \\
\hline CHEMBL458328 & 688249 & 6.0799 & 3.7525 & TST & \\
\hline CHEMBL1455226 & 688249 & 6.9101 & 6.2745 & TRN & \\
\hline
\end{tabular}




\begin{tabular}{|c|c|c|c|c|c|}
\hline & & \multicolumn{4}{|c|}{ Supplemental Table S2.txt } \\
\hline CHEMBL1445488 & 688249 & 3.9872 & 4.0664 & TRN & \\
\hline CHEMBL1336605 & 688249 & 3.0 & 3.4564 & TRN & \\
\hline CHEMBL1443281 & 688249 & 3.0 & 2.9987 & TRN & \\
\hline CHEMBL570345 & 688249 & 3.8508 & 3.4167 & TST & \\
\hline CHEMBL1467623 & 688249 & 4.104 & 3.9477 & TRN & \\
\hline CHEMBL1426947 & 688249 & 4.0 & 3.1618 & TRN & \\
\hline CHEMBL1376870 & 688249 & 4.0 & 4.8083 & TRN & \\
\hline CHEMBL1449836 & 688249 & 4.0 & 4.1135 & TRN & \\
\hline CHEMBL1583199 & 688249 & 5.9788 & 5.0425 & TRN & \\
\hline CHEMBL1701224 & 688249 & 4.5638 & 4.3728 & TRN & \\
\hline CHEMBL1337575 & 688249 & 4.0 & 3.4036 & TRN & \\
\hline CHEMBL1526171 & 688249 & 4.0 & 3.9479 & TRN & \\
\hline CHEMBL1415156 & 688249 & 4.0137 & 4.0069 & TRN & \\
\hline CHEMBL1427609 & 688249 & 4.9586 & 4.3794 & TRN & \\
\hline CHEMBL599924 & 688249 & 6.9101 & 6.3389 & TRN & \\
\hline CHEMBL 213432 & 688249 & 4.0 & 3.6627 & TRN & \\
\hline CHEMBL1385743 & 688249 & 2.8013 & 3.50600 & 00000000002 & TRN \\
\hline CHEMBL1555938 & 688249 & 3.0 & 3.4268 & TRN & \\
\hline CHEMBL1334970 & 688249 & 4.7645 & 5.1411 & TRN & \\
\hline CHEMBL1403497 & 688249 & 4.0 & 4.7525 & TRN & \\
\hline CHEMBL1402456 & 688249 & 3.0 & 3.2165 & TRN & \\
\hline CHEMBL1608642 & 688249 & 2.8013 & 2.3455 & TRN & \\
\hline CHEMBL1321933 & 688249 & 4.7905 & 3.9735 & TRN & \\
\hline CHEMBL3193786 & 688249 & 4.1391 & 3.8443 & TRN & \\
\hline CHEMBL1453902 & 688249 & 4.6144 & 4.2956 & TRN & \\
\hline CHEMBL1329141 & 688249 & 6.9101 & 5.9813 & TRN & \\
\hline CHEMBL1996572 & 688249 & 2.8013 & 3.2932 & TRN & \\
\hline CHEMBL1324382 & 688249 & 4.7235 & 4.1422 & TRN & \\
\hline CHEMBL1548812 & 688249 & 3.9469 & 3.6119 & TST & \\
\hline CHEMBL1304193 & 688249 & 2.8013 & 2.4334 & TRN & \\
\hline CHEMBL1390703 & 688249 & 4.5884 & 4.5487 & TRN & \\
\hline CHEMBL1528227 & 688249 & 3.0 & 4.2761 & TST & \\
\hline CHEMBL1322542 & 688249 & 2.8013 & 2.6017 & TRN & \\
\hline CHEMBL1605172 & 688249 & 2.8013 & 2.8158 & TRN & \\
\hline CHEMBL1537922 & 688249 & 2.8013 & 3.1807 & TRN & \\
\hline CHEMBL1504738 & 688249 & 3.0 & 2.5643 & TRN & \\
\hline CHEMBL1424694 & 688249 & 5.4841 & 5.4745 & TRN & \\
\hline CHEMBL1324051 & 688249 & 4.0 & 4.8251 & TRN & \\
\hline CHEMBL1325945 & 688249 & 6.9101 & 5.9441 & TRN & \\
\hline CHEMBL1381644 & 688249 & 4.0 & 3.3668 & TST & \\
\hline CHEMBL3145364 & 688249 & 5.1543 & 4.5513 & TRN & \\
\hline CHEMBL1321572 & 688249 & 3.9469 & 3.9178 & TRN & \\
\hline CHEMBL3212539 & 688249 & 2.8013 & 3.6573 & TRN & \\
\hline CHEMBL1528814 & 688249 & 4.0 & 4.203 & TRN & \\
\hline CHEMBL1391196 & 688249 & 3.0 & 2.7983 & TRN & \\
\hline CHEMBL1506716 & 688249 & 4.0 & 3.7484 & TST & \\
\hline CHEMBL1578670 & 688249 & 4.1457 & 3.1293 & TST & \\
\hline CHEMBL1439815 & 688249 & 5.0716 & 4.3258 & TRN & \\
\hline
\end{tabular}




\begin{tabular}{|c|c|c|c|c|c|}
\hline \multicolumn{6}{|c|}{ Supplemental Table S2.txt } \\
\hline CHEMBL1566081 & 688249 & 2.8013 & 2.928 & TRN & \\
\hline CHEMBL1387693 & 688249 & 5.0438 & 5.0707 & TRN & \\
\hline CHEMBL1407203 & 688249 & 2.8013 & 2.3931 & TRN & \\
\hline CHEMBL1384370 & 688249 & 2.8013 & 3.8695 & TRN & \\
\hline CHEMBL1441794 & 688249 & 2.8013 & 3.4014 & TRN & \\
\hline CHEMBL1408579 & 688249 & 2.8013 & 2.9854 & TST & \\
\hline CHEMBL66953 & 688249 & 4.5346 & 3.7181 & TST & \\
\hline CHEMBL1527520 & 688249 & 4.0 & 4.2824 & TRN & \\
\hline CHEMBL1981200 & 688249 & 3.9355 & 3.6795 & TRN & \\
\hline CHEMBL3191015 & 688249 & 4.0443 & 4.3808 & TRN & \\
\hline CHEMBL1376711 & 688249 & 5.8665 & 6.6471 & TRN & \\
\hline CHEMBL1407368 & 688249 & 4.1238 & 4.1456 & TRN & \\
\hline CHEMBL1307459 & 688249 & 4.0 & 4.5518 & TST & \\
\hline CHEMBL1369981 & 688249 & 3.0 & 3.3304 & TRN & \\
\hline CHEMBL1313807 & 688249 & 4.1599 & 4.7825 & TRN & \\
\hline CHEMBL1517649 & 688249 & 3.0 & 3.2281 & TRN & \\
\hline CHEMBL1488035 & 688249 & 6.6216 & 6.0723 & TRN & \\
\hline CHEMBL555689 & 688249 & 5.7033 & 5.8897 & TRN & \\
\hline CHEMBL 3392041 & 688249 & 4.9666 & 4.1759 & TRN & \\
\hline CHEMBL1539325 & 688249 & 4.0 & 4.2308 & TRN & \\
\hline CHEMBL1384172 & 688249 & 4.0 & 4.0098 & TRN & \\
\hline CHEMBL1305050 & 688249 & 4.9957 & 4.8885 & TRN & \\
\hline CHEMBL1580684 & 688249 & 4.5229 & 4.8837 & TRN & \\
\hline CHEMBL 259355 & 688249 & 4.0 & 3.3256 & TRN & \\
\hline CHEMBL3192879 & 688249 & 4.6198 & 4.1052 & TRN & \\
\hline CHEMBL1504939 & 688249 & 2.8013 & 3.0055 & TRN & \\
\hline CHEMBL1612116 & 688249 & 2.8013 & 3.3142 & TRN & \\
\hline CHEMBL1379593 & 688249 & 3.0 & 4.1054 & TST & \\
\hline CHEMBL1463091 & 688249 & 3.0 & 2.66899 & 99999999996 & TRN \\
\hline CHEMBL1505300 & 688249 & 4.0 & 4.1902 & TRN & \\
\hline CHEMBL1971015 & 688249 & 4.5918 & 4.1297 & TRN & \\
\hline CHEMBL1385949 & 688249 & 2.8013 & 3.3348 & TRN & \\
\hline CHEMBL57978 & 688249 & 5.4283 & 3.844 & TRN & \\
\hline CHEMBL1305391 & 688249 & 4.0 & 4.155 & TRN & \\
\hline CHEMBL1393151 & 688249 & 4.1152 & 4.3384 & TRN & \\
\hline CHEMBL 256098 & 688249 & 5.1024 & 5.2097 & TRN & \\
\hline CHEMBL1519773 & 688249 & 4.0 & 3.6908 & TRN & \\
\hline CHEMBL1373132 & 688249 & 4.51 & 4.3036 & TRN & \\
\hline CHEMBL 2001743 & 688249 & 2.8013 & 3.7042 & TRN & \\
\hline CHEMBL1379677 & 688249 & 5.9245 & 4.7836 & TST & \\
\hline CHEMBL1421970 & 688249 & 2.8013 & 3.1269 & TST & \\
\hline CHEMBL1982888 & 688249 & 3.9101 & 4.6699 & TRN & \\
\hline CHEMBL1447034 & 688249 & 4.0 & 4.6165 & TRN & \\
\hline CHEMBL1438469 & 688249 & 3.0 & 4.0123 & TRN & \\
\hline CHEMBL1471409 & 688249 & 2.8013 & 3.3048 & TST & \\
\hline CHEMBL578512 & 688249 & 5.6345 & 6.2532 & TRN & \\
\hline CHEMBL 1995948 & 688249 & 4.0 & 4.1317 & TRN & \\
\hline CHEMBL1536896 & 688249 & 3.9957 & 4.2283 & TRN & \\
\hline
\end{tabular}




\begin{tabular}{|c|c|c|c|c|}
\hline \multicolumn{5}{|c|}{ Supplemental Table S2.txt } \\
\hline CHEMBL1530147 & 688249 & 3.0 & 3.4899 & TRN \\
\hline CHEMBL1988133 & 688249 & 4.3979 & 4.9101 & TRN \\
\hline CHEMBL1328748 & 688249 & 3.0 & 3.2807 & TST \\
\hline CHEMBL1478825 & 688249 & 3.0 & 3.545 & TRN \\
\hline CHEMBL3199879 & 688249 & 4.9208 & 5.0506 & TRN \\
\hline CHEMBL1353989 & 688249 & 4.0 & 3.5975 & TRN \\
\hline CHEMBL1526088 & 688249 & 4.0731 & 4.0502 & TRN \\
\hline CHEMBL1334684 & 688249 & 5.7375 & 4.7992 & TRN \\
\hline CHEMBL1672292 & 688249 & 2.8013 & 3.5348 & TRN \\
\hline CHEMBL1575586 & 688249 & 5.1688 & 4.7631 & TRN \\
\hline CHEMBL1981446 & 688249 & 4.1284 & 4.1547 & TRN \\
\hline CHEMBL1463659 & 688249 & 6.9101 & 6.0257 & TST \\
\hline CHEMBL1364583 & 688249 & 4.0 & 4.0239 & TST \\
\hline CHEMBL1325664 & 688249 & 2.8013 & 4.2568 & TST \\
\hline CHEMBL1334633 & 688249 & 4.0 & 4.2493 & TST \\
\hline CHEMBL1325523 & 688249 & 3.0 & 3.2464 & TST \\
\hline CHEMBL1467092 & 688249 & 4.4342 & 3.3945 & TST \\
\hline CHEMBL1372387 & 688249 & 2.8013 & 4.0777 & TST \\
\hline CHEMBL1430983 & 688249 & 2.8013 & 3.5123 & TST \\
\hline CHEMBL1460470 & 688249 & 2.8013 & 3.3502 & TST \\
\hline CHEMBL1435313 & 688249 & 3.0 & 4.3806 & TST \\
\hline CHEMBL1382722 & 688249 & 3.0 & 3.1138 & TST \\
\hline CHEMBL1966168 & 688249 & 4.1163 & 4.1026 & TST \\
\hline CHEMBL1568497 & 688249 & 4.0 & 4.3787 & TST \\
\hline CHEMBL580819 & 688249 & 5.6021 & 4.6209 & TST \\
\hline CHEMBL1991573 & 688249 & 3.9281 & 4.8864 & TST \\
\hline CHEMBL1584392 & 688249 & 4.5086 & 3.7091 & TST \\
\hline CHEMBL1478587 & 688249 & 4.0155 & 4.3546 & TST \\
\hline CHEMBL140270 & 41751 & 6.1457 & 6.1935 & TRN \\
\hline CHEMBL143266 & 41751 & 6.3979 & 6.7909 & TRN \\
\hline CHEMBL357445 & 41751 & 6.4365 & 6.6244 & TRN \\
\hline CHEMBL142318 & 41751 & 7.3565 & 6.9183 & TRN \\
\hline CHEMBL141713 & 41751 & 6.4597 & 6.2163 & TRN \\
\hline CHEMBL143814 & 41751 & 6.6498 & 7.0014 & TRN \\
\hline CHEMBL142160 & 41751 & 6.4306 & 6.7123 & TRN \\
\hline CHEMBL142199 & 41751 & 7.1079 & 6.8034 & TRN \\
\hline CHEMBL141020 & 41751 & 6.6861 & 6.1054 & TRN \\
\hline CHEMBL422115 & 41751 & 5.3969 & 6.3298 & TST \\
\hline CHEMBL 358596 & 41751 & 6.2336 & 6.2327 & TRN \\
\hline CHEMBL344989 & 41751 & 7.0088 & 6.5737 & TRN \\
\hline CHEMBL141817 & 41751 & 6.4449 & 6.2098 & TRN \\
\hline CHEMBL125111 & 41751 & 6.6126 & 6.9202 & TRN \\
\hline CHEMBL142107 & 41751 & 5.8462 & 6.0256 & TRN \\
\hline CHEMBL423734 & 41751 & 6.2924 & 6.5126 & TRN \\
\hline CHEMBL143059 & 41751 & 7.2676 & 6.5458 & TRN \\
\hline CHEMBL141127 & 41751 & 8.0969 & 6.5377 & TST \\
\hline CHEMBL342721 & 41751 & 6.3925 & 6.3847 & TRN \\
\hline CHEMBL344324 & 41751 & 7.4815 & 7.1099 & TRN \\
\hline
\end{tabular}




\begin{tabular}{|c|c|c|c|c|c|}
\hline \multicolumn{6}{|c|}{ Supplemental Table S2.txt } \\
\hline CHEMBL356718 & 41751 & 6.3915 & 7.0278 & TRN & \\
\hline CHEMBL143825 & 41751 & 6.3372 & 6.8683 & TRN & \\
\hline CHEMBL142244 & 41751 & 6.6925 & 6.5605 & TST & \\
\hline CHEMBL358283 & 41751 & 6.0429 & 6.0115 & TRN & \\
\hline CHEMBL142263 & 41751 & 6.0419 & 6.2683 & TRN & \\
\hline CHEMBL143942 & 41751 & 6.3344 & 6.4007 & TRN & \\
\hline CHEMBL357434 & 41751 & 6.8861 & 6.893 & TRN & \\
\hline CHEMBL344751 & 41751 & 5.9914 & 6.2442 & TRN & \\
\hline CHEMBL142004 & 41751 & 6.9355 & 6.6904 & TRN & \\
\hline CHEMBL343032 & 41751 & 5.9252 & 6.4529 & TST & \\
\hline CHEMBL2112832 & 41751 & 6.8665 & 6.7504 & TRN & \\
\hline CHEMBL142676 & 41751 & 6.6326 & 6.459 & TRN & \\
\hline CHEMBL143840 & 41751 & 6.3675 & 6.6189 & TRN & \\
\hline CHEMBL143449 & 41751 & 6.6308 & 6.6889 & TST & \\
\hline CHEMBL357919 & 41751 & 5.3915 & 6.6135 & TRN & \\
\hline CHEMBL356099 & 41751 & 8.2218 & 6.5191 & TST & \\
\hline CHEMBL2112830 & 41751 & 5.1249 & 6.3709 & TST & \\
\hline CHEMBL356764 & 41751 & 6.5143 & 6.6196 & TRN & \\
\hline CHEMBL143499 & 41751 & 7.0362 & 6.3597 & TRN & \\
\hline CHEMBL145106 & 41751 & 6.011 & 6.2853 & TRN & \\
\hline CHEMBL435480 & 41751 & 5.8761 & 6.3553 & TRN & \\
\hline CHEMBL 342444 & 41751 & 6.6861 & 6.3443 & TRN & \\
\hline CHEMBL34166 & 41751 & 7.284 & 6.7316 & TRN & \\
\hline CHEMBL 343680 & 41751 & 7.2757 & 7.0641 & TRN & \\
\hline CHEMBL141387 & 41751 & 6.6271 & 6.4734 & TRN & \\
\hline CHEMBL142628 & 41751 & 5.9374 & 6.2474 & TRN & \\
\hline CHEMBL341840 & 41751 & 6.8069 & 6.3939 & TRN & \\
\hline CHEMBL142620 & 41751 & 7.0044 & 6.8099 & TRN & \\
\hline CHEMBL343511 & 41751 & 7.4685 & 6.88899 & 9999999999 & TST \\
\hline CHEMBL142798 & 41751 & 6.1024 & 6.5172 & TRN & \\
\hline CHEMBL142161 & 41751 & 6.2733 & 6.6907 & TRN & \\
\hline CHEMBL435485 & 41751 & 7.5376 & 6.5741 & TST & \\
\hline CHEMBL346205 & 41751 & 6.8928 & 6.4635 & TRN & \\
\hline CHEMBL143350 & 41751 & 7.6576 & 6.6787 & TST & \\
\hline CHEMBL142713 & 41751 & 6.4145 & 6.5279 & TRN & \\
\hline CHEMBL344499 & 41751 & 5.4647 & 5.8696 & TRN & \\
\hline CHEMBL142752 & 41751 & 8.0458 & 6.9636 & TST & \\
\hline CHEMBL143741 & 41751 & 6.0 & 6.1661 & TRN & \\
\hline CHEMBL 344073 & 41751 & 7.2518 & 6.6976 & TST & \\
\hline CHEMBL143492 & 41751 & 7.6198 & 6.8721 & TST & \\
\hline CHEMBL143690 & 41751 & 6.3036 & 6.477 & TRN & \\
\hline CHEMBL433746 & 41751 & 7.3468 & 6.7962 & TST & \\
\hline CHEMBL142468 & 41751 & 7.1308 & 6.5709 & TRN & \\
\hline CHEMBL 344075 & 41751 & 6.8153 & 6.595 & TRN & \\
\hline CHEMBL143374 & 41751 & 7.6576 & 6.1909 & TST & \\
\hline CHEMBL341769 & 41751 & 6.2055 & 6.75 & TST & \\
\hline CHEMBL141829 & 41751 & 6.7852 & 6.5414 & TST & \\
\hline CHEMBL142191 & 41751 & 7.2924 & 6.8287 & TRN & \\
\hline
\end{tabular}




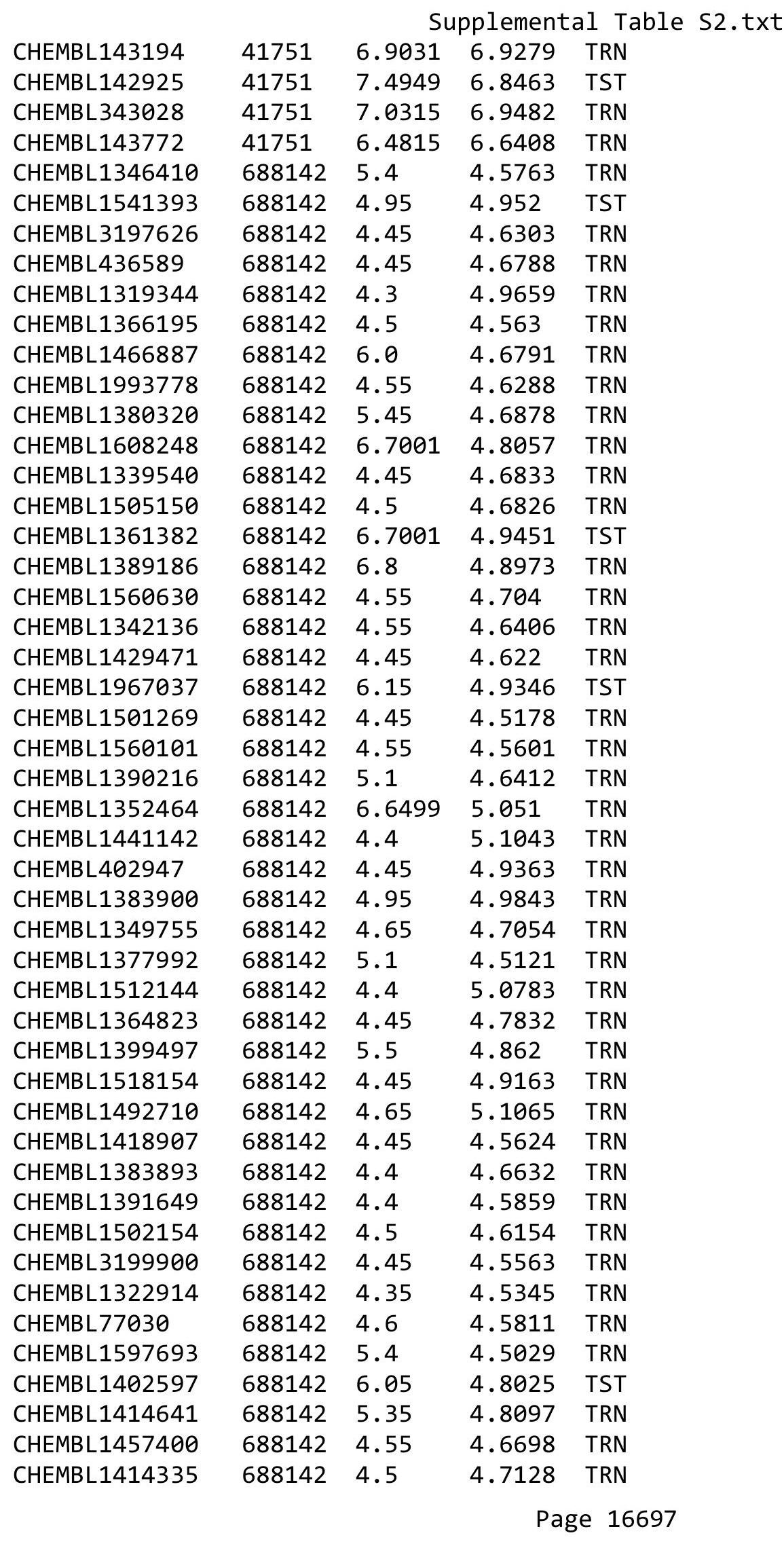




\begin{tabular}{|c|c|c|c|c|}
\hline \multicolumn{5}{|c|}{ Supplemental Table S2.txt } \\
\hline CHEMBL1511690 & 688142 & 4.4 & 4.54 & TST \\
\hline CHEMBL1456255 & 688142 & 4.6 & 4.4532 & TRN \\
\hline CHEMBL1338205 & 688142 & 4.4 & 4.7683 & TRN \\
\hline CHEMBL1604772 & 688142 & 4.35 & 4.6157 & TRN \\
\hline CHEMBL1967241 & 688142 & 4.45 & 4.7558 & TRN \\
\hline CHEMBL1321293 & 688142 & 4.95 & 4.9748 & TRN \\
\hline CHEMBL1309188 & 688142 & 5.65 & 5.0 & TRN \\
\hline CHEMBL1312746 & 688142 & 4.3 & 5.3694 & TRN \\
\hline CHEMBL1450788 & 688142 & 4.3 & 4.8846 & TRN \\
\hline CHEMBL1493014 & 688142 & 4.5 & 4.4796 & TRN \\
\hline CHEMBL1584523 & 688142 & 4.45 & 4.6259 & TRN \\
\hline CHEMBL1577139 & 688142 & 4.45 & 5.0273 & TST \\
\hline CHEMBL1341531 & 688142 & 4.45 & 4.6364 & TRN \\
\hline CHEMBL1347490 & 688142 & 4.5 & 4.5598 & TRN \\
\hline CHEMBL1599890 & 688142 & 4.5 & 4.9298 & TRN \\
\hline CHEMBL1562864 & 688142 & 4.4 & 4.4266 & TRN \\
\hline CHEMBL1329285 & 688142 & 5.95 & 4.9142 & TRN \\
\hline CHEMBL1509239 & 688142 & 5.85 & 4.5412 & TST \\
\hline CHEMBL1352439 & 688142 & 4.55 & 4.9566 & TRN \\
\hline CHEMBL1422352 & 688142 & 4.55 & 4.6385 & TRN \\
\hline CHEMBL1577972 & 688142 & 4.7 & 4.8616 & TRN \\
\hline CHEMBL1423795 & 688142 & 4.45 & 4.57 & TRN \\
\hline CHEMBL1583956 & 688142 & 4.5 & 4.688 & TRN \\
\hline CHEMBL3191224 & 688142 & 5.8 & 4.8614 & TRN \\
\hline CHEMBL1441773 & 688142 & 6.1 & 4.8386 & TRN \\
\hline CHEMBL1517406 & 688142 & 4.3 & 4.9483 & TRN \\
\hline CHEMBL1530639 & 688142 & 6.7501 & 4.8141 & TRN \\
\hline CHEMBL1375499 & 688142 & 4.5 & 4.9175 & TST \\
\hline CHEMBL1587141 & 688142 & 4.3 & 4.9741 & TRN \\
\hline CHEMBL1427888 & 688142 & 4.55 & 4.6298 & TRN \\
\hline CHEMBL1328814 & 688142 & 6.95 & 5.153 & TRN \\
\hline CHEMBL1431276 & 688142 & 4.3 & 4.5729 & TRN \\
\hline CHEMBL1302690 & 688142 & 4.55 & 4.5807 & TRN \\
\hline CHEMBL1526257 & 688142 & 4.55 & 4.648 & TRN \\
\hline CHEMBL1439156 & 688142 & 6.7501 & 5.0062 & TRN \\
\hline CHEMBL1344123 & 688142 & 4.5 & 4.6555 & TRN \\
\hline CHEMBL1497915 & 688142 & 4.75 & 4.4886 & TRN \\
\hline CHEMBL1517838 & 688142 & 5.4 & 4.9522 & TRN \\
\hline CHEMBL1384311 & 688142 & 4.45 & 4.5874 & TRN \\
\hline CHEMBL1346587 & 688142 & 4.3 & 4.869 & TRN \\
\hline CHEMBL1497839 & 688142 & 4.4 & 4.8175 & TST \\
\hline CHEMBL1554791 & 688142 & 4.4 & 4.7146 & TRN \\
\hline CHEMBL1391502 & 688142 & 5.2 & 4.8414 & TST \\
\hline CHEMBL1371958 & 688142 & 5.0 & 4.5354 & TRN \\
\hline CHEMBL1329349 & 688142 & 4.9 & 5.1477 & TRN \\
\hline CHEMBL1347215 & 688142 & 4.35 & 4.8421 & TST \\
\hline CHEMBL1575831 & 688142 & 4.35 & 5.1312 & TRN \\
\hline CHEMBL1452604 & 688142 & 4.5 & 4.9348 & TST \\
\hline
\end{tabular}




\begin{tabular}{|c|c|c|c|c|}
\hline \multicolumn{5}{|c|}{ Supplemental Table S2.txt } \\
\hline CHEMBL1439189 & 688142 & 4.45 & 4.7508 & TRN \\
\hline CHEMBL1537907 & 688142 & 4.35 & 4.5134 & TRN \\
\hline CHEMBL1404841 & 688142 & 4.4 & 4.5667 & TRN \\
\hline CHEMBL1470253 & 688142 & 6.1 & 4.8266 & TRN \\
\hline CHEMBL1345439 & 688142 & 4.35 & 4.8845 & TRN \\
\hline CHEMBL1307593 & 688142 & 5.35 & 5.1216 & TRN \\
\hline CHEMBL1609015 & 688142 & 4.95 & 4.8479 & TRN \\
\hline CHEMBL1581473 & 688142 & 4.3 & 4.537 & TST \\
\hline CHEMBL1383270 & 688142 & 4.4 & 4.6151 & TRN \\
\hline CHEMBL1300509 & 688142 & 4.6 & 4.7899 & TRN \\
\hline CHEMBL1308939 & 688142 & 4.95 & 4.9414 & TST \\
\hline CHEMBL1377872 & 688142 & 4.3 & 4.8393 & TRN \\
\hline CHEMBL1601545 & 688142 & 4.45 & 4.5929 & TRN \\
\hline CHEMBL1564889 & 688142 & 4.35 & 4.9709 & TRN \\
\hline CHEMBL1489392 & 688142 & 6.0 & 4.9729 & TST \\
\hline CHEMBL1372231 & 688142 & 4.6 & 4.5748 & TRN \\
\hline CHEMBL1322694 & 688142 & 4.4 & 4.5462 & TRN \\
\hline CHEMBL1311741 & 688142 & 4.5 & 4.5686 & TRN \\
\hline CHEMBL1461855 & 688142 & 6.7501 & 4.8177 & TRN \\
\hline CHEMBL1602301 & 688142 & 4.9 & 4.8154 & TRN \\
\hline CHEMBL3194678 & 688142 & 6.0 & 4.9082 & TRN \\
\hline CHEMBL1443766 & 688142 & 4.5 & 4.9088 & TST \\
\hline CHEMBL1442864 & 688142 & 4.45 & 4.5709 & TRN \\
\hline CHEMBL1344205 & 688142 & 4.5 & 4.6462 & TRN \\
\hline CHEMBL1309869 & 688142 & 4.55 & 4.5569 & TRN \\
\hline CHEMBL1349568 & 688142 & 5.4 & 4.6512 & TRN \\
\hline CHEMBL153064 & 688142 & 4.4 & 4.5004 & TRN \\
\hline CHEMBL1301487 & 688142 & 4.45 & 4.6215 & TRN \\
\hline CHEMBL1562342 & 688142 & 4.55 & 4.6651 & TRN \\
\hline CHEMBL1327979 & 688142 & 4.4 & 4.5888 & TRN \\
\hline CHEMBL1349382 & 688142 & 5.55 & 5.0356 & TRN \\
\hline CHEMBL 71851 & 688142 & 6.0 & 4.626 & TRN \\
\hline CHEMBL1544648 & 688142 & 6.4 & 5.0583 & TRN \\
\hline CHEMBL358644 & 688142 & 4.6 & 4.5367 & TRN \\
\hline CHEMBL1563359 & 688142 & 4.55 & 4.5568 & TRN \\
\hline CHEMBL1478440 & 688142 & 4.6 & 4.5727 & TRN \\
\hline CHEMBL1529401 & 688142 & 6.15 & 4.9349 & TRN \\
\hline CHEMBL1485577 & 688142 & 4.45 & 4.5426 & TRN \\
\hline CHEMBL1609089 & 688142 & 4.5 & 4.6554 & TRN \\
\hline CHEMBL1401054 & 688142 & 4.3 & 4.662 & TST \\
\hline CHEMBL1407833 & 688142 & 4.35 & 5.0094 & TST \\
\hline CHEMBL1449473 & 688142 & 4.45 & 4.6602 & TRN \\
\hline CHEMBL1600163 & 688142 & 4.35 & 4.5901 & TST \\
\hline CHEMBL1589723 & 688142 & 4.4 & 4.9072 & TRN \\
\hline CHEMBL1361474 & 688142 & 4.6 & 4.907 & TRN \\
\hline CHEMBL1382670 & 688142 & 4.45 & 4.6886 & TRN \\
\hline CHEMBL1329224 & 688142 & 4.6 & 4.6002 & TRN \\
\hline CHEMBL1485161 & 688142 & 4.5 & 5.0857 & TRN \\
\hline
\end{tabular}




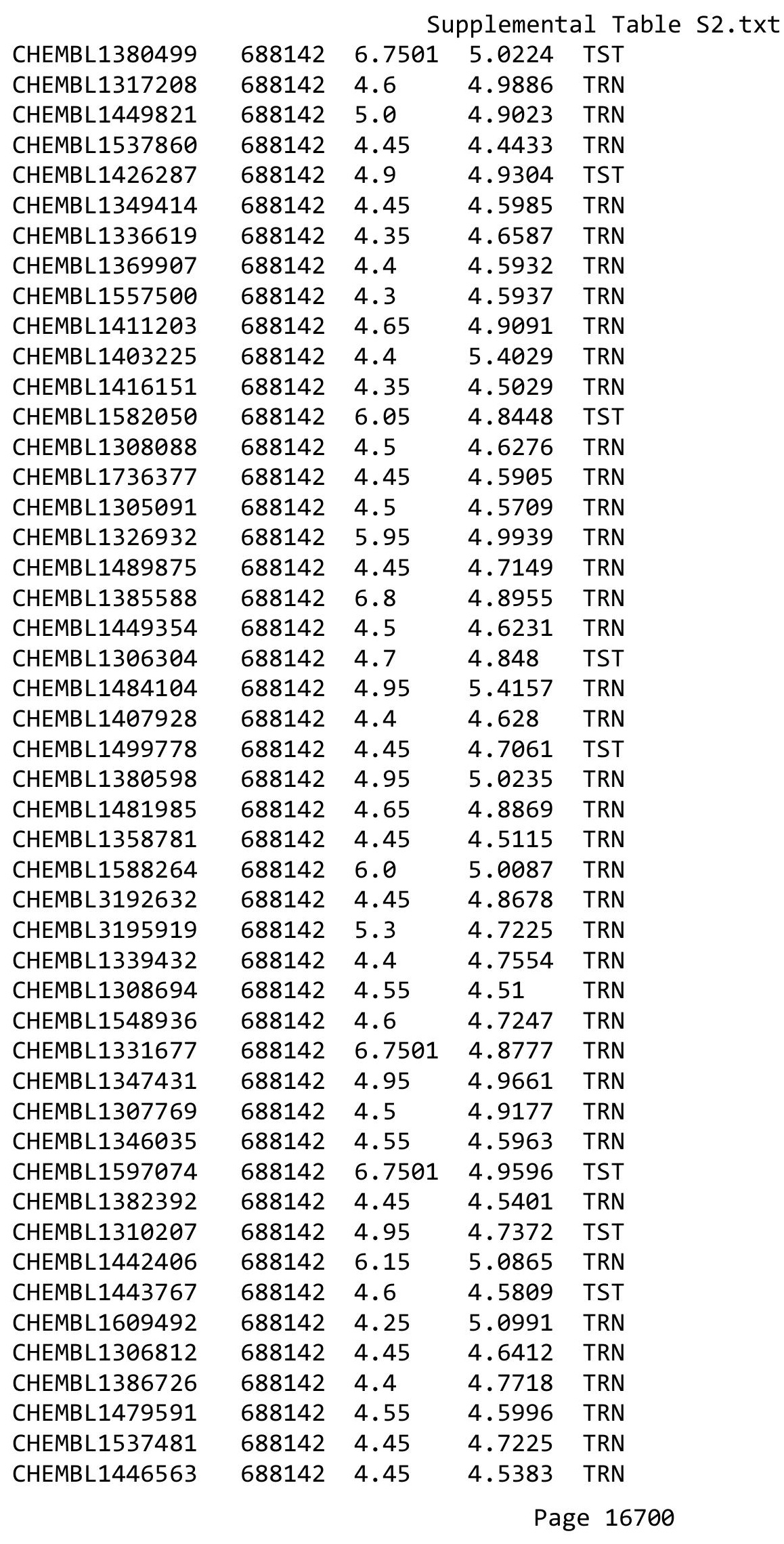




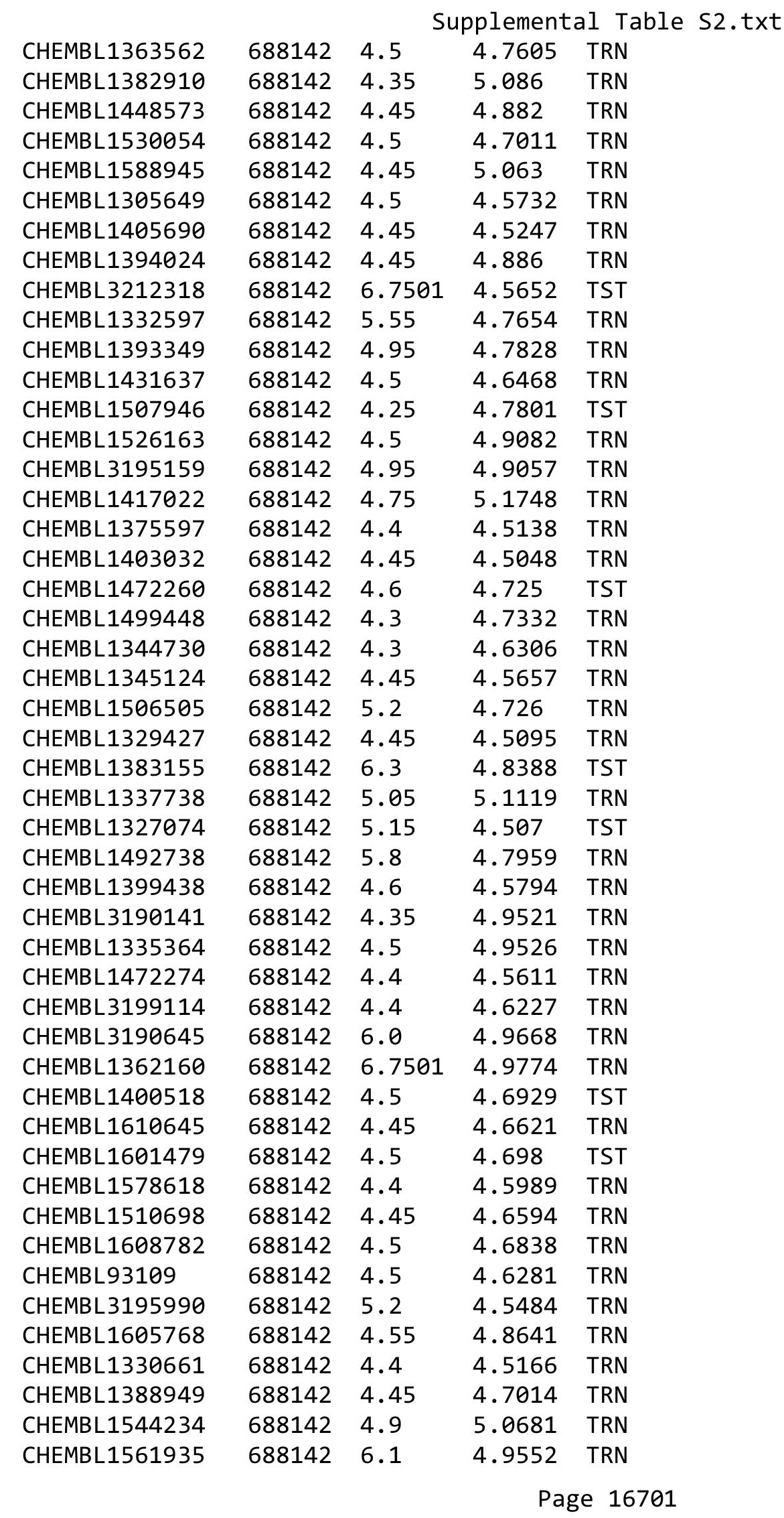




\begin{tabular}{|c|c|c|c|c|c|}
\hline & & \multicolumn{4}{|c|}{ Supplemental Table S2.txt } \\
\hline CHEMBL1329111 & 688142 & 4.5 & 4.5515 & TRN & \\
\hline CHEMBL3189665 & 688142 & 6.7501 & 4.8679 & TRN & \\
\hline CHEMBL1579057 & 688142 & 4.3 & 4.703 & TRN & \\
\hline CHEMBL1561717 & 688142 & 4.45 & 5.0143 & TRN & \\
\hline CHEMBL1424834 & 688142 & 4.85 & 4.875 & TRN & \\
\hline CHEMBL1373221 & 688142 & 4.45 & 4.9432 & TST & \\
\hline CHEMBL1348850 & 688142 & 4.65 & 4.8645 & TRN & \\
\hline CHEMBL1312229 & 688142 & 4.45 & 4.6394 & TRN & \\
\hline CHEMBL1327684 & 688142 & 4.4 & 4.60800 & 00000000005 & TRN \\
\hline CHEMBL1484167 & 688142 & 5.8 & 4.8275 & TST & \\
\hline CHEMBL1530299 & 688142 & 4.35 & 5.0032 & TRN & \\
\hline CHEMBL1547414 & 688142 & 4.45 & 4.6015 & TRN & \\
\hline CHEMBL1314077 & 688142 & 4.5 & 4.9462 & TRN & \\
\hline CHEMBL1519723 & 688142 & 4.5 & 4.5718 & TRN & \\
\hline CHEMBL1444429 & 688142 & 6.8 & 4.9955 & TST & \\
\hline CHEMBL1489651 & 688142 & 6.7501 & 5.0389 & TRN & \\
\hline CHEMBL1467135 & 688142 & 4.4 & 4.8304 & TST & \\
\hline CHEMBL1530671 & 688142 & 5.05 & 4.5914 & TRN & \\
\hline CHEMBL3191854 & 688142 & 4.5 & 4.7842 & TRN & \\
\hline CHEMBL1613265 & 688142 & 6.8 & 5.0417 & TRN & \\
\hline CHEMBL1340688 & 688142 & 4.95 & 4.9652 & TRN & \\
\hline CHEMBL3190350 & 688142 & 4.9 & 4.8441 & TRN & \\
\hline CHEMBL1486992 & 688142 & 4.45 & 4.4413 & TRN & \\
\hline CHEMBL1600733 & 688142 & 4.5 & 4.7381 & TRN & \\
\hline CHEMBL1462788 & 688142 & 4.4 & 4.8358 & TRN & \\
\hline CHEMBL1415429 & 688142 & 4.4 & 4.6098 & TRN & \\
\hline CHEMBL1575690 & 688142 & 4.6 & 4.8423 & TRN & \\
\hline CHEMBL1363530 & 688142 & 5.8 & 5.02 & TRN & \\
\hline CHEMBL1368068 & 688142 & 4.55 & 4.5245 & TRN & \\
\hline CHEMBL1410636 & 688142 & 6.05 & 4.9715 & TRN & \\
\hline CHEMBL1300133 & 688142 & 4.35 & 4.4928 & TRN & \\
\hline CHEMBL1477620 & 688142 & 5.05 & 4.6815 & TRN & \\
\hline CHEMBL1450682 & 688142 & 5.9 & 4.7044 & TRN & \\
\hline CHEMBL1583076 & 688142 & 4.3 & 4.5868 & TRN & \\
\hline CHEMBL1549718 & 688142 & 4.45 & 4.6539 & TRN & \\
\hline CHEMBL1393700 & 688142 & 4.45 & 4.7659 & TRN & \\
\hline CHEMBL1411083 & 688142 & 4.4 & 4.4348 & TRN & \\
\hline CHEMBL282489 & 688142 & 4.55 & 4.8561 & TST & \\
\hline CHEMBL280074 & 688142 & 4.85 & 4.9989 & TRN & \\
\hline CHEMBL1508743 & 688142 & 4.45 & 4.436 & TRN & \\
\hline CHEMBL1541622 & 688142 & 6.7501 & 5.0925 & TRN & \\
\hline CHEMBL1547006 & 688142 & 4.45 & 4.4488 & TRN & \\
\hline CHEMBL1576872 & 688142 & 6.1 & 4.9108 & TST & \\
\hline CHEMBL1439954 & 688142 & 4.55 & 4.4689 & TRN & \\
\hline CHEMBL3192121 & 688142 & 6.1 & 4.9406 & TRN & \\
\hline CHEMBL1335945 & 688142 & 4.3 & 4.6098 & TST & \\
\hline CHEMBL1383558 & 688142 & 4.45 & 4.5536 & TRN & \\
\hline CHEMBL1391613 & 688142 & 4.35 & 4.6277 & TRN & \\
\hline
\end{tabular}




\begin{tabular}{|c|c|c|c|c|c|}
\hline \multicolumn{6}{|c|}{ Supplemental Table S2.txt } \\
\hline CHEMBL1607568 & 688142 & 4.9 & 4.9939 & TRN & \\
\hline CHEMBL487711 & 688142 & 4.45 & 4.4521 & TRN & \\
\hline CHEMBL1369045 & 688142 & 4.5 & 4.6172 & TRN & \\
\hline CHEMBL1526072 & 688142 & 4.4 & 5.0036 & TRN & \\
\hline CHEMBL1344422 & 688142 & 4.7 & 4.6554 & TRN & \\
\hline CHEMBL3191733 & 688142 & 5.1 & 4.6996 & TRN & \\
\hline CHEMBL1506333 & 688142 & 4.45 & 4.5752 & TRN & \\
\hline CHEMBL1546597 & 688142 & 4.45 & 4.6614 & TRN & \\
\hline CHEMBL 3194380 & 688142 & 6.7001 & 5.088 & TST & \\
\hline CHEMBL6703 & 688142 & 4.45 & 4.4106 & TRN & \\
\hline CHEMBL568385 & 688142 & 4.35 & 4.4877 & TRN & \\
\hline CHEMBL1320460 & 688142 & 4.45 & 4.4846 & TRN & \\
\hline CHEMBL1566534 & 688142 & 4.95 & 4.5975 & TRN & \\
\hline CHEMBL1445916 & 688142 & 4.45 & 4.5927 & TRN & \\
\hline CHEMBL1426219 & 688142 & 4.4 & 4.5174 & TRN & \\
\hline CHEMBL1389755 & 688142 & 4.45 & 4.6236 & TRN & \\
\hline CHEMBL150924 & 688142 & 4.3 & 4.4803 & TRN & \\
\hline CHEMBL1352221 & 688142 & 4.65 & 4.9509 & TST & \\
\hline CHEMBL1443903 & 688142 & 4.45 & 4.5956 & TRN & \\
\hline CHEMBL1370630 & 688142 & 4.4 & 4.6049 & TRN & \\
\hline CHEMBL1256878 & 688142 & 6.0 & 5.0556 & TRN & \\
\hline CHEMBL1340474 & 688142 & 4.9 & 4.9096 & TST & \\
\hline CHEMBL1374985 & 688142 & 6.7001 & 5.0725 & TRN & \\
\hline CHEMBL1504991 & 688142 & 4.3 & 4.6042 & TRN & \\
\hline CHEMBL181568 & 688142 & 6.0 & 5.1751 & TST & \\
\hline CHEMBL1330960 & 688142 & 5.45 & 4.7664 & TRN & \\
\hline CHEMBL3198016 & 688142 & 5.0 & 4.8124 & TST & \\
\hline CHEMBL1392137 & 688142 & 4.6 & 4.6454 & TRN & \\
\hline CHEMBL1418168 & 688142 & 4.4 & 4.8105 & TRN & \\
\hline CHEMBL1506224 & 688142 & 4.3 & 4.9452 & TRN & \\
\hline CHEMBL1351920 & 688142 & 4.4 & 4.6225 & TRN & \\
\hline CHEMBL1509378 & 688142 & 6.7501 & 4.7296 & TRN & \\
\hline CHEMBL1535395 & 688142 & 4.55 & 4.5464 & TRN & \\
\hline CHEMBL1431857 & 688142 & 4.4 & 4.6529 & TRN & \\
\hline CHEMBL1579198 & 688142 & 4.35 & 4.88899 & 9999999999 & TRN \\
\hline CHEMBL1371995 & 688142 & 6.5 & 5.0489 & TRN & \\
\hline CHEMBL1524819 & 688142 & 5.4 & 5.0591 & TRN & \\
\hline CHEMBL3197460 & 688142 & 5.65 & 4.6404 & TST & \\
\hline CHEMBL1319243 & 688142 & 4.65 & 4.8108 & TRN & \\
\hline CHEMBL1587583 & 688142 & 6.45 & 4.7019 & TST & \\
\hline CHEMBL1319276 & 688142 & 6.1 & 4.8763 & TRN & \\
\hline CHEMBL3211934 & 688142 & 4.4 & 4.8372 & TRN & \\
\hline CHEMBL1341200 & 688142 & 5.25 & 4.7637 & TRN & \\
\hline CHEMBL1598952 & 688142 & 4.55 & 4.5505 & TRN & \\
\hline CHEMBL1095486 & 688142 & 4.65 & 5.0635 & TST & \\
\hline CHEMBL1546958 & 688142 & 6.1 & 4.9212 & TRN & \\
\hline CHEMBL1563734 & 688142 & 6.05 & 4.5678 & TST & \\
\hline CHEMBL1361889 & 688142 & 4.8 & 4.7318 & TRN & \\
\hline
\end{tabular}




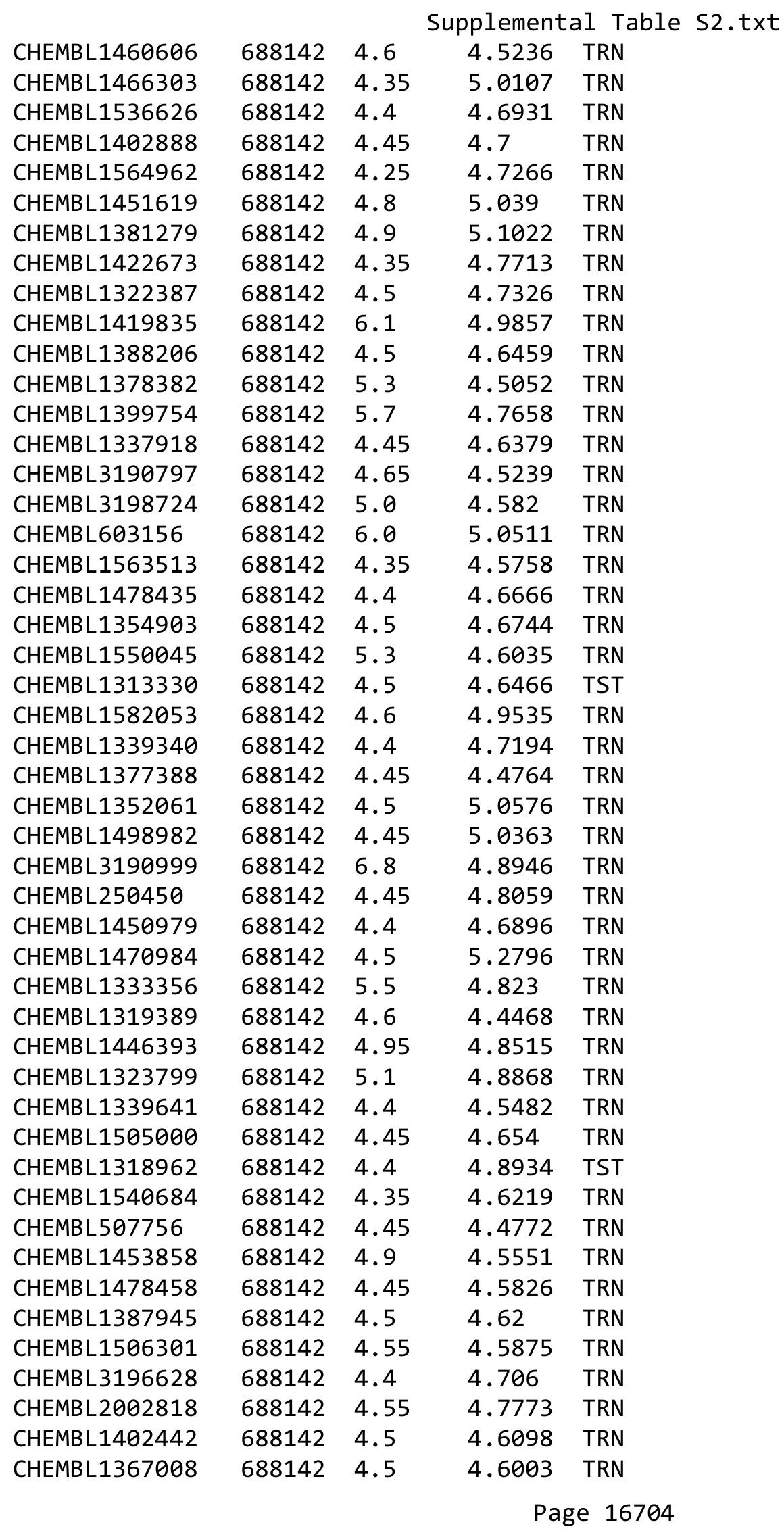




\begin{tabular}{|c|c|c|c|c|c|}
\hline \multicolumn{6}{|c|}{ Supplemental Table S2.txt } \\
\hline CHEMBL1402853 & 688142 & 4.45 & 4.6669 & TRN & \\
\hline CHEMBL1605517 & 688142 & 5.35 & 4.9338 & TRN & \\
\hline CHEMBL3199935 & 688142 & 4.5 & 4.6727 & TRN & \\
\hline CHEMBL1327279 & 688142 & 4.45 & 4.7604 & TRN & \\
\hline CHEMBL1423452 & 688142 & 4.45 & 4.4847 & TRN & \\
\hline CHEMBL1408323 & 688142 & 6.7501 & 4.9836 & TRN & \\
\hline CHEMBL1416843 & 688142 & 4.35 & 4.6113 & TRN & \\
\hline CHEMBL1482002 & 688142 & 4.4 & 4.7757 & TST & \\
\hline CHEMBL1349908 & 688142 & 4.4 & 4.6455 & TRN & \\
\hline CHEMBL1442915 & 688142 & 4.45 & 4.4942 & TRN & \\
\hline CHEMBL1449968 & 688142 & 4.45 & 4.599 & TRN & \\
\hline CHEMBL1420551 & 688142 & 4.45 & 4.7339 & TRN & \\
\hline CHEMBL1350196 & 688142 & 4.45 & 4.5086 & TRN & \\
\hline CHEMBL1494471 & 688142 & 4.45 & 4.7154 & TRN & \\
\hline CHEMBL3193298 & 688142 & 4.3 & 4.5223 & TRN & \\
\hline CHEMBL1421867 & 688142 & 4.5 & 4.4524 & TRN & \\
\hline CHEMBL1393118 & 688142 & 4.5 & 4.5922 & TRN & \\
\hline CHEMBL1377218 & 688142 & 6.15 & 4.9407 & TST & \\
\hline CHEMBL1459529 & 688142 & 4.4 & 4.4546 & TRN & \\
\hline CHEMBL1346664 & 688142 & 4.35 & 4.6316 & TRN & \\
\hline CHEMBL1497365 & 688142 & 4.95 & 4.841 & TST & \\
\hline CHEMBL1409667 & 688142 & 5.95 & 5.0626 & TST & \\
\hline CHEMBL1300297 & 688142 & 4.35 & 4.6367 & TRN & \\
\hline CHEMBL1571668 & 688142 & 6.8 & 4.8457 & TRN & \\
\hline CHEMBL1468589 & 688142 & 6.7501 & 5.0756 & TRN & \\
\hline CHEMBL3191519 & 688142 & 4.5 & 4.6554 & TRN & \\
\hline CHEMBL1529581 & 688142 & 4.45 & 4.5567 & TRN & \\
\hline CHEMBL1509532 & 688142 & 4.35 & 4.7686 & TRN & \\
\hline CHEMBL3212452 & 688142 & 4.55 & 4.5943 & TST & \\
\hline CHEMBL1472121 & 688142 & 4.75 & 4.7497 & TRN & \\
\hline CHEMBL1413764 & 688142 & 6.7501 & 5.14 & TRN & \\
\hline CHEMBL1522705 & 688142 & 4.45 & 4.9428 & TRN & \\
\hline CHEMBL1333600 & 688142 & 4.35 & 4.6989 & TST & \\
\hline CHEMBL3208428 & 688142 & 4.9 & 4.9414 & TST & \\
\hline CHEMBL1518801 & 688142 & 4.45 & 4.7965 & TRN & \\
\hline CHEMBL1450406 & 688142 & 4.4 & 4.4784 & TRN & \\
\hline CHEMBL1337529 & 688142 & 4.4 & 4.5082 & TRN & \\
\hline CHEMBL1460366 & 688142 & 6.0 & 5.0577 & TRN & \\
\hline CHEMBL1448023 & 688142 & 5.9 & 4.8216 & TRN & \\
\hline CHEMBL1494544 & 688142 & 4.3 & 4.7197 & TRN & \\
\hline CHEMBL1518855 & 688142 & 4.6 & 4.646 & TRN & \\
\hline CHEMBL1493119 & 688142 & 4.4 & 4.8836 & TRN & \\
\hline CHEMBL1378073 & 688142 & 4.45 & 4.4511 & TRN & \\
\hline CHEMBL1410812 & 688142 & 4.55 & 5.1488 & TST & \\
\hline CHEMBL1550441 & 688142 & 4.45 & 4.4832 & TRN & \\
\hline CHEMBL1965162 & 688142 & 4.45 & 4.7434 & TRN & \\
\hline CHEMBL1323565 & 688142 & 5.0 & 4.5895 & TRN & \\
\hline CHEMBL1384191 & 688142 & 4.5 & 4.82600 & 00000000005 & TST \\
\hline & & & & 16705 & \\
\hline
\end{tabular}




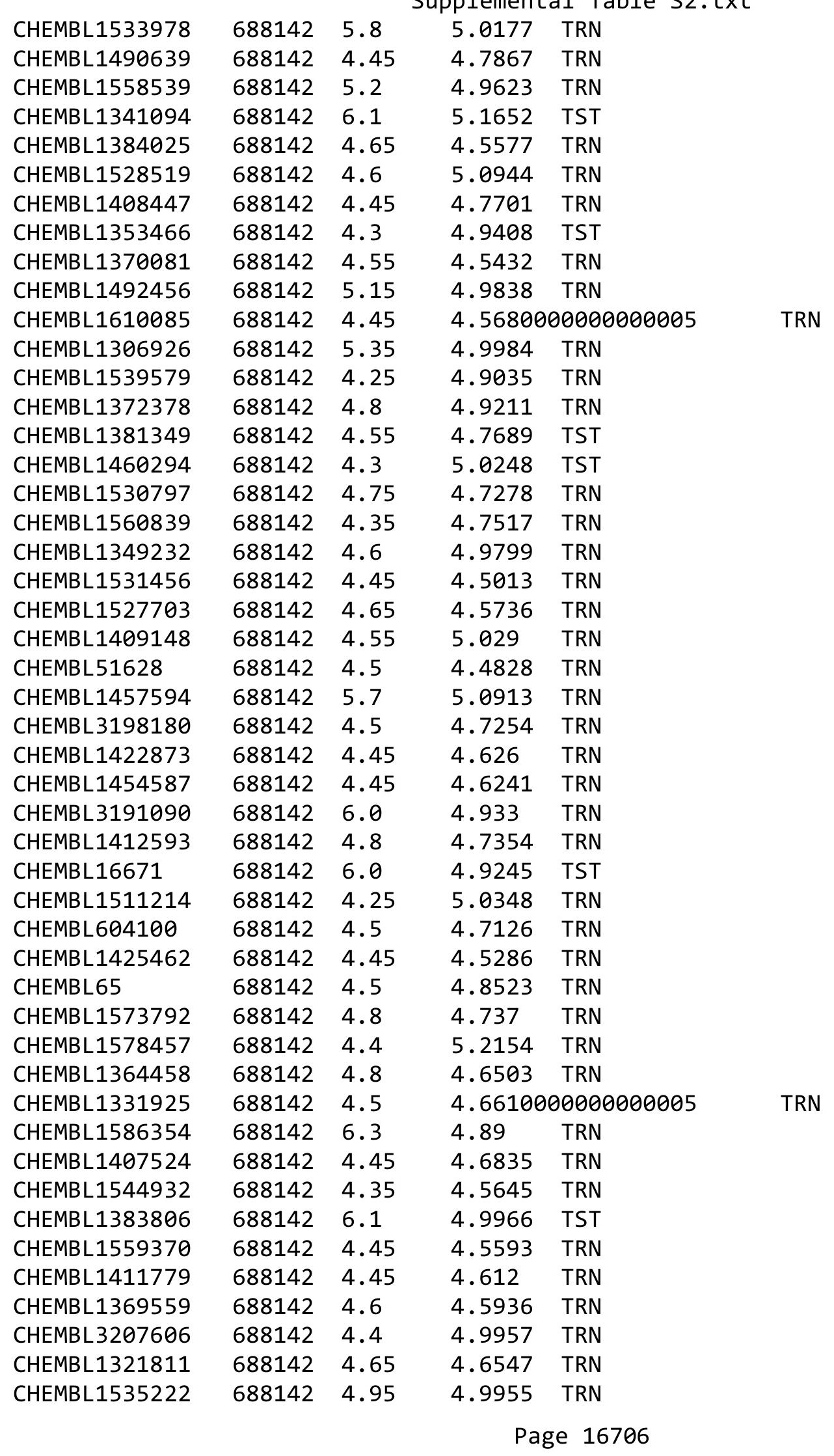




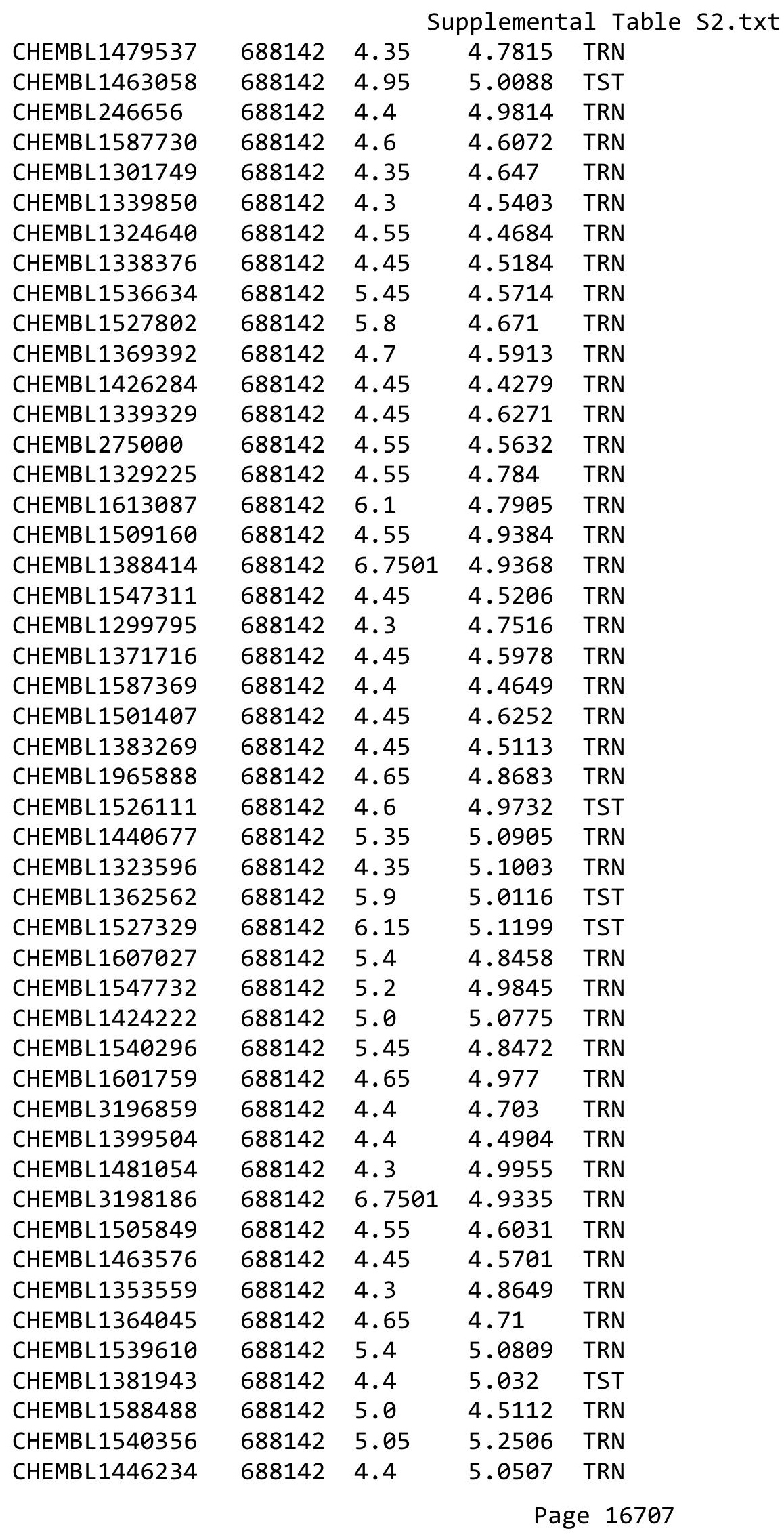




\begin{tabular}{|c|c|c|c|c|c|}
\hline \multirow{3}{*}{$\begin{array}{l}\text { CHEMBL } 3199373 \\
\text { CHFMBI } 1479872\end{array}$} & & \multicolumn{4}{|c|}{ Supplemental Table s2.txt } \\
\hline & 688142 & 4.55 & 4.6560 & 0000000001 & TRN \\
\hline & 688142 & 4.4 & 4.6437 & TRN & \\
\hline CHEMBL1405863 & 688142 & 4.45 & 4.5192 & TRN & \\
\hline CHEMBL1559344 & 688142 & 4.3 & 4.6418 & TRN & \\
\hline CHEMBL1587073 & 688142 & 5.9 & 5.1125 & TST & \\
\hline CHEMBL1586296 & 688142 & 5.0 & 4.8754 & TRN & \\
\hline CHEMBL1466054 & 688142 & 4.3 & 5.2197 & TRN & \\
\hline CHEMBL1407953 & 688142 & 4.4 & 4.8326 & TRN & \\
\hline CHEMBL1611632 & 688142 & 4.5 & 4.6148 & TRN & \\
\hline CHEMBL1163279 & 688142 & 4.45 & 4.6685 & TRN & \\
\hline CHEMBL1579999 & 688142 & 4.45 & 4.7025 & TRN & \\
\hline CHEMBL1589451 & 688142 & 4.25 & 5.2403 & TRN & \\
\hline CHEMBL1588601 & 688142 & 5.55 & 5.1734 & TST & \\
\hline CHEMBL1419514 & 688142 & 4.3 & 4.9407 & TRN & \\
\hline CHEMBL1611681 & 688142 & 4.45 & 4.5356 & TRN & \\
\hline CHEMBL1975975 & 688142 & 4.5 & 4.64 & TRN & \\
\hline CHEMBL1588196 & 688142 & 4.95 & 4.6499 & TRN & \\
\hline CHEMBL3192906 & 688142 & 4.8 & 4.8158 & TRN & \\
\hline CHEMBL 1377282 & 688142 & 4.35 & 4.6568 & TRN & \\
\hline CHEMBL1609498 & 688142 & 4.3 & 4.9379 & TRN & \\
\hline CHEMBL1351716 & 688142 & 4.8 & 4.5472 & TRN & \\
\hline CHEMBL1351743 & 688142 & 4.55 & 5.1755 & TRN & \\
\hline CHEMBL1365545 & 688142 & 4.4 & 4.6641 & TST & \\
\hline CHEMBL1415135 & 688142 & 4.65 & 4.6809 & TRN & \\
\hline CHEMBL1587708 & 688142 & 4.3 & 4.5203 & TRN & \\
\hline CHEMBL1379019 & 688142 & 4.85 & 5.1828 & TRN & \\
\hline CHEMBL1324919 & 688142 & 4.95 & 5.2844 & TRN & \\
\hline CHEMBL1533357 & 688142 & 4.5 & 4.728 & TRN & \\
\hline CHEMBL246657 & 688142 & 4.65 & 4.9869 & TRN & \\
\hline CHEMBL1322929 & 688142 & 4.5 & 4.5848 & TRN & \\
\hline CHEMBL1522348 & 688142 & 4.55 & 4.9321 & TST & \\
\hline CHEMBL490510 & 688142 & 4.6 & 5.1374 & TRN & \\
\hline CHEMBL3199462 & 688142 & 4.4 & 4.5729 & TRN & \\
\hline CHEMBL1559017 & 688142 & 6.1 & 5.0884 & TRN & \\
\hline CHEMBL1575977 & 688142 & 4.4 & 4.4725 & TRN & \\
\hline CHEMBL3193719 & 688142 & 4.4 & 4.6757 & TRN & \\
\hline CHEMBL3198280 & 688142 & 4.55 & 4.6337 & TRN & \\
\hline CHEMBL 249190 & 688142 & 4.55 & 5.1609 & TRN & \\
\hline CHEMBL1603004 & 688142 & 4.9 & 4.5638 & TRN & \\
\hline CHEMBL1336444 & 688142 & 4.45 & 4.5326 & TRN & \\
\hline CHEMBL1603085 & 688142 & 4.3 & 4.4925 & TRN & \\
\hline CHEMBL1470795 & 688142 & 4.55 & 4.5756 & TST & \\
\hline CHEMBL1412417 & 688142 & 4.4 & 4.7859 & TRN & \\
\hline CHEMBL1868202 & 688142 & 4.45 & 4.7173 & TRN & \\
\hline CHEMBL1479116 & 688142 & 6.7501 & 5.1503 & TRN & \\
\hline CHEMBL1508674 & 688142 & 4.45 & 4.5823 & TRN & \\
\hline CHEMBL1506514 & 688142 & 4.55 & 4.8525 & TRN & \\
\hline CHEMBL1559245 & 688142 & 4.45 & 4.8199 & TRN & \\
\hline
\end{tabular}




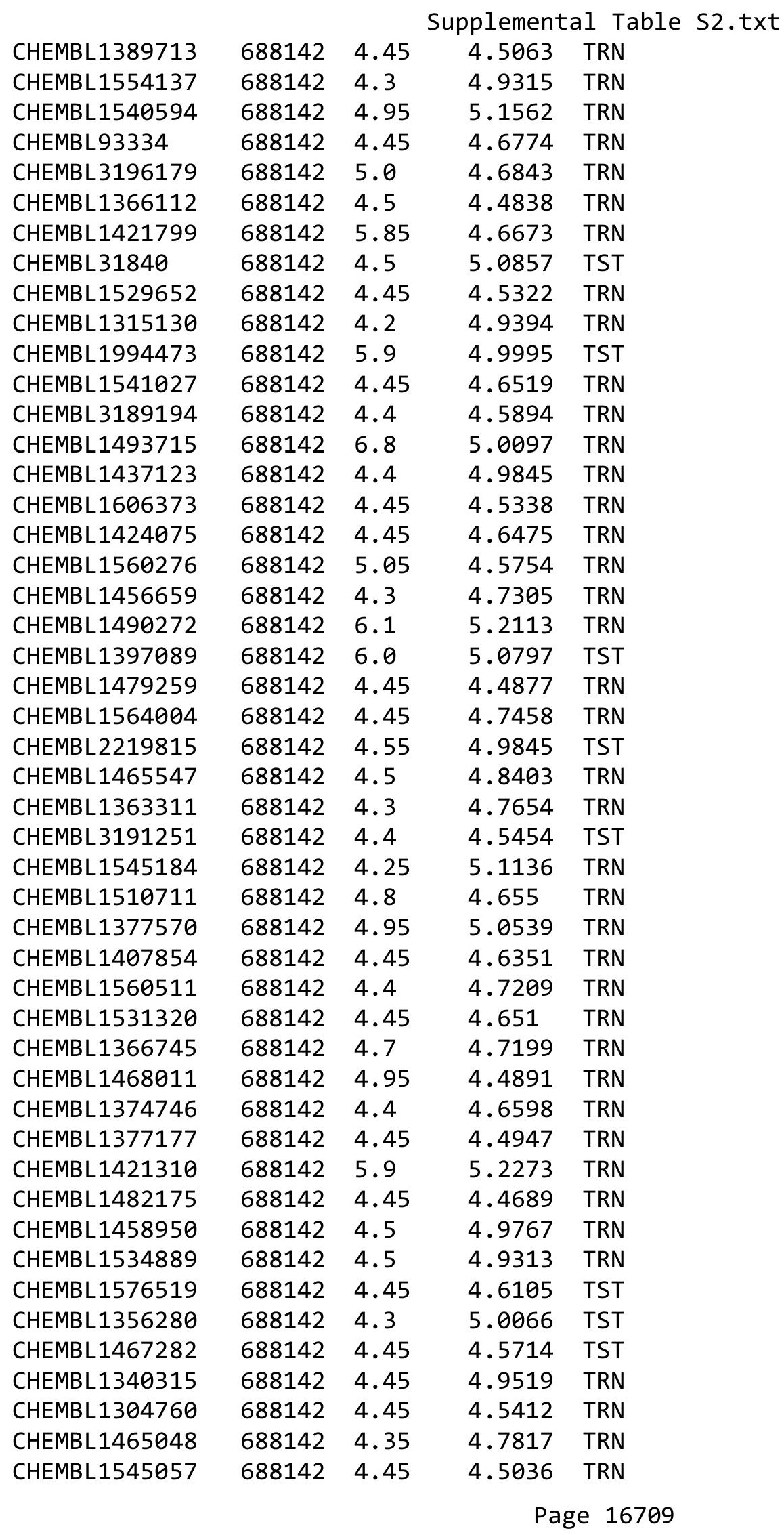




\begin{tabular}{|c|c|c|c|c|}
\hline \multicolumn{5}{|c|}{ Supplemental Table S2.txt } \\
\hline CHEMBL1521607 & 688142 & 4.4 & 4.4482 & TRN \\
\hline CHEMBL1542775 & 688142 & 4.5 & 4.6562 & TRN \\
\hline CHEMBL1519938 & 688142 & 4.4 & 4.9968 & TST \\
\hline CHEMBL1605233 & 688142 & 4.45 & 4.9636 & TRN \\
\hline CHEMBL1523314 & 688142 & 4.95 & 4.8954 & TRN \\
\hline CHEMBL1408657 & 688142 & 4.3 & 4.9598 & TST \\
\hline CHEMBL1371586 & 688142 & 4.45 & 4.9738 & TRN \\
\hline CHEMBL1370974 & 688142 & 4.65 & 4.5258 & TRN \\
\hline CHEMBL1418459 & 688142 & 4.3 & 4.8826 & TRN \\
\hline CHEMBL1324955 & 688142 & 4.4 & 4.7471 & TRN \\
\hline CHEMBL1453190 & 688142 & 4.4 & 4.6685 & TRN \\
\hline CHEMBL1563936 & 688142 & 4.5 & 4.7269 & TRN \\
\hline CHEMBL1565093 & 688142 & 4.45 & 5.0053 & TRN \\
\hline CHEMBL1381308 & 688142 & 5.05 & 4.7377 & TRN \\
\hline CHEMBL1523023 & 688142 & 4.45 & 4.5466 & TST \\
\hline CHEMBL 145 & 688142 & 4.4 & 4.828 & TRN \\
\hline CHEMBL1548519 & 688142 & 5.6 & 4.7986 & TRN \\
\hline CHEMBL1383163 & 688142 & 4.3 & 4.7898 & TST \\
\hline CHEMBL1482210 & 688142 & 4.35 & 5.182 & TRN \\
\hline CHEMBL1572527 & 688142 & 4.3 & $4.8210 €$ & 0000000001 \\
\hline CHEMBL1363267 & 688142 & 4.65 & 4.5477 & TRN \\
\hline CHEMBL1588086 & 688142 & 4.5 & 4.6216 & TRN \\
\hline CHEMBL1366118 & 688142 & 4.45 & 4.6418 & TRN \\
\hline CHEMBL50175 & 688142 & 4.55 & 4.7995 & TRN \\
\hline CHEMBL1536483 & 688142 & 4.6 & 4.641 & TRN \\
\hline CHEMBL428496 & 688142 & 4.5 & 5.0809 & TST \\
\hline CHEMBL1482965 & 688142 & 5.9 & 4.7839 & TRN \\
\hline CHEMBL1575442 & 688142 & 4.4 & 5.099 & TRN \\
\hline CHEMBL1411761 & 688142 & 4.65 & 4.7388 & TRN \\
\hline CHEMBL1490881 & 688142 & 4.3 & 5.1421 & TST \\
\hline CHEMBL1399924 & 688142 & 4.5 & 4.6584 & TRN \\
\hline CHEMBL1582073 & 688142 & 4.4 & 4.833 & TRN \\
\hline CHEMBL1318821 & 688142 & 5.0 & 4.9669 & TST \\
\hline CHEMBL1566723 & 688142 & 4.4 & 4.5403 & TRN \\
\hline CHEMBL1368302 & 688142 & 4.45 & 4.6334 & TRN \\
\hline CHEMBL1528890 & 688142 & 4.45 & 4.7302 & TRN \\
\hline CHEMBL1547633 & 688142 & 4.35 & 4.6442 & TRN \\
\hline CHEMBL1577830 & 688142 & 4.3 & 4.9623 & TRN \\
\hline CHEMBL1445846 & 688142 & 4.3 & 4.9421 & TRN \\
\hline CHEMBL1357247 & 688142 & 4.7 & 4.7212 & TST \\
\hline CHEMBL1416245 & 688142 & 4.3 & 4.8673 & TST \\
\hline CHEMBL1430257 & 688142 & 4.35 & 5.1545 & TRN \\
\hline CHEMBL1580514 & 688142 & 4.9 & 5.055 & TRN \\
\hline CHEMBL1576041 & 688142 & 4.55 & 4.6258 & TRN \\
\hline CHEMBL299155 & 688142 & 6.6 & 4.7957 & TRN \\
\hline CHEMBL1610101 & 688142 & 4.45 & 4.6004 & TRN \\
\hline CHEMBL 1445796 & 688142 & 4.45 & 4.4554 & TRN \\
\hline CHEMBL1455898 & 688142 & 4.5 & 4.4578 & TRN \\
\hline
\end{tabular}

TRN 


\begin{tabular}{|c|c|c|c|c|c|}
\hline & & \multicolumn{4}{|c|}{ Supplemental Table s2.txt } \\
\hline CHEMBL3192104 & 688142 & 4.45 & 4.4988 & TRN & \\
\hline CHEMBL1568604 & 688142 & 4.3 & 4.6562 & TRN & \\
\hline CHEMBL1323252 & 688142 & 4.4 & 4.6777 & TRN & \\
\hline CHEMBL1565531 & 688142 & 4.45 & 4.4844 & TRN & \\
\hline CHEMBL1359455 & 688142 & 4.5 & 4.5698 & TRN & \\
\hline CHEMBL1533322 & 688142 & 4.45 & 4.5515 & TRN & \\
\hline CHEMBL1379183 & 688142 & 5.8 & 5.0673 & TST & \\
\hline CHEMBL1421698 & 688142 & 4.45 & 4.5969 & TRN & \\
\hline CHEMBL1487479 & 688142 & 4.55 & 4.4508 & TRN & \\
\hline CHEMBL504791 & 688142 & 4.45 & 4.6604 & TRN & \\
\hline CHEMBL1320424 & 688142 & 4.45 & 4.6168 & TRN & \\
\hline CHEMBL146525 & 688142 & 4.5 & 4.6005 & TRN & \\
\hline CHEMBL1435520 & 688142 & 4.45 & 4.9016 & TRN & \\
\hline CHEMBL1374915 & 688142 & 5.0 & 4.6469 & TRN & \\
\hline CHEMBL1555865 & 688142 & 4.4 & 4.8674 & TST & \\
\hline CHEMBL1523556 & 688142 & 4.45 & 4.5637 & TRN & \\
\hline CHEMBL1477983 & 688142 & 4.45 & 4.5566 & TRN & \\
\hline CHEMBL1510348 & 688142 & 4.55 & 4.88399 & 99999999995 & TRN \\
\hline CHEMBL1539635 & 688142 & 4.95 & 5.0373 & TRN & \\
\hline CHEMBL1392448 & 688142 & 4.3 & 5.0566 & TRN & \\
\hline CHEMBL1312044 & 688142 & 4.4 & 4.6676 & TRN & \\
\hline CHEMBL1517978 & 688142 & 4.75 & 4.8455 & TRN & \\
\hline CHEMBL1403821 & 688142 & 4.3 & 5.1452 & TST & \\
\hline CHEMBL12019 & 688142 & 4.4 & 4.4795 & TRN & \\
\hline CHEMBL3196338 & 688142 & 4.5 & 4.5327 & TRN & \\
\hline CHEMBL538595 & 688142 & 4.45 & 5.1223 & TRN & \\
\hline CHEMBL1556143 & 688142 & 4.45 & 4.6897 & TST & \\
\hline CHEMBL3214076 & 688142 & 4.6 & 4.6963 & TRN & \\
\hline CHEMBL1096400 & 688142 & 4.6 & 5.1135 & TST & \\
\hline CHEMBL1362307 & 688142 & 4.45 & 4.4795 & TRN & \\
\hline CHEMBL1392754 & 688142 & 7.0 & 4.9059 & TRN & \\
\hline CHEMBL1432801 & 688142 & 4.55 & 4.6505 & TRN & \\
\hline CHEMBL1498283 & 688142 & 6.2 & 4.9083 & TRN & \\
\hline CHEMBL1373722 & 688142 & 4.4 & 4.6408 & TRN & \\
\hline CHEMBL1524184 & 688142 & 4.35 & 5.0969 & TRN & \\
\hline CHEMBL1392232 & 688142 & 4.3 & 4.9961 & TRN & \\
\hline CHEMBL1501839 & 688142 & 5.2 & 4.6037 & TRN & \\
\hline CHEMBL1302493 & 688142 & 6.6 & 5.1068 & TRN & \\
\hline CHEMBL1465173 & 688142 & 4.95 & 5.1184 & TRN & \\
\hline CHEMBL1390362 & 688142 & 4.7 & 4.6063 & TRN & \\
\hline CHEMBL 251785 & 688142 & 4.45 & 5.4225 & TRN & \\
\hline CHEMBL1562125 & 688142 & 4.45 & 4.6108 & TRN & \\
\hline CHEMBL1336866 & 688142 & 4.4 & 4.7125 & TRN & \\
\hline CHEMBL1409828 & 688142 & 4.45 & 4.5313 & TRN & \\
\hline CHEMBL1402171 & 688142 & 4.5 & 4.6054 & TRN & \\
\hline CHEMBL1379970 & 688142 & 4.35 & 4.8252 & TST & \\
\hline CHEMBL1505810 & 688142 & 4.95 & 5.1969 & TRN & \\
\hline CHEMBL1422694 & 688142 & 4.95 & 5.1226 & TRN & \\
\hline
\end{tabular}




\begin{tabular}{|c|c|c|c|c|}
\hline \multicolumn{5}{|c|}{ Supplemental Table s2.txt } \\
\hline CHEMBL1612183 & 688142 & 6.7501 & 4.8667 & TRN \\
\hline CHEMBL1565276 & 688142 & 4.5 & 4.5702 & TRN \\
\hline CHEMBL1509124 & 688142 & 4.55 & 4.8785 & TRN \\
\hline CHEMBL1557617 & 688142 & 4.45 & 4.9567 & TRN \\
\hline CHEMBL1201091 & 688142 & 6.0 & 5.43 & TRN \\
\hline CHEMBL1523224 & 688142 & 4.55 & 4.7087 & TRN \\
\hline CHEMBL311226 & 688142 & 6.0 & 4.8915 & TST \\
\hline CHEMBL1419909 & 688142 & 5.15 & 5.0131 & TST \\
\hline CHEMBL1327707 & 688142 & 4.55 & 4.5768 & TRN \\
\hline CHEMBL3190658 & 688142 & 4.95 & 4.5672 & TRN \\
\hline CHEMBL1440857 & 688142 & 4.45 & 5.1463 & TST \\
\hline CHEMBL1408894 & 688142 & 4.45 & 4.5395 & TRN \\
\hline CHEMBL1460674 & 688142 & 4.5 & 4.5431 & TRN \\
\hline CHEMBL1698217 & 688142 & 4.45 & 4.5594 & TRN \\
\hline CHEMBL1348849 & 688142 & 4.4 & 4.4598 & TRN \\
\hline CHEMBL1544426 & 688142 & 4.5 & 4.4348 & TRN \\
\hline CHEMBL1498102 & 688142 & 4.4 & 4.9408 & TRN \\
\hline CHEMBL 3196023 & 688142 & 4.8 & 4.7009 & TRN \\
\hline CHEMBL 1585817 & 688142 & 5.4 & 5.0196 & TRN \\
\hline CHEMBL1438751 & 688142 & 4.45 & 4.7806 & TST \\
\hline CHEMBL1559248 & 688142 & 6.35 & 5.0189 & TST \\
\hline CHEMBL1344739 & 688142 & 6.15 & 4.9233 & TRN \\
\hline CHEMBL1411544 & 688142 & 4.6 & 4.489 & TRN \\
\hline CHEMBL1339653 & 688142 & 6.05 & 5.2008 & TRN \\
\hline CHEMBL1540509 & 688142 & 4.55 & 5.5052 & TRN \\
\hline CHEMBL1399358 & 688142 & 4.55 & 4.5838 & TRN \\
\hline CHEMBL1421005 & 688142 & 4.5 & 4.5866 & TRN \\
\hline CHEMBL1383480 & 688142 & 5.55 & 4.9664 & TRN \\
\hline CHEMBL 1313700 & 688142 & 4.95 & 5.3368 & TST \\
\hline CHEMBL1544804 & 688142 & 4.3 & 4.7754 & TRN \\
\hline CHEMBL1348582 & 688142 & 4.3 & 5.1237 & TST \\
\hline CHEMBL1402656 & 688142 & 4.55 & 4.9499 & TRN \\
\hline CHEMBL1347564 & 688142 & 4.45 & 4.7071 & TRN \\
\hline CHEMBL1579546 & 688142 & 4.4 & 4.5722 & TST \\
\hline CHEMBL1572669 & 688142 & 4.85 & 4.7053 & TRN \\
\hline CHEMBL1371305 & 688142 & 4.55 & 4.8387 & TRN \\
\hline CHEMBL1407374 & 688142 & 4.7 & 4.898 & TRN \\
\hline CHEMBL3192946 & 688142 & 4.95 & 4.5381 & TRN \\
\hline CHEMBL1432030 & 688142 & 4.4 & 4.7226 & TRN \\
\hline CHEMBL 1446630 & 688142 & 4.45 & 4.5583 & TRN \\
\hline CHEMBL1427373 & 688142 & 6.0 & 4.9157 & TST \\
\hline CHEMBL1302195 & 688142 & 6.8 & 4.9285 & TRN \\
\hline CHEMBL1555500 & 688142 & 4.45 & 4.5119 & TRN \\
\hline CHEMBL1610756 & 688142 & 6.6 & 4.7622 & TRN \\
\hline CHEMBL1483246 & 688142 & 4.4 & 4.6505 & TRN \\
\hline CHEMBL1551618 & 688142 & 4.3 & 4.9416 & TRN \\
\hline CHEMBL1323974 & 688142 & 4.35 & 5.1594 & TRN \\
\hline CHEMBL1370790 & 688142 & 4.45 & 4.4908 & TRN \\
\hline
\end{tabular}




\begin{tabular}{|c|c|c|c|c|}
\hline \multicolumn{5}{|c|}{ Supplemental Table S2.txt } \\
\hline CHEMBL1392405 & 688142 & 4.5 & 5.5141 & TRN \\
\hline CHEMBL1471617 & 688142 & 4.35 & 4.7757 & TRN \\
\hline CHEMBL1536252 & 688142 & 4.45 & 4.5185 & TRN \\
\hline CHEMBL1400479 & 688142 & 6.8 & 4.5108 & TST \\
\hline CHEMBL1442155 & 688142 & 4.3 & 4.8387 & TST \\
\hline CHEMBL1366443 & 688142 & 4.75 & 4.9254 & TRN \\
\hline CHEMBL1585171 & 688142 & 4.55 & 4.5442 & TRN \\
\hline CHEMBL1312946 & 688142 & 4.25 & 4.9547 & TRN \\
\hline CHEMBL1331420 & 688142 & 4.3 & 4.8937 & TRN \\
\hline CHEMBL1415252 & 688142 & 5.0 & 5.0092 & TRN \\
\hline CHEMBL1356902 & 688142 & 4.35 & 4.9011 & TRN \\
\hline CHEMBL1560080 & 688142 & 4.55 & 4.5596 & TRN \\
\hline CHEMBL1996376 & 688142 & 5.75 & 4.8174 & TST \\
\hline CHEMBL1399519 & 688142 & 4.65 & 4.4666 & TRN \\
\hline CHEMBL1326151 & 688142 & 4.4 & 4.9752 & TST \\
\hline CHEMBL3194360 & 688142 & 4.3 & 4.6511 & TRN \\
\hline CHEMBL1418866 & 688142 & 4.5 & 5.0071 & TST \\
\hline CHEMBL1541981 & 688142 & 4.25 & 4.8127 & TST \\
\hline CHEMBL1485219 & 688142 & 4.5 & 4.8875 & TRN \\
\hline CHEMBL71191 & 688142 & 6.0 & 4.8069 & TRN \\
\hline CHEMBL1420994 & 688142 & 4.5 & 4.7865 & TRN \\
\hline CHEMBL1557224 & 688142 & 5.8 & 4.808 & TST \\
\hline CHEMBL1335319 & 688142 & 4.45 & 4.4566 & TRN \\
\hline CHEMBL3190696 & 688142 & 5.95 & 4.9003 & TST \\
\hline CHEMBL1558482 & 688142 & 4.35 & 4.9732 & TST \\
\hline CHEMBL1479671 & 688142 & 4.3 & 4.9437 & TST \\
\hline CHEMBL1601816 & 688142 & 4.45 & 4.478 & TRN \\
\hline CHEMBL1608299 & 688142 & 5.9 & 5.056 & TRN \\
\hline CHEMBL1307244 & 688142 & 4.55 & 4.4896 & TRN \\
\hline CHEMBL1447870 & 688142 & 4.45 & 4.5348 & TRN \\
\hline CHEMBL1430744 & 688142 & 4.9 & 4.7805 & TRN \\
\hline CHEMBL1377163 & 688142 & 4.5 & 4.6443 & TRN \\
\hline CHEMBL1393046 & 688142 & 4.5 & 4.6824 & TRN \\
\hline CHEMBL1530257 & 688142 & 4.45 & 4.7261 & TRN \\
\hline CHEMBL3199084 & 688142 & 4.5 & 5.0531 & TST \\
\hline CHEMBL1509314 & 688142 & 4.4 & 4.6244 & TRN \\
\hline CHEMBL 1380228 & 688142 & 4.3 & 4.7833 & TRN \\
\hline CHEMBL1455655 & 688142 & 4.4 & 5.3143 & TRN \\
\hline CHEMBL1328765 & 688142 & 6.2 & 5.0882 & TRN \\
\hline CHEMBL1604191 & 688142 & 5.2 & 4.9179 & TST \\
\hline CHEMBL3195467 & 688142 & 4.35 & 4.78 & TRN \\
\hline CHEMBL1502192 & 688142 & 4.45 & 4.5968 & TRN \\
\hline CHEMBL1382813 & 688142 & 4.45 & 4.4978 & TRN \\
\hline CHEMBL1570730 & 688142 & 4.35 & 4.5722 & TRN \\
\hline CHEMBL1501332 & 688142 & 4.45 & 4.52 & TRN \\
\hline CHEMBL1506271 & 688142 & 5.05 & 4.9774 & TRN \\
\hline CHEMBL1466323 & 688142 & 6.7501 & 5.0743 & TST \\
\hline CHEMBL1300620 & 688142 & 4.45 & 4.6645 & TRN \\
\hline
\end{tabular}




\begin{tabular}{|c|c|c|c|c|c|}
\hline & & \\
\hline CHEMBL1600490 & 688142 & 4.5 & 4.6895 & TRN & \\
\hline CHEMBL1388127 & 688142 & 4.5 & 4.6613 & TRN & \\
\hline CHEMBL345083 & 688142 & 4.35 & 4.9824 & TST & \\
\hline CHEMBL1556332 & 688142 & 4.45 & 4.9258 & TST & \\
\hline CHEMBL1419786 & 688142 & 4.3 & 4.7487 & TRN & \\
\hline CHEMBL1408978 & 688142 & 4.35 & 5.0888 & TRN & \\
\hline CHEMBL1315183 & 688142 & 4.45 & 4.9221 & TRN & \\
\hline CHEMBL1441897 & 688142 & 4.5 & 4.5825 & TRN & \\
\hline CHEMBL1427890 & 688142 & 4.4 & 4.5568 & TRN & \\
\hline CHEMBL1566778 & 688142 & 4.3 & 4.9325 & TRN & \\
\hline CHEMBL1991112 & 688142 & 4.2 & 6.0037 & TRN & \\
\hline CHEMBL1380117 & 688142 & 6.7501 & 5.0424 & TRN & \\
\hline CHEMBL1449066 & 688142 & 4.45 & 4.5365 & TRN & \\
\hline CHEMBL3199789 & 688142 & 4.25 & 5.0716 & TST & \\
\hline CHEMBL240331 & 688142 & 4.4 & 4.6756 & TRN & \\
\hline CHEMBL1429873 & 688142 & 4.6 & 4.5357 & TRN & \\
\hline CHEMBL1512614 & 688142 & 4.3 & 4.9173 & TRN & \\
\hline CHEMBL1410321 & 688142 & 4.5 & 4.8327 & TRN & \\
\hline CHEMBL1432927 & 688142 & 4.4 & 4.6058 & TRN & \\
\hline CHEMBL1533401 & 688142 & 4.45 & 4.6129 & TRN & \\
\hline CHEMBL1390589 & 688142 & 4.45 & 4.5849 & TRN & \\
\hline CHEMBL60859 & 688142 & 4.85 & 4.9362 & TST & \\
\hline CHEMBL1361867 & 688142 & 4.55 & 4.6349 & TST & \\
\hline CHEMBL1324487 & 688142 & 4.45 & 4.5702 & TST & \\
\hline CHEMBL267160 & 688142 & 4.5 & 4.5313 & TST & \\
\hline CHEMBL1506325 & 688142 & 4.45 & 4.62 & TST & \\
\hline CHEMBL1381002 & 688142 & 4.5 & 4.6176 & TST & \\
\hline CHEMBL1528645 & 688142 & 4.3 & 5.1225 & TST & \\
\hline CHEMBL1409507 & 688142 & 5.0 & 4.8183 & TST & \\
\hline CHEMBL1576215 & 688142 & 4.95 & 5.0464 & TST & \\
\hline CHEMBL1505358 & 688142 & 4.3 & 5.5425 & TST & \\
\hline CHEMBL1447076 & 688142 & 4.5 & 4.4406 & TST & \\
\hline CHEMBL 1348648 & 688142 & 4.45 & 4.7392 & TST & \\
\hline CHEMBL1540441 & 688142 & 4.7 & 5.063 & TST & \\
\hline CHEMBL1429261 & 688142 & 4.75 & 4.9676 & TST & \\
\hline CHEMBL1341323 & 688142 & 4.95 & 4.6083 & TST & \\
\hline CHEMBL1307748 & 688142 & 4.45 & 4.6627 & TST & \\
\hline CHEMBL1422643 & 688142 & 5.0 & 4.7769 & TST & \\
\hline CHEMBL1609300 & 688142 & 4.3 & 4.6976 & TST & \\
\hline CHEMBL1415035 & 688142 & 4.6 & 5.0807 & TST & \\
\hline CHEMBL1565290 & 688142 & 4.45 & 4.617 & TST & \\
\hline CHEMBL1391063 & 688142 & 4.4 & 5.1457 & TST & \\
\hline CHEMBL1966657 & 688142 & 4.3 & 4.9363 & TST & \\
\hline CHEMBL1555421 & 688142 & 4.65 & 4.6969 & TST & \\
\hline CHEMBL1414220 & 688142 & 4.45 & 4.8574 & TST & \\
\hline CHEMBL1607915 & 688142 & 4.9 & 5.0424 & TST & \\
\hline CHEMBL1364856 & 688142 & 4.6 & 4.5834 & TST & \\
\hline CHEMBL1495645 & 688142 & 4.4 & $4.5280 e$ & 00000000005 & TST \\
\hline & & & & 16714 & \\
\hline
\end{tabular}




\begin{tabular}{|c|c|c|c|c|}
\hline \multicolumn{5}{|c|}{ Supplemental Table s2.txt } \\
\hline CHEMBL1307801 & 688142 & 5.1 & 4.9261 & TST \\
\hline CHEMBL261634 & 688142 & 4.8 & 4.9604 & TST \\
\hline CHEMBL1516947 & 688142 & 4.3 & 4.7016 & TST \\
\hline CHEMBL1374247 & 688142 & 4.45 & 4.6071 & TST \\
\hline CHEMBL1347514 & 688142 & 5.5 & 4.5915 & TST \\
\hline CHEMBL 2002776 & 688142 & 4.4 & 4.7218 & TST \\
\hline CHEMBL1377624 & 688142 & 4.25 & 4.8805 & TST \\
\hline CHEMBL1380440 & 688142 & 4.45 & 4.7695 & TST \\
\hline CHEMBL1472705 & 688142 & 4.3 & 4.8222 & TST \\
\hline CHEMBL1359620 & 688142 & 4.45 & 4.5857 & TST \\
\hline CHEMBL1324965 & 688142 & 4.8 & 4.7618 & TST \\
\hline CHEMBL 251055 & 688142 & 5.15 & 4.9468 & TST \\
\hline CHEMBL1611299 & 688142 & 4.55 & 4.5206 & TST \\
\hline CHEMBL1485763 & 688142 & 4.45 & 4.622 & TST \\
\hline CHEMBL1299470 & 688142 & 4.3 & 4.93 & TST \\
\hline CHEMBL3192978 & 688142 & 4.45 & 4.8805 & TST \\
\hline CHEMBL1300662 & 688142 & 5.45 & 4.5523 & TST \\
\hline CHEMBL 2005664 & 688142 & 4.65 & 5.0147 & TST \\
\hline CHEMBL1326170 & 688142 & 4.3 & 4.993 & TST \\
\hline CHEMBL1371777 & 688142 & 6.7501 & 4.9315 & TST \\
\hline CHEMBL1489003 & 688142 & 4.5 & 5.0874 & TST \\
\hline CHEMBL1571270 & 688142 & 6.05 & 4.9793 & TST \\
\hline CHEMBL1363105 & 688142 & 6.7501 & 4.798 & TST \\
\hline CHEMBL1377376 & 688142 & 4.7 & 4.8745 & TST \\
\hline CHEMBL1467168 & 688142 & 4.45 & 4.538 & TST \\
\hline CHEMBL1361191 & 688142 & 6.6 & 4.9254 & TST \\
\hline CHEMBL1380386 & 688142 & 4.3 & 4.7724 & TST \\
\hline CHEMBL1532984 & 688142 & 6.0 & 4.8232 & TST \\
\hline CHEMBL1434042 & 688142 & 6.0 & 4.708 & TST \\
\hline CHEMBL1382693 & 688142 & 4.4 & 4.9186 & TST \\
\hline CHEMBL1413811 & 688142 & 4.5 & 4.6278 & TST \\
\hline CHEMBL1316156 & 688142 & 4.95 & 4.8831 & TST \\
\hline CHEMBL 270672 & 688142 & 4.45 & 4.5436 & TST \\
\hline CHEMBL1400866 & 688142 & 6.7501 & 4.7359 & TST \\
\hline CHEMBL1322470 & 688142 & 4.9 & 5.0136 & TST \\
\hline CHEMBL1440540 & 688142 & 4.45 & 4.573 & TST \\
\hline CHEMBL1573961 & 688142 & 4.4 & 4.5831 & TST \\
\hline CHEMBL1329690 & 688142 & 5.8 & 5.1696 & TST \\
\hline CHEMBL1484447 & 688142 & 4.45 & 5.0709 & TST \\
\hline CHEMBL3199579 & 688142 & 4.95 & 4.685 & TST \\
\hline CHEMBL30707 & 688142 & 4.45 & 4.5136 & TST \\
\hline CHEMBL1397123 & 688142 & 4.45 & 5.0607 & TST \\
\hline CHEMBL1413619 & 688142 & 6.05 & 4.9703 & TST \\
\hline CHEMBL1536055 & 688142 & 7.0 & 5.0772 & TST \\
\hline CHEMBL1299818 & 688142 & 4.5 & 4.7555 & TST \\
\hline CHEMBL1442207 & 688142 & 4.4 & 4.7431 & TST \\
\hline CHEMBL1526342 & 688142 & 4.55 & 4.9858 & TST \\
\hline CHEMBL3194082 & 688142 & 5.3 & 4.8669 & TST \\
\hline
\end{tabular}




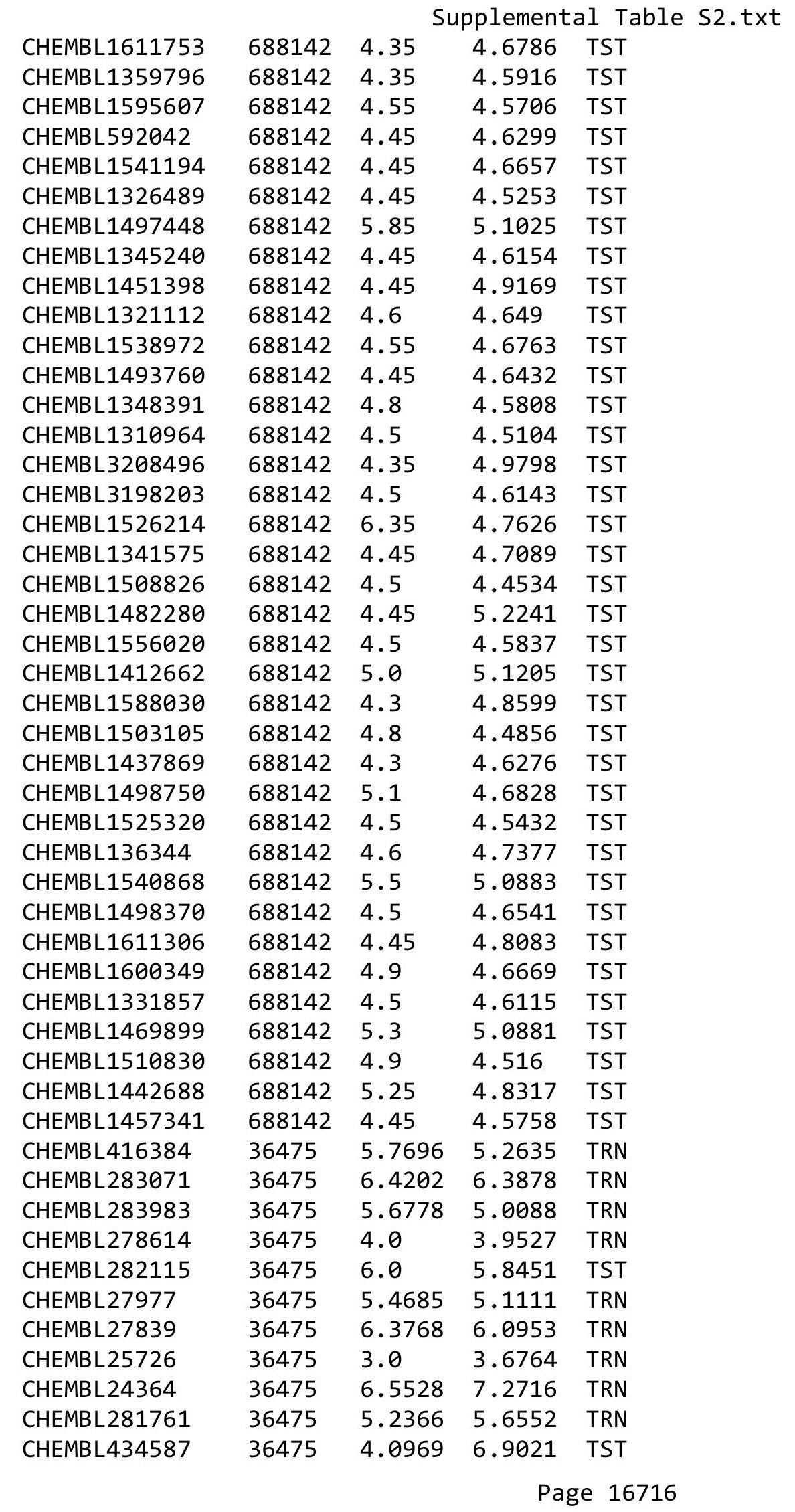




\begin{tabular}{|c|c|c|c|c|c|}
\hline \multicolumn{6}{|c|}{ Supplemental Table S2.txt } \\
\hline CHEMBL27454 & 36475 & 5.2757 & 5.3876 & TRN & \\
\hline CHEMBL282283 & 36475 & 5.9208 & 4.6577 & TST & \\
\hline CHEMBL282491 & 36475 & 6.7212 & 6.6508 & TRN & \\
\hline CHEMBL25686 & 36475 & 5.7959 & 5.1094 & TRN & \\
\hline CHEMBL 26673 & 36475 & 5.5686 & 5.2812 & TRN & \\
\hline CHEMBL 24880 & 36475 & 4.0 & 4.1531 & TRN & \\
\hline CHEMBL 28044 & 36475 & 3.0 & 3.605 & TRN & \\
\hline CHEMBL278617 & 36475 & 4.0 & 4.5792 & TRN & \\
\hline CHEMBL434586 & 36475 & 4.0 & 4.6329 & TST & \\
\hline CHEMBL26712 & 36475 & 5.6383 & 6.0303 & TRN & \\
\hline CHEMBL 25031 & 36475 & 7.0969 & 7.2537 & TRN & \\
\hline CHEMBL 24849 & 36475 & 4.5528 & 4.40300 & 00000000005 & TRN \\
\hline CHEMBL280528 & 36475 & 4.3979 & 4.8626 & TRN & \\
\hline CHEMBL281589 & 36475 & 7.4949 & 7.4892 & TRN & \\
\hline CHEMBL 27725 & 36475 & 6.3979 & 6.858 & TRN & \\
\hline CHEMBL 26727 & 36475 & 5.8861 & 5.7516 & TRN & \\
\hline CHEMBL282090 & 36475 & 5.1249 & 6.0253 & TST & \\
\hline CHEMBL28425 & 36475 & 5.1612 & 5.1252 & TRN & \\
\hline CHEMBL284426 & 36475 & 4.8861 & 4.6215 & TST & \\
\hline CHEMBL27168 & 36475 & 4.0 & 5.4089 & TST & \\
\hline CHEMBL 27321 & 36475 & 4.4202 & 4.835 & TST & \\
\hline CHEMBL 28391 & 36475 & 6.301 & 6.2927 & TRN & \\
\hline CHEMBL 28011 & 36475 & 6.7212 & 6.9233 & TRN & \\
\hline CHEMBL284184 & 36475 & 4.0 & 3.8317 & TRN & \\
\hline CHEMBL281068 & 36475 & 5.4202 & 4.9237 & TST & \\
\hline CHEMBL 280800 & 36475 & 4.3372 & 4.4269 & TRN & \\
\hline CHEMBL24934 & 36475 & 6.1024 & 6.1525 & TRN & \\
\hline CHEMBL 25528 & 36475 & 4.3979 & 4.4068 & TST & \\
\hline CHEMBL25574 & 36475 & 4.4949 & 4.3465 & TRN & \\
\hline CHEMBL276956 & 36475 & 7.3768 & 7.7264 & TRN & \\
\hline CHEMBL27836 & 36475 & 4.3979 & 4.7475 & TRN & \\
\hline CHEMBL27166 & 36475 & 3.5229 & 4.2901 & TRN & \\
\hline CHEMBL281054 & 36475 & 4.0 & 3.6615 & TRN & \\
\hline CHEMBL280868 & 36475 & 6.2441 & 5.1372 & TRN & \\
\hline CHEMBL279683 & 36475 & 3.8239 & 4.4866 & TST & \\
\hline CHEMBL26935 & 36475 & 5.2291 & 5.2198 & TRN & \\
\hline CHEMBL262958 & 36475 & 6.8539 & 6.3151 & TRN & \\
\hline CHEMBL281514 & 36475 & 5.9586 & 6.7686 & TST & \\
\hline CHEMBL25555 & 36475 & 4.5686 & 4.6088 & TRN & \\
\hline CHEMBL 286028 & 36475 & 6.0915 & 5.8416 & TRN & \\
\hline CHEMBL25694 & 36475 & 4.7212 & 4.6727 & TST & \\
\hline CHEMBL 284425 & 36475 & 7.9208 & 7.6612 & TRN & \\
\hline CHEMBL24952 & 36475 & 4.8239 & 3.9415 & TST & \\
\hline CHEMBL 279747 & 36475 & 4.9586 & 4.6876 & TRN & \\
\hline CHEMBL 283431 & 36475 & 4.0757 & 4.8827 & TRN & \\
\hline CHEMBL 280768 & 36475 & 4.9586 & 4.3169 & TRN & \\
\hline CHEMBL 27401 & 36475 & 5.0969 & 5.3372 & TRN & \\
\hline CHEMBL24512 & 36475 & 6.301 & 5.6709 & TRN & \\
\hline
\end{tabular}




\begin{tabular}{|c|c|c|c|c|c|}
\hline \multicolumn{6}{|c|}{ Supplemental Table S2.txt } \\
\hline CHEMBL282594 & 36475 & 4.0 & 3.9322 & TRN & \\
\hline CHEMBL26765 & 36475 & 5.5528 & 6.1277 & TST & \\
\hline CHEMBL1744348 & 36475 & 7.7447 & 6.8065 & TRN & \\
\hline CHEMBL25677 & 36475 & 5.2441 & 6.2527 & TRN & \\
\hline CHEMBL280193 & 36475 & 5.5086 & 4.7881 & TST & \\
\hline CHEMBL 2036191 & 822749 & 5.5528 & 5.5509 & TRN & \\
\hline CHEMBL 2036165 & 822749 & 6.0088 & 5.9792 & TRN & \\
\hline CHEMBL 2036176 & 822749 & 6.301 & 6.312 & TRN & \\
\hline CHEMBL 2036197 & 822749 & 5.2218 & 5.1609 & TRN & \\
\hline CHEMBL 2036171 & 822749 & 5.5376 & 5.4352 & TRN & \\
\hline CHEMBL 2036373 & 822749 & 4.0 & 3.9799 & TRN & \\
\hline CHEMBL 2036187 & 822749 & 5.3565 & 5.4128 & TRN & \\
\hline CHEMBL 2036372 & 822749 & 6.301 & 6.3289 & TRN & \\
\hline CHEMBL 2036375 & 822749 & 5.5528 & 5.63299 & 7999999999 & TRN \\
\hline CHEMBL 2036190 & 822749 & 5.6021 & 5.5304 & TRN & \\
\hline CHEMBL29097 & 822749 & 7.7696 & 3.1637 & TST & \\
\hline CHEMBL 2036186 & 822749 & 6.301 & 6.2633 & TRN & \\
\hline CHEMBL 2036194 & 822749 & 4.0 & 3.9888 & TRN & \\
\hline CHEMBL 2036175 & 822749 & 4.0 & 4.0468 & TRN & \\
\hline CHEMBL 2036181 & 822749 & 6.3565 & 6.3362 & TRN & \\
\hline CHEMBL 2036382 & 822749 & 6.7959 & 6.7653 & TRN & \\
\hline CHEMBL 2036182 & 822749 & 6.6021 & 6.5892 & TRN & \\
\hline CHEMBL 2036170 & 822749 & 5.6383 & 5.6378 & TRN & \\
\hline CHEMBL 2036378 & 822749 & 6.7212 & 6.7084 & TRN & \\
\hline CHEMBL 2034994 & 822749 & 5.301 & 5.3275 & TRN & \\
\hline CHEMBL 2036196 & 822749 & 4.0 & 4.0037 & TRN & \\
\hline CHEMBL 2036379 & 822749 & 6.7447 & 6.7309 & TRN & \\
\hline CHEMBL 2036195 & 822749 & 5.0 & 5.015 & TRN & \\
\hline CHEMBL 2036174 & 822749 & 4.0 & 3.9674 & TRN & \\
\hline CHEMBL 2036172 & 822749 & 5.4202 & 5.473 & TRN & \\
\hline CHEMBL 2036188 & 822749 & 4.0 & 3.9903 & TRN & \\
\hline CHEMBL 2036166 & 822749 & 5.3188 & 5.296 & TRN & \\
\hline CHEMBL 2036193 & 822749 & 5.3565 & 5.3624 & TRN & \\
\hline CHEMBL 2036158 & 822749 & 4.0 & 2.2558 & TST & \\
\hline CHEMBL 2036169 & 822749 & 5.3098 & 5.3501 & TRN & \\
\hline CHEMBL 2036376 & 822749 & 5.5229 & 5.4616 & TRN & \\
\hline CHEMBL 2036162 & 822749 & 4.0 & 4.0856 & TST & \\
\hline CHEMBL 2036178 & 822749 & 6.3468 & 6.375 & TRN & \\
\hline CHEMBL 2036381 & 822749 & 6.0809 & 6.1422 & TRN & \\
\hline CHEMBL 2036168 & 822749 & 5.4685 & 5.4158 & TRN & \\
\hline CHEMBL2036160 & 822749 & 5.0555 & 4.317 & TST & \\
\hline CHEMBL 2036371 & 822749 & 4.0 & 4.0331 & TRN & \\
\hline CHEMBL 2036377 & 822749 & 6.9208 & 6.8786 & TRN & \\
\hline CHEMBL 2036183 & 822749 & 5.3979 & 5.3909 & TRN & \\
\hline CHEMBL 2036164 & 822749 & 5.3565 & 4.199 & TST & \\
\hline CHEMBL 2036179 & 822749 & 5.3468 & 5.3474 & TRN & \\
\hline CHEMBL 2036159 & 822749 & 4.0 & 2.3241 & TST & \\
\hline CHEMBL 2036161 & 822749 & 5.041 & 3.2851 & TST & \\
\hline
\end{tabular}




\begin{tabular}{|c|c|c|c|c|}
\hline \multicolumn{5}{|c|}{ Supplemental Table S2.txt } \\
\hline CHEMBL 2036180 & 822749 & 6.6021 & 6.6566 & TRN \\
\hline CHEMBL 2036192 & 822749 & 5.71 & 5.7531 & TRN \\
\hline CHEMBL2036163 & 822749 & 6.5086 & 6.5427 & TRN \\
\hline CHEMBL 2036157 & 822749 & 4.0 & 2.1555 & TST \\
\hline CHEMBL314360 & 822749 & 6.9586 & 3.8379 & TST \\
\hline CHEMBL 2036189 & 822749 & 5.0269 & 5.0607 & TRN \\
\hline CHEMBL 2036173 & 822749 & 5.1427 & 5.3689 & TST \\
\hline CHEMBL2036374 & 822749 & 6.1549 & 5.4118 & TST \\
\hline CHEMBL 2036177 & 822749 & 6.1549 & 6.0481 & TST \\
\hline CHEMBL 2036380 & 822749 & 4.0 & 6.6492 & TST \\
\hline CHEMBL 2036167 & 822749 & 5.2218 & 5.3698 & TST \\
\hline CHEMBL 2371246 & 211948 & 1.301 & 1.2918 & TRN \\
\hline CHEMBL2371231 & 211948 & 4.5376 & 2.6091 & TST \\
\hline CHEMBL 2371244 & 211948 & 1.5229 & 1.5386 & TRN \\
\hline CHEMBL161769 & 211948 & 4.4815 & 4.5379 & TRN \\
\hline CHEMBL57338 & 211948 & 2.9431 & 3.0609 & TRN \\
\hline CHEMBL171132 & 211948 & 1.301 & 1.28 & TRN \\
\hline CHEMBL2371251 & 211948 & 4.8539 & 4.9074 & TRN \\
\hline CHEMBL 2371236 & 211948 & 5.0458 & 4.7994 & TRN \\
\hline CHEMBL55523 & 211948 & 2.0458 & 2.1602 & TST \\
\hline CHEMBL 2371243 & 211948 & 4.9586 & 4.9801 & TRN \\
\hline CHEMBL189368 & 211948 & 4.8539 & 2.0013 & TST \\
\hline CHEMBL52461 & 211948 & 2.301 & 1.9677 & TST \\
\hline CHEMBL157814 & 211948 & 3.6778 & 3.6166 & TRN \\
\hline CHEMBL 2371263 & 211948 & 2.699 & 2.5632 & TRN \\
\hline CHEMBL 2371250 & 211948 & 3.9431 & 2.9754 & TST \\
\hline CHEMBL 2371257 & 211948 & 4.699 & 4.6349 & TST \\
\hline CHEMBL162249 & 211948 & 4.0969 & 4.0786 & TRN \\
\hline CHEMBL1221711 & 211948 & 3.9586 & 4.0496 & TRN \\
\hline CHEMBL 2371242 & 211948 & 3.5376 & 3.5175 & TRN \\
\hline CHEMBL 2371265 & 211948 & 2.699 & 2.6998 & TRN \\
\hline CHEMBL 2371270 & 211948 & 4.2218 & 4.2207 & TRN \\
\hline CHEMBL 2371256 & 211948 & 2.8447 & 3.0006 & TRN \\
\hline CHEMBL 2371253 & 211948 & 4.6576 & 4.6104 & TRN \\
\hline CHEMBL 2371233 & 211948 & 4.699 & 4.7601 & TRN \\
\hline CHEMBL161844 & 211948 & 1.5229 & 1.5136 & TRN \\
\hline CHEMBL161110 & 211948 & 1.301 & 1.3328 & TRN \\
\hline CHEMBL54552 & 211948 & 2.7773 & 2.6364 & TST \\
\hline CHEMBL161367 & 211948 & 2.6778 & 2.6932 & TRN \\
\hline CHEMBL 2372349 & 211948 & 1.301 & 1.2273 & TRN \\
\hline CHEMBL 208960 & 211948 & 2.7773 & 2.8872 & TRN \\
\hline CHEMBL 2371241 & 211948 & 4.1805 & 4.4445 & TRN \\
\hline CHEMBL 2371248 & 211948 & 3.2218 & 2.385 & TST \\
\hline CHEMBL 2371254 & 211948 & 5.5229 & 5.4635 & TRN \\
\hline CHEMBL 2371239 & 211948 & 3.2441 & 3.2838 & TRN \\
\hline CHEMBL 2371249 & 211948 & 4.5376 & 4.4816 & TRN \\
\hline CHEMBL 2371232 & 211948 & 3.6383 & 3.7251 & TRN \\
\hline CHEMBL 2371258 & 211948 & 4.301 & 4.2934 & TRN \\
\hline
\end{tabular}




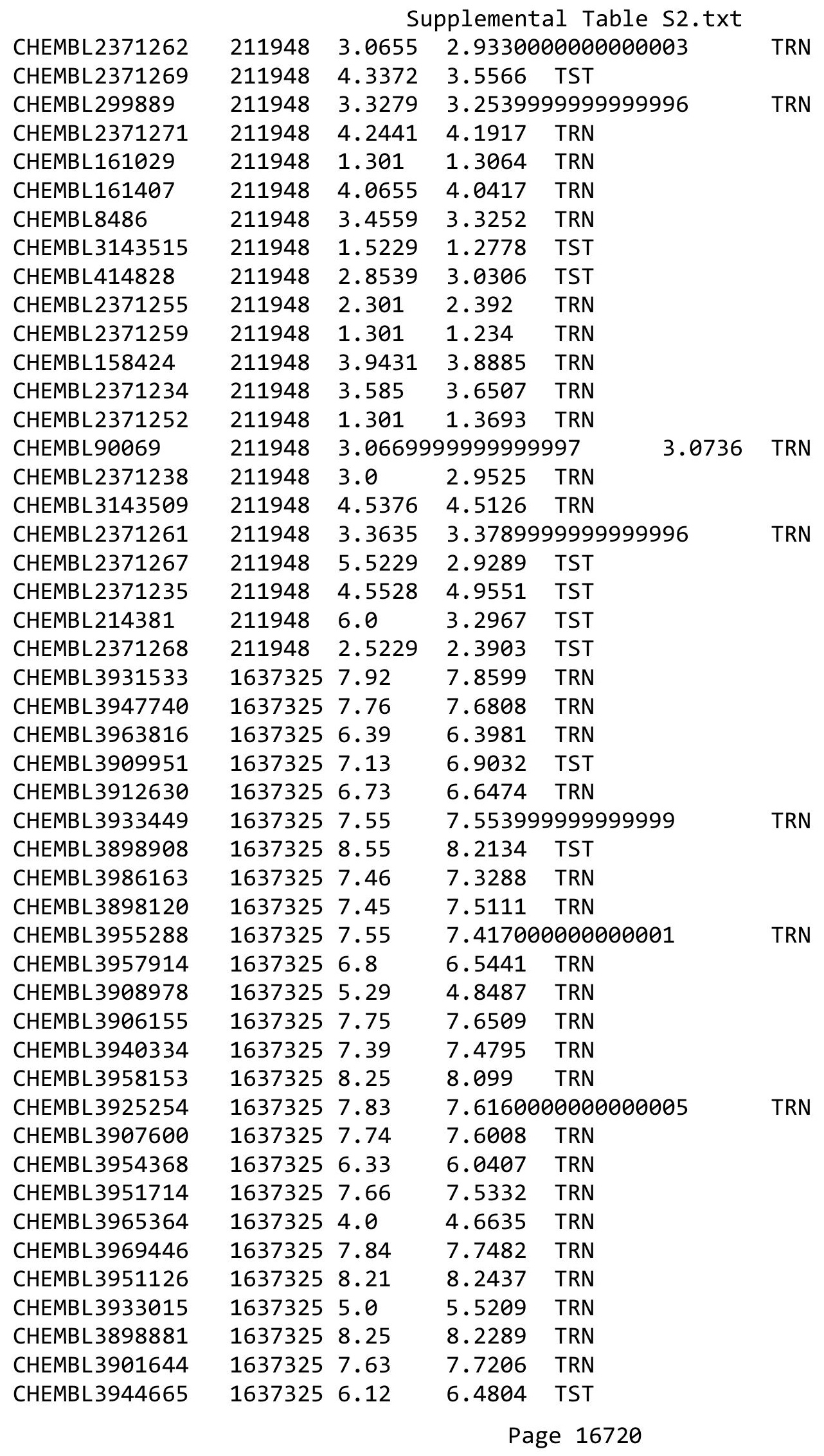


Supplemental Table S2.txt

\begin{tabular}{|c|c|c|c|c|c|}
\hline CHEMBL3947293 & 1637325 & 6.59 & 6.4939 & TRN & \\
\hline CHEMBL3947826 & 1637325 & 5.0 & 5.4519 & TST & \\
\hline CHEMBL3985692 & 1637325 & 8.37 & 8.1393 & TST & \\
\hline CHEMBL3947990 & 1637325 & 7.51 & 7.3535 & TST & \\
\hline CHEMBL3925306 & 1637325 & 7.92 & 7.8955 & TRN & \\
\hline CHEMBL3951245 & 1637325 & 8.35 & 8.2205 & TST & \\
\hline CHEMBL3948623 & 1637325 & 7.52 & 7.3961 & TRN & \\
\hline CHEMBL3892018 & 1637325 & 7.95 & 7.858 & TRN & \\
\hline CHEMBL3987037 & 1637325 & 7.8 & 7.7492 & TRN & \\
\hline CHEMBL3921313 & 1637325 & 7.49 & 7.4188 & TRN & \\
\hline CHEMBL3927327 & 1637325 & 7.64 & 7.5075 & TRN & \\
\hline CHEMBL3976280 & 1637325 & 7.46 & 7.7594 & TRN & \\
\hline CHEMBL3973820 & 1637325 & 7.38 & 7.324 & TRN & \\
\hline CHEMBL3918011 & 1637325 & 6.99 & 6.9961 & TRN & \\
\hline CHEMBL3915235 & 1637325 & 7.28 & 7.3521 & TRN & \\
\hline CHEMBL3965673 & 1637325 & 5.0 & 4.5151 & TRN & \\
\hline CHEMBL3968094 & 1637325 & 7.09 & 6.8276 & TRN & \\
\hline CHEMBL3918751 & 1637325 & 8.13 & 8.0688 & TRN & \\
\hline CHEMBL3956164 & 1637325 & 6.93 & 7.1776 & TRN & \\
\hline CHEMBL3908829 & 1637325 & 7.37 & 7.4911 & TRN & \\
\hline CHEMBL3911573 & 1637325 & 7.42 & 7.7249 & TRN & \\
\hline CHEMBL3969879 & 1637325 & 6.95 & 6.8934 & TRN & \\
\hline CHEMBL3972564 & 1637325 & 6.5 & 6.0997 & TRN & \\
\hline CHEMBL3927875 & 1637325 & 7.76 & 7.9848 & TRN & \\
\hline CHEMBL3930634 & 1637325 & 6.18 & 5.7427 & TRN & \\
\hline CHEMBL3901627 & 1637325 & 7.97 & 7.8157 & TST & \\
\hline CHEMBL3904329 & 1637325 & 7.8 & 7.8297 & TRN & \\
\hline CHEMBL3969408 & 1637325 & 4.0 & 4.6788 & TRN & \\
\hline CHEMBL3985853 & 1637325 & 7.33 & 7.5444 & TRN & \\
\hline CHEMBL3908326 & 1637325 & 7.17 & 7.6745 & TRN & \\
\hline CHEMBL3918092 & 1637325 & 8.51 & 8.4108 & TRN & \\
\hline CHEMBL3964675 & 1637325 & 7.24 & 7.4133 & TRN & \\
\hline CHEMBL3955706 & 1637325 & 8.01 & 8.258 & TRN & \\
\hline CHEMBL3937533 & 1637325 & 7.61 & 7.5895 & TRN & \\
\hline CHEMBL3962814 & 1637325 & 7.0 & 7.3207 & TRN & \\
\hline CHEMBL3931674 & 1637325 & 6.71 & 7.1522 & TRN & \\
\hline CHEMBL3976219 & 1637325 & 7.28 & \multicolumn{2}{|c|}{7.5760000000000005} & TRN \\
\hline CHEMBL3924872 & 1637325 & 7.32 & 6.8417 & TRN & \\
\hline CHEMBL3908529 & 1637325 & 7.09 & 7.2892 & TRN & \\
\hline CHEMBL3962805 & 1637325 & 7.37 & 7.4959 & TRN & \\
\hline CHEMBL3960128 & 1637325 & 6.12 & \multicolumn{2}{|c|}{6.872000000000001} & TST \\
\hline CHEMBL3909565 & 1637325 & 8.07 & 8.1204 & TRN & \\
\hline CHEMBL3948321 & 1637325 & 7.33 & 7.7235 & TRN & \\
\hline CHEMBL3985750 & 1637325 & 7.6 & 7.7918 & TRN & \\
\hline CHEMBL3983115 & 1637325 & 7.52 & 7.6439 & TRN & \\
\hline CHEMBL3926311 & 1637325 & 7.07 & \multicolumn{2}{|c|}{7.047999999999999} & TRN \\
\hline CHEMBL3926406 & 1637325 & 7.58 & 7.568 & TRN & \\
\hline CHEMBL3979490 & 1637325 & 8.31 & 8.2531 & TST & \\
\hline
\end{tabular}




\begin{tabular}{|c|c|c|c|c|c|}
\hline \multicolumn{6}{|c|}{ Supplemental Table S2.txt } \\
\hline CHEMBL3898355 & 1637325 & 8.11 & 8.0519 & TST & \\
\hline CHEMBL3940725 & 1637325 & 7.59 & 7.2893 & TRN & \\
\hline CHEMBL3973531 & 1637325 & 7.92 & 7.4816 & TRN & \\
\hline CHEMBL 3913757 & 1637325 & 8.4 & 8.2319 & TRN & \\
\hline CHEMBL 3961210 & 1637325 & 8.18 & 8.1069 & TRN & \\
\hline CHEMBL3936765 & 1637325 & 5.0 & 5.2208 & TRN & \\
\hline CHEMBL3951156 & 1637325 & 7.42 & 7.6503 & TRN & \\
\hline CHEMBL3979170 & 1637325 & 8.14 & 7.8239 & TST & \\
\hline CHEMBL3921618 & 1637325 & 8.91 & 8.7404 & TRN & \\
\hline CHEMBL3969815 & 1637325 & 7.78 & 7.9123 & TRN & \\
\hline CHEMBL 3961872 & 1637325 & 8.14 & 8.0004 & TST & \\
\hline CHEMBL 3985222 & 1637325 & 8.09 & 8.0695 & TRN & \\
\hline CHEMBL 3974664 & 1637325 & 7.65 & 7.8663 & TRN & \\
\hline CHEMBL 3972173 & 1637325 & 7.43 & 7.0668 & TRN & \\
\hline CHEMBL3919173 & 1637325 & 8.78 & 8.7099 & TRN & \\
\hline CHEMBL3956737 & 1637325 & 5.0 & 5.2723 & TRN & \\
\hline CHEMBL3966022 & 1637325 & 7.61 & 7.3949 & TRN & \\
\hline CHEMBL3968499 & 1637325 & 8.37 & 8.2997 & TRN & \\
\hline CHEMBL3912505 & 1637325 & 5.0 & 5.6005 & TRN & \\
\hline CHEMBL 3915158 & 1637325 & 5.0 & 5.3131 & TRN & \\
\hline CHEMBL3950262 & 1637325 & 7.02 & 7.4348 & TRN & \\
\hline CHEMBL3949470 & 1637325 & 8.17 & 8.0779 & TRN & \\
\hline CHEMBL3893008 & 1637325 & 8.09 & 8.0658 & TRN & \\
\hline CHEMBL 3889493 & 1637325 & 7.59 & 7.2874 & TRN & \\
\hline CHEMBL 3984548 & 1637325 & 7.66 & 7.74100 & 00000000005 & TRN \\
\hline CHEMBL3920908 & 1637325 & 7.5 & 7.6731 & TST & \\
\hline CHEMBL3939278 & 1637325 & 7.87 & 8.11 & TRN & \\
\hline CHEMBL3974693 & 1637325 & 7.59 & 7.5698 & TRN & \\
\hline CHEMBL 3972208 & 1637325 & 5.0 & 5.3216 & TRN & \\
\hline CHEMBL3950907 & 1637325 & 7.51 & 7.5114 & TRN & \\
\hline CHEMBL3931421 & 1637325 & 8.33 & 8.2091 & TRN & \\
\hline CHEMBL 3923296 & 1637325 & 8.14 & 8.131 & TRN & \\
\hline CHEMBL3918495 & 1637325 & 7.8 & 7.9525 & TRN & \\
\hline CHEMBL3945369 & 1637325 & 5.0 & 5.2116 & TRN & \\
\hline CHEMBL3961267 & 1637325 & 7.04 & 6.8783 & TRN & \\
\hline CHEMBL3984039 & 1637325 & 8.39 & 8.378 & TRN & \\
\hline CHEMBL 3928627 & 1637325 & 6.49 & 6.064 & TST & \\
\hline CHEMBL 3908877 & 1637325 & 7.69 & 7.7638 & TST & \\
\hline CHEMBL 3907488 & 1637325 & 7.39 & 6.9181 & TST & \\
\hline CHEMBL 3929803 & 1637325 & 7.85 & 7.6727 & TRN & \\
\hline CHEMBL3970430 & 1637325 & 8.14 & 8.1656 & TRN & \\
\hline CHEMBL3969475 & 1637325 & 8.0 & 7.7963 & TRN & \\
\hline CHEMBL3963728 & 1637325 & 5.0 & 5.4323 & TST & \\
\hline CHEMBL 3944224 & 1637325 & 7.66 & 7.6678 & TRN & \\
\hline CHEMBL 3909318 & 1637325 & 7.65 & 7.5013 & TRN & \\
\hline CHEMBL3982668 & 1637325 & 7.72 & 7.5889 & TRN & \\
\hline CHEMBL 3980232 & 1637325 & 8.33 & 7.9696 & TST & \\
\hline CHEMBL3937633 & 1637325 & 8.04 & 8.0273 & TRN & \\
\hline
\end{tabular}




\begin{tabular}{|c|c|c|c|c|c|}
\hline \multicolumn{6}{|c|}{ Supplemental Table s2.txt } \\
\hline CHEMBL 3955563 & 1637325 & 8.28 & 8.116 & TRN & \\
\hline CHEMBL 3890607 & 1637325 & 7.66 & 7.5708 & TRN & \\
\hline CHEMBL 3893373 & 1637325 & 7.33 & 7.4295 & TRN & \\
\hline CHEMBL 3954298 & 1637325 & 8.27 & 8.1469 & TRN & \\
\hline CHEMBL 3900620 & 1637325 & 7.78 & 7.7572 & TRN & \\
\hline CHEMBL3983996 & 1637325 & 7.99 & 7.8223 & TRN & \\
\hline CHEMBL3935124 & 1637325 & 7.35 & 7.1012 & TRN & \\
\hline CHEMBL 3973645 & 1637325 & 5.0 & 6.0855 & TST & \\
\hline CHEMBL 3971073 & 1637325 & 7.04 & 7.178 & TRN & \\
\hline CHEMBL3957264 & 1637325 & 7.9 & 8.0234 & TRN & \\
\hline CHEMBL 3969096 & 1637325 & 6.51 & 6.7686 & TRN & \\
\hline CHEMBL 3905212 & 1637325 & 7.85 & 7.3231 & TST & \\
\hline CHEMBL3897034 & 1637325 & 7.46 & 7.4479 & TRN & \\
\hline CHEMBL 3979885 & 1637325 & 7.35 & 7.5083 & TRN & \\
\hline CHEMBL 3982334 & 1637325 & 6.51 & 6.3054 & TRN & \\
\hline CHEMBL3919730 & 1637325 & 8.29 & 8.1875 & TRN & \\
\hline CHEMBL3922453 & 1637325 & 7.75 & 7.9655 & TRN & \\
\hline CHEMBL3959345 & 1637325 & 7.85 & 8.0608 & TRN & \\
\hline CHEMBL 3959201 & 1637325 & 7.86 & 7.5019 & TST & \\
\hline CHEMBL3915233 & 1637325 & 6.61 & 6.3769 & TRN & \\
\hline CHEMBL3912569 & 1637325 & 8.68 & 8.6431 & TRN & \\
\hline CHEMBL3975954 & 1637325 & 7.88 & 8.0041 & TRN & \\
\hline CHEMBL 3966748 & 1637325 & 8.16 & 8.2299 & TST & \\
\hline CHEMBL 3929648 & 1637325 & 7.16 & 6.8752 & TRN & \\
\hline CHEMBL 3926964 & 1637325 & 5.0 & 5.4043 & TRN & \\
\hline CHEMBL3891619 & 1637325 & 7.35 & 7.2174 & TRN & \\
\hline CHEMBL3986661 & 1637325 & 7.3 & 7.46700 & 00000000005 & TRN \\
\hline CHEMBL 3943043 & 1637325 & 7.93 & 8.0278 & TRN & \\
\hline CHEMBL 3904745 & 1637325 & 7.6 & 7.4426 & TRN & \\
\hline CHEMBL 3965614 & 1637325 & 7.35 & 7.7732 & TRN & \\
\hline CHEMBL 3968009 & 1637325 & 8.42 & 8.1009 & TST & \\
\hline CHEMBL 3906122 & 1637325 & 7.63 & 7.4423 & TST & \\
\hline CHEMBL3900268 & 1637325 & 6.59 & 6.4008 & TRN & \\
\hline CHEMBL 3951728 & 1637325 & 7.37 & 7.4187 & TRN & \\
\hline CHEMBL 3962554 & 1637325 & 6.98 & 7.395 & TRN & \\
\hline CHEMBL 3913970 & 1637325 & 7.6 & 7.6897 & TST & \\
\hline CHEMBL3972979 & 1637325 & 8.29 & 8.1025 & TRN & \\
\hline CHEMBL 3975447 & 1637325 & 8.46 & 8.3964 & TRN & \\
\hline CHEMBL3911516 & 1637325 & 7.7 & 7.6743 & TRN & \\
\hline CHEMBL3958756 & 1637325 & 6.21 & 6.9526 & TRN & \\
\hline CHEMBL3956120 & 1637325 & 7.49 & 7.2362 & TRN & \\
\hline CHEMBL3907551 & 1637325 & 6.15 & 5.5499 & TRN & \\
\hline CHEMBL3904777 & 1637325 & 7.47 & 6.9918 & TST & \\
\hline CHEMBL3975007 & 1637325 & 6.58 & 6.4908 & TRN & \\
\hline CHEMBL3972517 & 1637325 & 7.7 & 7.9204 & TRN & \\
\hline CHEMBL 3928956 & 1637325 & 6.64 & 6.3874 & TRN & \\
\hline CHEMBL 3919270 & 1637325 & 7.12 & 7.2036 & TRN & \\
\hline CHEMBL3941705 & 1637325 & 6.9 & 7.4206 & TRN & \\
\hline
\end{tabular}




\begin{tabular}{|c|c|c|c|c|c|}
\hline \multicolumn{6}{|c|}{ Supplemental Table s2.txt } \\
\hline CHEMBL 3982570 & 1637325 & 6.15 & 6.1092 & TRN & \\
\hline CHEMBL3920007 & 1637325 & 7.78 & 7.8054 & TRN & \\
\hline CHEMBL3922698 & 1637325 & 8.35 & 7.9913 & TRN & \\
\hline CHEMBL 3957533 & 1637325 & 7.59 & 7.4548 & TRN & \\
\hline CHEMBL3969373 & 1637325 & 7.97 & 7.9449 & TRN & \\
\hline CHEMBL3905485 & 1637325 & 8.18 & 8.1892 & TRN & \\
\hline CHEMBL3904674 & 1637325 & 8.54 & 8.4602 & TRN & \\
\hline CHEMBL 3945845 & 1637325 & 7.84 & 7.7456 & TRN & \\
\hline CHEMBL3951694 & 1637325 & 8.09 & 7.9302 & TRN & \\
\hline CHEMBL3929914 & 1637325 & 8.0 & 7.6427 & TST & \\
\hline CHEMBL 3971277 & 1637325 & 8.17 & 7.8642 & TRN & \\
\hline CHEMBL3891892 & 1637325 & 8.58 & 8.632 & TRN & \\
\hline CHEMBL3985498 & 1637325 & 7.26 & 6.9446 & TRN & \\
\hline CHEMBL 3912831 & 1637325 & 8.19 & 8.5327 & TRN & \\
\hline CHEMBL3931154 & 1637325 & 7.66 & 7.7297 & TRN & \\
\hline CHEMBL3893718 & 1637325 & 7.51 & 7.4615 & TRN & \\
\hline CHEMBL3973321 & 1637325 & 7.73 & 7.6541 & TRN & \\
\hline CHEMBL3960327 & 1637325 & 7.94 & 7.778 & TRN & \\
\hline CHEMBL3956571 & 1637325 & 7.14 & 7.178 & TRN & \\
\hline CHEMBL3907314 & 1637325 & 8.72 & 8.4897 & TRN & \\
\hline CHEMBL3904561 & 1637325 & 8.19 & 7.9352 & TST & \\
\hline CHEMBL 3945264 & 1637325 & 8.05 & 7.7601 & TRN & \\
\hline CHEMBL3942594 & 1637325 & 7.98 & 7.8516 & TRN & \\
\hline CHEMBL3915268 & 1637325 & 8.0 & 8.0183 & TRN & \\
\hline CHEMBL3925081 & 1637325 & 8.24 & 8.099 & TRN & \\
\hline CHEMBL3959849 & 1637325 & 8.15 & 8.0627 & TST & \\
\hline CHEMBL3962549 & 1637325 & 7.14 & 7.2333 & TRN & \\
\hline CHEMBL3966626 & 1637325 & 6.59 & 5.9597 & TRN & \\
\hline CHEMBL3969192 & 1637325 & 6.35 & 5.8691 & TRN & \\
\hline CHEMBL3975986 & 1637325 & 5.0 & 5.24700 & 0000000001 & TRN \\
\hline CHEMBL3979996 & 1637325 & 6.0 & 5.5373 & TRN & \\
\hline CHEMBL3891474 & 1637325 & 7.42 & 7.4275 & TST & \\
\hline CHEMBL3892135 & 1637325 & 8.17 & 7.8745 & TRN & \\
\hline CHEMBL3969824 & 1637325 & 7.64 & 7.6655 & TRN & \\
\hline CHEMBL3932285 & 1637325 & 8.12 & 7.8417 & TRN & \\
\hline CHEMBL 3922586 & 1637325 & 8.18 & 8.0396 & TRN & \\
\hline CHEMBL3901682 & 1637325 & 5.0 & 5.8473 & TRN & \\
\hline CHEMBL3927733 & 1637325 & 7.17 & 7.0643 & TRN & \\
\hline CHEMBL3976053 & 1637325 & 7.93 & 7.8197 & TST & \\
\hline CHEMBL3973587 & 1637325 & 7.7 & 7.4436 & TRN & \\
\hline CHEMBL3936828 & 1637325 & 7.84 & 7.7298 & TRN & \\
\hline CHEMBL3934039 & 1637325 & 7.49 & 7.1839 & TRN & \\
\hline CHEMBL3981418 & 1637325 & 8.22 & 8.10799 & 9999999999 & TST \\
\hline CHEMBL3972694 & 1637325 & 7.51 & 7.0897 & TST & \\
\hline CHEMBL3921457 & 1637325 & 8.33 & 7.8492 & TST & \\
\hline CHEMBL3918739 & 1637325 & 8.15 & 7.9591 & TRN & \\
\hline CHEMBL3968793 & 1637325 & 7.6 & 7.5831 & TRN & \\
\hline CHEMBL3966305 & 1637325 & 8.19 & 7.9756 & TRN & \\
\hline
\end{tabular}




\begin{tabular}{|c|c|c|c|c|c|}
\hline \multicolumn{6}{|c|}{ Supplemental Table S2.txt } \\
\hline CHEMBL3891115 & 1637325 & 5.0 & 5.7163 & TST & \\
\hline CHEMBL3979662 & 1637325 & 5.0 & 5.4315 & TST & \\
\hline CHEMBL3983387 & 1637325 & 7.36 & 7.5138 & TST & \\
\hline CHEMBL3986068 & 1637325 & 8.27 & 8.0772 & TRN & \\
\hline CHEMBL3916975 & 1637325 & 7.98 & 7.9299 & TRN & \\
\hline CHEMBL3919709 & 1637325 & 8.32 & 7.83899 & 99999999995 & TRN \\
\hline CHEMBL3975791 & 1637325 & 8.36 & 7.83899 & 99999999995 & TRN \\
\hline CHEMBL3963323 & 1637325 & 8.22 & 7.92899 & 9999999999 & TRN \\
\hline CHEMBL3945373 & 1637325 & 8.49 & 8.2028 & TRN & \\
\hline CHEMBL 3893344 & 1637325 & 7.84 & 7.7792 & TRN & \\
\hline CHEMBL 3896052 & 1637325 & 7.97 & 7.8724 & TRN & \\
\hline CHEMBL 3947361 & 1637325 & 7.81 & 7.7594 & TRN & \\
\hline CHEMBL3944739 & 1637325 & 6.88 & 6.9797 & TST & \\
\hline CHEMBL3909551 & 1637325 & 8.08 & 8.0978 & TRN & \\
\hline CHEMBL3899692 & 1637325 & 8.17 & 8.32 & TRN & \\
\hline CHEMBL 3961400 & 1637325 & 8.1 & 7.7202 & TRN & \\
\hline CHEMBL3958708 & 1637325 & 8.05 & 7.8037 & TRN & \\
\hline CHEMBL 3974080 & 1637325 & 6.74 & 6.5796 & TRN & \\
\hline CHEMBL3921197 & 1637325 & 8.07 & 7.7384 & TST & \\
\hline CHEMBL3898568 & 1637325 & 7.89 & 7.6658 & TRN & \\
\hline CHEMBL 3924422 & 1637325 & 7.54 & $7.3870 e$ & 00000000005 & TRN \\
\hline CHEMBL3959193 & 1637325 & 6.94 & 7.3892 & TRN & \\
\hline CHEMBL3961923 & 1637325 & 7.65 & 7.6543 & TRN & \\
\hline CHEMBL3936087 & 1637325 & 8.4 & 8.1907 & TRN & \\
\hline CHEMBL3893070 & 1637325 & 7.4 & 7.3141 & TRN & \\
\hline CHEMBL 3977904 & 1637325 & 7.16 & 7.2309 & TST & \\
\hline CHEMBL3904441 & 1637325 & 7.75 & 7.3983 & TRN & \\
\hline CHEMBL3945159 & 1637325 & 8.47 & 8.3797 & TRN & \\
\hline CHEMBL3915021 & 1637325 & 7.24 & 7.44 & TST & \\
\hline CHEMBL3892776 & 1637325 & 8.37 & 8.0191 & TRN & \\
\hline CHEMBL3981077 & 1637325 & 7.46 & 7.3823 & TST & \\
\hline CHEMBL3930819 & 1637325 & 7.01 & 7.0528 & TRN & \\
\hline CHEMBL 3926082 & 1637325 & 8.36 & 8.254 & TRN & \\
\hline CHEMBL3970423 & 1637325 & 8.0 & 7.9605 & TRN & \\
\hline CHEMBL3950089 & 1637325 & 8.0 & 7.9865 & TRN & \\
\hline CHEMBL3959573 & 1637325 & 8.32 & 8.0528 & TRN & \\
\hline CHEMBL3912310 & 1637325 & 7.3 & 7.2805 & TRN & \\
\hline CHEMBL3914955 & 1637325 & 7.7 & 7.8003 & TRN & \\
\hline CHEMBL 3973263 & 1637325 & 7.62 & 7.631 & TRN & \\
\hline CHEMBL 3975714 & 1637325 & 7.26 & 7.1544 & TRN & \\
\hline CHEMBL3933707 & 1637325 & 8.11 & 8.1541 & TRN & \\
\hline CHEMBL3950069 & 1637325 & 7.95 & 8.0372 & TRN & \\
\hline CHEMBL3979013 & 1637325 & 8.26 & 8.2031 & TRN & \\
\hline CHEMBL3942811 & 1637325 & 7.58 & 7.6141 & TRN & \\
\hline CHEMBL 3940175 & 1637325 & 8.12 & 8.10799 & 9999999999 & TST \\
\hline CHEMBL3968038 & 1637325 & 6.92 & 7.0915 & TRN & \\
\hline CHEMBL3965640 & 1637325 & 6.85 & 6.9915 & TRN & \\
\hline CHEMBL3928393 & 1637325 & 8.79 & 8.2262 & TST & \\
\hline
\end{tabular}




\begin{tabular}{|c|c|c|c|c|c|}
\hline \multicolumn{6}{|c|}{ Supplemental Table S2.txt } \\
\hline CHEMBL3918704 & 1637325 & 7.06 & 7.2629 & TRN & \\
\hline CHEMBL3947189 & 1637325 & 8.13 & 7.92 & TRN & \\
\hline CHEMBL 3944438 & 1637325 & 7.36 & 7.5843 & TRN & \\
\hline CHEMBL 3964574 & 1637325 & 8.65 & 8.4773 & TRN & \\
\hline CHEMBL 3942328 & 1637325 & 8.1 & 8.1787 & TRN & \\
\hline CHEMBL3951847 & 1637325 & 8.07 & 7.9088 & TRN & \\
\hline CHEMBL3930298 & 1637325 & 6.97 & 7.3037 & TST & \\
\hline CHEMBL3933000 & 1637325 & 8.43 & 8.1428 & TST & \\
\hline CHEMBL 3891464 & 1637325 & 7.34 & 7.5785 & TRN & \\
\hline CHEMBL3950910 & 1637325 & 8.37 & 8.2023 & TRN & \\
\hline CHEMBL 3901420 & 1637325 & 7.55 & 7.3009 & TRN & \\
\hline CHEMBL 3905866 & 1637325 & 8.17 & 8.3896 & TRN & \\
\hline CHEMBL 3903198 & 1637325 & 7.81 & 7.7772 & TRN & \\
\hline CHEMBL 3943933 & 1637325 & 6.73 & 7.223 & TRN & \\
\hline CHEMBL 3925077 & 1637325 & 7.54 & 7.6957 & TRN & \\
\hline CHEMBL 3946674 & 1637325 & 7.43 & 7.7342 & TRN & \\
\hline CHEMBL3931790 & 1637325 & 8.1 & 7.8388 & TRN & \\
\hline CHEMBL3934487 & 1637325 & 7.78 & 7.7734 & TRN & \\
\hline CHEMBL 3893786 & 1637325 & 8.42 & 8.2536 & TRN & \\
\hline CHEMBL 3917141 & 1637325 & 7.93 & 7.8297 & TRN & \\
\hline CHEMBL 3941700 & 1637325 & 8.11 & 7.9421 & TRN & \\
\hline CHEMBL3969665 & 1637325 & 7.77 & 7.5631 & TST & \\
\hline CHEMBL3981076 & 1637325 & 7.3 & 7.37299 & & TRN \\
\hline CHEMBL 3983529 & 1637325 & 7.54 & 7.7271 & TRN & \\
\hline CHEMBL 3935457 & 1637325 & 8.06 & 7.9919 & TRN & \\
\hline CHEMBL 3905048 & 1637325 & 7.62 & 7.7698 & TRN & \\
\hline CHEMBL3925610 & 1637325 & 7.96 & 7.7083 & TST & \\
\hline CHEMBL3928261 & 1637325 & 7.97 & 8.0227 & TRN & \\
\hline CHEMBL3985259 & 1637325 & 7.6 & 7.643 & TST & \\
\hline CHEMBL3890205 & 1637325 & 6.47 & 6.6792 & TST & \\
\hline CHEMBL3944610 & 1637325 & 8.01 & 8.0799 & TRN & \\
\hline CHEMBL 3944320 & 1637325 & 7.92 & 7.8031 & TRN & \\
\hline CHEMBL3979908 & 1637325 & 6.99 & 6.90600 & 0000000001 & TRN \\
\hline CHEMBL 3934355 & 1637325 & 7.52 & 7.2275 & TRN & \\
\hline CHEMBL 3919750 & 1637325 & 7.15 & 6.8635 & TRN & \\
\hline CHEMBL3969112 & 1637325 & 7.6 & 7.6366 & TRN & \\
\hline CHEMBL3966560 & 1637325 & 7.57 & 7.6784 & TRN & \\
\hline CHEMBL 3910444 & 1637325 & 8.13 & 8.0908 & TRN & \\
\hline CHEMBL 3907642 & 1637325 & 8.24 & 7.7701 & TRN & \\
\hline CHEMBL3973929 & 1637325 & 7.73 & 7.8878 & TRN & \\
\hline CHEMBL3972617 & 1637325 & 7.08 & 7.2586 & TRN & \\
\hline CHEMBL3908149 & 1637325 & 8.3 & 8.2439 & TRN & \\
\hline CHEMBL 3943080 & 1637325 & 6.89 & 7.0882 & TRN & \\
\hline CHEMBL 3904294 & 1637325 & 7.72 & 7.7158 & TRN & \\
\hline CHEMBL 3907063 & 1637325 & 7.11 & 7.0198 & TRN & \\
\hline CHEMBL 3896623 & 1637325 & 7.85 & 7.82 & TRN & \\
\hline CHEMBL3893950 & 1637325 & 7.89 & 7.8537 & TRN & \\
\hline CHEMBL3955745 & 1637325 & 7.38 & 7.1544 & TRN & \\
\hline
\end{tabular}


Supplemental Table S2.txt

\begin{tabular}{|c|c|c|c|c|c|}
\hline CHEMBL3953117 & 1637325 & 6.97 & 7.3472 & TST & \\
\hline CHEMBL3951360 & 1637325 & 7.66 & 7.8519 & TRN & \\
\hline CHEMBL3930158 & 1637325 & 7.03 & 7.1757 & TRN & \\
\hline CHEMBL3911746 & 1637325 & 7.32 & 7.4203 & TST & \\
\hline CHEMBL3917295 & 1637325 & 7.71 & 7.7995 & TRN & \\
\hline CHEMBL3902110 & 1637325 & 7.58 & 7.5751 & TRN & \\
\hline CHEMBL3904814 & 1637325 & 6.51 & 6.6247 & TST & \\
\hline CHEMBL3911948 & 1637325 & 6.82 & 6.7323 & TST & \\
\hline CHEMBL3928239 & 1637325 & 7.91 & 8.024 & TRN & \\
\hline CHEMBL3979028 & 1637325 & 6.93 & 7.1483 & TRN & \\
\hline CHEMBL3890378 & 1637325 & 7.79 & 7.9803 & TRN & \\
\hline CHEMBL3932363 & 1637325 & 7.66 & 7.7329 & TRN & \\
\hline CHEMBL3932756 & 1637325 & 7.75 & 7.8542 & TRN & \\
\hline CHEMBL3919479 & 1637325 & 8.22 & 8.3321 & TRN & \\
\hline CHEMBL3968818 & 1637325 & 7.94 & 8.0609 & TRN & \\
\hline CHEMBL3966316 & 1637325 & 7.08 & 7.0823 & TRN & \\
\hline CHEMBL3943610 & 1637325 & 7.22 & 7.3863 & TRN & \\
\hline CHEMBL 3940940 & 1637325 & 7.4 & 7.3759 & TST & \\
\hline CHEMBL3982107 & 1637325 & 7.21 & 7.4418 & TRN & \\
\hline CHEMBL3979670 & 1637325 & 7.94 & 8.0852 & TRN & \\
\hline CHEMBL3911738 & 1637325 & 7.45 & 7.6448 & TRN & \\
\hline CHEMBL3951090 & 1637325 & 6.63 & 7.271 & TRN & \\
\hline CHEMBL3960571 & 1637325 & 8.13 & 8.1002 & TRN & \\
\hline CHEMBL3949508 & 1637325 & 6.61 & 6.8984 & TRN & \\
\hline CHEMBL3901612 & 1637325 & 7.95 & 7.646 & TRN & \\
\hline CHEMBL3974206 & 1637325 & 8.01 & 8.0398 & TST & \\
\hline CHEMBL 3889711 & 1637325 & 7.67 & 7.7047 & TRN & \\
\hline CHEMBL3927585 & 1637325 & 7.34 & 7.4261 & TRN & \\
\hline CHEMBL3946103 & 1637325 & 7.23 & 7.4302 & TRN & \\
\hline CHEMBL3936421 & 1637325 & 7.03 & 7.0134 & TRN & \\
\hline CHEMBL3901119 & 1637325 & 8.34 & 8.1359 & TST & \\
\hline CHEMBL 3919884 & 1637325 & 7.89 & 8.0279 & TST & \\
\hline CHEMBL3942606 & 1637325 & 7.94 & 7.6981 & TST & \\
\hline CHEMBL3945277 & 1637325 & 7.78 & 8.0275 & TRN & \\
\hline CHEMBL3897523 & 1637325 & 7.99 & 7.5822 & TRN & \\
\hline CHEMBL3907327 & 1637325 & 7.5 & 7.0129 & TRN & \\
\hline CHEMBL3956579 & 1637325 & 6.94 & 7.4414 & TST & \\
\hline CHEMBL3959260 & 1637325 & 7.49 & 7.792006 & 0000000001 & TRN \\
\hline CHEMBL 3890852 & 1637325 & 8.25 & 7.8483 & TST & \\
\hline CHEMBL3893642 & 1637325 & 7.66 & 7.9223 & TRN & \\
\hline CHEMBL3950156 & 1637325 & 7.88 & 8.0011 & TRN & \\
\hline CHEMBL3952866 & 1637325 & 7.41 & 7.6415 & TST & \\
\hline CHEMBL3925114 & 1637325 & 7.98 & 8.0957 & TRN & \\
\hline CHEMBL 3897155 & 1637325 & 7.86 & 7.7356 & TST & \\
\hline CHEMBL3937972 & 1637325 & 8.43 & 8.644 & TRN & \\
\hline CHEMBL3935177 & 1637325 & 7.42 & 7.434 & TRN & \\
\hline CHEMBL3962492 & 1637325 & 7.77 & 7.8978 & TRN & \\
\hline CHEMBL3903823 & 1637325 & 6.8 & 7.296 & TRN & \\
\hline
\end{tabular}




\begin{tabular}{|c|c|c|c|c|c|}
\hline \multicolumn{6}{|c|}{ Supplemental Table S2.txt } \\
\hline CHEMBL3964096 & 1637325 & 7.74 & 8.126 & TST & \\
\hline CHEMBL3948755 & 1637325 & 7.47 & 7.3729 & TST & \\
\hline CHEMBL3892155 & 1637325 & 7.7 & 7.7848 & TRN & \\
\hline CHEMBL3987162 & 1637325 & 6.81 & 6.836 & TRN & \\
\hline CHEMBL3921441 & 1637325 & 8.27 & 8.2289 & TRN & \\
\hline CHEMBL3905015 & 1637325 & 6.82 & 6.812 & TRN & \\
\hline CHEMBL3921817 & 1637325 & 7.68 & 7.9176 & TRN & \\
\hline CHEMBL3927219 & 1637325 & 7.59 & 7.5831 & TRN & \\
\hline CHEMBL 3902434 & 1637325 & 7.5 & 7.5563 & TRN & \\
\hline CHEMBL3927158 & 1637325 & 7.04 & 6.6678 & TRN & \\
\hline CHEMBL3985182 & 1637325 & 7.53 & 7.5911 & TRN & \\
\hline CHEMBL3933442 & 1637325 & 7.27 & 7.41799 & 9999999999 & TRN \\
\hline CHEMBL3934080 & 1637325 & 8.06 & 8.2187 & TRN & \\
\hline CHEMBL3895443 & 1637325 & 7.9 & 7.724 & TRN & \\
\hline CHEMBL3904736 & 1637325 & 6.27 & 6.2061 & TRN & \\
\hline CHEMBL3914473 & 1637325 & 5.0 & 5.6601 & TRN & \\
\hline CHEMBL3898926 & 1637325 & 7.35 & 7.3015 & TRN & \\
\hline CHEMBL3952277 & 1637325 & 7.77 & 8.0575 & TRN & \\
\hline CHEMBL3926245 & 1637325 & 6.91 & 7.1615 & TST & \\
\hline CHEMBL3978617 & 1637325 & 7.75 & 7.8139 & TRN & \\
\hline CHEMBL3966071 & 1637325 & 8.12 & 7.8428 & TST & \\
\hline CHEMBL3966200 & 1637325 & 7.81 & 8.0578 & TRN & \\
\hline CHEMBL3940672 & 1637325 & 7.66 & 7.7738 & TST & \\
\hline CHEMBL3979328 & 1637325 & 7.8 & 7.7545 & TRN & \\
\hline CHEMBL3983918 & 1637325 & 8.79 & 8.6182 & TST & \\
\hline CHEMBL3975193 & 1637325 & 7.64 & 7.6409 & TRN & \\
\hline CHEMBL3924172 & 1637325 & 8.16 & 8.0178 & TRN & \\
\hline CHEMBL3921469 & 1637325 & 8.25 & 8.3871 & TRN & \\
\hline CHEMBL3900551 & 1637325 & 6.15 & 5.7575 & TRN & \\
\hline CHEMBL3897783 & 1637325 & 7.64 & 7.8639 & TRN & \\
\hline CHEMBL3891525 & 1637325 & 7.77 & 7.9731 & TRN & \\
\hline CHEMBL3935838 & 1637325 & 7.72 & 7.3562 & TST & \\
\hline CHEMBL3977010 & 1637325 & 8.11 & 7.8302 & TRN & \\
\hline CHEMBL3967761 & 1637325 & 7.89 & 7.9386 & TRN & \\
\hline CHEMBL 3893556 & 1637325 & 6.96 & 6.9012 & TRN & \\
\hline CHEMBL3896249 & 1637325 & 8.19 & 8.1057 & TRN & \\
\hline CHEMBL3952789 & 1637325 & 7.94 & 7.6373 & TRN & \\
\hline CHEMBL3955385 & 1637325 & 7.36 & 6.9775 & TRN & \\
\hline CHEMBL3977708 & 1637325 & 7.54 & 7.6695 & TRN & \\
\hline CHEMBL3980069 & 1637325 & 8.07 & 8.2646 & TRN & \\
\hline CHEMBL3946938 & 1637325 & 7.91 & 8.099 & TRN & \\
\hline CHEMBL3941337 & 1637325 & 6.23 & 6.0235 & TRN & \\
\hline CHEMBL3983585 & 1637325 & 5.0 & 6.1907 & TRN & \\
\hline CHEMBL3918638 & 1637325 & 8.21 & 7.83899 & 99999999995 & TRN \\
\hline CHEMBL3920637 & 1637325 & 7.71 & 7.5999 & TRN & \\
\hline CHEMBL3917908 & 1637325 & 7.71 & 8.0217 & TRN & \\
\hline CHEMBL3980712 & 1637325 & 6.42 & 6.1622 & TRN & \\
\hline CHEMBL3978349 & 1637325 & 7.84 & 7.4652 & TST & \\
\hline
\end{tabular}




\begin{tabular}{|c|c|c|c|c|c|}
\hline \multicolumn{6}{|c|}{ Supplemental Table s2.txt } \\
\hline CHEMBL 3976721 & 1637325 & 7.16 & 6.9574 & TRN & \\
\hline CHEMBL 3974273 & 1637325 & 7.04 & 6.7875 & TRN & \\
\hline CHEMBL 3898255 & 1637325 & 7.11 & 6.5239 & TST & \\
\hline CHEMBL 3927794 & 1637325 & 6.92 & 6.4113 & TST & \\
\hline CHEMBL 3953833 & 1637325 & 7.98 & 7.7497 & TRN & \\
\hline CHEMBL 3964043 & 1637325 & 7.95 & 7.8742 & TRN & \\
\hline CHEMBL 3945658 & 1637325 & 6.43 & 6.4154 & TRN & \\
\hline CHEMBL3948306 & 1637325 & 6.16 & 6.0012 & TRN & \\
\hline CHEMBL 3984035 & 1637325 & 6.68 & 7.1795 & TST & \\
\hline CHEMBL3986725 & 1637325 & 7.49 & 7.1408 & TST & \\
\hline CHEMBL 3896142 & 1637325 & 7.89 & 7.834 & TST & \\
\hline CHEMBL 3908707 & 1637325 & 7.71 & 7.996 & TRN & \\
\hline CHEMBL3941227 & 1637325 & 6.83 & 7.1813 & TST & \\
\hline CHEMBL 3943917 & 1637325 & 7.55 & 7.5144 & TRN & \\
\hline CHEMBL3979972 & 1637325 & 7.2 & 7.0735 & TRN & \\
\hline CHEMBL3982399 & 1637325 & 7.75 & 7.401 & TRN & \\
\hline CHEMBL3932817 & 1637325 & 7.42 & 7.1835 & TST & \\
\hline CHEMBL 3930088 & 1637325 & 7.19 & 7.4323 & TST & \\
\hline CHEMBL 3972445 & 1637325 & 6.18 & 6.1415 & TRN & \\
\hline CHEMBL3969747 & 1637325 & 6.41 & 6.6427 & TST & \\
\hline CHEMBL3918426 & 1637325 & 7.69 & 7.6565 & TST & \\
\hline CHEMBL3906938 & 1637325 & 7.54 & 7.5611 & TRN & \\
\hline CHEMBL 3956028 & 1637325 & 6.27 & 5.8615 & TRN & \\
\hline CHEMBL 3964762 & 1637325 & 7.45 & 7.5584 & TRN & \\
\hline CHEMBL 3948234 & 1637325 & 7.16 & 7.7023 & TST & \\
\hline CHEMBL 3932022 & 1637325 & 7.69 & 7.7609 & TST & \\
\hline CHEMBL 3957473 & 1637325 & 7.69 & 7.7757 & TRN & \\
\hline CHEMBL3950496 & 1637325 & 7.48 & 7.3838 & TRN & \\
\hline CHEMBL 3902961 & 1637325 & 8.33 & 7.99299 & 9999999999 & TRN \\
\hline CHEMBL 3905633 & 1637325 & 7.58 & 7.5135 & TST & \\
\hline CHEMBL 3937212 & 1637325 & 7.02 & 7.0574 & TST & \\
\hline CHEMBL3966929 & 1637325 & 7.65 & 7.5831 & TRN & \\
\hline CHEMBL 3922100 & 1637325 & 7.65 & 7.5187 & TST & \\
\hline CHEMBL 3906284 & 1637325 & 7.9 & 8.2289 & TRN & \\
\hline CHEMBL 3921787 & 1637325 & 6.85 & 6.7322 & TRN & \\
\hline CHEMBL 3951171 & 1637325 & 7.78 & 7.7703 & TRN & \\
\hline CHEMBL3983694 & 1637325 & 7.56 & 7.7065 & TRN & \\
\hline CHEMBL3981207 & 1637325 & 6.73 & 7.1923 & TRN & \\
\hline CHEMBL 3986631 & 1637325 & 6.82 & 6.4 & TRN & \\
\hline CHEMBL3969667 & 1637325 & 7.45 & 7.7406 & TRN & \\
\hline CHEMBL 3933908 & 1637325 & 7.46 & 7.6074 & TRN & \\
\hline CHEMBL3936673 & 1637325 & 7.17 & 7.0963 & TRN & \\
\hline CHEMBL3980417 & 1637325 & 7.83 & 8.1422 & TRN & \\
\hline CHEMBL3921190 & 1637325 & 8.01 & 7.9473 & TRN & \\
\hline CHEMBL3920274 & 1637325 & 5.0 & 5.7995 & TST & \\
\hline CHEMBL 3953771 & 1637325 & 7.83 & 7.6123 & TST & \\
\hline CHEMBL 3950292 & 1637325 & 7.4 & 7.4363 & TRN & \\
\hline CHEMBL3959787 & 1637325 & 6.64 & 6.5191 & TRN & \\
\hline
\end{tabular}




\begin{tabular}{|c|c|c|c|c|c|}
\hline \multicolumn{6}{|c|}{ Supplemental Table S2.txt } \\
\hline CHEMBL3986861 & 1637325 & 6.89 & 6.934 & TST & \\
\hline CHEMBL3891816 & 1637325 & 6.84 & 6.9457 & TST & \\
\hline CHEMBL3927140 & 1637325 & 8.3 & 8.0396 & TRN & \\
\hline CHEMBL3929849 & 1637325 & 6.76 & 6.8575 & TRN & \\
\hline CHEMBL3966941 & 1637325 & 7.06 & 6.9505 & TST & \\
\hline CHEMBL3939018 & 1637325 & 7.56 & 7.7445 & TRN & \\
\hline CHEMBL3912757 & 1637325 & 7.26 & 7.0124 & TRN & \\
\hline CHEMBL3915450 & 1637325 & 7.13 & 6.9392 & TRN & \\
\hline CHEMBL3956493 & 1637325 & 7.81 & 7.841 & TRN & \\
\hline CHEMBL3964931 & 1637325 & 7.28 & 7.2841 & TRN & \\
\hline CHEMBL3918956 & 1637325 & 7.19 & 6.8171 & TRN & \\
\hline CHEMBL3894754 & 1637325 & 7.5 & 7.6131 & TRN & \\
\hline CHEMBL3963296 & 1637325 & 7.33 & 7.2308 & TRN & \\
\hline CHEMBL3890187 & 1637325 & 5.0 & 6.3155 & TST & \\
\hline CHEMBL3978313 & 1637325 & 7.32 & 7.3042 & TRN & \\
\hline CHEMBL3889604 & 1637325 & 7.2 & 7.2506 & TRN & \\
\hline CHEMBL3939332 & 1637325 & 7.48 & 7.38200 & 0000000001 & TRN \\
\hline CHEMBL3912250 & 1637325 & 7.09 & 6.916 & TRN & \\
\hline CHEMBL3901265 & 1637325 & 7.19 & 7.6742 & TRN & \\
\hline CHEMBL3903973 & 1637325 & 8.67 & 8.4327 & TRN & \\
\hline CHEMBL3957928 & 1637325 & 7.18 & 7.148 & TRN & \\
\hline CHEMBL3960591 & 1637325 & 7.03 & 7.1083 & TST & \\
\hline CHEMBL3899721 & 1637325 & 6.63 & 6.7873 & TRN & \\
\hline CHEMBL3934772 & 1637325 & 7.27 & 7.3504 & TRN & \\
\hline CHEMBL3909752 & 1637325 & 7.41 & 6.9311 & TRN & \\
\hline CHEMBL3906945 & 1637325 & 6.95 & 7.2851 & TRN & \\
\hline CHEMBL3954396 & 1637325 & 7.95 & 8.2814 & TRN & \\
\hline CHEMBL3944937 & 1637325 & 6.27 & 6.728 & TRN & \\
\hline CHEMBL3895267 & 1637325 & 7.86 & 8.1182 & TRN & \\
\hline CHEMBL3892529 & 1637325 & 8.56 & 8.3466 & TRN & \\
\hline CHEMBL3935597 & 1637325 & 8.45 & 8.4605 & TRN & \\
\hline CHEMBL3932893 & 1637325 & 6.31 & 6.3513 & TST & \\
\hline CHEMBL3952706 & 1637325 & 7.12 & 7.0615 & TST & \\
\hline CHEMBL3939860 & 1637325 & 7.86 & 7.6107 & TST & \\
\hline CHEMBL3976275 & 1637325 & 8.36 & 8.4769 & TRN & \\
\hline CHEMBL3978754 & 1637325 & 8.5 & 8.5345 & TST & \\
\hline CHEMBL3942716 & 1637325 & 7.69 & 7.9704 & TRN & \\
\hline CHEMBL3982718 & 1637325 & 7.0 & 7.2252 & TRN & \\
\hline CHEMBL3892005 & 1637325 & 6.87 & 6.9251 & TST & \\
\hline CHEMBL 3894762 & 1637325 & 8.32 & 8.0764 & TST & \\
\hline CHEMBL3896514 & 1637325 & 7.0 & 7.0919 & TST & \\
\hline CHEMBL3906253 & 1637325 & 7.21 & 7.3758 & TRN & \\
\hline CHEMBL3946877 & 1637325 & 5.0 & 5.9403 & TST & \\
\hline CHEMBL3944241 & 1637325 & 6.5 & 6.8162 & TST & \\
\hline CHEMBL3947664 & 1637325 & 7.79 & 7.6745 & TRN & \\
\hline CHEMBL3899151 & 1637325 & 7.88 & 8.0571 & TRN & \\
\hline CHEMBL3960877 & 1637325 & 8.25 & 8.2775 & TRN & \\
\hline CHEMBL3958209 & 1637325 & 8.42 & 8.5365 & TRN & \\
\hline
\end{tabular}


Supplemental Table S2.txt

\begin{tabular}{|c|c|c|c|c|}
\hline CHEMBL 3951253 & 1637325 & 7.85 & 8.1127 & TRN \\
\hline CHEMBL3948629 & 1637325 & 5.0 & 5.7936 & TST \\
\hline CHEMBL3913492 & 1637325 & 8.13 & 8.2995 & TRN \\
\hline CHEMBL 3933492 & 1637325 & 4.0 & 4.0881 & TRN \\
\hline CHEMBL3982416 & 1637325 & 5.1 & 4.9361 & TRN \\
\hline CHEMBL3984969 & 1637325 & 4.0 & 4.683 & TRN \\
\hline CHEMBL3953206 & 1637325 & 5.5 & 4.8791 & TRN \\
\hline CHEMBL3946591 & 1637325 & 6.5 & 6.8806 & TST \\
\hline CHEMBL3942179 & 1637325 & 6.91 & 7.0017 & TST \\
\hline CHEMBL3930685 & 1637325 & 5.0 & 6.3175 & TST \\
\hline CHEMBL3910555 & 1637325 & 7.14 & 7.0752 & TST \\
\hline CHEMBL3918036 & 1637325 & 5.0 & 4.9268 & TST \\
\hline CHEMBL3926088 & 1637325 & 5.0 & 4.9181 & TST \\
\hline CHEMBL3948043 & 1637325 & 5.0 & 7.83899 & 99999999995 \\
\hline CHEMBL3972657 & 1637325 & 6.64 & 6.5875 & TST \\
\hline CHEMBL3918892 & 1637325 & 5.0 & 5.2739 & TST \\
\hline CHEMBL3966660 & 1637325 & 6.42 & 6.0998 & TST \\
\hline CHEMBL3899891 & 1637325 & 6.66 & 6.5428 & TST \\
\hline CHEMBL 3890118 & 1637325 & 7.32 & 7.0476 & TST \\
\hline CHEMBL3950169 & 1637325 & 8.33 & 7.331 & TST \\
\hline CHEMBL3952885 & 1637325 & 6.07 & 6.0224 & TST \\
\hline CHEMBL 3890870 & 1637325 & 6.89 & 6.7928 & TST \\
\hline CHEMBL3893659 & 1637325 & 5.0 & 3.9607 & TST \\
\hline CHEMBL3928923 & 1637325 & 6.63 & 6.5011 & TST \\
\hline CHEMBL 3938712 & 1637325 & 6.35 & 5.9436 & TST \\
\hline CHEMBL3975295 & 1637325 & 6.49 & 6.1267 & TST \\
\hline CHEMBL 3977791 & 1637325 & 6.52 & 5.7875 & TST \\
\hline CHEMBL3916904 & 1637325 & 6.04 & 5.6127 & TST \\
\hline CHEMBL3974131 & 1637325 & 6.47 & 6.0154 & TST \\
\hline CHEMBL 3925322 & 1637325 & 6.64 & 5.9945 & TST \\
\hline CHEMBL 3922592 & 1637325 & 5.0 & 5.0996 & TST \\
\hline CHEMBL 3985007 & 1637325 & 5.0 & 5.8624 & TST \\
\hline CHEMBL3982466 & 1637325 & 5.0 & 4.3755 & TST \\
\hline CHEMBL3910921 & 1637325 & 7.23 & 6.8046 & TST \\
\hline CHEMBL 3908141 & 1637325 & 5.0 & 4.7576 & TST \\
\hline CHEMBL3971947 & 1637325 & 6.42 & 6.5789 & TST \\
\hline CHEMBL3960102 & 1637325 & 5.0 & 6.2244 & TST \\
\hline CHEMBL3891736 & 1637325 & 6.87 & 6.728 & TST \\
\hline CHEMBL3932123 & 1637325 & 5.0 & 6.4677 & TST \\
\hline CHEMBL 3952488 & 1637325 & 6.73 & 6.8391 & TST \\
\hline CHEMBL 2070050 & 834212 & 7.284 & 7.1332 & TRN \\
\hline CHEMBL 2069937 & 834212 & 4.2041 & 3.0656 & TST \\
\hline CHEMBL 2070048 & 834212 & 7.7447 & \multicolumn{2}{|c|}{7.827999999999999} \\
\hline CHEMBL 2070060 & 834212 & 7.0458 & 7.2753 & TRN \\
\hline CHEMBL 2070077 & 834212 & 6.7959 & 6.9637 & TRN \\
\hline CHEMBL 2070079 & 834212 & 7.5376 & 7.4084 & TRN \\
\hline CHEMBL 2070045 & 834212 & 7.6778 & 7.6631 & TRN \\
\hline CHEMBL 2070044 & 834212 & 4.2041 & 4.2687 & TRN \\
\hline
\end{tabular}

Page 16731 
Supplemental Table S2.txt

\begin{tabular}{|c|c|c|c|c|}
\hline CHEMBL 2069952 & 834212 & 6.9208 & 6.7973 & TRN \\
\hline CHEMBL 2069936 & 834212 & 4.2041 & 4.8167 & TST \\
\hline CHEMBL 2070081 & 834212 & 6.8539 & 6.7686 & TRN \\
\hline CHEMBL 2069946 & 834212 & 6.8239 & 5.6316 & TST \\
\hline CHEMBL 2070068 & 834212 & 7.8861 & 7.7656 & TRN \\
\hline CHEMBL 2070063 & 834212 & 6.8861 & 6.9966 & TRN \\
\hline CHEMBL 2070070 & 834212 & 6.0 & 5.7525 & TRN \\
\hline CHEMBL1231371 & 834212 & 6.4559 & \multicolumn{2}{|c|}{6.781000000000001} \\
\hline CHEMBL 2070089 & 834212 & 5.9208 & 6.222 & TRN \\
\hline CHEMBL 2070071 & 834212 & 6.0177 & 5.9392 & TRN \\
\hline CHEMBL 2069315 & 834212 & 6.9208 & 7.0137 & TRN \\
\hline CHEMBL 2069944 & 834212 & 8.5229 & 8.5888 & TRN \\
\hline CHEMBL 2070059 & 834212 & 6.6778 & 6.9209 & TRN \\
\hline CHEMBL 2070052 & 834212 & 6.4815 & 6.5753 & TRN \\
\hline CHEMBL 2070056 & 834212 & 6.7959 & 6.8084 & TRN \\
\hline CHEMBL 2070080 & 834212 & 7.4559 & 7.5208 & TRN \\
\hline CHEMBL 2070088 & 834212 & 6.7447 & 6.8632 & TRN \\
\hline CHEMBL 2070072 & 834212 & 6.0132 & 5.9707 & TRN \\
\hline CHEMBL 2069958 & 834212 & 6.2007 & 5.7811 & TRN \\
\hline CHEMBL 2070066 & 834212 & 7.9208 & 8.1313 & TRN \\
\hline CHEMBL 2070047 & 834212 & 6.3872 & 6.2725 & TRN \\
\hline CHEMBL 2069949 & 834212 & 4.2041 & 3.4311 & TST \\
\hline CHEMBL 2070087 & 834212 & 7.0 & 6.7671 & TRN \\
\hline CHEMBL 2070078 & 834212 & 6.4685 & 6.3462 & TRN \\
\hline CHEMBL 2069938 & 834212 & 6.6383 & 6.6486 & TRN \\
\hline CHEMBL 2070076 & 834212 & 7.0458 & 6.9455 & TRN \\
\hline CHEMBL 2070074 & 834212 & 7.3468 & 7.3766 & TRN \\
\hline CHEMBL1241489 & 834212 & 7.1427 & 7.0031 & TRN \\
\hline CHEMBL 2069961 & 834212 & 6.9586 & 6.7561 & TRN \\
\hline CHEMBL 2069960 & 834212 & 4.2041 & 4.3896 & TRN \\
\hline CHEMBL 2069314 & 834212 & 5.6576 & 4.4102 & TST \\
\hline CHEMBL 2070062 & 834212 & 8.4815 & 8.3208 & TRN \\
\hline CHEMBL 2070053 & 834212 & 6.301 & 6.2535 & TRN \\
\hline CHEMBL 2069943 & 834212 & 7.0969 & 7.9674 & TST \\
\hline CHEMBL 2070086 & 834212 & 7.3098 & \multicolumn{2}{|c|}{7.138999999999999} \\
\hline CHEMBL 2070061 & 834212 & 7.2218 & 6.9218 & TRN \\
\hline CHEMBL 2069951 & 834212 & 7.3565 & 7.0475 & TST \\
\hline CHEMBL 2070046 & 834212 & 8.0 & 7.8795 & TST \\
\hline CHEMBL 2070054 & 834212 & 8.0 & 8.0923 & TST \\
\hline CHEMBL 2070051 & 834212 & 7.2366 & 7.2537 & TRN \\
\hline CHEMBL 2070082 & 834212 & 6.4815 & 6.4557 & TRN \\
\hline CHEMBL 2070057 & 834212 & 6.5086 & 7.2008 & TST \\
\hline CHEMBL 2069953 & 834212 & 4.2041 & 4.3635 & TRN \\
\hline CHEMBL 2070085 & 834212 & 6.8539 & \multicolumn{2}{|c|}{7.196000000000001} \\
\hline CHEMBL 2069941 & 834212 & 7.3872 & 7.2513 & TST \\
\hline CHEMBL 2070069 & 834212 & 6.3372 & 6.2368 & TRN \\
\hline CHEMBL 2069948 & 834212 & 6.5686 & 5.3194 & TST \\
\hline CHEMBL 2070064 & 834212 & 6.8539 & 7.0954 & TST \\
\hline
\end{tabular}





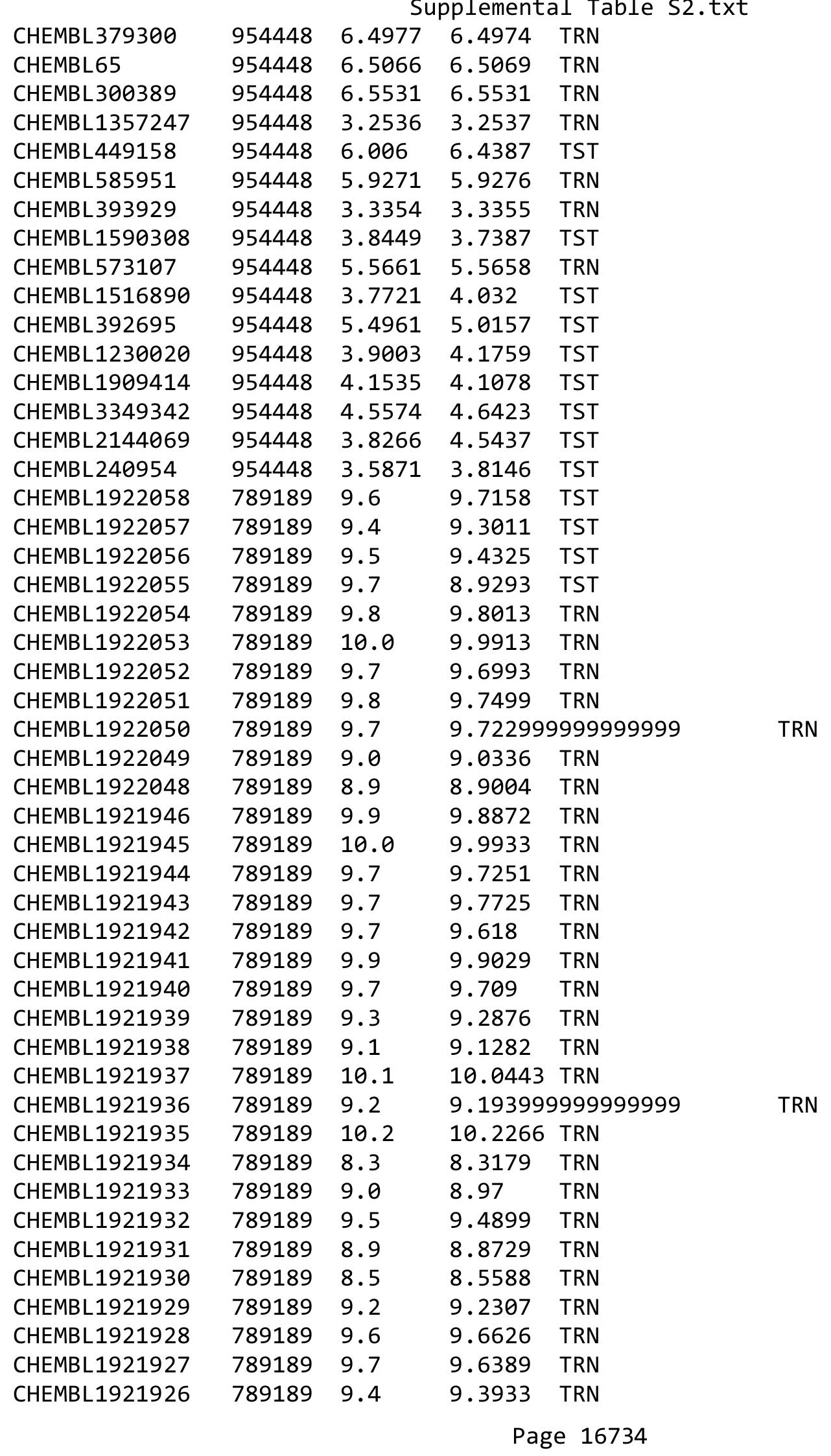



Supplemental Table S2.txt

\begin{tabular}{|c|c|c|c|c|}
\hline CHEMBL1808524 & 759348 & 6.1871 & 6.289 & TRN \\
\hline CHEMBL1808500 & 759348 & 4.7212 & 4.7699 & TRN \\
\hline CHEMBL1808529 & 759348 & 6.3372 & 6.3659 & TRN \\
\hline CHEMBL1808504 & 759348 & 5.2441 & 5.2087 & TRN \\
\hline CHEMBL1808479 & 759348 & 4.5376 & 4.5817 & TRN \\
\hline CHEMBL1808532 & 759348 & 6.4685 & 6.4944 & TRN \\
\hline CHEMBL1808505 & 759348 & 4.4202 & 4.4186 & TRN \\
\hline CHEMBL1808526 & 759348 & 6.1612 & 6.1419 & TRN \\
\hline CHEMBL1808481 & 759348 & 5.4089 & 5.4463 & TRN \\
\hline CHEMBL1808492 & 759348 & 4.6021 & 4.5887 & TRN \\
\hline CHEMBL1808499 & 759348 & 5.7696 & 5.7483 & TRN \\
\hline CHEMBL1808523 & 759348 & 6.6198 & 6.6556 & TRN \\
\hline CHEMBL1808490 & 759348 & 5.5086 & 5.5256 & TRN \\
\hline CHEMBL1808516 & 759348 & 6.5086 & 6.5397 & TRN \\
\hline CHEMBL1808520 & 759348 & 5.7212 & 5.8504 & TRN \\
\hline CHEMBL1808488 & 759348 & 4.4202 & 4.3996 & TRN \\
\hline CHEMBL1808491 & 759348 & 4.4815 & 4.9287 & TST \\
\hline CHEMBL1808514 & 759348 & 6.8861 & 6.8044 & TRN \\
\hline CHEMBL1808518 & 759348 & 6.3979 & 6.2993 & TRN \\
\hline CHEMBL1808482 & 759348 & 5.2147 & 5.1735 & TRN \\
\hline CHEMBL1808486 & 759348 & 5.0915 & 5.1241 & TRN \\
\hline CHEMBL1808534 & 759348 & 6.3979 & 6.3892 & TRN \\
\hline CHEMBL1808497 & 759348 & 4.4437 & 4.4336 & TRN \\
\hline CHEMBL1808519 & 759348 & 6.1079 & 6.0178 & TRN \\
\hline CHEMBL1808521 & 759348 & 5.7212 & 5.7417 & TRN \\
\hline CHEMBL1808503 & 759348 & 5.7696 & 5.7514 & TRN \\
\hline CHEMBL1808545 & 759348 & 4.6576 & 6.0895 & TST \\
\hline CHEMBL1808493 & 759348 & 5.5086 & 5.5012 & TRN \\
\hline CHEMBL1806518 & 759348 & 6.0969 & 6.0863 & TRN \\
\hline CHEMBL1808483 & 759348 & 4.9586 & 4.9836 & TRN \\
\hline CHEMBL1808525 & 759348 & 6.1192 & 6.027 & TRN \\
\hline CHEMBL1808531 & 759348 & 6.2924 & 6.1831 & TRN \\
\hline CHEMBL1808522 & 759348 & 6.1549 & 6.2206 & TRN \\
\hline CHEMBL1808528 & 759348 & 6.585 & 6.6332 & TRN \\
\hline CHEMBL1808527 & 759348 & 6.2924 & 6.2705 & TRN \\
\hline CHEMBL1808487 & 759348 & 5.7447 & 5.7388 & TRN \\
\hline CHEMBL1808535 & 759348 & 6.7447 & 6.7837 & TRN \\
\hline CHEMBL1808478 & 759348 & 6.0315 & 5.9886 & TRN \\
\hline CHEMBL1808494 & 759348 & 6.3979 & 6.4264 & TRN \\
\hline CHEMBL1808477 & 759348 & 4.4685 & 4.449 & TRN \\
\hline CHEMBL1808515 & 759348 & 6.2596 & 6.2708 & TRN \\
\hline CHEMBL1808530 & 759348 & 6.0506 & 6.2513 & TST \\
\hline CHEMBL1808485 & 759348 & 5.2291 & 5.2682 & TST \\
\hline CHEMBL1808496 & 759348 & 6.3872 & 6.3101 & TST \\
\hline CHEMBL1808495 & 759348 & 4.284 & 4.7372 & TST \\
\hline CHEMBL1808513 & 759348 & 7.0506 & 7.1197 & TST \\
\hline CHEMBL1808507 & 759348 & 6.0315 & 5.8077 & TST \\
\hline CHEMBL1808547 & 759348 & 5.0 & 6.0343 & TST \\
\hline
\end{tabular}


Supplemental Table S2.txt

\begin{tabular}{|c|c|c|c|c|c|}
\hline CHEMBL1808533 & 759348 & 5.3188 & 6.3733 & TST & \\
\hline CHEMBL1808512 & 759348 & 5.7959 & 6.37799 & 9999999999 & TST \\
\hline CHEMBL1808536 & 759348 & 6.3188 & 6.2066 & TST & \\
\hline CHEMBL1808508 & 759348 & 4.5528 & 4.8913 & TST & \\
\hline CHEMBL1808476 & 759348 & 6.3768 & 5.8779 & TST & \\
\hline CHEMBL582547 & 842694 & 4.9508 & 4.9524 & TRN & \\
\hline CHEMBL591623 & 842694 & 4.3925 & 4.8117 & TST & \\
\hline CHEMBL601528 & 842694 & 4.4572 & 4.4574 & TRN & \\
\hline CHEMBL581225 & 842694 & 6.0438 & 5.318 & TST & \\
\hline CHEMBL582478 & 842694 & 4.6421 & 4.6416 & TRN & \\
\hline CHEMBL 2028063 & 842694 & 5.4547 & 5.4543 & TRN & \\
\hline CHEMBL106525 & 842694 & 6.1844 & 6.1849 & TRN & \\
\hline CHEMBL591362 & 842694 & 5.4306 & 5.4315 & TRN & \\
\hline CHEMBL 2028043 & 842694 & 5.8665 & 5.8663 & TRN & \\
\hline CHEMBL579331 & 842694 & 4.8508 & 4.8506 & TRN & \\
\hline CHEMBL602234 & 842694 & 5.308 & 5.3101 & TRN & \\
\hline CHEMBL532015 & 842694 & 4.3872 & 4.3852 & TRN & \\
\hline CHEMBL600374 & 842694 & 5.2449 & 5.245 & TRN & \\
\hline CHEMBL10835 & 842694 & 5.1871 & 5.1855 & TRN & \\
\hline CHEMBL581860 & 842694 & 5.1439 & 5.1482 & TRN & \\
\hline CHEMBL598279 & 842694 & 5.5867 & 5.5884 & TRN & \\
\hline CHEMBL602413 & 842694 & 5.2596 & 5.2567 & TRN & \\
\hline CHEMBL596856 & 842694 & 3.0 & 2.9998 & TRN & \\
\hline CHEMBL470514 & 842694 & 4.7399 & 4.7394 & TRN & \\
\hline CHEMBL1485159 & 842694 & 5.1772 & 5.1764 & TRN & \\
\hline CHEMBL602312 & 842694 & 5.5654 & 5.564 & TRN & \\
\hline CHEMBL590944 & 842694 & 4.9547 & 4.9556 & TRN & \\
\hline CHEMBL547825 & 842694 & 5.3197 & 5.3197 & TRN & \\
\hline CHEMBL590933 & 842694 & 5.4855 & 5.481 & TRN & \\
\hline CHEMBL584237 & 842694 & 3.0 & 2.9997 & TRN & \\
\hline CHEMBL548209 & 842694 & 5.6108 & 5.19 & TST & \\
\hline CHEMBL578294 & 842694 & 5.1612 & 5.1593 & TRN & \\
\hline CHEMBL584235 & 842694 & 5.3242 & 5.3269 & TRN & \\
\hline CHEMBL588501 & 842694 & 5.5935 & 5.5943 & TRN & \\
\hline CHEMBL494669 & 842694 & 5.6904 & 5.6899 & TRN & \\
\hline CHEMBL597248 & 842694 & 5.3809 & 5.3787 & TRN & \\
\hline CHEMBL528437 & 842694 & 5.7986 & 5.7981 & TRN & \\
\hline CHEMBL1616787 & 842694 & 5.1871 & 5.1857 & TRN & \\
\hline CHEMBL579105 & 842694 & 5.1439 & 5.1449 & TRN & \\
\hline CHEMBL601122 & 842694 & 5.4034 & 5.4044 & TRN & \\
\hline CHEMBL548374 & 842694 & 5.1593 & 5.1603 & TRN & \\
\hline CHEMBL583555 & 842694 & 5.5467 & 5.5479 & TRN & \\
\hline CHEMBL587892 & 842694 & 4.9626 & 4.962 & TRN & \\
\hline CHEMBL527730 & 842694 & 5.4067 & 5.4076 & TRN & \\
\hline CHEMBL537778 & 842694 & 5.5702 & 5.569 & TRN & \\
\hline CHEMBL527541 & 842694 & 4.0052 & 4.007 & TRN & \\
\hline CHEMBL577014 & 842694 & 5.0883 & 5.0886 & TRN & \\
\hline CHEMBL1437888 & 842694 & 5.8153 & 5.7617 & TST & \\
\hline
\end{tabular}




\begin{tabular}{|c|c|c|c|c|c|}
\hline \multicolumn{6}{|c|}{ Supplemental Table S2.txt } \\
\hline CHEMBL589733 & 842694 & 6.0044 & 6.0042 & TRN & \\
\hline CHEMBL588855 & 842694 & 5.3546 & 5.3562 & TRN & \\
\hline CHEMBL529348 & 842694 & 5.1487 & 5.1482 & TRN & \\
\hline CHEMBL525826 & 842694 & 4.585 & 5.1519 & TST & \\
\hline CHEMBL546162 & 842694 & 5.3036 & 5.1015 & TST & \\
\hline CHEMBL590919 & 842694 & 5.0799 & 5.599 & TST & \\
\hline CHEMBL582767 & 842694 & 5.7496 & 5.4834 & TST & \\
\hline CHEMBL591637 & 842694 & 4.9172 & 5.4227 & TST & \\
\hline CHEMBL591393 & 842694 & 5.3635 & 5.2993 & TST & \\
\hline CHEMBL582072 & 842694 & 5.27 & 5.2694 & TST & \\
\hline CHEMBL459199 & 842694 & 4.7305 & 5.1889 & TST & \\
\hline CHEMBL578030 & 842694 & 5.1319 & 5.2836 & TST & \\
\hline CHEMBL 2028050 & 842694 & 5.5784 & 5.1597 & TST & \\
\hline CHEMBL580516 & 842694 & 5.6421 & 5.3162 & TST & \\
\hline CHEMBL3134363 & 1300393 & 4.8894 & 5.1219 & TRN & \\
\hline CHEMBL3134365 & 1300393 & 4.6271 & 4.519 & TRN & \\
\hline CHEMBL3134336 & 1300393 & 2.7258 & 2.9697 & TRN & \\
\hline CHEMBL 3134321 & 1300393 & 4.5702 & 4.5089 & TRN & \\
\hline CHEMBL3134351 & 1300393 & 4.5834 & 4.4959 & TRN & \\
\hline CHEMBL3134346 & 1300393 & 4.7423 & 4.7571 & TRN & \\
\hline CHEMBL3134329 & 1300393 & 2.7258 & 3.6138 & TST & \\
\hline CHEMBL 3134344 & 1300393 & 4.9872 & 4.6556 & TRN & \\
\hline CHEMBL 3134371 & 1300393 & 4.5287 & 4.6892 & TRN & \\
\hline CHEMBL3134331 & 1300393 & 2.7258 & 2.6515 & TRN & \\
\hline CHEMBL3134358 & 1300393 & 4.9914 & 4.9208 & TRN & \\
\hline CHEMBL3134339 & 1300393 & 4.3605 & 4.4865 & TRN & \\
\hline CHEMBL3134345 & 1300393 & 4.8794 & 4.5532 & TRN & \\
\hline CHEMBL 3134376 & 1300393 & 7.3979 & 3.3751 & TST & \\
\hline CHEMBL 3134348 & 1300393 & 4.762 & 4.9627 & TRN & \\
\hline CHEMBL 3134341 & 1300393 & 5.1249 & 4.7784 & TRN & \\
\hline CHEMBL 3134323 & 1300393 & 2.7258 & 4.2155 & TST & \\
\hline CHEMBL3134360 & 1300393 & 4.8633 & 4.8191 & TRN & \\
\hline CHEMBL3134317 & 1300393 & 2.7258 & 4.115 & TST & \\
\hline CHEMBL3134310 & 1300393 & 3.9172 & 3.8011 & TST & \\
\hline CHEMBL3134361 & 1300393 & 4.7545 & 4.6486 & TRN & \\
\hline CHEMBL3134347 & 1300393 & 5.0223 & 5.2879 & TRN & \\
\hline CHEMBL3134364 & 1300393 & 4.7799 & 4.9949 & TRN & \\
\hline CHEMBL3134332 & 1300393 & 4.067 & 4.4883 & TRN & \\
\hline CHEMBL3134359 & 1300393 & 4.2104 & 4.5089 & TRN & \\
\hline CHEMBL3134377 & 1300393 & 7.5229 & 3.0373 & TST & \\
\hline CHEMBL3134330 & 1300393 & 2.7258 & 5.0474 & TST & \\
\hline CHEMBL3134372 & 1300393 & 4.7905 & 4.8729 & TRN & \\
\hline CHEMBL1609289 & 1300393 & 2.7258 & 2.83600 & 00000000003 & TRN \\
\hline CHEMBL3134324 & 1300393 & 2.7258 & 4.0032 & TST & \\
\hline CHEMBL3134373 & 1300393 & 4.4237 & 4.3756 & TST & \\
\hline CHEMBL3134366 & 1300393 & 4.7212 & 4.5999 & TRN & \\
\hline CHEMBL3134334 & 1300393 & 4.3526 & 3.8909 & TRN & \\
\hline CHEMBL3134375 & 1300393 & 7.1549 & 3.1894 & TST & \\
\hline
\end{tabular}


Supplemental Table S2.txt

\begin{tabular}{|c|c|c|c|c|}
\hline HEMBL3134322 & 00393 & 4.2441 & 183 & TST \\
\hline & 300393 & 4.3645 & 4.3861 & \\
\hline FMRI: & 00393 & 4.2449 & & \\
\hline AEMBL3134362 & 300393 & 4.4572 & & \\
\hline AEMBL3134340 & 300393 & 4.1189 & 038 & \\
\hline HEMBL3134357 & 300393 & 4.8633 & 997 & \\
\hline HEMBL 3134353 & 300393 & 4.7144 & & \\
\hline HEMBL: & 300393 & 4.308 & & \\
\hline HEMBL3134338 & 1300393 & 4.7645 & 643 & \\
\hline HEMBL3134343 & 300393 & 4.3969 & 18 & \\
\hline CHEMBL & 93 & 4.8633 & & \\
\hline AEMBL & 93 & 4.6925 & 75 & \\
\hline AEMB & 93 & 2.7258 & & \\
\hline HEMBL3134354 & 1300393 & 4.4425 & 541 & \\
\hline HEMBL3134352 & 1300393 & 4.556 & & \\
\hline CHEMBL & 130 & 2.7258 & & \\
\hline HEMB & 130 & 4. & & \\
\hline AEMBL & 130 & 967 & & \\
\hline HEMBL: & 1300393 & 4.585 & & \\
\hline AEMBL. & 93 & 013 & & \\
\hline $\mathrm{CHEl}$ & 130 & 302 & & \\
\hline HEME & 130 & 258 & & \\
\hline HEMB & 130 & 258 & 89 & \\
\hline 16 & 300393 & 3.9101 & & \\
\hline CHEMBL & 30 & 374 & & \\
\hline $\mathrm{CHE}$ & 130 & & & \\
\hline $\mathrm{CHE}$ & 76 & 21 & & \\
\hline$C H 5$ & 9 & 21 & & \\
\hline & 76 & 21 & & \\
\hline נחיוזות & 76 & 021 & & \\
\hline & 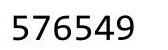 & 21 & & \\
\hline & 9 & & & \\
\hline $\mathrm{CHE}$ & 9 & 21 & & \\
\hline & 76 & 021 & & $T R$ \\
\hline CHEMBL: & 76 & 3.6021 & 72 & \\
\hline & 9 & & & \\
\hline $\mathrm{CH}$ & 9 & 21 & & \\
\hline $\mathrm{CHE}$ & 9 & 458 & & $\Gamma R$ \\
\hline CHEMBL & 765 & & & $\Gamma R$ \\
\hline CHEMPI & 765 & 6. & & \\
\hline $\mathrm{CH}$ & 576 & 21 & & \\
\hline CHEMBL & 576 & 3.6021 & 44 & \\
\hline CHEMBL: & 576 & 5.5229 & 76 & $\ln$ \\
\hline CHEMBL: & 765 & 6 . & 984 & TS \\
\hline CHEMBL & (5) & 3. & 75 & \\
\hline $\mathrm{CH}$ & 576 & & & \\
\hline CHEMBL5 & 576549 & 6.699 & 5.4736 & \\
\hline CHFMRI & 576549 & 3.6021 & 5.2619 & \\
\hline
\end{tabular}

Page 16739 


\begin{tabular}{|c|c|c|c|c|c|}
\hline & & \multicolumn{4}{|c|}{ Supplemental Table S2.txt } \\
\hline CHEMBL563015 & 576549 & 5.301 & 5.0176 & TRN & \\
\hline CHEMBL550764 & 576549 & 5.3979 & 5.3363 & TRN & \\
\hline CHEMBL550569 & 576549 & 3.6021 & 3.0136 & TRN & \\
\hline CHEMBL554302 & 576549 & 5.0 & 4.8748 & TRN & \\
\hline CHEMBL556476 & 576549 & 5.699 & 5.8181 & TRN & \\
\hline CHEMBL561913 & 576549 & 3.6021 & 4.2661 & TST & \\
\hline CHEMBL552252 & 576549 & 3.6021 & 4.45 & TST & \\
\hline CHEMBL551968 & 576549 & 5.0 & 4.6411 & TST & \\
\hline CHEMBL565180 & 576549 & 3.6021 & 4.5857 & TRN & \\
\hline CHEMBL561247 & 576549 & 3.6021 & 4.0572 & TRN & \\
\hline CHEMBL552387 & 576549 & 4.699 & 4.3566 & TRN & \\
\hline CHEMBL562821 & 576549 & 5.0 & 4.1356 & TST & \\
\hline CHEMBL564714 & 576549 & 6.0969 & 5.2201 & TRN & \\
\hline CHEMBL555120 & 576549 & 3.6021 & 4.9742 & TRN & \\
\hline CHEMBL551775 & 576549 & 5.0 & 4.3668 & TRN & \\
\hline CHEMBL565166 & 576549 & 3.6021 & 3.4703 & TRN & \\
\hline CHEMBL551249 & 576549 & 6.0 & 5.045 & TRN & \\
\hline CHEMBL560509 & 576549 & 4.699 & 3.9343 & TRN & \\
\hline CHEMBL562252 & 576549 & 3.6021 & 4.3197 & TRN & \\
\hline CHEMBL562944 & 576549 & 3.6021 & 4.2539 & TRN & \\
\hline CHEMBL549349 & 576549 & 5.699 & 4.9047 & TST & \\
\hline CHEMBL554274 & 576549 & 3.6021 & 4.2823 & TRN & \\
\hline CHEMBL550093 & 576549 & 5.0458 & 4.4611 & TRN & \\
\hline CHEMBL564783 & 576549 & 6.3979 & 4.2482 & TST & \\
\hline CHEMBL563969 & 576549 & 5.0 & 5.6151 & TST & \\
\hline CHEMBL564157 & 576549 & 3.6021 & 5.7529 & TST & \\
\hline CHEMBL551853 & 576549 & 6.0 & 5.5498 & TRN & \\
\hline CHEMBL559290 & 576549 & 3.6021 & 4.737 & TST & \\
\hline CHEMBL1743790 & 193337 & 8.1367 & 8.2043 & TRN & \\
\hline CHEMBL1743778 & 193337 & 6.3458 & 6.53100 & 0000000001 & TRN \\
\hline CHEMBL32797 & 193337 & 7.1675 & 6.9091 & TST & \\
\hline CHEMBL285902 & 193337 & 6.9586 & 7.0003 & TRN & \\
\hline CHEMBL1743799 & 193337 & 6.9066 & 6.7659 & TRN & \\
\hline CHEMBL33769 & 193337 & 6.5258 & 6.6353 & TRN & \\
\hline CHEMBL1743783 & 193337 & 7.0 & 6.9856 & TRN & \\
\hline CHEMBL32726 & 193337 & 8.3468 & 7.5423 & TRN & \\
\hline CHEMBL 1743773 & 193337 & 6.0 & 5.9397 & TRN & \\
\hline CHEMBL1743803 & 193337 & 6.0 & 6.1407 & TRN & \\
\hline CHEMBL284367 & 193337 & 6.0 & 5.8326 & TRN & \\
\hline CHEMBL1743793 & 193337 & 6.0 & 5.8815 & TRN & \\
\hline CHEMBL1743823 & 193337 & 7.3635 & 7.0628 & TRN & \\
\hline CHEMBL 32497 & 193337 & 6.38200 & 00000000 & 6.2603 & TRN \\
\hline CHEMBL1743810 & 193337 & 7.3565 & 7.3942 & TRN & \\
\hline CHEMBL1743805 & 193337 & 6.7305 & 7.9984 & TST & \\
\hline CHEMBL1743767 & 193337 & 7.4214 & 7.4948 & TRN & \\
\hline CHEMBL1743822 & 193337 & 6.0 & 6.8092 & TST & \\
\hline CHEMBL 286455 & 193337 & 6.7696 & 7.2683 & TST & \\
\hline CHEMBL1743791 & 193337 & 8.2596 & 8.5052 & TRN & \\
\hline
\end{tabular}




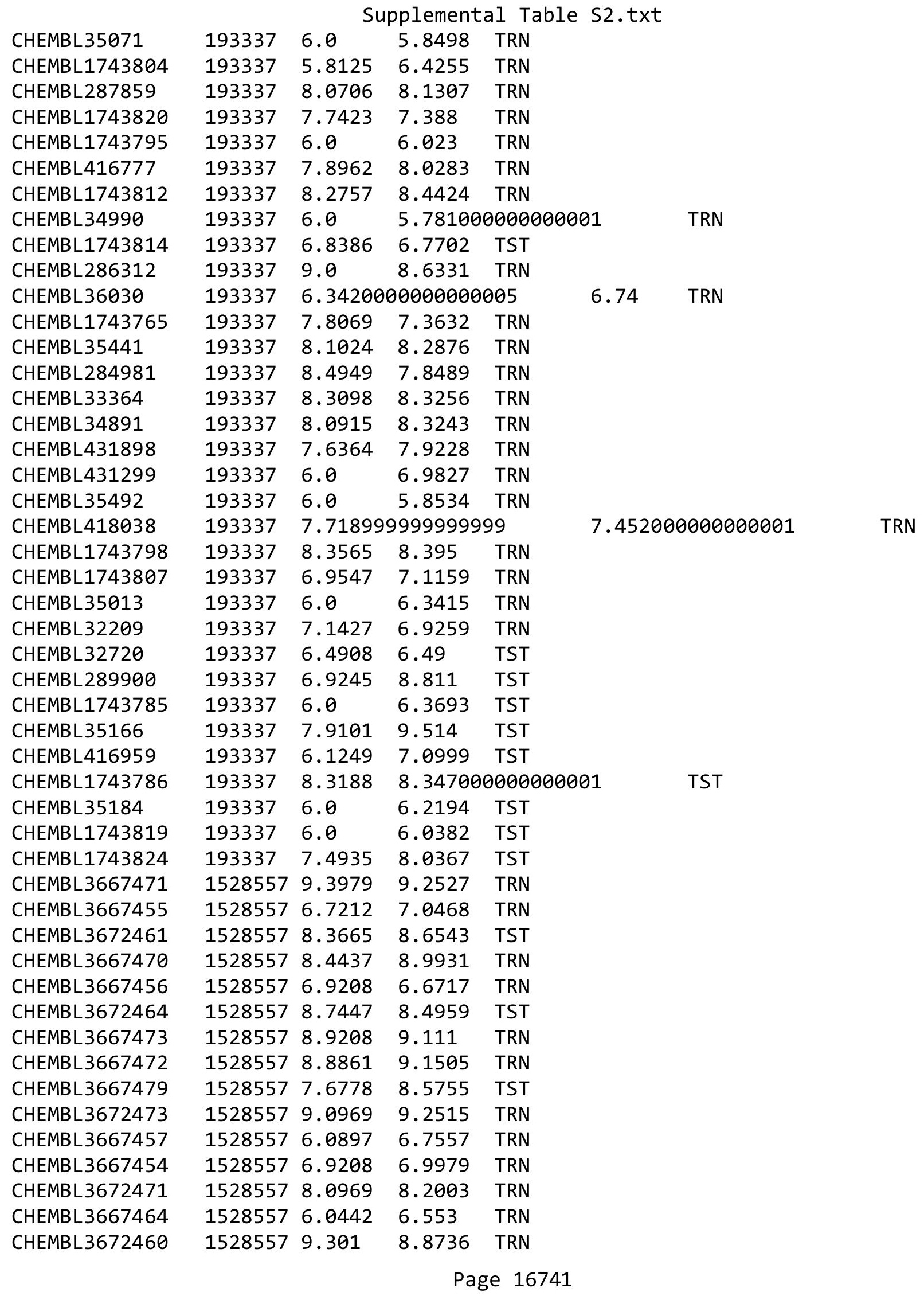


Supplemental Table S2.txt

\begin{tabular}{|c|c|c|c|c|}
\hline $2+12$ & & & & \\
\hline HEMBL3672457 & 528557 & 8.3279 & 4323 & \\
\hline HEMBL; & 57 & 9.5229 & 1956 & \\
\hline 7475 & & & & \\
\hline 72454 & 57 & & & RN \\
\hline AEMBL3667459 & 528557 & 7.0969 & 9494 & \\
\hline HEMBL3672475 & 528557 & 8.2076 & .6972 & \\
\hline HEMBL3672452 & 557 & 8.7212 & & \\
\hline HEMBL3 & 57 & 9.301 & 84 & \\
\hline HEMBL 3672474 & & & 27 & \\
\hline HEMBL3667458 & 528557 & 6.9586 & .2592 & \\
\hline HEMBL3672450 & 528557 & 8.0458 & 3.066 & \\
\hline HEMBL 366 & $52 \varepsilon$ & 9.0 & 7116 & \\
\hline HEMBL3 & 57 & 99 & 2602 & \\
\hline HEMBL3 & 57 & & 09 & \\
\hline HEMBL3667482 & 528557 & 8.1192 & 8.0345 & \\
\hline HEMBL3672465 & 557 & 9. & 55 & \\
\hline HEMBL3 & 52 & 8 . & 141 & \\
\hline HEN & א כ & 9. & 58 & \\
\hline HEM & 57 & & & \\
\hline HEMBL3672453 & 57 & 9.699 & 9.7091 & \\
\hline AEMBL3667 & 57 & & & \\
\hline HEMBL36 & 52 & 9. & 76 & 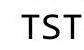 \\
\hline HEN & 1 & & & \\
\hline HEM & 57 & & & \\
\hline 83 & & & & 10 \\
\hline AEMBL3667486 & 57 & & & IV \\
\hline HEMBL36 & 52 & & 47 & RN \\
\hline HEN & 1 & & 4 & KIV \\
\hline 58 & 57 & 8 . & 77 & ST \\
\hline HEMBL3 & & & & IRN \\
\hline AEMBL 3667 & 57 & 7.2 & 326 & $\mathrm{IK}_{\mathrm{S}}$ \\
\hline AEMBL3 & 57 & & & ST \\
\hline 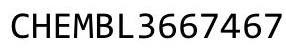 & 1 & 9. & 42 & RN \\
\hline 7 & & 8 . & 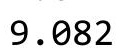 & TRN \\
\hline AEMBL3672468 & 52 & 8. & & TST \\
\hline AEMBL 3672463 & 57 & 9. & & TS \\
\hline & & & & IST \\
\hline 9 & 1 & 9. & 32 & RN \\
\hline HEMBL & 57 & 9. & 09 & TST \\
\hline AEMBL3667462 & 57 & 7.23 & 08 & TST \\
\hline HEMBL3 & 57 & 9 . & & TRN \\
\hline & & 6 & & \\
\hline HEMBL3 & 62 & & & \\
\hline HEMBL3 & 162 & 6.5867 & 5.2584 & ST \\
\hline AEMBL 3968 & 853 & 8.2218 & 8.1845 & $R$ \\
\hline & & & & \\
\hline & 1622 & & & \\
\hline
\end{tabular}

Page 16742 
Supplemental Table S2.txt

\begin{tabular}{|c|c|c|c|c|}
\hline $\boldsymbol{I}$ & & & & \\
\hline HEMBL3979902 & 622853 & 8.0969 & 7.697 & \\
\hline 825 & 22853 & & & \\
\hline 340 & 22853 & 7.284 & 5508 & \\
\hline JEMBL3916048 & 022853 & 7.8861 & 8175 & \\
\hline AEMBL3910085 & 622853 & 7.6021 & 8217 & \\
\hline HEMBL3961356 & 622853 & 6.6861 & 442 & \\
\hline AEMBL3S & 522853 & 861 & 351 & \\
\hline IEMBL39 & 622853 & & 33 & \\
\hline AEMBL3938021 & 622853 & 7.9586 & 9845 & \\
\hline HEMBL3986638 & 622853 & 7.2596 & 2701 & \\
\hline AEMBL39 & 62285 & 7.1308 & 019 & \\
\hline AEMBL3 & & & & \\
\hline HEMBL & 622853 & 003 & & \\
\hline AEMBL3S & 622853 & 652 & 95 & \\
\hline AEMBL3942836 & $0<<0$ & 3861 & 7852 & \\
\hline HEMBL3 & 62285 & 8 & 356 & \\
\hline HEMBL3 & 622853 & & & \\
\hline HEMBL3 & 622853 & 8. & 818 & \\
\hline AEMBL3S & 53 & & 917 & RN \\
\hline EMBL39 & $0 \angle 2853$ & 7. & 7333 & \\
\hline HEMBL3S & 8 & 19 & 284 & \\
\hline HEMBL3S & & & 102 & \\
\hline 799 & & 7. & & בM \\
\hline AEMBL3S & 3 & 8 & 907 & RIV \\
\hline BL3 & 2853 & & & RN \\
\hline AEMBL3 & 853 & & 977 & - \\
\hline 527 & & & 65 & \\
\hline HEMBL3 & & & & RN \\
\hline AEMBL3S & 353 & 4 & 908 & RN \\
\hline AEMBL3 & 353 & & 335 & RN \\
\hline 167 & 3 & & 56 & KIV \\
\hline 16 & & & & RN \\
\hline HEMBL39 & & & & RN \\
\hline AEMBL39 & 62 & 6. & 815 & RN \\
\hline AEMBL3 & 853 & 14 & 818 & \\
\hline $15 \mathrm{MPI}=$ & & & & RN \\
\hline HEMBL3976890 & & & 058 & RN \\
\hline HEMBL3930876 & 622853 & 7.699 & $\$ 326$ & RN \\
\hline AEMBL3S & 2853 & 696 & 8872 & RN \\
\hline HEMBL3 3 & 16228 & 218 & 872 & -5 \\
\hline HEMBL39 & & & & RN \\
\hline HEMBL3927837 & 622853 & 4.0458 & 4739 & RN \\
\hline HEMBL3902886 & 622853 & 7.8861 & 8673 & RN \\
\hline 00 & 6228 & 4 & 741 & In \\
\hline HEMBL3 & 1622853 & & 3.1789 & \\
\hline HEMBL 39 & 302203 & 458 & 7.557 & \\
\hline CHEMBL3915547 & 1622853 & 7.8539 & 7.7627 & RN \\
\hline
\end{tabular}

Page 16743 
Supplemental Table S2.txt

\begin{tabular}{|c|}
\hline IBL395006 \\
\hline \\
\hline CHEMBL \\
\hline CHEMBL3919009 \\
\hline CHEMBL3951240 \\
\hline CHEMBL3918060 \\
\hline CHEMBL3906825 \\
\hline CHEMBL3970445 \\
\hline CHEMBL3969267 \\
\hline CHEMBL3898062 \\
\hline CHEMBL 3943761 \\
\hline CHEMBL3914936 \\
\hline CHEMBL3889862 \\
\hline CHEMBL3939715 \\
\hline CHEMBL3916909 \\
\hline CHEMBL 3941448 \\
\hline CHEMBL3947185 \\
\hline CHEMBL3897240 \\
\hline CHEMBL3936568 \\
\hline CHEMBL3985310 \\
\hline CHEMBL3934795 \\
\hline CHEMBL3925915 \\
\hline CHEMBL3890307 \\
\hline CHEMBL3951580 \\
\hline CHEMBL 3898772 \\
\hline CHEMBL 3926201 \\
\hline CHEMBL3956823 \\
\hline CHEMBL3982832 \\
\hline CHEMBL 3924174 \\
\hline CHEMBL 3931239 \\
\hline CHEMBL3948466 \\
\hline CHEMBL3906199 \\
\hline CHEMBL3959377 \\
\hline CHEMBL3923097 \\
\hline CHEMBL 3978193 \\
\hline CHEMBL3925393 \\
\hline CHEMBL410463 \\
\hline CHEMBL 258836 \\
\hline CHEMBL260338 \\
\hline CHEMBL406298 \\
\hline CHEMBL 257756 \\
\hline CHEMBL402172 \\
\hline CHEMBL 260788 \\
\hline CHEMBL 258960 \\
\hline CHEMBL261203 \\
\hline CHEMBL196436 \\
\hline CHEMBL256153 \\
\hline \\
\hline
\end{tabular}

$\begin{array}{llll}1622853 & 6.857 & 6.6972 & \text { TRN } \\ 1622853 & 8.0969 & 8.2157 & \text { TRN } \\ 1622853 & 7.0223 & 7.0926 & \text { TRN } \\ 1622853 & 6.8297 & 6.6088 & \text { TRN } \\ 1622853 & 6.0496 & 5.9814 & \text { TRN } \\ 1622853 & 8.2218 & 8.4498 & \text { TRN } \\ 1622853 & 8.3979 & 8.3138 & \text { TRN } \\ 1622853 & 5.7989 & 6.522 & \text { TST } \\ 1622853 & 6.6478 & 6.9407 & \text { TRN } \\ 1622853 & 6.8761 & 7.4822 & \text { TRN } \\ 1622853 & 8.0969 & 7.9298 & \text { TRN } \\ 1622853 & 8.0969 & 7.9028 & \text { TRN } \\ 1622853 & 7.8539 & 8.1789 & \text { TRN } \\ 1622853 & 7.9208 & 7.9691 & \text { TRN } \\ 1622853 & 6.5513 & 6.5196 & \text { TRN } \\ 1622853 & 8.0 & 8.0457 & \text { TRN } \\ 1622853 & 6.2147 & 6.2262 & \text { TRN } \\ 1622853 & 8.1549 & 8.0782 & \text { TRN } \\ 1622853 & 6.3251 & 6.2115 & \text { TRN } \\ 1622853 & 7.9208 & 7.7217 & \text { TRN } \\ 1622853 & 7.3372 & 7.3987 & \text { TRN } \\ 1622853 & 7.8239 & 7.6485 & \text { TRN } \\ 1622853 & 6.7852 & 6.8114 & \text { TST } \\ 1622853 & 7.6021 & 7.257000000000001 \\ 1622853 & 7.9208 & 7.4185 & \text { TST } \\ 1622853 & 7.8861 & 7.8735 & \text { TST } \\ 1622853 & 7.9208 & 8.0382 & \text { TST } \\ 1622853 & 4.0 & 4.6634 & \text { TST } \\ 1622853 & 8.301 & 8.3604 & \text { TST } \\ 1622853 & 8.0458 & 8.1991 & \text { TST } \\ 1622853 & 6.6144 & 6.5106 & \text { TST } \\ 1622853 & 8.3979 & 8.3282 & \text { TST } \\ 1622853 & 7.585 & 7.3009 & \text { TST } \\ 1622853 & 5.767 & 4.6397 & \text { TST } \\ 1622853 & 8.0 & 7.9238 & \text { TST } \\ 1622853 & 7.0 & 6.9192 & \text { TST } \\ 479714 & 5.1891 & 4.7169 & \text { TRN } \\ 479714 & 5.5645 & 6.2413 & \text { TRN } \\ 479714 & 5.1394 & 5.3674 & \text { TRN } \\ 479714 & 6.3197 & 6.2506 & \text { TST } \\ 479714 & 6.1421 & 6.596 & \text { TRN } \\ 479714 & 6.5986 & 6.7712 & \text { TRN } \\ 479714 & 5.395 & 5.6061 & \text { TRN } \\ 479714 & 6.0783 & 6.5202 & \text { TRN } \\ 479714 & 7.7696 & 7.2024 & \text { TRN } \\ 479714 & 5.4783 & 5.5093 & \text { TRN } \\ 479714 & 5.7932 & 5.8388 & \text { TRN } \\ 479714 & 5.2392 & 4.9523 & \text { TRN } \\ & & & \end{array}$




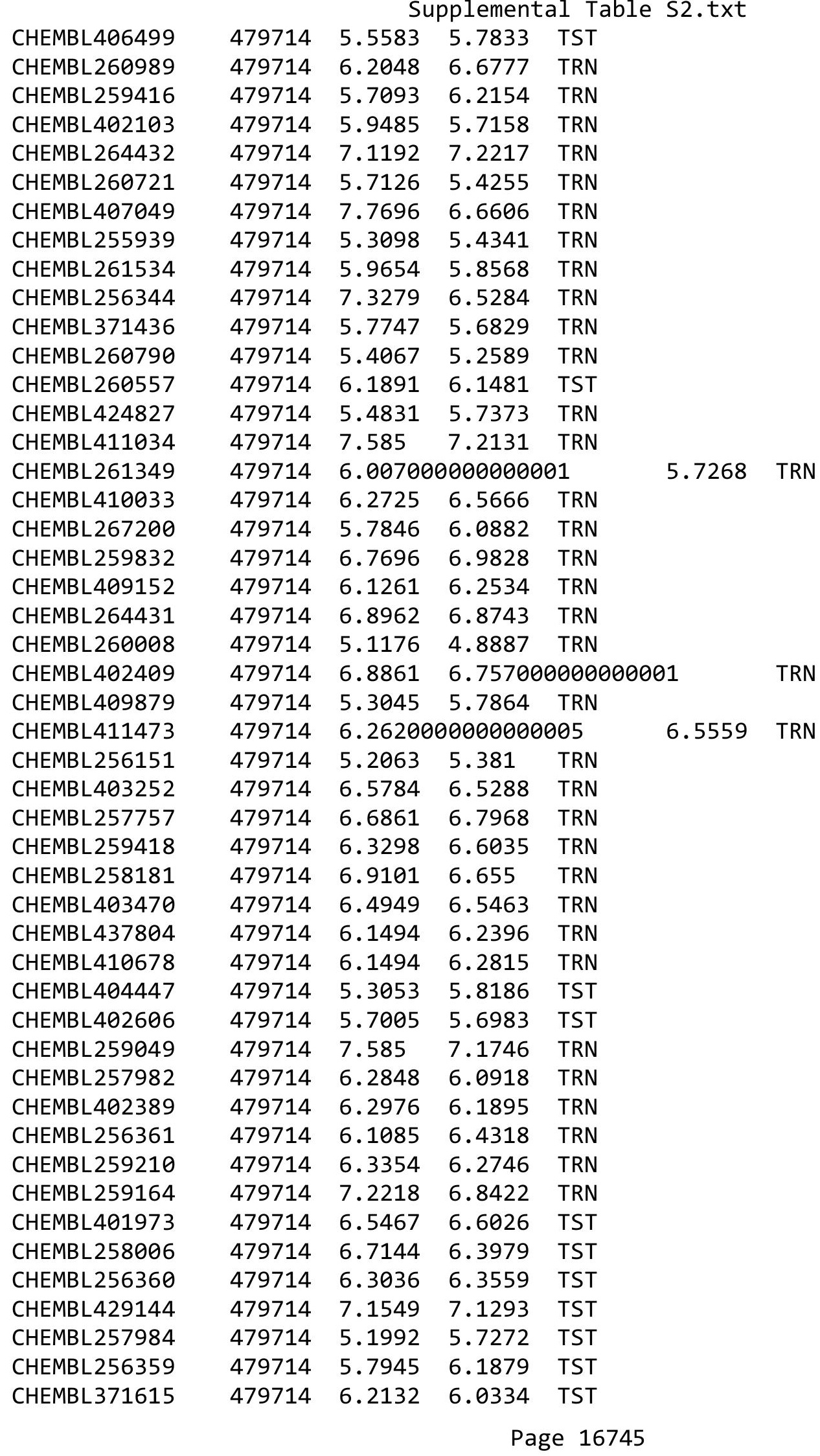




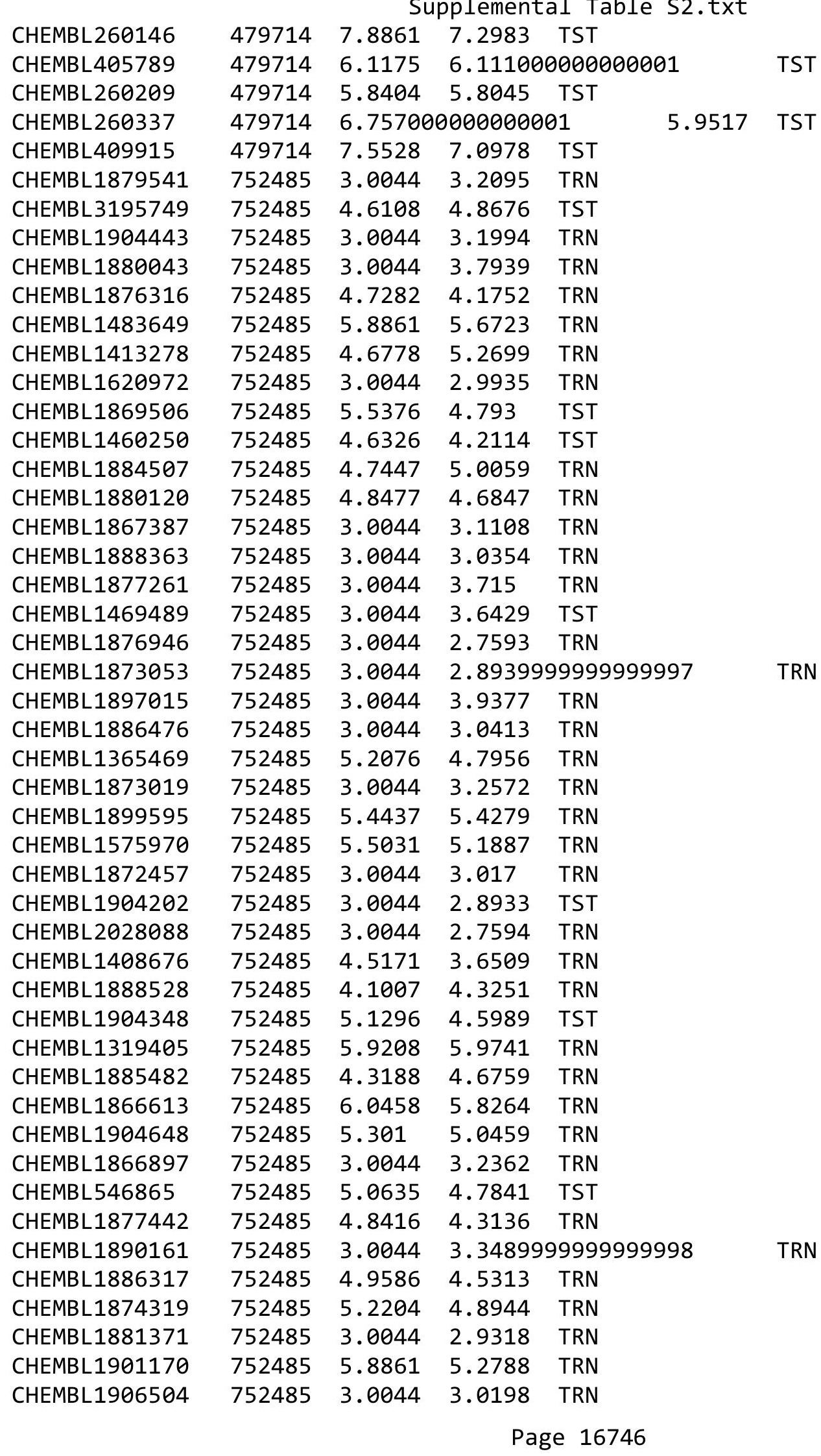




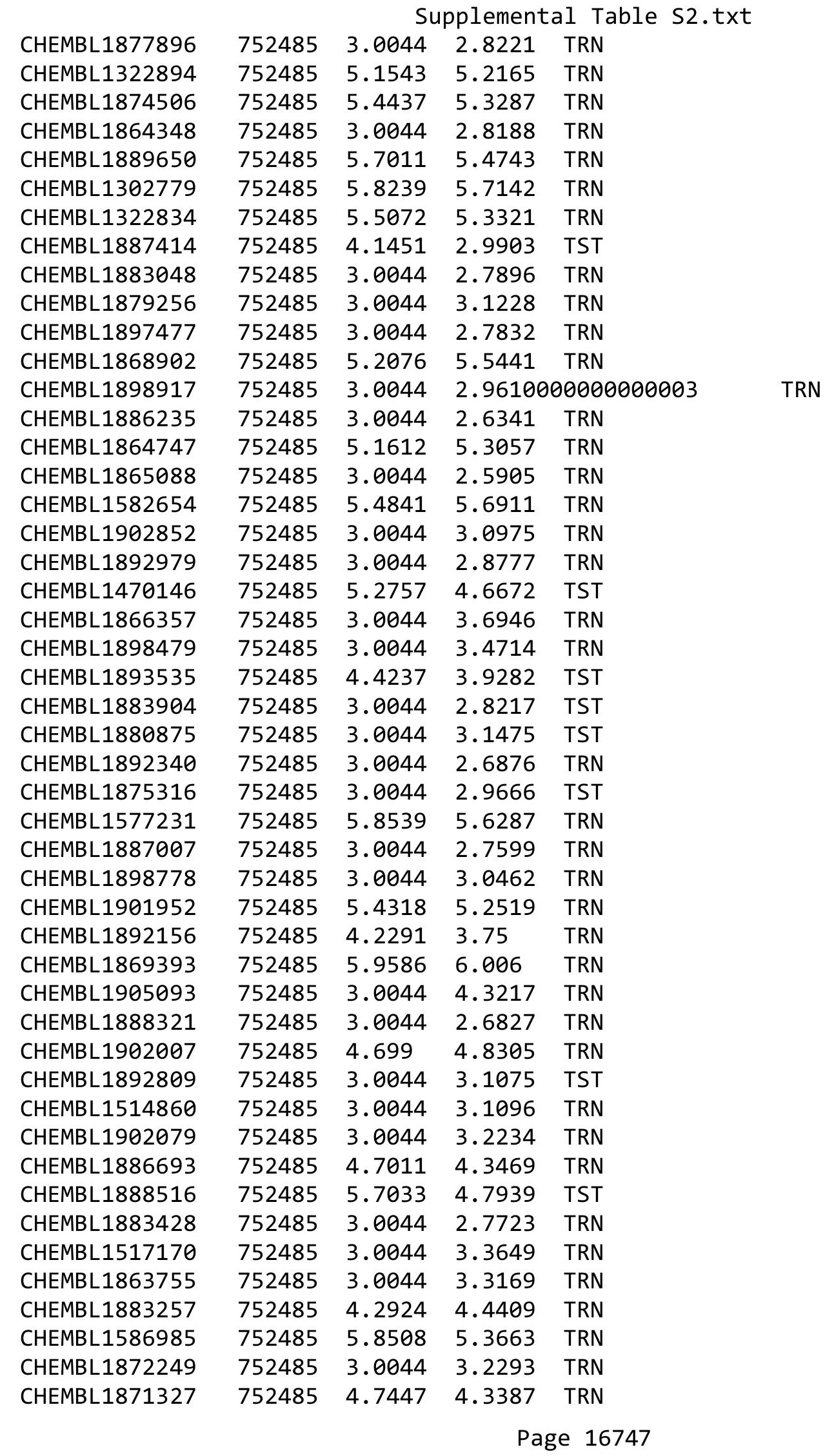




\begin{tabular}{|c|c|c|c|c|c|}
\hline \multicolumn{6}{|c|}{ Supplemental Table S2.txt } \\
\hline CHEMBL1506656 & 752485 & 3.0044 & 3.1133 & TST & \\
\hline CHEMBL1886298 & 752485 & 3.0044 & 2.9084 & TRN & \\
\hline CHEMBL1571012 & 752485 & 4.8268 & 4.1455 & TST & \\
\hline CHEMBL1370991 & 752485 & 4.3936 & 4.5303 & TRN & \\
\hline CHEMBL1867839 & 752485 & 3.0044 & 2.75600 & 00000000002 & TRN \\
\hline CHEMBL1874988 & 752485 & 4.2676 & 4.2399 & TRN & \\
\hline CHEMBL1887272 & 752485 & 4.9586 & 4.4151 & TRN & \\
\hline CHEMBL1905817 & 752485 & 5.1403 & 4.7693 & TRN & \\
\hline CHEMBL1888458 & 752485 & 3.0044 & 2.7624 & TST & \\
\hline CHEMBL1890591 & 752485 & 5.3546 & 5.0754 & TST & \\
\hline CHEMBL1899086 & 752485 & 3.0044 & 2.7359 & TRN & \\
\hline CHEMBL1894672 & 752485 & 3.0044 & 3.0993 & TRN & \\
\hline CHEMBL1899989 & 752485 & 5.3565 & 5.7226 & TRN & \\
\hline CHEMBL233119 & 752485 & $4.9830 e$ & 30000000 & 4.7454 & TRN \\
\hline CHEMBL1883288 & 752485 & 3.0044 & 2.91899 & 99999999996 & TST \\
\hline CHEMBL1867713 & 752485 & 3.0044 & 3.2648 & TRN & \\
\hline CHEMBL1895637 & 752485 & 4.699 & 4.5453 & TRN & \\
\hline CHEMBL1891206 & 752485 & 6.2676 & 6.1385 & TRN & \\
\hline CHEMBL1869876 & 752485 & 3.0044 & 3.2706 & TRN & \\
\hline CHEMBL1865625 & 752485 & 4.4685 & 4.3374 & TRN & \\
\hline CHEMBL1477200 & 752485 & 3.0044 & 3.40100 & 00000000002 & TRN \\
\hline CHEMBL1872841 & 752485 & 4.3279 & 4.3435 & TRN & \\
\hline CHEMBL1893046 & 752485 & 3.0044 & 3.0843 & TRN & \\
\hline CHEMBL1609828 & 752485 & 5.3107 & 4.6547 & TST & \\
\hline CHEMBL1477061 & 752485 & 3.0044 & 4.681 & TRN & \\
\hline CHEMBL1901962 & 752485 & 3.0044 & 3.0097 & TRN & \\
\hline CHEMBL1876373 & 752485 & 3.0044 & 3.2808 & TRN & \\
\hline CHEMBL1877822 & 752485 & 3.0044 & 3.2222 & TRN & \\
\hline CHEMBL1871384 & 752485 & 3.0044 & 2.7344 & TRN & \\
\hline CHEMBL1876217 & 752485 & 5.9626 & 5.7511 & TRN & \\
\hline CHEMBL1875486 & 752485 & 3.0044 & 3.2209 & TRN & \\
\hline CHEMBL1613216 & 752485 & 6.1296 & 5.0453 & TST & \\
\hline CHEMBL1885809 & 752485 & 4.6253 & 4.6998 & TRN & \\
\hline CHEMBL1877317 & 752485 & 3.0044 & 2.6036 & TRN & \\
\hline CHEMBL1868306 & 752485 & 3.0044 & 2.8189 & TRN & \\
\hline CHEMBL1316867 & 752485 & 6.2924 & 5.8675 & TRN & \\
\hline CHEMBL1897885 & 752485 & 4.284 & 4.2701 & TRN & \\
\hline CHEMBL1865565 & 752485 & 3.0044 & 2.6541 & TST & \\
\hline CHEMBL1881878 & 752485 & 3.0044 & 2.8868 & TRN & \\
\hline CHEMBL 2448581 & 752485 & 3.0044 & 2.9932 & TRN & \\
\hline CHEMBL1510959 & 752485 & 3.0044 & 3.055 & TST & \\
\hline CHEMBL1534143 & 752485 & 5.699 & 5.5156 & TRN & \\
\hline CHEMBL1876647 & 752485 & 3.0044 & 2.6819 & TRN & \\
\hline CHEMBL1554455 & 752485 & 3.0044 & 3.1535 & TRN & \\
\hline CHEMBL1870597 & 752485 & 3.0044 & 2.9306 & TRN & \\
\hline CHEMBL1888478 & 752485 & 3.0044 & 2.9454 & TRN & \\
\hline CHEMBL1878043 & 752485 & 4.6198 & 4.9573 & TRN & \\
\hline CHEMBL1902151 & 752485 & 3.0044 & 2.7714 & TRN & \\
\hline
\end{tabular}




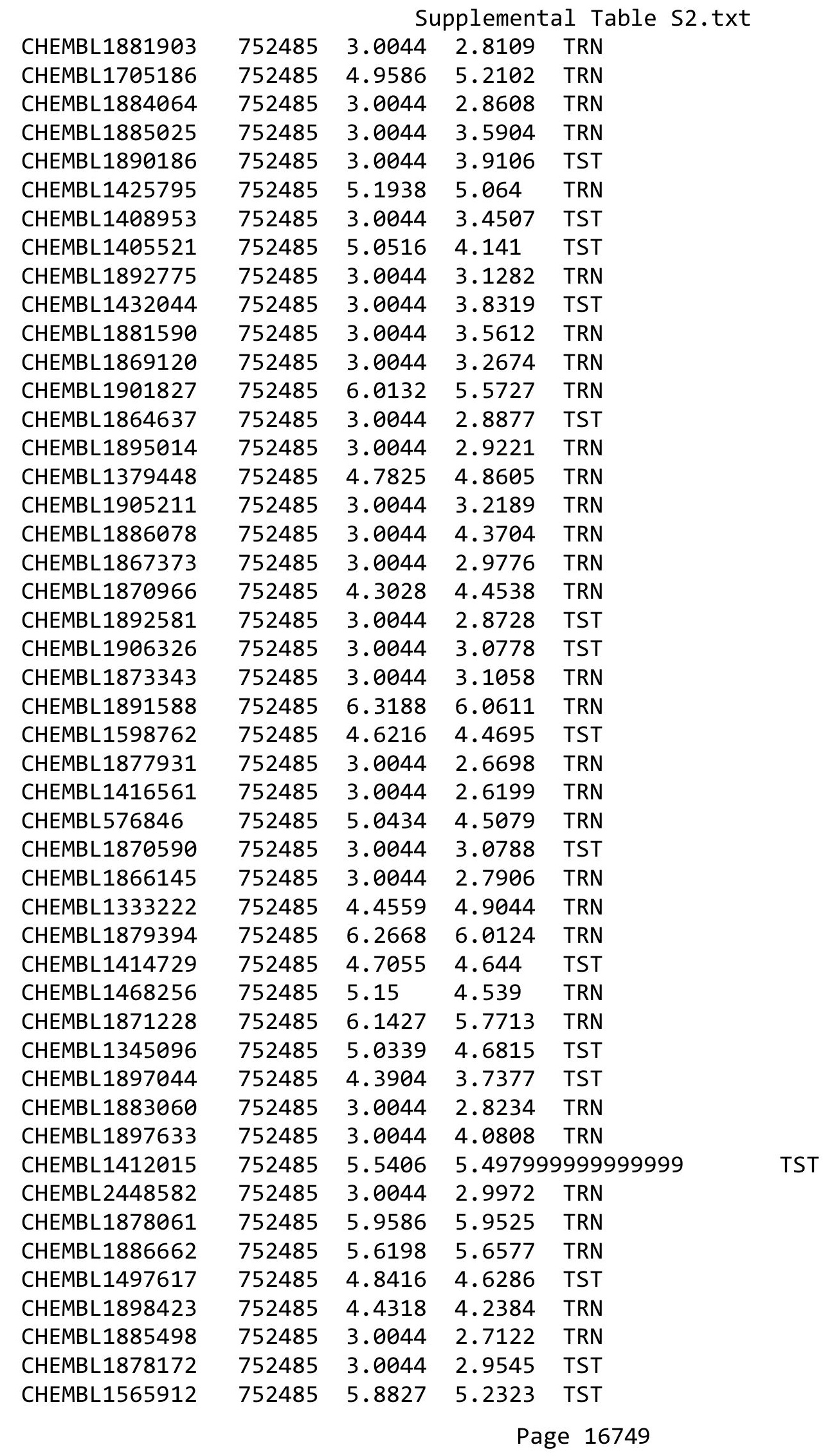


Supplemental Table S2.txt

\begin{tabular}{|c|c|c|c|c|}
\hline & & & & \\
\hline AEMBL3144856 & 2485 & 342 & 276 & \\
\hline IEMBL1884442 & 2485 & 1367 & 062 & \\
\hline HEMBL1893628 & 52485 & 0044 & 0135 & \\
\hline AEMBL1893076 & 2485 & 044 & 5841 & \\
\hline IEMBL1880833 & 2485 & 044 & 5946 & \\
\hline AEMBL1902173 & 52485 & 5.7167 & .2242 & \\
\hline AEMBL1891751 & 52485 & .8861 & .9182 & \\
\hline AEMBL1494979 & 52485 & 4.2857 & .447 & \\
\hline AEMBL1877777 & 52485 & & 9341 & \\
\hline AEMBL 1875 & & 244 & 878 & \\
\hline AEMBL1873177 & 52485 & 044 & 9937 & \\
\hline AEMBL1892009 & 85 & 044 & 538 & \\
\hline IEMBL1773 & 35 & & 127 & \\
\hline AEMBL1905 & 35 & 44 & 739 & \\
\hline AEMBL1869875 & & & 768 & \\
\hline AEMBL1897928 & 52485 & 44 & 634 & \\
\hline AEMBL1884437 & & 044 & .726 & \\
\hline IEMBL1906 & 35 & 44 & 75 & \\
\hline AEMBL189 & 35 & & 447 & \\
\hline AEMBL 187 & & & 773 & \\
\hline AEMBL1900215 & 85 & 44 & 2.6585 & \\
\hline IEMBL1892270 & & 95 & & \\
\hline IEMBL 186 & 35 & 44 & 063 & \\
\hline AEMBL18 & & 44 & 094 & \\
\hline AFMB 155 & 35 & 96 & 168 & \\
\hline AEMBL1899771 & & & 517 & \\
\hline AEMBL1903693 & & 14 & & \\
\hline HEMBL 188 & 35 & 044 & 187 & \\
\hline 189 & 35 & 44 & 253 & \\
\hline 91 & 35 & 44 & 818 & \\
\hline AEMBL1525161 & & & 089 & \\
\hline AEMBL1903194 & & & 027 & \\
\hline IEMBL1900453 & 85 & 163 & 878 & \\
\hline AFMBI 139 & 35 & 4. & 133 & \\
\hline 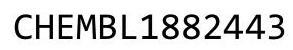 & & & 275 & \\
\hline AEMBL1896157 & 35 & 044 & 111 & \\
\hline AEMBL1870914 & 35 & & & \\
\hline EMBL 186 & 35 & 244 & 152 & \\
\hline רי 1 & 35 & 29 & 888 & \\
\hline HEMBL16 & & 18 & 027 & 10 \\
\hline AEMBL1449672 & 52485 & 5.0814 & 4.8219 & RI \\
\hline IEMBL1495 & 35 & 244 & & \\
\hline HEMBL187 & & 3. & 095 & \\
\hline HEMBL189 & & & & \\
\hline CHEMBL1868274 & & 427 & 5.4337 & \\
\hline HEMBL1486906 & 52485 & 3.0044 & 2.7424 & \\
\hline HFMRI 1561590 & 752485 & 4.6021 & 4.2509 & \\
\hline
\end{tabular}

Page 16750 


\begin{tabular}{|c|c|c|c|c|c|}
\hline & & \multicolumn{4}{|c|}{ Supplemental Table S2.txt } \\
\hline CHEMBL1893952 & 752485 & 3.0044 & 3.227 & TRN & \\
\hline CHEMBL1547213 & 752485 & 4.5513 & 4.2312 & TRN & \\
\hline CHEMBL1544489 & 752485 & 5.1079 & 5.4014 & TST & \\
\hline CHEMBL1871956 & 752485 & 3.0044 & 3.3151 & TST & \\
\hline CHEMBL1903946 & 752485 & 3.0044 & 2.8493 & TRN & \\
\hline CHEMBL1877788 & 752485 & 3.0044 & 2.7405 & TST & \\
\hline CHEMBL1898553 & 752485 & 3.0044 & 3.2512 & TST & \\
\hline CHEMBL68442 & 752485 & 3.0044 & 2.8785 & TRN & \\
\hline CHEMBL1864057 & 752485 & 3.0044 & 3.4406 & TRN & \\
\hline CHEMBL1896263 & 752485 & 5.3979 & 5.5166 & TRN & \\
\hline CHEMBL1870930 & 752485 & 4.9208 & 4.9909 & TRN & \\
\hline CHEMBL1884495 & 752485 & 5.6383 & 5.8868 & TRN & \\
\hline CHEMBL1599544 & 752485 & 3.0044 & 2.9509 & TST & \\
\hline CHEMBL1898076 & 752485 & 3.0044 & 2.6978 & TRN & \\
\hline CHEMBL1895018 & 752485 & 4.2848 & 3.21199 & 99999999997 & TRN \\
\hline CHEMBL1906573 & 752485 & 3.0044 & 3.694 & TRN & \\
\hline CHEMBL1898951 & 752485 & 3.0044 & 2.9479 & TRN & \\
\hline CHEMBL1863714 & 752485 & 3.0044 & 3.1424 & TRN & \\
\hline CHEMBL1532745 & 752485 & 3.0044 & 2.6199 & TRN & \\
\hline CHEMBL1894366 & 752485 & 3.0044 & 3.1859 & TRN & \\
\hline CHEMBL1471498 & 752485 & 3.0044 & 3.7399 & TST & \\
\hline CHEMBL1879721 & 752485 & 4.4437 & 4.2347 & TRN & \\
\hline CHEMBL1876157 & 752485 & 3.0044 & 2.6263 & TRN & \\
\hline CHEMBL 1905576 & 752485 & 3.0044 & 3.0928 & TRN & \\
\hline CHEMBL1880304 & 752485 & 3.0044 & 3.1727 & TRN & \\
\hline CHEMBL1542557 & 752485 & 4.9872 & 4.2516 & TST & \\
\hline CHEMBL1866663 & 752485 & 3.0044 & 3.2462 & TRN & \\
\hline CHEMBL1896895 & 752485 & 4.0969 & 3.6338 & TRN & \\
\hline CHEMBL1864262 & 752485 & 3.0044 & 2.9343 & TRN & \\
\hline CHEMBL1306211 & 752485 & 3.0044 & 3.1953 & TST & \\
\hline CHEMBL1885269 & 752485 & 5.9586 & 5.7009 & TRN & \\
\hline CHEMBL1978271 & 809120 & 4.6 & 4.4462 & TRN & \\
\hline CHEMBL 2007266 & 809120 & 4.4 & 4.4515 & TRN & \\
\hline CHEMBL 202721 & 809120 & 6.7 & 6.4669 & TRN & \\
\hline CHEMBL 2000568 & 809120 & 4.4 & 4.7431 & TRN & \\
\hline CHEMBL1994308 & 809120 & 4.4 & 4.418 & TRN & \\
\hline CHEMBL 2007097 & 809120 & 4.3 & 4.3648 & TRN & \\
\hline CHEMBL1825138 & 809120 & 4.4 & 4.635 & TST & \\
\hline CHEMBL1974328 & 809120 & 5.9 & 6.2402 & TRN & \\
\hline CHEMBL509032 & 809120 & 6.3 & 6.2698 & TRN & \\
\hline CHEMBL388311 & 809120 & 6.5 & 6.2843 & TRN & \\
\hline CHEMBL1964948 & 809120 & 4.4 & 3.9742 & TRN & \\
\hline CHEMBL 2002202 & 809120 & 4.0 & 3.8337 & TRN & \\
\hline CHEMBL1973013 & 809120 & 4.4 & 4.9104 & TRN & \\
\hline CHEMBL1987430 & 809120 & 4.4 & 4.4754 & TRN & \\
\hline CHEMBL1993413 & 809120 & 4.4 & 4.4021 & TRN & \\
\hline CHEMBL 205415 & 809120 & 4.4 & 4.4871 & TRN & \\
\hline CHEMBL1975927 & 809120 & 5.6 & 5.6645 & TRN & \\
\hline
\end{tabular}




\begin{tabular}{|c|c|c|c|c|c|}
\hline \\
\hline CHEMBL1986943 & 809120 & 7.3 & 7.3546 & TRN & \\
\hline CHEMBL1997119 & 809120 & 4.3 & 4.2423 & TRN & \\
\hline CHEMBL1977138 & 809120 & 4.4 & 4.8632 & TRN & \\
\hline CHEMBL 2000879 & 809120 & 4.1 & 4.456 & TST & \\
\hline CHEMBL1978448 & 809120 & 4.4 & 4.5488 & TST & \\
\hline CHEMBL1980329 & 809120 & 4.4 & 5.1357 & TRN & \\
\hline CHEMBL 2004515 & 809120 & 5.2 & 5.3118 & TRN & \\
\hline CHEMBL1992042 & 809120 & 6.4 & 5.3288 & TRN & \\
\hline CHEMBL1986265 & 809120 & 4.4 & 4.478 & TRN & \\
\hline CHEMBL1991734 & 809120 & 5.8 & 5.4687 & TRN & \\
\hline CHEMBL 21156 & 809120 & 6.4 & 5.723 & TRN & \\
\hline CHEMBL1994724 & 809120 & 4.4 & 4.4408 & TRN & \\
\hline CHEMBL1989267 & 809120 & 7.2 & 7.1622 & TRN & \\
\hline CHEMBL1991782 & 809120 & 3.1 & 3.6936 & TRN & \\
\hline CHEMBL1983348 & 809120 & 6.1 & 5.6073 & TRN & \\
\hline CHEMBL1974574 & 809120 & 4.4 & 4.699 & TRN & \\
\hline CHEMBL1970290 & 809120 & 6.0 & 5.5244 & TRN & \\
\hline CHEMBL1993877 & 809120 & 6.1 & 5.4643 & TRN & \\
\hline CHEMBL1974480 & 809120 & 5.7 & 4.9975 & TST & \\
\hline CHEMBL1996500 & 809120 & 4.4 & 4.2848 & TRN & \\
\hline CHEMBL1980671 & 809120 & 4.4 & 4.6085 & TRN & \\
\hline CHEMBL1973363 & 809120 & 5.8 & 5.1453 & TRN & \\
\hline CHEMBL1986177 & 809120 & 4.4 & 4.5552 & TRN & \\
\hline CHEMBL1989708 & 809120 & 6.5 & 6.5218 & TRN & \\
\hline CHEMBL1976420 & 809120 & 4.4 & 3.8928 & TRN & \\
\hline CHEMBL1998253 & 809120 & 4.4 & 4.765 & TST & \\
\hline CHEMBL1981744 & 809120 & 4.4 & 4.9889 & TRN & \\
\hline CHEMBL1989423 & 809120 & 4.1 & 4.2037 & TST & \\
\hline CHEMBL1985367 & 809120 & 5.5 & 5.3365 & TRN & \\
\hline CHEMBL1996510 & 809120 & 5.9 & 5.932 & TRN & \\
\hline CHEMBL 2000029 & 809120 & 4.4 & 4.5202 & TRN & \\
\hline CHEMBL1995172 & 809120 & 4.0 & 4.4006 & TST & \\
\hline CHEMBL 2001584 & 809120 & 4.4 & 4.7139 & 99999999995 & TRN \\
\hline CHEMBL1973961 & 809120 & 4.4 & 4.6563 & TRN & \\
\hline CHEMBL1971227 & 809120 & 5.7 & 5.3641 & TST & \\
\hline CHEMBL1967998 & 809120 & 7.0 & 7.0485 & TRN & \\
\hline CHEMBL1978562 & 809120 & 4.4 & 5.4353 & TRN & \\
\hline CHEMBL1994977 & 809120 & 4.6 & 4.4649 & TRN & \\
\hline CHEMBL 2001149 & 809120 & 5.8 & 4.7951 & TRN & \\
\hline CHEMBL2005478 & 809120 & 4.4 & 5.4465 & TRN & \\
\hline CHEMBL1996646 & 809120 & 5.7 & 5.9851 & TRN & \\
\hline CHEMBL1979773 & 809120 & 4.4 & 4.2215 & TRN & \\
\hline CHEMBL1989471 & 809120 & 4.4 & 4.1447 & TST & \\
\hline CHEMBL 2002099 & 809120 & 4.4 & 5.1475 & TRN & \\
\hline CHEMBL1996702 & 809120 & 4.4 & 4.7085 & TRN & \\
\hline CHEMBL 2007124 & 809120 & 4.4 & 4.0267 & TRN & \\
\hline CHEMBL1978195 & 809120 & 6.0 & 5.7238 & TRN & \\
\hline CHEMBL1985681 & 809120 & 6.1 & 5.4289 & TRN & \\
\hline & & & & 16752 & \\
\hline
\end{tabular}




\begin{tabular}{|c|c|c|c|c|}
\hline & & & ient & al Ta \\
\hline CHEMBL1982711 & 809120 & 6.2 & 6.0639 & TRN \\
\hline CHEMBL262623 & 809120 & 5.2 & 5.1758 & TRN \\
\hline CHEMBL1984842 & 809120 & 4.4 & 4.3981 & TRN \\
\hline CHEMBL 2004118 & 809120 & 4.4 & 4.9431 & TRN \\
\hline CHEMBL1996795 & 809120 & 5.6 & 5.1059 & TST \\
\hline CHEMBL1996345 & 809120 & 4.4 & 4.5308 & TRN \\
\hline CHEMBL 2004025 & 809120 & 6.2 & 5.6645 & TRN \\
\hline CHEMBL1996048 & 809120 & 5.7 & 5.34 & TRN \\
\hline CHEMBL50894 & 809120 & 4.4 & 4.3994 & TRN \\
\hline CHEMBL1995211 & 809120 & 5.8 & 5.7516 & TRN \\
\hline CHEMBL1965033 & 809120 & 4.4 & 4.0453 & TRN \\
\hline CHEMBL461876 & 809120 & 4.4 & 4.4524 & TRN \\
\hline CHEMBL 2006299 & 809120 & 4.4 & 4.3208 & TRN \\
\hline CHEMBL1971519 & 809120 & 5.9 & 5.5741 & TRN \\
\hline CHEMBL1997335 & 809120 & 4.4 & 4.6043 & TRN \\
\hline CHEMBL1965169 & 809120 & 4.4 & 4.5484 & TRN \\
\hline CHEMBL1081312 & 809120 & 6.0 & 6.3358 & TRN \\
\hline CHEMBL1965170 & 809120 & 6.0 & 6.1146 & TRN \\
\hline CHEMBL1994808 & 809120 & 4.3 & 4.4074 & TRN \\
\hline CHEMBL 2005792 & 809120 & 4.4 & 4.4307 & TRN \\
\hline CHEMBL1986503 & 809120 & 4.4 & 4.5958 & TST \\
\hline CHEMBL1972355 & 809120 & 6.4 & 6.0004 & TRN \\
\hline CHEMBL1997892 & 809120 & 4.4 & 4.2657 & TRN \\
\hline CHEMBL 2001641 & 809120 & 4.6 & 4.5403 & TRN \\
\hline CHEMBL1997193 & 809120 & 5.8 & 4.5842 & TST \\
\hline CHEMBL1964902 & 809120 & 4.4 & 4.4688 & TRN \\
\hline CHEMBL1973868 & 809120 & 4.4 & 4.0985 & TRN \\
\hline CHEMBL1972462 & 809120 & 4.4 & 4.4187 & TRN \\
\hline CHEMBL1983715 & 809120 & 6.1 & 6.2733 & TRN \\
\hline CHEMBL1984500 & 809120 & 3.1 & 3.1944 & TRN \\
\hline CHEMBL 2002992 & 809120 & 4.7 & 4.2307 & TRN \\
\hline CHEMBL1982700 & 809120 & 4.4 & 4.5163 & TRN \\
\hline CHEMBL10 & 809120 & 4.4 & 4.5207 & TRN \\
\hline CHEMBL1980763 & 809120 & 5.5 & 4.7514 & TRN \\
\hline CHEMBL1977634 & 809120 & 4.4 & 4.5445 & TRN \\
\hline CHEMBL 2004887 & 809120 & 4.1 & 4.2116 & TRN \\
\hline CHEMBL1969156 & 809120 & 4.9 & 4.7602 & TRN \\
\hline CHEMBL 2007479 & 809120 & 4.4 & 4.397 & TRN \\
\hline CHEMBL1971606 & 809120 & 4.4 & 4.3249 & TRN \\
\hline CHEMBL1972220 & 809120 & 7.0 & 6.9431 & TRN \\
\hline CHEMBL1981215 & 809120 & 4.4 & 4.5494 & TRN \\
\hline CHEMBL 2003785 & 809120 & 4.4 & 4.8157 & TRN \\
\hline CHEMBL1973720 & 809120 & 7.5 & 7.375 & TRN \\
\hline CHEMBL1999414 & 809120 & 6.4 & 6.1607 & TRN \\
\hline CHEMBL1967336 & 809120 & 4.4 & 4.4084 & TRN \\
\hline CHEMBL 2001923 & 809120 & 4.4 & 4.4406 & TRN \\
\hline CHEMBL1983070 & 809120 & 4.4 & 4.4811 & TRN \\
\hline CHEMBL 2003514 & 809120 & 4.4 & 4.4912 & TRN \\
\hline
\end{tabular}




\begin{tabular}{|c|c|c|c|c|c|}
\hline \\
\hline CHEMBL1970340 & 809120 & 5.1 & 5.2292 & TRN & \\
\hline CHEMBL1967992 & 809120 & 4.4 & 4.0944 & TRN & \\
\hline CHEMBL1989043 & 809120 & 4.4 & 4.8851 & TRN & \\
\hline CHEMBL2006450 & 809120 & 4.4 & 4.4083 & TRN & \\
\hline CHEMBL2001987 & 809120 & 4.4 & 4.4255 & TRN & \\
\hline CHEMBL1994555 & 809120 & 4.4 & 4.3334 & TRN & \\
\hline CHEMBL1164180 & 809120 & 4.4 & 4.5316 & TST & \\
\hline CHEMBL1975121 & 809120 & 4.4 & 4.2105 & TRN & \\
\hline CHEMBL1983640 & 809120 & 4.4 & 4.606 & TRN & \\
\hline CHEMBL1997611 & 809120 & 4.4 & 4.8732 & TST & \\
\hline CHEMBL1971943 & 809120 & 4.4 & 5.1128 & TRN & \\
\hline CHEMBL 2002723 & 809120 & 5.8 & 5.1351 & TRN & \\
\hline CHEMBL1984686 & 809120 & 4.4 & 4.4546 & TST & \\
\hline CHEMBL1973793 & 809120 & 4.4 & 4.3538 & TRN & \\
\hline CHEMBL1992073 & 809120 & 4.4 & 4.5553 & TRN & \\
\hline CHEMBL1990254 & 809120 & 4.4 & 4.2314 & TRN & \\
\hline CHEMBL1986143 & 809120 & 4.4 & 4.2657 & TRN & \\
\hline CHEMBL1972934 & 809120 & 4.2 & 4.5169 & 99999999995 & TRN \\
\hline CHEMBL2007559 & 809120 & 4.4 & 4.5089 & TRN & \\
\hline CHEMBL1992581 & 809120 & 4.4 & 5.1211 & TRN & \\
\hline CHEMBL 2004290 & 809120 & 5.6 & 5.9815 & TRN & \\
\hline CHEMBL1975921 & 809120 & 4.3 & 4.2931 & TRN & \\
\hline CHEMBL1975923 & 809120 & 5.9 & 4.7714 & TST & \\
\hline CHEMBL 2004033 & 809120 & 5.8 & 5.0838 & TST & \\
\hline CHEMBL1984847 & 809120 & 4.4 & 4.5347 & TST & \\
\hline CHEMBL1996576 & 809120 & 4.4 & 4.5864 & TST & \\
\hline CHEMBL 2005449 & 809120 & 4.4 & 4.5805 & TRN & \\
\hline CHEMBL1991678 & 809120 & 4.4 & 4.4608 & TRN & \\
\hline CHEMBL1987998 & 809120 & 4.4 & 4.507 & TRN & \\
\hline CHEMBL1990496 & 809120 & 4.4 & 4.7647 & TRN & \\
\hline CHEMBL242865 & 809120 & 5.6 & 5.9512 & TRN & \\
\hline CHEMBL235157 & 809120 & 4.4 & 4.1328 & TRN & \\
\hline CHEMBL2004159 & 809120 & 4.4 & 4.4073 & TRN & \\
\hline CHEMBL1978371 & 809120 & 6.3 & 5.6286 & TST & \\
\hline CHEMBL440084 & 809120 & 4.4 & 4.5637 & TRN & \\
\hline CHEMBL1998110 & 809120 & 4.4 & 4.3474 & TRN & \\
\hline CHEMBL1978166 & 809120 & 6.3 & 6.2598 & TRN & \\
\hline CHEMBL1990590 & 809120 & 4.4 & 4.506 & TRN & \\
\hline CHEMBL1977814 & 809120 & 4.4 & 4.6262 & TST & \\
\hline CHEMBL1974617 & 809120 & 4.8 & 4.8936 & TRN & \\
\hline CHEMBL1965660 & 809120 & 4.4 & 5.2482 & TRN & \\
\hline CHEMBL1992125 & 809120 & 6.3 & 5.9311 & TRN & \\
\hline CHEMBL1966175 & 809120 & 4.4 & 4.4362 & TRN & \\
\hline CHEMBL 2007375 & 809120 & 5.5 & 4.4753 & TRN & \\
\hline CHEMBL379975 & 809120 & 7.4 & 6.4899 & TRN & \\
\hline CHEMBL1973016 & 809120 & 4.4 & 4.4495 & TRN & \\
\hline CHEMBL1965387 & 809120 & 4.4 & 4.7858 & TRN & \\
\hline CHEMBL2001539 & 809120 & 4.5 & 4.7451 & TST & \\
\hline & & & & 16754 & \\
\hline
\end{tabular}




\begin{tabular}{|c|c|c|c|c|c|}
\hline & & & & & \\
\hline CHEMBL388978 & 809120 & 6.2 & 7.4887 & TST & \\
\hline CHEMBL1997041 & 809120 & 5.4 & 5.1415 & TRN & \\
\hline CHEMBL550418 & 809120 & 4.4 & 4.3015 & TRN & \\
\hline CHEMBL398951 & 809120 & 4.4 & 4.3135 & TRN & \\
\hline CHEMBL1971289 & 809120 & 4.4 & 4.3929 & TST & \\
\hline CHEMBL1988437 & 809120 & 4.4 & 4.4063 & TST & \\
\hline CHEMBL1421720 & 809120 & 6.1 & 5.268 & TRN & \\
\hline CHEMBL1233887 & 809120 & 4.4 & 4.3558 & TRN & \\
\hline CHEMBL 2003689 & 809120 & 4.4 & 4.377 & TRN & \\
\hline CHEMBL1996649 & 809120 & 6.4 & 6.3217 & TRN & \\
\hline CHEMBL1986756 & 809120 & 4.4 & 4.6596 & TRN & \\
\hline CHEMBL1949855 & 809120 & 4.1 & 4.1018 & TRN & \\
\hline CHEMBL3109278 & 809120 & 7.3 & 7.2188 & TRN & \\
\hline CHEMBL1974998 & 809120 & 4.4 & 4.5779 & TRN & \\
\hline CHEMBL1990223 & 809120 & 4.4 & 4.535 & TRN & \\
\hline CHEMBL 2004438 & 809120 & 4.4 & 4.1986 & TRN & \\
\hline CHEMBL1964382 & 809120 & 4.4 & 4.2726 & TST & \\
\hline CHEMBL101311 & 809120 & 5.5 & 5.3615 & TRN & \\
\hline CHEMBL191003 & 809120 & 5.4 & 5.1324 & TRN & \\
\hline CHEMBL 2002471 & 809120 & 5.9 & 4.5463 & TRN & \\
\hline CHEMBL1973359 & 809120 & 6.0 & 5.4443 & TST & \\
\hline CHEMBL1988581 & 809120 & 6.9 & 6.5101 & TST & \\
\hline CHEMBL 2005699 & 809120 & 4.4 & 4.435 & TRN & \\
\hline CHEMBL 2006564 & 809120 & 6.3 & 6.4603 & TRN & \\
\hline CHEMBL1979690 & 809120 & 6.8 & 6.9094 & TRN & \\
\hline CHEMBL1965789 & 809120 & 5.5 & 4.7632 & TST & \\
\hline CHEMBL 234085 & 809120 & 4.4 & 4.3968 & TRN & \\
\hline CHEMBL1978167 & 809120 & 4.4 & 4.43 & TRN & \\
\hline CHEMBL418203 & 809120 & 4.4 & 4.5701 & TRN & \\
\hline CHEMBL225519 & 809120 & 4.4 & 4.175 & TRN & \\
\hline CHEMBL1994159 & 809120 & 4.2 & 4.4434 & TRN & \\
\hline CHEMBL1976376 & 809120 & 8.2 & 7.8421 & TRN & \\
\hline CHEMBL1983575 & 809120 & 4.4 & 5.9796 & TRN & \\
\hline CHEMBL1968868 & 809120 & 5.4 & 4.3945 & TRN & \\
\hline CHEMBL1981047 & 809120 & 4.4 & 4.3644 & TRN & \\
\hline CHEMBL1998470 & 809120 & 4.4 & 3.9646 & TRN & \\
\hline CHEMBL1976196 & 809120 & 4.4 & 4.6172 & TRN & \\
\hline CHEMBL 2002432 & 809120 & 5.9 & 4.9476 & TRN & \\
\hline CHEMBL1997197 & 809120 & 4.4 & 4.5784 & TRN & \\
\hline CHEMBL1975903 & 809120 & 4.4 & 4.7698 & TRN & \\
\hline CHEMBL1983630 & 809120 & 4.3 & 4.2926 & TRN & \\
\hline CHEMBL1988805 & 809120 & 4.4 & 4.6435 & TRN & \\
\hline CHEMBL458997 & 809120 & 5.5 & 5.0919 & TRN & \\
\hline CHEMBL1969942 & 809120 & 4.4 & 4.7273 & TRN & \\
\hline CHEMBL1982660 & 809120 & 4.4 & 4.2559 & TRN & \\
\hline CHEMBL1978567 & 809120 & 4.4 & 4.3474 & TRN & \\
\hline CHEMBL1995765 & 809120 & 4.4 & 4.1425 & TRN & \\
\hline CHEMBL1984760 & 809120 & 5.5 & $5.3270 e$ & 2000000001 & TRN \\
\hline & & & & 16755 & \\
\hline
\end{tabular}




\begin{tabular}{|c|c|c|c|c|c|}
\hline \multicolumn{6}{|c|}{ Supplemental Table s2.txt } \\
\hline CHEMBL360847 & 809120 & 4.4 & 4.8626 & TRN & \\
\hline CHEMBL1995811 & 809120 & 4.4 & 4.6655 & TRN & \\
\hline CHEMBL1983111 & 809120 & 6.6 & 6.6036 & TRN & \\
\hline CHEMBL1988141 & 809120 & 6.7 & 6.2953 & TST & \\
\hline CHEMBL1992937 & 809120 & 4.6 & 4.4754 & TRN & \\
\hline CHEMBL451401 & 809120 & 4.6 & 4.7532 & TRN & \\
\hline CHEMBL1977134 & 809120 & 4.4 & 4.3136 & TRN & \\
\hline CHEMBL1985206 & 809120 & 4.4 & 4.2533 & TRN & \\
\hline CHEMBL1977749 & 809120 & 4.4 & 4.2369 & TST & \\
\hline CHEMBL 2002450 & 809120 & 4.0 & 4.5834 & TRN & \\
\hline CHEMBL1975212 & 809120 & 5.2 & 5.7849 & TRN & \\
\hline CHEMBL 261849 & 809120 & 4.4 & 4.038 & TRN & \\
\hline CHEMBL1983923 & 809120 & 6.5 & 5.5862 & TRN & \\
\hline CHEMBL1993904 & 809120 & 6.1 & 5.4431 & TRN & \\
\hline CHEMBL1997275 & 809120 & 5.9 & 5.7001 & TRN & \\
\hline CHEMBL1967513 & 809120 & 4.4 & 4.5674 & TRN & \\
\hline CHEMBL 2000724 & 809120 & 4.4 & 4.4534 & TRN & \\
\hline CHEMBL1982413 & 809120 & 5.5 & 5.8007 & TRN & \\
\hline CHEMBL1987535 & 809120 & 5.5 & 5.3146 & TRN & \\
\hline CHEMBL1983393 & 809120 & 4.4 & 4.8126 & TRN & \\
\hline CHEMBL1981792 & 809120 & 4.4 & 5.1267 & TRN & \\
\hline CHEMBL 2002586 & 809120 & 4.4 & 5.1866 & TRN & \\
\hline CHEMBL1987815 & 809120 & 5.0 & 5.0003 & TRN & \\
\hline CHEMBL 2006674 & 809120 & 4.4 & 4.7906 & TST & \\
\hline CHEMBL1992371 & 809120 & 4.4 & 4.4086 & TRN & \\
\hline CHEMBL 383264 & 809120 & 4.4 & 4.7226 & TRN & \\
\hline CHEMBL1984236 & 809120 & 4.4 & 4.9616 & TST & \\
\hline CHEMBL 2007421 & 809120 & 4.4 & 4.6163 & TRN & \\
\hline CHEMBL1973138 & 809120 & 4.4 & 4.71399 & 99999999995 & TRN \\
\hline CHEMBL 2002599 & 809120 & 4.4 & 4.5344 & TRN & \\
\hline CHEMBL1969151 & 809120 & 6.5 & 6.8692 & TST & \\
\hline CHEMBL1967252 & 809120 & 5.0 & 4.6363 & TST & \\
\hline CHEMBL1993335 & 809120 & 5.6 & 5.5699 & TST & \\
\hline CHEMBL 2007574 & 809120 & 6.0 & 5.7879 & TST & \\
\hline CHEMBL1988692 & 809120 & 6.0 & 5.2994 & TST & \\
\hline CHEMBL 2004637 & 809120 & 5.9 & 5.0289 & TST & \\
\hline CHEMBL1993374 & 809120 & 4.4 & 4.478 & TST & \\
\hline CHEMBL1994318 & 809120 & 4.4 & 4.4233 & TST & \\
\hline CHEMBL1998680 & 809120 & 4.4 & 4.6349 & TST & \\
\hline CHEMBL592030 & 809120 & 4.4 & 4.5069 & TST & \\
\hline CHEMBL1999506 & 809120 & 4.4 & 4.4637 & TST & \\
\hline CHEMBL1605605 & 809120 & 4.4 & 4.441 & TST & \\
\hline CHEMBL1997007 & 809120 & 5.5 & 5.3555 & TST & \\
\hline CHEMBL1970352 & 809120 & 4.4 & 4.988 & TST & \\
\hline CHEMBL 2002690 & 809120 & 4.4 & 4.2488 & TST & \\
\hline CHEMBL1980167 & 809120 & 6.5 & 5.3291 & TST & \\
\hline CHEMBL 278041 & 809120 & 4.4 & 4.3391 & TST & \\
\hline CHEMBL 215152 & 809120 & 4.4 & 4.91 & TST & \\
\hline
\end{tabular}




\begin{tabular}{|c|c|c|c|c|c|}
\hline \\
\hline CHEMBL2006765 & 809120 & 6.6 & 6.2245 & TST & \\
\hline CHEMBL1986590 & 809120 & 4.4 & 5.3586 & TST & \\
\hline CHEMBL1870106 & 809120 & 4.4 & 4.5231 & TST & \\
\hline CHEMBL406845 & 809120 & 6.4 & 6.9127 & TST & \\
\hline CHEMBL1998477 & 809120 & 5.5 & 4.5043 & TST & \\
\hline CHEMBL1980246 & 809120 & 4.4 & 4.9174 & TST & \\
\hline CHEMBL1983980 & 809120 & 6.2 & 5.6781 & TST & \\
\hline CHEMBL1999484 & 809120 & 6.0 & 6.0375 & TST & \\
\hline CHEMBL482538 & 809120 & 5.1 & 5.4217 & TST & \\
\hline CHEMBL1984296 & 809120 & 5.5 & 4.7605 & TST & \\
\hline CHEMBL1986899 & 809120 & 4.4 & 4.7826 & TST & \\
\hline CHEMBL1996837 & 809120 & 4.4 & 4.6367 & TST & \\
\hline CHEMBL1984038 & 809120 & 4.4 & 4.4609 & TST & \\
\hline CHEMBL1993661 & 809120 & 7.2 & 6.7772 & TST & \\
\hline CHEMBL1968705 & 809120 & 5.5 & 5.2297 & TST & \\
\hline CHEMBL1991410 & 809120 & 4.4 & 4.3567 & TST & \\
\hline CHEMBL1964441 & 809120 & 4.4 & 5.1213 & TST & \\
\hline CHEMBL546797 & 809120 & 5.6 & 5.1204 & TST & \\
\hline CHEMBL 310340 & 105516 & 8.0362 & 8.0421 & TRN & \\
\hline CHEMBL 78299 & 105516 & 8.0458 & 8.2392 & TST & \\
\hline CHEMBL80183 & 105516 & 7.9586 & 8.0307 & TRN & \\
\hline CHEMBL77505 & 105516 & 6.1878 & 6.1462 & TRN & \\
\hline CHEMBL 76137 & 105516 & 7.8861 & 7.8356 & TRN & \\
\hline CHEMBL 309311 & 105516 & 8.5229 & 8.435 & TRN & \\
\hline CHEMBL 78369 & 105516 & 8.5229 & 8.4056 & TRN & \\
\hline CHEMBL 79433 & 105516 & 9.0 & 9.0059 & TRN & \\
\hline CHEMBL 78709 & 105516 & 6.4271 & 6.3932 & TRN & \\
\hline CHEMBL 78478 & 105516 & 8.5229 & 8.3858 & TRN & \\
\hline CHEMBL 309492 & 105516 & 8.3979 & 8.6044 & TRN & \\
\hline CHEMBL 78255 & 105516 & 8.0 & 8.0297 & TRN & \\
\hline CHEMBL 310342 & 105516 & 6.4389 & 6.3511 & TRN & \\
\hline CHEMBL419648 & 105516 & 8.0 & 7.9219 & TRN & \\
\hline CHEMBL80321 & 105516 & 7.8539 & 7.9304 & TRN & \\
\hline CHEMBL 312432 & 105516 & 8.2218 & 8.2204 & TRN & \\
\hline CHEMBL 81763 & 105516 & 6.8601 & 6.6886 & TST & \\
\hline CHEMBL80732 & 105516 & 8.699 & 8.5707 & TRN & \\
\hline CHEMBL 76836 & 105516 & 8.5229 & 8.6179 & TRN & \\
\hline CHEMBL311357 & 105516 & 9.0 & 8.92799 & 9999999999 & TRN \\
\hline CHEMBL 76856 & 105516 & 7.9208 & 7.9422 & TRN & \\
\hline CHEMBL310057 & 105516 & 7.3468 & 7.5159 & TRN & \\
\hline CHEMBL310324 & 105516 & 6.3449 & 6.455 & TRN & \\
\hline CHEMBL 80453 & 105516 & 7.3565 & 7.5052 & TRN & \\
\hline CHEMBL80798 & 105516 & 8.2218 & 8.1857 & TRN & \\
\hline CHEMBL 312770 & 105516 & 7.8861 & 7.7576 & TRN & \\
\hline CHEMBL276119 & 105516 & 8.0458 & 7.9732 & TRN & \\
\hline CHEMBL 309416 & 105516 & 7.7959 & 7.8159 & TRN & \\
\hline CHEMBL77176 & 105516 & 7.7696 & 7.7219 & TRN & \\
\hline CHEMBL 78549 & 105516 & 9.0 & 8.8626 & TRN & \\
\hline & & & & 16757 & \\
\hline
\end{tabular}




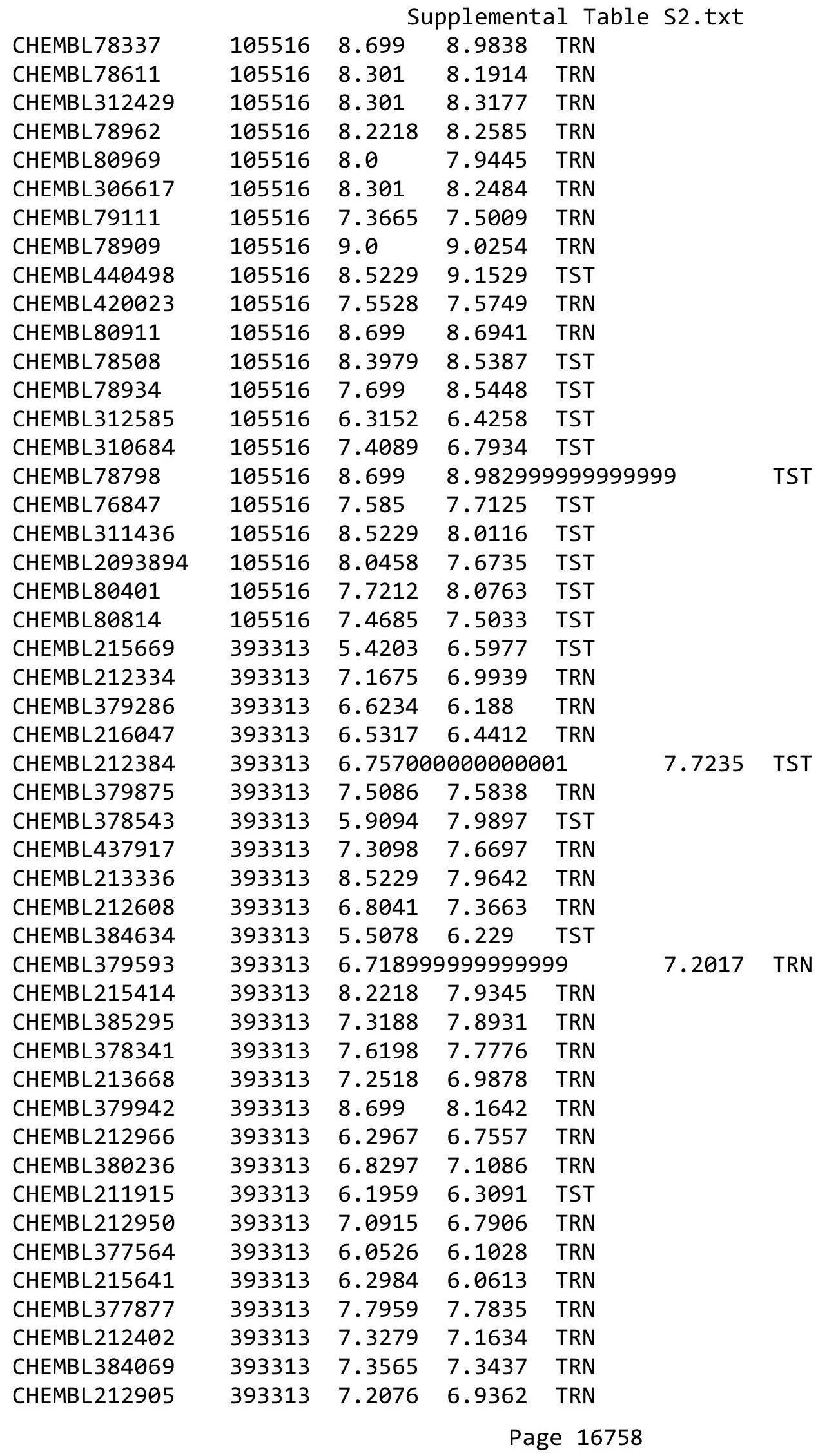




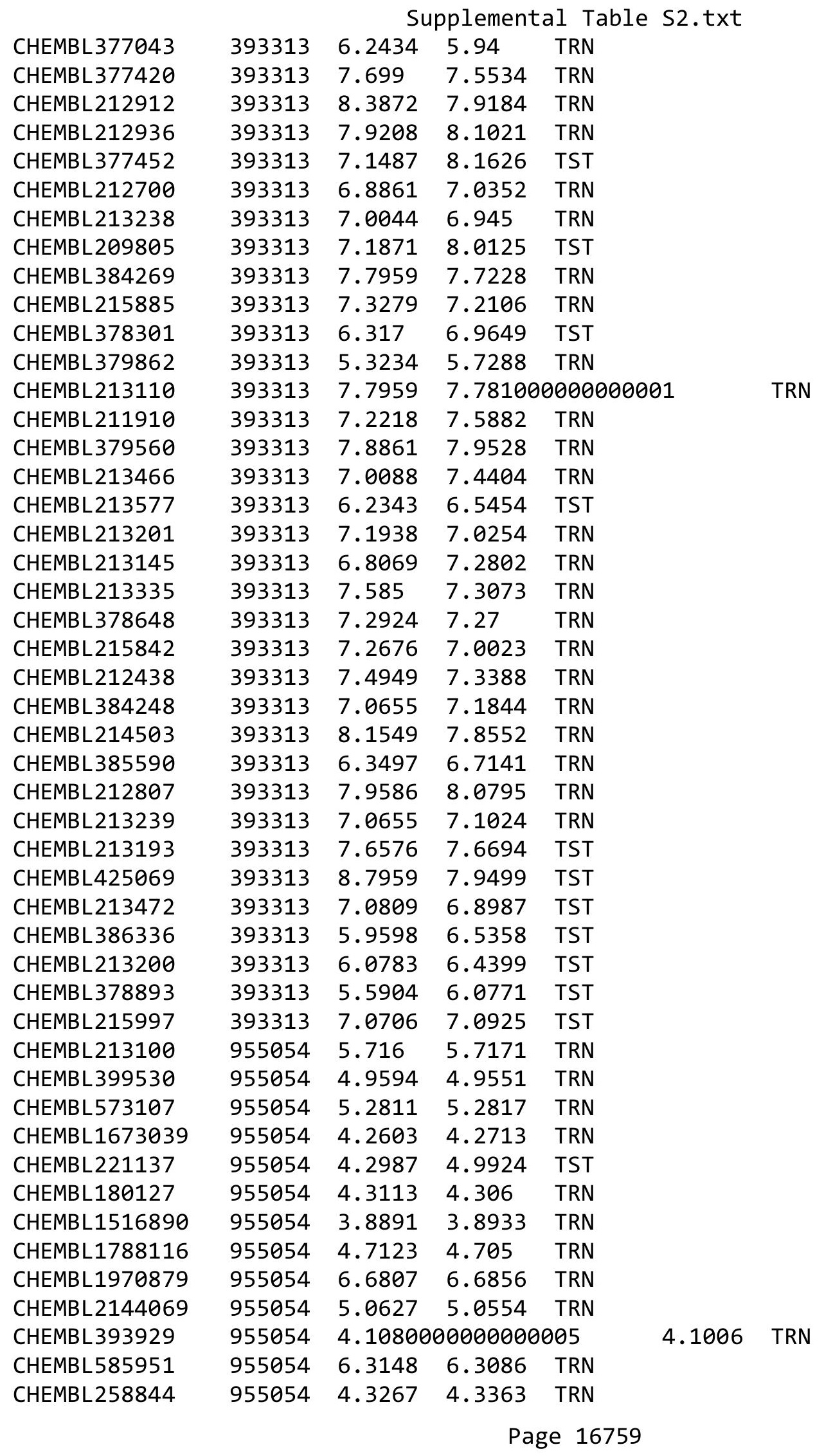




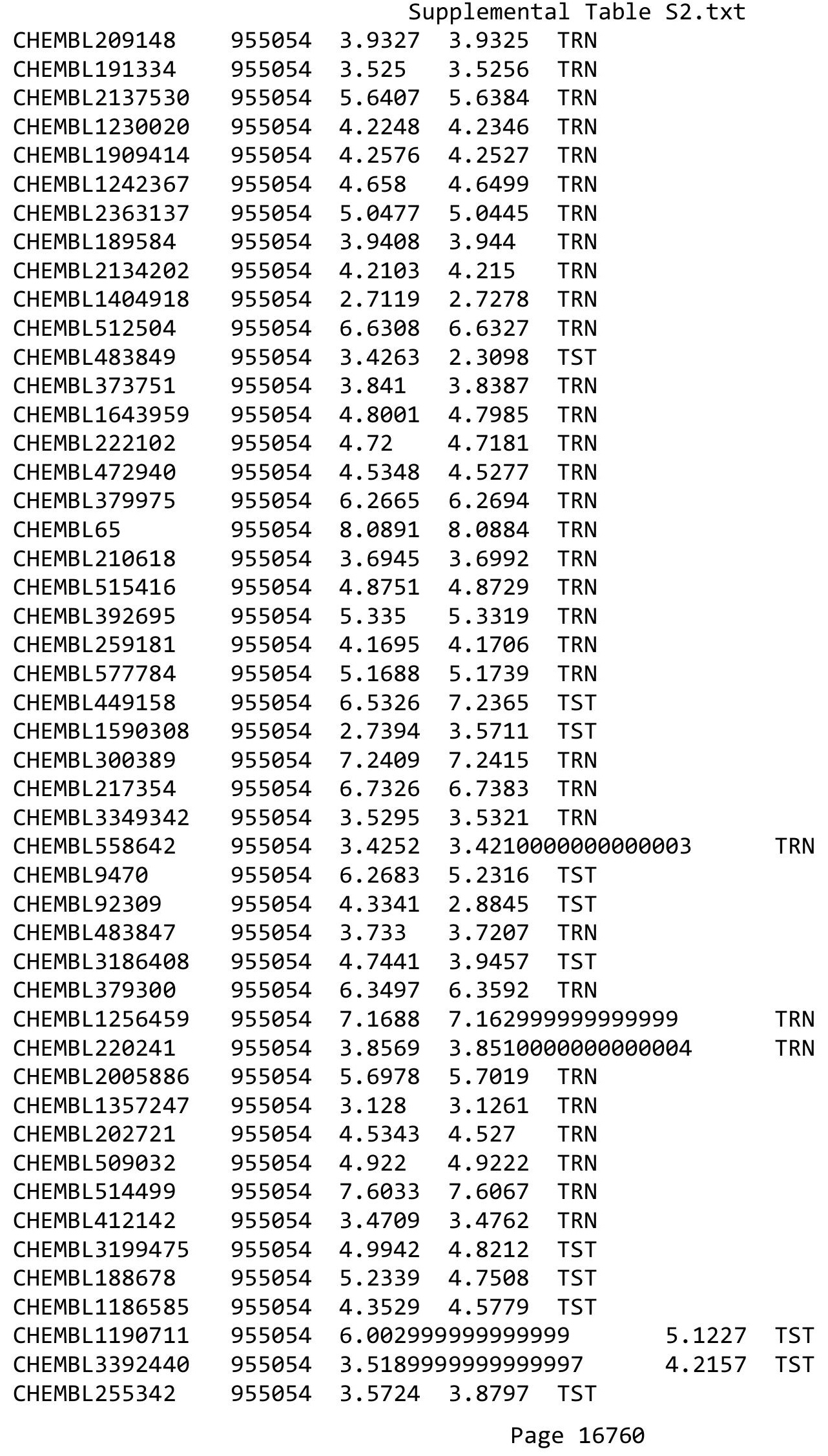




\begin{tabular}{|c|c|c|c|c|c|}
\hline & & \multicolumn{4}{|c|}{ Supplemental Table S2.txt } \\
\hline CHEMBL102714 & 955054 & 2.8142 & 3.1951 & TST & \\
\hline CHEMBL135561 & 955054 & 4.3322 & 4.2636 & TST & \\
\hline CHEMBL240954 & 955054 & 3.7796 & 4.1785 & TST & \\
\hline CHEMBL192566 & 955054 & 7.2403 & 8.4216 & TST & \\
\hline CHEMBL35001 & 100169 & 6.0 & 4.8491 & TRN & \\
\hline CHEMBL35211 & 100169 & 4.1938 & 3.9888 & TRN & \\
\hline CHEMBL35333 & 100169 & 3.699 & 5.1205 & TST & \\
\hline CHEMBL35967 & 100169 & 7.0 & 6.8121 & TRN & \\
\hline CHEMBL35458 & 100169 & 6.301 & 5.402 & TRN & \\
\hline CHEMBL284809 & 100169 & 5.699 & 6.48 & TRN & \\
\hline CHEMBL35024 & 100169 & 3.699 & 6.2396 & TRN & \\
\hline CHEMBL35387 & 100169 & 3.699 & 5.2751 & TRN & \\
\hline CHEMBL32553 & 100169 & 7.1249 & 7.0664 & TRN & \\
\hline CHEMBL 284343 & 100169 & 5.0458 & 5.8086 & TST & \\
\hline CHEMBL35615 & 100169 & 4.9208 & 5.5701 & TRN & \\
\hline CHEMBL34886 & 100169 & 6.0969 & 6.04200 & 0000000001 & TRN \\
\hline CHEMBL35165 & 100169 & 7.301 & 6.5648 & TRN & \\
\hline CHEMBL286394 & 100169 & 7.8239 & 7.3936 & TRN & \\
\hline CHEMBL34749 & 100169 & 5.8239 & 5.3309 & TRN & \\
\hline CHEMBL286925 & 100169 & 6.7959 & 6.4193 & TRN & \\
\hline CHEMBL36501 & 100169 & 7.2218 & 6.4072 & TST & \\
\hline CHEMBL422579 & 100169 & 7.5686 & 6.7466 & TRN & \\
\hline CHEMBL 34940 & 100169 & 3.699 & 5.3228 & TRN & \\
\hline CHEMBL34138 & 100169 & 6.7696 & 6.3782 & TRN & \\
\hline CHEMBL289005 & 100169 & 4.301 & 4.9359 & TRN & \\
\hline CHEMBL35582 & 100169 & 6.5229 & 5.8452 & TRN & \\
\hline CHEMBL32938 & 100169 & 6.5229 & 6.7573 & TST & \\
\hline CHEMBL418404 & 100169 & 7.0 & 6.9586 & TRN & \\
\hline CHEMBL 32592 & 100169 & 4.9208 & 5.2439 & TST & \\
\hline CHEMBL286185 & 100169 & 6.2596 & 5.6769 & TRN & \\
\hline CHEMBL35787 & 100169 & 6.0223 & 6.1329 & TRN & \\
\hline CHEMBL286875 & 100169 & 5.6021 & 5.5061 & TRN & \\
\hline CHEMBL 35255 & 100169 & 3.1938 & 4.006 & TRN & \\
\hline CHEMBL35254 & 100169 & 3.1938 & 4.7309 & TRN & \\
\hline CHEMBL35481 & 100169 & 5.6021 & 5.0521 & TRN & \\
\hline CHEMBL34585 & 100169 & 6.7212 & 5.9077 & TRN & \\
\hline CHEMBL34893 & 100169 & 4.7959 & 5.3401 & TRN & \\
\hline CHEMBL 284685 & 100169 & 4.301 & 6.2221 & TRN & \\
\hline CHEMBL34938 & 100169 & 6.9208 & 7.1776 & TST & \\
\hline CHEMBL33877 & 100169 & 6.301 & 5.8643 & TRN & \\
\hline CHEMBL 32731 & 100169 & 7.1549 & 6.0941 & TST & \\
\hline CHEMBL 34140 & 100169 & 5.8239 & 4.382 & TRN & \\
\hline CHEMBL34636 & 100169 & 6.3979 & 5.0242 & TRN & \\
\hline CHEMBL 33823 & 100169 & 6.301 & 5.4144 & TRN & \\
\hline CHEMBL36057 & 100169 & 4.9586 & 5.1607 & TST & \\
\hline CHEMBL35006 & 100169 & 7.0 & 5.6504 & TRN & \\
\hline CHEMBL35964 & 100169 & 3.1938 & 5.5229 & TRN & \\
\hline CHEMBL11825 & 100169 & 3.3979 & 5.2996 & TST & \\
\hline
\end{tabular}




\begin{tabular}{|c|c|c|c|c|}
\hline & & & oplement & al Ta \\
\hline CHEMBL418604 & 100169 & 7.2218 & 7.0019 & TST \\
\hline CHEMBL35564 & 100169 & 7.301 & 7.475 & TRN \\
\hline CHEMBL35453 & 100169 & 6.2218 & 5.3598 & TRN \\
\hline CHEMBL35049 & 100169 & 5.8239 & 5.3632 & TRN \\
\hline CHEMBL33773 & 100169 & 7.0 & 6.6898 & TRN \\
\hline CHEMBL418417 & 100169 & 5.284 & 7.4193 & TRN \\
\hline CHEMBL35806 & 100169 & 5.8539 & 5.3788 & TRN \\
\hline CHEMBL284111 & 100169 & 7.3979 & 6.5407 & TRN \\
\hline CHEMBL 286639 & 100169 & 7.1249 & 6.5246 & TRN \\
\hline CHEMBL35951 & 100169 & 4.301 & 5.8588 & TST \\
\hline CHEMBL32894 & 100169 & 7.4559 & 6.996 & TRN \\
\hline CHEMBL35508 & 100169 & 7.8239 & 7.3581 & TRN \\
\hline CHEMBL36035 & 100169 & 4.3979 & 4.923 & TRN \\
\hline CHEMBL 290583 & 100169 & 6.1871 & 6.0178 & TST \\
\hline CHEMBL35388 & 100169 & 7.8239 & 7.7075 & TRN \\
\hline CHEMBL36197 & 100169 & 4.1938 & 5.0122 & TRN \\
\hline CHEMBL33960 & 100169 & 6.699 & 6.6494 & TRN \\
\hline CHEMBL34077 & 100169 & 4.5086 & 5.3728 & TST \\
\hline CHEMBL35051 & 100169 & 6.8539 & 7.1368 & TST \\
\hline CHEMBL34896 & 100169 & 8.2218 & 7.6367 & TST \\
\hline CHEMBL34078 & 100169 & 3.699 & 5.2838 & TST \\
\hline CHEMBL35245 & 100169 & 4.301 & 6.4354 & TST \\
\hline CHEMBL1964290 & 809256 & 5.8 & 5.2815 & TRN \\
\hline CHEMBL 2003768 & 809256 & 4.0 & 3.9893 & TRN \\
\hline CHEMBL213505 & 809256 & 4.0 & 4.3637 & TRN \\
\hline CHEMBL1982880 & 809256 & 5.1 & 4.6281 & TRN \\
\hline CHEMBL1987034 & 809256 & 6.9 & 7.3057 & TRN \\
\hline CHEMBL1993941 & 809256 & 4.0 & 4.0533 & TRN \\
\hline CHEMBL1980435 & 809256 & 5.2 & 5.0845 & TRN \\
\hline CHEMBL1989293 & 809256 & 5.8 & 5.2698 & TRN \\
\hline CHEMBL377383 & 809256 & 4.0 & 3.7162 & TRN \\
\hline CHEMBL 2005886 & 809256 & 6.2 & 5.545 & TST \\
\hline CHEMBL481491 & 809256 & 4.0 & 4.1933 & TST \\
\hline CHEMBL1682345 & 809256 & 4.0 & 4.2707 & TRN \\
\hline CHEMBL1973145 & 809256 & 4.0 & 4.0654 & TRN \\
\hline CHEMBL1982924 & 809256 & 5.6 & 4.8963 & TRN \\
\hline CHEMBL 2005936 & 809256 & 4.0 & 4.0202 & TRN \\
\hline CHEMBL1807515 & 809256 & 7.3 & 7.6854 & TRN \\
\hline CHEMBL1971141 & 809256 & 4.0 & 3.8811 & TRN \\
\hline CHEMBL1995813 & 809256 & 8.3 & 7.3106 & TRN \\
\hline CHEMBL1979718 & 809256 & 4.0 & 4.0873 & TRN \\
\hline CHEMBL206236 & 809256 & 4.0 & 3.9244 & TRN \\
\hline CHEMBL 2003500 & 809256 & 4.0 & 3.9583 & TRN \\
\hline CHEMBL1964288 & 809256 & 5.4 & 4.9247 & TRN \\
\hline CHEMBL523823 & 809256 & 4.0 & 4.3281 & TST \\
\hline CHEMBL1562756 & 809256 & 4.0 & 4.2156 & TST \\
\hline CHEMBL 244378 & 809256 & 6.6 & 6.9892 & TRN \\
\hline CHEMBL2001957 & 809256 & 4.0 & 4.029 & TRN \\
\hline
\end{tabular}




\begin{tabular}{|c|c|c|c|c|c|}
\hline \multirow[b]{2}{*}{ CHEMBL1969372 } & \multirow{2}{*}{809256} & \\
\hline & & 4.0 & 4.1957 & TRN & \\
\hline CHEMBL1990583 & 809256 & 6.5 & 4.4239 & TRN & \\
\hline CHEMBL1986943 & 809256 & 7.4 & 7.2716 & TRN & \\
\hline CHEMBL1988662 & 809256 & 6.8 & 5.2596 & TRN & \\
\hline CHEMBL1993584 & 809256 & 4.0 & 4.3587 & TRN & \\
\hline CHEMBL1986263 & 809256 & 6.0 & 5.7202 & TRN & \\
\hline CHEMBL 2000114 & 809256 & 5.7 & 5.4145 & TRN & \\
\hline CHEMBL210618 & 809256 & 4.0 & 3.8162 & TRN & \\
\hline CHEMBL1975647 & 809256 & 4.0 & 4.2643 & TRN & \\
\hline CHEMBL1968380 & 809256 & 5.6 & 4.1617 & TRN & \\
\hline CHEMBL1997643 & 809256 & 4.0 & 4.8675 & TRN & \\
\hline CHEMBL1964644 & 809256 & 4.0 & 3.7105 & TRN & \\
\hline CHEMBL1981782 & 809256 & 4.0 & 4.0972 & TRN & \\
\hline CHEMBL1977681 & 809256 & 5.3 & 4.4163 & TRN & \\
\hline CHEMBL1970142 & 809256 & 4.0 & 3.8882 & TRN & \\
\hline CHEMBL1990912 & 809256 & 4.0 & 4.6372 & TRN & \\
\hline CHEMBL1988163 & 809256 & 7.3 & 7.16700 & 0000000001 & TRN \\
\hline CHEMBL1995592 & 809256 & 5.8 & 4.742 & TRN & \\
\hline CHEMBL 2006493 & 809256 & 4.0 & 4.1252 & TST & \\
\hline CHEMBL1996923 & 809256 & 4.0 & 4.3957 & TST & \\
\hline CHEMBL1983449 & 809256 & 4.0 & 3.6483 & TRN & \\
\hline CHEMBL1992323 & 809256 & 4.0 & 4.3208 & TST & \\
\hline CHEMBL1969735 & 809256 & 4.0 & 3.9825 & TRN & \\
\hline CHEMBL 2003524 & 809256 & 4.0 & 4.7893 & TST & \\
\hline CHEMBL 2002649 & 809256 & 5.7 & 6.07 & TRN & \\
\hline CHEMBL437747 & 809256 & 5.6 & 4.8524 & TRN & \\
\hline CHEMBL1995172 & 809256 & 4.0 & 4.3368 & TST & \\
\hline CHEMBL507936 & 809256 & 4.0 & 3.7806 & TRN & \\
\hline CHEMBL104264 & 809256 & 4.0 & 5.2784 & TST & \\
\hline CHEMBL1994321 & 809256 & 4.0 & 3.843 & TRN & \\
\hline CHEMBL1997129 & 809256 & 6.3 & 5.6285 & TRN & \\
\hline CHEMBL1984788 & 809256 & 4.0 & 4.099 & TRN & \\
\hline CHEMBL451964 & 809256 & 4.0 & 4.1705 & TRN & \\
\hline CHEMBL1996604 & 809256 & 4.0 & 4.6316 & TRN & \\
\hline CHEMBL1964307 & 809256 & 4.0 & 5.125 & TRN & \\
\hline CHEMBL 2000508 & 809256 & 4.0 & 3.9175 & TRN & \\
\hline CHEMBL1971694 & 809256 & 4.0 & 4.2448 & TST & \\
\hline CHEMBL 2001547 & 809256 & 4.0 & 4.1896 & TRN & \\
\hline CHEMBL 210928 & 809256 & 4.0 & 3.7318 & TRN & \\
\hline CHEMBL1994361 & 809256 & 4.0 & 4.1974 & TRN & \\
\hline CHEMBL1986603 & 809256 & 4.0 & 3.8951 & TST & \\
\hline CHEMBL1972840 & 809256 & 5.3 & 4.8655 & TRN & \\
\hline CHEMBL1977148 & 809256 & 4.0 & 3.8903 & TRN & \\
\hline CHEMBL 2004443 & 809256 & 4.0 & 4.7381 & TRN & \\
\hline CHEMBL 2003286 & 809256 & 4.0 & 4.1652 & TRN & \\
\hline CHEMBL1992306 & 809256 & 4.0 & 4.1736 & TRN & \\
\hline CHEMBL 2002165 & 809256 & 4.0 & 4.2206 & TRN & \\
\hline CHEMBL 2001668 & 809256 & 5.1 & 4.83899 & 99999999995 & TRN \\
\hline & & & & 16763 & \\
\hline
\end{tabular}




\begin{tabular}{|c|c|c|c|c|c|}
\hline \multicolumn{6}{|c|}{ Supplemental Table S2.txt } \\
\hline CHEMBL1979318 & 809256 & 4.0 & 4.5344 & TST & \\
\hline CHEMBL206382 & 809256 & 4.0 & 4.1886 & TRN & \\
\hline CHEMBL1998585 & 809256 & 4.0 & 4.8577 & TRN & \\
\hline CHEMBL127898 & 809256 & 4.0 & 3.7553 & TST & \\
\hline CHEMBL519697 & 809256 & 5.4 & 4.4996 & TST & \\
\hline CHEMBL 2004934 & 809256 & 4.0 & 4.1251 & TRN & \\
\hline CHEMBL1981947 & 809256 & 4.0 & 4.0189 & TST & \\
\hline CHEMBL1968459 & 809256 & 6.0 & 6.3711 & TRN & \\
\hline CHEMBL1975128 & 809256 & 5.5 & 4.72199 & 99999999995 & TRN \\
\hline CHEMBL1996048 & 809256 & 6.5 & 5.1849 & TST & \\
\hline CHEMBL1970369 & 809256 & 4.0 & 3.8679 & TRN & \\
\hline CHEMBL461876 & 809256 & 5.0 & 5.5506 & TST & \\
\hline CHEMBL 2001485 & 809256 & 4.0 & 3.9276 & TRN & \\
\hline CHEMBL504950 & 809256 & 5.3 & 5.3351 & TRN & \\
\hline CHEMBL1966425 & 809256 & 5.9 & 5.4187 & TRN & \\
\hline CHEMBL1984363 & 809256 & 4.0 & 4.8933 & TRN & \\
\hline CHEMBL1978099 & 809256 & 5.6 & 6.0831 & TRN & \\
\hline CHEMBL1977041 & 809256 & 6.6 & 4.7507 & TRN & \\
\hline CHEMBL1968070 & 809256 & 4.0 & 4.9048 & TRN & \\
\hline CHEMBL184847 & 809256 & 4.0 & 4.334 & TRN & \\
\hline CHEMBL1984367 & 809256 & 4.0 & 4.0188 & TRN & \\
\hline CHEMBL178737 & 809256 & 4.0 & 5.0334 & TST & \\
\hline CHEMBL226898 & 809256 & 6.4 & 6.1812 & TRN & \\
\hline CHEMBL1982563 & 809256 & 4.0 & 3.9126 & TRN & \\
\hline CHEMBL539474 & 809256 & 4.0 & 4.7662 & TST & \\
\hline CHEMBL575824 & 809256 & 5.8 & 5.0304 & TRN & \\
\hline CHEMBL1988387 & 809256 & 4.0 & 4.4484 & TRN & \\
\hline CHEMBL1997759 & 809256 & 4.0 & 4.2021 & TRN & \\
\hline CHEMBL1990288 & 809256 & 4.0 & 4.0354 & TRN & \\
\hline CHEMBL1989708 & 809256 & 4.0 & 4.2211 & TRN & \\
\hline CHEMBL1974803 & 809256 & 4.0 & 4.9623 & TST & \\
\hline CHEMBL1970074 & 809256 & 4.0 & 4.6768 & TRN & \\
\hline CHEMBL1986970 & 809256 & 4.0 & 3.8805 & TRN & \\
\hline CHEMBL 2002456 & 809256 & 6.6 & 5.5335 & TRN & \\
\hline CHEMBL 2005112 & 809256 & 4.0 & 4.1857 & TST & \\
\hline CHEMBL1958401 & 809256 & 5.7 & 5.135 & TRN & \\
\hline CHEMBL1984044 & 809256 & 5.4 & 4.0961 & TRN & \\
\hline CHEMBL1966816 & 809256 & 4.0 & 4.8367 & TRN & \\
\hline CHEMBL1972584 & 809256 & 4.0 & 4.3102 & TRN & \\
\hline CHEMBL 2002992 & 809256 & 5.6 & 5.0888 & TRN & \\
\hline CHEMBL560813 & 809256 & 4.0 & 4.2488 & TRN & \\
\hline CHEMBL207253 & 809256 & 4.0 & 4.0061 & TRN & \\
\hline CHEMBL1890036 & 809256 & 4.0 & 3.9046 & TST & \\
\hline CHEMBL1990635 & 809256 & 5.1 & 4.4957 & TST & \\
\hline CHEMBL1968791 & 809256 & 5.4 & 4.3776 & TRN & \\
\hline CHEMBL326282 & 809256 & 4.0 & 4.3626 & TST & \\
\hline CHEMBL 2002682 & 809256 & 4.0 & 4.5292 & TST & \\
\hline CHEMBL1992732 & 809256 & 4.0 & 3.5972 & TST & \\
\hline
\end{tabular}




\begin{tabular}{|c|c|c|c|c|}
\hline & & & oplem & \\
\hline CHEMBL1971186 & 809256 & 4.0 & 3.9778 & TRN \\
\hline CHEMBL 2003482 & 809256 & 4.0 & 3.7846 & TRN \\
\hline CHEMBL1973211 & 809256 & 4.0 & 4.1145 & TRN \\
\hline CHEMBL1984700 & 809256 & 4.0 & 3.897 & TRN \\
\hline CHEMBL 2007151 & 809256 & 4.0 & 4.4235 & TRN \\
\hline CHEMBL1987899 & 809256 & 5.0 & 4.2845 & TRN \\
\hline CHEMBL1964340 & 809256 & 5.4 & 6.0925 & TRN \\
\hline CHEMBL1972125 & 809256 & 4.0 & 4.167 & TRN \\
\hline CHEMBL1461728 & 809256 & 4.0 & 4.0624 & TRN \\
\hline CHEMBL1995448 & 809256 & 4.0 & 4.8447 & TRN \\
\hline CHEMBL1999279 & 809256 & 7.8 & 7.0168 & TRN \\
\hline CHEMBL1972158 & 809256 & 4.0 & 4.4601 & TRN \\
\hline CHEMBL1974457 & 809256 & 4.0 & 4.0262 & TRN \\
\hline CHEMBL1967662 & 809256 & 5.8 & 6.1346 & TRN \\
\hline CHEMBL 2006580 & 809256 & 4.0 & 4.6203 & TRN \\
\hline CHEMBL 2006581 & 809256 & 4.0 & 3.9836 & TRN \\
\hline CHEMBL 2006481 & 809256 & 4.0 & 3.9164 & TRN \\
\hline CHEMBL1979855 & 809256 & 4.0 & 4.043 & TST \\
\hline CHEMBL 2005186 & 809256 & 4.0 & 4.2317 & TRN \\
\hline CHEMBL1995927 & 809256 & 4.0 & 4.0313 & TST \\
\hline CHEMBL1975534 & 809256 & 6.0 & 5.0358 & TST \\
\hline CHEMBL1993424 & 809256 & 5.9 & 6.3665 & TRN \\
\hline CHEMBL243518 & 809256 & 5.4 & 6.1487 & TRN \\
\hline CHEMBL1969561 & 809256 & 4.0 & 4.0406 & TRN \\
\hline CHEMBL1975121 & 809256 & 4.0 & 4.0399 & TRN \\
\hline CHEMBL1997554 & 809256 & 7.4 & 6.5769 & TRN \\
\hline CHEMBL1997023 & 809256 & 4.0 & 3.9495 & TST \\
\hline CHEMBL1964687 & 809256 & 4.0 & 4.4387 & TRN \\
\hline CHEMBL1971943 & 809256 & 6.7 & 6.1604 & TRN \\
\hline CHEMBL1999918 & 809256 & 5.4 & 4.9859 & TRN \\
\hline CHEMBL1974254 & 809256 & 5.0 & 3.842 & TRN \\
\hline CHEMBL1969049 & 809256 & 4.0 & 3.8785 & TRN \\
\hline CHEMBL 2005828 & 809256 & 5.6 & 4.9672 & TRN \\
\hline CHEMBL 2002240 & 809256 & 4.0 & 3.7079 & TRN \\
\hline CHEMBL1991143 & 809256 & 4.0 & 3.6952 & TRN \\
\hline CHEMBL485556 & 809256 & 6.4 & 4.5837 & TST \\
\hline CHEMBL255822 & 809256 & 4.0 & 4.5085 & TRN \\
\hline CHEMBL1972221 & 809256 & 4.0 & 3.9809 & TRN \\
\hline CHEMBL 2006778 & 809256 & 4.0 & 4.6859 & TRN \\
\hline CHEMBL1981511 & 809256 & 5.7 & 5.1504 & TRN \\
\hline CHEMBL378627 & 809256 & 4.0 & 3.6238 & TRN \\
\hline CHEMBL1996979 & 809256 & 5.9 & 5.0332 & TRN \\
\hline CHEMBL1997025 & 809256 & 5.0 & 3.9687 & TRN \\
\hline CHEMBL1968406 & 809256 & 4.0 & 4.2343 & TRN \\
\hline CHEMBL1982476 & 809256 & 4.0 & 4.6796 & TRN \\
\hline CHEMBL1984274 & 809256 & 4.0 & 5.1018 & TST \\
\hline CHEMBL1998545 & 809256 & 4.0 & 3.9715 & TRN \\
\hline CHEMBL1986869 & 809256 & 4.0 & 3.7925 & TST \\
\hline
\end{tabular}




\begin{tabular}{|c|c|c|c|c|}
\hline & & & pplement & al $\mathrm{Ta}$ \\
\hline CHEMBL 2006010 & 809256 & 4.0 & 3.9266 & TRN \\
\hline CHEMBL1990496 & 809256 & 4.0 & 4.2188 & TST \\
\hline CHEMBL1975937 & 809256 & 5.4 & 4.8245 & TRN \\
\hline CHEMBL1998068 & 809256 & 6.1 & 6.0828 & TRN \\
\hline CHEMBL1997623 & 809256 & 4.0 & 4.2904 & TRN \\
\hline CHEMBL2002479 & 809256 & 5.2 & 5.1348 & TRN \\
\hline CHEMBL1993166 & 809256 & 5.7 & 5.3651 & TRN \\
\hline CHEMBL1966035 & 809256 & 4.0 & 4.0168 & TRN \\
\hline CHEMBL 2003341 & 809256 & 4.0 & 3.6992 & TRN \\
\hline CHEMBL1992645 & 809256 & 4.0 & 4.1884 & TST \\
\hline CHEMBL1990708 & 809256 & 4.0 & 4.5234 & TRN \\
\hline CHEMBL1982992 & 809256 & 5.3 & 4.7021 & TRN \\
\hline CHEMBL1974363 & 809256 & 5.6 & 4.1793 & TRN \\
\hline CHEMBL1981079 & 809256 & 6.1 & 5.4801 & TRN \\
\hline CHEMBL1972276 & 809256 & 4.0 & 4.3232 & TRN \\
\hline CHEMBL1980489 & 809256 & 4.0 & 3.9393 & TRN \\
\hline CHEMBL 2000832 & 809256 & 6.7 & 5.2349 & TRN \\
\hline CHEMBL1967116 & 809256 & 4.0 & 4.1308 & TRN \\
\hline CHEMBL1977814 & 809256 & 4.0 & 4.3031 & TRN \\
\hline CHEMBL513846 & 809256 & 5.5 & 4.3645 & TRN \\
\hline CHEMBL1965660 & 809256 & 6.2 & 5.6093 & TRN \\
\hline CHEMBL1985309 & 809256 & 4.0 & 4.2462 & TRN \\
\hline CHEMBL1998112 & 809256 & 4.0 & 4.4778 & TRN \\
\hline CHEMBL1969126 & 809256 & 4.0 & 3.5063 & TRN \\
\hline CHEMBL1980896 & 809256 & 4.0 & 4.2387 & TRN \\
\hline CHEMBL1975208 & 809256 & 4.0 & 4.0682 & TST \\
\hline CHEMBL1970104 & 809256 & 6.0 & 5.9786 & TRN \\
\hline CHEMBL1991429 & 809256 & 4.0 & 3.471 & TRN \\
\hline CHEMBL1964777 & 809256 & 4.0 & 4.802 & TRN \\
\hline CHEMBL1971149 & 809256 & 4.0 & 4.0463 & TRN \\
\hline CHEMBL1999714 & 809256 & 4.0 & 4.4622 & TRN \\
\hline CHEMBL1987533 & 809256 & 4.0 & 4.3284 & TRN \\
\hline CHEMBL1994040 & 809256 & 4.0 & 4.0407 & TRN \\
\hline CHEMBL 388978 & 809256 & 8.0 & 6.2458 & TST \\
\hline CHEMBL579246 & 809256 & 5.8 & 4.8778 & TRN \\
\hline CHEMBL398951 & 809256 & 4.0 & 4.9155 & TST \\
\hline CHEMBL1982506 & 809256 & 4.0 & 4.6383 & TST \\
\hline CHEMBL 2004716 & 809256 & 5.1 & 4.5356 & TRN \\
\hline CHEMBL1968127 & 809256 & 4.0 & 4.1395 & TRN \\
\hline CHEMBL1975233 & 809256 & 4.0 & 4.5769 & TRN \\
\hline CHEMBL1985406 & 809256 & 4.0 & 4.1514 & TRN \\
\hline CHEMBL 207400 & 809256 & 4.0 & 3.8739 & TRN \\
\hline CHEMBL 2000894 & 809256 & 4.0 & 4.6744 & TRN \\
\hline CHEMBL 2002553 & 809256 & 4.0 & 4.397 & TST \\
\hline CHEMBL1982135 & 809256 & 4.0 & 4.0572 & TRN \\
\hline CHEMBL1976090 & 809256 & 5.7 & 5.7526 & TRN \\
\hline CHEMBL 2004771 & 809256 & 5.4 & 4.7022 & TRN \\
\hline CHEMBL1992922 & 809256 & 6.8 & 6.3052 & TRN \\
\hline
\end{tabular}




\begin{tabular}{|c|c|c|c|c|}
\hline & & & Supplement & \\
\hline CHEMBL399021 & 809256 & 4.0 & 4.3871 & TRN \\
\hline CHEMBL1997597 & 809256 & 4.0 & 4.5441 & TRN \\
\hline CHEMBL1976093 & 809256 & 4.0 & 4.3947 & TRN \\
\hline CHEMBL 210032 & 809256 & 4.0 & 4.0329 & TRN \\
\hline CHEMBL1996543 & 809256 & 4.0 & 4.3157 & TRN \\
\hline CHEMBL1975256 & 809256 & 4.0 & 3.4344 & TST \\
\hline CHEMBL508928 & 809256 & 5.2 & 4.4102 & TRN \\
\hline CHEMBL1991356 & 809256 & 4.0 & 4.753 & TST \\
\hline CHEMBL1983309 & 809256 & 4.0 & 4.0284 & TRN \\
\hline CHEMBL1999126 & 809256 & 4.0 & 4.1229 & TST \\
\hline CHEMBL1997503 & 809256 & 4.0 & 3.7739 & TST \\
\hline CHEMBL116070 & 809256 & 4.0 & 4.5193 & TRN \\
\hline CHEMBL1990821 & 809256 & 4.0 & 4.371 & TST \\
\hline CHEMBL1970314 & 809256 & 6.3 & 4.3995 & TRN \\
\hline CHEMBL 2004871 & 809256 & 4.0 & 4.0119 & TRN \\
\hline CHEMBL 2004872 & 809256 & 4.0 & 3.9296 & TRN \\
\hline CHEMBL1727312 & 809256 & 4.0 & 4.6123 & TRN \\
\hline CHEMBL1969879 & 809256 & 4.0 & 4.2367 & TST \\
\hline CHEMBL1995932 & 809256 & 6.3 & 6.3787 & TRN \\
\hline CHEMBL1981720 & 809256 & 5.4 & 4.751 & TRN \\
\hline CHEMBL1967704 & 809256 & 5.4 & 5.0733 & TRN \\
\hline CHEMBL419932 & 809256 & 4.0 & 4.477 & TRN \\
\hline CHEMBL262433 & 809256 & 4.0 & 3.9651 & TRN \\
\hline CHEMBL 306380 & 809256 & 5.0 & 5.0976 & TRN \\
\hline CHEMBL1966722 & 809256 & 4.0 & 4.4139 & TST \\
\hline CHEMBL1975500 & 809256 & 6.4 & 5.329 & TRN \\
\hline CHEMBL1976328 & 809256 & 4.0 & 4.1151 & TRN \\
\hline CHEMBL394619 & 809256 & 5.6 & 4.337 & TRN \\
\hline CHEMBL1964399 & 809256 & 4.0 & 5.1318 & TRN \\
\hline CHEMBL1996831 & 809256 & 4.0 & 4.2205 & TST \\
\hline CHEMBL411903 & 809256 & 5.2 & 4.8738 & TRN \\
\hline CHEMBL1965988 & 809256 & 4.0 & 4.213 & TRN \\
\hline CHEMBL1969221 & 809256 & 4.0 & 4.3522 & TRN \\
\hline CHEMBL418203 & 809256 & 5.3 & 4.7832 & TST \\
\hline CHEMBL1989646 & 809256 & 4.0 & 4.4761 & TRN \\
\hline CHEMBL1682357 & 809256 & 4.0 & 4.1855 & TRN \\
\hline CHEMBL 225519 & 809256 & 5.1 & 5.0305 & TRN \\
\hline CHEMBL209534 & 809256 & 4.0 & 3.8485 & TRN \\
\hline CHEMBL1978200 & 809256 & 4.0 & 4.1857 & TRN \\
\hline CHEMBL 2006631 & 809256 & 5.1 & 4.5688 & TRN \\
\hline CHEMBL1970522 & 809256 & 5.3 & 4.6224 & TRN \\
\hline CHEMBL402846 & 809256 & 4.1 & 3.9075 & TRN \\
\hline CHEMBL1966087 & 809256 & 4.0 & 4.296 & TRN \\
\hline CHEMBL1986767 & 809256 & 4.0 & 4.725 & TRN \\
\hline CHEMBL1964692 & 809256 & 4.0 & 4.2844 & TRN \\
\hline CHEMBL1996931 & 809256 & 4.0 & 3.8746 & TRN \\
\hline CHEMBL1964413 & 809256 & 4.0 & 3.6305 & TRN \\
\hline CHEMBL1973483 & 809256 & 4.0 & 4.082 & TRN \\
\hline
\end{tabular}




\begin{tabular}{|c|c|c|c|c|c|}
\hline \multirow[b]{2}{*}{ CHEMBL1984432 } & \multirow[b]{2}{*}{809256} & \\
\hline & & 4.0 & 3.8736 & TRN & \\
\hline CHEMBL1970735 & 809256 & 4.0 & 3.6931 & TRN & \\
\hline CHEMBL219722 & 809256 & 5.9 & 5.2472 & TRN & \\
\hline CHEMBL1969920 & 809256 & 6.7 & 6.1 & TRN & \\
\hline CHEMBL1997340 & 809256 & 4.0 & 3.8185 & TRN & \\
\hline CHEMBL 2004365 & 809256 & 4.0 & 3.8661 & TST & \\
\hline CHEMBL1522508 & 809256 & 4.0 & 4.6256 & TRN & \\
\hline CHEMBL1989474 & 809256 & 4.0 & 4.0786 & TRN & \\
\hline CHEMBL1090360 & 809256 & 4.0 & 3.8662 & TRN & \\
\hline CHEMBL226232 & 809256 & 5.2 & 4.9393 & TRN & \\
\hline CHEMBL 210887 & 809256 & 7.1 & 4.4804 & TST & \\
\hline CHEMBL458997 & 809256 & 6.7 & 6.4654 & TRN & \\
\hline CHEMBL1971021 & 809256 & 4.0 & 4.1241 & TRN & \\
\hline CHEMBL227271 & 809256 & 6.1 & 5.8961 & TRN & \\
\hline CHEMBL583144 & 809256 & 4.0 & 4.8035 & TST & \\
\hline CHEMBL1974310 & 809256 & 5.3 & 5.0165 & TRN & \\
\hline CHEMBL1982660 & 809256 & 5.3 & 4.758 & TRN & \\
\hline CHEMBL1994693 & 809256 & 4.0 & 4.2518 & TRN & \\
\hline CHEMBL1725279 & 809256 & 6.8 & 5.9135 & TST & \\
\hline CHEMBL2002346 & 809256 & 6.2 & 6.6665 & TRN & \\
\hline CHEMBL1975138 & 809256 & 4.0 & 4.3218 & TST & \\
\hline CHEMBL424872 & 809256 & 4.0 & 3.62100 & 00000000004 & TRN \\
\hline CHEMBL2006836 & 809256 & 4.1 & 3.8174 & TST & \\
\hline CHEMBL1971947 & 809256 & 4.0 & 4.1797 & TRN & \\
\hline CHEMBL412142 & 809256 & 4.0 & 4.2089 & TST & \\
\hline CHEMBL1985153 & 809256 & 4.0 & 5.0772 & TRN & \\
\hline CHEMBL 2003271 & 809256 & 5.2 & 5.20700 & 0000000001 & TST \\
\hline CHEMBL1966808 & 809256 & 4.0 & 3.5815 & TST & \\
\hline CHEMBL 2004447 & 809256 & 4.0 & 4.1702 & TST & \\
\hline CHEMBL1983111 & 809256 & 6.8 & 6.86600 & 00000000005 & TRN \\
\hline CHEMBL1977713 & 809256 & 4.0 & 4.0421 & TRN & \\
\hline CHEMBL260135 & 809256 & 4.0 & 4.7898 & TRN & \\
\hline CHEMBL220241 & 809256 & 4.0 & 4.414 & TST & \\
\hline CHEMBL 2004544 & 809256 & 4.0 & 4.4289 & TST & \\
\hline CHEMBL1983157 & 809256 & 7.1 & 5.4433 & TRN & \\
\hline CHEMBL1966040 & 809256 & 5.1 & 5.9999 & TRN & \\
\hline CHEMBL1999496 & 809256 & 4.0 & 3.8092 & TRN & \\
\hline CHEMBL2006933 & 809256 & 4.0 & 4.8332 & TST & \\
\hline CHEMBL1991078 & 809256 & 5.6 & 5.6985 & TRN & \\
\hline CHEMBL1987359 & 809256 & 4.0 & 4.2106 & TST & \\
\hline CHEMBL2000685 & 809256 & 6.4 & 5.92200 & 2000000001 & TRN \\
\hline CHEMBL1985311 & 809256 & 6.0 & 4.9275 & TRN & \\
\hline CHEMBL1989265 & 809256 & 4.0 & 3.6678 & TST & \\
\hline CHEMBL 2004647 & 809256 & 4.0 & 4.2977 & TST & \\
\hline CHEMBL1965910 & 809256 & 4.0 & 4.6339 & TRN & \\
\hline CHEMBL1996447 & 809256 & 6.2 & 5.4102 & TRN & \\
\hline CHEMBL1682553 & 809256 & 4.0 & 4.3808 & TRN & \\
\hline CHEMBL1971430 & 809256 & 4.0 & 4.0284 & TST & \\
\hline & & & & 167 & \\
\hline
\end{tabular}




\begin{tabular}{|c|c|c|c|c|c|}
\hline & & & & & \\
\hline CHEMBL1983963 & 809256 & 5.3 & 4.6605 & TRN & \\
\hline CHEMBL1997764 & 809256 & 5.8 & 4.7217 & TRN & \\
\hline CHEMBL 2000271 & 809256 & 6.1 & 5.6249 & TRN & \\
\hline CHEMBL1985092 & 809256 & 5.1 & 4.7824 & TST & \\
\hline CHEMBL 2004692 & 809256 & 4.0 & 3.5659 & TST & \\
\hline CHEMBL1981410 & 809256 & 4.0 & 4.23300 & 20000000005 & TRN \\
\hline CHEMBL1996234 & 809256 & 4.0 & 3.8163 & TRN & \\
\hline CHEMBL1991434 & 809256 & 4.0 & 4.0632 & TRN & \\
\hline CHEMBL1967544 & 809256 & 4.0 & 4.3978 & TRN & \\
\hline CHEMBL223367 & 809256 & 4.0 & 5.456 & TST & \\
\hline CHEMBL340384 & 809256 & 6.1 & 4.9738 & TRN & \\
\hline CHEMBL1996587 & 809256 & 4.0 & 3.7889 & TRN & \\
\hline CHEMBL443962 & 809256 & 4.0 & 4.4779 & TST & \\
\hline CHEMBL1996282 & 809256 & 4.0 & 4.5482 & TRN & \\
\hline CHEMBL 2000354 & 809256 & 5.3 & 4.7464 & TRN & \\
\hline CHEMBL1965507 & 809256 & 4.0 & 4.8679 & TRN & \\
\hline CHEMBL 274064 & 809256 & 4.0 & 4.4921 & TRN & \\
\hline CHEMBL1967564 & 809256 & 4.0 & 4.2397 & TRN & \\
\hline CHEMBL592030 & 809256 & 5.1 & 6.2959 & TST & \\
\hline CHEMBL 2000071 & 809256 & 6.7 & 6.2464 & TRN & \\
\hline CHEMBL1979176 & 809256 & 4.0 & 4.2021 & TRN & \\
\hline CHEMBL1970317 & 809256 & 4.0 & 4.2129 & TRN & \\
\hline CHEMBL 2000408 & 809256 & 4.0 & 3.9436 & TRN & \\
\hline CHEMBL248757 & 809256 & 4.0 & 5.1377 & TST & \\
\hline CHEMBL1978014 & 809256 & 4.0 & $3.5180 e$ & 00000000002 & TRN \\
\hline CHEMBL1974250 & 809256 & 5.2 & 4.7423 & TRN & \\
\hline CHEMBL1994538 & 809256 & 4.0 & 3.9544 & TRN & \\
\hline CHEMBL1983195 & 809256 & 4.0 & 4.118 & TST & \\
\hline CHEMBL1975490 & 809256 & 5.5 & 5.483 & TRN & \\
\hline CHEMBL1964444 & 809256 & 4.0 & 4.3335 & TRN & \\
\hline CHEMBL1989957 & 809256 & 4.0 & 4.0711 & TRN & \\
\hline CHEMBL 2006567 & 809256 & 4.0 & 3.9017 & TRN & \\
\hline CHEMBL1986139 & 809256 & 4.0 & 4.5698 & TRN & \\
\hline CHEMBL383527 & 809256 & 4.0 & 4.2484 & TRN & \\
\hline CHEMBL1980540 & 809256 & 4.0 & 3.7067 & TRN & \\
\hline CHEMBL 2003229 & 809256 & 6.4 & 5.4318 & TRN & \\
\hline CHEMBL1979883 & 809256 & 4.0 & 4.1108 & TRN & \\
\hline CHEMBL1984162 & 809256 & 5.1 & 4.6453 & TRN & \\
\hline CHEMBL1988331 & 809256 & 4.0 & 6.0631 & TRN & \\
\hline CHEMBL491758 & 809256 & 6.2 & 5.9381 & TRN & \\
\hline CHEMBL549730 & 809256 & 4.0 & 3.7951 & TRN & \\
\hline CHEMBL1998826 & 809256 & 5.5 & 4.8779 & TRN & \\
\hline CHEMBL1682360 & 809256 & 4.0 & 4.4396 & TRN & \\
\hline CHEMBL1970189 & 809256 & 4.0 & 4.5608 & TST & \\
\hline CHEMBL371206 & 809256 & 5.1 & 4.7383 & TRN & \\
\hline CHEMBL1974288 & 809256 & 4.0 & 4.1204 & TRN & \\
\hline CHEMBL 213207 & 809256 & 6.5 & 6.8601 & TRN & \\
\hline CHEMBL196363 & 809256 & 4.0 & 4.5674 & TRN & \\
\hline & & & & 16769 & \\
\hline
\end{tabular}




\begin{tabular}{|c|c|c|c|c|c|}
\hline \multicolumn{6}{|c|}{ Supplemental Table S2.txt } \\
\hline CHEMBL1190711 & 809256 & 4.0 & 4.9853 & TRN & \\
\hline CHEMBL1990346 & 809256 & 4.0 & 5.4231 & TRN & \\
\hline CHEMBL1968705 & 809256 & 4.0 & 4.6521 & TRN & \\
\hline CHEMBL404367 & 809256 & 5.6 & 4.0668 & TRN & \\
\hline CHEMBL1967887 & 809256 & 4.0 & 5.0785 & TRN & \\
\hline CHEMBL 2000568 & 809256 & 5.0 & 4.6875 & TRN & \\
\hline CHEMBL 2000335 & 809256 & 4.0 & 5.1545 & TRN & \\
\hline CHEMBL1977604 & 809256 & 4.0 & 3.5635 & TST & \\
\hline CHEMBL1993648 & 809256 & 5.6 & 5.68 & TRN & \\
\hline CHEMBL1988717 & 809256 & 4.0 & 4.1559 & TRN & \\
\hline CHEMBL1974328 & 809256 & 7.3 & 6.2969 & TRN & \\
\hline CHEMBL573339 & 809256 & 4.0 & 4.5578 & TST & \\
\hline CHEMBL1971951 & 809256 & 5.3 & 4.9078 & TRN & \\
\hline CHEMBL 2000429 & 809256 & 4.0 & 3.7552 & TRN & \\
\hline CHEMBL1972576 & 809256 & 4.0 & 4.6534 & TRN & \\
\hline CHEMBL1992555 & 809256 & 4.0 & 4.0048 & TST & \\
\hline CHEMBL 2003682 & 809256 & 5.7 & 4.9388 & TRN & \\
\hline CHEMBL1164265 & 809256 & 4.0 & 4.6885 & TST & \\
\hline CHEMBL535331 & 809256 & 5.4 & 4.6332 & TST & \\
\hline CHEMBL1982980 & 809256 & 4.0 & 4.6732 & TST & \\
\hline CHEMBL1965423 & 809256 & 4.0 & 3.8777 & TRN & \\
\hline CHEMBL1983025 & 809256 & 4.0 & 4.2093 & TRN & \\
\hline CHEMBL205415 & 809256 & 5.6 & 4.773 & TRN & \\
\hline CHEMBL1999153 & 809256 & 6.7 & 6.9396 & TRN & \\
\hline CHEMBL1969473 & 809256 & 4.0 & 4.6828 & TRN & \\
\hline CHEMBL1977135 & 809256 & 4.0 & 3.5395 & TRN & \\
\hline CHEMBL 2001920 & 809256 & 5.1 & 4.6724 & TST & \\
\hline CHEMBL1985654 & 809256 & 5.6 & 5.9031 & TRN & \\
\hline CHEMBL2002322 & 809256 & 4.0 & 4.34399 & 7999999999 & TRN \\
\hline CHEMBL 2002323 & 809256 & 4.0 & 4.0356 & TST & \\
\hline CHEMBL1241473 & 809256 & 7.5 & 6.7239 & TRN & \\
\hline CHEMBL1978448 & 809256 & 4.0 & 4.9683 & TST & \\
\hline CHEMBL 2004513 & 809256 & 5.4 & 4.3304 & TRN & \\
\hline CHEMBL1972258 & 809256 & 4.0 & 4.1503 & TRN & \\
\hline CHEMBL1983855 & 809256 & 4.0 & 5.1647 & TRN & \\
\hline CHEMBL2001257 & 809256 & 4.0 & 3.7706 & TRN & \\
\hline CHEMBL 2005548 & 809256 & 4.0 & 4.1116 & TRN & \\
\hline CHEMBL1987793 & 809256 & 4.0 & 4.5013 & TST & \\
\hline CHEMBL1992536 & 809256 & 4.0 & 4.0133 & TRN & \\
\hline CHEMBL1992740 & 809256 & 4.0 & 4.147 & TRN & \\
\hline CHEMBL439340 & 809256 & 4.0 & 3.8564 & TRN & \\
\hline CHEMBL 2006188 & 809256 & 4.0 & 3.9595 & TRN & \\
\hline CHEMBL1967531 & 809256 & 5.4 & 5.1988 & TRN & \\
\hline CHEMBL1970913 & 809256 & 4.0 & 4.0391 & TRN & \\
\hline CHEMBL1973893 & 809256 & 4.0 & 4.1446 & TRN & \\
\hline CHEMBL 2004631 & 809256 & 4.0 & 4.5929 & TRN & \\
\hline CHEMBL1997534 & 809256 & 4.0 & 4.1816 & TRN & \\
\hline CHEMBL1996500 & 809256 & 4.0 & 4.2111 & TRN & \\
\hline
\end{tabular}




\begin{tabular}{|c|c|c|c|c|c|}
\hline \multicolumn{6}{|c|}{ oplemental } \\
\hline CHEMBL1985095 & 809256 & 4.0 & 5.4529 & TST & \\
\hline CHEMBL1998551 & 809256 & 4.0 & 3.7793 & TRN & \\
\hline CHEMBL1977374 & 809256 & 4.0 & 3.9075 & TRN & \\
\hline CHEMBL1991180 & 809256 & 4.0 & 4.6692 & TST & \\
\hline CHEMBL1983315 & 809256 & 4.0 & 5.1341 & TRN & \\
\hline CHEMBL1978656 & 809256 & 4.0 & 4.1297 & TRN & \\
\hline CHEMBL1976420 & 809256 & 5.3 & 5.4065 & TST & \\
\hline CHEMBL413779 & 809256 & 4.0 & 5.5363 & TST & \\
\hline CHEMBL1994864 & 809256 & 4.0 & 3.9359 & TRN & \\
\hline CHEMBL2002446 & 809256 & 4.0 & 4.2504 & TST & \\
\hline CHEMBL497151 & 809256 & 4.0 & 4.4069 & TRN & \\
\hline CHEMBL1973961 & 809256 & 4.0 & 4.5136 & TRN & \\
\hline CHEMBL 246970 & 809256 & 4.0 & 5.50299 & 9999999999 & TRN \\
\hline CHEMBL1980497 & 809256 & 5.6 & 4.7175 & TRN & \\
\hline CHEMBL340921 & 809256 & 4.0 & 4.6705 & TRN & \\
\hline CHEMBL373598 & 809256 & 4.0 & 5.4572 & TST & \\
\hline CHEMBL1999718 & 809256 & 4.0 & 3.6772 & TRN & \\
\hline CHEMBL1987073 & 809256 & 4.0 & 5.0874 & TRN & \\
\hline CHEMBL1276446 & 809256 & 5.8 & 6.3847 & TST & \\
\hline CHEMBL1977346 & 809256 & 4.0 & 5.4108 & TRN & \\
\hline CHEMBL1971649 & 809256 & 4.0 & 3.8269 & TRN & \\
\hline CHEMBL 2003657 & 809256 & 4.0 & 3.7882 & TRN & \\
\hline CHEMBL1975440 & 809256 & 7.2 & 6.3149 & TRN & \\
\hline CHEMBL1998435 & 809256 & 4.0 & 3.9044 & TRN & \\
\hline CHEMBL2006439 & 809256 & 6.8 & 6.6189 & TRN & \\
\hline CHEMBL2006156 & 809256 & 4.0 & 4.57100 & 0000000001 & TST \\
\hline CHEMBL1969190 & 809256 & 4.0 & 4.4432 & TRN & \\
\hline CHEMBL1973937 & 809256 & 4.0 & 4.5606 & TRN & \\
\hline CHEMBL1991674 & 809256 & 6.5 & 6.6786 & TRN & \\
\hline CHEMBL1987982 & 809256 & 4.0 & 4.5631 & TST & \\
\hline CHEMBL1984842 & 809256 & 4.0 & 4.1658 & TRN & \\
\hline CHEMBL1969102 & 809256 & 4.0 & 4.4772 & TRN & \\
\hline CHEMBL1682346 & 809256 & 4.0 & 4.9076 & TRN & \\
\hline CHEMBL 2007044 & 809256 & 4.0 & 4.9948 & TST & \\
\hline CHEMBL 2001998 & 809256 & 4.0 & 4.5643 & TST & \\
\hline CHEMBL1994241 & 809256 & 5.3 & 5.5105 & TRN & \\
\hline CHEMBL 223460 & 809256 & 4.0 & 5.3055 & TST & \\
\hline CHEMBL1998829 & 809256 & 4.0 & 4.5892 & TRN & \\
\hline CHEMBL50894 & 809256 & 4.0 & 4.9021 & TRN & \\
\hline CHEMBL1988838 & 809256 & 6.1 & 6.4794 & TRN & \\
\hline CHEMBL1981725 & 809256 & 4.0 & 4.71899 & 9999999999 & TRN \\
\hline CHEMBL375284 & 809256 & 4.0 & 4.3278 & TRN & \\
\hline CHEMBL1982866 & 809256 & 4.0 & 3.9238 & TRN & \\
\hline CHEMBL 2004156 & 809256 & 4.0 & 4.7219 & TRN & \\
\hline CHEMBL2005792 & 809256 & 4.0 & 4.135 & TRN & \\
\hline CHEMBL1968926 & 809256 & 4.0 & 4.2216 & TRN & \\
\hline CHEMBL1984206 & 809256 & 4.0 & 3.6057 & TRN & \\
\hline CHEMBL462120 & 809256 & 4.0 & 4.5916 & TST & \\
\hline
\end{tabular}




\begin{tabular}{|c|c|c|c|c|}
\hline & & & & al Table S2 \\
\hline CHEMBL1991577 & 809256 & 4.0 & 3.9665 & TRN \\
\hline CHEMBL1965570 & 809256 & 4.0 & 4.6285 & TRN \\
\hline CHEMBL 2007592 & 809256 & 4.0 & 3.9492 & TST \\
\hline CHEMBL 210963 & 809256 & 4.0 & 3.5369 & TRN \\
\hline CHEMBL 2005387 & 809256 & 5.6 & 6.0675 & TRN \\
\hline CHEMBL1082440 & 809256 & 4.0 & 5.0349 & TST \\
\hline CHEMBL1614705 & 809256 & 4.0 & 4.1748 & TRN \\
\hline CHEMBL1972362 & 809256 & 4.0 & 4.6175 & TRN \\
\hline CHEMBL1982400 & 809256 & 6.2 & 4.8729 & TRN \\
\hline CHEMBL1984633 & 809256 & 4.0 & 3.8965 & TRN \\
\hline CHEMBL1965845 & 809256 & 6.1 & 5.6549 & TRN \\
\hline CHEMBL 2007372 & 809256 & 4.0 & 4.1472 & TRN \\
\hline CHEMBL1982167 & 809256 & 4.0 & 4.215 & TRN \\
\hline CHEMBL 2006715 & 809256 & 4.0 & 3.5716 & TRN \\
\hline CHEMBL1986597 & 809256 & 4.0 & 4.3981 & TRN \\
\hline CHEMBL1971017 & 809256 & 5.6 & 4.8961 & TRN \\
\hline CHEMBL1990482 & 809256 & 4.0 & 4.6401 & TRN \\
\hline CHEMBL1990904 & 809256 & 4.0 & 4.0032 & TRN \\
\hline CHEMBL 2005475 & 809256 & 4.0 & 4.0247 & TRN \\
\hline CHEMBL 2000104 & 809256 & 4.0 & 4.3691 & TRN \\
\hline CHEMBL1997349 & 809256 & 4.0 & 4.2755 & TST \\
\hline CHEMBL183844 & 809256 & 4.0 & 3.9612 & TRN \\
\hline CHEMBL220057 & 809256 & 6.1 & 5.0 & TRN \\
\hline CHEMBL1682545 & 809256 & 4.0 & 4.2418 & TRN \\
\hline CHEMBL383541 & 809256 & 5.0 & 4.4999 & TRN \\
\hline CHEMBL 2001224 & 809256 & 4.0 & 4.5822 & TRN \\
\hline CHEMBL10 & 809256 & 4.0 & 4.5314 & TRN \\
\hline CHEMBL1982982 & 809256 & 4.0 & 4.0272 & TRN \\
\hline CHEMBL1976732 & 809256 & 4.0 & 3.6545 & TRN \\
\hline CHEMBL1964937 & 809256 & 5.6 & 5.6596 & TRN \\
\hline CHEMBL1980163 & 809256 & 4.0 & 4.4707 & TRN \\
\hline CHEMBL590109 & 809256 & 4.0 & 6.2177 & TST \\
\hline CHEMBL1970879 & 809256 & 4.0 & 4.1992 & TRN \\
\hline CHEMBL1989856 & 809256 & 5.4 & 4.08899 & 99999999995 \\
\hline CHEMBL 2005899 & 809256 & 4.0 & 3.8416 & TRN \\
\hline CHEMBL1682552 & 809256 & 4.0 & 4.4636 & TRN \\
\hline CHEMBL 259850 & 809256 & 4.0 & 3.6665 & TRN \\
\hline CHEMBL1972568 & 809256 & 4.0 & 4.2277 & TRN \\
\hline CHEMBL1996155 & 809256 & 5.5 & 4.042 & TST \\
\hline CHEMBL1987745 & 809256 & 6.0 & 5.255 & TRN \\
\hline CHEMBL229799 & 809256 & 6.8 & 6.1932 & TRN \\
\hline CHEMBL105739 & 809256 & 6.0 & 5.7474 & TRN \\
\hline CHEMBL1682359 & 809256 & 4.0 & 4.2447 & TRN \\
\hline CHEMBL 379300 & 809256 & 6.1 & 5.9563 & TRN \\
\hline CHEMBL 203673 & 809256 & 4.0 & 3.9608 & TRN \\
\hline CHEMBL1969523 & 809256 & 4.0 & 5.023 & TRN \\
\hline CHEMBL207995 & 809256 & 4.0 & 4.7141 & TRN \\
\hline CHEMBL1988995 & 809256 & 4.0 & 3.8402 & TRN \\
\hline
\end{tabular}




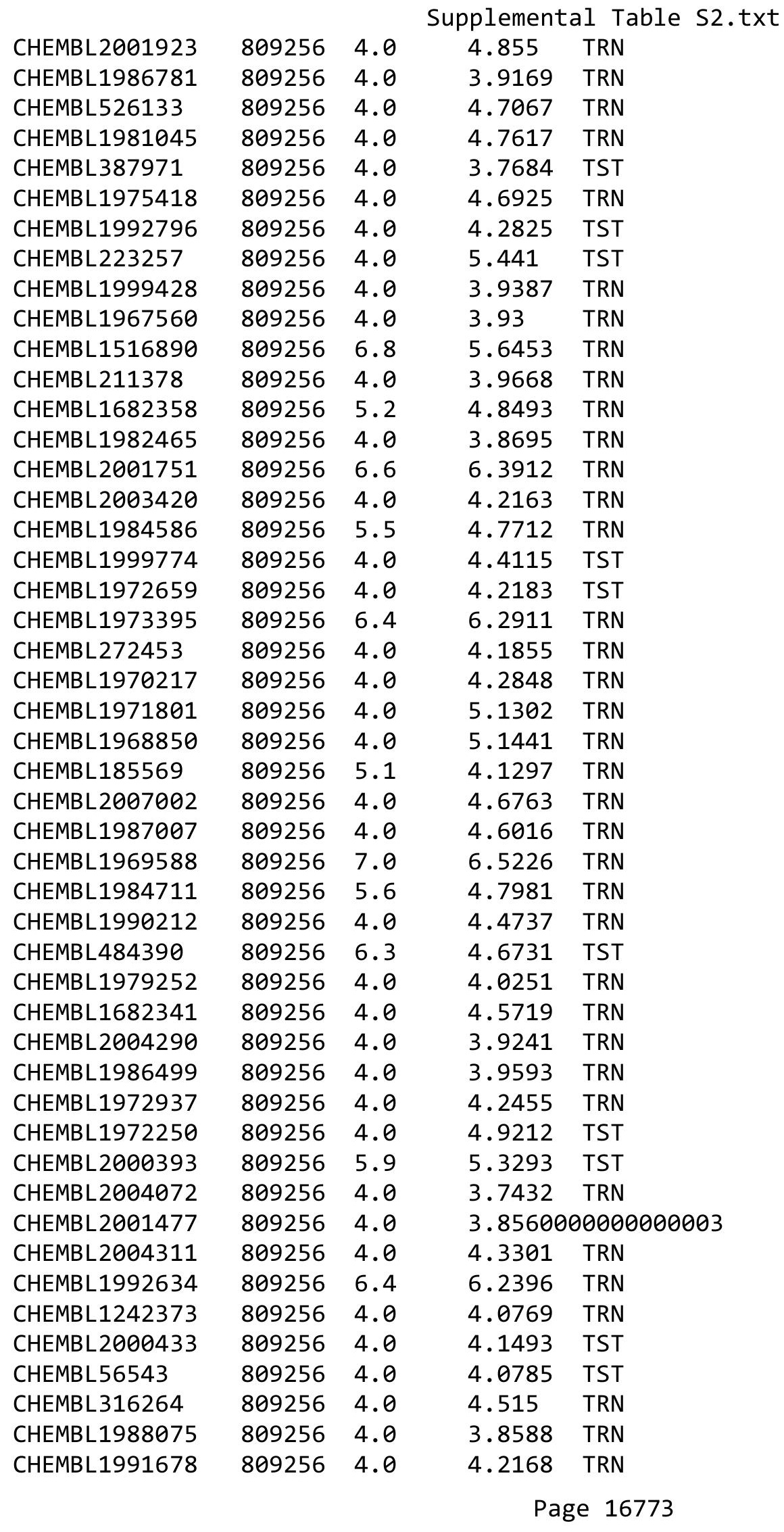




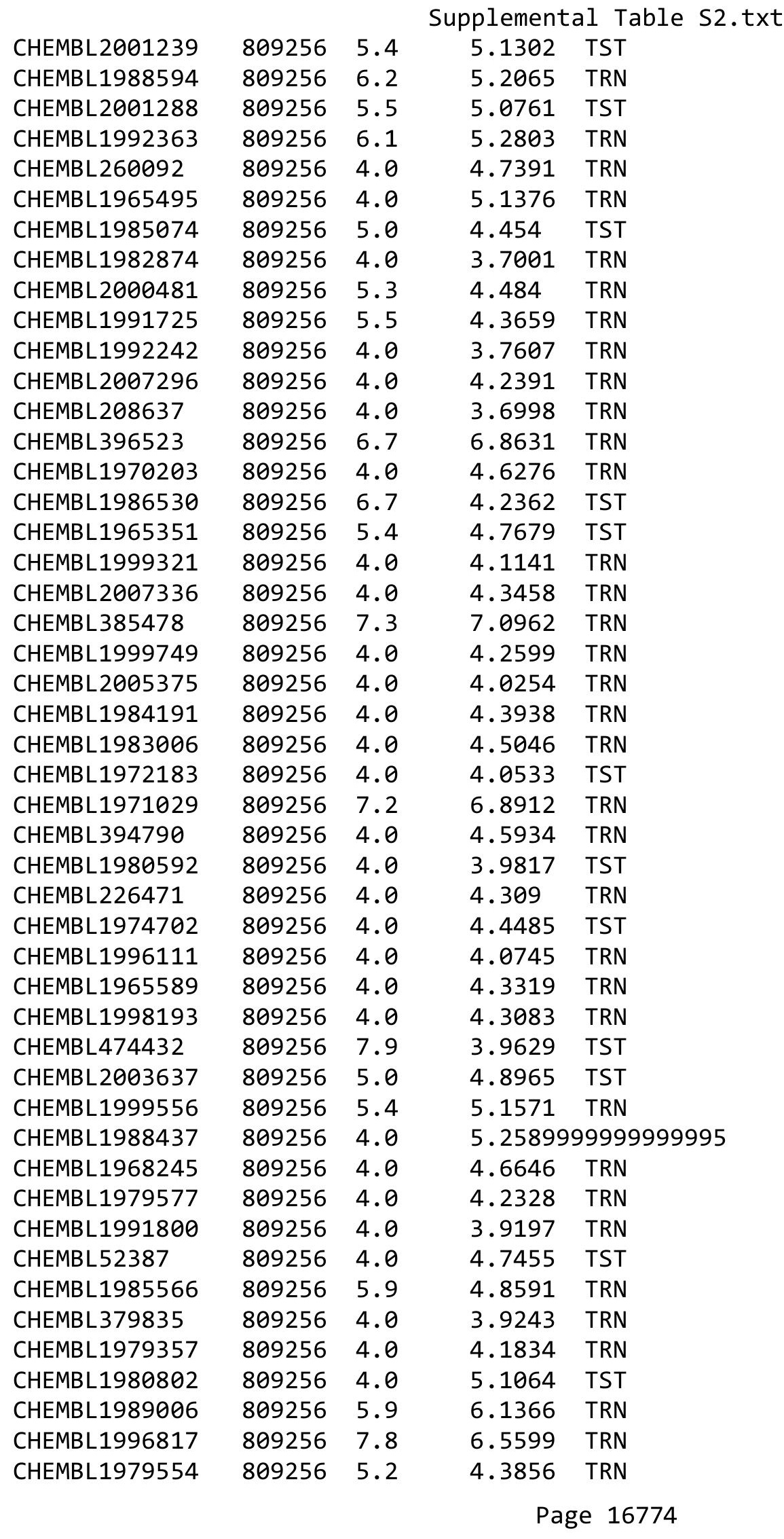




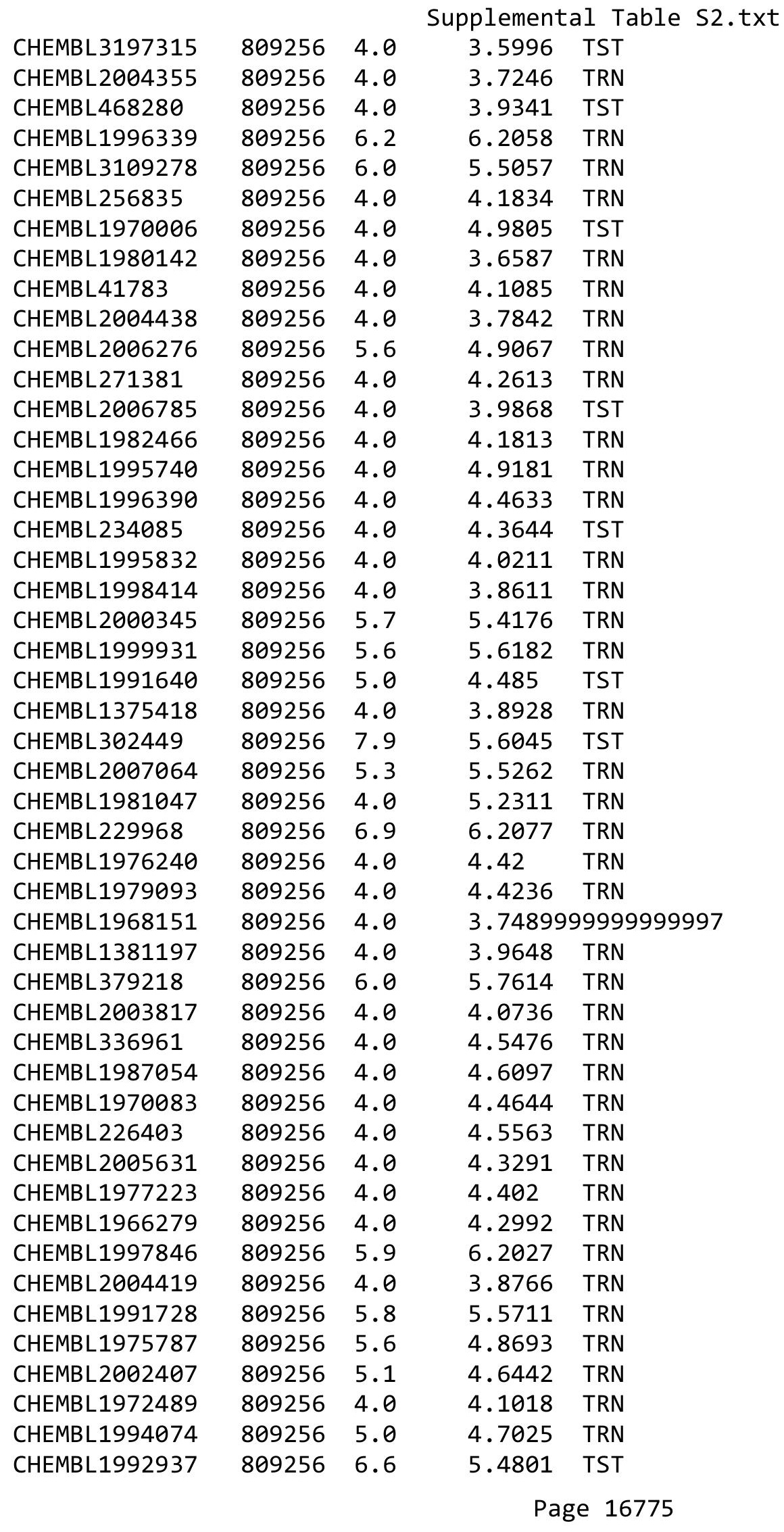




\begin{tabular}{|c|c|c|c|c|c|}
\hline \multicolumn{6}{|c|}{ Supplemental Table S2.txt } \\
\hline CHEMBL536151 & 809256 & 4.0 & 4.205 & TST & \\
\hline CHEMBL1972119 & 809256 & 4.0 & 3.6743 & TRN & \\
\hline CHEMBL1986328 & 809256 & 4.0 & 4.2064 & TST & \\
\hline CHEMBL95692 & 809256 & 4.0 & 4.2049 & TRN & \\
\hline CHEMBL1090356 & 809256 & 4.0 & 3.9862 & TRN & \\
\hline CHEMBL1976455 & 809256 & 5.5 & 4.9203 & TRN & \\
\hline CHEMBL1983923 & 809256 & 6.4 & 5.32799 & 9999999999 & TST \\
\hline CHEMBL1970950 & 809256 & 4.0 & 5.0561 & TRN & \\
\hline CHEMBL1983534 & 809256 & 4.0 & 4.1199 & TRN & \\
\hline CHEMBL1982361 & 809256 & 4.0 & 4.1204 & TRN & \\
\hline CHEMBL1999112 & 809256 & 4.0 & 3.9058 & TST & \\
\hline CHEMBL1982122 & 809256 & 4.0 & 4.3709 & TRN & \\
\hline CHEMBL 2000801 & 809256 & 4.0 & 3.6753 & TRN & \\
\hline CHEMBL1682546 & 809256 & 4.0 & 4.0695 & TRN & \\
\hline CHEMBL1991395 & 809256 & 4.0 & 4.1843 & TRN & \\
\hline CHEMBL1971245 & 809256 & 5.5 & 4.5361 & TRN & \\
\hline CHEMBL1987648 & 809256 & 4.0 & 4.1015 & TRN & \\
\hline CHEMBL1996780 & 809256 & 4.0 & 4.3466 & TRN & \\
\hline CHEMBL1972142 & 809256 & 4.0 & 4.2842 & TRN & \\
\hline CHEMBL1966514 & 809256 & 4.0 & 4.3516 & TRN & \\
\hline CHEMBL 2003638 & 809256 & 5.2 & 5.2304 & TRN & \\
\hline CHEMBL296586 & 809256 & 4.0 & 4.8262 & TRN & \\
\hline CHEMBL1996066 & 809256 & 6.5 & 4.3718 & TST & \\
\hline CHEMBL516429 & 809256 & 5.8 & 5.0519 & TRN & \\
\hline CHEMBL1972152 & 809256 & 4.0 & 4.5358 & TST & \\
\hline CHEMBL1993722 & 809256 & 5.8 & 4.973 & TRN & \\
\hline CHEMBL1970806 & 809256 & 4.0 & 3.759 & TST & \\
\hline CHEMBL 202635 & 809256 & 4.0 & 4.5386 & TRN & \\
\hline CHEMBL1979970 & 809256 & 4.0 & 4.1036 & TRN & \\
\hline CHEMBL 249282 & 809256 & 4.0 & 4.8722 & TST & \\
\hline CHEMBL1970821 & 809256 & 5.3 & 6.2052 & TRN & \\
\hline CHEMBL1969264 & 809256 & 4.0 & 4.3462 & TRN & \\
\hline CHEMBL1973711 & 809256 & 4.0 & 4.1424 & TST & \\
\hline CHEMBL2006237 & 809256 & 4.0 & 4.218 & TRN & \\
\hline CHEMBL1967720 & 809256 & 5.0 & 4.3603 & TRN & \\
\hline CHEMBL1572266 & 809256 & 4.0 & 3.7686 & TST & \\
\hline CHEMBL1991138 & 809256 & 4.0 & 3.8691 & TRN & \\
\hline CHEMBL1969755 & 809256 & 4.0 & 3.7124 & TRN & \\
\hline CHEMBL1979516 & 809256 & 4.0 & 4.0378 & TST & \\
\hline CHEMBL1972820 & 809256 & 4.0 & 4.0555 & TST & \\
\hline CHEMBL1605605 & 809256 & 4.0 & 4.19600 & 0000000001 & TST \\
\hline CHEMBL1996208 & 809256 & 5.6 & 4.7997 & TST & \\
\hline CHEMBL1989029 & 809256 & 6.2 & 4.8334 & TST & \\
\hline CHEMBL392642 & 809256 & 4.0 & 5.5685 & TST & \\
\hline CHEMBL514499 & 809256 & 4.0 & 4.0152 & TST & \\
\hline CHEMBL1965631 & 809256 & 4.0 & 4.1302 & TST & \\
\hline CHEMBL1980144 & 809256 & 5.4 & 4.5626 & TST & \\
\hline CHEMBL1991188 & 809256 & 4.0 & 4.1123 & TST & \\
\hline
\end{tabular}




\begin{tabular}{|c|c|c|c|c|}
\hline \multicolumn{5}{|c|}{ Supplemental Table s2.txt } \\
\hline CHEMBL1682554 & 809256 & 4.0 & 4.6804 & TST \\
\hline CHEMBL1972849 & 809256 & 4.0 & 3.6351 & TST \\
\hline CHEMBL377408 & 809256 & 4.0 & 3.7298 & TST \\
\hline CHEMBL215152 & 809256 & 4.0 & 4.3939 & TST \\
\hline CHEMBL231209 & 809256 & 4.0 & 4.4637 & TST \\
\hline CHEMBL1975357 & 809256 & 4.0 & 4.0087 & TST \\
\hline CHEMBL1989136 & 809256 & 5.6 & 4.9465 & TST \\
\hline CHEMBL1976220 & 809256 & 4.0 & 4.5653 & TST \\
\hline CHEMBL259922 & 809256 & 4.0 & 4.0275 & TST \\
\hline CHEMBL1997617 & 809256 & 6.2 & 4.9744 & TST \\
\hline CHEMBL1982383 & 809256 & 4.0 & 4.0302 & TST \\
\hline CHEMBL1969301 & 809256 & 7.0 & 4.6484 & TST \\
\hline CHEMBL17370 & 809256 & 4.0 & 4.3374 & TST \\
\hline CHEMBL1987910 & 809256 & 5.3 & 4.0945 & TST \\
\hline CHEMBL1983932 & 809256 & 4.0 & 4.7568 & TST \\
\hline CHEMBL1966069 & 809256 & 4.0 & 4.5115 & TST \\
\hline CHEMBL1991285 & 809256 & 4.0 & 4.6029 & TST \\
\hline CHEMBL1997822 & 809256 & 4.0 & 4.2747 & TST \\
\hline CHEMBL 243088 & 809256 & 6.4 & 6.4121 & TST \\
\hline CHEMBL1984038 & 809256 & 4.0 & 4.8149 & TST \\
\hline CHEMBL1993661 & 809256 & 8.4 & 7.2972 & TST \\
\hline CHEMBL1974416 & 809256 & 5.3 & 4.7158 & TST \\
\hline CHEMBL1984039 & 809256 & 4.0 & 4.3179 & TST \\
\hline CHEMBL1997872 & 809256 & 4.0 & 4.2657 & TST \\
\hline CHEMBL509032 & 809256 & 7.4 & 7.2074 & TST \\
\hline CHEMBL1978271 & 809225 & 4.4 & 4.7617 & TRN \\
\hline CHEMBL 2007266 & 809225 & 4.4 & 4.5226 & TRN \\
\hline CHEMBL 202721 & 809225 & 6.9 & 5.9479 & TRN \\
\hline CHEMBL 2000568 & 809225 & 4.4 & 4.2047 & TRN \\
\hline CHEMBL1994308 & 809225 & 4.4 & 4.5409 & TRN \\
\hline CHEMBL 2007097 & 809225 & 4.0 & 4.4809 & TRN \\
\hline CHEMBL1974328 & 809225 & 6.1 & 6.461 & TRN \\
\hline CHEMBL509032 & 809225 & 9.1 & 7.9922 & TRN \\
\hline CHEMBL 388311 & 809225 & 5.8 & 5.7935 & TRN \\
\hline CHEMBL1964948 & 809225 & 4.4 & 4.4079 & TRN \\
\hline CHEMBL1973013 & 809225 & 6.1 & 5.7741 & TRN \\
\hline CHEMBL1987430 & 809225 & 4.4 & 4.4453 & TRN \\
\hline CHEMBL1993413 & 809225 & 4.4 & 4.0682 & TRN \\
\hline CHEMBL 205415 & 809225 & 4.4 & 4.6218 & TRN \\
\hline CHEMBL1975927 & 809225 & 6.4 & 6.4947 & TRN \\
\hline CHEMBL1986943 & 809225 & 5.5 & 5.3071 & TRN \\
\hline CHEMBL1977138 & 809225 & 7.0 & 6.7237 & TRN \\
\hline CHEMBL1978448 & 809225 & 4.4 & 5.4327 & TST \\
\hline CHEMBL1980329 & 809225 & 4.4 & 5.4223 & TRN \\
\hline CHEMBL 2004515 & 809225 & 5.2 & 5.0811 & TRN \\
\hline CHEMBL1992042 & 809225 & 4.4 & 4.2336 & TRN \\
\hline CHEMBL1986265 & 809225 & 4.4 & 4.6477 & TRN \\
\hline CHEMBL1991734 & 809225 & 6.2 & 5.7798 & TRN \\
\hline
\end{tabular}




\begin{tabular}{|c|c|c|c|c|c|}
\hline \multicolumn{6}{|c|}{ Supplemental Table S2.txt } \\
\hline CHEMBL21156 & 809225 & 6.9 & 5.7124 & TRN & \\
\hline CHEMBL1994724 & 809225 & 4.4 & 4.4344 & TRN & \\
\hline CHEMBL1989267 & 809225 & 6.8 & 7.2181 & TRN & \\
\hline CHEMBL1991782 & 809225 & 3.1 & 3.8379 & TRN & \\
\hline CHEMBL2002105 & 809225 & 4.4 & 4.1978 & TRN & \\
\hline CHEMBL1983348 & 809225 & 4.4 & 5.405 & TRN & \\
\hline CHEMBL1974574 & 809225 & 4.4 & 4.4114 & TRN & \\
\hline CHEMBL1970290 & 809225 & 5.9 & 6.1679 & TRN & \\
\hline CHEMBL1993877 & 809225 & 5.7 & 5.5718 & TRN & \\
\hline CHEMBL 2000934 & 809225 & 4.4 & 4.3977 & TRN & \\
\hline CHEMBL1996500 & 809225 & 4.4 & 4.2969 & TRN & \\
\hline CHEMBL1980671 & 809225 & 5.8 & 4.7517 & TRN & \\
\hline CHEMBL1973363 & 809225 & 5.5 & 4.522 & TRN & \\
\hline CHEMBL1986177 & 809225 & 4.4 & 4.5153 & TRN & \\
\hline CHEMBL1989708 & 809225 & 7.5 & 7.3348 & TRN & \\
\hline CHEMBL1976420 & 809225 & 6.5 & 5.3537 & TRN & \\
\hline CHEMBL1998253 & 809225 & 4.4 & 4.3034 & TRN & \\
\hline CHEMBL1981744 & 809225 & 4.4 & 4.4613 & TRN & \\
\hline CHEMBL1985367 & 809225 & 4.4 & 5.5474 & TRN & \\
\hline CHEMBL1996510 & 809225 & 4.4 & 4.5285 & TRN & \\
\hline CHEMBL 2000029 & 809225 & 4.4 & 4.716 & TRN & \\
\hline CHEMBL1995172 & 809225 & 4.4 & 4.2873 & TST & \\
\hline CHEMBL 2001584 & 809225 & 4.4 & 5.1321 & TRN & \\
\hline CHEMBL1973961 & 809225 & 5.6 & 5.5078 & TRN & \\
\hline CHEMBL1967998 & 809225 & 7.2 & 7.7987 & TRN & \\
\hline CHEMBL1978562 & 809225 & 4.4 & 4.6396 & TRN & \\
\hline CHEMBL1994977 & 809225 & 4.4 & 4.5192 & TRN & \\
\hline CHEMBL2001149 & 809225 & 4.4 & 4.2982 & TRN & \\
\hline CHEMBL1974875 & 809225 & 4.0 & 4.6551 & TST & \\
\hline CHEMBL 2005478 & 809225 & 4.4 & 4.5696 & TRN & \\
\hline CHEMBL1996646 & 809225 & 5.5 & 5.0989 & TRN & \\
\hline CHEMBL1979773 & 809225 & 4.4 & 4.688 & TRN & \\
\hline CHEMBL1989471 & 809225 & 4.4 & 5.29299 & 9999999999 & TST \\
\hline CHEMBL1996702 & 809225 & 5.8 & 5.4803 & TRN & \\
\hline CHEMBL 2007124 & 809225 & 4.4 & 4.6455 & TRN & \\
\hline CHEMBL1978195 & 809225 & 4.4 & 4.4435 & TRN & \\
\hline CHEMBL 2006439 & 809225 & 4.4 & 4.458 & TRN & \\
\hline CHEMBL1985681 & 809225 & 4.4 & 4.5582 & TRN & \\
\hline CHEMBL1991674 & 809225 & 4.4 & 4.5848 & TRN & \\
\hline CHEMBL1982711 & 809225 & 4.4 & 4.32100 & 0000000001 & TRN \\
\hline CHEMBL262623 & 809225 & 4.4 & 4.5077 & TRN & \\
\hline CHEMBL1984842 & 809225 & 4.4 & 4.2075 & TRN & \\
\hline CHEMBL 2004118 & 809225 & 4.4 & 5.0913 & TRN & \\
\hline CHEMBL1996345 & 809225 & 4.4 & 4.525 & TRN & \\
\hline CHEMBL 2004025 & 809225 & 4.4 & 4.7504 & TRN & \\
\hline CHEMBL1996048 & 809225 & 6.1 & 4.995 & TRN & \\
\hline CHEMBL50894 & 809225 & 4.4 & 4.6749 & TRN & \\
\hline CHEMBL1995211 & 809225 & 4.4 & 4.371 & TRN & \\
\hline
\end{tabular}




\begin{tabular}{|c|c|c|c|c|}
\hline & & & enI & \\
\hline CHEMBL1965033 & 809225 & 4.4 & 4.4153 & TRN \\
\hline CHEMBL461876 & 809225 & 5.7 & 5.845 & TRN \\
\hline CHEMBL1982753 & 809225 & 4.4 & 5.0098 & TRN \\
\hline CHEMBL 2006299 & 809225 & 4.4 & 4.1282 & TRN \\
\hline CHEMBL1972346 & 809225 & 6.2 & 5.6646 & TST \\
\hline CHEMBL1971519 & 809225 & 4.8 & 4.8512 & TRN \\
\hline CHEMBL1997335 & 809225 & 5.9 & 5.6288 & TRN \\
\hline CHEMBL1965169 & 809225 & 4.4 & 4.2125 & TRN \\
\hline CHEMBL1081312 & 809225 & 6.4 & 6.6156 & TRN \\
\hline CHEMBL1971132 & 809225 & 4.4 & 4.7395 & TRN \\
\hline CHEMBL1965170 & 809225 & 7.9 & 7.1968 & TRN \\
\hline CHEMBL 2005792 & 809225 & 4.4 & 4.0726 & TRN \\
\hline CHEMBL1991867 & 809225 & 4.1 & 4.6406 & TRN \\
\hline CHEMBL1986503 & 809225 & 4.4 & 4.3732 & TST \\
\hline CHEMBL1972355 & 809225 & 4.4 & 5.3406 & TRN \\
\hline CHEMBL1997892 & 809225 & 4.4 & 4.6137 & TRN \\
\hline CHEMBL1997193 & 809225 & 5.6 & 4.3331 & TST \\
\hline CHEMBL1964902 & 809225 & 4.4 & 4.3231 & TRN \\
\hline CHEMBL1973868 & 809225 & 4.4 & 4.4609 & TRN \\
\hline CHEMBL1972462 & 809225 & 6.5 & 4.6258 & TRN \\
\hline CHEMBL1983715 & 809225 & 6.6 & 6.7002 & TRN \\
\hline CHEMBL1984500 & 809225 & 3.1 & 3.5835 & TRN \\
\hline CHEMBL 2002992 & 809225 & 4.4 & 4.8398 & TRN \\
\hline CHEMBL1982700 & 809225 & 4.4 & 4.6551 & TRN \\
\hline CHEMBL10 & 809225 & 4.4 & 4.8785 & TRN \\
\hline CHEMBL1980763 & 809225 & 5.4 & 5.2956 & TRN \\
\hline CHEMBL1977634 & 809225 & 4.4 & 4.2967 & TRN \\
\hline CHEMBL 2004887 & 809225 & 4.8 & 4.4337 & TRN \\
\hline CHEMBL 2007479 & 809225 & 4.4 & 4.2081 & TRN \\
\hline CHEMBL1998953 & 809225 & 4.4 & 4.0484 & TRN \\
\hline CHEMBL1971606 & 809225 & 4.4 & 4.3545 & TRN \\
\hline CHEMBL1971223 & 809225 & 4.4 & 4.7119 & TRN \\
\hline CHEMBL1999120 & 809225 & 4.6 & 4.6405 & TST \\
\hline CHEMBL1972220 & 809225 & 7.8 & 7.9329 & TRN \\
\hline CHEMBL1981215 & 809225 & 4.4 & 4.4946 & TRN \\
\hline CHEMBL 2003785 & 809225 & 4.6 & 4.4897 & TRN \\
\hline CHEMBL1973720 & 809225 & 5.7 & 5.5982 & TRN \\
\hline CHEMBL1999414 & 809225 & 5.8 & 6.2485 & TRN \\
\hline CHEMBL1967336 & 809225 & 4.4 & 4.1858 & TRN \\
\hline CHEMBL2001923 & 809225 & 5.4 & 4.8511 & TRN \\
\hline CHEMBL 2003514 & 809225 & 4.4 & 4.2079 & TRN \\
\hline CHEMBL1970340 & 809225 & 4.6 & 4.7745 & TRN \\
\hline CHEMBL1967992 & 809225 & 4.4 & 4.2327 & TRN \\
\hline CHEMBL1989043 & 809225 & 4.4 & 4.6429 & TRN \\
\hline CHEMBL1981671 & 809225 & 4.4 & 4.5675 & TRN \\
\hline CHEMBL 2006450 & 809225 & 4.4 & 4.1292 & TRN \\
\hline CHEMBL 2001987 & 809225 & 4.4 & 4.7812 & TRN \\
\hline CHEMBL1994555 & 809225 & 4.4 & 4.8652 & TRN \\
\hline
\end{tabular}




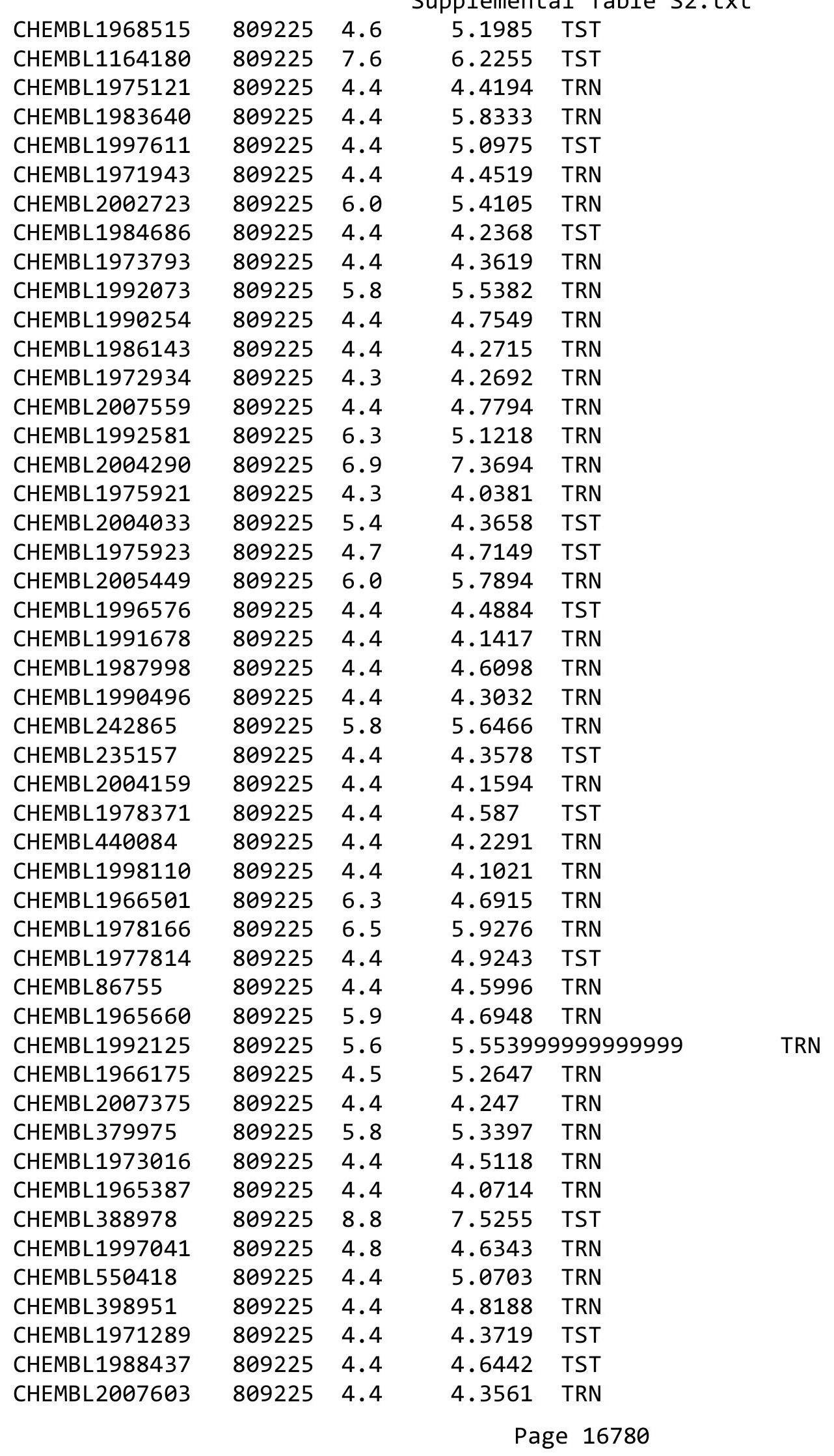




\begin{tabular}{|c|c|c|c|c|c|}
\hline & & \multicolumn{4}{|c|}{ Supplemental Table S2.txt } \\
\hline CHEMBL1421720 & 809225 & 4.4 & \multicolumn{2}{|c|}{4.553999999999999} & TRN \\
\hline CHEMBL1233887 & 809225 & 4.4 & 4.7463 & TRN & \\
\hline CHEMBL1968130 & 809225 & 4.4 & 4.5147 & TST & \\
\hline CHEMBL 2003689 & 809225 & 4.4 & 4.3925 & TRN & \\
\hline CHEMBL1996649 & 809225 & 5.9 & 5.8652 & TRN & \\
\hline CHEMBL1986756 & 809225 & 4.4 & 4.5028 & TRN & \\
\hline CHEMBL1949855 & 809225 & 4.9 & 5.2384 & TRN & \\
\hline CHEMBL3109278 & 809225 & 4.5 & 4.8152 & TRN & \\
\hline CHEMBL1974998 & 809225 & 4.4 & 4.629 & TRN & \\
\hline CHEMBL1990223 & 809225 & 4.4 & 4.6905 & TRN & \\
\hline CHEMBL2004438 & 809225 & 4.4 & 4.623 & TRN & \\
\hline CHEMBL1964382 & 809225 & 4.4 & 4.5303 & TST & \\
\hline CHEMBL101311 & 809225 & 6.6 & 6.4111 & TRN & \\
\hline CHEMBL191003 & 809225 & 4.5 & 4.7948 & TRN & \\
\hline CHEMBL1973359 & 809225 & 6.6 & 5.5191 & TST & \\
\hline CHEMBL1988581 & 809225 & 7.2 & \multicolumn{2}{|c|}{6.4910000000000005} & TST \\
\hline CHEMBL2005699 & 809225 & 4.4 & 4.3605 & TRN & \\
\hline CHEMBL 2006564 & 809225 & 7.1 & 7.0503 & TRN & \\
\hline CHEMBL1979690 & 809225 & 7.2 & 7.8011 & TRN & \\
\hline CHEMBL1991008 & 809225 & 4.1 & 4.3478 & TRN & \\
\hline CHEMBL234085 & 809225 & 4.4 & 4.6926 & TRN & \\
\hline CHEMBL1978167 & 809225 & 4.4 & 4.1542 & TRN & \\
\hline CHEMBL418203 & 809225 & 4.4 & 4.9383 & TRN & \\
\hline CHEMBL225519 & 809225 & 4.4 & 4.6554 & TST & \\
\hline CHEMBL1976376 & 809225 & 6.5 & 6.5429 & TRN & \\
\hline CHEMBL1983575 & 809225 & 6.2 & 5.7815 & TRN & \\
\hline CHEMBL1968868 & 809225 & 4.4 & 4.4714 & TRN & \\
\hline CHEMBL1981047 & 809225 & 7.0 & 6.9752 & TRN & \\
\hline CHEMBL1998470 & 809225 & 4.4 & 4.0369 & TRN & \\
\hline CHEMBL1976196 & 809225 & 4.4 & 4.8047 & TRN & \\
\hline CHEMBL1997197 & 809225 & 4.4 & \multicolumn{2}{|c|}{4.218999999999999} & TRN \\
\hline CHEMBL1975903 & 809225 & 4.4 & 4.5861 & TRN & \\
\hline CHEMBL1522508 & 809225 & 4.7 & 4.5262 & TRN & \\
\hline CHEMBL1988805 & 809225 & 4.4 & 4.2839 & TRN & \\
\hline CHEMBL458997 & 809225 & 7.4 & 6.9507 & TRN & \\
\hline CHEMBL1969942 & 809225 & 4.4 & 4.3119 & TRN & \\
\hline CHEMBL1982660 & 809225 & 4.4 & 4.185 & TRN & \\
\hline CHEMBL1978567 & 809225 & 4.4 & 4.1021 & TRN & \\
\hline CHEMBL1995765 & 809225 & 4.3 & 4.4541 & TRN & \\
\hline CHEMBL1984760 & 809225 & 4.4 & 4.7047 & TRN & \\
\hline CHEMBL1997846 & 809225 & 4.4 & 4.4374 & TRN & \\
\hline CHEMBL424872 & 809225 & 4.4 & 4.3885 & TRN & \\
\hline CHEMBL360847 & 809225 & 4.4 & 4.4801 & TRN & \\
\hline CHEMBL1995811 & 809225 & 4.4 & 4.8188 & TRN & \\
\hline CHEMBL 2002802 & 809225 & 4.1 & 4.6635 & TRN & \\
\hline CHEMBL1983111 & 809225 & 7.2 & 6.9603 & TRN & \\
\hline CHEMBL1988141 & 809225 & 6.2 & 5.598 & TST & \\
\hline CHEMBL1992937 & 809225 & 4.4 & 3.8221 & TRN & \\
\hline
\end{tabular}




\begin{tabular}{|c|c|c|c|c|}
\hline & & & Supplement & \\
\hline CHEMBL451401 & 809225 & 4.5 & 4.0351 & TRN \\
\hline CHEMBL1977134 & 809225 & 6.7 & 5.9836 & TRN \\
\hline CHEMBL1985206 & 809225 & 4.4 & 4.16 & TRN \\
\hline CHEMBL1991078 & 809225 & 4.4 & 5.1346 & TRN \\
\hline CHEMBL1977749 & 809225 & 4.4 & 5.0137 & TST \\
\hline CHEMBL1975212 & 809225 & 5.1 & 5.1214 & TRN \\
\hline CHEMBL2001613 & 809225 & 4.5 & 4.6745 & TRN \\
\hline CHEMBL261849 & 809225 & 4.4 & 4.6433 & TST \\
\hline CHEMBL1983923 & 809225 & 6.0 & 6.0002 & TRN \\
\hline CHEMBL1993904 & 809225 & 4.4 & 4.4379 & TRN \\
\hline CHEMBL1997275 & 809225 & 4.4 & 4.3891 & TRN \\
\hline CHEMBL1967513 & 809225 & 4.4 & 4.4217 & TRN \\
\hline CHEMBL1982413 & 809225 & 4.4 & 4.6259 & TRN \\
\hline CHEMBL1987535 & 809225 & 4.4 & 4.5787 & TRN \\
\hline CHEMBL1983393 & 809225 & 4.4 & 4.2767 & TRN \\
\hline CHEMBL1981792 & 809225 & 4.4 & 4.4367 & TRN \\
\hline CHEMBL2002586 & 809225 & 6.2 & 5.9819 & TRN \\
\hline CHEMBL 2006674 & 809225 & 4.4 & 4.7117 & TST \\
\hline CHEMBL383264 & 809225 & 4.4 & 4.6942 & TRN \\
\hline CHEMBL1992371 & 809225 & 4.4 & 4.5424 & TRN \\
\hline CHEMBL1984236 & 809225 & 4.4 & 4.3727 & TST \\
\hline CHEMBL2007421 & 809225 & 7.6 & 6.7968 & TRN \\
\hline CHEMBL1973138 & 809225 & 4.4 & 4.919 & TRN \\
\hline CHEMBL2002599 & 809225 & 4.4 & 4.4219 & TST \\
\hline CHEMBL1992673 & 809225 & 4.7 & 4.7311 & TST \\
\hline CHEMBL1969151 & 809225 & 4.4 & 5.3027 & TST \\
\hline CHEMBL1967252 & 809225 & 4.3 & 4.3595 & TST \\
\hline CHEMBL1993335 & 809225 & 4.4 & 4.5652 & TST \\
\hline CHEMBL2007574 & 809225 & 4.4 & 3.7915 & TST \\
\hline CHEMBL1988692 & 809225 & 6.4 & 5.7047 & TST \\
\hline CHEMBL 2004637 & 809225 & 5.8 & 5.7836 & TST \\
\hline CHEMBL1993374 & 809225 & 4.4 & 5.5128 & TST \\
\hline CHEMBL1994318 & 809225 & 4.4 & 4.6872 & TST \\
\hline CHEMBL1998680 & 809225 & 4.4 & 4.3323 & TST \\
\hline CHEMBL592030 & 809225 & 4.4 & 4.4398 & TST \\
\hline CHEMBL1999506 & 809225 & 4.4 & 4.5062 & TST \\
\hline CHEMBL1970317 & 809225 & 6.0 & 6.5107 & TST \\
\hline CHEMBL1605605 & 809225 & 4.4 & 4.6571 & TST \\
\hline CHEMBL1997007 & 809225 & 4.4 & 4.3189 & TST \\
\hline CHEMBL1970352 & 809225 & 4.4 & 4.9626 & TST \\
\hline CHEMBL1964444 & 809225 & 4.4 & 4.6424 & TST \\
\hline CHEMBL 2002690 & 809225 & 4.4 & 3.8504 & TST \\
\hline CHEMBL1980167 & 809225 & 4.4 & 4.1205 & TST \\
\hline CHEMBL 377408 & 809225 & 4.4 & 4.2751 & TST \\
\hline CHEMBL278041 & 809225 & 4.4 & 4.8842 & TST \\
\hline CHEMBL215152 & 809225 & 4.4 & 4.7248 & TST \\
\hline CHEMBL 2006765 & 809225 & 6.7 & 6.0819 & TST \\
\hline CHEMBL1986590 & 809225 & 4.4 & 4.5323 & TST \\
\hline
\end{tabular}




\begin{tabular}{|c|c|c|c|c|c|}
\hline \\
\hline CHEMBL1870106 & 809225 & 4.4 & 4.8037 & TST & \\
\hline CHEMBL406845 & 809225 & 6.0 & 6.6859 & TST & \\
\hline CHEMBL1980246 & 809225 & 4.4 & 4.2094 & TST & \\
\hline CHEMBL1983980 & 809225 & 5.4 & 4.8205 & TST & \\
\hline CHEMBL1999484 & 809225 & 6.8 & 6.4272 & TST & \\
\hline CHEMBL1984296 & 809225 & 4.4 & 5.0118 & TST & \\
\hline CHEMBL1986899 & 809225 & 4.4 & 4.5419 & TST & \\
\hline CHEMBL1984038 & 809225 & 4.7 & 4.8233 & TST & \\
\hline CHEMBL1993661 & 809225 & 8.4 & 8.3492 & TST & \\
\hline CHEMBL1968705 & 809225 & 4.4 & 4.7495 & TST & \\
\hline CHEMBL1991410 & 809225 & 4.4 & 4.5078 & TST & \\
\hline CHEMBL1964441 & 809225 & 6.0 & 5.37299 & 9999999999 & TST \\
\hline CHEMBL546797 & 809225 & 4.4 & 4.4113 & TST & \\
\hline CHEMBL 271160 & 468964 & 8.4685 & 8.3672 & TRN & \\
\hline CHEMBL 272885 & 468964 & 5.0 & 4.8216 & TRN & \\
\hline CHEMBL 269850 & 468964 & 6.1612 & 6.1452 & TRN & \\
\hline CHEMBL272684 & 468964 & 7.7212 & 7.7274 & TST & \\
\hline CHEMBL411426 & 468964 & 8.6021 & 8.5794 & TRN & \\
\hline CHEMBL 272171 & 468964 & 6.0 & 6.8698 & TST & \\
\hline CHEMBL 271843 & 468964 & 7.3372 & 7.3631 & TRN & \\
\hline CHEMBL 273061 & 468964 & 7.4685 & 7.5768 & TRN & \\
\hline CHEMBL411887 & 468964 & 8.699 & 8.6911 & TRN & \\
\hline CHEMBL270054 & 468964 & 7.3665 & 7.6007 & TRN & \\
\hline CHEMBL409104 & 468964 & 7.8861 & 7.53 & TRN & \\
\hline CHEMBL411425 & 468964 & 8.1024 & 8.1815 & TRN & \\
\hline CHEMBL409892 & 468964 & 8.7959 & 8.8278 & TST & \\
\hline CHEMBL 271777 & 468964 & 5.0 & 4.9301 & TRN & \\
\hline CHEMBL272668 & 468964 & 7.5528 & 7.6884 & TRN & \\
\hline CHEMBL 269882 & 468964 & 8.6576 & 8.4191 & TST & \\
\hline CHEMBL409868 & 468964 & 7.7696 & 7.91299 & 9999999999 & TRN \\
\hline CHEMBL 271182 & 468964 & 7.6778 & 7.3864 & TRN & \\
\hline CHEMBL 271594 & 468964 & 7.1249 & 7.2818 & TRN & \\
\hline CHEMBL408210 & 468964 & 8.0506 & 7.6068 & TST & \\
\hline CHEMBL271595 & 468964 & 8.5528 & 8.6092 & TST & \\
\hline CHEMBL409731 & 468964 & 8.6778 & 8.4932 & TRN & \\
\hline CHEMBL 271822 & 468964 & 7.2676 & 7.4139 & TRN & \\
\hline CHEMBL 272414 & 468964 & 6.5086 & 6.6972 & TRN & \\
\hline CHEMBL 270132 & 468964 & 8.6021 & 8.5434 & TRN & \\
\hline CHEMBL 272028 & 468964 & 7.9208 & 8.0183 & TRN & \\
\hline CHEMBL271137 & 468964 & 7.2676 & 7.3698 & TST & \\
\hline CHEMBL445945 & 468964 & 8.8239 & 8.7542 & TST & \\
\hline CHEMBL 270544 & 468964 & 8.8239 & 8.718 & TRN & \\
\hline CHEMBL269883 & 468964 & 8.5229 & 8.5658 & TRN & \\
\hline CHEMBL 271183 & 468964 & 7.3665 & 7.1939 & TRN & \\
\hline CHEMBL429142 & 468964 & 8.7212 & 8.5104 & TRN & \\
\hline CHEMBL314397 & 468964 & 8.3372 & 7.7877 & TST & \\
\hline CHEMBL410517 & 468964 & 5.0 & 4.155 & TRN & \\
\hline CHEMBL411865 & 468964 & 7.9208 & 7.9767 & TRN & \\
\hline
\end{tabular}




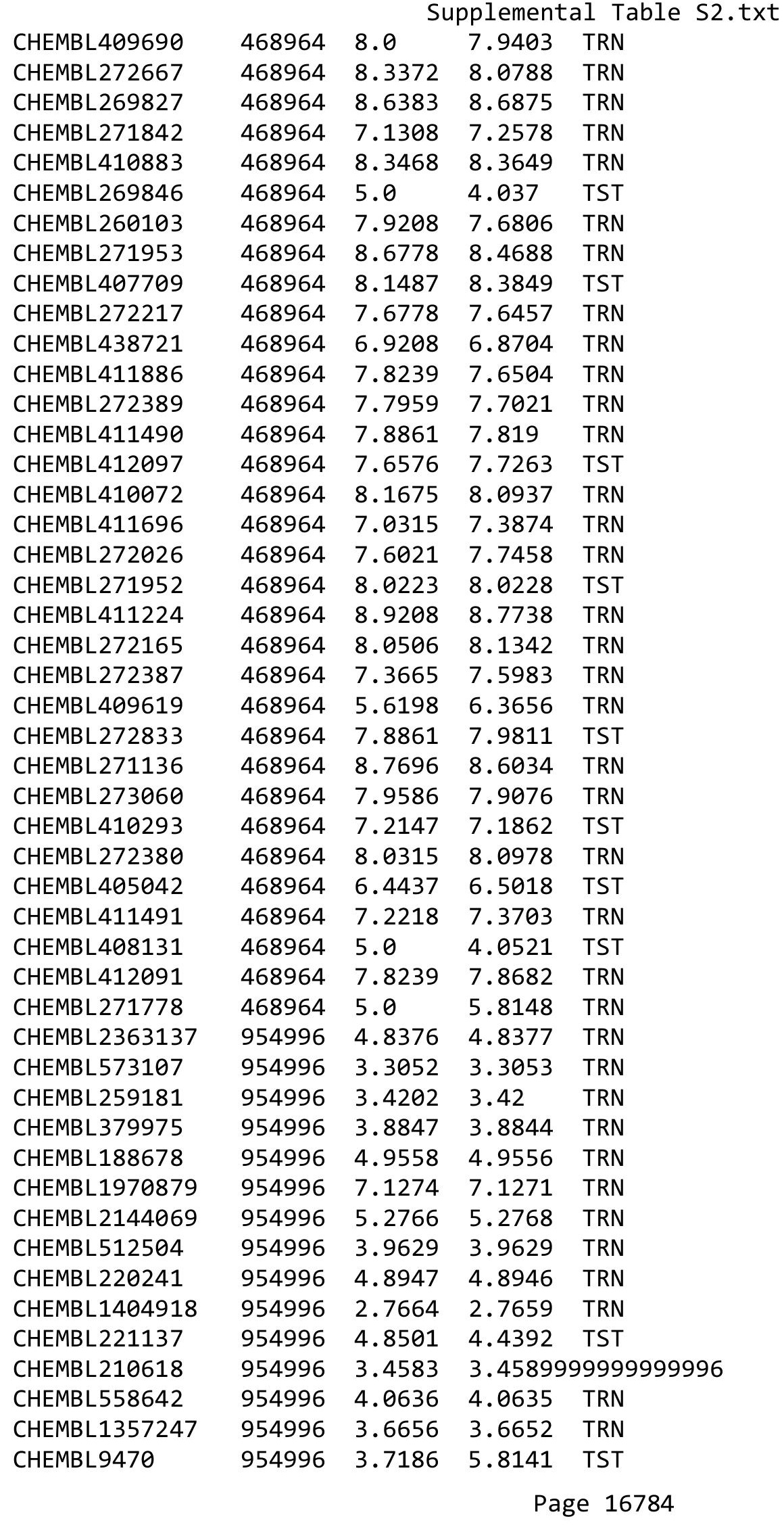

TRN 


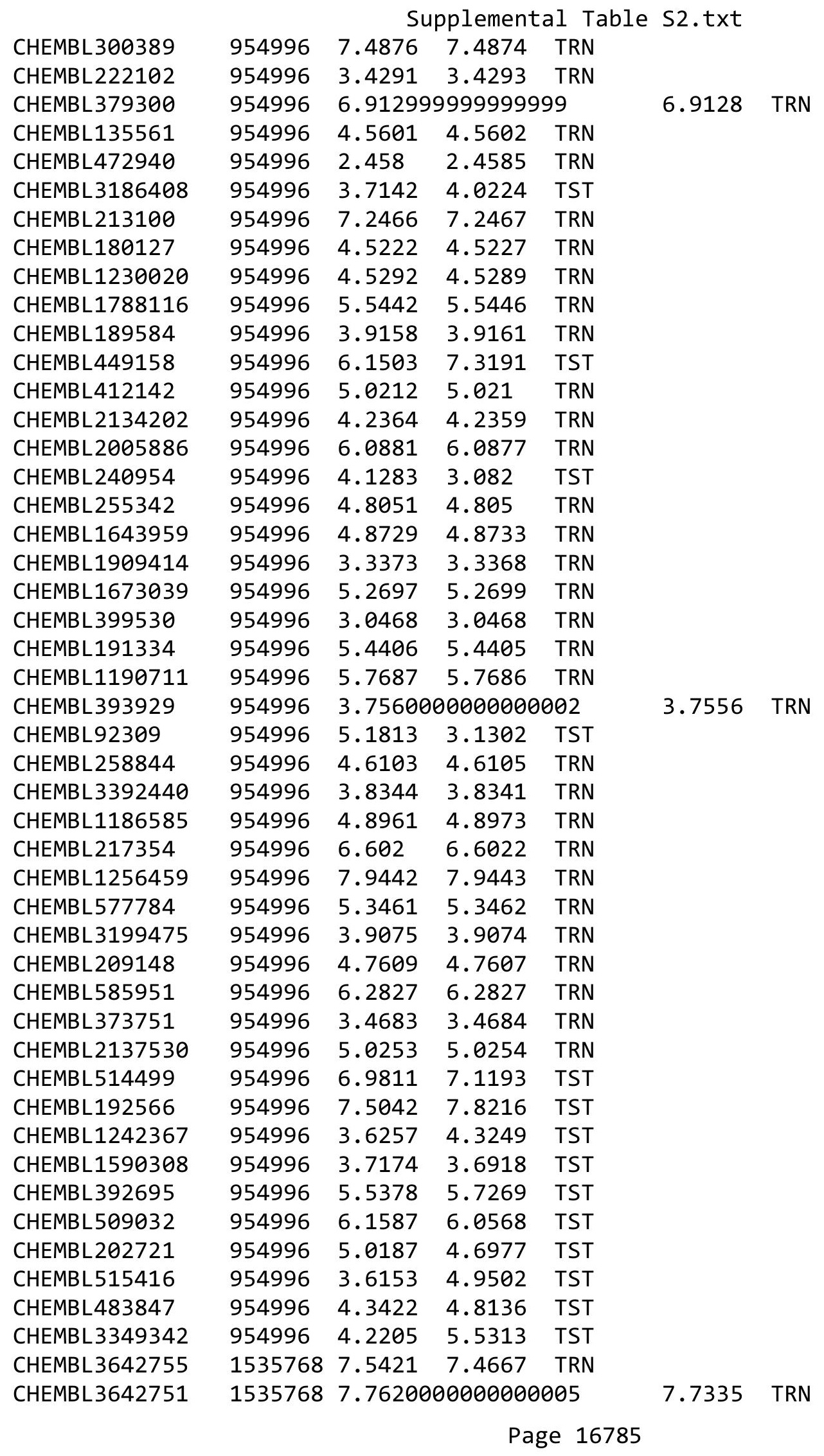


Supplemental Table S2.txt

\begin{tabular}{|c|c|c|c|c|}
\hline 6 & & 6.7135 & & . \\
\hline & & 7.6402 & & \\
\hline$A$ AEMRI & 68 & & & \\
\hline IEMBL & & 05 & & \\
\hline AEMBL3642681 & 535768 & 8.0555 & 1491 & \\
\hline HEMBL 3642764 & 535768 & 7.6021 & 6942 & \\
\hline 704 & & & & \\
\hline AEMBL: & & & & \\
\hline HEMBL3642765 & 535768 & 7.4802 & .5699 & \\
\hline HEMBL3642715 & 535768 & 7.9586 & & \\
\hline HEMBL 364 & 58 & & & \\
\hline IEME & 68 & & & \\
\hline HEMBL; & & & & \\
\hline HEMBL3642747 & 535768 & 69 & 9837 & \\
\hline AEMBL3642687 & 535768 & & & \\
\hline HEMBL3 & 8 & 7. & 45 & \\
\hline HEMBL & & & & \\
\hline HEMBL. & & & & \\
\hline HEMBI 3 & 68 & & & \\
\hline HEMBL 364 & 58 & 8. & 23 & 1 \\
\hline HEMBL & 58 & & 31 & RN \\
\hline HEM & & & & \\
\hline HEMBL & 68 & & & \\
\hline HEMBL & & & & TST \\
\hline HEMBL364 & 58 & 8. & 91 & RN \\
\hline HEMBL & ס & & & ST \\
\hline HEME & & & & RN \\
\hline 25 & & & & ST \\
\hline AEMBL & & & & is \\
\hline HEMBL364 & 535768 & & 54 & TRN \\
\hline AEMBL & 8 & & & RN \\
\hline 9 & & & & 「RN \\
\hline & & & & ST \\
\hline HEMBL3 & 58 & & & $\mathrm{RN}$ \\
\hline HEMBL3642782 & 68 & & 1027 & ST \\
\hline ICMP & 8 & & 32 & ГST \\
\hline 0 & & & & ГRN \\
\hline HEMBL3 & & & & 「RN \\
\hline HEMBL3 & 58 & & 354 & TST \\
\hline Th & & & & R \\
\hline HEMBL3 & & & 15 & TRN \\
\hline HEMBL3 & 768 & & 5.8926 & RN \\
\hline HEMBL 364 & 535768 & 8.02 & .8922 & TST \\
\hline HEMBL3 & 68 & & & TR \\
\hline 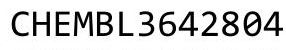 & & & & \\
\hline HEMBL3 & & & 8.0169 & \\
\hline CHEMBL3 & .535768 & 7.9136 & 7.869 & \\
\hline CHEMBL3642758 & 1535768 & 7.6421 & 7.6574 & in \\
\hline
\end{tabular}

Page 16786 
Supplemental Table S2.txt

\begin{tabular}{|c|c|c|c|c|c|c|}
\hline CHEMBL3642680 & 1535768 & 8.1938 & 8.28 & TRN & & \\
\hline CHEMBL3642712 & 1535768 & 7.61799 & 99999999 & 99 & 7.6267 & TRN \\
\hline CHEMBL3642769 & 1535768 & 7.6364 & 7.7114 & TRN & & \\
\hline CHEMBL 3642807 & 1535768 & 7.1759 & 7.2056 & TRN & & \\
\hline CHEMBL3642754 & 1535768 & 7.9586 & 7.9858 & TRN & & \\
\hline CHEMBL3642738 & 1535768 & 6.0 & 5.9874 & TRN & & \\
\hline CHEMBL 3642700 & 1535768 & 8.6576 & 8.8001 & TST & & \\
\hline CHEMBL 3642713 & 1535768 & 7.8761 & 7.767 & TRN & & \\
\hline CHEMBL3642692 & 1535768 & 8.1675 & 8.4794 & TST & & \\
\hline CHEMBL3642779 & 1535768 & 6.5935 & 6.8375 & TST & & \\
\hline CHEMBL3642722 & 1535768 & 7.9547 & 7.9351 & TRN & & \\
\hline CHEMBL3642729 & 1535768 & 7.9957 & 8.0438 & TRN & & \\
\hline CHEMBL3642793 & 1535768 & 7.8861 & 7.8951 & TRN & & \\
\hline CHEMBL 3642721 & 1535768 & 8.1175 & 8.0812 & TRN & & \\
\hline CHEMBL3642684 & 1535768 & 7.9872 & 8.0083 & TRN & & \\
\hline CHEMBL3642727 & 1535768 & 7.4045 & 8.0107 & TST & & \\
\hline CHEMBL3642728 & 1535768 & 7.8633 & 7.8466 & TRN & & \\
\hline CHEMBL3642815 & 1535768 & 7.5171 & 7.4358 & TRN & & \\
\hline CHEMBL 3642740 & 1535768 & 7.9547 & 7.8595 & TRN & & \\
\hline CHEMBL3642682 & 1535768 & 8.1871 & 8.2071 & TRN & & \\
\hline CHEMBL3642759 & 1535768 & 7.9136 & 7.86700 & 0000000001 & & TRN \\
\hline CHEMBL3642726 & 1535768 & 7.7545 & 8.0195 & TST & & \\
\hline CHEMBL3642723 & 1535768 & 7.8297 & 7.8016 & TRN & & \\
\hline CHEMBL 3642763 & 1535768 & 7.6216 & 7.5634 & TRN & & \\
\hline CHEMBL3642778 & 1535768 & 7.2328 & 7.1788 & TST & & \\
\hline CHEMBL3642785 & 1535768 & 7.7055 & 7.3563 & TST & & \\
\hline CHEMBL3642739 & 1535768 & 8.4413 & 8.4927 & TRN & & \\
\hline CHEMBL 3642720 & 1535768 & 8.2007 & 8.2058 & TRN & & \\
\hline CHEMBL 3642795 & 1535768 & 7.8069 & 7.9839 & TRN & & \\
\hline CHEMBL3642693 & 1535768 & 8.4815 & 8.3001 & TST & & \\
\hline CHEMBL3642688 & 1535768 & 8.2147 & 8.2605 & TRN & & \\
\hline CHEMBL3642733 & 1535768 & 7.7167 & 7.6953 & TRN & & \\
\hline CHEMBL 3642784 & 1535768 & 7.1707 & 6.8996 & TST & & \\
\hline CHEMBL 3642749 & 1535768 & 7.7905 & 7.7669 & TRN & & \\
\hline CHEMBL 3642710 & 1535768 & 8.2291 & 8.1058 & TRN & & \\
\hline CHEMBL3642742 & 1535768 & 7.8268 & 7.7224 & TRN & & \\
\hline CHEMBL3642711 & 1535768 & 7.6968 & 7.7791 & TRN & & \\
\hline CHEMBL 3642790 & 1535768 & 7.7423 & 7.7048 & TRN & & \\
\hline CHEMBL 3642772 & 1535768 & 7.5287 & 7.4653 & TRN & & \\
\hline CHEMBL 3642811 & 1535768 & 6.0 & 6.1018 & TRN & & \\
\hline CHEMBL3642792 & 1535768 & 7.8097 & 7.778 & TRN & & \\
\hline CHEMBL3642814 & 1535768 & 7.1518 & 8.1241 & TST & & \\
\hline CHEMBL3642803 & 1535768 & 7.3107 & 7.1059 & TST & & \\
\hline CHEMBL 3642734 & 1535768 & 8.3449 & 8.3144 & TRN & & \\
\hline CHEMBL3642685 & 1535768 & 8.2518 & 8.2797 & TRN & & \\
\hline CHEMBL3642695 & 1535768 & 8.2757 & 8.4225 & TST & & \\
\hline CHEMBL3642794 & 1535768 & 8.3458 & 8.287 & TRN & & \\
\hline CHEMBL3642750 & 1535768 & 7.8761 & 7.8153 & TRN & & \\
\hline
\end{tabular}


Supplemental Table S2.txt

\begin{tabular}{|c|c|c|c|c|c|}
\hline CHEMBL3642817 & 1535768 & 7.6478 & 7.5807 & TRN & \\
\hline CHEMBL3642735 & 1535768 & 8.2277 & 8.3469 & TRN & \\
\hline CHEMBL3642770 & 1535768 & 7.6091 & 7.7165 & TRN & \\
\hline CHEMBL3642776 & 1535768 & 7.061 & 7.0902 & TRN & \\
\hline CHEMBL3642683 & 1535768 & 8.0915 & 8.0772 & TRN & \\
\hline CHEMBL3642746 & 1535768 & 6.0 & 6.24 & TRN & \\
\hline CHEMBL3642752 & 1535768 & 7.9914 & 7.9973 & TRN & \\
\hline CHEMBL3642730 & 1535768 & 8.1959 & 8.1066 & TRN & \\
\hline CHEMBL3642773 & 1535768 & 7.1238 & 7.1358 & TRN & \\
\hline CHEMBL3642690 & 1535768 & 8.1308 & 8.1388 & TRN & \\
\hline CHEMBL3639415 & 1535768 & 8.041 & 7.9549 & TRN & \\
\hline CHEMBL 3642783 & 1535768 & 7.9208 & 7.388 & TST & \\
\hline CHEMBL3642753 & 1535768 & 7.8794 & 7.8498 & TRN & \\
\hline CHEMBL3642737 & 1535768 & 7.9586 & 7.9248 & TRN & \\
\hline CHEMBL3642698 & 1535768 & 8.6021 & 8.5702 & TST & \\
\hline CHEMBL3642701 & 1535768 & 8.5229 & 8.5566 & TST & \\
\hline CHEMBL3642777 & 1535768 & 6.6676 & 6.7414 & TST & \\
\hline CHEMBL3642716 & 1535768 & 7.7932 & 7.7656 & TRN & \\
\hline CHEMBL3642802 & 1535768 & 7.4449 & 7.4186 & TRN & \\
\hline CHEMBL3642708 & 1535768 & 8.5376 & 8.7629 & TST & \\
\hline CHEMBL3642691 & 1535768 & 8.3565 & 8.3555 & TRN & \\
\hline CHEMBL3642796 & 1535768 & 7.9101 & 7.934 & TRN & \\
\hline CHEMBL3642719 & 1535768 & 8.0044 & 8.2307 & TRN & \\
\hline CHEMBL3642774 & 1535768 & 7.5935 & 7.46 & TRN & \\
\hline CHEMBL3642756 & 1535768 & 7.7167 & 7.8613 & TRN & \\
\hline CHEMBL3642786 & 1535768 & 7.3565 & 7.0131 & TST & \\
\hline CHEMBL3642809 & 1535768 & 7.6162 & 7.5703 & TRN & \\
\hline CHEMBL3642812 & 1535768 & \multicolumn{2}{|c|}{ 7. 382999999999999} & 7.4075 & TRN \\
\hline CHEMBL3642767 & 1535768 & 7.6498 & 7.8093 & TRN & \\
\hline CHEMBL3642697 & 1535768 & 8.4559 & 8.4846 & TST & \\
\hline CHEMBL3642788 & 1535768 & 7.9431 & 7.8176 & TRN & \\
\hline CHEMBL3642801 & 1535768 & 7.7799 & 7.8133 & TRN & \\
\hline CHEMBL3186408 & 954499 & 4.5082 & 4.0428 & TST & \\
\hline CHEMBL1788116 & 954499 & 5.0882 & 5.0589 & TRN & \\
\hline CHEMBL2134202 & 954499 & 3.8095 & 3.8873 & TRN & \\
\hline CHEMBL1190711 & 954499 & 6.0472 & 6.063 & TRN & \\
\hline CHEMBL191334 & 954499 & 3.2521 & 3.246006 & 00000000004 & TRN \\
\hline CHEMBL135561 & 954499 & 4.3833 & 4.3264 & TRN & \\
\hline CHEMBL300389 & 954499 & 7.8187 & 7.7963 & TRN & \\
\hline CHEMBL 9470 & 954499 & 4.1486 & 5.5831 & TST & \\
\hline CHEMBL577784 & 954499 & 5.5539 & 5.5204 & TRN & \\
\hline CHEMBL399530 & 954499 & 5.3222 & 5.3256 & TRN & \\
\hline CHEMBL2005886 & 954499 & 6.4029 & 6.4788 & TRN & \\
\hline CHEMBL3349342 & 954499 & 6.7029 & 6.7515 & TRN & \\
\hline CHEMBL240954 & 954499 & 3.8622 & 3.9329 & TST & \\
\hline CHEMBL3392440 & 954499 & 4.2596 & 4.277 & TRN & \\
\hline CHEMBL92309 & 954499 & 2.0204 & 3.2165 & TST & \\
\hline CHEMBL483849 & 954499 & 2.7099 & 2.8104 & TST & \\
\hline
\end{tabular}




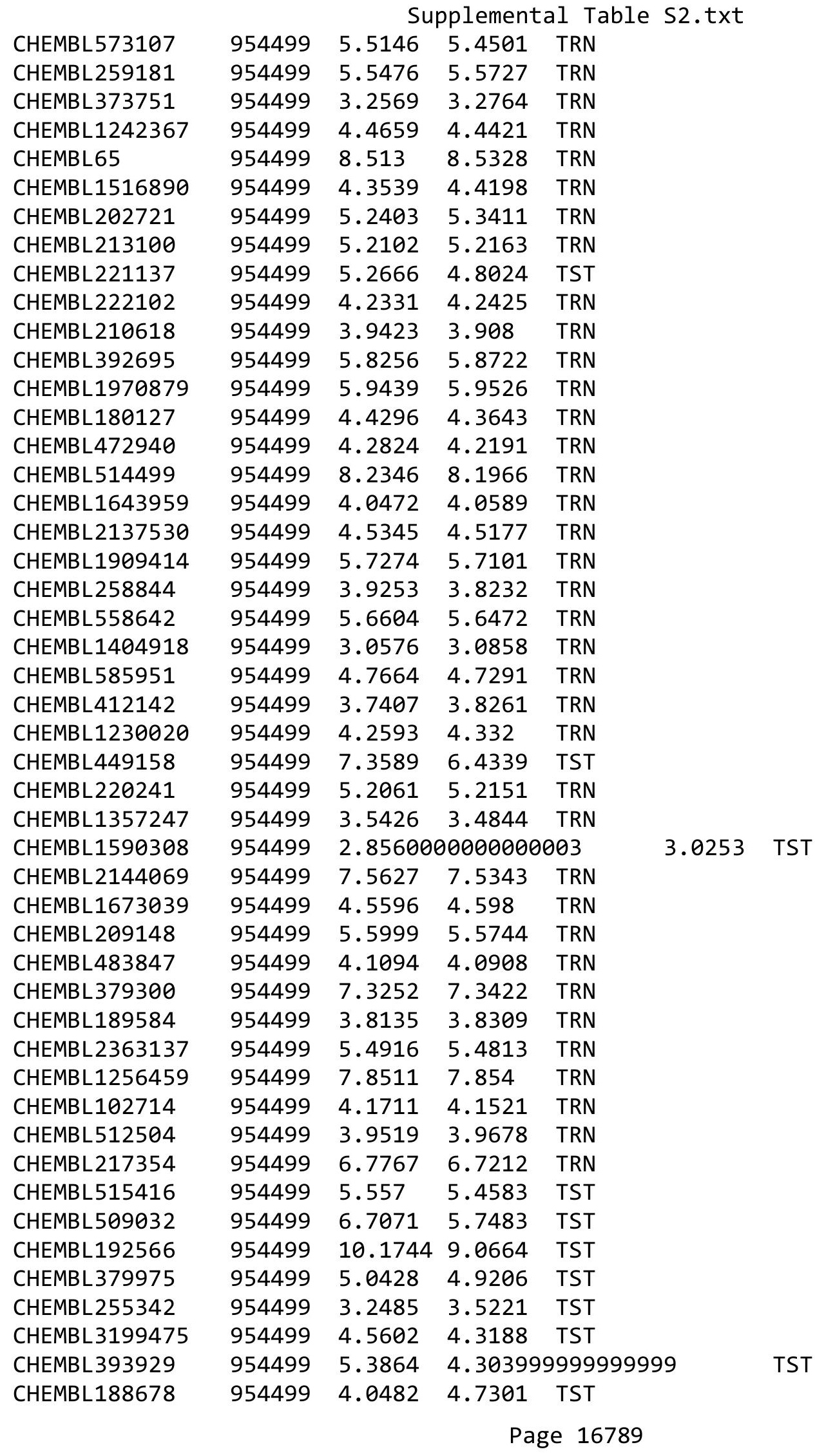


Supplemental Table S2.txt

\begin{tabular}{|c|c|c|c|c|}
\hline CHEMBL1186585 & 954499 & 2.9562 & 4.0111 & TST \\
\hline CHEMBL3939432 & 1640703 & 7.6576 & 7.1324 & TRN \\
\hline CHEMBL3936942 & 1640703 & 6.9208 & 7.2842 & TRN \\
\hline CHEMBL3952391 & 1640703 & 5.2218 & 5.6952 & TRN \\
\hline CHEMBL3954021 & 1640703 & 5.0969 & 6.3188 & TRN \\
\hline CHEMBL3924088 & 1640703 & 7.6778 & 6.4857 & TRN \\
\hline CHEMBL3895705 & 1640703 & 6.3372 & 6.2725 & TRN \\
\hline CHEMBL 2164595 & 1640703 & 5.699 & 5.5354 & TRN \\
\hline CHEMBL3918979 & 1640703 & 6.5528 & 6.7297 & TRN \\
\hline CHEMBL3900438 & 1640703 & 6.2076 & 6.2927 & TRN \\
\hline CHEMBL3965409 & 1640703 & 6.301 & 6.7917 & TRN \\
\hline CHEMBL3966689 & 1640703 & 7.1612 & 6.1448 & TRN \\
\hline CHEMBL3933715 & 1640703 & 5.3979 & 6.6929 & TRN \\
\hline CHEMBL3944389 & 1640703 & 7.6778 & 7.0838 & TRN \\
\hline CHEMBL3904461 & 1640703 & 7.284 & 5.9221 & TRN \\
\hline CHEMBL3931754 & 1640703 & 6.7696 & 6.2705 & TRN \\
\hline CHEMBL3931939 & 1640703 & 5.8239 & 5.7487 & TRN \\
\hline CHEMBL3898465 & 1640703 & 5.2218 & 5.621 & TRN \\
\hline CHEMBL3957629 & 1640703 & 6.4437 & 6.2635 & TRN \\
\hline CHEMBL3907775 & 1640703 & 6.0 & 6.5422 & TRN \\
\hline CHEMBL3948352 & 1640703 & 5.699 & 6.0326 & TRN \\
\hline CHEMBL3953969 & 1640703 & 5.0 & 5.9854 & TRN \\
\hline CHEMBL 2164596 & 1640703 & 8.0458 & 6.6273 & TRN \\
\hline CHEMBL3960017 & 1640703 & 4.0 & 4.7 & TRN \\
\hline CHEMBL3959218 & 1640703 & 6.0 & 5.9655 & TST \\
\hline CHEMBL1794181 & 1640703 & 4.0 & 4.1604 & TRN \\
\hline CHEMBL3951775 & 1640703 & 7.0 & 6.3304 & TRN \\
\hline CHEMBL3958799 & 1640703 & 7.0223 & 6.5894 & TRN \\
\hline CHEMBL1619418 & 1640703 & 5.699 & 4.6315 & TST \\
\hline CHEMBL3942561 & 1640703 & 5.301 & 6.9387 & TRN \\
\hline CHEMBL3950147 & 1640703 & 6.5686 & 6.1847 & TST \\
\hline CHEMBL3983408 & 1640703 & 7.301 & 7.0504 & TRN \\
\hline CHEMBL3952451 & 1640703 & 4.0 & 4.7189 & TRN \\
\hline CHEMBL3907492 & 1640703 & 6.3188 & 6.4801 & TST \\
\hline CHEMBL3958802 & 1640703 & 5.2218 & 5.7897 & TRN \\
\hline CHEMBL3981262 & 1640703 & 5.8861 & 5.4076 & TRN \\
\hline CHEMBL3944197 & 1640703 & 6.6576 & \multicolumn{2}{|c|}{6.297000000000001} \\
\hline CHEMBL3980344 & 1640703 & 4.0 & 5.3231 & TRN \\
\hline CHEMBL3949650 & 1640703 & 7.7696 & 7.0279 & TRN \\
\hline CHEMBL3922842 & 1640703 & 5.7959 & 6.8997 & TRN \\
\hline CHEMBL3919995 & 1640703 & 7.7212 & 7.8716 & TRN \\
\hline CHEMBL3907927 & 1640703 & 6.4559 & 6.5457 & TRN \\
\hline CHEMBL3960887 & 1640703 & 6.699 & 6.8872 & TRN \\
\hline CHEMBL3922544 & 1640703 & 7.1367 & 6.4006 & TRN \\
\hline CHEMBL3944835 & 1640703 & 6.9586 & 6.6825 & TRN \\
\hline CHEMBL3977441 & 1640703 & 6.6198 & 7.3354 & TRN \\
\hline CHEMBL3921178 & 1640703 & 6.1612 & 5.7598 & TST \\
\hline CHEMBL3913585 & 1640703 & 7.1871 & 6.9667 & TRN \\
\hline
\end{tabular}


Supplemental Table S2.txt

\begin{tabular}{|c|c|c|c|c|}
\hline CHEMBL3910058 & 1640703 & 6.9208 & 6.4803 & TRN \\
\hline CHEMBL3942175 & 1640703 & 5.6383 & 5.6015 & TST \\
\hline CHEMBL3908902 & 1640703 & 5.5229 & 7.1248 & TRN \\
\hline CHEMBL 3953529 & 1640703 & 6.3372 & \multicolumn{2}{|c|}{6.5089999999999995} \\
\hline CHEMBL 3935727 & 1640703 & 7.2291 & 6.6843 & TRN \\
\hline CHEMBL 3976010 & 1640703 & 5.4559 & 5.7637 & TRN \\
\hline CHEMBL3913379 & 1640703 & 7.5376 & 6.7342 & TRN \\
\hline CHEMBL 3982688 & 1640703 & 6.2291 & 6.2649 & TRN \\
\hline CHEMBL3984497 & 1640703 & 6.5528 & 5.7289 & TRN \\
\hline CHEMBL 3942596 & 1640703 & 6.699 & \multicolumn{2}{|c|}{6.922999999999999} \\
\hline CHEMBL 3894445 & 1640703 & 6.699 & 5.935 & TRN \\
\hline CHEMBL3925659 & 1640703 & 6.7959 & 7.0509 & TRN \\
\hline CHEMBL 3944804 & 1640703 & 6.8861 & 6.0825 & TRN \\
\hline CHEMBL3970307 & 1640703 & 6.6778 & 6.3366 & TRN \\
\hline CHEMBL 3952351 & 1640703 & 7.0605 & 6.5851 & TRN \\
\hline CHEMBL3925992 & 1640703 & 6.7447 & 6.2523 & TRN \\
\hline CHEMBL3968670 & 1640703 & 5.7959 & 6.2946 & TRN \\
\hline CHEMBL3963369 & 1640703 & 5.699 & 6.0486 & TRN \\
\hline CHEMBL3921056 & 1640703 & 6.4815 & 6.1372 & TST \\
\hline CHEMBL 3929968 & 1640703 & 7.0969 & 6.7667 & TST \\
\hline CHEMBL3890932 & 1640703 & 5.3979 & 5.7536 & TRN \\
\hline CHEMBL 3950263 & 1640703 & 7.585 & 6.2272 & TST \\
\hline CHEMBL 3982240 & 1640703 & 6.3279 & 6.2884 & TST \\
\hline CHEMBL2164599 & 1640703 & 8.0458 & 6.4563 & TST \\
\hline CHEMBL3956448 & 1640703 & 7.0 & 6.9895 & TRN \\
\hline CHEMBL3911047 & 1640703 & 7.5686 & 6.3179 & TRN \\
\hline CHEMBL3950111 & 1640703 & 6.3872 & 6.1858 & TRN \\
\hline CHEMBL 3893043 & 1640703 & 5.0969 & 6.0526 & TRN \\
\hline CHEMBL 2164594 & 1640703 & 7.0969 & \multicolumn{2}{|c|}{6.082000000000001} \\
\hline CHEMBL 3897595 & 1640703 & 5.7696 & 4.9099 & TST \\
\hline CHEMBL3958959 & 1640703 & 7.7212 & 6.5115 & TST \\
\hline CHEMBL 3958207 & 1640703 & 6.7696 & 6.9963 & TRN \\
\hline CHEMBL3924509 & 1640703 & 6.6021 & 7.1701 & TRN \\
\hline CHEMBL3917351 & 1640703 & 5.7447 & 5.8086 & TRN \\
\hline CHEMBL3922376 & 1640703 & 5.2218 & 6.388 & TST \\
\hline CHEMBL3930126 & 1640703 & 6.2676 & 5.8799 & TRN \\
\hline CHEMBL 3984894 & 1640703 & 7.6198 & 6.2462 & TST \\
\hline CHEMBL1585451 & 1640703 & 6.0 & 5.5819 & TST \\
\hline CHEMBL 3905681 & 1640703 & 6.8861 & 6.5779 & TST \\
\hline CHEMBL3976425 & 1640703 & 6.9208 & 7.4043 & TRN \\
\hline CHEMBL3970343 & 1640703 & 6.5376 & 6.775 & TRN \\
\hline CHEMBL 3952481 & 1640703 & 6.2007 & 5.7685 & TRN \\
\hline CHEMBL 3968749 & 1640703 & 6.5686 & 5.0336 & TST \\
\hline CHEMBL3982333 & 1640703 & 7.4815 & 7.4983 & TRN \\
\hline CHEMBL3981728 & 1640703 & 7.2676 & 7.1328 & TST \\
\hline CHEMBL3934803 & 1640703 & 7.6383 & 6.9307 & TRN \\
\hline CHEMBL 3961548 & 1640703 & 7.5528 & 6.3944 & TST \\
\hline CHEMBL 3892190 & 1640703 & 5.7959 & 6.6808 & TST \\
\hline
\end{tabular}


Supplemental Table S2.txt

\begin{tabular}{|c|c|c|c|c|}
\hline CHEMBL3915522 & 1640703 & 5.0969 & 4.3421 & TST \\
\hline CHEMBL3952458 & 1640703 & 5.699 & 5.7656 & TRN \\
\hline CHEMBL3979415 & 1640703 & 4.0 & \multicolumn{2}{|c|}{5.071000000000001} \\
\hline CHEMBL3894722 & 1640703 & 6.4318 & 6.5021 & TST \\
\hline CHEMBL3901099 & 1640703 & 6.4437 & 6.1428 & TRN \\
\hline CHEMBL3936987 & 1640703 & 6.699 & 6.5462 & TRN \\
\hline CHEMBL3939594 & 1640703 & 7.699 & 7.1029 & TRN \\
\hline CHEMBL 2164598 & 1640703 & 7.7447 & 6.0902 & TST \\
\hline CHEMBL 2164600 & 1640703 & 7.1612 & 6.3511 & TST \\
\hline CHEMBL3968643 & 1640703 & 7.4949 & 6.0457 & TRN \\
\hline CHEMBL3984041 & 1640703 & 5.5229 & 5.3979 & TRN \\
\hline CHEMBL3978478 & 1640703 & 7.2441 & 6.6201 & TRN \\
\hline CHEMBL 2164592 & 1640703 & 5.9586 & 5.848 & TST \\
\hline CHEMBL3910161 & 1640703 & 5.3979 & 4.962 & TST \\
\hline CHEMBL 3952197 & 1640703 & 7.2147 & 6.8752 & TRN \\
\hline CHEMBL3938086 & 1640703 & 6.6198 & 7.0802 & TST \\
\hline CHEMBL3922585 & 1640703 & 7.1739 & 7.0598 & TRN \\
\hline CHEMBL3951708 & 1640703 & 5.699 & 5.8271 & TRN \\
\hline CHEMBL3968976 & 1640703 & 7.1249 & 6.8673 & TST \\
\hline CHEMBL3955877 & 1640703 & 6.6576 & 5.7606 & TRN \\
\hline CHEMBL3901525 & 1640703 & 5.699 & 5.9895 & TRN \\
\hline CHEMBL3969150 & 1640703 & 6.6576 & 7.2237 & TRN \\
\hline CHEMBL3978604 & 1640703 & 7.3188 & 7.3392 & TRN \\
\hline CHEMBL3946699 & 1640703 & 5.3468 & 5.6287 & TRN \\
\hline CHEMBL3952986 & 1640703 & 5.0458 & 6.4986 & TST \\
\hline CHEMBL3937599 & 1640703 & 6.4202 & 7.06 & TRN \\
\hline CHEMBL3976543 & 1640703 & 5.9586 & 6.1083 & TRN \\
\hline CHEMBL 2164593 & 1640703 & 6.3279 & 5.4111 & TST \\
\hline CHEMBL3984457 & 1640703 & 5.6021 & 5.8205 & TRN \\
\hline CHEMBL3893259 & 1640703 & 4.0 & 5.9292 & TRN \\
\hline CHEMBL3979543 & 1640703 & 5.8861 & 5.6121 & TRN \\
\hline CHEMBL 3891017 & 1640703 & 7.0809 & 6.8288 & TRN \\
\hline CHEMBL3927945 & 1640703 & 6.0 & 6.6669 & TRN \\
\hline CHEMBL3905329 & 1640703 & 6.6383 & 6.4671 & TRN \\
\hline CHEMBL 2236599 & 1499866 & 4.5498 & 4.669 & TRN \\
\hline CHEMBL3582056 & 1499866 & 4.8097 & 4.6742 & TRN \\
\hline CHEMBL 3582042 & 1499866 & 3.301 & 3.3303 & TRN \\
\hline CHEMBL3582064 & 1499866 & 4.7905 & 4.0497 & TRN \\
\hline CHEMBL3582068 & 1499866 & 3.301 & 3.8935 & TST \\
\hline CHEMBL3582065 & 1499866 & 3.301 & 4.0176 & TRN \\
\hline CHEMBL 2236600 & 1499866 & 7.699 & 6.6141 & TRN \\
\hline CHEMBL3582061 & 1499866 & 3.301 & 3.2152 & TRN \\
\hline CHEMBL3582063 & 1499866 & 3.301 & 3.9056 & TRN \\
\hline CHEMBL3582038 & 1499866 & 6.0 & 5.0711 & TRN \\
\hline CHEMBL3582062 & 1499866 & 4.8601 & 4.4659 & TRN \\
\hline CHEMBL3582074 & 1499866 & 4.7696 & 4.3722 & TRN \\
\hline CHEMBL3582051 & 1499866 & 3.301 & 3.9723 & TRN \\
\hline CHEMBL3582048 & 1499866 & 3.301 & 3.378 & TRN \\
\hline
\end{tabular}


Supplemental Table S2.txt

\begin{tabular}{|c|c|c|c|c|}
\hline HEMBL & 499866 & 3.301 & 3.7541 & TS \\
\hline НГМР & & & 3.1964 & \\
\hline HFMRI & 366 & & 1075 & \\
\hline HEMBL & 866 & 301 & 35 & \\
\hline AEMBL3582058 & 499866 & .0605 & 9177 & \\
\hline HEMBL3582047 & 866 & 4.4895 & .4009 & \\
\hline 045 & & 3.301 & & \\
\hline AEMBL3 & & 3.301 & & \\
\hline HEMBL3582070 & 866 & 4.6308 & . 7984 & \\
\hline HEMBL3582049 & 866 & 4.52 & .9216 & \\
\hline HEMBL3582071 & 00 & 3.301 & 4375 & \\
\hline HEMBL & & 01 & 893 & \\
\hline HEMBL3 & & 01 & 348 & \\
\hline HEMBL3582043 & 366 & 3.301 & .5765 & \\
\hline HEMBL3582040 & & 3.301 & & \\
\hline HEMBL3 & & 3. & 7345 & \\
\hline HEMBL & & 01 & 806 & r \\
\hline HEMBL; & & 3.301 & 1854 & \\
\hline HEMBL3 & & 5.0 & . 1778 & \\
\hline HEMBL3582041 & & & 338 & \\
\hline HEMBL3 & & & 503 & RIV \\
\hline HEMBL & & & 05 & ST \\
\hline HEMBL; & & 36 & 113 & RN \\
\hline HEMBL 2 & & 5 . & 2753 & $\Gamma \mathrm{RN}$ \\
\hline HEMBL3 & & 5.585 & 5372 & IRN \\
\hline HEMBL3 & & 3. & 1035 & ST \\
\hline HEMBL & & & 59 & $\mathrm{RN}$ \\
\hline HEME & & 595 & 29 & 「RN \\
\hline HEMBL3 & & 3.301 & & IRN \\
\hline HEMBL 2236589 & 66 & 5.585 & 3747 & TST \\
\hline HEMBL & & 3 & 408 & IST \\
\hline HFN & & 6 & 27 & TRN \\
\hline 603 & & 3 . & & 「RN \\
\hline HEMBL3 & & & & 「RN \\
\hline HEMBL3582067 & 66 & 01 & & ГST \\
\hline AEMRI 3 & & 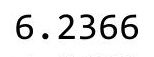 & 64 & TST \\
\hline 6 & & 8 & & IST \\
\hline HEMBL3: & & 5 . & & TST \\
\hline HEMBL 2 & & 5 . & 311 & TST \\
\hline 93 & & 3 & 387 & RN \\
\hline HEMBL 2 & & 959 & 83 & TRN \\
\hline HEMBL 2 & & 6.9208 & 6.9384 & RN \\
\hline HEMBL2335629 & & 7.301 & 7.3106 & TRN \\
\hline HEMBL2 & & 6 & 288 & TR \\
\hline U & & & & \\
\hline HEMBL 2 & & 1. & 7.5595 & \\
\hline CHEMBL2335988 & 944914 & 7.1871 & 7.1947 & \\
\hline CHEMBL2335621 & 944914 & 5.0862 & 5.1049 & $n$ \\
\hline
\end{tabular}

Page 16793 


\begin{tabular}{|c|c|c|c|c|c|}
\hline \multicolumn{6}{|c|}{ Supplemental Table S2.txt } \\
\hline CHEMBL600928 & 944914 & 8.0458 & 7.983 & TRN & \\
\hline CHEMBL 2335601 & 944914 & 5.2218 & 5.2333 & TRN & \\
\hline CHEMBL 2335612 & 944914 & 5.8239 & 5.8243 & TRN & \\
\hline CHEMBL 2335625 & 944914 & 5.3098 & 6.2363 & TST & \\
\hline CHEMBL 2335627 & 944914 & 4.4724 & 5.32700 & 0000000001 & TST \\
\hline CHEMBL 2335633 & 944914 & 6.2076 & 6.2446 & TRN & \\
\hline CHEMBL 2335989 & 944914 & 7.5686 & 7.5692 & TRN & \\
\hline CHEMBL 2335591 & 944914 & 7.2007 & 7.2063 & TRN & \\
\hline CHEMBL 2335616 & 944914 & 5.6778 & 5.6778 & TRN & \\
\hline CHEMBL 2335609 & 944914 & 6.7212 & 6.7829 & TRN & \\
\hline CHEMBL 2335985 & 944914 & 6.0 & 6.0058 & TRN & \\
\hline CHEMBL 2335600 & 944914 & 7.1487 & 7.1271 & TRN & \\
\hline CHEMBL2335592 & 944914 & 7.585 & 7.5526 & TRN & \\
\hline CHEMBL 2335613 & 944914 & 6.0862 & 6.0824 & TRN & \\
\hline CHEMBL 2335986 & 944914 & 7.4202 & 7.4246 & TRN & \\
\hline CHEMBL 2335620 & 944914 & 6.2596 & 6.223 & TRN & \\
\hline CHEMBL2335602 & 944914 & 6.7212 & 6.7227 & TRN & \\
\hline CHEMBL 2335626 & 944914 & 4.752 & 5.3454 & TST & \\
\hline CHEMBL 2335987 & 944914 & 7.4949 & 7.4806 & TRN & \\
\hline CHEMBL 2335608 & 944914 & 6.3188 & 6.3022 & TRN & \\
\hline CHEMBL 2335622 & 944914 & 6.5686 & 6.6025 & TRN & \\
\hline CHEMBL 2335597 & 944914 & 7.3468 & 7.329 & TRN & \\
\hline CHEMBL 2335624 & 944914 & 5.2441 & 5.6902 & TST & \\
\hline CHEMBL 2335617 & 944914 & 5.3565 & 5.3561 & TRN & \\
\hline CHEMBL2335623 & 944914 & 5.6778 & 5.6306 & TRN & \\
\hline CHEMBL 2335611 & 944914 & 7.699 & 7.7146 & TRN & \\
\hline CHEMBL 2335610 & 944914 & 6.3279 & 6.2747 & TRN & \\
\hline CHEMBL 2335599 & 944914 & 5.6383 & 5.6511 & TRN & \\
\hline CHEMBL 2335594 & 944914 & 8.0969 & 8.099 & TRN & \\
\hline CHEMBL 2335590 & 944914 & 6.8861 & 7.0325 & TST & \\
\hline CHEMBL 2335628 & 944914 & 6.5229 & 6.5395 & TRN & \\
\hline CHEMBL 2335598 & 944914 & 5.7959 & 5.8175 & TRN & \\
\hline CHEMBL 2335168 & 944914 & 5.7696 & 5.74799 & 9999999999 & TRN \\
\hline CHEMBL 2335596 & 944914 & 5.2147 & 5.2089 & TRN & \\
\hline CHEMBL 2335606 & 944914 & 7.0506 & 7.079 & TRN & \\
\hline CHEMBL 2335991 & 944914 & 7.6778 & 7.7012 & TRN & \\
\hline CHEMBL 2335618 & 944914 & 6.5376 & 6.5371 & TRN & \\
\hline CHEMBL 2335593 & 944914 & 5.3468 & 5.3451 & TRN & \\
\hline CHEMBL 2335631 & 944914 & 6.3665 & 5.9548 & TST & \\
\hline CHEMBL 2335607 & 944914 & 7.1135 & 7.1063 & TRN & \\
\hline CHEMBL 2335171 & 944914 & 6.1871 & 6.1879 & TRN & \\
\hline CHEMBL 2335984 & 944914 & 6.2366 & 6.1968 & TRN & \\
\hline CHEMBL 2335615 & 944914 & 5.2596 & 6.2944 & TST & \\
\hline CHEMBL 2335605 & 944914 & 6.5229 & 6.6927 & TST & \\
\hline CHEMBL 2335169 & 944914 & 5.4089 & 5.8833 & TST & \\
\hline CHEMBL599921 & 944914 & 8.1549 & 6.6654 & TST & \\
\hline CHEMBL 2335990 & 944914 & 7.7212 & 7.6106 & TST & \\
\hline CHEMBL 2335589 & 944914 & 5.8861 & 7.6114 & TST & \\
\hline
\end{tabular}


Supplemental Table S2.txt

\begin{tabular}{|c|c|c|c|c|}
\hline CHEMBL1602168 & 944914 & 7.1871 & 6.7259 & TST \\
\hline CHEMBL 2335983 & 944914 & 5.8539 & 5.5462 & TST \\
\hline CHEMBL 2335614 & 944914 & 5.6021 & 6.3321 & TST \\
\hline CHEMBL 2335603 & 944914 & 5.7696 & 6.765 & TST \\
\hline CHEMBL1566170 & 688591 & 3.4506 & \multicolumn{2}{|c|}{3.5410000000000004} \\
\hline CHEMBL1309183 & 688591 & 3.4506 & 4.0527 & TRN \\
\hline CHEMBL1411218 & 688591 & 3.4506 & 3.4533 & TRN \\
\hline CHEMBL1586118 & 688591 & 3.4506 & 3.4082 & TRN \\
\hline CHEMBL1431891 & 688591 & 4.5548 & 4.4065 & TRN \\
\hline CHEMBL3194195 & 688591 & 5.0034 & 4.7967 & TRN \\
\hline CHEMBL1573112 & 688591 & 3.4506 & 3.5275 & TRN \\
\hline CHEMBL1548605 & 688591 & 4.8296 & 5.2972 & TRN \\
\hline CHEMBL1995800 & 688591 & 3.4506 & 4.0281 & TRN \\
\hline CHEMBL1348298 & 688591 & 4.5604 & 3.5853 & TRN \\
\hline CHEMBL1380897 & 688591 & 3.4506 & 3.4371 & TRN \\
\hline CHEMBL1529667 & 688591 & 3.4506 & 3.5004 & TRN \\
\hline CHEMBL1412141 & 688591 & 3.4506 & 3.4738 & TRN \\
\hline CHEMBL1342462 & 688591 & 4.9085 & 5.1517 & TRN \\
\hline CHEMBL1519263 & 688591 & 4.9762 & 4.5673 & TST \\
\hline CHEMBL1578798 & 688591 & 3.4506 & 3.4172 & TRN \\
\hline CHEMBL1374954 & 688591 & 5.1769 & 4.2585 & TRN \\
\hline CHEMBL1471202 & 688591 & 4.7724 & 4.5178 & TRN \\
\hline CHEMBL1392858 & 688591 & 4.7028 & 4.3977 & TRN \\
\hline CHEMBL1454903 & 688591 & 5.4651 & 4.8646 & TRN \\
\hline CHEMBL3208904 & 688591 & 3.4506 & 3.3654 & TRN \\
\hline CHEMBL1418821 & 688591 & 3.4506 & 4.4502 & TRN \\
\hline CHEMBL1544847 & 688591 & 4.8223 & 3.9845 & TRN \\
\hline CHEMBL3192204 & 688591 & 4.5794 & 4.4944 & TRN \\
\hline CHEMBL1336098 & 688591 & 3.4506 & 3.8664 & TRN \\
\hline CHEMBL1504701 & 688591 & 4.4967 & 3.9609 & TRN \\
\hline CHEMBL1427691 & 688591 & 3.4506 & 3.7272 & TRN \\
\hline CHEMBL1461853 & 688591 & 3.4506 & 3.7424 & TRN \\
\hline CHEMBL1426686 & 688591 & 3.4506 & 3.408 & TRN \\
\hline CHEMBL1595361 & 688591 & 5.4375 & 4.971 & TRN \\
\hline CHEMBL1490782 & 688591 & 3.4506 & 4.1783 & TRN \\
\hline CHEMBL3209562 & 688591 & 3.4506 & 4.1562 & TRN \\
\hline CHEMBL1329027 & 688591 & 4.8616 & 4.5961 & TRN \\
\hline CHEMBL1388940 & 688591 & 3.4506 & 3.4847 & TRN \\
\hline CHEMBL1366987 & 688591 & 4.9379 & 4.7651 & TRN \\
\hline CHEMBL1345141 & 688591 & 3.4506 & 4.2565 & TRN \\
\hline CHEMBL1376288 & 688591 & 3.4506 & 3.5036 & TRN \\
\hline CHEMBL1386851 & 688591 & 3.4506 & 3.4327 & TRN \\
\hline CHEMBL3197361 & 688591 & 3.4506 & 3.4369 & TRN \\
\hline CHEMBL3213319 & 688591 & 4.9455 & 4.7409 & TST \\
\hline CHEMBL1322039 & 688591 & 4.9938 & 4.204 & TRN \\
\hline CHEMBL1547757 & 688591 & 4.8813 & 4.6154 & TRN \\
\hline CHEMBL1583097 & 688591 & 4.8049 & 4.6272 & TRN \\
\hline CHEMBL1303340 & 688591 & 3.4506 & 3.6509 & TRN \\
\hline
\end{tabular}

Page 16795 


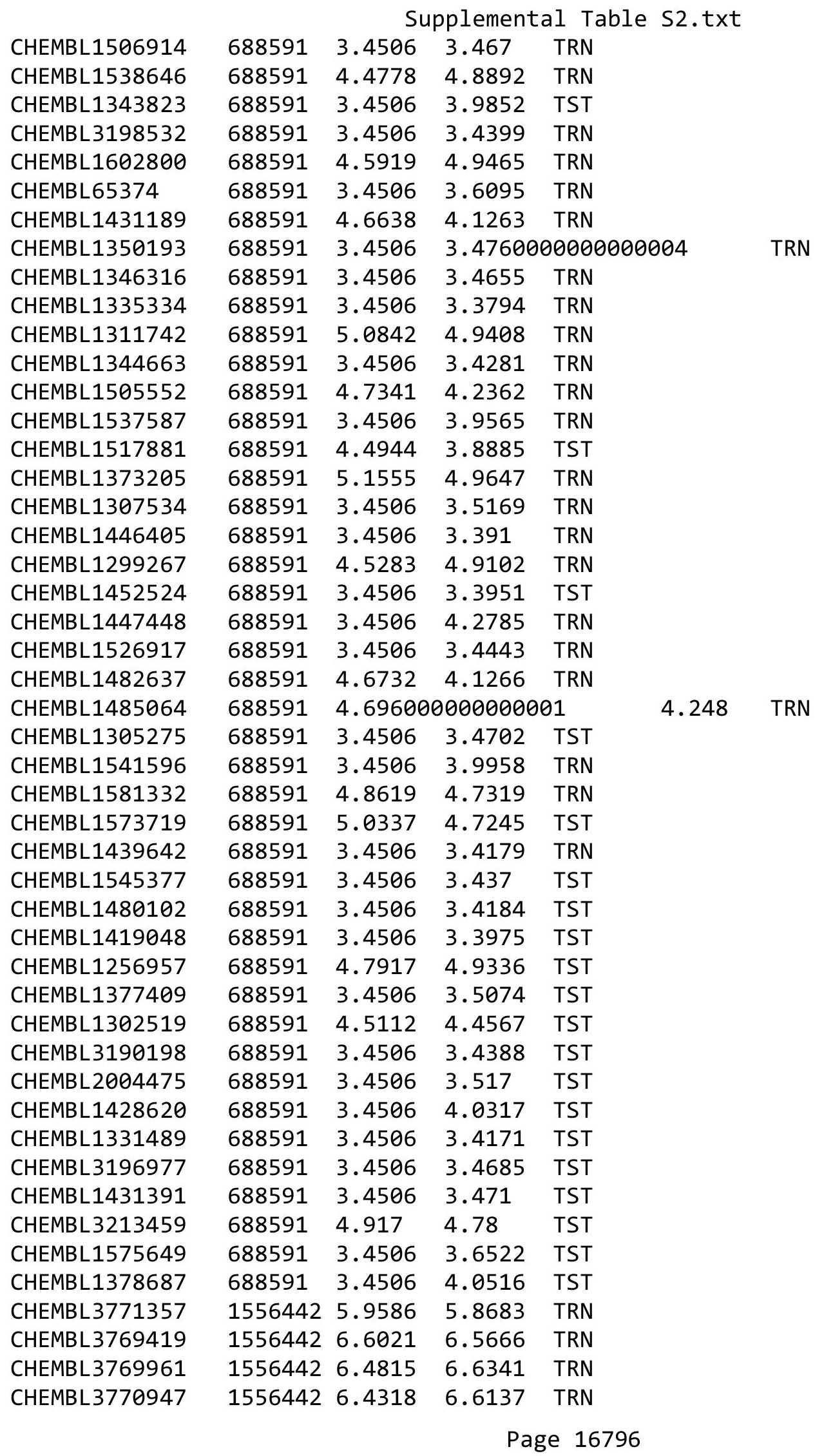


Supplemental Table S2.txt

\begin{tabular}{|c|c|c|c|c|}
\hline CHEMBL 3771241 & 1556442 & 5.699 & 4.7382 & TST \\
\hline CHEMBL3769495 & 1556442 & 6.1308 & 6.1264 & TRN \\
\hline CHEMBL3771172 & 1556442 & 3.0 & 5.0324 & TST \\
\hline CHEMBL 3770467 & 1556442 & 5.9208 & 5.8635 & TRN \\
\hline CHEMBL3769655 & 1556442 & 5.9208 & 5.9923 & TRN \\
\hline CHEMBL 3769614 & 1556442 & 5.585 & 5.5841 & TRN \\
\hline CHEMBL 3770529 & 1556442 & 4.9208 & 5.1416 & TRN \\
\hline CHEMBL 3770977 & 1556442 & 6.6576 & 6.5962 & TRN \\
\hline CHEMBL 3769932 & 1556442 & 6.699 & 6.8144 & TRN \\
\hline CHEMBL3770721 & 1556442 & 6.4089 & 4.9565 & TST \\
\hline CHEMBL 3771202 & 1556442 & 3.0 & 3.0571 & TRN \\
\hline CHEMBL3770523 & 1556442 & 4.4318 & 4.4887 & TRN \\
\hline CHEMBL 3770453 & 1556442 & 5.2076 & 5.1706 & TRN \\
\hline CHEMBL 3771321 & 1556442 & 5.2596 & 5.4032 & TRN \\
\hline CHEMBL 3771181 & 1556442 & 5.3872 & 4.7405 & TST \\
\hline CHEMBL 3771078 & 1556442 & 6.1079 & 6.204 & TRN \\
\hline CHEMBL3769474 & 1556442 & 5.7959 & 5.5947 & TRN \\
\hline CHEMBL 3769662 & 1556442 & 5.4685 & 5.3341 & TRN \\
\hline CHEMBL 3770158 & 1556442 & 4.7447 & 4.7338 & TRN \\
\hline CHEMBL 3771311 & 1556442 & 5.5086 & 5.4038 & TRN \\
\hline CHEMBL 3770557 & 1556442 & 5.0088 & 4.8629 & TST \\
\hline CHEMBL3770114 & 1556442 & 4.7447 & 4.6225 & TRN \\
\hline CHEMBL3771159 & 1556442 & 5.3665 & 5.3502 & TRN \\
\hline CHEMBL3769565 & 1556442 & 5.3372 & 5.2249 & TRN \\
\hline CHEMBL3770286 & 1556442 & 6.0655 & 4.4243 & TST \\
\hline CHEMBL3769620 & 1556442 & 6.301 & 6.267 & TRN \\
\hline CHEMBL3769617 & 1556442 & 6.3768 & 6.4449 & TRN \\
\hline CHEMBL 3769587 & 1556442 & 5.2007 & 5.2702 & TRN \\
\hline CHEMBL 3771211 & 1556442 & 4.5229 & 5.6406 & TST \\
\hline CHEMBL3770645 & 1556442 & 5.3979 & 5.2912 & TRN \\
\hline CHEMBL3771251 & 1556442 & 5.0757 & 4.5092 & TST \\
\hline CHEMBL3769843 & 1556442 & 4.3565 & 3.9608 & TRN \\
\hline CHEMBL3770646 & 1556442 & 3.0 & 3.315 & TRN \\
\hline CHEMBL3770060 & 1556442 & 5.0044 & 5.0935 & TRN \\
\hline CHEMBL3771199 & 1556442 & 5.3872 & 5.3206 & TRN \\
\hline CHEMBL3769875 & 1556442 & 5.2596 & 5.4628 & TRN \\
\hline CHEMBL3769461 & 1556442 & 6.0315 & 6.095 & TRN \\
\hline CHEMBL3770107 & 1556442 & 5.9208 & 5.8977 & TRN \\
\hline CHEMBL3769484 & 1556442 & 6.1135 & 5.8729 & TRN \\
\hline CHEMBL3770311 & 1556442 & 5.5229 & 6.007999 & 9999999999 \\
\hline CHEMBL3770427 & 1556442 & 6.3372 & 6.3474 & TRN \\
\hline CHEMBL3770804 & 1556442 & 5.6198 & 5.62 & TRN \\
\hline CHEMBL3771255 & 1556442 & 5.8239 & 4.9508 & TST \\
\hline CHEMBL3770641 & 1556442 & 6.2596 & 6.2979 & TRN \\
\hline CHEMBL 3770914 & 1556442 & 6.1549 & 5.0803 & TST \\
\hline CHEMBL 3770470 & 1556442 & 5.8861 & 6.0015 & TRN \\
\hline CHEMBL3770350 & 1556442 & 5.3279 & 5.2884 & TST \\
\hline CHEMBL3770585 & 1556442 & 7.1871 & 6.9619 & TRN \\
\hline
\end{tabular}




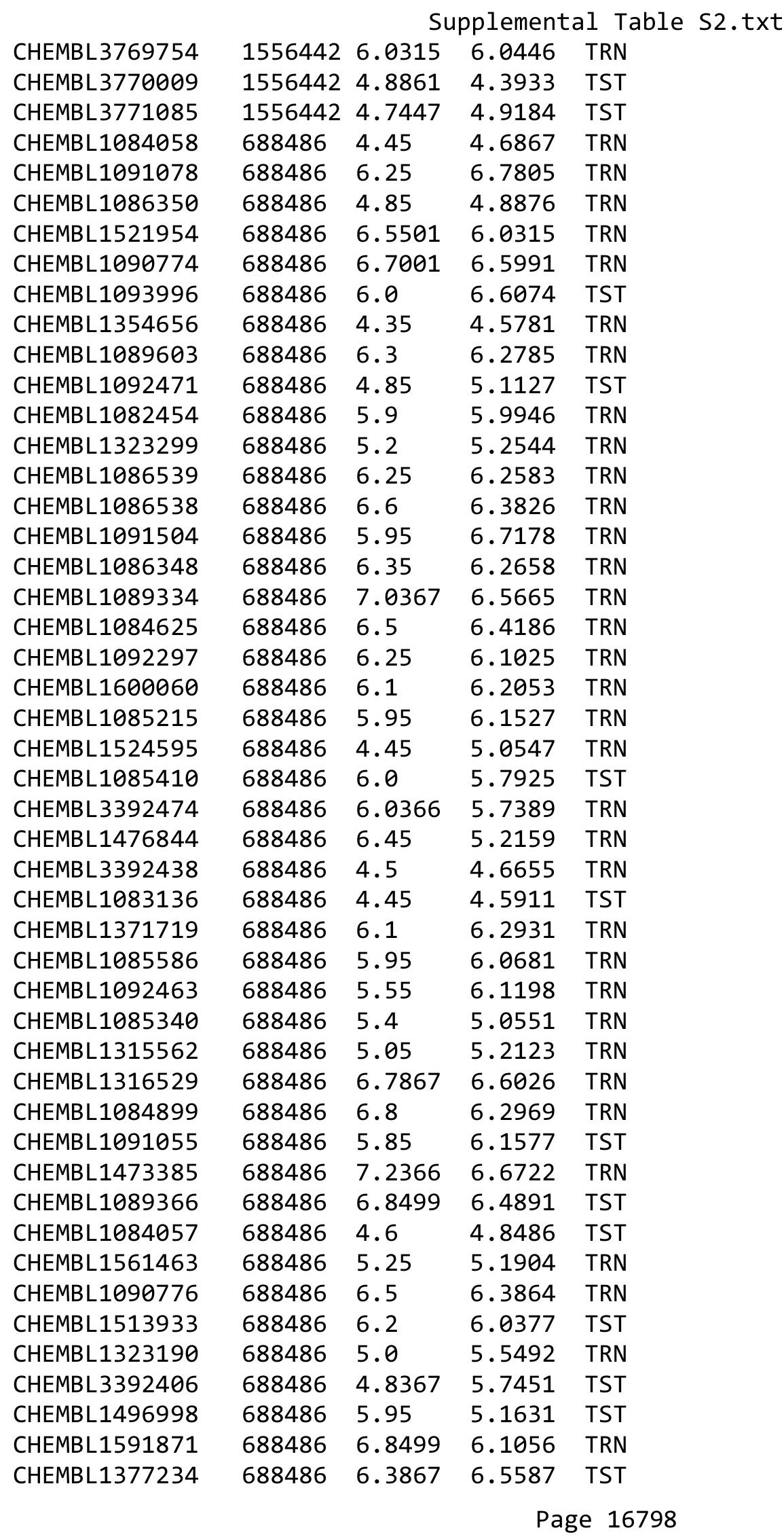




\begin{tabular}{|c|c|c|c|c|c|}
\hline \\
\hline CHEMBL1090777 & 688486 & 6.0 & 6.6679 & TRN & \\
\hline CHEMBL1555167 & 688486 & 5.7 & 5.6064 & TRN & \\
\hline CHEMBL1082815 & 688486 & 6.3367 & 6.3258 & TRN & \\
\hline CHEMBL1086320 & 688486 & 5.9 & 6.0684 & TRN & \\
\hline CHEMBL1082797 & 688486 & 6.4 & 5.9463 & TRN & \\
\hline CHEMBL1321318 & 688486 & 6.2 & 6.3421 & TRN & \\
\hline CHEMBL1086540 & 688486 & 6.45 & 6.0542 & TRN & \\
\hline CHEMBL3392435 & 688486 & 6.8499 & 6.285 & TRN & \\
\hline CHEMBL1091761 & 688486 & 6.6866 & 6.6919 & TST & \\
\hline CHEMBL3392473 & 688486 & 5.5367 & 5.7202 & TST & \\
\hline CHEMBL1515029 & 688486 & 6.15 & 6.1651 & TRN & \\
\hline CHEMBL1524808 & 688486 & 5.35 & 6.1653 & TRN & \\
\hline CHEMBL1475784 & 688486 & 4.45 & 5.3474 & TRN & \\
\hline CHEMBL1319524 & 688486 & 6.25 & 6.0228 & TRN & \\
\hline CHEMBL1486545 & 688486 & 7.9508 & 5.8558 & TRN & \\
\hline CHEMBL3392425 & 688486 & 5.1867 & 5.71700 & 00000000005 & TST \\
\hline CHEMBL3392381 & 688486 & 4.7367 & 5.7724 & TST & \\
\hline CHEMBL3392387 & 688486 & 4.8367 & 5.73799 & 99999999995 & TST \\
\hline CHEMBL1084029 & 688486 & 6.8 & 6.4716 & TRN & \\
\hline CHEMBL1323369 & 688486 & 6.7366 & 6.4701 & TST & \\
\hline CHEMBL1085648 & 688486 & 6.8499 & 6.3357 & TRN & \\
\hline CHEMBL1481562 & 688486 & 7.1864 & 6.2424 & TRN & \\
\hline CHEMBL1085412 & 688486 & 5.45 & 5.9068 & TRN & \\
\hline CHEMBL3392486 & 688486 & 5.9867 & 5.7367 & TST & \\
\hline CHEMBL1555015 & 688486 & 4.75 & 5.0384 & TRN & \\
\hline CHEMBL1082456 & 688486 & 6.7001 & 6.3631 & TRN & \\
\hline CHEMBL1091501 & 688486 & 6.0 & 6.6566 & TRN & \\
\hline CHEMBL1396401 & 688486 & 5.75 & 6.1541 & TRN & \\
\hline CHEMBL1435175 & 688486 & 6.25 & 6.0175 & TRN & \\
\hline CHEMBL1090775 & 688486 & 6.0 & 6.3369 & TRN & \\
\hline CHEMBL1090711 & 688486 & 6.0 & 6.4666 & TST & \\
\hline CHEMBL1318844 & 688486 & 5.55 & 4.8068 & TRN & \\
\hline CHEMBL1090753 & 688486 & 6.45 & 6.4601 & TRN & \\
\hline CHEMBL1091760 & 688486 & 7.1367 & 6.6545 & TST & \\
\hline CHEMBL1094006 & 688486 & 6.35 & 6.4022 & TRN & \\
\hline CHEMBL1093688 & 688486 & 6.0 & 5.7064 & TRN & \\
\hline CHEMBL3392414 & 688486 & 4.85 & 4.8915 & TRN & \\
\hline CHEMBL1475598 & 688486 & 5.0 & 4.7573 & TRN & \\
\hline CHEMBL1092472 & 688486 & 4.55 & 5.0484 & TST & \\
\hline CHEMBL1083882 & 688486 & 6.8 & 6.4726 & TRN & \\
\hline CHEMBL1085873 & 688486 & 6.0 & 5.9014 & TRN & \\
\hline CHEMBL1094007 & 688486 & 5.55 & 6.1876 & TRN & \\
\hline CHEMBL1591839 & 688486 & 6.9367 & 6.1961 & TST & \\
\hline CHEMBL1356359 & 688486 & 5.05 & 5.8493 & TRN & \\
\hline CHEMBL1083165 & 688486 & 6.2 & 6.325 & TRN & \\
\hline CHEMBL1089607 & 688486 & 6.8365 & 6.6469 & TRN & \\
\hline CHEMBL3392370 & 688486 & 6.3367 & 5.6979 & TRN & \\
\hline CHEMBL1085147 & 688486 & 6.4 & 5.9541 & TRN & \\
\hline
\end{tabular}




\begin{tabular}{|c|c|c|c|c|c|}
\hline \multicolumn{6}{|c|}{ Supplemental Table s2.txt } \\
\hline CHEMBL1360157 & 688486 & 5.25 & 4.9168 & TRN & \\
\hline CHEMBL1394261 & 688486 & 5.5 & 5.4841 & TRN & \\
\hline CHEMBL1083728 & 688486 & 6.3 & 6.017 & TRN & \\
\hline CHEMBL1089059 & 688486 & 5.6 & 5.9437 & TRN & \\
\hline CHEMBL 3392377 & 688486 & 6.7366 & 6.6097 & TST & \\
\hline CHEMBL1090756 & 688486 & 6.3 & 6.5162 & TRN & \\
\hline CHEMBL1093096 & 688486 & 5.55 & 5.6199 & TRN & \\
\hline CHEMBL1083166 & 688486 & 5.85 & 6.1444 & TRN & \\
\hline CHEMBL1338626 & 688486 & 6.25 & \multicolumn{2}{|c|}{6.337000000000001} & TRN \\
\hline CHEMBL1595109 & 688486 & 7.2865 & 6.4621 & TST & \\
\hline CHEMBL1085874 & 688486 & 6.45 & 5.9431 & TRN & \\
\hline CHEMBL1358451 & 688486 & 4.85 & 5.9989 & TRN & \\
\hline CHEMBL1082457 & 688486 & 6.7501 & 6.2935 & TRN & \\
\hline CHEMBL1083137 & 688486 & 6.7001 & 6.1506 & TRN & \\
\hline CHEMBL1083475 & 688486 & 5.6 & 5.9949 & TRN & \\
\hline CHEMBL1316556 & 688486 & 6.4366 & 6.5015 & TRN & \\
\hline CHEMBL1085413 & 688486 & 4.65 & 4.6902 & TRN & \\
\hline CHEMBL1086566 & 688486 & 6.4 & 6.691 & TRN & \\
\hline CHEMBL 3392463 & 688486 & 6.0867 & 5.6471 & TRN & \\
\hline CHEMBL1085647 & 688486 & 6.5501 & 6.7123 & TRN & \\
\hline CHEMBL1089031 & 688486 & 5.35 & 5.5561 & TRN & \\
\hline CHEMBL1091502 & 688486 & 6.0 & 6.4691 & TST & \\
\hline CHEMBL1085588 & 688486 & 6.5367 & 6.3953 & TRN & \\
\hline CHEMBL1089333 & 688486 & 6.0 & 6.6164 & TST & \\
\hline CHEMBL1082455 & 688486 & 5.65 & 5.6422 & TRN & \\
\hline CHEMBL1555112 & 688486 & 4.75 & 5.4591 & TRN & \\
\hline CHEMBL1085587 & 688486 & 6.0 & 6.2362 & TRN & \\
\hline CHEMBL 3392479 & 688486 & 4.5 & 5.1 & TRN & \\
\hline CHEMBL1086565 & 688486 & 6.15 & 6.6381 & TRN & \\
\hline CHEMBL1082796 & 688486 & 5.9 & 5.7388 & TRN & \\
\hline CHEMBL1091457 & 688486 & 6.05 & 6.3043 & TRN & \\
\hline CHEMBL1591824 & 688486 & 5.7 & 5.76200 & 00000000005 & TRN \\
\hline CHEMBL1454553 & 688486 & 5.8867 & 6.4368 & TST & \\
\hline CHEMBL1085649 & 688486 & 4.8 & 5.0431 & TRN & \\
\hline CHEMBL1093369 & 688486 & 6.0 & 6.7261 & TST & \\
\hline CHEMBL1092462 & 688486 & 6.25 & 6.6222 & TRN & \\
\hline CHEMBL3392462 & 688486 & 10.2 & 6.352 & TST & \\
\hline CHEMBL3392363 & 688486 & 4.4 & 4.7538 & TRN & \\
\hline CHEMBL1093687 & 688486 & 6.15 & 6.4556 & TST & \\
\hline CHEMBL1091503 & 688486 & 6.35 & 7.114 & TST & \\
\hline CHEMBL1085794 & 688486 & 6.8499 & 6.5132 & TRN & \\
\hline CHEMBL3392384 & 688486 & 5.5867 & 5.6787 & TST & \\
\hline CHEMBL1612651 & 688486 & 4.5 & 6.2066 & TST & \\
\hline CHEMBL1088762 & 688486 & 6.25 & 6.5759 & TST & \\
\hline CHEMBL1316291 & 688486 & 6.15 & 5.9144 & TST & \\
\hline CHEMBL1314228 & 688486 & 4.55 & 6.24299 & 9999999999 & TST \\
\hline CHEMBL1085411 & 688486 & 5.3 & 5.5256 & TRN & \\
\hline CHEMBL1086349 & 688486 & 6.6 & 6.689 & TRN & \\
\hline
\end{tabular}




\begin{tabular}{|c|c|c|c|c|}
\hline & & & oplement & al $\mathrm{Tc}$ \\
\hline CHEMBL519381 & 958516 & 3.5229 & 3.4515 & TRN \\
\hline CHEMBL510842 & 958516 & 4.7503 & 4.8085 & TRN \\
\hline CHEMBL453565 & 958516 & 4.8431 & 4.8921 & TRN \\
\hline CHEMBL2380790 & 958516 & 3.5229 & 4.4293 & TST \\
\hline CHEMBL1912051 & 958516 & 3.5229 & 3.5155 & TRN \\
\hline CHEMBL372877 & 958516 & 3.5229 & 3.5302 & TRN \\
\hline CHEMBL520363 & 958516 & 3.5229 & 3.7621 & TRN \\
\hline CHEMBL452752 & 958516 & 4.7791 & 4.6156 & TRN \\
\hline CHEMBL206765 & 958516 & 5.5302 & 5.3133 & TRN \\
\hline CHEMBL483867 & 958516 & 4.5278 & 4.7797 & TRN \\
\hline CHEMBL1644102 & 958516 & 3.5229 & 4.968 & TST \\
\hline CHEMBL2380800 & 958516 & 4.4913 & 4.2379 & TRN \\
\hline CHEMBL270060 & 958516 & 3.5229 & 4.699 & TST \\
\hline CHEMBL 2380781 & 958516 & 5.3298 & 5.2748 & TRN \\
\hline CHEMBL2380795 & 958516 & 5.0762 & 5.1055 & TRN \\
\hline CHEMBL452753 & 958516 & 4.6704 & 4.5474 & TRN \\
\hline CHEMBL371358 & 958516 & 6.2007 & 5.9826 & TRN \\
\hline CHEMBL89311 & 958516 & 3.5229 & 4.4619 & TST \\
\hline CHEMBL1257707 & 958516 & 4.7467 & 4.8353 & TRN \\
\hline CHEMBL 2380796 & 958516 & 4.6321 & 4.6393 & TRN \\
\hline CHEMBL 2380791 & 958516 & 3.5229 & 4.5031 & TST \\
\hline CHEMBL 2380798 & 958516 & 5.3251 & 5.2753 & TRN \\
\hline CHEMBL359555 & 958516 & 3.5229 & 3.5895 & TRN \\
\hline CHEMBL 2380797 & 958516 & 4.4731 & 4.4561 & TRN \\
\hline CHEMBL 2380782 & 958516 & 5.0655 & 5.1005 & TRN \\
\hline CHEMBL 270297 & 958516 & 6.1487 & 5.9849 & TRN \\
\hline CHEMBL88985 & 958516 & 5.0205 & 4.8268 & TST \\
\hline CHEMBL 2380786 & 958516 & 5.6556 & 5.6483 & TRN \\
\hline CHEMBL2380787 & 958516 & 5.8041 & 5.5779 & TRN \\
\hline CHEMBL3193163 & 958516 & 4.5134 & 4.6538 & TRN \\
\hline CHEMBL 2380317 & 958516 & 4.9151 & 4.8016 & TRN \\
\hline CHEMBL2380801 & 958516 & 3.5229 & 3.4363 & TRN \\
\hline CHEMBL 2380784 & 958516 & 5.4168 & 5.2129 & TRN \\
\hline CHEMBL463060 & 958516 & 5.5346 & 5.5094 & TRN \\
\hline CHEMBL 2380780 & 958516 & 4.7997 & 4.8172 & TRN \\
\hline CHEMBL522604 & 958516 & 4.8623 & 5.0056 & TRN \\
\hline CHEMBL1592975 & 958516 & 4.6264 & 4.4782 & TST \\
\hline CHEMBL3186408 & 958516 & 4.7592 & 4.7439 & TRN \\
\hline CHEMBL2380793 & 958516 & 3.5229 & 4.5642 & TST \\
\hline CHEMBL2380799 & 958516 & 4.8871 & 4.8369 & TRN \\
\hline CHEMBL2380789 & 958516 & 4.8788 & 4.5486 & TST \\
\hline CHEMBL 2380788 & 958516 & 3.5229 & 4.6029 & TST \\
\hline CHEMBL2332646 & 958516 & 3.5229 & 3.5281 & TRN \\
\hline CHEMBL 2380794 & 958516 & 4.8719 & 4.982 & TRN \\
\hline CHEMBL189707 & 958516 & 5.6216 & 5.8874 & TRN \\
\hline CHEMBL425554 & 958516 & 4.7518 & 4.927 & TRN \\
\hline CHEMBL137803 & 958516 & 4.716 & 4.8681 & TRN \\
\hline CHEMBL2380785 & 958516 & 5.0182 & 5.3404 & TRN \\
\hline
\end{tabular}


Supplemental Table S2.txt

\begin{tabular}{|c|c|c|c|c|c|c|}
\hline CHEMBL2380783 & 958516 & 4.6702 & 4.7613 & TRN & & \\
\hline CHEMBL429762 & 958516 & 3.5229 & 3.3646 & TRN & & \\
\hline CHEMBL453279 & 958516 & 4.5248 & 4.3988 & TRN & & \\
\hline CHEMBL1644108 & 958516 & 4.5938 & 4.6904 & TRN & & \\
\hline CHEMBL1276311 & 958516 & 3.5229 & 4.2743 & TST & & \\
\hline CHEMBL 2380792 & 958516 & \multicolumn{3}{|c|}{4.656000000000001} & 5.0534 & TST \\
\hline CHEMBL2380779 & 958516 & 3.5229 & 5.0732 & TST & & \\
\hline CHEMBL 364038 & 958516 & 5.5952 & 5.6291 & TST & & \\
\hline CHEMBL 2206431 & 958516 & \multicolumn{3}{|c|}{ 4.7589999999999995 } & 4.7479 & TST \\
\hline CHEMBL2348899 & 950589 & 3.2218 & 3.0274 & TRN & & \\
\hline CHEMBL 2348866 & 950589 & 4.7959 & 4.5778 & TST & & \\
\hline CHEMBL 2348924 & 950589 & 3.2218 & 3.5542 & TST & & \\
\hline CHEMBL 2348867 & 950589 & 4.3372 & 3.5452 & TRN & & \\
\hline CHEMBL 2346688 & 950589 & 3.2218 & 3.199 & TRN & & \\
\hline CHEMBL2349037 & 950589 & 3.2218 & 3.4171 & TRN & & \\
\hline CHEMBL 2348893 & 950589 & 3.2218 & 2.89399 & 9999999999 & & TST \\
\hline CHEMBL2349056 & 950589 & 3.2218 & $3.45300 t$ & 0000000000 & & TRN \\
\hline CHEMBL 2348895 & 950589 & 3.2218 & 3.2125 & TRN & & \\
\hline CHEMBL2348918 & 950589 & 3.2218 & 3.2783 & TRN & & \\
\hline CHEMBL2348869 & 950589 & 5.1805 & 5.2564 & TRN & & \\
\hline CHEMBL 2349041 & 950589 & 3.2218 & 3.8944 & TST & & \\
\hline CHEMBL 2349032 & 950589 & 3.2218 & 3.2297 & TRN & & \\
\hline CHEMBL 2348879 & 950589 & 3.2218 & 3.4879 & TRN & & \\
\hline CHEMBL2348896 & 950589 & 3.2218 & 3.1474 & TRN & & \\
\hline CHEMBL2349054 & 950589 & 3.2218 & 3.2405 & TRN & & \\
\hline CHEMBL2348890 & 950589 & 3.2218 & 3.2027 & TRN & & \\
\hline CHEMBL 2349053 & 950589 & 3.2218 & 3.3362 & TRN & & \\
\hline CHEMBL 2349047 & 950589 & 3.2218 & 3.9736 & TST & & \\
\hline CHEMBL2349055 & 950589 & 3.2218 & 3.608 & TST & & \\
\hline CHEMBL2349043 & 950589 & 3.2218 & 3.8736 & TST & & \\
\hline CHEMBL2349039 & 950589 & 3.2218 & 3.2799 & TRN & & \\
\hline CHEMBL 2349028 & 950589 & 3.2218 & 2.9628 & TRN & & \\
\hline CHEMBL2348917 & 950589 & 3.2218 & 3.1277 & TRN & & \\
\hline CHEMBL2349057 & 950589 & 3.2218 & 3.5277 & TST & & \\
\hline CHEMBL2348909 & 950589 & 3.2218 & 3.2734 & TRN & & \\
\hline CHEMBL2348875 & 950589 & 3.2218 & 3.7227 & TRN & & \\
\hline CHEMBL 2348915 & 950589 & 3.2218 & 3.2313 & TRN & & \\
\hline CHEMBL 2348898 & 950589 & 3.2218 & 3.2268 & TRN & & \\
\hline CHEMBL 2348881 & 950589 & 3.2218 & 3.5378 & TRN & & \\
\hline CHEMBL2348880 & 950589 & 3.2218 & 3.2781 & TRN & & \\
\hline CHEMBL2349046 & 950589 & 3.2218 & 3.4735 & TST & & \\
\hline CHEMBL 2348916 & 950589 & 3.2218 & 3.1674 & TRN & & \\
\hline CHEMBL2348902 & 950589 & 3.2218 & 3.1686 & TRN & & \\
\hline CHEMBL 2348883 & 950589 & 3.2218 & 3.1562 & TRN & & \\
\hline CHEMBL 2348874 & 950589 & 5.4437 & 5.2779 & TRN & & \\
\hline CHEMBL2348906 & 950589 & 3.2218 & 3.3603 & TRN & & \\
\hline CHEMBL2349042 & 950589 & 3.2218 & 3.5878 & TST & & \\
\hline CHEMBL 2348894 & 950589 & 3.2218 & 3.0679 & TRN & & \\
\hline
\end{tabular}




\begin{tabular}{|c|c|c|c|c|c|}
\hline \multirow[b]{2}{*}{ CHEMBL 2348920} & \multicolumn{5}{|c|}{ Supplemental Table S2.txt } \\
\hline & 950589 & 3.2218 & 3.3913 & TRN & \\
\hline CHEMBL 2348891 & 950589 & 3.2218 & 3.8385 & TRN & \\
\hline CHEMBL 2348871 & 950589 & 4.4089 & 4.2924 & TRN & \\
\hline CHEMBL 2348870 & 950589 & 4.699 & 4.6563 & TRN & \\
\hline CHEMBL 2348876 & 950589 & 3.2218 & 4.1172 & TST & \\
\hline CHEMBL 2349051 & 950589 & 3.2218 & 3.4745 & TST & \\
\hline CHEMBL 2348927 & 950589 & 3.2218 & 3.133 & TRN & \\
\hline CHEMBL 2349040 & 950589 & 3.2218 & 3.576 & TST & \\
\hline CHEMBL 2348872 & 950589 & 4.6198 & 4.38899 & 9999999999 & TRN \\
\hline CHEMBL2349045 & 950589 & 3.2218 & 3.8819 & TST & \\
\hline CHEMBL 2348912 & 950589 & 4.2291 & 4.0144 & TRN & \\
\hline CHEMBL 2348873 & 950589 & 3.2218 & 3.9515 & TRN & \\
\hline CHEMBL 2348907 & 950589 & 3.2218 & 3.2634 & TRN & \\
\hline CHEMBL 2349052 & 950589 & 3.2218 & 3.4394 & TST & \\
\hline CHEMBL 2349031 & 950589 & 3.2218 & 3.1523 & TRN & \\
\hline CHEMBL 2348914 & 950589 & 3.2218 & 3.1114 & TRN & \\
\hline CHEMBL 2348892 & 950589 & 3.2218 & 3.0305 & TRN & \\
\hline CHEMBL 2349030 & 950589 & 3.2218 & 3.1723 & TRN & \\
\hline CHEMBL 2348923 & 950589 & 3.2218 & 3.5236 & TST & \\
\hline CHEMBL 2349035 & 950589 & 3.2218 & 3.3051 & TRN & \\
\hline CHEMBL 2348919 & 950589 & 3.2218 & 3.0512 & TRN & \\
\hline CHEMBL 2348889 & 950589 & 3.2218 & 3.2637 & TRN & \\
\hline CHEMBL 2348877 & 950589 & 3.2218 & 3.2698 & TRN & \\
\hline CHEMBL 2348905 & 950589 & 4.9747 & 3.4858 & TST & \\
\hline CHEMBL 2348926 & 950589 & 3.2218 & 3.2495 & TRN & \\
\hline CHEMBL 2348910 & 950589 & 3.2218 & 3.4231 & TRN & \\
\hline CHEMBL 2348903 & 950589 & 3.2218 & 3.4655 & TST & \\
\hline CHEMBL 2348911 & 950589 & 3.2218 & 3.0312 & TRN & \\
\hline CHEMBL 2348908 & 950589 & 3.2218 & 3.5668 & TRN & \\
\hline CHEMBL 2349036 & 950589 & 3.2218 & 3.0891 & TRN & \\
\hline CHEMBL 2348887 & 950589 & 4.301 & 3.7595 & TRN & \\
\hline CHEMBL 2349034 & 950589 & 3.2218 & 3.2009 & TRN & \\
\hline CHEMBL 2349033 & 950589 & 3.2218 & 3.2299 & TRN & \\
\hline CHEMBL 2349044 & 950589 & 3.2218 & 3.6961 & TST & \\
\hline CHEMBL 2348886 & 950589 & 3.2218 & 3.4226 & TRN & \\
\hline CHEMBL 2349048 & 950589 & 3.2218 & 3.3915 & TST & \\
\hline CHEMBL 2348888 & 950589 & 3.2218 & 3.1236 & TRN & \\
\hline CHEMBL 2349049 & 950589 & 3.2218 & 3.5214 & TST & \\
\hline CHEMBL 2348882 & 950589 & 4.4202 & 3.9917 & TRN & \\
\hline CHEMBL 2348922 & 950589 & 3.2218 & 3.22899 & 99999999996 & TRN \\
\hline CHEMBL 2349058 & 950589 & 3.2218 & 3.6615 & TST & \\
\hline CHEMBL 2348900 & 950589 & 3.2218 & 3.3582 & TRN & \\
\hline CHEMBL 2348904 & 950589 & 3.2218 & 3.1219 & TRN & \\
\hline CHEMBL 2348878 & 950589 & 3.2218 & 3.2973 & TRN & \\
\hline CHEMBL 2348885 & 950589 & 3.2218 & 3.2751 & TRN & \\
\hline CHEMBL 2348897 & 950589 & 3.2218 & 3.1644 & TRN & \\
\hline CHEMBL 2348884 & 950589 & 4.5086 & 3.783 & TST & \\
\hline CHEMBL 2349027 & 950589 & 3.2218 & 3.3452 & TRN & \\
\hline
\end{tabular}




\begin{tabular}{|c|c|c|c|c|c|c|}
\hline & & \multicolumn{5}{|c|}{ Supplemental Table S2.txt } \\
\hline CHEMBL2348901 & 950589 & 3.2218 & 3.1318 & TRN & & \\
\hline CHEMBL2348913 & 950589 & 3.2218 & 3.0774 & TRN & & \\
\hline CHEMBL2348868 & 950589 & 5.2366 & 4.9673 & TRN & & \\
\hline CHEMBL2348925 & 950589 & 3.2218 & 3.4087 & TRN & & \\
\hline CHEMBL2349029 & 950589 & 3.2218 & 3.3428 & TRN & & \\
\hline CHEMBL 2349050 & 950589 & 3.2218 & 3.2957 & TST & & \\
\hline CHEMBL2349038 & 950589 & 3.2218 & 3.2404 & TRN & & \\
\hline CHEMBL 2348921 & 950589 & 3.2218 & 3.2032 & TRN & & \\
\hline CHEMBL1346462 & 737075 & 4.349 & 4.4533 & TRN & & \\
\hline CHEMBL1419870 & 737075 & 4.6981 & 5.4229 & TRN & & \\
\hline CHEMBL1462634 & 737075 & 5.5745 & 4.9012 & TRN & & \\
\hline CHEMBL1605867 & 737075 & 5.1487 & 4.9595 & TRN & & \\
\hline CHEMBL1584752 & 737075 & 4.8722 & 4.8825 & TRN & & \\
\hline CHEMBL1373182 & 737075 & 5.5438 & 5.0311 & TRN & & \\
\hline CHEMBL1987419 & 737075 & 5.0641 & 5.32 & TRN & & \\
\hline CHEMBL1538209 & 737075 & 4.6533 & 5.1743 & TRN & & \\
\hline CHEMBL1421354 & 737075 & 5.4022 & 4.8807 & TRN & & \\
\hline CHEMBL1522732 & 737075 & 4.5988 & 4.8358 & TRN & & \\
\hline CHEMBL1703507 & 737075 & 4.4063 & 4.4571 & TRN & & \\
\hline CHEMBL1389024 & 737075 & 5.2955 & 4.8645 & TRN & & \\
\hline CHEMBL1578365 & 737075 & 4.9867 & 4.9583 & TRN & & \\
\hline CHEMBL316034 & 737075 & 5.8038 & 5.1487 & TST & & \\
\hline CHEMBL1444349 & 737075 & 4.5167 & 5.2358 & TRN & & \\
\hline CHEMBL1327514 & 737075 & 4.6682 & 4.6725 & TRN & & \\
\hline CHEMBL1734788 & 737075 & \multicolumn{3}{|c|}{5.172000000000001} & 4.8794 & TRN \\
\hline CHEMBL3197601 & 737075 & 5.0515 & 5.4195 & TRN & & \\
\hline CHEMBL1559336 & 737075 & 5.0925 & 5.1583 & TRN & & \\
\hline CHEMBL1459860 & 737075 & 4.9355 & 4.7358 & TRN & & \\
\hline CHEMBL1526167 & 737075 & 4.9776 & 5.4026 & TRN & & \\
\hline CHEMBL1566909 & 737075 & 5.9104 & 5.2776 & TRN & & \\
\hline CHEMBL3194112 & 737075 & 5.6992 & 5.3487 & TRN & & \\
\hline CHEMBL1523196 & 737075 & 3.2218 & 4.6397 & TRN & & \\
\hline CHEMBL1425516 & 737075 & 4.6885 & 5.084 & TST & & \\
\hline CHEMBL1550207 & 737075 & 4.5764 & 4.885 & TST & & \\
\hline CHEMBL1518248 & 737075 & 4.9473 & 4.9241 & TRN & & \\
\hline CHEMBL1479199 & 737075 & 5.118 & 5.0056 & TRN & & \\
\hline CHEMBL578512 & 737075 & 6.2665 & 6.1959 & TRN & & \\
\hline CHEMBL1508461 & 737075 & 4.3973 & 4.9928 & TRN & & \\
\hline CHEMBL1511981 & 737075 & 5.2651 & 5.0875 & TRN & & \\
\hline CHEMBL1965172 & 737075 & 5.1369 & 5.3084 & TRN & & \\
\hline CHEMBL1727509 & 737075 & 4.6964 & 4.5725 & TRN & & \\
\hline CHEMBL1442399 & 737075 & 4.6055 & 4.4326 & TRN & & \\
\hline CHEMBL1546861 & 737075 & 4.7349 & 4.6824 & TRN & & \\
\hline CHEMBL1412782 & 737075 & 4.9179 & 4.5847 & TRN & & \\
\hline CHEMBL1447038 & 737075 & 5.2494 & 5.0596 & TST & & \\
\hline CHEMBL1463659 & 737075 & 6.0592 & 6.0425 & TRN & & \\
\hline CHEMBL1403497 & 737075 & 4.9496 & 4.9986 & TRN & & \\
\hline \multirow[t]{2}{*}{ CHEMBL1307692 } & 737075 & 5.1535 & 5.00899 & 99999 & & TRN \\
\hline & & \multicolumn{5}{|c|}{ Page 16804} \\
\hline
\end{tabular}




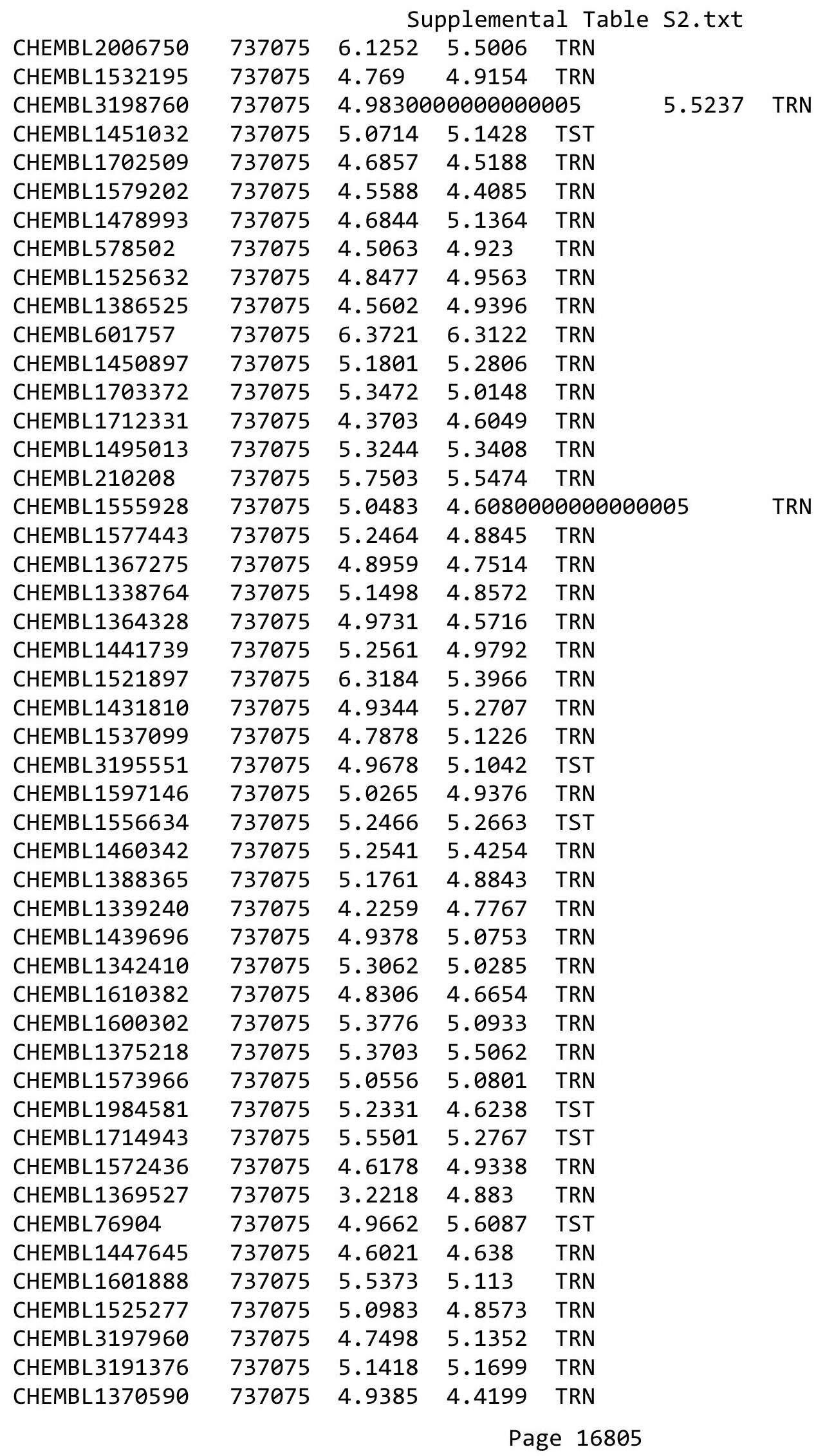




\begin{tabular}{|c|c|c|c|c|c|}
\hline & & \multicolumn{4}{|c|}{ Supplemental Table S2.txt } \\
\hline CHEMBL3199539 & 737075 & 6.0816 & 5.5843 & TRN & \\
\hline CHEMBL1982032 & 737075 & 6.4114 & 5.5273 & TST & \\
\hline CHEMBL1480064 & 737075 & 5.0034 & 5.0209 & TRN & \\
\hline CHEMBL3207505 & 737075 & 4.7445 & 4.9379 & TST & \\
\hline CHEMBL542700 & 737075 & 4.8179 & 5.2353 & TRN & \\
\hline CHEMBL1728484 & 737075 & 4.8827 & 4.4756 & TST & \\
\hline CHEMBL1611675 & 737075 & 4.8321 & 5.0035 & TRN & \\
\hline CHEMBL1425181 & 737075 & 3.2218 & 4.91100 & 00000000005 & TRN \\
\hline CHEMBL1329141 & 737075 & 5.3308 & 4.9879 & TRN & \\
\hline CHEMBL1342337 & 737075 & 4.8844 & 5.0624 & TRN & \\
\hline CHEMBL1489477 & 737075 & 5.0038 & 4.6673 & TRN & \\
\hline CHEMBL1422588 & 737075 & 3.2218 & 4.8932 & TST & \\
\hline CHEMBL1419243 & 737075 & 3.2218 & 4.7744 & TRN & \\
\hline CHEMBL1372809 & 737075 & 5.3962 & 5.0602 & TRN & \\
\hline CHEMBL1426955 & 737075 & 6.0223 & 5.2995 & TRN & \\
\hline CHEMBL1383244 & 737075 & \multicolumn{3}{|c|}{5.9270000000000005} & TRN \\
\hline CHEMBL1331562 & 737075 & 5.9144 & 4.8929 & TRN & \\
\hline CHEMBL1604990 & 737075 & 4.6515 & 4.9709 & TRN & \\
\hline CHEMBL1426692 & 737075 & 5.2678 & 4.7953 & TRN & \\
\hline CHEMBL1603855 & 737075 & 5.6045 & 5.1838 & TRN & \\
\hline CHEMBL1518089 & 737075 & 5.9638 & 4.8492 & TRN & \\
\hline CHEMBL 1357436 & 737075 & 3.2218 & 4.3934 & TRN & \\
\hline CHEMBL1431042 & 737075 & 4.9983 & 4.8629 & TRN & \\
\hline CHEMBL1520012 & 737075 & 4.9654 & 4.6819 & TRN & \\
\hline CHEMBL1390278 & 737075 & 5.4371 & 5.1673 & TRN & \\
\hline CHEMBL1546396 & 737075 & 5.3269 & 5.0691 & TRN & \\
\hline CHEMBL1571258 & 737075 & 4.9731 & 5.1674 & TRN & \\
\hline CHEMBL1381433 & 737075 & 5.2699 & 5.2644 & TRN & \\
\hline CHEMBL1438779 & 737075 & 6.097 & 5.0885 & TRN & \\
\hline CHEMBL1352532 & 737075 & 4.3322 & 5.2486 & TRN & \\
\hline CHEMBL1577302 & 737075 & 5.0539 & 5.277 & TRN & \\
\hline CHEMBL1579475 & 737075 & 4.5334 & 4.9035 & TRN & \\
\hline CHEMBL1560141 & 737075 & 4.9427 & 5.1149 & TST & \\
\hline CHEMBL 2004417 & 737075 & 5.5133 & 5.6154 & TRN & \\
\hline CHEMBL1404277 & 737075 & 5.2177 & 5.2467 & TST & \\
\hline CHEMBL1370800 & 737075 & 5.0361 & 5.345 & TRN & \\
\hline CHEMBL 1424725 & 737075 & 4.9763 & 5.0226 & TRN & \\
\hline CHEMBL 2000342 & 737075 & 6.1746 & 5.2931 & TST & \\
\hline CHEMBL1342118 & 737075 & 4.9957 & 4.7615 & TRN & \\
\hline CHEMBL1320553 & 737075 & 5.0466 & 5.0912 & TRN & \\
\hline CHEMBL1563898 & 737075 & 5.7055 & 5.6153 & TST & \\
\hline CHEMBL1301372 & 737075 & 4.9496 & 5.2598 & TST & \\
\hline CHEMBL1609381 & 737075 & 5.7552 & 4.8705 & TST & \\
\hline CHEMBL1299353 & 737075 & 5.0359 & 4.8768 & TST & \\
\hline CHEMBL1973669 & 737075 & 5.568 & 5.5877 & TST & \\
\hline CHEMBL1312781 & 737075 & 5.1677 & 5.0677 & TST & \\
\hline CHEMBL 1728647 & 737075 & 5.061 & 5.1957 & TST & \\
\hline CHEMBL1303728 & 737075 & 5.1854 & 4.9481 & TST & \\
\hline
\end{tabular}




\begin{tabular}{|c|c|c|c|c|c|c|}
\hline \multicolumn{7}{|c|}{ s2.txt } \\
\hline CHEMBL75412 & 737075 & 4.4082 & 5.193 & TST & & \\
\hline CHEMBL1415289 & 737075 & 4.8179 & 5.0638 & TST & & \\
\hline CHEMBL1459787 & 737075 & 4.9151 & 4.9197 & TST & & \\
\hline CHEMBL1520677 & 737075 & 4.8814 & 5.0629 & TST & & \\
\hline CHEMBL1574002 & 737075 & 4.9767 & 4.8499 & TST & & \\
\hline CHEMBL1729501 & 737075 & 4.9465 & 4.9016 & TST & & \\
\hline CHEMBL3193400 & 737075 & 5.3955 & 5.0987 & TST & & \\
\hline CHEMBL1484826 & 737075 & 5.1183 & 4.9168 & TST & & \\
\hline CHEMBL1581881 & 737075 & 4.7716 & 4.9952 & TST & & \\
\hline CHEMBL1489812 & 737075 & 5.19799 & 9999999 & 995 & 5.2860000000000005 & TST \\
\hline CHEMBL1442773 & 737075 & 4.60800 & 00000006 & 005 & 5.252999999999999 & TST \\
\hline CHEMBL1378659 & 737075 & 4.9516 & 5.3029 & TST & & \\
\hline CHEMBL 211850 & 384211 & 8.4 & 8.5402 & TRN & & \\
\hline CHEMBL380264 & 384211 & 7.2 & 7.4227 & TRN & & \\
\hline CHEMBL211190 & 384211 & 6.9 & 6.7863 & TRN & & \\
\hline CHEMBL211103 & 384211 & 7.3 & 7.3298 & TST & & \\
\hline CHEMBL209424 & 384211 & 6.9 & 6.9337 & TRN & & \\
\hline CHEMBL209900 & 384211 & 6.7 & 6.7028 & TRN & & \\
\hline CHEMBL213839 & 384211 & 9.1 & 9.134 & TRN & & \\
\hline CHEMBL212064 & 384211 & 8.3 & 8.2769 & TRN & & \\
\hline CHEMBL 213272 & 384211 & 8.2 & 8.4157 & TRN & & \\
\hline CHEMBL213328 & 384211 & 7.9 & 8.0097 & TRN & & \\
\hline CHEMBL377174 & 384211 & 9.5 & 9.3194 & TRN & & \\
\hline CHEMBL210053 & 384211 & 8.9 & 8.8055 & TRN & & \\
\hline CHEMBL212886 & 384211 & 8.3 & 8.3776 & TRN & & \\
\hline CHEMBL 386431 & 384211 & 8.2 & 8.0707 & TRN & & \\
\hline CHEMBL211466 & 384211 & 8.1 & 8.1316 & TRN & & \\
\hline CHEMBL215864 & 384211 & 8.5 & 8.2624 & TRN & & \\
\hline CHEMBL 386332 & 384211 & 8.8 & 9.0375 & TRN & & \\
\hline CHEMBL209431 & 384211 & 7.9 & 7.8315 & TRN & & \\
\hline CHEMBL209432 & 384211 & 8.4 & 8.5445 & TRN & & \\
\hline CHEMBL212270 & 384211 & 8.6 & 8.6239 & TRN & & \\
\hline CHEMBL208894 & 384211 & 8.1 & 8.2804 & TRN & & \\
\hline CHEMBL 211267 & 384211 & 8.2 & 8.2054 & TRN & & \\
\hline CHEMBL210124 & 384211 & 8.1 & 8.0685 & TRN & & \\
\hline CHEMBL209573 & 384211 & 8.5 & 8.484 & TRN & & \\
\hline CHEMBL376962 & 384211 & 8.4 & 8.4469 & TRN & & \\
\hline CHEMBL209735 & 384211 & 7.9 & 7.8558 & TRN & & \\
\hline CHEMBL385921 & 384211 & 7.9 & 7.9963 & TRN & & \\
\hline CHEMBL211980 & 384211 & 7.0 & 6.9015 & TRN & & \\
\hline CHEMBL439504 & 384211 & 7.9 & 7.9003 & TRN & & \\
\hline CHEMBL213368 & 384211 & 6.1 & 6.1515 & TRN & & \\
\hline CHEMBL383942 & 384211 & 6.5 & 6.7893 & TST & & \\
\hline CHEMBL 386215 & 384211 & 7.6 & 7.5872 & TRN & & \\
\hline CHEMBL213358 & 384211 & 7.0 & 6.9882 & TRN & & \\
\hline CHEMBL 379861 & 384211 & 6.4 & 6.3876 & TRN & & \\
\hline CHEMBL379336 & 384211 & 7.9 & 7.8584 & TRN & & \\
\hline CHEMBL209387 & 384211 & 7.6 & 7.2844 & TST & & \\
\hline
\end{tabular}




\begin{tabular}{|c|c|c|c|c|c|}
\hline & & & & & \\
\hline CHEMBL214397 & 384211 & 7.0 & 7.8252 & TST & \\
\hline CHEMBL214398 & 384211 & 8.3 & 8.2096 & TST & \\
\hline CHEMBL212769 & 384211 & 8.3 & 8.0647 & TST & \\
\hline CHEMBL213958 & 384211 & 7.0 & 7.20200 & 0000000001 & TST \\
\hline CHEMBL211719 & 384211 & 7.7 & 7.4438 & TST & \\
\hline CHEMBL209727 & 384211 & 7.8 & 7.2435 & TST & \\
\hline CHEMBL427398 & 384211 & 8.0 & 7.6535 & TST & \\
\hline CHEMBL 209674 & 384211 & 8.0 & 7.974 & TST & \\
\hline CHEMBL212686 & 384211 & 7.7 & 7.2513 & TST & \\
\hline CHEMBL210007 & 384211 & 8.3 & 8.3673 & TRN & \\
\hline CHEMBL 210059 & 384211 & 8.0 & 8.0407 & TRN & \\
\hline CHEMBL387022 & 384211 & 8.3 & 8.2067 & TRN & \\
\hline CHEMBL 380020 & 384211 & 8.2 & 8.1315 & TRN & \\
\hline CHEMBL438963 & 384211 & 8.2 & 8.1186 & TRN & \\
\hline CHEMBL426684 & 384211 & 6.7 & 7.5043 & TST & \\
\hline CHEMBL 212482 & 384211 & 6.9 & 8.1079 & TST & \\
\hline CHEMBL213987 & 384211 & 9.1 & 8.6968 & TRN & \\
\hline CHEMBL21728 & 1284012 & 5.9586 & 5.4729 & TRN & \\
\hline CHEMBL3104214 & 1284012 & 7.4815 & 7.3673 & TRN & \\
\hline CHEMBL3104186 & 1284012 & 6.0809 & 6.2646 & TRN & \\
\hline CHEMBL3104208 & 1284012 & 7.1549 & 7.1968 & TRN & \\
\hline CHEMBL417100 & 1284012 & 5.6383 & 5.3417 & TRN & \\
\hline CHEMBL 3104178 & 1284012 & 7.4685 & 7.1443 & TST & \\
\hline CHEMBL3104217 & 1284012 & 4.7696 & 5.1419 & TRN & \\
\hline CHEMBL 3104203 & 1284012 & 6.5229 & 7.1901 & TST & \\
\hline CHEMBL20965 & 1284012 & 4.5229 & 5.2655 & TST & \\
\hline CHEMBL 20549 & 1284012 & 5.2757 & 5.1582 & TRN & \\
\hline CHEMBL20400 & 1284012 & 4.9208 & 5.1705 & TRN & \\
\hline CHEMBL21679 & 1284012 & 5.4949 & 5.2469 & TRN & \\
\hline CHEMBL3104212 & 1284012 & 6.5229 & 7.0354 & TRN & \\
\hline CHEMBL3104113 & 1284012 & 6.9586 & 6.4295 & TRN & \\
\hline CHEMBL 3104221 & 1284012 & 4.9586 & 5.3319 & TRN & \\
\hline CHEMBL 3104206 & 1284012 & 7.1427 & 7.1278 & TST & \\
\hline CHEMBL3104177 & 1284012 & 7.4202 & 7.244 & TST & \\
\hline CHEMBL 3104184 & 1284012 & 6.8861 & 6.4376 & TRN & \\
\hline CHEMBL20773 & 1284012 & 5.5528 & 5.2205 & TRN & \\
\hline CHEMBL3104228 & 1284012 & 6.1427 & 6.9913 & TST & \\
\hline CHEMBL22119 & 1284012 & 4.8239 & 5.2354 & TRN & \\
\hline CHEMBL21907 & 1284012 & 5.4437 & 5.353 & TRN & \\
\hline CHEMBL 3104191 & 1284012 & 6.699 & 7.3243 & TRN & \\
\hline CHEMBL21019 & 1284012 & 5.0506 & 5.2884 & TRN & \\
\hline CHEMBL3104196 & 1284012 & 7.585 & 7.5277 & TRN & \\
\hline CHEMBL3104182 & 1284012 & 7.0706 & 6.5392 & TRN & \\
\hline CHEMBL441516 & 1284012 & 4.5229 & 5.1716 & TRN & \\
\hline CHEMBL 21071 & 1284012 & 5.0 & 5.3839 & TRN & \\
\hline CHEMBL283106 & 1284012 & 5.4815 & 5.2904 & TRN & \\
\hline CHEMBL3104116 & 1284012 & 6.2218 & 6.45100 & 00000000005 & TRN \\
\hline CHEMBL20553 & 1284012 & 5.7212 & 5.3772 & TRN & \\
\hline & & & & 6808 & \\
\hline
\end{tabular}


Supplemental Table S2.txt

\begin{tabular}{|c|c|c|c|c|c|}
\hline CHEMBL265065 & 1284012 & 6.0969 & 5.6361 & TRN & \\
\hline CHEMBL3104219 & 1284012 & 7.4559 & 7.1783 & TST & \\
\hline CHEMBL3104176 & 1284012 & 6.8239 & 7.1951 & TST & \\
\hline CHEMBL 3104211 & 1284012 & 5.5229 & \multicolumn{2}{|c|}{7.0520000000000005} & TRN \\
\hline CHEMBL279289 & 1284012 & 4.585 & 5.2588 & TRN & \\
\hline CHEMBL 21652 & 1284012 & 5.4089 & 5.2779 & TRN & \\
\hline CHEMBL21877 & 1284012 & 6.0 & 5.5019 & TRN & \\
\hline CHEMBL 3104175 & 1284012 & 6.5376 & 7.1333 & TST & \\
\hline CHEMBL22056 & 1284012 & 5.5229 & 5.2428 & TRN & \\
\hline CHEMBL3104122 & 1284012 & 7.1079 & 6.4486 & TRN & \\
\hline CHEMBL 3104204 & 1284012 & 7.699 & 7.3845 & TRN & \\
\hline CHEMBL 3104180 & 1284012 & 7.9586 & 6.5952 & TRN & \\
\hline CHEMBL 3104223 & 1284012 & 5.0362 & 5.4552 & TST & \\
\hline CHEMBL3104195 & 1284012 & 7.3565 & 7.4637 & TRN & \\
\hline CHEMBL3104209 & 1284012 & 7.0969 & 7.135 & TRN & \\
\hline CHEMBL416005 & 1284012 & 5.3979 & 5.1722 & TRN & \\
\hline CHEMBL21507 & 1284012 & 6.2218 & 5.6548 & TRN & \\
\hline CHEMBL3104185 & 1284012 & 6.6576 & 6.4686 & TRN & \\
\hline CHEMBL 3104193 & 1284012 & 7.3565 & \multicolumn{2}{|c|}{7.5360000000000005} & TRN \\
\hline CHEMBL3104187 & 1284012 & 5.71 & 6.3713 & TRN & \\
\hline CHEMBL3102871 & 1284012 & 6.3768 & \multicolumn{2}{|c|}{6.236000000000001} & TRN \\
\hline CHEMBL3104207 & 1284012 & 7.699 & 7.2657 & TRN & \\
\hline CHEMBL3104216 & 1284012 & 7.3979 & 7.5501 & TRN & \\
\hline CHEMBL 3104114 & 1284012 & 6.6198 & 6.4742 & TRN & \\
\hline CHEMBL 3104181 & 1284012 & 8.1549 & 7.2124 & TST & \\
\hline CHEMBL3104201 & 1284012 & 7.6021 & 7.2015 & TRN & \\
\hline CHEMBL 279236 & 1284012 & 5.4559 & 5.1292 & TRN & \\
\hline CHEMBL3104118 & 1284012 & 6.7959 & 6.4372 & TRN & \\
\hline CHEMBL 3104188 & 1284012 & 6.4685 & 6.3167 & TRN & \\
\hline CHEMBL281387 & 1284012 & 5.8539 & 5.3053 & TRN & \\
\hline CHEMBL3104119 & 1284012 & 5.0 & 6.3931 & TRN & \\
\hline CHEMBL 3104121 & 1284012 & 6.1308 & 6.0788 & TRN & \\
\hline CHEMBL 279493 & 1284012 & 4.5229 & 5.145 & TST & \\
\hline CHEMBL 21523 & 1284012 & 4.5229 & \multicolumn{2}{|c|}{5.202000000000001} & TRN \\
\hline CHEMBL3104215 & 1284012 & 7.301 & 7.3049 & TRN & \\
\hline CHEMBL3104117 & 1284012 & 6.3188 & 6.3679 & TRN & \\
\hline CHEMBL 3104125 & 1284012 & 7.5686 & 7.0906 & TST & \\
\hline CHEMBL21737 & 1284012 & 4.5229 & 5.2631 & TST & \\
\hline CHEMBL 3104115 & 1284012 & 6.5686 & 6.3252 & TRN & \\
\hline CHEMBL3104179 & 1284012 & 7.4815 & 6.9592 & TST & \\
\hline CHEMBL3104205 & 1284012 & 7.7959 & 7.3771 & TRN & \\
\hline CHEMBL 278795 & 1284012 & 4.5229 & 5.0587 & TRN & \\
\hline CHEMBL3104194 & 1284012 & 7.7447 & 7.5583 & TRN & \\
\hline CHEMBL 21992 & 1284012 & 4.5376 & \multicolumn{2}{|c|}{5.372999999999999} & TRN \\
\hline CHEMBL3104123 & 1284012 & 6.6198 & 7.1191 & TST & \\
\hline CHEMBL429389 & 1284012 & 5.3188 & 5.4311 & TRN & \\
\hline CHEMBL3104218 & 1284012 & 7.585 & 7.3222 & TRN & \\
\hline CHEMBL21753 & 1284012 & 5.4437 & 5.2407 & TST & \\
\hline
\end{tabular}


Supplemental Table S2.txt

\begin{tabular}{|c|c|c|c|c|c|}
\hline CHEMBL 3104200 & 1284012 & 7.9208 & 7.1125 & TST & \\
\hline CHEMBL22105 & 1284012 & 4.7447 & 5.2669 & TST & \\
\hline CHEMBL3104183 & 1284012 & 7.3872 & 6.5534 & TRN & \\
\hline CHEMBL21605 & 1284012 & 5.6021 & 5.3027 & TST & \\
\hline CHEMBL22046 & 1284012 & 5.5528 & 5.1948 & TST & \\
\hline CHEMBL3104213 & 1284012 & 7.1549 & 7.2365 & TRN & \\
\hline CHEMBL 3104124 & 1284012 & 7.5686 & 7.153 & TST & \\
\hline CHEMBL3104192 & 1284012 & 7.0 & 7.3146 & TRN & \\
\hline CHEMBL 3104227 & 1284012 & 6.7696 & 7.1571 & TST & \\
\hline CHEMBL3104199 & 1284012 & 6.8239 & 7.261 & TRN & \\
\hline CHEMBL3104189 & 1284012 & 6.3372 & 6.3591 & TRN & \\
\hline CHEMBL3104202 & 1284012 & 7.8539 & 7.3006 & TRN & \\
\hline CHEMBL3104220 & 1284012 & 4.5229 & 5.2323 & TST & \\
\hline CHEMBL3104197 & 1284012 & 7.0 & 7.2868 & TRN & \\
\hline CHEMBL3104210 & 1284012 & 7.1871 & 7.2177 & TRN & \\
\hline CHEMBL3104198 & 1284012 & 6.4815 & 7.343 & TRN & \\
\hline CHEMBL3104120 & 1284012 & 6.0458 & 6.222 & TRN & \\
\hline CHEMBL282667 & 1284012 & 4.6576 & 5.1635 & TST & \\
\hline CHEMBL3104190 & 1284012 & 6.0915 & 6.1936 & TRN & \\
\hline CHEMBL1402286 & 737115 & 4.7122 & 5.3067 & TRN & \\
\hline CHEMBL1731605 & 737115 & 6.0 & 5.2822 & TRN & \\
\hline CHEMBL1529285 & 737115 & 4.4522 & 3.9238 & TRN & \\
\hline CHEMBL390401 & 737115 & 3.0 & 3.2258 & TRN & \\
\hline CHEMBL3209299 & 737115 & 3.0 & 2.9857 & TRN & \\
\hline CHEMBL1727199 & 737115 & 5.2218 & 3.8841 & TST & \\
\hline CHEMBL1705734 & 737115 & 3.0 & 3.0588 & TRN & \\
\hline CHEMBL1710999 & 737115 & 4.6498 & 3.7018 & TST & \\
\hline CHEMBL1530437 & 737115 & 5.567 & 5.3477 & TRN & \\
\hline CHEMBL1707879 & 737115 & 3.0 & 2.9516 & TRN & \\
\hline CHEMBL1715541 & 737115 & 4.7033 & 3.7969 & TST & \\
\hline CHEMBL1722739 & 737115 & 5.3344 & 5.3923 & TRN & \\
\hline CHEMBL1706750 & 737115 & 5.3979 & 4.9158 & TRN & \\
\hline CHEMBL1981214 & 737115 & 3.0 & 3.7232 & TST & \\
\hline CHEMBL1732302 & 737115 & 3.0 & 3.71199 & 99999999997 & TST \\
\hline CHEMBL1379448 & 737115 & 3.0 & 3.9001 & TST & \\
\hline CHEMBL1736753 & 737115 & 5.6517 & 5.3108 & TRN & \\
\hline CHEMBL1315122 & 737115 & 3.0 & 2.85100 & 00000000004 & TRN \\
\hline CHEMBL1721976 & 737115 & 3.0 & 2.7533 & TRN & \\
\hline CHEMBL1728939 & 737115 & 4.9393 & 5.1136 & TRN & \\
\hline CHEMBL1402456 & 737115 & 5.1993 & 3.9363 & TST & \\
\hline CHEMBL1727351 & 737115 & 5.5834 & 5.136 & TRN & \\
\hline CHEMBL1468192 & 737115 & 4.2882 & 4.3771 & TRN & \\
\hline CHEMBL1417070 & 737115 & 4.5702 & 4.0058 & TRN & \\
\hline CHEMBL1518888 & 737115 & 5.3904 & 5.3192 & TRN & \\
\hline CHEMBL1443688 & 737115 & 4.1481 & 4.0689 & TRN & \\
\hline CHEMBL1732031 & 737115 & 5.218999 & 79999999 & 5.1664 & TRN \\
\hline CHEMBL1361703 & 737115 & 5.2366 & 5.164 & TRN & \\
\hline CHEMBL1994935 & 737115 & 4.9031 & 3.8674 & TST & \\
\hline
\end{tabular}




\begin{tabular}{|c|c|c|c|c|c|c|}
\hline & & \multicolumn{5}{|c|}{ Supplemental Table S2.txt } \\
\hline CHEMBL1709903 & 737115 & 3.0 & \multicolumn{3}{|c|}{2.7969999999999997} & TRN \\
\hline CHEMBL3194407 & 737115 & 4.5686 & 4.4588 & TRN & & \\
\hline CHEMBL1731392 & 737115 & 4.5287 & 5.1782 & TRN & & \\
\hline CHEMBL1733142 & 737115 & 3.0 & 3.0333 & TRN & & \\
\hline CHEMBL1729323 & 737115 & 3.0 & 3.5591 & TRN & & \\
\hline CHEMBL1706851 & 737115 & 5.1146 & 5.2467 & TRN & & \\
\hline CHEMBL1706280 & 737115 & 6.0 & 5.2251 & TRN & & \\
\hline CHEMBL1734781 & 737115 & 3.0 & 3.8785 & TST & & \\
\hline CHEMBL1464539 & 737115 & 4.317 & 5.2108 & TRN & & \\
\hline CHEMBL1711163 & 737115 & 5.4248 & 5.2987 & TRN & & \\
\hline CHEMBL1562142 & 737115 & 4.1878 & 3.9122 & TST & & \\
\hline CHEMBL1405964 & 737115 & 5.3768 & 5.3802 & TRN & & \\
\hline CHEMBL1562713 & 737115 & \multicolumn{3}{|c|}{5.2139999999999995} & 3.8407 & TST \\
\hline CHEMBL1577412 & 737115 & 4.0888 & 3.6499 & TST & & \\
\hline CHEMBL 1713480 & 737115 & 5.6861 & 5.3084 & TRN & & \\
\hline CHEMBL1715245 & 737115 & 4.8327 & 5.0944 & TRN & & \\
\hline CHEMBL1700951 & 737115 & 4.7825 & 5.0859 & TRN & & \\
\hline CHEMBL1415513 & 737115 & 3.0 & 3.5583 & TST & & \\
\hline CHEMBL1719957 & 737115 & 5.6615 & 5.4663 & TRN & & \\
\hline CHEMBL1381243 & 737115 & 4.6925 & 5.4841 & TRN & & \\
\hline CHEMBL1531763 & 737115 & 4.5421 & 3.7151 & TST & & \\
\hline CHEMBL1727666 & 737115 & 5.0246 & 3.7926 & TST & & \\
\hline CHEMBL1735822 & 737115 & 4.7471 & 5.2003 & TRN & & \\
\hline CHEMBL1734823 & 737115 & 3.0 & 3.0768 & TRN & & \\
\hline CHEMBL1977596 & 737115 & 4.9469 & 3.8265 & TST & & \\
\hline CHEMBL1720079 & 737115 & 5.3335 & 5.2338 & TRN & & \\
\hline CHEMBL1982202 & 737115 & 3.0 & 3.7927 & TST & & \\
\hline CHEMBL 3198174 & 737115 & 4.0862 & 3.9278 & TST & & \\
\hline CHEMBL1530147 & 737115 & 4.8041 & 4.9294 & TRN & & \\
\hline CHEMBL1518374 & 737115 & 5.7144 & 5.2993 & TRN & & \\
\hline CHEMBL1302463 & 737115 & 4.8729 & 3.8144 & TST & & \\
\hline CHEMBL3195531 & 737115 & 4.3595 & 4.449 & TRN & & \\
\hline CHEMBL1993401 & 737115 & 4.6536 & 3.8575 & TRN & & \\
\hline CHEMBL1710742 & 737115 & 3.0 & 3.0578 & TRN & & \\
\hline CHEMBL1612112 & 737115 & 5.3675 & 5.1562 & TRN & & \\
\hline CHEMBL1703238 & 737115 & 5.4724 & 5.1507 & TRN & & \\
\hline CHEMBL1575869 & 737115 & 4.9626 & 5.1579 & TRN & & \\
\hline CHEMBL1550415 & 737115 & \multicolumn{3}{|c|}{ 4. 7669999999999995} & 5.0905 & TRN \\
\hline CHEMBL1518098 & 737115 & 5.3851 & 4.1912 & TST & & \\
\hline CHEMBL1509755 & 737115 & 4.6946 & 4.4666 & TRN & & \\
\hline CHEMBL1731180 & 737115 & 4.5214 & 4.5915 & TRN & & \\
\hline CHEMBL1372651 & 737115 & 4.9208 & 3.8712 & TST & & \\
\hline CHEMBL1699571 & 737115 & 4.3635 & 4.6055 & TRN & & \\
\hline CHEMBL1418005 & 737115 & 3.0 & 3.6255 & TRN & & \\
\hline CHEMBL1728000 & 737115 & 5.1871 & 5.3402 & TRN & & \\
\hline CHEMBL1446655 & 737115 & 5.3028 & 5.5622 & TRN & & \\
\hline CHEMBL1722076 & 737115 & 5.4168 & 5.33799 & 99999 & & TRN \\
\hline CHEMBL1698818 & 737115 & 4.8327 & 4.4432 & TRN & & \\
\hline
\end{tabular}


Supplemental Table S2.txt

\begin{tabular}{|c|c|c|c|c|c|}
\hline CHEMBL1420189 & 737115 & 4.0752 & 4.0649 & TST & \\
\hline CHEMBL1342081 & 737115 & 4.3862 & 4.2478 & TRN & \\
\hline CHEMBL1707853 & 737115 & 3.0 & 4.2293 & TRN & \\
\hline CHEMBL1393615 & 737115 & 4.1993 & 4.2402 & TRN & \\
\hline CHEMBL1719209 & 737115 & 3.0 & 3.1338 & TRN & \\
\hline CHEMBL1698101 & 737115 & 4.4134 & 5.166 & TRN & \\
\hline CHEMBL3196108 & 737115 & 3.0 & 3.5464 & TST & \\
\hline CHEMBL1308068 & 737115 & 5.1811 & 5.1606 & TRN & \\
\hline CHEMBL1508839 & 737115 & 3.0 & 4.1047 & TST & \\
\hline CHEMBL1535613 & 737115 & 5.6968 & 5.4313 & TRN & \\
\hline CHEMBL3214310 & 737115 & 4.5884 & 4.4587 & TST & \\
\hline CHEMBL1718552 & 737115 & 4.5346 & 4.2803 & TST & \\
\hline CHEMBL1374955 & 737115 & 4.3036 & 4.1961 & TRN & \\
\hline CHEMBL1725449 & 737115 & 4.8894 & 5.0724 & TRN & \\
\hline CHEMBL1714309 & 737115 & 5.2907 & 5.3301 & TRN & \\
\hline CHEMBL1708498 & 737115 & 4.5969 & 5.1782 & TRN & \\
\hline CHEMBL1399979 & 737115 & 5.5751 & 5.2545 & TRN & \\
\hline CHEMBL1703530 & 737115 & 5.6003 & 5.1369 & TRN & \\
\hline CHEMBL1981464 & 737115 & 3.0 & 2.8503 & TRN & \\
\hline CHEMBL1507308 & 737115 & 5.58 & 5.312 & TRN & \\
\hline CHEMBL1736986 & 737115 & 5.6038 & 5.3897 & TRN & \\
\hline CHEMBL1721196 & 737115 & 3.0 & 3.0751 & TRN & \\
\hline CHEMBL1498353 & 737115 & 4.2218 & 4.2298 & TRN & \\
\hline CHEMBL1438520 & 737115 & 4.025 & 3.9324 & TRN & \\
\hline CHEMBL1368287 & 737115 & 3.0 & 3.1938 & TRN & \\
\hline CHEMBL1716258 & 737115 & 3.0 & 3.2542 & TRN & \\
\hline CHEMBL1423198 & 737115 & 3.0 & 3.86 & TST & \\
\hline CHEMBL1721038 & 737115 & 5.61799 & 99999999 & 99 & 5.2042 \\
\hline CHEMBL3190603 & 737115 & 3.0 & 2.8246 & TRN & \\
\hline CHEMBL3650113 & 1528242 & 8.7696 & 8.7678 & TRN & \\
\hline CHEMBL3650089 & 1528242 & 6.5482 & 6.5246 & TRN & \\
\hline CHEMBL3650126 & 1528242 & 8.3098 & 8.2968 & TRN & \\
\hline CHEMBL3650130 & 1528242 & 9.301 & 9.3236 & TRN & \\
\hline CHEMBL3650124 & 1528242 & 6.9208 & 6.9377 & TRN & \\
\hline CHEMBL3650110 & 1528242 & 7.2218 & 7.2362 & TRN & \\
\hline CHEMBL3650088 & 1528242 & 8.2596 & 8.2558 & TRN & \\
\hline CHEMBL3650112 & 1528242 & 8.5376 & 8.5451 & TRN & \\
\hline CHEMBL3639489 & 1528242 & 7.3665 & 7.4096 & TRN & \\
\hline CHEMBL 3650120 & 1528242 & 8.2518 & 8.2404 & TRN & \\
\hline CHEMBL 3650140 & 1528242 & 7.8861 & 7.8611 & TRN & \\
\hline CHEMBL 3650094 & 1528242 & 7.8539 & 7.8716 & TRN & \\
\hline CHEMBL3650101 & 1528242 & 9.2218 & 9.2118 & TRN & \\
\hline CHEMBL3650093 & 1528242 & 9.0 & 8.9663 & TRN & \\
\hline CHEMBL3650131 & 1528242 & 7.3979 & 7.3793 & TRN & \\
\hline CHEMBL3650122 & 1528242 & 8.4437 & 8.452 & TRN & \\
\hline CHEMBL 3650141 & 1528242 & 7.3665 & 7.2436 & TST & \\
\hline CHEMBL3650136 & 1528242 & 8.8861 & 8.8966 & TST & \\
\hline CHEMBL3650135 & 1528242 & 8.6576 & 9.0125 & TST & \\
\hline
\end{tabular}




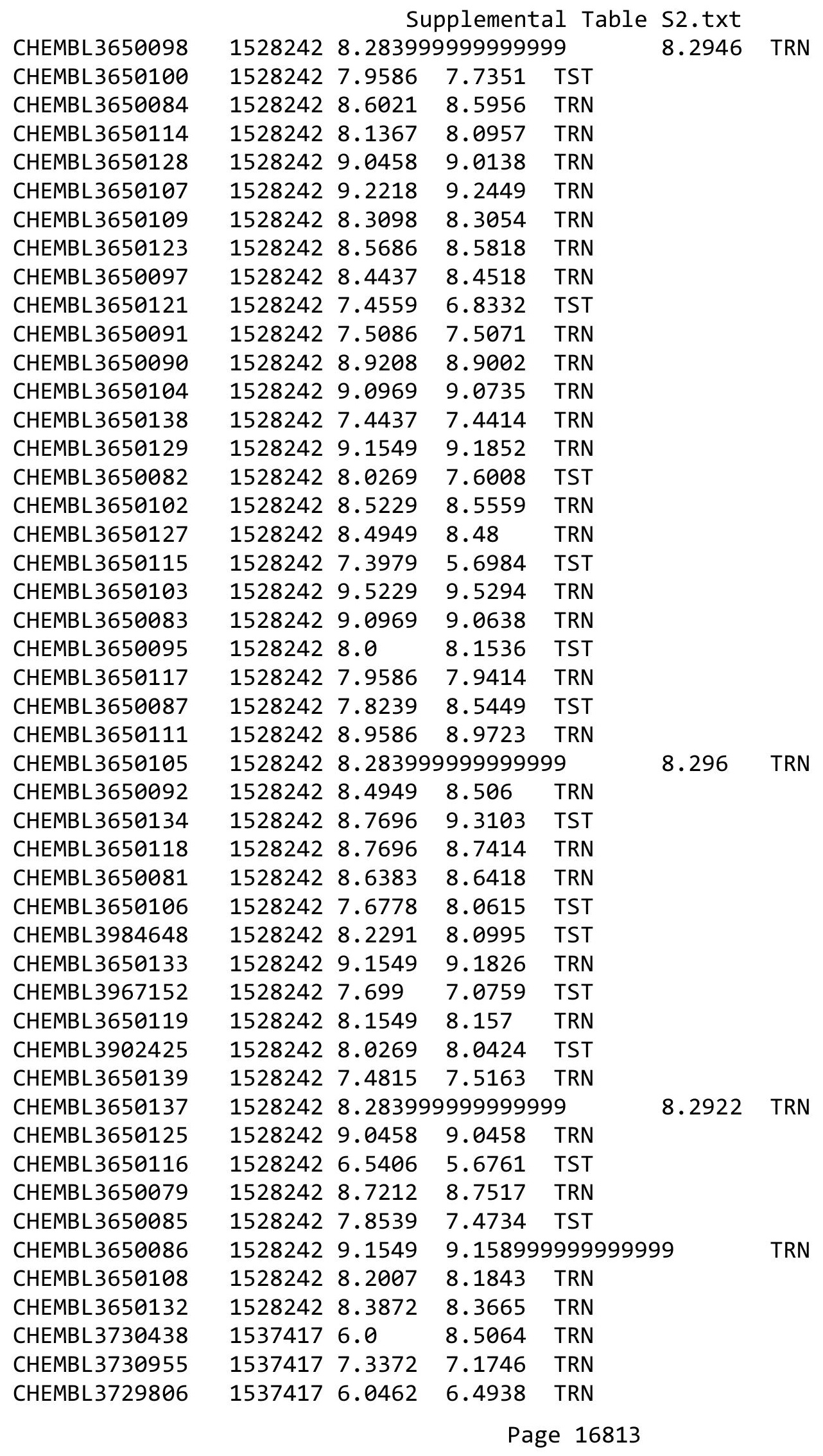


Supplemental Table S2.txt

\begin{tabular}{|c|c|c|c|c|c|}
\hline CHEMBL3730255 & 1537417 & 7.0862 & 6.4564 & TST & \\
\hline CHEMBL3732504 & 1537417 & 7.9208 & 7.8754 & TRN & \\
\hline CHEMBL3732907 & 1537417 & 3.6021 & 4.405 & TRN & \\
\hline CHEMBL3729807 & 1537417 & 7.1549 & 6.8954 & TST & \\
\hline CHEMBL3732930 & 1537417 & 7.1024 & 5.8324 & TRN & \\
\hline CHEMBL3732416 & 1537417 & 7.0969 & 8.0929 & TRN & \\
\hline CHEMBL3730714 & 1537417 & 8.041 & 6.9811 & TST & \\
\hline CHEMBL3732566 & 1537417 & 8.8861 & 8.7691 & TRN & \\
\hline CHEMBL3730873 & 1537417 & 7.3979 & 5.8152 & TRN & \\
\hline CHEMBL3729706 & 1537417 & 5.0605 & 5.5873 & TRN & \\
\hline CHEMBL3727840 & 1537417 & 8.4685 & 8.1556 & TRN & \\
\hline CHEMBL3727914 & 1537417 & 6.9208 & 6.434 & TRN & \\
\hline CHEMBL3732870 & 1537417 & 7.2147 & 6.8537 & TST & \\
\hline CHEMBL3732049 & 1537417 & 8.4089 & 7.982 & TRN & \\
\hline CHEMBL3729765 & 1537417 & 6.4815 & 5.8437 & TST & \\
\hline CHEMBL3728771 & 1537417 & 7.6198 & 7.6406 & TRN & \\
\hline CHEMBL3729813 & 1537417 & 7.0132 & 7.8366 & TRN & \\
\hline CHEMBL3732392 & 1537417 & 6.289 & 6.1574 & TRN & \\
\hline CHEMBL3732086 & 1537417 & 8.1024 & 7.2017 & TRN & \\
\hline CHEMBL3728739 & 1537417 & 8.2147 & 8.1804 & TRN & \\
\hline CHEMBL3729189 & 1537417 & 8.0809 & 8.1981 & TRN & \\
\hline CHEMBL3729352 & 1537417 & 8.0223 & 8.1854 & TRN & \\
\hline CHEMBL3728341 & 1537417 & 5.0128 & 4.8938 & TRN & \\
\hline CHEMBL3732281 & 1537417 & 5.0048 & 4.6537 & TST & \\
\hline CHEMBL3730283 & 1537417 & 7.6778 & 7.9306 & TST & \\
\hline CHEMBL3728852 & 1537417 & 7.699 & 8.4969 & TRN & \\
\hline CHEMBL3728104 & 1537417 & 6.0535 & 6.8847 & TRN & \\
\hline CHEMBL3731461 & 1537417 & 9.0 & 8.3974 & TRN & \\
\hline CHEMBL3733201 & 1537417 & 5.0434 & 5.1023 & TRN & \\
\hline CHEMBL3732885 & 1537417 & 6.0467 & 6.5749 & TRN & \\
\hline CHEMBL3733198 & 1537417 & 5.1612 & 6.0311 & TRN & \\
\hline CHEMBL3730690 & 1537417 & 5.0 & 4.6335 & TRN & \\
\hline CHEMBL3732418 & 1537417 & 7.1367 & 7.1663 & TRN & \\
\hline CHEMBL3727588 & 1537417 & 6.3344 & 6.0069 & TRN & \\
\hline CHEMBL3728558 & 1537417 & 7.0177 & 6.6403 & TST & \\
\hline CHEMBL3730852 & 1537417 & 8.4949 & 8.0608 & TRN & \\
\hline CHEMBL3729170 & 1537417 & 6.0 & 6.7982 & TRN & \\
\hline CHEMBL3733280 & 1537417 & 7.585 & 7.848 & TST & \\
\hline CHEMBL3732163 & 1537417 & 5.1986 & 6.4403 & TRN & \\
\hline CHEMBL3732253 & 1537417 & 8.0458 & 7.7279 & TRN & \\
\hline CHEMBL3729916 & 1537417 & 6.4559 & 6.7086 & TRN & \\
\hline CHEMBL3732087 & 1537417 & 5.1018 & 4.9481 & TRN & \\
\hline CHEMBL3728843 & 1537417 & $6.7620 e$ & 000000000 & 205 & 6.7178 \\
\hline CHEMBL3731163 & 1537417 & 6.0 & 7.3136 & TRN & \\
\hline CHEMBL3732621 & 1537417 & 9.3872 & 8.6727 & TRN & \\
\hline CHEMBL3727646 & 1537417 & 7.2676 & 7.2959 & TRN & \\
\hline CHEMBL3729480 & 1537417 & 3.6021 & 5.0659 & TRN & \\
\hline CHEMBL3728809 & 1537417 & 5.0414 & 5.9131 & TRN & \\
\hline
\end{tabular}


Supplemental Table S2.txt

\begin{tabular}{|c|c|c|c|c|c|c|}
\hline CHEMBL3729966 & 1537417 & 6.9172 & 6.0622 & TRN & & \\
\hline CHEMBL 3732201 & 1537417 & \multicolumn{3}{|c|}{6.172000000000001} & 6.7564 & TRN \\
\hline CHEMBL3732159 & 1537417 & 6.8356 & 6.9223 & TRN & & \\
\hline CHEMBL 3729885 & 1537417 & 7.6576 & 7.5673 & TRN & & \\
\hline CHEMBL3728805 & 1537417 & 6.7959 & 6.5992 & TRN & & \\
\hline CHEMBL3732799 & 1537417 & 6.2441 & 5.5773 & TRN & & \\
\hline CHEMBL 3731785 & 1537417 & 6.4157 & 7.07 & TST & & \\
\hline CHEMBL3729617 & 1537417 & 7.9208 & 7.3572 & TRN & & \\
\hline CHEMBL3732017 & 1537417 & 6.8894 & 7.7222 & TRN & & \\
\hline CHEMBL3729495 & 1537417 & 5.1051 & 5.6606 & TRN & & \\
\hline CHEMBL 3730289 & 1537417 & 5.8097 & 6.0589 & TRN & & \\
\hline CHEMBL3731406 & 1537417 & 8.0177 & 8.2796 & TRN & & \\
\hline CHEMBL3732166 & 1537417 & 6.9469 & 7.3022 & TRN & & \\
\hline CHEMBL3732090 & 1537417 & 8.301 & 8.3156 & TRN & & \\
\hline CHEMBL3731426 & 1537417 & 7.3279 & 6.4843 & TRN & & \\
\hline CHEMBL3731167 & 1537417 & 8.7447 & 7.8024 & TRN & & \\
\hline CHEMBL3728012 & 1537417 & 7.7959 & 7.516 & TST & & \\
\hline CHEMBL3727668 & 1537417 & 6.4737 & 4.885 & TST & & \\
\hline CHEMBL3728585 & 1537417 & 6.699 & 7.3025 & TRN & & \\
\hline CHEMBL 3728649 & 1537417 & 8.3872 & 8.4881 & TRN & & \\
\hline CHEMBL3729032 & 1537417 & 6.4283 & 7.103 & TST & & \\
\hline CHEMBL3730036 & 1537417 & 7.0177 & 7.5699 & TRN & & \\
\hline CHEMBL 3728342 & 1537417 & 7.1487 & 5.9684 & TRN & & \\
\hline CHEMBL3730632 & 1537417 & 6.6716 & 6.7384 & TRN & & \\
\hline CHEMBL 3728538 & 1537417 & 7.1612 & 6.8483 & TRN & & \\
\hline CHEMBL3728437 & 1537417 & 6.4353 & 7.29200 & 000000000 & & $\mathrm{TR}$ \\
\hline CHEMBL 3731680 & 1537417 & 6.5214 & 6.8598 & TRN & & \\
\hline CHEMBL3732516 & 1537417 & 6.9281 & 5.8569 & TST & & \\
\hline CHEMBL3729228 & 1537417 & 9.0088 & 8.354 & TRN & & \\
\hline CHEMBL3731308 & 1537417 & 8.2676 & 8.0441 & TRN & & \\
\hline CHEMBL 3729198 & 1537417 & 6.9031 & 6.7843 & TRN & & \\
\hline CHEMBL 3731064 & 1537417 & $4.9830 e$ & 00000000 & 205 & 5.2901 & TST \\
\hline CHEMBL3729899 & 1537417 & 3.6021 & 4.0543 & TRN & & \\
\hline CHEMBL3729434 & 1537417 & 9.3979 & 8.4411 & TRN & & \\
\hline CHEMBL3730596 & 1537417 & 6.2765 & 5.7564 & TRN & & \\
\hline CHEMBL3731396 & 1537417 & 8.301 & 7.7784 & TRN & & \\
\hline CHEMBL 3728722 & 1537417 & 4.9747 & 5.4499 & TRN & & \\
\hline CHEMBL 3728546 & 1537417 & 7.6383 & 7.0605 & TST & & \\
\hline CHEMBL3732803 & 1537417 & 8.2676 & 6.3167 & TST & & \\
\hline CHEMBL 3728883 & 1537417 & 6.71899 & 99999999 & 99 & 7.0628 & I RIV \\
\hline CHEMBL 3732842 & 1537417 & 5.7447 & 4.5812 & TRN & & \\
\hline CHEMBL3728857 & 1537417 & 7.585 & 6.9581 & TRN & & \\
\hline CHEMBL3728165 & 1537417 & 6.04 & 5.7746 & TRN & & \\
\hline CHEMBL3728965 & 1537417 & 5.2418 & 5.7721 & TRN & & \\
\hline CHEMBL3731737 & 1537417 & 3.6021 & 3.9997 & TRN & & \\
\hline CHEMBL3728633 & 1537417 & 7.1871 & 7.1294 & TRN & & \\
\hline CHEMBL 3727702 & 1537417 & 6.4776 & 6.9663 & TRN & & \\
\hline CHEMBL3728604 & 1537417 & 6.5017 & 6.8407 & TRN & & \\
\hline
\end{tabular}

Page 16815 
Supplemental Table S2.txt

\begin{tabular}{|c|c|c|c|c|c|}
\hline CHEMBL3733253 & 1537417 & 6.5376 & 5.5126 & TRN & \\
\hline CHEMBL3730156 & 1537417 & 5.4202 & 7.0352 & TRN & \\
\hline CHEMBL3729576 & 1537417 & 3.6021 & 4.7048 & TRN & \\
\hline CHEMBL3730324 & 1537417 & 7.2441 & 7.6881 & TRN & \\
\hline CHEMBL3729697 & 1537417 & 5.8125 & 6.5792 & TRN & \\
\hline CHEMBL3727690 & 1537417 & 7.3565 & 6.5172 & TRN & \\
\hline CHEMBL3727442 & 1537417 & 8.1739 & 8.1712 & TRN & \\
\hline CHEMBL3730231 & 1537417 & 7.4685 & 8.2591 & TRN & \\
\hline CHEMBL3729293 & 1537417 & 8.1192 & 7.6349 & TRN & \\
\hline CHEMBL3728603 & 1537417 & 6.2967 & 6.3096 & TRN & \\
\hline CHEMBL3730502 & 1537417 & 8.5528 & 8.2001 & TRN & \\
\hline CHEMBL3728237 & 1537417 & 6.17200 & 000000000 & 6.6215 & TRN \\
\hline CHEMBL3731635 & 1537417 & 9.0506 & 8.4448 & TRN & \\
\hline CHEMBL3730675 & 1537417 & 6.9101 & 6.9105 & TST & \\
\hline CHEMBL3733191 & 1537417 & 5.055 & 6.0856 & TRN & \\
\hline CHEMBL3730781 & 1537417 & 6.6271 & 7.035 & TRN & \\
\hline CHEMBL3732371 & 1537417 & 6.0 & 7.6821 & TST & \\
\hline CHEMBL 3728573 & 1537417 & 8.8539 & 7.9285 & TRN & \\
\hline CHEMBL3728190 & 1537417 & 7.3372 & 5.5733 & TRN & \\
\hline CHEMBL3730211 & 1537417 & 7.5086 & 7.9329 & TRN & \\
\hline CHEMBL3732345 & 1537417 & 7.3979 & 6.8807 & TRN & \\
\hline CHEMBL3730197 & 1537417 & 8.9208 & 6.6524 & TST & \\
\hline CHEMBL3733305 & 1537417 & 6.2549 & 6.0291 & TRN & \\
\hline CHEMBL3728150 & 1537417 & 5.4089 & 4.8159 & TRN & \\
\hline CHEMBL3729543 & 1537417 & 7.1427 & 7.621 & TRN & \\
\hline CHEMBL3727801 & 1537417 & 8.1249 & 8.6646 & TRN & \\
\hline CHEMBL3730658 & 1537417 & 7.0132 & \multicolumn{2}{|c|}{6.8020000000000005} & TRN \\
\hline CHEMBL3728389 & 1537417 & 6.6904 & 6.6459 & TST & \\
\hline CHEMBL3727655 & 1537417 & 6.2581 & 6.7271 & TST & \\
\hline CHEMBL3732223 & 1537417 & 7.2676 & 7.1496 & TST & \\
\hline CHEMBL3731458 & 1537417 & 6.7747 & 6.7805 & TST & \\
\hline CHEMBL3728753 & 1537417 & 8.4815 & 7.5151 & TST & \\
\hline CHEMBL3729979 & 1537417 & 7.0088 & 7.1715 & TRN & \\
\hline CHEMBL3730960 & 1537417 & 8.2441 & 7.7187 & TRN & \\
\hline CHEMBL3731359 & 1537417 & 6.3344 & 4.7742 & TST & \\
\hline CHEMBL3729306 & 1537417 & 8.5686 & 7.5436 & TST & \\
\hline CHEMBL3731214 & 1537417 & 6.4535 & 6.7215 & TRN & \\
\hline CHEMBL3731379 & 1537417 & 6.8153 & 6.4817 & TRN & \\
\hline CHEMBL3727378 & 1537417 & 7.1192 & \multicolumn{2}{|c|}{7.3389999999999995} & TRN \\
\hline CHEMBL3727450 & 1537417 & 3.6021 & 4.0036 & TST & \\
\hline CHEMBL3729542 & 1537417 & 8.2366 & 8.1488 & TST & \\
\hline CHEMBL3732365 & 1537417 & 6.1361 & 4.7891 & TRN & \\
\hline CHEMBL3728932 & 1537417 & 9.699 & 8.2091 & TST & \\
\hline CHEMBL3731186 & 1537417 & 5.1192 & 4.7723 & TRN & \\
\hline CHEMBL3731092 & 1537417 & 6.3215 & 6.6503 & TST & \\
\hline CHEMBL 3727544 & 1537417 & 7.8861 & 8.4832 & TRN & \\
\hline CHEMBL3729427 & 1537417 & 6.5638 & 7.263 & TRN & \\
\hline CHEMBL3729471 & 1537417 & 7.4318 & 5.8261 & TST & \\
\hline
\end{tabular}


Supplemental Table S2.txt

\begin{tabular}{|c|c|c|c|c|c|}
\hline CHEMBL 3728092 & 1537417 & 7.1135 & 6.7571 & TST & \\
\hline CHEMBL3731221 & 1537417 & 7.3768 & \multicolumn{2}{|c|}{6.6370000000000005} & TRN \\
\hline CHEMBL 3730534 & 1537417 & 5.2211 & 5.5049 & TRN & \\
\hline CHEMBL 3731053 & 1537417 & 7.8539 & 7.7464 & TRN & \\
\hline CHEMBL 3728471 & 1537417 & 7.2218 & 6.5062 & TRN & \\
\hline CHEMBL3732146 & 1537417 & 5.0737 & 4.8718 & TRN & \\
\hline CHEMBL3731561 & 1537417 & 7.5686 & 7.2265 & TRN & \\
\hline CHEMBL 3732493 & 1537417 & 8.3768 & 7.4562 & TRN & \\
\hline CHEMBL3729585 & 1537417 & 5.098 & 5.5521 & TRN & \\
\hline CHEMBL3730982 & 1537417 & 4.6216 & 4.6414 & TRN & \\
\hline CHEMBL 3728511 & 1537417 & 4.6216 & \multicolumn{2}{|c|}{5.8020000000000005} & TRN \\
\hline CHEMBL3731494 & 1537417 & 5.1249 & 6.0394 & TRN & \\
\hline CHEMBL 3727408 & 1537417 & 6.0 & 6.5732 & TRN & \\
\hline CHEMBL 3730330 & 1537417 & 8.8861 & 7.1997 & TST & \\
\hline CHEMBL3728159 & 1537417 & 6.2848 & 6.6519 & TRN & \\
\hline CHEMBL3729485 & 1537417 & 7.0862 & 7.4731 & TRN & \\
\hline CHEMBL3730506 & 1537417 & 7.3098 & 7.1253 & TRN & \\
\hline CHEMBL 3733047 & 1537417 & 6.9872 & 6.2366 & TRN & \\
\hline CHEMBL3728521 & 1537417 & 8.2076 & 7.6088 & TST & \\
\hline CHEMBL 3730950 & 1537417 & 3.6021 & 3.2026 & TRN & \\
\hline CHEMBL3731632 & 1537417 & 8.0223 & 7.2966 & TST & \\
\hline CHEMBL3730856 & 1537417 & 8.0915 & 7.3077 & TRN & \\
\hline CHEMBL3731200 & 1537417 & 6.2874 & 6.4976 & TRN & \\
\hline CHEMBL 3730424 & 1537417 & 6.6198 & 6.7544 & TRN & \\
\hline CHEMBL 3731600 & 1537417 & 7.9208 & 8.0608 & TRN & \\
\hline CHEMBL3728238 & 1537417 & 8.6778 & 8.3199 & TRN & \\
\hline CHEMBL3728174 & 1537417 & 5.04 & 5.8099 & TST & \\
\hline CHEMBL3729214 & 1537417 & 9.6198 & 8.2619 & TRN & \\
\hline CHEMBL3729760 & 1537417 & 3.6021 & 4.1548 & TST & \\
\hline CHEMBL 3727613 & 1537417 & 6.0 & 8.3092 & TRN & \\
\hline CHEMBL3730991 & 1537417 & 8.0862 & 8.0232 & TRN & \\
\hline CHEMBL3728194 & 1537417 & 6.3307 & 6.8038 & TRN & \\
\hline CHEMBL3731489 & 1537417 & 6.9431 & 6.7655 & TRN & \\
\hline CHEMBL3729615 & 1537417 & 6.9281 & 7.5835 & TST & \\
\hline CHEMBL 3729752 & 1537417 & 8.6198 & 8.3386 & TRN & \\
\hline CHEMBL3732990 & 1537417 & 5.0114 & 6.1495 & TRN & \\
\hline CHEMBL 3729034 & 1537417 & 8.0177 & 8.2072 & TRN & \\
\hline CHEMBL 3728025 & 1537417 & 8.0 & 7.4108 & TRN & \\
\hline CHEMBL 3730451 & 1537417 & 8.1024 & 6.9107 & TRN & \\
\hline CHEMBL 3731849 & 1537417 & 8.9586 & 8.5062 & TRN & \\
\hline CHEMBL3730618 & 1537417 & 5.1726 & 5.058 & TRN & \\
\hline CHEMBL 3733084 & 1537417 & 8.699 & 8.5276 & TST & \\
\hline CHEMBL3732041 & 1537417 & 7.1427 & 6.4861 & TRN & \\
\hline CHEMBL 3728870 & 1537417 & 5.1739 & 5.7724 & TRN & \\
\hline CHEMBL 3732014 & 1537417 & 7.0862 & 7.601 & TRN & \\
\hline CHEMBL 3730978 & 1537417 & 6.0164 & 5.9052 & TST & \\
\hline CHEMBL 3727620 & 1537417 & 7.6778 & 7.0863 & TRN & \\
\hline CHEMBL 3730523 & 1537417 & 5.0013 & 5.0988 & TRN & \\
\hline
\end{tabular}

Page 16817 
Supplemental Table S2.txt

\begin{tabular}{|c|c|c|c|c|c|}
\hline CHEMBL3729027 & 1537417 & 6.4101 & 5.6415 & TRN & \\
\hline CHEMBL 3732432 & 1537417 & 7.0223 & 5.5962 & TRN & \\
\hline CHEMBL3728279 & 1537417 & 4.9547 & 4.792 & TRN & \\
\hline CHEMBL3727795 & 1537417 & 7.6576 & 7.6372 & TRN & \\
\hline CHEMBL3732978 & 1537417 & 5.1965 & \multicolumn{2}{|c|}{5.297000000000001} & TRN \\
\hline CHEMBL3728119 & 1537417 & 6.9245 & 6.3924 & TRN & \\
\hline CHEMBL 3729184 & 1537417 & 7.3468 & 7.71 & TRN & \\
\hline CHEMBL3727528 & 1537417 & 6.1261 & 6.2678 & TRN & \\
\hline CHEMBL3729208 & 1537417 & 6.58 & 7.2853 & TRN & \\
\hline CHEMBL3731492 & 1537417 & 7.284 & 6.2663 & TRN & \\
\hline CHEMBL3728125 & 1537417 & 7.5086 & 6.1712 & TRN & \\
\hline CHEMBL3730215 & 1537417 & 7.0862 & 8.3388 & TST & \\
\hline CHEMBL3733039 & 1537417 & 6.0904 & 6.7016 & TST & \\
\hline CHEMBL3732225 & 1537417 & 8.6198 & 8.4569 & TRN & \\
\hline CHEMBL3729130 & 1537417 & 8.6778 & 7.9665 & TRN & \\
\hline CHEMBL3732009 & 1537417 & 6.1568 & 6.5598 & TST & \\
\hline CHEMBL 3732748 & 1537417 & 7.7959 & 7.9076 & TRN & \\
\hline CHEMBL 3731113 & 1537417 & 9.0862 & 8.4658 & TST & \\
\hline CHEMBL3730548 & 1537417 & 7.7696 & 7.2396 & TRN & \\
\hline CHEMBL3732195 & 1537417 & 6.9172 & 6.8637 & TRN & \\
\hline CHEMBL 3730944 & 1537417 & 7.4685 & 7.2587 & TRN & \\
\hline CHEMBL 3727591 & 1537417 & 6.8097 & 6.7002 & TRN & \\
\hline CHEMBL3727461 & 1537417 & 6.0026 & 6.6522 & TRN & \\
\hline CHEMBL3731035 & 1537417 & 8.6383 & 8.3494 & TRN & \\
\hline CHEMBL3732729 & 1537417 & 8.041 & 8.1557 & TRN & \\
\hline CHEMBL3727798 & 1537417 & 8.1487 & 7.5918 & TRN & \\
\hline CHEMBL3731297 & 1537417 & 8.3098 & 8.2252 & TRN & \\
\hline CHEMBL3729822 & 1537417 & 8.1367 & 8.3765 & TRN & \\
\hline CHEMBL3728337 & 1537417 & 6.3215 & 6.2653 & TRN & \\
\hline CHEMBL3730279 & 1537417 & 8.4318 & 7.9756 & TRN & \\
\hline CHEMBL3729699 & 1537417 & 5.8761 & 6.3024 & TRN & \\
\hline CHEMBL3732252 & 1537417 & 5.3261 & 5.2921 & TRN & \\
\hline CHEMBL3732149 & 1537417 & 6.8665 & 5.8249 & TRN & \\
\hline CHEMBL3731316 & 1537417 & 5.9245 & 6.3465 & TRN & \\
\hline CHEMBL3727911 & 1537417 & 5.0013 & 5.6778 & TRN & \\
\hline CHEMBL3730609 & 1537417 & 7.2007 & 7.7489 & TST & \\
\hline CHEMBL3733130 & 1537417 & 8.1367 & 8.2409 & TRN & \\
\hline CHEMBL 3729600 & 1537417 & 7.2147 & 7.2827 & TRN & \\
\hline CHEMBL3728252 & 1537417 & 6.4078 & 7.5075 & TRN & \\
\hline CHEMBL3730904 & 1537417 & 6.0783 & 6.2348 & TST & \\
\hline CHEMBL3730306 & 1537417 & 6.6615 & 6.4824 & TST & \\
\hline CHEMBL3728769 & 1537417 & 10.0 & 8.396 & TRN & \\
\hline CHEMBL3729343 & 1537417 & 6.8327 & 7.468 & TST & \\
\hline CHEMBL 3730760 & 1537417 & 6.0 & 8.2161 & TST & \\
\hline CHEMBL3728562 & 1537417 & 8.4089 & 7.1679 & TST & \\
\hline CHEMBL 3729013 & 1537417 & 9.0269 & 8.3253 & TST & \\
\hline CHEMBL 3730257 & 1537417 & 5.065 & 4.4968 & TRN & \\
\hline CHEMBL 3728166 & 1537417 & 6.4962 & 5.79299 & 7999999999 & TRN \\
\hline & & & & 16818 & \\
\hline
\end{tabular}


Supplemental Table S2.txt

\begin{tabular}{|c|c|c|c|c|c|c|}
\hline CHEMBL3729552 & 1537417 & 6.0 & 7.0564 & TRN & & \\
\hline CHEMBL 3732404 & 1537417 & 8.8539 & 8.706 & TRN & & \\
\hline CHEMBL 3730922 & 1537417 & 7.9586 & 6.9097 & TRN & & \\
\hline CHEMBL 3728781 & 1537417 & 4.9872 & 4.4101 & TRN & & \\
\hline CHEMBL 3728109 & 1537417 & 6.45100 & 0000000 & 305 & 7.1252 & TRN \\
\hline CHEMBL 3728506 & 1537417 & 7.4949 & 7.1369 & TRN & & \\
\hline CHEMBL3732039 & 1537417 & 5.0 & 5.5337 & TRN & & \\
\hline CHEMBL 3733217 & 1537417 & 7.8861 & 7.6335 & TRN & & \\
\hline CHEMBL 3728613 & 1537417 & 6.699 & 6.972 & TRN & & \\
\hline CHEMBL 3731311 & 1537417 & 7.9586 & 7.4462 & TRN & & \\
\hline CHEMBL 3733163 & 1537417 & 7.2596 & 7.0734 & TRN & & \\
\hline CHEMBL 3729738 & 1537417 & 5.8996 & 5.9876 & TRN & & \\
\hline CHEMBL 3730033 & 1537417 & 6.6655 & 7.8293 & TST & & \\
\hline CHEMBL 3729626 & 1537417 & 6.8761 & 6.6391 & TRN & & \\
\hline CHEMBL 3733127 & 1537417 & 6.7423 & 6.5136 & TRN & & \\
\hline CHEMBL 3733076 & 1537417 & 6.5406 & 6.6027 & TRN & & \\
\hline CHEMBL 3730203 & 1537417 & 5.5361 & 6.1138 & TRN & & \\
\hline CHEMBL 3729010 & 1537417 & 3.6021 & 4.6136 & TST & & \\
\hline CHEMBL 3728947 & 1537417 & 7.0969 & 6.655 & TRN & & \\
\hline CHEMBL 3730024 & 1537417 & 8.3768 & 8.6602 & TST & & \\
\hline CHEMBL 3731705 & 1537417 & 6.1337 & 6.5913 & TST & & \\
\hline CHEMBL 3729225 & 1537417 & 6.6517 & 6.3868 & TRN & & \\
\hline CHEMBL 3729977 & 1537417 & 7.9586 & 7.6855 & TRN & & \\
\hline CHEMBL 3730874 & 1537417 & 9.3372 & 8.8173 & TRN & & \\
\hline CHEMBL 3728133 & 1537417 & 5.5817 & 4.8612 & TRN & & \\
\hline CHEMBL 3730234 & 1537417 & 5.1302 & 6.6664 & TRN & & \\
\hline CHEMBL 3730881 & 1537417 & 7.6198 & 6.4011 & TST & & \\
\hline CHEMBL 3728344 & 1537417 & 7.0362 & 6.7253 & TRN & & \\
\hline CHEMBL 3730858 & 1537417 & 3.6021 & 3.9293 & TRN & & \\
\hline CHEMBL 3728508 & 1537417 & 7.6383 & 7.6798 & TRN & & \\
\hline CHEMBL 3732502 & 1537417 & 7.2366 & 7.7376 & TST & & \\
\hline CHEMBL 3731817 & 1537417 & 8.2291 & 7.8425 & TRN & & \\
\hline CHEMBL 3730671 & 1537417 & 7.3098 & 6.763 & TRN & & \\
\hline CHEMBL 3728812 & 1537417 & 5.983 & 6.7013 & TRN & & \\
\hline CHEMBL 3731259 & 1537417 & 9.3468 & 8.523 & TRN & & \\
\hline CHEMBL 3730683 & 1537417 & 6.8013 & 7.5459 & TRN & & \\
\hline CHEMBL 3731739 & 1537417 & 8.3872 & 8.185 & TRN & & \\
\hline CHEMBL 3729642 & 1537417 & 5.1302 & 5.8651 & TRN & & \\
\hline CHEMBL 3731223 & 1537417 & 7.2147 & 5.5865 & TST & & \\
\hline CHEMBL 3730474 & 1537417 & 6.9508 & 6.2676 & TST & & \\
\hline CHEMBL 3727792 & 1537417 & 6.6716 & 6.7756 & TRN & & \\
\hline CHEMBL 3728646 & 1537417 & 6.308 & \multicolumn{3}{|c|}{7.082000000000001} & 13 \\
\hline CHEMBL 3728830 & 1537417 & 6.9318 & 7.3006 & TRN & & \\
\hline CHEMBL 3731893 & 1537417 & 6.7696 & 6.0353 & TRN & & \\
\hline CHEMBL 3728352 & 1537417 & 6.6655 & 5.3728 & TST & & \\
\hline CHEMBL 3729500 & 1537417 & 8.8861 & 7.9979 & TST & & \\
\hline CHEMBL 3731676 & 1537417 & 6.5986 & 5.7453 & TST & & \\
\hline CHEMBL 3730815 & 1537417 & 7.2291 & 7.6227 & TRN & & \\
\hline
\end{tabular}

Page 16819 
Supplemental Table S2.txt

\begin{tabular}{|c|c|c|c|c|c|}
\hline CHEMBL3728559 & 1537417 & 8.7447 & 8.7496 & TRN & \\
\hline CHEMBL3728062 & 1537417 & 7.7447 & 6.755 & TST & \\
\hline CHEMBL3729761 & 1537417 & 6.5272 & 6.6377 & TRN & \\
\hline CHEMBL3730629 & 1537417 & 8.3188 & 7.9067 & TRN & \\
\hline CHEMBL 3727697 & 1537417 & 8.0809 & 7.4222 & TST & \\
\hline CHEMBL 3729111 & 1537417 & 5.0521 & 5.2323 & TRN & \\
\hline CHEMBL3732094 & 1537417 & 7.6198 & 7.7471 & TRN & \\
\hline CHEMBL3728716 & 1537417 & 5.1415 & 5.8455 & TRN & \\
\hline CHEMBL3731384 & 1537417 & 6.433 & 6.1158 & TST & \\
\hline CHEMBL3730804 & 1537417 & 7.0315 & 6.6856 & TRN & \\
\hline CHEMBL3727975 & 1537417 & 5.7595 & 5.8026 & TST & \\
\hline CHEMBL3730902 & 1537417 & 7.9208 & 7.4728 & TRN & \\
\hline CHEMBL3729633 & 1537417 & 5.6861 & 6.3354 & TRN & \\
\hline CHEMBL3727532 & 1537417 & 5.0783 & 5.2771 & TRN & \\
\hline CHEMBL3730777 & 1537417 & 7.9586 & 7.9148 & TRN & \\
\hline CHEMBL 3729273 & 1537417 & 6.4572 & 7.5806 & TRN & \\
\hline CHEMBL3727417 & 1537417 & 7.8861 & 5.4039 & TST & \\
\hline CHEMBL 3731370 & 1537417 & 3.6021 & 5.519 & TST & \\
\hline CHEMBL3730664 & 1537417 & 6.0 & 6.7022 & TST & \\
\hline CHEMBL3733330 & 1537417 & 6.5884 & 7.0016 & TRN & \\
\hline CHEMBL3733261 & 1537417 & 5.0825 & 5.29200 & 0000000001 & TRN \\
\hline CHEMBL3732602 & 1537417 & 7.2007 & 7.5183 & TRN & \\
\hline CHEMBL 3730358 & 1537417 & 7.0223 & 6.0809 & TRN & \\
\hline CHEMBL3732403 & 1537417 & 8.0269 & 7.2762 & TRN & \\
\hline CHEMBL 3729342 & 1537417 & 7.5528 & 7.2676 & TRN & \\
\hline CHEMBL3731172 & 1537417 & 3.6021 & 5.7279 & TST & \\
\hline CHEMBL3728007 & 1537417 & 7.0 & 7.6805 & TST & \\
\hline CHEMBL 3732601 & 1537417 & 7.2291 & 7.2014 & TRN & \\
\hline CHEMBL3732419 & 1537417 & 8.1871 & 8.5705 & TRN & \\
\hline CHEMBL 3732008 & 1537417 & 7.0969 & 7.2723 & TST & \\
\hline CHEMBL3732902 & 1537417 & 9.0605 & 8.192 & TRN & \\
\hline CHEMBL3731273 & 1537417 & 8.0506 & 7.8926 & TRN & \\
\hline CHEMBL 3730081 & 1537417 & 6.8069 & 7.9809 & TRN & \\
\hline CHEMBL3731822 & 1537417 & 3.6021 & 4.0409 & TRN & \\
\hline CHEMBL 3728644 & 1537417 & 9.2757 & 8.1316 & TRN & \\
\hline CHEMBL3729231 & 1537417 & 7.0555 & 6.4315 & TRN & \\
\hline CHEMBL3732539 & 1537417 & 6.4353 & 7.2137 & TRN & \\
\hline CHEMBL3727729 & 1537417 & 6.5157 & 7.0846 & TRN & \\
\hline CHEMBL3731971 & 1537417 & 3.6021 & 4.8097 & TRN & \\
\hline CHEMBL 3729487 & 1537417 & 8.8239 & 8.2823 & TST & \\
\hline CHEMBL3729805 & 1537417 & 7.4202 & 8.0983 & TRN & \\
\hline CHEMBL3732650 & 1537417 & 6.5186 & 6.129 & TST & \\
\hline CHEMBL3729199 & 1537417 & 5.0164 & 4.944 & TRN & \\
\hline CHEMBL3728370 & 1537417 & 6.4377 & 5.8881 & TRN & \\
\hline CHEMBL 3731595 & 1537417 & 3.6021 & 5.6324 & TRN & \\
\hline CHEMBL3728451 & 1537417 & 7.7696 & 7.5324 & TRN & \\
\hline CHEMBL3728393 & 1537417 & 7.1367 & 6.5858 & TRN & \\
\hline CHEMBL3727924 & 1537417 & 7.7212 & 6.9905 & TST & \\
\hline
\end{tabular}


Supplemental Table S2.txt

\begin{tabular}{|c|c|c|c|c|c|c|}
\hline CHEMBL3733207 & 1537417 & 6.9872 & 7.0982 & TRN & & \\
\hline CHEMBL3733287 & 1537417 & 7.4815 & 6.718 & TRN & & \\
\hline CHEMBL3732583 & 1537417 & 6.5258 & 5.7559 & TST & & \\
\hline CHEMBL 3731671 & 1537417 & 9.4559 & 8.9694 & TRN & & \\
\hline CHEMBL3728401 & 1537417 & 8.3468 & 7.9601 & TRN & & \\
\hline CHEMBL3730819 & 1537417 & 5.644 & 4.6825 & TRN & & \\
\hline CHEMBL3730082 & 1537417 & 6.7747 & 7.0469 & TRN & & \\
\hline CHEMBL3727601 & 1537417 & 9.301 & 8.0657 & TRN & & \\
\hline CHEMBL3729722 & 1537417 & 6.0 & 6.7221 & TRN & & \\
\hline CHEMBL3731469 & 1537417 & 8.5686 & 8.3921 & TRN & & \\
\hline CHEMBL3729988 & 1537417 & 8.0 & 8.672 & TRN & & \\
\hline CHEMBL 3731244 & 1537417 & 5.4908 & 6.0754 & TRN & & \\
\hline CHEMBL3733264 & 1537417 & 7.6383 & 7.4272 & TST & & \\
\hline CHEMBL 3731264 & 1537417 & 6.8539 & 6.36 & TRN & & \\
\hline CHEMBL 3727453 & 1537417 & 6.5376 & 7.1887 & TRN & & \\
\hline CHEMBL3728536 & 1537417 & 8.3188 & 8.3517 & TRN & & \\
\hline CHEMBL3730354 & 1537417 & 8.4949 & 7.7211 & TST & & \\
\hline CHEMBL3727736 & 1537417 & 3.6021 & 4.8676 & TST & & \\
\hline CHEMBL3731133 & 1537417 & 7.8239 & 7.7116 & TRN & & \\
\hline CHEMBL 3728553 & 1537417 & 6.6517 & 7.4044 & TST & & \\
\hline CHEMBL3728360 & 1537417 & 6.8013 & 6.0477 & TST & & \\
\hline CHEMBL3732051 & 1537417 & 5.0921 & 6.0841 & TRN & & \\
\hline CHEMBL3729866 & 1537417 & 6.8356 & 7.91 & TRN & & \\
\hline CHEMBL3732192 & 1537417 & 7.5086 & 6.0303 & TST & & \\
\hline CHEMBL 3728297 & 1537417 & 6.0 & 6.5434 & TRN & & \\
\hline CHEMBL3731677 & 1537417 & 5.3546 & 5.8552 & TRN & & \\
\hline CHEMBL3727426 & 1537417 & 6.0 & 7.3175 & TRN & & \\
\hline CHEMBL3732960 & 1537417 & 7.5528 & 6.5784 & TRN & & \\
\hline CHEMBL 3728826 & 1537417 & 6.71899 & 79999999 & 99 & 6.7625 & TRN \\
\hline CHEMBL 3731870 & 1537417 & 7.0605 & 7.0806 & TST & & \\
\hline CHEMBL3729242 & 1537417 & 7.7959 & 8.7798 & TRN & & \\
\hline CHEMBL3731166 & 1537417 & 9.2596 & 8.5617 & TRN & & \\
\hline CHEMBL3727847 & 1537417 & 5.1129 & 5.2729 & TRN & & \\
\hline CHEMBL3729493 & 1537417 & 5.1146 & 4.9934 & TRN & & \\
\hline CHEMBL3730133 & 1537417 & 6.0 & 7.8343 & TRN & & \\
\hline CHEMBL3730542 & 1537417 & 4.9872 & 4.7268 & TRN & & \\
\hline CHEMBL 3729817 & 1537417 & 6.8539 & 6.3458 & TRN & & \\
\hline CHEMBL 3729083 & 1537417 & 6.5768 & 6.8952 & TRN & & \\
\hline CHEMBL3733012 & 1537417 & 8.7447 & 7.9331 & TRN & & \\
\hline CHEMBL 3729082 & 1537417 & 6.0 & 6.8656 & TRN & & \\
\hline CHEMBL3729299 & 1537417 & 8.3565 & 8.2599 & TRN & & \\
\hline CHEMBL 3730217 & 1537417 & 10.1549 & 8.46 & TRN & & \\
\hline CHEMBL3732612 & 1537417 & 5.4377 & 6.0147 & TST & & \\
\hline CHEMBL3727715 & 1537417 & 6.8827 & 6.4498 & TRN & & \\
\hline CHEMBL3732895 & 1537417 & 7.6576 & 8.1458 & TRN & & \\
\hline CHEMBL3732081 & 1537417 & 9.1549 & 8.5326 & TRN & & \\
\hline CHEMBL3731251 & 1537417 & 6.7595 & 5.5387 & TST & & \\
\hline CHEMBL 3728708 & 1537417 & 6.7122 & 6.9694 & TRN & & \\
\hline
\end{tabular}

Page 16821 
Supplemental Table S2.txt

\begin{tabular}{|c|c|c|c|c|}
\hline CHEMBL 3730919 & 1537417 & 7.8861 & 7.5761 & TRN \\
\hline CHEMBL 3732813 & 1537417 & 7.1487 & 5.6005 & TST \\
\hline CHEMBL3728499 & 1537417 & 7.1487 & 7.7288 & TRN \\
\hline CHEMBL 3731889 & 1537417 & 8.8861 & 7.362 & TRN \\
\hline CHEMBL3730013 & 1537417 & 7.7447 & 7.8703 & TST \\
\hline CHEMBL3727812 & 1537417 & 8.2147 & 8.2933 & TST \\
\hline CHEMBL 3730378 & 1537417 & 6.5607 & 6.0483 & TST \\
\hline CHEMBL 3730697 & 1537417 & 7.284 & 7.2565 & TST \\
\hline CHEMBL 3729460 & 1537417 & 9.1805 & 8.185 & TST \\
\hline CHEMBL3728768 & 1537417 & 6.8827 & 6.9403 & TST \\
\hline CHEMBL3731107 & 1537417 & 9.3468 & 7.9617 & TST \\
\hline CHEMBL 3730490 & 1537417 & 7.0969 & 7.5945 & TST \\
\hline CHEMBL3730159 & 1537417 & 9.1427 & 8.2361 & TST \\
\hline CHEMBL 3729246 & 1537417 & 9.0 & 8.1854 & TST \\
\hline CHEMBL3731544 & 1537417 & 6.9393 & 5.9145 & TST \\
\hline CHEMBL3733176 & 1537417 & 6.7799 & 6.7961 & TST \\
\hline CHEMBL3733092 & 1537417 & 6.9747 & 5.3772 & TST \\
\hline CHEMBL 3127060 & 1294967 & 3.699 & 3.7721 & TRN \\
\hline CHEMBL 3127050 & 1294967 & 7.3979 & 7.2407 & TRN \\
\hline CHEMBL3126875 & 1294967 & 3.699 & 4.1897 & TRN \\
\hline CHEMBL3126893 & 1294967 & 3.699 & 3.8062 & TRN \\
\hline CHEMBL 3127044 & 1294967 & 4.8041 & 3.7104 & TST \\
\hline CHEMBL 3126869 & 1294967 & 3.699 & 3.7671 & TRN \\
\hline CHEMBL1269812 & 1294967 & 7.5229 & 6.476 & TST \\
\hline CHEMBL 3126892 & 1294967 & 3.699 & 3.6161 & TRN \\
\hline CHEMBL3126865 & 1294967 & 3.699 & 3.9024 & TST \\
\hline CHEMBL 3126887 & 1294967 & 3.699 & 3.7369 & TRN \\
\hline CHEMBL3126912 & 1294967 & 3.0 & 3.3883 & TRN \\
\hline CHEMBL3126888 & 1294967 & 3.699 & 3.6277 & TRN \\
\hline CHEMBL 3126908 & 1294967 & 7.3979 & 7.5225 & TRN \\
\hline CHEMBL 3127063 & 1294967 & 3.699 & 3.8489 & TRN \\
\hline CHEMBL 3126886 & 1294967 & 3.699 & 3.6833 & TRN \\
\hline CHEMBL3127058 & 1294967 & 6.6383 & 6.4482 & TRN \\
\hline CHEMBL3127053 & 1294967 & 3.699 & 3.6981 & TRN \\
\hline CHEMBL 3126898 & 1294967 & 3.699 & 3.6276 & TST \\
\hline CHEMBL3126914 & 1294967 & 3.699 & 4.1576 & TST \\
\hline CHEMBL3126874 & 1294967 & 4.8477 & 4.8701 & TRN \\
\hline CHEMBL 3126868 & 1294967 & 3.699 & 3.8682 & TRN \\
\hline CHEMBL 3126894 & 1294967 & 3.0 & 3.1598 & TRN \\
\hline CHEMBL 3127047 & 1294967 & 5.3915 & 5.4647 & TST \\
\hline CHEMBL3126905 & 1294967 & 6.7447 & 6.1007 & TST \\
\hline CHEMBL3126880 & 1294967 & 4.9872 & 4.9736 & TRN \\
\hline CHEMBL3126878 & 1294967 & 3.0 & 2.7338 & TRN \\
\hline CHEMBL3126911 & 1294967 & 6.3372 & 5.902 & TRN \\
\hline CHEMBL3126909 & 1294967 & 3.699 & 3.5902 & TRN \\
\hline CHEMBL3126885 & 1294967 & 3.699 & 3.7404 & TRN \\
\hline CHEMBL 3127054 & 1294967 & 3.699 & 3.6356 & TRN \\
\hline CHEMBL319177 & 1294967 & 3.0 & 2.2244 & TST \\
\hline
\end{tabular}


Supplemental Table S2.txt

\begin{tabular}{|c|c|c|c|c|c|}
\hline CHEMBL 3127051 & 1294967 & 3.699 & \multicolumn{2}{|c|}{3.6189999999999998} & \multirow[t]{2}{*}{ TRN } \\
\hline CHEMBL 3127049 & 1294967 & 7.699 & 7.9142 & TRN & \\
\hline CHEMBL1814767 & 1294967 & 7.5229 & 7.5353 & TRN & \\
\hline CHEMBL 3127064 & 1294967 & 3.699 & 3.7742 & TST & \\
\hline CHEMBL3126907 & 1294967 & 7.0458 & 6.9441 & TST & \\
\hline CHEMBL 3126876 & 1294967 & 3.699 & 3.8253 & TRN & \\
\hline CHEMBL 3126871 & 1294967 & 3.699 & 3.5104 & TRN & \\
\hline CHEMBL3126889 & 1294967 & 3.699 & 3.7193 & TRN & \\
\hline CHEMBL 3126884 & 1294967 & 3.699 & 3.6388 & TRN & \\
\hline CHEMBL3126883 & 1294967 & 3.699 & 3.6847 & TRN & \\
\hline CHEMBL3126896 & 1294967 & 3.699 & 3.7953 & TST & \\
\hline CHEMBL 3126881 & 1294967 & 3.699 & 3.6849 & TRN & \\
\hline CHEMBL 3127059 & 1294967 & 3.699 & 3.7957 & TRN & \\
\hline CHEMBL 3126866 & 1294967 & 3.699 & 3.5539 & TRN & \\
\hline CHEMBL3124960 & 1294967 & 3.699 & 3.5464 & TRN & \\
\hline CHEMBL3126899 & 1294967 & 6.6021 & 6.8359 & TRN & \\
\hline CHEMBL3126877 & 1294967 & 3.699 & 3.6829 & TRN & \\
\hline CHEMBL 3126897 & 1294967 & 3.699 & 3.1479 & TST & \\
\hline CHEMBL 3126903 & 1294967 & 3.699 & 3.3817 & TRN & \\
\hline CHEMBL3126900 & 1294967 & 3.699 & 3.8338 & TRN & \\
\hline CHEMBL3126913 & 1294967 & 3.699 & 3.6946 & TRN & \\
\hline CHEMBL 3127067 & 1294967 & 7.0969 & 6.9377 & TRN & \\
\hline CHEMBL 3127046 & 1294967 & 4.8601 & 4.8923 & TRN & \\
\hline CHEMBL3126879 & 1294967 & 4.7375 & 4.6496 & TRN & \\
\hline CHEMBL 3127052 & 1294967 & 3.699 & 3.7333 & TRN & \\
\hline CHEMBL1814768 & 1294967 & 8.0 & 7.8659 & TRN & \\
\hline CHEMBL 3126873 & 1294967 & 3.699 & 3.66399 & 99999999997 & TRN \\
\hline CHEMBL 3127068 & 1294967 & 6.9208 & 6.9707 & TRN & \\
\hline CHEMBL 3127062 & 1294967 & 3.699 & 3.5693 & TRN & \\
\hline CHEMBL 3126901 & 1294967 & 3.699 & 3.5321 & TRN & \\
\hline CHEMBL 3126882 & 1294967 & 3.0 & 3.6628 & TST & \\
\hline CHEMBL3127066 & 1294967 & 6.9586 & 6.9435 & TRN & \\
\hline CHEMBL403715 & 1294967 & 3.699 & 3.2224 & TST & \\
\hline CHEMBL3126870 & 1294967 & 3.699 & 3.6026 & TRN & \\
\hline CHEMBL 3127055 & 1294967 & 7.5229 & 7.5504 & TST & \\
\hline CHEMBL 3127056 & 1294967 & 3.699 & 4.1579 & TST & \\
\hline CHEMBL3126904 & 1294967 & 3.699 & 3.9201 & TRN & \\
\hline CHEMBL 3127048 & 1294967 & 3.699 & 3.9092 & TST & \\
\hline CHEMBL 3126872 & 1294967 & 3.699 & 3.3266 & TST & \\
\hline CHEMBL 3127065 & 1294967 & 7.3979 & 7.4159 & TRN & \\
\hline CHEMBL3126906 & 1294967 & 4.7352 & 4.1852 & TST & \\
\hline CHEMBL3126915 & 1294967 & 5.3261 & 4.1118 & TST & \\
\hline CHEMBL3126890 & 1294967 & 3.699 & 3.53800 & 00000000003 & TRN \\
\hline CHEMBL3126910 & 1294967 & 3.699 & 3.7902 & TRN & \\
\hline CHEMBL 3126891 & 1294967 & 3.699 & 3.6165 & TRN & \\
\hline CHEMBL3126867 & 1294967 & 3.699 & 3.7907 & TRN & \\
\hline CHEMBL3126902 & 1294967 & 3.699 & 3.7585 & TRN & \\
\hline CHEMBL3127057 & 1294967 & 3.699 & 3.9407 & TST & \\
\hline
\end{tabular}


Supplemental Table S2.txt

\begin{tabular}{|c|c|c|c|c|}
\hline CHEMBL3126895 & 1294967 & 3.699 & 3.7561 & TRN \\
\hline CHEMBL 3127061 & 1294967 & 3.699 & 3.7255 & TRN \\
\hline CHEMBL 3127045 & 1294967 & 3.699 & 3.8102 & TRN \\
\hline CHEMBL1834790 & 772990 & 4.9208 & 4.9433 & TRN \\
\hline CHEMBL1834641 & 772990 & 4.6021 & 4.6489 & TRN \\
\hline CHEMBL1834635 & 772990 & 6.0757 & 6.0078 & TRN \\
\hline CHEMBL1834632 & 772990 & 5.9586 & 5.9418 & TRN \\
\hline CHEMBL1834792 & 772990 & 3.301 & 4.2163 & TST \\
\hline CHEMBL1834793 & 772990 & 4.3565 & 4.3478 & TRN \\
\hline CHEMBL1834651 & 772990 & 5.7212 & 5.6781 & TRN \\
\hline CHEMBL1834854 & 772990 & 7.9586 & 6.73799 & 99999999995 \\
\hline CHEMBL1834644 & 772990 & 5.2518 & 5.274 & TRN \\
\hline CHEMBL1834795 & 772990 & 4.5086 & 4.4506 & TRN \\
\hline CHEMBL1834788 & 772990 & 4.5686 & 4.5724 & TRN \\
\hline CHEMBL1834637 & 772990 & 5.2076 & 5.2476 & TRN \\
\hline CHEMBL 1834853 & 772990 & 7.7959 & 6.2887 & TST \\
\hline CHEMBL1834640 & 772990 & 5.0969 & 5.1152 & TRN \\
\hline CHEMBL1834645 & 772990 & 5.301 & 5.2764 & TRN \\
\hline CHEMBL1834780 & 772990 & 5.6021 & 5.5871 & TRN \\
\hline CHEMBL1834791 & 772990 & 4.7447 & 4.7449 & TRN \\
\hline CHEMBL1834638 & 772990 & 4.6198 & 4.5863 & TRN \\
\hline CHEMBL1834783 & 772990 & 5.8539 & 5.4957 & TST \\
\hline CHEMBL1834785 & 772990 & 5.0 & 5.0097 & TRN \\
\hline CHEMBL1834717 & 772990 & 5.3279 & 5.3342 & TRN \\
\hline CHEMBL1834782 & 772990 & 4.6021 & 4.586 & TRN \\
\hline CHEMBL1834789 & 772990 & 4.6198 & 4.591 & TRN \\
\hline CHEMBL1834786 & 772990 & 4.9208 & 4.9475 & TRN \\
\hline CHEMBL1834643 & 772990 & 4.4949 & 4.4756 & TRN \\
\hline CHEMBL1834720 & 772990 & 5.2518 & 7.12299 & 9999999999 \\
\hline CHEMBL1833983 & 772990 & 6.301 & 6.29899 & \\
\hline CHEMBL1834798 & 772990 & 4.6383 & 4.6419 & TRN \\
\hline CHEMBL1834718 & 772990 & 4.9208 & 5.0006 & TRN \\
\hline CHEMBL1834652 & 772990 & 5.1192 & 5.1408 & TRN \\
\hline CHEMBL1834797 & 772990 & 4.6021 & 4.5924 & TRN \\
\hline CHEMBL1834646 & 772990 & 4.5229 & 4.5045 & TRN \\
\hline CHEMBL1834787 & 772990 & 4.4437 & 4.4278 & TRN \\
\hline CHEMBL1834779 & 772990 & 5.4318 & 5.4053 & TRN \\
\hline CHEMBL1834781 & 772990 & 4.699 & 4.7113 & TRN \\
\hline CHEMBL1834642 & 772990 & 4.4949 & 4.4662 & TRN \\
\hline CHEMBL1834852 & 772990 & 8.0605 & 8.0974 & TRN \\
\hline CHEMBL 1834633 & 772990 & 5.0223 & 5.048 & TRN \\
\hline CHEMBL1834648 & 772990 & 5.1308 & 5.1427 & TRN \\
\hline CHEMBL1834634 & 772990 & 5.6021 & 5.5547 & TRN \\
\hline CHEMBL1834636 & 772990 & 4.4685 & 4.8177 & TST \\
\hline CHEMBL1834647 & 772990 & 5.3468 & 5.3374 & TRN \\
\hline CHEMBL1834794 & 772990 & 4.5686 & 4.6389 & TRN \\
\hline CHEMBL1834784 & 772990 & 5.3872 & 5.3934 & TRN \\
\hline CHEMBL1834851 & 772990 & 6.301 & 6.3026 & TRN \\
\hline
\end{tabular}




\begin{tabular}{|c|c|c|c|c|}
\hline \multicolumn{5}{|c|}{ Supplemental Table S2.txt } \\
\hline CHEMBL 2092884 & 772990 & 4.4949 & 5.0848 & TST \\
\hline CHEMBL1834649 & 772990 & 3.301 & 3.3246 & TRN \\
\hline CHEMBL1834631 & 772990 & 5.9208 & 4.8803 & TST \\
\hline CHEMBL1834796 & 772990 & 3.301 & 4.218 & TST \\
\hline CHEMBL1834650 & 772990 & 4.6383 & 4.4257 & TST \\
\hline CHEMBL1834719 & 772990 & 5.041 & 4.9958 & TST \\
\hline CHEMBL1834639 & 772990 & 5.5086 & 4.8802 & TST \\
\hline CHEMBL1834799 & 772990 & 4.7696 & 5.0355 & TST \\
\hline CHEMBL1834721 & 772990 & 5.1192 & 5.0633 & TST \\
\hline CHEMBL1964290 & 809196 & 7.6 & 6.0635 & TRN \\
\hline CHEMBL 2003768 & 809196 & 4.1 & 5.1041 & TRN \\
\hline CHEMBL 213505 & 809196 & 4.1 & 3.8469 & TRN \\
\hline CHEMBL1987034 & 809196 & 6.9 & 7.2249 & TRN \\
\hline CHEMBL1993941 & 809196 & 5.7 & 4.2752 & TRN \\
\hline CHEMBL1980435 & 809196 & 4.3 & 5.2692 & TRN \\
\hline CHEMBL377383 & 809196 & 4.1 & 3.8873 & TRN \\
\hline CHEMBL 2005886 & 809196 & 6.2 & 5.7117 & TRN \\
\hline CHEMBL481491 & 809196 & 5.4 & 4.2302 & TST \\
\hline CHEMBL1973142 & 809196 & 6.2 & 6.181 & TRN \\
\hline CHEMBL1973145 & 809196 & 4.1 & 4.0664 & TRN \\
\hline CHEMBL1982924 & 809196 & 6.0 & 5.1329 & TRN \\
\hline CHEMBL 2005936 & 809196 & 6.3 & 6.6896 & TRN \\
\hline CHEMBL1964948 & 809196 & 4.3 & 4.5476 & TRN \\
\hline CHEMBL1971141 & 809196 & 4.1 & 4.0251 & TRN \\
\hline CHEMBL1995813 & 809196 & 6.6 & 7.6501 & TRN \\
\hline CHEMBL 206236 & 809196 & 6.2 & 6.1959 & TRN \\
\hline CHEMBL 244378 & 809196 & 6.6 & 7.4542 & TRN \\
\hline CHEMBL 2001957 & 809196 & 4.1 & 4.0543 & TRN \\
\hline CHEMBL1969372 & 809196 & 4.1 & 4.2119 & TRN \\
\hline CHEMBL1993413 & 809196 & 4.3 & 5.1687 & TRN \\
\hline CHEMBL1986943 & 809196 & 8.1 & 7.8874 & TRN \\
\hline CHEMBL 2006263 & 809196 & 4.1 & 4.6016 & TST \\
\hline CHEMBL1993584 & 809196 & 6.1 & 6.4308 & TRN \\
\hline CHEMBL1986263 & 809196 & 6.2 & 5.8362 & TRN \\
\hline CHEMBL 2000114 & 809196 & 4.1 & 4.9687 & TRN \\
\hline CHEMBL210618 & 809196 & 4.1 & 3.9638 & TRN \\
\hline CHEMBL1971172 & 809196 & 6.7 & 6.9029 & TRN \\
\hline CHEMBL1975647 & 809196 & 4.1 & 4.5793 & TRN \\
\hline CHEMBL1968380 & 809196 & 4.1 & 4.2286 & TRN \\
\hline CHEMBL1964644 & 809196 & 4.1 & 4.0262 & TRN \\
\hline CHEMBL1981782 & 809196 & 6.0 & 6.5838 & TRN \\
\hline CHEMBL1977681 & 809196 & 5.4 & 4.8986 & TRN \\
\hline CHEMBL1970142 & 809196 & 4.1 & 4.2379 & TRN \\
\hline CHEMBL1990912 & 809196 & 4.1 & 4.7015 & TRN \\
\hline CHEMBL1988163 & 809196 & 6.7 & 6.7654 & TRN \\
\hline CHEMBL 2006493 & 809196 & 4.1 & 3.9283 & TST \\
\hline CHEMBL1996923 & 809196 & 4.1 & 4.0897 & TST \\
\hline CHEMBL1983449 & 809196 & 5.3 & 5.5194 & TRN \\
\hline
\end{tabular}




\begin{tabular}{|c|c|c|c|c|c|}
\hline & & & & & \\
\hline CHEMBL1992323 & 809196 & 5.1 & 3.9421 & TRN & \\
\hline CHEMBL1969735 & 809196 & 4.1 & 4.2667 & TRN & \\
\hline CHEMBL 2002649 & 809196 & 6.1 & 5.2793 & TRN & \\
\hline CHEMBL 2005718 & 809196 & 7.3 & 6.9877 & TRN & \\
\hline CHEMBL1995172 & 809196 & 4.1 & 3.9773 & TST & \\
\hline CHEMBL1994321 & 809196 & 4.1 & 4.3053 & TRN & \\
\hline CHEMBL1997129 & 809196 & 7.4 & 5.8783 & TRN & \\
\hline CHEMBL1984788 & 809196 & 4.1 & 4.0319 & TRN & \\
\hline CHEMBL 2000508 & 809196 & 4.1 & 4.4637 & TRN & \\
\hline CHEMBL1971694 & 809196 & 4.1 & 4.1577 & TST & \\
\hline CHEMBL 2001547 & 809196 & 4.1 & 3.97606 & 20000000004 & TRN \\
\hline CHEMBL210928 & 809196 & 4.1 & 3.7904 & TRN & \\
\hline CHEMBL1986603 & 809196 & 4.1 & 3.978 & TST & \\
\hline CHEMBL1977148 & 809196 & 4.1 & 4.0323 & TRN & \\
\hline CHEMBL1966842 & 809196 & 4.3 & 4.5545 & TRN & \\
\hline CHEMBL 2003286 & 809196 & 4.1 & 4.3109 & TRN & \\
\hline CHEMBL1992306 & 809196 & 4.1 & 3.9916 & TRN & \\
\hline CHEMBL 2002165 & 809196 & 5.6 & 4.689 & TRN & \\
\hline CHEMBL 2001668 & 809196 & 4.1 & 4.1771 & TST & \\
\hline CHEMBL1979318 & 809196 & 4.1 & 3.7265 & TST & \\
\hline CHEMBL206382 & 809196 & 6.8 & 5.8997 & TRN & \\
\hline CHEMBL1998585 & 809196 & 4.1 & 4.3811 & TRN & \\
\hline CHEMBL127898 & 809196 & 4.1 & 4.1046 & TST & \\
\hline CHEMBL519697 & 809196 & 6.0 & 4.1366 & TST & \\
\hline CHEMBL 2004934 & 809196 & 6.4 & 6.7564 & TRN & \\
\hline CHEMBL1987261 & 809196 & 7.7 & 6.9882 & TRN & \\
\hline CHEMBL1975128 & 809196 & 6.6 & 7.5781 & TRN & \\
\hline CHEMBL1996048 & 809196 & 6.6 & 5.7435 & TST & \\
\hline CHEMBL1970369 & 809196 & 4.1 & 4.1958 & TRN & \\
\hline CHEMBL461876 & 809196 & 4.1 & 4.753 & TRN & \\
\hline CHEMBL 2001485 & 809196 & 4.1 & 4.0874 & TRN & \\
\hline CHEMBL1966425 & 809196 & 5.1 & 5.4781 & TRN & \\
\hline CHEMBL1984363 & 809196 & 4.1 & 5.6256 & TRN & \\
\hline CHEMBL1978099 & 809196 & 5.8 & 5.5929 & TRN & \\
\hline CHEMBL1988608 & 809196 & 7.3 & 6.9551 & TRN & \\
\hline CHEMBL184847 & 809196 & 4.1 & 4.3501 & TRN & \\
\hline CHEMBL1984367 & 809196 & 4.1 & 4.5495 & TRN & \\
\hline CHEMBL1985723 & 809196 & 7.7 & 7.3665 & TRN & \\
\hline CHEMBL178737 & 809196 & 5.8 & 4.4272 & TST & \\
\hline CHEMBL 226898 & 809196 & 7.6 & 7.3103 & TRN & \\
\hline CHEMBL1982563 & 809196 & 4.1 & 4.2379 & TRN & \\
\hline CHEMBL1991377 & 809196 & 4.3 & 4.4912 & TRN & \\
\hline CHEMBL539474 & 809196 & 4.1 & 4.8147 & TST & \\
\hline CHEMBL575824 & 809196 & 6.3 & 6.8999 & TRN & \\
\hline CHEMBL1988387 & 809196 & 4.1 & 4.706 & TRN & \\
\hline CHEMBL1977128 & 809196 & 4.3 & 4.90306 & 00000000005 & TRN \\
\hline CHEMBL1990288 & 809196 & 4.1 & 4.3053 & TRN & \\
\hline CHEMBL1989708 & 809196 & 4.1 & 4.4572 & TRN & \\
\hline
\end{tabular}




\begin{tabular}{|c|c|c|c|c|}
\hline \multicolumn{5}{|c|}{ Supplemental Table S2.txt } \\
\hline CHEMBL1974803 & 809196 & 4.1 & 4.5358 & TST \\
\hline CHEMBL1970074 & 809196 & 4.1 & 4.3911 & TRN \\
\hline CHEMBL1965702 & 809196 & 7.0 & 6.8775 & TRN \\
\hline CHEMBL1986970 & 809196 & 6.0 & 6.1691 & TRN \\
\hline CHEMBL 2005112 & 809196 & 4.1 & 3.7917 & TST \\
\hline CHEMBL1958401 & 809196 & 4.1 & 4.5833 & TRN \\
\hline CHEMBL1984044 & 809196 & 4.1 & 4.4301 & TRN \\
\hline CHEMBL2003456 & 809196 & 4.1 & 4.5622 & TRN \\
\hline CHEMBL1966816 & 809196 & 4.1 & 4.2011 & TRN \\
\hline CHEMBL1972584 & 809196 & 5.2 & 4.2559 & TRN \\
\hline CHEMBL 2002992 & 809196 & 6.7 & 6.3991 & TRN \\
\hline CHEMBL560813 & 809196 & 4.1 & 4.4502 & TRN \\
\hline CHEMBL207253 & 809196 & 4.1 & 3.8737 & TST \\
\hline CHEMBL1990635 & 809196 & 5.6 & 5.1536 & TST \\
\hline CHEMBL1968791 & 809196 & 4.1 & 5.199 & TRN \\
\hline CHEMBL 2002682 & 809196 & 5.6 & 4.7329 & TST \\
\hline CHEMBL1971186 & 809196 & 4.1 & 4.2499 & TRN \\
\hline CHEMBL2003482 & 809196 & 4.1 & 4.1661 & TRN \\
\hline CHEMBL 2006456 & 809196 & 8.0 & 7.1235 & TRN \\
\hline CHEMBL1973211 & 809196 & 4.1 & 4.4731 & TRN \\
\hline CHEMBL1984700 & 809196 & 4.1 & 3.9099 & TRN \\
\hline CHEMBL1972125 & 809196 & 4.1 & 4.6755 & TRN \\
\hline CHEMBL1461728 & 809196 & 4.1 & 4.4065 & TRN \\
\hline CHEMBL1976134 & 809196 & 5.7 & 5.8456 & TRN \\
\hline CHEMBL1965131 & 809196 & 6.1 & 6.2175 & TRN \\
\hline CHEMBL1972158 & 809196 & 6.5 & 7.1108 & TRN \\
\hline CHEMBL 2006580 & 809196 & 4.1 & 4.265 & TRN \\
\hline CHEMBL 2001228 & 809196 & 4.3 & 4.7312 & TRN \\
\hline CHEMBL 2006481 & 809196 & 4.1 & 4.2506 & TRN \\
\hline CHEMBL1979855 & 809196 & 4.1 & 4.0807 & TRN \\
\hline CHEMBL1970340 & 809196 & 4.1 & 4.7932 & TRN \\
\hline CHEMBL 2005186 & 809196 & 4.1 & 4.9784 & TRN \\
\hline CHEMBL1995927 & 809196 & 4.1 & 4.0108 & TST \\
\hline CHEMBL 2006450 & 809196 & 4.3 & 5.5403 & TRN \\
\hline CHEMBL1975534 & 809196 & 4.1 & 5.0098 & TRN \\
\hline CHEMBL1993424 & 809196 & 7.0 & 6.3591 & TRN \\
\hline CHEMBL1966703 & 809196 & 4.1 & 4.2727 & TST \\
\hline CHEMBL1969561 & 809196 & 6.6 & 6.7198 & TRN \\
\hline CHEMBL1997023 & 809196 & 6.6 & 4.4876 & TST \\
\hline CHEMBL1964687 & 809196 & 4.1 & 4.5497 & TRN \\
\hline CHEMBL1971943 & 809196 & 6.4 & 6.4108 & TRN \\
\hline CHEMBL1974254 & 809196 & 4.1 & 4.3246 & TRN \\
\hline CHEMBL1997924 & 809196 & 7.2 & 5.6947 & TST \\
\hline CHEMBL1988537 & 809196 & 6.0 & 5.6654 & TST \\
\hline CHEMBL1969049 & 809196 & 6.9 & 6.7497 & TRN \\
\hline CHEMBL 2005828 & 809196 & 4.1 & 4.3634 & TRN \\
\hline CHEMBL 2002240 & 809196 & 4.1 & 4.0254 & TRN \\
\hline CHEMBL1978267 & 809196 & 4.3 & 4.505 & TRN \\
\hline
\end{tabular}




\begin{tabular}{|c|c|c|c|c|}
\hline & & & pplement & al $\mathrm{Ta}$ \\
\hline CHEMBL1971485 & 809196 & 4.3 & 4.5648 & TRN \\
\hline CHEMBL1991143 & 809196 & 4.1 & 3.6813 & TST \\
\hline CHEMBL1980178 & 809196 & 7.4 & 6.6167 & TRN \\
\hline CHEMBL1998611 & 809196 & 6.4 & 5.675 & TRN \\
\hline CHEMBL1975900 & 809196 & 6.4 & 6.4988 & TRN \\
\hline CHEMBL 255822 & 809196 & 4.1 & 4.547 & TRN \\
\hline CHEMBL1972221 & 809196 & 5.2 & 4.8891 & TRN \\
\hline CHEMBL2006778 & 809196 & 4.1 & 4.7549 & TRN \\
\hline CHEMBL378627 & 809196 & 4.1 & 3.9794 & TRN \\
\hline CHEMBL1996979 & 809196 & 6.2 & 5.2486 & TRN \\
\hline CHEMBL1997025 & 809196 & 4.1 & 4.4836 & TRN \\
\hline CHEMBL1968406 & 809196 & 4.1 & 4.3105 & TRN \\
\hline CHEMBL1984274 & 809196 & 4.1 & 4.3769 & TST \\
\hline CHEMBL1998545 & 809196 & 5.3 & 5.3734 & TRN \\
\hline CHEMBL1986869 & 809196 & 4.1 & 4.4917 & TRN \\
\hline CHEMBL 2006010 & 809196 & 4.1 & 4.1707 & TRN \\
\hline CHEMBL1682558 & 809196 & 4.1 & 4.2165 & TRN \\
\hline CHEMBL1990496 & 809196 & 5.6 & 5.3498 & TRN \\
\hline CHEMBL 2002479 & 809196 & 5.5 & 5.7012 & TRN \\
\hline CHEMBL1967094 & 809196 & 5.9 & 4.6655 & TRN \\
\hline CHEMBL1966035 & 809196 & 4.1 & 4.8071 & TRN \\
\hline CHEMBL2003341 & 809196 & 6.3 & 6.039 & TRN \\
\hline CHEMBL1982992 & 809196 & 5.3 & 4.7173 & TRN \\
\hline CHEMBL1999590 & 809196 & 4.1 & 4.0018 & TST \\
\hline CHEMBL1981079 & 809196 & 7.2 & 5.7947 & TRN \\
\hline CHEMBL1972276 & 809196 & 4.1 & 4.261 & TRN \\
\hline CHEMBL1980489 & 809196 & 6.3 & 6.0556 & TRN \\
\hline CHEMBL 2000832 & 809196 & 6.4 & 5.8528 & TRN \\
\hline CHEMBL1967116 & 809196 & 4.1 & 4.7223 & TRN \\
\hline CHEMBL1990590 & 809196 & 4.3 & 4.7562 & TRN \\
\hline CHEMBL513846 & 809196 & 4.1 & 4.5187 & TRN \\
\hline CHEMBL1970709 & 809196 & 4.1 & 5.3831 & TRN \\
\hline CHEMBL1965660 & 809196 & 7.7 & 6.4833 & TRN \\
\hline CHEMBL1998112 & 809196 & 6.0 & 4.4251 & TRN \\
\hline CHEMBL1972290 & 809196 & 8.3 & 7.3448 & TRN \\
\hline CHEMBL1969126 & 809196 & 4.1 & 4.3287 & TRN \\
\hline CHEMBL1980896 & 809196 & 4.1 & 4.2652 & TRN \\
\hline CHEMBL1975208 & 809196 & 4.1 & 3.8491 & TST \\
\hline CHEMBL1970104 & 809196 & 6.3 & 5.4603 & TRN \\
\hline CHEMBL1991429 & 809196 & 4.1 & 4.603 & TRN \\
\hline CHEMBL1964777 & 809196 & 5.6 & 5.265 & TST \\
\hline CHEMBL1971149 & 809196 & 4.1 & 4.0728 & TRN \\
\hline CHEMBL1999714 & 809196 & 4.1 & 3.7815 & TRN \\
\hline CHEMBL1987533 & 809196 & 5.2 & 4.751 & TRN \\
\hline CHEMBL1994040 & 809196 & 4.1 & 3.9353 & TRN \\
\hline CHEMBL388978 & 809196 & 9.1 & 8.4711 & TST \\
\hline CHEMBL1984548 & 809196 & 7.3 & 6.8442 & TRN \\
\hline CHEMBL579246 & 809196 & 6.6 & 7.0496 & TRN \\
\hline
\end{tabular}




\begin{tabular}{|c|c|c|c|c|c|}
\hline \multicolumn{6}{|c|}{ Supplemental Table S2.txt } \\
\hline CHEMBL398951 & 809196 & 4.1 & 4.1239 & TRN & \\
\hline CHEMBL1982506 & 809196 & 4.1 & 4.5349 & TST & \\
\hline CHEMBL 2004716 & 809196 & 5.3 & 4.7413 & TRN & \\
\hline CHEMBL1968127 & 809196 & 4.1 & 4.1786 & TRN & \\
\hline CHEMBL1975233 & 809196 & 4.1 & 3.8642 & TRN & \\
\hline CHEMBL1985406 & 809196 & 4.1 & 4.2496 & TRN & \\
\hline CHEMBL207400 & 809196 & 4.1 & 3.9198 & TST & \\
\hline CHEMBL2000894 & 809196 & 6.5 & 6.5027 & TST & \\
\hline CHEMBL1982135 & 809196 & 4.1 & 4.1404 & TRN & \\
\hline CHEMBL1976090 & 809196 & 6.3 & 5.7823 & TRN & \\
\hline CHEMBL1993243 & 809196 & 4.1 & 4.2726 & TRN & \\
\hline CHEMBL 2004771 & 809196 & 5.4 & 5.0489 & TRN & \\
\hline CHEMBL1992922 & 809196 & 6.2 & 6.2369 & TRN & \\
\hline CHEMBL1997597 & 809196 & 5.9 & 5.5003 & TRN & \\
\hline CHEMBL1969537 & 809196 & 4.1 & 4.2686 & TST & \\
\hline CHEMBL1976093 & 809196 & 4.1 & 4.1588 & TRN & \\
\hline CHEMBL210032 & 809196 & 4.1 & 4.0591 & TRN & \\
\hline CHEMBL1975256 & 809196 & 5.3 & 4.5378 & TST & \\
\hline CHEMBL508928 & 809196 & 4.1 & 4.5937 & TRN & \\
\hline CHEMBL1991356 & 809196 & 4.1 & 4.2483 & TST & \\
\hline CHEMBL1983309 & 809196 & 4.1 & 4.3833 & TRN & \\
\hline CHEMBL 2004892 & 809196 & 6.2 & 5.2652 & TRN & \\
\hline CHEMBL1999126 & 809196 & 4.1 & 3.804 & TST & \\
\hline CHEMBL1997503 & 809196 & 4.1 & 4.048 & TST & \\
\hline CHEMBL1972339 & 809196 & 6.8 & 7.0324 & TRN & \\
\hline CHEMBL116070 & 809196 & 6.0 & 5.2224 & TST & \\
\hline CHEMBL1990821 & 809196 & 4.1 & 4.2432 & TST & \\
\hline CHEMBL1970314 & 809196 & 4.1 & 4.4081 & TRN & \\
\hline CHEMBL 2004871 & 809196 & 4.1 & 3.9677 & TRN & \\
\hline CHEMBL 2004872 & 809196 & 5.4 & 6.17200 & 0000000001 & TRN \\
\hline CHEMBL1727312 & 809196 & 4.1 & 3.4131 & TRN & \\
\hline CHEMBL1969879 & 809196 & 5.4 & 4.7752 & TRN & \\
\hline CHEMBL1981720 & 809196 & 5.1 & 5.1477 & TRN & \\
\hline CHEMBL419932 & 809196 & 6.5 & 6.2553 & TRN & \\
\hline CHEMBL 262433 & 809196 & 4.1 & 3.8827 & TRN & \\
\hline CHEMBL306380 & 809196 & 4.1 & 4.7682 & TRN & \\
\hline CHEMBL1966722 & 809196 & 4.1 & 4.3896 & TST & \\
\hline CHEMBL1983595 & 809196 & 4.3 & 5.0486 & TRN & \\
\hline CHEMBL1975500 & 809196 & 5.6 & 5.5553 & TRN & \\
\hline CHEMBL394619 & 809196 & 4.1 & 4.3882 & TRN & \\
\hline CHEMBL1996831 & 809196 & 4.1 & 4.2827 & TST & \\
\hline CHEMBL411903 & 809196 & 5.2 & 5.4172 & TRN & \\
\hline CHEMBL1980253 & 809196 & 7.1 & 7.0268 & TRN & \\
\hline CHEMBL1965988 & 809196 & 5.3 & 4.8221 & TRN & \\
\hline CHEMBL418203 & 809196 & 5.3 & 5.0303 & TST & \\
\hline CHEMBL1989646 & 809196 & 6.3 & 6.7542 & TRN & \\
\hline CHEMBL225519 & 809196 & 8.3 & 6.2287 & TRN & \\
\hline CHEMBL1978200 & 809196 & 4.1 & 4.1983 & TRN & \\
\hline
\end{tabular}




\begin{tabular}{|c|c|c|c|c|}
\hline \multicolumn{5}{|c|}{ Supplemental Table S2.txt } \\
\hline CHEMBL 2006631 & 809196 & 5.1 & 4.2766 & TRN \\
\hline CHEMBL1970522 & 809196 & 4.1 & 4.5026 & TRN \\
\hline CHEMBL1990415 & 809196 & 4.1 & 4.6239 & TRN \\
\hline CHEMBL1966087 & 809196 & 6.2 & 5.0849 & TRN \\
\hline CHEMBL1964692 & 809196 & 4.1 & 4.2216 & TRN \\
\hline CHEMBL1996931 & 809196 & 5.1 & 5.2669 & TRN \\
\hline CHEMBL1964413 & 809196 & 4.1 & 4.9786 & TRN \\
\hline CHEMBL1973483 & 809196 & 4.1 & 4.4104 & TRN \\
\hline CHEMBL1998470 & 809196 & 5.5 & 5.6579 & TRN \\
\hline CHEMBL1996980 & 809196 & 7.8 & 7.6905 & TRN \\
\hline CHEMBL1970735 & 809196 & 5.1 & 4.004 & TRN \\
\hline CHEMBL1997340 & 809196 & 4.1 & 4.2896 & TRN \\
\hline CHEMBL1994669 & 809196 & 7.4 & 6.9646 & TRN \\
\hline CHEMBL 2004365 & 809196 & 4.1 & 4.1892 & TST \\
\hline CHEMBL1522508 & 809196 & 4.1 & 3.9243 & TRN \\
\hline CHEMBL1989474 & 809196 & 4.1 & 3.8635 & TRN \\
\hline CHEMBL1090360 & 809196 & 4.1 & 4.1826 & TRN \\
\hline CHEMBL 210887 & 809196 & 4.1 & 4.3202 & TST \\
\hline CHEMBL458997 & 809196 & 4.1 & 4.9446 & TRN \\
\hline CHEMBL1971021 & 809196 & 4.1 & 4.2224 & TRN \\
\hline CHEMBL227271 & 809196 & 7.2 & 7.9634 & TRN \\
\hline CHEMBL583144 & 809196 & 5.8 & 5.0263 & TRN \\
\hline CHEMBL1974310 & 809196 & 5.2 & 5.2787 & TST \\
\hline CHEMBL1982660 & 809196 & 4.3 & 4.9555 & TRN \\
\hline CHEMBL1994693 & 809196 & 4.1 & 4.118 & TRN \\
\hline CHEMBL1982957 & 809196 & 6.6 & 6.0827 & TRN \\
\hline CHEMBL1725279 & 809196 & 4.1 & 5.394 & TST \\
\hline CHEMBL1975138 & 809196 & 5.2 & 4.0713 & TST \\
\hline CHEMBL424872 & 809196 & 4.1 & 4.0179 & TRN \\
\hline CHEMBL 2006836 & 809196 & 4.1 & 3.8255 & TST \\
\hline CHEMBL412142 & 809196 & 4.1 & 4.3485 & TST \\
\hline CHEMBL1980704 & 809196 & 4.1 & 4.082 & TST \\
\hline CHEMBL 2003271 & 809196 & 6.4 & 6.2486 & TRN \\
\hline CHEMBL1966808 & 809196 & 4.1 & 3.4808 & TST \\
\hline CHEMBL 2004447 & 809196 & 4.1 & 3.9626 & TST \\
\hline CHEMBL1992231 & 809196 & 4.3 & 4.6097 & TRN \\
\hline CHEMBL1983111 & 809196 & 6.3 & 7.0201 & TST \\
\hline CHEMBL1973860 & 809196 & 5.1 & 4.9087 & TRN \\
\hline CHEMBL1977713 & 809196 & 4.1 & 4.4499 & TRN \\
\hline CHEMBL260135 & 809196 & 5.1 & 4.7176 & TRN \\
\hline CHEMBL220241 & 809196 & 7.6 & 6.6552 & TRN \\
\hline CHEMBL 2004544 & 809196 & 4.1 & 4.3005 & TST \\
\hline CHEMBL1982610 & 809196 & 4.1 & 4.2204 & TST \\
\hline CHEMBL1989569 & 809196 & 5.4 & 4.8573 & TRN \\
\hline CHEMBL1999496 & 809196 & 4.1 & 4.5933 & TRN \\
\hline CHEMBL1988300 & 809196 & 4.1 & 4.4543 & TRN \\
\hline CHEMBL1991078 & 809196 & 6.3 & 5.723 & TRN \\
\hline CHEMBL1987359 & 809196 & 4.1 & 4.0047 & TST \\
\hline
\end{tabular}




\begin{tabular}{|c|c|c|c|c|c|}
\hline \\
\hline CHEMBL1994438 & 809196 & 7.2 & 7.2969 & TRN & \\
\hline CHEMBL 2000724 & 809196 & 4.3 & 4.5158 & TRN & \\
\hline CHEMBL1989265 & 809196 & 4.1 & 4.2395 & TST & \\
\hline CHEMBL 2004647 & 809196 & 4.1 & 4.037 & TST & \\
\hline CHEMBL1969502 & 809196 & 7.4 & 6.9576 & TRN & \\
\hline CHEMBL1682553 & 809196 & 6.2 & 6.5925 & TRN & \\
\hline CHEMBL1971430 & 809196 & 4.1 & 4.7308 & TRN & \\
\hline CHEMBL1983963 & 809196 & 4.1 & 4.3276 & TRN & \\
\hline CHEMBL1997764 & 809196 & 5.9 & 5.0313 & TRN & \\
\hline CHEMBL1985092 & 809196 & 6.3 & 6.0993 & TRN & \\
\hline CHEMBL 2004692 & 809196 & 4.1 & 4.2994 & TST & \\
\hline CHEMBL1981410 & 809196 & 4.1 & 4.58 & TRN & \\
\hline CHEMBL1996234 & 809196 & 4.1 & 4.2852 & TRN & \\
\hline CHEMBL383264 & 809196 & 7.5 & 6.456 & TRN & \\
\hline CHEMBL1991434 & 809196 & 4.1 & 3.9158 & TRN & \\
\hline CHEMBL1967544 & 809196 & 6.5 & 6.6554 & TRN & \\
\hline CHEMBL223367 & 809196 & 4.1 & 4.1386 & TST & \\
\hline CHEMBL340384 & 809196 & 7.5 & 7.1943 & TST & \\
\hline CHEMBL1969151 & 809196 & 8.0 & 7.3932 & TRN & \\
\hline CHEMBL1996587 & 809196 & 4.1 & 4.079 & TRN & \\
\hline CHEMBL1964804 & 809196 & 6.3 & 6.5901 & TRN & \\
\hline CHEMBL443962 & 809196 & 4.1 & 4.3618 & TST & \\
\hline CHEMBL 2000354 & 809196 & 4.1 & 4.4138 & TRN & \\
\hline CHEMBL1965507 & 809196 & 5.4 & 4.6659 & TRN & \\
\hline CHEMBL274064 & 809196 & 4.1 & 4.6535 & TRN & \\
\hline CHEMBL1967564 & 809196 & 4.1 & 4.3331 & TRN & \\
\hline CHEMBL592030 & 809196 & 6.5 & 7.685 & TST & \\
\hline CHEMBL 2000071 & 809196 & 5.8 & 6.0753 & TRN & \\
\hline CHEMBL1979176 & 809196 & 4.1 & 4.5584 & TRN & \\
\hline CHEMBL 2002613 & 809196 & 4.3 & 4.9849 & TRN & \\
\hline CHEMBL 2000408 & 809196 & 4.1 & 4.2576 & TRN & \\
\hline CHEMBL248757 & 809196 & 4.1 & 4.26699 & 99999999995 & TST \\
\hline CHEMBL1978014 & 809196 & 4.1 & 4.276 & TRN & \\
\hline CHEMBL1994538 & 809196 & 4.1 & 4.6453 & TRN & \\
\hline CHEMBL1983195 & 809196 & 4.1 & 4.0893 & TST & \\
\hline CHEMBL1975490 & 809196 & 5.1 & 5.4286 & TRN & \\
\hline CHEMBL1964444 & 809196 & 4.1 & 4.3304 & TRN & \\
\hline CHEMBL1989957 & 809196 & 4.1 & 4.3282 & TRN & \\
\hline CHEMBL1986139 & 809196 & 4.1 & 3.9769 & TRN & \\
\hline CHEMBL1980540 & 809196 & 4.1 & 3.96199 & 99999999997 & TRN \\
\hline CHEMBL1979883 & 809196 & 4.1 & 4.4426 & TRN & \\
\hline CHEMBL1984162 & 809196 & 4.1 & 4.9492 & TRN & \\
\hline CHEMBL1997051 & 809196 & 4.3 & 4.724 & TRN & \\
\hline CHEMBL1998432 & 809196 & 8.6 & 7.4766 & TRN & \\
\hline CHEMBL491758 & 809196 & 4.1 & 5.188 & TRN & \\
\hline CHEMBL549730 & 809196 & 5.1 & 4.7101 & TRN & \\
\hline CHEMBL1970189 & 809196 & 4.1 & 3.7657 & TST & \\
\hline CHEMBL1996791 & 809196 & 4.1 & 4.4708 & TRN & \\
\hline & & & & 16831 & \\
\hline
\end{tabular}




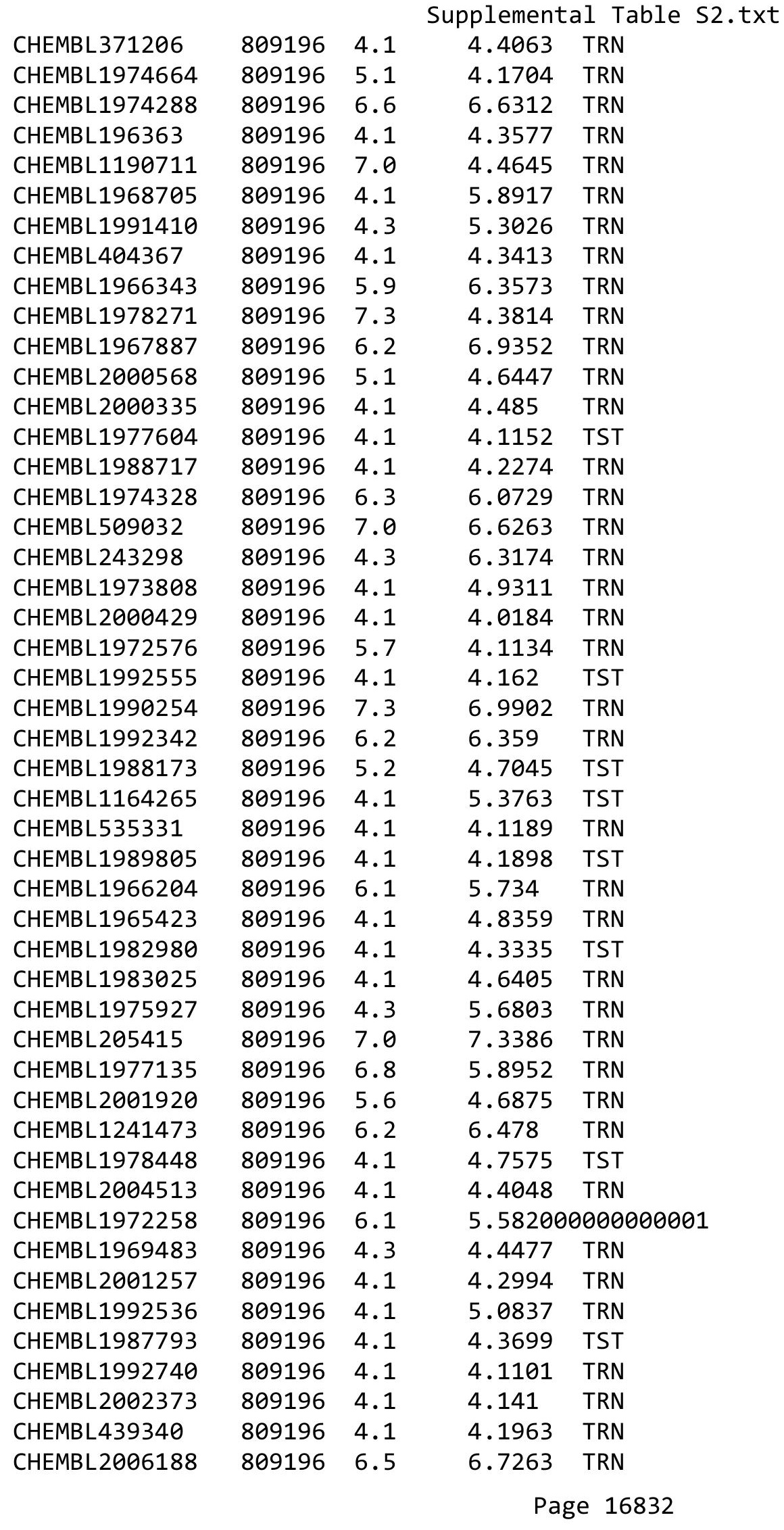




\begin{tabular}{|c|c|c|c|c|}
\hline & & & Supplement & \\
\hline CHEMBL1967531 & 809196 & 4.1 & 4.4587 & TRN \\
\hline CHEMBL1970913 & 809196 & 4.1 & 4.1031 & TRN \\
\hline CHEMBL1973893 & 809196 & 5.2 & 5.0149 & TRN \\
\hline CHEMBL1995736 & 809196 & 4.1 & 4.6627 & TRN \\
\hline CHEMBL1997534 & 809196 & 7.8 & 6.8136 & TRN \\
\hline CHEMBL1996500 & 809196 & 4.1 & 4.0968 & TRN \\
\hline CHEMBL1985095 & 809196 & 7.1 & 6.78 & TST \\
\hline CHEMBL1998551 & 809196 & 4.1 & 4.1051 & TRN \\
\hline CHEMBL1977374 & 809196 & 4.1 & 4.1601 & TRN \\
\hline CHEMBL1682540 & 809196 & 5.2 & 5.5505 & TRN \\
\hline CHEMBL1976420 & 809196 & 4.2 & 4.4814 & TST \\
\hline CHEMBL1994864 & 809196 & 6.1 & 5.6904 & TRN \\
\hline CHEMBL 2002446 & 809196 & 5.4 & 4.6135 & TRN \\
\hline CHEMBL497151 & 809196 & 6.1 & 5.4174 & TST \\
\hline CHEMBL1973961 & 809196 & 4.2 & 4.508 & TRN \\
\hline CHEMBL 246970 & 809196 & 5.3 & 5.5921 & TRN \\
\hline CHEMBL340921 & 809196 & 6.7 & 6.3337 & TST \\
\hline CHEMBL1994977 & 809196 & 8.2 & 4.495 & TRN \\
\hline CHEMBL1999718 & 809196 & 4.1 & 4.3361 & TRN \\
\hline CHEMBL1987073 & 809196 & 4.3 & 5.024 & TRN \\
\hline CHEMBL 2000078 & 809196 & 4.3 & 4.5202 & TRN \\
\hline CHEMBL1276446 & 809196 & 8.2 & 6.4423 & TST \\
\hline CHEMBL1995712 & 809196 & 6.4 & 6.5569 & TRN \\
\hline CHEMBL1979773 & 809196 & 4.3 & 4.5025 & TRN \\
\hline CHEMBL1977346 & 809196 & 4.1 & 4.4278 & TRN \\
\hline CHEMBL1971649 & 809196 & 4.1 & 4.0405 & TRN \\
\hline CHEMBL 2005482 & 809196 & 4.3 & 4.5825 & TRN \\
\hline CHEMBL1997909 & 809196 & 4.3 & 4.3987 & TRN \\
\hline CHEMBL1998435 & 809196 & 4.1 & 4.4683 & TRN \\
\hline CHEMBL 2006439 & 809196 & 6.6 & 6.5008 & TRN \\
\hline CHEMBL 2006156 & 809196 & 4.1 & 4.0911 & TST \\
\hline CHEMBL1969190 & 809196 & 4.1 & 4.1317 & TRN \\
\hline CHEMBL 2002660 & 809196 & 4.3 & 4.5071 & TRN \\
\hline CHEMBL1973937 & 809196 & 4.1 & 4.5315 & TRN \\
\hline CHEMBL1991674 & 809196 & 7.9 & 7.3855 & TRN \\
\hline CHEMBL1982711 & 809196 & 6.7 & 6.8884 & TRN \\
\hline CHEMBL1987982 & 809196 & 4.1 & 4.8142 & TST \\
\hline CHEMBL 2007044 & 809196 & 4.1 & 3.9577 & TRN \\
\hline CHEMBL1994241 & 809196 & 4.1 & 4.9439 & TST \\
\hline CHEMBL 223460 & 809196 & 4.1 & 4.1317 & TST \\
\hline CHEMBL1998829 & 809196 & 6.0 & 4.4199 & TRN \\
\hline CHEMBL50894 & 809196 & 6.1 & 4.7958 & TST \\
\hline CHEMBL1988838 & 809196 & 5.6 & 6.2308 & TRN \\
\hline CHEMBL1981725 & 809196 & 5.4 & 4.6635 & TRN \\
\hline CHEMBL1980562 & 809196 & 6.9 & 7.0697 & TRN \\
\hline CHEMBL1982866 & 809196 & 4.1 & 3.9457 & TRN \\
\hline CHEMBL1968926 & 809196 & 4.1 & 4.2478 & TRN \\
\hline CHEMBL462120 & 809196 & 5.1 & 4.3271 & TST \\
\hline
\end{tabular}




\begin{tabular}{|c|c|c|c|c|c|}
\hline \\
\hline CHEMBL1979933 & 809196 & 5.4 & 5.0628 & TRN & \\
\hline CHEMBL1965570 & 809196 & 4.1 & 4.1723 & TRN & \\
\hline CHEMBL 2007592 & 809196 & 4.1 & 3.73100 & 00000000003 & TST \\
\hline CHEMBL1976936 & 809196 & 7.7 & 7.1993 & TRN & \\
\hline CHEMBL 210963 & 809196 & 4.1 & 3.8307 & TRN & \\
\hline CHEMBL1082440 & 809196 & 6.1 & 6.0865 & TST & \\
\hline CHEMBL1614705 & 809196 & 4.1 & 4.4952 & TRN & \\
\hline CHEMBL1984633 & 809196 & 5.8 & 6.2357 & TRN & \\
\hline CHEMBL1972988 & 809196 & 5.6 & 6.1379 & TRN & \\
\hline CHEMBL 2007372 & 809196 & 4.1 & 3.8498 & TRN & \\
\hline CHEMBL1965845 & 809196 & 7.6 & 7.6549 & TRN & \\
\hline CHEMBL 2006715 & 809196 & 4.1 & 4.6772 & TRN & \\
\hline CHEMBL1986597 & 809196 & 4.1 & 4.3167 & TRN & \\
\hline CHEMBL1990482 & 809196 & 7.4 & 5.6409 & TRN & \\
\hline CHEMBL1990904 & 809196 & 4.1 & 4.2051 & TRN & \\
\hline CHEMBL1987448 & 809196 & 7.0 & 6.7203 & TRN & \\
\hline CHEMBL2005475 & 809196 & 5.6 & 4.8934 & TRN & \\
\hline CHEMBL402846 & 809196 & 4.1 & 4.226 & TRN & \\
\hline CHEMBL1997349 & 809196 & 4.1 & 4.1469 & TST & \\
\hline CHEMBL183844 & 809196 & 4.1 & 4.0297 & TRN & \\
\hline CHEMBL 220057 & 809196 & 5.3 & 5.3955 & TRN & \\
\hline CHEMBL1682545 & 809196 & 5.5 & 5.1302 & TRN & \\
\hline CHEMBL383541 & 809196 & 7.7 & 7.1361 & TRN & \\
\hline CHEMBL 2001224 & 809196 & 4.1 & 3.8223 & TRN & \\
\hline CHEMBL10 & 809196 & 4.1 & 4.3274 & TRN & \\
\hline CHEMBL1976732 & 809196 & 4.1 & 4.1291 & TRN & \\
\hline CHEMBL2005216 & 809196 & 7.2 & 7.0962 & TRN & \\
\hline CHEMBL1969506 & 809196 & 5.5 & 4.5014 & TRN & \\
\hline CHEMBL1964937 & 809196 & 6.6 & 7.0249 & TRN & \\
\hline CHEMBL1980163 & 809196 & 4.1 & 3.9142 & TRN & \\
\hline CHEMBL2005899 & 809196 & 4.1 & 4.7997 & TRN & \\
\hline CHEMBL1682552 & 809196 & 5.7 & 6.249 & TRN & \\
\hline CHEMBL1972568 & 809196 & 5.5 & 5.0922 & TRN & \\
\hline CHEMBL229799 & 809196 & 7.8 & 8.1294 & TRN & \\
\hline CHEMBL1971223 & 809196 & 6.4 & 4.854 & TRN & \\
\hline CHEMBL105739 & 809196 & 5.9 & 5.2335 & TRN & \\
\hline CHEMBL 379300 & 809196 & 8.3 & 8.2095 & TRN & \\
\hline CHEMBL1969523 & 809196 & 6.0 & 4.9339 & TRN & \\
\hline CHEMBL1988995 & 809196 & 4.1 & 4.1163 & TRN & \\
\hline CHEMBL1986781 & 809196 & 4.1 & 4.16100 & 00000000005 & TRN \\
\hline CHEMBL1983070 & 809196 & 4.3 & 4.5766 & TRN & \\
\hline CHEMBL526133 & 809196 & 5.2 & 4.84699 & 99999999995 & TRN \\
\hline CHEMBL1979057 & 809196 & 4.1 & 4.4584 & TRN & \\
\hline CHEMBL387971 & 809196 & 4.1 & 4.1813 & TRN & \\
\hline CHEMBL1164180 & 809196 & 5.4 & 5.4671 & TST & \\
\hline CHEMBL1999428 & 809196 & 6.5 & 6.5385 & TRN & \\
\hline CHEMBL1967560 & 809196 & 4.1 & 3.9394 & TRN & \\
\hline CHEMBL1516890 & 809196 & 5.6 & 5.3412 & TRN & \\
\hline
\end{tabular}




\begin{tabular}{|c|c|c|c|c|}
\hline & & & plem & \\
\hline CHEMBL211378 & 809196 & 4.1 & 3.7914 & TRN \\
\hline CHEMBL1982465 & 809196 & 4.1 & 4.5182 & TRN \\
\hline CHEMBL 2001751 & 809196 & 8.3 & 8.7488 & TRN \\
\hline CHEMBL 2003420 & 809196 & 4.1 & 3.9141 & TRN \\
\hline CHEMBL1984586 & 809196 & 4.1 & 4.2677 & TRN \\
\hline CHEMBL1972659 & 809196 & 7.2 & 4.873 & TST \\
\hline CHEMBL272453 & 809196 & 4.1 & 4.2126 & TRN \\
\hline CHEMBL1970217 & 809196 & 7.1 & 6.7538 & TRN \\
\hline CHEMBL 2005528 & 809196 & 4.1 & 4.8051 & TST \\
\hline CHEMBL185569 & 809196 & 4.1 & 4.2396 & TRN \\
\hline CHEMBL1969843 & 809196 & 5.2 & 4.7752 & TRN \\
\hline CHEMBL 2007002 & 809196 & 4.1 & 4.2628 & TRN \\
\hline CHEMBL1987007 & 809196 & 5.3 & 4.7428 & TRN \\
\hline CHEMBL1969588 & 809196 & 8.6 & 7.9354 & TRN \\
\hline CHEMBL1984711 & 809196 & 4.1 & 4.5403 & TRN \\
\hline CHEMBL484390 & 809196 & 5.5 & 3.9711 & TST \\
\hline CHEMBL1979252 & 809196 & 5.9 & 6.1148 & TRN \\
\hline CHEMBL 2004290 & 809196 & 4.1 & 4.2774 & TRN \\
\hline CHEMBL1986499 & 809196 & 6.2 & 7.0054 & TRN \\
\hline CHEMBL1972937 & 809196 & 4.1 & 3.9195 & TRN \\
\hline CHEMBL 2000393 & 809196 & 6.8 & 5.824 & TST \\
\hline CHEMBL 2004311 & 809196 & 4.1 & 4.2408 & TRN \\
\hline CHEMBL1992634 & 809196 & 6.0 & 5.7563 & TRN \\
\hline CHEMBL1242373 & 809196 & 4.1 & 4.2851 & TRN \\
\hline CHEMBL56543 & 809196 & 4.1 & 4.1717 & TRN \\
\hline CHEMBL1984847 & 809196 & 4.3 & 4.7219 & TRN \\
\hline CHEMBL1988075 & 809196 & 4.1 & 4.1896 & TRN \\
\hline CHEMBL316264 & 809196 & 4.1 & 4.3422 & TRN \\
\hline CHEMBL1988076 & 809196 & 4.3 & 4.4519 & TRN \\
\hline CHEMBL1991678 & 809196 & 4.1 & 4.2753 & TRN \\
\hline CHEMBL 2001239 & 809196 & 6.0 & 5.5213 & TST \\
\hline CHEMBL1988594 & 809196 & 5.3 & 4.7292 & TRN \\
\hline CHEMBL 2001288 & 809196 & 4.1 & 4.1075 & TRN \\
\hline CHEMBL1992363 & 809196 & 5.9 & 5.8966 & TRN \\
\hline CHEMBL1999811 & 809196 & 5.9 & 5.5673 & TST \\
\hline CHEMBL235157 & 809196 & 4.3 & 4.9836 & TST \\
\hline CHEMBL1985074 & 809196 & 4.1 & 4.3775 & TST \\
\hline CHEMBL1982874 & 809196 & 4.1 & 4.6696 & TRN \\
\hline CHEMBL 2000481 & 809196 & 5.2 & 5.112 & TRN \\
\hline CHEMBL1991725 & 809196 & 4.1 & 6.2662 & TRN \\
\hline CHEMBL1992242 & 809196 & 4.1 & 3.9426 & TRN \\
\hline CHEMBL1982271 & 809196 & 7.4 & 7.4543 & TRN \\
\hline CHEMBL 2007296 & 809196 & 6.1 & 6.3984 & TRN \\
\hline CHEMBL208637 & 809196 & 5.1 & 4.1754 & TRN \\
\hline CHEMBL396523 & 809196 & 6.7 & 7.356 & TRN \\
\hline CHEMBL1970203 & 809196 & 4.1 & 4.0347 & TRN \\
\hline CHEMBL1986530 & 809196 & 4.1 & 4.2646 & TST \\
\hline CHEMBL1999321 & 809196 & 4.1 & 4.3023 & TRN \\
\hline
\end{tabular}




\begin{tabular}{|c|c|c|c|c|}
\hline & & & ipplemen & al $\mathrm{T}$ \\
\hline CHEMBL1968590 & 809196 & 4.1 & 4.4107 & TRN \\
\hline CHEMBL 2005375 & 809196 & 4.1 & 4.1194 & TRN \\
\hline CHEMBL1984191 & 809196 & 4.1 & 4.5306 & TRN \\
\hline CHEMBL1972183 & 809196 & 4.1 & 4.1608 & TST \\
\hline CHEMBL1971029 & 809196 & 6.8 & 6.4763 & TRN \\
\hline CHEMBL394790 & 809196 & 4.1 & 4.3351 & TRN \\
\hline CHEMBL226471 & 809196 & 4.1 & 4.8469 & TRN \\
\hline CHEMBL1974702 & 809196 & 4.1 & 4.3529 & TRN \\
\hline CHEMBL1996111 & 809196 & 6.1 & 6.3866 & TRN \\
\hline CHEMBL1966175 & 809196 & 6.5 & 6.1692 & TRN \\
\hline CHEMBL1965589 & 809196 & 4.1 & 4.2463 & TRN \\
\hline CHEMBL1998193 & 809196 & 4.1 & 3.9735 & TRN \\
\hline CHEMBL379975 & 809196 & 6.5 & 6.0259 & TST \\
\hline CHEMBL474432 & 809196 & 5.3 & 4.6645 & TST \\
\hline CHEMBL1988153 & 809196 & 4.1 & 4.744 & TST \\
\hline CHEMBL1986666 & 809196 & 5.7 & 5.8837 & TRN \\
\hline CHEMBL1988437 & 809196 & 6.0 & 4.6999 & TST \\
\hline CHEMBL1979577 & 809196 & 5.3 & 4.5664 & TRN \\
\hline CHEMBL1998121 & 809196 & 7.7 & 6.9457 & TRN \\
\hline CHEMBL1233887 & 809196 & 4.3 & 4.7053 & TST \\
\hline CHEMBL1991800 & 809196 & 4.1 & 3.9253 & TRN \\
\hline CHEMBL52387 & 809196 & 4.1 & 4.1743 & TST \\
\hline CHEMBL379835 & 809196 & 4.1 & 3.6696 & TST \\
\hline CHEMBL1979357 & 809196 & 6.1 & 6.2307 & TRN \\
\hline CHEMBL1996817 & 809196 & 6.7 & 6.4865 & TRN \\
\hline CHEMBL3197315 & 809196 & 4.1 & 4.3058 & TST \\
\hline CHEMBL468280 & 809196 & 4.1 & 3.9993 & TST \\
\hline CHEMBL1990884 & 809196 & 4.1 & 4.3328 & TRN \\
\hline CHEMBL 3109278 & 809196 & 5.6 & 5.2961 & TRN \\
\hline CHEMBL256835 & 809196 & 4.1 & 4.2564 & TRN \\
\hline CHEMBL1974998 & 809196 & 4.3 & 4.4228 & TRN \\
\hline CHEMBL1980142 & 809196 & 4.1 & 4.1834 & TRN \\
\hline CHEMBL41783 & 809196 & 5.3 & 4.2063 & TRN \\
\hline CHEMBL 2006276 & 809196 & 6.3 & 4.7573 & TRN \\
\hline CHEMBL271381 & 809196 & 4.1 & 4.0763 & TRN \\
\hline CHEMBL 2006785 & 809196 & 4.1 & 4.1601 & TRN \\
\hline CHEMBL1982466 & 809196 & 4.1 & 4.2707 & TRN \\
\hline CHEMBL1995740 & 809196 & 4.1 & 5.1235 & TRN \\
\hline CHEMBL1990162 & 809196 & 5.4 & 5.2096 & TRN \\
\hline CHEMBL1992220 & 809196 & 7.4 & 7.6793 & TRN \\
\hline CHEMBL 234085 & 809196 & 6.6 & 5.2395 & TRN \\
\hline CHEMBL1995832 & 809196 & 4.1 & 4.2362 & TRN \\
\hline CHEMBL1998414 & 809196 & 4.1 & 4.1558 & TRN \\
\hline CHEMBL1969042 & 809196 & 5.8 & 5.6284 & TRN \\
\hline CHEMBL 2000345 & 809196 & 5.2 & 4.8037 & TST \\
\hline CHEMBL1999931 & 809196 & 6.5 & 6.3478 & TRN \\
\hline CHEMBL1375418 & 809196 & 4.1 & 4.0313 & TRN \\
\hline CHEMBL 2007064 & 809196 & 6.0 & 5.4418 & TRN \\
\hline
\end{tabular}




\begin{tabular}{|c|c|c|c|c|c|}
\hline & & & & & \\
\hline CHEMBL1981047 & 809196 & 5.3 & 4.9214 & TRN & \\
\hline CHEMBL 229968 & 809196 & 7.7 & 8.2283 & TRN & \\
\hline CHEMBL1976240 & 809196 & 7.4 & 7.4594 & TRN & \\
\hline CHEMBL1987948 & 809196 & 6.6 & $6.5360 e$ & 00000000005 & TRN \\
\hline CHEMBL1979093 & 809196 & 4.1 & 4.1135 & TRN & \\
\hline CHEMBL1968151 & 809196 & 5.2 & 3.7971 & TST & \\
\hline CHEMBL1987009 & 809196 & 6.0 & 5.1277 & TRN & \\
\hline CHEMBL379218 & 809196 & 7.0 & 7.8562 & TRN & \\
\hline CHEMBL 2003817 & 809196 & 4.1 & 4.9244 & TRN & \\
\hline CHEMBL1994830 & 809196 & 4.1 & 4.9702 & TST & \\
\hline CHEMBL226403 & 809196 & 4.2 & 5.1629 & TRN & \\
\hline CHEMBL2005631 & 809196 & 4.1 & 4.43 & TRN & \\
\hline CHEMBL1994938 & 809196 & 5.1 & 4.6258 & TRN & \\
\hline CHEMBL1977223 & 809196 & 4.1 & 4.9361 & TRN & \\
\hline CHEMBL1236126 & 809196 & 4.1 & 4.3464 & TST & \\
\hline CHEMBL1966279 & 809196 & 4.1 & 4.4794 & TRN & \\
\hline CHEMBL1997846 & 809196 & 6.9 & 6.2746 & TRN & \\
\hline CHEMBL2004419 & 809196 & 4.1 & 4.6876 & TRN & \\
\hline CHEMBL 2007073 & 809196 & 5.5 & 4.5109 & TRN & \\
\hline CHEMBL1995811 & 809196 & 4.3 & 4.6489 & TRN & \\
\hline CHEMBL1972489 & 809196 & 4.1 & 4.1536 & TRN & \\
\hline CHEMBL1994074 & 809196 & 4.1 & 4.56 & TRN & \\
\hline CHEMBL1992937 & 809196 & 4.1 & 4.51699 & 99999999995 & TST \\
\hline CHEMBL1968930 & 809196 & 8.6 & 7.5161 & TRN & \\
\hline CHEMBL1972119 & 809196 & 4.1 & 4.0103 & TRN & \\
\hline CHEMBL1986328 & 809196 & 4.1 & 4.0126 & TST & \\
\hline CHEMBL95692 & 809196 & 4.1 & 4.455 & TRN & \\
\hline CHEMBL1090356 & 809196 & 4.1 & 4.2692 & TRN & \\
\hline CHEMBL1976455 & 809196 & 4.1 & 5.0516 & TRN & \\
\hline CHEMBL1983923 & 809196 & 4.1 & 4.5528 & TST & \\
\hline CHEMBL1983534 & 809196 & 6.8 & 5.4172 & TRN & \\
\hline CHEMBL1982361 & 809196 & 6.4 & 6.1006 & TRN & \\
\hline CHEMBL1999112 & 809196 & 4.1 & 3.9131 & TST & \\
\hline CHEMBL1982122 & 809196 & 6.9 & 6.0533 & TRN & \\
\hline CHEMBL2000801 & 809196 & 4.1 & 4.0152 & TRN & \\
\hline CHEMBL1682546 & 809196 & 6.2 & 5.1877 & TRN & \\
\hline CHEMBL1991395 & 809196 & 4.1 & 4.2165 & TRN & \\
\hline CHEMBL1971245 & 809196 & 4.1 & 4.3661 & TRN & \\
\hline CHEMBL1972142 & 809196 & 5.8 & 4.8526 & TRN & \\
\hline CHEMBL1966514 & 809196 & 4.1 & 4.4979 & TRN & \\
\hline CHEMBL2003638 & 809196 & 5.5 & 5.78799 & 9999999999 & TRN \\
\hline CHEMBL1996066 & 809196 & 4.1 & 4.75899 & 99999999995 & TST \\
\hline CHEMBL1972152 & 809196 & 4.1 & 4.2907 & TST & \\
\hline CHEMBL1993722 & 809196 & 4.1 & 5.4459 & TST & \\
\hline CHEMBL1970806 & 809196 & 4.1 & 3.6046 & TST & \\
\hline CHEMBL1375640 & 809196 & 5.8 & 5.309 & TST & \\
\hline CHEMBL1979970 & 809196 & 4.1 & 4.0615 & TST & \\
\hline CHEMBL249282 & 809196 & 4.1 & 4.1271 & TST & \\
\hline & & & & 16837 & \\
\hline
\end{tabular}




\begin{tabular}{|c|c|c|c|c|c|}
\hline \\
\hline CHEMBL1992473 & 809196 & 4.3 & 4.6283 & TST & \\
\hline CHEMBL2006237 & 809196 & 4.1 & 4.3513 & TST & \\
\hline CHEMBL1967720 & 809196 & 4.1 & 4.8419 & TST & \\
\hline CHEMBL2005509 & 809196 & 7.6 & 7.6808 & TST & \\
\hline CHEMBL1572266 & 809196 & 4.1 & 4.2485 & TST & \\
\hline CHEMBL1991138 & 809196 & 4.1 & 4.4773 & TST & \\
\hline CHEMBL1969755 & 809196 & 4.1 & 4.9041 & TST & \\
\hline CHEMBL1979516 & 809196 & 4.1 & 4.4401 & TST & \\
\hline CHEMBL1605605 & 809196 & 7.0 & 5.3799 & TST & \\
\hline CHEMBL1972820 & 809196 & 4.1 & 3.9387 & TST & \\
\hline CHEMBL1996208 & 809196 & 4.1 & 4.2076 & TST & \\
\hline CHEMBL1989029 & 809196 & 4.1 & 4.5324 & TST & \\
\hline CHEMBL392642 & 809196 & 5.9 & 5.456 & TST & \\
\hline CHEMBL514499 & 809196 & 4.1 & 4.5199 & TST & \\
\hline CHEMBL1965631 & 809196 & 4.1 & 4.9044 & TST & \\
\hline CHEMBL1980144 & 809196 & 4.1 & 4.70100 & 00000000005 & TST \\
\hline CHEMBL1991188 & 809196 & 6.9 & 6.5459 & TST & \\
\hline CHEMBL1972849 & 809196 & 4.1 & 4.0618 & TST & \\
\hline CHEMBL 377408 & 809196 & 4.1 & 4.1338 & TST & \\
\hline CHEMBL1986855 & 809196 & 6.8 & 7.0535 & TST & \\
\hline CHEMBL231209 & 809196 & 4.1 & 4.3306 & TST & \\
\hline CHEMBL1975357 & 809196 & 4.1 & 4.1858 & TST & \\
\hline CHEMBL1976220 & 809196 & 4.1 & 4.4342 & TST & \\
\hline CHEMBL 259922 & 809196 & 4.1 & 4.0051 & TST & \\
\hline CHEMBL1997617 & 809196 & 4.1 & 4.9122 & TST & \\
\hline CHEMBL1982383 & 809196 & 4.1 & 4.265 & TST & \\
\hline CHEMBL1969301 & 809196 & 6.1 & 3.9947 & TST & \\
\hline CHEMBL17370 & 809196 & 4.1 & 4.6559 & TST & \\
\hline CHEMBL1987910 & 809196 & 4.1 & 4.3342 & TST & \\
\hline CHEMBL1983932 & 809196 & 4.1 & 4.7462 & TST & \\
\hline CHEMBL1999484 & 809196 & 5.9 & 5.6393 & TST & \\
\hline CHEMBL1997822 & 809196 & 4.1 & 4.7056 & TST & \\
\hline CHEMBL1991285 & 809196 & 4.1 & 3.8313 & TST & \\
\hline CHEMBL 243088 & 809196 & 5.9 & 6.5794 & TST & \\
\hline CHEMBL1984038 & 809196 & 4.1 & 4.3181 & TST & \\
\hline CHEMBL1993661 & 809196 & 7.1 & 7.1743 & TST & \\
\hline CHEMBL1974416 & 809196 & 5.9 & 5.078 & TST & \\
\hline CHEMBL2004615 & 809196 & 4.1 & 4.6847 & TST & \\
\hline CHEMBL1984039 & 809196 & 4.1 & 4.3232 & TST & \\
\hline CHEMBL1997872 & 809196 & 4.1 & 4.1685 & TST & \\
\hline CHEMBL526418 & 1592860 & 5.8665 & 5.7949 & TRN & \\
\hline CHEMBL602226 & 1592860 & 5.5058 & 5.5808 & TRN & \\
\hline CHEMBL529986 & 1592860 & 5.7878 & 5.8618 & TRN & \\
\hline CHEMBL581971 & 1592860 & 5.7773 & 5.6501 & TRN & \\
\hline CHEMBL532350 & 1592860 & 6.0706 & 5.5799 & TRN & \\
\hline CHEMBL526214 & 1592860 & 6.0088 & 6.0222 & TRN & \\
\hline CHEMBL587398 & 1592860 & 5.71 & 5.8178 & TRN & \\
\hline CHEMBL 3637842 & 1592860 & 5.5143 & 5.9236 & TRN & \\
\hline
\end{tabular}


Supplemental Table S2.txt

\begin{tabular}{|c|c|c|c|c|c|}
\hline CHEMBL531591 & 1592860 & 5.5361 & 5.4955 & TRN & \\
\hline CHEMBL586872 & 1592860 & 6.1739 & 5.875 & TRN & \\
\hline CHEMBL3637885 & 1592860 & 4.699 & 4.7119 & TRN & \\
\hline CHEMBL525112 & 1592860 & 5.8697 & 5.8531 & TRN & \\
\hline CHEMBL586583 & 1592860 & 5.5622 & 6.0089 & TRN & \\
\hline CHEMBL581767 & 1592860 & 5.6946 & 5.8819 & TRN & \\
\hline CHEMBL587161 & 1592860 & 6.3188 & 6.1468 & TRN & \\
\hline CHEMBL535286 & 1592860 & 5.6345 & 5.6051 & TST & \\
\hline CHEMBL579902 & 1592860 & 5.8761 & 5.8272 & TRN & \\
\hline CHEMBL3637887 & 1592860 & 4.699 & 4.5935 & TRN & \\
\hline CHEMBL532369 & 1592860 & 5.7878 & 5.7943 & TRN & \\
\hline CHEMBL580794 & 1592860 & 6.0044 & 5.8318 & TRN & \\
\hline CHEMBL599305 & 1592860 & 5.6091 & 5.8643 & TRN & \\
\hline CHEMBL3637881 & 1592860 & 6.3768 & 6.1311 & TRN & \\
\hline CHEMBL601337 & 1592860 & 5.7011 & 5.5698 & TRN & \\
\hline CHEMBL586794 & 1592860 & 5.5654 & 5.8177 & TRN & \\
\hline CHEMBL534797 & 1592860 & 5.9245 & 5.9019 & TRN & \\
\hline CHEMBL529716 & 1592860 & 6.0 & 6.0356 & TRN & \\
\hline CHEMBL230001 & 1592860 & 7.0458 & 6.9002 & TRN & \\
\hline CHEMBL582371 & 1592860 & 5.2984 & 5.5831 & TRN & \\
\hline CHEMBL587715 & 1592860 & 6.2596 & 6.0244 & TRN & \\
\hline CHEMBL1197790 & 1592860 & 6.3872 & 5.9881 & TST & \\
\hline CHEMBL578464 & 1592860 & 5.8996 & 5.7022 & TRN & \\
\hline CHEMBL3637876 & 1592860 & 5.6038 & 5.8247 & TRN & \\
\hline CHEMBL604099 & 1592860 & 6.6383 & 6.1081 & TRN & \\
\hline CHEMBL3637880 & 1592860 & 5.7878 & 5.8398 & TRN & \\
\hline CHEMBL531393 & 1592860 & 5.8761 & 5.903 & TRN & \\
\hline CHEMBL530160 & 1592860 & 5.7959 & 5.9153 & TST & \\
\hline CHEMBL601970 & 1592860 & 6.6778 & 6.181 & TRN & \\
\hline CHEMBL546835 & 1592860 & 5.6003 & 5.829 & TRN & \\
\hline CHEMBL3637872 & 1592860 & 5.9547 & 5.6936 & TRN & \\
\hline CHEMBL524742 & 1592860 & 5.762006 & 00000000 & 205 & 5.8232 \\
\hline CHEMBL546398 & 1592860 & 5.7447 & 5.8908 & TRN & \\
\hline CHEMBL567341 & 1592860 & 6.0269 & 5.9092 & TST & \\
\hline CHEMBL528922 & 1592860 & 6.699 & 6.5622 & TST & \\
\hline CHEMBL611077 & 1592860 & 6.1192 & 5.6848 & TRN & \\
\hline CHEMBL528061 & 1592860 & 5.6402 & 5.7357 & TRN & \\
\hline CHEMBL582507 & 1592860 & 5.7258 & 6.0095 & TRN & \\
\hline CHEMBL545853 & 1592860 & 5.6861 & 5.8254 & TRN & \\
\hline CHEMBL526813 & 1592860 & 5.9066 & 5.9784 & TRN & \\
\hline CHEMBL586864 & 1592860 & 5.5498 & 5.76 & TRN & \\
\hline CHEMBL531095 & 1592860 & 6.1079 & 5.8214 & TRN & \\
\hline CHEMBL581128 & 1592860 & 5.8239 & 5.9368 & TRN & \\
\hline CHEMBL1552197 & 1592860 & 4.699 & 5.5459 & TRN & \\
\hline CHEMBL585651 & 1592860 & 4.699 & 5.5112 & TRN & \\
\hline CHEMBL528966 & 1592860 & 6.8539 & 6.6317 & TRN & \\
\hline CHEMBL3637891 & 1592860 & 5.6498 & 5.7278 & TST & \\
\hline CHEMBL597266 & 1592860 & 5.4868 & 6.062 & TRN & \\
\hline
\end{tabular}


Supplemental Table S2.txt

\begin{tabular}{|c|c|c|c|c|c|}
\hline CHEMBL 3637877 & 1592860 & 4.699 & 4.8285 & TRN & \\
\hline CHEMBL587139 & 1592860 & 6.1308 & 5.8328 & TST & \\
\hline CHEMBL530887 & 1592860 & 5.6716 & 5.7362 & TST & \\
\hline CHEMBL3637879 & 1592860 & 6.0 & 5.8898 & TRN & \\
\hline CHEMBL1404608 & 1592860 & 6.2147 & 6.1981 & TRN & \\
\hline CHEMBL588781 & 1592860 & 4.699 & 5.7668 & TRN & \\
\hline CHEMBL525702 & 1592860 & 6.6383 & 6.2269 & TRN & \\
\hline CHEMBL3637882 & 1592860 & 4.699 & 4.8589 & TST & \\
\hline CHEMBL546977 & 1592860 & 6.1675 & 6.0741 & TRN & \\
\hline CHEMBL533421 & 1592860 & 5.8327 & 6.0196 & TRN & \\
\hline CHEMBL587947 & 1592860 & 6.6576 & 6.3221 & TRN & \\
\hline CHEMBL580816 & 1592860 & 5.8794 & 6.0096 & TRN & \\
\hline CHEMBL527297 & 1592860 & 5.5157 & 5.7199 & TRN & \\
\hline CHEMBL587610 & 1592860 & 8.0 & 6.9207 & TRN & \\
\hline CHEMBL534391 & 1592860 & 6.0706 & 6.3658 & TRN & \\
\hline CHEMBL525292 & 1592860 & 6.1938 & 5.7595 & TRN & \\
\hline CHEMBL545949 & 1592860 & 5.2857 & 5.6235 & TRN & \\
\hline CHEMBL600161 & 1592860 & 5.8327 & 4.8008 & TRN & \\
\hline CHEMBL586383 & 1592860 & 5.8239 & 5.9991 & TRN & \\
\hline CHEMBL600894 & 1592860 & 4.699 & 5.8196 & TST & \\
\hline CHEMBL529610 & 1592860 & 5.8827 & 5.8529 & TRN & \\
\hline CHEMBL531497 & 1592860 & 6.1135 & 5.7192 & TRN & \\
\hline CHEMBL534395 & 1592860 & 6.1612 & 5.9361 & TRN & \\
\hline CHEMBL139814 & 1592860 & 5.9586 & 5.9625 & TRN & \\
\hline CHEMBL546400 & 1592860 & 6.0362 & 5.9543 & TRN & \\
\hline CHEMBL 3637873 & 1592860 & 6.1079 & 6.03299 & 99999999995 & TRN \\
\hline CHEMBL582027 & 1592860 & 5.8508 & 5.8508 & TRN & \\
\hline CHEMBL 3637884 & 1592860 & 4.699 & 4.5792 & TRN & \\
\hline CHEMBL535002 & 1592860 & 5.3872 & 6.1624 & TRN & \\
\hline CHEMBL532242 & 1592860 & 6.6198 & 6.3058 & TRN & \\
\hline CHEMBL598495 & 1592860 & 4.699 & 5.6888 & TRN & \\
\hline CHEMBL580352 & 1592860 & 5.7852 & 5.6957 & TRN & \\
\hline CHEMBL536678 & 1592860 & 5.8239 & 5.8951 & TST & \\
\hline CHEMBL536144 & 1592860 & 6.0915 & 6.075 & TRN & \\
\hline CHEMBL 3637874 & 1592860 & 5.767 & 5.7686 & TRN & \\
\hline CHEMBL597856 & 1592860 & 5.699 & 4.8444 & TRN & \\
\hline CHEMBL529152 & 1592860 & 6.1308 & 6.3343 & TRN & \\
\hline CHEMBL3637886 & 1592860 & 4.699 & 4.6284 & TRN & \\
\hline CHEMBL580443 & 1592860 & 5.7799 & 5.7714 & TRN & \\
\hline CHEMBL531326 & 1592860 & 6.9586 & 6.6772 & TST & \\
\hline CHEMBL548417 & 1592860 & 5.5086 & 5.8295 & TST & \\
\hline CHEMBL596639 & 1592860 & 6.0132 & 5.9983 & TST & \\
\hline CHEMBL580702 & 1592860 & 6.699 & 6.2651 & TST & \\
\hline CHEMBL267274 & 1592860 & 6.2218 & \multicolumn{2}{|c|}{6.087999999999999} & TST \\
\hline CHEMBL2375614 & 1592860 & 4.699 & 4.6305 & TST & \\
\hline CHEMBL529068 & 1592860 & 6.7212 & 6.0444 & TST & \\
\hline CHEMBL524204 & 1592860 & 6.4089 & \multicolumn{2}{|c|}{6.178999999999999} & TST \\
\hline CHEMBL530228 & 1592860 & 6.2007 & 6.0042 & TST & \\
\hline
\end{tabular}


Supplemental Table S2.txt

\begin{tabular}{|c|c|c|c|c|c|}
\hline CHEMBL601821 & 1592860 & 6.0506 & 5.9166 & TST & \\
\hline CHEMBL 3637883 & 1592860 & 4.699 & 4.7213 & TST & \\
\hline CHEMBL602219 & 1592860 & 4.699 & 5.6314 & TST & \\
\hline CHEMBL1324287 & 1592860 & 6.585 & 6.2072 & TST & \\
\hline CHEMBL537372 & 1592860 & 6.1739 & 6.0058 & TST & \\
\hline CHEMBL536806 & 1592860 & 6.585 & 6.5302 & TST & \\
\hline CHEMBL 270317 & 1592860 & 5.8153 & 5.6258 & TST & \\
\hline CHEMBL 3637875 & 1592860 & 5.6778 & 5.6613 & TST & \\
\hline CHEMBL598494 & 1592860 & 6.8239 & 6.6568 & TST & \\
\hline CHEMBL1543104 & 1495406 & 3.0 & 3.0383 & TRN & \\
\hline CHEMBL1524910 & 1495406 & 3.0 & 3.2126 & TRN & \\
\hline CHEMBL1465969 & 1495406 & 3.0 & $2.87100 t$ & 00000000004 & TRN \\
\hline CHEMBL3191780 & 1495406 & 6.7347 & 3.3215 & TST & \\
\hline CHEMBL1332241 & 1495406 & 6.0879 & 3.4556 & TRN & \\
\hline CHEMBL 2360241 & 1495406 & 3.0 & 3.3381 & TRN & \\
\hline CHEMBL1569224 & 1495406 & 3.0 & 2.6414 & TRN & \\
\hline CHEMBL1444488 & 1495406 & 3.0 & 2.9175 & TRN & \\
\hline CHEMBL1311510 & 1495406 & 3.0 & 2.7664 & TRN & \\
\hline CHEMBL1527971 & 1495406 & 3.1323 & 3.1591 & TRN & \\
\hline CHEMBL1351304 & 1495406 & 3.0 & 3.1245 & TRN & \\
\hline CHEMBL1714915 & 1495406 & 3.0 & 3.3945 & TRN & \\
\hline CHEMBL1421400 & 1495406 & 3.0 & 3.1152 & TRN & \\
\hline CHEMBL1878847 & 1495406 & 3.0 & 2.7204 & TRN & \\
\hline CHEMBL1446854 & 1495406 & 3.0 & 2.7455 & TRN & \\
\hline CHEMBL428064 & 1495406 & 3.0 & 3.0704 & TST & \\
\hline CHEMBL1579477 & 1495406 & 3.0 & 2.8762 & TRN & \\
\hline CHEMBL1454911 & 1495406 & 3.0 & 3.0125 & TRN & \\
\hline CHEMBL1708840 & 1495406 & 3.0 & 2.9358 & TRN & \\
\hline CHEMBL1447879 & 1495406 & 3.0 & 3.4316 & TRN & \\
\hline CHEMBL1318963 & 1495406 & 3.0 & 3.0951 & TRN & \\
\hline CHEMBL1486081 & 1495406 & 3.0 & 3.0695 & TST & \\
\hline CHEMBL1380699 & 1495406 & 3.0 & 3.0563 & TST & \\
\hline CHEMBL1494676 & 1495406 & 3.0 & 2.9416 & TRN & \\
\hline CHEMBL1572563 & 1495406 & 3.0 & 3.0091 & TST & \\
\hline CHEMBL1548232 & 1495406 & 3.0 & 3.0193 & TST & \\
\hline CHEMBL3191343 & 1495406 & 3.301 & 3.0285 & TRN & \\
\hline CHEMBL1371834 & 1495406 & 3.0 & 2.9922 & TRN & \\
\hline CHEMBL1483770 & 1495406 & 3.0 & 3.0325 & TRN & \\
\hline CHEMBL1428889 & 1495406 & 3.0 & 3.5183 & TRN & \\
\hline CHEMBL1432334 & 1495406 & 3.0 & 3.2138 & TRN & \\
\hline CHEMBL1506831 & 1495406 & 3.0 & 2.7886 & TRN & \\
\hline CHEMBL3213843 & 1495406 & 3.0 & 3.293 & TRN & \\
\hline CHEMBL1708452 & 1495406 & 3.0 & 2.9986 & TRN & \\
\hline CHEMBL1426375 & 1495406 & 3.0 & 2.9575 & TRN & \\
\hline CHEMBL3190226 & 1495406 & 3.0 & 3.0736 & TRN & \\
\hline CHEMBL1549582 & 1495406 & 3.0 & 3.1798 & TRN & \\
\hline CHEMBL1426219 & 1495406 & 3.0 & 3.0657 & TRN & \\
\hline CHEMBL568415 & 1495406 & 3.0 & 3.0556 & TRN & \\
\hline
\end{tabular}




\begin{tabular}{|c|c|c|c|c|c|}
\hline \multicolumn{6}{|c|}{ Supplemental Table S2.txt } \\
\hline CHEMBL1420817 & 1495406 & 3.0 & 2.9999 & TRN & \\
\hline CHEMBL3207656 & 1495406 & 3.0 & 3.1015 & TRN & \\
\hline CHEMBL1300713 & 1495406 & 3.0 & 3.2656 & TRN & \\
\hline CHEMBL1372824 & 1495406 & 3.0 & 3.1326 & TRN & \\
\hline CHEMBL3199415 & 1495406 & 3.0 & 3.0411 & TRN & \\
\hline CHEMBL1408300 & 1495406 & 3.0 & 2.9955 & TRN & \\
\hline CHEMBL1423265 & 1495406 & 3.0 & 2.6617 & TRN & \\
\hline CHEMBL1500249 & 1495406 & 7.71 & 3.7419 & TST & \\
\hline CHEMBL1425459 & 1495406 & 3.0 & 3.1775 & TST & \\
\hline CHEMBL1498586 & 1495406 & 3.0 & 2.9844 & TRN & \\
\hline CHEMBL1587983 & 1495406 & 3.0 & 2.9252 & TRN & \\
\hline CHEMBL1471890 & 1495406 & 3.0 & 2.989 & TRN & \\
\hline CHEMBL3194764 & 1495406 & 3.0 & 2.9406 & TRN & \\
\hline CHEMBL1456005 & 1495406 & 3.0 & 3.0775 & TRN & \\
\hline CHEMBL1445774 & 1495406 & 3.0 & 2.7926 & TRN & \\
\hline CHEMBL1450015 & 1495406 & 3.0 & 2.8649 & TRN & \\
\hline CHEMBL1567692 & 1495406 & 3.2874 & 2.7295 & TRN & \\
\hline CHEMBL1344387 & 1495406 & 3.0 & 3.4326 & TRN & \\
\hline CHEMBL1345809 & 1495406 & 3.0 & 3.0001 & TRN & \\
\hline CHEMBL1334791 & 1495406 & 3.0 & 2.7797 & TRN & \\
\hline CHEMBL1478955 & 1495406 & 3.0 & 3.3227 & TST & \\
\hline CHEMBL1706291 & 1495406 & 3.0 & 3.1834 & TRN & \\
\hline CHEMBL1438567 & 1495406 & 3.2936 & 2.7823 & TRN & \\
\hline CHEMBL1432465 & 1495406 & 3.0 & 3.0141 & TRN & \\
\hline CHEMBL1388485 & 1495406 & 3.0 & 2.95300 & 00000000003 & TRN \\
\hline CHEMBL1432206 & 1495406 & 3.0 & 3.092 & TRN & \\
\hline CHEMBL1548317 & 1495406 & 3.0 & 3.2055 & TST & \\
\hline CHEMBL1610049 & 1495406 & 3.0 & 3.20300 & 00000000003 & TRN \\
\hline CHEMBL1360892 & 1495406 & 3.0 & 3.2817 & TST & \\
\hline CHEMBL1573839 & 1495406 & 3.0 & 3.1311 & TRN & \\
\hline CHEMBL1348840 & 1495406 & 3.301 & 3.5655 & TRN & \\
\hline CHEMBL1533634 & 1495406 & 3.0 & 2.8318 & TRN & \\
\hline CHEMBL1518296 & 1495406 & 3.0 & 3.0251 & TRN & \\
\hline CHEMBL1723797 & 1495406 & 3.0 & 2.9375 & TRN & \\
\hline CHEMBL1541748 & 1495406 & 3.0 & 3.0231 & TRN & \\
\hline CHEMBL1728953 & 1495406 & 3.0 & 3.1027 & TST & \\
\hline CHEMBL1447444 & 1495406 & 3.0 & 3.3165 & TRN & \\
\hline CHEMBL1488870 & 1495406 & 3.9031 & 2.7436 & TRN & \\
\hline CHEMBL555260 & 1495406 & 3.0 & 2.8642 & TRN & \\
\hline CHEMBL1563861 & 1495406 & 3.2912 & 3.2115 & TRN & \\
\hline CHEMBL1346707 & 1495406 & 3.0 & 2.8957 & TRN & \\
\hline CHEMBL1540763 & 1495406 & 3.0 & 3.0412 & TRN & \\
\hline CHEMBL1716881 & 1495406 & 3.0 & 2.9599 & TRN & \\
\hline CHEMBL1450484 & 1495406 & 3.0 & 3.089 & TRN & \\
\hline CHEMBL1425032 & 1495406 & 3.0 & 3.0551 & TST & \\
\hline CHEMBL1570909 & 1495406 & 3.0 & 2.7824 & TRN & \\
\hline CHEMBL1497978 & 1495406 & 3.0 & 2.845 & TRN & \\
\hline CHEMBL1573337 & 1495406 & 3.0 & 3.0206 & TRN & \\
\hline
\end{tabular}


Supplemental Table S2.txt

\begin{tabular}{|c|c|c|c|c|c|}
\hline CHEMBL1433062 & 1495406 & 3.0 & 3.4324 & TRN & \\
\hline CHEMBL1329271 & 1495406 & 3.0 & 2.9524 & TRN & \\
\hline CHEMBL1523488 & 1495406 & 3.0 & 3.0192 & TRN & \\
\hline CHEMBL1415169 & 1495406 & 3.2966 & 2.7556 & TRN & \\
\hline CHEMBL1489847 & 1495406 & 3.0 & 3.0871 & TRN & \\
\hline CHEMBL1588778 & 1495406 & 3.0 & 3.0776 & TRN & \\
\hline CHEMBL1500403 & 1495406 & 3.0 & 2.9874 & TRN & \\
\hline CHEMBL1444447 & 1495406 & 3.0 & 3.0583 & TRN & \\
\hline CHEMBL1612931 & 1495406 & 3.301 & 3.085 & TRN & \\
\hline CHEMBL1494363 & 1495406 & 3.0 & 3.2955 & TST & \\
\hline CHEMBL1552295 & 1495406 & 3.0 & 3.0903 & TRN & \\
\hline CHEMBL1365578 & 1495406 & 3.0 & 3.3459 & TRN & \\
\hline CHEMBL1427849 & 1495406 & 3.0 & 2.813999 & 99999999996 & TRN \\
\hline CHEMBL1412418 & 1495406 & 3.0 & 3.2583 & TRN & \\
\hline CHEMBL1302742 & 1495406 & 3.0 & 2.9778 & TRN & \\
\hline CHEMBL1388169 & 1495406 & 3.0 & 3.2813 & TRN & \\
\hline CHEMBL1439642 & 1495406 & 3.2185 & 2.8285 & TRN & \\
\hline CHEMBL1455912 & 1495406 & 3.2959 & 2.9558 & TRN & \\
\hline CHEMBL1705906 & 1495406 & 3.0 & 2.9848 & TRN & \\
\hline CHEMBL1549607 & 1495406 & 3.0 & 3.0672 & TST & \\
\hline CHEMBL1401862 & 1495406 & 3.0 & 3.0782 & TRN & \\
\hline CHEMBL1464093 & 1495406 & 3.0 & 2.9696 & TRN & \\
\hline CHEMBL1558834 & 1495406 & 3.0 & 3.0719 & TRN & \\
\hline CHEMBL1546396 & 1495406 & 7.71 & 4.4941 & TRN & \\
\hline CHEMBL1528106 & 1495406 & 3.2875 & 3.3174 & TRN & \\
\hline CHEMBL1309324 & 1495406 & 3.0 & 3.2446 & TST & \\
\hline CHEMBL1496732 & 1495406 & 3.2955 & 2.8577 & TRN & \\
\hline CHEMBL3198910 & 1495406 & 3.0 & 3.1467 & TRN & \\
\hline CHEMBL1574907 & 1495406 & 3.0 & 3.0334 & TRN & \\
\hline CHEMBL1494731 & 1495406 & 3.0 & 2.9317 & TRN & \\
\hline CHEMBL1352752 & 1495406 & 3.0 & 3.115 & TRN & \\
\hline CHEMBL1528814 & 1495406 & 7.4001 & 5.2773 & TRN & \\
\hline CHEMBL1537409 & 1495406 & 3.0 & 2.9725 & TRN & \\
\hline CHEMBL1378063 & 1495406 & 3.0 & 3.0581 & TRN & \\
\hline CHEMBL1539086 & 1495406 & \multicolumn{3}{|c|}{ 3. 2889999999999997} & TRN \\
\hline CHEMBL1428916 & 1495406 & 3.0 & 2.9662 & TRN & \\
\hline CHEMBL610508 & 1495406 & 3.0 & \multicolumn{2}{|c|}{ 3.3989999999999996 } & TRA \\
\hline CHEMBL1391063 & 1495406 & 7.71 & 4.086 & TST & \\
\hline CHEMBL3199579 & 1495406 & 3.0 & 3.2784 & TST & \\
\hline CHEMBL1561809 & 1495406 & 3.0 & 3.2045 & TRN & \\
\hline CHEMBL1707215 & 1495406 & 3.0 & 3.395 & TRN & \\
\hline CHEMBL1503756 & 1495406 & 3.0 & 3.2643 & TRN & \\
\hline CHEMBL3192212 & 1495406 & 3.0 & 3.0507 & TRN & \\
\hline CHEMBL1607109 & 1495406 & 3.0 & 3.0062 & TRN & \\
\hline CHEMBL1561726 & 1495406 & 3.0 & 3.1926 & TRN & \\
\hline CHEMBL1392113 & 1495406 & 3.0 & 3.3449 & TRN & \\
\hline CHEMBL1710608 & 1495406 & 3.0 & 2.7633 & TRN & \\
\hline CHEMBL1570611 & 1495406 & 3.0 & 3.0561 & TRN & \\
\hline
\end{tabular}


Supplemental Table S2.txt

\begin{tabular}{|c|c|c|c|c|}
\hline CHEMBL1544852 & 1495406 & 3.0 & 2.9284 & TRN \\
\hline CHEMBL1455656 & 1495406 & 3.0 & 2.7628 & TRN \\
\hline CHEMBL1388842 & 1495406 & 3.0 & 3.0796 & TRN \\
\hline CHEMBL1444050 & 1495406 & 3.0 & 3.2251 & TRN \\
\hline CHEMBL1576598 & 1495406 & 3.0 & 2.9774 & TRN \\
\hline CHEMBL1389080 & 1495406 & 3.0 & 2.9668 & TRN \\
\hline CHEMBL1449709 & 1495406 & 3.0 & 2.7697 & TRN \\
\hline CHEMBL1596965 & 1495406 & 3.0 & 2.9767 & TST \\
\hline CHEMBL1572867 & 1495406 & 3.0 & 2.9629 & TRN \\
\hline CHEMBL1338478 & 1495406 & 3.0 & 2.987 & TRN \\
\hline CHEMBL1386272 & 1495406 & 3.0 & 3.1407 & TRN \\
\hline CHEMBL1725621 & 1495406 & 3.0 & 2.7775 & TRN \\
\hline CHEMBL1543330 & 1495406 & 3.0 & 3.3334 & TRN \\
\hline CHEMBL1471686 & 1495406 & 3.0 & 3.0486 & TRN \\
\hline CHEMBL1524564 & 1495406 & 3.0 & 3.2211 & TRN \\
\hline CHEMBL1437962 & 1495406 & 3.0 & 3.10600 & 00000000003 \\
\hline CHEMBL1300046 & 1495406 & 3.0 & 2.7535 & TRN \\
\hline CHEMBL1566903 & 1495406 & 3.0 & 3.3954 & TST \\
\hline CHEMBL1559616 & 1495406 & 3.0 & 3.2909 & TRN \\
\hline CHEMBL1347871 & 1495406 & 3.0 & 3.0662 & TRN \\
\hline CHEMBL1443909 & 1495406 & 3.0 & 3.0374 & TRN \\
\hline CHEMBL1505465 & 1495406 & 3.0 & 2.9049 & TRN \\
\hline CHEMBL1568805 & 1495406 & 3.0 & 3.2358 & TST \\
\hline CHEMBL1517045 & 1495406 & 3.0 & 3.5452 & TRN \\
\hline CHEMBL1364663 & 1495406 & 3.0 & 2.8676 & TST \\
\hline CHEMBL1565236 & 1495406 & 3.0 & 3.10399 & 99999999996 \\
\hline CHEMBL1502275 & 1495406 & 3.0 & 3.0001 & TRN \\
\hline CHEMBL1423325 & 1495406 & 3.0 & 3.0333 & TRN \\
\hline CHEMBL1557913 & 1495406 & 3.1987 & 3.0932 & TRN \\
\hline CHEMBL3192756 & 1495406 & 3.0 & 3.0905 & TRN \\
\hline CHEMBL1545352 & 1495406 & 3.0 & 2.9744 & TRN \\
\hline CHEMBL1417053 & 1495406 & 3.0 & 3.0206 & TRN \\
\hline CHEMBL523200 & 1495406 & 3.0 & 3.2958 & TRN \\
\hline CHEMBL1309683 & 1495406 & 3.2796 & 3.2936 & TST \\
\hline CHEMBL1352566 & 1495406 & 3.0 & 2.8564 & TRN \\
\hline CHEMBL1537485 & 1495406 & 3.0 & 2.9503 & TST \\
\hline CHEMBL1339368 & 1495406 & 3.0 & 2.8396 & TRN \\
\hline CHEMBL1469975 & 1495406 & 3.0 & 2.8384 & TRN \\
\hline CHEMBL1312638 & 1495406 & 3.0 & 3.0714 & TRN \\
\hline CHEMBL1822229 & 1495406 & 3.0 & 2.9623 & TRN \\
\hline CHEMBL1544477 & 1495406 & 3.0 & 3.035 & TST \\
\hline CHEMBL1722506 & 1495406 & 3.0 & 2.7215 & TRN \\
\hline CHEMBL1323979 & 1495406 & 3.0 & 3.1007 & TRN \\
\hline CHEMBL1978236 & 1495406 & 3.2959 & 3.2178 & TRN \\
\hline CHEMBL1464777 & 1495406 & 3.0 & 3.1009 & TRN \\
\hline CHEMBL1339840 & 1495406 & 3.0 & 3.21 & TRN \\
\hline CHEMBL551604 & 1495406 & 3.0 & 2.9028 & TRN \\
\hline CHEMBL1725148 & 1495406 & 3.0 & 2.8968 & TRN \\
\hline
\end{tabular}




\begin{tabular}{|c|c|c|c|c|c|c|}
\hline \multicolumn{7}{|c|}{ Supplemental Table S2.txt } \\
\hline CHEMBL1383536 & 1495406 & 3.0 & 2.9699 & TRN & & \\
\hline CHEMBL1499745 & 1495406 & 3.0 & 3.0423 & TRN & & \\
\hline CHEMBL1332702 & 1495406 & 3.0 & 3.3425 & TRN & & \\
\hline CHEMBL1415867 & 1495406 & 3.0 & 2.978 & TRN & & \\
\hline CHEMBL1331097 & 1495406 & 3.0 & 2.7138 & TRN & & \\
\hline CHEMBL1982545 & 1495406 & 3.0 & 3.427 & TRN & & \\
\hline CHEMBL1406137 & 1495406 & 3.0 & 3.3245 & TRN & & \\
\hline CHEMBL1574614 & 1495406 & 3.0 & 3.053 & TRN & & \\
\hline CHEMBL1337795 & 1495406 & 3.0 & 3.5143 & TRN & & \\
\hline CHEMBL1992382 & 1495406 & 3.0 & 3.3142 & TRN & & \\
\hline CHEMBL1414325 & 1495406 & 3.0 & 3.3107 & TRN & & \\
\hline CHEMBL3192640 & 1495406 & 3.0 & 3.1123 & TRN & & \\
\hline CHEMBL1401094 & 1495406 & 3.0 & 2.9557 & TRN & & \\
\hline CHEMBL1542911 & 1495406 & 3.0 & 3.3606 & TST & & \\
\hline CHEMBL1456128 & 1495406 & 3.0 & 3.1382 & TRN & & \\
\hline CHEMBL1458663 & 1495406 & 3.0 & 3.4007 & TRN & & \\
\hline CHEMBL1606730 & 1495406 & 3.0 & 3.0635 & TRN & & \\
\hline CHEMBL1572952 & 1495406 & 3.0 & 2.7946 & TST & & \\
\hline CHEMBL1600955 & 1495406 & 3.0 & 3.0956 & TRN & & \\
\hline CHEMBL1529441 & 1495406 & 3.0 & 3.0356 & TRN & & \\
\hline CHEMBL1486598 & 1495406 & 3.0 & 2.9441 & TRN & & \\
\hline CHEMBL567850 & 1495406 & 3.0 & 2.9501 & TRN & & \\
\hline CHEMBL1544879 & 1495406 & 3.0 & 3.0005 & TRN & & \\
\hline CHEMBL1521727 & 1495406 & 3.0 & 3.2108 & TRN & & \\
\hline CHEMBL1526266 & 1495406 & 3.0 & 3.0298 & TRN & & \\
\hline CHEMBL1347042 & 1495406 & 3.0 & 3.5144 & TRN & & \\
\hline CHEMBL1335659 & 1495406 & 3.0 & 2.9221 & TRN & & \\
\hline CHEMBL1550954 & 1495406 & 3.0 & 3.125 & TST & & \\
\hline CHEMBL1466560 & 1495406 & 3.0 & 2.9563 & TRN & & \\
\hline CHEMBL1332050 & 1495406 & 3.0 & 3.0201 & TST & & \\
\hline CHEMBL1741708 & 1495406 & 3.0 & 3.1094 & TRN & & \\
\hline CHEMBL1318718 & 1495406 & 3.0 & 2.9967 & TRN & & \\
\hline CHEMBL1300164 & 1495406 & 3.0 & 3.4008 & TRN & & \\
\hline CHEMBL1561788 & 1495406 & 3.0 & 2.915 & TRN & & \\
\hline CHEMBL1299346 & 1495406 & 3.27399 & 99999999 & 996 & 3.3298 & TST \\
\hline CHEMBL1380482 & 1495406 & 3.0 & 3.0023 & TST & & \\
\hline CHEMBL1342556 & 1495406 & 3.0 & 3.0205 & TRN & & \\
\hline CHEMBL1439912 & 1495406 & 3.0 & 2.9779 & TRN & & \\
\hline CHEMBL1523317 & 1495406 & 7.71 & 2.9466 & TST & & \\
\hline CHEMBL1306571 & 1495406 & 3.0 & 3.0385 & TST & & \\
\hline CHEMBL1464595 & 1495406 & 3.6021 & 3.7513 & TST & & \\
\hline CHEMBL1299528 & 1495406 & 3.0 & 3.0292 & TRN & & \\
\hline CHEMBL1573422 & 1495406 & 3.0 & 2.892 & TRN & & \\
\hline CHEMBL1335491 & 1495406 & 3.0 & 3.0473 & TRN & & \\
\hline CHEMBL1524927 & 1495406 & 3.175 & 3.7809 & TRN & & \\
\hline CHEMBL1324051 & 1495406 & 3.4609 & 4.2323 & TRN & & \\
\hline CHEMBL1720594 & 1495406 & 3.0 & 2.7363 & TRN & & \\
\hline CHEMBL1546439 & 1495406 & 3.0 & 3.0734 & TRN & & \\
\hline
\end{tabular}




\begin{tabular}{|c|c|c|c|c|c|}
\hline \multicolumn{6}{|c|}{ Supplemental Table S2.txt } \\
\hline CHEMBL1379335 & 1495406 & 3.0 & 2.8944 & TRN & \\
\hline CHEMBL1430058 & 1495406 & 3.0 & 2.9452 & TRN & \\
\hline CHEMBL558842 & 1495406 & 3.0 & 3.0534 & TRN & \\
\hline CHEMBL475885 & 1495406 & 3.0 & 2.9933 & TST & \\
\hline CHEMBL1705635 & 1495406 & 3.0 & 2.661 & TRN & \\
\hline CHEMBL1472192 & 1495406 & 3.0 & 3.0808 & TRN & \\
\hline CHEMBL1568772 & 1495406 & 3.0 & 2.8258 & TRN & \\
\hline CHEMBL1482069 & 1495406 & 3.0 & 3.3431 & TRN & \\
\hline CHEMBL1459055 & 1495406 & 3.0 & 3.1295 & TRN & \\
\hline CHEMBL1523847 & 1495406 & 3.0 & 2.8227 & TRN & \\
\hline CHEMBL1904310 & 1495406 & 3.0 & 3.0287 & TRN & \\
\hline CHEMBL1319745 & 1495406 & 3.0 & 2.9112 & TRN & \\
\hline CHEMBL1537008 & 1495406 & 3.0 & 2.9926 & TRN & \\
\hline CHEMBL1598798 & 1495406 & 3.0 & 3.1868 & TRN & \\
\hline CHEMBL1470525 & 1495406 & 3.0 & 2.9479 & TRN & \\
\hline CHEMBL1612419 & 1495406 & 3.0 & 3.1409 & TRN & \\
\hline CHEMBL3194523 & 1495406 & 3.0 & 3.00600 & 00000000002 & TRN \\
\hline CHEMBL1471651 & 1495406 & 3.0 & 2.7948 & TST & \\
\hline CHEMBL1456730 & 1495406 & 3.0 & 3.8384 & TRN & \\
\hline CHEMBL1367841 & 1495406 & 3.0 & 2.8044 & TRN & \\
\hline CHEMBL1497731 & 1495406 & 3.24 & 3.2033 & TRN & \\
\hline CHEMBL1710816 & 1495406 & 3.0 & 3.2279 & TRN & \\
\hline CHEMBL1580770 & 1495406 & 3.0 & 2.8362 & TRN & \\
\hline CHEMBL1523876 & 1495406 & 3.0 & 3.2499 & TRN & \\
\hline CHEMBL1313033 & 1495406 & 3.0 & 3.2222 & TRN & \\
\hline CHEMBL1469377 & 1495406 & 3.0 & 2.833 & TRN & \\
\hline CHEMBL3193151 & 1495406 & 3.256 & 79999999 & 3.5969 & TRN \\
\hline CHEMBL1516854 & 1495406 & 3.0 & 2.9533 & TRN & \\
\hline CHEMBL1422800 & 1495406 & 3.0 & 3.0048 & TRN & \\
\hline CHEMBL3214057 & 1495406 & 3.0 & 3.0062 & TRN & \\
\hline CHEMBL1378405 & 1495406 & 3.0 & 3.0383 & TRN & \\
\hline CHEMBL1321711 & 1495406 & 3.0 & 2.7434 & TRN & \\
\hline CHEMBL1522582 & 1495406 & 3.0 & 2.9695 & TRN & \\
\hline CHEMBL3560242 & 1495406 & 3.0 & 2.9783 & TRN & \\
\hline CHEMBL1452930 & 1495406 & 3.0 & 3.0273 & TRN & \\
\hline CHEMBL1335245 & 1495406 & 3.0 & 2.95399 & 99999999997 & TRN \\
\hline CHEMBL1466841 & 1495406 & 3.0 & 2.9772 & TRN & \\
\hline CHEMBL1463954 & 1495406 & 3.0 & 3.2177 & TRN & \\
\hline CHEMBL1465568 & 1495406 & 3.0 & 3.0164 & TRN & \\
\hline CHEMBL1306287 & 1495406 & 3.0 & 3.1092 & TRN & \\
\hline CHEMBL1611386 & 1495406 & 3.0 & 3.139 & TRN & \\
\hline CHEMBL1509013 & 1495406 & 3.0 & 3.0524 & TRN & \\
\hline CHEMBL1508573 & 1495406 & 3.0 & 3.0956 & TRN & \\
\hline CHEMBL1487668 & 1495406 & 3.0 & 3.2772 & TRN & \\
\hline CHEMBL1442617 & 1495406 & 3.0 & 3.147 & TRN & \\
\hline CHEMBL3210410 & 1495406 & 3.0 & 2.9791 & TST & \\
\hline CHEMBL3190393 & 1495406 & 3.0 & 2.9995 & TRN & \\
\hline CHEMBL1576463 & 1495406 & 3.0 & 3.0163 & TRN & \\
\hline
\end{tabular}




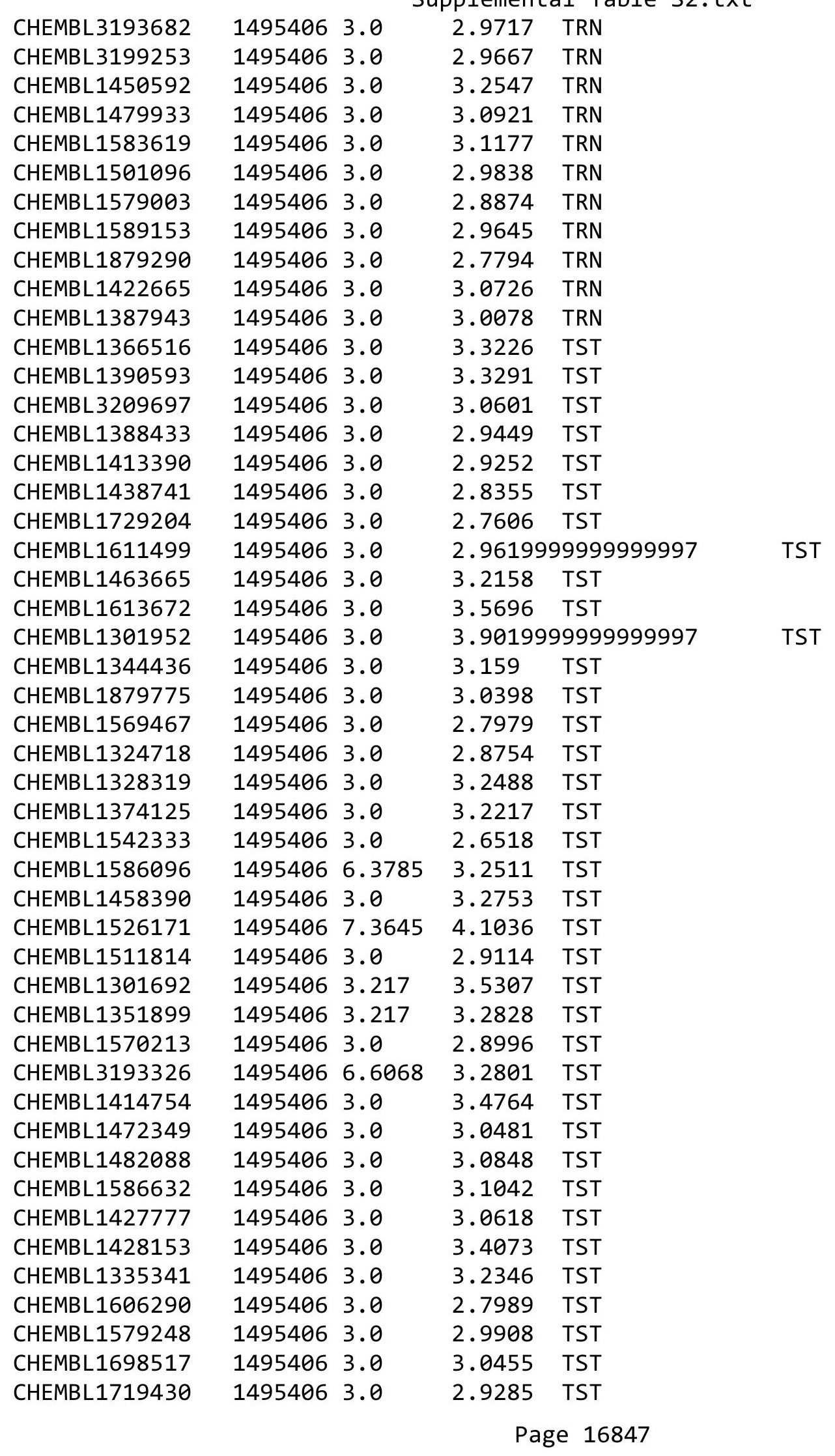




\begin{tabular}{|c|c|c|c|c|c|}
\hline \multicolumn{6}{|c|}{ Supplemental Table S2.txt } \\
\hline CHEMBL1367569 & 1495406 & 3.0 & 2.7204 & TST & \\
\hline CHEMBL1449615 & 1495406 & 3.0 & 3.0364 & TST & \\
\hline CHEMBL1430855 & 1495406 & 3.0 & 3.3181 & TST & \\
\hline CHEMBL1471272 & 1495406 & 3.0 & 3.1201 & TST & \\
\hline CHEMBL1700051 & 1495406 & 3.0 & 2.9726 & TST & \\
\hline CHEMBL1532566 & 1495406 & 3.0 & 3.0613 & TST & \\
\hline CHEMBL3209756 & 1495406 & 3.0 & 3.2206 & TST & \\
\hline CHEMBL1702270 & 1495406 & 3.0 & 2.9299 & TST & \\
\hline CHEMBL1509350 & 1495406 & 3.0 & 3.0225 & TST & \\
\hline CHEMBL3920309 & 1528490 & 7.8861 & 8.1392 & TST & \\
\hline CHEMBL3694694 & 1528490 & 6.8239 & 6.5852 & TRN & \\
\hline CHEMBL3694717 & 1528490 & 6.1637 & 6.2412 & TST & \\
\hline CHEMBL3957271 & 1528490 & 7.9586 & 8.2566 & TST & \\
\hline CHEMBL3690527 & 1528490 & 6.3778 & 6.4559 & TRN & \\
\hline CHEMBL3690534 & 1528490 & 6.1891 & 5.6138 & TRN & \\
\hline CHEMBL3690505 & 1528490 & 6.2358 & 6.0267 & TRN & \\
\hline CHEMBL3694684 & 1528490 & 6.8239 & 6.7709 & TRN & \\
\hline CHEMBL3690407 & 1528490 & 6.5452 & 6.6056 & TST & \\
\hline CHEMBL3694663 & 1528490 & 6.1739 & 6.5238 & TRN & \\
\hline CHEMBL3690472 & 1528490 & 6.4001 & 6.3921 & TRN & \\
\hline CHEMBL3958378 & 1528490 & 7.9393 & 7.9425 & TST & \\
\hline CHEMBL3690582 & 1528490 & 7.0315 & 6.86299 & 99999999995 & TRN \\
\hline CHEMBL 3690378 & 1528490 & 6.9469 & 6.6858 & TRN & \\
\hline CHEMBL3925050 & 1528490 & 7.9508 & 8.1777 & TST & \\
\hline CHEMBL3690535 & 1528490 & 6.8239 & 6.9696 & TRN & \\
\hline CHEMBL3690453 & 1528490 & 6.6289 & 6.4994 & TRN & \\
\hline CHEMBL3690485 & 1528490 & 7.8729 & 7.4396 & TRN & \\
\hline CHEMBL 3690504 & 1528490 & 6.8041 & 7.1551 & TST & \\
\hline CHEMBL3690487 & 1528490 & 5.9957 & 5.8953 & TRN & \\
\hline CHEMBL3694653 & 1528490 & 6.8539 & 6.9091 & TRN & \\
\hline CHEMBL3690465 & 1528490 & 6.5719 & 6.4267 & TRN & \\
\hline CHEMBL3690461 & 1528490 & 7.2343 & 7.0416 & TRN & \\
\hline CHEMBL3925109 & 1528490 & 7.6819 & 8.0711 & TST & \\
\hline CHEMBL3690406 & 1528490 & 6.2269 & 6.5191 & TRN & \\
\hline CHEMBL3690506 & 1528490 & 7.8153 & 7.5979 & TRN & \\
\hline CHEMBL3694664 & 1528490 & 8.0 & 7.2459 & TRN & \\
\hline CHEMBL3690566 & 1528490 & 6.0 & 6.8851 & TRN & \\
\hline CHEMBL 3690571 & 1528490 & 6.2518 & 6.0987 & TRN & \\
\hline CHEMBL3694665 & 1528490 & 7.4559 & 7.2595 & TRN & \\
\hline CHEMBL3690473 & 1528490 & 6.5045 & 6.4057 & TRN & \\
\hline CHEMBL3690409 & 1528490 & 7.9872 & 8.0243 & TRN & \\
\hline CHEMBL3690558 & 1528490 & 7.3768 & 7.186 & TRN & \\
\hline CHEMBL3690451 & 1528490 & 6.8861 & 6.8983 & TRN & \\
\hline CHEMBL3690494 & 1528490 & 6.3325 & 5.879 & TRN & \\
\hline CHEMBL 3690442 & 1528490 & 7.1343 & 7.1549 & TRN & \\
\hline CHEMBL3690567 & 1528490 & 7.6576 & 7.4619 & TRN & \\
\hline CHEMBL3690462 & 1528490 & 6.7447 & 6.9096 & TRN & \\
\hline CHEMBL3690564 & 1528490 & 4.0 & 6.8564 & TRN & \\
\hline
\end{tabular}


Supplemental Table S2.txt

\begin{tabular}{|c|c|c|c|c|c|}
\hline CHEMBL3690568 & 1528490 & 6.9586 & 7.2569 & TST & \\
\hline CHEMBL3690384 & 1528490 & 6.4572 & 6.3965 & TRN & \\
\hline CHEMBL3690492 & 1528490 & 8.0119 & 8.2632 & TRN & \\
\hline CHEMBL3690457 & 1528490 & 7.0788 & 7.0918 & TRN & \\
\hline CHEMBL3690428 & 1528490 & 6.9586 & 6.91 & TRN & \\
\hline CHEMBL3690569 & 1528490 & 6.8239 & 6.7188 & TRN & \\
\hline CHEMBL3690454 & 1528490 & 7.5702 & 7.6447 & TRN & \\
\hline CHEMBL3694723 & 1528490 & 6.3439 & 6.249 & TRN & \\
\hline CHEMBL3694647 & 1528490 & 6.8539 & 6.4335 & TRN & \\
\hline CHEMBL3690513 & 1528490 & 7.0119 & 7.0393 & TST & \\
\hline CHEMBL3690520 & 1528490 & 6.4789 & 6.1799 & TRN & \\
\hline CHEMBL3690551 & 1528490 & 6.0862 & 6.1379 & TRN & \\
\hline CHEMBL3690463 & 1528490 & 6.4828 & 6.4829 & TRN & \\
\hline CHEMBL 3690425 & 1528490 & 7.4698 & 7.2495 & TRN & \\
\hline CHEMBL3690417 & 1528490 & 7.7399 & 7.4401 & TST & \\
\hline CHEMBL3953693 & 1528490 & 7.2941 & 7.9116 & TST & \\
\hline CHEMBL3694702 & 1528490 & 6.4685 & 6.5751 & TRN & \\
\hline CHEMBL3690387 & 1528490 & 8.1051 & 7.6243 & TST & \\
\hline CHEMBL3690561 & 1528490 & 5.5229 & 6.8694 & TRN & \\
\hline CHEMBL3690398 & 1528490 & 7.2226 & 7.0897 & TRN & \\
\hline CHEMBL3694687 & 1528490 & 6.3565 & 5.7153 & TRN & \\
\hline CHEMBL3690553 & 1528490 & 6.284 & 6.2633 & TRN & \\
\hline CHEMBL3690589 & 1528490 & 6.6576 & 7.2217 & TST & \\
\hline CHEMBL3690550 & 1528490 & 6.2441 & 6.0655 & TRN & \\
\hline CHEMBL3690497 & 1528490 & $6.3420 e$ & 00000000 & 305 & 5.9885 \\
\hline CHEMBL3639892 & 1528490 & 7.2924 & 7.4187 & TRN & \\
\hline CHEMBL3690449 & 1528490 & 6.8239 & 6.7905 & TRN & \\
\hline CHEMBL3690542 & 1528490 & 3.5229 & 4.9433 & TRN & \\
\hline CHEMBL 3694690 & 1528490 & 6.0195 & 5.4533 & TRN & \\
\hline CHEMBL3690537 & 1528490 & 6.767 & 6.4668 & TRN & \\
\hline CHEMBL3690528 & 1528490 & 6.4078 & 6.1003 & TRN & \\
\hline CHEMBL3690427 & 1528490 & 6.9031 & 6.8604 & TRN & \\
\hline CHEMBL3694696 & 1528490 & 6.7696 & 6.5737 & TRN & \\
\hline CHEMBL 3690444 & 1528490 & 7.8268 & 8.1745 & TRN & \\
\hline CHEMBL3690383 & 1528490 & 6.7033 & 6.641 & TRN & \\
\hline CHEMBL3694656 & 1528490 & 7.7212 & 7.6183 & TST & \\
\hline CHEMBL 3690470 & 1528490 & 7.4895 & 7.3448 & TRN & \\
\hline CHEMBL3690484 & 1528490 & 7.7328 & 7.9659 & TRN & \\
\hline CHEMBL3690529 & 1528490 & 5.0 & 5.5766 & TRN & \\
\hline CHEMBL3690415 & 1528490 & 7.4318 & 7.2954 & TRN & \\
\hline CHEMBL3690381 & 1528490 & 6.0223 & 6.4423 & TRN & \\
\hline CHEMBL3690488 & 1528490 & 7.4157 & 7.4182 & TRN & \\
\hline CHEMBL3690386 & 1528490 & 7.0947 & 6.8908 & TRN & \\
\hline CHEMBL3690521 & 1528490 & 6.284 & 6.0553 & TRN & \\
\hline CHEMBL3694673 & 1528490 & 3.0 & 5.2052 & TRN & \\
\hline CHEMBL3690469 & 1528490 & 7.6696 & 7.2216 & TRN & \\
\hline CHEMBL3690411 & 1528490 & 7.8097 & 7.8578 & TST & \\
\hline CHEMBL3690382 & 1528490 & 7.1871 & 7.1483 & TST & \\
\hline
\end{tabular}


Supplemental Table S2.txt

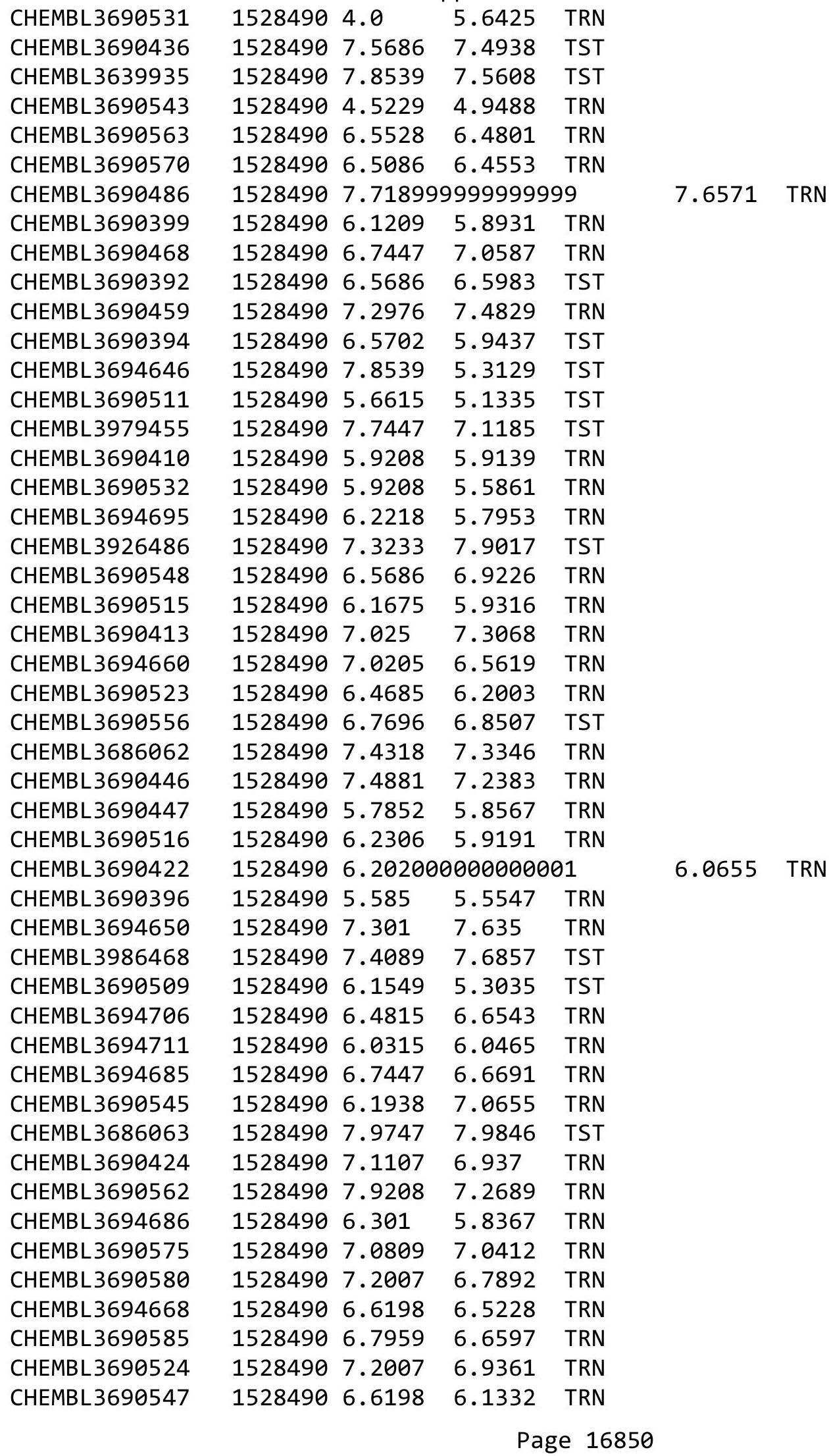




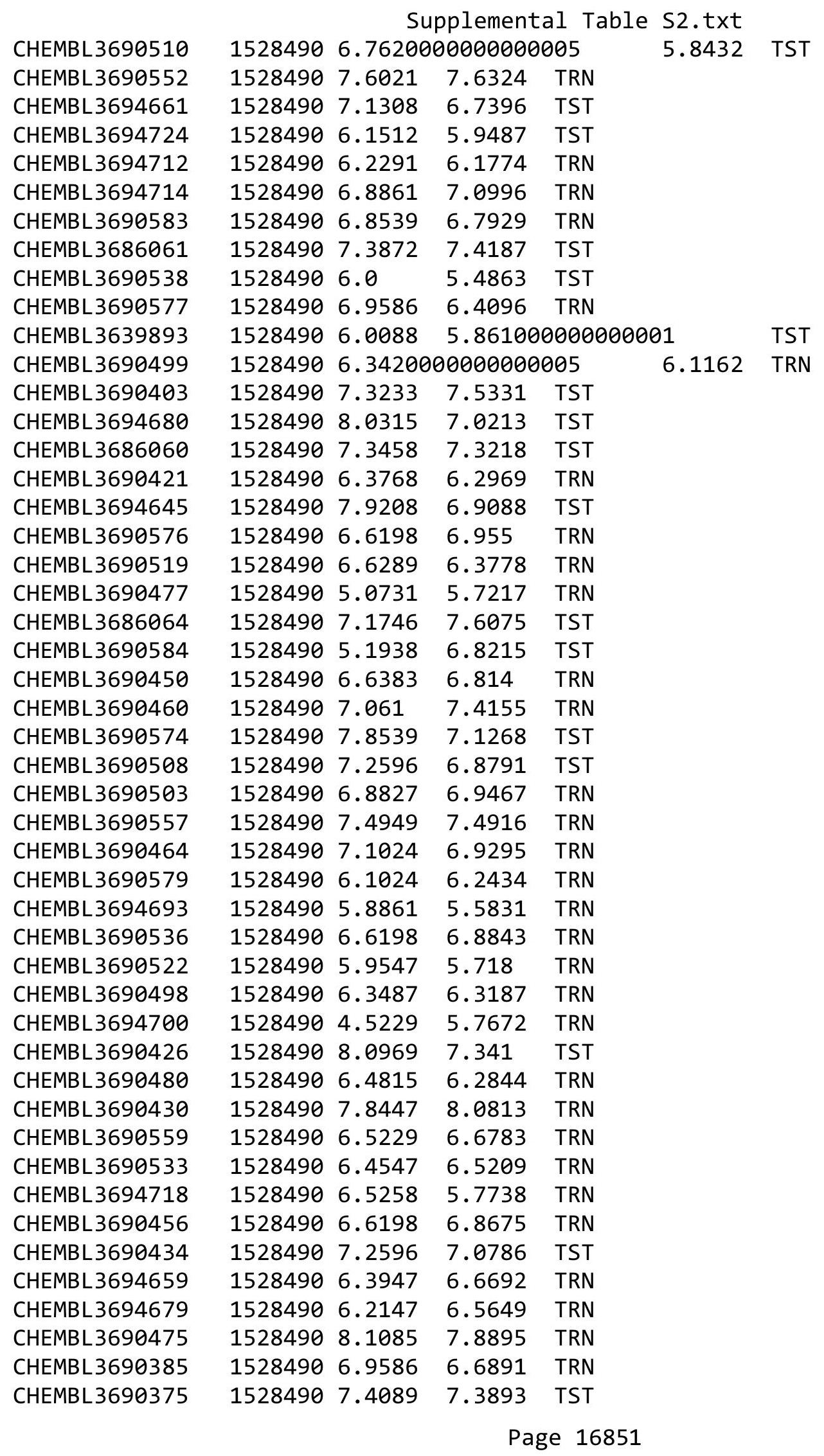


Supplemental Table S2.txt

\begin{tabular}{|c|c|c|c|c|}
\hline CHEMBL3694703 & 1528490 & 6.0862 & 6.0837 & TRN \\
\hline CHEMBL3690493 & 1528490 & 6.7235 & 7.0448 & TRN \\
\hline CHEMBL3694698 & 1528490 & 6.9208 & 6.8245 & TRN \\
\hline CHEMBL 3690500 & 1528490 & 7.4522 & 7.1515 & TST \\
\hline CHEMBL3690377 & 1528490 & 7.8761 & 7.9973 & TRN \\
\hline CHEMBL3690507 & 1528490 & 7.3655 & 7.0398 & TST \\
\hline CHEMBL3690549 & 1528490 & 6.7696 & 6.5269 & TRN \\
\hline CHEMBL3690495 & 1528490 & 6.9431 & 7.0575 & TRN \\
\hline CHEMBL3690441 & 1528490 & 7.2299 & 7.0778 & TRN \\
\hline CHEMBL3686065 & 1528490 & 7.8729 & 7.9016 & TST \\
\hline CHEMBL3690588 & 1528490 & 6.4685 & 5.9432 & TRN \\
\hline CHEMBL3694688 & 1528490 & 5.8861 & 5.3661 & TRN \\
\hline CHEMBL3931244 & 1528490 & 7.0904 & 7.0214 & TST \\
\hline CHEMBL 3694719 & 1528490 & 8.301 & 7.0612 & TRN \\
\hline CHEMBL 3690401 & 1528490 & 7.8996 & 7.8054 & TST \\
\hline CHEMBL3690496 & 1528490 & 6.585 & 6.3686 & TRN \\
\hline CHEMBL3694708 & 1528490 & 7.6216 & 7.4862 & TST \\
\hline CHEMBL3690565 & 1528490 & 7.5528 & 6.70700 & 0000000001 \\
\hline CHEMBL3690555 & 1528490 & 7.2291 & 7.2497 & TRN \\
\hline CHEMBL3690400 & 1528490 & 8.0429 & 8.0156 & TRN \\
\hline CHEMBL3690466 & 1528490 & 6.8861 & 7.1447 & TRN \\
\hline CHEMBL3694689 & 1528490 & 6.5686 & 5.9809 & TRN \\
\hline CHEMBL3690389 & 1528490 & 7.0491 & 6.5156 & TST \\
\hline CHEMBL3694657 & 1528490 & 6.4962 & 6.1936 & TRN \\
\hline CHEMBL 3694648 & 1528490 & 5.0 & 5.4957 & TRN \\
\hline CHEMBL3694655 & 1528490 & 6.8239 & 6.9389 & TRN \\
\hline CHEMBL3694670 & 1528490 & 6.8861 & 6.7478 & TRN \\
\hline CHEMBL3690373 & 1528490 & 7.6038 & 7.3959 & TST \\
\hline CHEMBL3690530 & 1528490 & 6.3188 & 6.5615 & TRN \\
\hline CHEMBL3690393 & 1528490 & 6.857 & 5.9948 & TST \\
\hline CHEMBL3690539 & 1528490 & 6.7447 & 6.7773 & TST \\
\hline CHEMBL3690482 & 1528490 & 6.4168 & 6.2581 & TRN \\
\hline CHEMBL3690438 & 1528490 & 8.0506 & 8.0241 & TRN \\
\hline CHEMBL3694671 & 1528490 & 5.6778 & 6.097 & TRN \\
\hline CHEMBL3690458 & 1528490 & 7.9208 & 8.1641 & TRN \\
\hline CHEMBL3690412 & 1528490 & 3.5229 & 6.0134 & TRN \\
\hline CHEMBL3694716 & 1528490 & 6.7011 & 6.0075 & TRN \\
\hline CHEMBL3690483 & 1528490 & 6.0721 & 6.0704 & TST \\
\hline CHEMBL3967812 & 1528490 & 6.4547 & 6.9379 & TST \\
\hline CHEMBL3690591 & 1528490 & 5.2487 & 5.4532 & TRN \\
\hline CHEMBL3690578 & 1528490 & 6.8539 & 5.8074 & TRN \\
\hline CHEMBL3690423 & 1528490 & 6.4559 & 6.3291 & TRN \\
\hline CHEMBL3694678 & 1528490 & 8.0706 & 6.9534 & TST \\
\hline CHEMBL3690391 & 1528490 & 6.3188 & 6.3766 & TRN \\
\hline CHEMBL3694710 & 1528490 & 7.7696 & 7.2795 & TRN \\
\hline CHEMBL3690546 & 1528490 & 7.4318 & 7.4162 & TRN \\
\hline CHEMBL3690491 & 1528490 & 7.7986 & 8.0945 & TRN \\
\hline CHEMBL 3690474 & 1528490 & 7.5017 & 7.5852 & TRN \\
\hline
\end{tabular}




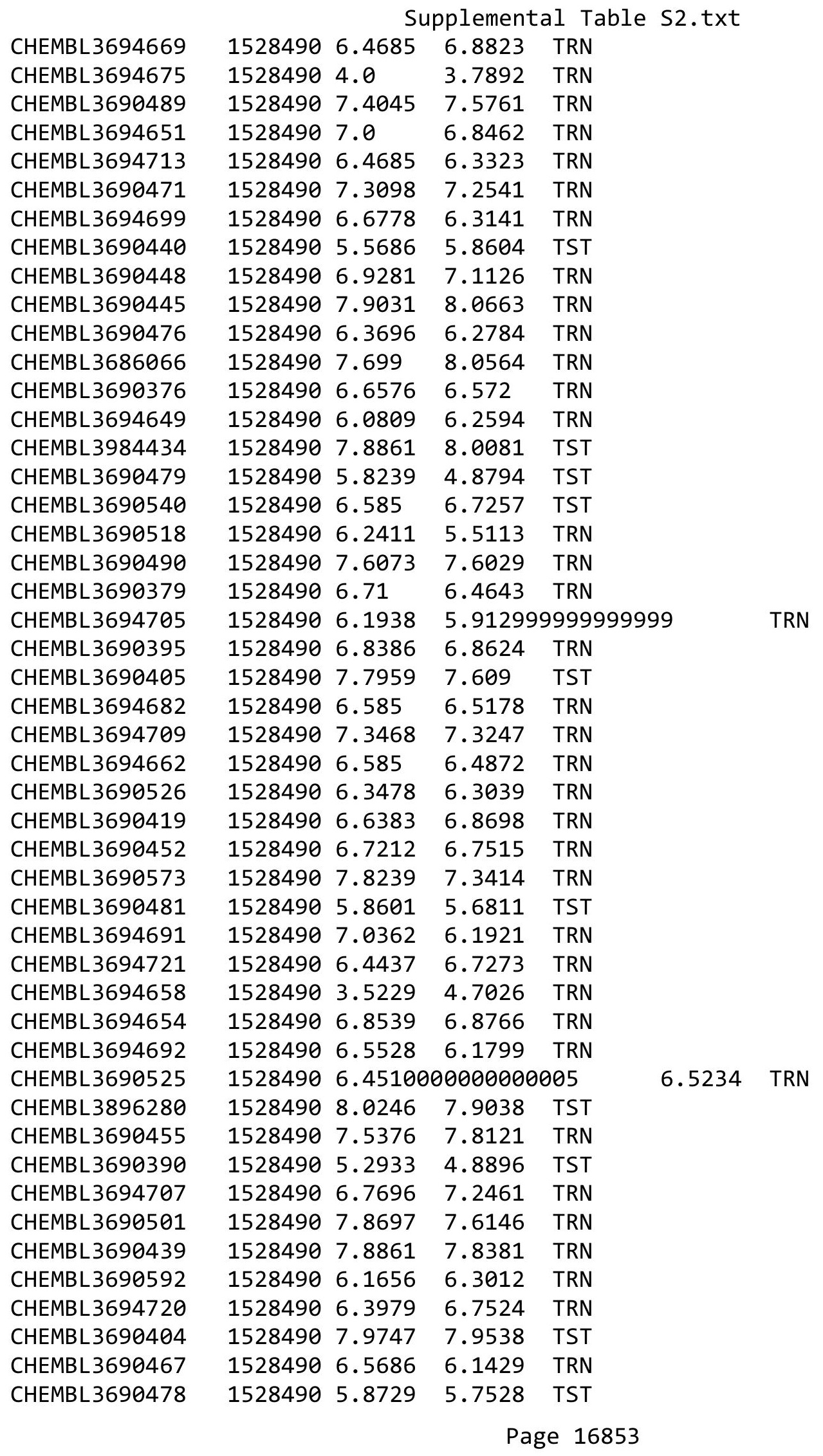


Supplemental Table S2.txt

\begin{tabular}{|c|c|c|c|c|c|c|}
\hline CHEMBL 3690554 & 1528490 & 7.5686 & 7.513 & TRN & & \\
\hline CHEMBL 3690414 & 1528490 & 7.5017 & 7.5801 & TRN & & \\
\hline CHEMBL3690590 & 1528490 & 7.8539 & 7.2469 & TRN & & \\
\hline CHEMBL 3690429 & 1528490 & 7.8861 & 7.6967 & TRN & & \\
\hline CHEMBL 3690443 & 1528490 & \multicolumn{3}{|c|}{7.752000000000001} & 9999999999 & TRN \\
\hline CHEMBL3694672 & 1528490 & 5.8601 & 5.5631 & TRN & & \\
\hline CHEMBL 3690416 & 1528490 & 8.1051 & 7.6994 & TST & & \\
\hline CHEMBL124913 & 35100 & 8.9208 & 7.9508 & TRN & & \\
\hline CHEMBL332152 & 35100 & 6.7986 & 6.9852 & TRN & & \\
\hline CHEMBL125533 & 35100 & 8.2757 & 7.7547 & TRN & & \\
\hline CHEMBL339709 & 35100 & 6.983 & 6.7401 & TRN & & \\
\hline CHEMBL435994 & 35100 & 7.9547 & 7.8621 & TRN & & \\
\hline CHEMBL125958 & 35100 & 8.1487 & 7.7043 & TST & & \\
\hline CHEMBL 333322 & 35100 & 6.0 & 6.789 & TST & & \\
\hline CHEMBL341456 & 35100 & 7.3958 & 7.8962 & TRN & & \\
\hline CHEMBL339404 & 35100 & 8.3188 & 8.7131 & TRN & & \\
\hline CHEMBL331042 & 35100 & 6.0 & 6.8919 & TRN & & \\
\hline CHEMBL 333058 & 35100 & 7.5086 & 6.88899 & 9999999999 & TRN & \\
\hline CHEMBL121718 & 35100 & 8.0088 & 7.7913 & TRN & & \\
\hline CHEMBL331121 & 35100 & 7.7496 & 8.12 & TRN & & \\
\hline CHEMBL 125697 & 35100 & 7.6596 & 8.3767 & TRN & & \\
\hline CHEMBL122912 & 35100 & 8.0969 & 7.8299 & TST & & \\
\hline CHEMBL123671 & 35100 & 6.0 & 6.7749 & TRN & & \\
\hline CHEMBL122966 & 35100 & 8.8239 & 7.5393 & TRN & & \\
\hline CHEMBL341131 & 35100 & 9.0458 & 7.712006 & 0000000001 & TRN & \\
\hline CHEMBL340882 & 35100 & 7.3197 & 7.6653 & TRN & & \\
\hline CHEMBL331219 & 35100 & 7.7721 & 7.6304 & TRN & & \\
\hline CHEMBL122443 & 35100 & 6.0 & 6.9311 & TRN & & \\
\hline CHEMBL125233 & 35100 & 6.9318 & 7.1203 & TRN & & \\
\hline CHEMBL121733 & 35100 & 7.8447 & 7.9135 & TRN & & \\
\hline CHEMBL331519 & 35100 & 8.4815 & 8.4855 & TRN & & \\
\hline CHEMBL123091 & 35100 & 7.7799 & 7.6328 & TRN & & \\
\hline CHEMBL338431 & 35100 & 7.1549 & 7.407 & TRN & & \\
\hline CHEMBL332766 & 35100 & 6.0 & 6.3753 & TST & & \\
\hline CHEMBL333411 & 35100 & 8.5229 & 6.3585 & TST & & \\
\hline CHEMBL122982 & 35100 & 8.3098 & 8.2429 & TRN & & \\
\hline CHEMBL331511 & 35100 & 8.4685 & 7.879 & TRN & & \\
\hline CHEMBL410878 & 35100 & 6.0535 & 6.0429 & TRN & & \\
\hline CHEMBL125835 & 35100 & 7.3206 & 7.8667 & TRN & & \\
\hline CHEMBL338123 & 35100 & 7.6216 & 7.8601 & TRN & & \\
\hline CHEMBL124141 & 35100 & 6.7033 & 7.3826 & TRN & & \\
\hline CHEMBL123593 & 35100 & 7.5952 & 8.1441 & TRN & & \\
\hline CHEMBL330942 & 35100 & 6.585 & 6.693 & TRN & & \\
\hline CHEMBL332323 & 35100 & 7.9066 & 6.8199 & TRN & & \\
\hline CHEMBL341151 & 35100 & 8.1938 & 7.5243 & TRN & & \\
\hline CHEMBL333126 & 35100 & 6.0 & 6.717006 & 00000000005 & TST & \\
\hline CHEMBL123670 & 35100 & 7.7545 & 7.6474 & TRN & & \\
\hline CHEMBL 341032 & 35100 & 8.2147 & 7.9246 & TRN & & \\
\hline
\end{tabular}




\begin{tabular}{|c|c|c|c|c|c|}
\hline \multicolumn{6}{|c|}{ plemental } \\
\hline CHEMBL126037 & 35100 & 6.0 & 6.7153 & TST & \\
\hline CHEMBL419421 & 35100 & 8.3768 & 8.2553 & TRN & \\
\hline CHEMBL126111 & 35100 & 6.0 & 6.8719 & TRN & \\
\hline CHEMBL122552 & 35100 & 8.0177 & 7.8071 & TRN & \\
\hline CHEMBL331081 & 35100 & 7.4609 & 7.7283 & TRN & \\
\hline CHEMBL338135 & 35100 & 7.5287 & 7.0466 & TST & \\
\hline CHEMBL334326 & 35100 & 7.3799 & 7.3967 & TRN & \\
\hline CHEMBL331546 & 35100 & 8.0969 & 8.3247 & TRN & \\
\hline CHEMBL340605 & 35100 & 7.8386 & 7.9566 & TRN & \\
\hline CHEMBL125273 & 35100 & 7.9957 & 7.86100 & 0000000001 & TRN \\
\hline CHEMBL122638 & 35100 & 8.4202 & 7.7718 & TRN & \\
\hline CHEMBL409136 & 35100 & 7.9547 & 7.7028 & TRN & \\
\hline CHEMBL122458 & 35100 & 8.0706 & 7.7744 & TRN & \\
\hline CHEMBL333722 & 35100 & 8.0809 & 7.9697 & TRN & \\
\hline CHEMBL124144 & 35100 & 7.8356 & 8.6904 & TRN & \\
\hline CHEMBL339544 & 35100 & 8.7212 & 7.0205 & TST & \\
\hline CHEMBL338514 & 35100 & 8.0706 & 7.9408 & TRN & \\
\hline CHEMBL339480 & 35100 & 7.9547 & 7.9551 & TRN & \\
\hline CHEMBL126170 & 35100 & 6.6108 & 7.0773 & TRN & \\
\hline CHEMBL421629 & 35100 & 8.0458 & 7.7708 & TRN & \\
\hline CHEMBL122494 & 35100 & 8.2366 & 6.8774 & TST & \\
\hline CHEMBL419058 & 35100 & 7.2636 & 7.5338 & TST & \\
\hline CHEMBL124925 & 35100 & 9.2218 & 7.0952 & TST & \\
\hline CHEMBL125766 & 35100 & 6.0 & 6.5416 & TST & \\
\hline CHEMBL121990 & 35100 & 7.4473 & 7.7034 & TST & \\
\hline CHEMBL125818 & 35100 & 6.0 & 6.2405 & TST & \\
\hline CHEMBL121854 & 35100 & 8.4559 & 7.5621 & TST & \\
\hline CHEMBL434242 & 35100 & 9.1549 & 7.2456 & TST & \\
\hline CHEMBL122490 & 35100 & 7.7328 & 7.329 & TST & \\
\hline CHEMBL212798 & 522127 & 4.7959 & 5.3928 & TRN & \\
\hline CHEMBL213593 & 522127 & 7.5528 & 7.4343 & TRN & \\
\hline CHEMBL452336 & 522127 & 6.9586 & 7.1683 & TRN & \\
\hline CHEMBL486868 & 522127 & 7.0177 & 7.1297 & TRN & \\
\hline CHEMBL488573 & 522127 & 6.4437 & 6.528 & TRN & \\
\hline CHEMBL272351 & 522127 & 7.2441 & 7.0597 & TST & \\
\hline CHEMBL379732 & 522127 & 7.3468 & 7.2896 & TRN & \\
\hline CHEMBL520537 & 522127 & 7.0362 & 7.1277 & TRN & \\
\hline CHEMBL438566 & 522127 & 7.5229 & 6.9498 & TST & \\
\hline CHEMBL520984 & 522127 & 6.7959 & 7.4032 & TST & \\
\hline CHEMBL209388 & 522127 & 7.2441 & 7.3572 & TRN & \\
\hline CHEMBL384829 & 522127 & 6.8239 & 6.5848 & TRN & \\
\hline CHEMBL508541 & 522127 & 7.1612 & 7.1713 & TRN & \\
\hline CHEMBL215900 & 522127 & 7.2291 & 7.2865 & TRN & \\
\hline CHEMBL486101 & 522127 & 6.9586 & 7.2013 & TRN & \\
\hline CHEMBL 272479 & 522127 & 7.585 & 6.4533 & TST & \\
\hline CHEMBL386398 & 522127 & 7.4815 & 7.50700 & $\partial 000000001$ & TST \\
\hline CHEMBL483786 & 522127 & 7.2291 & 6.9948 & TRN & \\
\hline CHEMBL212933 & 522127 & 5.4089 & 5.1736 & TST & \\
\hline
\end{tabular}




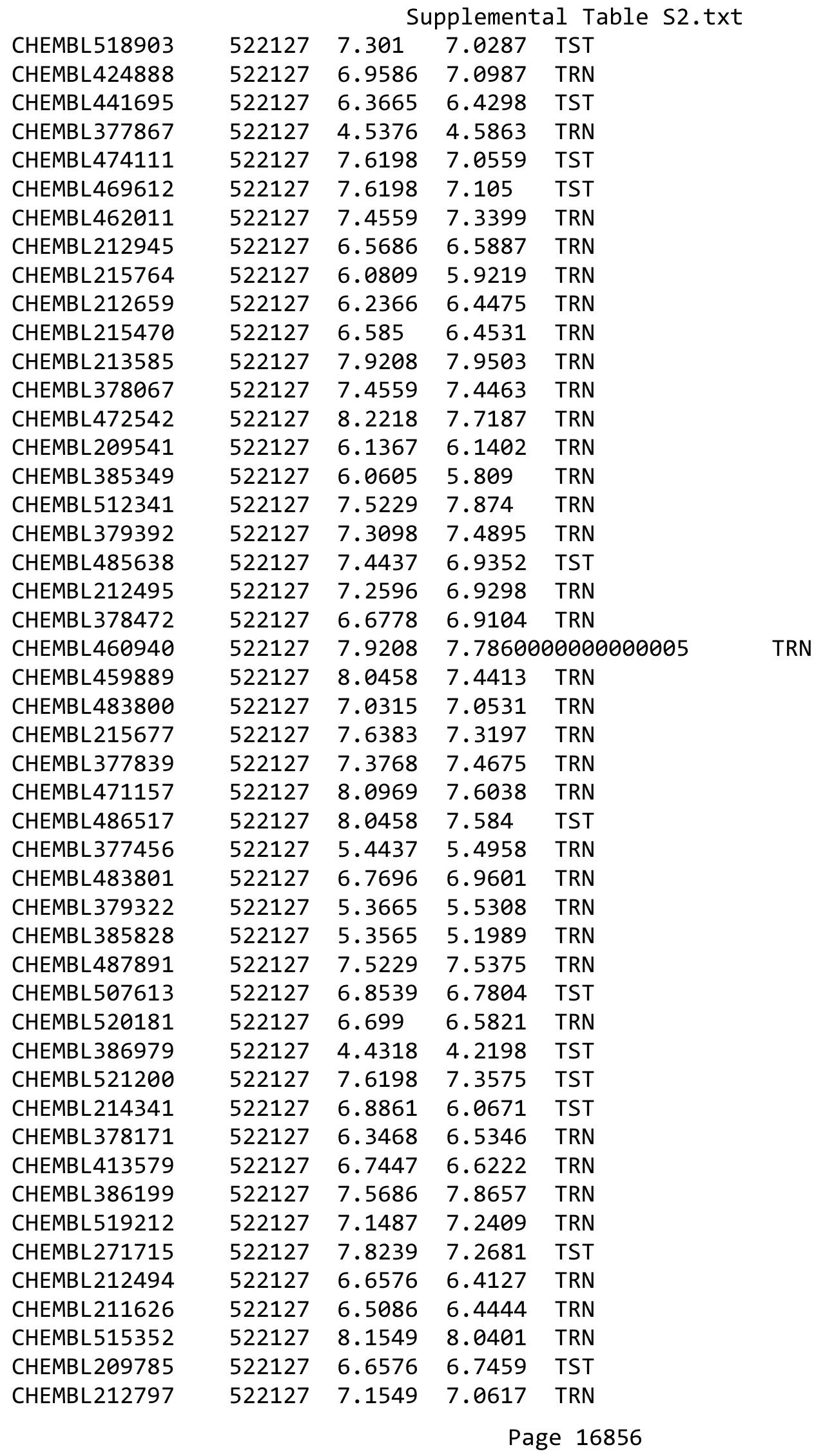


Supplemental Table S2.txt

\begin{tabular}{|c|c|c|c|c|c|}
\hline CHEMBL526721 & 522127 & 5.9586 & 6.2856 & TRN & \\
\hline CHEMBL520182 & 522127 & 7.6383 & 6.9596 & TRN & \\
\hline CHEMBL521065 & 522127 & 6.9586 & 6.6272 & TRN & \\
\hline CHEMBL 213475 & 522127 & 6.2076 & 6.0648 & TRN & \\
\hline CHEMBL 214208 & 522127 & 7.3768 & 7.3988 & TRN & \\
\hline CHEMBL 212646 & 522127 & 7.2007 & 7.4914 & TRN & \\
\hline CHEMBL 256480 & 522127 & 7.585 & 7.1533 & TST & \\
\hline CHEMBL475524 & 522127 & 7.4815 & 6.8705 & TST & \\
\hline CHEMBL379975 & 522127 & 7.9586 & 7.7952 & TRN & \\
\hline CHEMBL213019 & 522127 & 5.7447 & 5.8319 & TRN & \\
\hline CHEMBL 214005 & 522127 & 6.585 & 6.645 & TRN & \\
\hline CHEMBL486100 & 522127 & 7.1938 & 7.3006 & TRN & \\
\hline CHEMBL474714 & 522127 & 7.699 & 6.9646 & TST & \\
\hline CHEMBL508516 & 522127 & 6.8539 & 6.9889 & TRN & \\
\hline CHEMBL379592 & 522127 & 6.5229 & 6.5973 & TRN & \\
\hline CHEMBL508412 & 522127 & 7.0862 & 7.2127 & TRN & \\
\hline CHEMBL470113 & 522127 & 6.4815 & 7.6389 & TRN & \\
\hline CHEMBL 215506 & 522127 & 7.4815 & 7.1351 & TRN & \\
\hline CHEMBL 384831 & 522127 & 6.8239 & 6.9322 & TRN & \\
\hline CHEMBL 209594 & 522127 & 7.6198 & 7.603 & TRN & \\
\hline CHEMBL519887 & 522127 & 6.5528 & 6.6952 & TRN & \\
\hline CHEMBL211929 & 522127 & 6.8239 & 6.8332 & TRN & \\
\hline CHEMBL 385047 & 522127 & 5.6383 & 5.1679 & TST & \\
\hline CHEMBL454908 & 522127 & 7.0 & 6.95299 & 9999999999 & TRN \\
\hline CHEMBL 210056 & 522127 & 5.6383 & 5.685 & TST & \\
\hline CHEMBL209907 & 522127 & 7.0132 & 6.0596 & TST & \\
\hline CHEMBL487031 & 522127 & 6.7696 & 7.1025 & TRN & \\
\hline CHEMBL 387078 & 522127 & 5.3979 & 5.2819 & TST & \\
\hline CHEMBL486728 & 522127 & 6.9208 & 7.03799 & 9999999999 & TRN \\
\hline CHEMBL487335 & 522127 & 7.6198 & 6.8931 & TRN & \\
\hline CHEMBL213525 & 522127 & 7.2757 & 7.0938 & TRN & \\
\hline CHEMBL 213117 & 522127 & 4.9208 & 4.7688 & TRN & \\
\hline CHEMBL 384369 & 522127 & 5.7959 & 5.0304 & TST & \\
\hline CHEMBL512342 & 522127 & 7.6778 & 7.8319 & TRN & \\
\hline CHEMBL469822 & 522127 & 7.7447 & 6.7613 & TST & \\
\hline CHEMBL209448 & 522127 & 6.7212 & 7.0068 & TRN & \\
\hline CHEMBL514192 & 522127 & 7.3372 & 7.565 & TST & \\
\hline CHEMBL520049 & 522127 & 6.5376 & 6.8123 & TRN & \\
\hline CHEMBL 384089 & 522127 & 7.7212 & 7.8031 & TRN & \\
\hline CHEMBL460939 & 522127 & 6.4089 & 7.3897 & TRN & \\
\hline CHEMBL472687 & 522127 & 7.1249 & 6.846 & TST & \\
\hline CHEMBL488054 & 522127 & 7.5686 & 7.2246 & TRN & \\
\hline CHEMBL 214253 & 522127 & 7.0132 & 6.6693 & TRN & \\
\hline CHEMBL 379825 & 522127 & 7.301 & 7.2171 & TRN & \\
\hline CHEMBL 214172 & 522127 & 6.2366 & 6.1935 & TRN & \\
\hline CHEMBL511991 & 522127 & 7.3468 & 7.6639 & TRN & \\
\hline CHEMBL386809 & 522127 & 6.4815 & 6.612 & TRN & \\
\hline CHEMBL484985 & 522127 & 4.3979 & 5.4942 & TRN & \\
\hline
\end{tabular}




\begin{tabular}{|c|c|c|c|c|c|}
\hline \multirow[b]{2}{*}{ CHEMBL452078 } & \multicolumn{5}{|c|}{ sирргепеть } \\
\hline & 522127 & 7.2076 & 7.1318 & TRN & \\
\hline CHEMBL212846 & 522127 & 5.4815 & 5.415 & TRN & \\
\hline CHEMBL213313 & 522127 & 7.6778 & 7.7275 & TRN & \\
\hline CHEMBL378756 & 522127 & 7.1079 & 6.7944 & TST & \\
\hline CHEMBL483611 & 522127 & 7.1938 & 7.1609 & TRN & \\
\hline CHEMBL383926 & 522127 & 6.2924 & 5.9268 & TRN & \\
\hline CHEMBL384635 & 522127 & 6.0177 & 6.0533 & TRN & \\
\hline CHEMBL410261 & 522127 & 7.2366 & 6.7424 & TST & \\
\hline CHEMBL487757 & 522127 & 7.7212 & 7.7208 & TST & \\
\hline CHEMBL211140 & 522127 & 7.699 & 7.5966 & TRN & \\
\hline CHEMBL379346 & 522127 & 6.2441 & 6.0981 & TRN & \\
\hline CHEMBL215815 & 522127 & 7.8861 & 7.7743 & TRN & \\
\hline CHEMBL378066 & 522127 & 7.699 & 7.8607 & TRN & \\
\hline CHEMBL384477 & 522127 & 7.5528 & 7.5448 & TRN & \\
\hline CHEMBL214140 & 522127 & 7.0506 & 6.9568 & TRN & \\
\hline CHEMBL386048 & 522127 & 7.7447 & 7.8344 & TRN & \\
\hline CHEMBL213422 & 522127 & 7.4202 & 7.5372 & TRN & \\
\hline CHEMBL509601 & 522127 & 6.699 & 7.1074 & TRN & \\
\hline CHEMBL461116 & 522127 & 7.8539 & 7.2751 & TRN & \\
\hline CHEMBL460079 & 522127 & 7.1308 & 7.5716 & TRN & \\
\hline CHEMBL471163 & 522127 & 8.1549 & 7.4531 & TRN & \\
\hline CHEMBL378347 & 522127 & 6.0862 & 6.1362 & TRN & \\
\hline CHEMBL380048 & 522127 & 6.6383 & 6.4586 & TRN & \\
\hline CHEMBL215762 & 522127 & 5.9208 & 5.8346 & TRN & \\
\hline CHEMBL214137 & 522127 & 6.7696 & 6.8498 & TRN & \\
\hline CHEMBL520240 & 522127 & 7.4815 & 7.6471 & TRN & \\
\hline CHEMBL209486 & 522127 & 6.8539 & 6.9314 & TST & \\
\hline CHEMBL530112 & 522127 & 7.2676 & 7.0671 & TRN & \\
\hline CHEMBL214090 & 522127 & 7.5376 & 7.82100 & 0000000001 & TRN \\
\hline CHEMBL213367 & 522127 & 7.6383 & 7.8586 & TRN & \\
\hline CHEMBL511280 & 522127 & 7.8239 & 7.7308 & TRN & \\
\hline CHEMBL411662 & 522127 & 8.0458 & 7.5159 & TRN & \\
\hline CHEMBL212660 & 522127 & 7.1739 & 6.7692 & TRN & \\
\hline CHEMBL213346 & 522127 & 6.3098 & 6.5557 & TRN & \\
\hline CHEMBL 211878 & 522127 & 6.1938 & 6.0722 & TST & \\
\hline CHEMBL379149 & 522127 & 6.7447 & 7.3518 & TST & \\
\hline CHEMBL209786 & 522127 & 7.3279 & 7.2456 & TRN & \\
\hline CHEMBL472689 & 522127 & 7.8239 & 7.3829 & TST & \\
\hline CHEMBL215485 & 522127 & 7.8239 & 7.7193 & TRN & \\
\hline CHEMBL483953 & 522127 & 6.5229 & 6.5468 & TST & \\
\hline CHEMBL475325 & 522127 & 7.6021 & 7.2373 & TRN & \\
\hline CHEMBL258067 & 522127 & 7.7212 & 7.1929 & TST & \\
\hline CHEMBL255416 & 522127 & 7.4685 & 6.7105 & TST & \\
\hline CHEMBL488783 & 522127 & 7.4437 & 6.8601 & TST & \\
\hline CHEMBL488571 & 522127 & 6.6383 & 6.62700 & 3000000001 & TRN \\
\hline CHEMBL385194 & 522127 & 7.1249 & 7.0157 & TRN & \\
\hline CHEMBL403679 & 522127 & 7.4318 & 7.1757 & TST & \\
\hline CHEMBL401746 & 522127 & 7.3098 & 6.5336 & TST & \\
\hline & & & & 16858 & \\
\hline
\end{tabular}




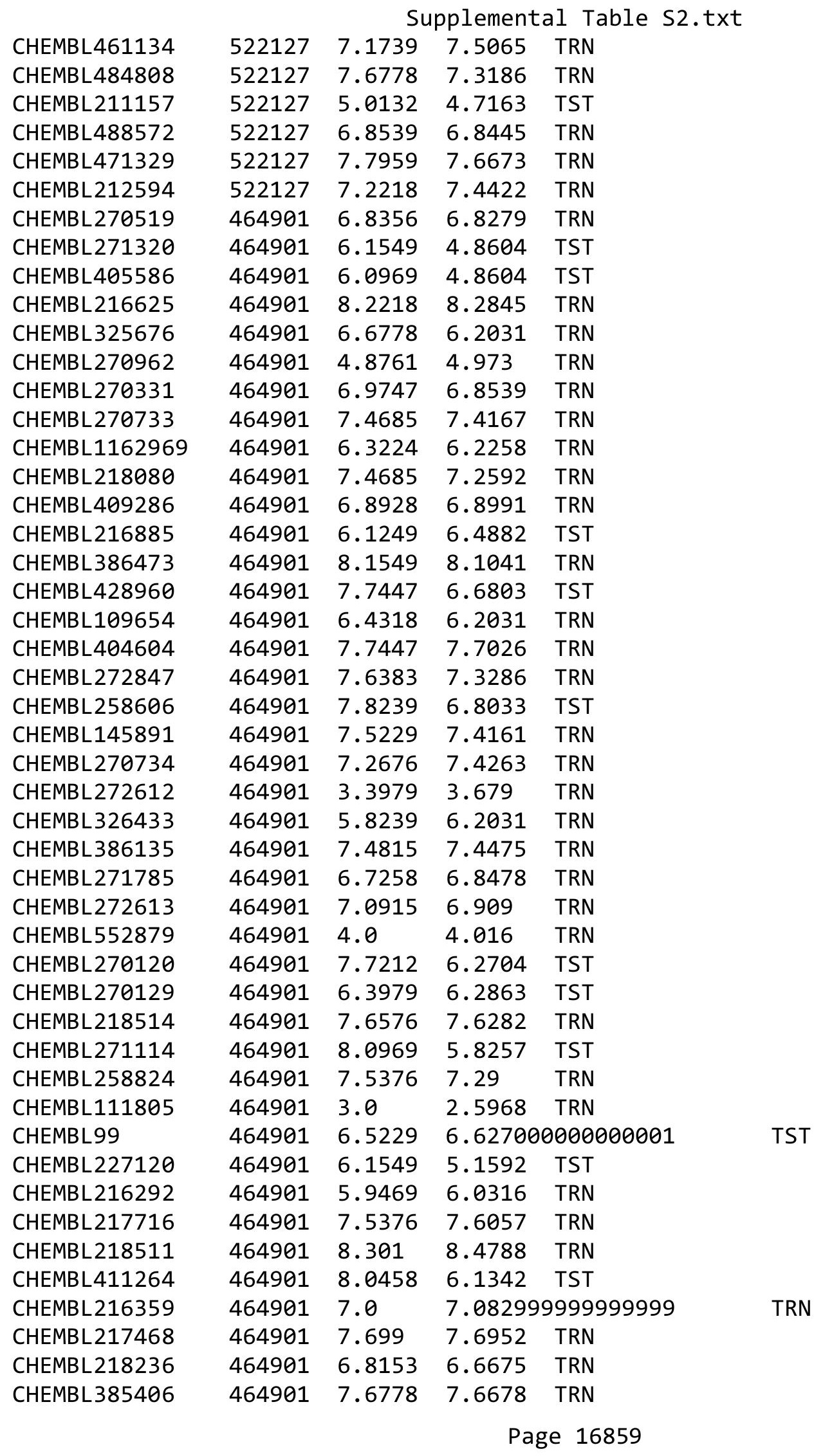


Supplemental Table S2.txt

\begin{tabular}{|c|c|c|c|c|}
\hline CHEMBL317814 & 464901 & 7.2291 & 7.3867 & TRN \\
\hline CHEMBL217098 & 464901 & 8.0458 & 8.1089 & TRN \\
\hline CHEMBL402451 & 464901 & 6.8239 & 6.3563 & TRN \\
\hline CHEMBL384961 & 464901 & 7.8861 & 7.7385 & TRN \\
\hline CHEMBL217816 & 464901 & 5.8996 & 5.835 & TRN \\
\hline CHEMBL178150 & 464901 & 4.6968 & 5.0093 & TRN \\
\hline CHEMBL217004 & 464901 & 8.301 & 8.4232 & TRN \\
\hline CHEMBL 270354 & 464901 & 6.8633 & 7.0175 & TRN \\
\hline CHEMBL410433 & 464901 & 7.9208 & 6.0479 & TST \\
\hline CHEMBL272638 & 464901 & 8.0969 & 6.2193 & TST \\
\hline CHEMBL 270333 & 464901 & 6.0969 & 4.5787 & TST \\
\hline CHEMBL410434 & 464901 & 7.9208 & 6.5152 & TST \\
\hline CHEMBL406161 & 464901 & 6.9101 & 6.978 & TRN \\
\hline CHEMBL 271115 & 464901 & 6.0 & 4.8604 & TST \\
\hline CHEMBL216509 & 464901 & 6.6144 & 6.6355 & TRN \\
\hline CHEMBL 217604 & 464901 & 6.9706 & 6.9049 & TRN \\
\hline CHEMBL434466 & 464901 & 7.1805 & 7.4161 & TRN \\
\hline CHEMBL426343 & 464901 & 8.0969 & 8.1197 & TRN \\
\hline CHEMBL178726 & 464901 & 3.3979 & 3.3749 & TRN \\
\hline CHEMBL114344 & 464901 & 5.2076 & 5.7861 & TRN \\
\hline CHEMBL111806 & 464901 & 5.1487 & 5.4031 & TRN \\
\hline CHEMBL1412043 & 688332 & 6.1367 & 5.0065 & TRN \\
\hline CHEMBL1503961 & 688332 & 4.4 & 4.2985 & TST \\
\hline CHEMBL1613004 & 688332 & 3.4 & 4.2957 & TST \\
\hline CHEMBL1342429 & 688332 & 3.7 & 4.8312 & TRN \\
\hline CHEMBL1432707 & 688332 & 5.85 & 5.2286 & TRN \\
\hline CHEMBL601757 & 688332 & 5.4 & 5.3589 & TST \\
\hline CHEMBL1497651 & 688332 & 4.6867 & 4.4492 & TST \\
\hline CHEMBL 272465 & 688332 & 4.1 & 4.30399 & 9999999999 \\
\hline CHEMBL1574945 & 688332 & 4.3 & 4.4176 & TRN \\
\hline CHEMBL1367879 & 688332 & 4.2 & 4.1428 & TRN \\
\hline CHEMBL1543129 & 688332 & 4.1 & 4.191 & TRN \\
\hline CHEMBL1477845 & 688332 & 4.3 & 4.2761 & TRN \\
\hline CHEMBL3190218 & 688332 & 4.4 & 4.2013 & TRN \\
\hline CHEMBL1504850 & 688332 & 4.2 & 4.4049 & TRN \\
\hline CHEMBL1608720 & 688332 & 3.8 & 4.6902 & TRN \\
\hline CHEMBL1405482 & 688332 & 4.2 & 4.0757 & TST \\
\hline CHEMBL1455110 & 688332 & 4.1 & 4.0252 & TRN \\
\hline CHEMBL1601846 & 688332 & 3.9 & 4.2441 & TRN \\
\hline CHEMBL1397706 & 688332 & 5.45 & 5.0831 & TST \\
\hline CHEMBL1557332 & 688332 & 4.0 & 4.0382 & TRN \\
\hline CHEMBL1480480 & 688332 & 4.2 & 4.1779 & TRN \\
\hline CHEMBL3213421 & 688332 & 4.0 & 4.5072 & TRN \\
\hline CHEMBL3192506 & 688332 & 3.9 & 3.9117 & TRN \\
\hline CHEMBL1408579 & 688332 & 4.2 & 4.296 & TRN \\
\hline CHEMBL1544374 & 688332 & 4.2 & 4.1649 & TRN \\
\hline CHEMBL1579564 & 688332 & 4.5 & 4.2888 & TRN \\
\hline CHEMBL1347567 & 688332 & 4.1 & 4.27800 & 00000000005 \\
\hline
\end{tabular}




\begin{tabular}{|c|c|c|c|c|c|}
\hline \multicolumn{6}{|c|}{ Supplemental Table S2.txt } \\
\hline CHEMBL1426115 & 688332 & 4.0 & 4.4839 & TRN & \\
\hline CHEMBL1370567 & 688332 & 3.9 & 4.0486 & TRN & \\
\hline CHEMBL1576815 & 688332 & 4.9 & 5.0366 & TST & \\
\hline CHEMBL1414890 & 688332 & 4.5 & 4.4377 & TRN & \\
\hline CHEMBL1564713 & 688332 & 4.6 & 4.2928 & TRN & \\
\hline CHEMBL1373462 & 688332 & 4.3 & 4.8549 & TST & \\
\hline CHEMBL 3207423 & 688332 & 4.8867 & 4.6122 & TRN & \\
\hline CHEMBL1304580 & 688332 & 4.0 & 4.4959 & TRN & \\
\hline CHEMBL3190169 & 688332 & 4.45 & 4.2238 & TRN & \\
\hline CHEMBL1353825 & 688332 & 4.7 & 4.5246 & TRN & \\
\hline CHEMBL449392 & 688332 & 4.1 & 4.2044 & TST & \\
\hline CHEMBL1501151 & 688332 & 3.9 & 4.668 & TRN & \\
\hline CHEMBL1366826 & 688332 & 3.8 & 4.1915 & TRN & \\
\hline CHEMBL1613270 & 688332 & 4.5 & 4.6273 & TRN & \\
\hline CHEMBL580421 & 688332 & 6.05 & 5.528 & TRN & \\
\hline CHEMBL1446929 & 688332 & 5.2867 & 5.2196 & TRN & \\
\hline CHEMBL1555585 & 688332 & 4.1 & 4.3632 & TRN & \\
\hline CHEMBL1300059 & 688332 & 4.1 & 4.6469 & TST & \\
\hline CHEMBL1401342 & 688332 & 4.5 & 4.2759 & TST & \\
\hline CHEMBL234338 & 688332 & 4.7367 & 4.7088 & TRN & \\
\hline CHEMBL1531298 & 688332 & 4.1 & 4.2811 & TST & \\
\hline CHEMBL1558183 & 688332 & 6.3367 & 5.6718 & TRN & \\
\hline CHEMBL1339149 & 688332 & 4.65 & 4.4861 & TRN & \\
\hline CHEMBL1344544 & 688332 & 4.1 & 4.3363 & TRN & \\
\hline CHEMBL1330109 & 688332 & 4.3 & 4.3378 & TRN & \\
\hline CHEMBL3190727 & 688332 & 3.8 & 4.7961 & TRN & \\
\hline CHEMBL1608402 & 688332 & 4.3 & 4.2143 & TRN & \\
\hline CHEMBL1333181 & 688332 & 4.4 & 3.9715 & TRN & \\
\hline CHEMBL3198956 & 688332 & 5.0867 & 4.7347 & TRN & \\
\hline CHEMBL1392310 & 688332 & 5.1867 & 4.7464 & TRN & \\
\hline CHEMBL1456371 & 688332 & 4.2 & 4.4581 & TRN & \\
\hline CHEMBL1384670 & 688332 & 3.9 & 4.4283 & TRN & \\
\hline CHEMBL75913 & 688332 & 4.5 & 4.3269 & TRN & \\
\hline CHEMBL1403877 & 688332 & 4.0 & 3.9381 & TRN & \\
\hline CHEMBL1463482 & 688332 & 3.9 & 4.4192 & TRN & \\
\hline CHEMBL3192075 & 688332 & 5.2867 & 4.7819 & TRN & \\
\hline CHEMBL1612597 & 688332 & 4.1 & 4.3015 & TRN & \\
\hline CHEMBL1586360 & 688332 & 4.4 & 4.2411 & TRN & \\
\hline CHEMBL1331149 & 688332 & 4.4 & 4.2497 & TRN & \\
\hline CHEMBL1462889 & 688332 & 3.5 & 4.13 & TRN & \\
\hline CHEMBL1581518 & 688332 & 4.1 & 4.0834 & TRN & \\
\hline CHEMBL1351412 & 688332 & 4.1 & 3.9667 & TRN & \\
\hline CHEMBL3197343 & 688332 & 4.6 & 4.00899 & 99999999995 & TRN \\
\hline CHEMBL3194609 & 688332 & 4.4 & 4.2488 & TRN & \\
\hline CHEMBL429095 & 688332 & 5.2 & 5.1597 & TRN & \\
\hline CHEMBL457665 & 688332 & 4.85 & 4.5089 & TST & \\
\hline CHEMBL1380684 & 688332 & 3.8 & 4.3935 & TRN & \\
\hline CHEMBL1406389 & 688332 & 4.1 & 4.3154 & TRN & \\
\hline
\end{tabular}




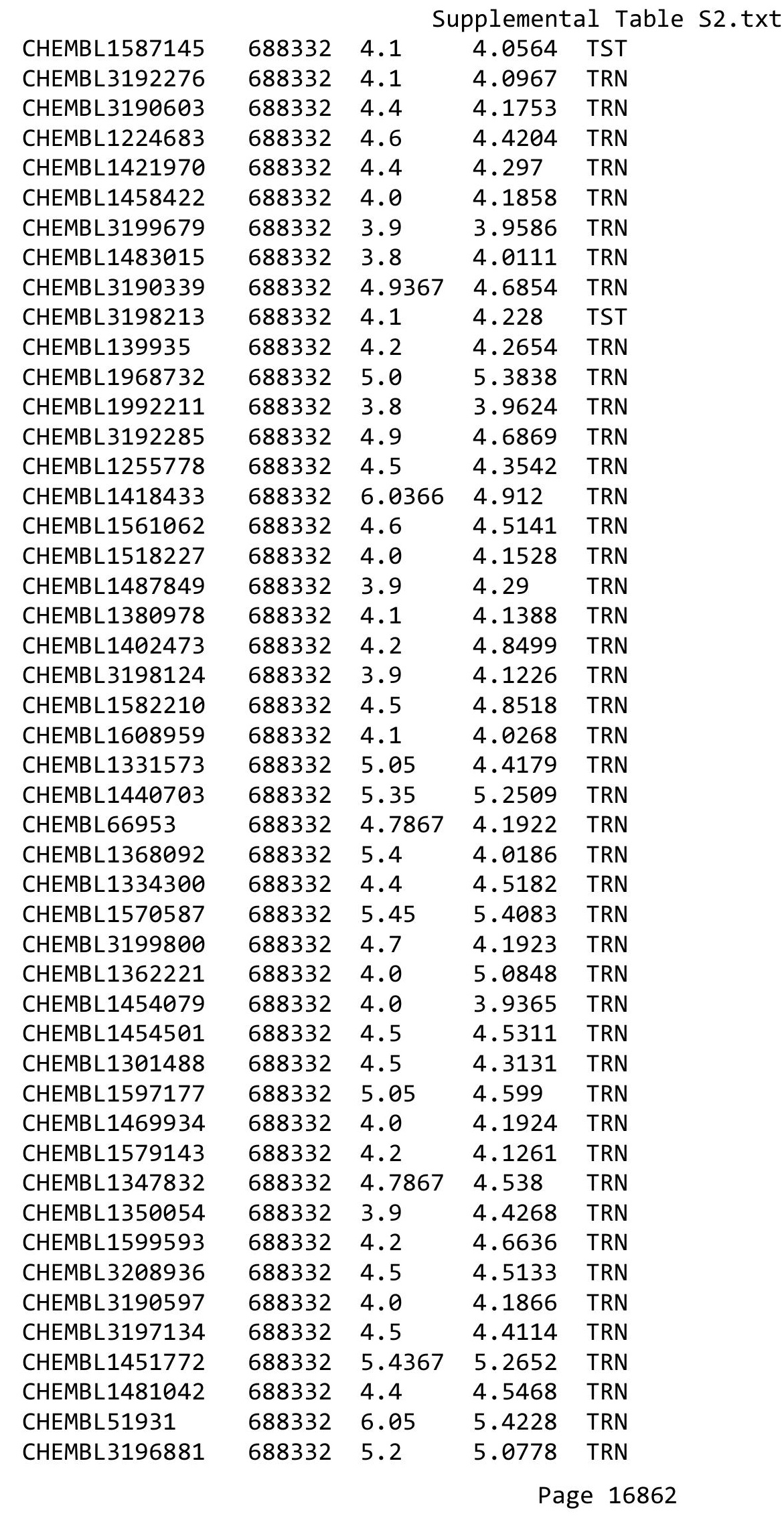




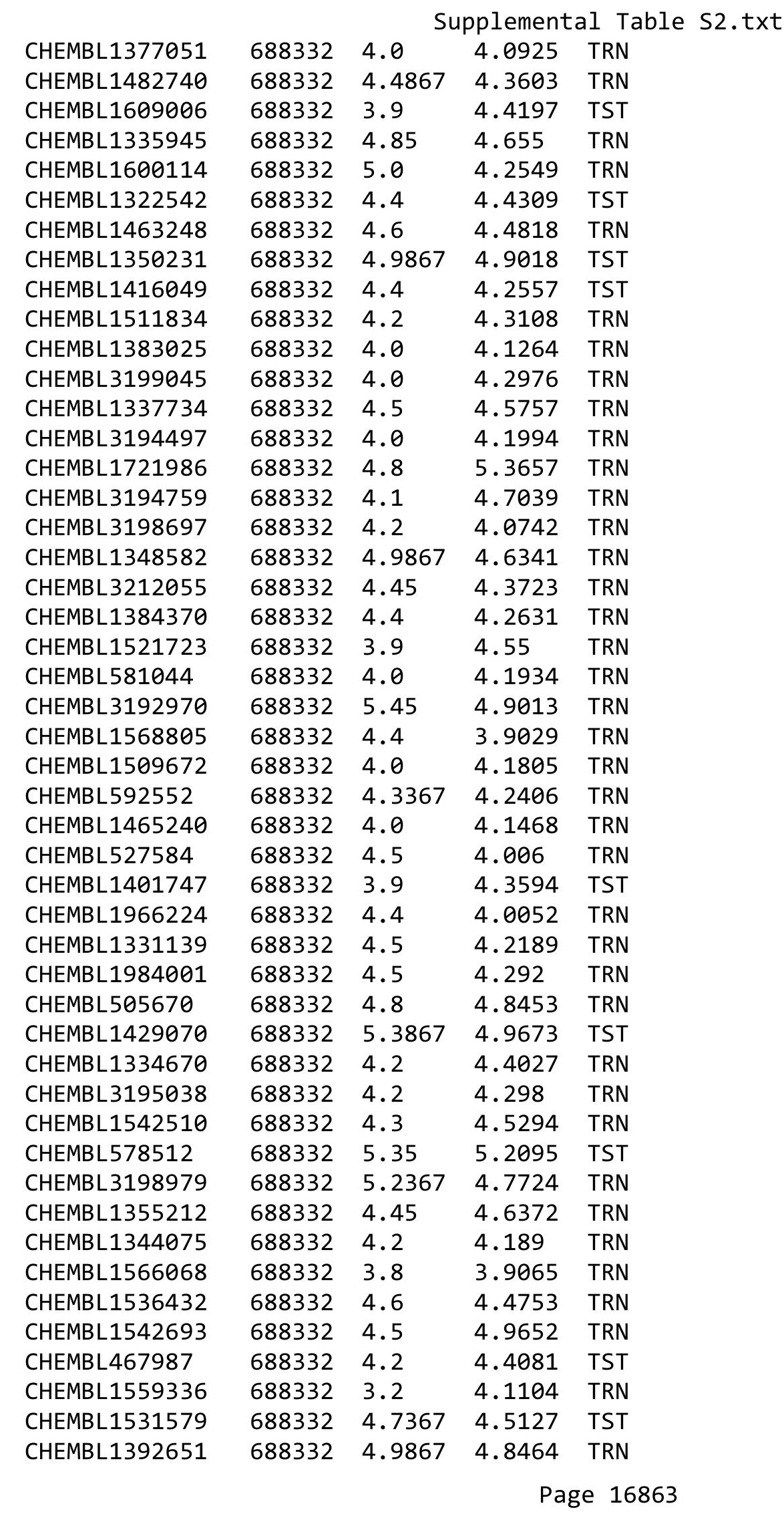




\begin{tabular}{|c|c|c|c|c|c|}
\hline \multicolumn{6}{|c|}{ Supplemental Table S2.txt } \\
\hline CHEMBL1461413 & 688332 & 4.3 & 4.1097 & TRN & \\
\hline CHEMBL1495170 & 688332 & 4.1 & 4.2837 & TRN & \\
\hline CHEMBL91153 & 688332 & 3.9 & 4.3897 & TRN & \\
\hline CHEMBL1984884 & 688332 & 4.8867 & 4.2884 & TRN & \\
\hline CHEMBL51085 & 688332 & 4.65 & 4.3118 & TRN & \\
\hline CHEMBL3194486 & 688332 & 4.4 & 4.0061 & TRN & \\
\hline CHEMBL406341 & 688332 & 4.6867 & 5.1424 & TST & \\
\hline CHEMBL1969548 & 688332 & 5.1867 & 5.225 & TST & \\
\hline CHEMBL1499701 & 688332 & 5.1867 & 4.3549 & TST & \\
\hline CHEMBL1386684 & 688332 & 4.4 & 4.6183 & TST & \\
\hline CHEMBL1590378 & 688332 & 5.5 & 5.2735 & TST & \\
\hline CHEMBL1478258 & 688332 & 4.4 & 4.0932 & TST & \\
\hline CHEMBL1402056 & 688332 & 4.1 & 4.2597 & TST & \\
\hline CHEMBL 3194044 & 688332 & 4.4 & 4.4885 & TST & \\
\hline CHEMBL1409039 & 688332 & 4.8867 & 4.8462 & TST & \\
\hline CHEMBL1499778 & 688332 & 4.3 & 4.38399 & 99999999995 & TST \\
\hline CHEMBL1379103 & 688332 & 4.1 & 4.2098 & TST & \\
\hline CHEMBL1580209 & 688332 & 3.9 & 4.2519 & TST & \\
\hline CHEMBL1489771 & 688332 & 4.3 & 4.1134 & TST & \\
\hline CHEMBL1519313 & 688332 & 5.05 & 5.1193 & TST & \\
\hline CHEMBL1556634 & 688332 & 4.4 & 4.4315 & TST & \\
\hline CHEMBL 2003806 & 688332 & 5.15 & 5.2805 & TST & \\
\hline CHEMBL322970 & 688332 & 3.9 & 4.6665 & TST & \\
\hline CHEMBL3189879 & 688332 & 4.1 & 4.2124 & TST & \\
\hline CHEMBL1464383 & 688332 & 4.4 & 4.0285 & TST & \\
\hline CHEMBL3392041 & 688332 & 4.1 & 4.4077 & TST & \\
\hline CHEMBL1403434 & 688332 & 5.45 & 4.2479 & TST & \\
\hline CHEMBL3196609 & 688332 & 3.9 & 4.0897 & TST & \\
\hline CHEMBL3198339 & 688332 & 4.3 & 4.2093 & TST & \\
\hline CHEMBL1598287 & 688332 & 4.0 & 4.5004 & TST & \\
\hline CHEMBL1429228 & 688332 & 3.9 & 3.9873 & TST & \\
\hline CHEMBL1606433 & 688332 & 4.5 & 4.4256 & TST & \\
\hline CHEMBL1549039 & 688332 & 4.1 & 4.335 & TST & \\
\hline CHEMBL1341758 & 688332 & 4.5 & 4.5408 & TST & \\
\hline CHEMBL1081402 & 621326 & 6.0 & 6.1309 & TRN & \\
\hline CHEMBL1081754 & 621326 & 4.301 & 4.3736 & TRN & \\
\hline CHEMBL1080639 & 621326 & 7.585 & 7.5748 & TRN & \\
\hline CHEMBL1081403 & 621326 & 7.1135 & 7.3391 & TRN & \\
\hline CHEMBL1081061 & 621326 & 6.8013 & 6.7829 & TRN & \\
\hline CHEMBL1079452 & 621326 & 5.6198 & 5.6146 & TRN & \\
\hline CHEMBL1079850 & 621326 & 7.3098 & 7.3211 & TRN & \\
\hline CHEMBL1080362 & 621326 & 4.301 & 4.3262 & TRN & \\
\hline CHEMBL1075666 & 621326 & 6.2857 & 6.2554 & TRN & \\
\hline CHEMBL1079795 & 621326 & 6.1284 & 6.1226 & TRN & \\
\hline CHEMBL1080190 & 621326 & 7.1805 & 7.2516 & TRN & \\
\hline CHEMBL1081198 & 621326 & 7.2076 & 6.9932 & TRN & \\
\hline CHEMBL1079750 & 621326 & 6.9031 & 6.8953 & TRN & \\
\hline CHEMBL1081222 & 621326 & 5.2676 & 5.2636 & TRN & \\
\hline
\end{tabular}


Supplemental Table S2.txt

\begin{tabular}{|c|c|c|c|c|}
\hline IE & 6 & 57 & & \\
\hline & 21326 & .9788 & 6.5817 & \\
\hline & & & & \\
\hline IEMBL1080207 & & 61 & & \\
\hline AEMBL1079500 & 1326 & & 1806 & \\
\hline HEMBL1081025 & 21326 & .7212 & 7101 & \\
\hline HEMBL1 & 326 & 278 & & \\
\hline 107 & & & & \\
\hline AEMBL1081013 & & & & \\
\hline HEMBL1079960 & 326 & 301 & 5903 & \\
\hline HEMBL1080668 & 326 & 2 & 06 & \\
\hline IEMBL1e & 26 & & & \\
\hline IEMBL1C & & & & \\
\hline HEMBL10 & 326 & & 093 & \\
\hline AEMBL10 & 26 & & 88 & \\
\hline AEMBL10 & & 17 & 73 & \\
\hline AEMBL1€ & & & 45 & \\
\hline HEMBL1C & & & & \\
\hline AEMBL10 & & & 7048 & \\
\hline IEMBL1C & & & & \\
\hline HEMBLIt & & & 711 & NIN \\
\hline AEMBL16 & & & 806 & +2 \\
\hline AEMBL16 & & & & \\
\hline 108 & & & & \\
\hline AEMBL1 & & & 56 & re \\
\hline HEMBL1 & & & 811 & \\
\hline HEMBL1 & & & 79 & \\
\hline HFMBI 1 & & & 32 & RN \\
\hline HEMBL1€ & & & & 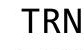 \\
\hline HEMBL10 & & & 25 & I RN \\
\hline HEMBL1€ & & & 978 & \\
\hline HEMBL1 & & & & זות \\
\hline 82 & & & 243 & ST \\
\hline HEMBL10 & & & & 15 \\
\hline HEMBL1079621 & & & 451 & TST \\
\hline HEMBL1€ & & & 29 & IST \\
\hline HᄃMPI 1 & & & & ST \\
\hline HEMBL10 & & & 7359 & ГST \\
\hline HEMBL1080359 & & & 5879 & TST \\
\hline EMBL1e & & & 407 & IST \\
\hline HEMBL 23 & & & 817 & \\
\hline HEMBL11 & & & & RN \\
\hline HEMBL 233 & & & 8.0499 & RN \\
\hline AEMBL2336780 & & 03 & 0067 & ГST \\
\hline MBL2 & & & 9877 & \\
\hline CHEMBL27 & & & & \\
\hline CHEMBL233633 & & 8.0405 & 8.0545 & \\
\hline THEMBL 2336788 & 948151 & 8.066 & 8.0919 & ГRN \\
\hline
\end{tabular}

Page 16865 


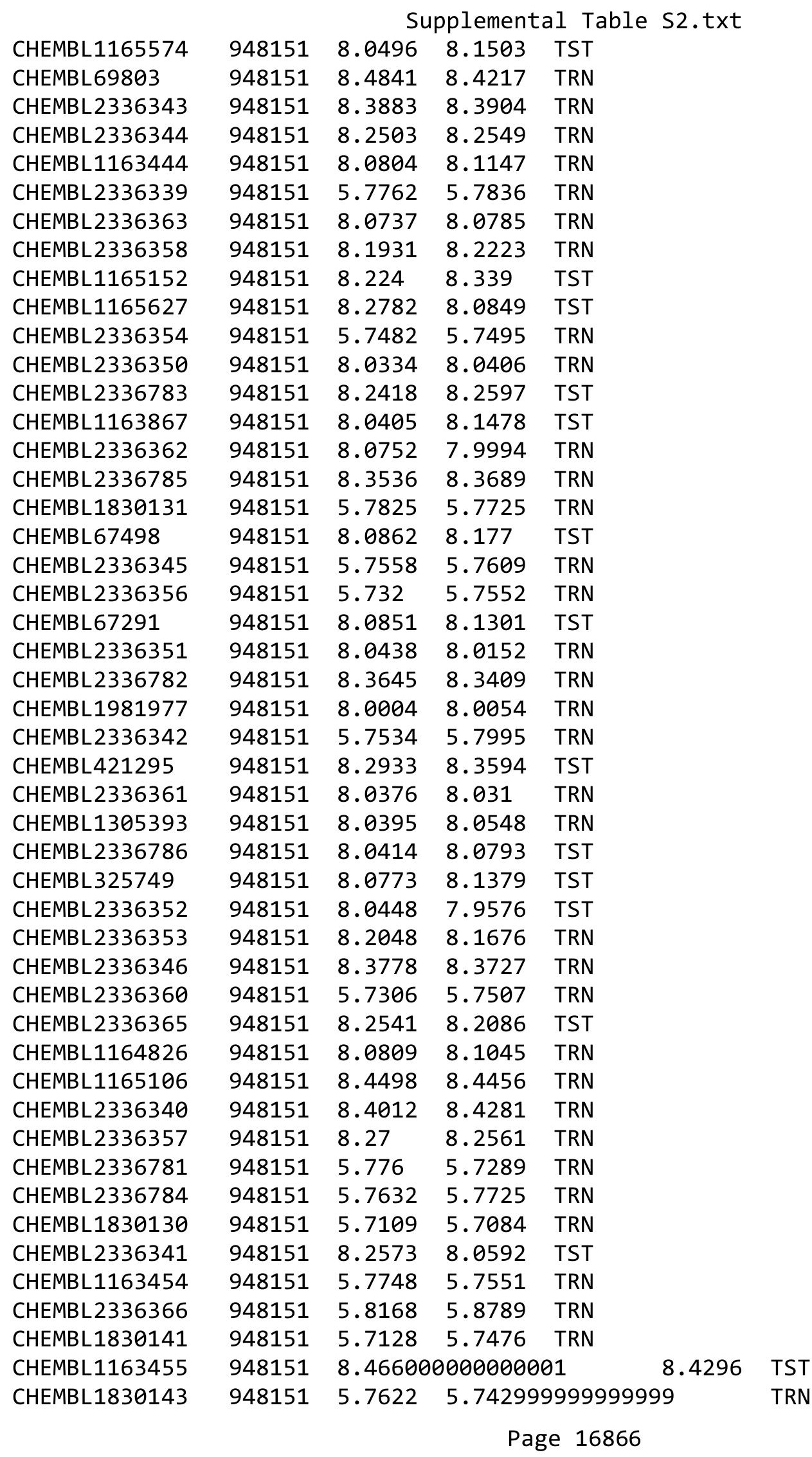




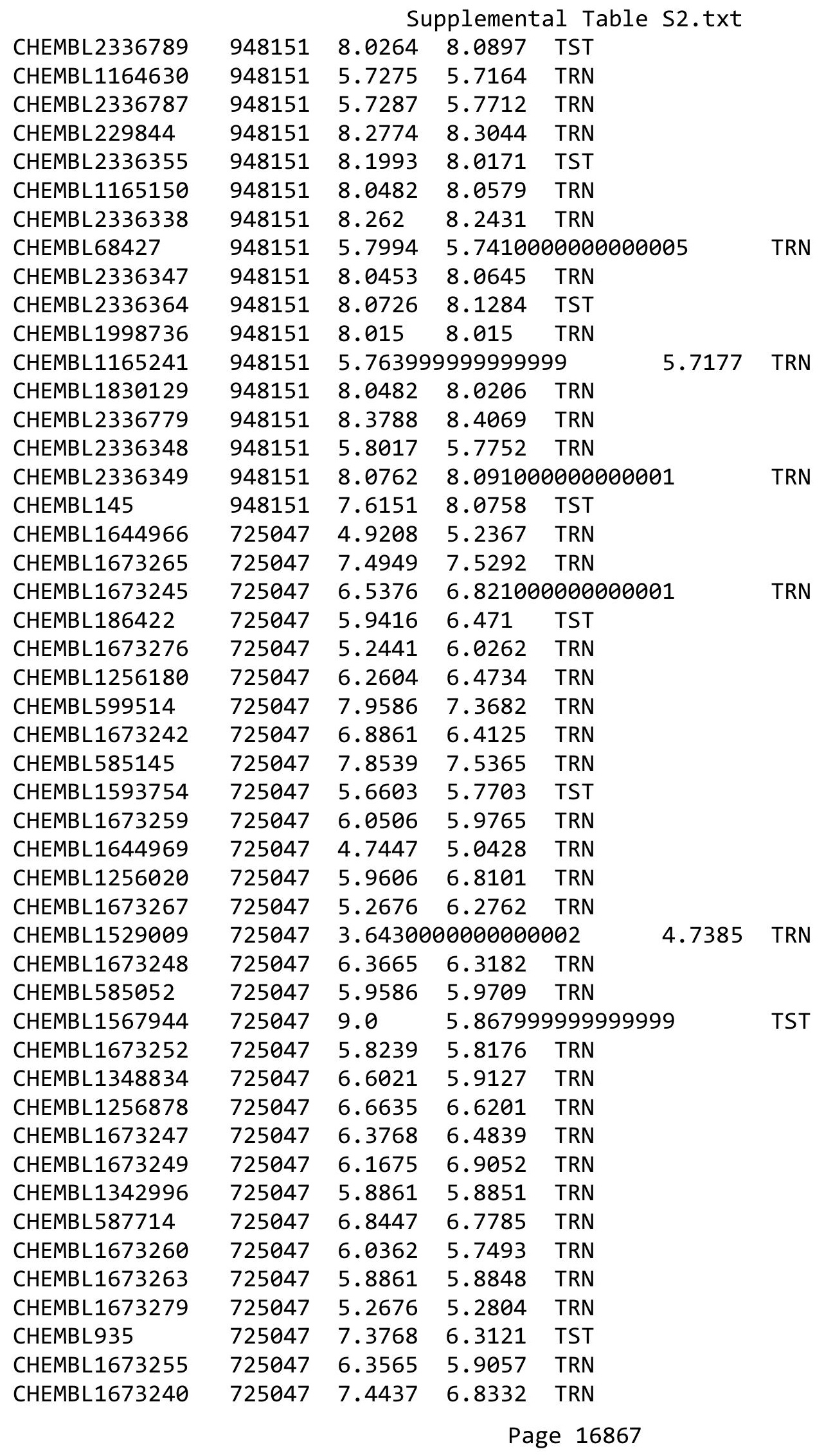


Supplemental Table S2.txt

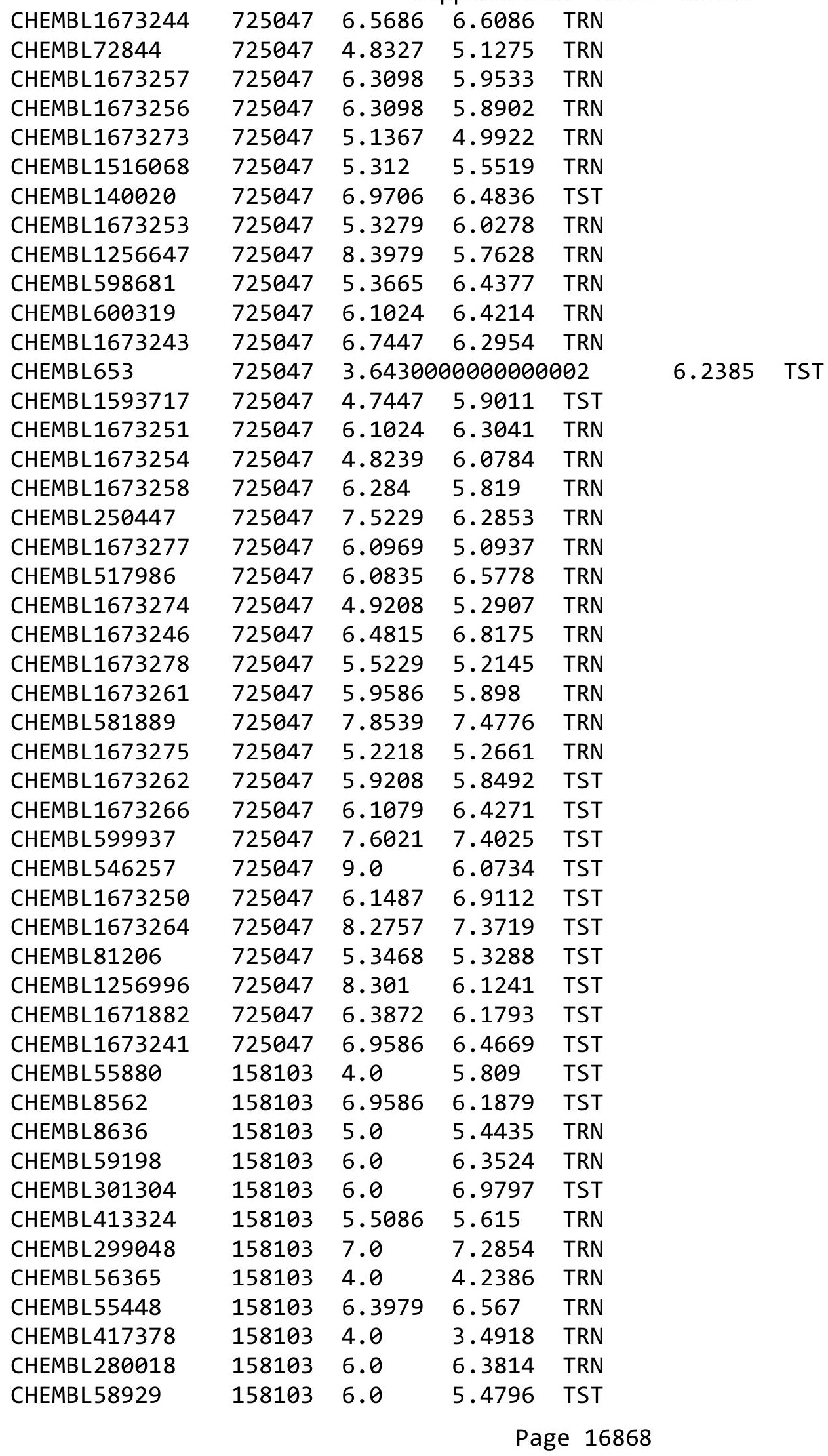




\begin{tabular}{|c|c|c|c|c|c|}
\hline \multirow[b]{2}{*}{ CHEMBL440480 } & \multicolumn{5}{|c|}{ 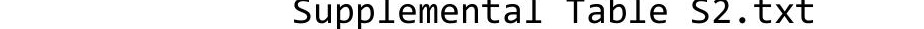 } \\
\hline & 158103 & 6.1079 & 5.9382 & TRN & \\
\hline CHEMBL434783 & 158103 & 5.8861 & 6.2531 & TRN & \\
\hline CHEMBL301017 & 158103 & 6.0 & 6.0762 & TRN & \\
\hline CHEMBL56422 & 158103 & 6.0 & 6.2174 & TRN & \\
\hline CHEMBL55217 & 158103 & 4.9586 & 5.4915 & TRN & \\
\hline CHEMBL292136 & 158103 & 6.9586 & 6.6143 & TST & \\
\hline CHEMBL293755 & 158103 & 5.8861 & 6.0121 & TRN & \\
\hline CHEMBL56563 & 158103 & 6.5229 & 6.7943 & TST & \\
\hline CHEMBL417379 & 158103 & 6.1249 & \multicolumn{2}{|c|}{5.992000000000001} & TRN \\
\hline CHEMBL56039 & 158103 & 5.6021 & 5.6623 & TRN & \\
\hline CHEMBL56531 & 158103 & 6.0 & 5.8302 & TRN & \\
\hline CHEMBL55389 & 158103 & 7.0 & 6.3687 & TRN & \\
\hline CHEMBL294003 & 158103 & 6.0 & 5.8854 & TRN & \\
\hline CHEMBL57016 & 158103 & 7.0 & 6.7749 & TRN & \\
\hline CHEMBL 8813 & 158103 & 6.2147 & 6.4061 & TRN & \\
\hline CHEMBL55960 & 158103 & 5.3768 & 5.5474 & TRN & \\
\hline CHEMBL56833 & 158103 & 6.1367 & 6.3013 & TRN & \\
\hline CHEMBL54221 & 158103 & 5.8239 & \multicolumn{2}{|c|}{5.1339999999999995} & TRN \\
\hline CHEMBL55680 & 158103 & 6.7212 & 6.3553 & TRN & \\
\hline CHEMBL56460 & 158103 & 7.0 & 6.5143 & TRN & \\
\hline CHEMBL293150 & 158103 & 7.0 & 6.7383 & TRN & \\
\hline CHEMBL54226 & 158103 & 4.0 & 6.0482 & TST & \\
\hline CHEMBL55293 & 158103 & 5.8539 & 6.0574 & TRN & \\
\hline CHEMBL414824 & 158103 & 6.585 & 5.87 & TRN & \\
\hline CHEMBL58990 & 158103 & 6.6383 & 6.4736 & TRN & \\
\hline CHEMBL293825 & 158103 & 5.8539 & 5.8805 & TRN & \\
\hline CHEMBL56196 & 158103 & 6.0 & 6.1109 & TRN & \\
\hline CHEMBL55737 & 158103 & 6.2291 & 6.5087 & TRN & \\
\hline CHEMBL58979 & 158103 & 6.0 & 5.9955 & TRN & \\
\hline CHEMBL266100 & 158103 & 7.4685 & 6.3792 & TRN & \\
\hline CHEMBL300159 & 158103 & 5.9586 & 5.5245 & TRN & \\
\hline CHEMBL442167 & 158103 & 4.0 & 3.8369 & TRN & \\
\hline CHEMBL 8842 & 158103 & 6.0 & 6.2289 & TRN & \\
\hline CHEMBL54169 & 158103 & 6.0 & 5.5656 & TRN & \\
\hline CHEMBL56461 & 158103 & 5.6021 & \multicolumn{2}{|c|}{5.832000000000001} & TRN \\
\hline CHEMBL55976 & 158103 & 6.0 & 6.0901 & TST & \\
\hline CHEMBL56798 & 158103 & 6.1079 & 6.0823 & TRN & \\
\hline CHEMBL300976 & 158103 & 6.0 & 5.6422 & TRN & \\
\hline CHEMBL56009 & 158103 & 6.2007 & 6.2879 & TST & \\
\hline CHEMBL8959 & 158103 & 4.0 & 5.3162 & TRN & \\
\hline CHEMBL417380 & 158103 & 6.0 & 6.4256 & TRN & \\
\hline CHEMBL56576 & 158103 & 5.8861 & 5.6685 & TRN & \\
\hline CHEMBL293821 & 158103 & 4.0 & 4.6563 & TRN & \\
\hline CHEMBL54227 & 158103 & 6.0 & 5.5074 & TST & \\
\hline CHEMBL58987 & 158103 & 6.1487 & 6.4712 & TST & \\
\hline CHEMBL57298 & 158103 & 6.0 & 6.8267 & TST & \\
\hline CHEMBL291710 & 158103 & 5.4949 & 5.2583 & TST & \\
\hline \multirow[t]{2}{*}{ CHEMBL8595 } & 158103 & 7.0 & 6.7984 & TST & \\
\hline & & \multicolumn{4}{|c|}{ Page 16869} \\
\hline
\end{tabular}




\begin{tabular}{|c|c|c|c|c|c|}
\hline \multicolumn{6}{|c|}{ Supplemental Table S2.txt } \\
\hline CHEMBL56551 & 158103 & 6.2924 & 5.8255 & TST & \\
\hline CHEMBL55435 & 158103 & 6.0 & 5.4321 & TST & \\
\hline CHEMBL 3928075 & 1637139 & 8.0 & 7.4481 & TRN & \\
\hline CHEMBL 3977421 & 1637139 & 7.0 & 6.5784 & TRN & \\
\hline CHEMBL3928507 & 1637139 & 7.0 & 6.96899 & 9999999999 & TRN \\
\hline CHEMBL3903656 & 1637139 & 6.301 & 6.6081 & TRN & \\
\hline CHEMBL 3917210 & 1637139 & 8.0 & 7.6055 & TST & \\
\hline CHEMBL3899285 & 1637139 & 8.0 & 7.6605 & TRN & \\
\hline CHEMBL 3935100 & 1637139 & 8.0 & 7.8972 & TRN & \\
\hline CHEMBL3981313 & 1637139 & 6.301 & 6.1339 & TRN & \\
\hline CHEMBL3919128 & 1637139 & 7.0 & 7.1069 & TRN & \\
\hline CHEMBL 3986998 & 1637139 & 7.0 & 6.9215 & TRN & \\
\hline CHEMBL3923610 & 1637139 & 7.0 & 7.0425 & TRN & \\
\hline CHEMBL 3917962 & 1637139 & 7.0 & 6.9868 & TRN & \\
\hline CHEMBL3919966 & 1637139 & 7.0 & 7.5084 & TRN & \\
\hline CHEMBL3967303 & 1637139 & 6.301 & 6.7948 & TRN & \\
\hline CHEMBL3941703 & 1637139 & 7.0 & 6.7476 & TRN & \\
\hline CHEMBL3940360 & 1637139 & 7.0 & 6.8511 & TRN & \\
\hline CHEMBL 3904645 & 1637139 & 8.0 & 7.7577 & TRN & \\
\hline CHEMBL3914107 & 1637139 & 6.0 & 6.2138 & TRN & \\
\hline CHEMBL3957835 & 1637139 & 7.0 & 7.0717 & TRN & \\
\hline CHEMBL3956999 & 1637139 & 7.0 & 6.9908 & TRN & \\
\hline CHEMBL3951586 & 1637139 & 6.301 & 5.9971 & TRN & \\
\hline CHEMBL 3897700 & 1637139 & 7.0 & 7.0584 & TRN & \\
\hline CHEMBL3928847 & 1637139 & 6.0 & 5.6307 & TRN & \\
\hline CHEMBL3896422 & 1637139 & 6.301 & 6.3494 & TRN & \\
\hline CHEMBL 3907740 & 1637139 & 7.0 & 7.3555 & TST & \\
\hline CHEMBL3966021 & 1637139 & 6.301 & 5.7846 & TST & \\
\hline CHEMBL 3979607 & 1637139 & 6.301 & 6.4275 & TST & \\
\hline CHEMBL3964025 & 1637139 & 7.0 & 7.1173 & TRN & \\
\hline CHEMBL3933168 & 1637139 & 7.0 & 7.0642 & TRN & \\
\hline CHEMBL 3918722 & 1637139 & 7.0 & 6.879 & TRN & \\
\hline CHEMBL3942988 & 1637139 & 7.0 & 7.1997 & TRN & \\
\hline CHEMBL3904681 & 1637139 & 6.301 & 6.2506 & TRN & \\
\hline CHEMBL3958968 & 1637139 & 8.0 & 7.504 & TST & \\
\hline CHEMBL3949599 & 1637139 & 6.301 & 6.5004 & TST & \\
\hline CHEMBL 3981425 & 1637139 & 8.0 & 7.7651 & TRN & \\
\hline CHEMBL3896039 & 1637139 & 8.0 & 7.6363 & TST & \\
\hline CHEMBL 3941565 & 1637139 & 8.0 & 7.5175 & TST & \\
\hline CHEMBL3916725 & 1637139 & 7.0 & 7.0134 & TRN & \\
\hline CHEMBL3939013 & 1637139 & 6.301 & 6.4604 & TRN & \\
\hline CHEMBL 3904980 & 1637139 & 8.0 & 7.4298 & TRN & \\
\hline CHEMBL3956565 & 1637139 & 6.301 & 6.3273 & TST & \\
\hline CHEMBL 3949992 & 1637139 & 8.0 & 7.2854 & TST & \\
\hline CHEMBL3981784 & 1637139 & 8.0 & 8.0959 & TRN & \\
\hline CHEMBL3909499 & 1637139 & 7.0 & 7.0131 & TRN & \\
\hline CHEMBL 3896589 & 1637139 & 7.0 & 7.0462 & TRN & \\
\hline CHEMBL3979361 & 1637139 & 7.0 & 7.2493 & TRN & \\
\hline
\end{tabular}


Supplemental Table S2.txt

\begin{tabular}{|c|c|c|c|c|c|}
\hline CHEMBL 3968497 & 1637139 & 6.301 & 6.5317 & TRN & \\
\hline CHEMBL3899101 & 1637139 & 6.301 & \multicolumn{2}{|c|}{5.8660000000000005} & TST \\
\hline CHEMBL3926189 & 1637139 & 7.0 & 6.6454 & TST & \\
\hline CHEMBL 3948349 & 1637139 & 7.0 & 6.7539 & TST & \\
\hline CHEMBL 3956643 & 1637139 & 7.0 & 6.8886 & TRN & \\
\hline CHEMBL 3921859 & 1637139 & 7.0 & 7.0623 & TRN & \\
\hline CHEMBL3952336 & 1637139 & 8.0 & 7.4427 & TST & \\
\hline CHEMBL3899027 & 1637139 & 7.0 & 7.0415 & TRN & \\
\hline CHEMBL 3912374 & 1637139 & 7.0 & 7.0045 & TRN & \\
\hline CHEMBL3971789 & 1637139 & 6.301 & 6.2216 & TRN & \\
\hline CHEMBL 3985717 & 1637139 & 8.0 & 7.3859 & TST & \\
\hline CHEMBL3961672 & 1637139 & 6.301 & 7.075 & TRN & \\
\hline CHEMBL3904333 & 1637139 & 7.0 & 7.0423 & TRN & \\
\hline CHEMBL 3985076 & 1637139 & 7.0 & 7.0297 & TRN & \\
\hline CHEMBL3942381 & 1637139 & 7.0 & 7.2128 & TRN & \\
\hline CHEMBL 3955478 & 1637139 & 8.0 & 7.3133 & TRN & \\
\hline CHEMBL3954395 & 1637139 & 7.0 & 6.9897 & TRN & \\
\hline CHEMBL3907402 & 1637139 & 8.0 & 7.9473 & TRN & \\
\hline CHEMBL 3948750 & 1637139 & 6.301 & 6.7522 & TRN & \\
\hline CHEMBL3913674 & 1637139 & 7.0 & 6.9365 & TST & \\
\hline CHEMBL 3968460 & 1637139 & 7.0 & 7.053 & TRN & \\
\hline CHEMBL3945707 & 1637139 & 7.0 & 6.8336 & TST & \\
\hline CHEMBL 3895266 & 1637139 & 7.0 & 7.0436 & TRN & \\
\hline CHEMBL3931676 & 1637139 & 6.301 & 6.8973 & TRN & \\
\hline CHEMBL3932389 & 1637139 & 7.0 & \multicolumn{2}{|c|}{7.087999999999999} & TRN \\
\hline CHEMBL 3893235 & 1637139 & 6.0 & 6.1083 & TST & \\
\hline CHEMBL3954978 & 1637139 & 8.0 & 7.2864 & TST & \\
\hline CHEMBL3968167 & 1637139 & 7.0 & 6.5094 & TRN & \\
\hline CHEMBL139825 & 75469 & 4.9586 & 5.2538 & TST & \\
\hline CHEMBL140470 & 75469 & 5.7447 & 5.7803 & TRN & \\
\hline CHEMBL342749 & 75469 & 5.2291 & 5.2287 & TRN & \\
\hline CHEMBL 358851 & 75469 & 3.5229 & 4.7973 & TST & \\
\hline CHEMBL 75001 & 75469 & 3.5229 & 4.6823 & TST & \\
\hline CHEMBL143097 & 75469 & 5.6383 & 5.6506 & TRN & \\
\hline CHEMBL140946 & 75469 & 4.8239 & 5.308 & TST & \\
\hline CHEMBL344492 & 75469 & 5.6383 & 5.6397 & TRN & \\
\hline CHEMBL140271 & 75469 & 4.7959 & 4.8003 & TRN & \\
\hline CHEMBL359079 & 75469 & 5.2924 & 5.2948 & TRN & \\
\hline CHEMBL422649 & 75469 & 3.5229 & 3.5189 & TRN & \\
\hline CHEMBL341978 & 75469 & 4.7959 & 4.7984 & TRN & \\
\hline CHEMBL171064 & 75469 & 6.3279 & 6.3379 & TRN & \\
\hline CHEMBL348203 & 75469 & 6.3665 & 6.3304 & TRN & \\
\hline CHEMBL344259 & 75469 & 5.4202 & 4.9298 & TST & \\
\hline CHEMBL143190 & 75469 & 3.5229 & 5.9741 & TST & \\
\hline CHEMBL142183 & 75469 & 3.5229 & 3.5208 & TRN & \\
\hline CHEMBL139897 & 75469 & 3.5229 & 3.5156 & TRN & \\
\hline CHEMBL143382 & 75469 & 3.5229 & 6.0119 & TST & \\
\hline CHEMBL336880 & 75469 & 5.1024 & 5.1015 & TRN & \\
\hline
\end{tabular}




\begin{tabular}{|c|c|c|c|c|c|}
\hline & & & & & \\
\hline CHEMBL358107 & 75469 & 4.585 & 3.9913 & TST & \\
\hline CHEMBL140684 & 75469 & 5.699 & 5.6845 & TRN & \\
\hline CHEMBL344802 & 75469 & 3.5229 & 4.6561 & TST & \\
\hline CHEMBL141285 & 75469 & 4.9208 & 4.9146 & TRN & \\
\hline CHEMBL141022 & 75469 & 5.8861 & 5.8529 & TRN & \\
\hline CHEMBL139557 & 75469 & 5.4559 & 5.4633 & TRN & \\
\hline CHEMBL141615 & 75469 & 5.2147 & 5.0052 & TST & \\
\hline CHEMBL342212 & 75469 & 3.5229 & 3.5173 & TRN & \\
\hline CHEMBL141880 & 75469 & 5.1135 & 5.1122 & TRN & \\
\hline CHEMBL143281 & 75469 & 5.9586 & 5.9616 & TRN & \\
\hline CHEMBL139724 & 75469 & 5.8539 & 5.8526 & TRN & \\
\hline CHEMBL141902 & 75469 & 3.5229 & 3.52699 & 99999999997 & TRN \\
\hline CHEMBL336923 & 75469 & 5.0655 & 5.0781 & TRN & \\
\hline CHEMBL141414 & 75469 & 4.7447 & 4.7488 & TRN & \\
\hline CHEMBL341965 & 75469 & 5.2076 & 5.2177 & TRN & \\
\hline CHEMBL142328 & 75469 & 4.8539 & 4.8441 & TRN & \\
\hline CHEMBL143583 & 75469 & 3.5229 & 3.5188 & TRN & \\
\hline CHEMBL335370 & 75469 & 3.5229 & 3.5278 & TRN & \\
\hline CHEMBL343080 & 75469 & 5.6576 & 5.6585 & TRN & \\
\hline CHEMBL139842 & 75469 & 3.5229 & 3.5267 & TRN & \\
\hline CHEMBL143752 & 75469 & 5.6576 & 5.6568 & TRN & \\
\hline CHEMBL143408 & 75469 & 5.585 & 5.5915 & TRN & \\
\hline CHEMBL143441 & 75469 & 5.5686 & 5.5646 & TRN & \\
\hline CHEMBL143548 & 75469 & 5.7959 & 5.7923 & TRN & \\
\hline CHEMBL341597 & 75469 & 3.5229 & 3.5243 & TRN & \\
\hline CHEMBL139827 & 75469 & 3.5229 & 3.5234 & TRN & \\
\hline CHEMBL357137 & 75469 & 5.8861 & 5.8902 & TRN & \\
\hline CHEMBL140642 & 75469 & 4.6198 & 4.7974 & TST & \\
\hline CHEMBL140609 & 75469 & 5.0809 & 5.0735 & TRN & \\
\hline CHEMBL143691 & 75469 & 5.7959 & 5.8025 & TRN & \\
\hline CHEMBL140453 & 75469 & 3.5229 & 3.522 & TRN & \\
\hline CHEMBL141798 & 75469 & 3.5229 & 4.5444 & TST & \\
\hline CHEMBL142761 & 75469 & 3.5229 & 3.5244 & TRN & \\
\hline CHEMBL142245 & 75469 & 3.5229 & 3.5197 & TRN & \\
\hline CHEMBL143180 & 75469 & 5.585 & 5.586 & TRN & \\
\hline CHEMBL140790 & 75469 & 5.3768 & 5.3789 & TRN & \\
\hline CHEMBL424478 & 75469 & 5.0 & 4.9932 & TRN & \\
\hline CHEMBL355915 & 75469 & 5.4202 & 5.4259 & TRN & \\
\hline CHEMBL141045 & 75469 & 3.5229 & 3.5257 & TRN & \\
\hline CHEMBL143751 & 75469 & 6.2218 & 6.2127 & TRN & \\
\hline CHEMBL142181 & 75469 & 5.51 & 5.5256 & TRN & \\
\hline CHEMBL143123 & 75469 & 3.5229 & 3.5221 & TRN & \\
\hline CHEMBL143099 & 75469 & 3.5229 & 5.2158 & TST & \\
\hline CHEMBL140051 & 75469 & 3.5229 & 3.5569 & TST & \\
\hline CHEMBL142247 & 75469 & 3.5229 & 6.227 & TST & \\
\hline CHEMBL140852 & 75469 & 3.5229 & 3.5186 & TRN & \\
\hline CHEMBL143495 & 75469 & 5.4685 & 6.1728 & TST & \\
\hline CHEMBL143144 & 75469 & 3.5229 & 4.5128 & TST & \\
\hline
\end{tabular}




\begin{tabular}{|c|c|c|c|c|c|}
\hline \multicolumn{6}{|c|}{ Supplemental Table S2.txt } \\
\hline CHEMBL93971 & 76069 & 5.4202 & 5.58 & TRN & \\
\hline CHEMBL91804 & 76069 & 7.301 & 6.5713 & TRN & \\
\hline CHEMBL 92450 & 76069 & 6.2924 & 5.5329 & TRN & \\
\hline CHEMBL96456 & 76069 & 6.8861 & 6.8519 & TRN & \\
\hline CHEMBL92850 & 76069 & 6.2924 & 6.7176 & TRN & \\
\hline CHEMBL93756 & 76069 & 7.4437 & 6.90799 & 99999999995 & TRN \\
\hline CHEMBL330222 & 76069 & 7.1871 & 7.149 & TRN & \\
\hline CHEMBL 96272 & 76069 & 6.4949 & 6.6809 & TRN & \\
\hline CHEMBL446158 & 76069 & 4.5229 & 5.1075 & TRN & \\
\hline CHEMBL319377 & 76069 & 5.6021 & 5.8935 & TRN & \\
\hline CHEMBL92087 & 76069 & 7.7212 & 7.4529 & TRN & \\
\hline CHEMBL 94374 & 76069 & 5.9706 & 7.12299 & 9999999999 & TRN \\
\hline CHEMBL92471 & 76069 & 5.4815 & 7.2078 & TST & \\
\hline CHEMBL330691 & 76069 & 6.4318 & 5.9816 & TRN & \\
\hline CHEMBL315880 & 76069 & 7.7212 & 7.2311 & TRN & \\
\hline CHEMBL94378 & 76069 & 7.4559 & 7.2378 & TRN & \\
\hline CHEMBL96790 & 76069 & 5.9208 & 7.1431 & TST & \\
\hline CHEMBL328372 & 76069 & 7.0 & 6.9591 & TRN & \\
\hline CHEMBL421746 & 76069 & 7.4685 & 7.0162 & TRN & \\
\hline CHEMBL93343 & 76069 & 5.8861 & 6.2652 & TRN & \\
\hline CHEMBL432001 & 76069 & 6.7696 & 7.1132 & TRN & \\
\hline CHEMBL329852 & 76069 & 7.3372 & 7.0936 & TRN & \\
\hline CHEMBL318203 & 76069 & 5.8794 & 5.9914 & TRN & \\
\hline CHEMBL330283 & 76069 & 7.4685 & 7.1252 & TRN & \\
\hline CHEMBL92756 & 76069 & 7.3768 & 7.2157 & TRN & \\
\hline CHEMBL92968 & 76069 & 7.1739 & 6.8156 & TST & \\
\hline CHEMBL327658 & 76069 & 5.3372 & 5.6434 & TRN & \\
\hline CHEMBL328578 & 76069 & 6.2291 & 6.2741 & TRN & \\
\hline CHEMBL95046 & 76069 & 6.9208 & 7.1695 & TRN & \\
\hline CHEMBL 92508 & 76069 & 5.699 & 6.1153 & TST & \\
\hline CHEMBL92764 & 76069 & 6.4437 & 6.8764 & TRN & \\
\hline CHEMBL93369 & 76069 & 7.0223 & 6.8565 & TRN & \\
\hline CHEMBL54511 & 76069 & 6.7447 & 5.9337 & TST & \\
\hline CHEMBL582356 & 76069 & 6.0269 & 5.8581 & TRN & \\
\hline CHEMBL 96544 & 76069 & 5.8861 & 6.7673 & TST & \\
\hline CHEMBL330716 & 76069 & 6.8539 & 7.0966 & TRN & \\
\hline CHEMBL96287 & 76069 & 6.2218 & 5.9854 & TRN & \\
\hline CHEMBL96590 & 76069 & 6.5229 & 6.8737 & TST & \\
\hline CHEMBL96877 & 76069 & 5.857 & 5.5964 & TRN & \\
\hline CHEMBL96619 & 76069 & 7.0 & 7.0546 & TRN & \\
\hline CHEMBL92451 & 76069 & 5.6459 & 5.2135 & TRN & \\
\hline CHEMBL318865 & 76069 & 5.7212 & 5.5966 & TRN & \\
\hline CHEMBL327418 & 76069 & 4.7959 & 5.8906 & TRN & \\
\hline CHEMBL421554 & 76069 & 7.0969 & 5.9223 & TRN & \\
\hline CHEMBL 91984 & 76069 & 7.1308 & 6.9136 & TST & \\
\hline CHEMBL330247 & 76069 & 7.6198 & 7.1541 & TRN & \\
\hline CHEMBL92510 & 76069 & 7.5528 & 6.5981 & TST & \\
\hline CHEMBL92391 & 76069 & 4.9355 & 5.4908 & TRN & \\
\hline
\end{tabular}




\begin{tabular}{|c|c|c|c|c|c|}
\hline & & \multicolumn{4}{|c|}{ Supplemental Table S2.txt } \\
\hline CHEMBL327983 & 76069 & 7.3872 & 7.2006 & TRN & \\
\hline CHEMBL420810 & 76069 & 5.699 & 5.591 & TRN & \\
\hline CHEMBL316926 & 76069 & 6.585 & 7.3282 & TRN & \\
\hline CHEMBL92962 & 76069 & 6.6021 & 6.5454 & TRN & \\
\hline CHEMBL95151 & 76069 & 6.2924 & 7.0728 & TRN & \\
\hline CHEMBL420621 & 76069 & 7.4949 & 7.0627 & TRN & \\
\hline CHEMBL92525 & 76069 & 6.4685 & 6.8494 & TRN & \\
\hline CHEMBL318271 & 76069 & 5.9586 & 6.2892 & TRN & \\
\hline CHEMBL92757 & 76069 & 7.6576 & 7.2402 & TRN & \\
\hline CHEMBL96324 & 76069 & 6.8861 & 5.8416 & TST & \\
\hline CHEMBL92888 & 76069 & 6.8861 & 7.0323 & TRN & \\
\hline CHEMBL330495 & 76069 & 7.6778 & 7.0088 & TST & \\
\hline CHEMBL96835 & 76069 & 7.7447 & 6.9421 & TST & \\
\hline CHEMBL92867 & 76069 & 6.1938 & 5.7994 & TST & \\
\hline CHEMBL92833 & 76069 & 7.6778 & 7.0855 & TST & \\
\hline CHEMBL92137 & 76069 & 6.0915 & 5.6637 & TST & \\
\hline CHEMBL421366 & 76069 & 5.4949 & 5.7168 & TST & \\
\hline CHEMBL327199 & 76069 & 6.6198 & 5.9832 & TST & \\
\hline CHEMBL1364985 & 688582 & 4.4 & 4.4186 & TRN & \\
\hline CHEMBL1330518 & 688582 & 4.3 & 4.2799 & TRN & \\
\hline CHEMBL508112 & 688582 & 4.3 & 4.2946 & TRN & \\
\hline CHEMBL1535689 & 688582 & 4.4 & 4.3682 & TRN & \\
\hline CHEMBL1602699 & 688582 & 5.3 & 5.279 & TRN & \\
\hline CHEMBL1609459 & 688582 & 5.1 & 5.1062 & TRN & \\
\hline CHEMBL1344952 & 688582 & 4.3 & 4.3157 & TRN & \\
\hline CHEMBL1393325 & 688582 & 4.3 & 4.4015 & TRN & \\
\hline CHEMBL44072 & 688582 & 4.5 & 4.4201 & TST & \\
\hline CHEMBL440287 & 688582 & 4.3 & 4.2834 & TRN & \\
\hline CHEMBL1338613 & 688582 & 4.4 & 4.3943 & TRN & \\
\hline CHEMBL230156 & 688582 & 4.5 & 4.5333 & TRN & \\
\hline CHEMBL8739 & 688582 & 4.4 & 4.3713 & TRN & \\
\hline CHEMBL57394 & 688582 & 4.4 & 4.4446 & TRN & \\
\hline CHEMBL 105712 & 688582 & 5.0 & 4.9121 & TRN & \\
\hline CHEMBL 224282 & 688582 & 4.3 & 4.2594 & TRN & \\
\hline CHEMBL443949 & 688582 & 4.4 & 4.3914 & TRN & \\
\hline CHEMBL1309179 & 688582 & 5.0 & 4.9507 & TRN & \\
\hline CHEMBL1531716 & 688582 & 4.1 & 4.0561 & TRN & \\
\hline CHEMBL1430204 & 688582 & 4.5 & 4.4654 & TRN & \\
\hline CHEMBL1408847 & 688582 & 5.2 & 5.2017 & TRN & \\
\hline CHEMBL1524617 & 688582 & 5.2 & 5.2121 & TST & \\
\hline CHEMBL1579130 & 688582 & 6.0 & 5.91100 & 00000000005 & TRN \\
\hline CHEMBL1522486 & 688582 & 4.5 & 4.5125 & TRN & \\
\hline CHEMBL1484480 & 688582 & 4.1 & 4.1501 & TRN & \\
\hline CHEMBL935 & 688582 & 4.4 & 4.4085 & TRN & \\
\hline CHEMBL144530 & 688582 & 4.4 & 4.4014 & TRN & \\
\hline CHEMBL1304981 & 688582 & 4.3 & 4.3538 & TRN & \\
\hline CHEMBL334255 & 688582 & 4.9 & 4.9086 & TRN & \\
\hline CHEMBL1371285 & 688582 & 4.1 & 4.0535 & TRN & \\
\hline
\end{tabular}




\begin{tabular}{|c|c|c|c|c|}
\hline \multicolumn{5}{|c|}{ lemental T } \\
\hline CHEMBL1562104 & 688582 & 5.6 & 5.5685 & TRN \\
\hline CHEMBL289277 & 688582 & 4.4 & 4.3743 & TRN \\
\hline CHEMBL1491899 & 688582 & 4.3 & 4.2607 & TRN \\
\hline CHEMBL1462419 & 688582 & 4.4 & 4.6708 & TST \\
\hline CHEMBL1407826 & 688582 & 4.5 & 4.9347 & TST \\
\hline CHEMBL 220845 & 688582 & 4.4 & 4.3449 & TRN \\
\hline CHEMBL1612246 & 688582 & 4.4 & 4.3239 & TRN \\
\hline CHEMBL85811 & 688582 & 4.3 & 4.3248 & TRN \\
\hline CHEMBL1314089 & 688582 & 4.3 & 4.3211 & TRN \\
\hline CHEMBL1366408 & 688582 & 4.4 & 4.3813 & TRN \\
\hline CHEMBL 1499545 & 688582 & 5.6 & 5.5857 & TRN \\
\hline CHEMBL194400 & 688582 & 4.2 & 4.4358 & TST \\
\hline CHEMBL1489568 & 688582 & 4.3 & 4.2814 & TRN \\
\hline CHEMBL1569493 & 688582 & 6.1 & 6.0613 & TRN \\
\hline CHEMBL1526721 & 688582 & 5.5 & 5.2652 & TST \\
\hline CHEMBL 1418603 & 688582 & 4.4 & 4.4138 & TRN \\
\hline CHEMBL1559341 & 688582 & 4.4 & 4.4674 & TRN \\
\hline CHEMBL1514512 & 688582 & 4.3 & 4.3241 & TRN \\
\hline CHEMBL1303139 & 688582 & 5.2 & 5.1548 & TRN \\
\hline CHEMBL1448387 & 688582 & 4.4 & 4.3854 & TRN \\
\hline CHEMBL1526319 & 688582 & 4.5 & 4.5404 & TRN \\
\hline CHEMBL1471289 & 688582 & 4.5 & 4.5161 & TRN \\
\hline CHEMBL1527567 & 688582 & 4.5 & 4.53 & TRN \\
\hline CHEMBL1600998 & 688582 & 5.3 & 5.3771 & TRN \\
\hline CHEMBL196537 & 688582 & 4.1 & 4.3022 & TST \\
\hline CHEMBL1549844 & 688582 & 4.8 & 4.8151 & TST \\
\hline CHEMBL445957 & 688582 & 4.3 & 4.3079 & TRN \\
\hline CHEMBL1496957 & 688582 & 4.6 & 4.6452 & TRN \\
\hline CHEMBL1308088 & 688582 & 4.8 & 4.8324 & TRN \\
\hline CHEMBL162598 & 688582 & 4.3 & 4.6896 & TST \\
\hline CHEMBL1450607 & 688582 & 4.6 & 4.6824 & TST \\
\hline CHEMBL1510786 & 688582 & 4.3 & 4.4629 & TST \\
\hline CHEMBL58835 & 688582 & 4.5 & 4.4187 & TRN \\
\hline CHEMBL1565705 & 688582 & 4.4 & 4.3952 & TRN \\
\hline CHEMBL1449018 & 688582 & 4.6 & 4.5714 & TRN \\
\hline CHEMBL1530684 & 688582 & 4.4 & 4.4149 & TRN \\
\hline CHEMBL295652 & 688582 & 5.8 & 5.8267 & TRN \\
\hline CHEMBL175193 & 688582 & 4.1 & 4.1448 & TRN \\
\hline CHEMBL402063 & 688582 & 4.4 & 5.6039 & TST \\
\hline CHEMBL153062 & 688582 & 4.1 & 4.0626 & TRN \\
\hline CHEMBL1492729 & 688582 & 4.7 & 4.6452 & TRN \\
\hline CHEMBL1585396 & 688582 & 4.3 & 4.4916 & TST \\
\hline CHEMBL1142 & 688582 & 4.5 & 4.3947 & TRN \\
\hline CHEMBL 242080 & 688582 & 4.3 & 4.3293 & TRN \\
\hline CHEMBL1399151 & 688582 & 4.3 & 4.3048 & TRN \\
\hline CHEMBL1235157 & 688582 & 4.1 & 4.4931 & TST \\
\hline CHEMBL486193 & 688582 & 4.3 & 4.4277 & TRN \\
\hline CHEMBL 28 & 688582 & 4.3 & 4.3635 & TRN \\
\hline
\end{tabular}




\begin{tabular}{|c|c|c|c|c|c|}
\hline & & & & & \\
\hline CHEMBL1414154 & 688582 & 4.3 & 4.252 & TRN & \\
\hline CHEMBL 8320 & 688582 & 4.3 & 4.4687 & TST & \\
\hline CHEMBL1566504 & 688582 & 4.4 & 4.6218 & TST & \\
\hline CHEMBL1485360 & 688582 & 4.7 & 4.8857 & TST & \\
\hline CHEMBL1562553 & 688582 & 4.5 & 4.4899 & TRN & \\
\hline CHEMBL509531 & 688582 & 4.6 & 4.7901 & TST & \\
\hline CHEMBL36296 & 688582 & 4.3 & 4.3611 & TRN & \\
\hline CHEMBL1569226 & 688582 & 5.3 & 5.3025 & TRN & \\
\hline CHEMBL1200471 & 688582 & 6.7001 & 6.6744 & TRN & \\
\hline CHEMBL1518369 & 688582 & 4.5 & 4.4392 & TRN & \\
\hline CHEMBL1492884 & 688582 & 4.4 & 4.4039 & TRN & \\
\hline CHEMBL1486465 & 688582 & 4.4 & 4.4226 & TRN & \\
\hline CHEMBL1576086 & 688582 & 4.4 & 4.4649 & TRN & \\
\hline CHEMBL1519327 & 688582 & 6.3 & 6.3697 & TRN & \\
\hline CHEMBL192627 & 688582 & 4.8 & 4.9136 & TST & \\
\hline CHEMBL1558796 & 688582 & 4.4 & 4.3777 & TRN & \\
\hline CHEMBL1451833 & 688582 & 4.4 & 4.6416 & TST & \\
\hline CHEMBL1448549 & 688582 & 4.4 & 4.4762 & TRN & \\
\hline CHEMBL1545634 & 688582 & 6.6 & 6.6225 & TRN & \\
\hline CHEMBL1331245 & 688582 & 4.3 & 4.2712 & TRN & \\
\hline CHEMBL1492104 & 688582 & 4.9 & 4.8322 & TST & \\
\hline CHEMBL418068 & 688582 & 4.1 & 4.05699 & 99999999995 & TRN \\
\hline CHEMBL1447588 & 688582 & 4.8 & 4.8639 & TST & \\
\hline CHEMBL1489064 & 688582 & 4.4 & 4.442 & TRN & \\
\hline CHEMBL1409985 & 688582 & 5.3 & 5.3242 & TRN & \\
\hline CHEMBL167423 & 688582 & 4.3 & 4.3167 & TST & \\
\hline CHEMBL140 & 688582 & 4.6 & 4.8201 & TST & \\
\hline CHEMBL1319452 & 688582 & 4.6 & 4.5849 & TST & \\
\hline CHEMBL1452158 & 688582 & 4.4 & 4.2222 & TST & \\
\hline CHEMBL1517425 & 688582 & 4.3 & 4.04 & TST & \\
\hline CHEMBL1602811 & 688735 & 6.7766 & 6.6502 & TRN & \\
\hline CHEMBL1584932 & 688735 & 5.4179 & 5.9216 & TRN & \\
\hline CHEMBL1364102 & 688735 & 5.3014 & 5.1395 & TRN & \\
\hline CHEMBL1368667 & 688735 & 5.7924 & 5.6887 & TRN & \\
\hline CHEMBL1391254 & 688735 & 5.5791 & 4.8418 & TRN & \\
\hline CHEMBL1363571 & 688735 & 4.3538 & 4.3113 & TRN & \\
\hline CHEMBL1560169 & 688735 & 5.1768 & 4.9895 & TRN & \\
\hline CHEMBL1342389 & 688735 & 5.2812 & 4.9473 & TRN & \\
\hline CHEMBL1358081 & 688735 & 5.8459 & 5.70100 & 00000000005 & TRN \\
\hline CHEMBL1369869 & 688735 & 5.4624 & 4.6985 & TRN & \\
\hline CHEMBL233149 & 688735 & 4.8468 & 4.0261 & TST & \\
\hline CHEMBL1303031 & 688735 & 5.2275 & 4.8903 & TST & \\
\hline CHEMBL1357156 & 688735 & 3.3998 & 4.345 & TRN & \\
\hline CHEMBL1531523 & 688735 & 5.3671 & 5.2322 & TRN & \\
\hline CHEMBL1562444 & 688735 & 5.6421 & 5.5333 & TRN & \\
\hline CHEMBL1571111 & 688735 & 3.3997 & 3.2455 & TRN & \\
\hline CHEMBL1425823 & 688735 & 3.4 & 3.7647 & TRN & \\
\hline CHEMBL1367791 & 688735 & 4.5989 & 3.9848 & TST & \\
\hline
\end{tabular}




\begin{tabular}{|c|c|c|c|c|c|}
\hline & & \multicolumn{4}{|c|}{ Supplemental Table S2.txt } \\
\hline CHEMBL1523808 & 688735 & 5.4707 & 5.1318 & TRN & \\
\hline CHEMBL1456984 & 688735 & 4.8946 & 4.3852 & TRN & \\
\hline CHEMBL1359865 & 688735 & 5.001 & 4.7969 & TRN & \\
\hline CHEMBL1456706 & 688735 & 5.1669 & 5.0082 & TRN & \\
\hline CHEMBL1402172 & 688735 & 4.8562 & 4.91 & TRN & \\
\hline CHEMBL1431253 & 688735 & 5.0356 & 4.9483 & TRN & \\
\hline CHEMBL1304585 & 688735 & 5.6792 & 5.8722 & TRN & \\
\hline CHEMBL1467089 & 688735 & 5.1522 & 5.006 & TRN & \\
\hline CHEMBL1302552 & 688735 & 5.8365 & 5.8275 & TRN & \\
\hline CHEMBL1410870 & 688735 & 5.6325 & 5.6704 & TRN & \\
\hline CHEMBL1575283 & 688735 & 5.3478 & 5.4857 & TRN & \\
\hline CHEMBL1459124 & 688735 & 5.2714 & 5.4571 & TRN & \\
\hline CHEMBL1337717 & 688735 & 3.3996 & 3.8831 & TRN & \\
\hline CHEMBL1471296 & 688735 & 5.4721 & 5.2813 & TRN & \\
\hline CHEMBL1534931 & 688735 & 3.3997 & 3.1652 & TRN & \\
\hline CHEMBL1542847 & 688735 & 5.3913 & 5.0504 & TRN & \\
\hline CHEMBL1375116 & 688735 & 5.524 & 5.55200 & 00000000005 & TRN \\
\hline CHEMBL1401891 & 688735 & 5.5036 & 5.6166 & TST & \\
\hline CHEMBL1304667 & 688735 & 5.4014 & 5.3722 & TRN & \\
\hline CHEMBL1539438 & 688735 & 5.4678 & 5.6973 & TRN & \\
\hline CHEMBL1544051 & 688735 & 5.4345 & 3.8253 & TST & \\
\hline CHEMBL1539768 & 688735 & 5.3686 & 5.2619 & TRN & \\
\hline CHEMBL1345305 & 688735 & 5.2346 & 5.5008 & TRN & \\
\hline CHEMBL1471788 & 688735 & 3.3993 & 3.7317 & TST & \\
\hline CHEMBL1543662 & 688735 & 5.1998 & 5.37 & TRN & \\
\hline CHEMBL1513785 & 688735 & 5.3507 & 5.2976 & TRN & \\
\hline CHEMBL1300912 & 688735 & 4.6342 & 4.7784 & TRN & \\
\hline CHEMBL1494994 & 688735 & 4.8087 & 4.1946 & TRN & \\
\hline CHEMBL600336 & 688735 & 5.0288 & 4.8891 & TRN & \\
\hline CHEMBL1442635 & 688735 & 5.4564 & 5.3002 & TRN & \\
\hline CHEMBL1601538 & 688735 & 5.3143 & 5.3935 & TRN & \\
\hline CHEMBL1607639 & 688735 & 5.5842 & 5.88 & TRN & \\
\hline CHEMBL1482795 & 688735 & 5.61299 & 99999999 & 5.229 & TRN \\
\hline CHEMBL1376894 & 688735 & 4.971 & 5.2496 & TRN & \\
\hline CHEMBL1431953 & 688735 & 4.7255 & 5.1013 & TST & \\
\hline CHEMBL1485768 & 688735 & 5.5694 & 5.8597 & TRN & \\
\hline CHEMBL1380313 & 688735 & 5.1479 & 5.1639 & TRN & \\
\hline CHEMBL1529161 & 688735 & 5.0537 & 5.426 & TST & \\
\hline CHEMBL1565040 & 688735 & 6.3243 & 6.313 & TRN & \\
\hline CHEMBL1589959 & 688735 & 5.0964 & 5.0593 & TRN & \\
\hline CHEMBL1348596 & 688735 & 3.3998 & 3.8639 & TRN & \\
\hline CHEMBL1508525 & 688735 & 5.0474 & 5.29700 & $\partial 000000001$ & TRN \\
\hline CHEMBL1354460 & 688735 & 5.4357 & 6.0639 & TRN & \\
\hline CHEMBL1320035 & 688735 & 4.7288 & 4.1218 & TRN & \\
\hline CHEMBL1462838 & 688735 & 5.3238 & 5.7276 & TRN & \\
\hline CHEMBL1318849 & 688735 & 5.2155 & 4.6914 & TST & \\
\hline CHEMBL1308652 & 688735 & 4.8717 & 4.9157 & TRN & \\
\hline CHEMBL1385747 & 688735 & 3.3997 & 4.5057 & TRN & \\
\hline
\end{tabular}




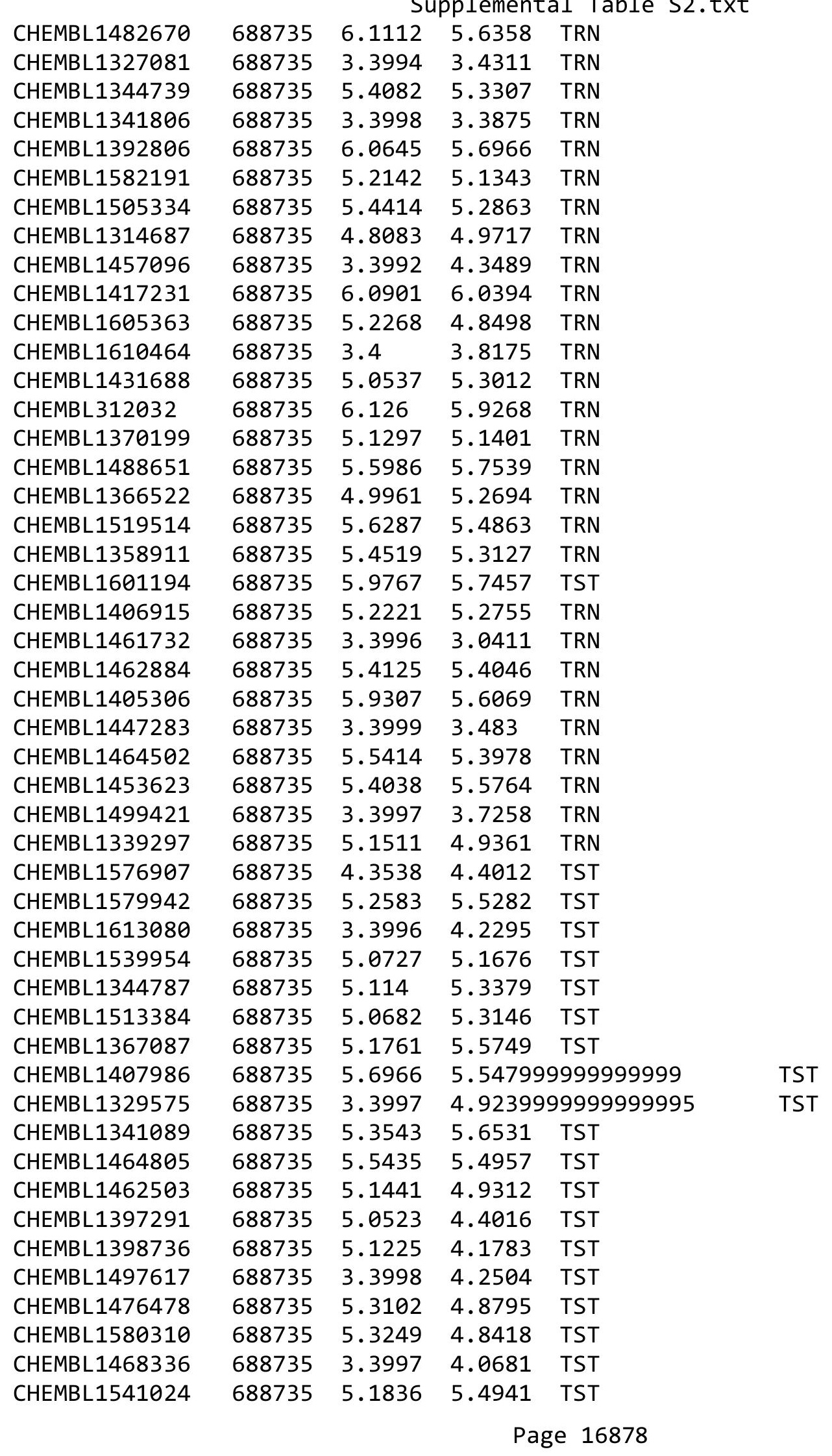




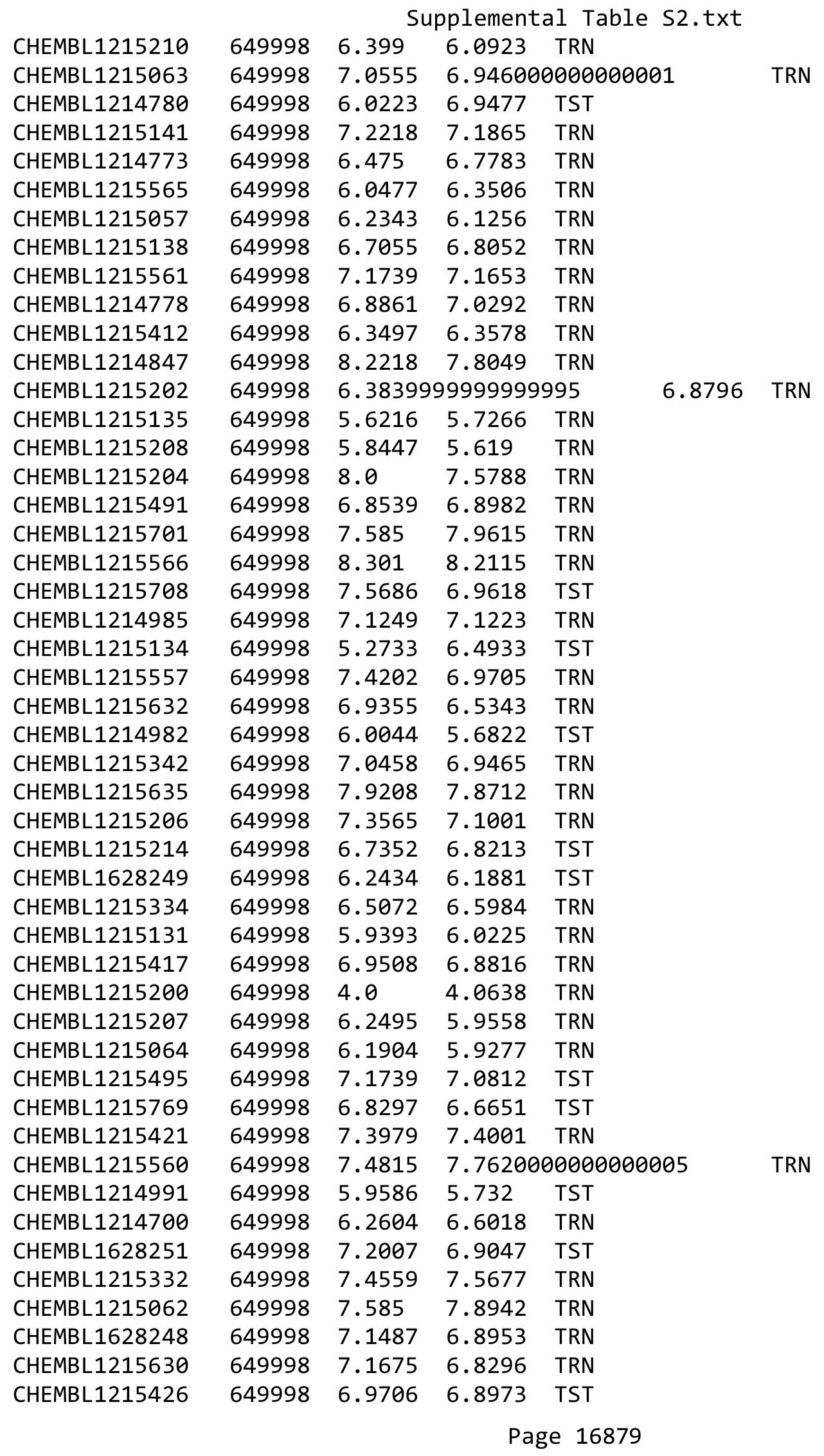




\begin{tabular}{|c|c|c|c|c|c|}
\hline & & & & & \\
\hline CHEMBL1215203 & 649998 & 7.2076 & 7.311 & TRN & \\
\hline CHEMBL1215765 & 649998 & 5.8633 & 5.855 & TRN & \\
\hline CHEMBL1214984 & 649998 & 5.4473 & 5.5389 & TST & \\
\hline CHEMBL1215139 & 649998 & 6.4776 & 6.7849 & TRN & \\
\hline CHEMBL1215143 & 649998 & 7.4685 & 7.5719 & TRN & \\
\hline CHEMBL1215697 & 649998 & 6.0958 & 6.1708 & TRN & \\
\hline CHEMBL1215136 & 649998 & 5.8416 & 5.8544 & TRN & \\
\hline CHEMBL1215634 & 649998 & 7.8239 & 8.0161 & TRN & \\
\hline CHEMBL1214695 & 649998 & 7.7959 & 7.7365 & TRN & \\
\hline CHEMBL1215144 & 649998 & 6.9914 & 7.1234 & TST & \\
\hline CHEMBL1215424 & 649998 & 7.2147 & 7.4163 & TRN & \\
\hline CHEMBL1628246 & 649998 & 6.1599 & 6.6635 & TST & \\
\hline CHEMBL1215775 & 649998 & 6.9788 & 6.94 & TST & \\
\hline CHEMBL1215558 & 649998 & 6.8697 & 6.67700 & 00000000005 & TRN \\
\hline CHEMBL1214983 & 649998 & 4.0 & 3.3949 & TST & \\
\hline CHEMBL1215568 & 649998 & 8.0969 & 8.14299 & 9999999999 & TRN \\
\hline CHEMBL1215489 & 649998 & 7.0088 & 6.8256 & TRN & \\
\hline CHEMBL1215773 & 649998 & 7.1079 & 6.984 & TST & \\
\hline CHEMBL1215340 & 649998 & 6.466 & 7.0231 & TST & \\
\hline CHEMBL1214979 & 649998 & 4.0 & 4.8438 & TST & \\
\hline CHEMBL1215209 & 649998 & 5.9066 & 5.9673 & TRN & \\
\hline CHEMBL1215496 & 649998 & 6.0804 & 6.5085 & TST & \\
\hline CHEMBL1215497 & 649998 & 5.8356 & 5.8674 & TRN & \\
\hline CHEMBL1215423 & 649998 & 7.3372 & 7.3183 & TRN & \\
\hline CHEMBL1628257 & 649998 & 6.6216 & 6.7303 & TST & \\
\hline CHEMBL1215696 & 649998 & 7.3565 & 7.1815 & TRN & \\
\hline CHEMBL1215338 & 649998 & 5.3325 & 5.4782 & TRN & \\
\hline CHEMBL1215266 & 649998 & 6.9172 & 7.1213 & TRN & \\
\hline CHEMBL1215060 & 649998 & 7.585 & 7.5317 & TRN & \\
\hline CHEMBL1214920 & 649998 & 6.4449 & 6.6229 & TRN & \\
\hline CHEMBL1215341 & 649998 & 4.0 & 4.7408 & TRN & \\
\hline CHEMBL1215638 & 649998 & 8.2218 & 8.168 & TRN & \\
\hline CHEMBL1214980 & 649998 & 5.7773 & 5.8023 & TST & \\
\hline CHEMBL1215707 & 649998 & 7.3372 & 7.6385 & TRN & \\
\hline CHEMBL1214986 & 649998 & 6.8697 & 6.8917 & TRN & \\
\hline CHEMBL1215698 & 649998 & 6.1831 & 5.9205 & TRN & \\
\hline CHEMBL1215706 & 649998 & 7.6778 & 7.8939 & TRN & \\
\hline CHEMBL1214849 & 649998 & 6.7033 & 7.2791 & TST & \\
\hline CHEMBL1215422 & 649998 & 7.1367 & 7.1908 & TRN & \\
\hline CHEMBL1215065 & 649998 & 8.2218 & 8.0929 & TRN & \\
\hline CHEMBL1215493 & 649998 & 7.5528 & 7.5806 & TRN & \\
\hline CHEMBL1215268 & 649998 & 6.2976 & 6.2929 & TRN & \\
\hline CHEMBL1214697 & 649998 & 6.4547 & 6.3743 & TRN & \\
\hline CHEMBL1214987 & 649998 & 6.7447 & 7.0383 & TRN & \\
\hline CHEMBL1628245 & 649998 & 5.8125 & 6.8865 & TST & \\
\hline CHEMBL1214698 & 649998 & 7.0132 & 6.9373 & TRN & \\
\hline CHEMBL1214988 & 649998 & 6.8761 & 7.2535 & TRN & \\
\hline CHEMBL1215058 & 649998 & 7.0362 & 6.7666 & TRN & \\
\hline
\end{tabular}




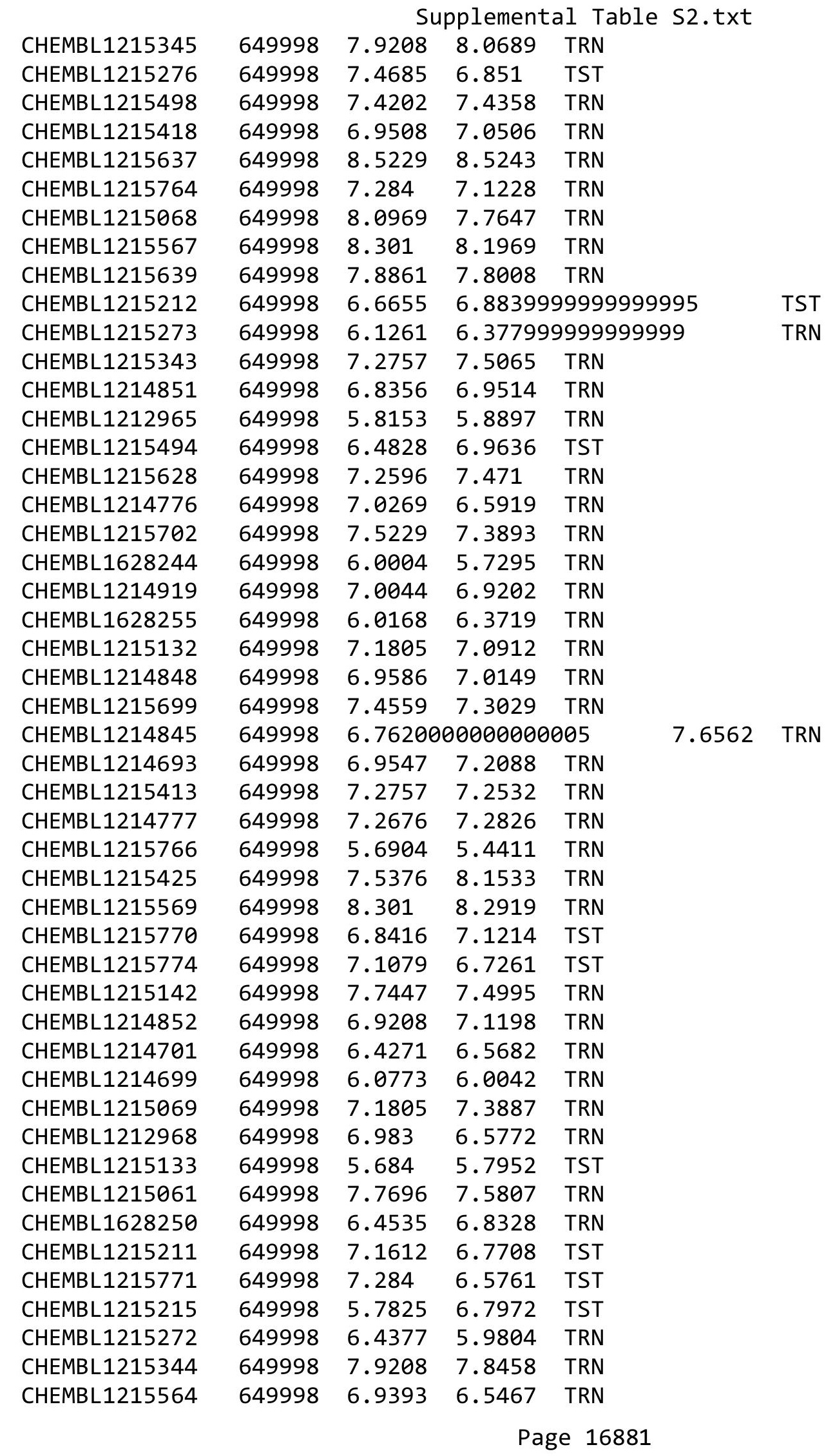


Supplemental Table S2.txt

\begin{tabular}{|c|c|c|c|c|}
\hline CHEMBL1215501 & 649998 & 8.3979 & 8.3396 & TRN \\
\hline CHEMBL1628247 & 649998 & 6.8928 & 7.0426 & TRN \\
\hline CHEMBL1215559 & 649998 & 5.2811 & 5.2391 & TRN \\
\hline CHEMBL1215339 & 649998 & 6.5072 & 6.4275 & TST \\
\hline CHEMBL1628254 & 649998 & 7.4318 & 7.0487 & TRN \\
\hline CHEMBL1214694 & 649998 & 8.2218 & 7.7392 & TRN \\
\hline CHEMBL1215636 & 649998 & 8.301 & 8.0877 & TRN \\
\hline CHEMBL1215629 & 649998 & 6.8013 & 6.9241 & TRN \\
\hline CHEMBL1214846 & 649998 & 7.9586 & 7.6562 & TRN \\
\hline CHEMBL1215333 & 649998 & 7.3872 & 7.5574 & TRN \\
\hline CHEMBL1215056 & 649998 & 6.0605 & 5.9277 & TST \\
\hline CHEMBL1628252 & 649998 & 6.6615 & 6.57600 & 00000000005 \\
\hline CHEMBL1214772 & 649998 & 7.3468 & 7.3886 & TRN \\
\hline CHEMBL1215492 & 649998 & 6.7375 & 6.6591 & TRN \\
\hline CHEMBL1215274 & 649998 & 6.8125 & 6.7993 & TRN \\
\hline CHEMBL1215772 & 649998 & 7.4089 & 7.1094 & TRN \\
\hline CHEMBL1215270 & 649998 & 6.2541 & 6.3608 & TRN \\
\hline CHEMBL1215201 & 649998 & 3.6021 & 4.3933 & TST \\
\hline CHEMBL1215277 & 649998 & 7.4949 & 7.6346 & TRN \\
\hline CHEMBL1215420 & 649998 & 7.5686 & 7.5789 & TRN \\
\hline CHEMBL1215067 & 649998 & 8.3979 & 8.2569 & TRN \\
\hline CHEMBL1215275 & 649998 & 6.1931 & 6.2054 & TRN \\
\hline CHEMBL1215271 & 649998 & 7.1612 & 7.2114 & TRN \\
\hline CHEMBL1215137 & 649998 & 6.5952 & 6.8343 & TRN \\
\hline CHEMBL1215633 & 649998 & 7.1805 & 7.2643 & TRN \\
\hline CHEMBL1215336 & 649998 & 7.2518 & 6.862 & TST \\
\hline CHEMBL1214774 & 649998 & 6.9788 & 6.6483 & TRN \\
\hline CHEMBL1215059 & 649998 & 6.8416 & 6.5144 & TST \\
\hline CHEMBL1215704 & 649998 & 6.7852 & 6.6189 & TRN \\
\hline CHEMBL1215279 & 649998 & 6.8386 & 6.9088 & TRN \\
\hline CHEMBL1212963 & 649998 & 6.8996 & 6.9394 & TRN \\
\hline CHEMBL1215500 & 649998 & 9.5229 & 8.7214 & TRN \\
\hline CHEMBL1214916 & 649998 & 7.3468 & 7.4067 & TRN \\
\hline CHEMBL1215055 & 649998 & 6.6904 & 6.1189 & TST \\
\hline CHEMBL1215140 & 649998 & 7.6778 & 7.7954 & TRN \\
\hline CHEMBL1215213 & 649998 & 6.8633 & 7.0733 & TST \\
\hline CHEMBL1215278 & 649998 & 7.4949 & 7.7582 & TRN \\
\hline CHEMBL1215490 & 649998 & 7.0706 & 7.2378 & TST \\
\hline CHEMBL1214696 & 649998 & 7.7696 & 7.539 & TRN \\
\hline CHEMBL1215767 & 649998 & 6.4815 & 6.7692 & TRN \\
\hline CHEMBL1215337 & 649998 & 8.0969 & 7.6392 & TST \\
\hline CHEMBL1215335 & 649998 & 6.5272 & 6.862 & TST \\
\hline CHEMBL1215066 & 649998 & 8.301 & 8.1142 & TRN \\
\hline CHEMBL1214775 & 649998 & 7.7959 & 7.6206 & TRN \\
\hline CHEMBL1215700 & 649998 & 8.3979 & 8.3724 & TRN \\
\hline CHEMBL1215267 & 649998 & 6.0655 & 6.2395 & TST \\
\hline CHEMBL1215499 & 649998 & 7.585 & 7.972 & TRN \\
\hline CHEMBL1215416 & 649998 & 7.6778 & 7.4438 & TST \\
\hline
\end{tabular}




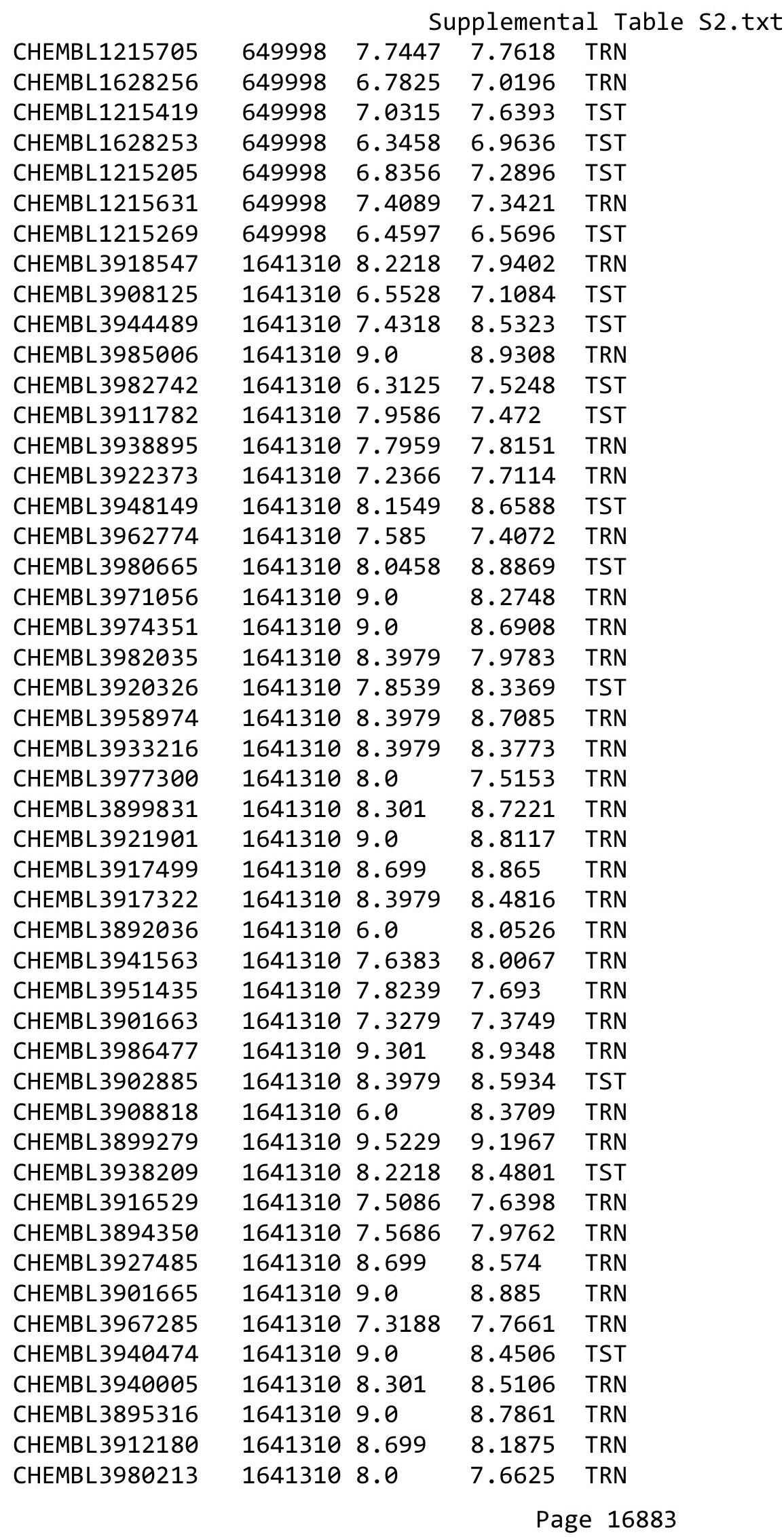




\begin{tabular}{|c|c|c|c|c|}
\hline \multicolumn{5}{|c|}{ Supplemental Table S2.txt } \\
\hline CHEMBL3914293 & 1641310 & 9.0 & 9.0865 & TRN \\
\hline CHEMBL3905581 & 1641310 & 10.0 & 8.0799 & TRN \\
\hline CHEMBL3952058 & 1641310 & 8.5229 & 8.6981 & TST \\
\hline CHEMBL3922426 & 1641310 & 8.2218 & 8.7822 & TST \\
\hline CHEMBL3896133 & 1641310 & 7.6778 & 8.4259 & TST \\
\hline CHEMBL3940550 & 1641310 & 8.2218 & 8.1569 & TRN \\
\hline CHEMBL 3890272 & 1641310 & 8.3979 & 8.0581 & TRN \\
\hline CHEMBL3966706 & 1641310 & 8.699 & 8.3202 & TRN \\
\hline CHEMBL3926820 & 1641310 & 7.7959 & 8.8319 & TRN \\
\hline CHEMBL3982099 & 1641310 & 8.5229 & 8.1179 & TRN \\
\hline CHEMBL3891095 & 1641310 & 7.4815 & 8.1588 & TST \\
\hline CHEMBL3964203 & 1641310 & 8.3979 & 7.6562 & TST \\
\hline CHEMBL3931545 & 1641310 & 7.9586 & 8.6388 & TST \\
\hline CHEMBL3921494 & 1641310 & 8.2218 & 8.9538 & TRN \\
\hline CHEMBL3956850 & 1641310 & 8.699 & 9.0103 & TRN \\
\hline CHEMBL3979016 & 1641310 & 7.4685 & 7.6455 & TRN \\
\hline CHEMBL3917675 & 1641310 & 7.1675 & 6.7711 & TRN \\
\hline CHEMBL3913061 & 1641310 & 8.3979 & 8.5824 & TST \\
\hline CHEMBL3981750 & 1641310 & 8.2218 & 7.7924 & TST \\
\hline CHEMBL3925350 & 1641310 & 8.5229 & 8.2849 & TRN \\
\hline CHEMBL3984468 & 1641310 & 9.0 & 9.0139 & TRN \\
\hline CHEMBL3907118 & 1641310 & 8.5229 & 8.0938 & TRN \\
\hline CHEMBL3954116 & 1641310 & 8.301 & 8.2275 & TRN \\
\hline CHEMBL3970456 & 1641310 & 9.3979 & 8.5033 & TRN \\
\hline CHEMBL3951530 & 1641310 & 9.0 & 8.4821 & TRN \\
\hline CHEMBL3916983 & 1641310 & 8.699 & 8.0981 & TRN \\
\hline CHEMBL3974991 & 1641310 & 9.0 & 9.0136 & TRN \\
\hline CHEMBL3896434 & 1641310 & 9.0 & 8.7834 & TRN \\
\hline CHEMBL3978738 & 1641310 & 8.0969 & 8.5651 & TRN \\
\hline CHEMBL3893149 & 1641310 & 8.699 & 8.5497 & TRN \\
\hline CHEMBL3926615 & 1641310 & 7.2596 & 7.2251 & TRN \\
\hline CHEMBL3925518 & 1641310 & 8.0969 & 8.1125 & TRN \\
\hline CHEMBL3912870 & 1641310 & 7.7959 & 7.6809 & TST \\
\hline CHEMBL3980161 & 1641310 & 8.5229 & 8.4475 & TRN \\
\hline CHEMBL3903412 & 1641310 & 8.1549 & 8.5148 & TRN \\
\hline CHEMBL3949824 & 1641310 & 8.699 & 8.471 & TRN \\
\hline CHEMBL3939248 & 1641310 & 6.7033 & 7.6607 & TRN \\
\hline CHEMBL3968777 & 1641310 & 7.5229 & 7.6609 & TRN \\
\hline CHEMBL3935009 & 1641310 & 8.2218 & 7.4895 & TRN \\
\hline CHEMBL3917131 & 1641310 & 9.0 & 8.9552 & TRN \\
\hline CHEMBL3932849 & 1641310 & 8.699 & 8.3621 & TRN \\
\hline CHEMBL3911174 & 1641310 & 7.3768 & 7.6887 & TRN \\
\hline CHEMBL3895485 & 1641310 & 9.0 & 8.3013 & TRN \\
\hline CHEMBL3914555 & 1641310 & 8.699 & 8.3831 & TRN \\
\hline CHEMBL3918428 & 1641310 & 7.0044 & 7.6069 & TST \\
\hline CHEMBL3972687 & 1641310 & 7.7212 & 8.05 & TRN \\
\hline CHEMBL3900424 & 1641310 & 8.699 & 7.932 & TRN \\
\hline CHEMBL3906483 & 1641310 & 7.8239 & 8.0891 & TRN \\
\hline
\end{tabular}




\begin{tabular}{|c|c|c|c|c|c|c|}
\hline & & & & & & \\
\hline CHEMBL3961149 & 1641310 & 9.0 & 9.0085 & TRN & & \\
\hline CHEMBL3901259 & 1641310 & 9.0 & 8.9634 & TRN & & \\
\hline CHEMBL3967981 & 1641310 & 9.0 & 8.4229 & TRN & & \\
\hline CHEMBL3940912 & 1641310 & 7.5528 & 8.3888 & TRN & & \\
\hline CHEMBL3904046 & 1641310 & 8.5229 & 7.2727 & TRN & & \\
\hline CHEMBL3918470 & 1641310 & 8.5229 & 8.4901 & TRN & & \\
\hline CHEMBL3976317 & 1641310 & 8.699 & 8.1995 & TRN & & \\
\hline CHEMBL3938108 & 1641310 & 6.9508 & 7.6963 & TRN & & \\
\hline CHEMBL3938074 & 1641310 & 9.0 & 8.6433 & TRN & & \\
\hline CHEMBL3908992 & 1641310 & 9.0 & 9.0963 & TRN & & \\
\hline CHEMBL3986940 & 1641310 & 8.2218 & 8.4101 & TRN & & \\
\hline CHEMBL3894522 & 1641310 & 9.3979 & 9.0608 & TRN & & \\
\hline CHEMBL3912920 & 1641310 & 9.699 & 9.1084 & TRN & & \\
\hline CHEMBL3936265 & 1641310 & 9.0 & 8.894 & TRN & & \\
\hline CHEMBL3915168 & 1641310 & 8.3979 & 7.6881 & TRN & & \\
\hline CHEMBL3975264 & 1641310 & 9.0 & 9.21 & TRN & & \\
\hline CHEMBL3916591 & 1641310 & 7.1612 & 7.7625 & TRN & & \\
\hline CHEMBL 3955201 & 1641310 & 8.699 & 9.2117 & TRN & & \\
\hline CHEMBL3921858 & 1641310 & 7.1079 & 7.5138 & TST & & \\
\hline CHEMBL3917642 & 1641310 & 8.699 & 8.3328 & TRN & & \\
\hline CHEMBL3931920 & 1641310 & 8.0458 & 8.0835 & TRN & & \\
\hline CHEMBL3926475 & 1641310 & 8.2218 & 8.4539 & TRN & & \\
\hline CHEMBL3926178 & 1641310 & 7.0177 & 7.3517 & TRN & & \\
\hline CHEMBL3892103 & 1641310 & 9.0 & 8.8437 & TRN & & \\
\hline CHEMBL 3907293 & 1641310 & 7.0458 & 7.7211 & TST & & \\
\hline CHEMBL3889614 & 1641310 & 6.9547 & 7.6585 & TRN & & \\
\hline CHEMBL3977272 & 1641310 & 7.8239 & 8.1058 & TRN & & \\
\hline CHEMBL3983801 & 1641310 & 7.8239 & 7.8384 & TRN & & \\
\hline CHEMBL3952363 & 1641310 & 6.5072 & 7.8657 & TST & & \\
\hline CHEMBL 3944008 & 1641310 & 10.0 & 8.7585 & TRN & & \\
\hline CHEMBL 3916554 & 1641310 & 8.3979 & 8.3003 & TRN & & \\
\hline CHEMBL3938795 & 1641310 & 5.9706 & 7.4474 & TST & & \\
\hline CHEMBL3975206 & 1641310 & 8.699 & 8.9006 & TRN & & \\
\hline CHEMBL3927930 & 1641310 & 8.2218 & 7.9808 & TRN & & \\
\hline CHEMBL 3953363 & 1641310 & 7.1249 & 7.4802 & TRN & & \\
\hline CHEMBL3894413 & 1641310 & 8.699 & 8.6142 & TST & & \\
\hline CHEMBL3960168 & 1641310 & 6.8861 & 8.2107 & TST & & \\
\hline CHEMBL3987090 & 1641310 & 8.3979 & 8.7697 & TRN & & \\
\hline CHEMBL3971111 & 1641310 & 9.301 & 9.4008 & TRN & & \\
\hline CHEMBL 3913741 & 1641310 & 9.0 & 8.6604 & TRN & & \\
\hline CHEMBL3964672 & 1641310 & 8.699 & 8.5328 & TRN & & \\
\hline CHEMBL3929563 & 1641310 & 8.2218 & 8.4406 & TRN & & \\
\hline CHEMBL3929621 & 1641310 & 6.3098 & 7.2394 & TRN & & \\
\hline CHEMBL3903462 & 1641310 & 9.0 & 8.9695 & TRN & & \\
\hline CHEMBL 3958550 & 1641310 & 6.26200 & 00000000 & 005 & 7.1237 & TRN \\
\hline CHEMBL3956258 & 1641310 & 6.9393 & 7.5991 & TRN & & \\
\hline CHEMBL3933035 & 1641310 & 8.699 & 8.5558 & TRN & & \\
\hline CHEMBL3889786 & 1641310 & 9.0 & 9.1486 & TRN & & \\
\hline
\end{tabular}


Supplemental Table S2.txt

\begin{tabular}{|c|c|c|c|c|c|}
\hline CHEMBL3900613 & 1641310 & 7.0362 & 7.5983 & TST & \\
\hline CHEMBL3890323 & 1641310 & 9.0 & 9.3326 & TRN & \\
\hline CHEMBL3893807 & 1641310 & 7.0555 & 7.1133 & TRN & \\
\hline CHEMBL3906246 & 1641310 & 6.8665 & 7.1406 & TRN & \\
\hline CHEMBL3964312 & 1641310 & 9.0 & 9.0957 & TRN & \\
\hline CHEMBL3927250 & 1641310 & 8.0458 & 8.0946 & TRN & \\
\hline CHEMBL3974112 & 1641310 & 8.0969 & 7.6682 & TRN & \\
\hline CHEMBL3952099 & 1641310 & 8.5229 & 8.8846 & TRN & \\
\hline CHEMBL3947074 & 1641310 & 7.6198 & 7.954 & TRN & \\
\hline CHEMBL3905362 & 1641310 & 7.8861 & 8.06899 & 9999999999 & TRN \\
\hline CHEMBL3935774 & 1641310 & 8.3979 & 8.4776 & TRN & \\
\hline CHEMBL3942864 & 1641310 & 7.7696 & 7.8586 & TRN & \\
\hline CHEMBL3931292 & 1641310 & 7.8239 & 7.6747 & TRN & \\
\hline CHEMBL3973196 & 1641310 & 9.0 & 8.8573 & TRN & \\
\hline CHEMBL3919018 & 1641310 & 8.2218 & 8.109 & TRN & \\
\hline CHEMBL3936959 & 1641310 & 9.0 & 8.5933 & TST & \\
\hline CHEMBL3978935 & 1641310 & 9.0 & 8.8475 & TRN & \\
\hline CHEMBL3892070 & 1641310 & 7.6383 & 7.834 & TRN & \\
\hline CHEMBL3936486 & 1641310 & 6.4067 & 7.434 & TST & \\
\hline CHEMBL3924716 & 1641310 & 10.0 & 8.908 & TRN & \\
\hline CHEMBL3932044 & 1641310 & 8.3979 & 8.7901 & TRN & \\
\hline CHEMBL3941059 & 1641310 & 8.301 & 8.4821 & TRN & \\
\hline CHEMBL3909669 & 1641310 & 7.8539 & 7.6875 & TRN & \\
\hline CHEMBL3901834 & 1641310 & 6.2874 & 7.75 & TST & \\
\hline CHEMBL3910696 & 1641310 & 9.0 & 8.762 & TRN & \\
\hline CHEMBL3957343 & 1641310 & 7.2676 & 7.9561 & TRN & \\
\hline CHEMBL3917619 & 1641310 & 7.8861 & 7.5645 & TRN & \\
\hline CHEMBL3898933 & 1641310 & 9.699 & 8.7147 & TRN & \\
\hline CHEMBL3890957 & 1641310 & 8.699 & 8.2778 & TRN & \\
\hline CHEMBL3927415 & 1641310 & 8.301 & 7.6885 & TRN & \\
\hline CHEMBL3923803 & 1641310 & 9.0 & 8.5203 & TRN & \\
\hline CHEMBL3899217 & 1641310 & 5.5243 & 7.0497 & TRN & \\
\hline CHEMBL3934720 & 1641310 & 7.3468 & 7.8093 & TRN & \\
\hline CHEMBL3946677 & 1641310 & 9.0 & 8.9981 & TRN & \\
\hline CHEMBL3948779 & 1641310 & 9.0 & 9.2447 & TRN & \\
\hline CHEMBL3937368 & 1641310 & 8.3979 & 8.8545 & TRN & \\
\hline CHEMBL3914785 & 1641310 & 8.699 & 8.7602 & TRN & \\
\hline CHEMBL3962330 & 1641310 & 8.699 & 9.1124 & TRN & \\
\hline CHEMBL3981664 & 1641310 & 8.0 & 8.44 & TRN & \\
\hline CHEMBL3929525 & 1641310 & 9.0 & 8.6428 & TST & \\
\hline CHEMBL3930468 & 1641310 & 9.0 & 8.3147 & TRN & \\
\hline CHEMBL3973654 & 1641310 & 8.0969 & 8.0843 & TRN & \\
\hline CHEMBL3925874 & 1641310 & 8.699 & 9.0594 & TRN & \\
\hline CHEMBL3974833 & 1641310 & 9.0 & 9.0268 & TRN & \\
\hline CHEMBL3935793 & 1641310 & 9.0 & 8.7393 & TRN & \\
\hline CHEMBL3961715 & 1641310 & 7.8539 & 7.7039 & TRN & \\
\hline CHEMBL3941049 & 1641310 & 7.8239 & 7.4343 & TRN & \\
\hline CHEMBL3967381 & 1641310 & 8.0969 & 8.3422 & TRN & \\
\hline
\end{tabular}


Supplemental Table S2.txt

\begin{tabular}{|c|c|c|c|c|}
\hline CHEMBL3896128 & 1641310 & 8.3979 & 9.0317 & TRN \\
\hline CHEMBL3979234 & 1641310 & 8.2218 & 7.9511 & TRN \\
\hline CHEMBL3894900 & 1641310 & 8.0 & 8.2598 & TRN \\
\hline CHEMBL3929775 & 1641310 & 9.0 & 7.9176 & TRN \\
\hline CHEMBL3956337 & 1641310 & 9.0 & 8.708 & TST \\
\hline CHEMBL3893962 & 1641310 & 7.0506 & 7.9722 & TST \\
\hline CHEMBL3945976 & 1641310 & 7.5686 & 8.0454 & TRN \\
\hline CHEMBL3919935 & 1641310 & 8.5229 & 7.8751 & TRN \\
\hline CHEMBL3923811 & 1641310 & 9.0 & 8.9028 & TRN \\
\hline CHEMBL3889671 & 1641310 & 7.1487 & 8.3513 & TRN \\
\hline CHEMBL3898014 & 1641310 & 8.5229 & 8.7941 & TRN \\
\hline CHEMBL3916566 & 1641310 & 7.699 & 7.4139 & TRN \\
\hline CHEMBL3981151 & 1641310 & 9.0 & 8.2155 & TRN \\
\hline CHEMBL3899775 & 1641310 & 7.2757 & 8.9467 & TST \\
\hline CHEMBL3917926 & 1641310 & 8.0969 & 7.66799 & 9999999999 \\
\hline CHEMBL3972743 & 1641310 & 9.0 & 8.5958 & TRN \\
\hline CHEMBL3966250 & 1641310 & 9.0 & 8.4265 & TRN \\
\hline CHEMBL3933373 & 1641310 & 7.1612 & 7.4483 & TRN \\
\hline CHEMBL3922970 & 1641310 & 6.3487 & 7.6829 & TST \\
\hline CHEMBL3938426 & 1641310 & 8.5229 & 9.0841 & TRN \\
\hline CHEMBL3938703 & 1641310 & 8.2218 & 8.6555 & TRN \\
\hline CHEMBL3923194 & 1641310 & 7.0 & 8.3564 & TST \\
\hline CHEMBL3951236 & 1641310 & 7.5229 & 8.0794 & TRN \\
\hline CHEMBL3982810 & 1641310 & 8.5229 & 9.0466 & TRN \\
\hline CHEMBL3949279 & 1641310 & 9.699 & 8.9666 & TRN \\
\hline CHEMBL3893096 & 1641310 & 7.7959 & 7.6633 & TRN \\
\hline CHEMBL3966312 & 1641310 & 8.5229 & 7.7162 & TRN \\
\hline CHEMBL3913694 & 1641310 & 7.1938 & 8.6344 & TST \\
\hline CHEMBL3909429 & 1641310 & 9.5229 & 8.59 & TST \\
\hline CHEMBL3936774 & 1641310 & 8.5229 & 8.8005 & TRN \\
\hline CHEMBL3889492 & 1641310 & 7.1135 & 6.9477 & TRN \\
\hline CHEMBL3901607 & 1641310 & 8.0969 & 8.4115 & TRN \\
\hline CHEMBL3982804 & 1641310 & 9.301 & 8.5247 & TST \\
\hline CHEMBL3968313 & 1641310 & 6.9626 & 8.1309 & TST \\
\hline CHEMBL3894983 & 1641310 & 8.699 & 8.3128 & TST \\
\hline CHEMBL3905608 & 1641310 & 9.0 & 9.1047 & TST \\
\hline CHEMBL3955848 & 1641310 & 8.5229 & 8.9983 & TST \\
\hline CHEMBL3958910 & 1641310 & 8.699 & 8.4751 & TST \\
\hline CHEMBL3977943 & 1641310 & 9.0 & 8.7795 & TST \\
\hline CHEMBL3941945 & 1641310 & 8.699 & 8.6328 & TST \\
\hline CHEMBL3942354 & 1641310 & 8.0458 & 7.7915 & TST \\
\hline CHEMBL3971552 & 1641310 & 8.3979 & 8.5477 & TST \\
\hline CHEMBL3902841 & 1641310 & 8.699 & 9.19 & TST \\
\hline CHEMBL3944204 & 1641310 & 6.5031 & 6.7332 & TST \\
\hline CHEMBL3939129 & 1641310 & 6.8182 & 7.4559 & TST \\
\hline CHEMBL3960240 & 1641310 & 8.0969 & 8.8108 & TST \\
\hline CHEMBL3896194 & 1641310 & 7.8539 & 7.7826 & TST \\
\hline CHEMBL3974735 & 1641310 & 8.3979 & 7.5198 & TST \\
\hline
\end{tabular}


Supplemental Table S2.txt

\begin{tabular}{|c|c|c|c|c|}
\hline HEMBL & 641310 & 8.699 & 8.2776 & II \\
\hline HEMBL3925131 & 641310 & 7.9586 & 7.7403 & \\
\hline HFMRI & 541310 & & 796 & \\
\hline AEMBL3903948 & 541310 & 9 & 3699 & \\
\hline AEMBL3918533 & 641310 & 9.0 & 3973 & \\
\hline HEMBL3674051 & 528132 & 7.6003 & .5895 & \\
\hline 079 & 132 & 7.1002 & 139 & \\
\hline 74088 & 132 & 6.0 & 9908 & \\
\hline HEMBL3674112 & 528132 & 6.0 & .0071 & \\
\hline HEMBL3674061 & 528132 & 7.7852 & .7442 & \\
\hline HEMBL3674068 & 132 & 7.3002 & .2918 & \\
\hline HEMBL3 & 132 & 7.4001 & 5499 & \\
\hline HEMBL3 & 32 & 7.8125 & 7873 & \\
\hline HEMBL3674102 & 132 & 6.0 & . 9993 & \\
\hline AEMBL3674075 & 132 & 6 & 62 & \\
\hline AEMBL3674136 & 32 & 6. & 5209 & ונ \\
\hline HEMBL & & & 52 & 列 \\
\hline HEMBL & 32 & 751 & 3682 & \\
\hline HEMBL3 & 32 & & 7311 & \\
\hline AEMBL3674118 & 32 & 6. & 9917 & nIv \\
\hline HEMBL3 & 32 & 7. & 19 & RN \\
\hline HEMBL & & & & NIV \\
\hline HEMBL & 32 & 003 & 009 & ST \\
\hline HEMBL3 & 32 & 7. & & $\Gamma \mathrm{RN}$ \\
\hline HEMBL 3674047 & 32 & 7. & 95 & RN \\
\hline HEMBL3 & 32 & 6 & 9912 & RN \\
\hline 881 & 32 & & 16 & $\mathrm{RN}$ \\
\hline 45 & & & 1058 & RN \\
\hline AEMBL & & 7 & 14 & RIN \\
\hline HEMBL3674074 & 32 & 7. & 7372 & ГRN \\
\hline AEMBL: & 32 & 8 & 422 & ST \\
\hline 44 & 32 & & 09 & RN \\
\hline & & & 67 & $\mathrm{RN}$ \\
\hline HEMBL3674037 & 32 & & 247 & ГRN \\
\hline HEMBL3674122 & 32 & 7.8996 & 9507 & IST \\
\hline HEMBL3674048 & 32 & 7. & 239 & TST \\
\hline & & 7. & & RN \\
\hline HEMBL3674071 & & 5.7 & 228 & TST \\
\hline HEMBL3674095 & 32 & 6 & 749 & TRN \\
\hline IEMBL3 & 32 & & 581 & TST \\
\hline HEMBL3674101 & & & & RN \\
\hline HEMBL3674065 & 32 & 7.11 & 1375 & $\Gamma \mathrm{RN}$ \\
\hline HEMBL3674072 & 32 & 7.2 & 2035 & TRN \\
\hline IEMBL367 & 32 & 7. & 6661 & RN \\
\hline HEMBL3639729 & & & 7.4139 & \\
\hline HEMBL3 & & & 7.3964 & RIN \\
\hline HEMBL3 & 132 & 7.6003 & 7.6121 & RN \\
\hline CHEMBL3674124 & 1528132 & 7.3002 & 7.32 & TRN \\
\hline
\end{tabular}

Page 16888 


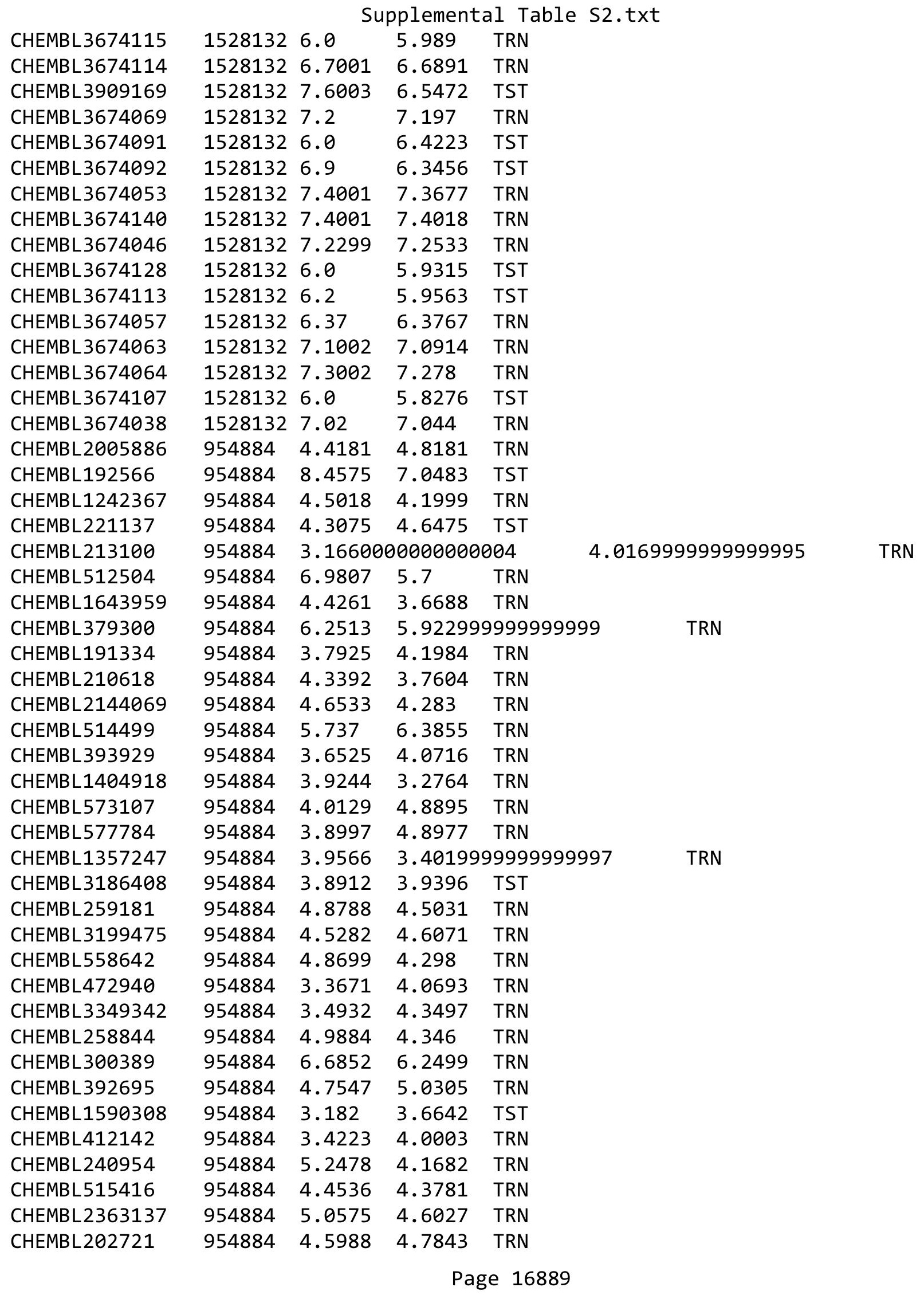




\begin{tabular}{|c|c|c|c|c|c|c|}
\hline \multirow[b]{2}{*}{ CHEMBL135561 } & & \multicolumn{5}{|c|}{ Supplemental Table S2.txt } \\
\hline & 954884 & 4.5483 & 4.3085 & TRN & & \\
\hline CHEMBL1230020 & 954884 & 4.3369 & 4.1454 & TRN & & \\
\hline CHEMBL1788116 & 954884 & 5.0624 & 4.3078 & TRN & & \\
\hline CHEMBL1909414 & 954884 & 4.1766 & 4.203 & TRN & & \\
\hline CHEMBL189584 & 954884 & 4.5246 & 4.658 & TRN & & \\
\hline CHEMBL1190711 & 954884 & 5.0049 & 5.0453 & TRN & & \\
\hline CHEMBL379975 & 954884 & \multicolumn{3}{|c|}{5.803999999999999} & 5.1688 & TRN \\
\hline CHEMBL92309 & 954884 & 1.7585 & 3.3675 & TST & & \\
\hline CHEMBL1970879 & 954884 & 2.9188 & 4.1074 & TRN & & \\
\hline CHEMBL483847 & 954884 & 3.6787 & 4.0755 & TRN & & \\
\hline CHEMBL9470 & 954884 & 6.4713 & 5.4566 & TST & & \\
\hline CHEMBL 373751 & 954884 & 3.2136 & 3.7929 & TRN & & \\
\hline CHEMBL220241 & 954884 & 3.4206 & 4.3722 & TRN & & \\
\hline CHEMBL180127 & 954884 & 4.5205 & 4.3035 & TRN & & \\
\hline CHEMBL449158 & 954884 & 6.381 & 6.0702 & TST & & \\
\hline CHEMBL188678 & 954884 & 4.6704 & 4.5711 & TRN & & \\
\hline CHEMBL222102 & 954884 & \multicolumn{3}{|c|}{4.6419999999999995} & 4.0698 & TST \\
\hline CHEMBL 209148 & 954884 & 4.061 & 4.3198 & TST & & \\
\hline CHEMBL509032 & 954884 & 5.8337 & 4.9728 & TST & & \\
\hline CHEMBL1673039 & 954884 & 4.842 & 4.6127 & TST & & \\
\hline CHEMBL3392440 & 954884 & 3.4565 & 3.9178 & TST & & \\
\hline CHEMBL585951 & 954884 & 6.3066 & 5.7673 & TST & & \\
\hline CHEMBL1256459 & 954884 & 6.4691 & 6.3283 & TST & & \\
\hline CHEMBL1967887 & 809128 & 4.7 & 5.2204 & TRN & & \\
\hline CHEMBL 213505 & 809128 & 7.5 & 7.1063 & TRN & & \\
\hline CHEMBL 2000568 & 809128 & 4.7 & 5.2887 & TRN & & \\
\hline CHEMBL 2000335 & 809128 & 7.7 & 7.9228 & TRN & & \\
\hline CHEMBL1988717 & 809128 & 8.4 & 7.3903 & TRN & & \\
\hline CHEMBL509032 & 809128 & 8.0 & 7.8378 & TRN & & \\
\hline CHEMBL1987034 & 809128 & 8.1 & 8.5029 & TRN & & \\
\hline CHEMBL1993941 & 809128 & 7.7 & 8.3291 & TRN & & \\
\hline CHEMBL 377383 & 809128 & 4.7 & 4.4497 & TRN & & \\
\hline CHEMBL 2005886 & 809128 & 7.7 & 7.2324 & TST & & \\
\hline CHEMBL1973808 & 809128 & 4.7 & 4.5538 & TRN & & \\
\hline CHEMBL 2000429 & 809128 & 4.7 & 4.6074 & TRN & & \\
\hline CHEMBL481491 & 809128 & 4.7 & 5.2771 & TST & & \\
\hline CHEMBL1973142 & 809128 & 4.7 & 5.2827 & TRN & & \\
\hline CHEMBL1972576 & 809128 & 6.5 & 6.4631 & TRN & & \\
\hline CHEMBL1990254 & 809128 & 4.7 & 4.6812 & TRN & & \\
\hline CHEMBL1973145 & 809128 & 7.0 & 6.2083 & TRN & & \\
\hline CHEMBL1982924 & 809128 & 6.1 & 5.9934 & TRN & & \\
\hline CHEMBL1992342 & 809128 & 4.7 & 4.912 & TRN & & \\
\hline CHEMBL2005936 & 809128 & 4.7 & 5.2438 & TRN & & \\
\hline CHEMBL1988173 & 809128 & 6.4 & 5.7182 & TRN & & \\
\hline CHEMBL1164265 & 809128 & 4.9 & 6.0251 & TST & & \\
\hline CHEMBL1971141 & 809128 & 4.7 & 5.1597 & TRN & & \\
\hline CHEMBL1989805 & 809128 & 5.8 & 5.1287 & TST & & \\
\hline CHEMBL206236 & 809128 & 4.7 & 4.6105 & TRN & & \\
\hline
\end{tabular}




\begin{tabular}{|c|c|c|c|c|c|}
\hline \multicolumn{6}{|c|}{ Supplemental Table S2.txt } \\
\hline CHEMBL1965423 & 809128 & 4.7 & 4.753 & TRN & \\
\hline CHEMBL 2001957 & 809128 & 4.7 & 4.4768 & TRN & \\
\hline CHEMBL1969372 & 809128 & 4.7 & 4.5926 & TRN & \\
\hline CHEMBL1983025 & 809128 & 7.8 & 7.9374 & TRN & \\
\hline CHEMBL205415 & 809128 & 4.7 & 4.9815 & TRN & \\
\hline CHEMBL1977135 & 809128 & 4.7 & 4.3946 & TRN & \\
\hline CHEMBL 2001920 & 809128 & 4.7 & 5.2976 & TRN & \\
\hline CHEMBL 2006263 & 809128 & 4.7 & 5.2139 & TRN & \\
\hline CHEMBL1241473 & 809128 & 7.4 & 7.9237 & TRN & \\
\hline CHEMBL1993584 & 809128 & 4.7 & 4.9164 & TRN & \\
\hline CHEMBL1986263 & 809128 & 6.1 & 6.5056 & TRN & \\
\hline CHEMBL 2000114 & 809128 & 4.7 & 5.5371 & TRN & \\
\hline CHEMBL 2001257 & 809128 & 8.4 & 7.6811 & TRN & \\
\hline CHEMBL210618 & 809128 & 4.7 & 4.4405 & TRN & \\
\hline CHEMBL1987793 & 809128 & 6.6 & 5.3114 & TST & \\
\hline CHEMBL1975647 & 809128 & 4.7 & 4.8883 & TRN & \\
\hline CHEMBL1992536 & 809128 & 4.7 & 4.6482 & TRN & \\
\hline CHEMBL1968380 & 809128 & 4.7 & 5.1320 & 0000000001 & TRN \\
\hline CHEMBL1964644 & 809128 & 4.7 & 4.5526 & TRN & \\
\hline CHEMBL1981782 & 809128 & 4.7 & 4.9551 & TRN & \\
\hline CHEMBL1992740 & 809128 & 4.7 & 4.7147 & TRN & \\
\hline CHEMBL1977681 & 809128 & 4.7 & 5.686 & TRN & \\
\hline CHEMBL1970142 & 809128 & 8.7 & 8.2955 & TRN & \\
\hline CHEMBL1990912 & 809128 & 4.7 & 4.7360 & 0000000001 & TRN \\
\hline CHEMBL 2002373 & 809128 & 4.7 & 4.4628 & TRN & \\
\hline CHEMBL1967531 & 809128 & 6.4 & 7.3063 & TRN & \\
\hline CHEMBL1970913 & 809128 & 4.7 & 4.4613 & TRN & \\
\hline CHEMBL1973893 & 809128 & 4.7 & 4.7903 & TRN & \\
\hline CHEMBL1975128 & 809128 & 4.7 & 5.7508 & TRN & \\
\hline CHEMBL1985095 & 809128 & 4.7 & 5.8034 & TST & \\
\hline CHEMBL1996500 & 809128 & 4.7 & 4.4547 & TRN & \\
\hline CHEMBL 2006493 & 809128 & 4.7 & 4.5964 & TST & \\
\hline CHEMBL1682540 & 809128 & 4.7 & 4.5262 & TRN & \\
\hline CHEMBL1983449 & 809128 & 4.7 & 4.7525 & TRN & \\
\hline CHEMBL1992323 & 809128 & 4.7 & 4.5376 & TRN & \\
\hline CHEMBL1969735 & 809128 & 4.7 & 4.474 & TRN & \\
\hline CHEMBL 2002649 & 809128 & 6.2 & 6.4068 & TRN & \\
\hline CHEMBL1994864 & 809128 & 4.7 & 4.698 & TRN & \\
\hline CHEMBL 2002446 & 809128 & 6.8 & 6.0036 & TRN & \\
\hline CHEMBL497151 & 809128 & 4.7 & 5.3939 & TST & \\
\hline CHEMBL1973961 & 809128 & 4.9 & 5.3887 & TRN & \\
\hline CHEMBL246970 & 809128 & 4.7 & 5.4503 & TRN & \\
\hline CHEMBL1994321 & 809128 & 8.9 & 8.2397 & TRN & \\
\hline CHEMBL340921 & 809128 & 4.7 & 4.9191 & TST & \\
\hline CHEMBL1997129 & 809128 & 7.3 & 6.1778 & TST & \\
\hline CHEMBL229799 & 809128 & 6.8 & 6.6826 & TRN & \\
\hline CHEMBL1276446 & 809128 & 7.7 & 7.3636 & TST & \\
\hline CHEMBL1977346 & 809128 & 4.7 & 5.1342 & TRN & \\
\hline
\end{tabular}




\begin{tabular}{|c|c|c|c|c|}
\hline \multicolumn{5}{|c|}{ Supplemental Table s2.txt } \\
\hline CHEMBL1971649 & 809128 & 6.5 & 5.6274 & TRN \\
\hline CHEMBL 2000508 & 809128 & 4.7 & 4.427 & TRN \\
\hline CHEMBL1971694 & 809128 & 4.7 & 4.6609 & TST \\
\hline CHEMBL2001547 & 809128 & 4.7 & 4.46899 & 9999999999 \\
\hline CHEMBL210928 & 809128 & 4.7 & 4.4547 & TRN \\
\hline CHEMBL1969190 & 809128 & 7.1 & 6.8664 & TRN \\
\hline CHEMBL1977148 & 809128 & 8.5 & 7.5521 & TRN \\
\hline CHEMBL1973937 & 809128 & 7.3 & 6.8367 & TRN \\
\hline CHEMBL 2003286 & 809128 & 4.7 & 4.6588 & TRN \\
\hline CHEMBL1992306 & 809128 & 7.4 & 6.4514 & TRN \\
\hline CHEMBL2002165 & 809128 & 7.7 & 8.5104 & TRN \\
\hline CHEMBL1982711 & 809128 & 6.2 & 6.0234 & TRN \\
\hline CHEMBL1979318 & 809128 & 4.7 & 4.7241 & TST \\
\hline CHEMBL206382 & 809128 & 4.7 & 4.4701 & TRN \\
\hline CHEMBL1998585 & 809128 & 8.9 & 8.3635 & TRN \\
\hline CHEMBL519697 & 809128 & 4.7 & 5.2565 & TST \\
\hline CHEMBL1994241 & 809128 & 6.1 & 5.7021 & TST \\
\hline CHEMBL2007044 & 809128 & 4.7 & 5.0814 & TRN \\
\hline CHEMBL223460 & 809128 & 4.7 & 5.2871 & TST \\
\hline CHEMBL1996048 & 809128 & 4.9 & 5.4927 & TRN \\
\hline CHEMBL1998829 & 809128 & 6.2 & 5.5659 & TRN \\
\hline CHEMBL50894 & 809128 & 4.7 & 5.4216 & TRN \\
\hline CHEMBL461876 & 809128 & 6.9 & 5.6513 & TRN \\
\hline CHEMBL1988838 & 809128 & 7.9 & 7.7875 & TRN \\
\hline CHEMBL2001485 & 809128 & 8.6 & 8.0837 & TRN \\
\hline CHEMBL1984363 & 809128 & 5.8 & 6.1966 & TRN \\
\hline CHEMBL1978099 & 809128 & 7.2 & 7.0951 & TRN \\
\hline CHEMBL1988608 & 809128 & 4.7 & 5.2013 & TRN \\
\hline CHEMBL184847 & 809128 & 4.7 & 5.5106 & TRN \\
\hline CHEMBL1982866 & 809128 & 4.7 & 4.535 & TRN \\
\hline CHEMBL1984367 & 809128 & 4.7 & 5.3431 & TRN \\
\hline CHEMBL462120 & 809128 & 4.7 & 4.7478 & TRN \\
\hline CHEMBL2007592 & 809128 & 4.7 & 4.4332 & TST \\
\hline CHEMBL1965570 & 809128 & 7.2 & 7.6197 & TRN \\
\hline CHEMBL226898 & 809128 & 4.7 & 6.5897 & TRN \\
\hline CHEMBL1982563 & 809128 & 4.7 & 4.5081 & TRN \\
\hline CHEMBL 575824 & 809128 & 4.7 & 5.0773 & TRN \\
\hline CHEMBL 210963 & 809128 & 4.7 & 4.3549 & TRN \\
\hline CHEMBL1988387 & 809128 & 8.7 & 8.7098 & TRN \\
\hline CHEMBL1082440 & 809128 & 4.7 & 5.4738 & TST \\
\hline CHEMBL1614705 & 809128 & 4.7 & 4.6948 & TRN \\
\hline CHEMBL1989708 & 809128 & 8.9 & 8.6006 & TRN \\
\hline CHEMBL1990288 & 809128 & 4.7 & 4.5845 & TRN \\
\hline CHEMBL1970074 & 809128 & 7.2 & 6.3409 & TRN \\
\hline CHEMBL1986970 & 809128 & 4.7 & 5.0083 & TRN \\
\hline CHEMBL1990482 & 809128 & 4.7 & 4.6643 & TRN \\
\hline CHEMBL1990904 & 809128 & 4.7 & 4.6673 & TRN \\
\hline CHEMBL2005475 & 809128 & 5.7 & 5.5938 & TRN \\
\hline
\end{tabular}

TRN 


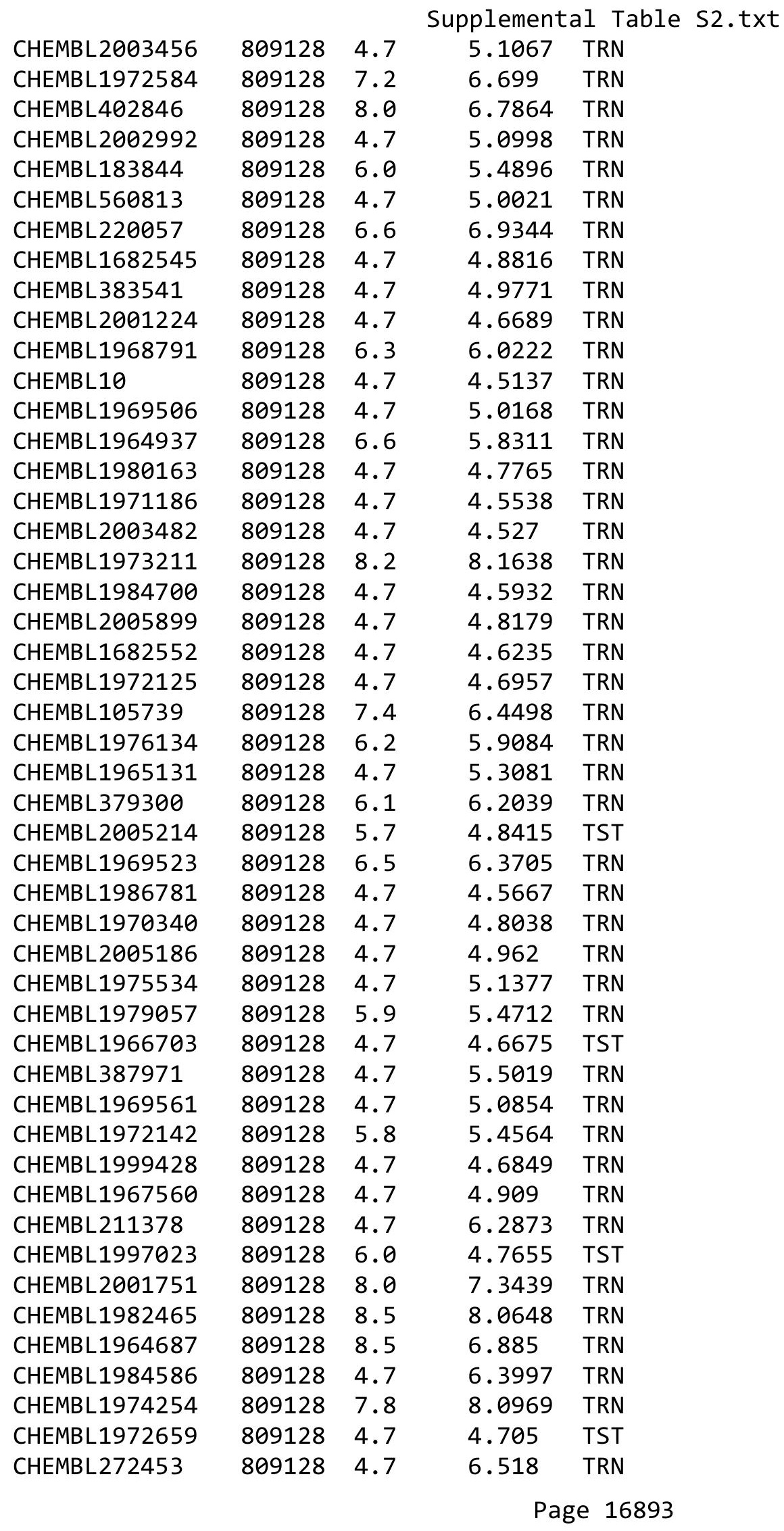




\begin{tabular}{|c|c|c|c|c|c|}
\hline & & & & & \\
\hline CHEMBL1988537 & 809128 & 5.7 & 5.4049 & TST & \\
\hline CHEMBL2005828 & 809128 & 5.9 & 6.6931 & TRN & \\
\hline CHEMBL 2005528 & 809128 & 4.7 & 4.785 & TST & \\
\hline CHEMBL185569 & 809128 & 4.7 & 6.0569 & TRN & \\
\hline CHEMBL1969843 & 809128 & 4.7 & 4.4847 & TRN & \\
\hline CHEMBL2007002 & 809128 & 4.7 & 5.13399 & 99999999995 & TRN \\
\hline CHEMBL1987007 & 809128 & 5.7 & 5.2034 & TRN & \\
\hline CHEMBL1998611 & 809128 & 4.7 & 5.2036 & TRN & \\
\hline CHEMBL1984711 & 809128 & 6.0 & 6.14 & TRN & \\
\hline CHEMBL1975900 & 809128 & 4.7 & 4.9017 & TRN & \\
\hline CHEMBL255822 & 809128 & 4.7 & 4.8662 & TRN & \\
\hline CHEMBL1972221 & 809128 & 4.7 & 4.7338 & TRN & \\
\hline CHEMBL 2006778 & 809128 & 6.6 & 7.195 & TRN & \\
\hline CHEMBL484390 & 809128 & 4.7 & 5.1773 & TST & \\
\hline CHEMBL1979252 & 809128 & 4.7 & 4.9843 & TRN & \\
\hline CHEMBL378627 & 809128 & 4.7 & 4.444 & TRN & \\
\hline CHEMBL1996979 & 809128 & 6.6 & 6.4235 & TRN & \\
\hline CHEMBL1997025 & 809128 & 4.7 & 4.9875 & TRN & \\
\hline CHEMBL1968406 & 809128 & 8.5 & 7.1599 & TRN & \\
\hline CHEMBL1972937 & 809128 & 4.7 & 4.6392 & TRN & \\
\hline CHEMBL 2004290 & 809128 & 8.2 & 7.8071 & TRN & \\
\hline CHEMBL 2000393 & 809128 & 4.7 & 6.4203 & TST & \\
\hline CHEMBL 2004311 & 809128 & 7.8 & 6.2372 & TRN & \\
\hline CHEMBL1992634 & 809128 & 4.7 & 6.2485 & TRN & \\
\hline CHEMBL1242373 & 809128 & 7.8 & 7.1747 & TRN & \\
\hline CHEMBL1998545 & 809128 & 4.7 & 4.42 & TRN & \\
\hline CHEMBL1986869 & 809128 & 4.7 & 4.577 & TRN & \\
\hline CHEMBL56543 & 809128 & 6.0 & 5.2063 & TRN & \\
\hline CHEMBL316264 & 809128 & 4.7 & 4.3561 & TRN & \\
\hline CHEMBL1988075 & 809128 & 7.0 & $7.5820 e$ & $\partial 000000001$ & TRN \\
\hline CHEMBL1991678 & 809128 & 4.7 & 4.4573 & TRN & \\
\hline CHEMBL1682558 & 809128 & 4.7 & 4.5692 & TRN & \\
\hline CHEMBL2001239 & 809128 & 4.7 & 5.6585 & TST & \\
\hline CHEMBL1990496 & 809128 & 4.7 & 4.7672 & TRN & \\
\hline CHEMBL1988594 & 809128 & 6.1 & 6.4035 & TRN & \\
\hline CHEMBL2001288 & 809128 & 4.7 & 5.0848 & TRN & \\
\hline CHEMBL1999811 & 809128 & 5.8 & 5.5294 & TST & \\
\hline CHEMBL1985074 & 809128 & 4.7 & 4.6311 & TST & \\
\hline CHEMBL1982874 & 809128 & 4.7 & 4.7786 & TRN & \\
\hline CHEMBL1992242 & 809128 & 4.7 & 5.2763 & TRN & \\
\hline CHEMBL1991725 & 809128 & 4.7 & 5.0966 & TRN & \\
\hline CHEMBL208637 & 809128 & 4.7 & 4.3435 & TRN & \\
\hline CHEMBL1967094 & 809128 & 5.9 & 5.6104 & TRN & \\
\hline CHEMBL2003341 & 809128 & 4.7 & 4.5659 & TRN & \\
\hline CHEMBL1970203 & 809128 & 7.3 & 6.436 & TRN & \\
\hline CHEMBL1968590 & 809128 & 4.7 & 6.3351 & TRN & \\
\hline CHEMBL2005375 & 809128 & 4.7 & 4.9037 & TRN & \\
\hline CHEMBL1984191 & 809128 & 4.7 & 4.7017 & TRN & \\
\hline & & & & 16894 & \\
\hline
\end{tabular}




\begin{tabular}{|c|c|c|c|c|c|}
\hline \multicolumn{6}{|c|}{ Supplemental Table S2.txt } \\
\hline CHEMBL1982992 & 809128 & 4.7 & 5.1602 & TRN & \\
\hline CHEMBL1999590 & 809128 & 4.7 & 5.1584 & TST & \\
\hline CHEMBL1971029 & 809128 & 7.2 & 8.0624 & TRN & \\
\hline CHEMBL 2000832 & 809128 & 4.7 & 5.5788 & TRN & \\
\hline CHEMBL1980489 & 809128 & 4.7 & 4.7758 & TRN & \\
\hline CHEMBL394790 & 809128 & 7.3 & 6.9427 & TRN & \\
\hline CHEMBL1970709 & 809128 & 4.7 & 4.7326 & TRN & \\
\hline CHEMBL226471 & 809128 & 5.8 & 5.1197 & TST & \\
\hline CHEMBL1974702 & 809128 & 4.7 & 4.816 & TRN & \\
\hline CHEMBL1996111 & 809128 & 4.7 & 5.1029 & TRN & \\
\hline CHEMBL1969126 & 809128 & 4.7 & 4.5625 & TRN & \\
\hline CHEMBL1965589 & 809128 & 4.7 & 4.6287 & TRN & \\
\hline CHEMBL1980896 & 809128 & 6.5 & 6.08899 & 99999999995 & TRN \\
\hline CHEMBL1970104 & 809128 & 7.2 & 6.5508 & TRN & \\
\hline CHEMBL474432 & 809128 & 6.6 & 6.0286 & TST & \\
\hline CHEMBL1999714 & 809128 & 4.7 & 4.4141 & TRN & \\
\hline CHEMBL1971149 & 809128 & 4.7 & 4.5638 & TRN & \\
\hline CHEMBL1994040 & 809128 & 4.7 & 4.5565 & TRN & \\
\hline CHEMBL1988153 & 809128 & 4.7 & 4.9884 & TST & \\
\hline CHEMBL579246 & 809128 & 5.7 & 5.3546 & TRN & \\
\hline CHEMBL398951 & 809128 & 4.7 & 5.1127 & TRN & \\
\hline CHEMBL1982506 & 809128 & 4.7 & 4.9003 & TST & \\
\hline CHEMBL1968127 & 809128 & 4.7 & 4.3808 & TRN & \\
\hline CHEMBL1975233 & 809128 & 4.7 & 4.7743 & TRN & \\
\hline CHEMBL1988437 & 809128 & 6.8 & 6.3326 & TST & \\
\hline CHEMBL1985406 & 809128 & 4.7 & 4.899 & TRN & \\
\hline CHEMBL 207400 & 809128 & 4.7 & 4.5523 & TST & \\
\hline CHEMBL 2000894 & 809128 & 4.7 & 4.9342 & TST & \\
\hline CHEMBL1979577 & 809128 & 8.1 & 8.2522 & TRN & \\
\hline CHEMBL1998121 & 809128 & 5.8 & 5.8959 & TRN & \\
\hline CHEMBL1982135 & 809128 & 6.2 & 6.2263 & TRN & \\
\hline CHEMBL1991800 & 809128 & 4.7 & 4.5406 & TRN & \\
\hline CHEMBL1976090 & 809128 & 6.6 & 5.4679 & TRN & \\
\hline CHEMBL52387 & 809128 & 4.7 & 4.8738 & TST & \\
\hline CHEMBL1993243 & 809128 & 6.0 & 6.6244 & TRN & \\
\hline CHEMBL1992922 & 809128 & 6.7 & 6.2192 & TRN & \\
\hline CHEMBL379835 & 809128 & 4.7 & 4.5656 & TST & \\
\hline CHEMBL1997597 & 809128 & 4.7 & 4.8252 & TRN & \\
\hline CHEMBL1969537 & 809128 & 4.7 & 5.4277 & TST & \\
\hline CHEMBL1976093 & 809128 & 4.7 & 4.3832 & TRN & \\
\hline CHEMBL1979357 & 809128 & 4.7 & 4.6592 & TRN & \\
\hline CHEMBL1996817 & 809128 & 7.0 & 6.6074 & TRN & \\
\hline CHEMBL1975256 & 809128 & 4.7 & 4.558 & TST & \\
\hline CHEMBL508928 & 809128 & 7.6 & 7.3472 & TRN & \\
\hline CHEMBL1991356 & 809128 & 4.7 & 4.6669 & TRN & \\
\hline CHEMBL 2004892 & 809128 & 4.7 & 4.8818 & TRN & \\
\hline CHEMBL468280 & 809128 & 4.7 & 4.5036 & TST & \\
\hline CHEMBL116070 & 809128 & 4.7 & 4.9703 & TST & \\
\hline
\end{tabular}




\begin{tabular}{|c|c|c|c|c|c|}
\hline \\
\hline CHEMBL1990884 & 809128 & 6.4 & 5.6729 & TRN & \\
\hline CHEMBL1990821 & 809128 & 6.4 & 5.2161 & TST & \\
\hline CHEMBL3109278 & 809128 & 7.8 & 6.8213 & TRN & \\
\hline CHEMBL256835 & 809128 & 4.7 & 4.6141 & TRN & \\
\hline CHEMBL1970314 & 809128 & 5.8 & 4.9016 & TRN & \\
\hline CHEMBL2004871 & 809128 & 4.7 & 4.4051 & TRN & \\
\hline CHEMBL41783 & 809128 & 4.7 & 4.529 & TRN & \\
\hline CHEMBL 2006276 & 809128 & 4.7 & 4.8112 & TRN & \\
\hline CHEMBL1981720 & 809128 & 4.7 & 4.8637 & TRN & \\
\hline CHEMBL271381 & 809128 & 7.8 & 7.1555 & TRN & \\
\hline CHEMBL419932 & 809128 & 4.7 & 4.956 & TRN & \\
\hline CHEMBL262433 & 809128 & 7.4 & 6.9279 & TRN & \\
\hline CHEMBL 2006785 & 809128 & 5.7 & 4.7334 & TRN & \\
\hline CHEMBL1982466 & 809128 & 8.2 & 8.3169 & TRN & \\
\hline CHEMBL306380 & 809128 & 4.7 & 5.891 & TRN & \\
\hline CHEMBL1966722 & 809128 & 6.4 & 5.4204 & TRN & \\
\hline CHEMBL1995740 & 809128 & 4.7 & 4.7878 & TRN & \\
\hline CHEMBL1975500 & 809128 & 4.7 & 5.3337 & TRN & \\
\hline CHEMBL394619 & 809128 & 7.8 & 7.0731 & TRN & \\
\hline CHEMBL1996831 & 809128 & 6.0 & 4.7721 & TST & \\
\hline CHEMBL411903 & 809128 & 8.1 & 7.76399 & 9999999999 & TRN \\
\hline CHEMBL234085 & 809128 & 4.7 & 4.8832 & TRN & \\
\hline CHEMBL1990432 & 809128 & 5.8 & 4.8611 & TST & \\
\hline CHEMBL1965988 & 809128 & 8.5 & 8.2295 & TRN & \\
\hline CHEMBL1995832 & 809128 & 4.7 & 4.5792 & TRN & \\
\hline CHEMBL418203 & 809128 & 6.0 & 5.1357 & TST & \\
\hline CHEMBL1969042 & 809128 & 4.7 & 5.4642 & TST & \\
\hline CHEMBL 2000345 & 809128 & 6.4 & 5.8594 & TST & \\
\hline CHEMBL225519 & 809128 & 4.7 & 4.9837 & TST & \\
\hline CHEMBL1978200 & 809128 & 4.7 & 4.5626 & TRN & \\
\hline CHEMBL1970522 & 809128 & 4.7 & 4.8971 & TRN & \\
\hline CHEMBL1375418 & 809128 & 4.7 & 4.5745 & TRN & \\
\hline CHEMBL 2007064 & 809128 & 6.7 & 6.5062 & TRN & \\
\hline CHEMBL1996931 & 809128 & 4.7 & 4.5288 & TRN & \\
\hline CHEMBL1964413 & 809128 & 4.7 & 4.6765 & TRN & \\
\hline CHEMBL229968 & 809128 & 6.7 & 6.5574 & TRN & \\
\hline CHEMBL1976240 & 809128 & 4.7 & 4.8137 & TRN & \\
\hline CHEMBL1997340 & 809128 & 4.7 & 4.4187 & TRN & \\
\hline CHEMBL1522508 & 809128 & 4.7 & 4.5153 & TRN & \\
\hline CHEMBL1979093 & 809128 & 7.3 & 6.9557 & TRN & \\
\hline CHEMBL1989474 & 809128 & 4.7 & 4.4378 & TRN & \\
\hline CHEMBL1987009 & 809128 & 6.3 & 5.8256 & TRN & \\
\hline CHEMBL379218 & 809128 & 4.7 & 6.1327 & TRN & \\
\hline CHEMBL 2003817 & 809128 & 4.7 & 4.8423 & TRN & \\
\hline CHEMBL1994830 & 809128 & 4.7 & 4.9075 & TST & \\
\hline CHEMBL210887 & 809128 & 4.7 & 4.9694 & TST & \\
\hline CHEMBL226403 & 809128 & 4.7 & 5.05699 & 99999999995 & TST \\
\hline CHEMBL227271 & 809128 & 6.1 & 6.4855 & TRN & \\
\hline & & & & 16896 & \\
\hline
\end{tabular}




\begin{tabular}{|c|c|c|c|c|}
\hline & & & pplement & al Table S2 \\
\hline CHEMBL1971021 & 809128 & 7.8 & 5.916 & TRN \\
\hline CHEMBL583144 & 809128 & 6.0 & 4.931 & TRN \\
\hline CHEMBL1974310 & 809128 & 4.7 & 5.3744 & TST \\
\hline CHEMBL1994693 & 809128 & 6.6 & 6.7142 & TRN \\
\hline CHEMBL1994938 & 809128 & 6.2 & 7.0425 & TRN \\
\hline CHEMBL1977223 & 809128 & 4.7 & 5.1477 & TRN \\
\hline CHEMBL1982957 & 809128 & 7.4 & 6.5699 & TRN \\
\hline CHEMBL1236126 & 809128 & 4.7 & 4.8531 & TST \\
\hline CHEMBL1975138 & 809128 & 6.6 & 5.2859 & TRN \\
\hline CHEMBL424872 & 809128 & 4.7 & 4.3917 & TRN \\
\hline CHEMBL 2006836 & 809128 & 6.1 & 4.9802 & TST \\
\hline CHEMBL 2004419 & 809128 & 4.7 & 4.5962 & TRN \\
\hline CHEMBL412142 & 809128 & 4.7 & 5.0747 & TST \\
\hline CHEMBL1980704 & 809128 & 4.7 & 4.7274 & TST \\
\hline CHEMBL 2003271 & 809128 & 4.7 & 5.3109 & TRN \\
\hline CHEMBL 2004447 & 809128 & 4.7 & 4.5867 & TST \\
\hline CHEMBL1973860 & 809128 & 4.7 & 4.6385 & TRN \\
\hline CHEMBL1972489 & 809128 & 4.7 & 4.5747 & TRN \\
\hline CHEMBL 260135 & 809128 & 4.7 & 4.5948 & TRN \\
\hline CHEMBL1994074 & 809128 & 4.7 & 5.023 & TRN \\
\hline CHEMBL1992937 & 809128 & 4.7 & 5.3497 & TST \\
\hline CHEMBL1982610 & 809128 & 4.7 & 4.6672 & TST \\
\hline CHEMBL1999496 & 809128 & 4.7 & 4.8113 & TRN \\
\hline CHEMBL1988300 & 809128 & 4.7 & 6.1792 & TRN \\
\hline CHEMBL1986328 & 809128 & 4.7 & 5.1382 & TST \\
\hline CHEMBL95692 & 809128 & 4.7 & 4.4963 & TRN \\
\hline CHEMBL1090356 & 809128 & 6.7 & 6.2541 & TRN \\
\hline CHEMBL1976455 & 809128 & 6.1 & 5.0614 & TRN \\
\hline CHEMBL1982361 & 809128 & 4.7 & 4.9267 & TRN \\
\hline CHEMBL1999112 & 809128 & 4.7 & 5.2772 & TST \\
\hline CHEMBL2000801 & 809128 & 4.7 & 5.386 & TRN \\
\hline CHEMBL1682546 & 809128 & 4.7 & 4.5749 & TRN \\
\hline CHEMBL1991395 & 809128 & 4.7 & 4.4246 & TRN \\
\hline CHEMBL1969502 & 809128 & 6.6 & 6.3298 & TST \\
\hline CHEMBL1682553 & 809128 & 4.7 & 4.6974 & TRN \\
\hline CHEMBL1966514 & 809128 & 7.4 & 7.7821 & TRN \\
\hline CHEMBL1971430 & 809128 & 4.7 & 4.7492 & TRN \\
\hline CHEMBL1983963 & 809128 & 7.8 & 7.2224 & TRN \\
\hline CHEMBL1997764 & 809128 & 6.4 & 5.7791 & TRN \\
\hline CHEMBL1985092 & 809128 & 6.1 & 5.431 & TST \\
\hline CHEMBL1981410 & 809128 & 4.7 & 6.27 & TRN \\
\hline CHEMBL1970806 & 809128 & 4.7 & 4.3774 & TST \\
\hline CHEMBL1993722 & 809128 & 4.7 & 6.2157 & TRN \\
\hline CHEMBL1991434 & 809128 & 4.7 & $4.6930 e$ & 00000000005 \\
\hline CHEMBL1967544 & 809128 & 4.7 & 4.9992 & TRN \\
\hline CHEMBL1375640 & 809128 & 4.7 & 5.0997 & TST \\
\hline CHEMBL1979970 & 809128 & 4.7 & 4.583 & TRN \\
\hline CHEMBL 223367 & 809128 & 4.7 & 5.2466 & TST \\
\hline
\end{tabular}

TRN 


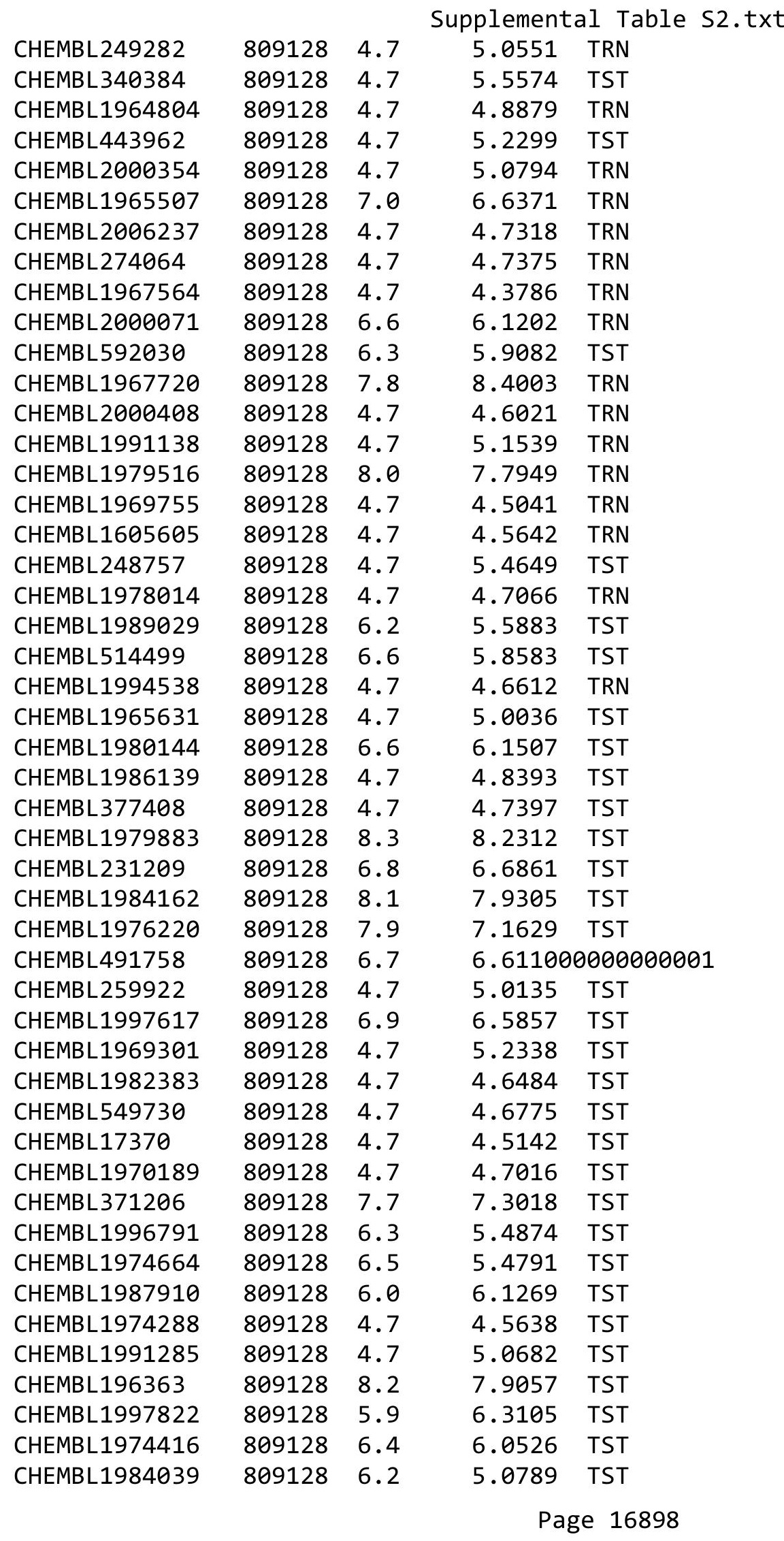




\begin{tabular}{|c|c|c|c|c|c|}
\hline \multicolumn{6}{|c|}{ Supplemental Table S2.txt } \\
\hline CHEMBL1997872 & 809128 & 4.7 & 5.2592 & TST & \\
\hline CHEMBL1966343 & 809128 & 4.7 & 5.0932 & TST & \\
\hline CHEMBL404367 & 809128 & 7.9 & 6.8154 & TST & \\
\hline CHEMBL 2153145 & 852360 & 4.0 & 4.8853 & TRN & \\
\hline CHEMBL 2153134 & 852360 & 7.1079 & 7.1933 & TRN & \\
\hline CHEMBL 2152982 & 852360 & 5.0691 & 4.563 & TRN & \\
\hline CHEMBL 2153137 & 852360 & 5.8153 & 5.5498 & TRN & \\
\hline CHEMBL 2152979 & 852360 & 4.0 & 4.4024 & TRN & \\
\hline CHEMBL 2152983 & 852360 & 5.0501 & 4.7395 & TST & \\
\hline CHEMBL 2153131 & 852360 & 6.9208 & 6.9034 & TRN & \\
\hline CHEMBL 2152998 & 852360 & 6.0177 & 6.3884 & TRN & \\
\hline CHEMBL 2153147 & 852360 & 4.0 & 4.0094 & TST & \\
\hline CHEMBL 2152984 & 852360 & 4.0 & 4.3946 & TST & \\
\hline CHEMBL 2152996 & 852360 & 5.6364 & 5.8764 & TRN & \\
\hline CHEMBL 2152995 & 852360 & 6.9586 & 6.5298 & TRN & \\
\hline CHEMBL 2153154 & 852360 & 6.585 & 6.3139 & TRN & \\
\hline CHEMBL 2152978 & 852360 & 5.3645 & 5.2906 & TRN & \\
\hline CHEMBL 2153123 & 852360 & 5.9172 & 5.6092 & TRN & \\
\hline CHEMBL 2152980 & 852360 & 4.0 & 4.2728 & TRN & \\
\hline CHEMBL 2152986 & 852360 & 5.0635 & 4.3507 & TST & \\
\hline CHEMBL 2153148 & 852360 & 4.0 & 4.0545 & TRN & \\
\hline CHEMBL 2152997 & 852360 & 5.5086 & 5.4117 & TRN & \\
\hline CHEMBL 2152975 & 852360 & 5.5784 & 5.3969 & TRN & \\
\hline CHEMBL 2153127 & 852360 & 5.9208 & 5.8009 & TST & \\
\hline CHEMBL 2153130 & 852360 & 5.0953 & 5.0683 & TRN & \\
\hline CHEMBL 2153135 & 852360 & 9.0 & 9.2358 & TRN & \\
\hline CHEMBL 2153151 & 852360 & 5.8477 & 6.1979 & TRN & \\
\hline CHEMBL 2153140 & 852360 & 4.0 & 3.9336 & TRN & \\
\hline CHEMBL2153143 & 852360 & 4.0 & 4.5477 & TRN & \\
\hline CHEMBL 2153139 & 852360 & 5.4237 & 5.1454 & TRN & \\
\hline CHEMBL 2153156 & 852360 & 5.3757 & 6.4619 & TST & \\
\hline CHEMBL 2153153 & 852360 & 6.5686 & 6.46299 & 9999999999 & TRN \\
\hline CHEMBL 2152985 & 852360 & 4.0 & 3.7785 & TRN & \\
\hline CHEMBL 2152974 & 852360 & 5.061 & 4.5867 & TRN & \\
\hline CHEMBL 2153152 & 852360 & 5.1593 & 5.0846 & TRN & \\
\hline CHEMBL2152989 & 852360 & 4.0 & 4.3617 & TRN & \\
\hline CHEMBL 2153142 & 852360 & 4.0 & 4.2291 & TRN & \\
\hline CHEMBL 2153150 & 852360 & 4.0 & 3.9177 & TRN & \\
\hline CHEMBL 2152992 & 852360 & 5.6596 & 6.7307 & TRN & \\
\hline CHEMBL 2153146 & 852360 & 5.279 & 5.1914 & TST & \\
\hline CHEMBL 2152988 & 852360 & 5.2 & 4.7308 & TRN & \\
\hline CHEMBL 2153129 & 852360 & 5.8356 & 6.1716 & TRN & \\
\hline CHEMBL 2153144 & 852360 & 4.0 & 4.1213 & TRN & \\
\hline CHEMBL 2152976 & 852360 & 4.0 & 3.9365 & TRN & \\
\hline CHEMBL 2152977 & 852360 & 4.0 & 3.6576 & TST & \\
\hline CHEMBL 2152993 & 852360 & 4.0 & 4.7022 & TST & \\
\hline CHEMBL 2153126 & 852360 & 6.2366 & 6.0942 & TST & \\
\hline CHEMBL67 & 852360 & 9.0 & 9.4982 & TST & \\
\hline
\end{tabular}


Supplemental Table S2.txt

\begin{tabular}{|c|c|c|c|c|c|}
\hline CHEMBL 2152994 & 852360 & 6.0362 & 6.3579 & TRN & \\
\hline CHEMBL 2153122 & 852360 & 6.1675 & 5.7296 & TRN & \\
\hline CHEMBL2153138 & 852360 & 6.0506 & 5.6018 & TRN & \\
\hline CHEMBL 2153133 & 852360 & 7.1427 & 7.5019 & TRN & \\
\hline CHEMBL2153132 & 852360 & 5.2358 & 5.9001 & TRN & \\
\hline CHEMBL2153141 & 852360 & 5.9788 & 5.6215 & TRN & \\
\hline CHEMBL 2152990 & 852360 & 5.8697 & 5.4862 & TST & \\
\hline CHEMBL2153155 & 852360 & 9.0 & 7.7756 & TRN & \\
\hline CHEMBL2152991 & 852360 & 4.0 & 5.6569 & TST & \\
\hline CHEMBL 2153124 & 852360 & 5.8182 & 5.7242 & TRN & \\
\hline CHEMBL2153149 & 852360 & 5.5901 & 5.4522 & TRN & \\
\hline CHEMBL 2153136 & 852360 & 6.0706 & 7.0885 & TST & \\
\hline CHEMBL2153128 & 852360 & 5.7305 & 5.6038 & TRN & \\
\hline CHEMBL 2152987 & 852360 & 4.0 & 4.3862 & TST & \\
\hline CHEMBL 2152981 & 852360 & 4.0 & 4.5766 & TST & \\
\hline CHEMBL 2153125 & 852360 & 6.0223 & 5.95200 & 0000000001 & TRN \\
\hline CHEMBL1721811 & 737159 & 3.6021 & 4.2175 & TST & \\
\hline CHEMBL1722247 & 737159 & 5.4613 & 5.3429 & TRN & \\
\hline CHEMBL1722923 & 737159 & 3.6021 & 3.3763 & TRN & \\
\hline CHEMBL45152 & 737159 & 5.9544 & 5.6604 & TRN & \\
\hline CHEMBL1709485 & 737159 & 5.2668 & 4.6881 & TRN & \\
\hline CHEMBL1698123 & 737159 & 5.721 & 5.48600 & 0000000001 & TRN \\
\hline CHEMBL1699039 & 737159 & 5.6326 & 5.6338 & TRN & \\
\hline CHEMBL1702793 & 737159 & 4.9724 & 4.5882 & TRN & \\
\hline CHEMBL1722696 & 737159 & 3.6021 & 3.1001 & TRN & \\
\hline CHEMBL309708 & 737159 & 3.6021 & 3.5482 & TRN & \\
\hline CHEMBL1713789 & 737159 & 3.6021 & 3.7726 & TRN & \\
\hline CHEMBL1708338 & 737159 & 3.6021 & 4.416 & TST & \\
\hline CHEMBL1729965 & 737159 & 5.7055 & 5.4195 & TRN & \\
\hline CHEMBL1702206 & 737159 & 3.6021 & 3.6836 & TRN & \\
\hline CHEMBL1727870 & 737159 & 3.6021 & 4.2865 & TRN & \\
\hline CHEMBL316658 & 737159 & 5.644 & 4.7884 & TRN & \\
\hline CHEMBL1711231 & 737159 & 5.0255 & 4.4366 & TRN & \\
\hline CHEMBL1708070 & 737159 & 5.1372 & 4.9506 & TRN & \\
\hline CHEMBL1732072 & 737159 & 3.6021 & 4.3427 & TST & \\
\hline CHEMBL1706548 & 737159 & 5.4067 & 5.3288 & TRN & \\
\hline CHEMBL1736289 & 737159 & 5.7399 & 5.8756 & TRN & \\
\hline CHEMBL251017 & 737159 & 3.6021 & 3.6355 & TRN & \\
\hline CHEMBL1710126 & 737159 & 5.3386 & 5.2041 & TRN & \\
\hline CHEMBL1707558 & 737159 & 3.6021 & 3.8686 & TRN & \\
\hline CHEMBL1707566 & 737159 & 3.6021 & 3.5052 & TRN & \\
\hline CHEMBL1381119 & 737159 & 3.6021 & 4.0545 & TRN & \\
\hline CHEMBL1718538 & 737159 & 3.6021 & 4.9695 & TST & \\
\hline CHEMBL1701237 & 737159 & 4.8608 & 4.6343 & TRN & \\
\hline CHEMBL1731514 & 737159 & 5.1423 & 4.7697 & TRN & \\
\hline CHEMBL1729861 & 737159 & 3.6021 & 3.6019 & TRN & \\
\hline CHEMBL1724924 & 737159 & 3.6021 & 3.8682 & TRN & \\
\hline CHEMBL1703189 & 737159 & 3.6021 & 4.2023 & TRN & \\
\hline
\end{tabular}


Supplemental Table S2.txt

\begin{tabular}{|c|c|c|c|c|c|}
\hline CHEMBL1712985 & 737159 & 5.3204 & 5.2598 & TRN & \\
\hline CHEMBL1718246 & 737159 & 3.6021 & 3.6412 & TST & \\
\hline CHEMBL1709419 & 737159 & 5.2055 & 5.3236 & TRN & \\
\hline CHEMBL1725042 & 737159 & 3.6021 & 4.2976 & TRN & \\
\hline CHEMBL1698461 & 737159 & 3.6021 & 3.9335 & TRN & \\
\hline CHEMBL1718987 & 737159 & 5.2636 & 5.673999 & 79999999995 & TRN \\
\hline CHEMBL1576159 & 737159 & 3.6021 & 4.2492 & TRN & \\
\hline CHEMBL1719870 & 737159 & 3.6021 & 4.1891 & TST & \\
\hline CHEMBL570468 & 737159 & 3.6021 & 3.6908 & TST & \\
\hline CHEMBL1709708 & 737159 & 3.6021 & 3.1672 & TRN & \\
\hline CHEMBL1723583 & 737159 & 3.6021 & 3.7033 & TRN & \\
\hline CHEMBL1336959 & 737159 & 5.5777 & 5.8666 & TRN & \\
\hline CHEMBL1703924 & 737159 & 4.8473 & 4.1909 & TRN & \\
\hline CHEMBL1721044 & 737159 & 3.6021 & 3.7697 & TRN & \\
\hline CHEMBL401412 & 737159 & 3.6021 & 3.3267 & TRN & \\
\hline CHEMBL1725906 & 737159 & 5.2496 & 4.9611 & TRN & \\
\hline CHEMBL1712440 & 737159 & 5.6509 & 5.4991 & TRN & \\
\hline CHEMBL1720128 & 737159 & 5.2857 & 5.2237 & TRN & \\
\hline CHEMBL401381 & 737159 & 3.6021 & 3.5654 & TRN & \\
\hline CHEMBL1720891 & 737159 & 5.55399 & 999999999 & 5.3219 & TRN \\
\hline CHEMBL1727551 & 737159 & 3.6021 & 4.3816 & TST & \\
\hline CHEMBL1702981 & 737159 & 5.6459 & 5.3767 & TRN & \\
\hline CHEMBL1708889 & 737159 & 3.6021 & 3.9672 & TRN & \\
\hline CHEMBL1735874 & 737159 & 5.4921 & 5.3414 & TRN & \\
\hline CHEMBL1712352 & 737159 & 3.6021 & 4.2008 & TRN & \\
\hline CHEMBL1710662 & 737159 & 5.6215 & 5.6539 & TRN & \\
\hline CHEMBL1711403 & 737159 & 5.4423 & 6.1846 & TRN & \\
\hline CHEMBL1730972 & 737159 & 3.6021 & 4.1389 & TRN & \\
\hline CHEMBL1705000 & 737159 & 5.3316 & 5.3207 & TRN & \\
\hline CHEMBL1733057 & 737159 & 3.6021 & 4.056999 & 99999999995 & TRN \\
\hline CHEMBL1704043 & 737159 & 3.6021 & 3.7619 & TRN & \\
\hline CHEMBL1721135 & 737159 & 5.3528 & 4.8656 & TRN & \\
\hline CHEMBL1703831 & 737159 & 5.3625 & 5.1363 & TRN & \\
\hline CHEMBL1719203 & 737159 & 5.5167 & 4.905 & TRN & \\
\hline CHEMBL1721588 & 737159 & 5.5236 & 5.5597 & TRN & \\
\hline CHEMBL1728599 & 737159 & 3.6021 & 3.4454 & TRN & \\
\hline CHEMBL1728963 & 737159 & 3.6021 & 4.0936 & TRN & \\
\hline CHEMBL1703200 & 737159 & 5.6364 & 5.5758 & TRN & \\
\hline CHEMBL1708578 & 737159 & 5.2366 & 5.0724 & TRN & \\
\hline CHEMBL1698309 & 737159 & 3.6021 & 3.3595 & TRN & \\
\hline CHEMBL1722317 & 737159 & 3.6021 & 4.8817 & TRN & \\
\hline CHEMBL1718927 & 737159 & 5.6737 & 4.8371 & TRN & \\
\hline CHEMBL1735472 & 737159 & 4.8109 & 4.2903 & TRN & \\
\hline CHEMBL1339149 & 737159 & 5.1175 & 5.3869 & TRN & \\
\hline CHEMBL1723387 & 737159 & 4.7466 & 4.2757 & TRN & \\
\hline CHEMBL1715916 & 737159 & 3.6021 & 4.8529 & TST & \\
\hline CHEMBL1706259 & 737159 & 3.6021 & 3.5761 & TST & \\
\hline CHEMBL1732137 & 737159 & 3.6021 & 4.0173 & TST & \\
\hline
\end{tabular}




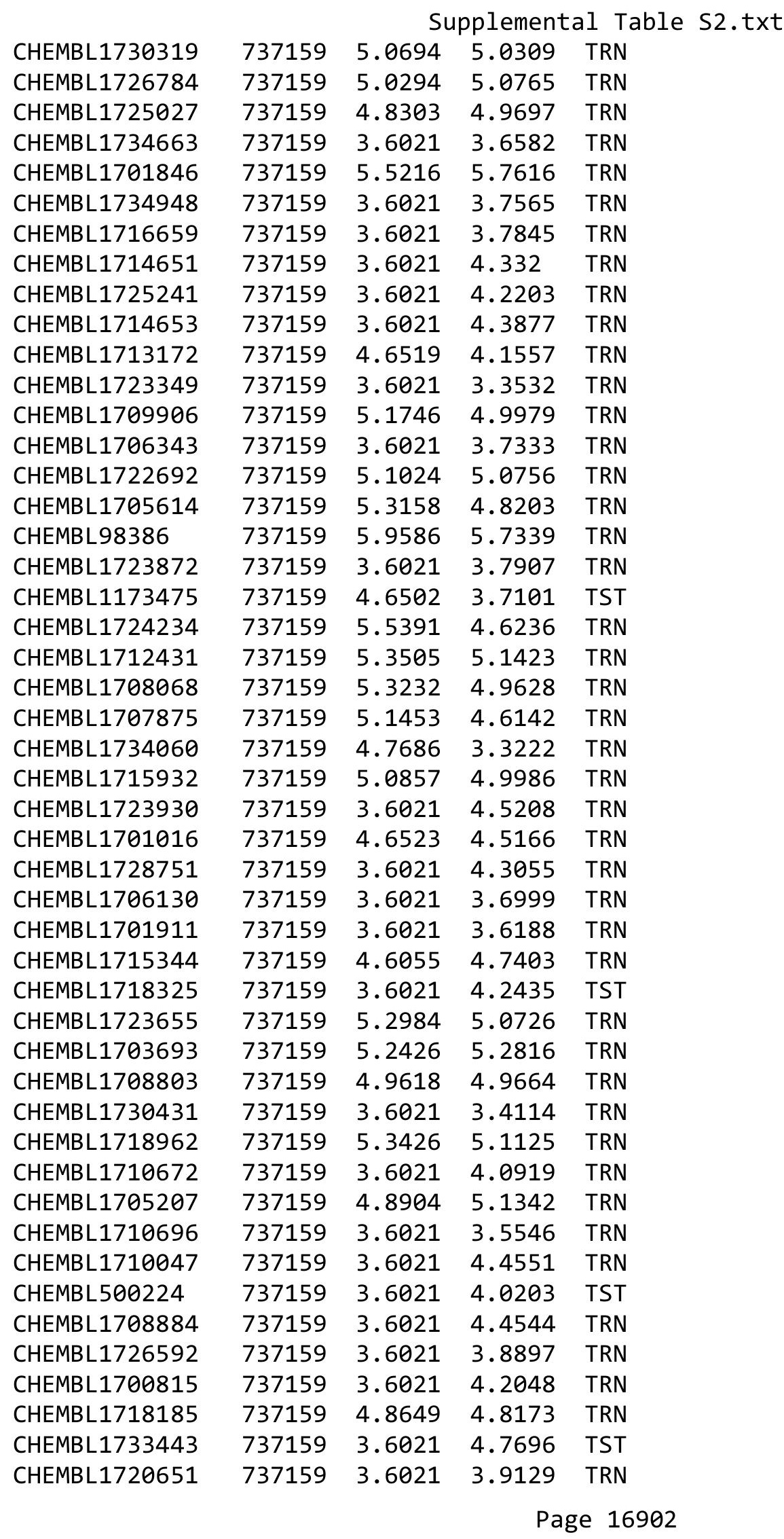


Supplemental Table S2.txt

\begin{tabular}{|c|c|c|c|c|c|}
\hline CHEMBL1715092 & 737159 & 3.6021 & 3.2731 & TRN & \\
\hline CHEMBL1703977 & 737159 & 3.6021 & \multicolumn{2}{|c|}{ 3. 2939999999999996} & TRN \\
\hline CHEMBL1722265 & 737159 & 3.6021 & 3.1138 & TRN & \\
\hline CHEMBL1701021 & 737159 & 4.9348 & 4.3807 & TRN & \\
\hline CHEMBL1723607 & 737159 & 3.6021 & 5.5514 & TST & \\
\hline CHEMBL1707071 & 737159 & 3.6021 & 3.3137 & TRN & \\
\hline CHEMBL1710337 & 737159 & 5.3813 & 4.948 & TST & \\
\hline CHEMBL1706338 & 737159 & 3.6021 & 5.6159 & TST & \\
\hline CHEMBL1715514 & 737159 & 3.6021 & 4.2352 & TRN & \\
\hline CHEMBL1717790 & 737159 & 3.6021 & 3.9806 & TRN & \\
\hline CHEMBL1728855 & 737159 & 3.6021 & 4.3145 & TST & \\
\hline CHEMBL1730116 & 737159 & 5.7143 & 5.4322 & TST & \\
\hline CHEMBL1716371 & 737159 & 3.6021 & 5.9019 & TST & \\
\hline CHEMBL1310318 & 737159 & 5.3188 & 5.6005 & TST & \\
\hline CHEMBL1703815 & 737159 & 3.6021 & 3.7879 & TRN & \\
\hline CHEMBL1704189 & 737159 & 3.6021 & 3.588 & TST & \\
\hline CHEMBL1723064 & 737159 & 4.7042 & 4.7154 & TST & \\
\hline CHEMBL1717968 & 737159 & 5.2388 & 4.8659 & TRN & \\
\hline CHEMBL1702372 & 737159 & 6.0107 & 5.7718 & TRN & \\
\hline CHEMBL1703503 & 737159 & 5.1765 & 5.3724 & TST & \\
\hline CHEMBL1736501 & 737159 & 3.6021 & 3.9491 & TRN & \\
\hline CHEMBL483542 & 737159 & 3.6021 & 3.3608 & TST & \\
\hline CHEMBL1717420 & 737159 & 5.3215 & 5.4585 & TST & \\
\hline CHEMBL1721948 & 737159 & 3.6021 & 3.6057 & TRN & \\
\hline CHEMBL1406130 & 737159 & 5.9872 & 5.7226 & TST & \\
\hline CHEMBL1712518 & 737159 & 3.6021 & 4.3365 & TRN & \\
\hline CHEMBL1729838 & 737159 & 3.6021 & \multicolumn{2}{|c|}{3.4810000000000003} & TRN \\
\hline CHEMBL1710477 & 737159 & 5.1569 & 4.8909 & TST & \\
\hline CHEMBL 327502 & 737159 & 5.2716 & 5.4748 & TST & \\
\hline CHEMBL212924 & 737159 & 3.6021 & 2.0958 & TST & \\
\hline CHEMBL1704485 & 737159 & 3.6021 & 3.1776 & TRN & \\
\hline CHEMBL1723596 & 737159 & 4.9021 & 4.7246 & TST & \\
\hline CHEMBL1711919 & 737159 & 5.5986 & 5.6096 & TST & \\
\hline CHEMBL1699355 & 737159 & 5.2984 & 5.275 & TST & \\
\hline CHEMBL99594 & 737159 & 4.8692 & 4.0312 & TST & \\
\hline CHEMBL1730008 & 737159 & 3.6021 & 4.2715 & TRN & \\
\hline CHEMBL1712414 & 737159 & 4.6021 & 3.8074 & TRN & \\
\hline CHEMBL1734741 & 737159 & 3.6021 & 3.7228 & TRN & \\
\hline CHEMBL1722873 & 737159 & 3.6021 & 3.6019 & TRN & \\
\hline CHEMBL1699712 & 737159 & 3.6021 & 4.0866 & TRN & \\
\hline CHEMBL1702711 & 737159 & 5.5272 & 5.1996 & TST & \\
\hline CHEMBL1703497 & 737159 & 3.6021 & 4.2458 & TST & \\
\hline CHEMBL1707676 & 737159 & 4.6836 & 4.5574 & TRN & \\
\hline CHEMBL1703786 & 737159 & 3.6021 & 4.5871 & TST & \\
\hline CHEMBL489895 & 737159 & 3.6021 & 4.4784 & TST & \\
\hline CHEMBL1704282 & 737159 & 5.0895 & 4.4636 & TST & \\
\hline CHEMBL1699568 & 737159 & 4.6021 & 4.4164 & TRN & \\
\hline CHEMBL1710798 & 737159 & 5.2 & 5.0405 & TST & \\
\hline
\end{tabular}


Supplemental Table S2.txt

\begin{tabular}{|c|c|c|c|c|c|}
\hline CHEMBL 8441 & 737159 & 3.6021 & 3.6922 & TST & \\
\hline CHEMBL1715540 & 737159 & 4.9566 & 4.9099 & TST & \\
\hline CHEMBL1725228 & 737159 & 5.2018 & 4.7325 & TST & \\
\hline CHEMBL1710725 & 737159 & 5.1398 & 5.0968 & TRN & \\
\hline CHEMBL1700363 & 737159 & 5.1041 & 5.16 & TST & \\
\hline CHEMBL1708051 & 737159 & 3.6021 & 4.5915 & TST & \\
\hline CHEMBL1711618 & 737159 & 5.1589 & 5.0776 & TRN & \\
\hline CHEMBL1725167 & 737159 & 4.9863 & 4.6249 & TRN & \\
\hline CHEMBL1714104 & 737159 & 5.8659 & 5.2398 & TRN & \\
\hline CHEMBL1717273 & 737159 & 3.6021 & 3.8684 & TRN & \\
\hline CHEMBL1708749 & 737159 & 3.6021 & 5.3874 & TST & \\
\hline CHEMBL1720981 & 737159 & 3.6021 & 3.6306 & TRN & \\
\hline CHEMBL1644204 & 701282 & 8.57 & 8.6511 & TRN & \\
\hline CHEMBL1644205 & 701282 & 5.77 & 5.8739 & TRN & \\
\hline CHEMBL1644206 & 701282 & 10.0 & 10.0104 & TRN & \\
\hline CHEMBL1644207 & 701282 & 10.7 & 10.6716 & TRN & \\
\hline CHEMBL1644208 & 701282 & 9.3 & 9.2556 & TRN & \\
\hline CHEMBL1644209 & 701282 & 8.15 & 8.2476 & TST & \\
\hline CHEMBL1644210 & 701282 & 8.3 & 8.363999 & 9999999999 & TST \\
\hline CHEMBL1644211 & 701282 & 9.4 & 9.6607 & TST & \\
\hline CHEMBL1644212 & 701282 & 9.3 & 8.4754 & TST & \\
\hline CHEMBL1644213 & 701282 & 9.52 & 9.433 & TST & \\
\hline CHEMBL1644214 & 701282 & 10.3 & 8.507 & TST & \\
\hline CHEMBL1644215 & 701282 & 7.42 & 8.2595 & TST & \\
\hline CHEMBL1644216 & 701282 & 8.44 & 7.3903 & TST & \\
\hline CHEMBL1644217 & 701282 & 9.1 & 8.9274 & TST & \\
\hline CHEMBL1644218 & 701282 & 6.98 & 6.9834 & TRN & \\
\hline CHEMBL1644219 & 701282 & 6.61 & 6.6091 & TRN & \\
\hline CHEMBL1644220 & 701282 & 6.26 & 6.2168 & TRN & \\
\hline CHEMBL1644221 & 701282 & 5.97 & 5.9194 & TRN & \\
\hline CHEMBL1644222 & 701282 & 7.49 & 7.5688 & TRN & \\
\hline CHEMBL1644223 & 701282 & 7.39 & 7.4254 & TRN & \\
\hline CHEMBL1644224 & 701282 & 9.05 & 9.0619 & TRN & \\
\hline CHEMBL1644225 & 701282 & 8.22 & 8.1595 & TRN & \\
\hline CHEMBL1644226 & 701282 & 8.12 & 8.0654 & TRN & \\
\hline CHEMBL1644227 & 701282 & 9.4 & 9.3986 & TRN & \\
\hline CHEMBL1641628 & 701282 & 7.59 & 7.7004 & TRN & \\
\hline CHEMBL1644228 & 701282 & 8.0 & 7.9007 & TRN & \\
\hline CHEMBL1644229 & 701282 & 7.19 & 7.1918 & TRN & \\
\hline CHEMBL1644230 & 701282 & 8.1 & 8.1606 & TRN & \\
\hline CHEMBL1644231 & 701282 & 7.92 & 6.9139 & TST & \\
\hline CHEMBL1644232 & 701282 & 8.3 & 8.338 & TRN & \\
\hline CHEMBL1644233 & 701282 & 8.22 & 8.2096 & TRN & \\
\hline CHEMBL1644234 & 701282 & 8.11 & 8.0997 & TRN & \\
\hline CHEMBL1644235 & 701282 & 8.59 & 8.5954 & TRN & \\
\hline CHEMBL1644236 & 701282 & 7.26 & 7.2819 & TRN & \\
\hline CHEMBL1644237 & 701282 & 7.77 & 7.7678 & TRN & \\
\hline CHEMBL1644238 & 701282 & 8.54 & 8.5732 & TRN & \\
\hline
\end{tabular}




\begin{tabular}{|c|c|c|c|c|}
\hline \multicolumn{5}{|c|}{ Supplemental Table S2.txt } \\
\hline CHEMBL1644239 & 701282 & 8.09 & 8.0272 & TRN \\
\hline CHEMBL1644240 & 701282 & 8.42 & 8.5113 & TRN \\
\hline CHEMBL1644241 & 701282 & 7.64 & 7.7892 & TST \\
\hline CHEMBL1644242 & 701282 & 6.67 & 6.6267 & TRN \\
\hline CHEMBL1644243 & 701282 & 6.18 & 6.4034 & TST \\
\hline CHEMBL1644244 & 701282 & 6.66 & 6.5635 & TRN \\
\hline CHEMBL1644245 & 701282 & 9.52 & 9.4563 & TST \\
\hline CHEMBL1644246 & 701282 & 7.85 & 7.9365 & TST \\
\hline CHEMBL1644247 & 701282 & 9.4 & 9.3701 & TRN \\
\hline CHEMBL1644248 & 701282 & 8.35 & 8.2702 & TRN \\
\hline CHEMBL1644249 & 701282 & 7.38 & 7.3858 & TRN \\
\hline CHEMBL1644250 & 701282 & 7.89 & 8.0178 & TRN \\
\hline CHEMBL1644251 & 701282 & 7.36 & 7.3369 & TRN \\
\hline CHEMBL1644252 & 701282 & 8.15 & 8.0706 & TRN \\
\hline CHEMBL1644253 & 701282 & 9.3 & 9.1974 & TRN \\
\hline CHEMBL1644254 & 701282 & 8.2 & 8.3196 & TRN \\
\hline CHEMBL1644255 & 701282 & 8.64 & 8.4901 & TRN \\
\hline CHEMBL1644256 & 701282 & 8.59 & 8.5751 & TRN \\
\hline CHEMBL1644257 & 701282 & 7.89 & 7.7783 & TRN \\
\hline CHEMBL1644258 & 701282 & 8.14 & 8.247 & TRN \\
\hline CHEMBL1644259 & 701282 & 7.96 & 7.9625 & TRN \\
\hline CHEMBL1644260 & 701282 & 8.64 & 8.7134 & TRN \\
\hline CHEMBL1644261 & 701282 & 8.29 & 8.3665 & TRN \\
\hline CHEMBL1644262 & 701282 & 6.61 & 8.3847 & TST \\
\hline CHEMBL1398855 & 1301419 & 5.0752 & 4.7111 & TRN \\
\hline CHEMBL1571034 & 1301419 & 6.5498 & 4.8931 & TST \\
\hline CHEMBL1271266 & 1301419 & 5.7447 & 4.8551 & TRN \\
\hline CHEMBL1737002 & 1301419 & 6.1267 & 5.019 & TRN \\
\hline CHEMBL1700468 & 1301419 & 3.699 & 3.8538 & TRN \\
\hline CHEMBL1723955 & 1301419 & 5.4225 & 5.2553 & TRN \\
\hline CHEMBL1606907 & 1301419 & 4.8589 & 5.1558 & TRN \\
\hline CHEMBL1503190 & 1301419 & 3.699 & 4.4476 & TRN \\
\hline CHEMBL1408320 & 1301419 & 5.083 & 5.0756 & TRN \\
\hline CHEMBL1309811 & 1301419 & 3.699 & 3.6369 & TRN \\
\hline CHEMBL3198784 & 1301419 & 5.7282 & 4.8459 & TRN \\
\hline CHEMBL1558213 & 1301419 & 4.7951 & 3.8396 & TST \\
\hline CHEMBL 1525715 & 1301419 & 3.699 & 3.909 & TRN \\
\hline CHEMBL1432707 & 1301419 & 6.3904 & 5.6257 & TRN \\
\hline CHEMBL1307247 & 1301419 & 3.699 & 4.1301 & TRN \\
\hline CHEMBL1502708 & 1301419 & 3.699 & 3.6788 & TRN \\
\hline CHEMBL1331791 & 1301419 & 5.1713 & 4.2285 & TRN \\
\hline CHEMBL1347107 & 1301419 & 4.7501 & 4.0911 & TST \\
\hline CHEMBL607979 & 1301419 & 6.3904 & 5.6039 & TRN \\
\hline CHEMBL1410602 & 1301419 & 3.699 & 4.8283 & TRN \\
\hline CHEMBL1558296 & 1301419 & 3.699 & 3.3842 & TRN \\
\hline CHEMBL3186541 & 1301419 & 5.3979 & 5.442 & TRN \\
\hline CHEMBL3189151 & 1301419 & 5.1046 & 5.7467 & TRN \\
\hline CHEMBL1543835 & 1301419 & 5.341 & 4.7323 & TRN \\
\hline
\end{tabular}


Supplemental Table S2.txt

\begin{tabular}{|c|c|c|c|c|}
\hline CHEMBL1309833 & 1301419 & 4.8041 & 3.9347 & TRN \\
\hline CHEMBL1457845 & 1301419 & 4.9978 & 4.8301 & TRN \\
\hline CHEMBL3197600 & 1301419 & 3.699 & 5.0078 & TRN \\
\hline CHEMBL1448671 & 1301419 & 3.699 & 4.3067 & TRN \\
\hline CHEMBL1528308 & 1301419 & 5.0975 & 4.6875 & TST \\
\hline CHEMBL 2143066 & 1301419 & 3.699 & 3.8016 & TRN \\
\hline CHEMBL1542895 & 1301419 & 3.699 & 3.608 & TRN \\
\hline CHEMBL1456440 & 1301419 & 5.3363 & 5.4094 & TRN \\
\hline CHEMBL1492667 & 1301419 & 3.699 & 4.4171 & TRN \\
\hline CHEMBL1323428 & 1301419 & 4.9303 & 5.0859 & TRN \\
\hline CHEMBL1334809 & 1301419 & 4.8002 & 3.8775 & TRN \\
\hline CHEMBL1599173 & 1301419 & 4.8993 & 4.5856 & TRN \\
\hline CHEMBL1399113 & 1301419 & 6.4647 & 6.3961 & TRN \\
\hline CHEMBL1999630 & 1301419 & 6.9318 & 6.1309 & TRN \\
\hline CHEMBL601070 & 1301419 & 3.699 & 3.8951 & TRN \\
\hline CHEMBL1463626 & 1301419 & 4.7222 & 5.4076 & TRN \\
\hline CHEMBL1469728 & 1301419 & 4.8416 & 4.563 & TRN \\
\hline CHEMBL483206 & 1301419 & 4.8884 & 5.0053 & TST \\
\hline CHEMBL1335687 & 1301419 & 4.7428 & 4.7935 & TRN \\
\hline CHEMBL1451772 & 1301419 & 5.2993 & 5.7973 & TRN \\
\hline CHEMBL3195409 & 1301419 & 4.9062 & 5.1824 & TRN \\
\hline CHEMBL1340285 & 1301419 & 4.8508 & 5.1469 & TRN \\
\hline CHEMBL1996376 & 1301419 & 5.6216 & 5.5291 & TRN \\
\hline CHEMBL 3189845 & 1301419 & 5.209 & 5.8646 & TRN \\
\hline CHEMBL584225 & 1301419 & 3.699 & 3.9952 & TST \\
\hline CHEMBL3190880 & 1301419 & 6.58 & 6.0425 & TRN \\
\hline CHEMBL1355280 & 1301419 & 5.2321 & 4.3727 & TRN \\
\hline CHEMBL1883935 & 1301419 & 3.699 & 3.569 & TRN \\
\hline CHEMBL1529471 & 1301419 & 5.0878 & 4.8918 & TRN \\
\hline CHEMBL1385413 & 1301419 & 3.699 & 4.4227 & TRN \\
\hline CHEMBL1417216 & 1301419 & 5.1192 & 5.2947 & TST \\
\hline CHEMBL1429639 & 1301419 & 3.699 & 4.4062 & TRN \\
\hline CHEMBL1443822 & 1301419 & 3.699 & 4.2586 & TRN \\
\hline CHEMBL1462779 & 1301419 & 3.699 & 4.07 & TRN \\
\hline CHEMBL1308633 & 1301419 & 5.0088 & 4.9717 & TRN \\
\hline CHEMBL1564810 & 1301419 & 5.0395 & 4.279 & TRN \\
\hline CHEMBL1482638 & 1301419 & 5.9355 & 4.539 & TST \\
\hline CHEMBL560919 & 1301419 & 3.699 & 4.4611 & TRN \\
\hline CHEMBL1478755 & 1301419 & 4.9326 & 4.8569 & TRN \\
\hline CHEMBL1708045 & 1301419 & 4.7535 & 4.6686 & TRN \\
\hline CHEMBL1571625 & 1301419 & 5.3809 & 4.3836 & TST \\
\hline CHEMBL1523317 & 1301419 & 5.3215 & 4.7277 & TRN \\
\hline CHEMBL3196993 & 1301419 & 3.699 & 5.13399 & 99999999995 \\
\hline CHEMBL1522218 & 1301419 & 3.699 & 5.2095 & TRN \\
\hline CHEMBL1502410 & 1301419 & 5.58 & 5.2694 & TRN \\
\hline CHEMBL1986829 & 1301419 & 3.699 & 4.0512 & TST \\
\hline CHEMBL1417929 & 1301419 & 3.699 & 4.989 & TRN \\
\hline CHEMBL1472327 & 1301419 & 4.7865 & 4.6441 & TST \\
\hline
\end{tabular}




$$
\text { Supplemental Table S2.txt }
$$

\begin{tabular}{|c|c|c|c|c|}
\hline CHEMBL 2000196 & 1301419 & 6.2612 & 5.5681 & TRN \\
\hline CHEMBL1307403 & 1301419 & 3.699 & 4.2187 & TST \\
\hline CHEMBL1378634 & 1301419 & 5.4698 & 5.7078 & TRN \\
\hline CHEMBL1417815 & 1301419 & 5.3716 & \multicolumn{2}{|c|}{5.2410000000000005} \\
\hline CHEMBL220259 & 1301419 & 5.1878 & 4.9044 & TRN \\
\hline CHEMBL1716028 & 1301419 & 5.6003 & 5.1676 & TRN \\
\hline CHEMBL1371887 & 1301419 & 3.699 & 3.4166 & TRN \\
\hline CHEMBL1561729 & 1301419 & 5.2314 & 5.08 & TRN \\
\hline CHEMBL1300776 & 1301419 & 3.699 & 4.1708 & TST \\
\hline CHEMBL585502 & 1301419 & 4.7597 & 5.1673 & TRN \\
\hline CHEMBL1500934 & 1301419 & 4.7181 & 4.5354 & TRN \\
\hline CHEMBL1478597 & 1301419 & 4.7577 & 4.2345 & TRN \\
\hline CHEMBL3191063 & 1301419 & 5.8729 & 5.0739 & TRN \\
\hline CHEMBL1539235 & 1301419 & 4.9183 & 5.1144 & TST \\
\hline CHEMBL1304357 & 1301419 & 3.699 & 3.7945 & TST \\
\hline CHEMBL1529285 & 1301419 & 4.9931 & 4.2186 & TRN \\
\hline CHEMBL1381243 & 1301419 & 5.1085 & 5.2237 & TRN \\
\hline CHEMBL1535216 & 1301419 & 3.699 & 4.1179 & TRN \\
\hline CHEMBL1423662 & 1301419 & 5.4647 & 4.4892 & TRN \\
\hline CHEMBL1459294 & 1301419 & 5.5157 & 4.6232 & TRN \\
\hline CHEMBL1418124 & 1301419 & 5.0467 & 4.7862 & TRN \\
\hline CHEMBL1327934 & 1301419 & 6.3316 & 5.1436 & TRN \\
\hline CHEMBL1489925 & 1301419 & 4.806 & 4.6087 & TST \\
\hline CHEMBL1402628 & 1301419 & 5.209 & 5.4357 & TRN \\
\hline CHEMBL1505549 & 1301419 & 3.699 & 4.0947 & TRN \\
\hline CHEMBL1604189 & 1301419 & 5.1739 & 5.1251 & TRN \\
\hline CHEMBL1510317 & 1301419 & 5.0039 & 4.9964 & TST \\
\hline CHEMBL1597938 & 1301419 & 3.699 & 4.4842 & TST \\
\hline CHEMBL1424694 & 1301419 & 6.1427 & 5.499 & TRN \\
\hline CHEMBL1440160 & 1301419 & 5.2874 & 5.3093 & TRN \\
\hline CHEMBL1706454 & 1301419 & 5.3526 & 5.5644 & TRN \\
\hline CHEMBL1343539 & 1301419 & 6.4461 & 5.9776 & TRN \\
\hline CHEMBL60824 & 1301419 & 5.7595 & 5.7963 & TRN \\
\hline CHEMBL1490436 & 1301419 & 5.3298 & 5.0094 & TRN \\
\hline CHEMBL1966984 & 1301419 & 5.2652 & 5.2846 & TRN \\
\hline CHEMBL1708493 & 1301419 & 5.4522 & 5.1644 & TRN \\
\hline CHEMBL1328964 & 1301419 & 3.699 & 3.8505 & TRN \\
\hline CHEMBL3192822 & 1301419 & 3.699 & 3.7514 & TRN \\
\hline CHEMBL3195145 & 1301419 & 3.699 & 4.2484 & TRN \\
\hline CHEMBL1342821 & 1301419 & 4.9776 & 4.2177 & TRN \\
\hline CHEMBL1387292 & 1301419 & 4.8821 & 4.8829 & TRN \\
\hline CHEMBL1459149 & 1301419 & 3.699 & 4.6318 & TST \\
\hline CHEMBL1594286 & 1301419 & 3.699 & 4.0788 & TRN \\
\hline CHEMBL1877805 & 1301419 & 3.699 & 4.8579 & TST \\
\hline CHEMBL1414834 & 1301419 & 3.699 & 4.5951 & TRN \\
\hline CHEMBL417727 & 1301419 & 6.5638 & 6.0208 & TRN \\
\hline CHEMBL1335833 & 1301419 & 4.769 & 4.3481 & TST \\
\hline CHEMBL1734083 & 1301419 & 6.8416 & 6.2251 & TRN \\
\hline
\end{tabular}


Supplemental Table S2.txt

\begin{tabular}{|c|c|c|c|c|c|}
\hline CHEMBL1709354 & 1301419 & 4.8824 & 5.4936 & TRN & \\
\hline CHEMBL1485960 & 1301419 & 5.983 & 4.9964 & TRN & \\
\hline CHEMBL1369552 & 1301419 & 3.699 & 3.6905 & TRN & \\
\hline CHEMBL1321572 & 1301419 & 5.7212 & \multicolumn{2}{|c|}{5.132000000000001} & TRN \\
\hline CHEMBL1580845 & 1301419 & 3.699 & 3.7076 & TRN & \\
\hline CHEMBL1504461 & 1301419 & 4.7167 & 4.289 & TRN & \\
\hline CHEMBL1374100 & 1301419 & 3.699 & 3.8948 & TRN & \\
\hline CHEMBL1384253 & 1301419 & 5.8761 & 5.8672 & TRN & \\
\hline CHEMBL1478931 & 1301419 & 4.8333 & 4.1848 & TRN & \\
\hline CHEMBL1726134 & 1301419 & 5.6498 & 5.2704 & TRN & \\
\hline CHEMBL1345195 & 1301419 & 5.8996 & 5.0688 & TRN & \\
\hline CHEMBL599924 & 1301419 & 7.056 & 5.8144 & TRN & \\
\hline CHEMBL1364967 & 1301419 & 3.699 & 3.9142 & TRN & \\
\hline CHEMBL1381627 & 1301419 & 6.1772 & 4.2444 & TST & \\
\hline CHEMBL1312576 & 1301419 & 3.699 & 4.5884 & TRN & \\
\hline CHEMBL 240836 & 1301419 & 4.8496 & 4.2407 & TRN & \\
\hline CHEMBL1454614 & 1301419 & 5.8601 & 5.9253 & TRN & \\
\hline CHEMBL1415540 & 1301419 & 3.699 & 5.0719 & TRN & \\
\hline CHEMBL1580854 & 1301419 & \multicolumn{2}{|c|}{5.1579999999999995} & 4.4325 & TST \\
\hline CHEMBL3144873 & 1301419 & 5.0214 & 4.7087 & TST & \\
\hline CHEMBL57013 & 1301419 & 3.699 & 4.6529 & TRN & \\
\hline CHEMBL1885228 & 1301419 & 5.5986 & 5.394 & TRN & \\
\hline CHEMBL1469043 & 1301419 & 3.699 & 4.0191 & TRN & \\
\hline CHEMBL1965172 & 1301419 & 4.9863 & 4.2828 & TRN & \\
\hline CHEMBL1575869 & 1301419 & 5.5719 & 5.681 & TRN & \\
\hline CHEMBL1541861 & 1301419 & 3.699 & 4.4084 & TRN & \\
\hline CHEMBL1400512 & 1301419 & 4.8722 & 4.2992 & TRN & \\
\hline CHEMBL1345683 & 1301419 & 3.699 & 3.7756 & TRN & \\
\hline CHEMBL1456904 & 1301419 & 4.9104 & 5.2517 & TRN & \\
\hline CHEMBL1464110 & 1301419 & 5.1759 & 4.3835 & TRN & \\
\hline CHEMBL1600440 & 1301419 & 4.8871 & 4.8636 & TRN & \\
\hline CHEMBL1729804 & 1301419 & 5.9066 & 5.6397 & TRN & \\
\hline CHEMBL1505679 & 1301419 & 4.9796 & 5.0385 & TRN & \\
\hline CHEMBL1563861 & 1301419 & 3.699 & 4.1829 & TRN & \\
\hline CHEMBL1447211 & 1301419 & 3.699 & 4.38 & TRN & \\
\hline CHEMBL1599965 & 1301419 & 5.8356 & 5.7201 & TRN & \\
\hline CHEMBL1349475 & 1301419 & 3.699 & 4.3549 & TRN & \\
\hline CHEMBL210208 & 1301419 & 6.8356 & 5.7072 & TRN & \\
\hline CHEMBL1613004 & 1301419 & 5.5302 & 4.5065 & TRN & \\
\hline CHEMBL1330787 & 1301419 & 3.699 & 4.7013 & TRN & \\
\hline CHEMBL1701931 & 1301419 & 3.699 & 3.7926 & TRN & \\
\hline CHEMBL2007178 & 1301419 & 5.1175 & 4.9897 & TRN & \\
\hline CHEMBL1721451 & 1301419 & 3.699 & 4.4849 & TRN & \\
\hline CHEMBL1725485 & 1301419 & 5.4318 & 6.177006 & 00000000005 & TRN \\
\hline CHEMBL1331211 & 1301419 & 5.7825 & 4.9332 & TRN & \\
\hline CHEMBL1698715 & 1301419 & 6.2749 & 5.2474 & TRN & \\
\hline CHEMBL1493011 & 1301419 & 5.1007 & 4.7775 & TST & \\
\hline CHEMBL1378605 & 1301419 & 4.8921 & 4.7765 & TRN & \\
\hline
\end{tabular}


Supplemental Table S2.txt

\begin{tabular}{|c|c|c|c|c|c|}
\hline CHEMBL1559734 & 1301419 & 4.8147 & 4.4359 & TRN & \\
\hline CHEMBL1382081 & 1301419 & 3.699 & 4.3299 & TRN & \\
\hline CHEMBL1320799 & 1301419 & 3.699 & 4.6992 & TRN & \\
\hline CHEMBL1383632 & 1301419 & 5.4976 & 5.4003 & TRN & \\
\hline CHEMBL1582403 & 1301419 & 4.7908 & 4.658 & TRN & \\
\hline CHEMBL1530440 & 1301419 & 4.7737 & 4.6687 & TRN & \\
\hline CHEMBL 2141749 & 1301419 & 4.7321 & 4.6187 & TRN & \\
\hline CHEMBL1338765 & 1301419 & 3.699 & 3.9351 & TRN & \\
\hline CHEMBL1497005 & 1301419 & 5.9031 & 4.6877 & TST & \\
\hline CHEMBL3199929 & 1301419 & 3.699 & 4.2727 & TRN & \\
\hline CHEMBL1404761 & 1301419 & 5.3072 & 4.8899 & TRN & \\
\hline CHEMBL1503182 & 1301419 & 4.8877 & 4.393 & TRN & \\
\hline CHEMBL1500740 & 1301419 & 3.699 & 4.2475 & TST & \\
\hline CHEMBL1566750 & 1301419 & 3.699 & 3.9302 & TRN & \\
\hline CHEMBL2001904 & 1301419 & 4.8348 & 4.9223 & TST & \\
\hline CHEMBL1407056 & 1301419 & 4.9755 & 5.1894 & TRN & \\
\hline CHEMBL1571704 & 1301419 & 5.4841 & 4.9715 & TRN & \\
\hline CHEMBL1413482 & 1301419 & 3.699 & \multicolumn{2}{|c|}{3.9010000000000002} & TRN \\
\hline CHEMBL1890165 & 1301419 & 5.5258 & 5.3763 & TRN & \\
\hline CHEMBL1373577 & 1301419 & 4.8874 & 5.5334 & TRN & \\
\hline CHEMBL1324303 & 1301419 & 3.699 & \multicolumn{2}{|c|}{ 4. 343999999999999} & TST \\
\hline CHEMBL1492590 & 1301419 & 3.699 & 4.2005 & TRN & \\
\hline CHEMBL1335030 & 1301419 & 4.9266 & 4.7011 & TRN & \\
\hline CHEMBL1460875 & 1301419 & 5.0809 & 5.0551 & TRN & \\
\hline CHEMBL1508839 & 1301419 & 3.699 & 3.7746 & TST & \\
\hline CHEMBL 2003564 & 1301419 & 5.5331 & 4.9575 & TRN & \\
\hline CHEMBL1562712 & 1301419 & 4.9252 & 3.9817 & TRN & \\
\hline CHEMBL1334670 & 1301419 & 4.8289 & 5.0278 & TRN & \\
\hline CHEMBL1451931 & 1301419 & 5.6655 & 5.4913 & TRN & \\
\hline CHEMBL1710427 & 1301419 & 4.9893 & 4.9118 & TST & \\
\hline CHEMBL1376540 & 1301419 & 5.1656 & 5.1616 & TRN & \\
\hline CHEMBL1550788 & 1301419 & 5.0168 & 4.7351 & TST & \\
\hline CHEMBL2362139 & 1301419 & 3.699 & 4.3488 & TRN & \\
\hline CHEMBL1445410 & 1301419 & 5.1337 & 5.7344 & TRN & \\
\hline CHEMBL1502832 & 1301419 & 3.699 & 4.1104 & TST & \\
\hline CHEMBL1573910 & 1301419 & 5.5918 & 4.6816 & TRN & \\
\hline CHEMBL1714335 & 1301419 & 5.1972 & 4.5396 & TRN & \\
\hline CHEMBL1528737 & 1301419 & 3.699 & 4.2234 & TRN & \\
\hline CHEMBL3195024 & 1301419 & 3.699 & 4.5354 & TRN & \\
\hline CHEMBL1310353 & 1301419 & 4.8128 & 4.1252 & TRN & \\
\hline CHEMBL1413381 & 1301419 & 3.699 & 3.9892 & TRN & \\
\hline CHEMBL1165723 & 1301419 & 4.7113 & \multicolumn{2}{|c|}{5.6610000000000005} & TRN \\
\hline CHEMBL1374603 & 1301419 & 3.699 & 4.1866 & TRN & \\
\hline CHEMBL1419015 & 1301419 & 5.2899 & 4.7112 & TRN & \\
\hline CHEMBL1874279 & 1301419 & 5.0128 & 5.0434 & TRN & \\
\hline CHEMBL1518905 & 1301419 & 3.699 & 4.3503 & TRN & \\
\hline CHEMBL1582771 & 1301419 & 5.2815 & 4.7313 & TRN & \\
\hline CHEMBL3199263 & 1301419 & 3.699 & 4.738 & TST & \\
\hline
\end{tabular}


Supplemental Table S2.txt

\begin{tabular}{|c|c|c|c|c|}
\hline CHEMBL1472210 & 1301419 & 3.699 & 4.4772 & TRN \\
\hline CHEMBL 3193184 & 1301419 & 3.699 & 4.163 & TRN \\
\hline CHEMBL1550238 & 1301419 & 4.7066 & 4.0387 & TRN \\
\hline CHEMBL1535938 & 1301419 & 4.9792 & 5.2798 & TRN \\
\hline CHEMBL 3197080 & 1301419 & 3.699 & 4.5782 & TRN \\
\hline CHEMBL 216973 & 1301419 & 3.699 & 4.9908 & TRN \\
\hline CHEMBL1384172 & 1301419 & 3.699 & 4.8716 & TRN \\
\hline CHEMBL1565762 & 1301419 & 4.9788 & 5.1722 & TRN \\
\hline CHEMBL1469091 & 1301419 & 5.0343 & 4.323 & TST \\
\hline CHEMBL1420511 & 1301419 & 3.699 & 3.3996 & TRN \\
\hline CHEMBL1310309 & 1301419 & 5.0434 & 4.7379 & TRN \\
\hline CHEMBL1705697 & 1301419 & 4.9838 & 4.9018 & TST \\
\hline CHEMBL1906185 & 1301419 & 4.7662 & 3.9911 & TRN \\
\hline CHEMBL1542748 & 1301419 & 5.1007 & 4.9475 & TRN \\
\hline CHEMBL 3193053 & 1301419 & 5.0565 & 5.6364 & TRN \\
\hline CHEMBL1310120 & 1301419 & 5.32700 & 00000000 & 4.8301 \\
\hline CHEMBL3195965 & 1301419 & 3.699 & 4.7309 & TRN \\
\hline CHEMBL 3183391 & 1301419 & 5.2676 & 5.3952 & TRN \\
\hline CHEMBL1470135 & 1301419 & 4.8447 & 5.1298 & TRN \\
\hline CHEMBL1359620 & 1301419 & 4.8049 & 5.2294 & TRN \\
\hline CHEMBL1732657 & 1301419 & 4.8976 & 3.9818 & TRN \\
\hline CHEMBL1508847 & 1301419 & 5.3809 & 5.7135 & TRN \\
\hline CHEMBL1555938 & 1301419 & 5.5834 & 5.3559 & TRN \\
\hline CHEMBL1411673 & 1301419 & 4.8941 & 4.6254 & TRN \\
\hline CHEMBL1518767 & 1301419 & 5.684 & 4.936 & TST \\
\hline CHEMBL1336922 & 1301419 & 3.699 & 3.9007 & TRN \\
\hline CHEMBL1969046 & 1301419 & 6.5935 & 5.8615 & TRN \\
\hline CHEMBL1473059 & 1301419 & 5.5622 & 4.2117 & TRN \\
\hline CHEMBL1324749 & 1301419 & 3.699 & 3.6111 & TRN \\
\hline CHEMBL1430005 & 1301419 & 4.8204 & 4.309 & TST \\
\hline CHEMBL1331573 & 1301419 & 3.699 & 5.2996 & TRN \\
\hline CHEMBL1504596 & 1301419 & 3.699 & 3.6146 & TRN \\
\hline CHEMBL1605094 & 1301419 & 4.7981 & 5.0359 & TRN \\
\hline CHEMBL1543029 & 1301419 & 5.0851 & 4.2922 & TST \\
\hline CHEMBL1429479 & 1301419 & 5.1035 & 4.6582 & TRN \\
\hline CHEMBL1870340 & 1301419 & 3.699 & 3.6535 & TRN \\
\hline CHEMBL66953 & 1301419 & 6.2741 & 5.0743 & TST \\
\hline CHEMBL1413866 & 1301419 & 5.2013 & 5.0913 & TST \\
\hline CHEMBL222190 & 1301419 & 5.0061 & 5.3943 & TRN \\
\hline CHEMBL1313485 & 1301419 & 4.761 & 4.7109 & TRN \\
\hline CHEMBL 3198994 & 1301419 & 4.9112 & 5.1218 & TRN \\
\hline CHEMBL1598744 & 1301419 & 3.699 & 3.5569 & TRN \\
\hline CHEMBL1982305 & 1301419 & 6.3747 & 5.8135 & TRN \\
\hline CHEMBL1385611 & 1301419 & 5.9031 & 4.6382 & TST \\
\hline CHEMBL1609454 & 1301419 & 3.699 & 4.1784 & TRN \\
\hline CHEMBL1517864 & 1301419 & 3.699 & 3.7854 & TRN \\
\hline CHEMBL1375346 & 1301419 & 3.699 & 3.9019 & TRN \\
\hline CHEMBL3195661 & 1301419 & 3.699 & 3.53800 & 30000000003 \\
\hline
\end{tabular}




$$
\text { Supplemental Table S2.txt }
$$

\begin{tabular}{|c|c|c|c|c|c|}
\hline CHEMBL1492110 & 1301419 & 5.2541 & 5.3171 & TRN & \\
\hline CHEMBL1403154 & 1301419 & 5.399 & 5.2063 & TRN & \\
\hline CHEMBL1304273 & 1301419 & 3.699 & 4.4931 & TRN & \\
\hline CHEMBL3304020 & 1301419 & 4.9404 & 4.7446 & TST & \\
\hline CHEMBL3188428 & 1301419 & 4.8502 & 4.8279 & TST & \\
\hline CHEMBL1163377 & 1301419 & 6.9666 & 5.919 & TRN & \\
\hline CHEMBL1370956 & 1301419 & 4.9066 & 4.314 & TRN & \\
\hline CHEMBL1550655 & 1301419 & 3.699 & 3.1641 & TRN & \\
\hline CHEMBL1387155 & 1301419 & 4.8395 & 4.3648 & TST & \\
\hline CHEMBL1501990 & 1301419 & 5.16299 & 999999999 & 5.379 & TRN \\
\hline CHEMBL 268855 & 1301419 & 4.8164 & 4.9675 & TRN & \\
\hline CHEMBL1421438 & 1301419 & 5.4191 & 4.8876 & TRN & \\
\hline CHEMBL1582178 & 1301419 & 4.7836 & 4.4851 & TST & \\
\hline CHEMBL 272465 & 1301419 & 4.9851 & 5.0445 & TRN & \\
\hline CHEMBL1982107 & 1301419 & 6.1296 & 5.5979 & TRN & \\
\hline CHEMBL1536970 & 1301419 & 3.699 & 3.7743 & TRN & \\
\hline CHEMBL1308055 & 1301419 & 5.058 & 4.7249 & TRN & \\
\hline CHEMBL1728280 & 1301419 & 5.8928 & 5.9882 & TRN & \\
\hline CHEMBL1362933 & 1301419 & 5.3536 & 5.0807 & TST & \\
\hline CHEMBL3198812 & 1301419 & 5.3288 & 4.7376 & TRN & \\
\hline CHEMBL1966224 & 1301419 & 6.1972 & 4.6061 & TST & \\
\hline CHEMBL1700996 & 1301419 & 5.1421 & 5.1788 & TRN & \\
\hline CHEMBL1506756 & 1301419 & 4.9017 & 4.7757 & TRN & \\
\hline CHEMBL1321993 & 1301419 & 4.9747 & 4.3047 & TRN & \\
\hline CHEMBL1346724 & 1301419 & 4.9374 & 4.8066 & TRN & \\
\hline CHEMBL1372237 & 1301419 & 3.699 & 3.3951 & TRN & \\
\hline CHEMBL1611796 & 1301419 & 3.699 & 4.3798 & TRN & \\
\hline CHEMBL1353524 & 1301419 & 3.699 & 3.6309 & TRN & \\
\hline CHEMBL1392911 & 1301419 & 5.4473 & 5.2914 & TRN & \\
\hline CHEMBL1343952 & 1301419 & 3.699 & 4.5873 & TRN & \\
\hline CHEMBL1699845 & 1301419 & 6.2233 & 5.7745 & TRN & \\
\hline CHEMBL1731329 & 1301419 & 3.699 & 3.9027 & TRN & \\
\hline CHEMBL1393480 & 1301419 & 4.9073 & 4.0096 & TRN & \\
\hline CHEMBL1437673 & 1301419 & 3.699 & 3.5536 & TRN & \\
\hline CHEMBL1611768 & 1301419 & 5.0731 & 5.0401 & TRN & \\
\hline CHEMBL3196108 & 1301419 & 5.6968 & 5.3337 & TRN & \\
\hline CHEMBL1352624 & 1301419 & 4.73 & 4.4348 & TRN & \\
\hline CHEMBL1475400 & 1301419 & 4.9389 & 4.7543 & TRN & \\
\hline CHEMBL1576140 & 1301419 & 5.3788 & 5.3943 & TRN & \\
\hline CHEMBL2142849 & 1301419 & 3.699 & 4.2576 & TRN & \\
\hline CHEMBL1608375 & 1301419 & 3.699 & 3.8667 & TST & \\
\hline CHEMBL1430659 & 1301419 & 3.699 & 4.9955 & TRN & \\
\hline CHEMBL3194941 & 1301419 & 4.7719 & 4.7874 & TRN & \\
\hline CHEMBL1527008 & 1301419 & 3.699 & 4.718999 & 9999999999 & TRN \\
\hline CHEMBL1575649 & 1301419 & 5.8268 & 5.3265 & TRN & \\
\hline CHEMBL1604260 & 1301419 & 3.699 & 3.6403 & TRN & \\
\hline CHEMBL3192803 & 1301419 & 3.699 & 4.3912 & TRN & \\
\hline CHEMBL258756 & 1301419 & 4.9259 & 4.5613 & TRN & \\
\hline
\end{tabular}


Supplemental Table S2.txt

\begin{tabular}{|c|c|c|c|c|}
\hline AEMBL1527004 & 301419 & 699 & & \\
\hline HEMBL1390521 & 301419 & 5.2668 & & \\
\hline & 301419 & & & \\
\hline IEMBL] & & & & \\
\hline HEMBL1 & 301419 & 699 & & \\
\hline AEMBL1379448 & 301419 & 8633 & 5923 & \\
\hline AEMBL: & 301 & 942 & & \\
\hline 868 & 19 & & & \\
\hline AEMBLI & 301419 & 599 & & \\
\hline 50986 & 301419 & 0467 & & \\
\hline AEMBL: & 301419 & 5.3958 & & \\
\hline IEMBL: & 301 & 713 & & \\
\hline IEMBL & 19 & & & \\
\hline AEMBL & 301419 & 2907 & & \\
\hline AEMBL: & 301419 & 7852 & & \\
\hline IEMBL & 301 & 337 & 73 & \\
\hline AEMBL & 301 & & & \\
\hline AEMBL & 19 & 385 & & \\
\hline IEMBL & 19 & 386 & & \\
\hline IEMBL & 9 & 115 & & KN \\
\hline IEMBL & 9 & 74 & & \\
\hline EMB & 9 & 2 & & \\
\hline 19 & 9 & & & \\
\hline 40 & 19 & 556 & & \\
\hline IEMBL: & 19 & 87 & & KI \\
\hline EMBL & 30 & & & \\
\hline EMB & 9 & 0 & & \\
\hline 84 & 19 & 17 & & RN \\
\hline IEMBL & 19 & 802 & & RN \\
\hline AEMBL: & 301 & 99 & & $S$ \\
\hline AEMBL: & 301 & & & ST \\
\hline 8 & 9 & 99 & & . \\
\hline 3 & 9 & 844 & & PN \\
\hline EMBL & 301 & 126 & & RI \\
\hline AEMBL] & 301 & 5.3161 & & RIV \\
\hline IEMBL & 301 & 268 & & $\mathrm{R} \Lambda$ \\
\hline 5 & & & & RN \\
\hline & 301 & & & RN \\
\hline AEMBL] & 301419 & 5.8996 & & $\mathrm{~S}$ \\
\hline EMBL & 301 & 599 & & ST \\
\hline HEMBL & 301419 & 5.3045 & 746 & -3 \\
\hline - ניחבים & 1301419 & & & RN \\
\hline HEMBL & 301 & 699 & & $\mathrm{RN}$ \\
\hline IEMBL: & 301 & 699 & 511 & RI \\
\hline 05 & 301 & 057 & & 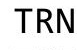 \\
\hline CHEMBL 1 & 301419 & & & \\
\hline CHEMBL: & 301419 & 3.699 & 4.9847 & \\
\hline CHEMBL1458891 & 1301419 & 5.4622 & 4.814 & $\mathrm{R}$ \\
\hline
\end{tabular}

Page 16912 
Supplemental Table S2.txt

\begin{tabular}{|c|c|c|c|c|}
\hline CHEMBL1302524 & 1301419 & 5.4828 & 5.9213 & TRN \\
\hline CHEMBL1559985 & 1301419 & 3.699 & 3.5913 & TRN \\
\hline CHEMBL1334307 & 1301419 & 3.699 & 4.3527 & TRN \\
\hline CHEMBL1424746 & 1301419 & 3.699 & 4.8035 & TRN \\
\hline CHEMBL1485524 & 1301419 & 4.8425 & 4.0519 & TST \\
\hline CHEMBL3145314 & 1301419 & 4.8548 & 4.0393 & TRN \\
\hline CHEMBL1540315 & 1301419 & 4.823 & 4.3908 & TST \\
\hline CHEMBL1389066 & 1301419 & 4.8233 & 4.9071 & TRN \\
\hline CHEMBL1351102 & 1301419 & 3.699 & 4.6755 & TRN \\
\hline CHEMBL1574857 & 1301419 & 5.6162 & 5.7686 & TRN \\
\hline CHEMBL1493528 & 1301419 & 5.1688 & 4.9933 & TRN \\
\hline CHEMBL1730876 & 1301419 & 3.699 & 4.2383 & TST \\
\hline CHEMBL1708263 & 1301419 & 3.699 & 3.8489 & TRN \\
\hline CHEMBL1707222 & 1301419 & 5.767 & 5.335 & TRN \\
\hline CHEMBL1888528 & 1301419 & 5.3072 & 5.1293 & TRN \\
\hline CHEMBL1441739 & 1301419 & 5.1481 & 5.1654 & TRN \\
\hline CHEMBL1359614 & 1301419 & 3.699 & 4.4983 & TRN \\
\hline CHEMBL3192701 & 1301419 & 3.699 & 4.7356 & TRN \\
\hline CHEMBL1700547 & 1301419 & 5.7471 & 5.6022 & TRN \\
\hline CHEMBL1488474 & 1301419 & 5.4976 & 5.8718 & TRN \\
\hline CHEMBL1464200 & 1301419 & 4.787 & 4.2688 & TRN \\
\hline CHEMBL1413690 & 1301419 & 3.699 & 3.9975 & TRN \\
\hline CHEMBL1448387 & 1301419 & 5.8153 & 4.7294 & TST \\
\hline CHEMBL1598356 & 1301419 & 4.9442 & 4.0547 & TST \\
\hline CHEMBL1713993 & 1301419 & 5.1238 & 5.3373 & TST \\
\hline CHEMBL1989853 & 1301419 & 5.0904 & 4.9885 & TRN \\
\hline CHEMBL1485730 & 1301419 & 3.699 & 4.0828 & TRN \\
\hline CHEMBL1378300 & 1301419 & 4.9531 & 5.0436 & TST \\
\hline CHEMBL1981122 & 1301419 & 5.767 & 4.6548 & TRN \\
\hline CHEMBL1560629 & 1301419 & 3.699 & 4.0433 & TRN \\
\hline CHEMBL1896348 & 1301419 & 5.3516 & 4.5219 & TRN \\
\hline CHEMBL3182716 & 1301419 & 5.4283 & 5.6394 & TRN \\
\hline CHEMBL1358863 & 1301419 & 3.699 & 4.4918 & TRN \\
\hline CHEMBL193872 & 1301419 & 5.1481 & 5.0238 & TRN \\
\hline CHEMBL1578670 & 1301419 & 5.1209 & 5.3158 & TRN \\
\hline CHEMBL1583598 & 1301419 & 3.699 & 4.1406 & TRN \\
\hline CHEMBL1436247 & 1301419 & 5.1135 & 5.6093 & TRN \\
\hline CHEMBL1567396 & 1301419 & 5.8386 & 4.9503 & TRN \\
\hline CHEMBL1463829 & 1301419 & 5.5317 & 5.6638 & TRN \\
\hline CHEMBL1518104 & 1301419 & 4.761 & 4.21 & TRN \\
\hline CHEMBL1866533 & 1301419 & 4.9702 & 4.1998 & TST \\
\hline CHEMBL1598762 & 1301419 & 6.3809 & 5.3988 & TRN \\
\hline CHEMBL1542926 & 1301419 & 6.1844 & 3.3699 & TST \\
\hline CHEMBL3193639 & 1301419 & 5.6144 & 5.2129 & TRN \\
\hline CHEMBL1400620 & 1301419 & 3.699 & 3.9912 & TRN \\
\hline CHEMBL1543965 & 1301419 & 5.1938 & 4.4142 & TRN \\
\hline CHEMBL1409552 & 1301419 & 3.699 & 3.6072 & TRN \\
\hline CHEMBL 2132857 & 1301419 & 3.699 & 4.9266 & TRN \\
\hline
\end{tabular}


Supplemental Table S2.txt

\begin{tabular}{|c|c|c|c|c|c|}
\hline CHEMBL1902527 & 1301419 & 5.3354 & 4.835 & TST & \\
\hline CHEMBL1311154 & 1301419 & 6.9469 & 6.0584 & TRN & \\
\hline CHEMBL1565749 & 1301419 & 3.699 & 4.555 & TRN & \\
\hline CHEMBL1521296 & 1301419 & 3.699 & 3.6476 & TRN & \\
\hline CHEMBL1541657 & 1301419 & 4.7565 & 4.3233 & TRN & \\
\hline CHEMBL1570005 & 1301419 & 4.7135 & 4.7364 & TRN & \\
\hline CHEMBL1361920 & 1301419 & 5.26200 & 0000000 & 4.4078 & TRN \\
\hline CHEMBL1439735 & 1301419 & 3.699 & 4.9842 & TRN & \\
\hline CHEMBL1702473 & 1301419 & 6.2147 & 5.3027 & TRN & \\
\hline CHEMBL1713464 & 1301419 & 4.9241 & 5.1864 & TRN & \\
\hline CHEMBL1510455 & 1301419 & 3.699 & 3.9227 & TRN & \\
\hline CHEMBL1901344 & 1301419 & 3.699 & 4.8435 & TST & \\
\hline CHEMBL224916 & 1301419 & 5.2815 & 5.2169 & TRN & \\
\hline CHEMBL1569566 & 1301419 & 5.2782 & 5.2244 & TRN & \\
\hline CHEMBL1537618 & 1301419 & 5.3089 & 5.3321 & TRN & \\
\hline CHEMBL1596295 & 1301419 & 3.699 & 3.2123 & TRN & \\
\hline CHEMBL1414222 & 1301419 & 3.699 & 4.7016 & TRN & \\
\hline CHEMBL1726141 & 1301419 & 3.699 & 3.9767 & TST & \\
\hline CHEMBL1577193 & 1301419 & 5.0506 & 5.3948 & TRN & \\
\hline CHEMBL1445897 & 1301419 & 3.699 & 4.53600 & 00000000005 & TRN \\
\hline CHEMBL1403262 & 1301419 & 4.9893 & 5.1076 & TST & \\
\hline CHEMBL1340288 & 1301419 & 4.9126 & 4.8283 & TST & \\
\hline CHEMBL1606706 & 1301419 & 3.699 & 4.0521 & TRN & \\
\hline CHEMBL1516638 & 1301419 & 4.923 & 4.8579 & TST & \\
\hline CHEMBL1323674 & 1301419 & 4.9855 & 4.8247 & TRN & \\
\hline CHEMBL1727678 & 1301419 & 5.5129 & 3.9946 & TRN & \\
\hline CHEMBL 3184468 & 1301419 & 4.9897 & 4.7264 & TST & \\
\hline CHEMBL1492642 & 1301419 & 5.0009 & 4.688 & TRN & \\
\hline CHEMBL1709883 & 1301419 & 5.9281 & 5.1083 & TRN & \\
\hline CHEMBL1604719 & 1301419 & 4.7335 & 5.1617 & TRN & \\
\hline CHEMBL1465938 & 1301419 & 5.4486 & 4.697 & TRN & \\
\hline CHEMBL156174 & 1301419 & 6.2628 & 6.1673 & TRN & \\
\hline CHEMBL1518895 & 1301419 & 3.699 & 4.6917 & TRN & \\
\hline CHEMBL1398645 & 1301419 & 4.923 & 5.0274 & TRN & \\
\hline CHEMBL1736648 & 1301419 & 5.1612 & 5.0994 & TRN & \\
\hline CHEMBL1563317 & 1301419 & 5.0443 & 4.5864 & TST & \\
\hline CHEMBL1901926 & 1301419 & 5.5528 & 4.3041 & TST & \\
\hline CHEMBL1395907 & 1301419 & 5.9547 & 5.7157 & TRN & \\
\hline CHEMBL1698802 & 1301419 & 6.1226 & 5.8341 & TRN & \\
\hline CHEMBL1576815 & 1301419 & 5.1278 & 4.6446 & TST & \\
\hline CHEMBL1609245 & 1301419 & 5.3134 & 5.2077 & TRN & \\
\hline CHEMBL1370095 & 1301419 & 3.699 & 4.0694 & TRN & \\
\hline CHEMBL1502018 & 1301419 & 4.9516 & 5.4966 & TRN & \\
\hline CHEMBL1585740 & 1301419 & 5.2716 & 5.1399 & TRN & \\
\hline CHEMBL1309165 & 1301419 & 5.6882 & 5.2852 & TRN & \\
\hline CHEMBL1566994 & 1301419 & 4.8788 & 5.1442 & TRN & \\
\hline CHEMBL1712631 & 1301419 & 4.7916 & 4.6207 & TST & \\
\hline CHEMBL1875561 & 1301419 & 4.8952 & 4.6962 & TRN & \\
\hline
\end{tabular}


Supplemental Table S2.txt

\begin{tabular}{|c|c|c|c|c|c|}
\hline CHEMBL1335869 & 1301419 & 4.9674 & 5.461 & TRN & \\
\hline CHEMBL1407103 & 1301419 & 3.699 & 4.3735 & TST & \\
\hline CHEMBL1733422 & 1301419 & 6.58 & 5.7952 & TRN & \\
\hline CHEMBL1362734 & 1301419 & 4.7219 & 4.7727 & TRN & \\
\hline CHEMBL1613510 & 1301419 & 3.699 & 4.243 & TRN & \\
\hline CHEMBL1990734 & 1301419 & 3.699 & 4.0582 & TRN & \\
\hline CHEMBL1311895 & 1301419 & 4.8748 & 5.2579 & TST & \\
\hline CHEMBL1430175 & 1301419 & 3.699 & 5.1619 & TRN & \\
\hline CHEMBL1995948 & 1301419 & 4.9136 & 4.8884 & TRN & \\
\hline CHEMBL1415156 & 1301419 & 4.9352 & \multicolumn{2}{|c|}{5.093999999999999} & TRN \\
\hline CHEMBL1872366 & 1301419 & 5.2027 & 5.237 & TST & \\
\hline CHEMBL1486359 & 1301419 & 3.699 & 4.7478 & TRN & \\
\hline CHEMBL171632 & 1301419 & 5.2464 & 4.4942 & TST & \\
\hline CHEMBL1721095 & 1301419 & 5.7696 & 5.6965 & TRN & \\
\hline CHEMBL1698288 & 1301419 & 3.699 & 4.8313 & TRN & \\
\hline CHEMBL1985664 & 1301419 & 5.2823 & 4.3657 & TRN & \\
\hline CHEMBL3188273 & 1301419 & 5.3391 & 4.7307 & TRN & \\
\hline CHEMBL3197637 & 1301419 & 6.2541 & 5.9662 & TRN & \\
\hline CHEMBL1588052 & 1301419 & 4.794 & 5.0646 & TRN & \\
\hline CHEMBL1477236 & 1301419 & 4.7657 & 4.3366 & TRN & \\
\hline CHEMBL1562466 & 1301419 & 5.317 & 5.2655 & TRN & \\
\hline CHEMBL1609006 & 1301419 & 5.4868 & \multicolumn{2}{|c|}{5.3839999999999995} & TRN \\
\hline CHEMBL1413740 & 1301419 & 3.699 & 4.2121 & TRN & \\
\hline CHEMBL1377031 & 1301419 & 4.8094 & 4.4855 & TRN & \\
\hline CHEMBL1517325 & 1301419 & 4.8008 & 5.035 & TRN & \\
\hline CHEMBL1457514 & 1301419 & 3.699 & 3.715 & TRN & \\
\hline CHEMBL3185407 & 1301419 & 5.055 & 6.0495 & TRN & \\
\hline CHEMBL3192715 & 1301419 & 5.0101 & 4.8008 & TRN & \\
\hline CHEMBL1458321 & 1301419 & 5.5003 & 5.4085 & TRN & \\
\hline CHEMBL1434792 & 1301419 & 5.0825 & 4.5693 & TRN & \\
\hline CHEMBL1419311 & 1301419 & 4.7757 & 3.9725 & TRN & \\
\hline CHEMBL3191670 & 1301419 & 5.0362 & 5.2078 & TRN & \\
\hline CHEMBL1993746 & 1301419 & 4.9838 & 5.0724 & TRN & \\
\hline CHEMBL1541863 & 1301419 & 3.699 & 4.322 & TRN & \\
\hline CHEMBL1513608 & 1301419 & 4.9101 & 4.8134 & TRN & \\
\hline CHEMBL1300612 & 1301419 & 4.9872 & 4.6669 & TRN & \\
\hline CHEMBL1869352 & 1301419 & 3.699 & 4.8486 & TST & \\
\hline CHEMBL3196591 & 1301419 & 5.7055 & 5.0353 & TRN & \\
\hline CHEMBL1421172 & 1301419 & 5.3261 & 5.1478 & TRN & \\
\hline CHEMBL1309949 & 1301419 & 4.9825 & 4.7121 & TRN & \\
\hline CHEMBL 255881 & 1301419 & 5.7878 & 5.5023 & TRN & \\
\hline CHEMBL1308904 & 1301419 & 5.4045 & 5.2484 & TRN & \\
\hline CHEMBL1300836 & 1301419 & 3.699 & 4.2764 & TRN & \\
\hline CHEMBL1401312 & 1301419 & 3.699 & 4.9712 & TRN & \\
\hline CHEMBL381033 & 1301419 & 4.8847 & 4.9057 & TRN & \\
\hline CHEMBL1514971 & 1301419 & 3.699 & 3.5824 & TST & \\
\hline CHEMBL1432959 & 1301419 & 3.699 & 3.7243 & TRN & \\
\hline CHEMBL1984240 & 1301419 & 5.9355 & 4.8007 & TST & \\
\hline
\end{tabular}


Supplemental Table S2.txt

\begin{tabular}{|c|c|c|c|c|c|}
\hline CHEMBL1382760 & 1301419 & 4.9759 & 4.9187 & TRN & \\
\hline CHEMBL 205040 & 1301419 & 5.1694 & 5.1942 & TRN & \\
\hline CHEMBL1468954 & 1301419 & 4.9996 & 5.7187 & TRN & \\
\hline CHEMBL1537553 & 1301419 & 5.9208 & 5.5333 & TRN & \\
\hline CHEMBL1874616 & 1301419 & 5.0921 & 4.9218 & TST & \\
\hline CHEMBL1713955 & 1301419 & 5.9747 & 4.4901 & TST & \\
\hline CHEMBL1451059 & 1301419 & 3.699 & 4.0371 & TRN & \\
\hline CHEMBL258590 & 1301419 & 3.699 & 5.4219 & TST & \\
\hline CHEMBL175434 & 1301419 & 5.5086 & 5.7566 & TRN & \\
\hline CHEMBL1433075 & 1301419 & 3.699 & 4.5695 & TRN & \\
\hline CHEMBL1369964 & 1301419 & 3.699 & 3.84 & TRN & \\
\hline CHEMBL1503852 & 1301419 & 3.699 & 5.0116 & TRN & \\
\hline CHEMBL1416601 & 1301419 & 4.7978 & 4.6154 & TRN & \\
\hline CHEMBL1381264 & 1301419 & 5.118 & 4.6527 & TRN & \\
\hline CHEMBL1411403 & 1301419 & 3.699 & 4.1237 & TRN & \\
\hline CHEMBL1412974 & 1301419 & 3.699 & 3.5253 & TRN & \\
\hline CHEMBL1705326 & 1301419 & 4.8834 & 4.9677 & TST & \\
\hline CHEMBL1369742 & 1301419 & 3.699 & 4.4082 & TST & \\
\hline CHEMBL1592490 & 1301419 & 5.1421 & 4.9639 & TST & \\
\hline CHEMBL1484139 & 1301419 & 3.699 & 4.0189 & TST & \\
\hline CHEMBL1573779 & 1301419 & 5.0424 & 3.7078 & TST & \\
\hline CHEMBL1460809 & 1301419 & 5.007 & 3.8643 & TST & \\
\hline CHEMBL1698845 & 1301419 & 5.9957 & 4.8916 & TST & \\
\hline CHEMBL1504679 & 1301419 & 5.3595 & 4.9864 & TST & \\
\hline CHEMBL1710157 & 1301419 & 5.0496 & 4.5491 & TST & \\
\hline CHEMBL1412423 & 1301419 & 5.3925 & 5.7633 & TST & \\
\hline CHEMBL1422133 & 1301419 & 5.21899 & 99999999 & 99 & 4.7012 \\
\hline CHEMBL1569215 & 1301419 & 3.699 & 4.4208 & TST & \\
\hline CHEMBL2134336 & 1301419 & 4.9578 & 4.4919 & TST & \\
\hline CHEMBL1587584 & 1301419 & 5.2733 & 4.8321 & TST & \\
\hline CHEMBL1521514 & 1301419 & 4.8477 & 4.4307 & TST & \\
\hline CHEMBL1736964 & 1301419 & 5.1772 & 5.121 & TST & \\
\hline CHEMBL1307301 & 1301419 & 5.0334 & 4.2111 & TST & \\
\hline CHEMBL1734152 & 1301419 & 6.059 & 5.5851 & TST & \\
\hline CHEMBL1464721 & 1301419 & 5.284 & 5.5597 & TST & \\
\hline CHEMBL1724600 & 1301419 & 5.6615 & 5.1608 & TST & \\
\hline CHEMBL1542693 & 1301419 & 5.3288 & 5.0189 & TST & \\
\hline CHEMBL1548104 & 1301419 & 4.9281 & 4.5234 & TST & \\
\hline CHEMBL1402863 & 1301419 & 3.699 & 3.7628 & TST & \\
\hline CHEMBL3196778 & 1301419 & 3.699 & 3.8216 & TST & \\
\hline CHEMBL133576 & 1301419 & 5.426 & 5.1691 & TST & \\
\hline CHEMBL1725173 & 1301419 & 5.6968 & 4.7714 & TST & \\
\hline CHEMBL364729 & 1301419 & 4.9508 & 5.5682 & TST & \\
\hline CHEMBL1605464 & 1301419 & 4.9241 & 3.5974 & TST & \\
\hline CHEMBL1588420 & 1301419 & 3.699 & 3.6201 & TST & \\
\hline CHEMBL1579683 & 1301419 & 3.699 & 3.7081 & TST & \\
\hline CHEMBL3191689 & 1301419 & 5.3261 & 5.4902 & TST & \\
\hline CHEMBL1906617 & 1301419 & 5.2765 & 4.039 & TST & \\
\hline
\end{tabular}


Supplemental Table S2.txt

\begin{tabular}{|c|c|c|c|c|c|}
\hline CHEMBL1716740 & 1301419 & 3.699 & 3.3415 & TST & \\
\hline CHEMBL1975615 & 1301419 & 3.699 & 5.5806 & TST & \\
\hline CHEMBL1536196 & 1301419 & 3.699 & 4.1885 & TST & \\
\hline CHEMBL1501392 & 1301419 & 5.4522 & 4.66 & TST & \\
\hline CHEMBL1303970 & 1301419 & 5.2373 & 5.0664 & TST & \\
\hline CHEMBL1564220 & 1301419 & 4.9957 & 4.7237 & TST & \\
\hline CHEMBL1981657 & 1301419 & 5.1209 & 3.8571 & TST & \\
\hline CHEMBL71466 & 1301419 & 5.3645 & 5.6961 & TST & \\
\hline CHEMBL1370257 & 1301419 & 4.8038 & 4.3379 & TST & \\
\hline CHEMBL1471498 & 1301419 & 3.699 & 4.565 & TST & \\
\hline CHEMBL1393861 & 1301419 & 3.699 & 4.05 & TST & \\
\hline CHEMBL339587 & 1301419 & 3.699 & 5.3418 & TST & \\
\hline CHEMBL1561101 & 1301419 & 3.699 & 3.5935 & TST & \\
\hline CHEMBL1605867 & 1301419 & 5.0883 & 5.2547 & TST & \\
\hline CHEMBL1997951 & 1301419 & 3.699 & 5.0289 & TST & \\
\hline CHEMBL 235504 & 1301419 & 6.0083 & 6.1966 & TST & \\
\hline CHEMBL1455014 & 1301419 & 5.0872 & 5.0073 & TST & \\
\hline CHEMBL1721330 & 1301419 & 5.1175 & 4.518 & TST & \\
\hline CHEMBL3197494 & 1301419 & 4.9842 & 4.7779 & TST & \\
\hline CHEMBL1503014 & 1301419 & 3.699 & 4.5502 & TST & \\
\hline CHEMBL140689 & 51162 & 5.38899 & 99999999 & 4.9513 & TRN \\
\hline CHEMBL141193 & 51162 & 6.2328 & 6.0713 & TRN & \\
\hline CHEMBL335363 & 51162 & 6.4815 & 6.2392 & TRN & \\
\hline CHEMBL143199 & 51162 & 4.5086 & 5.171 & TRN & \\
\hline CHEMBL143528 & 51162 & 6.2218 & 5.1891 & TRN & \\
\hline CHEMBL139564 & 51162 & 6.7959 & 6.3751 & TRN & \\
\hline CHEMBL139621 & 51162 & 5.9073 & 5.8906 & TRN & \\
\hline CHEMBL143491 & 51162 & 5.1061 & 4.9678 & TRN & \\
\hline CHEMBL143516 & 51162 & 6.0458 & 6.3748 & TRN & \\
\hline CHEMBL433745 & 51162 & 5.2612 & 6.2031 & TRN & \\
\hline CHEMBL143719 & 51162 & 6.5229 & 6.7441 & TRN & \\
\hline CHEMBL344600 & 51162 & 7.3468 & 7.1292 & TRN & \\
\hline CHEMBL356513 & 51162 & 6.3468 & 7.4693 & TRN & \\
\hline CHEMBL139712 & 51162 & 5.1079 & 5.6925 & TRN & \\
\hline CHEMBL337599 & 51162 & 5.6321 & 5.4282 & TRN & \\
\hline CHEMBL142648 & 51162 & 6.2076 & 5.7352 & TRN & \\
\hline CHEMBL143465 & 51162 & 7.3279 & 7.7677 & TST & \\
\hline CHEMBL143259 & 51162 & $6.7570 e$ & 00000000 & 7.1892 & TST \\
\hline CHEMBL415729 & 51162 & 5.2798 & 5.1299 & TRN & \\
\hline CHEMBL 358560 & 51162 & 7.4202 & 7.3579 & TRN & \\
\hline CHEMBL143777 & 51162 & 4.922 & 5.1242 & TRN & \\
\hline CHEMBL140100 & 51162 & 6.0269 & 6.1817 & TRN & \\
\hline CHEMBL357875 & 51162 & 5.9326 & 5.8681 & TRN & \\
\hline CHEMBL143534 & 51162 & 8.2218 & 7.8641 & TRN & \\
\hline CHEMBL141016 & 51162 & 5.301 & \multicolumn{2}{|c|}{6.4110000000000005} & TST \\
\hline CHEMBL346640 & 51162 & 6.5272 & 6.3566 & TRN & \\
\hline CHEMBL139547 & 51162 & 5.7387 & 5.0137 & TRN & \\
\hline CHEMBL341879 & 51162 & 3.3979 & 4.1563 & TRN & \\
\hline
\end{tabular}




\begin{tabular}{|c|c|c|c|c|c|c|}
\hline & & \multicolumn{5}{|c|}{ Supplemental Table S2.txt } \\
\hline CHEMBL343483 & 51162 & 5.8539 & 5.2925 & TRN & & \\
\hline CHEMBL140194 & 51162 & 6.5229 & 6.3478 & TRN & & \\
\hline CHEMBL142284 & 51162 & 5.364 & 5.7023 & TRN & & \\
\hline CHEMBL141068 & 51162 & $5.3820 e$ & 0000000 & & 5.6317 & TRN \\
\hline CHEMBL143446 & 51162 & 5.6778 & 6.8127 & TST & & \\
\hline CHEMBL143280 & 51162 & 5.7825 & 6.6032 & TRN & & \\
\hline CHEMBL139949 & 51162 & 5.8539 & 6.0874 & TRN & & \\
\hline CHEMBL141073 & 51162 & 3.3979 & 5.0346 & TST & & \\
\hline CHEMBL358057 & 51162 & 8.0458 & 8.0676 & TRN & & \\
\hline CHEMBL422111 & 51162 & 5.7781 & 6.5191 & TST & & \\
\hline CHEMBL140272 & 51162 & 6.6778 & 7.5746 & TST & & \\
\hline CHEMBL140925 & 51162 & 6.7399 & 7.7677 & TST & & \\
\hline CHEMBL445126 & 51162 & 7.8861 & 7.3581 & TRN & & \\
\hline CHEMBL143147 & 51162 & 7.4949 & 7.6214 & TRN & & \\
\hline CHEMBL143443 & 51162 & 6.8539 & 7.6386 & TRN & & \\
\hline CHEMBL139653 & 51162 & 8.0969 & 7.3635 & TRN & & \\
\hline CHEMBL141017 & 51162 & 5.5436 & 5.5247 & TRN & & \\
\hline CHEMBL141018 & 51162 & 8.3979 & 7.9064 & TRN & & \\
\hline CHEMBL140808 & 51162 & 8.3979 & 8.2546 & TRN & & \\
\hline CHEMBL356603 & 51162 & 5.8254 & 5.9635 & TRN & & \\
\hline CHEMBL344812 & 51162 & 7.4685 & 7.5453 & TRN & & \\
\hline CHEMBL139950 & 51162 & 5.5607 & 5.8459 & TRN & & \\
\hline CHEMBL274181 & 51162 & 7.0706 & 6.6242 & TRN & & \\
\hline CHEMBL421763 & 51162 & 7.9586 & 7.9064 & TRN & & \\
\hline CHEMBL344045 & 51162 & 6.8386 & 6.8105 & TRN & & \\
\hline CHEMBL423547 & 51162 & 3.3979 & 5.1488 & TST & & \\
\hline CHEMBL422296 & 51162 & 6.7986 & 6.5278 & TST & & \\
\hline CHEMBL343119 & 51162 & 6.7212 & 6.3653 & TST & & \\
\hline CHEMBL140907 & 51162 & 5.4815 & 6.3769 & TST & & \\
\hline CHEMBL142619 & 51162 & 9.1549 & 7.70799 & 9999999999 & & TST \\
\hline CHEMBL140373 & 51162 & 6.2573 & 5.9141 & TST & & \\
\hline CHEMBL342613 & 51162 & 4.8697 & 7.1093 & TST & & \\
\hline CHEMBL 2022402 & 816438 & 1.9853 & 2.3947 & TRN & & \\
\hline CHEMBL 2022401 & 816438 & 1.9311 & 1.9702 & TST & & \\
\hline CHEMBL 2022388 & 816438 & 1.8768 & 1.8189 & TRN & & \\
\hline CHEMBL 2022390 & 816438 & 1.8132 & 1.784 & TRN & & \\
\hline CHEMBL 2022383 & 816438 & 1.909 & 1.8436 & TRN & & \\
\hline CHEMBL 2024640 & 816438 & 1.8562 & 1.9586 & TRN & & \\
\hline CHEMBL 2023709 & 816438 & 1.9298 & 2.213 & TST & & \\
\hline CHEMBL 2024638 & 816438 & 1.7157 & 1.885 & TRN & & \\
\hline CHEMBL 2024632 & 816438 & 1.7415 & 1.8329 & TRN & & \\
\hline CHEMBL 2022393 & 816438 & 1.6852 & 1.8177 & TRN & & \\
\hline CHEMBL 2022392 & 816438 & 1.8676 & 1.7881 & TRN & & \\
\hline CHEMBL 2024629 & 816438 & 1.8396 & 1.9487 & TRN & & \\
\hline CHEMBL 2024639 & 816438 & 1.9015 & 1.9586 & TRN & & \\
\hline CHEMBL 2022399 & 816438 & 2.0057 & 2.3683 & TRN & & \\
\hline CHEMBL 2022381 & 816438 & 1.7326 & 1.8009 & TRN & & \\
\hline CHEMBL 2022397 & 816438 & 1.9323 & 2.1344 & TRN & & \\
\hline
\end{tabular}


Supplemental Table S2.txt

\begin{tabular}{|c|c|c|c|c|}
\hline CHEMBL 2022389 & 816438 & 1.9458 & 1.8072 & TRN \\
\hline CHEMBL 2024642 & 816438 & 4.2459 & 2.1138 & TRN \\
\hline CHEMBL2024631 & 816438 & 1.9577 & 1.8468 & TRN \\
\hline CHEMBL 2023711 & 816438 & 2.025 & 2.077 & TST \\
\hline CHEMBL2024625 & 816438 & 1.6363 & 1.8433 & TRN \\
\hline CHEMBL1269516 & 816438 & 1.6973 & 1.7325 & TRN \\
\hline CHEMBL 2024635 & 816438 & 1.9285 & 1.8722 & TRN \\
\hline CHEMBL2024623 & 816438 & 4.4314 & 2.0845 & TST \\
\hline CHEMBL487933 & 816438 & 1.8618 & 1.8361 & TRN \\
\hline CHEMBL2024643 & 816438 & 1.7577 & 2.1182 & TRN \\
\hline CHEMBL 2022387 & 816438 & 1.9164 & 1.8485 & TRN \\
\hline CHEMBL 2024630 & 816438 & 1.9881 & 1.9487 & TRN \\
\hline CHEMBL 2024636 & 816438 & 1.7652 & 1.9163 & TRN \\
\hline CHEMBL1271483 & 816438 & 1.7584 & 1.8601 & TRN \\
\hline CHEMBL2022400 & 816438 & 2.0463 & 2.1663 & TRN \\
\hline CHEMBL 2024634 & 816438 & 1.8563 & 1.9448 & TRN \\
\hline CHEMBL 2024633 & 816438 & 1.7179 & 1.8482 & TRN \\
\hline CHEMBL 2023712 & 816438 & 1.7434 & 1.8367 & TST \\
\hline CHEMBL450046 & 816438 & 4.308 & 1.9776 & TST \\
\hline CHEMBL2023706 & 816438 & 1.9992 & 2.197 & TRN \\
\hline CHEMBL 2024624 & 816438 & 3.6342 & 2.35699 & 99999999998 \\
\hline CHEMBL 2022394 & 816438 & 1.8286 & 1.9305 & TST \\
\hline CHEMBL 2022395 & 816438 & 1.8239 & 1.8271 & TRN \\
\hline CHEMBL1341255 & 816438 & 2.3306 & 1.8208 & TST \\
\hline CHEMBL2023707 & 816438 & 1.9651 & 1.9919 & TST \\
\hline CHEMBL2023710 & 816438 & 3.5993 & 2.5302 & TRN \\
\hline CHEMBL2022380 & 816438 & 1.8814 & 1.8174 & TRN \\
\hline CHEMBL 2024627 & 816438 & 1.7559 & 1.8617 & TRN \\
\hline CHEMBL 2022384 & 816438 & 2.0942 & 1.8604 & TRN \\
\hline CHEMBL 2022385 & 816438 & 1.8623 & 1.7924 & TRN \\
\hline CHEMBL2024641 & 816438 & 1.9196 & 1.9996 & TRN \\
\hline CHEMBL2024628 & 816438 & 1.7705 & 1.9487 & TRN \\
\hline CHEMBL 2023708 & 816438 & 1.9109 & 2.6145 & TRN \\
\hline CHEMBL2024626 & 816438 & 2.006 & 1.9533 & TRN \\
\hline CHEMBL2022396 & 816438 & 1.8163 & 1.8931 & TRN \\
\hline CHEMBL2022391 & 816438 & 1.77 & 1.8185 & TRN \\
\hline CHEMBL2022398 & 816438 & 1.9556 & 1.9781 & TST \\
\hline CHEMBL 2024637 & 816438 & 1.9526 & 1.9459 & TST \\
\hline CHEMBL2022386 & 816438 & 1.7689 & 1.8378 & TST \\
\hline CHEMBL 2022382 & 816438 & 2.0063 & 1.797 & TST \\
\hline CHEMBL3353492 & 1440135 & 5.3498 & 5.3352 & TST \\
\hline CHEMBL3353521 & 1440135 & 6.1785 & 6.2239 & TRN \\
\hline CHEMBL3353483 & 1440135 & 7.4437 & 7.3104 & TRN \\
\hline CHEMBL3352999 & 1440135 & 5.0 & 5.5107 & TST \\
\hline CHEMBL3353491 & 1440135 & 5.475 & 5.7224 & TRN \\
\hline CHEMBL3353529 & 1440135 & 6.1481 & 6.051 & TRN \\
\hline CHEMBL3352828 & 1440135 & 5.475 & 5.6583 & TRN \\
\hline CHEMBL3353001 & 1440135 & 6.5622 & 5.9939 & TRN \\
\hline
\end{tabular}

Page 16919 
Supplemental Table S2.txt

\begin{tabular}{|c|c|c|c|c|}
\hline HEM & לנגטדיד & 7.3565 & 0842 & \\
\hline 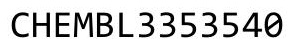 & & 6.8601 & .8045 & \\
\hline 18 & - & & & \\
\hline HEMBL & & & & $\mathrm{MI}$ \\
\hline AEMBL3353499 & כד & & 8066 & \\
\hline HEMBL3353512 & 440135 & 6.4597 & 9341 & \\
\hline 487 & 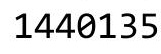 & & & \\
\hline IEMBL & & & & 等 \\
\hline HEMBL3353477 & & 675 & 1132 & \\
\hline HEMBL3353524 & 44 & 88 & .4471 & \\
\hline AEMBL3353522 & 44 & 5.5447 & .6257 & \\
\hline IEMBL & 44 & 06 & 3428 & \\
\hline HEMBL; & & & & RN \\
\hline HEMBL3353490 & $\Delta$ & 366 & 4.9238 & \\
\hline AEMBL33 & 42 & 4 & 6346 & \\
\hline AEMBL3353478 & 44 & 6 & 4598 & \\
\hline AEMBL33 & Th & & 68 & . \\
\hline HEMBL3: & & & 301 & \\
\hline HEMBL33 & & & 4.4467 & \\
\hline AEMBL3: & & 4 & 74 & \\
\hline AEMBL3 & 44 & 9 & 79 & IRN \\
\hline AEMBL: & 42 & & 48 & RN \\
\hline HEMBL & & & 91 & \\
\hline 2998 & & 5. & 1114 & \\
\hline AEMBL33 & & & 35 & 15 \\
\hline HEMBL3: & 4 & & 5721 & RN \\
\hline HEMBL & 44 & & 318 & RN \\
\hline HEMBL 33 & $\Delta$ & & 927 & \\
\hline HEMBL3353523 & & & 6.7508 & $\ln$ \\
\hline HEMBL33535 & & 5 . & 5.8618 & ISI \\
\hline HEMBL335 & 44 & & 4255 & ГST \\
\hline HEMBL3 & 44 & 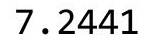 & 047 & RN \\
\hline HEMBL3 & & 5 & & M \\
\hline HEMBL3353484 & & & 274 & IRN \\
\hline HEMBL 3353465 & 44 & 6 . & 6.6881 & TRN \\
\hline HEMBL33 & 44 & 77 & $\partial 15$ & RN \\
\hline HFMRI 3 & 1 & 6 & 86 & $\Gamma \mathrm{RN}$ \\
\hline HEMBL3 & & 4 . & 691 & TRN \\
\hline HEMBL3353509 & & 4 & 3.512 & TRN \\
\hline AEMBL335 & & & 5.7049 & TRN \\
\hline HEMBL33 & 4 & 7. & .4332 & TRN \\
\hline CHEMBL 33 & & & & TRN \\
\hline HEMBL3353000 & & & 3106 & TRN \\
\hline HEMBL3353532 & 44 & 7.3188 & 7.8692 & $\Gamma R$ \\
\hline MBL3 & & & 5.4488 & $\mathrm{~N}$ \\
\hline HEMBL 33 & 44 & & 5.303 & \\
\hline CHEMBL 3353479 & & 7.1192 & 7.1061 & \\
\hline HEMBL3353535 & 1440135 & 7.0223 & 6.4438 & ГRN \\
\hline
\end{tabular}

Page 16920 


$$
\text { Supplemental Table S2.txt }
$$

\begin{tabular}{|c|c|c|c|c|c|c|}
\hline CHEMBL3353536 & 1440135 & 6.5834 & 6.3121 & TRN & & \\
\hline CHEMBL3353468 & 1440135 & 6.9101 & 6.6716 & TRN & & \\
\hline CHEMBL3353464 & 1440135 & 5.9179 & 5.9481 & TRN & & \\
\hline CHEMBL3353497 & 1440135 & 4.0 & 6.0104 & TST & & \\
\hline CHEMBL3353533 & 1440135 & 7.4437 & 7.5346 & TRN & & \\
\hline CHEMBL3353004 & 1440135 & 5.0 & 5.8164 & TRN & & \\
\hline CHEMBL3353467 & 1440135 & 6.4425 & 6.2681 & TRN & & \\
\hline CHEMBL3353526 & 1440135 & 7.0706 & 7.1423 & TRN & & \\
\hline CHEMBL3353502 & 1440135 & 6.9281 & 7.4342 & TRN & & \\
\hline CHEMBL3353486 & 1440135 & 4.0 & 4.3567 & TRN & & \\
\hline CHEMBL3353493 & 1440135 & 4.0 & 4.8648 & TST & & \\
\hline CHEMBL3353525 & 1440135 & 5.475 & 4.8526 & TRN & & \\
\hline CHEMBL3353475 & 1440135 & 7.1192 & 6.6986 & TRN & & \\
\hline CHEMBL3706689 & 1440135 & 6.644 & 6.535 & TRN & & \\
\hline CHEMBL3353476 & 1440135 & 6.4724 & 6.2714 & TRN & & \\
\hline CHEMBL3353511 & 1440135 & 7.2007 & 6.9363 & TRN & & \\
\hline CHEMBL3353520 & 1440135 & 6.2373 & 5.8893 & TST & & \\
\hline CHEMBL3353482 & 1440135 & 6.556 & 6.6438 & TST & & \\
\hline CHEMBL3353507 & 1440135 & 4.0 & 4.9412 & TST & & \\
\hline CHEMBL3353516 & 1440135 & 6.9393 & 7.4397 & TST & & \\
\hline CHEMBL3353515 & 1440135 & 7.2007 & 7.7759 & TST & & \\
\hline CHEMBL3353510 & 1440135 & 5.9416 & 6.6873 & TST & & \\
\hline CHEMBL3353472 & 1440135 & 6.2924 & 6.2973 & TST & & \\
\hline CHEMBL3353531 & 1440135 & 6.301 & 5.7507 & TST & & \\
\hline CHEMBL3353506 & 1440135 & 4.0 & 6.1144 & TST & & \\
\hline CHEMBL3353003 & 1440135 & 5.475 & 6.6736 & TST & & \\
\hline CHEMBL3353519 & 1440135 & 4.0 & 5.1765 & TST & & \\
\hline CHEMBL3353513 & 1440135 & 6.5918 & 6.9569 & TST & & \\
\hline CHEMBL3353517 & 1440135 & 6.8861 & 7.3627 & TST & & \\
\hline CHEMBL3979100 & 1640862 & 7.5735 & 6.5054 & TRN & & \\
\hline CHEMBL3936861 & 1640862 & 7.4841 & 7.1274 & TRN & & \\
\hline CHEMBL3900969 & 1640862 & 8.28399 & 999999999 & 99 & 8.555 & TRN \\
\hline CHEMBL3965854 & 1640862 & 7.5702 & 7.4972 & TRN & & \\
\hline CHEMBL3897910 & 1640862 & 8.9586 & 8.9802 & TRN & & \\
\hline CHEMBL3981819 & 1640862 & 6.0 & 6.2309 & TRN & & \\
\hline CHEMBL3905575 & 1640862 & 7.284 & 7.0814 & TRN & & \\
\hline CHEMBL3982355 & 1640862 & 6.0 & 6.1075 & TRN & & \\
\hline CHEMBL3897663 & 1640862 & 6.684 & 6.5053 & TRN & & \\
\hline CHEMBL3913652 & 1640862 & 7.1811 & 8.4545 & TST & & \\
\hline CHEMBL3951086 & 1640862 & 6.0 & 6.8066 & TST & & \\
\hline CHEMBL3942767 & 1640862 & 6.0 & 5.8785 & TRN & & \\
\hline CHEMBL3974910 & 1640862 & 6.0 & 7.0761 & TST & & \\
\hline CHEMBL3983286 & 1640862 & 7.4486 & 7.4665 & TRN & & \\
\hline CHEMBL 3890878 & 1640862 & 7.2306 & 7.0153 & TRN & & \\
\hline CHEMBL3890743 & 1640862 & 7.7721 & 7.7049 & TRN & & \\
\hline CHEMBL3891800 & 1640862 & 6.0159 & 5.9025 & TRN & & \\
\hline CHEMBL3911227 & 1640862 & 6.0 & 6.3659 & TRN & & \\
\hline CHEMBL 3623828 & 1640862 & 6.0 & 5.9667 & TRN & & \\
\hline
\end{tabular}


Supplemental Table S2.txt

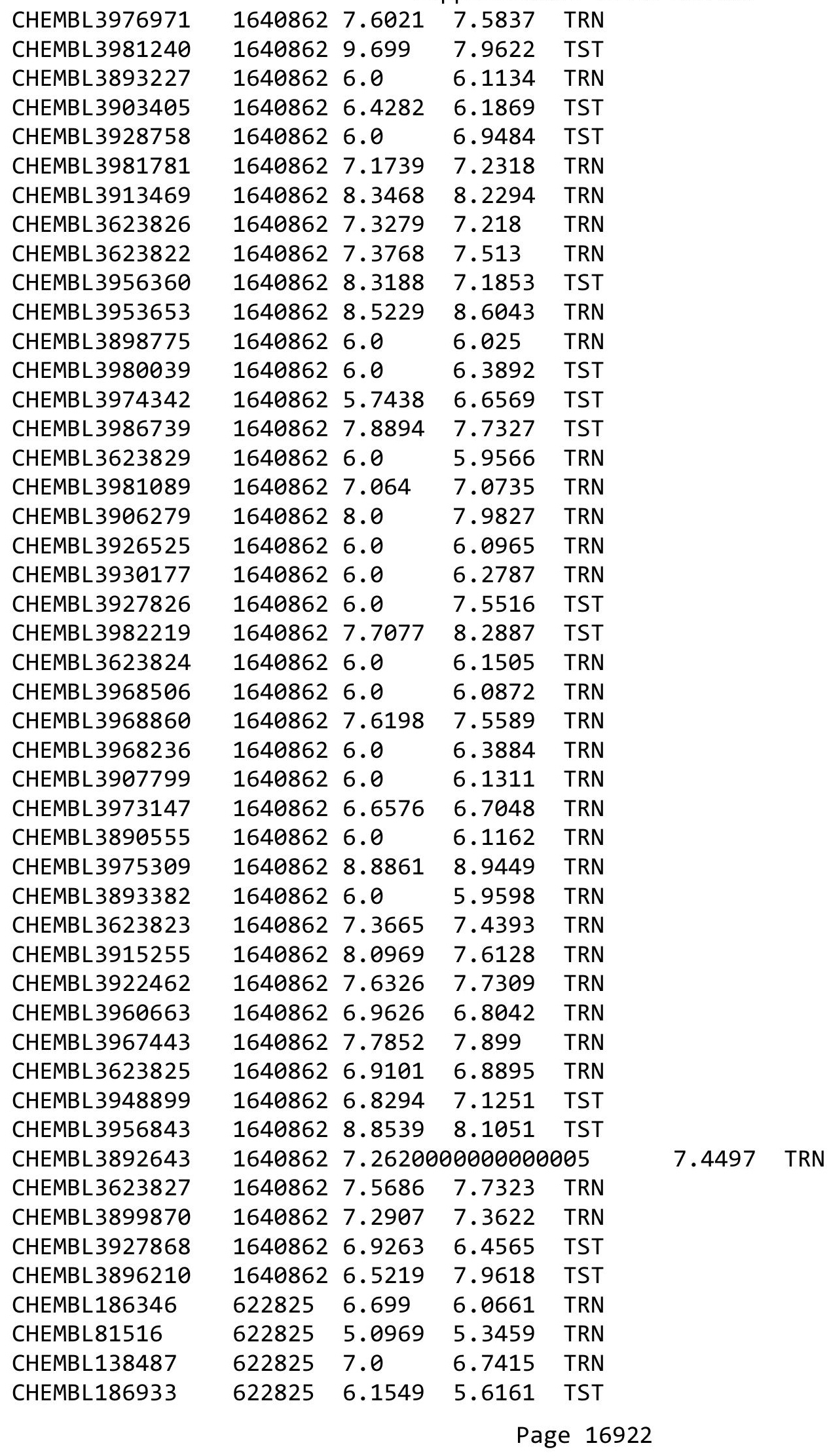




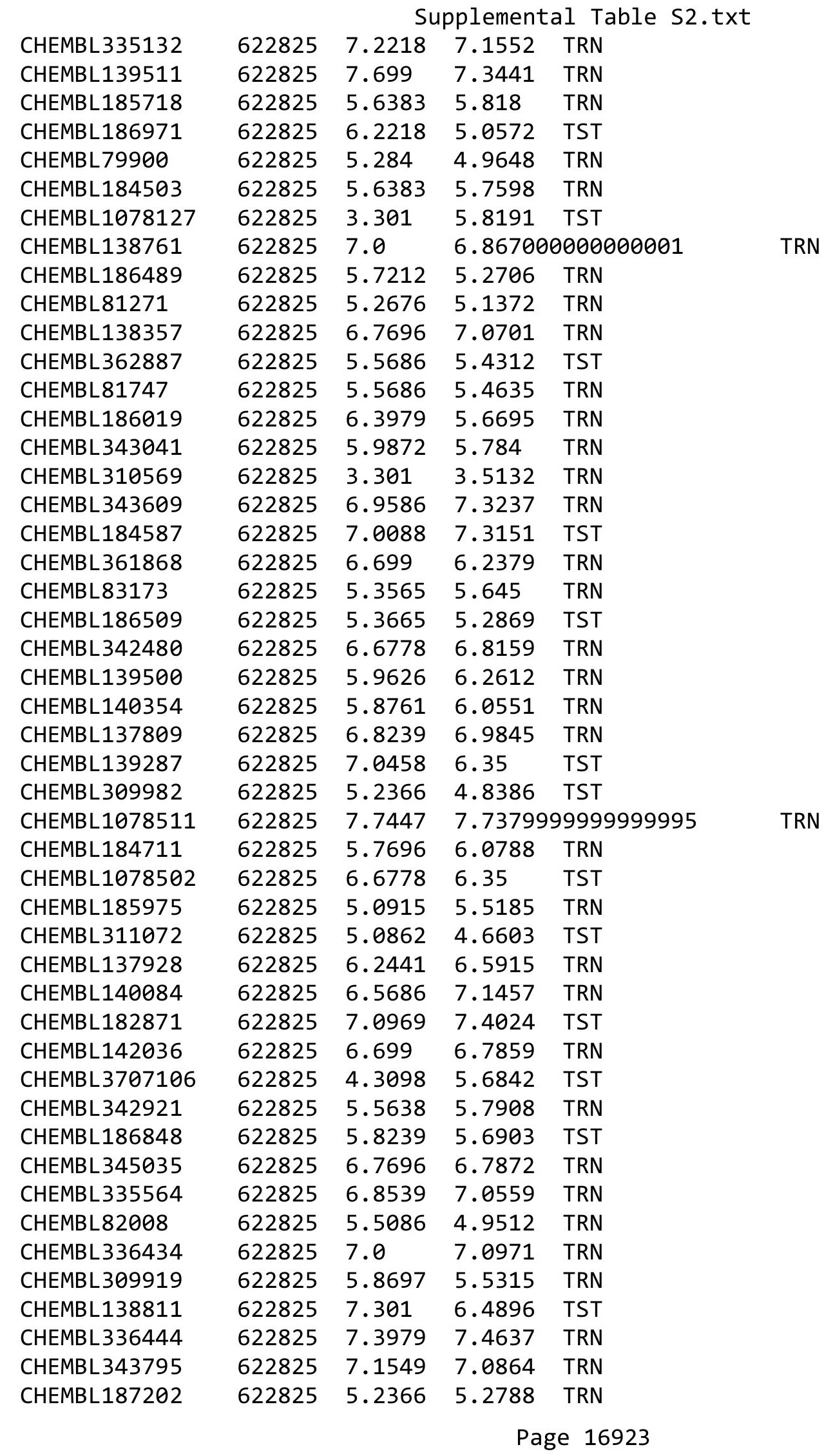




\begin{tabular}{|c|c|c|c|c|c|c|}
\hline & & \multicolumn{5}{|c|}{ Supplemental Table S2.txt } \\
\hline CHEMBL311055 & 622825 & 5.3872 & 5.4492 & TST & & \\
\hline CHEMBL336417 & 622825 & 7.2218 & 6.8417 & TRN & & \\
\hline CHEMBL141661 & 622825 & 7.0 & 6.7983 & TRN & & \\
\hline CHEMBL 310838 & 622825 & 3.301 & 4.9512 & TRN & & \\
\hline CHEMBL138187 & 622825 & 7.0969 & 7.1022 & TRN & & \\
\hline CHEMBL141540 & 622825 & 7.301 & 6.7451 & TRN & & \\
\hline CHEMBL 365070 & 622825 & 5.7696 & 5.8937 & TRN & & \\
\hline CHEMBL187955 & 622825 & 5.2291 & 5.5061 & TRN & & \\
\hline CHEMBL335819 & 622825 & 7.1308 & 7.3814 & TRN & & \\
\hline CHEMBL3707104 & 622825 & 5.7212 & 5.9086 & TST & & \\
\hline CHEMBL1078222 & 622825 & 6.5735 & 6.5228 & TRN & & \\
\hline CHEMBL181970 & 622825 & 6.4976 & 6.4637 & TRN & & \\
\hline CHEMBL365069 & 622825 & 5.6383 & 5.6883 & TRN & & \\
\hline CHEMBL337762 & 622825 & 7.0969 & 7.355 & TRN & & \\
\hline CHEMBL141740 & 622825 & 6.3372 & 6.1652 & TRN & & \\
\hline CHEMBL421143 & 622825 & 3.301 & 3.4243 & TRN & & \\
\hline CHEMBL3707105 & 622825 & 6.699 & 6.7859 & TST & & \\
\hline CHEMBL 81268 & 622825 & 5.5528 & 4.9512 & TRN & & \\
\hline CHEMBL139443 & 622825 & 6.2218 & 6.1658 & TRN & & \\
\hline CHEMBL431404 & 622825 & 5.585 & 5.3876 & TST & & \\
\hline CHEMBL341985 & 622825 & 6.301 & 6.5125 & TRN & & \\
\hline CHEMBL137973 & 622825 & 6.6778 & 6.358 & TST & & \\
\hline CHEMBL140180 & 622825 & 7.7447 & 7.1981 & TRN & & \\
\hline CHEMBL138369 & 622825 & 5.8894 & 5.4606 & TRN & & \\
\hline CHEMBL483847 & 954893 & 3.5794 & 3.5794 & TRN & & \\
\hline CHEMBL65 & 954893 & 8.7867 & 8.7867 & TRN & & \\
\hline CHEMBL 209148 & 954893 & 5.0253 & 5.0253 & TRN & & \\
\hline CHEMBL 2005886 & 954893 & 4.7907 & 4.7907 & TRN & & \\
\hline CHEMBL399530 & 954893 & 5.1348 & 5.1347 & TRN & & \\
\hline CHEMBL135561 & 954893 & 3.6636 & 3.6636 & TRN & & \\
\hline CHEMBL102714 & 954893 & 3.3778 & 3.3778 & TRN & & \\
\hline CHEMBL558642 & 954893 & 3.0003 & 3.0003 & TRN & & \\
\hline CHEMBL255342 & 954893 & 3.1187 & 3.1187 & TRN & & \\
\hline CHEMBL191334 & 954893 & 3.2156 & 3.2156 & TRN & & \\
\hline CHEMBL240954 & 954893 & 3.0034 & 3.1766 & TST & & \\
\hline CHEMBL2363137 & 954893 & 4.8457 & 4.8457 & TRN & & \\
\hline CHEMBL449158 & 954893 & 6.1747 & 6.5801 & TST & & \\
\hline CHEMBL 2144069 & 954893 & 5.53100 & 30000000 & $\partial 1$ & 5.5311 & TRN \\
\hline CHEMBL221137 & 954893 & 4.5699 & 4.6427 & TST & & \\
\hline CHEMBL1256459 & 954893 & 7.6151 & 7.6151 & TRN & & \\
\hline CHEMBL 213100 & 954893 & 3.6507 & 3.6507 & TRN & & \\
\hline CHEMBL412142 & 954893 & 3.4929 & 3.4929 & TRN & & \\
\hline CHEMBL1590308 & 954893 & 3.9263 & 3.3494 & TST & & \\
\hline CHEMBL180127 & 954893 & 4.7006 & 4.7006 & TRN & & \\
\hline CHEMBL393929 & 954893 & 4.9505 & 4.9506 & TRN & & \\
\hline CHEMBL 2134202 & 954893 & 3.7306 & 3.7306 & TRN & & \\
\hline CHEMBL 202721 & 954893 & 4.5973 & 4.5973 & TRN & & \\
\hline CHEMBL192566 & 954893 & 7.75700 & 30000000 & & 8.5964 & ונו \\
\hline
\end{tabular}




\begin{tabular}{|c|c|c|c|c|c|}
\hline & & & & & \\
\hline CHEMBL188678 & 954893 & 4.3003 & 4.3003 & TRN & \\
\hline CHEMBL1909414 & 954893 & 4.584 & 4.584 & TRN & \\
\hline CHEMBL514499 & 954893 & 7.1782 & 7.1783 & TRN & \\
\hline CHEMBL3349342 & 954893 & 6.0525 & 6.0525 & TRN & \\
\hline CHEMBL 2137530 & 954893 & 5.1265 & 5.1266 & TRN & \\
\hline CHEMBL585951 & 954893 & 5.9423 & 5.9423 & TRN & \\
\hline CHEMBL3392440 & 954893 & 3.7369 & 3.7369 & TRN & \\
\hline CHEMBL509032 & 954893 & 5.5042 & 5.5041 & TRN & \\
\hline CHEMBL573107 & 954893 & 5.473 & 5.473 & TRN & \\
\hline CHEMBL392695 & 954893 & 5.6505 & 5.6505 & TRN & \\
\hline CHEMBL 217354 & 954893 & 6.4032 & 6.4031 & TRN & \\
\hline CHEMBL3186408 & 954893 & 4.1698 & 3.7622 & TST & \\
\hline CHEMBL3199475 & 954893 & 4.4886 & 4.4887 & TRN & \\
\hline CHEMBL577784 & 954893 & 5.4119 & 5.4119 & TRN & \\
\hline CHEMBL1230020 & 954893 & 3.9681 & 3.9681 & TRN & \\
\hline CHEMBL483849 & 954893 & 2.7089 & 2.7088 & TRN & \\
\hline CHEMBL1516890 & 954893 & 4.7519 & 4.7518 & TRN & \\
\hline CHEMBL379300 & 954893 & 5.7509 & 5.7509 & TRN & \\
\hline CHEMBL515416 & 954893 & 5.602 & 5.602 & TRN & \\
\hline CHEMBL 210618 & 954893 & 3.2703 & 3.2703 & TRN & \\
\hline CHEMBL1190711 & 954893 & 5.0339 & 5.0339 & TRN & \\
\hline CHEMBL1357247 & 954893 & 2.7787 & 2.7786 & TRN & \\
\hline CHEMBL1673039 & 954893 & 4.5184 & 4.5184 & TRN & \\
\hline CHEMBL1788116 & 954893 & 3.8476 & 3.8476 & TRN & \\
\hline CHEMBL1186585 & 954893 & 3.6387 & 3.6387 & TRN & \\
\hline CHEMBL1970879 & 954893 & 5.3114 & 5.3114 & TRN & \\
\hline CHEMBL189584 & 954893 & 3.4748 & 3.4748 & TRN & \\
\hline CHEMBL 222102 & 954893 & 3.1432 & 3.1432 & TRN & \\
\hline CHEMBL9470 & 954893 & 6.3278 & 5.9324 & TST & \\
\hline CHEMBL1404918 & 954893 & 3.1989 & 3.199 & TRN & \\
\hline CHEMBL 220241 & 954893 & 4.5983 & 4.5983 & TRN & \\
\hline CHEMBL1242367 & 954893 & 3.8744 & 4.239 & TST & \\
\hline CHEMBL 258844 & 954893 & 3.2139 & 4.1129 & TST & \\
\hline CHEMBL472940 & 954893 & 2.7651 & 3.9217 & TST & \\
\hline CHEMBL1643959 & 954893 & 2.9441 & 2.8009 & TST & \\
\hline CHEMBL259181 & 954893 & 4.4336 & 4.9025 & TST & \\
\hline CHEMBL92309 & 954893 & 2.8291 & 2.9931 & TST & \\
\hline CHEMBL 300389 & 954893 & 7.2204 & 6.7704 & TST & \\
\hline CHEMBL 373751 & 954893 & 3.2821 & 3.7705 & TST & \\
\hline CHEMBL512504 & 954893 & 6.83 & 4.5382 & TST & \\
\hline CHEMBL 86428 & 45424 & 7.1612 & 7.16200 & 0000000001 & TRN \\
\hline CHEMBL6685 & 45424 & 7.7696 & 7.7694 & TRN & \\
\hline CHEMBL6753 & 45424 & 6.4498 & 6.8342 & TST & \\
\hline CHEMBL327604 & 45424 & 6.5171 & 6.5164 & TRN & \\
\hline CHEMBL 88232 & 45424 & 7.7447 & 7.7458 & TRN & \\
\hline CHEMBL315592 & 45424 & 7.1024 & 7.1006 & TRN & \\
\hline CHEMBL 280071 & 45424 & 6.9208 & 6.9209 & TRN & \\
\hline CHEMBL89455 & 45424 & 7.1024 & 7.1022 & TRN & \\
\hline
\end{tabular}




\begin{tabular}{|c|c|c|c|c|c|}
\hline \multicolumn{6}{|c|}{ Supplemental Table S2.txt } \\
\hline CHEMBL89163 & 45424 & 8.0 & 8.0006 & TRN & \\
\hline CHEMBL35118 & 45424 & 7.7212 & 7.7215 & TRN & \\
\hline CHEMBL313123 & 45424 & 6.5086 & 6.5077 & TRN & \\
\hline CHEMBL268177 & 45424 & 6.9031 & 6.2545 & TST & \\
\hline CHEMBL266240 & 45424 & 6.7959 & 6.3757 & TST & \\
\hline CHEMBL 88120 & 45424 & 7.3372 & 7.3363 & TRN & \\
\hline CHEMBL91420 & 45424 & 6.5229 & 6.5227 & TRN & \\
\hline CHEMBL90492 & 45424 & 6.8239 & 6.8235 & TRN & \\
\hline CHEMBL86751 & 45424 & 6.5157 & 6.5157 & TRN & \\
\hline CHEMBL327669 & 45424 & 6.5229 & 6.5234 & TRN & \\
\hline CHEMBL 85120 & 45424 & 7.7212 & 7.7204 & TRN & \\
\hline CHEMBL6853 & 45424 & 6.7447 & 6.33 & TST & \\
\hline CHEMBL 7092 & 45424 & 6.4949 & 6.0878 & TST & \\
\hline CHEMBL420610 & 45424 & 8.0458 & 8.0451 & TRN & \\
\hline CHEMBL88969 & 45424 & 7.2076 & 7.2077 & TRN & \\
\hline CHEMBL6784 & 45424 & 6.3468 & 6.347 & TRN & \\
\hline CHEMBL316037 & 45424 & 8.0458 & 8.0455 & TRN & \\
\hline CHEMBL313925 & 45424 & 7.8861 & 7.8857 & TRN & \\
\hline CHEMBL 90218 & 45424 & 7.1805 & 7.1819 & TRN & \\
\hline CHEMBL330346 & 45424 & 6.7696 & 6.7708 & TRN & \\
\hline CHEMBL6852 & 45424 & 5.6576 & 5.4808 & TST & \\
\hline CHEMBL 87141 & 45424 & 7.3565 & 7.3564 & TRN & \\
\hline CHEMBL316140 & 45424 & 7.1249 & 7.125 & TRN & \\
\hline CHEMBL 7087 & 45424 & 5.6108 & 5.61100 & 0000000001 & TRN \\
\hline CHEMBL89945 & 45424 & 6.9788 & 6.9795 & TRN & \\
\hline CHEMBL432818 & 45424 & 7.1612 & 7.1618 & TRN & \\
\hline CHEMBL 327933 & 45424 & 7.1549 & 7.1554 & TRN & \\
\hline CHEMBL88519 & 45424 & 7.2218 & 7.2231 & TRN & \\
\hline CHEMBL269628 & 45424 & 6.75700 & 00000000 & 6.3521 & TST \\
\hline CHEMBL6724 & 45424 & 7.1805 & 6.2982 & TST & \\
\hline CHEMBL265674 & 45424 & 6.2676 & 6.7283 & TST & \\
\hline CHEMBL6705 & 45424 & 5.8827 & 5.3925 & TST & \\
\hline CHEMBL13646 & 45424 & 6.9031 & 6.9034 & TRN & \\
\hline CHEMBL 7204 & 45424 & 5.4928 & 5.4926 & TRN & \\
\hline CHEMBL88173 & 45424 & 7.2676 & 7.2677 & TRN & \\
\hline CHEMBL6919 & 45424 & 6.2518 & 6.2512 & TRN & \\
\hline CHEMBL92116 & 45424 & 6.5452 & 6.5455 & TRN & \\
\hline CHEMBL327487 & 45424 & 7.7447 & 7.7886 & TST & \\
\hline CHEMBL88860 & 45424 & 7.3979 & 7.3974 & TRN & \\
\hline CHEMBL89634 & 45424 & 7.2596 & 7.2589 & TRN & \\
\hline CHEMBL 287117 & 45424 & 7.8239 & 7.8234 & TRN & \\
\hline CHEMBL328946 & 45424 & 7.3188 & 7.3176 & TRN & \\
\hline CHEMBL314929 & 45424 & 7.9586 & 7.9593 & TRN & \\
\hline CHEMBL 90382 & 45424 & 8.0 & 8.0 & TRN & \\
\hline CHEMBL315661 & 45424 & 7.1549 & 7.1796 & TST & \\
\hline CHEMBL85079 & 45424 & 7.6778 & 7.7263 & TST & \\
\hline CHEMBL 313770 & 45424 & 7.7696 & 7.8037 & TST & \\
\hline CHEMBL 3659934 & 1527862 & 6.9957 & 6.8797 & TRN & \\
\hline
\end{tabular}

Page 16926 
Supplemental Table S2.txt

\begin{tabular}{|c|c|c|c|c|c|c|}
\hline CHEMBL3659945 & 1527862 & 6.5498 & 6.8995 & TRN & & \\
\hline CHEMBL3659964 & 1527862 & 8.0969 & 7.5707 & TST & & \\
\hline CHEMBL3659905 & 1527862 & 6.9747 & 7.2953 & TRN & & \\
\hline CHEMBL3659946 & 1527862 & 6.82100 & 000000000 & 31 & 7.1465 & TRN \\
\hline CHEMBL3659959 & 1527862 & 6.5834 & 6.4105 & TST & & \\
\hline CHEMBL3659960 & 1527862 & 6.7212 & 6.4618 & TRN & & \\
\hline CHEMBL3659915 & 1527862 & 8.301 & 7.5195 & TST & & \\
\hline CHEMBL 3659940 & 1527862 & 6.7328 & 6.4893 & TRN & & \\
\hline CHEMBL3659950 & 1527862 & 6.6716 & 6.8134 & TRN & & \\
\hline CHEMBL3659910 & 1527862 & 8.1549 & 7.6608 & TST & & \\
\hline CHEMBL3659919 & 1527862 & 7.9208 & 7.6585 & TRN & & \\
\hline CHEMBL3659949 & 1527862 & 6.6402 & 7.0975 & TRN & & \\
\hline CHEMBL3659936 & 1527862 & 6.5302 & 6.5815 & TRN & & \\
\hline CHEMBL3659922 & 1527862 & 7.585 & 7.1928 & TRN & & \\
\hline CHEMBL3659928 & 1527862 & 7.5229 & 7.3507 & TRN & & \\
\hline CHEMBL3659938 & 1527862 & 7.1549 & 7.1055 & TRN & & \\
\hline CHEMBL3659916 & 1527862 & 8.3979 & 7.3387 & TST & & \\
\hline CHEMBL3659955 & 1527862 & 6.2343 & 6.2252 & TRN & & \\
\hline CHEMBL 3659965 & 1527862 & 7.7447 & 6.94 & TST & & \\
\hline CHEMBL3659939 & 1527862 & 6.82100 & 000000000 & 1 & 6.8018 & TRN \\
\hline CHEMBL3659921 & 1527862 & 6.8539 & 6.8391 & TRN & & \\
\hline CHEMBL3659963 & 1527862 & 8.3979 & 7.6354 & TST & & \\
\hline CHEMBL3659931 & 1527862 & 7.301 & 6.7986 & TRN & & \\
\hline CHEMBL3659920 & 1527862 & 7.2441 & 7.3177 & TRN & & \\
\hline CHEMBL3659906 & 1527862 & 6.5003 & 7.1326 & TST & & \\
\hline CHEMBL3659927 & 1527862 & 7.6198 & 7.2639 & TRN & & \\
\hline CHEMBL3659935 & 1527862 & 6.3655 & 6.9034 & TRN & & \\
\hline CHEMBL3659948 & 1527862 & 6.5017 & 6.314 & TRN & & \\
\hline CHEMBL3659926 & 1527862 & 6.3224 & 6.2332 & TRN & & \\
\hline CHEMBL3659929 & 1527862 & 7.6021 & 6.9613 & TRN & & \\
\hline CHEMBL3659954 & 1527862 & 6.2976 & 6.3021 & TRN & & \\
\hline CHEMBL3659951 & 1527862 & 6.4389 & 6.375 & TRN & & \\
\hline CHEMBL3659958 & 1527862 & 7.6383 & 7.8529 & TST & & \\
\hline CHEMBL3659932 & 1527862 & 6.1952 & 6.3588 & TRN & & \\
\hline CHEMBL3659941 & 1527862 & 6.5901 & 6.6051 & TRN & & \\
\hline CHEMBL3659925 & 1527862 & 6.6478 & 6.754 & TRN & & \\
\hline CHEMBL3659924 & 1527862 & 8.0458 & 8.0974 & TRN & & \\
\hline CHEMBL3659908 & 1527862 & 7.9586 & 7.4519 & TST & & \\
\hline CHEMBL3639587 & 1527862 & 6.6498 & 7.1283 & TST & & \\
\hline CHEMBL3659962 & 1527862 & 5.7913 & 5.8754 & TRN & & \\
\hline CHEMBL3659957 & 1527862 & 6.3197 & 6.0456 & TRN & & \\
\hline CHEMBL3659967 & 1527862 & 8.301 & 7.9155 & TST & & \\
\hline CHEMBL3659943 & 1527862 & 6.3536 & 6.2461 & TRN & & \\
\hline CHEMBL3659947 & 1527862 & 6.5436 & 6.7453 & TRN & & \\
\hline CHEMBL3659918 & 1527862 & 7.4559 & 7.0749 & TRN & & \\
\hline CHEMBL3659966 & 1527862 & 7.9586 & 7.7222 & TST & & \\
\hline CHEMBL3659930 & 1527862 & 6.2941 & 6.4948 & TRN & & \\
\hline CHEMBL3659909 & 1527862 & 7.4949 & 7.9347 & TRN & & \\
\hline
\end{tabular}

Page 16927 
Supplemental Table S2.txt

\begin{tabular}{|c|c|c|c|c|c|}
\hline CHEMBL3659912 & 1527862 & 8.1549 & 7.85 & TRN & \\
\hline CHEMBL3659956 & 1527862 & 6.3045 & 6.0662 & TRN & \\
\hline CHEMBL3659923 & 1527862 & 7.3565 & 7.5795 & TST & \\
\hline CHEMBL 3659944 & 1527862 & 6.7696 & 6.6435 & TRN & \\
\hline CHEMBL 3659937 & 1527862 & 6.4634 & 6.5639 & TRN & \\
\hline CHEMBL3659917 & 1527862 & 7.9208 & 7.8422 & TRN & \\
\hline CHEMBL3659953 & 1527862 & 6.2573 & 6.1769 & TRN & \\
\hline CHEMBL3659961 & 1527862 & 6.5702 & 6.4505 & TRN & \\
\hline CHEMBL 3659952 & 1527862 & 6.2757 & 6.2168 & TRN & \\
\hline CHEMBL3659913 & 1527862 & 7.8239 & 7.4912 & TRN & \\
\hline CHEMBL 3659942 & 1527862 & 6.5406 & 6.59399 & 9999999999 & TRN \\
\hline CHEMBL3659933 & 1527862 & 5.8365 & 6.744 & TRN & \\
\hline CHEMBL 3659914 & 1527862 & 8.3979 & 7.5988 & TST & \\
\hline CHEMBL3659911 & 1527862 & 5.6861 & 6.5803 & TRN & \\
\hline CHEMBL 3659907 & 1527862 & 4.8539 & 6.3474 & TST & \\
\hline CHEMBL 3774688 & 1561972 & 4.0555 & 4.048 & TRN & \\
\hline CHEMBL3775277 & 1561972 & 7.301 & 7.2868 & TRN & \\
\hline CHEMBL3775130 & 1561972 & 7.2441 & 7.2354 & TRN & \\
\hline CHEMBL 3775465 & 1561972 & 7.3872 & 7.3843 & TRN & \\
\hline CHEMBL 3774747 & 1561972 & 7.1079 & \multicolumn{2}{|c|}{7.0760000000000005} & TRN \\
\hline CHEMBL 3774392 & 1561972 & 7.3872 & 7.39 & TRN & \\
\hline CHEMBL3770256 & 1561972 & 5.699 & 5.2673 & TST & \\
\hline CHEMBL3774692 & 1561972 & 7.9208 & 5.1841 & TST & \\
\hline CHEMBL 3775823 & 1561972 & 6.9245 & 6.919 & TRN & \\
\hline CHEMBL 3775545 & 1561972 & 7.4685 & 7.4684 & TRN & \\
\hline CHEMBL 3774765 & 1561972 & 6.1367 & 6.1396 & TRN & \\
\hline CHEMBL3774710 & 1561972 & 6.8239 & 6.7991 & TRN & \\
\hline CHEMBL3775145 & 1561972 & 7.0969 & 7.0883 & TRN & \\
\hline CHEMBL 3775636 & 1561972 & 6.0809 & 5.5347 & TST & \\
\hline CHEMBL3775095 & 1561972 & 7.2218 & 6.0022 & TST & \\
\hline CHEMBL 3774672 & 1561972 & 5.0757 & 5.0806 & TRN & \\
\hline CHEMBL 3775548 & 1561972 & 7.1549 & 7.1537 & TRN & \\
\hline CHEMBL 2094865 & 1561972 & 4.1433 & 4.5149 & TST & \\
\hline CHEMBL3775933 & 1561972 & 6.9136 & 5.1463 & TST & \\
\hline CHEMBL 3775987 & 1561972 & 3.9855 & 5.5662 & TST & \\
\hline CHEMBL3774456 & 1561972 & 6.8996 & 6.894 & TRN & \\
\hline CHEMBL 3775894 & 1561972 & 7.2924 & 7.3136 & TRN & \\
\hline CHEMBL 3774940 & 1561972 & 7.6383 & 7.6562 & TRN & \\
\hline CHEMBL3775956 & 1561972 & 7.301 & 7.31 & TRN & \\
\hline CHEMBL 3775040 & 1561972 & 7.6778 & 7.6792 & TRN & \\
\hline CHEMBL3774665 & 1561972 & 7.4949 & 7.5096 & TRN & \\
\hline CHEMBL 3775500 & 1561972 & 6.466 & 6.5169 & TRN & \\
\hline CHEMBL3774457 & 1561972 & 6.8477 & 6.8391 & TRN & \\
\hline CHEMBL 3775121 & 1561972 & 7.2676 & 7.2753 & TRN & \\
\hline CHEMBL 3775295 & 1561972 & 3.0 & 3.0039 & TRN & \\
\hline CHEMBL 3775668 & 1561972 & 7.3372 & 7.3319 & TRN & \\
\hline CHEMBL 3774437 & 1561972 & 5.7696 & 5.013 & TST & \\
\hline CHEMBL 3775362 & 1561972 & 7.5229 & 5.9487 & TST & \\
\hline
\end{tabular}


Supplemental Table S2.txt

\begin{tabular}{|c|c|c|c|c|}
\hline - & 561972 & 6.3565 & & \\
\hline & 561972 & 7.6198 & 5974 & \\
\hline & & & & \\
\hline AEMBL37758 & & & & \\
\hline HEMBL3775782 & 561972 & & & \\
\hline HEMBL2098433 & 561972 & 2774 & 5322 & \\
\hline 4 & 972 & 685 & & \\
\hline |FMRI & 972 & & & \\
\hline HEMBL37 & 561972 & & 086 & \\
\hline HEMBL3775977 & 561972 & & .1715 & \\
\hline HEMBL 3774537 & 561972 & 7. & . 1976 & \\
\hline AEMBL3 & 72 & & 947 & \\
\hline AEMBL & & & & \\
\hline HEMBL37 & 72 & 65 & 6.8561 & \\
\hline AEMBL37 & 72 & & 337 & \\
\hline AEMBL3 & 72 & $\partial 2$ & ת & \\
\hline HEMBL3 & 72 & 38 & & \\
\hline HEMBL3 & & & & \\
\hline HEMBL37 & & & 3373 & \\
\hline AEMBL37 & & & & \\
\hline AEMBL3 & 72 & & 32 & RIV \\
\hline HEMBLI & כ & & 75 & 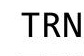 \\
\hline HEMBL3 & & & & \\
\hline HEMBL1\& & & & & \\
\hline AEMBL13 & & & & 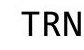 \\
\hline HEMBL1 & 36 & & 607 & II \\
\hline HEMBL: & J & & 89 & 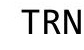 \\
\hline HFMBI 1 & 5 & & 19 & \\
\hline HEMBL1 & & & & iv \\
\hline HEMBL15 & & & 927 & 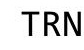 \\
\hline HEMBL1 & 36 & & 064 & RN \\
\hline HEMBL & & & 45 & RN \\
\hline HEMBL1 & & & 429 & $\mathrm{RN}$ \\
\hline HEMBL14 & & & & IRN \\
\hline HEMBL13211 & 30 & & 3.4084 & TST \\
\hline HEMBL1 & 30 & & 2309 & TST \\
\hline HFMRI & & & & RN \\
\hline HEMBL1 & & & 204 & IRN \\
\hline HEMBL172108 & 55 & 3. & 3542 & TRN \\
\hline AEMBL1 & 30 & & 9509 & TST \\
\hline HEMBL1 & כל & 389 & 553 & \\
\hline CHEMBL13 & & & & RIV \\
\hline HEMBL1324435 & 55 & 3.2 & 3.7819 & $\Gamma \mathrm{RN}$ \\
\hline HEMBL31965 & 30 & 3.1578 & 3.3735 & TST \\
\hline MBL1 & 20 & & 5293 & $\mathrm{~K}$ \\
\hline HEMBL1 & & & .1203 & \\
\hline HEMBL 14 & & .5438 & 3.6386 & \\
\hline LHEMBL1901560 & 1301555 & 5.0531 & 4.3451 & ГST \\
\hline
\end{tabular}

Page 16929 
Supplemental Table S2.txt

\begin{tabular}{|c|c|c|c|c|}
\hline CHEMBL1594956 & 1301555 & 4.112 & 4.0254 & TST \\
\hline CHEMBL1315929 & 1301555 & 3.1579 & 3.1806 & TRN \\
\hline CHEMBL1463272 & 1301555 & 3.158 & 3.7695 & TRN \\
\hline CHEMBL1609089 & 1301555 & 3.158 & 3.1758 & TRN \\
\hline CHEMBL1508604 & 1301555 & 3.158 & 2.9031 & TRN \\
\hline CHEMBL1439267 & 1301555 & 3.1579 & 4.0883 & TRN \\
\hline CHEMBL1506063 & 1301555 & 4.2975 & 4.1266 & TRN \\
\hline CHEMBL1353321 & 1301555 & 4.6119 & 4.1583 & TRN \\
\hline CHEMBL1473797 & 1301555 & 3.158 & 3.2252 & TRN \\
\hline CHEMBL39947 & 1301555 & 3.1579 & 3.8337 & TST \\
\hline CHEMBL1606476 & 1301555 & 3.1578 & 3.0992 & TRN \\
\hline CHEMBL1611295 & 1301555 & 3.1579 & 2.9658 & TRN \\
\hline CHEMBL1887359 & 1301555 & 3.1579 & 3.6662 & TRN \\
\hline CHEMBL 2142513 & 1301555 & 4.638 & 4.2419 & TRN \\
\hline CHEMBL 2134346 & 1301555 & 5.0776 & 4.3319 & TST \\
\hline CHEMBL1456083 & 1301555 & 3.158 & 4.5508 & TRN \\
\hline CHEMBL1508966 & 1301555 & 4.7521 & 4.3387 & TRN \\
\hline CHEMBL1422579 & 1301555 & 3.1579 & 4.5225 & TST \\
\hline CHEMBL1430729 & 1301555 & 3.1581 & 3.3275 & TRN \\
\hline CHEMBL1607383 & 1301555 & 4.4988 & 4.3085 & TRN \\
\hline CHEMBL 2141662 & 1301555 & 3.1578 & 4.1892 & TRN \\
\hline CHEMBL1487256 & 1301555 & 3.1581 & 3.1919 & TRN \\
\hline CHEMBL1326667 & 1301555 & 5.6796 & 4.7816 & TRN \\
\hline CHEMBL1409138 & 1301555 & 3.1582 & 3.7922 & TRN \\
\hline CHEMBL1302721 & 1301555 & 5.157 & 4.369 & TRN \\
\hline CHEMBL1388398 & 1301555 & 3.158 & 4.2571 & TRN \\
\hline CHEMBL1602449 & 1301555 & 4.2737 & 4.058 & TRN \\
\hline CHEMBL1545415 & 1301555 & 3.1579 & 3.3282 & TRN \\
\hline CHEMBL1611892 & 1301555 & 3.1582 & 3.7821 & TRN \\
\hline CHEMBL1736377 & 1301555 & 4.1943 & 4.1194 & TRN \\
\hline CHEMBL1327318 & 1301555 & 3.1578 & 3.6336 & TRN \\
\hline CHEMBL3185348 & 1301555 & 3.1582 & 4.0464 & TRN \\
\hline CHEMBL1384559 & 1301555 & 5.085 & 4.6927 & TRN \\
\hline CHEMBL1865502 & 1301555 & 3.1578 & 4.3365 & TST \\
\hline CHEMBL1967761 & 1301555 & 3.1582 & 3.2011 & TRN \\
\hline CHEMBL 2137070 & 1301555 & 3.158 & 3.1285 & TRN \\
\hline CHEMBL1360923 & 1301555 & 4.8789 & 4.3238 & TRN \\
\hline CHEMBL1441379 & 1301555 & 4.1123 & 3.4704 & TRN \\
\hline CHEMBL1505436 & 1301555 & 5.0655 & 4.9772 & TRN \\
\hline CHEMBL1584603 & 1301555 & 3.158 & 3.1295 & TRN \\
\hline CHEMBL1473647 & 1301555 & 3.6351 & 3.2437 & TRN \\
\hline CHEMBL1347514 & 1301555 & 3.1579 & 3.2456 & TRN \\
\hline CHEMBL1358781 & 1301555 & 3.1581 & 3.3587 & TRN \\
\hline CHEMBL1329807 & 1301555 & 3.1581 & \multicolumn{2}{|c|}{3.6689999999999996} \\
\hline CHEMBL1590875 & 1301555 & 4.7262 & 4.7488 & TRN \\
\hline CHEMBL1504616 & 1301555 & 4.7863 & 3.9602 & TRN \\
\hline CHEMBL1460295 & 1301555 & 3.158 & 3.0836 & TRN \\
\hline CHEMBL1968290 & 1301555 & 3.158 & 4.1199 & TRN \\
\hline
\end{tabular}


Supplemental Table S2.txt

\begin{tabular}{|c|c|c|c|c|}
\hline TL & & 3.158 & 3.7987 & \\
\hline & & 4.5974 & 3.8692 & \\
\hline HFMRI 1 & 55 & 582 & & \\
\hline HEMBL1 & 5 & 12 & & \\
\hline AEMBL1451464 & 301555 & 336 & 1991 & \\
\hline HEMBL1605781 & 30 & 972 & 9654 & \\
\hline HEMBL2 & 5 & & 528 & \\
\hline AEMBL13 & & & & \\
\hline HEMBL1435925 & 301555 & 4.3656 & .775 & \\
\hline HEMBL1537147 & 301555 & 5.4851 & 2414 & \\
\hline HEMBL13 & 30 & 3.635 & 0291 & \\
\hline AEMBL1 & שנ & 591 & 1197 & \\
\hline HEMBL3] & 5 & & & \\
\hline HEMBL1583091 & 55 & 4.1123 & .5408 & \\
\hline HEMBL1586506 & (2) & 4.1731 & & \\
\hline HEMBL3: & 30 & 58 & 212 & \\
\hline HEMBL1. & 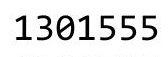 & & & \\
\hline HEMBL 2 & 5 & 578 & 85 & \\
\hline HEMBL14 & 55 & 3.1578 & 1292 & \\
\hline AEMBL13 & 30 & 4.3909 & $\partial 815$ & \\
\hline HEMBL: & 30 & 266 & 664 & SI \\
\hline HEMBL; & 36 & & & RN \\
\hline HEMBL 1 & כל & 577 & 795 & \\
\hline HEMBL15 & & & 1844 & IST \\
\hline HEMBL31 & 36 & 53 & 1845 & $R N$ \\
\hline HEMBL1\& & 36 & 76 & 102 & RN \\
\hline HFMBI 1 & & 6 & & II \\
\hline HEMP I & & 25 & 05 & $\mathrm{RN}$ \\
\hline AEMBL16 & & & & $S$ \\
\hline HEMBL14 & 30 & & 2293 & TRN \\
\hline HEMBL14 & 30 & 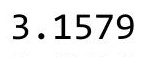 & 99 & RN \\
\hline 6 & & & & RN \\
\hline ב & & & & RN \\
\hline HEMBL15 & & & & ГST \\
\hline AEMBL17 & 30 & & 2516 & RN \\
\hline AFMRI 1 & $30+\div$ & & & TRN \\
\hline 10 & & & & RN \\
\hline HEMBL15 & & & 3.2921 & 「RN \\
\hline HEMBL1C & & & 91 & $\Gamma R$ \\
\hline Th & 30 & & 49 & RN \\
\hline HEMBL1: & 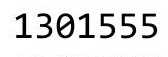 & 41 & 337 & RIV \\
\hline HEMBL15 & & 3.1578 & & RN \\
\hline HEMBL15 & & 3.1579 & 0767 & {$[R$} \\
\hline HEMBL1C & 36 & & & TR \\
\hline CHFMRI $2 A C$ & & & & \\
\hline HEMBL14 & 130 & 4.5892 & & \\
\hline HEMBL13 & 120 & 3.158 & 458 & \\
\hline CHEMBL1880540 & 1301555 & 3.158 & 3.9882 & \\
\hline
\end{tabular}

Page 16931 
Supplemental Table S2.txt

\begin{tabular}{|c|c|c|c|c|}
\hline CHEMBL1373003 & 1301555 & 4.5889 & 4.7027 & TRN \\
\hline CHEMBL1990646 & 1301555 & 3.1579 & 3.2636 & TRN \\
\hline CHEMBL1492496 & 1301555 & 4.742 & 4.7019 & TRN \\
\hline CHEMBL1416214 & 1301555 & 4.8422 & 4.4034 & TRN \\
\hline CHEMBL1364037 & 1301555 & 3.1578 & 3.2431 & TRN \\
\hline CHEMBL1467282 & 1301555 & 3.6349 & 3.6506 & TRN \\
\hline CHEMBL1456259 & 1301555 & 4.2727 & 3.4397 & TST \\
\hline CHEMBL1717752 & 1301555 & 5.0634 & 4.4561 & TRN \\
\hline CHEMBL1357484 & 1301555 & 3.158 & 3.2776 & TRN \\
\hline CHEMBL1711735 & 1301555 & 5.0034 & 4.329 & TRN \\
\hline CHEMBL3193648 & 1301555 & 4.5496 & 4.2297 & TRN \\
\hline CHEMBL1347247 & 1301555 & 3.1581 & 3.161 & TRN \\
\hline CHEMBL 2130963 & 1301555 & 5.1222 & 5.0149 & TRN \\
\hline CHEMBL1530437 & 1301555 & 4.8306 & 3.927 & TRN \\
\hline CHEMBL1435494 & 1301555 & 3.1582 & 3.4958 & TRN \\
\hline CHEMBL3193564 & 1301555 & 3.1577 & 3.4128 & TRN \\
\hline CHEMBL1306753 & 1301555 & 3.1579 & 3.3124 & TRN \\
\hline CHEMBL1336039 & 1301555 & 3.158 & 3.2114 & TST \\
\hline CHEMBL1373593 & 1301555 & 3.1577 & 4.1295 & TRN \\
\hline CHEMBL1360402 & 1301555 & 3.1576 & 2.9213 & TRN \\
\hline CHEMBL1365686 & 1301555 & 4.1738 & 3.5102 & TRN \\
\hline CHEMBL1863771 & 1301555 & 5.1886 & 4.6562 & TST \\
\hline CHEMBL1727517 & 1301555 & 3.1578 & 3.3664 & TRN \\
\hline CHEMBL1601559 & 1301555 & 3.1579 & 3.3363 & TRN \\
\hline CHEMBL1718195 & 1301555 & 3.1578 & 3.9542 & TST \\
\hline CHEMBL1447523 & 1301555 & 4.4395 & 3.7223 & TRN \\
\hline CHEMBL1995038 & 1301555 & 4.266 & 3.947 & TRN \\
\hline CHEMBL1543409 & 1301555 & 4.1119 & 4.3908 & TRN \\
\hline CHEMBL1587269 & 1301555 & 3.1579 & 4.1177 & TRN \\
\hline CHEMBL1506178 & 1301555 & 3.1578 & 3.0562 & TRN \\
\hline CHEMBL1321896 & 1301555 & 3.1579 & 3.16399 & 99999999997 \\
\hline CHEMBL1373781 & 1301555 & 4.8721 & 4.5019 & TST \\
\hline CHEMBL3182096 & 1301555 & 4.9928 & 4.0996 & TRN \\
\hline CHEMBL1585947 & 1301555 & 3.158 & 3.0131 & TRN \\
\hline CHEMBL1346802 & 1301555 & 3.158 & 3.4697 & TRN \\
\hline CHEMBL1881965 & 1301555 & 3.1579 & 3.27600 & 00000000002 \\
\hline CHEMBL1424288 & 1301555 & 3.158 & 4.1428 & TRN \\
\hline CHEMBL1490757 & 1301555 & 5.2971 & 4.7618 & TRN \\
\hline CHEMBL3192104 & 1301555 & 3.1579 & 3.1835 & TRN \\
\hline CHEMBL1479448 & 1301555 & 4.5129 & 4.7162 & TRN \\
\hline CHEMBL1454412 & 1301555 & 3.1579 & 3.23 & TRN \\
\hline CHEMBL1735346 & 1301555 & 3.1579 & 3.444 & TRN \\
\hline CHEMBL1598114 & 1301555 & 3.1579 & 3.2033 & TRN \\
\hline CHEMBL1315592 & 1301555 & 3.1579 & 2.9633 & TRN \\
\hline CHEMBL1699044 & 1301555 & 3.158 & 3.988 & TRN \\
\hline CHEMBL1502451 & 1301555 & 3.158 & 3.3023 & TRN \\
\hline CHEMBL1451599 & 1301555 & 4.9551 & 4.5395 & TRN \\
\hline CHEMBL1317985 & 1301555 & 3.1579 & 3.2711 & TRN \\
\hline
\end{tabular}


Supplemental Table S2.txt

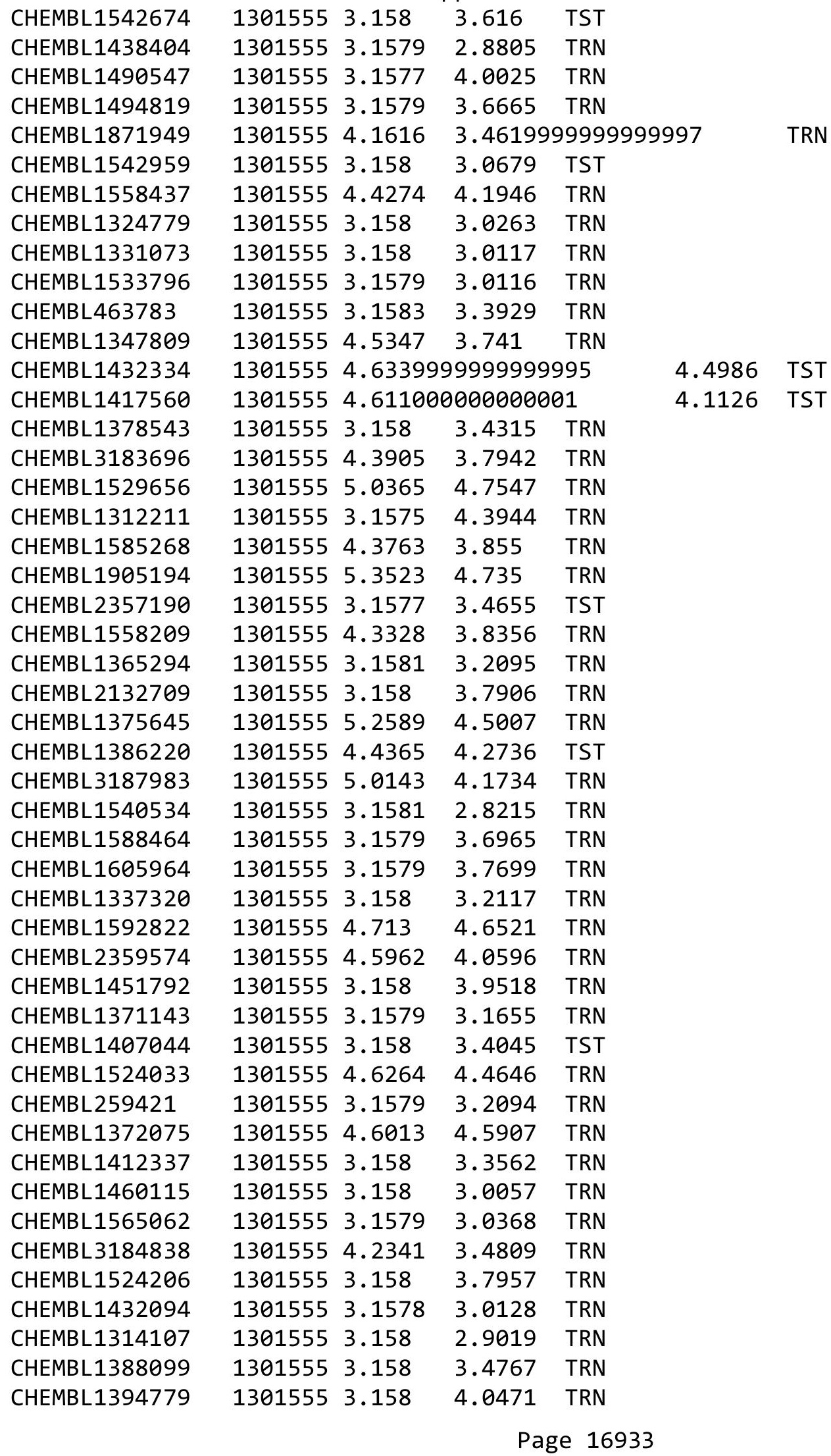




\begin{tabular}{|c|c|c|c|c|c|c|}
\hline \multicolumn{7}{|c|}{ Supplemental Table S2.txt } \\
\hline CHEMBL1330051 & 1301555 & 4.1119 & 3.8507 & TRN & & \\
\hline CHEMBL1422332 & 1301555 & 3.158 & 3.8751 & TST & & \\
\hline CHEMBL1457571 & 1301555 & 3.158 & 3.6714 & TST & & \\
\hline CHEMBL1489077 & 1301555 & 3.1578 & 3.9276 & TST & & \\
\hline CHEMBL1699547 & 1301555 & 3.1581 & 3.3162 & TST & & \\
\hline CHEMBL1887044 & 1301555 & 3.1581 & 3.2639 & TST & & \\
\hline CHEMBL1530163 & 1301555 & 4.53100 & 00000000 & 01 & 4.2983 & TST \\
\hline CHEMBL1398750 & 1301555 & 3.1577 & 3.8668 & TST & & \\
\hline CHEMBL1569787 & 1301555 & 5.0126 & 4.5379 & TST & & \\
\hline CHEMBL 2133347 & 1301555 & 3.1579 & 3.9094 & TST & & \\
\hline CHEMBL1703160 & 1301555 & 4.7574 & 4.6849 & TST & & \\
\hline CHEMBL1576280 & 1301555 & 3.158 & 3.1239 & TST & & \\
\hline CHEMBL1444202 & 1301555 & 5.61600 & 0000000 & 005 & 4.5383 & TST \\
\hline CHEMBL 2357780 & 1301555 & 3.1587 & 3.1752 & TST & & \\
\hline CHEMBL1344679 & 1301555 & 5.0621 & 4.1394 & TST & & \\
\hline CHEMBL1550191 & 1301555 & 3.158 & 3.2398 & TST & & \\
\hline CHEMBL1329900 & 1301555 & 3.1579 & 3.0294 & TST & & \\
\hline CHEMBL1705631 & 1301555 & 5.1067 & 4.3205 & TST & & \\
\hline CHEMBL1573508 & 1301555 & 3.1582 & 4.6323 & TST & & \\
\hline CHEMBL1895868 & 1301555 & 3.6351 & 3.85399 & 9999999999 & 96 & TST \\
\hline CHEMBL1601623 & 1301555 & 3.1579 & 4.3102 & TST & & \\
\hline CHEMBL1400479 & 1301555 & 4.1122 & 4.2902 & TST & & \\
\hline CHEMBL1431032 & 1301555 & 3.1578 & 3.1054 & TST & & \\
\hline CHEMBL1363933 & 1301555 & 5.0672 & 4.2595 & TST & & \\
\hline CHEMBL1704039 & 1301555 & 3.158 & 3.2232 & TST & & \\
\hline CHEMBL1361500 & 1301555 & 3.1582 & 4.1861 & TST & & \\
\hline CHEMBL464404 & 1301555 & 4.1118 & 4.1661 & TST & & \\
\hline CHEMBL1378955 & 1301555 & 3.158 & 3.9087 & TST & & \\
\hline CHEMBL1502597 & 1301555 & 3.158 & 4.0295 & TST & & \\
\hline CHEMBL3962624 & 1528882 & 7.1938 & 6.5182 & TRN & & \\
\hline CHEMBL3667007 & 1528882 & 7.8861 & 7.9184 & TRN & & \\
\hline CHEMBL3666927 & 1528882 & 8.1549 & 8.3722 & TRN & & \\
\hline CHEMBL3895376 & 1528882 & 8.9586 & 9.099 & TRN & & \\
\hline CHEMBL3662261 & 1528882 & 7.0969 & 7.3927 & TRN & & \\
\hline CHEMBL 3666929 & 1528882 & 7.2366 & 7.3817 & TRN & & \\
\hline CHEMBL3948509 & 1528882 & 6.0 & 6.4255 & TRN & & \\
\hline CHEMBL 3944626 & 1528882 & 8.6198 & 8.5032 & TRN & & \\
\hline CHEMBL3666946 & 1528882 & 6.8861 & 6.8526 & TRN & & \\
\hline CHEMBL3666950 & 1528882 & 6.0809 & 6.3067 & TST & & \\
\hline CHEMBL 3954835 & 1528882 & 8.3565 & 8.2032 & TRN & & \\
\hline CHEMBL3666911 & 1528882 & 8.4815 & 8.102 & TST & & \\
\hline CHEMBL 3662284 & 1528882 & 7.2924 & 7.3742 & TRN & & \\
\hline CHEMBL3666895 & 1528882 & 6.5376 & 6.7442 & TST & & \\
\hline CHEMBL3666970 & 1528882 & 8.1308 & 8.3544 & TRN & & \\
\hline CHEMBL 3667008 & 1528882 & 7.8239 & 7.9182 & TRN & & \\
\hline CHEMBL3921519 & 1528882 & 8.0132 & 8.0575 & TRN & & \\
\hline CHEMBL3961020 & 1528882 & 8.3768 & 8.5314 & TST & & \\
\hline CHEMBL3963509 & 1528882 & 8.9586 & 8.8661 & TRN & & \\
\hline
\end{tabular}


Supplemental Table S2.txt

\begin{tabular}{|c|c|c|c|c|c|}
\hline CHEMBL 3697388 & 1528882 & 7.2147 & 7.166 & TST & \\
\hline CHEMBL3949092 & 1528882 & 8.4437 & 8.2457 & TRN & \\
\hline CHEMBL3666959 & 1528882 & 7.6198 & 7.7394 & TRN & \\
\hline CHEMBL3957708 & 1528882 & 8.1249 & 8.0676 & TRN & \\
\hline CHEMBL3927623 & 1528882 & 7.1249 & \multicolumn{2}{|c|}{ 7.071000000000001 } & TST \\
\hline CHEMBL 3897521 & 1528882 & 8.9208 & 9.2478 & TRN & \\
\hline CHEMBL3889497 & 1528882 & 7.5686 & 7.7667 & TRN & \\
\hline CHEMBL3914465 & 1528882 & 7.9208 & 8.0539 & TRN & \\
\hline CHEMBL3667009 & 1528882 & 7.6021 & 7.7098 & TRN & \\
\hline CHEMBL3697390 & 1528882 & 7.6383 & 7.47 & TST & \\
\hline CHEMBL 3938018 & 1528882 & 9.0757 & 8.8401 & TRN & \\
\hline CHEMBL3697393 & 1528882 & 8.1427 & 7.4721 & TRN & \\
\hline CHEMBL 3666960 & 1528882 & 8.5376 & 8.59 & TST & \\
\hline CHEMBL 3662266 & 1528882 & 6.0 & 6.5091 & TRN & \\
\hline CHEMBL3666903 & 1528882 & 7.2218 & 7.392 & TST & \\
\hline CHEMBL 3901576 & 1528882 & 7.9208 & 8.0609 & TRN & \\
\hline CHEMBL3906240 & 1528882 & 6.0 & 6.4115 & TRN & \\
\hline CHEMBL3666915 & 1528882 & 8.2291 & 8.1516 & TRN & \\
\hline CHEMBL3902241 & 1528882 & 8.8539 & 8.8075 & TST & \\
\hline CHEMBL 3662255 & 1528882 & 7.7447 & 7.5575 & TRN & \\
\hline CHEMBL3964743 & 1528882 & 8.8539 & 8.5873 & TRN & \\
\hline CHEMBL 3662247 & 1528882 & 7.2518 & \multicolumn{2}{|c|}{7.2410000000000005} & TST \\
\hline CHEMBL3666901 & 1528882 & 6.0 & 5.9219 & TRN & \\
\hline CHEMBL3662239 & 1528882 & 6.0 & 5.9296 & TRN & \\
\hline CHEMBL 3662275 & 1528882 & 5.7258 & 5.7512 & TRN & \\
\hline CHEMBL3917825 & 1528882 & 6.0 & 6.4128 & TRN & \\
\hline CHEMBL3667013 & 1528882 & 6.6778 & 6.6541 & TRN & \\
\hline CHEMBL3666949 & 1528882 & 6.8239 & 6.6928 & TST & \\
\hline CHEMBL3666957 & 1528882 & 7.8539 & 7.9101 & TRN & \\
\hline CHEMBL3666967 & 1528882 & 9.3279 & 9.5968 & TRN & \\
\hline CHEMBL 3890074 & 1528882 & 6.0 & 6.1227 & TRN & \\
\hline CHEMBL3975988 & 1528882 & 8.5376 & 8.4203 & TST & \\
\hline CHEMBL3666892 & 1528882 & 8.2218 & 8.1039 & TST & \\
\hline CHEMBL3667000 & 1528882 & 6.0 & 6.8972 & TRN & \\
\hline CHEMBL3967529 & 1528882 & 8.6021 & 8.0408 & TRN & \\
\hline CHEMBL3667006 & 1528882 & \multicolumn{2}{|c|}{8.283999999999999} & 8.1446 & TRN \\
\hline CHEMBL3916534 & 1528882 & 7.4949 & 7.3059 & TRN & \\
\hline CHEMBL3907679 & 1528882 & 7.8239 & 8.2069 & TST & \\
\hline CHEMBL3662281 & 1528882 & 7.3372 & 7.2301 & TRN & \\
\hline CHEMBL3945180 & 1528882 & 6.0 & 6.0055 & TRN & \\
\hline CHEMBL 3666942 & 1528882 & 6.0 & 6.2001 & TST & \\
\hline CHEMBL3901015 & 1528882 & 8.1805 & 8.183 & TRN & \\
\hline CHEMBL3943186 & 1528882 & 6.0 & 6.2093 & TRN & \\
\hline CHEMBL3662276 & 1528882 & 7.0 & 6.8816 & TRN & \\
\hline CHEMBL3662256 & 1528882 & 7.9586 & 7.8927 & TRN & \\
\hline CHEMBL3666935 & 1528882 & 7.3979 & 7.4438 & TRN & \\
\hline CHEMBL3662252 & 1528882 & 8.0969 & 8.1537 & TRN & \\
\hline CHEMBL3666923 & 1528882 & 6.6021 & 6.7032 & TRN & \\
\hline
\end{tabular}

Page 16935 
Supplemental Table S2.txt

\begin{tabular}{|c|c|c|c|c|}
\hline HEMBL: & & 6.0 & 12 & TR \\
\hline HEMPI 3667910 & 528882 & 7.5229 & 7.6703 & \\
\hline HEMBL & 28882 & 7959 & & \\
\hline AEMBL3 & 528882 & 5198 & 5929 & \\
\hline HEMBL3666907 & 528882 & 7.6778 & 4707 & \\
\hline HEMBL & 528882 & 8.2924 & & \\
\hline AFMBL & 28882 & & & \\
\hline HEMBL; & 528882 & 6.3665 & 4065 & \\
\hline HEMBL3 & 528882 & 7.8861 & .225 & \\
\hline HEMBL3666966 & 528882 & 8.6021 & .1667 & \\
\hline HEMBL3 & 528882 & & .7532 & \\
\hline HEMBL: & 528882 & 36 & & \\
\hline HEMBL & .528882 & 6.0269 & & \\
\hline AEMBL3 & 528882 & 6.0 & 74 & \\
\hline HEMBL36 & 528882 & 08 & 7519 & \\
\hline AEMBL & 28882 & 49 & 71 & \\
\hline AEMBL & 8882 & & & \\
\hline HEMBL; & 528882 & & 16 & \\
\hline HEMBL3 & 528882 & 6.0 & & \\
\hline AEMBL3 & 528882 & 376 & 67 & KIV \\
\hline AEMBL & 8882 & & 92 & RN \\
\hline HEME & 882 & & & KIV \\
\hline HEMBL. & 528882 & 6 & & \\
\hline AEMBL & 882 & & & \\
\hline AEMBL3 & 528882 & 7. & & $5 T$ \\
\hline AEMBL: & 3882 & 78 & & RN \\
\hline AEME & 882 & & & ST \\
\hline 72 & 882 & & & \\
\hline AEMBL & 382 & & & ГRN \\
\hline AEMBL3 & 528882 & 6 & 44 & RN \\
\hline EMBL & 3882 & & & ST \\
\hline 6 & 882 & & & ST \\
\hline & & & & IST \\
\hline AEMBL3 & 528882 & & & ГRN \\
\hline HEMBL3 & 528882 & 19 & 879 & 「RN \\
\hline ICMPI & 528882 & & 66 & ГRN \\
\hline & & & & ST \\
\hline HEMBL & & & & TRN \\
\hline AEMBL3 & 528882 & 6. & & TRI \\
\hline EMBL & 882 & & & RN \\
\hline HEMBL3 & 528882 & 7. & & TST \\
\hline HEMBL3 & .528882 & 7.6198 & & TRN \\
\hline HEMBL3 & 528882 & & & TRN \\
\hline AEMBL3 & 528882 & 7.2 & & TRN \\
\hline 7 & 82 & & & $\mathbf{m}$ \\
\hline HEMBL3 & 52888 & & & \\
\hline HEMBL 3 & .528882 & 7.0706 & & \\
\hline CHEMBL3666975 & 1528882 & 7.4437 & 7.5812 & ГST \\
\hline
\end{tabular}

Page 16936 
Supplemental Table S2.txt

\begin{tabular}{|c|c|c|c|c|c|}
\hline CHEMBL3931434 & 1528882 & 8.4318 & 8.4101 & TRN & \\
\hline CHEMBL3906740 & 1528882 & 7.5229 & 7.6765 & TRN & \\
\hline CHEMBL3662259 & 1528882 & 6.0 & 6.1201 & TRN & \\
\hline CHEMBL 3662242 & 1528882 & 7.7447 & \multicolumn{2}{|c|}{7.656000000000001} & TST \\
\hline CHEMBL3662251 & 1528882 & 6.1249 & 6.1957 & TRN & \\
\hline CHEMBL3666996 & 1528882 & 7.0 & 7.1823 & TST & \\
\hline CHEMBL3897729 & 1528882 & 8.2676 & 8.3135 & TRN & \\
\hline CHEMBL3666954 & 1528882 & 6.0 & 6.2014 & TRN & \\
\hline CHEMBL3667011 & 1528882 & 8.1367 & 6.4182 & TRN & \\
\hline CHEMBL3957866 & 1528882 & 8.585 & 8.4861 & TRN & \\
\hline CHEMBL3947987 & 1528882 & 7.7212 & 7.5997 & TRN & \\
\hline CHEMBL3963003 & 1528882 & 8.8861 & 9.2415 & TRN & \\
\hline CHEMBL3667001 & 1528882 & 9.3768 & 9.4676 & TRN & \\
\hline CHEMBL3666900 & 1528882 & 7.7696 & 7.7618 & TRN & \\
\hline CHEMBL3930056 & 1528882 & 8.1024 & 8.1769 & TST & \\
\hline CHEMBL3662253 & 1528882 & 6.0 & \multicolumn{2}{|c|}{6.236000000000001} & TRN \\
\hline CHEMBL1448153 & 1301478 & 5.0182 & 5.1208 & TRN & \\
\hline CHEMBL1386466 & 1301478 & 4.8573 & 4.9339 & TRN & \\
\hline CHEMBL 2135896 & 1301478 & 4.9355 & 5.124 & TRN & \\
\hline CHEMBL1553553 & 1301478 & 4.9435 & 4.8122 & TRN & \\
\hline CHEMBL1384654 & 1301478 & 5.2013 & 4.9696 & TRN & \\
\hline CHEMBL1534441 & 1301478 & 4.7945 & 5.0624 & TRN & \\
\hline CHEMBL1412795 & 1301478 & 5.1244 & 5.1376 & TST & \\
\hline CHEMBL1540513 & 1301478 & 4.6326 & 4.644 & TRN & \\
\hline CHEMBL 3185370 & 1301478 & 4.6635 & 4.5977 & TRN & \\
\hline CHEMBL1561956 & 1301478 & 5.4306 & 5.3102 & TRN & \\
\hline CHEMBL1573883 & 1301478 & 5.4962 & 5.4833 & TRN & \\
\hline CHEMBL1366417 & 1301478 & 5.0101 & 5.0865 & TRN & \\
\hline CHEMBL1325658 & 1301478 & 5.2612 & 4.9956 & TRN & \\
\hline CHEMBL1476877 & 1301478 & 5.4698 & 5.5846 & TRN & \\
\hline CHEMBL1569984 & 1301478 & 5.6576 & 5.2387 & TRN & \\
\hline CHEMBL1590615 & 1301478 & 4.7615 & 4.6148 & TST & \\
\hline CHEMBL 3184207 & 1301478 & 6.0 & 5.9312 & TRN & \\
\hline CHEMBL1602614 & 1301478 & 5.5331 & \multicolumn{2}{|c|}{5.497000000000001} & TST \\
\hline CHEMBL1548672 & 1301478 & 5.0205 & 4.981 & TRN & \\
\hline CHEMBL1597627 & 1301478 & 6.1325 & 6.1365 & TRN & \\
\hline CHEMBL1542378 & 1301478 & 5.5575 & 5.7331 & TRN & \\
\hline CHEMBL 2137423 & 1301478 & 4.7833 & 4.8173 & TRN & \\
\hline CHEMBL1382538 & 1301478 & 5.0477 & 5.0903 & TRN & \\
\hline CHEMBL3198732 & 1301478 & 5.4976 & 5.5775 & TRN & \\
\hline CHEMBL1456271 & 1301478 & 5.1244 & 5.0233 & TRN & \\
\hline CHEMBL1493614 & 1301478 & 4.9059 & 5.0381 & TRN & \\
\hline CHEMBL1486109 & 1301478 & \multicolumn{3}{|c|}{6.382000000000001} & TRN \\
\hline CHEMBL1726230 & 1301478 & 4.9481 & 4.8498 & TRN & \\
\hline CHEMBL1895747 & 1301478 & 5.0079 & 4.7148 & TST & \\
\hline CHEMBL1340855 & 1301478 & 5.5622 & \multicolumn{2}{|c|}{5.553999999999999} & TRN \\
\hline CHEMBL267099 & 1301478 & 5.5575 & 5.4892 & TST & \\
\hline CHEMBL1572001 & 1301478 & 4.9223 & 4.8701 & TST & \\
\hline
\end{tabular}


Supplemental Table S2.txt

\begin{tabular}{|c|c|c|c|c|c|c|}
\hline CHEMBL1459468 & 1301478 & 6.6635 & 6.6452 & TRN & & \\
\hline CHEMBL1436393 & 1301478 & 5.6055 & 5.8393 & TRN & & \\
\hline CHEMBL1553183 & 1301478 & 5.0487 & 4.7976 & TRN & & \\
\hline CHEMBL1488020 & 1301478 & 5.34200 & 0000000 & 205 & 5.5143 & TRN \\
\hline CHEMBL1872338 & 1301478 & 5.5622 & 5.3907 & TRN & & \\
\hline CHEMBL1591171 & 1301478 & 4.4182 & 5.1986 & TST & & \\
\hline CHEMBL1391972 & 1301478 & 5.3054 & 5.3584 & TRN & & \\
\hline CHEMBL1511219 & 1301478 & 8.1675 & 7.8455 & TRN & & \\
\hline CHEMBL1483193 & 1301478 & 5.3335 & 5.3404 & TRN & & \\
\hline CHEMBL261693 & 1301478 & 5.9547 & 5.6791 & TRN & & \\
\hline CHEMBL 2133586 & 1301478 & 5.1433 & 5.05699 & 9999999999 & 95 & TST \\
\hline CHEMBL1383534 & 1301478 & 6.1918 & 6.0042 & TRN & & \\
\hline CHEMBL 2144728 & 1301478 & 4.52800 & 00000000 & 205 & 4.5228 & TST \\
\hline CHEMBL1376288 & 1301478 & 4.857 & 5.7082 & TRN & & \\
\hline CHEMBL3187421 & 1301478 & 4.189 & 4.2078 & TRN & & \\
\hline CHEMBL1490537 & 1301478 & 5.3925 & 5.5674 & TST & & \\
\hline CHEMBL1394527 & 1301478 & 5.4949 & 5.5479 & TRN & & \\
\hline CHEMBL1461129 & 1301478 & 6.2328 & 6.3991 & TRN & & \\
\hline CHEMBL1489637 & 1301478 & 4.934 & 4.8597 & TRN & & \\
\hline CHEMBL1877386 & 1301478 & 5.4647 & 5.2763 & TRN & & \\
\hline CHEMBL1481616 & 1301478 & 5.5969 & 5.6109 & TRN & & \\
\hline CHEMBL1344677 & 1301478 & 6.6091 & 6.4027 & TRN & & \\
\hline CHEMBL1355823 & 1301478 & 4.5575 & 4.9765 & TRN & & \\
\hline CHEMBL1539398 & 1301478 & 5.1512 & 5.308 & TRN & & \\
\hline CHEMBL1575124 & 1301478 & 5.6364 & 5.6393 & TRN & & \\
\hline CHEMBL3185534 & 1301478 & 4.2942 & 4.5434 & TST & & \\
\hline CHEMBL1732332 & 1301478 & 6.3904 & 5.9341 & TST & & \\
\hline CHEMBL1491541 & 1301478 & 4.7296 & 4.8271 & TST & & \\
\hline CHEMBL1584960 & 1301478 & 5.308 & 5.2816 & TRN & & \\
\hline CHEMBL1501859 & 1301478 & 4.8013 & 4.8516 & TRN & & \\
\hline CHEMBL1321622 & 1301478 & 6.1772 & 5.9523 & TRN & & \\
\hline CHEMBL3183027 & 1301478 & 6.0 & 5.6439 & TST & & \\
\hline CHEMBL3188673 & 1301478 & 4.8925 & 4.9865 & TRN & & \\
\hline CHEMBL1318675 & 1301478 & 5.032 & 5.2469 & TRN & & \\
\hline CHEMBL 2133510 & 1301478 & 4.3622 & 4.3006 & TRN & & \\
\hline CHEMBL1556786 & 1301478 & 5.1688 & 5.1439 & TRN & & \\
\hline CHEMBL1724656 & 1301478 & 5.5918 & 5.6091 & TST & & \\
\hline CHEMBL1873061 & 1301478 & 5.0074 & 5.1029 & TST & & \\
\hline CHEMBL1978643 & 1301478 & 5.1811 & 5.2236 & TRN & & \\
\hline CHEMBL1356587 & 1301478 & 5.1878 & 4.8146 & TRN & & \\
\hline CHEMBL1486329 & 1301478 & 4.7493 & 4.6875 & TRN & & \\
\hline CHEMBL1448774 & 1301478 & 5.1261 & 4.9928 & TRN & & \\
\hline CHEMBL1363219 & 1301478 & 5.5969 & 5.5398 & TRN & & \\
\hline CHEMBL595840 & 1301478 & 5.5114 & 5.4504 & TRN & & \\
\hline CHEMBL1440303 & 1301478 & 5.5884 & 5.6165 & TRN & & \\
\hline CHEMBL1575970 & 1301478 & 5.5129 & 5.4753 & TRN & & \\
\hline CHEMBL2131028 & 1301478 & 4.3864 & 4.7152 & TST & & \\
\hline CHEMBL1896333 & 1301478 & 4.8914 & 5.4793 & TRN & & \\
\hline
\end{tabular}


Supplemental Table S2.txt

\begin{tabular}{|c|c|c|c|c|c|}
\hline CHEMBL1352995 & 1301478 & 5.1858 & 4.962 & TRN & \\
\hline CHEMBL1601647 & 1301478 & 5.8416 & 5.5991 & TRN & \\
\hline CHEMBL1409963 & 1301478 & 5.0297 & 4.9664 & TST & \\
\hline CHEMBL1725682 & 1301478 & 5.5935 & 5.5768 & TRN & \\
\hline CHEMBL1488948 & 1301478 & 4.7414 & 4.7877 & TRN & \\
\hline CHEMBL1605021 & 1301478 & 5.8386 & 5.8161 & TST & \\
\hline CHEMBL1582665 & 1301478 & 5.5143 & 5.5637 & TRN & \\
\hline CHEMBL1549599 & 1301478 & 5.091 & 5.1481 & TRN & \\
\hline CHEMBL1384167 & 1301478 & 5.1029 & 4.9396 & TRN & \\
\hline CHEMBL1570216 & 1301478 & 6.2865 & 6.4365 & TRN & \\
\hline CHEMBL1502192 & 1301478 & 5.1079 & 5.5181 & TRN & \\
\hline CHEMBL1551577 & 1301478 & 4.908 & 4.7428 & TRN & \\
\hline CHEMBL1513654 & 1301478 & 4.7435 & 4.7311 & TST & \\
\hline CHEMBL1559461 & 1301478 & 5.3655 & 5.1517 & TRN & \\
\hline CHEMBL1277151 & 1301478 & 4.9215 & 4.6275 & TST & \\
\hline CHEMBL1488712 & 1301478 & 5.4559 & 5.4132 & TRN & \\
\hline CHEMBL1898104 & 1301478 & 6.58 & 6.3762 & TRN & \\
\hline CHEMBL1504453 & 1301478 & 4.5324 & 4.6975 & TRN & \\
\hline CHEMBL1995726 & 1301478 & 5.1409 & 5.1441 & TRN & \\
\hline CHEMBL286593 & 1301478 & 5.4023 & 5.4553 & TRN & \\
\hline CHEMBL1390421 & 1301478 & 5.1469 & 5.0025 & TRN & \\
\hline CHEMBL1332533 & 1301478 & 5.3893 & \multicolumn{2}{|c|}{5.257000000000001} & TRN \\
\hline CHEMBL1423927 & 1301478 & 6.0862 & 5.9005 & TRN & \\
\hline CHEMBL1380459 & 1301478 & 4.7956 & 4.7016 & TRN & \\
\hline CHEMBL1579902 & 1301478 & 5.6778 & 5.55 & TRN & \\
\hline CHEMBL1981570 & 1301478 & 6.2418 & 6.1322 & TRN & \\
\hline CHEMBL1530216 & 1301478 & 4.7799 & 4.7159 & TRN & \\
\hline CHEMBL1464608 & 1301478 & 5.2596 & 5.2498 & TRN & \\
\hline CHEMBL1436748 & 1301478 & 5.5498 & 5.2968 & TRN & \\
\hline CHEMBL1329650 & 1301478 & 5.0894 & 5.2434 & TRN & \\
\hline CHEMBL 2354532 & 1301478 & 5.1675 & \multicolumn{2}{|c|}{5.1610000000000005} & TRN \\
\hline CHEMBL1899738 & 1301478 & 4.6664 & 4.681 & TRN & \\
\hline CHEMBL1499752 & 1301478 & 5.2993 & 5.2058 & TRN & \\
\hline CHEMBL1311094 & 1301478 & 6.0297 & 6.1307 & TRN & \\
\hline CHEMBL1299361 & 1301478 & 4.521 & 4.8177 & TST & \\
\hline CHEMBL1871360 & 1301478 & 4.6227 & 4.6882 & TST & \\
\hline CHEMBL1893675 & 1301478 & 5.1805 & 5.0838 & TST & \\
\hline CHEMBL1361936 & 1301478 & 5.5391 & 5.5715 & TRN & \\
\hline CHEMBL1899585 & 1301478 & 5.0035 & 4.9519 & TRN & \\
\hline CHEMBL 2358899 & 1301478 & 6.0 & 5.7558 & TST & \\
\hline CHEMBL1421199 & 1301478 & 5.2815 & 5.1953 & TST & \\
\hline CHEMBL3184701 & 1301478 & 4.3904 & 4.9839 & TST & \\
\hline CHEMBL3187852 & 1301478 & 4.6914 & 4.6471 & TST & \\
\hline CHEMBL490083 & 1301478 & 5.5935 & 5.5657 & TRN & \\
\hline CHEMBL1488923 & 1301478 & 6.4535 & 6.3709 & TRN & \\
\hline CHEMBL486569 & 1301478 & 4.997 & 5.3675 & TRN & \\
\hline CHEMBL1422176 & 1301478 & 5.0857 & 5.0694 & TRN & \\
\hline CHEMBL3194248 & 1301478 & 5.8861 & 5.9686 & TRN & \\
\hline
\end{tabular}


Supplemental Table S2.txt

\begin{tabular}{|c|c|c|c|c|c|}
\hline CHEMBL1594369 & 1301478 & 4.8891 & 4.678 & TST & \\
\hline CHEMBL1336419 & 1301478 & 4.5283 & 5.2571 & TST & \\
\hline CHEMBL1607801 & 1301478 & 6.8996 & 7.0631 & TRN & \\
\hline CHEMBL1486726 & 1301478 & 5.4828 & 5.5164 & TRN & \\
\hline CHEMBL1995375 & 1301478 & 4.9496 & 5.0405 & TRN & \\
\hline CHEMBL1323174 & 1301478 & 5.2907 & 5.4481 & TRN & \\
\hline CHEMBL1584761 & 1301478 & 4.9796 & 5.0626 & TRN & \\
\hline CHEMBL1408307 & 1301478 & 6.0218 & 5.8966 & TRN & \\
\hline CHEMBL1579644 & 1301478 & 4.6774 & 4.6132 & TST & \\
\hline CHEMBL1427265 & 1301478 & 5.7033 & 5.5318 & TRN & \\
\hline CHEMBL1490041 & 1301478 & 5.2048 & 4.9693 & TRN & \\
\hline CHEMBL1382215 & 1301478 & 5.3458 & 5.0555 & TRN & \\
\hline CHEMBL1392611 & 1301478 & 7.0958 & 7.689 & TRN & \\
\hline CHEMBL1465893 & 1301478 & 4.4609 & \multicolumn{2}{|c|}{5.3629999999999995} & TRN \\
\hline CHEMBL 252403 & 1301478 & 5.7721 & 5.5731 & TRN & \\
\hline CHEMBL473735 & 1301478 & 6.2069 & 5.8436 & TRN & \\
\hline CHEMBL1714393 & 1301478 & 5.6055 & \multicolumn{2}{|c|}{5.377000000000001} & TRN \\
\hline CHEMBL1500112 & 1301478 & 5.0947 & 5.2081 & TRN & \\
\hline CHEMBL1572605 & 1301478 & 5.308 & 5.352 & TST & \\
\hline CHEMBL1412573 & 1301478 & 4.6409 & 5.308 & TRN & \\
\hline CHEMBL1383991 & 1301478 & 5.699 & 5.5743 & TRN & \\
\hline CHEMBL1717333 & 1301478 & 4.8874 & 4.961 & TRN & \\
\hline CHEMBL1468011 & 1301478 & 6.1255 & \multicolumn{2}{|c|}{6.156000000000001} & TRN \\
\hline CHEMBL 234378 & 1301478 & 5.6421 & 5.4119 & TRN & \\
\hline CHEMBL1315904 & 1301478 & 5.2464 & 5.2502 & TRN & \\
\hline CHEMBL1342393 & 1301478 & 4.4515 & 5.2549 & TRN & \\
\hline CHEMBL 3185023 & 1301478 & 4.3405 & 4.4482 & TST & \\
\hline CHEMBL1562575 & 1301478 & 8.1675 & 7.2939 & TRN & \\
\hline CHEMBL1468355 & 1301478 & 5.8013 & 5.8208 & TRN & \\
\hline CHEMBL1899921 & 1301478 & 4.5322 & 4.5545 & TST & \\
\hline CHEMBL 3184262 & 1301478 & 4.8486 & 4.7133 & TRN & \\
\hline CHEMBL1374200 & 1301478 & 4.856 & 4.8435 & TST & \\
\hline CHEMBL1872364 & 1301478 & 4.6979 & 4.9702 & TRN & \\
\hline CHEMBL 2362144 & 1301478 & 5.5817 & 5.5439 & TRN & \\
\hline CHEMBL2361605 & 1301478 & 4.8297 & 4.8195 & TRN & \\
\hline CHEMBL1710219 & 1301478 & 4.7535 & 4.5336 & TRN & \\
\hline CHEMBL1346147 & 1301478 & 5.8928 & 5.8161 & TRN & \\
\hline CHEMBL1439384 & 1301478 & 5.5784 & 5.3405 & TRN & \\
\hline CHEMBL1527433 & 1301478 & 5.2636 & 5.2836 & TRN & \\
\hline CHEMBL1373664 & 1301478 & 5.3161 & 5.4919 & TRN & \\
\hline CHEMBL1361922 & 1301478 & 6.9172 & 6.8546 & TRN & \\
\hline CHEMBL1490190 & 1301478 & 4.3392 & 5.4142 & TRN & \\
\hline CHEMBL460508 & 1301478 & 5.6635 & 5.7567 & TRN & \\
\hline CHEMBL 3186350 & 1301478 & 4.3599 & 4.4491 & TST & \\
\hline CHEMBL1718787 & 1301478 & 5.4401 & \multicolumn{2}{|c|}{5.422000000000001} & TRN \\
\hline CHEMBL1575720 & 1301478 & 5.6003 & 5.4939 & TST & \\
\hline CHEMBL1478962 & 1301478 & 5.5045 & 5.3665 & TRN & \\
\hline CHEMBL1406361 & 1301478 & 8.1675 & 7.5982 & TRN & \\
\hline
\end{tabular}

Page 16940 
Supplemental Table S2.txt

\begin{tabular}{|c|c|c|c|c|c|}
\hline CHEMBL1386689 & 1301478 & 5.2118 & 5.274 & TRN & \\
\hline CHEMBL1419938 & 1301478 & 6.1244 & 5.7484 & TRN & \\
\hline CHEMBL1396351 & 1301478 & 4.8447 & 4.6454 & TRN & \\
\hline CHEMBL1531502 & 1301478 & 4.5464 & 4.535 & TRN & \\
\hline CHEMBL 2355520 & 1301478 & 5.2573 & 4.9816 & TRN & \\
\hline CHEMBL1604245 & 1301478 & 5.6108 & 5.7084 & TRN & \\
\hline CHEMBL1426107 & 1301478 & 5.295 & \multicolumn{2}{|c|}{5.1770000000000005} & TRN \\
\hline CHEMBL1547570 & 1301478 & 5.3152 & 5.6345 & TRN & \\
\hline CHEMBL523200 & 1301478 & 4.6029 & 4.6555 & TRN & \\
\hline CHEMBL 2136434 & 1301478 & 4.6529 & 4.8812 & TST & \\
\hline CHEMBL1517072 & 1301478 & 5.4437 & 5.666 & TRN & \\
\hline CHEMBL1314602 & 1301478 & 5.1805 & 5.1895 & TRN & \\
\hline CHEMBL1698291 & 1301478 & 4.5885 & 4.5609 & TST & \\
\hline CHEMBL1611128 & 1301478 & 8.1675 & 7.819 & TRN & \\
\hline CHEMBL3185539 & 1301478 & 4.6994 & 4.5104 & TRN & \\
\hline CHEMBL1597669 & 1301478 & 5.5331 & 5.7453 & TRN & \\
\hline CHEMBL1472145 & 1301478 & 4.731 & 4.6439 & TST & \\
\hline CHEMBL1518734 & 1301478 & 4.4212 & 4.37 & TRN & \\
\hline CHEMBL1440781 & 1301478 & 5.0004 & 4.8604 & TRN & \\
\hline CHEMBL1328504 & 1301478 & 6.1057 & 5.8569 & TRN & \\
\hline CHEMBL2359034 & 1301478 & 4.8611 & 4.5662 & TRN & \\
\hline CHEMBL1550664 & 1301478 & 5.4572 & 5.3977 & TRN & \\
\hline CHEMBL1880578 & 1301478 & 4.5417 & 5.4447 & TRN & \\
\hline CHEMBL1372039 & 1301478 & 4.9241 & 5.0682 & TRN & \\
\hline CHEMBL598885 & 1301478 & 6.7423 & 6.4549 & TRN & \\
\hline CHEMBL1601310 & 1301478 & 4.9788 & 5.1094 & TRN & \\
\hline CHEMBL 3185444 & 1301478 & 4.8019 & 4.8756 & TRN & \\
\hline CHEMBL1380276 & 1301478 & 5.3152 & \multicolumn{2}{|c|}{5.093999999999999} & TRN \\
\hline CHEMBL1726559 & 1301478 & 4.6019 & 4.5763 & TST & \\
\hline CHEMBL1309228 & 1301478 & 4.8742 & 4.8487 & TRN & \\
\hline CHEMBL2355407 & 1301478 & 5.6478 & 5.4717 & TRN & \\
\hline CHEMBL2354885 & 1301478 & 6.1391 & 6.1441 & TST & \\
\hline CHEMBL1877321 & 1301478 & 4.7387 & 4.8152 & TRN & \\
\hline CHEMBL1356694 & 1301478 & 5.5751 & 5.3066 & TRN & \\
\hline CHEMBL3186317 & 1301478 & 5.1101 & 5.3489 & TRN & \\
\hline CHEMBL1462900 & 1301478 & 5.0742 & 5.3695 & TRN & \\
\hline CHEMBL1484208 & 1301478 & 5.2857 & 5.2235 & TRN & \\
\hline CHEMBL1610938 & 1301478 & 5.5768 & 5.7455 & TRN & \\
\hline CHEMBL1418175 & 1301478 & 5.3497 & 5.2647 & TRN & \\
\hline CHEMBL1446067 & 1301478 & 5.1409 & 5.4419 & TRN & \\
\hline CHEMBL1428850 & 1301478 & 5.4921 & 5.6173 & TRN & \\
\hline CHEMBL1360295 & 1301478 & 5.4377 & 5.4402 & TRN & \\
\hline CHEMBL1549310 & 1301478 & 5.3768 & 5.2956 & TRN & \\
\hline CHEMBL1602085 & 1301478 & 5.2967 & 5.4945 & TRN & \\
\hline CHEMBL1597245 & 1301478 & 6.0794 & 6.1661 & TRN & \\
\hline CHEMBL3185012 & 1301478 & 4.7268 & 4.7745 & TRN & \\
\hline CHEMBL1607086 & 1301478 & 6.3904 & 6.3549 & TRN & \\
\hline CHEMBL2132815 & 1301478 & 4.7883 & 4.7373 & TRN & \\
\hline
\end{tabular}

Page 16941 
Supplemental Table S2.txt

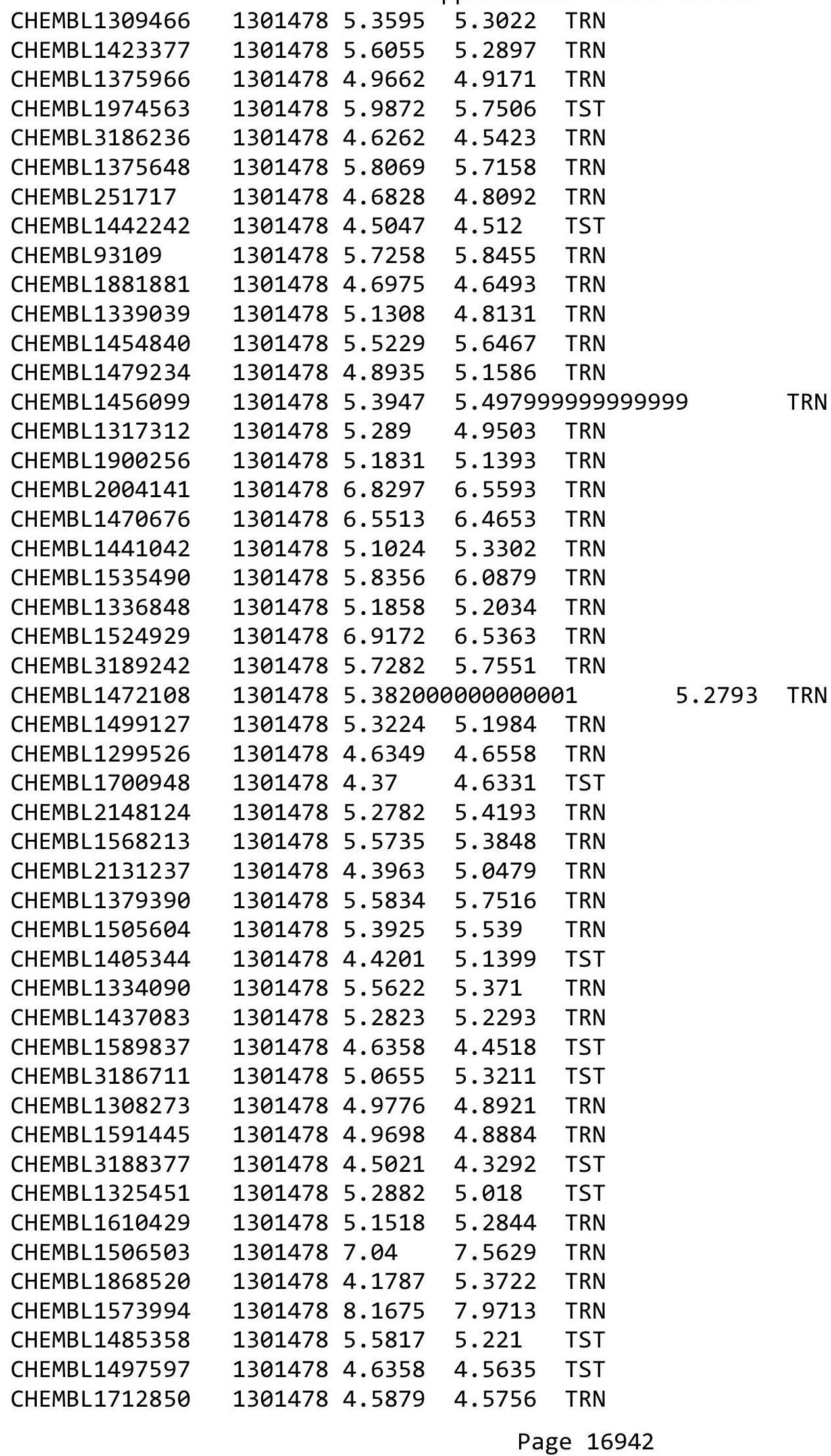


Supplemental Table S2.txt

\begin{tabular}{|c|c|c|c|c|c|}
\hline CHEMBL1312318 & 1301478 & 5.7645 & 5.6718 & TRN & \\
\hline CHEMBL 2355651 & 1301478 & 4.787 & 4.6684 & TRN & \\
\hline CHEMBL429335 & 1301478 & 5.5346 & 5.5496 & TRN & \\
\hline CHEMBL1488371 & 1301478 & 5.4547 & 5.5662 & TRN & \\
\hline CHEMBL1518629 & 1301478 & 4.988 & 4.8347 & TRN & \\
\hline CHEMBL1313090 & 1301478 & 5.0022 & 5.7899 & TRN & \\
\hline CHEMBL1479340 & 1301478 & 4.5533 & 4.5774 & TST & \\
\hline CHEMBL1374745 & 1301478 & 5.6421 & 5.5553 & TRN & \\
\hline CHEMBL 2359013 & 1301478 & 4.9038 & 5.2073 & TRN & \\
\hline CHEMBL3182316 & 1301478 & 4.3916 & 4.2836 & TRN & \\
\hline CHEMBL1705423 & 1301478 & 4.8353 & 4.9521 & TST & \\
\hline CHEMBL1864879 & 1301478 & 4.4637 & 4.5308 & TRN & \\
\hline CHEMBL1359120 & 1301478 & 6.15799 & 99999999 & 995 & 5.6714 \\
\hline CHEMBL607553 & 1301478 & 4.691 & 4.5635 & TRN & \\
\hline CHEMBL1608301 & 1301478 & 5.007 & 5.1738 & TRN & \\
\hline CHEMBL1590661 & 1301478 & 4.6036 & 4.6171 & TRN & \\
\hline CHEMBL 3183787 & 1301478 & 4.9718 & 4.8388 & TRN & \\
\hline CHEMBL1545203 & 1301478 & 6.0004 & 5.7941 & TRN & \\
\hline CHEMBL 2357966 & 1301478 & 6.0 & 5.7127 & TRN & \\
\hline CHEMBL1577174 & 1301478 & 5.6517 & 5.685 & TRN & \\
\hline CHEMBL1567568 & 1301478 & 5.3979 & 5.3804 & TST & \\
\hline CHEMBL1515530 & 1301478 & 4.4285 & 5.3515 & TRN & \\
\hline CHEMBL1451293 & 1301478 & 5.6716 & 5.7386 & TRN & \\
\hline CHEMBL1453723 & 1301478 & 6.3098 & 6.4109 & TRN & \\
\hline CHEMBL1581094 & 1301478 & 4.6651 & 4.8435 & TRN & \\
\hline CHEMBL1878940 & 1301478 & 5.4724 & 5.3018 & TST & \\
\hline CHEMBL535307 & 1301478 & 6.6596 & 6.7259 & TST & \\
\hline CHEMBL3197099 & 1301478 & 5.6925 & 5.9319 & TRN & \\
\hline CHEMBL1393189 & 1301478 & 4.8814 & 5.0063 & TRN & \\
\hline CHEMBL 3186003 & 1301478 & 4.7167 & 4.8061 & TRN & \\
\hline CHEMBL1610597 & 1301478 & 6.0915 & 5.9793 & TST & \\
\hline CHEMBL1904760 & 1301478 & 5.015 & 5.4214 & TRN & \\
\hline CHEMBL1866397 & 1301478 & 4.5662 & 4.7533 & TST & \\
\hline CHEMBL509617 & 1301478 & 6.3556 & 5.7618 & TST & \\
\hline CHEMBL1587121 & 1301478 & 5.4685 & 5.1842 & TST & \\
\hline CHEMBL1877015 & 1301478 & 5.0372 & 4.795 & TST & \\
\hline CHEMBL1479296 & 1301478 & 5.5986 & 5.4725 & TRN & \\
\hline CHEMBL1516047 & 1301478 & 5.644 & 5.5937 & TRN & \\
\hline CHEMBL1448943 & 1301478 & 5.6038 & 5.1053 & TRN & \\
\hline CHEMBL1585400 & 1301478 & 5.5302 & 5.4173 & TRN & \\
\hline CHEMBL1383915 & 1301478 & 4.9859 & 5.1232 & TRN & \\
\hline CHEMBL1513263 & 1301478 & 4.2699 & 5.267 & TST & \\
\hline CHEMBL1506926 & 1301478 & 5.9508 & 5.9347 & TRN & \\
\hline CHEMBL1463529 & 1301478 & 5.7423 & 5.8103 & TRN & \\
\hline CHEMBL1429164 & 1301478 & 4.8254 & 4.8544 & TRN & \\
\hline CHEMBL1374258 & 1301478 & 5.1445 & 5.0908 & TRN & \\
\hline CHEMBL 2355635 & 1301478 & 5.0395 & 5.5766 & TRN & \\
\hline CHEMBL1481861 & 1301478 & 5.3002 & 5.3844 & TRN & \\
\hline
\end{tabular}


Supplemental Table S2.txt

\begin{tabular}{|c|c|c|c|c|c|}
\hline CHEMBL1588387 & 1301478 & 4.2466 & 4.5471 & TRN & \\
\hline CHEMBL1328462 & 1301478 & 4.9296 & 5.2209 & TRN & \\
\hline CHEMBL3186645 & 1301478 & 4.6887 & 4.6289 & TST & \\
\hline CHEMBL1582244 & 1301478 & 5.3188 & 5.2804 & TRN & \\
\hline CHEMBL1404788 & 1301478 & 5.1238 & 5.0303 & TRN & \\
\hline CHEMBL1521051 & 1301478 & 5.2255 & 5.2266 & TRN & \\
\hline CHEMBL1868562 & 1301478 & 4.5452 & 4.5243 & TRN & \\
\hline CHEMBL1535021 & 1301478 & 5.4283 & 5.1302 & TRN & \\
\hline CHEMBL1895744 & 1301478 & 4.9485 & 4.9818 & TRN & \\
\hline CHEMBL1538625 & 1301478 & 5.5986 & 5.5343 & TRN & \\
\hline CHEMBL1389748 & 1301478 & 5.0264 & 5.7812 & TRN & \\
\hline CHEMBL1361072 & 1301478 & 4.8008 & 4.8116 & TST & \\
\hline CHEMBL405317 & 1301478 & 6.6271 & 6.5595 & TRN & \\
\hline CHEMBL1407659 & 1301478 & 4.8601 & 4.8602 & TRN & \\
\hline CHEMBL1365689 & 1301478 & 5.4377 & 5.3617 & TRN & \\
\hline CHEMBL1544685 & 1301478 & 5.6655 & 5.5569 & TRN & \\
\hline CHEMBL1329803 & 1301478 & 5.0477 & 5.0686 & TRN & \\
\hline CHEMBL1528067 & 1301478 & 5.2381 & 5.0648 & TRN & \\
\hline CHEMBL1409101 & 1301478 & 5.1296 & 5.3748 & TRN & \\
\hline CHEMBL1442326 & 1301478 & 5.6326 & 5.5772 & TRN & \\
\hline CHEMBL1435056 & 1301478 & 5.2048 & 5.0646 & TST & \\
\hline CHEMBL1507515 & 1301478 & 4.8456 & 4.7436 & TRN & \\
\hline CHEMBL 78765 & 1301478 & 6.1791 & 6.0443 & TRN & \\
\hline CHEMBL1597705 & 1301478 & 5.1986 & 5.2128 & TRN & \\
\hline CHEMBL1315401 & 1301478 & 5.8356 & 5.9063 & TST & \\
\hline CHEMBL1438758 & 1301478 & 5.6968 & 5.6161 & TRN & \\
\hline CHEMBL1490336 & 1301478 & 5.699 & 5.6426 & TRN & \\
\hline CHEMBL1488730 & 1301478 & 5.9136 & 5.8496 & TRN & \\
\hline CHEMBL1488586 & 1301478 & 5.2668 & 5.3378 & TRN & \\
\hline CHEMBL1494038 & 1301478 & 5.6144 & \multicolumn{2}{|c|}{5.667000000000001} & TRN \\
\hline CHEMBL1372760 & 1301478 & 5.2716 & 5.1297 & TRN & \\
\hline CHEMBL3182522 & 1301478 & 4.699 & 4.8365 & TRN & \\
\hline CHEMBL1404547 & 1301478 & 5.295 & 5.2427 & TRN & \\
\hline CHEMBL530609 & 1301478 & 5.7905 & 5.6031 & TRN & \\
\hline CHEMBL1419031 & 1301478 & 5.9547 & 5.7708 & TRN & \\
\hline CHEMBL1713163 & 1301478 & 4.3078 & 5.166 & TST & \\
\hline CHEMBL600572 & 1301478 & 4.8901 & 4.7124 & TRN & \\
\hline CHEMBL1595582 & 1301478 & 5.6882 & 5.7603 & TRN & \\
\hline CHEMBL1349759 & 1301478 & 4.7001 & 4.7354 & TRN & \\
\hline CHEMBL3185532 & 1301478 & 4.6824 & 4.6149 & TRN & \\
\hline CHEMBL1576166 & 1301478 & 5.3279 & 5.3206 & TRN & \\
\hline CHEMBL1876680 & 1301478 & 5.7235 & 5.5424 & TRN & \\
\hline CHEMBL1500923 & 1301478 & 5.4318 & 5.6527 & TRN & \\
\hline CHEMBL1489293 & 1301478 & 5.4134 & 5.3543 & TRN & \\
\hline CHEMBL1373194 & 1301478 & 5.2233 & 5.3733 & TRN & \\
\hline CHEMBL1900154 & 1301478 & 4.54 & 4.4349 & TRN & \\
\hline CHEMBL1385499 & 1301478 & 4.8348 & 4.7339 & TST & \\
\hline CHEMBL1600275 & 1301478 & 5.2503 & 5.0544 & TRN & \\
\hline
\end{tabular}


Supplemental Table S2.txt

\begin{tabular}{|c|c|c|c|c|c|}
\hline CHEMBL1599344 & 1301478 & 5.2708 & 5.1261 & TRN & \\
\hline CHEMBL1302266 & 1301478 & 5.4908 & 5.3189 & TRN & \\
\hline CHEMBL1527400 & 1301478 & 5.5768 & 6.0292 & TRN & \\
\hline CHEMBL1473464 & 1301478 & 5.6234 & 5.6217 & TRN & \\
\hline CHEMBL1309142 & 1301478 & 5.3768 & 5.4999 & TRN & \\
\hline CHEMBL1597322 & 1301478 & 4.512 & 4.7916 & TRN & \\
\hline CHEMBL1517002 & 1301478 & 5.1261 & 4.8721 & TRN & \\
\hline CHEMBL414890 & 1301478 & 4.6688 & 4.7969 & TST & \\
\hline CHEMBL1408238 & 1301478 & 5.4318 & 5.13399 & & TRN \\
\hline CHEMBL2359997 & 1301478 & 4.9555 & 4.8451 & TRN & \\
\hline CHEMBL 3188022 & 1301478 & 5.224 & 5.3031 & TRN & \\
\hline CHEMBL1461730 & 1301478 & 6.6144 & 6.4167 & TRN & \\
\hline CHEMBL1878853 & 1301478 & 4.7228 & 4.5445 & TRN & \\
\hline CHEMBL1310496 & 1301478 & 5.3706 & 5.1589 & TRN & \\
\hline CHEMBL1531169 & 1301478 & 4.4566 & 5.018 & TST & \\
\hline CHEMBL1301042 & 1301478 & 8.1675 & 7.7274 & TRN & \\
\hline CHEMBL1539359 & 1301478 & 5.8041 & 5.6195 & TRN & \\
\hline CHEMBL1585064 & 1301478 & 5.4191 & 5.3137 & TRN & \\
\hline CHEMBL1486874 & 1301478 & 8.1675 & 6.7078 & TRN & \\
\hline CHEMBL1402439 & 1301478 & 5.209 & 5.2836 & TRN & \\
\hline CHEMBL1374367 & 1301478 & 5.9101 & 5.5732 & TST & \\
\hline CHEMBL1483331 & 1301478 & 4.6525 & 4.9037 & TST & \\
\hline CHEMBL1559529 & 1301478 & 5.8153 & 5.8246 & TRN & \\
\hline CHEMBL1369200 & 1301478 & 4.5442 & 5.1391 & TRN & \\
\hline CHEMBL1422160 & 1301478 & 4.7486 & 4.6675 & TRN & \\
\hline CHEMBL1475514 & 1301478 & 5.1993 & 5.027 & TRN & \\
\hline CHEMBL1587117 & 1301478 & 6.9281 & 6.9189 & TRN & \\
\hline CHEMBL 2139564 & 1301478 & 4.7788 & 4.831 & TST & \\
\hline CHEMBL1256656 & 1301478 & 4.6442 & 4.599 & TRN & \\
\hline CHEMBL 3182923 & 1301478 & 4.368 & 4.9291 & TST & \\
\hline CHEMBL1496788 & 1301478 & 5.209 & 5.0927 & TRN & \\
\hline CHEMBL 2142817 & 1301478 & 5.9208 & 5.8014 & TRN & \\
\hline CHEMBL1425919 & 1301478 & 5.585 & 5.1274 & TRN & \\
\hline CHEMBL 2360439 & 1301478 & 4.7247 & 5.2249 & TRN & \\
\hline CHEMBL1520753 & 1301478 & 5.4012 & 5.3375 & TRN & \\
\hline CHEMBL1385573 & 1301478 & 5.0953 & 4.9696 & TRN & \\
\hline CHEMBL213580 & 1301478 & 5.3363 & 5.3746 & TRN & \\
\hline CHEMBL1535375 & 1301478 & 4.4943 & 4.5785 & TST & \\
\hline CHEMBL261123 & 1301478 & 6.0747 & 5.6406 & TRN & \\
\hline CHEMBL1466997 & 1301478 & 5.4522 & 5.4285 & TRN & \\
\hline CHEMBL 3188935 & 1301478 & 4.6444 & 4.5759 & TST & \\
\hline CHEMBL1421255 & 1301478 & 5.5638 & 5.63899 & 9999999999 & TST \\
\hline CHEMBL137586 & 1301478 & 5.2628 & 5.13399 & 99999999995 & TRN \\
\hline CHEMBL1467999 & 1301478 & 5.0883 & 4.9038 & TRN & \\
\hline CHEMBL1309573 & 1301478 & 5.9172 & 5.8429 & TRN & \\
\hline CHEMBL1325945 & 1301478 & 5.26200 & 000000006 & 5.3404 & TRN \\
\hline CHEMBL1396619 & 1301478 & 6.0685 & 5.9629 & TRN & \\
\hline CHEMBL1521269 & 1301478 & 5.1163 & 4.9569 & TRN & \\
\hline
\end{tabular}


Supplemental Table S2.txt

\begin{tabular}{|c|c|c|c|c|c|c|}
\hline CHEMBL1873775 & 1301478 & 5.0306 & 4.9938 & TRN & & \\
\hline CHEMBL1432977 & 1301478 & 5.2757 & 5.2298 & TST & & \\
\hline CHEMBL1610783 & 1301478 & 5.1255 & 5.1109 & TRN & & \\
\hline CHEMBL1546205 & 1301478 & 4.5967 & 4.5077 & TRN & & \\
\hline CHEMBL1539400 & 1301478 & 5.8416 & 5.7598 & TRN & & \\
\hline CHEMBL1535919 & 1301478 & 4.6103 & 4.8344 & TRN & & \\
\hline CHEMBL1486546 & 1301478 & 4.7277 & 4.6975 & TRN & & \\
\hline CHEMBL1454738 & 1301478 & 4.3955 & 4.7066 & TRN & & \\
\hline CHEMBL1612044 & 1301478 & 6.5607 & 6.5479 & TRN & & \\
\hline CHEMBL1350432 & 1301478 & 4.7491 & 4.7833 & TST & & \\
\hline CHEMBL1573261 & 1301478 & 5.3028 & 4.9088 & TRN & & \\
\hline CHEMBL1348884 & 1301478 & 5.1013 & 5.0311 & TRN & & \\
\hline CHEMBL1896073 & 1301478 & 4.6923 & 4.7183 & TRN & & \\
\hline CHEMBL1463659 & 1301478 & 5.5901 & 5.5949 & TRN & & \\
\hline CHEMBL1609784 & 1301478 & 4.4799 & 4.5044 & TRN & & \\
\hline CHEMBL1427736 & 1301478 & 5.2388 & 5.4068 & TRN & & \\
\hline CHEMBL 2136405 & 1301478 & 4.4802 & 4.4264 & TST & & \\
\hline CHEMBL1421287 & 1301478 & 4.9821 & 5.1588 & TRN & & \\
\hline CHEMBL1455421 & 1301478 & 5.1791 & 5.3307 & TRN & & \\
\hline CHEMBL1391313 & 1301478 & 5.5607 & 5.6884 & TRN & & \\
\hline CHEMBL1427072 & 1301478 & 5.8894 & 5.8823 & TRN & & \\
\hline CHEMBL1997132 & 1301478 & 5.1051 & 4.9975 & TRN & & \\
\hline CHEMBL1503463 & 1301478 & 5.1904 & 4.9001 & TRN & & \\
\hline CHEMBL1563176 & 1301478 & 4.63399 & 999999999 & 995 & 4.6666 & TS \\
\hline CHEMBL 3187578 & 1301478 & 4.744 & 4.5813 & TRN & & \\
\hline CHEMBL1707441 & 1301478 & 4.3586 & 4.6537 & TST & & \\
\hline CHEMBL1302164 & 1301478 & 5.301 & 5.3882 & TRN & & \\
\hline CHEMBL1988859 & 1301478 & 4.6366 & 5.3492 & TRN & & \\
\hline CHEMBL1485101 & 1301478 & 5.17200 & 000000000 & & 5.1318 & TRN \\
\hline CHEMBL1493724 & 1301478 & 4.727 & 4.8489 & TST & & \\
\hline CHEMBL1422720 & 1301478 & 5.1232 & 5.0595 & TRN & & \\
\hline CHEMBL1484344 & 1301478 & 4.745 & 5.0471 & TRN & & \\
\hline CHEMBL1474280 & 1301478 & 5.1255 & 5.2779 & TRN & & \\
\hline CHEMBL1578053 & 1301478 & 4.8755 & 5.0461 & TRN & & \\
\hline CHEMBL1891068 & 1301478 & 4.8592 & 4.9765 & TST & & \\
\hline CHEMBL591598 & 1301478 & 5.5376 & 5.3143 & TRN & & \\
\hline CHEMBL1884029 & 1301478 & 4.7537 & 4.6216 & TRN & & \\
\hline CHEMBL 2356186 & 1301478 & 5.9136 & 5.8915 & TRN & & \\
\hline CHEMBL1546172 & 1301478 & 5.32700 & 000000000 & 1 & 5.2356 & TS \\
\hline CHEMBL1523206 & 1301478 & 4.7031 & 4.6949 & TST & & \\
\hline CHEMBL1329798 & 1301478 & 6.5287 & 6.5204 & TRN & & \\
\hline CHEMBL1305566 & 1301478 & 5.24799 & 999999999 & 99 & 5.1536 & I RI \\
\hline CHEMBL 3188942 & 1301478 & 4.5226 & 4.1875 & TST & & \\
\hline CHEMBL1460869 & 1301478 & 5.1457 & 5.0447 & TRN & & \\
\hline CHEMBL1371507 & 1301478 & 6.1746 & 6.0166 & TRN & & \\
\hline CHEMBL1363706 & 1301478 & 5.5157 & 5.4675 & TRN & & \\
\hline CHEMBL 2362844 & 1301478 & 4.7815 & 4.9739 & TRN & & \\
\hline CHEMBL 3183439 & 1301478 & 4.5616 & 4.4507 & TST & & \\
\hline
\end{tabular}


Supplemental Table S2.txt

\begin{tabular}{|c|c|c|c|c|}
\hline CHEMBL1428735 & 1301478 & 6.2262 & 6.3489 & TRN \\
\hline CHEMBL1455756 & 1301478 & 5.4989 & 5.5091 & TRN \\
\hline CHEMBL1456521 & 1301478 & 5.2636 & 5.1732 & TRN \\
\hline CHEMBL1313954 & 1301478 & 5.0381 & 4.9892 & TRN \\
\hline CHEMBL1425034 & 1301478 & 5.7122 & 5.9686 & TRN \\
\hline CHEMBL1902024 & 1301478 & 4.8649 & 4.8958 & TRN \\
\hline CHEMBL1413841 & 1301478 & 5.5607 & 5.3954 & TRN \\
\hline CHEMBL1902247 & 1301478 & 4.6919 & 4.6687 & TRN \\
\hline CHEMBL1903021 & 1301478 & 4.871 & 4.9985 & TRN \\
\hline CHEMBL1553265 & 1301478 & 5.1884 & 5.0143 & TRN \\
\hline CHEMBL1866836 & 1301478 & 5.1385 & 5.4717 & TRN \\
\hline CHEMBL1451470 & 1301478 & 5.0731 & 5.0964 & TST \\
\hline CHEMBL 3187031 & 1301478 & 4.2124 & 5.0704 & TRN \\
\hline CHEMBL 3185466 & 1301478 & 4.6659 & 4.637 & TST \\
\hline CHEMBL1378392 & 1301478 & 5.38399 & 799999999 & 5.3546 \\
\hline CHEMBL199194 & 1301478 & 5.5654 & 5.3655 & TST \\
\hline CHEMBL 3183714 & 1301478 & 4.4901 & 4.5952 & TST \\
\hline CHEMBL1606999 & 1301478 & 5.4067 & 5.4186 & TRN \\
\hline CHEMBL1608629 & 1301478 & 5.224 & 5.0202 & TRN \\
\hline CHEMBL1392228 & 1301478 & 6.2916 & 6.1271 & TRN \\
\hline CHEMBL1522279 & 1301478 & 5.1192 & 5.1573 & TRN \\
\hline CHEMBL1438983 & 1301478 & 4.7169 & 4.6886 & TST \\
\hline CHEMBL1402010 & 1301478 & 6.5591 & 6.6569 & TRN \\
\hline CHEMBL1706877 & 1301478 & 4.5484 & 4.6655 & TRN \\
\hline CHEMBL1337227 & 1301478 & 5.1481 & 4.8393 & TRN \\
\hline CHEMBL1349442 & 1301478 & 4.7675 & 4.8707 & TRN \\
\hline CHEMBL1476017 & 1301478 & 5.3279 & 5.3227 & TRN \\
\hline CHEMBL191015 & 1301478 & 4.8407 & 4.7775 & TRN \\
\hline CHEMBL1440317 & 1301478 & 5.6364 & 5.6699 & TRN \\
\hline CHEMBL 2139358 & 1301478 & 4.8979 & 4.8562 & TRN \\
\hline CHEMBL1409883 & 1301478 & 5.7328 & 5.6117 & TRN \\
\hline CHEMBL1547229 & 1301478 & 4.7022 & 4.3959 & TST \\
\hline CHEMBL1904071 & 1301478 & 6.1612 & 6.1486 & TRN \\
\hline CHEMBL1428820 & 1301478 & 5.6882 & 5.627999 & 9999999999 \\
\hline CHEMBL1309463 & 1301478 & 4.9266 & 4.7191 & TST \\
\hline CHEMBL1555066 & 1301478 & 5.6055 & 5.5947 & TRN \\
\hline CHEMBL1734467 & 1301478 & 4.5782 & 4.7056 & TRN \\
\hline CHEMBL1351688 & 1301478 & 4.3173 & 5.1579 & TST \\
\hline CHEMBL1421941 & 1301478 & 5.8268 & 5.7394 & TRN \\
\hline CHEMBL1567944 & 1301478 & 6.5901 & 6.4193 & TST \\
\hline CHEMBL1549324 & 1301478 & 5.2924 & 5.2145 & TRN \\
\hline CHEMBL1718952 & 1301478 & 5.1878 & 5.3634 & TST \\
\hline CHEMBL1892565 & 1301478 & 4.5043 & 4.5993 & TRN \\
\hline CHEMBL1729737 & 1301478 & 6.7496 & 6.5807 & TRN \\
\hline CHEMBL1586425 & 1301478 & 5.4271 & 5.4402 & TRN \\
\hline CHEMBL1470242 & 1301478 & 5.3152 & 5.4017 & TRN \\
\hline CHEMBL 2355370 & 1301478 & 5.6716 & 5.6209 & TRN \\
\hline CHEMBL1495028 & 1301478 & 5.1385 & 5.1025 & TST \\
\hline
\end{tabular}


Supplemental Table S2.txt

\begin{tabular}{|c|c|c|}
\hline 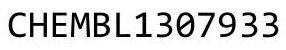 & & \\
\hline CHEMBL3184527 & 301478 & \\
\hline AEMBL1486102 & 301478 & \\
\hline HEMBL1606351 & 301478 & \\
\hline HEMBL1352521 & 301478 & \\
\hline HEMBL1303280 & 1301478 & \\
\hline HEMBL1413454 & 1301478 & \\
\hline HEMBL1213608 & 1301478 & \\
\hline HEMBL2359853 & 1301478 & \\
\hline HEMBL1878022 & 1301478 & \\
\hline HEMBL1720155 & 1301478 & \\
\hline HEMBL1595632 & 1301478 & \\
\hline HEMBL1315789 & 1301478 & 4.83 \\
\hline HEMBL1525789 & 1301478 & \\
\hline HEMBL1376674 & 1301478 & \\
\hline HEMBL1446234 & 1301478 & \\
\hline HEMBL1360928 & 1301478 & \\
\hline HEMBL1377992 & 1301478 & \\
\hline HEMBL3187897 & 1301 & \\
\hline HEMBL1332512 & 1301 & \\
\hline CHEMBL 2359438 & 1301478 & \\
\hline HEMBL1336447 & 1301478 & \\
\hline HEMBL1528342 & 1301478 & \\
\hline HEMBL1301480 & 1301478 & \\
\hline HEMBL 2133546 & 1301 & \\
\hline CHEMBL1352223 & 1301478 & \\
\hline CHEMBL3187767 & 1301478 & 5.0 \\
\hline CHEMBL1492399 & 1301 & \\
\hline CHEMBL1521187 & 1301478 & \\
\hline CHEMBL1342147 & 1301 & \\
\hline CHEMBL1502891 & 1301478 & \\
\hline CHEMBL1991779 & 1301 & \\
\hline CHEMBL1345558 & 1301478 & \\
\hline CHEMBL1444050 & 1301478 & \\
\hline CHEMBL1594126 & 1301478 & \\
\hline CHEMBL1537106 & 1301 & \\
\hline CHEMBL1453565 & 1301478 & \\
\hline CHEMBL 2136235 & 1301478 & \\
\hline CHEMBL1409400 & 1301478 & \\
\hline CHEMBL1386622 & 1301478 & \\
\hline CHEMBL1543215 & 1301478 & \\
\hline CHEMBL1484410 & 1301478 & 4.3 \\
\hline CHEMBL1881477 & 1301478 & 4.6 \\
\hline CHEMBL1416853 & 1301478 & \\
\hline CHEMBL1351908 & 1301478 & \\
\hline CHEMBL1595274 & 1301478 & \\
\hline CHEMBL1315275 & 1301478 & \\
\hline CHEMBL1468323 & 1301478 & \\
\hline
\end{tabular}

$\begin{array}{ll}5.4196 & \text { TRN } \\ 5.0121 & \text { TST } \\ 4.7311 & \text { TRN } \\ 5.8083 & \text { TRN } \\ 6.3536 & \text { TRN } \\ 5.7157 & \text { TRN } \\ 4.6586 & \text { TRN } \\ 5.8279 & \text { TRN } \\ 4.621 & \text { TRN } \\ 4.6224 & \text { TRN } \\ 4.5809 & \text { TRN } \\ 6.0796 & \text { TRN } \\ 4.7106 & \text { TRN } \\ 6.095 & \text { TRN } \\ 6.6235 & \text { TRN } \\ 4.6473 & \text { TST } \\ 5.8244 & \text { TRN } \\ 5.7731 & \text { TRN } \\ 4.6295 & \text { TRN } \\ 6.0568 & \text { TRN } \\ 4.6021 & \text { TST } \\ 5.156000000000001 \\ 5.4314 & \text { TRN } \\ 4.9074 & \text { TRN } \\ 4.7001 & \text { TRN } \\ 5.1866 & \text { TRN } \\ 4.9798 & \text { TRN } \\ 6.0219 & \text { TRN } \\ 5.4378 & \text { TRN } \\ 5.2324 & \text { TRN } \\ 5.7261 & \text { TRN } \\ 5.4674 & \text { TST } \\ 4.6011 & \text { TRN } \\ 4.8026 & \text { TRN } \\ 4.5574 & \text { TRN } \\ 5.2108 & \text { TRN } \\ 5.5058 & \text { TRN } \\ 4.8154 & \text { TST } \\ 5.595 & \text { TRN } \\ 5.2145 & \text { TST } \\ 6.2377 & \text { TRN } \\ 5.2299 & \text { TST } \\ 4.8482 & \text { TRN } \\ 5.4094 & \text { TRN } \\ 7.7494 & \text { TRN } \\ 5.4664 & \text { TRN } \\ 5.3463 & \text { TRN } \\ 6.5802 & \text { TRN } \\ & \end{array}$

TRN

Page 16948 
Supplemental Table S2.txt

\begin{tabular}{|c|c|c|c|c|c|c|}
\hline CHEMBL1409423 & 1301478 & 4.8925 & 4.9896 & TRN & & \\
\hline CHEMBL3187125 & 1301478 & 5.0545 & 4.8298 & TRN & & \\
\hline CHEMBL 2357026 & 1301478 & 4.4636 & 4.3912 & TRN & & \\
\hline CHEMBL512749 & 1301478 & 5.475 & 5.806 & TRN & & \\
\hline CHEMBL1414808 & 1301478 & 5.0531 & 4.8686 & TST & & \\
\hline CHEMBL1349863 & 1301478 & 6.0 & 6.3334 & TRN & & \\
\hline CHEMBL 2134655 & 1301478 & 4.4652 & 4.65 & TST & & \\
\hline CHEMBL1597726 & 1301478 & 5.0137 & 4.8824 & TRN & & \\
\hline CHEMBL1391158 & 1301478 & 5.3565 & 5.3201 & TRN & & \\
\hline CHEMBL1507537 & 1301478 & 4.6953 & 4.58 & TRN & & \\
\hline CHEMBL1558021 & 1301478 & 4.5017 & 4.4077 & TRN & & \\
\hline CHEMBL1349231 & 1301478 & 5.38399 & 999999999 & 995 & 5.43 & TRN \\
\hline CHEMBL367376 & 1301478 & 6.8601 & 6.6976 & TST & & \\
\hline CHEMBL1710184 & 1301478 & 4.7471 & 4.6521 & TRN & & \\
\hline CHEMBL1304031 & 1301478 & 4.3763 & 4.3872 & TRN & & \\
\hline CHEMBL1482964 & 1301478 & 5.341 & 5.2625 & TRN & & \\
\hline CHEMBL1338961 & 1301478 & 5.2175 & 5.3295 & TRN & & \\
\hline CHEMBL610198 & 1301478 & 4.721 & 4.6966 & TRN & & \\
\hline CHEMBL1564490 & 1301478 & 5.1475 & 5.1508 & TRN & & \\
\hline CHEMBL1876725 & 1301478 & 4.5933 & 4.6013 & TRN & & \\
\hline CHEMBL1444124 & 1301478 & 4.7303 & 4.8627 & TRN & & \\
\hline CHEMBL1415412 & 1301478 & 5.2041 & 5.1517 & TRN & & \\
\hline CHEMBL1316631 & 1301478 & 5.062 & 5.2277 & TRN & & \\
\hline CHEMBL1481849 & 1301478 & 4.8351 & 4.6368 & TST & & \\
\hline CHEMBL1438614 & 1301478 & 5.1232 & 5.08 & TST & & \\
\hline CHEMBL1502487 & 1301478 & 4.7345 & 4.628 & TRN & & \\
\hline CHEMBL1366321 & 1301478 & 5.1152 & 5.1228 & TRN & & \\
\hline CHEMBL1450386 & 1301478 & 5.055 & 5.0004 & TRN & & \\
\hline CHEMBL1563317 & 1301478 & 5.1925 & 5.1854 & TST & & \\
\hline CHEMBL3181899 & 1301478 & 4.7003 & 4.6755 & TRN & & \\
\hline CHEMBL1303404 & 1301478 & 5.5935 & 5.7017 & TRN & & \\
\hline CHEMBL1430096 & 1301478 & 6.6676 & 6.8327 & TRN & & \\
\hline CHEMBL1387923 & 1301478 & 5.4841 & 5.1871 & TRN & & \\
\hline CHEMBL1519965 & 1301478 & 6.585 & 6.4181 & TRN & & \\
\hline CHEMBL1367759 & 1301478 & 5.7932 & 5.6596 & TRN & & \\
\hline CHEMBL3184385 & 1301478 & 4.7575 & 4.5707 & TRN & & \\
\hline CHEMBL1734568 & 1301478 & 4.6434 & 4.57 & TST & & \\
\hline CHEMBL1374009 & 1301478 & 5.75200 & 000000000 & 91 & 5.6662 & TRN \\
\hline CHEMBL1540839 & 1301478 & 5.1249 & 5.1247 & TRN & & \\
\hline CHEMBL1379493 & 1301478 & 4.5103 & 4.5922 & TST & & \\
\hline CHEMBL1309162 & 1301478 & 5.6904 & 6.2889 & TST & & \\
\hline CHEMBL3184516 & 1301478 & 5.2907 & 5.185 & TST & & \\
\hline CHEMBL1457060 & 1301478 & 5.426 & 5.3597 & TST & & \\
\hline CHEMBL1736766 & 1301478 & 6.4413 & 6.4729 & TST & & \\
\hline CHEMBL 2357924 & 1301478 & 5.2668 & 5.3455 & TST & & \\
\hline CHEMBL1608430 & 1301478 & 5.2118 & 5.1927 & TST & & \\
\hline CHEMBL3182459 & 1301478 & 5.0035 & 4.883 & TST & & \\
\hline CHEMBL1533657 & 1301478 & 4.5789 & 4.6884 & TST & & \\
\hline
\end{tabular}


Supplemental Table S2.txt

\begin{tabular}{|c|c|c|c|c|c|}
\hline CHEMBL1373146 & 1301478 & 5.4056 & 5.4365 & TST & \\
\hline CHEMBL1317322 & 1301478 & 5.4202 & 5.3982 & TST & \\
\hline CHEMBL1487964 & 1301478 & 4.506 & 4.6178 & TST & \\
\hline CHEMBL1410197 & 1301478 & 4.6964 & 4.9516 & TST & \\
\hline CHEMBL1415374 & 1301478 & 5.5272 & 5.917000 & 0000000001 & TST \\
\hline CHEMBL1613147 & 1301478 & 6.5186 & 6.4505 & TST & \\
\hline CHEMBL1897363 & 1301478 & 4.6876 & 4.7519 & TST & \\
\hline CHEMBL1428452 & 1301478 & 5.1759 & 5.2864 & TST & \\
\hline CHEMBL2362612 & 1301478 & 5.5884 & 5.4592 & TST & \\
\hline CHEMBL595825 & 1301478 & 5.7773 & 5.4986 & TST & \\
\hline CHEMBL1331514 & 1301478 & 5.1475 & 4.8962 & TST & \\
\hline CHEMBL1510327 & 1301478 & 5.2874 & 5.2324 & TST & \\
\hline CHEMBL1458038 & 1301478 & 5.0888 & 5.1254 & TST & \\
\hline CHEMBL1457961 & 1301478 & 5.16299 & 999999999 & 5.0663 & TST \\
\hline CHEMBL1732740 & 1301478 & 5.2549 & 5.4291 & TST & \\
\hline CHEMBL1869875 & 1301478 & 5.6676 & 5.7947 & TST & \\
\hline CHEMBL1734045 & 1301478 & 5.0506 & 4.9545 & TST & \\
\hline CHEMBL3183001 & 1301478 & 6.0 & 5.8558 & TST & \\
\hline CHEMBL1421442 & 1301478 & 5.2269 & 4.8964 & TST & \\
\hline CHEMBL1397452 & 1301478 & 6.0701 & 5.6915 & TST & \\
\hline CHEMBL3182659 & 1301478 & 4.9531 & 4.9827 & TST & \\
\hline CHEMBL1343831 & 1301478 & 5.4647 & 5.3912 & TST & \\
\hline CHEMBL1975935 & 1301478 & 5.082 & 4.9079 & TST & \\
\hline CHEMBL1978733 & 1301478 & 5.0788 & 5.1016 & TST & \\
\hline CHEMBL 3188410 & 1301478 & 5.6271 & 5.5114 & TST & \\
\hline CHEMBL1450748 & 1301478 & 6.4365 & 6.2181 & TST & \\
\hline CHEMBL1529404 & 1301478 & 5.7986 & 6.051 & TST & \\
\hline CHEMBL125044 & 1301478 & 5.3556 & 5.3611 & TST & \\
\hline CHEMBL1530972 & 1301478 & 4.3649 & 5.4106 & TST & \\
\hline CHEMBL1549208 & 1301478 & 4.9367 & 5.1196 & TST & \\
\hline CHEMBL3187793 & 1301478 & 4.3332 & 4.6986 & TST & \\
\hline CHEMBL1393635 & 1301478 & 4.7994 & 4.6839 & TST & \\
\hline CHEMBL1502544 & 1301478 & 5.0141 & 5.2835 & TST & \\
\hline CHEMBL1408542 & 1301478 & 5.4389 & 5.5409 & TST & \\
\hline CHEMBL1548433 & 1301478 & 5.2418 & 5.1575 & TST & \\
\hline CHEMBL1453108 & 1301478 & 5.3363 & 5.2682 & TST & \\
\hline CHEMBL1479010 & 1301478 & 5.24799 & 999999999 & 5.0741 & TST \\
\hline CHEMBL1995376 & 1301478 & 4.6611 & 4.4382 & TST & \\
\hline CHEMBL1399193 & 1301478 & 4.7378 & 4.9025 & TST & \\
\hline CHEMBL 3980753 & 1642106 & 8.7282 & 9.1081 & TST & \\
\hline CHEMBL3966496 & 1642106 & 6.4193 & 6.4526 & TRN & \\
\hline CHEMBL3908539 & 1642106 & 7.8557 & 7.8985 & TRN & \\
\hline CHEMBL3956788 & 1642106 & 9.0969 & 8.1706 & TST & \\
\hline CHEMBL3914496 & 1642106 & 6.5411 & 6.5396 & TRN & \\
\hline CHEMBL 3942308 & 1642106 & 8.8013 & 8.7612 & TRN & \\
\hline CHEMBL3919625 & 1642106 & 6.5799 & 6.6508 & TST & \\
\hline CHEMBL 3943254 & 1642106 & 7.2526 & 7.2205 & TRN & \\
\hline CHEMBL3955474 & 1642106 & 7.5346 & 7.5635 & TRN & \\
\hline
\end{tabular}


Supplemental Table S2.txt

\begin{tabular}{|c|c|c|c|c|}
\hline CHEMBL 3909588 & 1642106 & 7.4808 & 8.7224 & TST \\
\hline CHEMBL 3960934 & 1642106 & 8.6925 & 8.6223 & TRN \\
\hline CHEMBL 3909251 & 1642106 & 6.5996 & 6.588999 & 79999999995 \\
\hline CHEMBL 3936487 & 1642106 & 9.0555 & 8.943 & TST \\
\hline CHEMBL3977007 & 1642106 & 8.1746 & 8.2028 & TRN \\
\hline CHEMBL 3964339 & 1642106 & 8.2865 & 7.9052 & TST \\
\hline CHEMBL 3940291 & 1642106 & 7.2118 & 6.9543 & TST \\
\hline CHEMBL 3914372 & 1642106 & 7.2473 & 7.2558 & TRN \\
\hline CHEMBL 3934290 & 1642106 & 6.9863 & 6.9812 & TRN \\
\hline CHEMBL3939989 & 1642106 & 9.6383 & 9.628 & TRN \\
\hline CHEMBL 3925478 & 1642106 & 8.4908 & 8.5135 & TRN \\
\hline CHEMBL 3920899 & 1642106 & 7.96899 & 999999999 & 7.9052 \\
\hline CHEMBL 3981267 & 1642106 & 8.3757 & 8.3377 & TRN \\
\hline CHEMBL 3982168 & 1642106 & 6.7665 & 6.7562 & TRN \\
\hline CHEMBL 3912952 & 1642106 & 7.4288 & 7.4058 & TRN \\
\hline CHEMBL 3967911 & 1642106 & 7.26 & 7.0129 & TST \\
\hline CHEMBL3923930 & 1642106 & 6.4802 & 6.4719 & TRN \\
\hline CHEMBL 3921749 & 1642106 & 8.4634 & 8.4889 & TRN \\
\hline CHEMBL 3930598 & 1642106 & 6.688 & 6.7367 & TRN \\
\hline CHEMBL 3891928 & 1642106 & 9.4559 & 9.4624 & TRN \\
\hline CHEMBL 3926789 & 1642106 & 9.2007 & 9.2072 & TRN \\
\hline CHEMBL3961546 & 1642106 & 7.9638 & 7.8958 & TRN \\
\hline CHEMBL3939591 & 1642106 & 6.476 & 6.4908 & TRN \\
\hline CHEMBL 3961380 & 1642106 & 8.3028 & 8.7307 & TST \\
\hline CHEMBL 3968422 & 1642106 & 7.1006 & 6.1943 & TST \\
\hline CHEMBL 3932452 & 1642106 & 6.7789 & 6.7575 & TRN \\
\hline CHEMBL3915989 & 1642106 & 7.4996 & 7.5735 & TRN \\
\hline CHEMBL 3956406 & 1642106 & 7.2029 & 7.2146 & TRN \\
\hline CHEMBL 3944716 & 1642106 & 8.4881 & 8.4959 & TRN \\
\hline CHEMBL 3946432 & 1642106 & 8.6716 & 8.6349 & TRN \\
\hline CHEMBL 3952690 & 1642106 & 8.0264 & 8.007 & TRN \\
\hline CHEMBL 3895478 & 1642106 & 7.4658 & 7.5601 & TRN \\
\hline CHEMBL 3954232 & 1642106 & 9.4437 & 9.4251 & TRN \\
\hline CHEMBL 3956484 & 1642106 & 9.1427 & 9.1229 & TRN \\
\hline CHEMBL 3952867 & 1642106 & 8.2541 & 8.4315 & TRN \\
\hline CHEMBL 3907097 & 1642106 & 8.8539 & 8.6509 & TRN \\
\hline CHEMBL 3907790 & 1642106 & 7.5578 & 7.7097 & TRN \\
\hline CHEMBL 3771125 & 1642106 & 9.8239 & 9.8119 & TRN \\
\hline CHEMBL 3980462 & 1642106 & 8.567 & 8.5654 & TRN \\
\hline CHEMBL 3938543 & 1642106 & 7.5453 & 7.4791 & TRN \\
\hline CHEMBL 3936632 & 1642106 & 7.7498 & 8.3451 & TST \\
\hline CHEMBL 3974163 & 1642106 & 9.5376 & 9.5603 & TRN \\
\hline CHEMBL 3892719 & 1642106 & 7.2376 & 5.5812 & TST \\
\hline CHEMBL 3976218 & 1642106 & 8.684 & 8.6722 & TRN \\
\hline CHEMBL 3971773 & 1642106 & 7.2961 & 7.2755 & TRN \\
\hline CHEMBL 3967493 & 1642106 & 7.6278 & 7.4542 & TRN \\
\hline CHEMBL 3954308 & 1642106 & 8.0857 & 8.217 & TRN \\
\hline CHEMBL 3897535 & 1642106 & 8.6655 & 8.6804 & TRN \\
\hline
\end{tabular}


Supplemental Table S2.txt

\begin{tabular}{|c|c|c|c|c|}
\hline 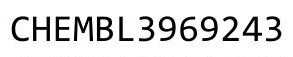 & 2106 & 6.9657 & & \\
\hline HEMPI 2061077 & & 6.5632 & 5516 & \\
\hline 68 & 106 & & & \\
\hline 908381 & & 252 & & Ne \\
\hline AEMBL3934495 & 106 & 1225 & & \\
\hline HEMBL3947736 & 642106 & 8.8794 & .8424 & \\
\hline HEMBL3968890 & 26 & 7.9923 & 767 & \\
\hline IFMRI 3890 & & & & \\
\hline HEMBL3910603 & & & 3081 & \\
\hline HEMBL3893837 & 06 & 24 & 2855 & \\
\hline HEMBL3899960 & 26 & 9.6576 & 86 & \\
\hline IEMBL394 & 26 & & 596 & \\
\hline IEMBL 397 & & & & \\
\hline HEMBL3898663 & 06 & & 8.4372 & \\
\hline AEMBL3964 & $\partial 6$ & 28 & 5764 & \\
\hline AEMBL3892 & 00 & 34 & 1155 & \\
\hline AEMBL396 & 6 & & 61 & \\
\hline HEMBL 394 & & & & \\
\hline HEMBL 3932 & & 6 . & .0004 & \\
\hline HEMBL396 & & & & \\
\hline HEIMBLSS & 10 & & 89 & 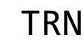 \\
\hline AEMBL39 & & & 45 & RN \\
\hline HEMBL39 & & & 73 & \\
\hline HFMRI 389 & & & 3315 & \\
\hline HEMBL 391 & & & & N \\
\hline AEMBL39 & 96 & & 523 & $\cdots$ \\
\hline HEMBL3 & & & 77 & RN \\
\hline HFMBI $3 c$ & & & 26 & \\
\hline HEMBL390 & & & 7.2138 & I KIV \\
\hline HEMBL3986366 & & & 955 & 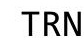 \\
\hline HEMBL396. & & & 402 & RN \\
\hline HEMBL & & & 91 & RN \\
\hline AEMBL; & & 8 & 8.3625 & N \\
\hline HEMBL3961021 & & & 3277 & IRN \\
\hline HEMBL 3962789 & & & 1817 & Th \\
\hline HEMBL395 & & & 572 & Niv \\
\hline HFMRI $=2$ & & 7 & 158 & $\Gamma \mathrm{RN}$ \\
\hline HEMBL3 & & & 8.5676 & RN \\
\hline HEMBL3970462 & 16 & 8. & & TRN \\
\hline HEMBL393 & 36 & & 2029 & TRN \\
\hline HEMBL397 & 16 & & 8.1628 & \\
\hline HEMBL 3889 & & & 7.2442 & 151 \\
\hline HEMBL3911 & $\partial 6$ & 8.0004 & 8.0292 & $\Gamma \mathrm{RN}$ \\
\hline AEMBL3985069 & 36 & 83 & .6367 & TRN \\
\hline MBL39 & & 7.0608 & $\partial 803$ & $\mathrm{~N}$ \\
\hline HEMBL3962 & & & 5.9297 & \\
\hline CHEMBL3947336 & & & 8.2824 & \\
\hline CHEMBL3981209 & 164210 & 7.5139 & 7.5249 & \\
\hline
\end{tabular}

Page 16952 
Supplemental Table S2.txt

\begin{tabular}{|c|c|c|c|c|}
\hline CHEMBL 3953643 & 1642106 & 8.9957 & 9.019 & TRN \\
\hline CHEMBL3944205 & 1642106 & 8.1649 & 8.1267 & TRN \\
\hline CHEMBL3975260 & 1642106 & 7.8508 & 7.8658 & TRN \\
\hline CHEMBL 3970822 & 1642106 & 9.0506 & 9.0591 & TRN \\
\hline CHEMBL3955396 & 1642106 & 9.0088 & 8.9976 & TRN \\
\hline CHEMBL3907370 & 1642106 & 7.0742 & 7.0554 & TRN \\
\hline CHEMBL3969145 & 1642106 & 7.7693 & 8.6848 & TST \\
\hline CHEMBL 3984104 & 1642106 & 7.0239 & \multicolumn{2}{|c|}{7.446000000000001} \\
\hline CHEMBL3960059 & 1642106 & 6.0 & 9.3339 & TST \\
\hline CHEMBL3960771 & 1642106 & 6.9798 & 7.9764 & TST \\
\hline CHEMBL3953514 & 1642106 & 6.3217 & 7.4218 & TST \\
\hline CHEMBL3964618 & 1642106 & 8.3747 & 8.7099 & TST \\
\hline CHEMBL3959808 & 1642106 & 8.8633 & 9.8649 & TST \\
\hline CHEMBL3946924 & 1642106 & 6.4931 & 8.0733 & TST \\
\hline CHEMBL3910147 & 1642106 & 9.3565 & 9.7972 & TST \\
\hline CHEMBL3979229 & 1642106 & 8.9136 & 9.439 & TST \\
\hline CHEMBL3962272 & 1642106 & 8.1726 & 8.9607 & TST \\
\hline CHEMBL3957857 & 1642106 & 9.3565 & 9.0547 & TST \\
\hline CHEMBL3925880 & 1642106 & 8.301 & 8.7727 & TST \\
\hline CHEMBL3919252 & 1642106 & 7.6902 & 8.0285 & TST \\
\hline CHEMBL3981364 & 1642106 & 8.2396 & 8.6581 & TST \\
\hline CHEMBL1699875 & 954343 & 6.5105 & 4.4179 & TRN \\
\hline CHEMBL1725000 & 954343 & 3.1705 & 3.4676 & TST \\
\hline CHEMBL2362741 & 954343 & 3.1704 & 3.5654 & TST \\
\hline CHEMBL1422471 & 954343 & 3.1707 & 3.5831 & TST \\
\hline CHEMBL 2000122 & 954343 & 3.1704 & 4.4019 & TRN \\
\hline CHEMBL1318263 & 954343 & 5.079 & 4.5644 & TRN \\
\hline CHEMBL1358011 & 954343 & 3.1709 & 3.3447 & TRN \\
\hline CHEMBL1391972 & 954343 & 5.5558 & 4.9669 & TRN \\
\hline CHEMBL1505427 & 954343 & 4.1253 & 3.9262 & TRN \\
\hline CHEMBL1447068 & 954343 & 3.1706 & 2.9648 & TRN \\
\hline CHEMBL1389029 & 954343 & 3.1705 & 3.4375 & TST \\
\hline CHEMBL1490918 & 954343 & 5.0787 & 4.0267 & TRN \\
\hline CHEMBL2362139 & 954343 & 3.1703 & 2.9938 & TRN \\
\hline CHEMBL1575293 & 954343 & 3.1704 & 3.0993 & TRN \\
\hline CHEMBL1905608 & 954343 & 3.1708 & 3.3442 & TRN \\
\hline CHEMBL1425826 & 954343 & 5.0789 & 5.11600 & 20000000005 \\
\hline CHEMBL1905073 & 954343 & 3.1706 & 4.0107 & TST \\
\hline CHEMBL1360618 & 954343 & 5.0794 & 4.5922 & TST \\
\hline CHEMBL1706389 & 954343 & 3.1707 & 3.1282 & TRN \\
\hline CHEMBL1317322 & 954343 & 3.1703 & 3.2036 & TRN \\
\hline CHEMBL1332818 & 954343 & 3.1702 & 3.2559 & TRN \\
\hline CHEMBL1467943 & 954343 & 3.1704 & 3.0319 & TRN \\
\hline CHEMBL1724096 & 954343 & 3.1705 & 3.2168 & TRN \\
\hline CHEMBL296586 & 954343 & 5.0791 & 3.9941 & TST \\
\hline CHEMBL1707904 & 954343 & 3.1711 & 3.8169 & TRN \\
\hline CHEMBL562051 & 954343 & 3.1704 & 3.0228 & TRN \\
\hline CHEMBL1521172 & 954343 & 5.5562 & 3.4377 & TRN \\
\hline
\end{tabular}

Page 16953 
Supplemental Table S2.txt

\begin{tabular}{|c|c|c|c|c|c|}
\hline CHEMBL1705389 & 954343 & 3.1702 & 3.4619 & TRN & \\
\hline CHEMBL1372039 & 954343 & 3.1704 & 4.265 & TST & \\
\hline CHEMBL1328145 & 954343 & 3.1706 & 4.8049 & TRN & \\
\hline CHEMBL1608383 & 954343 & 6.0334 & 4.2564 & TRN & \\
\hline CHEMBL1346941 & 954343 & 3.1704 & 2.9712 & TRN & \\
\hline CHEMBL1408708 & 954343 & 3.1705 & 3.3177 & TRN & \\
\hline CHEMBL1599090 & 954343 & 3.1703 & 3.7312 & TRN & \\
\hline CHEMBL1386689 & 954343 & 3.1705 & 4.5047 & TRN & \\
\hline CHEMBL1421477 & 954343 & 3.1705 & 3.6169 & TST & \\
\hline CHEMBL1343831 & 954343 & 3.1704 & 3.7618 & TRN & \\
\hline CHEMBL 2142604 & 954343 & 3.1703 & 4.1818 & TRN & \\
\hline CHEMBL 2136335 & 954343 & 3.1705 & 3.8328 & TST & \\
\hline CHEMBL3213707 & 954343 & 3.1704 & 3.7389 & TST & \\
\hline CHEMBL1337583 & 954343 & 5.0789 & 4.7886 & TRN & \\
\hline CHEMBL1595473 & 954343 & 3.1705 & 3.4046 & TRN & \\
\hline CHEMBL19167 & 954343 & 3.1701 & 3.8977 & TRN & \\
\hline CHEMBL3214571 & 954343 & 3.1705 & 4.0859 & TRN & \\
\hline CHEMBL 2139705 & 954343 & 3.1705 & 3.4084 & TRN & \\
\hline CHEMBL 2007256 & 954343 & 3.1703 & 3.4815 & TRN & \\
\hline CHEMBL1582052 & 954343 & 3.1704 & 3.5946 & TRN & \\
\hline CHEMBL1992104 & 954343 & 3.1708 & 3.9226 & TRN & \\
\hline CHEMBL1881877 & 954343 & 3.1701 & 3.3733 & TRN & \\
\hline CHEMBL1310496 & 954343 & 4.6017 & 3.9042 & TRN & \\
\hline CHEMBL1340462 & 954343 & 3.1702 & 3.2608 & TRN & \\
\hline CHEMBL1514622 & 954343 & 3.1707 & 3.2071 & TRN & \\
\hline CHEMBL1597334 & 954343 & 3.1708 & 3.7769 & TRN & \\
\hline CHEMBL1868012 & 954343 & 3.1703 & 3.5801 & TRN & \\
\hline CHEMBL1336651 & 954343 & 3.1702 & 3.6658 & TRN & \\
\hline CHEMBL1706279 & 954343 & 6.6123 & 4.4144 & TRN & \\
\hline CHEMBL21260 & 954343 & 3.1704 & 4.4329 & TRN & \\
\hline CHEMBL1454840 & 954343 & 3.1703 & 3.8698 & TRN & \\
\hline CHEMBL1524921 & 954343 & 5.8441 & 5.184 & TRN & \\
\hline CHEMBL1902481 & 954343 & 3.1701 & 2.9552 & TRN & \\
\hline CHEMBL260451 & 954343 & 6.0334 & 5.7041 & TRN & \\
\hline CHEMBL1422450 & 954343 & 3.1706 & 3.425 & TRN & \\
\hline CHEMBL 2134831 & 954343 & 4.6017 & 3.8462 & TRN & \\
\hline CHEMBL1416018 & 954343 & 3.1705 & 3.2327 & TRN & \\
\hline CHEMBL1404110 & 954343 & 3.1707 & 3.112 & TRN & \\
\hline CHEMBL1904064 & 954343 & 3.1703 & 3.8109 & TRN & \\
\hline CHEMBL1506679 & 954343 & 5.1022 & 3.8758 & TST & \\
\hline CHEMBL1594867 & 954343 & 3.1706 & 4.5338 & TRN & \\
\hline CHEMBL 2144833 & 954343 & 3.1706 & 3.5805 & TRN & \\
\hline CHEMBL1368561 & 954343 & 3.1704 & 4.0505 & TRN & \\
\hline CHEMBL1736693 & 954343 & 3.1705 & 3.3973 & TRN & \\
\hline CHEMBL 2132199 & 954343 & 3.1705 & \multicolumn{2}{|c|}{3.4339999999999997} & TST \\
\hline CHEMBL1489779 & 954343 & 3.1704 & 3.2254 & TST & \\
\hline CHEMBL1575708 & 954343 & 3.1704 & 4.5619 & TRN & \\
\hline CHEMBL3199267 & 954343 & 5.67899 & 9999999 & 4.3413 & TST \\
\hline
\end{tabular}


Supplemental Table S2.txt

\begin{tabular}{|c|c|c|c|c|}
\hline CHEMBL1383700 & 954343 & 3.1704 & 3.2462 & TRN \\
\hline CHEMBL1322487 & 954343 & 4.6069 & 3.5583 & TRN \\
\hline CHEMBL1334674 & 954343 & 5.5558 & 4.0474 & TRN \\
\hline CHEMBL1459841 & 954343 & 3.1704 & 3.5808 & TST \\
\hline CHEMBL1451293 & 954343 & 6.0337 & 4.7553 & TRN \\
\hline CHEMBL1872713 & 954343 & 3.1706 & 2.7012 & TRN \\
\hline CHEMBL1526661 & 954343 & 3.1705 & 3.4761 & TRN \\
\hline CHEMBL1725760 & 954343 & 3.1704 & 3.5239 & TRN \\
\hline CHEMBL1418045 & 954343 & 3.1704 & 3.376006 & 00000000003 \\
\hline CHEMBL1466074 & 954343 & 3.1705 & 2.9039 & TRN \\
\hline CHEMBL1703663 & 954343 & 3.1704 & 2.889 & TRN \\
\hline CHEMBL275391 & 954343 & 3.17 & 3.2572 & TRN \\
\hline CHEMBL1565955 & 954343 & 3.1704 & 3.5957 & TRN \\
\hline CHEMBL 2362612 & 954343 & 6.0334 & 4.9999 & TRN \\
\hline CHEMBL1318506 & 954343 & 3.1704 & 3.4474 & TRN \\
\hline CHEMBL1404453 & 954343 & 3.1703 & 3.1041 & TRN \\
\hline CHEMBL19980 & 954343 & 6.8721 & 4.0914 & TST \\
\hline CHEMBL1373146 & 954343 & 5.5561 & 4.0252 & TRN \\
\hline CHEMBL1599863 & 954343 & 5.0789 & 4.2969 & TRN \\
\hline CHEMBL1728616 & 954343 & 3.1705 & 3.4992 & TRN \\
\hline CHEMBL1079664 & 954343 & 3.1708 & 3.2626 & TRN \\
\hline CHEMBL1904501 & 954343 & 6.0331 & 4.8625 & TRN \\
\hline CHEMBL 281870 & 954343 & 3.1701 & 3.6702 & TRN \\
\hline CHEMBL1366027 & 954343 & 3.17 & 4.474 & TRN \\
\hline CHEMBL1310773 & 954343 & 3.1701 & 3.2606 & TRN \\
\hline CHEMBL 3191874 & 954343 & 5.0789 & 4.0034 & TRN \\
\hline CHEMBL1500581 & 954343 & 3.1703 & 4.195 & TST \\
\hline CHEMBL1563383 & 954343 & 5.5564 & 4.3132 & TRN \\
\hline CHEMBL1431826 & 954343 & 3.1705 & 3.2125 & TRN \\
\hline CHEMBL1433494 & 954343 & 3.1704 & 3.321 & TRN \\
\hline CHEMBL1428850 & 954343 & 5.079 & 3.8963 & TRN \\
\hline CHEMBL1457060 & 954343 & 3.1704 & 4.074 & TRN \\
\hline CHEMBL 3193610 & 954343 & 3.1709 & 2.9474 & TRN \\
\hline CHEMBL1878855 & 954343 & 3.1708 & 3.8572 & TRN \\
\hline CHEMBL1463386 & 954343 & 3.1705 & 2.7509 & TRN \\
\hline CHEMBL1374258 & 954343 & 3.1705 & 3.1828 & TRN \\
\hline CHEMBL1571647 & 954343 & 6.0334 & 3.5543 & TRN \\
\hline CHEMBL1537781 & 954343 & 5.5561 & 4.8205 & TRN \\
\hline CHEMBL 3211385 & 954343 & 3.1708 & 3.4228 & TRN \\
\hline CHEMBL 277648 & 954343 & 6.5105 & 3.9762 & TRN \\
\hline CHEMBL1991510 & 954343 & 3.1705 & 3.2005 & TRN \\
\hline CHEMBL1370490 & 954343 & 6.0334 & 5.3335 & TRN \\
\hline CHEMBL1575124 & 954343 & 3.1701 & 4.0927 & TRN \\
\hline CHEMBL1383204 & 954343 & 3.1704 & 3.3485 & TRN \\
\hline CHEMBL1526249 & 954343 & 5.5563 & 4.8435 & TRN \\
\hline CHEMBL1583256 & 954343 & 3.1703 & \multicolumn{2}{|c|}{3.7039999999999997} \\
\hline CHEMBL1580834 & 954343 & 3.1704 & 3.9269 & TRN \\
\hline CHEMBL1394919 & 954343 & 3.1701 & 3.1226 & TRN \\
\hline
\end{tabular}


Supplemental Table S2.txt

\begin{tabular}{|c|c|c|c|c|c|}
\hline CHEMBL1393107 & 954343 & 3.1705 & 2.9446 & TRN & \\
\hline CHEMBL1732354 & 954343 & 3.1703 & 2.8621 & TRN & \\
\hline CHEMBL1454300 & 954343 & 3.1701 & 3.8792 & TRN & \\
\hline CHEMBL1460962 & 954343 & 3.17 & 3.6252 & TRN & \\
\hline CHEMBL1524148 & 954343 & 3.1702 & 3.995 & TRN & \\
\hline CHEMBL1713020 & 954343 & 3.1705 & 2.8596 & TRN & \\
\hline CHEMBL1732613 & 954343 & 3.1709 & 3.9398 & TRN & \\
\hline CHEMBL1368103 & 954343 & 3.1704 & 2.9504 & TRN & \\
\hline CHEMBL1410006 & 954343 & 3.1704 & 3.825 & TRN & \\
\hline CHEMBL18936 & 954343 & 3.1709 & 3.6531 & TRN & \\
\hline CHEMBL1464327 & 954343 & 3.6475 & 3.9823 & TST & \\
\hline CHEMBL1458147 & 954343 & 3.1703 & 3.0083 & TRN & \\
\hline CHEMBL 77552 & 954343 & 4.4561 & 3.3483 & TRN & \\
\hline CHEMBL1436421 & 954343 & 3.1709 & 2.9731 & TRN & \\
\hline CHEMBL1572931 & 954343 & 5.5564 & 4.8092 & TRN & \\
\hline CHEMBL1313954 & 954343 & 3.1705 & 3.5107 & TRN & \\
\hline CHEMBL1390171 & 954343 & 3.1703 & 2.948 & TRN & \\
\hline CHEMBL1718241 & 954343 & 4.9866 & 4.584 & TRN & \\
\hline CHEMBL1531903 & 954343 & 3.17 & 3.7132 & TRN & \\
\hline CHEMBL1437846 & 954343 & 6.4134 & 3.7814 & TST & \\
\hline CHEMBL1394299 & 954343 & 3.1704 & 2.324 & TRN & \\
\hline CHEMBL1487732 & 954343 & 3.1705 & 2.98199 & 99999999998 & TRN \\
\hline CHEMBL 3208847 & 954343 & 3.1704 & 4.3852 & TRN & \\
\hline CHEMBL 2132769 & 954343 & 3.1704 & 3.25100 & 00000000003 & TRN \\
\hline CHEMBL1580774 & 954343 & 3.1701 & 3.674 & TST & \\
\hline CHEMBL2143132 & 954343 & 3.1703 & 3.2681 & TRN & \\
\hline CHEMBL1720670 & 954343 & 3.1705 & 3.5138 & TRN & \\
\hline CHEMBL1500223 & 954343 & 3.1708 & 3.7681 & TST & \\
\hline CHEMBL 3189872 & 954343 & 3.1708 & 3.9477 & TRN & \\
\hline CHEMBL1375043 & 954343 & 3.1708 & 4.4591 & TST & \\
\hline CHEMBL1522952 & 954343 & 3.1706 & 3.0412 & TRN & \\
\hline CHEMBL1552047 & 954343 & 3.1705 & 3.823 & TRN & \\
\hline CHEMBL1331300 & 954343 & 5.5562 & 4.2273 & TRN & \\
\hline CHEMBL1481616 & 954343 & 5.5562 & 4.7146 & TRN & \\
\hline CHEMBL1892464 & 954343 & 3.1697 & 4.027 & TST & \\
\hline CHEMBL3197431 & 954343 & 5.556 & 5.0494 & TRN & \\
\hline CHEMBL1475147 & 954343 & 3.1708 & 3.8759 & TRN & \\
\hline CHEMBL1573766 & 954343 & 6.0334 & 4.5738 & TRN & \\
\hline CHEMBL1511277 & 954343 & 3.1704 & 2.6492 & TRN & \\
\hline CHEMBL 3195200 & 954343 & 3.1703 & 4.1676 & TRN & \\
\hline CHEMBL1964966 & 954343 & 3.1702 & 3.307 & TRN & \\
\hline CHEMBL1405742 & 954343 & 3.1705 & 3.2501 & TRN & \\
\hline CHEMBL1736008 & 954343 & 4.8013 & 3.2537 & TRN & \\
\hline CHEMBL1420725 & 954343 & 3.1706 & 3.6604 & TRN & \\
\hline CHEMBL1868139 & 954343 & 3.1708 & 2.9527 & TRN & \\
\hline CHEMBL3192850 & 954343 & 3.1704 & 3.9967 & TRN & \\
\hline CHEMBL1383030 & 954343 & 3.17 & 3.6585 & TRN & \\
\hline CHEMBL1551577 & 954343 & 3.1705 & 3.1434 & TRN & \\
\hline
\end{tabular}




\begin{tabular}{|c|c|c|c|c|}
\hline & & & oplement & al Ta \\
\hline CHEMBL1354361 & 954343 & 3.1706 & 3.5558 & TRN \\
\hline CHEMBL1357867 & 954343 & 5.5561 & 4.1932 & TST \\
\hline CHEMBL577455 & 954343 & 4.853 & 3.9296 & TST \\
\hline CHEMBL 2137128 & 954343 & 3.1703 & 3.9169 & TRN \\
\hline CHEMBL1451245 & 954343 & 3.1705 & 4.4883 & TRN \\
\hline CHEMBL1453121 & 954343 & 3.1704 & 3.3297 & TRN \\
\hline CHEMBL1325986 & 954343 & 3.1704 & 3.7045 & TRN \\
\hline CHEMBL1405698 & 954343 & 3.1704 & 3.0852 & TRN \\
\hline CHEMBL1593612 & 954343 & 3.1704 & 3.5794 & TRN \\
\hline CHEMBL1324620 & 954343 & 4.4983 & 3.4027 & TRN \\
\hline CHEMBL1598222 & 954343 & 3.1704 & 4.5176 & TRN \\
\hline CHEMBL1484968 & 954343 & 4.6022 & 3.7042 & TRN \\
\hline CHEMBL1317739 & 954343 & 3.1708 & 3.292 & TRN \\
\hline CHEMBL1368684 & 954343 & 3.1702 & 3.5473 & TRN \\
\hline CHEMBL2359584 & 954343 & 3.1702 & 3.5071 & TRN \\
\hline CHEMBL2143334 & 954343 & 3.1702 & 3.3085 & TRN \\
\hline CHEMBL1727807 & 954343 & 3.1709 & 2.9959 & TRN \\
\hline CHEMBL320802 & 954343 & 3.1704 & 4.3404 & TRN \\
\hline CHEMBL3195396 & 954343 & 3.17 & 3.4948 & TRN \\
\hline CHEMBL1479172 & 954343 & 5.5562 & 4.2948 & TRN \\
\hline CHEMBL3193565 & 954343 & 3.1705 & 3.9265 & TRN \\
\hline CHEMBL293776 & 954343 & 5.079 & 3.4196 & TRN \\
\hline CHEMBL1386036 & 954343 & 3.1704 & 3.7072 & TST \\
\hline CHEMBL 2138821 & 954343 & 3.1704 & 3.0938 & TRN \\
\hline CHEMBL1408353 & 954343 & 3.1709 & 3.6586 & TST \\
\hline CHEMBL1902073 & 954343 & 3.1704 & 3.0325 & TRN \\
\hline CHEMBL1575970 & 954343 & 3.1705 & 4.4912 & TRN \\
\hline CHEMBL1349455 & 954343 & 3.1705 & 3.2755 & TRN \\
\hline CHEMBL1438512 & 954343 & 3.1705 & 3.3651 & TRN \\
\hline CHEMBL1600275 & 954343 & 3.1704 & 3.4044 & TRN \\
\hline CHEMBL199194 & 954343 & 3.1702 & 3.8973 & TRN \\
\hline CHEMBL1515696 & 954343 & 3.1706 & 3.1013 & TRN \\
\hline CHEMBL1497602 & 954343 & 3.1705 & 3.6944 & TRN \\
\hline CHEMBL1569621 & 954343 & 5.0789 & 4.4561 & TRN \\
\hline CHEMBL117 & 954343 & 3.1698 & 3.7016 & TRN \\
\hline CHEMBL1321427 & 954343 & 3.1702 & 3.5158 & TRN \\
\hline CHEMBL1707859 & 954343 & 5.5662 & 3.8332 & TST \\
\hline CHEMBL1532083 & 954343 & 3.1702 & 3.575 & TST \\
\hline CHEMBL1874770 & 954343 & 5.079 & 3.8821 & TST \\
\hline CHEMBL1975210 & 954343 & 3.1708 & 3.7612 & TST \\
\hline CHEMBL1321603 & 954343 & 3.1701 & 3.7877 & TST \\
\hline CHEMBL1725682 & 954343 & 5.5558 & 3.6451 & TST \\
\hline CHEMBL1546405 & 954343 & 3.1705 & 3.2901 & TST \\
\hline CHEMBL1360273 & 954343 & 3.1702 & 3.585 & TST \\
\hline CHEMBL1432396 & 954343 & 3.1704 & 3.3553 & TST \\
\hline CHEMBL1439241 & 954343 & 3.1704 & 2.3448 & TST \\
\hline CHEMBL434976 & 954343 & 6.6736 & 4.3465 & TST \\
\hline CHEMBL1371974 & 954343 & 5.5561 & 3.9503 & TST \\
\hline
\end{tabular}


Supplemental Table S2.txt

\begin{tabular}{|c|c|c|c|c|}
\hline CHEMBL1376166 & 954343 & 3.1705 & 3.0935 & TST \\
\hline CHEMBL1213769 & 954343 & 3.1701 & 3.4933 & TST \\
\hline CHEMBL1557623 & 954343 & 3.1705 & 3.8842 & TST \\
\hline CHEMBL1417839 & 954343 & 3.1706 & 3.3095 & TST \\
\hline CHEMBL1995193 & 954343 & 3.1706 & 3.8293 & TST \\
\hline CHEMBL1429268 & 954343 & 3.1706 & 3.4076 & TST \\
\hline CHEMBL 221190 & 954343 & 3.1703 & 4.2847 & TST \\
\hline CHEMBL 2131524 & 954343 & 3.1704 & 3.6832 & TST \\
\hline CHEMBL 2134913 & 954343 & 3.1711 & 2.7834 & TST \\
\hline CHEMBL1463432 & 954343 & 3.1704 & 3.2867 & TST \\
\hline CHEMBL1728344 & 954343 & 3.1705 & 2.4671 & TST \\
\hline CHEMBL1530023 & 954343 & 3.1709 & 3.2304 & TST \\
\hline CHEMBL1868938 & 954343 & 3.1705 & 3.5785 & TST \\
\hline CHEMBL1567097 & 954343 & 4.7556 & 4.7846 & TST \\
\hline CHEMBL1612027 & 954343 & 3.1703 & 2.9689 & TST \\
\hline CHEMBL1593042 & 954343 & 3.1704 & 3.1554 & TST \\
\hline CHEMBL1610783 & 954343 & 3.1705 & 4.0218 & TST \\
\hline CHEMBL 3190795 & 954343 & 3.1703 & 3.7046 & TST \\
\hline CHEMBL1486005 & 954343 & 3.1703 & 3.2329 & TST \\
\hline CHEMBL1399766 & 954343 & 3.1704 & 2.403 & TST \\
\hline CHEMBL122386 & 157766 & 4.5528 & 4.6486 & TRN \\
\hline CHEMBL123271 & 157766 & 3.5229 & 3.9453 & TRN \\
\hline CHEMBL 273643 & 157766 & 3.5229 & 3.58399 & 99999999996 \\
\hline CHEMBL339332 & 157766 & 4.7447 & 4.3966 & TRN \\
\hline CHEMBL421615 & 157766 & 5.5229 & 4.9692 & TRN \\
\hline CHEMBL124951 & 157766 & 5.3979 & 5.2398 & TRN \\
\hline CHEMBL332779 & 157766 & 3.5229 & 3.7894 & TRN \\
\hline CHEMBL121693 & 157766 & 5.3979 & 5.7836 & TRN \\
\hline CHEMBL338978 & 157766 & 3.5229 & 3.3856 & TRN \\
\hline CHEMBL126090 & 157766 & 4.9208 & 5.1881 & TRN \\
\hline CHEMBL333179 & 157766 & 3.5229 & 2.6133 & TST \\
\hline CHEMBL123692 & 157766 & 5.3979 & 5.3958 & TRN \\
\hline CHEMBL126813 & 157766 & 3.5229 & 4.5215 & TST \\
\hline CHEMBL125337 & 157766 & 3.5229 & 3.1585 & TRN \\
\hline CHEMBL121770 & 157766 & 3.5229 & 3.5897 & TRN \\
\hline CHEMBL125254 & 157766 & 3.5229 & 3.37 & TRN \\
\hline CHEMBL415019 & 157766 & 4.5229 & 4.0722 & TRN \\
\hline CHEMBL126057 & 157766 & 5.2218 & 4.7433 & TRN \\
\hline CHEMBL127993 & 157766 & 3.5229 & 3.6127 & TRN \\
\hline CHEMBL124241 & 157766 & 3.5229 & 3.9323 & TST \\
\hline CHEMBL124264 & 157766 & 4.699 & 4.9599 & TRN \\
\hline CHEMBL126105 & 157766 & 5.2218 & 5.1513 & TRN \\
\hline CHEMBL123148 & 157766 & 5.699 & 5.53799 & 9999999999 \\
\hline CHEMBL104546 & 157766 & 3.5229 & 3.7674 & TRN \\
\hline CHEMBL125762 & 157766 & 4.6021 & 4.4701 & TST \\
\hline CHEMBL122022 & 157766 & 5.3979 & 5.4727 & TRN \\
\hline CHEMBL125592 & 157766 & 4.9208 & 4.5834 & TRN \\
\hline CHEMBL123161 & 157766 & 4.8861 & 4.8131 & TRN \\
\hline
\end{tabular}




\begin{tabular}{|c|c|c|c|c|c|}
\hline \\
\hline CHEMBL43612 & 157766 & 4.7696 & 4.0818 & TST & \\
\hline CHEMBL321185 & 157766 & 3.5229 & 3.4968 & TRN & \\
\hline CHEMBL286494 & 157766 & 3.5229 & 3.7647 & TST & \\
\hline CHEMBL125942 & 157766 & 3.5229 & 3.5397 & TRN & \\
\hline CHEMBL333452 & 157766 & 5.0 & 5.2563 & TRN & \\
\hline CHEMBL125175 & 157766 & 4.6778 & 4.7675 & TRN & \\
\hline CHEMBL274056 & 157766 & 5.5229 & 3.99899 & 99999999997 & TST \\
\hline CHEMBL106514 & 157766 & 3.5229 & 3.6286 & TRN & \\
\hline CHEMBL421625 & 157766 & 4.5686 & 4.8649 & TRN & \\
\hline CHEMBL412821 & 157766 & 3.5229 & 3.6163 & TRN & \\
\hline CHEMBL126056 & 157766 & 5.0969 & 5.0769 & TRN & \\
\hline CHEMBL123886 & 157766 & 3.5229 & 3.7293 & TRN & \\
\hline CHEMBL125427 & 157766 & 3.5229 & 3.9563 & TRN & \\
\hline CHEMBL122196 & 157766 & 3.5229 & 3.8524 & TRN & \\
\hline CHEMBL122192 & 157766 & 4.8539 & 4.567 & TRN & \\
\hline CHEMBL123326 & 157766 & 5.0458 & 4.5186 & TRN & \\
\hline CHEMBL125822 & 157766 & 5.0969 & 5.3893 & TRN & \\
\hline CHEMBL123724 & 157766 & 5.3979 & 5.1903 & TRN & \\
\hline CHEMBL123787 & 157766 & 5.1549 & 4.1208 & TST & \\
\hline CHEMBL124440 & 157766 & 5.699 & 4.9138 & TST & \\
\hline CHEMBL125765 & 157766 & 5.2218 & 4.5218 & TST & \\
\hline CHEMBL125389 & 157766 & 3.5229 & 4.5846 & TST & \\
\hline CHEMBL125388 & 157766 & 3.5229 & 4.6006 & TST & \\
\hline CHEMBL125502 & 157766 & 3.5229 & 4.4948 & TST & \\
\hline CHEMBL125328 & 157766 & 5.0 & 3.4749 & TST & \\
\hline CHEMBL583579 & 592925 & 5.2076 & 5.0916 & TRN & \\
\hline CHEMBL576463 & 592925 & 4.6576 & 4.26 & TRN & \\
\hline CHEMBL569179 & 592925 & 4.5528 & 4.5319 & TRN & \\
\hline CHEMBL568943 & 592925 & 2.6778 & 2.5436 & TRN & \\
\hline CHEMBL579228 & 592925 & 4.0809 & 4.0989 & TRN & \\
\hline CHEMBL570816 & 592925 & 4.5686 & 4.7294 & TRN & \\
\hline CHEMBL578555 & 592925 & 4.8861 & 4.9509 & TRN & \\
\hline CHEMBL569418 & 592925 & 4.5086 & 4.3681 & TRN & \\
\hline CHEMBL565456 & 592925 & 5.1675 & 5.2902 & TRN & \\
\hline CHEMBL569417 & 592925 & 4.5376 & 4.5175 & TRN & \\
\hline CHEMBL575019 & 592925 & 5.0915 & 5.1329 & TRN & \\
\hline CHEMBL565673 & 592925 & 4.3872 & 4.19 & TRN & \\
\hline CHEMBL575020 & 592925 & 4.7447 & 6.63700 & 00000000005 & TST \\
\hline CHEMBL566963 & 592925 & 4.6021 & 4.6787 & TRN & \\
\hline CHEMBL577328 & 592925 & 4.3188 & 4.1804 & TRN & \\
\hline CHEMBL571251 & 592925 & 4.3188 & 4.2272 & TRN & \\
\hline CHEMBL570583 & 592925 & 5.1024 & 4.9777 & TRN & \\
\hline CHEMBL576699 & 592925 & 4.5376 & 5.2101 & TST & \\
\hline CHEMBL571472 & 592925 & 3.9586 & 4.0295 & TRN & \\
\hline CHEMBL566743 & 592925 & 4.6198 & 4.8093 & TRN & \\
\hline CHEMBL569890 & 592925 & 2.7447 & 2.7768 & TRN & \\
\hline CHEMBL565506 & 592925 & 4.8539 & 4.868 & TRN & \\
\hline CHEMBL565455 & 592925 & 4.3468 & 4.2372 & TRN & \\
\hline
\end{tabular}




\begin{tabular}{|c|c|c|c|c|c|}
\hline \multicolumn{6}{|c|}{ Supplemental Table S2.txt } \\
\hline CHEMBL575230 & 592925 & 4.2518 & 4.2545 & TRN & \\
\hline CHEMBL585929 & 592925 & 4.2007 & 5.0104 & TST & \\
\hline CHEMBL577334 & 592925 & 4.3979 & 4.7252 & TST & \\
\hline CHEMBL568726 & 592925 & 4.7447 & 4.7399 & TRN & \\
\hline CHEMBL571471 & 592925 & 3.7959 & 3.7561 & TRN & \\
\hline CHEMBL568047 & 592925 & 4.7959 & 5.1095 & TST & \\
\hline CHEMBL570129 & 592925 & 2.6383 & 2.6703 & TRN & \\
\hline CHEMBL570817 & 592925 & 5.0458 & 5.0856 & TRN & \\
\hline CHEMBL579024 & 592925 & 3.7959 & 3.9706 & TRN & \\
\hline CHEMBL566744 & 592925 & 4.6198 & 3.9986 & TRN & \\
\hline CHEMBL585745 & 592925 & 4.2147 & 4.14199 & 99999999995 & TRN \\
\hline CHEMBL578831 & 592925 & 4.1487 & 4.315 & TRN & \\
\hline CHEMBL577468 & 592925 & 4.5528 & 4.5965 & TRN & \\
\hline CHEMBL583463 & 592925 & 3.6576 & 3.6993 & TRN & \\
\hline CHEMBL565505 & 592925 & 4.1135 & 4.3331 & TRN & \\
\hline CHEMBL577467 & 592925 & 4.1675 & 4.3857 & TRN & \\
\hline CHEMBL571051 & 592925 & 3.699 & 4.4405 & TST & \\
\hline CHEMBL568268 & 592925 & 5.2596 & 5.45799 & 9999999999 & TST \\
\hline CHEMBL571256 & 592925 & 3.7696 & 3.9024 & TRN & \\
\hline CHEMBL568969 & 592925 & 4.5376 & 4.4958 & TRN & \\
\hline CHEMBL571034 & 592925 & 4.6778 & 4.7579 & TRN & \\
\hline CHEMBL569180 & 592925 & 4.5376 & 4.3177 & TRN & \\
\hline CHEMBL585919 & 592925 & 2.7212 & 3.2697 & TRN & \\
\hline CHEMBL571035 & 592925 & 4.8239 & 4.835 & TST & \\
\hline CHEMBL565717 & 592925 & 2.699 & 3.7635 & TST & \\
\hline CHEMBL575017 & 592925 & 5.0 & 4.7408 & TST & \\
\hline CHEMBL565457 & 592925 & 2.6198 & 3.6505 & TST & \\
\hline CHEMBL565672 & 592925 & 2.7447 & 2.8047 & TST & \\
\hline CHEMBL575018 & 592925 & 4.9586 & 5.2465 & TST & \\
\hline CHEMBL570825 & 592925 & 4.5376 & 4.5903 & TST & \\
\hline CHEMBL449158 & 954832 & 6.2086 & 6.09 & TST & \\
\hline CHEMBL1242367 & 954832 & 4.8898 & 4.9002 & TRN & \\
\hline CHEMBL1970879 & 954832 & 3.3499 & 3.3506 & TRN & \\
\hline CHEMBL222102 & 954832 & 4.2422 & 4.2117 & TRN & \\
\hline CHEMBL558642 & 954832 & 3.7341 & 3.7492 & TRN & \\
\hline CHEMBL188678 & 954832 & 4.2299 & 4.2542 & TRN & \\
\hline CHEMBL1357247 & 954832 & 3.1123 & 3.1087 & TRN & \\
\hline CHEMBL 2363137 & 954832 & 5.1126 & 5.1071 & TRN & \\
\hline CHEMBL191334 & 954832 & 4.834 & 4.8439 & TRN & \\
\hline CHEMBL 2144069 & 954832 & 4.332 & 4.3444 & TRN & \\
\hline CHEMBL209148 & 954832 & 5.0504 & 5.0477 & TRN & \\
\hline CHEMBL65 & 954832 & 9.031 & 9.0301 & TRN & \\
\hline CHEMBL1590308 & 954832 & 3.2801 & 3.2288 & TST & \\
\hline CHEMBL 2137530 & 954832 & 4.928 & 4.9246 & TRN & \\
\hline CHEMBL509032 & 954832 & 3.9699 & 3.9596 & TRN & \\
\hline CHEMBL255342 & 954832 & 3.7606 & 3.7665 & TRN & \\
\hline CHEMBL1643959 & 954832 & 3.3609 & 3.3686 & TRN & \\
\hline CHEMBL1673039 & 954832 & 2.9799 & 2.9755 & TRN & \\
\hline
\end{tabular}




\begin{tabular}{|c|c|c|c|c|c|}
\hline & & \multicolumn{4}{|c|}{ Supplemental Table S2.txt } \\
\hline CHEMBL392695 & 954832 & 3.6785 & 3.6835 & TRN & \\
\hline CHEMBL 2134202 & 954832 & 4.725 & 4.7184 & TRN & \\
\hline CHEMBL192566 & 954832 & 8.3869 & 8.3519 & TST & \\
\hline CHEMBL210618 & 954832 & 4.418 & 4.4285 & TRN & \\
\hline CHEMBL 217354 & 954832 & 6.4455 & 6.4411 & TRN & \\
\hline CHEMBL472940 & 954832 & 4.944 & 4.9372 & TRN & \\
\hline CHEMBL 221137 & 954832 & 4.8137 & 5.1011 & TST & \\
\hline CHEMBL189584 & 954832 & 3.9977 & 4.0004 & TRN & \\
\hline CHEMBL3199475 & 954832 & 5.4586 & 5.4724 & TRN & \\
\hline CHEMBL102714 & 954832 & 4.5039 & 4.4925 & TRN & \\
\hline CHEMBL 213100 & 954832 & 3.7664 & 3.7632 & TRN & \\
\hline CHEMBL577784 & 954832 & 5.5812 & 5.5829 & TRN & \\
\hline CHEMBL135561 & 954832 & 4.0775 & 4.0656 & TRN & \\
\hline CHEMBL393929 & 954832 & 5.0396 & 5.0229 & TRN & \\
\hline CHEMBL573107 & 954832 & 5.0433 & 5.0511 & TRN & \\
\hline CHEMBL1516890 & 954832 & 4.2384 & 4.2483 & TRN & \\
\hline CHEMBL1404918 & 954832 & 3.4156 & 3.4152 & TRN & \\
\hline CHEMBL 2005886 & 954832 & 4.1114 & 4.1129 & TRN & \\
\hline CHEMBL399530 & 954832 & 4.8892 & 4.8756 & TRN & \\
\hline CHEMBL3349342 & 954832 & 3.7678 & 3.7645 & TRN & \\
\hline CHEMBL220241 & 954832 & 4.3719 & 4.3698 & TRN & \\
\hline CHEMBL515416 & 954832 & 4.9237 & 4.9393 & TRN & \\
\hline CHEMBL3392440 & 954832 & 3.5063 & 3.5021 & TRN & \\
\hline CHEMBL585951 & 954832 & 5.9627 & 5.9663 & TRN & \\
\hline CHEMBL379975 & 954832 & 4.6291 & 4.6207 & TRN & \\
\hline CHEMBL3186408 & 954832 & 3.0391 & 3.2597 & TST & \\
\hline CHEMBL 258844 & 954832 & 4.9458 & 4.9494 & TRN & \\
\hline CHEMBL412142 & 954832 & 3.5681 & 3.557 & TRN & \\
\hline CHEMBL514499 & 954832 & 4.6877 & 4.6828 & TRN & \\
\hline CHEMBL92309 & 954832 & 3.1545 & 3.5108 & TST & \\
\hline CHEMBL9470 & 954832 & 6.1828 & 5.5808 & TST & \\
\hline CHEMBL259181 & 954832 & 5.17700 & 00000000 & 005 & 5.1635 \\
\hline CHEMBL1190711 & 954832 & 5.519 & 5.5211 & TRN & \\
\hline CHEMBL483847 & 954832 & 4.7585 & 4.7679 & TRN & \\
\hline CHEMBL 240954 & 954832 & 3.457 & 4.0256 & TST & \\
\hline CHEMBL1186585 & 954832 & 4.0594 & 4.0579 & TRN & \\
\hline CHEMBL373751 & 954832 & 2.5235 & 2.5251 & TRN & \\
\hline CHEMBL483849 & 954832 & 2.9582 & 2.6022 & TST & \\
\hline CHEMBL512504 & 954832 & 4.1183 & 4.1279 & TRN & \\
\hline CHEMBL1788116 & 954832 & 4.5907 & 4.2905 & TST & \\
\hline CHEMBL1909414 & 954832 & 3.3162 & 4.1485 & TST & \\
\hline CHEMBL379300 & 954832 & 5.4594 & 4.9772 & TST & \\
\hline CHEMBL202721 & 954832 & 6.325 & 4.8287 & TST & \\
\hline CHEMBL1230020 & 954832 & 3.888 & 4.4481 & TST & \\
\hline CHEMBL300389 & 954832 & 6.0199 & 6.1711 & TST & \\
\hline CHEMBL1256459 & 954832 & 4.3064 & 5.6106 & TST & \\
\hline CHEMBL180127 & 954832 & 3.1227 & 3.898 & TST & \\
\hline CHEMBL2207062 & 883875 & 6.4559 & 6.3795 & TST & \\
\hline
\end{tabular}




\begin{tabular}{|c|c|c|c|c|c|}
\hline & & \multicolumn{4}{|c|}{ Supplemental Table S2.txt } \\
\hline CHEMBL 2207479 & 883875 & 5.0458 & 5.2073 & TRN & \\
\hline CHEMBL 2207012 & 883875 & 6.5376 & 6.3179 & TRN & \\
\hline CHEMBL 2206993 & 883875 & 7.0 & 7.0299 & TRN & \\
\hline CHEMBL 2207050 & 883875 & 6.9586 & 6.54899 & 99999999995 & TRN \\
\hline CHEMBL 2152865 & 883875 & 6.2218 & 6.7326 & TRN & \\
\hline CHEMBL 2207477 & 883875 & 4.8861 & 5.3229 & TRN & \\
\hline CHEMBL 2207483 & 883875 & 6.4815 & 6.6866 & TST & \\
\hline CHEMBL 2207469 & 883875 & 7.3279 & 7.4585 & TRN & \\
\hline CHEMBL 2207056 & 883875 & 6.4559 & 6.4857 & TST & \\
\hline CHEMBL2207027 & 883875 & 5.041 & 5.7301 & TRN & \\
\hline CHEMBL 2207068 & 883875 & 5.5229 & 5.8165 & TRN & \\
\hline CHEMBL 2207020 & 883875 & 5.8861 & 6.2977 & TRN & \\
\hline CHEMBL 2207014 & 883875 & 6.2757 & 6.3814 & TRN & \\
\hline CHEMBL 2207005 & 883875 & 7.1675 & 6.9334 & TRN & \\
\hline CHEMBL 2207471 & 883875 & 3.699 & 5.279 & TRN & \\
\hline CHEMBL 2207475 & 883875 & 7.2218 & 5.92399 & 99999999995 & TST \\
\hline CHEMBL2207476 & 883875 & 6.8861 & 6.2479 & TST & \\
\hline CHEMBL 2207456 & 883875 & 5.1308 & 5.4877 & TRN & \\
\hline CHEMBL2152889 & 883875 & 6.7696 & 6.9239 & TST & \\
\hline CHEMBL 2207447 & 883875 & 6.699 & 6.7913 & TRN & \\
\hline CHEMBL2207026 & 883875 & 6.4559 & 6.1522 & TRN & \\
\hline CHEMBL 2152870 & 883875 & 7.2518 & 7.1633 & TST & \\
\hline CHEMBL 2207461 & 883875 & 6.5229 & 6.6616 & TRN & \\
\hline CHEMBL2207454 & 883875 & 6.6576 & 6.2252 & TRN & \\
\hline CHEMBL 2207015 & 883875 & 6.2518 & 6.0719 & TRN & \\
\hline CHEMBL 2207058 & 883875 & 6.1079 & 6.3938 & TRN & \\
\hline CHEMBL 2207478 & 883875 & 6.2366 & 5.8532 & TST & \\
\hline CHEMBL 2207023 & 883875 & 5.8861 & 5.9686 & TST & \\
\hline CHEMBL 2207036 & 883875 & 6.7696 & 6.5807 & TRN & \\
\hline CHEMBL 2207473 & 883875 & 7.1549 & 6.2925 & TRN & \\
\hline CHEMBL 2207472 & 883875 & 3.699 & 5.7315 & TST & \\
\hline CHEMBL 2207451 & 883875 & 6.0362 & 6.0144 & TRN & \\
\hline CHEMBL 2207032 & 883875 & 6.2147 & 5.9579 & TRN & \\
\hline CHEMBL 2207041 & 883875 & 6.0 & 6.2517 & TRN & \\
\hline CHEMBL 2207030 & 883875 & 6.3768 & 6.0792 & TRN & \\
\hline CHEMBL 2203325 & 883875 & 6.0506 & 5.8601 & TRN & \\
\hline CHEMBL 2207064 & 883875 & 6.1612 & 5.864 & TRN & \\
\hline CHEMBL 2207000 & 883875 & 7.1871 & 7.3186 & TRN & \\
\hline CHEMBL 2207057 & 883875 & 5.9208 & 6.526 & TST & \\
\hline CHEMBL 2207011 & 883875 & 6.0 & 6.319 & TRN & \\
\hline CHEMBL 2207025 & 883875 & 5.8861 & 5.9312 & TRN & \\
\hline CHEMBL 2207049 & 883875 & 6.8861 & 6.4225 & TRN & \\
\hline CHEMBL2206999 & 883875 & 6.8539 & 6.6592 & TRN & \\
\hline CHEMBL 2207480 & 883875 & 5.2441 & 5.3271 & TRN & \\
\hline CHEMBL 2152880 & 883875 & 6.7696 & 6.6387 & TRN & \\
\hline CHEMBL2207446 & 883875 & 6.585 & 6.5884 & TST & \\
\hline CHEMBL 2207482 & 883875 & 6.6198 & 6.8489 & TST & \\
\hline CHEMBL2152895 & 883875 & 6.8861 & 7.2204 & TRN & \\
\hline
\end{tabular}


Supplemental Table S2.txt

\begin{tabular}{|c|c|c|c|c|}
\hline CHEMBL 2207443 & 883875 & 6.1871 & 6.6908 & TST \\
\hline CHEMBL 2207022 & 883875 & 6.9586 & 6.4632 & TST \\
\hline CHEMBL 2207463 & 883875 & 6.2924 & 6.3903 & TRN \\
\hline CHEMBL 2207018 & 883875 & 6.5528 & 6.1938 & TST \\
\hline CHEMBL2207459 & 883875 & 6.7959 & 7.0281 & TRN \\
\hline CHEMBL 2207006 & 883875 & 6.4949 & \multicolumn{2}{|c|}{6.5920000000000005} \\
\hline CHEMBL 2207016 & 883875 & 6.3098 & 6.3677 & TST \\
\hline CHEMBL 2207031 & 883875 & 5.7464 & 5.8735 & TRN \\
\hline CHEMBL 2206995 & 883875 & 6.7696 & 6.9143 & TRN \\
\hline CHEMBL2207004 & 883875 & 6.1487 & 6.0451 & TST \\
\hline CHEMBL 2207449 & 883875 & 6.1549 & 6.2158 & TRN \\
\hline CHEMBL 2206987 & 883875 & 6.6383 & 6.6631 & TRN \\
\hline CHEMBL 2206998 & 883875 & 6.4437 & 6.4157 & TRN \\
\hline CHEMBL 2207453 & 883875 & 6.5086 & 6.192 & TRN \\
\hline CHEMBL 2207457 & 883875 & 6.4437 & 5.8649 & TRN \\
\hline CHEMBL 2206991 & 883875 & 6.4559 & 6.4053 & TRN \\
\hline CHEMBL 2207039 & 883875 & 6.0 & 6.2933 & TRN \\
\hline CHEMBL 2207044 & 883875 & 6.5686 & 6.5505 & TRN \\
\hline CHEMBL 2207048 & 883875 & 5.6383 & \multicolumn{2}{|c|}{6.0360000000000005} \\
\hline CHEMBL 2206992 & 883875 & 6.3979 & 6.4892 & TRN \\
\hline CHEMBL 2207464 & 883875 & 6.8539 & 6.3645 & TRN \\
\hline CHEMBL 2207462 & 883875 & 7.0 & 6.8654 & TRN \\
\hline CHEMBL 2207033 & 883875 & 6.5528 & 5.9253 & TRN \\
\hline CHEMBL 2207055 & 883875 & 6.0757 & 6.7883 & TST \\
\hline CHEMBL 2207001 & 883875 & 7.2147 & 7.0584 & TST \\
\hline CHEMBL2206986 & 883875 & 6.6021 & 6.7553 & TRN \\
\hline CHEMBL 2207067 & 883875 & 6.4685 & 6.218 & TRN \\
\hline CHEMBL 2206996 & 883875 & 6.9208 & 7.5243 & TRN \\
\hline CHEMBL 2206997 & 883875 & 6.8239 & 7.5074 & TRN \\
\hline CHEMBL 2207037 & 883875 & 6.7212 & 6.3171 & TRN \\
\hline CHEMBL2207066 & 883875 & 6.3565 & 5.982 & TRN \\
\hline CHEMBL 2207444 & 883875 & 6.3188 & 6.2716 & TST \\
\hline CHEMBL 2207034 & 883875 & 7.041 & 6.5946 & TRN \\
\hline CHEMBL 2207052 & 883875 & 6.5086 & 6.6652 & TRN \\
\hline CHEMBL 2207466 & 883875 & 4.7696 & 5.5126 & TRN \\
\hline CHEMBL2207470 & 883875 & 5.7959 & \multicolumn{2}{|c|}{5.821000000000001} \\
\hline CHEMBL2207035 & 883875 & 5.8239 & 5.5976 & TRN \\
\hline CHEMBL2207069 & 883875 & 7.041 & 6.8154 & TST \\
\hline CHEMBL2203329 & 883875 & 5.3372 & 5.3954 & TRN \\
\hline CHEMBL2207013 & 883875 & 6.1135 & 6.6291 & TST \\
\hline CHEMBL 2207002 & 883875 & 6.6198 & 6.2844 & TRN \\
\hline CHEMBL2207445 & 883875 & 6.2366 & 6.3386 & TST \\
\hline CHEMBL 2207468 & 883875 & 6.3279 & 6.0199 & TRN \\
\hline CHEMBL 2207024 & 883875 & 6.1192 & 5.9409 & TRN \\
\hline CHEMBL 2207046 & 883875 & 6.6198 & 6.4789 & TRN \\
\hline CHEMBL 2207021 & 883875 & 6.5528 & 6.2512 & TST \\
\hline CHEMBL2207045 & 883875 & 6.585 & 6.5592 & TRN \\
\hline CHEMBL 2207042 & 883875 & 6.6021 & 6.874 & TRN \\
\hline
\end{tabular}




\begin{tabular}{|c|c|c|c|c|c|}
\hline \multirow[b]{2}{*}{ CHEMBL 2207474} & \multicolumn{5}{|c|}{ Supplemental Table S2.txt } \\
\hline & 883875 & 7.1549 & 6.0651 & TRN & \\
\hline CHEMBL 2207051 & 883875 & 6.3665 & 6.3828 & TRN & \\
\hline CHEMBL 2207017 & 883875 & 6.1549 & 6.1004 & TST & \\
\hline CHEMBL 2207460 & 883875 & 6.9208 & 6.6203 & TRN & \\
\hline CHEMBL 2207019 & 883875 & 6.3979 & 6.3721 & TST & \\
\hline CHEMBL 2207065 & 883875 & 6.5686 & 6.3044 & TRN & \\
\hline CHEMBL 2207029 & 883875 & 5.5229 & 6.0263 & TRN & \\
\hline CHEMBL 2207448 & 883875 & 6.6778 & 6.73 & TRN & \\
\hline CHEMBL 2206988 & 883875 & 6.8239 & 6.6755 & TRN & \\
\hline CHEMBL 2207007 & 883875 & 6.4089 & 6.5835 & TST & \\
\hline CHEMBL 2207455 & 883875 & 5.4685 & 5.8279 & TRN & \\
\hline CHEMBL 2207458 & 883875 & 7.2757 & 7.3823 & TRN & \\
\hline CHEMBL 2207047 & 883875 & 6.2676 & 6.2189 & TRN & \\
\hline CHEMBL 2207054 & 883875 & 6.5686 & 6.5542 & TRN & \\
\hline CHEMBL 2207450 & 883875 & 6.0223 & 5.9263 & TRN & \\
\hline CHEMBL 2207063 & 883875 & 5.3565 & 6.0933 & TST & \\
\hline CHEMBL 2207003 & 883875 & 6.6576 & 6.6748 & TRN & \\
\hline CHEMBL 2207043 & 883875 & 6.6778 & 6.4582 & TRN & \\
\hline CHEMBL 2206994 & 883875 & 7.0 & 6.8659 & TRN & \\
\hline CHEMBL 2206985 & 883875 & 6.7696 & 6.8128 & TRN & \\
\hline CHEMBL 2207061 & 883875 & 6.0 & 5.9377 & TRN & \\
\hline CHEMBL 2207053 & 883875 & 6.2007 & 6.6342 & TRN & \\
\hline CHEMBL 2207028 & 883875 & 6.1249 & 5.9634 & TRN & \\
\hline CHEMBL1536177 & 688202 & 4.6479 & 5.8751 & TRN & \\
\hline CHEMBL1604955 & 688202 & 3.9742 & 6.7556 & TRN & \\
\hline CHEMBL3189877 & 688202 & 3.301 & 4.996 & TRN & \\
\hline CHEMBL1596516 & 688202 & 6.4544 & 5.3528 & TRN & \\
\hline CHEMBL1559715 & 688202 & 3.301 & 5.4924 & TRN & \\
\hline CHEMBL1310309 & 688202 & 4.0277 & 5.37200 & 000000001 & TRN \\
\hline CHEMBL1324051 & 688202 & 3.301 & 5.0518 & TRN & \\
\hline CHEMBL1377510 & 688202 & 8.6383 & 5.5891 & TRN & \\
\hline CHEMBL1586096 & 688202 & 5.2975 & 4.6434 & TST & \\
\hline CHEMBL1331469 & 688202 & 7.1007 & 6.0897 & TRN & \\
\hline CHEMBL1307923 & 688202 & 4.4873 & 4.3699 & TRN & \\
\hline CHEMBL1526851 & 688202 & 4.0426 & 5.0836 & TRN & \\
\hline CHEMBL1542518 & 688202 & 4.8189 & 4.6905 & TRN & \\
\hline CHEMBL1505467 & 688202 & 5.816 & 4.9602 & TRN & \\
\hline CHEMBL1520373 & 688202 & 6.6889 & 5.0207 & TRN & \\
\hline CHEMBL1538696 & 688202 & 2.9618 & 5.5418 & TST & \\
\hline CHEMBL1493034 & 688202 & 4.7548 & 5.74700 & 0000000001 & TRN \\
\hline CHEMBL1426947 & 688202 & 6.1526 & 5.2974 & TRN & \\
\hline CHEMBL1408395 & 688202 & 6.4583 & 5.5755 & TST & \\
\hline CHEMBL1564253 & 688202 & 3.301 & 5.8157 & TST & \\
\hline CHEMBL1347312 & 688202 & 4.9145 & 6.0851 & TRN & \\
\hline CHEMBL1573389 & 688202 & 2.9618 & 5.4876 & TRN & \\
\hline CHEMBL1582403 & 688202 & 3.301 & 4.8344 & TRN & \\
\hline CHEMBL600336 & 688202 & 2.9618 & 4.5249 & TRN & \\
\hline CHEMBL1477682 & 688202 & 3.991 & 5.6176 & TRN & \\
\hline
\end{tabular}




\begin{tabular}{|c|c|c|c|c|c|c|}
\hline & & \multicolumn{5}{|c|}{ Supplemental Table S2.txt } \\
\hline CHEMBL1431555 & 688202 & 4.4302 & 6.4907 & TRN & & \\
\hline CHEMBL1548822 & 688202 & 5.3869 & 4.7633 & TRN & & \\
\hline CHEMBL1374536 & 688202 & 3.301 & 4.7172 & TRN & & \\
\hline CHEMBL1567315 & 688202 & 4.9753 & 4.998 & TRN & & \\
\hline CHEMBL1582133 & 688202 & 3.301 & 5.211 & TRN & & \\
\hline CHEMBL3189442 & 688202 & 6.4557 & 5.4412 & TRN & & \\
\hline CHEMBL1389163 & 688202 & 5.2535 & 5.0144 & TRN & & \\
\hline CHEMBL1470395 & 688202 & 8.6383 & 5.68 & TRN & & \\
\hline CHEMBL1353227 & 688202 & 3.301 & 6.1491 & TRN & & \\
\hline CHEMBL1410526 & 688202 & 5.4667 & 5.5486 & TRN & & \\
\hline CHEMBL1586116 & 688202 & 7.0398 & 4.9215 & TRN & & \\
\hline CHEMBL1300534 & 688202 & 6.2307 & 5.9322 & TRN & & \\
\hline CHEMBL1559043 & 688202 & \multicolumn{3}{|c|}{7.2139999999999995} & 5.6504 & TRN \\
\hline CHEMBL1423062 & 688202 & 6.0895 & 6.2483 & TRN & & \\
\hline CHEMBL1541353 & 688202 & 7.2319 & 4.485 & TRN & & \\
\hline CHEMBL1405769 & 688202 & 3.301 & 5.91200 & 0000000001 & & TRN \\
\hline CHEMBL1545787 & 688202 & 4.0282 & 6.126 & TST & & \\
\hline CHEMBL1370794 & 688202 & 7.2382 & 6.2131 & TRN & & \\
\hline CHEMBL1398769 & 688202 & 3.301 & 4.2839 & TRN & & \\
\hline CHEMBL1549371 & 688202 & 8.6383 & 7.0076 & TRN & & \\
\hline CHEMBL1324399 & 688202 & 8.6383 & 5.4094 & TST & & \\
\hline CHEMBL1438722 & 688202 & 8.6383 & 5.4512 & TRN & & \\
\hline CHEMBL1544707 & 688202 & 5.5039 & 5.7434 & TRN & & \\
\hline CHEMBL1567745 & 688202 & 7.1959 & 5.5504 & TRN & & \\
\hline CHEMBL1491936 & 688202 & 4.3306 & 6.0216 & TRN & & \\
\hline CHEMBL1418568 & 688202 & \multicolumn{3}{|c|}{6.2010000000000005} & 5.5634 & TST \\
\hline CHEMBL1565585 & 688202 & 6.066 & 5.8283 & TST & & \\
\hline CHEMBL1423417 & 688202 & 7.595 & 5.5821 & TST & & \\
\hline CHEMBL1566266 & 688202 & 5.7044 & 5.2769 & TRN & & \\
\hline CHEMBL1412123 & 688202 & 8.6383 & 6.4349 & TRN & & \\
\hline CHEMBL1528124 & 688202 & 4.4938 & 5.5588 & TRN & & \\
\hline CHEMBL1378869 & 688202 & 3.301 & 5.2619 & TRN & & \\
\hline CHEMBL1469246 & 688202 & 5.2669 & 5.5512 & TRN & & \\
\hline CHEMBL3198515 & 688202 & 5.2488 & 4.7862 & TRN & & \\
\hline CHEMBL1342645 & 688202 & 5.5138 & 5.7678 & TST & & \\
\hline CHEMBL1501342 & 688202 & 8.6383 & 6.0849 & TRN & & \\
\hline CHEMBL1499638 & 688202 & 7.4883 & 5.5885 & TRN & & \\
\hline CHEMBL 28626 & 688202 & 5.5336 & 5.3258 & TST & & \\
\hline CHEMBL1300662 & 688202 & 8.6383 & 5.1649 & TRN & & \\
\hline CHEMBL1447732 & 688202 & 3.301 & 4.1846 & TRN & & \\
\hline CHEMBL1309624 & 688202 & 5.3922 & 5.8641 & TRN & & \\
\hline CHEMBL1583106 & 688202 & 8.6383 & 6.6958 & TRN & & \\
\hline CHEMBL1547376 & 688202 & 4.0166 & 4.6975 & TST & & \\
\hline CHEMBL1431996 & 688202 & 5.2039 & 4.6197 & TRN & & \\
\hline CHEMBL1530431 & 688202 & 4.7699 & 5.1315 & TRN & & \\
\hline CHEMBL1528726 & 688202 & 5.0211 & 4.7312 & TRN & & \\
\hline CHEMBL1393548 & 688202 & 2.9618 & 5.1537 & TRN & & \\
\hline CHEMBL1589300 & 688202 & 3.301 & 4.4942 & TRN & & \\
\hline
\end{tabular}




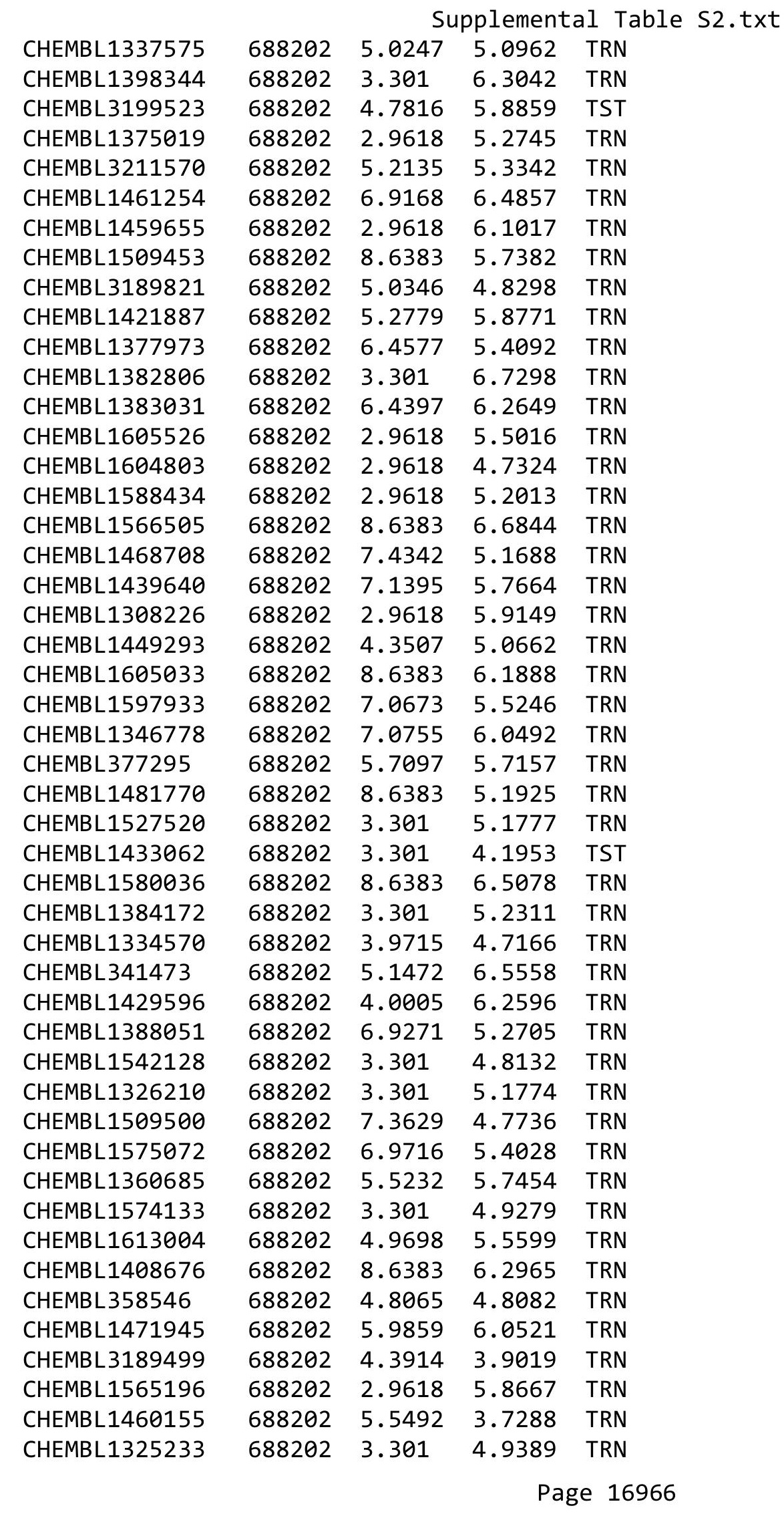




\begin{tabular}{|c|c|c|c|c|}
\hline & & & oplement & al $\mathrm{T}$ \\
\hline CHEMBL1404075 & 688202 & 4.9865 & 5.6346 & TST \\
\hline CHEMBL1597177 & 688202 & 5.269 & 5.2656 & TRN \\
\hline CHEMBL1506716 & 688202 & 6.7929 & 5.1804 & TST \\
\hline CHEMBL1390729 & 688202 & 4.5783 & 4.5398 & TRN \\
\hline CHEMBL1384515 & 688202 & 4.4316 & 4.4673 & TRN \\
\hline CHEMBL1402138 & 688202 & 6.3868 & 6.3156 & TRN \\
\hline CHEMBL1573735 & 688202 & 8.6383 & 5.5674 & TRN \\
\hline CHEMBL1307301 & 688202 & 5.737 & 5.8137 & TRN \\
\hline CHEMBL1488584 & 688202 & 7.1983 & 6.6294 & TRN \\
\hline CHEMBL1460126 & 688202 & 7.2582 & 4.8586 & TRN \\
\hline CHEMBL1384049 & 688202 & 5.1137 & 6.2314 & TRN \\
\hline CHEMBL1449334 & 688202 & 3.301 & 4.885 & TRN \\
\hline CHEMBL1577661 & 688202 & 5.7133 & 5.6358 & TRN \\
\hline CHEMBL1334484 & 688202 & 5.4683 & 5.0642 & TRN \\
\hline CHEMBL1446668 & 688202 & 8.6383 & 4.7067 & TRN \\
\hline CHEMBL1469865 & 688202 & 7.3297 & 6.138 & TRN \\
\hline CHEMBL3197914 & 688202 & 3.301 & 6.1415 & TRN \\
\hline CHEMBL1599140 & 688202 & 4.825 & 5.9237 & TRN \\
\hline CHEMBL1374573 & 688202 & 3.9907 & 4.8981 & TRN \\
\hline CHEMBL1588072 & 688202 & 4.8748 & 5.8249 & TRN \\
\hline CHEMBL577758 & 688202 & 8.6383 & 5.9578 & TRN \\
\hline CHEMBL1410021 & 688202 & 3.301 & 4.0642 & TRN \\
\hline CHEMBL1533166 & 688202 & 5.0219 & 4.9091 & TRN \\
\hline CHEMBL1367450 & 688202 & 8.6383 & 4.4719 & TST \\
\hline CHEMBL 3193592 & 688202 & 7.2142 & 5.5718 & TRN \\
\hline CHEMBL1386982 & 688202 & 2.9618 & 4.9448 & TRN \\
\hline CHEMBL1455258 & 688202 & 6.8951 & 6.5042 & TRN \\
\hline CHEMBL305978 & 688202 & 8.6383 & 5.0431 & TRN \\
\hline CHEMBL1473381 & 688202 & 7.4642 & 5.6318 & TRN \\
\hline CHEMBL1255778 & 688202 & 5.5151 & 5.36 & TST \\
\hline CHEMBL1413557 & 688202 & 3.301 & 5.0846 & TRN \\
\hline CHEMBL1490194 & 688202 & 3.301 & 5.0866 & TRN \\
\hline CHEMBL1612543 & 688202 & 3.301 & 4.6834 & TRN \\
\hline CHEMBL1440196 & 688202 & 6.142 & 5.4694 & TRN \\
\hline CHEMBL1972915 & 688202 & 3.301 & 5.572 & TST \\
\hline CHEMBL1444824 & 688202 & 3.301 & 5.1738 & TRN \\
\hline CHEMBL1583687 & 688202 & 5.4921 & 5.8662 & TRN \\
\hline CHEMBL1500491 & 688202 & 6.8093 & 5.436 & TRN \\
\hline CHEMBL57978 & 688202 & 5.4902 & 4.8666 & TRN \\
\hline CHEMBL1346172 & 688202 & 5.3098 & 4.9721 & TRN \\
\hline CHEMBL1431490 & 688202 & 8.6383 & 5.2032 & TRN \\
\hline CHEMBL1506123 & 688202 & 5.048 & 4.6994 & TRN \\
\hline CHEMBL1607897 & 688202 & 4.8538 & 5.0718 & TRN \\
\hline CHEMBL1442966 & 688202 & 3.301 & 5.4592 & TRN \\
\hline CHEMBL1581251 & 688202 & 5.6985 & 5.6713 & TRN \\
\hline CHEMBL1345363 & 688202 & 8.6383 & 5.5218 & TST \\
\hline CHEMBL1577184 & 688202 & 7.3 & 5.0144 & TRN \\
\hline CHEMBL1449547 & 688202 & 4.8425 & 6.2099 & TRN \\
\hline
\end{tabular}




\begin{tabular}{|c|c|c|c|c|c|}
\hline \multicolumn{6}{|c|}{ Supplemental Table S2.txt } \\
\hline CHEMBL1516388 & 688202 & 3.301 & 5.7886 & TST & \\
\hline CHEMBL1463954 & 688202 & 5.9793 & 5.9405 & TRN & \\
\hline CHEMBL1331084 & 688202 & 8.6383 & 4.9324 & TRN & \\
\hline CHEMBL 3208465 & 688202 & 6.4622 & 6.6167 & TRN & \\
\hline CHEMBL1498999 & 688202 & 3.9894 & 5.9582 & TRN & \\
\hline CHEMBL1612328 & 688202 & 3.301 & 6.513 & TRN & \\
\hline CHEMBL1569742 & 688202 & 5.1137 & 6.2651 & TRN & \\
\hline CHEMBL1447631 & 688202 & 4.9769 & 5.2627 & TRN & \\
\hline CHEMBL1496473 & 688202 & 8.6383 & 6.16 & TST & \\
\hline CHEMBL1416417 & 688202 & 3.301 & 4.6909 & TST & \\
\hline CHEMBL1525366 & 688202 & 7.1588 & 6.9859 & TRN & \\
\hline CHEMBL1425721 & 688202 & 8.6383 & 6.5258 & TRN & \\
\hline CHEMBL1566298 & 688202 & 5.1137 & 6.3586 & TRN & \\
\hline CHEMBL1448985 & 688202 & 5.5867 & 4.7307 & TRN & \\
\hline CHEMBL1396046 & 688202 & 7.5209 & 5.3523 & TRN & \\
\hline CHEMBL1495411 & 688202 & 7.251 & 5.7686 & TRN & \\
\hline CHEMBL1434189 & 688202 & 6.0189 & 4.9974 & TRN & \\
\hline CHEMBL522990 & 688202 & 5.2106 & 4.4888 & TRN & \\
\hline CHEMBL1406789 & 688202 & 3.301 & 4.8136 & TRN & \\
\hline CHEMBL1323006 & 688202 & 5.3998 & 5.396 & TRN & \\
\hline CHEMBL1592951 & 688202 & 4.4809 & 5.1743 & TRN & \\
\hline CHEMBL1467399 & 688202 & 5.1137 & 4.8549 & TRN & \\
\hline CHEMBL1603599 & 688202 & 4.0024 & 5.9489 & TST & \\
\hline CHEMBL1548361 & 688202 & 5.9353 & 6.2679 & TRN & \\
\hline CHEMBL3192116 & 688202 & 5.2859 & 5.5338 & TRN & \\
\hline CHEMBL1507981 & 688202 & 3.301 & 4.5997 & TRN & \\
\hline CHEMBL1310699 & 688202 & 6.3209 & 5.0049 & TRN & \\
\hline CHEMBL1340051 & 688202 & 8.6383 & 5.55200 & 00000000005 & TRN \\
\hline CHEMBL1407268 & 688202 & 4.8281 & 5.1873 & TRN & \\
\hline CHEMBL1407483 & 688202 & 6.8892 & 5.8609 & TST & \\
\hline CHEMBL1532174 & 688202 & 6.5913 & 5.6674 & TST & \\
\hline CHEMBL1458938 & 688202 & 8.6383 & 6.1839 & TRN & \\
\hline CHEMBL1505049 & 688202 & 2.9618 & 4.9917 & TRN & \\
\hline CHEMBL1445192 & 688202 & 3.301 & 4.7799 & TST & \\
\hline CHEMBL1373720 & 688202 & 5.9572 & 6.4218 & TRN & \\
\hline CHEMBL1501334 & 688202 & 4.8827 & 5.3009 & TST & \\
\hline CHEMBL495123 & 688202 & 4.0592 & 5.853 & TRN & \\
\hline CHEMBL1878162 & 688202 & 5.7158 & 4.8615 & TRN & \\
\hline CHEMBL1524916 & 688202 & 4.6869 & 5.59 & TST & \\
\hline CHEMBL1495173 & 688202 & 8.6383 & 4.3236 & TST & \\
\hline CHEMBL1462307 & 688202 & 3.301 & 5.0858 & TRN & \\
\hline CHEMBL1381495 & 688202 & 6.2744 & 5.3173 & TST & \\
\hline CHEMBL1605393 & 688202 & 5.5548 & 4.8792 & TST & \\
\hline CHEMBL1335170 & 688202 & 5.0278 & 5.5049 & TRN & \\
\hline CHEMBL1424486 & 688202 & 3.9947 & 5.1051 & TRN & \\
\hline CHEMBL1518374 & 688202 & 3.301 & 4.3252 & TRN & \\
\hline CHEMBL 1471193 & 688202 & 4.8993 & 5.2387 & TRN & \\
\hline CHEMBL1584730 & 688202 & 8.6383 & 5.0676 & TRN & \\
\hline
\end{tabular}


Supplemental Table S2.txt

\begin{tabular}{|c|c|c|c|c|c|}
\hline CHEMBL1342063 & 688202 & 6.9475 & 5.4733 & TRN & \\
\hline CHEMBL1359893 & 688202 & 2.9618 & 4.55399 & 9999999999 & TRN \\
\hline CHEMBL1415426 & 688202 & 4.8404 & 5.5067 & TRN & \\
\hline CHEMBL1329271 & 688202 & 4.8326 & 6.1117 & TRN & \\
\hline CHEMBL1478395 & 688202 & 6.6192 & 5.728 & TST & \\
\hline CHEMBL1365170 & 688202 & 4.7478 & 4.7721 & TRN & \\
\hline CHEMBL1406018 & 688202 & 2.9618 & 5.7459 & TRN & \\
\hline CHEMBL1995948 & 688202 & 8.6383 & 5.1661 & TRN & \\
\hline CHEMBL1391159 & 688202 & 8.6383 & 5.4355 & TRN & \\
\hline CHEMBL1484657 & 688202 & 5.2201 & 5.1419 & TRN & \\
\hline CHEMBL1468811 & 688202 & 2.9618 & 3.6791 & TRN & \\
\hline CHEMBL1504655 & 688202 & 5.2145 & 5.3183 & TRN & \\
\hline CHEMBL1343453 & 688202 & 5.1663 & 5.53600 & 00000000005 & TRN \\
\hline CHEMBL1469743 & 688202 & 3.301 & 4.9645 & TRN & \\
\hline CHEMBL1381306 & 688202 & 4.8441 & 4.9068 & TRN & \\
\hline CHEMBL1576374 & 688202 & 8.6383 & 6.2865 & TRN & \\
\hline CHEMBL1509057 & 688202 & 5.1137 & 5.481 & TRN & \\
\hline CHEMBL1530097 & 688202 & 3.301 & 4.0643 & TRN & \\
\hline CHEMBL1441401 & 688202 & 5.3558 & 4.9281 & TRN & \\
\hline CHEMBL1549732 & 688202 & 5.9856 & 5.4797 & TST & \\
\hline CHEMBL1595235 & 688202 & 3.301 & 3.957 & TRN & \\
\hline CHEMBL1427879 & 688202 & 8.6383 & 6.6085 & TRN & \\
\hline CHEMBL1483607 & 688202 & 8.6383 & 5.6249 & TRN & \\
\hline CHEMBL1578546 & 688202 & 3.301 & 5.8525 & TRN & \\
\hline CHEMBL1990772 & 688202 & 7.2305 & 4.5603 & TST & \\
\hline CHEMBL1511693 & 688202 & 8.6383 & 6.5435 & TRN & \\
\hline CHEMBL1531320 & 688202 & 3.301 & 4.7185 & TRN & \\
\hline CHEMBL1303477 & 688202 & 2.9618 & 4.9483 & TRN & \\
\hline CHEMBL1510117 & 688202 & 3.301 & 5.6983 & TRN & \\
\hline CHEMBL1372307 & 688202 & 3.301 & 5.2913 & TRN & \\
\hline CHEMBL482642 & 688202 & 4.0022 & 5.0998 & TRN & \\
\hline CHEMBL1597328 & 688202 & 7.4292 & 5.7288 & TRN & \\
\hline CHEMBL1522300 & 688202 & 3.301 & 4.8758 & TRN & \\
\hline CHEMBL1716742 & 688202 & 4.7399 & 5.3576 & TRN & \\
\hline CHEMBL3213380 & 688202 & 4.1051 & 5.1074 & TST & \\
\hline CHEMBL1390871 & 688202 & 5.1835 & 6.018 & TRN & \\
\hline CHEMBL1400764 & 688202 & 3.9861 & 5.442 & TRN & \\
\hline CHEMBL1529439 & 688202 & 6.1515 & 5.3932 & TRN & \\
\hline CHEMBL1539824 & 688202 & 4.6077 & 5.2957 & TRN & \\
\hline CHEMBL1606497 & 688202 & 8.6383 & 5.7924 & TRN & \\
\hline CHEMBL1342384 & 688202 & 6.487 & 6.5768 & TRN & \\
\hline CHEMBL1597481 & 688202 & 6.1495 & 5.1967 & TRN & \\
\hline CHEMBL1421557 & 688202 & 3.301 & 4.2378 & TRN & \\
\hline CHEMBL1570659 & 688202 & 7.3905 & 5.2165 & TRN & \\
\hline CHEMBL1336791 & 688202 & 3.301 & 6.2105 & TRN & \\
\hline CHEMBL1569157 & 688202 & 4.638 & 6.3899 & TRN & \\
\hline CHEMBL1411756 & 688202 & 5.5448 & 5.4214 & TST & \\
\hline CHEMBL1432915 & 688202 & 6.3296 & 5.4541 & TRN & \\
\hline
\end{tabular}




\begin{tabular}{|c|c|c|c|c|c|}
\hline & & \multicolumn{4}{|c|}{ Supplemental Table S2.txt } \\
\hline CHEMBL1448466 & 688202 & 8.6383 & 6.8276 & TRN & \\
\hline CHEMBL1323132 & 688202 & 7.2236 & 7.1394 & TRN & \\
\hline CHEMBL294209 & 688202 & 4.1046 & 5.6567 & TST & \\
\hline CHEMBL422471 & 688202 & 7.2375 & 6.0282 & TST & \\
\hline CHEMBL1363249 & 688202 & 5.6212 & 5.3109 & TRN & \\
\hline CHEMBL1413056 & 688202 & 4.715 & 5.2596 & TRN & \\
\hline CHEMBL1601624 & 688202 & 3.301 & 4.6246 & TRN & \\
\hline CHEMBL1403448 & 688202 & 8.6383 & 4.96 & TRN & \\
\hline CHEMBL1584646 & 688202 & 5.3985 & 5.1978 & TST & \\
\hline CHEMBL1481077 & 688202 & 3.301 & 5.3221 & TRN & \\
\hline CHEMBL1427643 & 688202 & 5.0345 & 5.4273 & TST & \\
\hline CHEMBL1572452 & 688202 & 5.5685 & 6.0111 & TRN & \\
\hline CHEMBL1602678 & 688202 & 6.9076 & 5.8187 & TRN & \\
\hline CHEMBL240331 & 688202 & 6.4729 & 4.9433 & TRN & \\
\hline CHEMBL3198962 & 688202 & 7.3189 & 4.8927 & TRN & \\
\hline CHEMBL1452728 & 688202 & 7.4449 & 6.0032 & TRN & \\
\hline CHEMBL1539325 & 688202 & 4.0307 & 5.9005 & TRN & \\
\hline CHEMBL1332007 & 688202 & 8.6383 & 5.4269 & TRN & \\
\hline CHEMBL1965461 & 688202 & 7.21899 & 99999999 & 4.8441 & TST \\
\hline CHEMBL3189964 & 688202 & 4.6658 & 6.3057 & TRN & \\
\hline CHEMBL1347387 & 688202 & 7.1556 & 6.3951 & TRN & \\
\hline CHEMBL1391455 & 688202 & 3.301 & 4.71 & TRN & \\
\hline CHEMBL1540767 & 688202 & 8.6383 & 5.4401 & TST & \\
\hline CHEMBL1480378 & 688202 & 2.9618 & 6.3495 & TST & \\
\hline CHEMBL3195986 & 688202 & 8.6383 & 5.334 & TST & \\
\hline CHEMBL1405097 & 688202 & 5.2145 & 6.0783 & TST & \\
\hline CHEMBL1525514 & 688202 & 4.3114 & 6.42399 & 99999999995 & TS \\
\hline CHEMBL1300008 & 688202 & 4.6037 & 5.4715 & TST & \\
\hline CHEMBL1522203 & 688202 & 3.301 & 5.3475 & TST & \\
\hline CHEMBL1464539 & 688202 & 5.9817 & 4.7205 & TST & \\
\hline CHEMBL1593395 & 688202 & 3.301 & 6.0549 & TST & \\
\hline CHEMBL1302802 & 688202 & 7.4989 & 5.9908 & TST & \\
\hline CHEMBL1611750 & 688202 & 5.7355 & 5.0942 & TST & \\
\hline CHEMBL1486827 & 688202 & 4.4616 & 5.3212 & TST & \\
\hline CHEMBL3208992 & 688202 & 2.9618 & 5.2615 & TST & \\
\hline CHEMBL330756 & 688202 & 6.4526 & 5.0856 & TST & \\
\hline CHEMBL1308068 & 688202 & 3.301 & 4.7736 & TST & \\
\hline CHEMBL1393131 & 688202 & 8.6383 & 4.9471 & TST & \\
\hline CHEMBL1383746 & 688202 & 5.0474 & 5.3817 & TST & \\
\hline CHEMBL1578407 & 688202 & 3.301 & 5.4939 & TST & \\
\hline CHEMBL1423705 & 688202 & 4.7313 & 5.6838 & TST & \\
\hline CHEMBL447111 & 688202 & 8.6383 & 5.6475 & TST & \\
\hline CHEMBL1465890 & 688202 & 8.6383 & 7.0322 & TST & \\
\hline CHEMBL1420184 & 688202 & 8.6383 & 5.5951 & TST & \\
\hline CHEMBL1387610 & 688202 & 2.9618 & 5.695 & TST & \\
\hline CHEMBL3196509 & 688202 & 6.4303 & 4.7018 & TST & \\
\hline CHEMBL1312996 & 688202 & 6.8492 & 4.6854 & TST & \\
\hline CHEMBL 3208784 & 688202 & 4.7312 & 5.4229 & TST & \\
\hline
\end{tabular}




\begin{tabular}{|c|c|c|c|c|c|c|}
\hline \multirow[b]{2}{*}{ CHEMBL1981243 } & & \multicolumn{5}{|c|}{ Supplemental Table S2.txt } \\
\hline & 688202 & 6.0058 & 4.3982 & TST & & \\
\hline CHEMBL1502852 & 688202 & $7.1610 e$ & 00000000 & 005 & 6.1065 & TST \\
\hline CHEMBL1389986 & 688202 & 5.5285 & 6.1251 & TST & & \\
\hline CHEMBL1444840 & 688202 & 5.4179 & 6.0672 & TST & & \\
\hline CHEMBL1466913 & 688202 & $4.0680 e$ & 00000000 & 005 & 5.6686 & TST \\
\hline CHEMBL1431081 & 688202 & 4.9539 & 5.9451 & TST & & \\
\hline CHEMBL1367590 & 688202 & 7.6169 & 5.1651 & TST & & \\
\hline CHEMBL1601001 & 688202 & 4.3518 & 6.0048 & TST & & \\
\hline CHEMBL1562870 & 688202 & 4.7157 & 6.5113 & TST & & \\
\hline CHEMBL1501269 & 688202 & 5.2817 & 5.9934 & TST & & \\
\hline CHEMBL1518838 & 688202 & 3.301 & 5.95700 & 0000000001 & & TST \\
\hline CHEMBL1352121 & 688202 & 3.301 & 4.9222 & TST & & \\
\hline CHEMBL1532996 & 688202 & 5.0367 & 5.5005 & TST & & \\
\hline CHEMBL1334452 & 688202 & 4.9417 & 5.0142 & TST & & \\
\hline CHEMBL3652296 & 1528019 & 6.6144 & 6.6606 & TRN & & \\
\hline CHEMBL3652298 & 1528019 & 6.0 & 5.65600 & 0000000001 & & TRN \\
\hline CHEMBL3652394 & 1528019 & 6.9136 & 6.501 & TRN & & \\
\hline CHEMBL3652409 & 1528019 & 8.7447 & 8.9279 & TRN & & \\
\hline CHEMBL3652359 & 1528019 & 6.38399 & 99999999 & 995 & 6.72 & TST \\
\hline CHEMBL3652312 & 1528019 & 6.0 & 5.7398 & TRN & & \\
\hline CHEMBL3652314 & 1528019 & 6.3655 & 6.3596 & TRN & & \\
\hline CHEMBL 3652310 & 1528019 & 5.7167 & 6.4502 & TRN & & \\
\hline CHEMBL3652365 & 1528019 & 6.1688 & 6.4928 & TST & & \\
\hline CHEMBL 3652378 & 1528019 & 7.4401 & 7.1179 & TRN & & \\
\hline CHEMBL 3652375 & 1528019 & 6.1421 & 6.359 & TRN & & \\
\hline CHEMBL3652277 & 1528019 & 7.4989 & 7.5197 & TRN & & \\
\hline CHEMBL3652317 & 1528019 & 7.4023 & 7.229 & TRN & & \\
\hline CHEMBL3652371 & 1528019 & 6.38299 & 99999999 & 99 & 6.4246 & TRN \\
\hline CHEMBL 3652324 & 1528019 & 5.9066 & 6.1619 & TRN & & \\
\hline CHEMBL3652392 & 1528019 & 6.567 & 6.9006 & TRN & & \\
\hline CHEMBL3652306 & 1528019 & 6.5607 & 6.9404 & TRN & & \\
\hline CHEMBL3652321 & 1528019 & 6.3089 & 6.1339 & TRN & & \\
\hline CHEMBL3652315 & 1528019 & 6.3625 & 6.2044 & TRN & & \\
\hline CHEMBL 3652345 & 1528019 & 6.3054 & 6.4077 & TRN & & \\
\hline CHEMBL3652335 & 1528019 & 6.0 & 5.6928 & TRN & & \\
\hline CHEMBL3652309 & 1528019 & 6.9101 & 6.6823 & TRN & & \\
\hline CHEMBL 3652357 & 1528019 & 6.3401 & 6.3578 & TRN & & \\
\hline CHEMBL3652358 & 1528019 & 7.2541 & 7.222 & TRN & & \\
\hline CHEMBL 3652313 & 1528019 & 6.1979 & 6.1203 & TRN & & \\
\hline CHEMBL 3652364 & 1528019 & 6.5436 & 6.4531 & TRN & & \\
\hline CHEMBL3652385 & 1528019 & 6.5186 & 6.515 & TRN & & \\
\hline CHEMBL3652288 & 1528019 & 5.0 & 6.5618 & TRN & & \\
\hline CHEMBL3652320 & 1528019 & 6.1232 & 6.3067 & TRN & & \\
\hline CHEMBL3652369 & 1528019 & 6.4134 & 6.5465 & TRN & & \\
\hline CHEMBL3652289 & 1528019 & 7.129 & 7.0632 & TRN & & \\
\hline CHEMBL3652396 & 1528019 & 6.2314 & 6.5803 & TRN & & \\
\hline CHEMBL3652360 & 1528019 & 7.015 & 6.8549 & TRN & & \\
\hline CHEMBL3639512 & 1528019 & 6.4609 & 6.6403 & TRN & & \\
\hline
\end{tabular}


Supplemental Table S2.txt

\begin{tabular}{|c|c|c|c|c|c|}
\hline CHEMBL 3652386 & 1528019 & 6.5258 & 6.5595 & TRN & \\
\hline CHEMBL 3652337 & 1528019 & 6.8928 & 6.3243 & TRN & \\
\hline CHEMBL 3652408 & 1528019 & 10.4342 & 9.8201 & TRN & \\
\hline CHEMBL 3652279 & 1528019 & 6.4698 & 6.7069 & TRN & \\
\hline CHEMBL 3652351 & 1528019 & 6.6882 & 7.1259 & TRN & \\
\hline CHEMBL 3916507 & 1528019 & 6.3439 & 6.3295 & TRN & \\
\hline CHEMBL 3652372 & 1528019 & 6.2336 & 6.4019 & TRN & \\
\hline CHEMBL3652399 & 1528019 & 7.3675 & 6.8537 & TRN & \\
\hline CHEMBL 3652374 & 1528019 & 6.5317 & 6.7106 & TRN & \\
\hline CHEMBL 3652377 & 1528019 & 6.4921 & 6.681 & TST & \\
\hline CHEMBL 3652352 & 1528019 & 7.0429 & 6.5519 & TRN & \\
\hline CHEMBL 3652280 & 1528019 & \multicolumn{2}{|c|}{6.218999999999999} & 6.4042 & TRN \\
\hline CHEMBL 3652323 & 1528019 & 6.1073 & 6.2299 & TRN & \\
\hline CHEMBL 3652361 & 1528019 & 7.0846 & 7.0839 & TST & \\
\hline CHEMBL 3652330 & 1528019 & 6.6536 & 6.7681 & TRN & \\
\hline CHEMBL 3969771 & 1528019 & 5.9245 & 6.3656 & TRN & \\
\hline CHEMBL3652336 & 1528019 & 6.3655 & 6.6564 & TRN & \\
\hline CHEMBL 3652302 & 1528019 & \multicolumn{2}{|c|}{6.821000000000001} & 6.6156 & TRN \\
\hline CHEMBL3652397 & 1528019 & 6.0 & 6.3317 & TRN & \\
\hline CHEMBL 3652388 & 1528019 & 6.5935 & 6.6226 & TRN & \\
\hline CHEMBL 3652293 & 1528019 & 6.7212 & 6.7235 & TRN & \\
\hline CHEMBL3652346 & 1528019 & 6.399 & 6.4647 & TRN & \\
\hline CHEMBL3652332 & 1528019 & 6.0701 & 6.3018 & TRN & \\
\hline CHEMBL3652393 & 1528019 & 6.4908 & 6.5561 & TRN & \\
\hline CHEMBL 3652405 & 1528019 & 8.8894 & 8.2963 & TRN & \\
\hline CHEMBL 3652291 & 1528019 & 6.6778 & 6.8853 & TST & \\
\hline CHEMBL3652347 & 1528019 & 6.9031 & 6.5211 & TRN & \\
\hline CHEMBL3652367 & 1528019 & 6.3354 & 6.6815 & TRN & \\
\hline CHEMBL3652328 & 1528019 & 6.7696 & 6.1998 & TRN & \\
\hline CHEMBL 3652349 & 1528019 & 6.5607 & 6.6373 & TRN & \\
\hline CHEMBL 3652290 & 1528019 & 6.1278 & 6.2978 & TRN & \\
\hline CHEMBL3652381 & 1528019 & 6.5317 & 7.0668 & TRN & \\
\hline CHEMBL3652331 & 1528019 & 6.6925 & 6.952999 & 7999999999 & TRN \\
\hline CHEMBL3652379 & 1528019 & 6.0899 & 6.3187 & TRN & \\
\hline CHEMBL 3652318 & 1528019 & 6.7773 & 6.7988 & TRN & \\
\hline CHEMBL3652292 & 1528019 & 6.308 & 6.5232 & TST & \\
\hline CHEMBL 3652333 & 1528019 & 6.6326 & 6.5002 & TRN & \\
\hline CHEMBL 3652373 & 1528019 & 6.5482 & 6.6966 & TST & \\
\hline CHEMBL3652316 & 1528019 & 6.4522 & 6.3729 & TRN & \\
\hline CHEMBL 3652383 & 1528019 & 6.9547 & 7.0127 & TRN & \\
\hline CHEMBL 3652382 & 1528019 & 6.8447 & 6.6846 & TRN & \\
\hline CHEMBL 3652283 & 1528019 & 6.6308 & $6.36600 e$ & 00000000005 & TRN \\
\hline CHEMBL3652308 & 1528019 & 6.0 & 5.7775 & TRN & \\
\hline CHEMBL 3652327 & 1528019 & 6.1669 & 6.2675 & TRN & \\
\hline CHEMBL3652282 & 1528019 & 5.4841 & 6.0596 & TRN & \\
\hline CHEMBL 3652319 & 1528019 & 6.4012 & 6.3544 & TRN & \\
\hline CHEMBL 3652403 & 1528019 & 8.4101 & 8.3405 & TRN & \\
\hline CHEMBL3652338 & 1528019 & 6.2418 & 6.2985 & TRN & \\
\hline
\end{tabular}

Page 16972 


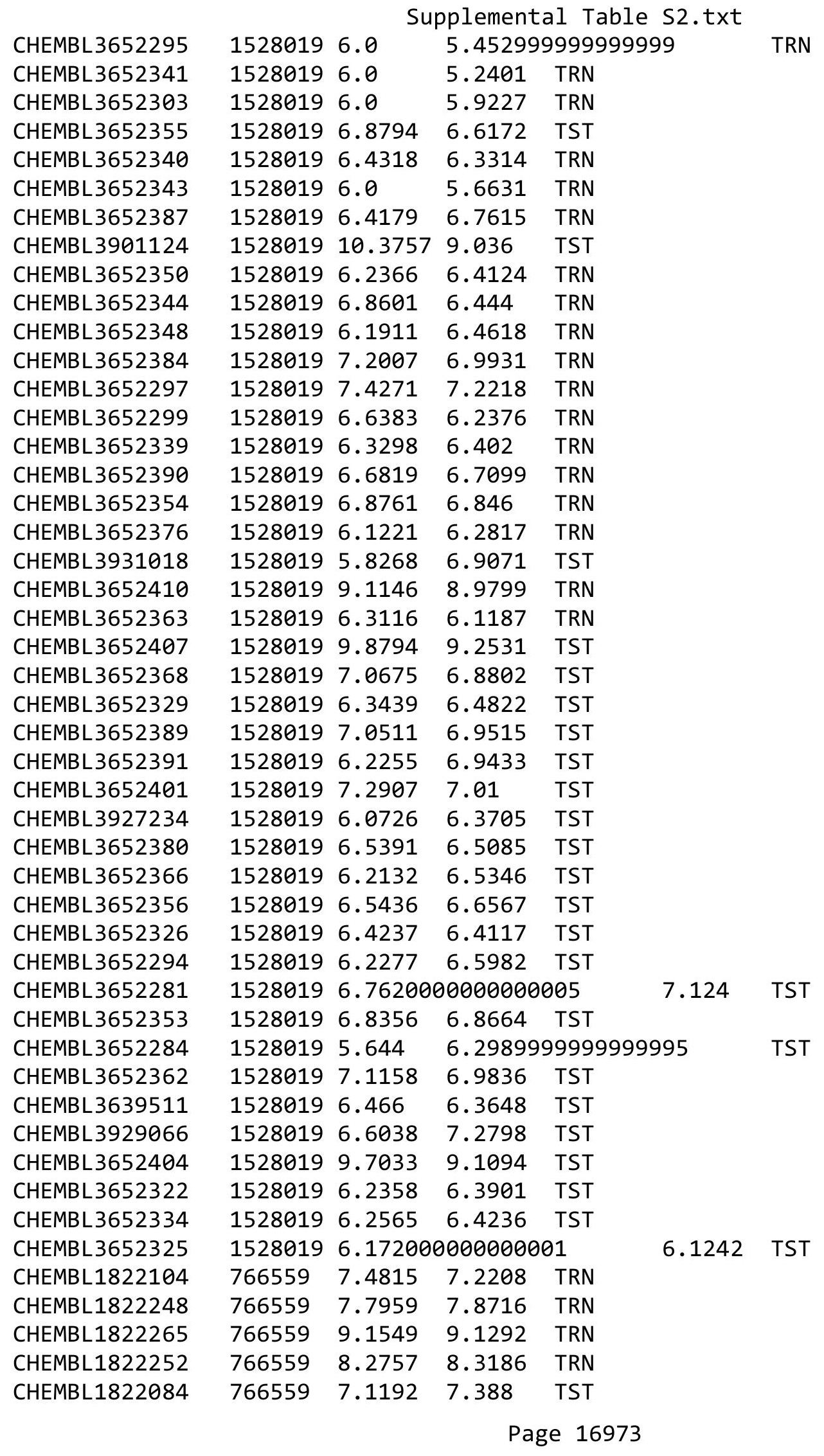


Supplemental Table S2.txt

\begin{tabular}{|c|c|c|c|c|}
\hline CHEMBL1822264 & 766559 & 9.699 & 9.6047 & TRN \\
\hline CHEMBL1822103 & 766559 & 7.5376 & 7.3344 & TRN \\
\hline CHEMBL1822262 & 766559 & 9.301 & 9.1688 & TRN \\
\hline CHEMBL1822078 & 766559 & 7.4202 & 7.1991 & TRN \\
\hline CHEMBL1822107 & 766559 & 6.699 & 6.7207 & TRN \\
\hline CHEMBL1822254 & 766559 & 8.3768 & 8.6456 & TRN \\
\hline CHEMBL1822087 & 766559 & 6.1675 & 6.2703 & TRN \\
\hline CHEMBL1822090 & 766559 & 8.3468 & 8.2285 & TRN \\
\hline CHEMBL1822241 & 766559 & 8.3979 & 8.8509 & TRN \\
\hline CHEMBL1822258 & 766559 & 9.1549 & 8.9916 & TRN \\
\hline CHEMBL1822105 & 766559 & 7.4202 & 6.9862 & TRN \\
\hline CHEMBL1822253 & 766559 & 8.4559 & 8.46 & TRN \\
\hline CHEMBL1822251 & 766559 & 8.6198 & 8.6745 & TRN \\
\hline CHEMBL1822079 & 766559 & 7.7696 & 8.5893 & TST \\
\hline CHEMBL1822075 & 766559 & 6.9586 & 7.1984 & TRN \\
\hline CHEMBL1822076 & 766559 & 5.585 & 6.409 & TRN \\
\hline CHEMBL1822072 & 766559 & 6.8239 & 7.2291 & TST \\
\hline CHEMBL1822249 & 766559 & 7.7212 & 7.8034 & TRN \\
\hline CHEMBL1822263 & 766559 & 6.4949 & 7.1363 & TST \\
\hline CHEMBL1822250 & 766559 & 8.2076 & 8.0476 & TRN \\
\hline CHEMBL1822242 & 766559 & 8.7447 & 8.7107 & TRN \\
\hline CHEMBL1822085 & 766559 & 7.7212 & 7.2678 & TST \\
\hline CHEMBL1822243 & 766559 & 7.9208 & 8.2328 & TRN \\
\hline CHEMBL1822091 & 766559 & 7.7696 & 7.7702 & TRN \\
\hline CHEMBL1822068 & 766559 & 8.7696 & 9.3803 & TRN \\
\hline CHEMBL1822080 & 766559 & 8.0809 & 8.0724 & TST \\
\hline CHEMBL1822102 & 766559 & 6.8539 & 7.53 & TST \\
\hline CHEMBL1822098 & 766559 & 7.5376 & 7.504 & TRN \\
\hline CHEMBL1822070 & 766559 & 7.8861 & 8.2211 & TRN \\
\hline CHEMBL1822074 & 766559 & 8.6383 & 7.9916 & TRN \\
\hline CHEMBL1822086 & 766559 & 6.7696 & 6.2923 & TST \\
\hline CHEMBL1822101 & 766559 & 7.7212 & 8.121 & TST \\
\hline CHEMBL1822092 & 766559 & 7.2007 & 7.3549 & TRN \\
\hline CHEMBL1822100 & 766559 & 7.3979 & 7.4912 & TST \\
\hline CHEMBL1822083 & 766559 & 6.6778 & 6.605 & TST \\
\hline CHEMBL1822259 & 766559 & 9.0 & 8.657 & TRN \\
\hline CHEMBL1822247 & 766559 & 8.6576 & 8.6826 & TRN \\
\hline CHEMBL1822095 & 766559 & 6.9586 & 7.3156 & TRN \\
\hline CHEMBL1822097 & 766559 & 7.7447 & 7.3766 & TRN \\
\hline CHEMBL1822109 & 766559 & 6.9208 & 7.5541 & TST \\
\hline CHEMBL1822089 & 766559 & 8.8861 & 8.588 & TRN \\
\hline CHEMBL1822088 & 766559 & 7.6021 & 7.5347 & TRN \\
\hline CHEMBL1822071 & 766559 & 7.2147 & 8.408 & TST \\
\hline CHEMBL1822257 & 766559 & 8.7447 & 8.6545 & TRN \\
\hline CHEMBL1822081 & 766559 & 7.0605 & 7.5082 & TST \\
\hline CHEMBL1822069 & 766559 & 8.8539 & 8.9287 & TRN \\
\hline CHEMBL1822244 & 766559 & 8.0362 & 8.0604 & TRN \\
\hline CHEMBL1822110 & 766559 & 7.7696 & 7.6361 & TST \\
\hline
\end{tabular}




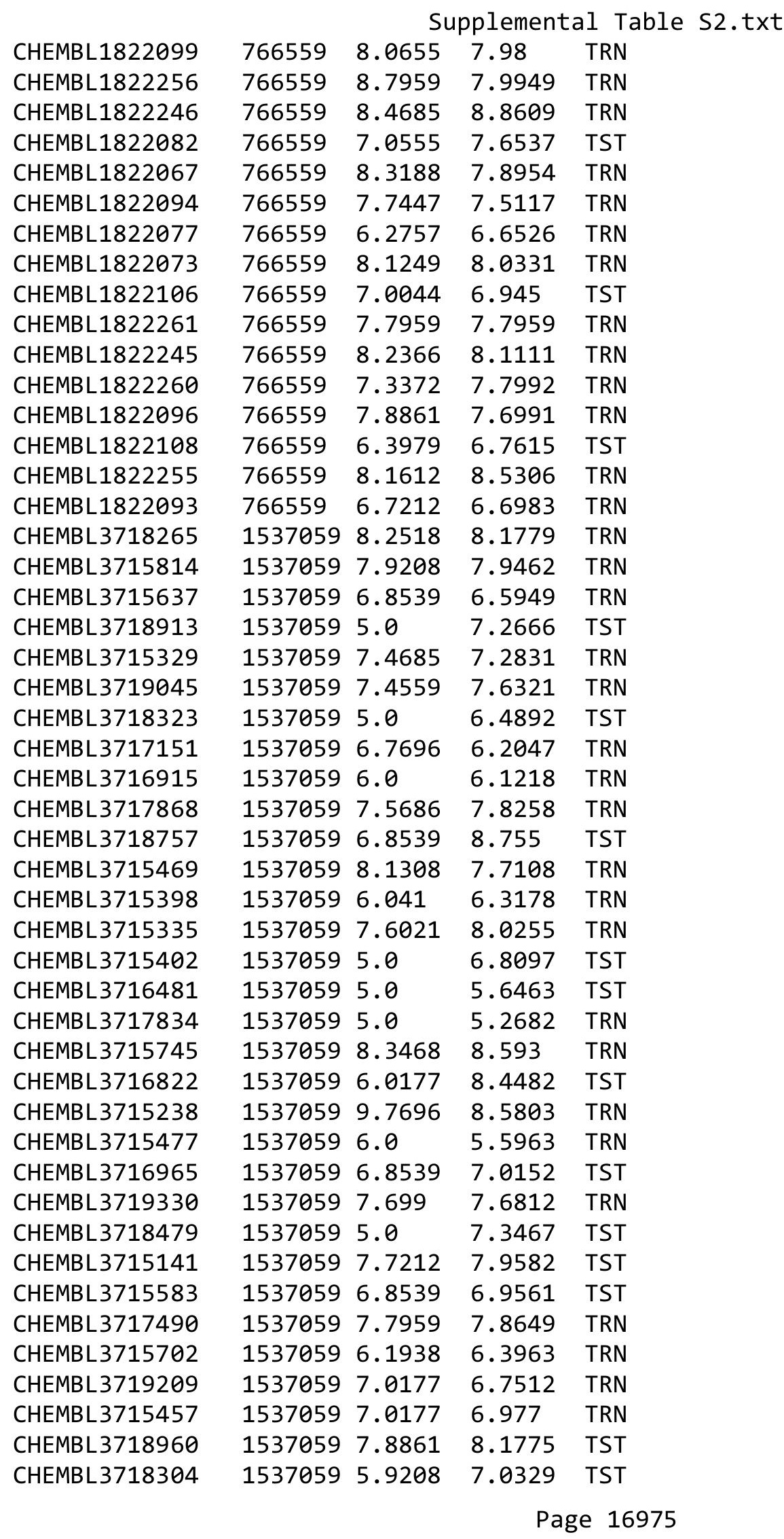


Supplemental Table S2.txt

\begin{tabular}{|c|c|c|c|c|c|}
\hline CHEMBL 3718754 & 1537059 & 7.9586 & 7.9203 & TRN & \\
\hline CHEMBL3715325 & 1537059 & 9.3188 & 8.3595 & TRN & \\
\hline CHEMBL3716760 & 1537059 & 8.8861 & 8.7407 & TRN & \\
\hline CHEMBL 3715323 & 1537059 & 7.6576 & 7.231 & TRN & \\
\hline CHEMBL3716053 & 1537059 & 7.7447 & 7.7517 & TRN & \\
\hline CHEMBL 3718590 & 1537059 & 5.0 & 4.9666 & TRN & \\
\hline CHEMBL 3714822 & 1537059 & 8.0915 & 8.3327 & TRN & \\
\hline CHEMBL3717336 & 1537059 & 6.7959 & 7.4624 & TST & \\
\hline CHEMBL3716132 & 1537059 & 7.9208 & 8.163 & TRN & \\
\hline CHEMBL3719126 & 1537059 & 6.8239 & 7.0533 & TRN & \\
\hline CHEMBL 3715142 & 1537059 & 6.0088 & 5.92899 & 9999999999 & TRN \\
\hline CHEMBL3715950 & 1537059 & 8.2366 & 8.0396 & TRN & \\
\hline CHEMBL3715147 & 1537059 & 6.1079 & 7.4095 & TST & \\
\hline CHEMBL 3717104 & 1537059 & 9.0 & 9.1136 & TRN & \\
\hline CHEMBL3716692 & 1537059 & 6.0269 & 6.1408 & TRN & \\
\hline CHEMBL3718347 & 1537059 & 7.1612 & 6.7948 & TRN & \\
\hline CHEMBL3717907 & 1537059 & 7.6778 & 7.7417 & TRN & \\
\hline CHEMBL3717817 & 1537059 & 6.7447 & 7.7612 & TST & \\
\hline CHEMBL3714788 & 1537059 & 7.041 & 7.5178 & TRN & \\
\hline CHEMBL3717119 & 1537059 & 7.7212 & 8.0197 & TRN & \\
\hline CHEMBL3718889 & 1537059 & 5.0 & 5.255 & TRN & \\
\hline CHEMBL3718282 & 1537059 & 6.5229 & 6.5453 & TRN & \\
\hline CHEMBL3718678 & 1537059 & 7.9586 & 8.6506 & TRN & \\
\hline CHEMBL3717882 & 1537059 & 8.1938 & 8.388 & TRN & \\
\hline CHEMBL3717925 & 1537059 & 6.0044 & 5.7744 & TRN & \\
\hline CHEMBL3718328 & 1537059 & 7.6021 & 7.8067 & TRN & \\
\hline CHEMBL3716506 & 1537059 & 7.2366 & 8.4387 & TST & \\
\hline CHEMBL3716701 & 1537059 & 5.0 & 5.5011 & TRN & \\
\hline CHEMBL3716510 & 1537059 & 7.4685 & 7.5526 & TRN & \\
\hline CHEMBL3719039 & 1537059 & 8.6198 & 8.4779 & TST & \\
\hline CHEMBL3715924 & 1537059 & 7.3279 & 7.2471 & TRN & \\
\hline CHEMBL3717559 & 1537059 & 8.3565 & 8.7274 & TRN & \\
\hline CHEMBL3717819 & 1537059 & 7.5086 & 7.5398 & TRN & \\
\hline CHEMBL3719016 & 1537059 & 7.4685 & 7.6199 & TRN & \\
\hline CHEMBL3715988 & 1537059 & 6.4559 & 5.7137 & TRN & \\
\hline CHEMBL3716431 & 1537059 & 5.0 & 7.7411 & TST & \\
\hline CHEMBL3718522 & 1537059 & 8.7959 & 8.8819 & TRN & \\
\hline CHEMBL3716456 & 1537059 & 7.8239 & 7.6296 & TRN & \\
\hline CHEMBL3716231 & 1537059 & 8.0269 & 8.3617 & TRN & \\
\hline CHEMBL3355006 & 1537059 & 6.5686 & 7.8963 & TST & \\
\hline CHEMBL3716708 & 1537059 & 8.3279 & 8.0671 & TRN & \\
\hline CHEMBL3714878 & 1537059 & 7.3872 & 7.9325 & TRN & \\
\hline CHEMBL3714884 & 1537059 & 8.3098 & 7.7674 & TRN & \\
\hline CHEMBL3716550 & 1537059 & 7.9586 & 7.7105 & TRN & \\
\hline CHEMBL3718210 & 1537059 & 6.2596 & 5.8492 & TRN & \\
\hline CHEMBL3718894 & 1537059 & 5.0 & 6.2284 & TRN & \\
\hline CHEMBL3717180 & 1537059 & 7.6198 & 7.7124 & TRN & \\
\hline CHEMBL3715836 & 1537059 & 7.6576 & 7.7807 & TRN & \\
\hline
\end{tabular}

Page 16976 
Supplemental Table S2.txt

\begin{tabular}{|c|c|c|c|c|}
\hline 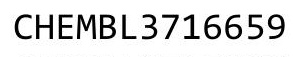 & & & & \\
\hline HEMBL3715688 & 537059 & 5.0 & 3112 & \\
\hline AEMBL3714843 & 37059 & 8 & 9605 & \\
\hline 377 & 59 & & 046 & \\
\hline IEMBL37 & 59 & & 615 & \\
\hline AEMBL3718242 & 537059 & 8.0362 & 5582 & \\
\hline AEMBL3716226 & 537059 & 9.7696 & .5685 & \\
\hline AEMBL37 & & & 011 & \\
\hline AEMBL3 & 59 & 685 & 263 & \\
\hline IEMBL37 & 59 & & 217 & \\
\hline AEMBL3355004 & 537059 & 6.9586 & 9118 & \\
\hline AEMBL3719147 & 537059 & 7.0 & 1735 & \\
\hline AEMBL3718982 & 59 & 7. & 584 & \\
\hline 18592 & 59 & & 236 & \\
\hline AEMBL3715256 & 59 & 5 . & & \\
\hline AEMBL3718307 & 59 & 6. & 656 & \\
\hline AEMBL3715610 & & & & \\
\hline 5246 & 9 & & 146 & \\
\hline 8090 & & & 01 & \\
\hline 5069 & 59 & & 15 & \\
\hline 5928 & 59 & & 246 & \\
\hline AEMBL37 & & 5 . & 95 & \\
\hline AEMBL & 9 & & 554 & \\
\hline 4890 & & & 771 & \\
\hline 893 & & & 286 & \\
\hline 8303 & & & 973 & \\
\hline EMBL37 & & & 568 & \\
\hline 4847 & & & 262 & \\
\hline 909 & & & 72 & \\
\hline 35 & & & 444 & \\
\hline AEMBL3715823 & & & 03 & \\
\hline AEMBL3717679 & & & 041 & \\
\hline & & & 252 & \\
\hline 6 & & & 83 & \\
\hline & & 5.0 & 205 & TST \\
\hline AEMBL3717099 & 537 & 6 . & 573 & TS \\
\hline IEMBL 3719037 & 59 & & 543 & F \\
\hline 7627 & 9 & & 233 & \\
\hline 6 & & & 365 & \\
\hline HEMBL3716658 & 153 & & & $\mathrm{RN}$ \\
\hline AEMBL3718912 & 53 & & 407 & $\mathrm{R}$ \\
\hline 3715274 & 53 & & 566 & \\
\hline AEMBL3717492 & & & 696 & \\
\hline HEMBL3715298 & & & & \\
\hline AEMBL3717610 & 1537059 & & .9149 & s \\
\hline AEMBL3355003 & 1537059 & 9.7696 & 9.2229 & TP \\
\hline & & 8. & & \\
\hline & & & & \\
\hline
\end{tabular}

Page 16977 
Supplemental Table S2.txt

\begin{tabular}{|c|c|c|c|c|}
\hline CHEMBL 3718292 & 1537059 & 8.2596 & 8.1023 & TRN \\
\hline CHEMBL 3716934 & 1537059 & 6.585 & 6.6191 & TRN \\
\hline CHEMBL3718576 & 1537059 & 7.2518 & 7.6637 & TRN \\
\hline CHEMBL 3717388 & 1537059 & 7.0862 & 6.9567 & TST \\
\hline CHEMBL3717966 & 1537059 & 8.3279 & 8.5427 & TRN \\
\hline CHEMBL3718563 & 1537059 & 6.9586 & 7.1556 & TST \\
\hline CHEMBL 3716424 & 1537059 & 7.3979 & 7.4575 & TRN \\
\hline CHEMBL 3716725 & 1537059 & 8.7212 & 8.4843 & TRN \\
\hline CHEMBL3716149 & 1537059 & 6.1938 & 6.3257 & TRN \\
\hline CHEMBL3715873 & 1537059 & 7.8861 & 8.0538 & TST \\
\hline CHEMBL 3715788 & 1537059 & 9.1739 & 8.4048 & TRN \\
\hline CHEMBL3716124 & 1537059 & 7.1192 & 7.1666 & TRN \\
\hline CHEMBL3715800 & 1537059 & 7.4949 & 7.902 & TRN \\
\hline CHEMBL 3716248 & 1537059 & 7.0757 & 7.0713 & TRN \\
\hline CHEMBL3718344 & 1537059 & 8.6383 & 8.6595 & TRN \\
\hline CHEMBL 3715127 & 1537059 & 6.4089 & 6.3563 & TRN \\
\hline CHEMBL3716545 & 1537059 & 8.4089 & 8.3586 & TRN \\
\hline CHEMBL3717481 & 1537059 & 8.5686 & 8.1973 & TRN \\
\hline CHEMBL 3717487 & 1537059 & 7.9586 & 7.9574 & TRN \\
\hline CHEMBL3715482 & 1537059 & 8.2596 & 8.2978 & TRN \\
\hline CHEMBL3717538 & 1537059 & 8.1024 & 8.076 & TRN \\
\hline CHEMBL3717094 & 1537059 & 7.3468 & 7.57700 & 0000000001 \\
\hline CHEMBL3714894 & 1537059 & 8.2291 & 8.3723 & TRN \\
\hline CHEMBL3719229 & 1537059 & 7.4685 & 7.2892 & TRN \\
\hline CHEMBL3355005 & 1537059 & 9.3979 & 9.5609 & TRN \\
\hline CHEMBL3717946 & 1537059 & 5.0 & 6.80399 & 9999999999 \\
\hline CHEMBL3718599 & 1537059 & 5.0 & 6.9322 & TST \\
\hline CHEMBL3718197 & 1537059 & 7.585 & 7.5044 & TRN \\
\hline CHEMBL3718839 & 1537059 & 6.585 & 6.2675 & TRN \\
\hline CHEMBL3717957 & 1537059 & 5.0 & 4.8402 & TRN \\
\hline CHEMBL3718859 & 1537059 & 6.7447 & 6.8641 & TRN \\
\hline CHEMBL 3718810 & 1537059 & 8.9208 & 8.5052 & TRN \\
\hline CHEMBL 3718873 & 1537059 & 6.9208 & 7.1484 & TRN \\
\hline CHEMBL3717314 & 1537059 & 7.5686 & 7.8276 & TST \\
\hline CHEMBL3715738 & 1537059 & 7.6576 & 7.4762 & TST \\
\hline CHEMBL3718750 & 1537059 & 6.0 & 6.3503 & TST \\
\hline CHEMBL3714987 & 1537059 & 8.0969 & 7.8848 & TST \\
\hline CHEMBL3717680 & 1537059 & 7.4685 & 8.3849 & TST \\
\hline CHEMBL3716363 & 1537059 & 7.6576 & 8.318 & TST \\
\hline CHEMBL3716111 & 1537059 & 5.0 & 6.8595 & TST \\
\hline CHEMBL3714930 & 1537059 & 7.5528 & 7.9934 & TST \\
\hline CHEMBL3718065 & 1537059 & 6.0915 & 6.6423 & TST \\
\hline CHEMBL1534513 & 688309 & 2.9499 & 2.978 & TRN \\
\hline CHEMBL1576148 & 688309 & 4.7298 & 3.1207 & TRN \\
\hline CHEMBL1303384 & 688309 & 5.3595 & 5.1708 & TRN \\
\hline CHEMBL1529787 & 688309 & 2.9499 & 3.4565 & TRN \\
\hline CHEMBL3198494 & 688309 & 6.1085 & 5.4444 & TRN \\
\hline CHEMBL1476816 & 688309 & 4.4994 & 4.7525 & TRN \\
\hline
\end{tabular}




\begin{tabular}{|c|c|c|c|c|c|}
\hline & & \multicolumn{4}{|c|}{ Supplemental Table S2.txt } \\
\hline CHEMBL1608396 & 688309 & 2.9499 & 3.7058 & TRN & \\
\hline CHEMBL1341067 & 688309 & 2.9499 & 3.2862 & TRN & \\
\hline CHEMBL1337066 & 688309 & 2.9499 & 3.2456 & TRN & \\
\hline CHEMBL1556766 & 688309 & 2.9499 & 2.9555 & TST & \\
\hline CHEMBL1456273 & 688309 & 2.9499 & 3.9866 & TRN & \\
\hline CHEMBL1612409 & 688309 & 2.9499 & 2.6066 & TRN & \\
\hline CHEMBL1545489 & 688309 & 2.9499 & 2.9514 & TRN & \\
\hline CHEMBL1477575 & 688309 & 5.2027 & 5.3397 & TRN & \\
\hline CHEMBL1986081 & 688309 & 4.5622 & 3.7033 & TRN & \\
\hline CHEMBL1513114 & 688309 & 5.5896 & 5.2871 & TRN & \\
\hline CHEMBL1564969 & 688309 & 2.9499 & 2.9333 & TRN & \\
\hline CHEMBL1392570 & 688309 & 6.3675 & 5.3096 & TRN & \\
\hline CHEMBL1381194 & 688309 & 2.9499 & 3.2535 & TRN & \\
\hline CHEMBL1304945 & 688309 & 4.4085 & 3.4745 & TRN & \\
\hline CHEMBL1543337 & 688309 & 5.5163 & 5.7749 & TST & \\
\hline CHEMBL1450797 & 688309 & 6.3019 & 5.3281 & TRN & \\
\hline CHEMBL1457108 & 688309 & 2.9499 & 3.2625 & TRN & \\
\hline CHEMBL1332236 & 688309 & 5.22 & 3.2279 & TST & \\
\hline CHEMBL1463879 & 688309 & 4.274 & 3.6044 & TRN & \\
\hline CHEMBL1368187 & 688309 & 2.9499 & 3.7016 & TRN & \\
\hline CHEMBL3199853 & 688309 & 2.9499 & 3.5265 & TRN & \\
\hline CHEMBL1541396 & 688309 & 2.9499 & 2.7504 & TRN & \\
\hline CHEMBL1559414 & 688309 & 5.5173 & 5.13399 & 99999999995 & TRN \\
\hline CHEMBL1557987 & 688309 & 4.9068 & 4.0774 & TRN & \\
\hline CHEMBL1387610 & 688309 & 5.9574 & 5.86 & TRN & \\
\hline CHEMBL1483824 & 688309 & 2.9499 & 3.1809 & TST & \\
\hline CHEMBL1401584 & 688309 & 2.9499 & 3.005 & TRN & \\
\hline CHEMBL1366347 & 688309 & 5.4089 & 5.3046 & TRN & \\
\hline CHEMBL1539622 & 688309 & 2.9499 & 3.1607 & TST & \\
\hline CHEMBL1558033 & 688309 & 4.2034 & 2.8974 & TRN & \\
\hline CHEMBL1462373 & 688309 & 6.2069 & 5.9472 & TRN & \\
\hline CHEMBL3191437 & 688309 & 5.5737 & 5.1904 & TRN & \\
\hline CHEMBL1558162 & 688309 & 2.9499 & 3.2253 & TRN & \\
\hline CHEMBL1612679 & 688309 & 2.9499 & 2.9271 & TRN & \\
\hline CHEMBL1439909 & 688309 & 5.3273 & 5.1325 & TRN & \\
\hline CHEMBL202965 & 688309 & 2.9499 & 3.1546 & TRN & \\
\hline CHEMBL1528779 & 688309 & 2.9499 & 3.43600 & 00000000004 & TRN \\
\hline CHEMBL1363200 & 688309 & 2.9499 & 3.8813 & TST & \\
\hline CHEMBL3209094 & 688309 & 2.9499 & 3.5134 & TRN & \\
\hline CHEMBL1378867 & 688309 & 2.9499 & 2.911 & TRN & \\
\hline CHEMBL1300964 & 688309 & 2.9499 & 3.0047 & TST & \\
\hline CHEMBL1581612 & 688309 & 2.9499 & 3.2436 & TRN & \\
\hline CHEMBL3198235 & 688309 & 4.7267 & 4.8548 & TRN & \\
\hline CHEMBL1553470 & 688309 & 2.9499 & 2.9429 & TRN & \\
\hline CHEMBL1573789 & 688309 & 4.8036 & 3.6336 & TST & \\
\hline CHEMBL1353602 & 688309 & 2.9499 & 3.4381 & TRN & \\
\hline CHEMBL3197774 & 688309 & 4.5449 & 3.8073 & TRN & \\
\hline CHEMBL1328371 & 688309 & 2.9499 & 3.7784 & TRN & \\
\hline
\end{tabular}




\begin{tabular}{|c|c|c|c|c|}
\hline \multicolumn{5}{|c|}{ Supplemental Table S2.txt } \\
\hline CHEMBL1555066 & 688309 & 5.7617 & 5.1952 & TRN \\
\hline CHEMBL1544047 & 688309 & 2.9499 & 3.0573 & TST \\
\hline CHEMBL1337356 & 688309 & 2.9499 & 3.0089 & TRN \\
\hline CHEMBL1323508 & 688309 & 2.9499 & 3.7193 & TRN \\
\hline CHEMBL1372420 & 688309 & 2.9499 & 3.2944 & TRN \\
\hline CHEMBL1541684 & 688309 & 4.2425 & 3.467 & TRN \\
\hline CHEMBL1343458 & 688309 & 5.8778 & 5.6776 & TRN \\
\hline CHEMBL1411861 & 688309 & 2.9499 & 3.2026 & TST \\
\hline CHEMBL1335481 & 688309 & 2.9499 & 3.0875 & TRN \\
\hline CHEMBL1269779 & 688309 & 2.9499 & 4.099 & TRN \\
\hline CHEMBL1527433 & 688309 & 4.8324 & 5.3278 & TRN \\
\hline CHEMBL1361529 & 688309 & 2.9499 & 3.2827 & TRN \\
\hline CHEMBL1397386 & 688309 & 5.1474 & 3.6794 & TRN \\
\hline CHEMBL1339775 & 688309 & 2.9499 & 4.0268 & TRN \\
\hline CHEMBL1417508 & 688309 & 6.9031 & 3.8644 & TRN \\
\hline CHEMBL3197960 & 688309 & 6.1593 & 4.1624 & TST \\
\hline CHEMBL1354361 & 688309 & 5.2838 & 4.6297 & TRN \\
\hline CHEMBL1344225 & 688309 & 5.2409 & 5.3925 & TRN \\
\hline CHEMBL1401297 & 688309 & 4.1886 & 3.0344 & TRN \\
\hline CHEMBL1385535 & 688309 & 2.9499 & 3.3719 & TST \\
\hline CHEMBL1446954 & 688309 & 2.9499 & 3.5688 & TST \\
\hline CHEMBL1525069 & 688309 & 2.9499 & 3.1571 & TRN \\
\hline CHEMBL1327598 & 688309 & 2.9499 & 3.3367 & TRN \\
\hline CHEMBL1550917 & 688309 & 2.9499 & 2.9898 & TRN \\
\hline CHEMBL3199499 & 688309 & 5.3551 & 5.1542 & TRN \\
\hline CHEMBL1455326 & 688309 & 2.9499 & 3.2846 & TRN \\
\hline CHEMBL3209179 & 688309 & 2.9499 & 3.8895 & TRN \\
\hline CHEMBL1453561 & 688309 & 2.9499 & 3.2218 & TRN \\
\hline CHEMBL1495271 & 688309 & 2.9499 & 3.0575 & TRN \\
\hline CHEMBL1366712 & 688309 & 5.0813 & 5.8197 & TRN \\
\hline CHEMBL1538854 & 688309 & 5.1095 & 5.0023 & TRN \\
\hline CHEMBL1399447 & 688309 & 2.9499 & 4.5488 & TRN \\
\hline CHEMBL1563383 & 688309 & 5.2177 & 5.2226 & TRN \\
\hline CHEMBL1386762 & 688309 & 2.9499 & 3.1128 & TRN \\
\hline CHEMBL1447487 & 688309 & 2.9499 & 3.2203 & TRN \\
\hline CHEMBL1608301 & 688309 & 5.8047 & 5.3849 & TRN \\
\hline CHEMBL1310137 & 688309 & 2.9499 & 2.3476 & TRN \\
\hline CHEMBL3211413 & 688309 & 5.8097 & 3.753 & TRN \\
\hline CHEMBL1405269 & 688309 & 2.9499 & 3.3891 & TRN \\
\hline CHEMBL1308965 & 688309 & 2.9499 & 3.8054 & TRN \\
\hline CHEMBL1395916 & 688309 & 2.9499 & 2.483 & TRN \\
\hline CHEMBL1404084 & 688309 & 2.9499 & 3.2738 & TRN \\
\hline CHEMBL225951 & 688309 & 5.7228 & 5.3334 & TRN \\
\hline CHEMBL1373335 & 688309 & 2.9499 & 3.6607 & TST \\
\hline CHEMBL1383162 & 688309 & 2.9499 & 3.4846 & TST \\
\hline CHEMBL1566445 & 688309 & 2.9499 & 3.6634 & TRN \\
\hline CHEMBL1928491 & 688309 & 6.5952 & 5.2991 & TRN \\
\hline CHEMBL1364277 & 688309 & 2.9499 & 3.5604 & TRN \\
\hline
\end{tabular}




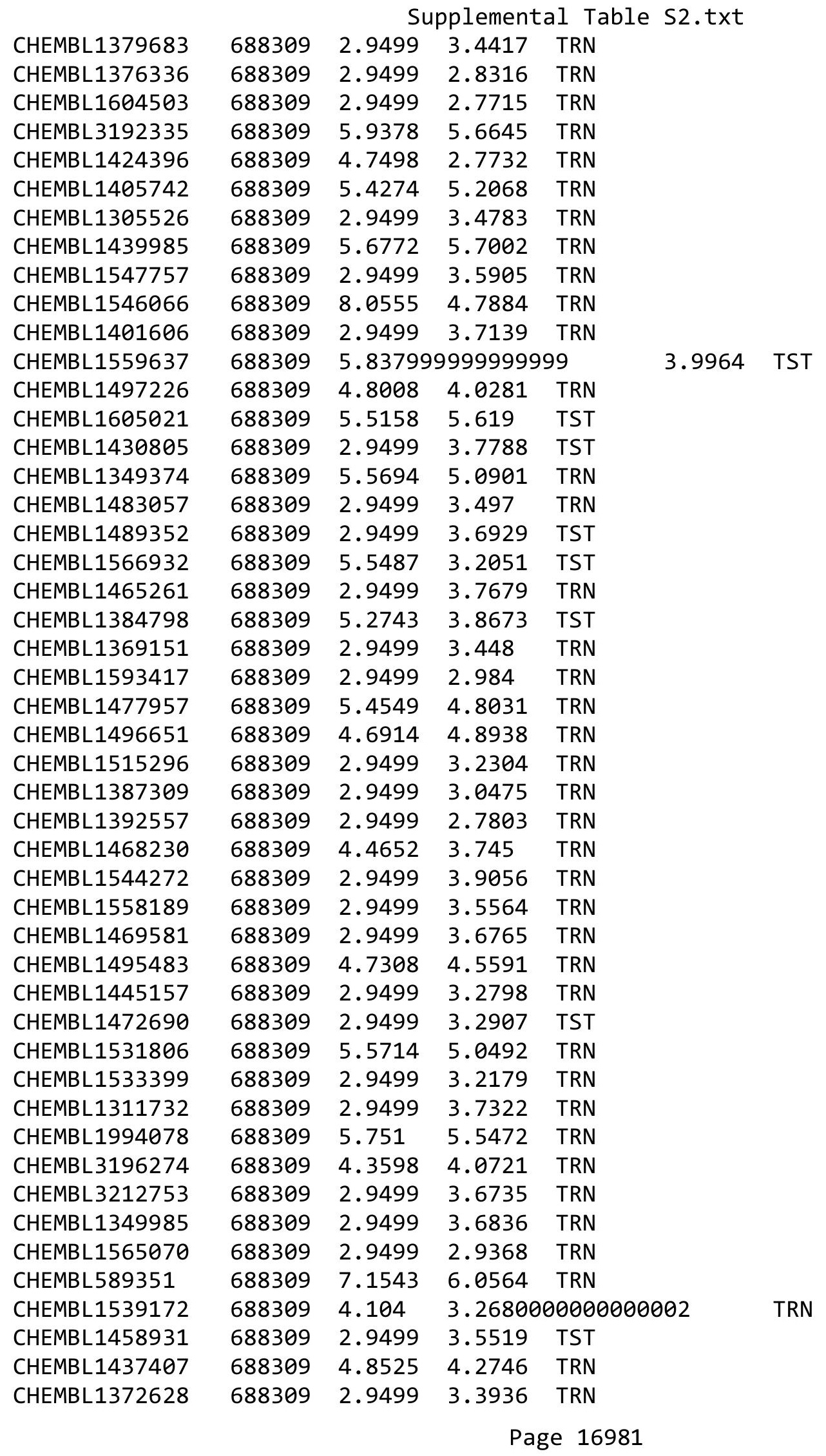




\begin{tabular}{|c|c|c|c|c|c|}
\hline & & \multicolumn{4}{|c|}{ Supplemental Table S2.txt } \\
\hline CHEMBL1548494 & 688309 & 2.9499 & 3.1334 & TRN & \\
\hline CHEMBL1346564 & 688309 & 5.3159 & 5.0091 & TRN & \\
\hline CHEMBL1452409 & 688309 & 5.9792 & 5.4986 & TRN & \\
\hline CHEMBL1337402 & 688309 & 2.9499 & 4.4574 & TST & \\
\hline CHEMBL1333973 & 688309 & 2.9499 & 3.1887 & TRN & \\
\hline CHEMBL1390088 & 688309 & 2.9499 & 3.7625 & TRN & \\
\hline CHEMBL1493777 & 688309 & 2.9499 & 2.845 & TRN & \\
\hline CHEMBL1548731 & 688309 & 4.3855 & 3.2821 & TST & \\
\hline CHEMBL1975825 & 688309 & 2.9499 & 3.0977 & TRN & \\
\hline CHEMBL1532939 & 688309 & 2.9499 & 3.8971 & TST & \\
\hline CHEMBL1604565 & 688309 & 2.9499 & 2.4967 & TRN & \\
\hline CHEMBL1610821 & 688309 & 6.1035 & 3.6296 & TST & \\
\hline CHEMBL3207589 & 688309 & 4.7571 & 2.9928 & TST & \\
\hline CHEMBL1453673 & 688309 & 2.9499 & 3.7549 & TST & \\
\hline CHEMBL1539252 & 688309 & 2.9499 & 3.4654 & TRN & \\
\hline CHEMBL1498744 & 688309 & 2.9499 & 3.8007 & TRN & \\
\hline CHEMBL1312760 & 688309 & 2.9499 & 3.5021 & TRN & \\
\hline CHEMBL1470247 & 688309 & 4.8184 & 3.1449 & TRN & \\
\hline CHEMBL1408291 & 688309 & 2.9499 & 3.5397 & TST & \\
\hline CHEMBL1578917 & 688309 & 2.9499 & 2.97 & TRN & \\
\hline CHEMBL1444802 & 688309 & 2.9499 & 2.8062 & TRN & \\
\hline CHEMBL1588813 & 688309 & 4.1505 & 3.23100 & 00000000003 & TST \\
\hline CHEMBL1470568 & 688309 & 5.9197 & 5.4803 & TRN & \\
\hline CHEMBL1533727 & 688309 & 2.9499 & 3.0301 & TRN & \\
\hline CHEMBL1336277 & 688309 & 5.3961 & 5.6397 & TRN & \\
\hline CHEMBL1480613 & 688309 & 5.649 & 6.5445 & TRN & \\
\hline CHEMBL1310341 & 688309 & 7.1543 & 4.9707 & TRN & \\
\hline CHEMBL1446415 & 688309 & 2.9499 & 3.4157 & TRN & \\
\hline CHEMBL1557678 & 688309 & 5.1538 & 5.3097 & TRN & \\
\hline CHEMBL1345944 & 688309 & 2.9499 & 4.148 & TST & \\
\hline CHEMBL1438962 & 688309 & 2.9499 & 3.5321 & TRN & \\
\hline CHEMBL1450158 & 688309 & 2.9499 & 3.2384 & TRN & \\
\hline CHEMBL1605090 & 688309 & 2.9499 & 2.8685 & TRN & \\
\hline CHEMBL1428826 & 688309 & 2.9499 & 3.23 & TST & \\
\hline CHEMBL1400773 & 688309 & 2.9499 & 3.7308 & TRN & \\
\hline CHEMBL1332181 & 688309 & 2.9499 & 3.2845 & TRN & \\
\hline CHEMBL1583460 & 688309 & 5.0339 & 5.1801 & TRN & \\
\hline CHEMBL1503605 & 688309 & 2.9499 & 2.7958 & TRN & \\
\hline CHEMBL3196355 & 688309 & 2.9499 & 3.4302 & TRN & \\
\hline CHEMBL1397497 & 688309 & 2.9499 & 3.1229 & TRN & \\
\hline CHEMBL1541966 & 688309 & 4.6014 & 2.7925 & TRN & \\
\hline CHEMBL1458858 & 688309 & 4.5576 & 3.5993 & TRN & \\
\hline CHEMBL1340899 & 688309 & 2.9499 & 3.0753 & TRN & \\
\hline CHEMBL1518907 & 688309 & 4.0253 & 3.5479 & TRN & \\
\hline CHEMBL1578056 & 688309 & 2.9499 & 3.2128 & TST & \\
\hline CHEMBL1461383 & 688309 & 2.9499 & 2.5541 & TRN & \\
\hline CHEMBL1327226 & 688309 & 2.9499 & 2.8718 & TRN & \\
\hline CHEMBL1560675 & 688309 & 2.9499 & 3.6784 & TRN & \\
\hline
\end{tabular}




\begin{tabular}{|c|c|c|c|c|c|}
\hline \multicolumn{6}{|c|}{ Supplemental Table S2.txt } \\
\hline CHEMBL1524404 & 688309 & 2.9499 & 3.1935 & TRN & \\
\hline CHEMBL1498862 & 688309 & 2.9499 & 3.1545 & TST & \\
\hline CHEMBL1569489 & 688309 & 8.0555 & 5.4369 & TRN & \\
\hline CHEMBL1572731 & 688309 & 2.9499 & 3.1035 & TRN & \\
\hline CHEMBL1431834 & 688309 & 2.9499 & 3.59899 & 99999999998 & TRN \\
\hline CHEMBL1309669 & 688309 & 2.9499 & 4.1663 & TRN & \\
\hline CHEMBL1596719 & 688309 & 5.3412 & 5.4845 & TRN & \\
\hline CHEMBL1522362 & 688309 & 2.9499 & 3.4528 & TRN & \\
\hline CHEMBL1301753 & 688309 & 2.9499 & 3.2655 & TRN & \\
\hline CHEMBL1360741 & 688309 & 2.9499 & 3.5128 & TRN & \\
\hline CHEMBL3199298 & 688309 & 5.279 & 5.8612 & TRN & \\
\hline CHEMBL1429929 & 688309 & 4.8502 & 3.9562 & TRN & \\
\hline CHEMBL3190132 & 688309 & 4.9623 & 5.57600 & 00000000005 & TRN \\
\hline CHEMBL1369683 & 688309 & 2.9499 & 3.8132 & TRN & \\
\hline CHEMBL1409939 & 688309 & 5.3589 & 5.0503 & TRN & \\
\hline CHEMBL1512743 & 688309 & 2.9499 & 2.67 & TRN & \\
\hline CHEMBL1342574 & 688309 & 5.2959 & 3.4361 & TST & \\
\hline CHEMBL1392904 & 688309 & 2.9499 & 3.4288 & TST & \\
\hline CHEMBL1362496 & 688309 & 2.9499 & 3.9882 & TRN & \\
\hline CHEMBL1502328 & 688309 & 2.9499 & 3.4741 & TRN & \\
\hline CHEMBL1307776 & 688309 & 3.9553 & 4.646 & TRN & \\
\hline CHEMBL1568027 & 688309 & 2.9499 & 3.1004 & TRN & \\
\hline CHEMBL1572127 & 688309 & 5.7796 & 4.2139 & TRN & \\
\hline CHEMBL1403415 & 688309 & 2.9499 & 3.3826 & TRN & \\
\hline CHEMBL 2005141 & 688309 & 2.9499 & 3.6546 & TST & \\
\hline CHEMBL1500900 & 688309 & 2.9499 & 3.7259 & TRN & \\
\hline CHEMBL1349067 & 688309 & 5.3995 & 4.8046 & TRN & \\
\hline CHEMBL1316069 & 688309 & 2.9499 & 2.6618 & TRN & \\
\hline CHEMBL1419515 & 688309 & 4.0276 & 2.9053 & TRN & \\
\hline CHEMBL3196633 & 688309 & 4.9712 & 4.7437 & TRN & \\
\hline CHEMBL1431049 & 688309 & 2.9499 & 3.0254 & TRN & \\
\hline CHEMBL1303429 & 688309 & 4.8247 & 4.5927 & TRN & \\
\hline CHEMBL1581845 & 688309 & 4.8304 & 4.0705 & TRN & \\
\hline CHEMBL1368148 & 688309 & 5.0392 & 3.7589 & TRN & \\
\hline CHEMBL1547928 & 688309 & 2.9499 & 2.9365 & TRN & \\
\hline CHEMBL1420035 & 688309 & 2.9499 & 3.082 & TRN & \\
\hline CHEMBL1520766 & 688309 & 4.2348 & 3.735 & TRN & \\
\hline CHEMBL1479010 & 688309 & 5.5918 & 5.0929 & TRN & \\
\hline CHEMBL1464533 & 688309 & 2.9499 & 2.9434 & TRN & \\
\hline CHEMBL1601293 & 688309 & 5.6863 & 5.5281 & TRN & \\
\hline CHEMBL3211417 & 688309 & 2.9499 & 3.412 & TRN & \\
\hline CHEMBL1542014 & 688309 & 4.8033 & 3.2068 & TRN & \\
\hline CHEMBL1570806 & 688309 & 2.9499 & 3.2223 & TST & \\
\hline CHEMBL1466375 & 688309 & 4.766 & 3.3132 & TST & \\
\hline CHEMBL1312155 & 688309 & 2.9499 & 3.0723 & TRN & \\
\hline CHEMBL1572014 & 688309 & 2.9499 & 3.0781 & TRN & \\
\hline CHEMBL1477386 & 688309 & 4.71 & 3.1915 & TRN & \\
\hline CHEMBL1565621 & 688309 & 4.8014 & 3.5861 & TRN & \\
\hline
\end{tabular}




\begin{tabular}{|c|c|c|c|c|c|}
\hline & & \multicolumn{4}{|c|}{ Supplemental Table s2.txt } \\
\hline CHEMBL1523955 & 688309 & 5.2389 & 5.739 & TRN & \\
\hline CHEMBL1400143 & 688309 & 5.6209 & 5.4618 & TRN & \\
\hline CHEMBL1491075 & 688309 & 2.9499 & 3.1645 & TRN & \\
\hline CHEMBL1490043 & 688309 & 5.6998 & 5.4477 & TRN & \\
\hline CHEMBL1330076 & 688309 & 2.9499 & 3.8096 & TRN & \\
\hline CHEMBL1423924 & 688309 & 2.9499 & 3.91300 & 00000000003 & TRN \\
\hline CHEMBL1482251 & 688309 & 2.9499 & 3.0556 & TRN & \\
\hline CHEMBL1464330 & 688309 & 2.9499 & 3.5305 & TST & \\
\hline CHEMBL1482896 & 688309 & 2.9499 & 5.1811 & TRN & \\
\hline CHEMBL1582610 & 688309 & 2.9499 & 2.8755 & TRN & \\
\hline CHEMBL1516626 & 688309 & 2.9499 & 3.1623 & TRN & \\
\hline CHEMBL1305810 & 688309 & 2.9499 & 3.6704 & TST & \\
\hline CHEMBL1539359 & 688309 & 6.6308 & 6.5437 & TRN & \\
\hline CHEMBL1547350 & 688309 & 2.9499 & 2.9946 & TRN & \\
\hline CHEMBL1380496 & 688309 & 2.9499 & 2.9465 & TRN & \\
\hline CHEMBL1527176 & 688309 & 5.1317 & 5.3482 & TRN & \\
\hline CHEMBL1346239 & 688309 & 2.9499 & 3.6842 & TRN & \\
\hline CHEMBL3198344 & 688309 & 5.6223 & 3.8291 & TRN & \\
\hline CHEMBL1452854 & 688309 & 2.9499 & 3.0237 & TRN & \\
\hline CHEMBL1399855 & 688309 & 2.9499 & 3.2405 & TST & \\
\hline CHEMBL1460127 & 688309 & 5.4496 & 3.799 & TRN & \\
\hline CHEMBL1504094 & 688309 & 2.9499 & 3.472 & TRN & \\
\hline CHEMBL112115 & 688309 & 2.9499 & 4.8521 & TRN & \\
\hline CHEMBL1497097 & 688309 & 5.9027 & 3.3933 & TST & \\
\hline CHEMBL1505074 & 688309 & 2.9499 & 2.9129 & TRN & \\
\hline CHEMBL1458626 & 688309 & 2.9499 & 2.7083 & TRN & \\
\hline CHEMBL1604913 & 688309 & 5.2311 & 3.162 & TST & \\
\hline CHEMBL1383312 & 688309 & 6.6819 & 5.9502 & TRN & \\
\hline CHEMBL1392444 & 688309 & 2.9499 & 3.3112 & TRN & \\
\hline CHEMBL1345918 & 688309 & 2.9499 & 3.9422 & TST & \\
\hline CHEMBL1408083 & 688309 & 2.9499 & 2.7171 & TRN & \\
\hline CHEMBL1420307 & 688309 & 2.9499 & 3.9066 & TRN & \\
\hline CHEMBL1404803 & 688309 & 2.9499 & 2.4997 & TRN & \\
\hline CHEMBL1490104 & 688309 & 2.9499 & 3.8083 & TRN & \\
\hline CHEMBL1517275 & 688309 & 2.9499 & 2.7493 & TRN & \\
\hline CHEMBL1483581 & 688309 & 2.9499 & 3.7605 & TRN & \\
\hline CHEMBL1972405 & 688309 & 5.3412 & 5.1429 & TRN & \\
\hline CHEMBL1501902 & 688309 & 2.9499 & 3.6411 & TRN & \\
\hline CHEMBL1349863 & 688309 & 4.9364 & 5.268 & TRN & \\
\hline CHEMBL1403141 & 688309 & 2.9499 & 3.6957 & TRN & \\
\hline CHEMBL3189629 & 688309 & 5.8794 & 5.2293 & TRN & \\
\hline CHEMBL1314349 & 688309 & 2.9499 & 3.0633 & TRN & \\
\hline CHEMBL1504553 & 688309 & 2.9499 & 3.2262 & TRN & \\
\hline CHEMBL1573366 & 688309 & 5.4725 & 5.6262 & TRN & \\
\hline CHEMBL1326128 & 688309 & 2.9499 & 3.66899 & 99999999996 & TRN \\
\hline CHEMBL1451032 & 688309 & 2.9499 & 3.8424 & TST & \\
\hline CHEMBL1438419 & 688309 & 2.9499 & 3.4187 & TST & \\
\hline CHEMBL1524978 & 688309 & 2.9499 & 3.4179 & TRN & \\
\hline
\end{tabular}


Supplemental Table S2.txt

\begin{tabular}{|c|c|c|c|c|c|}
\hline CHEMBL1537594 & 688309 & 4.7297 & 2.5543 & TRN & \\
\hline CHEMBL1330058 & 688309 & 6.3233 & 6.0085 & TRN & \\
\hline CHEMBL1560223 & 688309 & 5.4604 & 5.6059 & TRN & \\
\hline CHEMBL1444779 & 688309 & 2.9499 & 3.1938 & TRN & \\
\hline CHEMBL1452108 & 688309 & 2.9499 & 3.6068 & TRN & \\
\hline CHEMBL1990529 & 688309 & 2.9499 & 3.3432 & TRN & \\
\hline CHEMBL3190377 & 688309 & 4.8283 & 3.3579 & TRN & \\
\hline CHEMBL1471899 & 688309 & 5.5399 & 4.726 & TST & \\
\hline CHEMBL1412754 & 688309 & 2.9499 & 3.2163 & TRN & \\
\hline CHEMBL34137 & 688309 & 5.9101 & 4.4883 & TRN & \\
\hline CHEMBL1466997 & 688309 & 5.3588 & 5.0091 & TRN & \\
\hline CHEMBL1572749 & 688309 & 4.9179 & 5.1457 & TRN & \\
\hline CHEMBL1502654 & 688309 & 2.9499 & 3.158 & TRN & \\
\hline CHEMBL1974563 & 688309 & 5.4217 & 5.71899 & 9999999999 & TRN \\
\hline CHEMBL1553597 & 688309 & 2.9499 & 2.7611 & TRN & \\
\hline CHEMBL1575068 & 688309 & 2.9499 & 2.8553 & TRN & \\
\hline CHEMBL1527992 & 688309 & 5.5016 & 5.865 & TST & \\
\hline CHEMBL1587018 & 688309 & 5.8918 & 5.8177 & TRN & \\
\hline CHEMBL1336241 & 688309 & 2.9499 & 3.1241 & TRN & \\
\hline CHEMBL1586325 & 688309 & 4.3306 & 3.4406 & TRN & \\
\hline CHEMBL1378362 & 688309 & 2.9499 & 2.9654 & TRN & \\
\hline CHEMBL1480031 & 688309 & 5.4436 & 4.3171 & TRN & \\
\hline CHEMBL1543209 & 688309 & 4.8123 & 3.4018 & TRN & \\
\hline CHEMBL1439343 & 688309 & 2.9499 & 3.4389 & TRN & \\
\hline CHEMBL3199673 & 688309 & 6.7696 & 6.6567 & TRN & \\
\hline CHEMBL1980658 & 688309 & 6.8601 & 5.7401 & TRN & \\
\hline CHEMBL1596334 & 688309 & 2.9499 & 3.6094 & TRN & \\
\hline CHEMBL1383991 & 688309 & 5.2042 & 5.1769 & TRN & \\
\hline CHEMBL1501609 & 688309 & 2.9499 & 3.4921 & TST & \\
\hline CHEMBL1540173 & 688309 & 2.9499 & 3.8873 & TRN & \\
\hline CHEMBL1445241 & 688309 & 2.9499 & 3.4362 & TRN & \\
\hline CHEMBL3190636 & 688309 & 5.2809 & 5.5868 & TRN & \\
\hline CHEMBL 2000321 & 688309 & 5.5265 & 4.697 & TRN & \\
\hline CHEMBL1986805 & 688309 & 5.9389 & 5.3262 & TRN & \\
\hline CHEMBL3199254 & 688309 & 4.9998 & 5.5679 & TRN & \\
\hline CHEMBL1404195 & 688309 & 2.9499 & 3.2935 & TRN & \\
\hline CHEMBL3210689 & 688309 & 4.8599 & 3.9547 & TST & \\
\hline CHEMBL1595743 & 688309 & 2.9499 & 2.8758 & TRN & \\
\hline CHEMBL1424060 & 688309 & 5.1509 & 4.7072 & TRN & \\
\hline CHEMBL1330584 & 688309 & 2.9499 & 3.3867 & TRN & \\
\hline CHEMBL1322539 & 688309 & 2.9499 & 3.9214 & TRN & \\
\hline CHEMBL1398602 & 688309 & 5.7945 & 5.6627 & TRN & \\
\hline CHEMBL1482341 & 688309 & 2.9499 & 3.5927 & TRN & \\
\hline CHEMBL1506522 & 688309 & 2.9499 & 3.5164 & TRN & \\
\hline CHEMBL1560698 & 688309 & 2.9499 & 2.842 & TST & \\
\hline CHEMBL1445248 & 688309 & 2.9499 & 3.3201 & TRN & \\
\hline CHEMBL1405526 & 688309 & 2.9499 & 3.3948 & TRN & \\
\hline CHEMBL1570658 & 688309 & 4.5731 & 4.1858 & TRN & \\
\hline
\end{tabular}




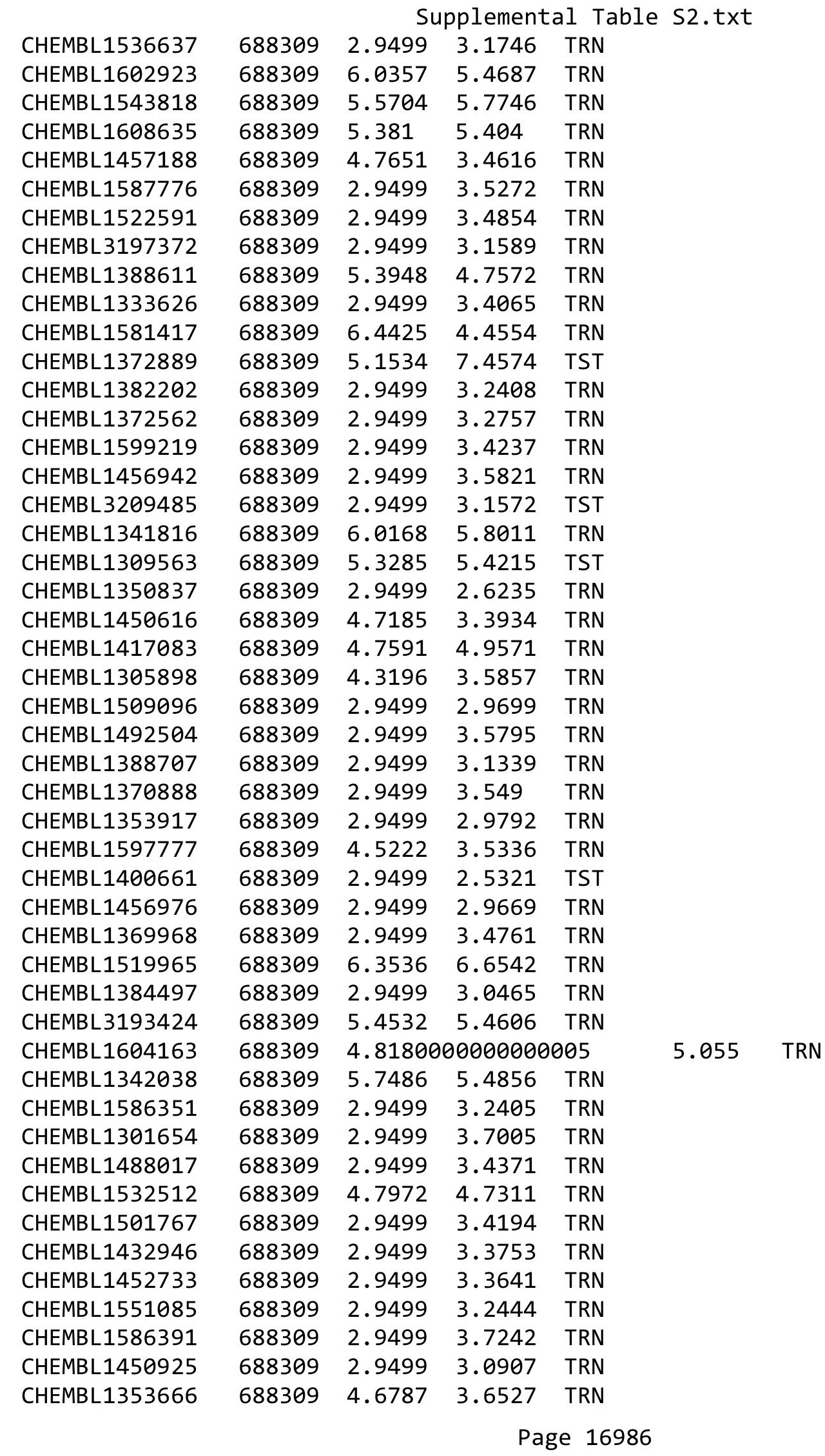




\begin{tabular}{|c|c|c|c|c|c|}
\hline & & \multicolumn{4}{|c|}{ Supplemental Table S2.txt } \\
\hline CHEMBL1459024 & 688309 & 2.9499 & 3.3395 & TRN & \\
\hline CHEMBL1387417 & 688309 & 2.9499 & 3.3955 & TST & \\
\hline CHEMBL1444534 & 688309 & 2.9499 & 3.2964 & TRN & \\
\hline CHEMBL1523854 & 688309 & 4.8299 & 2.6728 & TRN & \\
\hline CHEMBL1485577 & 688309 & 4.6022 & 4.8205 & TRN & \\
\hline CHEMBL1376218 & 688309 & 2.9499 & 2.84899 & 99999999998 & TRN \\
\hline CHEMBL1790005 & 688309 & 4.7219 & 4.2367 & TST & \\
\hline CHEMBL1460048 & 688309 & 2.9499 & 3.1889 & TRN & \\
\hline CHEMBL1427156 & 688309 & 2.9499 & 3.1099 & TRN & \\
\hline CHEMBL1537144 & 688309 & 2.9499 & 3.33600 & 00000000003 & TRN \\
\hline CHEMBL1302515 & 688309 & 2.9499 & 4.1968 & TRN & \\
\hline CHEMBL3190606 & 688309 & 5.9931 & 4.8487 & TRN & \\
\hline CHEMBL1412749 & 688309 & 2.9499 & 3.4824 & TRN & \\
\hline CHEMBL1557637 & 688309 & 6.6021 & 4.0331 & TRN & \\
\hline CHEMBL3212828 & 688309 & 2.9499 & 3.27399 & 99999999996 & TRN \\
\hline CHEMBL1467845 & 688309 & 5.5662 & 3.3142 & TRN & \\
\hline CHEMBL1301440 & 688309 & 2.9499 & 3.3337 & TRN & \\
\hline CHEMBL1510591 & 688309 & 2.9499 & 3.4585 & TRN & \\
\hline CHEMBL1401676 & 688309 & 6.0283 & 5.5093 & TRN & \\
\hline CHEMBL1368422 & 688309 & 2.9499 & 3.5315 & TRN & \\
\hline CHEMBL1554376 & 688309 & 2.9499 & 3.0048 & TRN & \\
\hline CHEMBL3196827 & 688309 & 5.2695 & 5.3129 & TRN & \\
\hline CHEMBL1339206 & 688309 & 2.9499 & 4.53600 & 00000000005 & TRN \\
\hline CHEMBL1377421 & 688309 & 2.9499 & 3.2515 & TRN & \\
\hline CHEMBL1414030 & 688309 & 2.9499 & 3.017 & TST & \\
\hline CHEMBL1543741 & 688309 & 4.7968 & 3.4561 & TRN & \\
\hline CHEMBL1303948 & 688309 & 5.8342 & 5.3246 & TRN & \\
\hline CHEMBL1424873 & 688309 & 2.9499 & 2.8628 & TRN & \\
\hline CHEMBL1512251 & 688309 & 2.9499 & 3.2499 & TRN & \\
\hline CHEMBL1403065 & 688309 & 2.9499 & 4.4692 & TRN & \\
\hline CHEMBL1498167 & 688309 & 2.9499 & 3.679 & TRN & \\
\hline CHEMBL1534065 & 688309 & 2.9499 & 3.4683 & TST & \\
\hline CHEMBL1587713 & 688309 & 4.5404 & 3.7473 & TST & \\
\hline CHEMBL1338085 & 688309 & 5.9219 & 5.2957 & TRN & \\
\hline CHEMBL1610058 & 688309 & 2.9499 & 3.2254 & TRN & \\
\hline CHEMBL1508499 & 688309 & 2.9499 & 2.9894 & TRN & \\
\hline CHEMBL1459468 & 688309 & 6.7077 & 6.2421 & TRN & \\
\hline CHEMBL1560954 & 688309 & 5.0374 & 3.2718 & TST & \\
\hline CHEMBL1362488 & 688309 & 2.9499 & 3.3846 & TST & \\
\hline CHEMBL3195761 & 688309 & 5.2803 & 5.8064 & TRN & \\
\hline CHEMBL1613662 & 688309 & 2.9499 & 3.1397 & TRN & \\
\hline CHEMBL1357378 & 688309 & 2.9499 & 3.0982 & TRN & \\
\hline CHEMBL1535200 & 688309 & 2.9499 & 3.3772 & TRN & \\
\hline CHEMBL1612413 & 688309 & 2.9499 & 3.4049 & TRN & \\
\hline CHEMBL1477100 & 688309 & 5.9666 & 4.8472 & TRN & \\
\hline CHEMBL1376224 & 688309 & 2.9499 & 3.3699 & TRN & \\
\hline CHEMBL3191048 & 688309 & 4.0722 & 5.6308 & TRN & \\
\hline CHEMBL1413292 & 688309 & 2.9499 & 3.4707 & TST & \\
\hline
\end{tabular}




\begin{tabular}{|c|c|c|c|c|c|}
\hline \multicolumn{6}{|c|}{ Supplemental Table S2.txt } \\
\hline CHEMBL1428482 & 688309 & 2.9499 & 3.4083 & TST & \\
\hline CHEMBL1465831 & 688309 & 2.9499 & 3.5093 & TRN & \\
\hline CHEMBL1593386 & 688309 & 2.9499 & 3.199 & TRN & \\
\hline CHEMBL1257013 & 688309 & 6.0491 & 6.2046 & TRN & \\
\hline CHEMBL1547361 & 688309 & 2.9499 & 3.105 & TRN & \\
\hline CHEMBL1302889 & 688309 & 5.0908 & 5.088 & TRN & \\
\hline CHEMBL1582460 & 688309 & 4.6665 & 3.5484 & TRN & \\
\hline CHEMBL1996068 & 688309 & 5.1858 & 5.7592 & TRN & \\
\hline CHEMBL3209305 & 688309 & 4.6782 & 3.657 & TRN & \\
\hline CHEMBL1352089 & 688309 & 2.9499 & 3.0733 & TST & \\
\hline CHEMBL171279 & 688309 & 2.9499 & 2.8093 & TRN & \\
\hline CHEMBL1304314 & 688309 & 2.9499 & 3.4036 & TRN & \\
\hline CHEMBL1604317 & 688309 & 2.9499 & 2.9377 & TRN & \\
\hline CHEMBL1580081 & 688309 & 2.9499 & 3.37899 & 99999999996 & TRN \\
\hline CHEMBL1409752 & 688309 & 4.7482 & 3.049 & TRN & \\
\hline CHEMBL3194638 & 688309 & 6.0904 & 4.7456 & TST & \\
\hline CHEMBL1461365 & 688309 & 2.9499 & 3.2236 & TRN & \\
\hline CHEMBL1986443 & 688309 & 5.2619 & 5.7733 & TST & \\
\hline CHEMBL 3197158 & 688309 & 2.9499 & 2.9699 & TRN & \\
\hline CHEMBL1524038 & 688309 & 4.9437 & 5.846 & TRN & \\
\hline CHEMBL1431368 & 688309 & 2.9499 & 3.5517 & TRN & \\
\hline CHEMBL1455604 & 688309 & 2.9499 & 2.8681 & TRN & \\
\hline CHEMBL1493607 & 688309 & 2.9499 & 3.6443 & TST & \\
\hline CHEMBL1558310 & 688309 & 5.1985 & 4.7835 & TRN & \\
\hline CHEMBL1329224 & 688309 & 4.3981 & 3.9459 & TRN & \\
\hline CHEMBL1519619 & 688309 & 5.3705 & 4.1751 & TST & \\
\hline CHEMBL1584490 & 688309 & 2.9499 & 3.01 & TRN & \\
\hline CHEMBL1360977 & 688309 & 4.9795 & 5.13700 & 00000000005 & TRN \\
\hline CHEMBL1586559 & 688309 & 2.9499 & 3.6448 & TRN & \\
\hline CHEMBL1598863 & 688309 & 2.9499 & 3.5371 & TRN & \\
\hline CHEMBL1517492 & 688309 & 2.9499 & 4.371 & TST & \\
\hline CHEMBL1325549 & 688309 & 5.8242 & 5.5535 & TRN & \\
\hline CHEMBL1365502 & 688309 & 2.9499 & 3.3385 & TRN & \\
\hline CHEMBL1544685 & 688309 & 5.314 & 4.2809 & TRN & \\
\hline CHEMBL1340758 & 688309 & 2.9499 & 3.2529 & TRN & \\
\hline CHEMBL1313232 & 688309 & 4.9003 & 3.5261 & TRN & \\
\hline CHEMBL1454313 & 688309 & 2.9499 & 3.0696 & TRN & \\
\hline CHEMBL1411333 & 688309 & 5.7275 & 3.7046 & TRN & \\
\hline CHEMBL1423749 & 688309 & 2.9499 & 3.0624 & TST & \\
\hline CHEMBL1374025 & 688309 & 2.9499 & 3.7048 & TRN & \\
\hline CHEMBL1375370 & 688309 & 2.9499 & 3.0156 & TST & \\
\hline CHEMBL546344 & 688309 & 5.6258 & 6.5483 & TRN & \\
\hline CHEMBL1313428 & 688309 & 5.5068 & 5.1504 & TRN & \\
\hline CHEMBL1453996 & 688309 & 5.7788 & 6.0665 & TRN & \\
\hline CHEMBL1492671 & 688309 & 6.1255 & 5.8606 & TRN & \\
\hline CHEMBL1435120 & 688309 & 7.1543 & 6.0633 & TRN & \\
\hline CHEMBL1471597 & 688309 & 2.9499 & 3.0432 & TRN & \\
\hline CHEMBL1388041 & 688309 & 2.9499 & 2.9834 & TRN & \\
\hline
\end{tabular}




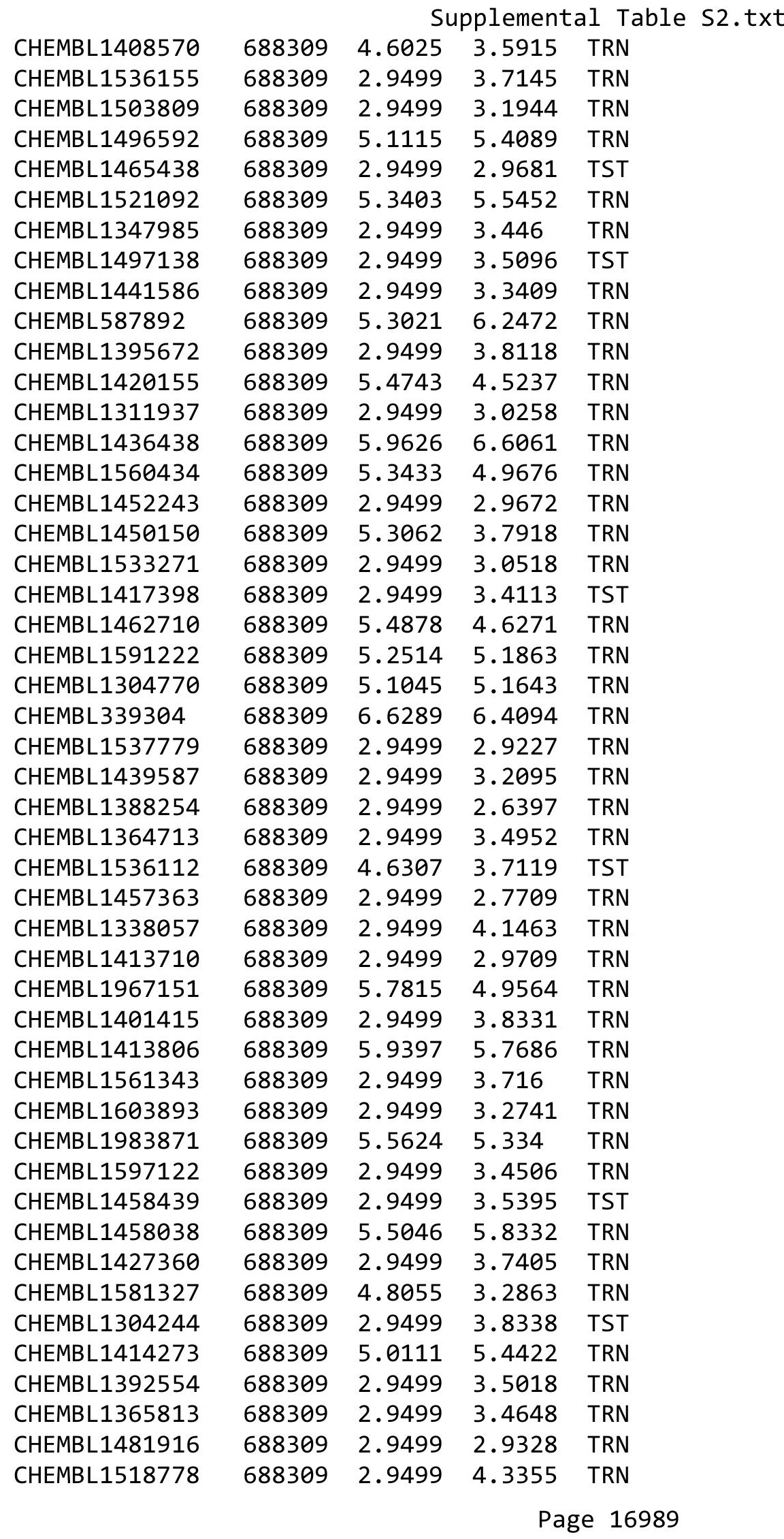




\begin{tabular}{|c|c|c|c|c|}
\hline \multicolumn{5}{|c|}{ Supplemental Tab. } \\
\hline CHEMBL1547895 & 688309 & 2.9499 & 3.2473 & TRN \\
\hline CHEMBL 1578636 & 688309 & 2.9499 & 2.3669 & TRN \\
\hline CHEMBL1572907 & 688309 & 2.9499 & 3.0747 & TRN \\
\hline CHEMBL1516719 & 688309 & 2.9499 & 2.225 & TST \\
\hline CHEMBL1585837 & 688309 & 2.9499 & 3.2942 & TRN \\
\hline CHEMBL1529461 & 688309 & 2.9499 & 2.4611 & TRN \\
\hline CHEMBL1533279 & 688309 & 4.6673 & 3.4695 & TST \\
\hline CHEMBL1486494 & 688309 & 2.9499 & 3.273 & TST \\
\hline CHEMBL1392877 & 688309 & 2.9499 & 3.23 & TRN \\
\hline CHEMBL1332325 & 688309 & 5.3641 & 3.8213 & TRN \\
\hline CHEMBL1497777 & 688309 & 2.9499 & 3.1273 & TST \\
\hline CHEMBL1334410 & 688309 & 5.1692 & 3.3611 & TRN \\
\hline CHEMBL1364120 & 688309 & 5.0032 & 4.7889 & TRN \\
\hline CHEMBL1508268 & 688309 & 5.4614 & 4.5819 & TRN \\
\hline CHEMBL1464775 & 688309 & 2.9499 & 3.4751 & TRN \\
\hline CHEMBL1424797 & 688309 & 2.9499 & 3.4415 & TST \\
\hline CHEMBL3190246 & 688309 & 4.5151 & 3.877 & TRN \\
\hline CHEMBL1571642 & 688309 & 2.9499 & 2.938 & TRN \\
\hline CHEMBL1603034 & 688309 & 4.6805 & 4.1937 & TRN \\
\hline CHEMBL1466584 & 688309 & 2.9499 & 3.3057 & TRN \\
\hline CHEMBL3208997 & 688309 & 4.6819 & 3.8932 & TRN \\
\hline CHEMBL3196809 & 688309 & 5.9504 & 6.3476 & TRN \\
\hline CHEMBL1347081 & 688309 & 2.9499 & 3.1387 & TRN \\
\hline CHEMBL1344399 & 688309 & 5.7916 & 5.1201 & TST \\
\hline CHEMBL1366593 & 688309 & 2.9499 & 3.7184 & TRN \\
\hline CHEMBL1495187 & 688309 & 2.9499 & 2.9646 & TRN \\
\hline CHEMBL1574879 & 688309 & 5.1977 & 5.6889 & TRN \\
\hline CHEMBL1427921 & 688309 & 2.9499 & 3.477 & TRN \\
\hline CHEMBL1418721 & 688309 & 2.9499 & 2.7209 & TRN \\
\hline CHEMBL1570531 & 688309 & 2.9499 & 3.46 & TRN \\
\hline CHEMBL1584473 & 688309 & 2.9499 & 3.065 & TRN \\
\hline CHEMBL3208326 & 688309 & 5.4503 & 3.8313 & TRN \\
\hline CHEMBL1497927 & 688309 & 5.16 & 4.5669 & TRN \\
\hline CHEMBL1404547 & 688309 & 5.704 & 5.018 & TRN \\
\hline CHEMBL1579042 & 688309 & 5.4113 & 5.093 & TRN \\
\hline CHEMBL1477473 & 688309 & 5.2456 & 5.0867 & TRN \\
\hline CHEMBL1978730 & 688309 & 5.1738 & 5.5885 & TRN \\
\hline CHEMBL1408307 & 688309 & 5.6702 & 4.7997 & TRN \\
\hline CHEMBL1493085 & 688309 & 2.9499 & 3.7228 & TRN \\
\hline CHEMBL1419433 & 688309 & 2.9499 & 2.9059 & TRN \\
\hline CHEMBL1336359 & 688309 & 2.9499 & 3.6278 & TRN \\
\hline CHEMBL1367229 & 688309 & 4.3008 & 3.0902 & TRN \\
\hline CHEMBL1428920 & 688309 & 2.9499 & 3.8666 & TST \\
\hline CHEMBL1480056 & 688309 & 7.1543 & 6.2423 & TRN \\
\hline CHEMBL1530379 & 688309 & 7.1543 & 5.6741 & TRN \\
\hline CHEMBL1339678 & 688309 & 5.8262 & 5.5007 & TRN \\
\hline CHEMBL1406458 & 688309 & 2.9499 & 3.2651 & TRN \\
\hline CHEMBL1985333 & 688309 & 5.8719 & 5.0335 & TRN \\
\hline
\end{tabular}




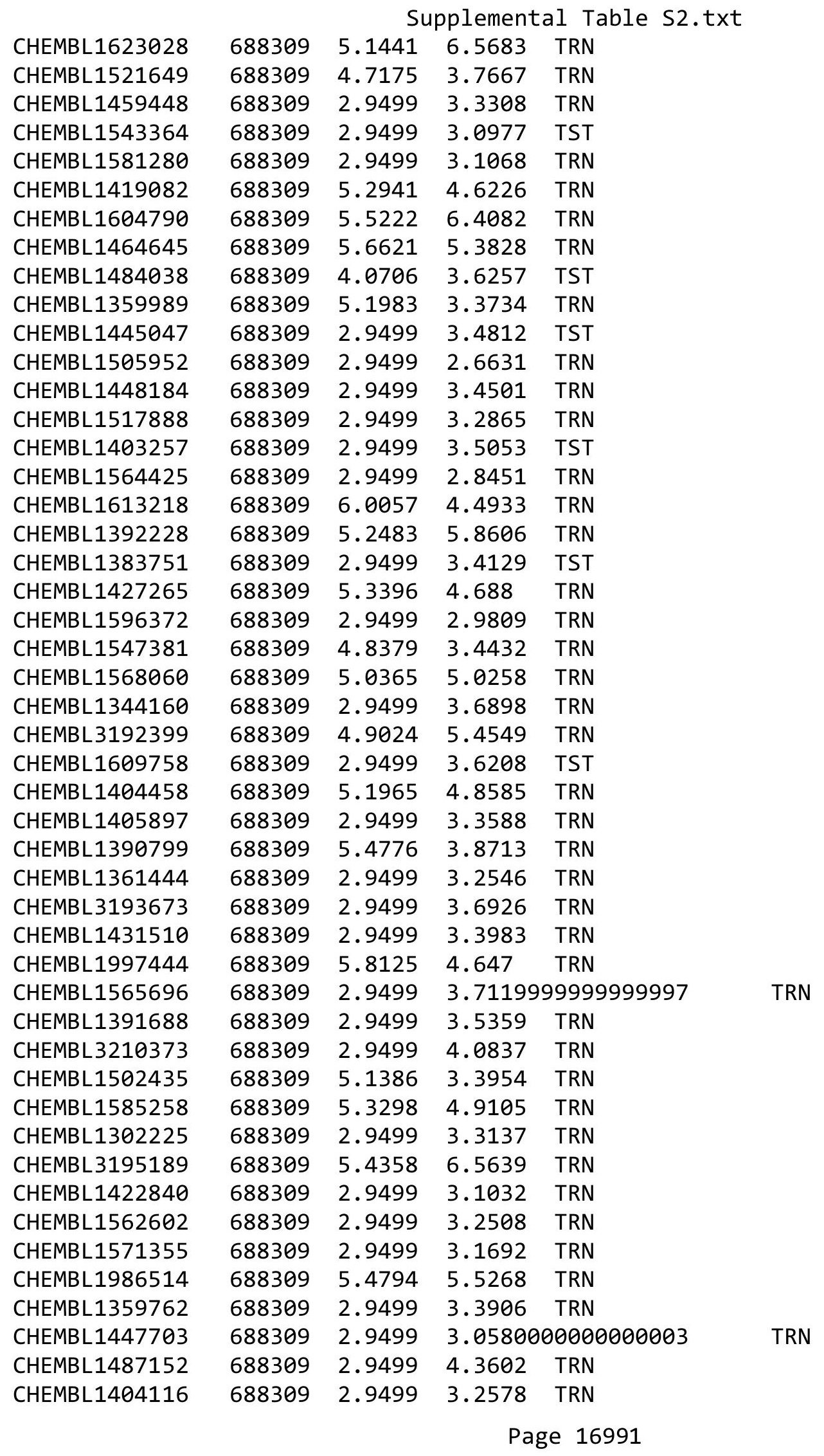




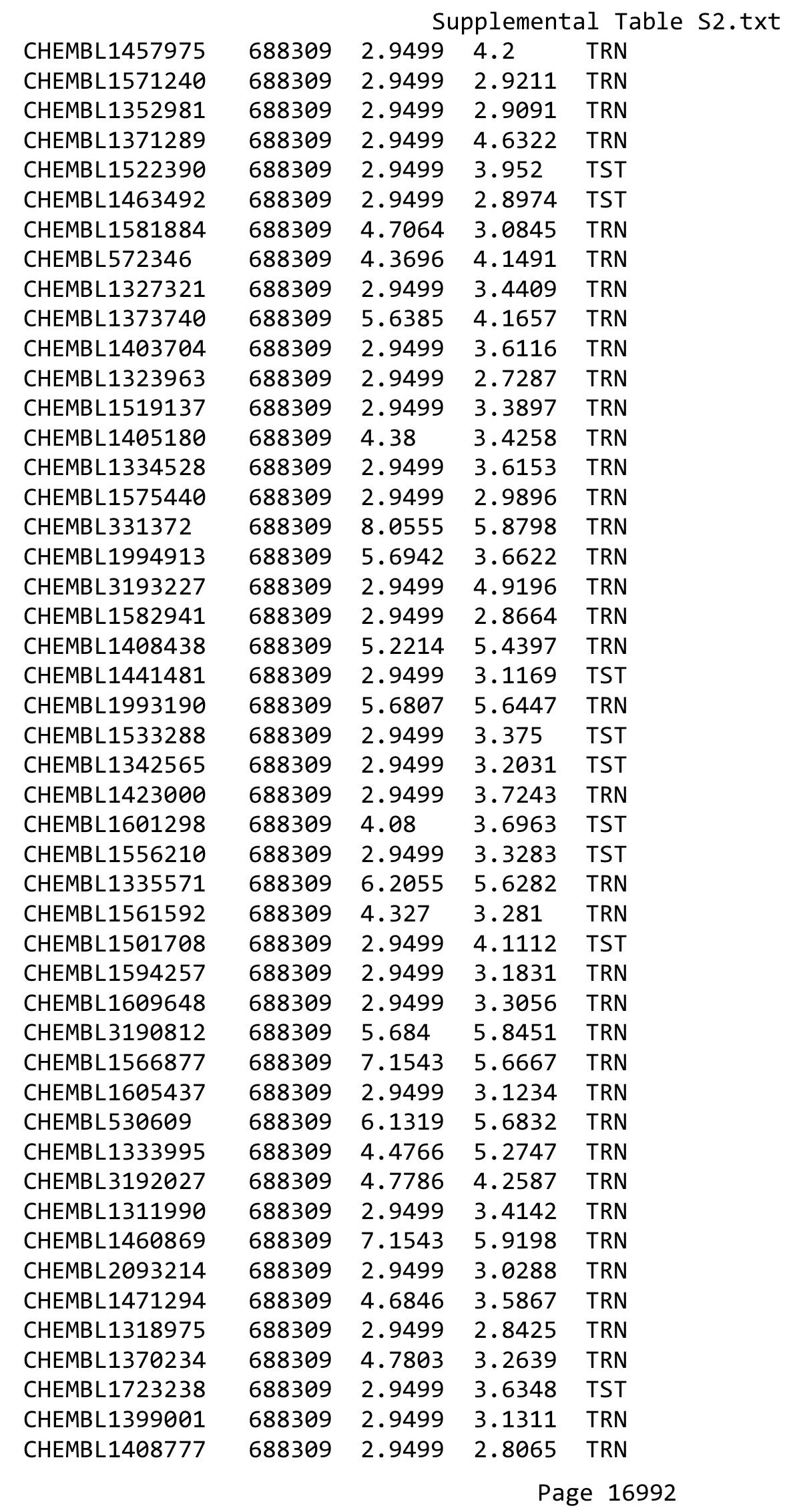




\begin{tabular}{|c|c|c|c|c|c|}
\hline \multirow[b]{2}{*}{ CHEMBL1353398 } & \multicolumn{5}{|c|}{ Supplemental Table s2.txt } \\
\hline & 688309 & 2.9499 & 3.1821 & TST & \\
\hline CHEMBL1380941 & 688309 & 4.8608 & 3.4138 & TRN & \\
\hline CHEMBL1330013 & 688309 & 2.9499 & 3.5627 & TST & \\
\hline CHEMBL1453723 & 688309 & 5.1415 & 5.52 & TRN & \\
\hline CHEMBL72135 & 688309 & 2.9499 & 3.8926 & TST & \\
\hline CHEMBL1444088 & 688309 & 2.9499 & 3.5341 & TRN & \\
\hline CHEMBL1484327 & 688309 & 6.475 & 5.8406 & TRN & \\
\hline CHEMBL1403024 & 688309 & 5.7953 & 5.3933 & TRN & \\
\hline CHEMBL1528665 & 688309 & 2.9499 & 3.1409 & TRN & \\
\hline CHEMBL1598628 & 688309 & 4.7317 & 3.25600 & 00000000002 & TRN \\
\hline CHEMBL1533771 & 688309 & 2.9499 & 3.4589 & TRN & \\
\hline CHEMBL1510748 & 688309 & 2.9499 & 3.4129 & TRN & \\
\hline CHEMBL1331429 & 688309 & 2.9499 & 3.3907 & TRN & \\
\hline CHEMBL1456224 & 688309 & 2.9499 & 2.87600 & 00000000003 & TRN \\
\hline CHEMBL1564893 & 688309 & 2.9499 & 2.8087 & TRN & \\
\hline CHEMBL1597941 & 688309 & 2.9499 & 2.9102 & TRN & \\
\hline CHEMBL1607729 & 688309 & 2.9499 & 3.5559 & TRN & \\
\hline CHEMBL1310785 & 688309 & 2.9499 & 3.0693 & TRN & \\
\hline CHEMBL1438213 & 688309 & 2.9499 & 3.2366 & TRN & \\
\hline CHEMBL1524929 & 688309 & 5.4023 & 6.00200 & 0000000001 & TRN \\
\hline CHEMBL1368846 & 688309 & 2.9499 & 3.5596 & TRN & \\
\hline CHEMBL1559801 & 688309 & 2.9499 & 2.9627 & TRN & \\
\hline CHEMBL1576682 & 688309 & 2.9499 & 3.2294 & TST & \\
\hline CHEMBL1348864 & 688309 & 2.9499 & 2.9673 & TST & \\
\hline CHEMBL1458138 & 688309 & 2.9499 & 3.2567 & TRN & \\
\hline CHEMBL1386322 & 688309 & 5.6144 & 5.1014 & TST & \\
\hline CHEMBL1579491 & 688309 & 2.9499 & 3.2364 & TST & \\
\hline CHEMBL1510527 & 688309 & 2.9499 & 3.2756 & TRN & \\
\hline CHEMBL1479930 & 688309 & 2.9499 & 3.0852 & TRN & \\
\hline CHEMBL1402519 & 688309 & 5.0678 & 3.2124 & TST & \\
\hline CHEMBL1420372 & 688309 & 2.9499 & 3.0142 & TST & \\
\hline CHEMBL1381263 & 688309 & 2.9499 & 2.9967 & TRN & \\
\hline CHEMBL3192141 & 688309 & 2.9499 & 3.7677 & TRN & \\
\hline CHEMBL1996752 & 688309 & 5.7926 & 4.9605 & TRN & \\
\hline CHEMBL3207928 & 688309 & 2.9499 & 4.17899 & 9999999999 & TRN \\
\hline CHEMBL1430094 & 688309 & 5.8128 & 6.1979 & TRN & \\
\hline CHEMBL1349397 & 688309 & 2.9499 & 3.5651 & TST & \\
\hline CHEMBL1392673 & 688309 & 5.4252 & 6.1709 & TRN & \\
\hline CHEMBL1494476 & 688309 & 2.9499 & 3.1779 & TRN & \\
\hline CHEMBL1372067 & 688309 & 2.9499 & 2.9648 & TST & \\
\hline CHEMBL1366510 & 688309 & 2.9499 & 3.2799 & TST & \\
\hline CHEMBL1406506 & 688309 & 2.9499 & 3.3102 & TRN & \\
\hline CHEMBL1350091 & 688309 & 2.9499 & 3.5743 & TRN & \\
\hline CHEMBL1385296 & 688309 & 2.9499 & 3.3281 & TRN & \\
\hline CHEMBL1557468 & 688309 & 5.7421 & 4.8941 & TRN & \\
\hline CHEMBL1501196 & 688309 & 2.9499 & 3.7409 & TRN & \\
\hline CHEMBL1365815 & 688309 & 4.8886 & 3.1207 & TRN & \\
\hline CHEMBL1413557 & 688309 & 2.9499 & 3.4037 & TRN & \\
\hline
\end{tabular}




\begin{tabular}{|c|c|c|c|c|c|}
\hline & & \multicolumn{4}{|c|}{ Supplemental Table S2.txt } \\
\hline CHEMBL1527239 & 688309 & 5.5318 & 4.5669 & TRN & \\
\hline CHEMBL1303835 & 688309 & 5.468 & 5.3795 & TRN & \\
\hline CHEMBL1323405 & 688309 & 2.9499 & 3.4846 & TRN & \\
\hline CHEMBL1476189 & 688309 & 5.2317 & 5.574 & TRN & \\
\hline CHEMBL1477272 & 688309 & 2.9499 & 3.4345 & TST & \\
\hline CHEMBL1500524 & 688309 & 2.9499 & 2.99899 & 99999999997 & TRN \\
\hline CHEMBL1329761 & 688309 & 2.9499 & 3.3414 & TRN & \\
\hline CHEMBL1300067 & 688309 & 2.9499 & 2.8617 & TRN & \\
\hline CHEMBL 260342 & 688309 & 6.6364 & 6.7493 & TRN & \\
\hline CHEMBL1390836 & 688309 & 4.695 & 4.1291 & TST & \\
\hline CHEMBL47875 & 688309 & 4.3234 & 5.25200 & 0000000001 & TRN \\
\hline CHEMBL1347016 & 688309 & 2.9499 & 3.7717 & TST & \\
\hline CHEMBL1427218 & 688309 & 5.7852 & 5.4806 & TRN & \\
\hline CHEMBL1300624 & 688309 & 2.9499 & 3.5198 & TRN & \\
\hline CHEMBL1353757 & 688309 & 2.9499 & 4.5689 & TRN & \\
\hline CHEMBL1340492 & 688309 & 5.3945 & 5.6217 & TRN & \\
\hline CHEMBL1409610 & 688309 & 2.9499 & 2.7307 & TRN & \\
\hline CHEMBL1413360 & 688309 & 2.9499 & 3.5972 & TRN & \\
\hline CHEMBL1533919 & 688309 & 2.9499 & 3.6857 & TRN & \\
\hline CHEMBL1465301 & 688309 & 2.9499 & 3.029 & TRN & \\
\hline CHEMBL1402404 & 688309 & 4.609 & 3.6953 & TST & \\
\hline CHEMBL1367027 & 688309 & 2.9499 & 3.4805 & TRN & \\
\hline CHEMBL1503930 & 688309 & 5.4058 & 5.8383 & TRN & \\
\hline CHEMBL1600364 & 688309 & 4.6976 & 3.4955 & TRN & \\
\hline CHEMBL1353266 & 688309 & 4.9605 & 4.7399 & TRN & \\
\hline CHEMBL1570099 & 688309 & 2.9499 & 3.154 & TRN & \\
\hline CHEMBL1504793 & 688309 & 2.9499 & 3.0428 & TRN & \\
\hline CHEMBL1309377 & 688309 & 4.6523 & 5.4123 & TRN & \\
\hline CHEMBL1374873 & 688309 & 2.9499 & 3.3267 & TST & \\
\hline CHEMBL1461445 & 688309 & 2.9499 & 3.5984 & TRN & \\
\hline CHEMBL1404692 & 688309 & 4.5175 & 4.9481 & TRN & \\
\hline CHEMBL1386646 & 688309 & 6.8268 & 4.6826 & TRN & \\
\hline CHEMBL1580851 & 688309 & 2.9499 & 3.4002 & TRN & \\
\hline CHEMBL1401891 & 688309 & 5.9322 & 3.8192 & TST & \\
\hline CHEMBL1388781 & 688309 & 2.9499 & 3.438 & TRN & \\
\hline CHEMBL1486017 & 688309 & 2.9499 & 2.9601 & TRN & \\
\hline CHEMBL1466254 & 688309 & 2.9499 & 3.1523 & TRN & \\
\hline CHEMBL1511023 & 688309 & 2.9499 & 3.8006 & TST & \\
\hline CHEMBL1391640 & 688309 & 2.9499 & 3.7496 & TRN & \\
\hline CHEMBL1497510 & 688309 & 2.9499 & 3.4848 & TRN & \\
\hline CHEMBL1594961 & 688309 & 5.6647 & 5.7181 & TRN & \\
\hline CHEMBL1595632 & 688309 & 6.4377 & 6.4687 & TRN & \\
\hline CHEMBL1311953 & 688309 & 2.9499 & 2.7891 & TRN & \\
\hline CHEMBL1417128 & 688309 & 4.8021 & 3.4446 & TRN & \\
\hline CHEMBL1414953 & 688309 & 2.9499 & 3.2811 & TRN & \\
\hline CHEMBL1457697 & 688309 & 4.3351 & 3.2402 & TRN & \\
\hline CHEMBL1576260 & 688309 & 2.9499 & 2.7992 & TST & \\
\hline CHEMBL1544466 & 688309 & 4.4422 & 3.9574 & TRN & \\
\hline
\end{tabular}




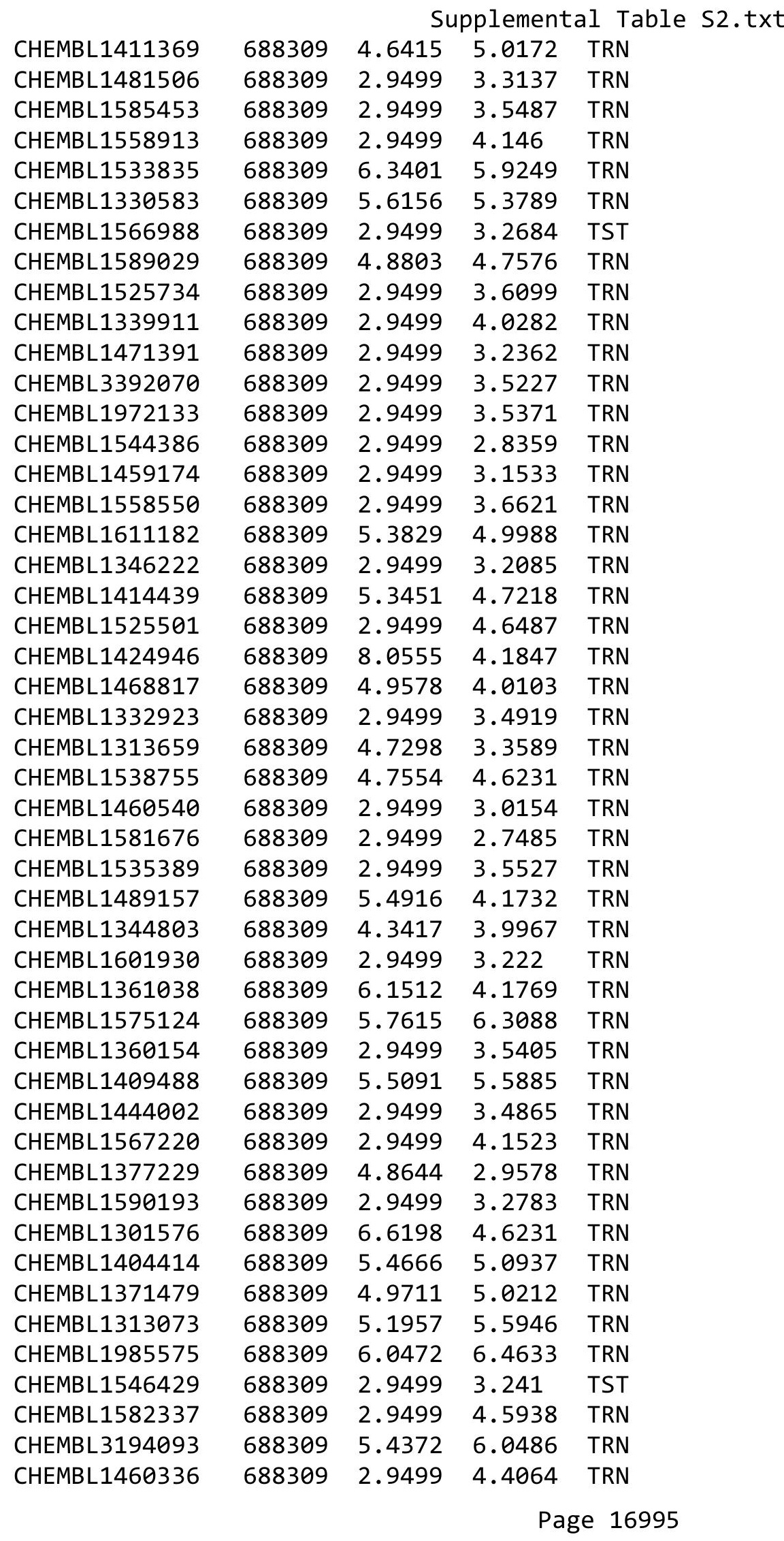




\begin{tabular}{|c|c|c|c|c|}
\hline & & & oplement & al $\mathrm{T}$ \\
\hline CHEMBL1341841 & 688309 & 2.9499 & 3.2408 & TRN \\
\hline CHEMBL1379363 & 688309 & 2.9499 & 3.2889 & TRN \\
\hline CHEMBL1471302 & 688309 & 2.9499 & 3.2718 & TRN \\
\hline CHEMBL1435852 & 688309 & 2.9499 & 2.6283 & TRN \\
\hline CHEMBL1556928 & 688309 & 2.9499 & 3.2945 & TRN \\
\hline CHEMBL1445662 & 688309 & 2.9499 & 3.6278 & TRN \\
\hline CHEMBL37400 & 688309 & 2.9499 & 3.2856 & TRN \\
\hline CHEMBL1559584 & 688309 & 2.9499 & 3.8543 & TST \\
\hline CHEMBL3198870 & 688309 & 5.5904 & 5.7519 & TRN \\
\hline CHEMBL1390792 & 688309 & 2.9499 & 3.2337 & TRN \\
\hline CHEMBL1464574 & 688309 & 2.9499 & 2.9796 & TRN \\
\hline CHEMBL1489087 & 688309 & 5.0661 & 6.2501 & TRN \\
\hline CHEMBL1507124 & 688309 & 2.9499 & 2.8459 & TRN \\
\hline CHEMBL1236872 & 688309 & 5.8088 & 7.3153 & TRN \\
\hline CHEMBL1401302 & 688309 & 5.3606 & 5.2817 & TRN \\
\hline CHEMBL1345927 & 688309 & 2.9499 & 3.8484 & TST \\
\hline CHEMBL1528998 & 688309 & 2.9499 & 3.655 & TST \\
\hline CHEMBL1454850 & 688309 & 2.9499 & 3.3839 & TRN \\
\hline CHEMBL1353184 & 688309 & 5.2343 & 5.0524 & TRN \\
\hline CHEMBL1371529 & 688309 & 2.9499 & 2.9047 & TRN \\
\hline CHEMBL1543836 & 688309 & 2.9499 & 3.5726 & TST \\
\hline CHEMBL1602976 & 688309 & 4.6726 & 2.73 & TRN \\
\hline CHEMBL1386716 & 688309 & 2.9499 & 3.7178 & TRN \\
\hline CHEMBL1452026 & 688309 & 2.9499 & 3.6113 & TRN \\
\hline CHEMBL1549379 & 688309 & 2.9499 & 3.0516 & TRN \\
\hline CHEMBL1399039 & 688309 & 2.9499 & 2.8081 & TRN \\
\hline CHEMBL1528106 & 688309 & 2.9499 & 3.2891 & TST \\
\hline CHEMBL3210725 & 688309 & 2.9499 & 3.4984 & TST \\
\hline CHEMBL1442280 & 688309 & 2.9499 & 3.5192 & TST \\
\hline CHEMBL1439683 & 688309 & 4.2796 & 3.4516 & TRN \\
\hline CHEMBL1352154 & 688309 & 5.3375 & 5.449 & TRN \\
\hline CHEMBL1545290 & 688309 & 4.6646 & 3.2083 & TRN \\
\hline CHEMBL1381197 & 688309 & 2.9499 & 3.0565 & TRN \\
\hline CHEMBL1995156 & 688309 & 5.1193 & 5.6779 & TRN \\
\hline CHEMBL1600454 & 688309 & 2.9499 & 3.0027 & TRN \\
\hline CHEMBL1488176 & 688309 & 2.9499 & 2.435 & TRN \\
\hline CHEMBL1424442 & 688309 & 2.9499 & 4.1311 & TRN \\
\hline CHEMBL1587915 & 688309 & 2.9499 & 3.5644 & TRN \\
\hline CHEMBL1489879 & 688309 & 2.9499 & 3.6052 & TRN \\
\hline CHEMBL1349101 & 688309 & 4.5937 & 4.3407 & TRN \\
\hline CHEMBL1488288 & 688309 & 2.9499 & 3.1612 & TRN \\
\hline CHEMBL1406284 & 688309 & 2.9499 & 3.2227 & TRN \\
\hline CHEMBL1465861 & 688309 & 2.9499 & 3.4407 & TRN \\
\hline CHEMBL1598423 & 688309 & 2.9499 & 3.6372 & TST \\
\hline CHEMBL149322 & 688309 & 4.6536 & 5.1228 & TRN \\
\hline CHEMBL1321728 & 688309 & 2.9499 & 3.5379 & TRN \\
\hline CHEMBL1379970 & 688309 & 5.2005 & 7.2479 & TST \\
\hline CHEMBL1560552 & 688309 & 2.9499 & 2.6268 & TRN \\
\hline
\end{tabular}




\begin{tabular}{|c|c|c|c|c|c|}
\hline & & \multicolumn{4}{|c|}{ Supplemental Table S2.txt } \\
\hline CHEMBL2005446 & 688309 & 5.4056 & 5.8428 & TRN & \\
\hline CHEMBL1426977 & 688309 & 2.9499 & 3.0377 & TRN & \\
\hline CHEMBL1606614 & 688309 & 2.9499 & 2.5605 & TRN & \\
\hline CHEMBL1349069 & 688309 & 2.9499 & 2.833 & TRN & \\
\hline CHEMBL1416653 & 688309 & 5.3141 & 3.8619 & TRN & \\
\hline CHEMBL1354276 & 688309 & 2.9499 & 3.7348 & TST & \\
\hline CHEMBL1358666 & 688309 & 2.9499 & 3.2818 & TRN & \\
\hline CHEMBL1300772 & 688309 & 5.1809 & 5.1386 & TRN & \\
\hline CHEMBL1468581 & 688309 & 2.9499 & 3.1593 & TRN & \\
\hline CHEMBL1994635 & 688309 & 4.9398 & 4.8006 & TRN & \\
\hline CHEMBL1584140 & 688309 & 2.9499 & 3.2491 & TRN & \\
\hline CHEMBL1420074 & 688309 & 2.9499 & 2.6606 & TRN & \\
\hline CHEMBL7747 & 688309 & 7.1543 & 6.5005 & TRN & \\
\hline CHEMBL1574549 & 688309 & 2.9499 & 3.1704 & TRN & \\
\hline CHEMBL1346923 & 688309 & 2.9499 & 3.4182 & TRN & \\
\hline CHEMBL1501760 & 688309 & 2.9499 & 3.5365 & TST & \\
\hline CHEMBL1492209 & 688309 & 4.1337 & 4.981 & TRN & \\
\hline CHEMBL1602702 & 688309 & 2.9499 & 3.1223 & TRN & \\
\hline CHEMBL1558747 & 688309 & 2.9499 & 3.2746 & TRN & \\
\hline CHEMBL1556732 & 688309 & 4.1396 & 3.6447 & TRN & \\
\hline CHEMBL1483647 & 688309 & 2.9499 & 2.81699 & 99999999997 & TRN \\
\hline CHEMBL1404797 & 688309 & 2.9499 & 3.5767 & TRN & \\
\hline CHEMBL1424110 & 688309 & 2.9499 & 3.1034 & TST & \\
\hline CHEMBL1327169 & 688309 & 5.1421 & 4.9972 & TRN & \\
\hline CHEMBL1462301 & 688309 & 5.2236 & 4.7362 & TRN & \\
\hline CHEMBL131037 & 688309 & 4.9301 & 4.7752 & TST & \\
\hline CHEMBL1326195 & 688309 & 4.2845 & 3.3849 & TST & \\
\hline CHEMBL1403900 & 688309 & 2.9499 & 3.2586 & TRN & \\
\hline CHEMBL1405699 & 688309 & 2.9499 & 3.9058 & TRN & \\
\hline CHEMBL1509175 & 688309 & 2.9499 & 3.935 & TRN & \\
\hline CHEMBL1581794 & 688309 & 2.9499 & 3.0787 & TST & \\
\hline CHEMBL1546367 & 688309 & 2.9499 & 3.1698 & TRN & \\
\hline CHEMBL1975118 & 688309 & 6.8665 & 5.3964 & TRN & \\
\hline CHEMBL1396887 & 688309 & 2.9499 & 3.3335 & TRN & \\
\hline CHEMBL1429659 & 688309 & 2.9499 & 3.1993 & TRN & \\
\hline CHEMBL1508973 & 688309 & 2.9499 & 3.6891 & TRN & \\
\hline CHEMBL1443750 & 688309 & 6.9393 & 4.7567 & TRN & \\
\hline CHEMBL1481516 & 688309 & 2.9499 & 3.5472 & TRN & \\
\hline CHEMBL3198883 & 688309 & 5.1268 & 4.916 & TRN & \\
\hline CHEMBL1497122 & 688309 & 2.9499 & 2.9411 & TRN & \\
\hline CHEMBL1430096 & 688309 & 5.6698 & 5.8417 & TST & \\
\hline CHEMBL1417677 & 688309 & 4.7573 & 3.7187 & TRN & \\
\hline CHEMBL1471946 & 688309 & 2.9499 & 3.2887 & TRN & \\
\hline CHEMBL473721 & 688309 & 5.61299 & 99999999 & 5.8735 & TRN \\
\hline CHEMBL378887 & 688309 & 5.1859 & 4.8387 & TRN & \\
\hline CHEMBL1612044 & 688309 & 6.8416 & 5.6731 & TRN & \\
\hline CHEMBL3213198 & 688309 & 2.9499 & 3.4153 & TST & \\
\hline CHEMBL3208919 & 688309 & 2.9499 & 3.755 & TRN & \\
\hline
\end{tabular}




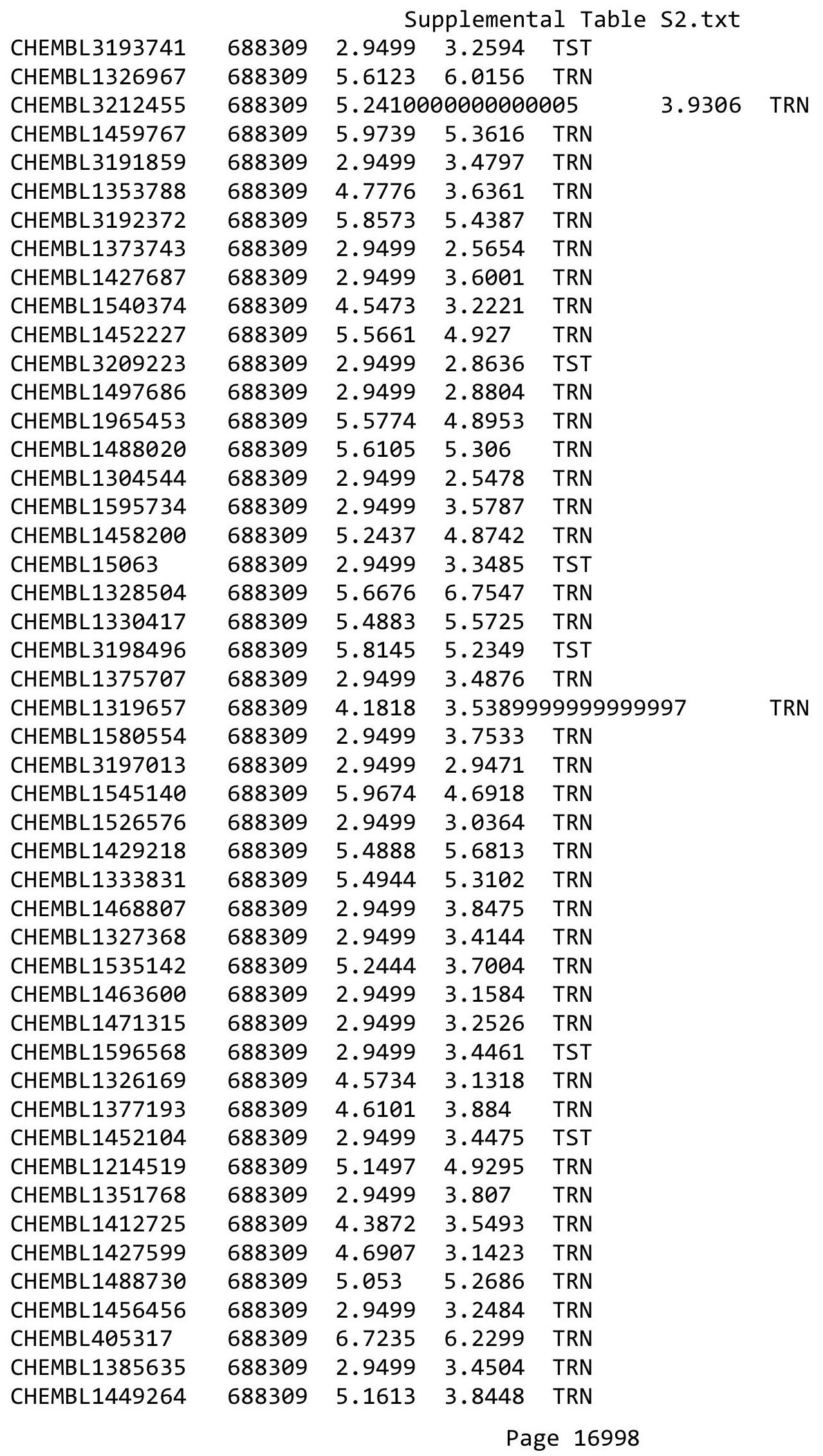




\begin{tabular}{|c|c|c|c|c|c|c|c|}
\hline \multicolumn{7}{|c|}{ Supplemental Table s2.txt } & \\
\hline CHEMBL1586230 & 688309 & 2.9499 & 3.2123 & TRN & & & \\
\hline CHEMBL1564595 & 688309 & 2.9499 & 2.7964 & TRN & & & \\
\hline CHEMBL1432374 & 688309 & 6.0883 & 3.4526 & TST & & & \\
\hline CHEMBL1308404 & 688309 & 5.3764 & 5.0722 & TRN & & & \\
\hline CHEMBL1582036 & 688309 & 2.9499 & 3.57899 & 9999 & 997 & TRN & \\
\hline CHEMBL1381870 & 688309 & 2.9499 & 3.5736 & TRN & & & \\
\hline CHEMBL1310213 & 688309 & 3.25100 & 00000000 & 003 & 3.4361 & TRN & \\
\hline CHEMBL1348884 & 688309 & 5.1714 & 5.1061 & TRN & & & \\
\hline CHEMBL1308506 & 688309 & 2.9499 & 3.6437 & TST & & & \\
\hline CHEMBL1509333 & 688309 & 2.9499 & 3.4334 & TRN & & & \\
\hline CHEMBL1560740 & 688309 & 4.7469 & 3.8798 & TRN & & & \\
\hline CHEMBL1445973 & 688309 & 2.9499 & 2.8661 & TRN & & & \\
\hline CHEMBL125044 & 688309 & 5.16299 & و9999999 & 99 & 6.08899 & 99999999995 & TRN \\
\hline CHEMBL1489717 & 688309 & 5.7109 & 4.7237 & TRN & & & \\
\hline CHEMBL1378443 & 688309 & 2.9499 & 3.1381 & TRN & & & \\
\hline CHEMBL1486981 & 688309 & 2.9499 & 3.2435 & TRN & & & \\
\hline CHEMBL1474667 & 688309 & 2.9499 & 3.5974 & TRN & & & \\
\hline CHEMBL1479862 & 688309 & 2.9499 & 3.5237 & TRN & & & \\
\hline CHEMBL1486516 & 688309 & 4.4151 & 3.137 & TRN & & & \\
\hline CHEMBL1491862 & 688309 & 4.3037 & 3.786 & TRN & & & \\
\hline CHEMBL1588099 & 688309 & 2.9499 & 2.8649 & TRN & & & \\
\hline CHEMBL1607613 & 688309 & 2.9499 & 3.4725 & TRN & & & \\
\hline CHEMBL 584074 & 688309 & 2.9499 & 3.7171 & TRN & & & \\
\hline CHEMBL1345908 & 688309 & 4.7391 & 3.7756 & TRN & & & \\
\hline CHEMBL1608077 & 688309 & 2.9499 & 4.1081 & TRN & & & \\
\hline CHEMBL1508121 & 688309 & 5.0547 & 3.7696 & TST & & & \\
\hline CHEMBL 285540 & 688309 & 4.9027 & 4.7808 & TRN & & & \\
\hline CHEMBL1603509 & 688309 & 5.1031 & 5.1993 & TRN & & & \\
\hline CHEMBL3191594 & 688309 & 5.46 & 6.0685 & TRN & & & \\
\hline CHEMBL1602449 & 688309 & 2.9499 & 4.2874 & TRN & & & \\
\hline CHEMBL1569988 & 688309 & 5.3183 & 5.28 & TRN & & & \\
\hline CHEMBL1380161 & 688309 & 4.52800 & 20000000 & 005 & 4.4896 & TRN & \\
\hline CHEMBL1514411 & 688309 & 2.9499 & 3.2755 & TRN & & & \\
\hline CHEMBL 1387436 & 688309 & 5.6212 & 5.8795 & TRN & & & \\
\hline CHEMBL1610324 & 688309 & 2.9499 & 3.7064 & TRN & & & \\
\hline CHEMBL1461995 & 688309 & 2.9499 & 3.10399 & 9999 & 996 & TRN & \\
\hline CHEMBL1511385 & 688309 & 2.9499 & 3.7111 & TRN & & & \\
\hline CHEMBL1483414 & 688309 & 5.2323 & 5.5137 & TRN & & & \\
\hline CHEMBL1324979 & 688309 & 2.9499 & 2.8605 & TRN & & & \\
\hline CHEMBL1397979 & 688309 & 2.9499 & 3.0332 & TRN & & & \\
\hline CHEMBL1337091 & 688309 & 2.9499 & 2.8293 & TRN & & & \\
\hline CHEMBL1556623 & 688309 & 2.9499 & 2.8627 & TRN & & & \\
\hline CHEMBL1441898 & 688309 & 2.9499 & 2.977 & TRN & & & \\
\hline CHEMBL1350144 & 688309 & 2.9499 & 3.3847 & TRN & & & \\
\hline CHEMBL1386592 & 688309 & 5.3946 & 4.5152 & TRN & & & \\
\hline CHEMBL1338042 & 688309 & 4.6553 & 3.7438 & TRN & & & \\
\hline CHEMBL1443148 & 688309 & 2.9499 & 3.0778 & TRN & & & \\
\hline CHEMBL290077 & 688309 & 8.0555 & 7.0034 & TRN & & & \\
\hline
\end{tabular}




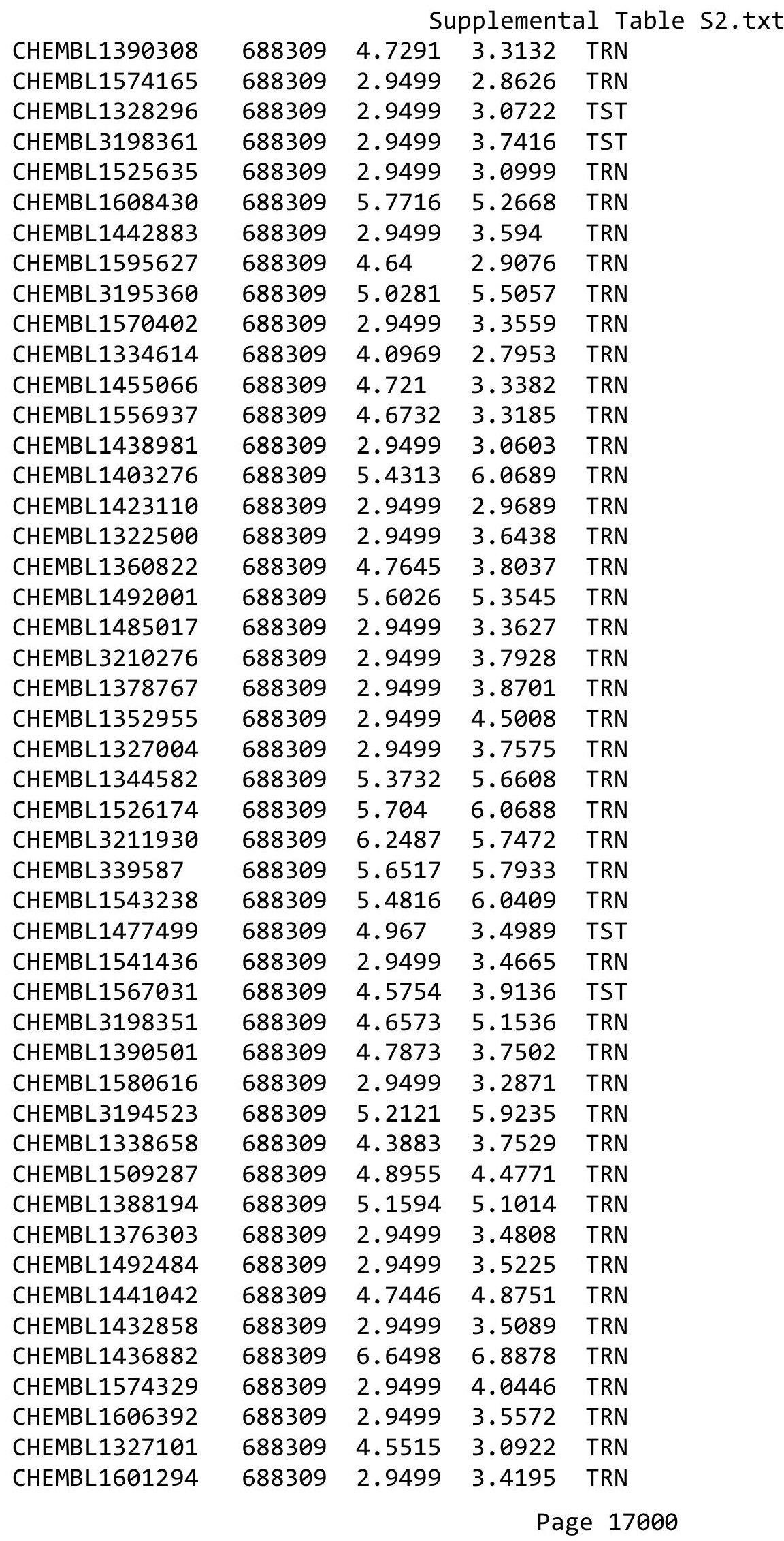




\begin{tabular}{|c|c|c|c|c|c|c|}
\hline \multicolumn{7}{|c|}{ Supplemental Table S2.txt } \\
\hline CHEMBL1501238 & 688309 & 5.76 & 4.9046 & TRN & & \\
\hline CHEMBL1407766 & 688309 & 2.9499 & 4.0446 & TRN & & \\
\hline CHEMBL1379740 & 688309 & 5.1535 & 5.1538 & TRN & & \\
\hline CHEMBL1349301 & 688309 & 2.9499 & 3.3936 & TST & & \\
\hline CHEMBL1585766 & 688309 & 4.9227 & 2.5762 & TRN & & \\
\hline CHEMBL1595861 & 688309 & 2.9499 & 2.8432 & TRN & & \\
\hline CHEMBL191015 & 688309 & 2.9499 & 4.243 & TRN & & \\
\hline CHEMBL1309913 & 688309 & 2.9499 & 3.2546 & TRN & & \\
\hline CHEMBL1344470 & 688309 & 2.9499 & 4.2916 & TRN & & \\
\hline CHEMBL1423495 & 688309 & 2.9499 & 3.4535 & TRN & & \\
\hline CHEMBL3198412 & 688309 & 6.0048 & 5.8986 & TRN & & \\
\hline CHEMBL1423965 & 688309 & 2.9499 & 3.1168 & TRN & & \\
\hline CHEMBL1362275 & 688309 & 4.73600 & g0000000 & & 3.7441 TRN & \\
\hline CHEMBL1610333 & 688309 & 2.9499 & 3.267 & TRN & & \\
\hline CHEMBL1591294 & 688309 & 8.0555 & 3.4541 & TST & & \\
\hline CHEMBL1474147 & 688309 & 2.9499 & 2.5686 & TRN & & \\
\hline CHEMBL1427301 & 688309 & 2.9499 & 3.6778 & TRN & & \\
\hline CHEMBL1475636 & 688309 & 2.9499 & 3.1396 & TRN & & \\
\hline CHEMBL1500110 & 688309 & 5.1654 & 4.4751 & TRN & & \\
\hline CHEMBL1367227 & 688309 & 2.9499 & 3.5156 & TST & & \\
\hline CHEMBL1454289 & 688309 & 2.9499 & 3.4286 & TRN & & \\
\hline CHEMBL1534556 & 688309 & 2.9499 & 2.8148 & TRN & & \\
\hline CHEMBL 2000529 & 688309 & 5.318 & 5.3026 & TRN & & \\
\hline CHEMBL1501676 & 688309 & 5.4484 & 4.5409 & TRN & & \\
\hline CHEMBL1416658 & 688309 & 2.9499 & 3.2028 & TRN & & \\
\hline CHEMBL1415440 & 688309 & 2.9499 & 2.7478 & TRN & & \\
\hline CHEMBL 2002776 & 688309 & 5.5082 & 5.4279 & TRN & & \\
\hline CHEMBL1564790 & 688309 & 2.9499 & 3.8755 & TRN & & \\
\hline CHEMBL1360469 & 688309 & 2.9499 & 2.9953 & TRN & & \\
\hline CHEMBL1309486 & 688309 & 2.9499 & 3.3905 & TST & & \\
\hline CHEMBL1604651 & 688309 & 2.9499 & 2.8386 & TRN & & \\
\hline CHEMBL1373766 & 688309 & 2.9499 & 3.6563 & TST & & \\
\hline CHEMBL3209709 & 688309 & 2.9499 & 3.9685 & TRN & & \\
\hline CHEMBL1546621 & 688309 & 2.9499 & 2.9431 & TST & & \\
\hline CHEMBL1485175 & 688309 & 2.9499 & 2.7804 & TST & & \\
\hline CHEMBL1612577 & 688309 & 2.9499 & 3.6193 & TST & & \\
\hline CHEMBL1572538 & 688309 & 2.9499 & 3.8925 & TRN & & \\
\hline CHEMBL1343626 & 688309 & 2.9499 & 2.7365 & TRN & & \\
\hline CHEMBL1364037 & 688309 & 2.9499 & 2.7079 & TRN & & \\
\hline CHEMBL1965132 & 688309 & 6.5258 & 5.2111 & TRN & & \\
\hline CHEMBL1989090 & 688309 & 5.38200 & 20000000 & $\partial 1$ & 5.247999999999999 & TRN \\
\hline CHEMBL1532736 & 688309 & 2.9499 & 3.6306 & TRN & & \\
\hline CHEMBL1465837 & 688309 & 2.9499 & 3.1817 & TRN & & \\
\hline CHEMBL1311780 & 688309 & 2.9499 & 3.3107 & TRN & & \\
\hline CHEMBL1542070 & 688309 & 2.9499 & 3.0557 & TRN & & \\
\hline CHEMBL1544776 & 688309 & 2.9499 & 3.4197 & TRN & & \\
\hline CHEMBL3209234 & 688309 & 2.9499 & 2.7748 & TRN & & \\
\hline CHEMBL1351880 & 688309 & 2.9499 & 2.9161 & TST & & \\
\hline
\end{tabular}




\begin{tabular}{|c|c|c|c|c|c|}
\hline & & \multicolumn{4}{|c|}{ Supplemental Table S2.txt } \\
\hline CHEMBL1491403 & 688309 & 2.9499 & 2.7195 & TRN & \\
\hline CHEMBL1304385 & 688309 & 4.2671 & 3.3554 & TRN & \\
\hline CHEMBL1389448 & 688309 & 4.7794 & 3.8009 & TRN & \\
\hline CHEMBL1415364 & 688309 & 2.9499 & 4.4928 & TRN & \\
\hline CHEMBL1374595 & 688309 & 2.9499 & 3.8373 & TRN & \\
\hline CHEMBL1534344 & 688309 & 2.9499 & 3.9186 & TRN & \\
\hline CHEMBL1309735 & 688309 & 2.9499 & 3.0831 & TRN & \\
\hline CHEMBL1500807 & 688309 & 2.9499 & 2.9621 & TRN & \\
\hline CHEMBL1506379 & 688309 & 2.9499 & 3.3932 & TRN & \\
\hline CHEMBL1463108 & 688309 & 2.9499 & 3.3878 & TRN & \\
\hline CHEMBL1570561 & 688309 & 2.9499 & 3.06699 & 99999999997 & TRN \\
\hline CHEMBL1354330 & 688309 & 2.9499 & 3.2835 & TRN & \\
\hline CHEMBL1340249 & 688309 & 2.9499 & 2.8753 & TRN & \\
\hline CHEMBL1493470 & 688309 & 2.9499 & 3.1855 & TRN & \\
\hline CHEMBL 2003508 & 688309 & 5.3828 & 5.8828 & TRN & \\
\hline CHEMBL1382194 & 688309 & 2.9499 & 3.1137 & TRN & \\
\hline CHEMBL1480775 & 688309 & 4.141 & 3.1942 & TRN & \\
\hline CHEMBL1530917 & 688309 & 4.3164 & 3.2313 & TST & \\
\hline CHEMBL1403233 & 688309 & 2.9499 & 3.7301 & TRN & \\
\hline CHEMBL1358201 & 688309 & 2.9499 & 2.9682 & TRN & \\
\hline CHEMBL1445725 & 688309 & 5.4154 & 5.4072 & TRN & \\
\hline CHEMBL1532980 & 688309 & 2.9499 & 3.29699 & 99999999997 & TRN \\
\hline CHEMBL 2007273 & 688309 & 6.4989 & 6.0565 & TRN & \\
\hline CHEMBL1355540 & 688309 & 2.9499 & 2.9875 & TRN & \\
\hline CHEMBL1394773 & 688309 & 2.9499 & 2.6719 & TRN & \\
\hline CHEMBL1595528 & 688309 & 2.9499 & 3.1152 & TRN & \\
\hline CHEMBL1993627 & 688309 & 5.1505 & 5.643 & TST & \\
\hline CHEMBL1496656 & 688309 & 2.9499 & 2.7874 & TRN & \\
\hline CHEMBL1301855 & 688309 & 2.9499 & 3.4716 & TRN & \\
\hline CHEMBL1323089 & 688309 & 2.9499 & 3.0024 & TRN & \\
\hline CHEMBL1478415 & 688309 & 2.9499 & 3.7605 & TST & \\
\hline CHEMBL1521187 & 688309 & 4.7277 & 5.1661 & TRN & \\
\hline CHEMBL1572634 & 688309 & 5.1281 & 5.0906 & TRN & \\
\hline CHEMBL1532657 & 688309 & 2.9499 & 2.6284 & TRN & \\
\hline CHEMBL1471944 & 688309 & 2.9499 & 3.387 & TRN & \\
\hline CHEMBL1337574 & 688309 & 2.9499 & 3.3481 & TRN & \\
\hline CHEMBL1321091 & 688309 & 2.9499 & 3.4679 & TRN & \\
\hline CHEMBL1502358 & 688309 & 4.3281 & 3.7148 & TST & \\
\hline CHEMBL1489620 & 688309 & 2.9499 & 2.6824 & TST & \\
\hline CHEMBL3194013 & 688309 & 6.2733 & 5.9263 & TRN & \\
\hline CHEMBL1547498 & 688309 & 2.9499 & 3.6704 & TRN & \\
\hline CHEMBL1585352 & 688309 & 4.1499 & 3.1679 & TRN & \\
\hline CHEMBL1359246 & 688309 & 2.9499 & 3.5097 & TST & \\
\hline CHEMBL1459140 & 688309 & 5.25200 & 00000000 & 4.8152 & TRN \\
\hline CHEMBL1600851 & 688309 & 5.4768 & 4.994 & TRN & \\
\hline CHEMBL1549091 & 688309 & 2.9499 & 3.5257 & TRN & \\
\hline CHEMBL1342654 & 688309 & 5.0572 & 4.1498 & TRN & \\
\hline CHEMBL1610081 & 688309 & 2.9499 & 3.1106 & TRN & \\
\hline
\end{tabular}




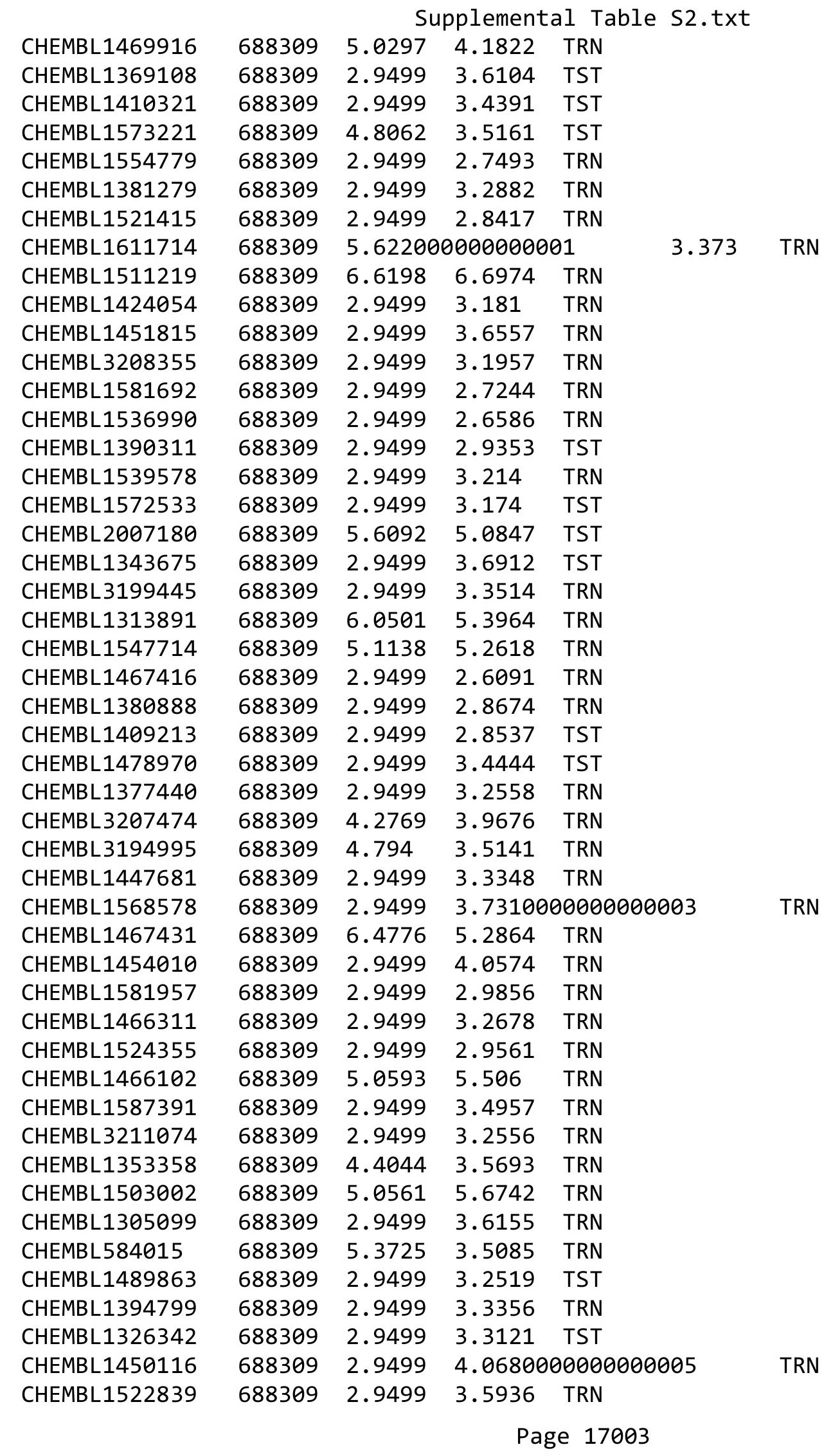




\begin{tabular}{|c|c|c|c|c|c|}
\hline & & \multicolumn{4}{|c|}{ Supplemental Table S2.txt } \\
\hline CHEMBL 2004183 & 688309 & 2.9499 & 4.2932 & TRN & \\
\hline CHEMBL1588563 & 688309 & 2.9499 & 3.0131 & TRN & \\
\hline CHEMBL1487967 & 688309 & 5.0907 & 5.2141 & TRN & \\
\hline CHEMBL1399363 & 688309 & 2.9499 & 2.9732 & TST & \\
\hline CHEMBL1531368 & 688309 & 2.9499 & 3.1459 & TRN & \\
\hline CHEMBL1548167 & 688309 & 4.6009 & 4.7703 & TRN & \\
\hline CHEMBL1578331 & 688309 & 2.9499 & 3.7051 & TST & \\
\hline CHEMBL1333533 & 688309 & 2.9499 & 3.465 & TRN & \\
\hline CHEMBL1481861 & 688309 & 4.9877 & 5.2681 & TRN & \\
\hline CHEMBL1495092 & 688309 & 6.2976 & 4.9116 & TRN & \\
\hline CHEMBL1455183 & 688309 & 2.9499 & 3.0492 & TRN & \\
\hline CHEMBL1575897 & 688309 & 2.9499 & 3.4636 & TRN & \\
\hline CHEMBL1369757 & 688309 & 2.9499 & 3.2379 & TRN & \\
\hline CHEMBL1482223 & 688309 & 2.9499 & 3.0592 & TRN & \\
\hline CHEMBL1379076 & 688309 & 2.9499 & 2.4431 & TRN & \\
\hline CHEMBL1352257 & 688309 & 5.6498 & 4.5669 & TRN & \\
\hline CHEMBL1375740 & 688309 & 5.9473 & 5.5015 & TRN & \\
\hline CHEMBL1380733 & 688309 & 4.7388 & 4.269 & TRN & \\
\hline CHEMBL1395404 & 688309 & 5.0523 & 5.2241 & TRN & \\
\hline CHEMBL1301241 & 688309 & 2.9499 & 3.2728 & TRN & \\
\hline CHEMBL3196042 & 688309 & 5.0527 & 5.4522 & TRN & \\
\hline CHEMBL1333774 & 688309 & 2.9499 & 3.6663 & TRN & \\
\hline CHEMBL1482760 & 688309 & 4.9649 & 5.0651 & TRN & \\
\hline CHEMBL1444847 & 688309 & 4.7897 & 2.8661 & TRN & \\
\hline CHEMBL1584332 & 688309 & 2.9499 & 2.8896 & TRN & \\
\hline CHEMBL1579322 & 688309 & 2.9499 & 3.2113 & TRN & \\
\hline CHEMBL 3210084 & 688309 & 2.9499 & 3.3286 & TST & \\
\hline CHEMBL1497019 & 688309 & 5.3352 & 5.4078 & TRN & \\
\hline CHEMBL1344378 & 688309 & 2.9499 & 3.5311 & TRN & \\
\hline CHEMBL1538494 & 688309 & 2.9499 & 3.8056 & TRN & \\
\hline CHEMBL3212557 & 688309 & 2.9499 & 3.469 & TRN & \\
\hline CHEMBL1383281 & 688309 & 5.8771 & 5.6778 & TRN & \\
\hline CHEMBL3210376 & 688309 & 2.9499 & 2.9002 & TRN & \\
\hline CHEMBL1513199 & 688309 & 2.9499 & 2.54 & TRN & \\
\hline CHEMBL1441315 & 688309 & 2.9499 & 3.2626 & TST & \\
\hline CHEMBL1512774 & 688309 & 2.9499 & 3.2163 & TRN & \\
\hline CHEMBL1303292 & 688309 & 2.9499 & 4.9059 & TRN & \\
\hline CHEMBL1971142 & 688309 & 8.0555 & 6.8672 & TRN & \\
\hline CHEMBL1519387 & 688309 & 5.1724 & 4.6795 & TRN & \\
\hline CHEMBL1425908 & 688309 & 2.9499 & 2.7953 & TRN & \\
\hline CHEMBL408850 & 688309 & 6.3298 & 6.325 & TRN & \\
\hline CHEMBL3208736 & 688309 & 5.5943 & 5.6834 & TRN & \\
\hline CHEMBL1489580 & 688309 & 2.9499 & 3.2578 & TST & \\
\hline CHEMBL1515601 & 688309 & 2.9499 & 3.1272 & TRN & \\
\hline CHEMBL1335066 & 688309 & 2.9499 & 3.1814 & TRN & \\
\hline CHEMBL1534616 & 688309 & 2.9499 & 3.16399 & 99999999997 & TRN \\
\hline CHEMBL1423319 & 688309 & 2.9499 & 3.0576 & TRN & \\
\hline CHEMBL1600679 & 688309 & 2.9499 & 3.5295 & TRN & \\
\hline
\end{tabular}

Page 17004 


\begin{tabular}{|c|c|c|c|c|c|c|}
\hline \multirow[b]{2}{*}{ CHEMBL1302512 } & & \multicolumn{5}{|c|}{ Supplemental Table S2.txt } \\
\hline & 688309 & 2.9499 & 2.8646 & TRN & & \\
\hline CHEMBL3190253 & 688309 & 2.9499 & 3.6204 & TST & & \\
\hline CHEMBL1982658 & 688309 & 5.5802 & 5.6024 & TRN & & \\
\hline CHEMBL3189921 & 688309 & 4.2037 & 3.6558 & TRN & & \\
\hline CHEMBL1574553 & 688309 & 6.0137 & 6.3148 & TRN & & \\
\hline CHEMBL 2007190 & 688309 & $5.7570 e$ & 00000000 & & 5.2537 & TRN \\
\hline CHEMBL1577306 & 688309 & 2.9499 & 3.4882 & TRN & & \\
\hline CHEMBL1363706 & 688309 & 5.7587 & 4.6235 & TRN & & \\
\hline CHEMBL 1457634 & 688309 & 5.4374 & 5.5118 & TRN & & \\
\hline CHEMBL1377098 & 688309 & 2.9499 & 3.3151 & TRN & & \\
\hline CHEMBL3196977 & 688309 & 2.9499 & 3.4652 & TRN & & \\
\hline CHEMBL1468318 & 688309 & 5.7635 & 5.8953 & TRN & & \\
\hline CHEMBL1598649 & 688309 & 5.1255 & 3.6763 & TRN & & \\
\hline CHEMBL1523396 & 688309 & 2.9499 & 3.0053 & TRN & & \\
\hline CHEMBL1374660 & 688309 & 2.9499 & 2.9801 & TRN & & \\
\hline CHEMBL1343565 & 688309 & 5.5707 & 5.9324 & TRN & & \\
\hline CHEMBL1524484 & 688309 & 6.4535 & 6.305 & TST & & \\
\hline CHEMBL 3213781 & 688309 & 2.9499 & 3.8057 & TRN & & \\
\hline CHEMBL1526637 & 688309 & 5.586 & 4.8358 & TRN & & \\
\hline CHEMBL1561773 & 688309 & 2.9499 & 3.1182 & TRN & & \\
\hline CHEMBL1380879 & 688309 & 2.9499 & 3.1046 & TRN & & \\
\hline CHEMBL1377834 & 688309 & 2.9499 & 3.0053 & TRN & & \\
\hline CHEMBL1333254 & 688309 & 5.2915 & 4.5451 & TRN & & \\
\hline CHEMBL3212781 & 688309 & 4.9551 & 4.9159 & TRN & & \\
\hline CHEMBL1330633 & 688309 & 2.9499 & 3.3678 & TRN & & \\
\hline CHEMBL1585869 & 688309 & 2.9499 & 3.0706 & TRN & & \\
\hline CHEMBL1996490 & 688309 & 4.9848 & 5.6846 & TRN & & \\
\hline CHEMBL1574393 & 688309 & 2.9499 & 4.012 & TST & & \\
\hline CHEMBL405358 & 688309 & 7.1543 & 5.7629 & TRN & & \\
\hline CHEMBL1460951 & 688309 & 2.9499 & 2.6731 & TRN & & \\
\hline CHEMBL 2373673 & 688309 & 2.9499 & 3.6542 & TST & & \\
\hline CHEMBL3194985 & 688309 & 5.96899 & 99999999 & 99 & 5.1947 & TRN \\
\hline CHEMBL1511820 & 688309 & 2.9499 & 3.1293 & TST & & \\
\hline CHEMBL1445579 & 688309 & 2.9499 & 3.7507 & TRN & & \\
\hline CHEMBL1594988 & 688309 & 5.4878 & 4.0766 & TRN & & \\
\hline CHEMBL1391738 & 688309 & 2.9499 & 2.8693 & TRN & & \\
\hline CHEMBL1536557 & 688309 & 2.9499 & 3.1599 & TST & & \\
\hline CHEMBL1606964 & 688309 & 2.9499 & 3.1687 & TRN & & \\
\hline CHEMBL3194273 & 688309 & 5.6262 & 5.7516 & TRN & & \\
\hline CHEMBL1307286 & 688309 & 2.9499 & 2.4734 & TRN & & \\
\hline CHEMBL1413193 & 688309 & 2.9499 & 3.4787 & TRN & & \\
\hline CHEMBL1508840 & 688309 & 2.9499 & 2.9465 & TRN & & \\
\hline CHEMBL1325612 & 688309 & 2.9499 & 2.8345 & TRN & & \\
\hline CHEMBL1528032 & 688309 & 2.9499 & 3.6682 & TRN & & \\
\hline CHEMBL3195878 & 688309 & 4.8575 & 5.7717 & TRN & & \\
\hline CHEMBL1542081 & 688309 & 2.9499 & 3.2291 & TRN & & \\
\hline CHEMBL3193650 & 688309 & 5.3857 & 4.9423 & TRN & & \\
\hline CHEMBL1369270 & 688309 & 2.9499 & 4.1495 & TRN & & \\
\hline
\end{tabular}




\begin{tabular}{|c|c|c|c|c|c|c|}
\hline & & \multicolumn{5}{|c|}{ Supplemental Table S2.txt } \\
\hline CHEMBL1376424 & 688309 & 2.9499 & 3.2577 & TRN & & \\
\hline CHEMBL1307161 & 688309 & 2.9499 & 3.6662 & TRN & & \\
\hline CHEMBL1563743 & 688309 & 2.9499 & 3.3441 & TRN & & \\
\hline CHEMBL1306132 & 688309 & 6.1319 & 5.6893 & TRN & & \\
\hline CHEMBL1339683 & 688309 & 2.9499 & 2.5514 & TRN & & \\
\hline CHEMBL1382566 & 688309 & 2.9499 & 3.4085 & TST & & \\
\hline CHEMBL1402126 & 688309 & 4.3561 & 3.6059 & TRN & & \\
\hline CHEMBL1463050 & 688309 & 2.9499 & 3.5485 & TRN & & \\
\hline CHEMBL1572418 & 688309 & \multicolumn{3}{|c|}{3.2510000000000003} & 3.0536 & TST \\
\hline CHEMBL3213574 & 688309 & 5.2913 & 5.0029 & TRN & & \\
\hline CHEMBL1319969 & 688309 & 5.2216 & 4.6884 & TRN & & \\
\hline CHEMBL1332533 & 688309 & 5.7665 & 5.5088 & TRN & & \\
\hline CHEMBL3199632 & 688309 & 4.9444 & 3.77 & TRN & & \\
\hline CHEMBL1466388 & 688309 & 2.9499 & 2.9551 & TRN & & \\
\hline CHEMBL1395528 & 688309 & 2.9499 & 3.7865 & TRN & & \\
\hline CHEMBL1554454 & 688309 & 2.9499 & 3.2771 & TRN & & \\
\hline CHEMBL1337186 & 688309 & 5.7399 & 5.9116 & TRN & & \\
\hline CHEMBL1312103 & 688309 & 2.9499 & 3.4992 & TST & & \\
\hline CHEMBL1366631 & 688309 & 2.9499 & 3.1345 & TRN & & \\
\hline CHEMBL1504458 & 688309 & 2.9499 & 3.4137 & TST & & \\
\hline CHEMBL1566692 & 688309 & 2.9499 & 2.6071 & TRN & & \\
\hline CHEMBL1305341 & 688309 & 4.3095 & 3.9592 & TRN & & \\
\hline CHEMBL1525300 & 688309 & 5.454 & 5.4208 & TRN & & \\
\hline CHEMBL1402831 & 688309 & 2.9499 & 3.5151 & TRN & & \\
\hline CHEMBL1599915 & 688309 & 5.3342 & 5.1471 & TRN & & \\
\hline CHEMBL1419488 & 688309 & 2.9499 & 4.2374 & TRN & & \\
\hline CHEMBL1595793 & 688309 & 2.9499 & 3.2216 & TRN & & \\
\hline CHEMBL1986907 & 688309 & 5.9547 & 5.8068 & TRN & & \\
\hline CHEMBL 2005284 & 688309 & 5.2703 & 4.7082 & TRN & & \\
\hline CHEMBL1989440 & 688309 & 5.442 & 5.1205 & TRN & & \\
\hline CHEMBL3191962 & 688309 & 5.6855 & 5.4724 & TRN & & \\
\hline CHEMBL1488007 & 688309 & 2.9499 & 2.6445 & TRN & & \\
\hline CHEMBL1564677 & 688309 & 5.1856 & 3.9162 & TRN & & \\
\hline CHEMBL1545660 & 688309 & 6.0079 & 5.5587 & TRN & & \\
\hline CHEMBL1370147 & 688309 & 2.9499 & 3.9354 & TST & & \\
\hline CHEMBL1340312 & 688309 & 2.9499 & 2.5846 & TRN & & \\
\hline CHEMBL1545043 & 688309 & 5.261 & 2.7766 & TST & & \\
\hline CHEMBL1428421 & 688309 & 2.9499 & 2.9582 & TST & & \\
\hline CHEMBL1550431 & 688309 & 2.9499 & 2.7856 & TST & & \\
\hline CHEMBL1479328 & 688309 & 4.5934 & 3.2526 & TRN & & \\
\hline CHEMBL1325243 & 688309 & 5.2198 & 5.2469 & TRN & & \\
\hline CHEMBL1540804 & 688309 & 4.8644 & 3.8416 & TRN & & \\
\hline CHEMBL1989500 & 688309 & 5.2891 & 4.4629 & TRN & & \\
\hline CHEMBL1562496 & 688309 & 5.5875 & 5.0976 & TRN & & \\
\hline CHEMBL1613251 & 688309 & 2.9499 & 3.4475 & TRN & & \\
\hline CHEMBL3210692 & 688309 & 2.9499 & 3.4671 & TST & & \\
\hline CHEMBL1332728 & 688309 & 7.1543 & 5.194 & TRN & & \\
\hline CHEMBL225903 & 688309 & 5.9965 & 5.5817 & TRN & & \\
\hline
\end{tabular}




\begin{tabular}{|c|c|c|c|c|}
\hline \multicolumn{5}{|c|}{ Supplemental Table } \\
\hline CHEMBL1467551 & 688309 & 2.9499 & 2.6049 & TST \\
\hline CHEMBL1334514 & 688309 & 5.0995 & 5.6368 & TRN \\
\hline CHEMBL1365952 & 688309 & 2.9499 & 3.3335 & TRN \\
\hline CHEMBL3198603 & 688309 & 5.3545 & 5.3883 & TST \\
\hline CHEMBL1567199 & 688309 & 2.9499 & 2.8975 & TRN \\
\hline CHEMBL1467334 & 688309 & 2.9499 & 3.1363 & TRN \\
\hline CHEMBL1320389 & 688309 & 2.9499 & 3.0883 & TRN \\
\hline CHEMBL1435336 & 688309 & 2.9499 & 3.8286 & TST \\
\hline CHEMBL1477354 & 688309 & 5.919 & 3.6789 & TRN \\
\hline CHEMBL1471786 & 688309 & 2.9499 & 3.0978 & TRN \\
\hline CHEMBL1453801 & 688309 & 5.4211 & 5.5603 & TRN \\
\hline CHEMBL1541658 & 688309 & 2.9499 & 3.3231 & TRN \\
\hline CHEMBL1325478 & 688309 & 2.9499 & 4.3618 & TRN \\
\hline CHEMBL1335291 & 688309 & 2.9499 & 3.2518 & TRN \\
\hline CHEMBL1536627 & 688309 & 2.9499 & 3.5635 & TRN \\
\hline CHEMBL1550756 & 688309 & 2.9499 & 2.7468 & TRN \\
\hline CHEMBL1502192 & 688309 & 4.7576 & 5.5168 & TRN \\
\hline CHEMBL1426973 & 688309 & 4.6679 & 2.8543 & TST \\
\hline CHEMBL1450686 & 688309 & 2.9499 & 3.2117 & TRN \\
\hline CHEMBL1385660 & 688309 & 2.9499 & 3.2452 & TRN \\
\hline CHEMBL3195435 & 688309 & 5.5038 & 5.8215 & TRN \\
\hline CHEMBL1342602 & 688309 & 5.2839 & 4.9815 & TRN \\
\hline CHEMBL1544877 & 688309 & 5.8164 & 5.7381 & TRN \\
\hline CHEMBL1378078 & 688309 & 2.9499 & 3.3581 & TRN \\
\hline CHEMBL1421712 & 688309 & 2.9499 & 4.2949 & TST \\
\hline CHEMBL1374047 & 688309 & 2.9499 & 3.5653 & TRN \\
\hline CHEMBL1373921 & 688309 & 2.9499 & 3.1267 & TRN \\
\hline CHEMBL1542638 & 688309 & 2.9499 & 3.805 & TRN \\
\hline CHEMBL1524570 & 688309 & 2.9499 & 3.1063 & TRN \\
\hline CHEMBL1528570 & 688309 & 2.9499 & 4.5112 & TST \\
\hline CHEMBL1535293 & 688309 & 2.9499 & 3.0539 & TST \\
\hline CHEMBL1562684 & 688309 & 5.0811 & 5.3296 & TRN \\
\hline CHEMBL1463685 & 688309 & 2.9499 & 3.4902 & TRN \\
\hline CHEMBL1528232 & 688309 & 2.9499 & 3.2508 & TRN \\
\hline CHEMBL3193970 & 688309 & 2.9499 & 3.0617 & TST \\
\hline CHEMBL1501191 & 688309 & 5.9859 & 5.2717 & TRN \\
\hline CHEMBL1976507 & 688309 & 5.1395 & 6.1568 & TST \\
\hline CHEMBL1336637 & 688309 & 2.9499 & 3.0979 & TST \\
\hline CHEMBL1308461 & 688309 & 2.9499 & 3.4462 & TST \\
\hline CHEMBL1469084 & 688309 & 4.7267 & 3.5659 & TST \\
\hline CHEMBL1573994 & 688309 & 5.6946 & 5.6576 & TST \\
\hline CHEMBL1584812 & 688309 & 2.9499 & 3.2875 & TST \\
\hline CHEMBL1608676 & 688309 & 2.9499 & 3.0084 & TST \\
\hline CHEMBL1371339 & 688309 & 5.0803 & 5.0105 & TST \\
\hline CHEMBL1304456 & 688309 & 2.9499 & 3.6981 & TST \\
\hline CHEMBL1332742 & 688309 & 5.2324 & 3.7874 & TST \\
\hline CHEMBL1299412 & 688309 & 2.9499 & 3.5477 & TST \\
\hline CHEMBL1973921 & 688309 & 6.8069 & 6.5379 & TST \\
\hline
\end{tabular}


Supplemental Table S2.txt

\begin{tabular}{|c|c|c|c|c|}
\hline CHEMBL1505003 & 688309 & 5.9197 & 5.3105 & TST \\
\hline CHEMBL1982744 & 688309 & 2.9499 & 3.1406 & TST \\
\hline CHEMBL1972249 & 688309 & 5.3623 & 5.1342 & TST \\
\hline CHEMBL1964891 & 688309 & 2.9499 & 3.7534 & TST \\
\hline CHEMBL1573883 & 688309 & 5.9682 & 5.6235 & TST \\
\hline CHEMBL1364668 & 688309 & 2.9499 & 4.1308 & TST \\
\hline CHEMBL1329548 & 688309 & 2.9499 & 4.8828 & TST \\
\hline CHEMBL1439717 & 688309 & 2.9499 & 4.7117 & TST \\
\hline CHEMBL1331020 & 688309 & 2.9499 & 3.7156 & TST \\
\hline CHEMBL1565445 & 688309 & 2.9499 & 3.6431 & TST \\
\hline CHEMBL1573499 & 688309 & 2.9499 & 3.3838 & TST \\
\hline CHEMBL1305971 & 688309 & 2.9499 & 3.2378 & TST \\
\hline CHEMBL1349416 & 688309 & 2.9499 & 3.1094 & TST \\
\hline CHEMBL1423192 & 688309 & 5.6805 & 6.9782 & TST \\
\hline CHEMBL1374515 & 688309 & 4.7179 & 5.2351 & TST \\
\hline CHEMBL1605424 & 688309 & 2.9499 & 3.7561 & TST \\
\hline CHEMBL1421853 & 688309 & 2.9499 & 3.4494 & TST \\
\hline CHEMBL1504089 & 688309 & 2.9499 & 4.4714 & TST \\
\hline CHEMBL1542478 & 688309 & 2.9499 & 3.1774 & TST \\
\hline CHEMBL1380801 & 688309 & 5.4503 & 4.4405 & TST \\
\hline CHEMBL1406276 & 688309 & 2.9499 & 3.3525 & TST \\
\hline CHEMBL1969298 & 688309 & 5.5144 & 6.4592 & TST \\
\hline CHEMBL1521226 & 688309 & 2.9499 & 3.6644 & TST \\
\hline CHEMBL1424324 & 688309 & 2.9499 & 3.392 & TST \\
\hline CHEMBL1417732 & 688309 & 5.6251 & 4.5159 & TST \\
\hline CHEMBL1416853 & 688309 & 5.2094 & 4.7819 & TST \\
\hline CHEMBL1326755 & 688309 & 5.1135 & 3.0664 & TST \\
\hline CHEMBL1965630 & 688309 & 4.9291 & 5.3786 & TST \\
\hline CHEMBL1506762 & 688309 & 2.9499 & 3.4111 & TST \\
\hline CHEMBL1598222 & 688309 & 5.4169 & 4.491006 & 00000000005 \\
\hline CHEMBL 2004186 & 688309 & 5.2193 & 4.5731 & TST \\
\hline CHEMBL1581455 & 688309 & 2.9499 & 3.6081 & TST \\
\hline CHEMBL1431794 & 688309 & 2.9499 & 2.7536 & TST \\
\hline CHEMBL1486109 & 688309 & 5.6676 & 5.9442 & TST \\
\hline CHEMBL1574452 & 688309 & 2.9499 & 2.9217 & TST \\
\hline CHEMBL1350152 & 688309 & 6.0315 & 5.8573 & TST \\
\hline CHEMBL1551203 & 688309 & 5.7404 & 4.6919 & TST \\
\hline CHEMBL1535927 & 688309 & 2.9499 & 3.8822 & TST \\
\hline CHEMBL1518866 & 688309 & 5.6855 & 6.8433 & TST \\
\hline CHEMBL406845 & 688309 & 5.2533 & 4.8126 & TST \\
\hline CHEMBL1404395 & 688309 & 2.9499 & 3.2822 & TST \\
\hline CHEMBL1498249 & 688309 & 2.9499 & 3.145 & TST \\
\hline CHEMBL1488983 & 688309 & 2.9499 & 2.9794 & TST \\
\hline CHEMBL1386131 & 688309 & 2.9499 & 3.3006 & TST \\
\hline CHEMBL1455176 & 688309 & 2.9499 & 3.4626 & TST \\
\hline CHEMBL1587764 & 688309 & 2.9499 & 3.221 & TST \\
\hline CHEMBL1604379 & 688309 & 2.9499 & 3.3302 & TST \\
\hline CHEMBL1308946 & 688309 & 5.8677 & 6.4155 & TST \\
\hline
\end{tabular}




\begin{tabular}{|c|c|c|c|c|c|c|}
\hline & & \multicolumn{5}{|c|}{ Supplemental Table S2.txt } \\
\hline CHEMBL1503348 & 688309 & 2.9499 & 3.3754 & TST & & \\
\hline CHEMBL1497939 & 688309 & 5.5993 & 5.7173 & TST & & \\
\hline CHEMBL1575708 & 688309 & 5.36100 & 00000000 & & 5.4606 & TST \\
\hline CHEMBL1328395 & 688309 & 4.7551 & 3.674 & TST & & \\
\hline CHEMBL1444431 & 688309 & 2.9499 & 2.4769 & TST & & \\
\hline CHEMBL1448153 & 688309 & 5.2832 & 6.7407 & TST & & \\
\hline CHEMBL1464431 & 688309 & 2.9499 & 3.3397 & TST & & \\
\hline CHEMBL 3192773 & 688309 & 5.7602 & 5.4214 & TST & & \\
\hline CHEMBL1581173 & 688309 & 5.1878 & 4.5279 & TST & & \\
\hline CHEMBL3192393 & 688309 & 6.3904 & 5.0758 & TST & & \\
\hline CHEMBL565657 & 688309 & 5.3328 & 5.0903 & TST & & \\
\hline CHEMBL1347197 & 688309 & 2.9499 & 3.1187 & TST & & \\
\hline CHEMBL1519698 & 688309 & 4.8117 & 3.7748 & TST & & \\
\hline CHEMBL1589612 & 688309 & 4.9986 & 4.9478 & TST & & \\
\hline CHEMBL1470619 & 688309 & 2.9499 & 3.7708 & TST & & \\
\hline CHEMBL285819 & 688309 & 7.1543 & 6.9584 & TST & & \\
\hline CHEMBL1552612 & 688309 & 2.9499 & 2.8814 & TST & & \\
\hline CHEMBL1528618 & 688309 & 4.3403 & 2.9942 & TST & & \\
\hline CHEMBL1409968 & 688309 & 2.9499 & 2.7058 & TST & & \\
\hline CHEMBL1390809 & 688309 & 4.7816 & 2.9158 & TST & & \\
\hline CHEMBL1545487 & 688309 & 2.9499 & 3.2624 & TST & & \\
\hline CHEMBL1539236 & 688309 & 2.9499 & 3.5249 & TST & & \\
\hline CHEMBL1548033 & 688309 & 3.96199 & 99999999 & 997 & 2.972 & TST \\
\hline CHEMBL1327810 & 688309 & 6.3615 & 4.7023 & TST & & \\
\hline CHEMBL1609763 & 688309 & 4.6357 & 3.5524 & TST & & \\
\hline CHEMBL1416364 & 688309 & 2.9499 & 3.6548 & TST & & \\
\hline CHEMBL1381307 & 688309 & 2.9499 & 2.5994 & TST & & \\
\hline CHEMBL1347071 & 688309 & 4.1889 & 4.8651 & TST & & \\
\hline CHEMBL1349226 & 688309 & 2.9499 & 3.5287 & TST & & \\
\hline CHEMBL1432329 & 688309 & 5.7883 & 4.7868 & TST & & \\
\hline CHEMBL3191815 & 688309 & 5.5674 & 3.8327 & TST & & \\
\hline CHEMBL1447914 & 688309 & 2.9499 & 3.4486 & TST & & \\
\hline CHEMBL1326985 & 688309 & 2.9499 & 3.7984 & TST & & \\
\hline CHEMBL1397255 & 688309 & 5.434 & 3.2437 & TST & & \\
\hline CHEMBL1579034 & 688309 & 2.9499 & 2.7434 & TST & & \\
\hline CHEMBL1381932 & 688309 & 2.9499 & 3.375 & TST & & \\
\hline CHEMBL1539053 & 688309 & 2.9499 & 3.3933 & TST & & \\
\hline CHEMBL1530966 & 688309 & 2.9499 & 4.0531 & TST & & \\
\hline CHEMBL1564396 & 688309 & 5.7781 & 5.5405 & TST & & \\
\hline CHEMBL1378527 & 688309 & 4.7577 & 3.3372 & TST & & \\
\hline CHEMBL1522242 & 688309 & 4.8095 & 3.1119 & TST & & \\
\hline CHEMBL1586912 & 688309 & 2.9499 & 3.2992 & TST & & \\
\hline CHEMBL1449173 & 688309 & 4.5669 & 5.1604 & TST & & \\
\hline CHEMBL1390012 & 688309 & 2.9499 & 3.7215 & TST & & \\
\hline CHEMBL1509068 & 688309 & 2.9499 & 2.9038 & TST & & \\
\hline CHEMBL1323348 & 688309 & 4.566 & 3.3582 & TST & & \\
\hline CHEMBL1490336 & 688309 & 5.2533 & 5.8463 & TST & & \\
\hline CHEMBL1584076 & 688309 & 2.9499 & 3.1786 & TST & & \\
\hline
\end{tabular}




\begin{tabular}{|c|c|c|c|c|c|}
\hline \multirow[b]{2}{*}{ CHEMBL3214499 } & \multirow[b]{2}{*}{688309} & \multicolumn{4}{|c|}{ Supplemental Table S2.txt } \\
\hline & & 2.9499 & 3.5552 & TST & \\
\hline CHEMBL1311416 & 688309 & 2.9499 & 3.1582 & TST & \\
\hline CHEMBL1381394 & 688309 & 5.3529 & 3.2331 & TST & \\
\hline CHEMBL1451245 & 688309 & 5.2116 & 5.7271 & TST & \\
\hline CHEMBL1531320 & 688309 & 5.7409 & \multicolumn{2}{|c|}{6.077000000000001} & TST \\
\hline CHEMBL1400414 & 688309 & 4.9192 & 3.8428 & TST & \\
\hline CHEMBL1966921 & 688309 & 5.5473 & 5.1207 & TST & \\
\hline CHEMBL1474711 & 688309 & 2.9499 & 2.7284 & TST & \\
\hline CHEMBL1345739 & 688309 & 2.9499 & 2.9174 & TST & \\
\hline CHEMBL1430755 & 688309 & 2.9499 & 3.1277 & TST & \\
\hline CHEMBL1366066 & 688309 & 2.9499 & 3.7559 & TST & \\
\hline CHEMBL1333243 & 688309 & 2.9499 & 2.9481 & TST & \\
\hline CHEMBL1350148 & 688309 & 2.9499 & 2.9203 & TST & \\
\hline CHEMBL1497635 & 688309 & 7.1543 & 5.3106 & TST & \\
\hline CHEMBL1987906 & 688309 & 5.2115 & 3.6673 & TST & \\
\hline CHEMBL1336068 & 688309 & 2.9499 & 2.9898 & TST & \\
\hline CHEMBL1319035 & 688309 & 2.9499 & 3.9496 & TST & \\
\hline CHEMBL1558433 & 688309 & 2.9499 & 3.5102 & TST & \\
\hline CHEMBL1490160 & 688309 & 2.9499 & 3.0468 & TST & \\
\hline CHEMBL1331561 & 688309 & \multicolumn{3}{|c|}{3.2510000000000003} & TST \\
\hline CHEMBL1490427 & 688309 & 5.1279 & 5.6861 & TST & \\
\hline CHEMBL1384906 & 688309 & 2.9499 & 2.9789 & TST & \\
\hline CHEMBL1608918 & 688309 & 2.9499 & 3.4166 & TST & \\
\hline CHEMBL1480311 & 688309 & 2.9499 & 2.5988 & TST & \\
\hline CHEMBL1537961 & 688309 & 2.9499 & 3.0241 & TST & \\
\hline CHEMBL1499276 & 688309 & 4.7711 & 4.6425 & TST & \\
\hline CHEMBL1306071 & 688309 & 2.9499 & 3.4543 & TST & \\
\hline CHEMBL1582317 & 688309 & 2.9499 & 2.6627 & TST & \\
\hline CHEMBL1429789 & 688309 & 5.8604 & 5.2452 & TST & \\
\hline CHEMBL1565176 & 688309 & 2.9499 & 2.8075 & TST & \\
\hline CHEMBL1314567 & 688309 & 2.9499 & 3.1439 & TST & \\
\hline CHEMBL1501197 & 688309 & 5.6284 & 6.1183 & TST & \\
\hline CHEMBL1370281 & 688309 & 4.6687 & 3.52100 & 00000000004 & TST \\
\hline CHEMBL1360618 & 688309 & 5.8327 & 6.3966 & TST & \\
\hline CHEMBL1491701 & 688309 & 2.9499 & 3.5859 & TST & \\
\hline CHEMBL1440311 & 688309 & 2.9499 & 2.9812 & TST & \\
\hline CHEMBL1550657 & 688309 & 5.227 & 3.7655 & TST & \\
\hline CHEMBL1608667 & 688309 & 4.8363 & 2.9426 & TST & \\
\hline CHEMBL1612693 & 688309 & 2.9499 & 3.1174 & TST & \\
\hline CHEMBL1399980 & 688309 & 4.6939 & 5.2143 & TST & \\
\hline CHEMBL1599564 & 688309 & 2.9499 & 3.0481 & TST & \\
\hline CHEMBL1574903 & 688309 & 2.9499 & 3.1671 & TST & \\
\hline CHEMBL3196469 & 688309 & 6.6799 & 5.6346 & TST & \\
\hline CHEMBL1375497 & 688309 & 2.9499 & 3.2985 & TST & \\
\hline CHEMBL1399399 & 688309 & 5.1392 & 3.5585 & TST & \\
\hline CHEMBL1346992 & 688309 & 2.9499 & 3.364 & TST & \\
\hline CHEMBL1472437 & 688309 & 5.1758 & 5.2175 & TST & \\
\hline CHEMBL1566293 & 688309 & 2.9499 & 2.8992 & TST & \\
\hline
\end{tabular}

Page 17010 


\begin{tabular}{|c|c|c|c|c|c|}
\hline \multirow{2}{*}{ CHEMBL1519788 } & \multirow[b]{2}{*}{688309} & \multicolumn{4}{|c|}{ ece } \\
\hline & & 5.7242 & 3.6106 & TST & \\
\hline CHEMBL1340293 & 688309 & 2.9499 & 2.6872 & TST & \\
\hline CHEMBL1375202 & 688309 & 2.9499 & 2.7909 & TST & \\
\hline CHEMBL1392611 & 688309 & 5.5645 & 5.8114 & TST & \\
\hline CHEMBL1977570 & 688309 & 5.6455 & 5.036006 & 00000000005 & TST \\
\hline CHEMBL1571574 & 688309 & 5.2925 & 5.5502 & TST & \\
\hline CHEMBL1464039 & 688309 & 2.9499 & 3.2245 & TST & \\
\hline CHEMBL1305869 & 688309 & 2.9499 & $3.04600 t$ & 00000000003 & TST \\
\hline CHEMBL1387982 & 688309 & 2.9499 & 3.4632 & TST & \\
\hline CHEMBL1568259 & 688309 & 2.9499 & 3.3899 & TST & \\
\hline CHEMBL1321177 & 688309 & 2.9499 & 3.2356 & TST & \\
\hline CHEMBL1386836 & 688309 & 4.8596 & 3.2869 & TST & \\
\hline CHEMBL1585865 & 688309 & 4.5543 & 2.8581 & TST & \\
\hline CHEMBL1407964 & 688309 & 5.4655 & 3.5107 & TST & \\
\hline CHEMBL1443034 & 688309 & 2.9499 & 3.1347 & TST & \\
\hline CHEMBL1558092 & 688309 & 5.227 & 4.5943 & TST & \\
\hline CHEMBL1349543 & 688309 & 2.9499 & 3.2031 & TST & \\
\hline CHEMBL1430286 & 688309 & 5.1967 & 3.5125 & TST & \\
\hline CHEMBL1983323 & 688309 & 5.4451 & 5.4669 & TST & \\
\hline CHEMBL1302990 & 688309 & 2.9499 & 3.173 & TST & \\
\hline CHEMBL1542915 & 688309 & 2.9499 & 2.9754 & TST & \\
\hline CHEMBL1429902 & 688309 & 2.9499 & 3.57899 & 99999999997 & TST \\
\hline CHEMBL1978607 & 688309 & 4.6556 & 4.8477 & TST & \\
\hline CHEMBL 2006611 & 688309 & 6.0615 & 5.5304 & TST & \\
\hline CHEMBL1994596 & 688309 & 6.7645 & 5.6331 & TST & \\
\hline CHEMBL1444056 & 688309 & 2.9499 & 3.8428 & TST & \\
\hline CHEMBL3212032 & 688309 & 2.9499 & 3.3186 & TST & \\
\hline CHEMBL1604007 & 688309 & 5.2388 & 4.6414 & TST & \\
\hline CHEMBL1509670 & 688309 & 6.6882 & 4.1255 & TST & \\
\hline CHEMBL371132 & 320876 & 8.0706 & 7.7395 & TRN & \\
\hline CHEMBL198827 & 320876 & 8.5229 & 8.2216 & TRN & \\
\hline CHEMBL372569 & 320876 & 8.0088 & 7.7757 & TST & \\
\hline CHEMBL194786 & 320876 & 8.0969 & 8.4625 & TRN & \\
\hline CHEMBL365774 & 320876 & 9.0 & 8.5454 & TRN & \\
\hline CHEMBL194307 & 320876 & 6.0 & 8.1848 & TRN & \\
\hline CHEMBL427184 & 320876 & 8.1549 & 7.7363 & TRN & \\
\hline CHEMBL369910 & 320876 & 7.9586 & 7.7921 & TRN & \\
\hline CHEMBL195018 & 320876 & 8.3979 & 7.942 & TRN & \\
\hline CHEMBL436124 & 320876 & 7.3098 & 7.3456 & TRN & \\
\hline CHEMBL 380777 & 320876 & 7.2366 & 7.8097 & TST & \\
\hline CHEMBL195621 & 320876 & 7.5575 & 7.5423 & TRN & \\
\hline CHEMBL196791 & 320876 & 7.6576 & 7.7889 & TRN & \\
\hline CHEMBL193450 & 320876 & 9.0 & 8.6942 & TRN & \\
\hline CHEMBL413525 & 320876 & 8.3979 & 8.0272 & TRN & \\
\hline CHEMBL 363843 & 320876 & 8.1549 & 7.8058 & TST & \\
\hline CHEMBL197397 & 320876 & 7.3979 & 7.5161 & TRN & \\
\hline CHEMBL 372373 & 320876 & 6.5974 & 7.8956 & TST & \\
\hline CHEMBL198766 & 320876 & 7.8539 & 7.6667 & TRN & \\
\hline
\end{tabular}




\begin{tabular}{|c|c|c|c|c|c|}
\hline \multicolumn{6}{|c|}{ Supplemental Table S2.txt } \\
\hline CHEMBL372033 & 320876 & 7.3565 & 7.5382 & TRN & \\
\hline CHEMBL 382297 & 320876 & 7.3188 & 7.6711 & TRN & \\
\hline CHEMBL196792 & 320876 & 7.7959 & 7.8144 & TRN & \\
\hline CHEMBL194750 & 320876 & 8.0 & 7.8264 & TST & \\
\hline CHEMBL196094 & 320876 & 8.1549 & 8.0733 & TRN & \\
\hline CHEMBL372364 & 320876 & 8.8239 & 7.9544 & TST & \\
\hline CHEMBL196619 & 320876 & 8.301 & 8.5286 & TRN & \\
\hline CHEMBL196466 & 320876 & 8.5229 & 8.4369 & TRN & \\
\hline CHEMBL371469 & 320876 & 8.1549 & 8.0794 & TRN & \\
\hline CHEMBL 383373 & 320876 & 8.5229 & 8.3633 & TRN & \\
\hline CHEMBL370507 & 320876 & 9.0 & 8.6817 & TRN & \\
\hline CHEMBL370935 & 320876 & 6.5666 & 7.8493 & TST & \\
\hline CHEMBL381871 & 320876 & 7.3497 & 7.7014 & TRN & \\
\hline CHEMBL193824 & 320876 & 8.3372 & 7.9002 & TRN & \\
\hline CHEMBL 363827 & 320876 & 8.0362 & 7.7991 & TRN & \\
\hline CHEMBL195922 & 320876 & 6.5471 & 7.2183 & TRN & \\
\hline CHEMBL 380772 & 320876 & 7.8239 & 8.3415 & TRN & \\
\hline CHEMBL370306 & 320876 & 7.585 & 7.7696 & TRN & \\
\hline CHEMBL194465 & 320876 & 7.6383 & 7.5428 & TRN & \\
\hline CHEMBL194590 & 320876 & 9.0 & 8.8247 & TRN & \\
\hline CHEMBL425197 & 320876 & 7.6576 & 7.3308 & TRN & \\
\hline CHEMBL 371318 & 320876 & 8.5229 & 7.7361 & TST & \\
\hline CHEMBL380556 & 320876 & 7.8539 & 8.40299 & 9999999999 & TRN \\
\hline CHEMBL 365753 & 320876 & 8.5229 & 8.4318 & TST & \\
\hline CHEMBL194568 & 320876 & 7.9788 & 7.8353 & TRN & \\
\hline CHEMBL198941 & 320876 & 7.9208 & 7.9722 & TRN & \\
\hline CHEMBL179592 & 320876 & 8.699 & 7.9851 & TRN & \\
\hline CHEMBL 370508 & 320876 & 7.4685 & 7.569 & TRN & \\
\hline CHEMBL365993 & 320876 & 7.4815 & 7.5233 & TRN & \\
\hline CHEMBL195987 & 320876 & 7.3799 & 7.6714 & TST & \\
\hline CHEMBL366012 & 320876 & 8.0458 & 8.3992 & TST & \\
\hline CHEMBL194311 & 320876 & 7.6021 & 7.3987 & TRN & \\
\hline CHEMBL194834 & 320876 & 7.3098 & 7.4518 & TRN & \\
\hline CHEMBL194904 & 320876 & 7.8861 & 7.6721 & TRN & \\
\hline CHEMBL196926 & 320876 & 7.8861 & 7.7482 & TRN & \\
\hline CHEMBL381887 & 320876 & 7.699 & 7.4353 & TRN & \\
\hline CHEMBL196692 & 320876 & 8.699 & 7.6608 & TST & \\
\hline CHEMBL370215 & 320876 & 8.301 & 8.1174 & TRN & \\
\hline CHEMBL197407 & 320876 & 7.7144 & 8.1078 & TRN & \\
\hline CHEMBL193657 & 320876 & 7.3665 & 7.4389 & TRN & \\
\hline CHEMBL197845 & 320876 & 8.0969 & 7.6537 & TST & \\
\hline CHEMBL194360 & 320876 & 6.9355 & 8.0605 & TST & \\
\hline CHEMBL193358 & 320876 & 8.699 & 8.513 & TST & \\
\hline CHEMBL196661 & 320876 & 7.6635 & 7.784 & TRN & \\
\hline CHEMBL362921 & 320876 & 7.644 & 7.7483 & TRN & \\
\hline CHEMBL370719 & 320876 & 7.699 & 7.638 & TRN & \\
\hline CHEMBL 371886 & 320876 & 8.0969 & 8.1011 & TRN & \\
\hline CHEMBL196743 & 320876 & 8.0 & 7.8096 & TST & \\
\hline
\end{tabular}




\begin{tabular}{|c|c|c|c|c|c|}
\hline \multicolumn{6}{|c|}{ Supplemental Table s2.txt } \\
\hline CHEMBL76237 & 320876 & 8.6383 & 7.8757 & TST & \\
\hline CHEMBL425196 & 320876 & 9.0 & 8.5353 & TST & \\
\hline CHEMBL3957378 & 1642448 & 5.4437 & 7.7173 & TST & \\
\hline CHEMBL 3963944 & 1642448 & 7.3665 & 7.2513 & TRN & \\
\hline CHEMBL3893992 & 1642448 & 6.8539 & 7.1027 & TRN & \\
\hline CHEMBL3918970 & 1642448 & 8.0 & 8.0597 & TRN & \\
\hline CHEMBL3907299 & 1642448 & 6.4559 & 6.5259 & TRN & \\
\hline CHEMBL3933338 & 1642448 & 7.2757 & 7.6745 & TST & \\
\hline CHEMBL 3948718 & 1642448 & 6.4318 & 7.5179 & TST & \\
\hline CHEMBL3936755 & 1642448 & 9.3979 & 9.3514 & TRN & \\
\hline CHEMBL3895064 & 1642448 & 7.0506 & 7.04799 & 9999999999 & TRN \\
\hline CHEMBL3891142 & 1642448 & 7.5086 & 7.5666 & TRN & \\
\hline CHEMBL3893864 & 1642448 & 5.3372 & 8.9956 & TST & \\
\hline CHEMBL3908939 & 1642448 & 6.0506 & 6.1279 & TRN & \\
\hline CHEMBL3920145 & 1642448 & 8.2218 & 8.218 & TRN & \\
\hline CHEMBL3976680 & 1642448 & 7.6198 & 7.6378 & TRN & \\
\hline CHEMBL3935056 & 1642448 & 6.9208 & 6.7759 & TRN & \\
\hline CHEMBL3934403 & 1642448 & 5.4815 & 8.2031 & TST & \\
\hline CHEMBL3961765 & 1642448 & 8.0458 & 8.1477 & TRN & \\
\hline CHEMBL3980736 & 1642448 & 8.699 & 7.349 & TST & \\
\hline CHEMBL3987061 & 1642448 & 8.1549 & 8.1006 & TRN & \\
\hline CHEMBL3901720 & 1642448 & 8.0969 & 8.0963 & TRN & \\
\hline CHEMBL3943133 & 1642448 & 9.0 & 8.9001 & TRN & \\
\hline CHEMBL3971670 & 1642448 & 7.5376 & 7.6559 & TRN & \\
\hline CHEMBL3911605 & 1642448 & 8.699 & 8.6346 & TRN & \\
\hline CHEMBL3966386 & 1642448 & 7.5086 & 7.2977 & TRN & \\
\hline CHEMBL3973570 & 1642448 & 6.0757 & 6.3093 & TRN & \\
\hline CHEMBL3890476 & 1642448 & 7.4949 & 7.4754 & TRN & \\
\hline CHEMBL 3975980 & 1642448 & 7.2218 & 7.1638 & TRN & \\
\hline CHEMBL3892760 & 1642448 & 8.0 & 7.9835 & TRN & \\
\hline CHEMBL 3927774 & 1642448 & 6.3372 & 6.2768 & TRN & \\
\hline CHEMBL3971635 & 1642448 & 7.7696 & 7.6685 & TRN & \\
\hline CHEMBL3914942 & 1642448 & 7.8239 & 7.5601 & TRN & \\
\hline CHEMBL 3933337 & 1642448 & 7.3768 & 7.5645 & TRN & \\
\hline CHEMBL3923068 & 1642448 & 7.3468 & 7.1588 & TRN & \\
\hline CHEMBL 3948456 & 1642448 & 7.2007 & 7.2036 & TRN & \\
\hline CHEMBL3961807 & 1642448 & 7.3565 & 7.3183 & TRN & \\
\hline CHEMBL3986752 & 1642448 & 7.7959 & 7.8126 & TRN & \\
\hline CHEMBL3909531 & 1642448 & 7.5528 & 7.3456 & TRN & \\
\hline CHEMBL3980174 & 1642448 & 8.301 & 8.3504 & TRN & \\
\hline CHEMBL3956413 & 1642448 & 7.9586 & 8.0505 & TRN & \\
\hline CHEMBL3914963 & 1642448 & 7.9586 & 8.2014 & TRN & \\
\hline CHEMBL3979729 & 1642448 & 7.6198 & 8.2662 & TST & \\
\hline CHEMBL3959098 & 1642448 & 7.3665 & 7.13299 & 9999999999 & TRN \\
\hline CHEMBL3947618 & 1642448 & 6.1612 & 7.3254 & TST & \\
\hline CHEMBL3935519 & 1642448 & 6.585 & 6.58799 & 9999999999 & TRN \\
\hline CHEMBL3918468 & 1642448 & 7.9586 & 7.7346 & TRN & \\
\hline CHEMBL3942927 & 1642448 & 6.8539 & 6.7149 & TRN & \\
\hline
\end{tabular}


Supplemental Table S2.txt

\begin{tabular}{|c|c|c|c|c|}
\hline CHEMBL3915509 & 1642448 & 7.6576 & 7.5257 & TRN \\
\hline CHEMBL 3910281 & 1642448 & 8.0458 & 7.9448 & TRN \\
\hline CHEMBL3959515 & 1642448 & 6.699 & 8.2295 & TST \\
\hline CHEMBL3920547 & 1642448 & 7.7696 & 8.0358 & TRN \\
\hline CHEMBL3897650 & 1642448 & 7.041 & 7.0479 & TRN \\
\hline CHEMBL3924401 & 1642448 & 6.8539 & 6.9208 & TRN \\
\hline CHEMBL3951978 & 1642448 & 8.1549 & 8.0764 & TRN \\
\hline CHEMBL3967394 & 1642448 & 7.6198 & 7.5193 & TRN \\
\hline CHEMBL3943469 & 1642448 & 7.0088 & 6.9727 & TRN \\
\hline CHEMBL3948271 & 1642448 & 6.7696 & 6.8181 & TRN \\
\hline CHEMBL3942946 & 1642448 & 7.0044 & 7.4083 & TST \\
\hline CHEMBL3911962 & 1642448 & 7.9586 & 7.9113 & TRN \\
\hline CHEMBL 3896384 & 1642448 & 7.0809 & 7.1884 & TRN \\
\hline CHEMBL3900867 & 1642448 & 7.585 & 7.593 & TRN \\
\hline CHEMBL3972525 & 1642448 & 7.1308 & 7.3317 & TRN \\
\hline CHEMBL3960586 & 1642448 & 7.3188 & 7.3864 & TRN \\
\hline CHEMBL3985727 & 1642448 & 7.3468 & 7.5177 & TRN \\
\hline CHEMBL3966526 & 1642448 & 9.3979 & 9.451 & TRN \\
\hline CHEMBL3920849 & 1642448 & 8.3979 & 7.6803 & TST \\
\hline CHEMBL3963121 & 1642448 & 6.1612 & 6.3822 & TRN \\
\hline CHEMBL3985179 & 1642448 & 8.0969 & 7.9278 & TRN \\
\hline CHEMBL3972698 & 1642448 & 9.0 & 9.0388 & TRN \\
\hline CHEMBL3891550 & 1642448 & 8.2218 & 8.013 & TRN \\
\hline CHEMBL3945517 & 1642448 & 8.301 & 8.6303 & TRN \\
\hline CHEMBL3910049 & 1642448 & 8.301 & 8.2344 & TST \\
\hline CHEMBL3953043 & 1642448 & 6.7447 & 8.1648 & TST \\
\hline CHEMBL 3942894 & 1642448 & 8.1549 & 7.8192 & TST \\
\hline CHEMBL3939578 & 1642448 & 6.9208 & 7.875 & TST \\
\hline CHEMBL3920905 & 1642448 & 7.2366 & 7.9089 & TST \\
\hline CHEMBL3921376 & 1642448 & 7.1675 & 8.0579 & TST \\
\hline CHEMBL3942192 & 1642448 & 7.9208 & 8.1318 & TST \\
\hline CHEMBL3900559 & 1642448 & 8.5229 & 8.5939 & TST \\
\hline CHEMBL3903990 & 1642448 & 7.2366 & 7.5505 & TST \\
\hline CHEMBL342679 & 45236 & 8.0 & 7.6189 & TRN \\
\hline CHEMBL140941 & 45236 & 7.6198 & 8.4781 & TST \\
\hline CHEMBL140486 & 45236 & 6.301 & 5.8546 & TRN \\
\hline CHEMBL140428 & 45236 & 8.0458 & 7.8734 & TST \\
\hline CHEMBL342038 & 45236 & 6.6383 & 7.1046 & TRN \\
\hline CHEMBL335353 & 45236 & 6.1221 & 6.2506 & TRN \\
\hline CHEMBL139763 & 45236 & 7.3979 & 7.9625 & TST \\
\hline CHEMBL141363 & 45236 & 7.6778 & 7.7197 & TRN \\
\hline CHEMBL141898 & 45236 & 8.5229 & 8.8222 & TST \\
\hline CHEMBL336455 & 45236 & 7.8239 & 7.856 & TST \\
\hline CHEMBL141757 & 45236 & 7.6576 & 7.7617 & TRN \\
\hline CHEMBL138920 & 45236 & 9.3979 & 8.9256 & TRN \\
\hline CHEMBL337328 & 45236 & 8.5229 & 8.929 & TRN \\
\hline CHEMBL138847 & 45236 & 8.699 & 8.51799 & 9999999999 \\
\hline CHEMBL342146 & 45236 & 7.0088 & 7.3317 & TRN \\
\hline
\end{tabular}




\begin{tabular}{|c|c|c|c|c|c|}
\hline \multicolumn{6}{|c|}{ Supplemental Table S2.txt } \\
\hline CHEMBL422639 & 45236 & 6.9031 & 7.2221 & TRN & \\
\hline CHEMBL343332 & 45236 & 6.8239 & 6.9982 & TRN & \\
\hline CHEMBL140805 & 45236 & 9.0 & 9.2687 & TRN & \\
\hline CHEMBL343046 & 45236 & 8.699 & 8.4751 & TRN & \\
\hline CHEMBL141965 & 45236 & 7.2218 & 7.0941 & TRN & \\
\hline CHEMBL140692 & 45236 & 7.4559 & 7.8228 & TST & \\
\hline CHEMBL140973 & 45236 & 4.6893 & 5.5848 & TST & \\
\hline CHEMBL138309 & 45236 & 6.2596 & 6.33 & TST & \\
\hline CHEMBL141351 & 45236 & 9.0458 & 9.0749 & TRN & \\
\hline CHEMBL141255 & 45236 & 7.9208 & 7.8093 & TST & \\
\hline CHEMBL141346 & 45236 & 7.8861 & 7.9081 & TRN & \\
\hline CHEMBL140554 & 45236 & 7.4202 & 7.2946 & TST & \\
\hline CHEMBL342485 & 45236 & 7.6383 & 7.3137 & TRN & \\
\hline CHEMBL140975 & 45236 & 4.8297 & 5.5322 & TRN & \\
\hline CHEMBL139563 & 45236 & 6.8069 & 7.2081 & TRN & \\
\hline CHEMBL139946 & 45236 & 8.699 & 8.8205 & TRN & \\
\hline CHEMBL140933 & 45236 & 7.1612 & 7.0623 & TRN & \\
\hline CHEMBL343098 & 45236 & 8.301 & 8.2689 & TST & \\
\hline CHEMBL141108 & 45236 & 8.1549 & 8.4182 & TRN & \\
\hline CHEMBL140116 & 45236 & 6.9586 & 6.7906 & TRN & \\
\hline CHEMBL344056 & 45236 & 7.2076 & 7.1769 & TRN & \\
\hline CHEMBL344861 & 45236 & 7.2676 & 7.1104 & TST & \\
\hline CHEMBL262561 & 45236 & 8.301 & 8.1875 & TRN & \\
\hline CHEMBL265112 & 45236 & 7.0088 & 6.7873 & TRN & \\
\hline CHEMBL343944 & 45236 & 7.9586 & 8.2622 & TRN & \\
\hline CHEMBL140379 & 45236 & 6.7959 & 6.9696 & TRN & \\
\hline CHEMBL141756 & 45236 & 8.5229 & 8.3425 & TRN & \\
\hline CHEMBL336249 & 45236 & 7.7212 & 7.1549 & TRN & \\
\hline CHEMBL142078 & 45236 & 5.2924 & 5.9508 & TST & \\
\hline CHEMBL140252 & 45236 & 7.0458 & 7.2408 & TRN & \\
\hline CHEMBL344181 & 45236 & 6.3143 & 6.5058 & TRN & \\
\hline CHEMBL343047 & 45236 & 7.4559 & 7.6271 & TRN & \\
\hline CHEMBL443483 & 45236 & 7.1739 & 6.8713 & TRN & \\
\hline CHEMBL422825 & 45236 & 8.0969 & 8.43799 & 9999999999 & TRN \\
\hline CHEMBL142132 & 45236 & 9.5229 & 9.5831 & TRN & \\
\hline CHEMBL344709 & 45236 & 7.301 & 7.3697 & TST & \\
\hline CHEMBL342407 & 45236 & 8.0969 & 7.735 & TRN & \\
\hline CHEMBL140820 & 45236 & 6.2596 & 5.7259 & TST & \\
\hline CHEMBL141049 & 45236 & 6.3716 & 6.5726 & TRN & \\
\hline CHEMBL138253 & 45236 & 9.5229 & 9.2454 & TRN & \\
\hline CHEMBL344156 & 45236 & 9.0458 & 9.1391 & TRN & \\
\hline CHEMBL140696 & 45236 & 7.5686 & 7.6678 & TRN & \\
\hline CHEMBL138009 & 45236 & 6.9706 & 7.1365 & TRN & \\
\hline CHEMBL141052 & 45236 & 7.2596 & 7.061 & TRN & \\
\hline CHEMBL140389 & 45236 & 7.2924 & 7.3513 & TRN & \\
\hline CHEMBL139940 & 45236 & 7.4437 & 7.6533 & TRN & \\
\hline CHEMBL139700 & 45236 & 6.2596 & 6.3948 & TRN & \\
\hline CHEMBL335337 & 45236 & 7.699 & 7.6302 & TRN & \\
\hline
\end{tabular}




\begin{tabular}{|c|c|c|c|c|}
\hline & & & plemen & \\
\hline CHEMBL342668 & 45236 & 6.7696 & 6.7503 & TRN \\
\hline CHEMBL344034 & 45236 & 8.699 & 8.4832 & TRN \\
\hline CHEMBL138603 & 45236 & 8.8239 & 9.2049 & TRN \\
\hline CHEMBL139549 & 45236 & 6.7447 & 6.7525 & TRN \\
\hline CHEMBL141624 & 45236 & 9.301 & 9.3035 & TRN \\
\hline CHEMBL138530 & 45236 & 7.7696 & 7.2482 & TRN \\
\hline CHEMBL140792 & 45236 & 9.2218 & 9.2757 & TRN \\
\hline CHEMBL344055 & 45236 & 7.6778 & 7.4351 & TRN \\
\hline CHEMBL142142 & 45236 & 7.2596 & 7.1661 & TRN \\
\hline CHEMBL141868 & 45236 & 8.699 & 8.5055 & TRN \\
\hline CHEMBL139023 & 45236 & 6.2218 & 5.7004 & TST \\
\hline CHEMBL436573 & 45236 & 7.8239 & 7.737 & TST \\
\hline CHEMBL140643 & 45236 & 6.1675 & 6.3637 & TRN \\
\hline CHEMBL140110 & 45236 & 9.699 & 9.6729 & TRN \\
\hline CHEMBL141309 & 45236 & 6.8239 & 7.3791 & TST \\
\hline CHEMBL141408 & 45236 & 6.9031 & 7.4952 & TST \\
\hline CHEMBL94836 & 45236 & 9.5229 & 9.2005 & TRN \\
\hline CHEMBL343916 & 45236 & 9.301 & 9.2889 & TRN \\
\hline CHEMBL142541 & 45236 & 7.7696 & 7.5289 & TST \\
\hline CHEMBL336691 & 45236 & 6.1367 & 5.4714 & TRN \\
\hline CHEMBL337771 & 45236 & 7.9208 & 7.9068 & TRN \\
\hline CHEMBL344887 & 45236 & 7.1427 & 6.8802 & TRN \\
\hline CHEMBL344001 & 45236 & 8.0969 & 8.5858 & TRN \\
\hline CHEMBL433685 & 45236 & 7.0177 & 6.9006 & TST \\
\hline CHEMBL337136 & 45236 & 7.6383 & 7.313 & TRN \\
\hline CHEMBL139539 & 45236 & 7.699 & 7.6837 & TRN \\
\hline CHEMBL140221 & 45236 & 6.8239 & 7.0222 & TST \\
\hline CHEMBL140616 & 45236 & 9.1549 & 8.9969 & TRN \\
\hline CHEMBL140007 & 45236 & 7.7447 & 7.8654 & TRN \\
\hline CHEMBL336483 & 45236 & 7.2924 & 6.9842 & TRN \\
\hline CHEMBL141425 & 45236 & 8.2218 & 8.6071 & TST \\
\hline CHEMBL344888 & 45236 & 7.4949 & 7.5633 & TRN \\
\hline CHEMBL343268 & 45236 & 6.9586 & 7.4882 & TST \\
\hline CHEMBL342622 & 45236 & 8.0 & 7.8801 & TRN \\
\hline CHEMBL141478 & 45236 & 6.1871 & 6.3917 & TRN \\
\hline CHEMBL344889 & 45236 & 7.9586 & 7.9663 & TRN \\
\hline CHEMBL140391 & 45236 & 7.7959 & 7.8001 & TRN \\
\hline CHEMBL140370 & 45236 & 9.0 & 8.9698 & TRN \\
\hline CHEMBL264879 & 45236 & 9.301 & 9.2862 & TRN \\
\hline CHEMBL343048 & 45236 & 8.8239 & 8.5946 & TRN \\
\hline CHEMBL142067 & 45236 & 6.3665 & 6.5486 & TRN \\
\hline CHEMBL344941 & 45236 & 7.699 & 7.5664 & TST \\
\hline CHEMBL138115 & 45236 & 5.983 & 5.5087 & TRN \\
\hline CHEMBL140446 & 45236 & 6.6021 & 6.7793 & TST \\
\hline CHEMBL344237 & 45236 & 6.3372 & 6.2955 & TST \\
\hline CHEMBL141899 & 45236 & 9.301 & 9.2982 & TRN \\
\hline CHEMBL139668 & 45236 & 8.5229 & 8.1964 & TRN \\
\hline CHEMBL141168 & 45236 & 9.0 & 9.289 & TRN \\
\hline
\end{tabular}




\begin{tabular}{|c|c|c|c|c|c|}
\hline \multirow[b]{2}{*}{ CHEMBL140452 } & \multicolumn{5}{|c|}{ Supplemental Table S2.txt } \\
\hline & 45236 & 7.6198 & 7.558 & TST & \\
\hline CHEMBL141562 & 45236 & 7.7959 & 7.6073 & TRN & \\
\hline CHEMBL138812 & 45236 & 8.5229 & 8.4804 & TRN & \\
\hline CHEMBL337369 & 45236 & 8.699 & 8.5919 & TRN & \\
\hline CHEMBL140169 & 45236 & 7.2676 & 7.4874 & TST & \\
\hline CHEMBL143294 & 45236 & 7.8239 & 7.8576 & TRN & \\
\hline CHEMBL138972 & 45236 & 5.301 & 5.7351 & TST & \\
\hline CHEMBL436400 & 45236 & 6.4145 & 6.11799 & 9999999999 & TST \\
\hline CHEMBL139649 & 45236 & 7.6021 & 7.3183 & TRN & \\
\hline CHEMBL140879 & 45236 & 8.699 & 8.8655 & TST & \\
\hline CHEMBL140791 & 45236 & 8.5229 & 8.575 & TRN & \\
\hline CHEMBL141410 & 45236 & 7.699 & 7.651 & TRN & \\
\hline CHEMBL342610 & 45236 & 8.699 & 8.6078 & TRN & \\
\hline CHEMBL141753 & 45236 & 9.301 & 9.2925 & TRN & \\
\hline CHEMBL140306 & 45236 & 8.0969 & 8.4021 & TRN & \\
\hline CHEMBL141618 & 45236 & 6.3872 & 6.0811 & TST & \\
\hline CHEMBL341760 & 45236 & 8.699 & 8.7131 & TRN & \\
\hline CHEMBL336247 & 45236 & 5.8861 & 5.3672 & TRN & \\
\hline CHEMBL341600 & 45236 & 6.3565 & 6.0963 & TST & \\
\hline CHEMBL342390 & 45236 & 6.2676 & 6.3302 & TST & \\
\hline CHEMBL96361 & 45236 & 7.8239 & 7.59399 & 9999999999 & TRN \\
\hline CHEMBL140095 & 45236 & 9.2218 & 9.1921 & TRN & \\
\hline CHEMBL141130 & 45236 & 8.3979 & 8.3513 & TRN & \\
\hline CHEMBL69149 & 45236 & 8.8239 & 8.9911 & TST & \\
\hline CHEMBL141028 & 45236 & 4.9626 & 5.7868 & TRN & \\
\hline CHEMBL138178 & 45236 & 6.9872 & 7.0379 & TRN & \\
\hline CHEMBL 281794 & 45236 & 7.1805 & 7.1638 & TRN & \\
\hline CHEMBL342026 & 45236 & 9.2218 & 9.1727 & TRN & \\
\hline CHEMBL140481 & 45236 & 9.1549 & 9.1492 & TRN & \\
\hline CHEMBL140942 & 45236 & 7.0 & 7.4611 & TRN & \\
\hline CHEMBL140544 & 45236 & 6.9031 & 7.2733 & TRN & \\
\hline CHEMBL139939 & 45236 & 8.301 & 8.5966 & TRN & \\
\hline CHEMBL341548 & 45236 & 7.1549 & 6.9597 & TRN & \\
\hline CHEMBL 343590 & 45236 & 7.8239 & 7.7027 & TST & \\
\hline CHEMBL344382 & 45236 & 8.699 & 8.7056 & TRN & \\
\hline CHEMBL140938 & 45236 & 4.7282 & 5.51399 & 9999999999 & TRN \\
\hline CHEMBL141526 & 45236 & 7.1612 & 7.0725 & TRN & \\
\hline CHEMBL140880 & 45236 & 7.4559 & 7.2857 & TST & \\
\hline CHEMBL 344030 & 45236 & 7.2076 & 7.1192 & TRN & \\
\hline CHEMBL2043004 & 823544 & 8.8861 & 8.94 & TRN & \\
\hline CHEMBL 2041191 & 823544 & 9.0 & 9.0019 & TRN & \\
\hline CHEMBL2043006 & 823544 & 8.8539 & 8.843 & TRN & \\
\hline CHEMBL 2041187 & 823544 & 8.9208 & 8.995 & TRN & \\
\hline CHEMBL2041189 & 823544 & 9.3979 & 9.3184 & TRN & \\
\hline CHEMBL2041176 & 823544 & 8.9586 & 8.9583 & TRN & \\
\hline CHEMBL 2041179 & 823544 & 8.4318 & 8.4175 & TRN & \\
\hline CHEMBL 2043002 & 823544 & 8.7447 & 8.7367 & TRN & \\
\hline CHEMBL 2043327 & 823544 & 8.7212 & 8.0799 & TST & \\
\hline
\end{tabular}


Supplemental Table S2.txt

\begin{tabular}{|c|c|c|c|c|}
\hline 3172 & & 8.9208 & & \\
\hline HEMBL2041168 & 23544 & 8.2218 & 8.2187 & \\
\hline MBI 2041188 & 3544 & & & \\
\hline EMBL204 & 3544 & 229 & & \\
\hline IEMBL 2041173 & 23544 & 6383 & 292 & \\
\hline HEMBL2043328 & 23544 & 7.7696 & 12 & \\
\hline 011 & 3544 & 9586 & & \\
\hline EMBL 204 & & 9.0 & & \\
\hline AEMBL2041167 & 23544 & 8.699 & 333 & \\
\hline HEMBL2041165 & 23544 & 8.2596 & & \\
\hline HEMBL 204 & 23544 & 9.5229 & & \\
\hline EMBL 204 & 44 & 99 & & \\
\hline AEMBL 204 & & & & \\
\hline HEMBL 2040896 & 23544 & 8.3468 & & \\
\hline IEMBL204 & & & & \\
\hline IEMBL 204 & 4 & 9.5 & & \\
\hline 397 & & .3979 & & \\
\hline EMBL 20 & & 9.3979 & & \\
\hline AEMBL 204 & & 8.0862 & & \\
\hline IEMBL 204 & & & & \\
\hline 70 & & 9. & & \\
\hline 75 & & & & \\
\hline 05 & & 8.7696 & & \\
\hline 395 & & 7.4 & & \\
\hline MBL204 & & & & \\
\hline 008 & & 8.6 & & \\
\hline 03 & & 39 & & \\
\hline 93 & & 9 & & \\
\hline 84 & & & & \\
\hline HEMBL 204 & & 9.5 & & \\
\hline 80 & & & & \\
\hline 26 & & 9 & & \\
\hline & & & & \\
\hline EMBL 204 & & & & \\
\hline HEMBL 204 & & 9.6 & & \\
\hline & & & & \\
\hline 74 & & & & \\
\hline & & & & \\
\hline IEMBL204 & 3544 & 9.0 & & \\
\hline MBL204 & & 8.6 & & \\
\hline 69 & & & & \\
\hline 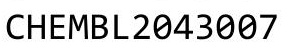 & & 8.8 & & \\
\hline CHEMBL 204 & & 9.1549 & & \\
\hline EMBL 20 & & 9.0 & & \\
\hline 24 & & 9.35 & & \\
\hline CHEMBL204 & & 9.699 & & \\
\hline CHEMBL 2041166 & 23544 & $8.251 \varepsilon$ & 8.3 & \\
\hline CHEMBL527593 & 1369402 & 5.0 & 5.0988 & \\
\hline
\end{tabular}

Page 17018 


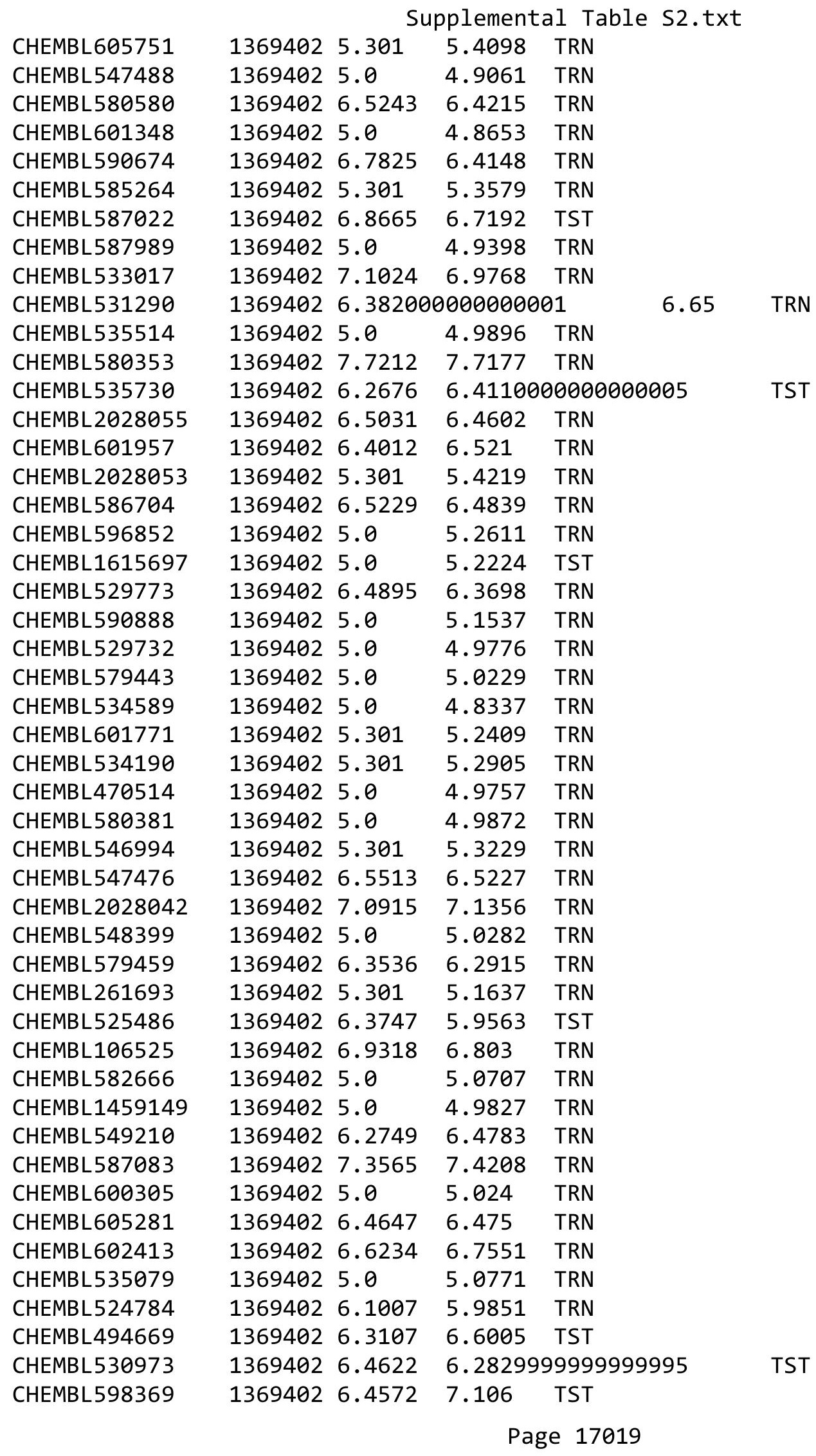




\begin{tabular}{|c|c|c|c|c|c|}
\hline \multicolumn{6}{|c|}{ splemental } \\
\hline CHEMBL586344 & 1369402 & 5.0 & 4.8762 & TST & \\
\hline CHEMBL124006 & 1369402 & 6.4437 & 7.1767 & TST & \\
\hline CHEMBL587410 & 1369402 & 5.0 & 5.3243 & TST & \\
\hline CHEMBL530223 & 1369402 & 6.6716 & 6.1454 & TST & \\
\hline CHEMBL532987 & 1369402 & 6.4271 & 6.1367 & TST & \\
\hline CHEMBL604323 & 1369402 & 5.0 & 4.8825 & TST & \\
\hline CHEMBL 206540 & 1369402 & 5.0 & 5.2501 & TST & \\
\hline CHEMBL317364 & 1369402 & 7.3979 & 7.6628 & TST & \\
\hline CHEMBL121559 & 106144 & 4.1871 & 4.2184 & TRN & \\
\hline CHEMBL123064 & 106144 & 4.3979 & 5.0483 & TST & \\
\hline CHEMBL123775 & 106144 & 8.3979 & 8.2959 & TRN & \\
\hline CHEMBL 333122 & 106144 & 4.0223 & 5.2923 & TST & \\
\hline CHEMBL122711 & 106144 & 8.2218 & 8.2786 & TRN & \\
\hline CHEMBL123041 & 106144 & 7.585 & 7.5254 & TRN & \\
\hline CHEMBL331342 & 106144 & 7.3565 & 7.4748 & TRN & \\
\hline CHEMBL 304281 & 106144 & 7.6198 & 7.5226 & TRN & \\
\hline CHEMBL340461 & 106144 & 8.2218 & 8.2073 & TRN & \\
\hline CHEMBL331669 & 106144 & 6.8239 & 6.84200 & 00000000005 & TRN \\
\hline CHEMBL120934 & 106144 & 4.1805 & 4.2032 & TRN & \\
\hline CHEMBL123105 & 106144 & 4.4685 & 4.4871 & TRN & \\
\hline CHEMBL123167 & 106144 & 6.8386 & 6.80200 & 00000000005 & TST \\
\hline CHEMBL121729 & 106144 & 4.3768 & 4.3312 & TRN & \\
\hline CHEMBL 332362 & 106144 & 6.0458 & 6.0357 & TRN & \\
\hline CHEMBL123404 & 106144 & 4.1487 & 4.1544 & TRN & \\
\hline CHEMBL262676 & 106144 & 8.1549 & 8.2362 & TRN & \\
\hline CHEMBL122651 & 106144 & 7.2676 & 7.4135 & TRN & \\
\hline CHEMBL432223 & 106144 & 8.0 & 8.06299 & 9999999999 & TRN \\
\hline CHEMBL 330950 & 106144 & 3.0 & 4.8807 & TST & \\
\hline CHEMBL 122109 & 106144 & 4.1549 & 5.1732 & TST & \\
\hline CHEMBL 293774 & 106144 & 7.5528 & 7.4543 & TRN & \\
\hline CHEMBL55110 & 106144 & 7.2076 & 7.4236 & TRN & \\
\hline CHEMBL440714 & 106144 & 7.2757 & 7.2226 & TRN & \\
\hline CHEMBL441084 & 106144 & 7.5229 & 7.4439 & TRN & \\
\hline CHEMBL 293503 & 106144 & 8.5229 & 8.3327 & TRN & \\
\hline CHEMBL98328 & 106144 & 6.0 & 5.1742 & TST & \\
\hline CHEMBL 333248 & 106144 & 5.699 & 6.6033 & TST & \\
\hline CHEMBL121592 & 106144 & 4.4318 & 4.3512 & TRN & \\
\hline CHEMBL 332439 & 106144 & 4.1308 & 5.1357 & TST & \\
\hline CHEMBL123233 & 106144 & 4.5376 & 4.5347 & TRN & \\
\hline CHEMBL450327 & 106144 & 7.4089 & 7.4911 & TRN & \\
\hline CHEMBL 301469 & 106144 & 4.1487 & 4.1812 & TRN & \\
\hline CHEMBL122836 & 106144 & 7.2218 & 7.5014 & TRN & \\
\hline CHEMBL120049 & 106144 & 6.8097 & 6.8034 & TRN & \\
\hline CHEMBL122719 & 106144 & 7.6021 & 7.487 & TRN & \\
\hline CHEMBL121501 & 106144 & 4.2291 & 5.3021 & TST & \\
\hline CHEMBL 311336 & 106144 & 7.3665 & 7.3594 & TRN & \\
\hline CHEMBL332145 & 106144 & 4.1308 & 4.1306 & TRN & \\
\hline CHEMBL332858 & 106144 & 5.699 & 6.5074 & TST & \\
\hline
\end{tabular}




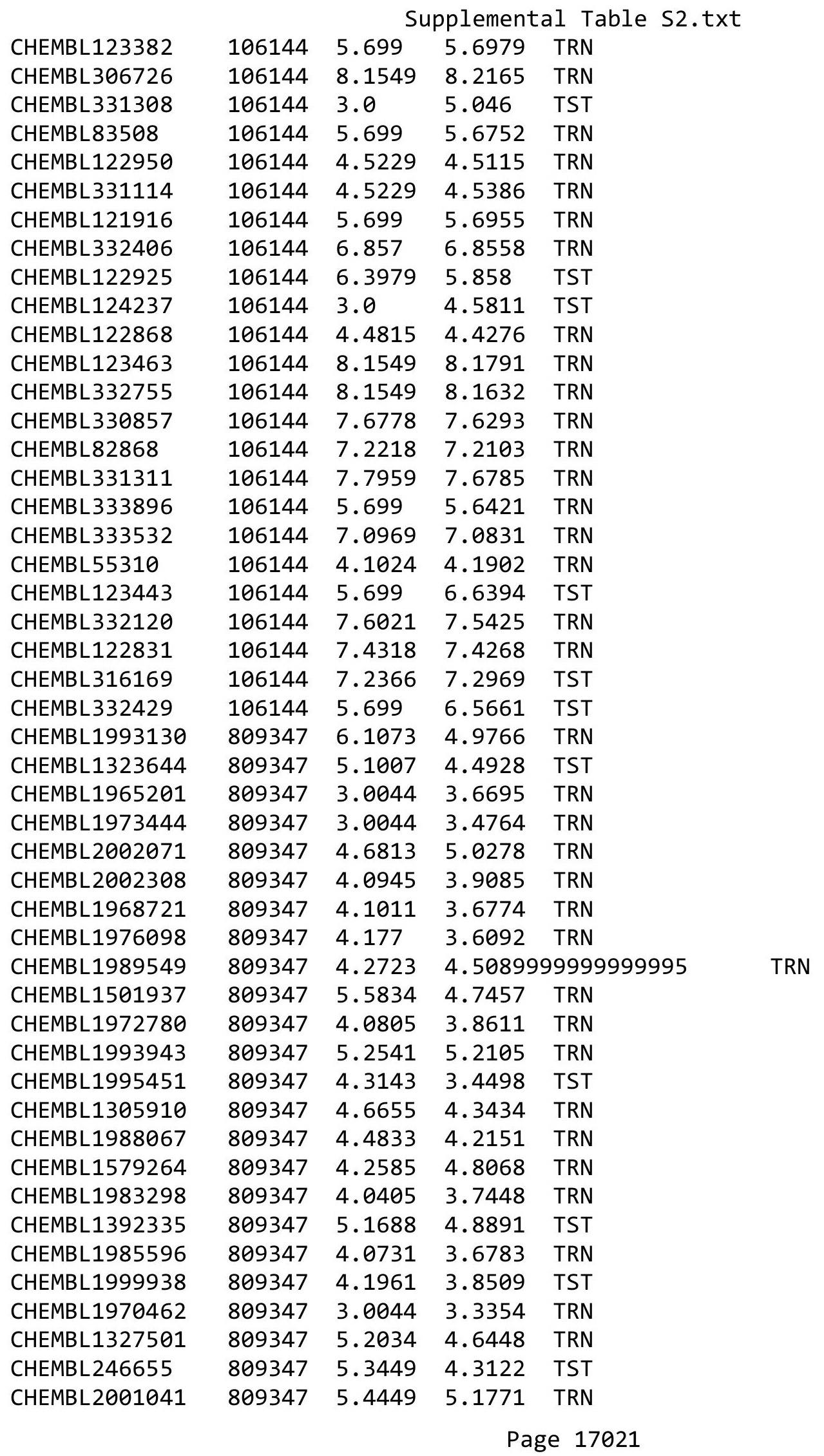




\begin{tabular}{|c|c|c|c|c|c|}
\hline \multirow[b]{2}{*}{ CHEMBL1372180 } & \multicolumn{5}{|c|}{ Supplemental Table S2.txt } \\
\hline & 809347 & 4.3566 & 4.2918 & TRN & \\
\hline CHEMBL 2003655 & 809347 & 4.2239 & 5.0982 & TRN & \\
\hline CHEMBL1869416 & 809347 & 4.0946 & 3.4882 & TRN & \\
\hline CHEMBL1967430 & 809347 & 3.0044 & 4.0045 & TRN & \\
\hline CHEMBL1309497 & 809347 & 4.3861 & 5.0525 & TST & \\
\hline CHEMBL1490308 & 809347 & 5.7986 & 4.0721 & TST & \\
\hline CHEMBL1974026 & 809347 & 3.0044 & 3.5355 & TRN & \\
\hline CHEMBL 2000599 & 809347 & 3.0044 & 3.4954 & TST & \\
\hline CHEMBL1993650 & 809347 & 4.1669 & 4.1156 & TRN & \\
\hline CHEMBL1500169 & 809347 & 4.4647 & 4.2343 & TST & \\
\hline CHEMBL1368914 & 809347 & 3.0044 & 3.2737 & TRN & \\
\hline CHEMBL1973984 & 809347 & 4.038 & 4.0375 & TRN & \\
\hline CHEMBL1964510 & 809347 & 3.0044 & 4.0002 & TRN & \\
\hline CHEMBL1965501 & 809347 & 4.1013 & 3.6273 & TRN & \\
\hline CHEMBL1997123 & 809347 & 3.0044 & 3.5629 & TRN & \\
\hline CHEMBL1977950 & 809347 & 4.6031 & 4.8094 & TRN & \\
\hline CHEMBL2001665 & 809347 & 3.0044 & 3.8757 & TRN & \\
\hline CHEMBL1974521 & 809347 & 5.3487 & 4.7647 & TST & \\
\hline CHEMBL1972310 & 809347 & 4.3519 & 4.5589 & TRN & \\
\hline CHEMBL1363112 & 809347 & 4.2997 & 5.0076 & TRN & \\
\hline CHEMBL1528822 & 809347 & 5.0141 & 4.4421 & TRN & \\
\hline CHEMBL1993276 & 809347 & 5.6162 & 5.3963 & TRN & \\
\hline CHEMBL1976235 & 809347 & 4.1393 & 4.119 & TRN & \\
\hline CHEMBL 2006869 & 809347 & 4.1005 & 3.9065 & TST & \\
\hline CHEMBL1964901 & 809347 & 4.7167 & 4.5423 & TRN & \\
\hline CHEMBL1977479 & 809347 & 4.1638 & 3.9823 & TST & \\
\hline CHEMBL1991688 & 809347 & 4.1637 & 3.7286 & TRN & \\
\hline CHEMBL1558834 & 809347 & 3.0044 & 3.3864 & TRN & \\
\hline CHEMBL1969207 & 809347 & 4.3722 & 4.9731 & TST & \\
\hline CHEMBL1385744 & 809347 & 4.1614 & 4.0941 & TRN & \\
\hline CHEMBL1975135 & 809347 & 3.0044 & 3.9889 & TRN & \\
\hline CHEMBL 2000042 & 809347 & 4.0796 & 3.9535 & TRN & \\
\hline CHEMBL1992176 & 809347 & 4.6861 & 5.3317 & TRN & \\
\hline CHEMBL1410842 & 809347 & 3.0044 & 2.91300 & 00000000003 & TRN \\
\hline CHEMBL1975823 & 809347 & 3.0044 & 3.3878 & TRN & \\
\hline CHEMBL1974840 & 809347 & 4.1457 & 3.4478 & TST & \\
\hline CHEMBL 2006017 & 809347 & 5.8633 & 5.5786 & TRN & \\
\hline CHEMBL1985130 & 809347 & 4.688 & 5.1575 & TRN & \\
\hline CHEMBL 2003811 & 809347 & 4.3907 & 5.0535 & TRN & \\
\hline CHEMBL1976967 & 809347 & 4.1722 & 3.9784 & TRN & \\
\hline CHEMBL1995255 & 809347 & 4.3675 & 4.0436 & TRN & \\
\hline CHEMBL1700836 & 809347 & 4.8477 & 4.4325 & TST & \\
\hline CHEMBL 2002845 & 809347 & 3.0044 & 3.4976 & TRN & \\
\hline CHEMBL 2006198 & 809347 & 4.0994 & 4.1645 & TRN & \\
\hline CHEMBL1336933 & 809347 & 3.0044 & 3.0134 & TRN & \\
\hline CHEMBL2005366 & 809347 & 4.2553 & 3.8242 & TRN & \\
\hline CHEMBL1995649 & 809347 & 4.1776 & 4.1913 & TRN & \\
\hline CHEMBL1973048 & 809347 & 4.1247 & 4.0839 & TRN & \\
\hline
\end{tabular}

Page 17022 
Supplemental Table S2.txt

\begin{tabular}{|c|c|c|c|c|c|}
\hline CHEMBL1966161 & 809347 & 4.0522 & \multicolumn{2}{|c|}{3.7969999999999997} & RA \\
\hline CHEMBL1977692 & 809347 & 4.3063 & 3.7453 & TRN & \\
\hline CHEMBL1351403 & 809347 & 4.2221 & 4.2969 & TRN & \\
\hline CHEMBL1995310 & 809347 & 3.0044 & 3.2913 & TRN & \\
\hline CHEMBL1966622 & 809347 & 5.0232 & 4.9062 & TST & \\
\hline CHEMBL1581799 & 809347 & 4.6897 & 4.8636 & TRN & \\
\hline CHEMBL1353222 & 809347 & 3.0044 & 3.7908 & TST & \\
\hline CHEMBL 2006714 & 809347 & 5.5901 & 5.0043 & TRN & \\
\hline CHEMBL1370417 & 809347 & 3.0044 & 4.0615 & TST & \\
\hline CHEMBL1992480 & 809347 & 4.1981 & 4.1552 & TRN & \\
\hline CHEMBL1968268 & 809347 & 4.7773 & 4.9129 & TRN & \\
\hline CHEMBL1549870 & 809347 & 5.2449 & 4.7418 & TST & \\
\hline CHEMBL1985704 & 809347 & 5.0376 & 4.8012 & TRN & \\
\hline CHEMBL1438570 & 809347 & 5.1669 & \multicolumn{2}{|c|}{ 4. 3069999999999995} & \\
\hline CHEMBL 2001815 & 809347 & 5.7696 & 5.2445 & TRN & \\
\hline CHEMBL1993743 & 809347 & 4.2085 & 4.1146 & TRN & \\
\hline CHEMBL1525481 & 809347 & 4.51 & 5.0623 & TST & \\
\hline CHEMBL1997796 & 809347 & 3.0044 & 3.6159 & TRN & \\
\hline CHEMBL1985970 & 809347 & 4.1385 & 4.1775 & TRN & \\
\hline CHEMBL1476102 & 809347 & 4.0881 & 3.3396 & TRN & \\
\hline CHEMBL1533040 & 809347 & 4.4 & 5.0092 & TRN & \\
\hline CHEMBL1981206 & 809347 & 4.0828 & 4.2184 & TST & \\
\hline CHEMBL1992722 & 809347 & 4.2238 & 4.5056 & TRN & \\
\hline CHEMBL1993417 & 809347 & 3.0044 & \multicolumn{2}{|c|}{3.5260000000000002} & \\
\hline CHEMBL1594483 & 809347 & 4.3757 & \multicolumn{2}{|c|}{3.9389999999999996} & \\
\hline CHEMBL1571839 & 809347 & 6.0937 & 5.0888 & TRN & \\
\hline CHEMBL1990867 & 809347 & 5.2882 & 4.5088 & TST & \\
\hline CHEMBL1709744 & 809347 & 3.0044 & 4.5996 & TRN & \\
\hline CHEMBL1347563 & 809347 & 5.3936 & 4.0769 & TRN & \\
\hline CHEMBL1580946 & 809347 & 4.2251 & 3.6884 & TRN & \\
\hline CHEMBL1967566 & 809347 & 5.0467 & 4.4508 & TST & \\
\hline CHEMBL1992193 & 809347 & 3.0044 & 4.1758 & TST & \\
\hline CHEMBL1475485 & 809347 & 4.4486 & 4.0143 & TRN & \\
\hline CHEMBL1989875 & 809347 & 3.0044 & 3.5546 & TRN & \\
\hline CHEMBL1520311 & 809347 & 4.9508 & 4.6791 & TST & \\
\hline CHEMBL1989640 & 809347 & 4.1891 & 3.6608 & TRN & \\
\hline CHEMBL1993844 & 809347 & 3.0044 & 3.4631 & TRN & \\
\hline CHEMBL1979770 & 809347 & 3.0044 & 3.4851 & TRN & \\
\hline CHEMBL1988776 & 809347 & 4.1644 & 3.3479 & TRN & \\
\hline CHEMBL1999373 & 809347 & 3.0044 & 3.9161 & TST & \\
\hline CHEMBL1983833 & 809347 & 3.0044 & 3.2452 & TRN & \\
\hline CHEMBL1995952 & 809347 & 5.3179 & 4.5456 & TRN & \\
\hline CHEMBL1969580 & 809347 & 4.8069 & 4.3479 & TRN & \\
\hline CHEMBL1311971 & 809347 & 3.0044 & 3.5788 & TRN & \\
\hline CHEMBL1565806 & 809347 & 4.3955 & 5.2936 & TRN & \\
\hline CHEMBL1979068 & 809347 & 4.0829 & 3.5921 & TRN & \\
\hline CHEMBL1507840 & 809347 & 3.0044 & 3.4372 & TST & \\
\hline CHEMBL1993846 & 809347 & 4.4439 & 4.3797 & TRN & \\
\hline
\end{tabular}

Page 17023 


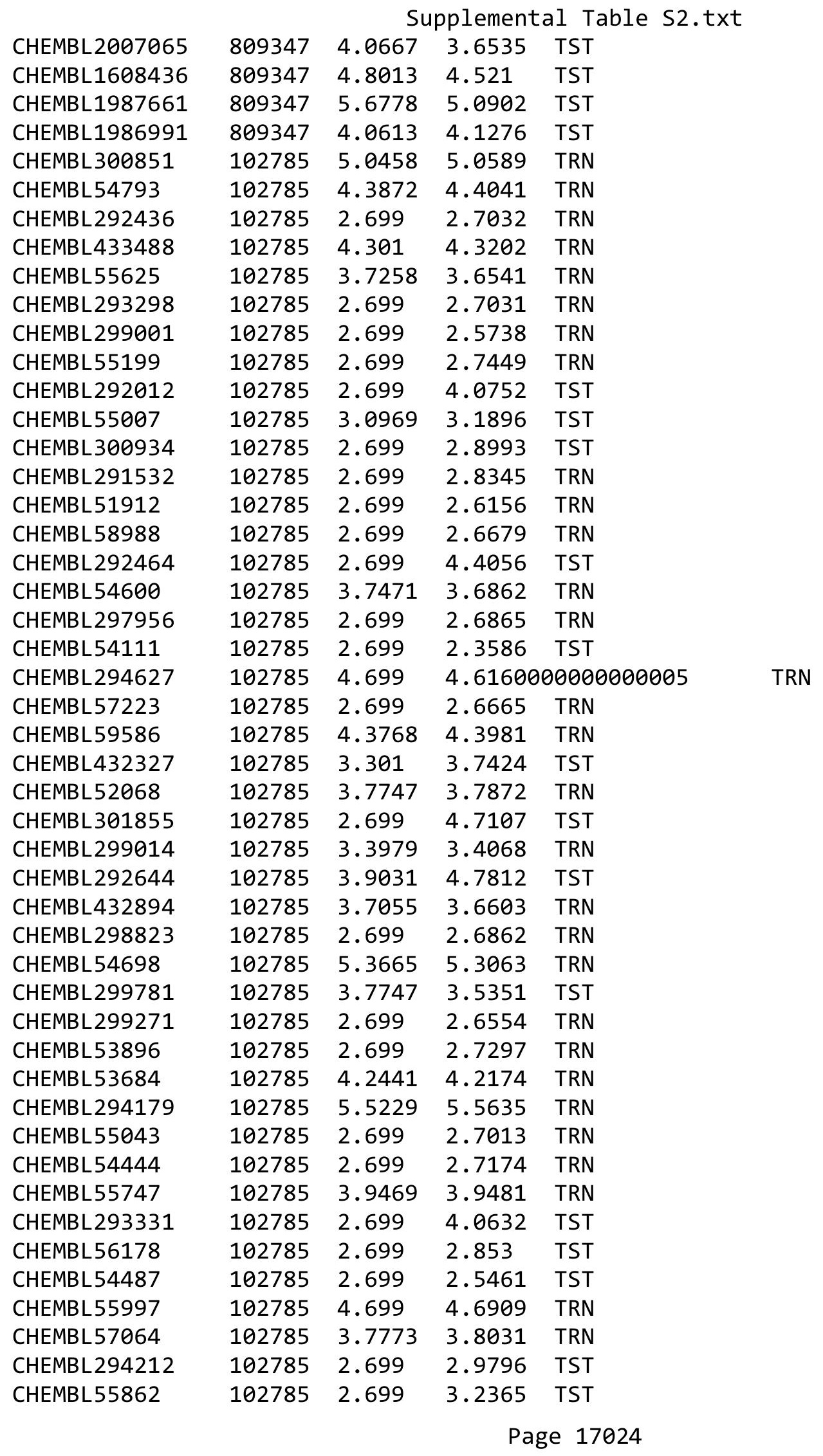




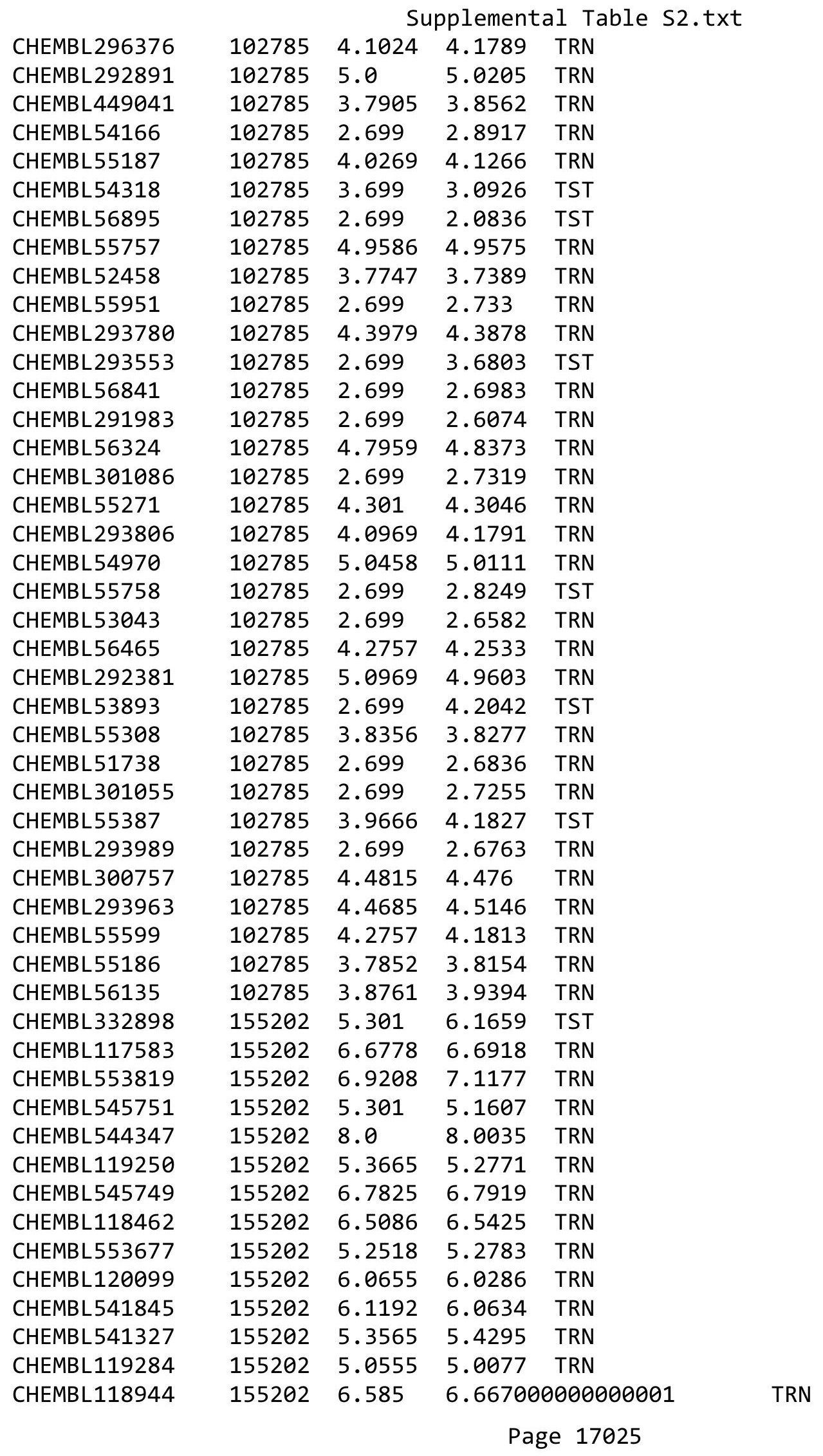


Supplemental Table S2.txt

\begin{tabular}{|c|c|c|c|c|}
\hline CHEMBL538031 & 155202 & 6.9788 & 7.0073 & TRN \\
\hline CHEMBL544818 & 155202 & 6.2676 & 5.9967 & TRN \\
\hline CHEMBL544348 & 155202 & 5.7696 & 5.70200 & 0000000001 \\
\hline CHEMBL539806 & 155202 & 8.5528 & 8.3011 & TRN \\
\hline CHEMBL118209 & 155202 & 5.6021 & 5.7806 & TRN \\
\hline CHEMBL545523 & 155202 & 5.5528 & 5.5322 & TRN \\
\hline CHEMBL324317 & 155202 & 4.9586 & 5.8215 & TST \\
\hline CHEMBL554051 & 155202 & 6.9586 & 6.8309 & TRN \\
\hline CHEMBL119449 & 155202 & 4.7328 & 5.5953 & TST \\
\hline CHEMBL554946 & 155202 & 6.6383 & 6.4957 & TRN \\
\hline CHEMBL544816 & 155202 & 7.585 & 7.6263 & TRN \\
\hline CHEMBL553583 & 155202 & 4.8861 & 4.9656 & TRN \\
\hline CHEMBL118193 & 155202 & 5.3372 & 5.3694 & TRN \\
\hline CHEMBL118538 & 155202 & 5.6676 & 5.6606 & TRN \\
\hline CHEMBL331514 & 155202 & 4.8239 & 4.8323 & TRN \\
\hline CHEMBL545518 & 155202 & 8.6383 & 8.6997 & TRN \\
\hline CHEMBL542216 & 155202 & 4.699 & 5.1447 & TST \\
\hline CHEMBL119328 & 155202 & 5.3665 & 5.6651 & TST \\
\hline CHEMBL119589 & 155202 & 5.1675 & 5.1875 & TST \\
\hline CHEMBL332686 & 155202 & 5.3279 & 5.5769 & TRN \\
\hline CHEMBL557022 & 155202 & 8.585 & 8.6311 & TRN \\
\hline CHEMBL118572 & 155202 & 4.6576 & 5.8262 & TST \\
\hline CHEMBL118781 & 155202 & 6.1308 & 6.1987 & TRN \\
\hline CHEMBL333093 & 155202 & 6.0969 & 6.0872 & TRN \\
\hline CHEMBL116371 & 155202 & 5.2076 & 5.1991 & TRN \\
\hline CHEMBL118812 & 155202 & 6.3768 & 6.394 & TRN \\
\hline CHEMBL 72650 & 155202 & 6.4949 & 6.0245 & TRN \\
\hline CHEMBL332732 & 155202 & 5.8861 & 5.8246 & TRN \\
\hline CHEMBL555463 & 155202 & 7.7959 & 7.7767 & TRN \\
\hline CHEMBL118959 & 155202 & 5.0458 & 5.0372 & TRN \\
\hline CHEMBL118376 & 155202 & 5.9586 & 5.9899 & TRN \\
\hline CHEMBL544584 & 155202 & 5.6383 & 5.5367 & TRN \\
\hline CHEMBL116818 & 155202 & 6.7212 & 6.7423 & TRN \\
\hline CHEMBL117108 & 155202 & 6.1427 & 6.2199 & TRN \\
\hline CHEMBL118717 & 155202 & 6.0969 & 6.1672 & TRN \\
\hline CHEMBL541847 & 155202 & 6.4437 & 6.2983 & TRN \\
\hline CHEMBL116890 & 155202 & 5.9208 & 6.0764 & TRN \\
\hline CHEMBL552952 & 155202 & 5.5229 & 5.6947 & TRN \\
\hline CHEMBL555184 & 155202 & 6.3188 & 6.2516 & TRN \\
\hline CHEMBL545520 & 155202 & 4.9586 & 4.9514 & TRN \\
\hline CHEMBL555218 & 155202 & 7.8539 & 7.7993 & TRN \\
\hline CHEMBL539033 & 155202 & 9.2757 & 9.3195 & TRN \\
\hline CHEMBL540318 & 155202 & 6.2007 & 6.2443 & TRN \\
\hline CHEMBL420539 & 155202 & 5.0655 & 5.2397 & TRN \\
\hline CHEMBL119309 & 155202 & 5.4437 & 5.407 & TST \\
\hline CHEMBL542707 & 155202 & 7.1427 & 7.2529 & TRN \\
\hline CHEMBL118415 & 155202 & 5.6198 & 5.4841 & TRN \\
\hline CHEMBL117509 & 155202 & 5.7212 & 5.9208 & TRN \\
\hline
\end{tabular}




\begin{tabular}{|c|c|c|c|c|c|c|}
\hline & & \multicolumn{5}{|c|}{ Supplemental Table S2.txt } \\
\hline CHEMBL555171 & 155202 & 6.0655 & 6.3938 & TST & & \\
\hline CHEMBL118696 & 155202 & 5.2596 & 5.5005 & TST & & \\
\hline CHEMBL119841 & 155202 & 6.3468 & 6.0307 & TST & & \\
\hline CHEMBL332520 & 155202 & 5.4089 & 5.3775 & TST & & \\
\hline CHEMBL119321 & 155202 & 4.8539 & 5.4425 & TST & & \\
\hline CHEMBL118481 & 155202 & 5.9208 & 5.8152 & TST & & \\
\hline CHEMBL119506 & 155202 & 5.6198 & 5.2496 & TST & & \\
\hline CHEMBL341679 & 155202 & 5.8861 & 6.7707 & TST & & \\
\hline CHEMBL422606 & 155202 & 5.2218 & 5.3375 & TST & & \\
\hline CHEMBL553820 & 155202 & 6.0 & 5.8158 & TST & & \\
\hline CHEMBL118217 & 155202 & 5.6383 & 5.065 & TST & & \\
\hline CHEMBL327756 & 194806 & 6.222 & 6.282 & TRN & & \\
\hline CHEMBL101716 & 194806 & 6.609 & 7.2605 & TRN & & \\
\hline CHEMBL293116 & 194806 & 6.46 & 6.5571 & TRN & & \\
\hline CHEMBL101407 & 194806 & 8.506 & 8.4465 & TRN & & \\
\hline CHEMBL100441 & 194806 & 8.41 & 8.6274 & TRN & & \\
\hline CHEMBL319519 & 194806 & 8.39 & 8.4225 & TRN & & \\
\hline CHEMBL97920 & 194806 & 5.93 & 6.3724 & TRN & & \\
\hline CHEMBL100835 & 194806 & 8.37 & 8.4518 & TRN & & \\
\hline CHEMBL 98080 & 194806 & 6.199 & 5.9929 & TRN & & \\
\hline CHEMBL101886 & 194806 & 8.89 & 8.5228 & TRN & & \\
\hline CHEMBL100508 & 194806 & 8.741 & 8.8222 & TRN & & \\
\hline CHEMBL318071 & 194806 & 7.98 & 7.5132 & TST & & \\
\hline CHEMBL316663 & 194806 & $7.9970 e$ & 30000000 & & 7.5846 & TRN \\
\hline CHEMBL54537 & 194806 & 8.586 & 8.9611 & TRN & & \\
\hline CHEMBL 98703 & 194806 & 8.301 & 6.8813 & TST & & \\
\hline CHEMBL100335 & 194806 & 8.29 & 8.3877 & TRN & & \\
\hline CHEMBL100827 & 194806 & 9.209 & 9.0995 & TRN & & \\
\hline CHEMBL 98787 & 194806 & 7.19 & 6.106 & TST & & \\
\hline CHEMBL101647 & 194806 & 6.803 & 5.7973 & TST & & \\
\hline CHEMBL318504 & 194806 & 6.732 & 6.624 & TRN & & \\
\hline CHEMBL99006 & 194806 & 5.65799 & 99999999 & 995 & 5.9794 & TST \\
\hline CHEMBL53982 & 194806 & 8.4 & 8.5976 & TRN & & \\
\hline CHEMBL 98476 & 194806 & 8.57 & 8.5242 & TRN & & \\
\hline CHEMBL323300 & 194806 & 7.734 & 7.8251 & TRN & & \\
\hline CHEMBL 301244 & 194806 & 8.407 & 8.4649 & TRN & & \\
\hline CHEMBL301247 & 194806 & 8.958 & 6.7798 & TST & & \\
\hline CHEMBL101472 & 194806 & 8.84 & 8.6273 & TRN & & \\
\hline CHEMBL97911 & 194806 & 7.75 & 5.494 & TST & & \\
\hline CHEMBL321075 & 194806 & 7.405 & 7.4923 & TRN & & \\
\hline CHEMBL98083 & 194806 & 6.053 & 5.7537 & TRN & & \\
\hline CHEMBL317338 & 194806 & 5.44 & 6.204 & TRN & & \\
\hline CHEMBL56073 & 194806 & 8.98 & 8.9539 & TRN & & \\
\hline CHEMBL101717 & 194806 & 7.142 & 6.9007 & TRN & & \\
\hline CHEMBL100830 & 194806 & 8.317 & 8.2336 & TRN & & \\
\hline CHEMBL101987 & 194806 & 5.619 & 5.5762 & TRN & & \\
\hline CHEMBL100295 & 194806 & 8.211 & 8.2802 & TRN & & \\
\hline CHEMBL101539 & 194806 & 8.15 & 8.4839 & TRN & & \\
\hline
\end{tabular}




\begin{tabular}{|c|c|c|c|c|c|c|}
\hline \\
\hline CHEMBL101230 & 194806 & 8.78 & 8.7921 & TRN & & \\
\hline CHEMBL317646 & 194806 & 8.29 & 6.9216 & TST & & \\
\hline CHEMBL55464 & 194806 & 8.57 & 8.209 & TRN & & \\
\hline CHEMBL101207 & 194806 & 8.705 & 7.6579 & TST & & \\
\hline CHEMBL 98629 & 194806 & 6.135 & 6.07299 & 99999 & 995 & TST \\
\hline CHEMBL 273286 & 194806 & 7.25299 & 99999999 & 99 & 7.6794 & TRN \\
\hline CHEMBL316844 & 194806 & 8.488 & 8.1153 & TRN & & \\
\hline CHEMBL100232 & 194806 & 7.74 & 7.6147 & TRN & & \\
\hline CHEMBL318861 & 194806 & 7.62 & 7.3154 & TRN & & \\
\hline CHEMBL432388 & 194806 & 4.754 & 5.2013 & TRN & & \\
\hline CHEMBL100831 & 194806 & 7.74 & 6.8588 & TST & & \\
\hline CHEMBL323299 & 194806 & 7.294 & 6.6205 & TST & & \\
\hline CHEMBL 98211 & 194806 & 7.176 & 6.6872 & TST & & \\
\hline CHEMBL100717 & 194806 & 5.711 & 5.709 & TST & & \\
\hline CHEMBL316913 & 194806 & 8.55 & 8.3726 & TRN & & \\
\hline CHEMBL102209 & 194806 & 7.745 & 7.7788 & TRN & & \\
\hline CHEMBL102185 & 194806 & 7.306 & 6.204 & TRN & & \\
\hline CHEMBL1087955 & 688398 & 5.1 & 5.2622 & TRN & & \\
\hline CHEMBL 1087576 & 688398 & 5.2 & 5.2762 & TRN & & \\
\hline CHEMBL1088001 & 688398 & 5.65 & 5.864 & TRN & & \\
\hline CHEMBL 1088509 & 688398 & 6.2 & 5.7123 & TRN & & \\
\hline CHEMBL 1088136 & 688398 & 5.0 & 5.2643 & TRN & & \\
\hline CHEMBL 2181097 & 688398 & 5.8367 & 5.1179 & TRN & & \\
\hline CHEMBL1099027 & 688398 & 4.6 & 5.2942 & TRN & & \\
\hline CHEMBL 2181098 & 688398 & 4.8867 & 4.6006 & TRN & & \\
\hline CHEMBL 216504 & 688398 & 4.35 & 5.1273 & TST & & \\
\hline CHEMBL 1434170 & 688398 & 5.55 & 5.4478 & TRN & & \\
\hline CHEMBL 2180816 & 688398 & 5.4867 & 4.7199 & TRN & & \\
\hline CHEMBL1088561 & 688398 & 6.8 & 6.1625 & TRN & & \\
\hline CHEMBL1087072 & 688398 & 4.95 & 5.581 & TRN & & \\
\hline CHEMBL1086980 & 688398 & 5.5 & 5.6441 & TRN & & \\
\hline CHEMBL 2181103 & 688398 & 6.0 & 5.4884 & TRN & & \\
\hline CHEMBL1086935 & 688398 & 5.6 & 5.7947 & TRN & & \\
\hline CHEMBL1088078 & 688398 & 5.2 & 5.482 & TRN & & \\
\hline CHEMBL1087703 & 688398 & 5.6 & 5.5237 & TRN & & \\
\hline CHEMBL1087109 & 688398 & 5.5 & 5.4557 & TRN & & \\
\hline CHEMBL 1087706 & 688398 & 5.75 & 5.3876 & TRN & & \\
\hline CHEMBL1489392 & 688398 & 6.7001 & 4.0731 & TST & & \\
\hline CHEMBL1086981 & 688398 & 5.55 & 5.6343 & TRN & & \\
\hline CHEMBL 2181094 & 688398 & 4.8254 & 4.6512 & TRN & & \\
\hline CHEMBL123 & 688398 & 4.45 & 4.1105 & TST & & \\
\hline CHEMBL1087226 & 688398 & 5.95 & 5.7876 & TRN & & \\
\hline CHEMBL34704 & 688398 & 4.35 & 4.0174 & TST & & \\
\hline CHEMBL1411034 & 688398 & 4.5 & 4.2401 & TRN & & \\
\hline CHEMBL1708234 & 688398 & 4.8254 & 4.5835 & TRN & & \\
\hline CHEMBL1437756 & 688398 & 4.4 & 4.226 & TRN & & \\
\hline CHEMBL 1088718 & 688398 & 5.9 & 5.9054 & TRN & & \\
\hline CHEMBL 1088510 & 688398 & 4.95 & 5.4364 & TRN & & \\
\hline
\end{tabular}




\begin{tabular}{|c|c|c|c|c|c|}
\hline & & \multicolumn{4}{|c|}{ Supplemental Table S2.txt } \\
\hline CHEMBL 2181091 & 688398 & 4.0254 & 4.5912 & TRN & \\
\hline CHEMBL1087974 & 688398 & 5.75 & 5.2223 & TRN & \\
\hline CHEMBL1087957 & 688398 & 4.5 & 5.0755 & TRN & \\
\hline CHEMBL 2180813 & 688398 & 4.7254 & 4.5182 & TST & \\
\hline CHEMBL1086979 & 688398 & 5.95 & 5.5438 & TRN & \\
\hline CHEMBL1087108 & 688398 & 5.95 & 5.6295 & TRN & \\
\hline CHEMBL 2180814 & 688398 & 5.6254 & 4.6184 & TST & \\
\hline CHEMBL1087187 & 688398 & 4.95 & 5.2404 & TRN & \\
\hline CHEMBL1329690 & 688398 & 5.9 & 4.4776 & TST & \\
\hline CHEMBL 2181089 & 688398 & 5.4867 & 4.82 & TST & \\
\hline CHEMBL1088383 & 688398 & 5.1 & 5.1996 & TRN & \\
\hline CHEMBL 2181095 & 688398 & 5.3867 & 4.6865 & TST & \\
\hline CHEMBL 2181090 & 688398 & 3.7254 & 4.6702 & TST & \\
\hline CHEMBL1088508 & 688398 & 5.1 & 5.2795 & TRN & \\
\hline CHEMBL1095821 & 688398 & 4.95 & 5.2539 & TRN & \\
\hline CHEMBL1087186 & 688398 & 4.95 & 5.5195 & TRN & \\
\hline CHEMBL1087577 & 688398 & 5.5 & 5.4286 & TRN & \\
\hline CHEMBL1087188 & 688398 & 5.6 & 5.3763 & TRN & \\
\hline CHEMBL1087829 & 688398 & 4.5 & 4.9554 & TRN & \\
\hline CHEMBL1365553 & 688398 & 4.3 & 5.103 & TST & \\
\hline CHEMBL 2181096 & 688398 & 4.4867 & 5.1238 & TST & \\
\hline CHEMBL261634 & 688398 & 5.15 & 4.1172 & TST & \\
\hline CHEMBL1095486 & 688398 & 5.7 & 5.4641 & TRN & \\
\hline CHEMBL 2181092 & 688398 & 3.7254 & 4.6525 & TST & \\
\hline CHEMBL1088003 & 688398 & 4.85 & 5.2506 & TRN & \\
\hline CHEMBL1087704 & 688398 & 6.15 & 5.5117 & TRN & \\
\hline CHEMBL 2181093 & 688398 & 3.6254 & 4.74 & TST & \\
\hline CHEMBL1095998 & 688398 & 5.15 & 5.4149 & TRN & \\
\hline CHEMBL1094230 & 688398 & 4.85 & 5.3006 & TRN & \\
\hline CHEMBL1088562 & 688398 & 6.1 & 5.9538 & TRN & \\
\hline CHEMBL1087705 & 688398 & 5.95 & 5.8615 & TRN & \\
\hline CHEMBL1095820 & 688398 & 5.05 & 5.3112 & TRN & \\
\hline CHEMBL 2180812 & 688398 & 4.0254 & 4.7828 & TST & \\
\hline CHEMBL1088002 & 688398 & 5.7 & 5.7085 & TRN & \\
\hline CHEMBL1490919 & 688398 & 4.55 & 5.0648 & TST & \\
\hline CHEMBL3950773 & 1617701 & 4.7696 & 4.5522 & TRN & \\
\hline CHEMBL3915348 & 1617701 & 4.0315 & 4.0368 & TRN & \\
\hline CHEMBL3986320 & 1617701 & 4.3872 & 4.4006 & TRN & \\
\hline CHEMBL3951335 & 1617701 & 4.5229 & 4.5465 & TRN & \\
\hline CHEMBL3924724 & 1617701 & 3.0 & 3.0625 & TRN & \\
\hline CHEMBL3934460 & 1617701 & 4.1612 & 3.9896 & TRN & \\
\hline CHEMBL3947198 & 1617701 & 3.0 & 3.31699 & 99999999997 & TRN \\
\hline CHEMBL3928317 & 1617701 & 4.4318 & 4.5908 & TRN & \\
\hline CHEMBL3942054 & 1617701 & 4.6778 & 4.9538 & TRN & \\
\hline CHEMBL3980253 & 1617701 & 4.3468 & 4.1447 & TRN & \\
\hline CHEMBL3983061 & 1617701 & 4.4318 & 4.3871 & TRN & \\
\hline CHEMBL3983712 & 1617701 & 4.6198 & 4.6091 & TRN & \\
\hline CHEMBL3922861 & 1617701 & 4.2596 & 4.439 & TRN & \\
\hline
\end{tabular}


Supplemental Table S2.txt

\begin{tabular}{|c|c|c|c|c|}
\hline CHEMBL3906378 & 1617701 & 4.1024 & 4.3144 & TRN \\
\hline CHEMBL3919412 & 1617701 & 4.8239 & 4.2339 & TRN \\
\hline CHEMBL3919336 & 1617701 & 4.5376 & 4.4159 & TST \\
\hline CHEMBL3975456 & 1617701 & 4.3565 & 4.6403 & TST \\
\hline CHEMBL3970551 & 1617701 & 4.7212 & 5.0784 & TRN \\
\hline CHEMBL3907505 & 1617701 & 3.0 & 3.2986 & TRN \\
\hline CHEMBL3978830 & 1617701 & 3.0 & 3.0578 & TRN \\
\hline CHEMBL3943318 & 1617701 & 4.4202 & 4.2114 & TRN \\
\hline CHEMBL 3933283 & 1617701 & 4.3098 & 3.9402 & TRN \\
\hline CHEMBL3894125 & 1617701 & 3.0 & 3.5907 & TST \\
\hline CHEMBL3115908 & 1617701 & 4.9586 & 4.5796 & TST \\
\hline CHEMBL3954893 & 1617701 & 4.7447 & 4.6527 & TRN \\
\hline CHEMBL3960743 & 1617701 & 3.0 & 3.2642 & TRN \\
\hline CHEMBL3979736 & 1617701 & 4.7959 & 4.5381 & TRN \\
\hline CHEMBL3894879 & 1617701 & 4.699 & 4.9273 & TRN \\
\hline CHEMBL3890411 & 1617701 & 4.7447 & 4.6735 & TRN \\
\hline CHEMBL3966262 & 1617701 & 4.5229 & 4.6364 & TRN \\
\hline CHEMBL3937258 & 1617701 & 3.0 & 4.01399 & 9999999999 \\
\hline CHEMBL 3938421 & 1617701 & 4.4318 & 4.8745 & TRN \\
\hline CHEMBL3908434 & 1617701 & 4.6778 & 4.273 & TRN \\
\hline CHEMBL3952045 & 1617701 & 3.0 & 3.2213 & TRN \\
\hline CHEMBL3913878 & 1617701 & 4.7212 & 4.5944 & TRN \\
\hline CHEMBL3912547 & 1617701 & 3.0 & 3.5486 & TRN \\
\hline CHEMBL3899371 & 1617701 & 4.301 & 4.0818 & TRN \\
\hline CHEMBL3924343 & 1617701 & 3.0 & 2.6445 & TRN \\
\hline CHEMBL3967047 & 1617701 & 4.0315 & 4.0665 & TRN \\
\hline CHEMBL3955935 & 1617701 & 4.4437 & 4.2245 & TRN \\
\hline CHEMBL3903813 & 1617701 & 4.7212 & 4.6175 & TRN \\
\hline CHEMBL 3947125 & 1617701 & 4.2366 & 4.0863 & TRN \\
\hline CHEMBL3040216 & 1617701 & 3.0 & 3.1152 & TST \\
\hline CHEMBL3978029 & 1617701 & 3.0 & 2.8052 & TST \\
\hline CHEMBL3910488 & 1617701 & 4.7212 & 4.3745 & TST \\
\hline CHEMBL3975683 & 1617701 & 4.7447 & 5.1497 & TST \\
\hline CHEMBL3952406 & 1617701 & 4.2596 & 4.276 & TST \\
\hline CHEMBL3934352 & 1617701 & 4.041 & 4.6927 & TST \\
\hline CHEMBL3953543 & 1617701 & 3.0 & 3.8725 & TST \\
\hline CHEMBL3904891 & 1617701 & 4.7696 & 5.3599 & TST \\
\hline CHEMBL3780717 & 1565337 & 6.6576 & 5.6303 & TRN \\
\hline CHEMBL 3781893 & 1565337 & 4.0 & 4.4509 & TRN \\
\hline CHEMBL3780403 & 1565337 & 4.0 & 3.6889 & TRN \\
\hline CHEMBL3780527 & 1565337 & 5.699 & 6.0976 & TRN \\
\hline CHEMBL3781157 & 1565337 & 4.0 & 5.5002 & TRN \\
\hline CHEMBL 3780144 & 1565337 & 4.0 & 4.9768 & TRN \\
\hline CHEMBL3781151 & 1565337 & 4.0 & 4.3056 & TRN \\
\hline CHEMBL3780372 & 1565337 & 6.2924 & 6.4681 & TRN \\
\hline CHEMBL3781827 & 1565337 & 5.8297 & 6.3061 & TRN \\
\hline CHEMBL3781149 & 1565337 & 7.2218 & 6.9946 & TRN \\
\hline CHEMBL 3781384 & 1565337 & 5.4815 & 5.722 & TST \\
\hline
\end{tabular}




$$
\text { Supplemental Table S2.txt }
$$

\begin{tabular}{|c|c|c|c|c|}
\hline CHEMBL3781913 & 1565337 & 7.6778 & 6.0111 & TRN \\
\hline CHEMBL3780845 & 1565337 & 5.3565 & 5.5647 & TRN \\
\hline CHEMBL3780785 & 1565337 & 5.4559 & 5.5633 & TST \\
\hline CHEMBL3780043 & 1565337 & 5.0 & 5.341 & TRN \\
\hline CHEMBL3781548 & 1565337 & 5.9586 & 5.6346 & TRN \\
\hline CHEMBL3780772 & 1565337 & 6.0458 & 5.6879 & TRN \\
\hline CHEMBL3781183 & 1565337 & 5.7696 & 4.7991 & TRN \\
\hline CHEMBL3781573 & 1565337 & 4.0 & 3.6409 & TRN \\
\hline CHEMBL3781757 & 1565337 & 5.301 & 5.4178 & TRN \\
\hline CHEMBL3780054 & 1565337 & 4.0 & 5.44799 & 99999999995 \\
\hline CHEMBL3781331 & 1565337 & 7.0 & 7.1471 & TRN \\
\hline CHEMBL3781654 & 1565337 & 5.9208 & 5.0566 & TRN \\
\hline CHEMBL3781668 & 1565337 & 4.0 & 4.7142 & TRN \\
\hline CHEMBL3780470 & 1565337 & 6.0555 & 4.6141 & TRN \\
\hline CHEMBL3780756 & 1565337 & 6.2218 & 5.5236 & TRN \\
\hline CHEMBL1551510 & 1565337 & 5.0 & 5.1314 & TRN \\
\hline CHEMBL3780729 & 1565337 & 5.6778 & 5.5482 & TST \\
\hline CHEMBL 3781741 & 1565337 & 4.0 & 4.0404 & TRN \\
\hline CHEMBL3780239 & 1565337 & 4.0 & 4.4116 & TRN \\
\hline CHEMBL3781347 & 1565337 & 6.0 & 6.1076 & TRN \\
\hline CHEMBL3780972 & 1565337 & 4.0 & 4.0753 & TRN \\
\hline CHEMBL 3780460 & 1565337 & 4.0 & 4.2861 & TRN \\
\hline CHEMBL3781447 & 1565337 & 4.0 & 4.7516 & TRN \\
\hline CHEMBL3781633 & 1565337 & 5.6021 & 5.4868 & TRN \\
\hline CHEMBL3781797 & 1565337 & 5.2218 & 5.7851 & TRN \\
\hline CHEMBL3780459 & 1565337 & 5.9508 & 5.5709 & TRN \\
\hline CHEMBL3781094 & 1565337 & 5.2226 & 5.1208 & TRN \\
\hline CHEMBL3781086 & 1565337 & 4.0 & 6.0628 & TST \\
\hline CHEMBL3781308 & 1565337 & 5.8539 & 5.8536 & TRN \\
\hline CHEMBL3781625 & 1565337 & 5.585 & 5.6308 & TRN \\
\hline CHEMBL3780349 & 1565337 & 5.0969 & 5.7173 & TRN \\
\hline CHEMBL3781535 & 1565337 & 5.1549 & 5.1457 & TST \\
\hline CHEMBL3781994 & 1565337 & 5.9172 & 4.8159 & TST \\
\hline CHEMBL3781161 & 1565337 & 4.0 & 4.9448 & TST \\
\hline CHEMBL3780235 & 1565337 & 5.9208 & 5.9663 & TST \\
\hline CHEMBL3780764 & 1565337 & 5.8665 & 5.8903 & TST \\
\hline CHEMBL3781194 & 1565337 & 4.0 & 4.6661 & TST \\
\hline CHEMBL3780534 & 1565337 & 5.0605 & 6.0679 & TST \\
\hline CHEMBL3781835 & 1565337 & 6.0223 & 5.9184 & TST \\
\hline CHEMBL3637896 & 1592866 & 6.2076 & 5.846 & TRN \\
\hline CHEMBL 3431223 & 1592866 & 3.1938 & 3.1132 & TRN \\
\hline CHEMBL458799 & 1592866 & 3.4948 & 4.3577 & TRN \\
\hline CHEMBL 2171461 & 1592866 & 5.3575 & 4.5896 & TRN \\
\hline CHEMBL 227667 & 1592866 & 3.4948 & 4.27 & TRN \\
\hline CHEMBL3637895 & 1592866 & 5.4191 & 6.0156 & TRN \\
\hline CHEMBL1197424 & 1592866 & 4.6024 & 3.9999 & TRN \\
\hline CHEMBL3431323 & 1592866 & 5.9208 & 6.1992 & TRN \\
\hline CHEMBL 3637894 & 1592866 & 6.0223 & 6.2268 & TRN \\
\hline
\end{tabular}


Supplemental Table S2.txt

\begin{tabular}{|c|c|c|c|c|}
\hline CHEMBL 3104526 & 1592866 & 8.0 & 6.9266 & TST \\
\hline CHEMBL 2441383 & 1592866 & 6.5686 & 6.2874 & TRN \\
\hline CHEMBL413331 & 1592866 & 6.1805 & 5.2399 & TRN \\
\hline CHEMBL 3431084 & 1592866 & 6.1487 & 6.324 & TRN \\
\hline CHEMBL45843 & 1592866 & 6.5376 & 5.6846 & TRN \\
\hline CHEMBL1836611 & 1592866 & 5.3936 & 6.7284 & TST \\
\hline CHEMBL1566634 & 1592866 & 7.2218 & 6.6205 & TRN \\
\hline CHEMBL1230468 & 1592866 & 6.0706 & 6.2473 & TRN \\
\hline CHEMBL3431272 & 1592866 & 5.684 & 6.0087 & TRN \\
\hline CHEMBL241634 & 1592866 & 4.7959 & 4.9019 & TRN \\
\hline CHEMBL 3637897 & 1592866 & 7.8861 & 7.0227 & TRN \\
\hline CHEMBL241427 & 1592866 & 4.7844 & 4.9185 & TRN \\
\hline CHEMBL1683016 & 1592866 & 5.5114 & 5.1068 & TST \\
\hline CHEMBL1683021 & 1592866 & 5.8665 & 6.4696 & TST \\
\hline CHEMBL519040 & 1592866 & 3.4948 & 3.9411 & TRN \\
\hline CHEMBL474899 & 1592866 & 6.0132 & 6.4419 & TRN \\
\hline CHEMBL3431191 & 1592866 & 5.5528 & 6.8055 & TRN \\
\hline CHEMBL394241 & 1592866 & 5.0283 & 5.2829 & TRN \\
\hline CHEMBL 3431411 & 1592866 & 5.1824 & 5.1377 & TRN \\
\hline CHEMBL466426 & 1592866 & 8.0 & 6.3705 & TST \\
\hline CHEMBL1836562 & 1592866 & 4.7665 & 5.2748 & TST \\
\hline CHEMBL3431166 & 1592866 & 3.1938 & 3.4807 & TRN \\
\hline CHEMBL 2229099 & 1592866 & 5.2716 & 5.2565 & TRN \\
\hline CHEMBL 3431007 & 1592866 & 4.4509 & 4.1663 & TRN \\
\hline CHEMBL3431105 & 1592866 & 5.7077 & 5.4633 & TRN \\
\hline CHEMBL3431063 & 1592866 & 3.1938 & 3.6321 & TRN \\
\hline CHEMBL 3431294 & 1592866 & 6.1367 & 5.95100 & 00000000005 \\
\hline CHEMBL3104375 & 1592866 & 8.0 & 6.5326 & TST \\
\hline CHEMBL1197423 & 1592866 & 3.4948 & 3.9239 & TRN \\
\hline CHEMBL472881 & 1592866 & 6.0555 & 5.9557 & TRN \\
\hline CHEMBL1872842 & 1592866 & 6.0362 & 5.6512 & TRN \\
\hline CHEMBL 3115821 & 1592866 & 7.8861 & 7.244 & TRN \\
\hline CHEMBL394474 & 1592866 & 4.7959 & 4.63 & TRN \\
\hline CHEMBL3431322 & 1592866 & 5.5686 & 6.035 & TRN \\
\hline CHEMBL1197563 & 1592866 & 4.667 & 4.4591 & TRN \\
\hline CHEMBL3431320 & 1592866 & 5.4101 & 5.4467 & TST \\
\hline CHEMBL1094051 & 1592866 & 5.3354 & 5.5511 & TRN \\
\hline CHEMBL3637899 & 1592866 & 5.7122 & 5.229 & TRN \\
\hline CHEMBL 3431330 & 1592866 & 6.3188 & 6.5666 & TRN \\
\hline CHEMBL 3637893 & 1592866 & 5.3947 & 6.025 & TRN \\
\hline CHEMBL3637898 & 1592866 & 6.0044 & 5.1454 & TST \\
\hline CHEMBL227240 & 1592866 & 5.3936 & 4.5698 & TRN \\
\hline CHEMBL511692 & 1592866 & 5.3716 & 6.1295 & TRN \\
\hline CHEMBL238442 & 1592866 & 5.3487 & 5.2642 & TRN \\
\hline CHEMBL520654 & 1592866 & 4.8752 & 4.4053 & TRN \\
\hline CHEMBL3431099 & 1592866 & 3.1938 & 3.8905 & TST \\
\hline CHEMBL393580 & 1592866 & 6.0862 & 5.8843 & TST \\
\hline CHEMBL 3637892 & 1592866 & 3.4948 & 3.7239 & TST \\
\hline
\end{tabular}

Page 17032 
Supplemental Table S2.txt

\begin{tabular}{|c|c|c|c|c|c|}
\hline CHEMBL1308225 & 1592866 & 5.6556 & 5.6466 & TST & \\
\hline CHEMBL472854 & 1592866 & 5.3526 & 5.3889 & TST & \\
\hline CHEMBL1198787 & 1592866 & 3.4948 & 4.12 & TST & \\
\hline CHEMBL 3126908 & 1294968 & 6.9586 & 6.9776 & TRN & \\
\hline CHEMBL3127050 & 1294968 & 6.5528 & 5.1071 & TRN & \\
\hline CHEMBL3126882 & 1294968 & 3.0 & 3.1906 & TRN & \\
\hline CHEMBL3126888 & 1294968 & 3.699 & 3.4773 & TRN & \\
\hline CHEMBL 3126870 & 1294968 & 3.699 & 3.4312 & TRN & \\
\hline CHEMBL3127066 & 1294968 & 5.9355 & 5.6076 & TRN & \\
\hline CHEMBL3127048 & 1294968 & 3.699 & 4.6668 & TST & \\
\hline CHEMBL3127064 & 1294968 & 3.699 & 4.0915 & TST & \\
\hline CHEMBL3126869 & 1294968 & 3.0 & 3.2665 & TRN & \\
\hline CHEMBL3127051 & 1294968 & 3.699 & 3.9521 & TRN & \\
\hline CHEMBL 3126887 & 1294968 & 3.0 & 3.3961 & TRN & \\
\hline CHEMBL 3127065 & 1294968 & 7.5229 & 6.986006 & 0000000001 & TRN \\
\hline CHEMBL3127052 & 1294968 & 3.699 & 3.7769 & TRN & \\
\hline CHEMBL3126894 & 1294968 & 3.699 & 3.4119 & TRN & \\
\hline CHEMBL3126896 & 1294968 & 3.699 & 4.0001 & TST & \\
\hline CHEMBL3126901 & 1294968 & 3.699 & 3.6543 & TRN & \\
\hline CHEMBL 3127054 & 1294968 & 3.699 & 3.7855 & TRN & \\
\hline CHEMBL 3126897 & 1294968 & 3.0 & 3.8484 & TST & \\
\hline CHEMBL 3126871 & 1294968 & 3.699 & 3.9623 & TRN & \\
\hline CHEMBL3126868 & 1294968 & 3.699 & 3.3956 & TRN & \\
\hline CHEMBL 3126879 & 1294968 & 3.699 & 4.4458 & TRN & \\
\hline CHEMBL 3126880 & 1294968 & 3.699 & 3.9989 & TRN & \\
\hline CHEMBL 3126873 & 1294968 & 3.699 & 3.7993 & TRN & \\
\hline CHEMBL3126915 & 1294968 & 4.9136 & 4.6298 & TST & \\
\hline CHEMBL3127059 & 1294968 & 3.699 & 3.6293 & TRN & \\
\hline CHEMBL3126865 & 1294968 & 4.9172 & 4.356 & TST & \\
\hline CHEMBL319177 & 1294968 & 3.0 & 3.4114 & TST & \\
\hline CHEMBL3126883 & 1294968 & 3.699 & 3.3311 & TRN & \\
\hline CHEMBL3126895 & 1294968 & 3.699 & 4.0498 & TRN & \\
\hline CHEMBL3127049 & 1294968 & 7.301 & 7.0472 & TRN & \\
\hline CHEMBL1814768 & 1294968 & 7.3979 & 7.0821 & TRN & \\
\hline CHEMBL3126900 & 1294968 & 3.699 & 4.101 & TRN & \\
\hline CHEMBL 3126874 & 1294968 & 3.699 & 4.3794 & TRN & \\
\hline CHEMBL3126875 & 1294968 & 3.699 & 3.6321 & TRN & \\
\hline CHEMBL403715 & 1294968 & 3.699 & 4.2179 & TST & \\
\hline CHEMBL3126892 & 1294968 & 3.699 & 3.5851 & TRN & \\
\hline CHEMBL3126884 & 1294968 & 3.699 & 3.7401 & TRN & \\
\hline CHEMBL3126891 & 1294968 & 3.699 & 3.4652 & TRN & \\
\hline CHEMBL3126881 & 1294968 & 3.699 & 3.3907 & TRN & \\
\hline CHEMBL3126885 & 1294968 & 3.699 & 3.4433 & TRN & \\
\hline CHEMBL 3126886 & 1294968 & 3.699 & 3.4661 & TRN & \\
\hline CHEMBL3126867 & 1294968 & 3.699 & 3.4171 & TRN & \\
\hline CHEMBL 3127053 & 1294968 & 3.699 & 3.551 & TRN & \\
\hline CHEMBL3126909 & 1294968 & 3.699 & 3.7481 & TRN & \\
\hline CHEMBL 3126904 & 1294968 & 3.699 & 3.4365 & TRN & \\
\hline
\end{tabular}


Supplemental Table S2.txt

\begin{tabular}{|c|c|c|c|c|c|}
\hline CHEMBL3126911 & 1294968 & 3.699 & 4.6997 & TRN & \\
\hline CHEMBL3126877 & 1294968 & 3.0 & 3.3985 & TRN & \\
\hline CHEMBL3126899 & 1294968 & 5.3372 & 6.0769 & TRN & \\
\hline CHEMBL3126898 & 1294968 & 3.699 & 4.2063 & TST & \\
\hline CHEMBL3127057 & 1294968 & 3.699 & 4.3483 & TST & \\
\hline CHEMBL3127063 & 1294968 & 3.699 & 3.3871 & TRN & \\
\hline CHEMBL 3127060 & 1294968 & 3.699 & 3.6461 & TRN & \\
\hline CHEMBL1814767 & 1294968 & 7.5229 & 7.6441 & TRN & \\
\hline CHEMBL 3127068 & 1294968 & 5.2865 & 5.4625 & TRN & \\
\hline CHEMBL3127067 & 1294968 & 5.3143 & 5.6169 & TRN & \\
\hline CHEMBL3126893 & 1294968 & 3.699 & 3.3581 & TRN & \\
\hline CHEMBL 3127055 & 1294968 & 6.8539 & 6.08299 & 9999999999 & TST \\
\hline CHEMBL3126913 & 1294968 & 3.699 & 3.7397 & TRN & \\
\hline CHEMBL 3127045 & 1294968 & 3.699 & 3.8822 & TRN & \\
\hline CHEMBL3127061 & 1294968 & 3.699 & 3.5867 & TRN & \\
\hline CHEMBL3126910 & 1294968 & 3.699 & 3.6363 & TRN & \\
\hline CHEMBL3126872 & 1294968 & 3.0 & 3.6194 & TST & \\
\hline CHEMBL3126905 & 1294968 & 6.4089 & 6.271 & TST & \\
\hline CHEMBL3124960 & 1294968 & 3.699 & 3.5969 & TRN & \\
\hline CHEMBL3127058 & 1294968 & 5.5901 & 5.615 & TRN & \\
\hline CHEMBL3126907 & 1294968 & 6.4685 & 6.1054 & TST & \\
\hline CHEMBL3126906 & 1294968 & 3.699 & 5.2443 & TST & \\
\hline CHEMBL1269812 & 1294968 & 7.5229 & 6.6611 & TST & \\
\hline CHEMBL3126866 & 1294968 & 3.699 & 3.6908 & TRN & \\
\hline CHEMBL3127044 & 1294968 & 3.699 & 4.4559 & TST & \\
\hline CHEMBL3126889 & 1294968 & 3.699 & 3.7135 & TRN & \\
\hline CHEMBL3126902 & 1294968 & 3.699 & 3.8151 & TRN & \\
\hline CHEMBL 3127047 & 1294968 & 5.0883 & 5.1181 & TST & \\
\hline CHEMBL 3127046 & 1294968 & 4.752 & 4.5498 & TRN & \\
\hline CHEMBL3127062 & 1294968 & 3.699 & 3.3835 & TRN & \\
\hline CHEMBL3126912 & 1294968 & 3.699 & 3.384 & TRN & \\
\hline CHEMBL3127056 & 1294968 & 3.699 & 4.7333 & TST & \\
\hline CHEMBL3126914 & 1294968 & 4.7167 & 5.1737 & TST & \\
\hline CHEMBL 3126890 & 1294968 & 3.699 & 3.8431 & TRN & \\
\hline CHEMBL3126878 & 1294968 & 3.0 & 3.2663 & TRN & \\
\hline CHEMBL3126903 & 1294968 & 3.0 & 3.4174 & TRN & \\
\hline CHEMBL3126876 & 1294968 & 3.699 & 3.5624 & TST & \\
\hline CHEMBL103880 & 53735 & 3.5607 & 3.4112 & TRN & \\
\hline CHEMBL318516 & 53735 & 2.0 & 3.4324 & TRN & \\
\hline CHEMBL321347 & 53735 & 5.7212 & 5.33299 & 9999999999 & TRN \\
\hline CHEMBL29299 & 53735 & 4.0809 & 3.4278 & TRN & \\
\hline CHEMBL75214 & 53735 & 3.9508 & 4.9162 & TRN & \\
\hline CHEMBL102933 & 53735 & 2.0 & 4.9689 & TST & \\
\hline CHEMBL102924 & 53735 & 4.0177 & 4.7931 & TRN & \\
\hline CHEMBL106117 & 53735 & 4.3188 & 4.9951 & TRN & \\
\hline CHEMBL 280222 & 53735 & 5.9208 & 5.3208 & TRN & \\
\hline CHEMBL103023 & 53735 & 2.0 & 4.9689 & TST & \\
\hline CHEMBL102740 & 53735 & 3.7471 & 4.8951 & TRN & \\
\hline
\end{tabular}




\begin{tabular}{|c|c|c|c|c|c|}
\hline & & \multicolumn{4}{|c|}{ Supplemental Table S2.txt } \\
\hline CHEMBL106009 & 53735 & 4.6778 & 4.9741 & TRN & \\
\hline CHEMBL102640 & 53735 & 3.1079 & 4.8087 & TST & \\
\hline CHEMBL28743 & 53735 & 4.3872 & 3.4379 & TRN & \\
\hline CHEMBL101419 & 53735 & 6.2596 & 5.2168 & TRN & \\
\hline CHEMBL317697 & 53735 & 4.3979 & 4.9419 & TRN & \\
\hline CHEMBL229457 & 53735 & 7.5229 & 4.8656 & TRN & \\
\hline CHEMBL105749 & 53735 & 3.4145 & 3.657 & TST & \\
\hline CHEMBL103266 & 53735 & 4.1308 & 5.2996 & TRN & \\
\hline CHEMBL322423 & 53735 & 4.2007 & 3.4324 & TRN & \\
\hline CHEMBL102951 & 53735 & 4.4202 & 4.9419 & TRN & \\
\hline CHEMBL102329 & 53735 & 5.4949 & 4.9209 & TRN & \\
\hline CHEMBL105338 & 53735 & 4.8861 & 5.2996 & TRN & \\
\hline CHEMBL102323 & 53735 & 5.0458 & 5.30399 & 9999999999 & TRN \\
\hline CHEMBL104233 & 53735 & 2.0 & 4.7996 & TST & \\
\hline CHEMBL102267 & 53735 & 3.9355 & 3.4324 & TRN & \\
\hline CHEMBL77045 & 53735 & 3.7399 & 4.9245 & TRN & \\
\hline CHEMBL28866 & 53735 & 3.6289 & 3.4145 & TRN & \\
\hline CHEMBL105951 & 53735 & 6.1549 & 5.4241 & TRN & \\
\hline CHEMBL36119 & 53735 & 3.2549 & 3.4042 & TRN & \\
\hline CHEMBL103897 & 53735 & 3.8794 & 5.2168 & TRN & \\
\hline CHEMBL105316 & 53735 & 2.0 & 4.8087 & TST & \\
\hline CHEMBL102800 & 53735 & 2.0 & 4.9689 & TST & \\
\hline CHEMBL102939 & 53735 & 6.5229 & 5.2996 & TRN & \\
\hline CHEMBL102715 & 53735 & 2.0 & 4.8087 & TST & \\
\hline CHEMBL102487 & 53735 & 5.4685 & 4.9162 & TRN & \\
\hline CHEMBL58343 & 53735 & 3.8069 & 4.8492 & TRN & \\
\hline CHEMBL 73634 & 53735 & 4.7932 & 4.9162 & TRN & \\
\hline CHEMBL105574 & 53735 & 3.9208 & 4.9689 & TST & \\
\hline CHEMBL103613 & 53735 & 6.7959 & 5.291 & TRN & \\
\hline CHEMBL103031 & 53735 & 2.0 & 4.8087 & TST & \\
\hline CHEMBL103941 & 53735 & 7.0969 & 4.9419 & TRN & \\
\hline CHEMBL101996 & 53735 & 5.1675 & 4.9162 & TRN & \\
\hline CHEMBL105668 & 53735 & 2.0 & 4.9689 & TST & \\
\hline CHEMBL 29910 & 53735 & 4.8861 & 3.5414 & TST & \\
\hline CHEMBL105647 & 53735 & 5.0969 & 5.0809 & TRN & \\
\hline CHEMBL102276 & 53735 & 5.4559 & 4.9419 & TRN & \\
\hline CHEMBL104907 & 53735 & 2.0 & 4.9689 & TST & \\
\hline CHEMBL103489 & 53735 & 4.5376 & 5.2168 & TRN & \\
\hline CHEMBL101802 & 53735 & 4.0 & 5.2996 & TRN & \\
\hline CHEMBL35633 & 53735 & 2.0 & 3.4324 & TRN & \\
\hline CHEMBL260692 & 471789 & 8.74 & 7.9691 & TST & \\
\hline CHEMBL 259733 & 471789 & 8.02 & 8.1036 & TRN & \\
\hline CHEMBL261068 & 471789 & 8.09 & 8.0556 & TST & \\
\hline CHEMBL 258568 & 471789 & 8.15 & 8.1813 & TRN & \\
\hline CHEMBL410297 & 471789 & 8.2 & 8.1433 & TRN & \\
\hline CHEMBL262333 & 471789 & 8.2 & 7.8852 & TRN & \\
\hline CHEMBL 262332 & 471789 & 8.28 & 7.7727 & TRN & \\
\hline CHEMBL412063 & 471789 & 8.38 & 8.3007 & TRN & \\
\hline
\end{tabular}




\begin{tabular}{|c|c|c|c|c|}
\hline & & & oplemen & \\
\hline CHEMBL440418 & 471789 & 8.44 & 8.2323 & TST \\
\hline CHEMBL411075 & 471789 & 8.46 & 8.1154 & TRN \\
\hline CHEMBL261056 & 471789 & 8.47 & 8.2634 & TRN \\
\hline CHEMBL 260693 & 471789 & 8.55 & 8.2199 & TRN \\
\hline CHEMBL407204 & 471789 & 7.96 & 8.2265 & TST \\
\hline CHEMBL 260051 & 471789 & 8.82 & 8.4495 & TRN \\
\hline CHEMBL411314 & 471789 & 6.32 & 7.5062 & TRN \\
\hline CHEMBL427602 & 471789 & 6.76 & 7.8387 & TRN \\
\hline CHEMBL412275 & 471789 & 7.15 & 7.8282 & TST \\
\hline CHEMBL260495 & 471789 & 7.23 & 7.6994 & TRN \\
\hline CHEMBL 259912 & 471789 & 7.24 & 7.1705 & TRN \\
\hline CHEMBL 259913 & 471789 & 7.27 & 7.6807 & TRN \\
\hline CHEMBL 258778 & 471789 & 7.29 & 7.2848 & TRN \\
\hline CHEMBL428605 & 471789 & 7.49 & 7.022 & TRN \\
\hline CHEMBL411720 & 471789 & 7.5 & 7.7824 & TST \\
\hline CHEMBL409725 & 471789 & 7.56 & 8.0084 & TRN \\
\hline CHEMBL409726 & 471789 & 7.69 & 7.7126 & TST \\
\hline CHEMBL 263895 & 471789 & 7.87 & 7.8339 & TRN \\
\hline CHEMBL 259529 & 471789 & 7.88 & 7.8076 & TRN \\
\hline CHEMBL412112 & 471789 & 8.69 & 8.4758 & TRN \\
\hline CHEMBL 259479 & 471789 & 8.98 & 8.3851 & TST \\
\hline CHEMBL409440 & 471789 & 7.0 & 8.1882 & TST \\
\hline CHEMBL 260434 & 471789 & 7.29 & 7.869 & TRN \\
\hline CHEMBL 260433 & 471789 & 7.41 & 7.855 & TRN \\
\hline CHEMBL407179 & 471789 & 7.61 & 8.0385 & TST \\
\hline CHEMBL 261792 & 471789 & 7.69 & 7.8883 & TRN \\
\hline CHEMBL402474 & 471789 & 7.98 & 8.4273 & TST \\
\hline CHEMBL 258979 & 471789 & 8.12 & 8.4174 & TRN \\
\hline CHEMBL 259870 & 471789 & 8.16 & 8.1355 & TRN \\
\hline CHEMBL 259871 & 471789 & 8.18 & 7.9693 & TST \\
\hline CHEMBL409514 & 471789 & 8.21 & 7.9365 & TRN \\
\hline CHEMBL 259057 & 471789 & 8.32 & 8.0191 & TRN \\
\hline CHEMBL 260221 & 471789 & 8.38 & 8.5247 & TRN \\
\hline CHEMBL411275 & 471789 & 7.16 & 8.0486 & TRN \\
\hline CHEMBL 259056 & 471789 & 7.59 & 7.9584 & TRN \\
\hline CHEMBL409481 & 471789 & 7.59 & 7.903 & TRN \\
\hline CHEMBL 259580 & 471789 & 7.82 & 8.2853 & TRN \\
\hline CHEMBL410934 & 471789 & 7.83 & 8.0677 & TRN \\
\hline CHEMBL 259581 & 471789 & 7.88 & 7.9364 & TRN \\
\hline CHEMBL408048 & 471789 & 7.93 & 7.975 & TRN \\
\hline CHEMBL 259874 & 471789 & 8.13 & 8.0284 & TRN \\
\hline CHEMBL409443 & 471789 & 8.22 & 8.3938 & TRN \\
\hline CHEMBL407202 & 471789 & 8.24 & 8.3787 & TST \\
\hline CHEMBL 261212 & 471789 & 8.31 & 7.7887 & TRN \\
\hline CHEMBL 258948 & 471789 & 8.37 & 8.3552 & TRN \\
\hline CHEMBL428604 & 471789 & 8.38 & 7.9825 & TST \\
\hline CHEMBL 259760 & 471789 & 7.67 & 7.8897 & TRN \\
\hline CHEMBL 260180 & 471789 & 7.68 & 7.8518 & TRN \\
\hline
\end{tabular}




\begin{tabular}{|c|c|c|c|c|c|c|}
\hline \multicolumn{7}{|c|}{ Supplemental Table s2.txt } \\
\hline CHEMBL258809 & 471789 & 7.87 & 7.9022 & TRN & & \\
\hline CHEMBL259869 & 471789 & 7.91 & 7.6071 & TRN & & \\
\hline CHEMBL258810 & 471789 & 7.95 & 7.9829 & TST & & \\
\hline CHEMBL259931 & 471789 & 8.02 & 7.6373 & TRN & & \\
\hline CHEMBL429512 & 471789 & 8.04 & 7.8295 & TRN & & \\
\hline CHEMBL259151 & 471789 & 8.21 & 7.4609 & TRN & & \\
\hline CHEMBL294223 & 471789 & 8.25 & 7.8305 & TRN & & \\
\hline CHEMBL259360 & 471789 & 8.54 & 8.1752 & TRN & & \\
\hline CHEMBL259857 & 471789 & 8.59 & 7.7957 & TRN & & \\
\hline CHEMBL265182 & 471789 & 6.05 & 6.8628 & TRN & & \\
\hline CHEMBL260179 & 471789 & 7.51 & 7.295 & TST & & \\
\hline CHEMBL259155 & 471789 & 6.77 & 7.0355 & TRN & & \\
\hline CHEMBL410066 & 471789 & 7.36 & 6.8879 & TRN & & \\
\hline CHEMBL261790 & 471789 & 7.77 & 7.6711 & TRN & & \\
\hline CHEMBL259104 & 471789 & 8.02 & 7.8543 & TRN & & \\
\hline CHEMBL259105 & 471789 & 8.06 & 7.6423 & TRN & & \\
\hline CHEMBL412293 & 471789 & 8.33 & 7.8672 & TST & & \\
\hline CHEMBL258978 & 471789 & 8.64 & 7.9072 & TRN & & \\
\hline CHEMBL 201750 & 471789 & 8.46 & 7.1848 & TST & & \\
\hline CHEMBL370378 & 471789 & 8.58 & 7.9229 & TST & & \\
\hline CHEMBL316194 & 37363 & 7.4437 & 7.4384 & TRN & & \\
\hline CHEMBL442753 & 37363 & 6.8633 & 6.0502 & TST & & \\
\hline CHEMBL315852 & 37363 & 6.3872 & 6.3703 & TRN & & \\
\hline CHEMBL87645 & 37363 & 7.6778 & 7.5836 & TRN & & \\
\hline CHEMBL316149 & 37363 & 7.0506 & 7.0818 & TRN & & \\
\hline CHEMBL87217 & 37363 & 6.2291 & 6.3267 & TRN & & \\
\hline CHEMBL86024 & 37363 & 7.5086 & 7.564 & TRN & & \\
\hline CHEMBL87027 & 37363 & 6.52 & 6.5305 & TRN & & \\
\hline CHEMBL86375 & 37363 & 6.3936 & 6.3814 & TRN & & \\
\hline CHEMBL 85348 & 37363 & 6.38299 & 99999999 & 99 & 6.3809 & TRN \\
\hline CHEMBL83453 & 37363 & 6.9469 & 6.9591 & TRN & & \\
\hline CHEMBL431022 & 37363 & 7.0969 & 7.1175 & TRN & & \\
\hline CHEMBL87272 & 37363 & 6.8827 & 6.9678 & TRN & & \\
\hline CHEMBL86556 & 37363 & 6.5017 & 6.4469 & TRN & & \\
\hline CHEMBL 87271 & 37363 & 6.45100 & 00000000 & 005 & 6.4676 & TRN \\
\hline CHEMBL314823 & 37363 & 6.2749 & 6.2857 & TRN & & \\
\hline CHEMBL420053 & 37363 & 7.0506 & 7.0604 & TRN & & \\
\hline CHEMBL85911 & 37363 & 7.6778 & 7.7187 & TRN & & \\
\hline CHEMBL 87662 & 37363 & 7.2218 & 7.2042 & TRN & & \\
\hline CHEMBL86611 & 37363 & 6.9431 & 6.9248 & TRN & & \\
\hline CHEMBL83627 & 37363 & 7.8861 & 7.9597 & TRN & & \\
\hline CHEMBL314580 & 37363 & 8.0132 & 8.0749 & TRN & & \\
\hline CHEMBL87115 & 37363 & 5.6114 & 5.6064 & TRN & & \\
\hline CHEMBL 315080 & 37363 & 6.5058 & 6.4698 & TRN & & \\
\hline CHEMBL83349 & 37363 & 7.5528 & 7.5779 & TRN & & \\
\hline CHEMBL315700 & 37363 & 6.8069 & 6.3416 & TST & & \\
\hline CHEMBL83571 & 37363 & 8.1938 & 8.1652 & TRN & & \\
\hline CHEMBL312907 & 37363 & 8.2441 & 6.3612 & TST & & \\
\hline
\end{tabular}




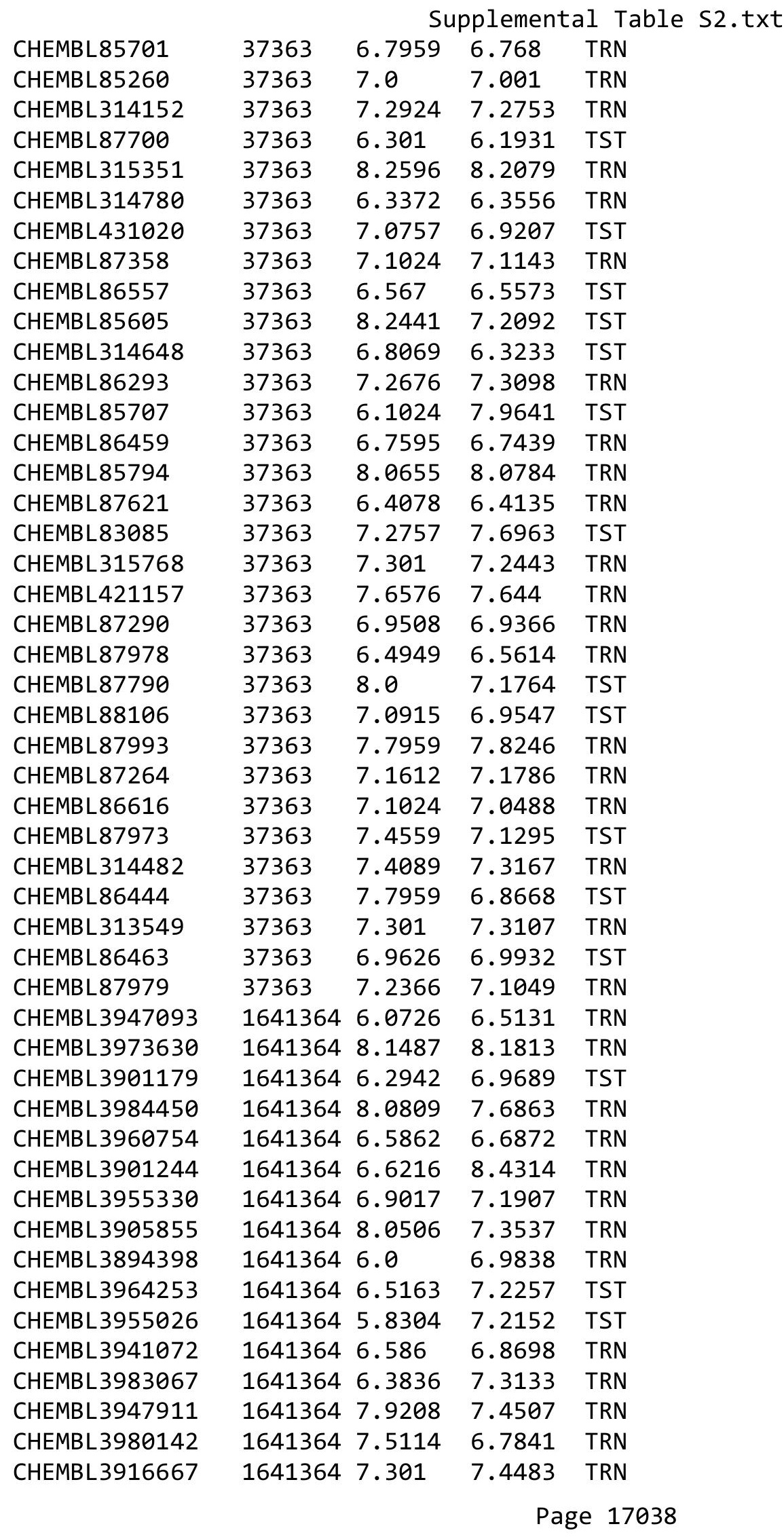


Supplemental Table S2.txt

\begin{tabular}{|c|c|c|c|c|c|c|}
\hline CHEMBL 3955301 & 1641364 & 6.9547 & 7.431 & TRN & & \\
\hline CHEMBL 3960308 & 1641364 & 7.7747 & 7.6831 & TRN & & \\
\hline CHEMBL3955332 & 1641364 & 6.5357 & 6.9646 & TST & & \\
\hline CHEMBL 3982760 & 1641364 & 7.011 & 7.3072 & TRN & & \\
\hline CHEMBL 3949863 & 1641364 & 6.7335 & 7.2957 & TST & & \\
\hline CHEMBL 3911416 & 1641364 & 6.9642 & 6.6106 & TST & & \\
\hline CHEMBL 3944695 & 1641364 & 6.7535 & 6.7415 & TRN & & \\
\hline CHEMBL 3899049 & 1641364 & 7.7799 & 7.7355 & TST & & \\
\hline CHEMBL3928520 & 1641364 & 7.2125 & 6.8601 & TRN & & \\
\hline CHEMBL3931943 & 1641364 & 8.0969 & 8.5878 & TST & & \\
\hline CHEMBL 3930967 & 1641364 & \multicolumn{3}{|c|}{6.537000000000001} & 6.6006 & TST \\
\hline CHEMBL 3970171 & 1641364 & 7.0132 & 6.6255 & TST & & \\
\hline CHEMBL 3936189 & 1641364 & 7.6402 & 7.2813 & TRN & & \\
\hline CHEMBL 3960865 & 1641364 & 7.8894 & 7.0347 & TRN & & \\
\hline CHEMBL 3952426 & 1641364 & 7.27 & 7.1598 & TRN & & \\
\hline CHEMBL 3899976 & 1641364 & 8.4089 & 8.368 & TRN & & \\
\hline CHEMBL 3960112 & 1641364 & 6.5117 & 6.3894 & TRN & & \\
\hline CHEMBL 3966497 & 1641364 & 7.6003 & 6.7843 & TST & & \\
\hline CHEMBL 3986428 & 1641364 & 7.1057 & 7.4484 & TRN & & \\
\hline CHEMBL 3963672 & 1641364 & 6.2868 & 6.0625 & TRN & & \\
\hline CHEMBL 3970448 & 1641364 & 6.6872 & 7.1667 & TRN & & \\
\hline CHEMBL 3961624 & 1641364 & 6.2042 & 6.444 & TST & & \\
\hline CHEMBL 3928599 & 1641364 & 6.4548 & 6.4882 & TRN & & \\
\hline CHEMBL 3947998 & 1641364 & \multicolumn{3}{|c|}{6.821000000000001} & 6.6008 & TRN \\
\hline CHEMBL 3925709 & 1641364 & 8.2441 & 7.1316 & TRN & & \\
\hline CHEMBL 3977861 & 1641364 & 7.2924 & 7.2278 & TRN & & \\
\hline CHEMBL 3889901 & 1641364 & 5.6907 & 7.159 & TST & & \\
\hline CHEMBL 3921874 & 1641364 & 7.1798 & 7.3637 & TRN & & \\
\hline CHEMBL3945771 & 1641364 & 7.5735 & 7.5427 & TRN & & \\
\hline CHEMBL 3984121 & 1641364 & 8.1427 & 7.6796 & TRN & & \\
\hline CHEMBL 3968015 & 1641364 & 8.1805 & 8.5307 & TRN & & \\
\hline CHEMBL 3939198 & 1641364 & 6.6803 & 6.6269 & TRN & & \\
\hline CHEMBL 3960368 & 1641364 & 7.3251 & 8.0699 & TRN & & \\
\hline CHEMBL3979708 & 1641364 & 6.6659 & 6.1931 & TST & & \\
\hline CHEMBL 3899730 & 1641364 & 7.8729 & 7.8786 & TRN & & \\
\hline CHEMBL3911409 & 1641364 & 8.0315 & 7.917006 & 0000000001 & & $1 \mathrm{~K}$ \\
\hline CHEMBL 3923528 & 1641364 & 6.9423 & 6.8067 & TRN & & \\
\hline CHEMBL 3940634 & 1641364 & 6.0985 & 6.1098 & TST & & \\
\hline CHEMBL 3923402 & 1641364 & 7.0004 & 6.3118 & TST & & \\
\hline CHEMBL 3900151 & 1641364 & 6.2722 & 6.6445 & TRN & & \\
\hline CHEMBL 3918340 & 1641364 & 7.2823 & 7.4546 & TRN & & \\
\hline CHEMBL 3929434 & 1641364 & 8.9208 & 8.5545 & TRN & & \\
\hline CHEMBL 3947805 & 1641364 & 6.5181 & 7.1126 & TST & & \\
\hline CHEMBL3914787 & 1641364 & 6.6676 & 7.83 & TRN & & \\
\hline CHEMBL 3918821 & 1641364 & 6.7199 & 7.6169 & TRN & & \\
\hline CHEMBL 3939355 & 1641364 & 7.9872 & 8.0723 & TRN & & \\
\hline CHEMBL 3902797 & 1641364 & 7.8729 & 8.1199 & TRN & & \\
\hline CHEMBL 3942088 & 1641364 & 6.3218 & 6.4747 & TRN & & \\
\hline
\end{tabular}

Page 17039 
Supplemental Table S2.txt

CHEMBL3949521 CHEMBL3929723

CHEMBL3916117

CHEMBL3932067

CHEMBL3924992

CHEMBL 3965420

CHEMBL3952801

CHEMBL3912120

CHEMBL3959114

CHEMBL3893213

CHEMBL3965308

CHEMBL3972732

CHEMBL3946782

CHEMBL3915279

CHEMBL3906625

CHEMBL3893333

CHEMBL3938098

CHEMBL3959029

CHEMBL3984883

CHEMBL3981738

CHEMBL3938109

CHEMBL3956348

CHEMBL3911075

CHEMBL3958669

CHEMBL3899354

CHEMBL3901519

CHEMBL3925228

CHEMBL3935297

CHEMBL3955150

CHEMBL3934815

CHEMBL3968642

CHEMBL3898091

CHEMBL3916188

CHEMBL3917914

CHEMBL3891493

CHEMBL3963383

CHEMBL3934189

CHEMBL3930575

CHEMBL3978368

CHEMBL3914543

CHEMBL3967292

CHEMBL3908071

CHEMBL3936958

CHEMBL3919875

CHEMBL3975296

CHEMBL3894289

CHEMBL3987034

CHEMBL3897189

7.4549 TRN

16413647.757000000000001

$\begin{array}{llll}1641364 & 8.6383 & 9.0943 & \text { TRN }\end{array}$

$\begin{array}{llll}1641364 & 6.3678 & 6.6564 & \text { TST }\end{array}$

$\begin{array}{lll}1641364 & 6.8589 & 7.287999999999999\end{array}$

$\begin{array}{llll}1641364 & 6.0 & 6.8564 & \text { TRN }\end{array}$

$\begin{array}{llll}1641364 & 8.7959 & 8.529 & \text { TRN }\end{array}$

$\begin{array}{llll}1641364 & 7.1124 & 6.9288 & \text { TST }\end{array}$

$\begin{array}{llll}1641364 & 7.1643 & 6.6925 & \text { TST }\end{array}$

$\begin{array}{llll}1641364 & 8.1938 & 7.3213 & \text { TRN }\end{array}$

$\begin{array}{llll}1641364 & 7.06 & 7.6672 & \text { TRN }\end{array}$

$\begin{array}{llll}1641364 & 6.7091 & 6.8793 & \text { TST }\end{array}$

$\begin{array}{llll}1641364 & 6.4597 & 6.564 & \text { TRN }\end{array}$

$\begin{array}{llll}1641364 & 7.2644 & 7.8031 & \text { TRN }\end{array}$

$\begin{array}{llll}1641364 & 6.0 & 7.4637 & \text { TRN }\end{array}$

$\begin{array}{llll}1641364 & 8.6198 & 8.7421 & \text { TST }\end{array}$

$\begin{array}{llll}1641364 & 6.0 & 6.6017 & \text { TST }\end{array}$

$\begin{array}{llll}1641364 & 7.5317 & 8.1116 & \text { TRN }\end{array}$

$\begin{array}{llll}1641364 & 8.0223 & 7.6775 & \text { TRN }\end{array}$

$\begin{array}{llll}1641364 & 6.4194 & 6.6007 & \text { TRN }\end{array}$

$\begin{array}{llll}1641364 & 6.9255 & 6.9502 & \text { TRN }\end{array}$

$\begin{array}{llll}1641364 & 7.8327 & 7.8999 & \text { TRN }\end{array}$

$\begin{array}{llll}1641364 & 7.8069 & 6.5072 & \text { TST }\end{array}$

$\begin{array}{llll}1641364 & 6.0 & 6.8771 & \text { TRN }\end{array}$

$\begin{array}{llll}1641364 & 8.4559 & 7.4543 & \text { TST }\end{array}$

$\begin{array}{llll}1641364 & 6.0 & 7.3138 & \text { TST }\end{array}$

$\begin{array}{llll}1641364 & 6.6503 & 6.7339 & \text { TRN }\end{array}$

$\begin{array}{llll}1641364 & 6.6629 & 6.5363 & \text { TRN }\end{array}$

$\begin{array}{llll}1641364 & 6.3546 & 6.3782 & \text { TST }\end{array}$

$\begin{array}{llll}1641364 & 8.699 & 9.1286 & \text { TRN }\end{array}$

$\begin{array}{llll}1641364 & 8.0862 & 7.8492 & \text { TST }\end{array}$

$\begin{array}{llll}1641364 & 7.8697 & 7.7308 & \text { TRN }\end{array}$

$\begin{array}{llll}1641364 & 6.6492 & 6.8992 & \text { TRN }\end{array}$

$\begin{array}{llll}1641364 & 6.249 & 6.2747 & \text { TST }\end{array}$

$\begin{array}{llll}1641364 & 8.3372 & 7.5165 & \text { TRN }\end{array}$

$\begin{array}{llll}1641364 & 7.1261 & 7.5123 & \text { TRN }\end{array}$

$\begin{array}{llll}1641364 & 6.6821 & 6.7395 & \text { TST }\end{array}$

16413646.5349

16413648.9586

16413646.6572

6.5520000000000005

8.6017 TRN

16413647.1878

16413647.2857

6.7153 TST

7.3878 TRN

16413647.9586

16413647.857

16413647.317

16413646.5824

16413646.1973

16413647.5591

$1641364 \quad 6.3217$

7.3751 TRN

7.6507 TRN

6.8846 TST

6.7168 TST

6.125 TST

6.5831 TST

7.4809 TRN

$6.367999999999999 \quad$ TST 
Supplemental Table S2.txt

\begin{tabular}{|c|c|c|c|c|}
\hline HEMB & 1364 & & & \\
\hline & & 6.7233 & 7537 & \\
\hline 04 & & 3716 & & \\
\hline AEMBL3921275 & & & 6283 & 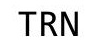 \\
\hline AEMBL3934807 & 364 & .9205 & 9765 & \\
\hline HEMBL3956121 & 364 & 7.2381 & 8232 & \\
\hline 321 & & & 5321 & \\
\hline 500 & & & 0023 & \\
\hline AEMBL3899538 & & 989 & .888 & \\
\hline HEMBL3947723 & 64 & 35 & .1374 & \\
\hline HEMBL3904932 & 54 & 6.7 & 7.2461 & \\
\hline IEMBL397 & 34 & 91 & 2239 & \\
\hline IEMBL 396 & & & & \\
\hline HEMBL3949579 & & & 5.9328 & \\
\hline AEMBL3974280 & 54 & & & \\
\hline AEMBL3896284 & 4 & 6 & 35 & \\
\hline AEMBL3S & 4 & & & \\
\hline HEMBL3S & & & & \\
\hline HEMBL39 & & & & \\
\hline AEMBL3S & & & & \\
\hline HEIMBLSS & 64 & & 83 & Niv \\
\hline HEMBL: & & & 82 & וזנה \\
\hline HEMBL & & & & \\
\hline 203 & & & & \\
\hline AEMBL3S & & & & I RIV \\
\hline HEMBL & 6 & 6. & & I RN \\
\hline AEMBL & & & 69 & NIV \\
\hline$H F M B I=$ & & & & \\
\hline HEMBL39 & & & & in \\
\hline HEMBL3937198 & & & & IK \\
\hline HEMBL39 & 44 & & 41 & RN \\
\hline HEMBL; & & & 17 & RN \\
\hline HEMBL3 & & & 162 & (ng) \\
\hline HEMBL3929481 & & & 531 & IRN \\
\hline HEMBL3983354 & 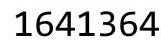 & & 336 & TRN \\
\hline HEMBL3S & & & 293 & TRN \\
\hline HFMRI 3 & & & & ST \\
\hline HEMBL3 & & & 2747 & RN \\
\hline HEMBL3906302 & 64 & 7. & & $\Gamma \mathrm{RN}$ \\
\hline AEMBL3944091 & 6 & & 322 & TRN \\
\hline HEMBL39 & 6 & & 564 & \\
\hline CHEMBL39 & & & 419 & RN \\
\hline HEMBL3942708 & 16 & & 7.1844 & TRN \\
\hline HEMBL3964164 & 364 & 8. & 6851 & TRN \\
\hline$M B L 3$ & & & 163 & \\
\hline HEMBL3982424 & & & 3758 & \\
\hline CHEMBL3959751 & & .2367 & 6.4754 & \\
\hline HEMBL3952323 & 1641364 & 6.4343 & 6.3076 & ГRN \\
\hline
\end{tabular}

Page 17041 
Supplemental Table S2.txt

\begin{tabular}{|c|c|c|c|c|c|c|c|}
\hline CHEMBL 3973724 & 1641364 & 6.3221 & 6.8807 & TRN & & & \\
\hline CHEMBL3925686 & 1641364 & 7.1925 & 7.6314 & TST & & & \\
\hline CHEMBL3943786 & 1641364 & 7.5686 & 7.4343 & TRN & & & \\
\hline CHEMBL 3954460 & 1641364 & 8.3279 & 7.9958 & TRN & & & \\
\hline CHEMBL 3976410 & 1641364 & 7.6536 & 7.7724 & TRN & & & \\
\hline CHEMBL3968971 & 1641364 & 6.8972 & 6.9714 & TRN & & & \\
\hline CHEMBL 3977674 & 1641364 & 7.3206 & 6.9265 & TST & & & \\
\hline CHEMBL3946858 & 1641364 & 7.58 & 7.1461 & TRN & & & \\
\hline CHEMBL3947166 & 1641364 & 7.2534 & 7.3511 & TRN & & & \\
\hline CHEMBL 3911366 & 1641364 & 7.1965 & 6.2755 & TST & & & \\
\hline CHEMBL3932478 & 1641364 & 6.9073 & 6.9406 & TRN & & & \\
\hline CHEMBL 3949123 & 1641364 & 7.0762 & 6.5381 & TRN & & & \\
\hline CHEMBL 3977983 & 1641364 & 7.38399 & 999999999 & 995 & 7.07299 & 99999999995 & TRN \\
\hline CHEMBL 3909476 & 1641364 & 8.4089 & 7.6247 & TRN & & & \\
\hline CHEMBL 3952168 & 1641364 & 6.3554 & 6.6373 & TST & & & \\
\hline CHEMBL3935837 & 1641364 & 8.0605 & 7.7095 & TST & & & \\
\hline CHEMBL3960990 & 1641364 & 7.8928 & 7.4585 & TRN & & & \\
\hline CHEMBL 3910298 & 1641364 & 6.3872 & 6.6134 & TST & & & \\
\hline CHEMBL3984650 & 1641364 & 7.7235 & 8.0496 & TRN & & & \\
\hline CHEMBL3920641 & 1641364 & 6.4959 & 6.9631 & TRN & & & \\
\hline CHEMBL3582018 & 1641364 & 7.4802 & 7.7144 & TRN & & & \\
\hline CHEMBL3933881 & 1641364 & \multicolumn{3}{|c|}{6.787000000000001} & 6.6858 & TRN & \\
\hline CHEMBL 3939087 & 1641364 & 8.2441 & 8.3199 & TRN & & & \\
\hline CHEMBL3945889 & 1641364 & 6.8592 & 7.3945 & TRN & & & \\
\hline CHEMBL 3914627 & 1641364 & 10.0 & 9.4271 & TRN & & & \\
\hline CHEMBL3910961 & 1641364 & 7.2132 & 6.7516 & TST & & & \\
\hline CHEMBL 3894382 & 1641364 & 8.0757 & 8.0899 & TRN & & & \\
\hline CHEMBL3922999 & 1641364 & 7.7799 & 6.9643 & TRN & & & \\
\hline CHEMBL3960116 & 1641364 & 8.4437 & 8.3266 & TRN & & & \\
\hline CHEMBL 3909495 & 1641364 & 7.4711 & 7.4625 & TRN & & & \\
\hline CHEMBL3970254 & 1641364 & 7.6091 & 7.7509 & TRN & & & \\
\hline CHEMBL 3907426 & 1641364 & 7.4377 & 7.1174 & TRN & & & \\
\hline CHEMBL3914978 & 1641364 & 8.9586 & 8.9585 & TRN & & & \\
\hline CHEMBL3980706 & 1641364 & 6.3381 & 6.6241 & TRN & & & \\
\hline CHEMBL3962065 & 1641364 & 8.8539 & 8.7874 & TRN & & & \\
\hline CHEMBL3941296 & 1641364 & 6.0 & 7.1877 & TRN & & & \\
\hline CHEMBL 3933871 & 1641364 & 7.3904 & 7.314 & TRN & & & \\
\hline CHEMBL 3904854 & 1641364 & 6.5385 & 6.1991 & TST & & & \\
\hline CHEMBL 3963244 & 1641364 & 8.7959 & 8.8469 & TRN & & & \\
\hline CHEMBL3932727 & 1641364 & 6.6757 & 6.7843 & TRN & & & \\
\hline CHEMBL3956138 & 1641364 & 7.699 & 7.2387 & TRN & & & \\
\hline CHEMBL3950352 & 1641364 & 7.5918 & 7.1473 & TST & & & \\
\hline CHEMBL 3948440 & 1641364 & 6.7612 & 6.9266 & TST & & & \\
\hline CHEMBL3913328 & 1641364 & 7.6162 & 7.037000 & 0000000001 & & TST & \\
\hline CHEMBL3929309 & 1641364 & 9.3979 & 8.748 & TRN & & & \\
\hline CHEMBL3947055 & 1641364 & 7.2984 & 7.0054 & TRN & & & \\
\hline CHEMBL3913820 & 1641364 & 8.1249 & 8.1887 & TRN & & & \\
\hline CHEMBL 3922433 & 1641364 & 6.0167 & 5.7931 & TST & & & \\
\hline
\end{tabular}

Page 17042 
Supplemental Table S2.txt

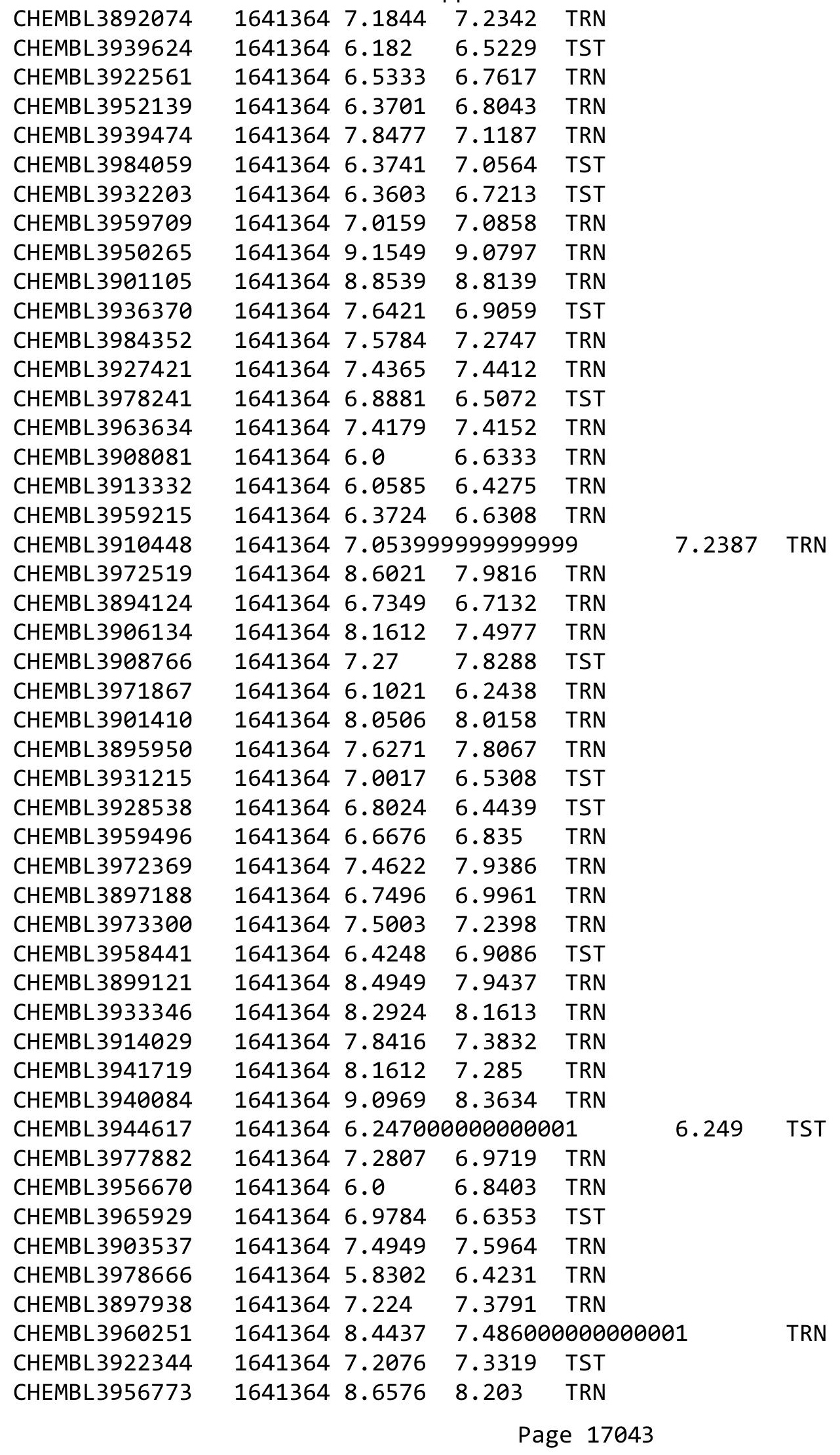


Supplemental Table S2.txt

\begin{tabular}{|c|c|c|c|c|c|c|}
\hline CHEMBL 3938202 & 1641364 & 8.3468 & 8.4618 & TRN & & \\
\hline CHEMBL 3984767 & 1641364 & 7.8794 & 7.5137 & TST & & \\
\hline CHEMBL3898565 & 1641364 & 8.5528 & 7.6725 & TRN & & \\
\hline CHEMBL 3890945 & 1641364 & 6.3802 & 6.7121 & TST & & \\
\hline CHEMBL3979647 & 1641364 & 6.7124 & 7.1605 & TRN & & \\
\hline CHEMBL 3898112 & 1641364 & 5.853 & 6.3983 & TRN & & \\
\hline CHEMBL3929609 & 1641364 & 6.9658 & 6.8321 & TRN & & \\
\hline CHEMBL3917096 & 1641364 & 8.5686 & 8.1806 & TRN & & \\
\hline CHEMBL3925192 & 1641364 & 8.3372 & 7.3882 & TRN & & \\
\hline CHEMBL3986467 & 1641364 & 7.0186 & 7.017 & TRN & & \\
\hline CHEMBL3899636 & 1641364 & 8.5229 & 7.4567 & TRN & & \\
\hline CHEMBL3961429 & 1641364 & 6.2311 & 6.9057 & TRN & & \\
\hline CHEMBL 3984375 & 1641364 & 7.301 & 6.9286 & TST & & \\
\hline CHEMBL3966833 & 1641364 & 8.5528 & 8.1745 & TRN & & \\
\hline CHEMBL 3942960 & 1641364 & 9.699 & 9.0462 & TRN & & \\
\hline CHEMBL3902630 & 1641364 & 6.3735 & 7.3481 & TST & & \\
\hline CHEMBL3900719 & 1641364 & 7.9393 & 7.7182 & TRN & & \\
\hline CHEMBL3947695 & 1641364 & 7.2411 & 6.5897 & TST & & \\
\hline CHEMBL3971343 & 1641364 & 8.3665 & 7.6288 & TRN & & \\
\hline CHEMBL3925671 & 1641364 & 6.6196 & 6.9214 & TRN & & \\
\hline CHEMBL3924535 & 1641364 & 7.9666 & 7.6313 & TRN & & \\
\hline CHEMBL3986365 & 1641364 & 7.6946 & 7.7091 & TST & & \\
\hline CHEMBL3969983 & 1641364 & 7.5157 & 7.5538 & TRN & & \\
\hline CHEMBL3915046 & 1641364 & 6.4928 & 6.6779 & TST & & \\
\hline CHEMBL3915763 & 1641364 & 7.6364 & 7.1127 & TRN & & \\
\hline CHEMBL 3947228 & 1641364 & 7.3298 & 7.1874 & TRN & & \\
\hline CHEMBL3907797 & 1641364 & 7.8416 & 7.4375 & TRN & & \\
\hline CHEMBL 3893664 & 1641364 & 6.1606 & 6.6588 & TST & & \\
\hline CHEMBL3964412 & 1641364 & 7.5784 & 7.0772 & TST & & \\
\hline CHEMBL3955963 & 1641364 & 6.7387 & 7.0395 & TRN & & \\
\hline CHEMBL3915066 & 1641364 & 6.4896 & 6.6079 & TST & & \\
\hline CHEMBL 3917885 & 1641364 & 7.6326 & 7.2709 & TRN & & \\
\hline CHEMBL3974437 & 1641364 & 8.3979 & 9.0525 & TRN & & \\
\hline CHEMBL3956544 & 1641364 & 6.8529 & 7.1851 & TRN & & \\
\hline CHEMBL3976333 & 1641364 & 6.8684 & 6.9463 & TRN & & \\
\hline CHEMBL3923668 & 1641364 & 6.8765 & 7.1407 & TRN & & \\
\hline CHEMBL3954663 & 1641364 & 6.4763 & 6.8302 & TRN & & \\
\hline CHEMBL3955761 & 1641364 & 7.6091 & 7.3777 & TST & & \\
\hline CHEMBL3917911 & 1641364 & 8.2924 & 7.0586 & TRN & & \\
\hline CHEMBL3952751 & 1641364 & 6.8871 & 6.6012 & TRN & & \\
\hline CHEMBL3901485 & 1641364 & 7.1013 & 6.9859 & TRN & & \\
\hline CHEMBL3968304 & 1641364 & 6.7206 & 6.8493 & TRN & & \\
\hline CHEMBL3950068 & 1641364 & 8.5086 & 7.8297 & TRN & & \\
\hline CHEMBL3914196 & 1641364 & 8.28399 & 799999995 & & 7.2010000000000005 & TRN \\
\hline CHEMBL3933825 & 1641364 & 6.9901 & 6.5257 & TRN & & \\
\hline CHEMBL 3898967 & 1641364 & 6.3824 & 5.9742 & TST & & \\
\hline CHEMBL 3981657 & 1641364 & 7.8125 & 7.5102 & TRN & & \\
\hline CHEMBL3938697 & 1641364 & 8.3468 & 8.5998 & TRN & & \\
\hline
\end{tabular}


Supplemental Table S2.txt

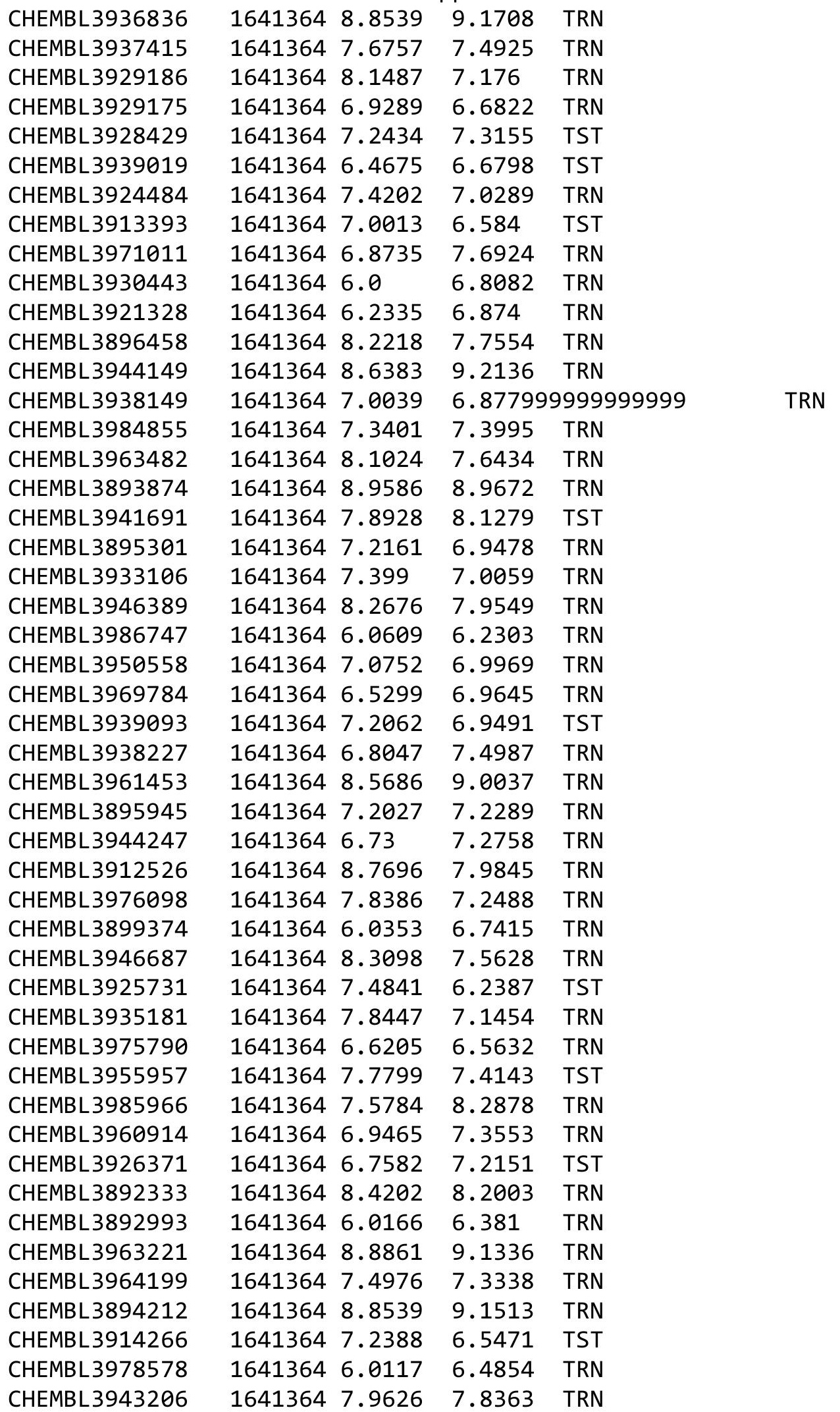

Page 17045 
Supplemental Table S2.txt

\begin{tabular}{|c|c|c|c|c|c|c|}
\hline CHEMBL3947963 & 1641364 & 6.8952 & 6.3151 & TRN & & \\
\hline CHEMBL3950329 & 1641364 & 6.25799 & 79999999 & 99 & 7.0499 & TRN \\
\hline CHEMBL3952505 & 1641364 & 6.9838 & 6.8199 & TRN & & \\
\hline CHEMBL3951612 & 1641364 & 7.2725 & 6.9584 & TST & & \\
\hline CHEMBL 3903077 & 1641364 & 7.4237 & 6.9356 & TRN & & \\
\hline CHEMBL3932050 & 1641364 & 6.0 & 7.4263 & TRN & & \\
\hline CHEMBL3950538 & 1641364 & 6.0 & 7.2169 & TRN & & \\
\hline CHEMBL3935858 & 1641364 & 6.7082 & 6.6278 & TRN & & \\
\hline CHEMBL 3958904 & 1641364 & 6.6041 & 7.1179 & TRN & & \\
\hline CHEMBL3967727 & 1640674 & 5.0894 & 4.5072 & TRN & & \\
\hline CHEMBL3947471 & 1640674 & 6.5058 & 6.5765 & TRN & & \\
\hline CHEMBL3983519 & 1640674 & 5.6234 & 5.3155 & TRN & & \\
\hline CHEMBL3959843 & 1640674 & 6.9355 & 6.5559 & TRN & & \\
\hline CHEMBL 3958804 & 1640674 & 7.3665 & 6.6447 & TRN & & \\
\hline CHEMBL3906552 & 1640674 & 6.1421 & 6.5273 & TRN & & \\
\hline CHEMBL3937739 & 1640674 & 4.8928 & 5.3561 & TST & & \\
\hline CHEMBL3928501 & 1640674 & 5.2596 & 5.6571 & TRN & & \\
\hline CHEMBL3984012 & 1640674 & 5.6676 & 6.3247 & TRN & & \\
\hline CHEMBL 3984897 & 1640674 & 6.4145 & 6.4005 & TRN & & \\
\hline CHEMBL3907930 & 1640674 & 7.4949 & 6.8546 & TRN & & \\
\hline CHEMBL3951739 & 1640674 & 6.0531 & 6.2671 & TRN & & \\
\hline CHEMBL3955855 & 1640674 & 6.9469 & 6.5169 & TRN & & \\
\hline CHEMBL 3932566 & 1640674 & 5.9914 & 6.2137 & TRN & & \\
\hline CHEMBL3927518 & 1640674 & 6.9957 & 6.6571 & TRN & & \\
\hline CHEMBL3899239 & 1640674 & 5.0424 & 5.8674 & TST & & \\
\hline CHEMBL3967569 & 1640674 & 5.1046 & 4.9912 & TRN & & \\
\hline CHEMBL3894951 & 1640674 & 6.8386 & 6.2194 & TRN & & \\
\hline CHEMBL3968018 & 1640674 & 6.4522 & 5.9477 & TRN & & \\
\hline CHEMBL3983978 & 1640674 & 6.466 & 6.4948 & TRN & & \\
\hline CHEMBL 3979370 & 1640674 & 5.4449 & \multicolumn{3}{|c|}{5.638999999999999} & TRN \\
\hline CHEMBL3970929 & 1640674 & 5.4737 & 6.0781 & TRN & & \\
\hline CHEMBL3932339 & 1640674 & 6.2055 & 6.2787 & TRN & & \\
\hline CHEMBL 3907429 & 1640674 & 6.8601 & 6.6989 & TRN & & \\
\hline CHEMBL3950346 & 1640674 & 6.9508 & 6.4904 & TRN & & \\
\hline CHEMBL3908108 & 1640674 & 5.1649 & 5.519 & TST & & \\
\hline CHEMBL3969227 & 1640674 & 5.0004 & \multicolumn{3}{|c|}{5.3420000000000005} & TRN \\
\hline CHEMBL3950113 & 1640674 & 5.5157 & 6.1125 & TRN & & \\
\hline CHEMBL3907055 & 1640674 & 6.1232 & 4.9209 & TRN & & \\
\hline CHEMBL 3941621 & 1640674 & 4.0 & 4.4577 & TRN & & \\
\hline CHEMBL3929112 & 1640674 & 7.1675 & 5.9157 & TST & & \\
\hline CHEMBL3901833 & 1640674 & 6.6635 & 6.5655 & TRN & & \\
\hline CHEMBL 3913382 & 1640674 & 5.041 & 4.9851 & TRN & & \\
\hline CHEMBL3970896 & 1640674 & 7.289 & 6.8249 & TRN & & \\
\hline CHEMBL3969118 & 1640674 & 6.5467 & 6.2103 & TRN & & \\
\hline CHEMBL3915530 & 1640674 & 6.0173 & 5.9117 & TRN & & \\
\hline CHEMBL3897746 & 1640674 & 5.5884 & 5.5329 & TRN & & \\
\hline CHEMBL 3937846 & 1640674 & 6.7721 & 6.6093 & TRN & & \\
\hline CHEMBL3952349 & 1640674 & 6.82100 & 00000000 & & 6.2939 & TRN \\
\hline
\end{tabular}


Supplemental Table S2.txt

\begin{tabular}{|c|c|c|c|c|c|}
\hline CHEMBL 3798040 & 1640674 & 7.4815 & 5.9704 & TST & \\
\hline CHEMBL3892995 & 1640674 & 5.0462 & 5.4504 & TRN & \\
\hline CHEMBL3982008 & 1640674 & 5.9281 & 5.6454 & TST & \\
\hline CHEMBL3908181 & 1640674 & 6.5498 & 6.5024 & TRN & \\
\hline CHEMBL3930568 & 1640674 & 5.9547 & 6.4248 & TRN & \\
\hline CHEMBL 3973565 & 1640674 & 6.5072 & 6.0178 & TRN & \\
\hline CHEMBL3970411 & 1640674 & 5.5129 & 5.3965 & TST & \\
\hline CHEMBL3950175 & 1640674 & 4.9245 & 5.4098 & TST & \\
\hline CHEMBL3897174 & 1640674 & 6.2336 & 6.7633 & TRN & \\
\hline CHEMBL3962592 & 1640674 & 5.0964 & 6.0092 & TST & \\
\hline CHEMBL 3972978 & 1640674 & 5.8477 & 5.7182 & TST & \\
\hline CHEMBL3955656 & 1640674 & 4.762 & 5.5646 & TRN & \\
\hline CHEMBL3958765 & 1640674 & 5.8268 & 6.2771 & TRN & \\
\hline CHEMBL3944839 & 1640674 & 6.4572 & 6.5434 & TRN & \\
\hline CHEMBL 3975540 & 1640674 & 6.8069 & 6.3858 & TST & \\
\hline CHEMBL3901929 & 1640674 & 6.4547 & 5.7769 & TRN & \\
\hline CHEMBL3930906 & 1640674 & 6.5031 & 6.726 & TRN & \\
\hline CHEMBL 3900600 & 1640674 & 6.7825 & 6.4046 & TRN & \\
\hline CHEMBL3973444 & 1640674 & 5.1965 & 6.0964 & TST & \\
\hline CHEMBL 3923616 & 1640674 & 5.2757 & 5.1579 & TST & \\
\hline CHEMBL3895394 & 1640674 & 5.1007 & 5.7763 & TRN & \\
\hline CHEMBL3918174 & 1640674 & 5.15 & 5.5568 & TRN & \\
\hline CHEMBL3977654 & 1640674 & 6.224 & 6.1368 & TRN & \\
\hline CHEMBL3946663 & 1640674 & 7.0315 & 6.5211 & TRN & \\
\hline CHEMBL 3900822 & 1640674 & 5.0788 & 4.7424 & TRN & \\
\hline CHEMBL3977560 & 1640674 & 5.9872 & 6.5356 & TRN & \\
\hline CHEMBL3921007 & 1640674 & 5.4112 & 5.7567 & TRN & \\
\hline CHEMBL3913712 & 1640674 & 5.8097 & 5.4287 & TRN & \\
\hline CHEMBL3895620 & 1640674 & 5.1911 & 5.5124 & TRN & \\
\hline CHEMBL 3933898 & 1640674 & 6.9355 & 6.5234 & TRN & \\
\hline CHEMBL3919518 & 1640674 & 6.1911 & 6.5003 & TRN & \\
\hline CHEMBL3914548 & 1640674 & 5.5591 & 6.4898 & TRN & \\
\hline CHEMBL3942548 & 1640674 & 6.3036 & 6.3141 & TRN & \\
\hline CHEMBL3977207 & 1640674 & 6.3872 & 6.6292 & TRN & \\
\hline CHEMBL3891609 & 1640674 & 7.0555 & 6.5187 & TRN & \\
\hline CHEMBL3937959 & 1640674 & 6.1068 & 6.3075 & TRN & \\
\hline CHEMBL3913233 & 1640674 & 5.0 & 5.6578 & TRN & \\
\hline CHEMBL3976080 & 1640674 & 6.75200 & 00000000 & 1 & 6.6394 \\
\hline CHEMBL3959958 & 1640674 & 6.6635 & 6.2947 & TRN & \\
\hline CHEMBL3913098 & 1640674 & 5.8125 & 6.5508 & TRN & \\
\hline CHEMBL3976079 & 1640674 & 4.9393 & 4.9616 & TRN & \\
\hline CHEMBL3935108 & 1640674 & 6.3706 & 5.9688 & TST & \\
\hline CHEMBL3894572 & 1640674 & 5.1319 & 5.8908 & TST & \\
\hline CHEMBL3922380 & 1640674 & 6.9666 & 5.939 & TST & \\
\hline CHEMBL3975979 & 1640674 & 5.8416 & 6.0734 & TST & \\
\hline CHEMBL3914154 & 1640674 & 6.3872 & 6.4043 & TST & \\
\hline CHEMBL3950739 & 1640674 & 5.0372 & 5.9754 & TST & \\
\hline CHEMBL3908290 & 1640674 & 5.2823 & 5.1611 & TST & \\
\hline
\end{tabular}


Supplemental Table S2.txt

\begin{tabular}{|c|c|c|c|c|}
\hline HEMBL3937590 & 1640674 & 6.8356 & 6.415 & TST \\
\hline CHEMBL3961520 & 1640674 & 6.7852 & 5.886 & \\
\hline HEMBL3952838 & 1640674 & 6.5952 & 153 & \\
\hline CHEMBL449174 & 514987 & 5.1844 & 712 & \\
\hline HEMBL454943 & 14987 & 4.0 & 3.8123 & \\
\hline HEMBL502884 & 14987 & 4.0 & 4.0916 & \\
\hline HEMBL488362 & 14987 & 4.0 & 4.151 & \\
\hline AEMBL490074 & 14987 & 6.1487 & 5.3861 & \\
\hline HEMBL489880 & 14987 & 6.1427 & 5.7832 & \\
\hline HEMBL517414 & 14987 & 4.1549 & 4.3563 & \\
\hline HEMBL472910 & 14987 & 5.4609 & 4.9638 & \\
\hline HEMBL490275 & 14987 & 4.301 & 5.1186 & \\
\hline HEMBL473109 & 14987 & 6.0915 & 818 & \\
\hline HEMBL473324 & 14987 & 5.5031 & 5.2058 & \\
\hline HEMBL453122 & 14987 & 5.4921 & 2.7906 & \\
\hline HEMBL489291 & 514987 & 5.3757 & 5.1244 & \\
\hline HEMBL472720 & 14987 & 6.0555 & 082 & \\
\hline HEMBL506804 & 14987 & 4.301 & 783 & \\
\hline HEMBL454946 & 14987 & 4.0 & 3.8746 & \\
\hline HEMBL522442 & 14987 & 3.699 & 911 & \\
\hline HEMBL510626 & 14987 & 5.6126 & 484 & \\
\hline HEMBL490289 & 87 & 6.1805 & 566 & RN \\
\hline HEMBL472919 & 87 & 4.0 & 383 & \\
\hline AEMBL454152 & 14987 & 5.6925 & 824 & \\
\hline HEMBL490076 & 87 & 6.0315 & 123 & I RN \\
\hline HEMBL490288 & 14987 & 6.4815 & 6.2421 & 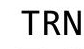 \\
\hline HEMBL490075 & 14987 & 6.1249 & 837 & 促 \\
\hline HEMBL475142 & 14987 & 3.699 & 923 & 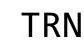 \\
\hline JEMBL472911 & 14987 & 4.0 & 259 & ГRN \\
\hline HEMBL445089 & 14987 & 5.52 & 4.9918 & RIN \\
\hline CHEMBL512752 & 514987 & 5.9957 & 462 & RIV \\
\hline CHEMBL51 & 14987 & 4.6 & 238 & Tho \\
\hline HEMBL4 & 87 & 3.699 & 733 & - \\
\hline HEMBL472719 & 14987 & 5.2343 & 5.0859 & 「RN \\
\hline CHEMBL516030 & 14987 & 5.8861 & 5.8572 & IRN \\
\hline CHEMBL445501 & 87 & 5.5575 & 5.8272 & 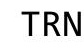 \\
\hline CHEMBL $4 \varepsilon$ & 37 & 5.2381 & 862 & NIV \\
\hline CHEMBL475132 & 14987 & 3.699 & 3.387 & $\mathrm{RN}$ \\
\hline CHEMBL460703 & 14987 & 5.6289 & 6.1966 & S \\
\hline HEMBL460705 & 14987 & 5.8327 & 5.8421 & TR \\
\hline CHEMBL472909 & 514987 & 6.3188 & 6.1953 & \\
\hline CHEMBL475131 & 514987 & 5.6402 & 5.5781 & \\
\hline CHEMBL522587 & 14987 & 4.0 & 4.081 & RN \\
\hline CHEMBL514296 & 14987 & 6.1367 & 6.325 & RI \\
\hline CHEMBL460704 & 514987 & 5.8097 & 6.0188 & 11 \\
\hline CHEMBL475143 & 514987 & 5.6676 & 5.7652 & \\
\hline CHEMBL460712 & 514987 & 4.0 & 4.17 & \\
\hline CHEMBL512751 & 514987 & 4.301 & 4.5125 & TR \\
\hline
\end{tabular}

Page 17048 


\begin{tabular}{|c|c|c|c|c|c|c|}
\hline \multicolumn{7}{|c|}{ S2.tx } \\
\hline CHEMBL460713 & 514987 & 4.0 & 3.3751 & TST & & \\
\hline CHEMBL514456 & 514987 & 6.0605 & 6.115 & TRN & & \\
\hline CHEMBL454945 & 514987 & 5.9281 & 2.6011 & TST & & \\
\hline CHEMBL451452 & 514987 & 5.8996 & 5.3686 & TRN & & \\
\hline CHEMBL453120 & 514987 & 4.0 & 3.895 & TST & & \\
\hline CHEMBL454151 & 514987 & 5.7144 & 5.6861 & TRN & & \\
\hline CHEMBL521926 & 514987 & 5.7696 & 4.9627 & TRN & & \\
\hline CHEMBL523618 & 514987 & 4.0 & 4.3209 & TRN & & \\
\hline CHEMBL454944 & 514987 & 4.1549 & 1.9437 & TST & & \\
\hline CHEMBL473520 & 514987 & 5.8962 & 6.4104 & TRN & & \\
\hline CHEMBL509458 & 514987 & 4.0 & 2.432 & TST & & \\
\hline CHEMBL475290 & 514987 & 5.4078 & 5.6054 & TRN & & \\
\hline CHEMBL475144 & 514987 & 5.5003 & 5.2217 & TRN & & \\
\hline CHEMBL523962 & 514987 & 5.8069 & 6.3973 & TST & & \\
\hline CHEMBL454362 & 514987 & 4.0 & 4.498 & TST & & \\
\hline CHEMBL 3661253 & 1640346 & 6.6196 & 6.5256 & TRN & & \\
\hline CHEMBL 3661274 & 1640346 & 6.9796 & 6.9811 & TRN & & \\
\hline CHEMBL 3661275 & 1640346 & 6.3461 & 6.2028 & TST & & \\
\hline CHEMBL 3661254 & 1640346 & 6.0403 & 6.0901 & TRN & & \\
\hline CHEMBL 3661205 & 1640346 & 5.9897 & 5.9812 & TRN & & \\
\hline CHEMBL 3661298 & 1640346 & 6.7324 & 6.7129 & TRN & & \\
\hline CHEMBL3661285 & 1640346 & 6.5645 & 6.6103 & TRN & & \\
\hline CHEMBL 3665861 & 1640346 & 7.7212 & 8.0065 & TST & & \\
\hline CHEMBL 3661276 & 1640346 & 7.6383 & 7.6354 & TST & & \\
\hline CHEMBL 3661279 & 1640346 & 6.6749 & 6.7424 & TRN & & \\
\hline CHEMBL 3661231 & 1640346 & 7.1451 & 7.185 & TRN & & \\
\hline CHEMBL3661291 & 1640346 & 6.9326 & 6.9714 & TRN & & \\
\hline CHEMBL3661211 & 1640346 & 5.8674 & 5.9767 & TRN & & \\
\hline CHEMBL 3661315 & 1640346 & 6.6267 & 6.7492 & TRN & & \\
\hline CHEMBL3661243 & 1640346 & 6.9805 & 7.0594 & TRN & & \\
\hline CHEMBL3661239 & 1640346 & 7.24799 & 99999999 & 99 & 7.2473 & TRN \\
\hline CHEMBL3661299 & 1640346 & 6.374 & 6.4475 & TRN & & \\
\hline CHEMBL3661229 & 1640346 & 6.4461 & 6.5194 & TRN & & \\
\hline CHEMBL3661215 & 1640346 & 6.0747 & 6.0832 & TRN & & \\
\hline CHEMBL 3661233 & 1640346 & 6.2643 & 6.2744 & TRN & & \\
\hline CHEMBL3661219 & 1640346 & 5.63 & 5.8475 & TRN & & \\
\hline CHEMBL 3661311 & 1640346 & 6.3263 & 6.4153 & TRN & & \\
\hline CHEMBL3661227 & 1640346 & 7.3251 & 7.2035 & TRN & & \\
\hline CHEMBL3661230 & 1640346 & 6.2392 & 6.0989 & TRN & & \\
\hline CHEMBL 3661305 & 1640346 & 6.596 & 6.5837 & TRN & & \\
\hline CHEMBL 3661208 & 1640346 & 5.9322 & 5.9803 & TRN & & \\
\hline CHEMBL 3665863 & 1640346 & 8.3468 & 8.1907 & TRN & & \\
\hline CHEMBL3661223 & 1640346 & 6.0713 & 6.2419 & TRN & & \\
\hline CHEMBL 3661290 & 1640346 & 6.5553 & 6.4905 & TRN & & \\
\hline CHEMBL 3661316 & 1640346 & 7.1494 & 7.1635 & TRN & & \\
\hline CHEMBL 3661201 & 1640346 & 6.1192 & 5.9693 & TRN & & \\
\hline CHEMBL 3661256 & 1640346 & 6.2542 & 6.2466 & TRN & & \\
\hline CHEMBL 3661300 & 1640346 & 6.7902 & 6.7105 & TST & & \\
\hline
\end{tabular}


Supplemental Table S2.txt

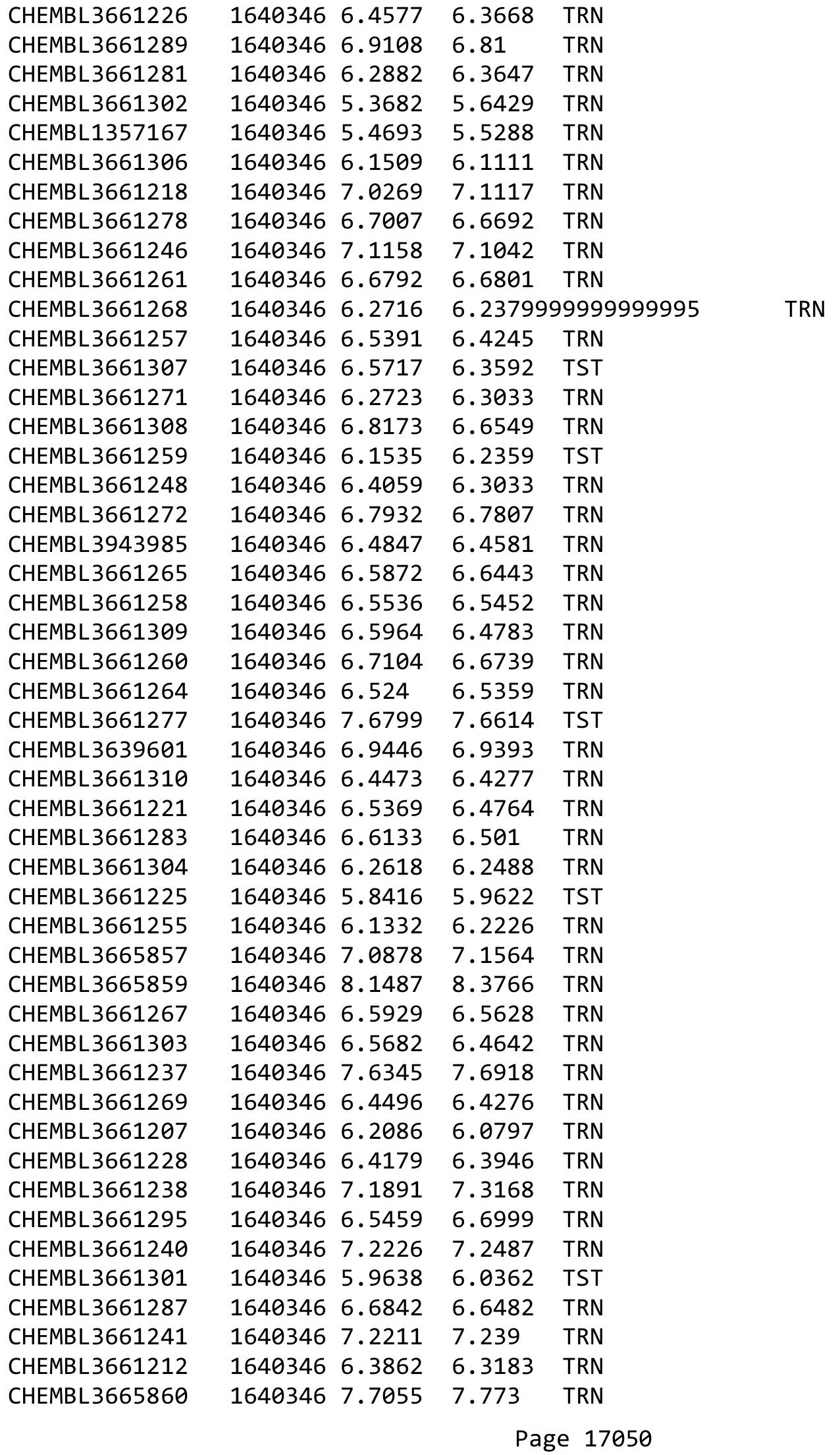


Supplemental Table S2.txt

\begin{tabular}{|c|c|c|c|c|c|}
\hline CHEMBL 3661204 & 1640346 & 5.9634 & 6.055 & TRN & \\
\hline CHEMBL 3661236 & 1640346 & 6.3664 & 6.3628 & TRN & \\
\hline CHEMBL 3661235 & 1640346 & 6.1984 & 6.1655 & TRN & \\
\hline CHEMBL 3661242 & 1640346 & 7.2865 & 7.3423 & TRN & \\
\hline CHEMBL3661312 & 1640346 & 6.0715 & 6.1827 & TST & \\
\hline CHEMBL 3661296 & 1640346 & 6.5787 & 6.5429 & TST & \\
\hline CHEMBL 3661203 & 1640346 & 7.4271 & 7.3174 & TRN & \\
\hline CHEMBL 3661273 & 1640346 & 6.8222 & 6.7957 & TST & \\
\hline CHEMBL 3665865 & 1640346 & 6.6645 & 7.1177 & TST & \\
\hline CHEMBL3661247 & 1640346 & 6.4664 & 6.5557 & TST & \\
\hline CHEMBL 3661245 & 1640346 & 6.8564 & 6.8401 & TRN & \\
\hline CHEMBL 3665862 & 1640346 & 7.6308 & 7.6113 & TRN & \\
\hline CHEMBL 3661249 & 1640346 & 7.0458 & 6.9019 & TRN & \\
\hline CHEMBL 3661294 & 1640346 & 6.9259 & 6.9053 & TST & \\
\hline CHEMBL3661292 & 1640346 & 6.2795 & 6.3329999 & 7999999999 & TRN \\
\hline CHEMBL 3661263 & 1640346 & 6.4309 & 6.7739 & TST & \\
\hline CHEMBL 3661232 & 1640346 & 6.803 & 6.7724 & TST & \\
\hline CHEMBL 3661313 & 1640346 & 6.4447 & $6.5263 \quad T$ & TST & \\
\hline CHEMBL 3661266 & 1640346 & 5.99700 & 0000000001 & 6.0167 & TST \\
\hline CHEMBL 3661288 & 1640346 & 6.5361 & 6.6003 & TST & \\
\hline CHEMBL 3661216 & 1640346 & 6.3439 & 6.4197 & TRN & \\
\hline CHEMBL 3665864 & 1640346 & 8.3468 & 8.1705 & TST & \\
\hline CHEMBL 3661251 & 1640346 & 6.856 & $6.9702 \quad T$ & TST & \\
\hline CHEMBL 3661222 & 1640346 & 6.1708 & $6.1968 \quad T$ & TRN & \\
\hline CHEMBL 3661214 & 1640346 & 5.74299 & 9999999999 & 5.6288 & TST \\
\hline CHEMBL 3661252 & 1640346 & 6.65600 & 0000000001 & 6.659 & TST \\
\hline CHEMBL 3661202 & 1640346 & 5.3125 & 5.4002 & TRN & \\
\hline CHEMBL 3661250 & 1640346 & 6.3127 & 6.289 & TST & \\
\hline CHEMBL 3661314 & 1640346 & 6.704 & 6.7887 & TST & \\
\hline CHEMBL 3661262 & 1640346 & 6.5417 & 6.6776 & TST & \\
\hline CHEMBL 3661224 & 1640346 & 6.1508 & 6.2024 & TST & \\
\hline CHEMBL 3661210 & 1640346 & 6.3271 & 6.0894 & TRN & \\
\hline CHEMBL 3661286 & 1640346 & 7.0004 & 7.108 & TST & \\
\hline CHEMBL 3661280 & 1640346 & 6.4478 & 6.5141 & TST & \\
\hline CHEMBL 3661284 & 1640346 & 6.7849 & 6.64 & TST & \\
\hline CHEMBL 3661270 & 1640346 & 6.2586 & 6.3002 & TST & \\
\hline CHEMBL 3661282 & 1640346 & 6.5342 & $6.4965 \quad T$ & TRN & \\
\hline CHEMBL 3661213 & 1640346 & 6.4237 & 6.192 & TRN & \\
\hline CHEMBL3661209 & 1640346 & 6.2823 & 6.2811 & TRN & \\
\hline CHEMBL 3661206 & 1640346 & 6.0917 & 6.2383 & TRN & \\
\hline CHEMBL 3661217 & 1640346 & 6.6737 & 6.6706 & TRN & \\
\hline CHEMBL 3665858 & 1640346 & 7.426 & \multicolumn{2}{|c|}{7.3020000000000005} & I KIV \\
\hline CHEMBL 3661220 & 1640346 & 6.24299 & 9999999999 & 6.2468 & TRN \\
\hline CHEMBL 3661293 & 1640346 & 6.1987 & 6.157 & TRN & \\
\hline CHEMBL 3661234 & 1640346 & 6.7414 & 6.8002 & TRN & \\
\hline CHEMBL1909651 & 776643 & 3.0 & 3.6043 & TRN & \\
\hline CHEMBL1910632 & 776643 & 3.0 & $3.7272 \quad T$ & TRN & \\
\hline CHEMBL1910744 & 776643 & 4.0434 & $4.1004 T$ & TRN & \\
\hline
\end{tabular}




\begin{tabular}{|c|c|c|c|c|c|c|}
\hline \multicolumn{7}{|c|}{ Supplemental Table S2.txt } \\
\hline CHEMBL1910597 & 776643 & 3.0 & 3.2448 & TRN & & \\
\hline CHEMBL1910761 & 776643 & 5.1818 & 3.3046 & TST & & \\
\hline CHEMBL1910748 & 776643 & 4.3143 & 4.0852 & TRN & & \\
\hline CHEMBL1910629 & 776643 & 4.0915 & 3.8598 & TRN & & \\
\hline CHEMBL1910627 & 776643 & 4.1024 & 3.8329 & TRN & & \\
\hline CHEMBL1910747 & 776643 & 4.158 & 3.6962 & TRN & & \\
\hline CHEMBL1910371 & 776643 & 3.0 & 3.4137 & TRN & & \\
\hline CHEMBL1910603 & 776643 & 3.0 & 3.1508 & TRN & & \\
\hline CHEMBL1910758 & 776643 & 4.2291 & 3.7055 & TRN & & \\
\hline CHEMBL1910601 & 776643 & 3.0 & 2.9895 & TRN & & \\
\hline CHEMBL1910616 & 776643 & 3.0 & 3.2721 & TST & & \\
\hline CHEMBL1910606 & 776643 & 4.7247 & 4.012 & TRN & & \\
\hline CHEMBL1910595 & 776643 & 3.699 & 3.3826 & TRN & & \\
\hline CHEMBL1910630 & 776643 & 4.0177 & 3.2412 & TRN & & \\
\hline CHEMBL1910746 & 776643 & 3.0 & 3.6148 & TST & & \\
\hline CHEMBL1910373 & 776643 & 4.0458 & 3.676 & TRN & & \\
\hline CHEMBL1910610 & 776643 & 3.699 & 3.9886 & TST & & \\
\hline CHEMBL1910752 & 776643 & 3.0 & 3.4405 & TRN & & \\
\hline CHEMBL1910628 & 776643 & 4.1707 & 3.2814 & TRN & & \\
\hline CHEMBL1910609 & 776643 & 3.699 & 3.3969 & TST & & \\
\hline CHEMBL1910599 & 776643 & 3.0 & 2.9483 & TRN & & \\
\hline CHEMBL1910759 & 776643 & 4.1079 & 4.0274 & TRN & & \\
\hline CHEMBL1910626 & 776643 & 4.0809 & 3.9177 & TRN & & \\
\hline CHEMBL1910598 & 776643 & 3.0 & 2.819 & TRN & & \\
\hline CHEMBL1910623 & 776643 & 3.0 & 3.22 & TRN & & \\
\hline CHEMBL1910625 & 776643 & 4.1037 & 4.0471 & TRN & & \\
\hline CHEMBL1910637 & 776643 & 3.0 & 3.8575 & TRN & & \\
\hline CHEMBL1910624 & 776643 & 3.699 & 3.1843 & TST & & \\
\hline CHEMBL1910633 & 776643 & 3.0 & 3.6391 & TRN & & \\
\hline CHEMBL1910635 & 776643 & 3.0 & 3.4466 & TRN & & \\
\hline CHEMBL1910602 & 776643 & 4.1107 & 3.7105 & TRN & & \\
\hline CHEMBL1910374 & 776643 & 4.38399 & 99999999 & 995 & 4.1398 & TRN \\
\hline CHEMBL1910750 & 776643 & 4.2291 & 3.7244 & TRN & & \\
\hline CHEMBL1910749 & 776643 & 4.30699 & 99999999 & 995 & 3.8126 & TRN \\
\hline CHEMBL1910604 & 776643 & 3.0 & 3.0493 & TRN & & \\
\hline CHEMBL1910757 & 776643 & 4.1871 & 3.1884 & TRN & & \\
\hline CHEMBL1910607 & 776643 & 4.248 & 3.8677 & TRN & & \\
\hline CHEMBL1910762 & 776643 & 4.4645 & 3.2672 & TST & & \\
\hline CHEMBL1910376 & 776643 & 3.699 & 3.3347 & TRN & & \\
\hline CHEMBL1910617 & 776643 & 3.0 & 3.2694 & TST & & \\
\hline CHEMBL1910375 & 776643 & 4.0292 & 3.7883 & TRN & & \\
\hline CHEMBL1910755 & 776643 & 3.0 & 3.4455 & TRN & & \\
\hline CHEMBL1910754 & 776643 & 3.0 & 3.8735 & TRN & & \\
\hline CHEMBL1910760 & 776643 & 3.0 & 3.6688 & TRN & & \\
\hline CHEMBL1910600 & 776643 & 3.0 & 3.395 & TRN & & \\
\hline CHEMBL1910614 & 776643 & 3.0 & 3.3418 & TRN & & \\
\hline CHEMBL1910636 & 776643 & 3.0 & 3.6927 & TRN & & \\
\hline CHEMBL1910634 & 776643 & 4.0458 & 4.1187 & TRN & & \\
\hline
\end{tabular}




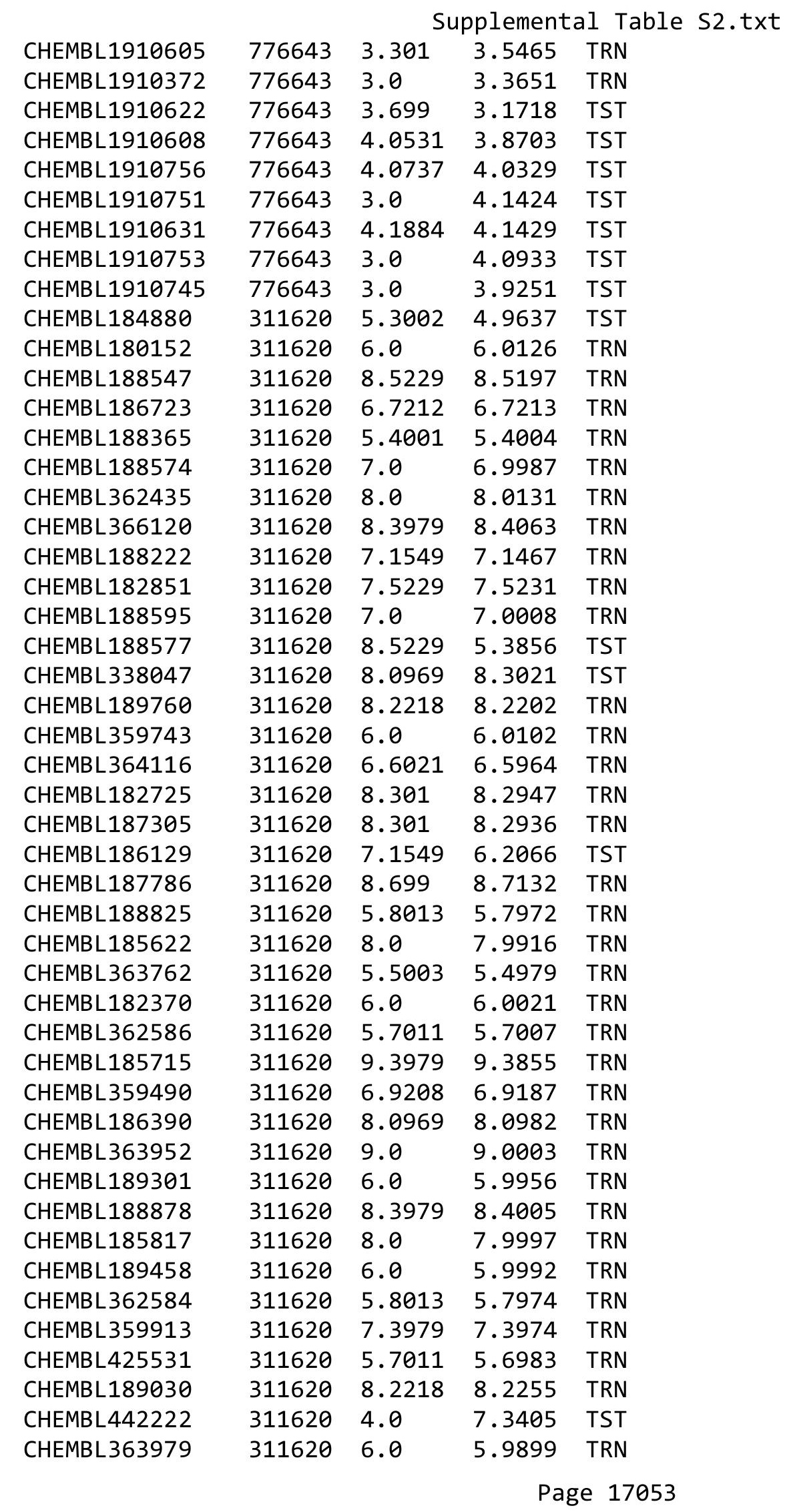




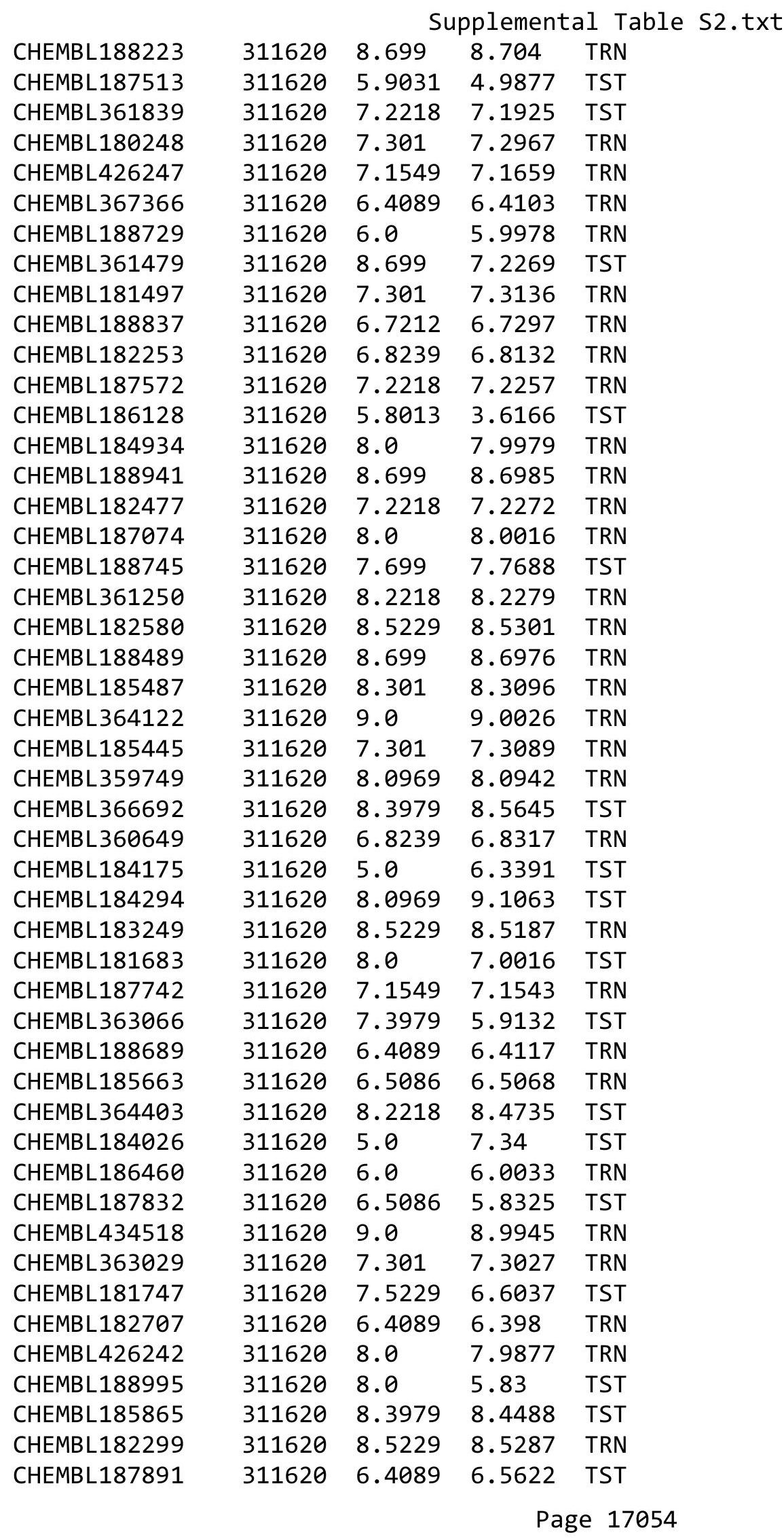




\begin{tabular}{|c|c|c|c|c|c|c|}
\hline & & \multicolumn{5}{|c|}{ Supplemental Table s2.txt } \\
\hline CHEMBL368028 & 311620 & 6.4089 & 6.4039 & TRN & & \\
\hline CHEMBL188877 & 311620 & 8.0 & 7.7547 & TST & & \\
\hline CHEMBL188580 & 311620 & 8.699 & 8.6988 & TRN & & \\
\hline CHEMBL175522 & 311620 & 8.699 & 8.6801 & TRN & & \\
\hline CHEMBL187515 & 311620 & 6.8239 & 6.5294 & TST & & \\
\hline CHEMBL182846 & 311620 & 8.699 & 8.696 & TRN & & \\
\hline CHEMBL526552 & 498611 & 6.5467 & 7.141 & TRN & & \\
\hline CHEMBL525951 & 498611 & \multicolumn{3}{|c|}{5.752000000000001} & 6.0546 & TRN \\
\hline CHEMBL524683 & 498611 & 8.1805 & 8.0468 & TRN & & \\
\hline CHEMBL525207 & 498611 & 7.5986 & 7.2401 & TRN & & \\
\hline CHEMBL501224 & 498611 & 5.9957 & 6.2967 & TRN & & \\
\hline CHEMBL526360 & 498611 & 8.1739 & 7.8701 & TRN & & \\
\hline CHEMBL526315 & 498611 & 8.2676 & 8.3983 & TRN & & \\
\hline CHEMBL501487 & 498611 & 7.3072 & 7.8835 & TST & & \\
\hline CHEMBL525591 & 498611 & 8.041 & 7.9863 & TRN & & \\
\hline CHEMBL526131 & 498611 & 7.8069 & 7.3464 & TST & & \\
\hline CHEMBL525957 & 498611 & 5.8477 & 5.18 & TRN & & \\
\hline CHEMBL499665 & 498611 & 8.0362 & 8.0602 & TRN & & \\
\hline CHEMBL501268 & 498611 & 6.1107 & 5.439 & TST & & \\
\hline CHEMBL524495 & 498611 & 8.0706 & 8.1695 & TST & & \\
\hline CHEMBL524494 & 498611 & 8.1549 & 8.2182 & TRN & & \\
\hline CHEMBL526328 & 498611 & 5.6904 & 6.04799 & 9999999999 & & TRN \\
\hline CHEMBL526899 & 498611 & 8.041 & 7.4679 & TRN & & \\
\hline CHEMBL1187422 & 498611 & 7.289 & 7.4371 & TRN & & \\
\hline CHEMBL445530 & 498611 & 7.9666 & 7.682 & TRN & & \\
\hline CHEMBL506517 & 498611 & 8.1427 & 8.3119 & TRN & & \\
\hline CHEMBL530121 & 498611 & 5.8097 & 5.6911 & TRN & & \\
\hline CHEMBL508607 & 498611 & 7.9469 & 7.1777 & TST & & \\
\hline CHEMBL506130 & 498611 & 5.8928 & 6.2523 & TRN & & \\
\hline CHEMBL530563 & 498611 & 8.2441 & 8.3438 & TRN & & \\
\hline CHEMBL524521 & 498611 & 5.8761 & 7.0499 & TRN & & \\
\hline CHEMBL524658 & 498611 & 6.0 & 7.7392 & TRN & & \\
\hline CHEMBL498867 & 498611 & 8.1024 & 7.0499 & TRN & & \\
\hline CHEMBL525611 & 498611 & 6.475 & 7.1648 & TST & & \\
\hline CHEMBL502619 & 498611 & 7.983 & 7.5099 & TRN & & \\
\hline CHEMBL525639 & 498611 & 7.2168 & 6.6442 & TRN & & \\
\hline CHEMBL501240 & 498611 & 7.9747 & 7.4723 & TRN & & \\
\hline CHEMBL525258 & 498611 & 8.0269 & 8.0126 & TRN & & \\
\hline CHEMBL526923 & 498611 & 6.8013 & 6.468 & TRN & & \\
\hline CHEMBL525267 & 498611 & 7.2464 & 7.2181 & TRN & & \\
\hline CHEMBL525817 & 498611 & 6.6819 & 7.8701 & TRN & & \\
\hline CHEMBL524675 & 498611 & 7.6655 & 6.5941 & TST & & \\
\hline CHEMBL507480 & 498611 & 8.3468 & 8.1349 & TRN & & \\
\hline CHEMBL502352 & 498611 & 8.0362 & 7.7392 & TRN & & \\
\hline CHEMBL527436 & 498611 & $5.7570 e$ & 00000000 & 01 & 5.5151 & TST \\
\hline CHEMBL526004 & 498611 & 7.0123 & 6.5719 & TRN & & \\
\hline CHEMBL526000 & 498611 & 7.9031 & 7.395 & TRN & & \\
\hline CHEMBL525566 & 498611 & 5.6635 & 5.3952 & TST & & \\
\hline
\end{tabular}


Supplemental Table S2.txt

\begin{tabular}{|c|c|c|c|c|}
\hline CHEMBL524528 & 498611 & 5.7033 & 5.4012 & TST \\
\hline CHEMBL527079 & 498611 & 5.4449 & 5.614 & TST \\
\hline CHEMBL525419 & 498611 & 8.3979 & 8.2226 & TRN \\
\hline CHEMBL500227 & 498611 & 8.0223 & 7.9121 & TRN \\
\hline CHEMBL499507 & 498611 & 8.0655 & 8.5417 & TST \\
\hline CHEMBL525392 & 498611 & 8.2924 & 7.4353 & TRN \\
\hline CHEMBL526154 & 498611 & 7.4634 & 7.1053 & TRN \\
\hline CHEMBL503123 & 498611 & 8.301 & 8.4455 & TRN \\
\hline CHEMBL524471 & 498611 & 7.9586 & 7.6425 & TRN \\
\hline CHEMBL525091 & 498611 & 8.007 & 7.7392 & TRN \\
\hline CHEMBL506840 & 498611 & 6.0 & 8.4669 & TST \\
\hline CHEMBL498948 & 498611 & 8.1249 & 8.1 & TST \\
\hline CHEMBL525089 & 498611 & 5.5017 & 6.1147 & TRN \\
\hline CHEMBL525613 & 498611 & 8.1871 & 8.3867 & TRN \\
\hline CHEMBL525453 & 498611 & 5.7122 & 6.5976 & TST \\
\hline CHEMBL505046 & 498611 & 8.0862 & 8.0029 & TRN \\
\hline CHEMBL501257 & 498611 & 6.0872 & 6.6327 & TRN \\
\hline CHEMBL500280 & 498611 & 8.1024 & 7.7392 & TRN \\
\hline CHEMBL524319 & 498611 & 7.0132 & 7.2718 & TRN \\
\hline CHEMBL500706 & 498611 & 6.2204 & 6.7466 & TRN \\
\hline CHEMBL526116 & 498611 & 6.5114 & 7.0328 & TRN \\
\hline CHEMBL525796 & 498611 & 5.5867 & 5.7351 & TST \\
\hline CHEMBL95897 & 566530 & 4.9586 & 5.1495 & TRN \\
\hline CHEMBL515419 & 566530 & 6.1805 & 6.4135 & TST \\
\hline CHEMBL503566 & 566530 & 3.0 & 4.61600 & 30000000005 \\
\hline CHEMBL62835 & 566530 & 4.9586 & 5.1548 & TST \\
\hline CHEMBL445974 & 566530 & 5.4089 & 5.0259 & TRN \\
\hline CHEMBL466850 & 566530 & 3.0 & 3.306 & TRN \\
\hline CHEMBL466044 & 566530 & 4.7959 & 5.1805 & TRN \\
\hline CHEMBL510907 & 566530 & 5.0706 & 5.0607 & TRN \\
\hline CHEMBL506888 & 566530 & 6.1367 & 6.2179 & TRN \\
\hline CHEMBL474396 & 566530 & 3.0 & 5.7603 & TST \\
\hline CHEMBL504495 & 566530 & 5.5086 & 4.8896 & TRN \\
\hline CHEMBL475030 & 566530 & 3.0 & 3.3461 & TRN \\
\hline CHEMBL475023 & 566530 & 5.0177 & 5.68 & TRN \\
\hline CHEMBL505633 & 566530 & 5.3979 & 5.6936 & TRN \\
\hline CHEMBL183 & 566530 & 6.8861 & 6.3441 & TST \\
\hline CHEMBL474058 & 566530 & 6.2076 & 6.1667 & TRN \\
\hline CHEMBL510288 & 566530 & 6.9208 & 6.6084 & TRN \\
\hline CHEMBL304009 & 566530 & 5.6576 & 5.5831 & TRN \\
\hline CHEMBL67199 & 566530 & 5.3872 & 5.6264 & TRN \\
\hline CHEMBL503376 & 566530 & 5.3098 & 5.5676 & TRN \\
\hline CHEMBL474623 & 566530 & 3.0 & 3.0721 & TRN \\
\hline CHEMBL447623 & 566530 & 3.0 & 3.3908 & TRN \\
\hline CHEMBL151071 & 566530 & 5.2147 & 5.6861 & TRN \\
\hline CHEMBL451363 & 566530 & 4.5229 & 3.6383 & TRN \\
\hline CHEMBL475456 & 566530 & 3.0 & 3.0815 & TRN \\
\hline CHEMBL445696 & 566530 & 5.0177 & 4.8815 & TRN \\
\hline
\end{tabular}




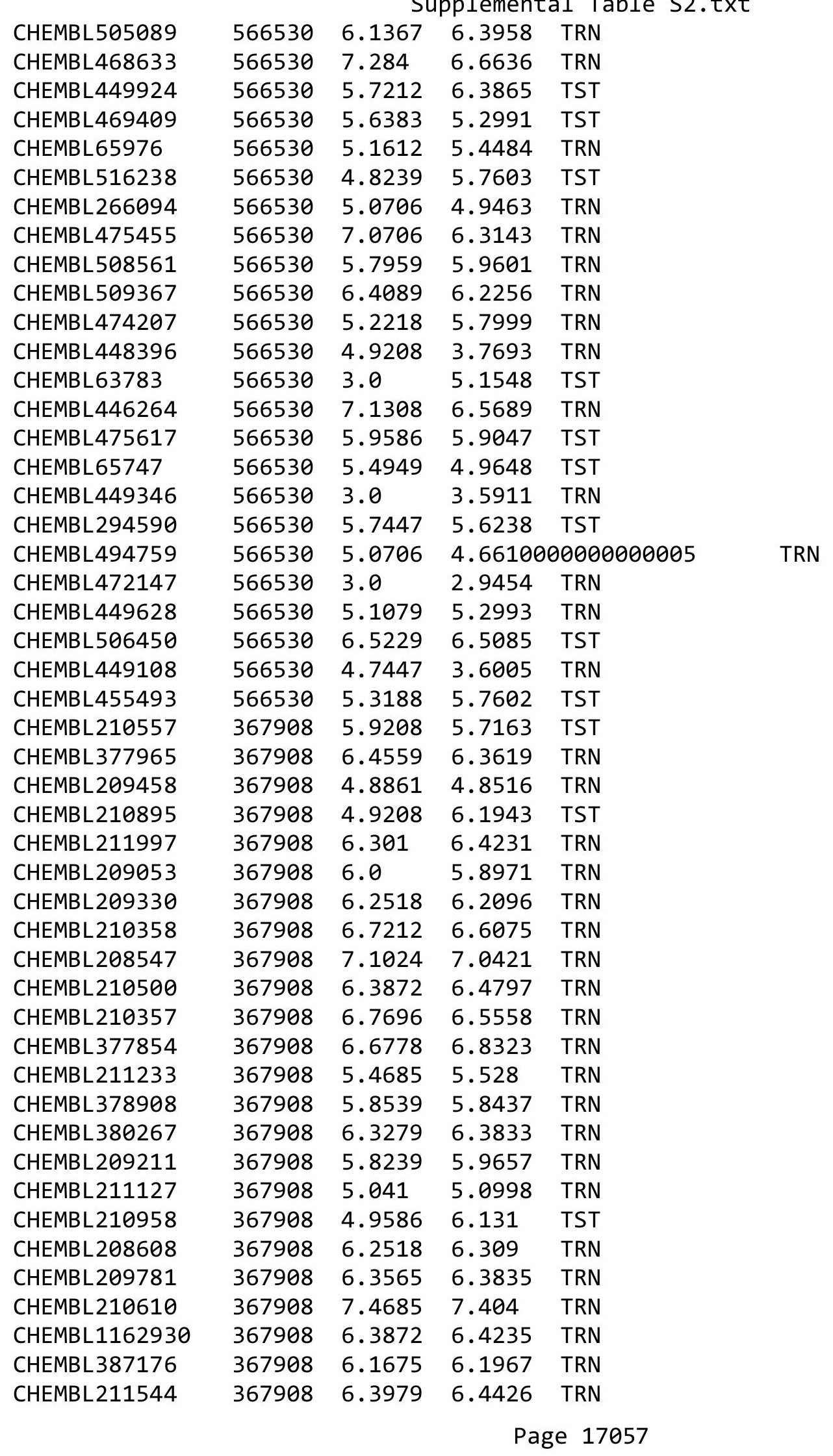


Supplemental Table S2.txt

\begin{tabular}{|c|c|c|c|c|c|}
\hline CHEMBL378561 & 367908 & 5.6021 & 5.8435 & TST & \\
\hline CHEMBL384911 & 367908 & 4.6383 & 4.6259 & TRN & \\
\hline CHEMBL209371 & 367908 & 6.5086 & 6.5549 & TRN & \\
\hline CHEMBL211859 & 367908 & 5.7212 & 5.7382 & TRN & \\
\hline CHEMBL 377888 & 367908 & 5.1367 & 6.0022 & TST & \\
\hline CHEMBL211271 & 367908 & 6.9208 & 6.9201 & TRN & \\
\hline CHEMBL380394 & 367908 & 5.3768 & 5.7259 & TST & \\
\hline CHEMBL212326 & 367908 & 5.6383 & 5.5814 & TRN & \\
\hline CHEMBL 212380 & 367908 & 4.585 & 4.5766 & TRN & \\
\hline CHEMBL426324 & 367908 & 6.0 & 6.114 & TRN & \\
\hline CHEMBL210559 & 367908 & 6.6778 & 6.5757 & TRN & \\
\hline CHEMBL211711 & 367908 & 6.2596 & 6.1421 & TST & \\
\hline CHEMBL209277 & 367908 & 5.7959 & 5.8873 & TST & \\
\hline CHEMBL 209012 & 367908 & 6.5528 & 6.5509 & TRN & \\
\hline CHEMBL 212745 & 367908 & 6.2924 & 6.4901 & TST & \\
\hline CHEMBL212257 & 367908 & 6.4437 & 6.4381 & TRN & \\
\hline CHEMBL211070 & 367908 & 6.7959 & 6.8985 & TRN & \\
\hline CHEMBL 211548 & 367908 & 6.7696 & 6.7333 & TRN & \\
\hline CHEMBL211277 & 367908 & 6.3098 & 6.2742 & TRN & \\
\hline CHEMBL210499 & 367908 & 6.699 & 6.7223 & TRN & \\
\hline CHEMBL378724 & 367908 & 6.1024 & 5.9384 & TST & \\
\hline CHEMBL 209721 & 367908 & 6.3872 & 6.50899 & 99999999995 & TRN \\
\hline CHEMBL438433 & 367908 & 6.7447 & 6.6796 & TRN & \\
\hline CHEMBL379170 & 367908 & 6.1675 & 6.0353 & TRN & \\
\hline CHEMBL377409 & 367908 & 6.3872 & 6.4043 & TRN & \\
\hline CHEMBL 377445 & 367908 & 4.4318 & 4.4572 & TRN & \\
\hline CHEMBL380194 & 367908 & 6.585 & 6.1101 & TST & \\
\hline CHEMBL209206 & 367908 & 5.4815 & 5.6404 & TST & \\
\hline CHEMBL211660 & 367908 & 5.9208 & 5.7807 & TST & \\
\hline CHEMBL 377912 & 367908 & 6.5686 & 6.4539 & TRN & \\
\hline CHEMBL208913 & 367908 & 5.2441 & 6.1928 & TST & \\
\hline CHEMBL 210342 & 367908 & 4.1805 & 4.1166 & TRN & \\
\hline CHEMBL377526 & 367908 & 6.3098 & 6.1852 & TRN & \\
\hline CHEMBL 377424 & 367908 & 7.5229 & 6.6126 & TST & \\
\hline CHEMBL1184942 & 367908 & 6.3098 & 6.2511 & TRN & \\
\hline CHEMBL378927 & 367908 & 3.0 & 5.8255 & TST & \\
\hline CHEMBL 209722 & 367908 & 6.3098 & 6.2675 & TRN & \\
\hline CHEMBL379479 & 367908 & 5.8539 & 5.7864 & TRN & \\
\hline CHEMBL209942 & 367908 & 6.1079 & 6.2209 & TRN & \\
\hline CHEMBL 377804 & 367908 & 5.0862 & 5.178 & TRN & \\
\hline CHEMBL208946 & 367908 & 6.3872 & 6.4098 & TRN & \\
\hline CHEMBL379518 & 367908 & 5.9208 & 5.89 & TRN & \\
\hline CHEMBL211155 & 367908 & 5.8539 & 5.7789 & TRN & \\
\hline CHEMBL212461 & 367908 & 6.1487 & 6.0892 & TRN & \\
\hline CHEMBL 377555 & 367908 & 6.7212 & 6.7403 & TRN & \\
\hline CHEMBL378993 & 367908 & 6.6198 & 6.7235 & TRN & \\
\hline CHEMBL 212407 & 367908 & 5.4437 & 5.5769 & TST & \\
\hline CHEMBL211607 & 367908 & 6.3188 & 6.2426 & TRN & \\
\hline
\end{tabular}

Page 17058 


\begin{tabular}{|c|c|c|c|c|}
\hline & & & pplement & al $\mathrm{Ta}$ \\
\hline CHEMBL377128 & 367908 & 6.0 & 6.0247 & TRN \\
\hline CHEMBL209207 & 367908 & 6.4685 & 6.482 & TRN \\
\hline CHEMBL211121 & 367908 & 6.6383 & 6.6332 & TST \\
\hline CHEMBL 211148 & 367908 & 6.7212 & 6.8244 & TRN \\
\hline CHEMBL 378982 & 367908 & 6.6778 & 6.7519 & TRN \\
\hline CHEMBL376940 & 367908 & 6.9208 & 6.9321 & TRN \\
\hline CHEMBL 210892 & 367908 & 6.0706 & 5.9588 & TRN \\
\hline CHEMBL211019 & 367908 & 6.3098 & 6.2599 & TST \\
\hline CHEMBL211763 & 367908 & 5.6778 & 5.7377 & TRN \\
\hline CHEMBL376985 & 367908 & 5.7696 & 5.7515 & TRN \\
\hline CHEMBL209686 & 367908 & 6.3565 & 6.3306 & TRN \\
\hline CHEMBL 211435 & 367908 & 6.8239 & 6.7479 & TRN \\
\hline CHEMBL 377964 & 367908 & 5.1135 & 5.0194 & TRN \\
\hline CHEMBL 379782 & 367908 & 6.2441 & 6.5446 & TST \\
\hline CHEMBL208947 & 367908 & 5.5229 & 5.6813 & TRN \\
\hline CHEMBL 212733 & 367908 & 5.2291 & 5.4169 & TRN \\
\hline CHEMBL380218 & 367908 & 6.2007 & 6.1622 & TRN \\
\hline CHEMBL209926 & 367908 & 5.4949 & 5.54 & TRN \\
\hline CHEMBL211687 & 367908 & 6.2518 & 6.2434 & TRN \\
\hline CHEMBL 210085 & 367908 & 6.8239 & 7.0355 & TST \\
\hline CHEMBL 212362 & 367908 & 6.2518 & 6.4724 & TST \\
\hline CHEMBL211788 & 367908 & 4.9586 & 4.9819 & TRN \\
\hline CHEMBL 209074 & 367908 & 6.7212 & 6.6791 & TRN \\
\hline CHEMBL 378631 & 367908 & 6.7212 & 6.0457 & TST \\
\hline CHEMBL1162929 & 367908 & 7.0757 & 6.8913 & TST \\
\hline CHEMBL 211080 & 367908 & 6.0223 & 6.0057 & TRN \\
\hline CHEMBL 209368 & 367908 & 5.5229 & 5.4695 & TRN \\
\hline CHEMBL209264 & 367908 & 5.9208 & 5.9458 & TRN \\
\hline CHEMBL379841 & 367908 & 6.3468 & 5.0057 & TST \\
\hline CHEMBL 377811 & 367908 & 6.3768 & 6.3234 & TRN \\
\hline CHEMBL 211453 & 367908 & 6.3372 & 5.3125 & TST \\
\hline CHEMBL209619 & 367908 & 6.0458 & 6.0677 & TRN \\
\hline CHEMBL 252965 & 459968 & 4.1612 & 4.3546 & TRN \\
\hline CHEMBL 254240 & 459968 & 4.6576 & 4.3918 & TRN \\
\hline CHEMBL249863 & 459968 & 2.8239 & 2.6195 & TRN \\
\hline CHEMBL254627 & 459968 & 4.4318 & 4.2631 & TRN \\
\hline CHEMBL249862 & 459968 & 2.8239 & 2.6411 & TRN \\
\hline CHEMBL400449 & 459968 & 3.9431 & 3.8675 & TRN \\
\hline CHEMBL 254821 & 459968 & 4.3372 & 4.1307 & TST \\
\hline CHEMBL400851 & 459968 & 2.8239 & 2.6195 & TRN \\
\hline CHEMBL398892 & 459968 & 4.5528 & 4.5167 & TRN \\
\hline CHEMBL255051 & 459968 & 4.3279 & 4.3515 & TRN \\
\hline CHEMBL 251424 & 459968 & 4.0044 & 3.7192 & TRN \\
\hline CHEMBL251426 & 459968 & 4.1249 & 3.9241 & TRN \\
\hline CHEMBL 254448 & 459968 & 4.0915 & 4.2813 & TRN \\
\hline CHEMBL250059 & 459968 & 3.9066 & 3.8461 & TRN \\
\hline CHEMBL 398662 & 459968 & 2.8239 & 3.6627 & TRN \\
\hline CHEMBL399998 & 459968 & 2.8239 & 3.3162 & TST \\
\hline
\end{tabular}




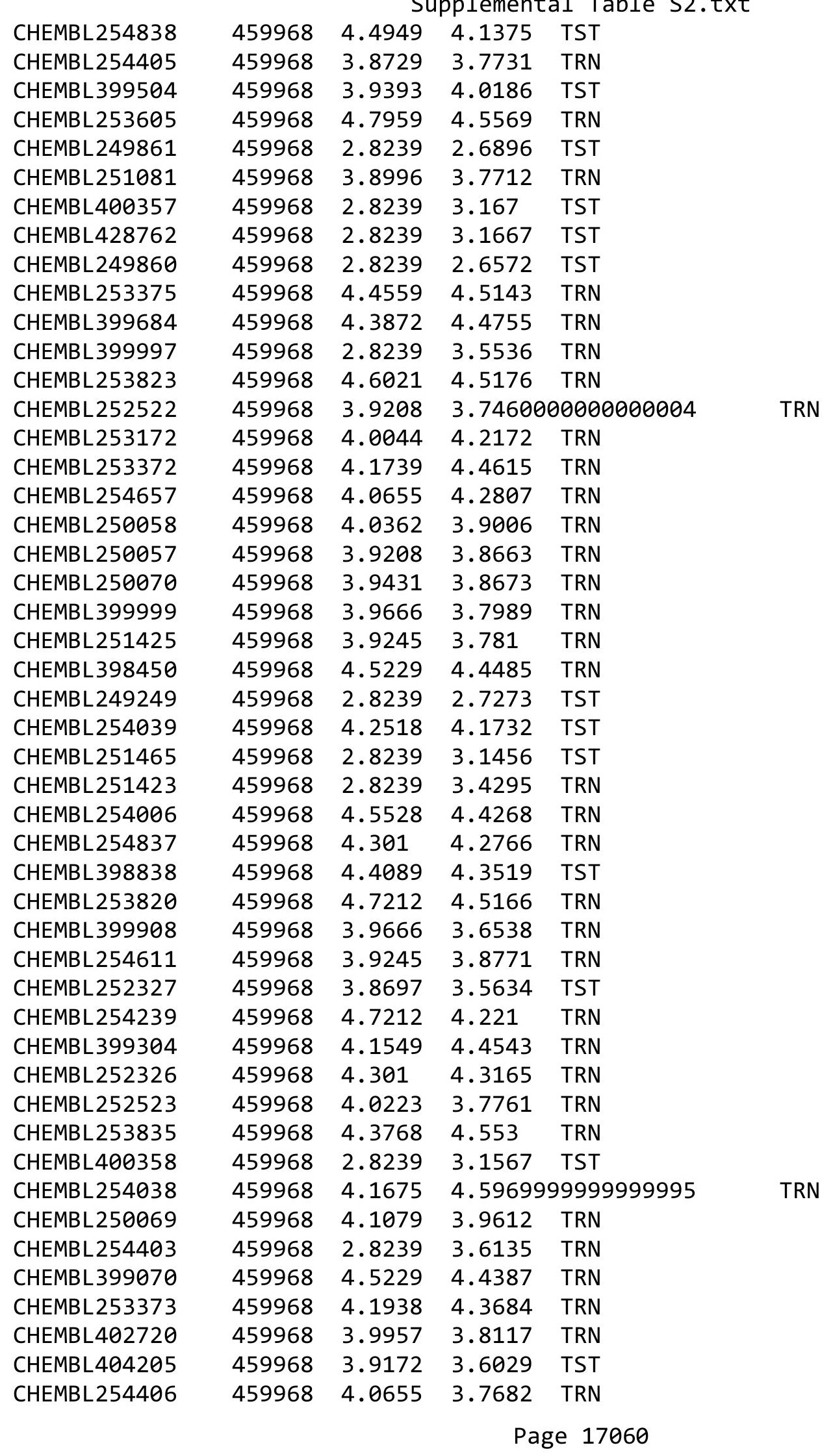


Supplemental Table S2.txt

\begin{tabular}{|c|c|c|c|c|}
\hline CHEMBL254238 & 459968 & 4.585 & 4.3867 & TRN \\
\hline CHEMBL253189 & 459968 & 3.8928 & 3.9867 & TRN \\
\hline CHEMBL249859 & 459968 & 3.9393 & 3.7174 & TRN \\
\hline CHEMBL251937 & 459968 & 4.6021 & 4.151 & TST \\
\hline CHEMBL254404 & 459968 & 2.8239 & 3.4767 & TRN \\
\hline CHEMBL253188 & 459968 & 4.1249 & 4.2631 & TST \\
\hline CHEMBL400850 & 459968 & 2.8239 & 2.6896 & TST \\
\hline CHEMBL438519 & 459968 & 4.2291 & 4.4369 & TRN \\
\hline CHEMBL253801 & 459968 & 4.1871 & 4.0879 & TRN \\
\hline CHEMBL442286 & 459968 & 3.9914 & 3.5935 & TST \\
\hline CHEMBL445939 & 459968 & 4.5086 & 4.2 & TST \\
\hline CHEMBL399685 & 459968 & 4.2924 & 4.3077 & TRN \\
\hline CHEMBL254610 & 459968 & 3.8601 & 3.8787 & TRN \\
\hline CHEMBL1162966 & 459968 & 4.6198 & 4.2465 & TRN \\
\hline CHEMBL253374 & 459968 & 4.6383 & 4.4511 & TRN \\
\hline CHEMBL1488085 & 954311 & 3.284 & 4.3468 & TRN \\
\hline CHEMBL 2356799 & 954311 & 3.284 & 3.5393 & TRN \\
\hline CHEMBL 2359801 & 954311 & 4.6444 & 5.1016 & TRN \\
\hline CHEMBL 2358960 & 954311 & 3.284 & 4.6461 & TRN \\
\hline CHEMBL2356982 & 954311 & 3.284 & 3.7611 & TRN \\
\hline CHEMBL 2355694 & 954311 & 4.8851 & 4.6751 & TRN \\
\hline CHEMBL 2361456 & 954311 & 4.3478 & 3.9106 & TRN \\
\hline CHEMBL 2359003 & 954311 & 4.4638 & 4.5649 & TRN \\
\hline CHEMBL 2361317 & 954311 & 4.6668 & 4.1958 & TRN \\
\hline CHEMBL1351525 & 954311 & 4.3147 & 3.3468 & TST \\
\hline CHEMBL1409219 & 954311 & 5.0762 & 3.8661 & TRN \\
\hline CHEMBL 2360173 & 954311 & 4.702 & 4.0299 & TRN \\
\hline CHEMBL1364899 & 954311 & 3.284 & 3.3281 & TRN \\
\hline CHEMBL1575537 & 954311 & 4.9311 & 4.3339 & TST \\
\hline CHEMBL 2362946 & 954311 & 3.284 & 3.4842 & TRN \\
\hline CHEMBL 2358344 & 954311 & 4.5456 & 4.1549 & TRN \\
\hline CHEMBL 2357894 & 954311 & 3.284 & 4.008999 & 99999999995 \\
\hline CHEMBL 2357633 & 954311 & 3.284 & 3.6967 & TRN \\
\hline CHEMBL 2362456 & 954311 & 3.3279 & 4.2844 & TRN \\
\hline CHEMBL 2355452 & 954311 & 5.3904 & 4.45 & TRN \\
\hline CHEMBL1353274 & 954311 & 3.284 & 4.1296 & TST \\
\hline CHEMBL1312088 & 954311 & 4.6453 & 3.9206 & TRN \\
\hline CHEMBL 2355598 & 954311 & 3.284 & 3.347 & TRN \\
\hline CHEMBL1522762 & 954311 & 3.284 & 3.5264 & TST \\
\hline CHEMBL1721546 & 954311 & 3.284 & 4.07 & TRN \\
\hline CHEMBL2360927 & 954311 & 4.3593 & 4.3013 & TRN \\
\hline CHEMBL1482840 & 954311 & 4.7703 & 4.51 & TST \\
\hline CHEMBL 2355897 & 954311 & 3.284 & 4.3964 & TRN \\
\hline CHEMBL1519302 & 954311 & 3.284 & 3.819 & TST \\
\hline CHEMBL 2361950 & 954311 & 3.3279 & 3.7691 & TRN \\
\hline CHEMBL2357682 & 954311 & 5.0044 & 4.6179 & TRN \\
\hline CHEMBL1305605 & 954311 & 3.284 & 2.7051 & TRN \\
\hline CHEMBL 2357287 & 954311 & 4.4907 & 4.1321 & TRN \\
\hline
\end{tabular}

Page 17061 


\begin{tabular}{|c|c|c|c|c|}
\hline \multicolumn{5}{|c|}{ Supplemental Table S2.txt } \\
\hline CHEMBL 2359833 & 954311 & 5.9355 & 4.4679 & TRN \\
\hline CHEMBL 2355140 & 954311 & 6.5784 & 5.0668 & TRN \\
\hline CHEMBL453207 & 954311 & 7.71 & 4.4439 & TST \\
\hline CHEMBL1322679 & 954311 & 3.284 & 3.1502 & TRN \\
\hline CHEMBL 2358333 & 954311 & 4.3708 & 4.7702 & TRN \\
\hline CHEMBL 2356202 & 954311 & 3.284 & 4.6353 & TRN \\
\hline CHEMBL 2354758 & 954311 & 4.3575 & 3.9844 & TRN \\
\hline CHEMBL1326919 & 954311 & 3.284 & 3.6571 & TRN \\
\hline CHEMBL1392483 & 954311 & 3.284 & 2.965 & TST \\
\hline CHEMBL1357005 & 954311 & 3.284 & 3.428 & TRN \\
\hline CHEMBL 2361657 & 954311 & 3.284 & 3.9791 & TRN \\
\hline CHEMBL3193305 & 954311 & 4.7555 & 4.2497 & TST \\
\hline CHEMBL2361534 & 954311 & 4.5555 & 4.0436 & TRN \\
\hline CHEMBL 2356351 & 954311 & 7.71 & 5.4563 & TRN \\
\hline CHEMBL 2356433 & 954311 & 4.7091 & 4.8262 & TRN \\
\hline CHEMBL 2356360 & 954311 & 3.284 & 3.6178 & TRN \\
\hline CHEMBL1331798 & 954311 & 4.5242 & 3.9523 & TRN \\
\hline CHEMBL 2357707 & 954311 & 3.284 & 4.3639 & TRN \\
\hline CHEMBL1418646 & 954311 & 3.284 & 3.4351 & TRN \\
\hline CHEMBL1879313 & 954311 & 3.284 & 3.9127 & TST \\
\hline CHEMBL 2360919 & 954311 & 3.284 & 4.0162 & TRN \\
\hline CHEMBL 2357001 & 954311 & 3.284 & 3.5313 & TRN \\
\hline CHEMBL1327412 & 954311 & 4.4209 & 3.7112 & TRN \\
\hline CHEMBL 2361662 & 954311 & 3.284 & 3.2652 & TRN \\
\hline CHEMBL1315275 & 954311 & 3.284 & 3.1811 & TRN \\
\hline CHEMBL1471585 & 954311 & 3.284 & 3.0881 & TRN \\
\hline CHEMBL 2360952 & 954311 & 4.8333 & 4.1499 & TRN \\
\hline CHEMBL 2355230 & 954311 & 4.6929 & 3.9996 & TRN \\
\hline CHEMBL 2359303 & 954311 & 4.4598 & 4.5882 & TRN \\
\hline CHEMBL 2356039 & 954311 & 3.1549 & 3.1708 & TST \\
\hline CHEMBL1534040 & 954311 & 3.284 & 3.5761 & TST \\
\hline CHEMBL 2360186 & 954311 & 4.6761 & 4.6637 & TRN \\
\hline CHEMBL 2359950 & 954311 & 4.5935 & 4.9714 & TRN \\
\hline CHEMBL 2354721 & 954311 & 3.2218 & 3.9416 & TRN \\
\hline CHEMBL 2362108 & 954311 & 3.284 & 3.6897 & TRN \\
\hline CHEMBL 2357706 & 954311 & 3.3279 & 3.8697 & TRN \\
\hline CHEMBL 3184262 & 954311 & 4.6938 & 4.6301 & TRN \\
\hline CHEMBL1889396 & 954311 & 3.284 & 4.395 & TRN \\
\hline CHEMBL 2356472 & 954311 & 4.9901 & 3.7783 & TRN \\
\hline CHEMBL 2356827 & 954311 & 4.5865 & 4.5783 & TRN \\
\hline CHEMBL 2361933 & 954311 & 3.284 & 3.5975 & TRN \\
\hline CHEMBL1592834 & 954311 & 3.284 & 3.3122 & TST \\
\hline CHEMBL582983 & 954311 & 4.8389 & 4.1798 & TST \\
\hline CHEMBL 2136720 & 954311 & 3.284 & 2.9992 & TRN \\
\hline CHEMBL 2356243 & 954311 & 4.2868 & 4.4226 & TRN \\
\hline CHEMBL 2357343 & 954311 & 4.4219 & 4.7585 & TRN \\
\hline CHEMBL 2355762 & 954311 & 3.284 & 3.6022 & TRN \\
\hline CHEMBL1331961 & 954311 & 3.284 & 3.3744 & TRN \\
\hline
\end{tabular}


Supplemental Table S2.txt

\begin{tabular}{|c|c|c|c|c|}
\hline CHEMBL 2360877 & 954311 & 4.4187 & 3.3928 & TRN \\
\hline CHEMBL 2354566 & 954311 & 3.3279 & 3.0409 & TRN \\
\hline CHEMBL2354798 & 954311 & 4.4109 & 4.1658 & TST \\
\hline CHEMBL 2357995 & 954311 & 4.3397 & 4.2595 & TST \\
\hline CHEMBL 2355642 & 954311 & 3.284 & 3.4328 & TST \\
\hline CHEMBL 2360549 & 954311 & 3.284 & 4.1677 & TST \\
\hline CHEMBL 2361965 & 954311 & 4.5646 & 4.2799 & TST \\
\hline CHEMBL 2360648 & 954311 & 4.6302 & 4.3596 & TST \\
\hline CHEMBL 2357913 & 954311 & 4.5491 & 3.7623 & TST \\
\hline CHEMBL 2145398 & 954311 & 3.284 & 4.0067 & TST \\
\hline CHEMBL1527601 & 954311 & 3.284 & \multicolumn{2}{|c|}{ 3.8289999999999997 } \\
\hline CHEMBL 2134355 & 954311 & 4.6964 & 4.3315 & TST \\
\hline CHEMBL138676 & 149253 & 4.4089 & 4.2869 & TRN \\
\hline CHEMBL139460 & 149253 & 4.5768 & 4.9754 & TST \\
\hline CHEMBL136422 & 149253 & 4.6021 & 4.5874 & TRN \\
\hline CHEMBL139805 & 149253 & 4.3665 & 4.1257 & TRN \\
\hline CHEMBL138662 & 149253 & 3.466 & 4.2135 & TRN \\
\hline CHEMBL137817 & 149253 & 5.3188 & 4.1345 & TST \\
\hline CHEMBL 8015 & 149253 & 4.5171 & 5.1706 & TRN \\
\hline CHEMBL 33298 & 149253 & 4.8013 & 4.739 & TRN \\
\hline CHEMBL336255 & 149253 & 4.6126 & 4.6932 & TRN \\
\hline CHEMBL140405 & 149253 & 4.5229 & 4.3176 & TRN \\
\hline CHEMBL139973 & 149253 & 4.4815 & 4.2504 & TRN \\
\hline CHEMBL7531 & 149253 & 4.4202 & 4.6886 & TRN \\
\hline CHEMBL137915 & 149253 & 3.5265 & 4.0666 & TRN \\
\hline CHEMBL33458 & 149253 & 4.3665 & 4.2583 & TRN \\
\hline CHEMBL141111 & 149253 & 4.6478 & 4.7581 & TRN \\
\hline CHEMBL342230 & 149253 & 4.6799 & 4.6679 & TST \\
\hline CHEMBL138650 & 149253 & 4.5719 & 4.4591 & TRN \\
\hline CHEMBL337311 & 149253 & 4.8416 & 4.4721 & TRN \\
\hline CHEMBL269163 & 149253 & 4.2097 & 4.4309 & TRN \\
\hline CHEMBL337821 & 149253 & 5.1549 & 4.4355 & TRN \\
\hline CHEMBL136174 & 149253 & 4.5513 & 4.4196 & TRN \\
\hline CHEMBL139035 & 149253 & 4.7055 & 4.2178 & TST \\
\hline CHEMBL140430 & 149253 & 3.9151 & 4.3655 & TRN \\
\hline CHEMBL140028 & 149253 & 4.6038 & 4.1695 & TST \\
\hline CHEMBL140412 & 149253 & 4.7878 & 4.3804 & TST \\
\hline CHEMBL139118 & 149253 & 4.5918 & 4.8016 & TRN \\
\hline CHEMBL140711 & 149253 & 4.1549 & 4.3653 & TRN \\
\hline CHEMBL7721 & 149253 & 4.7352 & 4.4882 & TRN \\
\hline CHEMBL137883 & 149253 & 5.2076 & 4.3063 & TRN \\
\hline CHEMBL137166 & 149253 & 4.5884 & 4.5288 & TRN \\
\hline CHEMBL137882 & 149253 & 4.8386 & 4.6438 & TRN \\
\hline CHEMBL141749 & 149253 & 4.7959 & 4.6038 & TST \\
\hline CHEMBL7709 & 149253 & 4.4802 & 4.5448 & TRN \\
\hline CHEMBL136175 & 149253 & 4.7825 & 4.4138 & TRN \\
\hline CHEMBL139446 & 149253 & 4.5817 & 4.7206 & TRN \\
\hline CHEMBL139622 & 149253 & 4.0278 & 4.1706 & TRN \\
\hline
\end{tabular}




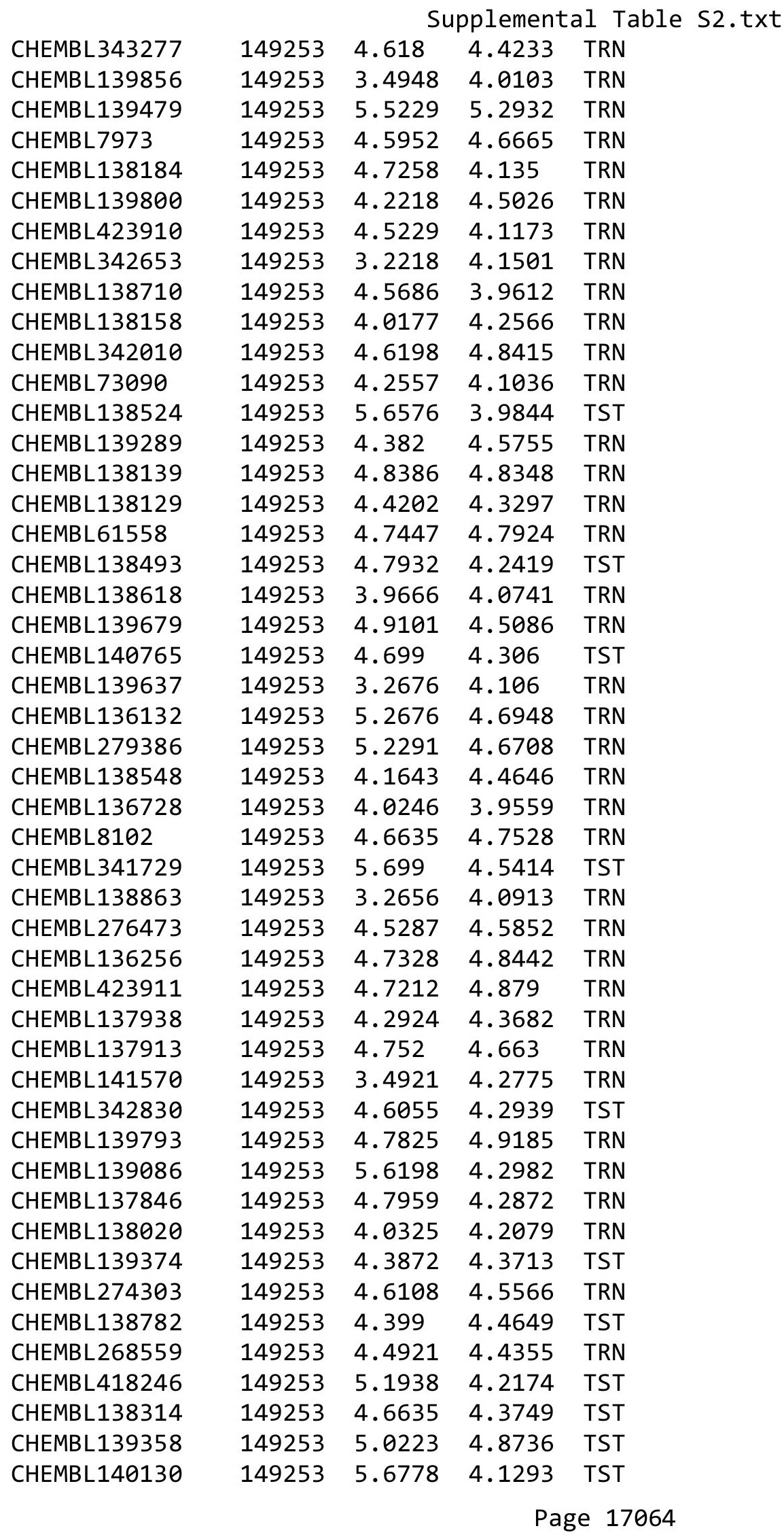




\begin{tabular}{|c|c|c|c|c|c|c|}
\hline & & \multicolumn{5}{|c|}{ Supplemental Table S2.txt } \\
\hline CHEMBL266780 & 149253 & 4.6904 & 4.6016 & TST & & \\
\hline CHEMBL337812 & 149253 & 4.0 & 4.1578 & TST & & \\
\hline CHEMBL137916 & 149253 & 4.5607 & 4.4336 & TST & & \\
\hline CHEMBL138506 & 149253 & 4.2487 & 4.1611 & TST & & \\
\hline CHEMBL221137 & 954464 & \multicolumn{3}{|c|}{5.4110000000000005} & 4.9536 & TST \\
\hline CHEMBL509032 & 954464 & 5.3041 & 4.4998 & TRN & & \\
\hline CHEMBL217354 & 954464 & 6.7641 & 5.9575 & TRN & & \\
\hline CHEMBL3392440 & 954464 & 3.1951 & 3.9168 & TRN & & \\
\hline CHEMBL379300 & 954464 & 3.8744 & 4.5378 & TRN & & \\
\hline CHEMBL202721 & 954464 & 5.4835 & 4.989 & TRN & & \\
\hline CHEMBL 2363137 & 954464 & 4.8344 & 4.9202 & TRN & & \\
\hline CHEMBL1643959 & 954464 & 2.7534 & 2.8585 & TRN & & \\
\hline CHEMBL 213100 & 954464 & 3.0757 & 2.8947 & TRN & & \\
\hline CHEMBL373751 & 954464 & 3.335 & 3.3415 & TRN & & \\
\hline CHEMBL 2137530 & 954464 & 3.8946 & 4.7677 & TRN & & \\
\hline CHEMBL3349342 & 954464 & 5.9196 & 4.9343 & TRN & & \\
\hline CHEMBL1673039 & 954464 & 3.4687 & 3.485 & TRN & & \\
\hline CHEMBL255342 & 954464 & 3.58 & 3.8626 & TRN & & \\
\hline CHEMBL449158 & 954464 & 6.1587 & 7.1306 & TST & & \\
\hline CHEMBL558642 & 954464 & 4.9094 & 3.7145 & TRN & & \\
\hline CHEMBL220241 & 954464 & 3.3432 & 4.1137 & TRN & & \\
\hline CHEMBL209148 & 954464 & 4.3543 & 3.7977 & TRN & & \\
\hline CHEMBL3199475 & 954464 & 6.0059 & 5.3999 & TRN & & \\
\hline CHEMBL483847 & 954464 & 3.6436 & 3.8047 & TRN & & \\
\hline CHEMBL512504 & 954464 & 7.4331 & 6.6208 & TRN & & \\
\hline CHEMBL1590308 & 954464 & 2.7286 & 2.7565 & TST & & \\
\hline CHEMBL379975 & 954464 & 5.2698 & 5.3278 & TRN & & \\
\hline CHEMBL180127 & 954464 & 2.5625 & 2.7672 & TRN & & \\
\hline CHEMBL393929 & 954464 & 3.3607 & 3.7395 & TRN & & \\
\hline CHEMBL1516890 & 954464 & 3.8336 & 4.0702 & TRN & & \\
\hline CHEMBL1357247 & 954464 & 3.5106 & 3.2705 & TRN & & \\
\hline CHEMBL1190711 & 954464 & 5.6044 & 5.6611 & TRN & & \\
\hline CHEMBL1788116 & 954464 & 3.5941 & 4.0857 & TRN & & \\
\hline CHEMBL1242367 & 954464 & 2.9739 & 3.3905 & TRN & & \\
\hline CHEMBL300389 & 954464 & 5.0741 & 5.3058 & TRN & & \\
\hline CHEMBL240954 & 954464 & 3.7177 & 3.8597 & TST & & \\
\hline CHEMBL191334 & 954464 & 5.3958 & 5.2302 & TRN & & \\
\hline CHEMBL258844 & 954464 & 6.2156 & 4.6122 & TRN & & \\
\hline CHEMBL585951 & 954464 & 6.3327 & 6.6449 & TRN & & \\
\hline CHEMBL210618 & 954464 & 3.1127 & 3.5474 & TRN & & \\
\hline CHEMBL222102 & 954464 & 4.0888 & 3.9972 & TRN & & \\
\hline CHEMBL65 & 954464 & 8.421 & 9.1572 & TRN & & \\
\hline CHEMBL135561 & 954464 & 4.5815 & 4.3754 & TRN & & \\
\hline CHEMBL3186408 & 954464 & 3.7373 & 3.6772 & TST & & \\
\hline CHEMBL1230020 & 954464 & 3.0081 & 3.8887 & TRN & & \\
\hline CHEMBL392695 & 954464 & 3.302 & 2.9611 & TRN & & \\
\hline CHEMBL188678 & 954464 & 3.9826 & 4.9167 & TRN & & \\
\hline CHEMBL514499 & 954464 & 4.694 & 3.9382 & TRN & & \\
\hline
\end{tabular}




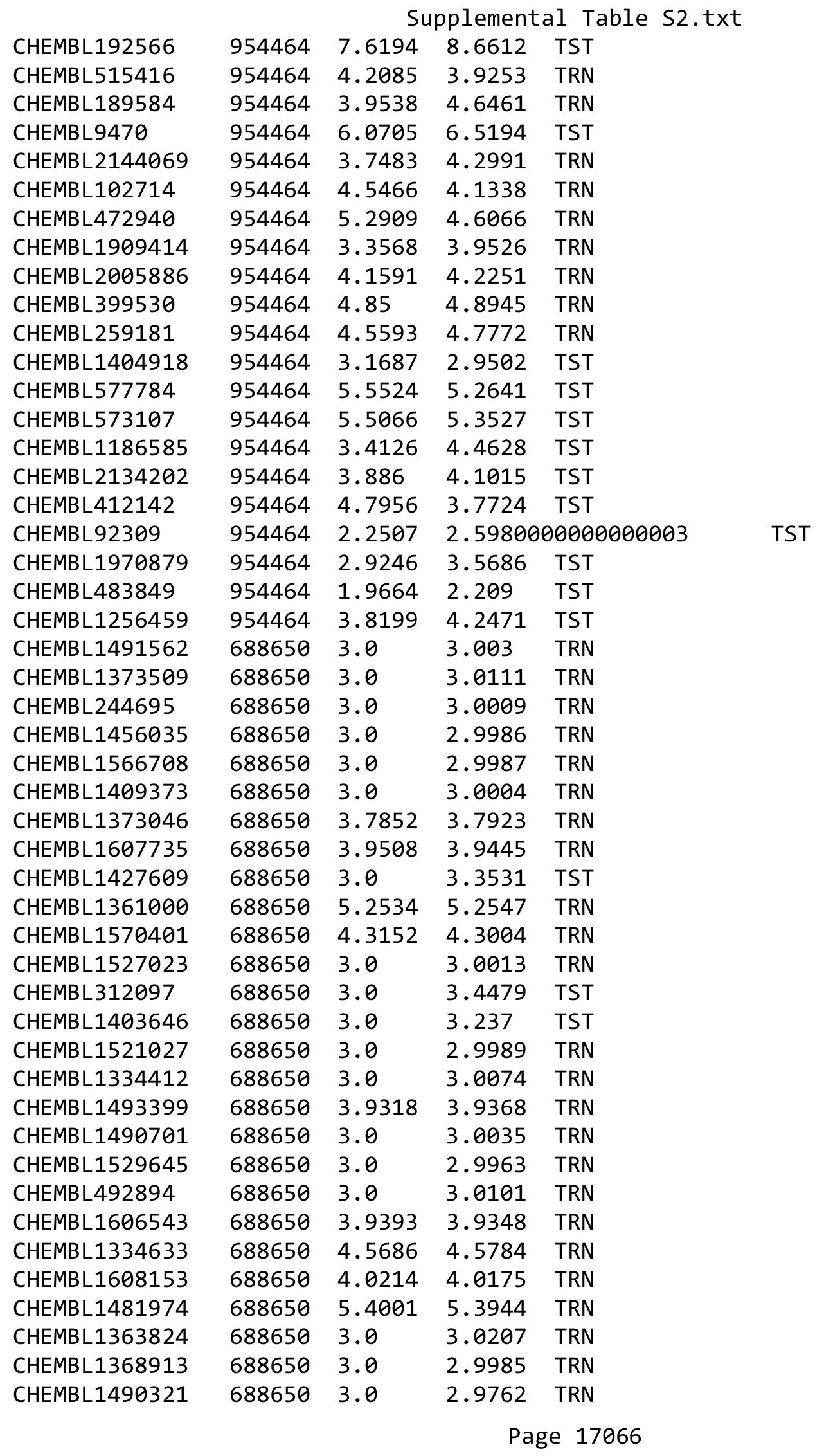




\begin{tabular}{|c|c|c|c|c|c|c|}
\hline & & \multicolumn{5}{|c|}{ Supplemental Table S2.txt } \\
\hline CHEMBL1430473 & 688650 & 3.75699 & 99999999 & 997 & 3.7576 & TRN \\
\hline CHEMBL1486659 & 688650 & 4.3726 & 4.3706 & TRN & & \\
\hline CHEMBL1570659 & 688650 & 3.0 & 2.9987 & TRN & & \\
\hline CHEMBL 271690 & 688650 & 4.0655 & 4.0518 & TRN & & \\
\hline CHEMBL14830 & 688650 & 6.5528 & 3.6997 & TST & & \\
\hline CHEMBL1527520 & 688650 & 4.2076 & 4.2103 & TRN & & \\
\hline CHEMBL1487801 & 688650 & 5.5638 & 5.5707 & TRN & & \\
\hline CHEMBL1447034 & 688650 & 4.6596 & 4.665 & TRN & & \\
\hline CHEMBL1527941 & 688650 & 3.0 & 3.0061 & TRN & & \\
\hline CHEMBL1454310 & 688650 & 3.0 & 3.0098 & TRN & & \\
\hline CHEMBL1403497 & 688650 & 3.0 & 3.4068 & TST & & \\
\hline CHEMBL1554052 & 688650 & 3.0 & 2.9829 & TRN & & \\
\hline CHEMBL1608225 & 688650 & 4.2757 & 4.2717 & TRN & & \\
\hline CHEMBL201289 & 688650 & 3.0 & 2.9881 & TRN & & \\
\hline CHEMBL1333555 & 688650 & 4.6946 & 4.6993 & TRN & & \\
\hline CHEMBL1570803 & 688650 & 3.0 & 4.0363 & TST & & \\
\hline CHEMBL1528814 & 688650 & 4.5986 & 4.0187 & TST & & \\
\hline CHEMBL1322709 & 688650 & 3.0 & 3.8313 & TST & & \\
\hline CHEMBL1376870 & 688650 & 3.0 & 3.2755 & TST & & \\
\hline CHEMBL1272154 & 688650 & 3.0 & 2.9817 & TST & & \\
\hline CHEMBL1336818 & 688650 & 3.0 & 3.2582 & TST & & \\
\hline CHEMBL1451516 & 688650 & 3.0 & 3.6648 & TST & & \\
\hline CHEMBL1363132 & 688650 & 4.8508 & 3.7404 & TST & & \\
\hline CHEMBL 3671221 & 1528698 & 5.7696 & 6.25799 & 9999999999 & & TRN \\
\hline CHEMBL 3671240 & 1528698 & 5.8861 & 6.2179 & TRN & & \\
\hline CHEMBL3671202 & 1528698 & 6.7212 & 6.4351 & TRN & & \\
\hline CHEMBL3671205 & 1528698 & 7.3979 & 6.5153 & TRN & & \\
\hline CHEMBL198654 & 1528698 & 7.1308 & 6.4573 & TRN & & \\
\hline CHEMBL3671239 & 1528698 & 6.2218 & 6.2413 & TRN & & \\
\hline CHEMBL 3671245 & 1528698 & 5.7696 & 6.1427 & TST & & \\
\hline CHEMBL3671199 & 1528698 & 6.9208 & 6.8912 & TRN & & \\
\hline CHEMBL3671214 & 1528698 & 6.9208 & 7.1934 & TRN & & \\
\hline CHEMBL370614 & 1528698 & 8.3768 & 7.5048 & TRN & & \\
\hline CHEMBL196551 & 1528698 & 7.3665 & 6.4716 & TRN & & \\
\hline CHEMBL3671235 & 1528698 & 5.6576 & 6.586 & TRN & & \\
\hline CHEMBL3671233 & 1528698 & 5.9586 & 6.8205 & TRN & & \\
\hline CHEMBL3671237 & 1528698 & 5.699 & 6.1864 & TRN & & \\
\hline CHEMBL3671215 & 1528698 & 7.2076 & 6.9619 & TRN & & \\
\hline CHEMBL3671223 & 1528698 & 6.5686 & 6.3905 & TRN & & \\
\hline CHEMBL3671246 & 1528698 & 6.8539 & 6.8381 & TRN & & \\
\hline CHEMBL 3671228 & 1528698 & 5.8861 & 7.5519 & TST & & \\
\hline CHEMBL3671238 & 1528698 & 5.699 & 6.5221 & TST & & \\
\hline CHEMBL3671213 & 1528698 & 6.0706 & 6.5923 & TRN & & \\
\hline CHEMBL 3671247 & 1528698 & 8.5528 & 8.0776 & TRN & & \\
\hline CHEMBL3671242 & 1528698 & 5.8861 & 6.1729 & TRN & & \\
\hline CHEMBL3671212 & 1528698 & 8.4815 & 8.1461 & TRN & & \\
\hline CHEMBL3671211 & 1528698 & 9.0 & 8.2808 & TRN & & \\
\hline CHEMBL3671248 & 1528698 & 6.4202 & 7.6036 & TRN & & \\
\hline
\end{tabular}

Page 17067 
Supplemental Table S2.txt

\begin{tabular}{|c|c|c|c|c|c|}
\hline CHEMBL3671208 & 1528698 & 7.8861 & 6.9896 & TRN & \\
\hline CHEMBL196589 & 1528698 & 5.8996 & 6.09 & TRN & \\
\hline CHEMBL3671204 & 1528698 & 6.8861 & 7.0287 & TRN & \\
\hline CHEMBL3671216 & 1528698 & 6.3188 & 7.2328 & TRN & \\
\hline CHEMBL3671203 & 1528698 & 6.1308 & 6.4325 & TST & \\
\hline CHEMBL197624 & 1528698 & 6.8539 & 6.3363 & TRN & \\
\hline CHEMBL 3671210 & 1528698 & 8.699 & 8.6075 & TRN & \\
\hline CHEMBL 3671220 & 1528698 & 6.3768 & 6.272 & TRN & \\
\hline CHEMBL3671232 & 1528698 & 7.301 & 6.5997 & TRN & \\
\hline CHEMBL3671200 & 1528698 & 5.9393 & 6.4935 & TST & \\
\hline CHEMBL3671219 & 1528698 & 7.3565 & 7.2673 & TRN & \\
\hline CHEMBL383361 & 1528698 & 6.5229 & 7.7924 & TRN & \\
\hline CHEMBL 3671244 & 1528698 & 6.3372 & 6.2013 & TRN & \\
\hline CHEMBL3671224 & 1528698 & 7.4815 & 6.4921 & TRN & \\
\hline CHEMBL 3671234 & 1528698 & 6.6778 & 6.8235 & TRN & \\
\hline CHEMBL3671225 & 1528698 & 5.699 & 6.3582 & TRN & \\
\hline CHEMBL3671218 & 1528698 & 5.9208 & 6.7926 & TRN & \\
\hline CHEMBL 3671227 & 1528698 & 7.0458 & 6.1195 & TRN & \\
\hline CHEMBL3671201 & 1528698 & 5.9245 & 6.6911 & TST & \\
\hline CHEMBL3671231 & 1528698 & 5.699 & 6.1114 & TRN & \\
\hline CHEMBL3671243 & 1528698 & 6.1367 & 6.2095 & TRN & \\
\hline CHEMBL 3671241 & 1528698 & 5.9208 & 6.22 & TST & \\
\hline CHEMBL3671226 & 1528698 & 6.0757 & 6.6534 & TST & \\
\hline CHEMBL 3671222 & 1528698 & 7.3979 & 6.855 & TST & \\
\hline CHEMBL 3671217 & 1528698 & 5.9586 & 7.1886 & TST & \\
\hline CHEMBL3671209 & 1528698 & 9.1549 & 8.371 & TST & \\
\hline CHEMBL 3671236 & 1528698 & 5.699 & 6.5889 & TST & \\
\hline CHEMBL197377 & 1528698 & 8.3979 & 7.7373 & TST & \\
\hline CHEMBL 3671250 & 1528698 & 6.301 & 6.4962 & TST & \\
\hline CHEMBL1701301 & 737232 & 3.699 & 4.5588 & TST & \\
\hline CHEMBL1706556 & 737232 & 3.699 & 5.0004 & TRN & \\
\hline CHEMBL1733129 & 737232 & 5.4089 & 5.3762 & TRN & \\
\hline CHEMBL1724571 & 737232 & 5.4559 & 5.1564 & TRN & \\
\hline CHEMBL1311692 & 737232 & 3.699 & 4.4918 & TST & \\
\hline CHEMBL1720022 & 737232 & 5.7696 & 5.5654 & TRN & \\
\hline CHEMBL1703562 & 737232 & 5.301 & 5.291 & TRN & \\
\hline CHEMBL 1706758 & 737232 & 4.9586 & 5.21200 & 0000000001 & TRN \\
\hline CHEMBL1707135 & 737232 & 5.2007 & 4.9977 & TRN & \\
\hline CHEMBL1724285 & 737232 & 4.7595 & 4.8265 & TRN & \\
\hline CHEMBL1723453 & 737232 & 5.2441 & 4.4883 & TRN & \\
\hline CHEMBL1710120 & 737232 & 3.699 & 4.3949 & TRN & \\
\hline CHEMBL1703306 & 737232 & 5.5086 & 5.17899 & 9999999999 & TRN \\
\hline CHEMBL1700476 & 737232 & 5.4685 & 5.4713 & TRN & \\
\hline CHEMBL1708907 & 737232 & 5.0969 & 4.977 & TRN & \\
\hline CHEMBL1703918 & 737232 & 5.1675 & 5.289 & TRN & \\
\hline CHEMBL1458112 & 737232 & 4.9957 & 4.9518 & TST & \\
\hline CHEMBL1701679 & 737232 & 4.9788 & 5.129 & TRN & \\
\hline CHEMBL1714617 & 737232 & 3.699 & 4.3777 & TRN & \\
\hline
\end{tabular}


Supplemental Table S2.txt

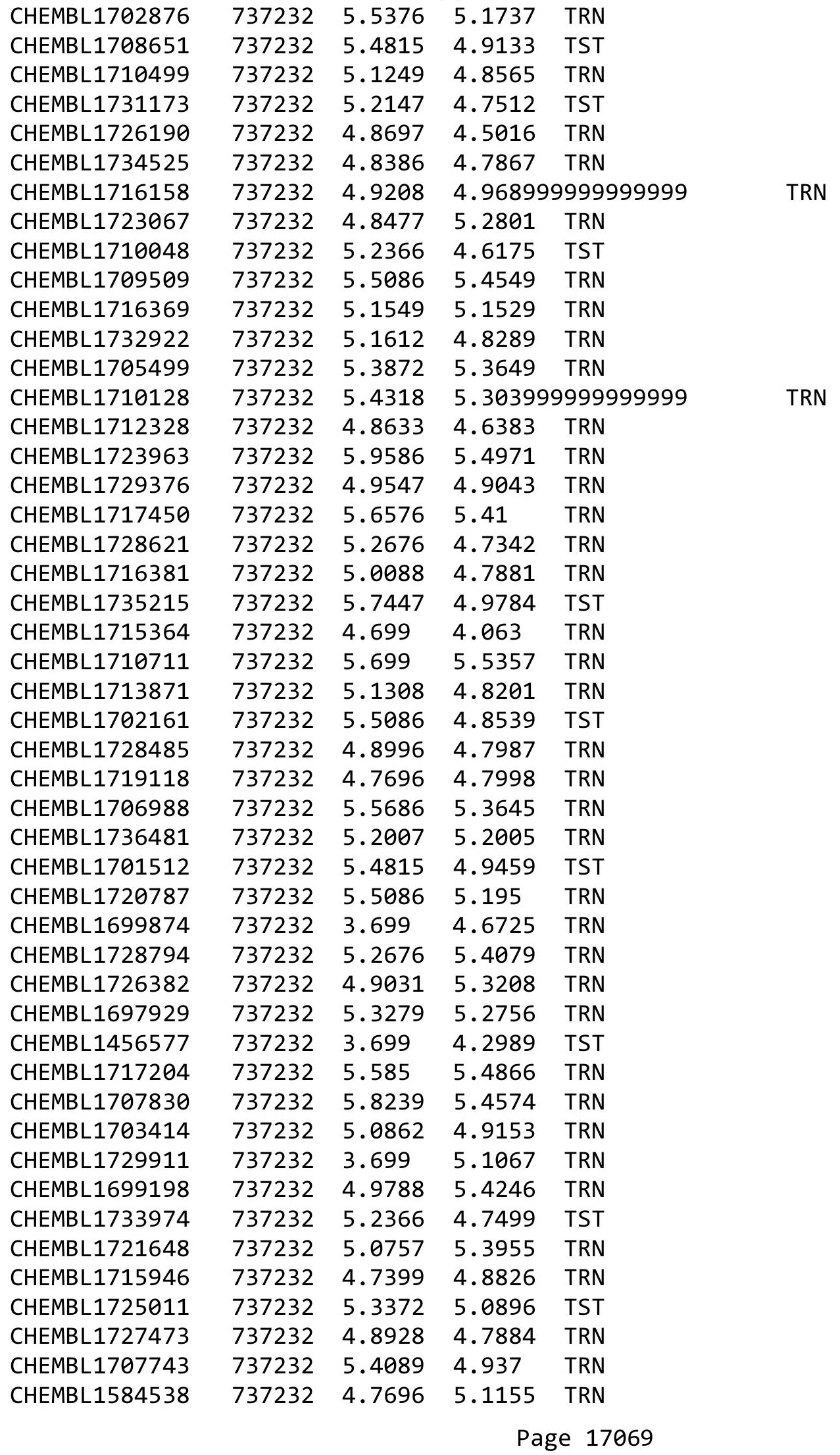


Supplemental Table S2.txt

\begin{tabular}{|c|c|c|c|c|}
\hline CHEMBL1698879 & 737232 & 5.2596 & 5.2003 & TRN \\
\hline CHEMBL1705920 & 737232 & 4.7986 & 5.0686 & TRN \\
\hline CHEMBL1720892 & 737232 & 4.9469 & 4.6932 & TST \\
\hline CHEMBL1698337 & 737232 & 5.3188 & 4.797 & TRN \\
\hline CHEMBL1731906 & 737232 & 5.5376 & 4.988 & TST \\
\hline CHEMBL1729987 & 737232 & 3.699 & 4.7006 & TRN \\
\hline CHEMBL1705448 & 737232 & 5.6778 & 5.4471 & TRN \\
\hline CHEMBL1729749 & 737232 & 5.2441 & 5.229 & TRN \\
\hline CHEMBL1729021 & 737232 & 5.4089 & 5.5267 & TRN \\
\hline CHEMBL1730555 & 737232 & 5.3979 & 5.1373 & TRN \\
\hline CHEMBL1734822 & 737232 & 5.1612 & 4.6704 & TST \\
\hline CHEMBL1735852 & 737232 & 6.1427 & 5.166 & TST \\
\hline CHEMBL1708047 & 737232 & 5.5086 & 4.7831 & TST \\
\hline CHEMBL1698073 & 737232 & 5.4318 & 5.2671 & TST \\
\hline CHEMBL1718965 & 737232 & 4.9136 & 5.2738 & TST \\
\hline CHEMBL1722551 & 737232 & 5.301 & 4.7155 & TST \\
\hline CHEMBL1713683 & 737232 & 5.0223 & 4.7852 & TST \\
\hline CHEMBL1350024 & 737232 & 3.699 & 4.4858 & TST \\
\hline CHEMBL487841 & 512395 & 6.516 & 6.5572 & TRN \\
\hline CHEMBL462136 & 512395 & 7.8827 & 7.04299 & 7999999999 \\
\hline CHEMBL509697 & 512395 & 6.3584 & 6.5744 & TRN \\
\hline CHEMBL516509 & 512395 & 7.4776 & 7.3482 & TST \\
\hline CHEMBL472171 & 512395 & 7.1403 & 6.4513 & TRN \\
\hline CHEMBL486452 & 512395 & 7.0477 & 6.986006 & 0000000001 \\
\hline CHEMBL461377 & 512395 & 7.7747 & 7.1933 & TRN \\
\hline CHEMBL452059 & 512395 & 7.2204 & 6.8876 & TRN \\
\hline CHEMBL520397 & 512395 & 7.4401 & 7.3494 & TRN \\
\hline CHEMBL461751 & 512395 & 6.8077 & 6.7076 & TST \\
\hline CHEMBL487845 & 512395 & 7.1367 & 7.1379 & TRN \\
\hline CHEMBL452556 & 512395 & 7.5768 & 7.0958 & TRN \\
\hline CHEMBL528109 & 512395 & 7.5654 & 7.3325 & TRN \\
\hline CHEMBL460071 & 512395 & 6.3917 & 6.5006 & TRN \\
\hline CHEMBL487641 & 512395 & 7.4001 & 7.3805 & TRN \\
\hline CHEMBL511308 & 512395 & 6.7622 & 6.6915 & TRN \\
\hline CHEMBL472350 & 512395 & 7.3054 & 6.9169 & TRN \\
\hline CHEMBL521368 & 512395 & 6.965 & 6.8733 & TST \\
\hline CHEMBL519398 & 512395 & 6.0 & 6.5557 & TRN \\
\hline CHEMBL486829 & 512395 & 7.0487 & 6.8732 & TST \\
\hline CHEMBL513069 & 512395 & 6.9374 & 6.5659 & TRN \\
\hline CHEMBL455124 & 512395 & 7.1079 & 7.3326 & TRN \\
\hline CHEMBL486663 & 512395 & 7.2807 & 7.3413 & TRN \\
\hline CHEMBL454870 & 512395 & 6.8611 & 6.7205 & TRN \\
\hline CHEMBL488498 & 512395 & 6.0 & 7.13399 & 99999999995 \\
\hline CHEMBL520740 & 512395 & 7.0996 & 7.3694 & TRN \\
\hline CHEMBL461561 & 512395 & 7.2684 & 6.9607 & TRN \\
\hline CHEMBL506586 & 512395 & 7.8182 & 7.1631 & TST \\
\hline CHEMBL471325 & 512395 & 6.2579 & 6.4317 & TRN \\
\hline CHEMBL461126 & 512395 & 7.3458 & 7.1584 & TRN \\
\hline
\end{tabular}




\begin{tabular}{|c|c|c|c|c|c|c|c|}
\hline \multicolumn{7}{|c|}{ Supplemental Table S2.txt } & \\
\hline CHEMBL462127 & 512395 & 7.5638 & 7.2288 & TRN & & & \\
\hline CHEMBL471311 & 512395 & 7.2757 & 7.0736 & TRN & & & \\
\hline CHEMBL510555 & 512395 & 6.0 & 6.9034 & TRN & & & \\
\hline CHEMBL487660 & 512395 & 6.7235 & 6.9633 & TST & & & \\
\hline CHEMBL516500 & 512395 & 6.1807 & 6.7744 & TST & & & \\
\hline CHEMBL487640 & 512395 & 7.5513 & 7.3935 & TRN & & & \\
\hline CHEMBL452557 & 512395 & 7.2993 & 7.1173 & TRN & & & \\
\hline CHEMBL510557 & 512395 & 6.3081 & 6.6149 & TRN & & & \\
\hline CHEMBL452062 & 512395 & 6.5638 & 7.0196 & TRN & & & \\
\hline CHEMBL518811 & 512395 & 7.6904 & 7.2584 & TRN & & & \\
\hline CHEMBL461756 & 512395 & 7.76200 & 00000000 & 205 & 7.4528 & TRN & \\
\hline CHEMBL488500 & 512395 & 6.0 & 7.1788 & TRN & & & \\
\hline CHEMBL488019 & 512395 & 6.8771 & 7.2788 & TST & & & \\
\hline CHEMBL511820 & 512395 & 7.4145 & 6.6217 & TRN & & & \\
\hline CHEMBL452315 & 512395 & 6.98799 & 99999999 & 995 & 7.13899 & 9999999999 & TRN \\
\hline CHEMBL528998 & 512395 & 7.4214 & 7.1415 & TRN & & & \\
\hline CHEMBL471152 & 512395 & 7.1403 & 7.1297 & TRN & & & \\
\hline CHEMBL486659 & 512395 & 6.9759 & 7.1054 & TRN & & & \\
\hline CHEMBL462377 & 512395 & 6.0 & 7.4501 & TRN & & & \\
\hline CHEMBL455125 & 512395 & 7.26200 & 00000000 & 205 & 7.1832 & TRN & \\
\hline CHEMBL452308 & 512395 & 6.92299 & 99999999 & & 7.1274 & TRN & \\
\hline CHEMBL507947 & 512395 & 7.0545 & 7.0416 & TRN & & & \\
\hline CHEMBL461127 & 512395 & 7.9706 & 7.0652 & TRN & & & \\
\hline CHEMBL472353 & 512395 & 7.0825 & 7.1969 & TRN & & & \\
\hline CHEMBL452305 & 512395 & 6.4479 & 6.7544 & TST & & & \\
\hline CHEMBL451799 & 512395 & 6.4283 & 6.6455 & TST & & & \\
\hline CHEMBL472186 & 512395 & 6.5064 & 6.888 & TST & & & \\
\hline CHEMBL472356 & 512395 & 6.0 & 6.6721 & TST & & & \\
\hline CHEMBL486454 & 512395 & 6.6743 & 6.5223 & TRN & & & \\
\hline CHEMBL518921 & 512395 & 6.0 & 7.3282 & TRN & & & \\
\hline CHEMBL461373 & 512395 & 6.524 & 6.6111 & TRN & & & \\
\hline CHEMBL471137 & 512395 & 6.0 & 6.8293 & TST & & & \\
\hline CHEMBL453848 & 512395 & 7.6091 & 7.1492 & TRN & & & \\
\hline CHEMBL488698 & 512395 & 7.0872 & 7.0268 & TRN & & & \\
\hline CHEMBL470970 & 512395 & 6.8814 & 6.6305 & TST & & & \\
\hline CHEMBL461758 & 512395 & 7.3036 & 7.386 & TRN & & & \\
\hline CHEMBL462126 & 512395 & 7.4168 & 7.26399 & 9999999999 & & TRN & \\
\hline CHEMBL452307 & 512395 & 6.0 & 6.5273 & TRN & & & \\
\hline CHEMBL527653 & 512395 & 7.1586 & 6.8663 & TST & & & \\
\hline CHEMBL511094 & 512395 & 7.4318 & 7.2906 & TRN & & & \\
\hline CHEMBL454103 & 512395 & 7.38299 & 99999999 & 99 & 7.2473 & TST & \\
\hline CHEMBL518502 & 512395 & 6.9473 & 6.8255 & TST & & & \\
\hline CHEMBL470097 & 512395 & 7.4815 & 7.0782 & TRN & & & \\
\hline CHEMBL519740 & 512395 & 7.426 & 6.689 & TRN & & & \\
\hline CHEMBL487470 & 512395 & 6.7662 & 6.6458 & TRN & & & \\
\hline CHEMBL506390 & 512395 & 6.0 & 7.2365 & TRN & & & \\
\hline CHEMBL471136 & 512395 & 7.2204 & 6.7938 & TST & & & \\
\hline CHEMBL452058 & 512395 & 6.87 & 6.8503 & TRN & & & \\
\hline
\end{tabular}




\begin{tabular}{|c|c|c|c|c|c|c|}
\hline \multicolumn{7}{|c|}{ Supplemental Table S2.txt } \\
\hline CHEMBL513626 & 512395 & 7.0066 & 6.8423 & TST & & \\
\hline CHEMBL472002 & 512395 & 7.3565 & 6.706 & TRN & & \\
\hline CHEMBL488828 & 512395 & 6.7585 & 6.9673 & TST & & \\
\hline CHEMBL487842 & 512395 & 6.0 & 6.9212 & TRN & & \\
\hline CHEMBL454102 & 512395 & 7.7144 & 7.231 & TRN & & \\
\hline CHEMBL511819 & 512395 & 6.6302 & 6.7312 & TST & & \\
\hline CHEMBL451788 & 512395 & 6.0 & 7.2236 & TRN & & \\
\hline CHEMBL453597 & 512395 & 7.5638 & 7.372006 & 00000000 & & TRN \\
\hline CHEMBL472185 & 512395 & 6.9115 & 6.9962 & TST & & \\
\hline CHEMBL488020 & 512395 & 7.2083 & 7.3843 & TRN & & \\
\hline CHEMBL486667 & 512395 & 6.0 & 6.3605 & TRN & & \\
\hline CHEMBL462135 & 512395 & 7.7852 & 7.1861 & TRN & & \\
\hline CHEMBL513551 & 512395 & 7.3458 & 7.1201 & TRN & & \\
\hline CHEMBL472352 & 512395 & 7.3799 & 7.3458 & TRN & & \\
\hline CHEMBL472520 & 512395 & 6.0 & 7.06 & TST & & \\
\hline CHEMBL487471 & 512395 & 6.9073 & 6.7909 & TST & & \\
\hline CHEMBL503729 & 512395 & 7.2175 & 7.1321 & TRN & & \\
\hline CHEMBL470109 & 512395 & 7.7595 & 7.2948 & TRN & & \\
\hline CHEMBL486453 & 512395 & 7.4559 & 7.1365 & TRN & & \\
\hline CHEMBL452063 & 512395 & 7.1391 & 7.0591 & TRN & & \\
\hline CHEMBL527879 & 512395 & 7.1549 & 7.3266 & TST & & \\
\hline CHEMBL486662 & 512395 & 6.4951 & 6.5696 & TRN & & \\
\hline CHEMBL527652 & 512395 & 7.1343 & 7.0494 & TRN & & \\
\hline CHEMBL512699 & 512395 & 7.3206 & 7.2002 & TRN & & \\
\hline CHEMBL461372 & 512395 & 6.0 & 7.1047 & TRN & & \\
\hline CHEMBL512536 & 512395 & 7.52 & 7.3927 & TRN & & \\
\hline CHEMBL510143 & 512395 & 7.0575 & 7.1025 & TRN & & \\
\hline CHEMBL518347 & 512395 & $7.8210 e$ & 00000000 & 01 & 7.1607 & TRN \\
\hline CHEMBL472001 & 512395 & 7.2007 & 6.54 & TRN & & \\
\hline CHEMBL508401 & 512395 & 7.5317 & 7.1408 & TRN & & \\
\hline CHEMBL461374 & 512395 & 6.0 & 6.4041 & TRN & & \\
\hline CHEMBL451135 & 512395 & 7.0535 & 7.1274 & TRN & & \\
\hline CHEMBL516638 & 512395 & 6.0 & 7.1272 & TRN & & \\
\hline CHEMBL470098 & 512395 & 7.4962 & 7.1441 & TRN & & \\
\hline CHEMBL512700 & 512395 & 7.0223 & 6.9155 & TRN & & \\
\hline CHEMBL471315 & 512395 & 7.1931 & 7.1347 & TRN & & \\
\hline CHEMBL471314 & 512395 & 7.4962 & 7.2302 & TST & & \\
\hline CHEMBL486830 & 512395 & 6.6921 & 6.7466 & TRN & & \\
\hline CHEMBL472000 & 512395 & 7.2765 & 7.3781 & TRN & & \\
\hline CHEMBL452314 & 512395 & 6.5996 & 6.5456 & TRN & & \\
\hline CHEMBL488863 & 512395 & 6.9792 & 6.6692 & TST & & \\
\hline CHEMBL487661 & 512395 & 6.7291 & 7.0509 & TST & & \\
\hline CHEMBL518503 & 512395 & 7.7747 & 7.2062 & TRN & & \\
\hline CHEMBL451801 & 512395 & 7.5287 & 7.27 & TST & & \\
\hline CHEMBL461943 & 512395 & 7.6498 & 7.2878 & TRN & & \\
\hline CHEMBL461936 & 512395 & 8.0269 & 7.4658 & TRN & & \\
\hline CHEMBL451800 & 512395 & 6.1846 & 6.5448 & TRN & & \\
\hline CHEMBL509132 & 512395 & 6.9674 & 7.0829 & TRN & & \\
\hline
\end{tabular}




\begin{tabular}{|c|c|c|c|c|c|c|}
\hline \multirow[b]{2}{*}{ CHEMBL461563 } & & \multicolumn{5}{|c|}{ Supplemental Table S2.txt } \\
\hline & 512395 & 7.8182 & 7.2693 & TRN & & \\
\hline CHEMBL512019 & 512395 & 8.0706 & 7.2034 & TRN & & \\
\hline CHEMBL471308 & 512395 & \multicolumn{3}{|c|}{7.4510000000000005} & 7.3272 & TST \\
\hline CHEMBL487472 & 512395 & 7.2636 & 7.2747 & TST & & \\
\hline CHEMBL528776 & 512395 & 6.7547 & 6.9312 & TRN & & \\
\hline CHEMBL488864 & 512395 & 7.0424 & 7.1126 & TRN & & \\
\hline CHEMBL488697 & 512395 & 6.9594 & 6.822 & TRN & & \\
\hline CHEMBL520892 & 512395 & 7.1798 & 6.9968 & TST & & \\
\hline CHEMBL461754 & 512395 & 6.0 & 6.5914 & TRN & & \\
\hline CHEMBL513048 & 512395 & 6.9809 & 6.6865 & TST & & \\
\hline CHEMBL517592 & 512395 & 6.4244 & 6.6216 & TRN & & \\
\hline CHEMBL461564 & 512395 & 7.5391 & 6.9529 & TST & & \\
\hline CHEMBL472174 & 512395 & 7.2636 & 6.4491 & TRN & & \\
\hline CHEMBL487829 & 512395 & 7.6003 & 7.2406 & TRN & & \\
\hline CHEMBL471140 & 512395 & 6.7857 & 6.9312 & TRN & & \\
\hline CHEMBL455123 & 512395 & \multicolumn{3}{|c|}{7.082000000000001} & 7.3672 & TRN \\
\hline CHEMBL488705 & 512395 & 7.0278 & 6.7784 & TST & & \\
\hline CHEMBL461757 & 512395 & 7.7352 & 7.4056 & TRN & & \\
\hline CHEMBL471135 & 512395 & 6.8368 & 6.6498 & TST & & \\
\hline CHEMBL451802 & 512395 & 7.8097 & 7.3821 & TRN & & \\
\hline CHEMBL472526 & 512395 & 6.0 & 6.6939 & TST & & \\
\hline CHEMBL510892 & 512395 & 7.1537 & 7.3778 & TRN & & \\
\hline CHEMBL516651 & 512395 & 7.4318 & 7.0012 & TST & & \\
\hline CHEMBL461368 & 512395 & 6.2863 & 6.6658 & TRN & & \\
\hline CHEMBL488860 & 512395 & 6.5842 & 6.5979 & TRN & & \\
\hline CHEMBL486660 & 512395 & 6.9574 & 6.6996 & TRN & & \\
\hline CHEMBL488694 & 512395 & 7.1107 & 6.9598 & TST & & \\
\hline CHEMBL472519 & 512395 & \multicolumn{3}{|c|}{ 7. 382999999999999} & 6.9573 & TST \\
\hline CHEMBL471151 & 512395 & 6.7284 & 7.2311 & TST & & \\
\hline CHEMBL452060 & 512395 & 6.7962 & 6.9977 & TST & & \\
\hline CHEMBL358095 & 512395 & 6.0 & 7.0152 & TRN & & \\
\hline CHEMBL487642 & 512395 & 7.6478 & 7.1956 & TRN & & \\
\hline CHEMBL511301 & 512395 & 6.0 & 6.7263 & TRN & & \\
\hline CHEMBL508870 & 512395 & 6.0 & 6.4041 & TRN & & \\
\hline CHEMBL509940 & 512395 & 7.6073 & 7.3079 & TRN & & \\
\hline CHEMBL462198 & 512395 & 7.7144 & 7.1884 & TRN & & \\
\hline CHEMBL452049 & 512395 & 6.0 & 7.1999 & TRN & & \\
\hline CHEMBL471310 & 512395 & 7.2291 & 7.2885 & TST & & \\
\hline CHEMBL471153 & 512395 & 7.4976 & 6.47 & TRN & & \\
\hline CHEMBL472361 & 512395 & 7.9586 & 7.2576 & TRN & & \\
\hline CHEMBL517255 & 512395 & 6.0 & 6.3605 & TRN & & \\
\hline CHEMBL488012 & 512395 & 7.0106 & 7.191 & TRN & & \\
\hline CHEMBL510885 & 512395 & 6.7433 & 6.5577 & TRN & & \\
\hline CHEMBL451787 & 512395 & 7.5834 & 7.1609 & TRN & & \\
\hline CHEMBL461376 & 512395 & 7.5622 & 7.4008 & TRN & & \\
\hline CHEMBL461125 & 512395 & 7.5784 & 7.182 & TRN & & \\
\hline CHEMBL461938 & 512395 & 7.5214 & 7.438 & TRN & & \\
\hline CHEMBL454874 & 512395 & 7.2916 & 7.3361 & TRN & & \\
\hline
\end{tabular}




\begin{tabular}{|c|c|c|c|c|c|c|}
\hline & & \multicolumn{5}{|c|}{ Supplemental Table S2.txt } \\
\hline CHEMBL471317 & 512395 & 6.8729 & 6.7048 & TRN & & \\
\hline CHEMBL529221 & 512395 & 6.7662 & 6.8379 & TST & & \\
\hline CHEMBL487844 & 512395 & 7.2299 & 7.0689 & TRN & & \\
\hline CHEMBL471143 & 512395 & 7.2027 & 7.1353 & TST & & \\
\hline CHEMBL488858 & 512395 & 7.52 & 7.1026 & TST & & \\
\hline CHEMBL511846 & 512395 & 7.1278 & 7.0472 & TST & & \\
\hline CHEMBL461755 & 512395 & 7.6421 & 7.3544 & TST & & \\
\hline CHEMBL459874 & 512395 & 6.28799 & 99999999 & 99 & 6.9155 & TRN \\
\hline CHEMBL521043 & 512395 & 6.3703 & 6.5526 & TRN & & \\
\hline CHEMBL512016 & 512395 & 7.063 & 6.9582 & TRN & & \\
\hline CHEMBL509669 & 512395 & 7.6345 & 7.3531 & TRN & & \\
\hline CHEMBL451786 & 512395 & 7.4584 & 7.3143 & TRN & & \\
\hline CHEMBL461562 & 512395 & 6.0 & 7.4203 & TRN & & \\
\hline CHEMBL471312 & 512395 & 7.3224 & 7.0592 & TRN & & \\
\hline CHEMBL488836 & 512395 & 6.6353 & 6.7728 & TRN & & \\
\hline CHEMBL508165 & 512395 & 6.9555 & 7.3226 & TRN & & \\
\hline CHEMBL527875 & 512395 & 6.0 & 7.2642 & TRN & & \\
\hline CHEMBL488870 & 512395 & 7.6517 & 7.1465 & TRN & & \\
\hline CHEMBL461937 & 512395 & 7.3915 & 7.317 & TRN & & \\
\hline CHEMBL470971 & 512395 & 7.2541 & 7.1936 & TST & & \\
\hline CHEMBL488668 & 512395 & 6.0 & 6.4317 & TRN & & \\
\hline CHEMBL471324 & 512395 & 6.8256 & 6.9582 & TRN & & \\
\hline CHEMBL471146 & 512395 & 7.0742 & 7.0327 & TRN & & \\
\hline CHEMBL3917339 & 1637319 & 9.301 & 9.3536 & TRN & & \\
\hline CHEMBL3921074 & 1637319 & 6.699 & 8.0459 & TRN & & \\
\hline CHEMBL3977176 & 1637319 & 9.301 & 8.5202 & TST & & \\
\hline CHEMBL3897634 & 1637319 & 9.301 & 9.2697 & TRN & & \\
\hline CHEMBL3970916 & 1637319 & 6.699 & 8.0952 & TST & & \\
\hline CHEMBL 3928974 & 1637319 & 7.301 & 8.3544 & TST & & \\
\hline CHEMBL3892706 & 1637319 & 9.301 & 8.9076 & TST & & \\
\hline CHEMBL3962003 & 1637319 & 9.301 & 8.436 & TST & & \\
\hline CHEMBL3895070 & 1637319 & 9.301 & 8.4085 & TST & & \\
\hline CHEMBL 3922657 & 1637319 & 9.301 & 9.3229 & TST & & \\
\hline CHEMBL3978536 & 1637319 & 9.301 & 9.3964 & TRN & & \\
\hline CHEMBL3983598 & 1637319 & 9.301 & 8.52799 & 9999999999 & & TRN \\
\hline CHEMBL3944041 & 1637319 & 7.301 & 8.1948 & TRN & & \\
\hline CHEMBL3964472 & 1637319 & 9.301 & 8.4402 & TRN & & \\
\hline CHEMBL 3895594 & 1637319 & 9.301 & 9.4117 & TRN & & \\
\hline CHEMBL3922040 & 1637319 & 9.301 & 9.1273 & TRN & & \\
\hline CHEMBL3974147 & 1637319 & 7.301 & 8.0049 & TRN & & \\
\hline CHEMBL3911659 & 1637319 & 7.301 & 8.3922 & TRN & & \\
\hline CHEMBL3967743 & 1637319 & 9.301 & 8.4629 & TRN & & \\
\hline CHEMBL3915302 & 1637319 & 9.301 & 8.5469 & TST & & \\
\hline CHEMBL3981766 & 1637319 & 9.301 & 9.3922 & TRN & & \\
\hline CHEMBL3984158 & 1637319 & 7.301 & 8.4852 & TST & & \\
\hline CHEMBL 3949720 & 1637319 & 9.301 & 9.1993 & TRN & & \\
\hline CHEMBL3915499 & 1637319 & 9.301 & 9.0854 & TST & & \\
\hline CHEMBL3977313 & 1637319 & 9.301 & 9.3837 & TRN & & \\
\hline
\end{tabular}

Page 17074 


\begin{tabular}{|c|c|c|c|c|c|}
\hline \multicolumn{6}{|c|}{ Supplemental Table S2.txt } \\
\hline CHEMBL 3908945 & 1637319 & 9.301 & 9.4283 & TRN & \\
\hline CHEMBL 3893843 & 1637319 & 6.5229 & 7.98600 & 0000000001 & TRN \\
\hline CHEMBL3949147 & 1637319 & 9.301 & 8.339 & TRN & \\
\hline CHEMBL 3973675 & 1637319 & 9.301 & 9.2052 & TST & \\
\hline CHEMBL3910630 & 1637319 & 7.301 & 8.5931 & TST & \\
\hline CHEMBL3906336 & 1637319 & 9.301 & 8.5035 & TRN & \\
\hline CHEMBL 3957208 & 1637319 & 9.301 & 9.4135 & TRN & \\
\hline CHEMBL 3956200 & 1637319 & 7.301 & 8.3914 & TRN & \\
\hline CHEMBL 3979530 & 1637319 & 7.301 & 8.4532 & TST & \\
\hline CHEMBL3908463 & 1637319 & 9.301 & 9.3351 & TRN & \\
\hline CHEMBL3926507 & 1637319 & 9.301 & 9.3813 & TRN & \\
\hline CHEMBL 3944093 & 1637319 & 9.301 & 8.4133 & TRN & \\
\hline CHEMBL3964271 & 1637319 & 9.301 & 9.3271 & TST & \\
\hline CHEMBL3932489 & 1637319 & 7.301 & 8.1645 & TRN & \\
\hline CHEMBL3971619 & 1637319 & 9.301 & 8.3455 & TRN & \\
\hline CHEMBL 3980875 & 1637319 & 9.301 & 8.5135 & TRN & \\
\hline CHEMBL3929735 & 1637319 & 6.699 & 8.166 & TST & \\
\hline CHEMBL3931636 & 1637319 & 9.301 & 8.5533 & TST & \\
\hline CHEMBL3918237 & 1637319 & 9.301 & 9.4675 & TRN & \\
\hline CHEMBL3911880 & 1637319 & 9.301 & 8.012 & TRN & \\
\hline CHEMBL3923848 & 1637319 & 7.301 & 8.1085 & TRN & \\
\hline CHEMBL3896630 & 1637319 & 9.301 & 8.559 & TRN & \\
\hline CHEMBL3961075 & 1637319 & 9.301 & 9.1955 & TRN & \\
\hline CHEMBL3941414 & 1637319 & 7.301 & 8.5661 & TRN & \\
\hline CHEMBL3908619 & 1637319 & 9.301 & 9.465 & TST & \\
\hline CHEMBL3913246 & 1637319 & 9.301 & 8.5523 & TRN & \\
\hline CHEMBL3918595 & 1637319 & 9.301 & 8.4306 & TRN & \\
\hline CHEMBL 3897688 & 1637319 & 7.301 & 8.4395 & TST & \\
\hline CHEMBL3983501 & 1637319 & 9.301 & 9.2359 & TRN & \\
\hline CHEMBL3920805 & 1637319 & 9.301 & 8.4581 & TRN & \\
\hline CHEMBL3924462 & 1637319 & 7.301 & 8.0853 & TRN & \\
\hline CHEMBL3906010 & 1637319 & 7.301 & 8.4153 & TRN & \\
\hline CHEMBL 3958893 & 1637319 & 9.301 & 9.2064 & TRN & \\
\hline CHEMBL3915630 & 1637319 & 7.301 & 7.9302 & TRN & \\
\hline CHEMBL3956061 & 1637319 & 7.301 & 8.3667 & TRN & \\
\hline CHEMBL3986291 & 1637319 & 9.301 & 9.4801 & TRN & \\
\hline CHEMBL3893627 & 1637319 & 6.699 & 8.4234 & TST & \\
\hline CHEMBL3931216 & 1637319 & 7.301 & 8.3632 & TRN & \\
\hline CHEMBL3973560 & 1637319 & 7.301 & 8.6273 & TRN & \\
\hline CHEMBL3960627 & 1637319 & 9.301 & 8.4168 & TRN & \\
\hline CHEMBL 3948793 & 1637319 & 7.301 & 8.5078 & TST & \\
\hline CHEMBL3952213 & 1637319 & 7.301 & 8.3387 & TRN & \\
\hline CHEMBL3928990 & 1637319 & 9.301 & 9.391 & TRN & \\
\hline CHEMBL3975089 & 1637319 & 7.301 & 8.1043 & TST & \\
\hline CHEMBL3908490 & 1637319 & 7.301 & 8.4954 & TST & \\
\hline CHEMBL 3927154 & 1637319 & 7.301 & 8.354 & TST & \\
\hline CHEMBL3924980 & 1637319 & 9.301 & 9.4482 & TRN & \\
\hline CHEMBL3947349 & 1637319 & 9.301 & 8.1139 & TRN & \\
\hline
\end{tabular}


Supplemental Table S2.txt

\begin{tabular}{|c|c|c|c|c|c|}
\hline CHEMBL 3907279 & 1637319 & 9.301 & 9.3732 & TST & \\
\hline CHEMBL3959500 & 1637319 & 9.301 & 8.5511 & TRN & \\
\hline CHEMBL3898930 & 1637319 & 9.301 & 9.3341 & TST & \\
\hline CHEMBL3914358 & 1637319 & 6.699 & 8.3734 & TST & \\
\hline CHEMBL 3921384 & 1637319 & 9.301 & 8.4422 & TRN & \\
\hline CHEMBL 3895027 & 1637319 & 9.301 & 8.3845 & TRN & \\
\hline CHEMBL3917271 & 1637319 & 9.301 & 9.2669 & TST & \\
\hline CHEMBL 3984476 & 1637319 & 9.301 & 9.4386 & TRN & \\
\hline CHEMBL 3895426 & 1637319 & 9.301 & \multicolumn{2}{|c|}{8.431000000000001} & TST \\
\hline CHEMBL 3965032 & 1637319 & 9.301 & 9.469 & TST & \\
\hline CHEMBL 3936845 & 1637319 & 7.301 & 8.0934 & TRN & \\
\hline CHEMBL3900894 & 1637319 & 9.301 & 8.5829 & TRN & \\
\hline CHEMBL 3967883 & 1637319 & 9.301 & 9.2667 & TRN & \\
\hline CHEMBL3983534 & 1637319 & 6.699 & 7.8862 & TRN & \\
\hline CHEMBL 3898273 & 1637319 & 9.301 & 9.2363 & TRN & \\
\hline CHEMBL3968973 & 1637319 & 9.301 & 8.3553 & TRN & \\
\hline CHEMBL3953337 & 1637319 & 7.301 & 9.4006 & TRN & \\
\hline CHEMBL3975689 & 1637319 & 9.301 & 8.439 & TRN & \\
\hline CHEMBL3945039 & 1637319 & 9.301 & 8.5204 & TST & \\
\hline CHEMBL3939733 & 1637319 & 9.301 & 7.8701 & TRN & \\
\hline CHEMBL3932974 & 1637319 & 9.301 & 9.2943 & TRN & \\
\hline CHEMBL3920589 & 1637319 & 9.301 & 8.4734 & TST & \\
\hline CHEMBL3930370 & 1637319 & 9.301 & 8.4494 & TST & \\
\hline CHEMBL 3946123 & 1637319 & 7.301 & 8.4903 & TRN & \\
\hline CHEMBL 3948999 & 1637319 & 9.301 & 8.6062 & TRN & \\
\hline CHEMBL 3974668 & 1637319 & 7.301 & 8.6518 & TRN & \\
\hline CHEMBL3894159 & 1637319 & 9.301 & 8.0863 & TRN & \\
\hline CHEMBL3930325 & 1637319 & 7.301 & 8.1529 & TRN & \\
\hline CHEMBL 3973234 & 1637319 & 9.301 & 8.7567 & TRN & \\
\hline CHEMBL3953617 & 1637319 & 9.301 & 9.4687 & TRN & \\
\hline CHEMBL3939938 & 1637319 & 9.301 & \multicolumn{2}{|c|}{8.431000000000001} & TRN \\
\hline CHEMBL 3900462 & 1637319 & 9.301 & 8.5135 & TST & \\
\hline CHEMBL3935448 & 1637319 & 9.301 & 9.1358 & TRN & \\
\hline CHEMBL 3986462 & 1637319 & 9.301 & 8.3551 & TRN & \\
\hline CHEMBL3954167 & 1637319 & 7.301 & 8.3697 & TRN & \\
\hline CHEMBL3927679 & 1637319 & 9.301 & 9.3351 & TRN & \\
\hline CHEMBL 3940750 & 1637319 & 6.699 & 8.0233 & TRN & \\
\hline CHEMBL 3958002 & 1637319 & 9.301 & 9.3404 & TRN & \\
\hline CHEMBL 3927538 & 1637319 & 9.301 & 9.2359 & TRN & \\
\hline CHEMBL3976508 & 1637319 & 9.301 & 8.3727 & TRN & \\
\hline CHEMBL 3986300 & 1637319 & 9.301 & 8.4507 & TRN & \\
\hline CHEMBL 3955753 & 1637319 & 9.301 & 9.2576 & TST & \\
\hline CHEMBL 3984673 & 1637319 & 9.301 & 8.6177 & TRN & \\
\hline CHEMBL 3948879 & 1637319 & 9.301 & 8.0399 & TRN & \\
\hline CHEMBL3966546 & 1637319 & 9.301 & 8.3239 & TRN & \\
\hline CHEMBL 3958544 & 1637319 & 9.301 & 8.3764 & TRN & \\
\hline CHEMBL 3954565 & 1637319 & 7.301 & 8.9076 & TST & \\
\hline CHEMBL 3948390 & 1637319 & 9.301 & 8.5932 & TRN & \\
\hline
\end{tabular}

Page 17076 
Supplemental Table S2.txt

\begin{tabular}{|c|c|c|c|c|}
\hline CHEMBL 3898123 & 1637319 & 9.301 & 9.2718 & TRN \\
\hline CHEMBL 3945016 & 1637319 & 7.301 & 8.5501 & TRN \\
\hline CHEMBL 3986743 & 1637319 & 7.301 & 8.4584 & TRN \\
\hline CHEMBL 3931371 & 1637319 & 7.301 & 8.3723 & TST \\
\hline CHEMBL 3925174 & 1637319 & 7.301 & 8.1232 & TRN \\
\hline CHEMBL 3977214 & 1637319 & 7.301 & 8.1949 & TRN \\
\hline CHEMBL 3966319 & 1637319 & 9.301 & 9.3483 & TRN \\
\hline CHEMBL 3912827 & 1637319 & 6.699 & 8.2627 & TST \\
\hline CHEMBL 3961888 & 1637319 & 7.301 & 8.2955 & TRN \\
\hline CHEMBL3915507 & 1637319 & 7.301 & 8.4684 & TST \\
\hline CHEMBL 3968145 & 1637319 & 9.301 & 8.4952 & TRN \\
\hline CHEMBL 3916632 & 1637319 & 7.301 & 8.4523 & TRN \\
\hline CHEMBL 3895291 & 1637319 & 9.301 & 9.3687 & TRN \\
\hline CHEMBL 3979671 & 1637319 & 9.301 & 8.4478 & TRN \\
\hline CHEMBL3908780 & 1637319 & 7.301 & 8.2969 & TRN \\
\hline CHEMBL 3941334 & 1637319 & 9.301 & 9.3229 & TRN \\
\hline CHEMBL3958933 & 1637319 & 7.301 & 8.3992 & TST \\
\hline CHEMBL 3944405 & 1637319 & 7.301 & 8.4 & TRN \\
\hline CHEMBL 3896322 & 1637319 & 9.301 & 9.4202 & TRN \\
\hline CHEMBL3917446 & 1637319 & 9.301 & 8.5237 & TRN \\
\hline CHEMBL 3983775 & 1637319 & 7.301 & 8.372 & TRN \\
\hline CHEMBL 3900185 & 1637319 & 9.301 & 8.3968 & TRN \\
\hline CHEMBL 3928484 & 1637319 & 9.301 & 8.1537 & TRN \\
\hline CHEMBL 3948991 & 1637319 & 9.301 & 8.394 & TST \\
\hline CHEMBL 3966182 & 1637319 & 9.301 & 9.40299 & 9999999999 \\
\hline CHEMBL 3903620 & 1637319 & 7.301 & 8.0907 & TRN \\
\hline CHEMBL 3969679 & 1637319 & 9.301 & 9.5467 & TRN \\
\hline CHEMBL 3925297 & 1637319 & 7.301 & 8.0931 & TRN \\
\hline CHEMBL 3951506 & 1637319 & 7.301 & 8.1135 & TRN \\
\hline CHEMBL 3940789 & 1637319 & 7.301 & 8.4468 & TST \\
\hline CHEMBL 3913887 & 1637319 & 6.699 & 8.2047 & TST \\
\hline CHEMBL 3914490 & 1637319 & 9.301 & 9.4054 & TRN \\
\hline CHEMBL 3895868 & 1637319 & 7.301 & 7.9075 & TRN \\
\hline CHEMBL 3943852 & 1637319 & 9.301 & 9.4081 & TRN \\
\hline CHEMBL 3932380 & 1637319 & 9.301 & 9.31299 & 7999999999 \\
\hline CHEMBL 3938515 & 1637319 & 9.301 & 9.2729 & TST \\
\hline CHEMBL 3951028 & 1637319 & 9.301 & 8.7616 & TRN \\
\hline CHEMBL 3958043 & 1637319 & 9.301 & 8.5183 & TRN \\
\hline CHEMBL 3926544 & 1637319 & 7.301 & 7.942 & TRN \\
\hline CHEMBL 3970431 & 1637319 & 7.301 & 8.5268 & TRN \\
\hline CHEMBL 3933570 & 1637319 & 7.301 & 8.4711 & TRN \\
\hline CHEMBL 3979504 & 1637319 & 9.301 & 8.5 & TRN \\
\hline CHEMBL 3956837 & 1637319 & 9.301 & 9.3398 & TRN \\
\hline CHEMBL 3948435 & 1637319 & 7.301 & 8.5198 & TRN \\
\hline CHEMBL 3984668 & 1637319 & 7.301 & 7.8901 & TRN \\
\hline CHEMBL 3937156 & 1637319 & 9.301 & 8.4984 & TRN \\
\hline CHEMBL 3924512 & 1637319 & 7.301 & 8.4801 & TST \\
\hline CHEMBL 3958382 & 1637319 & 9.301 & 8.487 & TST \\
\hline
\end{tabular}


Supplemental Table S2.txt

\begin{tabular}{|c|c|c|}
\hline 24 & 1637319 & 736 \\
\hline CHEMBL3967338 & 1637319 & 9.301 \\
\hline CHEMBL3984226 & 1637319 & 301 \\
\hline HEMBL3964438 & 1637319 & 7.301 \\
\hline AEMBL3934511 & 1637319 & 9.30 \\
\hline HEMBL3975381 & 1637319 & 7.301 \\
\hline HEMBL3925144 & 637319 & 9.301 \\
\hline HEMBL 3914084 & 1637319 & 9.301 \\
\hline HEMBL3914532 & 1637319 & 7.301 \\
\hline HEMBL 3890357 & 1637319 & 7.301 \\
\hline HEMBL3927704 & 1637319 & 9.301 \\
\hline HEMBL3945897 & 1637319 & 9.301 \\
\hline HEMBL3982556 & 1637319 & 7.30 \\
\hline HEMBL3968632 & 1637319 & 9.301 \\
\hline CHEMBL3976504 & 1637319 & 7.301 \\
\hline HEMBL3924081 & 1637319 & .301 \\
\hline HEMBL3912772 & 1637319 & 7.301 \\
\hline CHEMBL3981082 & 1637319 & 7.301 \\
\hline HEMBL3935288 & 1637319 & 9.301 \\
\hline CHEMBL3955118 & 1637319 & 9.301 \\
\hline CHEMBL3944955 & 1637319 & 9.301 \\
\hline HEMBL3965587 & 319 & 9.301 \\
\hline CHEMBL3907633 & 1637319 & 9.30 \\
\hline CHEMBL 3976626 & 1637319 & 9.301 \\
\hline CHEMBL3941898 & 1637319 & 7.301 \\
\hline CHEMBL3976720 & 1637319 & 9.301 \\
\hline CHEMBL3934692 & 163 & 7.301 \\
\hline CHEMBL3952353 & 1637319 & 9.30 \\
\hline CHEMBL3932892 & 1637319 & 9.301 \\
\hline CHEMBL3935680 & 1637319 & 7.301 \\
\hline CHEMBL3910532 & 1637319 & 9.301 \\
\hline CHEMBL3890938 & 1637319 & 9.301 \\
\hline CHEMBL3955045 & 1637319 & 9.30 \\
\hline CHEMBL 3913286 & 1637319 & 9.301 \\
\hline CHEMBL3977160 & 1637319 & 7.301 \\
\hline CHEMBL3956227 & 1637319 & 7.301 \\
\hline CHEMBL3936415 & 1637319 & 9.301 \\
\hline CHEMBL3981971 & 1637319 & 9.301 \\
\hline CHEMBL3980275 & 1637319 & 7.301 \\
\hline CHEMBL3981748 & 1637319 & 7.301 \\
\hline CHEMBL3936966 & 1637319 & 9.301 \\
\hline CHEMBL3945214 & 163731 & 9.301 \\
\hline CHEMBL3939666 & 1637319 & 9.301 \\
\hline CHEMBL3908773 & 1637319 & 9.301 \\
\hline CHEMBL3953383 & 1637319 & 9.301 \\
\hline CHEMBL3890948 & 1637319 & 9.301 \\
\hline CHEMBL3903569 & 163731 & 7.36 \\
\hline CHEMBL3951065 & & \\
\hline
\end{tabular}

\begin{tabular}{ll}
8.1976 & TST \\
8.5443 & TST \\
9.3309 & TRN \\
8.3932 & TRN \\
8.3229 & TRN \\
8.3899 & TRN \\
8.4434 & TRN \\
9.367 & TRN \\
8.5262 & TST \\
8.0681 & TRN \\
8.4554 & TRN \\
9.3524 & TRN \\
8.195 & TST \\
9.4982 & TRN \\
8.4897 & TST \\
8.0843 & TST \\
8.1289 & TRN \\
7.8784 & TRN \\
9.3442 & TRN \\
8.5316 & TRN \\
8.4356 & TRN \\
8.6457 & TRN \\
8.4374 & TRN \\
8.3804 & TRN \\
8.2366 & TRN \\
8.5858 & TRN \\
8.3782 & TST \\
8.605 & TRN \\
8.5034 & TRN \\
8.1238 & TRN \\
9.2527 & TRN \\
8.4437 & TRN \\
8.727 & TRN \\
8.1516 & TRN \\
8.9822 & TRN \\
8.2158 & TRN \\
8.5137 & TRN \\
9.4696 & TRN \\
8.4341 & TRN \\
8.7303 & TRN \\
$\mathbf{8 . 9 3 8 8}$ & TRN \\
8.5316 & TRN \\
8.4337 & TRN \\
9.5036 & TRN \\
9.1669 & TST \\
8.6183 & TRN \\
\hline .4078 & TRN \\
& TRN
\end{tabular}

Page 17078 
Supplemental Table S2.txt

\begin{tabular}{|c|c|c|}
\hline CHEMBL3907920 & 1637319 & 730 \\
\hline CHEMBL3895021 & 1637319 & 9.301 \\
\hline CHEMBL3961498 & 1637319 & 301 \\
\hline HEMBL3973843 & 1637319 & 7.301 \\
\hline HEMBL 3915198 & 1637319 & 7.30 \\
\hline HEMBL3947572 & 1637319 & . 301 \\
\hline HEMBL3984184 & 1637319 & 9.301 \\
\hline HEMBL 3898382 & 1637319 & 7.301 \\
\hline HEMBL 3973120 & 1637319 & 7.301 \\
\hline AEMBL3978627 & 1637319 & 9.301 \\
\hline HEMBL3952888 & 1637319 & 7.301 \\
\hline HEMBL3982699 & 1637319 & 9.301 \\
\hline HEMBL3898620 & 1637319 & 9.30 \\
\hline HEMBL 3958880 & 1637319 & 9.301 \\
\hline CHEMBL 3943023 & 1637319 & .301 \\
\hline HEMBL 3970607 & 1637319 & 9.301 \\
\hline HEMBL3963339 & 1637319 & 9.301 \\
\hline CHEMBL3959944 & 1637319 & 6.699 \\
\hline HEMBL3977459 & 1637319 & 7.301 \\
\hline CHEMBL 3985568 & 1637319 & 7.301 \\
\hline CHEMBL3958200 & 1637319 & 9.301 \\
\hline HEMBL3913894 & 319 & 9.301 \\
\hline CHEMBL3945802 & 1637319 & 9.30 \\
\hline CHEMBL3961956 & 1637319 & 7.301 \\
\hline CHEMBL 3 & 1637319 & 9.301 \\
\hline CHEMBL 3974704 & 1637319 & 6.699 \\
\hline CHEMBL3923756 & 163 & 9.301 \\
\hline CHEMBL3918195 & 1637319 & 9.30 \\
\hline CHEMBL 39 & 1637319 & 9.301 \\
\hline CHEMBL3931280 & 1637319 & 9.301 \\
\hline CHEMBL 3978490 & 1637319 & 9.301 \\
\hline CHEMBL 3934142 & 1637319 & 9.301 \\
\hline CHEMBL3935274 & 1637319 & 9.30 \\
\hline CHEMBL 3961564 & 1637319 & 6.699 \\
\hline CHEMBL 3976063 & 1637319 & 9.301 \\
\hline CHEMBL3952589 & 1637319 & 9.301 \\
\hline CHEMBL 3938051 & 1637319 & 9.301 \\
\hline CHEMBL 3922382 & 1637319 & 9.301 \\
\hline CHEMBL 3945402 & 1637319 & 9.301 \\
\hline CHEMBL 3892282 & 1637319 & 7.301 \\
\hline CHEMBL 3916000 & 1637319 & 9.301 \\
\hline CHEMBL 3898820 & 163731 & 9.301 \\
\hline CHEMBL 3910628 & 1637319 & 6.699 \\
\hline CHEMBL 3897382 & 1637319 & 7.301 \\
\hline CHEMBL 3940108 & 1637319 & 9.301 \\
\hline CHEMBL 3951864 & 1637319 & 9.301 \\
\hline CHEMBL 3904301 & 163731 & 9.301 \\
\hline CHEMBL 3932590 & & \\
\hline
\end{tabular}

\begin{tabular}{|c|c|}
\hline & \\
\hline 965 & \\
\hline 281 & \\
\hline 399 & \\
\hline & \\
\hline 6 & \\
\hline 224 & IS \\
\hline 4077 & IS \\
\hline & \\
\hline & T \\
\hline 3826 & RN \\
\hline 396 & 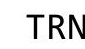 \\
\hline & \\
\hline 58 & וד \\
\hline & RN \\
\hline & RN \\
\hline & \\
\hline 38 & RI \\
\hline 1 & RN \\
\hline & $\mathrm{RN}$ \\
\hline & 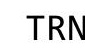 \\
\hline & R॥ \\
\hline 71 & S \\
\hline 29 & RN \\
\hline 2 & $\mathrm{RN}$ \\
\hline & RN \\
\hline & RN \\
\hline 77 & RN \\
\hline 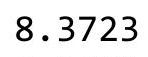 & RN \\
\hline 5 & ST \\
\hline & $\mathrm{R \Lambda}$ \\
\hline & ST \\
\hline 36 & rRN \\
\hline 7 & ST \\
\hline 34 & $\mathrm{RN}$ \\
\hline & RN \\
\hline & SST \\
\hline & rRN \\
\hline 9 & rRN \\
\hline 1292 & ST \\
\hline 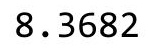 & RN \\
\hline 32 & RN \\
\hline 1 & SST \\
\hline .3 & IRN \\
\hline & $\mathrm{RN}$ \\
\hline & $\mathrm{R}$ \\
\hline & \\
\hline & \\
\hline
\end{tabular}

Page 17079 
Supplemental Table S2.txt

\begin{tabular}{|c|c|c|c|c|c|}
\hline CHEMBL 3913953 & 1637319 & 9.301 & 8.4261 & TRN & \\
\hline CHEMBL 3978964 & 1637319 & 9.301 & 8.059 & TRN & \\
\hline CHEMBL3949497 & 1637319 & 9.301 & 8.3316 & TRN & \\
\hline CHEMBL 3927670 & 1637319 & 7.301 & 8.6635 & TST & \\
\hline CHEMBL 3943519 & 1637319 & 9.301 & 9.3744 & TRN & \\
\hline CHEMBL3946142 & 1637319 & 7.301 & 8.1603 & TST & \\
\hline CHEMBL3928999 & 1637319 & 9.301 & 9.3244 & TRN & \\
\hline CHEMBL3924659 & 1637319 & 9.301 & \multicolumn{2}{|c|}{9.152999999999999} & TRN \\
\hline CHEMBL 3928285 & 1637319 & 6.699 & 8.3784 & TRN & \\
\hline CHEMBL 3944722 & 1637319 & 9.301 & 8.4256 & TRN & \\
\hline CHEMBL 3904877 & 1637319 & 9.301 & \multicolumn{2}{|c|}{9.261000000000001} & TRN \\
\hline CHEMBL 3890434 & 1637319 & 7.301 & 8.0025 & TRN & \\
\hline CHEMBL 3984246 & 1637319 & 9.301 & 9.3809 & TRN & \\
\hline CHEMBL 3943415 & 1637319 & 7.301 & 8.4081 & TRN & \\
\hline CHEMBL 3900135 & 1637319 & 9.301 & 8.4324 & TRN & \\
\hline CHEMBL 3976158 & 1637319 & 9.301 & 8.0469 & TRN & \\
\hline CHEMBL3914549 & 1637319 & 9.301 & 9.4627 & TRN & \\
\hline CHEMBL 3946326 & 1637319 & 9.301 & 8.3591 & TRN & \\
\hline CHEMBL3937622 & 1637319 & 9.301 & 8.0225 & TRN & \\
\hline CHEMBL 3929672 & 1637319 & 9.301 & 8.4237 & TRN & \\
\hline CHEMBL 3924438 & 1637319 & 7.301 & 8.5779 & TST & \\
\hline CHEMBL3980119 & 1637319 & 7.301 & 8.4445 & TRN & \\
\hline CHEMBL 3927209 & 1637319 & 7.301 & 8.3943 & TST & \\
\hline CHEMBL3954991 & 1637319 & 9.301 & 9.3982 & TRN & \\
\hline CHEMBL 3982495 & 1637319 & 9.301 & 8.4156 & TRN & \\
\hline CHEMBL 3938229 & 1637319 & 6.699 & 8.0612 & TRN & \\
\hline CHEMBL3947131 & 1637319 & 9.301 & 8.0399 & TRN & \\
\hline CHEMBL 3925310 & 1637319 & 9.301 & 9.4076 & TRN & \\
\hline CHEMBL3973035 & 1637319 & 7.301 & 8.2441 & TRN & \\
\hline CHEMBL 3981303 & 1637319 & 9.301 & 8.4906 & TRN & \\
\hline CHEMBL3912101 & 1637319 & 7.301 & 8.1794 & TRN & \\
\hline CHEMBL 3977397 & 1637319 & 7.301 & 8.1052 & TRN & \\
\hline CHEMBL 3892108 & 1637319 & 9.301 & 8.4657 & TRN & \\
\hline CHEMBL3983841 & 1637319 & 7.301 & 8.0816 & TST & \\
\hline CHEMBL 3928482 & 1637319 & 9.301 & 8.5404 & TRN & \\
\hline CHEMBL3958836 & 1637319 & 7.301 & 8.2202 & TRN & \\
\hline CHEMBL3917371 & 1637319 & 9.301 & 8.052999 & э999999999 & TRN \\
\hline CHEMBL 3970498 & 1637319 & 7.301 & 8.1666 & TRN & \\
\hline CHEMBL 3949598 & 1637319 & 7.301 & 8.0984 & TRN & \\
\hline CHEMBL 3904053 & 1637319 & 9.301 & 9.3298 & TRN & \\
\hline CHEMBL 3977847 & 1637319 & 9.301 & 9.425 & TRN & \\
\hline CHEMBL 3914575 & 1637319 & 9.301 & 8.3958 & TRN & \\
\hline CHEMBL 3930452 & 1637319 & 9.301 & 8.3831 & TRN & \\
\hline CHEMBL3954206 & 1637319 & 7.301 & 8.1099 & TRN & \\
\hline CHEMBL 3967417 & 1637319 & 9.301 & 8.3721 & TRN & \\
\hline CHEMBL 3908824 & 1637319 & 9.301 & 8.4746 & TRN & \\
\hline CHEMBL 3947205 & 1637319 & 9.301 & 8.4613 & TRN & \\
\hline CHEMBL3965177 & 1637319 & 9.301 & 8.4554 & TRN & \\
\hline
\end{tabular}


Supplemental Table S2.txt

\begin{tabular}{|c|c|c|c|c|}
\hline $\mathrm{F}$ & 319 & 301 & 55 & $T$ \\
\hline HEMBL3986198 & 637319 & 9.301 & 8.9822 & \\
\hline 867 & 7319 & 9.301 & 656 & \\
\hline 05971 & 537319 & 7.301 & 3923 & DP \\
\hline AEMBL3981886 & 637319 & 9.301 & .6005 & \\
\hline HEMBL 3896874 & 637319 & 9.301 & .1212 & \\
\hline HEMBL3965049 & 637319 & 9.301 & .2937 & \\
\hline HEMBL3918254 & 537319 & 7.301 & 1091 & \\
\hline AEMBL3920989 & 637319 & 6.699 & 7.9927 & \\
\hline HEMBL3904170 & 637319 & 7.301 & .5987 & \\
\hline HEMBL3936342 & 637319 & 7.301 & .5587 & \\
\hline HEMBL3901336 & 637319 & 9.301 & .2676 & \\
\hline HEMBL 391 & 319 & 7.301 & & RN \\
\hline HEMBL3894266 & 319 & 7.301 & 3.2674 & \\
\hline HEMBL3928468 & 637319 & 9.301 & .606 & \\
\hline HEMBL3983330 & 637319 & 9.301 & 8.7157 & \\
\hline HEMBL3972221 & 319 & 6.699 & .9536 & SI \\
\hline HEMBL3898099 & 319 & 7.301 & & RN \\
\hline HEMBL3933201 & 319 & 9.301 & 9.326 & \\
\hline HEMBL3947866 & 319 & 7.301 & 7033 & TRN \\
\hline HEMBL3979825 & 319 & 9.301 & 03 & RI \\
\hline HEMBL3913298 & 319 & 7.301 & 48 & RN \\
\hline HEMBL3950173 & 319 & 7.301 & 8.32 & \\
\hline HEMBL3890137 & 319 & 9.301 & 9.2401 & RN \\
\hline HEMBL391 & 19 & 9.301 & 85 & IRN \\
\hline HEMBL3902928 & 19 & 9.301 & 8.4051 & RN \\
\hline HEMBL3912283 & 319 & 7.301 & 3.5547 & RN \\
\hline HEMBL 390 & 319 & 9.301 & 9.3389 & \\
\hline HEMBL3930982 & 319 & 9.301 & 339 & $1 \mathrm{R}$ \\
\hline HEMBL3907114 & 19 & 7.301 & 3.3765 & TST \\
\hline HEMBL3941704 & 19 & 9.301 & 9. 3491 & 「RN \\
\hline HEMBL3921362 & 19 & 7.301 & 112 & TST \\
\hline HEMBL39 & 19 & 01 & 9.2174 & TRN \\
\hline HEMBL3907878 & 319 & 9.301 & 8.7146 & TRN \\
\hline HEMBL3924975 & 637319 & 9.301 & 8.4864 & TST \\
\hline HEMBL3974722 & 319 & 7.301 & .5345 & ГST \\
\hline HEMBL393 & 19 & 9. & 046 & RN \\
\hline HEMBL 3898766 & 19 & 7.301 & 8.1108 & TRN \\
\hline HEMBL3938623 & 637319 & 9.301 & 9.3639 & TRN \\
\hline HEMBL3889651 & 637319 & 7.301 & 3.5828 & TRN \\
\hline HEMBL3930823 & 1637319 & 9.301 & .1964 & TRN \\
\hline CHEMBL 3899050 & 1637319 & 9.301 & 3.4864 & RN \\
\hline HEMBL3926335 & 1637319 & 7.301 & 8.1289 & TRN \\
\hline HEMBL3936441 & 1637319 & 7.301 & 3.4729 & TRN \\
\hline HEMBL3941400 & 1637319 & 7.301 & 3.1394 & TRN \\
\hline CHEMBL3933071 & 1637319 & 9.301 & 8. 3964 & \\
\hline CHEMBL3984360 & 1637319 & 9.301 & 8.5293 & RN \\
\hline CHEMBL3971101 & 1637319 & 7.301 & 8.405 & TST \\
\hline
\end{tabular}

Page 17081 
Supplemental Table S2.txt

\begin{tabular}{|c|c|c|c|c|}
\hline HEMBL & 1637319 & 9.301 & 9.4476 & TRN \\
\hline HEMBL3939415 & 637319 & 7.301 & 8.2312 & \\
\hline 818 & 537319 & 7.301 & 5364 & \\
\hline AEMBL3967511 & 637319 & 9.301 & 1083 & RN \\
\hline HEMBL3938282 & 637319 & 7.301 & .2811 & \\
\hline HEMBL3894187 & 637319 & 9.301 & .3593 & \\
\hline HEMBL3941336 & 637319 & 9.301 & 8.1549 & \\
\hline HEMBL3965794 & 319 & 6.699 & 0091 & \\
\hline AEMBL3911726 & 637319 & 9.301 & 8.3446 & \\
\hline HEMBL3959899 & 637319 & 7.301 & 8.3874 & \\
\hline HEMBL3962987 & 637319 & 9.301 & 9.338 & \\
\hline HEMBL3941550 & 637319 & 7.301 & 8.4298 & \\
\hline HEMBL 393 & 319 & 6.699 & & ST \\
\hline HEMBL3961088 & 319 & 9.301 & 8.5466 & \\
\hline HEMBL3892276 & 637319 & 9.301 & 5418 & \\
\hline HEMBL 3977874 & 637319 & 9.301 & 8.3502 & ST \\
\hline HEMBL3934393 & 319 & 9.301 & 9.4109 & ST \\
\hline HEMBL393 & 319 & 9.301 & 696 & \\
\hline HEMBL3980116 & 319 & 6.699 & 8.369 & \\
\hline HEMBL3973731 & 19 & 7.301 & 5217 & ST \\
\hline HEMBL3972573 & 319 & 7.301 & 5258 & S \\
\hline HEMBL3955708 & 19 & 9.301 & 1615 & ST \\
\hline HEMBL3907726 & 19 & 9.301 & 53 & \\
\hline HEMBL3933284 & 19 & 9.301 & 9.3219 & $\mathrm{~T}$ \\
\hline HEMBL 398 & 319 & 7.301 & 99 & ST \\
\hline AEMBL543271 & 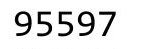 & 6.4815 & 387 & RN \\
\hline HEMBL 55 & 97 & 8 & & $\mathrm{RN}$ \\
\hline HEN & & 291 & 551 & RN \\
\hline HEMBL542070 & 5597 & 555 & 01 & IV \\
\hline HEMBL543 & 7 & 6.0757 & 966 & 15 \\
\hline HEMBL543 & 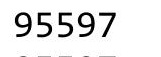 & 0655 & 5722 & ST \\
\hline HEMBL 55 & 7 & 92 & 534 & RN \\
\hline HEM & & 665 & 316 & RN \\
\hline HEMBL554213 & & 5 . & 915 & IRN \\
\hline HEMBL543746 & 5597 & 6.1871 & 5.9036 & IRN \\
\hline HEMBL5532 & 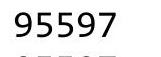 & 487 & 6.4648 & RN \\
\hline HEMBL54 & & 08 & 113 & $\mathrm{RN}$ \\
\hline HEMBL556209 & & 6.3188 & 6.5967 & TRN \\
\hline HEMBL543743 & 5597 & 6.5086 & 6.1144 & TRN \\
\hline HEMBL545155 & 55 & 6.4089 & 915 & TRN \\
\hline CHEMBL538975 & 95597 & 7.4949 & 6.734 & $\mathrm{RN}$ \\
\hline CHEMBL544215 & & 6.1739 & 6.7293 & $\mathrm{RN}$ \\
\hline HEMBL553769 & 95597 & 5.8239 & 6.5999 & IST \\
\hline HEMBL543272 & 5597 & 6.1079 & 6.0763 & TRN \\
\hline HEMBL553589 & 550 & 7959 & 6.1076 & KIV \\
\hline CHEMBL540007 & 95597 & 6.4089 & 6.6858 & I \\
\hline CHEMBL539233 & 95597 & 6.3565 & 6.0749 & RN \\
\hline CHEMBL542322 & 95597 & 5.9586 & 5.954 & IRIN \\
\hline
\end{tabular}

Page 17082 


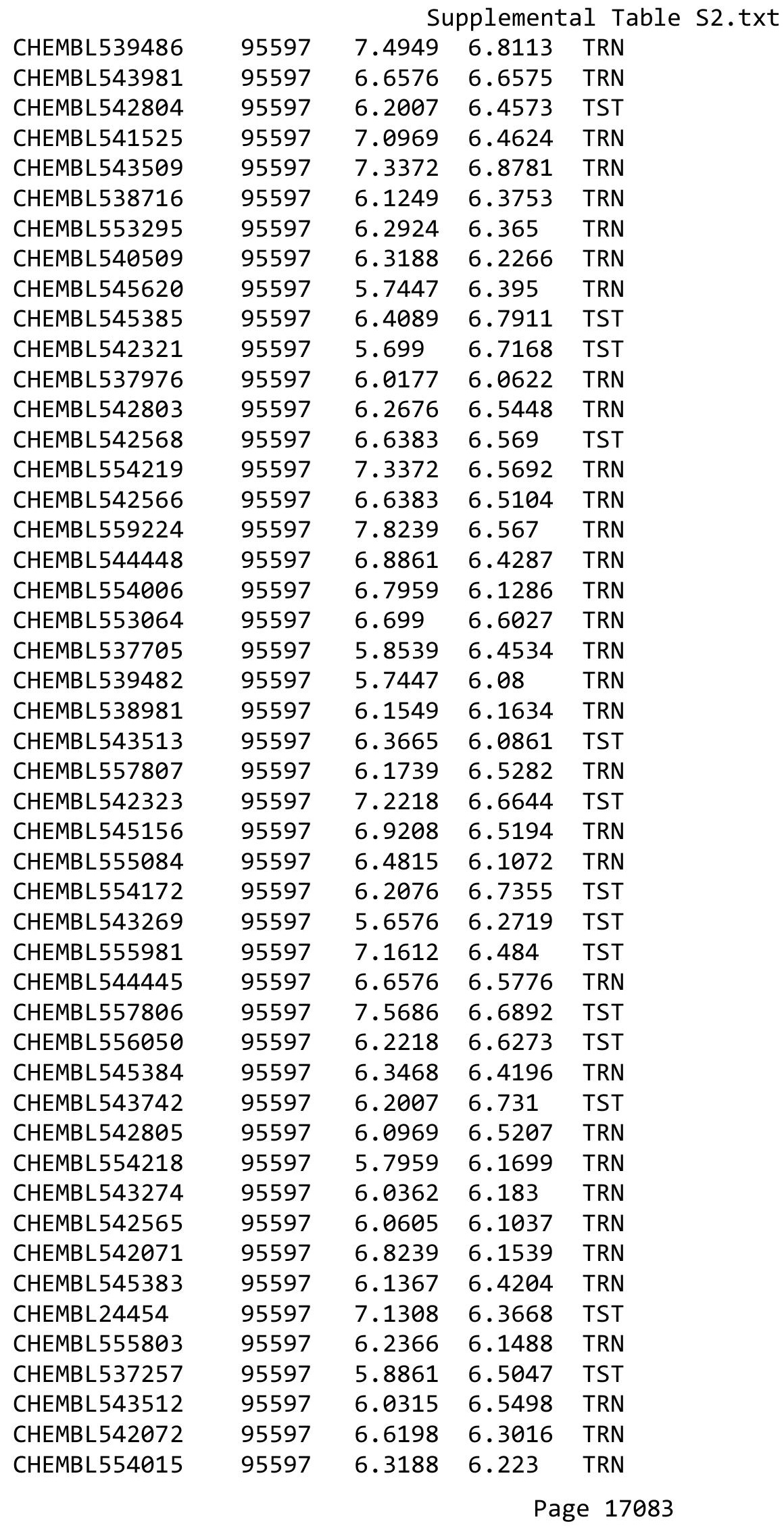




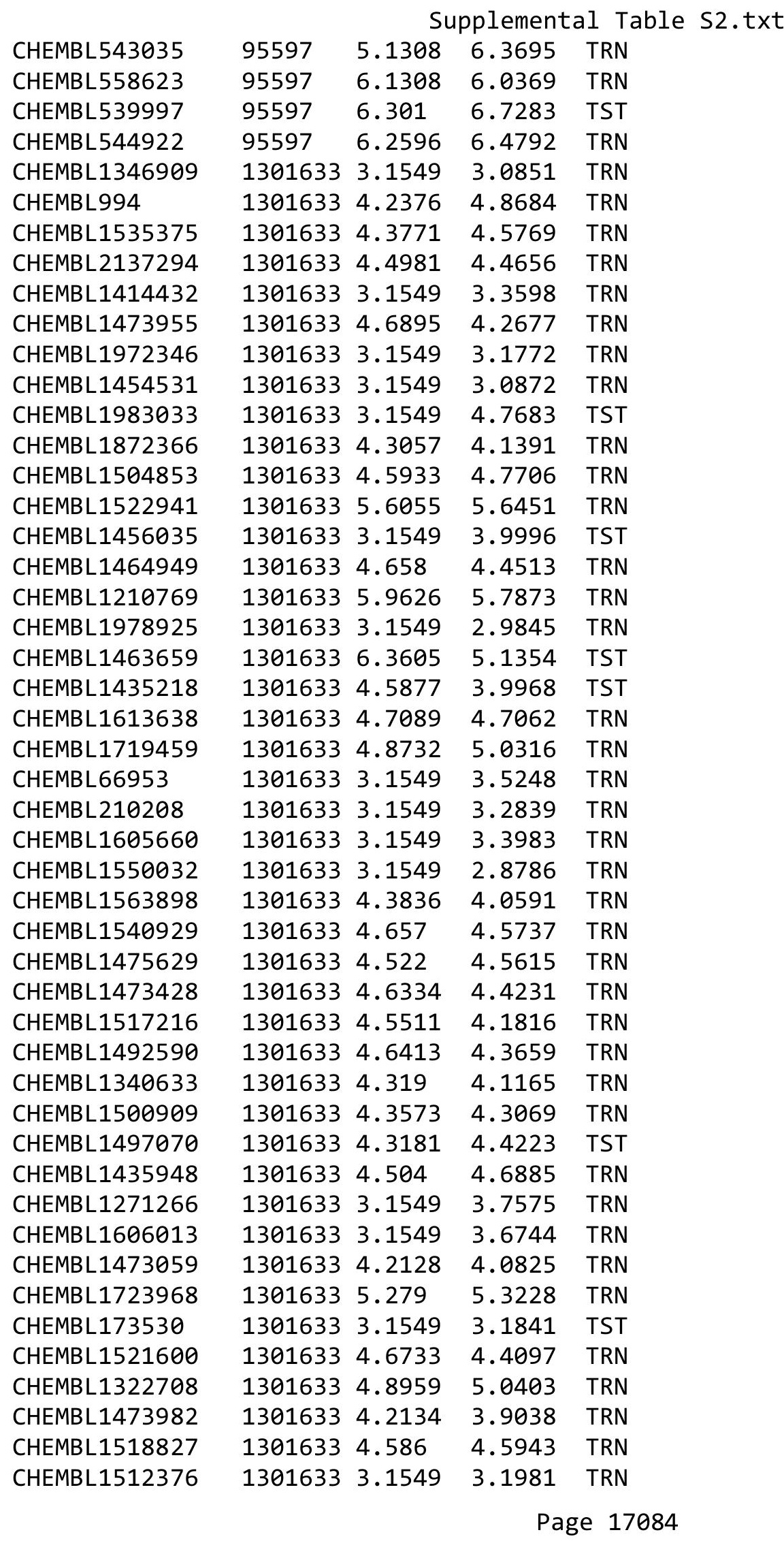


Supplemental Table S2.txt

\begin{tabular}{|c|c|c|c|c|c|}
\hline CHEMBL1520233 & 1301633 & 4.4274 & 4.2925 & TRN & \\
\hline CHEMBL1478064 & 1301633 & 4.3363 & 3.7905 & TRN & \\
\hline CHEMBL1878046 & 1301633 & 4.6786 & 4.8457 & TRN & \\
\hline CHEMBL1397916 & 1301633 & 3.1549 & 3.5525 & TRN & \\
\hline CHEMBL1434555 & 1301633 & 3.1549 & 3.319 & TRN & \\
\hline CHEMBL1707033 & 1301633 & 5.2118 & 5.3071 & TST & \\
\hline CHEMBL1475961 & 1301633 & 4.7305 & 4.6105 & TST & \\
\hline CHEMBL1436778 & 1301633 & 4.7547 & 4.4983 & TST & \\
\hline CHEMBL1376200 & 1301633 & 3.1549 & 3.9495 & TST & \\
\hline CHEMBL1364567 & 1301633 & 3.1549 & 3.4857 & TST & \\
\hline CHEMBL1458444 & 1301633 & 4.6931 & 4.1873 & TST & \\
\hline CHEMBL1434792 & 1301633 & 4.6242 & 4.1762 & TST & \\
\hline CHEMBL1562896 & 1301633 & 4.2309 & 3.7313 & TST & \\
\hline CHEMBL1325945 & 1301633 & 6.5086 & 4.5992 & TST & \\
\hline CHEMBL3957613 & 1640415 & 7.2757 & 6.8254 & TST & \\
\hline CHEMBL3963796 & 1640415 & 7.9586 & 6.7943 & TST & \\
\hline CHEMBL3910641 & 1640415 & 5.5941 & 5.7875 & TRN & \\
\hline CHEMBL3961584 & 1640415 & 5.4536 & 5.9895 & TRN & \\
\hline CHEMBL3890409 & 1640415 & 6.9914 & 6.9627 & TRN & \\
\hline CHEMBL3925829 & 1640415 & 7.7959 & 6.8995 & TST & \\
\hline CHEMBL3925202 & 1640415 & 5.53299 & 99999999 & 995 & 5.9309 \\
\hline CHEMBL3895643 & 1640415 & 6.7747 & 6.8583 & TST & \\
\hline CHEMBL3963586 & 1640415 & 6.0 & 6.13 & TRN & \\
\hline CHEMBL3970305 & 1640415 & 5.5661 & 6.729 & TST & \\
\hline CHEMBL3920363 & 1640415 & 6.1403 & 6.7112 & TST & \\
\hline CHEMBL3892785 & 1640415 & 6.58 & 6.121 & TRN & \\
\hline CHEMBL3986742 & 1640415 & 7.4949 & 6.6812 & TRN & \\
\hline CHEMBL3945212 & 1640415 & 5.8342 & 6.9183 & TRN & \\
\hline CHEMBL3918184 & 1640415 & 5.1919 & 5.5477 & TRN & \\
\hline CHEMBL3967669 & 1640415 & 6.059 & 6.0955 & TRN & \\
\hline CHEMBL3929176 & 1640415 & 8.0458 & 7.165 & TRN & \\
\hline CHEMBL3962910 & 1640415 & 5.5369 & 5.5984 & TRN & \\
\hline CHEMBL3955972 & 1640415 & 6.0888 & 6.6609 & TRN & \\
\hline CHEMBL3900395 & 1640415 & 5.4772 & 6.5225 & TST & \\
\hline CHEMBL3911689 & 1640415 & 6.3851 & 6.7702 & TRN & \\
\hline CHEMBL3894666 & 1640415 & 7.0315 & 6.7628 & TST & \\
\hline CHEMBL3897522 & 1640415 & 7.4949 & 6.8533 & TRN & \\
\hline CHEMBL3897024 & 1640415 & 7.3665 & 6.8606 & TST & \\
\hline CHEMBL 3924256 & 1640415 & 5.9296 & 6.8442 & TST & \\
\hline CHEMBL3911572 & 1640415 & 6.4214 & 6.7517 & TRN & \\
\hline CHEMBL3907985 & 1640415 & 6.8962 & 6.7171 & TRN & \\
\hline CHEMBL3934122 & 1640415 & 6.5607 & 6.9363 & TRN & \\
\hline CHEMBL3917264 & 1640415 & 6.0 & 6.87 & TST & \\
\hline CHEMBL3977537 & 1640415 & 6.0 & 6.4128 & TST & \\
\hline CHEMBL3948419 & 1640415 & 6.5884 & 6.6717 & TRN & \\
\hline CHEMBL3979985 & 1640415 & 7.3279 & 6.6663 & TST & \\
\hline CHEMBL3953899 & 1640415 & 5.4614 & 5.3403 & TRN & \\
\hline CHEMBL3912704 & 1640415 & 5.0348 & 5.8855 & TRN & \\
\hline
\end{tabular}


Supplemental Table S2.txt

\begin{tabular}{|c|c|c|c|c|}
\hline 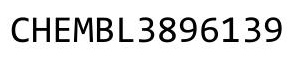 & & & 5.99 & \\
\hline HEMBL3915226 & & 5.2394 & ᄃ 241 & \\
\hline & & & & \\
\hline 00943 & 15 & & & \\
\hline AEMBL3893559 & 540415 & 2449 & 7205 & \\
\hline AEMBL3950677 & 640415 & 6.9393 & 039 & \\
\hline HEMBL3934758 & 15 & 969 & 9092 & \\
\hline 957395 & 5 & & 5292 & \\
\hline IEMBL 3955595 & 5 & & .1423 & \\
\hline AEMBL3902531 & 640 & 6.12 & .8997 & \\
\hline HEMBL3893594 & 640 & 6.0 & 9294 & \\
\hline AEMBL3926254 & 546 & 395 & 1236 & \\
\hline AEM & & & & \\
\hline HEMBL3897196 & 5 & & .8586 & \\
\hline AEMBL3902676 & 5 & 757 & 8614 & \\
\hline HEMBL3898522 & כ & 069 & 8378 & \\
\hline HEMBL3899052 & 15 & 864 & 412 & \\
\hline HEMBL 3924 & & 726 & & \\
\hline HEMBL 3892 & & 366 & 3041 & \\
\hline HEMBL 394 & 5 & 51 & 9343 & \\
\hline HEMBL 3963629 & 5 & 5.7314 & 3863 & KIV \\
\hline HEMBL3S & 5 & 188 & 67 & \\
\hline HEMBL3S & & 556 & 27 & \\
\hline 93 & & & 95 & \\
\hline AEMBL 3962 & 64 & 362 & 34 & RIN \\
\hline MBL392 & 5 & 36 & 992 & RN \\
\hline L391 & 5 & 253 & 606 & \\
\hline 30 & & & & RN \\
\hline HEMBL397 & 5 & & & TRN \\
\hline AEMBL39201 & 64 & 4 & 153 & RN \\
\hline IEMBL39 & 64 & 42 & 5.47 & ST \\
\hline 8 & & & 352 & RN \\
\hline 5 & & & & RN \\
\hline HEMBL3910 & & & 117 & ST \\
\hline AEMBL3964 & 64 & & .097 & RN \\
\hline IEMBL397 & 64 & & 55 & \\
\hline 2 & & 72 & & ST \\
\hline & & 6 . & 156 & $\mathrm{RN}$ \\
\hline HEMBL3973375 & 15 & 7.6778 & 7.0025 & TRN \\
\hline AEMBL 39842 & 64 & 61 & 5.9687 & RN \\
\hline HEMBL3953 & 64 & 5.2687 & 5.7194 & 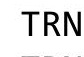 \\
\hline HEMBL3926996 & & & & RN \\
\hline HEMBL3981 & 5 & 7.8539 & 6.8171 & TRN \\
\hline HEMBL3955834 & 640 & 6.0872 & 5.8483 & TRN \\
\hline 390 & $c$ & 3013 & 6.7507 & IS \\
\hline HEMBL 3946 & 1640 & 5.0964 & 5.4605 & \\
\hline CHEMBL3916974 & 1640 & 6.2487 & 5.5843 & \\
\hline CHEMBL3969862 & 1640415 & 6.7696 & 6.6142 & RN \\
\hline
\end{tabular}

Page 17086 
Supplemental Table S2.txt

\begin{tabular}{|c|c|c|c|c|c|}
\hline CHEMBL 3937187 & 1640415 & 7.699 & 6.7808 & TRN & \\
\hline CHEMBL 3921695 & 1640415 & 5.2313 & 5.3409 & TRN & \\
\hline CHEMBL 3893112 & 1640415 & 6.1838 & 6.4638 & TST & \\
\hline CHEMBL 3916973 & 1640415 & 7.2007 & 6.6927 & TRN & \\
\hline CHEMBL3915290 & 1640415 & 6.1831 & 5.9687 & TRN & \\
\hline CHEMBL 3967703 & 1640415 & 5.8187 & 6.7359 & TST & \\
\hline CHEMBL 3901602 & 1640415 & 5.669 & 6.5904 & TRN & \\
\hline CHEMBL 3890110 & 1640415 & 6.51 & 6.0998 & TRN & \\
\hline CHEMBL 3961967 & 1640415 & 7.0506 & 6.909 & TRN & \\
\hline CHEMBL 3908603 & 1640415 & 5.1191 & 5.7019 & TRN & \\
\hline CHEMBL 3911717 & 1640415 & 7.4318 & 6.8906 & TRN & \\
\hline CHEMBL 3954459 & 1640415 & 7.6198 & 6.7807 & TST & \\
\hline CHEMBL 3930301 & 1640415 & 5.8871 & 6.2651 & TRN & \\
\hline CHEMBL 3906382 & 1640415 & 7.6576 & 6.8478 & TRN & \\
\hline CHEMBL 3930463 & 1640415 & 7.4685 & 6.8662 & TST & \\
\hline CHEMBL 3981701 & 1640415 & 5.82100 & 00000000 & 1 & 5.5883 \\
\hline CHEMBL 3895659 & 1640415 & 7.3188 & 6.8248 & TRN & \\
\hline CHEMBL 3907612 & 1640415 & 6.129 & 6.7272 & TRN & \\
\hline CHEMBL 3931860 & 1640415 & 6.0 & 5.9879 & TRN & \\
\hline CHEMBL 3934088 & 1640415 & 6.0 & 5.9833 & TRN & \\
\hline CHEMBL 3943482 & 1640415 & 6.0 & 6.0663 & TRN & \\
\hline CHEMBL 3901434 & 1640415 & 6.3215 & 6.6192 & TRN & \\
\hline CHEMBL3981739 & 1640415 & 5.8887 & 5.2714 & TRN & \\
\hline CHEMBL 3985062 & 1640415 & 5.2841 & 6.0392 & TRN & \\
\hline CHEMBL 3946062 & 1640415 & 5.5988 & 5.6124 & TRN & \\
\hline CHEMBL 2441599 & 1640415 & 4.4772 & 6.8194 & TST & \\
\hline CHEMBL 3955945 & 1640415 & 6.8069 & 6.7939 & TRN & \\
\hline CHEMBL 3923625 & 1640415 & 5.7617 & 5.5019 & TRN & \\
\hline CHEMBL 3978458 & 1640415 & 6.0 & 6.4987 & TRN & \\
\hline CHEMBL 3967083 & 1640415 & 7.5528 & 6.7593 & TRN & \\
\hline CHEMBL 3970154 & 1640415 & 6.06 & 5.8227 & TRN & \\
\hline CHEMBL 3977988 & 1640415 & 6.3947 & 5.886 & TRN & \\
\hline CHEMBL 3970593 & 1640415 & 7.4437 & 6.8128 & TST & \\
\hline CHEMBL 3932589 & 1640415 & 7.9586 & 7.0447 & TRN & \\
\hline CHEMBL 3939662 & 1640415 & 5.1838 & 6.7385 & TRN & \\
\hline CHEMBL3940699 & 1640415 & 5.1236 & 5.9605 & TRN & \\
\hline CHEMBL 3982608 & 1640415 & 5.7438 & 5.2714 & TRN & \\
\hline CHEMBL 3964622 & 1640415 & 6.0 & 5.7875 & TRN & \\
\hline CHEMBL 3956480 & 1640415 & 7.0223 & 6.8782 & TRN & \\
\hline CHEMBL 3289978 & 1366807 & 9.0969 & 8.845 & TRN & \\
\hline CHEMBL 3289709 & 1366807 & 8.7696 & 8.8509 & TRN & \\
\hline CHEMBL 3289993 & 1366807 & 8.9208 & 8.8334 & TRN & \\
\hline CHEMBL3290016 & 1366807 & 9.699 & 8.9094 & TST & \\
\hline CHEMBL 3289973 & 1366807 & 6.4202 & 6.746 & TST & \\
\hline CHEMBL 3290012 & 1366807 & 8.7959 & 8.704 & TRN & \\
\hline CHEMBL3289996 & 1366807 & 8.3565 & 8.399 & TRN & \\
\hline CHEMBL 3286432 & 1366807 & 8.2757 & 8.2429 & TRN & \\
\hline CHEMBL3289975 & 1366807 & 7.0269 & 6.289 & TST & \\
\hline
\end{tabular}


Supplemental Table S2.txt

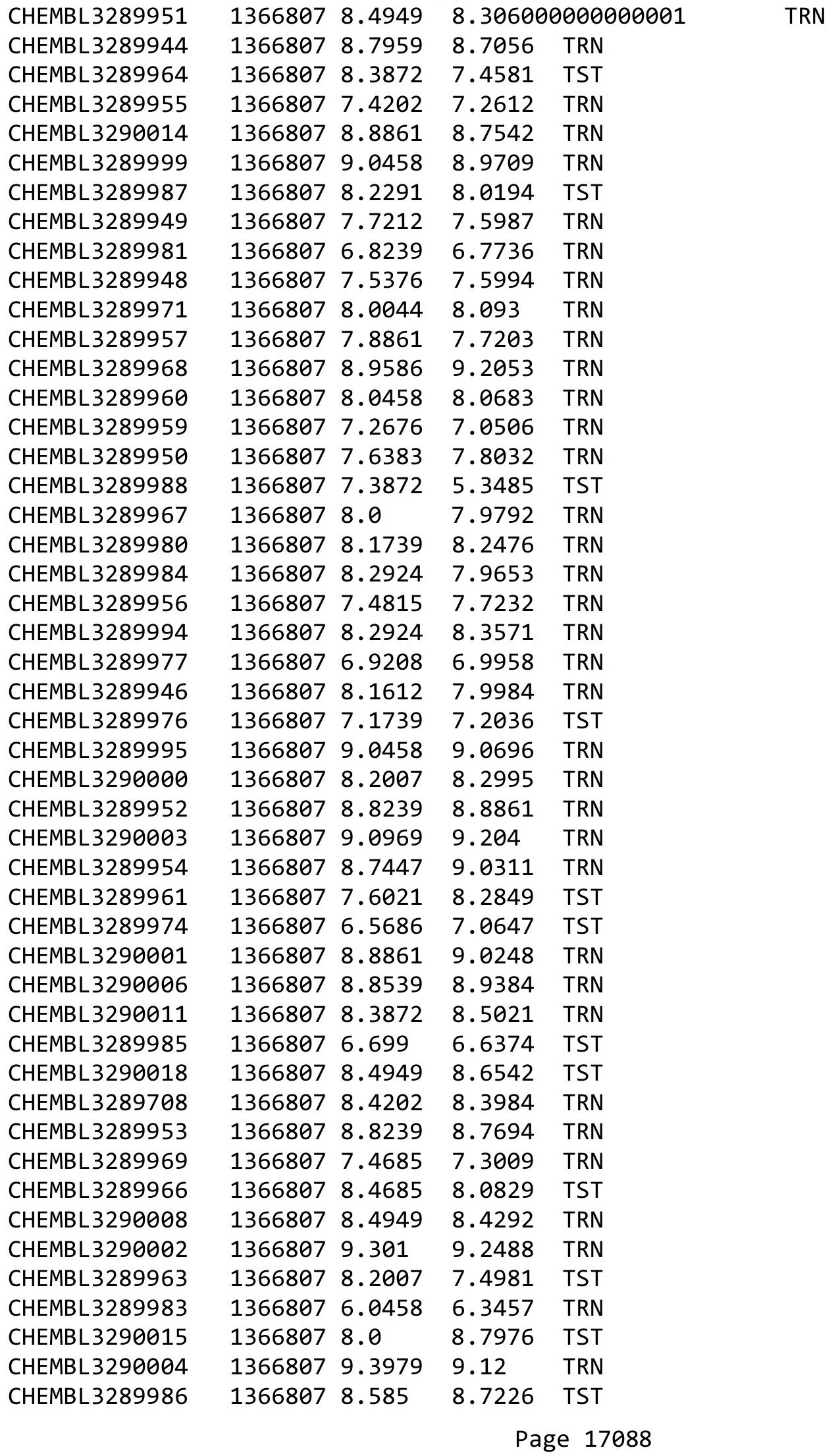


Supplemental Table S2.txt

\begin{tabular}{|c|c|c|c|c|}
\hline CHEMBL3289947 & 1366807 & 8.0223 & 8.0416 & TRN \\
\hline CHEMBL3289992 & 1366807 & 8.8239 & 8.5417 & TRN \\
\hline CHEMBL3289990 & 1366807 & 8.9586 & 8.9121 & TRN \\
\hline CHEMBL3289972 & 1366807 & 10.0 & 9.9312 & TRN \\
\hline CHEMBL3290005 & 1366807 & 9.0969 & 9.0836 & TRN \\
\hline CHEMBL3289945 & 1366807 & 7.699 & 7.8282 & TRN \\
\hline CHEMBL3289962 & 1366807 & 8.3372 & 8.4514 & TST \\
\hline CHEMBL3290013 & 1366807 & 7.4685 & 7.7398 & TRN \\
\hline CHEMBL3290010 & 1366807 & 8.3665 & 8.307 & TRN \\
\hline CHEMBL3289989 & 1366807 & 7.2441 & 5.7381 & TST \\
\hline CHEMBL3290019 & 1366807 & 7.8539 & 7.8874 & TST \\
\hline CHEMBL3289991 & 1366807 & 9.2218 & 9.3205 & TRN \\
\hline CHEMBL3289970 & 1366807 & 9.1549 & 9.3033 & TRN \\
\hline CHEMBL3289979 & 1366807 & 5.6021 & 5.5035 & TRN \\
\hline CHEMBL 3290017 & 1366807 & 9.1549 & 9.15 & TST \\
\hline CHEMBL 3290021 & 1366807 & 7.8861 & 8.1336 & TRN \\
\hline CHEMBL3289998 & 1366807 & 7.8239 & 7.7469 & TRN \\
\hline CHEMBL 3290007 & 1366807 & 7.7447 & 7.8176 & TRN \\
\hline CHEMBL3289958 & 1366807 & 8.0044 & 8.1322 & TRN \\
\hline CHEMBL3289982 & 1366807 & 6.7447 & 6.8251 & TRN \\
\hline CHEMBL3289997 & 1366807 & 8.0555 & 8.2048 & TRN \\
\hline CHEMBL 3289965 & 1366807 & 8.699 & 8.4024 & TST \\
\hline CHEMBL 3290020 & 1366807 & 8.8861 & 8.6222 & TRN \\
\hline CHEMBL3290009 & 1366807 & 9.0458 & 8.7208 & TST \\
\hline CHEMBL249249 & 459971 & 4.2147 & 3.2311 & TRN \\
\hline CHEMBL250058 & 459971 & 3.8962 & 4.1165 & TRN \\
\hline CHEMBL399908 & 459971 & 4.0177 & 3.9865 & TRN \\
\hline CHEMBL251425 & 459971 & 3.8697 & 3.93300 & 0000000003 \\
\hline CHEMBL253373 & 459971 & 4.1675 & 4.1268 & TRN \\
\hline CHEMBL253172 & 459971 & 3.9788 & 4.1165 & TRN \\
\hline CHEMBL 253820 & 459971 & 4.2007 & 4.2679 & TRN \\
\hline CHEMBL253605 & 459971 & 4.5086 & 4.3767 & TRN \\
\hline CHEMBL399997 & 459971 & 2.8239 & 3.7193 & TRN \\
\hline CHEMBL404205 & 459971 & 3.8356 & 3.8903 & TST \\
\hline CHEMBL254821 & 459971 & 4.1192 & 4.0049 & TST \\
\hline CHEMBL252522 & 459971 & 3.9318 & 3.8512 & TRN \\
\hline CHEMBL251081 & 459971 & 3.9393 & 4.0313 & TRN \\
\hline CHEMBL399070 & 459971 & 4.1612 & 4.0977 & TRN \\
\hline CHEMBL250070 & 459971 & 3.9626 & 3.9457 & TRN \\
\hline CHEMBL249859 & 459971 & 3.9788 & 4.0098 & TRN \\
\hline CHEMBL445939 & 459971 & 4.1739 & 4.0601 & TST \\
\hline CHEMBL251423 & 459971 & 2.8239 & 3.5734 & TRN \\
\hline CHEMBL251465 & 459971 & 2.8239 & 3.3892 & TST \\
\hline CHEMBL251426 & 459971 & 4.284 & 4.0454 & TRN \\
\hline CHEMBL398892 & 459971 & 4.7959 & 4.3831 & TRN \\
\hline CHEMBL399685 & 459971 & 4.1675 & 4.0072 & TRN \\
\hline CHEMBL1162966 & 459971 & 4.1938 & 4.1367 & TRN \\
\hline CHEMBL254448 & 459971 & 3.9788 & 4.0953 & TRN \\
\hline
\end{tabular}

Page 17089 
Supplemental Table S2.txt

\begin{tabular}{|c|c|c|c|c|}
\hline CHEMBL252523 & 459971 & 4.0706 & 3.8674 & TRN \\
\hline CHEMBL400358 & 459971 & 2.8239 & 3.3868 & TST \\
\hline CHEMBL251424 & 459971 & 3.9957 & 3.8494 & TRN \\
\hline CHEMBL254006 & 459971 & 4.0862 & 4.2624 & TRN \\
\hline CHEMBL438519 & 459971 & 4.1024 & 4.1223 & TRN \\
\hline CHEMBL254837 & 459971 & 4.1487 & 4.1327 & TRN \\
\hline CHEMBL254627 & 459971 & 4.1739 & 4.1553 & TRN \\
\hline CHEMBL252327 & 459971 & 2.8239 & 3.863 & TST \\
\hline CHEMBL253372 & 459971 & 4.0862 & 4.1365 & TRN \\
\hline CHEMBL398838 & 459971 & 4.2076 & 4.1318 & TST \\
\hline CHEMBL399504 & 459971 & 3.9547 & 3.7726 & TST \\
\hline CHEMBL400449 & 459971 & 4.7696 & 4.2183 & TRN \\
\hline CHEMBL253375 & 459971 & 4.2218 & 4.2704 & TRN \\
\hline CHEMBL250057 & 459971 & 3.9508 & 4.126 & TRN \\
\hline CHEMBL255051 & 459971 & 4.1675 & 4.0107 & TRN \\
\hline CHEMBL250059 & 459971 & 3.9747 & 4.1407 & TRN \\
\hline CHEMBL254404 & 459971 & 4.0915 & 4.0289 & TRN \\
\hline CHEMBL254239 & 459971 & 4.3565 & 3.9347 & TRN \\
\hline CHEMBL253823 & 459971 & 4.3372 & 4.3134 & TRN \\
\hline CHEMBL399304 & 459971 & 4.0 & 4.3672 & TRN \\
\hline CHEMBL254238 & 459971 & 4.3279 & \multicolumn{2}{|c|}{4.196000000000001} \\
\hline CHEMBL399998 & 459971 & 2.8239 & 3.5098 & TST \\
\hline CHEMBL252965 & 459971 & 4.1612 & 4.2503 & TRN \\
\hline CHEMBL399684 & 459971 & 4.699 & 4.3751 & TRN \\
\hline CHEMBL399999 & 459971 & 4.0315 & 3.9676 & TRN \\
\hline CHEMBL 254405 & 459971 & 3.8729 & 4.0597 & TRN \\
\hline CHEMBL253188 & 459971 & 4.0132 & 4.0082 & TST \\
\hline CHEMBL254406 & 459971 & 4.1079 & 4.1111 & TRN \\
\hline CHEMBL249862 & 459971 & 2.8239 & 2.968 & TRN \\
\hline CHEMBL398450 & 459971 & 4.2518 & 4.2917 & TRN \\
\hline CHEMBL 254240 & 459971 & 4.5086 & \multicolumn{2}{|c|}{ 4. 2219999999999995} \\
\hline CHEMBL253835 & 459971 & 4.0044 & 4.2232 & TRN \\
\hline CHEMBL249860 & 459971 & 2.8239 & 3.2412 & TST \\
\hline CHEMBL252326 & 459971 & 4.1675 & 4.1643 & TRN \\
\hline CHEMBL428762 & 459971 & 2.8239 & 3.5394 & TST \\
\hline CHEMBL253801 & 459971 & 4.1612 & 4.2051 & TRN \\
\hline CHEMBL249863 & 459971 & 2.8239 & 2.985 & TRN \\
\hline CHEMBL254611 & 459971 & 3.821 & 4.2167 & TRN \\
\hline CHEMBL442286 & 459971 & 4.0605 & 3.8868 & TST \\
\hline CHEMBL254657 & 459971 & 4.1549 & 4.096 & TRN \\
\hline CHEMBL398662 & 459971 & 4.0269 & 3.9595 & TRN \\
\hline CHEMBL400850 & 459971 & 2.8239 & 3.2394 & TST \\
\hline CHEMBL253374 & 459971 & 4.1871 & 4.2978 & TRN \\
\hline CHEMBL250069 & 459971 & 4.1487 & 4.0383 & TRN \\
\hline CHEMBL254610 & 459971 & 4.1079 & 3.9844 & TRN \\
\hline CHEMBL251937 & 459971 & 4.2924 & 4.0286 & TST \\
\hline CHEMBL253189 & 459971 & 3.9788 & 4.0304 & TRN \\
\hline CHEMBL400851 & 459971 & 2.8239 & 3.0087 & TST \\
\hline
\end{tabular}

Page 17090 


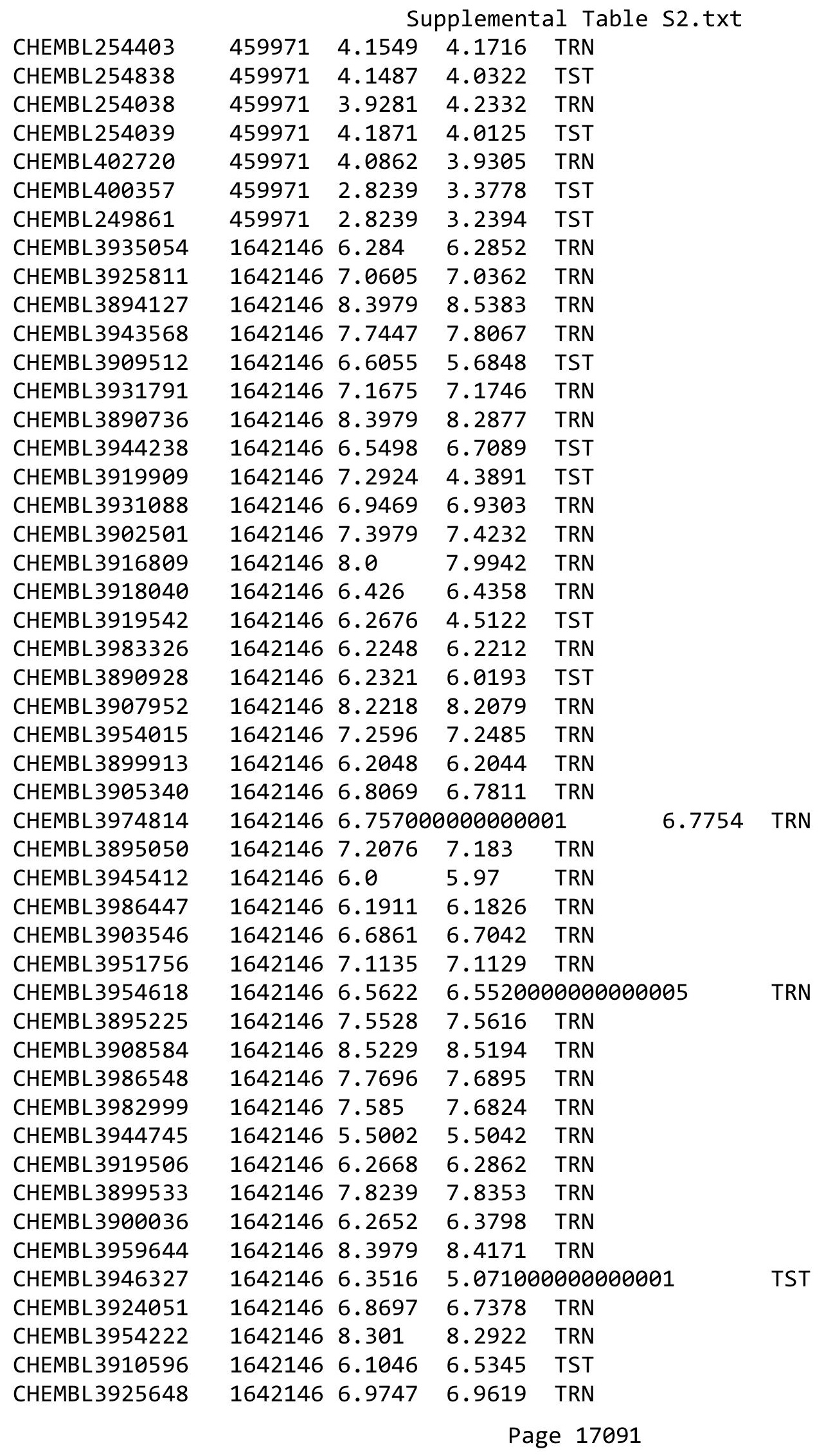


Supplemental Table S2.txt

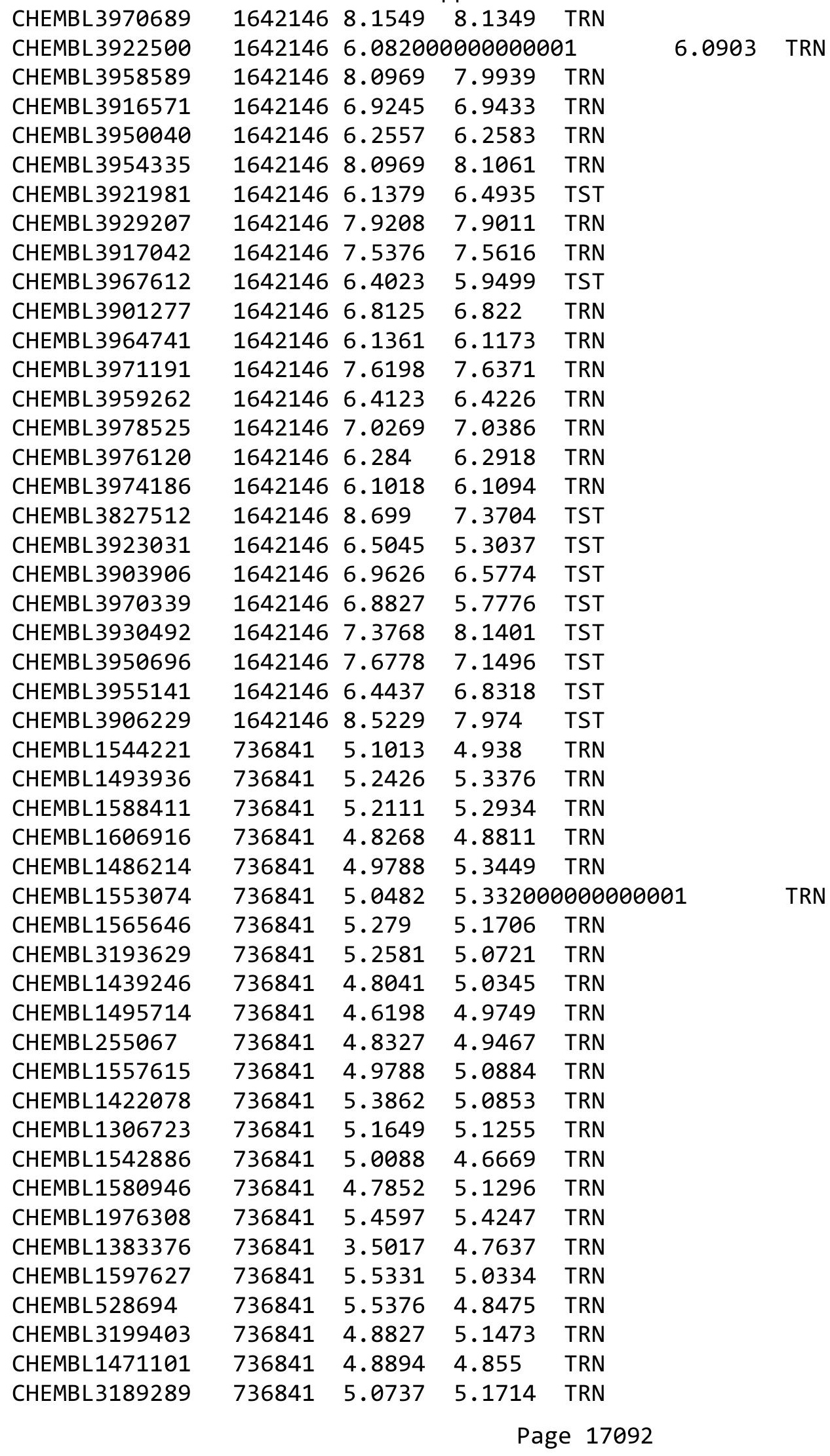




\begin{tabular}{|c|c|c|c|c|c|c|}
\hline & & \multicolumn{5}{|c|}{ Supplemental Table S2.txt } \\
\hline CHEMBL3212029 & 736841 & 5.2083 & 5.2609 & TRN & & \\
\hline CHEMBL 3195898 & 736841 & 5.426 & 5.2532 & TRN & & \\
\hline CHEMBL1428935 & 736841 & 5.4389 & 5.3654 & TST & & \\
\hline CHEMBL3192235 & 736841 & 5.3072 & 4.9375 & TRN & & \\
\hline CHEMBL1487635 & 736841 & 5.5901 & 5.7657 & TRN & & \\
\hline CHEMBL 3145316 & 736841 & 5.1993 & 5.5914 & TST & & \\
\hline CHEMBL1529511 & 736841 & 4.6655 & 4.9748 & TST & & \\
\hline CHEMBL1405968 & 736841 & 5.7258 & 5.0853 & TRN & & \\
\hline CHEMBL1522851 & 736841 & 4.857 & 5.314 & TRN & & \\
\hline CHEMBL1368523 & 736841 & 4.8069 & 4.9226 & TRN & & \\
\hline CHEMBL1445491 & 736841 & 5.5498 & 4.9255 & TRN & & \\
\hline CHEMBL1572356 & 736841 & 5.1337 & 5.0031 & TRN & & \\
\hline CHEMBL1578607 & 736841 & 5.2565 & 5.1416 & TRN & & \\
\hline CHEMBL270605 & 736841 & 5.1057 & 5.7198 & TRN & & \\
\hline CHEMBL1510156 & 736841 & 5.6696 & 5.2017 & TST & & \\
\hline CHEMBL1539624 & 736841 & 5.3072 & 5.2958 & TRN & & \\
\hline CHEMBL1578482 & 736841 & 5.3134 & 5.3873 & TRN & & \\
\hline CHEMBL1307050 & 736841 & 4.8633 & 5.1398 & TRN & & \\
\hline CHEMBL3195226 & 736841 & 4.9547 & 5.2329 & TRN & & \\
\hline CHEMBL1987579 & 736841 & 5.8013 & 5.5345 & TRN & & \\
\hline CHEMBL1420325 & 736841 & 5.3354 & 5.0456 & TST & & \\
\hline CHEMBL3195760 & 736841 & \multicolumn{3}{|c|}{5.4510000000000005} & 5.1288 & TRN \\
\hline CHEMBL1576301 & 736841 & 7.0088 & 6.8703 & TRN & & \\
\hline CHEMBL 1456130 & 736841 & 5.266 & 5.0415 & TST & & \\
\hline CHEMBL1385690 & 736841 & \multicolumn{3}{|c|}{5.2620000000000005} & 5.2337 & TRN \\
\hline CHEMBL 3192432 & 736841 & 5.9747 & 5.3204 & TRN & & \\
\hline CHEMBL1455045 & 736841 & 5.6635 & 5.2246 & TRN & & \\
\hline CHEMBL428064 & 736841 & 5.8861 & 5.4734 & TRN & & \\
\hline CHEMBL1979954 & 736841 & 4.6536 & 4.878 & TST & & \\
\hline CHEMBL1579152 & 736841 & 4.7932 & 5.1327 & TST & & \\
\hline CHEMBL1310734 & 736841 & 4.9987 & 4.7373 & TST & & \\
\hline CHEMBL1490336 & 736841 & 5.1864 & 4.9912 & TRN & & \\
\hline CHEMBL1560839 & 736841 & 7.0088 & 6.5102 & TRN & & \\
\hline CHEMBL1299526 & 736841 & 4.8894 & 5.0407 & TST & & \\
\hline CHEMBL546170 & 736841 & 5.7905 & 4.8655 & TRN & & \\
\hline CHEMBL1391094 & 736841 & 5.0835 & 5.0873 & TST & & \\
\hline CHEMBL1309573 & 736841 & 5.3372 & 5.0021 & TRN & & \\
\hline CHEMBL3196139 & 736841 & 4.8356 & 4.8149 & TRN & & \\
\hline CHEMBL1344225 & 736841 & 5.4248 & 5.1591 & TRN & & \\
\hline CHEMBL1572001 & 736841 & 5.4342 & 5.25299 & 9999999999 & & TRN \\
\hline CHEMBL1976317 & 736841 & 5.0306 & 5.9181 & TRN & & \\
\hline CHEMBL1586491 & 736841 & 4.8416 & 4.9816 & TRN & & \\
\hline CHEMBL1417204 & 736841 & 4.6421 & 4.8468 & TRN & & \\
\hline CHEMBL1455427 & 736841 & 4.9788 & 5.2187 & TRN & & \\
\hline CHEMBL1323553 & 736841 & 5.0696 & 5.6946 & TRN & & \\
\hline CHEMBL1458833 & 736841 & 5.1415 & 4.9622 & TRN & & \\
\hline CHEMBL1558590 & 736841 & 5.3335 & 5.1087 & TST & & \\
\hline CHEMBL3199851 & 736841 & 5.0438 & 4.8674 & TRN & & \\
\hline
\end{tabular}




\begin{tabular}{|c|c|c|c|c|c|c|}
\hline \multirow[b]{2}{*}{ CHEMBL1304363 } & \multicolumn{6}{|c|}{ Supplemental Table S2.txt } \\
\hline & 736841 & 3.5017 & 4.668 & TRN & & \\
\hline CHEMBL1463088 & 736841 & 5.06800 & 30000000 & 205 & 5.154 & TRN \\
\hline CHEMBL1311879 & 736841 & 5.6345 & 5.2066 & TRN & & \\
\hline CHEMBL 3210072 & 736841 & 5.4962 & 5.2544 & TRN & & \\
\hline CHEMBL1302178 & 736841 & 4.8761 & 4.7498 & TRN & & \\
\hline CHEMBL1522211 & 736841 & 5.0996 & 4.6802 & TRN & & \\
\hline CHEMBL1383537 & 736841 & 4.8928 & 4.9514 & TRN & & \\
\hline CHEMBL1368060 & 736841 & 4.5969 & 5.0227 & TRN & & \\
\hline CHEMBL1557648 & 736841 & 5.1624 & 4.9151 & TRN & & \\
\hline CHEMBL1462003 & 736841 & 5.0164 & 4.8541 & TRN & & \\
\hline CHEMBL1375133 & 736841 & 4.9469 & 5.059 & TST & & \\
\hline CHEMBL1421427 & 736841 & 4.8239 & 4.6667 & TRN & & \\
\hline CHEMBL2373602 & 736841 & 6.1558 & 5.1615 & TST & & \\
\hline CHEMBL1485010 & 736841 & 4.7258 & 4.8594 & TST & & \\
\hline CHEMBL1411665 & 736841 & 5.2782 & 5.1482 & TRN & & \\
\hline CHEMBL1448582 & 736841 & 5.0241 & 5.1116 & TRN & & \\
\hline CHEMBL3198868 & 736841 & 4.8996 & 4.7624 & TRN & & \\
\hline CHEMBL1350780 & 736841 & 5.2277 & 5.5376 & TRN & & \\
\hline CHEMBL3199359 & 736841 & 5.0155 & 5.005 & TST & & \\
\hline CHEMBL455284 & 736841 & 5.4855 & 5.23600 & 0000000001 & & TRN \\
\hline CHEMBL1965132 & 736841 & 5.1018 & 4.7324 & TRN & & \\
\hline CHEMBL1311831 & 736841 & 5.5003 & 5.1102 & TRN & & \\
\hline CHEMBL1562926 & 736841 & 5.301 & 4.7292 & TRN & & \\
\hline CHEMBL1585944 & 736841 & 6.1524 & 5.0664 & TST & & \\
\hline CHEMBL1311826 & 736841 & 3.5017 & 5.2095 & TRN & & \\
\hline CHEMBL1542074 & 736841 & 3.5017 & 3.9941 & TRN & & \\
\hline CHEMBL1302391 & 736841 & 5.1141 & 5.9145 & TRN & & \\
\hline CHEMBL2094567 & 736841 & 5.5528 & 5.3852 & TRN & & \\
\hline CHEMBL1456232 & 736841 & 4.9431 & 5.0475 & TRN & & \\
\hline CHEMBL1981951 & 736841 & 5.0241 & 5.0466 & TST & & \\
\hline CHEMBL3189245 & 736841 & 5.0675 & 5.2321 & TRN & & \\
\hline CHEMBL1598011 & 736841 & 5.082 & 5.0867 & TST & & \\
\hline CHEMBL1337227 & 736841 & 5.2588 & 5.189 & TST & & \\
\hline CHEMBL1426792 & 736841 & 5.2269 & 5.1279 & TST & & \\
\hline CHEMBL1384550 & 736841 & 5.0615 & 5.5048 & TRN & & \\
\hline CHEMBL1334809 & 736841 & 4.9626 & 4.8797 & TST & & \\
\hline CHEMBL534353 & 736841 & 3.5017 & 4.2303 & TRN & & \\
\hline CHEMBL1421770 & 736841 & 5.4789 & 4.8216 & TST & & \\
\hline CHEMBL3193056 & 736841 & 4.9957 & 5.3844 & TRN & & \\
\hline CHEMBL1324005 & 736841 & 5.2457 & 5.0726 & TRN & & \\
\hline CHEMBL1545369 & 736841 & 5.1331 & 4.9588 & TRN & & \\
\hline CHEMBL1596609 & 736841 & 4.8794 & 4.8858 & TRN & & \\
\hline CHEMBL1464745 & 736841 & 5.1135 & 5.1753 & TRN & & \\
\hline CHEMBL1497139 & 736841 & 5.3458 & 5.1335 & TST & & \\
\hline CHEMBL1491626 & 736841 & 5.3036 & 5.0043 & TRN & & \\
\hline CHEMBL1423597 & 736841 & 5.1421 & 5.3233 & TRN & & \\
\hline CHEMBL1492017 & 736841 & 5.1475 & 5.1475 & TRN & & \\
\hline CHEMBL1998521 & 736841 & 3.5017 & 4.9899 & TRN & & \\
\hline
\end{tabular}

Page 17094 


\begin{tabular}{|c|c|c|c|c|}
\hline \multicolumn{5}{|c|}{ Supplemental Table S2.txt } \\
\hline CHEMBL1597655 & 736841 & 4.8539 & 4.9111 & TRN \\
\hline CHEMBL1460585 & 736841 & 4.9101 & 4.9855 & TRN \\
\hline CHEMBL1387605 & 736841 & 5.7471 & 5.1685 & TRN \\
\hline CHEMBL1351467 & 736841 & 4.7375 & 5.0756 & TRN \\
\hline CHEMBL1455766 & 736841 & 6.0419 & 5.4145 & TRN \\
\hline CHEMBL1310782 & 736841 & 5.1302 & 5.2286 & TRN \\
\hline CHEMBL1610025 & 736841 & 5.0883 & 5.3842 & TRN \\
\hline CHEMBL1377737 & 736841 & 5.2823 & 5.0332 & TRN \\
\hline CHEMBL1460705 & 736841 & 5.3516 & 4.6643 & TRN \\
\hline CHEMBL1427431 & 736841 & 4.9245 & 5.0975 & TRN \\
\hline CHEMBL1353124 & 736841 & 3.5017 & 4.4835 & TRN \\
\hline CHEMBL1301723 & 736841 & 5.3134 & 5.0467 & TST \\
\hline CHEMBL1332111 & 736841 & 5.059 & 4.9329 & TRN \\
\hline CHEMBL 3145108 & 736841 & 5.0419 & 5.151 & TRN \\
\hline CHEMBL1387060 & 736841 & 5.0947 & 5.0147 & TRN \\
\hline CHEMBL1400298 & 736841 & 5.2907 & 5.1879 & TRN \\
\hline CHEMBL3190827 & 736841 & 5.3134 & 5.5119 & TRN \\
\hline CHEMBL1984876 & 736841 & 5.7399 & 5.2155 & TRN \\
\hline CHEMBL1964873 & 736841 & 5.1701 & 4.8858 & TRN \\
\hline CHEMBL1609419 & 736841 & 5.3002 & 5.4399 & TRN \\
\hline CHEMBL1300269 & 736841 & 5.5719 & 5.3326 & TRN \\
\hline CHEMBL1343705 & 736841 & 5.5784 & 5.0917 & TRN \\
\hline CHEMBL1363376 & 736841 & 5.0223 & 4.9926 & TRN \\
\hline CHEMBL3193639 & 736841 & 4.9172 & 4.9947 & TRN \\
\hline CHEMBL 256042 & 736841 & 5.2557 & 5.8043 & TRN \\
\hline CHEMBL1999049 & 736841 & 4.9281 & 5.1014 & TST \\
\hline CHEMBL1336535 & 736841 & 4.9666 & 4.8129 & TRN \\
\hline CHEMBL1358924 & 736841 & 5.1035 & 4.9244 & TRN \\
\hline CHEMBL1461661 & 736841 & 5.4584 & 4.9432 & TRN \\
\hline CHEMBL131037 & 736841 & 4.9281 & 4.9153 & TST \\
\hline CHEMBL1530899 & 736841 & 5.1972 & 5.0417 & TRN \\
\hline CHEMBL 2005961 & 736841 & 4.9208 & 5.0188 & TRN \\
\hline CHEMBL3197021 & 736841 & 5.3382 & 5.1617 & TRN \\
\hline CHEMBL1370719 & 736841 & 4.9245 & 5.2185 & TRN \\
\hline CHEMBL1539016 & 736841 & 4.6925 & 5.0512 & TRN \\
\hline CHEMBL1605583 & 736841 & 5.0752 & 4.8187 & TRN \\
\hline CHEMBL1432227 & 736841 & 4.757 & 4.7562 & TRN \\
\hline CHEMBL1416089 & 736841 & 5.1831 & 5.3967 & TRN \\
\hline CHEMBL3190555 & 736841 & 5.3116 & 5.5833 & TRN \\
\hline CHEMBL 1608776 & 736841 & 5.0141 & 4.753 & TRN \\
\hline CHEMBL1390716 & 736841 & 5.1701 & 4.9316 & TRN \\
\hline CHEMBL1377278 & 736841 & 5.3179 & 5.1183 & TRN \\
\hline CHEMBL586135 & 736841 & 6.1267 & 5.4062 & TRN \\
\hline CHEMBL1384246 & 736841 & 5.1945 & 5.067 & TRN \\
\hline CHEMBL1566610 & 736841 & 4.8729 & 5.1792 & TST \\
\hline CHEMBL1384726 & 736841 & 5.5817 & 5.1319 & TRN \\
\hline CHEMBL1505604 & 736841 & 5.0835 & 4.9435 & TRN \\
\hline CHEMBL1548770 & 736841 & 4.8962 & 4.8795 & TRN \\
\hline
\end{tabular}




\begin{tabular}{|c|c|c|c|c|c|c|}
\hline \multirow[b]{2}{*}{ CHEMBL1359415 } & \multicolumn{6}{|c|}{ Supplemental Table S2.txt } \\
\hline & 736841 & 5.1238 & 4.8418 & TRN & & \\
\hline CHEMBL3190274 & 736841 & 4.9872 & 5.3501 & TST & & \\
\hline CHEMBL1303426 & 736841 & 5.38299 & 99999999 & 99 & 5.3733 & TRN \\
\hline CHEMBL1412078 & 736841 & 4.301 & 4.6623 & TRN & & \\
\hline CHEMBL140425 & 736841 & 5.1649 & 5.3485 & TRN & & \\
\hline CHEMBL1602250 & 736841 & 4.8268 & 5.4705 & TRN & & \\
\hline CHEMBL3199421 & 736841 & 4.9066 & 5.1037 & TRN & & \\
\hline CHEMBL1333440 & 736841 & 4.301 & 4.7755 & TRN & & \\
\hline CHEMBL1372698 & 736841 & 3.5017 & 3.9174 & TRN & & \\
\hline CHEMBL1546739 & 736841 & 5.1656 & 5.2591 & TRN & & \\
\hline CHEMBL1442120 & 736841 & 5.6576 & 4.9359 & TST & & \\
\hline CHEMBL1350432 & 736841 & 5.1385 & 4.9533 & TST & & \\
\hline CHEMBL3192010 & 736841 & 5.1593 & 5.1405 & TRN & & \\
\hline CHEMBL1500450 & 736841 & 4.9101 & 5.245 & TRN & & \\
\hline CHEMBL3193535 & 736841 & 3.5017 & 4.9035 & TST & & \\
\hline CHEMBL1973773 & 736841 & 7.0088 & 5.9509 & TRN & & \\
\hline CHEMBL1574879 & 736841 & 5.1487 & 4.8449 & TRN & & \\
\hline CHEMBL1341190 & 736841 & 6.3215 & 5.2438 & TST & & \\
\hline CHEMBL1585390 & 736841 & 5.5287 & 5.386 & TRN & & \\
\hline CHEMBL1504142 & 736841 & 5.0079 & 4.9044 & TST & & \\
\hline CHEMBL1319867 & 736841 & 5.5391 & 5.3382 & TRN & & \\
\hline CHEMBL3194040 & 736841 & 5.0022 & 5.0364 & TRN & & \\
\hline CHEMBL1964464 & 736841 & 5.2993 & 5.3495 & TST & & \\
\hline CHEMBL1447284 & 736841 & 5.2487 & 5.1359 & TST & & \\
\hline CHEMBL1557816 & 736841 & 4.71899 & 99999999 & 99 & 5.0929 & TST \\
\hline CHEMBL1978355 & 736841 & 5.0773 & 4.8767 & TST & & \\
\hline CHEMBL1471189 & 736841 & 5.0343 & 4.9144 & TST & & \\
\hline CHEMBL1442698 & 736841 & 5.7747 & 5.2659 & TST & & \\
\hline CHEMBL1554920 & 736841 & 5.0453 & 4.9068 & TST & & \\
\hline CHEMBL1433128 & 736841 & 4.6345 & 4.9875 & TST & & \\
\hline CHEMBL1520214 & 736841 & 5.5918 & 5.4209 & TST & & \\
\hline CHEMBL1570958 & 736841 & 5.3925 & 5.2136 & TST & & \\
\hline CHEMBL1477640 & 736841 & 5.0757 & 4.9101 & TST & & \\
\hline CHEMBL1477197 & 736841 & 5.1469 & 5.0312 & TST & & \\
\hline CHEMBL1472570 & 736841 & 5.1805 & 5.035 & TST & & \\
\hline CHEMBL1599708 & 736841 & 5.266 & 4.7405 & TST & & \\
\hline CHEMBL1461585 & 736841 & 5.0888 & 5.1607 & TST & & \\
\hline CHEMBL1431014 & 736841 & 3.5017 & 5.1291 & TST & & \\
\hline CHEMBL1990174 & 736841 & 5.6696 & 5.4821 & TST & & \\
\hline CHEMBL1979800 & 736841 & 3.5017 & 5.1215 & TST & & \\
\hline CHEMBL3658523 & 1528722 & 7.7696 & 7.8171 & TRN & & \\
\hline CHEMBL 3658594 & 1528722 & 8.0458 & 7.9587 & TRN & & \\
\hline CHEMBL 3658510 & 1528722 & 7.7212 & 7.8051 & TRN & & \\
\hline CHEMBL3658604 & 1528722 & 7.2147 & 7.9908 & TST & & \\
\hline CHEMBL 3658484 & 1528722 & 6.9208 & 7.0541 & TRN & & \\
\hline CHEMBL3658505 & 1528722 & 6.9172 & 6.7948 & TRN & & \\
\hline CHEMBL 3658520 & 1528722 & 7.3279 & 7.3097 & TRN & & \\
\hline CHEMBL3658525 & 1528722 & 7.585 & 7.2689 & TRN & & \\
\hline
\end{tabular}


Supplemental Table S2.txt

\begin{tabular}{|c|c|c|c|c|}
\hline AEMBL36 & 528722 & 7.0132 & & \\
\hline & 528722 & 8.1549 & 7.7866 & \\
\hline & 528722 & & & \\
\hline IEMBL3 & 528722 & 3872 & & \\
\hline AEMBL: & 528722 & 6383 & & \\
\hline AEMBL3658549 & 528722 & 7.2676 & 848 & \\
\hline AEMB & 722 & 7.1612 & & \\
\hline EMBL & 722 & 7.3979 & & \\
\hline IEMBL36 & 528722 & 7.7696 & & \\
\hline AEMBL36 & 528722 & 7.3768 & 67 & \\
\hline AEMBL3 & 528722 & .0969 & & \\
\hline IEMBL & 528722 & 1549 & & \\
\hline EMBL & 722 & & & \\
\hline AEMBL. & 722 & 0969 & & \\
\hline IEMBL & 722 & $\partial 969$ & & \\
\hline EMBL: & 22 & 5229 & & \\
\hline AEMBL & 22 & 7.7959 & & RIN \\
\hline AEMBL & 22 & 7.4202 & & \\
\hline IEMBL & 722 & 7.1249 & & \\
\hline IEMBL & 22 & 1 & & \\
\hline IEMBL & 2 & 6 & & $\mathrm{~K} / \mathrm{T}$ \\
\hline EMB & 2 & 6 & & 舟 \\
\hline EMB & 22 & 366 & & \\
\hline 540 & 722 & & & \\
\hline IEMBL: & 22 & & & RI \\
\hline IEMBL & 22 & 7 & & $\cdots$ \\
\hline EMB & 2 & & & ST \\
\hline EMB & 22 & 97 & & \\
\hline IEMBL & 22 & 6.5229 & & RN \\
\hline IEMBL3 & 22 & 71 & & $\mathrm{RI}$ \\
\hline AEMBL: & 22 & 35 & & $m$ \\
\hline FMB & 22 & 8 & & . \\
\hline AEMBL & 22 & 78 & & 20 \\
\hline AEMBL & 528722 & 596 & & $\mathrm{RN}$ \\
\hline AEMBL3658495 & 528722 & 376 & & ГRN \\
\hline IEMB & 22 & & & $\mathrm{R}$ \\
\hline 5 & 22 & & & $x^{2}+2+2$ \\
\hline & 22 & 7. & & RN \\
\hline AEMBL3658497 & 528722 & 6.8239 & & RN \\
\hline IEMBL3 & 528722 & 7. & & ST \\
\hline HEMBL & 22 & & & $\mathrm{TR}$ \\
\hline HEMBL; & 1528722 & & & 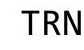 \\
\hline HEMBL & 528722 & 8.2218 & & $\mathrm{RI}$ \\
\hline AEMBL3 & 528722 & 7.4318 & 359 & $R$ \\
\hline AEMBL & 528722 & 6.3969 & & $\mathrm{n}$ \\
\hline CHEMBL: & 52 & & & \\
\hline CHEMBL 3 & 528722 & 3.2218 & & \\
\hline CHEMBL3658555 & 1528722 & 7.7959 & 7.7924 & is \\
\hline
\end{tabular}

Page 17097 
Supplemental Table S2.txt

\begin{tabular}{|c|c|c|c|c|c|}
\hline CHEMBL3658472 & 1528722 & 6.7447 & 6.6419 & TRN & \\
\hline CHEMBL3658479 & 1528722 & 6.9208 & 6.7435 & TRN & \\
\hline CHEMBL3658500 & 1528722 & 6.699 & 6.6613 & TRN & \\
\hline CHEMBL 3658518 & 1528722 & 6.0 & 7.9943 & TST & \\
\hline CHEMBL3658591 & 1528722 & 8.1549 & 8.0881 & TRN & \\
\hline CHEMBL3658586 & 1528722 & 7.0506 & 7.7992 & TST & \\
\hline CHEMBL3658512 & 1528722 & 7.7696 & 7.9264 & TRN & \\
\hline CHEMBL3658599 & 1528722 & 7.5528 & 7.8464 & TST & \\
\hline CHEMBL3658551 & 1528722 & 7.9586 & 7.9149 & TRN & \\
\hline CHEMBL3658556 & 1528722 & 7.8861 & 7.9064 & TRN & \\
\hline CHEMBL3658528 & 1528722 & 7.9208 & 7.9377 & TRN & \\
\hline CHEMBL3658529 & 1528722 & 7.5086 & 7.5463 & TRN & \\
\hline CHEMBL3658546 & 1528722 & 7.6778 & 7.4783 & TRN & \\
\hline CHEMBL 3658575 & 1528722 & 7.5686 & 7.8468 & TRN & \\
\hline CHEMBL3658537 & 1528722 & 6.5575 & 7.6984 & TST & \\
\hline CHEMBL3658524 & 1528722 & 8.0458 & 7.6305 & TRN & \\
\hline CHEMBL3658593 & 1528722 & 8.0969 & 7.9129 & TRN & \\
\hline CHEMBL 3658543 & 1528722 & 8.2218 & 7.8887 & TRN & \\
\hline CHEMBL3658535 & 1528722 & 7.9586 & \multicolumn{2}{|c|}{7.872999999999999} & TST \\
\hline CHEMBL 3658473 & 1528722 & 6.5086 & 6.721 & TRN & \\
\hline CHEMBL3658486 & 1528722 & 8.0655 & 7.7307 & TRN & \\
\hline CHEMBL3658578 & 1528722 & 7.6021 & 7.2273 & TRN & \\
\hline CHEMBL3658531 & 1528722 & 7.7447 & 7.5434 & TRN & \\
\hline CHEMBL3658475 & 1528722 & 7.4318 & 7.4054 & TST & \\
\hline CHEMBL 3658587 & 1528722 & 7.8239 & 7.8944 & TRN & \\
\hline CHEMBL 3658580 & 1528722 & 7.3565 & 7.1042 & TRN & \\
\hline CHEMBL3658534 & 1528722 & 6.8794 & 7.468 & TST & \\
\hline CHEMBL3658584 & 1528722 & 7.1487 & 7.4807 & TST & \\
\hline CHEMBL3658503 & 1528722 & 6.8239 & 6.8906 & TRN & \\
\hline CHEMBL 3658565 & 1528722 & 7.7696 & 7.8836 & TST & \\
\hline CHEMBL3658589 & 1528722 & 8.3979 & \multicolumn{2}{|c|}{7.837000000000001} & TST \\
\hline CHEMBL 3658590 & 1528722 & 8.1549 & 7.8868 & TRN & \\
\hline CHEMBL 3658502 & 1528722 & 7.4318 & 7.254 & TRN & \\
\hline CHEMBL3658574 & 1528722 & 6.983 & 7.2946 & TRN & \\
\hline CHEMBL 3658514 & 1528722 & 6.5969 & 6.5915 & TRN & \\
\hline CHEMBL3658493 & 1528722 & 7.1079 & 7.2288 & TRN & \\
\hline CHEMBL3658567 & 1528722 & 7.699 & 7.6746 & TST & \\
\hline CHEMBL3658539 & 1528722 & 7.585 & 7.8147 & TST & \\
\hline CHEMBL3658506 & 1528722 & 6.9747 & 6.8761 & TRN & \\
\hline CHEMBL3658476 & 1528722 & 7.8239 & 7.8023 & TRN & \\
\hline CHEMBL3658504 & 1528722 & 6.9245 & \multicolumn{2}{|c|}{6.837000000000001} & TRN \\
\hline CHEMBL 3658550 & 1528722 & 7.8239 & 7.9081 & TST & \\
\hline CHEMBL3658538 & 1528722 & 7.6383 & 7.8145 & TST & \\
\hline CHEMBL3658554 & 1528722 & 7.6198 & 7.7224 & TRN & \\
\hline CHEMBL3658492 & 1528722 & 7.4089 & 7.371 & TRN & \\
\hline CHEMBL 3658564 & 1528722 & 7.5086 & 7.7858 & TRN & \\
\hline CHEMBL3658521 & 1528722 & 7.6021 & 7.2644 & TRN & \\
\hline CHEMBL3658559 & 1528722 & 7.8539 & 7.8802 & TRN & \\
\hline
\end{tabular}

Page 17098 
Supplemental Table S2.txt

\begin{tabular}{|c|c|c|}
\hline (1) & & \\
\hline CHEMBL & & 27 \\
\hline AEMBL3 & 28722 & 00 \\
\hline AEMBL3658515 & 528722 & 795 \\
\hline HEN & 528722 & 6.928 \\
\hline HEMBL 3 & 528722 & 795 \\
\hline AEMBL3658480 & 1528722 & 958 \\
\hline HEMBL3 & 1528722 & 096 \\
\hline AEMBL 3658488 & 1528722 & 7.193 \\
\hline 487 & 1528722 & 6.823 \\
\hline 68 & 1528722 & 7.886 \\
\hline AEMBL & 1528722 & 8.699 \\
\hline 598 & 1528722 & 7.744 \\
\hline 8606 & 1528722 & 7.148 \\
\hline 508 & 1528722 & $6.571 \mathrm{~s}$ \\
\hline 517 & 1528722 & 513 \\
\hline 577 & 1528722 & 7.619 \\
\hline 516 & 22 & 735 \\
\hline 3582 & 1528722 & 7.522 \\
\hline 478 & 152 & 1945 \\
\hline 526 & 152 & 7959 \\
\hline 83 & 1528722 & 7.9586 \\
\hline 588 & 22 & 8.522 \\
\hline 3557 & 152 & 7.886 \\
\hline 481 & 152 & 8.0 \\
\hline 05 & 152 & 7.1675 \\
\hline 558 & 722 & 5383 \\
\hline 98 & & 93 \\
\hline AEMBL3658562 & 1528722 & 7.468 \\
\hline 3570 & 152 & 7.119 \\
\hline 161 & 143 & \\
\hline 119 & & 6.301 \\
\hline 76 & 143 & 7.2676 \\
\hline AEMBL3335160 & 1433001 & 7.0915 \\
\hline 335162 & 1433001 & 7.8239 \\
\hline 129 & 143 & 7.9586 \\
\hline AEMBL3335153 & 1433001 & 8.1549 \\
\hline HEMBL3335163 & 1433001 & 6.8535 \\
\hline AEMBL3335128 & 1433001 & $8.397 c$ \\
\hline 3335149 & 1433001 & 7.8861 \\
\hline CHEMBL 3335148 & 143 & 7.1549 \\
\hline CHEMBL3335121 & 1433001 & 6.4089 \\
\hline CHEMBL3335143 & 1433001 & 7.275 \\
\hline HEMBL 3335145 & 1433001 & 7.244 \\
\hline CHEMBL3335147 & 1433001 & 7.721 \\
\hline CHEMBL 3335164 & 1433001 & 9.0 \\
\hline CHEMBL3335152 & 1433001 & 7.0 \\
\hline CHEMBL3335173 & 1433001 & 9.0 \\
\hline
\end{tabular}

\begin{abstract}
7.5229 TST
\end{abstract}
7.4944 TST

7.8562 TRN

6.7187 TRN

7.0412 TRN

7.7781 TRN

7.0193 TRN

8.0086 TRN

6.9518 TRN

6.8937 TRN

8.0353 TRN

7.9992 TRN

7.5028 TST

7.8196 TRN

6.5688 TRN

6.5934 TRN

7.4885 TRN

6.5875 TRN

7.3273 TRN

7.7194 TST

8.0101 TRN

7.6781 TRN

7.9586 TST

7.8676 TST

7.8436 TST

7.7271 TST

$7.696000000000001 \quad$ TST

7.0 TST

7.459 TST

7.4944 TST

8.9975 TRN

7.7319 TST

7.2692 TRN

7.0938 TRN

7.8245 TRN

7.9625 TRN

8.1543 TRN

6.8467 TRN

8.4037 TRN

7.8812 TRN

7.1531 TRN

6.4212 TRN

7.2823 TRN

7.2406 TRN

7.7235 TRN

8.9974 TRN

7.4107 TST

9.0059 TRN

Page 17099 
Supplemental Table S2.txt

\begin{tabular}{|c|c|c|c|c|}
\hline 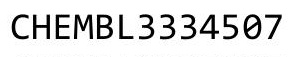 & & 0 & 9866 & \\
\hline HEMBL3335127 & 3001 & 7.2757 & 2831 & \\
\hline HEMBL3335150 & & 7.2007 & 8565 & \\
\hline 159 & 001 & & & \\
\hline 35171 & 3001 & 7.4685 & 4749 & \\
\hline AEMBL3335122 & 433001 & 6.301 & 2935 & \\
\hline HEMBL3335178 & 433001 & 6.284 & 2793 & \\
\hline 35165 & 3001 & 2218 & 0757 & \\
\hline 158 & 433001 & 9.0 & 0041 & \\
\hline IEMBL & 3001 & 8.0969 & 0878 & \\
\hline HEMBL3335126 & 3001 & 7.7447 & 7424 & \\
\hline HEMBL3335144 & 3001 & 7.6198 & 6248 & \\
\hline HEMBL3335166 & 433001 & 8.3979 & 7595 & \\
\hline 335170 & 001 & 69 & 1306 & \\
\hline 154 & 3001 & 362 & 413 & \\
\hline 35125 & 3001 & 7.699 & 68 & \\
\hline HEMBL3335146 & 3001 & 959 & 7915 & \\
\hline HEMBL3 & 001 & 9.0 & 056 & SI \\
\hline HEMBL & 001 & & 3841 & \\
\hline HEME & 001 & & 6534 & \\
\hline HEMBL3 & 001 & & 5966 & \\
\hline AEMBL3335151 & 001 & & 017 & SI \\
\hline HEMB & 01 & 7. & 413 & RN \\
\hline HEM & 01 & & 2159 & NIV \\
\hline HEM & 001 & & 5188 & RN \\
\hline 35174 & 001 & & 1634 & 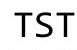 \\
\hline AEMBL3335123 & 433001 & 383 & 5327 & $\mathrm{R}$ \\
\hline HEMBL3335177 & 3001 & 3. & 7.4829 & I \\
\hline HEM & 01 & 9. & 041 & RN \\
\hline HEME & 001 & & 9145 & ST \\
\hline HEMBL3335140 & 001 & & & IRN \\
\hline HEMBL3335142 & 433001 & 229 & 5258 & RN \\
\hline HEMBL3335141 & 3001 & & 049 & RN \\
\hline 1 & 61 & & 01 & RN \\
\hline HEMBL2151935 & & & 74 & RN \\
\hline HEMBL3112690 & 528661 & & & IST \\
\hline HEMBL3696265 & 3661 & 6. & 263 & RN \\
\hline HEMBL3696256 & 661 & 7 & 549 & RN \\
\hline 46 & & & & RN \\
\hline HEMBL3696281 & & & 9786 & ST \\
\hline HEMBL3696253 & 8661 & & 1809 & RN \\
\hline HEMBL3696262 & 661 & & 326 & RN \\
\hline HEMBL3696279 & 528661 & 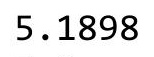 & 5.0212 & \\
\hline HEMBL3696254 & & & 4.9047 & RN \\
\hline HEMBL3696257 & & 0 & .9464 & RN \\
\hline HEMBL3696273 & 8661 & 92 & 1314 & RN \\
\hline - & & & & \\
\hline ר & & & & \\
\hline
\end{tabular}

Page 17100 
Supplemental Table S2.txt

\begin{tabular}{|c|c|c|c|c|}
\hline CHEMBL3696259 & 1528661 & 6.3979 & 5.7164 & TRN \\
\hline CHEMBL 2151048 & 1528661 & 7.0315 & 6.9671 & TRN \\
\hline CHEMBL 3696252 & 1528661 & 5.0 & 5.4484 & TRN \\
\hline CHEMBL3696272 & 1528661 & 6.8633 & 6.9635 & TRN \\
\hline CHEMBL 2151929 & 1528661 & 5.2108 & 5.5888 & TRN \\
\hline CHEMBL3696270 & 1528661 & 6.0931 & \multicolumn{2}{|c|}{6.218999999999999} \\
\hline CHEMBL 2151926 & 1528661 & 6.9355 & 6.8858 & TRN \\
\hline CHEMBL 2151924 & 1528661 & 7.6383 & 6.4658 & TRN \\
\hline CHEMBL 2151928 & 1528661 & 5.2317 & 4.9936 & TRN \\
\hline CHEMBL 3696255 & 1528661 & 6.3188 & 6.4007 & TRN \\
\hline CHEMBL3696268 & 1528661 & 6.644 & 6.7609 & TRN \\
\hline CHEMBL3696243 & 1528661 & 5.0 & 5.561 & TRN \\
\hline CHEMBL 2151921 & 1528661 & 7.0 & 6.8979 & TRN \\
\hline CHEMBL 2151922 & 1528661 & 6.0706 & 6.4087 & TRN \\
\hline CHEMBL 3696244 & 1528661 & 6.4559 & 6.0907 & TRN \\
\hline CHEMBL3696250 & 1528661 & 5.4395 & 5.6069 & TRN \\
\hline CHEMBL 2151927 & 1528661 & 6.4976 & 6.5215 & TRN \\
\hline CHEMBL 2151819 & 1528661 & 6.1385 & 5.9637 & TRN \\
\hline CHEMBL3639951 & 1528661 & 6.1325 & 6.2787 & TRN \\
\hline CHEMBL3696286 & 1528661 & 6.1871 & 5.9203 & TRN \\
\hline CHEMBL3696282 & 1528661 & 6.6021 & 6.9062 & TRN \\
\hline CHEMBL2151919 & 1528661 & 7.4089 & 7.1234 & TRN \\
\hline CHEMBL3696251 & 1528661 & 6.2154 & 6.0473 & TRN \\
\hline CHEMBL3696242 & 1528661 & 5.8814 & 5.4805 & TRN \\
\hline CHEMBL3696263 & 1528661 & 5.6024 & 6.1285 & TST \\
\hline CHEMBL 3696284 & 1528661 & 5.2696 & 5.598 & TST \\
\hline CHEMBL 2151920 & 1528661 & 5.8477 & 6.5452 & TRN \\
\hline CHEMBL3696258 & 1528661 & 6.5376 & 6.5248 & TRN \\
\hline CHEMBL 2151822 & 1528661 & 5.4562 & 5.9934 & TRN \\
\hline CHEMBL 2151925 & 1528661 & 6.767 & 6.8123 & TRN \\
\hline CHEMBL3696264 & 1528661 & 6.4609 & 6.5279 & TRN \\
\hline CHEMBL 2151820 & 1528661 & 6.2441 & 6.6826 & TST \\
\hline CHEMBL3696260 & 1528661 & 6.2604 & 6.1386 & TST \\
\hline CHEMBL3696238 & 1528661 & 6.1993 & 6.0736 & TST \\
\hline CHEMBL3696274 & 1528661 & 6.3799 & 6.4425 & TST \\
\hline CHEMBL3696261 & 1528661 & 6.5114 & 6.3676 & TST \\
\hline CHEMBL3696234 & 1528661 & 6.9914 & 5.9519 & TST \\
\hline CHEMBL3696240 & 1528661 & 5.8294 & 6.8411 & TST \\
\hline CHEMBL3696271 & 1528661 & 5.0 & 6.0748 & TST \\
\hline CHEMBL3696267 & 1528661 & 5.1726 & 5.675 & TST \\
\hline CHEMBL1941080 & 798935 & 6.6383 & 6.3271 & TRN \\
\hline CHEMBL1940923 & 798935 & 3.0 & 6.6163 & TST \\
\hline CHEMBL1940930 & 798935 & 7.6198 & 7.8325 & TRN \\
\hline CHEMBL1940932 & 798935 & 7.5528 & 7.84200 & 00000000005 \\
\hline CHEMBL1940919 & 798935 & 7.0706 & 6.4917 & TRN \\
\hline CHEMBL1941065 & 798935 & 6.6021 & 7.3995 & TRN \\
\hline CHEMBL1940940 & 798935 & 7.6198 & 7.3646 & TRN \\
\hline CHEMBL1941071 & 798935 & 7.3188 & 7.9041 & TRN \\
\hline
\end{tabular}

Page 17101 


\begin{tabular}{|c|c|c|c|c|c|}
\hline \multicolumn{6}{|c|}{ Supplemental Table S2.txt } \\
\hline CHEMBL1941062 & 798935 & 7.7212 & 7.7477 & TRN & \\
\hline CHEMBL1941076 & 798935 & 7.8239 & 7.9177 & TRN & \\
\hline CHEMBL1940920 & 798935 & 6.7773 & 6.7474 & TRN & \\
\hline CHEMBL1941068 & 798935 & 8.0 & 7.7211 & TRN & \\
\hline CHEMBL1940915 & 798935 & 6.7878 & 6.8112 & TRN & \\
\hline CHEMBL1940926 & 798935 & 7.3872 & 7.5702 & TRN & \\
\hline CHEMBL1941058 & 798935 & 7.4949 & 7.7145 & TRN & \\
\hline CHEMBL1940925 & 798935 & 7.2596 & 7.91200 & 0000000001 & TRN \\
\hline CHEMBL1941064 & 798935 & 7.6576 & 8.1295 & TRN & \\
\hline CHEMBL1941072 & 798935 & 7.2076 & 7.78600 & 00000000005 & TST \\
\hline CHEMBL1940916 & 798935 & 6.8861 & 6.8274 & TRN & \\
\hline CHEMBL1941063 & 798935 & 7.0757 & 7.6185 & TRN & \\
\hline CHEMBL1941070 & 798935 & 6.585 & 7.7589 & TRN & \\
\hline CHEMBL1941083 & 798935 & 5.7959 & 6.5185 & TST & \\
\hline CHEMBL1941082 & 798935 & 6.2076 & 6.7078 & TST & \\
\hline CHEMBL1940924 & 798935 & 6.7747 & 6.2805 & TRN & \\
\hline CHEMBL1940939 & 798935 & 9.301 & 7.96 & TRN & \\
\hline CHEMBL1940914 & 798935 & 6.7352 & 6.7602 & TRN & \\
\hline CHEMBL1941055 & 798935 & 7.1487 & 7.1398 & TRN & \\
\hline CHEMBL1941078 & 798935 & 9.301 & 8.2521 & TRN & \\
\hline CHEMBL1940931 & 798935 & 7.5229 & 7.2752 & TRN & \\
\hline CHEMBL1940917 & 798935 & 7.1308 & 6.5922 & TRN & \\
\hline CHEMBL1941074 & 798935 & 7.4685 & 7.8098 & TRN & \\
\hline CHEMBL1941059 & 798935 & 7.6576 & 7.1676 & TRN & \\
\hline CHEMBL1941069 & 798935 & 7.4437 & 7.90799 & 99999999995 & TST \\
\hline CHEMBL1940927 & 798935 & 6.7212 & 7.5526 & TRN & \\
\hline CHEMBL1941067 & 798935 & 7.3979 & 7.6058 & TST & \\
\hline CHEMBL1941081 & 798935 & 6.3665 & 6.7597 & TRN & \\
\hline CHEMBL1940942 & 798935 & 7.4089 & 7.5689 & TRN & \\
\hline CHEMBL1940929 & 798935 & 6.6198 & 7.2026 & TRN & \\
\hline CHEMBL1941057 & 798935 & 7.4949 & 7.4584 & TRN & \\
\hline CHEMBL1938422 & 798935 & 8.0655 & 7.8673 & TRN & \\
\hline CHEMBL1940944 & 798935 & 7.8996 & 7.7936 & TRN & \\
\hline CHEMBL1941075 & 798935 & 7.699 & 7.6655 & TST & \\
\hline CHEMBL1941053 & 798935 & 7.4685 & 7.6131 & TRN & \\
\hline CHEMBL1940934 & 798935 & 8.2676 & 8.5081 & TRN & \\
\hline CHEMBL1940928 & 798935 & 6.585 & 7.2037 & TRN & \\
\hline CHEMBL1941052 & 798935 & 7.585 & 7.7925 & TRN & \\
\hline CHEMBL1941077 & 798935 & 9.301 & 8.4979 & TRN & \\
\hline CHEMBL1940935 & 798935 & 9.301 & 8.5226 & TRN & \\
\hline CHEMBL1941061 & 798935 & 7.699 & 7.6386 & TRN & \\
\hline CHEMBL1941056 & 798935 & 7.6198 & 7.1218 & TRN & \\
\hline CHEMBL1940936 & 798935 & 9.301 & 8.2234 & TRN & \\
\hline CHEMBL1941051 & 798935 & 6.9208 & 7.2523 & TRN & \\
\hline CHEMBL1941060 & 798935 & 7.6198 & 7.9774 & TRN & \\
\hline CHEMBL1941066 & 798935 & 7.5686 & 7.7058 & TRN & \\
\hline CHEMBL1940921 & 798935 & 6.6021 & 6.4556 & TRN & \\
\hline CHEMBL1941073 & 798935 & 7.4815 & 7.9469 & TST & \\
\hline
\end{tabular}




\begin{tabular}{|c|c|c|c|c|c|}
\hline \multicolumn{5}{|c|}{ Supplemental Table S2.txt } & \\
\hline CHEMBL1940943 & 798935 & 7.8539 & 7.5973 & TRN & \\
\hline CHEMBL1940918 & 798935 & 7.4318 & 6.8016 & TST & \\
\hline CHEMBL1941054 & 798935 & 7.4685 & 7.8236 & TST & \\
\hline CHEMBL1941050 & 798935 & 6.6696 & 7.2866 & TST & \\
\hline CHEMBL1940913 & 798935 & 6.8153 & 6.5966 & TST & \\
\hline CHEMBL1940933 & 798935 & 7.3979 & 7.9407 & TST & \\
\hline CHEMBL1940922 & 798935 & 6.7959 & 6.4238 & TST & \\
\hline CHEMBL1940941 & 798935 & 9.301 & 7.83200 & 0000000001 & \\
\hline CHEMBL1940949 & 798935 & 7.9208 & 7.4905 & TST & \\
\hline CHEMBL1941079 & 798935 & 7.3979 & 7.0952 & TST & \\
\hline CHEMBL3942728 & 1641703 & 10.2596 & 9.4928 & TRN & \\
\hline CHEMBL3937204 & 1641703 & 9.2596 & 9.7616 & TRN & \\
\hline CHEMBL3955757 & 1641703 & 9.2596 & 9.31899 & 9999999999 & \\
\hline CHEMBL3968548 & 1641703 & 9.2596 & 9.5194 & TST & \\
\hline CHEMBL3955948 & 1641703 & 9.2596 & 9.4433 & TST & \\
\hline CHEMBL3933796 & 1641703 & 9.2596 & 9.6685 & TRN & \\
\hline CHEMBL3940099 & 1641703 & 9.2596 & 9.8126 & TRN & \\
\hline CHEMBL3982255 & 1641703 & 9.2596 & 9.6068 & TRN & \\
\hline CHEMBL3982307 & 1641703 & 9.2596 & 9.497 & TRN & \\
\hline CHEMBL3900044 & 1641703 & 7.064 & 7.3185 & TRN & \\
\hline CHEMBL3893327 & 1641703 & 10.2596 & 9.8288 & TRN & \\
\hline CHEMBL3949963 & 1641703 & 9.2596 & 8.8986 & TRN & \\
\hline CHEMBL3902351 & 1641703 & 9.2596 & 9.5549 & TRN & \\
\hline CHEMBL3925605 & 1641703 & 10.2596 & 9.6014 & TRN & \\
\hline CHEMBL3890208 & 1641703 & 10.2596 & 9.7274 & TRN & \\
\hline CHEMBL3952555 & 1641703 & 9.2596 & 9.4252 & TRN & \\
\hline CHEMBL3919799 & 1641703 & 9.2596 & 8.6759 & TRN & \\
\hline CHEMBL3899672 & 1641703 & 9.2596 & 9.6413 & TRN & \\
\hline CHEMBL3941211 & 1641703 & 10.2596 & 9.6242 & TRN & \\
\hline CHEMBL3977452 & 1641703 & 9.2596 & 9.753 & TRN & \\
\hline CHEMBL3973848 & 1641703 & 9.2596 & 9.554 & TRN & \\
\hline CHEMBL3934942 & 1641703 & 9.2596 & 9.63 & TRN & \\
\hline CHEMBL3926059 & 1641703 & 9.2596 & 9.7012 & TRN & \\
\hline CHEMBL3959421 & 1641703 & 6.3036 & 6.7275 & TRN & \\
\hline CHEMBL3951700 & 1641703 & 10.2596 & 9.6051 & TRN & \\
\hline CHEMBL3976708 & 1641703 & 9.2596 & 9.4667 & TRN & \\
\hline CHEMBL3910875 & 1641703 & 9.2596 & 9.1377 & TST & \\
\hline CHEMBL3915857 & 1641703 & 9.2596 & 9.4733 & TRN & \\
\hline CHEMBL3946118 & 1641703 & 6.2823 & 6.4537 & TRN & \\
\hline CHEMBL3925768 & 1641703 & 9.2596 & 9.7064 & TRN & \\
\hline CHEMBL3980318 & 1641703 & 9.2596 & 8.6341 & TRN & \\
\hline CHEMBL3896837 & 1641703 & 9.2596 & 9.7652 & TRN & \\
\hline CHEMBL3926930 & 1641703 & 9.2596 & 9.6938 & TRN & \\
\hline CHEMBL3914438 & 1641703 & 9.2596 & 9.7757 & TRN & \\
\hline CHEMBL3952191 & 1641703 & 9.2596 & 8.7844 & TRN & \\
\hline CHEMBL3890701 & 1641703 & 9.2596 & 8.6807 & TRN & \\
\hline CHEMBL3951623 & 1641703 & 10.2596 & 9.7329 & TRN & \\
\hline CHEMBL3905748 & 1641703 & 9.2596 & 9.7386 & TRN & \\
\hline
\end{tabular}


Supplemental Table S2.txt

\begin{tabular}{|c|c|c|c|c|c|}
\hline CHEMBL3937835 & 1641703 & 10.2596 & 9.6004 & TRN & \\
\hline CHEMBL3984764 & 1641703 & 9.2596 & 9.7297 & TRN & \\
\hline CHEMBL3897417 & 1641703 & 9.2596 & 9.6155 & TRN & \\
\hline CHEMBL3930750 & 1641703 & 9.2596 & 9.6025 & TRN & \\
\hline CHEMBL3954558 & 1641703 & 9.2596 & 9.128 & TST & \\
\hline CHEMBL3920581 & 1641703 & 9.2596 & 9.612 & TRN & \\
\hline CHEMBL3914739 & 1641703 & 9.2596 & 9.6425 & TST & \\
\hline CHEMBL 3903286 & 1641703 & 9.2596 & 9.3558 & TST & \\
\hline CHEMBL3925815 & 1641703 & 9.2596 & 8.5789 & TRN & \\
\hline CHEMBL3906885 & 1641703 & 9.2596 & 9.3676 & TRN & \\
\hline CHEMBL3902542 & 1641703 & 9.2596 & 9.4266 & TRN & \\
\hline CHEMBL3917906 & 1641703 & 10.2596 & 9.656 & TRN & \\
\hline CHEMBL3933735 & 1641703 & 6.4444 & 7.3162 & TRN & \\
\hline CHEMBL3955368 & 1641703 & 6.8041 & 4.905 & TST & \\
\hline CHEMBL3956882 & 1641703 & 10.2596 & 9.7299 & TRN & \\
\hline CHEMBL3975440 & 1641703 & 9.2596 & 8.4129 & TRN & \\
\hline CHEMBL3920484 & 1641703 & 10.2596 & 9.5991 & TRN & \\
\hline CHEMBL3984793 & 1641703 & 9.2596 & 9.2738 & TST & \\
\hline CHEMBL3913220 & 1641703 & 9.2596 & 9.5752 & TST & \\
\hline CHEMBL3961850 & 1641703 & 9.2596 & 9.7163 & TST & \\
\hline CHEMBL3930290 & 1641703 & 10.2596 & 9.5373 & TST & \\
\hline CHEMBL3960416 & 1641703 & 10.2596 & 9.6174 & TST & \\
\hline CHEMBL 3962448 & 1641703 & 9.2596 & 9.6433 & TST & \\
\hline CHEMBL3921320 & 1641703 & 9.2596 & 9.4119 & TST & \\
\hline CHEMBL3960213 & 1641703 & 9.2596 & 8.7934 & TST & \\
\hline CHEMBL3261515 & 1350156 & 2.9031 & 4.5376 & TRN & \\
\hline CHEMBL3261245 & 1350156 & 2.9031 & 3.2199 & TRN & \\
\hline CHEMBL172094 & 1350156 & 2.9031 & 2.7476 & TRN & \\
\hline CHEMBL3261517 & 1350156 & 4.9747 & 4.6005 & TRN & \\
\hline CHEMBL3261489 & 1350156 & 4.466 & 3.4854 & TRN & \\
\hline CHEMBL3261236 & 1350156 & 2.9031 & 2.7735 & TRN & \\
\hline CHEMBL 3261234 & 1350156 & 2.9031 & 2.8462 & TRN & \\
\hline CHEMBL65312 & 1350156 & 2.9031 & 2.7096 & TRN & \\
\hline CHEMBL3261503 & 1350156 & 2.9031 & 3.0002 & TRN & \\
\hline CHEMBL 3261237 & 1350156 & 2.9031 & 2.9707 & TRN & \\
\hline CHEMBL3261235 & 1350156 & 2.9031 & 2.8345 & TRN & \\
\hline CHEMBL3261518 & 1350156 & 4.7399 & 3.9278 & TST & \\
\hline CHEMBL3261516 & 1350156 & 5.153 & \multicolumn{2}{|c|}{4.6610000000000005} & TRN \\
\hline CHEMBL3261504 & 1350156 & 2.9031 & 2.9268 & TRN & \\
\hline CHEMBL3261229 & 1350156 & 2.9031 & 2.8345 & TRN & \\
\hline CHEMBL3261502 & 1350156 & 2.9031 & 2.8669 & TRN & \\
\hline CHEMBL3261494 & 1350156 & 2.9031 & 3.2187 & TRN & \\
\hline CHEMBL3261508 & 1350156 & 2.9031 & 2.7106 & TRN & \\
\hline CHEMBL3261491 & 1350156 & 4.2832 & 3.1189 & TRN & \\
\hline CHEMBL3261511 & 1350156 & 2.9031 & 4.266 & TRN & \\
\hline CHEMBL3261230 & 1350156 & 2.9031 & 2.8037 & TRN & \\
\hline CHEMBL3261497 & 1350156 & 2.9031 & 3.3082 & TST & \\
\hline CHEMBL3261231 & 1350156 & 2.9031 & 2.8348 & TRN & \\
\hline
\end{tabular}

Page 17104 
Supplemental Table S2.txt

\begin{tabular}{|c|c|c|c|c|c|}
\hline CHEMBL3261512 & 1350156 & 4.4572 & 4.3004 & TRN & \\
\hline CHEMBL3261240 & 1350156 & 2.9031 & 3.4408 & TRN & \\
\hline CHEMBL3261490 & 1350156 & 2.9031 & 3.113 & TRN & \\
\hline CHEMBL 3261495 & 1350156 & 2.9031 & 3.1739 & TST & \\
\hline CHEMBL3261500 & 1350156 & 6.1549 & 4.5081 & TRN & \\
\hline CHEMBL3259834 & 1350156 & 2.9031 & \multicolumn{2}{|c|}{2.8139999999999996} & TRN \\
\hline CHEMBL3261505 & 1350156 & 2.9031 & 3.3198 & TRN & \\
\hline CHEMBL3261506 & 1350156 & 2.9031 & 2.867 & TRN & \\
\hline CHEMBL3261492 & 1350156 & 2.9031 & 3.0708 & TRN & \\
\hline CHEMBL3261243 & 1350156 & 2.9031 & 2.8626 & TRN & \\
\hline CHEMBL3261493 & 1350156 & 2.9031 & 3.1677 & TRN & \\
\hline CHEMBL3261514 & 1350156 & 5.7399 & 5.0466 & TRN & \\
\hline CHEMBL3261501 & 1350156 & 2.9031 & 2.8315 & TRN & \\
\hline CHEMBL3261244 & 1350156 & 2.9031 & 3.1777 & TRN & \\
\hline CHEMBL 3261228 & 1350156 & 2.9031 & 2.8358 & TRN & \\
\hline CHEMBL3261233 & 1350156 & 2.9031 & 2.8121 & TRN & \\
\hline CHEMBL3261241 & 1350156 & 2.9031 & \multicolumn{2}{|c|}{3.7539999999999996} & TRN \\
\hline CHEMBL 3261488 & 1350156 & 2.9031 & 3.4772 & TRN & \\
\hline CHEMBL3261510 & 1350156 & 2.9031 & 2.761 & TRN & \\
\hline CHEMBL3261232 & 1350156 & 2.9031 & 2.8659 & TST & \\
\hline CHEMBL3261513 & 1350156 & 4.4584 & 4.4691 & TST & \\
\hline CHEMBL 3261242 & 1350156 & 2.9031 & 3.4933 & TST & \\
\hline CHEMBL3261499 & 1350156 & 5.2434 & \multicolumn{2}{|c|}{3.4010000000000002} & TST \\
\hline CHEMBL3261239 & 1350156 & 2.9031 & 3.6074 & TST & \\
\hline CHEMBL3261498 & 1350156 & 5.9208 & \multicolumn{2}{|c|}{3.4789999999999996} & TST \\
\hline CHEMBL3261496 & 1350156 & 2.9031 & 3.4124 & TST & \\
\hline CHEMBL3261507 & 1350156 & 2.9031 & 2.9368 & TST & \\
\hline CHEMBL3261509 & 1350156 & 2.9031 & 2.8382 & TST & \\
\hline CHEMBL3261238 & 1350156 & 2.9031 & 3.3889 & TST & \\
\hline CHEMBL 2170142 & 864727 & 4.1249 & 4.1905 & TRN & \\
\hline CHEMBL 2170152 & 864727 & 2.4776 & 2.6168 & TRN & \\
\hline CHEMBL538427 & 864727 & 4.5686 & 4.721 & TRN & \\
\hline CHEMBL 2170162 & 864727 & 4.8861 & 4.3005 & TST & \\
\hline CHEMBL1957774 & 864727 & 3.9547 & 3.8932 & TRN & \\
\hline CHEMBL 2170165 & 864727 & 3.9547 & 3.5512 & TST & \\
\hline CHEMBL 2170138 & 864727 & 4.2924 & 4.3659 & TRN & \\
\hline CHEMBL 296407 & 864727 & 2.4776 & 2.612 & TRN & \\
\hline CHEMBL 2170121 & 864727 & 5.585 & 5.9432 & TRN & \\
\hline CHEMBL 2170146 & 864727 & 3.9547 & 3.9452 & TRN & \\
\hline CHEMBL73820 & 864727 & 2.4776 & 2.4385 & TRN & \\
\hline CHEMBL310798 & 864727 & 2.4776 & 3.0877 & TST & \\
\hline CHEMBL 2170160 & 864727 & 2.4776 & 3.4913 & TST & \\
\hline CHEMBL24057 & 864727 & 4.5086 & 2.8649 & TST & \\
\hline CHEMBL 2170129 & 864727 & 4.585 & 4.3506 & TRN & \\
\hline CHEMBL2170159 & 864727 & 2.4776 & 3.6318 & TST & \\
\hline CHEMBL 2170147 & 864727 & 4.699 & 4.643 & TRN & \\
\hline CHEMBL 2170161 & 864727 & 3.9547 & 3.6141 & TST & \\
\hline CHEMBL496786 & 864727 & 2.4776 & 2.5571 & TRN & \\
\hline
\end{tabular}


Supplemental Table S2.txt

\begin{tabular}{|c|c|c|c|c|}
\hline 149 & & & & $T$ \\
\hline HEMBL 2170124 & 64727 & & & \\
\hline 30 & & & & \\
\hline 345 & 27 & & & \\
\hline IEMBL 2170131 & 64727 & & & \\
\hline IEMBL 2170140 & 64727 & 5528 & 664 & \\
\hline EMBL 2170126 & 27 & & 61 & \\
\hline 155 & 27 & & & \\
\hline EMBL2170139 & 27 & & 001 & \\
\hline AEMBL2170143 & 27 & 4.3372 & 06 & \\
\hline AEMBL 2170150 & 27 & & 973 & \\
\hline EMBL 2170120 & 27 & & 926 & \\
\hline 43 & & & & \\
\hline IEMBL 77030 & 27 & & 4.5208 & \\
\hline IEMBL 2170148 & 27 & & & \\
\hline 0122 & 27 & & 333 & \\
\hline 0135 & 7 & & 13 & \\
\hline 0153 & & & 83 & \\
\hline 0125 & 27 & & & \\
\hline 70128 & & & & \\
\hline 2136 & 7 & & 83 & \\
\hline 0127 & 7 & & 85 & \\
\hline 0158 & & & & \\
\hline 134 & & & & \\
\hline 370 & & & & \\
\hline 2133 & 7 & & 58 & RI \\
\hline 0156 & & & & \\
\hline 2123 & & & & \\
\hline 145 & & & & \\
\hline$\partial 154$ & 7 & & & $S$ \\
\hline$\partial 164$ & 7 & & & S \\
\hline 0132 & & & & RN \\
\hline 144 & & & & \\
\hline 9274 & & & & \\
\hline IEMBL 2170141 & 7 & & & \\
\hline 137 & 7 & & & R \\
\hline 163 & 7 & & 17 & ונ \\
\hline 2157 & & & & ST \\
\hline IEMBL1406323 & 864 & & & \\
\hline 5167 & 01 & 5 . & & $S$ \\
\hline 2289 & 16 & 4. & & \\
\hline & & 5 . & & \\
\hline 5683 & 01 & 4.0 & 57 & RI \\
\hline MBL3983827 & 501 & 5.412 & 5.8292 & \\
\hline 076 & & 4 & & 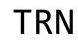 \\
\hline 9788 & & & & \\
\hline 3969319 & 16 & 4.0 & 3.8915 & \\
\hline CHEMBL3986566 & 1640501 & 5.5283 & 5.7367 & \\
\hline
\end{tabular}

Page 17106 


\begin{tabular}{|c|c|c|c|c|}
\hline \multicolumn{5}{|c|}{ Supplemental Table S2.txt } \\
\hline CHEMBL3936477 & 1640501 & 4.0 & 4.0511 & TRN \\
\hline CHEMBL3896468 & 1640501 & 4.0 & 4.3624 & TRN \\
\hline CHEMBL3915060 & 1640501 & 4.0 & 4.2438 & TST \\
\hline CHEMBL3898326 & 1640501 & 7.0605 & 4.9043 & TST \\
\hline CHEMBL3952358 & 1640501 & 4.0 & 4.9006 & TRN \\
\hline CHEMBL3949231 & 1640501 & 4.0 & 3.8619 & TRN \\
\hline CHEMBL3954545 & 1640501 & 4.0 & 4.234 & TRN \\
\hline CHEMBL3906150 & 1640501 & 5.6778 & 4.8232 & TRN \\
\hline CHEMBL3963551 & 1640501 & 5.0237 & 5.1021 & TST \\
\hline CHEMBL3905018 & 1640501 & 5.2976 & 5.3474 & TST \\
\hline CHEMBL3969907 & 1640501 & 4.0 & 3.9759 & TRN \\
\hline CHEMBL3970833 & 1640501 & 5.7212 & 4.3937 & TST \\
\hline CHEMBL3911420 & 1640501 & 4.0 & 4.4482 & TST \\
\hline CHEMBL3951952 & 1640501 & 5.3565 & 5.6698 & TRN \\
\hline CHEMBL3970027 & 1640501 & 4.0 & 3.5238 & TST \\
\hline CHEMBL3912230 & 1640501 & 5.8404 & 5.4514 & TRN \\
\hline CHEMBL3943892 & 1640501 & 4.0 & 4.0323 & TRN \\
\hline CHEMBL3954271 & 1640501 & 5.5129 & 5.2168 & TRN \\
\hline CHEMBL 3924494 & 1640501 & 4.0 & 4.0821 & TST \\
\hline CHEMBL3973425 & 1640501 & 4.1427 & 4.5054 & TRN \\
\hline CHEMBL3945169 & 1640501 & 6.7595 & 5.3253 & TST \\
\hline CHEMBL3950899 & 1640501 & 6.0329 & 5.1266 & TST \\
\hline CHEMBL 3974020 & 1640501 & 5.4045 & 5.544 & TRN \\
\hline CHEMBL 3941267 & 1640501 & 5.767 & 5.4422 & TST \\
\hline CHEMBL3903485 & 1640501 & 7.1024 & 5.86 & TST \\
\hline CHEMBL3894827 & 1640501 & 6.3298 & 6.3984 & TRN \\
\hline CHEMBL3909708 & 1640501 & 5.3179 & 3.9051 & TST \\
\hline CHEMBL 3915048 & 1640501 & 4.0 & 4.1523 & TRN \\
\hline CHEMBL3904381 & 1640501 & 5.7953 & 5.6586 & TRN \\
\hline CHEMBL3914913 & 1640501 & 4.0 & 4.7052 & TRN \\
\hline CHEMBL3939461 & 1640501 & 5.2366 & 5.0838 & TRN \\
\hline CHEMBL3896907 & 1640501 & 4.0 & 4.6587 & TRN \\
\hline CHEMBL3957262 & 1640501 & 6.0899 & 5.8924 & TRN \\
\hline CHEMBL3904337 & 1640501 & 4.0 & 4.5335 & TRN \\
\hline CHEMBL3909036 & 1640501 & 4.0 & 4.5896 & TRN \\
\hline CHEMBL3928171 & 1640501 & 4.0 & 3.8463 & TST \\
\hline CHEMBL3942682 & 1640501 & 5.4382 & 5.2705 & TRN \\
\hline CHEMBL3948113 & 1640501 & 4.0 & 4.3188 & TRN \\
\hline CHEMBL 3909760 & 1640501 & 4.0 & 4.1003 & TRN \\
\hline CHEMBL 3915648 & 1640501 & 4.0 & 4.0732 & TRN \\
\hline CHEMBL3901218 & 1640501 & 5.5302 & 5.2408 & TRN \\
\hline CHEMBL3982586 & 1640501 & 6.6716 & 7.0483 & TRN \\
\hline CHEMBL3937989 & 1640501 & 5.6383 & 5.6368 & TRN \\
\hline CHEMBL 3918830 & 1640501 & 5.4134 & 4.7362 & TST \\
\hline CHEMBL3914585 & 1640501 & 4.0 & 3.3689 & TRN \\
\hline CHEMBL3970627 & 1640501 & 5.1209 & 5.3019 & TRN \\
\hline CHEMBL3976288 & 1640501 & 5.8665 & 5.35 & TRN \\
\hline CHEMBL3935750 & 1640501 & 4.0 & 4.3118 & TRN \\
\hline
\end{tabular}




\begin{tabular}{|c|c|c|c|c|}
\hline \multicolumn{5}{|c|}{ Supplemental Table S2.txt } \\
\hline CHEMBL3944119 & 1640501 & 4.0 & 4.1606 & TRN \\
\hline CHEMBL 3984997 & 1640501 & 4.0 & 3.8867 & TST \\
\hline CHEMBL 3924639 & 1640501 & 4.0 & 3.6378 & TRN \\
\hline CHEMBL 3945623 & 1640501 & 5.8827 & 5.8055 & TRN \\
\hline CHEMBL 3980955 & 1640501 & 7.0 & 5.1601 & TST \\
\hline CHEMBL 3892574 & 1640501 & 5.3655 & 4.3103 & TST \\
\hline CHEMBL 3970745 & 1640501 & 4.0 & 3.7876 & TRN \\
\hline CHEMBL 3896558 & 1640501 & 4.0 & 3.7607 & TRN \\
\hline CHEMBL 3981392 & 1640501 & 5.3645 & 4.8871 & TRN \\
\hline CHEMBL3943617 & 1640501 & 4.0 & 3.8808 & TRN \\
\hline CHEMBL 3955193 & 1640501 & 5.4202 & 5.1521 & TRN \\
\hline CHEMBL 3953002 & 1640501 & 4.0 & 4.5114 & TRN \\
\hline CHEMBL 3919008 & 1640501 & 4.0 & 3.7325 & TRN \\
\hline CHEMBL 3972628 & 1640501 & 6.4935 & 6.0648 & TRN \\
\hline CHEMBL3912425 & 1640501 & 5.9066 & 5.5917 & TRN \\
\hline CHEMBL3969513 & 1640501 & 4.0 & 3.9866 & TRN \\
\hline CHEMBL 3897204 & 1640501 & 5.2541 & 4.5482 & TST \\
\hline CHEMBL3899327 & 1640501 & 5.5317 & 4.9562 & TRN \\
\hline CHEMBL 3936252 & 1640501 & 4.0 & 3.9371 & TRN \\
\hline CHEMBL 3938220 & 1640501 & 5.1805 & 4.8864 & TRN \\
\hline CHEMBL3967736 & 1640501 & 4.0 & 4.2201 & TRN \\
\hline CHEMBL 3983092 & 1640501 & 4.0 & 3.5465 & TRN \\
\hline CHEMBL3984825 & 1640501 & 5.7305 & 4.6536 & TRN \\
\hline CHEMBL 3959841 & 1640501 & 5.8125 & 6.2301 & TRN \\
\hline CHEMBL 3936062 & 1640501 & 4.0 & 4.0319 & TRN \\
\hline CHEMBL3928694 & 1640501 & 5.6271 & 4.4295 & TST \\
\hline CHEMBL 3955316 & 1640501 & 4.0 & 3.7311 & TRN \\
\hline CHEMBL3944386 & 1640501 & 5.1811 & 5.141 & TRN \\
\hline CHEMBL 3975008 & 1640501 & 6.2441 & 6.4991 & TRN \\
\hline CHEMBL 3975621 & 1640501 & 4.0 & 4.0614 & TRN \\
\hline CHEMBL 3904948 & 1640501 & 5.8356 & 4.727 & TST \\
\hline CHEMBL3906075 & 1640501 & 4.0 & 4.302 & TRN \\
\hline CHEMBL3911954 & 1640501 & 4.0 & 4.1739 & TRN \\
\hline CHEMBL 3978467 & 1640501 & 4.0 & 4.905 & TST \\
\hline CHEMBL3899512 & 1640501 & 5.2457 & 4.9023 & TRN \\
\hline CHEMBL 3956206 & 1640501 & 4.0 & 3.793 & TST \\
\hline CHEMBL 3898334 & 1640501 & 5.1854 & 4.1359 & TST \\
\hline CHEMBL3906633 & 1640501 & 4.0 & 4.2552 & TRN \\
\hline CHEMBL 3894665 & 1640501 & 4.0 & 4.0358 & TRN \\
\hline CHEMBL3915101 & 1640501 & 5.4622 & 5.3059 & TRN \\
\hline CHEMBL 3956322 & 1640501 & 4.0 & 4.2826 & TRN \\
\hline CHEMBL3894647 & 1640501 & 4.0 & 4.6203 & TST \\
\hline CHEMBL3910206 & 1640501 & 4.0 & 4.4271 & TRN \\
\hline CHEMBL 3955062 & 1640501 & 4.0 & 3.8047 & TRN \\
\hline CHEMBL3976821 & 1640501 & 5.2314 & 4.9426 & TRN \\
\hline CHEMBL 3976753 & 1640501 & 4.0 & 4.0197 & TST \\
\hline CHEMBL 3899047 & 1640501 & 5.1891 & 5.5572 & TRN \\
\hline CHEMBL3961744 & 1640501 & 4.0 & 5.2538 & TST \\
\hline
\end{tabular}




\section{Supplemental Table S2.txt}

\begin{tabular}{|c|c|c|c|c|c|}
\hline CHEMBL 3947641 & 1640501 & 5.9431 & 4.7085 & TST & \\
\hline CHEMBL3984896 & 1640501 & 5.064 & 4.9434 & TRN & \\
\hline CHEMBL3941599 & 1640501 & 4.0 & 4.0437 & TRN & \\
\hline CHEMBL3959575 & 1640501 & 4.0 & 4.5621 & TST & \\
\hline CHEMBL3976928 & 1640501 & 4.0 & 4.2908 & TRN & \\
\hline CHEMBL3930831 & 1640501 & 5.1675 & 5.4687 & TRN & \\
\hline CHEMBL3913253 & 1640501 & 5.0343 & 4.6361 & TRN & \\
\hline CHEMBL 3912834 & 1640501 & 4.0 & 4.0305 & TRN & \\
\hline CHEMBL 3978752 & 1640501 & 5.0535 & 4.8175 & TRN & \\
\hline CHEMBL3922301 & 1640501 & 6.0 & 3.7324 & TST & \\
\hline CHEMBL3891810 & 1640501 & 4.0 & 4.0434 & TRN & \\
\hline CHEMBL3944530 & 1640501 & 4.0 & 3.6857 & TRN & \\
\hline CHEMBL3961518 & 1640501 & 4.0 & 3.8715 & TRN & \\
\hline CHEMBL3906660 & 1640501 & 5.8665 & 4.671 & TST & \\
\hline CHEMBL3892916 & 1640501 & 4.0 & 3.6871 & TST & \\
\hline CHEMBL 3977525 & 1640501 & 4.0 & 3.5894 & TST & \\
\hline CHEMBL3978660 & 1640501 & 6.7011 & 5.6261 & TRN & \\
\hline CHEMBL 3981628 & 1640501 & 5.3768 & 4.8228 & TST & \\
\hline CHEMBL3914977 & 1640501 & 4.0 & 3.9833 & TRN & \\
\hline CHEMBL3924065 & 1640501 & 5.3768 & 4.1673 & TST & \\
\hline CHEMBL3953184 & 1640501 & 6.7986 & 6.6794 & TRN & \\
\hline CHEMBL3907351 & 1640501 & 4.0 & 3.9382 & TRN & \\
\hline CHEMBL3981126 & 1640501 & 6.9872 & 5.8138 & TST & \\
\hline CHEMBL 3936728 & 1640501 & 5.9101 & 5.4819 & TRN & \\
\hline CHEMBL3970894 & 1640501 & 4.0 & 4.9963 & TRN & \\
\hline CHEMBL3927107 & 1640501 & 5.3335 & 5.4062 & TRN & \\
\hline CHEMBL3902096 & 1640501 & 4.0 & 4.261 & TRN & \\
\hline CHEMBL3982081 & 1640501 & 4.0 & 4.7878 & TRN & \\
\hline CHEMBL 3898823 & 1640501 & 5.6383 & 5.7766 & TST & \\
\hline CHEMBL3958463 & 1640501 & 6.21899 & 999999999 & 99 & 4.9589 \\
\hline CHEMBL3915652 & 1640501 & 4.0 & 4.3062 & TRN & \\
\hline CHEMBL3946500 & 1640501 & 4.0 & 4.3642 & TRN & \\
\hline CHEMBL3927688 & 1640501 & 5.6657 & 5.8727 & TRN & \\
\hline CHEMBL 3976146 & 1640501 & 5.8665 & 5.2168 & TRN & \\
\hline CHEMBL3929170 & 1640501 & 4.6498 & 4.3065 & TRN & \\
\hline CHEMBL3906651 & 1640501 & 4.0 & 4.0934 & TRN & \\
\hline CHEMBL3946655 & 1640501 & 4.0 & 3.4577 & TRN & \\
\hline CHEMBL3899745 & 1640501 & 5.4271 & 5.2473 & TRN & \\
\hline CHEMBL 3983518 & 1640501 & 5.4908 & 5.0163 & TST & \\
\hline CHEMBL3932273 & 1640501 & 5.5229 & 4.8299 & TRN & \\
\hline CHEMBL3970512 & 1640501 & 4.0 & 4.3111 & TRN & \\
\hline CHEMBL3893570 & 1640501 & 4.0 & 3.9326 & TST & \\
\hline CHEMBL 3927742 & 1640501 & 4.0 & 3.9529 & TRN & \\
\hline CHEMBL3963623 & 1640501 & 5.5751 & 5.5976 & TRN & \\
\hline CHEMBL3940347 & 1640501 & 4.0 & 3.9771 & TRN & \\
\hline CHEMBL3974718 & 1640501 & 4.0 & 4.1068 & TRN & \\
\hline CHEMBL3977285 & 1640501 & 4.0 & 3.6114 & TST & \\
\hline CHEMBL3909894 & 1640501 & 4.0 & 4.1156 & TRN & \\
\hline
\end{tabular}




\begin{tabular}{|c|c|c|c|c|}
\hline \multicolumn{5}{|c|}{ Supplemental Table S2.txt } \\
\hline CHEMBL 3916167 & 1640501 & 4.0 & 3.9515 & TRN \\
\hline CHEMBL 3921660 & 1640501 & 4.0 & 3.6776 & TRN \\
\hline CHEMBL 3982990 & 1640501 & 5.7235 & 5.0399 & TRN \\
\hline CHEMBL 3923382 & 1640501 & 5.3979 & 5.2495 & TRN \\
\hline CHEMBL 3946609 & 1640501 & 5.5421 & 5.3058 & TRN \\
\hline CHEMBL3965936 & 1640501 & 5.1355 & 5.1906 & TST \\
\hline CHEMBL 3892705 & 1640501 & 6.251 & 5.3004 & TST \\
\hline CHEMBL 3890547 & 1640501 & 6.3261 & 5.7241 & TRN \\
\hline CHEMBL 3975060 & 1640501 & 4.0 & 3.7814 & TST \\
\hline CHEMBL3937154 & 1640501 & 4.0 & 3.9805 & TRN \\
\hline CHEMBL 3892946 & 1640501 & 4.0 & 3.4678 & TRN \\
\hline CHEMBL 3919993 & 1640501 & 5.426 & 5.2273 & TRN \\
\hline CHEMBL 3895113 & 1640501 & 4.0 & 3.9231 & TRN \\
\hline CHEMBL 3928536 & 1640501 & 4.0 & 3.7901 & TST \\
\hline CHEMBL3984640 & 1640501 & 4.1427 & 4.6723 & TRN \\
\hline CHEMBL 3945702 & 1640501 & 5.2063 & 5.1431 & TRN \\
\hline CHEMBL 3967784 & 1640501 & 6.3152 & 6.0472 & TRN \\
\hline CHEMBL3958894 & 1640501 & 4.0 & 4.0437 & TRN \\
\hline CHEMBL 3890540 & 1640501 & 4.0 & 4.4303 & TRN \\
\hline CHEMBL3966011 & 1640501 & 5.4123 & 3.489 & TST \\
\hline CHEMBL3959624 & 1640501 & 5.6326 & 5.6335 & TRN \\
\hline CHEMBL 3960354 & 1640501 & 4.0 & 3.8583 & TRN \\
\hline CHEMBL3932628 & 1640501 & 4.0 & 4.0212 & TST \\
\hline CHEMBL 3975159 & 1640501 & 5.6891 & 5.3538 & TRN \\
\hline CHEMBL 3893108 & 1640501 & 4.0 & 3.9114 & TRN \\
\hline CHEMBL 3974594 & 1640501 & 4.0 & 4.4587 & TRN \\
\hline CHEMBL 3968766 & 1640501 & 4.0 & 4.1982 & TRN \\
\hline CHEMBL 3985385 & 1640501 & 4.0 & 4.1125 & TRN \\
\hline CHEMBL 3985232 & 1640501 & 5.1427 & 5.118 & TRN \\
\hline CHEMBL 3899980 & 1640501 & 4.0 & 3.8745 & TRN \\
\hline CHEMBL 3890590 & 1640501 & 5.4976 & 5.693 & TRN \\
\hline CHEMBL 3950980 & 1640501 & 4.0 & 4.319 & TRN \\
\hline CHEMBL3897742 & 1640501 & 4.0 & 3.9795 & TRN \\
\hline CHEMBL 3966219 & 1640501 & 4.0 & 4.221 & TRN \\
\hline CHEMBL 3908213 & 1640501 & 5.4535 & 5.56 & TRN \\
\hline CHEMBL 3890517 & 1640501 & 4.0 & 3.8146 & TRN \\
\hline CHEMBL 3979520 & 1640501 & 4.0 & 4.5978 & TRN \\
\hline CHEMBL3890695 & 1640501 & 5.1284 & 4.1253 & TST \\
\hline CHEMBL 3892525 & 1640501 & 5.9747 & 6.1094 & TRN \\
\hline CHEMBL3941317 & 1640501 & 4.0 & 4.0708 & TRN \\
\hline CHEMBL 3960573 & 1640501 & 5.6757 & 5.5409 & TRN \\
\hline CHEMBL3983141 & 1640501 & 5.0278 & 3.7013 & TST \\
\hline CHEMBL 3899666 & 1640501 & 5.9439 & 5.6777 & TRN \\
\hline CHEMBL 3952837 & 1640501 & 7.0088 & 6.3681 & TRN \\
\hline CHEMBL3954867 & 1640501 & 4.0 & 3.8445 & TRN \\
\hline CHEMBL 3971848 & 1640501 & 4.0 & 4.6405 & TRN \\
\hline CHEMBL 3933002 & 1640501 & 7.4318 & 6.4424 & TST \\
\hline CHEMBL3932385 & 1640501 & 6.4868 & 6.777 & TRN \\
\hline
\end{tabular}


Supplemental Table S2.txt

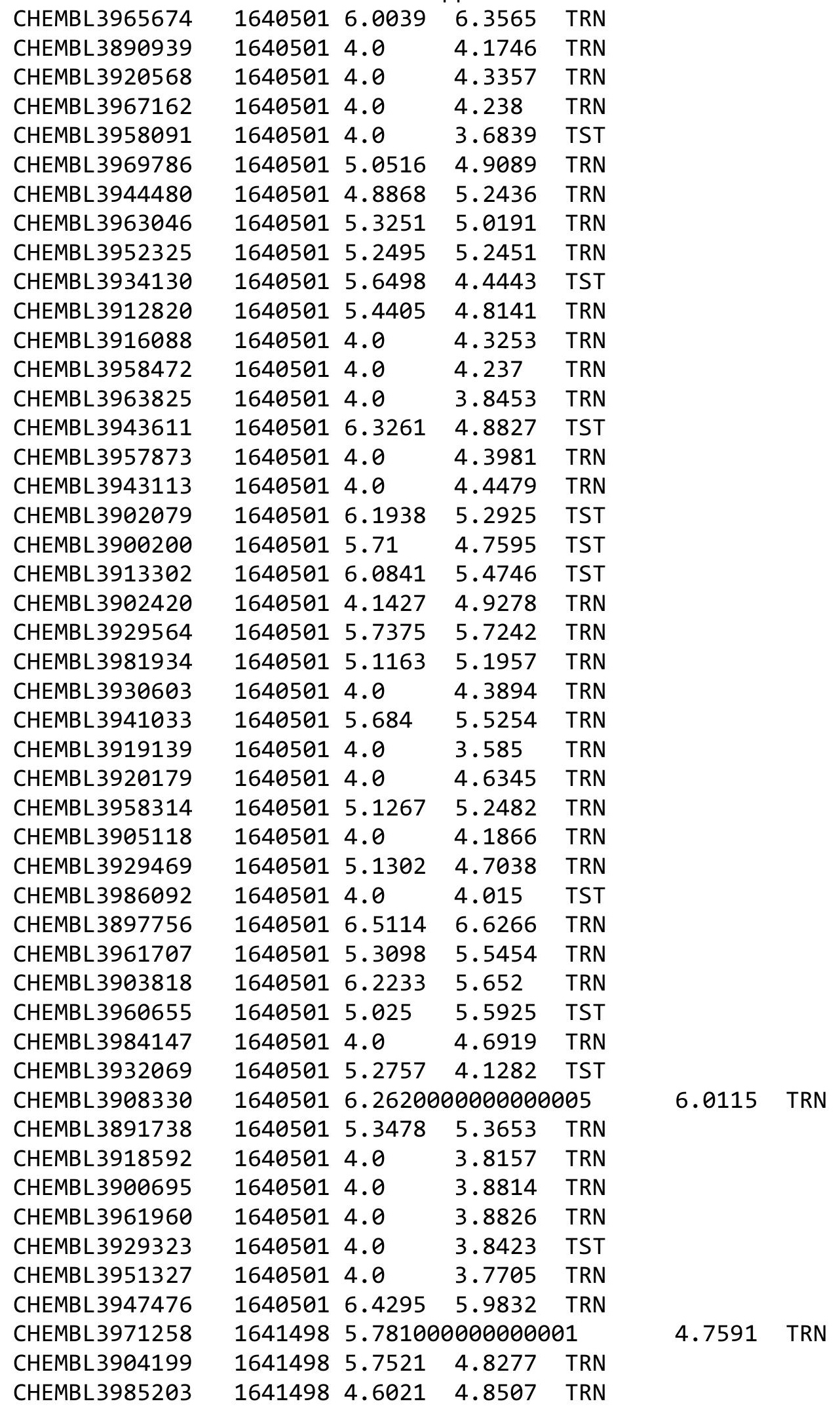

Page 17111 
Supplemental Table S2.txt

\begin{tabular}{|c|c|c|c|c|}
\hline W & 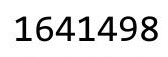 & & & \\
\hline & 641498 & 4.6021 & 5.2357 & \\
\hline & & & & \\
\hline AEMBL & & 6021 & 8861 & $\mathrm{MI}$ \\
\hline AEMBL3920480 & 498 & 6021 & & \\
\hline HEMBL3957383 & 641498 & 5.8403 & 2532 & \\
\hline 260 & & 021 & & \\
\hline 949 & & & & \\
\hline AEMBL3974348 & 498 & 6.0 & 9885 & \\
\hline HEMBL3897042 & 498 & 021 & 7373 & \\
\hline HEMBL3942118 & 198 & 4.6021 & 8091 & \\
\hline IEMBL39 & 98 & 021 & 504 & \\
\hline AEMBL39 & & & & \\
\hline HEMBL3911556 & & 4.6021 & 7014 & \\
\hline AEMBL3953645 & 98 & 47 & 355 & \\
\hline AEMBL3973717 & 62 & 4 . & 697 & \\
\hline AEMBL39 & 98 & 4 & 32 & \\
\hline HEMBL39 & & & & \\
\hline HEMBL39 & & 124 & 7741 & \\
\hline AEMBL39 & & 35 & & \\
\hline HEIMBLSS & 6 & 4 & 93 & 1SI \\
\hline AEMBL & & 4 & 02 & RN \\
\hline AEMBL3S & & & & \\
\hline 842 & & 4 & & \\
\hline AEMBL 394 & & & & TST \\
\hline HEMBL3S & 6 & 4 & 24 & I RN \\
\hline HEMBL3 & & & 316 & RN \\
\hline HFMBI $3 c$ & & & 742 & \\
\hline HEMBL3S & & & & 「RN \\
\hline HEMBL3926090 & & & & I RN \\
\hline HEMBL3938985 & & 4 & 51 & RIV \\
\hline HEMBL & & 1 & 18 & ST \\
\hline 508 & & 4 & 346 & TRN \\
\hline HEMBL3929690 & & & 249 & R \\
\hline HEMBL3979917 & & 4 . & 204 & TRN \\
\hline HEMBL39 & & 4 & 964 & ST \\
\hline HFMRI & 8 & 1 & & RN \\
\hline HEMBL3 & & & 367 & RN \\
\hline HEMBL3917549 & & 5 . & 8642 & TST \\
\hline JEMBL3959057 & & 1 & 7687 & TRN \\
\hline HEMBL3S & 6 & 1 & 3016 & \\
\hline HEMBL 39 & & & & RN \\
\hline HEMBL3936378 & & 4.6021 & 2223 & ГST \\
\hline AEMBL3962963 & 98 & 4.6021 & 3198 & TRN \\
\hline $\mathrm{MBI} 3$ & & 1 & 34 & 13 \\
\hline HEMBL3S & & + & & \\
\hline LHEMBL 3978092 & & 4.6021 & 0563 & \\
\hline HEMBL395695 & 164149 & 4.6021 & 4.7617 & IST \\
\hline
\end{tabular}

Page 17112 
Supplemental Table S2.txt

\begin{tabular}{|c|c|c|c|c|}
\hline CHEMBL3911588 & 1641498 & 4.6021 & 4.7638 & TRN \\
\hline CHEMBL 3902320 & 1641498 & 5.8866 & 5.1007 & TST \\
\hline CHEMBL3921379 & 1641498 & 4.6021 & 4.7662 & TRN \\
\hline CHEMBL3917709 & 1641498 & 4.6021 & 4.7405 & TRN \\
\hline CHEMBL3932580 & 1641498 & 4.6021 & 5.1272 & TRN \\
\hline CHEMBL3921643 & 1641498 & 6.2122 & 5.2208 & TRN \\
\hline CHEMBL3978983 & 1641498 & 4.6021 & 5.1925 & TRN \\
\hline CHEMBL3965468 & 1641498 & 5.6318 & 4.7118 & TRN \\
\hline CHEMBL3945278 & 1641498 & 5.6948 & 5.23 & TRN \\
\hline CHEMBL3916404 & 1641498 & 4.6021 & 4.7823 & TRN \\
\hline CHEMBL3947317 & 1641498 & 5.7054 & 5.1966 & TRN \\
\hline CHEMBL3948375 & 1641498 & 4.6021 & 5.0894 & TST \\
\hline CHEMBL3948958 & 1641498 & 4.6021 & 5.0022 & TRN \\
\hline CHEMBL3905032 & 1641498 & 4.6021 & 5.2227 & TRN \\
\hline CHEMBL3902965 & 1641498 & 4.6021 & 4.7827 & TRN \\
\hline CHEMBL3981518 & 1641498 & 6.6799 & 5.266 & TST \\
\hline CHEMBL3920529 & 1641498 & 4.6021 & 4.6638 & TRN \\
\hline CHEMBL3977510 & 1641498 & 6.4449 & 5.0671 & TST \\
\hline CHEMBL3935120 & 1641498 & 4.6021 & 5.2303 & TRN \\
\hline CHEMBL3974366 & 1641498 & 4.6021 & 5.1644 & TRN \\
\hline CHEMBL3948434 & 1641498 & 4.6021 & 4.6793 & TRN \\
\hline CHEMBL3889942 & 1641498 & 4.6021 & 4.8054 & TRN \\
\hline CHEMBL3978531 & 1641498 & 5.61100 & 0000000 & 5.4392 \\
\hline CHEMBL3903854 & 1641498 & 4.6021 & 5.0738 & TRN \\
\hline CHEMBL3974695 & 1641498 & 4.6021 & 5.3422 & TRN \\
\hline CHEMBL3934699 & 1641498 & 4.6021 & 4.8706 & TST \\
\hline CHEMBL3895918 & 1641498 & 4.6021 & 4.7938 & TRN \\
\hline CHEMBL3958984 & 1641498 & 4.6021 & 4.962 & TRN \\
\hline CHEMBL3894683 & 1641498 & 4.6021 & 4.6837 & TRN \\
\hline CHEMBL3918075 & 1641498 & 4.6021 & 4.9821 & TST \\
\hline CHEMBL3978793 & 1641498 & 4.6021 & 4.851 & TST \\
\hline CHEMBL3927192 & 1641498 & 6.5357 & 5.218 & TST \\
\hline CHEMBL3984790 & 1641498 & 5.8107 & 4.6364 & TRN \\
\hline CHEMBL3926628 & 1641498 & 4.6021 & 5.41200 & 0000000001 \\
\hline CHEMBL3915346 & 1641498 & 4.6021 & 5.0964 & TRN \\
\hline CHEMBL3928555 & 1641498 & 4.6021 & 5.0816 & TRN \\
\hline CHEMBL3929226 & 1641498 & 4.6021 & 4.9264 & TST \\
\hline CHEMBL3971456 & 1641498 & 5.9084 & 5.3337 & TRN \\
\hline CHEMBL3897914 & 1641498 & 4.6021 & 4.938 & TRN \\
\hline CHEMBL3931188 & 1641498 & 4.6021 & 4.7882 & TRN \\
\hline CHEMBL3916305 & 1641498 & 4.6021 & 4.7512 & TRN \\
\hline CHEMBL3957598 & 1641498 & 4.6021 & 4.7383 & TRN \\
\hline CHEMBL3962994 & 1641498 & 4.6021 & 4.8105 & TRN \\
\hline CHEMBL3901645 & 1641498 & 4.6021 & 4.6416 & TRN \\
\hline CHEMBL3971190 & 1641498 & 4.6021 & 4.6653 & TRN \\
\hline CHEMBL3985351 & 1641498 & 5.8995 & 4.9149 & TRN \\
\hline CHEMBL3983802 & 1641498 & 5.9503 & 5.4939 & TRN \\
\hline CHEMBL3924091 & 1641498 & 4.6021 & 4.6839 & TRN \\
\hline
\end{tabular}

Page 17113 
Supplemental Table S2.txt

\begin{tabular}{|c|c|c|c|c|}
\hline CHEMBL3890127 & 1641498 & 4.6021 & 5.0809 & TST \\
\hline CHEMBL3960545 & 1641498 & 5.6895 & 4.7997 & TRN \\
\hline CHEMBL3904250 & 1641498 & 5.8839 & 4.8461 & TST \\
\hline CHEMBL 3895486 & 1641498 & 4.6021 & 4.7168 & TRN \\
\hline CHEMBL3947407 & 1641498 & 6.057 & 5.2035 & TRN \\
\hline CHEMBL3980859 & 1641498 & 4.6021 & 5.1567 & TST \\
\hline CHEMBL3947824 & 1641498 & 4.6021 & 5.0886 & TRN \\
\hline CHEMBL3952044 & 1641498 & 4.6021 & 4.9504 & TRN \\
\hline CHEMBL3924427 & 1641498 & 5.9054 & 4.8314 & TRN \\
\hline CHEMBL3912415 & 1641498 & 4.6021 & 4.7463 & TRN \\
\hline CHEMBL3942029 & 1641498 & 4.6021 & 5.2764 & TRN \\
\hline CHEMBL3893330 & 1641498 & 6.5465 & 5.0833 & TST \\
\hline CHEMBL3968807 & 1641498 & 4.6021 & 4.6425 & TRN \\
\hline CHEMBL3909815 & 1641498 & 4.6021 & 5.0167 & TST \\
\hline CHEMBL 3890988 & 1641498 & 4.6021 & 4.6055 & TRN \\
\hline CHEMBL3963062 & 1641498 & 6.0 & 5.2048 & TRN \\
\hline CHEMBL3929751 & 1641498 & 6.0516 & 5.0712 & TRN \\
\hline CHEMBL3962483 & 1641498 & 4.6021 & 4.763 & TRN \\
\hline CHEMBL3953661 & 1641498 & 4.6021 & 4.7323 & TRN \\
\hline CHEMBL3939190 & 1641498 & 4.6021 & 5.1772 & TRN \\
\hline CHEMBL3977133 & 1641498 & 4.6021 & 4.8418 & TRN \\
\hline CHEMBL3956043 & 1641498 & 4.6021 & 5.187 & TRN \\
\hline CHEMBL3942613 & 1641498 & 4.6021 & 4.8293 & TRN \\
\hline CHEMBL3929829 & 1641498 & 4.6021 & 4.8016 & TRN \\
\hline CHEMBL 3934224 & 1641498 & 4.6021 & 5.1514 & TRN \\
\hline CHEMBL3935699 & 1641498 & 4.6021 & 4.9218 & TRN \\
\hline CHEMBL3901452 & 1641498 & 4.6021 & 4.8906 & TST \\
\hline CHEMBL3982380 & 1641498 & 6.001 & 5.1426 & TRN \\
\hline CHEMBL3953536 & 1641498 & 4.6021 & 5.1168 & TST \\
\hline CHEMBL 3948295 & 1641498 & 4.6021 & 4.6826 & TRN \\
\hline CHEMBL3959717 & 1641498 & 4.6021 & 4.8615 & TRN \\
\hline CHEMBL3928114 & 1641498 & 6.7038 & 5.119 & TST \\
\hline CHEMBL3964394 & 1641498 & 4.6021 & 4.7715 & TRN \\
\hline CHEMBL3933986 & 1641498 & 4.6021 & 4.8636 & TST \\
\hline CHEMBL3953264 & 1641498 & 4.6021 & 4.8367 & TRN \\
\hline CHEMBL3897057 & 1641498 & 4.6021 & 4.812 & TRN \\
\hline CHEMBL3901960 & 1641498 & 4.6021 & 4.65 & TRN \\
\hline CHEMBL3935434 & 1641498 & 4.6021 & 5.19600 & 0000000001 \\
\hline CHEMBL3962867 & 1641498 & 4.6021 & 4.8625 & TST \\
\hline CHEMBL3981867 & 1641498 & 4.6021 & 5.1715 & TRN \\
\hline CHEMBL3931738 & 1641498 & 4.6021 & 4.7278 & TRN \\
\hline CHEMBL3932249 & 1641498 & 4.6021 & 4.8435 & TST \\
\hline CHEMBL3918713 & 1641498 & 4.6021 & 4.6753 & TRN \\
\hline CHEMBL3934380 & 1641498 & 4.6021 & 5.216 & TRN \\
\hline CHEMBL3969071 & 1641498 & 4.6021 & 5.2548 & TRN \\
\hline CHEMBL3924583 & 1641498 & 4.6021 & 4.8363 & TRN \\
\hline CHEMBL3933068 & 1641498 & 4.6021 & 4.8694 & TST \\
\hline CHEMBL3902781 & 1641498 & 4.6021 & 5.273 & TRN \\
\hline
\end{tabular}


Supplemental Table S2.txt

\begin{tabular}{|c|c|c|c|c|c|}
\hline CHEMBL3963504 & 1641498 & 4.6021 & 4.7166 & TRN & \\
\hline CHEMBL3918299 & 1641498 & 4.6021 & 4.8912 & TRN & \\
\hline CHEMBL3900837 & 1641498 & 4.6021 & 4.7619 & TRN & \\
\hline CHEMBL3952701 & 1641498 & 4.6021 & 4.7917 & TRN & \\
\hline CHEMBL3962149 & 1641498 & 4.6021 & 5.096 & TRN & \\
\hline CHEMBL3963958 & 1641498 & 4.6021 & 4.8175 & TRN & \\
\hline CHEMBL3921577 & 1641498 & 4.6021 & 4.7866 & TRN & \\
\hline CHEMBL3957145 & 1641498 & 6.2688 & 5.1242 & TRN & \\
\hline CHEMBL3957320 & 1641498 & 6.1844 & 4.9826 & TRN & \\
\hline CHEMBL3982683 & 1641498 & 4.6021 & 5.3332 & TRN & \\
\hline CHEMBL3896971 & 1641498 & 5.8418 & 4.789 & TRN & \\
\hline CHEMBL3917369 & 1641498 & 4.6021 & 4.9106 & TST & \\
\hline CHEMBL3959176 & 1641498 & 4.6021 & 5.4214 & TST & \\
\hline CHEMBL3934660 & 1641498 & 4.6021 & 4.9955 & TRN & \\
\hline CHEMBL3960121 & 1641498 & 4.6021 & 4.7554 & TRN & \\
\hline CHEMBL3902036 & 1641498 & 4.6021 & 4.7757 & TRN & \\
\hline CHEMBL3935654 & 1641498 & 6.1465 & 4.9055 & TRN & \\
\hline CHEMBL3910585 & 1641498 & 4.6021 & 5.3035 & TRN & \\
\hline CHEMBL3903626 & 1641498 & 4.6021 & 4.7493 & TRN & \\
\hline CHEMBL3942940 & 1641498 & 4.6021 & 5.2936 & TRN & \\
\hline CHEMBL3905261 & 1641498 & 4.6021 & 4.801 & TRN & \\
\hline CHEMBL3968207 & 1641498 & 4.6021 & 4.7187 & TRN & \\
\hline CHEMBL3910508 & 1641498 & 4.6021 & 4.8721 & TST & \\
\hline CHEMBL3952887 & 1641498 & 4.6021 & 5.1225 & TRN & \\
\hline CHEMBL3940271 & 1641498 & 4.6021 & 5.4292 & TRN & \\
\hline CHEMBL3931567 & 1641498 & 4.6021 & 5.0614 & TST & \\
\hline CHEMBL3933087 & 1641498 & 4.6021 & 4.7608 & TRN & \\
\hline CHEMBL3903735 & 1641498 & 4.6021 & 4.8615 & TST & \\
\hline CHEMBL3970820 & 1641498 & 4.6021 & \multicolumn{2}{|c|}{5.247000000000001} & TRN \\
\hline CHEMBL3976346 & 1641498 & 6.3288 & 5.3814 & TRN & \\
\hline CHEMBL3919525 & 1641498 & 4.6021 & 5.0749 & TRN & \\
\hline CHEMBL 3897470 & 1641498 & 4.6021 & 4.9126 & TRN & \\
\hline CHEMBL3902029 & 1641498 & 4.6021 & 4.8235 & TRN & \\
\hline CHEMBL3939079 & 1641498 & 4.6021 & 4.8932 & TRN & \\
\hline CHEMBL3902293 & 1641498 & 4.6021 & 4.8443 & TST & \\
\hline CHEMBL3919052 & 1641498 & 4.6021 & \multicolumn{2}{|c|}{4.7330000000000005} & TRN \\
\hline CHEMBL3965414 & 1641498 & 4.6021 & 5.4461 & TRN & \\
\hline CHEMBL 3948410 & 1641498 & 4.6021 & 4.8183 & TST & \\
\hline CHEMBL3933273 & 1641498 & 5.9961 & 4.8717 & TRN & \\
\hline CHEMBL3898728 & 1641498 & 4.6021 & 4.8307 & TST & \\
\hline CHEMBL3950973 & 1641498 & 4.6021 & 4.7789 & TRN & \\
\hline CHEMBL3896981 & 1641498 & 4.6021 & 4.7946 & TST & \\
\hline CHEMBL3894485 & 1641498 & 6.0502 & 5.1775 & TRN & \\
\hline CHEMBL3912390 & 1641498 & 5.8559 & 4.9935 & TST & \\
\hline CHEMBL3924670 & 1641498 & 4.6021 & 4.7925 & TRN & \\
\hline CHEMBL3982344 & 1641498 & 4.6021 & 4.7794 & TRN & \\
\hline CHEMBL3900029 & 1641498 & 4.6021 & 4.7185 & TST & \\
\hline CHEMBL3954025 & 1641498 & 5.6891 & 5.0003 & TST & \\
\hline
\end{tabular}


Supplemental Table S2.txt

\begin{tabular}{|c|c|c|c|c|c|c|}
\hline CHEMBL 3949438 & 1641498 & 5.7984 & 5.184 & TST & & \\
\hline CHEMBL3949243 & 1641498 & 6.0912 & 4.7498 & TRN & & \\
\hline CHEMBL3946755 & 1641498 & 4.6021 & 4.9327 & TST & & \\
\hline CHEMBL3965903 & 1641498 & 4.6021 & 5.1706 & TST & & \\
\hline CHEMBL3941242 & 1641498 & 4.6021 & 5.0437 & TST & & \\
\hline CHEMBL3947780 & 1641498 & 6.1544 & 5.4794 & TRN & & \\
\hline CHEMBL3917809 & 1641498 & 4.6021 & 4.8682 & TRN & & \\
\hline CHEMBL 3909628 & 1641498 & 4.6021 & 4.7452 & TRN & & \\
\hline CHEMBL3895989 & 1641498 & 4.6021 & 4.8174 & TRN & & \\
\hline CHEMBL3933340 & 1641498 & 4.6021 & 5.2317 & TRN & & \\
\hline CHEMBL3979743 & 1641498 & 4.6021 & 4.5553 & TRN & & \\
\hline CHEMBL3929369 & 1641498 & 4.6021 & 5.1628 & TRN & & \\
\hline CHEMBL3920779 & 1641498 & 4.6021 & 4.8275 & TRN & & \\
\hline CHEMBL3969132 & 1641498 & 5.6902 & 5.3256 & TRN & & \\
\hline CHEMBL3949912 & 1641498 & 4.6021 & 4.8211 & TRN & & \\
\hline CHEMBL3917705 & 1641498 & 5.6575 & 5.2257 & TRN & & \\
\hline CHEMBL3893056 & 1641498 & 5.7277 & 4.83 & TRN & & \\
\hline CHEMBL3960471 & 1641498 & 4.6021 & 4.9807 & TST & & \\
\hline CHEMBL3947630 & 1641498 & 4.6021 & 4.8157 & TRN & & \\
\hline CHEMBL3959771 & 1641498 & 4.6021 & 5.3216 & TRN & & \\
\hline CHEMBL3984800 & 1641498 & 4.6021 & 4.72 & TRN & & \\
\hline CHEMBL3950185 & 1641498 & 4.6021 & 4.7164 & TRN & & \\
\hline CHEMBL 3923742 & 1641498 & 4.6021 & 4.8846 & TRN & & \\
\hline CHEMBL3933040 & 1641498 & 5.6056 & 5.2551 & TRN & & \\
\hline CHEMBL3954928 & 1641498 & 6.5275 & 5.3531 & TST & & \\
\hline CHEMBL3932791 & 1641498 & 5.6488 & 5.3184 & TST & & \\
\hline CHEMBL 3954481 & 1641498 & 5.6567 & 5.3043 & TRN & & \\
\hline CHEMBL3920846 & 1641498 & 4.6021 & 5.1588 & TRN & & \\
\hline CHEMBL3986306 & 1641498 & 4.6021 & 4.8037 & TRN & & \\
\hline CHEMBL 3970280 & 1641498 & 5.7399 & 4.9711 & TST & & \\
\hline CHEMBL3901345 & 1641498 & 4.6021 & 4.8554 & TRN & & \\
\hline CHEMBL3960928 & 1641498 & 7.0 & 4.7502 & TRN & & \\
\hline CHEMBL3911988 & 1641498 & 5.7633 & 4.8261 & TRN & & \\
\hline CHEMBL3953595 & 1641498 & \multicolumn{3}{|c|}{6.0729999999999995} & 5.1672 & TST \\
\hline CHEMBL3949007 & 1641498 & 4.6021 & 5.4616 & TRN & & \\
\hline CHEMBL3933296 & 1641498 & 4.6021 & 5.3716 & TRN & & \\
\hline CHEMBL3894196 & 1641498 & 4.6021 & 4.7148 & TRN & & \\
\hline CHEMBL 3943317 & 1641498 & 5.7089 & 5.0632 & TRN & & \\
\hline CHEMBL3943537 & 1641498 & 4.6021 & 5.1243 & TRN & & \\
\hline CHEMBL3925178 & 1641498 & 4.6021 & 4.7941 & TRN & & \\
\hline CHEMBL3931967 & 1641498 & 4.6021 & 5.109 & TRN & & \\
\hline CHEMBL3912234 & 1641498 & 6.1524 & 5.4729 & TRN & & \\
\hline CHEMBL3981449 & 1641498 & 4.6021 & 4.7184 & TRN & & \\
\hline CHEMBL3925888 & 1641498 & 4.6021 & 4.8877 & TRN & & \\
\hline CHEMBL3961757 & 1641498 & 4.6021 & 5.3033 & TRN & & \\
\hline CHEMBL3906930 & 1641498 & 4.6021 & 5.1089 & TRN & & \\
\hline CHEMBL3919649 & 1641498 & 6.0 & 5.1467 & TRN & & \\
\hline CHEMBL3979608 & 1641498 & 4.6021 & 5.0902 & TRN & & \\
\hline
\end{tabular}

Page 17116 
Supplemental Table S2.txt

\begin{tabular}{|c|c|c|c|c|c|}
\hline CHEMBL3953721 & 1641498 & 4.6021 & 4.8813 & TST & \\
\hline CHEMBL3965601 & 1641498 & 4.6021 & 4.7552 & TRN & \\
\hline CHEMBL3904803 & 1641498 & 5.9506 & 4.8201 & TRN & \\
\hline CHEMBL 3985773 & 1641498 & 4.6021 & 4.6952 & TRN & \\
\hline CHEMBL3905820 & 1641498 & 5.8035 & 5.1368 & TRN & \\
\hline CHEMBL3920670 & 1641498 & 4.6021 & 5.0824 & TRN & \\
\hline CHEMBL3955319 & 1641498 & 4.6021 & 4.7511 & TRN & \\
\hline CHEMBL3896788 & 1641498 & 5.612999 & 79999999ऽ & 995 & 4.7644 \\
\hline CHEMBL 3958073 & 1641498 & 4.6021 & 4.9757 & TST & \\
\hline CHEMBL3964265 & 1641498 & 4.6021 & 4.7694 & TRN & \\
\hline CHEMBL3894819 & 1641498 & 6.062 & 5.197 & TRN & \\
\hline CHEMBL3936125 & 1641498 & 4.6021 & 5.0052 & TST & \\
\hline CHEMBL3896470 & 1641498 & 6.0575 & 5.0915 & TST & \\
\hline CHEMBL3889467 & 1641498 & 6.3236 & 5.5102 & TRN & \\
\hline CHEMBL3894600 & 1641498 & 4.6021 & 4.8047 & TRN & \\
\hline CHEMBL3897318 & 1641498 & 6.2612 & 5.1508 & TRN & \\
\hline CHEMBL3898169 & 1641498 & 4.6021 & 4.6908 & TRN & \\
\hline CHEMBL3985598 & 1641498 & 4.6021 & 5.1395 & TRN & \\
\hline CHEMBL3984526 & 1641498 & 4.6021 & 4.8417 & TST & \\
\hline CHEMBL3963967 & 1641498 & 4.6021 & 4.9093 & TRN & \\
\hline CHEMBL 3907103 & 1641498 & 4.6021 & 5.1301 & TST & \\
\hline CHEMBL3892695 & 1641498 & 6.1502 & 5.1187 & TST & \\
\hline CHEMBL3914346 & 1641498 & 4.6021 & 4.8549 & TRN & \\
\hline CHEMBL 3940234 & 1641498 & 6.3756 & 5.3877 & TRN & \\
\hline CHEMBL3908859 & 1641498 & 4.6021 & 5.3834 & TST & \\
\hline CHEMBL 3942253 & 1641498 & 5.9455 & 5.0795 & TRN & \\
\hline CHEMBL3918964 & 1641498 & 4.6021 & 4.8789 & TRN & \\
\hline CHEMBL3973926 & 1641498 & 4.6021 & 4.7881 & TRN & \\
\hline CHEMBL3981522 & 1641498 & 4.6021 & 4.8041 & TRN & \\
\hline CHEMBL3918554 & 1641498 & 4.6021 & 4.8152 & TRN & \\
\hline CHEMBL3924142 & 1641498 & 4.6021 & 4.8008 & TRN & \\
\hline CHEMBL3936530 & 1641498 & 4.6021 & 4.812 & TRN & \\
\hline CHEMBL3954706 & 1641498 & 6.6623 & 5.1626 & TST & \\
\hline CHEMBL3950893 & 1641498 & 4.6021 & 4.8412 & TST & \\
\hline CHEMBL3947644 & 1641498 & 4.6021 & 4.7662 & TRN & \\
\hline CHEMBL3919262 & 1641498 & 6.1002 & 4.8148 & TRN & \\
\hline CHEMBL3926144 & 1641498 & 6.1681 & 5.1403 & TRN & \\
\hline CHEMBL3960014 & 1641498 & 5.8648 & 4.8626 & TRN & \\
\hline CHEMBL3934541 & 1641498 & 4.6021 & 4.8333 & TRN & \\
\hline CHEMBL3963628 & 1641498 & 4.6021 & 4.7392 & TRN & \\
\hline CHEMBL3978900 & 1641498 & 5.9243 & 5.0862 & TST & \\
\hline CHEMBL3946556 & 1641498 & 4.6021 & 4.816 & TRN & \\
\hline CHEMBL3985204 & 1641498 & 4.6021 & 4.8336 & TRN & \\
\hline CHEMBL3969078 & 1641498 & 4.6021 & 4.9603 & TST & \\
\hline CHEMBL3921343 & 1641498 & 5.8423 & 5.0419 & TST & \\
\hline CHEMBL3982318 & 1641498 & 5.8438 & 5.0475 & TST & \\
\hline CHEMBL3930352 & 1641498 & 5.7249 & 4.8502 & TST & \\
\hline CHEMBL 3904843 & 1641498 & 4.6021 & 4.8694 & TRN & \\
\hline
\end{tabular}

Page 17117 
Supplemental Table S2.txt

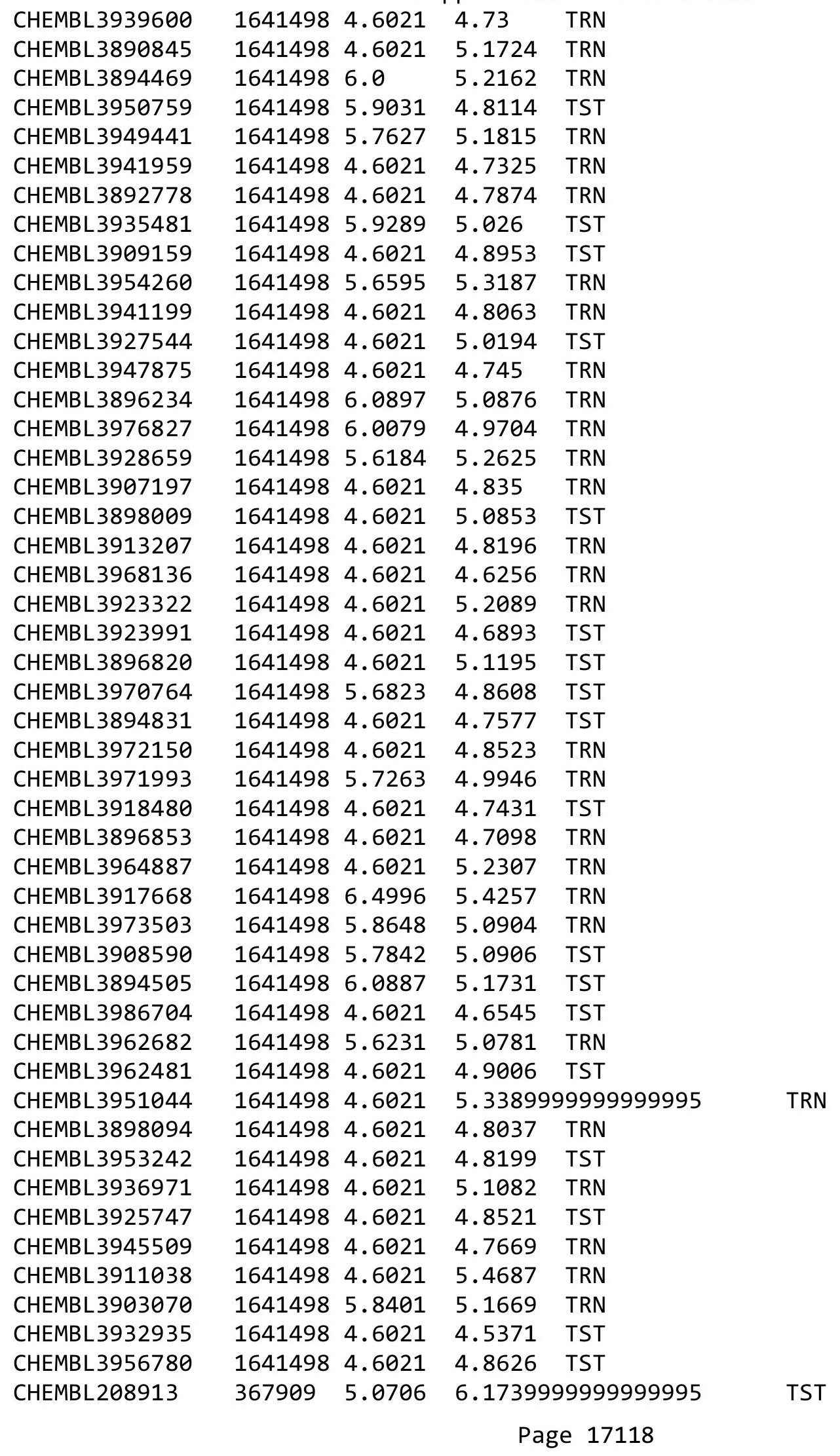




\begin{tabular}{|c|c|c|c|c|c|}
\hline \multicolumn{6}{|c|}{ Supplemental Table s2.txt } \\
\hline CHEMBL377128 & 367909 & 6.0 & 7.1264 & TRN & \\
\hline CHEMBL211997 & 367909 & 5.5528 & 5.8806 & TRN & \\
\hline CHEMBL209721 & 367909 & 6.1135 & 5.8594 & TRN & \\
\hline CHEMBL211148 & 367909 & 7.6198 & 7.0195 & TRN & \\
\hline CHEMBL212326 & 367909 & 6.1805 & 5.9958 & TRN & \\
\hline CHEMBL208608 & 367909 & 6.1024 & 6.3755 & TRN & \\
\hline CHEMBL210958 & 367909 & 4.7696 & 6.5402 & TST & \\
\hline CHEMBL210500 & 367909 & 5.9208 & 5.8061 & TRN & \\
\hline CHEMBL212362 & 367909 & 6.5376 & 6.9236 & TRN & \\
\hline CHEMBL377555 & 367909 & 7.4202 & 7.5157 & TRN & \\
\hline CHEMBL378724 & 367909 & 6.4202 & 6.358 & TST & \\
\hline CHEMBL209330 & 367909 & 7.0177 & 6.1475 & TRN & \\
\hline CHEMBL377409 & 367909 & 6.1938 & 6.2707 & TRN & \\
\hline CHEMBL378993 & 367909 & 7.4559 & 6.7845 & TRN & \\
\hline CHEMBL378631 & 367909 & 6.5686 & 6.6154 & TST & \\
\hline CHEMBL212380 & 367909 & 5.3098 & 4.9035 & TRN & \\
\hline CHEMBL211607 & 367909 & 6.2676 & 6.2189 & TRN & \\
\hline CHEMBL377912 & 367909 & 6.8239 & 6.8514 & TRN & \\
\hline CHEMBL211687 & 367909 & 5.8861 & 6.04799 & э999999999 & TRN \\
\hline CHEMBL210895 & 367909 & 5.699 & 5.97 & TST & \\
\hline CHEMBL209458 & 367909 & 4.0 & 4.565 & TRN & \\
\hline CHEMBL210499 & 367909 & 6.2596 & 5.8193 & TRN & \\
\hline CHEMBL211019 & 367909 & 7.3768 & 7.102 & TRN & \\
\hline CHEMBL211080 & 367909 & 6.8539 & 6.2836 & TRN & \\
\hline CHEMBL209781 & 367909 & 6.0132 & 5.8164 & TRN & \\
\hline CHEMBL379841 & 367909 & 5.7959 & 5.7901 & TST & \\
\hline CHEMBL378908 & 367909 & 5.5086 & 5.5818 & TRN & \\
\hline CHEMBL1162929 & 367909 & 7.4437 & 7.8071 & TRN & \\
\hline CHEMBL210342 & 367909 & 7.6778 & 6.8418 & TRN & \\
\hline CHEMBL211660 & 367909 & 6.3372 & 6.2948 & TST & \\
\hline CHEMBL210557 & 367909 & 6.8861 & 6.3128 & TST & \\
\hline CHEMBL379518 & 367909 & 6.2924 & 6.1004 & TRN & \\
\hline CHEMBL384911 & 367909 & 5.8239 & 6.2989 & TRN & \\
\hline CHEMBL379479 & 367909 & 5.9586 & 5.9307 & TRN & \\
\hline CHEMBL 377445 & 367909 & 5.3665 & 5.2965 & TRN & \\
\hline CHEMBL379782 & 367909 & 7.3768 & 7.0822 & TST & \\
\hline CHEMBL380218 & 367909 & 6.3372 & 6.3915 & TRN & \\
\hline CHEMBL212407 & 367909 & 6.0223 & 6.3573 & TST & \\
\hline CHEMBL211121 & 367909 & 6.9586 & 7.1749 & TST & \\
\hline CHEMBL212461 & 367909 & 6.1612 & 6.0994 & TRN & \\
\hline CHEMBL209012 & 367909 & 6.585 & 7.0877 & TRN & \\
\hline CHEMBL377811 & 367909 & 6.301 & 6.1791 & TRN & \\
\hline CHEMBL211233 & 367909 & 6.4559 & 6.6445 & TRN & \\
\hline CHEMBL210357 & 367909 & 5.6778 & 5.7044 & TRN & \\
\hline CHEMBL208947 & 367909 & 5.0809 & 6.4275 & TRN & \\
\hline CHEMBL377964 & 367909 & 4.8861 & 5.7392 & TRN & \\
\hline CHEMBL211127 & 367909 & 5.8861 & 6.1329 & TRN & \\
\hline CHEMBL211070 & 367909 & 6.284 & 5.9416 & TRN & \\
\hline
\end{tabular}




\begin{tabular}{|c|c|c|c|c|c|}
\hline \\
\hline CHEMBL378927 & 367909 & 5.1427 & 5.4406 & TST & \\
\hline CHEMBL379170 & 367909 & 5.6021 & 5.6127 & TRN & \\
\hline CHEMBL387176 & 367909 & 6.4559 & 6.2997 & TRN & \\
\hline CHEMBL209264 & 367909 & 6.284 & 6.2356 & TRN & \\
\hline CHEMBL377804 & 367909 & 5.2076 & 5.6051 & TRN & \\
\hline CHEMBL380394 & 367909 & 5.6198 & 6.0247 & TST & \\
\hline CHEMBL208946 & 367909 & 4.8539 & 5.718 & TRN & \\
\hline CHEMBL212733 & 367909 & 6.4949 & 5.7332 & TRN & \\
\hline CHEMBL 210610 & 367909 & 6.9208 & 6.7472 & TRN & \\
\hline CHEMBL1162930 & 367909 & 6.5376 & 7.1445 & TRN & \\
\hline CHEMBL209722 & 367909 & 6.0809 & 6.2485 & TRN & \\
\hline CHEMBL211155 & 367909 & 5.1612 & 5.6169 & TRN & \\
\hline CHEMBL209207 & 367909 & 6.0757 & 6.5839 & TRN & \\
\hline CHEMBL 210892 & 367909 & 5.5086 & 5.6094 & TRN & \\
\hline CHEMBL377526 & 367909 & 6.5528 & 6.1869 & TRN & \\
\hline CHEMBL438433 & 367909 & 7.6383 & 7.3865 & TRN & \\
\hline CHEMBL376940 & 367909 & 7.2924 & 7.4215 & TRN & \\
\hline CHEMBL378561 & 367909 & 6.4318 & 6.3224 & TST & \\
\hline CHEMBL209619 & 367909 & 6.0362 & 6.1782 & TRN & \\
\hline CHEMBL 208547 & 367909 & 8.2218 & 7.9456 & TRN & \\
\hline CHEMBL209926 & 367909 & 5.6778 & 6.1381 & TRN & \\
\hline CHEMBL 377424 & 367909 & 6.6021 & 7.1346 & TST & \\
\hline CHEMBL212745 & 367909 & 7.0555 & 7.0981 & TST & \\
\hline CHEMBL 211453 & 367909 & 4.8239 & 6.4023 & TST & \\
\hline CHEMBL209371 & 367909 & 6.4815 & 6.5018 & TRN & \\
\hline CHEMBL209686 & 367909 & 7.1367 & 6.83799 & 9999999999 & TRN \\
\hline CHEMBL 210559 & 367909 & 6.3188 & 6.4238 & TRN & \\
\hline CHEMBL 211763 & 367909 & 6.3872 & 6.1491 & TRN & \\
\hline CHEMBL 209053 & 367909 & 7.1675 & 6.6968 & TRN & \\
\hline CHEMBL 211788 & 367909 & 5.8539 & 5.7401 & TRN & \\
\hline CHEMBL 211711 & 367909 & 6.8539 & 6.0423 & TST & \\
\hline CHEMBL 380194 & 367909 & 6.0706 & 6.5625 & TST & \\
\hline CHEMBL 376985 & 367909 & 5.0 & 5.471 & TRN & \\
\hline CHEMBL 211544 & 367909 & 6.9586 & 6.266 & TRN & \\
\hline CHEMBL 211271 & 367909 & 7.6198 & 7.309 & TST & \\
\hline CHEMBL209211 & 367909 & 5.6576 & 5.9842 & TRN & \\
\hline CHEMBL 210358 & 367909 & 5.9586 & 5.5383 & TRN & \\
\hline CHEMBL 211548 & 367909 & 7.5686 & 7.388 & TST & \\
\hline CHEMBL 380267 & 367909 & 6.7212 & 6.2558 & TRN & \\
\hline CHEMBL 209942 & 367909 & 6.2147 & 6.3934 & TRN & \\
\hline CHEMBL1184942 & 367909 & 7.0706 & 6.2218 & TRN & \\
\hline CHEMBL211435 & 367909 & 6.4318 & 6.0753 & TRN & \\
\hline CHEMBL210085 & 367909 & 7.1549 & 7.4762 & TST & \\
\hline CHEMBL 209368 & 367909 & 5.2924 & 5.5717 & TRN & \\
\hline CHEMBL209206 & 367909 & 5.5376 & 6.2262 & TST & \\
\hline CHEMBL377965 & 367909 & 6.1549 & 6.544 & TRN & \\
\hline CHEMBL 212257 & 367909 & 6.7959 & 6.239 & TRN & \\
\hline CHEMBL377854 & 367909 & 6.3665 & 6.4943 & TRN & \\
\hline
\end{tabular}


Supplemental Table S2.txt

\begin{tabular}{|c|c|c|c|c|c|}
\hline CHEMBL209277 & 367909 & 6.5376 & 6.2724 & TST & \\
\hline CHEMBL377888 & 367909 & 5.2076 & 6.4514 & TST & \\
\hline CHEMBL209074 & 367909 & 6.4318 & 5.8136 & TRN & \\
\hline CHEMBL211859 & 367909 & 6.5376 & 6.26 & TRN & \\
\hline CHEMBL378982 & 367909 & 7.5086 & 7.38 & TST & \\
\hline CHEMBL426324 & 367909 & 5.585 & 6.0207 & TRN & \\
\hline CHEMBL211277 & 367909 & 6.0 & 6.3293 & TRN & \\
\hline CHEMBL379958 & 373922 & 6.2366 & 6.0202 & TRN & \\
\hline CHEMBL 212271 & 373922 & 5.8539 & 5.9471 & TRN & \\
\hline CHEMBL211086 & 373922 & 6.9208 & 6.4136 & TRN & \\
\hline CHEMBL209586 & 373922 & 6.7696 & 6.7056 & TRN & \\
\hline CHEMBL379586 & 373922 & 5.301 & 5.0228 & TRN & \\
\hline CHEMBL208586 & 373922 & 5.301 & 5.3209 & TRN & \\
\hline CHEMBL 211754 & 373922 & 4.8861 & 5.2079 & TRN & \\
\hline CHEMBL211209 & 373922 & 5.7696 & 6.287006 & 0000000001 & TRN \\
\hline CHEMBL212209 & 373922 & 5.3768 & 5.3635 & TRN & \\
\hline CHEMBL212538 & 373922 & 5.8861 & 5.6555 & TRN & \\
\hline CHEMBL379186 & 373922 & 5.2676 & 5.2447 & TRN & \\
\hline CHEMBL 378830 & 373922 & 7.2924 & 7.3394 & TRN & \\
\hline CHEMBL3706845 & 373922 & 6.3768 & 6.1477 & TRN & \\
\hline CHEMBL 379960 & 373922 & 5.0269 & 5.2696 & TRN & \\
\hline CHEMBL212577 & 373922 & 5.1549 & 5.0337 & TRN & \\
\hline CHEMBL379075 & 373922 & 6.3372 & 6.0472 & TRN & \\
\hline CHEMBL437307 & 373922 & 4.8861 & 4.9483 & TRN & \\
\hline CHEMBL379357 & 373922 & 5.7447 & 5.4205 & TRN & \\
\hline CHEMBL209334 & 373922 & 5.585 & 5.3839 & TRN & \\
\hline CHEMBL 211794 & 373922 & 5.5229 & 5.502006 & 0000000001 & TST \\
\hline CHEMBL379957 & 373922 & 6.585 & 6.2981 & TST & \\
\hline CHEMBL210771 & 373922 & 6.9586 & 6.9627 & TRN & \\
\hline CHEMBL212031 & 373922 & 4.699 & 4.9653 & TRN & \\
\hline CHEMBL379194 & 373922 & 4.5686 & 4.827 & TRN & \\
\hline CHEMBL380221 & 373922 & 5.7447 & 5.5311 & TRN & \\
\hline CHEMBL211939 & 373922 & 6.6778 & 6.5677 & TRN & \\
\hline CHEMBL426501 & 373922 & 5.6021 & 5.7314 & TRN & \\
\hline CHEMBL211367 & 373922 & 5.8861 & 5.7608 & TST & \\
\hline CHEMBL 212310 & 373922 & 6.7212 & 6.7441 & TRN & \\
\hline CHEMBL210386 & 373922 & 5.9208 & 5.4534 & TST & \\
\hline CHEMBL3706844 & 373922 & 7.2676 & 6.9161 & TRN & \\
\hline CHEMBL211401 & 373922 & 5.0555 & 5.1097 & TRN & \\
\hline CHEMBL378657 & 373922 & 5.2218 & 5.1757 & TRN & \\
\hline CHEMBL 210244 & 373922 & 5.7959 & 5.3391 & TST & \\
\hline CHEMBL211549 & 373922 & 5.8239 & 5.6939 & TRN & \\
\hline CHEMBL3706847 & 373922 & 5.7447 & 6.3486 & TRN & \\
\hline CHEMBL438959 & 373922 & 5.6021 & 5.0987 & TST & \\
\hline CHEMBL209794 & 373922 & 6.6778 & 6.7804 & TRN & \\
\hline CHEMBL 378643 & 373922 & 7.0044 & 6.9974 & TRN & \\
\hline CHEMBL209963 & 373922 & 6.3098 & 5.3781 & TST & \\
\hline CHEMBL212616 & 373922 & 5.4815 & 5.3236 & TST & \\
\hline
\end{tabular}


Supplemental Table S2.txt

\begin{tabular}{|c|c|c|c|c|}
\hline CHEMBL 377627 & 73922 & 6.5229 & 5.9458 & 8 \\
\hline CHEMBL212014 & 73922 & 4.6778 & 4.7654 & \\
\hline CHEMBL 211659 & 73922 & 6.7696 & 6.9036 & \\
\hline HEMBL107955 & 73922 & 6.3098 & 1305 & \\
\hline HEMBL 210189 & 73922 & 4.9208 & 3755 & 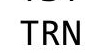 \\
\hline HEMBL 210815 & 73922 & 6.2218 & .6697 & $\mathrm{~N}$ \\
\hline HEMBL 209841 & 73922 & 6.699 & 5.4698 & \\
\hline HEMBL 378192 & 73922 & 5.3979 & 672 & RN \\
\hline AEMBL 380220 & 73922 & 6.5686 & 6.6192 & ST \\
\hline HEMBL 209910 & 73922 & 6.2076 & 5.393 & \\
\hline HEMBL 377763 & 73922 & 4.7959 & 5.1246 & ST \\
\hline HEMBL3706846 & 73922 & 6.3768 & 6.2925 & \\
\hline HEMBL 379068 & 73922 & 5.3979 & 5.0993 & \\
\hline HEMBL 208094 & 63882 & 3.6021 & 3.5991 & RN \\
\hline HEMBL 377872 & 53882 & 3.3979 & 3.3957 & $\mathrm{RN}$ \\
\hline HEMBL380047 & 63882 & 3.3468 & 3.4882 & $\mathrm{RN}$ \\
\hline HEMBL 382777 & 63882 & 3.4089 & 462 & RN \\
\hline HEMBL 378713 & 53882 & 3. & 077 & RN \\
\hline HEMBL 208922 & 3882 & & 1.9985 & $\mathrm{RN}$ \\
\hline HEMBL371194 & 3882 & 69 & & STT \\
\hline HEMBL 379332 & 53882 & 26 & 696 & TRN \\
\hline CHEMBL299759 & 63882 & 3.284 & 302 & $\mathrm{~N}$ \\
\hline CHEMBL 210850 & 53882 & 3.2924 & 729 & rRN \\
\hline HEMBL] & 53882 & 05 & 3. & TRN \\
\hline HEMBL: & 3882 & 69 & 022 & TRN \\
\hline HEMBL 53400 & 63882 & 08 & 738 & TRN \\
\hline CHEMBL379810 & 63882 & 3.8861 & 3.9029 & TRN \\
\hline CHEMBL3321985 & 3882 & & 985 & TST \\
\hline HEMBL & 882 & 89 & 3. & TRN \\
\hline HEMBL420061 & 882 & 31 & 2.8717 & TRN \\
\hline HEMBL417979 & 53882 & & 508 & TRN \\
\hline CHEMBL327588 & 63882 & 367 & 3.0816 & TRN \\
\hline CHEMBL: & & & & TRN \\
\hline HEME & 82 & 97 & 756 & TRN \\
\hline CHEMBL54552 & 363882 & & 3. & TRN \\
\hline HEMBL 292467 & 63882 & 3.0862 & 2. & TST \\
\hline CHEMBL318315 & 63882 & 3.2076 & 41 & TRN \\
\hline CHEMBL & & & & TRN \\
\hline CHEMBL & 363882 & 3. & 65 & TRN \\
\hline CHEMBL421171 & 363882 & 3.0915 & 3.0538 & TRN \\
\hline HEMBL 54933 & 53882 & 3.7696 & 3.7625 & TRN \\
\hline CHEMBL & 63882 & 2. & 827 & TST \\
\hline CHEMBL9] & 882 & & 3. & TRN \\
\hline CHEMBL210851 & 363882 & 4.0 & 3.9713 & TRN \\
\hline CHEMBL188866 & 63882 & 3.58 & 3.625 & TRN \\
\hline CHEMBL191057 & 63882 & 3.5528 & 3.4569 & TRN \\
\hline CHEMBL: & 363882 & & 4.1811 & TRN \\
\hline CHEMBL59426 & 363882 & .7959 & 1.9642 & TST \\
\hline
\end{tabular}

Page 17122 


\begin{tabular}{|c|c|c|c|c|c|c|}
\hline & & \multicolumn{5}{|c|}{ Supplemental Table S2.txt } \\
\hline CHEMBL429950 & 363882 & 4.1549 & 4.1693 & TRN & & \\
\hline CHEMBL39159 & 363882 & 4.0458 & 4.0423 & TRN & & \\
\hline CHEMBL91241 & 363882 & 2.7399 & 2.7596 & TRN & & \\
\hline CHEMBL286852 & 363882 & 3.6021 & 3.6524 & TRN & & \\
\hline CHEMBL378907 & 363882 & 4.699 & 4.6219 & TRN & & \\
\hline CHEMBL89956 & 363882 & 3.4815 & 3.508 & TRN & & \\
\hline CHEMBL296756 & 363882 & 2.1361 & 2.1227 & TRN & & \\
\hline CHEMBL380174 & 363882 & 3.6383 & 3.6433 & TRN & & \\
\hline CHEMBL209765 & 363882 & 3.0223 & 3.0481 & TRN & & \\
\hline CHEMBL210616 & 363882 & 2.5243 & 2.5273 & TRN & & \\
\hline CHEMBL91792 & 363882 & 3.585 & 3.5924 & TRN & & \\
\hline CHEMBL 209341 & 363882 & 3.6198 & 3.6614 & TRN & & \\
\hline CHEMBL 380024 & 363882 & 2.09099 & 99999999 & 997 & 2.1523 & TRN \\
\hline CHEMBL91392 & 363882 & 3.4202 & 3.2972 & TRN & & \\
\hline CHEMBL190027 & 363882 & 1.9101 & 2.1081 & TST & & \\
\hline CHEMBL377325 & 363882 & 0.7959 & 1.9335 & TST & & \\
\hline CHEMBL314532 & 363882 & 3.1871 & 3.3058 & TRN & & \\
\hline CHEMBL210490 & 363882 & 2.8827 & 2.9317 & TRN & & \\
\hline CHEMBL293494 & 363882 & 3.2076 & 3.3212 & TST & & \\
\hline CHEMBL365790 & 363882 & 3.0862 & 3.0632 & TRN & & \\
\hline CHEMBL54278 & 363882 & 2.9706 & 2.7058 & TST & & \\
\hline CHEMBL39179 & 363882 & 4.0969 & 4.0774 & TRN & & \\
\hline CHEMBL94016 & 363882 & 3.7696 & 3.8282 & TRN & & \\
\hline CHEMBL441685 & 363882 & 3.5086 & 3.4727 & TRN & & \\
\hline CHEMBL93127 & 363882 & 3.0915 & 3.08 & TST & & \\
\hline CHEMBL299889 & 363882 & 3.7696 & 3.8132 & TRN & & \\
\hline CHEMBL316103 & 363882 & 3.9586 & 3.9588 & TRN & & \\
\hline CHEMBL95286 & 363882 & 4.2218 & 4.2704 & TRN & & \\
\hline CHEMBL 80548 & 363882 & 3.4815 & 2.9904 & TST & & \\
\hline CHEMBL 209083 & 363882 & 0.7959 & 2.7365 & TST & & \\
\hline CHEMBL91561 & 363882 & 3.4202 & 3.0083 & TST & & \\
\hline CHEMBL190704 & 363882 & 2.0381 & 2.0892 & TST & & \\
\hline CHEMBL52461 & 363882 & 3.6021 & 3.2301 & TST & & \\
\hline CHEMBL438960 & 363882 & 3.8239 & 2.9324 & TST & & \\
\hline CHEMBL 209670 & 363882 & 3.0088 & 4.3411 & TST & & \\
\hline CHEMBL380183 & 363882 & 2.1427 & 2.1523 & TST & & \\
\hline CHEMBL 258960 & 479713 & 7.2518 & 7.153 & TRN & & \\
\hline CHEMBL429144 & 479713 & 9.0 & 9.0572 & TRN & & \\
\hline CHEMBL196436 & 479713 & 7.3979 & 7.6386 & TRN & & \\
\hline CHEMBL409915 & 479713 & 9.0 & 8.9958 & TRN & & \\
\hline CHEMBL257984 & 479713 & 5.8788 & 5.8463 & TRN & & \\
\hline CHEMBL260989 & 479713 & 8.2218 & 8.3515 & TRN & & \\
\hline CHEMBL256153 & 479713 & 6.9245 & 6.9324 & TRN & & \\
\hline CHEMBL410445 & 479713 & 6.4295 & 6.4568 & TRN & & \\
\hline CHEMBL260146 & 479713 & 9.0 & 8.4941 & TST & & \\
\hline CHEMBL407049 & 479713 & 8.3979 & 8.3972 & TRN & & \\
\hline CHEMBL404447 & 479713 & 6.5834 & 6.8148 & TST & & \\
\hline CHEMBL410463 & 479713 & 5.3867 & 5.4233 & TRN & & \\
\hline
\end{tabular}




\begin{tabular}{|c|c|c|c|c|}
\hline & & & oplement & al $\mathrm{T}$ \\
\hline CHEMBL261203 & 479713 & 9.0 & 9.0177 & TRN \\
\hline CHEMBL258836 & 479713 & 6.9914 & 7.0059 & TRN \\
\hline CHEMBL260338 & 479713 & 5.7233 & 5.9298 & TRN \\
\hline CHEMBL402389 & 479713 & 7.7696 & 7.7448 & TRN \\
\hline CHEMBL258006 & 479713 & 8.0458 & 7.9427 & TRN \\
\hline CHEMBL259164 & 479713 & 7.7696 & 7.6286 & TRN \\
\hline CHEMBL 259418 & 479713 & 8.5229 & 8.2064 & TRN \\
\hline CHEMBL256151 & 479713 & 5.7916 & 5.7376 & TRN \\
\hline CHEMBL410678 & 479713 & 7.7959 & 8.0001 & TRN \\
\hline CHEMBL411473 & 479713 & 7.8861 & 8.0613 & TRN \\
\hline CHEMBL 256344 & 479713 & 8.2218 & 8.5862 & TRN \\
\hline CHEMBL 256360 & 479713 & 8.3979 & 8.1871 & TRN \\
\hline CHEMBL259832 & 479713 & 8.699 & 8.463 & TRN \\
\hline CHEMBL257982 & 479713 & 7.9208 & 7.9826 & TRN \\
\hline CHEMBL411034 & 479713 & 9.0 & 9.1588 & TRN \\
\hline CHEMBL 264431 & 479713 & 7.8861 & 7.9106 & TRN \\
\hline CHEMBL409879 & 479713 & 6.6861 & 6.5604 & TRN \\
\hline CHEMBL401973 & 479713 & 8.699 & 8.7259 & TRN \\
\hline CHEMBL424827 & 479713 & 8.2218 & 7.9765 & TRN \\
\hline CHEMBL409152 & 479713 & 7.6383 & 7.3946 & TRN \\
\hline CHEMBL260209 & 479713 & 8.301 & 8.2648 & TRN \\
\hline CHEMBL402409 & 479713 & 8.699 & 8.72 & TRN \\
\hline CHEMBL437804 & 479713 & 7.4437 & 7.5806 & TRN \\
\hline CHEMBL406298 & 479713 & 7.8539 & 7.8295 & TST \\
\hline CHEMBL371436 & 479713 & 8.1549 & 8.0977 & TRN \\
\hline CHEMBL255939 & 479713 & 5.6807 & 5.8189 & TRN \\
\hline CHEMBL256359 & 479713 & 7.585 & 7.6367 & TRN \\
\hline CHEMBL 260788 & 479713 & 7.6383 & 7.6515 & TRN \\
\hline CHEMBL256361 & 479713 & 8.3979 & 8.3886 & TRN \\
\hline CHEMBL402606 & 479713 & 7.1487 & 6.6734 & TST \\
\hline CHEMBL403470 & 479713 & 8.0969 & 8.1517 & TRN \\
\hline CHEMBL259416 & 479713 & 7.5528 & 7.4362 & TRN \\
\hline CHEMBL259049 & 479713 & 9.0 & 9.1379 & TRN \\
\hline CHEMBL402103 & 479713 & 6.4685 & 6.6041 & TRN \\
\hline CHEMBL 260008 & 479713 & 6.1085 & 6.1083 & TRN \\
\hline CHEMBL402172 & 479713 & 8.5229 & 8.2598 & TRN \\
\hline CHEMBL410033 & 479713 & 8.0969 & 8.1773 & TRN \\
\hline CHEMBL258181 & 479713 & 8.3979 & 8.3541 & TRN \\
\hline CHEMBL260337 & 479713 & 6.8697 & 6.8338 & TRN \\
\hline CHEMBL406499 & 479713 & 6.6162 & 6.7363 & TST \\
\hline CHEMBL 267200 & 479713 & 7.7959 & 7.6717 & TRN \\
\hline CHEMBL257757 & 479713 & 9.0 & 8.8193 & TST \\
\hline CHEMBL260790 & 479713 & 7.0706 & 7.609 & TST \\
\hline CHEMBL261349 & 479713 & 8.0969 & 8.2596 & TST \\
\hline CHEMBL 260721 & 479713 & 7.3468 & 7.9273 & TST \\
\hline CHEMBL 264432 & 479713 & 9.0 & 8.3305 & TST \\
\hline CHEMBL403252 & 479713 & 8.3979 & 8.5656 & TST \\
\hline CHEMBL371615 & 479713 & 8.5229 & 8.3891 & TST \\
\hline
\end{tabular}


Supplemental Table S2.txt

\begin{tabular}{|c|c|c|c|c|c|}
\hline CHEMBL259210 & 479713 & 6.9586 & 7.6905 & TST & \\
\hline CHEMBL261534 & 479713 & 8.2218 & 7.7222 & TST & \\
\hline CHEMBL260557 & 479713 & 7.3188 & 7.3847 & TST & \\
\hline CHEMBL405789 & 479713 & 7.3468 & 7.3433 & TST & \\
\hline CHEMBL257756 & 479713 & 8.0458 & 8.3502 & TST & \\
\hline CHEMBL3356671 & 1527753 & 7.8633 & 7.2578 & TRN & \\
\hline CHEMBL3664383 & 1527753 & 6.0 & 6.6226 & TST & \\
\hline CHEMBL3664282 & 1527753 & 6.9281 & 6.6394 & TRN & \\
\hline CHEMBL3664317 & 1527753 & 7.3686 & 7.1808 & TRN & \\
\hline CHEMBL3669277 & 1527753 & 6.3261 & 6.1848 & TRN & \\
\hline CHEMBL 3664242 & 1527753 & 7.699 & 8.0 & TRN & \\
\hline CHEMBL3669291 & 1527753 & 5.9281 & 6.1038 & TRN & \\
\hline CHEMBL 3664324 & 1527753 & 9.5229 & 8.2105 & TST & \\
\hline CHEMBL 3664278 & 1527753 & 7.0665 & 6.7548 & TRN & \\
\hline CHEMBL 3664281 & 1527753 & 7.4473 & 6.8283 & TRN & \\
\hline CHEMBL3664323 & 1527753 & 8.9586 & 8.0068 & TRN & \\
\hline CHEMBL3669264 & 1527753 & 5.9586 & 6.0177 & TRN & \\
\hline CHEMBL 3664314 & 1527753 & 7.3382 & 7.3066 & TRN & \\
\hline CHEMBL3664291 & 1527753 & 6.4237 & 6.9169 & TRN & \\
\hline CHEMBL 3664286 & 1527753 & 6.8097 & 6.9467 & TRN & \\
\hline CHEMBL 3664310 & 1527753 & 7.8268 & 7.0002 & TST & \\
\hline CHEMBL 3664238 & 1527753 & 5.5243 & 6.7231 & TRN & \\
\hline CHEMBL 3664376 & 1527753 & 6.9281 & 5.8961 & TRN & \\
\hline CHEMBL 3664373 & 1527753 & 5.8996 & 5.8236 & TRN & \\
\hline CHEMBL3356660 & 1527753 & 6.284 & 6.8654 & TRN & \\
\hline CHEMBL 3669274 & 1527753 & 6.5591 & 6.2464 & TRN & \\
\hline CHEMBL3664309 & 1527753 & 7.2716 & 7.6637 & TRN & \\
\hline CHEMBL3356663 & 1527753 & 7.9788 & 7.6444 & TRN & \\
\hline CHEMBL3664372 & 1527753 & 5.3705 & 5.7717 & TRN & \\
\hline CHEMBL3669248 & 1527753 & 6.0 & 6.3118 & TST & \\
\hline CHEMBL3664316 & 1527753 & 6.7595 & 7.6057 & TST & \\
\hline CHEMBL 3664258 & 1527753 & 6.4239 & 6.2843 & TRN & \\
\hline CHEMBL 3664342 & 1527753 & 7.1688 & 7.4596 & TRN & \\
\hline CHEMBL3669292 & 1527753 & 5.9318 & 6.1068 & TRN & \\
\hline CHEMBL3356652 & 1527753 & $8.0110 e$ & 00000000 & 7.8906 & TRN \\
\hline CHEMBL3664236 & 1527753 & 7.3507 & 6.609 & TRN & \\
\hline CHEMBL 3669270 & 1527753 & 6.7033 & 6.1292 & TRN & \\
\hline CHEMBL3669227 & 1527753 & 6.6271 & 5.8605 & TRN & \\
\hline CHEMBL3356659 & 1527753 & 6.9066 & 6.8226 & TRN & \\
\hline CHEMBL3669251 & 1527753 & 6.0 & 6.2207 & TRN & \\
\hline CHEMBL 3664343 & 1527753 & 7.1884 & 7.5844 & TRN & \\
\hline CHEMBL3664313 & 1527753 & 8.0132 & 7.3779 & TRN & \\
\hline CHEMBL 3664377 & 1527753 & 5.9991 & 5.684 & TRN & \\
\hline CHEMBL3356655 & 1527753 & 7.0237 & 6.9857 & TRN & \\
\hline CHEMBL3356667 & 1527753 & 7.8239 & 7.576006 & 00000000005 & TRN \\
\hline CHEMBL 3669299 & 1527753 & 7.2916 & 7.6241 & TRN & \\
\hline CHEMBL3669269 & 1527753 & 4.0 & 5.8525 & TRN & \\
\hline CHEMBL 3669254 & 1527753 & 6.1614 & 6.5817 & TRN & \\
\hline
\end{tabular}

Page 17125 
Supplemental Table S2.txt

\begin{tabular}{|c|c|c|c|c|c|c|}
\hline CHEMBL 3664366 & 1527753 & 7.1152 & 7.6612 & TRN & & \\
\hline CHEMBL 3664247 & 1527753 & 7.6861 & 7.9445 & TRN & & \\
\hline CHEMBL 3664284 & 1527753 & 7.0762 & 6.7157 & TRN & & \\
\hline CHEMBL 3664226 & 1527753 & 6.5638 & 6.4721 & TRN & & \\
\hline CHEMBL 3664270 & 1527753 & 7.5143 & 6.7385 & TRN & & \\
\hline CHEMBL 3664360 & 1527753 & 7.1141 & 6.6171 & TST & & \\
\hline CHEMBL 3669279 & 1527753 & 4.2388 & 6.0863 & TST & & \\
\hline CHEMBL 3664330 & 1527753 & 7.4377 & 6.8048 & TST & & \\
\hline CHEMBL3669293 & 1527753 & 5.75200 & 00000000 & & 6.1881 & TRN \\
\hline CHEMBL 3669265 & 1527753 & 6.08200 & 00000000 & & 5.795 & TRN \\
\hline CHEMBL 3669294 & 1527753 & 5.8268 & 5.8909 & TRN & & \\
\hline CHEMBL 3664249 & 1527753 & 6.1656 & 6.7571 & TRN & & \\
\hline CHEMBL 3356662 & 1527753 & 8.0141 & 7.0865 & TRN & & \\
\hline CHEMBL 3664307 & 1527753 & 6.8297 & 7.2521 & TRN & & \\
\hline CHEMBL 3356684 & 1527753 & 8.5376 & 7.4083 & TRN & & \\
\hline CHEMBL 3356649 & 1527753 & 8.3615 & 7.1197 & TRN & & \\
\hline CHEMBL 3664350 & 1527753 & 7.3873 & 6.2408 & TRN & & \\
\hline CHEMBL 3664303 & 1527753 & 6.9586 & 7.4276 & TST & & \\
\hline CHEMBL 3664351 & 1527753 & 8.1892 & 6.5493 & TRN & & \\
\hline CHEMBL 3664315 & 1527753 & 6.5952 & 7.2856 & TRN & & \\
\hline CHEMBL 3664290 & 1527753 & 7.4034 & 7.2873 & TRN & & \\
\hline CHEMBL 3664267 & 1527753 & 7.7352 & 7.9662 & TRN & & \\
\hline CHEMBL 3664356 & 1527753 & 6.5498 & 6.9464 & TST & & \\
\hline CHEMBL 3664365 & 1527753 & 6.0524 & 6.4503 & TRN & & \\
\hline CHEMBL 3664229 & 1527753 & 7.2118 & 6.9222 & TRN & & \\
\hline CHEMBL 3664325 & 1527753 & 6.8069 & 6.9272 & TST & & \\
\hline CHEMBL 3356307 & 1527753 & 7.4225 & 7.2766 & TRN & & \\
\hline CHEMBL 3664228 & 1527753 & 7.3605 & 6.7348 & TRN & & \\
\hline CHEMBL 3664237 & 1527753 & 7.5302 & 6.9199 & TRN & & \\
\hline CHEMBL 3664367 & 1527753 & 7.8477 & 7.7162 & TST & & \\
\hline CHEMBL 3664389 & 1527753 & 6.7481 & 6.8803 & TST & & \\
\hline CHEMBL 3664375 & 1527753 & \multicolumn{3}{|c|}{5.7829999999999995} & 5.8369 & TRN \\
\hline CHEMBL 3356675 & 1527753 & 8.1079 & 7.3341 & TRN & & \\
\hline CHEMBL 3356664 & 1527753 & 7.6326 & 7.6938 & TRN & & \\
\hline CHEMBL 3669298 & 1527753 & 5.4461 & 5.9112 & TRN & & \\
\hline CHEMBL 3664363 & 1527753 & 5.1001 & 6.3055 & TRN & & \\
\hline CHEMBL 3664329 & 1527753 & 6.644 & 6.9067 & TST & & \\
\hline CHEMBL 3664252 & 1527753 & 7.3915 & 7.3485 & TRN & & \\
\hline CHEMBL 3669281 & 1527753 & 5.5452 & 5.9986 & TRN & & \\
\hline CHEMBL 3664346 & 1527753 & 5.7852 & 6.7554 & TRN & & \\
\hline CHEMBL 3669263 & 1527753 & 5.5287 & 5.9133 & TRN & & \\
\hline CHEMBL 3664296 & 1527753 & 6.0 & 7.3967 & TRN & & \\
\hline CHEMBL 3664386 & 1527753 & 6.0537 & 6.3563 & TRN & & \\
\hline CHEMBL 3664293 & 1527753 & 6.0372 & 7.1257 & TRN & & \\
\hline CHEMBL 3664240 & 1527753 & 9.6402 & 7.9071 & TRN & & \\
\hline CHEMBL 3669237 & 1527753 & 6.7011 & 6.0408 & TRN & & \\
\hline CHEMBL 3669287 & 1527753 & 6.0857 & 6.1716 & TRN & & \\
\hline CHEMBL3356668 & 1527753 & 7.3645 & 7.5083 & TRN & & \\
\hline
\end{tabular}

Page 17126 
Supplemental Table S2.txt

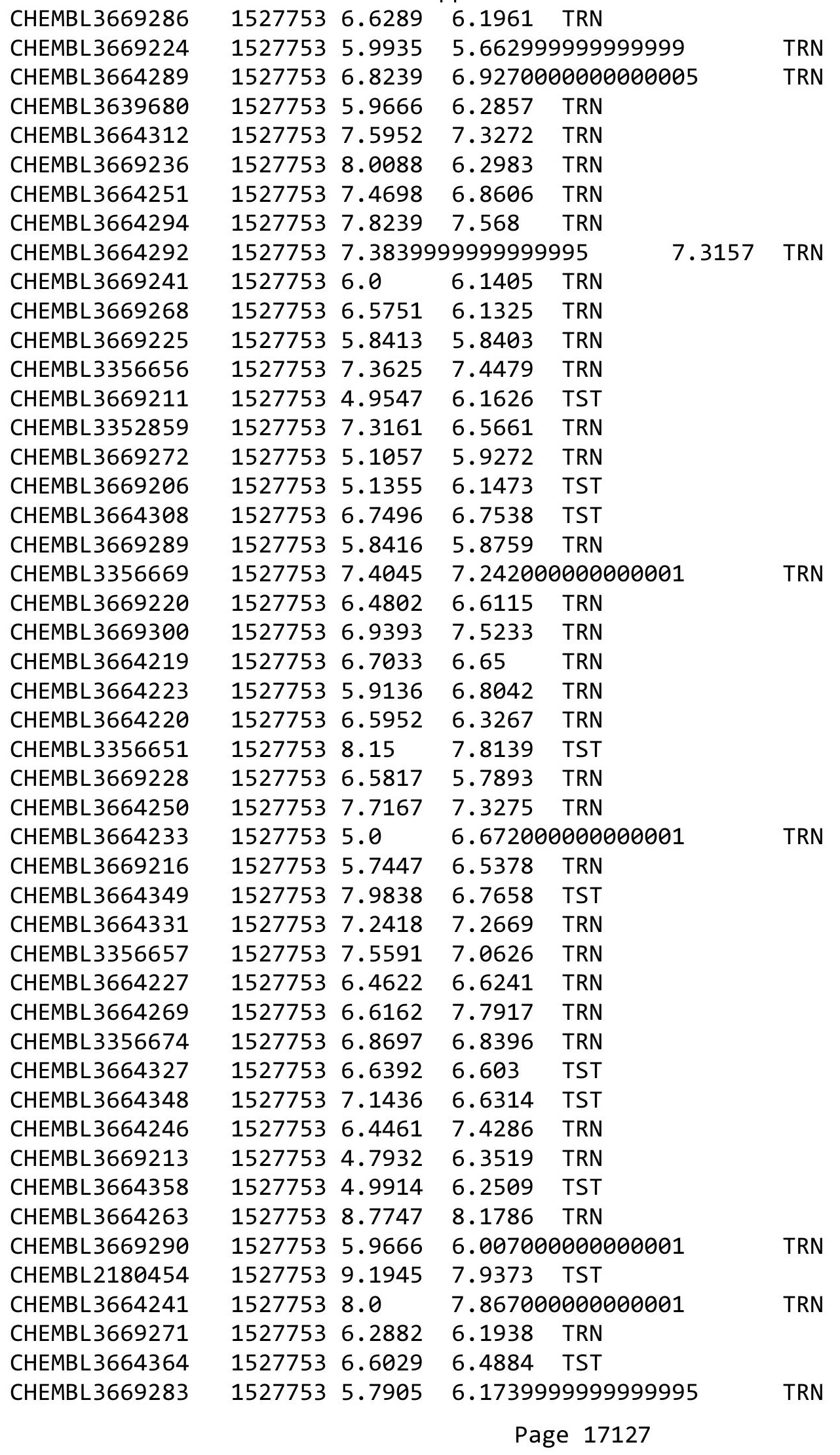


Supplemental Table S2.txt

\begin{tabular}{|c|c|c|c|c|}
\hline CHEMBL3356677 & 1527753 & 7.0605 & 6.7934 & TRN \\
\hline CHEMBL3356681 & 1527753 & 8.0762 & 6.9918 & TRN \\
\hline CHEMBL3669288 & 1527753 & 7.0177 & 6.2884 & TRN \\
\hline CHEMBL3669219 & 1527753 & 5.9961 & 6.2426 & TRN \\
\hline CHEMBL 3669252 & 1527753 & 6.4613 & 6.762000 & 0000000005 \\
\hline CHEMBL3664398 & 1527753 & 6.0026 & 6.3555 & TRN \\
\hline CHEMBL3664256 & 1527753 & 7.20200 & 000000000 & 6.754 \\
\hline CHEMBL 3669247 & 1527753 & 6.0 & 6.3766 & TRN \\
\hline CHEMBL3664396 & 1527753 & 6.1046 & 6.756 & TRN \\
\hline CHEMBL3669231 & 1527753 & 6.6289 & 6.2918 & TRN \\
\hline CHEMBL3669214 & 1527753 & 6.0 & 6.2536 & TRN \\
\hline CHEMBL3664221 & 1527753 & 6.0 & 6.7739 & TRN \\
\hline CHEMBL 3664334 & 1527753 & 6.9626 & 7.0095 & TST \\
\hline CHEMBL3356654 & 1527753 & 7.5834 & 6.9227 & TRN \\
\hline CHEMBL 3664387 & 1527753 & 6.9355 & 6.1431 & TRN \\
\hline CHEMBL3664305 & 1527753 & 6.6003 & 7.0076 & TRN \\
\hline CHEMBL3664266 & 1527753 & 6.585 & 7.6356 & TRN \\
\hline CHEMBL3664299 & 1527753 & 6.0 & 7.1042 & TRN \\
\hline CHEMBL3669285 & 1527753 & 5.5214 & 5.8556 & TRN \\
\hline CHEMBL3356670 & 1527753 & 5.9136 & 6.872000 & 000000001 \\
\hline CHEMBL3664304 & 1527753 & 7.3401 & 7.3875 & TRN \\
\hline CHEMBL3664393 & 1527753 & 6.7921 & 6.5351 & TRN \\
\hline CHEMBL3669257 & 1527753 & 5.8539 & 5.7766 & TRN \\
\hline CHEMBL3669233 & 1527753 & 6.6402 & 6.1229 & TRN \\
\hline CHEMBL3664328 & 1527753 & 6.6536 & 6.6451 & TST \\
\hline CHEMBL3669208 & 1527753 & 5.4449 & 6.7436 & TST \\
\hline CHEMBL3664382 & 1527753 & 6.0 & 6.4732 & TST \\
\hline CHEMBL3664332 & 1527753 & 8.1752 & 7.7256 & TRN \\
\hline CHEMBL3669284 & 1527753 & 6.0013 & 6.2495 & TRN \\
\hline CHEMBL 3664392 & 1527753 & 4.3783 & 6.5114 & TST \\
\hline CHEMBL3356647 & 1527753 & 6.0 & 7.1892 & TRN \\
\hline CHEMBL3664275 & 1527753 & 5.9508 & 6.7963 & TRN \\
\hline CHEMBL3669221 & 1527753 & 5.6218 & 5.654 & TRN \\
\hline CHEMBL 3669267 & 1527753 & 6.4157 & 6.0721 & TRN \\
\hline CHEMBL 3669261 & 1527753 & 5.9318 & 6.1991 & TRN \\
\hline CHEMBL3669256 & 1527753 & 7.2002 & 6.9179 & TST \\
\hline CHEMBL3669212 & 1527753 & 5.2676 & 6.0911 & TST \\
\hline CHEMBL3356672 & 1527753 & 7.6108 & 7.0626 & TRN \\
\hline CHEMBL3669295 & 1527753 & 6.2534 & 6.1253 & TRN \\
\hline CHEMBL3356658 & 1527753 & 7.4012 & 6.6825 & TRN \\
\hline CHEMBL3669234 & 1527753 & 5.7416 & 6.1595 & TST \\
\hline CHEMBL 3664224 & 1527753 & 6.3947 & 6.4393 & TRN \\
\hline CHEMBL 3664265 & 1527753 & 7.2218 & 7.8418 & TRN \\
\hline CHEMBL 3664234 & 1527753 & 6.4763 & 6.6825 & TRN \\
\hline CHEMBL3356665 & 1527753 & 7.0173 & 7.2059 & TRN \\
\hline CHEMBL3669207 & 1527753 & 5.5751 & 6.9576 & TST \\
\hline CHEMBL 3669238 & 1527753 & 6.0 & 6.3787 & TRN \\
\hline CHEMBL 3664248 & 1527753 & 7.8356 & 7.7574 & TRN \\
\hline
\end{tabular}

Page 17128 
Supplemental Table S2.txt

\begin{tabular}{|c|c|c|c|c|}
\hline HEM & בע & & & \\
\hline & & 6.8416 & 7.6808 & \\
\hline & : & 553 & & \\
\hline AEMBL & 27753 & 8182 & 29 & \\
\hline AEMBL3 & $52 / / 35$ & & & \\
\hline HEMBL3669255 & 527753 & 8.3863 & .2541 & \\
\hline 59 & 527 & 635 & & \\
\hline AFMR & & & & \\
\hline HEMBL & 52 & 9172 & & \\
\hline HEMBL3664257 & 753 & 9526 & 2862 & \\
\hline HEMBL3356680 & 52 & 8.4815 & & \\
\hline AEMBL: & 53 & 16 & & \\
\hline AEMBL & & & & \\
\hline HEMBL3 & 57 & 993 & 5225 & \\
\hline AEMBL3669229 & 3 & 778 & & \\
\hline AEMBL36642 & 52 & 49 & 39 & \\
\hline AEMBL & 2 & & & \\
\hline HEMBL & & & & \\
\hline HEMBL3 & 53 & 443 & & \\
\hline AEMBL3 & & 6. & & \\
\hline AEMIBL & כנו & 31 & & \\
\hline AEMBL & & & & \\
\hline HEMBL & & & & \\
\hline AFMR & & & & \\
\hline AEMBL3669 & & & 75 & $\mathrm{RN}$ \\
\hline HEMBL; & 3 & 962 & 73 & \\
\hline HEMBL & & 25 & & \\
\hline AFMB & 3 & 58 & & \\
\hline HEMBL3 & & & & TRN \\
\hline HEMBL36692 & 52 & 5. & 57 & IRN \\
\hline HEMBL3 & & 144 & & \\
\hline HFMBI & & & & וד \\
\hline 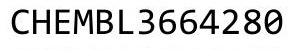 & & & & RN \\
\hline HEMBL3356682 & & & & R \\
\hline HEMBL3669258 & -2 & 5 . & 13 & ГRN \\
\hline HEMBL3 & & 21 & 32 & \\
\hline HCMDI & & & & ST \\
\hline HEMBL3 & & & & ST \\
\hline HEMBL3664255 & 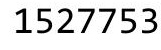 & 34 & 6.7774 & $\Gamma \mathrm{RN}$ \\
\hline IEMBL: & 52 & 22 & & \\
\hline HEMBL3 & & 372 & 95 & \\
\hline CHEMBL3 & & 931 & & ST \\
\hline HEMBL3664 & 753 & & 5.8324 & TST \\
\hline HEMBL36692 & 75 & 7.1593 & 757 & ГRN \\
\hline MPI & & & & th \\
\hline HEMBL3 & & & & \\
\hline CHEMBL36692 & 753 & .5969 & .1005 & \\
\hline CHEMBL3664243 & 1527753 & 7.6162 & 7.8147 & ГRN \\
\hline
\end{tabular}

Page 17129 
Supplemental Table S2.txt

\begin{tabular}{|c|c|c|c|c|c|c|}
\hline CHEMBL3669240 & 1527753 & 6.0 & 6.2405 & TST & & \\
\hline CHEMBL3664319 & 1527753 & 8.4815 & 8.3605 & TRN & & \\
\hline CHEMBL 3664374 & 1527753 & 5.9292 & 5.8059 & TST & & \\
\hline CHEMBL 3664295 & 1527753 & 7.9508 & 7.5232 & TRN & & \\
\hline CHEMBL 3664352 & 1527753 & 7.38299 & و9999999 & 99 & 6.6092 & TST \\
\hline CHEMBL3669296 & 1527753 & 5.9208 & 6.1064 & TRN & & \\
\hline CHEMBL3664232 & 1527753 & 7.065 & 6.7147 & TRN & & \\
\hline CHEMBL 3664260 & 1527753 & 6.7305 & 6.5132 & TST & & \\
\hline CHEMBL 3664347 & 1527753 & 6.3803 & 6.9641 & TRN & & \\
\hline CHEMBL 3664297 & 1527753 & 7.6421 & 7.5889 & TRN & & \\
\hline CHEMBL 3664231 & 1527753 & 6.5031 & 6.9167 & TRN & & \\
\hline CHEMBL 3664301 & 1527753 & 7.4486 & 7.3839 & TST & & \\
\hline CHEMBL 3664311 & 1527753 & 6.4401 & 7.3023 & TST & & \\
\hline CHEMBL3639632 & 1527753 & 6.9423 & 6.5709 & TST & & \\
\hline CHEMBL 3664344 & 1527753 & 7.1624 & 6.9267 & TRN & & \\
\hline CHEMBL 3664274 & 1527753 & 7.2248 & 6.5853 & TRN & & \\
\hline CHEMBL3664391 & 1527753 & 5.0788 & 6.3854 & TST & & \\
\hline CHEMBL3669209 & 1527753 & 5.9101 & 6.8133 & TST & & \\
\hline CHEMBL 3664326 & 1527753 & 5.1168 & 6.5974 & TST & & \\
\hline CHEMBL3664279 & 1527753 & 7.0778 & 7.0201 & TRN & & \\
\hline CHEMBL 3664285 & 1527753 & 6.5258 & 6.9747 & TRN & & \\
\hline CHEMBL3669273 & 1527753 & 6.9031 & 6.2949 & TRN & & \\
\hline CHEMBL 3664287 & 1527753 & 7.0773 & 6.9611 & TRN & & \\
\hline CHEMBL3639631 & 1527753 & 7.1618 & 6.907 & TRN & & \\
\hline CHEMBL 3356308 & 1527753 & 7.8539 & 7.2861 & TRN & & \\
\hline CHEMBL 3664322 & 1527753 & 9.699 & 8.2479 & TRN & & \\
\hline CHEMBL3669253 & 1527753 & 7.3622 & 7.0785 & TST & & \\
\hline CHEMBL 3664245 & 1527753 & 5.8729 & 7.5562 & TRN & & \\
\hline CHEMBL 3664235 & 1527753 & 6.0 & 7.1969 & TRN & & \\
\hline CHEMBL3669282 & 1527753 & 5.9788 & 6.1756 & TRN & & \\
\hline CHEMBL 3664355 & 1527753 & 9.4089 & 7.9682 & TST & & \\
\hline CHEMBL3664394 & 1527753 & 6.8582 & 6.1522 & TST & & \\
\hline CHEMBL 3669262 & 1527753 & 5.8297 & 5.8981 & TRN & & \\
\hline CHEMBL3664302 & 1527753 & 7.4908 & 7.1114 & TST & & \\
\hline CHEMBL3664381 & 1527753 & 5.0511 & 5.9245 & TST & & \\
\hline CHEMBL 3664337 & 1527753 & 7.0209 & 7.0223 & TRN & & \\
\hline CHEMBL 3664261 & 1527753 & \multicolumn{3}{|c|}{7.821000000000001} & 7.6277 & TRN \\
\hline CHEMBL 3664277 & 1527753 & 6.9586 & 6.7925 & TRN & & \\
\hline CHEMBL3664395 & 1527753 & 4.9097 & 6.7332 & TST & & \\
\hline CHEMBL3669246 & 1527753 & 6.0 & 6.4565 & TRN & & \\
\hline CHEMBL 3664362 & 1527753 & 7.6755 & 6.4423 & TST & & \\
\hline CHEMBL 3664321 & 1527753 & 6.0 & 7.6507 & TRN & & \\
\hline CHEMBL3669266 & 1527753 & 5.6576 & 5.9645 & TRN & & \\
\hline CHEMBL 3664298 & 1527753 & 7.2958 & 7.4016 & TRN & & \\
\hline CHEMBL 3664338 & 1527753 & 7.0357 & 6.8999 & TRN & & \\
\hline CHEMBL 3664268 & 1527753 & 7.3288 & 7.1994 & TRN & & \\
\hline CHEMBL3669259 & 1527753 & 5.8508 & 5.7867 & TRN & & \\
\hline CHEMBL 3664306 & 1527753 & 7.7212 & 7.3519 & TRN & & \\
\hline
\end{tabular}

Page 17130 
Supplemental Table S2.txt

\begin{tabular}{|c|c|c|c|c|c|c|}
\hline CHEMBL 3664370 & 1527753 & 6.0044 & 6.0368 & TST & & \\
\hline CHEMBL3664271 & 1527753 & 5.8962 & 6.8424 & TRN & & \\
\hline CHEMBL 3664283 & 1527753 & 7.0883 & 7.0314 & TRN & & \\
\hline CHEMBL 3664244 & 1527753 & 7.1325 & 7.5291 & TRN & & \\
\hline CHEMBL3664254 & 1527753 & 7.1739 & 6.9983 & TRN & & \\
\hline CHEMBL3664320 & 1527753 & 9.5229 & 8.1496 & TRN & & \\
\hline CHEMBL 3664340 & 1527753 & 7.4449 & 6.9836 & TRN & & \\
\hline CHEMBL 2180767 & 1527753 & 6.0 & 7.3873 & TRN & & \\
\hline CHEMBL 3664369 & 1527753 & 6.5865 & 6.391 & TST & & \\
\hline CHEMBL3664357 & 1527753 & 7.9208 & 6.6429 & TRN & & \\
\hline CHEMBL3669278 & 1527753 & 6.9957 & 6.2223 & TRN & & \\
\hline CHEMBL3356666 & 1527753 & 7.0057 & 7.2237 & TRN & & \\
\hline CHEMBL 3664371 & 1527753 & 5.435 & 5.862 & TST & & \\
\hline CHEMBL 3669297 & 1527753 & 4.0 & 6.228 & TRN & & \\
\hline CHEMBL3356653 & 1527753 & 7.9066 & 7.3526 & TRN & & \\
\hline CHEMBL3356679 & 1527753 & 6.5129 & 7.4147 & TST & & \\
\hline CHEMBL3664276 & 1527753 & 6.71 & 6.5557 & TRN & & \\
\hline CHEMBL3669260 & 1527753 & 6.8601 & 5.8266 & TRN & & \\
\hline CHEMBL3356673 & 1527753 & 7.0857 & 7.1172 & TRN & & \\
\hline CHEMBL3664353 & 1527753 & 6.678 & 6.407 & TST & & \\
\hline CHEMBL39683 & 103101 & 3.0026 & 3.5708 & TRN & & \\
\hline CHEMBL38556 & 103101 & 3.4783 & 4.0691 & TST & & \\
\hline CHEMBL39115 & 103101 & \multicolumn{3}{|c|}{2.7910000000000004} & 3.4475 & TRN \\
\hline CHEMBL39608 & 103101 & 3.4629 & 3.9104 & TRN & & \\
\hline CHEMBL290648 & 103101 & 3.4016 & 3.7335 & TST & & \\
\hline CHEMBL291259 & 103101 & 3.3014 & 3.763 & TST & & \\
\hline CHEMBL287755 & 103101 & 2.8716 & 3.5608 & TST & & \\
\hline CHEMBL39414 & 103101 & 5.4698 & 5.1097 & TST & & \\
\hline CHEMBL40059 & 103101 & 2.4542 & 2.4982 & TRN & & \\
\hline CHEMBL289913 & 103101 & 3.3407 & 3.5479 & TRN & & \\
\hline CHEMBL289785 & 103101 & 5.8069 & 4.8565 & TRN & & \\
\hline CHEMBL291072 & 103101 & 2.7428 & 2.4722 & TRN & & \\
\hline CHEMBL39135 & 103101 & 4.934 & 4.1448 & TRN & & \\
\hline CHEMBL290020 & 103101 & 3.4124 & 4.2845 & TST & & \\
\hline CHEMBL289090 & 103101 & 2.7279 & 2.7615 & TRN & & \\
\hline CHEMBL288706 & 103101 & 2.8323 & 3.1674 & TRN & & \\
\hline CHEMBL288161 & 103101 & 2.8982 & 2.9504 & TST & & \\
\hline CHEMBL38489 & 103101 & 5.9872 & 4.2488 & TRN & & \\
\hline CHEMBL285907 & 103101 & 5.301 & 5.5803 & TST & & \\
\hline CHEMBL289208 & 103101 & 2.6573 & 3.0571 & TST & & \\
\hline CHEMBL288727 & 103101 & 3.3497 & 3.7773 & TRN & & \\
\hline CHEMBL39101 & 103101 & 2.7205 & 2.6264 & TRN & & \\
\hline CHEMBL289379 & 103101 & 2.9718 & 2.9952 & TST & & \\
\hline CHEMBL38602 & 103101 & 2.9657 & 4.2572 & TRN & & \\
\hline CHEMBL288587 & 103101 & 5.1574 & 5.0966 & TRN & & \\
\hline CHEMBL39431 & 103101 & 2.5057 & 2.7131 & TRN & & \\
\hline CHEMBL39499 & 103101 & 2.5842 & 2.6787 & TRN & & \\
\hline CHEMBL289337 & 103101 & 3.3756 & 3.7449 & TST & & \\
\hline
\end{tabular}

Page 17131 


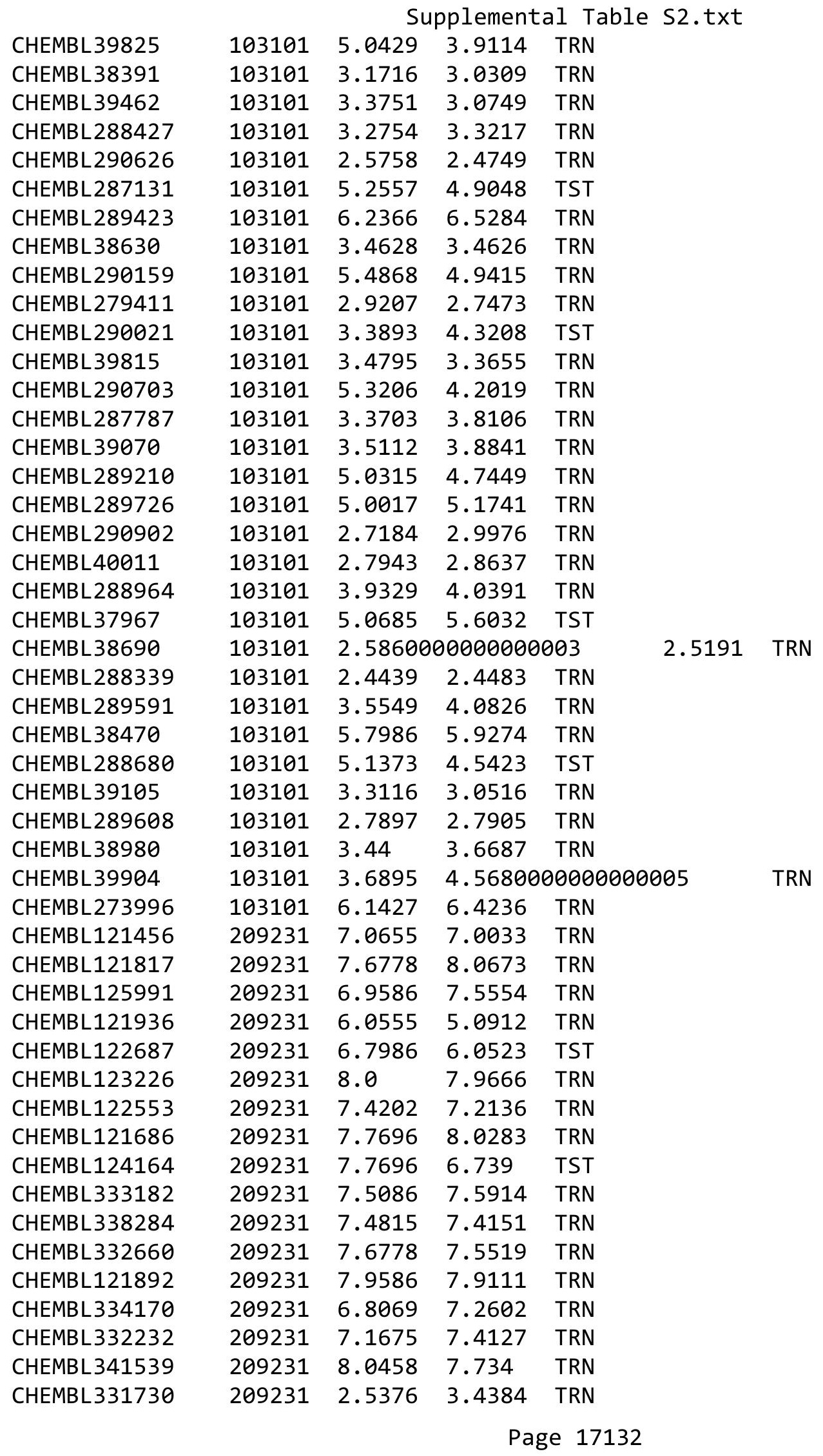




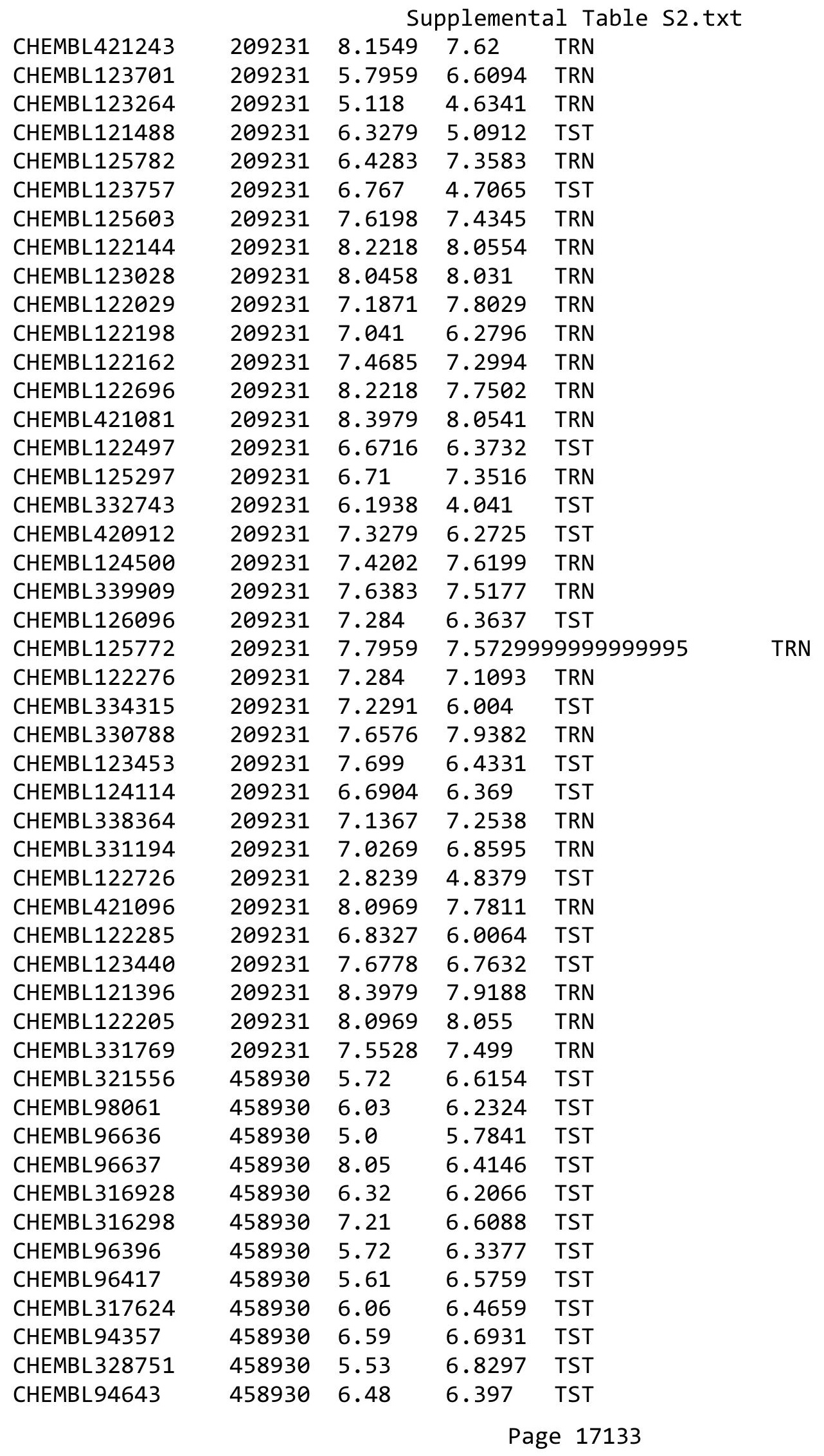




\begin{tabular}{|c|c|c|c|c|c|}
\hline \multicolumn{6}{|c|}{ Supplemental Table s2.txt } \\
\hline CHEMBL94948 & 458930 & 5.39 & 6.4461 & TST & \\
\hline CHEMBL92927 & 458930 & 5.94 & 6.5051 & TST & \\
\hline CHEMBL94363 & 458930 & 5.0 & 6.0675 & TST & \\
\hline CHEMBL 254400 & 458930 & 7.22 & 7.2491 & TRN & \\
\hline CHEMBL249242 & 458930 & 4.72 & 4.7044 & TRN & \\
\hline CHEMBL254819 & 458930 & 5.74 & 5.8665 & TRN & \\
\hline CHEMBL 3828556 & 458930 & 6.16 & 6.1471 & TRN & \\
\hline CHEMBL401146 & 458930 & 5.46 & 5.4883 & TRN & \\
\hline CHEMBL 254608 & 458930 & 6.75 & 6.5796 & TRN & \\
\hline CHEMBL254402 & 458930 & 6.7 & 6.704 & TRN & \\
\hline CHEMBL 254401 & 458930 & 7.35 & 7.3755 & TRN & \\
\hline CHEMBL400967 & 458930 & 6.47 & 6.4862 & TRN & \\
\hline CHEMBL288671 & 458930 & 6.06 & 6.1542 & TRN & \\
\hline CHEMBL35989 & 458930 & 6.02 & 5.9423 & TRN & \\
\hline CHEMBL 287871 & 458930 & 5.99 & 7.4497 & TST & \\
\hline CHEMBL 289604 & 458930 & 5.38 & 5.3375 & TRN & \\
\hline CHEMBL34660 & 458930 & 5.51 & 5.4376 & TRN & \\
\hline CHEMBL36999 & 458930 & 6.46 & 6.4793 & TRN & \\
\hline CHEMBL 290948 & 458930 & 6.72 & 6.6774 & TRN & \\
\hline CHEMBL 289411 & 458930 & 6.82 & 6.8613 & TRN & \\
\hline CHEMBL38106 & 458930 & 6.7 & 6.63399 & 99999999995 & TRN \\
\hline CHEMBL 35433 & 458930 & 7.0 & 7.1045 & TRN & \\
\hline CHEMBL37788 & 458930 & 6.87 & 6.9017 & TRN & \\
\hline CHEMBL 290952 & 458930 & 6.82 & 6.8431 & TRN & \\
\hline CHEMBL34808 & 458930 & 7.34 & 7.3212 & TRN & \\
\hline CHEMBL 285546 & 458930 & 7.12 & 7.1033 & TRN & \\
\hline CHEMBL34411 & 458930 & 6.03 & 6.0528 & TRN & \\
\hline CHEMBL 287823 & 458930 & 6.76 & 6.7226 & TRN & \\
\hline CHEMBL 287820 & 458930 & 7.11 & 7.09399 & 9999999999 & TRN \\
\hline CHEMBL36021 & 458930 & 6.76 & 6.7221 & TRN & \\
\hline CHEMBL38352 & 458930 & 7.19 & 7.24299 & 9999999999 & TRN \\
\hline CHEMBL37837 & 458930 & 6.65 & 6.6713 & TRN & \\
\hline CHEMBL418053 & 458930 & 6.76 & 6.836 & TRN & \\
\hline CHEMBL36191 & 458930 & 6.97 & 6.9326 & TRN & \\
\hline CHEMBL252718 & 458930 & 5.8 & 5.7175 & TRN & \\
\hline CHEMBL 252514 & 458930 & 6.28 & 6.2397 & TRN & \\
\hline CHEMBL 253332 & 458930 & 6.92 & 6.9457 & TRN & \\
\hline CHEMBL399102 & 458930 & 5.11 & 5.1064 & TRN & \\
\hline CHEMBL608523 & 458930 & 5.8 & 5.8472 & TRN & \\
\hline CHEMBL399952 & 458930 & 6.72 & 6.685 & TRN & \\
\hline CHEMBL 251902 & 458930 & 6.92 & 6.9389 & TRN & \\
\hline CHEMBL251686 & 458930 & 6.51 & 6.57700 & $\partial 000000001$ & TRN \\
\hline CHEMBL400992 & 458930 & 6.22 & 6.2394 & TRN & \\
\hline CHEMBL251685 & 458930 & 6.66 & 6.699 & TRN & \\
\hline CHEMBL249839 & 458930 & 5.89 & 5.9049 & TRN & \\
\hline CHEMBL 249838 & 458930 & 5.57 & 5.5651 & TRN & \\
\hline CHEMBL439408 & 458930 & 5.59 & 5.6169 & TRN & \\
\hline CHEMBL250893 & 458930 & 6.51 & 6.5322 & TRN & \\
\hline
\end{tabular}




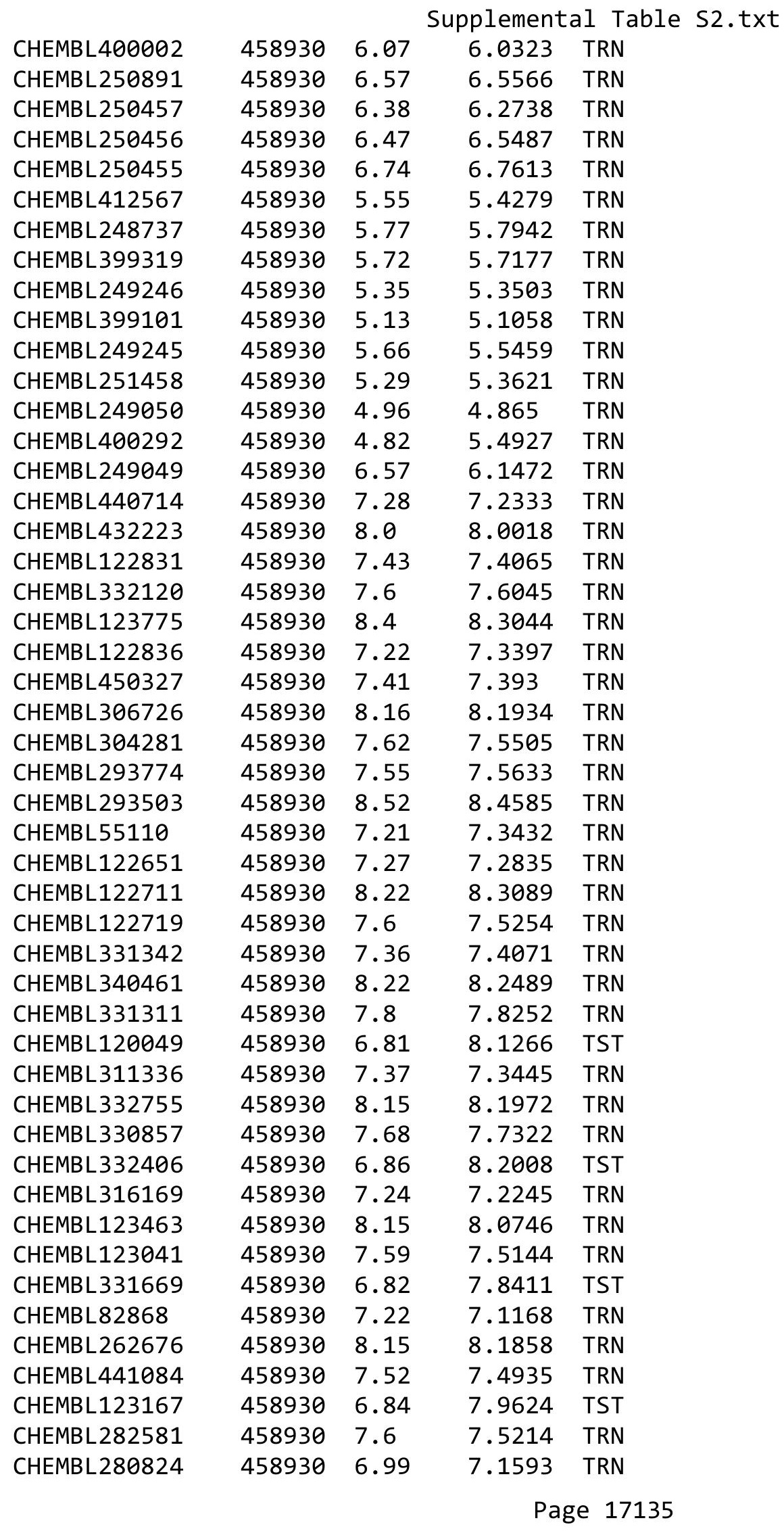




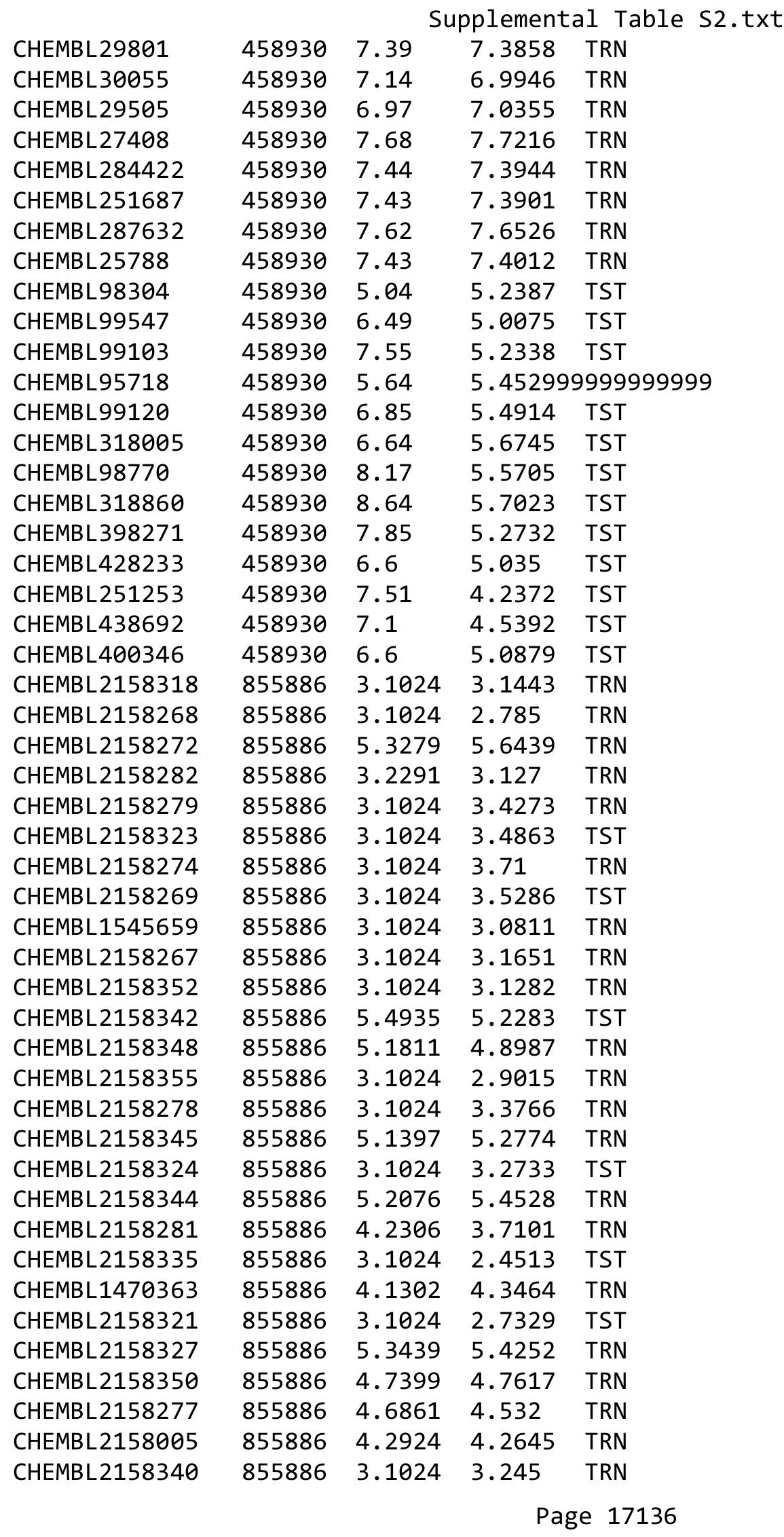




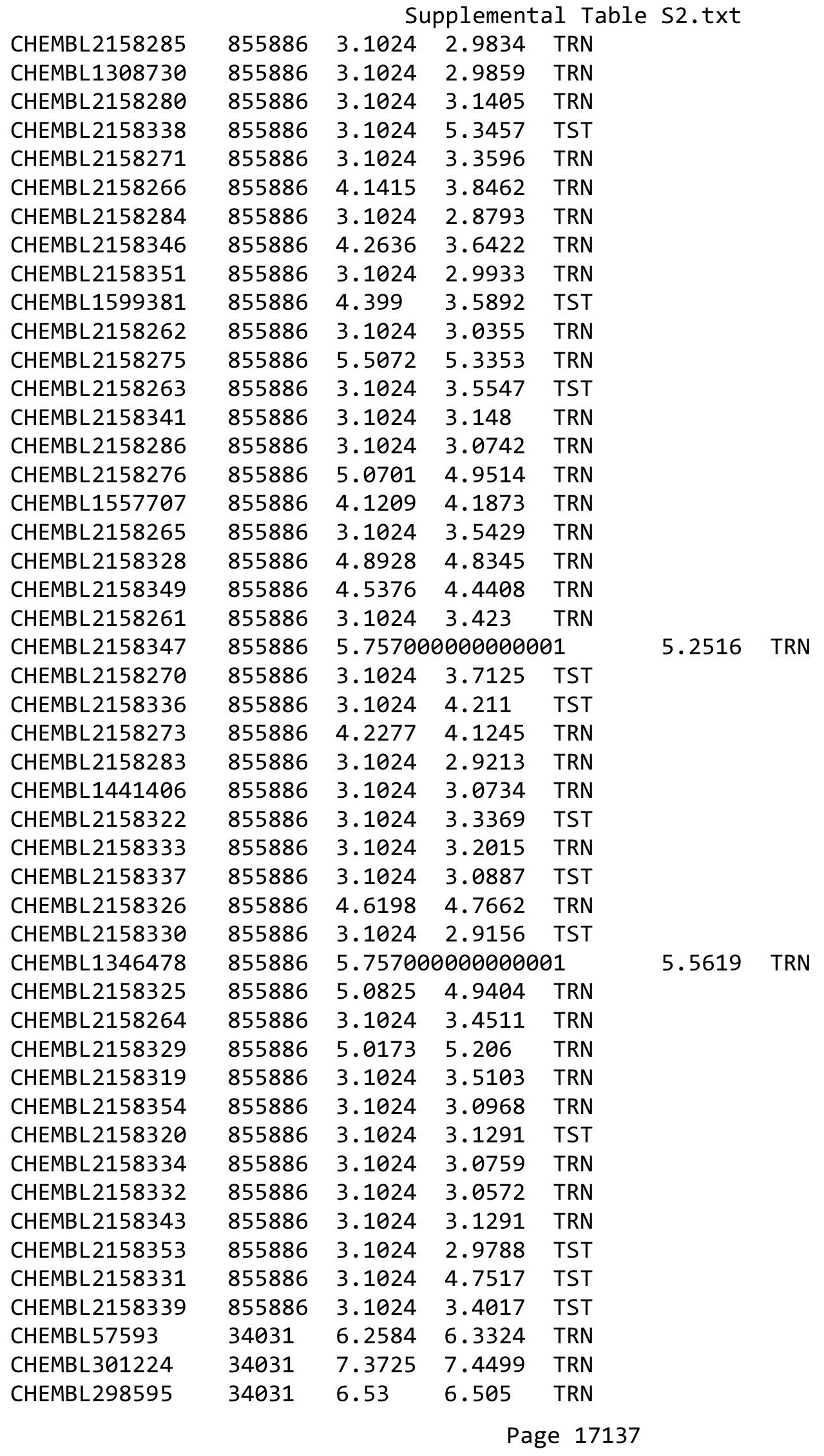




\begin{tabular}{|c|c|c|c|c|c|}
\hline & & & & & \\
\hline CHEMBL13647 & 34031 & 6.3057 & 6.3474 & TRN & \\
\hline CHEMBL56 & 34031 & 5.6815 & 6.6833 & TST & \\
\hline CHEMBL 301019 & 34031 & 5.0 & 4.9919 & TRN & \\
\hline CHEMBL431354 & 34031 & 6.9234 & 6.9382 & TRN & \\
\hline CHEMBL55882 & 34031 & 6.9223 & 6.9237 & TRN & \\
\hline CHEMBL440118 & 34031 & 6.9254 & 6.9195 & TRN & \\
\hline CHEMBL56869 & 34031 & 6.4243 & 6.4212 & TRN & \\
\hline CHEMBL56438 & 34031 & 6.8928 & 6.8413 & TRN & \\
\hline CHEMBL 292366 & 34031 & 7.5653 & 6.9952 & TST & \\
\hline CHEMBL58476 & 34031 & 5.0 & 4.9862 & TRN & \\
\hline CHEMBL 299253 & 34031 & 7.2682 & 6.44600 & 0000000001 & TST \\
\hline CHEMBL57098 & 34031 & 6.2001 & 6.2011 & TRN & \\
\hline CHEMBL55319 & 34031 & 8.5452 & 8.5383 & TRN & \\
\hline CHEMBL57097 & 34031 & 5.8185 & 5.8127 & TRN & \\
\hline CHEMBL57540 & 34031 & 7.5339 & 6.4566 & TST & \\
\hline CHEMBL57882 & 34031 & 5.0 & 5.0087 & TRN & \\
\hline CHEMBL57317 & 34031 & 7.2232 & 7.224 & TRN & \\
\hline CHEMBL 299454 & 34031 & 7.0577 & 7.0304 & TRN & \\
\hline CHEMBL60583 & 34031 & 8.451 & 8.4455 & TRN & \\
\hline CHEMBL 293968 & 34031 & 5.4743 & 5.4754 & TRN & \\
\hline CHEMBL56899 & 34031 & 6.9429 & 6.9345 & TRN & \\
\hline CHEMBL56620 & 34031 & 7.1658 & 7.1557 & TRN & \\
\hline CHEMBL 294646 & 34031 & 7.0364 & 7.0292 & TRN & \\
\hline CHEMBL57364 & 34031 & 5.0 & 5.0043 & TRN & \\
\hline CHEMBL 292399 & 34031 & 6.3829 & 7.1223 & TST & \\
\hline CHEMBL 293539 & 34031 & 6.9678 & 6.9672 & TRN & \\
\hline CHEMBL 292686 & 34031 & 5.0 & 5.0038 & TRN & \\
\hline CHEMBL57868 & 34031 & 6.2983 & 6.3048 & TRN & \\
\hline CHEMBL 291908 & 34031 & 6.2335 & 6.2278 & TRN & \\
\hline CHEMBL55790 & 34031 & 6.1044 & 6.2045 & TST & \\
\hline CHEMBL 300152 & 34031 & 6.7289 & 7.9277 & TST & \\
\hline CHEMBL55655 & 34031 & 7.3569 & 7.358 & TRN & \\
\hline CHEMBL58384 & 34031 & 6.3192 & 6.32299 & 99999999995 & TRN \\
\hline CHEMBL 293734 & 34031 & 5.0 & 4.9935 & TRN & \\
\hline CHEMBL56292 & 34031 & 8.6968 & 8.7063 & TRN & \\
\hline CHEMBL55654 & 34031 & 6.7207 & 6.7209 & TRN & \\
\hline CHEMBL 299691 & 34031 & 5.0 & 5.0072 & TRN & \\
\hline CHEMBL59149 & 34031 & 6.9012 & 6.898 & TRN & \\
\hline CHEMBL 299022 & 34031 & 6.6704 & 6.6622 & TRN & \\
\hline CHEMBL 294235 & 34031 & 7.1086 & 7.1056 & TRN & \\
\hline CHEMBL431943 & 34031 & 6.3751 & 6.3499 & TRN & \\
\hline CHEMBL57859 & 34031 & 7.2642 & 7.2375 & TRN & \\
\hline CHEMBL56804 & 34031 & 7.96299 & 79999999 & 7.7066 & TST \\
\hline CHEMBL556313 & 34031 & 6.8693 & 5.5369 & TST & \\
\hline CHEMBL59262 & 34031 & 8.7423 & 7.7918 & TST & \\
\hline CHEMBL60699 & 34031 & 6.5311 & 5.9149 & TST & \\
\hline CHEMBL417939 & 34031 & 5.0 & 7.0356 & TST & \\
\hline CHEMBL 293111 & 34031 & 6.4808 & 6.7005 & TST & \\
\hline
\end{tabular}




\begin{tabular}{|c|c|c|c|c|c|}
\hline \multirow{3}{*}{ CHEMBL 3717320} & \multirow{2}{*}{1536775} & \multirow[b]{2}{*}{8.0} & \multirow{2}{*}{\multicolumn{3}{|c|}{7.2892 TRN }} \\
\hline & & & & & \\
\hline & 1536775 & 8.0 & 7.8595 & TRN & \\
\hline CHEMBL3718322 & 1536775 & 8.0 & 7.5011 & TST & \\
\hline CHEMBL3718967 & 1536775 & 8.0 & 7.6776 & TRN & \\
\hline CHEMBL3715242 & 1536775 & 6.0 & 7.3069 & TRN & \\
\hline CHEMBL3717896 & 1536775 & 7.0 & 7.6974 & TRN & \\
\hline CHEMBL3718738 & 1536775 & 6.0 & 6.4255 & TST & \\
\hline CHEMBL3717222 & 1536775 & 8.0 & 7.7485 & TRN & \\
\hline CHEMBL3716824 & 1536775 & 8.0 & 7.3515 & TRN & \\
\hline CHEMBL3719028 & 1536775 & 7.0 & 7.3757 & TRN & \\
\hline CHEMBL3716297 & 1536775 & 8.0 & 7.5567 & TRN & \\
\hline CHEMBL3715827 & 1536775 & 8.0 & 7.4708 & TST & \\
\hline CHEMBL3715221 & 1536775 & 8.0 & 7.7455 & TRN & \\
\hline CHEMBL3714947 & 1536775 & 8.0 & 7.8423 & TST & \\
\hline CHEMBL 3718822 & 1536775 & 8.0 & 6.3958 & TRN & \\
\hline CHEMBL3714868 & 1536775 & 8.0 & 7.7575 & TRN & \\
\hline CHEMBL3716303 & 1536775 & 6.0 & 6.4187 & TRN & \\
\hline CHEMBL3718779 & 1536775 & 6.0 & 5.87799 & 9999999999 & TRN \\
\hline CHEMBL3716851 & 1536775 & 7.0 & 7.6191 & TRN & \\
\hline CHEMBL 3717238 & 1536775 & 8.0 & 7.7558 & TRN & \\
\hline CHEMBL3715301 & 1536775 & 8.0 & 7.6924 & TRN & \\
\hline CHEMBL3717576 & 1536775 & 7.0 & 7.7867 & TST & \\
\hline CHEMBL3716267 & 1536775 & 8.0 & 7.7777 & TRN & \\
\hline CHEMBL3715269 & 1536775 & 8.0 & 7.4836 & TST & \\
\hline CHEMBL3715191 & 1536775 & 8.0 & 7.6959 & TRN & \\
\hline CHEMBL 3716880 & 1536775 & 8.0 & 7.5205 & TRN & \\
\hline CHEMBL3715287 & 1536775 & 7.0 & 7.6167 & TST & \\
\hline CHEMBL3719213 & 1536775 & 7.0 & 7.6718 & TRN & \\
\hline CHEMBL3716706 & 1536775 & 7.0 & 7.6181 & TRN & \\
\hline CHEMBL3716042 & 1536775 & 8.0 & 7.7974 & TST & \\
\hline CHEMBL 3718571 & 1536775 & 6.0 & 6.0348 & TRN & \\
\hline CHEMBL3715134 & 1536775 & 6.0 & 6.475 & TRN & \\
\hline CHEMBL3716905 & 1536775 & 7.0 & 7.2012 & TST & \\
\hline CHEMBL3717749 & 1536775 & 7.0 & 7.5759 & TRN & \\
\hline CHEMBL3714848 & 1536775 & 8.0 & 7.7662 & TST & \\
\hline CHEMBL 3717223 & 1536775 & 8.0 & 7.6948 & TRN & \\
\hline CHEMBL3717232 & 1536775 & 8.0 & 7.7702 & TRN & \\
\hline CHEMBL3718089 & 1536775 & 8.0 & 7.8545 & TRN & \\
\hline CHEMBL3715487 & 1536775 & 8.0 & 7.5824 & TRN & \\
\hline CHEMBL3715204 & 1536775 & 7.0 & 7.6597 & TRN & \\
\hline CHEMBL 3717984 & 1536775 & 7.0 & 7.6214 & TST & \\
\hline CHEMBL3716748 & 1536775 & 7.0 & 7.5692 & TRN & \\
\hline CHEMBL3714925 & 1536775 & 8.0 & 7.7961 & TRN & \\
\hline CHEMBL3719367 & 1536775 & 8.0 & 7.7538 & TRN & \\
\hline CHEMBL3715810 & 1536775 & 7.0 & 7.2116 & TRN & \\
\hline CHEMBL3718112 & 1536775 & 7.0 & 7.5674 & TST & \\
\hline CHEMBL3719056 & 1536775 & 8.0 & 7.46399 & 99999999995 & TRN \\
\hline CHEMBL3716071 & 1536775 & 6.0 & 7.6837 & TRN & \\
\hline & & & & 17139 & \\
\hline
\end{tabular}




\begin{tabular}{|c|c|c|c|c|}
\hline & & & & 1 labıe \\
\hline CHEMBL3715272 & 1536775 & 8.0 & 7.4905 & TRN \\
\hline CHEMBL3715314 & 1536775 & 6.0 & 6.3114 & TST \\
\hline CHEMBL3717793 & 1536775 & 8.0 & 7.7165 & TST \\
\hline CHEMBL 3715268 & 1536775 & 8.0 & 7.7413 & TST \\
\hline CHEMBL3716295 & 1536775 & 8.0 & 7.7943 & TRN \\
\hline CHEMBL3716181 & 1536775 & 8.0 & $7.7420 e$ & 0000000001 \\
\hline CHEMBL3719297 & 1536775 & 6.0 & 6.501 & TRN \\
\hline CHEMBL3714920 & 1536775 & 7.0 & 7.6077 & TRN \\
\hline CHEMBL3718096 & 1536775 & 6.0 & 5.9685 & TRN \\
\hline CHEMBL3717556 & 1536775 & 6.0 & 6.3692 & TST \\
\hline CHEMBL3717342 & 1536775 & 8.0 & 7.553 & TRN \\
\hline CHEMBL3718370 & 1536775 & 8.0 & 7.4502 & TRN \\
\hline CHEMBL3717061 & 1536775 & 7.0 & 7.5699 & TRN \\
\hline CHEMBL3719098 & 1536775 & 8.0 & 7.7548 & TRN \\
\hline CHEMBL 3718419 & 1536775 & 7.0 & 7.6986 & TST \\
\hline CHEMBL3716345 & 1536775 & 6.0 & 6.3061 & TRN \\
\hline CHEMBL3718414 & 1536775 & 8.0 & 7.8224 & TST \\
\hline CHEMBL 3718525 & 1536775 & 8.0 & 7.817 & TRN \\
\hline CHEMBL 3717715 & 1536775 & 8.0 & 6.9795 & TRN \\
\hline CHEMBL3719075 & 1536775 & 7.0 & 7.7093 & TRN \\
\hline CHEMBL 3716542 & 1536775 & 8.0 & 7.6233 & TRN \\
\hline CHEMBL 3718771 & 1536775 & 8.0 & 7.4242 & TRN \\
\hline CHEMBL3718056 & 1536775 & 8.0 & 7.5944 & TST \\
\hline CHEMBL3718031 & 1536775 & 8.0 & 7.2749 & TRN \\
\hline CHEMBL3719306 & 1536775 & 7.0 & 7.8781 & TST \\
\hline CHEMBL 3718270 & 1536775 & 7.0 & 7.3105 & TRN \\
\hline CHEMBL3719064 & 1536775 & 7.0 & 7.4627 & TRN \\
\hline CHEMBL3715881 & 1536775 & 8.0 & 7.6797 & TRN \\
\hline CHEMBL3718339 & 1536775 & 8.0 & 7.7153 & TRN \\
\hline CHEMBL3715591 & 1536775 & 7.0 & 7.3389 & TRN \\
\hline CHEMBL3718417 & 1536775 & 7.0 & 7.4698 & TRN \\
\hline CHEMBL3717859 & 1536775 & 8.0 & 7.4423 & TRN \\
\hline CHEMBL3719122 & 1536775 & 7.0 & 7.5606 & TRN \\
\hline CHEMBL3718816 & 1536775 & 7.0 & 7.5592 & TRN \\
\hline CHEMBL3719300 & 1536775 & 6.0 & 6.1409 & TST \\
\hline CHEMBL 3714940 & 1536775 & 7.0 & 7.7463 & TST \\
\hline CHEMBL3714992 & 1536775 & 8.0 & 7.5336 & TRN \\
\hline CHEMBL3715768 & 1536775 & 6.0 & 5.9811 & TST \\
\hline CHEMBL3716513 & 1536775 & 8.0 & 7.6211 & TRN \\
\hline CHEMBL3718207 & 1536775 & 8.0 & 7.5411 & TRN \\
\hline CHEMBL 3715444 & 1536775 & 8.0 & 7.8155 & TRN \\
\hline CHEMBL3718394 & 1536775 & 8.0 & 7.546 & TRN \\
\hline CHEMBL3717165 & 1536775 & 6.0 & 6.3349 & TST \\
\hline CHEMBL 3717501 & 1536775 & 8.0 & 7.778 & TRN \\
\hline CHEMBL3715565 & 1536775 & 7.0 & 7.5347 & TRN \\
\hline CHEMBL 3718491 & 1536775 & 6.0 & 6.4365 & TRN \\
\hline CHEMBL3716565 & 1536775 & 7.0 & 7.7982 & TRN \\
\hline CHEMBL3716651 & 1536775 & 8.0 & 7.6349 & TRN \\
\hline
\end{tabular}

TRN 


\begin{tabular}{|c|c|c|c|c|c|}
\hline \multicolumn{6}{|c|}{ Supplemental Table S2.txt } \\
\hline CHEMBL 3717380 & 1536775 & 8.0 & 7.6923 & TRN & \\
\hline CHEMBL 3717474 & 1536775 & 7.0 & 7.7907 & TRN & \\
\hline CHEMBL3718191 & 1536775 & 6.0 & 6.1584 & TRN & \\
\hline CHEMBL 3719382 & 1536775 & 7.0 & 7.4377 & TRN & \\
\hline CHEMBL 3717340 & 1536775 & 6.0 & 6.0404 & TRN & \\
\hline CHEMBL 3716210 & 1536775 & 7.0 & 7.4429 & TST & \\
\hline CHEMBL3714927 & 1536775 & 8.0 & 7.0412 & TST & \\
\hline CHEMBL174726 & 312106 & 7.301 & 7.0158 & TRN & \\
\hline CHEMBL367956 & 312106 & 8.301 & 8.15200 & 0000000001 & TRN \\
\hline CHEMBL178043 & 312106 & 4.6 & 5.2864 & TRN & \\
\hline CHEMBL176207 & 312106 & 7.7959 & 7.8839 & TST & \\
\hline CHEMBL 369148 & 312106 & 6.5003 & 6.5888 & TRN & \\
\hline CHEMBL175823 & 312106 & 8.0 & 7.7582 & TRN & \\
\hline CHEMBL 369066 & 312106 & 8.3979 & 8.1798 & TST & \\
\hline CHEMBL366811 & 312106 & 4.0 & 4.323 & TRN & \\
\hline CHEMBL366598 & 312106 & 7.2007 & 6.9585 & TST & \\
\hline CHEMBL128569 & 312106 & 5.4 & 5.0999 & TRN & \\
\hline CHEMBL179736 & 312106 & 4.3 & 4.9802 & TRN & \\
\hline CHEMBL180008 & 312106 & 8.3979 & 8.2471 & TRN & \\
\hline CHEMBL177744 & 312106 & 8.301 & 7.6482 & TRN & \\
\hline CHEMBL177383 & 312106 & 5.2 & 4.5716 & TST & \\
\hline CHEMBL129144 & 312106 & 6.4001 & 5.9868 & TRN & \\
\hline CHEMBL426046 & 312106 & 9.0 & 9.0954 & TRN & \\
\hline CHEMBL174340 & 312106 & 7.7959 & 7.5261 & TRN & \\
\hline CHEMBL338047 & 312106 & 8.0969 & 7.9726 & TRN & \\
\hline CHEMBL175873 & 312106 & 8.301 & 8.4457 & TRN & \\
\hline CHEMBL424972 & 312106 & 7.699 & 7.8272 & TRN & \\
\hline CHEMBL175925 & 312106 & 6.8996 & 7.0836 & TRN & \\
\hline CHEMBL177961 & 312106 & 6.4001 & 7.7801 & TST & \\
\hline CHEMBL338936 & 312106 & 7.1024 & 7.5627 & TRN & \\
\hline CHEMBL175692 & 312106 & 8.5229 & 8.3828 & TRN & \\
\hline CHEMBL178061 & 312106 & 6.8013 & 6.8006 & TRN & \\
\hline CHEMBL177275 & 312106 & 9.0 & 8.8696 & TRN & \\
\hline CHEMBL 367745 & 312106 & 8.0 & 8.3934 & TRN & \\
\hline CHEMBL178689 & 312106 & 8.0969 & 8.0498 & TST & \\
\hline CHEMBL175534 & 312106 & 7.7959 & 7.0971 & TRN & \\
\hline CHEMBL368039 & 312106 & 8.699 & 8.9795 & TRN & \\
\hline CHEMBL435522 & 312106 & 4.0 & 4.0929 & TRN & \\
\hline CHEMBL 175655 & 312106 & 6.2 & 6.3521 & TRN & \\
\hline CHEMBL175693 & 312106 & 8.699 & 8.3331 & TST & \\
\hline CHEMBL177253 & 312106 & 5.5 & 4.6022 & TRN & \\
\hline CHEMBL369599 & 312106 & 7.7959 & 8.1717 & TRN & \\
\hline CHEMBL176107 & 312106 & 8.3979 & 8.4874 & TRN & \\
\hline CHEMBL 366692 & 312106 & 8.3979 & 8.105 & TRN & \\
\hline CHEMBL435904 & 312106 & 7.7959 & 6.9943 & TST & \\
\hline CHEMBL174536 & 312106 & 7.8861 & 8.2263 & TRN & \\
\hline CHEMBL424772 & 312106 & 9.0 & 8.2061 & TST & \\
\hline CHEMBL177978 & 312106 & 7.301 & 7.0489 & TRN & \\
\hline
\end{tabular}




\begin{tabular}{|c|c|c|c|c|}
\hline & & & pplement & al $\mathrm{T}$ \\
\hline CHEMBL369697 & 312106 & 9.0 & 8.2515 & TST \\
\hline CHEMBL177563 & 312106 & 8.0969 & 8.5502 & TRN \\
\hline CHEMBL368999 & 312106 & 6.1002 & 6.4988 & TRN \\
\hline CHEMBL175522 & 312106 & 8.6021 & 7.4156 & TST \\
\hline CHEMBL360957 & 312106 & 7.8996 & 7.8334 & TRN \\
\hline CHEMBL369460 & 312106 & 5.1 & 7.5286 & TST \\
\hline CHEMBL177666 & 312106 & 9.0 & 8.6384 & TRN \\
\hline CHEMBL177709 & 312106 & 8.2218 & 7.846 & TRN \\
\hline CHEMBL177491 & 312106 & 6.6003 & 6.7572 & TRN \\
\hline CHEMBL179056 & 312106 & 8.0 & 7.2682 & TST \\
\hline CHEMBL339511 & 312106 & 8.0 & 7.8016 & TRN \\
\hline CHEMBL178936 & 312106 & 7.6021 & 7.6834 & TRN \\
\hline CHEMBL366618 & 312106 & 7.0 & 7.2545 & TST \\
\hline CHEMBL174339 & 312106 & 7.7959 & 8.1927 & TRN \\
\hline CHEMBL355496 & 688325 & 4.8 & 4.7913 & TRN \\
\hline CHEMBL56731 & 688325 & 4.6 & 4.598 & TRN \\
\hline CHEMBL1336166 & 688325 & 5.3 & 5.3 & TRN \\
\hline CHEMBL1253351 & 688325 & 4.5 & 4.4867 & TRN \\
\hline CHEMBL 1255755 & 688325 & 4.9 & 4.9015 & TRN \\
\hline CHEMBL72631 & 688325 & 8.1024 & 8.1012 & TRN \\
\hline CHEMBL1434950 & 688325 & 8.1024 & 8.1067 & TRN \\
\hline CHEMBL8145 & 688325 & 4.6 & 4.6055 & TRN \\
\hline CHEMBL129795 & 688325 & 4.8 & 4.8015 & TRN \\
\hline CHEMBL1461491 & 688325 & 6.7001 & 6.6947 & TRN \\
\hline CHEMBL51085 & 688325 & 5.0 & 4.9963 & TRN \\
\hline CHEMBL 1257130 & 688325 & 5.0 & 4.4584 & TST \\
\hline CHEMBL1972346 & 688325 & 5.6 & 5.5977 & TRN \\
\hline CHEMBL 305881 & 688325 & 7.8996 & 7.8971 & TRN \\
\hline CHEMBL371811 & 688325 & 5.6 & 5.5937 & TRN \\
\hline CHEMBL297784 & 688325 & 5.2 & 5.2009 & TRN \\
\hline CHEMBL216504 & 688325 & 4.6 & 4.6036 & TRN \\
\hline CHEMBL553503 & 688325 & 8.2007 & 8.2006 & TRN \\
\hline CHEMBL126077 & 688325 & 4.9 & 4.9051 & TRN \\
\hline CHEMBL 1256623 & 688325 & 6.4 & 6.4022 & TRN \\
\hline CHEMBL296586 & 688325 & 5.5 & 5.5009 & TRN \\
\hline CHEMBL1437244 & 688325 & 4.8 & 5.7037 & TST \\
\hline CHEMBL76232 & 688325 & 8.301 & 8.2952 & TRN \\
\hline CHEMBL68534 & 688325 & 4.7 & 4.6996 & TRN \\
\hline CHEMBL1256364 & 688325 & 4.6 & 4.6052 & TRN \\
\hline CHEMBL453066 & 688325 & 5.6 & 5.6003 & TRN \\
\hline CHEMBL429711 & 688325 & 4.7 & 4.705 & TRN \\
\hline CHEMBL1256814 & 688325 & 4.4 & 4.3987 & TRN \\
\hline CHEMBL77030 & 688325 & 4.4 & 4.4072 & TRN \\
\hline CHEMBL405358 & 688325 & 5.2 & 5.1981 & TRN \\
\hline CHEMBL1365553 & 688325 & 4.7 & 4.7005 & TRN \\
\hline CHEMBL1367076 & 688325 & 4.8 & 4.8006 & TRN \\
\hline CHEMBL76589 & 688325 & 4.5 & 4.5009 & TRN \\
\hline CHEMBL428496 & 688325 & 8.7959 & 7.0984 & TST \\
\hline
\end{tabular}




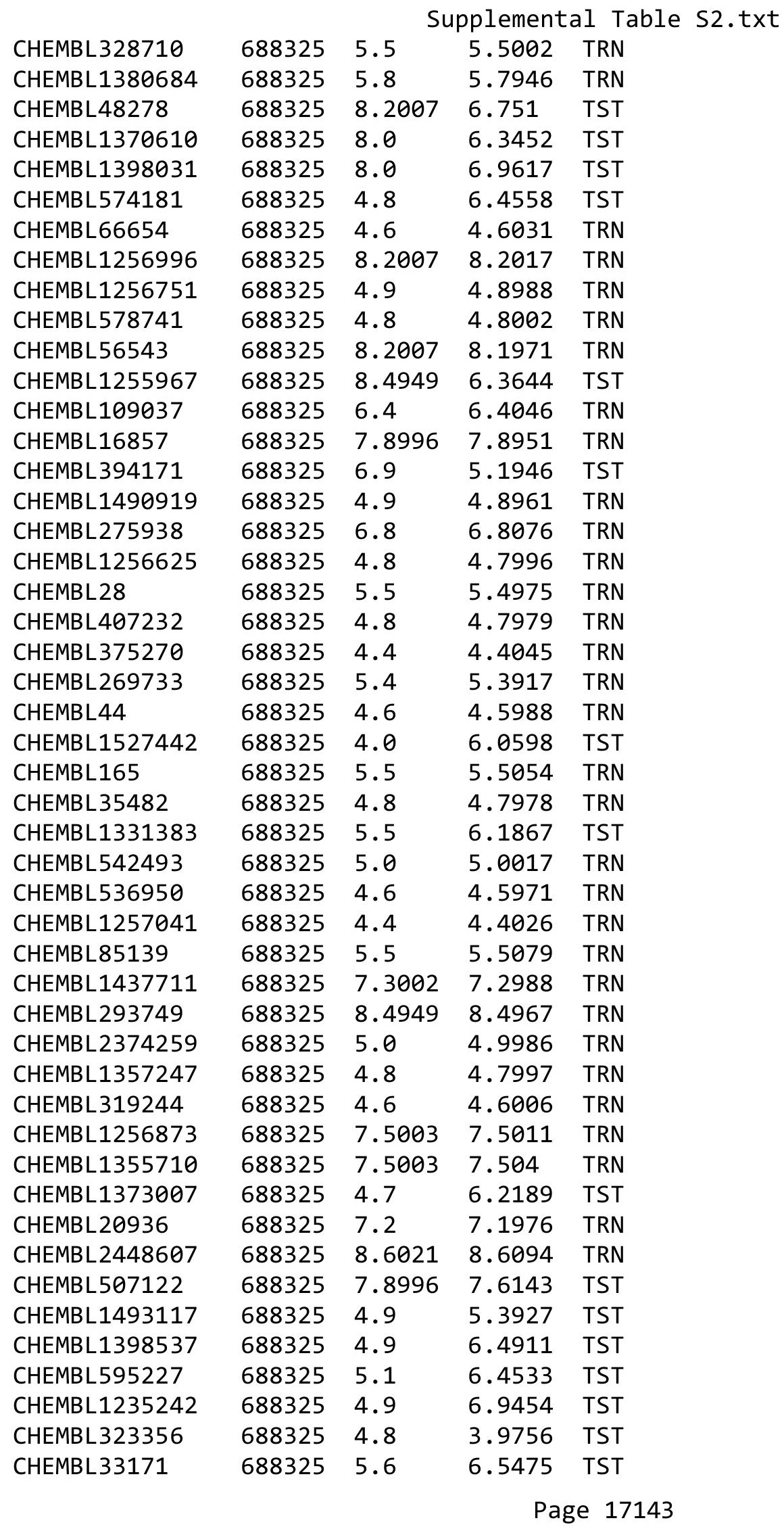




\begin{tabular}{|c|c|c|c|c|c|}
\hline \multicolumn{6}{|c|}{ plemental } \\
\hline CHEMBL24510 & 688325 & 6.6 & 6.8146 & TST & \\
\hline CHEMBL168461 & 688325 & 8.1024 & 7.6761 & TST & \\
\hline CHEMBL97760 & 688325 & 5.4 & 4.5824 & TST & \\
\hline CHEMBL489777 & 649306 & 3.0 & 2.97300 & 30000000003 & TRN \\
\hline CHEMBL489981 & 649306 & 3.0 & 3.0908 & TRN & \\
\hline CHEMBL518440 & 649306 & 5.4559 & 5.5111 & TRN & \\
\hline CHEMBL1215024 & 649306 & 3.5528 & 3.5956 & TRN & \\
\hline CHEMBL478859 & 649306 & 3.1739 & 3.3014 & TRN & \\
\hline CHEMBL452676 & 649306 & 4.7447 & 4.7204 & TRN & \\
\hline CHEMBL489779 & 649306 & 4.0969 & 4.0728 & TRN & \\
\hline CHEMBL522753 & 649306 & 3.1675 & 3.0732 & TRN & \\
\hline CHEMBL1088991 & 649306 & 6.0969 & 4.481 & TST & \\
\hline CHEMBL517807 & 649306 & 3.1308 & 2.6978 & TST & \\
\hline CHEMBL418899 & 649306 & 5.7696 & 4.958 & TST & \\
\hline CHEMBL522585 & 649306 & 5.2218 & 5.1907 & TRN & \\
\hline CHEMBL510108 & 649306 & 3.2291 & 3.2734 & TRN & \\
\hline CHEMBL489776 & 649306 & 3.5086 & 3.4911 & TRN & \\
\hline CHEMBL477177 & 649306 & 4.2218 & 4.1992 & TRN & \\
\hline CHEMBL505701 & 649306 & 4.0655 & 3.9863 & TRN & \\
\hline CHEMBL477823 & 649306 & 4.3372 & 4.336 & TRN & \\
\hline CHEMBL476983 & 649306 & 5.301 & 5.2566 & TRN & \\
\hline CHEMBL478860 & 649306 & 3.6778 & 3.597 & TRN & \\
\hline CHEMBL470505 & 649306 & 4.6778 & 4.6401 & TRN & \\
\hline CHEMBL502222 & 649306 & 3.2518 & 3.2444 & TRN & \\
\hline CHEMBL445306 & 649306 & 3.699 & 3.7123 & TRN & \\
\hline CHEMBL477606 & 649306 & 3.5528 & 3.6347 & TRN & \\
\hline CHEMBL1215240 & 649306 & 3.1024 & 3.2439 & TST & \\
\hline CHEMBL476783 & 649306 & 3.7447 & 3.1157 & TST & \\
\hline CHEMBL470987 & 649306 & 5.1549 & 5.1115 & TRN & \\
\hline CHEMBL489169 & 649306 & 3.5229 & 3.5639 & TRN & \\
\hline CHEMBL477596 & 649306 & 3.3188 & 3.3679 & TRN & \\
\hline CHEMBL515944 & 649306 & 3.8539 & 2.8028 & TST & \\
\hline CHEMBL476148 & 649306 & 4.9586 & 4.9801 & TRN & \\
\hline CHEMBL464086 & 649306 & 3.0 & 2.9609 & TRN & \\
\hline CHEMBL478880 & 649306 & 5.2596 & 5.2816 & TRN & \\
\hline CHEMBL508059 & 649306 & 4.3979 & 4.3475 & TRN & \\
\hline CHEMBL476974 & 649306 & 3.2366 & 3.2038 & TRN & \\
\hline CHEMBL159895 & 649306 & 5.8239 & 4.5177 & TST & \\
\hline CHEMBL448665 & 649306 & 3.0 & 2.9905 & TRN & \\
\hline CHEMBL476973 & 649306 & 4.9208 & 4.8935 & TRN & \\
\hline CHEMBL477607 & 649306 & 3.2147 & 3.1502 & TRN & \\
\hline CHEMBL450720 & 649306 & 4.0 & 3.9864 & TRN & \\
\hline CHEMBL476992 & 649306 & 3.0 & 3.2925 & TST & \\
\hline CHEMBL490061 & 649306 & 3.2218 & 3.2625 & TRN & \\
\hline CHEMBL452739 & 649306 & 3.0 & 2.9798 & TRN & \\
\hline CHEMBL1203972 & 649306 & 3.0 & 3.338 & TST & \\
\hline CHEMBL442892 & 649306 & 4.7447 & 4.7613 & TRN & \\
\hline CHEMBL476358 & 649306 & 4.6778 & 4.6819 & TRN & \\
\hline
\end{tabular}




\begin{tabular}{|c|c|c|c|c|c|}
\hline \\
\hline CHEMBL446474 & 649306 & 4.7959 & 4.7848 & TRN & \\
\hline CHEMBL450704 & 649306 & 4.0 & 4.0234 & TRN & \\
\hline CHEMBL476147 & 649306 & 5.0458 & 5.3077 & TST & \\
\hline CHEMBL478881 & 649306 & 4.699 & 4.4351 & TST & \\
\hline CHEMBL448063 & 649306 & 4.2147 & 4.2187 & TRN & \\
\hline CHEMBL1215095 & 649306 & 4.7212 & 5.1182 & TST & \\
\hline CHEMBL476918 & 649306 & 4.0458 & 4.0661 & TRN & \\
\hline CHEMBL489982 & 649306 & 3.7447 & 3.7781 & TRN & \\
\hline CHEMBL490761 & 649306 & 3.0 & 3.01 & TRN & \\
\hline CHEMBL518286 & 649306 & 4.0 & 3.7217 & TST & \\
\hline CHEMBL499938 & 649306 & 3.1938 & 3.2285 & TRN & \\
\hline CHEMBL1093511 & 649306 & 6.0 & 3.81100 & 00000000004 & TST \\
\hline CHEMBL522098 & 649306 & 3.4559 & 3.4515 & TRN & \\
\hline CHEMBL477550 & 649306 & 3.0 & 3.0192 & TRN & \\
\hline CHEMBL478882 & 649306 & 3.4437 & 3.5312 & TST & \\
\hline CHEMBL477176 & 649306 & 4.7212 & 4.7392 & TRN & \\
\hline CHEMBL448446 & 649306 & 3.5229 & 3.4297 & TRN & \\
\hline CHEMBL502905 & 649306 & 4.9586 & 5.0358 & TRN & \\
\hline CHEMBL476784 & 649306 & 3.6576 & 2.8118 & TST & \\
\hline CHEMBL448250 & 649306 & 6.0969 & 6.1074 & TRN & \\
\hline CHEMBL477187 & 649306 & 5.0 & 4.5553 & TST & \\
\hline CHEMBL425989 & 422201 & 5.4202 & 5.4216 & TRN & \\
\hline CHEMBL216795 & 422201 & 6.7212 & 6.7286 & TRN & \\
\hline CHEMBL218903 & 422201 & 6.6576 & 6.6615 & TRN & \\
\hline CHEMBL384105 & 422201 & 4.7905 & 4.7431 & TST & \\
\hline CHEMBL 218937 & 422201 & 6.5528 & 6.5686 & TRN & \\
\hline CHEMBL 218936 & 422201 & 5.301 & 5.309 & TRN & \\
\hline CHEMBL 219605 & 422201 & 6.5229 & 6.5139 & TRN & \\
\hline CHEMBL 374340 & 422201 & 5.7696 & 5.7673 & TRN & \\
\hline CHEMBL219604 & 422201 & 6.6021 & 6.63 & TRN & \\
\hline CHEMBL216919 & 422201 & 6.2218 & 6.2127 & TRN & \\
\hline CHEMBL425108 & 422201 & 6.5528 & 6.5559 & TRN & \\
\hline CHEMBL 373928 & 422201 & 3.3188 & 4.7853 & TST & \\
\hline CHEMBL 219422 & 422201 & 6.6778 & 6.6712 & TRN & \\
\hline CHEMBL374036 & 422201 & 4.2441 & 4.2649 & TRN & \\
\hline CHEMBL424930 & 422201 & 5.6576 & 5.6626 & TRN & \\
\hline CHEMBL 385089 & 422201 & 6.7696 & 6.7627 & TRN & \\
\hline CHEMBL415051 & 422201 & 3.0 & 2.9988 & TRN & \\
\hline CHEMBL216975 & 422201 & 6.5686 & 6.5709 & TRN & \\
\hline CHEMBL386158 & 422201 & 6.5686 & 6.5706 & TRN & \\
\hline CHEMBL 219242 & 422201 & 7.0969 & 7.098 & TRN & \\
\hline CHEMBL 219294 & 422201 & 3.4948 & 4.7754 & TST & \\
\hline CHEMBL415050 & 422201 & 6.301 & 6.2975 & TRN & \\
\hline CHEMBL 219052 & 422201 & 6.8239 & 6.8331 & TRN & \\
\hline CHEMBL 219200 & 422201 & 6.9208 & 6.9182 & TRN & \\
\hline CHEMBL 219173 & 422201 & 5.3979 & 5.3644 & TRN & \\
\hline CHEMBL 219057 & 422201 & 5.8239 & 5.8192 & TRN & \\
\hline CHEMBL 376739 & 422201 & 5.6778 & 5.6883 & TRN & \\
\hline
\end{tabular}


Supplemental Table S2.txt

\begin{tabular}{|c|c|c|c|c|}
\hline 66 & & 6.6778 & 6.6743 & \\
\hline CHFMBI 348812 & 22201 & 5.0 & 6.3847 & \\
\hline AEMBL219515 & 22201 & 0969 & 9841 & \\
\hline IEMBL 374033 & 22201 & 5.699 & 9934 & \\
\hline HEMBL 373550 & 22201 & 7.0 & 0046 & \\
\hline HEMBL 2 & 22201 & 6.3098 & 22 & \\
\hline AEMBL2 & 22201 & & & \\
\hline IEMBL219383 & 22201 & 6.8539 & 6.8576 & \\
\hline HEMBL219506 & 22201 & 6.6383 & 5554 & \\
\hline HEMBL436969 & 22201 & 3.0555 & 468 & \\
\hline HEMBL2 & 22201 & 5.7212 & 158 & \\
\hline AEMBL2 & 201 & 5.6778 & & \\
\hline HEMBL 2 & 22201 & 6.8861 & 858 & \\
\hline AEMBL 2 & 22201 & 6.6198 & 136 & \\
\hline AEMBL3 & 22201 & 6.9208 & & \\
\hline 92 & 201 & 549 & 45 & \\
\hline$\partial 0$ & 01 & & & \\
\hline AEMBL 2 & 201 & 706 & 711 & \\
\hline AFMRI 3 & 201 & 979 & & \\
\hline HEMBL 2 & 201 & 83 & 95 & \\
\hline 9 & 201 & 59 & & \\
\hline 1 & 01 & & & \\
\hline IEMBL 3 & 01 & 239 & 97 & \\
\hline 33 & & 29 & & \\
\hline 53 & 01 & 6. & 09 & \\
\hline 8 & 01 & 39 & 26 & \\
\hline 6 & 01 & & & \\
\hline .06 & 147 & & & \\
\hline 593 & 147 & & & \\
\hline MBL3 & 1642147 & 8. & 94 & \\
\hline$\partial 81$ & 147 & & 38 & \\
\hline 23 & 47 & & & \\
\hline & 147 & & & \\
\hline 886 & 2147 & & & \\
\hline 889 & 2147 & 8. & 94 & \\
\hline 923 & 147 & 8 . & 99 & \\
\hline & & & & \\
\hline 659 & 2147 & 7.3 & & \\
\hline 366 & 2147 & 086 & & \\
\hline 90 & 147 & 8.2218 & & \\
\hline 772 & 1642147 & 9 . & 828 & \\
\hline & 2147 & & 6.9327 & \\
\hline CHEMBL3 & 1642147 & 7.0862 & 7.48 & $n$ \\
\hline CHEMBL 3 & 2147 & 8.0 & 53 & \\
\hline 85 & 147 & 5 . & & \\
\hline CHEMBL 3 & 1642147 & 8.0458 & 8.3249 & \\
\hline CHEMBL 38 & 1642147 & 8.0969 & 7.6359 & \\
\hline CHEMBL3963610 & 1642147 & 6.9031 & 7.3695 & \\
\hline
\end{tabular}

Page 17146 
Supplemental Table S2.txt

\begin{tabular}{|c|c|c|c|c|c|}
\hline CHEMBL3980623 & 1642147 & 8.0969 & 8.2396 & TRN & \\
\hline CHEMBL3951762 & 1642147 & 7.9586 & 8.3327 & TRN & \\
\hline CHEMBL3919425 & 1642147 & 8.699 & 8.9347 & TRN & \\
\hline CHEMBL 3809225 & 1642147 & 7.2147 & 7.5006 & TRN & \\
\hline CHEMBL3952620 & 1642147 & 6.5834 & 7.2509 & TST & \\
\hline CHEMBL3901276 & 1642147 & 7.5686 & 7.688 & TRN & \\
\hline CHEMBL3896197 & 1642147 & 7.3098 & 7.8801 & TRN & \\
\hline CHEMBL3914865 & 1642147 & 7.8861 & 7.8704 & TST & \\
\hline CHEMBL3969292 & 1642147 & 7.1549 & 7.2272 & TST & \\
\hline CHEMBL3943831 & 1642147 & 8.3979 & 8.5236 & TRN & \\
\hline CHEMBL3957023 & 1642147 & 8.301 & 7.7248 & TRN & \\
\hline CHEMBL3809279 & 1642147 & 6.8356 & 7.5512 & TRN & \\
\hline CHEMBL3959834 & 1642147 & 5.0 & 7.2136 & TRN & \\
\hline CHEMBL3940708 & 1642147 & 8.699 & 8.8496 & TRN & \\
\hline CHEMBL3968037 & 1642147 & 7.7696 & 7.7229 & TRN & \\
\hline CHEMBL3810035 & 1642147 & 6.6308 & 7.1425 & TRN & \\
\hline CHEMBL3924360 & 1642147 & 8.2218 & 8.324 & TRN & \\
\hline CHEMBL 3934282 & 1642147 & 8.1549 & 7.7599 & TST & \\
\hline CHEMBL3935221 & 1642147 & 7.9586 & 8.1231 & TRN & \\
\hline CHEMBL3919267 & 1642147 & 8.699 & 8.9657 & TRN & \\
\hline CHEMBL3810081 & 1642147 & 7.1612 & 7.4749 & TRN & \\
\hline CHEMBL3976113 & 1642147 & 7.9208 & 7.7244 & TRN & \\
\hline CHEMBL3944328 & 1642147 & 8.301 & 8.2899 & TRN & \\
\hline CHEMBL3810036 & 1642147 & 6.1765 & 6.2717 & TRN & \\
\hline CHEMBL3943684 & 1642147 & 7.0605 & 6.8225 & TRN & \\
\hline CHEMBL3958743 & 1642147 & 7.0315 & 8.1478 & TST & \\
\hline CHEMBL 3939747 & 1642147 & 8.5229 & 8.3898 & TRN & \\
\hline CHEMBL3901354 & 1642147 & 8.1549 & 8.184 & TRN & \\
\hline CHEMBL3900491 & 1642147 & 8.301 & 8.5696 & TRN & \\
\hline CHEMBL3970871 & 1642147 & 8.5229 & 8.316 & TRN & \\
\hline CHEMBL3940472 & 1642147 & 8.0969 & 7.8319 & TRN & \\
\hline CHEMBL3943432 & 1642147 & 8.699 & 8.2185 & TRN & \\
\hline CHEMBL3901646 & 1642147 & 7.3372 & 7.6232 & TST & \\
\hline CHEMBL3943003 & 1642147 & 8.0969 & 7.9158 & TRN & \\
\hline CHEMBL3892320 & 1642147 & 6.5331 & 7.7773 & TST & \\
\hline CHEMBL3980945 & 1642147 & 7.5086 & 7.7678 & TRN & \\
\hline CHEMBL3905145 & 1642147 & 8.0969 & 7.995 & TRN & \\
\hline CHEMBL3967835 & 1642147 & 7.7696 & 7.5455 & TRN & \\
\hline CHEMBL3983562 & 1642147 & 8.2218 & 8.0176 & TRN & \\
\hline CHEMBL3976531 & 1642147 & 7.8539 & 7.5836 & TRN & \\
\hline CHEMBL3975586 & 1642147 & 7.7696 & 7.37799 & 9999999999 & TRN \\
\hline CHEMBL3893289 & 1642147 & 7.5528 & 7.2087 & TRN & \\
\hline CHEMBL3927553 & 1642147 & 8.301 & 8.6595 & TST & \\
\hline CHEMBL3934109 & 1642147 & 7.9586 & 7.3988 & TST & \\
\hline CHEMBL3947135 & 1642147 & 8.3979 & 7.5255 & TST & \\
\hline CHEMBL3955250 & 1642147 & 8.3979 & 7.8883 & TRN & \\
\hline CHEMBL3809656 & 1642147 & 8.0969 & 7.5201 & TRN & \\
\hline CHEMBL3936402 & 1642147 & 8.1549 & 8.0194 & TRN & \\
\hline
\end{tabular}


Supplemental Table S2.txt

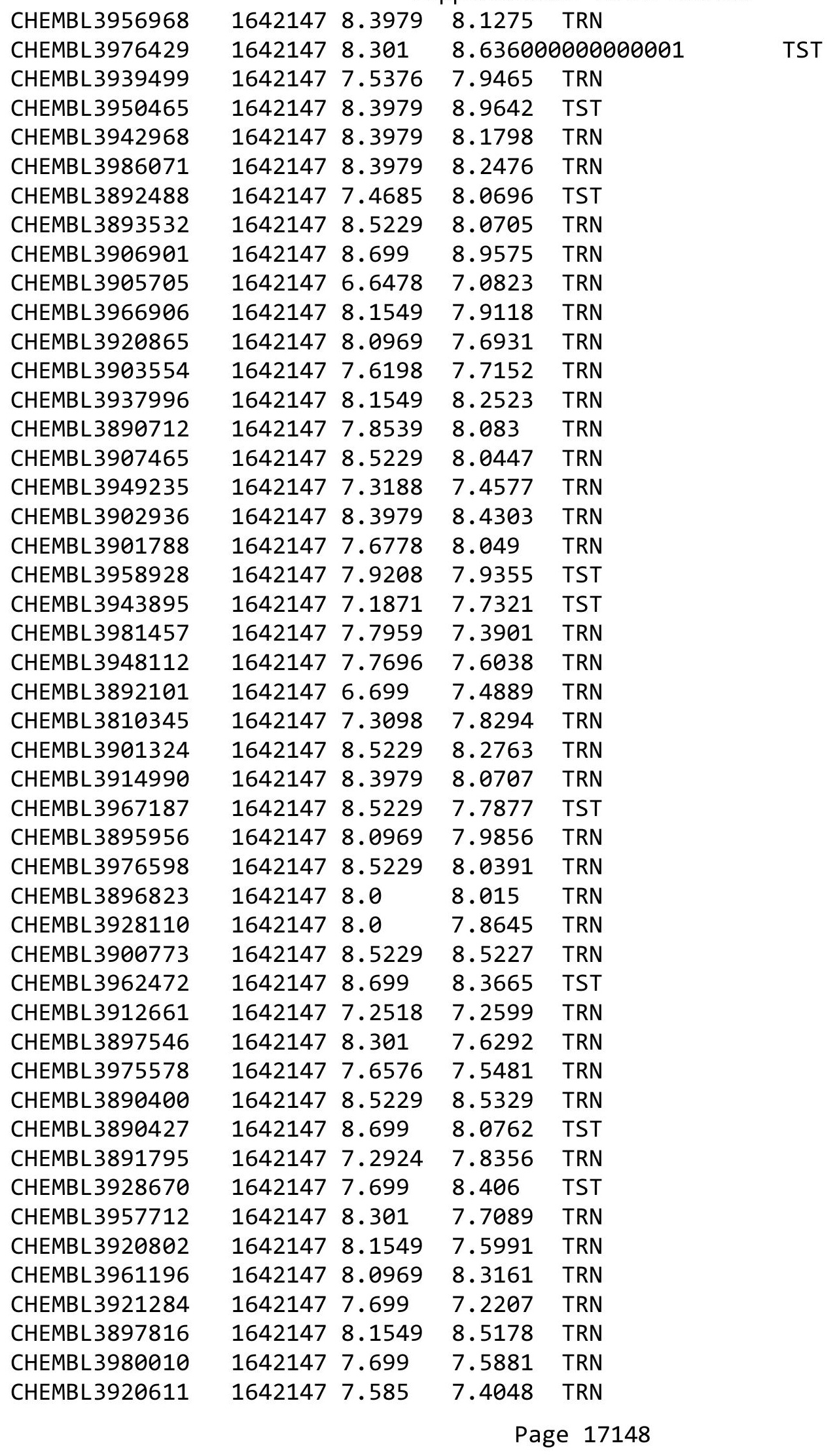


Supplemental Table S2.txt

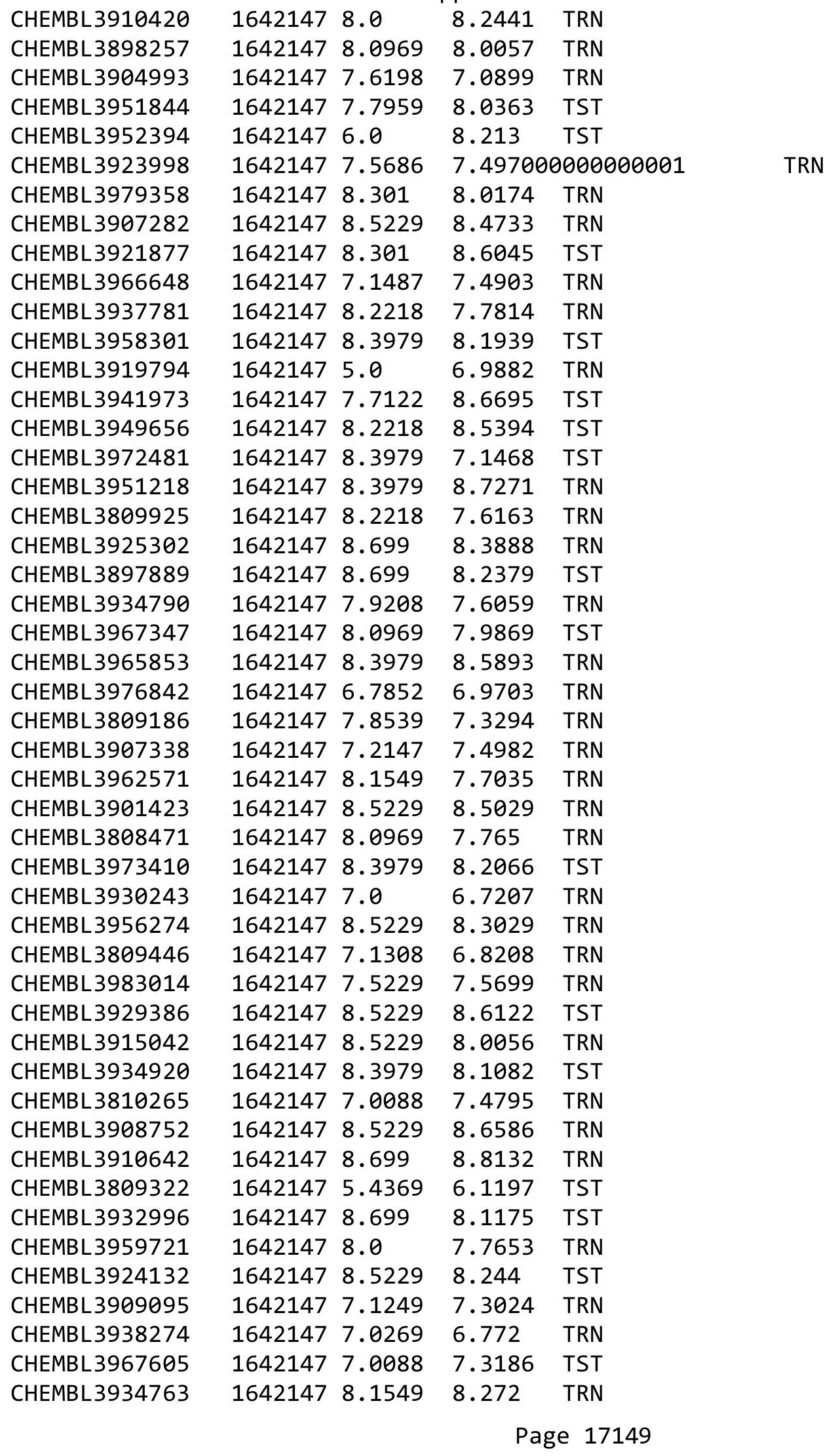


Supplemental Table S2.txt

\begin{tabular}{|c|c|c|c|c|}
\hline CHEMBL 3808500 & 1642147 & 8.0458 & 7.3252 & TRN \\
\hline CHEMBL 3920481 & 1642147 & 8.5229 & 8.9169 & TRN \\
\hline CHEMBL 3961298 & 1642147 & 7.9586 & 7.6677 & TST \\
\hline CHEMBL 3925962 & 1642147 & 8.5229 & 8.3399 & TRN \\
\hline CHEMBL3961036 & 1642147 & 8.301 & 8.4927 & TRN \\
\hline CHEMBL 3935276 & 1642147 & 8.0969 & 8.0516 & TST \\
\hline CHEMBL 3941982 & 1642147 & 8.5229 & 7.9939 & TRN \\
\hline CHEMBL 3930682 & 1642147 & 7.9208 & 8.1025 & TRN \\
\hline CHEMBL 3912815 & 1642147 & 7.3468 & 7.3538 & TRN \\
\hline CHEMBL3809287 & 1642147 & 8.0969 & 8.0892 & TRN \\
\hline CHEMBL 3913764 & 1642147 & 8.2218 & 8.4166 & TST \\
\hline CHEMBL 3928170 & 1642147 & 9.0 & 8.579 & TST \\
\hline CHEMBL 3984927 & 1642147 & 7.8539 & 8.048 & TRN \\
\hline CHEMBL 3956249 & 1642147 & 7.4685 & 8.307 & TST \\
\hline CHEMBL3966905 & 1642147 & 8.5229 & 8.856 & TRN \\
\hline CHEMBL 3981825 & 1642147 & 7.0 & 7.5064 & TRN \\
\hline CHEMBL3915815 & 1642147 & 7.1079 & 6.7706 & TST \\
\hline CHEMBL 3959503 & 1642147 & 8.0 & 7.4579 & TST \\
\hline CHEMBL 3809219 & 1642147 & 8.0969 & 8.1051 & TRN \\
\hline CHEMBL3918557 & 1642147 & 7.9208 & 7.9331 & TRN \\
\hline CHEMBL 3943079 & 1642147 & 8.2218 & 7.5975 & TRN \\
\hline CHEMBL 3896346 & 1642147 & 7.4815 & 7.667000 & 0000000001 \\
\hline CHEMBL 3808838 & 1642147 & 7.6778 & 7.7862 & TRN \\
\hline CHEMBL 3911532 & 1642147 & 8.1549 & 8.5892 & TST \\
\hline CHEMBL 3917528 & 1642147 & 8.5229 & 8.2669 & TST \\
\hline CHEMBL3920395 & 1642147 & 7.4089 & 7.6108 & TRN \\
\hline CHEMBL 3955235 & 1642147 & 8.0458 & 8.892999 & 9999999999 \\
\hline CHEMBL 3892853 & 1642147 & 7.9586 & 7.8493 & TRN \\
\hline CHEMBL 3907428 & 1642147 & 8.5229 & 8.7908 & TST \\
\hline CHEMBL 3946383 & 1642147 & 8.699 & 8.5541 & TST \\
\hline CHEMBL 3936006 & 1642147 & 7.6021 & 7.5974 & TRN \\
\hline CHEMBL 3911468 & 1642147 & 8.699 & 7.5908 & TRN \\
\hline CHEMBL 3984606 & 1642147 & 6.9508 & 7.718 & TST \\
\hline CHEMBL 3929447 & 1642147 & 8.0458 & 8.0337 & TRN \\
\hline CHEMBL 3944189 & 1642147 & 8.5229 & 8.2433 & TRN \\
\hline CHEMBL 2030297 & 820207 & 6.7905 & 7.0161 & TRN \\
\hline CHEMBL 2030331 & 820207 & 5.0 & 6.0808 & TST \\
\hline CHEMBL 2030493 & 820207 & 5.0 & 4.7807 & TRN \\
\hline CHEMBL 2030324 & 820207 & 6.9872 & 6.5832 & TRN \\
\hline CHEMBL 2030306 & 820207 & 5.0 & 5.7288 & TRN \\
\hline CHEMBL 2030332 & 820207 & 5.0 & 6.0552 & TRN \\
\hline CHEMBL 2030313 & 820207 & 6.9914 & 6.4117 & TRN \\
\hline CHEMBL 2030314 & 820207 & 6.6596 & 6.6817 & TRN \\
\hline CHEMBL 2030315 & 820207 & 6.2549 & 5.2237 & TRN \\
\hline CHEMBL 2030310 & 820207 & 6.4634 & 6.1442 & TRN \\
\hline CHEMBL 2030305 & 820207 & 6.4283 & 6.3983 & TRN \\
\hline CHEMBL 2030321 & 820207 & 6.9626 & 6.7665 & TRN \\
\hline CHEMBL 2030330 & 820207 & 6.4962 & 6.2429 & TST \\
\hline
\end{tabular}




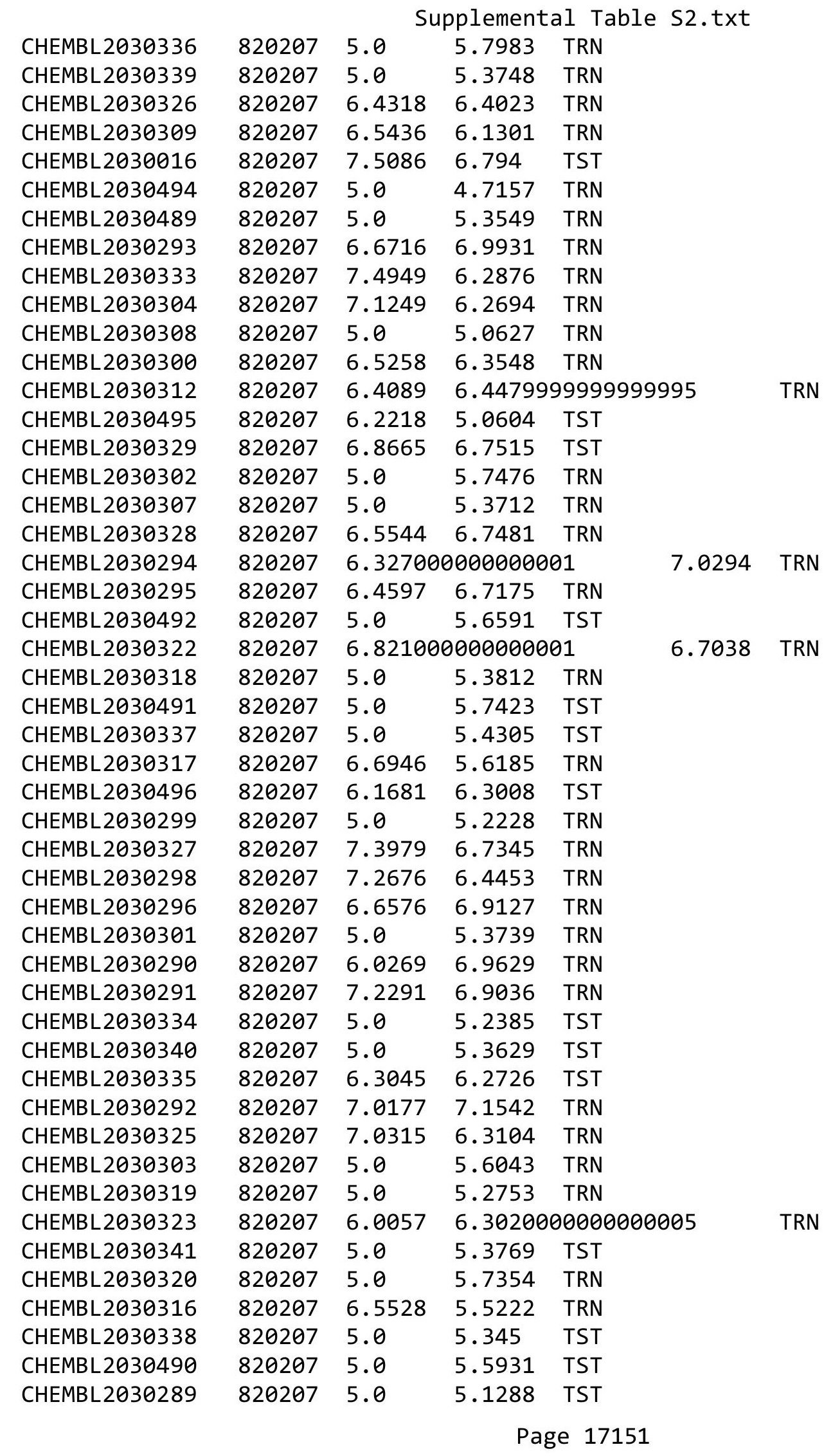


Supplemental Table S2.txt

\begin{tabular}{|c|c|c|c|c|}
\hline CHEMBL2030311 & 820207 & 6.4089 & 6.4335 & TRN \\
\hline CHEMBL476061 & 564968 & 4.4802 & 4.522 & TRN \\
\hline CHEMBL514018 & 564968 & 3.7077 & 3.6795 & TRN \\
\hline CHEMBL509748 & 564968 & 3.6091 & 3.5001 & TRN \\
\hline CHEMBL476013 & 564968 & 3.6402 & 3.7078 & TRN \\
\hline CHEMBL477869 & 564968 & 3.6536 & 3.7357 & TRN \\
\hline CHEMBL476652 & 564968 & 4.4157 & 4.4618 & TRN \\
\hline CHEMBL514996 & 564968 & 4.58 & 4.5377 & TRN \\
\hline CHEMBL478495 & 564968 & 3.7773 & 2.9307 & TST \\
\hline CHEMBL470445 & 564968 & 3.8508 & 3.7746 & TRN \\
\hline CHEMBL474071 & 564968 & 3.8928 & 4.0787 & TRN \\
\hline CHEMBL473670 & 564968 & 5.0655 & 4.8434 & TRN \\
\hline CHEMBL514833 & 564968 & 3.6021 & 3.761 & TRN \\
\hline CHEMBL475985 & 564968 & 3.8239 & 3.8153 & TRN \\
\hline CHEMBL475886 & 564968 & 4.5591 & 4.5634 & TRN \\
\hline CHEMBL514079 & 564968 & 3.8601 & 4.0779 & TST \\
\hline CHEMBL478698 & 564968 & 3.7595 & 2.6485 & TST \\
\hline CHEMBL448334 & 564968 & 3.7932 & 3.9279 & TRN \\
\hline CHEMBL516252 & 564968 & 3.8386 & 3.7259 & TRN \\
\hline CHEMBL450904 & 564968 & 4.6556 & 4.6441 & TRN \\
\hline CHEMBL473051 & 564968 & 3.6778 & 3.656 & TRN \\
\hline CHEMBL507262 & 564968 & 3.9281 & 3.9085 & TRN \\
\hline CHEMBL449379 & 564968 & 3.7305 & 3.8655 & TRN \\
\hline CHEMBL478061 & 564968 & 3.8097 & 3.8593 & TST \\
\hline CHEMBL476390 & 564968 & 3.6596 & 3.7399 & TRN \\
\hline CHEMBL476654 & 564968 & 3.6021 & 3.691999 & 9999999997 \\
\hline CHEMBL514531 & 564968 & 3.6021 & 3.4461 & TRN \\
\hline CHEMBL478128 & 564968 & 5.0794 & 4.4059 & TRN \\
\hline CHEMBL478075 & 564968 & 3.6234 & 4.4059 & TRN \\
\hline CHEMBL476234 & 564968 & 4.9586 & 5.0112 & TRN \\
\hline CHEMBL510241 & 564968 & 3.6021 & 3.5915 & TRN \\
\hline CHEMBL514834 & 564968 & 4.684 & 4.2321 & TST \\
\hline CHEMBL476383 & 564968 & 3.6478 & 3.6797 & TRN \\
\hline CHEMBL475978 & 564968 & 4.9031 & 4.6564 & TRN \\
\hline CHEMBL478697 & 564968 & 3.8153 & 3.0922 & TST \\
\hline CHEMBL515300 & 564968 & 3.7986 & 3.8484 & TRN \\
\hline CHEMBL515148 & 564968 & 4.0255 & 3.826 & TST \\
\hline CHEMBL474471 & 564968 & 3.6326 & 3.7556 & TRN \\
\hline CHEMBL478515 & 564968 & 4.7144 & 4.7735 & TRN \\
\hline CHEMBL478060 & 564968 & 3.762 & 3.6347 & TRN \\
\hline CHEMBL515464 & 564968 & 3.6021 & 3.5208 & TRN \\
\hline CHEMBL476068 & 564968 & 5.4112 & 4.919 & TST \\
\hline CHEMBL514628 & 564968 & 4.0004 & 4.0722 & TRN \\
\hline CHEMBL449459 & 564968 & 5.0501 & 4.9471 & TRN \\
\hline CHEMBL476653 & 564968 & 4.4976 & 4.5414 & TRN \\
\hline CHEMBL515931 & 564968 & 3.6345 & 3.5208 & TRN \\
\hline CHEMBL477875 & 564968 & 5.0731 & 5.1626 & TRN \\
\hline CHEMBL449068 & 564968 & 3.8633 & 3.8936 & TRN \\
\hline
\end{tabular}

Page 17152 
Supplemental Table S2.txt

\begin{tabular}{|c|c|c|c|c|}
\hline CHEMBL478325 & 564968 & 4.6073 & 4.26 & TST \\
\hline CHEMBL475979 & 564968 & 3.6655 & 3.5999 & TRN \\
\hline CHEMBL506941 & 564968 & 3.8069 & 4.055 & TST \\
\hline CHEMBL515961 & 564968 & 3.6925 & 3.5199 & TST \\
\hline CHEMBL499436 & 564968 & 4.7011 & 4.5032 & TST \\
\hline CHEMBL478494 & 564968 & 3.7905 & 3.2738 & TST \\
\hline CHEMBL474880 & 564968 & 3.7986 & 3.73 & TRN \\
\hline CHEMBL476012 & 564968 & 3.7595 & 3.2906 & TST \\
\hline CHEMBL476027 & 564968 & 4.8633 & 4.8007 & TRN \\
\hline CHEMBL3648568 & 1527913 & 8.5086 & 8.55299 & 9999999999 \\
\hline CHEMBL3648581 & 1527913 & 8.8239 & 8.7934 & TRN \\
\hline CHEMBL3648613 & 1527913 & 8.7212 & 8.7642 & TRN \\
\hline CHEMBL3942491 & 1527913 & 8.6778 & 9.148 & TRN \\
\hline CHEMBL 3648516 & 1527913 & 8.7447 & 8.1979 & TST \\
\hline CHEMBL 3648540 & 1527913 & 8.8539 & 9.219 & TRN \\
\hline CHEMBL3648548 & 1527913 & 8.6198 & 8.39200 & 2000000001 \\
\hline CHEMBL3648583 & 1527913 & 8.7212 & 8.8215 & TRN \\
\hline CHEMBL3648519 & 1527913 & 8.5229 & 6.9741 & TST \\
\hline CHEMBL3648515 & 1527913 & 8.6778 & 6.9037 & TST \\
\hline CHEMBL3648518 & 1527913 & 8.5229 & 7.5476 & TST \\
\hline CHEMBL3953226 & 1527913 & 8.699 & 8.7805 & TRN \\
\hline CHEMBL3648627 & 1527913 & 8.6778 & 8.7511 & TRN \\
\hline CHEMBL3648536 & 1527913 & 8.5376 & 8.3767 & TRN \\
\hline CHEMBL3648560 & 1527913 & 8.7212 & 8.6507 & TRN \\
\hline CHEMBL3648607 & 1527913 & 8.5528 & 8.5243 & TRN \\
\hline CHEMBL3648551 & 1527913 & 6.0 & 6.1659 & TRN \\
\hline CHEMBL3648602 & 1527913 & 8.4949 & 8.6219 & TRN \\
\hline CHEMBL3648567 & 1527913 & 8.7212 & 8.6185 & TRN \\
\hline CHEMBL3892965 & 1527913 & 8.7959 & 8.0063 & TRN \\
\hline CHEMBL 3648571 & 1527913 & 8.6021 & 8.5305 & TRN \\
\hline CHEMBL3648529 & 1527913 & 8.6576 & 8.5715 & TRN \\
\hline CHEMBL3648586 & 1527913 & 8.6021 & 8.8552 & TST \\
\hline CHEMBL3648639 & 1527913 & 6.0 & 7.4928 & TRN \\
\hline CHEMBL3648629 & 1527913 & 8.9208 & 9.224 & TRN \\
\hline CHEMBL3651825 & 1527913 & 8.6778 & 7.3308 & TST \\
\hline CHEMBL3648561 & 1527913 & 8.4559 & 8.6587 & TRN \\
\hline CHEMBL3648617 & 1527913 & 8.6778 & 8.5661 & TRN \\
\hline CHEMBL3648585 & 1527913 & 6.0 & 6.8005 & TRN \\
\hline CHEMBL3648625 & 1527913 & 8.6576 & 7.4708 & TRN \\
\hline CHEMBL3648603 & 1527913 & 8.7212 & 8.7369 & TRN \\
\hline CHEMBL3648577 & 1527913 & 8.7212 & 8.7781 & TRN \\
\hline CHEMBL 3648584 & 1527913 & 8.6383 & 8.5335 & TRN \\
\hline CHEMBL3648605 & 1527913 & 8.6778 & 8.8257 & TRN \\
\hline CHEMBL3648549 & 1527913 & 8.7212 & 8.6542 & TRN \\
\hline CHEMBL3954654 & 1527913 & 8.7212 & 8.5835 & TRN \\
\hline CHEMBL3648611 & 1527913 & 8.7447 & 8.7628 & TRN \\
\hline CHEMBL 3648633 & 1527913 & 8.699 & 8.7181 & TRN \\
\hline \multirow[t]{2}{*}{ CHEMBL3648539 } & 1527913 & 8.8861 & 8.43700 & 0000000001 \\
\hline & & & \multicolumn{2}{|c|}{ Page 17153} \\
\hline
\end{tabular}


Supplemental Table S2.txt

\begin{tabular}{|c|c|c|c|c|}
\hline HEMB & 527913 & .5528 & 1025 & 1 \\
\hline HEMPI 2510502 & 527913 & 8.6778 & 9.4896 & \\
\hline & 13 & & & \\
\hline AEMBL 394 & 27913 & 5383 & 407 & \\
\hline HEMBL3648609 & 527913 & 6.0 & 5512 & \\
\hline HEMBL3648638 & 527913 & 8.7959 & 3099 & \\
\hline 619 & 13 & & 223 & \\
\hline IEMBL36 & & & 199 & RN \\
\hline HEMBL 364 & 913 & 8.72 & 5396 & \\
\hline HEMBL 364 & 527913 & 8.585 & 239 & \\
\hline HEMBL 364 & 913 & 8.7 & 8.4232 & \\
\hline AEMBL36 & 13 & 61 & 424 & \\
\hline AEMBL36 & & & & \\
\hline HEMBL36 36 & 13 & 8.6198 & 875 & \\
\hline AEMBL 364 & 3 & & 3601 & \\
\hline AEMBL364 & 52 & 8. & 7103 & \\
\hline HEMBL36 & J & 98 & 871 & \\
\hline HEMBL36 & & & & \\
\hline HEMBL 36 & 13 & & 454 & \\
\hline AEMBL36 & & & & \\
\hline HEMBL3 & 13 & 8 & & RIV \\
\hline HEMBL36 & & & & 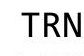 \\
\hline HEMBL3 & & 959 & & \\
\hline HEMBL 36 & & 6 . & 1474 & \\
\hline JEMBL 36 & & & & 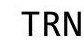 \\
\hline HEMBL36 & 13 & & 101 & KIV \\
\hline HEMBL & & & 39 & RN \\
\hline HFMBI 3 & 3 & 6 & 24 & RN \\
\hline HEMBL36 & & 6 & 1442 & I KIV \\
\hline HEMBL 364 & & 9. & 266 & I RIN \\
\hline HEMBL3S & & 8 . & 5734 & RN \\
\hline HEMBL; & 3 & 6 . & 945 & RN \\
\hline HEMBL & & 8. & 895 & RN \\
\hline HEMBL 364 & & & 197 & IRN \\
\hline HEMBL 364 & & & 2837 & TRN \\
\hline HEMBL36 & & & 64 & ST \\
\hline HFMRI 3 & & 2 & 63 & $\Gamma \mathrm{RN}$ \\
\hline HEMBL3 & & & 7687 & IST \\
\hline HEMBL364 & 3 & 8.6576 & 9192 & TRN \\
\hline HEMBL 36 & $57-2+3$ & & 637 & TRN \\
\hline HEMBL36 & & & 086 & \\
\hline CHEMBL 36 & & & 8818 & TRN \\
\hline HEMBL $36 \angle$ & 13 & 8.7 & 9161 & TST \\
\hline HEMBL 364 & 52 & 8. & 5949 & TRN \\
\hline $\mathrm{MRI}=2+2$ & & & & \\
\hline HEMBL 36 & & & 8137 & \\
\hline CHEMBL $36 \angle$ & & 8.7447 & 8.5646 & \\
\hline CHEMBL3648599 & 1527913 & 8.5086 & 8.7431 & ГRN \\
\hline
\end{tabular}

Page 17154 
Supplemental Table S2.txt

\begin{tabular}{|c|c|c|c|c|}
\hline HEN & - & & & \\
\hline & 527913 & 8.7696 & 6384 & \\
\hline & 13 & & & \\
\hline AEMBL & & 5383 & & \\
\hline HEMBL 364 & 527913 & & & \\
\hline HEMBL3648626 & 527913 & 8.6576 & 6163 & \\
\hline HEMBL; & 13 & & 547 & \\
\hline 38 & & & & \\
\hline HEMBL363 & 13 & 8.6778 & 5107 & \\
\hline HEMBL 364 & 913 & 686 & 5227 & \\
\hline AEMBL 364 & 913 & 6.0 & 5.6881 & \\
\hline AEMBL36 & 13 & 576 & 364 & \\
\hline IEMBL36 & & & & \\
\hline HEMBL364 & 13 & 3539 & 8076 & \\
\hline AEMBL 364 & 13 & 6.0 & 5.7881 & \\
\hline AEMBL364 & . & 8 & .7436 & \\
\hline AEMBL36 & J & & 51 & \\
\hline HEMBL36 & & & & \\
\hline HEMBL 36 & & & 8.4181 & \\
\hline AEMBL36 & & & & \\
\hline HEIMBLSS & L3 & 17 & 28 & NIV \\
\hline AEMBL: & & & & \\
\hline HEMBL & & & & \\
\hline AFMRI 36 & & 39 & 502 & \\
\hline AEMBL 36 & & & & I RIV \\
\hline HEMBL36 & 5 & & 91 & RN \\
\hline HEMBL 3 & & & & No \\
\hline$H F M B I=$ & & & 52 & \\
\hline HEMBL36 & & & & $\ln$ \\
\hline HEMBL 364 & & & & IK \\
\hline HEMBL36 & & 8. & 106 & SI \\
\hline HEMBL; & & & 88 & ST \\
\hline HEMBL & & 39 & 34 & 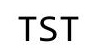 \\
\hline HEMBL 364 & & & & is \\
\hline HEMBL 365 & & 8.7959 & 864 & TST \\
\hline HEMBL36 & & & 511 & TST \\
\hline HᄃMP = & & & 65 & ST \\
\hline HEMBL3 & & & 8.5154 & TST \\
\hline HEMBL 364 & 3 & 8.699 & 2008 & TST \\
\hline IEMBL36 & 52 & & 5831 & TST \\
\hline HEMBL36 & & 96 & .5341 & \\
\hline CHEMBL 36 & & & & TST \\
\hline HEMBL 36 & & 7.4559 & 7.5286 & TRN \\
\hline HEMBL369 & 50 & 7.3565 & 7.3708 & TR \\
\hline $1=2+3$ & & & 6.4354 & ב \\
\hline HEMBL39 & & & 5.1261 & \\
\hline CHEMBL 392 & & .8601 & 6.8714 & \\
\hline CHEMBL3922847 & 1622750 & 6.6946 & 6.3765 & ГST \\
\hline
\end{tabular}

Page 17155 
Supplemental Table S2.txt

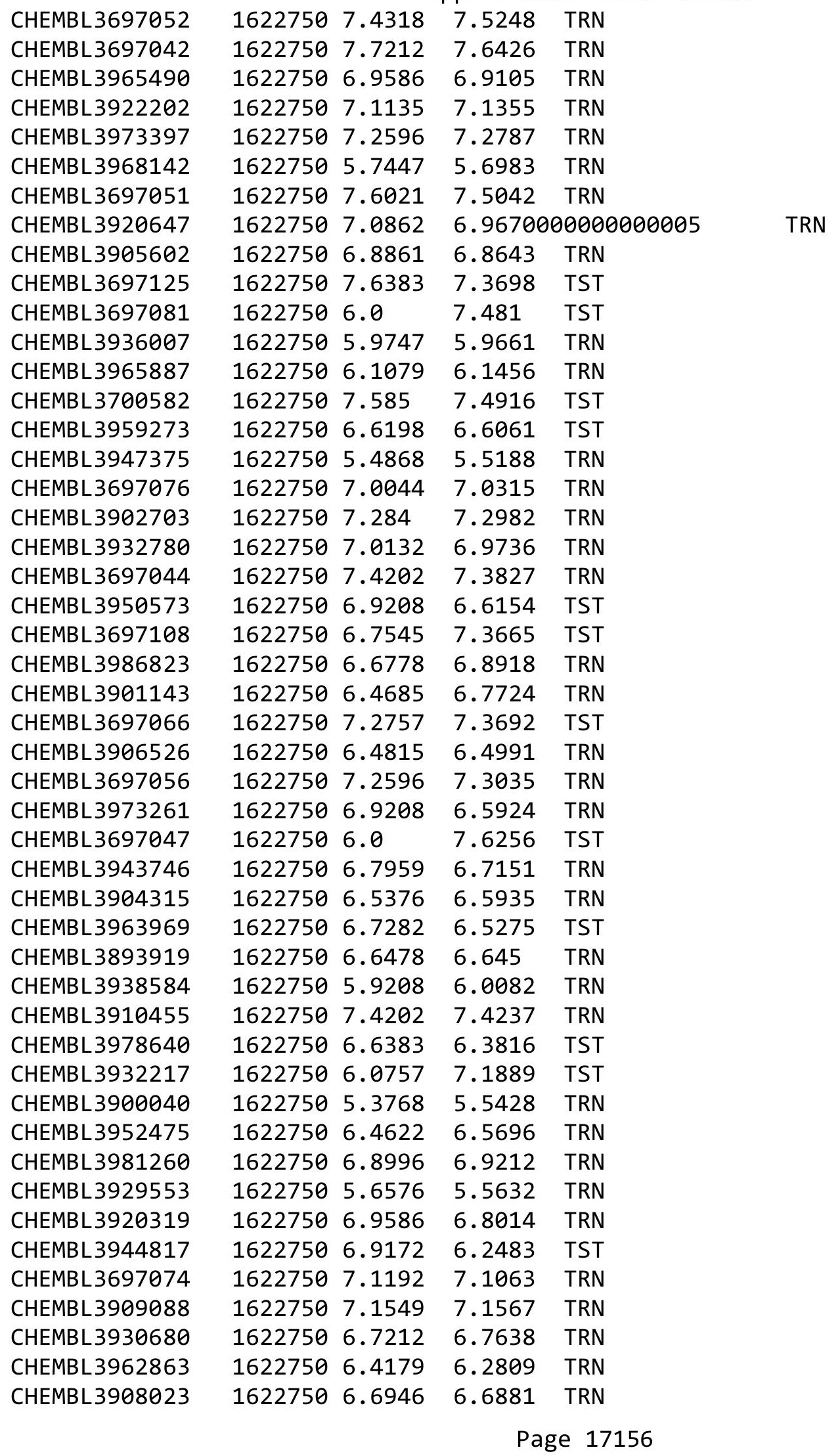




\begin{tabular}{|c|c|c|c|c|c|}
\hline \multicolumn{6}{|c|}{ pıementa } \\
\hline CHEMBL1834830 & 772808 & 7.8861 & 8.0715 & TRN & \\
\hline CHEMBL1834772 & 772808 & 8.0 & 7.9056 & TRN & \\
\hline CHEMBL1834988 & 772808 & 7.5686 & 7.4082 & TRN & \\
\hline CHEMBL1834905 & 772808 & 6.6517 & 6.6219 & TRN & \\
\hline CHEMBL1834989 & 772808 & 7.5528 & 7.5086 & TRN & \\
\hline CHEMBL1834826 & 772808 & 8.0458 & 8.2188 & TRN & \\
\hline CHEMBL1834839 & 772808 & 7.4949 & 7.6914 & TRN & \\
\hline CHEMBL1834976 & 772808 & 7.8861 & 7.28700 & 0000000001 & TRN \\
\hline CHEMBL1834768 & 772808 & 7.3979 & 7.733 & TRN & \\
\hline CHEMBL1834991 & 772808 & 7.4089 & 7.7804 & TRN & \\
\hline CHEMBL1835111 & 772808 & 6.1427 & 7.0502 & TRN & \\
\hline CHEMBL1835101 & 772808 & 7.0458 & 7.2505 & TST & \\
\hline CHEMBL1834848 & 772808 & 6.6003 & 7.2258 & TRN & \\
\hline CHEMBL1835090 & 772808 & 7.3872 & 7.4552 & TST & \\
\hline CHEMBL1834977 & 772808 & 7.8239 & 7.5484 & TRN & \\
\hline CHEMBL1835094 & 772808 & 7.2596 & 7.6464 & TST & \\
\hline CHEMBL1834712 & 772808 & 7.5086 & 7.4277 & TRN & \\
\hline CHEMBL1834982 & 772808 & 7.699 & 7.70700 & 0000000001 & TRN \\
\hline CHEMBL1834760 & 772808 & 5.6271 & 6.5612 & TRN & \\
\hline CHEMBL1834714 & 772808 & 6.7905 & 7.2711 & TRN & \\
\hline CHEMBL1834769 & 772808 & 7.6576 & 7.6482 & TRN & \\
\hline CHEMBL1835100 & 772808 & 7.0506 & 7.1452 & TRN & \\
\hline CHEMBL1834709 & 772808 & 7.7447 & 7.3337 & TRN & \\
\hline CHEMBL1835109 & 772808 & 6.6819 & 7.1086 & TRN & \\
\hline CHEMBL1834833 & 772808 & 7.0177 & 7.2286 & TRN & \\
\hline CHEMBL1834770 & 772808 & 7.3372 & 7.494 & TRN & \\
\hline CHEMBL1834710 & 772808 & 9.0 & 8.8312 & TRN & \\
\hline CHEMBL1834973 & 772808 & 7.9586 & 8.0325 & TRN & \\
\hline CHEMBL1834828 & 772808 & 7.9586 & 7.9384 & TRN & \\
\hline CHEMBL1834713 & 772808 & 6.5272 & 7.2849 & TRN & \\
\hline CHEMBL1834759 & 772808 & 7.2676 & 7.3005 & TRN & \\
\hline CHEMBL1834831 & 772808 & 7.5376 & 7.6304 & TRN & \\
\hline CHEMBL1834970 & 772808 & 8.3979 & 7.854 & TST & \\
\hline CHEMBL1834845 & 772808 & 7.5376 & 7.5314 & TRN & \\
\hline CHEMBL1834776 & 772808 & 7.9586 & 7.8385 & TRN & \\
\hline CHEMBL1834981 & 772808 & 7.699 & 7.4674 & TRN & \\
\hline CHEMBL1835103 & 772808 & 6.9281 & 7.4676 & TST & \\
\hline CHEMBL1834913 & 772808 & 7.5086 & 6.3584 & TST & \\
\hline CHEMBL1834974 & 772808 & 7.9586 & 7.1217 & TRN & \\
\hline CHEMBL1834910 & 772808 & 6.5452 & 6.9796 & TRN & \\
\hline CHEMBL1834992 & 772808 & 7.4089 & 7.0317 & TRN & \\
\hline CHEMBL1834975 & 772808 & 7.8861 & 7.6496 & TRN & \\
\hline CHEMBL1835098 & 772808 & 7.1249 & 6.99100 & 00000000005 & TRN \\
\hline CHEMBL1834777 & 772808 & 5.8655 & 6.7594 & TRN & \\
\hline CHEMBL1835105 & 772808 & 6.8928 & 7.2185 & TST & \\
\hline CHEMBL1834908 & 772808 & 7.0362 & 6.9064 & TRN & \\
\hline CHEMBL1834774 & 772808 & 6.9747 & 6.6205 & TRN & \\
\hline CHEMBL1834844 & 772808 & 7.699 & 7.8987 & TRN & \\
\hline
\end{tabular}




\begin{tabular}{|c|c|c|c|c|c|}
\hline & & \multicolumn{4}{|c|}{ Supplemental Table S2.txt } \\
\hline CHEMBL1835106 & 772808 & 6.8794 & 7.2827 & TRN & \\
\hline CHEMBL1834911 & 772808 & 5.9378 & 6.1861 & TRN & \\
\hline CHEMBL1834906 & 772808 & 6.2233 & 6.0942 & TRN & \\
\hline CHEMBL1834980 & 772808 & 7.7212 & 7.7832 & TST & \\
\hline CHEMBL1834972 & 772808 & 8.0458 & 7.5033 & TST & \\
\hline CHEMBL1835089 & 772808 & 7.3979 & 7.1703 & TST & \\
\hline CHEMBL1835107 & 772808 & 6.8601 & 7.4224 & TST & \\
\hline CHEMBL1835108 & 772808 & 6.7545 & 7.4796 & TST & \\
\hline CHEMBL1834827 & 772808 & 6.5031 & 7.51200 & 00000000005 & TST \\
\hline CHEMBL1834986 & 772808 & 7.5686 & 7.3683 & TRN & \\
\hline CHEMBL1834715 & 772808 & 8.0458 & 7.3016 & TST & \\
\hline CHEMBL1835102 & 772808 & 6.9355 & 7.2724 & TRN & \\
\hline CHEMBL1834979 & 772808 & 7.7696 & 7.6852 & TRN & \\
\hline CHEMBL1834761 & 772808 & 7.4202 & 7.5496 & TRN & \\
\hline CHEMBL1834763 & 772808 & 7.8539 & 8.3709 & TRN & \\
\hline CHEMBL1834838 & 772808 & 8.0969 & 8.2489 & TRN & \\
\hline CHEMBL1834990 & 772808 & 7.4685 & 7.2793 & TRN & \\
\hline CHEMBL1835091 & 772808 & 7.3872 & 7.29799 & 9999999999 & TRN \\
\hline CHEMBL1834764 & 772808 & 7.9208 & 6.9466 & TRN & \\
\hline CHEMBL1834775 & 772808 & 7.1427 & 7.3641 & TRN & \\
\hline CHEMBL1834914 & 772808 & 6.8416 & 6.6425 & TRN & \\
\hline CHEMBL1834773 & 772808 & 6.8633 & 6.7112 & TRN & \\
\hline CHEMBL1834912 & 772808 & 7.4815 & 7.0505 & TRN & \\
\hline CHEMBL1834842 & 772808 & 7.7447 & 7.3423 & TRN & \\
\hline CHEMBL1835092 & 772808 & 7.3372 & 7.5356 & TST & \\
\hline CHEMBL1834847 & 772808 & 6.1524 & 6.8134 & TST & \\
\hline CHEMBL1835097 & 772808 & 7.1805 & 7.2534 & TRN & \\
\hline CHEMBL1834909 & 772808 & 8.0458 & 7.8823 & TRN & \\
\hline CHEMBL1835088 & 772808 & 7.3979 & 7.1078 & TRN & \\
\hline CHEMBL1834771 & 772808 & 7.8239 & 7.8436 & TRN & \\
\hline CHEMBL1834765 & 772808 & 7.2676 & 7.0921 & TRN & \\
\hline CHEMBL 1834840 & 772808 & 7.8861 & 7.7845 & TRN & \\
\hline CHEMBL1834708 & 772808 & 8.1549 & 7.2087 & TRN & \\
\hline CHEMBL1834829 & 772808 & 7.5086 & 7.7 & TRN & \\
\hline CHEMBL1834971 & 772808 & 8.0458 & 7.8083 & TRN & \\
\hline CHEMBL1835093 & 772808 & 7.301 & 7.8592 & TST & \\
\hline CHEMBL 1834716 & 772808 & 7.5686 & 7.3893 & TST & \\
\hline CHEMBL1835099 & 772808 & 7.0655 & 7.4124 & TST & \\
\hline CHEMBL1834969 & 772808 & 8.0458 & 8.1689 & TRN & \\
\hline CHEMBL1834835 & 772808 & 7.7447 & 7.5453 & TRN & \\
\hline CHEMBL1834907 & 772808 & 6.5467 & 6.9033 & TRN & \\
\hline CHEMBL 1834762 & 772808 & 8.3979 & 7.7763 & TRN & \\
\hline CHEMBL1834841 & 772808 & 7.2676 & 7.4672 & TRN & \\
\hline CHEMBL1835110 & 772808 & 6.2358 & 7.3781 & TST & \\
\hline CHEMBL1834978 & 772808 & 7.7696 & 7.886 & TRN & \\
\hline CHEMBL1835087 & 772808 & 7.3979 & 7.2851 & TST & \\
\hline CHEMBL1834711 & 772808 & 7.585 & 7.7412 & TST & \\
\hline CHEMBL1834987 & 772808 & 7.5686 & 7.2295 & TST & \\
\hline
\end{tabular}


Supplemental Table S2.txt

\begin{tabular}{|c|c|c|c|c|c|}
\hline CHEMBL1834846 & 772808 & 7.699 & 7.5331 & TST & \\
\hline CHEMBL1835104 & 772808 & 6.8962 & 7.2091 & TRN & \\
\hline CHEMBL1834834 & 772808 & 7.7696 & 7.6294 & TRN & \\
\hline CHEMBL1834767 & 772808 & 7.9586 & 7.9988 & TRN & \\
\hline CHEMBL1834985 & 772808 & 7.6021 & 7.815 & TRN & \\
\hline CHEMBL1834836 & 772808 & 7.9586 & 7.6941 & TRN & \\
\hline CHEMBL1835096 & 772808 & 7.2441 & 7.2873 & TST & \\
\hline CHEMBL1834766 & 772808 & 7.8239 & 7.5027 & TRN & \\
\hline CHEMBL1834837 & 772808 & 7.7212 & 7.6373 & TRN & \\
\hline CHEMBL1834984 & 772808 & 7.6383 & 7.585 & TRN & \\
\hline CHEMBL1834843 & 772808 & 7.6021 & 7.4526 & TRN & \\
\hline CHEMBL1834832 & 772808 & 7.585 & 7.224 & TRN & \\
\hline CHEMBL1835095 & 772808 & 7.2518 & 7.2222 & TST & \\
\hline CHEMBL1834983 & 772808 & 7.6576 & 7.6924 & TRN & \\
\hline CHEMBL1834778 & 772808 & 5.9547 & 6.901 & TST & \\
\hline CHEMBL1834707 & 772808 & 8.3979 & 7.9327 & TST & \\
\hline CHEMBL66654 & 467917 & 8.0 & 8.5718 & TST & \\
\hline CHEMBL257222 & 467917 & 7.0 & 6.9859 & TRN & \\
\hline CHEMBL257223 & 467917 & 7.4 & 7.3966 & TRN & \\
\hline CHEMBL404486 & 467917 & 6.5 & \multicolumn{2}{|c|}{6.531000000000001} & TRN \\
\hline CHEMBL257436 & 467917 & 6.4 & 6.4109 & TRN & \\
\hline CHEMBL403362 & 467917 & 6.9 & 6.9141 & TRN & \\
\hline CHEMBL257693 & 467917 & 5.9 & 5.9082 & TRN & \\
\hline CHEMBL401816 & 467917 & 5.4 & 5.392 & TST & \\
\hline CHEMBL 257312 & 467917 & 6.2 & 5.8938 & TST & \\
\hline CHEMBL404283 & 467917 & 6.8 & 6.8171 & TRN & \\
\hline CHEMBL271005 & 467917 & 6.6 & 6.5169 & TRN & \\
\hline CHEMBL271216 & 467917 & 6.7 & 6.745 & TRN & \\
\hline CHEMBL272376 & 467917 & 5.9 & 5.9259 & TRN & \\
\hline CHEMBL411499 & 467917 & 8.0 & 7.9775 & TRN & \\
\hline CHEMBL258050 & 467917 & 7.9 & 7.8252 & TRN & \\
\hline CHEMBL428778 & 467917 & 7.7 & 7.7299 & TRN & \\
\hline CHEMBL258293 & 467917 & 6.9 & 6.9355 & TRN & \\
\hline CHEMBL404883 & 467917 & 7.7 & 7.6824 & TRN & \\
\hline CHEMBL 272940 & 467917 & 6.8 & 6.8851 & TRN & \\
\hline CHEMBL429781 & 467917 & 7.7 & 7.5857 & TRN & \\
\hline CHEMBL401652 & 467917 & 6.6 & 6.6472 & TRN & \\
\hline CHEMBL402733 & 467917 & 7.3 & 7.2543 & TRN & \\
\hline CHEMBL272585 & 467917 & 6.7 & 6.7262 & TRN & \\
\hline CHEMBL 258263 & 467917 & 7.0 & 7.081 & TRN & \\
\hline CHEMBL258262 & 467917 & 5.8 & 5.7306 & TRN & \\
\hline CHEMBL405018 & 467917 & 7.3 & \multicolumn{2}{|c|}{7.332999999999999} & TRN \\
\hline CHEMBL257314 & 467917 & 7.1 & 7.1123 & TRN & \\
\hline CHEMBL257313 & 467917 & 6.3 & 6.2952 & TRN & \\
\hline CHEMBL 257504 & 467917 & 5.8 & 5.8228 & TRN & \\
\hline CHEMBL438156 & 467917 & 8.1 & 8.1335 & TRN & \\
\hline CHEMBL403327 & 467917 & 6.5 & \multicolumn{2}{|c|}{6.5760000000000005} & TRN \\
\hline CHEMBL255747 & 467917 & 6.4 & 6.3031 & TRN & \\
\hline
\end{tabular}




\begin{tabular}{|c|c|c|c|c|c|}
\hline \multicolumn{6}{|c|}{ Supplemental Table S2.txt } \\
\hline CHEMBL255748 & 467917 & 3.8 & 3.8368 & TRN & \\
\hline CHEMBL 255749 & 467917 & 3.8 & 3.7193 & TRN & \\
\hline CHEMBL404278 & 467917 & 3.8 & 3.8613 & TRN & \\
\hline CHEMBL402082 & 467917 & 8.5 & 8.5556 & TRN & \\
\hline CHEMBL 257322 & 467917 & 6.7 & 6.6668 & TRN & \\
\hline CHEMBL 255402 & 467917 & 7.7 & 7.6485 & TRN & \\
\hline CHEMBL403390 & 467917 & 9.4 & 9.3487 & TRN & \\
\hline CHEMBL408041 & 467917 & 7.8 & 7.834 & TRN & \\
\hline CHEMBL 257880 & 467917 & 9.1 & 9.1136 & TRN & \\
\hline CHEMBL257879 & 467917 & 8.5 & 8.4465 & TRN & \\
\hline CHEMBL270399 & 467917 & 5.3 & 5.2543 & TRN & \\
\hline CHEMBL256213 & 467917 & 5.0 & 5.0193 & TRN & \\
\hline CHEMBL 256422 & 467917 & 3.9 & 5.1793 & TST & \\
\hline CHEMBL403008 & 467917 & 3.9 & 3.8738 & TRN & \\
\hline CHEMBL 272800 & 467917 & 8.0 & 7.9534 & TRN & \\
\hline CHEMBL 270633 & 467917 & 6.1 & 6.136 & TRN & \\
\hline CHEMBL 271273 & 467917 & 3.9 & 3.928 & TRN & \\
\hline CHEMBL428426 & 467917 & 7.2 & 6.0969 & TST & \\
\hline CHEMBL401869 & 467917 & 7.3 & 7.3215 & TRN & \\
\hline CHEMBL402328 & 467917 & 3.9 & 5.1141 & TST & \\
\hline CHEMBL 272362 & 467917 & 6.3 & 6.2741 & TRN & \\
\hline CHEMBL406954 & 467917 & 7.3 & 7.2958 & TRN & \\
\hline CHEMBL401977 & 467917 & 7.1 & 7.1182 & TRN & \\
\hline CHEMBL 255530 & 467917 & 3.8 & 3.8205 & TRN & \\
\hline CHEMBL 256875 & 467917 & 3.8 & 3.8085 & TRN & \\
\hline CHEMBL401981 & 467917 & 3.8 & 3.8984 & TRN & \\
\hline CHEMBL428771 & 467917 & 3.8 & 3.7861 & TRN & \\
\hline CHEMBL404279 & 467917 & 5.7 & 5.6568 & TRN & \\
\hline CHEMBL255958 & 467917 & 7.0 & 7.0904 & TRN & \\
\hline CHEMBL429128 & 467917 & 3.8 & 3.745 & TRN & \\
\hline CHEMBL 271028 & 467917 & 3.8 & 3.7848 & TRN & \\
\hline CHEMBL404681 & 467917 & 5.3 & 5.2921 & TRN & \\
\hline CHEMBL403607 & 467917 & 6.9 & 6.9056 & TRN & \\
\hline CHEMBL255204 & 467917 & 3.9 & 3.889 & TRN & \\
\hline CHEMBL255206 & 467917 & 3.9 & 3.9066 & TRN & \\
\hline CHEMBL255205 & 467917 & 6.1 & 6.055 & TRN & \\
\hline CHEMBL407707 & 467917 & 3.9 & 3.8801 & TRN & \\
\hline CHEMBL 271093 & 467917 & 7.9 & 7.8028 & TRN & \\
\hline CHEMBL 257882 & 467917 & 7.6 & 7.6481 & TRN & \\
\hline CHEMBL 257881 & 467917 & 7.0 & 7.0235 & TRN & \\
\hline CHEMBL 270400 & 467917 & 7.8 & 7.7901 & TRN & \\
\hline CHEMBL401982 & 467917 & 6.5 & 6.53299 & 99999999995 & TRN \\
\hline CHEMBL538165 & 467917 & 7.1 & 7.1458 & TRN & \\
\hline CHEMBL401794 & 467917 & 7.2 & 7.2796 & TRN & \\
\hline CHEMBL 270612 & 467917 & 5.7 & 5.6683 & TRN & \\
\hline CHEMBL256423 & 467917 & 6.8 & 6.8217 & TRN & \\
\hline CHEMBL 273024 & 467917 & 3.8 & 3.6989 & TRN & \\
\hline CHEMBL444375 & 467917 & 6.4 & 6.357 & TRN & \\
\hline
\end{tabular}

Supplemental Table S2.txt 


\begin{tabular}{|c|c|c|c|c|c|}
\hline \\
\hline CHEMBL257033 & 467917 & 4.4 & 4.4074 & TRN & \\
\hline CHEMBL257237 & 467917 & 3.8 & 3.8505 & TRN & \\
\hline CHEMBL402890 & 467917 & 6.7 & 7.2618 & TST & \\
\hline CHEMBL271676 & 467917 & 6.5 & 6.1729 & TST & \\
\hline CHEMBL271885 & 467917 & 6.3 & 7.3476 & TST & \\
\hline CHEMBL403338 & 467917 & 6.8 & 8.0331 & TST & \\
\hline CHEMBL257699 & 467917 & 6.9 & 6.9172 & TRN & \\
\hline CHEMBL271065 & 467917 & 8.2 & 8.468 & TST & \\
\hline CHEMBL271275 & 467917 & 8.0 & 7.9435 & TRN & \\
\hline CHEMBL271274 & 467917 & 7.3 & 7.4742 & TST & \\
\hline CHEMBL273025 & 467917 & 7.8 & 8.1385 & TST & \\
\hline CHEMBL272069 & 467917 & 7.1 & 7.8983 & TST & \\
\hline CHEMBL270167 & 467917 & 7.0 & 6.9879 & TST & \\
\hline CHEMBL404237 & 467917 & 8.9 & 9.2305 & TST & \\
\hline CHEMBL404238 & 467917 & 7.4 & 7.4753 & TST & \\
\hline CHEMBL 257238 & 467917 & 6.8 & 7.8569 & TST & \\
\hline CHEMBL256830 & 467917 & 3.9 & 5.3119 & TST & \\
\hline CHEMBL404101 & 467917 & 5.7 & 6.49200 & 0000000001 & TST \\
\hline CHEMBL257701 & 467917 & 6.5 & 7.0044 & TST & \\
\hline CHEMBL257700 & 467917 & 3.9 & 6.0666 & TST & \\
\hline CHEMBL257885 & 467917 & 6.2 & 5.8246 & TST & \\
\hline CHEMBL414000 & 467917 & 7.8 & 7.8103 & TST & \\
\hline CHEMBL271276 & 467917 & 9.4 & 6.7506 & TST & \\
\hline CHEMBL271477 & 467917 & 8.6 & 7.8324 & TST & \\
\hline CHEMBL256455 & 467917 & 7.5 & 7.1345 & TST & \\
\hline CHEMBL498304 & 514432 & 8.0177 & 7.9154 & TRN & \\
\hline CHEMBL498531 & 514432 & 8.3468 & 7.6365 & TRN & \\
\hline CHEMBL526472 & 514432 & 8.6198 & 8.0478 & TRN & \\
\hline CHEMBL498303 & 514432 & 6.0 & 7.5122 & TRN & \\
\hline CHEMBL456772 & 514432 & 8.0458 & 8.1728 & TRN & \\
\hline CHEMBL 457840 & 514432 & 7.4815 & 8.2156 & TRN & \\
\hline CHEMBL497453 & 514432 & 8.2366 & 7.8252 & TRN & \\
\hline CHEMBL271576 & 514432 & 8.1739 & 7.801 & TST & \\
\hline CHEMBL527037 & 514432 & 6.0 & 7.4825 & TRN & \\
\hline CHEMBL 450842 & 514432 & 7.4202 & 7.8167 & TRN & \\
\hline CHEMBL498519 & 514432 & 7.4318 & 7.7423 & TRN & \\
\hline CHEMBL 457847 & 514432 & 9.1079 & 9.1552 & TRN & \\
\hline CHEMBL503209 & 514432 & 8.4437 & 9.0011 & TRN & \\
\hline CHEMBL525358 & 514432 & 7.6198 & 7.7462 & TRN & \\
\hline CHEMBL456352 & 514432 & 8.2757 & 8.2199 & TRN & \\
\hline CHEMBL498145 & 514432 & 8.2218 & 8.4191 & TRN & \\
\hline CHEMBL497115 & 514432 & 7.7959 & 7.9432 & TRN & \\
\hline CHEMBL456971 & 514432 & 9.1024 & 8.5536 & TRN & \\
\hline CHEMBL458271 & 514432 & 7.8861 & 8.0374 & TST & \\
\hline CHEMBL456972 & 514432 & 7.5528 & 8.3354 & TRN & \\
\hline CHEMBL463181 & 514432 & 8.7447 & 8.8243 & TRN & \\
\hline CHEMBL514094 & 514432 & 8.4949 & 8.0097 & TRN & \\
\hline CHEMBL496467 & 514432 & 7.6576 & 7.7135 & TRN & \\
\hline
\end{tabular}


Supplemental Table S2.txt

\begin{tabular}{|c|c|c|c|c|c|}
\hline CHEMBL462780 & 514432 & 7.699 & 8.1139 & TRN & \\
\hline CHEMBL497280 & 514432 & 8.2441 & 7.9504 & TST & \\
\hline CHEMBL498302 & 514432 & 8.5528 & 7.7743 & TRN & \\
\hline CHEMBL516002 & 514432 & 9.0706 & 8.392999 & & TRN \\
\hline CHEMBL456353 & 514432 & 8.8861 & 8.2796 & TRN & \\
\hline CHEMBL457839 & 514432 & 8.4559 & 8.3258 & TRN & \\
\hline CHEMBL59765 & 514432 & 7.7959 & 7.8248 & TST & \\
\hline CHEMBL457199 & 514432 & 9.1549 & 9.0927 & TRN & \\
\hline CHEMBL498305 & 514432 & 7.4089 & 7.7428 & TRN & \\
\hline CHEMBL497847 & 514432 & 8.1487 & 7.8974 & TRN & \\
\hline CHEMBL458923 & 514432 & 9.1135 & 8.4131 & TRN & \\
\hline CHEMBL498703 & 514432 & 8.8327 & 7.9336 & TRN & \\
\hline CHEMBL459133 & 514432 & 8.8539 & 8.8627 & TRN & \\
\hline CHEMBL458927 & 514432 & 8.699 & 8.9667 & TRN & \\
\hline CHEMBL463182 & 514432 & 8.3872 & 8.2819 & TRN & \\
\hline CHEMBL456795 & 514432 & 8.3279 & 9.1306 & TRN & \\
\hline CHEMBL497281 & 514432 & 8.0 & 7.7471 & TRN & \\
\hline CHEMBL409828 & 514432 & 7.4089 & 7.8906 & TST & \\
\hline CHEMBL509729 & 514432 & 9.1079 & 8.073 & TRN & \\
\hline CHEMBL514265 & 514432 & 8.7447 & 8.9649 & TST & \\
\hline CHEMBL498704 & 514432 & 7.3098 & 7.9525 & TST & \\
\hline CHEMBL497113 & 514432 & 8.4949 & 8.2431 & TST & \\
\hline CHEMBL457629 & 514432 & 9.0915 & 8.8867 & TST & \\
\hline CHEMBL515349 & 514432 & 9.0 & 8.1219 & TST & \\
\hline CHEMBL456578 & 514432 & 8.3188 & 8.4045 & TST & \\
\hline CHEMBL452129 & 514432 & 7.5376 & 7.8669 & TST & \\
\hline CHEMBL514102 & 514432 & 9.4202 & 8.5439 & TST & \\
\hline CHEMBL199449 & 327488 & 7.2147 & 6.8478 & TRN & \\
\hline CHEMBL200810 & 327488 & 5.983 & 5.5283 & TRN & \\
\hline CHEMBL 369930 & 327488 & 7.0862 & 6.8957 & TRN & \\
\hline CHEMBL 200122 & 327488 & 6.7011 & 6.5937 & TRN & \\
\hline CHEMBL 381468 & 327488 & 4.0 & 4.5766 & TRN & \\
\hline CHEMBL 200305 & 327488 & 6.6345 & 6.1518 & TST & \\
\hline CHEMBL199372 & 327488 & 5.2612 & 6.1922 & TRN & \\
\hline CHEMBL383398 & 327488 & 7.0362 & \multicolumn{2}{|c|}{6.537000000000001} & TRN \\
\hline CHEMBL200207 & 327488 & 6.0825 & 6.1918 & TRN & \\
\hline CHEMBL 202137 & 327488 & 4.0 & 4.4186 & TRN & \\
\hline CHEMBL199459 & 327488 & 5.2373 & 5.2275 & TRN & \\
\hline CHEMBL199339 & 327488 & 6.4855 & 6.8301 & TRN & \\
\hline CHEMBL199794 & 327488 & 6.5952 & 6.9439 & TRN & \\
\hline CHEMBL200916 & 327488 & 6.5421 & 6.649 & TRN & \\
\hline CHEMBL 382718 & 327488 & 6.3458 & 6.6892 & TRN & \\
\hline CHEMBL 200943 & 327488 & 6.8962 & 7.4111 & TRN & \\
\hline CHEMBL199526 & 327488 & 6.1739 & 5.2444 & TST & \\
\hline CHEMBL 382928 & 327488 & 4.0 & 4.4393 & TRN & \\
\hline CHEMBL199855 & 327488 & 6.1278 & 6.2216 & TRN & \\
\hline CHEMBL199579 & 327488 & 6.6198 & 6.9073 & TRN & \\
\hline CHEMBL197971 & 327488 & 5.9469 & 6.6798 & TRN & \\
\hline
\end{tabular}




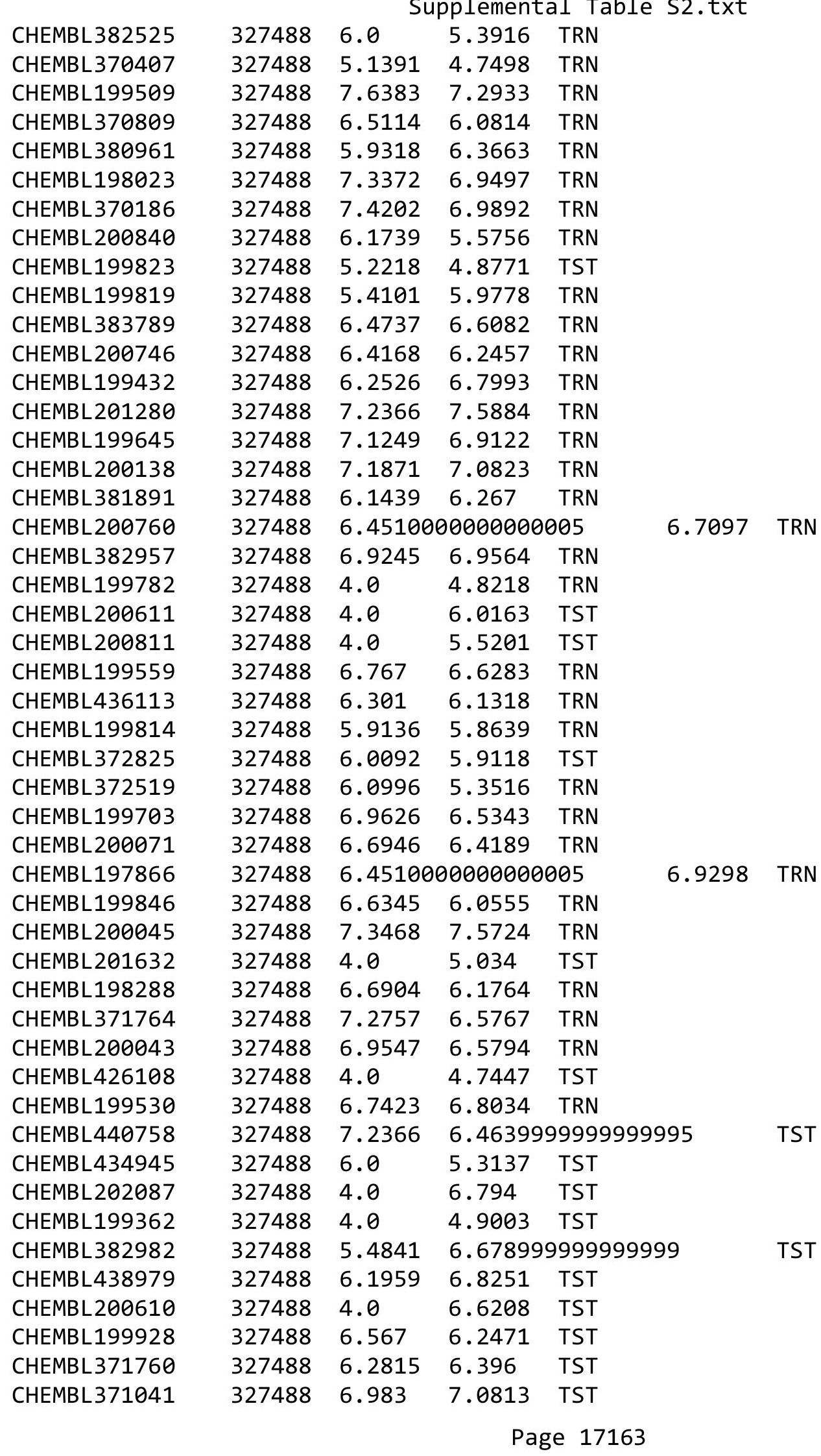




\begin{tabular}{|c|c|c|c|c|c|}
\hline & & \multicolumn{4}{|c|}{ Supplemental Table s2.txt } \\
\hline CHEMBL1380444 & 954278 & 6.0944 & 6.267 & TRN & \\
\hline CHEMBL1583186 & 954278 & 5.8897 & 5.8344 & TRN & \\
\hline CHEMBL1705098 & 954278 & 6.8004 & 6.2214 & TRN & \\
\hline CHEMBL1591058 & 954278 & 3.5241 & 4.6443 & TRN & \\
\hline CHEMBL1522108 & 954278 & 5.7366 & 6.4135 & TRN & \\
\hline CHEMBL1401965 & 954278 & 5.5585 & 5.5074 & TRN & \\
\hline CHEMBL1515567 & 954278 & 5.8099 & 5.2028 & TRN & \\
\hline CHEMBL1300327 & 954278 & 6.398 & 5.5807 & TRN & \\
\hline CHEMBL1364108 & 954278 & 5.8139 & 5.3472 & TRN & \\
\hline CHEMBL1332119 & 954278 & 3.5242 & 4.578 & TRN & \\
\hline CHEMBL1523593 & 954278 & 3.5242 & 5.5063 & TRN & \\
\hline CHEMBL1399125 & 954278 & 6.0017 & 6.0005 & TRN & \\
\hline CHEMBL1460627 & 954278 & 5.8864 & 5.3418 & TRN & \\
\hline CHEMBL1547232 & 954278 & 5.9066 & 5.5204 & TRN & \\
\hline CHEMBL536166 & 954278 & 4.9555 & 5.0168 & TRN & \\
\hline CHEMBL1344346 & 954278 & 3.5242 & 5.0747 & TST & \\
\hline CHEMBL1416660 & 954278 & 4.9969 & 5.6475 & TST & \\
\hline CHEMBL1556915 & 954278 & 3.5243 & 4.2264 & TRN & \\
\hline CHEMBL1544054 & 954278 & 6.0177 & 6.2038 & TRN & \\
\hline CHEMBL1584471 & 954278 & 5.6855 & 5.4135 & TRN & \\
\hline CHEMBL1734666 & 954278 & 5.9401 & 5.4013 & TRN & \\
\hline CHEMBL1379369 & 954278 & 3.5242 & 4.5012 & TRN & \\
\hline CHEMBL1604200 & 954278 & 6.4806 & 5.3059 & TRN & \\
\hline CHEMBL1422386 & 954278 & 3.5243 & 4.7401 & TRN & \\
\hline CHEMBL1349075 & 954278 & 3.5243 & 5.23600 & 0000000001 & TST \\
\hline CHEMBL1337567 & 954278 & 5.4349 & 5.204 & TRN & \\
\hline CHEMBL1486272 & 954278 & 3.5238 & 5.4933 & TRN & \\
\hline CHEMBL1550278 & 954278 & 6.8914 & 5.6405 & TRN & \\
\hline CHEMBL1341031 & 954278 & 4.9555 & 4.9999 & TRN & \\
\hline CHEMBL1711360 & 954278 & 6.4406 & 6.4242 & TRN & \\
\hline CHEMBL1325226 & 954278 & 5.6445 & 5.5899 & TRN & \\
\hline CHEMBL1566487 & 954278 & 4.9555 & 5.0556 & TRN & \\
\hline CHEMBL1301887 & 954278 & 5.5384 & 4.8375 & TRN & \\
\hline CHEMBL1524322 & 954278 & 5.683 & 6.0523 & TRN & \\
\hline CHEMBL1607568 & 954278 & 4.4782 & 4.5842 & TST & \\
\hline CHEMBL 2145430 & 954278 & 3.5249 & 5.1167 & TRN & \\
\hline CHEMBL1328481 & 954278 & 5.7423 & 4.2345 & TST & \\
\hline CHEMBL1510261 & 954278 & 5.8047 & 5.4009 & TRN & \\
\hline CHEMBL1413466 & 954278 & 3.5246 & 4.03 & TRN & \\
\hline CHEMBL553503 & 954278 & 5.4166 & 4.6914 & TST & \\
\hline CHEMBL1377607 & 954278 & 5.9965 & 5.4675 & TRN & \\
\hline CHEMBL1531245 & 954278 & 4.4785 & 4.8039 & TRN & \\
\hline CHEMBL1319304 & 954278 & 6.8299 & 6.2736 & TRN & \\
\hline CHEMBL2362703 & 954278 & 5.9751 & 5.6256 & TRN & \\
\hline CHEMBL568092 & 954278 & 5.8914 & 4.9993 & TRN & \\
\hline CHEMBL1600776 & 954278 & 5.9031 & 5.46700 & 00000000005 & TRN \\
\hline CHEMBL1361461 & 954278 & 5.8459 & 5.7217 & TRN & \\
\hline CHEMBL1386646 & 954278 & 5.7637 & 4.7364 & TRN & \\
\hline
\end{tabular}




\begin{tabular}{|c|c|c|c|c|c|c|}
\hline & & \multicolumn{5}{|c|}{ Supplemental Table S2.txt } \\
\hline CHEMBL3196315 & 954278 & 5.4958 & 5.1325 & TST & & \\
\hline CHEMBL1878609 & 954278 & 6.8985 & 6.3508 & TRN & & \\
\hline CHEMBL1337089 & 954278 & 4.9555 & 5.3236 & TRN & & \\
\hline CHEMBL601933 & 954278 & 5.7104 & 4.9993 & TRN & & \\
\hline CHEMBL1330576 & 954278 & 3.5243 & 4.3462 & TRN & & \\
\hline CHEMBL1523981 & 954278 & 3.5243 & 6.1352 & TRN & & \\
\hline CHEMBL1557584 & 954278 & 6.0503 & 5.6846 & TRN & & \\
\hline CHEMBL1903414 & 954278 & 6.4578 & 6.2113 & TRN & & \\
\hline CHEMBL1445257 & 954278 & 3.5243 & 4.1111 & TRN & & \\
\hline CHEMBL1712594 & 954278 & \multicolumn{3}{|c|}{3.5239999999999996} & 4.0288 & TRN \\
\hline CHEMBL2359888 & 954278 & \multicolumn{3}{|c|}{4.8389999999999995} & 4.8872 & TST \\
\hline CHEMBL1344025 & 954278 & 5.6863 & 5.9362 & TRN & & \\
\hline CHEMBL1424583 & 954278 & 6.3989 & 6.0651 & TRN & & \\
\hline CHEMBL1452130 & 954278 & 5.8755 & 6.3742 & TRN & & \\
\hline CHEMBL1556805 & 954278 & 3.5242 & 5.0075 & TST & & \\
\hline CHEMBL2355112 & 954278 & 6.3976 & 5.7567 & TRN & & \\
\hline CHEMBL1896103 & 954278 & 3.5243 & 4.4999 & TRN & & \\
\hline CHEMBL1587630 & 954278 & 5.8407 & 5.0661 & TRN & & \\
\hline CHEMBL1523520 & 954278 & 5.6641 & 4.2557 & TRN & & \\
\hline CHEMBL1538212 & 954278 & 3.5241 & 4.0936 & TRN & & \\
\hline CHEMBL1725454 & 954278 & 3.5242 & 5.2026 & TST & & \\
\hline CHEMBL1470764 & 954278 & 4.7764 & 3.9539 & TRN & & \\
\hline CHEMBL1371941 & 954278 & 5.4174 & 4.9583 & TRN & & \\
\hline CHEMBL1425860 & 954278 & 4.8872 & 4.8102 & TST & & \\
\hline CHEMBL1412747 & 954278 & 6.0584 & 6.2799 & TRN & & \\
\hline CHEMBL1423004 & 954278 & 7.0611 & 6.6354 & TRN & & \\
\hline CHEMBL1599462 & 954278 & 5.5314 & 6.4348 & TRN & & \\
\hline CHEMBL1437030 & 954278 & 6.3773 & 6.1401 & TRN & & \\
\hline CHEMBL1448690 & 954278 & 5.9094 & 5.6478 & TRN & & \\
\hline CHEMBL1544190 & 954278 & 5.8303 & 6.192 & TRN & & \\
\hline CHEMBL1375102 & 954278 & 3.5243 & 4.6774 & TST & & \\
\hline CHEMBL2136078 & 954278 & 5.0752 & 4.8564 & TST & & \\
\hline CHEMBL1428928 & 954278 & 3.5242 & 5.0107 & TRN & & \\
\hline CHEMBL 2135951 & 954278 & 3.5242 & 5.5468 & TRN & & \\
\hline CHEMBL530291 & 954278 & 5.0753 & 4.8592 & TRN & & \\
\hline CHEMBL1392033 & 954278 & 5.7089 & 5.1467 & TRN & & \\
\hline CHEMBL1386344 & 954278 & 6.8476 & 5.4292 & TST & & \\
\hline CHEMBL1710219 & 954278 & 3.5234 & 4.8558 & TRN & & \\
\hline CHEMBL1889047 & 954278 & 4.4786 & 4.38 & TRN & & \\
\hline CHEMBL1976677 & 954278 & 4.0013 & 4.4168 & TRN & & \\
\hline CHEMBL 225963 & 954278 & 8.1824 & 6.3219 & TRN & & \\
\hline CHEMBL1569489 & 954278 & 6.4351 & 4.8687 & TRN & & \\
\hline CHEMBL1549500 & 954278 & 5.5127 & 4.7683 & TRN & & \\
\hline CHEMBL1335610 & 954278 & 3.5242 & 5.1843 & TRN & & \\
\hline CHEMBL1543980 & 954278 & 4.9997 & 5.2668 & TRN & & \\
\hline CHEMBL 2130641 & 954278 & 5.4008 & 5.8195 & TRN & & \\
\hline CHEMBL1494282 & 954278 & 6.26200 & j000000e & 205 & .787 & RN \\
\hline CHEMBL1583610 & 954278 & 5.449 & 6.405 & TRN & & \\
\hline
\end{tabular}


Supplemental Table S2.txt

\begin{tabular}{|c|c|c|c|c|}
\hline CHEMBL1457690 & 954278 & 5.2991 & 5.8267 & TST \\
\hline CHEMBL1422429 & 954278 & 6.6084 & 5.4595 & TST \\
\hline CHEMBL1541596 & 954278 & 4.8931 & 5.0039 & TST \\
\hline CHEMBL1471092 & 954278 & 3.5242 & 5.6361 & TST \\
\hline CHEMBL1716038 & 954278 & 6.0 & 5.085 & TRN \\
\hline CHEMBL1405288 & 954278 & 6.3492 & 6.0905 & TRN \\
\hline CHEMBL1437139 & 954278 & 3.5245 & 4.7798 & TST \\
\hline CHEMBL1492752 & 954278 & 6.6197 & 6.3838 & TRN \\
\hline CHEMBL1981589 & 954278 & 6.4456 & 5.8756 & TRN \\
\hline CHEMBL366205 & 954278 & 5.9578 & 4.1278 & TST \\
\hline CHEMBL1340112 & 954278 & 6.8024 & 5.519 & TRN \\
\hline CHEMBL1610300 & 954278 & 6.3895 & 6.4333 & TRN \\
\hline CHEMBL1446412 & 954278 & 6.2899 & 4.9597 & TRN \\
\hline CHEMBL 2357531 & 954278 & 5.4332 & 5.7054 & TRN \\
\hline CHEMBL1581949 & 954278 & 5.8523 & 5.4161 & TRN \\
\hline CHEMBL1481347 & 954278 & 4.9555 & 4.8592 & TRN \\
\hline CHEMBL1373162 & 954278 & 5.9172 & 5.7872 & TRN \\
\hline CHEMBL1499501 & 954278 & 5.8814 & 6.5022 & TRN \\
\hline CHEMBL1721330 & 954278 & 5.8814 & 5.4055 & TST \\
\hline CHEMBL1421463 & 954278 & 3.5241 & 4.1378 & TRN \\
\hline CHEMBL1603001 & 954278 & 6.3663 & 6.5538 & TRN \\
\hline CHEMBL1725453 & 954278 & 6.8534 & 5.4856 & TRN \\
\hline CHEMBL1889401 & 954278 & 4.9547 & 4.7067 & TRN \\
\hline CHEMBL1516566 & 954278 & 5.5693 & 5.3495 & TRN \\
\hline CHEMBL1525599 & 954278 & 4.9555 & 5.3921 & TST \\
\hline CHEMBL1417355 & 954278 & 5.8536 & 5.5964 & TRN \\
\hline CHEMBL1413056 & 954278 & 6.3169 & 5.5136 & TRN \\
\hline CHEMBL1567331 & 954278 & 5.53 & 6.117006 & 0000000001 \\
\hline CHEMBL1603032 & 954278 & 5.5585 & 5.2961 & TRN \\
\hline CHEMBL1482468 & 954278 & 5.9278 & 6.3208 & TRN \\
\hline CHEMBL1414465 & 954278 & 6.0146 & 4.7353 & TRN \\
\hline CHEMBL1878306 & 954278 & 5.2427 & 5.1994 & TST \\
\hline CHEMBL1559053 & 954278 & 5.9055 & 4.7289 & TST \\
\hline CHEMBL1462076 & 954278 & 5.66 & 4.995 & TRN \\
\hline CHEMBL1875054 & 954278 & 5.8582 & 5.4135 & TRN \\
\hline CHEMBL1387556 & 954278 & 5.1491 & 4.0148 & TRN \\
\hline CHEMBL1497024 & 954278 & 5.9547 & 5.6212 & TRN \\
\hline CHEMBL1705059 & 954278 & 5.5421 & 5.3718 & TRN \\
\hline CHEMBL1493864 & 954278 & 6.3476 & 6.2312 & TRN \\
\hline CHEMBL1375338 & 954278 & 3.5241 & 4.4317 & TRN \\
\hline CHEMBL1500445 & 954278 & 5.4508 & 5.1939 & TST \\
\hline CHEMBL95431 & 954278 & 6.5184 & 4.9388 & TRN \\
\hline CHEMBL1482038 & 954278 & 3.5241 & 4.1565 & TRN \\
\hline CHEMBL1172020 & 954278 & 3.5241 & 5.1433 & TRN \\
\hline CHEMBL1499354 & 954278 & 6.8105 & 5.0497 & TRN \\
\hline CHEMBL1466305 & 954278 & 4.9555 & 5.1418 & TRN \\
\hline CHEMBL1487720 & 954278 & 6.0587 & 5.8174 & TRN \\
\hline CHEMBL1540808 & 954278 & 5.7464 & 4.942 & TST \\
\hline
\end{tabular}




\begin{tabular}{|c|c|c|c|c|c|c|}
\hline & & \multicolumn{5}{|c|}{ Supplemental Table S2.txt } \\
\hline CHEMBL1545631 & 954278 & 5.6996 & 6.3493 & TRN & & \\
\hline CHEMBL1721095 & 954278 & 4.4782 & 4.8577 & TST & & \\
\hline CHEMBL 3214310 & 954278 & 5.4698 & 4.8882 & TRN & & \\
\hline CHEMBL1462215 & 954278 & 6.3937 & 5.2058 & TST & & \\
\hline CHEMBL1545848 & 954278 & 5.9698 & 5.4871 & TRN & & \\
\hline CHEMBL1560229 & 954278 & 3.5241 & 4.447 & TRN & & \\
\hline CHEMBL1425552 & 954278 & \multicolumn{3}{|c|}{6.492000000000001} & 6.2024 & 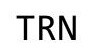 \\
\hline CHEMBL3214406 & 954278 & 5.4148 & 5.2705 & TRN & & \\
\hline CHEMBL1899895 & 954278 & 5.9626 & 4.7141 & TST & & \\
\hline CHEMBL1300536 & 954278 & 5.4269 & 4.7014 & TRN & & \\
\hline CHEMBL1463000 & 954278 & 3.5249 & 4.8973 & TST & & \\
\hline CHEMBL1309273 & 954278 & 5.8383 & 4.9842 & TRN & & \\
\hline CHEMBL1353992 & 954278 & 3.5239 & 5.0247 & TRN & & \\
\hline CHEMBL1344311 & 954278 & 3.5245 & 4.8871 & TRN & & \\
\hline CHEMBL1383532 & 954278 & 3.5242 & 4.2415 & TRN & & \\
\hline CHEMBL1321005 & 954278 & 6.0306 & 5.1285 & TRN & & \\
\hline CHEMBL1709973 & 954278 & \multicolumn{3}{|c|}{5.962999999999999} & .5094 & \\
\hline CHEMBL1344808 & 954278 & 5.8871 & 5.8014 & TRN & & \\
\hline CHEMBL1478533 & 954278 & 5.0878 & 5.1683 & TRN & & \\
\hline CHEMBL 2002430 & 954278 & 4.9559 & 4.9175 & TST & & \\
\hline CHEMBL1368174 & 954278 & 3.5237 & 4.2056 & TRN & & \\
\hline CHEMBL1603519 & 954278 & 3.5242 & 4.5156 & TRN & & \\
\hline CHEMBL171699 & 954278 & 5.9957 & 5.0235 & TRN & & \\
\hline CHEMBL1428566 & 954278 & \multicolumn{3}{|c|}{6.417000000000001} & 5.5244 & TRN \\
\hline CHEMBL1429996 & 954278 & 3.5245 & 4.7811 & TRN & & \\
\hline CHEMBL1594107 & 954278 & 5.9093 & 4.6975 & TST & & \\
\hline CHEMBL46703 & 954278 & 5.4327 & 5.296 & TRN & & \\
\hline CHEMBL2359911 & 954278 & 5.9048 & 4.8759 & TST & & \\
\hline CHEMBL1384771 & 954278 & 4.9551 & 4.8445 & TST & & \\
\hline CHEMBL1319737 & 954278 & 5.2708 & 4.9527 & TRN & & \\
\hline CHEMBL1357535 & 954278 & 5.8726 & 5.7489 & TRN & & \\
\hline CHEMBL1588926 & 954278 & 5.9098 & 5.1886 & TST & & \\
\hline CHEMBL1469379 & 954278 & 5.9755 & 6.0918 & TRN & & \\
\hline CHEMBL1335918 & 954278 & 3.5242 & 5.2749 & TRN & & \\
\hline CHEMBL1603921 & 954278 & 5.7513 & 6.046 & TRN & & \\
\hline CHEMBL1409445 & 954278 & 5.7106 & 4.9888 & TRN & & \\
\hline CHEMBL1449874 & 954278 & 5.0846 & 4.4324 & TRN & & \\
\hline CHEMBL1432721 & 954278 & 5.9126 & 5.7027 & TRN & & \\
\hline CHEMBL1323872 & 954278 & 6.8918 & 5.3013 & TST & & \\
\hline CHEMBL1455957 & 954278 & 5.6866 & 4.3745 & TST & & \\
\hline CHEMBL1444764 & 954278 & 6.0 & 5.9314 & TRN & & \\
\hline CHEMBL1488936 & 954278 & 3.5241 & 4.6859 & TRN & & \\
\hline CHEMBL1367597 & 954278 & 5.3526 & 5.5367 & TRN & & \\
\hline CHEMBL1403484 & 954278 & 5.9488 & 6.2705 & TRN & & \\
\hline CHEMBL1342238 & 954278 & 3.5242 & 4.9928 & TRN & & \\
\hline CHEMBL1717339 & 954278 & 6.2034 & 5.7116 & TRN & & \\
\hline CHEMBL571295 & 954278 & 5.9614 & 4.5061 & TST & & \\
\hline CHEMBL1369262 & 954278 & 5.7786 & 6.23799 & 9999 & & \\
\hline
\end{tabular}




\begin{tabular}{|c|c|c|c|c|c|}
\hline & & \multicolumn{4}{|c|}{ Supplemental Table S2.txt } \\
\hline CHEMBL3197447 & 954278 & 5.9115 & 4.9742 & TRN & \\
\hline CHEMBL1478769 & 954278 & 5.6716 & 4.9053 & TRN & \\
\hline CHEMBL1717082 & 954278 & 5.5436 & 5.9929 & TRN & \\
\hline CHEMBL1478397 & 954278 & 4.9555 & 5.3257 & TRN & \\
\hline CHEMBL1533321 & 954278 & 6.0057 & 5.7544 & TRN & \\
\hline CHEMBL1321513 & 954278 & 5.226 & 5.6601 & TRN & \\
\hline CHEMBL1461631 & 954278 & 6.8447 & 6.7194 & TRN & \\
\hline CHEMBL1573635 & 954278 & 3.5244 & 4.6766 & TST & \\
\hline CHEMBL1490503 & 954278 & 6.2359 & 6.6751 & TRN & \\
\hline CHEMBL1720771 & 954278 & 5.5484 & 5.5134 & TRN & \\
\hline CHEMBL1534042 & 954278 & 5.6872 & 6.11 & TRN & \\
\hline CHEMBL1873644 & 954278 & 7.766 & 5.4324 & TST & \\
\hline CHEMBL1399389 & 954278 & 5.3556 & 4.9407 & TRN & \\
\hline CHEMBL1407572 & 954278 & 5.4946 & 6.2543 & TRN & \\
\hline CHEMBL1300302 & 954278 & 5.6934 & 5.8525 & TRN & \\
\hline CHEMBL 2361231 & 954278 & 4.8846 & 4.9766 & TST & \\
\hline CHEMBL1423660 & 954278 & 6.4301 & 6.7259 & TRN & \\
\hline CHEMBL1361038 & 954278 & 5.6413 & 4.308 & TST & \\
\hline CHEMBL1884207 & 954278 & 6.2986 & 4.3776 & TST & \\
\hline CHEMBL1546066 & 954278 & 6.5843 & 4.5259 & TST & \\
\hline CHEMBL1342790 & 954278 & 5.4353 & 5.0208 & TST & \\
\hline CHEMBL1547757 & 954278 & 5.4494 & 5.0788 & TST & \\
\hline CHEMBL1522672 & 954278 & 5.7199 & 5.4022 & TST & \\
\hline CHEMBL1417067 & 954278 & 5.246 & 3.9085 & TST & \\
\hline CHEMBL1412887 & 954278 & 5.8775 & 5.8938 & TST & \\
\hline CHEMBL1427664 & 954278 & 6.0 & 4.3916 & TST & \\
\hline CHEMBL224869 & 954278 & 5.6985 & 4.2744 & TST & \\
\hline CHEMBL1520388 & 954278 & 5.432 & 5.1228 & TST & \\
\hline CHEMBL1376266 & 954278 & 6.11799 & 9999999 & 5.4778 & TST \\
\hline CHEMBL1451015 & 954278 & 5.856 & 5.7369 & TST & \\
\hline CHEMBL 2136916 & 954278 & 6.407 & 5.4234 & TST & \\
\hline CHEMBL1400272 & 954278 & 6.4217 & 5.483 & TST & \\
\hline CHEMBL575655 & 587661 & 3.1871 & 3.4462 & TRN & \\
\hline CHEMBL573370 & 587661 & 3.0 & 3.6898 & TST & \\
\hline CHEMBL418899 & 587661 & 3.0 & 3.5151 & TST & \\
\hline CHEMBL574100 & 587661 & 3.0 & 3.2685 & TRN & \\
\hline CHEMBL564201 & 587661 & 5.9208 & 3.5527 & TST & \\
\hline CHEMBL574549 & 587661 & 3.301 & 3.3057 & TST & \\
\hline CHEMBL583512 & 587661 & 3.699 & 3.91300 & 00000000003 & TRN \\
\hline CHEMBL575209 & 587661 & 4.1549 & 4.1057 & TRN & \\
\hline CHEMBL572646 & 587661 & 3.0458 & 3.3827 & TRN & \\
\hline CHEMBL575426 & 587661 & 3.0 & 3.0856 & TRN & \\
\hline CHEMBL573619 & 587661 & 3.0 & 3.3667 & TRN & \\
\hline CHEMBL574095 & 587661 & 3.4559 & 3.8015 & TRN & \\
\hline CHEMBL573606 & 587661 & 3.5229 & 4.0037 & TRN & \\
\hline CHEMBL573541 & 587661 & 3.0 & 3.1358 & TRN & \\
\hline CHEMBL575432 & 587661 & 5.0969 & 3.5557 & TRN & \\
\hline CHEMBL575862 & 587661 & 3.4815 & 4.073 & TRN & \\
\hline
\end{tabular}




\begin{tabular}{|c|c|c|c|c|}
\hline & & & oplement & al $\mathrm{Ta}$ \\
\hline CHEMBL574096 & 587661 & 4.699 & 3.1986 & TRN \\
\hline CHEMBL573864 & 587661 & 4.2218 & 3.2702 & TRN \\
\hline CHEMBL573752 & 587661 & 3.0 & 3.6055 & TST \\
\hline CHEMBL573542 & 587661 & 3.0458 & 3.075 & TRN \\
\hline CHEMBL575861 & 587661 & 3.2218 & 3.2591 & TST \\
\hline CHEMBL584804 & 587661 & 3.0 & 3.3297 & TRN \\
\hline CHEMBL573626 & 587661 & 3.0 & 3.778 & TRN \\
\hline CHEMBL573371 & 587661 & 3.0458 & 3.4257 & TRN \\
\hline CHEMBL583948 & 587661 & 5.0969 & 4.2407 & TRN \\
\hline CHEMBL573609 & 587661 & 3.1871 & 3.7148 & TRN \\
\hline CHEMBL574322 & 587661 & 3.0969 & 3.2625 & TST \\
\hline CHEMBL573628 & 587661 & 3.0 & 3.1199 & TRN \\
\hline CHEMBL573607 & 587661 & 4.6021 & 3.8187 & TRN \\
\hline CHEMBL575208 & 587661 & 3.0969 & 3.4743 & TST \\
\hline CHEMBL573611 & 587661 & 5.5229 & 4.2521 & TRN \\
\hline CHEMBL574101 & 587661 & 3.0 & 3.0809 & TRN \\
\hline CHEMBL573372 & 587661 & 3.0 & 3.9495 & TRN \\
\hline CHEMBL573850 & 587661 & 5.0969 & 3.3169 & TRN \\
\hline CHEMBL572449 & 587661 & 3.0 & 3.0849 & TRN \\
\hline CHEMBL584359 & 587661 & 3.301 & 3.5957 & TRN \\
\hline CHEMBL573539 & 587661 & 3.0706 & 3.0317 & TRN \\
\hline CHEMBL575433 & 587661 & 3.2218 & 3.7155 & TRN \\
\hline CHEMBL575650 & 587661 & 3.5229 & 3.9334 & TRN \\
\hline CHEMBL575656 & 587661 & 3.0 & 3.8483 & TST \\
\hline CHEMBL573624 & 587661 & 3.0 & 3.1414 & TRN \\
\hline CHEMBL573842 & 587661 & 3.6021 & 3.7734 & TRN \\
\hline CHEMBL575210 & 587661 & 3.0809 & 3.2616 & TRN \\
\hline CHEMBL573352 & 587661 & 3.0 & 3.4536 & TST \\
\hline CHEMBL573608 & 587661 & 3.8239 & 3.4738 & TST \\
\hline CHEMBL573618 & 587661 & 5.0 & 4.3858 & TRN \\
\hline CHEMBL573132 & 587661 & 3.3979 & 3.8444 & TRN \\
\hline CHEMBL572677 & 587661 & 3.2218 & 3.5128 & TRN \\
\hline CHEMBL575657 & 587661 & 3.1249 & 3.4035 & TRN \\
\hline CHEMBL573369 & 587661 & 3.3468 & 3.448 & TRN \\
\hline CHEMBL573625 & 587661 & 4.699 & 3.9769 & TRN \\
\hline CHEMBL583379 & 587661 & 3.3979 & 3.8301 & TRN \\
\hline CHEMBL585009 & 587661 & 3.2596 & 3.2664 & TRN \\
\hline CHEMBL573540 & 587661 & 3.0458 & 4.0335 & TRN \\
\hline CHEMBL573627 & 587661 & 4.8239 & 4.03 & TRN \\
\hline CHEMBL575651 & 587661 & 3.6021 & 3.9034 & TRN \\
\hline CHEMBL573852 & 587661 & 3.0969 & 3.3036 & TST \\
\hline CHEMBL577182 & 587661 & 5.0 & 4.3155 & TST \\
\hline CHEMBL583763 & 587661 & 3.2366 & 3.9149 & TST \\
\hline CHEMBL583739 & 587661 & 4.1367 & 3.0771 & TST \\
\hline CHEMBL575652 & 587661 & 3.0 & 3.7224 & TST \\
\hline CHEMBL604338 & 611264 & 5.4067 & 5.6354 & TRN \\
\hline CHEMBL611509 & 611264 & 6.3872 & 6.2111 & TRN \\
\hline CHEMBL603908 & 611264 & 6.1192 & 5.7044 & TRN \\
\hline
\end{tabular}




\begin{tabular}{|c|c|c|c|c|c|}
\hline CHEMBL601444 & 611264 & 6.3279 & 6.3443 & TRN & \\
\hline CHEMBL601648 & 611264 & 7.0969 & \multicolumn{2}{|c|}{7.132000000000001} & TRN \\
\hline CHEMBL601443 & 611264 & 5.1101 & 5.319 & TRN & \\
\hline CHEMBL601847 & 611264 & 6.1871 & 5.9865 & TRN & \\
\hline CHEMBL606418 & 611264 & 5.1791 & 5.1899 & TRN & \\
\hline CHEMBL601846 & 611264 & 6.5376 & 6.6744 & TRN & \\
\hline CHEMBL604327 & 611264 & 6.2007 & 6.1828 & TRN & \\
\hline CHEMBL600014 & 611264 & 3.6021 & 3.4275 & TRN & \\
\hline CHEMBL600823 & 611264 & 3.6021 & 3.7364 & TRN & \\
\hline CHEMBL601649 & 611264 & 6.1367 & 6.2419 & TRN & \\
\hline CHEMBL600015 & 611264 & 3.6021 & 3.4526 & TRN & \\
\hline CHEMBL602270 & 611264 & 6.585 & 6.8094 & TRN & \\
\hline CHEMBL602496 & 611264 & 7.1549 & 7.2346 & TRN & \\
\hline CHEMBL601460 & 611264 & 4.2041 & 4.5065 & TRN & \\
\hline CHEMBL600813 & 611264 & 6.6021 & 6.5143 & TRN & \\
\hline CHEMBL605587 & 611264 & 5.767 & 5.9905 & TRN & \\
\hline CHEMBL601654 & 611264 & 6.8239 & 6.9111 & TRN & \\
\hline CHEMBL604332 & 611264 & 7.0 & 6.8572 & TRN & \\
\hline CHEMBL601461 & 611264 & 4.6509 & 4.5109 & TRN & \\
\hline CHEMBL600601 & 611264 & 6.1871 & 6.2637 & TRN & \\
\hline CHEMBL600995 & 611264 & 6.8539 & 6.2596 & TRN & \\
\hline CHEMBL600623 & 611264 & 3.6021 & 3.5309 & TRN & \\
\hline CHEMBL605586 & 611264 & 6.5376 & 6.5892 & TRN & \\
\hline CHEMBL605989 & 611264 & 6.4949 & 5.1425 & TST & \\
\hline CHEMBL600812 & 611264 & 7.0 & 6.9999 & TRN & \\
\hline CHEMBL599886 & 611264 & 5.3458 & 5.5421 & TRN & \\
\hline CHEMBL601655 & 611264 & 7.0969 & 6.9714 & TRN & \\
\hline CHEMBL602271 & 611264 & 6.1427 & 6.11 & TRN & \\
\hline CHEMBL604754 & 611264 & 3.6021 & 3.7698 & TST & \\
\hline CHEMBL601676 & 611264 & 6.585 & 6.5426 & TRN & \\
\hline CHEMBL602879 & 611264 & 6.1938 & 6.2396 & TRN & \\
\hline CHEMBL602497 & 611264 & 6.8239 & 6.9508 & TRN & \\
\hline CHEMBL601656 & 611264 & 6.8539 & 6.3879 & TRN & \\
\hline CHEMBL601845 & 611264 & 5.6144 & 6.6427 & TST & \\
\hline CHEMBL604750 & 611264 & 6.6198 & 6.4573 & TRN & \\
\hline CHEMBL600808 & 611264 & 6.9586 & 7.0016 & TRN & \\
\hline CHEMBL605157 & 611264 & 5.7773 & 5.86799 & 9999999999 & TRN \\
\hline CHEMBL606417 & 611264 & 6.0862 & 6.1922 & TRN & \\
\hline CHEMBL600824 & 611264 & 6.1427 & 6.7375 & TST & \\
\hline CHEMBL602885 & 611264 & 4.6815 & 5.7616 & TST & \\
\hline CHEMBL606333 & 611264 & 3.6021 & 3.7849 & TST & \\
\hline CHEMBL601236 & 611264 & 5.5544 & 5.6357 & TRN & \\
\hline CHEMBL603919 & 611264 & 7.2218 & 7.2352 & TRN & \\
\hline CHEMBL599765 & 611264 & 5.2774 & 5.2177 & TRN & \\
\hline CHEMBL604745 & 611264 & 6.0555 & 6.0474 & TRN & \\
\hline CHEMBL597507 & 611264 & 7.0458 & 6.7133 & TRN & \\
\hline CHEMBL601017 & 611264 & 5.0985 & 5.7035 & TRN & \\
\hline CHEMBL605369 & 611264 & 6.3372 & 6.536006 & 00000000005 & TRN \\
\hline & & & & 17170 & \\
\hline
\end{tabular}




\begin{tabular}{|c|c|c|c|c|c|}
\hline \multirow[b]{2}{*}{ CHEMBL597506 } & \multicolumn{5}{|c|}{ Supplemental Table S2.txt } \\
\hline & 611264 & 5.2154 & 5.2386 & TRN & \\
\hline CHEMBL605794 & 611264 & 6.2757 & 6.3151 & TRN & \\
\hline CHEMBL600389 & 611264 & 5.718999 & 79999999 & 5.6267 & TRN \\
\hline CHEMBL605913 & 611264 & 3.6021 & $3.34800 t$ & 00000000003 & TST \\
\hline CHEMBL602077 & 611264 & 4.7545 & 4.0289 & TST & \\
\hline CHEMBL606419 & 611264 & 3.6021 & 5.9865 & TST & \\
\hline CHEMBL599992 & 611264 & 4.9965 & 6.8668 & TST & \\
\hline CHEMBL603087 & 611264 & 5.8508 & 7.4697 & TST & \\
\hline CHEMBL603236 & 611264 & 5.5768 & 5.5985 & TST & \\
\hline CHEMBL591218 & 611264 & 6.8239 & 7.1684 & TST & \\
\hline CHEMBL602498 & 611264 & 6.0605 & 5.1049 & TST & \\
\hline CHEMBL601230 & 611264 & 6.9208 & 7.0276 & TST & \\
\hline CHEMBL608087 & 611264 & 6.5376 & 4.6345 & TST & \\
\hline CHEMBL603709 & 611264 & 6.2147 & 4.655 & TST & \\
\hline CHEMBL342913 & 65814 & 6.4089 & 6.4479 & TRN & \\
\hline CHEMBL343768 & 65814 & 6.6198 & 6.6807 & TRN & \\
\hline CHEMBL136634 & 65814 & 6.7959 & 6.4609 & TRN & \\
\hline CHEMBL336563 & 65814 & 7.8239 & 7.7479 & TRN & \\
\hline CHEMBL344473 & 65814 & 5.5528 & 5.8242 & TRN & \\
\hline CHEMBL422464 & 65814 & 5.7696 & 5.2781 & TRN & \\
\hline CHEMBL136210 & 65814 & 6.6778 & 6.5937 & TRN & \\
\hline CHEMBL1791007 & 65814 & 6.6383 & 6.9355 & TRN & \\
\hline CHEMBL1791015 & 65814 & 5.3768 & 5.9707 & TRN & \\
\hline CHEMBL3301647 & 65814 & 5.1739 & 5.6403 & TRN & \\
\hline CHEMBL134562 & 65814 & 6.699 & 6.6805 & TRN & \\
\hline CHEMBL404763 & 65814 & 6.4815 & 7.0185 & TRN & \\
\hline CHEMBL132542 & 65814 & 7.4949 & 7.8043 & TRN & \\
\hline CHEMBL343959 & 65814 & 3.0 & 6.9215 & TST & \\
\hline CHEMBL335863 & 65814 & 4.3979 & 6.6833 & TST & \\
\hline CHEMBL433853 & 65814 & 7.3098 & 7.33899 & 99999999995 & TRN \\
\hline CHEMBL335416 & 65814 & 6.9208 & 7.0386 & TRN & \\
\hline CHEMBL137361 & 65814 & 6.7447 & 6.4609 & TRN & \\
\hline CHEMBL335128 & 65814 & 6.8239 & 6.4609 & TRN & \\
\hline CHEMBL137569 & 65814 & 4.6021 & 5.5053 & TRN & \\
\hline CHEMBL341994 & 65814 & 7.7212 & 7.7355 & TRN & \\
\hline CHEMBL1791006 & 65814 & 6.5686 & 6.5496 & TRN & \\
\hline CHEMBL342617 & 65814 & 6.8539 & 6.5689 & TRN & \\
\hline CHEMBL337031 & 65814 & 6.7959 & 6.4589 & TRN & \\
\hline CHEMBL337897 & 65814 & 6.3872 & 6.0145 & TRN & \\
\hline CHEMBL137716 & 65814 & 7.5376 & 7.0251 & TST & \\
\hline CHEMBL135906 & 65814 & 6.7212 & 5.2853 & TRN & \\
\hline CHEMBL424285 & 65814 & 3.0 & 6.59399 & 9999999999 & TST \\
\hline CHEMBL342615 & 65814 & 7.6778 & 6.9772 & TRN & \\
\hline CHEMBL407771 & 65814 & 7.2076 & 6.9397 & TRN & \\
\hline CHEMBL335143 & 65814 & 6.9586 & 6.522 & TRN & \\
\hline CHEMBL343379 & 65814 & 5.8539 & 6.1547 & TST & \\
\hline CHEMBL342840 & 65814 & 6.7959 & 6.6455 & TRN & \\
\hline CHEMBL137671 & 65814 & 6.8239 & 6.6789 & TRN & \\
\hline
\end{tabular}




\begin{tabular}{|c|c|c|c|c|c|}
\hline \multicolumn{6}{|c|}{ Supplemental Table S2.txt } \\
\hline CHEMBL341443 & 65814 & 6.6021 & 6.6788 & TRN & \\
\hline CHEMBL342215 & 65814 & 5.8239 & 8.2226 & TST & \\
\hline CHEMBL343062 & 65814 & 7.699 & 8.1117 & TRN & \\
\hline CHEMBL407639 & 65814 & 6.8539 & 7.4491 & TRN & \\
\hline CHEMBL263537 & 65814 & 7.4685 & 7.944 & TRN & \\
\hline CHEMBL137011 & 65814 & 5.2518 & 5.4472 & TRN & \\
\hline CHEMBL341751 & 65814 & 5.0706 & 5.2597 & TRN & \\
\hline CHEMBL137754 & 65814 & 6.585 & 6.6255 & TRN & \\
\hline CHEMBL337567 & 65814 & 6.8861 & 7.0215 & TRN & \\
\hline CHEMBL263025 & 65814 & 4.4559 & 4.2538 & TRN & \\
\hline CHEMBL2370830 & 65814 & 7.8861 & 7.3924 & TRN & \\
\hline CHEMBL342440 & 65814 & 7.3279 & 7.1227 & TRN & \\
\hline CHEMBL343516 & 65814 & 7.7447 & 6.9609 & TST & \\
\hline CHEMBL335126 & 65814 & 3.0 & 4.3166 & TRN & \\
\hline CHEMBL335780 & 65814 & 6.6198 & 6.5948 & TRN & \\
\hline CHEMBL136583 & 65814 & 6.2757 & 6.4609 & TRN & \\
\hline CHEMBL422285 & 65814 & 7.4815 & 7.0187 & TST & \\
\hline CHEMBL135907 & 65814 & 6.3565 & 5.8224 & TRN & \\
\hline CHEMBL 343582 & 65814 & 7.6198 & 6.6807 & TST & \\
\hline CHEMBL138120 & 65814 & 7.4559 & 6.8518 & TST & \\
\hline CHEMBL336087 & 65814 & 4.8239 & 6.7109 & TST & \\
\hline CHEMBL 2370825 & 65814 & 7.7447 & 7.4931 & TST & \\
\hline CHEMBL1269102 & 65814 & 7.6576 & 7.1481 & TST & \\
\hline CHEMBL133257 & 65814 & 8.3979 & 6.7694 & TST & \\
\hline CHEMBL414165 & 65814 & 8.5229 & 7.1953 & TST & \\
\hline CHEMBL 2041801 & 823825 & 5.8633 & 5.6621 & TRN & \\
\hline CHEMBL 2041827 & 823825 & 6.5969 & 6.4683 & TRN & \\
\hline CHEMBL 2041812 & 823825 & 4.4572 & 4.2756 & TRN & \\
\hline CHEMBL 2041840 & 823825 & 6.0 & 6.4909 & TRN & \\
\hline CHEMBL 2041805 & 823825 & 7.3468 & 7.3047 & TRN & \\
\hline CHEMBL 2041803 & 823825 & 5.1858 & 5.4408 & TRN & \\
\hline CHEMBL 2041814 & 823825 & 5.2147 & 5.0859 & TRN & \\
\hline CHEMBL 2041802 & 823825 & 5.5817 & 5.515 & TRN & \\
\hline CHEMBL 2041795 & 823825 & 6.7212 & 6.96299 & 9999999999 & TRN \\
\hline CHEMBL 2041830 & 823825 & 7.3665 & 7.053 & TRN & \\
\hline CHEMBL 2041811 & 823825 & 6.0555 & 6.1169 & TRN & \\
\hline CHEMBL539632 & 823825 & 6.7696 & 6.8051 & TRN & \\
\hline CHEMBL601067 & 823825 & 5.8447 & 6.2144 & TRN & \\
\hline CHEMBL 2041828 & 823825 & 6.5229 & 6.7883 & TST & \\
\hline CHEMBL601707 & 823825 & 5.0788 & 5.1081 & TRN & \\
\hline CHEMBL 2041846 & 823825 & 5.0701 & 5.2084 & TRN & \\
\hline CHEMBL2041831 & 823825 & 6.284 & 6.2593 & TST & \\
\hline CHEMBL2041842 & 823825 & 7.9208 & 7.0871 & TRN & \\
\hline CHEMBL601066 & 823825 & 6.4437 & 6.2975 & TRN & \\
\hline CHEMBL605979 & 823825 & 4.5662 & 4.6784 & TRN & \\
\hline CHEMBL 2041816 & 823825 & 3.0 & 2.832 & TRN & \\
\hline CHEMBL 2041844 & 823825 & 6.8239 & 6.8527 & TRN & \\
\hline CHEMBL 2041829 & 823825 & 6.8539 & 6.9598 & TRN & \\
\hline
\end{tabular}

Page 17172 


\begin{tabular}{|c|c|c|c|c|c|}
\hline \multirow[b]{2}{*}{ CHEMBL2041839 } & \multicolumn{5}{|c|}{ Supplemental Table s2.txt } \\
\hline & 823825 & 6.8539 & 6.7788 & TST & \\
\hline CHEMBL598176 & 823825 & 4.7508 & 4.94600 & 0000000001 & TRN \\
\hline CHEMBL2041798 & 823825 & 6.3979 & 6.426 & TRN & \\
\hline CHEMBL 2041845 & 823825 & 7.2441 & 6.9874 & TRN & \\
\hline CHEMBL601065 & 823825 & 5.6778 & 5.3934 & TRN & \\
\hline CHEMBL 2041806 & 823825 & 7.4815 & 7.3205 & TRN & \\
\hline CHEMBL 2041807 & 823825 & 7.3279 & 7.2662 & TRN & \\
\hline CHEMBL2041834 & 823825 & 5.0044 & 5.6463 & TST & \\
\hline CHEMBL 2041821 & 823825 & 7.3665 & 7.1186 & TRN & \\
\hline CHEMBL2041815 & 823825 & 6.8239 & 6.7739 & TRN & \\
\hline CHEMBL2041617 & 823825 & 7.0969 & 6.9593 & TRN & \\
\hline CHEMBL598801 & 823825 & 4.4761 & 4.3684 & TRN & \\
\hline CHEMBL596746 & 823825 & 3.0 & 3.5747 & TRN & \\
\hline CHEMBL601706 & 823825 & 5.8794 & 6.0932 & TRN & \\
\hline CHEMBL2041619 & 823825 & 6.7959 & 6.581 & TRN & \\
\hline CHEMBL596744 & 823825 & 3.0 & 3.2047 & TRN & \\
\hline CHEMBL2041797 & 823825 & 6.4815 & 6.3816 & TRN & \\
\hline CHEMBL 2041618 & 823825 & 7.1308 & 6.9247 & TRN & \\
\hline CHEMBL 2041824 & 823825 & 6.0 & 6.4836 & TRN & \\
\hline CHEMBL2041623 & 823825 & 5.8633 & 6.0227 & TRN & \\
\hline CHEMBL 2041620 & 823825 & 6.4949 & 6.7751 & TRN & \\
\hline CHEMBL 2041833 & 823825 & 5.4214 & 5.4877 & TST & \\
\hline CHEMBL 2041971 & 823825 & 6.4949 & 5.8099 & TRN & \\
\hline CHEMBL2041799 & 823825 & 6.5528 & 6.5627 & TST & \\
\hline CHEMBL601069 & 823825 & 4.4711 & 5.0936 & TST & \\
\hline CHEMBL 2041817 & 823825 & 6.6576 & 6.5905 & TRN & \\
\hline CHEMBL605561 & 823825 & 4.5411 & 4.5716 & TRN & \\
\hline CHEMBL 2041832 & 823825 & 5.9914 & 5.9296 & TRN & \\
\hline CHEMBL 2041837 & 823825 & 6.4698 & 6.5125 & TST & \\
\hline CHEMBL2041624 & 823825 & 7.1135 & 7.2965 & TRN & \\
\hline CHEMBL 2041810 & 823825 & 6.0969 & 5.8572 & TRN & \\
\hline CHEMBL590504 & 823825 & 5.6819 & 5.5363 & TRN & \\
\hline CHEMBL 2041835 & 823825 & 3.0 & 4.0674 & TST & \\
\hline CHEMBL2041616 & 823825 & 7.6778 & 7.9039 & TRN & \\
\hline CHEMBL590266 & 823825 & 7.2147 & 7.2662 & TRN & \\
\hline CHEMBL 2041622 & 823825 & 5.6778 & 5.8121 & TRN & \\
\hline CHEMBL2041836 & 823825 & 3.0 & 4.2772 & TST & \\
\hline CHEMBL601068 & 823825 & 6.6198 & 6.7285 & TRN & \\
\hline CHEMBL2041820 & 823825 & 7.0269 & 7.16 & TRN & \\
\hline CHEMBL2041796 & 823825 & 6.3872 & 6.1419 & TST & \\
\hline CHEMBL 2041813 & 823825 & 4.7328 & 4.3724 & TRN & \\
\hline CHEMBL590505 & 823825 & 6.7399 & 6.6612 & TRN & \\
\hline CHEMBL2041809 & 823825 & 4.8665 & 5.17700 & 00000000005 & TRN \\
\hline CHEMBL 2041838 & 823825 & 6.7696 & 6.7738 & TST & \\
\hline CHEMBL2041621 & 823825 & 6.284 & 6.215 & TRN & \\
\hline CHEMBL 2041843 & 823825 & 7.8861 & 8.4451 & TRN & \\
\hline CHEMBL2041804 & 823825 & 5.3372 & 5.2671 & TST & \\
\hline CHEMBL2041970 & 823825 & 6.4318 & 5.9294 & TST & \\
\hline
\end{tabular}




\begin{tabular}{|c|c|c|c|c|c|}
\hline & & \multicolumn{4}{|c|}{ Supplemental Table S2.txt } \\
\hline CHEMBL2041818 & 823825 & 8.0969 & 7.4099 & TST & \\
\hline CHEMBL 2041819 & 823825 & 4.3316 & 4.391 & TST & \\
\hline CHEMBL601708 & 823825 & 6.6383 & 6.0243 & TST & \\
\hline CHEMBL 2041826 & 823825 & 7.6021 & 7.0945 & TST & \\
\hline CHEMBL590385 & 823825 & 6.585 & 6.2625 & TST & \\
\hline CHEMBL 2041800 & 823825 & 6.3979 & 6.4371 & TST & \\
\hline CHEMBL120692 & 538268 & 6.0 & 6.0181 & TRN & \\
\hline CHEMBL118952 & 538268 & 5.8861 & 5.6765 & TRN & \\
\hline CHEMBL444597 & 538268 & 6.2218 & 5.9275 & TRN & \\
\hline CHEMBL460830 & 538268 & 5.5229 & 5.5034 & TST & \\
\hline CHEMBL 291880 & 538268 & 4.9208 & 5.1967 & TST & \\
\hline CHEMBL292491 & 538268 & 4.8861 & 5.3119 & TST & \\
\hline CHEMBL518079 & 538268 & 4.6021 & 4.56 & TRN & \\
\hline CHEMBL459552 & 538268 & 5.5686 & 5.7651 & TRN & \\
\hline CHEMBL459545 & 538268 & 6.0 & 5.7129 & TRN & \\
\hline CHEMBL 258869 & 538268 & 5.2218 & 5.1775 & TRN & \\
\hline CHEMBL326484 & 538268 & 5.9208 & 6.0424 & TRN & \\
\hline CHEMBL461459 & 538268 & 5.9208 & 5.8653 & TRN & \\
\hline CHEMBL462306 & 538268 & 5.4202 & 5.8808 & TST & \\
\hline CHEMBL120545 & 538268 & 5.8861 & 5.6801 & TRN & \\
\hline CHEMBL455901 & 538268 & 5.0269 & 5.301 & TRN & \\
\hline CHEMBL118131 & 538268 & 6.0 & 5.6526 & TRN & \\
\hline CHEMBL326581 & 538268 & 5.8539 & 5.6346 & TRN & \\
\hline CHEMBL517274 & 538268 & 6.0 & 5.8134 & TRN & \\
\hline CHEMBL460181 & 538268 & 5.699 & 5.6025 & TRN & \\
\hline CHEMBL118991 & 538268 & 5.3979 & 5.6432 & TRN & \\
\hline CHEMBL118426 & 538268 & 6.0 & 5.5883 & TRN & \\
\hline CHEMBL513785 & 538268 & 5.7696 & 5.7953 & TRN & \\
\hline CHEMBL119287 & 538268 & 4.6021 & 5.5017 & TST & \\
\hline CHEMBL64347 & 538268 & 5.1871 & 5.11100 & 0000000001 & TST \\
\hline CHEMBL118994 & 538268 & 5.9586 & 5.6297 & TRN & \\
\hline CHEMBL61813 & 538268 & 4.9208 & 5.191 & TRN & \\
\hline CHEMBL411277 & 538268 & 4.6778 & 4.5914 & TRN & \\
\hline CHEMBL115696 & 538268 & 5.2596 & 5.6973 & TRN & \\
\hline CHEMBL61158 & 538268 & 4.699 & 4.53600 & 00000000005 & TRN \\
\hline CHEMBL509496 & 538268 & 4.1249 & 4.331 & TRN & \\
\hline CHEMBL455956 & 538268 & 4.2218 & 4.4733 & TRN & \\
\hline CHEMBL443807 & 538268 & 6.2218 & 6.0315 & TST & \\
\hline CHEMBL59906 & 538268 & 4.2218 & 4.3851 & TRN & \\
\hline CHEMBL504278 & 538268 & 5.6021 & 5.653 & TRN & \\
\hline CHEMBL513273 & 538268 & 5.5229 & 5.5022 & TST & \\
\hline CHEMBL515513 & 538268 & 4.5086 & 4.5084 & TRN & \\
\hline CHEMBL513264 & 538268 & 5.5229 & 5.6497 & TRN & \\
\hline CHEMBL118136 & 538268 & 5.6021 & 5.6148 & TRN & \\
\hline CHEMBL460819 & 538268 & 5.8239 & 5.7573 & TRN & \\
\hline CHEMBL456595 & 538268 & 5.4559 & 5.231 & TRN & \\
\hline CHEMBL 259488 & 538268 & 4.301 & 4.499 & TRN & \\
\hline CHEMBL330961 & 538268 & 5.6021 & 5.6028 & TRN & \\
\hline
\end{tabular}




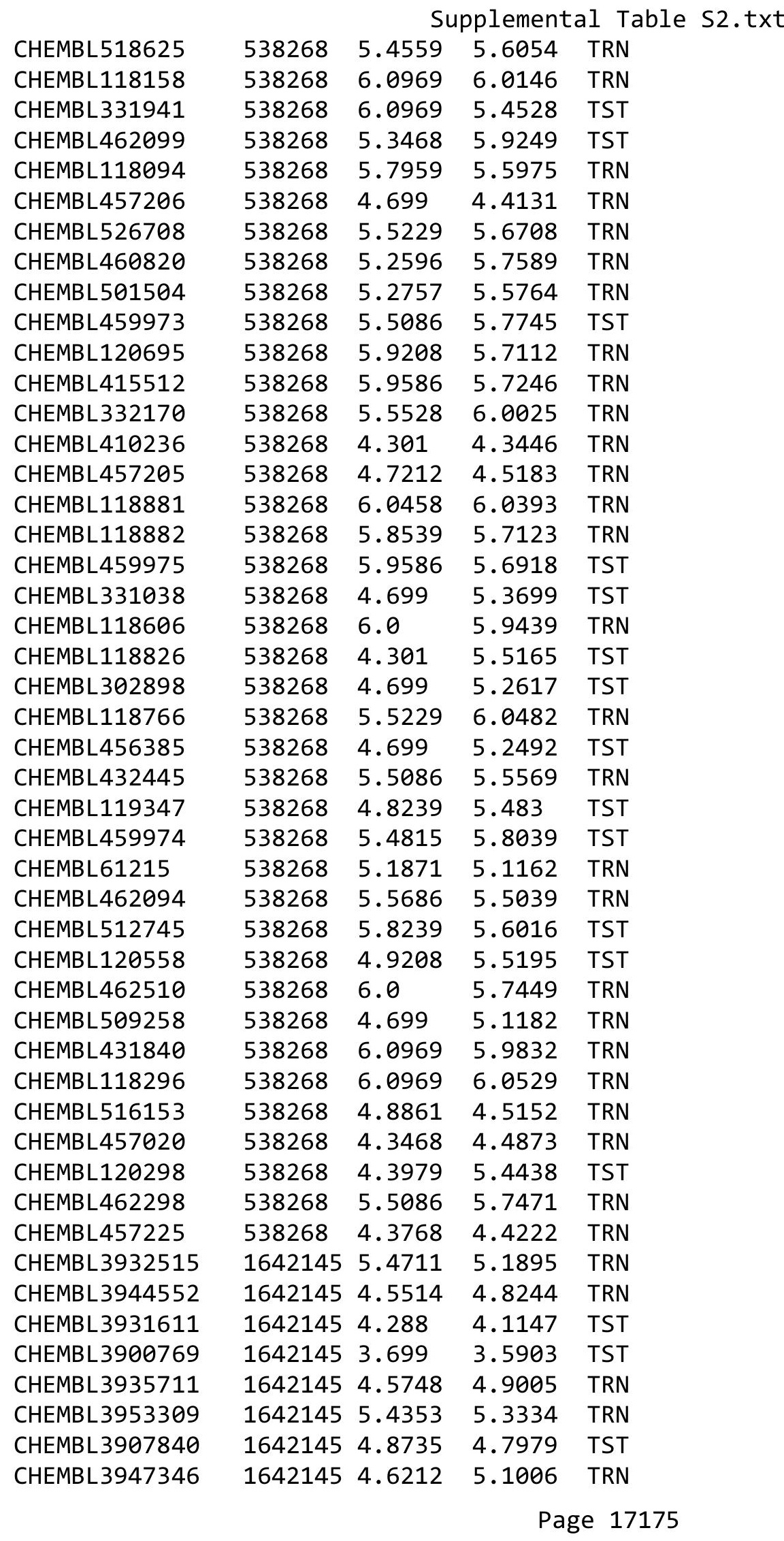


Supplemental Table S2.txt

$\begin{array}{lllll}\text { CHEMBL3963476 } & 1642145 & 3.8008 & 3.9714 & \text { TRN } \\ \text { CHEMBL3915310 } & 1642145 & 5.041 & 4.8003 & \text { TRN } \\ \text { CHEMBL3909167 } & 1642145 & 3.9472 & 4.1037 & \text { TST } \\ \text { CHEMBL3905420 } & 1642145 & 5.0269 & 5.5477 & \text { TRN } \\ \text { CHEMBL3927195 } & 1642145 & 4.6073 & 5.0109 & \text { TRN } \\ \text { CHEMBL3965644 } & 1642145 & 4.0001 & 3.9054 & \text { TRN } \\ \text { CHEMBL3930167 } & 1642145 & 4.6334 & 4.6925 & \text { TRN } \\ \text { CHEMBL3914519 } & 1642145 & 3.699 & 3.6888 & \text { TST } \\ \text { CHEMBL3934508 } & 1642145 & 4.4917 & 4.8566 & \text { TRN } \\ \text { CHEMBL3935931 } & 1642145 & 4.331 & 4.431 & \text { TRN } \\ \text { CHEMBL3916427 } & 1642145 & 5.5143 & 5.3124 & \text { TRN } \\ \text { CHEMBL3962934 } & 1642145 & 3.7996 & 4.4754 & \text { TRN } \\ \text { CHEMBL3951398 } & 1642145 & 4.5331 & 4.59 & \text { TRN } \\ \text { CHEMBL3915731 } & 1642145 & 3.9946 & 3.6851 & \text { TRN } \\ \text { CHEMBL3945129 } & 1642145 & 5.3325 & 5.3048 & \text { TRN } \\ \text { CHEMBL3985165 } & 1642145 & 5.0195 & 5.0355 & \text { TRN } \\ \text { CHEMBL3984344 } & 1642145 & 4.141 & 3.9205 & \text { TST } \\ \text { CHEMBL3978897 } & 1642145 & 6.0 & 5.277 & \text { TRN } \\ \text { CHEMBL3914953 } & 1642145 & 5.3768 & 5.261 & \text { TRN } \\ \text { CHEMBL3927977 } & 1642145 & 4.6151 & 4.8968 & \text { TRN } \\ \text { CHEMBL3919532 } & 1642145 & 5.4283 & 5.2577 & \text { TRN } \\ \text { CHEMBL3911115 } & 1642145 & 4.2847 & 4.1737 & \text { TRN } \\ \text { CHEMBL3906123 } & 1642145 & 3.699 & 3.9226 & \text { TST } \\ \text { CHEMBL3958567 } & 1642145 & 5.5406 & 5.5687 & \text { TST } \\ \text { CHEMBL3958511 } & 1642145 & 3.699 & 3.6929 & \text { TRN } \\ \text { CHEMBL3895011 } & 1642145 & 2.699 & 3.301 & \text { TRN } \\ \text { CHEMBL3960131 } & 1642145 & 4.2494 & 4.2861 & \text { TST } \\ \text { CHEMBL3985504 } & 1642145 & 5.0246 & 4.7931 & \text { TRN } \\ \text { CHEMBL3897397 } & 1642145 & 4.0534 & 4.0929 & \text { TRN } \\ \text { CHEMBL3924721 } & 1642145 & 4.1137 & 3.9397 & \text { TRN } \\ \text { CHEMBMB } 3904269 & 1642145 & 3.7455 & 3.5847 & \text { TRN } \\ \text { CHEMBL3905554 } & 1642145 & 4.0302 & 3.9009 & \text { TST } \\ \text { CHEMBL3909836 } & 1642145 & 4.6178 & 4.4881 & \text { TST } \\ \text { CHEMB } & & & \end{array}$

Page 17176 
Supplemental Table S2.txt

\begin{tabular}{|c|c|c|c|c|c|}
\hline CHEMBL3958522 & 1642145 & 3.8162 & 3.4513 & TRN & \\
\hline CHEMBL3936843 & 1642145 & 4.6807 & 4.6139 & TRN & \\
\hline CHEMBL3961958 & 1642145 & 4.6828 & 4.9237 & TRN & \\
\hline CHEMBL 3942538 & 1642145 & 3.9498 & 4.0698 & TRN & \\
\hline CHEMBL3924386 & 1642145 & 5.4089 & 5.5438 & TRN & \\
\hline CHEMBL3979450 & 1642145 & 3.9261 & 3.9708 & TRN & \\
\hline CHEMBL3957455 & 1642145 & 3.699 & 3.8766 & TRN & \\
\hline CHEMBL3905274 & 1642145 & 6.0 & 5.3959 & TRN & \\
\hline CHEMBL3925417 & 1642145 & 5.1409 & 5.0817 & TRN & \\
\hline CHEMBL3985474 & 1642145 & 3.7429 & 3.7916 & TRN & \\
\hline CHEMBL3970759 & 1642145 & 5.3054 & 5.3604 & TRN & \\
\hline CHEMBL3914279 & 1642145 & 5.2823 & 5.6247 & TRN & \\
\hline CHEMBL3902935 & 1642145 & 5.3969 & 5.467000 & 30000000005 & TRN \\
\hline CHEMBL3927491 & 1642145 & 4.0231 & 3.7403 & TST & \\
\hline CHEMBL3893705 & 1642145 & 5.6778 & 5.7295 & TRN & \\
\hline CHEMBL3934104 & 1642145 & 4.4285 & 4.535 & TST & \\
\hline CHEMBL3964092 & 1642145 & 5.2924 & 5.2248 & TRN & \\
\hline CHEMBL3922095 & 1642145 & 4.5594 & 4.7505 & TRN & \\
\hline CHEMBL3897439 & 1642145 & 5.3197 & 5.5136 & TRN & \\
\hline CHEMBL3919954 & 1642145 & 4.4021 & 4.5617 & TST & \\
\hline CHEMBL3904114 & 1642145 & 5.0706 & 5.1642 & TRN & \\
\hline CHEMBL3930135 & 1642145 & 4.0607 & 3.2411 & TST & \\
\hline CHEMBL3894195 & 1642145 & 6.1487 & 5.9207 & TRN & \\
\hline CHEMBL 3938773 & 1642145 & 4.1281 & 4.2341 & TST & \\
\hline CHEMBL3927164 & 1642145 & 5.0872 & 4.8771 & TRN & \\
\hline CHEMBL3919071 & 1642145 & 4.5245 & 4.4949 & TRN & \\
\hline CHEMBL3894876 & 1642145 & 5.7055 & 5.4472 & TRN & \\
\hline CHEMBL3981062 & 1642145 & 3.699 & 3.3316 & TST & \\
\hline CHEMBL3919396 & 1642145 & 4.9266 & 4.8788 & TRN & \\
\hline CHEMBL3961990 & 1642145 & 5.04 & 5.3809 & TRN & \\
\hline CHEMBL3898469 & 1642145 & 4.2491 & 3.7907 & TST & \\
\hline CHEMBL3933422 & 1642145 & 4.82100 & 000000000 & 4.8662 & TRN \\
\hline CHEMBL3985331 & 1642145 & 4.8665 & \multicolumn{3}{|c|}{$4.4910000000000005 \quad$ TRN } \\
\hline CHEMBL3949428 & 1642145 & 4.5103 & 4.5149 & TRN & \\
\hline CHEMBL3951332 & 1642145 & 4.5154 & 4.4189 & TRN & \\
\hline CHEMBL3951211 & 1642145 & 5.2175 & 5.3093 & TST & \\
\hline CHEMBL3918140 & 1642145 & 4.2098 & 4.3516 & TRN & \\
\hline CHEMBL 3949848 & 1642145 & 4.3397 & 4.7901 & TRN & \\
\hline CHEMBL3939572 & 1642145 & 4.8069 & 4.9895 & TRN & \\
\hline CHEMBL3939854 & 1642145 & 5.7447 & 5.8869 & TRN & \\
\hline CHEMBL3964557 & 1642145 & 4.8972 & 4.373 & TRN & \\
\hline CHEMBL3965983 & 1642145 & 3.699 & 3.3444 & TST & \\
\hline CHEMBL3904518 & 1642145 & 6.0 & 5.3171 & TRN & \\
\hline CHEMBL 3985211 & 1642145 & 5.3206 & 5.4123 & TRN & \\
\hline CHEMBL3905572 & 1642145 & 4.8996 & 5.36 & TRN & \\
\hline CHEMBL3909096 & 1642145 & 6.0 & 5.3261 & TRN & \\
\hline CHEMBL3923592 & 1642145 & 5.129 & 5.1537 & TRN & \\
\hline CHEMBL 3973992 & 1642145 & 4.6902 & 4.9796 & TRN & \\
\hline
\end{tabular}

Page 17177 
Supplemental Table S2.txt

\begin{tabular}{|c|c|c|c|c|c|c|}
\hline CHEMBL 3943829 & 1642145 & 5.1549 & 4.9358 & TRN & & \\
\hline CHEMBL3941206 & 1642145 & 4.9154 & 5.362 & TRN & & \\
\hline CHEMBL3907495 & 1642145 & 4.4748 & 4.184 & TST & & \\
\hline CHEMBL 3902157 & 1642145 & 3.9437 & 3.3624 & TRN & & \\
\hline CHEMBL3932529 & 1642145 & 2.699 & 3.1427 & TRN & & \\
\hline CHEMBL3915191 & 1642145 & 4.6297 & 4.7618 & TST & & \\
\hline CHEMBL3979445 & 1642145 & 4.9007 & 5.0367 & TRN & & \\
\hline CHEMBL3899677 & 1642145 & 3.699 & 3.9963 & TST & & \\
\hline CHEMBL 3890493 & 1642145 & 3.741 & 3.6757 & TST & & \\
\hline CHEMBL3911999 & 1642145 & 5.0685 & 5.0617 & TRN & & \\
\hline CHEMBL3923583 & 1642145 & 6.0 & 5.5526 & TRN & & \\
\hline CHEMBL3908087 & 1642145 & 3.9529 & 3.3556 & TST & & \\
\hline CHEMBL3986190 & 1642145 & 2.699 & 3.8016 & TST & & \\
\hline CHEMBL3968328 & 1642145 & 4.8729 & 4.5608 & TRN & & \\
\hline CHEMBL3950331 & 1642145 & 4.9586 & 5.2036 & TRN & & \\
\hline CHEMBL3930984 & 1642145 & 5.76200 & 00000000 & 205 & 5.5305 & TRN \\
\hline CHEMBL3971267 & 1642145 & 4.83 & 4.5632 & TST & & \\
\hline CHEMBL3924186 & 1642145 & 4.678 & 4.8738 & TST & & \\
\hline CHEMBL3925927 & 1642145 & 6.0 & 5.3304 & TRN & & \\
\hline CHEMBL3898845 & 1642145 & 4.3193 & 4.4971 & TRN & & \\
\hline CHEMBL 3935725 & 1642145 & 4.6325 & 5.0037 & TRN & & \\
\hline CHEMBL3928851 & 1642145 & 4.1861 & 4.0187 & TRN & & \\
\hline CHEMBL3950407 & 1642145 & 5.2557 & 5.4989 & TRN & & \\
\hline CHEMBL3969658 & 1642145 & 4.4225 & 4.2213 & TST & & \\
\hline CHEMBL3983370 & 1642145 & 5.8539 & 5.9151 & TRN & & \\
\hline CHEMBL 3957570 & 1642145 & 5.5482 & 5.7298 & TRN & & \\
\hline CHEMBL3960753 & 1642145 & 3.9508 & 3.8615 & TRN & & \\
\hline CHEMBL3893184 & 1642145 & 4.6112 & 4.0715 & TST & & \\
\hline CHEMBL3942878 & 1642145 & 4.2592 & 4.1639 & TRN & & \\
\hline CHEMBL3976287 & 1642145 & 4.2887 & 4.4482 & TST & & \\
\hline CHEMBL3986270 & 1642145 & 4.2476 & 4.4267 & TST & & \\
\hline CHEMBL3953733 & 1642145 & 3.699 & 3.4197 & TRN & & \\
\hline CHEMBL3901774 & 1642145 & 5.2226 & 4.9863 & TRN & & \\
\hline CHEMBL3935577 & 1642145 & 4.1998 & 4.1416 & TRN & & \\
\hline CHEMBL3904422 & 1642145 & 4.9851 & 5.271 & TRN & & \\
\hline CHEMBL3971858 & 1642145 & 5.6757 & 5.5967 & TRN & & \\
\hline CHEMBL3933571 & 1642145 & 4.561 & 4.3684 & TRN & & \\
\hline CHEMBL3984390 & 1642145 & 3.7169 & 4.4135 & TST & & \\
\hline CHEMBL3909207 & 1642145 & 4.2779 & 4.6229 & TRN & & \\
\hline CHEMBL3893046 & 1642145 & 3.699 & 3.8399 & TRN & & \\
\hline CHEMBL3970083 & 1642145 & 3.8021 & 4.0778 & TST & & \\
\hline CHEMBL 3942423 & 1642145 & 4.1101 & 4.3687 & TST & & \\
\hline CHEMBL3922989 & 1642145 & 4.7314 & 4.7418 & TRN & & \\
\hline CHEMBL3919762 & 1642145 & 4.3507 & 4.7082 & TRN & & \\
\hline CHEMBL3975703 & 1642145 & 3.737 & 4.0583 & TRN & & \\
\hline CHEMBL3928868 & 1642145 & 4.2715 & 4.4782 & TRN & & \\
\hline CHEMBL3978003 & 1642145 & 4.5711 & 4.7466 & TRN & & \\
\hline CHEMBL3960202 & 1642145 & 4.7095 & 4.8097 & TRN & & \\
\hline
\end{tabular}

Page 17178 
Supplemental Table S2.txt

\begin{tabular}{|c|c|c|c|c|c|}
\hline CHEMBL3971099 & 1642145 & 3.699 & 3.8835 & TRN & \\
\hline CHEMBL3909910 & 1642145 & 6.0 & 5.2815 & TRN & \\
\hline CHEMBL3942261 & 1642145 & 5.5607 & 5.7671 & TRN & \\
\hline CHEMBL 3943957 & 1642145 & 5.4559 & 5.0724 & TRN & \\
\hline CHEMBL3911949 & 1642145 & 5.4034 & 5.345 & TRN & \\
\hline CHEMBL3915762 & 1642145 & 4.9234 & 4.7798 & TRN & \\
\hline CHEMBL3924752 & 1642145 & 4.5397 & 4.3829 & TRN & \\
\hline CHEMBL 3976225 & 1642145 & 5.6615 & 5.7271 & TRN & \\
\hline CHEMBL3926169 & 1642145 & 5.7905 & 5.5638 & TST & \\
\hline CHEMBL567204 & 591253 & 7.5003 & 7.5855 & TRN & \\
\hline CHEMBL575464 & 591253 & 7.3001 & 6.8451 & TRN & \\
\hline CHEMBL574592 & 591253 & 5.5 & 5.3618 & TRN & \\
\hline CHEMBL565703 & 591253 & 6.6003 & 6.4067 & TRN & \\
\hline CHEMBL565689 & 591253 & 6.9031 & 6.4938 & TST & \\
\hline CHEMBL572509 & 591253 & 6.1002 & 6.2724 & TRN & \\
\hline CHEMBL568526 & 591253 & 7.5003 & 7.71399 & 99999999995 & TRN \\
\hline CHEMBL567215 & 591253 & 6.2007 & 6.2442 & TRN & \\
\hline CHEMBL567214 & 591253 & 6.3002 & 6.3198 & TRN & \\
\hline CHEMBL566547 & 591253 & 6.9031 & 6.5797 & TRN & \\
\hline CHEMBL565891 & 591253 & 7.0 & 6.86600 & 00000000005 & TRN \\
\hline CHEMBL565903 & 591253 & 7.3002 & 6.8977 & TRN & \\
\hline CHEMBL574164 & 591253 & 6.8013 & 6.9193 & TRN & \\
\hline CHEMBL583428 & 591253 & 6.0 & 6.0276 & TRN & \\
\hline CHEMBL338047 & 591253 & 6.6003 & 5.1792 & TST & \\
\hline CHEMBL574141 & 591253 & 6.7011 & 6.4654 & TRN & \\
\hline CHEMBL568496 & 591253 & 6.9031 & 6.6705 & TRN & \\
\hline CHEMBL573699 & 591253 & 6.5003 & 6.6459 & TRN & \\
\hline CHEMBL577276 & 591253 & 6.9031 & 6.9526 & TRN & \\
\hline CHEMBL584137 & 591253 & 6.2007 & 6.2611 & TRN & \\
\hline CHEMBL566750 & 591253 & 6.9031 & 7.032 & TRN & \\
\hline CHEMBL573960 & 591253 & 5.6002 & 5.6223 & TRN & \\
\hline CHEMBL578764 & 591253 & 7.4001 & 7.3182 & TRN & \\
\hline CHEMBL566555 & 591253 & 7.0 & 6.8498 & TRN & \\
\hline CHEMBL366692 & 591253 & 6.8013 & 5.6171 & TST & \\
\hline CHEMBL565702 & 591253 & 6.9031 & 6.9083 & TRN & \\
\hline CHEMBL566751 & 591253 & 6.8013 & 6.6924 & TRN & \\
\hline CHEMBL574834 & 591253 & 6.9031 & 6.7997 & TRN & \\
\hline CHEMBL576592 & 591253 & 6.6003 & 6.4683 & TRN & \\
\hline CHEMBL233664 & 591253 & 7.3002 & 6.659 & TRN & \\
\hline CHEMBL572507 & 591253 & 7.3001 & 7.6612 & TRN & \\
\hline CHEMBL573700 & 591253 & 5.9003 & 5.8739 & TRN & \\
\hline CHEMBL578376 & 591253 & 6.5003 & 7.1288 & TRN & \\
\hline CHEMBL565712 & 591253 & 5.5 & 5.6436 & TRN & \\
\hline CHEMBL568065 & 591253 & 7.3002 & 7.0432 & TRN & \\
\hline CHEMBL574163 & 591253 & 7.5003 & 7.4149 & TRN & \\
\hline CHEMBL573467 & 591253 & 6.5003 & 6.6528 & TRN & \\
\hline CHEMBL583425 & 591253 & 6.8013 & 6.3952 & TST & \\
\hline CHEMBL584409 & 591253 & 7.8013 & 7.6768 & TRN & \\
\hline
\end{tabular}




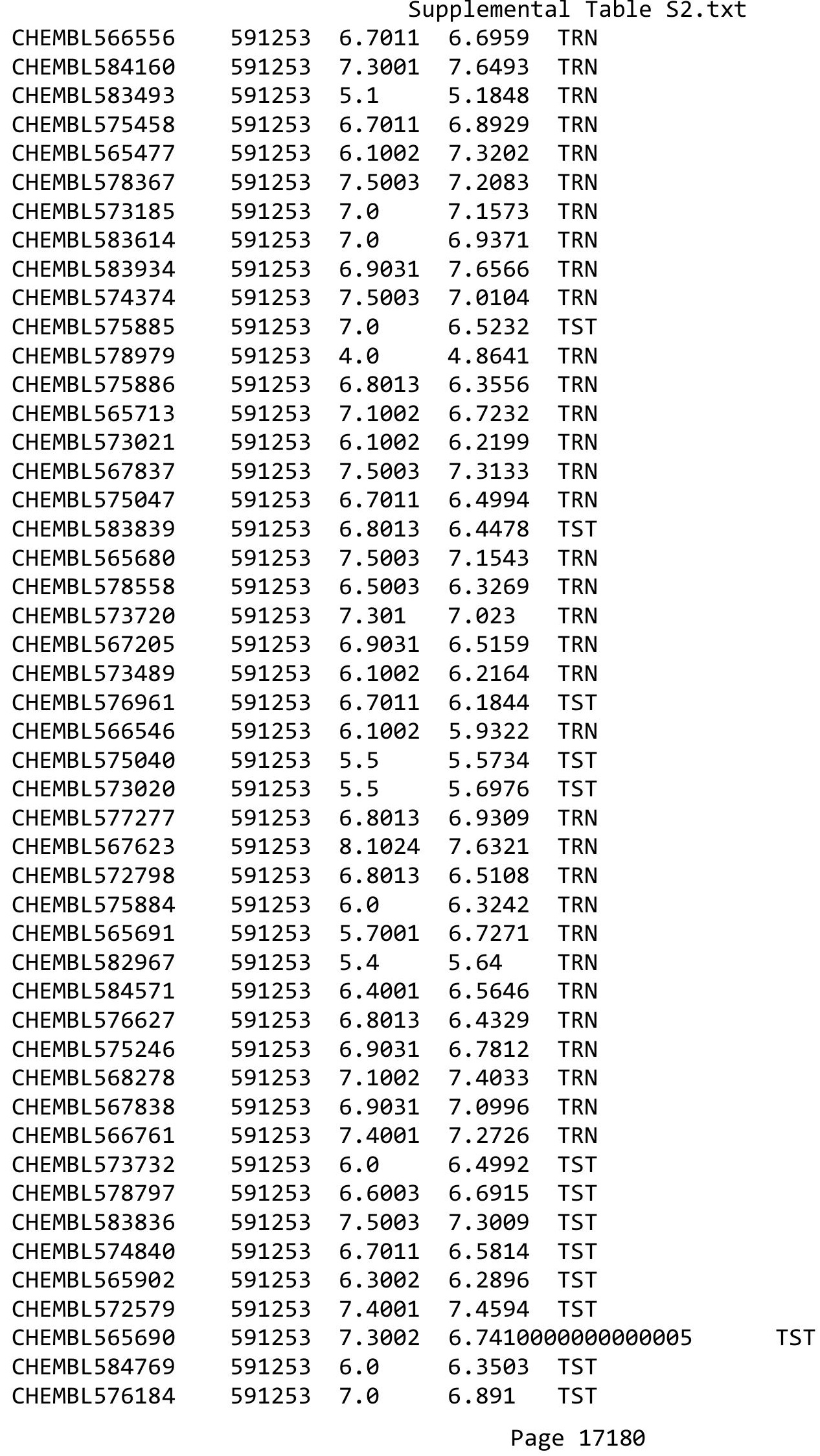




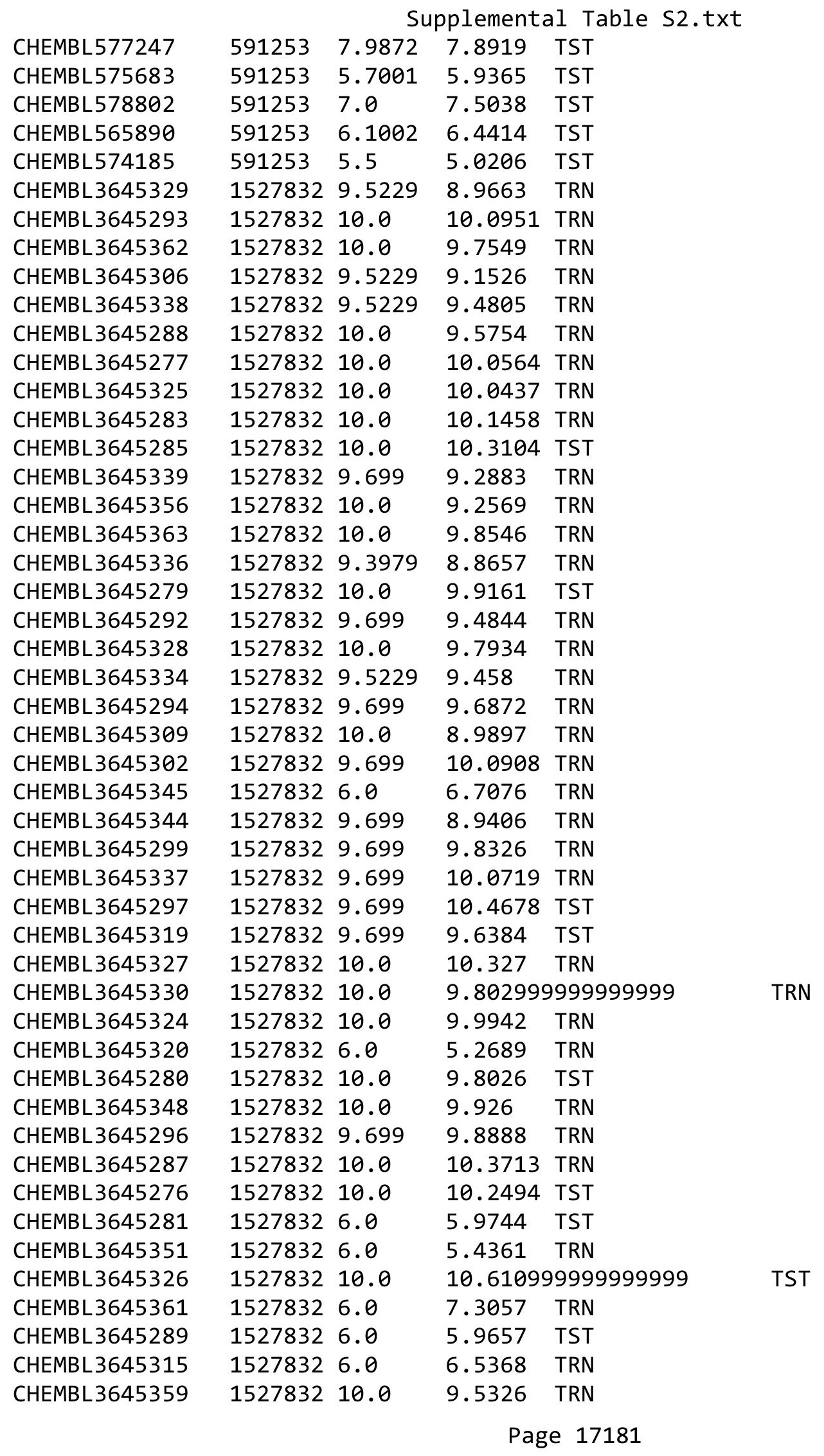




\begin{tabular}{|c|c|c|c|c|c|c|}
\hline \multicolumn{7}{|c|}{ Supplemental Table S2.txt } \\
\hline CHEMBL 3645353 & 1527832 & 6.0 & 5.7344 & TRN & & \\
\hline CHEMBL 3645274 & 1527832 & 10.0 & 10.1292 & TST & & \\
\hline CHEMBL 3645340 & 1527832 & 9.5229 & 9.5461 & TRN & & \\
\hline CHEMBL 3645298 & 1527832 & 10.0 & 10.207 & TRN & & \\
\hline CHEMBL 3645358 & 1527832 & 10.0 & 9.4599 & TRN & & \\
\hline CHEMBL 3645286 & 1527832 & 10.0 & 10.5444 & TST & & \\
\hline CHEMBL 3645278 & 1527832 & 10.0 & 10.5386 & TST & & \\
\hline CHEMBL 3645341 & 1527832 & 6.0 & 5.98 & TRN & & \\
\hline CHEMBL 3645284 & 1527832 & 10.0 & 10.1909 & TST & & \\
\hline CHEMBL3645331 & 1527832 & 6.0 & 8.9406 & TRN & & \\
\hline CHEMBL 3645312 & 1527832 & 9.699 & 9.2838 & TRN & & \\
\hline CHEMBL 3645275 & 1527832 & 10.0 & 10.1762 & TST & & \\
\hline CHEMBL3645349 & 1527832 & 6.0 & 5.2561 & TRN & & \\
\hline CHEMBL 3645360 & 1527832 & 10.0 & 8.9667 & TST & & \\
\hline CHEMBL3645364 & 1527832 & 10.0 & 9.7969 & TRN & & \\
\hline CHEMBL 3645357 & 1527832 & 9.699 & 9.9403 & TRN & & \\
\hline CHEMBL3645335 & 1527832 & 10.0 & 9.4862 & TRN & & \\
\hline CHEMBL 3645317 & 1527832 & 9.699 & 9.4705 & TST & & \\
\hline CHEMBL 3645311 & 1527832 & 6.0 & 6.8124 & TRN & & \\
\hline CHEMBL3645332 & 1527832 & 6.0 & 6.0247 & TRN & & \\
\hline CHEMBL 3645295 & 1527832 & 10.0 & 10.1799 & TRN & & \\
\hline CHEMBL 3645318 & 1527832 & 10.0 & 9.2438 & TST & & \\
\hline CHEMBL 3645322 & 1527832 & 6.0 & 7.2164 & TRN & & \\
\hline CHEMBL 3645310 & 1527832 & 9.699 & 9.8537 & TRN & & \\
\hline CHEMBL76119 & 214674 & 10.0969 & 10.2351 & TRN & & \\
\hline CHEMBL94107 & 214674 & 9.4559 & 9.211 & TRN & & \\
\hline CHEMBL 327701 & 214674 & 8.8447 & 8.7569 & TRN & & \\
\hline CHEMBL 313632 & 214674 & 9.5528 & 9.9247 & TRN & & \\
\hline CHEMBL 88608 & 214674 & 9.7959 & 9.4167 & TRN & & \\
\hline CHEMBL91172 & 214674 & 8.0 & 9.6073 & TST & & \\
\hline CHEMBL91319 & 214674 & 9.0458 & 9.2116 & TRN & & \\
\hline CHEMBL 90198 & 214674 & 9.8239 & 9.7807 & TRN & & \\
\hline CHEMBL 330340 & 214674 & 9.283999 & 99999999 & 99 & 9.2625 & TRN \\
\hline CHEMBL 90995 & 214674 & 6.7167 & 7.1927 & TRN & & \\
\hline CHEMBL91031 & 214674 & 9.301 & 9.2603 & TRN & & \\
\hline CHEMBL88478 & 214674 & 9.8861 & 9.8848 & TST & & \\
\hline CHEMBL90580 & 214674 & 9.6576 & 9.6924 & TRN & & \\
\hline CHEMBL 91572 & 214674 & 9.3979 & 9.3598 & TRN & & \\
\hline CHEMBL91877 & 214674 & 9.9586 & 10.0621 & TRN & & \\
\hline CHEMBL92106 & 214674 & 8.9914 & 9.0411 & TRN & & \\
\hline CHEMBL329356 & 214674 & 8.8153 & 8.7753 & TRN & & \\
\hline CHEMBL91737 & 214674 & 10.0458 & 10.1066 & TRN & & \\
\hline CHEMBL 92200 & 214674 & 8.9508 & 9.0362 & TRN & & \\
\hline CHEMBL91775 & 214674 & 9.6383 & 9.591006 & 0000000001 & & TRN \\
\hline CHEMBL328973 & 214674 & 9.6198 & 9.5605 & TRN & & \\
\hline CHEMBL56511 & 214674 & 10.0969 & 9.7917 & TRN & & \\
\hline CHEMBL424616 & 214674 & 9.8861 & 10.1807 & TRN & & \\
\hline CHEMBL90315 & 214674 & 9.6576 & 9.1341 & TRN & & \\
\hline
\end{tabular}




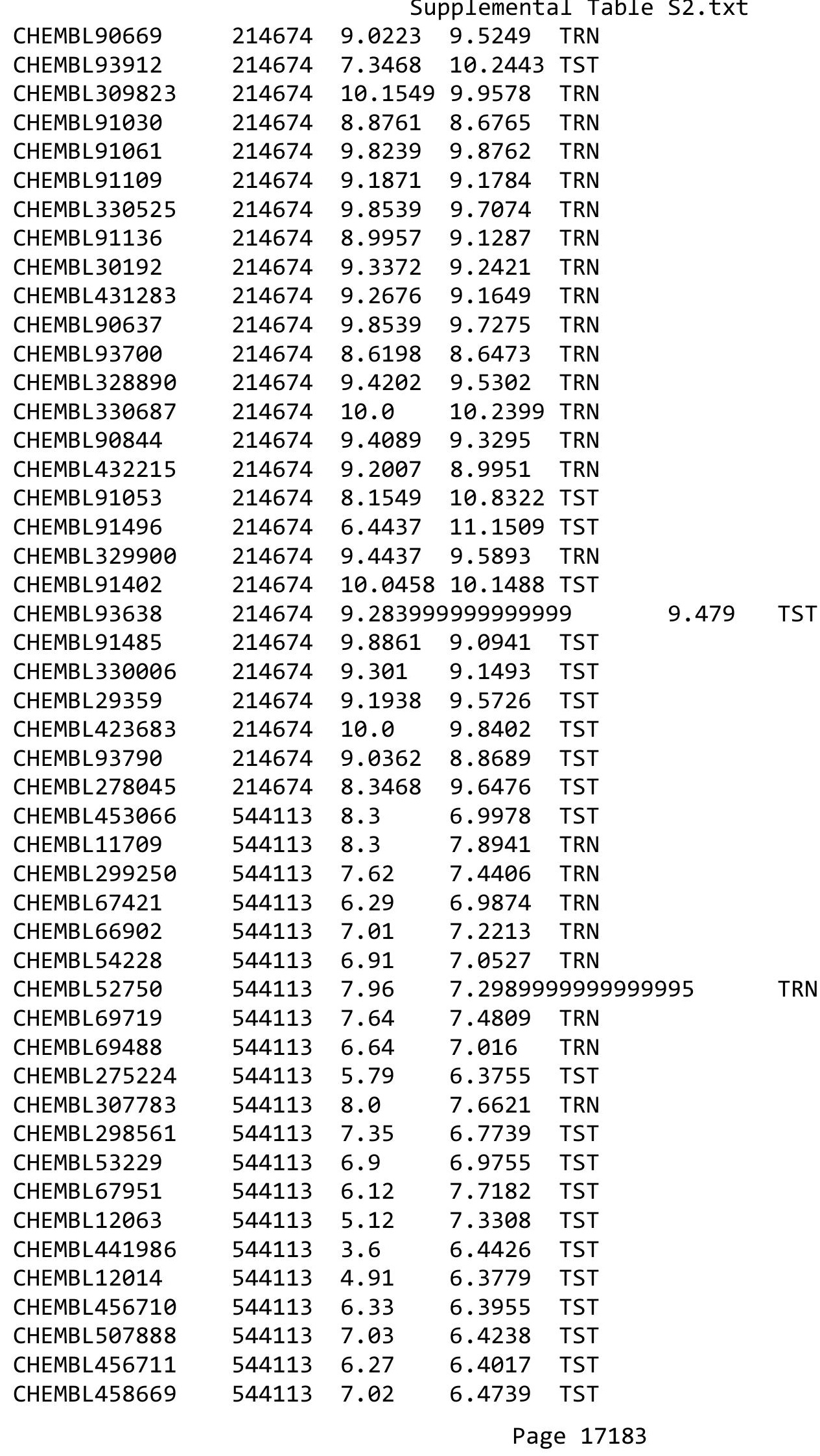




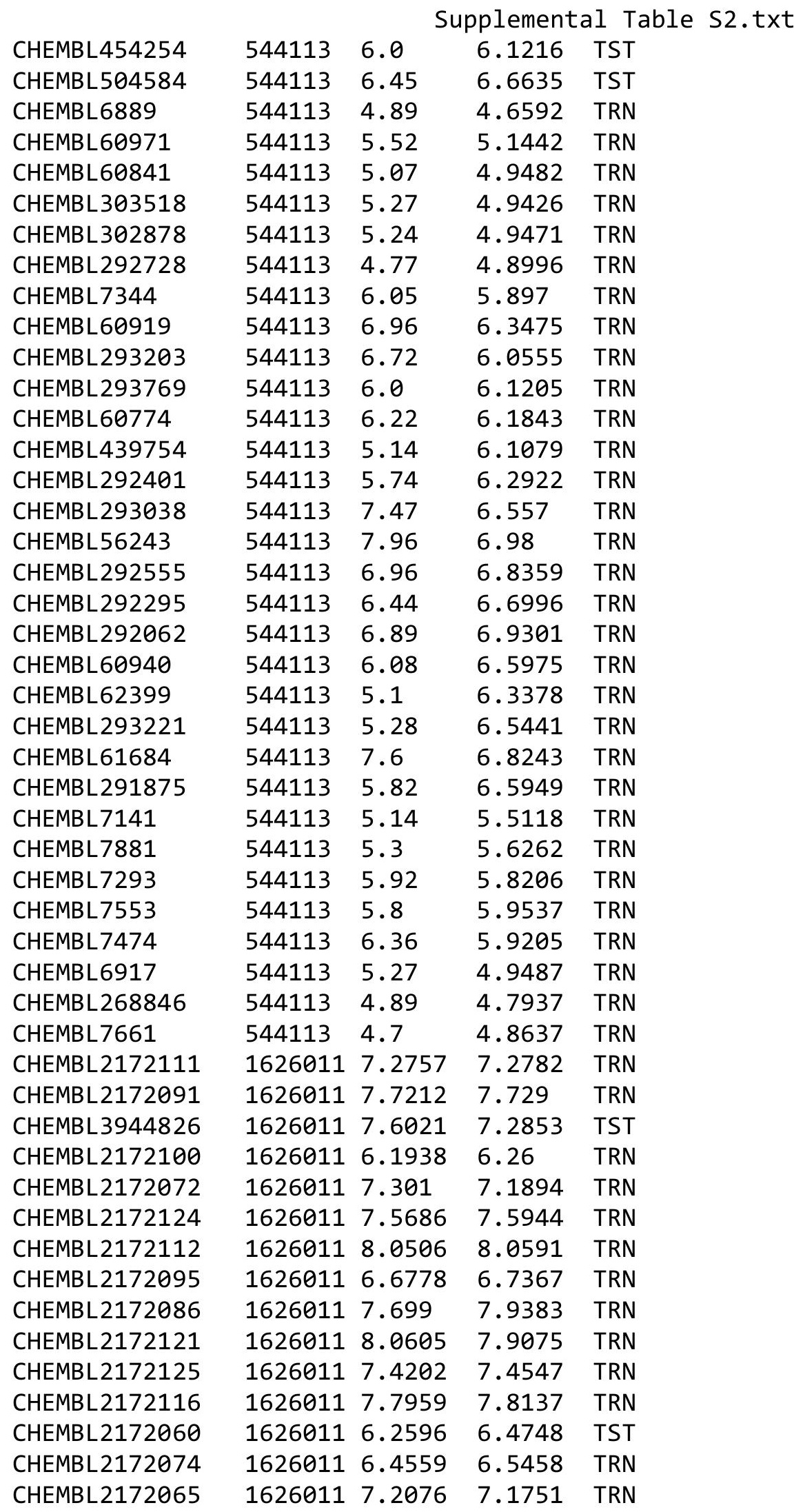

Page 17184 
Supplemental Table S2.txt

\begin{tabular}{|c|c|c|c|c|c|}
\hline CHEMBL 2172088 & 1626011 & 7.8539 & 7.6243 & TRN & \\
\hline CHEMBL 2172079 & 1626011 & 6.4202 & 6.7781 & TST & \\
\hline CHEMBL2169909 & 1626011 & 6.6576 & 6.7062 & TRN & \\
\hline CHEMBL 2172106 & 1626011 & 6.699 & 6.6618 & TRN & \\
\hline CHEMBL 2172093 & 1626011 & 7.3768 & 7.4016 & TRN & \\
\hline CHEMBL 2172096 & 1626011 & 6.8539 & 6.7867 & TRN & \\
\hline CHEMBL 2172107 & 1626011 & 6.2218 & 6.801 & TST & \\
\hline CHEMBL1698807 & 1626011 & 5.9066 & 5.925 & TRN & \\
\hline CHEMBL 2172085 & 1626011 & 7.6778 & 7.7759 & TRN & \\
\hline CHEMBL 2172122 & 1626011 & 8.2147 & 7.9769 & TRN & \\
\hline CHEMBL1443272 & 1626011 & 7.3279 & 7.4255 & TRN & \\
\hline CHEMBL 3935879 & 1626011 & 7.8861 & 7.5365 & TST & \\
\hline CHEMBL3941773 & 1626011 & 5.8827 & 5.8457 & TRN & \\
\hline CHEMBL 2172113 & 1626011 & 7.9586 & 7.9466 & TRN & \\
\hline CHEMBL2172119 & 1626011 & 7.6576 & 7.6634 & TRN & \\
\hline CHEMBL 2172092 & 1626011 & 6.7959 & 6.9602 & TRN & \\
\hline CHEMBL1871992 & 1626011 & 6.6576 & 6.5193 & TRN & \\
\hline CHEMBL 3907919 & 1626011 & 6.4089 & 7.2549 & TST & \\
\hline CHEMBL 3923444 & 1626011 & 7.1079 & 7.055 & TRN & \\
\hline CHEMBL 2172061 & 1626011 & 6.1308 & 7.1611 & TST & \\
\hline CHEMBL 2172094 & 1626011 & 6.4815 & 6.1779 & TST & \\
\hline CHEMBL 2172084 & 1626011 & 7.7696 & 7.6969 & TRN & \\
\hline CHEMBL 2172123 & 1626011 & 7.4089 & 7.5934 & TRN & \\
\hline CHEMBL 2172221 & 1626011 & 7.3768 & 7.3802 & TRN & \\
\hline CHEMBL 2172081 & 1626011 & 6.301 & 6.631 & TST & \\
\hline CHEMBL 2172098 & 1626011 & 5.8416 & 6.3751 & TST & \\
\hline CHEMBL 3953458 & 1626011 & 7.3768 & 6.9108 & TST & \\
\hline CHEMBL 2172068 & 1626011 & 6.7696 & 6.7449 & TRN & \\
\hline CHEMBL 2172099 & 1626011 & 6.2757 & 6.4937 & TST & \\
\hline CHEMBL 2172110 & 1626011 & 8.0655 & 8.1324 & TRN & \\
\hline CHEMBL 2172114 & 1626011 & 7.9586 & 7.9928 & TRN & \\
\hline CHEMBL 2172064 & 1626011 & 4.6126 & 6.5285 & TST & \\
\hline CHEMBL 2172071 & 1626011 & 6.0458 & 6.0164 & TRN & \\
\hline CHEMBL 2172097 & 1626011 & 6.1308 & 6.4805 & TST & \\
\hline CHEMBL 2172063 & 1626011 & 6.4089 & 6.8611 & TST & \\
\hline CHEMBL2172117 & 1626011 & 7.7959 & 7.7241 & TRN & \\
\hline CHEMBL 2172225 & 1626011 & 6.6778 & 6.6197 & TRN & \\
\hline CHEMBL 2172090 & 1626011 & 7.5376 & 7.4815 & TRN & \\
\hline CHEMBL 2172087 & 1626011 & 7.9208 & 7.9999 & TRN & \\
\hline CHEMBL 2172108 & 1626011 & 7.1675 & 6.1805 & TST & \\
\hline CHEMBL 2172073 & 1626011 & 7.2757 & 7.2523 & TRN & \\
\hline CHEMBL 2172115 & 1626011 & 7.8539 & 7.91299 & 9999999999 & TRN \\
\hline CHEMBL 2172075 & 1626011 & 7.2366 & 7.2871 & TRN & \\
\hline CHEMBL 2172220 & 1626011 & 7.8861 & 7.7698 & TRN & \\
\hline CHEMBL 2172120 & 1626011 & 7.5376 & 7.4493 & TRN & \\
\hline CHEMBL 3984247 & 1626011 & 6.3468 & 6.4395 & TRN & \\
\hline CHEMBL 2172118 & 1626011 & 7.7696 & 7.7505 & TRN & \\
\hline CHEMBL 2172089 & 1626011 & 7.4685 & 7.4885 & TRN & \\
\hline
\end{tabular}

Page 17185 


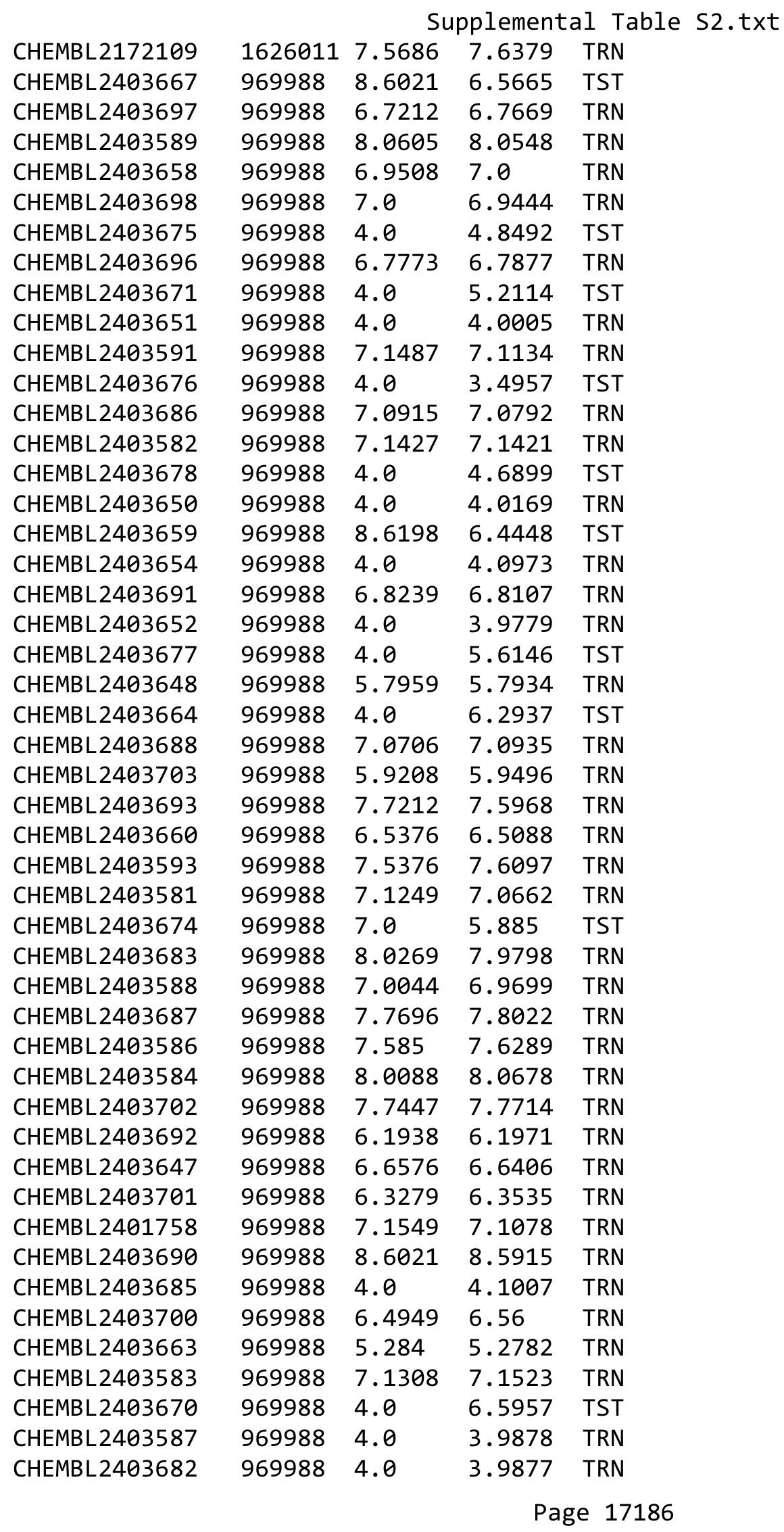




\begin{tabular}{|c|c|c|c|c|c|}
\hline \multirow{2}{*}{ CHEMBL 2403657} & & \multicolumn{4}{|c|}{ Supplemental Table s2.txt } \\
\hline & 969988 & 6.6021 & 6.66799 & 9999999999 & TRN \\
\hline CHEMBL 2403661 & 969988 & 5.6021 & 7.5629 & TST & \\
\hline CHEMBL 2403662 & 969988 & 5.8239 & 6.5418 & TST & \\
\hline CHEMBL 2403699 & 969988 & 6.5376 & 6.6232 & TRN & \\
\hline CHEMBL 2403684 & 969988 & 8.4089 & 8.3781 & TRN & \\
\hline CHEMBL 2403695 & 969988 & 6.1024 & 5.9725 & TRN & \\
\hline CHEMBL 2403649 & 969988 & 4.0 & 3.9888 & TRN & \\
\hline CHEMBL 2403592 & 969988 & 7.9586 & 7.9851 & TRN & \\
\hline CHEMBL 2403656 & 969988 & 4.0 & 3.8413 & TRN & \\
\hline CHEMBL 2403672 & 969988 & 4.0 & 4.9032 & TST & \\
\hline CHEMBL 2403594 & 969988 & 6.7959 & 6.7326 & TRN & \\
\hline CHEMBL 2403668 & 969988 & 4.0 & 3.2965 & TST & \\
\hline CHEMBL 2403655 & 969988 & 6.8239 & 6.7887 & TRN & \\
\hline CHEMBL 2403689 & 969988 & 7.7447 & 7.7575 & TRN & \\
\hline CHEMBL 2403585 & 969988 & 7.2757 & 7.2819 & TRN & \\
\hline CHEMBL 2403590 & 969988 & 7.5229 & 7.5209 & TRN & \\
\hline CHEMBL 2403665 & 969988 & 4.0 & 6.5193 & TST & \\
\hline CHEMBL 2403679 & 969988 & 4.0 & 6.021 & TST & \\
\hline CHEMBL 2403653 & 969988 & 4.0 & 4.093 & TRN & \\
\hline CHEMBL 2403673 & 969988 & 6.9586 & 7.2147 & TST & \\
\hline CHEMBL 2403681 & 969988 & 4.0 & 3.9588 & TRN & \\
\hline CHEMBL 2403680 & 969988 & 4.0 & 4.0569 & TRN & \\
\hline CHEMBL 2403580 & 969988 & 4.0 & 3.9384 & TRN & \\
\hline CHEMBL 2403669 & 969988 & 7.4685 & 6.3564 & TST & \\
\hline CHEMBL 2403666 & 969988 & 7.2924 & 6.5897 & TST & \\
\hline CHEMBL 2403694 & 969988 & 6.8861 & 6.8964 & TRN & \\
\hline CHEMBL181888 & 305569 & 6.2757 & 6.7728 & TST & \\
\hline CHEMBL360104 & 305569 & 8.7212 & 8.9218 & TRN & \\
\hline CHEMBL181720 & 305569 & 7.2757 & 7.2087 & TRN & \\
\hline CHEMBL180360 & 305569 & 8.7447 & 8.5996 & TRN & \\
\hline CHEMBL181164 & 305569 & 7.4949 & 7.5832 & TRN & \\
\hline CHEMBL426241 & 305569 & 8.1549 & 8.0975 & TRN & \\
\hline CHEMBL181875 & 305569 & 8.5086 & 8.6173 & TRN & \\
\hline CHEMBL180507 & 305569 & 6.4685 & 6.65799 & 99999999995 & TRN \\
\hline CHEMBL362215 & 305569 & 7.1805 & 7.1016 & TRN & \\
\hline CHEMBL 362650 & 305569 & 6.6778 & 6.5816 & TRN & \\
\hline CHEMBL360783 & 305569 & 8.5376 & 8.6659 & TRN & \\
\hline CHEMBL 360673 & 305569 & 7.4559 & 7.2371 & TRN & \\
\hline CHEMBL182241 & 305569 & 6.3188 & 6.4561 & TRN & \\
\hline CHEMBL361003 & 305569 & 6.3979 & 6.439 & TRN & \\
\hline CHEMBL178243 & 305569 & 7.2366 & 7.1864 & TRN & \\
\hline CHEMBL181016 & 305569 & 6.6778 & 7.0096 & TST & \\
\hline CHEMBL182141 & 305569 & 7.5086 & 7.6083 & TST & \\
\hline CHEMBL180028 & 305569 & 7.3872 & 7.5887 & TRN & \\
\hline CHEMBL178446 & 305569 & 7.7447 & 7.8015 & TRN & \\
\hline CHEMBL361785 & 305569 & 7.7447 & 7.817 & TRN & \\
\hline CHEMBL359865 & 305569 & 8.4559 & 8.5963 & TRN & \\
\hline CHEMBL180447 & 305569 & 7.4949 & 7.8266 & TST & \\
\hline
\end{tabular}




\begin{tabular}{|c|c|c|c|c|c|}
\hline & & \multicolumn{4}{|c|}{ Supplemental Table S2.txt } \\
\hline CHEMBL360474 & 305569 & 7.3665 & 7.6024 & TRN & \\
\hline CHEMBL 2113009 & 305569 & 8.2366 & 8.3328 & TRN & \\
\hline CHEMBL180409 & 305569 & 8.1427 & 8.1892 & TRN & \\
\hline CHEMBL359500 & 305569 & 7.284 & 7.2389 & TRN & \\
\hline CHEMBL179779 & 305569 & 7.7447 & 7.6576 & TRN & \\
\hline CHEMBL181629 & 305569 & 8.2007 & 8.4217 & TST & \\
\hline CHEMBL360723 & 305569 & 8.4685 & 8.1756 & TRN & \\
\hline CHEMBL179787 & 305569 & 8.0969 & 7.946006 & 0000000001 & TST \\
\hline CHEMBL182948 & 305569 & 7.7696 & 7.90799 & 99999999995 & TRN \\
\hline CHEMBL362192 & 305569 & 8.8239 & 8.6201 & TRN & \\
\hline CHEMBL180252 & 305569 & 5.2218 & 6.5705 & TST & \\
\hline CHEMBL362219 & 305569 & 8.5686 & 8.0231 & TST & \\
\hline CHEMBL425163 & 305569 & 8.7696 & 8.749 & TRN & \\
\hline CHEMBL361519 & 305569 & 8.4685 & 8.3462 & TST & \\
\hline CHEMBL181088 & 305569 & 5.5528 & 7.3218 & TST & \\
\hline CHEMBL367819 & 305569 & 8.8861 & 8.3926 & TST & \\
\hline CHEMBL180394 & 305569 & 8.28399 & 99999999 & 8.2984 & TRN \\
\hline CHEMBL180648 & 305569 & 7.0223 & 7.2371 & TRN & \\
\hline CHEMBL360763 & 305569 & 8.8539 & 8.4299 & TRN & \\
\hline CHEMBL360711 & 305569 & 7.1871 & 7.1608 & TRN & \\
\hline CHEMBL361020 & 305569 & 8.7447 & 8.7622 & TRN & \\
\hline CHEMBL 361152 & 305569 & 7.6576 & 7.4225 & TRN & \\
\hline CHEMBL180564 & 305569 & 7.2518 & 6.9522 & TRN & \\
\hline CHEMBL180154 & 305569 & 6.3372 & 6.2128 & TRN & \\
\hline CHEMBL178987 & 305569 & 5.699 & 7.0201 & TST & \\
\hline CHEMBL179901 & 305569 & 8.8861 & 9.0892 & TRN & \\
\hline CHEMBL361119 & 305569 & 7.9586 & 7.925 & TST & \\
\hline CHEMBL425527 & 305569 & 8.5086 & 8.2994 & TST & \\
\hline CHEMBL180861 & 305569 & 7.6778 & 7.9134 & TRN & \\
\hline CHEMBL180077 & 305569 & 5.8861 & 6.0791 & TRN & \\
\hline CHEMBL425870 & 305569 & 8.7212 & 8.4164 & TRN & \\
\hline CHEMBL426601 & 305569 & 8.2218 & 8.2388 & TRN & \\
\hline CHEMBL138666 & 208672 & 5.6576 & 5.6232 & TRN & \\
\hline CHEMBL139190 & 208672 & 8.1192 & 7.9351 & TRN & \\
\hline CHEMBL140299 & 208672 & 8.8239 & 8.6387 & TRN & \\
\hline CHEMBL137255 & 208672 & 8.6383 & 8.8922 & TRN & \\
\hline CHEMBL135028 & 208672 & 7.8239 & 7.3967 & TRN & \\
\hline CHEMBL344646 & 208672 & 8.4815 & 8.2891 & TRN & \\
\hline CHEMBL139903 & 208672 & 8.1938 & 8.1621 & TRN & \\
\hline CHEMBL140303 & 208672 & 6.8861 & 6.9549 & TRN & \\
\hline CHEMBL136305 & 208672 & 8.7959 & 8.7933 & TRN & \\
\hline CHEMBL139057 & 208672 & 7.7959 & 7.534 & TRN & \\
\hline CHEMBL336261 & 208672 & 8.3372 & 8.7165 & TRN & \\
\hline CHEMBL 137580 & 208672 & 8.7447 & 8.5756 & TRN & \\
\hline CHEMBL138825 & 208672 & 8.7696 & 8.6325 & TRN & \\
\hline CHEMBL138130 & 208672 & 6.8861 & 7.095 & TRN & \\
\hline CHEMBL335788 & 208672 & 8.699 & 8.6238 & TRN & \\
\hline CHEMBL336715 & 208672 & 7.9208 & 7.8511 & TST & \\
\hline
\end{tabular}




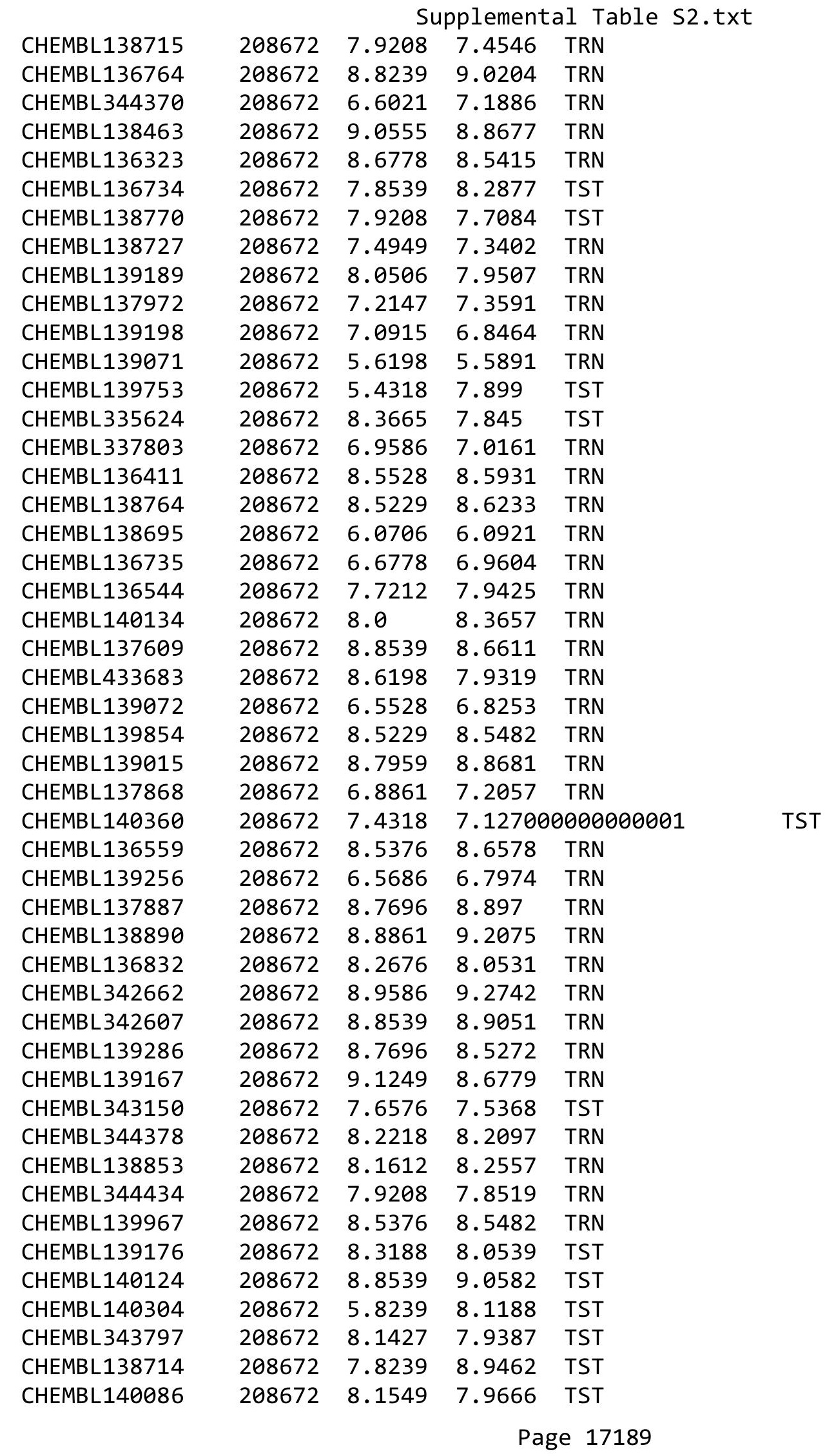




\begin{tabular}{|c|c|c|c|c|c|}
\hline \multicolumn{6}{|c|}{ Supplemental Table S2.txt } \\
\hline CHEMBL139569 & 208672 & 8.301 & 7.7607 & TST & \\
\hline CHEMBL137792 & 208672 & 6.8539 & 7.7791 & TST & \\
\hline CHEMBL139226 & 208672 & 8.7447 & 9.1437 & TST & \\
\hline CHEMBL138269 & 208672 & 7.8539 & 8.5064 & TST & \\
\hline CHEMBL140023 & 208672 & 8.28399 & 99999999 & 8.4016 & TST \\
\hline CHEMBL 3113748 & 1290418 & 7.5528 & 7.5527 & TRN & \\
\hline CHEMBL3113771 & 1290418 & 6.9136 & 6.91700 & 0000000001 & TRN \\
\hline CHEMBL3113746 & 1290418 & 8.699 & 8.6973 & TRN & \\
\hline CHEMBL3113767 & 1290418 & 6.1129 & 6.1127 & TRN & \\
\hline CHEMBL3113551 & 1290418 & 6.295 & 6.2928 & TRN & \\
\hline CHEMBL3113749 & 1290418 & 8.0458 & 8.0443 & TRN & \\
\hline CHEMBL3113544 & 1290418 & 7.6778 & 7.0001 & TST & \\
\hline CHEMBL3113755 & 1290418 & 7.1871 & 7.1895 & TRN & \\
\hline CHEMBL3113759 & 1290418 & 6.0487 & 6.046 & TRN & \\
\hline CHEMBL3113536 & 1290418 & 6.8125 & 6.8143 & TRN & \\
\hline CHEMBL3113547 & 1290418 & 7.5376 & 7.5463 & TRN & \\
\hline CHEMBL3113757 & 1290418 & 6.2299 & 6.2305 & TRN & \\
\hline CHEMBL3113552 & 1290418 & 7.3279 & 7.3288 & TRN & \\
\hline CHEMBL3113754 & 1290418 & 7.0315 & 7.0305 & TRN & \\
\hline CHEMBL3113772 & 1290418 & 7.7959 & 7.7964 & TRN & \\
\hline CHEMBL3113539 & 1290418 & 6.4034 & 6.4048 & TRN & \\
\hline CHEMBL3113752 & 1290418 & 8.5229 & 8.5234 & TRN & \\
\hline CHEMBL3112599 & 1290418 & 4.0 & 6.6374 & TST & \\
\hline CHEMBL3113549 & 1290418 & 7.1427 & 7.1412 & TRN & \\
\hline CHEMBL3113773 & 1290418 & 6.8013 & 6.8004 & TRN & \\
\hline CHEMBL 3113534 & 1290418 & 6.1972 & 6.1963 & TRN & \\
\hline CHEMBL3113537 & 1290418 & 6.7932 & 6.7942 & TRN & \\
\hline CHEMBL3113550 & 1290418 & 7.5528 & 7.556 & TRN & \\
\hline CHEMBL3113751 & 1290418 & 8.2218 & 8.2207 & TRN & \\
\hline CHEMBL3113766 & 1290418 & 6.5986 & 6.5944 & TRN & \\
\hline CHEMBL3113760 & 1290418 & 6.5272 & 6.5277 & TRN & \\
\hline CHEMBL3113750 & 1290418 & 7.0969 & 7.0992 & TRN & \\
\hline CHEMBL3113775 & 1290418 & 7.1308 & 7.1295 & TRN & \\
\hline CHEMBL 3113545 & 1290418 & 7.0269 & 7.0304 & TRN & \\
\hline CHEMBL3113535 & 1290418 & 6.5719 & 6.5703 & TRN & \\
\hline CHEMBL3113744 & 1290418 & 7.4685 & 7.4709 & TRN & \\
\hline CHEMBL3113768 & 1290418 & 4.0 & 6.1094 & TST & \\
\hline CHEMBL3113546 & 1290418 & 7.4559 & 7.4554 & TRN & \\
\hline CHEMBL3113761 & 1290418 & 5.8891 & 5.8905 & TRN & \\
\hline CHEMBL3113740 & 1290418 & 5.9991 & 5.9973 & TRN & \\
\hline CHEMBL3113747 & 1290418 & 7.7212 & 7.7191 & TRN & \\
\hline CHEMBL3113742 & 1290418 & 8.3979 & 8.3983 & TRN & \\
\hline CHEMBL3113762 & 1290418 & 5.9666 & 5.9694 & TRN & \\
\hline CHEMBL 3113540 & 1290418 & 6.9747 & 6.9726 & TRN & \\
\hline CHEMBL 3113741 & 1290418 & 7.9208 & 7.9185 & TRN & \\
\hline CHEMBL3113769 & 1290418 & 5.9706 & 6.4055 & TST & \\
\hline CHEMBL3113745 & 1290418 & 8.0969 & 8.0967 & TRN & \\
\hline CHEMBL3113756 & 1290418 & 7.0655 & 7.0651 & TRN & \\
\hline
\end{tabular}


Supplemental Table S2.txt

\begin{tabular}{|c|c|c|c|c|c|}
\hline CHEMBL 3113548 & 1290418 & 7.3768 & 7.3693 & TRN & \\
\hline CHEMBL3113739 & 1290418 & 6.6635 & 6.5932 & TST & \\
\hline CHEMBL3113758 & 1290418 & 6.3872 & 6.5301 & TST & \\
\hline CHEMBL3113542 & 1290418 & 4.0 & 6.5849 & TST & \\
\hline CHEMBL3113753 & 1290418 & 8.2218 & 7.9668 & TST & \\
\hline CHEMBL3113538 & 1290418 & 7.4318 & 6.8948 & TST & \\
\hline CHEMBL 3113541 & 1290418 & 6.3809 & 7.2305 & TST & \\
\hline CHEMBL3113543 & 1290418 & 5.8758 & 6.8857 & TST & \\
\hline CHEMBL3113770 & 1290418 & 8.0458 & 7.5833 & TST & \\
\hline CHEMBL3113743 & 1290418 & 7.3665 & 7.9122 & TST & \\
\hline CHEMBL3113774 & 1290418 & 7.6021 & 7.1628 & TST & \\
\hline CHEMBL269218 & 28965 & 9.0969 & 9.1083 & TRN & \\
\hline CHEMBL11002 & 28965 & \multicolumn{3}{|c|}{10.300999999999998} & 10.3318 TRN \\
\hline CHEMBL62350 & 28965 & 8.5229 & 8.5566 & TRN & \\
\hline CHEMBL555624 & 28965 & 7.9872 & 7.7158 & TST & \\
\hline CHEMBL429032 & 28965 & 6.4559 & 6.4982 & TRN & \\
\hline CHEMBL 275793 & 28965 & 8.2596 & 8.2203 & TRN & \\
\hline CHEMBL 275262 & 28965 & 7.4365 & 7.4639 & TRN & \\
\hline CHEMBL10579 & 28965 & 7.5229 & 7.6574 & TST & \\
\hline CHEMBL 276603 & 28965 & 8.699 & 8.7316 & TST & \\
\hline CHEMBL 275263 & 28965 & 9.1249 & 9.2758 & TRN & \\
\hline CHEMBL11048 & 28965 & 7.301 & 7.3345 & TRN & \\
\hline CHEMBL 273295 & 28965 & 8.4815 & 8.4618 & TRN & \\
\hline CHEMBL27047 & 28965 & 8.699 & 8.6562 & TRN & \\
\hline CHEMBL11439 & 28965 & 7.699 & 7.7314 & TRN & \\
\hline CHEMBL415971 & 28965 & 9.8239 & 8.8616 & TST & \\
\hline CHEMBL 268701 & 28965 & 8.699 & 8.6751 & TRN & \\
\hline CHEMBL11332 & 28965 & 8.7447 & 8.8317 & TRN & \\
\hline CHEMBL 269633 & 28965 & 7.8861 & 7.9313 & TRN & \\
\hline CHEMBL158507 & 28965 & 9.1549 & 9.3832 & TRN & \\
\hline CHEMBL11120 & 28965 & 8.2596 & 8.2181 & TRN & \\
\hline CHEMBL11033 & 28965 & 8.0 & 8.0415 & TRN & \\
\hline CHEMBL11000 & 28965 & 8.0969 & 8.0707 & TRN & \\
\hline CHEMBL416884 & 28965 & 8.0969 & 8.1353 & TRN & \\
\hline CHEMBL11271 & 28965 & 8.8861 & 8.9125 & TRN & \\
\hline CHEMBL11146 & 28965 & 5.6021 & 5.5954 & TRN & \\
\hline CHEMBL11049 & 28965 & 8.1871 & 8.1756 & TRN & \\
\hline CHEMBL 274594 & 28965 & 7.5317 & 7.4485 & TST & \\
\hline CHEMBL415248 & 28965 & 8.0 & 8.0316 & TRN & \\
\hline CHEMBL11037 & 28965 & 8.6021 & 8.5488 & TRN & \\
\hline CHEMBL9069 & 28965 & 8.6021 & 8.5668 & TST & \\
\hline CHEMBL11206 & 28965 & 8.3768 & 7.6712 & TST & \\
\hline CHEMBL10937 & 28965 & 8.1871 & 8.1296 & TRN & \\
\hline CHEMBL11348 & 28965 & 8.5229 & 8.3388 & TRN & \\
\hline CHEMBL10984 & 28965 & 8.1549 & 7.4145 & TST & \\
\hline CHEMBL11177 & 28965 & 5.9416 & 5.9298 & TRN & \\
\hline CHEMBL11240 & 28965 & 7.0969 & 7.1317 & TST & \\
\hline CHEMBL11288 & 28965 & 8.301 & 8.3448 & TRN & \\
\hline
\end{tabular}




\begin{tabular}{|c|c|c|c|c|c|c|}
\hline & & \multicolumn{5}{|c|}{ Supplemental Table S2.txt } \\
\hline CHEMBL10995 & 28965 & 9.0969 & 8.9012 & TST & & \\
\hline CHEMBL11636 & 28965 & 7.6478 & 7.6716 & TRN & & \\
\hline CHEMBL11036 & 28965 & 10.0969 & 9.7452 & TST & & \\
\hline CHEMBL 276201 & 28965 & 8.4815 & 8.9831 & TST & & \\
\hline CHEMBL10906 & 28965 & 7.8861 & 7.8209 & TRN & & \\
\hline CHEMBL 273370 & 28965 & 7.0969 & 7.01399 & 999999999 & & TRN \\
\hline CHEMBL11220 & 28965 & 8.3979 & 8.4177 & TRN & & \\
\hline CHEMBL268026 & 28965 & 9.0969 & 8.9815 & TRN & & \\
\hline CHEMBL11104 & 28965 & 9.1249 & 8.9559 & TST & & \\
\hline CHEMBL545362 & 28965 & 10.1549 & 9.4746 & TST & & \\
\hline CHEMBL 268964 & 28965 & 9.4559 & 9.4944 & TRN & & \\
\hline CHEMBL11385 & 28965 & 7.301 & 7.3148 & TRN & & \\
\hline CHEMBL 273671 & 28965 & 10.3009 & 79999999 & 998 & 10.1412 & TST \\
\hline CHEMBL11077 & 28965 & 8.3979 & 8.4048 & TRN & & \\
\hline CHEMBL11141 & 28965 & 6.1221 & 6.6274 & TRN & & \\
\hline CHEMBL11410 & 28965 & 9.0969 & 8.1171 & TST & & \\
\hline CHEMBL 275329 & 28965 & 7.9031 & 7.9109 & TRN & & \\
\hline CHEMBL11635 & 28965 & 8.8239 & 8.8755 & TRN & & \\
\hline CHEMBL 8488 & 28965 & 7.6596 & 7.5381 & TRN & & \\
\hline CHEMBL 273953 & 28965 & 6.0 & 6.0047 & TRN & & \\
\hline CHEMBL11054 & 28965 & 8.2218 & 8.2212 & TRN & & \\
\hline CHEMBL10913 & 28965 & 8.7959 & 8.3799 & TST & & \\
\hline CHEMBL418333 & 28965 & 8.4685 & 8.1666 & TRN & & \\
\hline CHEMBL273508 & 28965 & 6.301 & 6.3255 & TRN & & \\
\hline CHEMBL11163 & 28965 & 8.699 & 8.6623 & TRN & & \\
\hline CHEMBL11027 & 28965 & 9.041 & 9.0798 & TRN & & \\
\hline CHEMBL11342 & 28965 & 9.0 & 8.8622 & TRN & & \\
\hline CHEMBL10873 & 28965 & 8.3979 & 7.8389 & TST & & \\
\hline CHEMBL 273267 & 28965 & 8.4559 & 8.3654 & TRN & & \\
\hline CHEMBL11127 & 28965 & 9.0969 & 9.0585 & TRN & & \\
\hline CHEMBL10895 & 28965 & 8.6021 & 8.5791 & TRN & & \\
\hline CHEMBL 268963 & 28965 & 7.0969 & 7.1478 & TRN & & \\
\hline CHEMBL 274778 & 28965 & 6.699 & 6.6074 & TRN & & \\
\hline CHEMBL 276830 & 28965 & 8.757 & 8.7712 & TRN & & \\
\hline CHEMBL 276401 & 28965 & 8.4559 & 8.4315 & TRN & & \\
\hline CHEMBL11154 & 28965 & 5.0745 & 4.9827 & TRN & & \\
\hline CHEMBL406993 & 28965 & 8.0 & 7.9769 & TRN & & \\
\hline CHEMBL 276227 & 28965 & 8.0 & 8.0578 & TRN & & \\
\hline CHEMBL11173 & 28965 & 9.6198 & 9.0607 & TST & & \\
\hline CHEMBL 3950096 & 1640978 & 6.4413 & 6.2951 & TRN & & \\
\hline CHEMBL 3945770 & 1640978 & 5.2889 & 5.4311 & TRN & & \\
\hline CHEMBL 3933478 & 1640978 & 6.2426 & 5.8147 & TRN & & \\
\hline CHEMBL 3927781 & 1640978 & 6.2204 & 6.3451 & TRN & & \\
\hline CHEMBL3912963 & 1640978 & 5.4184 & 5.6376 & TRN & & \\
\hline CHEMBL 3939043 & 1640978 & 6.5287 & 6.4151 & TRN & & \\
\hline CHEMBL 3894931 & 1640978 & 5.7208 & 5.6638 & TRN & & \\
\hline CHEMBL 3934036 & 1640978 & 6.04 & 5.4751 & TST & & \\
\hline CHEMBL 3928250 & 1640978 & 5.4769 & 5.5286 & TRN & & \\
\hline
\end{tabular}


Supplemental Table S2.txt

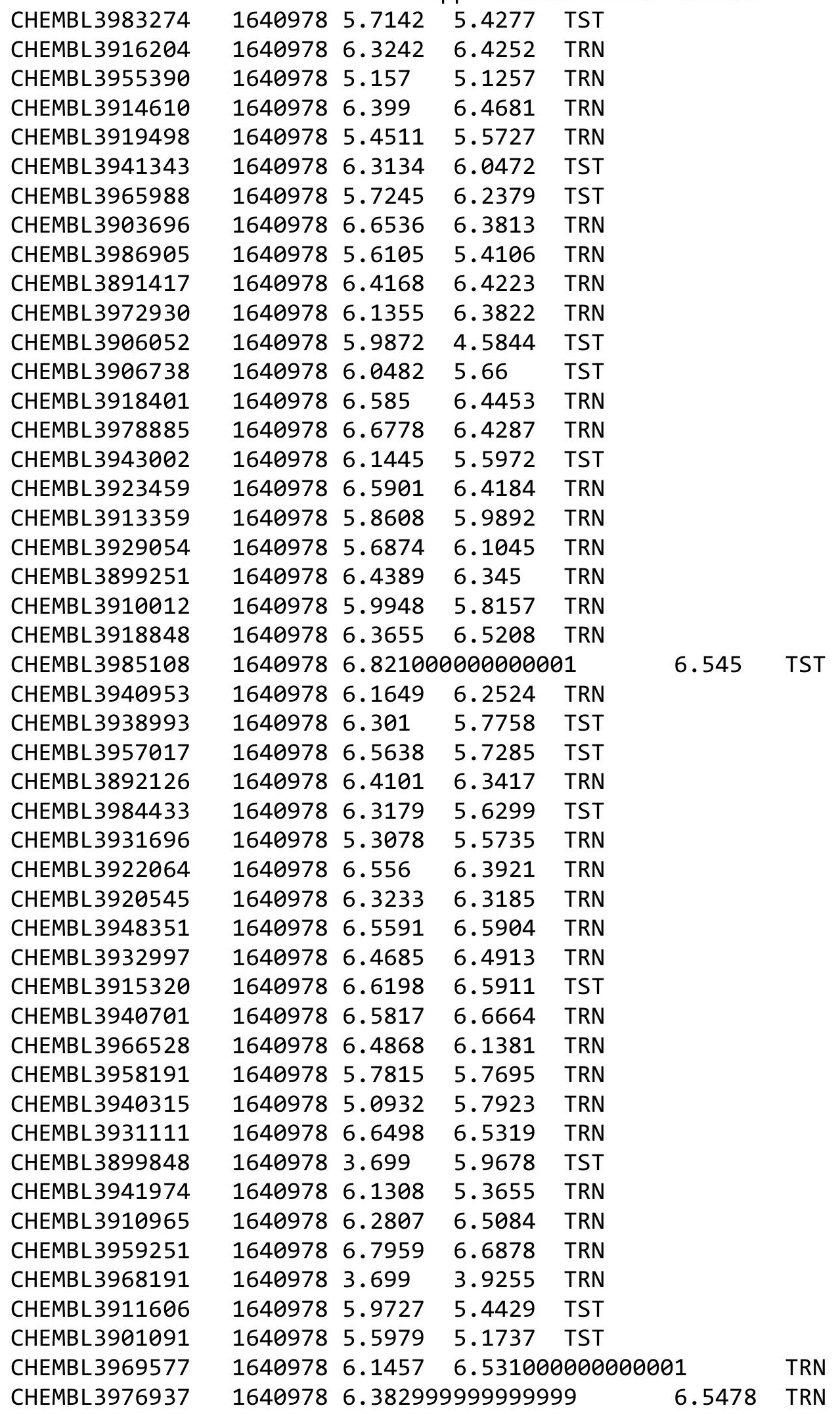

Page 17193 
Supplemental Table S2.txt

\begin{tabular}{|c|c|c|c|c|c|}
\hline CHEMBL3984875 & 1640978 & 6.4622 & 6.3552 & TRN & \\
\hline CHEMBL3937053 & 1640978 & 6.2708 & 5.8884 & TRN & \\
\hline CHEMBL3930065 & 1640978 & 6.063 & 6.1666 & TST & \\
\hline CHEMBL3893439 & 1640978 & 6.2604 & 6.4422 & TRN & \\
\hline CHEMBL3934427 & 1641396 & 6.0 & 5.8342 & TRN & \\
\hline CHEMBL3911382 & 1641396 & 6.0 & 6.2074 & TRN & \\
\hline CHEMBL3975411 & 1641396 & 7.4815 & 7.1003 & TRN & \\
\hline CHEMBL3951208 & 1641396 & 7.7959 & 6.6767 & TRN & \\
\hline CHEMBL3946214 & 1641396 & 6.0 & 5.4686 & TRN & \\
\hline CHEMBL3949549 & 1641396 & 8.7959 & 6.074 & TST & \\
\hline CHEMBL3945372 & 1641396 & 6.0 & 6.4005 & TST & \\
\hline CHEMBL3958716 & 1641396 & 6.0 & 6.0736 & TRN & \\
\hline CHEMBL3899926 & 1641396 & 6.0 & 6.2887 & TRN & \\
\hline CHEMBL3958139 & 1641396 & 8.6021 & 8.2871 & TRN & \\
\hline CHEMBL3906701 & 1641396 & 6.0 & 6.1937 & TRN & \\
\hline CHEMBL3915443 & 1641396 & 7.5086 & 7.0011 & TRN & \\
\hline CHEMBL3928052 & 1641396 & 6.0 & 5.5544 & TRN & \\
\hline CHEMBL3931855 & 1641396 & 8.1675 & 6.5902 & TST & \\
\hline CHEMBL3902335 & 1641396 & 6.0 & 5.8504 & TRN & \\
\hline CHEMBL3907162 & 1641396 & 9.0 & 7.4002 & TRN & \\
\hline CHEMBL3984565 & 1641396 & 7.7959 & 7.1142 & TRN & \\
\hline CHEMBL 3957854 & 1641396 & 6.0 & 6.1172 & TST & \\
\hline CHEMBL3934750 & 1641396 & 6.0 & 5.9433 & TRN & \\
\hline CHEMBL3986645 & 1641396 & 6.0 & 6.3826 & TRN & \\
\hline CHEMBL3895364 & 1641396 & 6.0 & 5.9689 & TRN & \\
\hline CHEMBL3898296 & 1641396 & 6.0 & 5.9447 & TRN & \\
\hline CHEMBL3963510 & 1641396 & 6.0 & 6.5051 & TRN & \\
\hline CHEMBL3928594 & 1641396 & 6.0 & 6.1852 & TRN & \\
\hline CHEMBL3931384 & 1641396 & 7.9586 & 6.8443 & TRN & \\
\hline CHEMBL3946073 & 1641396 & 6.0 & 6.4777 & TRN & \\
\hline CHEMBL3961051 & 1641396 & 6.0 & 6.3177 & TRN & \\
\hline CHEMBL3901093 & 1641396 & 6.0 & 6.386 & TRN & \\
\hline CHEMBL3942475 & 1641396 & 8.0605 & 7.7205 & TRN & \\
\hline CHEMBL 3964447 & 1641396 & 6.0 & 6.50899 & 99999999995 & TRN \\
\hline CHEMBL3890944 & 1641396 & 6.0 & 6.3356 & TRN & \\
\hline CHEMBL3909851 & 1641396 & 7.1367 & 6.7044 & TRN & \\
\hline CHEMBL3951209 & 1641396 & 7.7959 & 7.5705 & TRN & \\
\hline CHEMBL3894191 & 1641396 & 6.0 & 7.0376 & TRN & \\
\hline CHEMBL 3977254 & 1641396 & 6.0 & 6.6187 & TST & \\
\hline CHEMBL3931132 & 1641396 & 6.0 & 6.4297 & TRN & \\
\hline CHEMBL3891954 & 1641396 & 6.0 & 6.57299 & 99999999995 & TRN \\
\hline CHEMBL3914468 & 1641396 & 7.8861 & 7.9487 & TRN & \\
\hline CHEMBL3922468 & 1641396 & 6.0 & 7.1518 & TRN & \\
\hline CHEMBL3956536 & 1641396 & 6.9208 & 6.0253 & TRN & \\
\hline CHEMBL3920076 & 1641396 & 6.0 & 6.3593 & TRN & \\
\hline CHEMBL3937042 & 1641396 & 6.0 & 6.7099 & TRN & \\
\hline CHEMBL 3914750 & 1641396 & 7.0605 & 6.6666 & TST & \\
\hline CHEMBL3920669 & 1641396 & 6.0 & 5.862 & TRN & \\
\hline
\end{tabular}




$$
\text { Supplemental Table S2.txt }
$$

\begin{tabular}{|c|c|c|c|c|c|}
\hline CHEMBL3951631 & 1641396 & 6.8539 & 6.6384 & TRN & \\
\hline CHEMBL3936216 & 1641396 & 8.8239 & 5.9966 & TST & \\
\hline CHEMBL3933410 & 1641396 & 6.0 & 5.9545 & TRN & \\
\hline CHEMBL 3960975 & 1641396 & 6.0 & 6.1407 & TRN & \\
\hline CHEMBL3982785 & 1641396 & 6.6383 & 6.4288 & TST & \\
\hline CHEMBL 3945858 & 1641396 & 8.4815 & 5.9134 & TST & \\
\hline CHEMBL3926306 & 1641396 & 8.3872 & 6.6093 & TST & \\
\hline CHEMBL3959187 & 1641396 & 8.0 & 7.2245 & TRN & \\
\hline CHEMBL 3905488 & 1641396 & 7.4685 & 7.5785 & TRN & \\
\hline CHEMBL3915449 & 1641396 & 6.0 & 6.2774 & TRN & \\
\hline CHEMBL 3982327 & 1641396 & 6.0 & 5.9666 & TST & \\
\hline CHEMBL3914634 & 1641396 & 6.0 & 5.2776 & TRN & \\
\hline CHEMBL3931728 & 1641396 & 6.0 & 6.7321 & TRN & \\
\hline CHEMBL 3921149 & 1641396 & 6.0 & 6.9842 & TRN & \\
\hline CHEMBL3897832 & 1641396 & 6.0 & 6.6073 & TRN & \\
\hline CHEMBL 3938674 & 1641396 & 6.0 & 6.7375 & TST & \\
\hline CHEMBL3927000 & 1641396 & 7.5528 & 6.9282 & TRN & \\
\hline CHEMBL3899876 & 1641396 & 7.7959 & 6.6737 & TRN & \\
\hline CHEMBL 3922913 & 1641396 & 6.0 & 6.5772 & TST & \\
\hline CHEMBL3906474 & 1641396 & 6.0 & 7.2438 & TRN & \\
\hline CHEMBL3916745 & 1641396 & 8.1549 & 6.6423 & TST & \\
\hline CHEMBL3946814 & 1641396 & 6.0 & 6.3484 & TST & \\
\hline CHEMBL3935712 & 1641396 & 6.0 & 5.7104 & TRN & \\
\hline CHEMBL 3889880 & 1641396 & 6.0 & 6.4585 & TRN & \\
\hline CHEMBL3937325 & 1641396 & 6.0 & 6.2361 & TRN & \\
\hline CHEMBL 3983144 & 1641396 & 6.0 & 6.67399 & 99999999995 & TRN \\
\hline CHEMBL3963448 & 1641396 & 6.2676 & 7.3006 & TST & \\
\hline CHEMBL3908359 & 1641396 & 7.284 & 6.5075 & TST & \\
\hline CHEMBL 3968637 & 1641396 & 7.0506 & 6.612 & TRN & \\
\hline CHEMBL3894933 & 1641396 & 6.0 & 7.1033 & TST & \\
\hline CHEMBL3928752 & 1641396 & 7.9586 & 7.7273 & TRN & \\
\hline CHEMBL3906815 & 1641396 & 6.0 & 6.5036 & TST & \\
\hline CHEMBL360497 & 305003 & 4.0 & 4.0659 & TRN & \\
\hline CHEMBL359738 & 305003 & 6.2518 & 6.2035 & TRN & \\
\hline CHEMBL178408 & 305003 & 7.5229 & 7.513 & TRN & \\
\hline CHEMBL426059 & 305003 & 7.0969 & 7.0774 & TRN & \\
\hline CHEMBL180379 & 305003 & 7.3979 & 7.459 & TRN & \\
\hline CHEMBL360520 & 305003 & 9.5229 & 9.5045 & TRN & \\
\hline CHEMBL179599 & 305003 & 7.1249 & 7.2171 & TRN & \\
\hline CHEMBL181616 & 305003 & 8.699 & 8.7909 & TRN & \\
\hline CHEMBL360095 & 305003 & 5.6778 & 5.69 & TRN & \\
\hline CHEMBL367363 & 305003 & 7.2076 & 7.263 & TRN & \\
\hline CHEMBL178535 & 305003 & 6.3768 & 6.3076 & TRN & \\
\hline CHEMBL554716 & 305003 & 8.0458 & 8.0261 & TRN & \\
\hline CHEMBL178108 & 305003 & 5.3468 & 5.4064 & TRN & \\
\hline CHEMBL182256 & 305003 & 6.5376 & 6.5437 & TRN & \\
\hline CHEMBL178452 & 305003 & 7.0605 & 5.2476 & TST & \\
\hline CHEMBL179511 & 305003 & 6.6021 & 6.516 & TRN & \\
\hline
\end{tabular}




\begin{tabular}{|c|c|c|c|c|c|c|}
\hline & & \\
\hline CHEMBL182209 & 305003 & 8.699 & 8.703 & TRN & & \\
\hline CHEMBL178183 & 305003 & 6.5686 & 6.4942 & TRN & & \\
\hline CHEMBL361862 & 305003 & 8.3979 & 7.8571 & TST & & \\
\hline CHEMBL425703 & 305003 & 5.1249 & 5.0804 & TRN & & \\
\hline CHEMBL181828 & 305003 & 6.8539 & 6.7783 & TRN & & \\
\hline CHEMBL180868 & 305003 & 5.0706 & 5.1596 & TRN & & \\
\hline CHEMBL362004 & 305003 & 7.1079 & 7.5883 & TST & & \\
\hline CHEMBL179588 & 305003 & 8.301 & 8.2113 & TRN & & \\
\hline CHEMBL368043 & 305003 & 7.5528 & 7.5237 & TRN & & \\
\hline CHEMBL181013 & 305003 & \multicolumn{3}{|c|}{5.757000000000001} & 5.7721 & TRN \\
\hline CHEMBL178750 & 305003 & 8.0 & 8.0503 & TRN & & \\
\hline CHEMBL360695 & 305003 & 6.8239 & 6.7524 & TRN & & \\
\hline CHEMBL440379 & 305003 & 6.585 & 6.6295 & TST & & \\
\hline CHEMBL359737 & 305003 & 6.7212 & 6.8158 & TRN & & \\
\hline CHEMBL179758 & 305003 & 6.1612 & 6.1185 & TRN & & \\
\hline CHEMBL178965 & 305003 & 6.2676 & 6.2426 & TRN & & \\
\hline CHEMBL179921 & 305003 & 6.6778 & 6.6493 & TRN & & \\
\hline CHEMBL181223 & 305003 & 7.5376 & 7.5733 & TRN & & \\
\hline CHEMBL360312 & 305003 & 6.699 & 6.7385 & TRN & & \\
\hline CHEMBL180265 & 305003 & 6.7959 & 6.8148 & TRN & & \\
\hline CHEMBL 362829 & 305003 & 7.4437 & 7.4993 & TRN & & \\
\hline CHEMBL179385 & 305003 & 6.2924 & 6.2832 & TRN & & \\
\hline CHEMBL181036 & 305003 & 8.699 & 8.579 & TRN & & \\
\hline CHEMBL178190 & 305003 & 8.0969 & 7.6451 & TST & & \\
\hline CHEMBL180378 & 305003 & 5.9393 & 5.9682 & TRN & & \\
\hline CHEMBL180715 & 305003 & 6.7447 & 6.7195 & TRN & & \\
\hline CHEMBL178107 & 305003 & 6.6778 & 6.5388 & TRN & & \\
\hline CHEMBL360149 & 305003 & 6.6778 & 6.7732 & TRN & & \\
\hline CHEMBL369785 & 305003 & 5.5452 & 5.50299 & 9999999999 & & TRN \\
\hline CHEMBL367798 & 305003 & 7.8239 & 7.7865 & TRN & & \\
\hline CHEMBL181992 & 305003 & 5.0915 & 4.9953 & TRN & & \\
\hline CHEMBL179710 & 305003 & 6.2218 & 6.2827 & TRN & & \\
\hline CHEMBL360334 & 305003 & 5.0 & 5.016 & TRN & & \\
\hline CHEMBL179112 & 305003 & 6.5086 & 6.5502 & TRN & & \\
\hline CHEMBL178717 & 305003 & 6.3372 & 7.6473 & TST & & \\
\hline CHEMBL180916 & 305003 & 6.4437 & 6.4643 & TRN & & \\
\hline CHEMBL178629 & 305003 & 8.0458 & 7.5343 & TST & & \\
\hline CHEMBL181790 & 305003 & 7.699 & 7.7984 & TRN & & \\
\hline CHEMBL434713 & 305003 & 5.7959 & 5.7388 & TRN & & \\
\hline CHEMBL435731 & 305003 & 6.0458 & 6.0799 & TRN & & \\
\hline CHEMBL178336 & 305003 & 5.9208 & 5.8364 & TRN & & \\
\hline CHEMBL178505 & 305003 & 6.7959 & 6.8258 & TRN & & \\
\hline CHEMBL359461 & 305003 & 7.5376 & 6.9006 & TST & & \\
\hline CHEMBL181791 & 305003 & 5.6778 & 5.8004 & TRN & & \\
\hline CHEMBL179548 & 305003 & 6.8539 & 6.8199 & TRN & & \\
\hline CHEMBL178478 & 305003 & 7.8861 & 8.1661 & TST & & \\
\hline CHEMBL178544 & 305003 & 6.2147 & 8.1338 & TST & & \\
\hline CHEMBL179020 & 305003 & 4.0 & 6.1723 & TST & & \\
\hline
\end{tabular}




\begin{tabular}{|c|c|c|c|c|c|}
\hline & & & & & \\
\hline CHEMBL178827 & 305003 & 8.0969 & 7.943 & TST & \\
\hline CHEMBL360480 & 305003 & 7.7447 & 7.6712 & TST & \\
\hline CHEMBL368433 & 305003 & 6.6778 & 6.3741 & TST & \\
\hline CHEMBL361595 & 305003 & 9.0 & 9.3399 & TST & \\
\hline CHEMBL369522 & 305003 & 7.5528 & 7.25299 & 9999999999 & TST \\
\hline CHEMBL362656 & 305003 & 7.4318 & 6.91799 & 9999999999 & TST \\
\hline CHEMBL178572 & 305003 & 7.699 & 9.3637 & TST & \\
\hline CHEMBL3675557 & 1535033 & 4.301 & 4.3116 & TRN & \\
\hline CHEMBL3675562 & 1535033 & 4.0 & 4.1432 & TRN & \\
\hline CHEMBL3675596 & 1535033 & 4.0 & 4.6922 & TRN & \\
\hline CHEMBL 3675570 & 1535033 & 5.0 & 5.0182 & TRN & \\
\hline CHEMBL 3675594 & 1535033 & 4.301 & 4.7693 & TRN & \\
\hline CHEMBL3675601 & 1535033 & 5.0 & 4.9718 & TRN & \\
\hline CHEMBL3675597 & 1535033 & 5.0 & 4.6922 & TRN & \\
\hline CHEMBL3675598 & 1535033 & 5.0 & 5.0552 & TRN & \\
\hline CHEMBL3675552 & 1535033 & 4.301 & 4.1232 & TRN & \\
\hline CHEMBL 3675547 & 1535033 & 4.301 & 4.4232 & TRN & \\
\hline CHEMBL3675595 & 1535033 & 4.0 & 4.5881 & TRN & \\
\hline CHEMBL3639695 & 1535033 & 5.0 & 4.8304 & TRN & \\
\hline CHEMBL3675582 & 1535033 & 5.0 & 5.17700 & 00000000005 & TRN \\
\hline CHEMBL3675602 & 1535033 & 4.301 & 4.4395 & TRN & \\
\hline CHEMBL 3670716 & 1535033 & 5.0 & 4.9658 & TST & \\
\hline CHEMBL3675543 & 1535033 & 6.26200 & 20000000 & 5.631 & TRN \\
\hline CHEMBL 3670704 & 1535033 & 5.0 & 4.6047 & TRN & \\
\hline CHEMBL3670706 & 1535033 & 5.0 & 4.6198 & TRN & \\
\hline CHEMBL3670691 & 1535033 & 5.0 & 5.0884 & TRN & \\
\hline CHEMBL3670711 & 1535033 & 4.301 & 4.1068 & TST & \\
\hline CHEMBL 3675544 & 1535033 & 4.301 & 4.6866 & TRN & \\
\hline CHEMBL3675590 & 1535033 & 5.0 & 4.6919 & TST & \\
\hline CHEMBL3675560 & 1535033 & 5.0 & 5.0464 & TRN & \\
\hline CHEMBL 3675583 & 1535033 & 5.0 & 4.9833 & TRN & \\
\hline CHEMBL3675564 & 1535033 & 5.0 & 4.9463 & TRN & \\
\hline CHEMBL3670701 & 1535033 & 5.0 & 5.0518 & TRN & \\
\hline CHEMBL 3670720 & 1535033 & 6.3585 & 6.4252 & TRN & \\
\hline CHEMBL1232489 & 1535033 & 5.0 & 4.5044 & TRN & \\
\hline CHEMBL3675569 & 1535033 & 5.0 & 4.5232 & TRN & \\
\hline CHEMBL3675542 & 1535033 & 6.3872 & 6.2137 & TRN & \\
\hline CHEMBL 3675545 & 1535033 & 5.0 & 4.6406 & TRN & \\
\hline CHEMBL 3670714 & 1535033 & 4.301 & 4.4924 & TRN & \\
\hline CHEMBL 3675567 & 1535033 & 5.0 & 4.5712 & TRN & \\
\hline CHEMBL3670709 & 1535033 & 4.301 & 4.4978 & TST & \\
\hline CHEMBL3670717 & 1535033 & 5.0 & 4.7168 & TRN & \\
\hline CHEMBL3670702 & 1535033 & 4.301 & 4.5881 & TRN & \\
\hline CHEMBL 3675548 & 1535033 & 4.301 & 4.5712 & TRN & \\
\hline CHEMBL 3675574 & 1535033 & 4.0 & 4.4232 & TRN & \\
\hline CHEMBL3670695 & 1535033 & 5.0 & 4.9235 & TRN & \\
\hline CHEMBL3675565 & 1535033 & 5.0 & 4.4232 & TRN & \\
\hline CHEMBL 3675546 & 1535033 & 4.301 & 4.4707 & TRN & \\
\hline
\end{tabular}


Supplemental Table S2.txt

\begin{tabular}{|c|c|c|c|c|}
\hline CHEMBL 3670698 & 1535033 & 4.301 & 4.9355 & TST \\
\hline CHEMBL 3675577 & 1535033 & 4.301 & 4.2065 & TRN \\
\hline CHEMBL 3639744 & 1535033 & 4.301 & \multicolumn{2}{|c|}{4.781000000000001} \\
\hline CHEMBL3675591 & 1535033 & 6.3665 & 5.4522 & TST \\
\hline CHEMBL 3675581 & 1535033 & 5.0 & 5.2077 & TRN \\
\hline CHEMBL3670712 & 1535033 & 4.301 & 4.8526 & TST \\
\hline CHEMBL3670721 & 1535033 & 4.301 & 4.7623 & TRN \\
\hline CHEMBL 3670700 & 1535033 & 5.0 & 4.4833 & TST \\
\hline CHEMBL 3675568 & 1535033 & 4.0 & 4.0349 & TRN \\
\hline CHEMBL3670707 & 1535033 & 4.0 & 4.152 & TST \\
\hline CHEMBL 3675573 & 1535033 & 6.1574 & 4.8977 & TST \\
\hline CHEMBL 3675558 & 1535033 & 4.0 & 4.0023 & TRN \\
\hline CHEMBL 3670713 & 1535033 & 5.0 & 4.7525 & TRN \\
\hline CHEMBL3670705 & 1535033 & 4.0 & 4.6198 & TST \\
\hline CHEMBL3675607 & 1535033 & 5.0 & 5.1176 & TRN \\
\hline CHEMBL 3670715 & 1535033 & 5.0 & 4.9831 & TRN \\
\hline CHEMBL3675561 & 1535033 & 4.0 & 3.8977 & TRN \\
\hline CHEMBL 3675593 & 1535033 & 5.0 & 4.9057 & TRN \\
\hline CHEMBL3675555 & 1535033 & 5.0 & 4.4996 & TRN \\
\hline CHEMBL3675592 & 1535033 & 5.0 & 4.8997 & TRN \\
\hline CHEMBL 3670710 & 1535033 & 5.0 & 4.7703 & TST \\
\hline CHEMBL3675559 & 1535033 & 4.0 & 4.1907 & TRN \\
\hline CHEMBL3675553 & 1535033 & 4.301 & 4.4566 & TST \\
\hline CHEMBL 3675572 & 1535033 & 5.0 & 4.4566 & TST \\
\hline CHEMBL3675584 & 1535033 & 5.0 & 5.0725 & TRN \\
\hline CHEMBL3675575 & 1535033 & 5.0 & 4.9114 & TRN \\
\hline CHEMBL 3675571 & 1535033 & 4.301 & 4.1232 & TRN \\
\hline CHEMBL3675588 & 1535033 & 5.0 & 5.336 & TRN \\
\hline CHEMBL3675585 & 1535033 & 5.0 & 5.1403 & TRN \\
\hline CHEMBL3675600 & 1535033 & 4.0 & 4.3664 & TRN \\
\hline CHEMBL 3675603 & 1535033 & 5.0 & 5.5628 & TST \\
\hline CHEMBL 3675587 & 1535033 & 5.0 & 4.8675 & TRN \\
\hline CHEMBL3675554 & 1535033 & 5.0 & 4.8977 & TST \\
\hline CHEMBL3670703 & 1535033 & 5.0 & 4.8495 & TST \\
\hline CHEMBL3675579 & 1535033 & 5.0 & 4.8431 & TRN \\
\hline CHEMBL3675578 & 1535033 & 4.0 & 3.9618 & TRN \\
\hline CHEMBL 3675556 & 1535033 & 4.0 & 3.9337 & TRN \\
\hline CHEMBL3675586 & 1535033 & 5.0 & 4.4443 & TRN \\
\hline CHEMBL3675541 & 1535033 & 5.0 & 5.42 & TRN \\
\hline CHEMBL3675550 & 1535033 & 4.0 & 4.5232 & TRN \\
\hline CHEMBL3670719 & 1535033 & 5.0 & 4.3232 & TST \\
\hline CHEMBL 3670718 & 1535033 & 5.0 & 4.5168 & TST \\
\hline CHEMBL3675599 & 1535033 & 5.0 & 5.0201 & TRN \\
\hline CHEMBL3670696 & 1535033 & 4.301 & 4.8331 & TST \\
\hline CHEMBL3670708 & 1535033 & 5.0 & 4.2393 & TST \\
\hline CHEMBL3670699 & 1535033 & 6.2573 & 4.2334 & TST \\
\hline CHEMBL3670697 & 1535033 & 4.0 & 4.1737 & TST \\
\hline CHEMBL3675551 & 1535033 & 5.0 & 5.0182 & TRN \\
\hline
\end{tabular}


Supplemental Table S2.txt

\begin{tabular}{|c|c|c|c|c|c|}
\hline CHEMBL3675549 & 1535033 & 4.301 & 4.0349 & TRN & \\
\hline CHEMBL3675604 & 1535033 & 4.301 & 4.7823 & TST & \\
\hline CHEMBL3675576 & 1535033 & 4.0 & 4.1679 & TRN & \\
\hline CHEMBL 3675605 & 1535033 & 6.9281 & 6.593 & TRN & \\
\hline CHEMBL3675589 & 1535033 & 5.0 & 4.6262 & TRN & \\
\hline CHEMBL3675580 & 1535033 & 4.0 & 3.9453 & TRN & \\
\hline CHEMBL3675566 & 1535033 & 4.301 & \multicolumn{2}{|c|}{ 4.781000000000001 } & TRN \\
\hline CHEMBL3655938 & 1535932 & 6.2314 & 6.3633 & TRN & \\
\hline CHEMBL3655992 & 1535932 & 7.9208 & 7.9111 & TRN & \\
\hline CHEMBL3655975 & 1535932 & 6.6216 & 6.506 & TRN & \\
\hline CHEMBL3656015 & 1535932 & 7.6576 & 7.6828 & TRN & \\
\hline CHEMBL3655964 & 1535932 & 6.9355 & 6.9804 & TRN & \\
\hline CHEMBL3655935 & 1535932 & 6.6055 & 6.6669 & TRN & \\
\hline CHEMBL3656014 & 1535932 & 6.8697 & 6.8941 & TRN & \\
\hline CHEMBL 3656023 & 1535932 & 5.7959 & 5.7403 & TRN & \\
\hline CHEMBL3655983 & 1535932 & 6.8761 & 6.8641 & TRN & \\
\hline CHEMBL3656007 & 1535932 & 7.3098 & 7.254 & TRN & \\
\hline CHEMBL3655960 & 1535932 & 6.3449 & 6.2095 & TRN & \\
\hline CHEMBL3652234 & 1535932 & 6.3439 & 6.4828 & TRN & \\
\hline CHEMBL3655953 & 1535932 & 6.2154 & 6.2558 & TRN & \\
\hline CHEMBL3656022 & 1535932 & 6.3089 & 6.3849 & TRN & \\
\hline CHEMBL3655977 & 1535932 & 5.3223 & 5.3417 & TRN & \\
\hline CHEMBL3652230 & 1535932 & 6.6364 & \multicolumn{2}{|c|}{6.577000000000001} & TRN \\
\hline CHEMBL3655912 & 1535932 & 6.0926 & 6.0626 & TST & \\
\hline CHEMBL3652239 & 1535932 & 6.3206 & 6.4168 & TRN & \\
\hline CHEMBL3655910 & 1535932 & 6.1549 & 6.182 & TRN & \\
\hline CHEMBL3655942 & 1535932 & 6.8477 & 6.7967 & TST & \\
\hline CHEMBL3656021 & 1535932 & 6.6576 & 6.4567 & TRN & \\
\hline CHEMBL3656011 & 1535932 & 7.6383 & 7.6634 & TRN & \\
\hline CHEMBL3655990 & 1535932 & 7.4949 & 7.3675 & TRN & \\
\hline CHEMBL3655925 & 1535932 & 7.0132 & 6.9243 & TRN & \\
\hline CHEMBL3652229 & 1535932 & 6.4034 & 6.5747 & TRN & \\
\hline CHEMBL3655926 & 1535932 & 6.9208 & 6.6893 & TST & \\
\hline CHEMBL3652227 & 1535932 & 6.4597 & 6.5103 & TRN & \\
\hline CHEMBL3652233 & 1535932 & 6.2 & 6.2895 & TST & \\
\hline CHEMBL3655921 & 1535932 & 6.1427 & 6.0587 & TRN & \\
\hline CHEMBL3655950 & 1535932 & 6.8928 & 6.8714 & TRN & \\
\hline CHEMBL3655996 & 1535932 & 7.2441 & 7.2713 & TRN & \\
\hline CHEMBL3652228 & 1535932 & 6.5376 & 6.6385 & TRN & \\
\hline CHEMBL3655930 & 1535932 & 6.4609 & 6.4278 & TRN & \\
\hline CHEMBL3655985 & 1535932 & 6.5045 & 6.3433 & TRN & \\
\hline CHEMBL3656006 & 1535932 & 7.6778 & 7.481 & TRN & \\
\hline CHEMBL3655956 & 1535932 & 5.7375 & 5.6408 & TRN & \\
\hline CHEMBL3655947 & 1535932 & 6.0123 & 6.0318 & TRN & \\
\hline CHEMBL3655949 & 1535932 & 5.0966 & 5.1849 & TRN & \\
\hline CHEMBL3655989 & 1535932 & 7.2757 & 7.3395 & TRN & \\
\hline CHEMBL3655920 & 1535932 & 6.8962 & 7.0067 & TRN & \\
\hline CHEMBL3655948 & 1535932 & 6.04 & 6.0612 & TRN & \\
\hline
\end{tabular}


Supplemental Table S2.txt

\begin{tabular}{|c|c|c|c|c|}
\hline TLTILL & & & & \\
\hline HFMRI 3655932 & & 6.4711 & 6.4381 & \\
\hline HEMBL & & 7.284 & 3527 & \\
\hline AEMBL: & 9932 & 6767 & 7101 & \\
\hline HEMBL3656019 & 535932 & 6.4815 & 4643 & \\
\hline HEMBL; & & 5.8887 & 3985 & \\
\hline AFMBI: & & & & \\
\hline HEMBL; & & .2815 & 2234 & \\
\hline HEMBL3639548 & 535932 & 5.9654 & 9655 & \\
\hline HEMBL3656012 & 535932 & 7.7696 & 9132 & \\
\hline AEMBL36 & 32 & 7.1079 & 3764 & \\
\hline HEMBL; & & & 667 & \\
\hline HEMBL & 32 & 36 & 545 & \\
\hline AEMBL3 & 32 & & 3988 & \\
\hline AEMBL3655918 & 32 & 6.8539 & $\partial 823$ & \\
\hline AEMBL: & 32 & 71 & 923 & \\
\hline AEMBL. & & & 328 & \\
\hline HEMBL; & 32 & 32 & 3529 & \\
\hline AEMBL3 & & & 407 & \\
\hline AEMBL 36 & 32 & 79 & 559 & KIV \\
\hline EMBL & & & 53 & RN \\
\hline EM & & & & NIV \\
\hline HEMBL & & & 995 & RN \\
\hline AEMBL3 & & & & \\
\hline AEMBL36 & 32 & 52 & 505 & $R N$ \\
\hline EMBL: & & & 06 & $\mathrm{RN}$ \\
\hline 3 & & & & $\mathrm{RN}$ \\
\hline 17 & & & 548 & \\
\hline AEMBL & & & & SI \\
\hline IEMBL3656008 & 3 & 97 & 978 & RN \\
\hline 974 & & & 977 & RIV \\
\hline 6 & & & & ST \\
\hline & & & & RN \\
\hline AEMBL3655971 & & & & 「RN \\
\hline AEMBL3652231 & 932 & & 785 & RN \\
\hline 914 & 32 & & 62 & RN \\
\hline & & & & RN \\
\hline HEMBL3 & & & & ГST \\
\hline AEMBL3655957 & 32 & & $\partial 22$ & $\Gamma R$ \\
\hline EBL3 3 & & & 071 & $\Gamma R$ \\
\hline HEMBL36 & & & 893 & \\
\hline & & & 1866 & RN \\
\hline HEMBL3652232 & & & 8883 & ГST \\
\hline AEMBL3656010 & 32 & 7. & 579 & TR \\
\hline r & & & & IST \\
\hline HEMBL 3656001 & & & 7.0007 & \\
\hline HEMBL 3655939 & & & 5.9985 & \\
\hline CHEMBL3655908 & 1535932 & 6.0278 & 6.0261 & \\
\hline
\end{tabular}

Page 17200 
Supplemental Table S2.txt

\begin{tabular}{|c|c|c|c|c|c|}
\hline CHEMBL3652226 & 1535932 & 6.6055 & 6.4267 & TRN & \\
\hline CHEMBL 3652243 & 1535932 & 6.4647 & \multicolumn{2}{|c|}{6.582000000000001} & TRN \\
\hline CHEMBL3652238 & 1535932 & 6.7696 & 6.6931 & TRN & \\
\hline CHEMBL3655999 & 1535932 & 6.7986 & 6.6024 & TST & \\
\hline CHEMBL3655988 & 1535932 & 6.1152 & 5.9996 & TST & \\
\hline CHEMBL3655936 & 1535932 & 7.5229 & 7.6493 & TRN & \\
\hline CHEMBL 3656000 & 1535932 & 7.7212 & 7.8158 & TST & \\
\hline CHEMBL3655933 & 1535932 & 5.8193 & 5.8982 & TRN & \\
\hline CHEMBL3655967 & 1535932 & 7.4437 & 7.4817 & TST & \\
\hline CHEMBL 3652237 & 1535932 & 6.7932 & 6.5264 & TRN & \\
\hline CHEMBL3655927 & 1535932 & 6.5969 & 6.6494 & TRN & \\
\hline CHEMBL3655919 & 1535932 & 7.1487 & 7.273 & TRN & \\
\hline CHEMBL3656017 & 1535932 & 6.2111 & 5.9542 & TST & \\
\hline CHEMBL 3656002 & 1535932 & 6.3161 & 6.1924 & TST & \\
\hline CHEMBL3656013 & 1535932 & 7.4685 & 7.5787 & TST & \\
\hline CHEMBL3655934 & 1535932 & 6.2048 & \multicolumn{2}{|c|}{6.1739999999999995} & TRN \\
\hline CHEMBL3655972 & 1535932 & 6.1415 & 6.3746 & TST & \\
\hline CHEMBL3655991 & 1535932 & 6.0467 & 5.9738 & TST & \\
\hline CHEMBL3655970 & 1535932 & 6.9706 & 7.1613 & TST & \\
\hline CHEMBL 3655997 & 1535932 & 7.7696 & 7.9085 & TST & \\
\hline CHEMBL3656016 & 1535932 & 7.1367 & 7.0707 & TST & \\
\hline CHEMBL 3655924 & 1535932 & 6.5867 & 6.5397 & TRN & \\
\hline CHEMBL3655946 & 1535932 & 6.6198 & 6.722 & TRN & \\
\hline CHEMBL3656004 & 1535932 & 6.9281 & \multicolumn{2}{|c|}{6.8629999999999995} & TST \\
\hline CHEMBL 3655984 & 1535932 & 8.0458 & 7.5518 & TRN & \\
\hline CHEMBL3656003 & 1535932 & 7.3979 & 7.2439 & TST & \\
\hline CHEMBL3655965 & 1535932 & 6.0097 & 5.9733 & TST & \\
\hline CHEMBL3655916 & 1535932 & 6.6459 & 6.7629 & TRN & \\
\hline CHEMBL 3655987 & 1535932 & 5.7875 & 5.6693 & TST & \\
\hline CHEMBL 3652241 & 1535932 & 6.279 & 6.2874 & TRN & \\
\hline CHEMBL3655969 & 1535932 & 5.6507 & 5.7681 & TRN & \\
\hline CHEMBL3655913 & 1535932 & 6.7423 & 6.8583 & TRN & \\
\hline CHEMBL3656020 & 1535932 & 6.3224 & 6.0342 & TST & \\
\hline CHEMBL3655976 & 1535932 & 6.4949 & 6.8523 & TST & \\
\hline CHEMBL3655979 & 1535932 & 7.6778 & 7.8494 & TST & \\
\hline CHEMBL3655923 & 1535932 & 7.2518 & 7.2209 & TRN & \\
\hline CHEMBL3655941 & 1535932 & 6.0888 & 6.0675 & TRN & \\
\hline CHEMBL3655981 & 1535932 & 5.9303 & 6.3545 & TST & \\
\hline CHEMBL3652235 & 1535932 & 5.857 & 5.7793 & TRN & \\
\hline CHEMBL3655962 & 1535932 & 7.0177 & 6.8378 & TST & \\
\hline CHEMBL3655952 & 1535932 & 6.015 & 5.8713 & TRN & \\
\hline CHEMBL 3655922 & 1535932 & 6.4123 & 6.3325 & TRN & \\
\hline CHEMBL3655982 & 1535932 & 6.4425 & 6.5608 & TST & \\
\hline CHEMBL3656018 & 1535932 & 6.4815 & 6.5454 & TST & \\
\hline CHEMBL3655909 & 1535932 & 6.4622 & 6.4775 & TRN & \\
\hline CHEMBL314763 & 155834 & 7.699 & 7.5199 & TRN & \\
\hline CHEMBL91368 & 155834 & 8.699 & 8.3983 & TRN & \\
\hline CHEMBL92363 & 155834 & 6.699 & 6.9069 & TST & \\
\hline
\end{tabular}




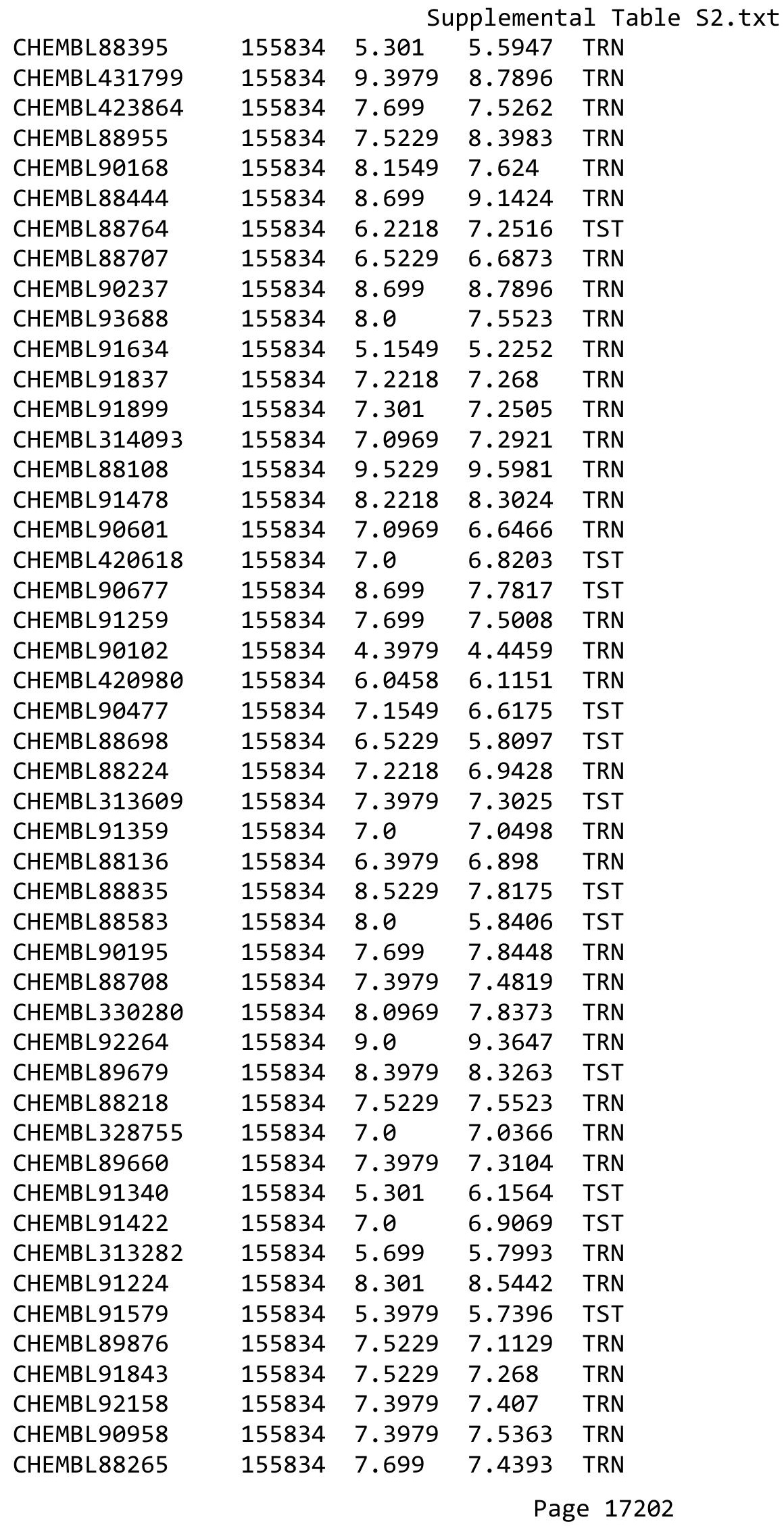




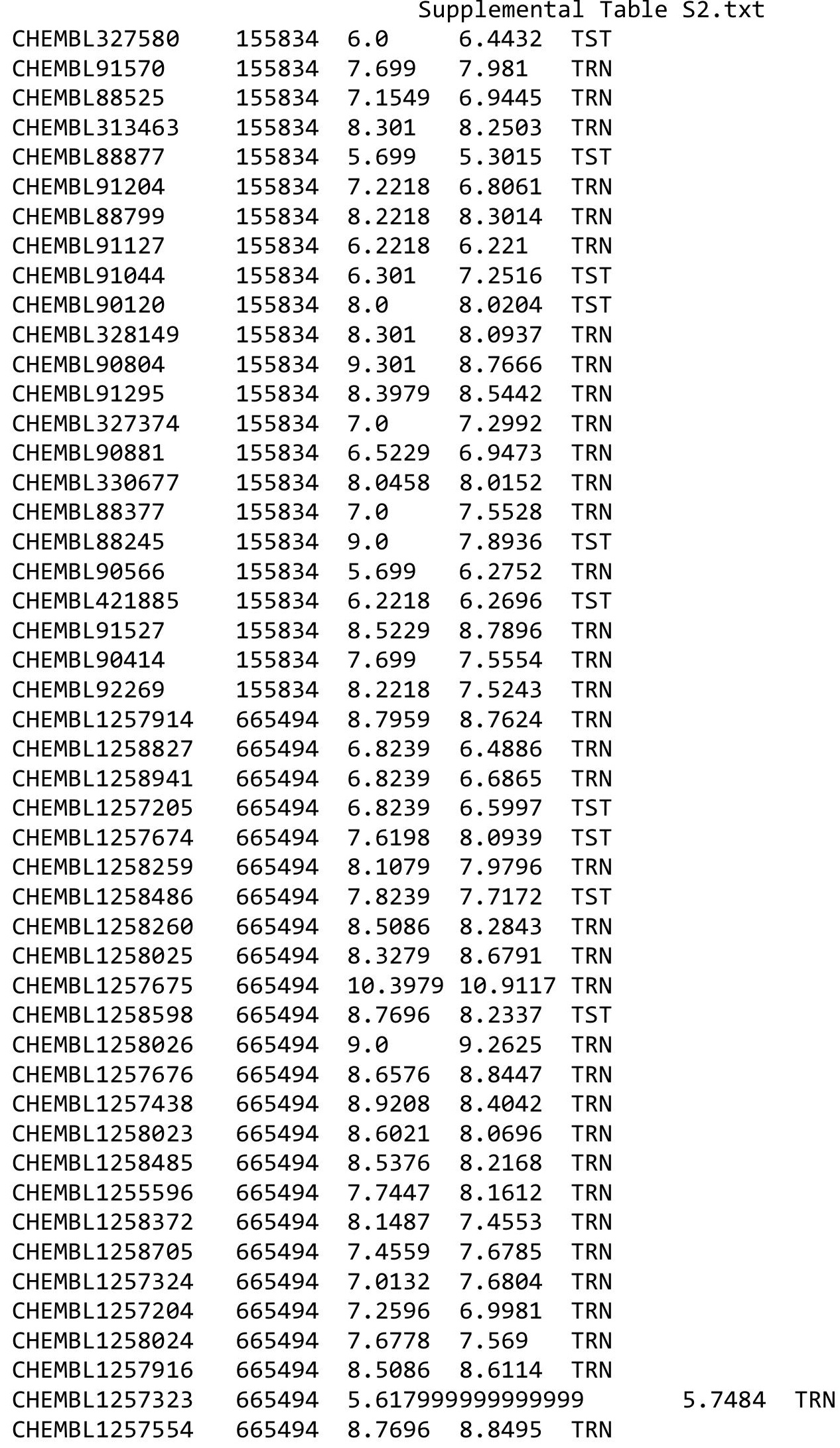

Page 17203 


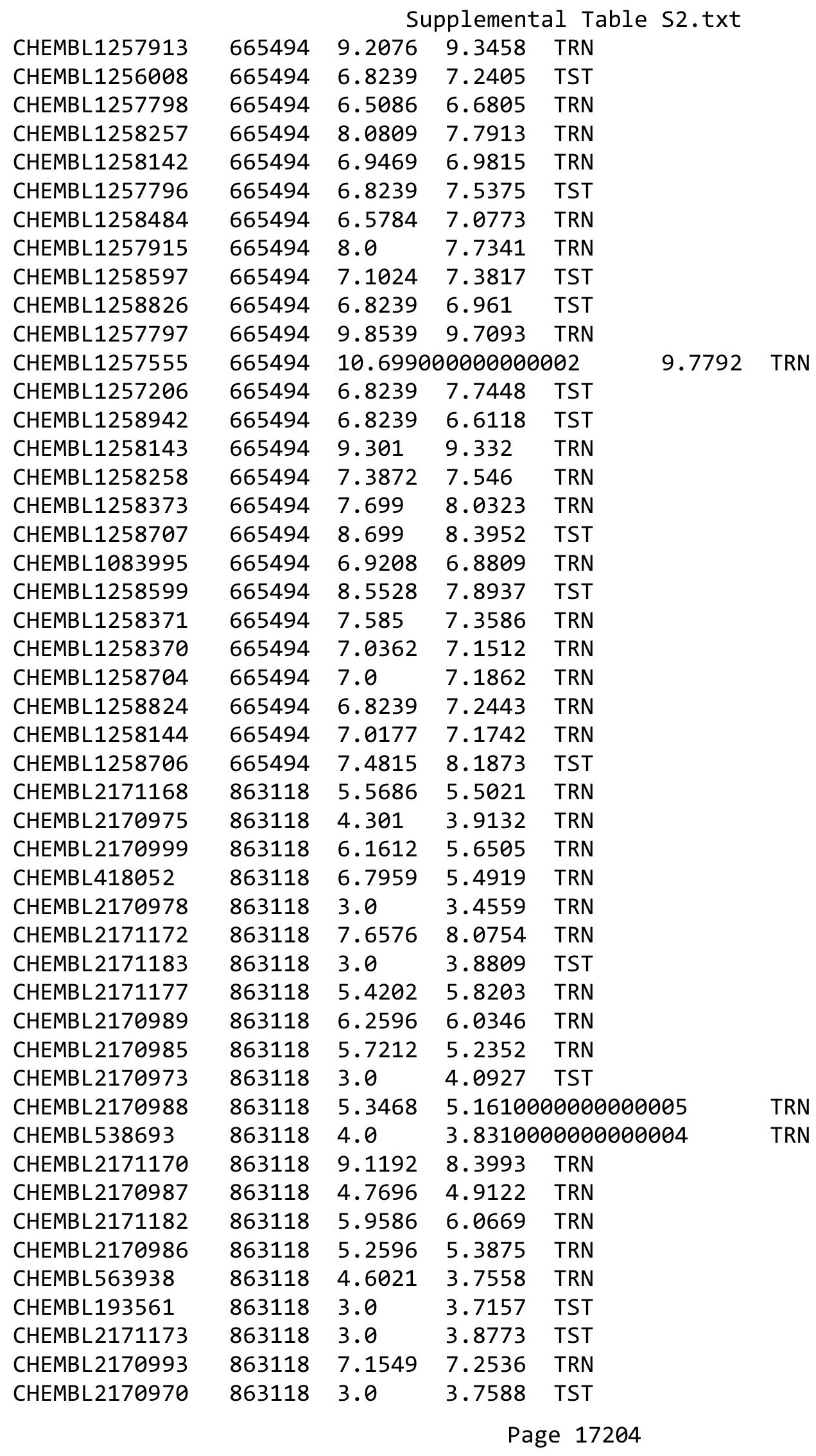




\begin{tabular}{|c|c|c|c|c|c|}
\hline & & \multicolumn{4}{|c|}{ Supplemental Table S2.txt } \\
\hline CHEMBL2170976 & 863118 & 4.3372 & 3.7659 & TRN & \\
\hline CHEMBL 2171176 & 863118 & 5.699 & 5.8893 & TRN & \\
\hline CHEMBL 2170980 & 863118 & 3.0 & 3.8623 & TRN & \\
\hline CHEMBL 2170990 & 863118 & 4.7447 & 5.9738 & TRN & \\
\hline CHEMBL 2171178 & 863118 & 5.5528 & 5.678 & TRN & \\
\hline CHEMBL 2170995 & 863118 & 6.7212 & 6.9557 & TRN & \\
\hline CHEMBL2171174 & 863118 & 6.5376 & 6.0397 & TRN & \\
\hline CHEMBL 2170974 & 863118 & 3.0 & 4.7291 & TST & \\
\hline CHEMBL 2171002 & 863118 & 7.0969 & 7.0748 & TRN & \\
\hline CHEMBL191917 & 863118 & 3.0 & 3.6045 & TRN & \\
\hline CHEMBL 2171179 & 863118 & 5.1079 & 6.121 & TST & \\
\hline CHEMBL2170994 & 863118 & 7.0862 & 7.0859 & TRN & \\
\hline CHEMBL 2171169 & 863118 & 9.3372 & 8.0489 & TRN & \\
\hline CHEMBL 2171171 & 863118 & 7.9208 & 8.0474 & TRN & \\
\hline CHEMBL 2170984 & 863118 & 4.7959 & 5.0172 & TRN & \\
\hline CHEMBL399890 & 863118 & 3.0 & 4.2764 & TST & \\
\hline CHEMBL2170992 & 863118 & 6.4559 & 7.2126 & TRN & \\
\hline CHEMBL 2170998 & 863118 & 6.8539 & 6.8341 & TRN & \\
\hline CHEMBL 2170996 & 863118 & 6.5686 & 6.65600 & 0000000001 & TRN \\
\hline CHEMBL 2170971 & 863118 & 3.0 & 4.6296 & TST & \\
\hline CHEMBL 2170991 & 863118 & 5.9586 & 6.1496 & TRN & \\
\hline CHEMBL 2170997 & 863118 & 7.2366 & 7.38899 & 9999999999 & TRN \\
\hline CHEMBL 2170981 & 863118 & 3.0 & 3.1453 & TRN & \\
\hline CHEMBL 2171181 & 863118 & 5.0506 & 6.0447 & TST & \\
\hline CHEMBL 2170979 & 863118 & 4.6576 & 4.875 & TRN & \\
\hline CHEMBL 2170972 & 863118 & 3.0 & 4.0667 & TST & \\
\hline CHEMBL2171000 & 863118 & 6.8861 & 6.7417 & TRN & \\
\hline CHEMBL 2170983 & 863118 & 4.6576 & 5.1535 & TRN & \\
\hline CHEMBL 2170977 & 863118 & 4.3279 & 3.7871 & TRN & \\
\hline CHEMBL 2171180 & 863118 & 5.1871 & 5.8301 & TST & \\
\hline CHEMBL 2171175 & 863118 & 5.699 & 6.0141 & TST & \\
\hline CHEMBL2170982 & 863118 & 3.0 & 2.8468 & TRN & \\
\hline CHEMBL 2171184 & 863118 & 3.0 & 3.8777 & TST & \\
\hline CHEMBL 2171001 & 863118 & 6.0 & 6.7481 & TRN & \\
\hline CHEMBL326294 & 1285708 & 4.0 & 0.8641 & TST & \\
\hline CHEMBL 3103276 & 1285708 & 7.0458 & 7.0443 & TRN & \\
\hline CHEMBL3103285 & 1285708 & 6.1871 & 6.1826 & TRN & \\
\hline CHEMBL 3103292 & 1285708 & 4.0 & 3.9936 & TRN & \\
\hline CHEMBL 3103270 & 1285708 & 7.5229 & 7.5664 & TRN & \\
\hline CHEMBL3103290 & 1285708 & 4.0 & 4.0019 & TRN & \\
\hline CHEMBL 3103266 & 1285708 & 7.3979 & 7.4011 & TRN & \\
\hline CHEMBL65 & 1285708 & 7.301 & 8.1292 & TST & \\
\hline CHEMBL 3103286 & 1285708 & 6.2076 & 6.1917 & TRN & \\
\hline CHEMBL 3103273 & 1285708 & 7.3979 & 7.3602 & TRN & \\
\hline CHEMBL3103301 & 1285708 & 5.0376 & 5.0313 & TRN & \\
\hline CHEMBL 3103303 & 1285708 & 4.0 & 4.0072 & TRN & \\
\hline CHEMBL3103296 & 1285708 & 5.2007 & 5.1847 & TRN & \\
\hline CHEMBL3103304 & 1285708 & 5.1267 & 5.1219 & TRN & \\
\hline
\end{tabular}


Supplemental Table S2.txt

\begin{tabular}{|c|c|c|c|c|}
\hline HEMBL & 285708 & 5.1073 & 1224 & \\
\hline & 285708 & 4.0 & 1.7965 & \\
\hline 3288 & 85708 & 6.0655 & & \\
\hline HEMBL & 85708 & 07 & 2063 & \\
\hline AEMBL3103281 & 285708 & 4.0 & 0034 & \\
\hline HEMBL 3103291 & 285708 & 6.0506 & 0654 & \\
\hline HEMBL3 & 285708 & 7.301 & .2994 & \\
\hline AEMBL3103263 & 285708 & 6.2757 & 2779 & DN \\
\hline HEMBL115897 & 285708 & 4.0 & 1.1056 & \\
\hline HEMBL3103278 & 285708 & 6.8239 & 6.8322 & \\
\hline HEMBL 116040 & 285708 & 4.0 & 1.4744 & \\
\hline HEMBL3 & 285708 & 959 & .7928 & RN \\
\hline HEMBL3 & 285708 & 979 & 3912 & \\
\hline HEMBL3103294 & 285708 & 5.1085 & 5.1213 & \\
\hline HEMBL3103268 & 285708 & 7.1549 & 7.1566 & \\
\hline HEMBL3 & 28 & 486 & 5.4209 & 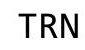 \\
\hline HEMBL & 8 & 7.3979 & 3922 & RN \\
\hline HEMBL & 285708 & 4.0 & 3.9969 & $\mathrm{RN}$ \\
\hline HEMBL3 & 285708 & 5.0017 & 296 & \\
\hline AEMBL3103261 & 285708 & 4. & 5788 & 151 \\
\hline HEMBL & 285 & 979 & 397 & RN \\
\hline AEM & 8 & 382 & 983 & RN \\
\hline HEMBL & 08 & 6. & 5843 & $\mathrm{RN}$ \\
\hline HEMBL3 & 708 & 319 & 184 & TRN \\
\hline AEMBL3 & $\partial 8$ & 6.7696 & 772 & IRN \\
\hline HEMBL3 & 285 & 604 & 2568 & 「RN \\
\hline HEMBL & 8 & 79 & 3991 & RN \\
\hline HEM & 38 & 18 & 5.6962 & IST \\
\hline HEMBL3 & & & 1788 & IRIN \\
\hline HEMBL3103282 & 285708 & 7. & 4461 & TRN \\
\hline HEMBL & 285 & 55 & 507 & TRN \\
\hline HFN & 8 & & 23 & ГST \\
\hline 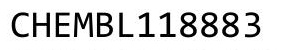 & & 4. & & $\pi \pi^{-1}$ \\
\hline HEMBL3 & $285^{\circ}$ & & 561 & TST \\
\hline HEMBL3103277 & 285708 & 6.6778 & 5634 & TST \\
\hline A & 285 & 6 & 627 & TST \\
\hline$\theta$ & & & 422 & IST \\
\hline HEMBL1 & 02286 & 5.26 & 7.2332 & TST \\
\hline HEMBL3 & 022 & 7. & 5754 & TRN \\
\hline IETID L & 02 & & 327 & 「RN \\
\hline HEMBL & 36 & 5 . & 5.8771 & TRN \\
\hline HEMBL4 & 02286 & 748 & 5.6202 & IST \\
\hline HEMBL9 & $\partial 2286$ & 7.3872 & 7.4521 & TRN \\
\hline HEMBL3 & 022 & 5.4752 & 31 & TR \\
\hline 201 & & & & \\
\hline HEMBL9 & 302286 & 7.21 & 7.1434 & \\
\hline HEMBL 1 & 302286 & 5.0 & 4.9018 & RN \\
\hline CHEMBL92928 & 302286 & 7.301 & 7.1388 & ГRN \\
\hline
\end{tabular}

Page 17206 


\begin{tabular}{|c|c|c|c|c|c|}
\hline \multirow[b]{2}{*}{ CHEMBL98240 } & \multicolumn{5}{|c|}{ Supplemental Table S2.txt } \\
\hline & 302286 & 6.6925 & 6.7794 & TRN & \\
\hline CHEMBL315645 & 302286 & 6.3768 & 6.249 & TRN & \\
\hline CHEMBL192851 & 302286 & 6.0177 & 5.7182 & TST & \\
\hline CHEMBL92144 & 302286 & 7.2924 & 7.11100 & 0000000001 & TRN \\
\hline CHEMBL193042 & 302286 & 6.8153 & 5.7687 & TST & \\
\hline CHEMBL363862 & 302286 & 5.8608 & 4.7711 & TST & \\
\hline CHEMBL443306 & 302286 & 5.5498 & 5.9619 & TST & \\
\hline CHEMBL192961 & 302286 & 6.3904 & 5.5406 & TST & \\
\hline CHEMBL316481 & 302286 & 5.3368 & 5.3269 & TRN & \\
\hline CHEMBL189969 & 302286 & 5.9477 & 7.068 & TST & \\
\hline CHEMBL329525 & 302286 & 7.8861 & 7.9312 & TRN & \\
\hline CHEMBL191937 & 302286 & 5.4062 & 5.2349 & TST & \\
\hline CHEMBL94696 & 302286 & 6.8069 & 6.8086 & TRN & \\
\hline CHEMBL421183 & 302286 & 6.2306 & 6.4224 & TRN & \\
\hline CHEMBL191922 & 302286 & 5.3942 & 5.3312 & TRN & \\
\hline CHEMBL193066 & 302286 & 5.0 & 5.2018 & TRN & \\
\hline CHEMBL318935 & 302286 & 6.58 & 6.5454 & TRN & \\
\hline CHEMBL432214 & 302286 & 6.6861 & 6.771 & TRN & \\
\hline CHEMBL431419 & 302286 & 7.4318 & 7.7322 & TRN & \\
\hline CHEMBL419884 & 302286 & 7.4089 & 7.2241 & TST & \\
\hline CHEMBL192522 & 302286 & 5.2076 & 4.8459 & TST & \\
\hline CHEMBL92616 & 302286 & 6.9031 & 7.0856 & TRN & \\
\hline CHEMBL192818 & 302286 & 5.8286 & 5.6936 & TRN & \\
\hline CHEMBL192011 & 302286 & 5.2944 & 4.9839 & TST & \\
\hline CHEMBL371386 & 302286 & 6.5143 & 6.098 & TST & \\
\hline CHEMBL193145 & 302286 & 5.8979 & 5.8297 & TRN & \\
\hline CHEMBL96129 & 302286 & 7.8861 & 7.6832 & TRN & \\
\hline CHEMBL318709 & 302286 & 7.2441 & 7.0143 & TRN & \\
\hline CHEMBL327253 & 302286 & 5.8091 & 5.6332 & TRN & \\
\hline CHEMBL97839 & 302286 & 5.7142 & 5.7243 & TRN & \\
\hline CHEMBL426275 & 302286 & 5.24 & 5.5582 & TRN & \\
\hline CHEMBL94399 & 302286 & 5.0 & 4.997 & TRN & \\
\hline CHEMBL192811 & 302286 & 6.8539 & 6.7261 & TRN & \\
\hline CHEMBL92613 & 302286 & 7.4437 & 7.3704 & TRN & \\
\hline CHEMBL94658 & 302286 & 7.3188 & 7.2818 & TRN & \\
\hline CHEMBL419325 & 302286 & 6.9066 & 7.0075 & TRN & \\
\hline CHEMBL96372 & 302286 & 7.5376 & 7.33799 & 9999999999 & TRN \\
\hline CHEMBL189049 & 302286 & 5.0 & 4.9429 & TRN & \\
\hline CHEMBL191682 & 302286 & 5.0 & 5.0422 & TRN & \\
\hline CHEMBL420078 & 302286 & 6.9747 & 6.7642 & TRN & \\
\hline CHEMBL318015 & 302286 & 5.7537 & 5.5632 & TRN & \\
\hline CHEMBL94651 & 302286 & 6.5129 & 6.4843 & TRN & \\
\hline CHEMBL365165 & 302286 & 5.0 & 5.6798 & TRN & \\
\hline CHEMBL97664 & 302286 & 5.3438 & $5.61100 t$ & 0000000001 & TRN \\
\hline CHEMBL330141 & 302286 & 7.3872 & 7.353 & TRN & \\
\hline CHEMBL95148 & 302286 & 7.3979 & 7.353 & TRN & \\
\hline CHEMBL373145 & 302286 & 5.6535 & 5.7438 & TST & \\
\hline CHEMBL190930 & 302286 & 5.5171 & 5.689 & TRN & \\
\hline
\end{tabular}





\begin{tabular}{|c|c|c|c|c|c|}
\hline & & & & & \\
\hline CHEMBL1916061 & 788179 & 6.8861 & 6.9186 & TRN & \\
\hline CHEMBL1916062 & 788179 & 7.3565 & 8.1778 & TRN & \\
\hline CHEMBL1916077 & 788179 & 7.1739 & 7.24299 & 9999999999 & TRN \\
\hline CHEMBL1916075 & 788179 & 7.2366 & 7.37799 & 9999999999 & TRN \\
\hline CHEMBL1915836 & 788179 & 8.9208 & 8.4408 & TRN & \\
\hline CHEMBL1915830 & 788179 & 6.0605 & 5.9562 & TRN & \\
\hline CHEMBL1915848 & 788179 & 5.1427 & 5.3299 & TRN & \\
\hline CHEMBL1915842 & 788179 & 4.0 & 4.3015 & TRN & \\
\hline CHEMBL1915846 & 788179 & 4.0 & 4.8372 & TST & \\
\hline CHEMBL1916067 & 788179 & 7.5376 & 6.9897 & TRN & \\
\hline CHEMBL1915850 & 788179 & 5.1549 & 6.8393 & TST & \\
\hline CHEMBL1916073 & 788179 & 7.5686 & 7.6416 & TRN & \\
\hline CHEMBL1915855 & 788179 & 6.7447 & 6.6919 & TRN & \\
\hline CHEMBL1916060 & 788179 & 7.5086 & 7.3582 & TRN & \\
\hline CHEMBL1916063 & 788179 & 7.5086 & 7.5686 & TRN & \\
\hline CHEMBL1915831 & 788179 & 6.4559 & 6.5037 & TRN & \\
\hline CHEMBL1915833 & 788179 & 6.5376 & 6.3373 & TRN & \\
\hline CHEMBL1915837 & 788179 & 7.9586 & 7.8537 & TRN & \\
\hline CHEMBL1915847 & 788179 & 5.2007 & 4.9866 & TRN & \\
\hline CHEMBL1915829 & 788179 & 6.2676 & 6.5709 & TRN & \\
\hline CHEMBL1915835 & 788179 & 5.6198 & 5.37700 & 0000000001 & TRN \\
\hline CHEMBL1915853 & 788179 & 7.3665 & 7.2246 & TRN & \\
\hline CHEMBL1915849 & 788179 & 5.5229 & 7.1131 & TST & \\
\hline CHEMBL1916076 & 788179 & 7.2441 & 7.3806 & TRN & \\
\hline CHEMBL1916069 & 788179 & 6.4202 & 6.2806 & TRN & \\
\hline CHEMBL1916064 & 788179 & 6.8539 & 6.9547 & TRN & \\
\hline CHEMBL1915834 & 788179 & 6.3565 & 6.6861 & TRN & \\
\hline CHEMBL1915852 & 788179 & 6.4815 & 6.5351 & TST & \\
\hline CHEMBL1915832 & 788179 & 6.1805 & 6.1749 & TRN & \\
\hline CHEMBL1916059 & 788179 & 6.6383 & 6.5795 & TRN & \\
\hline CHEMBL1914473 & 788179 & 6.8239 & 7.2343 & TRN & \\
\hline CHEMBL1915828 & 788179 & 6.2218 & 6.4465 & TRN & \\
\hline CHEMBL1916065 & 788179 & 6.8861 & 6.9696 & TRN & \\
\hline CHEMBL1915845 & 788179 & 4.0 & 4.5016 & TRN & \\
\hline CHEMBL1915840 & 788179 & 5.2596 & 5.1272 & TRN & \\
\hline CHEMBL1916066 & 788179 & 7.1739 & 6.9794 & TRN & \\
\hline CHEMBL1916068 & 788179 & 7.2676 & 7.0764 & TRN & \\
\hline CHEMBL1915844 & 788179 & 5.585 & 5.3437 & TRN & \\
\hline CHEMBL1915841 & 788179 & 5.2676 & 5.0557 & TRN & \\
\hline CHEMBL1915839 & 788179 & 5.3188 & 4.9973 & TST & \\
\hline CHEMBL1915854 & 788179 & 7.3188 & 6.8132 & TRN & \\
\hline CHEMBL1916058 & 788179 & 7.0 & 7.0963 & TRN & \\
\hline CHEMBL1916070 & 788179 & 5.5528 & 6.3257 & TST & \\
\hline CHEMBL1915851 & 788179 & 4.0 & 5.9584 & TST & \\
\hline CHEMBL1916074 & 788179 & 6.6198 & 6.4359 & TST & \\
\hline CHEMBL67 & 788179 & 7.9586 & 7.1237 & TST & \\
\hline CHEMBL1916071 & 788179 & 7.1805 & 7.2623 & TST & \\
\hline CHEMBL1915843 & 788179 & 6.1249 & 4.9392 & TST & \\
\hline
\end{tabular}




\begin{tabular}{|c|c|c|c|c|c|}
\hline \multicolumn{6}{|c|}{ Supplemental Table S2.txt } \\
\hline CHEMBL1916072 & 788179 & 7.5086 & 7.5502 & TST & \\
\hline CHEMBL1915838 & 788179 & 6.699 & 7.6685 & TST & \\
\hline CHEMBL3979657 & 1528852 & 6.9914 & 6.9893 & TRN & \\
\hline CHEMBL3699202 & 1528852 & 5.7277 & 5.7288 & TRN & \\
\hline CHEMBL3699197 & 1528852 & 7.6778 & 7.6767 & TRN & \\
\hline CHEMBL3699172 & 1528852 & 6.7167 & 6.7142 & TRN & \\
\hline CHEMBL3699180 & 1528852 & 6.7375 & 6.7362 & TRN & \\
\hline CHEMBL3699186 & 1528852 & 8.0458 & 8.0465 & TRN & \\
\hline CHEMBL3699188 & 1528852 & 9.301 & 9.2978 & TRN & \\
\hline CHEMBL3699179 & 1528852 & 9.301 & 9.3021 & TRN & \\
\hline CHEMBL3699196 & 1528852 & 6.0278 & 6.0297 & TRN & \\
\hline CHEMBL 3970049 & 1528852 & 9.301 & 6.0249 & TST & \\
\hline CHEMBL3699208 & 1528852 & 8.1805 & 6.8869 & TST & \\
\hline CHEMBL3699163 & 1528852 & 8.2218 & 8.2206 & TRN & \\
\hline CHEMBL3699213 & 1528852 & 6.2366 & 6.2361 & TRN & \\
\hline CHEMBL 3699204 & 1528852 & 6.5072 & 6.50899 & 99999999995 & TRN \\
\hline CHEMBL3896858 & 1528852 & 9.301 & 4.8102 & TST & \\
\hline CHEMBL3699230 & 1528852 & 5.3813 & 6.0446 & TST & \\
\hline CHEMBL3699206 & 1528852 & 6.4547 & 6.4561 & TRN & \\
\hline CHEMBL3699228 & 1528852 & 6.1707 & 6.1702 & TRN & \\
\hline CHEMBL3978236 & 1528852 & 5.6633 & 5.6647 & TRN & \\
\hline CHEMBL3639980 & 1528852 & 9.301 & 7.2305 & TST & \\
\hline CHEMBL 3978644 & 1528852 & 5.3055 & 6.8178 & TST & \\
\hline CHEMBL3699212 & 1528852 & 9.301 & 9.2998 & TRN & \\
\hline CHEMBL3676167 & 1528852 & 9.301 & 9.2964 & TRN & \\
\hline CHEMBL 3699198 & 1528852 & 9.301 & 9.3027 & TRN & \\
\hline CHEMBL3699227 & 1528852 & 6.0237 & 6.0239 & TRN & \\
\hline CHEMBL3699199 & 1528852 & 9.301 & 9.3029 & TRN & \\
\hline CHEMBL3947448 & 1528852 & 6.1965 & 6.1947 & TRN & \\
\hline CHEMBL3699201 & 1528852 & 9.301 & 9.301 & TRN & \\
\hline CHEMBL3699177 & 1528852 & 7.6198 & 7.6225 & TRN & \\
\hline CHEMBL3965574 & 1528852 & 7.5376 & 7.5369 & TRN & \\
\hline CHEMBL 3908322 & 1528852 & 9.301 & 9.3005 & TRN & \\
\hline CHEMBL3967993 & 1528852 & 9.301 & 6.6318 & TST & \\
\hline CHEMBL3699203 & 1528852 & 6.6635 & 6.66100 & 00000000005 & TRN \\
\hline CHEMBL3699215 & 1528852 & 5.8788 & 5.8806 & TRN & \\
\hline CHEMBL3973358 & 1528852 & 9.301 & 9.3014 & TRN & \\
\hline CHEMBL3699162 & 1528852 & 6.6038 & 6.6036 & TRN & \\
\hline CHEMBL3699195 & 1528852 & 7.6383 & 7.6387 & TRN & \\
\hline CHEMBL3948222 & 1528852 & 5.9759 & 5.9774 & TRN & \\
\hline CHEMBL3699175 & 1528852 & 6.6925 & 6.6894 & TRN & \\
\hline CHEMBL3699184 & 1528852 & 6.341 & 6.3447 & TRN & \\
\hline CHEMBL3699161 & 1528852 & 7.4685 & 7.4706 & TRN & \\
\hline CHEMBL3699220 & 1528852 & 6.1331 & 6.1332 & TRN & \\
\hline CHEMBL3699214 & 1528852 & 5.4144 & 5.4141 & TRN & \\
\hline CHEMBL 3699185 & 1528852 & 6.8761 & 6.8735 & TRN & \\
\hline CHEMBL3699219 & 1528852 & 9.301 & 9.3059 & TRN & \\
\hline CHEMBL3699231 & 1528852 & 6.2426 & 6.2401 & TRN & \\
\hline
\end{tabular}


Supplemental Table S2.txt

\begin{tabular}{|c|c|c|c|c|c|}
\hline CHEMBL3699165 & 1528852 & 5.3453 & 5.3443 & TRN & \\
\hline CHEMBL3699218 & 1528852 & 6.5287 & 6.5292 & TRN & \\
\hline CHEMBL3699205 & 1528852 & 5.5346 & 5.5343 & TRN & \\
\hline CHEMBL 3916180 & 1528852 & 9.301 & 9.3016 & TRN & \\
\hline CHEMBL3699216 & 1528852 & 6.3615 & 6.3651 & TRN & \\
\hline CHEMBL3699211 & 1528852 & 6.5391 & 6.539 & TRN & \\
\hline CHEMBL3973539 & 1528852 & 5.2094 & 6.0491 & TST & \\
\hline CHEMBL 3944908 & 1528852 & 6.0168 & 8.4667 & TST & \\
\hline CHEMBL 3699200 & 1528852 & 9.301 & 9.3008 & TRN & \\
\hline CHEMBL3699232 & 1528852 & 9.301 & 9.3015 & TRN & \\
\hline CHEMBL 3699190 & 1528852 & 7.7212 & 7.72 & TRN & \\
\hline CHEMBL3699217 & 1528852 & 5.4124 & 5.41299 & 9999999999 & TRN \\
\hline CHEMBL 3699173 & 1528852 & 7.699 & 7.6993 & TRN & \\
\hline CHEMBL 3923340 & 1528852 & 9.301 & 7.5391 & TST & \\
\hline CHEMBL3963745 & 1528852 & 9.301 & 9.3009 & TRN & \\
\hline CHEMBL3965035 & 1528852 & 5.5253 & 5.5257 & TRN & \\
\hline CHEMBL3971545 & 1528852 & 8.0458 & 7.2223 & TST & \\
\hline CHEMBL3699164 & 1528852 & 7.0177 & 7.0202 & TRN & \\
\hline CHEMBL 3896840 & 1528852 & 9.301 & 9.3015 & TRN & \\
\hline CHEMBL3933916 & 1528852 & 7.6021 & 7.6014 & TRN & \\
\hline CHEMBL3699209 & 1528852 & 6.2104 & 6.2064 & TRN & \\
\hline CHEMBL3699226 & 1528852 & 9.301 & 7.4971 & TST & \\
\hline CHEMBL 3699210 & 1528852 & 6.5686 & 5.0069 & TST & \\
\hline CHEMBL 3699207 & 1528852 & 9.301 & 7.1319 & TST & \\
\hline CHEMBL 3699187 & 1528852 & 5.7582 & 6.2054 & TST & \\
\hline CHEMBL 3971572 & 1528852 & 6.8041 & 6.5566 & TST & \\
\hline CHEMBL3699181 & 1528852 & 5.5259 & 5.5119 & TST & \\
\hline CHEMBL 3891480 & 1528852 & 9.301 & 6.7086 & TST & \\
\hline CHEMBL 3699194 & 1528852 & 6.9547 & 6.6765 & TST & \\
\hline CHEMBL189584 & 954781 & 3.5877 & 3.866 & TRN & \\
\hline CHEMBL 220241 & 954781 & 4.3225 & \multicolumn{2}{|c|}{ 4. 281000000000001} & TRN \\
\hline CHEMBL 222102 & 954781 & 2.8638 & 3.8397 & TRN & \\
\hline CHEMBL9470 & 954781 & 4.8032 & 6.0837 & TST & \\
\hline CHEMBL 2363137 & 954781 & 6.0806 & 5.6849 & TRN & \\
\hline CHEMBL1590308 & 954781 & 3.3231 & 3.4036 & TST & \\
\hline CHEMBL1186585 & 954781 & 5.3726 & 4.8135 & TRN & \\
\hline CHEMBL412142 & 954781 & 3.9326 & 4.0106 & TRN & \\
\hline CHEMBL1256459 & 954781 & 6.7815 & 7.2569 & TRN & \\
\hline CHEMBL3349342 & 954781 & 4.8166 & 5.0331 & TRN & \\
\hline CHEMBL192566 & 954781 & 8.3201 & 7.9403 & TST & \\
\hline CHEMBL300389 & 954781 & 5.5154 & 6.346 & TRN & \\
\hline CHEMBL1230020 & 954781 & 3.0137 & 3.9371 & TRN & \\
\hline CHEMBL483849 & 954781 & 3.1352 & 2.1527 & TST & \\
\hline CHEMBL135561 & 954781 & 4.3892 & 4.2999 & TRN & \\
\hline CHEMBL514499 & 954781 & 7.4347 & 7.2803 & TRN & \\
\hline CHEMBL2137530 & 954781 & 4.2194 & 5.0747 & TRN & \\
\hline CHEMBL2144069 & 954781 & 7.2884 & 5.928 & TRN & \\
\hline CHEMBL449158 & 954781 & 6.5791 & 6.5273 & TST & \\
\hline
\end{tabular}




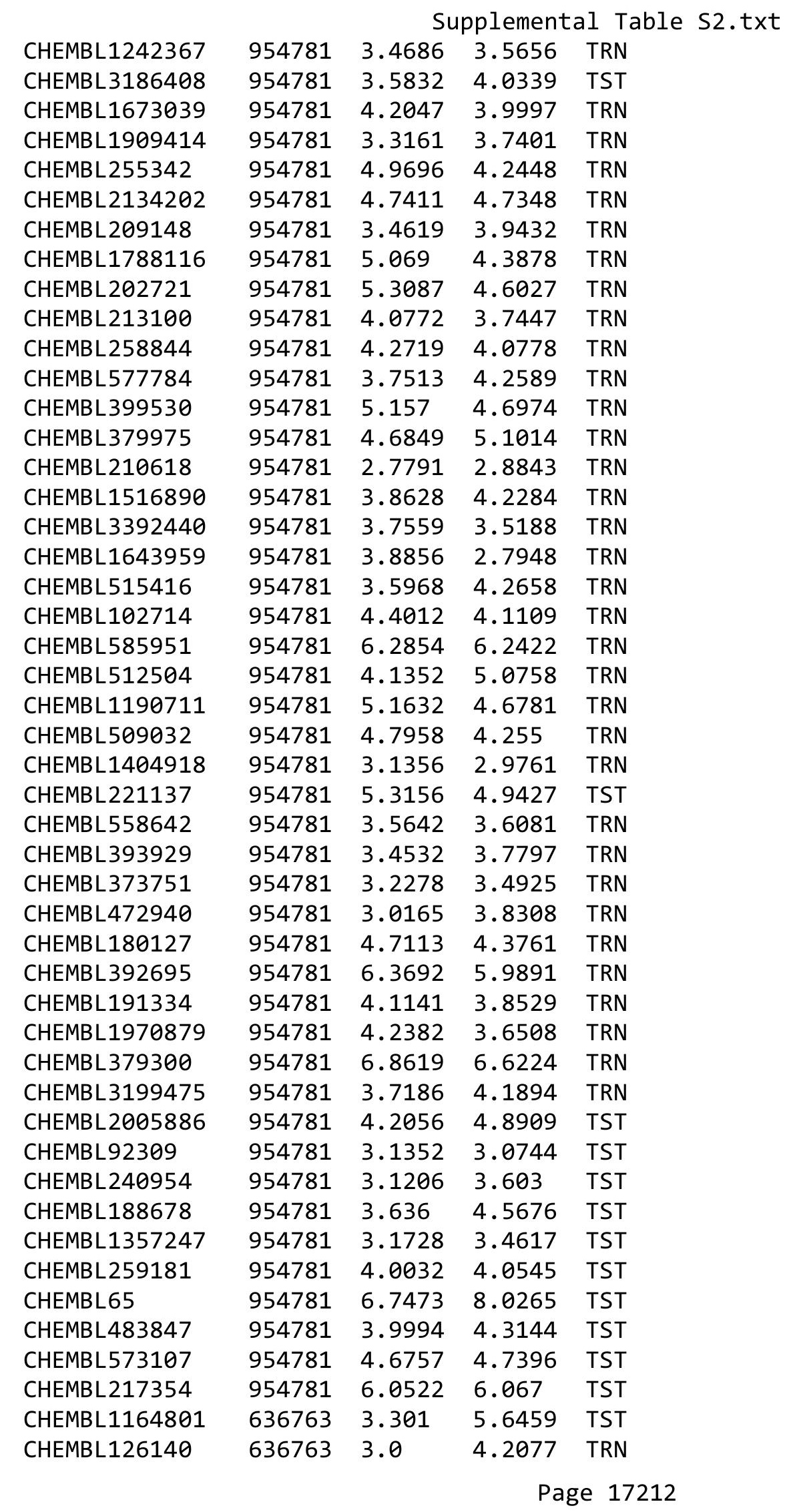




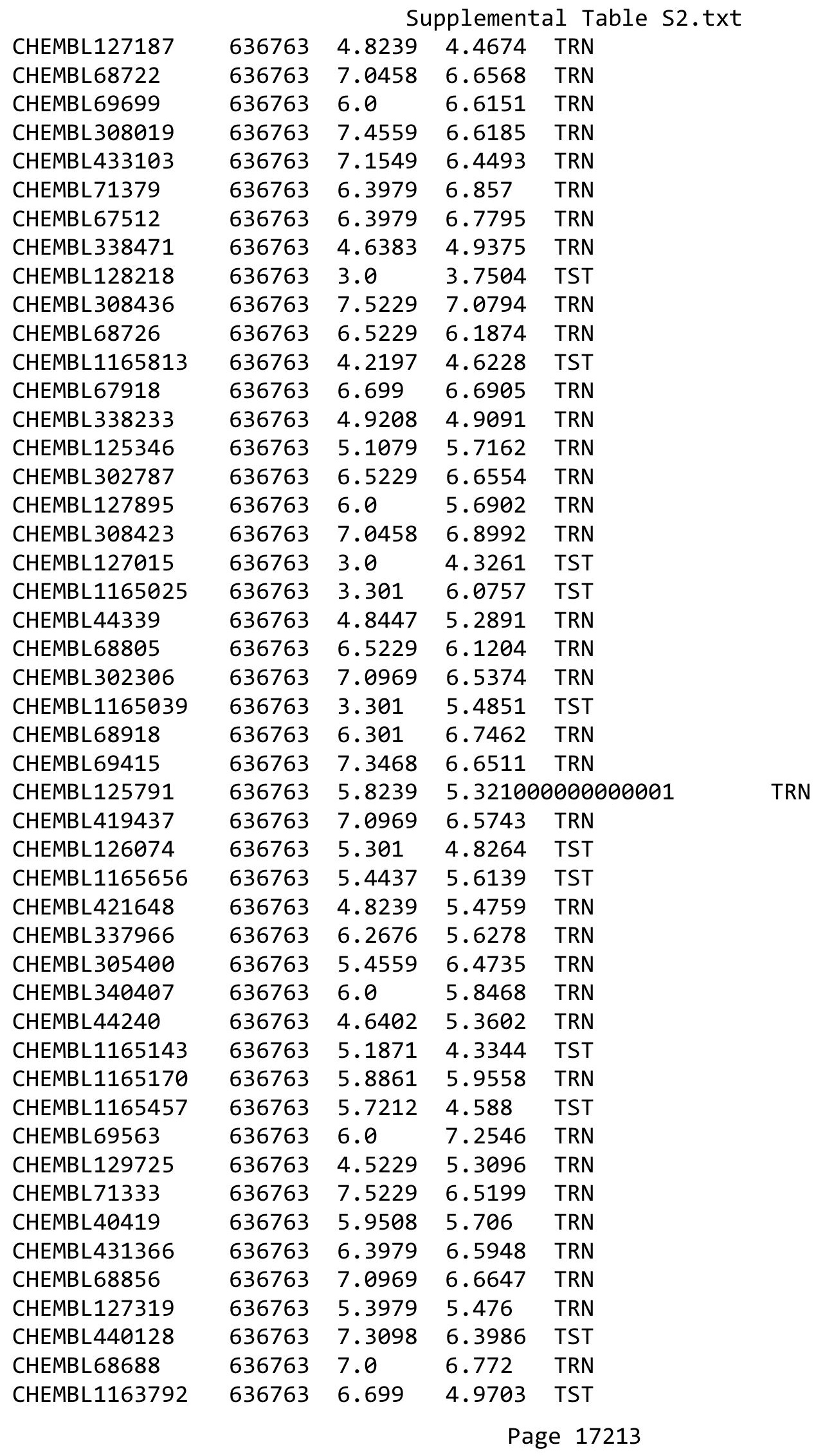




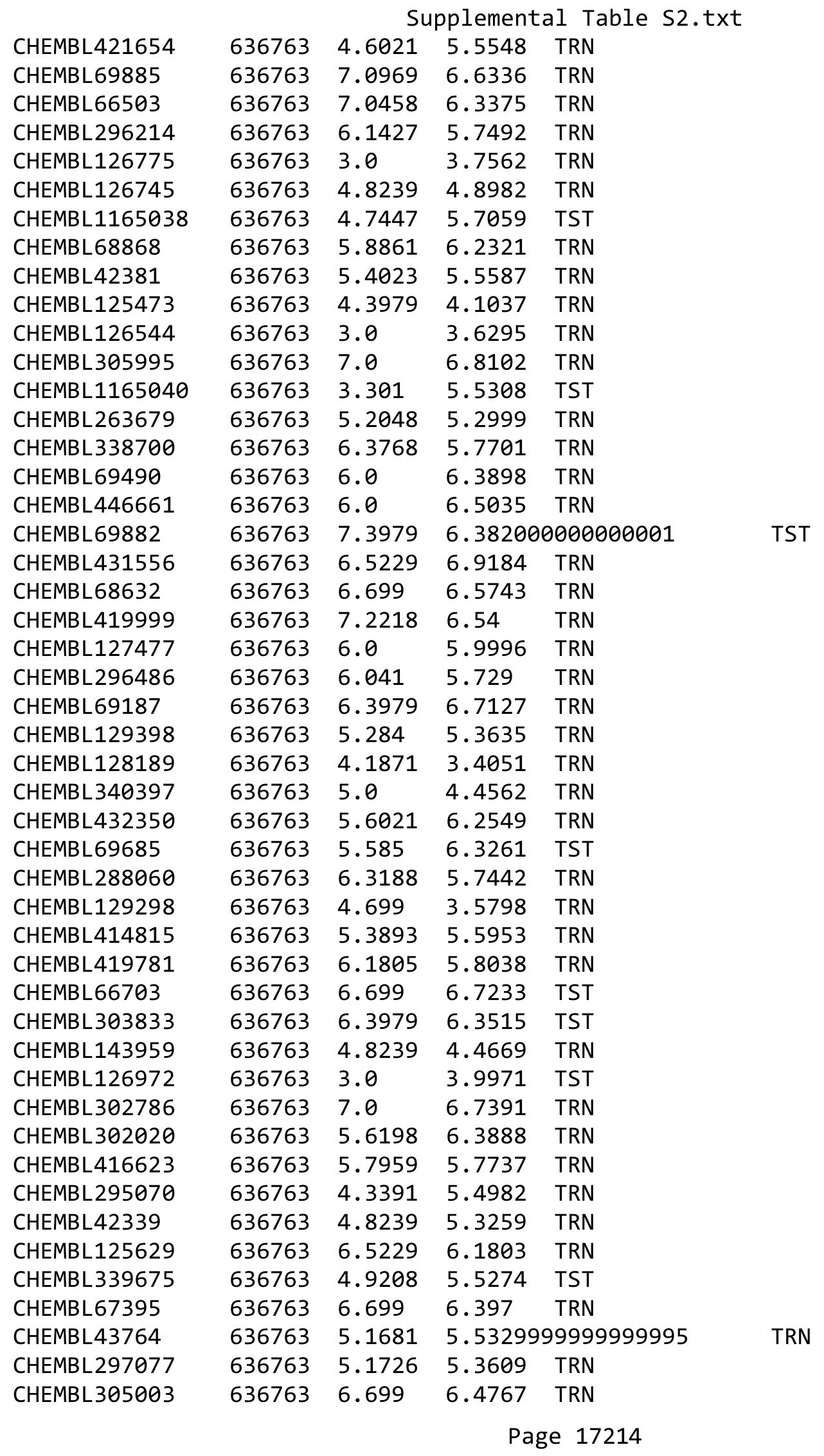




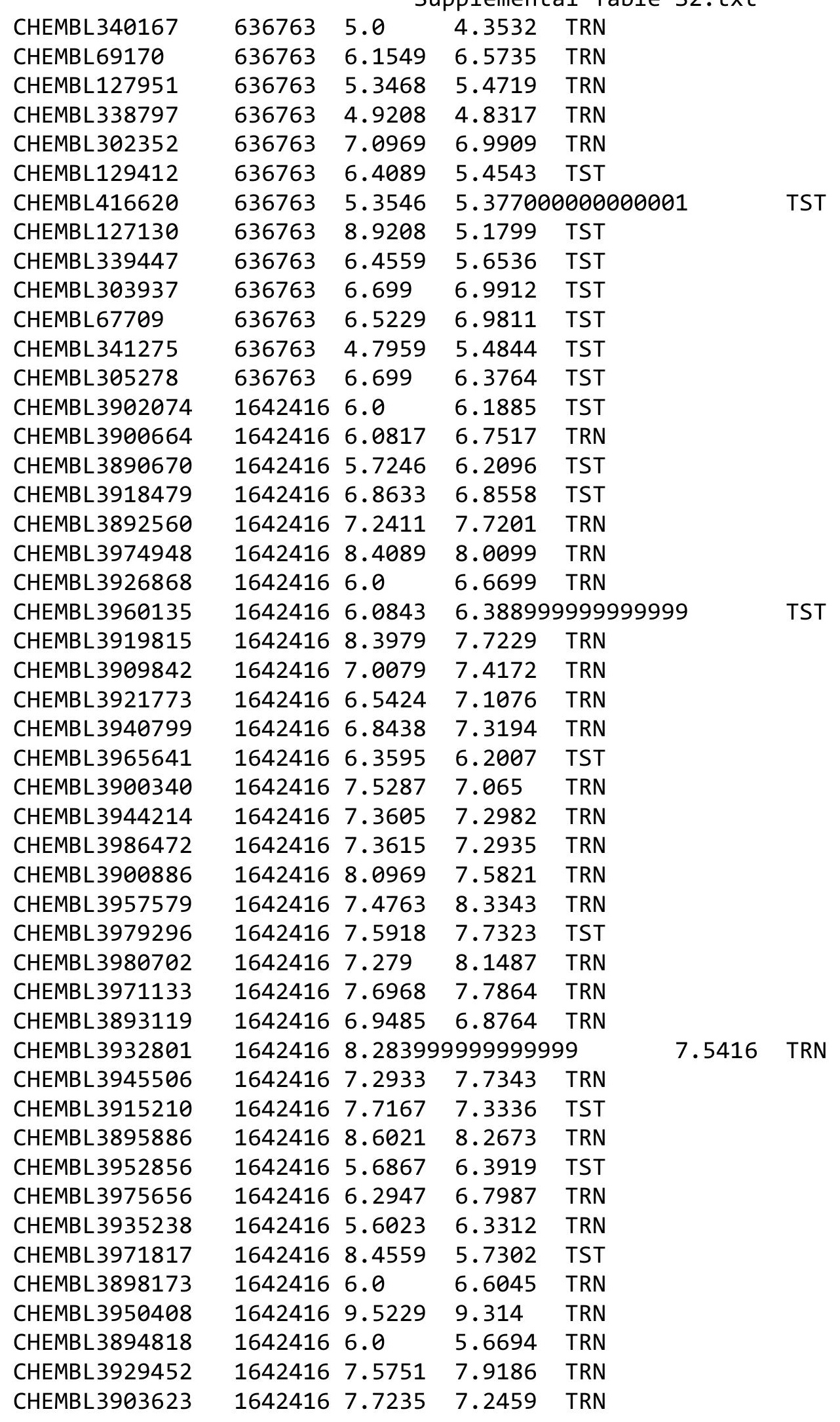

Page 17215 
Supplemental Table S2.txt

\begin{tabular}{|c|c|c|c|c|}
\hline Th & 2416 & 8.7959 & & \\
\hline & & 7.8861 & & \\
\hline 95 & & 6.0 & 379 & \\
\hline HEMBL 396 & & 6.0 & 1947 & $\mathrm{MI}$ \\
\hline AEMBL3961764 & 16 & 5.6001 & 6469 & \\
\hline HEMBL3905624 & 642416 & 6.0 & .4445 & \\
\hline 870 & & 6.54 & 333 & \\
\hline IFMRI 390 & & & & \\
\hline AEMBL3932905 & 16 & 8.4949 & 3821 & \\
\hline HEMBL3914146 & 16 & 6.4438 & 0784 & \\
\hline HEMBL3971752 & 16 & 6.3629 & 6423 & \\
\hline IEMBL39 & 6 & 557 & 7418 & \\
\hline AEMBL3S & & & & \\
\hline HEMBL 390 & 16 & 7.4056 & 4633 & \\
\hline AEMBL3902799 & 16 & 8.9586 & 295 & \\
\hline IEMBL395 & 6 & 7.3565 & 3989 & \\
\hline AEMBL39 & 6 & 788 & 24 & \\
\hline HEMBL39 & & 7.3002 & 1644 & \\
\hline HEMBL396 & & 8.699 & 6438 & \\
\hline AEMBL39 & 6 & 815 & 77 & \\
\hline HEIMBLSS & 6 & 7. & 97 & 1 \\
\hline AEMBL: & & 9. & 65 & הות \\
\hline AEMBL3 & & $\partial 8$ & & \\
\hline 012 & & 7.7645 & 272 & \\
\hline AEMBL39 & & 5.9333 & & I RIV \\
\hline HEMBL3S & 6 & 6 & 27 & RN \\
\hline HEMBL3S & & . & 63 & Niv \\
\hline AFMBI $3 c$ & 16 & 7. & 11 & \\
\hline HEMBL39 & & & & I \\
\hline HEMBL3941684 & & 979 & 026 & IK \\
\hline HEMBL 394 & & 928 & 244 & RN \\
\hline HEMBL3 & 6 & 872 & 997 & RN \\
\hline HEMBL; & & 6 . & & \\
\hline HEMBL3917358 & 16 & & 189 & $\mathrm{IR}$ \\
\hline HEMBL3939738 & 6 & 7.9508 & 278 & 「RN \\
\hline HEMBL39 & & 251 & 861 & RN \\
\hline HFMRI 3 & 6 & 9 . & 525 & $\Gamma \mathrm{RN}$ \\
\hline HEMBL3 & & 7. & 285 & IRN \\
\hline HEMBL3919554 & 16 & 7.295 & 984 & TRN \\
\hline HEMBL390 & & & 865 & TRN \\
\hline HEMBL39 & 6 & 022 & 268 & \\
\hline CHEMBL396 & & & 553 & RN \\
\hline HEMBL392 & & 6.8589 & 7.3952 & TRN \\
\hline HEMBL398 & 16 & 8.3872 & 3065 & TS \\
\hline MBL391 & & 696 & 848 & \\
\hline HEMBL 39 & & 3815 & 7725 & \\
\hline CHEMBL 3974698 & 16 & 7.4377 & 7.8312 & \\
\hline CHEMBL3927124 & 1642416 & 6.0 & 5.7146 & ГRN \\
\hline
\end{tabular}

Page 17216 
Supplemental Table S2.txt

\begin{tabular}{|c|c|c|}
\hline ra & & \\
\hline & & ० 0200 \\
\hline$\Gamma 0$ & & \\
\hline HEMBL390 & 16 & 817 \\
\hline AEMBL3947724 & & - \\
\hline HEMBL3933901 & 642416 & 6.8156 \\
\hline 504 & 16 & 8.6778 \\
\hline IFMBI 390 & & 7.556 \\
\hline HEMBL3911027 & & 8.1308 \\
\hline HEMBL3895949 & 16 & 8.2518 \\
\hline HEMBL3946932 & 16 & 8.3665 \\
\hline IEMBL395 & 16 & \\
\hline AEMBL 392 & & 7.3979 \\
\hline HEMBL3939787 & 416 & 6.572 \\
\hline HEMBL 392 & 16 & 9.301 \\
\hline AEMBL397 & 16 & 8.2 \\
\hline HEMBL393 & 16 & \\
\hline HEMBL 391 & 16 & 6.8348 \\
\hline HEMBL 391 & & 8.6778 \\
\hline HEMBL397 & 16 & 8.9 \\
\hline AEMBL396 & 16 & 6.5645 \\
\hline HEMBL39 & 6 & 235 \\
\hline HEMBL 397 & 16 & 5.8084 \\
\hline HEMBL392 & 16 & 8.699 \\
\hline HEMBL 397 & & 8.585 \\
\hline HEMBL 391 & 16 & 6. \\
\hline HEMBL3\& & 16 & 9. \\
\hline HEMBL39 & 16 & 6 \\
\hline HEMBL390 & 16 & 7.4776 \\
\hline HEMBL 390 & 16 & 7.556 \\
\hline HEMBL 397 & 16 & 6 \\
\hline HEMBL3S & 16 & 6 \\
\hline HEMBL3 & 16 & 6 \\
\hline HEMBL3970767 & 16 & 7.5969 \\
\hline HEMBL3945460 & 16 & 8.8239 \\
\hline HEMBL39 & 16 & \\
\hline HEMBL3\& & 16 & 3861 \\
\hline HEMBL 390 & 16 & 7.8996 \\
\hline HEMBL3973702 & 16 & 5.0004 \\
\hline HEMBL3984826 & 16 & 7.4145 \\
\hline CHEMBL398 & 16 & 7.1785 \\
\hline CHEMBL398 & 164 & 9.0 \\
\hline CHEMBL 391 & 16 & 8.2291 \\
\hline HEMBL393 & 16 & 7.4868 \\
\hline CHEMBL3915 & 16 & 7.6478 \\
\hline CHEMBL397 & 16 & 8.7696 \\
\hline CHEMBL 393 & 164 & 8.657 \\
\hline & & $-n^{2}+2$ \\
\hline
\end{tabular}

\begin{tabular}{ll}
7.4086 & TST \\
7.8367 & TRN \\
6.7333 & TRN \\
7.2711 & TST \\
8.6609 & TRN \\
7.0236 & TRN \\
8.1406 & TRN \\
7.9287 & TRN \\
7.1719 & TRN \\
7.37299999999999 \\
8.4734 & TRN \\
6.9015 & TRN \\
8.0011 & TST \\
7.0191 & TRN \\
6.5621 & TST \\
9.1326 & TRN \\
6.657 & TRN \\
6.6968 & TRN \\
8.5252 & TRN \\
8.7588 & TRN \\
6.4842 & TST \\
5.7481 & TST \\
6.1567 & TRN \\
8.6949 & TRN \\
8.3907 & TRN \\
6.7071 & TRN \\
8.5742 & TRN \\
6.4924 & TRN \\
7.3501 & TRN \\
7.6072 & TRN \\
6.2063 & TRN \\
5.7986 & TRN \\
5.5071 & TST \\
7.5558 & TST \\
8.959 & TRN \\
7.7479 & TRN \\
9.0663 & TRN \\
7.8142 & TRN \\
6.8308 & TST \\
7.2205 & TST \\
8.0297 & TST \\
7.4177 & TRN \\
7.7257 & TRN \\
7.3785 & TRN \\
7.6419 & TST \\
7.8294 & TRN \\
7.8685 & TST \\
6.3794 & TRN \\
& \\
\hline 7
\end{tabular}


Supplemental Table S2.txt

\begin{tabular}{|c|c|c|c|c|c|}
\hline CHEMBL 3972902 & 1642416 & 7.1694 & 7.6783 & TRN & \\
\hline CHEMBL3895239 & 1642416 & 8.2924 & 7.9427 & TRN & \\
\hline CHEMBL 3895348 & 1642416 & 6.0 & \multicolumn{2}{|c|}{6.5760000000000005} & TRN \\
\hline CHEMBL 3983704 & 1642416 & 7.5751 & 7.1522 & TST & \\
\hline CHEMBL 3927652 & 1642416 & 8.1871 & 8.2975 & TRN & \\
\hline CHEMBL3956381 & 1642416 & 6.0 & 5.7642 & TRN & \\
\hline CHEMBL3902832 & 1642416 & 6.9062 & 6.7854 & TRN & \\
\hline CHEMBL3953959 & 1642416 & 8.3372 & 8.4087 & TST & \\
\hline CHEMBL3908541 & 1642416 & 9.301 & 8.1133 & TRN & \\
\hline CHEMBL3948576 & 1642416 & 8.3188 & 7.3765 & TST & \\
\hline CHEMBL3923677 & 1642416 & 8.6576 & 9.2189 & TRN & \\
\hline CHEMBL3912277 & 1642416 & 8.7696 & 7.3756 & TST & \\
\hline CHEMBL 3900637 & 1642416 & 8.2518 & 7.7097 & TRN & \\
\hline CHEMBL 3905302 & 1642416 & 6.669 & \multicolumn{2}{|c|}{7.553999999999999} & TRN \\
\hline CHEMBL3928552 & 1642416 & 6.1047 & 6.7666 & TRN & \\
\hline CHEMBL 3890735 & 1642416 & 7.9872 & 6.9196 & TST & \\
\hline CHEMBL3908667 & 1642416 & 6.7038 & 6.7616 & TRN & \\
\hline CHEMBL3932272 & 1642416 & 6.0 & 6.4712 & TRN & \\
\hline CHEMBL3917049 & 1642416 & 7.7645 & 7.2279 & TRN & \\
\hline CHEMBL3983166 & 1642416 & 7.2549 & 7.4848 & TRN & \\
\hline CHEMBL 3979004 & 1642416 & 6.7249 & 6.8769 & TRN & \\
\hline CHEMBL3908144 & 1642416 & 6.4049 & 6.3028 & TRN & \\
\hline CHEMBL3949981 & 1642416 & 9.1549 & 8.7314 & TRN & \\
\hline CHEMBL3926524 & 1642416 & 8.2076 & 7.7203 & TRN & \\
\hline CHEMBL 3914186 & 1642416 & 7.2161 & 8.3442 & TST & \\
\hline CHEMBL 3984807 & 1642416 & 7.7852 & 7.6765 & TRN & \\
\hline CHEMBL3976930 & 1642416 & 8.4202 & 7.4944 & TRN & \\
\hline CHEMBL3891310 & 1642416 & 8.5686 & 7.1489 & TRN & \\
\hline CHEMBL3918725 & 1642416 & 8.0809 & 8.0002 & TRN & \\
\hline CHEMBL3967938 & 1642416 & 7.3429 & 6.6229 & TRN & \\
\hline CHEMBL3919814 & 1642416 & 6.8242 & 6.5335 & TRN & \\
\hline CHEMBL3922853 & 1642416 & 6.9359 & 7.0501 & TRN & \\
\hline CHEMBL3918569 & 1642416 & 6.0 & 6.1978 & TRN & \\
\hline CHEMBL3942181 & 1642416 & 7.2749 & 7.9524 & TRN & \\
\hline CHEMBL3911618 & 1642416 & 6.6146 & 7.1513 & TRN & \\
\hline CHEMBL3903186 & 1642416 & 5.8695 & 5.9625 & TST & \\
\hline CHEMBL 3895372 & 1642416 & 8.1249 & 7.3189 & TRN & \\
\hline CHEMBL3940117 & 1642416 & 6.8655 & 7.5948 & TRN & \\
\hline CHEMBL 3972763 & 1642416 & 7.1878 & 6.6482 & TRN & \\
\hline CHEMBL3919850 & 1642416 & 5.9362 & 6.1985 & TRN & \\
\hline CHEMBL 3903043 & 1642416 & 7.1904 & 6.7369 & TRN & \\
\hline CHEMBL3921016 & 1642416 & 6.4755 & 6.8379 & TRN & \\
\hline CHEMBL3949293 & 1642416 & 9.5229 & 9.7241 & TRN & \\
\hline CHEMBL 3895354 & 1642416 & 7.8327 & 7.2935 & TRN & \\
\hline CHEMBL3933475 & 1642416 & 6.0 & 5.8217 & TRN & \\
\hline CHEMBL 3948722 & 1642416 & 6.8844 & 7.1903 & TRN & \\
\hline CHEMBL3946662 & 1642416 & 7.3261 & 6.9776 & TRN & \\
\hline CHEMBL3941142 & 1642416 & 8.6778 & 7.0522 & TRN & \\
\hline
\end{tabular}

Page 17218 
Supplemental Table S2.txt

\begin{tabular}{|c|c|c|c|c|}
\hline CHEMBL3912641 & 1642416 & 6.0 & 7.5126 & TRN \\
\hline CHEMBL 3893342 & 1642416 & 6.0 & 6.3588 & TRN \\
\hline CHEMBL 3896435 & 1642416 & 9.0969 & 8.6682 & TRN \\
\hline CHEMBL3966738 & 1642416 & 7.3224 & 6.7145 & TRN \\
\hline CHEMBL3960639 & 1642416 & 7.8356 & 8.4158 & TRN \\
\hline CHEMBL 3929794 & 1642416 & 8.2441 & 7.7225 & TRN \\
\hline CHEMBL 3927247 & 1642416 & 8.8861 & 8.6697 & TRN \\
\hline CHEMBL3910611 & 1642416 & 7.5969 & 8.1057 & TRN \\
\hline CHEMBL3900792 & 1642416 & 7.2211 & 7.0565 & TRN \\
\hline CHEMBL3971995 & 1642416 & 6.0 & 5.7865 & TRN \\
\hline CHEMBL3976460 & 1642416 & 7.9666 & 7.1271 & TRN \\
\hline CHEMBL 3981605 & 1642416 & 5.8976 & 7.0155 & TST \\
\hline CHEMBL 3926846 & 1642416 & 7.3904 & 6.8367 & TRN \\
\hline CHEMBL 3927271 & 1642416 & 6.9034 & 6.7256 & TST \\
\hline CHEMBL 3975226 & 1642416 & 8.0862 & 7.8659 & TST \\
\hline CHEMBL3958431 & 1642416 & 7.8013 & 8.5712 & TRN \\
\hline CHEMBL3918292 & 1642416 & 7.8827 & 8.0359 & TST \\
\hline CHEMBL 3967293 & 1642416 & 6.8156 & 8.5114 & TST \\
\hline CHEMBL3936207 & 1642416 & 8.7212 & 9.2627 & TRN \\
\hline CHEMBL 3909545 & 1642416 & 5.5488 & 7.0591 & TRN \\
\hline CHEMBL 3893973 & 1642416 & 8.8239 & 9.1093 & TRN \\
\hline CHEMBL 3925072 & 1642416 & 7.7447 & 7.1442 & TRN \\
\hline CHEMBL3918412 & 1642416 & 8.4437 & 7.38899 & 9999999999 \\
\hline CHEMBL3960884 & 1642416 & 6.8159 & 6.9786 & TRN \\
\hline CHEMBL3912684 & 1642416 & 6.6105 & 8.0198 & TST \\
\hline CHEMBL3926222 & 1642416 & 8.8539 & 9.1491 & TRN \\
\hline CHEMBL 3900847 & 1642416 & 9.0969 & 7.6847 & TRN \\
\hline CHEMBL 3900861 & 1642416 & 7.9706 & 7.5498 & TRN \\
\hline CHEMBL3985354 & 1642416 & 8.3188 & 7.9842 & TRN \\
\hline CHEMBL 3932004 & 1642416 & 7.0773 & 6.8149 & TST \\
\hline CHEMBL3939209 & 1642416 & 7.2168 & 7.3802 & TRN \\
\hline CHEMBL3950913 & 1642416 & 6.495 & 7.42700 & 00000000005 \\
\hline CHEMBL3920026 & 1642416 & 6.0 & 7.4853 & TST \\
\hline CHEMBL3921496 & 1642416 & 8.3979 & 8.3146 & TST \\
\hline CHEMBL3974109 & 1642416 & 7.1391 & 7.3023 & TRN \\
\hline CHEMBL3894865 & 1642416 & 7.644 & 8.2347 & TST \\
\hline CHEMBL 3893555 & 1642416 & 6.0 & 5.8577 & TRN \\
\hline CHEMBL 3910248 & 1642416 & 8.7696 & 8.1761 & TST \\
\hline CHEMBL 3950745 & 1642416 & 6.7007 & 6.7477 & TST \\
\hline CHEMBL3956210 & 1642416 & 7.644 & 8.2732 & TST \\
\hline CHEMBL3919936 & 1642416 & 8.4559 & 8.4965 & TRN \\
\hline CHEMBL 3948537 & 1642416 & 6.0 & 5.9959 & TRN \\
\hline CHEMBL 3897246 & 1642416 & 7.6819 & 7.6644 & TST \\
\hline CHEMBL3901508 & 1642416 & 8.1487 & 8.0252 & TRN \\
\hline CHEMBL 3890475 & 1642416 & 8.8861 & 9.4389 & TRN \\
\hline CHEMBL3936493 & 1642416 & 7.0595 & 7.3974 & TRN \\
\hline CHEMBL 3925002 & 1642416 & 7.3134 & 7.7194 & TST \\
\hline CHEMBL 3889958 & 1642416 & 6.1468 & 6.8316 & TST \\
\hline
\end{tabular}


Supplemental Table S2.txt

\begin{tabular}{|c|c|c|c|c|c|c|}
\hline CHEMBL3919696 & 1642416 & 7.0778 & 8.0287 & TRN & & \\
\hline CHEMBL3955311 & 1642416 & 7.2958 & 6.9553 & TRN & & \\
\hline CHEMBL3913699 & 1642416 & 9.301 & 9.4881 & TRN & & \\
\hline CHEMBL3959211 & 1642416 & 7.2418 & 7.7374 & TRN & & \\
\hline CHEMBL3934247 & 1642416 & \multicolumn{3}{|c|}{7.821000000000001} & 7.4003 & TRN \\
\hline CHEMBL3918526 & 1642416 & 9.2218 & 7.5975 & TST & & \\
\hline CHEMBL3899407 & 1642416 & 7.5702 & 6.3855 & TST & & \\
\hline CHEMBL3909652 & 1642416 & 8.8861 & 8.5754 & TRN & & \\
\hline CHEMBL3960690 & 1642416 & 8.2924 & \multicolumn{3}{|c|}{8.017000000000001} & TST \\
\hline CHEMBL3984063 & 1642416 & 7.9586 & 7.7495 & TST & & \\
\hline CHEMBL3979780 & 1642416 & 8.699 & 7.9363 & TRN & & \\
\hline CHEMBL3904911 & 1642416 & 8.5528 & \multicolumn{3}{|c|}{9.107000000000001} & TRN \\
\hline CHEMBL3955400 & 1642416 & 8.0969 & 8.0145 & TST & & \\
\hline CHEMBL3946727 & 1642416 & \multicolumn{3}{|c|}{8.283999999999999} & 7.4365 & TST \\
\hline CHEMBL3927237 & 1642416 & 8.7212 & 8.3271 & TRN & & \\
\hline CHEMBL3899215 & 1642416 & 9.5229 & 9.8429 & TRN & & \\
\hline CHEMBL3924590 & 1642416 & 7.5935 & 6.7577 & TST & & \\
\hline CHEMBL3942144 & 1642416 & 7.1062 & 7.3925 & TRN & & \\
\hline CHEMBL3926095 & 1642416 & 7.4572 & \multicolumn{3}{|c|}{6.321000000000001} & TRN \\
\hline CHEMBL3919845 & 1642416 & 7.2161 & 6.6812 & TRN & & \\
\hline CHEMBL3977321 & 1642416 & 5.1953 & 6.3205 & TST & & \\
\hline CHEMBL 3914222 & 1642416 & 8.3872 & 7.7925 & TRN & & \\
\hline CHEMBL3982641 & 1642416 & 6.0 & 6.1722 & TRN & & \\
\hline CHEMBL26306 & 1512 & 7.66 & 7.8169 & TRN & & \\
\hline CHEMBL25857 & 1512 & 8.02 & 8.1181 & TRN & & \\
\hline CHEMBL25812 & 1512 & 6.44 & 6.8243 & TRN & & \\
\hline CHEMBL 287655 & 1512 & 6.73 & 6.5997 & TRN & & \\
\hline CHEMBL542948 & 1512 & 6.82 & 7.0392 & TRN & & \\
\hline CHEMBL27192 & 1512 & 6.91 & 7.0054 & TRN & & \\
\hline CHEMBL 724 & 1512 & 5.85 & 5.4331 & TST & & \\
\hline CHEMBL26906 & 1512 & 7.49 & 7.3804 & TRN & & \\
\hline CHEMBL27447 & 1512 & 7.36 & 7.7093 & TRN & & \\
\hline CHEMBL27655 & 1512 & 8.11 & 8.1236 & TRN & & \\
\hline CHEMBL26018 & 1512 & 9.0 & 9.1108 & TRN & & \\
\hline CHEMBL286250 & 1512 & 9.15 & 8.6388 & TRN & & \\
\hline CHEMBL27098 & 1512 & 8.12 & 7.8449 & TRN & & \\
\hline CHEMBL19264 & 1512 & 5.8 & 6.0624 & TST & & \\
\hline CHEMBL28143 & 1512 & 9.6 & 9.1575 & TRN & & \\
\hline CHEMBL27649 & 1512 & 5.52 & 7.1967 & TST & & \\
\hline CHEMBL 7154 & 1512 & 6.77 & 7.0187 & TST & & \\
\hline CHEMBL286986 & 1512 & 6.6 & 6.5879 & TRN & & \\
\hline CHEMBL 25913 & 1512 & 7.72 & 7.7112 & TRN & & \\
\hline CHEMBL27314 & 1512 & 6.67 & 7.0465 & TRN & & \\
\hline CHEMBL26626 & 1512 & 5.97 & 7.5355 & TST & & \\
\hline CHEMBL26922 & 1512 & 6.52 & 7.3293 & TRN & & \\
\hline CHEMBL24462 & 1512 & 8.48 & 7.1653 & TST & & \\
\hline CHEMBL287097 & 1512 & 7.43 & 7.2239 & TRN & & \\
\hline CHEMBL282367 & 1512 & 4.83 & 4.6145 & TRN & & \\
\hline
\end{tabular}




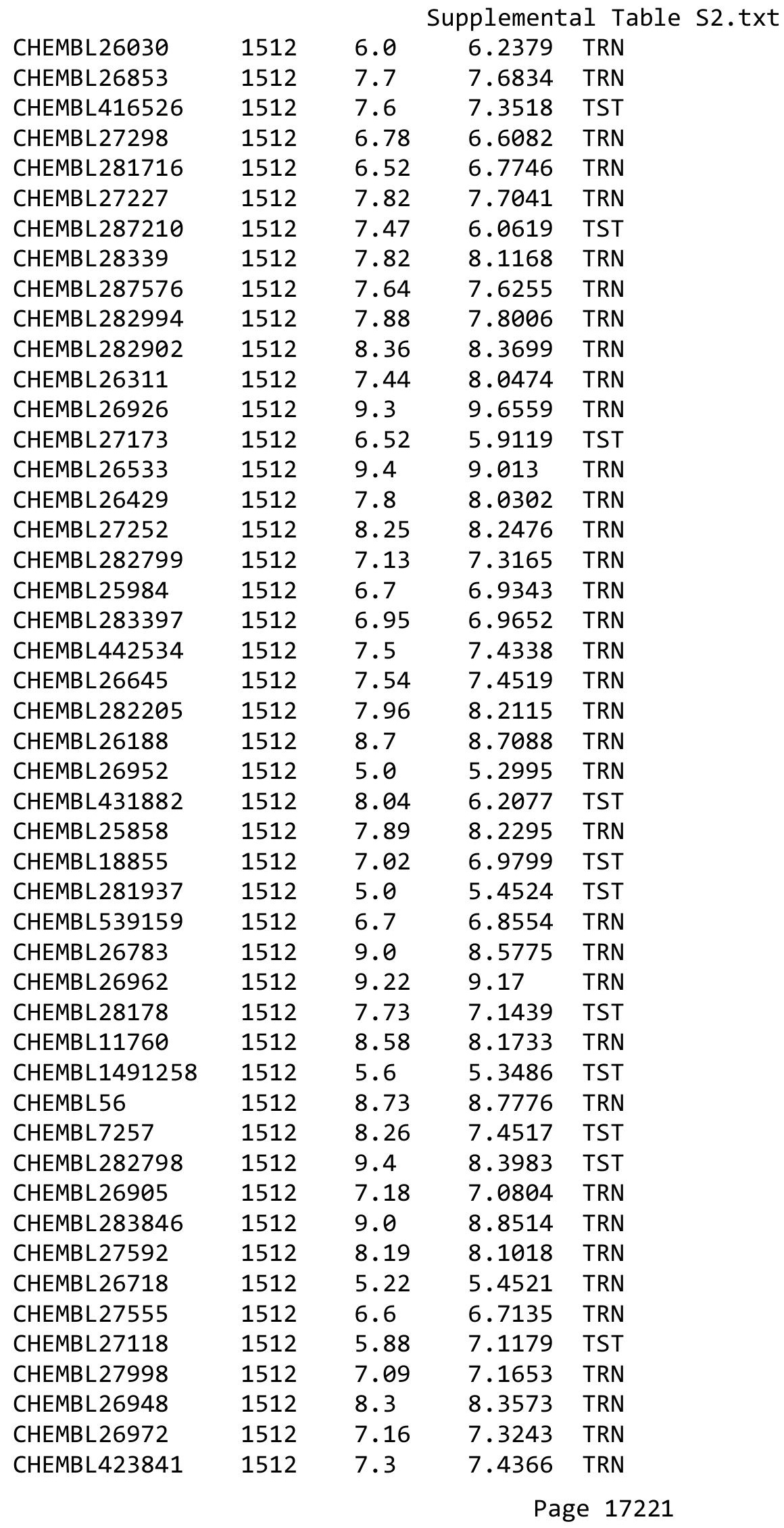




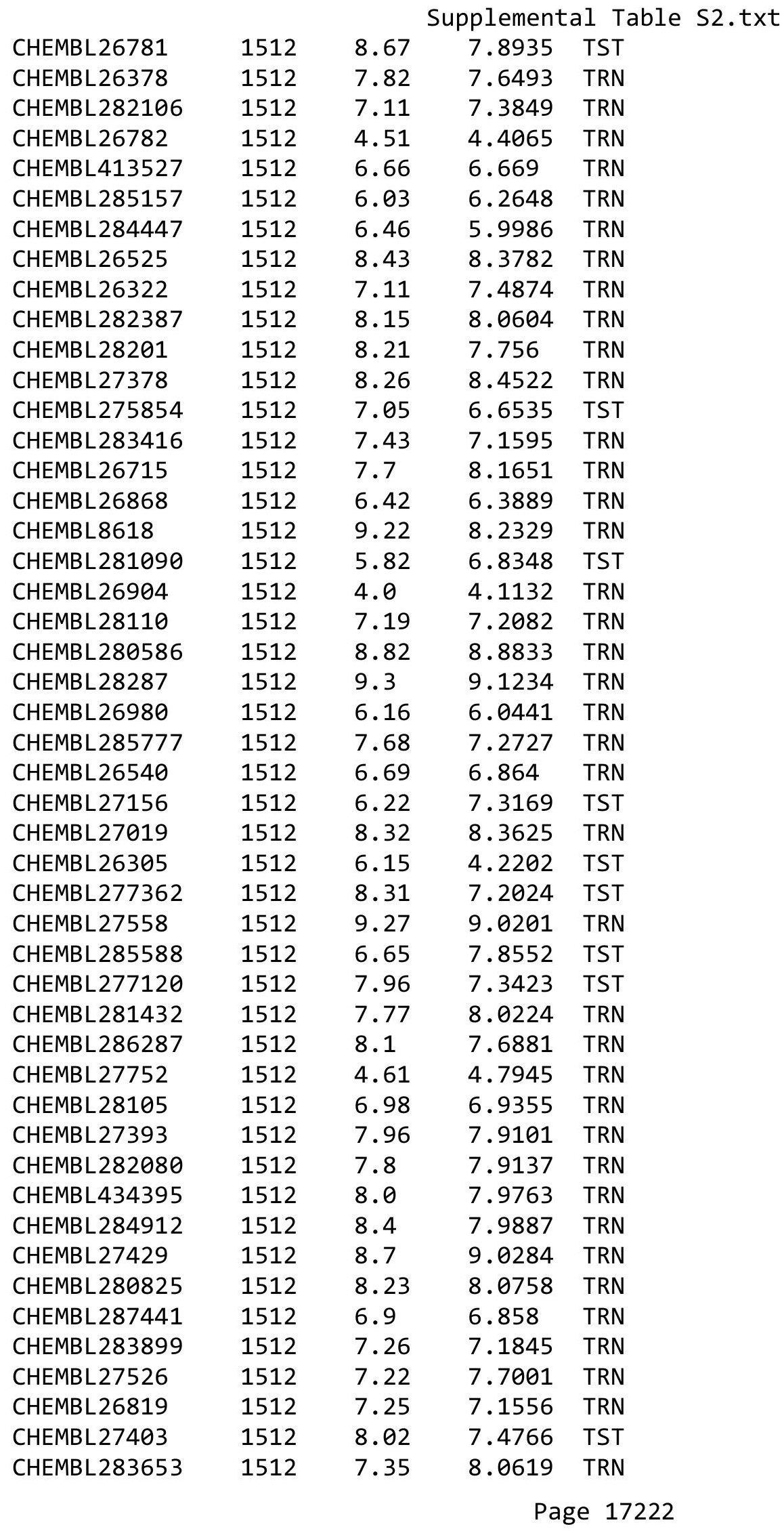




\begin{tabular}{|c|c|c|c|c|c|}
\hline & & & pplement & al Table S2. & \\
\hline CHEMBL 26848 & 1512 & 8.4 & 8.2488 & TRN & \\
\hline CHEMBL26796 & 1512 & 6.82 & $6.0360 e$ & 00000000005 & TRN \\
\hline CHEMBL283398 & 1512 & 8.28 & 8.2243 & TRN & \\
\hline CHEMBL 26650 & 1512 & 7.74 & 7.7085 & TRN & \\
\hline CHEMBL27705 & 1512 & 8.05 & 8.1142 & TRN & \\
\hline CHEMBL26833 & 1512 & 5.0 & 8.1695 & TST & \\
\hline CHEMBL 286961 & 1512 & 5.48 & 5.2476 & TST & \\
\hline CHEMBL28404 & 1512 & 8.1 & 8.1378 & TRN & \\
\hline CHEMBL 6640 & 1512 & 6.77 & 5.8667 & TST & \\
\hline CHEMBL 284888 & 1512 & 6.8 & 6.6606 & TRN & \\
\hline CHEMBL26835 & 1512 & 8.77 & 9.0379 & TRN & \\
\hline CHEMBL417470 & 1512 & 7.6 & 7.6699 & TRN & \\
\hline CHEMBL27279 & 1512 & 5.49 & 7.0213 & TST & \\
\hline CHEMBL26988 & 1512 & 8.77 & 9.0201 & TRN & \\
\hline CHEMBL21008 & 1512 & 9.0 & 9.0542 & TRN & \\
\hline CHEMBL416564 & 1512 & 6.35 & 7.2044 & TST & \\
\hline CHEMBL18840 & 1512 & 9.53 & 7.7144 & TST & \\
\hline CHEMBL410826 & 1512 & 9.15 & 9.5833 & TRN & \\
\hline CHEMBL25919 & 1512 & 7.19 & $7.0770 e$ & $\partial 000000001$ & TRN \\
\hline CHEMBL416382 & 1512 & 7.7 & 7.4323 & TRN & \\
\hline CHEMBL 24515 & 1512 & 8.44 & 8.5631 & TRN & \\
\hline CHEMBL279906 & 1512 & 8.57 & 8.6739 & TRN & \\
\hline CHEMBL27991 & 1512 & 9.7 & 9.919 & TRN & \\
\hline CHEMBL25800 & 1512 & 5.58 & 4.3483 & TST & \\
\hline CHEMBL26425 & 1512 & 6.89 & 6.7649 & TRN & \\
\hline CHEMBL26917 & 1512 & 4.72 & 6.4743 & TST & \\
\hline CHEMBL28342 & 1512 & 8.0 & 8.065 & TRN & \\
\hline CHEMBL478 & 1512 & 6.84 & 6.7801 & TRN & \\
\hline CHEMBL 283207 & 1512 & 8.6 & 7.9946 & TRN & \\
\hline CHEMBL265494 & 1512 & 6.0 & 6.50899 & 99999999995 & TRN \\
\hline CHEMBL281497 & 1512 & 7.07 & 6.8483 & TST & \\
\hline CHEMBL28000 & 1512 & 9.25 & 8.9511 & TST & \\
\hline CHEMBL 27457 & 1512 & 9.3 & 8.9582 & TRN & \\
\hline CHEMBL 283185 & 1512 & 7.58 & 7.309 & TRN & \\
\hline CHEMBL283174 & 1512 & 8.74 & 6.8105 & TST & \\
\hline CHEMBL 28292 & 1512 & 8.16 & 8.3001 & TRN & \\
\hline CHEMBL11592 & 1512 & 10.0 & 9.481 & TRN & \\
\hline CHEMBL 285351 & 1512 & 8.72 & 8.926 & TRN & \\
\hline CHEMBL 280822 & 1512 & 6.22 & 8.6363 & TST & \\
\hline CHEMBL27611 & 1512 & 6.46 & 6.9472 & TST & \\
\hline CHEMBL 284107 & 1512 & 7.26 & 7.4337 & TRN & \\
\hline CHEMBL28312 & 1512 & 9.3 & 9.3601 & TRN & \\
\hline CHEMBL26427 & 1512 & 5.57 & 5.5417 & TST & \\
\hline CHEMBL26587 & 1512 & 9.0 & 8.8189 & TRN & \\
\hline CHEMBL281512 & 1512 & 7.95 & 7.5048 & TRN & \\
\hline CHEMBL 26189 & 1512 & 8.4 & 8.3984 & TRN & \\
\hline CHEMBL27039 & 1512 & 5.56 & 5.7046 & TST & \\
\hline CHEMBL 283450 & 1512 & 7.22 & 7.3244 & TRN & \\
\hline & & & & 1722 & \\
\hline
\end{tabular}




\begin{tabular}{|c|c|c|c|c|c|}
\hline & & \multicolumn{4}{|c|}{ Supplemental Table S2.txt } \\
\hline CHEMBL274866 & 1512 & 6.76 & 6.6139 & TRN & \\
\hline CHEMBL 26789 & 1512 & 6.89 & 7.7095 & TRN & \\
\hline CHEMBL27021 & 1512 & 8.74 & 7.8766 & TRN & \\
\hline CHEMBL26900 & 1512 & 7.6 & 7.9063 & TRN & \\
\hline CHEMBL26379 & 1512 & 7.79 & 7.5912 & TRN & \\
\hline CHEMBL27060 & 1512 & 9.3 & 9.0381 & TRN & \\
\hline CHEMBL27310 & 1512 & 6.7 & \multicolumn{2}{|c|}{6.5889999999999995} & TRN \\
\hline CHEMBL26355 & 1512 & 8.1 & 9.0201 & TRN & \\
\hline CHEMBL26430 & 1512 & 6.6 & 6.6495 & TRN & \\
\hline CHEMBL26975 & 1512 & 8.7 & 8.6864 & TRN & \\
\hline CHEMBL27590 & 1512 & 7.1 & 7.2823 & TRN & \\
\hline CHEMBL26836 & 1512 & 7.21 & 7.1427 & TRN & \\
\hline CHEMBL27995 & 1512 & 8.7 & 8.079 & TRN & \\
\hline CHEMBL27650 & 1512 & 9.3 & 8.9531 & TRN & \\
\hline CHEMBL26526 & 1512 & 7.62 & 7.7717 & TRN & \\
\hline CHEMBL28111 & 1512 & 8.68 & 8.5658 & TRN & \\
\hline CHEMBL39 & 1512 & 8.32 & 6.1147 & TST & \\
\hline CHEMBL26850 & 1512 & 5.75 & 5.5439 & TRN & \\
\hline CHEMBL26655 & 1512 & 6.84 & 6.9285 & TRN & \\
\hline CHEMBL27720 & 1512 & 7.43 & 7.6369 & TRN & \\
\hline CHEMBL27254 & 1512 & 8.4 & 8.5765 & TRN & \\
\hline CHEMBL280779 & 1512 & 6.66 & 7.0859 & TST & \\
\hline CHEMBL18785 & 1512 & 7.96 & 7.7325 & TST & \\
\hline CHEMBL26716 & 1512 & 5.0 & 7.9374 & TST & \\
\hline CHEMBL26139 & 1512 & 6.65 & 7.4038 & TST & \\
\hline CHEMBL26921 & 1512 & 6.26 & 6.523 & TST & \\
\hline CHEMBL27025 & 1512 & 7.17 & 6.8676 & TST & \\
\hline CHEMBL284887 & 1512 & 4.31 & 4.4098 & TRN & \\
\hline CHEMBL27034 & 1512 & 7.21 & 7.2817 & TRN & \\
\hline CHEMBL284820 & 1512 & 7.25 & 7.4717 & TRN & \\
\hline CHEMBL28174 & 1512 & 7.11 & 6.984 & TRN & \\
\hline CHEMBL28288 & 1512 & 7.92 & 7.9434 & TRN & \\
\hline CHEMBL417290 & 1512 & 5.0 & 4.8501 & TRN & \\
\hline CHEMBL 27313 & 1512 & 8.22 & 7.978 & TRN & \\
\hline CHEMBL283936 & 1512 & 7.06 & 7.2011 & TST & \\
\hline CHEMBL 27643 & 1512 & 7.72 & 8.5697 & TST & \\
\hline CHEMBL28200 & 1512 & 8.25 & 8.95 & TRN & \\
\hline CHEMBL26484 & 1512 & 7.72 & 7.8989 & TRN & \\
\hline CHEMBL8165 & 1512 & 7.97 & \multicolumn{2}{|c|}{5.8389999999999995} & TST \\
\hline CHEMBL417841 & 1512 & 6.42 & 8.5898 & TST & \\
\hline CHEMBL286264 & 1512 & 6.73 & 7.2017 & TST & \\
\hline CHEMBL281918 & 1512 & 6.9 & 6.7454 & TRN & \\
\hline CHEMBL281434 & 1512 & 7.64 & 8.1797 & TST & \\
\hline CHEMBL284643 & 1512 & 6.06 & 6.8256 & TST & \\
\hline CHEMBL26539 & 1512 & 7.92 & 8.1078 & TRN & \\
\hline CHEMBL412876 & 1512 & 6.02 & 6.9911 & TST & \\
\hline CHEMBL26890 & 1512 & 8.33 & 8.0909 & TRN & \\
\hline CHEMBL27937 & 1512 & 8.7 & 8.7138 & TRN & \\
\hline
\end{tabular}




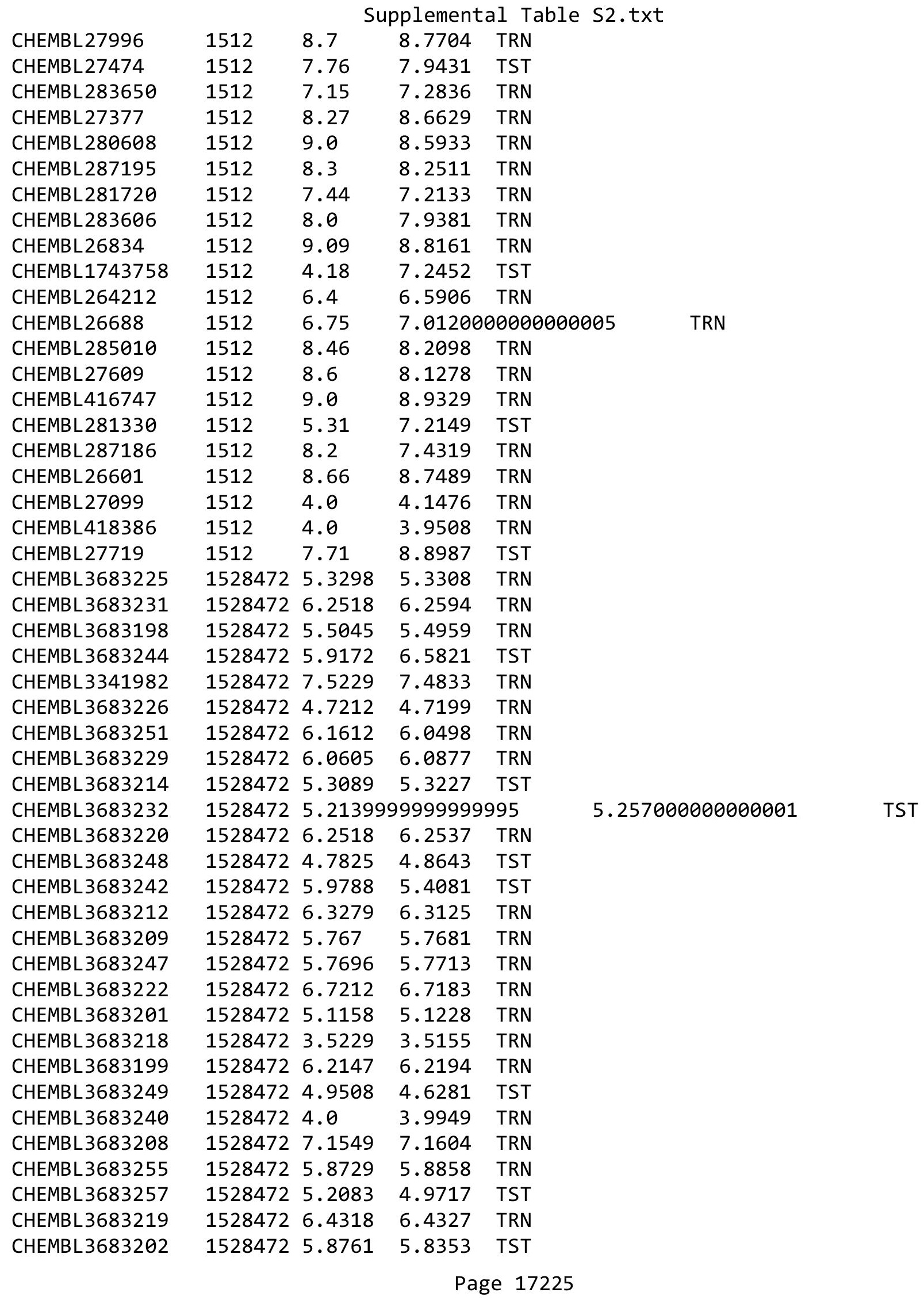


Supplemental Table S2.txt

\begin{tabular}{|c|c|c|c|c|c|}
\hline CHEMBL 3683230 & 1528472 & 6.0269 & \multicolumn{2}{|c|}{6.002999999999999} & TRN \\
\hline CHEMBL3683233 & 1528472 & 4.8356 & 4.8334 & TRN & \\
\hline CHEMBL3683197 & 1528472 & 5.2366 & 5.231 & TRN & \\
\hline CHEMBL3683206 & 1528472 & 5.266 & 5.2565 & TRN & \\
\hline CHEMBL 3683204 & 1528472 & 5.4522 & 5.505 & TRN & \\
\hline CHEMBL3683196 & 1528472 & 5.6968 & 5.6874 & TRN & \\
\hline CHEMBL3683216 & 1528472 & 5.6576 & 5.6618 & TRN & \\
\hline CHEMBL 3683253 & 1528472 & 4.9172 & 4.9215 & TRN & \\
\hline CHEMBL 3683252 & 1528472 & 5.9318 & 5.9843 & TRN & \\
\hline CHEMBL 3683228 & 1528472 & 6.585 & 6.6073 & TRN & \\
\hline CHEMBL3683205 & 1528472 & 7.0458 & 7.0408 & TRN & \\
\hline CHEMBL3683217 & 1528472 & 6.1739 & 6.1727 & TRN & \\
\hline CHEMBL3683213 & 1528472 & 6.0969 & 5.973 & TST & \\
\hline CHEMBL 3683245 & 1528472 & 5.0942 & 5.0668 & TST & \\
\hline CHEMBL 3683254 & 1528472 & 5.1343 & 5.1362 & TRN & \\
\hline CHEMBL3683227 & 1528472 & 5.7167 & 5.6902 & TRN & \\
\hline CHEMBL3683223 & 1528472 & 7.301 & 7.2906 & TRN & \\
\hline CHEMBL3683195 & 1528472 & 6.9208 & 6.9372 & TRN & \\
\hline CHEMBL3683246 & 1528472 & 6.1938 & 6.1309 & TST & \\
\hline CHEMBL 3683224 & 1528472 & 6.7696 & 6.7714 & TRN & \\
\hline CHEMBL 3683250 & 1528472 & 6.6576 & 6.7141 & TRN & \\
\hline CHEMBL3683203 & 1528472 & 3.5229 & 3.5262 & TRN & \\
\hline CHEMBL3683207 & 1528472 & 6.4559 & 6.4536 & TRN & \\
\hline CHEMBL 3683200 & 1528472 & 5.1273 & 4.7283 & TST & \\
\hline CHEMBL 3683221 & 1528472 & 5.7595 & 5.3742 & TST & \\
\hline CHEMBL1423340 & 954258 & 4.3898 & 4.7489 & TST & \\
\hline CHEMBL1331798 & 954258 & 4.6857 & 4.8443 & TRN & \\
\hline CHEMBL1520338 & 954258 & 4.2264 & 4.5912 & TRN & \\
\hline CHEMBL 2360848 & 954258 & 3.1549 & 4.1296 & TRN & \\
\hline CHEMBL 2358697 & 954258 & 4.9674 & 5.2525 & TRN & \\
\hline CHEMBL1529462 & 954258 & 4.2691 & 4.6381 & TST & \\
\hline CHEMBL 2362728 & 954258 & 3.1549 & 4.1388 & TRN & \\
\hline CHEMBL2360806 & 954258 & 3.1549 & 4.5628 & TST & \\
\hline CHEMBL1903585 & 954258 & 4.3058 & 4.9891 & TRN & \\
\hline CHEMBL1470131 & 954258 & 4.9727 & 4.8139 & TST & \\
\hline CHEMBL1443902 & 954258 & 5.5072 & 4.8559 & TRN & \\
\hline CHEMBL1987343 & 954258 & 4.8914 & 4.9753 & TST & \\
\hline CHEMBL1604436 & 954258 & 3.1549 & 4.6836 & TST & \\
\hline CHEMBL1315275 & 954258 & 4.6191 & 4.8675 & TST & \\
\hline CHEMBL2359733 & 954258 & 4.184 & 4.4497 & TRN & \\
\hline CHEMBL1484387 & 954258 & 4.6786 & 5.1058 & TRN & \\
\hline CHEMBL2361895 & 954258 & 3.1549 & 3.9715 & TRN & \\
\hline CHEMBL1509962 & 954258 & 4.6398 & 4.977 & TST & \\
\hline CHEMBL 2354591 & 954258 & 5.2716 & 5.0485 & TRN & \\
\hline CHEMBL1448489 & 954258 & 4.9516 & 4.824 & TST & \\
\hline CHEMBL2356096 & 954258 & 3.1549 & 4.1917 & TRN & \\
\hline CHEMBL2357884 & 954258 & 3.1549 & 4.5377 & TRN & \\
\hline CHEMBL2358056 & 954258 & 4.4739 & 4.7474 & TRN & \\
\hline
\end{tabular}


Supplemental Table S2.txt

\begin{tabular}{|c|c|c|c|c|c|}
\hline CHEMBL1409219 & 954258 & 4.823 & 4.8294 & TST & \\
\hline CHEMBL 2139731 & 954258 & 4.5206 & 4.9396 & TST & \\
\hline CHEMBL2360807 & 954258 & 4.1712 & 4.0232 & TRN & \\
\hline CHEMBL1603847 & 954258 & 4.8088 & 4.7451 & TST & \\
\hline CHEMBL453207 & 954258 & 5.6655 & 4.3328 & TST & \\
\hline CHEMBL2356078 & 954258 & 4.3933 & 4.6871 & TRN & \\
\hline CHEMBL 2362324 & 954258 & 5.9666 & 4.3434 & TRN & \\
\hline CHEMBL1418028 & 954258 & 4.1714 & 4.8124 & TST & \\
\hline CHEMBL 2362529 & 954258 & 6.3197 & 4.4154 & TST & \\
\hline CHEMBL2361287 & 954258 & 4.5321 & 5.137000 & 30000000005 & TRN \\
\hline CHEMBL2354869 & 954258 & 3.1549 & 4.3882 & TST & \\
\hline CHEMBL1732029 & 954258 & 4.9948 & 4.826006 & 00000000005 & TRN \\
\hline CHEMBL1885001 & 954258 & 7.585 & 4.9777 & TRN & \\
\hline CHEMBL1452526 & 954258 & 4.8965 & 4.9074 & TST & \\
\hline CHEMBL2355214 & 954258 & 3.1549 & 4.0921 & TRN & \\
\hline CHEMBL 2361377 & 954258 & 3.1549 & 4.2038 & TRN & \\
\hline CHEMBL1499761 & 954258 & 5.0429 & 4.9443 & TRN & \\
\hline CHEMBL 2360570 & 954258 & 5.2907 & 4.0478 & TRN & \\
\hline CHEMBL 2355059 & 954258 & 4.5092 & 5.0056 & TRN & \\
\hline CHEMBL2356207 & 954258 & 4.5131 & 4.1407 & TRN & \\
\hline CHEMBL2362942 & 954258 & 4.2712 & 4.1454 & TRN & \\
\hline CHEMBL2360325 & 954258 & 4.1714 & 4.345 & TRN & \\
\hline CHEMBL 2358676 & 954258 & 4.191 & 4.0435 & TRN & \\
\hline CHEMBL1413893 & 954258 & 5.2692 & 5.2087 & TRN & \\
\hline CHEMBL1347888 & 954258 & 4.797 & 5.1152 & TRN & \\
\hline CHEMBL1460223 & 954258 & 5.1469 & 4.8297 & TST & \\
\hline CHEMBL1567775 & 954258 & 5.5969 & 4.8822 & TRN & \\
\hline CHEMBL 2355642 & 954258 & 6.0 & 5.1135 & TRN & \\
\hline CHEMBL 2357668 & 954258 & 5.2 & 4.9616 & TRN & \\
\hline CHEMBL 2360608 & 954258 & 3.1549 & 4.4444 & TRN & \\
\hline CHEMBL2362071 & 954258 & 5.0904 & 4.2537 & TRN & \\
\hline CHEMBL582983 & 954258 & 7.585 & 4.5346 & TST & \\
\hline CHEMBL2361195 & 954258 & 3.1549 & 4.0866 & TRN & \\
\hline CHEMBL1521932 & 954258 & \multicolumn{3}{|c|}{5.0569999999999995} & TRN \\
\hline CHEMBL2356913 & 954258 & 4.0283 & 4.7456 & TST & \\
\hline CHEMBL1349879 & 954258 & 4.6801 & 4.9004 & TST & \\
\hline CHEMBL1328589 & 954258 & 5.1046 & 4.8444 & TRN & \\
\hline CHEMBL2362630 & 954258 & 4.3785 & 4.2667 & TRN & \\
\hline CHEMBL 2357517 & 954258 & 5.4225 & 4.4166 & TRN & \\
\hline CHEMBL 2358960 & 954258 & 3.1549 & 4.5935 & TRN & \\
\hline CHEMBL2359550 & 954258 & 4.6897 & 5.0929 & TRN & \\
\hline CHEMBL2359306 & 954258 & 4.9759 & 5.0356 & TRN & \\
\hline CHEMBL1323741 & 954258 & 3.1549 & 4.9929 & TRN & \\
\hline CHEMBL1333311 & 954258 & 5.0851 & 4.9041 & TRN & \\
\hline CHEMBL 2355818 & 954258 & 4.6323 & 4.3973 & TRN & \\
\hline CHEMBL3185258 & 954258 & 4.474 & 4.6214 & TRN & \\
\hline CHEMBL2355680 & 954258 & 5.1726 & 4.5337 & TRN & \\
\hline CHEMBL1367461 & 954258 & 6.3344 & 4.9591 & TRN & \\
\hline
\end{tabular}

Page 17227 


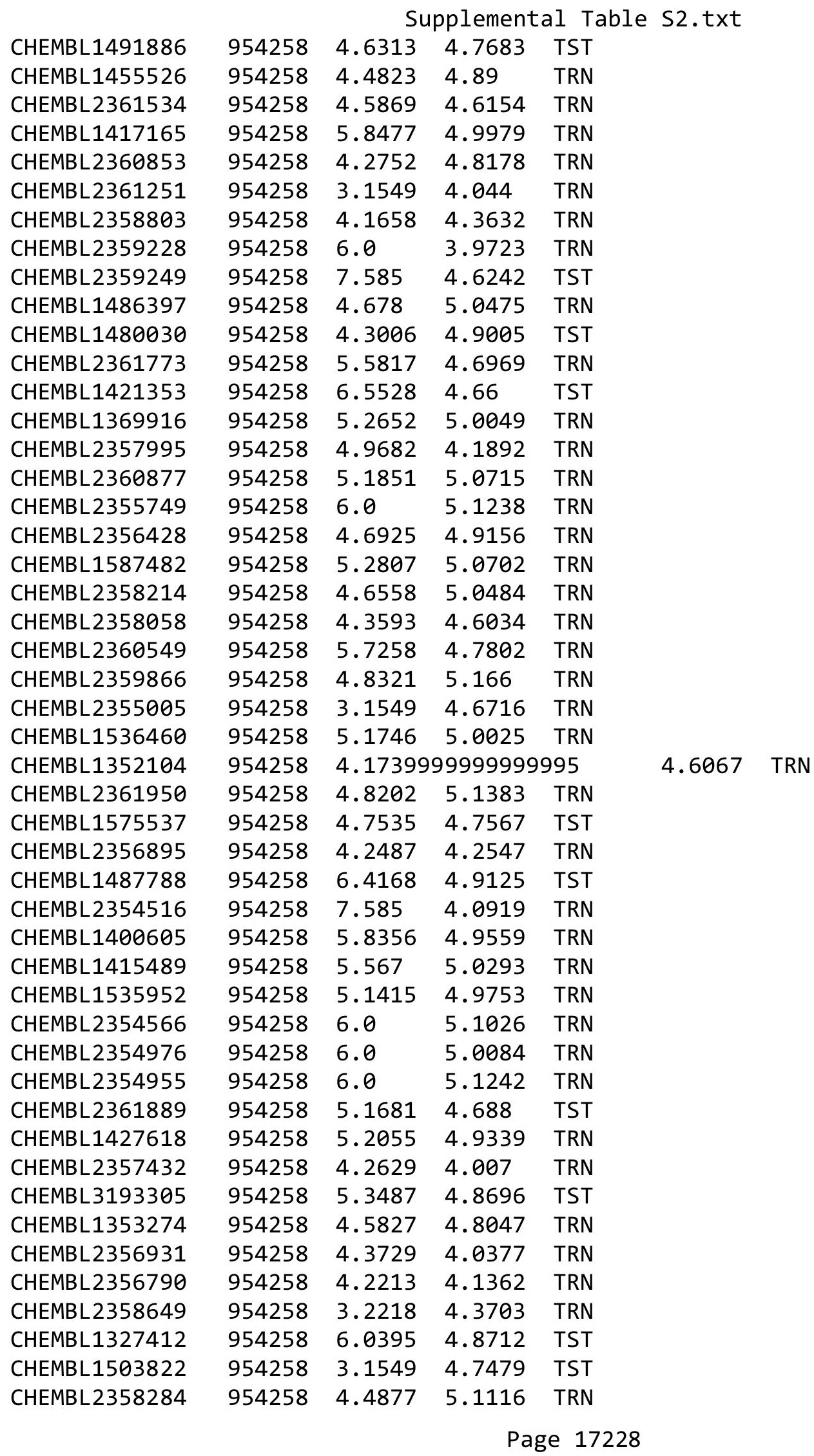




\begin{tabular}{|c|c|c|c|c|}
\hline & & & oplement & al $\mathrm{T}$ \\
\hline CHEMBL 2360267 & 954258 & 4.3611 & 4.2913 & TRN \\
\hline CHEMBL1606873 & 954258 & 4.8941 & 5.2134 & TRN \\
\hline CHEMBL2359876 & 954258 & 4.3264 & 4.5702 & TRN \\
\hline CHEMBL2360427 & 954258 & 5.2168 & 4.5662 & TRN \\
\hline CHEMBL1970100 & 954258 & 5.5638 & 4.8791 & TST \\
\hline CHEMBL1343802 & 954258 & 4.1733 & 4.8035 & TST \\
\hline CHEMBL 2354617 & 954258 & 4.3165 & 4.3628 & TRN \\
\hline CHEMBL1451017 & 954258 & 4.8784 & 5.0481 & TRN \\
\hline CHEMBL1530968 & 954258 & 4.7567 & 4.6387 & TRN \\
\hline CHEMBL2358879 & 954258 & 4.3392 & 4.0879 & TRN \\
\hline CHEMBL2360624 & 954258 & 3.1549 & 4.5668 & TRN \\
\hline CHEMBL2355984 & 954258 & 5.2233 & 5.0744 & TRN \\
\hline CHEMBL1333899 & 954258 & 5.2503 & 5.2481 & TRN \\
\hline CHEMBL1384796 & 954258 & 5.1361 & 4.9535 & TRN \\
\hline CHEMBL2361226 & 954258 & 4.3492 & 4.5089 & TRN \\
\hline CHEMBL1543935 & 954258 & 4.363 & 5.1197 & TRN \\
\hline CHEMBL2354975 & 954258 & 4.3334 & 4.232 & TRN \\
\hline CHEMBL1534040 & 954258 & 4.721 & 4.7834 & TST \\
\hline CHEMBL2355598 & 954258 & 4.6436 & 5.1001 & TRN \\
\hline CHEMBL 2357001 & 954258 & 3.1549 & 4.5769 & TRN \\
\hline CHEMBL1311282 & 954258 & 5.0521 & 5.1178 & TRN \\
\hline CHEMBL 2354721 & 954258 & 6.0 & 5.0483 & TRN \\
\hline CHEMBL2355591 & 954258 & 3.1549 & 4.8329 & TST \\
\hline CHEMBL1605732 & 954258 & 6.0555 & 4.999 & TRN \\
\hline CHEMBL1398520 & 954258 & 6.0 & 5.1801 & TRN \\
\hline CHEMBL 2362268 & 954258 & 4.2135 & 4.1448 & TRN \\
\hline CHEMBL 2356960 & 954258 & 4.3737 & 4.2389 & TRN \\
\hline CHEMBL 2356541 & 954258 & 3.1549 & 4.0374 & TRN \\
\hline CHEMBL 2357225 & 954258 & 5.6676 & 4.6115 & TRN \\
\hline CHEMBL1516509 & 954258 & 6.0665 & 5.0043 & TRN \\
\hline CHEMBL 2357323 & 954258 & 4.5414 & 4.3561 & TRN \\
\hline CHEMBL2355860 & 954258 & 4.3649 & 4.1662 & TRN \\
\hline CHEMBL 2362108 & 954258 & 4.942 & 5.1242 & TRN \\
\hline CHEMBL1420729 & 954258 & 4.5173 & 4.9849 & TRN \\
\hline CHEMBL2355299 & 954258 & 3.1549 & 4.4401 & TRN \\
\hline CHEMBL 2142558 & 954258 & 3.1549 & 4.4432 & TRN \\
\hline CHEMBL1452759 & 954258 & 5.5467 & 5.3132 & TRN \\
\hline CHEMBL2354885 & 954258 & 3.1549 & 4.2817 & TRN \\
\hline CHEMBL1367630 & 954258 & 3.1549 & 4.5765 & TRN \\
\hline CHEMBL535315 & 954258 & 6.426 & 4.842 & TST \\
\hline CHEMBL1439138 & 954258 & 4.8022 & 4.9769 & TRN \\
\hline CHEMBL1437766 & 954258 & 4.6586 & 4.6747 & TST \\
\hline CHEMBL1889396 & 954258 & 5.3799 & 4.0461 & TRN \\
\hline CHEMBL1366182 & 954258 & 4.4594 & 4.7345 & TRN \\
\hline CHEMBL2359643 & 954258 & 5.1662 & 5.012 & TRN \\
\hline CHEMBL1331961 & 954258 & 4.9248 & 5.0756 & TRN \\
\hline CHEMBL1525665 & 954258 & 4.4082 & 4.547 & TST \\
\hline CHEMBL2361873 & 954258 & 4.8844 & 5.1746 & TRN \\
\hline
\end{tabular}




\begin{tabular}{|c|c|c|c|c|c|}
\hline \multicolumn{6}{|c|}{ Supplemental Table S2.txt } \\
\hline CHEMBL 2356861 & 954258 & 3.1549 & 4.34 & TRN & \\
\hline CHEMBL 1426584 & 954258 & 5.0164 & 4.9435 & TST & \\
\hline CHEMBL1364899 & 954258 & 4.8649 & 5.0942 & TRN & \\
\hline CHEMBL1559261 & 954258 & 3.9209 & 5.1084 & TRN & \\
\hline CHEMBL1319591 & 954258 & 4.6737 & 4.8891 & TRN & \\
\hline CHEMBL 2359570 & 954258 & 5.3288 & 4.1314 & TRN & \\
\hline CHEMBL 2360744 & 954258 & 4.1646 & 4.5351 & TRN & \\
\hline CHEMBL1303997 & 954258 & 5.8894 & 4.7194 & TST & \\
\hline CHEMBL 2359099 & 954258 & 6.0 & 4.1887 & TRN & \\
\hline CHEMBL 2358936 & 954258 & 4.2016 & 4.0151 & TRN & \\
\hline CHEMBL1497475 & 954258 & 4.9097 & 5.0845 & TRN & \\
\hline CHEMBL 2357524 & 954258 & 4.6457 & 5.1769 & TRN & \\
\hline CHEMBL1531708 & 954258 & 4.4657 & 5.0719 & TRN & \\
\hline CHEMBL1511039 & 954258 & 4.3593 & 4.5258 & TRN & \\
\hline CHEMBL 2354415 & 954258 & 4.1761 & 4.1846 & TRN & \\
\hline CHEMBL 2361734 & 954258 & 5.308 & 4.8851 & TRN & \\
\hline CHEMBL 2355013 & 954258 & 3.1549 & 3.9773 & TRN & \\
\hline CHEMBL 2356770 & 954258 & 6.0 & 4.8882 & TRN & \\
\hline CHEMBL1521852 & 954258 & 4.6794 & 4.9526 & TRN & \\
\hline CHEMBL1527216 & 954258 & 5.8268 & 4.8899 & TRN & \\
\hline CHEMBL1569771 & 954258 & 4.8083 & 5.1153 & TRN & \\
\hline CHEMBL 2356697 & 954258 & 5.1574 & 4.4436 & TST & \\
\hline CHEMBL1410204 & 954258 & 3.1549 & 4.8144 & TST & \\
\hline CHEMBL1320524 & 954258 & 4.9901 & 5.0963 & TST & \\
\hline CHEMBL2358993 & 954258 & 6.1215 & 4.4556 & TST & \\
\hline CHEMBL1330844 & 954258 & 4.957 & 4.9105 & TST & \\
\hline CHEMBL 2358734 & 954258 & 4.1552 & 4.8214 & TST & \\
\hline CHEMBL 2357125 & 954258 & 3.1549 & 3.988 & TST & \\
\hline CHEMBL1447827 & 954258 & 4.2694 & 5.0927 & TST & \\
\hline CHEMBL2360064 & 954258 & 3.1549 & 4.1777 & TST & \\
\hline CHEMBL 2360317 & 954258 & 5.4168 & 4.838 & TST & \\
\hline CHEMBL54714 & 69841 & 6.62 & 6.6774 & TRN & \\
\hline CHEMBL 301247 & 69841 & 6.51 & 6.5375 & TRN & \\
\hline CHEMBL56011 & 69841 & 6.44 & 6.3919 & TRN & \\
\hline CHEMBL294191 & 69841 & 6.38 & 6.3259 & TRN & \\
\hline CHEMBL56253 & 69841 & 6.8 & 5.62200 & 3000000001 & TST \\
\hline CHEMBL55557 & 69841 & 6.74 & 6.7414 & TRN & \\
\hline CHEMBL55358 & 69841 & 5.98 & 5.921 & TST & \\
\hline CHEMBL 293522 & 69841 & 5.27 & 5.233 & TRN & \\
\hline CHEMBL55608 & 69841 & 6.68 & 6.4006 & TRN & \\
\hline CHEMBL56255 & 69841 & 6.46 & 6.468 & TRN & \\
\hline CHEMBL56073 & 69841 & 6.31 & 6.4078 & TRN & \\
\hline CHEMBL54004 & 69841 & 5.63 & 5.2058 & TRN & \\
\hline CHEMBL52137 & 69841 & 5.49 & 5.1482 & TST & \\
\hline CHEMBL56556 & 69841 & 4.78 & 4.7761 & TRN & \\
\hline CHEMBL55837 & 69841 & 5.19 & 5.2058 & TRN & \\
\hline CHEMBL294192 & 69841 & 6.77 & 6.6965 & TRN & \\
\hline CHEMBL54747 & 69841 & 5.17 & 5.1919 & TRN & \\
\hline
\end{tabular}




\begin{tabular}{|c|c|c|c|c|c|}
\hline \multicolumn{6}{|c|}{ Supplemental Table s2.txt } \\
\hline CHEMBL301065 & 69841 & 6.8 & 6.811 & TRN & \\
\hline CHEMBL416301 & 69841 & 5.11 & 5.2058 & TRN & \\
\hline CHEMBL291736 & 69841 & 6.68 & 6.6693 & TRN & \\
\hline CHEMBL412889 & 69841 & 5.61 & 5.62200 & 0000000001 & TST \\
\hline CHEMBL55572 & 69841 & 5.17 & 5.2058 & TRN & \\
\hline CHEMBL149321 & 69841 & 4.37 & 6.3097 & TST & \\
\hline CHEMBL292224 & 69841 & 4.39 & 5.6667 & TST & \\
\hline CHEMBL54472 & 69841 & 6.29 & 5.1482 & TST & \\
\hline CHEMBL294478 & 69841 & 6.11 & 6.0753 & TRN & \\
\hline CHEMBL55959 & 69841 & 5.89 & 5.9466 & TRN & \\
\hline CHEMBL293116 & 69841 & 5.73 & 5.7894 & TRN & \\
\hline CHEMBL298852 & 69841 & 5.47 & 5.2058 & TRN & \\
\hline CHEMBL55264 & 69841 & 5.23 & 5.2058 & TRN & \\
\hline CHEMBL434024 & 69841 & 6.85 & 6.8445 & TRN & \\
\hline CHEMBL54480 & 69841 & 5.94 & 5.9803 & TRN & \\
\hline CHEMBL299717 & 69841 & 5.78 & 6.0125 & TRN & \\
\hline CHEMBL417932 & 69841 & 4.36 & 4.3438 & TRN & \\
\hline CHEMBL316844 & 69841 & 6.35 & 6.3627 & TRN & \\
\hline CHEMBL 280463 & 69841 & 5.02 & 5.0593 & TRN & \\
\hline CHEMBL 301244 & 69841 & 6.51 & 6.4324 & TRN & \\
\hline CHEMBL54537 & 69841 & 6.31 & 6.2965 & TRN & \\
\hline CHEMBL55352 & 69841 & 5.03 & 5.018 & TRN & \\
\hline CHEMBL417549 & 69841 & 6.05 & 5.9357 & TRN & \\
\hline CHEMBL291727 & 69841 & 6.37 & 6.0977 & TST & \\
\hline CHEMBL100483 & 69841 & 5.85 & 6.4073 & TST & \\
\hline CHEMBL299563 & 69841 & 4.12 & 4.9588 & TST & \\
\hline CHEMBL55856 & 69841 & 6.31 & 6.2749 & TRN & \\
\hline CHEMBL55464 & 69841 & 6.6 & 6.6723 & TRN & \\
\hline CHEMBL55779 & 69841 & 4.82 & 4.8887 & TST & \\
\hline CHEMBL55140 & 69841 & 6.95 & 6.9694 & TST & \\
\hline CHEMBL54926 & 69841 & 5.49 & 5.7462 & TST & \\
\hline CHEMBL298771 & 69841 & 5.36 & 5.3844 & TRN & \\
\hline CHEMBL431735 & 69841 & 4.97 & 4.9355 & TRN & \\
\hline CHEMBL54344 & 69841 & 4.74 & 4.7157 & TRN & \\
\hline CHEMBL298547 & 69841 & 4.7 & 5.2058 & TRN & \\
\hline CHEMBL56254 & 69841 & 5.76 & 5.9357 & TRN & \\
\hline CHEMBL58830 & 69841 & 6.27 & 5.7567 & TST & \\
\hline CHEMBL55886 & 69841 & 5.87 & 5.8657 & TRN & \\
\hline CHEMBL485235 & 537481 & 7.699 & 7.0477 & TRN & \\
\hline CHEMBL520654 & 537481 & 7.4949 & 7.7596 & TRN & \\
\hline CHEMBL518085 & 537481 & 7.1308 & 7.6359 & TRN & \\
\hline CHEMBL485424 & 537481 & 6.2874 & 6.4975 & TRN & \\
\hline CHEMBL456434 & 537481 & 6.1965 & 6.2667 & TRN & \\
\hline CHEMBL464601 & 537481 & 6.224 & 6.58299 & 9999999999 & TRN \\
\hline CHEMBL485410 & 537481 & 7.1367 & 7.064 & TRN & \\
\hline CHEMBL483571 & 537481 & 6.4802 & 6.87700 & 0000000001 & TRN \\
\hline CHEMBL484181 & 537481 & 7.2291 & 6.6493 & TRN & \\
\hline CHEMBL353802 & 537481 & 9.0 & 7.8216 & TRN & \\
\hline
\end{tabular}


Supplemental Table S2.txt

\begin{tabular}{|c|c|c|c|c|}
\hline CHEMBL483572 & 37481 & 7.1192 & 7.6943 & TRN \\
\hline HEMBL521501 & 37481 & 7.5086 & 7.808 & \\
\hline HEMBL 485573 & 7481 & 229 & 5053 & \\
\hline HEMBL & 37481 & 3979 & 5713 & \\
\hline HEMBL485417 & 37481 & 5528 & .8249 & \\
\hline HEMBL484563 & 37481 & .1871 & 7.7704 & \\
\hline 4194 & 7481 & 188 & .2374 & \\
\hline HEMBL483399 & 37481 & & 7.5852 & $C T$ \\
\hline HEMBL447285 & 37481 & 3979 & 7.5368 & . \\
\hline HEMBL484351 & 37481 & 3979 & 7.3271 & TST \\
\hline HEMBL464397 & 37481 & 1549 & 7.2671 & נח- \\
\hline HEMBL5 & 481 & & 8101 & RN \\
\hline HEMBL4 & & & 6956 & \\
\hline HEMBL484195 & 37481 & 518 & 6.9827 & TRN \\
\hline HEMBL 354342 & 481 & 79 & 7.7566 & TST \\
\hline HEMBL4 & 481 & 79 & 7.4849 & $\mathrm{RN}$ \\
\hline HEMBL & & & 108 & ST \\
\hline HEMBL5 & 81 & & 201 & $\mathrm{RN}$ \\
\hline HEMBL5 & 81 & & 4396 & $1 \mathrm{KIV}$ \\
\hline HEMBL500330 & 81 & 29 & 399 & TST \\
\hline HEMBL5 & & & 319 & $\mathrm{RN}$ \\
\hline HEMBL & & & 977 & $\mathrm{RN}$ \\
\hline HEMBL & & & 7.8166 & TST \\
\hline HEMBL4 & & & 312 & TRN \\
\hline HEMBL520485 & 81 & 82 & 7.5726 & IRI \\
\hline HEMBL4 & & & 7.5677 & ST \\
\hline HEMBL & & & 42 & TST \\
\hline HEMBL & & & 7.6839 & TST \\
\hline HEMBL4 & & & 34 & IRIN \\
\hline HEMBL464396 & 81 & 31 & 6.6321 & TRN \\
\hline HEMBL4 & & 26 & 5888 & IST \\
\hline HEM & & & & ГST \\
\hline HEMBL $\angle$ & & & 1485 & TRN \\
\hline HEMBL520807 & & & 5076 & TST \\
\hline HEMBL520518 & 81 & & 7.7688 & TRN \\
\hline HEMBL4 & & & 209 & TRN \\
\hline THEMBL: & & & 27 & RN \\
\hline CHEMBL484548 & & & 7.597 & TST \\
\hline HEMBL485224 & 81 & & 056 & TRN \\
\hline HEMBL5 & & & 3631 & TRN \\
\hline CHEMBL1 & & 5 . & 5.7935 & TRN \\
\hline CHEMBL1 & & 3. & 3.7697 & TRN \\
\hline CHEMBL1688006 & 455 & 5.2464 & 5.3637 & TRN \\
\hline CHEMBL548963 & & & 3838 & $\mathrm{TR}$ \\
\hline CHEMBL1 & & & 5.4421 & TIV \\
\hline CHEMBL1688012 & 729455 & 5.7423 & 5.6207 & \\
\hline CHEMBL1687995 & 729455 & 6.1612 & 6.3153 & RN \\
\hline CHEMBL1254871 & 729455 & 5.58 & 5.5717 & IRI \\
\hline
\end{tabular}

Page 17232 


\begin{tabular}{|c|c|c|c|c|}
\hline & & & pplement & al $\mathrm{T}$ \\
\hline CHEMBL1687945 & 729455 & 3.8239 & 3.9165 & TRN \\
\hline CHEMBL524969 & 729455 & 5.5045 & 5.4871 & TRN \\
\hline CHEMBL524922 & 729455 & 7.5086 & 7.5074 & TRN \\
\hline CHEMBL1687983 & 729455 & 6.6576 & 6.6189 & TRN \\
\hline CHEMBL1687986 & 729455 & 6.2218 & 6.155 & TRN \\
\hline CHEMBL1688028 & 729455 & 5.5302 & 5.4736 & TRN \\
\hline CHEMBL1688029 & 729455 & 7.7959 & 6.6091 & TST \\
\hline CHEMBL1687993 & 729455 & 5.6596 & 5.6312 & TRN \\
\hline CHEMBL1688027 & 729455 & 3.8239 & 4.9036 & TST \\
\hline CHEMBL1687984 & 729455 & 5.5702 & 5.7142 & TRN \\
\hline CHEMBL1688022 & 729455 & 4.9694 & 5.0838 & TRN \\
\hline CHEMBL1688007 & 729455 & 5.4672 & 5.6002 & TRN \\
\hline CHEMBL1688000 & 729455 & 5.8125 & 5.6527 & TRN \\
\hline CHEMBL1688018 & 729455 & 3.8239 & 3.7627 & TRN \\
\hline CHEMBL1688009 & 729455 & 5.2147 & 5.1723 & TRN \\
\hline CHEMBL1254870 & 729455 & 5.5591 & 5.4149 & TRN \\
\hline CHEMBL1687999 & 729455 & 5.6676 & 5.5804 & TRN \\
\hline CHEMBL439259 & 729455 & 7.2757 & 7.2991 & TRN \\
\hline CHEMBL547264 & 729455 & 5.6968 & 5.7768 & TRN \\
\hline CHEMBL1688024 & 729455 & 3.8239 & 4.0807 & TRN \\
\hline CHEMBL1687985 & 729455 & 5.3585 & 5.2466 & TRN \\
\hline CHEMBL1688014 & 729455 & 3.8239 & 3.9802 & TRN \\
\hline CHEMBL1688030 & 729455 & 5.2941 & 5.1478 & TST \\
\hline CHEMBL1688019 & 729455 & 5.1439 & 4.7342 & TRN \\
\hline CHEMBL1688001 & 729455 & 3.8239 & 3.9654 & TRN \\
\hline CHEMBL1688020 & 729455 & 3.8239 & 3.7409 & TRN \\
\hline CHEMBL1688017 & 729455 & 5.3546 & 5.3389 & TRN \\
\hline CHEMBL1687994 & 729455 & 6.0269 & 5.914 & TRN \\
\hline CHEMBL1687996 & 729455 & 5.8861 & 5.8553 & TRN \\
\hline CHEMBL1687987 & 729455 & 6.0458 & 6.0969 & TRN \\
\hline CHEMBL1687997 & 729455 & 5.4724 & 5.612 & TRN \\
\hline CHEMBL1687991 & 729455 & 5.7235 & 5.8687 & TRN \\
\hline CHEMBL1254783 & 729455 & 5.2692 & 5.2577 & TRN \\
\hline CHEMBL1688011 & 729455 & 5.251 & 5.3194 & TRN \\
\hline CHEMBL1688005 & 729455 & 5.6882 & 5.7094 & TRN \\
\hline CHEMBL1687988 & 729455 & 5.9788 & 6.1414 & TRN \\
\hline CHEMBL1688013 & 729455 & 5.5952 & 5.5362 & TRN \\
\hline CHEMBL1688010 & 729455 & 5.5436 & 5.6151 & TRN \\
\hline CHEMBL1687998 & 729455 & 5.6253 & 5.4953 & TRN \\
\hline CHEMBL1688016 & 729455 & 4.9931 & 4.8868 & TRN \\
\hline CHEMBL1687990 & 729455 & 6.3279 & 5.4188 & TST \\
\hline CHEMBL1688002 & 729455 & 6.4949 & 4.2064 & TST \\
\hline CHEMBL1688026 & 729455 & 5.466 & 5.9506 & TST \\
\hline CHEMBL1687989 & 729455 & 5.684 & 5.9376 & TST \\
\hline CHEMBL1688004 & 729455 & 5.7055 & 4.3592 & TST \\
\hline CHEMBL587639 & 729455 & 5.6925 & 5.5957 & TST \\
\hline CHEMBL1688008 & 729455 & 5.983 & 5.9763 & TST \\
\hline CHEMBL1688025 & 729455 & 3.8239 & 4.1202 & TST \\
\hline
\end{tabular}




\begin{tabular}{|c|c|c|c|c|c|}
\hline & & \multicolumn{4}{|c|}{ Supplemental Table S2.txt } \\
\hline CHEMBL1688023 & 729455 & 3.8239 & 3.9926 & TST & \\
\hline CHEMBL1688031 & 729455 & 5.9626 & 5.9729 & TST & \\
\hline CHEMBL1688021 & 729455 & 4.8817 & 3.7607 & TST & \\
\hline CHEMBL225782 & 435461 & 7.8861 & 7.7338 & TRN & \\
\hline CHEMBL225696 & 435461 & 7.8861 & 7.8816 & TRN & \\
\hline CHEMBL226486 & 435461 & 9.3979 & 9.4317 & TRN & \\
\hline CHEMBL387630 & 435461 & 8.2218 & 8.1184 & TRN & \\
\hline CHEMBL 389409 & 435461 & 8.0 & 8.1639 & TRN & \\
\hline CHEMBL225781 & 435461 & 8.0458 & 7.6545 & TRN & \\
\hline CHEMBL225694 & 435461 & 7.1249 & 7.2648 & TRN & \\
\hline CHEMBL390827 & 435461 & 7.6021 & 7.8248 & TRN & \\
\hline CHEMBL375255 & 435461 & 8.0 & 7.8642 & TRN & \\
\hline CHEMBL 226428 & 435461 & 7.4202 & 7.67200 & 0000000001 & TRN \\
\hline CHEMBL 225695 & 435461 & 8.5229 & 8.4049 & TRN & \\
\hline CHEMBL 225877 & 435461 & 7.301 & 7.5773 & TRN & \\
\hline CHEMBL375060 & 435461 & 6.6655 & 6.9045 & TRN & \\
\hline CHEMBL225671 & 435461 & 8.5229 & 8.6257 & TRN & \\
\hline CHEMBL 226449 & 435461 & 5.0 & 6.1139 & TST & \\
\hline CHEMBL 225679 & 435461 & 7.7447 & 7.8666 & TRN & \\
\hline CHEMBL 225670 & 435461 & 8.2218 & 8.5875 & TRN & \\
\hline CHEMBL216119 & 435461 & 7.699 & 7.4699 & TRN & \\
\hline CHEMBL226394 & 435461 & 5.0 & 6.9528 & TST & \\
\hline CHEMBL 225727 & 435461 & 8.2218 & 8.3223 & TRN & \\
\hline CHEMBL 225722 & 435461 & 6.301 & 6.4698 & TRN & \\
\hline CHEMBL 225633 & 435461 & 8.5229 & 8.1635 & TRN & \\
\hline CHEMBL226451 & 435461 & 5.0 & 4.768 & TRN & \\
\hline CHEMBL225729 & 435461 & 9.0 & 8.7575 & TRN & \\
\hline CHEMBL438476 & 435461 & 8.0969 & 8.1413 & TRN & \\
\hline CHEMBL 225672 & 435461 & 9.0 & 8.7194 & TRN & \\
\hline CHEMBL388192 & 435461 & 7.7447 & 7.7398 & TRN & \\
\hline CHEMBL 226504 & 435461 & 8.0969 & 8.2345 & TRN & \\
\hline CHEMBL449402 & 435461 & 9.0 & 9.1359 & TRN & \\
\hline CHEMBL 225887 & 435461 & 7.8539 & 8.1332 & TRN & \\
\hline CHEMBL226503 & 435461 & 7.4202 & 6.8052 & TST & \\
\hline CHEMBL225706 & 435461 & 7.0458 & 7.3784 & TRN & \\
\hline CHEMBL376844 & 435461 & 7.585 & 7.5581 & TRN & \\
\hline CHEMBL376831 & 435461 & 6.2218 & 6.2241 & TRN & \\
\hline CHEMBL 226392 & 435461 & 8.301 & 8.0007 & TRN & \\
\hline CHEMBL387629 & 435461 & 7.0969 & 7.3245 & TST & \\
\hline CHEMBL 387486 & 435461 & 8.0 & 8.0136 & TRN & \\
\hline CHEMBL427272 & 435461 & 7.8539 & 7.7105 & TRN & \\
\hline CHEMBL 376830 & 435461 & 6.5229 & 5.2598 & TST & \\
\hline CHEMBL 216697 & 435461 & 8.699 & 8.5353 & TRN & \\
\hline CHEMBL 225705 & 435461 & 7.6576 & 7.6397 & TRN & \\
\hline CHEMBL 225773 & 435461 & 7.3665 & 7.1211 & TRN & \\
\hline CHEMBL 225680 & 435461 & 6.9957 & 7.0139 & TRN & \\
\hline CHEMBL 226505 & 435461 & 7.8861 & 7.8372 & TRN & \\
\hline CHEMBL 225834 & 435461 & 7.3468 & 7.4692 & TRN & \\
\hline
\end{tabular}

Page 17234 
Supplemental Table S2.txt

\begin{tabular}{|c|c|c|c|c|}
\hline CHEMBL225728 & 435461 & 7.2076 & 7.226 & TRN \\
\hline CHEMBL226393 & 435461 & 6.0 & 6.1705 & TRN \\
\hline CHEMBL387628 & 435461 & 7.0 & 7.4786 & TST \\
\hline CHEMBL225707 & 435461 & 7.2218 & 7.2357 & TRN \\
\hline CHEMBL375294 & 435461 & 7.7959 & 7.52 & TRN \\
\hline CHEMBL 225774 & 435461 & 7.3665 & 7.5515 & TST \\
\hline CHEMBL226515 & 435461 & 7.699 & 7.5888 & TST \\
\hline CHEMBL226450 & 435461 & 6.5229 & 7.5731 & TST \\
\hline CHEMBL225886 & 435461 & 8.0969 & 8.2124 & TST \\
\hline CHEMBL386316 & 435461 & 8.0458 & 7.5502 & TST \\
\hline CHEMBL225833 & 435461 & 7.7696 & 8.3651 & TST \\
\hline CHEMBL276470 & 435461 & 5.0 & 7.6365 & TST \\
\hline CHEMBL225678 & 435461 & 7.1427 & 7.0599 & TST \\
\hline CHEMBL425305 & 435461 & 5.0 & 7.1531 & TST \\
\hline CHEMBL1652491 & 714442 & 4.6576 & 4.2317 & TST \\
\hline CHEMBL1652502 & 714442 & 3.8239 & 4.01699 & 9999999995 \\
\hline CHEMBL1652506 & 714442 & 4.2441 & 4.2185 & TRN \\
\hline CHEMBL1652498 & 714442 & 4.1308 & 4.2219 & TRN \\
\hline CHEMBL1652499 & 714442 & 4.4559 & 4.1931 & TRN \\
\hline CHEMBL1652494 & 714442 & 4.0605 & 4.0133 & TST \\
\hline CHEMBL1652514 & 714442 & 2.9208 & 3.3755 & TRN \\
\hline CHEMBL1652509 & 714442 & 4.5686 & 4.2204 & TRN \\
\hline CHEMBL1652496 & 714442 & 2.5528 & 3.8484 & TST \\
\hline CHEMBL1652495 & 714442 & 3.4559 & 3.7833 & TRN \\
\hline CHEMBL1652515 & 714442 & 4.2596 & 4.1826 & TRN \\
\hline CHEMBL1652524 & 714442 & 5.0 & 5.0219 & TRN \\
\hline CHEMBL1652534 & 714442 & 4.9586 & 5.0322 & TRN \\
\hline CHEMBL1652484 & 714442 & 4. 2291 & 4.21399 & 9999999995 \\
\hline CHEMBL1652501 & 714442 & 4.3979 & 4.2173 & TRN \\
\hline CHEMBL1652526 & 714442 & 4.2366 & 4.2337 & TRN \\
\hline CHEMBL 1652520 & 714442 & 4.4815 & 4.291 & TRN \\
\hline CHEMBL1652510 & 714442 & 4.0706 & 4.1324 & TRN \\
\hline CHEMBL1652535 & 714442 & 4.699 & 5.0458 & TRN \\
\hline CHEMBL1652531 & 714442 & 4.6021 & 4.3471 & TRN \\
\hline CHEMBL1652500 & 714442 & 4.0862 & 4.1821 & TRN \\
\hline CHEMBL1652493 & 714442 & 4.9208 & 4.0957 & TST \\
\hline CHEMBL1652503 & 714442 & 4.1249 & 3.9654 & TRN \\
\hline CHEMBL1652492 & 714442 & 5.0 & 4.1433 & TST \\
\hline CHEMBL1652497 & 714442 & 1.6198 & 3.8285 & TST \\
\hline CHEMBL452545 & 714442 & 4.0655 & 4.0077 & TRN \\
\hline CHEMBL1652513 & 714442 & 4.4949 & 4.0026 & TRN \\
\hline CHEMBL1652508 & 714442 & 4.3372 & 4.2117 & TRN \\
\hline CHEMBL1649612 & 714442 & 4.1192 & 3.9639 & TRN \\
\hline CHEMBL452807 & 714442 & 3.3372 & 3.8474 & TST \\
\hline CHEMBL1652517 & 714442 & 4.2924 & 4.1045 & TRN \\
\hline CHEMBL1652530 & 714442 & 4.4685 & 4.3224 & TRN \\
\hline CHEMBL1652527 & 714442 & 3.6383 & 4.1011 & TRN \\
\hline CHEMBL1652528 & 714442 & 3.8239 & 4.1942 & TRN \\
\hline
\end{tabular}

Page 17235 
Supplemental Table S2.txt

\begin{tabular}{|c|c|c|c|c|c|}
\hline CHEMBL1652505 & 714442 & 4.0223 & 4.1661 & TRN & \\
\hline CHEMBL1652529 & 714442 & 4.6778 & 4.7339 & TRN & \\
\hline CHEMBL1652507 & 714442 & 4.1308 & 4.1131 & TRN & \\
\hline CHEMBL1652521 & 714442 & 4.5229 & 4.2843 & TRN & \\
\hline CHEMBL1652504 & 714442 & 4.4949 & 4.2923 & TRN & \\
\hline CHEMBL1652523 & 714442 & 4.2147 & 4.64 & TRN & \\
\hline CHEMBL1652518 & 714442 & 3.7696 & 3.9945 & TRN & \\
\hline CHEMBL1652519 & 714442 & 4.2518 & 4.2304 & TRN & \\
\hline CHEMBL1652512 & 714442 & 4.2924 & 4.2197 & TRN & \\
\hline CHEMBL1652522 & 714442 & 4.4815 & 4.3671 & TRN & \\
\hline CHEMBL1652533 & 714442 & 4.2366 & 4.3585 & TST & \\
\hline CHEMBL1652525 & 714442 & 3.3098 & 4.8626 & TST & \\
\hline CHEMBL1652511 & 714442 & 2.8239 & 4.0355 & TST & \\
\hline CHEMBL1652485 & 714442 & 4.4318 & 4.1422 & TST & \\
\hline CHEMBL1652532 & 714442 & 4.6383 & 4.2807 & TST & \\
\hline CHEMBL1652516 & 714442 & 1.7696 & 3.9809 & TST & \\
\hline CHEMBL3973287 & 1642275 & 8.3565 & 8.4573 & TRN & \\
\hline CHEMBL3927910 & 1642275 & 8.9208 & 8.8596 & TRN & \\
\hline CHEMBL 3942856 & 1642275 & 8.9586 & 8.8243 & TRN & \\
\hline CHEMBL 3913520 & 1642275 & 8.0969 & 7.959 & TRN & \\
\hline CHEMBL3958864 & 1642275 & 8.3768 & 8.4006 & TRN & \\
\hline CHEMBL3917516 & 1642275 & 8.2147 & 8.1193 & TRN & \\
\hline CHEMBL 3963248 & 1642275 & 8.2291 & 8.1965 & TRN & \\
\hline CHEMBL 3890332 & 1642275 & 8.5528 & 8.5576 & TRN & \\
\hline CHEMBL 3936210 & 1642275 & 8.2291 & 7.9592 & TRN & \\
\hline CHEMBL3949368 & 1642275 & 8.4089 & 8.4655 & TRN & \\
\hline CHEMBL3973511 & 1642275 & 8.2757 & 8.7873 & TST & \\
\hline CHEMBL3922444 & 1642275 & 8.0458 & 8.0389 & TRN & \\
\hline CHEMBL 3908821 & 1642275 & 8.4437 & 8.5056 & TRN & \\
\hline CHEMBL3907704 & 1642275 & 7.7033 & 7.8998 & TST & \\
\hline CHEMBL3935662 & 1642275 & 8.5229 & 8.5905 & TRN & \\
\hline CHEMBL3937711 & 1642275 & 8.2518 & \multicolumn{2}{|c|}{8.931000000000001} & TST \\
\hline CHEMBL 3904090 & 1642275 & 8.3979 & 8.4787 & TRN & \\
\hline CHEMBL 3973864 & 1642275 & 8.5086 & 8.4286 & TRN & \\
\hline CHEMBL 3938736 & 1642275 & 6.0 & 5.9971 & TRN & \\
\hline CHEMBL3957457 & 1642275 & 8.6576 & 8.6743 & TRN & \\
\hline CHEMBL 3896264 & 1642275 & 8.1675 & 8.2626 & TRN & \\
\hline CHEMBL3980081 & 1642275 & 8.6576 & 8.6688 & TRN & \\
\hline CHEMBL3899917 & 1642275 & 9.5229 & 9.5178 & TRN & \\
\hline CHEMBL3952688 & 1642275 & 8.9586 & 8.9181 & TRN & \\
\hline CHEMBL3968963 & 1642275 & 8.3768 & 8.4548 & TRN & \\
\hline CHEMBL3965169 & 1642275 & 8.6198 & 8.8788 & TST & \\
\hline CHEMBL3980209 & 1642275 & 8.4089 & 8.3652 & TRN & \\
\hline CHEMBL3922507 & 1642275 & 9.0 & 8.9866 & TRN & \\
\hline CHEMBL 3891603 & 1642275 & 8.5229 & 8.6519 & TRN & \\
\hline CHEMBL 3985826 & 1642275 & 8.1612 & \multicolumn{2}{|c|}{8.722000000000001} & TST \\
\hline CHEMBL 3896771 & 1642275 & 8.2366 & 8.3098 & TRN & \\
\hline CHEMBL3966881 & 1642275 & 8.1024 & 8.2013 & TRN & \\
\hline
\end{tabular}

Page 17236 
Supplemental Table S2.txt

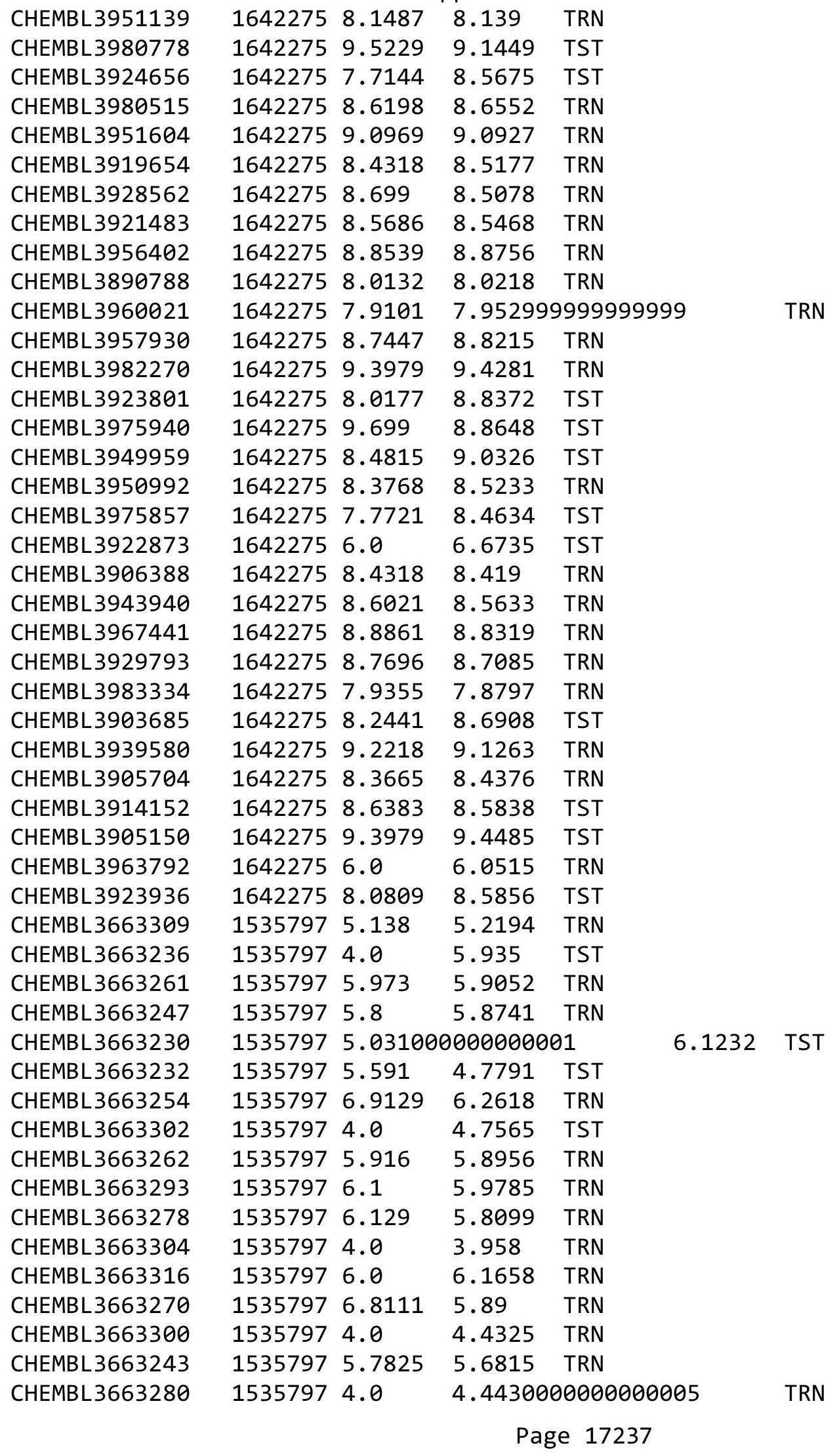


Supplemental Table S2.txt

\begin{tabular}{|c|c|c|c|c|c|c|}
\hline CHEMBL3663268 & 1535797 & 4.702 & 5.7309 & TRN & & \\
\hline CHEMBL 3663271 & 1535797 & 4.843 & 4.7536 & TRN & & \\
\hline CHEMBL3663307 & 1535797 & 5.808 & 5.7384 & TRN & & \\
\hline CHEMBL3663308 & 1535797 & 5.21899 & 99999999 & & 5.2841 & TST \\
\hline CHEMBL3663313 & 1535797 & 5.516 & 7.2196 & TST & & \\
\hline CHEMBL3663259 & 1535797 & 6.75799 & 99999999 & 99 & 6.1443 & TRN \\
\hline CHEMBL3663256 & 1535797 & 6.871 & 6.5236 & TRN & & \\
\hline CHEMBL3663263 & 1535797 & 5.584 & 5.4128 & TRN & & \\
\hline CHEMBL 3663248 & 1535797 & 5.5 & 4.8459 & TRN & & \\
\hline CHEMBL3663255 & 1535797 & 6.7261 & 6.6616 & TRN & & \\
\hline CHEMBL3663252 & 1535797 & 6.426 & 5.7788 & TRN & & \\
\hline CHEMBL3663297 & 1535797 & 6.9 & 6.7635 & TRN & & \\
\hline CHEMBL 3663257 & 1535797 & 7.7959 & 7.3555 & TRN & & \\
\hline CHEMBL 3663282 & 1535797 & 5.942 & 5.7759 & TRN & & \\
\hline CHEMBL3663269 & 1535797 & 4.9 & 5.1207 & TRN & & \\
\hline CHEMBL3663310 & 1535797 & 4.7 & 4.9449 & TST & & \\
\hline CHEMBL3663306 & 1535797 & 5.86299 & 99999999 & 995 & 4.98 & TST \\
\hline CHEMBL 3663301 & 1535797 & 4.383 & 4.2317 & TST & & \\
\hline CHEMBL3663253 & 1535797 & 8.1612 & 8.1255 & TRN & & \\
\hline CHEMBL3663258 & 1535797 & 4.84399 & 99999999 & 99 & 5.6711 & TRN \\
\hline CHEMBL3663305 & 1535797 & 6.15 & 6.6585 & TST & & \\
\hline CHEMBL 3663244 & 1535797 & 6.5 & 6.5494 & TRN & & \\
\hline CHEMBL3663296 & 1535797 & 8.2924 & 8.5296 & TRN & & \\
\hline CHEMBL3663292 & 1535797 & 6.4 & 6.3592 & TRN & & \\
\hline CHEMBL3663283 & 1535797 & 4.0 & 3.4146 & TRN & & \\
\hline CHEMBL 3663246 & 1535797 & 5.7 & 5.6172 & TRN & & \\
\hline CHEMBL3663311 & 1535797 & 4.724 & 3.8052 & TST & & \\
\hline CHEMBL 3663277 & 1535797 & 7.7545 & 7.5991 & TRN & & \\
\hline CHEMBL3663265 & 1535797 & 5.885 & 5.7489 & TRN & & \\
\hline CHEMBL3663250 & 1535797 & 4.0 & 4.6735 & TRN & & \\
\hline CHEMBL3663266 & 1535797 & 5.556 & 5.754 & TRN & & \\
\hline CHEMBL3663291 & 1535797 & 7.9281 & 7.9662 & TRN & & \\
\hline CHEMBL 3663274 & 1535797 & 4.0 & 4.0562 & TRN & & \\
\hline CHEMBL3663279 & 1535797 & 6.084 & \multicolumn{3}{|c|}{5.4639999999999995} & TRN \\
\hline CHEMBL3663229 & 1535797 & 5.062 & 4.8537 & TST & & \\
\hline CHEMBL3663276 & 1535797 & 4.0 & 3.8795 & TRN & & \\
\hline CHEMBL3663298 & 1535797 & 6.8 & 7.1834 & TRN & & \\
\hline CHEMBL 3663234 & 1535797 & 4.0 & 4.1657 & TST & & \\
\hline CHEMBL 3663264 & 1535797 & 5.062 & 5.596 & TRN & & \\
\hline CHEMBL3663251 & 1535797 & \multicolumn{3}{|c|}{5.502000000000001} & 6.2157 & TRN \\
\hline CHEMBL3663249 & 1535797 & 5.9135 & 5.8579 & TRN & & \\
\hline CHEMBL3663260 & 1535797 & 7.9747 & 8.0 & TRN & & \\
\hline CHEMBL3663275 & 1535797 & 5.041 & 5.171 & TRN & & \\
\hline CHEMBL3663281 & 1535797 & \multicolumn{3}{|c|}{4.6080000000000005} & 5.401 & TRN \\
\hline CHEMBL3663295 & 1535797 & 6.8771 & 6.9782 & TRN & & \\
\hline CHEMBL3663231 & 1535797 & 4.0 & 7.7303 & TST & & \\
\hline CHEMBL3663285 & 1535797 & 6.0 & 5.9814 & TRN & & \\
\hline CHEMBL3663235 & 1535797 & 4.0 & 4.7107 & TST & & \\
\hline
\end{tabular}




\begin{tabular}{|c|c|c|c|c|c|c|}
\hline \multicolumn{7}{|c|}{ Supplemental Table S2.txt } \\
\hline CHEMBL 3663273 & 1535797 & 4.0 & 4.2048 & TRN & & \\
\hline CHEMBL 3663245 & 1535797 & 5.5 & 5.6054 & TRN & & \\
\hline CHEMBL3663303 & 1535797 & 4.955 & 6.6941 & TST & & \\
\hline CHEMBL 3639621 & 1535797 & 6.265 & 6.4796 & TRN & & \\
\hline CHEMBL3663299 & 1535797 & \multicolumn{3}{|c|}{5.486000000000001} & 4.7941 & TST \\
\hline CHEMBL 3663233 & 1535797 & 4.0 & 5.5687 & TST & & \\
\hline CHEMBL 3663267 & 1535797 & 4.0 & 4.9022 & TRN & & \\
\hline CHEMBL 3663228 & 1535797 & 4.547 & 5.21899 & 9999999999 & & TST \\
\hline CHEMBL 3663290 & 1535797 & \multicolumn{3}{|c|}{6.5489999999999995} & 6.3065 & TRN \\
\hline CHEMBL 3663272 & 1535797 & 4.878 & 3.9816 & TRN & & \\
\hline CHEMBL 28637 & 830582 & 6.7055 & 7.1979 & TRN & & \\
\hline CHEMBL1862922 & 830582 & 6.9208 & 7.1657 & TRN & & \\
\hline CHEMBL1862958 & 830582 & 7.1079 & 7.1931 & TRN & & \\
\hline CHEMBL1863443 & 830582 & 5.9706 & 6.1149 & TST & & \\
\hline CHEMBL1863251 & 830582 & 7.4559 & 6.8629 & TRN & & \\
\hline CHEMBL1863074 & 830582 & 6.8416 & 6.9294 & TRN & & \\
\hline CHEMBL1862846 & 830582 & 4.6402 & 4.5884 & TRN & & \\
\hline CHEMBL1862871 & 830582 & 6.6968 & 6.7217 & TRN & & \\
\hline CHEMBL1863172 & 830582 & 6.6383 & 6.8683 & TST & & \\
\hline CHEMBL1862879 & 830582 & 8.301 & 8.0941 & TRN & & \\
\hline CHEMBL1862893 & 830582 & 5.1518 & 5.1903 & TRN & & \\
\hline CHEMBL137192 & 830582 & 6.5686 & 6.5054 & TRN & & \\
\hline CHEMBL1863174 & 830582 & 6.3507 & 6.8883 & TRN & & \\
\hline CHEMBL1863447 & 830582 & 6.8539 & 7.08799 & 9999999999 & & TRN \\
\hline CHEMBL1862803 & 830582 & 6.4318 & 6.944 & TRN & & \\
\hline CHEMBL1862909 & 830582 & 8.2218 & 7.9765 & TRN & & \\
\hline CHEMBL1863484 & 830582 & 6.3565 & 5.7505 & TRN & & \\
\hline CHEMBL1863284 & 830582 & 7.8861 & 7.1983 & TRN & & \\
\hline CHEMBL1863497 & 830582 & 7.699 & 7.5177 & TST & & \\
\hline CHEMBL1863007 & 830582 & 8.0969 & 7.9861 & TRN & & \\
\hline CHEMBL1863118 & 830582 & 6.5171 & 6.9764 & TRN & & \\
\hline CHEMBL1863067 & 830582 & 7.6778 & 7.3476 & TST & & \\
\hline CHEMBL1863004 & 830582 & 8.3979 & 8.2054 & TRN & & \\
\hline CHEMBL 2057985 & 830582 & 7.0862 & 7.3983 & TRN & & \\
\hline CHEMBL337750 & 830582 & 7.1549 & 7.6114 & TRN & & \\
\hline CHEMBL1862982 & 830582 & 8.699 & 8.1386 & TRN & & \\
\hline CHEMBL1863383 & 830582 & 8.699 & 8.211 & TRN & & \\
\hline CHEMBL1862902 & 830582 & 7.5229 & 7.3806 & TRN & & \\
\hline CHEMBL1862842 & 830582 & 7.0458 & 6.9652 & TST & & \\
\hline CHEMBL29669 & 830582 & 6.1656 & 6.6139 & TST & & \\
\hline CHEMBL 286965 & 830582 & 6.0757 & 6.6259 & TRN & & \\
\hline CHEMBL 2058277 & 830582 & 7.585 & 8.203 & TRN & & \\
\hline CHEMBL1863504 & 830582 & 6.9586 & 7.0852 & TRN & & \\
\hline CHEMBL1863135 & 830582 & 7.699 & 7.8475 & TRN & & \\
\hline CHEMBL1863160 & 830582 & 8.699 & 7.4372 & TRN & & \\
\hline CHEMBL1863183 & 830582 & 5.8153 & 6.7456 & TRN & & \\
\hline CHEMBL1863096 & 830582 & 8.0969 & 7.9098 & TRN & & \\
\hline CHEMBL 2058278 & 830582 & 6.585 & 6.8826 & TRN & & \\
\hline
\end{tabular}




\begin{tabular}{|c|c|c|c|c|c|}
\hline \multirow[b]{2}{*}{ CHEMBL1863146 } & \multicolumn{5}{|c|}{ Supplemental Table S2.txt } \\
\hline & 830582 & 7.5229 & 6.6336 & TRN & \\
\hline CHEMBL1862793 & 830582 & 7.6778 & 7.9568 & TRN & \\
\hline CHEMBL1862937 & 830582 & 7.3979 & 7.57700 & $\partial 000000001$ & TRN \\
\hline CHEMBL1863216 & 830582 & 7.7959 & 7.9161 & TRN & \\
\hline CHEMBL1863499 & 830582 & 9.0 & 8.5585 & TRN & \\
\hline CHEMBL 29904 & 830582 & 6.6576 & 6.7984 & TRN & \\
\hline CHEMBL28971 & 830582 & 6.4559 & 5.9604 & TRN & \\
\hline CHEMBL135115 & 830582 & 7.0223 & 7.3552 & TRN & \\
\hline CHEMBL1863224 & 830582 & 7.585 & 7.6045 & TRN & \\
\hline CHEMBL1863489 & 830582 & 7.6198 & 6.9778 & TRN & \\
\hline CHEMBL1863401 & 830582 & 4.5686 & 4.5639 & TRN & \\
\hline CHEMBL1862910 & 830582 & 7.7959 & 8.0396 & TRN & \\
\hline CHEMBL1863258 & 830582 & 7.2218 & 7.0692 & TRN & \\
\hline CHEMBL1863283 & 830582 & 7.1549 & 7.1446 & TRN & \\
\hline CHEMBL1863117 & 830582 & 7.1549 & 6.9954 & TRN & \\
\hline CHEMBL1862999 & 830582 & 7.5086 & 7.517 & TRN & \\
\hline CHEMBL1863223 & 830582 & 7.0458 & 6.8071 & TST & \\
\hline CHEMBL1863321 & 830582 & 8.5229 & 8.545 & TRN & \\
\hline CHEMBL1863482 & 830582 & 7.7959 & 7.69 & TRN & \\
\hline CHEMBL1863282 & 830582 & 7.301 & 6.8837 & TST & \\
\hline CHEMBL1862827 & 830582 & 7.585 & 7.8521 & TRN & \\
\hline CHEMBL1862806 & 830582 & 7.8239 & 7.8344 & TRN & \\
\hline CHEMBL1863082 & 830582 & 7.2676 & 7.3954 & TRN & \\
\hline CHEMBL138538 & 830582 & 7.7696 & 7.7915 & TRN & \\
\hline CHEMBL1862839 & 830582 & 4.8377 & 5.5792 & TST & \\
\hline CHEMBL1863179 & 830582 & 7.1549 & 7.0915 & TRN & \\
\hline CHEMBL1862913 & 830582 & 6.3098 & 6.7422 & TRN & \\
\hline CHEMBL1863266 & 830582 & 6.8539 & 6.4931 & TST & \\
\hline CHEMBL1863325 & 830582 & 8.699 & 7.8699 & TST & \\
\hline CHEMBL1863379 & 830582 & 7.9208 & 7.3199 & TST & \\
\hline CHEMBL1862838 & 830582 & 8.0 & 7.7013 & TST & \\
\hline CHEMBL1863450 & 830582 & 6.9208 & 7.0558 & TST & \\
\hline CHEMBL1863039 & 830582 & 7.6021 & 7.44600 & 0000000001 & TST \\
\hline CHEMBL1862867 & 830582 & 6.2175 & 6.7479 & TST & \\
\hline CHEMBL1863502 & 830582 & 7.0 & 7.4628 & TST & \\
\hline CHEMBL415725 & 830582 & 7.0969 & 7.2684 & TST & \\
\hline CHEMBL1863197 & 830582 & 7.2218 & 7.4721 & TST & \\
\hline CHEMBL1987231 & 809074 & 3.0044 & 2.9195 & TRN & \\
\hline CHEMBL 290545 & 809074 & 3.0044 & 2.9664 & TRN & \\
\hline CHEMBL 2007483 & 809074 & 3.0044 & 2.9039 & TRN & \\
\hline CHEMBL1393565 & 809074 & 3.0044 & 3.0419 & TRN & \\
\hline CHEMBL1989363 & 809074 & 3.0044 & 3.0507 & TRN & \\
\hline CHEMBL1458018 & 809074 & 3.0044 & 2.968 & TRN & \\
\hline CHEMBL1503187 & 809074 & 5.7144 & 5.6426 & TRN & \\
\hline CHEMBL1999757 & 809074 & 3.0044 & 3.0237 & TRN & \\
\hline CHEMBL1991968 & 809074 & 3.0044 & 2.9466 & TRN & \\
\hline CHEMBL1587532 & 809074 & 3.0044 & 3.1091 & TRN & \\
\hline CHEMBL 2000190 & 809074 & 3.0044 & 2.95399 & 99999999997 & TRN \\
\hline & & & & 172 & \\
\hline
\end{tabular}




\begin{tabular}{|c|c|c|c|c|c|}
\hline \multirow[b]{2}{*}{ CHEMBL2001755 } & \multicolumn{5}{|c|}{ Supplemental Table S2.txt } \\
\hline & 809074 & 3.0044 & 2.9049 & TRN & \\
\hline CHEMBL1976925 & 809074 & 4.2434 & 3.5059 & TST & \\
\hline CHEMBL3198803 & 809074 & 3.0044 & 2.9647 & TRN & \\
\hline CHEMBL1310492 & 809074 & 3.0044 & 3.0245 & TRN & \\
\hline CHEMBL1301786 & 809074 & 3.0044 & 2.9993 & TRN & \\
\hline CHEMBL1992643 & 809074 & 3.0044 & 3.0067 & TRN & \\
\hline CHEMBL1974234 & 809074 & 3.0044 & 2.9801 & TRN & \\
\hline CHEMBL1511078 & 809074 & 3.0044 & 3.1166 & TRN & \\
\hline CHEMBL1741927 & 809074 & 3.0044 & 3.0026 & TRN & \\
\hline CHEMBL1330039 & 809074 & 4.8416 & $2.8510 €$ & 00000000004 & TST \\
\hline CHEMBL1984384 & 809074 & 3.0044 & 2.9849 & TRN & \\
\hline CHEMBL1986350 & 809074 & 3.0044 & 3.0144 & TRN & \\
\hline CHEMBL1985139 & 809074 & 3.0044 & 3.0085 & TRN & \\
\hline CHEMBL1993655 & 809074 & 3.0044 & 2.9481 & TRN & \\
\hline CHEMBL1984849 & 809074 & 3.0044 & 3.014 & TRN & \\
\hline CHEMBL1990762 & 809074 & 3.0044 & 3.0265 & TRN & \\
\hline CHEMBL1974783 & 809074 & 3.0044 & 2.8619 & TST & \\
\hline CHEMBL1965135 & 809074 & 3.0044 & 2.9368 & TRN & \\
\hline CHEMBL1975650 & 809074 & 3.0044 & 3.0195 & TRN & \\
\hline CHEMBL1981516 & 809074 & 3.0044 & 3.0148 & TRN & \\
\hline CHEMBL1709150 & 809074 & 3.0044 & 2.5489 & TST & \\
\hline CHEMBL1975000 & 809074 & 3.0044 & 3.008 & TRN & \\
\hline CHEMBL1724713 & 809074 & 4.8928 & 4.3338 & TST & \\
\hline CHEMBL 2002163 & 809074 & 3.0044 & 3.0033 & TRN & \\
\hline CHEMBL 2005398 & 809074 & 3.0044 & 2.948 & TRN & \\
\hline CHEMBL1984047 & 809074 & 3.0044 & 3.0899 & TRN & \\
\hline CHEMBL1983259 & 809074 & 3.0044 & 2.6039 & TST & \\
\hline CHEMBL 2000496 & 809074 & 3.0044 & 2.9698 & TRN & \\
\hline CHEMBL1386524 & 809074 & 3.0044 & 3.0961 & TRN & \\
\hline CHEMBL1587985 & 809074 & 3.0044 & 2.9516 & TRN & \\
\hline CHEMBL1582492 & 809074 & 4.7799 & 4.7361 & TRN & \\
\hline CHEMBL1987113 & 809074 & 3.0044 & 2.8928 & TRN & \\
\hline CHEMBL 2028107 & 809074 & 3.0044 & 2.9718 & TRN & \\
\hline CHEMBL2001306 & 809074 & 3.0044 & 2.9956 & TRN & \\
\hline CHEMBL1973976 & 809074 & 3.0044 & 3.0169 & TRN & \\
\hline CHEMBL1994995 & 809074 & 3.0044 & 2.9778 & TST & \\
\hline CHEMBL1989633 & 809074 & 3.0044 & 2.9771 & TRN & \\
\hline CHEMBL1985081 & 809074 & 3.0044 & $2.9760 e$ & 00000000004 & TRN \\
\hline CHEMBL1996364 & 809074 & 3.0044 & 3.0715 & TRN & \\
\hline CHEMBL3192708 & 809074 & 4.5406 & 2.8748 & TST & \\
\hline CHEMBL1970596 & 809074 & 3.0044 & 3.3263 & TST & \\
\hline CHEMBL1988369 & 809074 & 3.0044 & $2.9930 e$ & 00000000003 & TRN \\
\hline CHEMBL1998530 & 809074 & 3.0044 & 3.0113 & TRN & \\
\hline CHEMBL1990131 & 809074 & 3.0044 & 3.0174 & TRN & \\
\hline CHEMBL1586803 & 809074 & 4.9706 & 3.1431 & TST & \\
\hline CHEMBL1986471 & 809074 & 3.0044 & 2.9763 & TST & \\
\hline CHEMBL1978234 & 809074 & 3.0044 & 3.034 & TRN & \\
\hline CHEMBL1386731 & 809074 & 3.0044 & 2.9646 & TRN & \\
\hline
\end{tabular}


Supplemental Table S2.txt

\begin{tabular}{|c|c|c|c|c|c|c|}
\hline CHEMBL1383031 & 809074 & 4.6925 & 3.0245 & TST & & \\
\hline CHEMBL1412746 & 809074 & 3.0044 & 3.0759 & TRN & & \\
\hline CHEMBL1979245 & 809074 & 3.0044 & 3.0119 & TRN & & \\
\hline CHEMBL1376754 & 809074 & 5.0329 & 3.3695 & TST & & \\
\hline CHEMBL1966498 & 809074 & 4.5622 & 2.9115 & TST & & \\
\hline CHEMBL1511826 & 809074 & \multicolumn{3}{|c|}{4.7669999999999995} & 4.7838 & TRN \\
\hline CHEMBL1983591 & 809074 & 3.0044 & 2.9735 & TRN & & \\
\hline CHEMBL1976492 & 809074 & 3.0044 & 3.0069 & TRN & & \\
\hline CHEMBL1999067 & 809074 & 3.0044 & 2.3218 & TST & & \\
\hline CHEMBL1993723 & 809074 & 3.0044 & 2.9841 & TRN & & \\
\hline CHEMBL1567396 & 809074 & 5.27 & 3.7022 & TST & & \\
\hline CHEMBL1974877 & 809074 & 3.0044 & 3.0103 & TRN & & \\
\hline CHEMBL1980903 & 809074 & 3.0044 & 3.0053 & TRN & & \\
\hline CHEMBL 2003536 & 809074 & 3.0044 & 2.8084 & TST & & \\
\hline CHEMBL 2005060 & 809074 & 3.0044 & 3.0203 & TRN & & \\
\hline CHEMBL 2000036 & 809074 & 3.0044 & 2.8516 & TST & & \\
\hline CHEMBL1990773 & 809074 & 5.0097 & 2.9144 & TST & & \\
\hline CHEMBL3209322 & 809074 & 3.0044 & 2.9767 & TRN & & \\
\hline CHEMBL1982446 & 809074 & 3.0044 & 3.0806 & TRN & & \\
\hline CHEMBL1978748 & 809074 & 3.0044 & 3.0494 & TST & & \\
\hline CHEMBL 2028094 & 809074 & 3.0044 & 3.1768 & TRN & & \\
\hline CHEMBL1987203 & 809074 & 3.0044 & 2.9819 & TRN & & \\
\hline CHEMBL1997264 & 809074 & 3.0044 & 3.0329 & TRN & & \\
\hline CHEMBL1447034 & 809074 & 5.1838 & 3.0515 & TST & & \\
\hline CHEMBL1977876 & 809074 & 3.0044 & 3.0588 & TRN & & \\
\hline CHEMBL1312653 & 809074 & 4.6925 & 4.6853 & TRN & & \\
\hline CHEMBL1334528 & 809074 & 3.0044 & 3.0147 & TRN & & \\
\hline CHEMBL255881 & 809074 & 5.9245 & 3.4388 & TST & & \\
\hline CHEMBL1498363 & 809074 & 3.0044 & 3.0547 & TRN & & \\
\hline CHEMBL1985725 & 809074 & 3.0044 & 2.9852 & TRN & & \\
\hline CHEMBL1965380 & 809074 & 3.0044 & 3.0371 & TRN & & \\
\hline CHEMBL1320566 & 809074 & 3.0044 & 3.6761 & TST & & \\
\hline CHEMBL1980590 & 809074 & 3.0044 & 2.9265 & TRN & & \\
\hline CHEMBL1970493 & 809074 & 4.3665 & 2.8039 & TST & & \\
\hline CHEMBL408994 & 809074 & 4.279 & 4.3248 & TRN & & \\
\hline CHEMBL1428519 & 809074 & 3.0044 & 3.0381 & TRN & & \\
\hline CHEMBL1733286 & 809074 & 3.0044 & 2.9851 & TST & & \\
\hline CHEMBL1976718 & 809074 & 3.0044 & 2.9771 & TRN & & \\
\hline CHEMBL1967269 & 809074 & 3.0044 & 3.0884 & TRN & & \\
\hline CHEMBL 74555 & 210789 & 4.5272 & 4.5611 & TRN & & \\
\hline CHEMBL77580 & 210789 & 4.8996 & 4.9137 & TRN & & \\
\hline CHEMBL424238 & 210789 & 4.4895 & 4.8876 & TRN & & \\
\hline CHEMBL75005 & 210789 & 4.6696 & 4.6151 & TRN & & \\
\hline CHEMBL305943 & 210789 & 5.4089 & 5.4064 & TRN & & \\
\hline CHEMBL 74971 & 210789 & 4.5186 & 4.4594 & TRN & & \\
\hline CHEMBL75389 & 210789 & 6.0472 & 6.0711 & TRN & & \\
\hline CHEMBL15901 & 210789 & 5.8477 & 6.0657 & TST & & \\
\hline CHEMBL77596 & 210789 & 4.7595 & 4.7773 & TRN & & \\
\hline
\end{tabular}

Page 17242 


\begin{tabular}{|c|c|c|c|c|c|c|}
\hline \multirow[b]{2}{*}{ CHEMBL 74196} & \multicolumn{6}{|c|}{ Supplemental Table S2.txt } \\
\hline & 210789 & 6.5686 & 6.636 & TRN & & \\
\hline CHEMBL 73634 & 210789 & 6.6003 & 6.33799 & 999999999 & & TRN \\
\hline CHEMBL74559 & 210789 & 4.7144 & 6.1267 & TRN & & \\
\hline CHEMBL73627 & 210789 & 7.3279 & 6.33799 & 999999999 & & TRN \\
\hline CHEMBL 75414 & 210789 & 7.3188 & 7.4019 & TRN & & \\
\hline CHEMBL 78033 & 210789 & 6.9281 & 6.8243 & TRN & & \\
\hline CHEMBL309002 & 210789 & 6.3279 & 5.9778 & TRN & & \\
\hline CHEMBL420564 & 210789 & 4.1475 & 5.244 & TST & & \\
\hline CHEMBL307601 & 210789 & 6.3439 & 6.1267 & TRN & & \\
\hline CHEMBL307260 & 210789 & 5.4112 & 5.4772 & TRN & & \\
\hline CHEMBL310704 & 210789 & 6.0088 & 4.7074 & TST & & \\
\hline CHEMBL423676 & 210789 & 5.3665 & 5.1783 & TRN & & \\
\hline CHEMBL308720 & 210789 & 5.1427 & 5.3284 & TRN & & \\
\hline CHEMBL307772 & 210789 & 4.6126 & 4.7699 & TRN & & \\
\hline CHEMBL74474 & 210789 & 4.9586 & 5.0551 & TRN & & \\
\hline CHEMBL75214 & 210789 & 5.0942 & 6.33799 & 999999999 & & TRN \\
\hline CHEMBL267337 & 210789 & 6.5003 & 6.5737 & TRN & & \\
\hline CHEMBL307407 & 210789 & 4.3316 & 4.3647 & TRN & & \\
\hline CHEMBL76507 & 210789 & 4.8601 & 4.9745 & TRN & & \\
\hline CHEMBL380216 & 210789 & 5.0506 & 5.1674 & TRN & & \\
\hline CHEMBL74212 & 210789 & 4.0737 & 4.2039 & TRN & & \\
\hline CHEMBL307634 & 210789 & 4.5591 & 4.5584 & TRN & & \\
\hline CHEMBL77633 & 210789 & 6.7932 & 6.1199 & TRN & & \\
\hline CHEMBL 74371 & 210789 & 5.8539 & 5.8243 & TRN & & \\
\hline CHEMBL77810 & 210789 & 5.3468 & 5.2676 & TRN & & \\
\hline CHEMBL 76504 & 210789 & 6.9706 & 6.1267 & TRN & & \\
\hline CHEMBL 74921 & 210789 & 5.5086 & 5.4164 & TRN & & \\
\hline CHEMBL 75849 & 210789 & 5.1487 & 5.0816 & TRN & & \\
\hline CHEMBL242759 & 210789 & 6.6576 & 7.2438 & TRN & & \\
\hline CHEMBL242102 & 210789 & 7.1612 & 7.0382 & TRN & & \\
\hline CHEMBL77045 & 210789 & 4.6737 & 4.8247 & TRN & & \\
\hline CHEMBL 77670 & 210789 & 5.585 & 5.3902 & TRN & & \\
\hline CHEMBL 74093 & 210789 & 4.7932 & 4.7424 & TRN & & \\
\hline CHEMBL 73297 & 210789 & 4.3788 & 6.1571 & TST & & \\
\hline CHEMBL539628 & 210789 & 6.38299 & 99999999 & 99 & 6.4307 & TRN \\
\hline CHEMBL76508 & 210789 & 4.2373 & 5.517 & TST & & \\
\hline CHEMBL 73758 & 210789 & 5.6882 & 5.63299 & 999999999 & & TRN \\
\hline CHEMBL 78158 & 210789 & 5.6198 & 4.9032 & TST & & \\
\hline CHEMBL 307289 & 210789 & 4.4989 & 4.6865 & TRN & & \\
\hline CHEMBL 77852 & 210789 & 5.3206 & 5.2031 & TRN & & \\
\hline CHEMBL 75847 & 210789 & 4.8539 & 5.0164 & TRN & & \\
\hline CHEMBL 76505 & 210789 & 6.6478 & 6.1267 & TRN & & \\
\hline CHEMBL77859 & 210789 & 4.1605 & 4.1601 & TRN & & \\
\hline CHEMBL149797 & 210789 & 5.3468 & 4.3698 & TST & & \\
\hline CHEMBL75538 & 210789 & 4.5867 & 4.4209 & TRN & & \\
\hline CHEMBL 74073 & 210789 & 3.9465 & 3.7861 & TRN & & \\
\hline CHEMBL312069 & 210789 & 4.8601 & 6.0136 & TST & & \\
\hline CHEMBL440685 & 210789 & 4.3089 & 4.6791 & TST & & \\
\hline
\end{tabular}




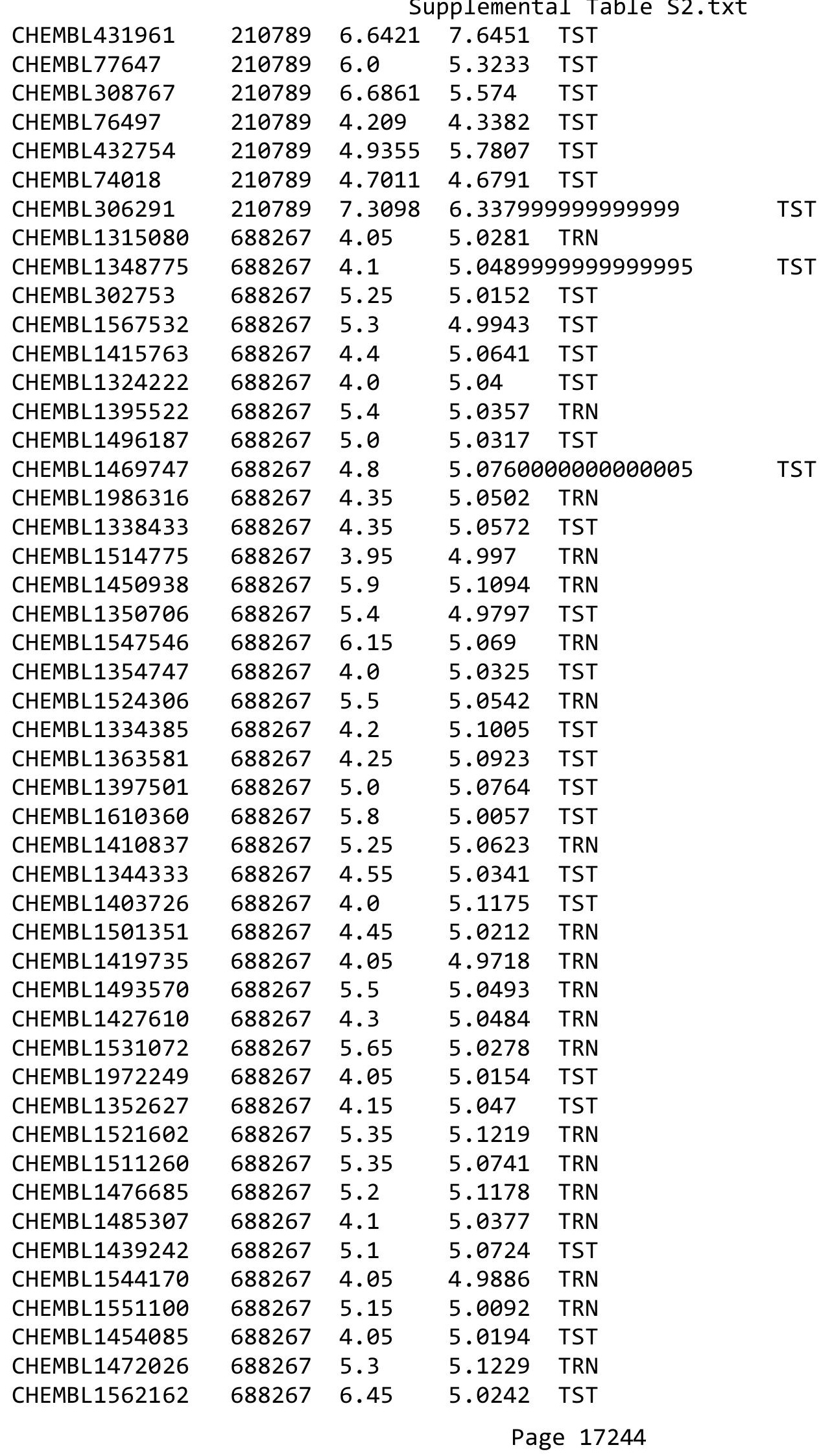




\begin{tabular}{|c|c|c|c|c|c|}
\hline \multicolumn{6}{|c|}{ Supplemental Table S2.txt } \\
\hline CHEMBL1328102 & 688267 & 6.25 & 5.0779 & TRN & \\
\hline CHEMBL1474163 & 688267 & 5.25 & 5.0452 & TRN & \\
\hline CHEMBL1496988 & 688267 & 5.95 & 5.0607 & TST & \\
\hline CHEMBL1602924 & 688267 & 4.0 & 5.0852 & TRN & \\
\hline CHEMBL1367889 & 688267 & 5.25 & 5.0476 & TRN & \\
\hline CHEMBL1433951 & 688267 & 4.4 & 5.045 & TRN & \\
\hline CHEMBL1471220 & 688267 & 3.95 & 5.0388 & TRN & \\
\hline CHEMBL1451732 & 688267 & 4.55 & 5.0867 & TST & \\
\hline CHEMBL1610475 & 688267 & 5.55 & 5.0238 & TRN & \\
\hline CHEMBL1607265 & 688267 & 4.05 & 5.0256 & TRN & \\
\hline CHEMBL1523138 & 688267 & 5.3 & 5.0384 & TRN & \\
\hline CHEMBL1327427 & 688267 & 5.45 & 5.0814 & TRN & \\
\hline CHEMBL1396730 & 688267 & 5.4 & 5.0854 & TRN & \\
\hline CHEMBL1491150 & 688267 & 4.05 & 5.0102 & TST & \\
\hline CHEMBL1610249 & 688267 & 4.65 & 5.0739 & TRN & \\
\hline CHEMBL1486080 & 688267 & 3.95 & 5.048 & TRN & \\
\hline CHEMBL1389895 & 688267 & 6.15 & 5.0817 & TRN & \\
\hline CHEMBL1328252 & 688267 & 4.5 & 5.067 & TRN & \\
\hline CHEMBL1528377 & 688267 & 4.4 & 5.0476 & TRN & \\
\hline CHEMBL1339896 & 688267 & 4.3 & 5.0332 & TRN & \\
\hline CHEMBL1534414 & 688267 & 4.0 & 5.048 & TRN & \\
\hline CHEMBL1523146 & 688267 & 5.9 & 5.0931 & TRN & \\
\hline CHEMBL1315811 & 688267 & 4.5 & 5.0405 & TRN & \\
\hline CHEMBL1513253 & 688267 & 6.2 & 5.0883 & TRN & \\
\hline CHEMBL1515322 & 688267 & 5.05 & 5.0622 & TRN & \\
\hline CHEMBL1496794 & 688267 & 4.0 & 5.0035 & TRN & \\
\hline CHEMBL1406690 & 688267 & 4.9 & 5.0173 & TST & \\
\hline CHEMBL1414367 & 688267 & 4.1 & 5.052 & TRN & \\
\hline CHEMBL1425785 & 688267 & 5.45 & 5.1135 & TRN & \\
\hline CHEMBL1528709 & 688267 & 5.3 & 5.0027 & TRN & \\
\hline CHEMBL3208241 & 688267 & 5.25 & 5.0161 & TST & \\
\hline CHEMBL1321530 & 688267 & 5.5 & 5.0376 & TST & \\
\hline CHEMBL1357043 & 688267 & 5.2 & 5.0048 & TRN & \\
\hline CHEMBL1587737 & 688267 & 4.4 & 5.0722 & TRN & \\
\hline CHEMBL1457911 & 688267 & 5.05 & 5.0719 & TRN & \\
\hline CHEMBL1395679 & 688267 & 4.6 & 5.0239 & TRN & \\
\hline CHEMBL1591311 & 688267 & 5.3 & 5.1221 & TRN & \\
\hline CHEMBL1579656 & 688267 & 5.25 & 5.0188 & TRN & \\
\hline CHEMBL1325178 & 688267 & 5.9 & 4.9861 & TRN & \\
\hline CHEMBL584860 & 688267 & 4.05 & 5.0226 & TRN & \\
\hline CHEMBL1551114 & 688267 & 4.35 & 5.1375 & TRN & \\
\hline CHEMBL1455716 & 688267 & 4.35 & 5.09699 & 99999999995 & TRN \\
\hline CHEMBL1439292 & 688267 & 5.2 & 5.0895 & TST & \\
\hline CHEMBL1554799 & 688267 & 6.2 & 5.1286 & TRN & \\
\hline CHEMBL1591941 & 688267 & 5.9 & 5.0725 & TST & \\
\hline CHEMBL1609215 & 688267 & 4.6 & 5.0168 & TRN & \\
\hline CHEMBL3198648 & 688267 & 4.25 & 5.037 & TST & \\
\hline CHEMBL1372094 & 688267 & 5.0 & 5.0127 & TRN & \\
\hline
\end{tabular}




\begin{tabular}{|c|c|c|c|c|c|}
\hline \multicolumn{6}{|c|}{ Supplemental Table S2.txt } \\
\hline CHEMBL1552467 & 688267 & 5.9 & 5.0574 & TRN & \\
\hline CHEMBL1346970 & 688267 & 4.6 & 4.9967 & TRN & \\
\hline CHEMBL1379468 & 688267 & 6.25 & 5.026 & TST & \\
\hline CHEMBL3190390 & 688267 & 4.0 & 5.0882 & TRN & \\
\hline CHEMBL1585450 & 688267 & 4.95 & 5.0432 & TRN & \\
\hline CHEMBL1415624 & 688267 & 5.3 & 5.039 & TRN & \\
\hline CHEMBL1563421 & 688267 & 5.35 & 5.0519 & TRN & \\
\hline CHEMBL1430522 & 688267 & 5.9 & 5.1337 & TST & \\
\hline CHEMBL1340769 & 688267 & 5.3 & 5.0841 & TRN & \\
\hline CHEMBL1578150 & 688267 & 4.0 & 5.0199 & TST & \\
\hline CHEMBL1532786 & 688267 & 4.65 & 5.1025 & TRN & \\
\hline CHEMBL3192768 & 688267 & 4.3 & 4.9353 & TRN & \\
\hline CHEMBL1332775 & 688267 & 4.9 & 4.9847 & TRN & \\
\hline CHEMBL1509226 & 688267 & 4.0 & 5.03 & TST & \\
\hline CHEMBL1494440 & 688267 & 4.5 & 5.0099 & TRN & \\
\hline CHEMBL1534311 & 688267 & 5.9 & 5.0849 & TST & \\
\hline CHEMBL1466360 & 688267 & 6.2 & 4.9952 & TRN & \\
\hline CHEMBL1607501 & 688267 & 6.15 & 5.0517 & TRN & \\
\hline CHEMBL1608612 & 688267 & 4.55 & 5.1253 & TST & \\
\hline CHEMBL1439822 & 688267 & 5.0 & 5.0967 & TRN & \\
\hline CHEMBL1531881 & 688267 & 4.65 & 5.1334 & TST & \\
\hline CHEMBL1345380 & 688267 & 4.25 & 5.039 & TST & \\
\hline CHEMBL1310680 & 688267 & 6.25 & 4.9965 & TRN & \\
\hline CHEMBL1552544 & 688267 & 5.15 & 5.0381 & TST & \\
\hline CHEMBL1525466 & 688267 & 6.2 & 5.0592 & TST & \\
\hline CHEMBL1447413 & 688267 & 5.05 & 5.1443 & TRN & \\
\hline CHEMBL1419259 & 688267 & 4.4 & 5.1014 & TRN & \\
\hline CHEMBL1530802 & 688267 & 4.35 & 5.0383 & TRN & \\
\hline CHEMBL3190790 & 688267 & 5.4 & 5.0445 & TRN & \\
\hline CHEMBL1592704 & 688267 & 6.2 & 5.0798 & TRN & \\
\hline CHEMBL1514237 & 688267 & 4.3 & 5.1438 & TRN & \\
\hline CHEMBL1613610 & 688267 & 4.05 & 5.0472 & TRN & \\
\hline CHEMBL1603770 & 688267 & 4.05 & 5.0482 & TRN & \\
\hline CHEMBL1401564 & 688267 & 4.0 & 5.0943 & TRN & \\
\hline CHEMBL1502748 & 688267 & 4.65 & 5.0907 & TST & \\
\hline CHEMBL567331 & 688267 & 6.45 & 5.0207 & TRN & \\
\hline CHEMBL1412913 & 688267 & 6.0 & 5.0507 & TRN & \\
\hline CHEMBL1303913 & 688267 & 4.0 & 5.045 & TST & \\
\hline CHEMBL1327301 & 688267 & 5.5 & 5.0606 & TRN & \\
\hline CHEMBL1387730 & 688267 & 4.6 & 5.0698 & TRN & \\
\hline CHEMBL1406685 & 688267 & 5.55 & $5.1110 e$ & 0000000001 & TRN \\
\hline CHEMBL3209488 & 688267 & 4.15 & 5.0741 & TST & \\
\hline CHEMBL1423600 & 688267 & 4.0 & 5.0554 & TRN & \\
\hline CHEMBL1474790 & 688267 & 4.0 & 5.0966 & TST & \\
\hline CHEMBL1381507 & 688267 & 6.2 & 5.0355 & TRN & \\
\hline CHEMBL1448572 & 688267 & 4.85 & 5.0916 & TRN & \\
\hline CHEMBL1560093 & 688267 & 4.35 & 5.1069 & TRN & \\
\hline CHEMBL1313778 & 688267 & 5.1 & 5.0079 & TRN & \\
\hline
\end{tabular}




\begin{tabular}{|c|c|c|c|c|}
\hline \multicolumn{5}{|c|}{ Supplemental Table S2.txt } \\
\hline CHEMBL1591858 & 688267 & 4.05 & 5.0119 & TRN \\
\hline CHEMBL1519318 & 688267 & 4.65 & 5.0703 & TST \\
\hline CHEMBL1497380 & 688267 & 7.2503 & 5.0866 & TST \\
\hline CHEMBL1373458 & 688267 & 4.55 & 5.1096 & TRN \\
\hline CHEMBL1395714 & 688267 & 5.35 & 5.0436 & TRN \\
\hline CHEMBL1446563 & 688267 & 4.4 & 5.0819 & TRN \\
\hline CHEMBL1464308 & 688267 & 4.55 & 4.9985 & TST \\
\hline CHEMBL3189854 & 688267 & 5.3 & 5.0658 & TRN \\
\hline CHEMBL1316815 & 688267 & 4.4 & 5.0394 & TST \\
\hline CHEMBL1592170 & 688267 & 5.9 & 5.0294 & TST \\
\hline CHEMBL58033 & 688267 & 5.3 & 5.143 & TST \\
\hline CHEMBL1513911 & 688267 & 4.45 & 5.016 & TRN \\
\hline CHEMBL1436590 & 688267 & 6.2 & 5.0717 & TRN \\
\hline CHEMBL1582403 & 688267 & 5.6 & 5.0089 & TRN \\
\hline CHEMBL1423648 & 688267 & 5.3 & 5.1058 & TRN \\
\hline CHEMBL1323093 & 688267 & 4.65 & 5.0312 & TRN \\
\hline CHEMBL3208594 & 688267 & 4.65 & 5.0058 & TRN \\
\hline CHEMBL1474148 & 688267 & 6.45 & 5.0585 & TRN \\
\hline CHEMBL1375822 & 688267 & 4.45 & 5.0146 & TRN \\
\hline CHEMBL3192760 & 688267 & 6.2 & 5.0721 & TRN \\
\hline CHEMBL1525663 & 688267 & 6.5 & 5.1194 & TRN \\
\hline CHEMBL1518426 & 688267 & 4.3 & 5.0495 & TST \\
\hline CHEMBL1553024 & 688267 & 4.0 & 4.9577 & TRN \\
\hline CHEMBL1359751 & 688267 & 4.5 & 5.0227 & TRN \\
\hline CHEMBL1577024 & 688267 & 4.35 & 5.0237 & TRN \\
\hline CHEMBL1315406 & 688267 & 4.25 & 5.0939 & TRN \\
\hline CHEMBL1372335 & 688267 & 3.95 & 5.0643 & TST \\
\hline CHEMBL1529264 & 688267 & 5.45 & 5.0677 & TRN \\
\hline CHEMBL1435475 & 688267 & 5.45 & 5.0859 & TRN \\
\hline CHEMBL1607835 & 688267 & 4.4 & 5.0661 & TRN \\
\hline CHEMBL1490744 & 688267 & 4.4 & 5.0041 & TRN \\
\hline CHEMBL1538826 & 688267 & 5.1 & 5.032 & TRN \\
\hline CHEMBL1340586 & 688267 & 5.1 & 5.1325 & TRN \\
\hline CHEMBL1605099 & 688267 & 4.7 & 4.9845 & TRN \\
\hline CHEMBL1613114 & 688267 & 6.2 & 5.0085 & TRN \\
\hline CHEMBL1411141 & 688267 & 4.0 & 5.0995 & TRN \\
\hline CHEMBL1337183 & 688267 & 6.4 & 5.0101 & TRN \\
\hline CHEMBL1305080 & 688267 & 6.2 & 5.0232 & TST \\
\hline CHEMBL1437785 & 688267 & 6.2 & 5.0561 & TRN \\
\hline CHEMBL1506832 & 688267 & 6.25 & 5.0452 & TRN \\
\hline CHEMBL1387369 & 688267 & 6.25 & 4.9978 & TRN \\
\hline CHEMBL1456326 & 688267 & 4.15 & 5.0455 & TRN \\
\hline CHEMBL1405878 & 688267 & 4.1 & 5.0681 & TRN \\
\hline CHEMBL1363550 & 688267 & 6.45 & 5.0281 & TRN \\
\hline CHEMBL1376037 & 688267 & 4.45 & 5.0734 & TST \\
\hline CHEMBL1342092 & 688267 & 6.2 & 5.0719 & TRN \\
\hline CHEMBL1573914 & 688267 & 6.2 & 5.0744 & TRN \\
\hline CHEMBL1428817 & 688267 & 4.6 & 5.0194 & TST \\
\hline
\end{tabular}




\begin{tabular}{|c|c|c|c|c|c|}
\hline \multirow[b]{2}{*}{ CHEMBL1395117 } & \multirow[b]{2}{*}{688267} & \multicolumn{4}{|c|}{ Supplemental Table s2.txt } \\
\hline & & 6.2 & 5.1012 & TRN & \\
\hline CHEMBL1599947 & 688267 & 5.8 & 5.0045 & TST & \\
\hline CHEMBL1314103 & 688267 & 5.95 & 5.0932 & TRN & \\
\hline CHEMBL1603945 & 688267 & 5.1 & 5.0438 & TRN & \\
\hline CHEMBL1461811 & 688267 & 5.95 & 5.12700 & 0000000001 & TRN \\
\hline CHEMBL3189360 & 688267 & 5.5 & 5.0109 & TRN & \\
\hline CHEMBL1590489 & 688267 & 6.0 & 5.0352 & TRN & \\
\hline CHEMBL1384542 & 688267 & 4.25 & 5.0228 & TRN & \\
\hline CHEMBL1473001 & 688267 & 5.75 & 5.1127 & TRN & \\
\hline CHEMBL566064 & 688267 & 4.4 & 5.0917 & TST & \\
\hline CHEMBL1405682 & 688267 & 4.4 & 5.0554 & TRN & \\
\hline CHEMBL1552072 & 688267 & 4.4 & 5.0894 & TRN & \\
\hline CHEMBL1383583 & 688267 & 5.15 & 5.0148 & TST & \\
\hline CHEMBL1399751 & 688267 & 4.3 & 4.9814 & TRN & \\
\hline CHEMBL1391627 & 688267 & 4.4 & 4.9942 & TRN & \\
\hline CHEMBL1512777 & 688267 & 5.45 & 5.0974 & TRN & \\
\hline CHEMBL1475521 & 688267 & 4.25 & 5.0416 & TRN & \\
\hline CHEMBL3198789 & 688267 & 4.6 & 5.0378 & TST & \\
\hline CHEMBL3190837 & 688267 & 4.1 & 5.0586 & TST & \\
\hline CHEMBL1571438 & 688267 & 5.25 & 5.0616 & TRN & \\
\hline CHEMBL1536125 & 688267 & 6.15 & 5.0522 & TRN & \\
\hline CHEMBL1995169 & 688267 & 4.5 & 5.0187 & TRN & \\
\hline CHEMBL1386587 & 688267 & 5.45 & 5.0035 & TRN & \\
\hline CHEMBL1571404 & 688267 & 5.95 & 5.0697 & TRN & \\
\hline CHEMBL1492344 & 688267 & 5.35 & 5.0383 & TRN & \\
\hline CHEMBL1593557 & 688267 & 5.75 & 5.106 & TRN & \\
\hline CHEMBL3213068 & 688267 & 3.9 & 5.0683 & TRN & \\
\hline CHEMBL1417655 & 688267 & 4.4 & 5.0781 & TST & \\
\hline CHEMBL1552914 & 688267 & 6.25 & 5.0912 & TST & \\
\hline CHEMBL1320480 & 688267 & 4.05 & 5.1218 & TRN & \\
\hline CHEMBL1594292 & 688267 & 6.2 & 5.1154 & TRN & \\
\hline CHEMBL1375882 & 688267 & 6.35 & 5.0602 & TRN & \\
\hline CHEMBL1539943 & 688267 & 5.3 & 5.0249 & TST & \\
\hline CHEMBL1499778 & 688267 & 4.35 & 5.0314 & TST & \\
\hline CHEMBL1537428 & 688267 & 4.0 & 5.0085 & TRN & \\
\hline CHEMBL1587717 & 688267 & 6.15 & 5.0508 & TRN & \\
\hline CHEMBL1360244 & 688267 & 4.7 & 5.1348 & TRN & \\
\hline CHEMBL1523468 & 688267 & 4.95 & 5.0499 & TRN & \\
\hline CHEMBL1505643 & 688267 & 4.35 & 5.0177 & TST & \\
\hline CHEMBL1367409 & 688267 & 5.65 & 5.0537 & TRN & \\
\hline CHEMBL1468575 & 688267 & 4.6 & 5.0351 & TRN & \\
\hline CHEMBL1482576 & 688267 & 4.05 & 5.0386 & TRN & \\
\hline CHEMBL1367765 & 688267 & 6.2 & 5.0558 & TRN & \\
\hline CHEMBL1587741 & 688267 & 4.6 & 5.0045 & TRN & \\
\hline CHEMBL1431081 & 688267 & 4.0 & 5.0414 & TRN & \\
\hline CHEMBL1496057 & 688267 & 6.15 & 5.0475 & TRN & \\
\hline CHEMBL 2369230 & 688267 & 5.65 & 5.0555 & TST & \\
\hline CHEMBL1488896 & 688267 & 4.35 & 5.0624 & TRN & \\
\hline
\end{tabular}




\begin{tabular}{|c|c|c|c|c|c|}
\hline \multicolumn{6}{|c|}{ Supplemental Table s2.txt } \\
\hline CHEMBL1572350 & 688267 & 4.35 & 5.0542 & TRN & \\
\hline CHEMBL1447844 & 688267 & 4.7 & 4.9815 & TRN & \\
\hline CHEMBL1515197 & 688267 & 4.0 & 5.1203 & TST & \\
\hline CHEMBL1315650 & 688267 & 4.05 & 5.0491 & TRN & \\
\hline CHEMBL1574898 & 688267 & 5.35 & 5.0719 & TST & \\
\hline CHEMBL1371382 & 688267 & 4.3 & 5.1 & TRN & \\
\hline CHEMBL 3214582 & 688267 & 5.8 & 5.0438 & TRN & \\
\hline CHEMBL1517180 & 688267 & 4.95 & 5.1241 & TRN & \\
\hline CHEMBL1339262 & 688267 & 6.2 & 5.024 & TRN & \\
\hline CHEMBL1325811 & 688267 & 6.2 & 5.0609 & TST & \\
\hline CHEMBL1500056 & 688267 & 3.95 & 5.0609 & TST & \\
\hline CHEMBL1517642 & 688267 & 4.7 & 5.1376 & TRN & \\
\hline CHEMBL1464140 & 688267 & 4.25 & 5.0837 & TST & \\
\hline CHEMBL1550855 & 688267 & 4.35 & 5.03 & TST & \\
\hline CHEMBL1561981 & 688267 & 3.95 & 5.0256 & TRN & \\
\hline CHEMBL1487200 & 688267 & 5.35 & 5.0299 & TRN & \\
\hline CHEMBL1595883 & 688267 & 4.3 & 5.0199 & TRN & \\
\hline CHEMBL1337154 & 688267 & 4.2 & 5.087 & TRN & \\
\hline CHEMBL1339433 & 688267 & 5.25 & 5.0712 & TRN & \\
\hline CHEMBL1504894 & 688267 & 4.0 & 5.0264 & TST & \\
\hline CHEMBL1370484 & 688267 & 6.15 & 5.0369 & TRN & \\
\hline CHEMBL1430263 & 688267 & 4.0 & 5.0424 & TST & \\
\hline CHEMBL3199112 & 688267 & 4.9 & $5.0710 e$ & 3000000001 & TST \\
\hline CHEMBL1575034 & 688267 & 5.25 & 5.1122 & TRN & \\
\hline CHEMBL1340006 & 688267 & 4.3 & 5.0815 & TRN & \\
\hline CHEMBL1355664 & 688267 & 5.25 & 5.0463 & TRN & \\
\hline CHEMBL1515150 & 688267 & 4.25 & 5.0584 & TST & \\
\hline CHEMBL1338912 & 688267 & 5.35 & 5.0351 & TRN & \\
\hline CHEMBL1338091 & 688267 & 5.5 & 5.0731 & TRN & \\
\hline CHEMBL1448864 & 688267 & 5.75 & 5.0715 & TRN & \\
\hline CHEMBL1566681 & 688267 & 3.95 & 5.0045 & TRN & \\
\hline CHEMBL1470199 & 688267 & 5.45 & 5.0135 & TST & \\
\hline CHEMBL1392268 & 688267 & 5.1 & 5.0236 & TRN & \\
\hline CHEMBL1335626 & 688267 & 4.1 & 5.0881 & TST & \\
\hline CHEMBL1322090 & 688267 & 5.55 & 5.1459 & TST & \\
\hline CHEMBL1570919 & 688267 & 6.2 & 5.033 & TRN & \\
\hline CHEMBL1365133 & 688267 & 6.2 & 5.0187 & TST & \\
\hline CHEMBL1473910 & 688267 & 4.05 & 5.0611 & TRN & \\
\hline CHEMBL1466696 & 688267 & 5.75 & 5.1146 & TST & \\
\hline CHEMBL1558821 & 688267 & 4.25 & 5.0709 & TST & \\
\hline CHEMBL1350760 & 688267 & 5.3 & 5.1393 & TRN & \\
\hline CHEMBL1483369 & 688267 & 5.85 & 5.0965 & TRN & \\
\hline CHEMBL1376046 & 688267 & 5.75 & 4.999 & TST & \\
\hline CHEMBL1433646 & 688267 & 4.35 & 5.0285 & TRN & \\
\hline CHEMBL1483140 & 688267 & 6.2 & 4.9959 & TRN & \\
\hline CHEMBL1490632 & 688267 & 5.05 & 5.0002 & TST & \\
\hline CHEMBL1356779 & 688267 & 5.7 & 5.0292 & TRN & \\
\hline CHEMBL1411490 & 688267 & 5.3 & 5.0799 & TRN & \\
\hline
\end{tabular}




\begin{tabular}{|c|c|c|c|c|c|}
\hline \multicolumn{6}{|c|}{ oplemental Table S } \\
\hline CHEMBL1563063 & 688267 & 4.85 & 5.0716 & TST & \\
\hline CHEMBL1608775 & 688267 & 4.05 & 5.0638 & TRN & \\
\hline CHEMBL1576396 & 688267 & 4.05 & 5.0759 & TRN & \\
\hline CHEMBL1594165 & 688267 & 5.25 & 5.0701 & TRN & \\
\hline CHEMBL1365548 & 688267 & 5.55 & 5.1278 & TRN & \\
\hline CHEMBL1430052 & 688267 & 4.55 & 5.0602 & TRN & \\
\hline CHEMBL1441992 & 688267 & 5.0 & 5.0328 & TRN & \\
\hline CHEMBL1388542 & 688267 & 4.5 & 5.0549 & TST & \\
\hline CHEMBL1338831 & 688267 & 5.35 & 5.1292 & TRN & \\
\hline CHEMBL1570957 & 688267 & 5.1 & 5.0616 & TRN & \\
\hline CHEMBL1546897 & 688267 & 6.25 & 5.0491 & TRN & \\
\hline CHEMBL1510225 & 688267 & 5.05 & 5.0764 & TRN & \\
\hline CHEMBL1605295 & 688267 & 5.85 & 5.1183 & TRN & \\
\hline CHEMBL1473256 & 688267 & 5.85 & 5.1792 & TST & \\
\hline CHEMBL1497063 & 688267 & 4.55 & 5.1221 & TST & \\
\hline CHEMBL1374455 & 688267 & 4.4 & 5.024 & TRN & \\
\hline CHEMBL1463238 & 688267 & 4.35 & 5.0436 & TRN & \\
\hline CHEMBL1449547 & 688267 & 5.2 & 5.0345 & TRN & \\
\hline CHEMBL1433437 & 688267 & 4.1 & 4.97199 & 99999999995 & TRN \\
\hline CHEMBL1519566 & 688267 & 4.4 & 5.0547 & TRN & \\
\hline CHEMBL1592391 & 688267 & 6.15 & 5.0228 & TRN & \\
\hline CHEMBL1483798 & 688267 & 6.15 & 5.0042 & TST & \\
\hline CHEMBL1576258 & 688267 & 4.2 & 4.9966 & TST & \\
\hline CHEMBL1459073 & 688267 & 6.2 & 5.0773 & TRN & \\
\hline CHEMBL1383055 & 688267 & 4.1 & 5.0456 & TRN & \\
\hline CHEMBL1562618 & 688267 & 4.6 & 4.9884 & TRN & \\
\hline CHEMBL1588628 & 688267 & 5.3 & 4.9957 & TST & \\
\hline CHEMBL1583530 & 688267 & 5.0 & 5.0663 & TRN & \\
\hline CHEMBL1468716 & 688267 & 4.65 & 5.1748 & TRN & \\
\hline CHEMBL1347792 & 688267 & 4.05 & 5.0204 & TRN & \\
\hline CHEMBL1365137 & 688267 & 4.2 & 5.0312 & TRN & \\
\hline CHEMBL1410327 & 688267 & 4.8 & 4.9755 & TRN & \\
\hline CHEMBL1974510 & 688267 & 4.4 & 5.0276 & TST & \\
\hline CHEMBL1316126 & 688267 & 6.15 & 5.103 & TRN & \\
\hline CHEMBL3196751 & 688267 & 5.95 & 4.9815 & TRN & \\
\hline CHEMBL1526223 & 688267 & 4.0 & 5.0561 & TST & \\
\hline CHEMBL1413914 & 688267 & 4.0 & 5.0894 & TRN & \\
\hline CHEMBL1514454 & 688267 & 4.1 & 5.0982 & TRN & \\
\hline CHEMBL1386521 & 688267 & 6.2 & 5.0698 & TRN & \\
\hline CHEMBL1364383 & 688267 & 5.75 & 5.03 & TRN & \\
\hline CHEMBL1372924 & 688267 & 4.1 & 5.0421 & TST & \\
\hline CHEMBL1302106 & 688267 & 5.9 & 5.0262 & TRN & \\
\hline CHEMBL1607836 & 688267 & 5.4 & 5.0632 & TRN & \\
\hline CHEMBL1535967 & 688267 & 4.05 & 5.1019 & TRN & \\
\hline CHEMBL1489470 & 688267 & 4.5 & 5.1018 & TST & \\
\hline CHEMBL1501762 & 688267 & 5.25 & 5.0396 & TRN & \\
\hline CHEMBL1336961 & 688267 & 5.5 & 5.0554 & TST & \\
\hline CHEMBL1410443 & 688267 & 5.35 & 5.0218 & TRN & \\
\hline
\end{tabular}




\begin{tabular}{|c|c|c|c|c|}
\hline & & & pplement & al $\mathrm{Ta}$ \\
\hline CHEMBL1408896 & 688267 & 3.95 & 5.1032 & TRN \\
\hline CHEMBL3194947 & 688267 & 4.3 & 4.9692 & TRN \\
\hline CHEMBL1339240 & 688267 & 5.35 & 5.0208 & TRN \\
\hline CHEMBL1351282 & 688267 & 3.9 & 5.1114 & TRN \\
\hline CHEMBL1554039 & 688267 & 6.2 & 5.0463 & TRN \\
\hline CHEMBL3189891 & 688267 & 6.15 & 4.9909 & TRN \\
\hline CHEMBL1461455 & 688267 & 4.2 & 5.0358 & TRN \\
\hline CHEMBL1602433 & 688267 & 6.15 & 5.0622 & TRN \\
\hline CHEMBL1609868 & 688267 & 5.55 & 4.9984 & TRN \\
\hline CHEMBL1534695 & 688267 & 5.65 & 5.0408 & TRN \\
\hline CHEMBL1580330 & 688267 & 5.9 & 5.1278 & TRN \\
\hline CHEMBL1592404 & 688267 & 5.0 & 5.1106 & TRN \\
\hline CHEMBL1447889 & 688267 & 6.45 & 5.1086 & TRN \\
\hline CHEMBL1522250 & 688267 & 5.05 & 5.021 & TST \\
\hline CHEMBL1371931 & 688267 & 4.05 & 5.1154 & TST \\
\hline CHEMBL1424964 & 688267 & 3.95 & 5.0906 & TST \\
\hline CHEMBL1534475 & 688267 & 6.0 & 5.0953 & TRN \\
\hline CHEMBL1585558 & 688267 & 4.5 & 5.0147 & TRN \\
\hline CHEMBL1532049 & 688267 & 4.7 & 5.0343 & TRN \\
\hline CHEMBL1338947 & 688267 & 4.35 & 5.0501 & TRN \\
\hline CHEMBL1412190 & 688267 & 4.1 & 5.0272 & TRN \\
\hline CHEMBL1531813 & 688267 & 5.35 & 5.0602 & TRN \\
\hline CHEMBL518634 & 688267 & 6.2 & 5.0236 & TRN \\
\hline CHEMBL1593708 & 688267 & 6.2 & 5.0636 & TRN \\
\hline CHEMBL1370059 & 688267 & 4.2 & 5.0323 & TRN \\
\hline CHEMBL1412539 & 688267 & 4.6 & 5.021 & TRN \\
\hline CHEMBL1319826 & 688267 & 4.5 & 5.0369 & TRN \\
\hline CHEMBL1432835 & 688267 & 5.45 & 5.0644 & TRN \\
\hline CHEMBL1372402 & 688267 & 4.4 & 5.0512 & TRN \\
\hline CHEMBL1418411 & 688267 & 4.0 & 5.0693 & TRN \\
\hline CHEMBL1511422 & 688267 & 6.25 & 5.1126 & TRN \\
\hline CHEMBL3210913 & 688267 & 5.0 & 4.9991 & TRN \\
\hline CHEMBL1466873 & 688267 & 5.7 & 5.0243 & TST \\
\hline CHEMBL1382754 & 688267 & 4.4 & 5.0894 & TRN \\
\hline CHEMBL1355026 & 688267 & 4.4 & 5.0579 & TST \\
\hline CHEMBL1569726 & 688267 & 4.35 & 5.1324 & TRN \\
\hline CHEMBL1352400 & 688267 & 4.95 & 5.0722 & TRN \\
\hline CHEMBL1442836 & 688267 & 6.15 & 5.0035 & TRN \\
\hline CHEMBL1378571 & 688267 & 3.95 & 5.1254 & TRN \\
\hline CHEMBL1509462 & 688267 & 6.2 & 5.0232 & TRN \\
\hline CHEMBL1394786 & 688267 & 4.45 & 5.0685 & TRN \\
\hline CHEMBL1337732 & 688267 & 5.85 & 5.0298 & TRN \\
\hline CHEMBL1469423 & 688267 & 4.9 & 5.0683 & TST \\
\hline CHEMBL1574877 & 688267 & 3.95 & 5.0613 & TST \\
\hline CHEMBL1514742 & 688267 & 4.9 & 5.0647 & TRN \\
\hline CHEMBL1590833 & 688267 & 5.6 & 5.0481 & TRN \\
\hline CHEMBL1393679 & 688267 & 4.8 & 4.9954 & TRN \\
\hline CHEMBL1456569 & 688267 & 4.4 & 5.0421 & TST \\
\hline
\end{tabular}




\begin{tabular}{|c|c|c|c|c|c|}
\hline \multicolumn{6}{|c|}{ splement } \\
\hline CHEMBL1455360 & 688267 & 6.15 & 5.0215 & TRN & \\
\hline CHEMBL1607045 & 688267 & 5.5 & 5.0338 & TRN & \\
\hline CHEMBL1308780 & 688267 & 5.3 & 5.0951 & TRN & \\
\hline CHEMBL1336640 & 688267 & 4.8 & 5.069 & TRN & \\
\hline CHEMBL1534177 & 688267 & 5.6 & 5.0844 & TRN & \\
\hline CHEMBL1449072 & 688267 & 5.7 & 5.0392 & TRN & \\
\hline CHEMBL1376679 & 688267 & 4.45 & 5.1328 & TRN & \\
\hline CHEMBL1515408 & 688267 & 5.5 & 5.0524 & TST & \\
\hline CHEMBL1538249 & 688267 & 5.6 & 5.0273 & TRN & \\
\hline CHEMBL1448107 & 688267 & 6.15 & 5.0682 & TRN & \\
\hline CHEMBL 2006988 & 688267 & 5.85 & 5.0301 & TST & \\
\hline CHEMBL1491781 & 688267 & 5.35 & 5.0386 & TRN & \\
\hline CHEMBL1465911 & 688267 & 5.0 & 5.0092 & TRN & \\
\hline CHEMBL1390835 & 688267 & 4.4 & 5.109 & TRN & \\
\hline CHEMBL1458615 & 688267 & 4.0 & 5.0684 & TRN & \\
\hline CHEMBL1503263 & 688267 & 5.0 & 5.0782 & TST & \\
\hline CHEMBL1314568 & 688267 & 5.25 & 5.0516 & TRN & \\
\hline CHEMBL1506784 & 688267 & 4.05 & 5.0291 & TST & \\
\hline CHEMBL1349633 & 688267 & 4.75 & 5.0615 & TRN & \\
\hline CHEMBL1397479 & 688267 & 4.0 & 5.0212 & TRN & \\
\hline CHEMBL1390484 & 688267 & 5.75 & 5.0312 & TRN & \\
\hline CHEMBL1474506 & 688267 & 6.45 & 5.0892 & TST & \\
\hline CHEMBL 3208863 & 688267 & 5.35 & 5.0433 & TST & \\
\hline CHEMBL1514148 & 688267 & 6.25 & 5.0389 & TRN & \\
\hline CHEMBL1303994 & 688267 & 6.2 & 5.0489 & TST & \\
\hline CHEMBL1513211 & 688267 & 4.0 & 5.0433 & TRN & \\
\hline CHEMBL1450194 & 688267 & 4.15 & 4.9845 & TRN & \\
\hline CHEMBL1348826 & 688267 & 5.35 & 5.0168 & TRN & \\
\hline CHEMBL1405703 & 688267 & 5.05 & 5.0847 & TRN & \\
\hline CHEMBL 3191607 & 688267 & 5.15 & 5.0337 & TST & \\
\hline CHEMBL1356995 & 688267 & 5.25 & 5.0189 & TRN & \\
\hline CHEMBL1516014 & 688267 & 6.2 & 5.0812 & TRN & \\
\hline CHEMBL1335518 & 688267 & 4.0 & 5.0388 & TRN & \\
\hline CHEMBL1401211 & 688267 & 5.45 & 5.0706 & TST & \\
\hline CHEMBL1375808 & 688267 & 5.15 & $5.0680 e$ & 30000000005 & TRN \\
\hline CHEMBL1402022 & 688267 & 5.85 & 5.0495 & TRN & \\
\hline CHEMBL1377223 & 688267 & 4.25 & 5.0683 & TRN & \\
\hline CHEMBL1591645 & 688267 & 4.0 & 5.0754 & TRN & \\
\hline CHEMBL1393756 & 688267 & 6.15 & 5.0617 & TRN & \\
\hline CHEMBL1509886 & 688267 & 4.95 & 5.0202 & TST & \\
\hline CHEMBL1330762 & 688267 & 4.8 & 5.0651 & TRN & \\
\hline CHEMBL1592983 & 688267 & 5.5 & 5.0544 & TRN & \\
\hline CHEMBL1486597 & 688267 & 4.65 & 5.0567 & TST & \\
\hline CHEMBL1544203 & 688267 & 5.55 & 5.091 & TRN & \\
\hline CHEMBL1570854 & 688267 & 5.0 & 4.9619 & TRN & \\
\hline CHEMBL1518388 & 688267 & 5.95 & 5.1093 & TRN & \\
\hline CHEMBL1600639 & 688267 & 6.2 & 5.0829 & TST & \\
\hline CHEMBL1455464 & 688267 & 4.55 & 5.0186 & TRN & \\
\hline
\end{tabular}




\begin{tabular}{|c|c|c|c|c|c|}
\hline \multicolumn{6}{|c|}{ Supplemental Table S2.txt } \\
\hline CHEMBL1512337 & 688267 & 4.35 & 5.1013 & TRN & \\
\hline CHEMBL1305171 & 688267 & 4.85 & 5.0669 & TST & \\
\hline CHEMBL1539956 & 688267 & 6.15 & 5.0768 & TRN & \\
\hline CHEMBL1472887 & 688267 & 4.0 & 5.0584 & TRN & \\
\hline CHEMBL1366714 & 688267 & 4.5 & 5.0113 & TRN & \\
\hline CHEMBL1610786 & 688267 & 6.15 & 5.1141 & TST & \\
\hline CHEMBL1357771 & 688267 & 5.15 & 5.0909 & TST & \\
\hline CHEMBL1501552 & 688267 & 5.35 & 5.0666 & TRN & \\
\hline CHEMBL1361038 & 688267 & 4.45 & 5.0479 & TST & \\
\hline CHEMBL1385790 & 688267 & 4.05 & 5.0945 & TRN & \\
\hline CHEMBL1374073 & 688267 & 5.5 & 5.0484 & TRN & \\
\hline CHEMBL1351115 & 688267 & 4.0 & 5.0111 & TRN & \\
\hline CHEMBL1197976 & 688267 & 5.65 & 5.1079 & TRN & \\
\hline CHEMBL1427371 & 688267 & 6.2 & 5.1329 & TRN & \\
\hline CHEMBL1349696 & 688267 & 5.25 & 5.0637 & TRN & \\
\hline CHEMBL1449658 & 688267 & 5.95 & 5.0925 & TRN & \\
\hline CHEMBL1365451 & 688267 & 5.3 & 5.033 & TRN & \\
\hline CHEMBL1489602 & 688267 & 4.05 & 5.0824 & TRN & \\
\hline CHEMBL1482089 & 688267 & 5.0 & 5.0846 & TRN & \\
\hline CHEMBL1377904 & 688267 & 4.4 & 5.0723 & TRN & \\
\hline CHEMBL1413983 & 688267 & 5.2 & 5.0985 & TRN & \\
\hline CHEMBL1420356 & 688267 & 6.2 & 5.1094 & TRN & \\
\hline CHEMBL1513001 & 688267 & 6.2 & 5.0419 & TRN & \\
\hline CHEMBL1382455 & 688267 & 4.0 & 5.0515 & TRN & \\
\hline CHEMBL1546893 & 688267 & 4.6 & 5.0495 & TST & \\
\hline CHEMBL1336441 & 688267 & 6.25 & 5.0181 & TRN & \\
\hline CHEMBL1341056 & 688267 & 4.05 & 5.0988 & TST & \\
\hline CHEMBL1373316 & 688267 & 4.3 & 5.0871 & TST & \\
\hline CHEMBL1465004 & 688267 & 5.4 & 5.0302 & TRN & \\
\hline CHEMBL1555252 & 688267 & 6.25 & 5.0357 & TRN & \\
\hline CHEMBL1512943 & 688267 & 5.3 & 5.0742 & TRN & \\
\hline CHEMBL1491367 & 688267 & 5.35 & 5.0393 & TRN & \\
\hline CHEMBL1441655 & 688267 & 5.9 & 5.0027 & TRN & \\
\hline CHEMBL3211295 & 688267 & 6.15 & 5.0399 & TST & \\
\hline CHEMBL1407918 & 688267 & 5.2 & 5.0254 & TRN & \\
\hline CHEMBL1390181 & 688267 & 5.25 & 5.05699 & 99999999995 & TST \\
\hline CHEMBL1353347 & 688267 & 4.0 & 5.1004 & TRN & \\
\hline CHEMBL1568801 & 688267 & 6.2 & 4.9949 & TRN & \\
\hline CHEMBL1400424 & 688267 & 4.0 & 5.045 & TRN & \\
\hline CHEMBL1481788 & 688267 & 6.15 & 5.1236 & TST & \\
\hline CHEMBL1489643 & 688267 & 5.5 & 5.05699 & 99999999995 & TRN \\
\hline CHEMBL1459425 & 688267 & 5.4 & 5.1255 & TRN & \\
\hline CHEMBL1317983 & 688267 & 6.2 & 5.0329 & TST & \\
\hline CHEMBL1422274 & 688267 & 6.5 & 5.0603 & TST & \\
\hline CHEMBL1405621 & 688267 & 4.0 & 4.9943 & TRN & \\
\hline CHEMBL1347001 & 688267 & 4.3 & 4.9768 & TRN & \\
\hline CHEMBL1356140 & 688267 & 5.95 & 5.0773 & TRN & \\
\hline CHEMBL1466013 & 688267 & 5.2 & 4.9632 & TRN & \\
\hline
\end{tabular}




\begin{tabular}{|c|c|c|c|c|}
\hline \multicolumn{5}{|c|}{ Supplemental Table S2.txt } \\
\hline CHEMBL1347124 & 688267 & 4.9 & 5.1028 & TRN \\
\hline CHEMBL1512581 & 688267 & 5.45 & 5.1412 & TRN \\
\hline CHEMBL1343599 & 688267 & 4.45 & 5.0086 & TRN \\
\hline CHEMBL1328844 & 688267 & 4.1 & 5.0081 & TRN \\
\hline CHEMBL1582109 & 688267 & 5.0 & 5.0563 & TST \\
\hline CHEMBL1466285 & 688267 & 4.0 & 5.0577 & TST \\
\hline CHEMBL1523208 & 688267 & 5.65 & 5.0932 & TRN \\
\hline CHEMBL1489323 & 688267 & 4.0 & 5.0999 & TRN \\
\hline CHEMBL1329398 & 688267 & 5.9 & 4.9883 & TRN \\
\hline CHEMBL1395872 & 688267 & 6.9 & 5.0919 & TRN \\
\hline CHEMBL1530226 & 688267 & 6.25 & 5.0548 & TRN \\
\hline CHEMBL1434582 & 688267 & 6.2 & 5.1428 & TRN \\
\hline CHEMBL1609104 & 688267 & 6.15 & 4.9978 & TST \\
\hline CHEMBL1432983 & 688267 & 5.5 & 5.042 & TRN \\
\hline CHEMBL1473047 & 688267 & 3.95 & 4.9765 & TRN \\
\hline CHEMBL1370607 & 688267 & 4.95 & 5.0432 & TST \\
\hline CHEMBL1495424 & 688267 & 5.5 & 5.0426 & TRN \\
\hline CHEMBL1370985 & 688267 & 4.0 & 5.0115 & TRN \\
\hline CHEMBL1595305 & 688267 & 6.5 & 5.023 & TRN \\
\hline CHEMBL1513015 & 688267 & 6.2 & 5.0843 & TRN \\
\hline CHEMBL1356301 & 688267 & 6.15 & 5.0817 & TRN \\
\hline CHEMBL1388875 & 688267 & 4.35 & 4.9839 & TRN \\
\hline CHEMBL1504485 & 688267 & 5.35 & 5.1103 & TRN \\
\hline CHEMBL1582727 & 688267 & 4.25 & 5.0718 & TRN \\
\hline CHEMBL1597511 & 688267 & 4.4 & 5.0259 & TRN \\
\hline CHEMBL1585264 & 688267 & 5.35 & 5.0454 & TRN \\
\hline CHEMBL1335781 & 688267 & 4.0 & 5.0602 & TRN \\
\hline CHEMBL1434905 & 688267 & 5.75 & 4.9911 & TRN \\
\hline CHEMBL1403792 & 688267 & 5.1 & 5.0798 & TRN \\
\hline CHEMBL1538668 & 688267 & 6.0 & 5.0075 & TRN \\
\hline CHEMBL1327588 & 688267 & 5.55 & 5.0424 & TST \\
\hline CHEMBL1490827 & 688267 & 5.0 & 5.0438 & TRN \\
\hline CHEMBL1597740 & 688267 & 3.95 & 5.0771 & TRN \\
\hline CHEMBL1373290 & 688267 & 7.8508 & 5.0341 & TRN \\
\hline CHEMBL1588247 & 688267 & 4.6 & 5.0956 & TST \\
\hline CHEMBL1304567 & 688267 & 5.95 & 5.013 & TRN \\
\hline CHEMBL1455089 & 688267 & 5.2 & 5.0233 & TRN \\
\hline CHEMBL1607715 & 688267 & 4.35 & 5.0809 & TST \\
\hline CHEMBL1405044 & 688267 & 4.05 & 5.0721 & TRN \\
\hline CHEMBL1565143 & 688267 & 5.7 & 5.0273 & TRN \\
\hline CHEMBL1420543 & 688267 & 4.6 & 5.011 & TRN \\
\hline CHEMBL1482887 & 688267 & 3.95 & 5.0861 & TRN \\
\hline CHEMBL3189415 & 688267 & 4.45 & 5.051 & TST \\
\hline CHEMBL1325283 & 688267 & 4.6 & 5.0515 & TRN \\
\hline CHEMBL1442686 & 688267 & 4.8 & 5.0927 & TRN \\
\hline CHEMBL1370258 & 688267 & 4.0 & 5.0565 & TRN \\
\hline CHEMBL1416930 & 688267 & 6.25 & 5.0506 & TRN \\
\hline CHEMBL1512864 & 688267 & 4.4 & 5.046 & TRN \\
\hline
\end{tabular}




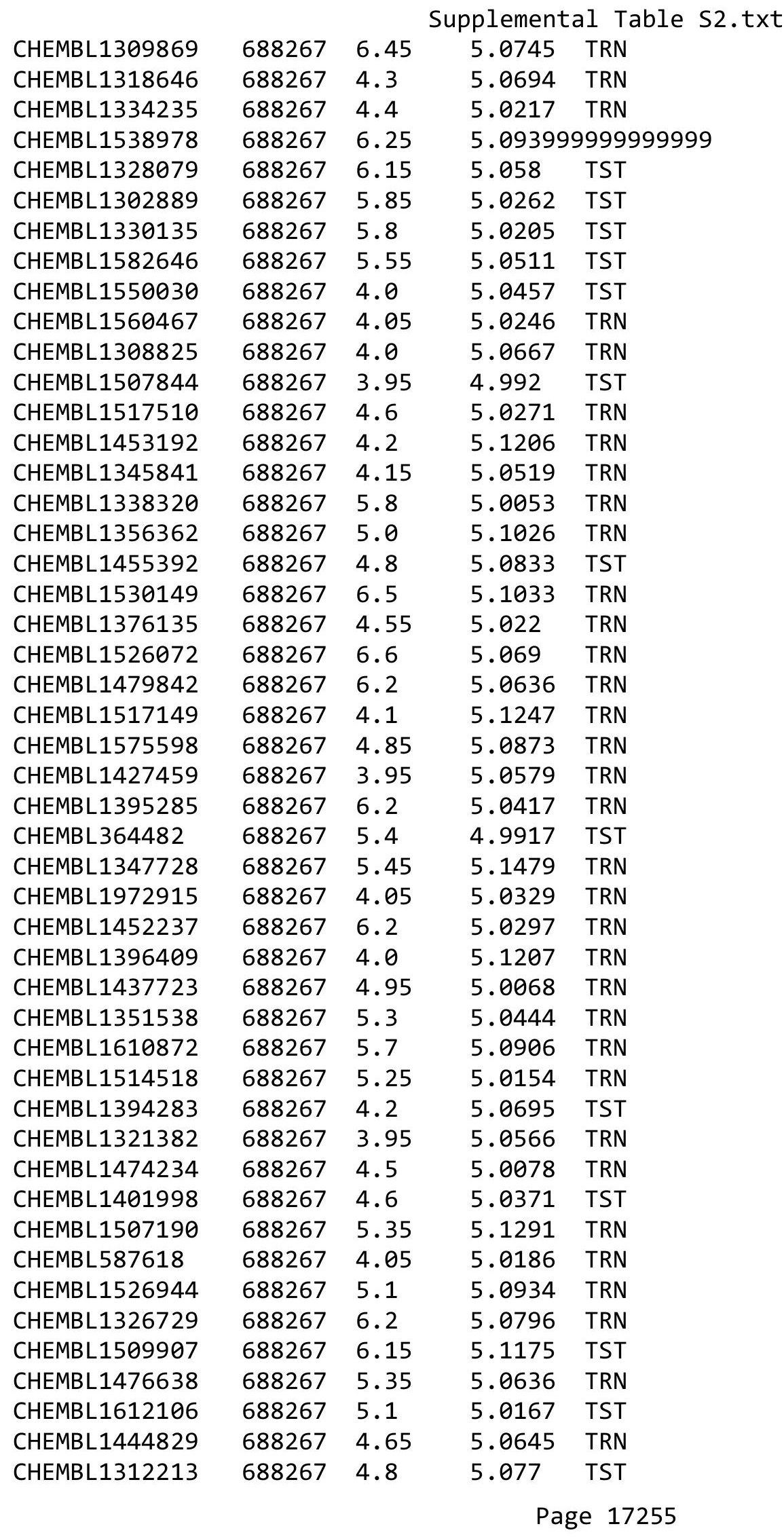

TRN 


\begin{tabular}{|c|c|c|c|c|}
\hline \multicolumn{5}{|c|}{ Supplemental Table S2.txt } \\
\hline CHEMBL1448853 & 688267 & 5.45 & 5.0318 & TRN \\
\hline CHEMBL 3189252 & 688267 & 5.6 & 5.0144 & TRN \\
\hline CHEMBL1585347 & 688267 & 5.5 & 5.0588 & TRN \\
\hline CHEMBL1381107 & 688267 & 4.5 & 5.0521 & TST \\
\hline CHEMBL1434273 & 688267 & 6.2 & 5.1346 & TRN \\
\hline CHEMBL1431871 & 688267 & 4.25 & 5.1234 & TRN \\
\hline CHEMBL1373951 & 688267 & 5.25 & 5.0844 & TRN \\
\hline CHEMBL1547066 & 688267 & 4.0 & 5.1419 & TRN \\
\hline CHEMBL1346164 & 688267 & 4.0 & 5.0171 & TRN \\
\hline CHEMBL1322069 & 688267 & 5.1 & 5.0779 & TRN \\
\hline CHEMBL1988666 & 688267 & 6.2 & 5.0201 & TST \\
\hline CHEMBL1502898 & 688267 & 4.0 & 5.0092 & TST \\
\hline CHEMBL1526788 & 688267 & 4.0 & 5.0777 & TRN \\
\hline CHEMBL1597499 & 688267 & 4.0 & 5.0411 & TRN \\
\hline CHEMBL1330507 & 688267 & 5.6 & 5.1437 & TRN \\
\hline CHEMBL1408788 & 688267 & 6.5 & 4.9563 & TST \\
\hline CHEMBL1591906 & 688267 & 4.6 & 5.0072 & TRN \\
\hline CHEMBL1443540 & 688267 & 4.05 & 5.1427 & TRN \\
\hline CHEMBL1501948 & 688267 & 4.05 & 5.0056 & TRN \\
\hline CHEMBL1530957 & 688267 & 4.2 & 5.0748 & TRN \\
\hline CHEMBL1465192 & 688267 & 4.05 & 5.1113 & TRN \\
\hline CHEMBL1551280 & 688267 & 3.95 & 5.0541 & TRN \\
\hline CHEMBL1600513 & 688267 & 5.6 & 5.0395 & TST \\
\hline CHEMBL521762 & 688267 & 5.45 & 5.0265 & TRN \\
\hline CHEMBL1409863 & 688267 & 4.3 & 5.0038 & TRN \\
\hline CHEMBL1609728 & 688267 & 5.05 & 5.0699 & TRN \\
\hline CHEMBL1574393 & 688267 & 5.1 & 5.0332 & TST \\
\hline CHEMBL1351233 & 688267 & 5.5 & 5.09 & TRN \\
\hline CHEMBL1486792 & 688267 & 4.4 & 5.0973 & TST \\
\hline CHEMBL1319657 & 688267 & 3.95 & 5.0167 & TST \\
\hline CHEMBL1450667 & 688267 & 5.1 & 5.1398 & TRN \\
\hline CHEMBL1556590 & 688267 & 5.6 & 5.0387 & TST \\
\hline CHEMBL1324399 & 688267 & 4.25 & 5.0734 & TST \\
\hline CHEMBL1549327 & 688267 & 6.2 & 5.0794 & TRN \\
\hline CHEMBL1360325 & 688267 & 5.6 & 5.0171 & TRN \\
\hline CHEMBL1424900 & 688267 & 4.85 & 5.1307 & TST \\
\hline CHEMBL1450979 & 688267 & 4.05 & 5.0426 & TST \\
\hline CHEMBL1497312 & 688267 & 6.15 & 5.0978 & TRN \\
\hline CHEMBL1320076 & 688267 & 4.3 & 5.0394 & TRN \\
\hline CHEMBL1510350 & 688267 & 5.4 & 5.1339 & TST \\
\hline CHEMBL1375402 & 688267 & 4.0 & 5.0693 & TST \\
\hline CHEMBL1425282 & 688267 & 4.5 & 5.0289 & TRN \\
\hline CHEMBL1514663 & 688267 & 4.1 & 5.0383 & TRN \\
\hline CHEMBL1413251 & 688267 & 5.55 & 5.0349 & TRN \\
\hline CHEMBL1545628 & 688267 & 4.0 & 5.0533 & TRN \\
\hline CHEMBL1408753 & 688267 & 5.35 & 5.0473 & TST \\
\hline CHEMBL1304470 & 688267 & 5.6 & 5.1254 & TRN \\
\hline CHEMBL1510133 & 688267 & 4.25 & 5.022 & TRN \\
\hline
\end{tabular}




\begin{tabular}{|c|c|c|c|c|c|}
\hline \\
\hline CHEMBL1444998 & 688267 & 4.6 & 5.0848 & TRN & \\
\hline CHEMBL1608323 & 688267 & 6.25 & 5.0112 & TRN & \\
\hline CHEMBL1420614 & 688267 & 5.0 & 5.0161 & TRN & \\
\hline CHEMBL1306648 & 688267 & 4.0 & 5.0737 & TST & \\
\hline CHEMBL1394838 & 688267 & 5.45 & 5.1079 & TRN & \\
\hline CHEMBL1472116 & 688267 & 6.2 & 5.046 & TRN & \\
\hline CHEMBL1312963 & 688267 & 6.2 & 5.0436 & TRN & \\
\hline CHEMBL1509012 & 688267 & 4.55 & 5.0257 & TRN & \\
\hline CHEMBL1364360 & 688267 & 6.2 & 5.09699 & 99999999995 & TRN \\
\hline CHEMBL1436287 & 688267 & 5.6 & 5.138 & TRN & \\
\hline CHEMBL1468009 & 688267 & 6.15 & 5.0688 & TRN & \\
\hline CHEMBL1516471 & 688267 & 4.3 & 5.1058 & TRN & \\
\hline CHEMBL1514944 & 688267 & 4.35 & 5.0828 & TRN & \\
\hline CHEMBL1422895 & 688267 & 5.05 & 5.0289 & TST & \\
\hline CHEMBL1506463 & 688267 & 6.5 & 5.0585 & TRN & \\
\hline CHEMBL1300053 & 688267 & 4.35 & 4.995 & TRN & \\
\hline CHEMBL1332878 & 688267 & 6.2 & 5.0454 & TST & \\
\hline CHEMBL1412449 & 688267 & 6.2 & 5.03 & TST & \\
\hline CHEMBL1393257 & 688267 & 5.45 & 5.0374 & TST & \\
\hline CHEMBL1473014 & 688267 & 5.35 & 4.9979 & TRN & \\
\hline CHEMBL1478972 & 688267 & 4.05 & 5.0583 & TRN & \\
\hline CHEMBL1476843 & 688267 & 4.05 & 5.0236 & TRN & \\
\hline CHEMBL1596930 & 688267 & 3.95 & 5.0237 & TRN & \\
\hline CHEMBL1591809 & 688267 & 5.55 & 5.0527 & TRN & \\
\hline CHEMBL1554043 & 688267 & 4.65 & 5.0306 & TRN & \\
\hline CHEMBL1525618 & 688267 & 4.4 & 5.0168 & TRN & \\
\hline CHEMBL1998863 & 688267 & 4.35 & 5.0199 & TRN & \\
\hline CHEMBL1569486 & 688267 & 4.5 & 5.0231 & TRN & \\
\hline CHEMBL1555095 & 688267 & 5.6 & 5.0672 & TST & \\
\hline CHEMBL1416817 & 688267 & 4.0 & 5.1249 & TST & \\
\hline CHEMBL1351196 & 688267 & 5.9 & 5.0751 & TRN & \\
\hline CHEMBL1518045 & 688267 & 6.15 & 5.1702 & TST & \\
\hline CHEMBL1405732 & 688267 & 4.05 & 5.0748 & TRN & \\
\hline CHEMBL1444751 & 688267 & 4.3 & 5.0167 & TST & \\
\hline CHEMBL1593795 & 688267 & 4.05 & 5.0373 & TRN & \\
\hline CHEMBL1391483 & 688267 & 5.95 & 5.0374 & TRN & \\
\hline CHEMBL1398998 & 688267 & 6.2 & 5.0703 & TRN & \\
\hline CHEMBL1585610 & 688267 & 4.65 & 5.0739 & TRN & \\
\hline CHEMBL1374049 & 688267 & 4.15 & 5.0181 & TST & \\
\hline CHEMBL1408340 & 688267 & 4.1 & 5.1307 & TRN & \\
\hline CHEMBL1370710 & 688267 & 4.0 & 5.0413 & TST & \\
\hline CHEMBL1444913 & 688267 & 5.85 & 5.0519 & TRN & \\
\hline CHEMBL1597871 & 688267 & 5.15 & 5.0406 & TRN & \\
\hline CHEMBL1489218 & 688267 & 4.45 & 5.0303 & TST & \\
\hline CHEMBL1312645 & 688267 & 5.5 & 5.033 & TRN & \\
\hline CHEMBL3196522 & 688267 & 4.5 & 5.0031 & TRN & \\
\hline CHEMBL1509063 & 688267 & 5.35 & 5.0636 & TRN & \\
\hline CHEMBL1460920 & 688267 & 4.05 & 4.9956 & TRN & \\
\hline
\end{tabular}




\begin{tabular}{|c|c|c|c|c|c|}
\hline \multicolumn{6}{|c|}{ Supplemental Table S2.txt } \\
\hline CHEMBL1583276 & 688267 & 4.45 & 5.0207 & TRN & \\
\hline CHEMBL1484794 & 688267 & 4.6 & 5.0449 & TRN & \\
\hline CHEMBL 2374021 & 688267 & 5.3 & 5.0463 & TRN & \\
\hline CHEMBL1436051 & 688267 & 5.8 & 5.061 & TRN & \\
\hline CHEMBL1576429 & 688267 & 5.9 & 5.0804 & TRN & \\
\hline CHEMBL1432818 & 688267 & 6.2 & 5.0257 & TRN & \\
\hline CHEMBL1529740 & 688267 & 4.65 & 5.1333 & TRN & \\
\hline CHEMBL1429476 & 688267 & 4.8 & 5.0267 & TST & \\
\hline CHEMBL1517746 & 688267 & 4.25 & 5.0423 & TRN & \\
\hline CHEMBL1389880 & 688267 & 4.75 & 4.9958 & TRN & \\
\hline CHEMBL3207501 & 688267 & 5.6 & 5.0847 & TRN & \\
\hline CHEMBL1477527 & 688267 & 5.8 & 5.0421 & TRN & \\
\hline CHEMBL1539392 & 688267 & 6.2 & 5.12 & TST & \\
\hline CHEMBL1360741 & 688267 & 4.3 & 5.0499 & TRN & \\
\hline CHEMBL1484099 & 688267 & 5.55 & 5.0456 & TST & \\
\hline CHEMBL1484750 & 688267 & 4.1 & 5.0145 & TRN & \\
\hline CHEMBL1410361 & 688267 & 4.0 & 5.0742 & TRN & \\
\hline CHEMBL1384002 & 688267 & 5.2 & 5.0699 & TST & \\
\hline CHEMBL1429083 & 688267 & 4.05 & 4.9936 & TRN & \\
\hline CHEMBL1396191 & 688267 & 6.2 & 5.0721 & TRN & \\
\hline CHEMBL1502005 & 688267 & 5.85 & 5.1191 & TRN & \\
\hline CHEMBL1438196 & 688267 & 5.55 & 5.0281 & TST & \\
\hline CHEMBL1425714 & 688267 & 4.0 & 5.1103 & TST & \\
\hline CHEMBL1355898 & 688267 & 4.0 & 4.9849 & TRN & \\
\hline CHEMBL1317238 & 688267 & 5.45 & 5.0384 & TRN & \\
\hline CHEMBL1538400 & 688267 & 6.2 & 5.0712 & TRN & \\
\hline CHEMBL1416219 & 688267 & 5.85 & 5.0538 & TST & \\
\hline CHEMBL1584718 & 688267 & 5.2 & 5.0271 & TRN & \\
\hline CHEMBL1397072 & 688267 & 4.65 & 5.1071 & TRN & \\
\hline CHEMBL1338304 & 688267 & 5.0 & 5.1317 & TRN & \\
\hline CHEMBL1307467 & 688267 & 5.25 & 4.9507 & TRN & \\
\hline CHEMBL1387516 & 688267 & 4.5 & 5.0552 & TRN & \\
\hline CHEMBL1486814 & 688267 & 5.15 & 5.1037 & TRN & \\
\hline CHEMBL1339134 & 688267 & 5.8 & 5.08899 & 99999999995 & TRN \\
\hline CHEMBL1474059 & 688267 & 6.2 & 4.9411 & TRN & \\
\hline CHEMBL1458738 & 688267 & 4.25 & 5.1061 & TST & \\
\hline CHEMBL1464584 & 688267 & 6.15 & 5.0549 & TST & \\
\hline CHEMBL1447447 & 688267 & 4.05 & 5.0201 & TRN & \\
\hline CHEMBL1376455 & 688267 & 4.0 & 5.0275 & TRN & \\
\hline CHEMBL1545433 & 688267 & 5.35 & 5.059 & TRN & \\
\hline CHEMBL1303243 & 688267 & 4.3 & 5.0249 & TST & \\
\hline CHEMBL1560326 & 688267 & 6.2 & 5.0228 & TRN & \\
\hline CHEMBL1604455 & 688267 & 5.3 & 5.0486 & TRN & \\
\hline CHEMBL1608563 & 688267 & 4.05 & 5.0433 & TRN & \\
\hline CHEMBL1527285 & 688267 & 4.85 & 5.0092 & TRN & \\
\hline CHEMBL1323516 & 688267 & 5.45 & 4.985 & TRN & \\
\hline CHEMBL3195375 & 688267 & 4.05 & 4.9808 & TRN & \\
\hline CHEMBL1425887 & 688267 & 6.5 & 5.0337 & TRN & \\
\hline
\end{tabular}




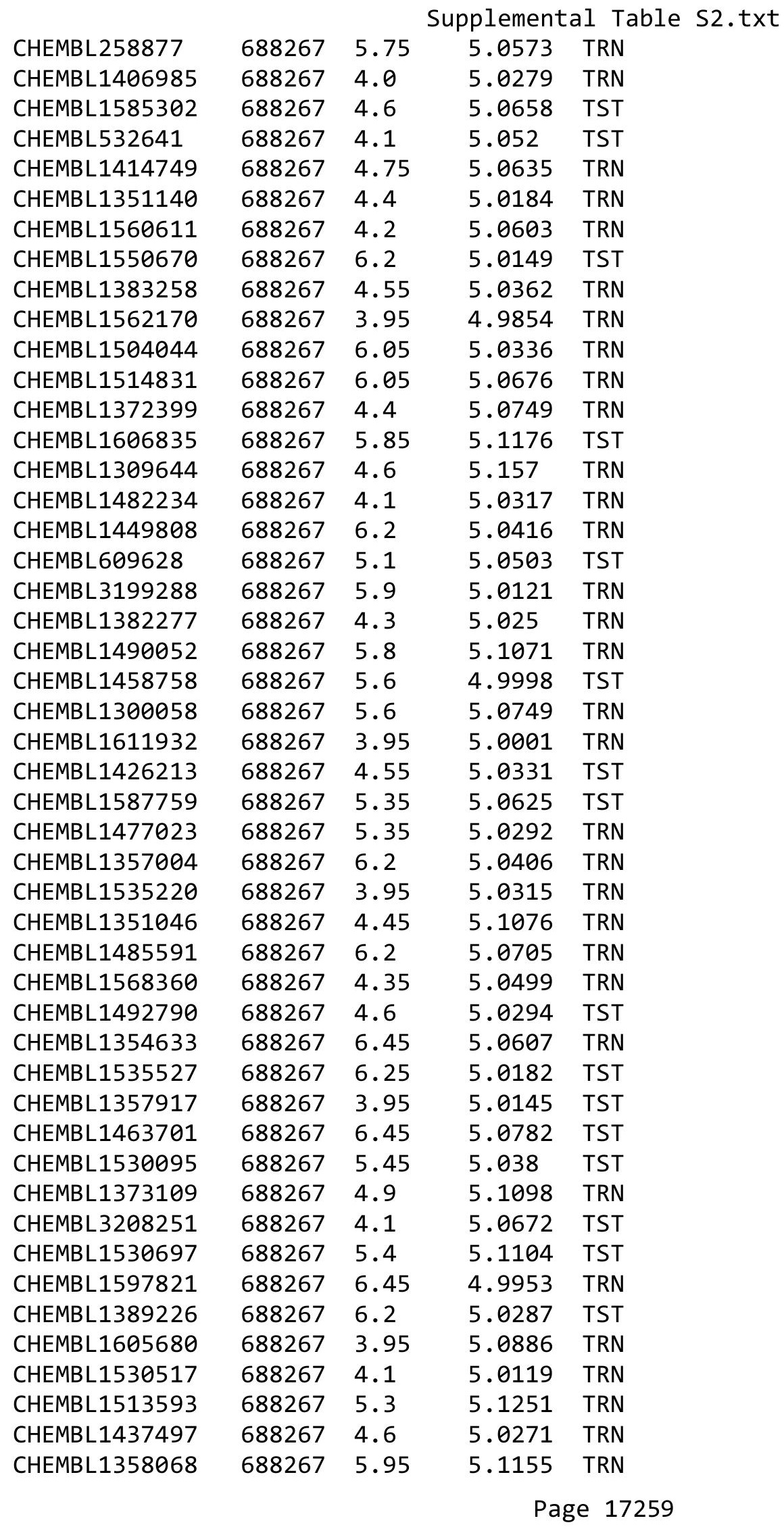




\begin{tabular}{|c|c|c|c|c|c|}
\hline \multicolumn{6}{|c|}{ Supplemental Table S2.txt } \\
\hline CHEMBL1444139 & 688267 & 4.6 & 5.0501 & TRN & \\
\hline CHEMBL1418493 & 688267 & 4.0 & 4.9895 & TRN & \\
\hline CHEMBL1487906 & 688267 & 5.45 & 4.984 & TRN & \\
\hline CHEMBL1499180 & 688267 & 5.3 & 5.0779 & TRN & \\
\hline CHEMBL1479047 & 688267 & 5.45 & 5.0101 & TRN & \\
\hline CHEMBL1589227 & 688267 & 4.6 & 5.0253 & TST & \\
\hline CHEMBL1469665 & 688267 & 4.6 & 5.0329 & TST & \\
\hline CHEMBL1547875 & 688267 & 4.45 & 5.0725 & TRN & \\
\hline CHEMBL1472698 & 688267 & 5.65 & 5.033 & TRN & \\
\hline CHEMBL1434940 & 688267 & 5.6 & 5.0901 & TRN & \\
\hline CHEMBL1484590 & 688267 & 5.3 & 5.1056 & TRN & \\
\hline CHEMBL1560793 & 688267 & 4.7 & 5.0314 & TRN & \\
\hline CHEMBL1377458 & 688267 & 6.45 & 5.0934 & TRN & \\
\hline CHEMBL1325476 & 688267 & 6.1 & 5.0239 & TRN & \\
\hline CHEMBL1509650 & 688267 & 6.2 & 5.0509 & TST & \\
\hline CHEMBL1471361 & 688267 & 4.7 & 4.9953 & TRN & \\
\hline CHEMBL1505623 & 688267 & 5.05 & 5.0293 & TRN & \\
\hline CHEMBL1575587 & 688267 & 4.0 & 5.0687 & TRN & \\
\hline CHEMBL1501986 & 688267 & 6.2 & 5.0531 & TRN & \\
\hline CHEMBL3196699 & 688267 & 4.4 & 4.9532 & TRN & \\
\hline CHEMBL1608588 & 688267 & 4.55 & 5.0405 & TST & \\
\hline CHEMBL1572625 & 688267 & 5.45 & 5.1251 & TRN & \\
\hline CHEMBL1593346 & 688267 & 4.45 & 5.0075 & TRN & \\
\hline CHEMBL1582679 & 688267 & 4.65 & 5.0224 & TRN & \\
\hline CHEMBL1462909 & 688267 & 6.2 & 5.1478 & TRN & \\
\hline CHEMBL1561554 & 688267 & 5.4 & 5.0761 & TST & \\
\hline CHEMBL1351129 & 688267 & 4.8 & 5.0292 & TRN & \\
\hline CHEMBL1450433 & 688267 & 4.3 & 5.1264 & TRN & \\
\hline CHEMBL1568240 & 688267 & 5.3 & 5.1018 & TRN & \\
\hline CHEMBL1339566 & 688267 & 4.35 & 5.03100 & 0000000001 & TRN \\
\hline CHEMBL1566345 & 688267 & 4.1 & 5.0322 & TRN & \\
\hline CHEMBL1310865 & 688267 & 4.05 & 5.0875 & TRN & \\
\hline CHEMBL1414218 & 688267 & 5.75 & 5.1403 & TRN & \\
\hline CHEMBL1400693 & 688267 & 4.4 & 5.1142 & TRN & \\
\hline CHEMBL1382856 & 688267 & 4.95 & 5.0587 & TRN & \\
\hline CHEMBL1416137 & 688267 & 4.55 & 5.0767 & TST & \\
\hline CHEMBL1525937 & 688267 & 4.65 & 5.0905 & TRN & \\
\hline CHEMBL1387112 & 688267 & 4.4 & 5.0634 & TRN & \\
\hline CHEMBL1388486 & 688267 & 4.45 & 5.1052 & TST & \\
\hline CHEMBL1483972 & 688267 & 5.2 & 5.0447 & TRN & \\
\hline CHEMBL1389692 & 688267 & 4.5 & 5.032 & TRN & \\
\hline CHEMBL1550032 & 688267 & 4.1 & 5.0177 & TRN & \\
\hline CHEMBL1401344 & 688267 & 5.25 & 5.0215 & TRN & \\
\hline CHEMBL 3213713 & 688267 & 4.3 & 4.9964 & TRN & \\
\hline CHEMBL1343199 & 688267 & 6.2 & 5.0627 & TST & \\
\hline CHEMBL1564998 & 688267 & 4.75 & 5.0651 & TST & \\
\hline CHEMBL1461859 & 688267 & 6.5 & 5.0563 & TRN & \\
\hline CHEMBL1412013 & 688267 & 6.1 & 5.0147 & TRN & \\
\hline
\end{tabular}




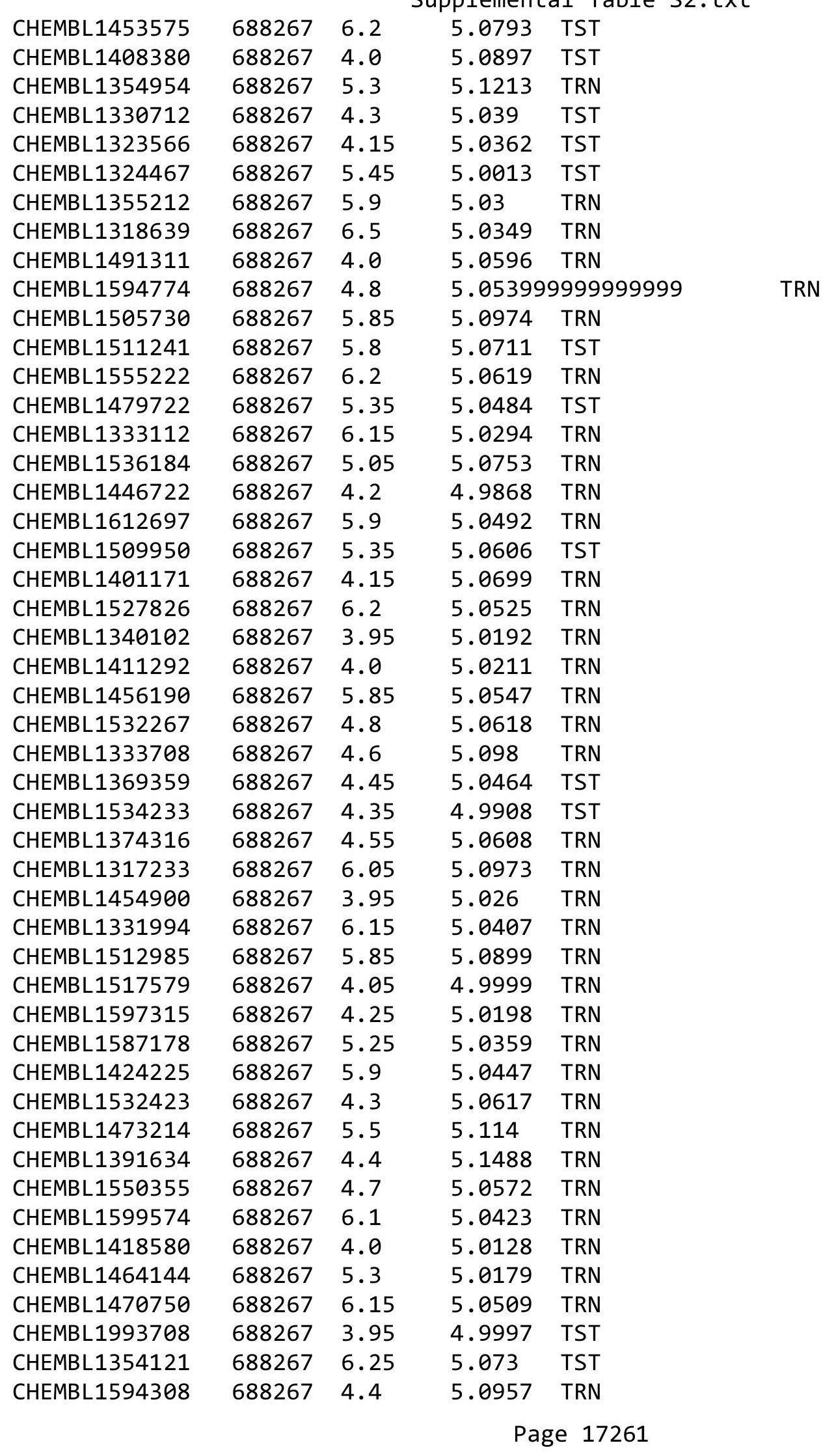




\begin{tabular}{|c|c|c|c|c|c|}
\hline \multicolumn{6}{|c|}{ Supplemental Table S2.txt } \\
\hline CHEMBL1384652 & 688267 & 5.75 & 5.0535 & TRN & \\
\hline CHEMBL1512464 & 688267 & 6.2 & 5.1101 & TRN & \\
\hline CHEMBL1577571 & 688267 & 5.25 & 5.0064 & TRN & \\
\hline CHEMBL1449870 & 688267 & 6.2 & 5.087 & TRN & \\
\hline CHEMBL1491387 & 688267 & 4.3 & 5.0327 & TRN & \\
\hline CHEMBL1415589 & 688267 & 4.05 & 5.0661 & TRN & \\
\hline CHEMBL1495479 & 688267 & 6.25 & 5.1094 & TRN & \\
\hline CHEMBL1314441 & 688267 & 6.2 & 5.0516 & TRN & \\
\hline CHEMBL1528981 & 688267 & 5.1 & 5.13299 & 9999999999 & TST \\
\hline CHEMBL1605281 & 688267 & 4.4 & 5.0677 & TST & \\
\hline CHEMBL3208433 & 688267 & 5.15 & 5.0049 & TRN & \\
\hline CHEMBL1596260 & 688267 & 4.2 & 5.0119 & TRN & \\
\hline CHEMBL1302526 & 688267 & 5.85 & 5.1705 & TRN & \\
\hline CHEMBL1394692 & 688267 & 3.95 & 5.0214 & TRN & \\
\hline CHEMBL3197514 & 688267 & 4.8 & 5.0202 & TST & \\
\hline CHEMBL1308968 & 688267 & 4.0 & 5.0248 & TRN & \\
\hline CHEMBL1494058 & 688267 & 4.35 & 5.0139 & TST & \\
\hline CHEMBL3193346 & 688267 & 5.95 & 5.0265 & TST & \\
\hline CHEMBL1361047 & 688267 & 5.55 & 5.0341 & TRN & \\
\hline CHEMBL1451120 & 688267 & 4.6 & 5.0874 & TRN & \\
\hline CHEMBL1604892 & 688267 & 4.3 & 5.1057 & TST & \\
\hline CHEMBL1333502 & 688267 & 4.55 & 5.0276 & TRN & \\
\hline CHEMBL1464509 & 688267 & 4.3 & 5.0085 & TST & \\
\hline CHEMBL1447329 & 688267 & 5.2 & 5.0635 & TST & \\
\hline CHEMBL1302242 & 688267 & 5.15 & 5.0506 & TST & \\
\hline CHEMBL1528707 & 688267 & 4.7 & 5.0105 & TST & \\
\hline CHEMBL1360910 & 688267 & 5.6 & 5.0762 & TRN & \\
\hline CHEMBL580955 & 688267 & 6.2 & 5.0624 & TRN & \\
\hline CHEMBL1491258 & 688267 & 5.3 & 5.0638 & TST & \\
\hline CHEMBL1398982 & 688267 & 5.4 & 5.0309 & TRN & \\
\hline CHEMBL1407532 & 688267 & 3.95 & 5.1732 & TRN & \\
\hline CHEMBL1386722 & 688267 & 4.3 & 5.0606 & TRN & \\
\hline CHEMBL3191213 & 688267 & 4.0 & 5.0323 & TRN & \\
\hline CHEMBL1374897 & 688267 & 4.65 & 5.0293 & TRN & \\
\hline CHEMBL1430837 & 688267 & 5.35 & 5.1359 & TRN & \\
\hline CHEMBL1481887 & 688267 & 5.45 & 5.1138 & TRN & \\
\hline CHEMBL1421003 & 688267 & 4.05 & 5.1374 & TRN & \\
\hline CHEMBL1558545 & 688267 & 5.1 & 5.0489 & TST & \\
\hline CHEMBL3208876 & 688267 & 4.05 & 4.9861 & TRN & \\
\hline CHEMBL1363194 & 688267 & 4.05 & 5.0795 & TRN & \\
\hline CHEMBL1517818 & 688267 & 4.9 & 5.1284 & TRN & \\
\hline CHEMBL1490687 & 688267 & 5.45 & 5.0704 & TST & \\
\hline CHEMBL1486761 & 688267 & 6.1 & 5.1047 & TRN & \\
\hline CHEMBL1549044 & 688267 & 4.3 & 5.0759 & TST & \\
\hline CHEMBL1333313 & 688267 & 5.1 & 5.0884 & TRN & \\
\hline CHEMBL1354787 & 688267 & 4.3 & 5.096 & TRN & \\
\hline CHEMBL1330498 & 688267 & 5.95 & 5.0672 & TRN & \\
\hline CHEMBL1527211 & 688267 & 5.8 & 5.1209 & TRN & \\
\hline
\end{tabular}




\begin{tabular}{|c|c|c|c|c|}
\hline \multicolumn{5}{|c|}{ Supplemental Tabl } \\
\hline CHEMBL1414433 & 688267 & 6.15 & 5.0389 & TRN \\
\hline CHEMBL1540737 & 688267 & 5.0 & 5.1064 & TRN \\
\hline CHEMBL1410494 & 688267 & 5.35 & 5.027 & TRN \\
\hline CHEMBL1377679 & 688267 & 4.6 & 5.052 & TRN \\
\hline CHEMBL1475726 & 688267 & 4.4 & 4.9755 & TRN \\
\hline CHEMBL3211904 & 688267 & 5.55 & 5.0434 & TRN \\
\hline CHEMBL1528982 & 688267 & 6.25 & 5.1052 & TST \\
\hline CHEMBL1525551 & 688267 & 4.45 & 5.0497 & TST \\
\hline CHEMBL1413520 & 688267 & 4.4 & 5.0091 & TRN \\
\hline CHEMBL1364483 & 688267 & 6.2 & 5.0485 & TRN \\
\hline CHEMBL1493648 & 688267 & 6.15 & 5.0695 & TST \\
\hline CHEMBL1497588 & 688267 & 4.35 & 5.0613 & TST \\
\hline CHEMBL592561 & 688267 & 5.7 & 5.0346 & TST \\
\hline CHEMBL1514700 & 688267 & 6.2 & 5.0948 & TRN \\
\hline CHEMBL1529863 & 688267 & 4.1 & 5.0703 & TST \\
\hline CHEMBL1162110 & 688267 & 3.95 & 5.0003 & TRN \\
\hline CHEMBL3208086 & 688267 & 5.25 & 5.0436 & TST \\
\hline CHEMBL1572702 & 688267 & 6.25 & 5.0591 & TRN \\
\hline CHEMBL1376591 & 688267 & 5.1 & 5.0632 & TRN \\
\hline CHEMBL1486291 & 688267 & 5.45 & 5.0578 & TST \\
\hline CHEMBL1453990 & 688267 & 3.95 & 4.9715 & TRN \\
\hline CHEMBL1512805 & 688267 & 6.2 & 5.0383 & TRN \\
\hline CHEMBL1393348 & 688267 & 5.05 & 5.0271 & TRN \\
\hline CHEMBL1419887 & 688267 & 4.35 & 5.0698 & TRN \\
\hline CHEMBL1426989 & 688267 & 5.6 & 5.0668 & TRN \\
\hline CHEMBL1443833 & 688267 & 6.2 & 5.0868 & TRN \\
\hline CHEMBL1520648 & 688267 & 4.35 & 5.0596 & TRN \\
\hline CHEMBL1311238 & 688267 & 6.15 & 5.0204 & TST \\
\hline CHEMBL1381746 & 688267 & 5.65 & 5.1082 & TRN \\
\hline CHEMBL1548934 & 688267 & 5.9 & 5.1274 & TRN \\
\hline CHEMBL1436651 & 688267 & 5.5 & 4.9837 & TRN \\
\hline CHEMBL1508229 & 688267 & 4.0 & 5.0376 & TST \\
\hline CHEMBL1419222 & 688267 & 4.05 & 5.0764 & TST \\
\hline CHEMBL1303185 & 688267 & 4.0 & 5.0581 & TRN \\
\hline CHEMBL1567064 & 688267 & 6.2 & 4.9959 & TST \\
\hline CHEMBL1320539 & 688267 & 4.0 & 5.0599 & TRN \\
\hline CHEMBL1396509 & 688267 & 5.3 & 5.0327 & TRN \\
\hline CHEMBL1521891 & 688267 & 4.35 & 5.0925 & TRN \\
\hline CHEMBL1584720 & 688267 & 5.3 & 5.0398 & TRN \\
\hline CHEMBL1435974 & 688267 & 5.75 & 5.0742 & TST \\
\hline CHEMBL1591509 & 688267 & 4.65 & 5.1096 & TRN \\
\hline CHEMBL1441886 & 688267 & 4.0 & 5.0281 & TRN \\
\hline CHEMBL1336313 & 688267 & 5.3 & 5.0984 & TRN \\
\hline CHEMBL 273103 & 688267 & 5.1 & 4.9883 & TRN \\
\hline CHEMBL1347968 & 688267 & 5.55 & 5.0669 & TRN \\
\hline CHEMBL1359632 & 688267 & 4.3 & 5.1011 & TRN \\
\hline CHEMBL1405220 & 688267 & 4.05 & 5.0132 & TST \\
\hline CHEMBL1577742 & 688267 & 5.35 & 5.0611 & TRN \\
\hline
\end{tabular}




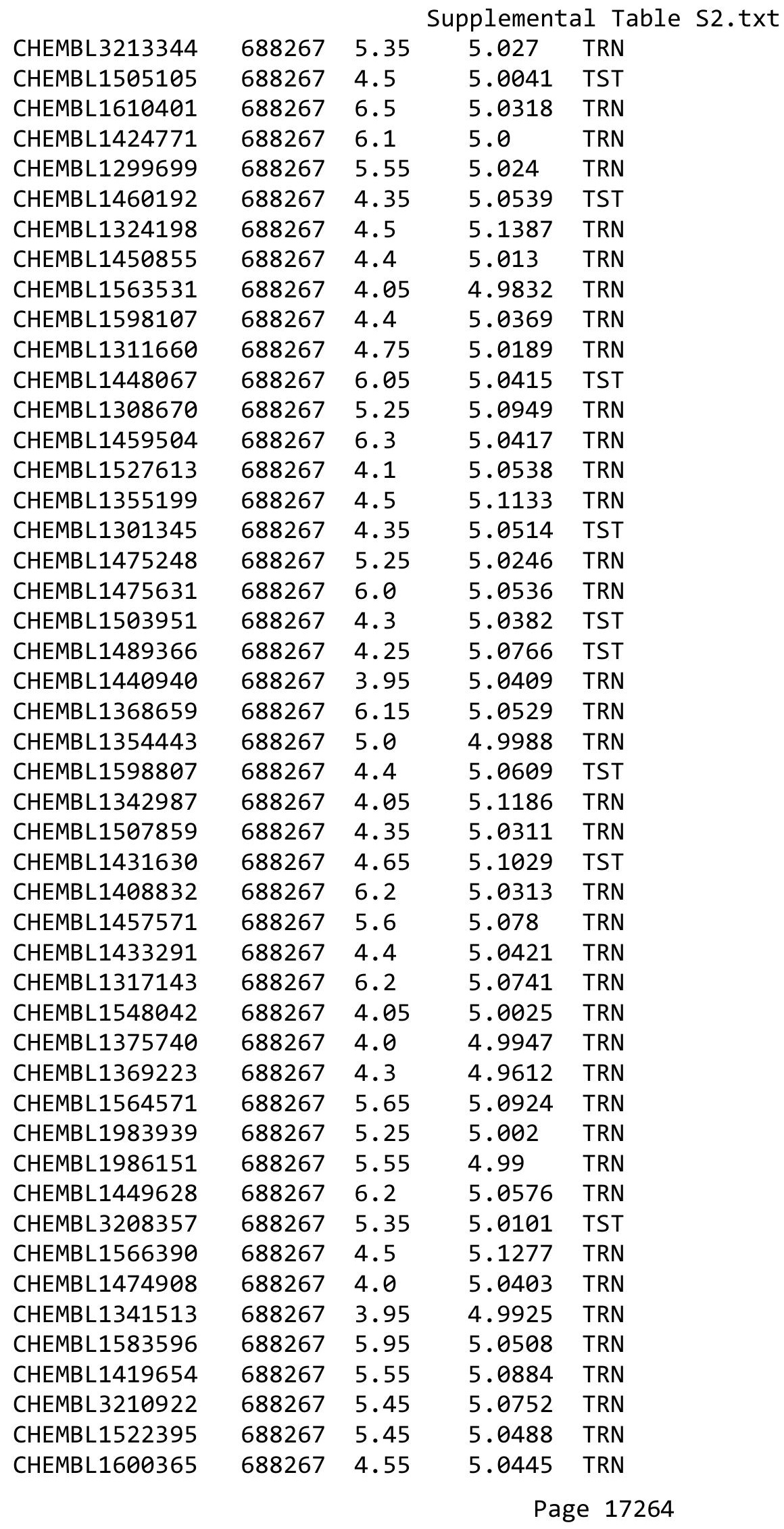




\begin{tabular}{|c|c|c|c|c|c|}
\hline \\
\hline CHEMBL1426534 & 688267 & 5.9 & 5.0661 & TRN & \\
\hline CHEMBL1487158 & 688267 & 6.15 & 5.0311 & TST & \\
\hline CHEMBL1602802 & 688267 & 6.2 & 5.0586 & TST & \\
\hline CHEMBL1398524 & 688267 & 6.2 & 5.1168 & TRN & \\
\hline CHEMBL1314330 & 688267 & 4.35 & 5.0269 & TRN & \\
\hline CHEMBL1597327 & 688267 & 5.25 & 5.0188 & TRN & \\
\hline CHEMBL1409728 & 688267 & 5.0 & 5.0198 & TRN & \\
\hline CHEMBL1419103 & 688267 & 4.05 & 5.0228 & TST & \\
\hline CHEMBL1341352 & 688267 & 4.35 & 5.0304 & TRN & \\
\hline CHEMBL1313291 & 688267 & 4.0 & 5.0381 & TRN & \\
\hline CHEMBL1306223 & 688267 & 5.9 & 5.0132 & TRN & \\
\hline CHEMBL1329790 & 688267 & 5.25 & 5.0448 & TST & \\
\hline CHEMBL1450097 & 688267 & 5.75 & 5.0336 & TRN & \\
\hline CHEMBL1408449 & 688267 & 3.95 & 5.0842 & TRN & \\
\hline CHEMBL1430688 & 688267 & 5.05 & 5.0561 & TRN & \\
\hline CHEMBL1353828 & 688267 & 5.3 & 5.0844 & TRN & \\
\hline CHEMBL1339258 & 688267 & 4.3 & 5.0927 & TST & \\
\hline CHEMBL1583174 & 688267 & 5.5 & 5.0735 & TST & \\
\hline CHEMBL1551322 & 688267 & 4.85 & 5.04899 & 99999999995 & TRN \\
\hline CHEMBL1516051 & 688267 & 5.95 & 5.0067 & TRN & \\
\hline CHEMBL1509685 & 688267 & 6.15 & 5.0766 & TRN & \\
\hline CHEMBL1599405 & 688267 & 6.1 & 5.0912 & TRN & \\
\hline CHEMBL1417490 & 688267 & 4.65 & 5.0685 & TST & \\
\hline CHEMBL1511087 & 688267 & 4.3 & 5.0655 & TRN & \\
\hline CHEMBL1527855 & 688267 & 4.0 & 5.1307 & TRN & \\
\hline CHEMBL1325688 & 688267 & 6.25 & 5.1444 & TRN & \\
\hline CHEMBL1316617 & 688267 & 6.2 & 5.1357 & TRN & \\
\hline CHEMBL1575907 & 688267 & 6.2 & 5.0942 & TRN & \\
\hline CHEMBL1349663 & 688267 & 4.05 & 5.0265 & TRN & \\
\hline CHEMBL1528625 & 688267 & 4.2 & 5.0702 & TRN & \\
\hline CHEMBL1570344 & 688267 & 3.95 & 5.0351 & TRN & \\
\hline CHEMBL1418181 & 688267 & 6.1 & 5.0489 & TRN & \\
\hline CHEMBL1601002 & 688267 & 6.15 & 5.0032 & TST & \\
\hline CHEMBL1468589 & 688267 & 4.0 & 5.0716 & TST & \\
\hline CHEMBL1392737 & 688267 & 6.25 & 5.0171 & TRN & \\
\hline CHEMBL1586270 & 688267 & 4.35 & 4.999 & TRN & \\
\hline CHEMBL1378586 & 688267 & 4.4 & 5.13299 & 9999999999 & TRN \\
\hline CHEMBL1301366 & 688267 & 4.4 & 5.0185 & TRN & \\
\hline CHEMBL1970600 & 688267 & 5.85 & 4.9953 & TRN & \\
\hline CHEMBL1485834 & 688267 & 5.0 & 5.0236 & TST & \\
\hline CHEMBL1473951 & 688267 & 4.0 & 5.098 & TRN & \\
\hline CHEMBL1600203 & 688267 & 4.95 & 5.0459 & TRN & \\
\hline CHEMBL1309915 & 688267 & 4.55 & 5.1119 & TST & \\
\hline CHEMBL1605536 & 688267 & 6.2 & 5.1142 & TRN & \\
\hline CHEMBL1306082 & 688267 & 5.5 & 5.0576 & TRN & \\
\hline CHEMBL1378127 & 688267 & 5.25 & 5.0723 & TRN & \\
\hline CHEMBL1316202 & 688267 & 4.15 & 5.0877 & TRN & \\
\hline CHEMBL1221957 & 688267 & 6.2 & 5.1197 & TRN & \\
\hline
\end{tabular}




\begin{tabular}{|c|c|c|c|c|c|}
\hline \\
\hline CHEMBL1396779 & 688267 & 6.5 & 5.1287 & TRN & \\
\hline CHEMBL1515550 & 688267 & 6.2 & 5.0024 & TRN & \\
\hline CHEMBL1353167 & 688267 & 4.3 & 5.0224 & TST & \\
\hline CHEMBL1566426 & 688267 & 6.0 & 5.0381 & TRN & \\
\hline CHEMBL1435785 & 688267 & 4.35 & 5.0861 & TRN & \\
\hline CHEMBL1330346 & 688267 & 6.25 & 4.9689 & TRN & \\
\hline CHEMBL1541037 & 688267 & 4.0 & 4.9915 & TRN & \\
\hline CHEMBL1532710 & 688267 & 3.4 & 5.1517 & TRN & \\
\hline CHEMBL1403649 & 688267 & 6.2 & 5.1194 & TRN & \\
\hline CHEMBL1510633 & 688267 & 5.4 & 4.9734 & TRN & \\
\hline CHEMBL1318819 & 688267 & 5.05 & 5.0942 & TST & \\
\hline CHEMBL1472290 & 688267 & 4.05 & 5.0277 & TRN & \\
\hline CHEMBL1393203 & 688267 & 5.0 & 5.0398 & TRN & \\
\hline CHEMBL1534088 & 688267 & 5.0 & 5.0754 & TRN & \\
\hline CHEMBL1256971 & 688267 & 5.05 & 5.0938 & TST & \\
\hline CHEMBL1465153 & 688267 & 4.7 & 5.05699 & 99999999995 & TRN \\
\hline CHEMBL1492659 & 688267 & 5.2 & 5.0943 & TRN & \\
\hline CHEMBL1595412 & 688267 & 4.55 & 4.9736 & TRN & \\
\hline CHEMBL1358186 & 688267 & 4.05 & 5.0373 & TRN & \\
\hline CHEMBL1559473 & 688267 & 6.45 & 5.05 & TRN & \\
\hline CHEMBL1501737 & 688267 & 4.3 & 5.0618 & TRN & \\
\hline CHEMBL1468806 & 688267 & 6.2 & 5.0783 & TRN & \\
\hline CHEMBL1578318 & 688267 & 4.05 & 5.1513 & TRN & \\
\hline CHEMBL3194965 & 688267 & 4.3 & 5.0747 & TRN & \\
\hline CHEMBL1305334 & 688267 & 5.35 & 5.1176 & TRN & \\
\hline CHEMBL1340186 & 688267 & 5.45 & 5.0191 & TRN & \\
\hline CHEMBL 282489 & 688267 & 5.35 & 5.0828 & TST & \\
\hline CHEMBL1316797 & 688267 & 5.3 & 5.0714 & TST & \\
\hline CHEMBL1456103 & 688267 & 4.3 & 5.0037 & TRN & \\
\hline CHEMBL1607783 & 688267 & 6.25 & 5.0412 & TRN & \\
\hline CHEMBL1370415 & 688267 & 5.35 & 5.0744 & TST & \\
\hline CHEMBL1364764 & 688267 & 6.25 & 5.0631 & TRN & \\
\hline CHEMBL1452007 & 688267 & 5.6 & 4.9711 & TRN & \\
\hline CHEMBL1348324 & 688267 & 6.2 & 4.9969 & TRN & \\
\hline CHEMBL1567125 & 688267 & 4.4 & 5.0904 & TRN & \\
\hline CHEMBL1740862 & 688267 & 6.2 & 5.0968 & TRN & \\
\hline CHEMBL1589916 & 688267 & 4.05 & 5.0326 & TRN & \\
\hline CHEMBL1340634 & 688267 & 5.6 & 5.0577 & TRN & \\
\hline CHEMBL1543614 & 688267 & 4.55 & 4.9986 & TRN & \\
\hline CHEMBL1409738 & 688267 & 4.9 & 5.086 & TST & \\
\hline CHEMBL1450154 & 688267 & 5.35 & 5.0556 & TST & \\
\hline CHEMBL1481687 & 688267 & 4.3 & 5.1393 & TRN & \\
\hline CHEMBL1543430 & 688267 & 4.4 & 5.0497 & TST & \\
\hline CHEMBL1498610 & 688267 & 4.95 & 5.0669 & TRN & \\
\hline CHEMBL1361450 & 688267 & 4.65 & 5.0796 & TRN & \\
\hline CHEMBL1328888 & 688267 & 6.5 & 5.0544 & TST & \\
\hline CHEMBL1527625 & 688267 & 4.0 & 5.1002 & TRN & \\
\hline CHEMBL1398215 & 688267 & 5.55 & 5.0886 & TRN & \\
\hline
\end{tabular}




\begin{tabular}{|c|c|c|c|c|}
\hline & & & pplement & $\mathrm{d} \perp$ \\
\hline CHEMBL1346627 & 688267 & 5.3 & 5.0869 & TST \\
\hline CHEMBL1319877 & 688267 & 3.95 & 5.0998 & TRN \\
\hline CHEMBL1420687 & 688267 & 5.3 & 5.0664 & TRN \\
\hline CHEMBL1564036 & 688267 & 4.6 & 5.0124 & TRN \\
\hline CHEMBL1473352 & 688267 & 4.6 & 5.0719 & TRN \\
\hline CHEMBL1345369 & 688267 & 4.9 & 5.0672 & TST \\
\hline CHEMBL1369564 & 688267 & 5.45 & 5.0845 & TRN \\
\hline CHEMBL1355315 & 688267 & 6.2 & 5.1616 & TRN \\
\hline CHEMBL1399639 & 688267 & 5.55 & 5.0604 & TRN \\
\hline CHEMBL1331780 & 688267 & 4.35 & 4.9888 & TRN \\
\hline CHEMBL1357301 & 688267 & 4.0 & 5.0321 & TRN \\
\hline CHEMBL1566002 & 688267 & 4.8 & 5.027 & TST \\
\hline CHEMBL1413052 & 688267 & 6.25 & 5.0725 & TRN \\
\hline CHEMBL1486310 & 688267 & 5.55 & 5.0023 & TRN \\
\hline CHEMBL1462947 & 688267 & 4.0 & 5.0632 & TRN \\
\hline CHEMBL1482523 & 688267 & 4.0 & 4.9998 & TRN \\
\hline CHEMBL1556564 & 688267 & 4.5 & 5.0486 & TST \\
\hline CHEMBL1396303 & 688267 & 4.2 & 5.0453 & TRN \\
\hline CHEMBL1519329 & 688267 & 5.45 & 5.0867 & TRN \\
\hline CHEMBL1582036 & 688267 & 4.8 & 5.0813 & TRN \\
\hline CHEMBL1371026 & 688267 & 5.65 & 5.0522 & TRN \\
\hline CHEMBL1425462 & 688267 & 5.25 & 5.0491 & TRN \\
\hline CHEMBL1518974 & 688267 & 5.3 & 5.0457 & TRN \\
\hline CHEMBL1555083 & 688267 & 6.05 & 5.1346 & TRN \\
\hline CHEMBL1602733 & 688267 & 4.0 & 4.9833 & TRN \\
\hline CHEMBL1423407 & 688267 & 6.2 & 4.989 & TRN \\
\hline CHEMBL1554483 & 688267 & 5.0 & 5.0617 & TRN \\
\hline CHEMBL1565246 & 688267 & 5.65 & 5.1265 & TRN \\
\hline CHEMBL1243269 & 688267 & 5.0 & 5.0995 & TST \\
\hline CHEMBL1561971 & 688267 & 5.4 & 5.0361 & TST \\
\hline CHEMBL1331865 & 688267 & 5.05 & 5.0081 & TST \\
\hline CHEMBL1314899 & 688267 & 6.15 & 5.047 & TRN \\
\hline CHEMBL1431409 & 688267 & 5.7 & 5.0665 & TRN \\
\hline CHEMBL1299542 & 688267 & 4.4 & 5.0118 & TRN \\
\hline CHEMBL1369635 & 688267 & 4.65 & 4.984 & TRN \\
\hline CHEMBL1505625 & 688267 & 4.5 & 5.0978 & TRN \\
\hline CHEMBL1508492 & 688267 & 4.4 & 5.1035 & TST \\
\hline CHEMBL1591864 & 688267 & 5.35 & 5.0886 & TRN \\
\hline CHEMBL1308561 & 688267 & 4.0 & 5.0296 & TST \\
\hline CHEMBL1361740 & 688267 & 4.25 & 5.0476 & TST \\
\hline CHEMBL1339218 & 688267 & 4.0 & 5.0284 & TRN \\
\hline CHEMBL1463775 & 688267 & 5.6 & 5.1246 & TRN \\
\hline CHEMBL1314905 & 688267 & 3.95 & 5.0042 & TRN \\
\hline CHEMBL1562295 & 688267 & 6.15 & 5.0914 & TRN \\
\hline CHEMBL1479236 & 688267 & 6.15 & 5.0333 & TRN \\
\hline CHEMBL1440079 & 688267 & 4.35 & 5.1015 & TRN \\
\hline CHEMBL1433010 & 688267 & 5.65 & 4.9748 & TRN \\
\hline CHEMBL1500442 & 688267 & 6.0 & 5.1017 & TST \\
\hline
\end{tabular}




\begin{tabular}{|c|c|c|c|c|c|}
\hline & & \multicolumn{4}{|c|}{ Supplemental Table s2.txt } \\
\hline CHEMBL1513072 & 688267 & 6.45 & 5.1115 & TRN & \\
\hline CHEMBL1502625 & 688267 & 6.2 & 5.0204 & TRN & \\
\hline CHEMBL1334339 & 688267 & 5.55 & 5.1032 & TRN & \\
\hline CHEMBL1352988 & 688267 & 4.4 & 5.0265 & TRN & \\
\hline CHEMBL1347057 & 688267 & 5.55 & 5.0159 & TRN & \\
\hline CHEMBL1484696 & 688267 & 4.3 & 4.9885 & TRN & \\
\hline CHEMBL1486102 & 688267 & 4.45 & 5.0279 & TST & \\
\hline CHEMBL 3207910 & 688267 & 4.55 & 5.1155 & TRN & \\
\hline CHEMBL1586255 & 688267 & 6.15 & 5.0351 & TRN & \\
\hline CHEMBL1446536 & 688267 & 5.35 & 5.0263 & TST & \\
\hline CHEMBL1408841 & 688267 & 6.25 & 5.0313 & TRN & \\
\hline CHEMBL1463111 & 688267 & 4.1 & 5.0071 & TRN & \\
\hline CHEMBL1338952 & 688267 & 4.55 & 5.0966 & TRN & \\
\hline CHEMBL1549877 & 688267 & 6.1 & 5.0021 & TRN & \\
\hline CHEMBL1523024 & 688267 & 6.2 & 5.1439 & TRN & \\
\hline CHEMBL1306376 & 688267 & 4.55 & 5.0434 & TST & \\
\hline CHEMBL1311994 & 688267 & 5.0 & 5.04899 & 99999999995 & TST \\
\hline CHEMBL1417257 & 688267 & 6.25 & 5.063 & TRN & \\
\hline CHEMBL1562028 & 688267 & 3.95 & 5.0584 & TST & \\
\hline CHEMBL1362301 & 688267 & 5.75 & 5.1155 & TRN & \\
\hline CHEMBL1360747 & 688267 & 4.55 & 5.1049 & TRN & \\
\hline CHEMBL1401236 & 688267 & 5.15 & 5.1328 & TRN & \\
\hline CHEMBL1576387 & 688267 & 6.15 & 5.0189 & TST & \\
\hline CHEMBL1482481 & 688267 & 6.15 & 5.1376 & TRN & \\
\hline CHEMBL1536794 & 688267 & 4.8 & 5.0552 & TRN & \\
\hline CHEMBL1581837 & 688267 & 6.2 & 5.1105 & TST & \\
\hline CHEMBL1440649 & 688267 & 4.05 & 5.0819 & TRN & \\
\hline CHEMBL3212678 & 688267 & 6.0 & 5.0176 & TRN & \\
\hline CHEMBL1405372 & 688267 & 5.55 & 4.9983 & TRN & \\
\hline CHEMBL1565421 & 688267 & 5.75 & 5.099 & TST & \\
\hline CHEMBL1968522 & 688267 & 4.35 & 4.9913 & TRN & \\
\hline CHEMBL1322153 & 688267 & 4.0 & 5.1273 & TST & \\
\hline CHEMBL1347780 & 688267 & 4.3 & 5.0937 & TRN & \\
\hline CHEMBL1306237 & 688267 & 6.1 & 4.9593 & TRN & \\
\hline CHEMBL1591191 & 688267 & 4.4 & 5.027 & TRN & \\
\hline CHEMBL1350577 & 688267 & 5.3 & 5.1226 & TRN & \\
\hline CHEMBL1415136 & 688267 & 5.3 & 4.9924 & TST & \\
\hline CHEMBL1445396 & 688267 & 5.0 & 5.0752 & TRN & \\
\hline CHEMBL1561306 & 688267 & 4.5 & 5.008 & TST & \\
\hline CHEMBL1535887 & 688267 & 6.05 & 5.0546 & TRN & \\
\hline CHEMBL1356934 & 688267 & 6.2 & 5.0926 & TRN & \\
\hline CHEMBL600070 & 688267 & 6.2 & 5.003 & TST & \\
\hline CHEMBL1992286 & 688267 & 5.75 & 5.0056 & TRN & \\
\hline CHEMBL1320346 & 688267 & 6.15 & 5.0899 & TRN & \\
\hline CHEMBL1582864 & 688267 & 5.85 & 5.0794 & TRN & \\
\hline CHEMBL1300569 & 688267 & 4.25 & 5.093 & TRN & \\
\hline CHEMBL1493699 & 688267 & 5.35 & 5.0873 & TRN & \\
\hline CHEMBL 2005518 & 688267 & 3.95 & 5.0077 & TST & \\
\hline
\end{tabular}




\begin{tabular}{|c|c|c|c|c|c|}
\hline \\
\hline CHEMBL1384687 & 688267 & 6.25 & 5.0653 & TRN & \\
\hline CHEMBL1519678 & 688267 & 4.05 & 5.0346 & TST & \\
\hline CHEMBL3197874 & 688267 & 4.5 & 5.0441 & TST & \\
\hline CHEMBL1539007 & 688267 & 5.2 & 5.0746 & TRN & \\
\hline CHEMBL1611710 & 688267 & 4.0 & 5.0631 & TST & \\
\hline CHEMBL1529715 & 688267 & 4.6 & 4.9891 & TRN & \\
\hline CHEMBL1399663 & 688267 & 4.35 & 5.07 & TST & \\
\hline CHEMBL1535388 & 688267 & 6.2 & 5.1146 & TRN & \\
\hline CHEMBL1533717 & 688267 & 4.2 & 5.0868 & TRN & \\
\hline CHEMBL1602162 & 688267 & 6.2 & 5.0262 & TRN & \\
\hline CHEMBL1364069 & 688267 & 4.35 & 5.1722 & TST & \\
\hline CHEMBL1430944 & 688267 & 4.0 & 4.9989 & TRN & \\
\hline CHEMBL3212247 & 688267 & 5.9 & 5.027 & TRN & \\
\hline CHEMBL1585929 & 688267 & 4.3 & 5.099 & TRN & \\
\hline CHEMBL1361822 & 688267 & 4.15 & 5.0064 & TRN & \\
\hline CHEMBL1612087 & 688267 & 5.85 & 5.0232 & TRN & \\
\hline CHEMBL1485030 & 688267 & 4.2 & 5.1232 & TRN & \\
\hline CHEMBL1453594 & 688267 & 5.6 & 5.0445 & TRN & \\
\hline CHEMBL1531567 & 688267 & 4.0 & 4.9749 & TST & \\
\hline CHEMBL1548266 & 688267 & 5.25 & 5.07600 & 00000000005 & TRN \\
\hline CHEMBL1591247 & 688267 & 4.0 & 5.0706 & TRN & \\
\hline CHEMBL1320668 & 688267 & 5.35 & 5.1039 & TRN & \\
\hline CHEMBL1524724 & 688267 & 5.0 & 5.1695 & TRN & \\
\hline CHEMBL1368780 & 688267 & 4.05 & 5.1225 & TRN & \\
\hline CHEMBL1418762 & 688267 & 6.2 & 5.1101 & TRN & \\
\hline CHEMBL 3212621 & 688267 & 6.15 & 4.9942 & TRN & \\
\hline CHEMBL1544471 & 688267 & 6.2 & 5.0244 & TRN & \\
\hline CHEMBL1558731 & 688267 & 5.95 & 5.0681 & TST & \\
\hline CHEMBL1390395 & 688267 & 5.05 & 5.0376 & TST & \\
\hline CHEMBL1578659 & 688267 & 4.05 & 5.0451 & TRN & \\
\hline CHEMBL1439060 & 688267 & 6.95 & 5.0192 & TRN & \\
\hline CHEMBL1539883 & 688267 & 5.3 & 5.0941 & TRN & \\
\hline CHEMBL1605158 & 688267 & 4.1 & 5.0427 & TRN & \\
\hline CHEMBL 2369289 & 688267 & 4.0 & 5.0118 & TST & \\
\hline CHEMBL1502851 & 688267 & 5.75 & 4.9774 & TST & \\
\hline CHEMBL1559121 & 688267 & 5.55 & 5.0855 & TRN & \\
\hline CHEMBL1598079 & 688267 & 4.95 & 5.0197 & TRN & \\
\hline CHEMBL1376075 & 688267 & 4.0 & 5.0729 & TST & \\
\hline CHEMBL1329793 & 688267 & 5.2 & 5.0107 & TRN & \\
\hline CHEMBL1410062 & 688267 & 6.0 & 5.0371 & TRN & \\
\hline CHEMBL1571276 & 688267 & 6.2 & 5.0662 & TRN & \\
\hline CHEMBL1554905 & 688267 & 5.95 & 5.0705 & TRN & \\
\hline CHEMBL1475429 & 688267 & 6.25 & 5.0355 & TRN & \\
\hline CHEMBL1494174 & 688267 & 6.05 & 5.0934 & TRN & \\
\hline CHEMBL1464272 & 688267 & 6.2 & 5.0757 & TRN & \\
\hline CHEMBL3189819 & 688267 & 5.0 & 5.0496 & TRN & \\
\hline CHEMBL 1459849 & 688267 & 6.2 & 5.0001 & TRN & \\
\hline CHEMBL1306294 & 688267 & 6.25 & 5.1528 & TST & \\
\hline
\end{tabular}




\begin{tabular}{|c|c|c|c|c|c|}
\hline \multicolumn{6}{|c|}{ Supplemental Table s2.txt } \\
\hline CHEMBL1541266 & 688267 & 4.25 & 5.0837 & TRN & \\
\hline CHEMBL1610544 & 688267 & 5.35 & 5.0607 & TST & \\
\hline CHEMBL1394866 & 688267 & 6.2 & 5.0346 & TRN & \\
\hline CHEMBL1458352 & 688267 & 5.1 & 5.0427 & TRN & \\
\hline CHEMBL1410803 & 688267 & 5.0 & 5.0543 & TRN & \\
\hline CHEMBL3199834 & 688267 & 4.1 & 4.9913 & TRN & \\
\hline CHEMBL1400660 & 688267 & 4.35 & 5.0594 & TST & \\
\hline CHEMBL1508107 & 688267 & 4.55 & 4.9907 & TRN & \\
\hline CHEMBL1496398 & 688267 & 4.1 & 5.0435 & TST & \\
\hline CHEMBL1476533 & 688267 & 4.95 & 5.0552 & TRN & \\
\hline CHEMBL1493385 & 688267 & 4.0 & 5.0008 & TRN & \\
\hline CHEMBL1330290 & 688267 & 4.6 & 5.0788 & TRN & \\
\hline CHEMBL1591611 & 688267 & 5.35 & 5.0399 & TST & \\
\hline CHEMBL1332428 & 688267 & 3.95 & 5.0456 & TRN & \\
\hline CHEMBL1575064 & 688267 & 4.0 & 5.0253 & TRN & \\
\hline CHEMBL3214312 & 688267 & 4.05 & 4.9868 & TRN & \\
\hline CHEMBL1370489 & 688267 & 5.35 & 5.0739 & TRN & \\
\hline CHEMBL1419733 & 688267 & 4.05 & 4.944 & TRN & \\
\hline CHEMBL1590147 & 688267 & 6.25 & 5.1158 & TRN & \\
\hline CHEMBL1329489 & 688267 & 6.2 & 5.0506 & TST & \\
\hline CHEMBL1377913 & 688267 & 4.55 & 5.0623 & TRN & \\
\hline CHEMBL1563154 & 688267 & 6.5 & 5.0588 & TST & \\
\hline CHEMBL1385555 & 688267 & 6.2 & 5.0309 & TRN & \\
\hline CHEMBL1579471 & 688267 & 4.4 & 5.01699 & 99999999995 & TRN \\
\hline CHEMBL1603398 & 688267 & 4.0 & 5.0381 & TRN & \\
\hline CHEMBL1602799 & 688267 & 5.65 & 5.0399 & TRN & \\
\hline CHEMBL1606843 & 688267 & 4.55 & 5.1106 & TRN & \\
\hline CHEMBL1574399 & 688267 & 5.4 & 5.1698 & TRN & \\
\hline CHEMBL1377387 & 688267 & 6.6 & 5.0274 & TRN & \\
\hline CHEMBL1537352 & 688267 & 5.65 & 5.1426 & TRN & \\
\hline CHEMBL1310917 & 688267 & 4.55 & 5.0844 & TRN & \\
\hline CHEMBL1600404 & 688267 & 4.9 & 5.1316 & TST & \\
\hline CHEMBL1592449 & 688267 & 5.85 & 5.1195 & TRN & \\
\hline CHEMBL1395357 & 688267 & 4.6 & 5.0015 & TRN & \\
\hline CHEMBL578939 & 688267 & 5.55 & 5.0309 & TST & \\
\hline CHEMBL1303029 & 688267 & 4.3 & 5.0358 & TST & \\
\hline CHEMBL1571786 & 688267 & 4.35 & 5.0015 & TRN & \\
\hline CHEMBL1344988 & 688267 & 4.45 & 4.9799 & TRN & \\
\hline CHEMBL1471840 & 688267 & 4.75 & 5.0998 & TST & \\
\hline CHEMBL1418114 & 688267 & 5.05 & 5.0208 & TST & \\
\hline CHEMBL1546560 & 688267 & 4.4 & 5.1396 & TRN & \\
\hline CHEMBL1461645 & 688267 & 3.95 & 5.0202 & TRN & \\
\hline CHEMBL1299617 & 688267 & 4.0 & 5.0394 & TRN & \\
\hline CHEMBL1523924 & 688267 & 5.9 & 5.0658 & TST & \\
\hline CHEMBL1544220 & 688267 & 4.0 & 5.0172 & TRN & \\
\hline CHEMBL1500784 & 688267 & 4.0 & 5.0361 & TST & \\
\hline CHEMBL1471300 & 688267 & 4.7 & 5.0419 & TST & \\
\hline CHEMBL1531155 & 688267 & 5.9 & 5.029 & TRN & \\
\hline
\end{tabular}




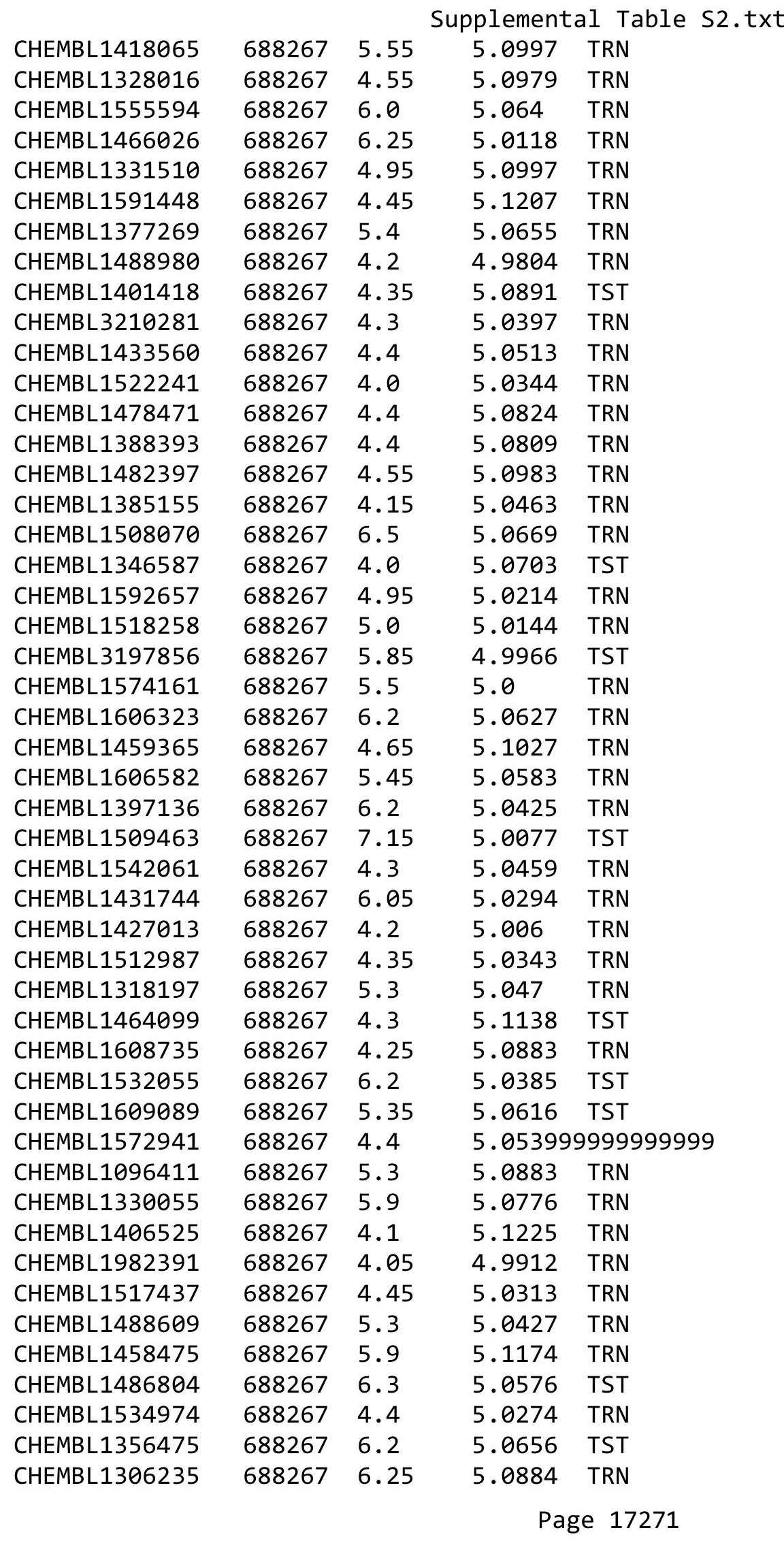




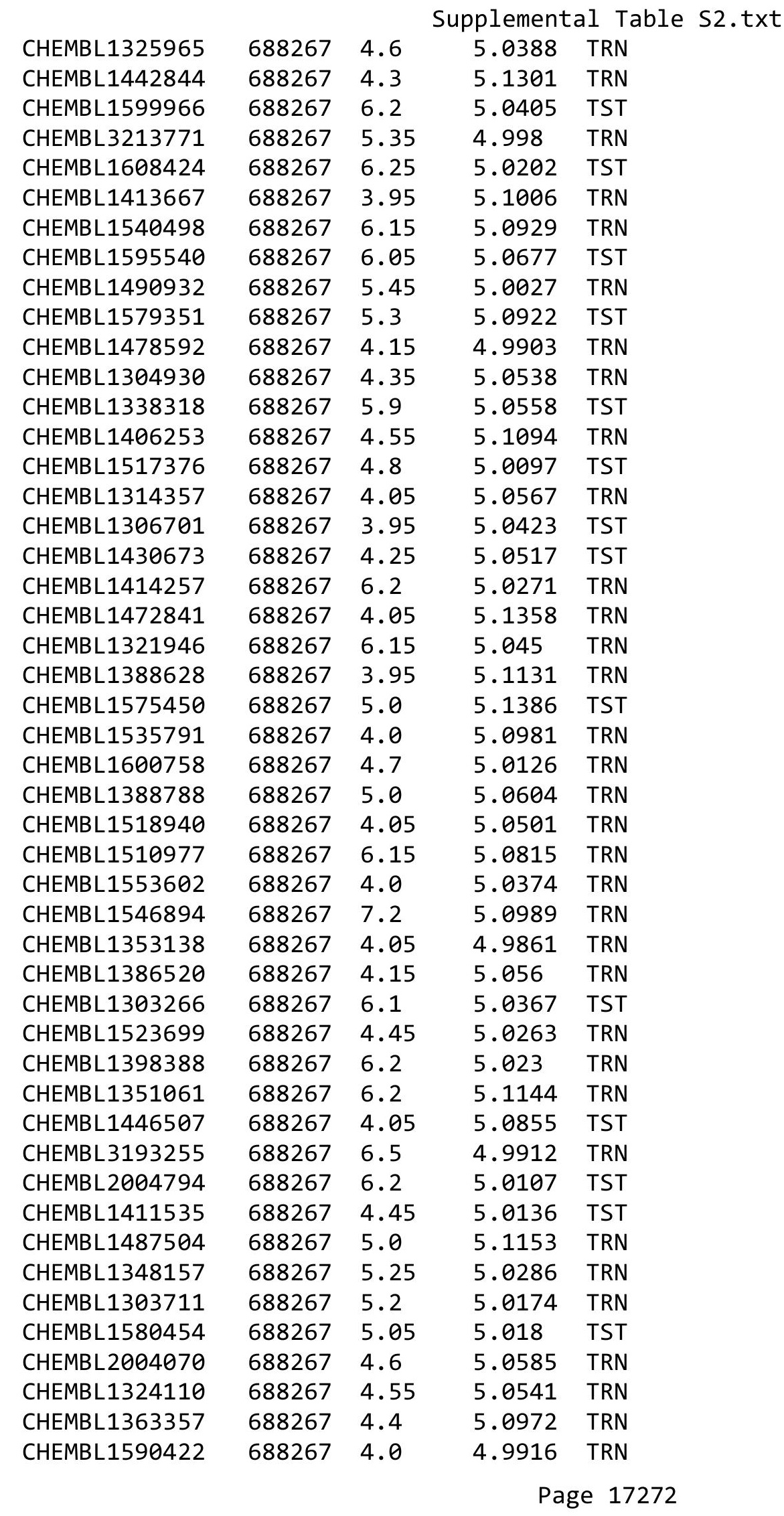




\begin{tabular}{|c|c|c|c|c|c|}
\hline \multicolumn{6}{|c|}{ Supplemental Table S2.txt } \\
\hline CHEMBL1375428 & 688267 & 5.05 & 4.993 & TRN & \\
\hline CHEMBL1415992 & 688267 & 5.5 & 5.0276 & TRN & \\
\hline CHEMBL1439071 & 688267 & 5.65 & 5.0606 & TRN & \\
\hline CHEMBL1359794 & 688267 & 6.2 & 5.0227 & TRN & \\
\hline CHEMBL1417699 & 688267 & 4.0 & 5.0696 & TRN & \\
\hline CHEMBL1427488 & 688267 & 5.95 & 5.0279 & TST & \\
\hline CHEMBL1492691 & 688267 & 5.3 & 5.0736 & TST & \\
\hline CHEMBL1611716 & 688267 & 4.05 & 5.0205 & TRN & \\
\hline CHEMBL1367010 & 688267 & 4.55 & 5.033 & TRN & \\
\hline CHEMBL1422506 & 688267 & 6.2 & 5.0288 & TRN & \\
\hline CHEMBL1581519 & 688267 & 5.85 & 5.0871 & TRN & \\
\hline CHEMBL1417138 & 688267 & 4.35 & 5.091 & TST & \\
\hline CHEMBL1523431 & 688267 & 4.05 & 5.0352 & TRN & \\
\hline CHEMBL1584861 & 688267 & 4.2 & 5.1135 & TRN & \\
\hline CHEMBL1497055 & 688267 & 5.4 & 5.0129 & TRN & \\
\hline CHEMBL1513370 & 688267 & 5.55 & 5.0449 & TRN & \\
\hline CHEMBL1475900 & 688267 & 6.15 & 5.1225 & TRN & \\
\hline CHEMBL1359688 & 688267 & 6.15 & 5.0891 & TRN & \\
\hline CHEMBL3195395 & 688267 & 4.05 & 4.9966 & TRN & \\
\hline CHEMBL1337767 & 688267 & 5.55 & 4.9966 & TRN & \\
\hline CHEMBL1397473 & 688267 & 3.95 & 5.0358 & TRN & \\
\hline CHEMBL1610985 & 688267 & 5.75 & 5.0538 & TRN & \\
\hline CHEMBL1588252 & 688267 & 6.2 & 5.0929 & TST & \\
\hline CHEMBL1447187 & 688267 & 6.25 & 5.027 & TRN & \\
\hline CHEMBL1388620 & 688267 & 5.0 & 4.9962 & TST & \\
\hline CHEMBL1310964 & 688267 & 5.55 & 5.1021 & TRN & \\
\hline CHEMBL1476891 & 688267 & 6.25 & 5.0498 & TRN & \\
\hline CHEMBL3208756 & 688267 & 5.45 & 5.0235 & TST & \\
\hline CHEMBL1428106 & 688267 & 4.3 & 5.0192 & TRN & \\
\hline CHEMBL1494126 & 688267 & 4.05 & 5.1244 & TRN & \\
\hline CHEMBL1395161 & 688267 & 5.35 & 5.0291 & TRN & \\
\hline CHEMBL1549734 & 688267 & 6.15 & 5.0336 & TST & \\
\hline CHEMBL1473041 & 688267 & 6.2 & 5.0591 & TST & \\
\hline CHEMBL1400197 & 688267 & 6.2 & 5.0947 & TRN & \\
\hline CHEMBL1537389 & 688267 & 5.7 & 5.0745 & TST & \\
\hline CHEMBL1385971 & 688267 & 5.45 & 5.0573 & TRN & \\
\hline CHEMBL1557532 & 688267 & 4.4 & 5.1039 & TRN & \\
\hline CHEMBL3193305 & 688267 & 6.2 & 5.0172 & TRN & \\
\hline CHEMBL3198959 & 688267 & 6.25 & 4.9949 & TRN & \\
\hline CHEMBL1318247 & 688267 & 4.0 & 5.0797 & TRN & \\
\hline CHEMBL1481967 & 688267 & 6.25 & 5.0614 & TRN & \\
\hline CHEMBL1496821 & 688267 & 4.55 & 4.9811 & TST & \\
\hline CHEMBL1304846 & 688267 & 5.9 & 5.01699 & 99999999995 & TRN \\
\hline CHEMBL1332378 & 688267 & 4.05 & 5.1238 & TRN & \\
\hline CHEMBL449329 & 688267 & 5.35 & 5.0979 & TRN & \\
\hline CHEMBL1397099 & 688267 & 3.95 & 5.0469 & TRN & \\
\hline CHEMBL1513960 & 688267 & 6.2 & 5.1052 & TRN & \\
\hline CHEMBL1363070 & 688267 & 4.5 & 5.0309 & TRN & \\
\hline
\end{tabular}




\begin{tabular}{|c|c|c|c|c|}
\hline \multicolumn{5}{|c|}{ Supplemental Table S2.txt } \\
\hline CHEMBL1334516 & 688267 & 4.05 & 5.0021 & TST \\
\hline CHEMBL1436629 & 688267 & 6.2 & 5.087 & TRN \\
\hline CHEMBL1472664 & 688267 & 5.15 & 5.0582 & TRN \\
\hline CHEMBL1536856 & 688267 & 5.55 & 4.9967 & TRN \\
\hline CHEMBL587229 & 688267 & 6.25 & 5.0675 & TRN \\
\hline CHEMBL1355366 & 688267 & 5.3 & 5.0299 & TRN \\
\hline CHEMBL1377142 & 688267 & 5.05 & 5.0912 & TRN \\
\hline CHEMBL1354688 & 688267 & 5.55 & 5.0338 & TRN \\
\hline CHEMBL1449874 & 688267 & 5.8 & 4.9662 & TRN \\
\hline CHEMBL1484019 & 688267 & 6.5501 & 5.0391 & TRN \\
\hline CHEMBL1592416 & 688267 & 4.1 & 5.0436 & TRN \\
\hline CHEMBL1606595 & 688267 & 6.2 & 5.0232 & TST \\
\hline CHEMBL1398706 & 688267 & 5.1 & 5.0922 & TRN \\
\hline CHEMBL1412265 & 688267 & 7.0 & 5.1091 & TRN \\
\hline CHEMBL1410775 & 688267 & 4.05 & 5.1674 & TRN \\
\hline CHEMBL1501513 & 688267 & 5.8 & 5.1505 & TRN \\
\hline CHEMBL1412734 & 688267 & 5.35 & 5.0258 & TST \\
\hline CHEMBL1332450 & 688267 & 4.3 & 5.0572 & TRN \\
\hline CHEMBL1480703 & 688267 & 4.35 & 5.1229 & TRN \\
\hline CHEMBL1331964 & 688267 & 6.25 & 5.09 & TRN \\
\hline CHEMBL1573423 & 688267 & 4.4 & 5.1045 & TRN \\
\hline CHEMBL1549164 & 688267 & 5.75 & 5.0555 & TRN \\
\hline CHEMBL1382210 & 688267 & 4.0 & 5.0889 & TRN \\
\hline CHEMBL1454989 & 688267 & 5.6 & 5.016 & TRN \\
\hline CHEMBL1475899 & 688267 & 5.45 & 5.1569 & TRN \\
\hline CHEMBL1534437 & 688267 & 4.0 & 5.1169 & TRN \\
\hline CHEMBL1427896 & 688267 & 3.95 & 5.0064 & TRN \\
\hline CHEMBL1409303 & 688267 & 5.3 & 5.0735 & TST \\
\hline CHEMBL1351327 & 688267 & 6.5 & 5.0388 & TRN \\
\hline CHEMBL1672291 & 688267 & 4.6 & 5.0515 & TRN \\
\hline CHEMBL1469865 & 688267 & 4.35 & 5.0125 & TRN \\
\hline CHEMBL1460134 & 688267 & 4.0 & 4.9987 & TST \\
\hline CHEMBL1436680 & 688267 & 4.0 & 5.0299 & TRN \\
\hline CHEMBL1368209 & 688267 & 5.5 & 5.0358 & TRN \\
\hline CHEMBL1407227 & 688267 & 6.2 & 5.1124 & TRN \\
\hline CHEMBL1314633 & 688267 & 6.2 & 5.0233 & TRN \\
\hline CHEMBL1574945 & 688267 & 6.2 & 5.0711 & TRN \\
\hline CHEMBL1320185 & 688267 & 6.2 & 5.0212 & TST \\
\hline CHEMBL1484931 & 688267 & 4.35 & 5.1179 & TRN \\
\hline CHEMBL1593398 & 688267 & 4.85 & 5.0405 & TRN \\
\hline CHEMBL1575775 & 688267 & 4.05 & 5.058 & TST \\
\hline CHEMBL1359872 & 688267 & 5.45 & 5.0414 & TRN \\
\hline CHEMBL1529006 & 688267 & 4.45 & 5.0984 & TRN \\
\hline CHEMBL1520937 & 688267 & 4.4 & 5.0406 & TRN \\
\hline CHEMBL1345763 & 688267 & 5.6 & 5.0665 & TRN \\
\hline CHEMBL1549054 & 688267 & 4.8 & 5.0529 & TRN \\
\hline CHEMBL1402611 & 688267 & 4.45 & 5.0341 & TRN \\
\hline CHEMBL1506028 & 688267 & 5.1 & 5.0731 & TRN \\
\hline
\end{tabular}




\begin{tabular}{|c|c|c|c|c|}
\hline \multicolumn{5}{|c|}{ Supplemental Table S2.txt } \\
\hline CHEMBL1585317 & 688267 & 5.3 & 5.0438 & TRN \\
\hline CHEMBL1531776 & 688267 & 5.9 & 5.022 & TRN \\
\hline CHEMBL1465129 & 688267 & 6.25 & 5.1303 & TST \\
\hline CHEMBL1594001 & 688267 & 5.25 & 5.034 & TRN \\
\hline CHEMBL1510847 & 688267 & 4.3 & 5.0345 & TST \\
\hline CHEMBL1547286 & 688267 & 5.45 & 5.0256 & TRN \\
\hline CHEMBL1476980 & 688267 & 4.0 & 5.0273 & TRN \\
\hline CHEMBL3193448 & 688267 & 4.0 & 5.0462 & TST \\
\hline CHEMBL1414235 & 688267 & 5.35 & 5.0518 & TST \\
\hline CHEMBL1369865 & 688267 & 5.3 & 5.0557 & TST \\
\hline CHEMBL1364529 & 688267 & 3.95 & 5.0352 & TRN \\
\hline CHEMBL1511419 & 688267 & 4.0 & 5.0792 & TST \\
\hline CHEMBL1465194 & 688267 & 6.2 & 5.0709 & TST \\
\hline CHEMBL1517312 & 688267 & 4.3 & 5.0647 & TRN \\
\hline CHEMBL1456986 & 688267 & 4.65 & 5.0982 & TRN \\
\hline CHEMBL1515960 & 688267 & 4.35 & 5.0838 & TRN \\
\hline CHEMBL1493275 & 688267 & 5.5 & 5.0263 & TST \\
\hline CHEMBL1344939 & 688267 & 5.55 & 4.9929 & TST \\
\hline CHEMBL1512785 & 688267 & 5.55 & 5.1404 & TRN \\
\hline CHEMBL1442009 & 688267 & 4.45 & 5.0223 & TST \\
\hline CHEMBL1356681 & 688267 & 4.4 & 5.0623 & TRN \\
\hline CHEMBL1475778 & 688267 & 4.1 & 5.0358 & TRN \\
\hline CHEMBL1471403 & 688267 & 5.1 & 5.0224 & TST \\
\hline CHEMBL1319973 & 688267 & 4.6 & 5.0123 & TRN \\
\hline CHEMBL1344070 & 688267 & 4.85 & 5.0729 & TRN \\
\hline CHEMBL3195810 & 688267 & 4.05 & 5.084 & TST \\
\hline CHEMBL1508675 & 688267 & 5.55 & 5.0803 & TRN \\
\hline CHEMBL1555155 & 688267 & 6.2 & 5.1014 & TRN \\
\hline CHEMBL1402296 & 688267 & 5.85 & 5.0302 & TRN \\
\hline CHEMBL1354576 & 688267 & 4.4 & 5.0886 & TRN \\
\hline CHEMBL1526767 & 688267 & 5.9 & 5.0534 & TRN \\
\hline CHEMBL1361361 & 688267 & 4.0 & 4.9967 & TRN \\
\hline CHEMBL1369047 & 688267 & 4.4 & 5.0357 & TST \\
\hline CHEMBL1540923 & 688267 & 5.9 & 5.0535 & TRN \\
\hline CHEMBL3197168 & 688267 & 5.75 & 5.0472 & TRN \\
\hline CHEMBL1451248 & 688267 & 5.55 & 5.038 & TST \\
\hline CHEMBL1343944 & 688267 & 6.2 & 5.0724 & TRN \\
\hline CHEMBL272942 & 688267 & 4.05 & 5.0636 & TRN \\
\hline CHEMBL1368651 & 688267 & 4.35 & 5.024 & TRN \\
\hline CHEMBL1308471 & 688267 & 4.75 & 5.0252 & TRN \\
\hline CHEMBL1320627 & 688267 & 6.15 & 5.0798 & TST \\
\hline CHEMBL1572180 & 688267 & 6.15 & 5.018 & TRN \\
\hline CHEMBL1480732 & 688267 & 5.6 & 5.0557 & TRN \\
\hline CHEMBL1390304 & 688267 & 6.5 & 5.13 & TRN \\
\hline CHEMBL1434119 & 688267 & 6.2 & 5.033 & TRN \\
\hline CHEMBL1544623 & 688267 & 6.15 & 5.0343 & TRN \\
\hline CHEMBL1554090 & 688267 & 5.35 & 5.0749 & TRN \\
\hline CHEMBL1359496 & 688267 & 4.0 & 5.0394 & TRN \\
\hline
\end{tabular}




\begin{tabular}{|c|c|c|c|c|}
\hline \multirow[b]{2}{*}{ CHEMBL1498297 } & \multicolumn{4}{|c|}{ Supplemental Table S2.txt } \\
\hline & 688267 & 5.8 & 4.9928 & TST \\
\hline CHEMBL1505637 & 688267 & 5.45 & 5.0796 & TRN \\
\hline CHEMBL1410854 & 688267 & 5.3 & 5.0451 & TRN \\
\hline CHEMBL1413239 & 688267 & 4.45 & 5.1058 & TRN \\
\hline CHEMBL1351339 & 688267 & 3.95 & 5.0648 & TRN \\
\hline CHEMBL1583487 & 688267 & 4.05 & 5.0319 & TRN \\
\hline CHEMBL1434766 & 688267 & 3.95 & 5.0643 & TST \\
\hline CHEMBL1603916 & 688267 & 5.85 & 5.0878 & TRN \\
\hline CHEMBL1612139 & 688267 & 5.05 & 5.0066 & TRN \\
\hline CHEMBL1463960 & 688267 & 4.45 & 5.0715 & TRN \\
\hline CHEMBL1314996 & 688267 & 6.2 & 5.0577 & TST \\
\hline CHEMBL1339484 & 688267 & 4.9 & 5.1004 & TST \\
\hline CHEMBL1472341 & 688267 & 5.5 & 5.0303 & TRN \\
\hline CHEMBL1567567 & 688267 & 5.15 & 5.0196 & TRN \\
\hline CHEMBL1467553 & 688267 & 6.15 & 5.0948 & TRN \\
\hline CHEMBL1498498 & 688267 & 5.8 & 5.0928 & TRN \\
\hline CHEMBL1554472 & 688267 & 4.05 & 5.0174 & TRN \\
\hline CHEMBL1358436 & 688267 & 5.35 & 5.0932 & TRN \\
\hline CHEMBL1343580 & 688267 & 6.2 & 5.061 & TST \\
\hline CHEMBL1399037 & 688267 & 5.6 & 5.0781 & TRN \\
\hline CHEMBL1536141 & 688267 & 4.35 & 5.0452 & TST \\
\hline CHEMBL1454704 & 688267 & 4.05 & 5.0453 & TST \\
\hline CHEMBL1463041 & 688267 & 6.2 & 5.1661 & TST \\
\hline CHEMBL1375137 & 688267 & 5.7 & 5.1031 & TRN \\
\hline CHEMBL1494720 & 688267 & 4.05 & 5.0349 & TRN \\
\hline CHEMBL1549379 & 688267 & 5.55 & 5.1131 & TRN \\
\hline CHEMBL3197081 & 688267 & 5.4 & 5.0081 & TRN \\
\hline CHEMBL1521067 & 688267 & 6.0 & 4.9982 & TRN \\
\hline CHEMBL1469331 & 688267 & 6.15 & 5.0117 & TST \\
\hline CHEMBL1360862 & 688267 & 5.55 & 5.0739 & TRN \\
\hline CHEMBL1336646 & 688267 & 5.6 & 5.0194 & TRN \\
\hline CHEMBL1567128 & 688267 & 5.55 & 5.0547 & TRN \\
\hline CHEMBL1406467 & 688267 & 6.1 & 5.0545 & TST \\
\hline CHEMBL1344700 & 688267 & 4.7 & 5.0785 & TST \\
\hline CHEMBL1426181 & 688267 & 4.5 & 5.0506 & TRN \\
\hline CHEMBL1606538 & 688267 & 5.0 & 5.0981 & TRN \\
\hline CHEMBL1551825 & 688267 & 5.55 & 5.0523 & TST \\
\hline CHEMBL1375683 & 688267 & 5.95 & 5.0407 & TRN \\
\hline CHEMBL1417272 & 688267 & 5.4 & 5.106 & TRN \\
\hline CHEMBL1456005 & 688267 & 6.25 & 5.0866 & TRN \\
\hline CHEMBL1402470 & 688267 & 4.0 & 5.0362 & TRN \\
\hline CHEMBL1365367 & 688267 & 3.95 & 5.0818 & TRN \\
\hline CHEMBL1554729 & 688267 & 5.95 & 5.0682 & TRN \\
\hline CHEMBL1599712 & 688267 & 6.2 & 5.0047 & TRN \\
\hline CHEMBL1455207 & 688267 & 4.0 & 4.9604 & TRN \\
\hline CHEMBL1353106 & 688267 & 5.8 & 5.1023 & TRN \\
\hline CHEMBL1600474 & 688267 & 4.35 & 5.1233 & TST \\
\hline CHEMBL1582361 & 688267 & 4.5 & 5.0531 & TRN \\
\hline
\end{tabular}




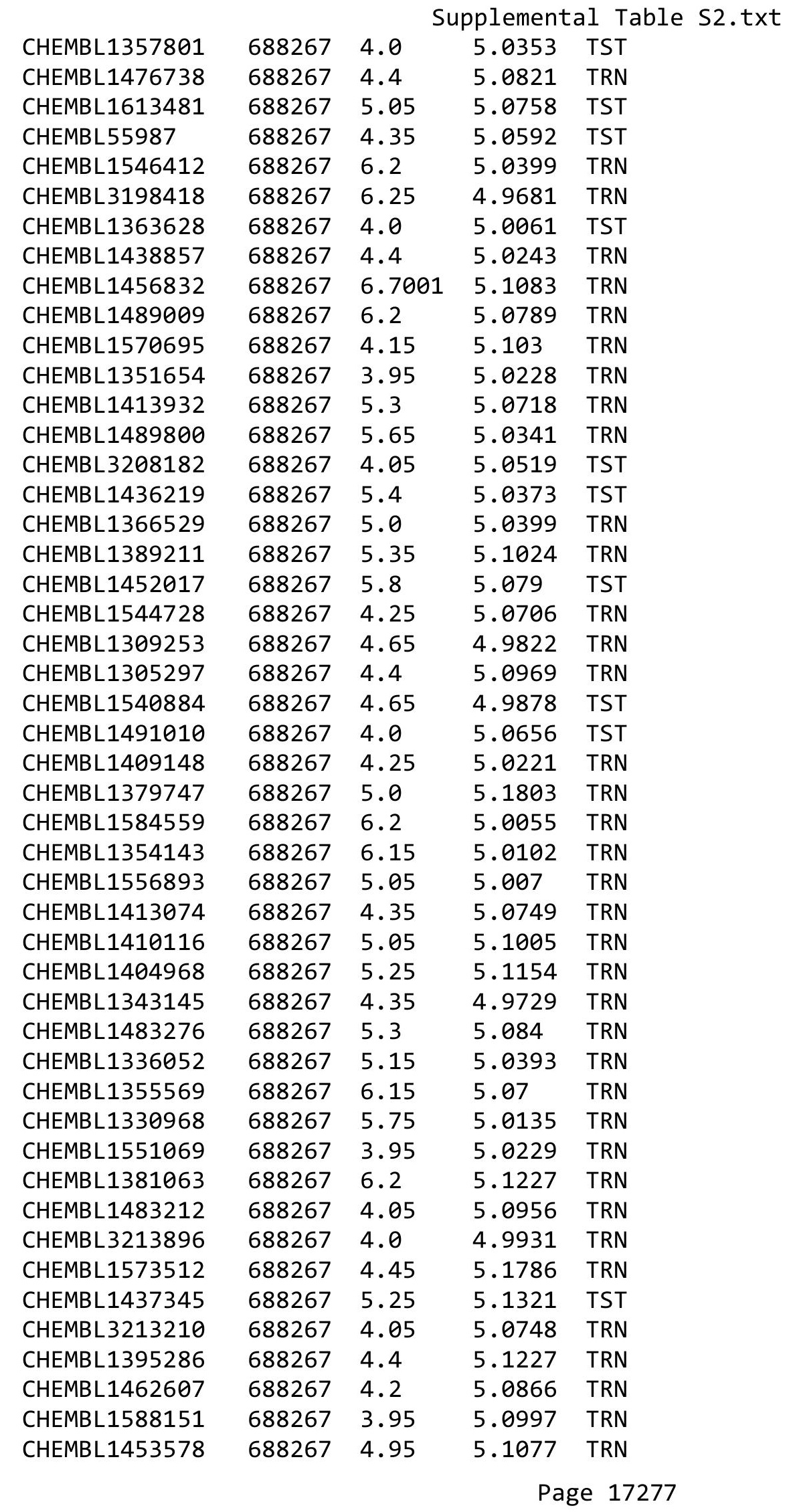




\begin{tabular}{|c|c|c|c|c|c|}
\hline \\
\hline CHEMBL1535807 & 688267 & 4.0 & 5.1157 & TRN & \\
\hline CHEMBL1430563 & 688267 & 5.05 & 5.0701 & TRN & \\
\hline CHEMBL1503282 & 688267 & 4.0 & 5.0286 & TRN & \\
\hline CHEMBL1341431 & 688267 & 4.65 & 5.0402 & TST & \\
\hline CHEMBL1372628 & 688267 & 4.3 & 5.0285 & TRN & \\
\hline CHEMBL1577164 & 688267 & 4.0 & 5.0283 & TRN & \\
\hline CHEMBL1504833 & 688267 & 4.05 & 5.0638 & TST & \\
\hline CHEMBL1420871 & 688267 & 5.95 & 5.0149 & TST & \\
\hline CHEMBL1427254 & 688267 & 5.8 & 5.0632 & TST & \\
\hline CHEMBL1477579 & 688267 & 4.4 & 5.0311 & TRN & \\
\hline CHEMBL1518171 & 688267 & 6.2 & 5.0059 & TRN & \\
\hline CHEMBL1610394 & 688267 & 4.65 & 5.0491 & TST & \\
\hline CHEMBL1361143 & 688267 & 4.0 & 5.0866 & TRN & \\
\hline CHEMBL1402442 & 688267 & 5.85 & 5.0247 & TST & \\
\hline CHEMBL1386653 & 688267 & 5.05 & 5.0622 & TRN & \\
\hline CHEMBL1378296 & 688267 & 6.2 & 5.024 & TRN & \\
\hline CHEMBL1526031 & 688267 & 6.0 & 5.1272 & TRN & \\
\hline CHEMBL1344967 & 688267 & 6.2 & 5.0003 & TRN & \\
\hline CHEMBL3191721 & 688267 & 5.8 & 5.1031 & TRN & \\
\hline CHEMBL1558579 & 688267 & 4.45 & 5.0544 & TRN & \\
\hline CHEMBL1482222 & 688267 & 4.9 & 5.1121 & TRN & \\
\hline CHEMBL1455270 & 688267 & 5.25 & 5.0493 & TRN & \\
\hline CHEMBL1460775 & 688267 & 4.25 & 5.0951 & TRN & \\
\hline CHEMBL1501575 & 688267 & 5.95 & 5.06800 & 00000000005 & TRN \\
\hline CHEMBL1427185 & 688267 & 5.4 & 5.0752 & TRN & \\
\hline CHEMBL1306292 & 688267 & 4.05 & 5.0838 & TST & \\
\hline CHEMBL1459296 & 688267 & 5.95 & 5.0706 & TST & \\
\hline CHEMBL1388732 & 688267 & 5.1 & 5.074 & TRN & \\
\hline CHEMBL1374681 & 688267 & 4.75 & 5.0769 & TRN & \\
\hline CHEMBL1470414 & 688267 & 6.25 & 5.0951 & TRN & \\
\hline CHEMBL1535570 & 688267 & 5.15 & 5.0595 & TRN & \\
\hline CHEMBL1459792 & 688267 & 5.35 & 5.0144 & TRN & \\
\hline CHEMBL1543566 & 688267 & 5.85 & 5.0844 & TST & \\
\hline CHEMBL1409984 & 688267 & 6.0 & 5.0562 & TRN & \\
\hline CHEMBL1403104 & 688267 & 4.2 & 5.0419 & TST & \\
\hline CHEMBL1585043 & 688267 & 4.7 & 5.0244 & TST & \\
\hline CHEMBL1420621 & 688267 & 5.05 & 5.0554 & TRN & \\
\hline CHEMBL1472430 & 688267 & 4.55 & 5.0931 & TRN & \\
\hline CHEMBL1570012 & 688267 & 4.4 & 5.0958 & TRN & \\
\hline CHEMBL1415961 & 688267 & 4.3 & 4.9962 & TRN & \\
\hline CHEMBL1306003 & 688267 & 4.0 & 5.018 & TRN & \\
\hline CHEMBL1552076 & 688267 & 4.3 & 5.0522 & TRN & \\
\hline CHEMBL1350795 & 688267 & 6.2 & 5.0398 & TRN & \\
\hline CHEMBL1599542 & 688267 & 5.95 & 5.0002 & TRN & \\
\hline CHEMBL1597034 & 688267 & 4.35 & 5.0787 & TRN & \\
\hline CHEMBL1350075 & 688267 & 4.7 & 5.0375 & TRN & \\
\hline CHEMBL1552125 & 688267 & 5.95 & 5.101 & TRN & \\
\hline CHEMBL1359425 & 688267 & 5.85 & 5.0954 & TRN & \\
\hline
\end{tabular}




\begin{tabular}{|c|c|c|c|c|c|}
\hline \multicolumn{6}{|c|}{ Supplemental Table s2.txt } \\
\hline CHEMBL1338996 & 688267 & 4.05 & 5.015 & TRN & \\
\hline CHEMBL1414941 & 688267 & 5.0 & 5.0258 & TST & \\
\hline CHEMBL1459172 & 688267 & 4.2 & 5.0668 & TRN & \\
\hline CHEMBL1385702 & 688267 & 4.7 & 5.0864 & TRN & \\
\hline CHEMBL1392162 & 688267 & 4.15 & 5.1047 & TRN & \\
\hline CHEMBL1377814 & 688267 & 4.25 & 5.0484 & TRN & \\
\hline CHEMBL1460385 & 688267 & 5.0 & 4.9823 & TRN & \\
\hline CHEMBL589313 & 688267 & 6.7501 & 5.0692 & TST & \\
\hline CHEMBL1478417 & 688267 & 6.45 & 5.0619 & TRN & \\
\hline CHEMBL1408512 & 688267 & 4.25 & 5.0957 & TRN & \\
\hline CHEMBL1522598 & 688267 & 4.15 & 5.0357 & TST & \\
\hline CHEMBL1472567 & 688267 & 4.05 & 5.0725 & TST & \\
\hline CHEMBL1595584 & 688267 & 4.3 & 4.9989 & TRN & \\
\hline CHEMBL1434246 & 688267 & 4.6 & 4.9929 & TRN & \\
\hline CHEMBL3210578 & 688267 & 5.0 & 5.0612 & TRN & \\
\hline CHEMBL1456085 & 688267 & 6.25 & 4.9641 & TRN & \\
\hline CHEMBL1357887 & 688267 & 5.45 & 5.064 & TRN & \\
\hline CHEMBL1312013 & 688267 & 4.55 & 5.0871 & TST & \\
\hline CHEMBL3189483 & 688267 & 6.2 & 5.063 & TST & \\
\hline CHEMBL1557767 & 688267 & 5.35 & 4.9642 & TRN & \\
\hline CHEMBL1311517 & 688267 & 4.3 & 5.0934 & TRN & \\
\hline CHEMBL1422144 & 688267 & 4.05 & 5.0653 & TST & \\
\hline CHEMBL1322012 & 688267 & 6.5 & 5.0958 & TST & \\
\hline CHEMBL1521870 & 688267 & 6.05 & 5.0186 & TRN & \\
\hline CHEMBL1497663 & 688267 & 4.9 & 5.1254 & TRN & \\
\hline CHEMBL315687 & 688267 & 5.65 & 5.0671 & TRN & \\
\hline CHEMBL3197517 & 688267 & 3.95 & 4.98600 & 0000000001 & TRN \\
\hline CHEMBL1396602 & 688267 & 5.8 & 5.1302 & TRN & \\
\hline CHEMBL 3209084 & 688267 & 4.95 & 5.0722 & TRN & \\
\hline CHEMBL1565370 & 688267 & 4.05 & 5.0156 & TST & \\
\hline CHEMBL1348551 & 688267 & 5.25 & 5.0333 & TST & \\
\hline CHEMBL1418485 & 688267 & 6.25 & 5.0122 & TRN & \\
\hline CHEMBL 3197520 & 688267 & 4.8 & 5.0563 & TRN & \\
\hline CHEMBL1491535 & 688267 & 5.4 & 4.9929 & TRN & \\
\hline CHEMBL1591388 & 688267 & 5.25 & 5.1223 & TRN & \\
\hline CHEMBL1426896 & 688267 & 4.05 & 5.0378 & TRN & \\
\hline CHEMBL1322903 & 688267 & 4.45 & 5.1049 & TRN & \\
\hline CHEMBL1562562 & 688267 & 4.95 & 5.1356 & TRN & \\
\hline CHEMBL1366922 & 688267 & 5.3 & 5.037 & TST & \\
\hline CHEMBL1592266 & 688267 & 5.95 & 5.1147 & TRN & \\
\hline CHEMBL1542601 & 688267 & 5.35 & 5.0845 & TST & \\
\hline CHEMBL1474551 & 688267 & 4.4 & 5.0542 & TST & \\
\hline CHEMBL1302816 & 688267 & 4.2 & 5.008 & TST & \\
\hline CHEMBL1323139 & 688267 & 4.05 & 5.04899 & 99999999995 & TST \\
\hline CHEMBL1546455 & 688267 & 5.2 & 5.0299 & TST & \\
\hline CHEMBL1342312 & 688267 & 5.4 & 5.0563 & TRN & \\
\hline CHEMBL1575346 & 688267 & 5.35 & 5.0879 & TRN & \\
\hline CHEMBL1368848 & 688267 & 5.4 & 5.0358 & TST & \\
\hline
\end{tabular}




\begin{tabular}{|c|c|c|c|c|}
\hline & & & upplement & $\mathrm{T}$ \\
\hline CHEMBL1318803 & 688267 & 4.15 & 5.018 & TRN \\
\hline CHEMBL1435689 & 688267 & 4.0 & 5.1076 & TST \\
\hline CHEMBL1475524 & 688267 & 5.7 & 5.0455 & TRN \\
\hline CHEMBL1346786 & 688267 & 5.8 & 5.0471 & TRN \\
\hline CHEMBL1529228 & 688267 & 4.95 & 5.0447 & TRN \\
\hline CHEMBL1540225 & 688267 & 4.65 & 5.0269 & TST \\
\hline CHEMBL 3210069 & 688267 & 4.85 & 5.0311 & TRN \\
\hline CHEMBL1479216 & 688267 & 5.8 & 5.0828 & TRN \\
\hline CHEMBL1347891 & 688267 & 4.9 & 5.0325 & TST \\
\hline CHEMBL1371379 & 688267 & 4.7 & 5.1021 & TRN \\
\hline CHEMBL1549324 & 688267 & 6.05 & 5.0378 & TRN \\
\hline CHEMBL1515963 & 688267 & 5.1 & 5.1559 & TRN \\
\hline CHEMBL1362084 & 688267 & 6.2 & 5.0782 & TST \\
\hline CHEMBL1451706 & 688267 & 6.2 & 5.0965 & TRN \\
\hline CHEMBL 241768 & 688267 & 4.05 & 5.0032 & TRN \\
\hline CHEMBL1515256 & 688267 & 6.0 & 5.0319 & TRN \\
\hline CHEMBL1453319 & 688267 & 4.3 & 5.0172 & TRN \\
\hline CHEMBL1596136 & 688267 & 6.2 & 5.1366 & TRN \\
\hline CHEMBL1576318 & 688267 & 5.45 & 5.032 & TST \\
\hline CHEMBL1519474 & 688267 & 5.55 & 5.0074 & TRN \\
\hline CHEMBL3190214 & 688267 & 4.4 & 4.9633 & TRN \\
\hline CHEMBL1332700 & 688267 & 5.6 & 5.0381 & TRN \\
\hline CHEMBL1514467 & 688267 & 4.55 & 5.0708 & TRN \\
\hline CHEMBL1469335 & 688267 & 6.2 & 5.0268 & TRN \\
\hline CHEMBL1305221 & 688267 & 5.55 & 5.0452 & TST \\
\hline CHEMBL1403633 & 688267 & 5.6 & 5.08 & TRN \\
\hline CHEMBL1389336 & 688267 & 4.4 & 5.0452 & TRN \\
\hline CHEMBL1997212 & 688267 & 4.0 & 4.9834 & TRN \\
\hline CHEMBL1565703 & 688267 & 4.0 & 5.0919 & TRN \\
\hline CHEMBL1300428 & 688267 & 6.25 & 5.0865 & TRN \\
\hline CHEMBL1392549 & 688267 & 5.15 & 5.0531 & TST \\
\hline CHEMBL1457507 & 688267 & 6.2 & 5.0844 & TST \\
\hline CHEMBL1401563 & 688267 & 4.35 & 5.0262 & TRN \\
\hline CHEMBL1596196 & 688267 & 4.4 & 5.1317 & TRN \\
\hline CHEMBL1363556 & 688267 & 4.0 & 5.0538 & TRN \\
\hline CHEMBL1471585 & 688267 & 5.3 & 5.0216 & TRN \\
\hline CHEMBL1603717 & 688267 & 4.1 & 5.0541 & TST \\
\hline CHEMBL1376285 & 688267 & 4.45 & 5.0721 & TST \\
\hline CHEMBL1450550 & 688267 & 4.95 & 5.06 & TRN \\
\hline CHEMBL1438398 & 688267 & 6.2 & 5.0314 & TST \\
\hline CHEMBL1522822 & 688267 & 5.4 & 5.1504 & TRN \\
\hline CHEMBL1495253 & 688267 & 4.25 & 5.0428 & TRN \\
\hline CHEMBL1490613 & 688267 & 6.2 & 5.0633 & TRN \\
\hline CHEMBL 3191467 & 688267 & 4.6 & 5.0154 & TST \\
\hline CHEMBL1501080 & 688267 & 5.3 & 5.0978 & TRN \\
\hline CHEMBL1583966 & 688267 & 5.05 & 4.9922 & TST \\
\hline CHEMBL1414487 & 688267 & 3.95 & 5.0642 & TRN \\
\hline CHEMBL1433515 & 688267 & 5.25 & 5.0633 & TRN \\
\hline
\end{tabular}




\begin{tabular}{|c|c|c|c|c|}
\hline \multicolumn{5}{|c|}{ Supplemental Table S2.txt } \\
\hline CHEMBL1562556 & 688267 & 4.3 & 5.1233 & TRN \\
\hline CHEMBL1398715 & 688267 & 5.8 & 5.0383 & TRN \\
\hline CHEMBL1327297 & 688267 & 5.75 & 5.119 & TRN \\
\hline CHEMBL1479684 & 688267 & 4.05 & 5.0816 & TRN \\
\hline CHEMBL1352991 & 688267 & 5.45 & 5.1216 & TRN \\
\hline CHEMBL1442949 & 688267 & 5.3 & 5.0582 & TRN \\
\hline CHEMBL1435641 & 688267 & 6.2 & 5.0544 & TRN \\
\hline CHEMBL1414952 & 688267 & 4.3 & 5.0952 & TRN \\
\hline CHEMBL 3214308 & 688267 & 5.05 & 4.9968 & TRN \\
\hline CHEMBL602927 & 688267 & 4.1 & 5.0122 & TRN \\
\hline CHEMBL1587474 & 688267 & 4.0 & 4.9908 & TRN \\
\hline CHEMBL3211794 & 688267 & 5.45 & 5.0229 & TRN \\
\hline CHEMBL1510703 & 688267 & 4.3 & 5.0463 & TST \\
\hline CHEMBL1314517 & 688267 & 4.0 & 5.0303 & TST \\
\hline CHEMBL1469721 & 688267 & 5.55 & 5.0567 & TRN \\
\hline CHEMBL1473324 & 688267 & 6.6499 & 5.1011 & TRN \\
\hline CHEMBL1551170 & 688267 & 4.35 & 5.0526 & TRN \\
\hline CHEMBL1349006 & 688267 & 4.3 & 5.0694 & TRN \\
\hline CHEMBL1438642 & 688267 & 4.35 & 5.0304 & TRN \\
\hline CHEMBL1381838 & 688267 & 5.2 & 5.0534 & TRN \\
\hline CHEMBL1432070 & 688267 & 6.15 & 5.056 & TST \\
\hline CHEMBL3209350 & 688267 & 5.3 & 5.018 & TRN \\
\hline CHEMBL1457810 & 688267 & 5.4 & 5.0546 & TRN \\
\hline CHEMBL1494315 & 688267 & 6.2 & 5.0703 & TRN \\
\hline CHEMBL1569311 & 688267 & 5.35 & 5.062 & TRN \\
\hline CHEMBL1601659 & 688267 & 6.2 & 5.0075 & TST \\
\hline CHEMBL1543001 & 688267 & 4.45 & 5.056 & TRN \\
\hline CHEMBL1486305 & 688267 & 6.05 & 5.0191 & TST \\
\hline CHEMBL1428459 & 688267 & 5.4 & 5.0307 & TRN \\
\hline CHEMBL1539636 & 688267 & 4.15 & 5.042 & TRN \\
\hline CHEMBL1967784 & 688267 & 4.05 & 5.0538 & TRN \\
\hline CHEMBL1399420 & 688267 & 6.2 & 5.1069 & TRN \\
\hline CHEMBL1362574 & 688267 & 4.1 & 4.9921 & TRN \\
\hline CHEMBL1559889 & 688267 & 5.85 & 5.0247 & TRN \\
\hline CHEMBL1330944 & 688267 & 5.55 & 5.0124 & TRN \\
\hline CHEMBL3213573 & 688267 & 5.65 & 5.0763 & TST \\
\hline CHEMBL1585069 & 688267 & 4.1 & 5.035 & TRN \\
\hline CHEMBL1552016 & 688267 & 6.2 & 5.1104 & TRN \\
\hline CHEMBL1479332 & 688267 & 4.65 & 5.0377 & TRN \\
\hline CHEMBL1595599 & 688267 & 4.05 & 5.0938 & TRN \\
\hline CHEMBL3207858 & 688267 & 6.2 & 5.0553 & TRN \\
\hline CHEMBL1389430 & 688267 & 4.4 & 5.0493 & TRN \\
\hline CHEMBL1525283 & 688267 & 5.75 & 5.1081 & TRN \\
\hline CHEMBL1539715 & 688267 & 4.0 & 5.0899 & TST \\
\hline CHEMBL1464510 & 688267 & 4.5 & 5.0395 & TST \\
\hline CHEMBL1301734 & 688267 & 4.05 & 5.016 & TST \\
\hline CHEMBL1523895 & 688267 & 5.0 & 5.0737 & TRN \\
\hline CHEMBL1369577 & 688267 & 4.1 & 5.0461 & TRN \\
\hline
\end{tabular}




\begin{tabular}{|c|c|c|c|c|c|}
\hline \multirow{3}{*}{$\begin{array}{l}\text { CHEMBL1519282 } \\
\text { CHEMBL3208084 }\end{array}$} & \multirow{3}{*}{$\begin{array}{l}688267 \\
688267\end{array}$} & \multicolumn{4}{|c|}{ Supplemental Table S2.txt } \\
\hline & & 6.0 & 4.96899 & 9999999999 & TRN \\
\hline & & 5.75 & 5.0805 & TST & \\
\hline CHEMBL1491784 & 688267 & 5.3 & 5.0272 & TRN & \\
\hline CHEMBL1471996 & 688267 & 4.55 & 5.0872 & TRN & \\
\hline CHEMBL1505453 & 688267 & 4.75 & 5.0927 & TST & \\
\hline CHEMBL1577347 & 688267 & 6.2 & 5.1423 & TRN & \\
\hline CHEMBL1413766 & 688267 & 4.0 & 5.0674 & TRN & \\
\hline CHEMBL1612344 & 688267 & 4.9 & 5.0475 & TRN & \\
\hline CHEMBL1327157 & 688267 & 4.85 & 5.1102 & TRN & \\
\hline CHEMBL1603975 & 688267 & 4.8 & 5.1451 & TRN & \\
\hline CHEMBL1592420 & 688267 & 6.2 & 5.1031 & TRN & \\
\hline CHEMBL1559005 & 688267 & 6.25 & 5.0755 & TRN & \\
\hline CHEMBL1386896 & 688267 & 4.9 & 5.061 & TST & \\
\hline CHEMBL1352610 & 688267 & 4.8 & 5.1423 & TRN & \\
\hline CHEMBL1467135 & 688267 & 4.6 & 5.0739 & TST & \\
\hline CHEMBL1483825 & 688267 & 4.6 & 5.0437 & TRN & \\
\hline CHEMBL1476565 & 688267 & 6.1 & 5.0849 & TRN & \\
\hline CHEMBL1560424 & 688267 & 6.1 & 5.0253 & TRN & \\
\hline CHEMBL1380365 & 688267 & 6.2 & 5.055 & TRN & \\
\hline CHEMBL1514460 & 688267 & 6.5 & 5.0351 & TRN & \\
\hline CHEMBL1306978 & 688267 & 5.8 & 5.0639 & TRN & \\
\hline CHEMBL1317992 & 688267 & 3.95 & 5.1056 & TRN & \\
\hline CHEMBL1520782 & 688267 & 5.3 & 5.0129 & TST & \\
\hline CHEMBL1343771 & 688267 & 5.8 & 5.0116 & TRN & \\
\hline CHEMBL1426238 & 688267 & 5.2 & 5.114 & TRN & \\
\hline CHEMBL1517703 & 688267 & 4.1 & 4.9791 & TRN & \\
\hline CHEMBL1483125 & 688267 & 4.4 & 4.9749 & TRN & \\
\hline CHEMBL1451461 & 688267 & 6.2 & 5.0842 & TRN & \\
\hline CHEMBL1397899 & 688267 & 6.2 & 5.001 & TRN & \\
\hline CHEMBL1521103 & 688267 & 6.15 & 5.0707 & TRN & \\
\hline CHEMBL1302089 & 688267 & 4.05 & 4.9988 & TST & \\
\hline CHEMBL1335685 & 688267 & 4.2 & 5.0196 & TRN & \\
\hline CHEMBL1576645 & 688267 & 5.4 & 5.1134 & TRN & \\
\hline CHEMBL1490022 & 688267 & 4.05 & 5.0026 & TST & \\
\hline CHEMBL1364968 & 688267 & 6.25 & 5.0542 & TRN & \\
\hline CHEMBL1394671 & 688267 & 6.2 & 5.0408 & TRN & \\
\hline CHEMBL1314767 & 688267 & 4.3 & 5.1276 & TRN & \\
\hline CHEMBL1414933 & 688267 & 4.0 & 5.0092 & TRN & \\
\hline CHEMBL1308369 & 688267 & 4.2 & 5.0388 & TRN & \\
\hline CHEMBL591404 & 688267 & 4.15 & 5.0331 & TST & \\
\hline CHEMBL1518736 & 688267 & 4.6 & 5.043 & TRN & \\
\hline CHEMBL1402658 & 688267 & 4.1 & 5.0632 & TRN & \\
\hline CHEMBL1454157 & 688267 & 4.35 & 5.0445 & TST & \\
\hline CHEMBL1459070 & 688267 & 4.25 & 5.0117 & TRN & \\
\hline CHEMBL1408112 & 688267 & 5.5 & 5.0573 & TRN & \\
\hline CHEMBL1529957 & 688267 & 5.5 & 5.0588 & TRN & \\
\hline CHEMBL1416363 & 688267 & 5.35 & 5.1232 & TST & \\
\hline CHEMBL1433383 & 688267 & 6.2 & 5.0843 & TRN & \\
\hline
\end{tabular}




\begin{tabular}{|c|c|c|c|c|}
\hline \multicolumn{5}{|c|}{ Supplemental Table S2.txt } \\
\hline CHEMBL1478658 & 688267 & 4.0 & 5.0149 & TST \\
\hline CHEMBL1357670 & 688267 & 6.5 & 5.0354 & TRN \\
\hline CHEMBL1582633 & 688267 & 5.8 & 5.0287 & TRN \\
\hline CHEMBL1493256 & 688267 & 6.5 & 5.0283 & TST \\
\hline CHEMBL1463832 & 688267 & 6.0 & 4.9919 & TRN \\
\hline CHEMBL1512400 & 688267 & 6.05 & 5.0161 & TRN \\
\hline CHEMBL1471647 & 688267 & 6.2 & 5.0411 & TST \\
\hline CHEMBL1487057 & 688267 & 4.0 & 5.0301 & TRN \\
\hline CHEMBL1602658 & 688267 & 4.1 & 5.1226 & TRN \\
\hline CHEMBL1432683 & 688267 & 4.1 & 5.0344 & TRN \\
\hline CHEMBL1593431 & 688267 & 5.35 & 5.151 & TRN \\
\hline CHEMBL1317271 & 688267 & 6.2 & 5.1338 & TRN \\
\hline CHEMBL1432428 & 688267 & 5.4 & 5.095 & TRN \\
\hline CHEMBL1457239 & 688267 & 5.15 & 5.0137 & TRN \\
\hline CHEMBL1494446 & 688267 & 4.4 & 5.0636 & TRN \\
\hline CHEMBL1525728 & 688267 & 6.2 & 5.1619 & TST \\
\hline CHEMBL3195723 & 688267 & 5.05 & 5.0294 & TST \\
\hline CHEMBL1583202 & 688267 & 5.9 & 5.083 & TST \\
\hline CHEMBL1559670 & 688267 & 4.05 & 5.0408 & TRN \\
\hline CHEMBL1389768 & 688267 & 4.25 & 5.0217 & TST \\
\hline CHEMBL1522018 & 688267 & 4.0 & 5.0068 & TST \\
\hline CHEMBL1517194 & 688267 & 4.65 & 5.0559 & TST \\
\hline CHEMBL1322828 & 688267 & 4.3 & 5.0069 & TRN \\
\hline CHEMBL1361668 & 688267 & 5.4 & 5.0502 & TRN \\
\hline CHEMBL1381069 & 688267 & 4.0 & 5.0901 & TRN \\
\hline CHEMBL1422860 & 688267 & 4.0 & 5.042 & TRN \\
\hline CHEMBL1563599 & 688267 & 5.1 & 5.064 & TRN \\
\hline CHEMBL1551531 & 688267 & 6.2 & 5.1089 & TRN \\
\hline CHEMBL1364575 & 688267 & 5.4 & 5.0265 & TST \\
\hline CHEMBL1452307 & 688267 & 4.25 & 4.9968 & TRN \\
\hline CHEMBL1307267 & 688267 & 6.2 & 5.0394 & TST \\
\hline CHEMBL1579715 & 688267 & 4.3 & 5.0593 & TRN \\
\hline CHEMBL1345988 & 688267 & 5.4 & 5.0099 & TRN \\
\hline CHEMBL1334302 & 688267 & 4.0 & 5.0259 & TST \\
\hline CHEMBL1981446 & 688267 & 5.75 & 5.0032 & TRN \\
\hline CHEMBL3194112 & 688267 & 5.55 & 4.9595 & TRN \\
\hline CHEMBL1530393 & 688267 & 5.5 & 5.0111 & TRN \\
\hline CHEMBL3194403 & 688267 & 5.55 & 5.0377 & TST \\
\hline CHEMBL1429289 & 688267 & 4.55 & 5.0872 & TRN \\
\hline CHEMBL1317816 & 688267 & 5.45 & 5.0566 & TST \\
\hline CHEMBL1381635 & 688267 & 6.15 & 5.0712 & TRN \\
\hline CHEMBL1425270 & 688267 & 4.65 & 5.0867 & TRN \\
\hline CHEMBL1583370 & 688267 & 4.55 & 5.0724 & TRN \\
\hline CHEMBL1508223 & 688267 & 4.5 & 5.0016 & TST \\
\hline CHEMBL1466705 & 688267 & 6.2 & 5.0132 & TRN \\
\hline CHEMBL1328235 & 688267 & 5.7 & 5.052 & TST \\
\hline CHEMBL1500576 & 688267 & 4.1 & 4.9887 & TRN \\
\hline CHEMBL1490382 & 688267 & 5.2 & 5.0335 & TRN \\
\hline
\end{tabular}




\begin{tabular}{|c|c|c|c|c|}
\hline & & & pplement & al $\mathrm{Ta}$ \\
\hline CHEMBL1504955 & 688267 & 4.5 & 5.0119 & TRN \\
\hline CHEMBL1606736 & 688267 & 6.2 & 5.0542 & TST \\
\hline CHEMBL1312659 & 688267 & 4.1 & 5.0492 & TST \\
\hline CHEMBL3211035 & 688267 & 4.35 & 5.0577 & TRN \\
\hline CHEMBL1552917 & 688267 & 4.4 & 5.1304 & TRN \\
\hline CHEMBL1532527 & 688267 & 6.15 & 5.0405 & TRN \\
\hline CHEMBL1430531 & 688267 & 4.35 & 5.1114 & TRN \\
\hline CHEMBL1474470 & 688267 & 6.2 & 5.0286 & TRN \\
\hline CHEMBL1389559 & 688267 & 4.6 & 4.9961 & TRN \\
\hline CHEMBL1386217 & 688267 & 6.15 & 5.0542 & TRN \\
\hline CHEMBL1310757 & 688267 & 4.75 & 5.1159 & TRN \\
\hline CHEMBL1438342 & 688267 & 4.0 & 5.0619 & TRN \\
\hline CHEMBL1474938 & 688267 & 4.0 & 4.9704 & TRN \\
\hline CHEMBL1393478 & 688267 & 5.75 & 5.0088 & TRN \\
\hline CHEMBL1360617 & 688267 & 3.95 & 5.085 & TRN \\
\hline CHEMBL1367268 & 688267 & 4.0 & 5.0557 & TRN \\
\hline CHEMBL1366748 & 688267 & 5.3 & 5.0451 & TRN \\
\hline CHEMBL1573685 & 688267 & 4.25 & 5.0741 & TRN \\
\hline CHEMBL1379429 & 688267 & 5.35 & 5.0409 & TST \\
\hline CHEMBL1471558 & 688267 & 4.5 & 5.0814 & TRN \\
\hline CHEMBL3194032 & 688267 & 4.0 & 5.0694 & TRN \\
\hline CHEMBL1327719 & 688267 & 4.1 & 5.0158 & TRN \\
\hline CHEMBL1333222 & 688267 & 4.0 & 4.9787 & TST \\
\hline CHEMBL1600129 & 688267 & 5.3 & 5.0495 & TRN \\
\hline CHEMBL1394993 & 688267 & 4.35 & 5.0515 & TRN \\
\hline CHEMBL1556511 & 688267 & 5.55 & 5.0322 & TRN \\
\hline CHEMBL1605886 & 688267 & 6.2 & 5.0455 & TST \\
\hline CHEMBL1528042 & 688267 & 4.35 & 5.0392 & TRN \\
\hline CHEMBL1491385 & 688267 & 6.2 & 5.0974 & TRN \\
\hline CHEMBL1405603 & 688267 & 4.05 & 5.0242 & TRN \\
\hline CHEMBL3213376 & 688267 & 5.6 & 5.0263 & TST \\
\hline CHEMBL1378576 & 688267 & 5.3 & 5.0554 & TRN \\
\hline CHEMBL1609783 & 688267 & 5.8 & 5.0836 & TRN \\
\hline CHEMBL1568811 & 688267 & 3.95 & 5.0384 & TRN \\
\hline CHEMBL1411631 & 688267 & 5.3 & 5.0744 & TST \\
\hline CHEMBL1428396 & 688267 & 5.25 & 4.9756 & TRN \\
\hline CHEMBL1484409 & 688267 & 5.45 & 5.1013 & TRN \\
\hline CHEMBL1572537 & 688267 & 4.65 & 5.0492 & TRN \\
\hline CHEMBL1477042 & 688267 & 5.55 & 5.0582 & TRN \\
\hline CHEMBL1583523 & 688267 & 5.45 & 5.0421 & TST \\
\hline CHEMBL1314921 & 688267 & 4.4 & 5.0596 & TST \\
\hline CHEMBL1387076 & 688267 & 5.5 & 5.0532 & TRN \\
\hline CHEMBL3193133 & 688267 & 4.4 & 5.0091 & TRN \\
\hline CHEMBL1373946 & 688267 & 4.6 & 4.9944 & TRN \\
\hline CHEMBL1301796 & 688267 & 4.75 & 5.0826 & TRN \\
\hline CHEMBL1553949 & 688267 & 5.55 & 5.0882 & TRN \\
\hline CHEMBL1506534 & 688267 & 4.05 & 5.0832 & TRN \\
\hline CHEMBL1307310 & 688267 & 4.55 & 5.0621 & TST \\
\hline
\end{tabular}




\begin{tabular}{|c|c|c|c|c|c|}
\hline \multicolumn{6}{|c|}{ Supplemental Table s2.txt } \\
\hline CHEMBL1372833 & 688267 & 5.3 & 5.1707 & TRN & \\
\hline CHEMBL1301853 & 688267 & 4.95 & 5.1049 & TRN & \\
\hline CHEMBL1598539 & 688267 & 5.35 & 5.0745 & TRN & \\
\hline CHEMBL1381676 & 688267 & 4.0 & 5.0316 & TRN & \\
\hline CHEMBL1528727 & 688267 & 4.25 & 5.0884 & TRN & \\
\hline CHEMBL1537783 & 688267 & 5.0 & 5.13899 & 9999999999 & TST \\
\hline CHEMBL1300629 & 688267 & 4.3 & 5.0416 & TST & \\
\hline CHEMBL1490753 & 688267 & 5.65 & 5.0685 & TST & \\
\hline CHEMBL1580535 & 688267 & 6.2 & 5.1166 & TRN & \\
\hline CHEMBL1306418 & 688267 & 5.1 & 4.9869 & TST & \\
\hline CHEMBL1572761 & 688267 & 5.25 & 5.0763 & TST & \\
\hline CHEMBL2374064 & 688267 & 5.5 & 5.0695 & TRN & \\
\hline CHEMBL1530142 & 688267 & 5.9 & 5.0089 & TST & \\
\hline CHEMBL1488945 & 688267 & 5.25 & 5.1311 & TST & \\
\hline CHEMBL1485240 & 688267 & 4.2 & 5.0769 & TST & \\
\hline CHEMBL1389244 & 688267 & 6.2 & 5.04 & TRN & \\
\hline CHEMBL1357922 & 688267 & 4.2 & 5.0899 & TRN & \\
\hline CHEMBL1346150 & 688267 & 5.05 & 5.0457 & TRN & \\
\hline CHEMBL1371954 & 688267 & 4.05 & 5.1228 & TRN & \\
\hline CHEMBL1570395 & 688267 & 4.9 & 5.0735 & TRN & \\
\hline CHEMBL1491572 & 688267 & 4.05 & 4.9979 & TRN & \\
\hline CHEMBL1552792 & 688267 & 5.9 & 5.1576 & TRN & \\
\hline CHEMBL1446297 & 688267 & 6.2 & 5.0919 & TST & \\
\hline CHEMBL1396856 & 688267 & 5.55 & 5.0365 & TRN & \\
\hline CHEMBL1471384 & 688267 & 4.05 & 5.0799 & TST & \\
\hline CHEMBL1486136 & 688267 & 6.25 & 5.0343 & TST & \\
\hline CHEMBL1306907 & 688267 & 5.45 & 5.1168 & TST & \\
\hline CHEMBL1450147 & 688267 & 5.25 & 5.0217 & TRN & \\
\hline CHEMBL1604200 & 688267 & 6.2 & 5.0365 & TRN & \\
\hline CHEMBL1374406 & 688267 & 4.6 & 5.0002 & TST & \\
\hline CHEMBL1496653 & 688267 & 4.7 & 5.1148 & TRN & \\
\hline CHEMBL3195960 & 688267 & 4.05 & 5.0931 & TST & \\
\hline CHEMBL1315027 & 688267 & 5.4 & 5.0998 & TRN & \\
\hline CHEMBL1562456 & 688267 & 5.55 & 5.0905 & TRN & \\
\hline CHEMBL1438571 & 688267 & 3.9 & 5.0311 & TRN & \\
\hline CHEMBL1561956 & 688267 & 5.9 & 4.9769 & TRN & \\
\hline CHEMBL1612890 & 688267 & 4.05 & 5.0257 & TRN & \\
\hline CHEMBL1509815 & 688267 & 6.45 & 5.1398 & TRN & \\
\hline CHEMBL1328380 & 688267 & 5.2 & 5.1573 & TRN & \\
\hline CHEMBL1433351 & 688267 & 6.15 & 5.1326 & TRN & \\
\hline CHEMBL1336754 & 688267 & 5.9 & 5.0113 & TRN & \\
\hline CHEMBL1593958 & 688267 & 4.0 & 5.0392 & TRN & \\
\hline CHEMBL1361019 & 688267 & 5.95 & 5.1731 & TRN & \\
\hline CHEMBL1476174 & 688267 & 4.0 & 5.0477 & TRN & \\
\hline CHEMBL1323407 & 688267 & 5.2 & 5.0477 & TST & \\
\hline CHEMBL1553580 & 688267 & 3.95 & 5.0318 & TRN & \\
\hline CHEMBL1499951 & 688267 & 4.55 & 5.0066 & TRN & \\
\hline CHEMBL1556911 & 688267 & 3.95 & 5.0071 & TRN & \\
\hline
\end{tabular}




\begin{tabular}{|c|c|c|c|c|}
\hline \multicolumn{5}{|c|}{ Supplemental Table S2.txt } \\
\hline CHEMBL1426505 & 688267 & 4.0 & 4.9835 & TST \\
\hline CHEMBL1470592 & 688267 & 5.6 & 5.1536 & TRN \\
\hline CHEMBL1313547 & 688267 & 4.3 & 5.0838 & TST \\
\hline CHEMBL1525874 & 688267 & 5.35 & 5.1022 & TRN \\
\hline CHEMBL1585441 & 688267 & 6.5 & 5.1046 & TRN \\
\hline CHEMBL1571137 & 688267 & 5.05 & 5.0833 & TRN \\
\hline CHEMBL1385902 & 688267 & 4.0 & 5.0735 & TRN \\
\hline CHEMBL1468138 & 688267 & 4.0 & 5.0657 & TRN \\
\hline CHEMBL1545568 & 688267 & 4.5 & 5.0844 & TRN \\
\hline CHEMBL1566317 & 688267 & 4.0 & 5.0973 & TRN \\
\hline CHEMBL1571434 & 688267 & 6.0 & 5.0441 & TRN \\
\hline CHEMBL1473298 & 688267 & 6.2 & 5.0429 & TRN \\
\hline CHEMBL1597325 & 688267 & 4.15 & 5.0639 & TRN \\
\hline CHEMBL1439064 & 688267 & 4.65 & 5.0483 & TRN \\
\hline CHEMBL1497817 & 688267 & 5.4 & 4.9983 & TRN \\
\hline CHEMBL1473890 & 688267 & 5.3 & 5.0606 & TRN \\
\hline CHEMBL1548323 & 688267 & 4.9 & 5.0616 & TRN \\
\hline CHEMBL 3189877 & 688267 & 4.6 & 4.9722 & TST \\
\hline CHEMBL1552652 & 688267 & 4.0 & 5.1006 & TRN \\
\hline CHEMBL1494160 & 688267 & 3.95 & 4.9918 & TRN \\
\hline CHEMBL1558588 & 688267 & 5.55 & 5.0245 & TRN \\
\hline CHEMBL1345922 & 688267 & 6.0 & 5.0918 & TRN \\
\hline CHEMBL1535217 & 688267 & 5.15 & 5.0812 & TRN \\
\hline CHEMBL1364240 & 688267 & 4.4 & 5.0503 & TST \\
\hline CHEMBL1580482 & 688267 & 6.1 & 5.05 & TRN \\
\hline CHEMBL1458001 & 688267 & 4.05 & 5.0302 & TRN \\
\hline CHEMBL1529632 & 688267 & 4.4 & 5.1409 & TRN \\
\hline CHEMBL 1600058 & 688267 & 5.9 & 4.9883 & TRN \\
\hline CHEMBL1533633 & 688267 & 5.5 & 5.0708 & TRN \\
\hline CHEMBL1602552 & 688267 & 4.2 & 5.064 & TST \\
\hline CHEMBL1573815 & 688267 & 3.95 & 5.0243 & TRN \\
\hline CHEMBL1587987 & 688267 & 4.55 & 4.9818 & TRN \\
\hline CHEMBL1476881 & 688267 & 5.8 & 5.0222 & TRN \\
\hline CHEMBL1467589 & 688267 & 5.05 & 5.0649 & TRN \\
\hline CHEMBL1397859 & 688267 & 6.15 & 5.1044 & TRN \\
\hline CHEMBL1517411 & 688267 & 4.4 & 5.0489 & TRN \\
\hline CHEMBL1539610 & 688267 & 6.15 & 5.0453 & TRN \\
\hline CHEMBL1535760 & 688267 & 6.15 & 4.9978 & TRN \\
\hline CHEMBL1414440 & 688267 & 6.15 & 5.0598 & TRN \\
\hline CHEMBL1354942 & 688267 & 5.9 & 5.0022 & TRN \\
\hline CHEMBL1510421 & 688267 & 5.45 & 5.0128 & TST \\
\hline CHEMBL1398236 & 688267 & 4.35 & 5.0973 & TRN \\
\hline CHEMBL1444641 & 688267 & 6.2 & 4.997 & TRN \\
\hline CHEMBL1608804 & 688267 & 4.25 & 5.0954 & TRN \\
\hline CHEMBL1584702 & 688267 & 3.95 & 5.0142 & TST \\
\hline CHEMBL1537386 & 688267 & 3.95 & 5.1088 & TRN \\
\hline CHEMBL1334066 & 688267 & 4.5 & $5.1110 e$ & 0000000001 \\
\hline CHEMBL1403245 & 688267 & 4.5 & 5.0743 & TST \\
\hline
\end{tabular}




\begin{tabular}{|c|c|c|c|c|}
\hline & & & upplement & al $\mathrm{T}$ \\
\hline CHEMBL1596648 & 688267 & 4.65 & 5.1381 & TST \\
\hline CHEMBL1397380 & 688267 & 4.0 & 5.0245 & TRN \\
\hline CHEMBL1543834 & 688267 & 4.05 & 5.1291 & TRN \\
\hline CHEMBL1610196 & 688267 & 6.5 & 5.0709 & TRN \\
\hline CHEMBL1332066 & 688267 & 4.05 & 5.0365 & TRN \\
\hline CHEMBL1372006 & 688267 & 3.95 & 5.0133 & TRN \\
\hline CHEMBL1573116 & 688267 & 5.25 & 4.9911 & TRN \\
\hline CHEMBL1356570 & 688267 & 6.2 & 5.0282 & TST \\
\hline CHEMBL3197978 & 688267 & 4.15 & 5.0164 & TRN \\
\hline CHEMBL1410634 & 688267 & 6.2 & 5.1079 & TRN \\
\hline CHEMBL1515124 & 688267 & 4.15 & 5.0254 & TRN \\
\hline CHEMBL1422856 & 688267 & 4.25 & 5.1273 & TST \\
\hline CHEMBL1590072 & 688267 & 5.45 & 5.1104 & TRN \\
\hline CHEMBL1608817 & 688267 & 5.8 & 5.0771 & TRN \\
\hline CHEMBL3211600 & 688267 & 4.55 & 5.0058 & TRN \\
\hline CHEMBL3190559 & 688267 & 6.25 & 4.9966 & TRN \\
\hline CHEMBL1574367 & 688267 & 4.7 & 5.0243 & TRN \\
\hline CHEMBL1334515 & 688267 & 4.4 & 5.0067 & TRN \\
\hline CHEMBL271622 & 688267 & 5.45 & 5.0313 & TRN \\
\hline CHEMBL1488698 & 688267 & 4.6 & 5.0353 & TST \\
\hline CHEMBL1555981 & 688267 & 4.1 & 5.0012 & TRN \\
\hline CHEMBL1377032 & 688267 & 5.7 & 5.0834 & TST \\
\hline CHEMBL1349256 & 688267 & 6.2 & 5.0512 & TRN \\
\hline CHEMBL1476870 & 688267 & 6.25 & 5.1 & TRN \\
\hline CHEMBL1307346 & 688267 & 5.55 & 5.0327 & TRN \\
\hline CHEMBL1355851 & 688267 & 6.1 & 5.0302 & TRN \\
\hline CHEMBL1381519 & 688267 & 4.4 & 5.126 & TRN \\
\hline CHEMBL1397413 & 688267 & 6.2 & 5.0752 & TRN \\
\hline CHEMBL1541953 & 688267 & 5.3 & 5.0893 & TRN \\
\hline CHEMBL1321180 & 688267 & 4.6 & 5.0264 & TST \\
\hline CHEMBL1387802 & 688267 & 3.95 & 5.0667 & TRN \\
\hline CHEMBL1321401 & 688267 & 4.05 & 5.0402 & TRN \\
\hline CHEMBL1440403 & 688267 & 3.95 & 5.0527 & TRN \\
\hline CHEMBL3209526 & 688267 & 5.55 & 5.0134 & TST \\
\hline CHEMBL1339266 & 688267 & 5.7 & 5.0989 & TRN \\
\hline CHEMBL1520018 & 688267 & 6.2 & 5.0238 & TST \\
\hline CHEMBL 1317370 & 688267 & 5.9 & 5.1465 & TRN \\
\hline CHEMBL1312547 & 688267 & 4.35 & 5.0337 & TST \\
\hline CHEMBL119870 & 688267 & 4.95 & 5.0054 & TST \\
\hline CHEMBL1499152 & 688267 & 4.35 & 5.0248 & TRN \\
\hline CHEMBL1527749 & 688267 & 5.35 & 5.1077 & TRN \\
\hline CHEMBL 225270 & 688267 & 6.15 & 4.9915 & TST \\
\hline CHEMBL1393545 & 688267 & 5.5 & 5.0104 & TRN \\
\hline CHEMBL1304125 & 688267 & 6.2 & 5.1034 & TRN \\
\hline CHEMBL1419360 & 688267 & 5.85 & 4.9922 & TRN \\
\hline CHEMBL3214235 & 688267 & 6.2 & 5.0156 & TST \\
\hline CHEMBL1312805 & 688267 & 6.2 & 5.093 & TRN \\
\hline CHEMBL1442067 & 688267 & 6.2 & 5.0335 & TST \\
\hline
\end{tabular}




\begin{tabular}{|c|c|c|c|c|}
\hline & & & oplement & \\
\hline CHEMBL1385956 & 688267 & 4.6 & 5.0619 & TRN \\
\hline CHEMBL1595329 & 688267 & 4.6 & 5.0344 & TST \\
\hline CHEMBL1341387 & 688267 & 6.1 & 5.0823 & TRN \\
\hline CHEMBL1558066 & 688267 & 4.4 & 5.0768 & TST \\
\hline CHEMBL3214059 & 688267 & 5.6 & 5.0363 & TRN \\
\hline CHEMBL1559233 & 688267 & 4.15 & 5.0526 & TRN \\
\hline CHEMBL1552673 & 688267 & 6.2 & 5.1082 & TRN \\
\hline CHEMBL1533322 & 688267 & 5.3 & 5.0783 & TRN \\
\hline CHEMBL1416605 & 688267 & 6.25 & 5.0613 & TRN \\
\hline CHEMBL1436060 & 688267 & 6.1 & 5.0631 & TRN \\
\hline CHEMBL1326134 & 688267 & 5.4 & 5.0057 & TST \\
\hline CHEMBL1325048 & 688267 & 4.75 & 5.0355 & TRN \\
\hline CHEMBL1428054 & 688267 & 3.95 & 4.9677 & TRN \\
\hline CHEMBL1475264 & 688267 & 6.2 & 5.0209 & TRN \\
\hline CHEMBL1385414 & 688267 & 6.2 & 5.0436 & TRN \\
\hline CHEMBL1435997 & 688267 & 6.5 & 5.0494 & TRN \\
\hline CHEMBL1398035 & 688267 & 4.8 & 5.0341 & TRN \\
\hline CHEMBL1309603 & 688267 & 4.55 & 5.0338 & TST \\
\hline CHEMBL1590231 & 688267 & 4.7 & 5.1071 & TRN \\
\hline CHEMBL1462393 & 688267 & 4.95 & 5.121 & TST \\
\hline CHEMBL1461978 & 688267 & 6.2 & 5.1296 & TRN \\
\hline CHEMBL1443536 & 688267 & 5.8 & 5.0935 & TRN \\
\hline CHEMBL1380618 & 688267 & 5.55 & 5.0959 & TRN \\
\hline CHEMBL1465786 & 688267 & 6.2 & 5.0032 & TST \\
\hline CHEMBL1351663 & 688267 & 5.35 & 5.0818 & TRN \\
\hline CHEMBL1559141 & 688267 & 4.1 & 5.0545 & TRN \\
\hline CHEMBL1408373 & 688267 & 4.05 & 4.998 & TRN \\
\hline CHEMBL1522610 & 688267 & 4.0 & 5.1056 & TRN \\
\hline CHEMBL1507193 & 688267 & 4.75 & 5.0611 & TST \\
\hline CHEMBL1548563 & 688267 & 5.35 & 5.1514 & TST \\
\hline CHEMBL3189359 & 688267 & 4.55 & 5.0137 & TST \\
\hline CHEMBL 1443388 & 688267 & 4.85 & 5.0711 & TST \\
\hline CHEMBL1527432 & 688267 & 4.8 & 5.0553 & TST \\
\hline CHEMBL1404873 & 688267 & 6.15 & 5.0446 & TRN \\
\hline CHEMBL1552175 & 688267 & 6.45 & 5.0704 & TRN \\
\hline CHEMBL1600655 & 688267 & 5.85 & 5.0292 & TRN \\
\hline CHEMBL 1425003 & 688267 & 5.55 & 5.0403 & TRN \\
\hline CHEMBL1448434 & 688267 & 6.2 & 5.1023 & TST \\
\hline CHEMBL1594117 & 688267 & 6.2 & 5.0676 & TST \\
\hline CHEMBL1537077 & 688267 & 4.35 & 5.0888 & TRN \\
\hline CHEMBL1496214 & 688267 & 4.05 & 5.0323 & TRN \\
\hline CHEMBL1338905 & 688267 & 5.35 & 5.098 & TRN \\
\hline CHEMBL1362575 & 688267 & 4.0 & 5.1236 & TRN \\
\hline CHEMBL1324857 & 688267 & 4.55 & 5.0695 & TRN \\
\hline CHEMBL1455677 & 688267 & 4.05 & 5.0984 & TRN \\
\hline CHEMBL1585201 & 688267 & 6.25 & 5.1025 & TST \\
\hline CHEMBL1522459 & 688267 & 5.25 & 5.0937 & TRN \\
\hline CHEMBL1598337 & 688267 & 5.4 & 5.0857 & TRN \\
\hline
\end{tabular}




\begin{tabular}{|c|c|c|c|c|c|}
\hline \multicolumn{6}{|c|}{ Supplemental Table S2.txt } \\
\hline CHEMBL1585493 & 688267 & 4.65 & 5.0546 & TRN & \\
\hline CHEMBL1371342 & 688267 & 4.5 & 5.0076 & TRN & \\
\hline CHEMBL1585779 & 688267 & 5.65 & 5.0437 & TST & \\
\hline CHEMBL1468193 & 688267 & 4.05 & 5.0859 & TRN & \\
\hline CHEMBL1565909 & 688267 & 3.95 & 4.9989 & TRN & \\
\hline CHEMBL1493641 & 688267 & 4.6 & 5.1132 & TRN & \\
\hline CHEMBL1526484 & 688267 & 4.45 & 4.9939 & TRN & \\
\hline CHEMBL1451349 & 688267 & 4.05 & 5.0015 & TRN & \\
\hline CHEMBL1602795 & 688267 & 3.95 & 5.0774 & TRN & \\
\hline CHEMBL1477293 & 688267 & 6.1 & 5.0985 & TST & \\
\hline CHEMBL1352452 & 688267 & 4.0 & 5.1016 & TRN & \\
\hline CHEMBL 1445860 & 688267 & 4.9 & 5.0919 & TST & \\
\hline CHEMBL1332931 & 688267 & 6.2 & 5.0212 & TRN & \\
\hline CHEMBL1368529 & 688267 & 3.95 & 5.0148 & TST & \\
\hline CHEMBL1338621 & 688267 & 4.35 & 5.0141 & TRN & \\
\hline CHEMBL1394479 & 688267 & 5.05 & 5.0228 & TRN & \\
\hline CHEMBL1310327 & 688267 & 6.15 & 5.0123 & TRN & \\
\hline CHEMBL1452095 & 688267 & 4.7 & 5.0813 & TST & \\
\hline CHEMBL1342450 & 688267 & 4.25 & 5.0549 & TST & \\
\hline CHEMBL1465975 & 688267 & 6.5 & 5.1179 & TRN & \\
\hline CHEMBL1593740 & 688267 & 6.15 & 5.1416 & TRN & \\
\hline CHEMBL1396379 & 688267 & 6.2 & 5.0446 & TRN & \\
\hline CHEMBL1460987 & 688267 & 5.25 & 5.15 & TRN & \\
\hline CHEMBL1553437 & 688267 & 6.2 & 4.9975 & TRN & \\
\hline CHEMBL1354469 & 688267 & 4.8 & 5.0388 & TST & \\
\hline CHEMBL145897 & 688267 & 6.2 & 5.0141 & TRN & \\
\hline CHEMBL1350436 & 688267 & 4.45 & 5.03100 & 0000000001 & TST \\
\hline CHEMBL1464301 & 688267 & 4.0 & 5.1072 & TRN & \\
\hline CHEMBL1322763 & 688267 & 6.2 & 4.9928 & TST & \\
\hline CHEMBL3189592 & 688267 & 5.95 & 4.9896 & TST & \\
\hline CHEMBL1312389 & 688267 & 6.45 & 5.1793 & TRN & \\
\hline CHEMBL1378709 & 688267 & 6.0 & 5.0398 & TST & \\
\hline CHEMBL1552831 & 688267 & 4.0 & 5.0692 & TRN & \\
\hline CHEMBL1478466 & 688267 & 4.0 & 5.0568 & TRN & \\
\hline CHEMBL1361713 & 688267 & 5.35 & 5.13200 & 2000000001 & TRN \\
\hline CHEMBL1431200 & 688267 & 6.1 & 5.0316 & TST & \\
\hline CHEMBL1574821 & 688267 & 5.3 & 5.0849 & TST & \\
\hline CHEMBL1559528 & 688267 & 6.2 & 5.0739 & TRN & \\
\hline CHEMBL1316237 & 688267 & 6.15 & 5.0777 & TRN & \\
\hline CHEMBL1408825 & 688267 & 4.65 & 5.0478 & TRN & \\
\hline CHEMBL3194862 & 688267 & 6.0 & 5.0336 & TST & \\
\hline CHEMBL1591960 & 688267 & 6.2 & 5.0963 & TST & \\
\hline CHEMBL1593894 & 688267 & 6.1 & 5.1424 & TRN & \\
\hline CHEMBL1593483 & 688267 & 4.4 & 5.0022 & TRN & \\
\hline CHEMBL 3212798 & 688267 & 4.45 & 5.0764 & TRN & \\
\hline CHEMBL1512897 & 688267 & 5.35 & 5.0906 & TRN & \\
\hline CHEMBL1498508 & 688267 & 5.3 & 5.0513 & TRN & \\
\hline CHEMBL1549152 & 688267 & 5.0 & 5.114 & TST & \\
\hline
\end{tabular}




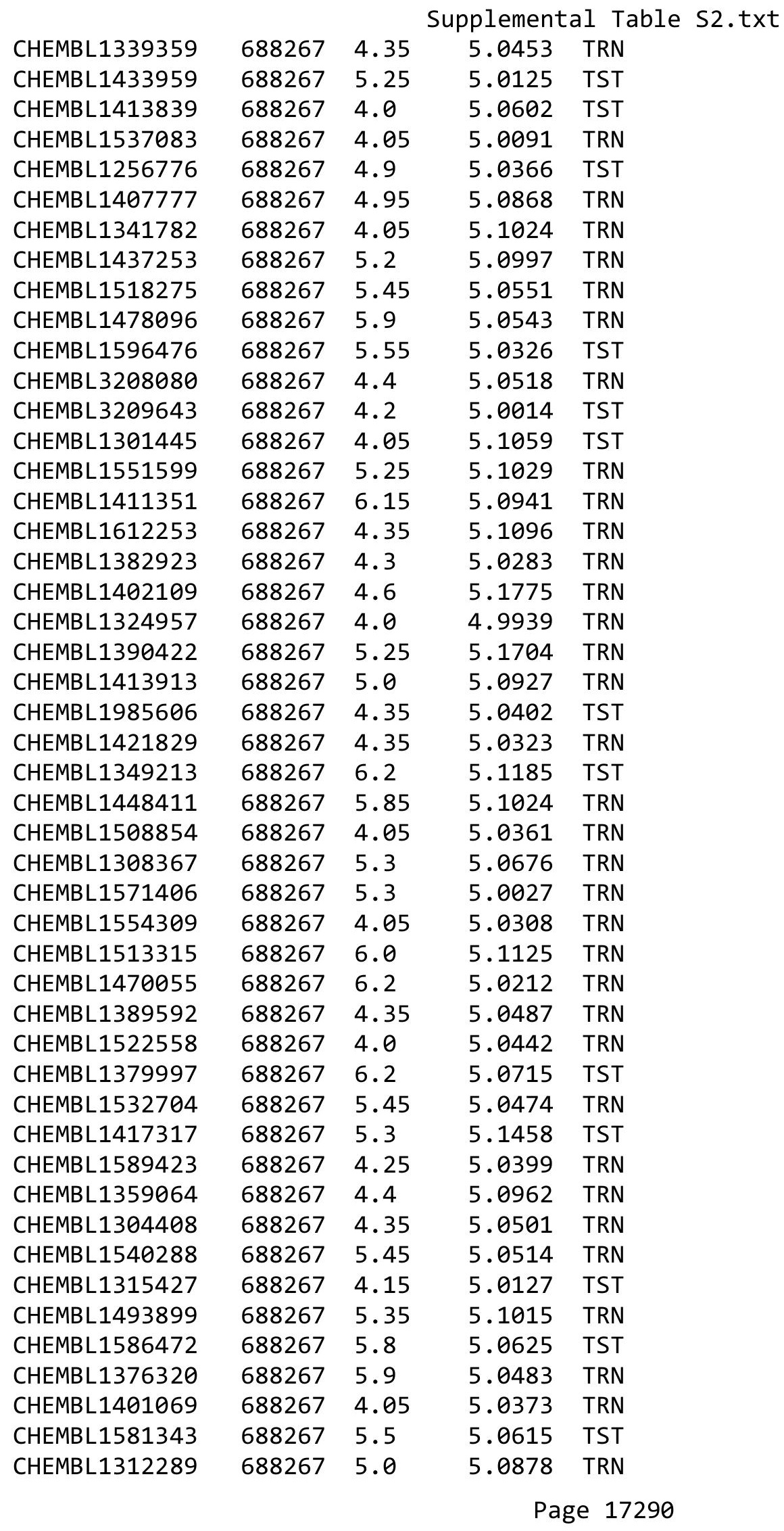




\begin{tabular}{|c|c|c|c|c|}
\hline \multicolumn{5}{|c|}{ Supplemental Table S2.txt } \\
\hline CHEMBL1564376 & 688267 & 4.3 & 5.0491 & TRN \\
\hline CHEMBL1451456 & 688267 & 4.05 & 4.9926 & TRN \\
\hline CHEMBL1608940 & 688267 & 4.05 & 5.0472 & TST \\
\hline CHEMBL1323642 & 688267 & 5.2 & 5.0355 & TST \\
\hline CHEMBL1418959 & 688267 & 5.55 & 5.0417 & TRN \\
\hline CHEMBL1389873 & 688267 & 5.55 & 5.0198 & TST \\
\hline CHEMBL1582017 & 688267 & 4.5 & 5.0302 & TST \\
\hline CHEMBL1310576 & 688267 & 5.05 & 5.0053 & TST \\
\hline CHEMBL1600127 & 688267 & 4.55 & 5.1266 & TST \\
\hline CHEMBL1567606 & 688267 & 4.3 & 5.0633 & TRN \\
\hline CHEMBL1579855 & 688267 & 4.4 & 5.0198 & TRN \\
\hline CHEMBL1393055 & 688267 & 4.1 & 5.0634 & TRN \\
\hline CHEMBL1434585 & 688267 & 6.15 & 5.159 & TRN \\
\hline CHEMBL1591396 & 688267 & 4.45 & 5.0154 & TRN \\
\hline CHEMBL1541921 & 688267 & 5.0 & 5.0786 & TRN \\
\hline CHEMBL1596922 & 688267 & 4.0 & 5.0703 & TRN \\
\hline CHEMBL1373521 & 688267 & 4.1 & 5.0141 & TRN \\
\hline CHEMBL1477522 & 688267 & 5.3 & 5.0114 & TRN \\
\hline CHEMBL1359303 & 688267 & 5.15 & 5.1188 & TRN \\
\hline CHEMBL1446322 & 688267 & 4.05 & 5.0369 & TST \\
\hline CHEMBL1313564 & 688267 & 5.55 & 5.0731 & TRN \\
\hline CHEMBL1564221 & 688267 & 5.5 & 4.9793 & TST \\
\hline CHEMBL1358751 & 688267 & 6.2 & 5.0381 & TST \\
\hline CHEMBL1511123 & 688267 & 4.3 & 5.119 & TRN \\
\hline CHEMBL1355510 & 688267 & 6.05 & 5.0286 & TRN \\
\hline CHEMBL1374490 & 688267 & 4.4 & 5.0194 & TRN \\
\hline CHEMBL1585057 & 688267 & 6.2 & 5.0632 & TST \\
\hline CHEMBL1573542 & 688267 & 3.95 & 5.0697 & TST \\
\hline CHEMBL1232416 & 688267 & 5.25 & 5.0768 & TST \\
\hline CHEMBL1565197 & 688267 & 4.05 & 5.0896 & TRN \\
\hline CHEMBL1589068 & 688267 & 4.9 & 5.0704 & TST \\
\hline CHEMBL1548091 & 688267 & 4.0 & 5.0682 & TST \\
\hline CHEMBL1416085 & 688267 & 6.5 & 5.1144 & TST \\
\hline CHEMBL1431614 & 688267 & 4.05 & 5.1054 & TRN \\
\hline CHEMBL1423996 & 688267 & 4.0 & 5.1093 & TRN \\
\hline CHEMBL1381836 & 688267 & 4.55 & 5.079 & TRN \\
\hline CHEMBL1389950 & 688267 & 4.4 & 5.0452 & TRN \\
\hline CHEMBL1413042 & 688267 & 4.35 & 5.0463 & TRN \\
\hline CHEMBL1526619 & 688267 & 6.5 & 5.0063 & TST \\
\hline CHEMBL1383748 & 688267 & 5.45 & 5.0262 & TRN \\
\hline CHEMBL1530128 & 688267 & 4.35 & 5.1562 & TRN \\
\hline CHEMBL1437366 & 688267 & 4.6 & 5.0934 & TRN \\
\hline CHEMBL1464074 & 688267 & 5.1 & 5.0728 & TRN \\
\hline CHEMBL1573760 & 688267 & 5.45 & 5.0769 & TRN \\
\hline CHEMBL1459516 & 688267 & 4.25 & 5.1776 & TRN \\
\hline CHEMBL1317518 & 688267 & 4.0 & 5.1287 & TRN \\
\hline CHEMBL1436227 & 688267 & 4.0 & 4.9973 & TRN \\
\hline CHEMBL1439021 & 688267 & 6.5 & 5.065 & TRN \\
\hline
\end{tabular}




\begin{tabular}{|c|c|c|c|c|c|}
\hline \\
\hline CHEMBL1568728 & 688267 & 6.2 & 5.0089 & TRN & \\
\hline CHEMBL1382247 & 688267 & 4.1 & 5.0564 & TRN & \\
\hline CHEMBL1605422 & 688267 & 5.3 & 5.0573 & TRN & \\
\hline CHEMBL1583400 & 688267 & 4.05 & 5.0681 & TRN & \\
\hline CHEMBL1403608 & 688267 & 6.2 & 5.078 & TRN & \\
\hline CHEMBL1387616 & 688267 & 5.05 & 5.0488 & TRN & \\
\hline CHEMBL1577686 & 688267 & 6.2 & 5.0839 & TRN & \\
\hline CHEMBL1482991 & 688267 & 4.9 & 5.0767 & TRN & \\
\hline CHEMBL1366639 & 688267 & 4.55 & 5.1005 & TRN & \\
\hline CHEMBL1405912 & 688267 & 4.3 & 5.0117 & TRN & \\
\hline CHEMBL1390347 & 688267 & 5.3 & 5.0098 & TST & \\
\hline CHEMBL1372792 & 688267 & 4.05 & 4.96899 & 9999999999 & TRN \\
\hline CHEMBL1424941 & 688267 & 4.0 & 5.0504 & TST & \\
\hline CHEMBL1377939 & 688267 & 5.25 & 5.078 & TRN & \\
\hline CHEMBL1316675 & 688267 & 4.1 & 5.0762 & TRN & \\
\hline CHEMBL1448991 & 688267 & 6.2 & 5.0232 & TRN & \\
\hline CHEMBL1327374 & 688267 & 4.6 & 5.0428 & TRN & \\
\hline CHEMBL3211960 & 688267 & 5.55 & 5.0659 & TRN & \\
\hline CHEMBL1416989 & 688267 & 4.05 & 4.9893 & TRN & \\
\hline CHEMBL1459484 & 688267 & 5.85 & 5.0542 & TRN & \\
\hline CHEMBL1597208 & 688267 & 4.25 & 5.0209 & TRN & \\
\hline CHEMBL1542583 & 688267 & 6.15 & 5.0736 & TST & \\
\hline CHEMBL1382491 & 688267 & 6.25 & 5.0005 & TRN & \\
\hline CHEMBL1521986 & 688267 & 6.5 & 5.0273 & TRN & \\
\hline CHEMBL1353475 & 688267 & 3.95 & 5.0355 & TRN & \\
\hline CHEMBL1538455 & 688267 & 5.95 & 5.1374 & TRN & \\
\hline CHEMBL1981242 & 688267 & 5.45 & 4.9838 & TRN & \\
\hline CHEMBL1599015 & 688267 & 5.8 & 5.0315 & TST & \\
\hline CHEMBL1444532 & 688267 & 5.35 & 5.0199 & TST & \\
\hline CHEMBL1312509 & 688267 & 6.2 & 5.0568 & TRN & \\
\hline CHEMBL1383903 & 688267 & 4.3 & 5.0459 & TST & \\
\hline CHEMBL1326608 & 688267 & 6.2 & 4.9783 & TRN & \\
\hline CHEMBL1475878 & 688267 & 4.35 & 5.0134 & TST & \\
\hline CHEMBL1589962 & 688267 & 5.65 & 5.0458 & TRN & \\
\hline CHEMBL1390647 & 688267 & 6.5 & 5.0238 & TST & \\
\hline CHEMBL1533019 & 688267 & 4.1 & 5.0441 & TRN & \\
\hline CHEMBL1411337 & 688267 & 3.95 & 5.0598 & TST & \\
\hline CHEMBL1581732 & 688267 & 5.55 & 5.0414 & TRN & \\
\hline CHEMBL1495566 & 688267 & 4.5 & 5.0334 & TRN & \\
\hline CHEMBL1403137 & 688267 & 6.25 & 5.0407 & TRN & \\
\hline CHEMBL1590404 & 688267 & 5.75 & 5.0398 & TRN & \\
\hline CHEMBL1396868 & 688267 & 5.95 & 5.1587 & TRN & \\
\hline CHEMBL1509245 & 688267 & 4.7 & 4.995 & TRN & \\
\hline CHEMBL1533992 & 688267 & 3.95 & 5.1611 & TRN & \\
\hline CHEMBL1412668 & 688267 & 6.2 & 5.1102 & TRN & \\
\hline CHEMBL3196244 & 688267 & 4.55 & 5.0167 & TRN & \\
\hline CHEMBL1361487 & 688267 & 6.05 & 4.9997 & TST & \\
\hline CHEMBL1368501 & 688267 & 4.2 & 5.015 & TRN & \\
\hline & & & & 17292 & \\
\hline
\end{tabular}




\begin{tabular}{|c|c|c|c|c|c|}
\hline \multicolumn{6}{|c|}{ Supplemental Table S2.txt } \\
\hline CHEMBL1607458 & 688267 & 6.15 & 5.0466 & TRN & \\
\hline CHEMBL1316967 & 688267 & 5.15 & 5.119 & TRN & \\
\hline CHEMBL1533031 & 688267 & 6.2 & 5.0701 & TST & \\
\hline CHEMBL1452203 & 688267 & 3.95 & 4.9926 & TRN & \\
\hline CHEMBL1512063 & 688267 & 4.6 & 5.0931 & TRN & \\
\hline CHEMBL1315940 & 688267 & 4.05 & 5.0324 & TRN & \\
\hline CHEMBL1515589 & 688267 & 6.0 & 5.0424 & TRN & \\
\hline CHEMBL1331524 & 688267 & 6.45 & 5.0589 & TRN & \\
\hline CHEMBL1392147 & 688267 & 4.4 & 5.1043 & TRN & \\
\hline CHEMBL1591726 & 688267 & 4.4 & 5.0034 & TRN & \\
\hline CHEMBL1414713 & 688267 & 4.0 & 5.0539 & TST & \\
\hline CHEMBL1411770 & 688267 & 5.6 & 5.041 & TRN & \\
\hline CHEMBL1462791 & 688267 & 4.8 & 5.0753 & TST & \\
\hline CHEMBL1433535 & 688267 & 6.15 & 5.1131 & TRN & \\
\hline CHEMBL1315795 & 688267 & 5.05 & 4.9477 & TRN & \\
\hline CHEMBL1532282 & 688267 & 5.4 & 5.0285 & TST & \\
\hline CHEMBL1532234 & 688267 & 5.8 & 5.1094 & TRN & \\
\hline CHEMBL1353144 & 688267 & 4.65 & 5.0417 & TRN & \\
\hline CHEMBL1535225 & 688267 & 6.15 & 4.9991 & TRN & \\
\hline CHEMBL1451297 & 688267 & 6.2 & 5.0489 & TRN & \\
\hline CHEMBL1454670 & 688267 & 4.65 & 5.0796 & TRN & \\
\hline CHEMBL1539673 & 688267 & 6.45 & 5.0456 & TRN & \\
\hline CHEMBL1382886 & 688267 & 4.95 & 5.0152 & TST & \\
\hline CHEMBL1488843 & 688267 & 5.25 & 5.052 & TRN & \\
\hline CHEMBL1401076 & 688267 & 5.5 & 5.0959 & TRN & \\
\hline CHEMBL1563192 & 688267 & 4.6 & 5.0947 & TST & \\
\hline CHEMBL1302171 & 688267 & 3.95 & 5.1734 & TRN & \\
\hline CHEMBL1552174 & 688267 & 4.05 & 5.1203 & TST & \\
\hline CHEMBL1511791 & 688267 & 5.0 & 5.0396 & TRN & \\
\hline CHEMBL1370556 & 688267 & 4.05 & 5.1138 & TRN & \\
\hline CHEMBL1407420 & 688267 & 6.5501 & 5.0425 & TRN & \\
\hline CHEMBL1337854 & 688267 & 4.6 & 5.0509 & TRN & \\
\hline CHEMBL1358320 & 688267 & 4.7 & 5.0457 & TRN & \\
\hline CHEMBL1553164 & 688267 & 6.2 & 5.0537 & TRN & \\
\hline CHEMBL1478771 & 688267 & 5.5 & 5.0473 & TRN & \\
\hline CHEMBL1475738 & 688267 & 4.3 & 5.0194 & TRN & \\
\hline CHEMBL1475776 & 688267 & 4.05 & 5.055 & TRN & \\
\hline CHEMBL1465038 & 688267 & 4.0 & 5.1196 & TRN & \\
\hline CHEMBL1567338 & 688267 & 5.5 & 5.0848 & TRN & \\
\hline CHEMBL1419446 & 688267 & 4.6 & 5.1953 & TRN & \\
\hline CHEMBL1570103 & 688267 & 6.2 & $5.0680 e$ & 00000000005 & TST \\
\hline CHEMBL1400029 & 688267 & 4.1 & 5.05399 & 9999999999 & TRN \\
\hline CHEMBL1534603 & 688267 & 5.3 & 5.0263 & TRN & \\
\hline CHEMBL1568345 & 688267 & 4.05 & 5.0563 & TST & \\
\hline CHEMBL1426332 & 688267 & 5.55 & 5.0471 & TRN & \\
\hline CHEMBL1371028 & 688267 & 5.35 & 5.0196 & TRN & \\
\hline CHEMBL1593294 & 688267 & 5.0 & 5.0831 & TRN & \\
\hline CHEMBL1351098 & 688267 & 6.2 & 5.0587 & TRN & \\
\hline
\end{tabular}




\begin{tabular}{|c|c|c|c|c|c|}
\hline \multicolumn{6}{|c|}{ plemental } \\
\hline CHEMBL1376881 & 688267 & 4.0 & 5.0626 & TRN & \\
\hline CHEMBL1602174 & 688267 & 5.9 & 5.0563 & TST & \\
\hline CHEMBL1400091 & 688267 & 6.05 & 5.0882 & TRN & \\
\hline CHEMBL1475047 & 688267 & 4.0 & 5.039 & TRN & \\
\hline CHEMBL1507550 & 688267 & 4.6 & 5.0647 & TRN & \\
\hline CHEMBL1493780 & 688267 & 4.75 & 5.1045 & TRN & \\
\hline CHEMBL1563264 & 688267 & 5.55 & 5.083 & TRN & \\
\hline CHEMBL1469112 & 688267 & 4.45 & 5.0269 & TST & \\
\hline CHEMBL1397241 & 688267 & 6.25 & 5.1213 & TRN & \\
\hline CHEMBL1589833 & 688267 & 4.1 & 5.1026 & TRN & \\
\hline CHEMBL1338193 & 688267 & 4.0 & 5.1068 & TRN & \\
\hline CHEMBL1302294 & 688267 & 4.05 & 5.0477 & TRN & \\
\hline CHEMBL1530996 & 688267 & 6.2 & 5.0972 & TST & \\
\hline CHEMBL172 & 688267 & 5.8 & 5.086 & TST & \\
\hline CHEMBL1462094 & 688267 & 5.65 & 5.1043 & TST & \\
\hline CHEMBL1391199 & 688267 & 4.5 & 5.0741 & TRN & \\
\hline CHEMBL1558487 & 688267 & 5.35 & 5.0528 & TST & \\
\hline CHEMBL1339116 & 688267 & 4.05 & 5.0396 & TST & \\
\hline CHEMBL1476243 & 688267 & 4.3 & 5.0612 & TST & \\
\hline CHEMBL1532266 & 688267 & 5.5 & 5.0687 & TRN & \\
\hline CHEMBL1329759 & 688267 & 4.15 & 5.0928 & TST & \\
\hline CHEMBL1485049 & 688267 & 3.95 & 5.1193 & TRN & \\
\hline CHEMBL1331785 & 688267 & 4.35 & 5.0247 & TRN & \\
\hline CHEMBL1551664 & 688267 & 3.95 & 5.0614 & TRN & \\
\hline CHEMBL3195404 & 688267 & 6.2 & 5.048 & TRN & \\
\hline CHEMBL1347952 & 688267 & 4.35 & 5.0287 & TRN & \\
\hline CHEMBL1535259 & 688267 & 4.6 & 5.0833 & TST & \\
\hline CHEMBL1488191 & 688267 & 4.6 & 5.0543 & TRN & \\
\hline CHEMBL1588557 & 688267 & 5.35 & 4.9908 & TST & \\
\hline CHEMBL1408280 & 688267 & 6.05 & 5.0828 & TRN & \\
\hline CHEMBL1575045 & 688267 & 6.2 & 5.07600 & 00000000005 & TST \\
\hline CHEMBL1506225 & 688267 & 6.2 & 5.0449 & TST & \\
\hline CHEMBL1407426 & 688267 & 6.2 & 5.048 & TRN & \\
\hline CHEMBL1342942 & 688267 & 6.15 & 5.0887 & TRN & \\
\hline CHEMBL3208277 & 688267 & 4.0 & 5.0026 & TRN & \\
\hline CHEMBL1386048 & 688267 & 4.0 & 5.0536 & TRN & \\
\hline CHEMBL1409774 & 688267 & 4.2 & 5.0124 & TRN & \\
\hline CHEMBL1371977 & 688267 & 5.15 & 5.1306 & TRN & \\
\hline CHEMBL1602570 & 688267 & 4.0 & 4.9995 & TRN & \\
\hline CHEMBL1577966 & 688267 & 5.35 & 5.0407 & TST & \\
\hline CHEMBL1559172 & 688267 & 5.9 & 5.08899 & 99999999995 & TRN \\
\hline CHEMBL1485342 & 688267 & 4.35 & 5.0843 & TST & \\
\hline CHEMBL1424763 & 688267 & 4.25 & 5.066 & TRN & \\
\hline CHEMBL1373914 & 688267 & 4.0 & 5.029 & TRN & \\
\hline CHEMBL1546905 & 688267 & 4.05 & 4.9927 & TRN & \\
\hline CHEMBL1448744 & 688267 & 4.05 & 5.0162 & TRN & \\
\hline CHEMBL1350103 & 688267 & 5.3 & 5.0717 & TRN & \\
\hline CHEMBL1394999 & 688267 & 4.05 & 5.0291 & TRN & \\
\hline
\end{tabular}




\begin{tabular}{|c|c|c|c|c|}
\hline & & & pplement & al $\mathrm{Ta}$ \\
\hline CHEMBL1388400 & 688267 & 5.3 & 5.0412 & TST \\
\hline CHEMBL1426701 & 688267 & 5.6 & 5.0903 & TRN \\
\hline CHEMBL1390346 & 688267 & 4.75 & 5.0352 & TRN \\
\hline CHEMBL1355976 & 688267 & 5.45 & 5.1088 & TRN \\
\hline CHEMBL1435553 & 688267 & 4.4 & 5.0473 & TRN \\
\hline CHEMBL1583850 & 688267 & 4.05 & 5.0173 & TST \\
\hline CHEMBL1609486 & 688267 & 4.4 & 5.0671 & TRN \\
\hline CHEMBL1531471 & 688267 & 5.35 & 5.0732 & TRN \\
\hline CHEMBL1386036 & 688267 & 4.15 & 5.0556 & TRN \\
\hline CHEMBL1552627 & 688267 & 4.4 & 5.0902 & TRN \\
\hline CHEMBL2000592 & 688267 & 4.25 & 4.9776 & TST \\
\hline CHEMBL1470611 & 688267 & 5.3 & 5.0874 & TRN \\
\hline CHEMBL3190050 & 688267 & 6.15 & 5.0134 & TRN \\
\hline CHEMBL1528262 & 688267 & 5.25 & 5.0164 & TRN \\
\hline CHEMBL1607213 & 688267 & 5.45 & 5.0358 & TRN \\
\hline CHEMBL1513506 & 688267 & 4.0 & 5.01 & TRN \\
\hline CHEMBL1559833 & 688267 & 5.55 & 5.0232 & TRN \\
\hline CHEMBL1425796 & 688267 & 6.25 & 5.1038 & TRN \\
\hline CHEMBL1360059 & 688267 & 6.2 & 5.0571 & TST \\
\hline CHEMBL1478154 & 688267 & 4.05 & 5.0176 & TST \\
\hline CHEMBL1609424 & 688267 & 6.15 & 5.0723 & TRN \\
\hline CHEMBL1304193 & 688267 & 4.3 & 5.0621 & TST \\
\hline CHEMBL1567301 & 688267 & 5.35 & 5.0522 & TRN \\
\hline CHEMBL1396744 & 688267 & 4.05 & 5.1082 & TRN \\
\hline CHEMBL1543924 & 688267 & 6.2 & 5.0304 & TST \\
\hline CHEMBL1423760 & 688267 & 4.55 & 5.0088 & TST \\
\hline CHEMBL1391553 & 688267 & 4.85 & 5.0127 & TRN \\
\hline CHEMBL1602384 & 688267 & 4.8 & 5.0647 & TST \\
\hline CHEMBL1484192 & 688267 & 6.5 & 5.0094 & TRN \\
\hline CHEMBL1354921 & 688267 & 5.75 & 5.0553 & TRN \\
\hline CHEMBL1600651 & 688267 & 6.2 & 5.0043 & TRN \\
\hline CHEMBL1599846 & 688267 & 5.35 & 5.0627 & TRN \\
\hline CHEMBL1502350 & 688267 & 5.25 & 5.1071 & TRN \\
\hline CHEMBL1595527 & 688267 & 4.5 & 4.994 & TRN \\
\hline CHEMBL1558244 & 688267 & 5.0 & 5.0893 & TST \\
\hline CHEMBL1314913 & 688267 & 5.6 & 5.0793 & TST \\
\hline CHEMBL1346812 & 688267 & 6.2 & 5.0362 & TST \\
\hline CHEMBL1421578 & 688267 & 5.3 & 5.1503 & TRN \\
\hline CHEMBL1480419 & 688267 & 4.4 & 5.0511 & TRN \\
\hline CHEMBL1572968 & 688267 & 4.5 & 4.9991 & TRN \\
\hline CHEMBL1441943 & 688267 & 4.4 & 5.0274 & TRN \\
\hline CHEMBL1582753 & 688267 & 3.95 & 5.0416 & TRN \\
\hline CHEMBL1549997 & 688267 & 3.95 & 5.0664 & TRN \\
\hline CHEMBL1327791 & 688267 & 4.3 & 5.0321 & TRN \\
\hline CHEMBL1592102 & 688267 & 6.25 & 5.0587 & TRN \\
\hline CHEMBL1463299 & 688267 & 4.4 & 5.0921 & TRN \\
\hline CHEMBL1535376 & 688267 & 4.0 & 5.0756 & TRN \\
\hline CHEMBL1440402 & 688267 & 4.6 & 5.1136 & TST \\
\hline
\end{tabular}




\begin{tabular}{|c|c|c|c|c|c|}
\hline \multirow[b]{2}{*}{ CHEMBL1310198 } & \multicolumn{5}{|c|}{ Supplemental Table S2.txt } \\
\hline & 688267 & 6.45 & 5.0743 & TRN & \\
\hline CHEMBL1333421 & 688267 & 4.05 & 5.1160 & 00000000005 & TRN \\
\hline CHEMBL1408909 & 688267 & 4.7 & 5.067 & TST & \\
\hline CHEMBL1379686 & 688267 & 4.55 & 5.0891 & TRN & \\
\hline CHEMBL1549298 & 688267 & 6.25 & 5.1841 & TRN & \\
\hline CHEMBL1481365 & 688267 & 6.2 & 5.0176 & TRN & \\
\hline CHEMBL18840 & 688267 & 6.2 & 5.0408 & TRN & \\
\hline CHEMBL1508079 & 688267 & 4.0 & 5.0346 & TRN & \\
\hline CHEMBL1384534 & 688267 & 4.05 & 5.0226 & TRN & \\
\hline CHEMBL1464255 & 688267 & 5.35 & 5.0851 & TRN & \\
\hline CHEMBL1305771 & 688267 & 4.05 & 5.0202 & TRN & \\
\hline CHEMBL1429382 & 688267 & 4.7 & 4.9926 & TRN & \\
\hline CHEMBL1429456 & 688267 & 4.05 & 5.0888 & TRN & \\
\hline CHEMBL1537460 & 688267 & 6.2 & 5.0123 & TRN & \\
\hline CHEMBL1341887 & 688267 & 4.55 & 5.0905 & TRN & \\
\hline CHEMBL1357426 & 688267 & 6.2 & 5.0229 & TRN & \\
\hline CHEMBL1398150 & 688267 & 6.15 & 5.0466 & TRN & \\
\hline CHEMBL1579289 & 688267 & 4.6 & 5.1524 & TRN & \\
\hline CHEMBL1532630 & 688267 & 4.05 & 4.9708 & TST & \\
\hline CHEMBL1613667 & 688267 & 4.55 & 5.0603 & TRN & \\
\hline CHEMBL1341254 & 688267 & 4.4 & 5.0572 & TRN & \\
\hline CHEMBL1371967 & 688267 & 5.4 & 5.0418 & TRN & \\
\hline CHEMBL1413820 & 688267 & 5.45 & 5.021 & TST & \\
\hline CHEMBL1564556 & 688267 & 4.05 & 4.9831 & TRN & \\
\hline CHEMBL1567407 & 688267 & 4.1 & 5.0594 & TRN & \\
\hline CHEMBL1396788 & 688267 & 4.4 & 5.1334 & TRN & \\
\hline CHEMBL1360695 & 688267 & 4.45 & 5.0523 & TRN & \\
\hline CHEMBL1581127 & 688267 & 5.6 & 5.0962 & TST & \\
\hline CHEMBL3210933 & 688267 & 6.6 & 5.0052 & TST & \\
\hline CHEMBL3211703 & 688267 & 5.3 & 5.0451 & TST & \\
\hline CHEMBL3212957 & 688267 & 5.4 & 5.0748 & TRN & \\
\hline CHEMBL1558239 & 688267 & 4.3 & 5.0326 & TST & \\
\hline CHEMBL1518733 & 688267 & 4.4 & 5.0944 & TRN & \\
\hline CHEMBL1421757 & 688267 & 5.35 & 5.0414 & TRN & \\
\hline CHEMBL1373925 & 688267 & 4.15 & 5.0835 & TRN & \\
\hline CHEMBL1398641 & 688267 & 5.3 & 5.0792 & TST & \\
\hline CHEMBL1580017 & 688267 & 4.65 & 5.02 & TRN & \\
\hline CHEMBL1578820 & 688267 & 4.5 & 5.1137 & TRN & \\
\hline CHEMBL1347241 & 688267 & 6.2 & 5.0362 & TRN & \\
\hline CHEMBL1313801 & 688267 & 4.9 & 5.0686 & TRN & \\
\hline CHEMBL1561813 & 688267 & 4.8 & 5.0701 & TRN & \\
\hline CHEMBL1490421 & 688267 & 6.2 & 5.0535 & TRN & \\
\hline CHEMBL1413692 & 688267 & 5.6 & 5.0463 & TRN & \\
\hline CHEMBL1532811 & 688267 & 6.2 & 5.0104 & TRN & \\
\hline CHEMBL1429939 & 688267 & 5.7 & 5.0974 & TRN & \\
\hline CHEMBL1380037 & 688267 & 6.15 & 5.0534 & TRN & \\
\hline CHEMBL1596209 & 688267 & 4.0 & 5.0224 & TRN & \\
\hline CHEMBL1432076 & 688267 & 4.05 & 5.006 & TST & \\
\hline
\end{tabular}




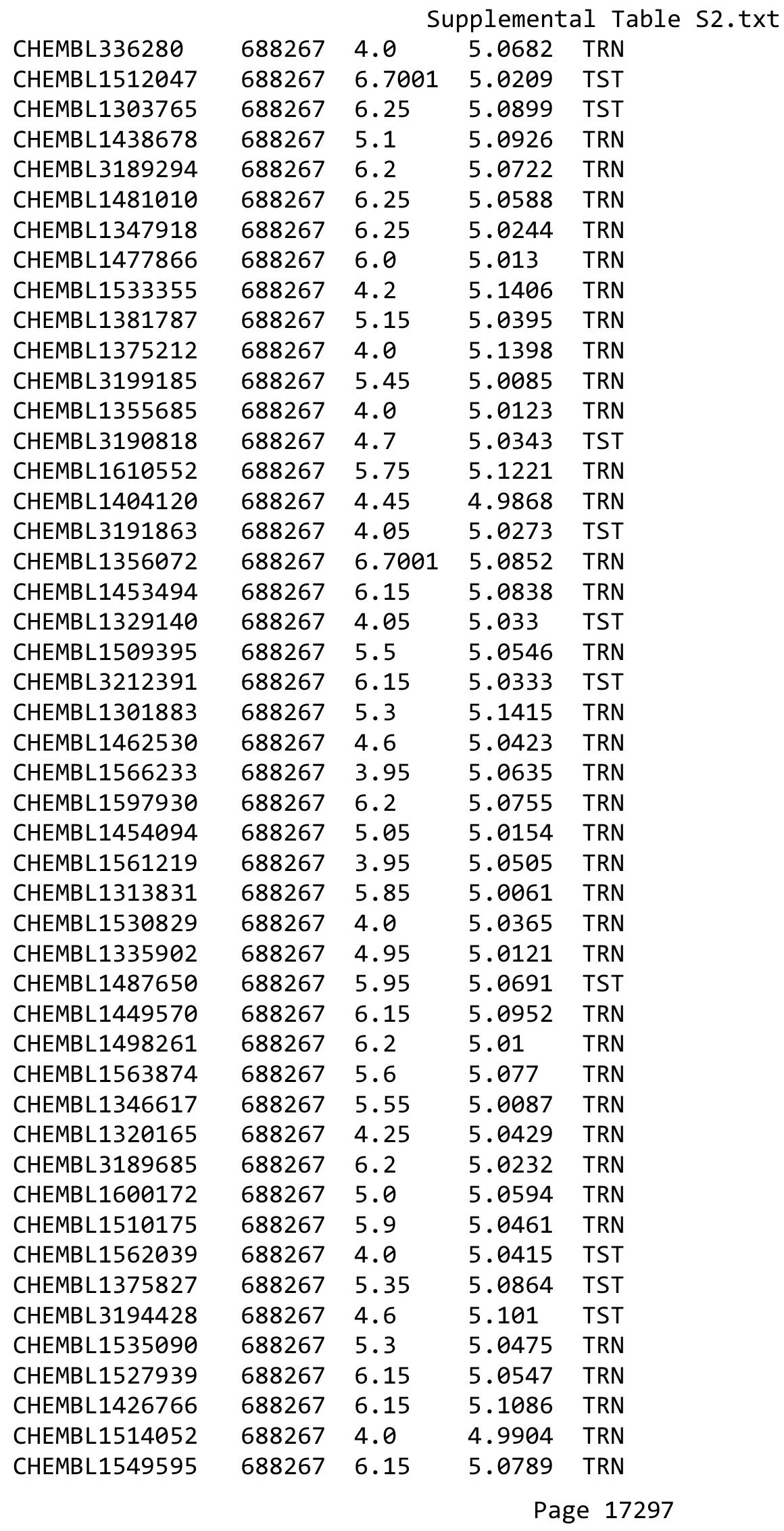




\begin{tabular}{|c|c|c|c|c|}
\hline \multicolumn{5}{|c|}{ Supplemental Table S2.txt } \\
\hline CHEMBL1570665 & 688267 & 4.0 & 5.039 & TRN \\
\hline CHEMBL1392702 & 688267 & 4.15 & 4.9849 & TST \\
\hline CHEMBL1477761 & 688267 & 5.4 & 5.1282 & TRN \\
\hline CHEMBL1582601 & 688267 & 5.45 & 5.0464 & TRN \\
\hline CHEMBL1407055 & 688267 & 5.15 & 5.1467 & TRN \\
\hline CHEMBL1515747 & 688267 & 3.95 & 5.1511 & TRN \\
\hline CHEMBL1545947 & 688267 & 5.35 & 5.0892 & TRN \\
\hline CHEMBL1526845 & 688267 & 4.3 & 5.0901 & TST \\
\hline CHEMBL1495586 & 688267 & 3.95 & 5.0275 & TRN \\
\hline CHEMBL1473354 & 688267 & 4.3 & 5.0154 & TRN \\
\hline CHEMBL1477172 & 688267 & 4.7 & 5.0892 & TRN \\
\hline CHEMBL1457010 & 688267 & 4.9 & 5.0129 & TRN \\
\hline CHEMBL1484689 & 688267 & 3.95 & 5.072 & TRN \\
\hline CHEMBL1581195 & 688267 & 4.2 & 5.0163 & TST \\
\hline CHEMBL1507234 & 688267 & 5.3 & 5.117 & TRN \\
\hline CHEMBL1422976 & 688267 & 4.0 & 5.0134 & TRN \\
\hline CHEMBL1375820 & 688267 & 5.45 & 5.0706 & TRN \\
\hline CHEMBL1537806 & 688267 & 4.35 & 5.1225 & TRN \\
\hline CHEMBL1464041 & 688267 & 5.55 & 5.0325 & TST \\
\hline CHEMBL1983530 & 688267 & 5.1 & 4.9874 & TST \\
\hline CHEMBL1339933 & 688267 & 6.05 & 5.0429 & TST \\
\hline CHEMBL1383811 & 688267 & 5.65 & 5.0464 & TRN \\
\hline CHEMBL1413740 & 688267 & 5.9 & 5.1072 & TST \\
\hline CHEMBL1485856 & 688267 & 4.25 & 5.0498 & TRN \\
\hline CHEMBL1493886 & 688267 & 4.1 & 5.0153 & TRN \\
\hline CHEMBL1082181 & 688267 & 3.95 & 5.0877 & TST \\
\hline CHEMBL1568512 & 688267 & 6.2 & 5.0625 & TRN \\
\hline CHEMBL1369941 & 688267 & 4.15 & 5.0933 & TRN \\
\hline CHEMBL1496519 & 688267 & 4.6 & 5.0405 & TRN \\
\hline CHEMBL1413421 & 688267 & 6.2 & 5.026 & TRN \\
\hline CHEMBL1316106 & 688267 & 4.8 & 5.0287 & TRN \\
\hline CHEMBL1513310 & 688267 & 4.35 & 5.0808 & TRN \\
\hline CHEMBL1396795 & 688267 & 5.6 & 5.0907 & TRN \\
\hline CHEMBL1566765 & 688267 & 4.0 & 5.0781 & TRN \\
\hline CHEMBL1592944 & 688267 & 6.2 & 4.9987 & TRN \\
\hline CHEMBL1310422 & 688267 & 4.25 & 5.0172 & TRN \\
\hline CHEMBL1537026 & 688267 & 5.55 & 5.0331 & TRN \\
\hline CHEMBL1601523 & 688267 & 5.05 & 5.0611 & TRN \\
\hline CHEMBL1448186 & 688267 & 3.95 & 5.0501 & TST \\
\hline CHEMBL1429373 & 688267 & 5.55 & 5.062 & TST \\
\hline CHEMBL1589349 & 688267 & 6.2 & 5.0354 & TST \\
\hline CHEMBL1488048 & 688267 & 6.15 & 5.0094 & TRN \\
\hline CHEMBL3210121 & 688267 & 4.5 & 5.0395 & TRN \\
\hline CHEMBL1532934 & 688267 & 4.7 & 5.1342 & TST \\
\hline CHEMBL1576769 & 688267 & 4.0 & 5.0737 & TRN \\
\hline CHEMBL1547569 & 688267 & 6.15 & 5.0105 & TST \\
\hline CHEMBL1498362 & 688267 & 4.0 & 5.0504 & TRN \\
\hline CHEMBL1519505 & 688267 & 4.05 & 5.1335 & TRN \\
\hline
\end{tabular}




\begin{tabular}{|c|c|c|c|c|c|}
\hline \multicolumn{6}{|c|}{ Supplemental Table S2.txt } \\
\hline CHEMBL1538136 & 688267 & 5.25 & 5.0263 & TST & \\
\hline CHEMBL1575253 & 688267 & 4.5 & 5.0604 & TRN & \\
\hline CHEMBL1597113 & 688267 & 3.95 & 5.1411 & TRN & \\
\hline CHEMBL1516960 & 688267 & 5.35 & 5.0343 & TST & \\
\hline CHEMBL 3194456 & 688267 & 6.2 & 5.0173 & TRN & \\
\hline CHEMBL1539234 & 688267 & 3.95 & 5.0125 & TST & \\
\hline CHEMBL1555450 & 688267 & 3.95 & 4.9886 & TRN & \\
\hline CHEMBL1546221 & 688267 & 5.6 & 5.0797 & TRN & \\
\hline CHEMBL1581031 & 688267 & 6.0 & 5.1246 & TRN & \\
\hline CHEMBL1433813 & 688267 & 5.75 & 5.164 & TRN & \\
\hline CHEMBL1560920 & 688267 & 4.25 & 5.0935 & TRN & \\
\hline CHEMBL1453798 & 688267 & 5.8 & 5.0084 & TST & \\
\hline CHEMBL1443483 & 688267 & 5.35 & 5.0663 & TRN & \\
\hline CHEMBL1493205 & 688267 & 4.3 & 4.9941 & TRN & \\
\hline CHEMBL1493977 & 688267 & 4.6 & 5.022 & TRN & \\
\hline CHEMBL1431034 & 688267 & 4.3 & 5.0374 & TRN & \\
\hline CHEMBL1551927 & 688267 & 5.15 & 5.0243 & TRN & \\
\hline CHEMBL1487422 & 688267 & 6.2 & 5.0242 & TRN & \\
\hline CHEMBL1305509 & 688267 & 4.0 & 5.0793 & TRN & \\
\hline CHEMBL1595137 & 688267 & 5.9 & 5.0628 & TRN & \\
\hline CHEMBL1482083 & 688267 & 5.4 & 5.0718 & TST & \\
\hline CHEMBL1508816 & 688267 & 3.95 & 5.0171 & TST & \\
\hline CHEMBL1592792 & 688267 & 5.9 & 5.0523 & TRN & \\
\hline CHEMBL1553872 & 688267 & 5.75 & 5.0443 & TRN & \\
\hline CHEMBL1367550 & 688267 & 4.75 & 5.0885 & TST & \\
\hline CHEMBL1484569 & 688267 & 5.75 & 5.125 & TRN & \\
\hline CHEMBL1387848 & 688267 & 4.3 & 5.0287 & TRN & \\
\hline CHEMBL1397775 & 688267 & 4.0 & 5.0536 & TRN & \\
\hline CHEMBL1381828 & 688267 & 6.25 & 5.12799 & 9999999999 & TRN \\
\hline CHEMBL1326519 & 688267 & 5.95 & 4.9925 & TRN & \\
\hline CHEMBL1529037 & 688267 & 4.55 & 5.0243 & TRN & \\
\hline CHEMBL1572608 & 688267 & 5.0 & 5.0218 & TST & \\
\hline CHEMBL3198564 & 688267 & 5.7 & 5.1179 & TST & \\
\hline CHEMBL1511079 & 688267 & 4.3 & 5.0976 & TRN & \\
\hline CHEMBL1473684 & 688267 & 4.4 & 5.1037 & TRN & \\
\hline CHEMBL1557110 & 688267 & 6.25 & 5.1065 & TRN & \\
\hline CHEMBL1612879 & 688267 & 4.85 & 4.9848 & TST & \\
\hline CHEMBL1386500 & 688267 & 4.6 & 5.0136 & TRN & \\
\hline CHEMBL1441253 & 688267 & 4.25 & 5.0191 & TRN & \\
\hline CHEMBL1443583 & 688267 & 5.3 & 5.1464 & TRN & \\
\hline CHEMBL1370934 & 688267 & 5.6 & 5.0445 & TRN & \\
\hline CHEMBL1356229 & 688267 & 4.4 & 5.0792 & TRN & \\
\hline CHEMBL1409525 & 688267 & 5.35 & 5.0161 & TST & \\
\hline CHEMBL1387880 & 688267 & 5.65 & 5.1623 & TRN & \\
\hline CHEMBL1521498 & 688267 & 5.25 & 5.0336 & TRN & \\
\hline CHEMBL1361500 & 688267 & 6.5 & 5.0214 & TRN & \\
\hline CHEMBL1441305 & 688267 & 4.0 & 5.0721 & TRN & \\
\hline CHEMBL1308694 & 688267 & 4.6 & 5.0039 & TRN & \\
\hline
\end{tabular}




\begin{tabular}{|c|c|c|c|c|c|}
\hline \multicolumn{6}{|c|}{ Supplemental Table S2.txt } \\
\hline CHEMBL1351782 & 688267 & 6.15 & 5.1404 & TRN & \\
\hline CHEMBL1424349 & 688267 & 5.3 & 5.0869 & TRN & \\
\hline CHEMBL1551856 & 688267 & 6.2 & 5.0484 & TRN & \\
\hline CHEMBL1363866 & 688267 & 4.55 & 5.015 & TRN & \\
\hline CHEMBL1550553 & 688267 & 4.1 & 5.0255 & TST & \\
\hline CHEMBL1309886 & 688267 & 6.2 & 5.1234 & TRN & \\
\hline CHEMBL1434897 & 688267 & 6.2 & 5.0339 & TRN & \\
\hline CHEMBL1493134 & 688267 & 4.8 & 5.0859 & TRN & \\
\hline CHEMBL1307907 & 688267 & 5.85 & 5.0572 & TST & \\
\hline CHEMBL1404450 & 688267 & 4.1 & 5.0357 & TST & \\
\hline CHEMBL1397306 & 688267 & 5.3 & 5.0636 & TRN & \\
\hline CHEMBL1584399 & 688267 & 5.4 & 5.118 & TRN & \\
\hline CHEMBL1466059 & 688267 & 5.7 & 5.0504 & TRN & \\
\hline CHEMBL1490527 & 688267 & 5.6 & 5.0838 & TRN & \\
\hline CHEMBL1463603 & 688267 & 4.55 & 5.0852 & TRN & \\
\hline CHEMBL1418940 & 688267 & 4.1 & 5.0829 & TST & \\
\hline CHEMBL1554116 & 688267 & 3.95 & 4.9837 & TRN & \\
\hline CHEMBL1560039 & 688267 & 6.6499 & 5.0601 & TRN & \\
\hline CHEMBL1404473 & 688267 & 3.95 & 5.0266 & TST & \\
\hline CHEMBL1347141 & 688267 & 5.45 & 5.1332 & TRN & \\
\hline CHEMBL1360709 & 688267 & 4.25 & 5.0599 & TRN & \\
\hline CHEMBL1599402 & 688267 & 4.0 & 5.0322 & TRN & \\
\hline CHEMBL1365802 & 688267 & 5.9 & 5.069 & TRN & \\
\hline CHEMBL1373226 & 688267 & 4.05 & 5.0393 & TRN & \\
\hline CHEMBL1317108 & 688267 & 4.3 & 5.0413 & TRN & \\
\hline CHEMBL3209436 & 688267 & 4.0 & 5.0183 & TRN & \\
\hline CHEMBL1613499 & 688267 & 4.5 & 4.9749 & TRN & \\
\hline CHEMBL1514281 & 688267 & 5.85 & 5.0889 & TRN & \\
\hline CHEMBL1326782 & 688267 & 5.8 & 5.0966 & TRN & \\
\hline CHEMBL1378407 & 688267 & 4.35 & 5.0586 & TRN & \\
\hline CHEMBL254255 & 688267 & 4.05 & 5.0422 & TRN & \\
\hline CHEMBL1418125 & 688267 & 4.0 & 5.0382 & TRN & \\
\hline CHEMBL1348567 & 688267 & 6.5501 & 5.0239 & TRN & \\
\hline CHEMBL1314671 & 688267 & 5.0 & 5.13706 & 00000000005 & TST \\
\hline CHEMBL3189234 & 688267 & 6.05 & 4.9928 & TRN & \\
\hline CHEMBL1316295 & 688267 & 3.95 & 5.0283 & TRN & \\
\hline CHEMBL1491379 & 688267 & 6.15 & 5.0776 & TRN & \\
\hline CHEMBL1339226 & 688267 & 5.35 & 5.052 & TRN & \\
\hline CHEMBL1610205 & 688267 & 4.95 & 5.0397 & TST & \\
\hline CHEMBL1986681 & 688267 & 5.3 & 5.0564 & TST & \\
\hline CHEMBL1302011 & 688267 & 4.2 & 5.0663 & TRN & \\
\hline CHEMBL1304391 & 688267 & 6.25 & 5.0697 & TRN & \\
\hline CHEMBL1518076 & 688267 & 4.25 & 5.1599 & TRN & \\
\hline CHEMBL1477669 & 688267 & 4.05 & 5.1056 & TRN & \\
\hline CHEMBL1487524 & 688267 & 4.3 & 5.1321 & TRN & \\
\hline CHEMBL1590844 & 688267 & 6.2 & 5.0825 & TRN & \\
\hline CHEMBL1469215 & 688267 & 4.35 & 5.0588 & TRN & \\
\hline CHEMBL1165028 & 688267 & 4.0 & 5.0 & TRN & \\
\hline
\end{tabular}




\begin{tabular}{|c|c|c|c|c|}
\hline \multicolumn{5}{|c|}{ Supplemental Tabl } \\
\hline CHEMBL1317290 & 688267 & 6.15 & 5.0463 & TRN \\
\hline CHEMBL1396944 & 688267 & 3.95 & 5.0837 & TRN \\
\hline CHEMBL1545804 & 688267 & 5.6 & 5.1263 & TRN \\
\hline CHEMBL1457036 & 688267 & 6.15 & 5.0287 & TRN \\
\hline CHEMBL1524316 & 688267 & 4.05 & 5.09 & TRN \\
\hline CHEMBL1535484 & 688267 & 5.05 & 5.1802 & TRN \\
\hline CHEMBL1509506 & 688267 & 4.75 & 5.105 & TRN \\
\hline CHEMBL1564358 & 688267 & 4.0 & 5.1084 & TST \\
\hline CHEMBL1606906 & 688267 & 5.1 & 5.0354 & TRN \\
\hline CHEMBL1486491 & 688267 & 5.15 & 5.107 & TRN \\
\hline CHEMBL602969 & 688267 & 5.35 & 5.0234 & TST \\
\hline CHEMBL1359829 & 688267 & 4.65 & 4.9984 & TST \\
\hline CHEMBL1410425 & 688267 & 4.3 & 5.0359 & TRN \\
\hline CHEMBL1604958 & 688267 & 5.85 & 5.0706 & TRN \\
\hline CHEMBL1475201 & 688267 & 6.2 & 5.1209 & TRN \\
\hline CHEMBL1502232 & 688267 & 5.35 & 5.0576 & TRN \\
\hline CHEMBL1586152 & 688267 & 4.55 & 5.0639 & TST \\
\hline CHEMBL1611279 & 688267 & 6.15 & 5.0113 & TRN \\
\hline CHEMBL1316344 & 688267 & 4.3 & 5.0474 & TRN \\
\hline CHEMBL1567278 & 688267 & 5.35 & 5.0168 & TST \\
\hline CHEMBL1540417 & 688267 & 5.85 & 5.0412 & TST \\
\hline CHEMBL1474398 & 688267 & 4.0 & 5.0888 & TRN \\
\hline CHEMBL1485739 & 688267 & 4.35 & 5.0289 & TRN \\
\hline CHEMBL1562324 & 688267 & 4.95 & 4.9838 & TRN \\
\hline CHEMBL1484911 & 688267 & 4.0 & 5.0167 & TRN \\
\hline CHEMBL1565599 & 688267 & 5.8 & 5.059 & TST \\
\hline CHEMBL1363739 & 688267 & 4.25 & 5.0323 & TRN \\
\hline CHEMBL1376035 & 688267 & 6.5 & 5.019 & TRN \\
\hline CHEMBL1337605 & 688267 & 4.8 & 5.0633 & TST \\
\hline CHEMBL1314759 & 688267 & 4.0 & 5.0294 & TRN \\
\hline CHEMBL1086722 & 688267 & 3.95 & 5.1257 & TRN \\
\hline CHEMBL1473642 & 688267 & 5.1 & 5.1073 & TRN \\
\hline CHEMBL1490051 & 688267 & 6.05 & 5.1269 & TRN \\
\hline CHEMBL1408578 & 688267 & 4.85 & 5.1047 & TRN \\
\hline CHEMBL1531988 & 688267 & 6.15 & 5.0321 & TRN \\
\hline CHEMBL1082898 & 688267 & 6.2 & 5.1047 & TRN \\
\hline CHEMBL1351466 & 688267 & 4.05 & 5.0503 & TRN \\
\hline CHEMBL1396887 & 688267 & 3.95 & 5.1229 & TRN \\
\hline CHEMBL1385276 & 688267 & 5.4 & 5.0344 & TST \\
\hline CHEMBL1309955 & 688267 & 4.0 & 5.1183 & TRN \\
\hline CHEMBL1596023 & 688267 & 4.0 & 5.1004 & TRN \\
\hline CHEMBL1408769 & 688267 & 3.95 & 5.0239 & TST \\
\hline CHEMBL1383416 & 688267 & 4.8 & 5.033 & TRN \\
\hline CHEMBL1563728 & 688267 & 5.05 & 5.0941 & TRN \\
\hline CHEMBL1434320 & 688267 & 6.1 & 5.0539 & TRN \\
\hline CHEMBL1511261 & 688267 & 4.6 & 5.0661 & TRN \\
\hline CHEMBL1504019 & 688267 & 4.0 & 5.0645 & TRN \\
\hline CHEMBL1328663 & 688267 & 5.7 & 5.1089 & TRN \\
\hline
\end{tabular}




\begin{tabular}{|c|c|c|c|c|}
\hline \multicolumn{5}{|c|}{ Supplemental Table S2.txt } \\
\hline CHEMBL1361923 & 688267 & 5.5 & 5.0663 & TRN \\
\hline CHEMBL1306926 & 688267 & 4.05 & 5.0753 & TRN \\
\hline CHEMBL1454037 & 688267 & 3.95 & 4.9934 & TRN \\
\hline CHEMBL1566703 & 688267 & 5.55 & 5.144 & TRN \\
\hline CHEMBL1423966 & 688267 & 5.35 & 5.0848 & TRN \\
\hline CHEMBL1523018 & 688267 & 4.95 & 5.0669 & TRN \\
\hline CHEMBL1446000 & 688267 & 6.5 & 5.1272 & TRN \\
\hline CHEMBL1570654 & 688267 & 5.5 & 5.0945 & TRN \\
\hline CHEMBL1440747 & 688267 & 4.05 & 5.1111 & TRN \\
\hline CHEMBL1509253 & 688267 & 4.4 & 5.0083 & TRN \\
\hline CHEMBL1321467 & 688267 & 6.05 & 5.067 & TRN \\
\hline CHEMBL1363076 & 688267 & 4.25 & 5.053 & TST \\
\hline CHEMBL1518250 & 688267 & 6.2 & 5.0112 & TRN \\
\hline CHEMBL1514641 & 688267 & 6.2 & 4.9986 & TRN \\
\hline CHEMBL1301877 & 688267 & 5.2 & 5.0621 & TRN \\
\hline CHEMBL469058 & 688267 & 3.95 & 5.1051 & TST \\
\hline CHEMBL1326075 & 688267 & 4.15 & 5.0343 & TRN \\
\hline CHEMBL1439257 & 688267 & 5.3 & 5.0202 & TRN \\
\hline CHEMBL1540388 & 688267 & 5.8 & 5.0287 & TRN \\
\hline CHEMBL1608072 & 688267 & 4.1 & 5.1148 & TRN \\
\hline CHEMBL1352239 & 688267 & 6.2 & 5.0385 & TRN \\
\hline CHEMBL1360920 & 688267 & 4.1 & 5.0447 & TRN \\
\hline CHEMBL365342 & 688267 & 4.85 & 5.045 & TRN \\
\hline CHEMBL1474330 & 688267 & 3.95 & 5.0065 & TRN \\
\hline CHEMBL129795 & 688267 & 3.95 & 5.0297 & TST \\
\hline CHEMBL1424325 & 688267 & 4.2 & 5.063 & TST \\
\hline CHEMBL1346246 & 688267 & 4.4 & 5.1043 & TRN \\
\hline CHEMBL1518230 & 688267 & 4.1 & 5.1094 & TRN \\
\hline CHEMBL 3213170 & 688267 & 4.15 & 5.0181 & TST \\
\hline CHEMBL1510095 & 688267 & 4.0 & 5.0502 & TST \\
\hline CHEMBL1473973 & 688267 & 3.95 & 5.0397 & TST \\
\hline CHEMBL1531126 & 688267 & 6.15 & 5.0737 & TRN \\
\hline CHEMBL1300521 & 688267 & 4.3 & 5.0898 & TRN \\
\hline CHEMBL1350347 & 688267 & 4.75 & 5.0623 & TRN \\
\hline CHEMBL1526620 & 688267 & 4.4 & 5.0158 & TRN \\
\hline CHEMBL576997 & 688267 & 6.0 & 5.1158 & TST \\
\hline CHEMBL1522899 & 688267 & 6.2 & 5.0141 & TRN \\
\hline CHEMBL1313787 & 688267 & 5.3 & 5.1133 & TRN \\
\hline CHEMBL1453592 & 688267 & 5.75 & 5.0539 & TRN \\
\hline CHEMBL1366974 & 688267 & 4.0 & 5.0163 & TRN \\
\hline CHEMBL1452836 & 688267 & 3.95 & 5.0724 & TRN \\
\hline CHEMBL1488077 & 688267 & 6.15 & 5.0561 & TRN \\
\hline CHEMBL1483522 & 688267 & 5.4 & 5.0494 & TRN \\
\hline CHEMBL1309066 & 688267 & 3.95 & 5.0185 & TRN \\
\hline CHEMBL1457750 & 688267 & 5.75 & 5.0473 & TST \\
\hline CHEMBL1476777 & 688267 & 3.95 & 5.1148 & TRN \\
\hline CHEMBL1473906 & 688267 & 4.05 & 5.0705 & TRN \\
\hline CHEMBL1391964 & 688267 & 4.05 & 5.0557 & TRN \\
\hline
\end{tabular}




\begin{tabular}{|c|c|c|c|c|c|}
\hline \multicolumn{6}{|c|}{ supplementa1 Tabıe S } \\
\hline CHEMBL1415453 & 688267 & 6.2 & 5.0431 & TRN & \\
\hline CHEMBL1531679 & 688267 & 7.0501 & 5.0633 & TRN & \\
\hline CHEMBL1500190 & 688267 & 6.2 & 5.0385 & TST & \\
\hline CHEMBL1538713 & 688267 & 4.55 & 5.0694 & TRN & \\
\hline CHEMBL1559217 & 688267 & 5.55 & 5.1233 & TRN & \\
\hline CHEMBL1606915 & 688267 & 4.0 & 5.0433 & TRN & \\
\hline CHEMBL1494311 & 688267 & 5.0 & 5.0269 & TST & \\
\hline CHEMBL1307079 & 688267 & 5.35 & 5.0427 & TRN & \\
\hline CHEMBL1588220 & 688267 & 6.45 & 5.0875 & TRN & \\
\hline CHEMBL1565292 & 688267 & 4.95 & 5.0378 & TRN & \\
\hline CHEMBL1590847 & 688267 & 6.15 & 5.1043 & TRN & \\
\hline CHEMBL1516856 & 688267 & 6.8 & 5.0345 & TRN & \\
\hline CHEMBL1418024 & 688267 & 4.05 & 5.0806 & TRN & \\
\hline CHEMBL1400269 & 688267 & 4.0 & 5.0377 & TRN & \\
\hline CHEMBL1376996 & 688267 & 6.15 & 5.1078 & TST & \\
\hline CHEMBL1523216 & 688267 & 6.2 & 5.1693 & TRN & \\
\hline CHEMBL1496088 & 688267 & 6.25 & 5.0434 & TRN & \\
\hline CHEMBL1716038 & 688267 & 5.3 & 5.0452 & TST & \\
\hline CHEMBL1592727 & 688267 & 4.45 & 5.0106 & TRN & \\
\hline CHEMBL1516753 & 688267 & 6.25 & 5.09399 & 9999999999 & TRN \\
\hline CHEMBL1569461 & 688267 & 5.25 & 5.033 & TRN & \\
\hline CHEMBL1343341 & 688267 & 4.3 & 5.1434 & TST & \\
\hline CHEMBL1350783 & 688267 & 4.05 & 5.1093 & TRN & \\
\hline CHEMBL1577734 & 688267 & 4.25 & 5.0418 & TST & \\
\hline CHEMBL1315852 & 688267 & 5.7 & 5.0811 & TRN & \\
\hline CHEMBL1368265 & 688267 & 7.0501 & 5.105 & TST & \\
\hline CHEMBL1350923 & 688267 & 4.3 & 5.0422 & TRN & \\
\hline CHEMBL1443387 & 688267 & 6.0 & 5.1098 & TST & \\
\hline CHEMBL1373507 & 688267 & 5.35 & 5.1263 & TRN & \\
\hline CHEMBL1374044 & 688267 & 4.05 & 5.0601 & TRN & \\
\hline CHEMBL1420004 & 688267 & 5.0 & 5.0267 & TST & \\
\hline CHEMBL1333465 & 688267 & 6.2 & 5.0751 & TRN & \\
\hline CHEMBL1563738 & 688267 & 4.6 & 5.1127 & TRN & \\
\hline CHEMBL1407738 & 688267 & 6.3 & 5.1063 & TRN & \\
\hline CHEMBL1548043 & 688267 & 5.05 & 5.0374 & TST & \\
\hline CHEMBL1333946 & 688267 & 4.05 & 5.0299 & TST & \\
\hline CHEMBL1413573 & 688267 & 4.5 & 5.1139 & TRN & \\
\hline CHEMBL1433681 & 688267 & 4.15 & 4.9919 & TRN & \\
\hline CHEMBL1505203 & 688267 & 5.25 & 5.0765 & TRN & \\
\hline CHEMBL1448460 & 688267 & 6.2 & 5.0526 & TST & \\
\hline CHEMBL1334128 & 688267 & 4.05 & 5.0632 & TRN & \\
\hline CHEMBL1358262 & 688267 & 4.05 & 5.1129 & TRN & \\
\hline CHEMBL1345273 & 688267 & 5.7 & 4.9833 & TRN & \\
\hline CHEMBL609607 & 688267 & 5.3 & 5.0487 & TRN & \\
\hline CHEMBL1509700 & 688267 & 6.25 & 5.0763 & TRN & \\
\hline CHEMBL1522511 & 688267 & 6.2 & 5.1376 & TRN & \\
\hline CHEMBL1369881 & 688267 & 4.5 & 5.0586 & TRN & \\
\hline CHEMBL1560147 & 688267 & 4.15 & 5.0209 & TST & \\
\hline
\end{tabular}




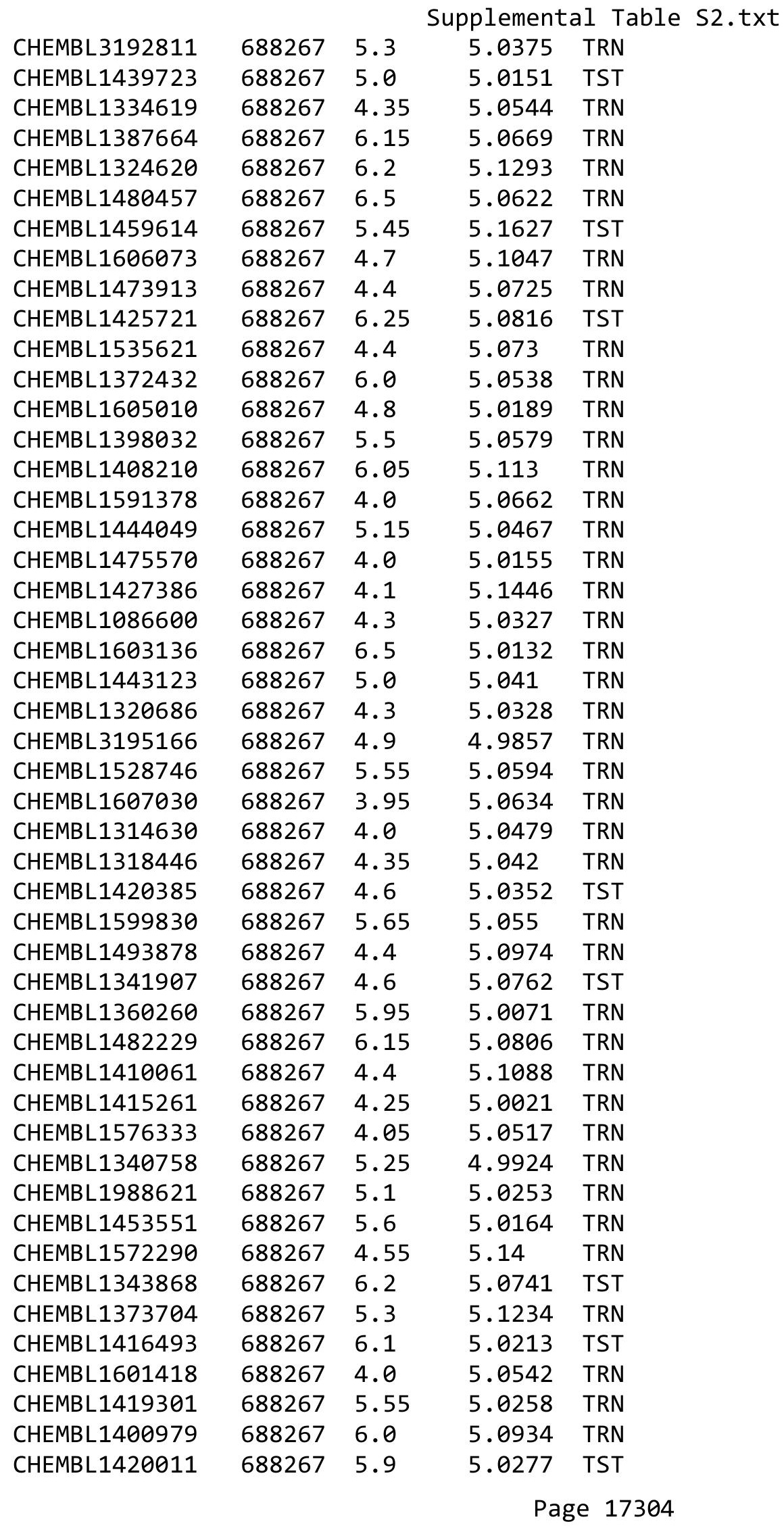




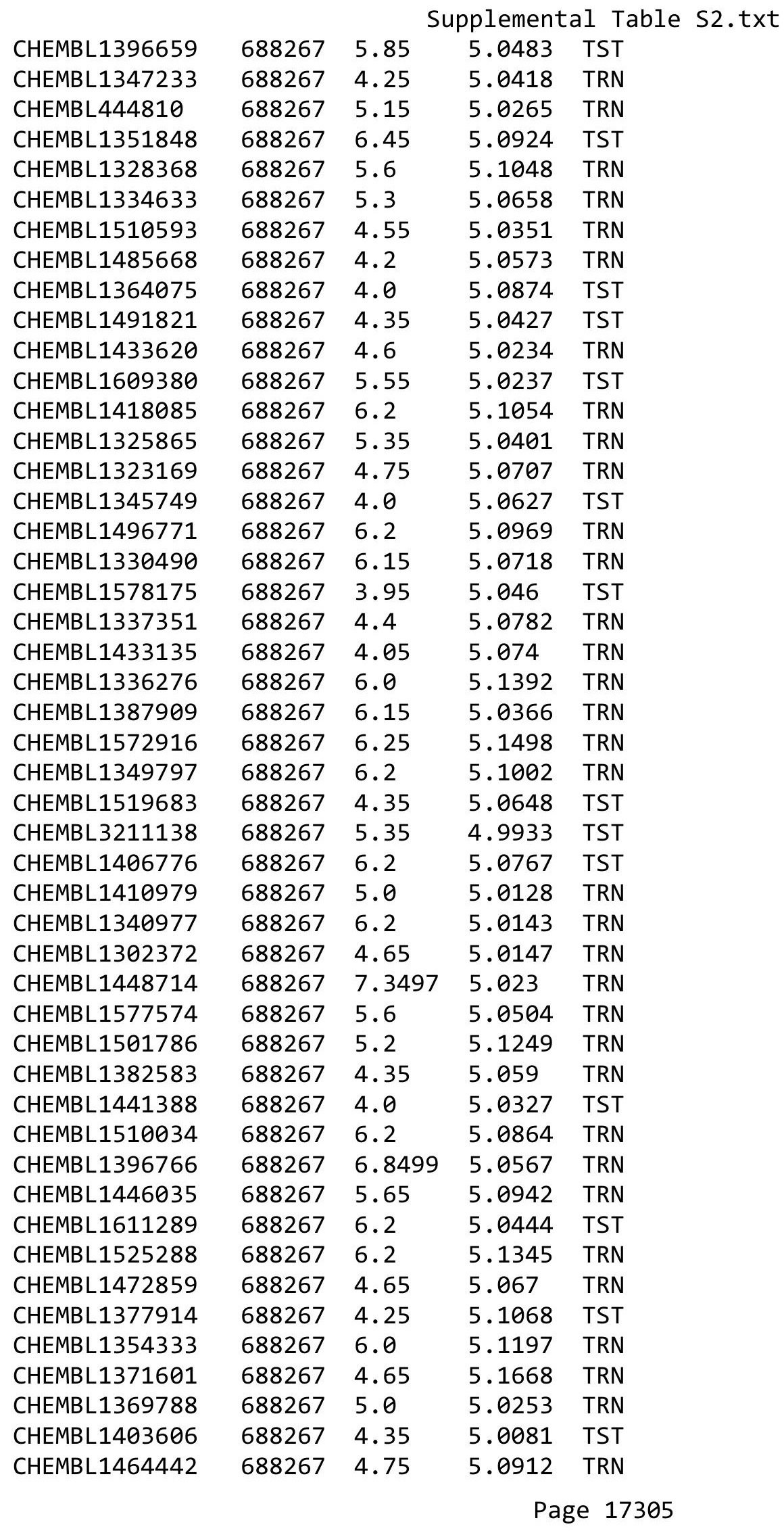




\begin{tabular}{|c|c|c|c|c|}
\hline & & & pplement & $T_{2}$ \\
\hline CHEMBL1365222 & 688267 & 4.0 & 5.0451 & TRN \\
\hline CHEMBL1985827 & 688267 & 3.95 & 4.9866 & TST \\
\hline CHEMBL1334729 & 688267 & 6.0 & 5.149 & TRN \\
\hline CHEMBL1561237 & 688267 & 5.5 & 4.9803 & TRN \\
\hline CHEMBL1581992 & 688267 & 6.25 & 5.0854 & TRN \\
\hline CHEMBL1398174 & 688267 & 4.35 & 5.0264 & TRN \\
\hline CHEMBL1606241 & 688267 & 5.3 & 5.0344 & TRN \\
\hline CHEMBL1414889 & 688267 & 6.2 & 4.9789 & TRN \\
\hline CHEMBL1448132 & 688267 & 6.2 & 5.0209 & TRN \\
\hline CHEMBL1485869 & 688267 & 5.85 & 5.0204 & TRN \\
\hline CHEMBL1463319 & 688267 & 4.4 & 5.0042 & TST \\
\hline CHEMBL1497205 & 688267 & 5.1 & 5.0576 & TRN \\
\hline CHEMBL1364381 & 688267 & 5.7 & 5.0659 & TRN \\
\hline CHEMBL1449538 & 688267 & 5.65 & 5.1041 & TRN \\
\hline CHEMBL1436423 & 688267 & 5.5 & 5.0563 & TRN \\
\hline CHEMBL1504969 & 688267 & 6.2 & 5.1299 & TRN \\
\hline CHEMBL1514066 & 688267 & 4.05 & 5.0939 & TRN \\
\hline CHEMBL1465279 & 688267 & 4.05 & 5.0543 & TST \\
\hline CHEMBL1594073 & 688267 & 4.4 & 5.1134 & TRN \\
\hline CHEMBL1538683 & 688267 & 5.4 & 5.0748 & TRN \\
\hline CHEMBL1559666 & 688267 & 6.2 & 5.0729 & TRN \\
\hline CHEMBL3210896 & 688267 & 6.2 & 4.9752 & TRN \\
\hline CHEMBL1538941 & 688267 & 4.1 & 5.0203 & TRN \\
\hline CHEMBL1485300 & 688267 & 4.05 & 5.0978 & TST \\
\hline CHEMBL1445602 & 688267 & 4.75 & 5.0797 & TRN \\
\hline CHEMBL1438706 & 688267 & 4.95 & 5.0417 & TRN \\
\hline CHEMBL1611816 & 688267 & 4.05 & 5.1376 & TRN \\
\hline CHEMBL3193054 & 688267 & 4.4 & 4.9916 & TRN \\
\hline CHEMBL1472177 & 688267 & 4.65 & 5.1025 & TRN \\
\hline CHEMBL1343352 & 688267 & 3.95 & 5.0271 & TRN \\
\hline CHEMBL1347670 & 688267 & 3.95 & 5.046 & TST \\
\hline CHEMBL1435850 & 688267 & 4.0 & 5.1252 & TRN \\
\hline CHEMBL1488930 & 688267 & 5.1 & 5.0653 & TRN \\
\hline CHEMBL1568246 & 688267 & 4.2 & 5.0588 & TRN \\
\hline CHEMBL3209732 & 688267 & 4.25 & 5.1087 & TRN \\
\hline CHEMBL1559773 & 688267 & 4.55 & 5.0659 & TST \\
\hline CHEMBL1584311 & 688267 & 5.95 & 5.1076 & TRN \\
\hline CHEMBL1213347 & 688267 & 5.05 & 5.062 & TRN \\
\hline CHEMBL1319412 & 688267 & 5.55 & 5.1258 & TRN \\
\hline CHEMBL1410186 & 688267 & 4.55 & 5.0107 & TRN \\
\hline CHEMBL1459075 & 688267 & 3.95 & 5.0874 & TRN \\
\hline CHEMBL1339352 & 688267 & 6.15 & 5.0524 & TRN \\
\hline CHEMBL1584829 & 688267 & 5.15 & 5.0317 & TRN \\
\hline CHEMBL1419228 & 688267 & 6.25 & 5.0389 & TRN \\
\hline CHEMBL1521074 & 688267 & 4.0 & 5.023 & TRN \\
\hline CHEMBL1468559 & 688267 & 4.4 & 5.0457 & TRN \\
\hline CHEMBL1514945 & 688267 & 5.15 & 5.06 & TRN \\
\hline CHEMBL1332773 & 688267 & 5.6 & 5.0444 & TRN \\
\hline
\end{tabular}




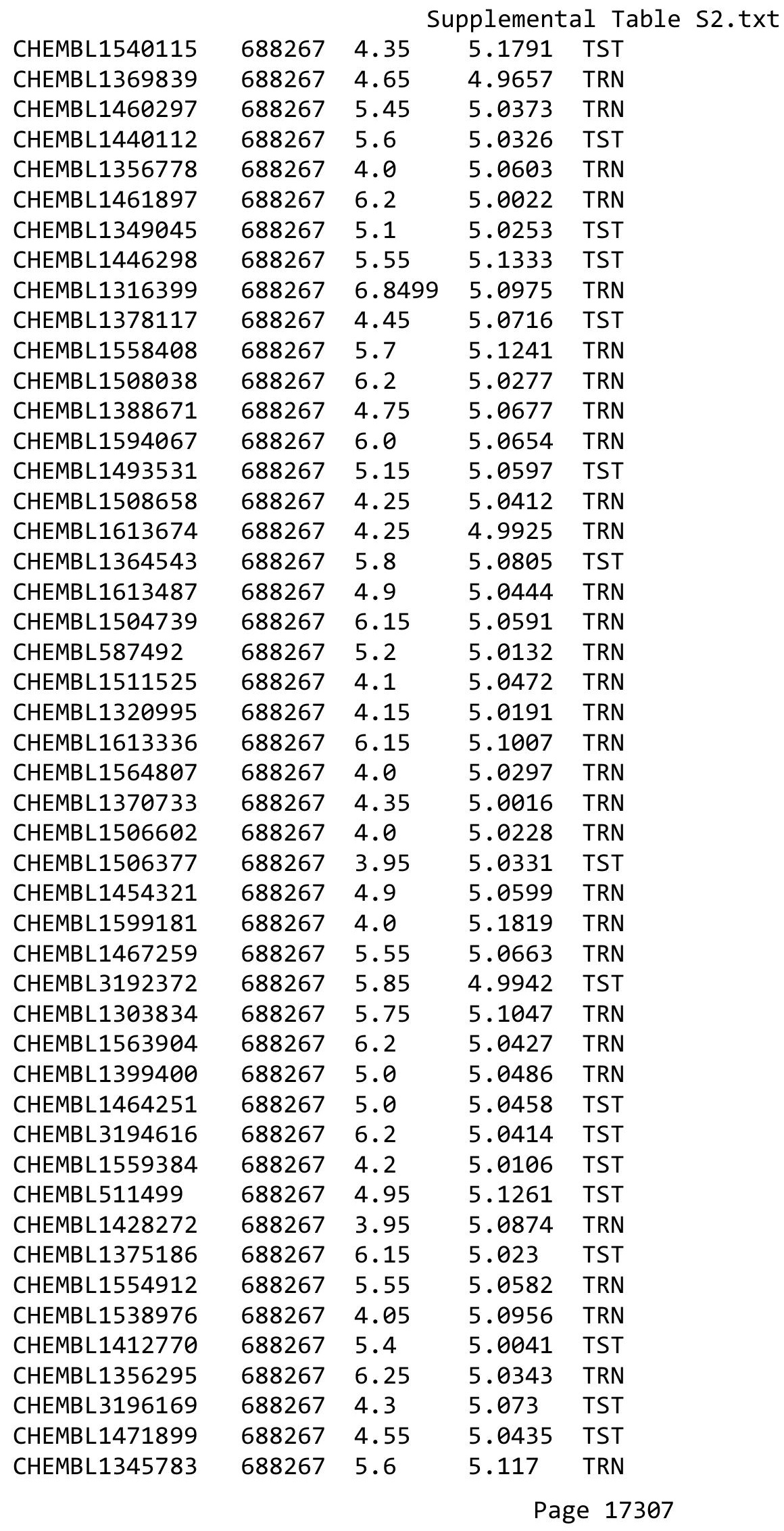




\begin{tabular}{|c|c|c|c|c|}
\hline \multicolumn{5}{|c|}{ Supplemental Tabl } \\
\hline CHEMBL1565880 & 688267 & 5.85 & 5.0062 & TRN \\
\hline CHEMBL1605355 & 688267 & 4.0 & 5.075 & TRN \\
\hline CHEMBL3207298 & 688267 & 6.2 & 5.0236 & TRN \\
\hline CHEMBL1338366 & 688267 & 4.35 & 5.0019 & TRN \\
\hline CHEMBL1566303 & 688267 & 5.45 & 5.0499 & TST \\
\hline CHEMBL1308428 & 688267 & 4.95 & 5.0827 & TST \\
\hline CHEMBL1565422 & 688267 & 6.25 & 5.0591 & TRN \\
\hline CHEMBL1405331 & 688267 & 4.55 & 5.1056 & TST \\
\hline CHEMBL1603144 & 688267 & 6.15 & 5.0272 & TST \\
\hline CHEMBL3210153 & 688267 & 5.2 & 5.0502 & TRN \\
\hline CHEMBL1611341 & 688267 & 5.95 & 5.0751 & TRN \\
\hline CHEMBL1565105 & 688267 & 4.55 & 5.0224 & TRN \\
\hline CHEMBL1404382 & 688267 & 6.25 & 5.0908 & TRN \\
\hline CHEMBL1522406 & 688267 & 3.95 & 5.0804 & TRN \\
\hline CHEMBL1300903 & 688267 & 4.3 & 5.0648 & TRN \\
\hline CHEMBL1316657 & 688267 & 5.65 & 5.0859 & TRN \\
\hline CHEMBL1509518 & 688267 & 6.2 & 5.1009 & TST \\
\hline CHEMBL1386358 & 688267 & 6.25 & 5.0416 & TRN \\
\hline CHEMBL1442433 & 688267 & 4.05 & 5.0265 & TRN \\
\hline CHEMBL1588024 & 688267 & 4.45 & 5.0378 & TRN \\
\hline CHEMBL1458300 & 688267 & 4.0 & 5.0072 & TRN \\
\hline CHEMBL1533755 & 688267 & 4.05 & 5.1509 & TRN \\
\hline CHEMBL1418969 & 688267 & 4.5 & 5.0576 & TST \\
\hline CHEMBL 3198080 & 688267 & 4.5 & 4.9968 & TST \\
\hline CHEMBL1396265 & 688267 & 5.2 & 5.0902 & TST \\
\hline CHEMBL1509011 & 688267 & 4.5 & 5.1279 & TRN \\
\hline CHEMBL1324583 & 688267 & 4.0 & 5.1717 & TRN \\
\hline CHEMBL1528115 & 688267 & 4.35 & 5.0326 & TST \\
\hline CHEMBL1418191 & 688267 & 6.2 & 5.0213 & TST \\
\hline CHEMBL1527369 & 688267 & 5.85 & 5.1264 & TRN \\
\hline CHEMBL1385140 & 688267 & 6.0 & 5.1183 & TRN \\
\hline CHEMBL1523311 & 688267 & 4.05 & 5.0519 & TRN \\
\hline CHEMBL1610116 & 688267 & 6.2 & 5.0484 & TRN \\
\hline CHEMBL1572613 & 688267 & 4.35 & 5.01 & TRN \\
\hline CHEMBL1391871 & 688267 & 4.05 & 5.0564 & TRN \\
\hline CHEMBL1441099 & 688267 & 4.3 & 4.9973 & TRN \\
\hline CHEMBL1599126 & 688267 & 5.35 & 5.0159 & TRN \\
\hline CHEMBL1534002 & 688267 & 4.35 & 5.0264 & TST \\
\hline CHEMBL1518048 & 688267 & 4.2 & 5.0435 & TRN \\
\hline CHEMBL1457794 & 688267 & 5.35 & 5.0339 & TST \\
\hline CHEMBL1352222 & 688267 & 5.2 & 5.0456 & TRN \\
\hline CHEMBL1407466 & 688267 & 4.35 & 5.078 & TRN \\
\hline CHEMBL1537711 & 688267 & 4.0 & 5.0518 & TRN \\
\hline CHEMBL1456436 & 688267 & 4.65 & 5.0399 & TRN \\
\hline CHEMBL1498374 & 688267 & 5.5 & 4.9876 & TRN \\
\hline CHEMBL1474323 & 688267 & 5.25 & 5.0166 & TRN \\
\hline CHEMBL1520187 & 688267 & 4.25 & 5.0556 & TRN \\
\hline CHEMBL1421932 & 688267 & 5.55 & 5.0651 & TST \\
\hline
\end{tabular}




\begin{tabular}{|c|c|c|c|c|c|}
\hline \multicolumn{6}{|c|}{ Supplemental Table S2.txt } \\
\hline CHEMBL1559544 & 688267 & 5.45 & 5.0724 & TRN & \\
\hline CHEMBL1548573 & 688267 & 5.9 & 5.0703 & TRN & \\
\hline CHEMBL1566897 & 688267 & 4.05 & 4.9921 & TRN & \\
\hline CHEMBL1448874 & 688267 & 4.15 & 4.9595 & TRN & \\
\hline CHEMBL 1434026 & 688267 & 5.65 & 5.0502 & TRN & \\
\hline CHEMBL1610688 & 688267 & 5.3 & 5.041 & TRN & \\
\hline CHEMBL3208633 & 688267 & 6.2 & 5.0386 & TST & \\
\hline CHEMBL1417526 & 688267 & 4.05 & 5.0123 & TRN & \\
\hline CHEMBL1435606 & 688267 & 6.25 & 5.0849 & TST & \\
\hline CHEMBL1389514 & 688267 & 4.25 & 5.096 & TST & \\
\hline CHEMBL1546075 & 688267 & 6.2 & 5.0943 & TRN & \\
\hline CHEMBL3193176 & 688267 & 4.0 & 4.9957 & TRN & \\
\hline CHEMBL1552901 & 688267 & 3.95 & 5.0102 & TST & \\
\hline CHEMBL1325686 & 688267 & 4.25 & 5.029 & TRN & \\
\hline CHEMBL1395317 & 688267 & 4.6 & 5.02800 & 00000000005 & TRN \\
\hline CHEMBL1402312 & 688267 & 6.5 & 5.0887 & TRN & \\
\hline CHEMBL1397272 & 688267 & 4.05 & 5.0581 & TRN & \\
\hline CHEMBL1542247 & 688267 & 6.25 & 5.0463 & TRN & \\
\hline CHEMBL1502174 & 688267 & 3.95 & 5.0735 & TRN & \\
\hline CHEMBL1322243 & 688267 & 4.45 & 5.1391 & TRN & \\
\hline CHEMBL1442757 & 688267 & 4.7 & 5.0702 & TRN & \\
\hline CHEMBL1312207 & 688267 & 5.1 & 5.0577 & TRN & \\
\hline CHEMBL1396466 & 688267 & 5.95 & 5.1123 & TRN & \\
\hline CHEMBL1471053 & 688267 & 5.6 & 4.9918 & TRN & \\
\hline CHEMBL1333256 & 688267 & 5.9 & 5.0378 & TRN & \\
\hline CHEMBL1447182 & 688267 & 5.45 & 5.0639 & TRN & \\
\hline CHEMBL1357088 & 688267 & 4.2 & 5.0848 & TRN & \\
\hline CHEMBL1575323 & 688267 & 6.15 & 5.0617 & TST & \\
\hline CHEMBL1491416 & 688267 & 4.0 & 5.0865 & TRN & \\
\hline CHEMBL1570075 & 688267 & 6.2 & 5.1315 & TRN & \\
\hline CHEMBL1409193 & 688267 & 5.35 & 5.0206 & TRN & \\
\hline CHEMBL1593670 & 688267 & 3.9 & 5.0014 & TRN & \\
\hline CHEMBL1490710 & 688267 & 6.1 & 5.0693 & TRN & \\
\hline CHEMBL1512110 & 688267 & 5.85 & 5.0414 & TRN & \\
\hline CHEMBL1448636 & 688267 & 5.1 & 5.1228 & TRN & \\
\hline CHEMBL1586251 & 688267 & 4.25 & 5.0664 & TST & \\
\hline CHEMBL1516330 & 688267 & 4.35 & 5.0851 & TRN & \\
\hline CHEMBL3214236 & 688267 & 6.25 & 5.0583 & TRN & \\
\hline CHEMBL1499626 & 688267 & 6.2 & 5.1505 & TRN & \\
\hline CHEMBL1430290 & 688267 & 4.0 & 5.1498 & TRN & \\
\hline CHEMBL1495848 & 688267 & 4.0 & 5.0615 & TST & \\
\hline CHEMBL1423130 & 688267 & 5.55 & 5.022 & TST & \\
\hline CHEMBL1564873 & 688267 & 6.25 & 5.1084 & TRN & \\
\hline CHEMBL1439861 & 688267 & 4.5 & 5.0436 & TST & \\
\hline CHEMBL1438282 & 688267 & 5.3 & 5.055 & TRN & \\
\hline CHEMBL1423021 & 688267 & 4.4 & 5.0467 & TST & \\
\hline CHEMBL1347333 & 688267 & 5.15 & 5.1005 & TST & \\
\hline CHEMBL1597127 & 688267 & 4.05 & 5.0239 & TRN & \\
\hline
\end{tabular}




\begin{tabular}{|c|c|c|c|c|c|}
\hline \multicolumn{6}{|c|}{ Supplemental Table S2.txt } \\
\hline CHEMBL1406362 & 688267 & 4.35 & 5.0537 & TRN & \\
\hline CHEMBL1354597 & 688267 & 6.2 & 5.0416 & TST & \\
\hline CHEMBL1495613 & 688267 & 5.9 & 5.1007 & TRN & \\
\hline CHEMBL1417726 & 688267 & 5.65 & 5.0682 & TRN & \\
\hline CHEMBL1395455 & 688267 & 4.55 & 5.1306 & TRN & \\
\hline CHEMBL1310104 & 688267 & 5.55 & 5.0534 & TRN & \\
\hline CHEMBL1447949 & 688267 & 5.35 & 5.0587 & TRN & \\
\hline CHEMBL1560134 & 688267 & 4.35 & 5.0895 & TST & \\
\hline CHEMBL1435642 & 688267 & 5.4 & 5.0765 & TRN & \\
\hline CHEMBL1551775 & 688267 & 4.05 & 4.9998 & TST & \\
\hline CHEMBL1466110 & 688267 & 4.85 & 5.1078 & TRN & \\
\hline CHEMBL1354255 & 688267 & 5.9 & 5.0202 & TST & \\
\hline CHEMBL3207589 & 688267 & 4.4 & 5.0179 & TST & \\
\hline CHEMBL1345854 & 688267 & 3.95 & 5.0601 & TRN & \\
\hline CHEMBL1335759 & 688267 & 5.35 & 5.1384 & TRN & \\
\hline CHEMBL1402369 & 688267 & 4.0 & 5.0431 & TRN & \\
\hline CHEMBL1410501 & 688267 & 5.55 & 5.0152 & TST & \\
\hline CHEMBL1330436 & 688267 & 6.2 & 5.0992 & TRN & \\
\hline CHEMBL1493821 & 688267 & 4.95 & 5.0264 & TRN & \\
\hline CHEMBL529138 & 688267 & 5.9 & 5.0884 & TRN & \\
\hline CHEMBL1489751 & 688267 & 6.2 & 5.0941 & TST & \\
\hline CHEMBL1538153 & 688267 & 4.15 & 5.1024 & TRN & \\
\hline CHEMBL 2094573 & 688267 & 5.3 & 5.0394 & TRN & \\
\hline CHEMBL1505755 & 688267 & 4.55 & 5.1076 & TST & \\
\hline CHEMBL1317796 & 688267 & 4.4 & 5.0874 & TRN & \\
\hline CHEMBL1512007 & 688267 & 5.25 & 5.1076 & TRN & \\
\hline CHEMBL1337923 & 688267 & 3.95 & 5.0487 & TRN & \\
\hline CHEMBL1404978 & 688267 & 6.2 & 5.0491 & TST & \\
\hline CHEMBL1507721 & 688267 & 5.65 & 5.0672 & TRN & \\
\hline CHEMBL1560718 & 688267 & 5.05 & 5.0251 & TST & \\
\hline CHEMBL1456851 & 688267 & 6.5 & 5.0456 & TRN & \\
\hline CHEMBL1436196 & 688267 & 6.2 & 4.9837 & TRN & \\
\hline CHEMBL1539797 & 688267 & 5.5 & 5.0316 & TRN & \\
\hline CHEMBL1325095 & 688267 & 5.75 & 5.1528 & TRN & \\
\hline CHEMBL1550063 & 688267 & 3.95 & 5.1277 & TRN & \\
\hline CHEMBL1445797 & 688267 & 5.0 & 5.0268 & TRN & \\
\hline CHEMBL1441733 & 688267 & 5.55 & 5.0911 & TRN & \\
\hline CHEMBL1305842 & 688267 & 6.15 & 5.0765 & TRN & \\
\hline CHEMBL1390797 & 688267 & 4.4 & 5.0056 & TST & \\
\hline CHEMBL1369829 & 688267 & 6.2 & 5.0839 & TST & \\
\hline CHEMBL1374670 & 688267 & 4.3 & 5.0219 & TST & \\
\hline CHEMBL1556956 & 688267 & 4.35 & 5.0364 & TRN & \\
\hline CHEMBL1523662 & 688267 & 4.0 & 5.0167 & TRN & \\
\hline CHEMBL1332114 & 688267 & 4.3 & 5.09 & TRN & \\
\hline CHEMBL1568671 & 688267 & 5.3 & 5.0147 & TRN & \\
\hline CHEMBL1483768 & 688267 & 4.5 & 5.0826 & TRN & \\
\hline CHEMBL1371501 & 688267 & 4.3 & 5.08899 & 99999999995 & TRN \\
\hline CHEMBL1459115 & 688267 & 5.4 & 5.0679 & TRN & \\
\hline
\end{tabular}




\begin{tabular}{|c|c|c|c|c|}
\hline \multicolumn{5}{|c|}{ Supplemental Table S2.txt } \\
\hline CHEMBL1451898 & 688267 & 4.2 & 5.0735 & TRN \\
\hline CHEMBL3213953 & 688267 & 5.9 & 5.0007 & TST \\
\hline CHEMBL1306536 & 688267 & 6.2 & 5.1066 & TRN \\
\hline CHEMBL1537609 & 688267 & 4.95 & 5.0749 & TRN \\
\hline CHEMBL1517096 & 688267 & 4.7 & 5.1153 & TST \\
\hline CHEMBL1541180 & 688267 & 5.1 & 5.0742 & TRN \\
\hline CHEMBL1081467 & 688267 & 4.1 & 5.0508 & TRN \\
\hline CHEMBL1612446 & 688267 & 5.5 & 5.0578 & TRN \\
\hline CHEMBL1488769 & 688267 & 6.5501 & 4.9975 & TRN \\
\hline CHEMBL1521035 & 688267 & 4.4 & 5.075 & TRN \\
\hline CHEMBL1474116 & 688267 & 4.25 & 5.0816 & TRN \\
\hline CHEMBL155625 & 688267 & 4.15 & 5.0134 & TRN \\
\hline CHEMBL1366407 & 688267 & 3.95 & 5.0186 & TST \\
\hline CHEMBL1377074 & 688267 & 4.35 & 5.0891 & TRN \\
\hline CHEMBL1477045 & 688267 & 4.35 & 5.0906 & TRN \\
\hline CHEMBL1531314 & 688267 & 4.1 & 5.0782 & TST \\
\hline CHEMBL1454438 & 688267 & 4.3 & 5.1008 & TRN \\
\hline CHEMBL1499130 & 688267 & 5.35 & 5.0799 & TRN \\
\hline CHEMBL1457232 & 688267 & 4.7 & 5.0976 & TRN \\
\hline CHEMBL1422969 & 688267 & 5.4 & 5.0855 & TRN \\
\hline CHEMBL3212969 & 688267 & 6.2 & 5.0082 & TRN \\
\hline CHEMBL1427804 & 688267 & 6.15 & 5.0961 & TRN \\
\hline CHEMBL3196102 & 688267 & 4.45 & 4.9593 & TRN \\
\hline CHEMBL1610202 & 688267 & 5.5 & 5.0585 & TST \\
\hline CHEMBL1300416 & 688267 & 4.85 & 5.0657 & TRN \\
\hline CHEMBL1542067 & 688267 & 5.15 & 4.9729 & TRN \\
\hline CHEMBL1368246 & 688267 & 5.9 & 5.0357 & TRN \\
\hline CHEMBL1431251 & 688267 & 3.95 & 5.0969 & TRN \\
\hline CHEMBL3195565 & 688267 & 5.55 & 5.0515 & TRN \\
\hline CHEMBL2369306 & 688267 & 6.2 & 5.0378 & TST \\
\hline CHEMBL1556660 & 688267 & 6.2 & 5.0413 & TRN \\
\hline CHEMBL1578014 & 688267 & 5.4 & 5.0111 & TRN \\
\hline CHEMBL205808 & 688267 & 4.9 & 5.1095 & TRN \\
\hline CHEMBL1311744 & 688267 & 5.85 & 5.0172 & TRN \\
\hline CHEMBL1543413 & 688267 & 5.25 & 5.0434 & TRN \\
\hline CHEMBL1454234 & 688267 & 4.05 & 5.0566 & TST \\
\hline CHEMBL1529111 & 688267 & 6.2 & 5.0108 & TRN \\
\hline CHEMBL1552568 & 688267 & 5.6 & 5.0615 & TRN \\
\hline CHEMBL1330217 & 688267 & 4.45 & 5.0496 & TST \\
\hline CHEMBL1570156 & 688267 & 6.2 & 5.029 & TRN \\
\hline CHEMBL1534909 & 688267 & 4.05 & 5.0584 & TRN \\
\hline CHEMBL1356185 & 688267 & 5.6 & 5.1307 & TRN \\
\hline CHEMBL1402130 & 688267 & 6.2 & 5.0649 & TRN \\
\hline CHEMBL1987063 & 688267 & 5.25 & 5.0704 & TST \\
\hline CHEMBL1454144 & 688267 & 6.2 & 5.0051 & TRN \\
\hline CHEMBL1331394 & 688267 & 4.45 & 5.0878 & TRN \\
\hline CHEMBL1336260 & 688267 & 6.15 & 5.1474 & TRN \\
\hline CHEMBL1541872 & 688267 & 4.7 & 5.0925 & TRN \\
\hline
\end{tabular}




\begin{tabular}{|c|c|c|c|c|c|}
\hline \multicolumn{6}{|c|}{ Supplemental Table S2.txt } \\
\hline CHEMBL1457327 & 688267 & 5.35 & 5.0599 & TRN & \\
\hline CHEMBL1419743 & 688267 & 4.5 & 5.1105 & TST & \\
\hline CHEMBL1486487 & 688267 & 6.0 & 5.0919 & TRN & \\
\hline CHEMBL1530376 & 688267 & 5.55 & 5.1233 & TRN & \\
\hline CHEMBL1546873 & 688267 & 3.95 & 5.0902 & TST & \\
\hline CHEMBL1503015 & 688267 & 6.25 & 5.0673 & TST & \\
\hline CHEMBL1374205 & 688267 & 5.6 & 5.0542 & TRN & \\
\hline CHEMBL1363908 & 688267 & 4.2 & 5.0692 & TST & \\
\hline CHEMBL1333986 & 688267 & 5.3 & 5.0509 & TRN & \\
\hline CHEMBL1498709 & 688267 & 6.2 & 5.0487 & TST & \\
\hline CHEMBL1554653 & 688267 & 4.35 & 5.0645 & TRN & \\
\hline CHEMBL1500113 & 688267 & 4.15 & 5.0603 & TRN & \\
\hline CHEMBL1449537 & 688267 & 6.5 & 5.0179 & TST & \\
\hline CHEMBL1582636 & 688267 & 6.15 & 5.0927 & TRN & \\
\hline CHEMBL1604954 & 688267 & 5.55 & 5.1181 & TRN & \\
\hline CHEMBL1392227 & 688267 & 4.05 & 5.12700 & 0000000001 & TST \\
\hline CHEMBL1400105 & 688267 & 4.1 & 5.0112 & TRN & \\
\hline CHEMBL1508896 & 688267 & 4.25 & 5.0732 & TRN & \\
\hline CHEMBL1562163 & 688267 & 4.05 & 5.0883 & TRN & \\
\hline CHEMBL1604611 & 688267 & 6.2 & 5.016 & TRN & \\
\hline CHEMBL1500302 & 688267 & 4.35 & 5.0533 & TRN & \\
\hline CHEMBL1350199 & 688267 & 6.2 & 5.0488 & TRN & \\
\hline CHEMBL1607398 & 688267 & 3.95 & 5.0045 & TRN & \\
\hline CHEMBL1471920 & 688267 & 4.6 & 5.0 & TRN & \\
\hline CHEMBL1557815 & 688267 & 4.05 & 5.0001 & TRN & \\
\hline CHEMBL1479682 & 688267 & 4.1 & 5.05399 & 9999999999 & TRN \\
\hline CHEMBL3192812 & 688267 & 5.3 & 5.0696 & TRN & \\
\hline CHEMBL1356905 & 688267 & 5.25 & 5.0108 & TRN & \\
\hline CHEMBL1441036 & 688267 & 4.35 & 5.1025 & TRN & \\
\hline CHEMBL1509985 & 688267 & 4.55 & 5.1424 & TRN & \\
\hline CHEMBL1333538 & 688267 & 5.3 & 5.0867 & TRN & \\
\hline CHEMBL1394311 & 688267 & 5.8 & 5.0604 & TST & \\
\hline CHEMBL1311248 & 688267 & 6.2 & 5.0446 & TRN & \\
\hline CHEMBL1467297 & 688267 & 3.95 & 5.0157 & TST & \\
\hline CHEMBL1512450 & 688267 & 5.55 & 5.1788 & TRN & \\
\hline CHEMBL1509473 & 688267 & 5.85 & 4.9999 & TRN & \\
\hline CHEMBL1520083 & 688267 & 5.0 & 5.1286 & TRN & \\
\hline CHEMBL1540035 & 688267 & 3.95 & 5.0469 & TRN & \\
\hline CHEMBL1487131 & 688267 & 5.75 & 4.9982 & TST & \\
\hline CHEMBL1388372 & 688267 & 6.25 & 4.9605 & TRN & \\
\hline CHEMBL3191190 & 688267 & 5.1 & 5.0391 & TRN & \\
\hline CHEMBL1371527 & 688267 & 4.0 & 5.0593 & TRN & \\
\hline CHEMBL1599087 & 688267 & 4.55 & 5.1213 & TRN & \\
\hline CHEMBL1401959 & 688267 & 4.45 & 4.9958 & TRN & \\
\hline CHEMBL1364161 & 688267 & 5.4 & 5.0305 & TRN & \\
\hline CHEMBL1350669 & 688267 & 4.3 & 5.0512 & TST & \\
\hline CHEMBL1604056 & 688267 & 6.5 & 5.1069 & TRN & \\
\hline CHEMBL1376730 & 688267 & 4.4 & 5.0288 & TRN & \\
\hline
\end{tabular}




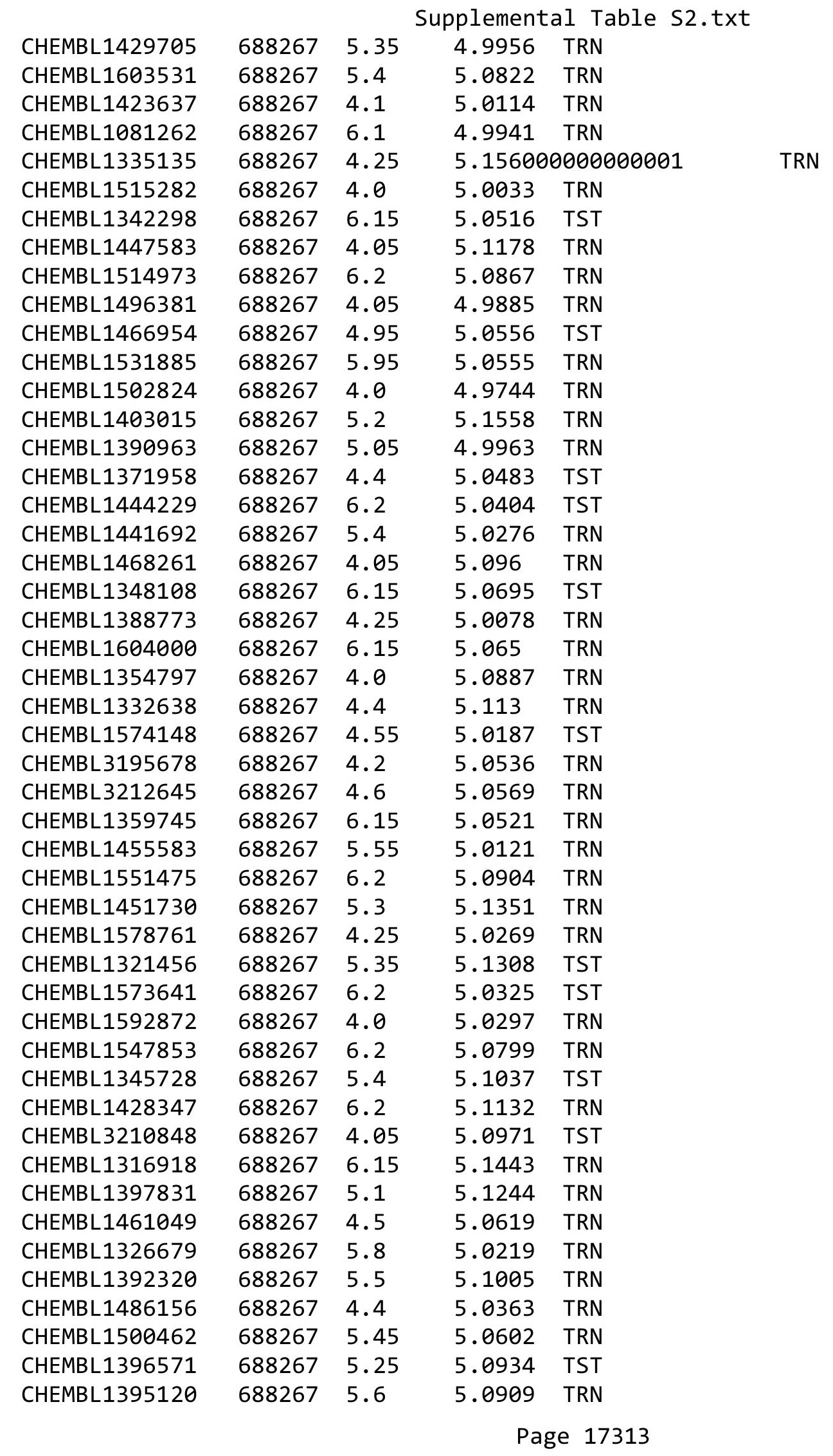




\begin{tabular}{|c|c|c|c|c|c|}
\hline \multicolumn{6}{|c|}{ Supplemental Table S2.txt } \\
\hline CHEMBL1426841 & 688267 & 4.6 & 5.0848 & TRN & \\
\hline CHEMBL1457181 & 688267 & 4.1 & 4.9784 & TRN & \\
\hline CHEMBL3209611 & 688267 & 4.35 & 5.0158 & TRN & \\
\hline CHEMBL1465673 & 688267 & 6.2 & 5.0438 & TST & \\
\hline CHEMBL1313954 & 688267 & 4.95 & 5.0182 & TST & \\
\hline CHEMBL1479653 & 688267 & 4.2 & 5.0379 & TRN & \\
\hline CHEMBL1571571 & 688267 & 5.2 & 5.1515 & TRN & \\
\hline CHEMBL1352939 & 688267 & 4.45 & 5.0119 & TRN & \\
\hline CHEMBL1516909 & 688267 & 4.3 & 5.0191 & TST & \\
\hline CHEMBL1325733 & 688267 & 4.4 & 5.0778 & TRN & \\
\hline CHEMBL1558032 & 688267 & 6.5 & 5.0865 & TRN & \\
\hline CHEMBL1465560 & 688267 & 5.5 & 5.0668 & TRN & \\
\hline CHEMBL1524505 & 688267 & 4.35 & 5.1007 & TST & \\
\hline CHEMBL 3207384 & 688267 & 4.0 & 5.0448 & TRN & \\
\hline CHEMBL1365687 & 688267 & 5.0 & 5.0536 & TRN & \\
\hline CHEMBL1573247 & 688267 & 5.05 & 5.0915 & TRN & \\
\hline CHEMBL1418430 & 688267 & 6.05 & 5.03 & TST & \\
\hline CHEMBL1369963 & 688267 & 5.25 & 5.033 & TRN & \\
\hline CHEMBL1483918 & 688267 & 6.2 & 5.0077 & TRN & \\
\hline CHEMBL1509533 & 688267 & 4.05 & 5.1185 & TRN & \\
\hline CHEMBL1441015 & 688267 & 4.1 & 5.0489 & TRN & \\
\hline CHEMBL1545943 & 688267 & 4.3 & 5.0277 & TRN & \\
\hline CHEMBL591385 & 688267 & 4.6 & 5.1116 & TRN & \\
\hline CHEMBL1443194 & 688267 & 4.15 & 5.0952 & TRN & \\
\hline CHEMBL1539353 & 688267 & 5.8 & 5.0762 & TRN & \\
\hline CHEMBL1393853 & 688267 & 6.15 & 5.0348 & TRN & \\
\hline CHEMBL1604522 & 688267 & 6.15 & 5.0394 & TRN & \\
\hline CHEMBL1372570 & 688267 & 5.25 & 5.07600 & 00000000005 & TRN \\
\hline CHEMBL1365884 & 688267 & 5.25 & 5.1248 & TRN & \\
\hline CHEMBL1561335 & 688267 & 5.85 & 5.06 & TRN & \\
\hline CHEMBL1355347 & 688267 & 6.0 & 5.1275 & TRN & \\
\hline CHEMBL 3213875 & 688267 & 5.55 & 5.0333 & TRN & \\
\hline CHEMBL1572806 & 688267 & 4.05 & 5.0858 & TRN & \\
\hline CHEMBL1492643 & 688267 & 4.0 & 5.027 & TRN & \\
\hline CHEMBL1392861 & 688267 & 5.05 & 5.0449 & TRN & \\
\hline CHEMBL1342263 & 688267 & 4.2 & 5.0628 & TRN & \\
\hline CHEMBL1363586 & 688267 & 4.0 & 5.0829 & TRN & \\
\hline CHEMBL1332510 & 688267 & 5.8 & 5.0709 & TRN & \\
\hline CHEMBL1539682 & 688267 & 4.4 & 5.0707 & TST & \\
\hline CHEMBL1397681 & 688267 & 5.85 & 5.0321 & TRN & \\
\hline CHEMBL1588494 & 688267 & 4.35 & 5.1169 & TRN & \\
\hline CHEMBL1978193 & 688267 & 4.55 & 5.0061 & TRN & \\
\hline CHEMBL1457942 & 688267 & 4.35 & 5.0076 & TRN & \\
\hline CHEMBL3208967 & 688267 & 5.0 & 5.0212 & TRN & \\
\hline CHEMBL1526982 & 688267 & 4.35 & 5.0275 & TRN & \\
\hline CHEMBL1416645 & 688267 & 4.15 & 5.0577 & TST & \\
\hline CHEMBL1501256 & 688267 & 5.45 & 5.006 & TRN & \\
\hline CHEMBL1353254 & 688267 & 4.35 & 5.0589 & TRN & \\
\hline
\end{tabular}




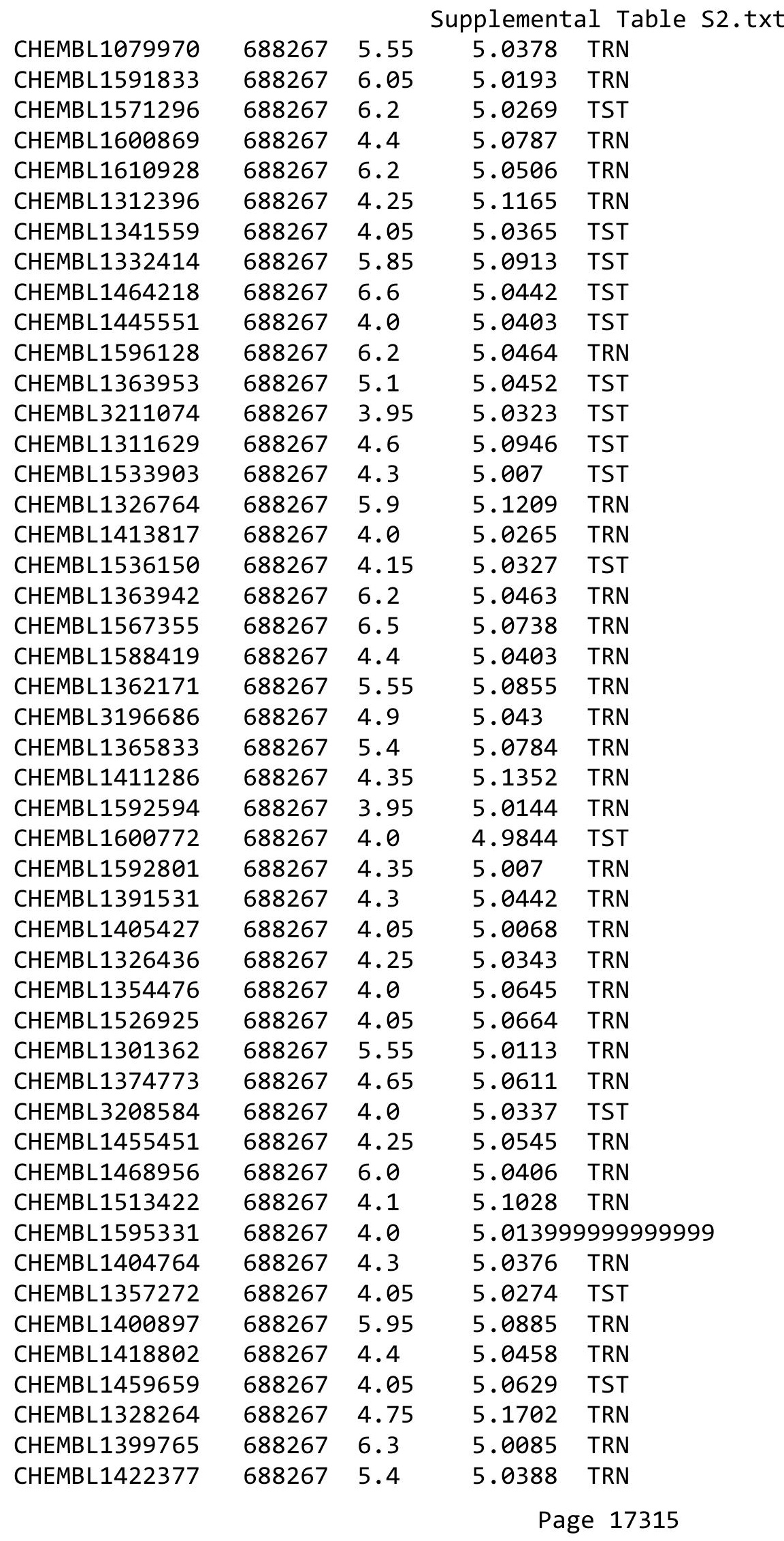




\begin{tabular}{|c|c|c|c|c|c|}
\hline \multicolumn{6}{|c|}{ Supplemental Table S2.txt } \\
\hline CHEMBL1386485 & 688267 & 6.15 & 5.0413 & TRN & \\
\hline CHEMBL1503194 & 688267 & 4.3 & 5.0958 & TRN & \\
\hline CHEMBL1496723 & 688267 & 5.5 & 5.1166 & TRN & \\
\hline CHEMBL1355533 & 688267 & 5.9 & 5.1527 & TRN & \\
\hline CHEMBL1535032 & 688267 & 5.55 & 5.0969 & TST & \\
\hline CHEMBL1590219 & 688267 & 5.35 & 5.0518 & TRN & \\
\hline CHEMBL1388714 & 688267 & 5.8 & 5.0731 & TRN & \\
\hline CHEMBL3194912 & 688267 & 4.25 & 5.0089 & TRN & \\
\hline CHEMBL1550140 & 688267 & 4.4 & 5.0887 & TST & \\
\hline CHEMBL1555880 & 688267 & 5.9 & 5.0849 & TRN & \\
\hline CHEMBL1583789 & 688267 & 6.0 & 4.9874 & TRN & \\
\hline CHEMBL1476803 & 688267 & 3.95 & 5.0335 & TRN & \\
\hline CHEMBL1540483 & 688267 & 4.55 & 5.0493 & TST & \\
\hline CHEMBL1467600 & 688267 & 7.1002 & 5.0436 & TST & \\
\hline CHEMBL1450100 & 688267 & 4.95 & 5.0635 & TST & \\
\hline CHEMBL1497493 & 688267 & 5.4 & 5.0265 & TRN & \\
\hline CHEMBL1459709 & 688267 & 6.2 & 5.0754 & TRN & \\
\hline CHEMBL1531113 & 688267 & 4.55 & 5.0181 & TRN & \\
\hline CHEMBL1562750 & 688267 & 5.95 & 5.0729 & TST & \\
\hline CHEMBL1364051 & 688267 & 4.85 & 5.0953 & TRN & \\
\hline CHEMBL1570250 & 688267 & 6.25 & 5.0256 & TRN & \\
\hline CHEMBL1421845 & 688267 & 6.2 & 5.1185 & TST & \\
\hline CHEMBL1382711 & 688267 & 4.4 & 5.03106 & 0000000001 & TRN \\
\hline CHEMBL1355681 & 688267 & 4.0 & 5.0591 & TST & \\
\hline CHEMBL1382400 & 688267 & 4.7 & 5.0715 & TRN & \\
\hline CHEMBL3194605 & 688267 & 5.3 & 5.0079 & TRN & \\
\hline CHEMBL1558574 & 688267 & 3.95 & 5.0427 & TST & \\
\hline CHEMBL1309501 & 688267 & 4.95 & 5.1065 & TRN & \\
\hline CHEMBL1342240 & 688267 & 5.3 & 5.0166 & TRN & \\
\hline CHEMBL1526894 & 688267 & 4.05 & 5.0748 & TRN & \\
\hline CHEMBL1536564 & 688267 & 5.65 & 5.0752 & TRN & \\
\hline CHEMBL1580407 & 688267 & 6.25 & 5.0126 & TST & \\
\hline CHEMBL1482929 & 688267 & 4.35 & 5.0729 & TRN & \\
\hline CHEMBL1574998 & 688267 & 4.45 & 5.0388 & TRN & \\
\hline CHEMBL1398423 & 688267 & 4.95 & $5.1080 €$ & 00000000005 & TRN \\
\hline CHEMBL1581294 & 688267 & 4.1 & 5.0164 & TRN & \\
\hline CHEMBL1560565 & 688267 & 4.0 & 5.0602 & TRN & \\
\hline CHEMBL1484919 & 688267 & 6.0 & 5.0965 & TRN & \\
\hline CHEMBL1506095 & 688267 & 4.0 & 5.0801 & TRN & \\
\hline CHEMBL1476307 & 688267 & 6.2 & 5.0563 & TRN & \\
\hline CHEMBL3212479 & 688267 & 4.35 & 5.0267 & TST & \\
\hline CHEMBL1399629 & 688267 & 5.65 & 5.0615 & TST & \\
\hline CHEMBL 1477712 & 688267 & 4.35 & 5.0319 & TRN & \\
\hline CHEMBL1698037 & 688267 & 4.85 & 4.994 & TRN & \\
\hline CHEMBL1512733 & 688267 & 6.2 & 4.9658 & TRN & \\
\hline CHEMBL1311795 & 688267 & 4.45 & 5.0186 & TST & \\
\hline CHEMBL1387588 & 688267 & 4.35 & 5.0362 & TRN & \\
\hline CHEMBL1405126 & 688267 & 5.35 & 5.0289 & TST & \\
\hline
\end{tabular}




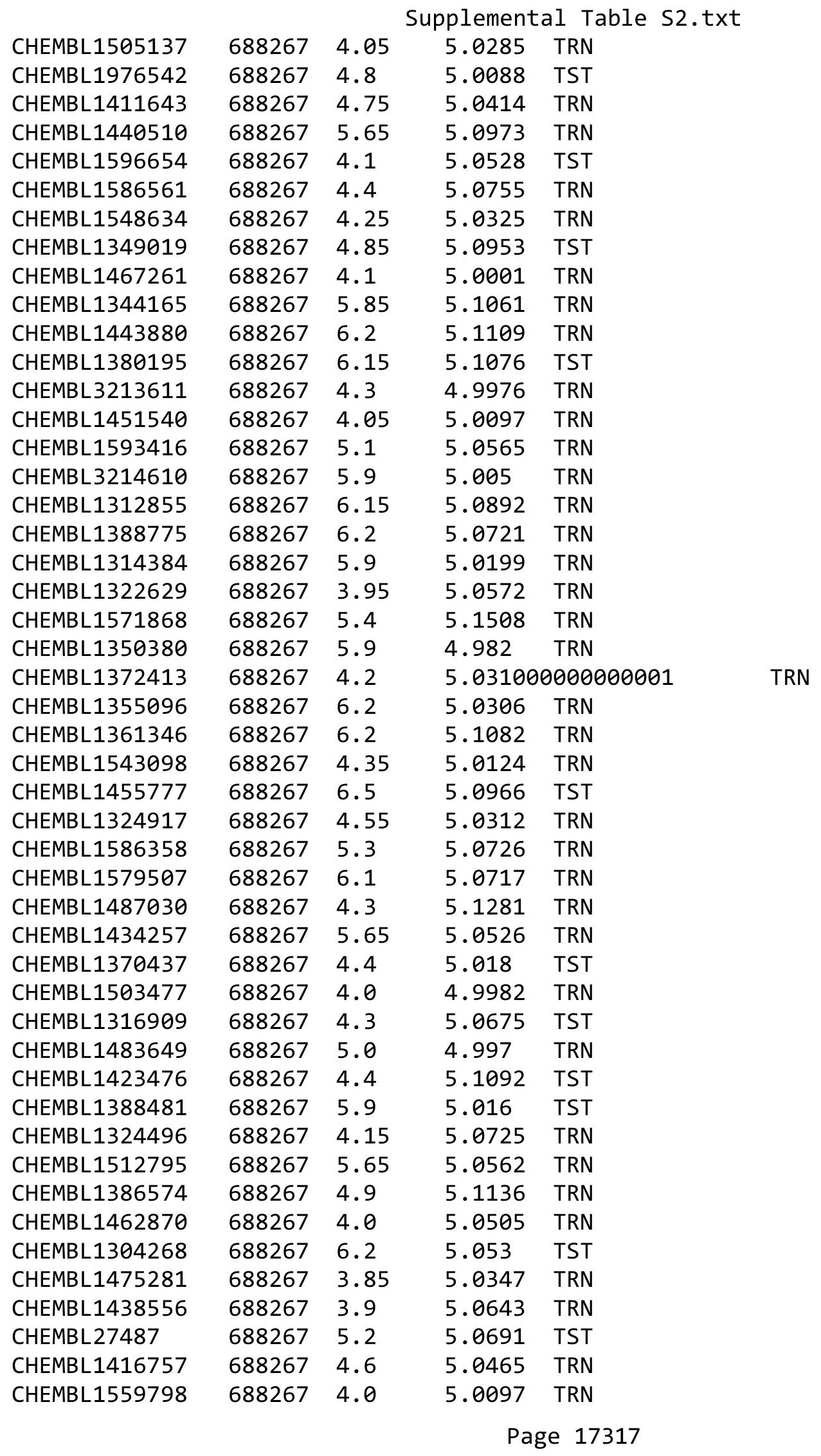




\begin{tabular}{|c|c|c|c|c|}
\hline & & & pplement & al $\mathrm{Ta}$ \\
\hline CHEMBL1371384 & 688267 & 6.2 & 5.0197 & TRN \\
\hline CHEMBL1447454 & 688267 & 5.5 & 5.0314 & TRN \\
\hline CHEMBL1488278 & 688267 & 5.45 & 5.0878 & TRN \\
\hline CHEMBL1412921 & 688267 & 4.6 & 5.0508 & TRN \\
\hline CHEMBL1367359 & 688267 & 6.2 & 5.0251 & TRN \\
\hline CHEMBL1330898 & 688267 & 5.85 & 5.1431 & TRN \\
\hline CHEMBL1568871 & 688267 & 4.35 & 5.0964 & TRN \\
\hline CHEMBL1591489 & 688267 & 4.0 & 5.0728 & TRN \\
\hline CHEMBL1388490 & 688267 & 5.0 & 5.0158 & TST \\
\hline CHEMBL1508240 & 688267 & 5.7 & 5.0298 & TRN \\
\hline CHEMBL1383105 & 688267 & 5.35 & 5.008 & TST \\
\hline CHEMBL1350023 & 688267 & 5.1 & 5.0226 & TRN \\
\hline CHEMBL1559216 & 688267 & 4.6 & 5.1144 & TRN \\
\hline CHEMBL1475964 & 688267 & 6.25 & 5.0361 & TST \\
\hline CHEMBL1595324 & 688267 & 6.15 & 5.0877 & TRN \\
\hline CHEMBL1450560 & 688267 & 5.9 & 5.0013 & TRN \\
\hline CHEMBL1078244 & 688267 & 6.1 & 5.0303 & TST \\
\hline CHEMBL1482238 & 688267 & 4.6 & 5.0989 & TRN \\
\hline CHEMBL1386018 & 688267 & 4.05 & 5.1001 & TST \\
\hline CHEMBL1539612 & 688267 & 5.3 & 5.0297 & TST \\
\hline CHEMBL1308044 & 688267 & 4.0 & 5.1161 & TRN \\
\hline CHEMBL1409588 & 688267 & 4.7 & 5.0283 & TST \\
\hline CHEMBL3208457 & 688267 & 4.6 & 4.9866 & TST \\
\hline CHEMBL1575359 & 688267 & 6.2 & 5.0887 & TRN \\
\hline CHEMBL1503352 & 688267 & 6.25 & 5.0766 & TRN \\
\hline CHEMBL3210128 & 688267 & 5.1 & 5.0627 & TST \\
\hline CHEMBL1405904 & 688267 & 5.95 & 5.1181 & TRN \\
\hline CHEMBL1494015 & 688267 & 5.65 & 5.0037 & TST \\
\hline CHEMBL1333364 & 688267 & 4.65 & 5.0231 & TRN \\
\hline CHEMBL1359249 & 688267 & 4.65 & 5.0853 & TRN \\
\hline CHEMBL24510 & 688267 & 5.0 & 5.0725 & TST \\
\hline CHEMBL1310390 & 688267 & 4.4 & 5.1201 & TRN \\
\hline CHEMBL1408217 & 688267 & 5.25 & 5.0488 & TRN \\
\hline CHEMBL1490845 & 688267 & 5.3 & 5.0175 & TRN \\
\hline CHEMBL1402547 & 688267 & 5.15 & 5.0482 & TRN \\
\hline CHEMBL1341913 & 688267 & 6.0 & 5.0253 & TST \\
\hline CHEMBL1505058 & 688267 & 5.3 & 5.0612 & TST \\
\hline CHEMBL1388654 & 688267 & 4.65 & 5.0848 & TST \\
\hline CHEMBL1609880 & 688267 & 4.45 & 5.0219 & TRN \\
\hline CHEMBL1361569 & 688267 & 3.95 & 5.0296 & TRN \\
\hline CHEMBL1518113 & 688267 & 6.15 & 5.0652 & TRN \\
\hline CHEMBL1603040 & 688267 & 4.1 & 5.0736 & TST \\
\hline CHEMBL1390643 & 688267 & 4.6 & 5.0461 & TST \\
\hline CHEMBL1442699 & 688267 & 4.55 & 5.0444 & TRN \\
\hline CHEMBL1517984 & 688267 & 4.75 & 5.0739 & TRN \\
\hline CHEMBL1475239 & 688267 & 3.95 & 5.03 & TRN \\
\hline CHEMBL1413628 & 688267 & 6.25 & 5.0526 & TRN \\
\hline CHEMBL1458517 & 688267 & 4.6 & 5.0571 & TRN \\
\hline
\end{tabular}




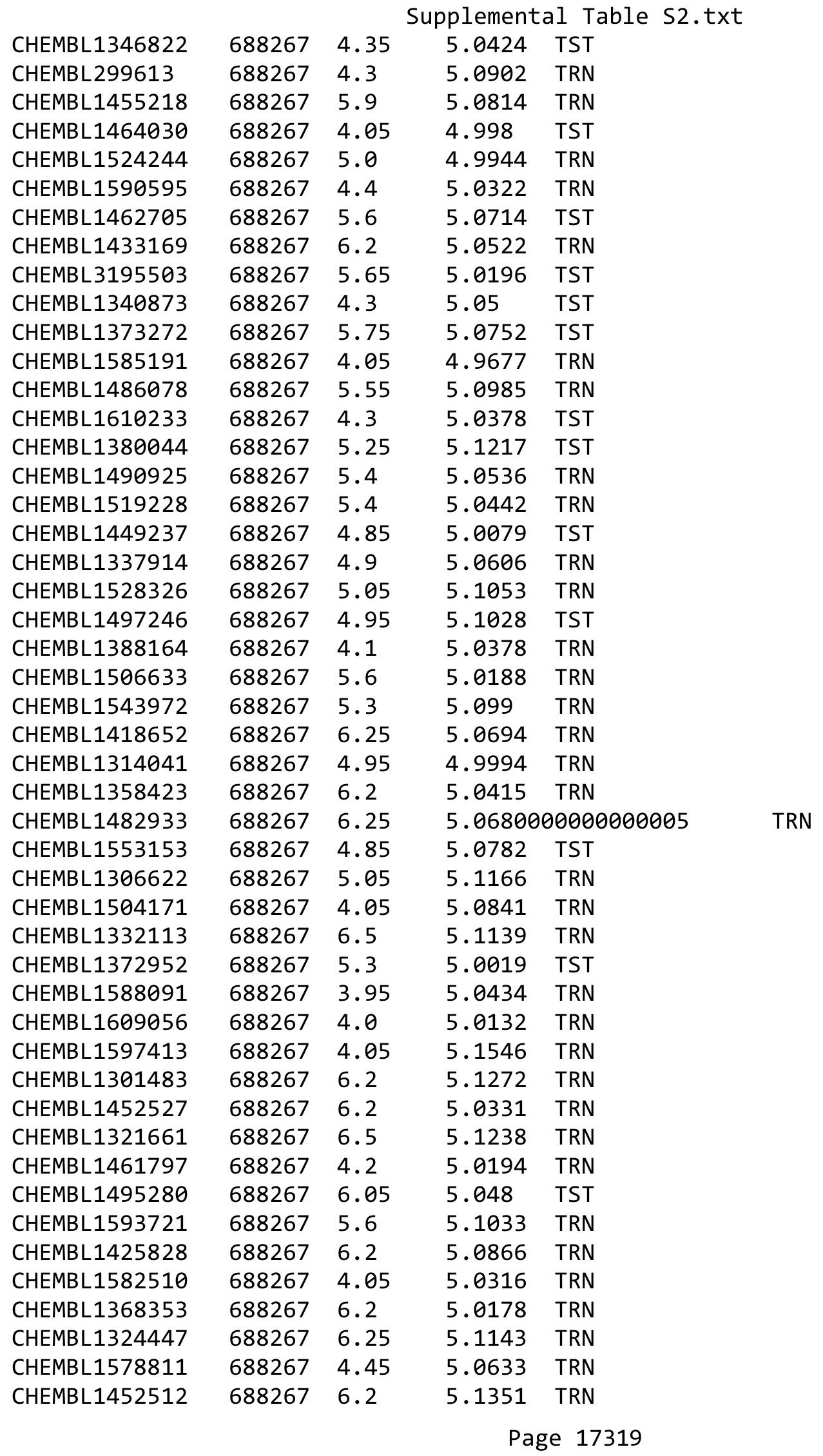




\begin{tabular}{|c|c|c|c|c|c|}
\hline \\
\hline CHEMBL1411500 & 688267 & 5.3 & 5.0364 & TRN & \\
\hline CHEMBL496727 & 688267 & 4.05 & 5.0395 & TST & \\
\hline CHEMBL1357031 & 688267 & 4.75 & 5.0118 & TRN & \\
\hline CHEMBL1397263 & 688267 & 6.45 & 5.0501 & TRN & \\
\hline CHEMBL1383695 & 688267 & 4.2 & 5.0994 & TRN & \\
\hline CHEMBL1523046 & 688267 & 4.6 & 5.0714 & TRN & \\
\hline CHEMBL3211266 & 688267 & 4.6 & 5.0005 & TST & \\
\hline CHEMBL1473599 & 688267 & 4.3 & 5.0953 & TRN & \\
\hline CHEMBL1433885 & 688267 & 4.8 & 5.037 & TRN & \\
\hline CHEMBL1340885 & 688267 & 5.55 & 5.1366 & TRN & \\
\hline CHEMBL1566503 & 688267 & 4.75 & 5.0271 & TRN & \\
\hline CHEMBL1354676 & 688267 & 5.6 & 5.0209 & TST & \\
\hline CHEMBL1554359 & 688267 & 6.5 & 4.9991 & TRN & \\
\hline CHEMBL1455151 & 688267 & 5.95 & 5.05699 & 99999999995 & TRN \\
\hline CHEMBL1563291 & 688267 & 4.8 & 5.0314 & TRN & \\
\hline CHEMBL1455029 & 688267 & 4.05 & 5.0479 & TST & \\
\hline CHEMBL1314546 & 688267 & 5.5 & 5.1521 & TRN & \\
\hline CHEMBL1512096 & 688267 & 6.25 & 5.0292 & TRN & \\
\hline CHEMBL1515842 & 688267 & 6.2 & 5.0369 & TRN & \\
\hline CHEMBL1519056 & 688267 & 6.2 & 5.0426 & TRN & \\
\hline CHEMBL1463114 & 688267 & 4.4 & 5.0521 & TRN & \\
\hline CHEMBL1499838 & 688267 & 5.0 & 5.0623 & TST & \\
\hline CHEMBL1573662 & 688267 & 4.65 & 5.0297 & TRN & \\
\hline CHEMBL1988883 & 688267 & 4.2 & 5.0398 & TST & \\
\hline CHEMBL1560114 & 688267 & 5.3 & 5.0752 & TRN & \\
\hline CHEMBL1521618 & 688267 & 5.3 & 5.0229 & TST & \\
\hline CHEMBL1545858 & 688267 & 4.0 & 5.0327 & TRN & \\
\hline CHEMBL1573328 & 688267 & 6.45 & 5.0476 & TRN & \\
\hline CHEMBL1604014 & 688267 & 4.35 & 5.0514 & TST & \\
\hline CHEMBL1570873 & 688267 & 4.4 & 5.0046 & TRN & \\
\hline CHEMBL1329586 & 688267 & 6.15 & 5.0869 & TRN & \\
\hline CHEMBL1463311 & 688267 & 6.2 & 5.056 & TST & \\
\hline CHEMBL1504895 & 688267 & 4.05 & 5.0042 & TRN & \\
\hline CHEMBL1469579 & 688267 & 4.5 & 5.0066 & TRN & \\
\hline CHEMBL1557502 & 688267 & 5.35 & 5.0569 & TRN & \\
\hline CHEMBL1526209 & 688267 & 6.2 & 5.0831 & TRN & \\
\hline CHEMBL1395642 & 688267 & 5.45 & 5.0184 & TRN & \\
\hline CHEMBL3207982 & 688267 & 4.05 & 5.008 & TRN & \\
\hline CHEMBL1514188 & 688267 & 4.05 & 5.093 & TRN & \\
\hline CHEMBL1370311 & 688267 & 4.3 & 5.0486 & TRN & \\
\hline CHEMBL1570290 & 688267 & 4.0 & 5.1273 & TST & \\
\hline CHEMBL1476888 & 688267 & 4.1 & 5.0253 & TRN & \\
\hline CHEMBL1323384 & 688267 & 5.35 & 5.0092 & TRN & \\
\hline CHEMBL1354716 & 688267 & 3.95 & 5.1179 & TST & \\
\hline CHEMBL1321104 & 688267 & 4.0 & 5.0204 & TRN & \\
\hline CHEMBL1441529 & 688267 & 5.7 & 5.1499 & TRN & \\
\hline CHEMBL1512871 & 688267 & 5.65 & 5.1441 & TRN & \\
\hline CHEMBL1517028 & 688267 & 4.4 & 5.0141 & TRN & \\
\hline
\end{tabular}




\begin{tabular}{|c|c|c|c|c|}
\hline \multicolumn{5}{|c|}{ Supplemental Table S2.txt } \\
\hline CHEMBL1574123 & 688267 & 4.1 & 5.0749 & TRN \\
\hline CHEMBL1612266 & 688267 & 5.75 & 5.0981 & TRN \\
\hline CHEMBL1464515 & 688267 & 4.4 & 5.0387 & TRN \\
\hline CHEMBL1548466 & 688267 & 4.0 & 5.0117 & TST \\
\hline CHEMBL3194291 & 688267 & 4.0 & 5.0321 & TRN \\
\hline CHEMBL1560987 & 688267 & 5.9 & 5.0717 & TRN \\
\hline CHEMBL1567808 & 688267 & 4.0 & 5.0651 & TRN \\
\hline CHEMBL1423328 & 688267 & 5.4 & 5.0817 & TRN \\
\hline CHEMBL1452922 & 688267 & 5.3 & 5.0859 & TRN \\
\hline CHEMBL3208139 & 688267 & 5.6 & 4.973 & TRN \\
\hline CHEMBL1369931 & 688267 & 4.0 & 5.1112 & TRN \\
\hline CHEMBL1566581 & 688267 & 5.55 & 5.0597 & TRN \\
\hline CHEMBL1422660 & 688267 & 4.6 & 5.0743 & TST \\
\hline CHEMBL1571956 & 688267 & 4.9 & 5.0759 & TRN \\
\hline CHEMBL1578477 & 688267 & 6.2 & 5.059 & TRN \\
\hline CHEMBL1508486 & 688267 & 6.05 & 5.1176 & TRN \\
\hline CHEMBL1541467 & 688267 & 4.25 & 4.99 & TRN \\
\hline CHEMBL1434141 & 688267 & 5.9 & 5.0013 & TRN \\
\hline CHEMBL1423841 & 688267 & 4.05 & 5.0781 & TRN \\
\hline CHEMBL1550159 & 688267 & 5.1 & 5.0521 & TST \\
\hline CHEMBL1455705 & 688267 & 6.1 & 5.0421 & TRN \\
\hline CHEMBL1595553 & 688267 & 4.1 & 5.0866 & TST \\
\hline CHEMBL1548791 & 688267 & 4.4 & 5.1107 & TST \\
\hline CHEMBL1398364 & 688267 & 3.95 & 4.9968 & TRN \\
\hline CHEMBL1593130 & 688267 & 4.0 & 5.0188 & TRN \\
\hline CHEMBL1543069 & 688267 & 5.15 & 5.0743 & TRN \\
\hline CHEMBL1358528 & 688267 & 5.35 & 5.0063 & TRN \\
\hline CHEMBL1585211 & 688267 & 4.55 & 5.0978 & TST \\
\hline CHEMBL1576047 & 688267 & 5.3 & 5.0931 & TRN \\
\hline CHEMBL1557553 & 688267 & 5.35 & 5.0721 & TRN \\
\hline CHEMBL3214421 & 688267 & 4.4 & 5.0159 & TRN \\
\hline CHEMBL1532937 & 688267 & 3.95 & 4.9924 & TRN \\
\hline CHEMBL1562156 & 688267 & 4.5 & 5.1252 & TRN \\
\hline CHEMBL1455104 & 688267 & 3.95 & 5.0915 & TRN \\
\hline CHEMBL3191824 & 688267 & 4.35 & 5.0478 & TST \\
\hline CHEMBL1574739 & 688267 & 4.35 & 5.042 & TRN \\
\hline CHEMBL 1377285 & 688267 & 4.0 & 5.0182 & TST \\
\hline CHEMBL 1457678 & 688267 & 3.95 & 5.08 & TRN \\
\hline CHEMBL1577009 & 688267 & 5.9 & 5.0719 & TST \\
\hline CHEMBL1300617 & 688267 & 4.3 & 5.0451 & TRN \\
\hline CHEMBL1612339 & 688267 & 4.45 & 5.1208 & TRN \\
\hline CHEMBL1489907 & 688267 & 4.15 & 5.1254 & TRN \\
\hline CHEMBL201152 & 688267 & 4.35 & 5.0424 & TST \\
\hline CHEMBL1461953 & 688267 & 4.25 & 5.0555 & TRN \\
\hline CHEMBL1601486 & 688267 & 4.55 & 5.0863 & TRN \\
\hline CHEMBL1389787 & 688267 & 6.45 & 5.0448 & TRN \\
\hline CHEMBL1498888 & 688267 & 6.2 & 5.0015 & TRN \\
\hline CHEMBL3189442 & 688267 & 4.0 & 5.024 & TRN \\
\hline
\end{tabular}




\begin{tabular}{|c|c|c|c|c|c|}
\hline \multirow{3}{*}{$\begin{array}{l}\text { CHEMBL1469036 } \\
\text { CHEMBL1565885 }\end{array}$} & \multirow{3}{*}{$\begin{array}{l}688267 \\
688267\end{array}$} & \multicolumn{4}{|c|}{ Supplemental Table S2.txt } \\
\hline & & 6.45 & \multicolumn{2}{|c|}{4.986000000000001} & TRN \\
\hline & & 3.95 & 5.0162 & TRN & \\
\hline CHEMBL1437036 & 688267 & 5.2 & 5.0719 & TRN & \\
\hline CHEMBL1357849 & 688267 & 5.55 & 5.0687 & TRN & \\
\hline CHEMBL1360118 & 688267 & 4.4 & 5.0362 & TRN & \\
\hline CHEMBL1606250 & 688267 & 6.15 & 5.0385 & TST & \\
\hline CHEMBL1443334 & 688267 & 5.35 & 5.0703 & TRN & \\
\hline CHEMBL1363547 & 688267 & 6.25 & 5.0598 & TRN & \\
\hline CHEMBL1438383 & 688267 & 5.95 & 5.0205 & TST & \\
\hline CHEMBL1377695 & 688267 & 4.7 & 5.0484 & TST & \\
\hline CHEMBL1556955 & 688267 & 4.05 & 4.9827 & TST & \\
\hline CHEMBL1492103 & 688267 & 5.8 & 5.0207 & TRN & \\
\hline CHEMBL1613135 & 688267 & 6.0 & 5.0907 & TRN & \\
\hline CHEMBL1468169 & 688267 & 4.35 & 5.0514 & TRN & \\
\hline CHEMBL1506122 & 688267 & 5.5 & 5.0846 & TRN & \\
\hline CHEMBL1515669 & 688267 & 4.25 & 5.0347 & TRN & \\
\hline CHEMBL1408729 & 688267 & 5.55 & 5.0732 & TRN & \\
\hline CHEMBL1348342 & 688267 & 4.8 & 5.023 & TRN & \\
\hline CHEMBL1594997 & 688267 & 5.35 & 5.109 & TST & \\
\hline CHEMBL1347083 & 688267 & 5.05 & 5.09399 & 9999999999 & TRN \\
\hline CHEMBL1602156 & 688267 & 4.0 & 5.0506 & TRN & \\
\hline CHEMBL1590619 & 688267 & 6.0 & 5.0742 & TRN & \\
\hline CHEMBL1565764 & 688267 & 4.05 & 5.0679 & TRN & \\
\hline CHEMBL1331229 & 688267 & 6.2 & 5.0128 & TRN & \\
\hline CHEMBL1441385 & 688267 & 4.05 & 5.0585 & TRN & \\
\hline CHEMBL1493344 & 688267 & 5.8 & 5.0066 & TRN & \\
\hline CHEMBL1349977 & 688267 & 5.3 & 5.0285 & TST & \\
\hline CHEMBL1321186 & 688267 & 4.65 & 5.0759 & TRN & \\
\hline CHEMBL1312217 & 688267 & 6.2 & 5.1237 & TRN & \\
\hline CHEMBL1404511 & 688267 & 3.95 & 5.0692 & TRN & \\
\hline CHEMBL1521038 & 688267 & 6.2 & 5.0729 & TRN & \\
\hline CHEMBL1383781 & 688267 & 4.0 & 5.0208 & TST & \\
\hline CHEMBL1555558 & 688267 & 4.4 & 5.0408 & TRN & \\
\hline CHEMBL1332581 & 688267 & 6.2 & 5.026 & TRN & \\
\hline CHEMBL1350901 & 688267 & 5.9 & 5.0404 & TRN & \\
\hline CHEMBL1440895 & 688267 & 5.35 & 5.1162 & TST & \\
\hline CHEMBL1561497 & 688267 & 4.65 & 5.0247 & TRN & \\
\hline CHEMBL1583837 & 688267 & 6.15 & 5.0484 & TRN & \\
\hline CHEMBL1315209 & 688267 & 5.3 & 5.0138 & TST & \\
\hline CHEMBL1531327 & 688267 & 5.8 & 5.0273 & TRN & \\
\hline CHEMBL1340563 & 688267 & 5.9 & 5.0741 & TST & \\
\hline CHEMBL1444531 & 688267 & 6.15 & 5.0298 & TRN & \\
\hline CHEMBL1418839 & 688267 & 4.0 & 5.047 & TRN & \\
\hline CHEMBL1414929 & 688267 & 6.2 & 5.0327 & TRN & \\
\hline CHEMBL1583253 & 688267 & 5.5 & 5.092 & TRN & \\
\hline CHEMBL1543591 & 688267 & 4.6 & 5.0346 & TRN & \\
\hline CHEMBL1430669 & 688267 & 4.4 & 5.0446 & TRN & \\
\hline CHEMBL1421217 & 688267 & 5.4 & 5.0158 & TST & \\
\hline
\end{tabular}




\begin{tabular}{|c|c|c|c|c|c|}
\hline \multicolumn{6}{|c|}{ Supplemental Table S2.txt } \\
\hline CHEMBL1462318 & 688267 & 4.15 & 5.0208 & TST & \\
\hline CHEMBL1302327 & 688267 & 4.4 & 5.0595 & TRN & \\
\hline CHEMBL3194966 & 688267 & 4.0 & 5.0455 & TRN & \\
\hline CHEMBL1414717 & 688267 & 5.9 & 5.0836 & TRN & \\
\hline CHEMBL1581995 & 688267 & 5.45 & 5.0526 & TRN & \\
\hline CHEMBL1461524 & 688267 & 4.6 & 5.0419 & TST & \\
\hline CHEMBL1519543 & 688267 & 6.2 & 5.062 & TRN & \\
\hline CHEMBL1406308 & 688267 & 5.4 & 5.0143 & TRN & \\
\hline CHEMBL1593577 & 688267 & 6.2 & 5.099 & TRN & \\
\hline CHEMBL1339573 & 688267 & 6.5501 & 5.0728 & TRN & \\
\hline CHEMBL3193330 & 688267 & 5.0 & 5.0468 & TRN & \\
\hline CHEMBL1490077 & 688267 & 4.0 & 4.9728 & TRN & \\
\hline CHEMBL1431107 & 688267 & 4.3 & 5.1294 & TRN & \\
\hline CHEMBL1368734 & 688267 & 5.1 & 5.0636 & TST & \\
\hline CHEMBL586793 & 688267 & 6.25 & 5.0188 & TRN & \\
\hline CHEMBL1596001 & 688267 & 5.1 & 5.0524 & TST & \\
\hline CHEMBL1457042 & 688267 & 6.2 & 5.0162 & TST & \\
\hline CHEMBL1361390 & 688267 & 4.35 & 5.0969 & TST & \\
\hline CHEMBL1333400 & 688267 & 4.35 & 5.11100 & $\partial 000000001$ & TST \\
\hline CHEMBL1527465 & 688267 & 4.3 & 4.9984 & TRN & \\
\hline CHEMBL1534187 & 688267 & 4.0 & 5.10800 & 30000000005 & TRN \\
\hline CHEMBL1593822 & 688267 & 5.55 & 5.006 & TRN & \\
\hline CHEMBL1563381 & 688267 & 4.0 & 5.0781 & TST & \\
\hline CHEMBL1532619 & 688267 & 4.3 & 5.0389 & TRN & \\
\hline CHEMBL1545097 & 688267 & 4.3 & 5.1185 & TST & \\
\hline CHEMBL1409101 & 688267 & 5.45 & 5.0169 & TRN & \\
\hline CHEMBL1474660 & 688267 & 3.95 & 5.1824 & TRN & \\
\hline CHEMBL1362364 & 688267 & 6.0 & 5.1159 & TST & \\
\hline CHEMBL1404347 & 688267 & 4.6 & 5.0435 & TRN & \\
\hline CHEMBL1347222 & 688267 & 5.25 & 5.0387 & TRN & \\
\hline CHEMBL1518325 & 688267 & 5.05 & 4.9992 & TRN & \\
\hline CHEMBL3210142 & 688267 & 4.35 & 5.0775 & TST & \\
\hline CHEMBL1554708 & 688267 & 4.05 & 5.1163 & TRN & \\
\hline CHEMBL1433867 & 688267 & 4.2 & 5.1113 & TRN & \\
\hline CHEMBL1489506 & 688267 & 5.6 & 5.0962 & TRN & \\
\hline CHEMBL1484364 & 688267 & 4.05 & 5.01399 & 9999999999 & TRN \\
\hline CHEMBL1506593 & 688267 & 5.3 & 5.0528 & TST & \\
\hline CHEMBL1361959 & 688267 & 4.9 & 5.0225 & TRN & \\
\hline CHEMBL1401374 & 688267 & 6.2 & 5.0717 & TRN & \\
\hline CHEMBL1515556 & 688267 & 3.95 & 5.0447 & TRN & \\
\hline CHEMBL1383540 & 688267 & 4.05 & 5.0196 & TRN & \\
\hline CHEMBL1572124 & 688267 & 4.1 & 5.1028 & TRN & \\
\hline CHEMBL1497449 & 688267 & 5.6 & 5.0473 & TRN & \\
\hline CHEMBL1548949 & 688267 & 3.95 & 5.0196 & TST & \\
\hline CHEMBL1544889 & 688267 & 5.75 & 5.1272 & TRN & \\
\hline CHEMBL1371039 & 688267 & 4.6 & 5.0503 & TRN & \\
\hline CHEMBL1382601 & 688267 & 5.2 & 5.0626 & TRN & \\
\hline CHEMBL1477743 & 688267 & 4.55 & 5.0545 & TRN & \\
\hline
\end{tabular}




\begin{tabular}{|c|c|c|c|c|c|}
\hline \\
\hline CHEMBL1575800 & 688267 & 4.25 & 5.0465 & TST & \\
\hline CHEMBL1363180 & 688267 & 4.05 & 4.9856 & TST & \\
\hline CHEMBL1477019 & 688267 & 5.25 & 5.0993 & TRN & \\
\hline CHEMBL1355255 & 688267 & 4.25 & 5.0239 & TRN & \\
\hline CHEMBL1528849 & 688267 & 6.2 & 5.043 & TST & \\
\hline CHEMBL1600945 & 688267 & 4.1 & 5.0777 & TST & \\
\hline CHEMBL1308605 & 688267 & 4.5 & 5.0873 & TRN & \\
\hline CHEMBL1484229 & 688267 & 5.25 & 5.0223 & TRN & \\
\hline CHEMBL1336147 & 688267 & 5.45 & 5.05399 & 9999999999 & TRN \\
\hline CHEMBL1449734 & 688267 & 6.15 & 5.1272 & TRN & \\
\hline CHEMBL1382229 & 688267 & 4.05 & 5.0864 & TST & \\
\hline CHEMBL1366965 & 688267 & 5.5 & 5.0842 & TRN & \\
\hline CHEMBL1300699 & 688267 & 5.75 & 5.1162 & TST & \\
\hline CHEMBL1570801 & 688267 & 5.4 & 5.1058 & TRN & \\
\hline CHEMBL1432540 & 688267 & 6.5 & 5.08899 & 99999999995 & TRN \\
\hline CHEMBL3195068 & 688267 & 4.65 & 5.0573 & TRN & \\
\hline CHEMBL1387778 & 688267 & 5.05 & 5.0195 & TRN & \\
\hline CHEMBL1521773 & 688267 & 5.35 & 5.0378 & TRN & \\
\hline CHEMBL1327766 & 688267 & 4.35 & 5.0362 & TRN & \\
\hline CHEMBL1305303 & 688267 & 4.25 & 5.0034 & TRN & \\
\hline CHEMBL1580124 & 688267 & 5.45 & 5.0301 & TRN & \\
\hline CHEMBL1486181 & 688267 & 4.8 & 5.0078 & TST & \\
\hline CHEMBL1410807 & 688267 & 6.2 & 5.1005 & TRN & \\
\hline CHEMBL1532263 & 688267 & 6.2 & 4.9928 & TRN & \\
\hline CHEMBL1380932 & 688267 & 4.65 & 4.9846 & TRN & \\
\hline CHEMBL1599233 & 688267 & 4.15 & 5.0521 & TRN & \\
\hline CHEMBL1457228 & 688267 & 4.1 & 5.0062 & TRN & \\
\hline CHEMBL1307772 & 688267 & 4.9 & 5.0953 & TRN & \\
\hline CHEMBL1416656 & 688267 & 4.0 & 5.0464 & TRN & \\
\hline CHEMBL1427260 & 688267 & 6.0 & 5.1085 & TST & \\
\hline CHEMBL1594445 & 688267 & 4.45 & 5.0718 & TRN & \\
\hline CHEMBL1369633 & 688267 & 4.05 & 5.0159 & TST & \\
\hline CHEMBL3208365 & 688267 & 4.45 & 5.0005 & TST & \\
\hline CHEMBL1589045 & 688267 & 5.15 & 5.0908 & TST & \\
\hline CHEMBL577758 & 688267 & 6.15 & 4.989 & TRN & \\
\hline CHEMBL1458930 & 688267 & 4.05 & 5.0972 & TST & \\
\hline CHEMBL1586897 & 688267 & 4.25 & 5.0731 & TRN & \\
\hline CHEMBL1396426 & 688267 & 4.0 & 5.0258 & TRN & \\
\hline CHEMBL1434531 & 688267 & 6.2 & 5.0851 & TRN & \\
\hline CHEMBL1325280 & 688267 & 5.45 & 5.0718 & TRN & \\
\hline CHEMBL1578164 & 688267 & 5.35 & 5.0475 & TRN & \\
\hline CHEMBL3199862 & 688267 & 4.05 & 4.9552 & TRN & \\
\hline CHEMBL1551993 & 688267 & 4.0 & 5.0375 & TRN & \\
\hline CHEMBL1539924 & 688267 & 3.95 & 4.9944 & TRN & \\
\hline CHEMBL1331427 & 688267 & 6.0 & 5.0906 & TRN & \\
\hline CHEMBL1320934 & 688267 & 4.45 & 5.0949 & TRN & \\
\hline CHEMBL1356212 & 688267 & 5.6 & 5.0655 & TRN & \\
\hline CHEMBL1545925 & 688267 & 4.05 & 5.0817 & TRN & \\
\hline
\end{tabular}




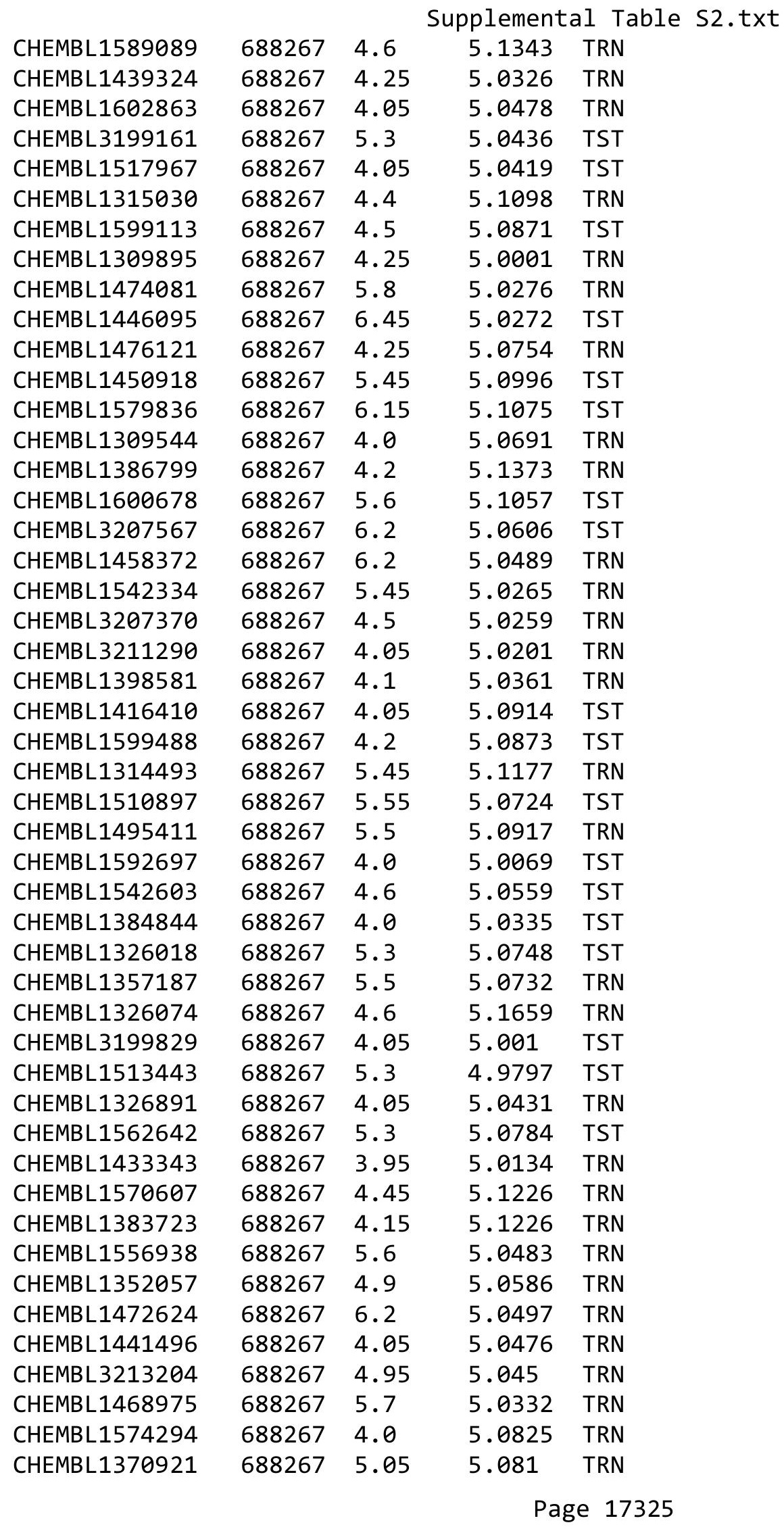




\begin{tabular}{|c|c|c|c|c|c|}
\hline \multicolumn{6}{|c|}{ Supplemental Table S2.txt } \\
\hline CHEMBL1325765 & 688267 & 4.75 & 5.0517 & TRN & \\
\hline CHEMBL1992261 & 688267 & 6.25 & 4.9791 & TRN & \\
\hline CHEMBL1352503 & 688267 & 5.9 & 5.0911 & TRN & \\
\hline CHEMBL1310768 & 688267 & 5.45 & 5.0745 & TRN & \\
\hline CHEMBL1321187 & 688267 & 4.0 & 5.0702 & TST & \\
\hline CHEMBL1346524 & 688267 & 6.2 & 5.0596 & TST & \\
\hline CHEMBL1546296 & 688267 & 5.85 & 5.1363 & TST & \\
\hline CHEMBL1334858 & 688267 & 4.3 & 5.0557 & TRN & \\
\hline CHEMBL1473581 & 688267 & 5.3 & 5.0567 & TRN & \\
\hline CHEMBL1329042 & 688267 & 4.0 & 5.1083 & TRN & \\
\hline CHEMBL1358875 & 688267 & 6.2 & 5.0365 & TRN & \\
\hline CHEMBL1327769 & 688267 & 4.3 & 5.0197 & TRN & \\
\hline CHEMBL1300016 & 688267 & 4.0 & 5.0676 & TRN & \\
\hline CHEMBL1411291 & 688267 & 5.8 & 5.0992 & TRN & \\
\hline CHEMBL1479919 & 688267 & 4.0 & 5.0501 & TRN & \\
\hline CHEMBL1482784 & 688267 & 4.7 & 5.0817 & TRN & \\
\hline CHEMBL3192077 & 688267 & 4.0 & 5.0261 & TST & \\
\hline CHEMBL1345022 & 688267 & 4.4 & 5.0732 & TST & \\
\hline CHEMBL1490861 & 688267 & 4.4 & 5.0184 & TRN & \\
\hline CHEMBL1398532 & 688267 & 6.7001 & 5.003 & TRN & \\
\hline CHEMBL1378354 & 688267 & 6.2 & 4.9795 & TRN & \\
\hline CHEMBL1456218 & 688267 & 6.2 & 5.1179 & TRN & \\
\hline CHEMBL1527630 & 688267 & 4.0 & 5.0268 & TST & \\
\hline CHEMBL1407526 & 688267 & 4.1 & 5.0118 & TRN & \\
\hline CHEMBL1442214 & 688267 & 4.6 & 5.1583 & TRN & \\
\hline CHEMBL1473263 & 688267 & 6.2 & 5.0598 & TRN & \\
\hline CHEMBL1402913 & 688267 & 5.45 & 5.0098 & TRN & \\
\hline CHEMBL1377231 & 688267 & 4.95 & 5.01399 & 9999999999 & TRN \\
\hline CHEMBL1333825 & 688267 & 5.3 & 5.0019 & TST & \\
\hline CHEMBL1516400 & 688267 & 5.65 & 5.085 & TRN & \\
\hline CHEMBL1342891 & 688267 & 4.0 & 5.019 & TRN & \\
\hline CHEMBL1302584 & 688267 & 5.1 & 5.0486 & TRN & \\
\hline CHEMBL1525847 & 688267 & 6.15 & 5.0211 & TRN & \\
\hline CHEMBL1318940 & 688267 & 4.4 & 5.0019 & TST & \\
\hline CHEMBL1546233 & 688267 & 4.7 & 5.0268 & TRN & \\
\hline CHEMBL1342814 & 688267 & 6.15 & 5.0948 & TRN & \\
\hline CHEMBL1408108 & 688267 & 4.0 & 5.0402 & TRN & \\
\hline CHEMBL1516022 & 688267 & 5.55 & 5.1194 & TRN & \\
\hline CHEMBL1381837 & 688267 & 5.3 & 4.9951 & TRN & \\
\hline CHEMBL1315689 & 688267 & 4.05 & 5.0821 & TRN & \\
\hline CHEMBL1535189 & 688267 & 4.05 & 5.0411 & TST & \\
\hline CHEMBL1434584 & 688267 & 4.0 & 5.0671 & TRN & \\
\hline CHEMBL1396643 & 688267 & 4.0 & 5.0387 & TRN & \\
\hline CHEMBL1447718 & 688267 & 6.2 & 5.0626 & TST & \\
\hline CHEMBL1494659 & 688267 & 4.0 & 5.0203 & TRN & \\
\hline CHEMBL1458514 & 688267 & 4.3 & 5.0124 & TRN & \\
\hline CHEMBL1391442 & 688267 & 4.0 & 5.0832 & TRN & \\
\hline CHEMBL1412282 & 688267 & 5.75 & 5.09 & TRN & \\
\hline
\end{tabular}




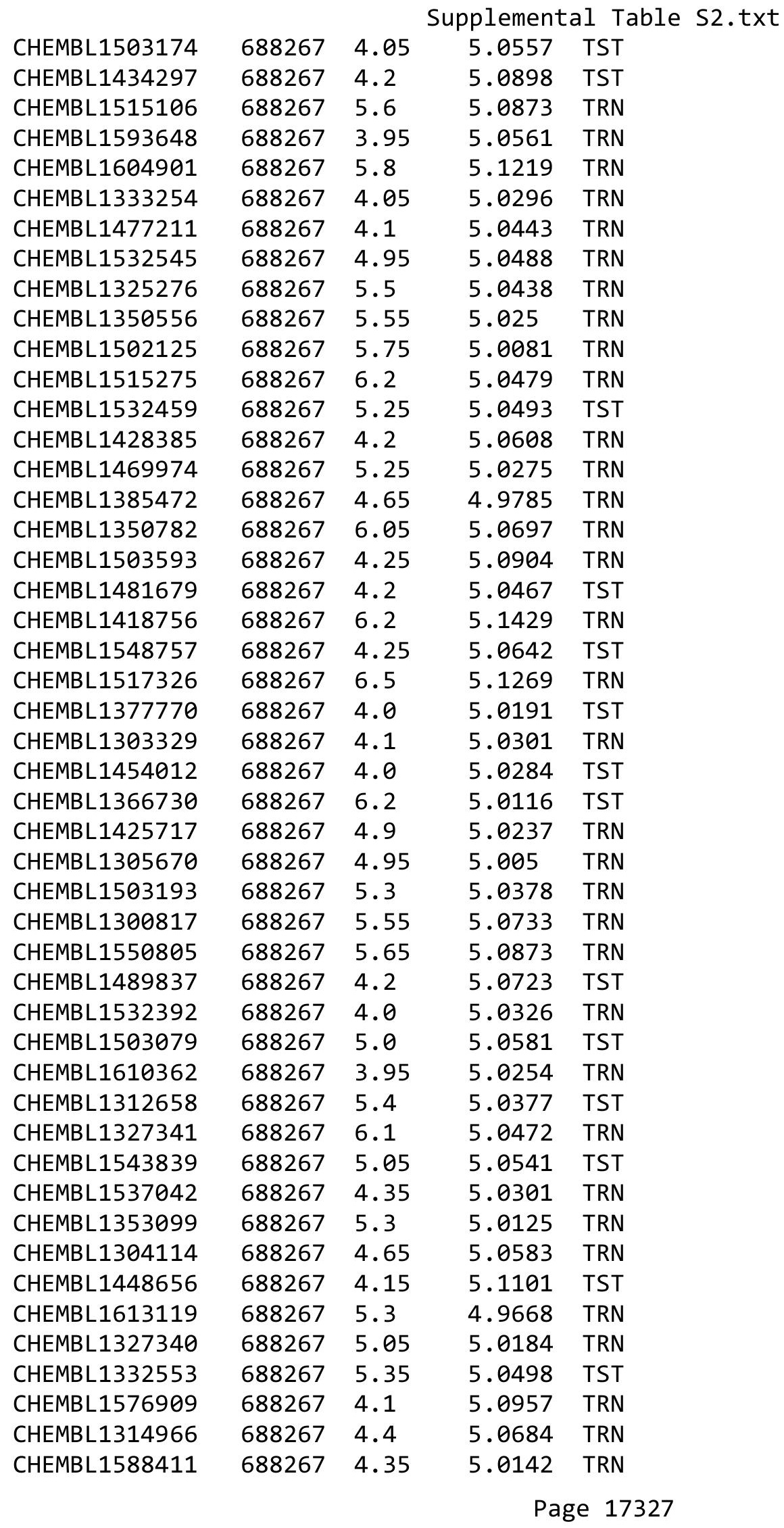




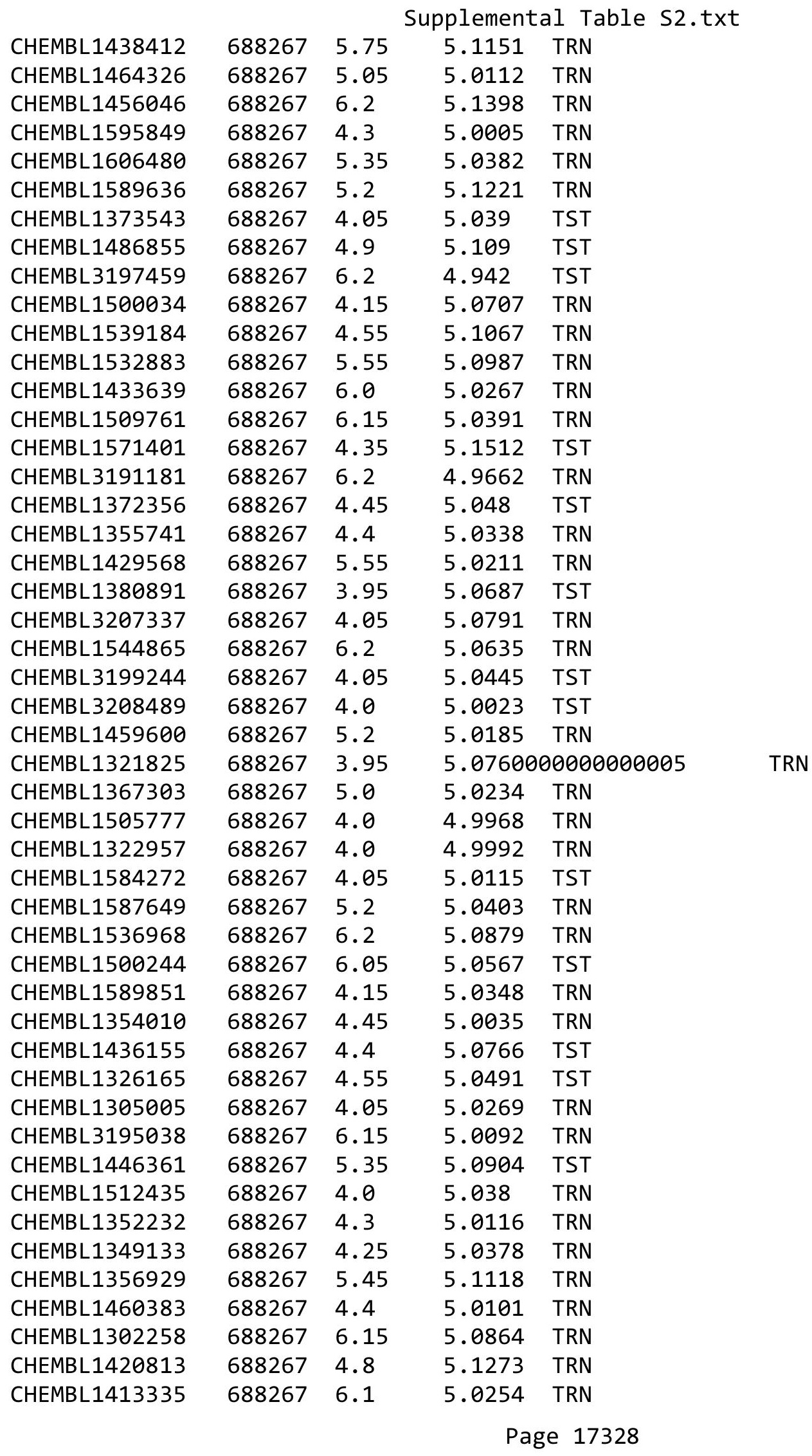




\begin{tabular}{|c|c|c|c|c|}
\hline & & & pplement & al $\mathrm{Ta}$ \\
\hline CHEMBL1607946 & 688267 & 4.05 & 5.0934 & TRN \\
\hline CHEMBL1609984 & 688267 & 4.3 & 5.0503 & TRN \\
\hline CHEMBL1561056 & 688267 & 6.2 & 5.0783 & TRN \\
\hline CHEMBL1542034 & 688267 & 5.3 & 5.1001 & TRN \\
\hline CHEMBL1342971 & 688267 & 5.85 & 5.0494 & TRN \\
\hline CHEMBL1497463 & 688267 & 4.45 & 4.9636 & TRN \\
\hline CHEMBL1418699 & 688267 & 3.95 & 5.0565 & TRN \\
\hline CHEMBL1354923 & 688267 & 4.95 & 5.0177 & TRN \\
\hline CHEMBL1358414 & 688267 & 4.6 & 5.0348 & TRN \\
\hline CHEMBL1579322 & 688267 & 4.05 & 5.0981 & TST \\
\hline CHEMBL1553851 & 688267 & 5.15 & 5.0696 & TST \\
\hline CHEMBL1520208 & 688267 & 3.95 & 5.073 & TRN \\
\hline CHEMBL3207702 & 688267 & 4.5 & 4.9943 & TRN \\
\hline CHEMBL1444473 & 688267 & 4.0 & 5.0876 & TST \\
\hline CHEMBL1569765 & 688267 & 4.4 & 5.0541 & TRN \\
\hline CHEMBL1345118 & 688267 & 4.05 & 5.0204 & TRN \\
\hline CHEMBL1304889 & 688267 & 4.4 & 5.0351 & TST \\
\hline CHEMBL1348426 & 688267 & 6.2 & 5.0926 & TST \\
\hline CHEMBL1454881 & 688267 & 4.8 & 5.0499 & TRN \\
\hline CHEMBL1320731 & 688267 & 5.1 & 5.0896 & TRN \\
\hline CHEMBL1358923 & 688267 & 4.35 & 5.1695 & TST \\
\hline CHEMBL1564512 & 688267 & 4.0 & 5.0162 & TRN \\
\hline CHEMBL1522990 & 688267 & 4.3 & 5.0003 & TRN \\
\hline CHEMBL1607108 & 688267 & 4.6 & 5.0708 & TRN \\
\hline CHEMBL1376588 & 688267 & 5.55 & 5.1076 & TRN \\
\hline CHEMBL1423325 & 688267 & 5.35 & 5.1321 & TRN \\
\hline CHEMBL1447510 & 688267 & 5.4 & 5.0356 & TRN \\
\hline CHEMBL1379709 & 688267 & 5.85 & 5.0852 & TRN \\
\hline CHEMBL1501048 & 688267 & 5.3 & 5.0678 & TRN \\
\hline CHEMBL1301782 & 688267 & 6.45 & 5.0532 & TRN \\
\hline CHEMBL1492466 & 688267 & 4.7 & 5.0161 & TRN \\
\hline CHEMBL1473774 & 688267 & 5.0 & 5.0596 & TRN \\
\hline CHEMBL1566841 & 688267 & 6.2 & 5.0661 & TRN \\
\hline CHEMBL1394851 & 688267 & 5.35 & 5.0321 & TST \\
\hline CHEMBL1556825 & 688267 & 4.05 & 5.0948 & TST \\
\hline CHEMBL1511728 & 688267 & 4.0 & 5.0415 & TRN \\
\hline CHEMBL1346186 & 688267 & 5.8 & 5.0581 & TRN \\
\hline CHEMBL1379974 & 688267 & 4.1 & 5.1422 & TST \\
\hline CHEMBL1590349 & 688267 & 5.3 & 5.1159 & TRN \\
\hline CHEMBL1519079 & 688267 & 4.25 & 5.0298 & TRN \\
\hline CHEMBL1484086 & 688267 & 5.45 & 5.0239 & TST \\
\hline CHEMBL 1477400 & 688267 & 4.0 & 5.0271 & TRN \\
\hline CHEMBL1441096 & 688267 & 5.45 & 5.0604 & TRN \\
\hline CHEMBL1377996 & 688267 & 6.25 & 5.1406 & TRN \\
\hline CHEMBL1545876 & 688267 & 5.9 & 4.9941 & TRN \\
\hline CHEMBL1561541 & 688267 & 4.55 & 5.0396 & TRN \\
\hline CHEMBL1548743 & 688267 & 6.2 & 4.9933 & TRN \\
\hline CHEMBL1419488 & 688267 & 5.9 & 5.0567 & TRN \\
\hline
\end{tabular}




\begin{tabular}{|c|c|c|c|c|}
\hline & & & pplement & al $\mathrm{Ta}$ \\
\hline CHEMBL1306874 & 688267 & 6.2 & 5.1128 & TST \\
\hline CHEMBL1569385 & 688267 & 5.95 & 5.1002 & TRN \\
\hline CHEMBL1586396 & 688267 & 4.3 & 5.0785 & TRN \\
\hline CHEMBL1407624 & 688267 & 4.05 & 5.013 & TRN \\
\hline CHEMBL1529867 & 688267 & 5.75 & 5.0272 & TST \\
\hline CHEMBL1371246 & 688267 & 4.0 & 5.0461 & TRN \\
\hline CHEMBL1378792 & 688267 & 5.45 & 5.0552 & TST \\
\hline CHEMBL3198888 & 688267 & 5.4 & 5.0186 & TRN \\
\hline CHEMBL1450515 & 688267 & 6.1 & 5.0822 & TRN \\
\hline CHEMBL1346657 & 688267 & 4.05 & 5.0519 & TST \\
\hline CHEMBL1432792 & 688267 & 6.2 & 5.0268 & TST \\
\hline CHEMBL1394376 & 688267 & 4.6 & 5.039 & TST \\
\hline CHEMBL1496826 & 688267 & 5.55 & 5.0641 & TRN \\
\hline CHEMBL1327916 & 688267 & 6.15 & 4.9867 & TRN \\
\hline CHEMBL1420665 & 688267 & 4.25 & 5.0401 & TST \\
\hline CHEMBL1405282 & 688267 & 4.0 & 5.0908 & TRN \\
\hline CHEMBL1357387 & 688267 & 6.15 & 5.0234 & TRN \\
\hline CHEMBL1383329 & 688267 & 5.6 & 5.1004 & TRN \\
\hline CHEMBL3925157 & 688267 & 4.0 & 5.0496 & TRN \\
\hline CHEMBL1387862 & 688267 & 6.0 & 5.0647 & TRN \\
\hline CHEMBL1587252 & 688267 & 5.6 & 5.0359 & TST \\
\hline CHEMBL1581492 & 688267 & 5.45 & 5.0765 & TST \\
\hline CHEMBL3197088 & 688267 & 6.15 & 5.0301 & TRN \\
\hline CHEMBL1374908 & 688267 & 4.4 & 5.1127 & TRN \\
\hline CHEMBL1454103 & 688267 & 4.35 & 5.0512 & TRN \\
\hline CHEMBL1364446 & 688267 & 4.8 & 5.0831 & TRN \\
\hline CHEMBL1992492 & 688267 & 4.0 & 4.9767 & TRN \\
\hline CHEMBL1410449 & 688267 & 3.95 & 5.0656 & TST \\
\hline CHEMBL1402705 & 688267 & 6.15 & 5.0644 & TRN \\
\hline CHEMBL1553201 & 688267 & 4.35 & 5.05 & TRN \\
\hline CHEMBL1567371 & 688267 & 4.55 & 5.0521 & TRN \\
\hline CHEMBL1490773 & 688267 & 4.35 & 5.0276 & TRN \\
\hline CHEMBL1596768 & 688267 & 5.2 & 5.0909 & TRN \\
\hline CHEMBL1503090 & 688267 & 5.05 & 5.1062 & TRN \\
\hline CHEMBL1590731 & 688267 & 5.35 & 5.0398 & TRN \\
\hline CHEMBL1517859 & 688267 & 5.25 & 5.1366 & TST \\
\hline CHEMBL1340535 & 688267 & 4.15 & 4.9902 & TRN \\
\hline CHEMBL1308915 & 688267 & 4.05 & 5.0447 & TST \\
\hline CHEMBL1375144 & 688267 & 4.45 & 5.0475 & TRN \\
\hline CHEMBL1370030 & 688267 & 4.05 & 5.0191 & TRN \\
\hline CHEMBL1338772 & 688267 & 5.25 & 5.0157 & TRN \\
\hline CHEMBL1369773 & 688267 & 6.2 & 5.136 & TST \\
\hline CHEMBL1611081 & 688267 & 4.6 & 5.0958 & TRN \\
\hline CHEMBL1559391 & 688267 & 4.4 & 5.0589 & TST \\
\hline CHEMBL1512138 & 688267 & 5.95 & 5.003 & TRN \\
\hline CHEMBL1446401 & 688267 & 4.7 & 5.0992 & TST \\
\hline CHEMBL1301134 & 688267 & 5.75 & 5.0892 & TRN \\
\hline CHEMBL1531350 & 688267 & 4.0 & 5.0598 & TRN \\
\hline
\end{tabular}




\begin{tabular}{|c|c|c|c|c|}
\hline \multicolumn{5}{|c|}{ Supplemental Table S2.txt } \\
\hline CHEMBL60518 & 688267 & 5.1 & 5.0931 & TRN \\
\hline CHEMBL1377969 & 688267 & 4.2 & 5.0694 & TRN \\
\hline CHEMBL1573429 & 688267 & 6.2 & 4.9835 & TRN \\
\hline CHEMBL1992447 & 688267 & 4.0 & 4.9923 & TRN \\
\hline CHEMBL1519849 & 688267 & 6.5 & 5.0253 & TRN \\
\hline CHEMBL1446938 & 688267 & 4.0 & 5.0854 & TRN \\
\hline CHEMBL1466077 & 688267 & 6.15 & 5.0038 & TRN \\
\hline CHEMBL1324544 & 688267 & 4.35 & 5.0522 & TST \\
\hline CHEMBL1489303 & 688267 & 5.4 & 5.1591 & TRN \\
\hline CHEMBL1368610 & 688267 & 5.35 & 5.0661 & TST \\
\hline CHEMBL1332087 & 688267 & 5.8 & 5.0703 & TRN \\
\hline CHEMBL1998379 & 688267 & 4.4 & 5.0275 & TST \\
\hline CHEMBL1515204 & 688267 & 5.55 & 5.1318 & TRN \\
\hline CHEMBL1593082 & 688267 & 4.95 & 5.0844 & TRN \\
\hline CHEMBL1465466 & 688267 & 3.95 & 5.1174 & TRN \\
\hline CHEMBL1371363 & 688267 & 5.45 & 5.1101 & TRN \\
\hline CHEMBL1454319 & 688267 & 6.5 & 5.1258 & TRN \\
\hline CHEMBL1355138 & 688267 & 5.85 & 5.0837 & TRN \\
\hline CHEMBL1408162 & 688267 & 6.45 & 5.0801 & TST \\
\hline CHEMBL1418388 & 688267 & 5.8 & 5.0595 & TRN \\
\hline CHEMBL1369844 & 688267 & 4.4 & 5.0231 & TRN \\
\hline CHEMBL1319789 & 688267 & 3.95 & 5.0461 & TRN \\
\hline CHEMBL1307189 & 688267 & 6.2 & 5.0494 & TRN \\
\hline CHEMBL1504823 & 688267 & 4.3 & 5.0523 & TST \\
\hline CHEMBL1401475 & 688267 & 6.25 & 5.0602 & TRN \\
\hline CHEMBL1482008 & 688267 & 5.6 & 5.0533 & TST \\
\hline CHEMBL1301841 & 688267 & 4.4 & 5.0205 & TST \\
\hline CHEMBL1549571 & 688267 & 5.3 & 5.0354 & TRN \\
\hline CHEMBL1506849 & 688267 & 6.25 & 5.0358 & TST \\
\hline CHEMBL1429517 & 688267 & 6.5 & 5.0179 & TRN \\
\hline CHEMBL1320617 & 688267 & 5.3 & 5.0563 & TRN \\
\hline CHEMBL1613046 & 688267 & 4.0 & 5.0789 & TRN \\
\hline CHEMBL1310794 & 688267 & 6.15 & 5.0764 & TRN \\
\hline CHEMBL1587540 & 688267 & 4.6 & 5.0054 & TRN \\
\hline CHEMBL1358615 & 688267 & 4.6 & 5.0061 & TRN \\
\hline CHEMBL1360263 & 688267 & 4.3 & 5.0753 & TST \\
\hline CHEMBL1352955 & 688267 & 5.15 & 5.0217 & TRN \\
\hline CHEMBL1317418 & 688267 & 4.0 & 5.0304 & TRN \\
\hline CHEMBL1330774 & 688267 & 6.2 & 5.1064 & TRN \\
\hline CHEMBL1555059 & 688267 & 5.9 & 5.0219 & TST \\
\hline CHEMBL1370434 & 688267 & 5.75 & 5.0084 & TST \\
\hline CHEMBL1334125 & 688267 & 6.15 & 5.0482 & TRN \\
\hline CHEMBL1385640 & 688267 & 4.85 & 5.1011 & TRN \\
\hline CHEMBL1327417 & 688267 & 4.4 & 5.0442 & TRN \\
\hline CHEMBL1517590 & 688267 & 4.35 & 5.0779 & TRN \\
\hline CHEMBL1398415 & 688267 & 4.3 & 5.1093 & TRN \\
\hline CHEMBL1490163 & 688267 & 5.6 & 5.0303 & TST \\
\hline CHEMBL1609929 & 688267 & 5.6 & 5.1298 & TRN \\
\hline
\end{tabular}




\begin{tabular}{|c|c|c|c|c|c|}
\hline \multicolumn{6}{|c|}{ Supplemental Table S2.txt } \\
\hline CHEMBL259018 & 688267 & 6.5 & 5.073 & TRN & \\
\hline CHEMBL1487725 & 688267 & 3.95 & 5.0213 & TRN & \\
\hline CHEMBL1476734 & 688267 & 6.2 & 5.1415 & TRN & \\
\hline CHEMBL1451777 & 688267 & 5.45 & 5.0669 & TRN & \\
\hline CHEMBL1613097 & 688267 & 5.75 & 5.0741 & TRN & \\
\hline CHEMBL1439220 & 688267 & 4.35 & 5.0697 & TST & \\
\hline CHEMBL1355329 & 688267 & 5.25 & 5.1083 & TRN & \\
\hline CHEMBL1318562 & 688267 & 4.4 & 5.0509 & TRN & \\
\hline CHEMBL1339137 & 688267 & 6.2 & 5.1016 & TRN & \\
\hline CHEMBL1347092 & 688267 & 6.0 & 5.0607 & TRN & \\
\hline CHEMBL1612878 & 688267 & 3.95 & 5.1122 & TRN & \\
\hline CHEMBL1341631 & 688267 & 5.85 & 5.0676 & TST & \\
\hline CHEMBL1402646 & 688267 & 5.25 & 5.1068 & TST & \\
\hline CHEMBL1312553 & 688267 & 6.2 & 5.0693 & TRN & \\
\hline CHEMBL1501561 & 688267 & 4.7 & 5.0633 & TRN & \\
\hline CHEMBL1557112 & 688267 & 5.55 & 5.0371 & TRN & \\
\hline CHEMBL1463383 & 688267 & 6.05 & 5.0524 & TRN & \\
\hline CHEMBL1424697 & 688267 & 4.0 & 4.9798 & TRN & \\
\hline CHEMBL1343703 & 688267 & 5.35 & 5.0696 & TRN & \\
\hline CHEMBL1321777 & 688267 & 4.05 & 5.0112 & TRN & \\
\hline CHEMBL1474573 & 688267 & 5.5 & 5.0143 & TRN & \\
\hline CHEMBL1503144 & 688267 & 5.25 & 5.0671 & TRN & \\
\hline CHEMBL1525218 & 688267 & 4.0 & 5.1049 & TRN & \\
\hline CHEMBL1519050 & 688267 & 6.15 & 5.1225 & TRN & \\
\hline CHEMBL1525008 & 688267 & 6.25 & 5.0509 & TRN & \\
\hline CHEMBL1498790 & 688267 & 5.9 & 5.0691 & TRN & \\
\hline CHEMBL1551574 & 688267 & 4.3 & 5.027 & TRN & \\
\hline CHEMBL1437334 & 688267 & 6.2 & 5.1246 & TST & \\
\hline CHEMBL1354369 & 688267 & 4.3 & 5.0529 & TRN & \\
\hline CHEMBL1386565 & 688267 & 4.65 & 5.0181 & TST & \\
\hline CHEMBL1558189 & 688267 & 4.0 & 5.10800 & 00000000005 & TRN \\
\hline CHEMBL1470501 & 688267 & 5.9 & 5.0377 & TRN & \\
\hline CHEMBL1576666 & 688267 & 5.5 & 5.0076 & TRN & \\
\hline CHEMBL1582969 & 688267 & 4.6 & 5.1204 & TRN & \\
\hline CHEMBL1364303 & 688267 & 5.85 & 5.0481 & TRN & \\
\hline CHEMBL1440927 & 688267 & 4.55 & 5.1139 & TRN & \\
\hline CHEMBL1334836 & 688267 & 4.5 & 5.0557 & TRN & \\
\hline CHEMBL1355072 & 688267 & 3.95 & 5.0316 & TRN & \\
\hline CHEMBL1381295 & 688267 & 3.95 & 5.0753 & TRN & \\
\hline CHEMBL1486857 & 688267 & 5.3 & 5.1264 & TRN & \\
\hline CHEMBL1602430 & 688267 & 4.0 & 5.0906 & TRN & \\
\hline CHEMBL1601603 & 688267 & 6.2 & 5.0246 & TST & \\
\hline CHEMBL1434851 & 688267 & 4.05 & 5.0982 & TRN & \\
\hline CHEMBL 3192378 & 688267 & 5.85 & 5.0103 & TRN & \\
\hline CHEMBL1362004 & 688267 & 5.8 & 5.0008 & TRN & \\
\hline CHEMBL1519993 & 688267 & 6.2 & 5.0514 & TST & \\
\hline CHEMBL1359069 & 688267 & 5.75 & 5.0638 & TRN & \\
\hline CHEMBL1549809 & 688267 & 4.0 & 5.0606 & TRN & \\
\hline
\end{tabular}




\begin{tabular}{|c|c|c|c|c|c|}
\hline \multicolumn{6}{|c|}{ Supplemental Table S2.txt } \\
\hline CHEMBL1425910 & 688267 & 5.25 & 5.0661 & TRN & \\
\hline CHEMBL1586894 & 688267 & 6.6499 & 5.0471 & TST & \\
\hline CHEMBL1300322 & 688267 & 6.2 & 5.0468 & TRN & \\
\hline CHEMBL1455852 & 688267 & 5.25 & 5.0313 & TRN & \\
\hline CHEMBL1372192 & 688267 & 4.0 & 5.0849 & TRN & \\
\hline CHEMBL1314766 & 688267 & 4.4 & 5.056 & TRN & \\
\hline CHEMBL1451746 & 688267 & 4.4 & 5.0442 & TRN & \\
\hline CHEMBL1518629 & 688267 & 5.8 & 5.0819 & TRN & \\
\hline CHEMBL1567579 & 688267 & 5.35 & 5.007 & TST & \\
\hline CHEMBL1478195 & 688267 & 4.2 & 5.0261 & TRN & \\
\hline CHEMBL1331000 & 688267 & 5.5 & 5.0168 & TRN & \\
\hline CHEMBL1539861 & 688267 & 5.65 & 5.0757 & TRN & \\
\hline CHEMBL1304703 & 688267 & 6.2 & 5.0805 & TRN & \\
\hline CHEMBL1373023 & 688267 & 5.75 & 5.0166 & TRN & \\
\hline CHEMBL1492928 & 688267 & 4.4 & 5.0506 & TRN & \\
\hline CHEMBL1553435 & 688267 & 4.3 & 5.03600 & 00000000005 & TRN \\
\hline CHEMBL1455887 & 688267 & 4.95 & 5.0733 & TRN & \\
\hline CHEMBL1306075 & 688267 & 6.15 & 5.1131 & TRN & \\
\hline CHEMBL3209706 & 688267 & 5.35 & 4.9891 & TST & \\
\hline CHEMBL1418523 & 688267 & 4.35 & 5.1391 & TST & \\
\hline CHEMBL1594915 & 688267 & 5.05 & 5.0556 & TRN & \\
\hline CHEMBL1302332 & 688267 & 4.45 & 5.0518 & TRN & \\
\hline CHEMBL1407813 & 688267 & 4.4 & 5.0437 & TRN & \\
\hline CHEMBL1345549 & 688267 & 4.55 & 5.0811 & TRN & \\
\hline CHEMBL1497425 & 688267 & 5.85 & 5.0486 & TRN & \\
\hline CHEMBL1342659 & 688267 & 4.35 & 5.0779 & TRN & \\
\hline CHEMBL1363751 & 688267 & 4.1 & 5.0471 & TRN & \\
\hline CHEMBL1422638 & 688267 & 5.55 & 5.0702 & TRN & \\
\hline CHEMBL1360925 & 688267 & 4.35 & 5.1086 & TRN & \\
\hline CHEMBL1608963 & 688267 & 4.2 & 5.0457 & TST & \\
\hline CHEMBL1335581 & 688267 & 5.25 & 5.0041 & TST & \\
\hline CHEMBL1539115 & 688267 & 5.55 & 5.0898 & TRN & \\
\hline CHEMBL1543320 & 688267 & 5.5 & 5.0751 & TRN & \\
\hline CHEMBL1514959 & 688267 & 5.85 & 5.0642 & TRN & \\
\hline CHEMBL1478680 & 688267 & 4.35 & 5.0617 & TRN & \\
\hline CHEMBL1463836 & 688267 & 4.25 & 5.1265 & TST & \\
\hline CHEMBL1590766 & 688267 & 4.6 & 5.1608 & TST & \\
\hline CHEMBL1607927 & 688267 & 5.95 & 5.1016 & TRN & \\
\hline CHEMBL1414401 & 688267 & 6.15 & 4.9812 & TRN & \\
\hline CHEMBL1456743 & 688267 & 6.05 & 5.0423 & TRN & \\
\hline CHEMBL1329232 & 688267 & 3.95 & 5.0647 & TRN & \\
\hline CHEMBL1303424 & 688267 & 5.85 & 5.0426 & TST & \\
\hline CHEMBL1450974 & 688267 & 6.2 & 5.1444 & TRN & \\
\hline CHEMBL1604253 & 688267 & 6.15 & 5.0433 & TRN & \\
\hline CHEMBL464198 & 688267 & 5.55 & 5.0704 & TST & \\
\hline CHEMBL1543779 & 688267 & 5.55 & 5.0348 & TRN & \\
\hline CHEMBL 1377058 & 688267 & 4.0 & 5.0644 & TST & \\
\hline CHEMBL1590541 & 688267 & 5.0 & 5.0206 & TRN & \\
\hline
\end{tabular}




\begin{tabular}{|c|c|c|c|c|c|}
\hline \\
\hline CHEMBL1410468 & 688267 & 4.5 & 5.0763 & TRN & \\
\hline CHEMBL1501994 & 688267 & 5.55 & 5.0235 & TRN & \\
\hline CHEMBL1444880 & 688267 & 4.75 & 5.0295 & TRN & \\
\hline CHEMBL1528440 & 688267 & 5.45 & 5.0305 & TRN & \\
\hline CHEMBL1361547 & 688267 & 4.3 & 5.0098 & TRN & \\
\hline CHEMBL3192072 & 688267 & 3.95 & 5.0599 & TRN & \\
\hline CHEMBL3213877 & 688267 & 4.05 & 5.032 & TST & \\
\hline CHEMBL1469085 & 688267 & 5.25 & 5.0588 & TRN & \\
\hline CHEMBL1335207 & 688267 & 5.55 & 5.0508 & TST & \\
\hline CHEMBL1479171 & 688267 & 5.25 & 5.0549 & TST & \\
\hline CHEMBL1565505 & 688267 & 5.85 & 5.0696 & TRN & \\
\hline CHEMBL1579496 & 688267 & 5.3 & 5.0683 & TRN & \\
\hline CHEMBL1536340 & 688267 & 4.4 & 5.0447 & TRN & \\
\hline CHEMBL3212497 & 688267 & 5.5 & 5.016 & TST & \\
\hline CHEMBL3210713 & 688267 & 4.0 & 5.0861 & TRN & \\
\hline CHEMBL1520609 & 688267 & 5.2 & 5.0478 & TRN & \\
\hline CHEMBL1448016 & 688267 & 4.35 & 5.1035 & TRN & \\
\hline CHEMBL1327530 & 688267 & 4.2 & 5.0697 & TRN & \\
\hline CHEMBL3211977 & 688267 & 3.95 & 5.0709 & TRN & \\
\hline CHEMBL1465601 & 688267 & 6.15 & 5.0277 & TST & \\
\hline CHEMBL1605823 & 688267 & 6.15 & 5.0785 & TRN & \\
\hline CHEMBL1340974 & 688267 & 5.1 & 5.015 & TRN & \\
\hline CHEMBL1488839 & 688267 & 4.7 & 5.0382 & TRN & \\
\hline CHEMBL1432154 & 688267 & 4.35 & 5.03600 & 00000000005 & TRN \\
\hline CHEMBL1474852 & 688267 & 5.8 & 5.065 & TRN & \\
\hline CHEMBL1464050 & 688267 & 6.0 & 5.0125 & TRN & \\
\hline CHEMBL1324412 & 688267 & 6.2 & 4.9909 & TRN & \\
\hline CHEMBL1573651 & 688267 & 5.75 & 5.0929 & TRN & \\
\hline CHEMBL1362724 & 688267 & 4.75 & 4.9712 & TRN & \\
\hline CHEMBL1342147 & 688267 & 6.2 & 4.9844 & TRN & \\
\hline CHEMBL1450248 & 688267 & 4.4 & 5.0518 & TST & \\
\hline CHEMBL1594877 & 688267 & 5.75 & 5.0526 & TRN & \\
\hline CHEMBL1386380 & 688267 & 6.2 & 5.0087 & TST & \\
\hline CHEMBL1535081 & 688267 & 4.7 & 5.0938 & TRN & \\
\hline CHEMBL1305482 & 688267 & 4.6 & 5.0693 & TST & \\
\hline CHEMBL1309378 & 688267 & 3.95 & 5.0198 & TRN & \\
\hline CHEMBL1316941 & 688267 & 4.1 & 5.0976 & TRN & \\
\hline CHEMBL1397319 & 688267 & 5.3 & 5.0265 & TRN & \\
\hline CHEMBL1355193 & 688267 & 5.55 & 5.1016 & TRN & \\
\hline CHEMBL1350392 & 688267 & 5.0 & 5.0335 & TRN & \\
\hline CHEMBL1333286 & 688267 & 4.4 & 5.0155 & TRN & \\
\hline CHEMBL1516003 & 688267 & 4.3 & 5.0765 & TRN & \\
\hline CHEMBL3193706 & 688267 & 5.45 & 5.0496 & TRN & \\
\hline CHEMBL1546751 & 688267 & 6.2 & 5.1062 & TST & \\
\hline CHEMBL1559130 & 688267 & 4.95 & 5.0035 & TRN & \\
\hline CHEMBL1584513 & 688267 & 4.35 & 5.1003 & TRN & \\
\hline CHEMBL1573170 & 688267 & 4.4 & 5.03100 & $\partial 000000001$ & TRN \\
\hline CHEMBL288861 & 688267 & 5.55 & 5.0296 & TST & \\
\hline & & & & 17334 & \\
\hline
\end{tabular}




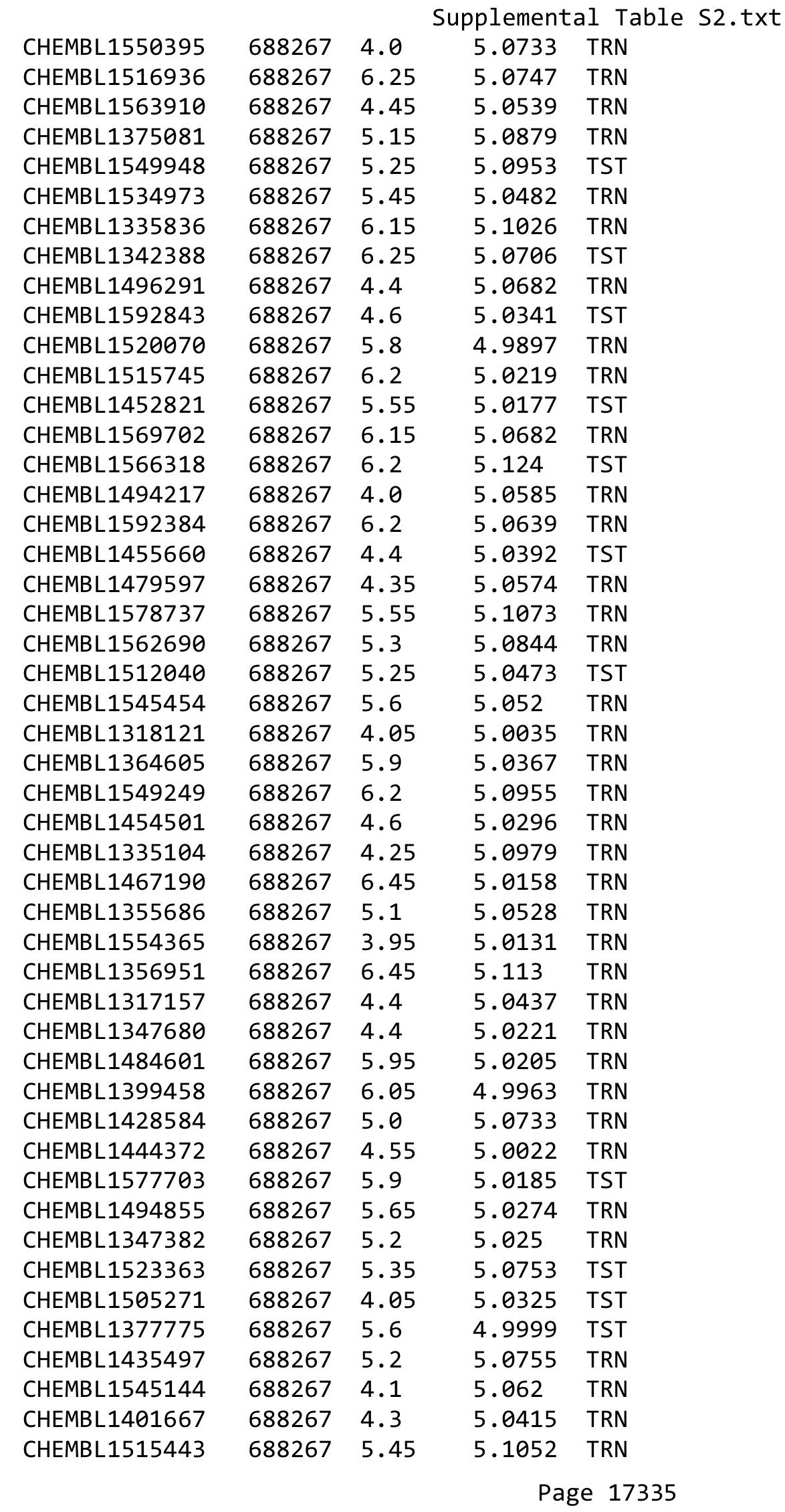




\begin{tabular}{|c|c|c|c|c|}
\hline \multicolumn{5}{|c|}{ Supplemental Table } \\
\hline CHEMBL1325936 & 688267 & 5.4 & 5.066 & TST \\
\hline CHEMBL1376095 & 688267 & 4.0 & 5.0147 & TRN \\
\hline CHEMBL1487614 & 688267 & 6.2 & 5.0358 & TST \\
\hline CHEMBL1537883 & 688267 & 6.15 & 5.007 & TST \\
\hline CHEMBL1448747 & 688267 & 5.85 & 5.0386 & TRN \\
\hline CHEMBL1443883 & 688267 & 5.75 & 5.1123 & TRN \\
\hline CHEMBL1315343 & 688267 & 4.05 & 5.073 & TRN \\
\hline CHEMBL1321524 & 688267 & 4.7 & 5.0305 & TRN \\
\hline CHEMBL1470993 & 688267 & 5.8 & 5.0006 & TRN \\
\hline CHEMBL3209098 & 688267 & 4.45 & 5.0039 & TRN \\
\hline CHEMBL1329784 & 688267 & 5.8 & 5.0709 & TRN \\
\hline CHEMBL1407313 & 688267 & 5.4 & 5.0374 & TRN \\
\hline CHEMBL1419546 & 688267 & 4.0 & 5.0373 & TST \\
\hline CHEMBL1551027 & 688267 & 6.2 & 5.112 & TRN \\
\hline CHEMBL1971454 & 688267 & 5.0 & 5.0137 & TRN \\
\hline CHEMBL1374290 & 688267 & 4.05 & 5.0404 & TST \\
\hline CHEMBL1558736 & 688267 & 5.7 & 5.022 & TST \\
\hline CHEMBL1328250 & 688267 & 5.45 & 5.0303 & TRN \\
\hline CHEMBL1378599 & 688267 & 5.15 & 5.0673 & TRN \\
\hline CHEMBL1380697 & 688267 & 6.0 & 5.0155 & TRN \\
\hline CHEMBL1596117 & 688267 & 4.25 & 5.0488 & TRN \\
\hline CHEMBL3194030 & 688267 & 4.05 & 5.0322 & TRN \\
\hline CHEMBL1359440 & 688267 & 4.55 & 5.0641 & TST \\
\hline CHEMBL1574580 & 688267 & 4.05 & 5.0461 & TRN \\
\hline CHEMBL1488307 & 688267 & 4.3 & 5.1524 & TST \\
\hline CHEMBL1321381 & 688267 & 6.2 & 5.0434 & TRN \\
\hline CHEMBL1473470 & 688267 & 4.05 & 5.0615 & TRN \\
\hline CHEMBL1375550 & 688267 & 4.2 & 5.0229 & TRN \\
\hline CHEMBL1357208 & 688267 & 4.25 & 5.0442 & TST \\
\hline CHEMBL1439034 & 688267 & 4.4 & 5.0104 & TRN \\
\hline CHEMBL1399395 & 688267 & 4.3 & 5.0408 & TRN \\
\hline CHEMBL1493297 & 688267 & 5.5 & 5.0354 & TRN \\
\hline CHEMBL1469531 & 688267 & 4.55 & 5.0628 & TRN \\
\hline CHEMBL1577076 & 688267 & 5.65 & 5.0298 & TRN \\
\hline CHEMBL1593166 & 688267 & 4.0 & 5.0018 & TRN \\
\hline CHEMBL1338846 & 688267 & 4.75 & 5.0452 & TRN \\
\hline CHEMBL1426072 & 688267 & 5.35 & 5.0734 & TRN \\
\hline CHEMBL1516706 & 688267 & 5.1 & 5.0549 & TST \\
\hline CHEMBL1306191 & 688267 & 4.5 & 5.118 & TST \\
\hline CHEMBL1369072 & 688267 & 4.45 & 5.0259 & TST \\
\hline CHEMBL1605681 & 688267 & 4.4 & 5.0252 & TST \\
\hline CHEMBL1549636 & 688267 & 4.0 & 5.0589 & TRN \\
\hline CHEMBL1354330 & 688267 & 6.2 & 5.0569 & TRN \\
\hline CHEMBL1516086 & 688267 & 6.2 & 5.0283 & TRN \\
\hline CHEMBL1402430 & 688267 & 4.0 & 5.0433 & TRN \\
\hline CHEMBL1475189 & 688267 & 5.4 & 5.0568 & TRN \\
\hline CHEMBL1605024 & 688267 & 6.2 & 5.1189 & TRN \\
\hline CHEMBL1535769 & 688267 & 5.15 & 5.0264 & TRN \\
\hline
\end{tabular}




\begin{tabular}{|c|c|c|c|c|c|}
\hline \\
\hline CHEMBL1416685 & 688267 & 6.2 & 5.0775 & TST & \\
\hline CHEMBL1368412 & 688267 & 5.95 & 5.0367 & TRN & \\
\hline CHEMBL1455420 & 688267 & 4.0 & 5.1506 & TRN & \\
\hline CHEMBL1549965 & 688267 & 5.65 & 5.1387 & TRN & \\
\hline CHEMBL1578078 & 688267 & 5.2 & 5.0677 & TRN & \\
\hline CHEMBL1365775 & 688267 & 6.2 & 5.1054 & TRN & \\
\hline CHEMBL1401365 & 688267 & 5.1 & 5.1342 & TST & \\
\hline CHEMBL1331500 & 688267 & 4.35 & 5.0318 & TRN & \\
\hline CHEMBL1411313 & 688267 & 4.1 & 5.0674 & TST & \\
\hline CHEMBL1488172 & 688267 & 6.2 & 5.0096 & TRN & \\
\hline CHEMBL1475687 & 688267 & 3.95 & 5.1145 & TRN & \\
\hline CHEMBL3210958 & 688267 & 5.95 & 5.0584 & TST & \\
\hline CHEMBL1482435 & 688267 & 4.45 & 5.0771 & TST & \\
\hline CHEMBL1514817 & 688267 & 6.0 & 5.0595 & TST & \\
\hline CHEMBL1392907 & 688267 & 4.15 & 5.0696 & TRN & \\
\hline CHEMBL1325300 & 688267 & 4.7 & 5.0806 & TRN & \\
\hline CHEMBL1452883 & 688267 & 4.65 & 5.0827 & TRN & \\
\hline CHEMBL1605844 & 688267 & 4.05 & 5.0572 & TRN & \\
\hline CHEMBL1574159 & 688267 & 6.2 & 5.0318 & TRN & \\
\hline CHEMBL1082026 & 688267 & 4.55 & 5.0848 & TRN & \\
\hline CHEMBL1358330 & 688267 & 6.2 & 5.0289 & TRN & \\
\hline CHEMBL1532223 & 688267 & 5.35 & 5.0844 & TRN & \\
\hline CHEMBL3192650 & 688267 & 5.45 & 5.0454 & TRN & \\
\hline CHEMBL1412858 & 688267 & 5.1 & 5.0206 & TRN & \\
\hline CHEMBL1375551 & 688267 & 5.15 & 5.0172 & TRN & \\
\hline CHEMBL1395694 & 688267 & 4.0 & 5.0359 & TST & \\
\hline CHEMBL1590214 & 688267 & 4.35 & 5.0336 & TRN & \\
\hline CHEMBL1400064 & 688267 & 6.2 & 5.0229 & TRN & \\
\hline CHEMBL1345338 & 688267 & 6.5 & 5.0145 & TRN & \\
\hline CHEMBL3191487 & 688267 & 4.8 & 5.0348 & TRN & \\
\hline CHEMBL1477976 & 688267 & 6.2 & 5.0689 & TST & \\
\hline CHEMBL1411293 & 688267 & 4.0 & 5.1371 & TRN & \\
\hline CHEMBL1436224 & 688267 & 4.25 & 5.0947 & TRN & \\
\hline CHEMBL1447028 & 688267 & 5.75 & 5.0604 & TRN & \\
\hline CHEMBL1567302 & 688267 & 4.4 & 5.0497 & TRN & \\
\hline CHEMBL1589335 & 688267 & 5.35 & 5.0321 & TST & \\
\hline CHEMBL1318529 & 688267 & 5.1 & 5.0391 & TST & \\
\hline CHEMBL429095 & 688267 & 5.3 & 5.0446 & TST & \\
\hline CHEMBL1474991 & 688267 & 4.55 & 5.1596 & TST & \\
\hline CHEMBL1310304 & 688267 & 5.8 & 5.1049 & TRN & \\
\hline CHEMBL1580244 & 688267 & 4.0 & 5.1059 & TST & \\
\hline CHEMBL1346138 & 688267 & 4.85 & $5.1370 e$ & 00000000005 & TRN \\
\hline CHEMBL1548725 & 688267 & 6.2 & 5.0601 & TST & \\
\hline CHEMBL1318418 & 688267 & 4.7 & 4.9861 & TRN & \\
\hline CHEMBL1594738 & 688267 & 4.6 & 5.0267 & TRN & \\
\hline CHEMBL1422511 & 688267 & 5.45 & 5.0098 & TRN & \\
\hline CHEMBL1411373 & 688267 & 5.4 & 5.0282 & TRN & \\
\hline CHEMBL1453985 & 688267 & 5.45 & 5.0114 & TRN & \\
\hline
\end{tabular}




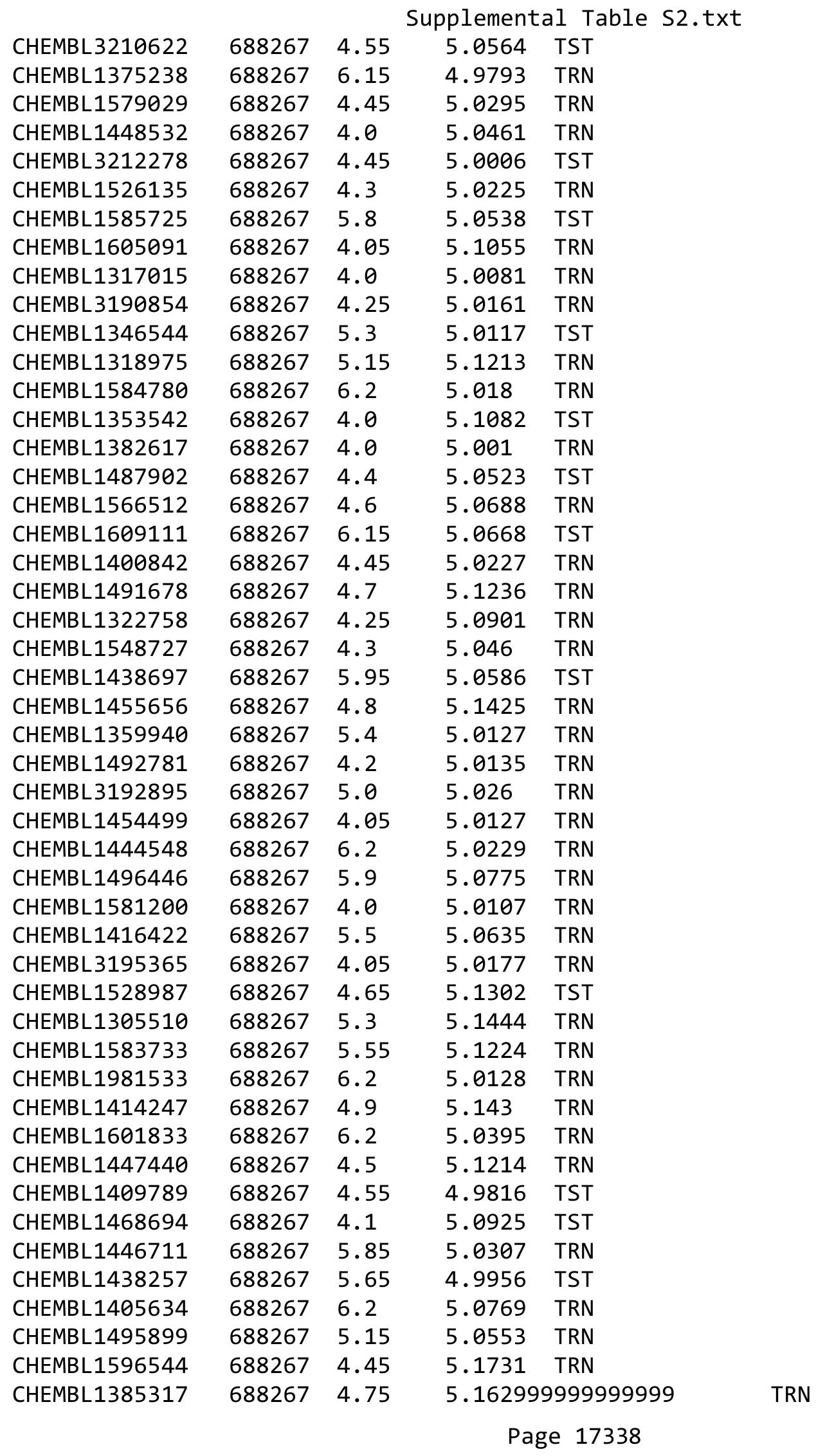




\begin{tabular}{|c|c|c|c|c|}
\hline \multicolumn{5}{|c|}{ Supplemental Table S2.txt } \\
\hline CHEMBL1392846 & 688267 & 5.55 & 5.0236 & TST \\
\hline CHEMBL3193108 & 688267 & 4.65 & 5.0186 & TRN \\
\hline CHEMBL1380260 & 688267 & 6.2 & 5.1005 & TRN \\
\hline CHEMBL1440784 & 688267 & 4.0 & 5.088 & TRN \\
\hline CHEMBL1498443 & 688267 & 5.55 & 5.0322 & TST \\
\hline CHEMBL1312592 & 688267 & 6.45 & 5.0778 & TRN \\
\hline CHEMBL1600694 & 688267 & 5.15 & 5.0659 & TRN \\
\hline CHEMBL1475800 & 688267 & 4.0 & 5.1202 & TRN \\
\hline CHEMBL1304020 & 688267 & 4.35 & 5.0194 & TRN \\
\hline CHEMBL1580028 & 688267 & 4.1 & 5.0756 & TST \\
\hline CHEMBL1318792 & 688267 & 4.75 & 5.1181 & TRN \\
\hline CHEMBL1597380 & 688267 & 5.15 & 5.0746 & TRN \\
\hline CHEMBL1380422 & 688267 & 4.05 & 5.0345 & TRN \\
\hline CHEMBL1365696 & 688267 & 4.75 & 5.0537 & TRN \\
\hline CHEMBL1327201 & 688267 & 4.95 & 5.0445 & TRN \\
\hline CHEMBL1376859 & 688267 & 4.4 & 5.0763 & TRN \\
\hline CHEMBL1341117 & 688267 & 5.35 & 5.0976 & TST \\
\hline CHEMBL1382965 & 688267 & 6.2 & 5.0283 & TST \\
\hline CHEMBL1537940 & 688267 & 4.25 & 5.0156 & TRN \\
\hline CHEMBL1375471 & 688267 & 4.85 & 5.0507 & TST \\
\hline CHEMBL1487154 & 688267 & 4.05 & 5.0284 & TRN \\
\hline CHEMBL1334327 & 688267 & 5.0 & 5.0579 & TST \\
\hline CHEMBL1374120 & 688267 & 4.3 & 5.0688 & TRN \\
\hline CHEMBL1500062 & 688267 & 6.2 & 5.0644 & TST \\
\hline CHEMBL1502213 & 688267 & 5.75 & 5.121 & TRN \\
\hline CHEMBL1601642 & 688267 & 6.5 & 5.1189 & TRN \\
\hline CHEMBL1359407 & 688267 & 4.3 & 4.9555 & TRN \\
\hline CHEMBL1541046 & 688267 & 4.05 & 5.078 & TRN \\
\hline CHEMBL1583381 & 688267 & 5.35 & 5.0781 & TST \\
\hline CHEMBL1561535 & 688267 & 6.15 & 5.0485 & TST \\
\hline CHEMBL1551580 & 688267 & 6.2 & 5.0137 & TRN \\
\hline CHEMBL1578343 & 688267 & 5.5 & 5.102 & TRN \\
\hline CHEMBL1480727 & 688267 & 6.2 & 5.0825 & TST \\
\hline CHEMBL 3194108 & 688267 & 4.4 & 5.0614 & TST \\
\hline CHEMBL1602167 & 688267 & 4.05 & 5.1041 & TRN \\
\hline CHEMBL1997392 & 688267 & 4.1 & 4.9399 & TRN \\
\hline CHEMBL1357744 & 688267 & 6.6 & 5.0522 & TRN \\
\hline CHEMBL1376671 & 688267 & 6.1 & 5.088 & TRN \\
\hline CHEMBL1340018 & 688267 & 4.45 & 5.0736 & TST \\
\hline CHEMBL1530618 & 688267 & 4.0 & 5.1054 & TST \\
\hline CHEMBL1605672 & 688267 & 6.2 & 5.043 & TRN \\
\hline CHEMBL1548758 & 688267 & 4.95 & 5.0699 & TRN \\
\hline CHEMBL1478446 & 688267 & 5.25 & 5.0627 & TRN \\
\hline CHEMBL1325503 & 688267 & 5.9 & 4.9871 & TRN \\
\hline CHEMBL1550038 & 688267 & 5.5 & 5.0189 & TRN \\
\hline CHEMBL1433016 & 688267 & 4.8 & 5.0982 & TRN \\
\hline CHEMBL1433995 & 688267 & 3.95 & 5.0557 & TRN \\
\hline CHEMBL1402588 & 688267 & 4.4 & 5.1058 & TRN \\
\hline
\end{tabular}




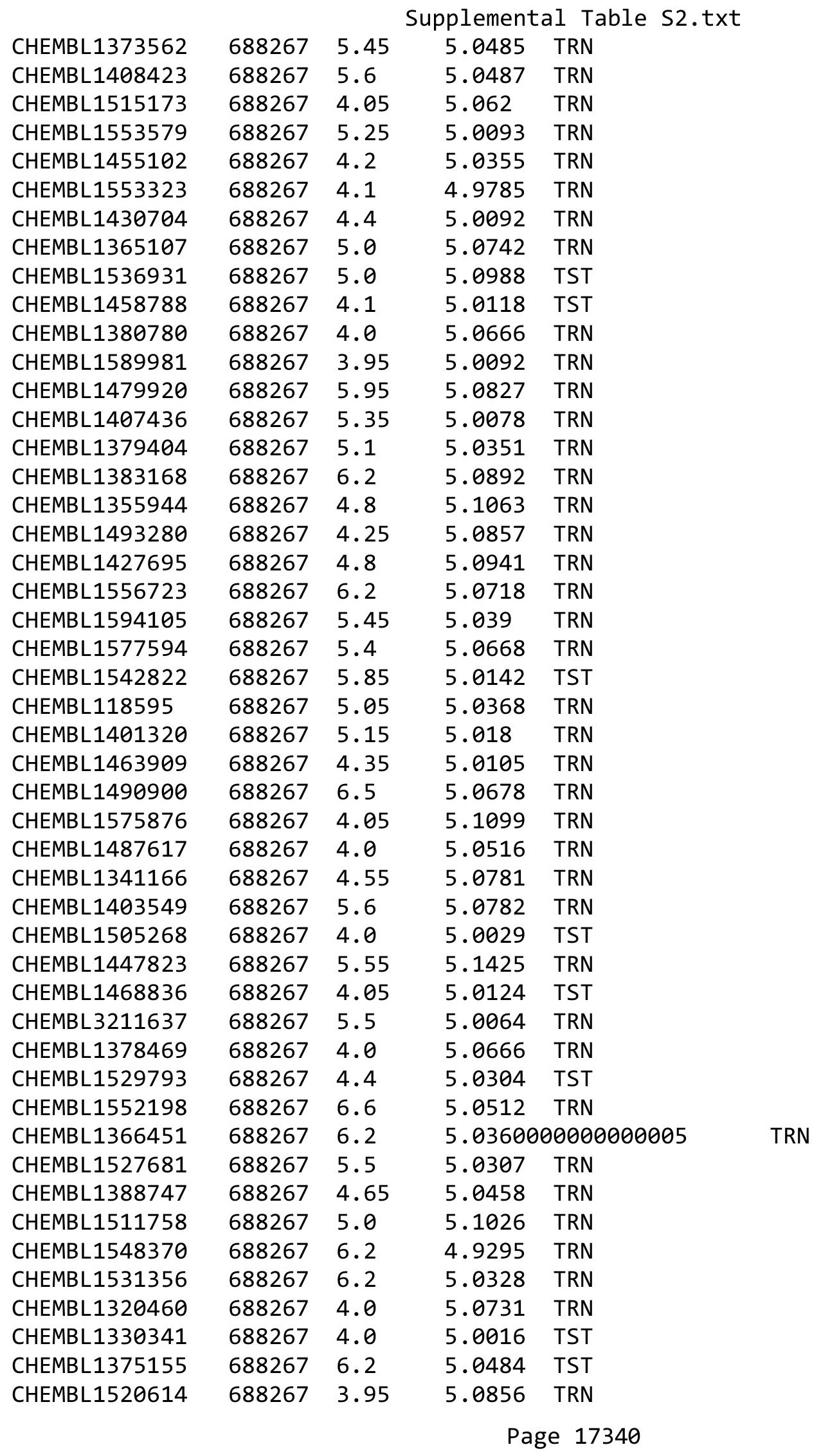




\begin{tabular}{|c|c|c|c|c|c|}
\hline \multicolumn{6}{|c|}{ pıementa } \\
\hline CHEMBL1314361 & 688267 & 4.6 & 5.0743 & TST & \\
\hline CHEMBL486569 & 688267 & 4.5 & 4.9751 & TRN & \\
\hline CHEMBL1384538 & 688267 & 5.15 & 5.02 & TST & \\
\hline CHEMBL1575867 & 688267 & 4.95 & 5.0985 & TRN & \\
\hline CHEMBL1440033 & 688267 & 6.5 & 5.1179 & TST & \\
\hline CHEMBL1535774 & 688267 & 6.2 & 5.0244 & TST & \\
\hline CHEMBL1403596 & 688267 & 4.0 & 5.0545 & TST & \\
\hline CHEMBL3189529 & 688267 & 5.3 & 4.9428 & TRN & \\
\hline CHEMBL1547967 & 688267 & 6.2 & 5.1235 & TRN & \\
\hline CHEMBL1311971 & 688267 & 3.95 & 5.0863 & TRN & \\
\hline CHEMBL1338375 & 688267 & 5.1 & 5.0105 & TRN & \\
\hline CHEMBL1488847 & 688267 & 3.95 & 5.0675 & TST & \\
\hline CHEMBL1481461 & 688267 & 4.3 & 5.0503 & TRN & \\
\hline CHEMBL1520900 & 688267 & 5.5 & 5.0146 & TRN & \\
\hline CHEMBL1407829 & 688267 & 4.3 & 4.9849 & TRN & \\
\hline CHEMBL1326659 & 688267 & 4.25 & 5.0888 & TRN & \\
\hline CHEMBL1588445 & 688267 & 5.5 & 5.1186 & TRN & \\
\hline CHEMBL1530347 & 688267 & 5.35 & 5.1082 & TRN & \\
\hline CHEMBL1313672 & 688267 & 5.0 & 5.0828 & TST & \\
\hline CHEMBL3208674 & 688267 & 4.3 & 5.0369 & TST & \\
\hline CHEMBL1612317 & 688267 & 4.45 & 5.0057 & TRN & \\
\hline CHEMBL1369780 & 688267 & 5.5 & 5.0463 & TRN & \\
\hline CHEMBL1446516 & 688267 & 4.0 & 5.0501 & TRN & \\
\hline CHEMBL1406620 & 688267 & 4.3 & 4.9817 & TRN & \\
\hline CHEMBL1347558 & 688267 & 6.45 & 5.1271 & TST & \\
\hline CHEMBL1992872 & 688267 & 6.2 & 4.9978 & TRN & \\
\hline CHEMBL1373626 & 688267 & 5.75 & 5.025 & TRN & \\
\hline CHEMBL1396253 & 688267 & 6.15 & 5.0833 & TRN & \\
\hline CHEMBL1394759 & 688267 & 4.05 & 5.0306 & TRN & \\
\hline CHEMBL1379019 & 688267 & 4.05 & 5.0351 & TRN & \\
\hline CHEMBL1310857 & 688267 & 5.9 & 4.9914 & TST & \\
\hline CHEMBL1450434 & 688267 & 6.45 & 5.0883 & TRN & \\
\hline CHEMBL1412120 & 688267 & 6.2 & 5.1054 & TRN & \\
\hline CHEMBL1389178 & 688267 & 6.5 & $5.0710 e$ & 0000000001 & TRN \\
\hline CHEMBL1509363 & 688267 & 4.05 & 4.9987 & TST & \\
\hline CHEMBL1417179 & 688267 & 4.0 & 5.1187 & TRN & \\
\hline CHEMBL1372448 & 688267 & 6.2 & 5.0469 & TRN & \\
\hline CHEMBL1448455 & 688267 & 4.4 & 5.0583 & TRN & \\
\hline CHEMBL1373098 & 688267 & 4.45 & 5.019 & TST & \\
\hline CHEMBL1304557 & 688267 & 6.25 & 5.0409 & TRN & \\
\hline CHEMBL1534439 & 688267 & 4.7 & 5.1266 & TRN & \\
\hline CHEMBL3212087 & 688267 & 6.45 & $5.0280 e$ & 00000000005 & TST \\
\hline CHEMBL1498815 & 688267 & 5.3 & 5.0618 & TST & \\
\hline CHEMBL1589576 & 688267 & 6.15 & 5.0596 & TRN & \\
\hline CHEMBL1564708 & 688267 & 6.2 & 5.0121 & TRN & \\
\hline CHEMBL1310141 & 688267 & 4.3 & 5.1359 & TRN & \\
\hline CHEMBL1376517 & 688267 & 6.15 & 4.9906 & TRN & \\
\hline CHEMBL1513792 & 688267 & 6.15 & 5.0233 & TRN & \\
\hline
\end{tabular}




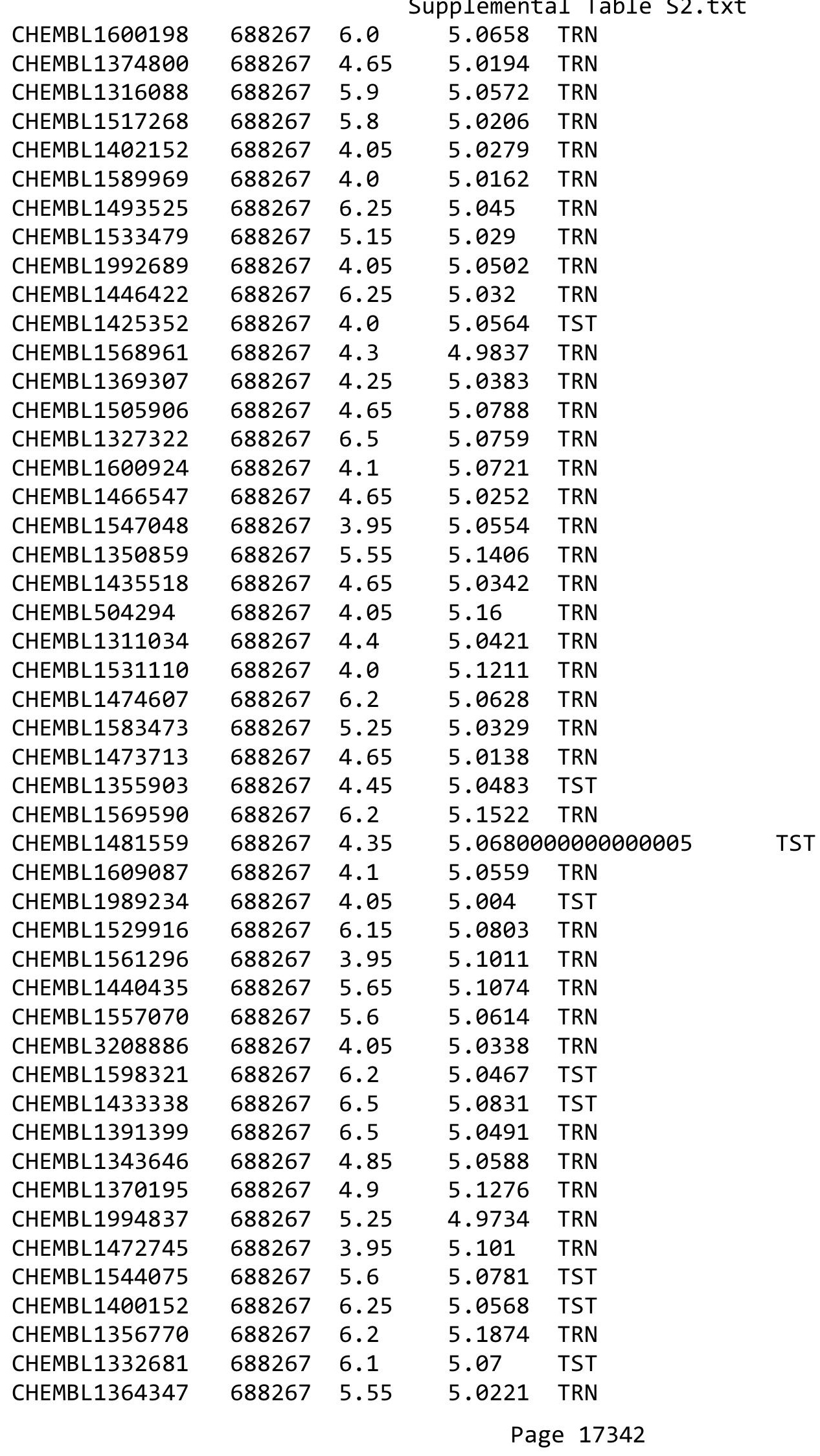




\begin{tabular}{|c|c|c|c|c|c|}
\hline \multirow{3}{*}{$\begin{array}{l}\text { CHEMBL1548668 } \\
\text { CHEMBL1514402 }\end{array}$} & \multirow{3}{*}{$\begin{array}{l}688267 \\
688267\end{array}$} & \multicolumn{4}{|c|}{ Supplemental Table S2.txt } \\
\hline & & 4.0 & \multicolumn{2}{|c|}{5.172999999999999} & TRN \\
\hline & & 4.0 & 5.1062 & TRN & \\
\hline CHEMBL1505354 & 688267 & 4.15 & 5.1028 & TRN & \\
\hline CHEMBL1453133 & 688267 & 4.3 & 5.0626 & TRN & \\
\hline CHEMBL1504401 & 688267 & 4.35 & 5.0602 & TRN & \\
\hline CHEMBL1588096 & 688267 & 5.0 & 5.0751 & TST & \\
\hline CHEMBL1425471 & 688267 & 4.9 & 5.0439 & TRN & \\
\hline CHEMBL1476847 & 688267 & 6.05 & 5.0485 & TRN & \\
\hline CHEMBL1299944 & 688267 & 5.15 & 5.0518 & TRN & \\
\hline CHEMBL1534012 & 688267 & 5.45 & 5.0588 & TRN & \\
\hline CHEMBL1492125 & 688267 & 4.0 & 5.0848 & TRN & \\
\hline CHEMBL1378858 & 688267 & 4.8 & 5.0899 & TRN & \\
\hline CHEMBL1303197 & 688267 & 5.65 & 5.0675 & TRN & \\
\hline CHEMBL1518779 & 688267 & 6.15 & 5.0218 & TRN & \\
\hline CHEMBL1535528 & 688267 & 4.9 & 5.0679 & TRN & \\
\hline CHEMBL1591215 & 688267 & 6.2 & 5.1144 & TRN & \\
\hline CHEMBL3193142 & 688267 & 4.25 & 4.9953 & TRN & \\
\hline CHEMBL1579564 & 688267 & 4.55 & 5.064 & TRN & \\
\hline CHEMBL1323265 & 688267 & 6.2 & 5.0485 & TRN & \\
\hline CHEMBL 3198672 & 688267 & 5.6 & 5.1131 & TST & \\
\hline CHEMBL1528563 & 688267 & 4.4 & 5.0273 & TRN & \\
\hline CHEMBL1310057 & 688267 & 5.3 & 5.0586 & TRN & \\
\hline CHEMBL1473106 & 688267 & 6.2 & 5.0173 & TRN & \\
\hline CHEMBL1493889 & 688267 & 4.05 & 4.9993 & TRN & \\
\hline CHEMBL1401011 & 688267 & 6.2 & 5.1417 & TRN & \\
\hline CHEMBL1343187 & 688267 & 4.6 & 5.0713 & TST & \\
\hline CHEMBL3196821 & 688267 & 6.2 & 5.0227 & TST & \\
\hline CHEMBL1357536 & 688267 & 4.35 & 5.0165 & TRN & \\
\hline CHEMBL3213807 & 688267 & 4.1 & 5.0521 & TRN & \\
\hline CHEMBL1458484 & 688267 & 4.35 & 5.047 & TST & \\
\hline CHEMBL1419319 & 688267 & 4.05 & 5.086 & TRN & \\
\hline CHEMBL1327789 & 688267 & 5.45 & 5.0983 & TRN & \\
\hline CHEMBL1483574 & 688267 & 5.05 & 5.0648 & TRN & \\
\hline CHEMBL1401110 & 688267 & 6.2 & 5.0451 & TRN & \\
\hline CHEMBL1565185 & 688267 & 5.1 & 5.0368 & TRN & \\
\hline CHEMBL1400609 & 688267 & 6.2 & 5.0006 & TRN & \\
\hline CHEMBL1406378 & 688267 & 5.85 & 5.1094 & TRN & \\
\hline CHEMBL1299260 & 688267 & 4.4 & 5.044 & TRN & \\
\hline CHEMBL1425171 & 688267 & 5.7 & 5.1177 & TRN & \\
\hline CHEMBL1437773 & 688267 & 5.9 & 5.1003 & TRN & \\
\hline CHEMBL1565919 & 688267 & 6.2 & 4.9856 & TRN & \\
\hline CHEMBL1346290 & 688267 & 6.5 & 5.0118 & TRN & \\
\hline CHEMBL3193415 & 688267 & 4.8 & 4.9662 & TRN & \\
\hline CHEMBL1452409 & 688267 & 3.95 & 4.9796 & TST & \\
\hline CHEMBL1490545 & 688267 & 6.2 & 5.1102 & TST & \\
\hline CHEMBL1500914 & 688267 & 6.2 & 5.0256 & TRN & \\
\hline CHEMBL1408869 & 688267 & 4.4 & 5.1241 & TRN & \\
\hline CHEMBL1567157 & 688267 & 4.1 & 5.0097 & TRN & \\
\hline
\end{tabular}




\begin{tabular}{|c|c|c|c|c|c|}
\hline \multicolumn{6}{|c|}{ Supplemental Table S2.txt } \\
\hline CHEMBL3208963 & 688267 & 4.4 & 5.0417 & TST & \\
\hline CHEMBL1330041 & 688267 & 5.35 & 5.0252 & TST & \\
\hline CHEMBL1536594 & 688267 & 5.35 & 5.0253 & TST & \\
\hline CHEMBL1512128 & 688267 & 4.5 & 5.1197 & TRN & \\
\hline CHEMBL1448025 & 688267 & 4.05 & 5.113 & TRN & \\
\hline CHEMBL1466924 & 688267 & 4.15 & 5.1219 & TRN & \\
\hline CHEMBL1578077 & 688267 & 4.0 & 5.006 & TRN & \\
\hline CHEMBL1534277 & 688267 & 5.25 & 5.0337 & TRN & \\
\hline CHEMBL1562680 & 688267 & 4.4 & 5.043 & TRN & \\
\hline CHEMBL1474802 & 688267 & 6.2 & 5.0581 & TRN & \\
\hline CHEMBL1594533 & 688267 & 4.3 & 5.0931 & TRN & \\
\hline CHEMBL1343454 & 688267 & 4.6 & 5.1234 & TST & \\
\hline CHEMBL 2093214 & 688267 & 5.45 & 5.0401 & TRN & \\
\hline CHEMBL1381545 & 688267 & 4.9 & 5.029 & TST & \\
\hline CHEMBL1405192 & 688267 & 4.0 & 5.0888 & TRN & \\
\hline CHEMBL1417328 & 688267 & 4.1 & 5.0835 & TST & \\
\hline CHEMBL1580990 & 688267 & 6.1 & 5.0049 & TRN & \\
\hline CHEMBL1610791 & 688267 & 4.35 & 5.13399 & 99999999995 & TRN \\
\hline CHEMBL1559998 & 688267 & 5.65 & 5.01 & TST & \\
\hline CHEMBL1450996 & 688267 & 4.05 & 5.1214 & TRN & \\
\hline CHEMBL1299305 & 688267 & 4.55 & 5.0782 & TRN & \\
\hline CHEMBL1452021 & 688267 & 6.2 & 5.02800 & 00000000005 & TRN \\
\hline CHEMBL1328522 & 688267 & 5.35 & 5.0275 & TRN & \\
\hline CHEMBL1355477 & 688267 & 4.65 & 5.0957 & TST & \\
\hline CHEMBL1388289 & 688267 & 5.4 & 4.9966 & TRN & \\
\hline CHEMBL1374419 & 688267 & 4.45 & 5.0663 & TRN & \\
\hline CHEMBL1428617 & 688267 & 4.6 & 5.05 & TRN & \\
\hline CHEMBL1415619 & 688267 & 6.15 & 5.0966 & TST & \\
\hline CHEMBL1375336 & 688267 & 4.0 & 5.0454 & TRN & \\
\hline CHEMBL1534428 & 688267 & 4.05 & 5.0848 & TRN & \\
\hline CHEMBL1454198 & 688267 & 6.0 & 5.0975 & TST & \\
\hline CHEMBL1415802 & 688267 & 4.05 & 5.0452 & TRN & \\
\hline CHEMBL1306979 & 688267 & 5.3 & 5.1261 & TRN & \\
\hline CHEMBL1472234 & 688267 & 4.15 & 5.0596 & TRN & \\
\hline CHEMBL1412892 & 688267 & 6.25 & 5.0652 & TRN & \\
\hline CHEMBL1574694 & 688267 & 4.0 & 4.9976 & TRN & \\
\hline CHEMBL1491771 & 688267 & 6.2 & 5.1371 & TRN & \\
\hline CHEMBL1431181 & 688267 & 4.0 & 5.0826 & TRN & \\
\hline CHEMBL1314689 & 688267 & 5.2 & 5.0556 & TRN & \\
\hline CHEMBL1580440 & 688267 & 4.9 & 5.0715 & TRN & \\
\hline CHEMBL1343513 & 688267 & 3.95 & 5.0747 & TST & \\
\hline CHEMBL3194409 & 688267 & 6.2 & 4.9979 & TRN & \\
\hline CHEMBL1555461 & 688267 & 4.3 & 5.106 & TST & \\
\hline CHEMBL1315407 & 688267 & 6.2 & 5.0869 & TRN & \\
\hline CHEMBL1476452 & 688267 & 4.05 & 5.0382 & TRN & \\
\hline CHEMBL1384338 & 688267 & 4.85 & 4.9861 & TRN & \\
\hline CHEMBL1409753 & 688267 & 4.35 & 5.0374 & TRN & \\
\hline CHEMBL1554457 & 688267 & 6.2 & 5.0263 & TST & \\
\hline
\end{tabular}




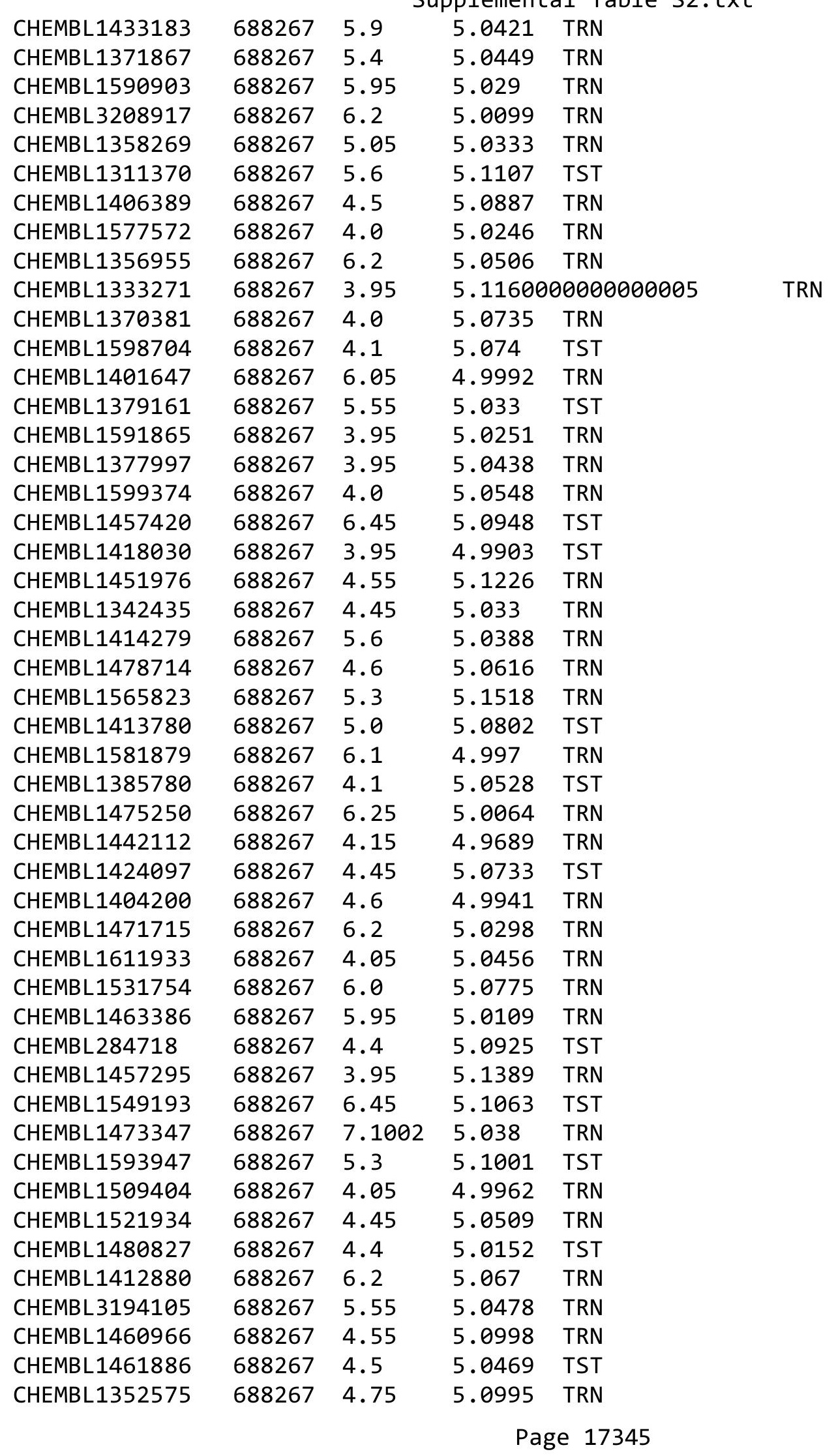




\begin{tabular}{|c|c|c|c|c|}
\hline \multirow[b]{2}{*}{ CHEMBL1314507 } & \multicolumn{4}{|c|}{ Supplemental Table S2.tx } \\
\hline & 688267 & 6.0 & 5.0022 & TST \\
\hline CHEMBL1548025 & 688267 & 6.15 & 4.9843 & TRN \\
\hline CHEMBL1566810 & 688267 & 4.4 & 5.0272 & TRN \\
\hline CHEMBL1369519 & 688267 & 5.1 & 5.0622 & TRN \\
\hline CHEMBL1436190 & 688267 & 6.2 & 5.0304 & TRN \\
\hline CHEMBL1390756 & 688267 & 4.05 & 5.0477 & TST \\
\hline CHEMBL1518892 & 688267 & 4.95 & 5.0377 & TRN \\
\hline CHEMBL1362193 & 688267 & 4.0 & 5.0334 & TRN \\
\hline CHEMBL1360720 & 688267 & 5.0 & 5.0634 & TRN \\
\hline CHEMBL1416811 & 688267 & 5.4 & 5.0395 & TST \\
\hline CHEMBL1466566 & 688267 & 4.5 & 5.0489 & TRN \\
\hline CHEMBL1436092 & 688267 & 5.9 & 5.0713 & TRN \\
\hline CHEMBL1513899 & 688267 & 5.8 & 5.1422 & TRN \\
\hline CHEMBL1381386 & 688267 & 5.35 & 5.0123 & TRN \\
\hline CHEMBL1382626 & 688267 & 6.25 & 5.0642 & TRN \\
\hline CHEMBL1352926 & 688267 & 6.2 & 5.0951 & TRN \\
\hline CHEMBL1568245 & 688267 & 5.55 & 5.0512 & TRN \\
\hline CHEMBL1307158 & 688267 & 4.3 & 5.1014 & TST \\
\hline CHEMBL1532203 & 688267 & 5.45 & 5.0139 & TRN \\
\hline CHEMBL1496242 & 688267 & 6.2 & 5.0808 & TRN \\
\hline CHEMBL1468699 & 688267 & 4.4 & 5.0549 & TRN \\
\hline CHEMBL1554000 & 688267 & 5.5 & 5.1033 & TRN \\
\hline CHEMBL1539708 & 688267 & 6.25 & 5.0481 & TRN \\
\hline CHEMBL1446862 & 688267 & 6.25 & 5.0297 & TRN \\
\hline CHEMBL 3192225 & 688267 & 6.25 & 5.0134 & TST \\
\hline CHEMBL1365834 & 688267 & 4.05 & 5.1014 & TRN \\
\hline CHEMBL1539597 & 688267 & 4.5 & 5.0446 & TRN \\
\hline CHEMBL1521633 & 688267 & 5.5 & 5.1336 & TST \\
\hline CHEMBL590186 & 688267 & 6.2 & 5.0323 & TST \\
\hline CHEMBL1347528 & 688267 & 6.15 & 5.0797 & TRN \\
\hline CHEMBL1593448 & 688267 & 6.2 & 5.0983 & TST \\
\hline CHEMBL1598925 & 688267 & 4.2 & 5.0678 & TRN \\
\hline CHEMBL1576320 & 688267 & 4.55 & 4.9856 & TRN \\
\hline CHEMBL1424219 & 688267 & 6.2 & 5.0963 & TRN \\
\hline CHEMBL1512163 & 688267 & 4.05 & 5.1109 & TRN \\
\hline CHEMBL1418104 & 688267 & 4.05 & 5.0387 & TRN \\
\hline CHEMBL1437124 & 688267 & 4.45 & 5.0228 & TST \\
\hline CHEMBL1329447 & 688267 & 6.0 & 4.9764 & TRN \\
\hline CHEMBL1593144 & 688267 & 6.15 & 5.1179 & TRN \\
\hline CHEMBL1465052 & 688267 & 4.0 & 5.0011 & TST \\
\hline CHEMBL1390506 & 688267 & 6.25 & 5.0532 & TRN \\
\hline CHEMBL1569782 & 688267 & 5.75 & 4.9688 & TRN \\
\hline CHEMBL1476840 & 688267 & 4.1 & 4.9988 & TRN \\
\hline CHEMBL1450418 & 688267 & 4.7 & 5.1386 & TRN \\
\hline CHEMBL1318809 & 688267 & 4.5 & 5.1135 & TRN \\
\hline CHEMBL1524545 & 688267 & 4.45 & 5.0843 & TST \\
\hline CHEMBL1532324 & 688267 & 4.05 & 5.1387 & TST \\
\hline CHEMBL1341679 & 688267 & 5.0 & 5.0801 & TRN \\
\hline
\end{tabular}




\begin{tabular}{|c|c|c|c|c|}
\hline & & & pplement & al $\mathrm{Ta}$ \\
\hline CHEMBL1608849 & 688267 & 6.25 & 5.087 & TRN \\
\hline CHEMBL1394312 & 688267 & 5.2 & 5.0437 & TRN \\
\hline CHEMBL1551412 & 688267 & 5.55 & 5.0826 & TRN \\
\hline CHEMBL1345974 & 688267 & 4.5 & 5.0424 & TST \\
\hline CHEMBL1566019 & 688267 & 4.1 & 5.092 & TRN \\
\hline CHEMBL1506346 & 688267 & 6.2 & 5.1093 & TRN \\
\hline CHEMBL1370028 & 688267 & 5.55 & 5.0565 & TRN \\
\hline CHEMBL1578350 & 688267 & 4.35 & 5.0208 & TST \\
\hline CHEMBL1568780 & 688267 & 6.15 & 5.1521 & TRN \\
\hline CHEMBL3190685 & 688267 & 5.1 & 5.0145 & TRN \\
\hline CHEMBL508648 & 688267 & 6.25 & 5.0529 & TST \\
\hline CHEMBL28324 & 688267 & 5.85 & 5.1032 & TST \\
\hline CHEMBL1535173 & 688267 & 5.0 & 5.0567 & TRN \\
\hline CHEMBL1591133 & 688267 & 5.55 & 5.0667 & TRN \\
\hline CHEMBL1527798 & 688267 & 5.05 & 5.0644 & TRN \\
\hline CHEMBL1527280 & 688267 & 4.05 & 5.0445 & TRN \\
\hline CHEMBL1557979 & 688267 & 5.35 & 5.1152 & TRN \\
\hline CHEMBL 3207712 & 688267 & 4.5 & 5.0377 & TST \\
\hline CHEMBL1568868 & 688267 & 6.2 & 5.0792 & TRN \\
\hline CHEMBL1309086 & 688267 & 4.9 & 5.1029 & TRN \\
\hline CHEMBL1520460 & 688267 & 6.5 & 5.0558 & TST \\
\hline CHEMBL1358880 & 688267 & 5.0 & 5.0724 & TRN \\
\hline CHEMBL1511970 & 688267 & 5.6 & 5.0429 & TST \\
\hline CHEMBL1475191 & 688267 & 4.65 & 5.0804 & TST \\
\hline CHEMBL1311435 & 688267 & 4.4 & 5.0361 & TRN \\
\hline CHEMBL1540296 & 688267 & 5.85 & 5.0277 & TRN \\
\hline CHEMBL1405984 & 688267 & 5.0 & 5.0896 & TRN \\
\hline CHEMBL1390830 & 688267 & 4.25 & 5.0286 & TST \\
\hline CHEMBL 3197928 & 688267 & 4.0 & 4.9566 & TRN \\
\hline CHEMBL1549505 & 688267 & 5.85 & 5.0628 & TRN \\
\hline CHEMBL1317915 & 688267 & 6.2 & 5.022 & TRN \\
\hline CHEMBL1518455 & 688267 & 4.05 & 5.11 & TST \\
\hline CHEMBL1411389 & 688267 & 4.1 & 5.0591 & TRN \\
\hline CHEMBL1453053 & 688267 & 5.2 & 5.0619 & TRN \\
\hline CHEMBL1335476 & 688267 & 5.2 & 5.0563 & TRN \\
\hline CHEMBL1552678 & 688267 & 4.0 & 5.0304 & TRN \\
\hline CHEMBL1436098 & 688267 & 6.05 & 5.0537 & TRN \\
\hline CHEMBL1520121 & 688267 & 4.85 & 4.995 & TRN \\
\hline CHEMBL1529539 & 688267 & 5.0 & 5.0272 & TRN \\
\hline CHEMBL460517 & 688267 & 5.35 & 4.9983 & TRN \\
\hline CHEMBL1564419 & 688267 & 5.95 & 5.0343 & TST \\
\hline CHEMBL1604960 & 688267 & 5.05 & 5.1071 & TRN \\
\hline CHEMBL3196954 & 688267 & 5.3 & 5.0371 & TRN \\
\hline CHEMBL1540641 & 688267 & 6.15 & 5.0181 & TRN \\
\hline CHEMBL1319187 & 688267 & 4.05 & 5.0176 & TRN \\
\hline CHEMBL1585880 & 688267 & 5.7 & 5.0408 & TRN \\
\hline CHEMBL1498720 & 688267 & 6.15 & 5.1088 & TRN \\
\hline CHEMBL1414643 & 688267 & 6.2 & 5.0648 & TRN \\
\hline
\end{tabular}




\begin{tabular}{|c|c|c|c|c|}
\hline & & & pplement & al $\mathrm{Ta}$ \\
\hline CHEMBL1558880 & 688267 & 4.35 & 5.1362 & TRN \\
\hline CHEMBL1432322 & 688267 & 6.15 & 5.1352 & TST \\
\hline CHEMBL1571607 & 688267 & 4.3 & 5.0195 & TRN \\
\hline CHEMBL3191336 & 688267 & 4.6 & 5.0161 & TST \\
\hline CHEMBL1477270 & 688267 & 6.25 & 4.9852 & TRN \\
\hline CHEMBL1534595 & 688267 & 4.1 & 5.0027 & TST \\
\hline CHEMBL1370501 & 688267 & 5.6 & 5.1454 & TST \\
\hline CHEMBL1585936 & 688267 & 3.95 & 5.0222 & TST \\
\hline CHEMBL1499210 & 688267 & 5.3 & 5.1083 & TRN \\
\hline CHEMBL1323241 & 688267 & 5.6 & 5.1176 & TST \\
\hline CHEMBL1583415 & 688267 & 4.35 & 5.038 & TRN \\
\hline CHEMBL1589424 & 688267 & 4.55 & 5.0831 & TRN \\
\hline CHEMBL1396036 & 688267 & 4.1 & 5.0541 & TRN \\
\hline CHEMBL1548210 & 688267 & 5.9 & 5.0563 & TRN \\
\hline CHEMBL1328111 & 688267 & 4.3 & 5.0672 & TRN \\
\hline CHEMBL1601654 & 688267 & 6.45 & 5.0197 & TRN \\
\hline CHEMBL3193003 & 688267 & 4.4 & 4.9908 & TST \\
\hline CHEMBL1431059 & 688267 & 4.6 & 5.0561 & TST \\
\hline CHEMBL1416091 & 688267 & 5.0 & 5.0724 & TRN \\
\hline CHEMBL1370896 & 688267 & 5.95 & 5.0588 & TRN \\
\hline CHEMBL1434039 & 688267 & 5.35 & 5.0349 & TRN \\
\hline CHEMBL1390401 & 688267 & 4.3 & 5.0324 & TST \\
\hline CHEMBL1378328 & 688267 & 4.0 & 5.0106 & TRN \\
\hline CHEMBL1545148 & 688267 & 5.8 & 5.0494 & TRN \\
\hline CHEMBL1582155 & 688267 & 6.2 & 5.008 & TRN \\
\hline CHEMBL1342688 & 688267 & 4.7 & 5.029 & TRN \\
\hline CHEMBL1464683 & 688267 & 4.1 & 4.9839 & TST \\
\hline CHEMBL1418971 & 688267 & 4.35 & 5.0117 & TST \\
\hline CHEMBL1333413 & 688267 & 4.0 & 5.0618 & TRN \\
\hline CHEMBL1378468 & 688267 & 3.95 & 5.0629 & TRN \\
\hline CHEMBL1520657 & 688267 & 4.1 & 5.0118 & TRN \\
\hline CHEMBL1323962 & 688267 & 4.0 & 5.0409 & TST \\
\hline CHEMBL1300705 & 688267 & 5.55 & 5.0979 & TST \\
\hline CHEMBL1468135 & 688267 & 4.75 & 5.1351 & TRN \\
\hline CHEMBL1554038 & 688267 & 5.85 & 5.0782 & TRN \\
\hline CHEMBL1605121 & 688267 & 6.15 & 5.05 & TRN \\
\hline CHEMBL1483580 & 688267 & 5.7 & 5.0923 & TRN \\
\hline CHEMBL1496463 & 688267 & 4.9 & 5.0672 & TRN \\
\hline CHEMBL1457112 & 688267 & 4.4 & 5.0072 & TST \\
\hline CHEMBL1578599 & 688267 & 4.7 & 5.0656 & TRN \\
\hline CHEMBL1444201 & 688267 & 4.75 & 5.0398 & TRN \\
\hline CHEMBL1396677 & 688267 & 6.9 & 5.05 & TRN \\
\hline CHEMBL1442006 & 688267 & 3.95 & 5.0555 & TST \\
\hline CHEMBL1519278 & 688267 & 4.4 & 5.0989 & TRN \\
\hline CHEMBL1433009 & 688267 & 5.85 & 5.0222 & TST \\
\hline CHEMBL1316703 & 688267 & 4.0 & 5.0123 & TRN \\
\hline CHEMBL1580785 & 688267 & 4.35 & 5.0307 & TRN \\
\hline CHEMBL1459030 & 688267 & 4.8 & 5.0096 & TRN \\
\hline
\end{tabular}




\begin{tabular}{|c|c|c|c|c|}
\hline & & & pplement & al $\mathrm{T}$ \\
\hline CHEMBL1577973 & 688267 & 4.5 & 5.1094 & TRN \\
\hline CHEMBL1481180 & 688267 & 4.4 & 5.1045 & TRN \\
\hline CHEMBL1333600 & 688267 & 4.2 & 5.093 & TST \\
\hline CHEMBL1497909 & 688267 & 6.2 & 5.0283 & TRN \\
\hline CHEMBL1415419 & 688267 & 4.05 & 5.0215 & TRN \\
\hline CHEMBL1552649 & 688267 & 3.95 & 5.0693 & TRN \\
\hline CHEMBL1488111 & 688267 & 4.1 & 5.1057 & TST \\
\hline CHEMBL1507842 & 688267 & 5.55 & 5.0439 & TRN \\
\hline CHEMBL1310700 & 688267 & 5.05 & 5.0801 & TRN \\
\hline CHEMBL1395890 & 688267 & 5.3 & 5.0379 & TST \\
\hline CHEMBL1301255 & 688267 & 5.2 & 5.0761 & TST \\
\hline CHEMBL1486996 & 688267 & 3.95 & 5.0483 & TST \\
\hline CHEMBL1541809 & 688267 & 4.4 & 5.0424 & TRN \\
\hline CHEMBL1368932 & 688267 & 6.2 & 5.0593 & TRN \\
\hline CHEMBL1508772 & 688267 & 5.4 & 5.042 & TRN \\
\hline CHEMBL1973866 & 688267 & 4.5 & 5.0247 & TST \\
\hline CHEMBL1605581 & 688267 & 4.55 & 5.015 & TRN \\
\hline CHEMBL1364583 & 688267 & 4.05 & 5.043 & TRN \\
\hline CHEMBL1492553 & 688267 & 6.15 & 5.0328 & TRN \\
\hline CHEMBL1600035 & 688267 & 5.85 & 5.0552 & TRN \\
\hline CHEMBL1582917 & 688267 & 4.75 & 5.1453 & TRN \\
\hline CHEMBL1325973 & 688267 & 6.25 & 5.0565 & TRN \\
\hline CHEMBL1540051 & 688267 & 5.0 & 4.9657 & TST \\
\hline CHEMBL1569684 & 688267 & 4.95 & 5.0046 & TRN \\
\hline CHEMBL1354793 & 688267 & 5.55 & 5.0197 & TRN \\
\hline CHEMBL1342516 & 688267 & 4.65 & 5.0897 & TRN \\
\hline CHEMBL1455123 & 688267 & 4.0 & 5.0688 & TRN \\
\hline CHEMBL1434135 & 688267 & 4.05 & 4.9767 & TRN \\
\hline CHEMBL1531303 & 688267 & 4.55 & 5.0607 & TRN \\
\hline CHEMBL1454557 & 688267 & 4.0 & 5.0042 & TRN \\
\hline CHEMBL1334111 & 688267 & 6.5 & 5.0565 & TST \\
\hline CHEMBL1329474 & 688267 & 4.75 & 5.0405 & TST \\
\hline CHEMBL1573623 & 688267 & 6.2 & 5.0132 & TRN \\
\hline CHEMBL1342151 & 688267 & 4.8 & 5.0559 & TRN \\
\hline CHEMBL1564333 & 688267 & 5.0 & 5.0292 & TRN \\
\hline CHEMBL1524518 & 688267 & 4.4 & 5.0512 & TRN \\
\hline CHEMBL1488689 & 688267 & 6.0 & 4.9853 & TRN \\
\hline CHEMBL1442829 & 688267 & 3.95 & 5.0944 & TRN \\
\hline CHEMBL1497094 & 688267 & 6.6 & 5.0662 & TRN \\
\hline CHEMBL1517605 & 688267 & 6.15 & 5.121 & TRN \\
\hline CHEMBL1317584 & 688267 & 4.9 & 5.0471 & TRN \\
\hline CHEMBL1515162 & 688267 & 5.05 & 5.0156 & TRN \\
\hline CHEMBL1360835 & 688267 & 5.7 & 5.0631 & TRN \\
\hline CHEMBL1497602 & 688267 & 6.0 & 5.0669 & TRN \\
\hline CHEMBL1607189 & 688267 & 6.2 & 5.0405 & TST \\
\hline CHEMBL1310212 & 688267 & 5.35 & 5.1469 & TST \\
\hline CHEMBL1322480 & 688267 & 4.0 & 5.1 & TRN \\
\hline CHEMBL1312366 & 688267 & 6.15 & 5.0725 & TST \\
\hline
\end{tabular}




\begin{tabular}{|c|c|c|c|c|}
\hline & & & pplement & al $\mathrm{T}$ \\
\hline CHEMBL1594749 & 688267 & 4.7 & 5.0462 & TRN \\
\hline CHEMBL1533284 & 688267 & 3.95 & 5.0395 & TRN \\
\hline CHEMBL1314738 & 688267 & 6.25 & 5.0516 & TRN \\
\hline CHEMBL3199326 & 688267 & 6.2 & 5.0221 & TRN \\
\hline CHEMBL1380559 & 688267 & 4.25 & 5.023 & TST \\
\hline CHEMBL1476817 & 688267 & 4.0 & 5.0165 & TRN \\
\hline CHEMBL1410940 & 688267 & 4.35 & 5.067 & TRN \\
\hline CHEMBL1598162 & 688267 & 4.9 & 5.0272 & TRN \\
\hline CHEMBL1397979 & 688267 & 4.1 & 5.1407 & TRN \\
\hline CHEMBL1353519 & 688267 & 5.3 & 5.1118 & TRN \\
\hline CHEMBL1355911 & 688267 & 4.0 & 5.0271 & TRN \\
\hline CHEMBL1382086 & 688267 & 3.95 & 5.0606 & TRN \\
\hline CHEMBL1530116 & 688267 & 4.05 & 4.9959 & TST \\
\hline CHEMBL1363823 & 688267 & 4.05 & 5.0832 & TST \\
\hline CHEMBL1309270 & 688267 & 5.0 & 5.1285 & TRN \\
\hline CHEMBL1314988 & 688267 & 6.15 & 5.0203 & TST \\
\hline CHEMBL1323235 & 688267 & 5.55 & 5.0484 & TRN \\
\hline CHEMBL1533988 & 688267 & 4.0 & 5.0352 & TRN \\
\hline CHEMBL1593671 & 688267 & 5.95 & 5.0604 & TST \\
\hline CHEMBL1318682 & 688267 & 5.5 & 5.0338 & TRN \\
\hline CHEMBL1559577 & 688267 & 6.15 & 5.075 & TRN \\
\hline CHEMBL1395169 & 688267 & 6.45 & 5.1031 & TRN \\
\hline CHEMBL1432957 & 688267 & 5.6 & 5.0313 & TST \\
\hline CHEMBL1323615 & 688267 & 6.0 & 5.0382 & TST \\
\hline CHEMBL1589949 & 688267 & 6.5 & 4.9997 & TRN \\
\hline CHEMBL1327968 & 688267 & 6.6499 & 5.039 & TRN \\
\hline CHEMBL1522738 & 688267 & 4.4 & 5.0458 & TRN \\
\hline CHEMBL1389425 & 688267 & 6.05 & 5.1238 & TRN \\
\hline CHEMBL1408743 & 688267 & 5.3 & 5.1079 & TRN \\
\hline CHEMBL1413960 & 688267 & 4.7 & 5.0894 & TRN \\
\hline CHEMBL1509677 & 688267 & 6.2 & 5.1282 & TRN \\
\hline CHEMBL1479681 & 688267 & 5.1 & 4.9956 & TST \\
\hline CHEMBL1558424 & 688267 & 5.1 & 5.135 & TRN \\
\hline CHEMBL1552010 & 688267 & 6.15 & 5.0372 & TRN \\
\hline CHEMBL1338012 & 688267 & 6.2 & 5.0177 & TRN \\
\hline CHEMBL1350141 & 688267 & 4.35 & 5.1014 & TRN \\
\hline CHEMBL 3196447 & 688267 & 5.0 & 5.0183 & TRN \\
\hline CHEMBL1401808 & 688267 & 6.15 & 5.0846 & TRN \\
\hline CHEMBL1536116 & 688267 & 4.05 & 5.0391 & TRN \\
\hline CHEMBL1405922 & 688267 & 4.35 & 5.0463 & TRN \\
\hline CHEMBL1531311 & 688267 & 5.95 & 4.9902 & TRN \\
\hline CHEMBL1428461 & 688267 & 5.05 & 5.0301 & TRN \\
\hline CHEMBL1503155 & 688267 & 6.25 & 5.0737 & TRN \\
\hline CHEMBL1532149 & 688267 & 6.5 & 5.0371 & TST \\
\hline CHEMBL1382323 & 688267 & 4.4 & 5.0282 & TRN \\
\hline CHEMBL1387242 & 688267 & 4.05 & 5.053 & TRN \\
\hline CHEMBL1483793 & 688267 & 4.4 & 5.0756 & TRN \\
\hline CHEMBL1415490 & 688267 & 4.0 & 5.1724 & TRN \\
\hline
\end{tabular}




\begin{tabular}{|c|c|c|c|c|}
\hline \multicolumn{5}{|c|}{ Supplemental Table } \\
\hline CHEMBL1435662 & 688267 & 4.45 & 5.0833 & TRN \\
\hline CHEMBL3207947 & 688267 & 5.9 & 5.0335 & TST \\
\hline CHEMBL1312608 & 688267 & 5.95 & 5.0489 & TRN \\
\hline CHEMBL1329211 & 688267 & 4.0 & 5.0315 & TRN \\
\hline CHEMBL 1356013 & 688267 & 4.1 & 5.0456 & TRN \\
\hline CHEMBL1377846 & 688267 & 4.55 & 5.0801 & TRN \\
\hline CHEMBL1413504 & 688267 & 6.1 & 5.0776 & TRN \\
\hline CHEMBL1504224 & 688267 & 5.1 & 5.0696 & TRN \\
\hline CHEMBL1422696 & 688267 & 4.0 & 5.0561 & TRN \\
\hline CHEMBL1351149 & 688267 & 4.35 & 5.0249 & TRN \\
\hline CHEMBL1404843 & 688267 & 4.05 & 5.0124 & TRN \\
\hline CHEMBL1365551 & 688267 & 4.5 & 5.0556 & TRN \\
\hline CHEMBL1441617 & 688267 & 6.5 & 5.0463 & TRN \\
\hline CHEMBL1306782 & 688267 & 4.25 & 5.0371 & TST \\
\hline CHEMBL1584532 & 688267 & 4.0 & 5.0749 & TRN \\
\hline CHEMBL1519545 & 688267 & 4.65 & 5.125 & TRN \\
\hline CHEMBL1543406 & 688267 & 5.05 & 5.0773 & TST \\
\hline CHEMBL1415205 & 688267 & 4.15 & 5.023 & TST \\
\hline CHEMBL1332320 & 688267 & 4.05 & 5.0952 & TRN \\
\hline CHEMBL1562022 & 688267 & 4.25 & 5.0635 & TRN \\
\hline CHEMBL1465519 & 688267 & 4.5 & 5.0345 & TRN \\
\hline CHEMBL1592166 & 688267 & 5.75 & 5.0 & TRN \\
\hline CHEMBL1604728 & 688267 & 5.5 & 5.0699 & TRN \\
\hline CHEMBL1472840 & 688267 & 4.1 & 5.1512 & TRN \\
\hline CHEMBL1472521 & 688267 & 4.35 & 5.0815 & TRN \\
\hline CHEMBL1552475 & 688267 & 4.05 & 5.0229 & TRN \\
\hline CHEMBL1311819 & 688267 & 5.0 & 5.0436 & TST \\
\hline CHEMBL3213514 & 688267 & 5.3 & 5.1137 & TST \\
\hline CHEMBL3191175 & 688267 & 6.25 & 5.0431 & TRN \\
\hline CHEMBL1538812 & 688267 & 5.9 & 5.1388 & TST \\
\hline CHEMBL1475424 & 688267 & 5.85 & 5.0577 & TRN \\
\hline CHEMBL1317253 & 688267 & 4.0 & 5.1441 & TRN \\
\hline CHEMBL1472614 & 688267 & 4.4 & 5.1311 & TRN \\
\hline CHEMBL1493635 & 688267 & 4.0 & 5.1234 & TRN \\
\hline CHEMBL1452241 & 688267 & 5.4 & 4.9862 & TRN \\
\hline CHEMBL1380720 & 688267 & 6.2 & 5.0767 & TRN \\
\hline CHEMBL1398004 & 688267 & 4.35 & 4.9978 & TST \\
\hline CHEMBL1388487 & 688267 & 4.65 & 5.0317 & TRN \\
\hline CHEMBL1495384 & 688267 & 5.75 & 5.064 & TST \\
\hline CHEMBL1478657 & 688267 & 3.95 & 5.1098 & TRN \\
\hline CHEMBL1574881 & 688267 & 3.95 & 5.0313 & TRN \\
\hline CHEMBL1524979 & 688267 & 3.95 & 5.0304 & TST \\
\hline CHEMBL1520065 & 688267 & 5.4 & 5.0176 & TRN \\
\hline CHEMBL1319235 & 688267 & 5.25 & 5.0966 & TRN \\
\hline CHEMBL1533061 & 688267 & 5.35 & 5.1383 & TRN \\
\hline CHEMBL1531886 & 688267 & 4.5 & 5.0124 & TRN \\
\hline CHEMBL1555729 & 688267 & 5.85 & 5.0236 & TRN \\
\hline CHEMBL1580919 & 688267 & 6.2 & 5.0289 & TRN \\
\hline
\end{tabular}




\begin{tabular}{|c|c|c|c|c|c|}
\hline \multirow{3}{*}{$\begin{array}{l}\text { CHEMBL1595979 } \\
\text { CHEMBL1554696 }\end{array}$} & \multirow{3}{*}{$\begin{array}{l}688267 \\
688267\end{array}$} & \multicolumn{4}{|c|}{ Supplemental Table S2.txt } \\
\hline & & 6.15 & \multicolumn{2}{|c|}{5.093999999999999} & TRN \\
\hline & & 4.65 & 5.0744 & TRN & \\
\hline CHEMBL1480874 & 688267 & 5.2 & 5.0572 & TRN & \\
\hline CHEMBL1567014 & 688267 & 4.65 & 5.045 & TRN & \\
\hline CHEMBL1343499 & 688267 & 4.6 & 5.0253 & TRN & \\
\hline CHEMBL1389082 & 688267 & 5.8 & 5.0654 & TRN & \\
\hline CHEMBL1375975 & 688267 & 5.55 & 5.042 & TRN & \\
\hline CHEMBL1579464 & 688267 & 4.1 & 5.0422 & TST & \\
\hline CHEMBL1600285 & 688267 & 7.699 & 5.0091 & TRN & \\
\hline CHEMBL1326035 & 688267 & 6.2 & 5.0314 & TRN & \\
\hline CHEMBL3190316 & 688267 & 3.95 & 4.992 & TRN & \\
\hline CHEMBL1494209 & 688267 & 6.0 & 5.0356 & TRN & \\
\hline CHEMBL1587601 & 688267 & 6.2 & 5.0119 & TRN & \\
\hline CHEMBL1578154 & 688267 & 4.35 & 5.0104 & TST & \\
\hline CHEMBL1445531 & 688267 & 4.25 & 5.131 & TRN & \\
\hline CHEMBL1438899 & 688267 & 5.35 & \multicolumn{2}{|c|}{5.1160000000000005} & TRN \\
\hline CHEMBL1334884 & 688267 & 3.95 & 5.0057 & TRN & \\
\hline CHEMBL3196695 & 688267 & 3.95 & 5.0191 & TST & \\
\hline CHEMBL1347495 & 688267 & 5.85 & 5.0688 & TRN & \\
\hline CHEMBL1524064 & 688267 & 3.95 & 5.0951 & TST & \\
\hline CHEMBL1519526 & 688267 & 4.05 & 5.1287 & TRN & \\
\hline CHEMBL1506204 & 688267 & 5.0 & 5.0382 & TRN & \\
\hline CHEMBL1380691 & 688267 & 4.55 & 5.0042 & TST & \\
\hline CHEMBL1387923 & 688267 & 6.5501 & 5.0156 & TRN & \\
\hline CHEMBL1429069 & 688267 & 4.2 & 5.0408 & TRN & \\
\hline CHEMBL602576 & 688267 & 4.0 & 5.06 & TRN & \\
\hline CHEMBL1970554 & 688267 & 5.65 & 5.0457 & TRN & \\
\hline CHEMBL1495052 & 688267 & 5.45 & 5.0833 & TRN & \\
\hline CHEMBL1522910 & 688267 & 6.15 & 5.0303 & TRN & \\
\hline CHEMBL1574560 & 688267 & 5.05 & 5.1135 & TRN & \\
\hline CHEMBL1432301 & 688267 & 4.45 & 5.021 & TRN & \\
\hline CHEMBL1390387 & 688267 & 4.45 & 5.086 & TST & \\
\hline CHEMBL1563771 & 688267 & 4.3 & 5.0205 & TRN & \\
\hline CHEMBL1394717 & 688267 & 6.2 & 5.0084 & TRN & \\
\hline CHEMBL1488672 & 688267 & 5.65 & 5.1227 & TRN & \\
\hline CHEMBL1481381 & 688267 & 4.05 & 5.0908 & TRN & \\
\hline CHEMBL1537732 & 688267 & 5.45 & 5.1079 & TRN & \\
\hline CHEMBL1484593 & 688267 & 3.9 & 5.048 & TRN & \\
\hline CHEMBL1374910 & 688267 & 5.8 & 5.0515 & TST & \\
\hline CHEMBL1311701 & 688267 & 5.55 & 5.0598 & TST & \\
\hline CHEMBL1609333 & 688267 & 4.35 & 5.0396 & TST & \\
\hline CHEMBL1579724 & 688267 & 5.55 & 5.1115 & TRN & \\
\hline CHEMBL1450151 & 688267 & 5.65 & 5.0178 & TRN & \\
\hline CHEMBL3192631 & 688267 & 6.25 & 5.0359 & TRN & \\
\hline CHEMBL1420307 & 688267 & 5.0 & 4.9978 & TRN & \\
\hline CHEMBL1986664 & 688267 & 4.4 & 5.0372 & TRN & \\
\hline CHEMBL1343155 & 688267 & 3.95 & 4.9945 & TRN & \\
\hline CHEMBL1587863 & 688267 & 4.05 & 5.0334 & TRN & \\
\hline
\end{tabular}




\begin{tabular}{|c|c|c|c|c|}
\hline \multicolumn{5}{|c|}{ Supplemental Table S2.txt } \\
\hline CHEMBL3210487 & 688267 & 5.45 & 5.0365 & TRN \\
\hline CHEMBL1368468 & 688267 & 4.05 & 5.0755 & TRN \\
\hline CHEMBL1580933 & 688267 & 3.95 & 5.0372 & TST \\
\hline CHEMBL1590240 & 688267 & 4.4 & 5.0482 & TST \\
\hline CHEMBL 1554772 & 688267 & 4.05 & 5.1015 & TRN \\
\hline CHEMBL1557478 & 688267 & 4.0 & 4.9879 & TRN \\
\hline CHEMBL1302748 & 688267 & 4.45 & 5.0482 & TRN \\
\hline CHEMBL1323142 & 688267 & 6.15 & 5.0743 & TRN \\
\hline CHEMBL1311091 & 688267 & 4.55 & 5.0789 & TRN \\
\hline CHEMBL3211052 & 688267 & 5.45 & 5.0451 & TST \\
\hline CHEMBL1543230 & 688267 & 5.85 & 5.0878 & TRN \\
\hline CHEMBL1389966 & 688267 & 4.45 & 5.0428 & TRN \\
\hline CHEMBL1319030 & 688267 & 4.0 & 5.0789 & TST \\
\hline CHEMBL3195886 & 688267 & 4.0 & 5.0313 & TRN \\
\hline CHEMBL1591257 & 688267 & 5.7 & 5.085 & TRN \\
\hline CHEMBL1469286 & 688267 & 4.4 & 5.1177 & TRN \\
\hline CHEMBL1350030 & 688267 & 4.55 & 5.0088 & TRN \\
\hline CHEMBL1396774 & 688267 & 6.25 & 5.0107 & TRN \\
\hline CHEMBL1433589 & 688267 & 5.35 & 5.1293 & TRN \\
\hline CHEMBL1570916 & 688267 & 4.05 & 4.9984 & TST \\
\hline CHEMBL1328763 & 688267 & 4.0 & 5.1194 & TRN \\
\hline CHEMBL1481520 & 688267 & 5.5 & 5.1075 & TRN \\
\hline CHEMBL1505068 & 688267 & 6.2 & 5.0254 & TST \\
\hline CHEMBL1531079 & 688267 & 4.6 & 5.0713 & TRN \\
\hline CHEMBL1450825 & 688267 & 5.45 & 5.0031 & TRN \\
\hline CHEMBL1601929 & 688267 & 5.95 & 5.0813 & TRN \\
\hline CHEMBL1311985 & 688267 & 5.55 & 5.0825 & TRN \\
\hline CHEMBL1398839 & 688267 & 4.05 & 5.1531 & TST \\
\hline CHEMBL1320547 & 688267 & 6.2 & 5.0612 & TRN \\
\hline CHEMBL1301004 & 688267 & 6.25 & 5.0859 & TRN \\
\hline CHEMBL1572462 & 688267 & 5.4 & 5.0733 & TRN \\
\hline CHEMBL1508798 & 688267 & 5.3 & 5.0725 & TST \\
\hline CHEMBL1502299 & 688267 & 5.0 & 5.1137 & TRN \\
\hline CHEMBL1487389 & 688267 & 4.0 & 5.0929 & TST \\
\hline CHEMBL1596049 & 688267 & 4.5 & 5.1741 & TRN \\
\hline CHEMBL1550709 & 688267 & 4.55 & 5.0742 & TST \\
\hline CHEMBL1529434 & 688267 & 6.15 & 5.0809 & TRN \\
\hline CHEMBL1393654 & 688267 & 6.25 & 5.0349 & TRN \\
\hline CHEMBL1426069 & 688267 & 5.75 & 5.0133 & TRN \\
\hline CHEMBL1421073 & 688267 & 4.4 & 5.1133 & TST \\
\hline CHEMBL1463081 & 688267 & 4.7 & 5.0001 & TRN \\
\hline CHEMBL1330609 & 688267 & 6.2 & 5.1555 & TRN \\
\hline CHEMBL1453973 & 688267 & 6.15 & 5.1799 & TRN \\
\hline CHEMBL1394589 & 688267 & 5.2 & 5.0922 & TRN \\
\hline CHEMBL1559805 & 688267 & 4.65 & 5.0791 & TST \\
\hline CHEMBL1331523 & 688267 & 5.25 & 5.0967 & TRN \\
\hline CHEMBL1444643 & 688267 & 4.0 & 5.0705 & TST \\
\hline CHEMBL1527233 & 688267 & 5.25 & 5.1167 & TRN \\
\hline
\end{tabular}




\begin{tabular}{|c|c|c|c|c|c|}
\hline \\
\hline CHEMBL1314369 & 688267 & 5.3 & 5.1064 & TRN & \\
\hline CHEMBL1475061 & 688267 & 6.1 & 4.9904 & TRN & \\
\hline CHEMBL1562372 & 688267 & 5.95 & 5.10800 & 00000000005 & TRN \\
\hline CHEMBL1441543 & 688267 & 5.05 & 5.0714 & TRN & \\
\hline CHEMBL1536510 & 688267 & 5.4 & 5.1201 & TST & \\
\hline CHEMBL1600246 & 688267 & 5.75 & 4.96899 & 9999999999 & TST \\
\hline CHEMBL1398204 & 688267 & 4.4 & 5.069 & TST & \\
\hline CHEMBL1525107 & 688267 & 5.8 & 5.0672 & TRN & \\
\hline CHEMBL3199463 & 688267 & 4.65 & 5.0732 & TST & \\
\hline CHEMBL1964943 & 688267 & 6.2 & 4.9719 & TST & \\
\hline CHEMBL1501801 & 688267 & 4.7 & 5.0433 & TST & \\
\hline CHEMBL1558550 & 688267 & 4.6 & 5.0174 & TRN & \\
\hline CHEMBL1313441 & 688267 & 4.55 & 5.1127 & TST & \\
\hline CHEMBL1464046 & 688267 & 3.95 & 5.0666 & TRN & \\
\hline CHEMBL1344023 & 688267 & 4.05 & 5.0367 & TRN & \\
\hline CHEMBL1553535 & 688267 & 5.25 & 5.0529 & TRN & \\
\hline CHEMBL1443132 & 688267 & 5.35 & 5.0576 & TST & \\
\hline CHEMBL1363038 & 688267 & 5.15 & 5.047 & TRN & \\
\hline CHEMBL1610797 & 688267 & 6.2 & 5.0075 & TRN & \\
\hline CHEMBL1542169 & 688267 & 5.15 & 5.0827 & TRN & \\
\hline CHEMBL1509527 & 688267 & 5.55 & 5.072 & TRN & \\
\hline CHEMBL1538164 & 688267 & 5.05 & 5.0162 & TRN & \\
\hline CHEMBL1349220 & 688267 & 5.35 & 5.0307 & TRN & \\
\hline CHEMBL1400026 & 688267 & 5.6 & 5.0691 & TRN & \\
\hline CHEMBL1587012 & 688267 & 4.05 & 5.0122 & TRN & \\
\hline CHEMBL1543882 & 688267 & 6.15 & 5.0293 & TRN & \\
\hline CHEMBL1468044 & 688267 & 4.0 & 5.0247 & TST & \\
\hline CHEMBL1445694 & 688267 & 4.6 & 5.0863 & TRN & \\
\hline CHEMBL1460637 & 688267 & 4.0 & 5.1301 & TRN & \\
\hline CHEMBL1425503 & 688267 & 4.1 & 5.0306 & TST & \\
\hline CHEMBL1405529 & 688267 & 4.4 & 5.0717 & TST & \\
\hline CHEMBL1442869 & 688267 & 5.15 & 5.047 & TST & \\
\hline CHEMBL1358049 & 688267 & 4.05 & 5.0474 & TRN & \\
\hline CHEMBL1419885 & 688267 & 4.0 & 5.1393 & TRN & \\
\hline CHEMBL1583199 & 688267 & 4.8 & 5.0968 & TST & \\
\hline CHEMBL1556940 & 688267 & 5.1 & 5.1498 & TRN & \\
\hline CHEMBL 2003358 & 688267 & 4.0 & 5.0404 & TST & \\
\hline CHEMBL1533729 & 688267 & 6.1 & 5.1225 & TRN & \\
\hline CHEMBL1308533 & 688267 & 4.0 & 5.1132 & TRN & \\
\hline CHEMBL1470254 & 688267 & 5.15 & 5.0487 & TRN & \\
\hline CHEMBL1481975 & 688267 & 4.2 & 5.1198 & TRN & \\
\hline CHEMBL1494565 & 688267 & 4.45 & 5.0745 & TRN & \\
\hline CHEMBL3210632 & 688267 & 4.55 & 5.0531 & TRN & \\
\hline CHEMBL1454467 & 688267 & 3.95 & 5.0346 & TRN & \\
\hline CHEMBL1520283 & 688267 & 4.0 & 5.00899 & 99999999995 & TST \\
\hline CHEMBL1523289 & 688267 & 5.9 & 5.0392 & TRN & \\
\hline CHEMBL1604440 & 688267 & 6.2 & 5.0778 & TRN & \\
\hline CHEMBL1316664 & 688267 & 5.6 & 5.0799 & TRN & \\
\hline
\end{tabular}




\begin{tabular}{|c|c|c|c|c|c|}
\hline \multicolumn{6}{|c|}{ Supplemental Table S2.txt } \\
\hline CHEMBL1512487 & 688267 & 4.75 & 5.0552 & TRN & \\
\hline CHEMBL1511345 & 688267 & 4.25 & 5.073 & TRN & \\
\hline CHEMBL1613297 & 688267 & 5.6 & 5.0605 & TST & \\
\hline CHEMBL1389682 & 688267 & 5.3 & 5.0877 & TRN & \\
\hline CHEMBL1334513 & 688267 & 6.2 & 5.0993 & TRN & \\
\hline CHEMBL1520311 & 688267 & 5.3 & 5.0553 & TRN & \\
\hline CHEMBL1569519 & 688267 & 5.65 & 5.0619 & TRN & \\
\hline CHEMBL1339146 & 688267 & 6.1 & 5.029 & TRN & \\
\hline CHEMBL1606616 & 688267 & 4.0 & 5.0343 & TRN & \\
\hline CHEMBL1350536 & 688267 & 5.3 & 5.0286 & TRN & \\
\hline CHEMBL1568611 & 688267 & 3.95 & 4.9968 & TRN & \\
\hline CHEMBL1490566 & 688267 & 5.6 & 5.1132 & TRN & \\
\hline CHEMBL1453428 & 688267 & 4.0 & 5.0948 & TRN & \\
\hline CHEMBL1320849 & 688267 & 6.05 & 4.9891 & TRN & \\
\hline CHEMBL1553769 & 688267 & 5.55 & 5.0042 & TRN & \\
\hline CHEMBL1403759 & 688267 & 3.95 & 5.0907 & TRN & \\
\hline CHEMBL1508734 & 688267 & 5.3 & 5.0343 & TRN & \\
\hline CHEMBL1600970 & 688267 & 4.8 & 5.0387 & TRN & \\
\hline CHEMBL1569825 & 688267 & 4.1 & 5.1497 & TRN & \\
\hline CHEMBL1587541 & 688267 & 5.15 & 5.0151 & TST & \\
\hline CHEMBL1590640 & 688267 & 6.2 & 5.07100 & 0000000001 & TRN \\
\hline CHEMBL1418779 & 688267 & 4.0 & 5.0515 & TRN & \\
\hline CHEMBL1481384 & 688267 & 5.85 & 5.0146 & TRN & \\
\hline CHEMBL1336529 & 688267 & 5.9 & 5.0745 & TRN & \\
\hline CHEMBL1545325 & 688267 & 4.6 & 5.0748 & TRN & \\
\hline CHEMBL1612248 & 688267 & 5.5 & 5.0518 & TRN & \\
\hline CHEMBL1470211 & 688267 & 4.9 & 5.0728 & TRN & \\
\hline CHEMBL1524446 & 688267 & 4.0 & 5.1102 & TST & \\
\hline CHEMBL1543183 & 688267 & 4.5 & 5.0295 & TST & \\
\hline CHEMBL1506347 & 688267 & 5.75 & 5.0714 & TST & \\
\hline CHEMBL1374740 & 688267 & 6.9 & 5.1466 & TRN & \\
\hline CHEMBL1365418 & 688267 & 5.3 & 5.0341 & TST & \\
\hline CHEMBL1607813 & 688267 & 4.05 & 5.0921 & TRN & \\
\hline CHEMBL1437781 & 688267 & 5.3 & 5.0463 & TST & \\
\hline CHEMBL1591320 & 688267 & 5.75 & 4.9786 & TRN & \\
\hline CHEMBL1373008 & 688267 & 4.7 & 5.1719 & TRN & \\
\hline CHEMBL1502447 & 688267 & 5.4 & 5.0835 & TRN & \\
\hline CHEMBL1486710 & 688267 & 5.8 & 5.0498 & TRN & \\
\hline CHEMBL1557753 & 688267 & 6.2 & 5.0652 & TRN & \\
\hline CHEMBL1551425 & 688267 & 4.05 & 5.0194 & TRN & \\
\hline CHEMBL1555297 & 688267 & 5.55 & 5.1077 & TRN & \\
\hline CHEMBL1477372 & 688267 & 5.3 & 5.0527 & TRN & \\
\hline CHEMBL3209005 & 688267 & 4.4 & 4.9695 & TRN & \\
\hline CHEMBL1521683 & 688267 & 4.35 & 5.0539 & TST & \\
\hline CHEMBL1321903 & 688267 & 5.05 & 5.0482 & TRN & \\
\hline CHEMBL1367285 & 688267 & 4.25 & 5.0684 & TST & \\
\hline CHEMBL3190435 & 688267 & 4.0 & 4.9789 & TRN & \\
\hline CHEMBL1576148 & 688267 & 6.2 & 5.0646 & TRN & \\
\hline
\end{tabular}




\begin{tabular}{|c|c|c|c|c|c|}
\hline & & & & & \\
\hline CHEMBL1597229 & 688267 & 6.1 & 5.027 & TRN & \\
\hline CHEMBL1322167 & 688267 & 5.55 & 5.0487 & TST & \\
\hline CHEMBL1410611 & 688267 & 6.0 & 5.1025 & TRN & \\
\hline CHEMBL1366385 & 688267 & 4.05 & 5.0441 & TRN & \\
\hline CHEMBL1336657 & 688267 & 4.45 & 5.0486 & TRN & \\
\hline CHEMBL1547269 & 688267 & 6.2 & 4.9851 & TRN & \\
\hline CHEMBL1408576 & 688267 & 6.1 & 5.1022 & TRN & \\
\hline CHEMBL 3213671 & 688267 & 5.75 & 5.0668 & TST & \\
\hline CHEMBL1358899 & 688267 & 4.0 & 5.1284 & TRN & \\
\hline CHEMBL1342470 & 688267 & 4.35 & 5.0465 & TRN & \\
\hline CHEMBL153208 & 688267 & 4.85 & 4.9932 & TRN & \\
\hline CHEMBL1573928 & 688267 & 5.3 & 5.0777 & TST & \\
\hline CHEMBL1355874 & 688267 & 4.5 & 5.0307 & TRN & \\
\hline CHEMBL1372789 & 688267 & 5.45 & 5.0193 & TRN & \\
\hline CHEMBL1344518 & 688267 & 4.45 & 5.0374 & TRN & \\
\hline CHEMBL1600638 & 688267 & 6.05 & 5.0101 & TRN & \\
\hline CHEMBL1365245 & 688267 & 6.15 & 5.0097 & TRN & \\
\hline CHEMBL3145314 & 688267 & 5.35 & 5.0013 & TST & \\
\hline CHEMBL1552570 & 688267 & 4.45 & 5.0634 & TST & \\
\hline CHEMBL1350483 & 688267 & 4.7 & 5.1022 & TRN & \\
\hline CHEMBL1492767 & 688267 & 6.2 & 5.0095 & TRN & \\
\hline CHEMBL1554366 & 688267 & 4.3 & 5.1504 & TRN & \\
\hline CHEMBL1574357 & 688267 & 4.2 & 5.0743 & TRN & \\
\hline CHEMBL1564272 & 688267 & 5.65 & 5.0292 & TRN & \\
\hline CHEMBL1371210 & 688267 & 4.1 & 5.0292 & TST & \\
\hline CHEMBL1321394 & 688267 & 4.3 & 5.0056 & TRN & \\
\hline CHEMBL1359800 & 688267 & 4.0 & 5.0797 & TST & \\
\hline CHEMBL1612748 & 688267 & 4.0 & 5.0001 & TRN & \\
\hline CHEMBL1421259 & 688267 & 5.65 & 5.0251 & TRN & \\
\hline CHEMBL1520394 & 688267 & 5.3 & 5.056 & TST & \\
\hline CHEMBL1346311 & 688267 & 4.05 & 5.1037 & TRN & \\
\hline CHEMBL1301069 & 688267 & 5.55 & 5.0088 & TRN & \\
\hline CHEMBL3211901 & 688267 & 4.25 & 5.0257 & TST & \\
\hline CHEMBL1578471 & 688267 & 5.25 & 5.07 & TST & \\
\hline CHEMBL1351983 & 688267 & 4.05 & 5.0325 & TST & \\
\hline CHEMBL1372183 & 688267 & 6.15 & 4.9881 & TRN & \\
\hline CHEMBL1383648 & 688267 & 5.4 & 5.0347 & TRN & \\
\hline CHEMBL1583711 & 688267 & 4.3 & 5.0593 & TST & \\
\hline CHEMBL1490883 & 688267 & 4.2 & 5.0392 & TRN & \\
\hline CHEMBL1977877 & 688267 & 6.2 & 5.0229 & TST & \\
\hline CHEMBL1545163 & 688267 & 5.45 & 5.0505 & TRN & \\
\hline CHEMBL1516070 & 688267 & 4.35 & 5.0142 & TRN & \\
\hline CHEMBL1546381 & 688267 & 5.05 & 5.0299 & TRN & \\
\hline CHEMBL1463163 & 688267 & 5.8 & 5.0405 & TRN & \\
\hline CHEMBL1556861 & 688267 & 5.6 & 5.1038 & TST & \\
\hline CHEMBL3197697 & 688267 & 4.55 & 5.029 & TRN & \\
\hline CHEMBL1368877 & 688267 & 4.5 & 5.0626 & TRN & \\
\hline CHEMBL1550699 & 688267 & 5.45 & 5.12200 & 0000000001 & TRN \\
\hline & & & & 17356 & \\
\hline
\end{tabular}




\begin{tabular}{|c|c|c|c|c|c|}
\hline \multicolumn{6}{|c|}{ Supplemental Table S2.txt } \\
\hline CHEMBL1405275 & 688267 & 5.85 & 5.0754 & TST & \\
\hline CHEMBL1579219 & 688267 & 6.25 & 5.0721 & TRN & \\
\hline CHEMBL1431046 & 688267 & 6.2 & 5.1524 & TRN & \\
\hline CHEMBL1572245 & 688267 & 4.05 & 5.0562 & TRN & \\
\hline CHEMBL 3193884 & 688267 & 4.3 & 4.9966 & TRN & \\
\hline CHEMBL1335477 & 688267 & 4.05 & 5.1148 & TRN & \\
\hline CHEMBL1397928 & 688267 & 5.8 & 5.1485 & TRN & \\
\hline CHEMBL1548055 & 688267 & 4.05 & 4.9879 & TST & \\
\hline CHEMBL 3190940 & 688267 & 4.2 & 4.9851 & TST & \\
\hline CHEMBL1357634 & 688267 & 4.7 & 5.0381 & TRN & \\
\hline CHEMBL1326874 & 688267 & 4.6 & 5.0927 & TRN & \\
\hline CHEMBL 3190247 & 688267 & 4.2 & 5.0157 & TRN & \\
\hline CHEMBL1400699 & 688267 & 6.05 & 5.0337 & TRN & \\
\hline CHEMBL1447978 & 688267 & 4.7 & 5.0565 & TRN & \\
\hline CHEMBL1303136 & 688267 & 5.5 & 5.0475 & TRN & \\
\hline CHEMBL1302984 & 688267 & 4.4 & 5.0391 & TRN & \\
\hline CHEMBL1555406 & 688267 & 6.2 & 5.0421 & TST & \\
\hline CHEMBL1489532 & 688267 & 5.9 & 5.0594 & TRN & \\
\hline CHEMBL1360106 & 688267 & 5.35 & 5.0589 & TRN & \\
\hline CHEMBL1536478 & 688267 & 4.55 & 4.9907 & TRN & \\
\hline CHEMBL1477523 & 688267 & 5.7 & 5.1227 & TST & \\
\hline CHEMBL1512986 & 688267 & 5.7 & 5.0825 & TRN & \\
\hline CHEMBL1326622 & 688267 & 4.6 & 5.0147 & TRN & \\
\hline CHEMBL1449048 & 688267 & 6.2 & 5.0452 & TRN & \\
\hline CHEMBL1305861 & 688267 & 3.95 & 5.011 & TRN & \\
\hline CHEMBL1386539 & 688267 & 4.25 & 5.0818 & TRN & \\
\hline CHEMBL1474264 & 688267 & 4.0 & 5.0164 & TRN & \\
\hline CHEMBL1302118 & 688267 & 5.0 & 5.0044 & TRN & \\
\hline CHEMBL1437858 & 688267 & 5.35 & 5.0756 & TST & \\
\hline CHEMBL1391650 & 688267 & 5.3 & 5.0327 & TRN & \\
\hline CHEMBL1412003 & 688267 & 4.0 & 5.086 & TRN & \\
\hline CHEMBL 3195783 & 688267 & 5.0 & 5.0276 & TST & \\
\hline CHEMBL1394471 & 688267 & 5.3 & 4.9845 & TRN & \\
\hline CHEMBL1592431 & 688267 & 4.0 & 5.0087 & TST & \\
\hline CHEMBL1569399 & 688267 & 5.1 & 5.0292 & TRN & \\
\hline CHEMBL1592977 & 688267 & 4.0 & 5.0485 & TRN & \\
\hline CHEMBL1366628 & 688267 & 4.6 & 5.082 & TRN & \\
\hline CHEMBL1476072 & 688267 & 4.6 & 5.0647 & TST & \\
\hline CHEMBL1418184 & 688267 & 4.55 & 5.07100 & 2000000001 & TRN \\
\hline CHEMBL1507694 & 688267 & 5.25 & 5.0401 & TST & \\
\hline CHEMBL1436792 & 688267 & 6.5 & 5.0756 & TRN & \\
\hline CHEMBL1435969 & 688267 & 6.15 & 5.05 & TRN & \\
\hline CHEMBL1537739 & 688267 & 4.1 & 5.0834 & TRN & \\
\hline CHEMBL1519672 & 688267 & 6.2 & 5.0257 & TRN & \\
\hline CHEMBL1586176 & 688267 & 4.35 & 5.0876 & TRN & \\
\hline CHEMBL1367720 & 688267 & 5.7 & 5.0515 & TRN & \\
\hline CHEMBL1400171 & 688267 & 6.15 & 5.0771 & TST & \\
\hline CHEMBL1533733 & 688267 & 5.65 & 5.0655 & TRN & \\
\hline
\end{tabular}




\begin{tabular}{|c|c|c|c|c|c|}
\hline \\
\hline CHEMBL1388109 & 688267 & 4.6 & 4.9859 & TRN & \\
\hline CHEMBL1583192 & 688267 & 5.6 & 5.0141 & TRN & \\
\hline CHEMBL1480897 & 688267 & 5.45 & 5.0786 & TRN & \\
\hline CHEMBL 3212480 & 688267 & 4.35 & 5.0195 & TRN & \\
\hline CHEMBL1334897 & 688267 & 5.65 & 5.0595 & TRN & \\
\hline CHEMBL1466479 & 688267 & 4.85 & 5.0407 & TRN & \\
\hline CHEMBL1533789 & 688267 & 5.45 & 5.0399 & TRN & \\
\hline CHEMBL1403062 & 688267 & 4.75 & 4.9927 & TRN & \\
\hline CHEMBL1361152 & 688267 & 4.1 & 5.0403 & TRN & \\
\hline CHEMBL1409329 & 688267 & 6.2 & 5.0367 & TRN & \\
\hline CHEMBL1435064 & 688267 & 3.95 & 5.1056 & TRN & \\
\hline CHEMBL1413292 & 688267 & 5.05 & 5.1163 & TRN & \\
\hline CHEMBL1315949 & 688267 & 4.9 & 5.0906 & TRN & \\
\hline CHEMBL1343615 & 688267 & 4.05 & 5.0701 & TST & \\
\hline CHEMBL1433573 & 688267 & 4.45 & 5.0886 & TRN & \\
\hline CHEMBL1497749 & 688267 & 5.5 & 5.0472 & TRN & \\
\hline CHEMBL3196191 & 688267 & 5.65 & 4.9993 & TRN & \\
\hline CHEMBL1305239 & 688267 & 5.45 & 4.9835 & TRN & \\
\hline CHEMBL13670 & 688267 & 5.15 & 5.0331 & TST & \\
\hline CHEMBL1341570 & 688267 & 6.5 & 5.1464 & TRN & \\
\hline CHEMBL1584687 & 688267 & 3.9 & 5.0168 & TST & \\
\hline CHEMBL1527270 & 688267 & 4.0 & 5.0924 & TRN & \\
\hline CHEMBL1507540 & 688267 & 6.2 & 5.03 & TRN & \\
\hline CHEMBL1406860 & 688267 & 4.9 & 5.0302 & TST & \\
\hline CHEMBL1495660 & 688267 & 6.2 & 5.1415 & TRN & \\
\hline CHEMBL1523881 & 688267 & 6.2 & 4.994 & TRN & \\
\hline CHEMBL1348864 & 688267 & 5.8 & 5.0626 & TRN & \\
\hline CHEMBL1545026 & 688267 & 5.9 & 5.1082 & TRN & \\
\hline CHEMBL1333435 & 688267 & 5.8 & 5.0258 & TRN & \\
\hline CHEMBL1348535 & 688267 & 6.15 & $5.0310 e$ & $\partial 000000001$ & TRN \\
\hline CHEMBL1528935 & 688267 & 5.55 & 5.0796 & TRN & \\
\hline CHEMBL1523851 & 688267 & 5.55 & 5.0414 & TRN & \\
\hline CHEMBL1566907 & 688267 & 4.55 & 5.0721 & TRN & \\
\hline CHEMBL1389242 & 688267 & 6.2 & 5.0656 & TRN & \\
\hline CHEMBL1373999 & 688267 & 4.25 & 5.1001 & TRN & \\
\hline CHEMBL1451641 & 688267 & 6.2 & 5.0646 & TRN & \\
\hline CHEMBL3212263 & 688267 & 5.45 & 5.0567 & TRN & \\
\hline CHEMBL1522763 & 688267 & 4.3 & 5.1065 & TRN & \\
\hline CHEMBL1365328 & 688267 & 6.2 & 5.088 & TRN & \\
\hline CHEMBL1443211 & 688267 & 5.15 & 5.042 & TRN & \\
\hline CHEMBL1572263 & 688267 & 4.0 & 4.9796 & TRN & \\
\hline CHEMBL1405633 & 688267 & 5.6 & 5.0143 & TST & \\
\hline CHEMBL1369040 & 688267 & 4.0 & 5.0373 & TRN & \\
\hline CHEMBL1353381 & 688267 & 5.05 & 5.0008 & TST & \\
\hline CHEMBL1423025 & 688267 & 5.15 & 5.1194 & TRN & \\
\hline CHEMBL1479425 & 688267 & 4.45 & 5.0776 & TRN & \\
\hline CHEMBL1557113 & 688267 & 4.55 & 5.0936 & TRN & \\
\hline CHEMBL1317497 & 688267 & 4.0 & 5.0712 & TRN & \\
\hline
\end{tabular}




\begin{tabular}{|c|c|c|c|c|c|}
\hline \\
\hline CHEMBL1527444 & 688267 & 4.0 & 5.0576 & TST & \\
\hline CHEMBL1604796 & 688267 & 5.5 & 5.0805 & TRN & \\
\hline CHEMBL1388619 & 688267 & 5.85 & 5.0416 & TRN & \\
\hline CHEMBL1594199 & 688267 & 4.45 & 5.0757 & TRN & \\
\hline CHEMBL1389993 & 688267 & 6.0 & 5.0673 & TRN & \\
\hline CHEMBL1549990 & 688267 & 4.05 & 4.994 & TRN & \\
\hline CHEMBL1587245 & 688267 & 4.0 & 5.0049 & TRN & \\
\hline CHEMBL1425976 & 688267 & 4.4 & 5.0019 & TST & \\
\hline CHEMBL1512648 & 688267 & 4.45 & 5.0369 & TRN & \\
\hline CHEMBL1347407 & 688267 & 5.4 & 5.126 & TRN & \\
\hline CHEMBL1424062 & 688267 & 4.55 & 5.0845 & TRN & \\
\hline CHEMBL1496886 & 688267 & 6.2 & 5.09399 & 9999999999 & TRN \\
\hline CHEMBL1454056 & 688267 & 4.05 & 5.0254 & TRN & \\
\hline CHEMBL3189832 & 688267 & 5.5 & 5.0506 & TRN & \\
\hline CHEMBL1327560 & 688267 & 4.55 & 5.147 & TST & \\
\hline CHEMBL1315220 & 688267 & 4.05 & 5.1519 & TRN & \\
\hline CHEMBL1589509 & 688267 & 5.85 & 5.0548 & TST & \\
\hline CHEMBL1562305 & 688267 & 3.95 & 5.0592 & TRN & \\
\hline CHEMBL309372 & 688267 & 5.55 & 5.0552 & TRN & \\
\hline CHEMBL3198465 & 688267 & 6.15 & 5.0005 & TRN & \\
\hline CHEMBL1576184 & 688267 & 4.6 & 5.0188 & TRN & \\
\hline CHEMBL1453407 & 688267 & 5.3 & 5.1031 & TRN & \\
\hline CHEMBL1368333 & 688267 & 4.85 & 5.0218 & TRN & \\
\hline CHEMBL1533822 & 688267 & 5.4 & 5.0911 & TST & \\
\hline CHEMBL1419427 & 688267 & 5.0 & 5.0112 & TRN & \\
\hline CHEMBL1518105 & 688267 & 5.35 & 5.0616 & TRN & \\
\hline CHEMBL1503873 & 688267 & 6.2 & 5.0583 & TRN & \\
\hline CHEMBL1553841 & 688267 & 5.85 & 5.0771 & TST & \\
\hline CHEMBL1605971 & 688267 & 5.25 & 5.0695 & TRN & \\
\hline CHEMBL1345526 & 688267 & 5.5 & 5.0514 & TRN & \\
\hline CHEMBL1397740 & 688267 & 6.5501 & 5.0112 & TRN & \\
\hline CHEMBL1316263 & 688267 & 4.25 & 5.027 & TRN & \\
\hline CHEMBL1341896 & 688267 & 4.1 & 5.0957 & TRN & \\
\hline CHEMBL1553499 & 688267 & 4.0 & 5.0172 & TRN & \\
\hline CHEMBL1565303 & 688267 & 5.8 & 5.0524 & TRN & \\
\hline CHEMBL1552594 & 688267 & 5.3 & 5.0379 & TRN & \\
\hline CHEMBL1453726 & 688267 & 6.0 & 5.0688 & TST & \\
\hline CHEMBL3189161 & 688267 & 4.2 & 5.0105 & TRN & \\
\hline CHEMBL1454768 & 688267 & 5.45 & 5.1118 & TST & \\
\hline CHEMBL1300323 & 688267 & 4.25 & 5.0303 & TRN & \\
\hline CHEMBL1569994 & 688267 & 5.75 & 5.0347 & TST & \\
\hline CHEMBL1443941 & 688267 & 5.0 & 5.0274 & TRN & \\
\hline CHEMBL1385921 & 688267 & 4.5 & 5.0543 & TRN & \\
\hline CHEMBL1573938 & 688267 & 4.75 & 5.0375 & TRN & \\
\hline CHEMBL1369060 & 688267 & 5.3 & 5.0548 & TRN & \\
\hline CHEMBL1459431 & 688267 & 5.15 & 5.0409 & TRN & \\
\hline CHEMBL1338890 & 688267 & 5.0 & 5.0583 & TST & \\
\hline CHEMBL239864 & 688267 & 6.2 & 5.0653 & TRN & \\
\hline
\end{tabular}




\begin{tabular}{|c|c|c|c|c|c|}
\hline \multicolumn{6}{|c|}{ Supplemental Table S2.txt } \\
\hline CHEMBL1399613 & 688267 & 5.0 & 5.0663 & TRN & \\
\hline CHEMBL1609461 & 688267 & 4.3 & 5.0768 & TRN & \\
\hline CHEMBL1451857 & 688267 & 5.35 & 5.0948 & TRN & \\
\hline CHEMBL1547654 & 688267 & 6.1 & 5.1176 & TRN & \\
\hline CHEMBL1346470 & 688267 & 6.2 & 5.1186 & TST & \\
\hline CHEMBL1408620 & 688267 & 6.2 & 5.0233 & TRN & \\
\hline CHEMBL1486613 & 688267 & 3.95 & 5.0467 & TRN & \\
\hline CHEMBL1329366 & 688267 & 5.35 & 5.0568 & TST & \\
\hline CHEMBL1470603 & 688267 & 5.5 & 5.1011 & TRN & \\
\hline CHEMBL1394409 & 688267 & 5.9 & 5.0639 & TRN & \\
\hline CHEMBL1433933 & 688267 & 5.9 & 5.1038 & TST & \\
\hline CHEMBL1577682 & 688267 & 5.35 & 5.0155 & TRN & \\
\hline CHEMBL1592491 & 688267 & 4.4 & 5.0797 & TRN & \\
\hline CHEMBL1391116 & 688267 & 4.35 & 5.0882 & TRN & \\
\hline CHEMBL1433758 & 688267 & 4.35 & 5.018 & TST & \\
\hline CHEMBL1391364 & 688267 & 4.0 & 5.0512 & TRN & \\
\hline CHEMBL1487241 & 688267 & 4.25 & 5.0485 & TRN & \\
\hline CHEMBL1509951 & 688267 & 4.0 & 5.0881 & TRN & \\
\hline CHEMBL1412988 & 688267 & 4.0 & 5.0132 & TRN & \\
\hline CHEMBL1429090 & 688267 & 4.05 & 5.032 & TRN & \\
\hline CHEMBL1360816 & 688267 & 5.55 & 5.0546 & TST & \\
\hline CHEMBL1566939 & 688267 & 4.0 & 5.059 & TRN & \\
\hline CHEMBL1549343 & 688267 & 4.05 & 4.9854 & TRN & \\
\hline CHEMBL1552285 & 688267 & 4.0 & 4.9544 & TRN & \\
\hline CHEMBL1422905 & 688267 & 6.5 & 5.0499 & TRN & \\
\hline CHEMBL1411212 & 688267 & 4.3 & 5.1064 & TRN & \\
\hline CHEMBL1417362 & 688267 & 4.35 & 5.0199 & TRN & \\
\hline CHEMBL1305968 & 688267 & 4.25 & 4.975 & TRN & \\
\hline CHEMBL1497999 & 688267 & 4.55 & 5.1301 & TRN & \\
\hline CHEMBL1574422 & 688267 & 4.0 & 5.0189 & TRN & \\
\hline CHEMBL1516075 & 688267 & 4.25 & 5.0535 & TRN & \\
\hline CHEMBL1330888 & 688267 & 5.35 & 5.0687 & TRN & \\
\hline CHEMBL1317870 & 688267 & 5.85 & 5.0225 & TRN & \\
\hline CHEMBL1567203 & 688267 & 5.45 & 5.1081 & TRN & \\
\hline CHEMBL1572864 & 688267 & 6.2 & $5.0710 e$ & 0000000001 & TRN \\
\hline CHEMBL1600268 & 688267 & 6.2 & 5.1068 & TRN & \\
\hline CHEMBL1593390 & 688267 & 5.45 & 4.9738 & TRN & \\
\hline CHEMBL1403145 & 688267 & 4.2 & 5.0616 & TRN & \\
\hline CHEMBL1396459 & 688267 & 4.4 & 4.9974 & TRN & \\
\hline CHEMBL1413073 & 688267 & 4.4 & 5.0747 & TRN & \\
\hline CHEMBL1501431 & 688267 & 6.15 & 5.0284 & TRN & \\
\hline CHEMBL1345689 & 688267 & 3.9 & 5.0911 & TRN & \\
\hline CHEMBL1484219 & 688267 & 5.8 & 4.9623 & TRN & \\
\hline CHEMBL1524078 & 688267 & 6.2 & 5.0866 & TRN & \\
\hline CHEMBL1476913 & 688267 & 6.45 & 5.1266 & TRN & \\
\hline CHEMBL1446218 & 688267 & 4.4 & 5.0195 & TRN & \\
\hline CHEMBL1356427 & 688267 & 5.9 & 5.0678 & TRN & \\
\hline CHEMBL1612555 & 688267 & 4.1 & 5.0477 & TST & \\
\hline
\end{tabular}




\begin{tabular}{|c|c|c|c|c|}
\hline \multicolumn{5}{|c|}{ Supplemental Table S2.txt } \\
\hline CHEMBL1482892 & 688267 & 5.9 & 5.1295 & TRN \\
\hline CHEMBL1364619 & 688267 & 5.45 & 5.0296 & TRN \\
\hline CHEMBL1427768 & 688267 & 4.55 & 5.0592 & TRN \\
\hline CHEMBL1472927 & 688267 & 4.0 & 5.0098 & TRN \\
\hline CHEMBL1492041 & 688267 & 6.1 & 5.0607 & TRN \\
\hline CHEMBL1402570 & 688267 & 5.6 & 5.0988 & TRN \\
\hline CHEMBL1080209 & 688267 & 4.85 & 5.0837 & TRN \\
\hline CHEMBL1438053 & 688267 & 4.0 & 4.9989 & TRN \\
\hline CHEMBL1307768 & 688267 & 4.1 & 5.0389 & TRN \\
\hline CHEMBL1304560 & 688267 & 3.95 & 5.0412 & TST \\
\hline CHEMBL1510203 & 688267 & 6.2 & 5.1321 & TRN \\
\hline CHEMBL1428923 & 688267 & 6.2 & 5.0395 & TST \\
\hline CHEMBL1384274 & 688267 & 4.0 & 5.0552 & TST \\
\hline CHEMBL1456121 & 688267 & 4.25 & 4.9825 & TRN \\
\hline CHEMBL1586899 & 688267 & 5.9 & 5.0813 & TST \\
\hline CHEMBL1479715 & 688267 & 4.4 & 5.0576 & TST \\
\hline CHEMBL1408873 & 688267 & 5.75 & 5.1313 & TRN \\
\hline CHEMBL1488218 & 688267 & 4.8 & 5.1186 & TRN \\
\hline CHEMBL1557371 & 688267 & 5.6 & 5.1187 & TRN \\
\hline CHEMBL1580181 & 688267 & 3.95 & 5.1108 & TRN \\
\hline CHEMBL1590350 & 688267 & 4.25 & 5.1118 & TRN \\
\hline CHEMBL1444598 & 688267 & 4.5 & 5.0639 & TST \\
\hline CHEMBL1331142 & 688267 & 4.4 & 5.0925 & TST \\
\hline CHEMBL1419708 & 688267 & 3.95 & 5.0186 & TRN \\
\hline CHEMBL1467387 & 688267 & 4.05 & 5.087 & TST \\
\hline CHEMBL1613401 & 688267 & 4.0 & 5.1119 & TRN \\
\hline CHEMBL1519817 & 688267 & 5.05 & 5.0161 & TRN \\
\hline CHEMBL1377430 & 688267 & 3.95 & 5.1038 & TRN \\
\hline CHEMBL3198283 & 688267 & 4.05 & 5.0549 & TST \\
\hline CHEMBL1579818 & 688267 & 6.8499 & 5.0293 & TRN \\
\hline CHEMBL1537458 & 688267 & 6.15 & 5.0244 & TST \\
\hline CHEMBL1336569 & 688267 & 4.9 & 5.119 & TRN \\
\hline CHEMBL1512142 & 688267 & 5.5 & 5.081 & TRN \\
\hline CHEMBL1394591 & 688267 & 5.1 & 5.0774 & TRN \\
\hline CHEMBL1457439 & 688267 & 5.55 & 5.0795 & TRN \\
\hline CHEMBL1422282 & 688267 & 3.95 & 5.1422 & TRN \\
\hline CHEMBL1382241 & 688267 & 5.5 & 4.9777 & TRN \\
\hline CHEMBL1589047 & 688267 & 6.15 & 5.1162 & TRN \\
\hline CHEMBL3207987 & 688267 & 4.6 & 5.0577 & TST \\
\hline CHEMBL1315068 & 688267 & 4.5 & 5.0214 & TRN \\
\hline CHEMBL1383109 & 688267 & 4.75 & 5.0596 & TST \\
\hline CHEMBL1324232 & 688267 & 5.1 & 5.1685 & TRN \\
\hline CHEMBL1597826 & 688267 & 4.5 & 5.1255 & TRN \\
\hline CHEMBL1389943 & 688267 & 5.55 & 5.0325 & TRN \\
\hline CHEMBL1332486 & 688267 & 4.6 & 5.0912 & TRN \\
\hline CHEMBL1522654 & 688267 & 4.8 & 5.0344 & TRN \\
\hline CHEMBL1516437 & 688267 & 5.4 & 5.1261 & TST \\
\hline CHEMBL1595163 & 688267 & 5.35 & 5.1008 & TRN \\
\hline
\end{tabular}




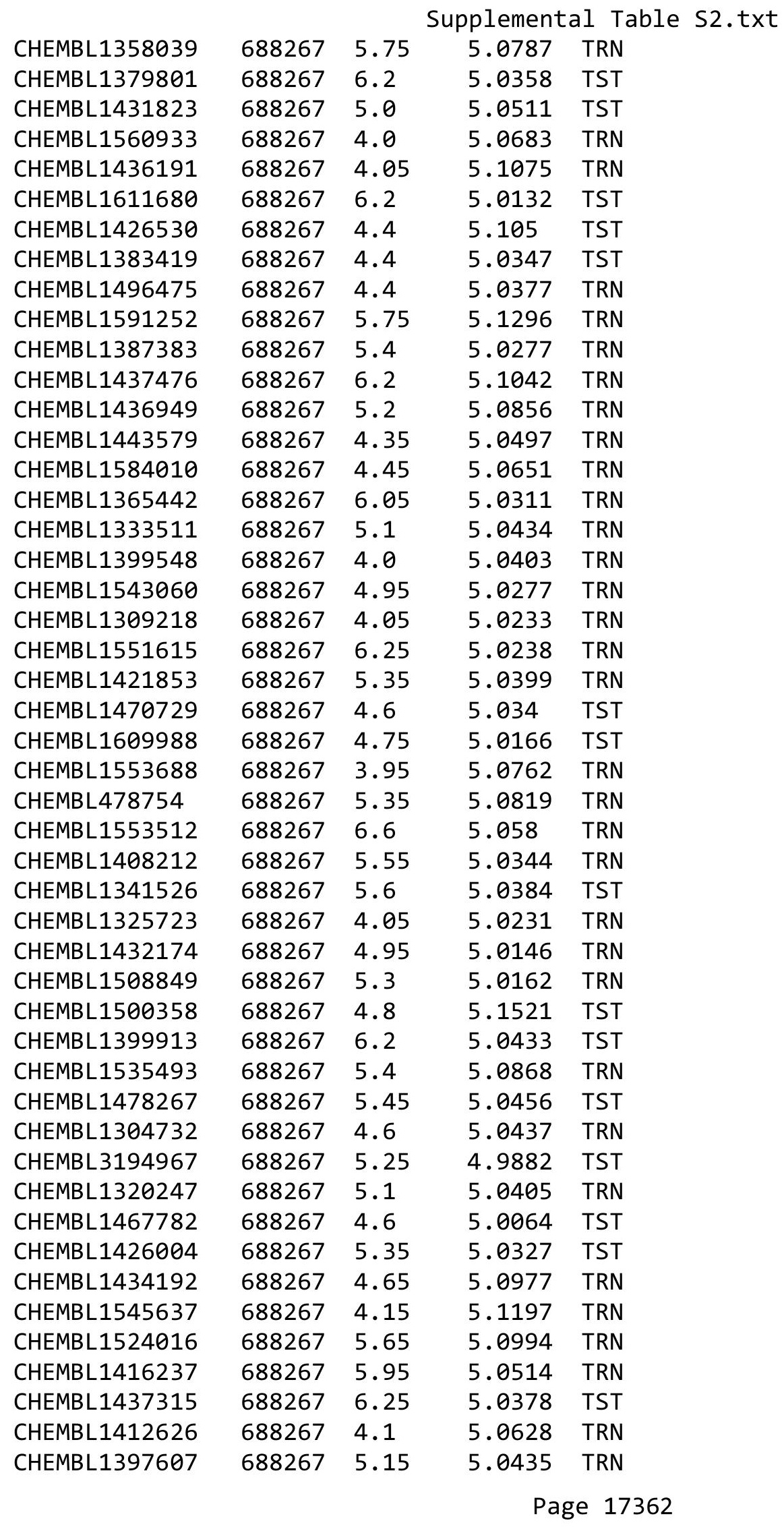




\begin{tabular}{|c|c|c|c|c|}
\hline & & & pplement & $\mathrm{d} \perp$ \\
\hline CHEMBL1511912 & 688267 & 5.8 & 5.0355 & TST \\
\hline CHEMBL1336057 & 688267 & 5.05 & 5.0267 & TST \\
\hline CHEMBL163428 & 688267 & 6.45 & 5.0796 & TRN \\
\hline CHEMBL1390158 & 688267 & 5.5 & 5.0415 & TRN \\
\hline CHEMBL1482631 & 688267 & 4.0 & 5.0525 & TRN \\
\hline CHEMBL1550141 & 688267 & 6.2 & 5.0739 & TST \\
\hline CHEMBL1345671 & 688267 & 6.5 & 5.0306 & TRN \\
\hline CHEMBL1579803 & 688267 & 4.65 & 5.0571 & TRN \\
\hline CHEMBL1535560 & 688267 & 3.95 & 5.1167 & TRN \\
\hline CHEMBL1406352 & 688267 & 5.0 & 5.0491 & TRN \\
\hline CHEMBL 1487032 & 688267 & 5.6 & 5.0176 & TRN \\
\hline CHEMBL1436844 & 688267 & 4.95 & 5.037 & TRN \\
\hline CHEMBL1529951 & 688267 & 6.2 & 5.0587 & TRN \\
\hline CHEMBL1604268 & 688267 & 4.05 & 4.9969 & TRN \\
\hline CHEMBL1421652 & 688267 & 4.25 & 5.0457 & TRN \\
\hline CHEMBL1441883 & 688267 & 5.4 & 5.1042 & TRN \\
\hline CHEMBL1531891 & 688267 & 4.75 & 5.0569 & TRN \\
\hline CHEMBL1355555 & 688267 & 4.5 & 5.0601 & TRN \\
\hline CHEMBL1355764 & 688267 & 4.0 & 5.0161 & TRN \\
\hline CHEMBL1378298 & 688267 & 6.7001 & 5.0256 & TST \\
\hline CHEMBL1319801 & 688267 & 5.45 & 5.0507 & TST \\
\hline CHEMBL3199618 & 688267 & 6.2 & 5.0225 & TRN \\
\hline CHEMBL1380240 & 688267 & 5.45 & 5.0391 & TRN \\
\hline CHEMBL1513433 & 688267 & 5.6 & 5.0675 & TRN \\
\hline CHEMBL1347549 & 688267 & 4.25 & 5.1087 & TST \\
\hline CHEMBL1333305 & 688267 & 5.15 & 5.077 & TRN \\
\hline CHEMBL1416413 & 688267 & 4.4 & 5.0093 & TRN \\
\hline CHEMBL1608457 & 688267 & 4.05 & 5.1473 & TRN \\
\hline CHEMBL1418721 & 688267 & 5.5 & 5.0747 & TRN \\
\hline CHEMBL1438976 & 688267 & 5.55 & 5.0535 & TRN \\
\hline CHEMBL1331944 & 688267 & 5.0 & 5.0615 & TRN \\
\hline CHEMBL1404906 & 688267 & 4.1 & 5.0543 & TRN \\
\hline CHEMBL1534383 & 688267 & 6.1 & 5.0282 & TRN \\
\hline CHEMBL1587471 & 688267 & 4.05 & 5.0094 & TST \\
\hline CHEMBL1392098 & 688267 & 5.45 & 4.9997 & TRN \\
\hline CHEMBL1608404 & 688267 & 4.05 & 5.0308 & TRN \\
\hline CHEMBL1336152 & 688267 & 5.45 & 5.0371 & TST \\
\hline CHEMBL1316522 & 688267 & 4.4 & 5.0135 & TRN \\
\hline CHEMBL1593231 & 688267 & 5.55 & 5.0462 & TRN \\
\hline CHEMBL1333991 & 688267 & 5.5 & 5.0689 & TST \\
\hline CHEMBL1519049 & 688267 & 4.55 & 5.0274 & TST \\
\hline CHEMBL1402566 & 688267 & 3.95 & 5.0874 & TRN \\
\hline CHEMBL1315682 & 688267 & 5.5 & 5.0863 & TRN \\
\hline CHEMBL1342513 & 688267 & 6.2 & 5.0406 & TST \\
\hline CHEMBL1604184 & 688267 & 5.5 & 5.0834 & TRN \\
\hline CHEMBL1563813 & 688267 & 5.0 & 5.0266 & TRN \\
\hline CHEMBL1487697 & 688267 & 5.45 & 5.1178 & TRN \\
\hline CHEMBL1382568 & 688267 & 4.4 & 5.0524 & TRN \\
\hline
\end{tabular}




\begin{tabular}{|c|c|c|c|c|c|}
\hline & & \multicolumn{4}{|c|}{ Supplemental Table S2.txt } \\
\hline CHEMBL1589795 & 688267 & 4.05 & 5.0873 & TRN & \\
\hline CHEMBL1716742 & 688267 & 4.9 & 5.0325 & TST & \\
\hline CHEMBL1605652 & 688267 & 5.0 & 5.1246 & TRN & \\
\hline CHEMBL1554663 & 688267 & 4.4 & \multicolumn{2}{|c|}{5.0489999999999995} & TRN \\
\hline CHEMBL1491532 & 688267 & 5.85 & 5.0021 & TRN & \\
\hline CHEMBL1552235 & 688267 & 4.1 & 5.102 & TRN & \\
\hline CHEMBL3197186 & 688267 & 4.6 & 5.0124 & TRN & \\
\hline CHEMBL1361291 & 688267 & 4.25 & 5.0165 & TST & \\
\hline CHEMBL1590636 & 688267 & 5.8 & 5.0256 & TRN & \\
\hline CHEMBL1307843 & 688267 & 5.85 & 5.0781 & TST & \\
\hline CHEMBL3199423 & 688267 & 5.4 & 5.0344 & TST & \\
\hline CHEMBL1566782 & 688267 & 4.4 & 5.0657 & TRN & \\
\hline CHEMBL1514433 & 688267 & 5.35 & 5.0672 & TRN & \\
\hline CHEMBL1565756 & 688267 & 5.25 & 5.0728 & TRN & \\
\hline CHEMBL1549157 & 688267 & 4.05 & 5.0641 & TRN & \\
\hline CHEMBL1547616 & 688267 & 4.6 & 5.0845 & TST & \\
\hline CHEMBL1365032 & 688267 & 6.2 & 5.0929 & TRN & \\
\hline CHEMBL3209108 & 688267 & 5.3 & 5.0443 & TRN & \\
\hline CHEMBL1397765 & 688267 & 4.05 & 5.0931 & TRN & \\
\hline CHEMBL1305250 & 688267 & 4.4 & 5.0563 & TST & \\
\hline CHEMBL1308036 & 688267 & 6.2 & 5.0781 & TRN & \\
\hline CHEMBL1511259 & 688267 & 4.0 & 5.0389 & TRN & \\
\hline CHEMBL1565062 & 688267 & 4.0 & 5.0613 & TRN & \\
\hline CHEMBL1352071 & 688267 & 5.2 & 5.0595 & TRN & \\
\hline CHEMBL1510490 & 688267 & 5.3 & 5.0413 & TRN & \\
\hline CHEMBL1569816 & 688267 & 4.05 & 5.0257 & TRN & \\
\hline CHEMBL1388656 & 688267 & 4.3 & 5.0346 & TRN & \\
\hline CHEMBL1597452 & 688267 & 4.05 & 5.0115 & TST & \\
\hline CHEMBL1318200 & 688267 & 4.0 & 5.1175 & TRN & \\
\hline CHEMBL1328675 & 688267 & 4.0 & \multicolumn{2}{|c|}{5.132000000000001} & TST \\
\hline CHEMBL1443783 & 688267 & 6.15 & 5.0546 & TRN & \\
\hline CHEMBL300797 & 688267 & 5.5 & 5.0489 & TST & \\
\hline CHEMBL1533096 & 688267 & 6.15 & 5.0046 & TRN & \\
\hline CHEMBL1600800 & 688267 & 4.55 & 5.0788 & TRN & \\
\hline CHEMBL1539069 & 688267 & 3.95 & 5.0558 & TRN & \\
\hline CHEMBL3209904 & 688267 & 4.0 & 5.0036 & TST & \\
\hline CHEMBL1471690 & 688267 & 6.15 & 5.0801 & TRN & \\
\hline CHEMBL1310888 & 688267 & 4.8 & 5.0445 & TST & \\
\hline CHEMBL1303548 & 688267 & 5.55 & 5.1089 & TRN & \\
\hline CHEMBL1381852 & 688267 & 5.75 & 5.1336 & TRN & \\
\hline CHEMBL1496419 & 688267 & 5.85 & 5.0077 & TRN & \\
\hline CHEMBL1489805 & 688267 & 6.2 & 5.1667 & TST & \\
\hline CHEMBL1454901 & 688267 & 5.4 & 5.0479 & TRN & \\
\hline CHEMBL1569599 & 688267 & 5.4 & 5.0525 & TST & \\
\hline CHEMBL1317291 & 688267 & 4.25 & 4.994 & TRN & \\
\hline CHEMBL1507259 & 688267 & 3.95 & 5.0314 & TST & \\
\hline CHEMBL1412305 & 688267 & 5.25 & \multicolumn{2}{|c|}{5.013999999999999} & TST \\
\hline CHEMBL1519126 & 688267 & 4.85 & 5.0523 & TST & \\
\hline
\end{tabular}




\begin{tabular}{|c|c|c|c|c|c|}
\hline \\
\hline CHEMBL1524583 & 688267 & 4.3 & 5.0912 & TRN & \\
\hline CHEMBL1557686 & 688267 & 4.0 & 5.039 & TRN & \\
\hline CHEMBL1492688 & 688267 & 5.55 & 5.119 & TRN & \\
\hline CHEMBL1569037 & 688267 & 4.2 & 4.9851 & TRN & \\
\hline CHEMBL1599243 & 688267 & 6.2 & 5.1186 & TRN & \\
\hline CHEMBL1540961 & 688267 & 4.1 & 5.1206 & TRN & \\
\hline CHEMBL3207417 & 688267 & 6.1 & 5.0327 & TRN & \\
\hline CHEMBL1319625 & 688267 & 4.0 & 5.0452 & TRN & \\
\hline CHEMBL1400727 & 688267 & 5.5 & 5.0401 & TRN & \\
\hline CHEMBL1419416 & 688267 & 4.4 & 5.0336 & TRN & \\
\hline CHEMBL1338792 & 688267 & 3.95 & 5.0269 & TRN & \\
\hline CHEMBL1388170 & 688267 & 4.05 & 5.149 & TRN & \\
\hline CHEMBL1415367 & 688267 & 4.3 & 5.1505 & TST & \\
\hline CHEMBL1317401 & 688267 & 4.4 & 5.0106 & TRN & \\
\hline CHEMBL1549239 & 688267 & 4.0 & 5.1862 & TRN & \\
\hline CHEMBL1541955 & 688267 & 4.55 & 5.1551 & TST & \\
\hline CHEMBL1552234 & 688267 & 4.4 & 5.0408 & TRN & \\
\hline CHEMBL1560439 & 688267 & 4.2 & 5.085 & TRN & \\
\hline CHEMBL1337425 & 688267 & 4.05 & 5.1175 & TRN & \\
\hline CHEMBL1571833 & 688267 & 5.5 & 5.0534 & TRN & \\
\hline CHEMBL1468802 & 688267 & 5.3 & 5.0458 & TRN & \\
\hline CHEMBL1411124 & 688267 & 4.4 & 4.9963 & TRN & \\
\hline CHEMBL1378236 & 688267 & 5.5 & 5.091 & TRN & \\
\hline CHEMBL1498003 & 688267 & 4.0 & $5.1320 e$ & 0000000001 & TRN \\
\hline CHEMBL1471162 & 688267 & 6.2 & 5.0595 & TRN & \\
\hline CHEMBL1600042 & 688267 & 4.05 & 5.0526 & TST & \\
\hline CHEMBL3193386 & 688267 & 6.25 & 5.0607 & TRN & \\
\hline CHEMBL1333322 & 688267 & 4.25 & 5.056 & TST & \\
\hline CHEMBL1364418 & 688267 & 4.05 & 5.0404 & TRN & \\
\hline CHEMBL1445001 & 688267 & 6.25 & 5.0786 & TST & \\
\hline CHEMBL1472442 & 688267 & 4.0 & 5.0958 & TRN & \\
\hline CHEMBL1418895 & 688267 & 4.3 & 5.0654 & TRN & \\
\hline CHEMBL1463117 & 688267 & 3.95 & 5.0657 & TRN & \\
\hline CHEMBL1467182 & 688267 & 3.95 & 5.0443 & TRN & \\
\hline CHEMBL1517803 & 688267 & 5.6 & 5.0758 & TRN & \\
\hline CHEMBL1487412 & 688267 & 5.5 & 5.0487 & TST & \\
\hline CHEMBL1363361 & 688267 & 5.45 & 5.0558 & TST & \\
\hline CHEMBL1432421 & 688267 & 6.2 & 5.0341 & TRN & \\
\hline CHEMBL1588996 & 688267 & 5.3 & 5.0867 & TRN & \\
\hline CHEMBL1513075 & 688267 & 5.4 & 5.1118 & TRN & \\
\hline CHEMBL1466271 & 688267 & 6.15 & 5.0566 & TRN & \\
\hline CHEMBL1348678 & 688267 & 5.55 & 5.0577 & TRN & \\
\hline CHEMBL1567450 & 688267 & 6.2 & 5.0753 & TRN & \\
\hline CHEMBL1494231 & 688267 & 5.35 & 5.015 & TRN & \\
\hline CHEMBL1542646 & 688267 & 6.2 & 4.9906 & TST & \\
\hline CHEMBL1321921 & 688267 & 4.4 & 5.0488 & TRN & \\
\hline CHEMBL1511752 & 688267 & 4.6 & 4.977 & TRN & \\
\hline CHEMBL1493892 & 688267 & 3.95 & 5.0288 & TST & \\
\hline
\end{tabular}




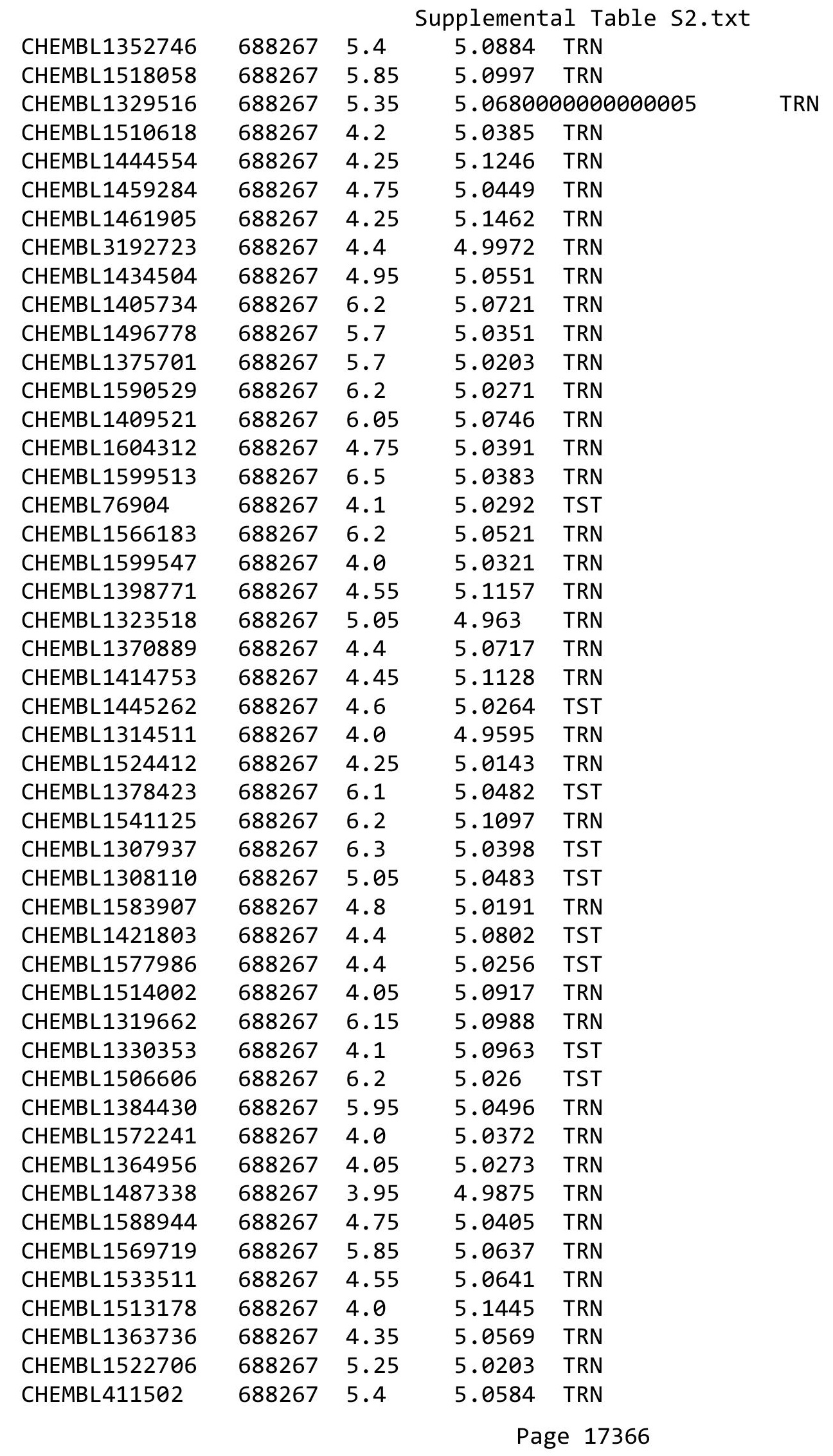




\begin{tabular}{|c|c|c|c|c|}
\hline \multicolumn{5}{|c|}{ Supplemental Table S2.txt } \\
\hline CHEMBL1471343 & 688267 & 5.3 & 4.9545 & TST \\
\hline CHEMBL1556732 & 688267 & 6.3 & 5.0029 & TRN \\
\hline CHEMBL1373713 & 688267 & 4.85 & 5.0623 & TRN \\
\hline CHEMBL1578558 & 688267 & 4.0 & 5.1044 & TST \\
\hline CHEMBL3199311 & 688267 & 4.5 & 4.9677 & TRN \\
\hline CHEMBL3199761 & 688267 & 4.8 & 5.0076 & TRN \\
\hline CHEMBL3213075 & 688267 & 4.0 & 5.0246 & TRN \\
\hline CHEMBL1354446 & 688267 & 5.45 & 5.0412 & TRN \\
\hline CHEMBL1544437 & 688267 & 4.0 & 5.0298 & TRN \\
\hline CHEMBL1598604 & 688267 & 4.4 & 5.0928 & TST \\
\hline CHEMBL1399453 & 688267 & 4.75 & 5.0497 & TRN \\
\hline CHEMBL3199050 & 688267 & 5.75 & 5.0577 & TST \\
\hline CHEMBL1412236 & 688267 & 5.8 & 5.045 & TRN \\
\hline CHEMBL1573977 & 688267 & 5.0 & 5.0807 & TRN \\
\hline CHEMBL1445218 & 688267 & 3.95 & 5.0229 & TST \\
\hline CHEMBL1451455 & 688267 & 4.25 & 5.039 & TST \\
\hline CHEMBL1552336 & 688267 & 6.2 & 5.1793 & TRN \\
\hline CHEMBL1311786 & 688267 & 4.5 & 5.0205 & TST \\
\hline CHEMBL3190947 & 688267 & 4.55 & 5.0458 & TRN \\
\hline CHEMBL591628 & 688267 & 6.15 & 5.0695 & TRN \\
\hline CHEMBL1305608 & 688267 & 4.05 & 5.0102 & TRN \\
\hline CHEMBL1526303 & 688267 & 4.15 & 5.0881 & TRN \\
\hline CHEMBL1548984 & 688267 & 4.05 & 5.035 & TRN \\
\hline CHEMBL1514667 & 688267 & 6.05 & 5.1189 & TRN \\
\hline CHEMBL1507431 & 688267 & 5.3 & 5.0913 & TRN \\
\hline CHEMBL1523497 & 688267 & 4.05 & 5.1105 & TST \\
\hline CHEMBL1429153 & 688267 & 5.2 & 5.188 & TRN \\
\hline CHEMBL1564429 & 688267 & 5.3 & 5.1351 & TRN \\
\hline CHEMBL1438409 & 688267 & 5.3 & 5.0622 & TRN \\
\hline CHEMBL1479571 & 688267 & 6.0 & 5.0311 & TRN \\
\hline CHEMBL1414141 & 688267 & 5.05 & 5.0309 & TRN \\
\hline CHEMBL1465136 & 688267 & 6.15 & 5.0591 & TRN \\
\hline CHEMBL1397154 & 688267 & 5.6 & 5.0474 & TST \\
\hline CHEMBL1514869 & 688267 & 5.45 & 5.0463 & TRN \\
\hline CHEMBL1344271 & 688267 & 5.35 & 5.074 & TST \\
\hline CHEMBL1308192 & 688267 & 4.55 & 5.0417 & TST \\
\hline CHEMBL1609634 & 688267 & 5.05 & 5.0785 & TRN \\
\hline CHEMBL1532891 & 688267 & 3.95 & 5.0705 & TRN \\
\hline CHEMBL1222728 & 688267 & 4.25 & 5.0642 & TRN \\
\hline CHEMBL1591526 & 688267 & 6.25 & 4.9743 & TRN \\
\hline CHEMBL1494284 & 688267 & 4.1 & 4.9766 & TRN \\
\hline CHEMBL1337311 & 688267 & 4.4 & 5.1434 & TRN \\
\hline CHEMBL1395711 & 688267 & 6.2 & 5.0481 & TST \\
\hline CHEMBL3211734 & 688267 & 4.3 & 5.0221 & TRN \\
\hline CHEMBL1367707 & 688267 & 4.55 & 4.9958 & TST \\
\hline CHEMBL1510995 & 688267 & 6.25 & 5.0836 & TRN \\
\hline CHEMBL1416491 & 688267 & 5.05 & 5.0314 & TRN \\
\hline CHEMBL1394844 & 688267 & 6.5 & 5.0296 & TRN \\
\hline
\end{tabular}




\begin{tabular}{|c|c|c|c|c|c|}
\hline \multicolumn{6}{|c|}{ Supplemental Table S2.txt } \\
\hline CHEMBL1612536 & 688267 & 4.15 & 5.0825 & TRN & \\
\hline CHEMBL1475747 & 688267 & 6.1 & 5.1119 & TRN & \\
\hline CHEMBL1497625 & 688267 & 4.7 & 5.0672 & TST & \\
\hline CHEMBL1502517 & 688267 & 4.0 & 5.0695 & TRN & \\
\hline CHEMBL1490702 & 688267 & 4.25 & 5.0454 & TRN & \\
\hline CHEMBL1435203 & 688267 & 4.0 & 5.0317 & TRN & \\
\hline CHEMBL1552321 & 688267 & 4.4 & 5.1381 & TRN & \\
\hline CHEMBL1601960 & 688267 & 4.35 & 5.1236 & TST & \\
\hline CHEMBL1302734 & 688267 & 5.05 & 5.0751 & TRN & \\
\hline CHEMBL1411298 & 688267 & 5.0 & 5.0722 & TRN & \\
\hline CHEMBL1335484 & 688267 & 4.05 & 5.1128 & TST & \\
\hline CHEMBL1454614 & 688267 & 4.0 & 5.0622 & TST & \\
\hline CHEMBL1541570 & 688267 & 4.4 & 5.0433 & TST & \\
\hline CHEMBL1498179 & 688267 & 3.95 & 5.0426 & TST & \\
\hline CHEMBL1325896 & 688267 & 4.55 & 5.0992 & TST & \\
\hline CHEMBL1511281 & 688267 & 4.2 & 5.0254 & TRN & \\
\hline CHEMBL1592161 & 688267 & 4.05 & 4.9826 & TRN & \\
\hline CHEMBL1385470 & 688267 & 5.35 & 5.0697 & TST & \\
\hline CHEMBL1335212 & 688267 & 6.1 & 5.0775 & TRN & \\
\hline CHEMBL1327516 & 688267 & 5.0 & 5.0724 & TRN & \\
\hline CHEMBL1533228 & 688267 & 5.05 & 5.0542 & TRN & \\
\hline CHEMBL1436670 & 688267 & 3.95 & 5.0997 & TRN & \\
\hline CHEMBL1873212 & 688267 & 6.2 & 5.0614 & TST & \\
\hline CHEMBL1455591 & 688267 & 3.95 & 5.1404 & TST & \\
\hline CHEMBL1595767 & 688267 & 5.5 & 5.0573 & TRN & \\
\hline CHEMBL1493642 & 688267 & 5.8 & 5.0419 & TRN & \\
\hline CHEMBL1561642 & 688267 & 5.6 & 5.0753 & TRN & \\
\hline CHEMBL1433610 & 688267 & 5.85 & 5.1066 & TRN & \\
\hline CHEMBL1530986 & 688267 & 5.25 & 5.0705 & TRN & \\
\hline CHEMBL1345323 & 688267 & 6.5501 & 5.1277 & TRN & \\
\hline CHEMBL1387319 & 688267 & 6.15 & 4.9844 & TRN & \\
\hline CHEMBL1532058 & 688267 & 4.8 & 5.0699 & TRN & \\
\hline CHEMBL1553038 & 688267 & 4.0 & 5.025 & TRN & \\
\hline CHEMBL1579976 & 688267 & 4.05 & 5.0427 & TRN & \\
\hline CHEMBL3197570 & 688267 & 4.7 & 5.0321 & TST & \\
\hline CHEMBL3193863 & 688267 & 6.35 & 5.0106 & TRN & \\
\hline CHEMBL3193085 & 688267 & 5.1 & 5.0126 & TST & \\
\hline CHEMBL1372771 & 688267 & 6.2 & 5.0245 & TRN & \\
\hline CHEMBL1522761 & 688267 & 4.4 & 5.1185 & TRN & \\
\hline CHEMBL1510427 & 688267 & 4.6 & 4.9834 & TRN & \\
\hline CHEMBL1395635 & 688267 & 4.0 & 5.0322 & TRN & \\
\hline CHEMBL1461121 & 688267 & 5.95 & 5.0861 & TST & \\
\hline CHEMBL1579436 & 688267 & 5.55 & 5.1235 & TRN & \\
\hline CHEMBL3193333 & 688267 & 5.8 & 5.00899 & 99999999995 & TRN \\
\hline CHEMBL1392891 & 688267 & 5.05 & 5.1536 & TRN & \\
\hline CHEMBL1353105 & 688267 & 5.05 & 5.0391 & TRN & \\
\hline CHEMBL1550276 & 688267 & 3.95 & 5.0216 & TST & \\
\hline CHEMBL1547496 & 688267 & 5.35 & 5.0655 & TRN & \\
\hline
\end{tabular}




\begin{tabular}{|c|c|c|c|c|c|}
\hline \multicolumn{6}{|c|}{ plemental } \\
\hline CHEMBL1496859 & 688267 & 4.7 & 5.1115 & TRN & \\
\hline CHEMBL1607048 & 688267 & 4.6 & 5.0081 & TRN & \\
\hline CHEMBL3197863 & 688267 & 5.9 & 5.0183 & TRN & \\
\hline CHEMBL1386613 & 688267 & 5.1 & 5.0134 & TST & \\
\hline CHEMBL1315803 & 688267 & 5.8 & 4.9992 & TRN & \\
\hline CHEMBL1515110 & 688267 & 5.5 & 5.0454 & TRN & \\
\hline CHEMBL1592969 & 688267 & 6.1 & 5.0357 & TRN & \\
\hline CHEMBL3193770 & 688267 & 5.55 & 4.999 & TST & \\
\hline CHEMBL1491446 & 688267 & 4.55 & 5.07 & TST & \\
\hline CHEMBL1445431 & 688267 & 4.0 & 5.0282 & TST & \\
\hline CHEMBL1415813 & 688267 & 5.3 & 5.0198 & TST & \\
\hline CHEMBL1551383 & 688267 & 5.85 & 5.0765 & TRN & \\
\hline CHEMBL1410289 & 688267 & 4.05 & 5.0444 & TRN & \\
\hline CHEMBL1433994 & 688267 & 5.3 & 5.1326 & TRN & \\
\hline CHEMBL1363186 & 688267 & 4.25 & 5.0418 & TRN & \\
\hline CHEMBL1410023 & 688267 & 4.0 & 5.0395 & TRN & \\
\hline CHEMBL1578422 & 688267 & 5.3 & 5.0634 & TST & \\
\hline CHEMBL1492627 & 688267 & 5.2 & 5.1035 & TST & \\
\hline CHEMBL1385136 & 688267 & 4.6 & 5.0778 & TRN & \\
\hline CHEMBL1517707 & 688267 & 3.95 & 5.0814 & TST & \\
\hline CHEMBL1407718 & 688267 & 4.05 & 5.0044 & TST & \\
\hline CHEMBL1386302 & 688267 & 5.55 & 5.0104 & TRN & \\
\hline CHEMBL 2374022 & 688267 & 6.1 & 5.0437 & TRN & \\
\hline CHEMBL1551120 & 688267 & 5.3 & 5.0446 & TRN & \\
\hline CHEMBL1595782 & 688267 & 4.05 & 5.0563 & TST & \\
\hline CHEMBL1530906 & 688267 & 5.8 & 5.091 & TST & \\
\hline CHEMBL1613322 & 688267 & 5.55 & 5.0807 & TRN & \\
\hline CHEMBL1444138 & 688267 & 4.55 & 5.0703 & TRN & \\
\hline CHEMBL1476158 & 688267 & 4.0 & 5.1348 & TRN & \\
\hline CHEMBL1995177 & 688267 & 4.05 & 5.0339 & TST & \\
\hline CHEMBL3213572 & 688267 & 4.55 & 5.0194 & TRN & \\
\hline CHEMBL1554226 & 688267 & 5.35 & 5.0429 & TRN & \\
\hline CHEMBL1459176 & 688267 & 6.25 & 5.1309 & TRN & \\
\hline CHEMBL1528026 & 688267 & 5.85 & 5.01399 & 9999999999 & TST \\
\hline CHEMBL3191356 & 688267 & 4.4 & 5.0523 & TST & \\
\hline CHEMBL1503425 & 688267 & 6.15 & 5.0058 & TRN & \\
\hline CHEMBL1410096 & 688267 & 3.95 & 5.0661 & TRN & \\
\hline CHEMBL1565010 & 688267 & 4.3 & 5.1181 & TST & \\
\hline CHEMBL1473567 & 688267 & 5.45 & 5.0178 & TRN & \\
\hline CHEMBL1543290 & 688267 & 5.3 & 5.0483 & TRN & \\
\hline CHEMBL1407150 & 688267 & 5.15 & 4.9943 & TRN & \\
\hline CHEMBL3212620 & 688267 & 4.0 & 5.0061 & TST & \\
\hline CHEMBL1365103 & 688267 & 6.2 & 5.0765 & TRN & \\
\hline CHEMBL1367305 & 688267 & 6.25 & 5.05699 & 99999999995 & TRN \\
\hline CHEMBL1553505 & 688267 & 5.1 & 5.0092 & TRN & \\
\hline CHEMBL1612054 & 688267 & 6.2 & 5.051 & TRN & \\
\hline CHEMBL1548384 & 688267 & 4.45 & 5.0259 & TRN & \\
\hline CHEMBL1443224 & 688267 & 5.15 & 5.0543 & TRN & \\
\hline
\end{tabular}




\begin{tabular}{|c|c|c|c|c|}
\hline \multicolumn{5}{|c|}{ Supplemental Table S2.txt } \\
\hline CHEMBL1491977 & 688267 & 4.0 & 5.0401 & TRN \\
\hline CHEMBL1449114 & 688267 & 5.3 & 5.0641 & TST \\
\hline CHEMBL1507208 & 688267 & 5.05 & 5.001 & TST \\
\hline CHEMBL1514211 & 688267 & 4.4 & 5.0502 & TRN \\
\hline CHEMBL1382743 & 688267 & 6.15 & 5.0389 & TRN \\
\hline CHEMBL1366253 & 688267 & 4.35 & 5.0716 & TST \\
\hline CHEMBL1540714 & 688267 & 5.65 & 5.0791 & TRN \\
\hline CHEMBL3207798 & 688267 & 5.0 & 5.0771 & TRN \\
\hline CHEMBL1362934 & 688267 & 6.25 & 5.0571 & TRN \\
\hline CHEMBL1439551 & 688267 & 6.25 & 5.0702 & TRN \\
\hline CHEMBL1522312 & 688267 & 5.25 & 4.977 & TRN \\
\hline CHEMBL1553943 & 688267 & 6.5 & 5.1528 & TRN \\
\hline CHEMBL272922 & 688267 & 6.15 & 5.1351 & TRN \\
\hline CHEMBL1439715 & 688267 & 5.55 & 5.0995 & TST \\
\hline CHEMBL1468668 & 688267 & 4.4 & 5.0367 & TST \\
\hline CHEMBL1554428 & 688267 & 6.25 & 5.064 & TRN \\
\hline CHEMBL1580507 & 688267 & 4.0 & 5.0004 & TRN \\
\hline CHEMBL1601204 & 688267 & 4.0 & 5.0725 & TST \\
\hline CHEMBL1602129 & 688267 & 4.05 & 5.0232 & TRN \\
\hline CHEMBL1514549 & 688267 & 6.25 & 5.0886 & TRN \\
\hline CHEMBL1551141 & 688267 & 6.15 & 5.0969 & TRN \\
\hline CHEMBL1569335 & 688267 & 4.25 & 5.0663 & TRN \\
\hline CHEMBL1607597 & 688267 & 4.05 & 5.1125 & TRN \\
\hline CHEMBL1358640 & 688267 & 3.95 & 5.0778 & TRN \\
\hline CHEMBL1400034 & 688267 & 4.0 & 5.067 & TRN \\
\hline CHEMBL1440627 & 688267 & 4.3 & 5.1226 & TRN \\
\hline CHEMBL1541775 & 688267 & 5.0 & 5.0198 & TRN \\
\hline CHEMBL1522005 & 688267 & 5.25 & 5.0405 & TRN \\
\hline CHEMBL1323893 & 688267 & 4.55 & 5.1003 & TRN \\
\hline CHEMBL1387727 & 688267 & 5.4 & 5.1462 & TRN \\
\hline CHEMBL1555790 & 688267 & 5.4 & 5.0314 & TRN \\
\hline CHEMBL1449976 & 688267 & 4.25 & 5.0815 & TRN \\
\hline CHEMBL1439131 & 688267 & 5.1 & 5.1578 & TRN \\
\hline CHEMBL1534560 & 688267 & 5.55 & 5.0677 & TRN \\
\hline CHEMBL1320159 & 688267 & 5.1 & 5.0689 & TRN \\
\hline CHEMBL1410731 & 688267 & 4.6 & 5.0985 & TRN \\
\hline CHEMBL1459455 & 688267 & 4.15 & 4.9789 & TRN \\
\hline CHEMBL1359819 & 688267 & 6.15 & 5.0743 & TRN \\
\hline CHEMBL1443178 & 688267 & 6.1 & 5.0852 & TRN \\
\hline CHEMBL1539220 & 688267 & 5.45 & 5.0466 & TST \\
\hline CHEMBL1538635 & 688267 & 4.5 & 5.1029 & TST \\
\hline CHEMBL 258275 & 688267 & 6.2 & 5.0536 & TRN \\
\hline CHEMBL1609721 & 688267 & 6.2 & 5.0626 & TRN \\
\hline CHEMBL1436710 & 688267 & 4.0 & 5.1357 & TRN \\
\hline CHEMBL1355455 & 688267 & 5.55 & 5.145 & TRN \\
\hline CHEMBL1373484 & 688267 & 6.2 & 5.1139 & TRN \\
\hline CHEMBL1525658 & 688267 & 3.9 & 5.1298 & TRN \\
\hline CHEMBL1361177 & 688267 & 5.85 & 5.0846 & TRN \\
\hline
\end{tabular}




\begin{tabular}{|c|c|c|c|c|c|}
\hline \multicolumn{6}{|c|}{ Supplemental Table S2.txt } \\
\hline CHEMBL1396441 & 688267 & 4.4 & 5.0811 & TRN & \\
\hline CHEMBL1466109 & 688267 & 3.95 & 4.9976 & TRN & \\
\hline CHEMBL1494705 & 688267 & 4.65 & 5.1178 & TRN & \\
\hline CHEMBL1320702 & 688267 & 4.6 & 5.0278 & TRN & \\
\hline CHEMBL1461525 & 688267 & 3.95 & 5.0409 & TST & \\
\hline CHEMBL1547123 & 688267 & 6.2 & 5.0297 & TST & \\
\hline CHEMBL1573522 & 688267 & 4.0 & 5.0879 & TRN & \\
\hline CHEMBL1323366 & 688267 & 4.8 & 5.0472 & TRN & \\
\hline CHEMBL1315872 & 688267 & 4.3 & 5.0518 & TST & \\
\hline CHEMBL1508355 & 688267 & 6.15 & 5.067 & TRN & \\
\hline CHEMBL1482191 & 688267 & 4.95 & 5.064 & TRN & \\
\hline CHEMBL1535579 & 688267 & 4.0 & 5.0047 & TRN & \\
\hline CHEMBL1314849 & 688267 & 5.9 & 5.0654 & TRN & \\
\hline CHEMBL1380945 & 688267 & 3.95 & 5.0863 & TRN & \\
\hline CHEMBL1445615 & 688267 & 5.2 & 5.0732 & TRN & \\
\hline CHEMBL1530590 & 688267 & 4.0 & 4.9986 & TRN & \\
\hline CHEMBL1462674 & 688267 & 5.95 & 4.9884 & TRN & \\
\hline CHEMBL1469206 & 688267 & 4.45 & 5.0991 & TRN & \\
\hline CHEMBL1370943 & 688267 & 6.2 & 5.0455 & TST & \\
\hline CHEMBL1537009 & 688267 & 6.5 & 5.0698 & TRN & \\
\hline CHEMBL1373901 & 688267 & 6.5 & 5.0604 & TST & \\
\hline CHEMBL1506952 & 688267 & 4.35 & 5.1099 & TRN & \\
\hline CHEMBL1601871 & 688267 & 4.2 & 5.1111 & TRN & \\
\hline CHEMBL1401593 & 688267 & 5.35 & 5.041 & TRN & \\
\hline CHEMBL1492487 & 688267 & 4.65 & 5.062 & TRN & \\
\hline CHEMBL1369858 & 688267 & 4.35 & 5.1081 & TRN & \\
\hline CHEMBL1324060 & 688267 & 6.2 & 5.0919 & TRN & \\
\hline CHEMBL1483123 & 688267 & 6.2 & 5.135 & TRN & \\
\hline CHEMBL1560364 & 688267 & 5.25 & 5.081 & TST & \\
\hline CHEMBL1516461 & 688267 & 5.65 & 5.0614 & TRN & \\
\hline CHEMBL1576735 & 688267 & 4.75 & 5.0556 & TRN & \\
\hline CHEMBL1334570 & 688267 & 4.05 & 5.0133 & TRN & \\
\hline CHEMBL1559775 & 688267 & 4.3 & 5.0753 & TRN & \\
\hline CHEMBL1572139 & 688267 & 4.0 & 5.0443 & TRN & \\
\hline CHEMBL1525889 & 688267 & 4.55 & 5.0755 & TST & \\
\hline CHEMBL1466214 & 688267 & 4.4 & 5.0215 & TST & \\
\hline CHEMBL1409258 & 688267 & 4.35 & 5.03100 & 0000000001 & TRN \\
\hline CHEMBL1311583 & 688267 & 5.5 & 5.0252 & TST & \\
\hline CHEMBL1451669 & 688267 & 4.4 & 5.0755 & TRN & \\
\hline CHEMBL1488628 & 688267 & 4.9 & 5.0888 & TST & \\
\hline CHEMBL1467839 & 688267 & 4.3 & 5.0367 & TST & \\
\hline CHEMBL1315375 & 688267 & 4.15 & 5.006 & TRN & \\
\hline CHEMBL1519346 & 688267 & 4.45 & 5.0988 & TRN & \\
\hline CHEMBL1495489 & 688267 & 4.0 & 5.09 & TST & \\
\hline CHEMBL1478524 & 688267 & 4.4 & 5.0424 & TRN & \\
\hline CHEMBL1331677 & 688267 & 4.25 & 4.9888 & TRN & \\
\hline CHEMBL1422025 & 688267 & 4.45 & 5.0182 & TRN & \\
\hline CHEMBL598680 & 688267 & 4.4 & 5.0784 & TRN & \\
\hline
\end{tabular}




\begin{tabular}{|c|c|c|c|c|c|}
\hline \multicolumn{6}{|c|}{ Supplemental Table S2.txt } \\
\hline CHEMBL1460655 & 688267 & 5.25 & 5.0944 & TST & \\
\hline CHEMBL1482372 & 688267 & 4.55 & 5.0649 & TRN & \\
\hline CHEMBL3209685 & 688267 & 5.4 & 5.0164 & TRN & \\
\hline CHEMBL3190552 & 688267 & 5.5 & 4.9875 & TRN & \\
\hline CHEMBL1325298 & 688267 & 4.3 & 5.03600 & 00000000005 & TRN \\
\hline CHEMBL1391829 & 688267 & 4.1 & 5.02 & TST & \\
\hline CHEMBL1600282 & 688267 & 5.9 & 5.0314 & TST & \\
\hline CHEMBL1606577 & 688267 & 4.4 & 5.0167 & TRN & \\
\hline CHEMBL1513195 & 688267 & 6.2 & 5.0438 & TRN & \\
\hline CHEMBL1592997 & 688267 & 4.3 & 5.0801 & TRN & \\
\hline CHEMBL1444171 & 688267 & 5.3 & 4.9798 & TRN & \\
\hline CHEMBL1590825 & 688267 & 4.05 & 5.0232 & TST & \\
\hline CHEMBL1422205 & 688267 & 4.15 & 5.0207 & TST & \\
\hline CHEMBL1340860 & 688267 & 5.55 & 5.0662 & TRN & \\
\hline CHEMBL1609434 & 688267 & 6.15 & 5.072 & TRN & \\
\hline CHEMBL1372507 & 688267 & 5.25 & 5.0484 & TRN & \\
\hline CHEMBL1609808 & 688267 & 4.4 & 5.0437 & TRN & \\
\hline CHEMBL1467999 & 688267 & 4.3 & 5.0106 & TRN & \\
\hline CHEMBL1491145 & 688267 & 5.3 & 5.0028 & TRN & \\
\hline CHEMBL1538259 & 688267 & 6.0 & 5.0414 & TRN & \\
\hline CHEMBL1565669 & 688267 & 5.15 & 5.078 & TRN & \\
\hline CHEMBL1479489 & 688267 & 4.55 & 4.9904 & TRN & \\
\hline CHEMBL1586848 & 688267 & 4.1 & 5.106 & TST & \\
\hline CHEMBL1488828 & 688267 & 5.55 & 5.0465 & TRN & \\
\hline CHEMBL1399441 & 688267 & 5.5 & 5.0791 & TST & \\
\hline CHEMBL1356781 & 688267 & 4.35 & 5.091 & TRN & \\
\hline CHEMBL1336009 & 688267 & 5.55 & 5.0512 & TRN & \\
\hline CHEMBL1456298 & 688267 & 4.15 & 4.9955 & TRN & \\
\hline CHEMBL1394069 & 688267 & 5.45 & 5.0463 & TRN & \\
\hline CHEMBL 2373620 & 688267 & 6.2 & 5.0485 & TRN & \\
\hline CHEMBL1592756 & 688267 & 5.1 & 5.0367 & TST & \\
\hline CHEMBL1537613 & 688267 & 4.15 & 5.0363 & TST & \\
\hline CHEMBL1372652 & 688267 & 4.6 & 5.0536 & TRN & \\
\hline CHEMBL1425302 & 688267 & 6.25 & 5.0171 & TRN & \\
\hline CHEMBL1425264 & 688267 & 4.5 & 5.0522 & TST & \\
\hline CHEMBL1585078 & 688267 & 4.05 & 5.0388 & TST & \\
\hline CHEMBL1350193 & 688267 & 6.2 & 5.0665 & TRN & \\
\hline CHEMBL1489781 & 688267 & 4.3 & 5.0902 & TRN & \\
\hline CHEMBL1593433 & 688267 & 5.5 & 5.0918 & TRN & \\
\hline CHEMBL1326452 & 688267 & 6.1 & 5.0921 & TRN & \\
\hline CHEMBL1314354 & 688267 & 5.3 & 5.0797 & TRN & \\
\hline CHEMBL1448987 & 688267 & 6.2 & 5.0951 & TRN & \\
\hline CHEMBL1590651 & 688267 & 6.2 & 5.0385 & TST & \\
\hline CHEMBL1477838 & 688267 & 5.45 & 4.9929 & TST & \\
\hline CHEMBL1395514 & 688267 & 5.35 & 5.0712 & TST & \\
\hline CHEMBL1471714 & 688267 & 4.0 & 5.0214 & TRN & \\
\hline CHEMBL1313917 & 688267 & 6.15 & 5.0737 & TST & \\
\hline CHEMBL1546845 & 688267 & 4.7 & 5.0362 & TST & \\
\hline
\end{tabular}




\begin{tabular}{|c|c|c|c|c|c|}
\hline & & \multicolumn{4}{|c|}{ Supplemental Table s2.txt } \\
\hline CHEMBL1488712 & 688267 & 4.75 & 4.9673 & TRN & \\
\hline CHEMBL3193717 & 688267 & 4.95 & 4.9838 & TRN & \\
\hline CHEMBL1309549 & 688267 & 4.25 & 5.0185 & TRN & \\
\hline CHEMBL1590572 & 688267 & 5.5 & 5.038 & TRN & \\
\hline CHEMBL1384892 & 688267 & 6.2 & 5.0533 & TST & \\
\hline CHEMBL1322155 & 688267 & 4.35 & 5.1128 & TST & \\
\hline CHEMBL1440058 & 688267 & 5.6 & 5.032 & TST & \\
\hline CHEMBL1559393 & 688267 & 6.2 & 5.0941 & TST & \\
\hline CHEMBL1354552 & 688267 & 3.95 & 5.0121 & TRN & \\
\hline CHEMBL1597756 & 688267 & 5.15 & 5.0519 & TRN & \\
\hline CHEMBL1351684 & 688267 & 4.0 & 5.0128 & TRN & \\
\hline CHEMBL1530977 & 688267 & 4.55 & 5.1772 & TRN & \\
\hline CHEMBL1477551 & 688267 & 5.4 & 5.0342 & TRN & \\
\hline CHEMBL1336909 & 688267 & 4.0 & 5.0938 & TRN & \\
\hline CHEMBL1538654 & 688267 & 6.2 & 5.1522 & TRN & \\
\hline CHEMBL1613263 & 688267 & 5.9 & 4.9815 & TRN & \\
\hline CHEMBL1321721 & 688267 & 4.35 & 5.00899 & 99999999995 & TRN \\
\hline CHEMBL1466769 & 688267 & 4.05 & 5.0671 & TRN & \\
\hline CHEMBL1522315 & 688267 & 4.4 & 5.0966 & TRN & \\
\hline CHEMBL1428319 & 688267 & 4.4 & 5.0534 & TST & \\
\hline CHEMBL1591792 & 688267 & 6.2 & 5.0789 & TRN & \\
\hline CHEMBL1559584 & 688267 & 4.95 & 5.1141 & TRN & \\
\hline CHEMBL1354516 & 688267 & 5.5 & 5.1115 & TRN & \\
\hline CHEMBL1368898 & 688267 & 4.1 & 4.9936 & TRN & \\
\hline CHEMBL1613548 & 688267 & 4.9 & 5.0787 & TST & \\
\hline CHEMBL1486230 & 688267 & 4.05 & 5.02 & TST & \\
\hline CHEMBL1427347 & 688267 & 6.2 & 5.0219 & TRN & \\
\hline CHEMBL1498885 & 688267 & 5.85 & 5.0554 & TRN & \\
\hline CHEMBL1574720 & 688267 & 4.6 & 5.0192 & TRN & \\
\hline CHEMBL1503914 & 688267 & 4.05 & 5.0886 & TRN & \\
\hline CHEMBL1473468 & 688267 & 6.2 & 5.0305 & TST & \\
\hline CHEMBL1461362 & 688267 & 4.4 & 5.0274 & TRN & \\
\hline CHEMBL1609057 & 688267 & 5.8 & 5.044 & TST & \\
\hline CHEMBL1346845 & 688267 & 3.95 & 5.0842 & TST & \\
\hline CHEMBL1552318 & 688267 & 4.05 & 5.0542 & TRN & \\
\hline CHEMBL1494929 & 688267 & 4.0 & 5.018 & TRN & \\
\hline CHEMBL1583978 & 688267 & 4.15 & 5.0185 & TRN & \\
\hline CHEMBL1592322 & 688267 & 5.6 & 5.0271 & TRN & \\
\hline CHEMBL1967862 & 688267 & 4.2 & 5.019 & TST & \\
\hline CHEMBL1372992 & 688267 & 6.15 & 5.0902 & TST & \\
\hline CHEMBL1410884 & 688267 & 5.5 & 5.0849 & TRN & \\
\hline CHEMBL1368930 & 688267 & 4.05 & 5.1282 & TRN & \\
\hline CHEMBL1553298 & 688267 & 5.7 & 5.004 & TRN & \\
\hline CHEMBL1307054 & 688267 & 4.4 & 5.0906 & TRN & \\
\hline CHEMBL1498839 & 688267 & 4.3 & 5.1009 & TRN & \\
\hline CHEMBL1407966 & 688267 & 5.6 & 5.0124 & TST & \\
\hline CHEMBL1489466 & 688267 & 5.3 & 5.0149 & TRN & \\
\hline CHEMBL1566899 & 688267 & 4.0 & 5.02 & TRN & \\
\hline
\end{tabular}




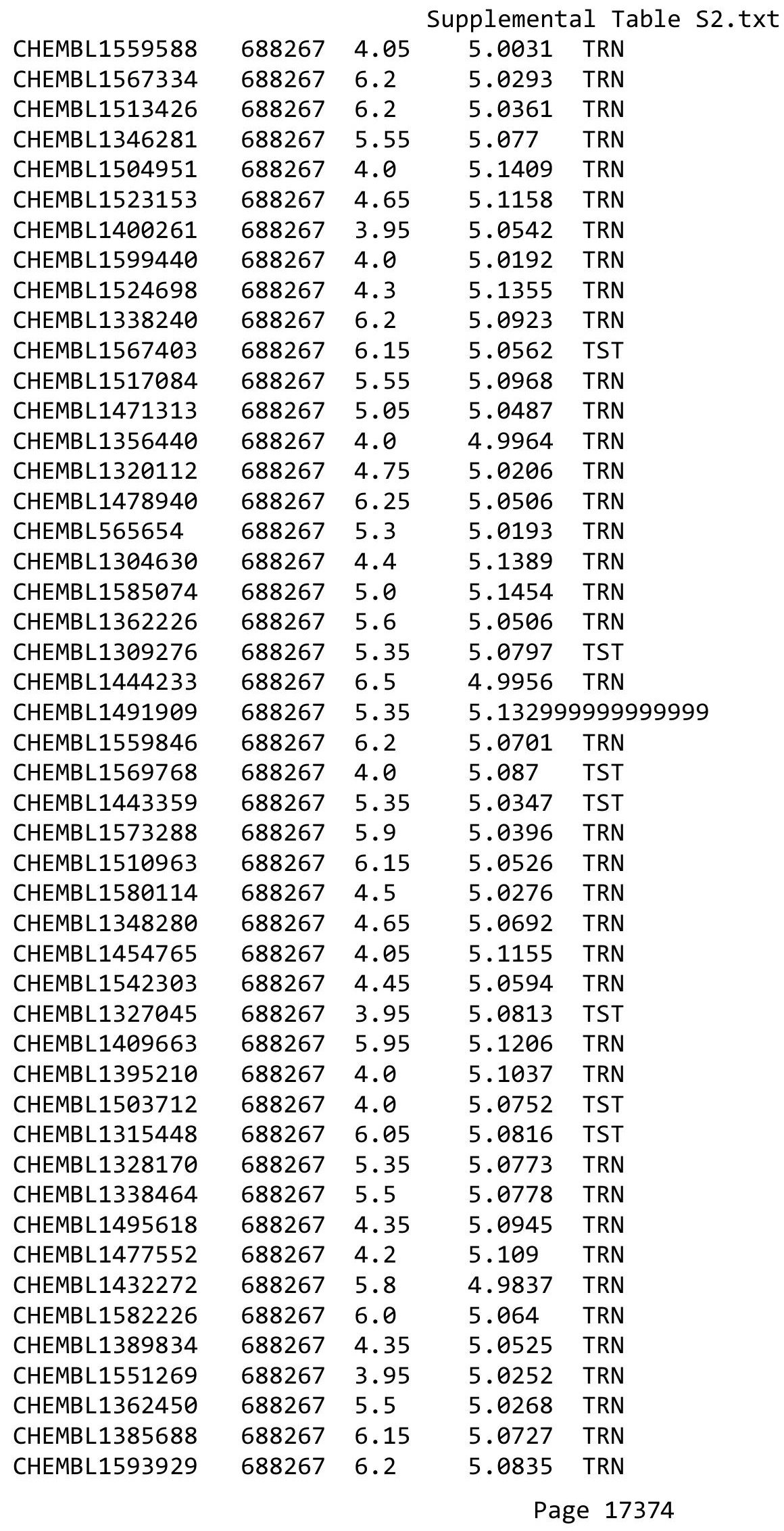




\begin{tabular}{|c|c|c|c|c|}
\hline & & & pplement & al $\mathrm{Ta}$ \\
\hline CHEMBL1364348 & 688267 & 5.8 & 5.0675 & TST \\
\hline CHEMBL1563163 & 688267 & 5.55 & 4.9935 & TST \\
\hline CHEMBL1299486 & 688267 & 4.4 & 5.0531 & TRN \\
\hline CHEMBL1472210 & 688267 & 5.55 & 5.032 & TST \\
\hline CHEMBL1403074 & 688267 & 4.45 & 5.0439 & TST \\
\hline CHEMBL1515558 & 688267 & 6.2 & 5.0509 & TRN \\
\hline CHEMBL3207893 & 688267 & 6.25 & 5.0371 & TRN \\
\hline CHEMBL1303964 & 688267 & 4.55 & 5.1347 & TRN \\
\hline CHEMBL1515554 & 688267 & 4.95 & 5.0447 & TRN \\
\hline CHEMBL1427810 & 688267 & 4.35 & 5.0107 & TRN \\
\hline CHEMBL1539847 & 688267 & 4.3 & 5.0298 & TRN \\
\hline CHEMBL1346471 & 688267 & 6.5 & 4.9994 & TRN \\
\hline CHEMBL1449554 & 688267 & 6.2 & 5.0502 & TRN \\
\hline CHEMBL1508547 & 688267 & 4.95 & 5.0063 & TRN \\
\hline CHEMBL1409573 & 688267 & 4.95 & 5.0445 & TRN \\
\hline CHEMBL1454291 & 688267 & 4.25 & 5.0997 & TRN \\
\hline CHEMBL1532245 & 688267 & 6.5 & 5.0573 & TRN \\
\hline CHEMBL1302899 & 688267 & 5.1 & 5.1664 & TRN \\
\hline CHEMBL1575227 & 688267 & 6.05 & 5.091 & TRN \\
\hline CHEMBL1460742 & 688267 & 5.25 & 5.0375 & TST \\
\hline CHEMBL1316000 & 688267 & 4.35 & 5.0229 & TRN \\
\hline CHEMBL1419870 & 688267 & 4.35 & 4.9882 & TRN \\
\hline CHEMBL1473598 & 688267 & 5.55 & 5.0615 & TRN \\
\hline CHEMBL1541605 & 688267 & 5.25 & 5.038 & TRN \\
\hline CHEMBL1445141 & 688267 & 4.35 & 5.0548 & TST \\
\hline CHEMBL1313305 & 688267 & 4.3 & 5.0605 & TST \\
\hline CHEMBL1489231 & 688267 & 6.15 & 5.0875 & TST \\
\hline CHEMBL1430160 & 688267 & 5.65 & 5.0665 & TRN \\
\hline CHEMBL1345900 & 688267 & 6.15 & 5.0981 & TRN \\
\hline CHEMBL1554939 & 688267 & 4.35 & 5.027 & TRN \\
\hline CHEMBL1329936 & 688267 & 5.25 & 5.0944 & TRN \\
\hline CHEMBL1591887 & 688267 & 5.45 & 5.0224 & TST \\
\hline CHEMBL1456098 & 688267 & 4.15 & 5.0331 & TRN \\
\hline CHEMBL1311803 & 688267 & 5.5 & 5.0461 & TRN \\
\hline CHEMBL1415151 & 688267 & 5.3 & 5.0559 & TRN \\
\hline CHEMBL1494897 & 688267 & 4.5 & 5.0505 & TST \\
\hline CHEMBL1606097 & 688267 & 4.5 & 4.9895 & TST \\
\hline CHEMBL1329728 & 688267 & 4.5 & 5.1038 & TRN \\
\hline CHEMBL1594295 & 688267 & 5.8 & 5.0683 & TST \\
\hline CHEMBL1488565 & 688267 & 6.25 & 5.16 & TRN \\
\hline CHEMBL1540878 & 688267 & 4.55 & 5.1058 & TST \\
\hline CHEMBL1490695 & 688267 & 4.0 & 5.0272 & TRN \\
\hline CHEMBL1362832 & 688267 & 4.45 & 5.0876 & TRN \\
\hline CHEMBL1379376 & 688267 & 5.0 & 5.0402 & TST \\
\hline CHEMBL1529866 & 688267 & 6.2 & 5.0896 & TRN \\
\hline CHEMBL1485670 & 688267 & 4.95 & 5.0608 & TRN \\
\hline CHEMBL1573081 & 688267 & 4.0 & 5.0809 & TST \\
\hline CHEMBL1446978 & 688267 & 6.2 & 5.0554 & TST \\
\hline
\end{tabular}




\begin{tabular}{|c|c|c|c|c|}
\hline \multicolumn{5}{|c|}{ Supplemental Table S2.txt } \\
\hline CHEMBL1501243 & 688267 & 5.1 & 5.0489 & TRN \\
\hline CHEMBL1465708 & 688267 & 4.4 & 5.0631 & TRN \\
\hline CHEMBL1564258 & 688267 & 5.65 & 5.0333 & TRN \\
\hline CHEMBL1583949 & 688267 & 3.95 & 5.0082 & TRN \\
\hline CHEMBL1575801 & 688267 & 4.35 & 5.0574 & TRN \\
\hline CHEMBL1430732 & 688267 & 4.75 & 5.0858 & TRN \\
\hline CHEMBL1439352 & 688267 & 4.5 & 5.0458 & TRN \\
\hline CHEMBL1356683 & 688267 & 6.1 & 5.0518 & TRN \\
\hline CHEMBL1459417 & 688267 & 4.95 & 5.0697 & TRN \\
\hline CHEMBL1328253 & 688267 & 4.65 & 5.1343 & TRN \\
\hline CHEMBL1482498 & 688267 & 3.95 & 5.0553 & TRN \\
\hline CHEMBL3207390 & 688267 & 4.6 & 5.0122 & TRN \\
\hline CHEMBL1564148 & 688267 & 5.95 & 5.0636 & TST \\
\hline CHEMBL1533520 & 688267 & 4.0 & 5.0947 & TRN \\
\hline CHEMBL1524627 & 688267 & 4.0 & 5.1179 & TRN \\
\hline CHEMBL1538789 & 688267 & 4.0 & 5.0251 & TRN \\
\hline CHEMBL1393628 & 688267 & 4.95 & 5.0379 & TRN \\
\hline CHEMBL1531920 & 688267 & 4.1 & 5.0303 & TST \\
\hline CHEMBL1483050 & 688267 & 4.0 & 5.0907 & TRN \\
\hline CHEMBL1588300 & 688267 & 4.05 & 5.0314 & TRN \\
\hline CHEMBL1473119 & 688267 & 3.95 & 5.0998 & TRN \\
\hline CHEMBL1367381 & 688267 & 4.0 & 5.1053 & TRN \\
\hline CHEMBL1580828 & 688267 & 4.15 & 5.0875 & TRN \\
\hline CHEMBL1574075 & 688267 & 6.2 & 5.0423 & TST \\
\hline CHEMBL1566493 & 688267 & 6.4 & 5.0943 & TRN \\
\hline CHEMBL1429991 & 688267 & 4.95 & 5.109 & TRN \\
\hline CHEMBL116890 & 688267 & 4.7 & 4.9839 & TRN \\
\hline CHEMBL3191201 & 688267 & 4.5 & 5.0011 & TRN \\
\hline CHEMBL1313800 & 688267 & 6.5 & 5.0739 & TST \\
\hline CHEMBL1470769 & 688267 & 4.0 & 5.0358 & TRN \\
\hline CHEMBL1458130 & 688267 & 4.4 & 5.0298 & TST \\
\hline CHEMBL1320100 & 688267 & 5.05 & 5.0611 & TRN \\
\hline CHEMBL1542618 & 688267 & 4.05 & 5.0541 & TST \\
\hline CHEMBL1377576 & 688267 & 3.95 & 5.0817 & TRN \\
\hline CHEMBL1592637 & 688267 & 5.7 & 5.1289 & TRN \\
\hline CHEMBL1484438 & 688267 & 4.45 & 5.0328 & TRN \\
\hline CHEMBL1551519 & 688267 & 4.0 & 5.055 & TRN \\
\hline CHEMBL1390450 & 688267 & 4.35 & 5.0342 & TRN \\
\hline CHEMBL3210593 & 688267 & 6.2 & 5.0259 & TRN \\
\hline CHEMBL1386568 & 688267 & 5.35 & 5.0238 & TRN \\
\hline CHEMBL1315191 & 688267 & 5.3 & 5.102 & TST \\
\hline CHEMBL1316071 & 688267 & 6.15 & 5.0892 & TRN \\
\hline CHEMBL1485066 & 688267 & 4.15 & 5.0713 & TST \\
\hline CHEMBL1504607 & 688267 & 5.9 & 5.0258 & TST \\
\hline CHEMBL1380947 & 688267 & 4.55 & 5.0653 & TRN \\
\hline CHEMBL1303809 & 688267 & 5.65 & 5.1224 & TST \\
\hline CHEMBL1475408 & 688267 & 5.95 & 5.0439 & TST \\
\hline CHEMBL1436079 & 688267 & 5.65 & 5.0351 & TRN \\
\hline
\end{tabular}




\begin{tabular}{|c|c|c|c|c|c|}
\hline \multicolumn{6}{|c|}{ Supplemental Table S2.txt } \\
\hline CHEMBL3194107 & 688267 & 5.75 & 5.0297 & TRN & \\
\hline CHEMBL1395584 & 688267 & 5.3 & 5.0981 & TRN & \\
\hline CHEMBL1397940 & 688267 & 3.95 & 5.0369 & TRN & \\
\hline CHEMBL1434025 & 688267 & 5.05 & 5.1271 & TRN & \\
\hline CHEMBL1506646 & 688267 & 4.05 & 5.0472 & TRN & \\
\hline CHEMBL1407278 & 688267 & 4.15 & 5.0699 & TRN & \\
\hline CHEMBL1373266 & 688267 & 6.25 & 5.0559 & TRN & \\
\hline CHEMBL1526155 & 688267 & 5.15 & 5.0812 & TRN & \\
\hline CHEMBL1330608 & 688267 & 4.05 & 5.0277 & TRN & \\
\hline CHEMBL1407192 & 688267 & 3.95 & 5.064 & TST & \\
\hline CHEMBL1394933 & 688267 & 4.0 & 5.0732 & TRN & \\
\hline CHEMBL1441777 & 688267 & 5.8 & 5.0793 & TRN & \\
\hline CHEMBL1525927 & 688267 & 6.15 & 5.0229 & TRN & \\
\hline CHEMBL1424231 & 688267 & 4.1 & 4.9972 & TST & \\
\hline CHEMBL1497728 & 688267 & 6.05 & 5.0981 & TRN & \\
\hline CHEMBL1555060 & 688267 & 6.2 & 5.0507 & TRN & \\
\hline CHEMBL1329410 & 688267 & 6.0 & 5.0782 & TRN & \\
\hline CHEMBL1406149 & 688267 & 5.6 & 5.0711 & TRN & \\
\hline CHEMBL1390131 & 688267 & 5.85 & 5.0742 & TRN & \\
\hline CHEMBL1433784 & 688267 & 4.3 & 4.985 & TST & \\
\hline CHEMBL1443195 & 688267 & 5.55 & 5.0419 & TRN & \\
\hline CHEMBL1583377 & 688267 & 6.5501 & 5.0589 & TST & \\
\hline CHEMBL1403798 & 688267 & 6.2 & 5.0827 & TRN & \\
\hline CHEMBL1316335 & 688267 & 5.0 & 5.1143 & TRN & \\
\hline CHEMBL1325098 & 688267 & 4.05 & 5.1068 & TRN & \\
\hline CHEMBL1493999 & 688267 & 5.6 & 5.0341 & TST & \\
\hline CHEMBL1335540 & 688267 & 4.0 & 5.0471 & TRN & \\
\hline CHEMBL1581329 & 688267 & 4.0 & 5.0254 & TST & \\
\hline CHEMBL1368218 & 688267 & 5.35 & 5.0333 & TRN & \\
\hline CHEMBL1301192 & 688267 & 4.3 & 5.0448 & TRN & \\
\hline CHEMBL1530298 & 688267 & 4.0 & 5.0756 & TRN & \\
\hline CHEMBL1586441 & 688267 & 4.6 & 5.0109 & TRN & \\
\hline CHEMBL1363326 & 688267 & 5.55 & 4.9977 & TRN & \\
\hline CHEMBL1543486 & 688267 & 4.05 & 5.0923 & TRN & \\
\hline CHEMBL1324905 & 688267 & 6.1 & 5.1335 & TRN & \\
\hline CHEMBL1368147 & 688267 & 4.55 & 5.0396 & TRN & \\
\hline CHEMBL1505133 & 688267 & 5.35 & 5.0291 & TRN & \\
\hline CHEMBL1391292 & 688267 & 4.35 & 5.0581 & TRN & \\
\hline CHEMBL1304919 & 688267 & 6.25 & 5.05699 & 99999999995 & TRN \\
\hline CHEMBL1438109 & 688267 & 4.3 & 5.0829 & TRN & \\
\hline CHEMBL1480951 & 688267 & 5.75 & 5.0176 & TST & \\
\hline CHEMBL1451310 & 688267 & 4.05 & 5.0183 & TRN & \\
\hline CHEMBL1440097 & 688267 & 5.85 & 5.0235 & TST & \\
\hline CHEMBL1556762 & 688267 & 5.3 & 5.0084 & TST & \\
\hline CHEMBL1475592 & 688267 & 4.45 & $5.1370 e$ & 00000000005 & TRN \\
\hline CHEMBL1549130 & 688267 & 5.3 & 4.9786 & TRN & \\
\hline CHEMBL1491094 & 688267 & 4.0 & 5.035 & TRN & \\
\hline CHEMBL2003794 & 688267 & 5.6 & 4.9855 & TRN & \\
\hline
\end{tabular}




\begin{tabular}{|c|c|c|c|c|c|}
\hline \\
\hline CHEMBL1460339 & 688267 & 5.7 & 5.0362 & TRN & \\
\hline CHEMBL1313417 & 688267 & 6.15 & 5.0861 & TST & \\
\hline CHEMBL1385284 & 688267 & 6.2 & 5.0949 & TRN & \\
\hline CHEMBL1317032 & 688267 & 4.0 & 5.0791 & TRN & \\
\hline CHEMBL1324218 & 688267 & 6.2 & 5.0035 & TRN & \\
\hline CHEMBL1537465 & 688267 & 6.0 & 5.0068 & TST & \\
\hline CHEMBL3194193 & 688267 & 5.35 & 5.0042 & TRN & \\
\hline CHEMBL1442490 & 688267 & 6.2 & 5.0677 & TRN & \\
\hline CHEMBL1319460 & 688267 & 4.05 & 5.0499 & TRN & \\
\hline CHEMBL1464798 & 688267 & 4.65 & 5.0589 & TRN & \\
\hline CHEMBL1312857 & 688267 & 4.05 & 5.0646 & TRN & \\
\hline CHEMBL1496424 & 688267 & 6.5 & 5.0482 & TRN & \\
\hline CHEMBL1609408 & 688267 & 4.25 & 5.0452 & TST & \\
\hline CHEMBL1360498 & 688267 & 5.55 & 5.0664 & TST & \\
\hline CHEMBL411070 & 688267 & 6.0 & 5.1089 & TST & \\
\hline CHEMBL1588705 & 688267 & 4.0 & 5.0362 & TST & \\
\hline CHEMBL1558663 & 688267 & 6.2 & 5.03 & TRN & \\
\hline CHEMBL1348552 & 688267 & 4.05 & 5.0381 & TST & \\
\hline CHEMBL1356420 & 688267 & 5.5 & 5.1281 & TRN & \\
\hline CHEMBL1596391 & 688267 & 4.2 & 5.0736 & TRN & \\
\hline CHEMBL1359324 & 688267 & 5.3 & 5.0806 & TST & \\
\hline CHEMBL1502962 & 688267 & 4.0 & 5.0418 & TST & \\
\hline CHEMBL1433990 & 688267 & 5.2 & 5.0853 & TRN & \\
\hline CHEMBL1591355 & 688267 & 5.8 & 5.0381 & TRN & \\
\hline CHEMBL1440037 & 688267 & 6.2 & 5.0199 & TRN & \\
\hline CHEMBL1436471 & 688267 & 5.35 & 5.0581 & TST & \\
\hline CHEMBL1563383 & 688267 & 4.75 & 4.9869 & TST & \\
\hline CHEMBL1332810 & 688267 & 6.2 & 5.0659 & TRN & \\
\hline CHEMBL1442671 & 688267 & 4.9 & 5.09399 & 9999999999 & TRN \\
\hline CHEMBL1335317 & 688267 & 4.4 & 5.0938 & TRN & \\
\hline CHEMBL1436915 & 688267 & 4.35 & 4.9896 & TRN & \\
\hline CHEMBL1553737 & 688267 & 4.65 & 5.0107 & TST & \\
\hline CHEMBL1458244 & 688267 & 4.05 & 4.9984 & TRN & \\
\hline CHEMBL1505902 & 688267 & 6.25 & 5.0466 & TST & \\
\hline CHEMBL 1457747 & 688267 & 4.2 & 5.0155 & TRN & \\
\hline CHEMBL1313896 & 688267 & 5.25 & 5.0933 & TRN & \\
\hline CHEMBL1332255 & 688267 & 5.25 & 5.0342 & TST & \\
\hline CHEMBL1334564 & 688267 & 4.65 & 5.0012 & TRN & \\
\hline CHEMBL1485203 & 688267 & 4.0 & 5.1059 & TRN & \\
\hline CHEMBL1496574 & 688267 & 5.5 & 5.0817 & TRN & \\
\hline CHEMBL1514407 & 688267 & 5.45 & 5.1017 & TRN & \\
\hline CHEMBL1312127 & 688267 & 6.2 & 5.1046 & TRN & \\
\hline CHEMBL1496672 & 688267 & 5.6 & 5.0186 & TRN & \\
\hline CHEMBL1499149 & 688267 & 5.25 & 5.0713 & TST & \\
\hline CHEMBL1575079 & 688267 & 3.95 & 5.0074 & TRN & \\
\hline CHEMBL1493135 & 688267 & 5.25 & 5.0647 & TRN & \\
\hline CHEMBL1404687 & 688267 & 5.05 & 5.0258 & TRN & \\
\hline CHEMBL1415905 & 688267 & 5.55 & 5.1183 & TRN & \\
\hline
\end{tabular}




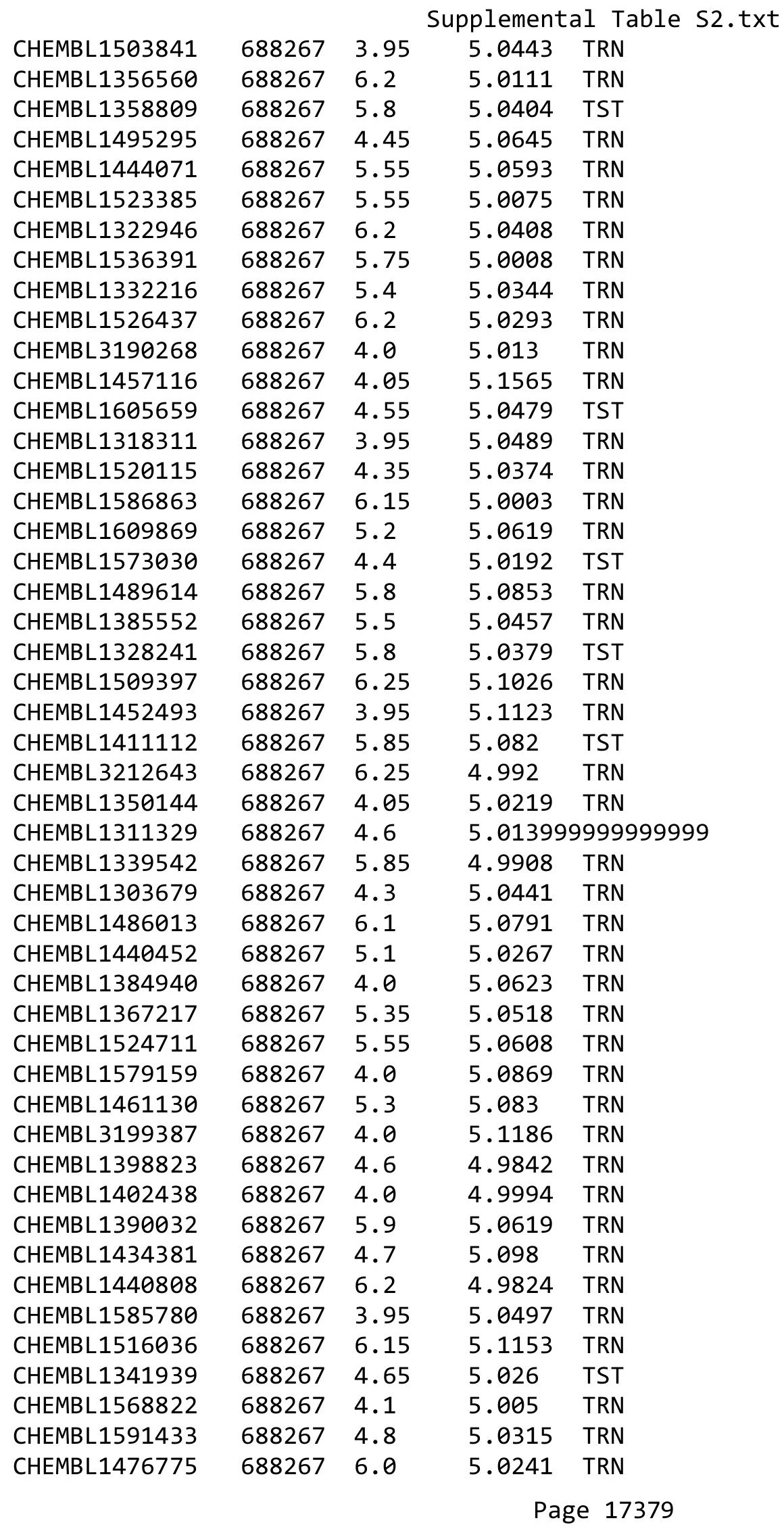




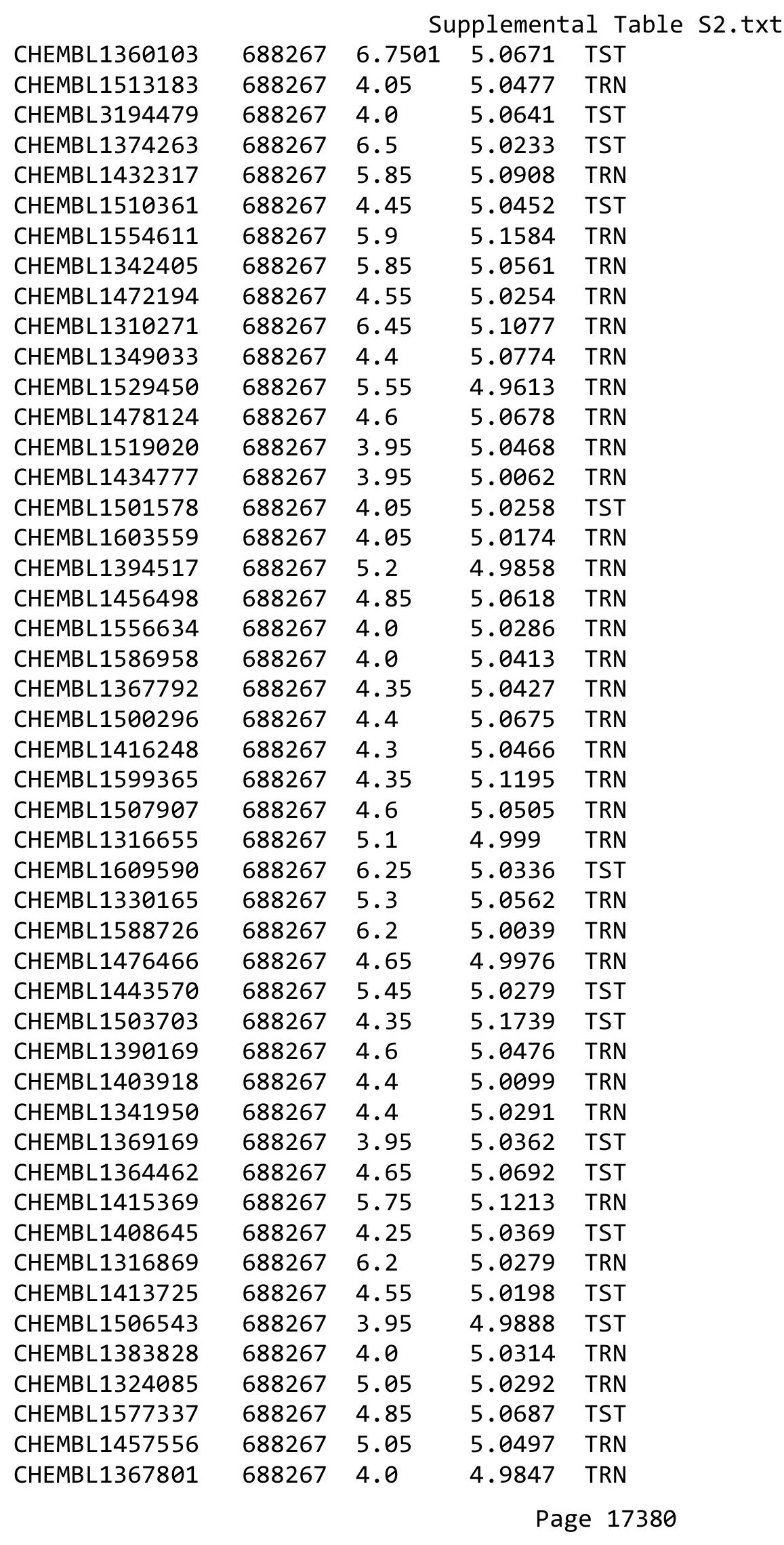




\begin{tabular}{|c|c|c|c|c|}
\hline \multicolumn{5}{|c|}{ Supplemental Table S2.txt } \\
\hline CHEMBL1346235 & 688267 & 4.05 & 4.9959 & TRN \\
\hline CHEMBL1442703 & 688267 & 4.05 & 5.0236 & TST \\
\hline CHEMBL1560805 & 688267 & 6.2 & 5.1027 & TRN \\
\hline CHEMBL1447250 & 688267 & 4.25 & 5.0277 & TRN \\
\hline CHEMBL1380885 & 688267 & 6.5 & 5.0933 & TRN \\
\hline CHEMBL1494285 & 688267 & 5.65 & 5.0528 & TST \\
\hline CHEMBL1490728 & 688267 & 4.0 & 5.0285 & TRN \\
\hline CHEMBL1498739 & 688267 & 6.2 & 5.0009 & TRN \\
\hline CHEMBL1359989 & 688267 & 4.55 & 5.0579 & TRN \\
\hline CHEMBL1525190 & 688267 & 4.05 & 4.9885 & TRN \\
\hline CHEMBL1597472 & 688267 & 4.05 & 5.1485 & TRN \\
\hline CHEMBL1460473 & 688267 & 6.25 & 5.0757 & TRN \\
\hline CHEMBL1311783 & 688267 & 5.7 & 5.0356 & TRN \\
\hline CHEMBL1363472 & 688267 & 6.2 & 5.0981 & TRN \\
\hline CHEMBL1472004 & 688267 & 4.0 & 5.1091 & TRN \\
\hline CHEMBL1578679 & 688267 & 5.5 & 5.0848 & TST \\
\hline CHEMBL1490191 & 688267 & 4.35 & 5.0712 & TRN \\
\hline CHEMBL1559144 & 688267 & 5.55 & 5.0066 & TRN \\
\hline CHEMBL1544144 & 688267 & 4.6 & 5.0185 & TRN \\
\hline CHEMBL1431089 & 688267 & 6.15 & 5.0442 & TRN \\
\hline CHEMBL1586622 & 688267 & 6.2 & 5.1029 & TRN \\
\hline CHEMBL1471622 & 688267 & 5.1 & 5.0818 & TRN \\
\hline CHEMBL1378446 & 688267 & 4.0 & 5.0155 & TRN \\
\hline CHEMBL1501135 & 688267 & 4.05 & 5.0042 & TST \\
\hline CHEMBL1590441 & 688267 & 4.5 & 5.035 & TRN \\
\hline CHEMBL1581117 & 688267 & 6.2 & 5.0331 & TRN \\
\hline CHEMBL1558627 & 688267 & 4.8 & 5.0681 & TRN \\
\hline CHEMBL1518448 & 688267 & 4.05 & 5.1029 & TST \\
\hline CHEMBL1518537 & 688267 & 5.45 & 5.0818 & TRN \\
\hline CHEMBL1445137 & 688267 & 5.35 & 5.0343 & TRN \\
\hline CHEMBL1571407 & 688267 & 5.3 & 5.1004 & TRN \\
\hline CHEMBL1367863 & 688267 & 4.35 & 5.0759 & TRN \\
\hline CHEMBL1503467 & 688267 & 5.3 & 5.0692 & TRN \\
\hline CHEMBL1366051 & 688267 & 4.25 & 5.0303 & TST \\
\hline CHEMBL1579970 & 688267 & 4.3 & 5.0618 & TRN \\
\hline CHEMBL3191099 & 688267 & 5.55 & 5.0932 & TRN \\
\hline CHEMBL 1438925 & 688267 & 5.75 & 5.01 & TRN \\
\hline CHEMBL1416746 & 688267 & 5.2 & 5.0887 & TRN \\
\hline CHEMBL1422060 & 688267 & 4.4 & 5.0864 & TRN \\
\hline CHEMBL1552468 & 688267 & 4.6 & 5.1412 & TRN \\
\hline CHEMBL1535815 & 688267 & 4.05 & 4.9976 & TRN \\
\hline CHEMBL1364784 & 688267 & 5.85 & 5.0526 & TRN \\
\hline CHEMBL1553206 & 688267 & 6.2 & 5.0602 & TRN \\
\hline CHEMBL1563544 & 688267 & 5.55 & 5.0434 & TRN \\
\hline CHEMBL1335331 & 688267 & 5.25 & 5.0869 & TRN \\
\hline CHEMBL1591403 & 688267 & 4.0 & 5.0796 & TRN \\
\hline CHEMBL1441115 & 688267 & 4.8 & 5.0537 & TRN \\
\hline CHEMBL1439594 & 688267 & 5.6 & 5.0333 & TRN \\
\hline
\end{tabular}




\begin{tabular}{|c|c|c|c|c|}
\hline \multicolumn{5}{|c|}{ Supplemental Table S2.txt } \\
\hline CHEMBL1532767 & 688267 & 5.35 & 5.0631 & TRN \\
\hline CHEMBL1472278 & 688267 & 3.95 & 5.0496 & TRN \\
\hline CHEMBL1432570 & 688267 & 4.05 & 5.0811 & TRN \\
\hline CHEMBL1535612 & 688267 & 6.2 & 5.0621 & TST \\
\hline CHEMBL1380252 & 688267 & 4.85 & 5.0334 & TRN \\
\hline CHEMBL1355374 & 688267 & 6.2 & 5.1225 & TRN \\
\hline CHEMBL1354122 & 688267 & 4.75 & 5.1042 & TRN \\
\hline CHEMBL1407382 & 688267 & 6.2 & 5.1173 & TRN \\
\hline CHEMBL3190349 & 688267 & 5.8 & 5.0157 & TRN \\
\hline CHEMBL1435392 & 688267 & 5.75 & 5.1124 & TRN \\
\hline CHEMBL1581999 & 688267 & 4.0 & 5.0661 & TST \\
\hline CHEMBL1369828 & 688267 & 6.2 & 5.0901 & TRN \\
\hline CHEMBL1481682 & 688267 & 4.3 & 5.1528 & TRN \\
\hline CHEMBL1462592 & 688267 & 5.8 & 5.0998 & TRN \\
\hline CHEMBL1558044 & 688267 & 4.45 & 5.0561 & TRN \\
\hline CHEMBL1325471 & 688267 & 5.8 & 5.125 & TST \\
\hline CHEMBL1324932 & 688267 & 6.2 & 5.119 & TRN \\
\hline CHEMBL1438158 & 688267 & 6.15 & 5.112 & TRN \\
\hline CHEMBL1567723 & 688267 & 5.35 & 5.1121 & TRN \\
\hline CHEMBL1535249 & 688267 & 4.55 & 5.0893 & TRN \\
\hline CHEMBL1331847 & 688267 & 5.3 & 5.124 & TRN \\
\hline CHEMBL1317227 & 688267 & 5.55 & 5.0416 & TRN \\
\hline CHEMBL1398770 & 688267 & 4.05 & 4.9642 & TST \\
\hline CHEMBL1456713 & 688267 & 6.15 & 5.034 & TRN \\
\hline CHEMBL1485273 & 688267 & 4.6 & 5.0342 & TRN \\
\hline CHEMBL1554909 & 688267 & 4.0 & 5.0025 & TRN \\
\hline CHEMBL1604909 & 688267 & 4.95 & 5.0362 & TRN \\
\hline CHEMBL1398669 & 688267 & 4.1 & 5.043 & TRN \\
\hline CHEMBL1419195 & 688267 & 3.95 & 5.0426 & TRN \\
\hline CHEMBL 3856089 & 688267 & 4.05 & 4.9755 & TRN \\
\hline CHEMBL1998717 & 688267 & 4.4 & 5.0305 & TRN \\
\hline CHEMBL1413864 & 688267 & 4.3 & 5.0587 & TRN \\
\hline CHEMBL 2003887 & 688267 & 4.25 & 4.9882 & TRN \\
\hline CHEMBL1552238 & 688267 & 5.4 & 5.0852 & TRN \\
\hline CHEMBL1511078 & 688267 & 6.15 & 5.0836 & TRN \\
\hline CHEMBL1344428 & 688267 & 5.4 & 4.9768 & TRN \\
\hline CHEMBL1345134 & 688267 & 5.55 & 5.1383 & TRN \\
\hline CHEMBL3190505 & 688267 & 6.1 & 5.0687 & TRN \\
\hline CHEMBL1607419 & 688267 & 6.2 & 5.0353 & TST \\
\hline CHEMBL1481210 & 688267 & 5.2 & 5.1459 & TST \\
\hline CHEMBL1464870 & 688267 & 3.95 & 5.0257 & TRN \\
\hline CHEMBL1445442 & 688267 & 4.5 & 5.0526 & TRN \\
\hline CHEMBL1314573 & 688267 & 6.2 & 5.0063 & TRN \\
\hline CHEMBL1385657 & 688267 & 6.2 & 4.9847 & TRN \\
\hline CHEMBL1312164 & 688267 & 3.95 & 5.1298 & TRN \\
\hline CHEMBL1341805 & 688267 & 5.15 & 5.0538 & TRN \\
\hline CHEMBL1481088 & 688267 & 5.3 & 5.1071 & TRN \\
\hline CHEMBL1999900 & 688267 & 4.1 & 5.0152 & TST \\
\hline
\end{tabular}




\begin{tabular}{|c|c|c|c|c|}
\hline \multicolumn{5}{|c|}{ Supplemental Table S2.txt } \\
\hline CHEMBL1582676 & 688267 & 6.2 & 5.0665 & TST \\
\hline CHEMBL1547125 & 688267 & 6.2 & 5.038 & TRN \\
\hline CHEMBL1416458 & 688267 & 4.05 & 5.0591 & TST \\
\hline CHEMBL1319036 & 688267 & 5.4 & 5.0515 & TRN \\
\hline CHEMBL1396342 & 688267 & 4.05 & 4.9989 & TRN \\
\hline CHEMBL1435778 & 688267 & 4.4 & 5.0854 & TRN \\
\hline CHEMBL291481 & 688267 & 4.0 & 5.086 & TST \\
\hline CHEMBL1322468 & 688267 & 5.9 & 5.0702 & TRN \\
\hline CHEMBL3210447 & 688267 & 4.3 & 5.0498 & TRN \\
\hline CHEMBL1353082 & 688267 & 4.4 & 5.1006 & TST \\
\hline CHEMBL1526063 & 688267 & 5.5 & 5.0869 & TST \\
\hline CHEMBL1275633 & 688267 & 6.2 & 4.9883 & TRN \\
\hline CHEMBL 3213480 & 688267 & 4.4 & 5.0268 & TRN \\
\hline CHEMBL1335867 & 688267 & 5.35 & 5.0525 & TST \\
\hline CHEMBL1489976 & 688267 & 5.0 & 5.1005 & TRN \\
\hline CHEMBL1478200 & 688267 & 6.5 & 5.0295 & TST \\
\hline CHEMBL1573786 & 688267 & 4.05 & 5.0132 & TST \\
\hline CHEMBL1495342 & 688267 & 4.7 & 5.0551 & TST \\
\hline CHEMBL1610412 & 688267 & 4.55 & 5.0705 & TRN \\
\hline CHEMBL1473651 & 688267 & 4.0 & 4.9974 & TST \\
\hline CHEMBL1453837 & 688267 & 4.1 & 5.0395 & TRN \\
\hline CHEMBL1604498 & 688267 & 6.25 & 4.9806 & TRN \\
\hline CHEMBL1504880 & 688267 & 4.05 & 4.9693 & TRN \\
\hline CHEMBL1585418 & 688267 & 4.75 & 5.0941 & TST \\
\hline CHEMBL451191 & 688267 & 4.5 & 5.0608 & TRN \\
\hline CHEMBL1577167 & 688267 & 5.6 & 5.081 & TRN \\
\hline CHEMBL1390221 & 688267 & 4.05 & 5.0384 & TRN \\
\hline CHEMBL1426199 & 688267 & 6.25 & 5.1022 & TST \\
\hline CHEMBL 3214188 & 688267 & 6.15 & 5.0252 & TST \\
\hline CHEMBL1389319 & 688267 & 6.2 & 5.0121 & TRN \\
\hline CHEMBL1464654 & 688267 & 6.2 & 5.1099 & TRN \\
\hline CHEMBL1390194 & 688267 & 4.0 & 5.0365 & TRN \\
\hline CHEMBL1312369 & 688267 & 4.4 & 5.0143 & TRN \\
\hline CHEMBL 3214280 & 688267 & 4.1 & 5.0011 & TST \\
\hline CHEMBL1493010 & 688267 & 5.5 & 5.0443 & TST \\
\hline CHEMBL1456016 & 688267 & 5.35 & 5.085 & TRN \\
\hline CHEMBL1512567 & 688267 & 6.2 & 5.0532 & TST \\
\hline CHEMBL1337232 & 688267 & 4.0 & 5.0778 & TRN \\
\hline CHEMBL1510045 & 688267 & 5.3 & 5.0911 & TST \\
\hline CHEMBL1538428 & 688267 & 5.4 & 5.0302 & TRN \\
\hline CHEMBL443771 & 688267 & 4.4 & 5.0347 & TRN \\
\hline CHEMBL1452181 & 688267 & 5.8 & 5.0893 & TST \\
\hline CHEMBL1576123 & 688267 & 5.15 & 5.0215 & TRN \\
\hline CHEMBL1601053 & 688267 & 4.6 & 5.0746 & TRN \\
\hline CHEMBL1588306 & 688267 & 5.35 & 5.058 & TST \\
\hline CHEMBL1418072 & 688267 & 5.65 & 5.0121 & TRN \\
\hline CHEMBL1398596 & 688267 & 4.45 & 5.0401 & TRN \\
\hline CHEMBL1384738 & 688267 & 6.0 & 5.0744 & TST \\
\hline
\end{tabular}




\begin{tabular}{|c|c|c|c|c|}
\hline & & & pplement & $\mathrm{a} \perp \mathrm{Ta}$ \\
\hline CHEMBL1536012 & 688267 & 4.0 & 5.0578 & TST \\
\hline CHEMBL1592052 & 688267 & 6.2 & 5.106 & TRN \\
\hline CHEMBL1530025 & 688267 & 5.8 & 5.0672 & TST \\
\hline CHEMBL1604820 & 688267 & 4.6 & 5.0237 & TRN \\
\hline CHEMBL1545665 & 688267 & 5.3 & 5.0389 & TRN \\
\hline CHEMBL1589316 & 688267 & 4.0 & 5.0581 & TST \\
\hline CHEMBL1307029 & 688267 & 4.6 & 5.037 & TST \\
\hline CHEMBL1531247 & 688267 & 6.0 & 5.0442 & TST \\
\hline CHEMBL1430480 & 688267 & 5.3 & 5.1041 & TRN \\
\hline CHEMBL1492728 & 688267 & 4.35 & 5.0588 & TRN \\
\hline CHEMBL1353696 & 688267 & 4.65 & 5.0993 & TST \\
\hline CHEMBL1424018 & 688267 & 4.15 & 5.0726 & TRN \\
\hline CHEMBL1461649 & 688267 & 5.5 & 5.0281 & TST \\
\hline CHEMBL1533784 & 688267 & 5.35 & 5.1438 & TRN \\
\hline CHEMBL1558905 & 688267 & 6.25 & 4.9959 & TRN \\
\hline CHEMBL1593956 & 688267 & 3.95 & 4.9929 & TRN \\
\hline CHEMBL1361897 & 688267 & 4.0 & 5.0211 & TST \\
\hline CHEMBL1470811 & 688267 & 6.2 & 5.1716 & TRN \\
\hline CHEMBL1430370 & 688267 & 4.4 & 5.007 & TRN \\
\hline CHEMBL1550807 & 688267 & 5.75 & 5.1469 & TRN \\
\hline CHEMBL1425273 & 688267 & 4.05 & 5.0472 & TST \\
\hline CHEMBL1413146 & 688267 & 4.0 & 5.0658 & TST \\
\hline CHEMBL1528647 & 688267 & 5.5 & 5.0017 & TRN \\
\hline CHEMBL546137 & 688267 & 6.25 & 5.0947 & TRN \\
\hline CHEMBL1321549 & 688267 & 5.1 & 5.1474 & TRN \\
\hline CHEMBL1456771 & 688267 & 6.15 & 5.0305 & TRN \\
\hline CHEMBL1345302 & 688267 & 4.5 & 5.0344 & TRN \\
\hline CHEMBL1495394 & 688267 & 4.3 & 5.0312 & TRN \\
\hline CHEMBL1469978 & 688267 & 5.55 & 5.0518 & TST \\
\hline CHEMBL1561128 & 688267 & 4.05 & 5.0202 & TRN \\
\hline CHEMBL1537838 & 688267 & 5.25 & 5.0164 & TRN \\
\hline CHEMBL1472770 & 688267 & 6.45 & 4.9986 & TST \\
\hline CHEMBL1416797 & 688267 & 5.95 & 5.0393 & TRN \\
\hline CHEMBL1464194 & 688267 & 4.75 & 5.0682 & TRN \\
\hline CHEMBL1359914 & 688267 & 4.65 & 5.0705 & TRN \\
\hline CHEMBL1306822 & 688267 & 5.0 & 5.1087 & TRN \\
\hline CHEMBL1530459 & 688267 & 4.0 & 5.0745 & TRN \\
\hline CHEMBL1551902 & 688267 & 6.15 & 5.0343 & TRN \\
\hline CHEMBL1454289 & 688267 & 6.45 & 5.0207 & TRN \\
\hline CHEMBL1581514 & 688267 & 4.15 & 5.0255 & TRN \\
\hline CHEMBL1504017 & 688267 & 6.15 & 5.1328 & TRN \\
\hline CHEMBL1513419 & 688267 & 6.2 & 5.0899 & TRN \\
\hline CHEMBL1523973 & 688267 & 6.2 & 5.0484 & TST \\
\hline CHEMBL1332548 & 688267 & 5.25 & 5.0597 & TRN \\
\hline CHEMBL1466714 & 688267 & 4.6 & 5.0401 & TRN \\
\hline CHEMBL1384025 & 688267 & 5.8 & 5.0674 & TRN \\
\hline CHEMBL1338121 & 688267 & 6.2 & 5.0334 & TRN \\
\hline CHEMBL 3196275 & 688267 & 4.6 & 5.0245 & TRN \\
\hline
\end{tabular}




\begin{tabular}{|c|c|c|c|c|}
\hline \multicolumn{5}{|c|}{ Supplemental Table S2.txt } \\
\hline CHEMBL1588704 & 688267 & 5.0 & 5.0183 & TRN \\
\hline CHEMBL1589953 & 688267 & 6.2 & 5.0254 & TRN \\
\hline CHEMBL1445973 & 688267 & 5.3 & 5.0346 & TRN \\
\hline CHEMBL1478995 & 688267 & 5.3 & 5.0328 & TRN \\
\hline CHEMBL1560929 & 688267 & 6.2 & 5.0089 & TST \\
\hline CHEMBL1605911 & 688267 & 5.4 & 5.0672 & TRN \\
\hline CHEMBL1530838 & 688267 & 6.2 & 5.1544 & TRN \\
\hline CHEMBL1612835 & 688267 & 3.95 & 5.0987 & TST \\
\hline CHEMBL1459041 & 688267 & 4.4 & 5.0409 & TST \\
\hline CHEMBL1518752 & 688267 & 4.25 & 5.1017 & TST \\
\hline CHEMBL1590116 & 688267 & 4.05 & 5.0793 & TRN \\
\hline CHEMBL1553832 & 688267 & 4.2 & 5.043 & TST \\
\hline CHEMBL3207564 & 688267 & 4.7 & 5.0347 & TRN \\
\hline CHEMBL1567104 & 688267 & 4.0 & 4.9999 & TRN \\
\hline CHEMBL1363720 & 688267 & 5.6 & 5.0133 & TRN \\
\hline CHEMBL465423 & 688267 & 6.5 & 5.0703 & TST \\
\hline CHEMBL1328687 & 688267 & 4.0 & 5.1084 & TRN \\
\hline CHEMBL1513099 & 688267 & 4.15 & 4.9948 & TRN \\
\hline CHEMBL1402077 & 688267 & 6.2 & 5.0434 & TRN \\
\hline CHEMBL1596288 & 688267 & 5.85 & 5.0268 & TRN \\
\hline CHEMBL1559699 & 688267 & 5.65 & 5.034 & TRN \\
\hline CHEMBL3194612 & 688267 & 5.3 & 5.001 & TST \\
\hline CHEMBL1445781 & 688267 & 5.35 & 5.0801 & TRN \\
\hline CHEMBL1303225 & 688267 & 4.05 & 5.004 & TST \\
\hline CHEMBL1328104 & 688267 & 5.3 & 5.0608 & TRN \\
\hline CHEMBL1568092 & 688267 & 6.15 & 5.0299 & TRN \\
\hline CHEMBL3194958 & 688267 & 4.3 & 5.0241 & TST \\
\hline CHEMBL1379176 & 688267 & 6.25 & 5.0205 & TRN \\
\hline CHEMBL1489763 & 688267 & 5.4 & 5.0899 & TRN \\
\hline CHEMBL1396828 & 688267 & 6.2 & 5.0581 & TST \\
\hline CHEMBL1397895 & 688267 & 4.0 & 5.1237 & TRN \\
\hline CHEMBL1592916 & 688267 & 4.0 & 5.053 & TRN \\
\hline CHEMBL3196999 & 688267 & 4.0 & 5.1444 & TRN \\
\hline CHEMBL 3192484 & 688267 & 4.6 & 5.0449 & TRN \\
\hline CHEMBL1539890 & 688267 & 6.15 & 5.0516 & TRN \\
\hline CHEMBL1430785 & 688267 & 5.1 & 5.0279 & TST \\
\hline CHEMBL1524494 & 688267 & 4.45 & 5.1015 & TRN \\
\hline CHEMBL3194175 & 688267 & 3.95 & 5.0038 & TST \\
\hline CHEMBL1347556 & 688267 & 6.2 & 5.039 & TST \\
\hline CHEMBL1424009 & 688267 & 6.25 & 5.0395 & TST \\
\hline CHEMBL535166 & 688267 & 4.05 & 5.0791 & TST \\
\hline CHEMBL1986805 & 688267 & 6.1 & 5.0352 & TST \\
\hline CHEMBL1373435 & 688267 & 6.05 & 5.0726 & TRN \\
\hline CHEMBL1321487 & 688267 & 4.0 & 5.0623 & TRN \\
\hline CHEMBL1428894 & 688267 & 4.5 & 5.0085 & TST \\
\hline CHEMBL1563846 & 688267 & 4.95 & 5.1414 & TRN \\
\hline CHEMBL1314944 & 688267 & 4.0 & 5.0115 & TRN \\
\hline CHEMBL1309133 & 688267 & 6.5 & 5.1295 & TRN \\
\hline
\end{tabular}




\begin{tabular}{|c|c|c|c|c|c|}
\hline & & \multicolumn{4}{|c|}{ Supplemental Table s2.txt } \\
\hline CHEMBL1340414 & 688267 & 5.55 & 5.0751 & TRN & \\
\hline CHEMBL1552629 & 688267 & 5.35 & 5.0394 & TRN & \\
\hline CHEMBL 3193562 & 688267 & 5.0 & 5.0315 & TRN & \\
\hline CHEMBL 1434837 & 688267 & 6.2 & 5.0127 & TRN & \\
\hline CHEMBL1583734 & 688267 & 5.75 & 4.9903 & TST & \\
\hline CHEMBL1980031 & 688267 & 6.45 & 5.0 & TRN & \\
\hline CHEMBL1346761 & 688267 & 5.0 & 5.1426 & TRN & \\
\hline CHEMBL1548078 & 688267 & 5.6 & 5.1678 & TRN & \\
\hline CHEMBL1561640 & 688267 & 5.4 & 4.9976 & TST & \\
\hline CHEMBL1548943 & 688267 & 4.75 & 5.0861 & TRN & \\
\hline CHEMBL1481746 & 688267 & 5.6 & 5.0102 & TST & \\
\hline CHEMBL1353079 & 688267 & 4.05 & 5.0387 & TST & \\
\hline CHEMBL1591294 & 688267 & 6.45 & 5.11100 & $\partial 000000001$ & TST \\
\hline CHEMBL1545585 & 688267 & 5.45 & 5.1181 & TRN & \\
\hline CHEMBL1569104 & 688267 & 4.0 & 5.0391 & TRN & \\
\hline CHEMBL1352959 & 688267 & 4.25 & 5.0176 & TRN & \\
\hline CHEMBL1513706 & 688267 & 4.4 & 5.1326 & TRN & \\
\hline CHEMBL1596880 & 688267 & 4.05 & 5.1349 & TRN & \\
\hline CHEMBL1488984 & 688267 & 4.1 & 5.0226 & TRN & \\
\hline CHEMBL 3208529 & 688267 & 5.3 & 5.0523 & TRN & \\
\hline CHEMBL1396273 & 688267 & 6.1 & 5.0341 & TRN & \\
\hline CHEMBL1564425 & 688267 & 5.65 & 5.0558 & TRN & \\
\hline CHEMBL1518712 & 688267 & 5.35 & 5.0146 & TST & \\
\hline CHEMBL1397178 & 688267 & 4.8 & 5.0864 & TST & \\
\hline CHEMBL1496724 & 688267 & 4.25 & 5.1207 & TRN & \\
\hline CHEMBL1316059 & 688267 & 5.2 & 5.0141 & TRN & \\
\hline CHEMBL1587206 & 688267 & 6.2 & 4.9963 & TRN & \\
\hline CHEMBL1485686 & 688267 & 5.05 & 5.0732 & TRN & \\
\hline CHEMBL1587906 & 688267 & 4.95 & 5.0814 & TRN & \\
\hline CHEMBL1435112 & 688267 & 4.1 & 5.0415 & TRN & \\
\hline CHEMBL1554477 & 688267 & 4.0 & 5.0862 & TRN & \\
\hline CHEMBL1508270 & 688267 & 4.05 & 5.0945 & TRN & \\
\hline CHEMBL1476254 & 688267 & 3.95 & 5.0713 & TST & \\
\hline CHEMBL1367527 & 688267 & 5.1 & 5.1095 & TRN & \\
\hline CHEMBL1503248 & 688267 & 4.3 & 5.0695 & TST & \\
\hline CHEMBL1382904 & 688267 & 4.1 & 5.0852 & TRN & \\
\hline CHEMBL1463079 & 688267 & 4.6 & 5.0352 & TRN & \\
\hline CHEMBL1396148 & 688267 & 6.2 & 5.107 & TRN & \\
\hline CHEMBL1597681 & 688267 & 5.6 & 5.0628 & TST & \\
\hline CHEMBL1503864 & 688267 & 4.4 & 5.09 & TST & \\
\hline CHEMBL1511604 & 688267 & 5.95 & 5.1213 & TRN & \\
\hline CHEMBL1510542 & 688267 & 3.95 & 5.033 & TRN & \\
\hline CHEMBL1409832 & 688267 & 6.2 & 5.0297 & TRN & \\
\hline CHEMBL1421809 & 688267 & 4.65 & 5.0449 & TST & \\
\hline CHEMBL1399574 & 688267 & 4.3 & 5.0528 & TRN & \\
\hline CHEMBL1437287 & 688267 & 6.2 & 5.022 & TRN & \\
\hline CHEMBL1479505 & 688267 & 4.2 & 5.0079 & TRN & \\
\hline CHEMBL1426470 & 688267 & 4.6 & 5.1042 & TRN & \\
\hline
\end{tabular}




\begin{tabular}{|c|c|c|c|c|c|}
\hline & & & & & \\
\hline CHEMBL1526713 & 688267 & 5.5 & 5.0625 & TRN & \\
\hline CHEMBL1452396 & 688267 & 4.05 & 5.0968 & TST & \\
\hline CHEMBL1545618 & 688267 & 6.25 & 5.0711 & TST & \\
\hline CHEMBL1484058 & 688267 & 4.4 & 5.0047 & TRN & \\
\hline CHEMBL1333822 & 688267 & 4.3 & 5.0497 & TRN & \\
\hline CHEMBL1364587 & 688267 & 4.05 & 5.0998 & TRN & \\
\hline CHEMBL1329629 & 688267 & 5.15 & 5.0928 & TRN & \\
\hline CHEMBL1466422 & 688267 & 4.4 & 5.0803 & TRN & \\
\hline CHEMBL1520140 & 688267 & 5.55 & 5.0647 & TRN & \\
\hline CHEMBL1503065 & 688267 & 6.2 & 5.062 & TRN & \\
\hline CHEMBL1481649 & 688267 & 4.0 & 5.0624 & TRN & \\
\hline CHEMBL1435329 & 688267 & 5.05 & 5.0112 & TST & \\
\hline CHEMBL1341413 & 688267 & 4.65 & 5.0762 & TRN & \\
\hline CHEMBL1476438 & 688267 & 5.4 & 5.0745 & TRN & \\
\hline CHEMBL1461472 & 688267 & 6.15 & 5.0255 & TRN & \\
\hline CHEMBL1367555 & 688267 & 4.2 & 5.0038 & TST & \\
\hline CHEMBL1393698 & 688267 & 6.5501 & 5.0367 & TRN & \\
\hline CHEMBL1483234 & 688267 & 4.35 & 5.0395 & TRN & \\
\hline CHEMBL1492714 & 688267 & 6.5 & 5.0056 & TRN & \\
\hline CHEMBL1510445 & 688267 & 5.25 & 5.1293 & TRN & \\
\hline CHEMBL1437823 & 688267 & 6.2 & 5.0897 & TRN & \\
\hline CHEMBL1527448 & 688267 & 5.3 & 5.0614 & TST & \\
\hline CHEMBL1357332 & 688267 & 4.4 & 5.0868 & TRN & \\
\hline CHEMBL1520703 & 688267 & 6.7001 & 5.0807 & TRN & \\
\hline CHEMBL1407094 & 688267 & 4.0 & 4.9818 & TRN & \\
\hline CHEMBL1607325 & 688267 & 6.2 & 5.0182 & TST & \\
\hline CHEMBL1592100 & 688267 & 4.55 & 5.0485 & TRN & \\
\hline CHEMBL1539148 & 688267 & 4.05 & 5.0977 & TST & \\
\hline CHEMBL1362442 & 688267 & 5.0 & 5.0786 & TRN & \\
\hline CHEMBL1515972 & 688267 & 6.2 & 5.1323 & TRN & \\
\hline CHEMBL1332191 & 688267 & 4.05 & 5.0732 & TRN & \\
\hline CHEMBL1405727 & 688267 & 4.0 & 5.03600 & 00000000005 & TRN \\
\hline CHEMBL1514948 & 688267 & 4.25 & 5.0271 & TRN & \\
\hline CHEMBL1356922 & 688267 & 4.25 & 5.0369 & TRN & \\
\hline CHEMBL1314829 & 688267 & 5.7 & 5.0682 & TRN & \\
\hline CHEMBL1375766 & 688267 & 6.25 & 5.1735 & TRN & \\
\hline CHEMBL 3199278 & 688267 & 4.0 & 5.0294 & TRN & \\
\hline CHEMBL1396099 & 688267 & 5.6 & 5.0305 & TST & \\
\hline CHEMBL1397861 & 688267 & 4.35 & 5.0817 & TRN & \\
\hline CHEMBL1425142 & 688267 & 5.65 & 5.0706 & TRN & \\
\hline CHEMBL3191087 & 688267 & 4.4 & 5.001 & TST & \\
\hline CHEMBL 1473476 & 688267 & 4.3 & 5.0718 & TRN & \\
\hline CHEMBL1476392 & 688267 & 4.6 & 5.0341 & TRN & \\
\hline CHEMBL1309130 & 688267 & 4.6 & 5.0568 & TRN & \\
\hline CHEMBL1437759 & 688267 & 6.2 & 5.041 & TRN & \\
\hline CHEMBL1310413 & 688267 & 4.55 & 5.0606 & TST & \\
\hline CHEMBL1585587 & 688267 & 4.75 & 5.1233 & TRN & \\
\hline CHEMBL1546813 & 688267 & 6.6 & 5.13899 & 9999999999 & TRN \\
\hline & & & & 17387 & \\
\hline
\end{tabular}




\begin{tabular}{|c|c|c|c|c|}
\hline & & & ipplement & al Table S2. \\
\hline CHEMBL1576960 & 688267 & 4.0 & 4.9834 & TRN \\
\hline CHEMBL1356872 & 688267 & 4.4 & 5.0449 & TRN \\
\hline CHEMBL1401000 & 688267 & 6.5 & 5.0565 & TRN \\
\hline CHEMBL1454594 & 688267 & 4.25 & 5.0311 & TRN \\
\hline CHEMBL1312667 & 688267 & 5.8 & 5.039 & TRN \\
\hline CHEMBL1436343 & 688267 & 4.0 & 5.029 & TRN \\
\hline CHEMBL1561594 & 688267 & 4.65 & 5.01699 & 99999999995 \\
\hline CHEMBL1581836 & 688267 & 5.35 & 5.0421 & TST \\
\hline CHEMBL1463854 & 688267 & 4.0 & 5.0582 & TST \\
\hline CHEMBL1326386 & 688267 & 5.05 & 5.0524 & TST \\
\hline CHEMBL1417396 & 688267 & 6.2 & 5.0858 & TRN \\
\hline CHEMBL1493318 & 688267 & 4.85 & 5.0587 & TST \\
\hline CHEMBL1449780 & 688267 & 3.95 & 5.0185 & TRN \\
\hline CHEMBL1443418 & 688267 & 5.8 & 5.0362 & TRN \\
\hline CHEMBL1534126 & 688267 & 5.75 & 5.0618 & TRN \\
\hline CHEMBL3214439 & 688267 & 4.4 & 5.0204 & TST \\
\hline CHEMBL1472695 & 688267 & 5.6 & 5.1118 & TRN \\
\hline CHEMBL1523325 & 688267 & 4.65 & 5.0616 & TRN \\
\hline CHEMBL1312914 & 688267 & 4.0 & 4.9923 & TRN \\
\hline CHEMBL1417369 & 688267 & 6.2 & 5.0702 & TRN \\
\hline CHEMBL1581690 & 688267 & 5.2 & 5.0575 & TST \\
\hline CHEMBL1549424 & 688267 & 5.45 & 5.0419 & TRN \\
\hline CHEMBL1563827 & 688267 & 4.35 & 5.0685 & TST \\
\hline CHEMBL1376168 & 688267 & 6.2 & 5.0611 & TRN \\
\hline CHEMBL1548492 & 688267 & 4.0 & 5.0687 & TRN \\
\hline CHEMBL1564877 & 688267 & 6.2 & 5.0732 & TRN \\
\hline CHEMBL1500070 & 688267 & 4.55 & 5.0232 & TRN \\
\hline CHEMBL1330789 & 688267 & 4.9 & 5.1131 & TRN \\
\hline CHEMBL1429640 & 688267 & 5.5 & 5.0547 & TRN \\
\hline CHEMBL1429850 & 688267 & 4.35 & 5.0435 & TST \\
\hline CHEMBL1506078 & 688267 & 4.1 & 5.0257 & TST \\
\hline CHEMBL3194800 & 688267 & 5.35 & 5.0181 & TRN \\
\hline CHEMBL1522090 & 688267 & 4.7 & 5.0915 & TRN \\
\hline CHEMBL1521526 & 688267 & 4.05 & 5.0288 & TRN \\
\hline CHEMBL1470413 & 688267 & 5.25 & 5.1142 & TRN \\
\hline CHEMBL1400651 & 688267 & 6.5 & 5.0222 & TRN \\
\hline CHEMBL1335029 & 688267 & 4.0 & 5.0481 & TRN \\
\hline CHEMBL1308563 & 688267 & 5.55 & 5.0923 & TRN \\
\hline CHEMBL1463588 & 688267 & 4.35 & 5.0906 & TRN \\
\hline CHEMBL1544172 & 688267 & 4.05 & 5.0906 & TRN \\
\hline CHEMBL1491105 & 688267 & 5.9 & 5.0735 & TRN \\
\hline CHEMBL1442171 & 688267 & 6.05 & 5.0329 & TRN \\
\hline CHEMBL1498944 & 688267 & 4.05 & 5.0265 & TRN \\
\hline CHEMBL1594277 & 688267 & 6.5 & 5.0308 & TRN \\
\hline CHEMBL1490907 & 688267 & 6.2 & 5.0933 & TRN \\
\hline CHEMBL1547210 & 688267 & 4.6 & 5.0599 & TST \\
\hline CHEMBL1504439 & 688267 & 5.0 & 5.062 & TRN \\
\hline CHEMBL1368406 & 688267 & 3.95 & 5.061 & TRN \\
\hline
\end{tabular}




\begin{tabular}{|c|c|c|c|c|}
\hline \multicolumn{5}{|c|}{ Supplemental Table S2.txt } \\
\hline CHEMBL1371638 & 688267 & 6.1 & 5.0344 & TRN \\
\hline CHEMBL1326269 & 688267 & 6.2 & 5.0354 & TRN \\
\hline CHEMBL3199144 & 688267 & 4.3 & 5.0068 & TRN \\
\hline CHEMBL1591078 & 688267 & 4.05 & 5.0454 & TRN \\
\hline CHEMBL1255841 & 688267 & 5.6 & 5.13899 & 9999999999 \\
\hline CHEMBL1312561 & 688267 & 4.0 & 5.0392 & TRN \\
\hline CHEMBL1483920 & 688267 & 4.4 & 5.0081 & TST \\
\hline CHEMBL1320744 & 688267 & 5.3 & 5.0839 & TRN \\
\hline CHEMBL1602791 & 688267 & 4.05 & 5.0165 & TRN \\
\hline CHEMBL1532954 & 688267 & 5.05 & 5.0962 & TRN \\
\hline CHEMBL 2004182 & 688267 & 6.2 & 4.996 & TRN \\
\hline CHEMBL1315816 & 688267 & 4.55 & 4.9789 & TRN \\
\hline CHEMBL1424572 & 688267 & 5.0 & 5.0703 & TRN \\
\hline CHEMBL1559569 & 688267 & 5.25 & 5.085 & TRN \\
\hline CHEMBL1435864 & 688267 & 4.0 & 5.0638 & TRN \\
\hline CHEMBL1411289 & 688267 & 5.55 & 5.0336 & TRN \\
\hline CHEMBL1411766 & 688267 & 5.3 & 5.0502 & TRN \\
\hline CHEMBL1316681 & 688267 & 5.95 & 5.0945 & TRN \\
\hline CHEMBL1409295 & 688267 & 5.3 & 5.035 & TST \\
\hline CHEMBL1515629 & 688267 & 6.2 & 4.9661 & TRN \\
\hline CHEMBL1357142 & 688267 & 5.05 & 5.0368 & TRN \\
\hline CHEMBL1509805 & 688267 & 4.35 & 5.0471 & TRN \\
\hline CHEMBL1537424 & 688267 & 6.2 & 5.0087 & TST \\
\hline CHEMBL1393612 & 688267 & 5.1 & 5.0832 & TRN \\
\hline CHEMBL1402659 & 688267 & 6.2 & 5.0947 & TST \\
\hline CHEMBL1431042 & 688267 & 4.4 & 5.0959 & TST \\
\hline CHEMBL1346760 & 688267 & 5.85 & 5.0212 & TST \\
\hline CHEMBL1429175 & 688267 & 4.1 & 5.0762 & TST \\
\hline CHEMBL1402949 & 688267 & 4.0 & 5.0833 & TRN \\
\hline CHEMBL1372989 & 688267 & 5.4 & 5.0527 & TST \\
\hline CHEMBL1449958 & 688267 & 4.0 & 5.0766 & TRN \\
\hline CHEMBL3196698 & 688267 & 4.6 & 5.046 & TRN \\
\hline CHEMBL1381209 & 688267 & 4.15 & 5.0298 & TRN \\
\hline CHEMBL1320918 & 688267 & 3.95 & 5.0576 & TRN \\
\hline CHEMBL1612962 & 688267 & 4.2 & 5.0597 & TST \\
\hline CHEMBL1560392 & 688267 & 6.15 & 5.0285 & TRN \\
\hline CHEMBL1538448 & 688267 & 4.65 & 5.029 & TRN \\
\hline CHEMBL1575672 & 688267 & 5.55 & 5.0346 & TRN \\
\hline CHEMBL1391892 & 688267 & 6.8 & 5.0238 & TRN \\
\hline CHEMBL1382279 & 688267 & 4.35 & 5.0583 & TST \\
\hline CHEMBL1478889 & 688267 & 4.1 & 5.0261 & TST \\
\hline CHEMBL1449822 & 688267 & 3.85 & 5.0817 & TRN \\
\hline CHEMBL1609433 & 688267 & 4.0 & 5.0539 & TRN \\
\hline CHEMBL1599543 & 688267 & 6.25 & 5.1294 & TRN \\
\hline CHEMBL1385320 & 688267 & 5.95 & 4.9949 & TRN \\
\hline CHEMBL1402806 & 688267 & 3.95 & 5.027 & TRN \\
\hline CHEMBL1559898 & 688267 & 5.3 & 5.0899 & TST \\
\hline CHEMBL1478705 & 688267 & 4.3 & 5.0622 & TST \\
\hline
\end{tabular}




\begin{tabular}{|c|c|c|c|c|}
\hline & & & oplement & al Ta \\
\hline CHEMBL1546160 & 688267 & 7.8013 & 5.0649 & TRN \\
\hline CHEMBL1610332 & 688267 & 4.3 & 4.9765 & TRN \\
\hline CHEMBL9352 & 688267 & 3.95 & 5.0679 & TST \\
\hline CHEMBL1591549 & 688267 & 5.35 & 5.0065 & TST \\
\hline CHEMBL1494156 & 688267 & 3.95 & 5.0763 & TRN \\
\hline CHEMBL1416719 & 688267 & 5.95 & 5.1069 & TRN \\
\hline CHEMBL1474707 & 688267 & 5.8 & 5.0841 & TRN \\
\hline CHEMBL437061 & 688267 & 4.2 & 5.0197 & TRN \\
\hline CHEMBL1599283 & 688267 & 6.25 & 5.0106 & TST \\
\hline CHEMBL1389096 & 688267 & 5.1 & 5.1192 & TRN \\
\hline CHEMBL1598235 & 688267 & 5.25 & 5.0533 & TRN \\
\hline CHEMBL1411074 & 688267 & 5.8 & 5.0759 & TRN \\
\hline CHEMBL1469367 & 688267 & 6.2 & 5.0982 & TRN \\
\hline CHEMBL1305391 & 688267 & 5.95 & 5.0746 & TRN \\
\hline CHEMBL1316594 & 688267 & 5.3 & 5.0524 & TRN \\
\hline CHEMBL1410190 & 688267 & 4.75 & 5.0534 & TRN \\
\hline CHEMBL1523726 & 688267 & 4.45 & 5.0657 & TST \\
\hline CHEMBL1602643 & 688267 & 5.65 & 5.0447 & TRN \\
\hline CHEMBL1585406 & 688267 & 4.55 & 5.0367 & TRN \\
\hline CHEMBL1561032 & 688267 & 4.2 & 4.9974 & TRN \\
\hline CHEMBL1513598 & 688267 & 4.05 & 5.1368 & TRN \\
\hline CHEMBL1486273 & 688267 & 6.2 & 5.0756 & TRN \\
\hline CHEMBL1584898 & 688267 & 6.15 & 5.0489 & TRN \\
\hline CHEMBL1392052 & 688267 & 5.5 & 5.0551 & TRN \\
\hline CHEMBL1344262 & 688267 & 6.25 & 5.1014 & TST \\
\hline CHEMBL1489095 & 688267 & 5.95 & 5.0045 & TST \\
\hline CHEMBL1366420 & 688267 & 5.2 & 5.0284 & TRN \\
\hline CHEMBL1599552 & 688267 & 4.8 & 5.0375 & TRN \\
\hline CHEMBL1354860 & 688267 & 4.85 & 5.1008 & TRN \\
\hline CHEMBL1350303 & 688267 & 5.55 & 5.0258 & TRN \\
\hline CHEMBL1440776 & 688267 & 5.4 & 5.0065 & TRN \\
\hline CHEMBL1459511 & 688267 & 5.55 & 4.9891 & TRN \\
\hline CHEMBL1358625 & 688267 & 6.2 & 5.0547 & TRN \\
\hline CHEMBL1410509 & 688267 & 6.5 & 5.0341 & TRN \\
\hline CHEMBL1574168 & 688267 & 5.6 & 5.043 & TST \\
\hline CHEMBL1458865 & 688267 & 4.05 & 5.0776 & TRN \\
\hline CHEMBL1435756 & 688267 & 4.85 & 5.1251 & TRN \\
\hline CHEMBL1425144 & 688267 & 5.75 & 5.045 & TST \\
\hline CHEMBL1573079 & 688267 & 4.05 & 5.1021 & TRN \\
\hline CHEMBL1467529 & 688267 & 4.4 & 5.0277 & TRN \\
\hline CHEMBL1440727 & 688267 & 5.8 & 4.9975 & TST \\
\hline CHEMBL1466125 & 688267 & 4.75 & 5.0549 & TST \\
\hline CHEMBL1498500 & 688267 & 4.95 & 4.9755 & TRN \\
\hline CHEMBL1356994 & 688267 & 4.4 & 5.023 & TRN \\
\hline CHEMBL3213162 & 688267 & 4.3 & 5.0711 & TRN \\
\hline CHEMBL1428146 & 688267 & 4.7 & 5.0182 & TRN \\
\hline CHEMBL2003605 & 688267 & 5.05 & 4.9439 & TRN \\
\hline CHEMBL1431602 & 688267 & 4.85 & 5.0006 & TRN \\
\hline
\end{tabular}




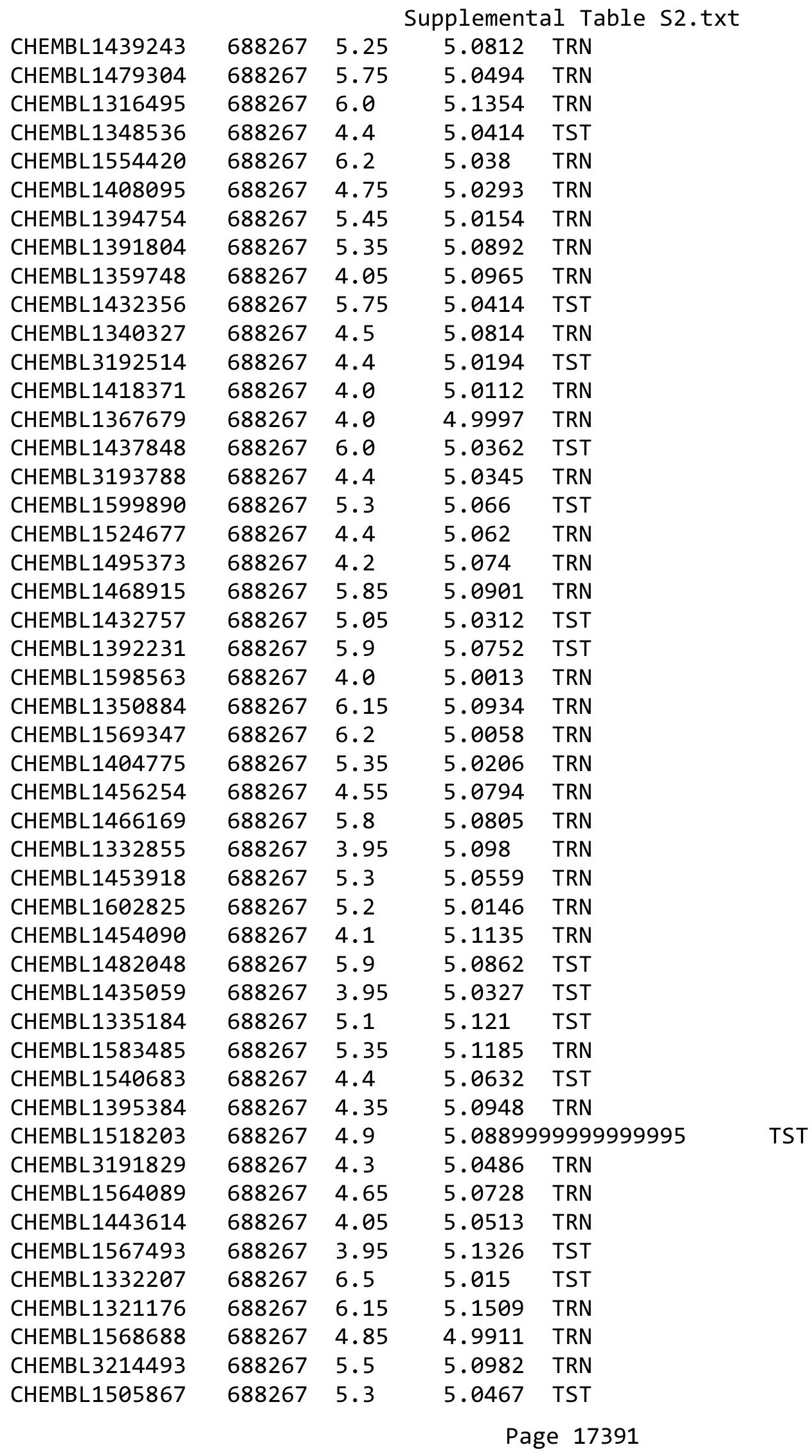




\begin{tabular}{|c|c|c|c|c|}
\hline & & & pplement & al $\mathrm{Ta}$ \\
\hline CHEMBL1515838 & 688267 & 4.25 & 5.0093 & TRN \\
\hline CHEMBL1434799 & 688267 & 5.3 & 5.0695 & TRN \\
\hline CHEMBL1980667 & 688267 & 5.9 & 4.9776 & TST \\
\hline CHEMBL 1400923 & 688267 & 4.05 & 5.1258 & TRN \\
\hline CHEMBL1412171 & 688267 & 5.55 & 5.0719 & TRN \\
\hline CHEMBL1436519 & 688267 & 4.75 & 5.0789 & TRN \\
\hline CHEMBL1595997 & 688267 & 6.2 & 5.0512 & TRN \\
\hline CHEMBL1424631 & 688267 & 6.2 & 5.0362 & TST \\
\hline CHEMBL1409954 & 688267 & 4.2 & 5.0462 & TRN \\
\hline CHEMBL1333049 & 688267 & 6.2 & 5.01 & TRN \\
\hline CHEMBL1610794 & 688267 & 5.2 & 5.0311 & TRN \\
\hline CHEMBL1532746 & 688267 & 4.05 & 5.0548 & TRN \\
\hline CHEMBL1414690 & 688267 & 5.6 & 5.1052 & TRN \\
\hline CHEMBL1396633 & 688267 & 4.15 & 5.1357 & TRN \\
\hline CHEMBL1505601 & 688267 & 4.4 & 5.0645 & TRN \\
\hline CHEMBL1496062 & 688267 & 4.05 & 5.0621 & TRN \\
\hline CHEMBL1414525 & 688267 & 5.9 & 5.0365 & TRN \\
\hline CHEMBL1417736 & 688267 & 4.1 & 5.0128 & TRN \\
\hline CHEMBL1382168 & 688267 & 4.25 & 5.1572 & TRN \\
\hline CHEMBL1452845 & 688267 & 6.2 & 5.0139 & TRN \\
\hline CHEMBL1485126 & 688267 & 5.95 & 4.9855 & TRN \\
\hline CHEMBL1613023 & 688267 & 4.4 & 5.1255 & TRN \\
\hline CHEMBL1507511 & 688267 & 4.3 & 5.0135 & TRN \\
\hline CHEMBL1580325 & 688267 & 5.55 & 5.0549 & TRN \\
\hline CHEMBL1331231 & 688267 & 5.45 & 5.0172 & TRN \\
\hline CHEMBL3209016 & 688267 & 6.15 & 5.0601 & TRN \\
\hline CHEMBL1575127 & 688267 & 5.65 & 5.0885 & TST \\
\hline CHEMBL1391995 & 688267 & 4.35 & 4.9527 & TRN \\
\hline CHEMBL1372630 & 688267 & 6.2 & 5.045 & TRN \\
\hline CHEMBL1317313 & 688267 & 5.25 & 5.0357 & TRN \\
\hline CHEMBL1402399 & 688267 & 3.95 & 5.0322 & TRN \\
\hline CHEMBL1554407 & 688267 & 4.55 & 5.1017 & TRN \\
\hline CHEMBL1313733 & 688267 & 4.05 & 5.0045 & TST \\
\hline CHEMBL1545888 & 688267 & 5.4 & 5.0662 & TST \\
\hline CHEMBL1425576 & 688267 & 4.5 & 4.9748 & TRN \\
\hline CHEMBL1344601 & 688267 & 4.55 & 5.0862 & TRN \\
\hline CHEMBL1553984 & 688267 & 6.2 & 5.1277 & TRN \\
\hline CHEMBL1449770 & 688267 & 6.45 & 5.0527 & TST \\
\hline CHEMBL1405626 & 688267 & 3.95 & 5.042 & TST \\
\hline CHEMBL1548728 & 688267 & 5.05 & 4.9988 & TRN \\
\hline CHEMBL1595569 & 688267 & 4.5 & 5.0637 & TRN \\
\hline CHEMBL1364083 & 688267 & 4.4 & 5.0877 & TST \\
\hline CHEMBL1430140 & 688267 & 5.8 & 5.0681 & TRN \\
\hline CHEMBL1373465 & 688267 & 5.8 & 5.055 & TRN \\
\hline CHEMBL1593564 & 688267 & 4.0 & 5.0693 & TRN \\
\hline CHEMBL1523350 & 688267 & 5.5 & 5.0303 & TST \\
\hline CHEMBL1325187 & 688267 & 5.3 & 5.0978 & TRN \\
\hline CHEMBL1547934 & 688267 & 5.45 & 5.0639 & TST \\
\hline
\end{tabular}




\begin{tabular}{|c|c|c|c|c|}
\hline \multicolumn{5}{|c|}{ Supplemental Table S2.txt } \\
\hline CHEMBL1323268 & 688267 & 5.55 & 5.0268 & TRN \\
\hline CHEMBL1514533 & 688267 & 3.95 & 5.0839 & TRN \\
\hline CHEMBL1563560 & 688267 & 6.2 & 5.0183 & TRN \\
\hline CHEMBL1410788 & 688267 & 4.3 & 5.0327 & TST \\
\hline CHEMBL1381290 & 688267 & 4.05 & 5.0269 & TST \\
\hline CHEMBL1559816 & 688267 & 5.85 & 5.0505 & TRN \\
\hline CHEMBL1379443 & 688267 & 5.8 & 5.0309 & TST \\
\hline CHEMBL1461544 & 688267 & 4.35 & 5.0506 & TRN \\
\hline CHEMBL1540418 & 688267 & 5.85 & 5.1475 & TRN \\
\hline CHEMBL1374202 & 688267 & 5.5 & 5.0641 & TST \\
\hline CHEMBL1470894 & 688267 & 4.75 & 5.0823 & TRN \\
\hline CHEMBL1321222 & 688267 & 4.65 & 5.1189 & TRN \\
\hline CHEMBL1318003 & 688267 & 4.15 & 5.0736 & TRN \\
\hline CHEMBL1577106 & 688267 & 5.85 & 5.0358 & TRN \\
\hline CHEMBL1340270 & 688267 & 5.25 & 5.0358 & TRN \\
\hline CHEMBL1389007 & 688267 & 4.4 & 5.0316 & TST \\
\hline CHEMBL1595350 & 688267 & 6.15 & 5.0357 & TST \\
\hline CHEMBL1583833 & 688267 & 4.45 & 5.0733 & TST \\
\hline CHEMBL1522412 & 688267 & 6.2 & 5.0885 & TRN \\
\hline CHEMBL1607929 & 688267 & 4.5 & 5.0362 & TST \\
\hline CHEMBL1569407 & 688267 & 4.4 & 5.033 & TRN \\
\hline CHEMBL1416938 & 688267 & 6.2 & 5.1037 & TRN \\
\hline CHEMBL1371776 & 688267 & 5.6 & 5.0365 & TST \\
\hline CHEMBL1458843 & 688267 & 6.05 & 5.0454 & TST \\
\hline CHEMBL1498916 & 688267 & 5.2 & 5.0493 & TRN \\
\hline CHEMBL1435592 & 688267 & 4.15 & 5.02 & TRN \\
\hline CHEMBL1339702 & 688267 & 5.55 & 5.026 & TRN \\
\hline CHEMBL1601794 & 688267 & 4.5 & 5.0072 & TRN \\
\hline CHEMBL1303416 & 688267 & 4.7 & 5.0824 & TST \\
\hline CHEMBL1516000 & 688267 & 5.55 & 5.1022 & TST \\
\hline CHEMBL3213464 & 688267 & 5.05 & 5.0322 & TRN \\
\hline CHEMBL1589685 & 688267 & 5.55 & 5.1477 & TRN \\
\hline CHEMBL1469144 & 688267 & 4.55 & 5.032 & TST \\
\hline CHEMBL1368896 & 688267 & 6.0 & 5.0221 & TRN \\
\hline CHEMBL1588793 & 688267 & 4.0 & 5.1202 & TRN \\
\hline CHEMBL1318077 & 688267 & 4.05 & 5.0655 & TST \\
\hline CHEMBL1461723 & 688267 & 5.55 & 5.0944 & TST \\
\hline CHEMBL1589103 & 688267 & 5.5 & 5.05 & TRN \\
\hline CHEMBL1420580 & 688267 & 4.05 & 5.0096 & TRN \\
\hline CHEMBL1502413 & 688267 & 4.3 & 5.0241 & TRN \\
\hline CHEMBL1344724 & 688267 & 4.05 & 5.1203 & TRN \\
\hline CHEMBL1389605 & 688267 & 5.8 & 5.0546 & TRN \\
\hline CHEMBL1561262 & 688267 & 6.2 & 5.1411 & TST \\
\hline CHEMBL1599336 & 688267 & 4.35 & 5.0279 & TRN \\
\hline CHEMBL1476601 & 688267 & 4.05 & 5.0318 & TRN \\
\hline CHEMBL1491120 & 688267 & 4.4 & 5.0094 & TST \\
\hline CHEMBL1509911 & 688267 & 5.15 & 5.1038 & TRN \\
\hline CHEMBL1445972 & 688267 & 5.3 & 5.0344 & TRN \\
\hline
\end{tabular}




\begin{tabular}{|c|c|c|c|c|c|}
\hline \multicolumn{6}{|c|}{ Supplemental Table S2.txt } \\
\hline CHEMBL1542153 & 688267 & 5.75 & 5.1206 & TRN & \\
\hline CHEMBL1527259 & 688267 & 4.4 & 5.02 & TRN & \\
\hline CHEMBL1514246 & 688267 & 5.25 & 5.0315 & TRN & \\
\hline CHEMBL1542183 & 688267 & 3.95 & 5.0343 & TST & \\
\hline CHEMBL1402663 & 688267 & 5.75 & 5.0678 & TRN & \\
\hline CHEMBL1357934 & 688267 & 6.2 & 4.98 & TRN & \\
\hline CHEMBL1439444 & 688267 & 5.5 & 5.0116 & TST & \\
\hline CHEMBL1337169 & 688267 & 4.05 & 5.0818 & TST & \\
\hline CHEMBL1346634 & 688267 & 6.05 & 5.117 & TST & \\
\hline CHEMBL1390827 & 688267 & 4.35 & 5.0633 & TRN & \\
\hline CHEMBL1348334 & 688267 & 5.75 & 5.0263 & TRN & \\
\hline CHEMBL1409030 & 688267 & 6.15 & 5.0833 & TRN & \\
\hline CHEMBL1308013 & 688267 & 4.7 & 5.079 & TST & \\
\hline CHEMBL1417576 & 688267 & 3.95 & 5.0574 & TST & \\
\hline CHEMBL1382888 & 688267 & 4.8 & 5.0814 & TRN & \\
\hline CHEMBL1354794 & 688267 & 4.65 & 4.9982 & TST & \\
\hline CHEMBL1350825 & 688267 & 4.4 & 5.0294 & TRN & \\
\hline CHEMBL1518693 & 688267 & 3.95 & 5.0098 & TRN & \\
\hline CHEMBL1371688 & 688267 & 5.2 & 5.0098 & TRN & \\
\hline CHEMBL1469394 & 688267 & 4.4 & 5.0295 & TRN & \\
\hline CHEMBL1315085 & 688267 & 6.15 & 5.051 & TRN & \\
\hline CHEMBL1497806 & 688267 & 6.25 & 5.0387 & TRN & \\
\hline CHEMBL1576001 & 688267 & 5.15 & 5.0286 & TRN & \\
\hline CHEMBL1435849 & 688267 & 6.0 & 5.1541 & TRN & \\
\hline CHEMBL1581676 & 688267 & 4.25 & 5.12299 & 9999999999 & TRN \\
\hline CHEMBL1490690 & 688267 & 3.95 & 5.0597 & TST & \\
\hline CHEMBL1485724 & 688267 & 6.05 & 5.0051 & TRN & \\
\hline CHEMBL1462346 & 688267 & 5.55 & 5.0193 & TST & \\
\hline CHEMBL1546558 & 688267 & 4.0 & 5.1394 & TRN & \\
\hline CHEMBL1593660 & 688267 & 5.9 & 5.0412 & TRN & \\
\hline CHEMBL1256924 & 688267 & 5.55 & 5.1396 & TST & \\
\hline CHEMBL3209998 & 688267 & 4.75 & 5.0263 & TRN & \\
\hline CHEMBL1435946 & 688267 & 4.8 & 5.0655 & TRN & \\
\hline CHEMBL1462480 & 688267 & 4.05 & 5.0513 & TST & \\
\hline CHEMBL1479076 & 688267 & 4.35 & 5.0202 & TRN & \\
\hline CHEMBL1333398 & 688267 & 4.55 & 5.1112 & TRN & \\
\hline CHEMBL1520049 & 688267 & 4.35 & 5.0383 & TRN & \\
\hline CHEMBL1475934 & 688267 & 4.4 & 5.0904 & TRN & \\
\hline CHEMBL1368800 & 688267 & 4.1 & 5.0548 & TRN & \\
\hline CHEMBL1611552 & 688267 & 5.55 & 5.0499 & TST & \\
\hline CHEMBL1514975 & 688267 & 4.1 & 5.13399 & 99999999995 & TRN \\
\hline CHEMBL1490260 & 688267 & 5.3 & 5.0222 & TST & \\
\hline CHEMBL1353380 & 688267 & 6.6 & 5.0644 & TRN & \\
\hline CHEMBL1458026 & 688267 & 5.0 & 5.1122 & TST & \\
\hline CHEMBL1386354 & 688267 & 4.45 & 5.0615 & TST & \\
\hline CHEMBL1504203 & 688267 & 5.5 & 5.0802 & TRN & \\
\hline CHEMBL1424979 & 688267 & 4.3 & 5.0472 & TST & \\
\hline CHEMBL1494238 & 688267 & 4.7 & 5.024 & TST & \\
\hline
\end{tabular}




\begin{tabular}{|c|c|c|c|c|c|}
\hline \multicolumn{6}{|c|}{ Supplemental Table s2.txt } \\
\hline CHEMBL1361791 & 688267 & 6.25 & 5.0481 & TRN & \\
\hline CHEMBL1437567 & 688267 & 5.9 & 5.019 & TRN & \\
\hline CHEMBL1484866 & 688267 & 5.4 & 5.05699 & 99999999995 & TST \\
\hline CHEMBL1394842 & 688267 & 4.05 & 5.1273 & TRN & \\
\hline CHEMBL1509763 & 688267 & 4.5 & 5.0688 & TRN & \\
\hline CHEMBL1305081 & 688267 & 6.5 & 5.0663 & TRN & \\
\hline CHEMBL1451648 & 688267 & 4.25 & 5.032 & TRN & \\
\hline CHEMBL1317269 & 688267 & 4.0 & 5.0149 & TRN & \\
\hline CHEMBL1385351 & 688267 & 5.35 & 5.0888 & TRN & \\
\hline CHEMBL1602916 & 688267 & 3.95 & 5.0526 & TRN & \\
\hline CHEMBL1463264 & 688267 & 4.85 & 5.0232 & TST & \\
\hline CHEMBL 3214090 & 688267 & 4.25 & 4.9922 & TST & \\
\hline CHEMBL1395720 & 688267 & 4.25 & 5.1569 & TRN & \\
\hline CHEMBL1513721 & 688267 & 6.2 & 5.1431 & TRN & \\
\hline CHEMBL1571569 & 688267 & 4.3 & 5.0544 & TRN & \\
\hline CHEMBL1478105 & 688267 & 6.2 & 5.0521 & TRN & \\
\hline CHEMBL1612125 & 688267 & 5.25 & 4.9726 & TRN & \\
\hline CHEMBL1361293 & 688267 & 5.3 & 5.0145 & TST & \\
\hline CHEMBL1587267 & 688267 & 4.65 & 4.9965 & TRN & \\
\hline CHEMBL1405338 & 688267 & 4.25 & 5.0961 & TRN & \\
\hline CHEMBL1593791 & 688267 & 4.0 & 5.1528 & TRN & \\
\hline CHEMBL1604924 & 688267 & 4.35 & 5.0598 & TRN & \\
\hline CHEMBL1601482 & 688267 & 4.55 & 5.0398 & TST & \\
\hline CHEMBL1484408 & 688267 & 4.8 & 5.0366 & TRN & \\
\hline CHEMBL1549984 & 688267 & 6.05 & 5.0854 & TST & \\
\hline CHEMBL1587868 & 688267 & 4.65 & 5.067 & TST & \\
\hline CHEMBL1419115 & 688267 & 3.95 & 5.0235 & TRN & \\
\hline CHEMBL1581588 & 688267 & 4.1 & 5.0955 & TRN & \\
\hline CHEMBL1453042 & 688267 & 4.05 & 5.0415 & TRN & \\
\hline CHEMBL1570570 & 688267 & 4.6 & 5.12 & TRN & \\
\hline CHEMBL1523161 & 688267 & 6.2 & 5.1271 & TST & \\
\hline CHEMBL1422599 & 688267 & 5.35 & 5.0481 & TST & \\
\hline CHEMBL1191301 & 688267 & 4.45 & 5.1212 & TRN & \\
\hline CHEMBL1427298 & 688267 & 5.5 & 4.9784 & TRN & \\
\hline CHEMBL1538119 & 688267 & 6.2 & 5.1339 & TRN & \\
\hline CHEMBL1594098 & 688267 & 4.35 & 5.0886 & TRN & \\
\hline CHEMBL1359814 & 688267 & 6.2 & 5.0236 & TST & \\
\hline CHEMBL1538726 & 688267 & 5.0 & 4.9982 & TRN & \\
\hline CHEMBL1574152 & 688267 & 4.35 & 5.0905 & TRN & \\
\hline CHEMBL1575213 & 688267 & 6.2 & 5.0612 & TRN & \\
\hline CHEMBL1510860 & 688267 & 4.65 & 4.9545 & TRN & \\
\hline CHEMBL1329711 & 688267 & 6.0 & 5.0157 & TRN & \\
\hline CHEMBL1602517 & 688267 & 6.0 & 5.0027 & TST & \\
\hline CHEMBL1564682 & 688267 & 6.15 & 5.0183 & TST & \\
\hline CHEMBL1345262 & 688267 & 3.95 & 4.9944 & TRN & \\
\hline CHEMBL1444840 & 688267 & 6.05 & 5.0748 & TRN & \\
\hline CHEMBL1493020 & 688267 & 4.8 & 5.0199 & TRN & \\
\hline CHEMBL1555539 & 688267 & 4.7 & 5.0623 & TRN & \\
\hline
\end{tabular}




\begin{tabular}{|c|c|c|c|c|}
\hline \multicolumn{5}{|c|}{ Supplemental Table S2.txt } \\
\hline CHEMBL1418836 & 688267 & 5.6 & 5.0417 & TRN \\
\hline CHEMBL1531359 & 688267 & 4.0 & 5.044 & TRN \\
\hline CHEMBL1360380 & 688267 & 4.0 & 5.0325 & TRN \\
\hline CHEMBL1423680 & 688267 & 5.35 & 5.1162 & TRN \\
\hline CHEMBL1500488 & 688267 & 3.95 & 5.0508 & TRN \\
\hline CHEMBL1366222 & 688267 & 4.4 & 5.1124 & TRN \\
\hline CHEMBL1377620 & 688267 & 4.05 & 5.03 & TRN \\
\hline CHEMBL1577570 & 688267 & 5.95 & 5.0293 & TRN \\
\hline CHEMBL1352548 & 688267 & 3.95 & 5.0483 & TRN \\
\hline CHEMBL1301594 & 688267 & 6.15 & 5.1389 & TRN \\
\hline CHEMBL1330595 & 688267 & 5.65 & 5.061 & TST \\
\hline CHEMBL1357544 & 688267 & 6.15 & 5.0378 & TRN \\
\hline CHEMBL445420 & 688267 & 4.35 & 4.9814 & TST \\
\hline CHEMBL1613239 & 688267 & 5.0 & 5.0248 & TRN \\
\hline CHEMBL1340061 & 688267 & 4.2 & 5.0734 & TRN \\
\hline CHEMBL3197000 & 688267 & 4.25 & 5.0468 & TST \\
\hline CHEMBL3193456 & 688267 & 4.3 & 5.1238 & TRN \\
\hline CHEMBL1590029 & 688267 & 4.05 & 5.0038 & TRN \\
\hline CHEMBL1516192 & 688267 & 4.35 & 5.1214 & TRN \\
\hline CHEMBL1434068 & 688267 & 4.0 & 5.0507 & TRN \\
\hline CHEMBL1607918 & 688267 & 4.05 & 4.9969 & TST \\
\hline CHEMBL1549422 & 688267 & 6.2 & 5.002 & TRN \\
\hline CHEMBL1356333 & 688267 & 4.0 & 5.1407 & TRN \\
\hline CHEMBL1556690 & 688267 & 4.35 & 5.0748 & TRN \\
\hline CHEMBL1515581 & 688267 & 6.2 & 5.1002 & TRN \\
\hline CHEMBL1449631 & 688267 & 5.85 & 4.9915 & TRN \\
\hline CHEMBL1522857 & 688267 & 4.1 & 5.0655 & TRN \\
\hline CHEMBL1607881 & 688267 & 4.05 & 5.0502 & TRN \\
\hline CHEMBL1527039 & 688267 & 5.25 & 5.0703 & TRN \\
\hline CHEMBL1305218 & 688267 & 4.35 & 5.0695 & TST \\
\hline CHEMBL3191853 & 688267 & 5.8 & 5.0279 & TRN \\
\hline CHEMBL1351496 & 688267 & 4.75 & 5.1325 & TRN \\
\hline CHEMBL1584268 & 688267 & 4.05 & 5.0233 & TRN \\
\hline CHEMBL1548128 & 688267 & 4.0 & 5.0197 & TRN \\
\hline CHEMBL1448244 & 688267 & 6.2 & 5.0217 & TRN \\
\hline CHEMBL1546199 & 688267 & 4.4 & 4.9819 & TST \\
\hline CHEMBL1574868 & 688267 & 5.65 & 5.1154 & TRN \\
\hline CHEMBL1613717 & 688267 & 6.1 & 5.1057 & TST \\
\hline CHEMBL1463585 & 688267 & 4.3 & 5.0781 & TRN \\
\hline CHEMBL1495516 & 688267 & 4.7 & 5.0378 & TRN \\
\hline CHEMBL1566416 & 688267 & 5.3 & 5.0858 & TRN \\
\hline CHEMBL1236872 & 688267 & 6.0 & 5.078 & TRN \\
\hline CHEMBL1470410 & 688267 & 5.9 & 5.1059 & TRN \\
\hline CHEMBL1578468 & 688267 & 5.55 & 5.0427 & TST \\
\hline CHEMBL1397112 & 688267 & 6.1 & 5.0307 & TRN \\
\hline CHEMBL1589277 & 688267 & 4.15 & 5.1109 & TRN \\
\hline CHEMBL1488147 & 688267 & 4.4 & 5.0229 & TRN \\
\hline CHEMBL1433837 & 688267 & 5.0 & 5.0605 & TRN \\
\hline
\end{tabular}




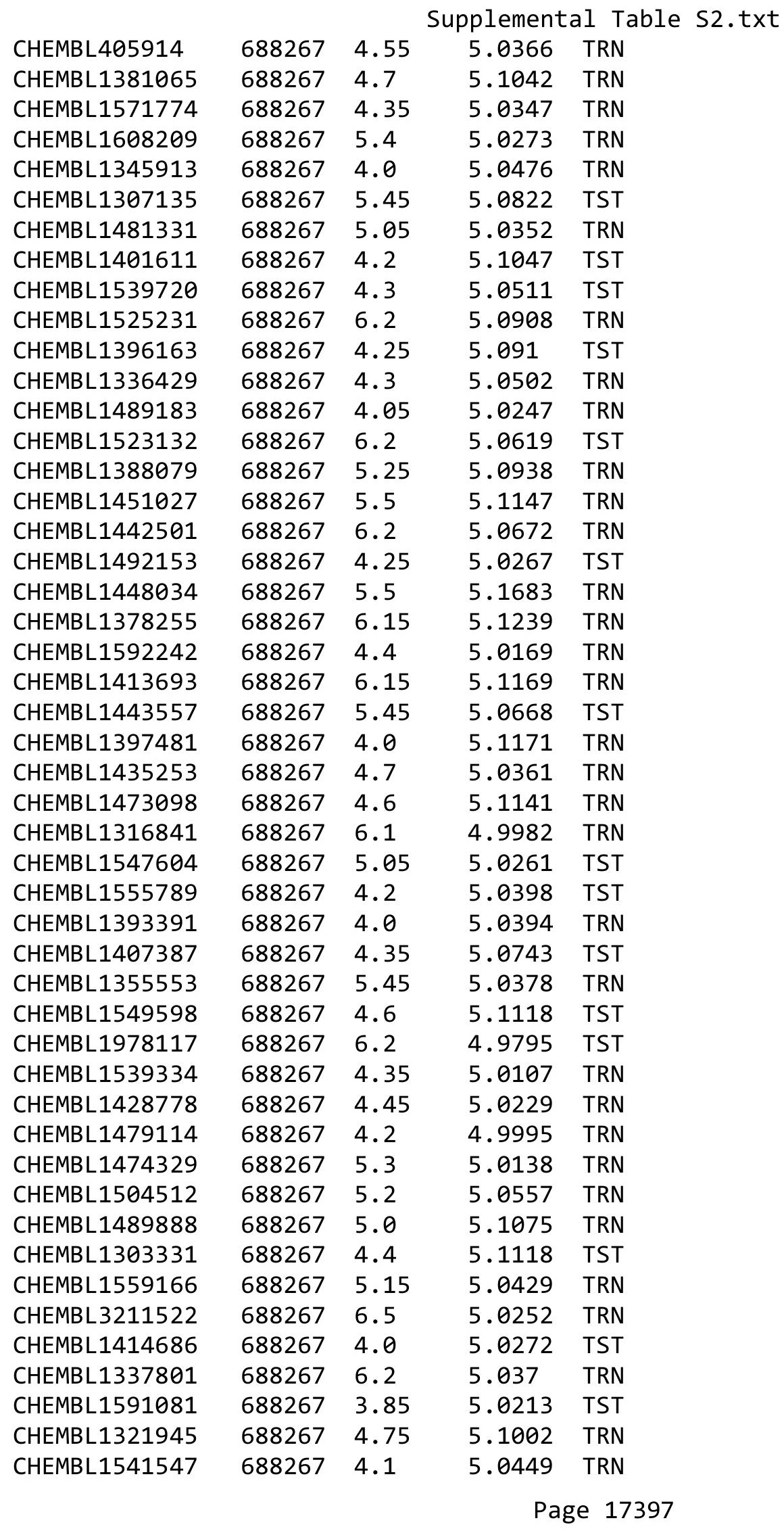




\begin{tabular}{|c|c|c|c|c|}
\hline \multicolumn{5}{|c|}{ Supplemental Table s2.txt } \\
\hline CHEMBL1579778 & 688267 & 4.5 & 5.1134 & TST \\
\hline CHEMBL1528256 & 688267 & 6.6 & 5.1265 & TRN \\
\hline CHEMBL1548781 & 688267 & 4.4 & 5.0522 & TST \\
\hline CHEMBL1440955 & 688267 & 6.15 & 4.9743 & TRN \\
\hline CHEMBL1484600 & 688267 & 5.85 & 5.0653 & TST \\
\hline CHEMBL1302857 & 688267 & 4.6 & 4.9789 & TRN \\
\hline CHEMBL1568463 & 688267 & 4.35 & 5.0454 & TRN \\
\hline CHEMBL1368681 & 688267 & 4.25 & 5.0159 & TST \\
\hline CHEMBL1347214 & 688267 & 5.0 & 5.1226 & TRN \\
\hline CHEMBL1403622 & 688267 & 5.25 & 5.0701 & TST \\
\hline CHEMBL1479084 & 688267 & 4.3 & 5.0241 & TST \\
\hline CHEMBL1571088 & 688267 & 4.4 & 5.0688 & TST \\
\hline CHEMBL1338195 & 688267 & 4.0 & 5.0406 & TST \\
\hline CHEMBL1390734 & 688267 & 4.65 & 5.0877 & TST \\
\hline CHEMBL1440485 & 688267 & 4.1 & 5.0455 & TRN \\
\hline CHEMBL1492509 & 688267 & 5.5 & 5.0166 & TRN \\
\hline CHEMBL1576519 & 688267 & 4.0 & 5.0782 & TST \\
\hline CHEMBL1520709 & 688267 & 3.95 & 5.0613 & TRN \\
\hline CHEMBL1609422 & 688267 & 4.7 & 5.0093 & TRN \\
\hline CHEMBL1306998 & 688267 & 4.05 & 5.0727 & TRN \\
\hline CHEMBL1465759 & 688267 & 6.2 & 5.0631 & TRN \\
\hline CHEMBL1301390 & 688267 & 5.3 & 5.0918 & TRN \\
\hline CHEMBL1322517 & 688267 & 4.0 & 5.0466 & TST \\
\hline CHEMBL1419260 & 688267 & 5.3 & 5.1091 & TRN \\
\hline CHEMBL1307179 & 688267 & 5.25 & 5.1278 & TRN \\
\hline CHEMBL1515901 & 688267 & 6.8499 & 5.0316 & TST \\
\hline CHEMBL1555343 & 688267 & 4.55 & 5.0626 & TRN \\
\hline CHEMBL1399906 & 688267 & 5.55 & 5.0075 & TRN \\
\hline CHEMBL1398486 & 688267 & 3.9 & 5.0871 & TRN \\
\hline CHEMBL1596176 & 688267 & 4.6 & 5.034 & TRN \\
\hline CHEMBL1436505 & 688267 & 6.5 & 5.0506 & TST \\
\hline CHEMBL1373090 & 688267 & 5.3 & 5.0817 & TRN \\
\hline CHEMBL1500349 & 688267 & 4.05 & 5.0463 & TRN \\
\hline CHEMBL1372460 & 688267 & 6.15 & 5.0687 & TRN \\
\hline CHEMBL1481744 & 688267 & 4.65 & 5.0243 & TST \\
\hline CHEMBL1604485 & 688267 & 4.05 & 5.0064 & TRN \\
\hline CHEMBL1585814 & 688267 & 6.45 & 5.0604 & TRN \\
\hline CHEMBL1316881 & 688267 & 4.05 & 5.0558 & TRN \\
\hline CHEMBL1478012 & 688267 & 4.05 & 5.0024 & TRN \\
\hline CHEMBL1393458 & 688267 & 6.0 & 5.0586 & TRN \\
\hline CHEMBL1495991 & 688267 & 4.65 & 5.0728 & TST \\
\hline CHEMBL1466674 & 688267 & 4.05 & 5.0814 & TRN \\
\hline CHEMBL1541231 & 688267 & 4.05 & 5.0863 & TRN \\
\hline CHEMBL1446898 & 688267 & 6.15 & 5.0717 & TST \\
\hline CHEMBL1543523 & 688267 & 5.35 & 5.0815 & TST \\
\hline CHEMBL1301956 & 688267 & 6.2 & 5.0536 & TRN \\
\hline CHEMBL1310420 & 688267 & 5.9 & 5.0461 & TST \\
\hline CHEMBL1342937 & 688267 & 4.3 & 5.0385 & TST \\
\hline
\end{tabular}




\begin{tabular}{|c|c|c|c|c|c|}
\hline \multicolumn{6}{|c|}{ Supplemental Table S2.txt } \\
\hline CHEMBL1401012 & 688267 & 4.05 & 5.0388 & TRN & \\
\hline CHEMBL1579125 & 688267 & 5.0 & 5.0586 & TRN & \\
\hline CHEMBL1534444 & 688267 & 5.6 & 5.0486 & TST & \\
\hline CHEMBL1492778 & 688267 & 5.7 & 5.0919 & TRN & \\
\hline CHEMBL1451868 & 688267 & 6.25 & 5.0542 & TRN & \\
\hline CHEMBL1448231 & 688267 & 6.05 & 5.0087 & TRN & \\
\hline CHEMBL1315017 & 688267 & 4.0 & 5.0256 & TRN & \\
\hline CHEMBL1570422 & 688267 & 4.35 & 5.0647 & TRN & \\
\hline CHEMBL1444888 & 688267 & 3.95 & 5.149 & TRN & \\
\hline CHEMBL1531105 & 688267 & 5.8 & 5.0821 & TRN & \\
\hline CHEMBL1540022 & 688267 & 5.35 & 5.04899 & 99999999995 & TRN \\
\hline CHEMBL1481962 & 688267 & 4.65 & 5.0676 & TST & \\
\hline CHEMBL1496837 & 688267 & 4.05 & 5.0441 & TRN & \\
\hline CHEMBL1336810 & 688267 & 5.55 & 5.1226 & TRN & \\
\hline CHEMBL1363155 & 688267 & 6.15 & 5.0976 & TRN & \\
\hline CHEMBL1372663 & 688267 & 6.2 & 5.0951 & TRN & \\
\hline CHEMBL1424791 & 688267 & 4.0 & 5.047 & TST & \\
\hline CHEMBL1563951 & 688267 & 5.1 & 5.1014 & TST & \\
\hline CHEMBL1426489 & 688267 & 5.3 & 5.1741 & TST & \\
\hline CHEMBL1386005 & 688267 & 4.2 & 5.0357 & TST & \\
\hline CHEMBL1315735 & 688267 & 3.95 & 5.0671 & TRN & \\
\hline CHEMBL1496912 & 688267 & 4.0 & 5.0125 & TRN & \\
\hline CHEMBL1583947 & 688267 & 4.05 & 5.1195 & TST & \\
\hline CHEMBL1490987 & 688267 & 6.0 & 5.0348 & TRN & \\
\hline CHEMBL 3214566 & 688267 & 4.05 & 5.0245 & TST & \\
\hline CHEMBL1581675 & 688267 & 3.95 & 5.1602 & TRN & \\
\hline CHEMBL1581843 & 688267 & 5.4 & 5.0668 & TRN & \\
\hline CHEMBL1483823 & 688267 & 5.65 & 5.0151 & TRN & \\
\hline CHEMBL1561228 & 688267 & 4.1 & 5.0629 & TRN & \\
\hline CHEMBL1527376 & 688267 & 5.4 & 5.0769 & TRN & \\
\hline CHEMBL1359163 & 688267 & 5.6 & 5.1737 & TRN & \\
\hline CHEMBL1603064 & 688267 & 4.8 & 5.1251 & TRN & \\
\hline CHEMBL1407454 & 688267 & 4.4 & 5.1105 & TRN & \\
\hline CHEMBL1378928 & 688267 & 5.2 & 5.0846 & TRN & \\
\hline CHEMBL1080897 & 688267 & 6.2 & 5.0889 & TRN & \\
\hline CHEMBL1479471 & 688267 & 4.4 & 5.045 & TRN & \\
\hline CHEMBL3208298 & 688267 & 6.2 & 5.0475 & TRN & \\
\hline CHEMBL1524432 & 688267 & 6.15 & 5.0263 & TST & \\
\hline CHEMBL1413103 & 688267 & 5.8 & 5.0084 & TST & \\
\hline CHEMBL1505626 & 688267 & 4.55 & 4.9944 & TST & \\
\hline CHEMBL1389743 & 688267 & 4.55 & 5.0154 & TRN & \\
\hline CHEMBL1393371 & 688267 & 5.05 & 5.0906 & TRN & \\
\hline CHEMBL1374402 & 688267 & 4.35 & 5.0895 & TRN & \\
\hline CHEMBL1612301 & 688267 & 4.5 & 5.0332 & TRN & \\
\hline CHEMBL1556862 & 688267 & 4.55 & 5.0595 & TRN & \\
\hline CHEMBL1331509 & 688267 & 6.2 & 5.0242 & TRN & \\
\hline CHEMBL1580253 & 688267 & 6.2 & 5.103 & TRN & \\
\hline CHEMBL1434684 & 688267 & 6.2 & 5.0415 & TRN & \\
\hline
\end{tabular}




\begin{tabular}{|c|c|c|c|c|c|}
\hline \multicolumn{6}{|c|}{ Supplemental Table S2.txt } \\
\hline CHEMBL1557517 & 688267 & 4.25 & 5.0219 & TST & \\
\hline CHEMBL1351758 & 688267 & 4.25 & 5.0294 & TST & \\
\hline CHEMBL1477341 & 688267 & 5.8 & 5.0101 & TST & \\
\hline CHEMBL 3199523 & 688267 & 5.75 & 5.0611 & TST & \\
\hline CHEMBL1373353 & 688267 & 6.15 & 5.0161 & TRN & \\
\hline CHEMBL1306527 & 688267 & 4.0 & 5.0484 & TST & \\
\hline CHEMBL1315712 & 688267 & 4.05 & 5.0501 & TRN & \\
\hline CHEMBL1302477 & 688267 & 4.8 & 5.0414 & TRN & \\
\hline CHEMBL1551573 & 688267 & 6.2 & 5.0331 & TRN & \\
\hline CHEMBL1342568 & 688267 & 4.05 & 5.086 & TRN & \\
\hline CHEMBL1477872 & 688267 & 5.25 & 5.1148 & TRN & \\
\hline CHEMBL1472787 & 688267 & 5.75 & 5.0679 & TRN & \\
\hline CHEMBL1499500 & 688267 & 6.2 & 5.0001 & TRN & \\
\hline CHEMBL1419551 & 688267 & 4.05 & 5.0043 & TST & \\
\hline CHEMBL1606078 & 688267 & 5.75 & 5.0747 & TST & \\
\hline CHEMBL 3198581 & 688267 & 5.65 & 5.0237 & TRN & \\
\hline CHEMBL1440449 & 688267 & 5.75 & 5.1333 & TRN & \\
\hline CHEMBL1399127 & 688267 & 5.8 & 5.0641 & TST & \\
\hline CHEMBL1376053 & 688267 & 6.25 & 5.0651 & TST & \\
\hline CHEMBL1305922 & 688267 & 6.2 & 4.9938 & TRN & \\
\hline CHEMBL1324535 & 688267 & 5.75 & 5.0298 & TST & \\
\hline CHEMBL1505610 & 688267 & 4.65 & 5.025 & TST & \\
\hline CHEMBL1487182 & 688267 & 4.35 & 5.0928 & TRN & \\
\hline CHEMBL1422770 & 688267 & 5.9 & 5.0891 & TRN & \\
\hline CHEMBL1490291 & 688267 & 4.65 & 5.0477 & TRN & \\
\hline CHEMBL1319165 & 688267 & 4.55 & 5.0424 & TRN & \\
\hline CHEMBL1582219 & 688267 & 4.45 & 5.0378 & TST & \\
\hline CHEMBL1549634 & 688267 & 4.8 & 5.0318 & TST & \\
\hline CHEMBL3196752 & 688267 & 4.05 & 5.11600 & 00000000005 & TRN \\
\hline CHEMBL1402078 & 688267 & 5.9 & 5.1204 & TRN & \\
\hline CHEMBL1451564 & 688267 & 6.15 & 5.0255 & TST & \\
\hline CHEMBL1311642 & 688267 & 6.0 & 5.0807 & TRN & \\
\hline CHEMBL1533359 & 688267 & 5.5 & 5.0005 & TRN & \\
\hline CHEMBL1311801 & 688267 & 3.95 & 5.0092 & TRN & \\
\hline CHEMBL1446241 & 688267 & 4.15 & 5.0401 & TST & \\
\hline CHEMBL1305111 & 688267 & 4.55 & 5.0146 & TRN & \\
\hline CHEMBL1443183 & 688267 & 6.05 & 5.0322 & TRN & \\
\hline CHEMBL1584337 & 688267 & 5.35 & 5.0149 & TRN & \\
\hline CHEMBL1550833 & 688267 & 6.45 & 5.102 & TRN & \\
\hline CHEMBL1354477 & 688267 & 4.1 & 5.0122 & TRN & \\
\hline CHEMBL3195394 & 688267 & 6.2 & 5.1183 & TST & \\
\hline CHEMBL1440546 & 688267 & 4.6 & 5.0746 & TRN & \\
\hline CHEMBL1595945 & 688267 & 5.25 & 5.0322 & TRN & \\
\hline CHEMBL1999060 & 688267 & 4.05 & 5.0604 & TST & \\
\hline CHEMBL1552592 & 688267 & 5.9 & 5.1001 & TRN & \\
\hline CHEMBL1538525 & 688267 & 6.2 & 5.0467 & TST & \\
\hline CHEMBL1313602 & 688267 & 4.0 & 5.021 & TRN & \\
\hline CHEMBL1587369 & 688267 & 5.05 & 5.0864 & TRN & \\
\hline
\end{tabular}




\begin{tabular}{|c|c|c|c|c|}
\hline \multirow[b]{2}{*}{ CHEMBL1381946 } & \multicolumn{4}{|c|}{ Supplemental Table S2.tx } \\
\hline & 688267 & 6.2 & 5.0704 & TST \\
\hline CHEMBL1560370 & 688267 & 5.25 & 5.0477 & TRN \\
\hline CHEMBL1345542 & 688267 & 5.1 & 5.087 & TRN \\
\hline CHEMBL1553294 & 688267 & 5.1 & 5.0795 & TRN \\
\hline CHEMBL1357623 & 688267 & 6.2 & 5.0028 & TRN \\
\hline CHEMBL 1400572 & 688267 & 5.7 & 5.0367 & TRN \\
\hline CHEMBL1463365 & 688267 & 5.65 & 5.1014 & TRN \\
\hline CHEMBL1362737 & 688267 & 5.4 & 5.0201 & TST \\
\hline CHEMBL1371077 & 688267 & 4.35 & 5.1221 & TRN \\
\hline CHEMBL1327188 & 688267 & 4.6 & 5.0828 & TST \\
\hline CHEMBL1332718 & 688267 & 6.2 & 5.0839 & TRN \\
\hline CHEMBL1590363 & 688267 & 5.3 & 5.0576 & TRN \\
\hline CHEMBL1593739 & 688267 & 5.55 & 5.0446 & TST \\
\hline CHEMBL1330992 & 688267 & 4.25 & 5.0016 & TST \\
\hline CHEMBL1325714 & 688267 & 4.0 & 5.045 & TST \\
\hline CHEMBL 168 & 688267 & 5.8 & 5.0884 & TST \\
\hline CHEMBL1370313 & 688267 & 4.65 & 5.1242 & TRN \\
\hline CHEMBL1531482 & 688267 & 5.55 & 5.0235 & TST \\
\hline CHEMBL1470537 & 688267 & 5.3 & 5.0368 & TST \\
\hline CHEMBL1478239 & 688267 & 5.5 & 5.0838 & TRN \\
\hline CHEMBL1414135 & 688267 & 4.0 & 5.0572 & TRN \\
\hline CHEMBL1358358 & 688267 & 4.45 & 5.0283 & TRN \\
\hline CHEMBL1358327 & 688267 & 6.05 & 5.0174 & TRN \\
\hline CHEMBL1376595 & 688267 & 4.05 & 5.0109 & TRN \\
\hline CHEMBL1480523 & 688267 & 5.4 & 5.0731 & TRN \\
\hline CHEMBL1412958 & 688267 & 4.7 & 5.1057 & TRN \\
\hline CHEMBL1520823 & 688267 & 4.05 & 5.0453 & TRN \\
\hline CHEMBL1611955 & 688267 & 4.4 & 5.1013 & TST \\
\hline CHEMBL1423438 & 688267 & 4.0 & 5.1108 & TRN \\
\hline CHEMBL1542516 & 688267 & 5.2 & 5.0188 & TST \\
\hline CHEMBL1487680 & 688267 & 4.45 & 5.1023 & TRN \\
\hline CHEMBL1332489 & 688267 & 4.7 & 5.0226 & TRN \\
\hline CHEMBL1611365 & 688267 & 4.7 & 4.9805 & TRN \\
\hline CHEMBL1528720 & 688267 & 4.0 & 5.1488 & TRN \\
\hline CHEMBL1557703 & 688267 & 5.35 & 5.0176 & TST \\
\hline CHEMBL1406437 & 688267 & 5.25 & 5.0434 & TRN \\
\hline CHEMBL1393546 & 688267 & 5.55 & 5.0377 & TRN \\
\hline CHEMBL1471196 & 688267 & 6.2 & 5.0531 & TRN \\
\hline CHEMBL1441514 & 688267 & 4.0 & 5.0565 & TST \\
\hline CHEMBL1442789 & 688267 & 4.7 & 5.0392 & TRN \\
\hline CHEMBL3195024 & 688267 & 4.5 & 5.008 & TST \\
\hline CHEMBL1460647 & 688267 & 6.05 & 5.0615 & TRN \\
\hline CHEMBL1581670 & 688267 & 4.65 & 5.0661 & TRN \\
\hline CHEMBL1352077 & 688267 & 6.15 & 5.1419 & TRN \\
\hline CHEMBL1467823 & 688267 & 5.0 & 5.1489 & TRN \\
\hline CHEMBL1391909 & 688267 & 5.6 & 5.1219 & TST \\
\hline CHEMBL1441679 & 688267 & 4.4 & 5.0434 & TRN \\
\hline CHEMBL1612032 & 688267 & 4.2 & 5.0738 & TRN \\
\hline
\end{tabular}




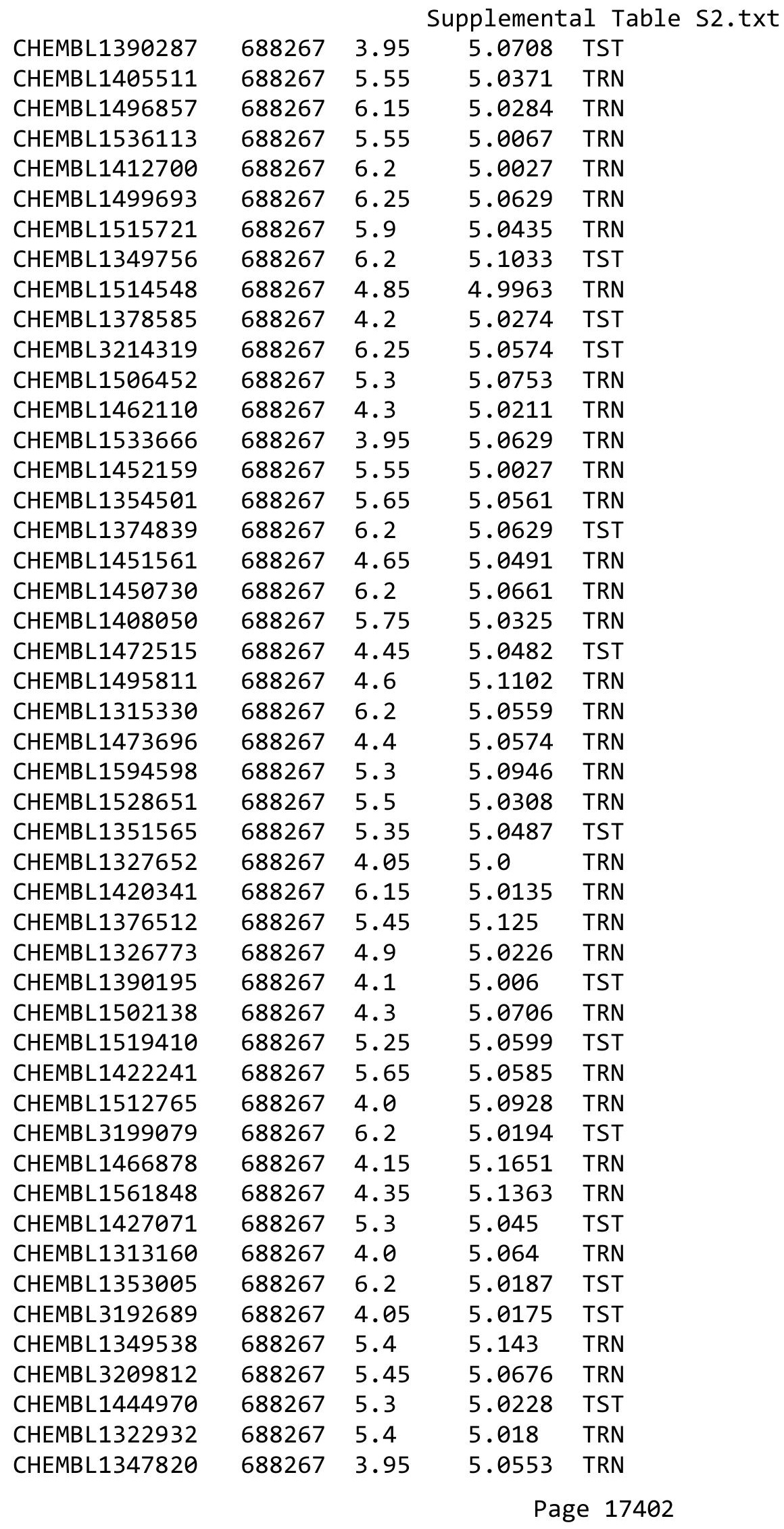




\begin{tabular}{|c|c|c|c|c|c|}
\hline \multicolumn{6}{|c|}{ Supplemental Table S2.txt } \\
\hline CHEMBL1337867 & 688267 & 5.65 & 5.0701 & TRN & \\
\hline CHEMBL1320633 & 688267 & 5.3 & 5.0856 & TRN & \\
\hline CHEMBL1578485 & 688267 & 4.1 & 4.9959 & TST & \\
\hline CHEMBL1591590 & 688267 & 6.2 & 5.0864 & TST & \\
\hline CHEMBL1314210 & 688267 & 3.95 & 5.0938 & TRN & \\
\hline CHEMBL1323784 & 688267 & 5.9 & 5.0434 & TST & \\
\hline CHEMBL1367138 & 688267 & 4.05 & 5.0222 & TRN & \\
\hline CHEMBL1413781 & 688267 & 4.05 & 5.0772 & TRN & \\
\hline CHEMBL1329393 & 688267 & 4.0 & 5.004 & TRN & \\
\hline CHEMBL1514112 & 688267 & 6.5 & 4.9993 & TRN & \\
\hline CHEMBL1332697 & 688267 & 4.25 & 5.0434 & TST & \\
\hline CHEMBL1537391 & 688267 & 5.35 & 5.0313 & TRN & \\
\hline CHEMBL1394716 & 688267 & 4.25 & 4.9973 & TRN & \\
\hline CHEMBL1585752 & 688267 & 6.0 & 5.004 & TRN & \\
\hline CHEMBL1372355 & 688267 & 6.2 & 5.0765 & TRN & \\
\hline CHEMBL1454724 & 688267 & 5.3 & 5.0867 & TRN & \\
\hline CHEMBL1482591 & 688267 & 4.3 & 5.0318 & TST & \\
\hline CHEMBL1354749 & 688267 & 5.3 & 5.0573 & TRN & \\
\hline CHEMBL1591873 & 688267 & 5.85 & 5.1165 & TRN & \\
\hline CHEMBL1417539 & 688267 & 6.15 & 5.0289 & TRN & \\
\hline CHEMBL1326591 & 688267 & 5.0 & 5.0754 & TRN & \\
\hline CHEMBL1381463 & 688267 & 4.0 & 4.99100 & 00000000005 & TRN \\
\hline CHEMBL1600255 & 688267 & 4.3 & 5.0208 & TRN & \\
\hline CHEMBL1530840 & 688267 & 4.95 & 5.0187 & TST & \\
\hline CHEMBL1337699 & 688267 & 5.1 & 5.0684 & TRN & \\
\hline CHEMBL1391304 & 688267 & 5.75 & 5.0598 & TRN & \\
\hline CHEMBL1440802 & 688267 & 4.6 & 5.1028 & TRN & \\
\hline CHEMBL1441640 & 688267 & 6.2 & 5.0942 & TST & \\
\hline CHEMBL3208476 & 688267 & 5.85 & 5.0217 & TST & \\
\hline CHEMBL1444491 & 688267 & 4.6 & 5.0567 & TRN & \\
\hline CHEMBL1339747 & 688267 & 5.5 & 5.056 & TRN & \\
\hline CHEMBL1396016 & 688267 & 4.3 & 5.0403 & TRN & \\
\hline CHEMBL1419432 & 688267 & 3.95 & 5.0128 & TRN & \\
\hline CHEMBL1595907 & 688267 & 4.25 & 5.1219 & TRN & \\
\hline CHEMBL1398131 & 688267 & 4.0 & 5.0298 & TRN & \\
\hline CHEMBL1453459 & 688267 & 4.0 & 5.0377 & TST & \\
\hline CHEMBL1572207 & 688267 & 6.2 & 5.074 & TRN & \\
\hline CHEMBL1311275 & 688267 & 5.55 & 5.0903 & TRN & \\
\hline CHEMBL1608418 & 688267 & 3.95 & 5.0548 & TRN & \\
\hline CHEMBL1492830 & 688267 & 4.35 & 5.007 & TRN & \\
\hline CHEMBL1586857 & 688267 & 5.65 & 5.0548 & TRN & \\
\hline CHEMBL1588645 & 688267 & 4.55 & 5.0885 & TRN & \\
\hline CHEMBL1447474 & 688267 & 6.2 & 5.0405 & TRN & \\
\hline CHEMBL1339617 & 688267 & 6.0 & 5.0175 & TRN & \\
\hline CHEMBL1494563 & 688267 & 4.2 & 5.0484 & TST & \\
\hline CHEMBL1495624 & 688267 & 4.45 & 5.0811 & TST & \\
\hline CHEMBL1591811 & 688267 & 5.05 & 5.0348 & TRN & \\
\hline CHEMBL1535324 & 688267 & 5.4 & 5.0016 & TRN & \\
\hline
\end{tabular}




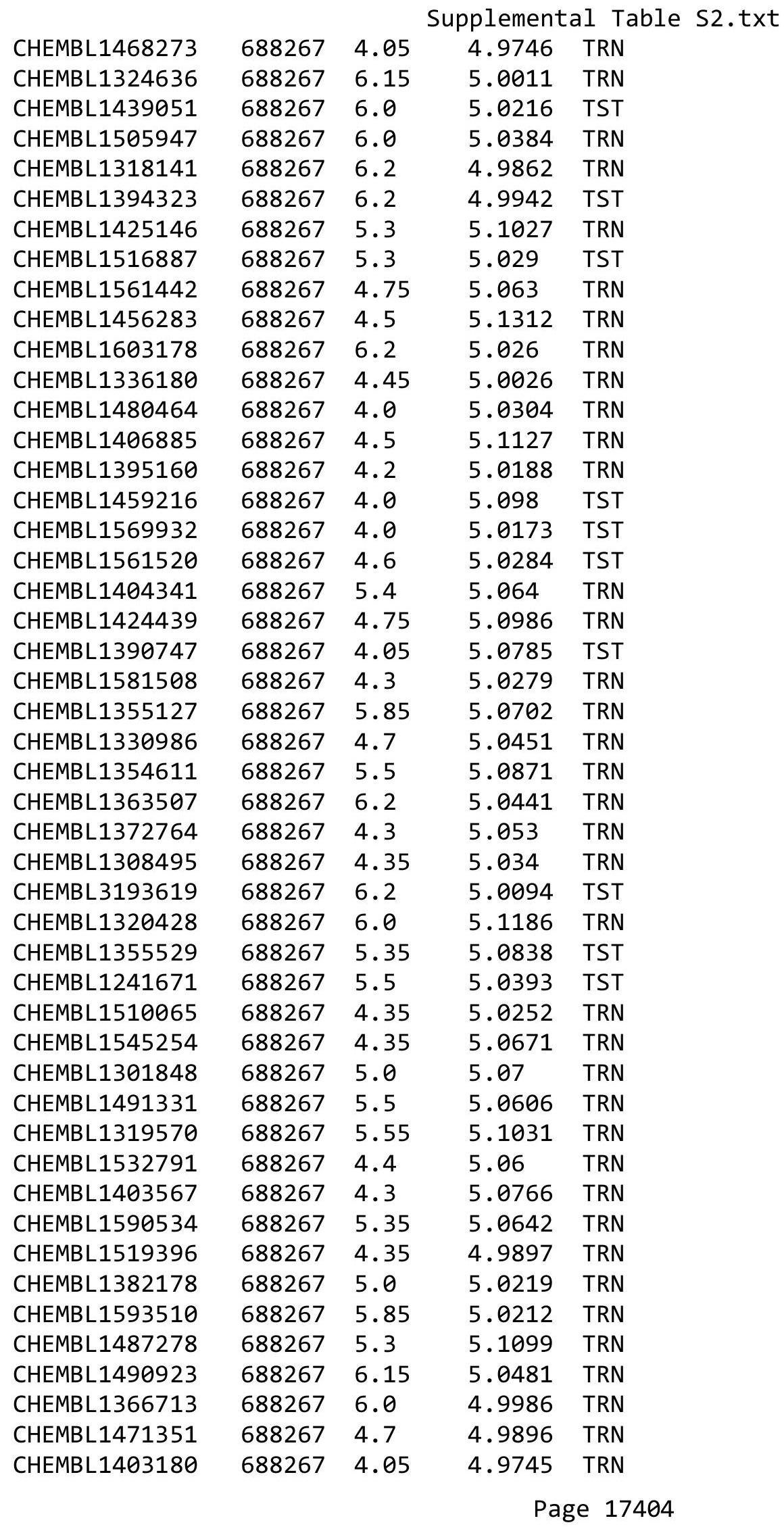




\begin{tabular}{|c|c|c|c|c|c|}
\hline \\
\hline CHEMBL1459388 & 688267 & 6.2 & 5.0364 & TRN & \\
\hline CHEMBL1378951 & 688267 & 6.2 & 5.021 & TRN & \\
\hline CHEMBL1590412 & 688267 & 5.5 & 5.0342 & TRN & \\
\hline CHEMBL1379873 & 688267 & 6.2 & 5.0401 & TRN & \\
\hline CHEMBL1512819 & 688267 & 6.15 & 5.069 & TRN & \\
\hline CHEMBL1416104 & 688267 & 5.55 & 4.9716 & TRN & \\
\hline CHEMBL3199422 & 688267 & 4.85 & 5.1286 & TRN & \\
\hline CHEMBL1347585 & 688267 & 6.0 & 5.0386 & TRN & \\
\hline CHEMBL3207931 & 688267 & 5.05 & 5.0584 & TRN & \\
\hline CHEMBL3213489 & 688267 & 6.2 & 5.0208 & TST & \\
\hline CHEMBL1552240 & 688267 & 5.2 & 5.0737 & TRN & \\
\hline CHEMBL1365571 & 688267 & 5.0 & 5.0374 & TRN & \\
\hline CHEMBL1532699 & 688267 & 4.1 & 5.0399 & TRN & \\
\hline CHEMBL1450029 & 688267 & 4.65 & 5.1339 & TST & \\
\hline CHEMBL1485654 & 688267 & 4.75 & 5.1156 & TST & \\
\hline CHEMBL1608067 & 688267 & 5.5 & 5.0434 & TST & \\
\hline CHEMBL1559529 & 688267 & 5.65 & 5.0168 & TRN & \\
\hline CHEMBL1485243 & 688267 & 4.35 & 5.0842 & TRN & \\
\hline CHEMBL1527617 & 688267 & 5.9 & 5.0203 & TRN & \\
\hline CHEMBL1455377 & 688267 & 5.05 & 4.9943 & TRN & \\
\hline CHEMBL1349303 & 688267 & 5.85 & $5.0710 e$ & 0000000001 & TRN \\
\hline CHEMBL1355333 & 688267 & 6.0 & 5.0995 & TRN & \\
\hline CHEMBL1352336 & 688267 & 5.2 & 5.0476 & TST & \\
\hline CHEMBL1305201 & 688267 & 6.5 & 5.0686 & TRN & \\
\hline CHEMBL1492436 & 688267 & 5.95 & 5.0687 & TRN & \\
\hline CHEMBL1094843 & 688267 & 5.3 & 5.0624 & TRN & \\
\hline CHEMBL1550267 & 688267 & 5.7 & 5.0841 & TRN & \\
\hline CHEMBL1600142 & 688267 & 4.05 & 5.0759 & TST & \\
\hline CHEMBL1375512 & 688267 & 5.85 & 5.0047 & TST & \\
\hline CHEMBL1309144 & 688267 & 6.15 & 5.0258 & TRN & \\
\hline CHEMBL1336452 & 688267 & 5.3 & 5.0693 & TRN & \\
\hline CHEMBL1426709 & 688267 & 5.0 & 5.0904 & TST & \\
\hline CHEMBL1409420 & 688267 & 6.2 & 4.9923 & TRN & \\
\hline CHEMBL1591335 & 688267 & 4.85 & 5.08 & TRN & \\
\hline CHEMBL1572214 & 688267 & 5.35 & 5.0567 & TST & \\
\hline CHEMBL1478526 & 688267 & 4.35 & 5.0689 & TST & \\
\hline CHEMBL1344111 & 688267 & 6.2 & 5.1761 & TRN & \\
\hline CHEMBL1601419 & 688267 & 6.2 & 5.0609 & TRN & \\
\hline CHEMBL1396892 & 688267 & 4.1 & 5.0294 & TRN & \\
\hline CHEMBL1358455 & 688267 & 4.4 & 5.1103 & TRN & \\
\hline CHEMBL1434292 & 688267 & 5.75 & 5.0135 & TRN & \\
\hline CHEMBL1552357 & 688267 & 5.5 & 5.01 & TST & \\
\hline CHEMBL1358770 & 688267 & 5.25 & 5.0409 & TRN & \\
\hline CHEMBL1585617 & 688267 & 5.7 & 5.0507 & TST & \\
\hline CHEMBL1449794 & 688267 & 4.55 & 5.0296 & TRN & \\
\hline CHEMBL1444125 & 688267 & 3.95 & 5.0722 & TRN & \\
\hline CHEMBL1520869 & 688267 & 4.35 & 5.1527 & TRN & \\
\hline CHEMBL1315617 & 688267 & 6.35 & 5.0651 & TRN & \\
\hline
\end{tabular}




\begin{tabular}{|c|c|c|c|c|}
\hline & & & upplement & al $\mathrm{T}$ \\
\hline CHEMBL1586331 & 688267 & 4.05 & 5.0597 & TST \\
\hline CHEMBL 2005944 & 688267 & 4.35 & 5.0238 & TRN \\
\hline CHEMBL1589011 & 688267 & 4.05 & 5.0102 & TST \\
\hline CHEMBL1384374 & 688267 & 4.3 & 5.0113 & TRN \\
\hline CHEMBL1479268 & 688267 & 6.2 & 5.0921 & TST \\
\hline CHEMBL1471096 & 688267 & 5.85 & 5.067 & TRN \\
\hline CHEMBL1384300 & 688267 & 4.0 & 5.0677 & TST \\
\hline CHEMBL1451469 & 688267 & 5.1 & 5.0276 & TST \\
\hline CHEMBL1568978 & 688267 & 4.9 & 5.0896 & TST \\
\hline CHEMBL1485487 & 688267 & 5.5 & 5.1163 & TRN \\
\hline CHEMBL1551837 & 688267 & 5.0 & 5.0212 & TRN \\
\hline CHEMBL1474637 & 688267 & 6.15 & 5.1242 & TRN \\
\hline CHEMBL1588131 & 688267 & 5.75 & 5.0858 & TRN \\
\hline CHEMBL1503290 & 688267 & 4.45 & 4.9948 & TRN \\
\hline CHEMBL1602993 & 688267 & 5.1 & 4.9994 & TRN \\
\hline CHEMBL1469221 & 688267 & 5.1 & 5.0174 & TRN \\
\hline CHEMBL1477683 & 688267 & 6.2 & 5.0528 & TRN \\
\hline CHEMBL1370525 & 688267 & 4.55 & 5.0787 & TRN \\
\hline CHEMBL1526041 & 688267 & 5.5 & 5.0651 & TRN \\
\hline CHEMBL1331447 & 688267 & 5.3 & 5.0611 & TRN \\
\hline CHEMBL1441378 & 688267 & 5.0 & 5.0588 & TRN \\
\hline CHEMBL1343175 & 688267 & 5.55 & 5.0968 & TRN \\
\hline CHEMBL1414277 & 688267 & 6.45 & 4.9938 & TRN \\
\hline CHEMBL1338771 & 688267 & 4.3 & 5.0296 & TRN \\
\hline CHEMBL1456225 & 688267 & 5.0 & 5.0344 & TRN \\
\hline CHEMBL1484290 & 688267 & 4.0 & 5.0516 & TRN \\
\hline CHEMBL1444387 & 688267 & 6.2 & 5.0194 & TRN \\
\hline CHEMBL1488522 & 688267 & 4.6 & 5.0349 & TRN \\
\hline CHEMBL1452777 & 688267 & 4.55 & 5.1117 & TRN \\
\hline CHEMBL1493031 & 688267 & 5.85 & 5.1033 & TRN \\
\hline CHEMBL1524386 & 688267 & 4.35 & 5.0275 & TRN \\
\hline CHEMBL1365357 & 688267 & 4.3 & 5.0132 & TRN \\
\hline CHEMBL1303248 & 688267 & 4.8 & 5.1004 & TRN \\
\hline CHEMBL1353025 & 688267 & 5.3 & 5.1012 & TRN \\
\hline CHEMBL1607562 & 688267 & 4.0 & 5.039 & TRN \\
\hline CHEMBL1457081 & 688267 & 4.05 & 5.0304 & TST \\
\hline CHEMBL1331713 & 688267 & 4.35 & 5.053 & TRN \\
\hline CHEMBL1528542 & 688267 & 4.35 & 5.1 & TRN \\
\hline CHEMBL1397239 & 688267 & 3.95 & 5.0366 & TRN \\
\hline CHEMBL1588241 & 688267 & 5.3 & 5.0281 & TST \\
\hline CHEMBL1300081 & 688267 & 4.35 & 5.1054 & TST \\
\hline CHEMBL1434677 & 688267 & 6.2 & 5.042 & TRN \\
\hline CHEMBL1318328 & 688267 & 5.45 & 5.1426 & TST \\
\hline CHEMBL1354634 & 688267 & 6.2 & 5.039 & TRN \\
\hline CHEMBL1332590 & 688267 & 4.65 & 5.0241 & TRN \\
\hline CHEMBL1388556 & 688267 & 4.85 & 5.0257 & TRN \\
\hline CHEMBL1502259 & 688267 & 6.35 & 5.0457 & TST \\
\hline CHEMBL1419352 & 688267 & 5.1 & 5.0862 & TST \\
\hline
\end{tabular}




\begin{tabular}{|c|c|c|c|c|c|}
\hline \\
\hline CHEMBL1472864 & 688267 & 4.5 & 5.0941 & TRN & \\
\hline CHEMBL1434110 & 688267 & 5.35 & 5.0243 & TRN & \\
\hline CHEMBL1612757 & 688267 & 5.85 & 5.1543 & TRN & \\
\hline CHEMBL1554265 & 688267 & 5.85 & 5.0931 & TRN & \\
\hline CHEMBL1350009 & 688267 & 5.35 & 5.0358 & TRN & \\
\hline CHEMBL1356054 & 688267 & 3.95 & 5.0222 & TRN & \\
\hline CHEMBL1551657 & 688267 & 4.35 & 5.1089 & TRN & \\
\hline CHEMBL1568595 & 688267 & 6.6499 & 5.1402 & TRN & \\
\hline CHEMBL1395248 & 688267 & 5.55 & 5.0916 & TRN & \\
\hline CHEMBL1306574 & 688267 & 4.35 & 4.9816 & TRN & \\
\hline CHEMBL1358395 & 688267 & 4.05 & 4.9975 & TRN & \\
\hline CHEMBL1353201 & 688267 & 4.7 & 5.0399 & TRN & \\
\hline CHEMBL1332129 & 688267 & 5.3 & 5.082 & TRN & \\
\hline CHEMBL1403456 & 688267 & 5.9 & 5.0701 & TRN & \\
\hline CHEMBL1466786 & 688267 & 4.4 & 5.0716 & TRN & \\
\hline CHEMBL1545054 & 688267 & 3.9 & 5.0197 & TRN & \\
\hline CHEMBL1308166 & 688267 & 6.2 & 5.0368 & TRN & \\
\hline CHEMBL444928 & 688267 & 6.0 & 5.0494 & TRN & \\
\hline CHEMBL1335163 & 688267 & 4.2 & 5.1052 & TST & \\
\hline CHEMBL1494629 & 688267 & 4.4 & 5.0214 & TST & \\
\hline CHEMBL306946 & 688267 & 6.05 & 5.0109 & TRN & \\
\hline CHEMBL3194806 & 688267 & 4.6 & 5.0653 & TST & \\
\hline CHEMBL1462688 & 688267 & 4.4 & 5.0083 & TRN & \\
\hline CHEMBL1565755 & 688267 & 4.1 & 5.0795 & TRN & \\
\hline CHEMBL1601052 & 688267 & 4.65 & 5.0661 & TST & \\
\hline CHEMBL1611558 & 688267 & 6.0 & 5.0567 & TRN & \\
\hline CHEMBL1564812 & 688267 & 6.15 & 5.0568 & TRN & \\
\hline CHEMBL1557943 & 688267 & 5.3 & 5.0243 & TST & \\
\hline CHEMBL1571934 & 688267 & 5.4 & 5.0585 & TRN & \\
\hline CHEMBL1355030 & 688267 & 5.1 & 5.1258 & TRN & \\
\hline CHEMBL1466022 & 688267 & 5.45 & 5.13299 & 9999999999 & TST \\
\hline CHEMBL1457628 & 688267 & 6.15 & 5.0297 & TRN & \\
\hline CHEMBL1417390 & 688267 & 6.25 & 5.0266 & TST & \\
\hline CHEMBL1389219 & 688267 & 5.45 & 5.0568 & TST & \\
\hline CHEMBL1480691 & 688267 & 4.0 & 5.0337 & TRN & \\
\hline CHEMBL1578019 & 688267 & 4.05 & 4.99100 & 20000000005 & TRN \\
\hline CHEMBL1573276 & 688267 & 5.95 & 5.0303 & TRN & \\
\hline CHEMBL1543888 & 688267 & 6.5 & 5.1222 & TRN & \\
\hline CHEMBL1504381 & 688267 & 5.65 & 5.1174 & TST & \\
\hline CHEMBL1587819 & 688267 & 4.25 & 5.0463 & TRN & \\
\hline CHEMBL1587629 & 688267 & 6.45 & 5.1104 & TRN & \\
\hline CHEMBL1455810 & 688267 & 5.05 & 5.0434 & TRN & \\
\hline CHEMBL1503401 & 688267 & 3.95 & 5.043 & TRN & \\
\hline CHEMBL3190289 & 688267 & 4.0 & 5.0243 & TST & \\
\hline CHEMBL1580152 & 688267 & 4.9 & 4.9771 & TRN & \\
\hline CHEMBL1576052 & 688267 & 4.0 & 5.0696 & TRN & \\
\hline CHEMBL1508567 & 688267 & 4.2 & 5.0585 & TRN & \\
\hline CHEMBL600554 & 688267 & 6.2 & 4.9899 & TRN & \\
\hline
\end{tabular}




\begin{tabular}{|c|c|c|c|c|c|}
\hline \\
\hline CHEMBL1384672 & 688267 & 5.6 & 5.0601 & TST & \\
\hline CHEMBL1604733 & 688267 & 6.2 & 5.039 & TST & \\
\hline CHEMBL1512032 & 688267 & 4.3 & 5.07600 & 00000000005 & TRN \\
\hline CHEMBL3213324 & 688267 & 4.6 & 5.0302 & TST & \\
\hline CHEMBL1345546 & 688267 & 5.65 & 5.0707 & TRN & \\
\hline CHEMBL1502164 & 688267 & 4.25 & 5.035 & TRN & \\
\hline CHEMBL1588490 & 688267 & 3.95 & 5.0691 & TST & \\
\hline CHEMBL1458487 & 688267 & 5.65 & 5.1112 & TRN & \\
\hline CHEMBL1382081 & 688267 & 5.35 & 5.0373 & TRN & \\
\hline CHEMBL1407417 & 688267 & 5.0 & 5.0892 & TST & \\
\hline CHEMBL1431374 & 688267 & 5.3 & 5.0659 & TRN & \\
\hline CHEMBL1397927 & 688267 & 4.9 & 5.0344 & TRN & \\
\hline CHEMBL1356915 & 688267 & 4.45 & 5.0466 & TRN & \\
\hline CHEMBL1556191 & 688267 & 6.2 & 4.9887 & TRN & \\
\hline CHEMBL600582 & 688267 & 6.3 & 5.0845 & TRN & \\
\hline CHEMBL1420391 & 688267 & 4.7 & 5.0931 & TST & \\
\hline CHEMBL1423934 & 688267 & 5.75 & 5.0632 & TRN & \\
\hline CHEMBL1389796 & 688267 & 4.3 & 5.0085 & TRN & \\
\hline CHEMBL1522479 & 688267 & 6.15 & 5.1181 & TRN & \\
\hline CHEMBL1534165 & 688267 & 5.3 & 5.1069 & TRN & \\
\hline CHEMBL1325020 & 688267 & 5.35 & 4.9899 & TRN & \\
\hline CHEMBL1396162 & 688267 & 5.3 & 5.0457 & TRN & \\
\hline CHEMBL1565793 & 688267 & 4.4 & 5.0544 & TRN & \\
\hline CHEMBL1578783 & 688267 & 6.2 & 5.0793 & TRN & \\
\hline CHEMBL1597071 & 688267 & 6.2 & 5.0271 & TRN & \\
\hline CHEMBL1414928 & 688267 & 4.05 & 5.037 & TRN & \\
\hline CHEMBL1539246 & 688267 & 6.15 & 5.0281 & TRN & \\
\hline CHEMBL1507475 & 688267 & 4.6 & 5.0375 & TST & \\
\hline CHEMBL1516089 & 688267 & 6.2 & 5.0937 & TRN & \\
\hline CHEMBL3195379 & 688267 & 5.9 & 4.9783 & TRN & \\
\hline CHEMBL1495470 & 688267 & 6.5 & 5.0391 & TRN & \\
\hline CHEMBL1354054 & 688267 & 4.5 & 5.0514 & TRN & \\
\hline CHEMBL1453191 & 688267 & 4.2 & 5.05399 & 9999999999 & TST \\
\hline CHEMBL1394694 & 688267 & 5.05 & 4.9941 & TRN & \\
\hline CHEMBL1541421 & 688267 & 5.55 & 5.0302 & TRN & \\
\hline CHEMBL1422175 & 688267 & 4.2 & 5.007 & TST & \\
\hline CHEMBL3196020 & 688267 & 6.15 & 4.9801 & TRN & \\
\hline CHEMBL1490945 & 688267 & 5.0 & 5.1215 & TRN & \\
\hline CHEMBL1398848 & 688267 & 5.8 & 5.1236 & TRN & \\
\hline CHEMBL1571564 & 688267 & 4.0 & 5.0673 & TRN & \\
\hline CHEMBL1540025 & 688267 & 4.3 & 5.0315 & TRN & \\
\hline CHEMBL1596229 & 688267 & 6.0 & 5.0747 & TRN & \\
\hline CHEMBL1561685 & 688267 & 5.55 & 5.0521 & TRN & \\
\hline CHEMBL1463451 & 688267 & 5.9 & 5.1006 & TRN & \\
\hline CHEMBL1386000 & 688267 & 4.55 & 5.0923 & TRN & \\
\hline CHEMBL 1460075 & 688267 & 4.0 & 5.0905 & TST & \\
\hline CHEMBL1590725 & 688267 & 6.1 & 5.0843 & TRN & \\
\hline CHEMBL1450799 & 688267 & 4.55 & 5.0968 & TRN & \\
\hline
\end{tabular}




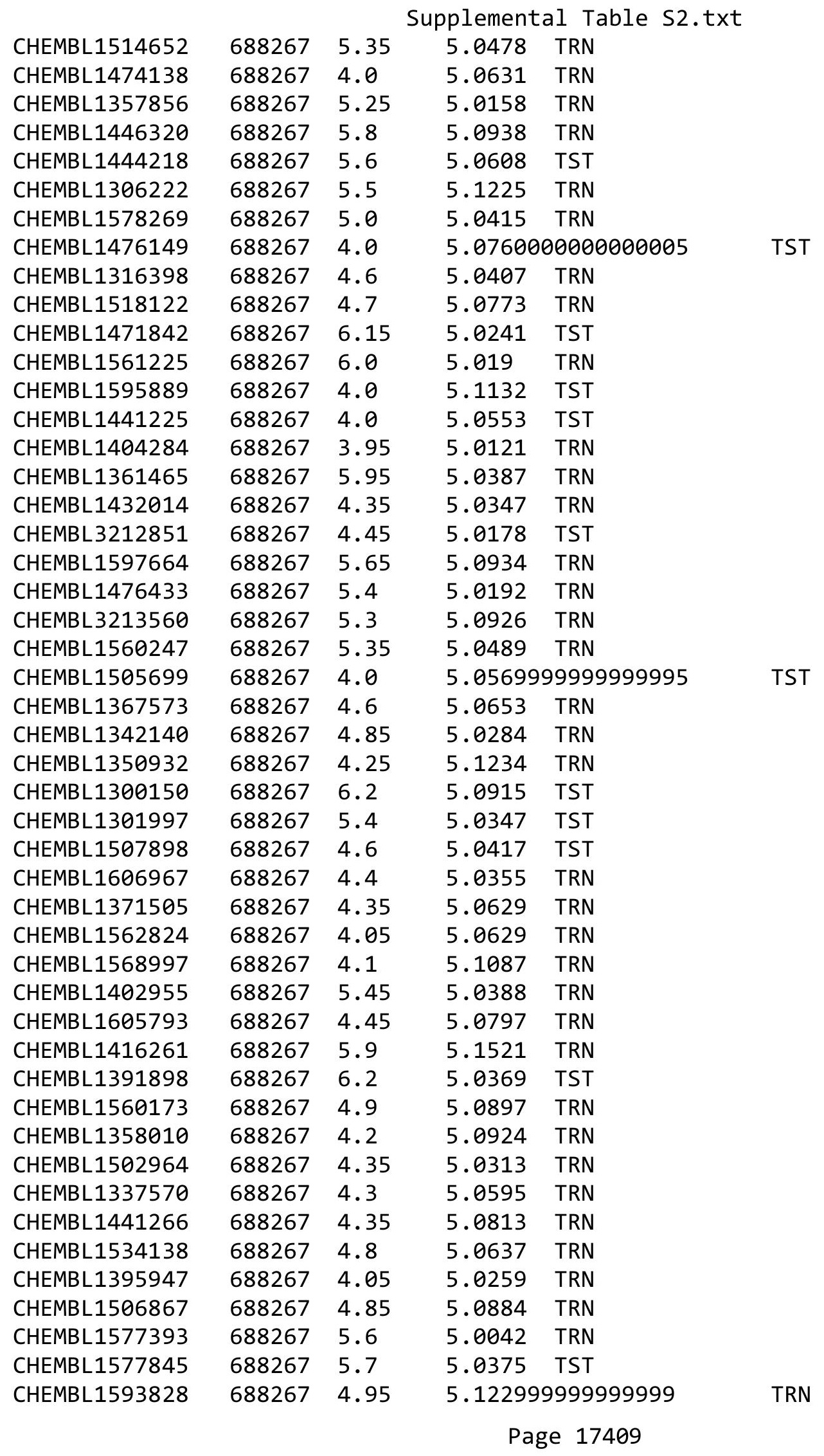




\begin{tabular}{|c|c|c|c|c|c|}
\hline \multicolumn{6}{|c|}{ Supplemental Table S2.txt } \\
\hline CHEMBL1406186 & 688267 & 4.05 & 5.1074 & TRN & \\
\hline CHEMBL1612382 & 688267 & 3.95 & 5.1071 & TST & \\
\hline CHEMBL1434492 & 688267 & 6.0 & 5.0269 & TRN & \\
\hline CHEMBL1471247 & 688267 & 5.95 & 5.0499 & TST & \\
\hline CHEMBL1088193 & 688267 & 4.9 & 5.1203 & TRN & \\
\hline CHEMBL1581658 & 688267 & 4.95 & 5.0482 & TRN & \\
\hline CHEMBL1500195 & 688267 & 5.4 & 5.09699 & 99999999995 & TRN \\
\hline CHEMBL1562736 & 688267 & 6.2 & 5.0702 & TRN & \\
\hline CHEMBL1309518 & 688267 & 5.6 & 5.0321 & TRN & \\
\hline CHEMBL1381918 & 688267 & 4.4 & 5.0064 & TRN & \\
\hline CHEMBL1463860 & 688267 & 4.65 & 4.9827 & TRN & \\
\hline CHEMBL1403197 & 688267 & 4.55 & 5.0516 & TRN & \\
\hline CHEMBL1449455 & 688267 & 4.4 & 5.0665 & TRN & \\
\hline CHEMBL1366630 & 688267 & 4.15 & 5.1126 & TST & \\
\hline CHEMBL1490113 & 688267 & 4.6 & 5.0438 & TRN & \\
\hline CHEMBL1410822 & 688267 & 3.95 & 5.1536 & TRN & \\
\hline CHEMBL1603052 & 688267 & 5.1 & 5.07600 & 00000000005 & TRN \\
\hline CHEMBL1492750 & 688267 & 3.95 & 5.1018 & TRN & \\
\hline CHEMBL1305184 & 688267 & 4.55 & 5.0363 & TRN & \\
\hline CHEMBL1452292 & 688267 & 6.0 & 5.0207 & TRN & \\
\hline CHEMBL1484042 & 688267 & 4.45 & 5.0524 & TRN & \\
\hline CHEMBL1305744 & 688267 & 4.3 & 4.9896 & TRN & \\
\hline CHEMBL1327733 & 688267 & 4.4 & 5.0949 & TRN & \\
\hline CHEMBL1367046 & 688267 & 4.05 & 5.0385 & TRN & \\
\hline CHEMBL1541459 & 688267 & 5.3 & 5.0043 & TRN & \\
\hline CHEMBL1400458 & 688267 & 6.25 & 5.0365 & TRN & \\
\hline CHEMBL1390781 & 688267 & 5.4 & 5.0751 & TRN & \\
\hline CHEMBL1395342 & 688267 & 3.95 & 5.0565 & TRN & \\
\hline CHEMBL1458451 & 688267 & 6.2 & 5.0249 & TRN & \\
\hline CHEMBL1300071 & 688267 & 5.35 & 5.0993 & TST & \\
\hline CHEMBL1413419 & 688267 & 4.95 & 5.0557 & TRN & \\
\hline CHEMBL1608631 & 688267 & 5.9 & 5.0023 & TST & \\
\hline CHEMBL1456605 & 688267 & 6.05 & 5.0593 & TRN & \\
\hline CHEMBL1311718 & 688267 & 4.1 & 5.0344 & TST & \\
\hline CHEMBL1383238 & 688267 & 4.3 & 5.0212 & TRN & \\
\hline CHEMBL1554257 & 688267 & 4.9 & 5.0955 & TST & \\
\hline CHEMBL1395740 & 688267 & 3.95 & 5.065 & TST & \\
\hline CHEMBL1507557 & 688267 & 5.95 & 5.0041 & TRN & \\
\hline CHEMBL1440590 & 688267 & 5.8 & 5.0609 & TRN & \\
\hline CHEMBL1493364 & 688267 & 4.35 & 5.1102 & TRN & \\
\hline CHEMBL1343680 & 688267 & 4.0 & 5.0589 & TRN & \\
\hline CHEMBL1403940 & 688267 & 5.9 & 5.0272 & TRN & \\
\hline CHEMBL1516221 & 688267 & 6.15 & 5.0526 & TRN & \\
\hline CHEMBL1410866 & 688267 & 4.35 & 5.0816 & TRN & \\
\hline CHEMBL1479849 & 688267 & 6.2 & 5.1341 & TRN & \\
\hline CHEMBL1543511 & 688267 & 6.2 & 4.9937 & TST & \\
\hline CHEMBL1392532 & 688267 & 5.65 & 5.0874 & TRN & \\
\hline CHEMBL1562371 & 688267 & 4.35 & 5.0131 & TRN & \\
\hline
\end{tabular}




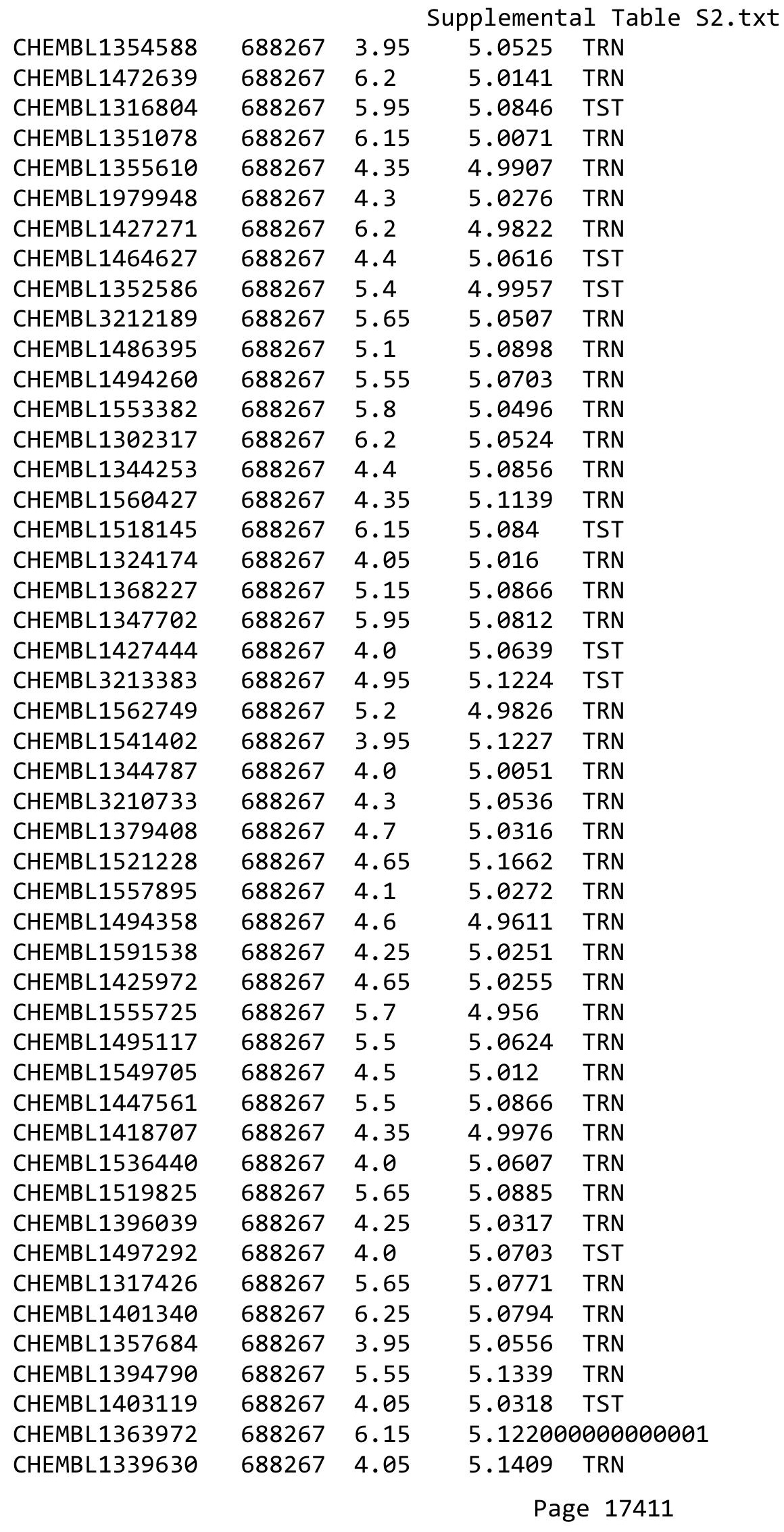




\begin{tabular}{|c|c|c|c|c|c|}
\hline \\
\hline CHEMBL1446693 & 688267 & 5.8 & 5.0857 & TRN & \\
\hline CHEMBL1550977 & 688267 & 6.5 & 5.1196 & TRN & \\
\hline CHEMBL1348129 & 688267 & 3.95 & 5.0517 & TRN & \\
\hline CHEMBL1560964 & 688267 & 4.05 & 5.08899 & 99999999995 & TRN \\
\hline CHEMBL236897 & 688267 & 6.15 & 5.0275 & TST & \\
\hline CHEMBL1439637 & 688267 & 4.45 & 5.1113 & TRN & \\
\hline CHEMBL1510137 & 688267 & 4.05 & 5.0758 & TRN & \\
\hline CHEMBL1537254 & 688267 & 5.95 & 5.1088 & TRN & \\
\hline CHEMBL1417731 & 688267 & 5.3 & 5.0702 & TST & \\
\hline CHEMBL1392347 & 688267 & 5.85 & 5.0998 & TRN & \\
\hline CHEMBL1372968 & 688267 & 6.2 & 5.0165 & TST & \\
\hline CHEMBL1584903 & 688267 & 5.55 & 5.0675 & TRN & \\
\hline CHEMBL1591564 & 688267 & 6.45 & 4.996 & TRN & \\
\hline CHEMBL1352583 & 688267 & 5.85 & 5.0368 & TRN & \\
\hline CHEMBL1595566 & 688267 & 4.55 & 5.0233 & TRN & \\
\hline CHEMBL1486215 & 688267 & 6.25 & 5.0339 & TRN & \\
\hline CHEMBL1535096 & 688267 & 5.8 & 5.0347 & TRN & \\
\hline CHEMBL1405891 & 688267 & 4.0 & 5.0314 & TRN & \\
\hline CHEMBL1480720 & 688267 & 4.25 & 5.0562 & TST & \\
\hline CHEMBL1331090 & 688267 & 4.0 & 5.0034 & TRN & \\
\hline CHEMBL71189 & 688267 & 5.25 & 5.0346 & TRN & \\
\hline CHEMBL1427740 & 688267 & 3.95 & 5.0433 & TST & \\
\hline CHEMBL1516165 & 688267 & 4.6 & 5.0683 & TRN & \\
\hline CHEMBL1611876 & 688267 & 3.95 & 5.0382 & TRN & \\
\hline CHEMBL1563600 & 688267 & 5.45 & 5.0183 & TRN & \\
\hline CHEMBL1574455 & 688267 & 4.35 & 5.1378 & TRN & \\
\hline CHEMBL1565407 & 688267 & 4.6 & 4.9922 & TRN & \\
\hline CHEMBL1409483 & 688267 & 6.15 & 5.0271 & TRN & \\
\hline CHEMBL1534978 & 688267 & 3.95 & 5.1327 & TRN & \\
\hline CHEMBL1420230 & 688267 & 6.15 & 5.0552 & TRN & \\
\hline CHEMBL1329295 & 688267 & 4.95 & 5.0091 & TRN & \\
\hline CHEMBL1431462 & 688267 & 3.95 & 5.1432 & TST & \\
\hline CHEMBL1467330 & 688267 & 5.25 & 5.0418 & TRN & \\
\hline CHEMBL1410370 & 688267 & 4.4 & 5.1317 & TRN & \\
\hline CHEMBL1329503 & 688267 & 4.0 & 5.0282 & TRN & \\
\hline CHEMBL1316289 & 688267 & 5.25 & 5.0151 & TRN & \\
\hline CHEMBL1479260 & 688267 & 6.2 & 4.9938 & TRN & \\
\hline CHEMBL1549098 & 688267 & 5.25 & 5.059 & TRN & \\
\hline CHEMBL1503996 & 688267 & 6.2 & 5.0415 & TRN & \\
\hline CHEMBL1603515 & 688267 & 4.1 & 5.0914 & TST & \\
\hline CHEMBL1589113 & 688267 & 5.4 & 4.9826 & TRN & \\
\hline CHEMBL1462839 & 688267 & 4.25 & 5.0334 & TRN & \\
\hline CHEMBL1364163 & 688267 & 5.8 & 5.0627 & TST & \\
\hline CHEMBL1329200 & 688267 & 4.15 & 4.988 & TST & \\
\hline CHEMBL1396286 & 688267 & 4.35 & 5.0366 & TRN & \\
\hline CHEMBL1428021 & 688267 & 4.0 & 5.0376 & TRN & \\
\hline CHEMBL536803 & 688267 & 4.55 & 5.0928 & TST & \\
\hline CHEMBL1375940 & 688267 & 5.5 & 5.124 & TST & \\
\hline
\end{tabular}




\begin{tabular}{|c|c|c|c|c|}
\hline & & & pplement & al $\mathrm{Ta}$ \\
\hline CHEMBL1500925 & 688267 & 5.9 & 5.0679 & TST \\
\hline CHEMBL1597099 & 688267 & 3.9 & 5.0838 & TRN \\
\hline CHEMBL1471865 & 688267 & 4.1 & 5.0515 & TST \\
\hline CHEMBL1420961 & 688267 & 4.4 & 5.0846 & TRN \\
\hline CHEMBL1342722 & 688267 & 6.2 & 5.0687 & TRN \\
\hline CHEMBL1413443 & 688267 & 4.3 & 5.0799 & TRN \\
\hline CHEMBL1604136 & 688267 & 4.0 & 5.0227 & TST \\
\hline CHEMBL1458407 & 688267 & 6.15 & 5.0315 & TST \\
\hline CHEMBL1481862 & 688267 & 4.0 & 5.0091 & TRN \\
\hline CHEMBL3207853 & 688267 & 5.5 & 4.978 & TRN \\
\hline CHEMBL1566734 & 688267 & 6.15 & 5.0271 & TRN \\
\hline CHEMBL1449210 & 688267 & 5.05 & 5.0514 & TRN \\
\hline CHEMBL 3197688 & 688267 & 6.2 & 5.0722 & TRN \\
\hline CHEMBL1467391 & 688267 & 4.3 & 5.0533 & TST \\
\hline CHEMBL1505155 & 688267 & 4.05 & 5.0846 & TRN \\
\hline CHEMBL1397985 & 688267 & 6.2 & 5.02 & TRN \\
\hline CHEMBL1431175 & 688267 & 6.5 & 5.0578 & TRN \\
\hline CHEMBL1554535 & 688267 & 6.2 & 5.073 & TRN \\
\hline CHEMBL1512103 & 688267 & 4.15 & 5.0744 & TRN \\
\hline CHEMBL1374167 & 688267 & 6.2 & 5.0584 & TRN \\
\hline CHEMBL1415964 & 688267 & 3.95 & 5.092 & TST \\
\hline CHEMBL1513765 & 688267 & 5.3 & 5.0303 & TRN \\
\hline CHEMBL1408827 & 688267 & 4.0 & 4.9985 & TRN \\
\hline CHEMBL1306697 & 688267 & 6.15 & 5.0089 & TST \\
\hline CHEMBL1534724 & 688267 & 4.4 & 5.079 & TRN \\
\hline CHEMBL1487233 & 688267 & 5.85 & 5.0287 & TRN \\
\hline CHEMBL1314087 & 688267 & 6.2 & 5.095 & TRN \\
\hline CHEMBL1519628 & 688267 & 4.0 & 5.033 & TRN \\
\hline CHEMBL1475353 & 688267 & 4.0 & 5.0494 & TRN \\
\hline CHEMBL1357487 & 688267 & 5.35 & 5.0006 & TRN \\
\hline CHEMBL1482215 & 688267 & 4.25 & 4.9783 & TST \\
\hline CHEMBL1522977 & 688267 & 4.45 & 5.1021 & TRN \\
\hline CHEMBL1554927 & 688267 & 4.3 & 5.0894 & TRN \\
\hline CHEMBL1407823 & 688267 & 6.2 & 5.1007 & TRN \\
\hline CHEMBL1551397 & 688267 & 5.25 & 5.1053 & TRN \\
\hline CHEMBL1299630 & 688267 & 3.95 & 5.0336 & TRN \\
\hline CHEMBL1578695 & 688267 & 4.5 & 5.0071 & TRN \\
\hline CHEMBL1409409 & 688267 & 6.15 & 5.104 & TRN \\
\hline CHEMBL1331745 & 688267 & 4.25 & 5.1258 & TRN \\
\hline CHEMBL1594622 & 688267 & 5.55 & 5.1165 & TRN \\
\hline CHEMBL1408933 & 688267 & 4.05 & 4.9879 & TRN \\
\hline CHEMBL1332181 & 688267 & 4.0 & 5.0883 & TRN \\
\hline CHEMBL1400380 & 688267 & 6.25 & 5.1145 & TRN \\
\hline CHEMBL 3198273 & 688267 & 6.4 & 5.0128 & TRN \\
\hline CHEMBL1522649 & 688267 & 4.55 & 5.0395 & TRN \\
\hline CHEMBL1401388 & 688267 & 4.25 & 5.1058 & TRN \\
\hline CHEMBL1486480 & 688267 & 6.2 & 5.029 & TST \\
\hline CHEMBL1356528 & 688267 & 4.0 & 5.0904 & TRN \\
\hline
\end{tabular}




\begin{tabular}{|c|c|c|c|c|}
\hline \multicolumn{5}{|c|}{ Supplemental Table S2.txt } \\
\hline CHEMBL1551527 & 688267 & 5.1 & 5.1389 & TRN \\
\hline CHEMBL1548526 & 688267 & 5.9 & 5.0937 & TRN \\
\hline CHEMBL3214268 & 688267 & 6.1 & 4.9982 & TST \\
\hline CHEMBL602234 & 688267 & 3.95 & 5.0595 & TRN \\
\hline CHEMBL1314856 & 688267 & 4.9 & 5.0662 & TRN \\
\hline CHEMBL1435719 & 688267 & 5.8 & 5.0503 & TRN \\
\hline CHEMBL1315057 & 688267 & 4.4 & 5.0712 & TRN \\
\hline CHEMBL1565495 & 688267 & 4.35 & 5.1145 & TRN \\
\hline CHEMBL1321651 & 688267 & 5.45 & 5.0984 & TRN \\
\hline CHEMBL3199868 & 688267 & 5.8 & 4.9982 & TRN \\
\hline CHEMBL1553065 & 688267 & 4.55 & 5.0166 & TRN \\
\hline CHEMBL 3209525 & 688267 & 4.7 & 5.1112 & TRN \\
\hline CHEMBL3212646 & 688267 & 4.4 & 5.0515 & TST \\
\hline CHEMBL3207785 & 688267 & 4.5 & 5.0252 & TST \\
\hline CHEMBL1367780 & 688267 & 6.25 & 4.9904 & TRN \\
\hline CHEMBL1541750 & 688267 & 6.2 & 5.1406 & TRN \\
\hline CHEMBL1485195 & 688267 & 5.85 & 5.1137 & TST \\
\hline CHEMBL1469942 & 688267 & 4.7 & 5.0701 & TST \\
\hline CHEMBL1336554 & 688267 & 3.95 & 5.0707 & TST \\
\hline CHEMBL1474333 & 688267 & 3.95 & 5.0107 & TRN \\
\hline CHEMBL1446316 & 688267 & 5.3 & 5.029 & TST \\
\hline CHEMBL1421008 & 688267 & 4.0 & 5.0706 & TST \\
\hline CHEMBL1394797 & 688267 & 4.8 & 5.1042 & TRN \\
\hline CHEMBL1516138 & 688267 & 4.35 & 5.0312 & TRN \\
\hline CHEMBL1456392 & 688267 & 4.0 & 4.9831 & TRN \\
\hline CHEMBL1381411 & 688267 & 6.2 & 5.0925 & TRN \\
\hline CHEMBL1610346 & 688267 & 4.0 & 5.0724 & TST \\
\hline CHEMBL1320286 & 688267 & 5.6 & 5.0694 & TRN \\
\hline CHEMBL1525004 & 688267 & 5.45 & 5.0174 & TRN \\
\hline CHEMBL1511349 & 688267 & 6.25 & 5.0515 & TRN \\
\hline CHEMBL1332423 & 688267 & 6.15 & 5.083 & TRN \\
\hline CHEMBL1456128 & 688267 & 5.5 & 5.0384 & TST \\
\hline CHEMBL1461979 & 688267 & 5.05 & 5.0522 & TRN \\
\hline CHEMBL602975 & 688267 & 6.2 & 5.01 & TST \\
\hline CHEMBL1422206 & 688267 & 4.9 & 5.0548 & TST \\
\hline CHEMBL1353511 & 688267 & 4.3 & 5.056 & TST \\
\hline CHEMBL1347845 & 688267 & 5.45 & 5.0747 & TRN \\
\hline CHEMBL1416876 & 688267 & 5.6 & 5.0705 & TRN \\
\hline CHEMBL1401792 & 688267 & 4.4 & 5.0224 & TRN \\
\hline CHEMBL1357504 & 688267 & 5.2 & 5.0717 & TRN \\
\hline CHEMBL1399436 & 688267 & 4.2 & 5.0469 & TST \\
\hline CHEMBL1477150 & 688267 & 4.5 & 5.0636 & TRN \\
\hline CHEMBL1302039 & 688267 & 5.85 & 5.065 & TRN \\
\hline CHEMBL1314918 & 688267 & 5.65 & 5.062 & TRN \\
\hline CHEMBL1315507 & 688267 & 4.45 & 5.0338 & TRN \\
\hline CHEMBL1508131 & 688267 & 4.05 & 5.129 & TRN \\
\hline CHEMBL1416230 & 688267 & 6.2 & 5.0903 & TRN \\
\hline CHEMBL1426924 & 688267 & 4.4 & 5.0298 & TRN \\
\hline
\end{tabular}




\begin{tabular}{|c|c|c|c|c|c|}
\hline \\
\hline CHEMBL1487766 & 688267 & 4.2 & 4.9933 & TRN & \\
\hline CHEMBL1576316 & 688267 & 4.6 & 5.0809 & TST & \\
\hline CHEMBL1389241 & 688267 & 4.0 & 5.0271 & TRN & \\
\hline CHEMBL1456924 & 688267 & 4.85 & 5.1318 & TRN & \\
\hline CHEMBL1373933 & 688267 & 4.35 & 5.0722 & TST & \\
\hline CHEMBL1435830 & 688267 & 5.85 & 5.0313 & TRN & \\
\hline CHEMBL1476743 & 688267 & 6.05 & 5.0101 & TRN & \\
\hline CHEMBL1413956 & 688267 & 6.2 & 5.0208 & TRN & \\
\hline CHEMBL1302731 & 688267 & 6.15 & 5.0782 & TST & \\
\hline CHEMBL3207442 & 688267 & 5.55 & 5.0255 & TRN & \\
\hline CHEMBL1516824 & 688267 & 5.8 & 5.05699 & 99999999995 & TRN \\
\hline CHEMBL1418499 & 688267 & 4.05 & 5.0669 & TRN & \\
\hline CHEMBL1500690 & 688267 & 6.45 & 5.0376 & TST & \\
\hline CHEMBL1402463 & 688267 & 4.9 & 5.1076 & TRN & \\
\hline CHEMBL3199046 & 688267 & 5.75 & 5.0167 & TST & \\
\hline CHEMBL1355980 & 688267 & 3.9 & 5.0589 & TRN & \\
\hline CHEMBL1387615 & 688267 & 4.0 & 5.0217 & TRN & \\
\hline CHEMBL1610992 & 688267 & 5.35 & 5.0205 & TST & \\
\hline CHEMBL1578462 & 688267 & 3.95 & 5.1186 & TST & \\
\hline CHEMBL1514716 & 688267 & 4.4 & 5.0706 & TRN & \\
\hline CHEMBL1314173 & 688267 & 5.95 & 5.0769 & TRN & \\
\hline CHEMBL1462066 & 688267 & 4.05 & 5.0563 & TST & \\
\hline CHEMBL1599366 & 688267 & 5.8 & 5.0944 & TRN & \\
\hline CHEMBL1379048 & 688267 & 4.9 & 5.1122 & TST & \\
\hline CHEMBL1411598 & 688267 & 4.65 & 5.0832 & TRN & \\
\hline CHEMBL1336891 & 688267 & 4.05 & 5.1035 & TRN & \\
\hline CHEMBL1529192 & 688267 & 6.25 & 5.0111 & TRN & \\
\hline CHEMBL 1300232 & 688267 & 6.2 & 5.0777 & TRN & \\
\hline CHEMBL210846 & 688267 & 5.75 & 4.9637 & TRN & \\
\hline CHEMBL1498293 & 688267 & 4.65 & 5.1783 & TRN & \\
\hline CHEMBL1312188 & 688267 & 5.6 & 4.9896 & TRN & \\
\hline CHEMBL1440093 & 688267 & 5.3 & 5.0166 & TRN & \\
\hline CHEMBL1610476 & 688267 & 4.55 & 5.0047 & TST & \\
\hline CHEMBL1552531 & 688267 & 4.35 & 5.0176 & TRN & \\
\hline CHEMBL1409445 & 688267 & 4.05 & 5.0547 & TRN & \\
\hline CHEMBL1497121 & 688267 & 6.15 & 5.1085 & TRN & \\
\hline CHEMBL202965 & 688267 & 5.85 & 5.1074 & TRN & \\
\hline CHEMBL1387301 & 688267 & 6.2 & 5.0523 & TRN & \\
\hline CHEMBL1444960 & 688267 & 6.1 & 5.0711 & TST & \\
\hline CHEMBL478483 & 688267 & 6.2 & 5.0323 & TRN & \\
\hline CHEMBL1423450 & 688267 & 6.2 & 5.10800 & 20000000005 & TST \\
\hline CHEMBL1488154 & 688267 & 4.85 & 4.9981 & TST & \\
\hline CHEMBL1544186 & 688267 & 6.15 & 5.0296 & TRN & \\
\hline CHEMBL1592873 & 688267 & 5.25 & 5.112 & TRN & \\
\hline CHEMBL1444730 & 688267 & 4.3 & 5.0332 & TRN & \\
\hline CHEMBL1586170 & 688267 & 4.4 & 5.0559 & TRN & \\
\hline CHEMBL1383544 & 688267 & 5.55 & 5.0647 & TRN & \\
\hline CHEMBL1480175 & 688267 & 6.2 & 5.0479 & TRN & \\
\hline
\end{tabular}




\begin{tabular}{|c|c|c|c|c|c|}
\hline \\
\hline CHEMBL1509368 & 688267 & 5.3 & 4.9873 & TRN & \\
\hline CHEMBL1381257 & 688267 & 5.4 & 5.0748 & TRN & \\
\hline CHEMBL1527807 & 688267 & 5.0 & 5.0492 & TRN & \\
\hline CHEMBL1337733 & 688267 & 6.2 & 5.0842 & TRN & \\
\hline CHEMBL1463355 & 688267 & 6.2 & 5.0929 & TRN & \\
\hline CHEMBL1408625 & 688267 & 6.15 & 5.0586 & TRN & \\
\hline CHEMBL1346077 & 688267 & 4.25 & 5.1221 & TRN & \\
\hline CHEMBL3211959 & 688267 & 6.1 & 5.1317 & TRN & \\
\hline CHEMBL1387147 & 688267 & 5.2 & 5.0402 & TRN & \\
\hline CHEMBL1401575 & 688267 & 5.55 & 5.0216 & TRN & \\
\hline CHEMBL1544053 & 688267 & 5.55 & 5.0221 & TST & \\
\hline CHEMBL1523035 & 688267 & 5.2 & 5.0335 & TRN & \\
\hline CHEMBL1419981 & 688267 & 4.5 & 5.1169 & TST & \\
\hline CHEMBL1992804 & 688267 & 6.25 & 5.0454 & TST & \\
\hline CHEMBL1495685 & 688267 & 6.15 & 5.0038 & TRN & \\
\hline CHEMBL1403183 & 688267 & 4.25 & 5.05 & TRN & \\
\hline CHEMBL1447967 & 688267 & 5.55 & 5.1372 & TRN & \\
\hline CHEMBL1304720 & 688267 & 4.0 & 5.0751 & TRN & \\
\hline CHEMBL1413972 & 688267 & 4.25 & 5.0574 & TRN & \\
\hline CHEMBL3190179 & 688267 & 6.15 & 4.9953 & TRN & \\
\hline CHEMBL1352732 & 688267 & 5.25 & 5.1069 & TST & \\
\hline CHEMBL1371579 & 688267 & 5.15 & 5.0054 & TRN & \\
\hline CHEMBL1359374 & 688267 & 4.05 & 5.1694 & TRN & \\
\hline CHEMBL1575626 & 688267 & 4.65 & 5.05399 & 9999999999 & TRN \\
\hline CHEMBL1335121 & 688267 & 4.55 & 5.0495 & TRN & \\
\hline CHEMBL1519592 & 688267 & 4.0 & 5.07600 & 00000000005 & TST \\
\hline CHEMBL1322056 & 688267 & 5.9 & 5.0162 & TRN & \\
\hline CHEMBL1338603 & 688267 & 3.95 & 5.0762 & TRN & \\
\hline CHEMBL1402208 & 688267 & 5.25 & 5.0633 & TRN & \\
\hline CHEMBL1561912 & 688267 & 5.85 & 5.0481 & TRN & \\
\hline CHEMBL1427463 & 688267 & 5.55 & 5.0772 & TRN & \\
\hline CHEMBL1368736 & 688267 & 4.25 & 5.0575 & TRN & \\
\hline CHEMBL1566382 & 688267 & 6.15 & 5.0352 & TRN & \\
\hline CHEMBL1361597 & 688267 & 3.95 & 5.1213 & TRN & \\
\hline CHEMBL3211088 & 688267 & 5.3 & 5.1016 & TRN & \\
\hline CHEMBL1475732 & 688267 & 5.3 & 5.0375 & TST & \\
\hline CHEMBL1361420 & 688267 & 4.65 & 5.0266 & TST & \\
\hline CHEMBL1421039 & 688267 & 4.4 & 5.0302 & TST & \\
\hline CHEMBL1477726 & 688267 & 5.8 & 5.0775 & TRN & \\
\hline CHEMBL1375066 & 688267 & 6.2 & 5.0183 & TRN & \\
\hline CHEMBL1530916 & 688267 & 6.25 & 5.0319 & TST & \\
\hline CHEMBL1555741 & 688267 & 5.0 & 5.0363 & TRN & \\
\hline CHEMBL1522994 & 688267 & 3.9 & 5.1112 & TRN & \\
\hline CHEMBL1562083 & 688267 & 6.5501 & 5.0319 & TRN & \\
\hline CHEMBL1547481 & 688267 & 4.4 & 4.9945 & TRN & \\
\hline CHEMBL1494934 & 688267 & 4.35 & 5.0635 & TRN & \\
\hline CHEMBL1485749 & 688267 & 3.95 & 5.0585 & TRN & \\
\hline CHEMBL1309521 & 688267 & 5.6 & 5.0107 & TRN & \\
\hline
\end{tabular}




\begin{tabular}{|c|c|c|c|c|}
\hline & & & upplement & al $\mathrm{T}$ \\
\hline CHEMBL1613079 & 688267 & 4.55 & 5.0528 & TST \\
\hline CHEMBL1532243 & 688267 & 4.4 & 5.0513 & TRN \\
\hline CHEMBL1491205 & 688267 & 5.85 & 5.0964 & TRN \\
\hline CHEMBL1362134 & 688267 & 5.5 & 5.0304 & TRN \\
\hline CHEMBL1580877 & 688267 & 6.2 & 5.1197 & TST \\
\hline CHEMBL1309520 & 688267 & 5.6 & 5.1452 & TRN \\
\hline CHEMBL1354383 & 688267 & 5.05 & 5.0661 & TST \\
\hline CHEMBL1400189 & 688267 & 6.05 & 5.013 & TRN \\
\hline CHEMBL1417986 & 688267 & 5.5 & 5.0346 & TRN \\
\hline CHEMBL1500903 & 688267 & 4.3 & 5.1194 & TRN \\
\hline CHEMBL1303230 & 688267 & 4.5 & 5.0835 & TST \\
\hline CHEMBL1605490 & 688267 & 5.25 & 5.0771 & TST \\
\hline CHEMBL1560020 & 688267 & 4.35 & 5.1149 & TST \\
\hline CHEMBL1319964 & 688267 & 4.05 & 5.1454 & TRN \\
\hline CHEMBL1516681 & 688267 & 6.25 & 5.0639 & TST \\
\hline CHEMBL1592291 & 688267 & 4.35 & 5.105 & TRN \\
\hline CHEMBL1521651 & 688267 & 6.15 & 5.0331 & TRN \\
\hline CHEMBL1570561 & 688267 & 3.9 & 5.0699 & TRN \\
\hline CHEMBL1347164 & 688267 & 6.45 & 5.059 & TRN \\
\hline CHEMBL1410758 & 688267 & 6.25 & 5.0303 & TRN \\
\hline CHEMBL1533808 & 688267 & 3.95 & 5.0675 & TRN \\
\hline CHEMBL1392956 & 688267 & 6.2 & 5.0733 & TRN \\
\hline CHEMBL1370423 & 688267 & 6.05 & 5.0614 & TRN \\
\hline CHEMBL1339684 & 688267 & 5.45 & 5.0185 & TST \\
\hline CHEMBL1604409 & 688267 & 4.3 & 4.9942 & TRN \\
\hline CHEMBL3191180 & 688267 & 4.0 & 5.0261 & TST \\
\hline CHEMBL1330180 & 688267 & 5.05 & 5.0585 & TRN \\
\hline CHEMBL1605520 & 688267 & 4.1 & 5.0277 & TRN \\
\hline CHEMBL1497532 & 688267 & 5.5 & 5.0273 & TST \\
\hline CHEMBL1570812 & 688267 & 5.55 & 5.0445 & TRN \\
\hline CHEMBL1460006 & 688267 & 5.0 & 5.0224 & TRN \\
\hline CHEMBL1609344 & 688267 & 5.55 & 5.0446 & TST \\
\hline CHEMBL1530701 & 688267 & 5.95 & 5.0846 & TST \\
\hline CHEMBL1332332 & 688267 & 4.35 & 5.0309 & TST \\
\hline CHEMBL1557018 & 688267 & 4.6 & 5.0417 & TRN \\
\hline CHEMBL1988536 & 688267 & 4.25 & 5.0348 & TRN \\
\hline CHEMBL1512792 & 688267 & 5.2 & 5.0865 & TRN \\
\hline CHEMBL1368088 & 688267 & 5.05 & 5.1139 & TRN \\
\hline CHEMBL1503923 & 688267 & 5.6 & 5.072 & TRN \\
\hline CHEMBL1554503 & 688267 & 5.1 & 5.082 & TRN \\
\hline CHEMBL1570673 & 688267 & 5.85 & 5.0353 & TST \\
\hline CHEMBL1348501 & 688267 & 5.3 & 5.0328 & TST \\
\hline CHEMBL1337746 & 688267 & 5.55 & 5.0613 & TST \\
\hline CHEMBL1393614 & 688267 & 5.15 & 5.1009 & TRN \\
\hline CHEMBL1551894 & 688267 & 4.35 & 5.0479 & TRN \\
\hline CHEMBL1311019 & 688267 & 4.1 & 5.1694 & TRN \\
\hline CHEMBL1589650 & 688267 & 5.5 & 5.0457 & TRN \\
\hline CHEMBL1301417 & 688267 & 5.25 & 5.0402 & TRN \\
\hline
\end{tabular}




\begin{tabular}{|c|c|c|c|c|c|}
\hline \multicolumn{6}{|c|}{ Supplemental Table s2.txt } \\
\hline CHEMBL1317917 & 688267 & 6.0 & 5.0815 & TRN & \\
\hline CHEMBL1481949 & 688267 & 4.8 & 5.0475 & TRN & \\
\hline CHEMBL1475538 & 688267 & 4.6 & 5.0448 & TST & \\
\hline CHEMBL1581432 & 688267 & 4.8 & 5.0243 & TRN & \\
\hline CHEMBL1367222 & 688267 & 6.25 & 5.07100 & 2000000001 & TRN \\
\hline CHEMBL1585135 & 688267 & 4.7 & 5.0937 & TST & \\
\hline CHEMBL1355850 & 688267 & 4.7 & 5.0256 & TRN & \\
\hline CHEMBL1514028 & 688267 & 4.95 & 5.0887 & TRN & \\
\hline CHEMBL1304030 & 688267 & 5.55 & 5.0184 & TRN & \\
\hline CHEMBL1592660 & 688267 & 5.6 & 5.0537 & TRN & \\
\hline CHEMBL1453170 & 688267 & 4.45 & 5.0955 & TST & \\
\hline CHEMBL1379258 & 688267 & 6.0 & 5.1254 & TRN & \\
\hline CHEMBL1600047 & 688267 & 4.05 & 5.0511 & TRN & \\
\hline CHEMBL 280998 & 688267 & 5.25 & 5.0141 & TST & \\
\hline CHEMBL1525294 & 688267 & 5.8 & 4.9946 & TRN & \\
\hline CHEMBL1486605 & 688267 & 6.1 & 5.0584 & TRN & \\
\hline CHEMBL1611393 & 688267 & 6.25 & 5.0176 & TRN & \\
\hline CHEMBL1407308 & 688267 & 3.95 & 5.0539 & TRN & \\
\hline CHEMBL1551301 & 688267 & 4.0 & 5.0598 & TRN & \\
\hline CHEMBL1581055 & 688267 & 5.5 & 4.9934 & TRN & \\
\hline CHEMBL1421057 & 688267 & 3.95 & 5.0007 & TRN & \\
\hline CHEMBL1448355 & 688267 & 5.35 & 5.0851 & TRN & \\
\hline CHEMBL1557422 & 688267 & 6.1 & 5.1217 & TRN & \\
\hline CHEMBL1445369 & 688267 & 6.15 & 5.0928 & TRN & \\
\hline CHEMBL1591741 & 688267 & 4.0 & 5.1429 & TRN & \\
\hline CHEMBL1597040 & 688267 & 3.95 & 5.0187 & TRN & \\
\hline CHEMBL1513937 & 688267 & 6.2 & 5.1133 & TRN & \\
\hline CHEMBL1503067 & 688267 & 4.0 & 5.0361 & TRN & \\
\hline CHEMBL1502721 & 688267 & 4.05 & 5.0411 & TRN & \\
\hline CHEMBL1402223 & 688267 & 4.05 & 5.1217 & TRN & \\
\hline CHEMBL1570201 & 688267 & 5.55 & 5.0085 & TST & \\
\hline CHEMBL1599477 & 688267 & 6.2 & 4.979 & TRN & \\
\hline CHEMBL3192879 & 688267 & 4.25 & 4.9959 & TRN & \\
\hline CHEMBL1484714 & 688267 & 4.15 & 5.0161 & TRN & \\
\hline CHEMBL1515062 & 688267 & 5.3 & 5.0155 & TRN & \\
\hline CHEMBL1404754 & 688267 & 4.65 & 4.993 & TST & \\
\hline CHEMBL1412896 & 688267 & 5.75 & 5.1215 & TRN & \\
\hline CHEMBL1371649 & 688267 & 6.25 & 5.0188 & TRN & \\
\hline CHEMBL1313109 & 688267 & 4.6 & 5.0461 & TST & \\
\hline CHEMBL1321358 & 688267 & 6.5 & 5.084 & TRN & \\
\hline CHEMBL1470103 & 688267 & 4.85 & 5.0788 & TRN & \\
\hline CHEMBL1355772 & 688267 & 4.3 & 5.0576 & TRN & \\
\hline CHEMBL1495224 & 688267 & 5.5 & 5.0847 & TST & \\
\hline CHEMBL1317838 & 688267 & 4.0 & 5.0237 & TRN & \\
\hline CHEMBL1467267 & 688267 & 5.4 & 5.1102 & TRN & \\
\hline CHEMBL1416294 & 688267 & 6.25 & 5.0192 & TRN & \\
\hline CHEMBL1594353 & 688267 & 5.55 & 5.1518 & TST & \\
\hline CHEMBL1448125 & 688267 & 4.45 & 5.1041 & TRN & \\
\hline
\end{tabular}




\begin{tabular}{|c|c|c|c|c|}
\hline \multicolumn{5}{|c|}{ Supplemental Table S2.txt } \\
\hline CHEMBL1358139 & 688267 & 4.6 & 5.093 & TST \\
\hline CHEMBL1437918 & 688267 & 5.55 & 5.0486 & TRN \\
\hline CHEMBL1557996 & 688267 & 4.4 & 5.0489 & TRN \\
\hline CHEMBL1455258 & 688267 & 4.45 & 5.1165 & TRN \\
\hline CHEMBL1318395 & 688267 & 4.8 & 5.1229 & TRN \\
\hline CHEMBL1317589 & 688267 & 4.5 & 5.0596 & TRN \\
\hline CHEMBL1308189 & 688267 & 6.2 & 5.1172 & TRN \\
\hline CHEMBL1318342 & 688267 & 4.35 & 5.0642 & TRN \\
\hline CHEMBL1595415 & 688267 & 4.9 & 5.0897 & TRN \\
\hline CHEMBL1434635 & 688267 & 4.05 & 5.1346 & TRN \\
\hline CHEMBL1521912 & 688267 & 6.2 & 5.0498 & TRN \\
\hline CHEMBL1511696 & 688267 & 4.3 & 5.0366 & TRN \\
\hline CHEMBL1530262 & 688267 & 4.5 & 5.1207 & TRN \\
\hline CHEMBL1548745 & 688267 & 4.1 & 5.0225 & TRN \\
\hline CHEMBL1595314 & 688267 & 5.55 & 5.0647 & TRN \\
\hline CHEMBL1557328 & 688267 & 4.35 & 5.1506 & TRN \\
\hline CHEMBL1357510 & 688267 & 3.25 & 5.067 & TRN \\
\hline CHEMBL1436375 & 688267 & 4.6 & 5.0965 & TRN \\
\hline CHEMBL1324560 & 688267 & 4.7 & 4.9797 & TRN \\
\hline CHEMBL1411285 & 688267 & 3.8 & 5.0315 & TST \\
\hline CHEMBL1413822 & 688267 & 4.25 & 5.0393 & TRN \\
\hline CHEMBL1571993 & 688267 & 5.85 & 5.0795 & TRN \\
\hline CHEMBL1442842 & 688267 & 4.55 & 5.051 & TRN \\
\hline CHEMBL1357677 & 688267 & 5.5 & 5.0291 & TRN \\
\hline CHEMBL1314299 & 688267 & 4.55 & 5.1135 & TRN \\
\hline CHEMBL1434188 & 688267 & 4.3 & 5.0124 & TRN \\
\hline CHEMBL1386848 & 688267 & 6.2 & 5.0146 & TRN \\
\hline CHEMBL1478474 & 688267 & 6.2 & 5.0783 & TRN \\
\hline CHEMBL1520950 & 688267 & 4.5 & 4.9968 & TRN \\
\hline CHEMBL1444258 & 688267 & 3.95 & 5.032 & TRN \\
\hline CHEMBL605492 & 688267 & 6.15 & 5.041 & TRN \\
\hline CHEMBL1405737 & 688267 & 5.85 & 5.1436 & TST \\
\hline CHEMBL1511470 & 688267 & 4.45 & 5.1642 & TRN \\
\hline CHEMBL1343402 & 688267 & 4.0 & 5.0425 & TRN \\
\hline CHEMBL1377120 & 688267 & 4.3 & 5.0691 & TST \\
\hline CHEMBL1323561 & 688267 & 4.3 & 5.0166 & TRN \\
\hline CHEMBL1328589 & 688267 & 6.15 & 5.0267 & TRN \\
\hline CHEMBL3191657 & 688267 & 5.5 & 5.0446 & TST \\
\hline CHEMBL1442041 & 688267 & 4.05 & 5.0482 & TST \\
\hline CHEMBL1325882 & 688267 & 4.65 & 5.0486 & TST \\
\hline CHEMBL1433374 & 688267 & 6.2 & 5.0249 & TST \\
\hline CHEMBL 1485610 & 688267 & 4.65 & 5.0431 & TRN \\
\hline CHEMBL1547477 & 688267 & 4.0 & 5.0526 & TST \\
\hline CHEMBL1351737 & 688267 & 4.4 & 5.0829 & TRN \\
\hline CHEMBL1467493 & 688267 & 4.95 & 5.0903 & TRN \\
\hline CHEMBL1448785 & 688267 & 4.05 & 5.0872 & TRN \\
\hline CHEMBL1545575 & 688267 & 5.05 & 5.0648 & TRN \\
\hline CHEMBL1401706 & 688267 & 5.8 & 5.0087 & TRN \\
\hline
\end{tabular}




\begin{tabular}{|c|c|c|c|c|}
\hline & & & pplement & al $\mathrm{Ta}$ \\
\hline CHEMBL1589575 & 688267 & 6.1 & 5.1093 & TST \\
\hline CHEMBL3196205 & 688267 & 6.1 & 5.0745 & TRN \\
\hline CHEMBL1526818 & 688267 & 6.15 & 5.0221 & TRN \\
\hline CHEMBL1565776 & 688267 & 6.2 & 5.0411 & TST \\
\hline CHEMBL1568625 & 688267 & 5.55 & 5.0905 & TRN \\
\hline CHEMBL1409875 & 688267 & 4.4 & 5.0392 & TRN \\
\hline CHEMBL1579275 & 688267 & 5.8 & 5.0621 & TRN \\
\hline CHEMBL1495523 & 688267 & 5.85 & 5.0326 & TRN \\
\hline CHEMBL1456566 & 688267 & 6.0 & 5.1087 & TRN \\
\hline CHEMBL1325730 & 688267 & 5.6 & 5.0331 & TRN \\
\hline CHEMBL1491190 & 688267 & 6.15 & 5.1228 & TRN \\
\hline CHEMBL175266 & 688267 & 4.0 & 5.05 & TST \\
\hline CHEMBL1559462 & 688267 & 5.45 & 5.1027 & TRN \\
\hline CHEMBL1572526 & 688267 & 4.0 & 5.106 & TRN \\
\hline CHEMBL1387023 & 688267 & 5.05 & 5.0494 & TRN \\
\hline CHEMBL1607622 & 688267 & 4.05 & 5.0746 & TST \\
\hline CHEMBL1406290 & 688267 & 6.5 & 5.1372 & TRN \\
\hline CHEMBL1552017 & 688267 & 4.0 & 5.1703 & TRN \\
\hline CHEMBL1410821 & 688267 & 4.0 & 5.0799 & TRN \\
\hline CHEMBL1612105 & 688267 & 5.95 & 5.1291 & TRN \\
\hline CHEMBL1336526 & 688267 & 5.45 & 5.0774 & TRN \\
\hline CHEMBL1613013 & 688267 & 4.45 & 4.9861 & TST \\
\hline CHEMBL1517141 & 688267 & 4.0 & 5.0738 & TST \\
\hline CHEMBL1320045 & 688267 & 4.45 & 5.0985 & TRN \\
\hline CHEMBL1563639 & 688267 & 4.0 & 5.018 & TRN \\
\hline CHEMBL1580526 & 688267 & 3.95 & 5.0669 & TRN \\
\hline CHEMBL1560024 & 688267 & 4.05 & 4.9884 & TRN \\
\hline CHEMBL1408478 & 688267 & 4.4 & 4.9915 & TRN \\
\hline CHEMBL1491100 & 688267 & 6.1 & 5.0304 & TRN \\
\hline CHEMBL1398856 & 688267 & 4.9 & 5.1546 & TRN \\
\hline CHEMBL1514302 & 688267 & 6.2 & 5.0316 & TRN \\
\hline CHEMBL1501928 & 688267 & 6.25 & 5.025 & TST \\
\hline CHEMBL1610894 & 688267 & 5.75 & 4.9752 & TRN \\
\hline CHEMBL1431961 & 688267 & 6.2 & 5.0634 & TRN \\
\hline CHEMBL1326592 & 688267 & 3.95 & 5.1502 & TRN \\
\hline CHEMBL1517978 & 688267 & 4.0 & 5.0545 & TRN \\
\hline CHEMBL1465049 & 688267 & 4.0 & 4.9926 & TRN \\
\hline CHEMBL1446188 & 688267 & 3.95 & 5.0716 & TRN \\
\hline CHEMBL1610371 & 688267 & 4.95 & 5.1232 & TRN \\
\hline CHEMBL1521072 & 688267 & 4.25 & 5.037 & TRN \\
\hline CHEMBL1532590 & 688267 & 6.15 & 5.0326 & TST \\
\hline CHEMBL1976412 & 688267 & 4.05 & 4.9882 & TST \\
\hline CHEMBL1330668 & 688267 & 6.2 & 5.1059 & TRN \\
\hline CHEMBL1533881 & 688267 & 6.2 & 5.0889 & TRN \\
\hline CHEMBL1392684 & 688267 & 4.45 & 5.0646 & TRN \\
\hline CHEMBL1329549 & 688267 & 4.05 & 5.0306 & TRN \\
\hline CHEMBL1318998 & 688267 & 5.35 & 5.0535 & TST \\
\hline CHEMBL3197562 & 688267 & 6.05 & 5.0037 & TST \\
\hline
\end{tabular}




\begin{tabular}{|c|c|c|c|c|c|}
\hline \\
\hline CHEMBL1491365 & 688267 & 6.1 & 5.0577 & TRN & \\
\hline CHEMBL1482250 & 688267 & 6.2 & 5.0577 & TST & \\
\hline CHEMBL1591418 & 688267 & 4.5 & 5.0995 & TRN & \\
\hline CHEMBL1506004 & 688267 & 4.65 & 5.1082 & TRN & \\
\hline CHEMBL1481878 & 688267 & 4.6 & 5.0284 & TRN & \\
\hline CHEMBL1402004 & 688267 & 5.65 & 5.08899 & 99999999995 & TRN \\
\hline CHEMBL1313191 & 688267 & 4.5 & 5.0878 & TST & \\
\hline CHEMBL1367047 & 688267 & 4.4 & 5.0714 & TRN & \\
\hline CHEMBL1456880 & 688267 & 5.6 & 5.0566 & TRN & \\
\hline CHEMBL1543953 & 688267 & 6.25 & 5.0752 & TRN & \\
\hline CHEMBL1495275 & 688267 & 4.0 & 5.0015 & TRN & \\
\hline CHEMBL1556916 & 688267 & 4.25 & 5.1105 & TRN & \\
\hline CHEMBL1374498 & 688267 & 6.2 & 5.126 & TRN & \\
\hline CHEMBL1571712 & 688267 & 5.3 & 5.0407 & TST & \\
\hline CHEMBL1337079 & 688267 & 4.4 & 5.025 & TST & \\
\hline CHEMBL1315718 & 688267 & 5.05 & 5.0853 & TRN & \\
\hline CHEMBL1568058 & 688267 & 5.6 & 5.0254 & TRN & \\
\hline CHEMBL1303754 & 688267 & 5.25 & 5.0864 & TRN & \\
\hline CHEMBL1421740 & 688267 & 4.35 & 5.0471 & TRN & \\
\hline CHEMBL1586745 & 688267 & 4.0 & 5.0896 & TRN & \\
\hline CHEMBL1571900 & 688267 & 5.4 & 5.0324 & TRN & \\
\hline CHEMBL1362520 & 688267 & 6.15 & 5.0327 & TRN & \\
\hline CHEMBL1436099 & 688267 & 4.0 & 5.0026 & TRN & \\
\hline CHEMBL1424787 & 688267 & 4.4 & 5.065 & TRN & \\
\hline CHEMBL1547361 & 688267 & 6.2 & 5.0607 & TST & \\
\hline CHEMBL1380103 & 688267 & 4.05 & 5.0291 & TRN & \\
\hline CHEMBL1464377 & 688267 & 4.65 & 5.1319 & TRN & \\
\hline CHEMBL1577615 & 688267 & 4.0 & 5.1042 & TRN & \\
\hline CHEMBL1428833 & 688267 & 4.65 & 5.0847 & TST & \\
\hline CHEMBL1593741 & 688267 & 3.95 & 4.9973 & TRN & \\
\hline CHEMBL1570358 & 688267 & 4.0 & 4.9937 & TRN & \\
\hline CHEMBL1525242 & 688267 & 6.2 & 5.008 & TRN & \\
\hline CHEMBL1310121 & 688267 & 4.3 & 5.0865 & TRN & \\
\hline CHEMBL1427802 & 688267 & 6.15 & 5.1341 & TRN & \\
\hline CHEMBL1404019 & 688267 & 3.95 & 5.0435 & TRN & \\
\hline CHEMBL1391358 & 688267 & 4.35 & 5.016 & TRN & \\
\hline CHEMBL1549837 & 688267 & 4.2 & 5.0569 & TRN & \\
\hline CHEMBL1515309 & 688267 & 4.35 & 5.0331 & TRN & \\
\hline CHEMBL1434434 & 688267 & 4.1 & 5.0153 & TRN & \\
\hline CHEMBL1445208 & 688267 & 5.75 & 5.0687 & TRN & \\
\hline CHEMBL1436866 & 688267 & 5.4 & 5.0609 & TRN & \\
\hline CHEMBL1569408 & 688267 & 6.45 & 5.0441 & TRN & \\
\hline CHEMBL1356310 & 688267 & 6.2 & 5.0919 & TRN & \\
\hline CHEMBL1608371 & 688267 & 6.2 & 5.1182 & TRN & \\
\hline CHEMBL1462887 & 688267 & 5.55 & 5.0156 & TRN & \\
\hline CHEMBL1313239 & 688267 & 4.75 & 5.0926 & TRN & \\
\hline CHEMBL1313263 & 688267 & 4.2 & 5.1237 & TST & \\
\hline CHEMBL1341915 & 688267 & 3.95 & 5.033 & TRN & \\
\hline
\end{tabular}




\begin{tabular}{|c|c|c|c|c|}
\hline & & & pplement & al Ta \\
\hline CHEMBL1368314 & 688267 & 6.5 & 5.1378 & TRN \\
\hline CHEMBL1410593 & 688267 & 5.3 & 4.9955 & TST \\
\hline CHEMBL1349252 & 688267 & 4.1 & 5.0611 & TST \\
\hline CHEMBL1312606 & 688267 & 4.5 & 5.0278 & TST \\
\hline CHEMBL1315385 & 688267 & 4.2 & 4.9704 & TRN \\
\hline CHEMBL1303932 & 688267 & 4.55 & 5.0965 & TRN \\
\hline CHEMBL406557 & 688267 & 4.05 & 4.9619 & TRN \\
\hline CHEMBL1459461 & 688267 & 4.35 & 5.0837 & TST \\
\hline CHEMBL1522300 & 688267 & 6.25 & 5.0686 & TRN \\
\hline CHEMBL1430391 & 688267 & 5.25 & 5.055 & TST \\
\hline CHEMBL1597129 & 688267 & 4.95 & 5.1621 & TRN \\
\hline CHEMBL1359561 & 688267 & 6.2 & 5.0113 & TST \\
\hline CHEMBL1331326 & 688267 & 5.25 & 5.0358 & TRN \\
\hline CHEMBL1566238 & 688267 & 4.0 & 4.9903 & TRN \\
\hline CHEMBL1565439 & 688267 & 4.05 & 5.0482 & TRN \\
\hline CHEMBL 3198846 & 688267 & 6.2 & 5.0798 & TRN \\
\hline CHEMBL1573972 & 688267 & 4.35 & 4.9924 & TRN \\
\hline CHEMBL1502726 & 688267 & 4.0 & 5.0515 & TRN \\
\hline CHEMBL1456056 & 688267 & 5.55 & 5.0649 & TRN \\
\hline CHEMBL1337981 & 688267 & 3.95 & 5.0372 & TRN \\
\hline CHEMBL1536796 & 688267 & 4.55 & 5.023 & TST \\
\hline CHEMBL1563077 & 688267 & 5.3 & 5.1438 & TRN \\
\hline CHEMBL1386172 & 688267 & 4.95 & 5.0513 & TRN \\
\hline CHEMBL1592351 & 688267 & 4.8 & 5.0938 & TRN \\
\hline CHEMBL1321354 & 688267 & 5.2 & 5.1193 & TRN \\
\hline CHEMBL1427126 & 688267 & 4.6 & 5.0903 & TRN \\
\hline CHEMBL1514225 & 688267 & 4.4 & 5.1577 & TRN \\
\hline CHEMBL1453051 & 688267 & 4.05 & 5.0929 & TRN \\
\hline CHEMBL1542572 & 688267 & 5.45 & 5.0539 & TRN \\
\hline CHEMBL1583221 & 688267 & 4.35 & 5.0703 & TRN \\
\hline CHEMBL1307593 & 688267 & 6.25 & 5.0457 & TRN \\
\hline CHEMBL1314811 & 688267 & 5.2 & 5.0282 & TRN \\
\hline CHEMBL1431383 & 688267 & 4.95 & 5.0134 & TRN \\
\hline CHEMBL3189312 & 688267 & 4.5 & 5.0791 & TST \\
\hline CHEMBL1490645 & 688267 & 4.45 & 5.0084 & TST \\
\hline CHEMBL1338416 & 688267 & 5.9 & 5.0684 & TST \\
\hline CHEMBL1506252 & 688267 & 6.15 & 5.0017 & TRN \\
\hline CHEMBL1412737 & 688267 & 5.55 & 5.086 & TRN \\
\hline CHEMBL1345393 & 688267 & 5.05 & 5.0521 & TRN \\
\hline CHEMBL1564293 & 688267 & 6.2 & 5.0455 & TRN \\
\hline CHEMBL1492224 & 688267 & 4.35 & 5.19 & TRN \\
\hline CHEMBL3194253 & 688267 & 5.9 & 5.1281 & TRN \\
\hline CHEMBL1365374 & 688267 & 5.85 & 5.1112 & TRN \\
\hline CHEMBL1455950 & 688267 & 4.0 & 5.0297 & TRN \\
\hline CHEMBL1348090 & 688267 & 5.4 & 4.9742 & TRN \\
\hline CHEMBL 3194592 & 688267 & 5.3 & 5.0301 & TRN \\
\hline CHEMBL1516369 & 688267 & 5.75 & 4.9983 & TRN \\
\hline CHEMBL1445622 & 688267 & 5.3 & 5.1292 & TRN \\
\hline
\end{tabular}




\begin{tabular}{|c|c|c|c|c|c|}
\hline & & \multicolumn{4}{|c|}{ Supplemental Table s2.txt } \\
\hline CHEMBL1427183 & 688267 & 5.55 & 5.034 & TRN & \\
\hline CHEMBL1474057 & 688267 & 4.75 & 5.0943 & TRN & \\
\hline CHEMBL1389536 & 688267 & 4.75 & 5.0695 & TRN & \\
\hline CHEMBL1464513 & 688267 & 4.6 & 5.0755 & TRN & \\
\hline CHEMBL1334528 & 688267 & 3.95 & 5.0188 & TST & \\
\hline CHEMBL1510395 & 688267 & 6.2 & 5.1107 & TRN & \\
\hline CHEMBL1973307 & 688267 & 4.65 & 5.0479 & TRN & \\
\hline CHEMBL1436998 & 688267 & 4.0 & 5.1072 & TRN & \\
\hline CHEMBL1316414 & 688267 & 4.3 & 5.0301 & TRN & \\
\hline CHEMBL1588817 & 688267 & 5.8 & 5.0767 & TRN & \\
\hline CHEMBL1366519 & 688267 & 5.8 & 5.1118 & TRN & \\
\hline CHEMBL1496402 & 688267 & 6.1 & 5.0754 & TRN & \\
\hline CHEMBL1354922 & 688267 & 6.2 & 5.008 & TRN & \\
\hline CHEMBL1430185 & 688267 & 6.2 & 5.0086 & TRN & \\
\hline CHEMBL1586388 & 688267 & 4.65 & 5.0528 & TRN & \\
\hline CHEMBL3192240 & 688267 & 6.2 & 5.0748 & TST & \\
\hline CHEMBL1567487 & 688267 & 6.15 & 5.0771 & TRN & \\
\hline CHEMBL1457313 & 688267 & 4.75 & 5.1395 & TST & \\
\hline CHEMBL1481367 & 688267 & 4.6 & 5.0861 & TRN & \\
\hline CHEMBL1458004 & 688267 & 4.05 & 5.0345 & TRN & \\
\hline CHEMBL1478747 & 688267 & 6.0 & 5.034 & TRN & \\
\hline CHEMBL1316373 & 688267 & 5.25 & 5.0743 & TRN & \\
\hline CHEMBL1449776 & 688267 & 4.0 & 5.0742 & TRN & \\
\hline CHEMBL1463764 & 688267 & 5.35 & 5.1267 & TRN & \\
\hline CHEMBL1505489 & 688267 & 4.7 & 5.0277 & TRN & \\
\hline CHEMBL1381081 & 688267 & 4.3 & 5.1195 & TRN & \\
\hline CHEMBL1386145 & 688267 & 5.55 & 5.0675 & TRN & \\
\hline CHEMBL1586949 & 688267 & 6.15 & 5.0496 & TST & \\
\hline CHEMBL1400297 & 688267 & 5.3 & 5.02800 & 00000000005 & TRN \\
\hline CHEMBL1385528 & 688267 & 6.2 & 5.0703 & TRN & \\
\hline CHEMBL1423699 & 688267 & 6.25 & 5.1968 & TRN & \\
\hline CHEMBL1364932 & 688267 & 4.0 & 5.0211 & TRN & \\
\hline CHEMBL1323949 & 688267 & 5.45 & 5.1356 & TRN & \\
\hline CHEMBL 2006817 & 688267 & 5.6 & 4.9876 & TST & \\
\hline CHEMBL1612534 & 688267 & 6.2 & 5.0493 & TRN & \\
\hline CHEMBL1460600 & 688267 & 4.05 & 5.0997 & TST & \\
\hline CHEMBL1475565 & 688267 & 4.0 & 5.0472 & TRN & \\
\hline CHEMBL1571340 & 688267 & 5.5 & 5.0468 & TRN & \\
\hline CHEMBL1424463 & 688267 & 6.2 & 5.044 & TRN & \\
\hline CHEMBL1456333 & 688267 & 4.1 & 5.0571 & TRN & \\
\hline CHEMBL1612969 & 688267 & 4.0 & 5.0528 & TRN & \\
\hline CHEMBL1532194 & 688267 & 6.4 & 4.9886 & TST & \\
\hline CHEMBL1530628 & 688267 & 6.0 & 5.0488 & TRN & \\
\hline CHEMBL1512167 & 688267 & 4.05 & 5.1096 & TRN & \\
\hline CHEMBL1417176 & 688267 & 4.5 & 5.1019 & TST & \\
\hline CHEMBL1378786 & 688267 & 4.6 & 5.0603 & TST & \\
\hline CHEMBL1389590 & 688267 & 4.3 & 5.1255 & TRN & \\
\hline CHEMBL1461997 & 688267 & 5.4 & 5.1182 & TRN & \\
\hline
\end{tabular}




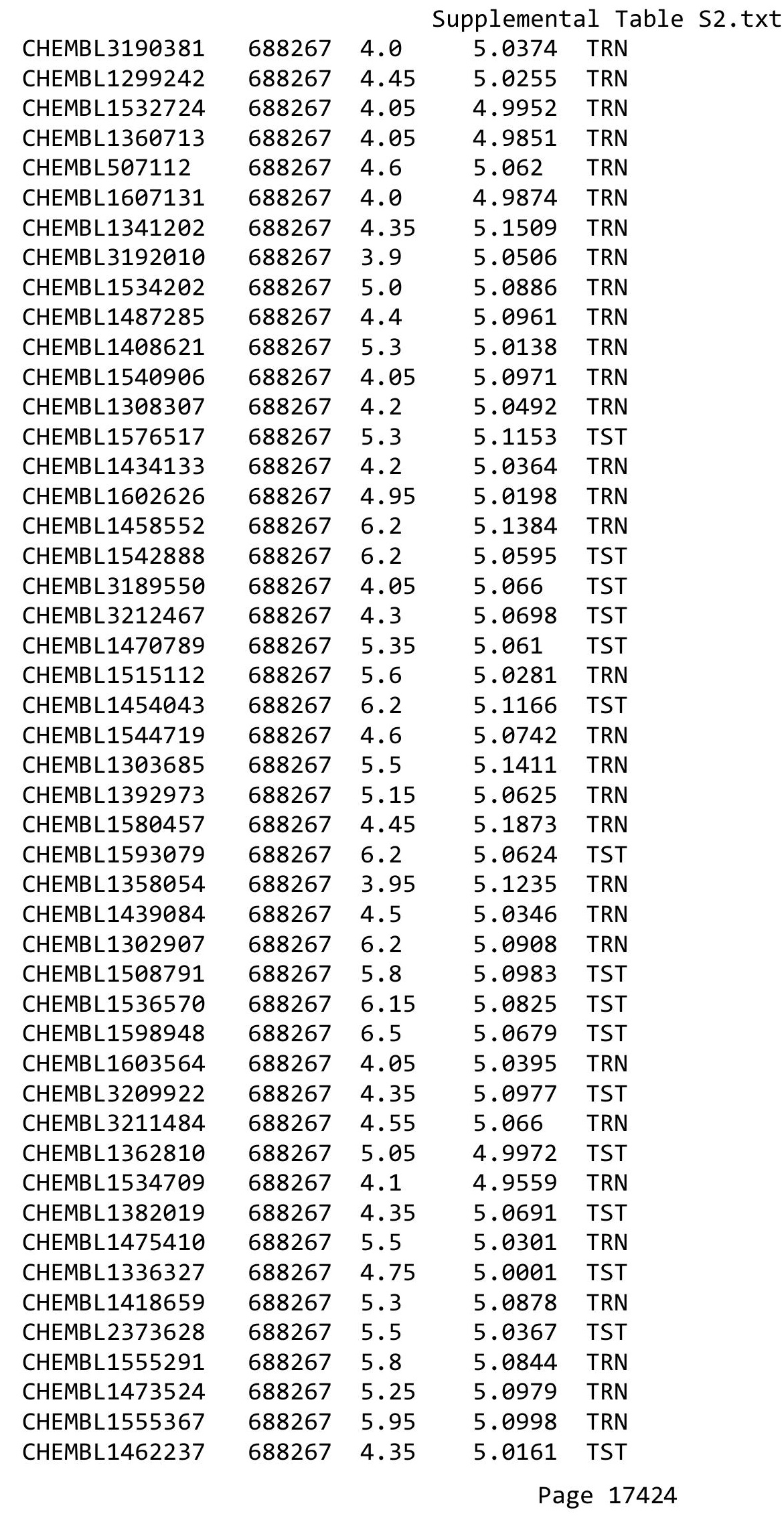




\begin{tabular}{|c|c|c|c|c|c|}
\hline \\
\hline CHEMBL1441780 & 688267 & 4.3 & 5.0862 & TRN & \\
\hline CHEMBL1592918 & 688267 & 4.15 & 5.0223 & TRN & \\
\hline CHEMBL1512076 & 688267 & 6.2 & 5.1035 & TRN & \\
\hline CHEMBL1561171 & 688267 & 6.25 & 4.9898 & TRN & \\
\hline CHEMBL1552899 & 688267 & 5.5 & 5.0913 & TRN & \\
\hline CHEMBL1394180 & 688267 & 5.45 & 5.0912 & TRN & \\
\hline CHEMBL1469213 & 688267 & 5.85 & 5.0512 & TRN & \\
\hline CHEMBL1484946 & 688267 & 4.0 & 5.0684 & TRN & \\
\hline CHEMBL1550273 & 688267 & 4.4 & 5.0542 & TRN & \\
\hline CHEMBL1366037 & 688267 & 6.2 & 5.0417 & TRN & \\
\hline CHEMBL1396032 & 688267 & 5.5 & 5.0712 & TRN & \\
\hline CHEMBL1320848 & 688267 & 5.1 & 5.0298 & TST & \\
\hline CHEMBL1546428 & 688267 & 6.2 & 5.0232 & TRN & \\
\hline CHEMBL1395842 & 688267 & 6.25 & 5.0651 & TRN & \\
\hline CHEMBL260451 & 688267 & 5.0 & 5.0163 & TST & \\
\hline CHEMBL1423323 & 688267 & 4.7 & $5.0360 e$ & j0000000005 & TST \\
\hline CHEMBL1325439 & 688267 & 4.3 & 5.045 & TRN & \\
\hline CHEMBL1463125 & 688267 & 5.8 & 5.0253 & TRN & \\
\hline CHEMBL1604415 & 688267 & 5.3 & 5.0378 & TST & \\
\hline CHEMBL1553995 & 688267 & 4.0 & 5.0614 & TRN & \\
\hline CHEMBL1380629 & 688267 & 5.5 & 4.9697 & TRN & \\
\hline CHEMBL1506876 & 688267 & 5.45 & 5.1394 & TRN & \\
\hline CHEMBL1403786 & 688267 & 5.45 & 5.0766 & TST & \\
\hline CHEMBL1326548 & 688267 & 5.45 & 5.0194 & TRN & \\
\hline CHEMBL1524255 & 688267 & 4.95 & 5.0761 & TST & \\
\hline CHEMBL1358989 & 688267 & 4.2 & 5.0106 & TST & \\
\hline CHEMBL1372426 & 688267 & 5.3 & 5.0493 & TRN & \\
\hline CHEMBL1591831 & 688267 & 4.0 & 5.1183 & TRN & \\
\hline CHEMBL1502409 & 688267 & 4.15 & 5.0656 & TRN & \\
\hline CHEMBL1352835 & 688267 & 5.85 & 5.0608 & TRN & \\
\hline CHEMBL1523623 & 688267 & 4.3 & 5.0415 & TRN & \\
\hline CHEMBL1375841 & 688267 & 4.05 & 5.0488 & TRN & \\
\hline CHEMBL1320008 & 688267 & 6.2 & 5.0537 & TRN & \\
\hline CHEMBL1481707 & 688267 & 5.7 & 5.1553 & TRN & \\
\hline CHEMBL1414502 & 688267 & 4.5 & 4.982 & TRN & \\
\hline CHEMBL1315869 & 688267 & 6.25 & 5.0176 & TRN & \\
\hline CHEMBL1363809 & 688267 & 5.45 & 5.0327 & TRN & \\
\hline CHEMBL1554371 & 688267 & 4.0 & 5.0168 & TRN & \\
\hline CHEMBL1356186 & 688267 & 5.85 & 5.113 & TRN & \\
\hline CHEMBL1548749 & 688267 & 6.2 & 5.0391 & TST & \\
\hline CHEMBL1303042 & 688267 & 5.4 & 5.0365 & TRN & \\
\hline CHEMBL1446701 & 688267 & 4.1 & 5.0077 & TRN & \\
\hline CHEMBL1483570 & 688267 & 5.0 & 5.0492 & TRN & \\
\hline CHEMBL1473681 & 688267 & 6.2 & 4.9824 & TRN & \\
\hline CHEMBL1476984 & 688267 & 4.2 & 4.9876 & TST & \\
\hline CHEMBL1543688 & 688267 & 6.5 & 5.0942 & TRN & \\
\hline CHEMBL1527808 & 688267 & 6.25 & 5.0511 & TRN & \\
\hline CHEMBL1513945 & 688267 & 5.5 & 5.1603 & TRN & \\
\hline
\end{tabular}




\begin{tabular}{|c|c|c|c|c|}
\hline & & & pplement & \\
\hline CHEMBL1388067 & 688267 & 6.2 & 5.0357 & TST \\
\hline CHEMBL1351622 & 688267 & 5.0 & 5.0551 & TRN \\
\hline CHEMBL1334600 & 688267 & 6.15 & 5.0884 & TRN \\
\hline CHEMBL1529949 & 688267 & 6.45 & 5.1346 & TRN \\
\hline CHEMBL1401901 & 688267 & 6.2 & 5.029 & TRN \\
\hline CHEMBL1514546 & 688267 & 4.0 & 5.0267 & TRN \\
\hline CHEMBL1309980 & 688267 & 4.25 & 5.1049 & TRN \\
\hline CHEMBL1322023 & 688267 & 3.95 & 5.0865 & TST \\
\hline CHEMBL1367783 & 688267 & 6.25 & 5.0606 & TRN \\
\hline CHEMBL1428114 & 688267 & 4.25 & 5.0521 & TST \\
\hline CHEMBL 3211824 & 688267 & 4.65 & 4.9942 & TRN \\
\hline CHEMBL1503879 & 688267 & 6.15 & 5.0887 & TRN \\
\hline CHEMBL1438816 & 688267 & 4.05 & 5.0349 & TST \\
\hline CHEMBL1371582 & 688267 & 4.0 & 5.0366 & TRN \\
\hline CHEMBL1562191 & 688267 & 4.35 & 5.0225 & TST \\
\hline CHEMBL1536109 & 688267 & 5.65 & 5.0814 & TRN \\
\hline CHEMBL1587019 & 688267 & 5.45 & 5.0645 & TRN \\
\hline CHEMBL1391716 & 688267 & 5.55 & 5.0707 & TRN \\
\hline CHEMBL1545884 & 688267 & 4.0 & 5.083 & TRN \\
\hline CHEMBL1592205 & 688267 & 4.0 & 5.0632 & TRN \\
\hline CHEMBL1432876 & 688267 & 4.0 & 4.9886 & TST \\
\hline CHEMBL1091501 & 688267 & 6.2 & 5.1271 & TRN \\
\hline CHEMBL1528588 & 688267 & 4.05 & 5.1061 & TRN \\
\hline CHEMBL1441259 & 688267 & 6.2 & 5.0879 & TRN \\
\hline CHEMBL1482267 & 688267 & 5.05 & 5.0736 & TRN \\
\hline CHEMBL1582089 & 688267 & 6.25 & 5.0733 & TRN \\
\hline CHEMBL1575732 & 688267 & 5.0 & 4.9868 & TRN \\
\hline CHEMBL1380958 & 688267 & 5.6 & 5.0507 & TST \\
\hline CHEMBL1389902 & 688267 & 4.25 & 5.0278 & TRN \\
\hline CHEMBL1439023 & 688267 & 6.5 & 5.0313 & TRN \\
\hline CHEMBL1307674 & 688267 & 5.0 & 5.0095 & TST \\
\hline CHEMBL1488301 & 688267 & 4.2 & 5.0766 & TRN \\
\hline CHEMBL1532939 & 688267 & 5.0 & 5.0293 & TRN \\
\hline CHEMBL1394390 & 688267 & 4.35 & 5.0587 & TRN \\
\hline CHEMBL1577672 & 688267 & 4.25 & 5.005 & TRN \\
\hline CHEMBL1483490 & 688267 & 5.3 & 5.001 & TRN \\
\hline CHEMBL1475836 & 688267 & 4.0 & 5.0453 & TRN \\
\hline CHEMBL 3208783 & 688267 & 5.95 & 5.0071 & TST \\
\hline CHEMBL1418559 & 688267 & 5.95 & 5.0906 & TRN \\
\hline CHEMBL1301422 & 688267 & 4.0 & 5.0557 & TRN \\
\hline CHEMBL1315578 & 688267 & 4.55 & 5.0337 & TRN \\
\hline CHEMBL1384833 & 688267 & 3.95 & 5.078 & TRN \\
\hline CHEMBL1522555 & 688267 & 5.6 & 5.0301 & TRN \\
\hline CHEMBL1560908 & 688267 & 4.0 & 4.996 & TST \\
\hline CHEMBL1419921 & 688267 & 5.5 & 5.0268 & TRN \\
\hline CHEMBL1315663 & 688267 & 5.55 & 5.1081 & TRN \\
\hline CHEMBL1451494 & 688267 & 6.15 & 5.0733 & TRN \\
\hline CHEMBL1383824 & 688267 & 4.2 & 4.9996 & TRN \\
\hline
\end{tabular}




\begin{tabular}{|c|c|c|c|c|c|}
\hline \multicolumn{6}{|c|}{ Supplemental Table S2.txt } \\
\hline CHEMBL1412448 & 688267 & 6.45 & 5.0398 & TRN & \\
\hline CHEMBL11405 & 688267 & 5.1 & 5.0959 & TRN & \\
\hline CHEMBL1319259 & 688267 & 6.5 & 5.0486 & TRN & \\
\hline CHEMBL1390966 & 688267 & 6.15 & 5.1095 & TRN & \\
\hline CHEMBL 3199590 & 688267 & 3.95 & 4.9728 & TRN & \\
\hline CHEMBL1595532 & 688267 & 4.4 & 5.0733 & TRN & \\
\hline CHEMBL1555884 & 688267 & 6.15 & 5.0549 & TST & \\
\hline CHEMBL1317350 & 688267 & 6.25 & 5.023 & TRN & \\
\hline CHEMBL1362922 & 688267 & 5.25 & 5.0697 & TRN & \\
\hline CHEMBL1366847 & 688267 & 4.8 & 5.0748 & TRN & \\
\hline CHEMBL1510365 & 688267 & 4.35 & 5.0863 & TST & \\
\hline CHEMBL1530293 & 688267 & 5.05 & 5.0646 & TRN & \\
\hline CHEMBL1415756 & 688267 & 4.4 & 5.0118 & TRN & \\
\hline CHEMBL1389893 & 688267 & 4.05 & 5.0777 & TRN & \\
\hline CHEMBL1488515 & 688267 & 4.6 & 4.9954 & TRN & \\
\hline CHEMBL1548817 & 688267 & 3.9 & 5.1098 & TRN & \\
\hline CHEMBL1597133 & 688267 & 5.6 & 5.0174 & TRN & \\
\hline CHEMBL1575911 & 688267 & 6.25 & 4.9922 & TRN & \\
\hline CHEMBL 3213173 & 688267 & 4.05 & 4.9908 & TST & \\
\hline CHEMBL1565260 & 688267 & 4.65 & 5.0344 & TRN & \\
\hline CHEMBL1586879 & 688267 & 6.25 & 4.9907 & TRN & \\
\hline CHEMBL1404162 & 688267 & 3.95 & 5.0314 & TRN & \\
\hline CHEMBL1425707 & 688267 & 4.35 & 5.0561 & TRN & \\
\hline CHEMBL1523611 & 688267 & 6.25 & 5.0797 & TRN & \\
\hline CHEMBL1441544 & 688267 & 6.2 & 5.0665 & TRN & \\
\hline CHEMBL1508495 & 688267 & 5.5 & 5.0916 & TST & \\
\hline CHEMBL1548680 & 688267 & 6.2 & 5.01399 & 9999999999 & TRN \\
\hline CHEMBL1532322 & 688267 & 5.55 & 5.0288 & TRN & \\
\hline CHEMBL1474893 & 688267 & 6.25 & 5.0562 & TRN & \\
\hline CHEMBL1548344 & 688267 & 5.85 & 5.0762 & TRN & \\
\hline CHEMBL1574942 & 688267 & 4.05 & 5.0244 & TRN & \\
\hline CHEMBL1315957 & 688267 & 4.0 & 5.1171 & TRN & \\
\hline CHEMBL1332088 & 688267 & 6.0 & 5.0413 & TST & \\
\hline CHEMBL1568647 & 688267 & 4.5 & 5.0366 & TST & \\
\hline CHEMBL1481517 & 688267 & 4.25 & 5.1088 & TST & \\
\hline CHEMBL591130 & 688267 & 5.5 & 5.0719 & TST & \\
\hline CHEMBL1314733 & 688267 & 5.8 & 5.0391 & TST & \\
\hline CHEMBL1591195 & 688267 & 5.3 & 5.1767 & TRN & \\
\hline CHEMBL1585861 & 688267 & 5.8 & 5.0035 & TRN & \\
\hline CHEMBL1455024 & 688267 & 4.55 & 5.0351 & TST & \\
\hline CHEMBL1573098 & 688267 & 4.6 & 5.0519 & TST & \\
\hline CHEMBL1514067 & 688267 & 6.1 & 5.0724 & TRN & \\
\hline CHEMBL3210014 & 688267 & 4.05 & 4.9971 & TST & \\
\hline CHEMBL1447597 & 688267 & 6.5 & 5.0182 & TRN & \\
\hline CHEMBL1469787 & 688267 & 6.2 & 5.0556 & TRN & \\
\hline CHEMBL1538130 & 688267 & 4.35 & 5.0075 & TST & \\
\hline CHEMBL1401824 & 688267 & 5.55 & 5.1523 & TRN & \\
\hline CHEMBL1416391 & 688267 & 4.3 & 4.9972 & TST & \\
\hline
\end{tabular}




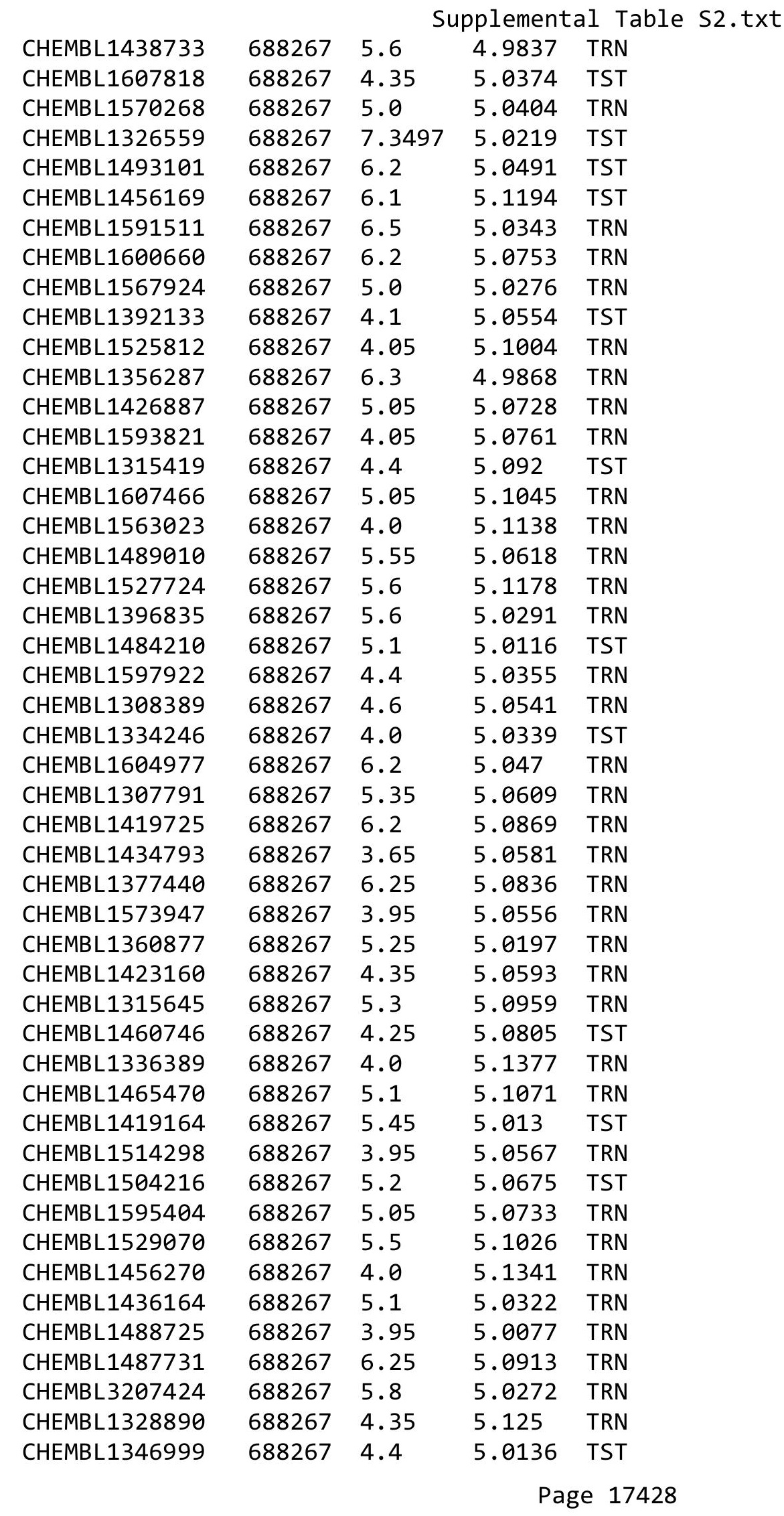




\begin{tabular}{|c|c|c|c|c|c|}
\hline \multicolumn{6}{|c|}{ Supplemental Table s2.txt } \\
\hline CHEMBL1613623 & 688267 & 5.55 & 5.0806 & TST & \\
\hline CHEMBL1317879 & 688267 & 6.25 & 5.0615 & TRN & \\
\hline CHEMBL1357066 & 688267 & 5.35 & 4.9537 & TRN & \\
\hline CHEMBL1430062 & 688267 & 4.55 & 5.0789 & TST & \\
\hline CHEMBL1546783 & 688267 & 4.55 & 5.0733 & TRN & \\
\hline CHEMBL1504245 & 688267 & 4.2 & \multicolumn{2}{|c|}{5.0489999999999995} & TST \\
\hline CHEMBL1337776 & 688267 & 6.25 & 5.0027 & TRN & \\
\hline CHEMBL1523979 & 688267 & 4.55 & 4.9683 & TRN & \\
\hline CHEMBL1609795 & 688267 & 5.1 & 5.0798 & TRN & \\
\hline CHEMBL1602116 & 688267 & 4.55 & 5.0066 & TRN & \\
\hline CHEMBL1571392 & 688267 & 4.55 & 5.0733 & TST & \\
\hline CHEMBL1327749 & 688267 & 4.7 & 5.0651 & TRN & \\
\hline CHEMBL1555695 & 688267 & 4.05 & 5.0096 & TST & \\
\hline CHEMBL1373300 & 688267 & 4.35 & 5.1062 & TRN & \\
\hline CHEMBL1432903 & 688267 & 5.2 & 5.0164 & TRN & \\
\hline CHEMBL1584802 & 688267 & 6.5 & 5.1044 & TRN & \\
\hline CHEMBL1421787 & 688267 & 4.7 & 5.0746 & TRN & \\
\hline CHEMBL1520756 & 688267 & 5.05 & 5.1079 & TRN & \\
\hline CHEMBL1361278 & 688267 & 6.2 & 5.0295 & TRN & \\
\hline CHEMBL1434908 & 688267 & 4.6 & 4.99 & TRN & \\
\hline CHEMBL1422437 & 688267 & 4.4 & 5.0759 & TST & \\
\hline CHEMBL1509324 & 688267 & 4.05 & \multicolumn{2}{|c|}{5.0569999999999995} & TRN \\
\hline CHEMBL1357318 & 688267 & 4.3 & 5.0229 & TRN & \\
\hline CHEMBL1564966 & 688267 & 4.35 & 5.0645 & TRN & \\
\hline CHEMBL1541660 & 688267 & 3.9 & 5.0481 & TRN & \\
\hline CHEMBL1590693 & 688267 & 6.2 & 5.0091 & TRN & \\
\hline CHEMBL1514418 & 688267 & 6.6499 & 5.1594 & TRN & \\
\hline CHEMBL1583053 & 688267 & 4.25 & 5.0376 & TST & \\
\hline CHEMBL1489238 & 688267 & 4.25 & 5.0893 & TRN & \\
\hline CHEMBL1438329 & 688267 & 4.05 & 5.0226 & TST & \\
\hline CHEMBL1437746 & 688267 & 4.05 & 5.0652 & TRN & \\
\hline CHEMBL1560213 & 688267 & 4.65 & 5.0368 & TRN & \\
\hline CHEMBL1314598 & 688267 & 5.3 & 5.0353 & TRN & \\
\hline CHEMBL3191726 & 688267 & 4.0 & 4.9863 & TRN & \\
\hline CHEMBL1329835 & 688267 & 6.2 & 5.0773 & TRN & \\
\hline CHEMBL1359583 & 688267 & 4.6 & 5.0435 & TST & \\
\hline CHEMBL1442264 & 688267 & 6.2 & \multicolumn{2}{|c|}{5.071000000000001} & TRN \\
\hline CHEMBL1535063 & 688267 & 4.6 & \multicolumn{2}{|c|}{5.111000000000001} & TST \\
\hline CHEMBL1598921 & 688267 & 5.35 & 5.0674 & TST & \\
\hline CHEMBL1344269 & 688267 & 4.5 & 5.0087 & TRN & \\
\hline CHEMBL1438654 & 688267 & 5.9 & 5.1404 & TRN & \\
\hline CHEMBL1575741 & 688267 & 4.5 & 5.015 & TST & \\
\hline CHEMBL1528925 & 688267 & 4.35 & 5.0186 & TST & \\
\hline CHEMBL3207844 & 688267 & 5.7 & \multicolumn{2}{|c|}{5.0360000000000005} & TRN \\
\hline CHEMBL1361192 & 688267 & 4.35 & 5.0152 & TRN & \\
\hline CHEMBL1512471 & 688267 & 6.2 & 5.0855 & TRN & \\
\hline CHEMBL1350794 & 688267 & 6.1 & 5.0207 & TST & \\
\hline CHEMBL3193005 & 688267 & 5.85 & 5.0103 & TST & \\
\hline
\end{tabular}




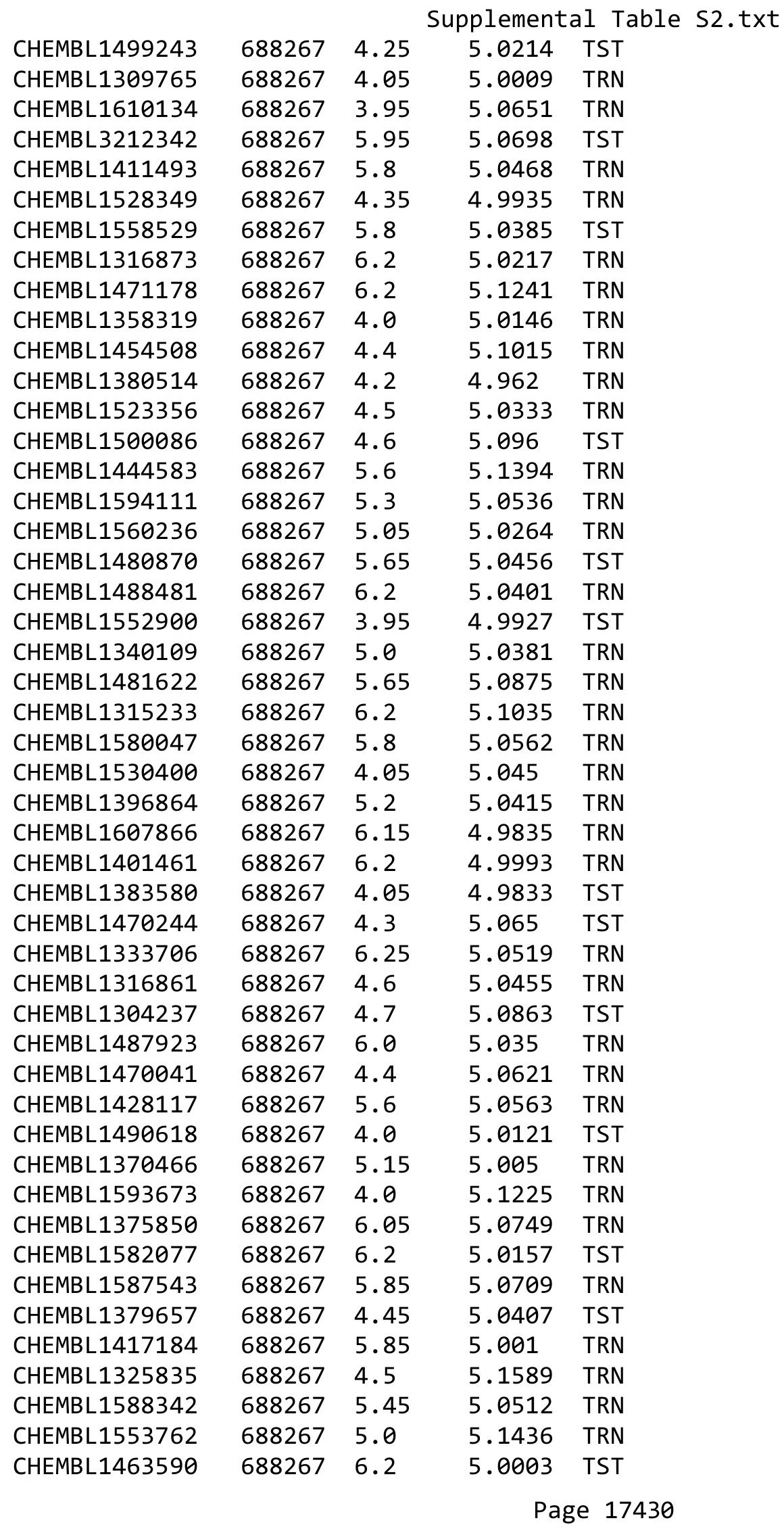




\begin{tabular}{|c|c|c|c|c|}
\hline \multicolumn{5}{|c|}{ Supplemental Tabl } \\
\hline CHEMBL1547829 & 688267 & 6.25 & 5.0309 & TRN \\
\hline CHEMBL1379140 & 688267 & 4.95 & 5.11 & TRN \\
\hline CHEMBL1368658 & 688267 & 6.1 & 5.0463 & TRN \\
\hline CHEMBL1497131 & 688267 & 4.45 & 5.0373 & TRN \\
\hline CHEMBL1408964 & 688267 & 4.4 & 5.0223 & TST \\
\hline CHEMBL1332619 & 688267 & 4.35 & 5.0733 & TST \\
\hline CHEMBL1580385 & 688267 & 6.2 & 5.1015 & TRN \\
\hline CHEMBL1576536 & 688267 & 4.05 & 5.0939 & TRN \\
\hline CHEMBL1453922 & 688267 & 5.95 & 5.1076 & TRN \\
\hline CHEMBL1302334 & 688267 & 5.45 & 4.9998 & TRN \\
\hline CHEMBL1475323 & 688267 & 5.5 & 5.0904 & TRN \\
\hline CHEMBL1484116 & 688267 & 4.95 & 5.0874 & TRN \\
\hline CHEMBL1452660 & 688267 & 6.2 & 5.0226 & TRN \\
\hline CHEMBL1513259 & 688267 & 3.95 & 5.1075 & TST \\
\hline CHEMBL1442437 & 688267 & 4.0 & 5.0827 & TRN \\
\hline CHEMBL1374661 & 688267 & 4.1 & 5.0943 & TRN \\
\hline CHEMBL1456372 & 688267 & 6.45 & 5.1109 & TRN \\
\hline CHEMBL1414920 & 688267 & 5.35 & 5.0478 & TRN \\
\hline CHEMBL1350117 & 688267 & 5.6 & 5.0276 & TRN \\
\hline CHEMBL1501590 & 688267 & 4.6 & 5.103 & TST \\
\hline CHEMBL1549899 & 688267 & 5.2 & 5.0906 & TRN \\
\hline CHEMBL1569403 & 688267 & 6.2 & 5.0434 & TST \\
\hline CHEMBL1497288 & 688267 & 6.15 & 5.0611 & TST \\
\hline CHEMBL1552256 & 688267 & 6.25 & 5.102 & TST \\
\hline CHEMBL1311995 & 688267 & 5.85 & 5.0713 & TRN \\
\hline CHEMBL1309080 & 688267 & 3.95 & 5.0538 & TRN \\
\hline CHEMBL1332722 & 688267 & 4.35 & 5.11 & TST \\
\hline CHEMBL1599232 & 688267 & 6.5 & 5.1627 & TST \\
\hline CHEMBL1401397 & 688267 & 6.15 & 4.9885 & TST \\
\hline CHEMBL1501018 & 688267 & 4.9 & 5.0232 & TST \\
\hline CHEMBL1392986 & 688267 & 4.35 & 5.0697 & TRN \\
\hline CHEMBL1609568 & 688267 & 3.95 & 5.0547 & TRN \\
\hline CHEMBL1447867 & 688267 & 4.5 & 5.0134 & TRN \\
\hline CHEMBL1540337 & 688267 & 5.85 & 5.0604 & TRN \\
\hline CHEMBL1517377 & 688267 & 4.85 & 5.0111 & TRN \\
\hline CHEMBL1601228 & 688267 & 4.55 & 5.0247 & TRN \\
\hline CHEMBL1510243 & 688267 & 5.6 & 5.0152 & TRN \\
\hline CHEMBL1456182 & 688267 & 5.55 & 5.1458 & TRN \\
\hline CHEMBL 1437410 & 688267 & 6.2 & 5.0146 & TST \\
\hline CHEMBL1414565 & 688267 & 5.55 & 5.0551 & TRN \\
\hline CHEMBL1397626 & 688267 & 4.05 & 5.0282 & TRN \\
\hline CHEMBL1468093 & 688267 & 4.05 & 5.0407 & TRN \\
\hline CHEMBL1508081 & 688267 & 4.0 & 5.1699 & TST \\
\hline CHEMBL1373469 & 688267 & 4.45 & 5.0154 & TRN \\
\hline CHEMBL1455897 & 688267 & 6.1 & 5.03 & TRN \\
\hline CHEMBL1461692 & 688267 & 4.0 & 4.9659 & TRN \\
\hline CHEMBL1439980 & 688267 & 6.2 & 5.0087 & TRN \\
\hline CHEMBL1455119 & 688267 & 6.45 & 4.9862 & TRN \\
\hline
\end{tabular}




\begin{tabular}{|c|c|c|c|c|c|}
\hline \multirow{2}{*}{\multicolumn{3}{|c|}{ CHEMBL1411020 }} & \\
\hline & & 5.0 & 5.1055 & TRN & \\
\hline CHEMBL1321699 & 688267 & 4.5 & 4.9718 & TRN & \\
\hline CHEMBL1469635 & 688267 & 4.25 & 5.0639 & TRN & \\
\hline CHEMBL3195599 & 688267 & 4.6 & 5.0317 & TST & \\
\hline CHEMBL1439299 & 688267 & 5.35 & 5.1102 & TRN & \\
\hline CHEMBL1573442 & 688267 & 4.05 & 5.0431 & TST & \\
\hline CHEMBL1329801 & 688267 & 4.25 & 5.0296 & TRN & \\
\hline CHEMBL1417587 & 688267 & 4.55 & 5.0832 & TST & \\
\hline CHEMBL1366938 & 688267 & 4.65 & 4.9974 & TST & \\
\hline CHEMBL1571965 & 688267 & 4.1 & 5.0498 & TRN & \\
\hline CHEMBL1573405 & 688267 & 4.0 & 4.9995 & TRN & \\
\hline CHEMBL1311764 & 688267 & 4.0 & 5.0875 & TST & \\
\hline CHEMBL1557105 & 688267 & 4.3 & 5.0748 & TRN & \\
\hline CHEMBL1432703 & 688267 & 4.7 & 5.1088 & TRN & \\
\hline CHEMBL1393764 & 688267 & 6.2 & 5.09399 & 9999999999 & TRN \\
\hline CHEMBL1504470 & 688267 & 6.15 & 5.0271 & TRN & \\
\hline CHEMBL1400276 & 688267 & 6.15 & 5.0738 & TRN & \\
\hline CHEMBL1510075 & 688267 & 6.25 & 5.0586 & TRN & \\
\hline CHEMBL1443357 & 688267 & 6.2 & 5.091 & TRN & \\
\hline CHEMBL1487539 & 688267 & 6.3 & 5.0198 & TRN & \\
\hline CHEMBL1556879 & 688267 & 5.5 & 5.0993 & TRN & \\
\hline CHEMBL1527114 & 688267 & 5.05 & 5.0668 & TRN & \\
\hline CHEMBL1496761 & 688267 & 4.6 & 5.0383 & TRN & \\
\hline CHEMBL1556662 & 688267 & 5.4 & 5.0064 & TRN & \\
\hline CHEMBL1535193 & 688267 & 5.25 & 5.0378 & TRN & \\
\hline CHEMBL1567505 & 688267 & 5.3 & 5.0718 & TRN & \\
\hline CHEMBL1561688 & 688267 & 4.4 & 5.093 & TRN & \\
\hline CHEMBL1441184 & 688267 & 6.2 & 5.0546 & TRN & \\
\hline CHEMBL1479325 & 688267 & 4.55 & 5.03100 & 0000000001 & TRN \\
\hline CHEMBL1359005 & 688267 & 5.85 & 5.09 & TRN & \\
\hline CHEMBL1392336 & 688267 & 5.7 & 5.0171 & TRN & \\
\hline CHEMBL3198633 & 688267 & 4.4 & 4.977 & TST & \\
\hline CHEMBL1535679 & 688267 & 6.1 & 5.0095 & TST & \\
\hline CHEMBL1316136 & 688267 & 5.25 & 4.9882 & TRN & \\
\hline CHEMBL1332434 & 688267 & 6.15 & 5.0169 & TST & \\
\hline CHEMBL1601892 & 688267 & 6.25 & 5.0579 & TRN & \\
\hline CHEMBL1376124 & 688267 & 6.2 & 5.0309 & TRN & \\
\hline CHEMBL1446681 & 688267 & 5.75 & 5.0038 & TST & \\
\hline CHEMBL1601894 & 688267 & 4.7 & 5.0529 & TRN & \\
\hline CHEMBL1472897 & 688267 & 4.65 & 4.9995 & TRN & \\
\hline CHEMBL1335170 & 688267 & 4.55 & 5.0459 & TRN & \\
\hline CHEMBL1478952 & 688267 & 4.55 & 5.0885 & TRN & \\
\hline CHEMBL1500562 & 688267 & 5.1 & 5.0293 & TRN & \\
\hline CHEMBL1422800 & 688267 & 4.7 & 5.0299 & TST & \\
\hline CHEMBL1485285 & 688267 & 6.2 & 5.0382 & TRN & \\
\hline CHEMBL1525861 & 688267 & 5.75 & 5.075 & TRN & \\
\hline CHEMBL1586333 & 688267 & 4.4 & 5.0653 & TRN & \\
\hline CHEMBL1555012 & 688267 & 5.25 & 5.03600 & 00000000005 & TRN \\
\hline & & & & 17432 & \\
\hline
\end{tabular}




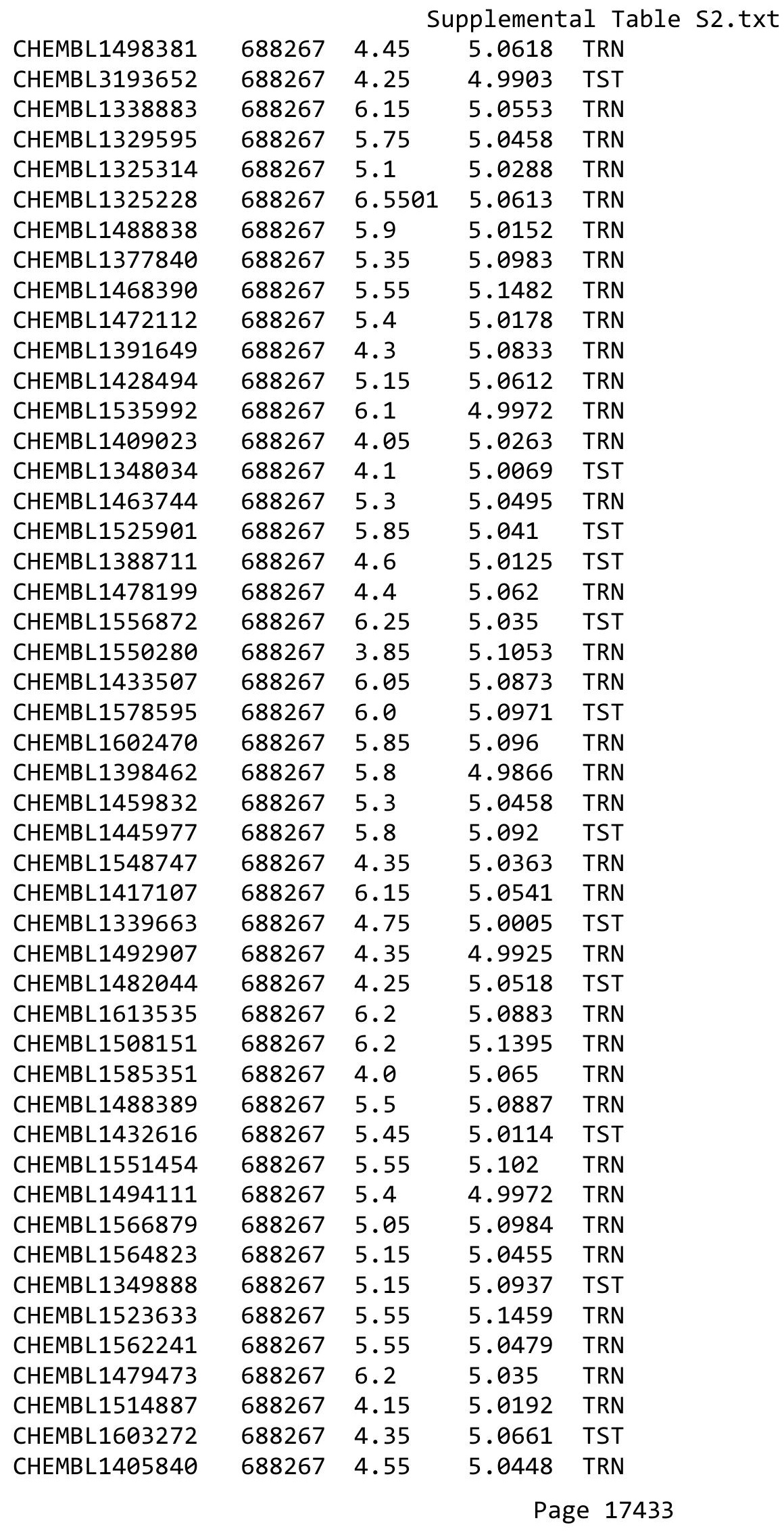




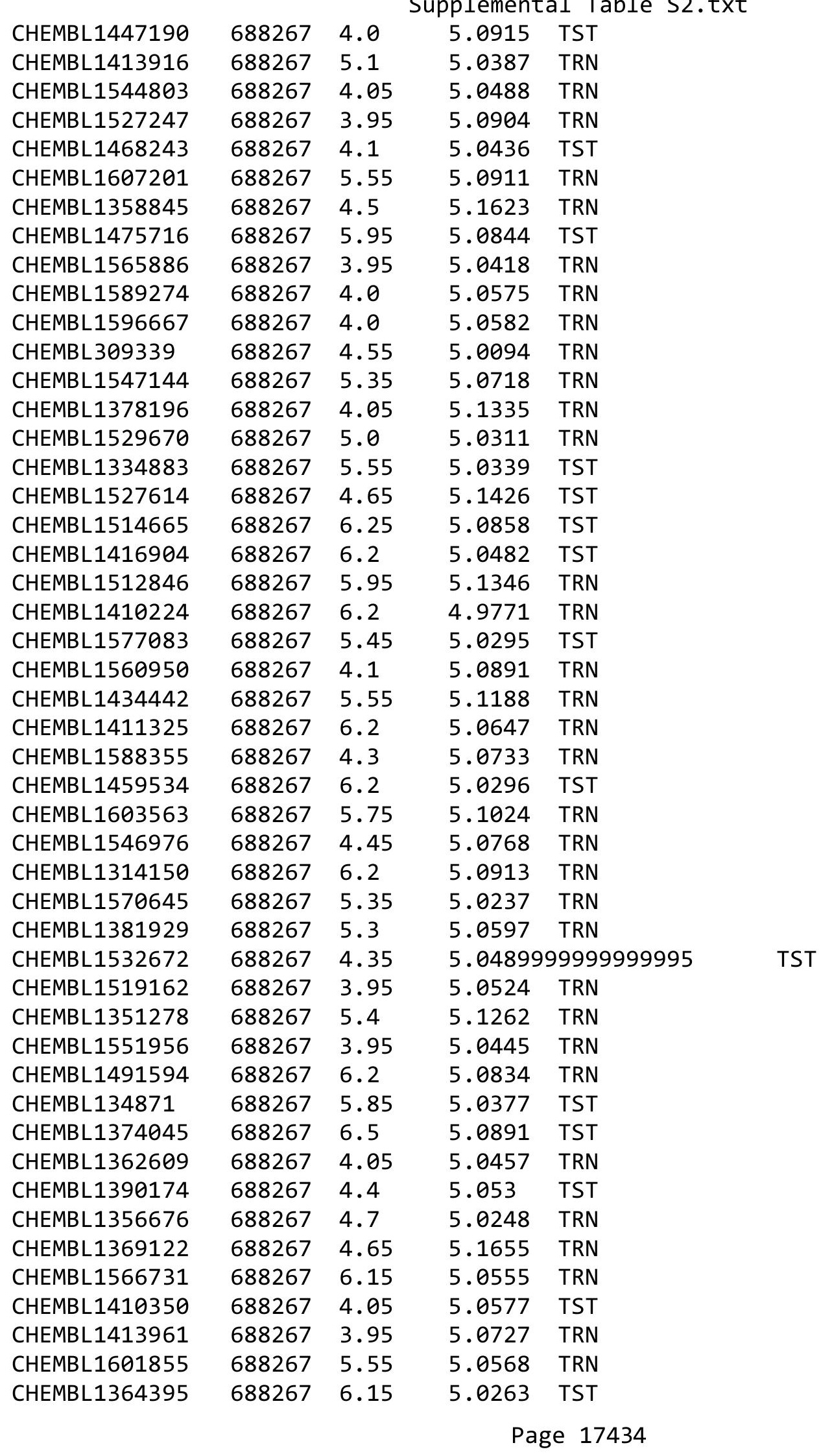




\begin{tabular}{|c|c|c|c|c|}
\hline & & & pplement & al $\mathrm{Ta}$ \\
\hline CHEMBL1417069 & 688267 & 4.0 & 5.0886 & TRN \\
\hline CHEMBL1575864 & 688267 & 4.05 & 5.0768 & TRN \\
\hline CHEMBL1573087 & 688267 & 3.95 & 5.0163 & TRN \\
\hline CHEMBL1490331 & 688267 & 6.2 & 5.0511 & TST \\
\hline CHEMBL1369697 & 688267 & 4.65 & 5.0271 & TRN \\
\hline CHEMBL1393281 & 688267 & 5.8 & 5.0741 & TRN \\
\hline CHEMBL1422881 & 688267 & 4.35 & 5.0747 & TRN \\
\hline CHEMBL1371945 & 688267 & 6.2 & 5.0847 & TRN \\
\hline CHEMBL1350520 & 688267 & 6.5 & 5.0813 & TST \\
\hline CHEMBL1613519 & 688267 & 6.1 & 5.0401 & TRN \\
\hline CHEMBL1398361 & 688267 & 4.0 & 5.0226 & TRN \\
\hline CHEMBL1559380 & 688267 & 5.2 & 5.0475 & TRN \\
\hline CHEMBL1984787 & 688267 & 6.25 & 4.9974 & TRN \\
\hline CHEMBL1343080 & 688267 & 5.85 & 5.0838 & TRN \\
\hline CHEMBL1386389 & 688267 & 5.35 & 5.048 & TRN \\
\hline CHEMBL1553508 & 688267 & 4.0 & 5.0947 & TST \\
\hline CHEMBL1342800 & 688267 & 4.35 & 5.0649 & TRN \\
\hline CHEMBL1560809 & 688267 & 4.0 & 5.1308 & TRN \\
\hline CHEMBL1454060 & 688267 & 4.75 & 5.0564 & TRN \\
\hline CHEMBL1309932 & 688267 & 5.35 & 5.0404 & TRN \\
\hline CHEMBL1535751 & 688267 & 4.4 & 5.0203 & TRN \\
\hline CHEMBL1431844 & 688267 & 5.1 & 5.0434 & TRN \\
\hline CHEMBL1476401 & 688267 & 5.05 & 5.027 & TST \\
\hline CHEMBL1313857 & 688267 & 5.55 & 5.0408 & TST \\
\hline CHEMBL1387176 & 688267 & 4.35 & 5.1721 & TRN \\
\hline CHEMBL1556466 & 688267 & 5.35 & 5.1212 & TST \\
\hline CHEMBL1595505 & 688267 & 5.8 & 5.1148 & TRN \\
\hline CHEMBL1537255 & 688267 & 4.95 & 5.0661 & TST \\
\hline CHEMBL1988699 & 688267 & 6.3 & 4.9914 & TRN \\
\hline CHEMBL1481651 & 688267 & 4.0 & 5.035 & TRN \\
\hline CHEMBL1542069 & 688267 & 4.35 & 5.0309 & TRN \\
\hline CHEMBL1348413 & 688267 & 5.5 & 5.0577 & TRN \\
\hline CHEMBL1534638 & 688267 & 4.0 & 5.1017 & TRN \\
\hline CHEMBL1469830 & 688267 & 4.0 & 5.0676 & TST \\
\hline CHEMBL1511095 & 688267 & 4.2 & 4.9853 & TRN \\
\hline CHEMBL1577506 & 688267 & 6.5 & 5.0691 & TRN \\
\hline CHEMBL1427551 & 688267 & 6.2 & 5.0628 & TRN \\
\hline CHEMBL1425191 & 688267 & 4.5 & 5.0377 & TRN \\
\hline CHEMBL3191647 & 688267 & 6.15 & 5.0597 & TRN \\
\hline CHEMBL1378632 & 688267 & 5.3 & 5.0493 & TRN \\
\hline CHEMBL1455516 & 688267 & 5.0 & 5.0529 & TRN \\
\hline CHEMBL1308108 & 688267 & 5.25 & 5.0332 & TRN \\
\hline CHEMBL1439771 & 688267 & 4.25 & 5.0676 & TRN \\
\hline CHEMBL 202273 & 688267 & 4.55 & 5.0727 & TRN \\
\hline CHEMBL1446943 & 688267 & 4.05 & 5.0292 & TRN \\
\hline CHEMBL1322656 & 688267 & 5.25 & 5.0829 & TRN \\
\hline CHEMBL1345939 & 688267 & 4.05 & 5.0814 & TRN \\
\hline CHEMBL1460785 & 688267 & 5.1 & 5.048 & TST \\
\hline
\end{tabular}




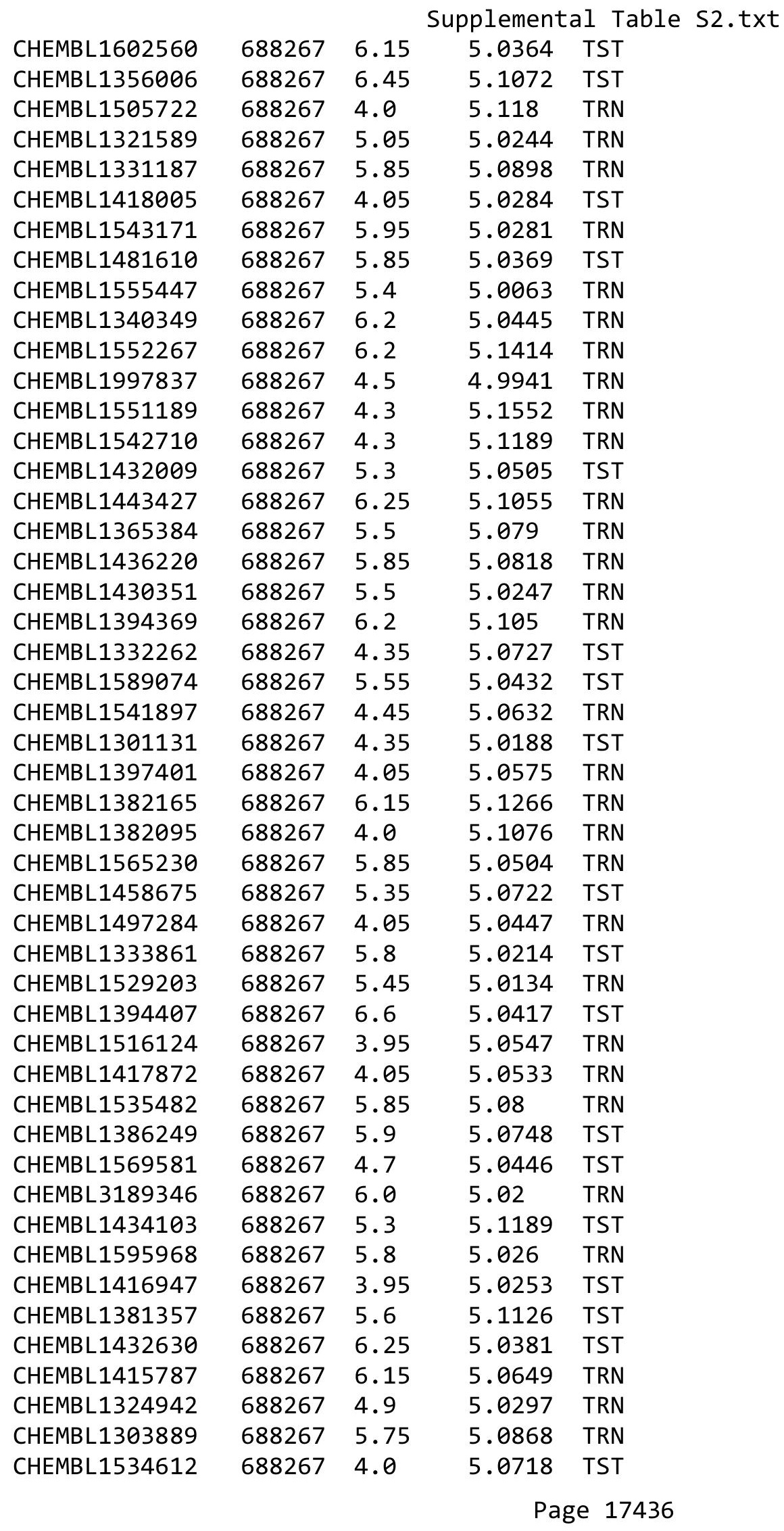




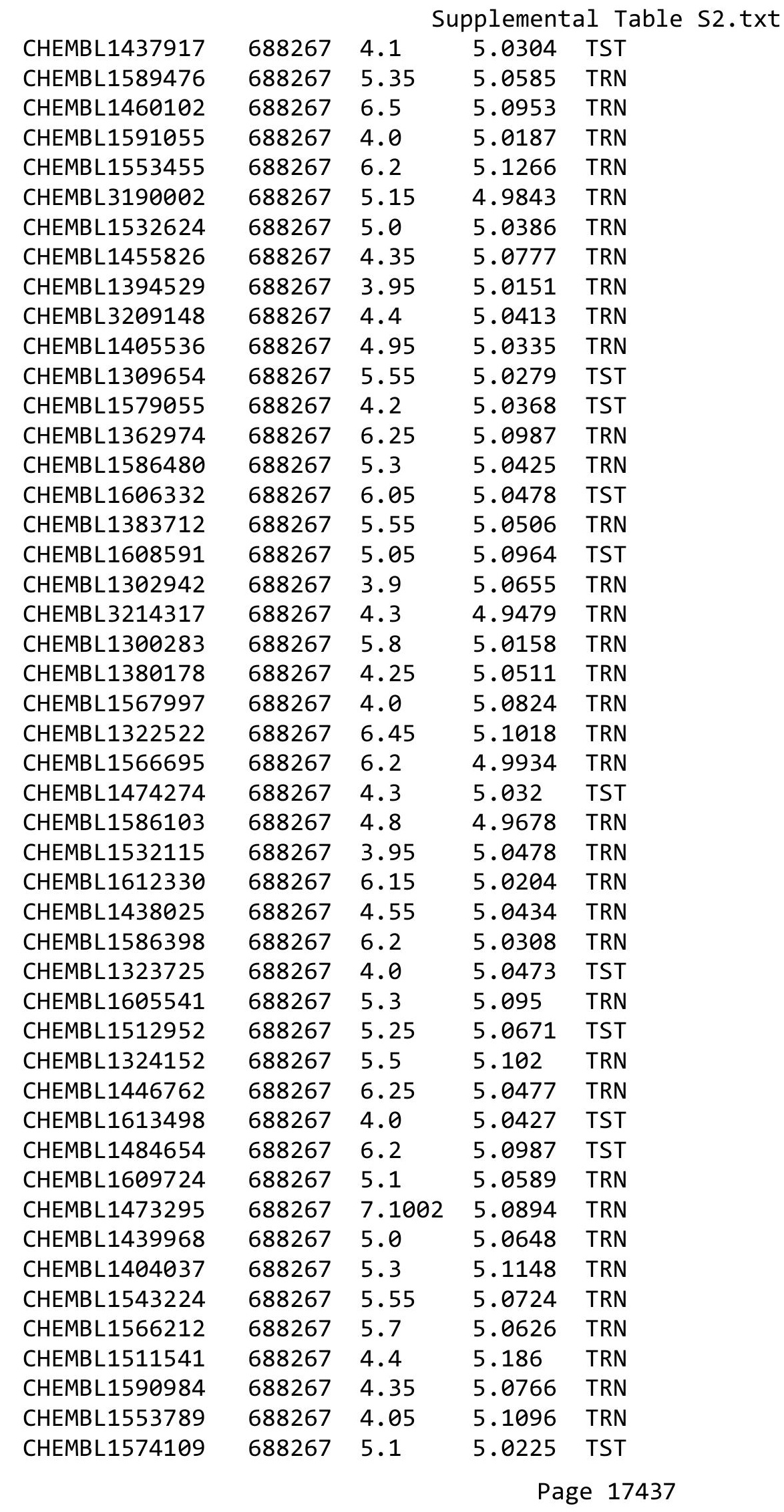




\begin{tabular}{|c|c|c|c|c|}
\hline \multicolumn{5}{|c|}{ splemental T } \\
\hline CHEMBL1338569 & 688267 & 4.5 & 5.1385 & TST \\
\hline CHEMBL1323715 & 688267 & 5.2 & 5.0486 & TST \\
\hline CHEMBL1596585 & 688267 & 4.05 & 5.0978 & TRN \\
\hline CHEMBL1412689 & 688267 & 5.5 & 5.1151 & TRN \\
\hline CHEMBL1351012 & 688267 & 3.95 & 5.0284 & TST \\
\hline CHEMBL1388363 & 688267 & 6.25 & 5.1096 & TST \\
\hline CHEMBL1313283 & 688267 & 3.95 & 5.077 & TRN \\
\hline CHEMBL1595927 & 688267 & 4.0 & 5.0451 & TRN \\
\hline CHEMBL1516321 & 688267 & 6.1 & 5.1344 & TST \\
\hline CHEMBL1405768 & 688267 & 5.85 & 5.1049 & TST \\
\hline CHEMBL1566795 & 688267 & 5.55 & 5.034 & TRN \\
\hline CHEMBL1541192 & 688267 & 4.35 & 5.1273 & TST \\
\hline CHEMBL1474662 & 688267 & 4.4 & 5.1068 & TRN \\
\hline CHEMBL1300499 & 688267 & 6.6499 & 5.0373 & TRN \\
\hline CHEMBL1518007 & 688267 & 4.0 & 5.0381 & TRN \\
\hline CHEMBL605629 & 688267 & 5.4 & 5.0187 & TRN \\
\hline CHEMBL1578351 & 688267 & 5.5 & 5.0844 & TRN \\
\hline CHEMBL3190518 & 688267 & 6.2 & 5.0093 & TRN \\
\hline CHEMBL1482642 & 688267 & 6.15 & 5.0633 & TST \\
\hline CHEMBL1611491 & 688267 & 6.15 & 5.125 & TRN \\
\hline CHEMBL1326635 & 688267 & 5.75 & 5.0693 & TRN \\
\hline CHEMBL1519511 & 688267 & 5.8 & 5.022 & TRN \\
\hline CHEMBL1399056 & 688267 & 5.55 & 5.0989 & TRN \\
\hline CHEMBL1310398 & 688267 & 4.0 & 5.0023 & TRN \\
\hline CHEMBL3192630 & 688267 & 5.0 & 5.0019 & TRN \\
\hline CHEMBL1367829 & 688267 & 4.4 & 5.0307 & TST \\
\hline CHEMBL1315676 & 688267 & 4.55 & 5.0466 & TRN \\
\hline CHEMBL1549793 & 688267 & 5.3 & 5.0502 & TRN \\
\hline CHEMBL1533362 & 688267 & 5.85 & 5.0913 & TRN \\
\hline CHEMBL3198706 & 688267 & 5.55 & 5.0207 & TST \\
\hline CHEMBL1596710 & 688267 & 4.0 & 5.0827 & TRN \\
\hline CHEMBL1538911 & 688267 & 5.1 & 5.0575 & TRN \\
\hline CHEMBL1442920 & 688267 & 5.55 & 5.0347 & TRN \\
\hline CHEMBL1334777 & 688267 & 5.15 & 5.039 & TST \\
\hline CHEMBL1337877 & 688267 & 5.95 & 5.0646 & TRN \\
\hline CHEMBL1542741 & 688267 & 5.05 & 5.0454 & TST \\
\hline CHEMBL1456613 & 688267 & 4.0 & 5.0148 & TST \\
\hline CHEMBL3191533 & 688267 & 4.6 & 5.0492 & TRN \\
\hline CHEMBL1305539 & 688267 & 5.65 & 5.0684 & TRN \\
\hline CHEMBL1323393 & 688267 & 5.65 & 5.1026 & TRN \\
\hline CHEMBL1991885 & 688267 & 3.95 & 4.9946 & TST \\
\hline CHEMBL1377375 & 688267 & 6.2 & 5.0236 & TRN \\
\hline CHEMBL1583575 & 688267 & 5.95 & 5.0627 & TRN \\
\hline CHEMBL1580332 & 688267 & 6.2 & 5.0399 & TST \\
\hline CHEMBL1329855 & 688267 & 4.45 & 5.0573 & TRN \\
\hline CHEMBL1464815 & 688267 & 4.55 & 4.9943 & TST \\
\hline CHEMBL1532752 & 688267 & 5.4 & 5.0833 & TST \\
\hline CHEMBL1404505 & 688267 & 6.05 & 5.0235 & TRN \\
\hline
\end{tabular}




\begin{tabular}{|c|c|c|c|c|c|}
\hline & & \multicolumn{4}{|c|}{ Supplemental Table S2.txt } \\
\hline CHEMBL1531041 & 688267 & 4.0 & 5.008 & TRN & \\
\hline CHEMBL1448172 & 688267 & 5.55 & 5.0673 & TRN & \\
\hline CHEMBL1464160 & 688267 & 3.4 & 5.0626 & TRN & \\
\hline CHEMBL 277148 & 688267 & 4.2 & 4.9725 & TRN & \\
\hline CHEMBL1526994 & 688267 & 5.3 & 5.0834 & TRN & \\
\hline CHEMBL1599226 & 688267 & 4.6 & 5.0421 & TRN & \\
\hline CHEMBL1321150 & 688267 & 6.15 & 5.0159 & TST & \\
\hline CHEMBL1513575 & 688267 & 5.9 & 5.1446 & TRN & \\
\hline CHEMBL 3212448 & 688267 & 4.05 & 4.9761 & TST & \\
\hline CHEMBL1570468 & 688267 & 4.05 & 5.0909 & TRN & \\
\hline CHEMBL1443248 & 688267 & 6.25 & 5.1052 & TST & \\
\hline CHEMBL1480119 & 688267 & 6.2 & 5.1347 & TRN & \\
\hline CHEMBL1319347 & 688267 & 4.3 & 5.0372 & TST & \\
\hline CHEMBL1447419 & 688267 & 5.75 & 5.1083 & TRN & \\
\hline CHEMBL1518666 & 688267 & 5.15 & 5.048 & TRN & \\
\hline CHEMBL1454706 & 688267 & 4.35 & 5.0517 & TRN & \\
\hline CHEMBL1580684 & 688267 & 4.0 & 5.0218 & TST & \\
\hline CHEMBL1586629 & 688267 & 4.2 & $5.0310 e$ & 2000000001 & TST \\
\hline CHEMBL1414790 & 688267 & 4.05 & 5.0366 & TRN & \\
\hline CHEMBL1538697 & 688267 & 5.55 & 5.0075 & TRN & \\
\hline CHEMBL1454035 & 688267 & 6.45 & 5.0322 & TRN & \\
\hline CHEMBL1449580 & 688267 & 4.75 & 5.0676 & TRN & \\
\hline CHEMBL1388713 & 688267 & 6.15 & 5.1483 & TRN & \\
\hline CHEMBL1379104 & 688267 & 5.6 & 5.1102 & TRN & \\
\hline CHEMBL1516291 & 688267 & 6.25 & 5.0624 & TRN & \\
\hline CHEMBL1526004 & 688267 & 5.25 & 5.0106 & TRN & \\
\hline CHEMBL1437031 & 688267 & 4.05 & 5.1095 & TST & \\
\hline CHEMBL1450196 & 688267 & 4.7 & 5.0502 & TRN & \\
\hline CHEMBL1518605 & 688267 & 4.05 & 5.0833 & TRN & \\
\hline CHEMBL1444188 & 688267 & 4.0 & 4.9772 & TST & \\
\hline CHEMBL1334054 & 688267 & 5.35 & 5.1104 & TRN & \\
\hline CHEMBL1326337 & 688267 & 5.6 & 5.1477 & TRN & \\
\hline CHEMBL 394917 & 688267 & 4.0 & 5.0813 & TRN & \\
\hline CHEMBL1423817 & 688267 & 4.2 & 5.046 & TRN & \\
\hline CHEMBL1602303 & 688267 & 6.2 & 4.9906 & TST & \\
\hline CHEMBL1477071 & 688267 & 4.75 & 5.0135 & TST & \\
\hline CHEMBL1418061 & 688267 & 5.3 & 5.0149 & TST & \\
\hline CHEMBL1409541 & 688267 & 5.25 & 5.0823 & TRN & \\
\hline CHEMBL1554876 & 688267 & 4.3 & 5.004 & TRN & \\
\hline CHEMBL1558067 & 688267 & 3.95 & 5.0805 & TST & \\
\hline CHEMBL1426923 & 688267 & 6.15 & 5.0285 & TRN & \\
\hline CHEMBL1576345 & 688267 & 3.95 & 5.0013 & TST & \\
\hline CHEMBL1373229 & 688267 & 4.6 & 5.0238 & TRN & \\
\hline CHEMBL1305680 & 688267 & 4.35 & 5.0716 & TRN & \\
\hline CHEMBL1392736 & 688267 & 4.05 & 5.1384 & TST & \\
\hline CHEMBL1341422 & 688267 & 4.1 & 5.0724 & TRN & \\
\hline CHEMBL1568497 & 688267 & 4.2 & 4.9955 & TRN & \\
\hline CHEMBL1553249 & 688267 & 5.4 & 5.0603 & TST & \\
\hline
\end{tabular}




\begin{tabular}{|c|c|c|c|c|c|}
\hline \multirow[b]{2}{*}{ CHEMBL1567828 } & \multicolumn{5}{|c|}{ Supplemental Table S2.txt } \\
\hline & 688267 & 4.25 & 5.1088 & TST & \\
\hline CHEMBL1446451 & 688267 & 3.95 & 5.0169 & 99999999995 & TRN \\
\hline CHEMBL1531766 & 688267 & 6.15 & 5.095 & TRN & \\
\hline CHEMBL1518919 & 688267 & 5.2 & 5.0128 & TRN & \\
\hline CHEMBL348639 & 688267 & 6.2 & 5.0717 & TRN & \\
\hline CHEMBL1500150 & 688267 & 5.2 & 5.0446 & TRN & \\
\hline CHEMBL1577306 & 688267 & 4.0 & 5.0111 & TRN & \\
\hline CHEMBL1391601 & 688267 & 4.95 & 5.0385 & TRN & \\
\hline CHEMBL1365441 & 688267 & 5.1 & 5.0602 & TRN & \\
\hline CHEMBL1333618 & 688267 & 4.35 & 5.0463 & TRN & \\
\hline CHEMBL1435661 & 688267 & 6.7501 & 5.0165 & TRN & \\
\hline CHEMBL1555857 & 688267 & 6.2 & 5.0388 & TRN & \\
\hline CHEMBL1475432 & 688267 & 6.45 & 5.0777 & TRN & \\
\hline CHEMBL1525702 & 688267 & 4.25 & 5.0642 & TST & \\
\hline CHEMBL1379806 & 688267 & 4.05 & 5.0569 & TRN & \\
\hline CHEMBL1538255 & 688267 & 5.95 & 5.1232 & TRN & \\
\hline CHEMBL1357806 & 688267 & 5.3 & 5.063 & TRN & \\
\hline CHEMBL1460423 & 688267 & 4.05 & 5.027 & TRN & \\
\hline CHEMBL1512079 & 688267 & 4.0 & 5.0838 & TST & \\
\hline CHEMBL1505774 & 688267 & 4.0 & 5.0029 & TRN & \\
\hline CHEMBL1347532 & 688267 & 5.6 & 5.0672 & TRN & \\
\hline CHEMBL1591030 & 688267 & 6.25 & 5.0212 & TRN & \\
\hline CHEMBL1590026 & 688267 & 4.0 & 5.0755 & TRN & \\
\hline CHEMBL1516200 & 688267 & 6.15 & 5.1214 & TRN & \\
\hline CHEMBL1505681 & 688267 & 6.15 & 5.0806 & TRN & \\
\hline CHEMBL1467225 & 688267 & 4.35 & 5.0263 & TRN & \\
\hline CHEMBL1378025 & 688267 & 4.1 & 5.0682 & TRN & \\
\hline CHEMBL1381589 & 688267 & 5.85 & 5.0045 & TST & \\
\hline CHEMBL1487217 & 688267 & 4.25 & 5.0593 & TRN & \\
\hline CHEMBL 1445875 & 688267 & 4.85 & 5.0109 & TRN & \\
\hline CHEMBL1502663 & 688267 & 6.25 & 5.0471 & TRN & \\
\hline CHEMBL1564218 & 688267 & 4.9 & 5.0626 & TST & \\
\hline CHEMBL1389529 & 688267 & 6.3 & 5.0453 & TRN & \\
\hline CHEMBL1564034 & 688267 & 6.5 & 5.0655 & TRN & \\
\hline CHEMBL1331522 & 688267 & 6.2 & 5.0396 & TRN & \\
\hline CHEMBL1514469 & 688267 & 4.05 & 5.1428 & TRN & \\
\hline CHEMBL1500606 & 688267 & 5.75 & 5.1474 & TRN & \\
\hline CHEMBL1440389 & 688267 & 4.35 & 5.1368 & TST & \\
\hline CHEMBL 3212923 & 688267 & 6.2 & 4.9944 & TRN & \\
\hline CHEMBL1510689 & 688267 & 4.35 & 5.0906 & TRN & \\
\hline CHEMBL1316933 & 688267 & 6.05 & 5.0619 & TRN & \\
\hline CHEMBL1382191 & 688267 & 4.8 & 5.0257 & TRN & \\
\hline CHEMBL1510283 & 688267 & 5.45 & 5.0739 & TRN & \\
\hline CHEMBL1444279 & 688267 & 6.2 & 4.9835 & TST & \\
\hline CHEMBL1308691 & 688267 & 6.2 & 5.0168 & TRN & \\
\hline CHEMBL1366473 & 688267 & 4.35 & 5.0601 & TRN & \\
\hline CHEMBL1521549 & 688267 & 5.8 & 5.0351 & TST & \\
\hline CHEMBL1353264 & 688267 & 4.15 & 5.0584 & TST & \\
\hline
\end{tabular}




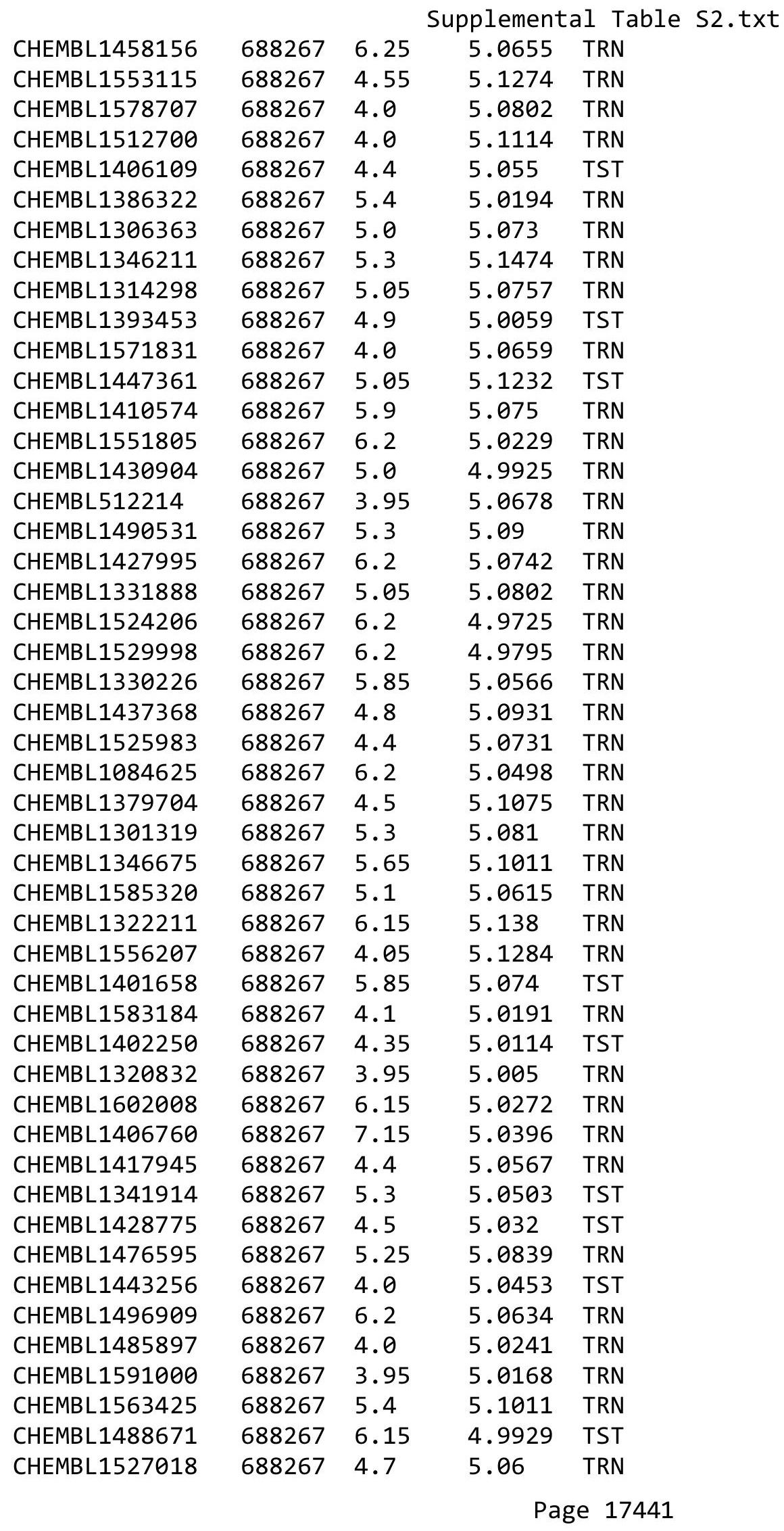




\begin{tabular}{|c|c|c|c|c|}
\hline \multicolumn{5}{|c|}{ Supplemental Table S2.txt } \\
\hline CHEMBL1319527 & 688267 & 4.6 & 5.0686 & TRN \\
\hline CHEMBL1466716 & 688267 & 6.15 & 5.0503 & TRN \\
\hline CHEMBL1365771 & 688267 & 4.0 & 5.0884 & TRN \\
\hline CHEMBL1400050 & 688267 & 6.5 & 5.0712 & TRN \\
\hline CHEMBL1590010 & 688267 & 4.15 & 5.0124 & TRN \\
\hline CHEMBL1357104 & 688267 & 4.0 & 5.1442 & TST \\
\hline CHEMBL1419142 & 688267 & 4.6 & 5.0119 & TRN \\
\hline CHEMBL1306993 & 688267 & 6.2 & 5.0477 & TRN \\
\hline CHEMBL1586038 & 688267 & 6.05 & 5.0956 & TRN \\
\hline CHEMBL1462415 & 688267 & 3.95 & 5.0998 & TRN \\
\hline CHEMBL1523257 & 688267 & 6.2 & 5.1687 & TST \\
\hline CHEMBL1364525 & 688267 & 4.0 & 5.088 & TRN \\
\hline CHEMBL1561434 & 688267 & 6.25 & 5.1113 & TST \\
\hline CHEMBL1383645 & 688267 & 5.2 & 5.11 & TRN \\
\hline CHEMBL 3213234 & 688267 & 4.4 & 5.0773 & TRN \\
\hline CHEMBL1543153 & 688267 & 4.3 & 5.1304 & TRN \\
\hline CHEMBL1585189 & 688267 & 6.2 & 5.0337 & TST \\
\hline CHEMBL1493865 & 688267 & 4.55 & 4.9916 & TRN \\
\hline CHEMBL1400405 & 688267 & 6.2 & 5.0126 & TRN \\
\hline CHEMBL1314661 & 688267 & 3.95 & 5.1279 & TRN \\
\hline CHEMBL3209513 & 688267 & 5.4 & 5.0204 & TST \\
\hline CHEMBL1432217 & 688267 & 5.9 & 5.0355 & TST \\
\hline CHEMBL1455644 & 688267 & 5.3 & 5.1092 & TRN \\
\hline CHEMBL1499569 & 688267 & 5.85 & 5.0964 & TRN \\
\hline CHEMBL1439301 & 688267 & 5.5 & 5.1091 & TST \\
\hline CHEMBL1496963 & 688267 & 5.3 & 5.0276 & TRN \\
\hline CHEMBL1573349 & 688267 & 4.35 & 5.0816 & TRN \\
\hline CHEMBL1493266 & 688267 & 4.0 & 5.0552 & TST \\
\hline CHEMBL1445843 & 688267 & 5.6 & 5.0979 & TRN \\
\hline CHEMBL1379075 & 688267 & 5.85 & 5.1012 & TRN \\
\hline CHEMBL1564032 & 688267 & 4.5 & 5.0462 & TRN \\
\hline CHEMBL1461171 & 688267 & 5.85 & 5.0194 & TST \\
\hline CHEMBL1455240 & 688267 & 3.9 & 5.0397 & TST \\
\hline CHEMBL1559840 & 688267 & 5.3 & 5.0753 & TRN \\
\hline CHEMBL3191506 & 688267 & 5.55 & 5.0397 & TRN \\
\hline CHEMBL1342029 & 688267 & 6.5 & 5.0156 & TST \\
\hline CHEMBL1370401 & 688267 & 5.55 & 5.0288 & TST \\
\hline CHEMBL1527526 & 688267 & 5.5 & 5.0785 & TRN \\
\hline CHEMBL1488807 & 688267 & 4.25 & 5.0842 & TRN \\
\hline CHEMBL1403426 & 688267 & 4.35 & 4.9827 & TRN \\
\hline CHEMBL1524247 & 688267 & 4.0 & 5.0971 & TST \\
\hline CHEMBL1361584 & 688267 & 5.75 & 5.0795 & TRN \\
\hline CHEMBL1303641 & 688267 & 5.2 & 5.0323 & TST \\
\hline CHEMBL1317594 & 688267 & 3.95 & 5.0484 & TRN \\
\hline CHEMBL1317332 & 688267 & 5.85 & 5.1026 & TRN \\
\hline CHEMBL1489593 & 688267 & 6.0 & 5.015 & TST \\
\hline CHEMBL1579758 & 688267 & 4.1 & 5.0619 & TRN \\
\hline CHEMBL1598270 & 688267 & 5.5 & 5.0352 & TST \\
\hline
\end{tabular}




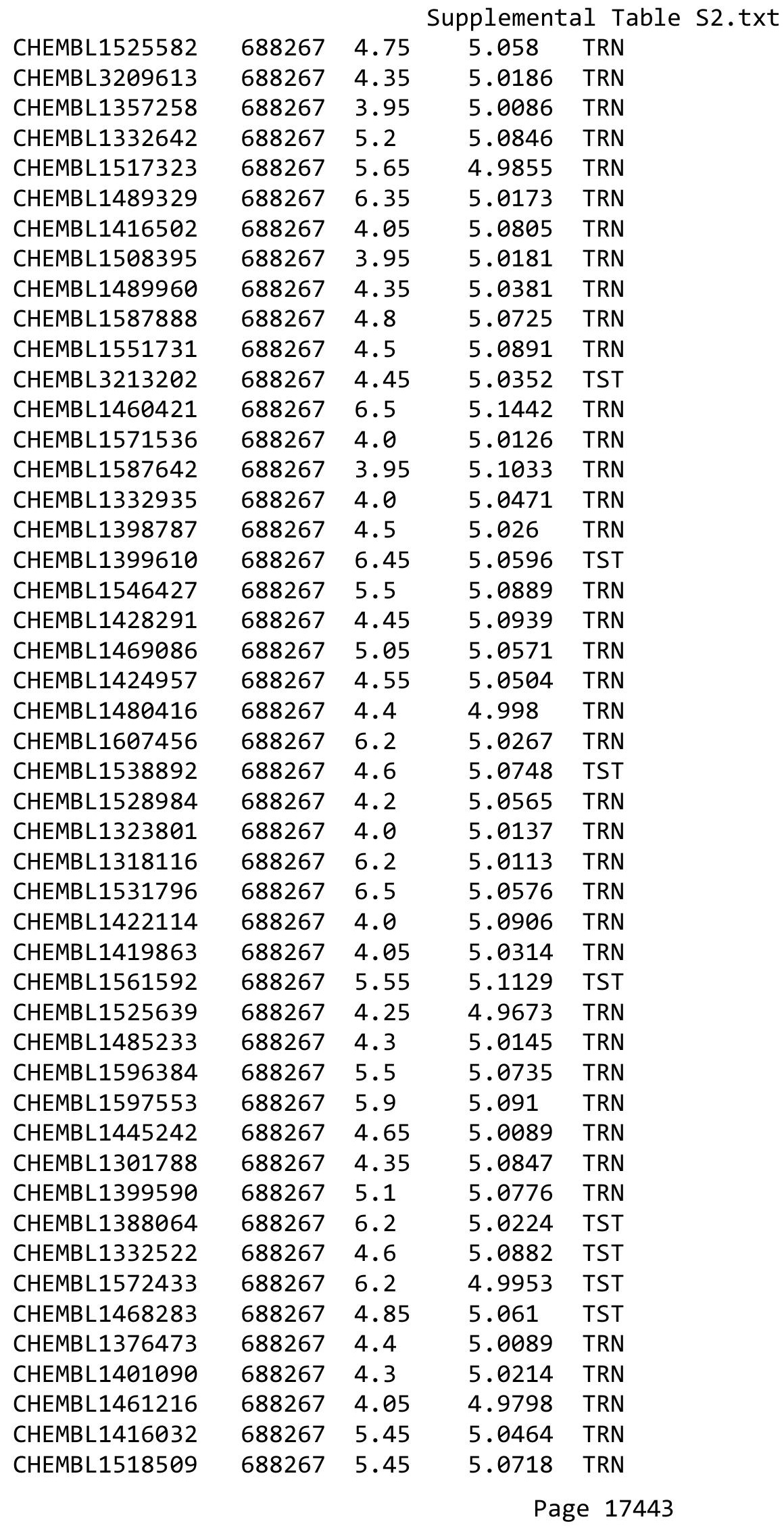




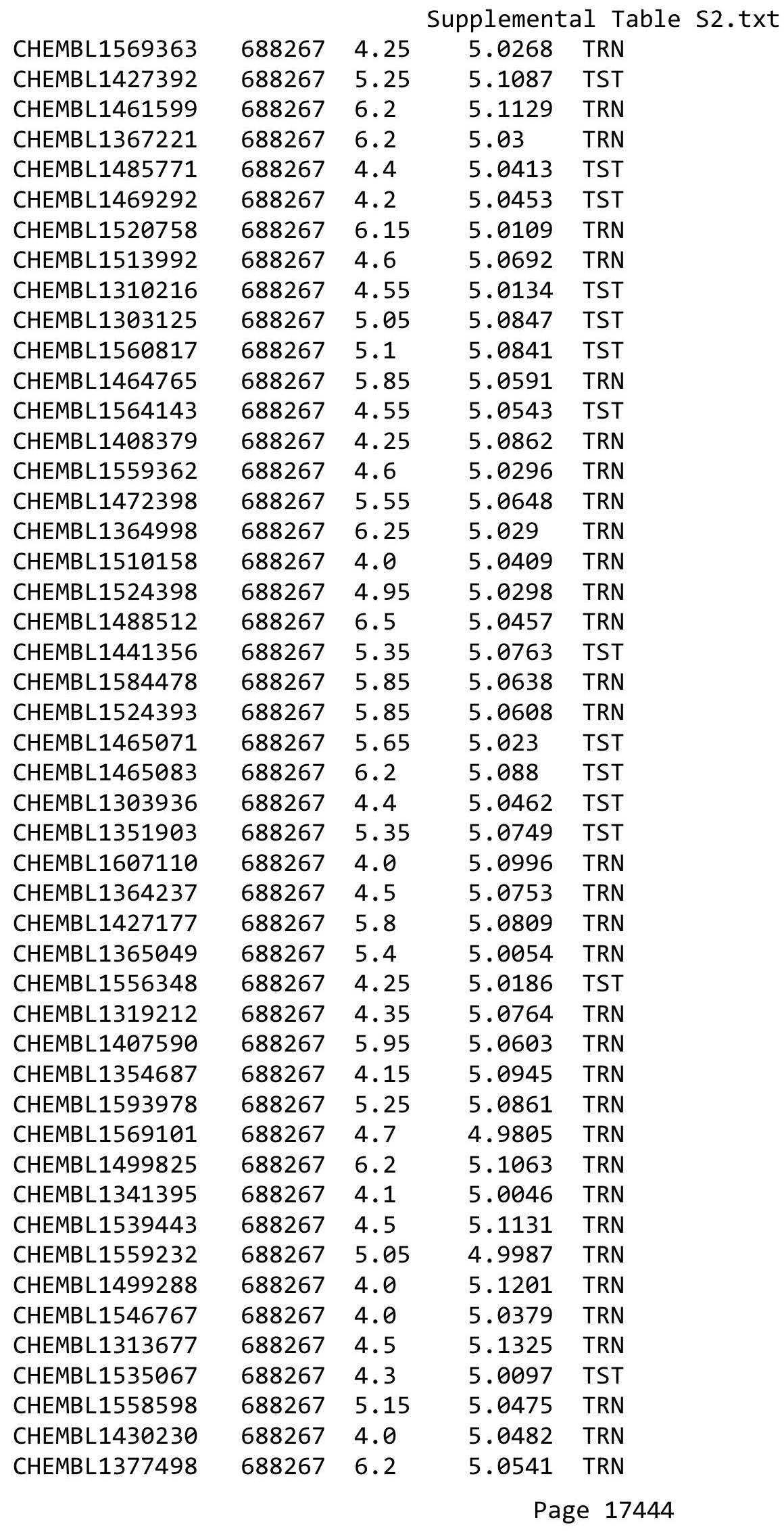




\begin{tabular}{|c|c|c|c|c|}
\hline & & & pplement & al $\mathrm{T}$ \\
\hline CHEMBL1585150 & 688267 & 6.15 & 5.0713 & TST \\
\hline CHEMBL1336334 & 688267 & 5.95 & 5.0992 & TRN \\
\hline CHEMBL1322393 & 688267 & 5.75 & 5.0547 & TRN \\
\hline CHEMBL1589830 & 688267 & 6.1 & 5.0244 & TRN \\
\hline CHEMBL1417190 & 688267 & 4.55 & 5.007 & TRN \\
\hline CHEMBL1164374 & 688267 & 6.2 & 5.1273 & TRN \\
\hline CHEMBL1488177 & 688267 & 4.5 & 5.0717 & TRN \\
\hline CHEMBL1406938 & 688267 & 3.95 & 5.0499 & TRN \\
\hline CHEMBL1491779 & 688267 & 4.05 & 5.039 & TST \\
\hline CHEMBL1341826 & 688267 & 5.95 & 5.039 & TRN \\
\hline CHEMBL1516967 & 688267 & 5.5 & 5.0279 & TRN \\
\hline CHEMBL1555666 & 688267 & 4.3 & 5.0571 & TST \\
\hline CHEMBL1593234 & 688267 & 5.85 & 5.029 & TRN \\
\hline CHEMBL1523141 & 688267 & 3.95 & 5.0319 & TRN \\
\hline CHEMBL1441899 & 688267 & 6.1 & 5.1513 & TRN \\
\hline CHEMBL1504024 & 688267 & 5.9 & 5.0463 & TRN \\
\hline CHEMBL1358869 & 688267 & 6.15 & 5.0517 & TRN \\
\hline CHEMBL1347146 & 688267 & 4.35 & 5.0469 & TRN \\
\hline CHEMBL1568376 & 688267 & 5.05 & 5.0344 & TRN \\
\hline CHEMBL1550222 & 688267 & 4.25 & 5.1259 & TST \\
\hline CHEMBL1556652 & 688267 & 4.5 & 5.1418 & TRN \\
\hline CHEMBL1472285 & 688267 & 5.65 & 5.1141 & TRN \\
\hline CHEMBL1520988 & 688267 & 5.35 & 5.0619 & TRN \\
\hline CHEMBL1488427 & 688267 & 5.8 & 5.0628 & TRN \\
\hline CHEMBL1457534 & 688267 & 4.05 & 5.0575 & TRN \\
\hline CHEMBL1509710 & 688267 & 5.55 & 5.0475 & TRN \\
\hline CHEMBL1333927 & 688267 & 4.45 & 5.037 & TRN \\
\hline CHEMBL1442103 & 688267 & 5.25 & 5.02 & TRN \\
\hline CHEMBL1525390 & 688267 & 4.6 & 4.9585 & TRN \\
\hline CHEMBL3214070 & 688267 & 5.85 & 5.0473 & TST \\
\hline CHEMBL1531147 & 688267 & 4.25 & 5.0944 & TRN \\
\hline CHEMBL1302073 & 688267 & 4.05 & 5.0318 & TRN \\
\hline CHEMBL1503587 & 688267 & 5.0 & 5.0184 & TRN \\
\hline CHEMBL1408712 & 688267 & 5.0 & 5.0169 & TRN \\
\hline CHEMBL1324987 & 688267 & 4.45 & 5.0805 & TRN \\
\hline CHEMBL1555345 & 688267 & 7.3002 & 5.0425 & TRN \\
\hline CHEMBL1321236 & 688267 & 5.55 & 5.1194 & TST \\
\hline CHEMBL1469323 & 688267 & 4.6 & 4.9847 & TRN \\
\hline CHEMBL3208257 & 688267 & 6.2 & 5.0096 & TST \\
\hline CHEMBL1441542 & 688267 & 5.75 & 5.0785 & TRN \\
\hline CHEMBL1577224 & 688267 & 5.9 & 4.9902 & TST \\
\hline CHEMBL1332346 & 688267 & 4.05 & 5.0622 & TRN \\
\hline CHEMBL1548076 & 688267 & 5.85 & 5.0243 & TST \\
\hline CHEMBL1500080 & 688267 & 6.25 & 5.1269 & TRN \\
\hline CHEMBL1421798 & 688267 & 4.25 & 5.0375 & TRN \\
\hline CHEMBL1313918 & 688267 & 4.55 & 4.9852 & TRN \\
\hline CHEMBL1534169 & 688267 & 5.35 & 5.1219 & TRN \\
\hline CHEMBL 3214401 & 688267 & 4.95 & 5.0702 & TST \\
\hline
\end{tabular}




\begin{tabular}{|c|c|c|c|c|c|}
\hline \multicolumn{6}{|c|}{ Supplemental Table S2.txt } \\
\hline CHEMBL1482672 & 688267 & 4.35 & 5.0156 & TRN & \\
\hline CHEMBL1591653 & 688267 & 5.9 & 5.0081 & TRN & \\
\hline CHEMBL1440341 & 688267 & 4.25 & 4.9623 & TRN & \\
\hline CHEMBL1387989 & 688267 & 5.8 & 5.0269 & TRN & \\
\hline CHEMBL 3191054 & 688267 & 6.1 & 4.9944 & TRN & \\
\hline CHEMBL1484557 & 688267 & 4.1 & 4.9999 & TRN & \\
\hline CHEMBL1605866 & 688267 & 4.05 & 5.0549 & TRN & \\
\hline CHEMBL1341747 & 688267 & 4.6 & 5.0459 & TST & \\
\hline CHEMBL1476208 & 688267 & 3.95 & 5.0405 & TRN & \\
\hline CHEMBL1495868 & 688267 & 4.0 & 4.9978 & TST & \\
\hline CHEMBL1388568 & 688267 & 4.7 & 5.0735 & TRN & \\
\hline CHEMBL1320516 & 688267 & 5.25 & 5.019 & TRN & \\
\hline CHEMBL1530214 & 688267 & 4.4 & 5.0038 & TST & \\
\hline CHEMBL1563550 & 688267 & 5.4 & 5.0864 & TRN & \\
\hline CHEMBL1320984 & 688267 & 5.35 & 5.058 & TRN & \\
\hline CHEMBL1463024 & 688267 & 6.2 & 5.0852 & TRN & \\
\hline CHEMBL1351135 & 688267 & 5.3 & 5.0524 & TST & \\
\hline CHEMBL1595835 & 688267 & 4.35 & 5.0683 & TRN & \\
\hline CHEMBL1446946 & 688267 & 5.85 & 5.0771 & TRN & \\
\hline CHEMBL3193049 & 688267 & 6.2 & 5.0322 & TST & \\
\hline CHEMBL1574170 & 688267 & 4.7 & 5.0646 & TRN & \\
\hline CHEMBL1458193 & 688267 & 3.95 & 5.0497 & TST & \\
\hline CHEMBL1395688 & 688267 & 5.65 & 5.082 & TRN & \\
\hline CHEMBL1517283 & 688267 & 6.2 & 5.1568 & TRN & \\
\hline CHEMBL1392701 & 688267 & 5.95 & 5.092 & TST & \\
\hline CHEMBL1355939 & 688267 & 5.2 & 5.0941 & TRN & \\
\hline CHEMBL1598117 & 688267 & 6.15 & 5.0314 & TRN & \\
\hline CHEMBL1495497 & 688267 & 5.25 & 5.0843 & TRN & \\
\hline CHEMBL1552882 & 688267 & 4.0 & 5.0875 & TRN & \\
\hline CHEMBL1357339 & 688267 & 5.2 & 5.0284 & TRN & \\
\hline CHEMBL1502686 & 688267 & 4.5 & 5.09399 & 9999999999 & TRN \\
\hline CHEMBL1429247 & 688267 & 5.85 & 5.043 & TRN & \\
\hline CHEMBL1410006 & 688267 & 5.75 & 5.0343 & TRN & \\
\hline CHEMBL1396893 & 688267 & 4.6 & 5.039 & TRN & \\
\hline CHEMBL1382185 & 688267 & 6.2 & 5.1101 & TRN & \\
\hline CHEMBL1409275 & 688267 & 4.0 & 5.0401 & TST & \\
\hline CHEMBL1369925 & 688267 & 5.85 & 5.0204 & TRN & \\
\hline CHEMBL1476694 & 688267 & 4.6 & 5.1044 & TRN & \\
\hline CHEMBL1352752 & 688267 & 6.2 & 5.1341 & TRN & \\
\hline CHEMBL1572990 & 688267 & 6.2 & 4.9897 & TRN & \\
\hline CHEMBL1517615 & 688267 & 6.15 & 5.052 & TRN & \\
\hline CHEMBL1395541 & 688267 & 4.55 & 5.0973 & TRN & \\
\hline CHEMBL1315565 & 688267 & 4.35 & 5.085 & TRN & \\
\hline CHEMBL1475884 & 688267 & 5.55 & 5.0157 & TRN & \\
\hline CHEMBL1367950 & 688267 & 4.05 & 5.0696 & TRN & \\
\hline CHEMBL1443516 & 688267 & 4.95 & 5.0267 & TST & \\
\hline CHEMBL1332449 & 688267 & 4.0 & 5.0603 & TST & \\
\hline CHEMBL1580186 & 688267 & 5.8 & 5.1235 & TRN & \\
\hline
\end{tabular}




\begin{tabular}{|c|c|c|c|c|c|}
\hline & & & & & \\
\hline CHEMBL1317267 & 688267 & 6.2 & 5.0732 & TST & \\
\hline CHEMBL1591804 & 688267 & 6.2 & 5.0403 & TRN & \\
\hline CHEMBL1484586 & 688267 & 4.0 & 4.9935 & TRN & \\
\hline CHEMBL1416643 & 688267 & 3.95 & 4.9981 & TRN & \\
\hline CHEMBL1397471 & 688267 & 3.95 & 5.0661 & TRN & \\
\hline CHEMBL1330910 & 688267 & 4.4 & 5.0385 & TRN & \\
\hline CHEMBL1448060 & 688267 & 4.1 & 5.0144 & TRN & \\
\hline CHEMBL1407775 & 688267 & 3.95 & 5.0823 & TRN & \\
\hline CHEMBL1483769 & 688267 & 5.5 & 5.0453 & TRN & \\
\hline CHEMBL1350476 & 688267 & 4.6 & 5.0474 & TRN & \\
\hline CHEMBL1312516 & 688267 & 5.45 & 5.0442 & TRN & \\
\hline CHEMBL1500974 & 688267 & 4.5 & 5.1364 & TRN & \\
\hline CHEMBL1339251 & 688267 & 4.3 & 5.1012 & TRN & \\
\hline CHEMBL1362699 & 688267 & 4.9 & 5.086 & TST & \\
\hline CHEMBL1412949 & 688267 & 5.35 & 5.1092 & TRN & \\
\hline CHEMBL1538927 & 688267 & 4.6 & 5.1061 & TRN & \\
\hline CHEMBL1488119 & 688267 & 4.05 & 5.0391 & TRN & \\
\hline CHEMBL1552987 & 688267 & 4.5 & 5.1151 & TRN & \\
\hline CHEMBL1508741 & 688267 & 6.15 & 5.0614 & TRN & \\
\hline CHEMBL1572971 & 688267 & 4.05 & 5.0435 & TST & \\
\hline CHEMBL1586297 & 688267 & 3.95 & 5.0793 & TST & \\
\hline CHEMBL1606161 & 688267 & 5.35 & 5.0172 & TST & \\
\hline CHEMBL 3214027 & 688267 & 4.0 & 5.0334 & TRN & \\
\hline CHEMBL1593939 & 688267 & 4.0 & 5.0999 & TRN & \\
\hline CHEMBL1543790 & 688267 & 3.95 & 5.0847 & TRN & \\
\hline CHEMBL1327150 & 688267 & 6.8499 & 5.0604 & TRN & \\
\hline CHEMBL3198604 & 688267 & 5.05 & 5.024 & TRN & \\
\hline CHEMBL1566059 & 688267 & 6.25 & 5.0741 & TRN & \\
\hline CHEMBL1523478 & 688267 & 5.35 & 5.0226 & TRN & \\
\hline CHEMBL1476845 & 688267 & 5.25 & 5.0807 & TRN & \\
\hline CHEMBL1534718 & 688267 & 4.55 & 5.079 & TRN & \\
\hline CHEMBL1597401 & 688267 & 6.5 & 5.0501 & TRN & \\
\hline CHEMBL 3214322 & 688267 & 4.0 & 5.0827 & TRN & \\
\hline CHEMBL1437766 & 688267 & 4.0 & 5.0688 & TST & \\
\hline CHEMBL1432829 & 688267 & 5.9 & 5.0322 & TRN & \\
\hline CHEMBL1613517 & 688267 & 5.45 & 5.0214 & TST & \\
\hline CHEMBL1430618 & 688267 & 5.5 & 5.0493 & TRN & \\
\hline CHEMBL1592357 & 688267 & 5.35 & 5.0622 & TRN & \\
\hline CHEMBL1445965 & 688267 & 3.95 & 5.1334 & TST & \\
\hline CHEMBL1329044 & 688267 & 4.25 & 5.0828 & TRN & \\
\hline CHEMBL1309083 & 688267 & 4.05 & 4.9926 & TRN & \\
\hline CHEMBL1562870 & 688267 & 6.0 & 5.07 & TRN & \\
\hline CHEMBL1592085 & 688267 & 3.95 & 5.0481 & TRN & \\
\hline CHEMBL1579476 & 688267 & 4.3 & 5.0213 & TRN & \\
\hline CHEMBL1414425 & 688267 & 5.4 & 5.0597 & TRN & \\
\hline CHEMBL1475322 & 688267 & 6.2 & 5.0881 & TRN & \\
\hline CHEMBL1457946 & 688267 & 4.05 & 5.1172 & TRN & \\
\hline CHEMBL1479355 & 688267 & 5.0 & 5.12799 & 9999999999 & TST \\
\hline & & & & 17447 & \\
\hline
\end{tabular}




\begin{tabular}{|c|c|c|c|c|}
\hline & & & pplement & \\
\hline CHEMBL1366409 & 688267 & 5.3 & 5.0548 & TRN \\
\hline CHEMBL1604388 & 688267 & 5.55 & 5.0241 & TRN \\
\hline CHEMBL3191656 & 688267 & 5.6 & 5.0035 & TST \\
\hline CHEMBL1414808 & 688267 & 6.05 & 5.0192 & TST \\
\hline CHEMBL1460259 & 688267 & 4.6 & 5.0721 & TRN \\
\hline CHEMBL1303489 & 688267 & 5.5 & 5.0481 & TRN \\
\hline CHEMBL1557276 & 688267 & 5.6 & 5.0908 & TRN \\
\hline CHEMBL1464273 & 688267 & 6.25 & 5.1384 & TST \\
\hline CHEMBL1315844 & 688267 & 5.5 & 5.0654 & TST \\
\hline CHEMBL1314270 & 688267 & 6.5 & 5.0969 & TRN \\
\hline CHEMBL1467260 & 688267 & 4.2 & 4.9958 & TRN \\
\hline CHEMBL1586079 & 688267 & 4.65 & 5.1041 & TRN \\
\hline CHEMBL1564233 & 688267 & 3.95 & 5.0232 & TST \\
\hline CHEMBL1509775 & 688267 & 3.95 & 5.0429 & TRN \\
\hline CHEMBL1465057 & 688267 & 5.5 & 5.1028 & TRN \\
\hline CHEMBL1399197 & 688267 & 4.4 & 5.0235 & TRN \\
\hline CHEMBL3199413 & 688267 & 4.95 & 5.0087 & TST \\
\hline CHEMBL1593808 & 688267 & 5.1 & 5.1068 & TRN \\
\hline CHEMBL1416717 & 688267 & 3.6 & 5.0189 & TRN \\
\hline CHEMBL1554244 & 688267 & 3.95 & 5.0542 & TRN \\
\hline CHEMBL1440508 & 688267 & 5.3 & 5.0296 & TST \\
\hline CHEMBL1604718 & 688267 & 5.25 & 5.0451 & TRN \\
\hline CHEMBL1371318 & 688267 & 4.2 & 5.0302 & TRN \\
\hline CHEMBL1567883 & 688267 & 4.2 & 5.0326 & TRN \\
\hline CHEMBL1419587 & 688267 & 4.35 & 5.1047 & TST \\
\hline CHEMBL1333559 & 688267 & 5.3 & 5.1007 & TRN \\
\hline CHEMBL1989158 & 688267 & 5.4 & 5.0909 & TRN \\
\hline CHEMBL1460625 & 688267 & 4.9 & 5.0305 & TST \\
\hline CHEMBL1431471 & 688267 & 4.4 & 5.1239 & TRN \\
\hline CHEMBL1600663 & 688267 & 4.7 & 5.0193 & TRN \\
\hline CHEMBL1393586 & 688267 & 5.4 & 5.1484 & TRN \\
\hline CHEMBL1485774 & 688267 & 4.25 & 5.0756 & TRN \\
\hline CHEMBL1472336 & 688267 & 4.0 & 5.125 & TRN \\
\hline CHEMBL1377552 & 688267 & 5.5 & 5.0123 & TRN \\
\hline CHEMBL1606864 & 688267 & 5.5 & 5.0516 & TRN \\
\hline CHEMBL1391336 & 688267 & 6.05 & 4.9749 & TST \\
\hline CHEMBL1403723 & 688267 & 6.5 & 5.1487 & TST \\
\hline CHEMBL1338351 & 688267 & 6.0 & 5.0684 & TRN \\
\hline CHEMBL1485102 & 688267 & 4.05 & 5.0236 & TST \\
\hline CHEMBL3208164 & 688267 & 6.5 & 5.0186 & TRN \\
\hline CHEMBL1446955 & 688267 & 5.6 & 5.0221 & TRN \\
\hline CHEMBL1484070 & 688267 & 4.4 & 5.1134 & TRN \\
\hline CHEMBL1522833 & 688267 & 3.95 & 5.0774 & TRN \\
\hline CHEMBL1356358 & 688267 & 6.25 & 5.079 & TRN \\
\hline CHEMBL1526183 & 688267 & 5.05 & 5.0025 & TST \\
\hline CHEMBL1557155 & 688267 & 5.35 & 5.0367 & TRN \\
\hline CHEMBL1466411 & 688267 & 5.2 & 5.1299 & TRN \\
\hline CHEMBL1516713 & 688267 & 5.3 & 5.075 & TST \\
\hline
\end{tabular}




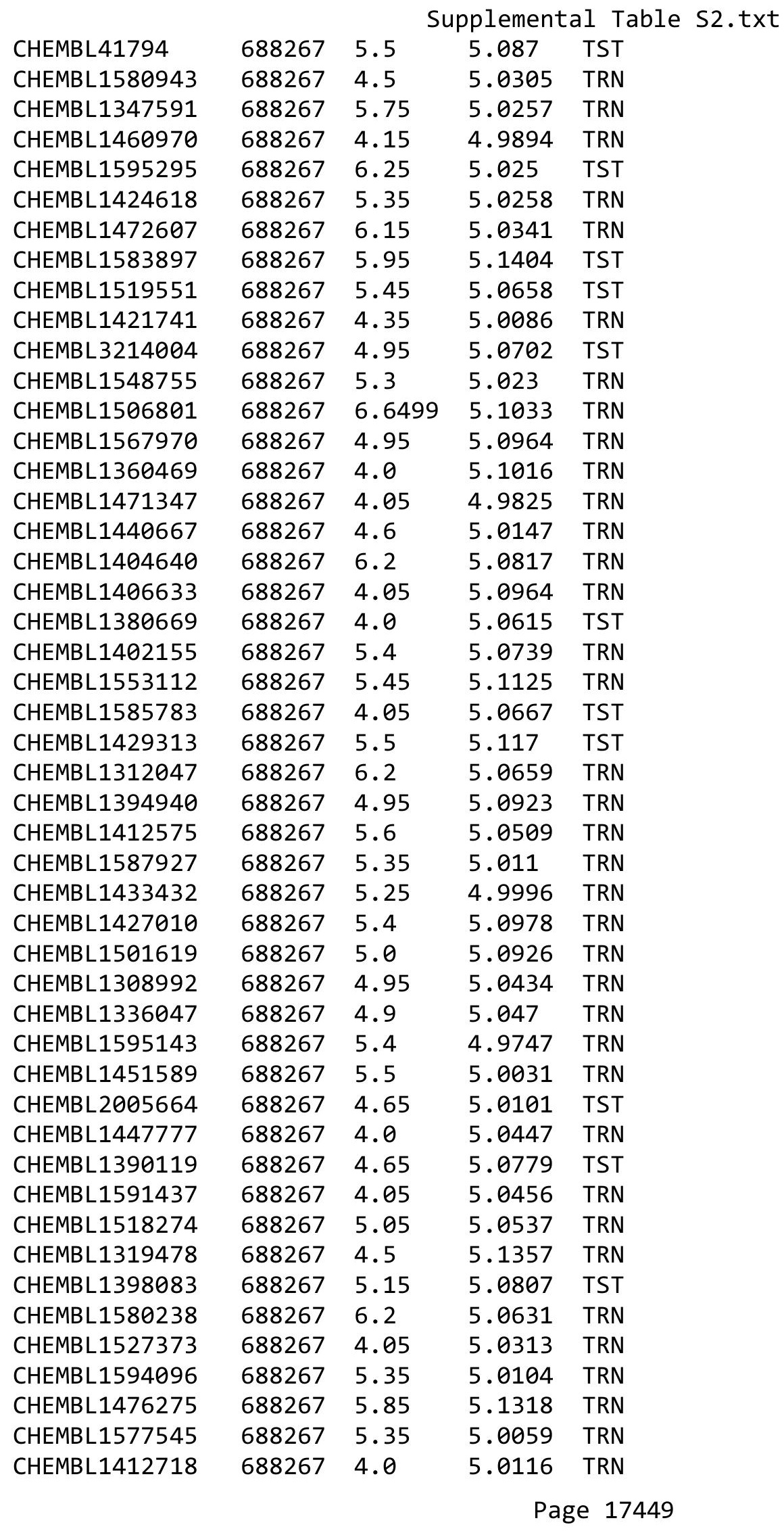




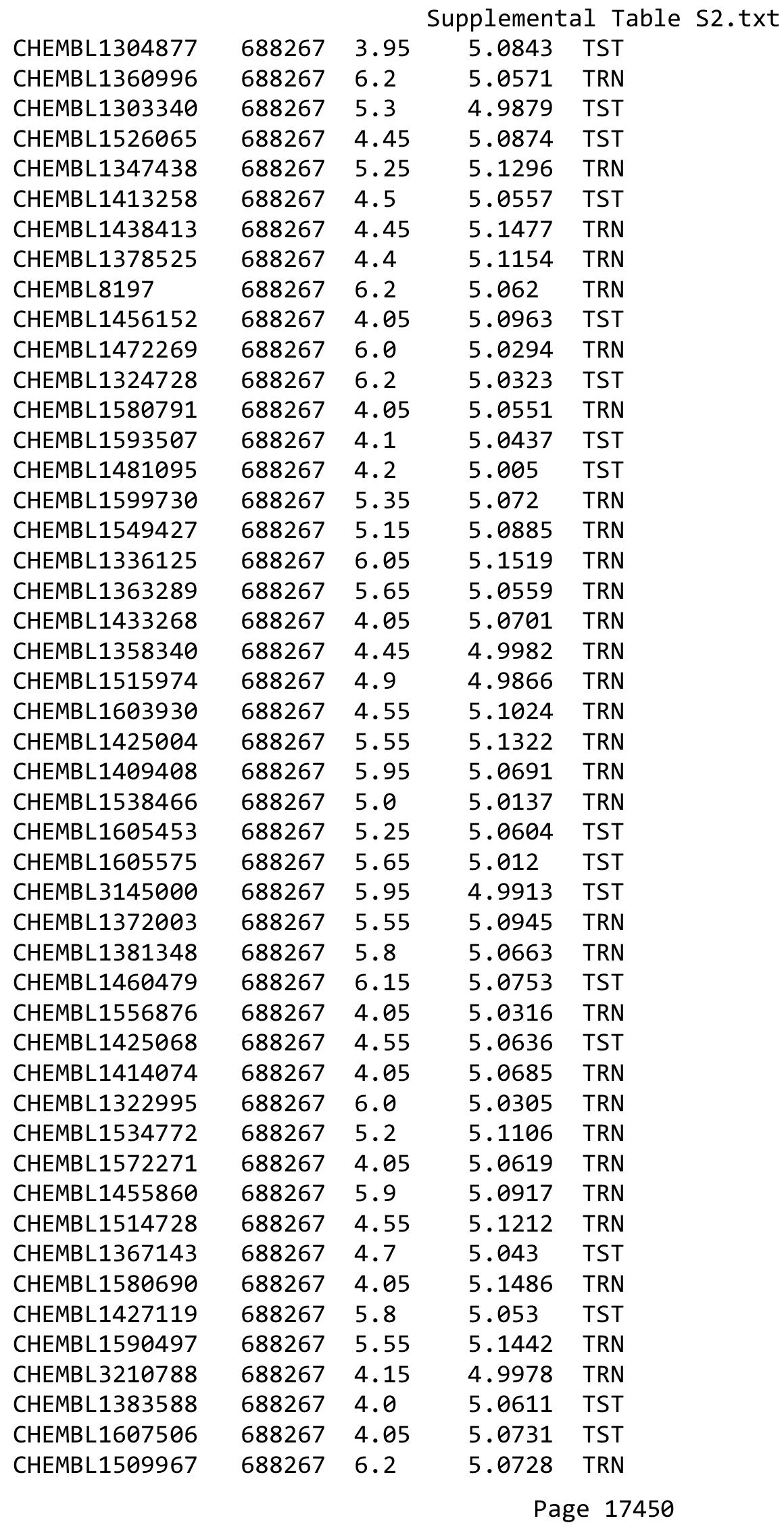




\begin{tabular}{|c|c|c|c|c|}
\hline \multicolumn{5}{|c|}{ Supplemental Table S2.txt } \\
\hline CHEMBL1329067 & 688267 & 4.6 & 5.0232 & TRN \\
\hline CHEMBL1450251 & 688267 & 5.3 & 5.0498 & TST \\
\hline CHEMBL1352647 & 688267 & 4.1 & 5.0019 & TRN \\
\hline CHEMBL1417764 & 688267 & 4.75 & 5.1017 & TRN \\
\hline CHEMBL1355344 & 688267 & 4.35 & 5.0491 & TRN \\
\hline CHEMBL1309496 & 688267 & 6.25 & 5.1004 & TST \\
\hline CHEMBL1612381 & 688267 & 4.1 & 5.004 & TRN \\
\hline CHEMBL1416163 & 688267 & 4.05 & 5.0489 & TST \\
\hline CHEMBL1572256 & 688267 & 4.55 & 5.0361 & TRN \\
\hline CHEMBL1365060 & 688267 & 4.65 & 5.0622 & TRN \\
\hline CHEMBL1349416 & 688267 & 4.0 & 5.0222 & TRN \\
\hline CHEMBL1357567 & 688267 & 6.25 & 5.0777 & TRN \\
\hline CHEMBL1494612 & 688267 & 4.75 & 4.9953 & TST \\
\hline CHEMBL1457152 & 688267 & 6.25 & 5.0981 & TRN \\
\hline CHEMBL1453627 & 688267 & 4.0 & 5.0713 & TRN \\
\hline CHEMBL1303025 & 688267 & 4.4 & 5.1623 & TRN \\
\hline CHEMBL1522780 & 688267 & 6.25 & 5.0439 & TST \\
\hline CHEMBL1415590 & 688267 & 4.9 & 5.0376 & TRN \\
\hline CHEMBL1505382 & 688267 & 5.15 & 5.1061 & TST \\
\hline CHEMBL1518411 & 688267 & 5.7 & 5.0496 & TRN \\
\hline CHEMBL1444621 & 688267 & 5.35 & 5.066 & TST \\
\hline CHEMBL1369155 & 688267 & 4.9 & 5.0551 & TST \\
\hline CHEMBL1420350 & 688267 & 6.2 & 5.0053 & TRN \\
\hline CHEMBL1433788 & 688267 & 6.2 & 5.0863 & TRN \\
\hline CHEMBL 3194944 & 688267 & 5.25 & 5.0099 & TST \\
\hline CHEMBL1442776 & 688267 & 4.4 & 5.0339 & TST \\
\hline CHEMBL1597160 & 688267 & 4.65 & 5.0482 & TRN \\
\hline CHEMBL1594185 & 688267 & 5.65 & 5.0774 & TRN \\
\hline CHEMBL1609114 & 688267 & 6.7501 & 5.0487 & TRN \\
\hline CHEMBL1315766 & 688267 & 6.0 & 5.1278 & TRN \\
\hline CHEMBL1436721 & 688267 & 5.8 & 5.1321 & TRN \\
\hline CHEMBL1367777 & 688267 & 6.5 & 5.0292 & TST \\
\hline CHEMBL1526810 & 688267 & 4.05 & 4.9638 & TRN \\
\hline CHEMBL1588983 & 688267 & 3.95 & 4.9984 & TST \\
\hline CHEMBL1302774 & 688267 & 4.35 & 5.1039 & TRN \\
\hline CHEMBL1435037 & 688267 & 5.8 & 5.0246 & TRN \\
\hline CHEMBL1318535 & 688267 & 3.95 & 4.9879 & TRN \\
\hline CHEMBL3199275 & 688267 & 4.6 & 5.0348 & TRN \\
\hline CHEMBL1493431 & 688267 & 5.15 & 5.0816 & TRN \\
\hline CHEMBL1429552 & 688267 & 4.9 & 5.1113 & TST \\
\hline CHEMBL1560375 & 688267 & 3.95 & 5.0901 & TRN \\
\hline CHEMBL1450374 & 688267 & 4.6 & 5.0506 & TST \\
\hline CHEMBL1517381 & 688267 & 4.35 & 5.0399 & TRN \\
\hline CHEMBL1436533 & 688267 & 4.0 & 4.9944 & TRN \\
\hline CHEMBL1435405 & 688267 & 4.0 & 5.0575 & TRN \\
\hline CHEMBL1539277 & 688267 & 5.4 & 5.0706 & TRN \\
\hline CHEMBL1606878 & 688267 & 6.2 & 5.0785 & TST \\
\hline CHEMBL1532371 & 688267 & 7.699 & 5.1125 & TRN \\
\hline
\end{tabular}




\begin{tabular}{|c|c|c|c|c|c|}
\hline \multicolumn{6}{|c|}{ Supplemental Table S2.txt } \\
\hline CHEMBL1547297 & 688267 & 5.65 & 5.0819 & TRN & \\
\hline CHEMBL1309559 & 688267 & 5.75 & 5.1173 & TRN & \\
\hline CHEMBL1501784 & 688267 & 4.35 & 5.0765 & TST & \\
\hline CHEMBL1375287 & 688267 & 3.95 & 5.0934 & TRN & \\
\hline CHEMBL1477597 & 688267 & 4.05 & 5.0334 & TST & \\
\hline CHEMBL1355726 & 688267 & 4.15 & 5.1223 & TRN & \\
\hline CHEMBL1533311 & 688267 & 5.45 & 5.0969 & TRN & \\
\hline CHEMBL1374572 & 688267 & 5.95 & 5.0124 & TRN & \\
\hline CHEMBL1531415 & 688267 & 6.1 & 5.0506 & TST & \\
\hline CHEMBL1463610 & 688267 & 4.05 & 5.0437 & TRN & \\
\hline CHEMBL1590920 & 688267 & 4.75 & 5.0478 & TRN & \\
\hline CHEMBL1436906 & 688267 & 6.45 & 5.1176 & TRN & \\
\hline CHEMBL1573445 & 688267 & 5.3 & 5.0113 & TST & \\
\hline CHEMBL1417910 & 688267 & 4.2 & 5.0002 & TRN & \\
\hline CHEMBL1479408 & 688267 & 4.55 & 5.0422 & TRN & \\
\hline CHEMBL1408124 & 688267 & 4.8 & 5.1088 & TRN & \\
\hline CHEMBL1494823 & 688267 & 5.35 & 5.0153 & TRN & \\
\hline CHEMBL1339970 & 688267 & 6.2 & 5.0377 & TRN & \\
\hline CHEMBL1514646 & 688267 & 5.3 & 5.0137 & TST & \\
\hline CHEMBL1538847 & 688267 & 4.0 & 5.0242 & TRN & \\
\hline CHEMBL1481924 & 688267 & 5.6 & 5.0724 & TRN & \\
\hline CHEMBL1501262 & 688267 & 5.55 & 5.1073 & TRN & \\
\hline CHEMBL1570040 & 688267 & 5.6 & 5.0086 & TRN & \\
\hline CHEMBL3197447 & 688267 & 5.2 & 5.0116 & TRN & \\
\hline CHEMBL1556487 & 688267 & 6.15 & 5.0284 & TRN & \\
\hline CHEMBL1543992 & 688267 & 4.4 & 5.1533 & TRN & \\
\hline CHEMBL400912 & 688267 & 3.95 & 5.0026 & TRN & \\
\hline CHEMBL1489756 & 688267 & 4.75 & 5.0679 & TST & \\
\hline CHEMBL1433034 & 688267 & 5.0 & 5.1344 & TRN & \\
\hline CHEMBL1512336 & 688267 & 4.35 & 5.0212 & TRN & \\
\hline CHEMBL1573352 & 688267 & 6.2 & 5.066 & TRN & \\
\hline CHEMBL1342740 & 688267 & 4.0 & 5.0836 & TST & \\
\hline CHEMBL1518945 & 688267 & 5.5 & 5.0993 & TRN & \\
\hline CHEMBL1368007 & 688267 & 6.2 & 5.0367 & TRN & \\
\hline CHEMBL1510238 & 688267 & 4.8 & 5.015 & TST & \\
\hline CHEMBL1478366 & 688267 & 4.0 & 5.0725 & TST & \\
\hline CHEMBL1335981 & 688267 & 5.7 & 5.0976 & TST & \\
\hline CHEMBL1505432 & 688267 & 4.6 & 5.0497 & TST & \\
\hline CHEMBL1549311 & 688267 & 4.05 & 5.0521 & TRN & \\
\hline CHEMBL1493833 & 688267 & 4.3 & 5.0598 & TRN & \\
\hline CHEMBL1409540 & 688267 & 6.25 & 5.0621 & TRN & \\
\hline CHEMBL3212954 & 688267 & 4.45 & 5.1018 & TRN & \\
\hline CHEMBL1539928 & 688267 & 4.3 & 5.1474 & TRN & \\
\hline CHEMBL1425805 & 688267 & 4.85 & 5.0375 & TST & \\
\hline CHEMBL1503450 & 688267 & 6.15 & 5.13200 & 0000000001 & TRN \\
\hline CHEMBL1361212 & 688267 & 5.9 & 5.1245 & TRN & \\
\hline CHEMBL1488833 & 688267 & 4.6 & 5.0113 & TST & \\
\hline CHEMBL1340480 & 688267 & 5.5 & 5.0318 & TRN & \\
\hline
\end{tabular}




\begin{tabular}{|c|c|c|c|c|c|}
\hline & & \multicolumn{4}{|c|}{ Supplemental Table S2.txt } \\
\hline CHEMBL3198923 & 688267 & 4.1 & 4.9997 & TRN & \\
\hline CHEMBL1434955 & 688267 & 3.95 & 5.0514 & TRN & \\
\hline CHEMBL1469961 & 688267 & 6.2 & 5.0586 & TRN & \\
\hline CHEMBL3211892 & 688267 & 3.95 & 5.0056 & TST & \\
\hline CHEMBL1416277 & 688267 & 6.2 & 5.0313 & TRN & \\
\hline CHEMBL1581971 & 688267 & 3.95 & 5.0529 & TRN & \\
\hline CHEMBL3207515 & 688267 & 4.5 & 5.0417 & TRN & \\
\hline CHEMBL1390215 & 688267 & 6.15 & 5.0489 & TRN & \\
\hline CHEMBL1584264 & 688267 & 6.2 & 5.0688 & TRN & \\
\hline CHEMBL1367884 & 688267 & 4.15 & 5.086 & TRN & \\
\hline CHEMBL1433222 & 688267 & 5.25 & 5.0932 & TST & \\
\hline CHEMBL1433701 & 688267 & 3.95 & 5.04 & TRN & \\
\hline CHEMBL1370040 & 688267 & 4.0 & 5.0243 & TRN & \\
\hline CHEMBL1464551 & 688267 & 4.6 & 5.1716 & TST & \\
\hline CHEMBL1358170 & 688267 & 3.95 & 5.0763 & TST & \\
\hline CHEMBL1566652 & 688267 & 4.0 & 5.0022 & TRN & \\
\hline CHEMBL1317377 & 688267 & 6.2 & 5.0885 & TST & \\
\hline CHEMBL1309941 & 688267 & 4.05 & 5.0298 & TRN & \\
\hline CHEMBL1518477 & 688267 & 6.2 & 5.0791 & TRN & \\
\hline CHEMBL1604064 & 688267 & 6.15 & 5.1197 & TRN & \\
\hline CHEMBL1611927 & 688267 & 5.3 & 5.0574 & TST & \\
\hline CHEMBL1524755 & 688267 & 4.0 & 5.1329 & TRN & \\
\hline CHEMBL1455241 & 688267 & 4.45 & 5.0697 & TST & \\
\hline CHEMBL1344573 & 688267 & 6.2 & 5.0368 & TRN & \\
\hline CHEMBL1585920 & 688267 & 5.5 & 5.0249 & TRN & \\
\hline CHEMBL1357374 & 688267 & 5.5 & 5.0579 & TRN & \\
\hline CHEMBL1573362 & 688267 & 6.15 & 5.0981 & TRN & \\
\hline CHEMBL1393497 & 688267 & 6.2 & 5.0924 & TRN & \\
\hline CHEMBL1502044 & 688267 & 4.05 & 5.1797 & TST & \\
\hline CHEMBL1597854 & 688267 & 5.25 & 5.0617 & TRN & \\
\hline CHEMBL1500171 & 688267 & 6.15 & 5.075 & TRN & \\
\hline CHEMBL1590234 & 688267 & 6.2 & 5.0008 & TRN & \\
\hline CHEMBL1337450 & 688267 & 6.25 & 5.0536 & TRN & \\
\hline CHEMBL1365422 & 688267 & 4.05 & 5.0277 & TRN & \\
\hline CHEMBL1455843 & 688267 & 6.2 & 5.0518 & TRN & \\
\hline CHEMBL1572349 & 688267 & 6.15 & 5.0360 & 00000000005 & TRN \\
\hline CHEMBL1329827 & 688267 & 5.85 & 5.0962 & TRN & \\
\hline CHEMBL1351875 & 688267 & 6.2 & 5.1152 & TRN & \\
\hline CHEMBL1544705 & 688267 & 6.2 & 5.087 & TRN & \\
\hline CHEMBL1552857 & 688267 & 4.05 & 5.0491 & TRN & \\
\hline CHEMBL1374469 & 688267 & 5.85 & 5.0482 & TRN & \\
\hline CHEMBL1598278 & 688267 & 6.2 & 5.07 & TRN & \\
\hline CHEMBL59653 & 688267 & 4.2 & 5.074 & TST & \\
\hline CHEMBL1391256 & 688267 & 4.3 & 5.0494 & TST & \\
\hline CHEMBL1536192 & 688267 & 4.0 & 5.0939 & 9999999999 & TRN \\
\hline CHEMBL1410024 & 688267 & 5.9 & 5.0939 & 9999999999 & TRN \\
\hline CHEMBL1549295 & 688267 & 6.2 & 5.0222 & TST & \\
\hline CHEMBL1348433 & 688267 & 5.45 & 5.012 & TST & \\
\hline
\end{tabular}




\begin{tabular}{|c|c|c|c|c|c|}
\hline \multicolumn{6}{|c|}{ Supplemental Table S2.txt } \\
\hline CHEMBL1533265 & 688267 & 4.5 & 5.0612 & TRN & \\
\hline CHEMBL3211062 & 688267 & 4.6 & 5.0313 & TRN & \\
\hline CHEMBL3208653 & 688267 & 4.05 & 4.9881 & TST & \\
\hline CHEMBL1529456 & 688267 & 4.45 & 5.0845 & TST & \\
\hline CHEMBL1452442 & 688267 & 5.3 & 5.0582 & TRN & \\
\hline CHEMBL 2000807 & 688267 & 5.6 & 5.0204 & TST & \\
\hline CHEMBL1519875 & 688267 & 5.75 & 5.01399 & 9999999999 & TRN \\
\hline CHEMBL1499701 & 688267 & 4.1 & 5.0451 & TST & \\
\hline CHEMBL1554719 & 688267 & 4.55 & 5.0493 & TRN & \\
\hline CHEMBL1545972 & 688267 & 4.2 & 5.0141 & TRN & \\
\hline CHEMBL1545490 & 688267 & 6.15 & 5.1518 & TST & \\
\hline CHEMBL1591718 & 688267 & 6.25 & 5.0118 & TRN & \\
\hline CHEMBL1373855 & 688267 & 4.4 & 5.0065 & TRN & \\
\hline CHEMBL1318945 & 688267 & 6.0 & 5.0489 & TST & \\
\hline CHEMBL1532749 & 688267 & 7.0501 & 5.0038 & TST & \\
\hline CHEMBL1345673 & 688267 & 5.75 & 5.0957 & TRN & \\
\hline CHEMBL1398300 & 688267 & 4.35 & 5.0884 & TRN & \\
\hline CHEMBL1477329 & 688267 & 4.9 & 5.0455 & TRN & \\
\hline CHEMBL3208050 & 688267 & 4.0 & 5.0085 & TST & \\
\hline CHEMBL1374597 & 688267 & 5.25 & 4.9947 & TRN & \\
\hline CHEMBL1392324 & 688267 & 4.75 & 5.0506 & TST & \\
\hline CHEMBL1384642 & 688267 & 4.0 & 5.1044 & TRN & \\
\hline CHEMBL 315708 & 688267 & 4.25 & 4.9844 & TST & \\
\hline CHEMBL1521409 & 688267 & 6.15 & 5.1043 & TRN & \\
\hline CHEMBL1530583 & 688267 & 7.5003 & 5.0575 & TRN & \\
\hline CHEMBL1397736 & 688267 & 6.2 & 4.9955 & TST & \\
\hline CHEMBL1386697 & 688267 & 4.0 & 5.1002 & TRN & \\
\hline CHEMBL1432003 & 688267 & 5.9 & 5.0021 & TST & \\
\hline CHEMBL1444351 & 688267 & 4.5 & 5.0566 & TST & \\
\hline CHEMBL1578369 & 688267 & 5.55 & 5.1211 & TRN & \\
\hline CHEMBL1402988 & 688267 & 4.55 & 5.0449 & TRN & \\
\hline CHEMBL1594121 & 688267 & 6.0 & 5.0251 & TRN & \\
\hline CHEMBL3197326 & 688267 & 4.0 & 5.0075 & TRN & \\
\hline CHEMBL1488280 & 688267 & 3.95 & 5.0204 & TRN & \\
\hline CHEMBL1396603 & 688267 & 4.4 & 5.0249 & TRN & \\
\hline CHEMBL1591664 & 688267 & 5.25 & 5.1324 & TRN & \\
\hline CHEMBL1504548 & 688267 & 4.3 & 5.0295 & TRN & \\
\hline CHEMBL1366488 & 688267 & 4.7 & 5.0072 & TRN & \\
\hline CHEMBL1395626 & 688267 & 5.25 & 5.1061 & TRN & \\
\hline CHEMBL1473695 & 688267 & 5.15 & 5.0688 & TRN & \\
\hline CHEMBL1525942 & 688267 & 4.6 & 5.0407 & TRN & \\
\hline CHEMBL1418263 & 688267 & 5.95 & 5.0265 & TRN & \\
\hline CHEMBL1366334 & 688267 & 4.1 & 5.0399 & TRN & \\
\hline CHEMBL1300911 & 688267 & 5.85 & 5.0438 & TRN & \\
\hline CHEMBL1488504 & 688267 & 5.55 & 5.1132 & TRN & \\
\hline CHEMBL1538306 & 688267 & 4.05 & 5.0278 & TST & \\
\hline CHEMBL1519667 & 688267 & 5.55 & 5.0135 & TST & \\
\hline CHEMBL1518728 & 688267 & 4.55 & 5.1607 & TRN & \\
\hline
\end{tabular}




\begin{tabular}{|c|c|c|c|c|c|}
\hline \multicolumn{6}{|c|}{ Supplemental Table S2.txt } \\
\hline CHEMBL1361020 & 688267 & 4.65 & 5.0584 & TST & \\
\hline CHEMBL1477051 & 688267 & 5.55 & 5.0529 & TRN & \\
\hline CHEMBL1505237 & 688267 & 4.75 & 5.0633 & TST & \\
\hline CHEMBL1314314 & 688267 & 6.2 & 5.0334 & TRN & \\
\hline CHEMBL1358867 & 688267 & 4.35 & 5.1144 & TRN & \\
\hline CHEMBL1440576 & 688267 & 4.4 & 5.0195 & TST & \\
\hline CHEMBL1366906 & 688267 & 4.9 & 5.0339 & TST & \\
\hline CHEMBL1462899 & 688267 & 4.3 & 5.0671 & TST & \\
\hline CHEMBL1532254 & 688267 & 5.85 & 5.0803 & TRN & \\
\hline CHEMBL1498746 & 688267 & 6.2 & 5.0664 & TRN & \\
\hline CHEMBL1404044 & 688267 & 4.9 & 5.10800 & 00000000005 & TRN \\
\hline CHEMBL1485666 & 688267 & 4.25 & 5.0334 & TST & \\
\hline CHEMBL1446406 & 688267 & 5.25 & 5.1178 & TRN & \\
\hline CHEMBL1305684 & 688267 & 5.5 & 4.9984 & TST & \\
\hline CHEMBL1555448 & 688267 & 5.65 & 5.1031 & TRN & \\
\hline CHEMBL1356609 & 688267 & 5.15 & 5.0484 & TRN & \\
\hline CHEMBL3189789 & 688267 & 5.15 & 4.9962 & TRN & \\
\hline CHEMBL1495763 & 688267 & 4.35 & 5.0691 & TRN & \\
\hline CHEMBL1583287 & 688267 & 6.05 & 4.977 & TRN & \\
\hline CHEMBL1502282 & 688267 & 5.05 & 5.0294 & TRN & \\
\hline CHEMBL1496261 & 688267 & 4.05 & 5.1121 & TRN & \\
\hline CHEMBL1343852 & 688267 & 4.35 & 5.1122 & TRN & \\
\hline CHEMBL1590991 & 688267 & 5.8 & 5.0429 & TRN & \\
\hline CHEMBL1494255 & 688267 & 5.3 & 5.0324 & TRN & \\
\hline CHEMBL1346237 & 688267 & 5.25 & 5.0425 & TRN & \\
\hline CHEMBL1401531 & 688267 & 6.5 & 5.0457 & TRN & \\
\hline CHEMBL1346505 & 688267 & 6.15 & 5.0589 & TRN & \\
\hline CHEMBL1372815 & 688267 & 6.45 & 5.0603 & TRN & \\
\hline CHEMBL1592262 & 688267 & 3.95 & 5.0469 & TRN & \\
\hline CHEMBL1612995 & 688267 & 5.1 & 5.005 & TST & \\
\hline CHEMBL1521211 & 688267 & 4.0 & 5.0509 & TST & \\
\hline CHEMBL1427595 & 688267 & 3.95 & 5.0298 & TRN & \\
\hline CHEMBL1599238 & 688267 & 6.2 & 5.0596 & TRN & \\
\hline CHEMBL1544330 & 688267 & 4.2 & 5.0249 & TST & \\
\hline CHEMBL1345104 & 688267 & 5.25 & 4.9965 & TST & \\
\hline CHEMBL1472098 & 688267 & 5.35 & 5.0645 & TRN & \\
\hline CHEMBL1535812 & 688267 & 5.7 & 5.0388 & TRN & \\
\hline CHEMBL1544936 & 688267 & 5.85 & 4.9416 & TST & \\
\hline CHEMBL1423188 & 688267 & 6.2 & 5.0987 & TRN & \\
\hline CHEMBL1368045 & 688267 & 5.85 & 5.0456 & TRN & \\
\hline CHEMBL1557352 & 688267 & 4.05 & 5.0543 & TRN & \\
\hline CHEMBL1390759 & 688267 & 4.9 & 5.0834 & TST & \\
\hline CHEMBL1596691 & 688267 & 3.95 & 5.0168 & TRN & \\
\hline CHEMBL1526113 & 688267 & 3.95 & 4.9953 & TRN & \\
\hline CHEMBL1388277 & 688267 & 4.25 & 5.0638 & TRN & \\
\hline CHEMBL1334199 & 688267 & 5.35 & 4.9861 & TRN & \\
\hline CHEMBL1471154 & 688267 & 5.35 & 5.0495 & TRN & \\
\hline CHEMBL1510699 & 688267 & 4.2 & 5.0042 & TRN & \\
\hline
\end{tabular}




\begin{tabular}{|c|c|c|c|c|c|}
\hline & & \multicolumn{4}{|c|}{ Supplemental Table S2.txt } \\
\hline CHEMBL1573536 & 688267 & 4.8 & 5.1166 & TRN & \\
\hline CHEMBL1445461 & 688267 & 4.4 & 5.1146 & TRN & \\
\hline CHEMBL1452388 & 688267 & 4.2 & 5.0737 & TRN & \\
\hline CHEMBL1460081 & 688267 & 6.2 & 5.0628 & TRN & \\
\hline CHEMBL1387082 & 688267 & 5.95 & 5.0356 & TST & \\
\hline CHEMBL1606942 & 688267 & 5.55 & 5.0581 & TRN & \\
\hline CHEMBL1579626 & 688267 & 4.7 & 5.0662 & TRN & \\
\hline CHEMBL1351586 & 688267 & 4.65 & 5.0296 & TRN & \\
\hline CHEMBL1525610 & 688267 & 4.45 & 5.0443 & TRN & \\
\hline CHEMBL1612647 & 688267 & 5.75 & 5.0329 & TST & \\
\hline CHEMBL1428448 & 688267 & 5.8 & 5.0747 & TST & \\
\hline CHEMBL1382713 & 688267 & 3.95 & 5.0051 & TRN & \\
\hline CHEMBL1552306 & 688267 & 4.4 & 5.1158 & TRN & \\
\hline CHEMBL3214366 & 688267 & 4.35 & 5.0214 & TST & \\
\hline CHEMBL1578241 & 688267 & 6.3 & 5.0919 & TRN & \\
\hline CHEMBL1330419 & 688267 & 5.55 & 5.1665 & TRN & \\
\hline CHEMBL1317833 & 688267 & 6.2 & 5.0471 & TRN & \\
\hline CHEMBL1553557 & 688267 & 4.65 & 5.0894 & TRN & \\
\hline CHEMBL1336871 & 688267 & 5.9 & 5.0361 & TRN & \\
\hline CHEMBL1395201 & 688267 & 5.5 & 5.0332 & TST & \\
\hline CHEMBL1591495 & 688267 & 6.15 & 5.01 & TRN & \\
\hline CHEMBL1543800 & 688267 & 4.35 & 4.9801 & TRN & \\
\hline CHEMBL1564698 & 688267 & 6.0 & 5.1223 & TRN & \\
\hline CHEMBL1586353 & 688267 & 4.1 & 5.1031 & TRN & \\
\hline CHEMBL1420645 & 688267 & 4.95 & 5.0112 & TRN & \\
\hline CHEMBL1409005 & 688267 & 3.95 & 5.0167 & TRN & \\
\hline CHEMBL1340711 & 688267 & 4.25 & 5.0203 & TRN & \\
\hline CHEMBL1469973 & 688267 & 5.45 & 5.0599 & TRN & \\
\hline CHEMBL1606665 & 688267 & 4.35 & 5.1491 & TRN & \\
\hline CHEMBL3191562 & 688267 & 4.0 & 5.0267 & TRN & \\
\hline CHEMBL1607690 & 688267 & 5.35 & 5.0224 & TRN & \\
\hline CHEMBL1402784 & 688267 & 6.3 & 5.09399 & 9999999999 & TRN \\
\hline CHEMBL1511067 & 688267 & 4.35 & 5.0343 & TRN & \\
\hline CHEMBL1406466 & 688267 & 5.55 & 5.0229 & TRN & \\
\hline CHEMBL1371037 & 688267 & 4.55 & 5.0495 & TRN & \\
\hline CHEMBL1480548 & 688267 & 4.7 & 5.01 & TST & \\
\hline CHEMBL1584961 & 688267 & 4.65 & 5.0194 & TST & \\
\hline CHEMBL1379909 & 688267 & 4.6 & 5.0197 & TRN & \\
\hline CHEMBL1422592 & 688267 & 6.2 & 5.0591 & TRN & \\
\hline CHEMBL1374262 & 688267 & 5.5 & 5.1488 & TRN & \\
\hline CHEMBL1474481 & 688267 & 4.6 & 5.1127 & TRN & \\
\hline CHEMBL1592302 & 688267 & 4.95 & 5.0908 & TST & \\
\hline CHEMBL1609498 & 688267 & 4.3 & 4.9945 & TRN & \\
\hline CHEMBL1524857 & 688267 & 5.15 & 5.0816 & TST & \\
\hline CHEMBL1543526 & 688267 & 4.0 & 5.0397 & TST & \\
\hline CHEMBL1329197 & 688267 & 4.25 & 5.0536 & TRN & \\
\hline CHEMBL1318192 & 688267 & 6.15 & 5.0482 & TRN & \\
\hline CHEMBL1475414 & 688267 & 5.8 & 5.0859 & TRN & \\
\hline
\end{tabular}




\begin{tabular}{|c|c|c|c|c|c|}
\hline \multicolumn{6}{|c|}{ Supplemental Table S2.txt } \\
\hline CHEMBL1493164 & 688267 & 4.35 & 5.1559 & TRN & \\
\hline CHEMBL1501567 & 688267 & 6.15 & 5.0059 & TST & \\
\hline CHEMBL1548812 & 688267 & 6.2 & 5.1119 & TST & \\
\hline CHEMBL1343729 & 688267 & 4.05 & 5.0095 & TRN & \\
\hline CHEMBL1479243 & 688267 & 4.95 & 5.053 & TST & \\
\hline CHEMBL1522113 & 688267 & 4.05 & 5.1163 & TST & \\
\hline CHEMBL1375083 & 688267 & 4.05 & 5.1398 & TRN & \\
\hline CHEMBL1445725 & 688267 & 4.75 & 5.022 & TRN & \\
\hline CHEMBL1395630 & 688267 & 4.3 & 5.0083 & TRN & \\
\hline CHEMBL1467661 & 688267 & 4.3 & 5.0676 & TST & \\
\hline CHEMBL1470294 & 688267 & 4.05 & 5.02800 & 00000000005 & TRN \\
\hline CHEMBL1255649 & 688267 & 4.95 & 5.1108 & TST & \\
\hline CHEMBL428258 & 688267 & 6.2 & 4.9863 & TRN & \\
\hline CHEMBL1444845 & 688267 & 5.25 & 5.0956 & TRN & \\
\hline CHEMBL1586368 & 688267 & 5.35 & 5.1117 & TRN & \\
\hline CHEMBL1434668 & 688267 & 4.25 & 5.006 & TRN & \\
\hline CHEMBL1481880 & 688267 & 5.05 & 5.1142 & TRN & \\
\hline CHEMBL1477639 & 688267 & 5.35 & 5.0086 & TRN & \\
\hline CHEMBL1479950 & 688267 & 6.25 & 4.9823 & TRN & \\
\hline CHEMBL 3209742 & 688267 & 4.0 & 5.001 & TRN & \\
\hline CHEMBL1446603 & 688267 & 6.2 & 5.0708 & TRN & \\
\hline CHEMBL1502319 & 688267 & 4.55 & 5.1376 & TST & \\
\hline CHEMBL1417420 & 688267 & 6.15 & 5.0148 & TRN & \\
\hline CHEMBL1483595 & 688267 & 5.25 & 5.0076 & TST & \\
\hline CHEMBL1492492 & 688267 & 3.95 & 5.023 & TRN & \\
\hline CHEMBL1506681 & 688267 & 5.6 & 5.0678 & TRN & \\
\hline CHEMBL1312889 & 688267 & 6.15 & 5.0671 & TST & \\
\hline CHEMBL1552967 & 688267 & 4.0 & 5.0689 & TST & \\
\hline CHEMBL1463621 & 688267 & 5.55 & 5.1421 & TRN & \\
\hline CHEMBL1412061 & 688267 & 6.0 & 5.067 & TRN & \\
\hline CHEMBL1328796 & 688267 & 5.0 & 5.119 & TRN & \\
\hline CHEMBL1315675 & 688267 & 4.35 & 5.0941 & TRN & \\
\hline CHEMBL1588288 & 688267 & 4.55 & 5.1378 & TRN & \\
\hline CHEMBL1378297 & 688267 & 6.15 & 5.0988 & TRN & \\
\hline CHEMBL1406124 & 688267 & 5.5 & 5.0758 & TRN & \\
\hline CHEMBL1528642 & 688267 & 3.95 & 4.9862 & TRN & \\
\hline CHEMBL1515395 & 688267 & 4.05 & 5.0544 & TRN & \\
\hline CHEMBL1492434 & 688267 & 5.85 & 5.0757 & TST & \\
\hline CHEMBL1506013 & 688267 & 5.45 & 5.0653 & TST & \\
\hline CHEMBL1335362 & 688267 & 4.1 & 5.088 & TRN & \\
\hline CHEMBL1319278 & 688267 & 4.35 & 4.9828 & TST & \\
\hline CHEMBL1479816 & 688267 & 6.2 & 5.0106 & TRN & \\
\hline CHEMBL1491791 & 688267 & 5.2 & 5.0895 & TRN & \\
\hline CHEMBL1576357 & 688267 & 4.0 & 5.0361 & TRN & \\
\hline CHEMBL1530833 & 688267 & 5.3 & 5.037 & TRN & \\
\hline CHEMBL1470216 & 688267 & 4.0 & 5.0274 & TRN & \\
\hline CHEMBL1460231 & 688267 & 4.05 & 5.1584 & TRN & \\
\hline CHEMBL1389925 & 688267 & 6.15 & 5.0336 & TRN & \\
\hline
\end{tabular}




\begin{tabular}{|c|c|c|c|c|}
\hline & & & pplement & al $\mathrm{Ta}$ \\
\hline CHEMBL1534278 & 688267 & 5.6 & 5.0382 & TST \\
\hline CHEMBL1523287 & 688267 & 4.45 & 5.0759 & TRN \\
\hline CHEMBL1599089 & 688267 & 3.9 & 5.0388 & TST \\
\hline CHEMBL1419831 & 688267 & 6.25 & 5.0795 & TRN \\
\hline CHEMBL1533531 & 688267 & 5.8 & 5.0494 & TRN \\
\hline CHEMBL1436728 & 688267 & 4.55 & 5.0298 & TST \\
\hline CHEMBL1379341 & 688267 & 4.35 & 5.0609 & TRN \\
\hline CHEMBL1349489 & 688267 & 4.25 & 5.1668 & TRN \\
\hline CHEMBL1521917 & 688267 & 4.4 & 5.0296 & TRN \\
\hline CHEMBL1392082 & 688267 & 4.35 & 5.0457 & TST \\
\hline CHEMBL1544877 & 688267 & 4.95 & 5.0304 & TRN \\
\hline CHEMBL1299965 & 688267 & 5.85 & 5.0647 & TRN \\
\hline CHEMBL1323334 & 688267 & 4.35 & 5.0523 & TST \\
\hline CHEMBL1607285 & 688267 & 6.2 & 5.0037 & TRN \\
\hline CHEMBL1551848 & 688267 & 4.55 & 5.1208 & TRN \\
\hline CHEMBL1419289 & 688267 & 5.5 & 4.9991 & TRN \\
\hline CHEMBL1379725 & 688267 & 4.2 & 5.0136 & TST \\
\hline CHEMBL1513590 & 688267 & 4.0 & 5.0838 & TRN \\
\hline CHEMBL1305582 & 688267 & 4.7 & 5.0198 & TRN \\
\hline CHEMBL1413511 & 688267 & 4.45 & 5.0353 & TRN \\
\hline CHEMBL1531469 & 688267 & 3.95 & 5.1145 & TRN \\
\hline CHEMBL1440612 & 688267 & 6.15 & 5.0901 & TRN \\
\hline CHEMBL1344103 & 688267 & 6.25 & 5.0544 & TRN \\
\hline CHEMBL1557439 & 688267 & 4.0 & 5.0303 & TST \\
\hline CHEMBL1335994 & 688267 & 5.45 & 5.0231 & TRN \\
\hline CHEMBL1402880 & 688267 & 6.2 & 5.0098 & TRN \\
\hline CHEMBL1611329 & 688267 & 3.95 & 5.0778 & TRN \\
\hline CHEMBL1397420 & 688267 & 6.25 & 5.0447 & TRN \\
\hline CHEMBL1491112 & 688267 & 6.25 & 5.0406 & TRN \\
\hline CHEMBL1534399 & 688267 & 4.65 & 5.0321 & TRN \\
\hline CHEMBL1357209 & 688267 & 4.15 & 5.0628 & TRN \\
\hline CHEMBL1326806 & 688267 & 6.2 & 5.0057 & TRN \\
\hline CHEMBL1565531 & 688267 & 4.55 & 5.0624 & TRN \\
\hline CHEMBL1485257 & 688267 & 5.0 & 5.0666 & TRN \\
\hline CHEMBL1433547 & 688267 & 5.1 & 5.0961 & TRN \\
\hline CHEMBL1343111 & 688267 & 6.15 & 5.0857 & TRN \\
\hline CHEMBL1426411 & 688267 & 4.75 & 5.0078 & TST \\
\hline CHEMBL1449091 & 688267 & 6.05 & 5.0487 & TRN \\
\hline CHEMBL1535195 & 688267 & 4.95 & 5.015 & TRN \\
\hline CHEMBL1322819 & 688267 & 5.5 & 5.0018 & TRN \\
\hline CHEMBL1529677 & 688267 & 4.0 & 5.0733 & TST \\
\hline CHEMBL1390898 & 688267 & 5.75 & 5.0912 & TRN \\
\hline CHEMBL1521558 & 688267 & 4.0 & 5.0471 & TRN \\
\hline CHEMBL1587431 & 688267 & 4.9 & 5.0542 & TRN \\
\hline CHEMBL1446048 & 688267 & 5.5 & 4.985 & TRN \\
\hline CHEMBL1405915 & 688267 & 4.05 & 5.0835 & TST \\
\hline CHEMBL3207956 & 688267 & 4.9 & 5.0085 & TST \\
\hline CHEMBL1494421 & 688267 & 6.15 & 5.0785 & TRN \\
\hline
\end{tabular}




\begin{tabular}{|c|c|c|c|c|}
\hline \multicolumn{5}{|c|}{ Supplemental Table S2.txt } \\
\hline CHEMBL1442687 & 688267 & 4.55 & 5.0847 & TRN \\
\hline CHEMBL1361698 & 688267 & 4.1 & 5.0997 & TRN \\
\hline CHEMBL1495919 & 688267 & 6.05 & 5.0529 & TRN \\
\hline CHEMBL1562646 & 688267 & 6.2 & 5.0538 & TRN \\
\hline CHEMBL1323918 & 688267 & 4.95 & 5.1133 & TRN \\
\hline CHEMBL1389596 & 688267 & 3.95 & 5.1342 & TRN \\
\hline CHEMBL1404274 & 688267 & 6.2 & 5.0524 & TST \\
\hline CHEMBL1343762 & 688267 & 5.05 & 5.0139 & TST \\
\hline CHEMBL3195181 & 688267 & 6.25 & 4.9676 & TST \\
\hline CHEMBL1376261 & 688267 & 6.25 & 5.1175 & TRN \\
\hline CHEMBL1484759 & 688267 & 5.8 & 5.0642 & TRN \\
\hline CHEMBL1449639 & 688267 & 5.1 & 5.0574 & TST \\
\hline CHEMBL1339549 & 688267 & 4.0 & 5.09 & TST \\
\hline CHEMBL1364354 & 688267 & 4.0 & 5.0372 & TRN \\
\hline CHEMBL1490880 & 688267 & 4.75 & 5.1102 & TRN \\
\hline CHEMBL1392790 & 688267 & 5.45 & 5.0804 & TRN \\
\hline CHEMBL1594616 & 688267 & 4.3 & 5.0563 & TST \\
\hline CHEMBL1326625 & 688267 & 4.0 & 5.1497 & TRN \\
\hline CHEMBL1493445 & 688267 & 3.95 & 5.0063 & TST \\
\hline CHEMBL1413577 & 688267 & 5.75 & 5.0774 & TRN \\
\hline CHEMBL1560686 & 688267 & 5.65 & 5.0828 & TST \\
\hline CHEMBL1444564 & 688267 & 4.9 & 5.0202 & TRN \\
\hline CHEMBL1986319 & 688267 & 5.15 & 5.0695 & TRN \\
\hline CHEMBL1494054 & 688267 & 4.55 & 5.1031 & TRN \\
\hline CHEMBL1533662 & 688267 & 5.8 & 5.0079 & TRN \\
\hline CHEMBL1606207 & 688267 & 5.5 & 4.9948 & TRN \\
\hline CHEMBL1375199 & 688267 & 6.2 & 5.0146 & TRN \\
\hline CHEMBL1550236 & 688267 & 6.5 & 5.0624 & TRN \\
\hline CHEMBL1456785 & 688267 & 6.05 & 5.0738 & TRN \\
\hline CHEMBL1574253 & 688267 & 6.2 & 5.0797 & TRN \\
\hline CHEMBL1379539 & 688267 & 4.5 & 5.0302 & TRN \\
\hline CHEMBL1452222 & 688267 & 4.0 & 5.0456 & TRN \\
\hline CHEMBL1357910 & 688267 & 3.95 & 5.0729 & TST \\
\hline CHEMBL1487243 & 688267 & 5.25 & 5.0637 & TRN \\
\hline CHEMBL1473330 & 688267 & 4.05 & 5.1232 & TRN \\
\hline CHEMBL1502337 & 688267 & 5.25 & 5.1124 & TRN \\
\hline CHEMBL1491593 & 688267 & 4.35 & 5.0615 & TST \\
\hline CHEMBL1341258 & 688267 & 4.0 & 4.992 & TST \\
\hline CHEMBL600660 & 688267 & 4.0 & 5.0803 & TST \\
\hline CHEMBL1317781 & 688267 & 4.9 & 5.1117 & TRN \\
\hline CHEMBL1524157 & 688267 & 3.95 & 5.0534 & TRN \\
\hline CHEMBL1350737 & 688267 & 4.05 & 5.0523 & TRN \\
\hline CHEMBL3207997 & 688267 & 5.8 & 5.0558 & TRN \\
\hline CHEMBL1317301 & 688267 & 6.2 & 5.0206 & TST \\
\hline CHEMBL1370478 & 688267 & 5.35 & 5.0059 & TRN \\
\hline CHEMBL1347927 & 688267 & 4.75 & 5.0934 & TST \\
\hline CHEMBL1465031 & 688267 & 5.6 & 5.0676 & TST \\
\hline CHEMBL1393629 & 688267 & 5.9 & 5.1653 & TRN \\
\hline
\end{tabular}




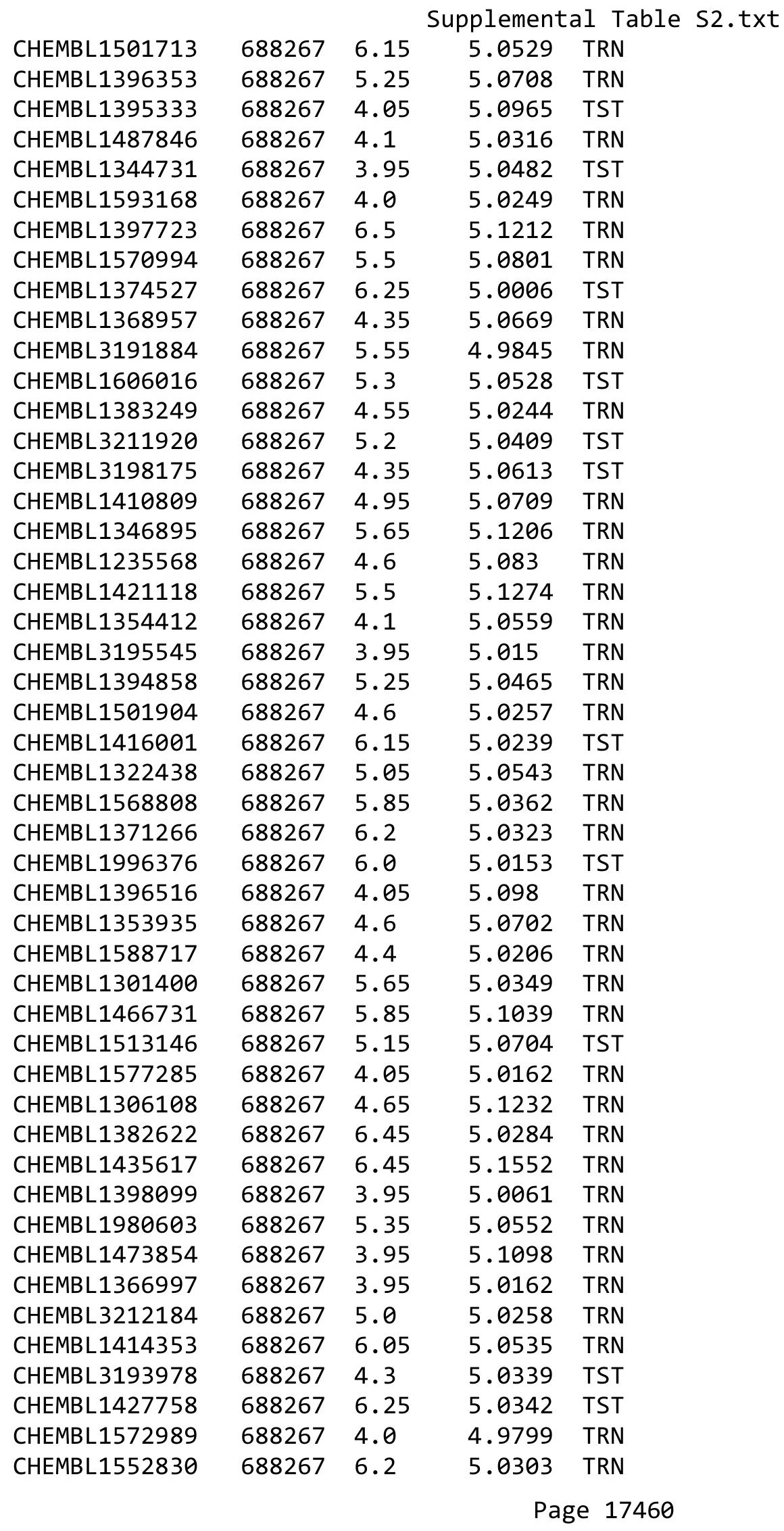




\begin{tabular}{|c|c|c|c|c|c|}
\hline \multicolumn{6}{|c|}{ Supplemental Table S2.txt } \\
\hline CHEMBL1314418 & 688267 & 3.95 & 5.0967 & TRN & \\
\hline CHEMBL1598029 & 688267 & 4.25 & 4.9746 & TRN & \\
\hline CHEMBL1512150 & 688267 & 4.4 & 5.0162 & TRN & \\
\hline CHEMBL1323722 & 688267 & 5.3 & 5.0228 & TRN & \\
\hline CHEMBL1558501 & 688267 & 4.35 & 5.0018 & TRN & \\
\hline CHEMBL3192120 & 688267 & 6.2 & 4.9745 & TRN & \\
\hline CHEMBL1507526 & 688267 & 4.05 & 5.0823 & TRN & \\
\hline CHEMBL1451055 & 688267 & 5.5 & 5.0776 & TRN & \\
\hline CHEMBL1463373 & 688267 & 4.95 & 5.0486 & TST & \\
\hline CHEMBL1538722 & 688267 & 6.2 & 5.0629 & TRN & \\
\hline CHEMBL1373582 & 688267 & 5.45 & 5.0751 & TRN & \\
\hline CHEMBL1516059 & 688267 & 4.95 & 5.0422 & TRN & \\
\hline CHEMBL1549334 & 688267 & 6.25 & 5.038 & TRN & \\
\hline CHEMBL1610679 & 688267 & 4.3 & 5.0558 & TST & \\
\hline CHEMBL1415985 & 688267 & 4.0 & 5.0705 & TRN & \\
\hline CHEMBL1612030 & 688267 & 4.05 & 5.0949 & TST & \\
\hline CHEMBL1315898 & 688267 & 5.55 & 5.001 & TST & \\
\hline CHEMBL1551865 & 688267 & 6.45 & 5.0717 & TRN & \\
\hline CHEMBL1420766 & 688267 & 4.9 & 5.0397 & TST & \\
\hline CHEMBL1365857 & 688267 & 4.05 & 5.0398 & TRN & \\
\hline CHEMBL1557642 & 688267 & 4.1 & 5.0391 & TRN & \\
\hline CHEMBL1577092 & 688267 & 5.3 & 5.0787 & TRN & \\
\hline CHEMBL1403032 & 688267 & 4.4 & 5.1007 & TRN & \\
\hline CHEMBL1448997 & 688267 & 5.35 & 5.0805 & TST & \\
\hline CHEMBL1381986 & 688267 & 5.5 & 5.0033 & TRN & \\
\hline CHEMBL1380917 & 688267 & 5.15 & 5.0779 & TST & \\
\hline CHEMBL1485957 & 688267 & 6.2 & 5.0372 & TRN & \\
\hline CHEMBL1455312 & 688267 & 6.45 & 5.1076 & TRN & \\
\hline CHEMBL1575493 & 688267 & 4.0 & 5.0619 & TRN & \\
\hline CHEMBL1370473 & 688267 & 5.5 & 5.0295 & TRN & \\
\hline CHEMBL3197023 & 688267 & 3.95 & 5.0414 & TRN & \\
\hline CHEMBL1452208 & 688267 & 6.2 & 5.0113 & TRN & \\
\hline CHEMBL3209329 & 688267 & 4.55 & 5.0289 & TST & \\
\hline CHEMBL1569876 & 688267 & 4.4 & 5.0948 & TRN & \\
\hline CHEMBL1349591 & 688267 & 6.15 & 5.11100 & 0000000001 & TST \\
\hline CHEMBL1503953 & 688267 & 4.4 & 5.0766 & TST & \\
\hline CHEMBL1592770 & 688267 & 5.85 & 5.0435 & TRN & \\
\hline CHEMBL1365652 & 688267 & 4.05 & 4.9804 & TRN & \\
\hline CHEMBL1525123 & 688267 & 6.05 & 5.0179 & TRN & \\
\hline CHEMBL1412453 & 688267 & 4.6 & 5.1258 & TRN & \\
\hline CHEMBL1547232 & 688267 & 4.4 & 5.0236 & TRN & \\
\hline CHEMBL1322691 & 688267 & 3.95 & 5.1095 & TRN & \\
\hline CHEMBL1550664 & 688267 & 4.05 & 4.966 & TRN & \\
\hline CHEMBL1516572 & 688267 & 6.15 & 5.0213 & TRN & \\
\hline CHEMBL1593163 & 688267 & 5.45 & 5.035 & TRN & \\
\hline CHEMBL1612052 & 688267 & 5.45 & 4.9983 & TRN & \\
\hline CHEMBL1608295 & 688267 & 5.5 & 5.0668 & TST & \\
\hline CHEMBL1592466 & 688267 & 4.0 & 5.0754 & TRN & \\
\hline
\end{tabular}




\begin{tabular}{|c|c|c|c|c|c|}
\hline \multicolumn{6}{|c|}{ Supplemental Table S2.txt } \\
\hline CHEMBL1347671 & 688267 & 4.1 & 5.1053 & TRN & \\
\hline CHEMBL1300152 & 688267 & 4.9 & 5.1067 & TRN & \\
\hline CHEMBL1596045 & 688267 & 5.8 & 5.084 & TST & \\
\hline CHEMBL1361093 & 688267 & 4.6 & 5.0176 & TRN & \\
\hline CHEMBL1304710 & 688267 & 4.55 & 5.0563 & TRN & \\
\hline CHEMBL1420181 & 688267 & 5.4 & 5.0124 & TRN & \\
\hline CHEMBL 3213030 & 688267 & 6.2 & 5.0 & TRN & \\
\hline CHEMBL1315332 & 688267 & 6.2 & 5.0406 & TST & \\
\hline CHEMBL1982956 & 688267 & 6.2 & 5.0177 & TRN & \\
\hline CHEMBL1343421 & 688267 & 3.95 & 5.0667 & TRN & \\
\hline CHEMBL1513509 & 688267 & 5.25 & 5.0417 & TRN & \\
\hline CHEMBL1385466 & 688267 & 5.3 & 5.0591 & TRN & \\
\hline CHEMBL3192488 & 688267 & 4.0 & 5.0262 & TRN & \\
\hline CHEMBL1463942 & 688267 & 8.0506 & 5.0611 & TST & \\
\hline CHEMBL1349389 & 688267 & 4.0 & 5.0472 & TRN & \\
\hline CHEMBL1476551 & 688267 & 4.05 & 5.052 & TRN & \\
\hline CHEMBL1478775 & 688267 & 6.15 & 5.0692 & TST & \\
\hline CHEMBL1364234 & 688267 & 5.5 & 5.0651 & TRN & \\
\hline CHEMBL1311755 & 688267 & 3.95 & 5.0321 & TRN & \\
\hline CHEMBL1318490 & 688267 & 6.2 & 5.115 & TRN & \\
\hline CHEMBL1527956 & 688267 & 3.95 & 5.0992 & TRN & \\
\hline CHEMBL1438542 & 688267 & 3.95 & 5.0166 & TRN & \\
\hline CHEMBL1577951 & 688267 & 3.95 & 5.0339 & TRN & \\
\hline CHEMBL1402444 & 688267 & 5.55 & 5.0377 & TRN & \\
\hline CHEMBL1562091 & 688267 & 4.95 & 5.0577 & TRN & \\
\hline CHEMBL1423007 & 688267 & 6.2 & 5.0303 & TST & \\
\hline CHEMBL1438806 & 688267 & 6.2 & 5.0167 & TRN & \\
\hline CHEMBL1347806 & 688267 & 4.65 & 5.0016 & TRN & \\
\hline CHEMBL1520563 & 688267 & 4.0 & 5.0063 & TRN & \\
\hline CHEMBL1380738 & 688267 & 5.5 & 5.1367 & TRN & \\
\hline CHEMBL1415760 & 688267 & 5.35 & 5.0217 & TST & \\
\hline CHEMBL1334881 & 688267 & 4.0 & 5.0005 & TRN & \\
\hline CHEMBL1542569 & 688267 & 5.6 & 5.1207 & TRN & \\
\hline CHEMBL1486990 & 688267 & 4.1 & 5.0852 & TRN & \\
\hline CHEMBL1327197 & 688267 & 5.6 & 5.0493 & TRN & \\
\hline CHEMBL1433913 & 688267 & 6.2 & 5.0483 & TRN & \\
\hline CHEMBL1580446 & 688267 & 4.05 & 5.0541 & TRN & \\
\hline CHEMBL1536847 & 688267 & 5.3 & 5.0684 & TRN & \\
\hline CHEMBL1353187 & 688267 & 6.1 & 5.0749 & TST & \\
\hline CHEMBL1605614 & 688267 & 4.35 & 5.056 & TRN & \\
\hline CHEMBL1314152 & 688267 & 6.25 & 5.1797 & TRN & \\
\hline CHEMBL1423588 & 688267 & 6.15 & 5.0591 & TRN & \\
\hline CHEMBL1314218 & 688267 & 4.0 & 5.085 & TRN & \\
\hline CHEMBL1363837 & 688267 & 6.25 & 4.98300 & 00000000005 & TRN \\
\hline CHEMBL1407185 & 688267 & 6.6 & 5.0462 & TST & \\
\hline CHEMBL1415368 & 688267 & 4.45 & 5.0523 & TRN & \\
\hline CHEMBL1576391 & 688267 & 3.95 & 5.1113 & TST & \\
\hline CHEMBL1600472 & 688267 & 5.05 & 4.9841 & TRN & \\
\hline
\end{tabular}




\begin{tabular}{|c|c|c|c|c|c|}
\hline & & \multicolumn{4}{|c|}{ Supplemental Table S2.txt } \\
\hline CHEMBL1332397 & 688267 & 4.4 & 5.0318 & TRN & \\
\hline CHEMBL1584251 & 688267 & 4.35 & 5.0561 & TST & \\
\hline CHEMBL3209359 & 688267 & 5.2 & 4.9942 & TRN & \\
\hline CHEMBL1361762 & 688267 & 4.4 & 5.0819 & TRN & \\
\hline CHEMBL1577138 & 688267 & 4.65 & 5.0965 & TRN & \\
\hline CHEMBL1412264 & 688267 & 4.35 & 5.0634 & TRN & \\
\hline CHEMBL1354861 & 688267 & 6.25 & 5.0553 & TRN & \\
\hline CHEMBL1592397 & 688267 & 4.35 & 5.0518 & TRN & \\
\hline CHEMBL1476269 & 688267 & 4.2 & 5.0243 & TRN & \\
\hline CHEMBL1588313 & 688267 & 4.05 & 5.0469 & TRN & \\
\hline CHEMBL1393494 & 688267 & 4.55 & 5.0423 & TST & \\
\hline CHEMBL1348642 & 688267 & 5.9 & 5.044 & TST & \\
\hline CHEMBL1429975 & 688267 & 4.0 & 4.994 & TRN & \\
\hline CHEMBL1500672 & 688267 & 5.75 & 5.05699 & 99999999995 & TRN \\
\hline CHEMBL1610173 & 688267 & 5.55 & 4.9782 & TST & \\
\hline CHEMBL1493720 & 688267 & 4.3 & 5.0045 & TST & \\
\hline CHEMBL1569680 & 688267 & 4.0 & 5.0856 & TRN & \\
\hline CHEMBL1392775 & 688267 & 4.9 & 5.0362 & TRN & \\
\hline CHEMBL1585349 & 688267 & 4.35 & 5.0067 & TRN & \\
\hline CHEMBL1453088 & 688267 & 5.3 & 5.0417 & TRN & \\
\hline CHEMBL1390871 & 688267 & 4.5 & 5.0962 & TRN & \\
\hline CHEMBL3196874 & 688267 & 4.35 & 5.0179 & TST & \\
\hline CHEMBL1325185 & 688267 & 4.05 & 5.0048 & TRN & \\
\hline CHEMBL3196906 & 688267 & 4.05 & 5.0227 & TST & \\
\hline CHEMBL1579780 & 688267 & 5.25 & 5.0438 & TRN & \\
\hline CHEMBL1361417 & 688267 & 5.3 & 5.0646 & TST & \\
\hline CHEMBL1544638 & 688267 & 4.5 & 5.0896 & TST & \\
\hline CHEMBL1409511 & 688267 & 4.55 & 5.0365 & TST & \\
\hline CHEMBL1344043 & 688267 & 5.55 & 5.07 & TRN & \\
\hline CHEMBL1574751 & 688267 & 4.05 & 4.9424 & TRN & \\
\hline CHEMBL1529669 & 688267 & 5.3 & 5.0995 & TRN & \\
\hline CHEMBL1496550 & 688267 & 6.2 & 5.08 & TRN & \\
\hline CHEMBL1484130 & 688267 & 4.1 & 5.0516 & TRN & \\
\hline CHEMBL1508700 & 688267 & 4.35 & 5.0296 & TST & \\
\hline CHEMBL1329327 & 688267 & 4.2 & 5.0316 & TRN & \\
\hline CHEMBL1536064 & 688267 & 5.55 & 5.0366 & TRN & \\
\hline CHEMBL1515377 & 688267 & 3.95 & 5.0906 & TRN & \\
\hline CHEMBL1604535 & 688267 & 4.35 & 5.0582 & TRN & \\
\hline CHEMBL1566594 & 688267 & 4.35 & 5.1366 & TRN & \\
\hline CHEMBL1475792 & 688267 & 6.2 & 5.0669 & TRN & \\
\hline CHEMBL1558036 & 688267 & 4.2 & 5.029 & TRN & \\
\hline CHEMBL1439063 & 688267 & 4.25 & 5.0306 & TST & \\
\hline CHEMBL1300250 & 688267 & 4.5 & 5.0243 & TRN & \\
\hline CHEMBL1370091 & 688267 & 5.05 & 5.0416 & TRN & \\
\hline CHEMBL1479440 & 688267 & 4.6 & 5.0825 & TRN & \\
\hline CHEMBL1532393 & 688267 & 4.35 & 5.1045 & TRN & \\
\hline CHEMBL1337888 & 688267 & 6.1 & 5.1206 & TRN & \\
\hline CHEMBL1471340 & 688267 & 4.4 & 5.1665 & TST & \\
\hline
\end{tabular}




\begin{tabular}{|c|c|c|c|c|}
\hline \multicolumn{5}{|c|}{ Supplemental Table S2.txt } \\
\hline CHEMBL1382036 & 688267 & 4.45 & 5.0249 & TST \\
\hline CHEMBL1351386 & 688267 & 4.3 & 5.0373 & TRN \\
\hline CHEMBL1395901 & 688267 & 5.85 & 5.1119 & TRN \\
\hline CHEMBL1300636 & 688267 & 4.6 & 5.0618 & TST \\
\hline CHEMBL1358815 & 688267 & 5.0 & 5.0815 & TRN \\
\hline CHEMBL1590285 & 688267 & 6.2 & 5.0131 & TST \\
\hline CHEMBL1425832 & 688267 & 4.2 & 5.0457 & TST \\
\hline CHEMBL1434892 & 688267 & 6.2 & 5.1265 & TRN \\
\hline CHEMBL1396246 & 688267 & 6.1 & 5.1085 & TRN \\
\hline CHEMBL1315371 & 688267 & 5.0 & 5.1456 & TRN \\
\hline CHEMBL1552876 & 688267 & 4.0 & 5.0499 & TRN \\
\hline CHEMBL1299280 & 688267 & 6.2 & 5.0073 & TST \\
\hline CHEMBL1613631 & 688267 & 5.35 & 5.0444 & TRN \\
\hline CHEMBL1517287 & 688267 & 4.0 & 5.0392 & TRN \\
\hline CHEMBL1307711 & 688267 & 4.05 & 5.0716 & TRN \\
\hline CHEMBL1454836 & 688267 & 4.35 & 5.0901 & TRN \\
\hline CHEMBL1560889 & 688267 & 6.05 & 5.0163 & TRN \\
\hline CHEMBL1356441 & 688267 & 6.2 & 5.0472 & TRN \\
\hline CHEMBL1416379 & 688267 & 5.4 & 5.1163 & TST \\
\hline CHEMBL1427140 & 688267 & 4.0 & 5.0556 & TRN \\
\hline CHEMBL1385416 & 688267 & 3.95 & 5.0385 & TST \\
\hline CHEMBL1300268 & 688267 & 4.4 & 5.1203 & TST \\
\hline CHEMBL1361227 & 688267 & 4.2 & 5.0133 & TRN \\
\hline CHEMBL1444409 & 688267 & 5.85 & 5.1059 & TST \\
\hline CHEMBL1608073 & 688267 & 5.55 & 5.0134 & TRN \\
\hline CHEMBL1376443 & 688267 & 5.95 & 5.0422 & TRN \\
\hline CHEMBL1504689 & 688267 & 4.05 & 5.0204 & TRN \\
\hline CHEMBL1436952 & 688267 & 4.65 & 5.0144 & TRN \\
\hline CHEMBL1515147 & 688267 & 4.0 & 5.0674 & TRN \\
\hline CHEMBL1580231 & 688267 & 4.85 & 5.1061 & TRN \\
\hline CHEMBL1401650 & 688267 & 4.0 & 5.0325 & TST \\
\hline CHEMBL1377793 & 688267 & 4.05 & 5.0064 & TRN \\
\hline CHEMBL1348175 & 688267 & 4.4 & 4.9872 & TRN \\
\hline CHEMBL1605351 & 688267 & 5.2 & 5.0581 & TST \\
\hline CHEMBL1384207 & 688267 & 3.9 & 5.0248 & TRN \\
\hline CHEMBL3209113 & 688267 & 4.05 & 5.0157 & TST \\
\hline CHEMBL1441347 & 688267 & 4.3 & 5.044 & TST \\
\hline CHEMBL1563454 & 688267 & 6.5 & 5.0859 & TRN \\
\hline CHEMBL1558968 & 688267 & 5.7 & 5.0493 & TRN \\
\hline CHEMBL1315708 & 688267 & 4.05 & 5.0271 & TRN \\
\hline CHEMBL1537217 & 688267 & 5.25 & 5.0988 & TRN \\
\hline CHEMBL1435163 & 688267 & 6.2 & 5.0527 & TRN \\
\hline CHEMBL1429202 & 688267 & 4.05 & 4.9888 & TRN \\
\hline CHEMBL1589510 & 688267 & 4.1 & 5.0973 & TRN \\
\hline CHEMBL1390172 & 688267 & 4.6 & 5.072 & TRN \\
\hline CHEMBL1417009 & 688267 & 5.25 & 5.142 & TRN \\
\hline CHEMBL1543539 & 688267 & 5.95 & 5.0122 & TST \\
\hline CHEMBL1331974 & 688267 & 4.35 & 4.997 & TST \\
\hline
\end{tabular}




\begin{tabular}{|c|c|c|c|c|}
\hline \multicolumn{5}{|c|}{ Supplemental Table S2.txt } \\
\hline CHEMBL1554794 & 688267 & 6.5 & 5.1136 & TRN \\
\hline CHEMBL1593332 & 688267 & 5.35 & 5.0163 & TRN \\
\hline CHEMBL1447726 & 688267 & 4.0 & 5.1345 & TRN \\
\hline CHEMBL1585011 & 688267 & 4.35 & 5.0496 & TST \\
\hline CHEMBL1490352 & 688267 & 5.35 & 5.084 & TST \\
\hline CHEMBL1466660 & 688267 & 4.0 & 5.0747 & TRN \\
\hline CHEMBL1336308 & 688267 & 6.45 & 5.0697 & TRN \\
\hline CHEMBL1608168 & 688267 & 4.2 & 5.1 & TRN \\
\hline CHEMBL1381015 & 688267 & 4.15 & 4.9846 & TRN \\
\hline CHEMBL1581485 & 688267 & 4.55 & 5.047 & TRN \\
\hline CHEMBL1426618 & 688267 & 5.3 & 5.0988 & TRN \\
\hline CHEMBL1578113 & 688267 & 5.85 & 5.0586 & TRN \\
\hline CHEMBL1567237 & 688267 & 5.5 & 5.0433 & TRN \\
\hline CHEMBL1363309 & 688267 & 5.55 & 5.0932 & TST \\
\hline CHEMBL1557372 & 688267 & 5.6 & 5.0395 & TST \\
\hline CHEMBL1545807 & 688267 & 6.2 & 5.0531 & TRN \\
\hline CHEMBL1514734 & 688267 & 4.0 & 5.0581 & TRN \\
\hline CHEMBL1557640 & 688267 & 6.0 & 5.0857 & TRN \\
\hline CHEMBL1552158 & 688267 & 4.05 & 5.0376 & TRN \\
\hline CHEMBL1339647 & 688267 & 4.25 & 5.0686 & TRN \\
\hline CHEMBL1596669 & 688267 & 4.45 & 5.025 & TST \\
\hline CHEMBL1332940 & 688267 & 4.8 & 5.0127 & TRN \\
\hline CHEMBL1363167 & 688267 & 6.2 & 5.065 & TRN \\
\hline CHEMBL1420091 & 688267 & 5.95 & 5.1417 & TST \\
\hline CHEMBL1335926 & 688267 & 4.0 & 5.0852 & TRN \\
\hline CHEMBL1430410 & 688267 & 6.2 & 5.0676 & TST \\
\hline CHEMBL1532244 & 688267 & 3.95 & 5.0214 & TRN \\
\hline CHEMBL 3199824 & 688267 & 4.05 & 4.9369 & TRN \\
\hline CHEMBL1567700 & 688267 & 5.6 & 5.1116 & TRN \\
\hline CHEMBL1387072 & 688267 & 5.35 & 5.0355 & TRN \\
\hline CHEMBL1316517 & 688267 & 4.4 & 5.0589 & TRN \\
\hline CHEMBL1585748 & 688267 & 4.3 & 5.0195 & TRN \\
\hline CHEMBL1549078 & 688267 & 5.3 & 5.1006 & TRN \\
\hline CHEMBL1478203 & 688267 & 4.45 & 5.0346 & TRN \\
\hline CHEMBL1465597 & 688267 & 6.2 & 5.0216 & TRN \\
\hline CHEMBL1353501 & 688267 & 4.25 & 5.0421 & TRN \\
\hline CHEMBL1501129 & 688267 & 6.7001 & 5.0787 & TST \\
\hline CHEMBL1341816 & 688267 & 6.2 & 5.0131 & TRN \\
\hline CHEMBL1554919 & 688267 & 5.8 & 5.0445 & TST \\
\hline CHEMBL1312092 & 688267 & 4.35 & 5.1247 & TRN \\
\hline CHEMBL1475467 & 688267 & 6.2 & 5.1164 & TRN \\
\hline CHEMBL1531999 & 688267 & 4.65 & 5.0482 & TST \\
\hline CHEMBL1537275 & 688267 & 5.2 & 5.0583 & TST \\
\hline CHEMBL1434697 & 688267 & 4.15 & 5.0454 & TRN \\
\hline CHEMBL1605559 & 688267 & 5.0 & 5.1506 & TRN \\
\hline CHEMBL1369710 & 688267 & 5.95 & 5.0213 & TRN \\
\hline CHEMBL1545886 & 688267 & 5.4 & 5.03600 & 00000000005 \\
\hline CHEMBL1544909 & 688267 & 5.55 & 5.0564 & TST \\
\hline
\end{tabular}




\begin{tabular}{|c|c|c|c|c|}
\hline \multicolumn{5}{|c|}{ Supplemental Table S2.txt } \\
\hline CHEMBL1396855 & 688267 & 3.95 & 5.0936 & TRN \\
\hline CHEMBL1573489 & 688267 & 6.2 & 5.0549 & TRN \\
\hline CHEMBL1457910 & 688267 & 5.35 & 5.0555 & TRN \\
\hline CHEMBL1573755 & 688267 & 3.95 & 5.0567 & TRN \\
\hline CHEMBL1525947 & 688267 & 4.65 & 5.0433 & TST \\
\hline CHEMBL1310246 & 688267 & 5.0 & 5.1025 & TRN \\
\hline CHEMBL1331269 & 688267 & 4.0 & 5.0775 & TRN \\
\hline CHEMBL1490723 & 688267 & 5.55 & 5.1117 & TRN \\
\hline CHEMBL1591780 & 688267 & 4.95 & 5.117 & TRN \\
\hline CHEMBL1576207 & 688267 & 5.3 & 5.0076 & TRN \\
\hline CHEMBL1592587 & 688267 & 6.5 & 5.0707 & TRN \\
\hline CHEMBL1310726 & 688267 & 4.2 & 4.993 & TST \\
\hline CHEMBL1487717 & 688267 & 4.35 & 5.0276 & TRN \\
\hline CHEMBL1432563 & 688267 & 5.45 & 5.0158 & TRN \\
\hline CHEMBL1396051 & 688267 & 4.85 & 5.0995 & TRN \\
\hline CHEMBL1569589 & 688267 & 5.55 & 5.0664 & TRN \\
\hline CHEMBL1540440 & 688267 & 6.2 & 5.0421 & TRN \\
\hline CHEMBL 275938 & 688267 & 5.05 & 5.0356 & TST \\
\hline CHEMBL1504877 & 688267 & 6.5501 & 5.0436 & TRN \\
\hline CHEMBL1324750 & 688267 & 5.85 & 5.0294 & TRN \\
\hline CHEMBL1570882 & 688267 & 6.5501 & 5.0262 & TRN \\
\hline CHEMBL 30095 & 688267 & 4.95 & 5.0102 & TRN \\
\hline CHEMBL1416115 & 688267 & 5.1 & 4.9985 & TRN \\
\hline CHEMBL80031 & 688267 & 6.15 & 5.0373 & TST \\
\hline CHEMBL1503016 & 688267 & 3.95 & 5.0454 & TRN \\
\hline CHEMBL1403466 & 688267 & 4.8 & 5.0861 & TST \\
\hline CHEMBL1437571 & 688267 & 5.35 & 4.9966 & TRN \\
\hline CHEMBL1544954 & 688267 & 4.55 & 5.0609 & TRN \\
\hline CHEMBL1302395 & 688267 & 4.0 & 5.1039 & TRN \\
\hline CHEMBL1470463 & 688267 & 5.2 & 4.9957 & TRN \\
\hline CHEMBL1483376 & 688267 & 6.2 & 5.035 & TST \\
\hline CHEMBL1433511 & 688267 & 5.85 & 4.9953 & TRN \\
\hline CHEMBL1342008 & 688267 & 5.55 & 5.0297 & TRN \\
\hline CHEMBL1521425 & 688267 & 6.5 & 5.0175 & TST \\
\hline CHEMBL1322009 & 688267 & 5.55 & 5.0637 & TRN \\
\hline CHEMBL1448269 & 688267 & 6.0 & 5.1027 & TST \\
\hline CHEMBL1347768 & 688267 & 4.3 & 5.0306 & TST \\
\hline CHEMBL1577981 & 688267 & 5.45 & 5.0173 & TST \\
\hline CHEMBL1561543 & 688267 & 4.45 & 5.1754 & TST \\
\hline CHEMBL1543271 & 688267 & 5.35 & 5.0525 & TST \\
\hline CHEMBL1344570 & 688267 & 5.35 & 5.0065 & TRN \\
\hline CHEMBL1354061 & 688267 & 4.9 & 5.0513 & TRN \\
\hline CHEMBL1326542 & 688267 & 5.95 & 5.0676 & TRN \\
\hline CHEMBL1570600 & 688267 & 4.05 & 5.035 & TST \\
\hline CHEMBL1600736 & 688267 & 4.05 & 5.1174 & TRN \\
\hline CHEMBL1512649 & 688267 & 6.2 & 5.0326 & TST \\
\hline CHEMBL48310 & 688267 & 5.45 & 5.048 & TST \\
\hline CHEMBL1443505 & 688267 & 6.25 & 5.0145 & TRN \\
\hline
\end{tabular}




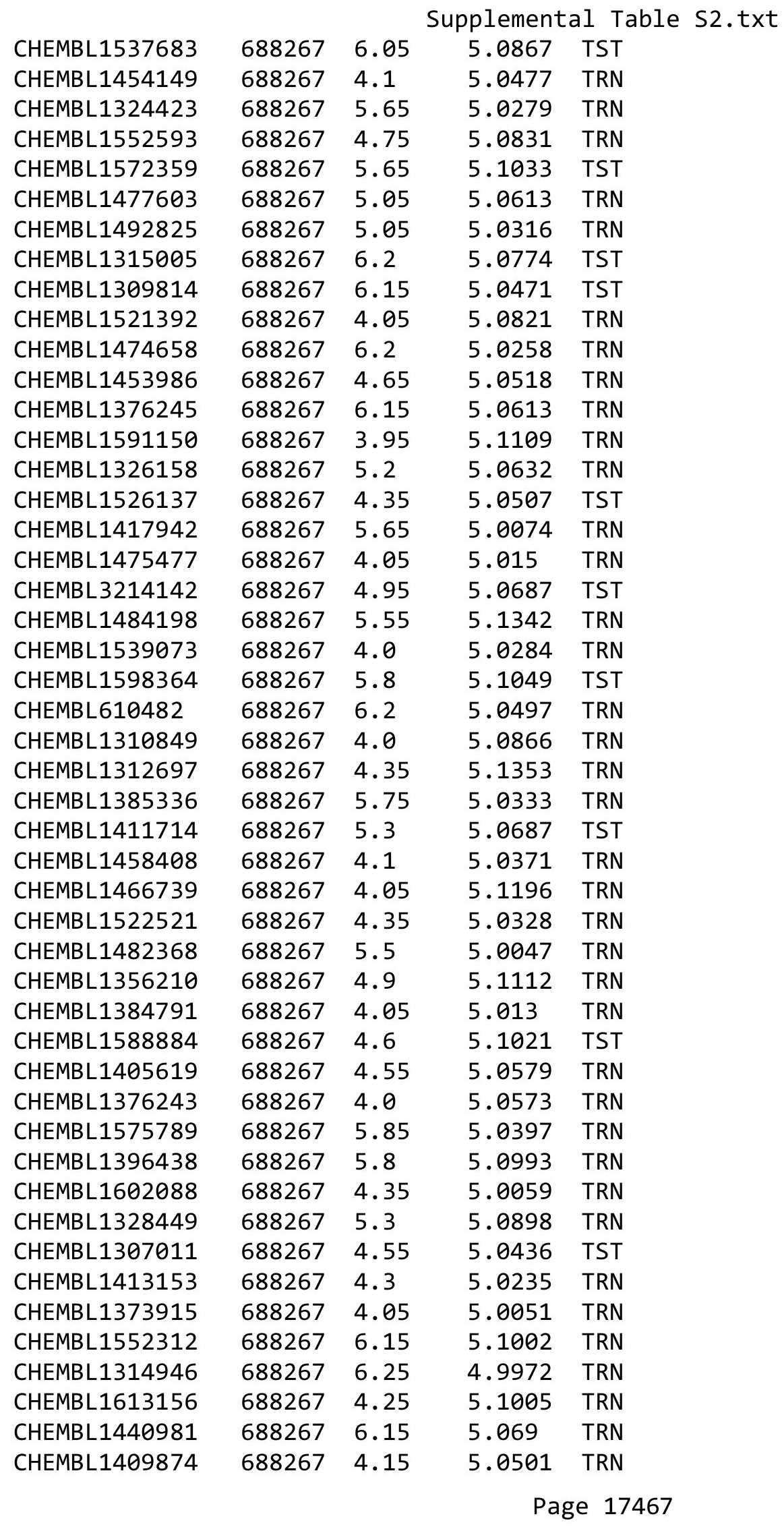




\begin{tabular}{|c|c|c|c|c|}
\hline & & & pplemen & al $\mathrm{T}$ \\
\hline CHEMBL1360364 & 688267 & 4.8 & 5.0931 & TRN \\
\hline CHEMBL3210869 & 688267 & 6.2 & 5.086 & TRN \\
\hline CHEMBL1380210 & 688267 & 4.0 & 5.0741 & TRN \\
\hline CHEMBL1581549 & 688267 & 4.0 & 5.0526 & TST \\
\hline CHEMBL1549614 & 688267 & 5.35 & 5.0502 & TRN \\
\hline CHEMBL1327486 & 688267 & 6.2 & 5.0274 & TRN \\
\hline CHEMBL1532798 & 688267 & 4.55 & 5.0936 & TRN \\
\hline CHEMBL1478575 & 688267 & 4.0 & 5.1013 & TRN \\
\hline CHEMBL1611084 & 688267 & 6.0 & 5.0319 & TST \\
\hline CHEMBL1592725 & 688267 & 4.55 & 5.0589 & TRN \\
\hline CHEMBL1603924 & 688267 & 4.0 & 5.0377 & TST \\
\hline CHEMBL1463559 & 688267 & 4.7 & 5.1263 & TRN \\
\hline CHEMBL1465411 & 688267 & 6.2 & 5.1103 & TRN \\
\hline CHEMBL1489829 & 688267 & 5.1 & 5.016 & TST \\
\hline CHEMBL1386332 & 688267 & 4.2 & 5.0549 & TST \\
\hline CHEMBL1362023 & 688267 & 4.0 & 5.051 & TST \\
\hline CHEMBL1416494 & 688267 & 3.95 & 5.0213 & TST \\
\hline CHEMBL1494353 & 688267 & 5.15 & 4.9899 & TRN \\
\hline CHEMBL1608234 & 688267 & 5.55 & 5.069 & TST \\
\hline CHEMBL1375580 & 688267 & 5.0 & 5.1042 & TRN \\
\hline CHEMBL1583466 & 688267 & 4.25 & 5.0605 & TST \\
\hline CHEMBL1358853 & 688267 & 4.3 & 5.0479 & TRN \\
\hline CHEMBL1459761 & 688267 & 4.4 & 5.0257 & TRN \\
\hline CHEMBL1508375 & 688267 & 4.05 & 4.9832 & TRN \\
\hline CHEMBL1552886 & 688267 & 6.25 & 5.0168 & TRN \\
\hline CHEMBL1392454 & 688267 & 6.3 & 5.0476 & TRN \\
\hline CHEMBL1552945 & 688267 & 4.1 & 5.0186 & TRN \\
\hline CHEMBL1470597 & 688267 & 5.0 & 5.1232 & TRN \\
\hline CHEMBL1389251 & 688267 & 4.65 & 5.1032 & TRN \\
\hline CHEMBL1590843 & 688267 & 4.25 & 5.0881 & TRN \\
\hline CHEMBL1305731 & 688267 & 5.55 & 5.0559 & TRN \\
\hline CHEMBL1591923 & 688267 & 3.95 & 5.0839 & TRN \\
\hline CHEMBL1571969 & 688267 & 6.2 & 5.0529 & TRN \\
\hline CHEMBL1578696 & 688267 & 4.7 & 5.0947 & TST \\
\hline CHEMBL1364005 & 688267 & 4.75 & 5.0858 & TRN \\
\hline CHEMBL1355136 & 688267 & 6.25 & 5.0465 & TRN \\
\hline CHEMBL1368413 & 688267 & 4.25 & 5.04 & TST \\
\hline CHEMBL1598339 & 688267 & 4.4 & 5.1018 & TRN \\
\hline CHEMBL1302269 & 688267 & 5.3 & 5.0802 & TRN \\
\hline CHEMBL1382395 & 688267 & 4.75 & 5.0668 & TST \\
\hline CHEMBL1407048 & 688267 & 6.2 & 5.0787 & TST \\
\hline CHEMBL1344886 & 688267 & 5.35 & 4.9791 & TRN \\
\hline CHEMBL1517245 & 688267 & 6.1 & 5.0582 & TRN \\
\hline CHEMBL1447246 & 688267 & 5.55 & 5.0638 & TRN \\
\hline CHEMBL1492494 & 688267 & 4.65 & 5.0952 & TRN \\
\hline CHEMBL1566231 & 688267 & 4.0 & 4.9861 & TRN \\
\hline CHEMBL1467415 & 688267 & 5.6 & 4.9753 & TST \\
\hline CHEMBL1588137 & 688267 & 6.15 & 5.0467 & TST \\
\hline
\end{tabular}




\begin{tabular}{|c|c|c|c|c|}
\hline \multicolumn{5}{|c|}{ Supplemental Table S2.txt } \\
\hline CHEMBL1303890 & 688267 & 4.95 & 5.0451 & TRN \\
\hline CHEMBL1400872 & 688267 & 4.7 & 5.0307 & TRN \\
\hline CHEMBL1406396 & 688267 & 4.5 & 5.0449 & TST \\
\hline CHEMBL1316635 & 688267 & 3.95 & 5.0513 & TST \\
\hline CHEMBL1456369 & 688267 & 6.15 & 5.0568 & TRN \\
\hline CHEMBL1392117 & 688267 & 4.0 & 5.051 & TST \\
\hline CHEMBL1383370 & 688267 & 6.2 & 5.0158 & TRN \\
\hline CHEMBL1589376 & 688267 & 4.25 & 5.0541 & TST \\
\hline CHEMBL1587424 & 688267 & 6.2 & 5.0897 & TRN \\
\hline CHEMBL1339085 & 688267 & 4.5 & 5.0384 & TRN \\
\hline CHEMBL1435305 & 688267 & 4.05 & 5.0937 & TRN \\
\hline CHEMBL1448506 & 688267 & 5.3 & 5.0413 & TRN \\
\hline CHEMBL1366602 & 688267 & 5.25 & 5.0907 & TRN \\
\hline CHEMBL1401610 & 688267 & 5.1 & 5.1211 & TRN \\
\hline CHEMBL1474136 & 688267 & 5.05 & 5.0286 & TRN \\
\hline CHEMBL1578684 & 688267 & 6.45 & 5.0618 & TRN \\
\hline CHEMBL3208121 & 688267 & 5.65 & 5.0719 & TST \\
\hline CHEMBL1372429 & 688267 & 6.15 & 5.1101 & TRN \\
\hline CHEMBL1517347 & 688267 & 4.15 & 5.0005 & TRN \\
\hline CHEMBL3198545 & 688267 & 4.35 & 4.9839 & TST \\
\hline CHEMBL1495125 & 688267 & 5.55 & 5.0595 & TRN \\
\hline CHEMBL1528056 & 688267 & 4.6 & 5.0029 & TST \\
\hline CHEMBL1496700 & 688267 & 4.05 & 5.0916 & TST \\
\hline CHEMBL1609815 & 688267 & 4.2 & 5.0926 & TST \\
\hline CHEMBL1408496 & 688267 & 5.7 & 5.0375 & TRN \\
\hline CHEMBL1340295 & 688267 & 5.5 & 5.0659 & TRN \\
\hline CHEMBL1548376 & 688267 & 4.4 & 5.0485 & TRN \\
\hline CHEMBL1423964 & 688267 & 4.05 & 5.1085 & TST \\
\hline CHEMBL1521315 & 688267 & 5.05 & 5.0671 & TRN \\
\hline CHEMBL 284104 & 688267 & 5.55 & 5.0488 & TST \\
\hline CHEMBL1365760 & 688267 & 5.9 & 5.1456 & TRN \\
\hline CHEMBL1349880 & 688267 & 6.45 & 5.0926 & TST \\
\hline CHEMBL1594586 & 688267 & 4.55 & 5.0277 & TRN \\
\hline CHEMBL1611664 & 688267 & 4.2 & 5.0507 & TST \\
\hline CHEMBL1603223 & 688267 & 5.6 & 5.046 & TRN \\
\hline CHEMBL3197804 & 688267 & 5.5 & 5.0333 & TST \\
\hline CHEMBL 1485780 & 688267 & 4.4 & 5.0881 & TRN \\
\hline CHEMBL1380609 & 688267 & 4.4 & 5.0388 & TRN \\
\hline CHEMBL1330863 & 688267 & 5.5 & 5.0023 & TRN \\
\hline CHEMBL1356477 & 688267 & 5.2 & 5.0429 & TRN \\
\hline CHEMBL1512433 & 688267 & 5.95 & 5.0823 & TRN \\
\hline CHEMBL1388853 & 688267 & 5.45 & 5.0637 & TRN \\
\hline CHEMBL1592337 & 688267 & 6.45 & 5.1624 & TRN \\
\hline CHEMBL1590200 & 688267 & 6.15 & 5.0186 & TRN \\
\hline CHEMBL1607257 & 688267 & 4.0 & 5.0433 & TRN \\
\hline CHEMBL1563655 & 688267 & 4.9 & 5.0265 & TST \\
\hline CHEMBL1364246 & 688267 & 4.05 & 5.027 & TRN \\
\hline CHEMBL1325491 & 688267 & 4.1 & 5.0248 & TRN \\
\hline
\end{tabular}




\begin{tabular}{|c|c|c|c|c|}
\hline & & & upplement & al $\mathrm{T}$ \\
\hline CHEMBL1472095 & 688267 & 3.95 & 5.0957 & TST \\
\hline CHEMBL1497978 & 688267 & 5.9 & 5.0831 & TRN \\
\hline CHEMBL1455236 & 688267 & 4.3 & 5.059 & TRN \\
\hline CHEMBL1586743 & 688267 & 4.15 & 5.1214 & TRN \\
\hline CHEMBL1574784 & 688267 & 5.15 & 5.0254 & TRN \\
\hline CHEMBL1513946 & 688267 & 4.9 & 5.0212 & TRN \\
\hline CHEMBL1376699 & 688267 & 6.25 & 5.1026 & TRN \\
\hline CHEMBL1336177 & 688267 & 5.85 & 5.1077 & TRN \\
\hline CHEMBL1481145 & 688267 & 4.0 & 5.0516 & TRN \\
\hline CHEMBL3211124 & 688267 & 5.05 & 5.0798 & TST \\
\hline CHEMBL1544362 & 688267 & 4.05 & 5.0525 & TRN \\
\hline CHEMBL1315873 & 688267 & 4.05 & 5.0155 & TRN \\
\hline CHEMBL1317476 & 688267 & 4.0 & 5.0245 & TRN \\
\hline CHEMBL1559710 & 688267 & 5.4 & 5.0703 & TRN \\
\hline CHEMBL1395625 & 688267 & 5.9 & 5.0479 & TST \\
\hline CHEMBL1348856 & 688267 & 6.8 & 5.0403 & TRN \\
\hline CHEMBL1424414 & 688267 & 6.15 & 5.1115 & TRN \\
\hline CHEMBL1457801 & 688267 & 6.2 & 5.0768 & TRN \\
\hline CHEMBL1328726 & 688267 & 4.55 & 5.0385 & TRN \\
\hline CHEMBL1382824 & 688267 & 4.15 & 5.0854 & TST \\
\hline CHEMBL1374941 & 688267 & 4.4 & 5.1298 & TRN \\
\hline CHEMBL1975361 & 688267 & 5.65 & 5.0324 & TRN \\
\hline CHEMBL1432532 & 688267 & 4.5 & 5.1087 & TRN \\
\hline CHEMBL1442933 & 688267 & 4.35 & 5.0068 & TRN \\
\hline CHEMBL1547189 & 688267 & 6.25 & 5.015 & TST \\
\hline CHEMBL1556378 & 688267 & 4.0 & 4.967 & TRN \\
\hline CHEMBL408850 & 688267 & 6.15 & 4.9918 & TRN \\
\hline CHEMBL1316362 & 688267 & 5.55 & 5.0415 & TRN \\
\hline CHEMBL1356163 & 688267 & 4.35 & 5.0399 & TST \\
\hline CHEMBL1300107 & 688267 & 5.9 & 5.0972 & TRN \\
\hline CHEMBL1559997 & 688267 & 6.2 & 5.0605 & TRN \\
\hline CHEMBL1320771 & 688267 & 4.2 & 5.0571 & TRN \\
\hline CHEMBL1392710 & 688267 & 4.25 & 5.1359 & TST \\
\hline CHEMBL1428869 & 688267 & 5.35 & 5.0275 & TRN \\
\hline CHEMBL1373519 & 688267 & 6.2 & 5.081 & TRN \\
\hline CHEMBL1571022 & 688267 & 6.05 & 5.0237 & TRN \\
\hline CHEMBL1480644 & 688267 & 5.3 & 5.011 & TRN \\
\hline CHEMBL1582898 & 688267 & 5.65 & 5.0834 & TST \\
\hline CHEMBL1575032 & 688267 & 6.15 & 5.0503 & TRN \\
\hline CHEMBL1539836 & 688267 & 4.95 & 5.0399 & TRN \\
\hline CHEMBL1332460 & 688267 & 3.95 & 5.0062 & TRN \\
\hline CHEMBL1595264 & 688267 & 4.0 & 5.0177 & TRN \\
\hline CHEMBL1359756 & 688267 & 4.65 & 5.0626 & TRN \\
\hline CHEMBL1441395 & 688267 & 5.05 & 5.0892 & TRN \\
\hline CHEMBL1482290 & 688267 & 4.0 & 5.0512 & TRN \\
\hline CHEMBL1446138 & 688267 & 5.3 & 5.0674 & TST \\
\hline CHEMBL1435468 & 688267 & 3.95 & 5.0406 & TRN \\
\hline CHEMBL1398254 & 688267 & 5.3 & 5.0138 & TRN \\
\hline
\end{tabular}




\begin{tabular}{|c|c|c|c|c|c|}
\hline \multicolumn{6}{|c|}{ Supplemental Table S2.txt } \\
\hline CHEMBL1612067 & 688267 & 4.35 & 5.0859 & TST & \\
\hline CHEMBL1323395 & 688267 & 4.6 & 5.0815 & TST & \\
\hline CHEMBL1416246 & 688267 & 5.95 & 5.0735 & TRN & \\
\hline CHEMBL1558297 & 688267 & 4.05 & 5.1169 & TRN & \\
\hline CHEMBL1472849 & 688267 & 5.85 & 4.9869 & TRN & \\
\hline CHEMBL1416053 & 688267 & 4.6 & 5.0434 & TRN & \\
\hline CHEMBL1588641 & 688267 & 6.2 & 4.9966 & TRN & \\
\hline CHEMBL1554809 & 688267 & 5.25 & 4.9852 & TRN & \\
\hline CHEMBL1403208 & 688267 & 4.1 & 5.0555 & TRN & \\
\hline CHEMBL1393981 & 688267 & 4.0 & 5.064 & TRN & \\
\hline CHEMBL1522726 & 688267 & 4.05 & 5.0159 & TRN & \\
\hline CHEMBL1585778 & 688267 & 4.5 & 5.1131 & TRN & \\
\hline CHEMBL1598598 & 688267 & 4.55 & 5.0447 & TRN & \\
\hline CHEMBL1320397 & 688267 & 4.95 & 5.0068 & TST & \\
\hline CHEMBL1510484 & 688267 & 4.9 & 5.0646 & TRN & \\
\hline CHEMBL1575019 & 688267 & 5.5 & 5.0943 & TRN & \\
\hline CHEMBL1364576 & 688267 & 6.2 & 5.0881 & TRN & \\
\hline CHEMBL1396883 & 688267 & 6.5 & 5.1278 & TRN & \\
\hline CHEMBL1394393 & 688267 & 4.4 & 5.0048 & TRN & \\
\hline CHEMBL1309602 & 688267 & 6.2 & 5.0386 & TRN & \\
\hline CHEMBL1548909 & 688267 & 5.5 & 5.129 & TRN & \\
\hline CHEMBL1372261 & 688267 & 6.2 & 5.0894 & TRN & \\
\hline CHEMBL1301815 & 688267 & 3.95 & 5.047 & TRN & \\
\hline CHEMBL1395078 & 688267 & 5.3 & 5.0528 & TST & \\
\hline CHEMBL1332527 & 688267 & 4.05 & 5.0387 & TRN & \\
\hline CHEMBL1393859 & 688267 & 5.35 & 5.0801 & TRN & \\
\hline CHEMBL1607649 & 688267 & 4.25 & 5.0268 & TST & \\
\hline CHEMBL1338382 & 688267 & 5.8 & 5.1238 & TST & \\
\hline CHEMBL1458257 & 688267 & 4.95 & 5.1059 & TRN & \\
\hline CHEMBL3211828 & 688267 & 4.75 & 5.0457 & TRN & \\
\hline CHEMBL1601643 & 688267 & 4.05 & 5.0156 & TRN & \\
\hline CHEMBL1578609 & 688267 & 6.5 & 5.0814 & TRN & \\
\hline CHEMBL1327797 & 688267 & 4.1 & 5.0775 & TRN & \\
\hline CHEMBL1598536 & 688267 & 4.1 & 5.08 & TRN & \\
\hline CHEMBL1439964 & 688267 & 4.0 & 5.10800 & 00000000005 & TRN \\
\hline CHEMBL1609978 & 688267 & 5.45 & 5.0602 & TRN & \\
\hline CHEMBL1383247 & 688267 & 6.15 & 5.0338 & TRN & \\
\hline CHEMBL 3212975 & 688267 & 4.6 & 4.9883 & TRN & \\
\hline CHEMBL1396939 & 688267 & 3.95 & 5.1363 & TRN & \\
\hline CHEMBL1362352 & 688267 & 5.5 & 5.0468 & TST & \\
\hline CHEMBL1480759 & 688267 & 6.2 & 5.043 & TST & \\
\hline CHEMBL1417136 & 688267 & 4.0 & 5.1084 & TRN & \\
\hline CHEMBL1411305 & 688267 & 5.05 & 5.1368 & TRN & \\
\hline CHEMBL1565477 & 688267 & 4.35 & 5.1363 & TST & \\
\hline CHEMBL1340230 & 688267 & 4.65 & 5.0685 & TRN & \\
\hline CHEMBL1351741 & 688267 & 5.55 & 5.0385 & TST & \\
\hline CHEMBL 3207835 & 688267 & 5.5 & 5.1213 & TST & \\
\hline CHEMBL1482547 & 688267 & 4.65 & 5.1034 & TST & \\
\hline
\end{tabular}




\begin{tabular}{|c|c|c|c|c|c|}
\hline \multicolumn{6}{|c|}{ Supplemental Table S2.txt } \\
\hline CHEMBL1513390 & 688267 & 5.45 & 5.0389 & TRN & \\
\hline CHEMBL1448932 & 688267 & 4.3 & 5.0392 & TRN & \\
\hline CHEMBL1549471 & 688267 & 5.1 & 4.9597 & TRN & \\
\hline CHEMBL1553018 & 688267 & 4.2 & 5.0001 & TRN & \\
\hline CHEMBL462628 & 688267 & 6.2 & 5.0399 & TST & \\
\hline CHEMBL1488069 & 688267 & 5.5 & 5.0464 & TST & \\
\hline CHEMBL1364757 & 688267 & 6.2 & 5.0703 & TRN & \\
\hline CHEMBL1514201 & 688267 & 4.4 & 5.0332 & TRN & \\
\hline CHEMBL1415665 & 688267 & 4.0 & 5.0568 & TST & \\
\hline CHEMBL1359368 & 688267 & 6.2 & 5.0486 & TST & \\
\hline CHEMBL1564842 & 688267 & 4.1 & 5.0267 & TRN & \\
\hline CHEMBL1420558 & 688267 & 5.05 & 5.0433 & TRN & \\
\hline CHEMBL1475196 & 688267 & 4.55 & 5.0768 & TRN & \\
\hline CHEMBL1380042 & 688267 & 6.15 & 5.0418 & TST & \\
\hline CHEMBL1358259 & 688267 & 4.35 & 5.1022 & TRN & \\
\hline CHEMBL 3193020 & 688267 & 4.1 & 4.9831 & TRN & \\
\hline CHEMBL1327160 & 688267 & 5.55 & 5.0222 & TRN & \\
\hline CHEMBL1318050 & 688267 & 5.4 & 5.0918 & TRN & \\
\hline CHEMBL1468646 & 688267 & 6.2 & 5.0721 & TST & \\
\hline CHEMBL1607031 & 688267 & 5.6 & 5.0378 & TST & \\
\hline CHEMBL1385092 & 688267 & 6.2 & 5.0686 & TRN & \\
\hline CHEMBL1388023 & 688267 & 5.65 & 5.0384 & TRN & \\
\hline CHEMBL1501677 & 688267 & 4.05 & 5.1073 & TST & \\
\hline CHEMBL1507053 & 688267 & 5.65 & 5.01699 & 79999999995 & TRN \\
\hline CHEMBL1442801 & 688267 & 4.05 & 5.1056 & TRN & \\
\hline CHEMBL1528060 & 688267 & 4.1 & 5.0995 & TRN & \\
\hline CHEMBL1354338 & 688267 & 4.05 & 5.0279 & TRN & \\
\hline CHEMBL1570587 & 688267 & 4.1 & 5.001 & TRN & \\
\hline CHEMBL1463066 & 688267 & 5.8 & 5.0646 & TST & \\
\hline CHEMBL1535923 & 688267 & 6.15 & 5.023 & TRN & \\
\hline CHEMBL1484791 & 688267 & 4.05 & 5.0235 & TST & \\
\hline CHEMBL1465002 & 688267 & 4.4 & 5.0495 & TRN & \\
\hline CHEMBL1434282 & 688267 & 6.15 & 5.1039 & TRN & \\
\hline CHEMBL1599041 & 688267 & 4.25 & 5.13899 & 7999999999 & TST \\
\hline CHEMBL1490377 & 688267 & 6.5 & 5.1059 & TRN & \\
\hline CHEMBL1317562 & 688267 & 5.2 & 5.1094 & TRN & \\
\hline CHEMBL1435839 & 688267 & 4.3 & 5.0533 & TRN & \\
\hline CHEMBL1591877 & 688267 & 4.95 & 5.112 & TRN & \\
\hline CHEMBL1552291 & 688267 & 6.2 & 5.0233 & TRN & \\
\hline CHEMBL1304200 & 688267 & 4.1 & 5.1045 & TRN & \\
\hline CHEMBL1438592 & 688267 & 5.25 & 5.0621 & TST & \\
\hline CHEMBL1526580 & 688267 & 5.0 & 5.0888 & TRN & \\
\hline CHEMBL1523862 & 688267 & 6.15 & 5.1489 & TRN & \\
\hline CHEMBL1370219 & 688267 & 5.2 & 5.0632 & TRN & \\
\hline CHEMBL1393031 & 688267 & 5.65 & 5.1062 & TRN & \\
\hline CHEMBL1505986 & 688267 & 6.2 & 5.0353 & TRN & \\
\hline CHEMBL1477141 & 688267 & 4.1 & 4.9982 & TRN & \\
\hline CHEMBL1360531 & 688267 & 4.25 & 5.065 & TRN & \\
\hline
\end{tabular}




\begin{tabular}{|c|c|c|c|c|c|}
\hline \multicolumn{6}{|c|}{ 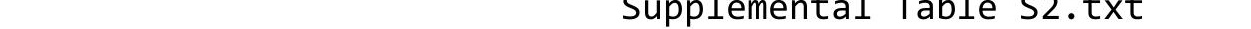 } \\
\hline CHEMBL1367619 & 688267 & 4.0 & 5.0604 & TRN & \\
\hline CHEMBL1608693 & 688267 & 4.95 & 5.1018 & TRN & \\
\hline CHEMBL1446228 & 688267 & 4.0 & 5.1268 & TRN & \\
\hline CHEMBL1605051 & 688267 & 4.3 & 5.0348 & TRN & \\
\hline CHEMBL1558689 & 688267 & 4.4 & $5.0680 e$ & 20000000005 & TST \\
\hline CHEMBL1328540 & 688267 & 4.4 & 5.0537 & TST & \\
\hline CHEMBL1539409 & 688267 & 6.15 & 5.0008 & TST & \\
\hline CHEMBL1349507 & 688267 & 6.15 & 5.0573 & TRN & \\
\hline CHEMBL1449970 & 688267 & 5.5 & 5.0529 & TRN & \\
\hline CHEMBL1375946 & 688267 & 4.2 & 5.0682 & TRN & \\
\hline CHEMBL1473054 & 688267 & 4.6 & 5.1123 & TRN & \\
\hline CHEMBL1486791 & 688267 & 5.8 & 5.0354 & TRN & \\
\hline CHEMBL1369021 & 688267 & 5.9 & 5.0722 & TRN & \\
\hline CHEMBL1455971 & 688267 & 5.0 & 5.0788 & TRN & \\
\hline CHEMBL1964591 & 688267 & 5.65 & 4.9944 & TRN & \\
\hline CHEMBL1493636 & 688267 & 4.4 & 5.0233 & TRN & \\
\hline CHEMBL1483360 & 688267 & 6.2 & 5.0459 & TRN & \\
\hline CHEMBL1609350 & 688267 & 5.65 & 5.0239 & TRN & \\
\hline CHEMBL1345634 & 688267 & 5.85 & 5.0144 & TRN & \\
\hline CHEMBL1612949 & 688267 & 5.25 & 5.1418 & TRN & \\
\hline CHEMBL1492109 & 688267 & 4.0 & 5.0193 & TST & \\
\hline CHEMBL1309632 & 688267 & 5.35 & 5.0197 & TST & \\
\hline CHEMBL1572018 & 688267 & 6.15 & 5.005 & TRN & \\
\hline CHEMBL1344424 & 688267 & 4.65 & 5.1506 & TRN & \\
\hline CHEMBL1324637 & 688267 & 5.0 & 4.9837 & TRN & \\
\hline CHEMBL1308942 & 688267 & 5.0 & 5.0507 & TRN & \\
\hline CHEMBL1530102 & 688267 & 5.25 & 5.022 & TRN & \\
\hline CHEMBL1335072 & 688267 & 5.15 & 5.0522 & TRN & \\
\hline CHEMBL1517555 & 688267 & 4.75 & 5.0825 & TRN & \\
\hline CHEMBL1480593 & 688267 & 5.4 & 5.0472 & TRN & \\
\hline CHEMBL1511997 & 688267 & 5.15 & 5.061 & TRN & \\
\hline CHEMBL1344953 & 688267 & 5.55 & 5.066 & TRN & \\
\hline CHEMBL1385537 & 688267 & 6.2 & 5.0629 & TRN & \\
\hline CHEMBL1478547 & 688267 & 4.0 & 5.0564 & TRN & \\
\hline CHEMBL1343857 & 688267 & 6.5 & 5.0559 & TST & \\
\hline CHEMBL1524651 & 688267 & 6.15 & 5.1023 & TRN & \\
\hline CHEMBL1533026 & 688267 & 6.2 & 5.1015 & TRN & \\
\hline CHEMBL1430878 & 688267 & 5.05 & 5.1055 & TST & \\
\hline CHEMBL1319977 & 688267 & 5.6 & 4.9638 & TRN & \\
\hline CHEMBL1474310 & 688267 & 5.3 & 5.0976 & TRN & \\
\hline CHEMBL1396753 & 688267 & 4.4 & 5.0672 & TST & \\
\hline CHEMBL1306413 & 688267 & 4.6 & 5.0687 & TRN & \\
\hline CHEMBL1443410 & 688267 & 5.6 & 5.0616 & TST & \\
\hline CHEMBL1444389 & 688267 & 4.7 & $5.0680 e$ & 00000000005 & TST \\
\hline CHEMBL1589379 & 688267 & 6.2 & 5.0843 & TRN & \\
\hline CHEMBL1604994 & 688267 & 5.4 & 4.9664 & TRN & \\
\hline CHEMBL1551056 & 688267 & 6.2 & 5.082 & TRN & \\
\hline CHEMBL1377309 & 688267 & 6.0 & 5.0803 & TRN & \\
\hline
\end{tabular}




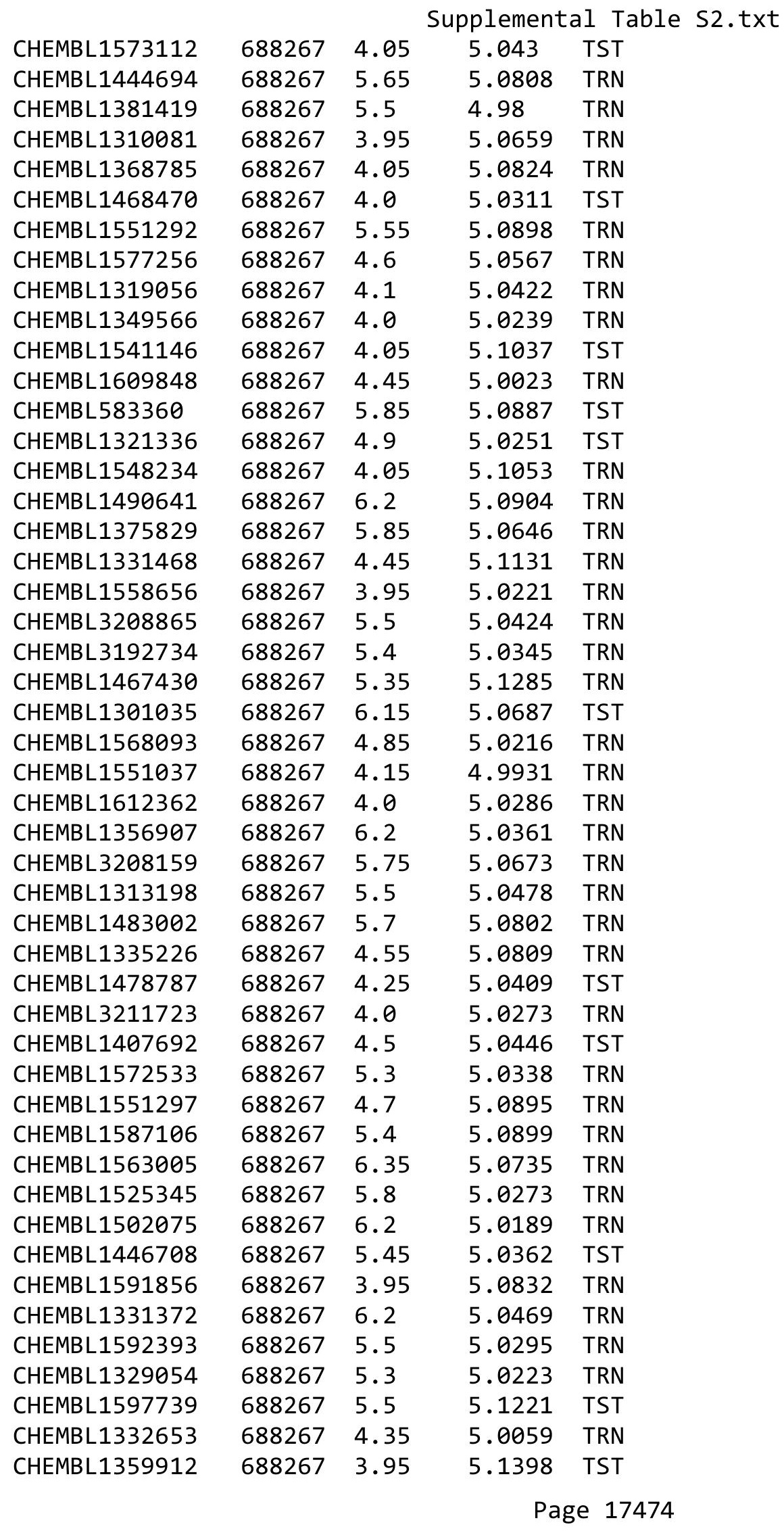




\begin{tabular}{|c|c|c|c|c|c|}
\hline & & \multicolumn{4}{|c|}{ Supplemental Table s2.txt } \\
\hline CHEMBL1407037 & 688267 & 5.65 & 5.0471 & TRN & \\
\hline CHEMBL1446271 & 688267 & 5.8 & 4.9798 & TRN & \\
\hline CHEMBL1430611 & 688267 & 3.95 & 5.0769 & TST & \\
\hline CHEMBL1514916 & 688267 & 4.35 & 5.0893 & TST & \\
\hline CHEMBL1591641 & 688267 & 4.1 & 5.004 & TRN & \\
\hline CHEMBL605003 & 688267 & 5.0 & 5.0965 & TST & \\
\hline CHEMBL1424303 & 688267 & 4.1 & 5.0567 & TRN & \\
\hline CHEMBL1507983 & 688267 & 5.3 & 5.0969 & TST & \\
\hline CHEMBL1458146 & 688267 & 4.15 & 5.1284 & TRN & \\
\hline CHEMBL1589666 & 688267 & 6.25 & 5.0241 & TRN & \\
\hline CHEMBL1475469 & 688267 & 5.6 & 5.0527 & TRN & \\
\hline CHEMBL1547942 & 688267 & 4.1 & 5.0429 & TRN & \\
\hline CHEMBL1583693 & 688267 & 5.8 & 5.0589 & TST & \\
\hline CHEMBL1377651 & 688267 & 4.45 & 5.0784 & TRN & \\
\hline CHEMBL1392619 & 688267 & 6.2 & 5.0622 & TRN & \\
\hline CHEMBL1571846 & 688267 & 4.0 & 5.1078 & TRN & \\
\hline CHEMBL1361251 & 688267 & 4.6 & 5.0715 & TRN & \\
\hline CHEMBL1569243 & 688267 & 5.8 & 5.07100 & 0000000001 & TST \\
\hline CHEMBL1417985 & 688267 & 5.25 & 5.0194 & TRN & \\
\hline CHEMBL3195534 & 688267 & 5.6 & 5.064 & TST & \\
\hline CHEMBL1487119 & 688267 & 5.1 & 5.1357 & TRN & \\
\hline CHEMBL1476332 & 688267 & 4.4 & 5.1007 & TRN & \\
\hline CHEMBL1498324 & 688267 & 4.05 & 5.0844 & TRN & \\
\hline CHEMBL1391578 & 688267 & 5.35 & 5.0944 & TST & \\
\hline CHEMBL1474747 & 688267 & 4.25 & 5.006 & TRN & \\
\hline CHEMBL1442613 & 688267 & 4.05 & 5.0616 & TRN & \\
\hline CHEMBL1406899 & 688267 & 4.25 & 5.0592 & TRN & \\
\hline CHEMBL388326 & 688267 & 6.25 & 5.1375 & TRN & \\
\hline CHEMBL1356885 & 688267 & 4.15 & 5.0507 & TRN & \\
\hline CHEMBL1561133 & 688267 & 4.4 & 5.0158 & TST & \\
\hline CHEMBL1410702 & 688267 & 6.2 & 5.0226 & TST & \\
\hline CHEMBL1473798 & 688267 & 3.95 & 5.0394 & TRN & \\
\hline CHEMBL1551553 & 688267 & 4.6 & 5.0174 & TRN & \\
\hline CHEMBL1422470 & 688267 & 4.15 & 5.0946 & TRN & \\
\hline CHEMBL3214219 & 688267 & 4.4 & 4.9874 & TST & \\
\hline CHEMBL1444066 & 688267 & 5.6 & 5.0035 & TRN & \\
\hline CHEMBL1466127 & 688267 & 4.55 & 5.0388 & TRN & \\
\hline CHEMBL1375910 & 688267 & 4.3 & 5.0886 & TRN & \\
\hline CHEMBL1521540 & 688267 & 5.95 & 5.0613 & TRN & \\
\hline CHEMBL1370050 & 688267 & 4.8 & 5.0765 & TST & \\
\hline CHEMBL1336586 & 688267 & 4.5 & 5.1249 & TRN & \\
\hline CHEMBL1488047 & 688267 & 5.2 & 5.1167 & TRN & \\
\hline CHEMBL1416374 & 688267 & 5.8 & 5.0657 & TRN & \\
\hline CHEMBL1582541 & 688267 & 5.3 & 5.0384 & TRN & \\
\hline CHEMBL1322562 & 688267 & 5.4 & 5.1106 & TST & \\
\hline CHEMBL1555657 & 688267 & 4.0 & 5.0401 & TRN & \\
\hline CHEMBL1408829 & 688267 & 4.0 & 5.0059 & TST & \\
\hline CHEMBL1593762 & 688267 & 5.45 & 5.0666 & TRN & \\
\hline
\end{tabular}




\begin{tabular}{|c|c|c|c|c|}
\hline \multicolumn{5}{|c|}{ Supplemental Table S2.txt } \\
\hline CHEMBL1536764 & 688267 & 5.55 & 5.1315 & TRN \\
\hline CHEMBL1432167 & 688267 & 5.1 & 5.0715 & TRN \\
\hline CHEMBL1540270 & 688267 & 4.0 & 5.0125 & TST \\
\hline CHEMBL1565045 & 688267 & 6.2 & 5.1176 & TRN \\
\hline CHEMBL 1447742 & 688267 & 6.0 & 5.0428 & TRN \\
\hline CHEMBL1598855 & 688267 & 3.95 & 5.0861 & TRN \\
\hline CHEMBL1491733 & 688267 & 4.0 & 5.0635 & TRN \\
\hline CHEMBL1322320 & 688267 & 5.3 & 5.0545 & TST \\
\hline CHEMBL1391883 & 688267 & 5.95 & 5.0013 & TRN \\
\hline CHEMBL1419908 & 688267 & 6.15 & 5.0401 & TRN \\
\hline CHEMBL1550575 & 688267 & 5.85 & 5.0241 & TRN \\
\hline CHEMBL1434551 & 688267 & 5.3 & 5.0365 & TRN \\
\hline CHEMBL1506501 & 688267 & 4.3 & 5.1041 & TST \\
\hline CHEMBL1613266 & 688267 & 5.4 & 4.9801 & TRN \\
\hline CHEMBL1558637 & 688267 & 6.15 & 5.0612 & TRN \\
\hline CHEMBL1482007 & 688267 & 6.2 & 4.9909 & TRN \\
\hline CHEMBL1392326 & 688267 & 4.5 & 5.0309 & TST \\
\hline CHEMBL1342446 & 688267 & 6.2 & 4.9967 & TRN \\
\hline CHEMBL1406888 & 688267 & 5.4 & 5.0809 & TRN \\
\hline CHEMBL1554019 & 688267 & 4.55 & 5.0902 & TRN \\
\hline CHEMBL1568832 & 688267 & 4.8 & 5.0195 & TRN \\
\hline CHEMBL1407388 & 688267 & 4.7 & 4.9686 & TRN \\
\hline CHEMBL1331507 & 688267 & 6.0 & 5.0209 & TRN \\
\hline CHEMBL1496405 & 688267 & 5.55 & 5.0321 & TRN \\
\hline CHEMBL1557000 & 688267 & 3.95 & 5.0876 & TRN \\
\hline CHEMBL1434420 & 688267 & 4.05 & 5.0624 & TRN \\
\hline CHEMBL1512214 & 688267 & 4.4 & 5.0792 & TRN \\
\hline CHEMBL1417893 & 688267 & 5.4 & 5.0205 & TST \\
\hline CHEMBL415270 & 688267 & 6.1 & 5.0629 & TST \\
\hline CHEMBL1421805 & 688267 & 4.05 & 5.1273 & TST \\
\hline CHEMBL1444069 & 688267 & 6.2 & 5.0846 & TRN \\
\hline CHEMBL1412044 & 688267 & 4.0 & 5.0843 & TST \\
\hline CHEMBL1502613 & 688267 & 4.0 & 5.0791 & TRN \\
\hline CHEMBL1386275 & 688267 & 4.0 & 5.0752 & TRN \\
\hline CHEMBL1437349 & 688267 & 4.35 & 5.0292 & TRN \\
\hline CHEMBL1535990 & 688267 & 5.85 & 5.0304 & TRN \\
\hline CHEMBL 1453588 & 688267 & 4.0 & 5.0942 & TRN \\
\hline CHEMBL1450176 & 688267 & 5.45 & 4.9859 & TRN \\
\hline CHEMBL1613470 & 688267 & 6.15 & 5.0846 & TRN \\
\hline CHEMBL1496615 & 688267 & 4.3 & 5.002 & TRN \\
\hline CHEMBL1515073 & 688267 & 4.1 & 5.0802 & TRN \\
\hline CHEMBL1426154 & 688267 & 5.55 & 5.1553 & TRN \\
\hline CHEMBL1392554 & 688267 & 4.55 & 5.0167 & TRN \\
\hline CHEMBL1435456 & 688267 & 4.0 & 5.0452 & TRN \\
\hline CHEMBL1409444 & 688267 & 3.9 & 5.0166 & TRN \\
\hline CHEMBL1431635 & 688267 & 5.4 & 5.0386 & TRN \\
\hline CHEMBL1566803 & 688267 & 5.0 & 5.1124 & TRN \\
\hline CHEMBL1572484 & 688267 & 4.9 & 5.0379 & TST \\
\hline
\end{tabular}




\begin{tabular}{|c|c|c|c|c|c|}
\hline & & & & & \\
\hline CHEMBL1426183 & 688267 & 5.4 & 5.0326 & TRN & \\
\hline CHEMBL1515453 & 688267 & 6.2 & 5.0643 & TRN & \\
\hline CHEMBL1362785 & 688267 & 5.5 & 5.0463 & TST & \\
\hline CHEMBL1354439 & 688267 & 5.0 & 5.0488 & TRN & \\
\hline CHEMBL1330435 & 688267 & 6.05 & 5.1138 & TRN & \\
\hline CHEMBL3189917 & 688267 & 4.0 & 4.9957 & TRN & \\
\hline CHEMBL1325322 & 688267 & 5.35 & 5.1608 & TRN & \\
\hline CHEMBL1335823 & 688267 & 5.0 & 5.0245 & TRN & \\
\hline CHEMBL1523288 & 688267 & 3.95 & 5.1096 & TRN & \\
\hline CHEMBL1480117 & 688267 & 5.95 & 5.0602 & TST & \\
\hline CHEMBL1412358 & 688267 & 3.95 & 4.9978 & TST & \\
\hline CHEMBL1359797 & 688267 & 4.75 & 4.9954 & TST & \\
\hline CHEMBL1422566 & 688267 & 4.15 & 5.0095 & TRN & \\
\hline CHEMBL1533409 & 688267 & 5.65 & 5.0648 & TRN & \\
\hline CHEMBL1349261 & 688267 & 5.05 & 5.1314 & TRN & \\
\hline CHEMBL1512318 & 688267 & 6.15 & 5.0425 & TRN & \\
\hline CHEMBL1469340 & 688267 & 4.2 & 5.0042 & TST & \\
\hline CHEMBL1393401 & 688267 & 4.6 & 5.0285 & TST & \\
\hline CHEMBL1425074 & 688267 & 4.35 & 5.0766 & TRN & \\
\hline CHEMBL1301863 & 688267 & 5.35 & 5.0231 & TRN & \\
\hline CHEMBL1324169 & 688267 & 6.0 & 5.0414 & TST & \\
\hline CHEMBL1387762 & 688267 & 4.0 & 5.0751 & TRN & \\
\hline CHEMBL1336170 & 688267 & 6.45 & 5.0845 & TRN & \\
\hline CHEMBL1506109 & 688267 & 5.85 & 5.0009 & TST & \\
\hline CHEMBL1418745 & 688267 & 4.9 & 4.9788 & TRN & \\
\hline CHEMBL1414521 & 688267 & 6.2 & 5.0787 & TRN & \\
\hline CHEMBL1479978 & 688267 & 4.35 & 5.0188 & TRN & \\
\hline CHEMBL1458622 & 688267 & 6.2 & 5.0391 & TRN & \\
\hline CHEMBL1602785 & 688267 & 5.2 & 5.0899 & TRN & \\
\hline CHEMBL1405532 & 688267 & 5.1 & 5.1285 & TRN & \\
\hline CHEMBL1506495 & 688267 & 4.0 & 5.0639 & TST & \\
\hline CHEMBL1391552 & 688267 & 4.4 & 5.025 & TST & \\
\hline CHEMBL1602071 & 688267 & 5.25 & 5.0197 & TRN & \\
\hline CHEMBL1551978 & 688267 & 4.5 & 5.1134 & TRN & \\
\hline CHEMBL1980308 & 688267 & 4.2 & 4.9863 & TRN & \\
\hline CHEMBL1523772 & 688267 & 5.85 & 5.1004 & TRN & \\
\hline CHEMBL1392291 & 688267 & 6.2 & 5.095 & TRN & \\
\hline CHEMBL1320219 & 688267 & 5.65 & 5.0286 & TRN & \\
\hline CHEMBL1300920 & 688267 & 4.25 & 5.0538 & TRN & \\
\hline CHEMBL1592730 & 688267 & 6.05 & 5.0002 & TRN & \\
\hline CHEMBL1365291 & 688267 & 5.8 & 5.0524 & TRN & \\
\hline CHEMBL1441707 & 688267 & 3.95 & 5.0434 & TRN & \\
\hline CHEMBL1386506 & 688267 & 4.05 & 5.0546 & TST & \\
\hline CHEMBL1511453 & 688267 & 4.25 & 5.0006 & TRN & \\
\hline CHEMBL1364911 & 688267 & 5.6 & 5.1052 & TRN & \\
\hline CHEMBL1409032 & 688267 & 5.55 & 5.0534 & TRN & \\
\hline CHEMBL1364857 & 688267 & 3.95 & $5.0280 e$ & 20000000005 & TRN \\
\hline CHEMBL1500410 & 688267 & 4.85 & 5.1418 & TRN & \\
\hline & & & & 17477 & \\
\hline
\end{tabular}




\begin{tabular}{|c|c|c|c|c|c|}
\hline \multicolumn{6}{|c|}{ Supplemental Table S2.txt } \\
\hline CHEMBL1484926 & 688267 & 4.15 & 4.9932 & TRN & \\
\hline CHEMBL1412985 & 688267 & 4.3 & 5.0755 & TRN & \\
\hline CHEMBL1367634 & 688267 & 5.05 & 5.018 & TST & \\
\hline CHEMBL1603115 & 688267 & 4.0 & 5.0828 & TRN & \\
\hline CHEMBL1475003 & 688267 & 4.05 & 5.0862 & TRN & \\
\hline CHEMBL1581571 & 688267 & 5.5 & 5.0531 & TST & \\
\hline CHEMBL1416810 & 688267 & 4.0 & 5.0213 & TRN & \\
\hline CHEMBL1522484 & 688267 & 5.9 & 5.03 & TRN & \\
\hline CHEMBL1486180 & 688267 & 4.05 & 5.0402 & TRN & \\
\hline CHEMBL1484725 & 688267 & 4.0 & 5.0434 & TST & \\
\hline CHEMBL1566373 & 688267 & 4.0 & 5.0243 & TST & \\
\hline CHEMBL1326587 & 688267 & 5.1 & 5.0759 & TRN & \\
\hline CHEMBL1380908 & 688267 & 3.95 & 5.0262 & TRN & \\
\hline CHEMBL1339917 & 688267 & 4.85 & 5.0882 & TRN & \\
\hline CHEMBL1598508 & 688267 & 4.4 & 5.01399 & 9999999999 & TRN \\
\hline CHEMBL1453263 & 688267 & 5.45 & 5.0441 & TRN & \\
\hline CHEMBL1323751 & 688267 & 4.55 & 5.0408 & TRN & \\
\hline CHEMBL1501322 & 688267 & 4.35 & 5.0722 & TST & \\
\hline CHEMBL1301593 & 688267 & 4.35 & 5.085 & TRN & \\
\hline CHEMBL1440147 & 688267 & 5.35 & 5.0008 & TST & \\
\hline CHEMBL1456934 & 688267 & 4.35 & 5.0706 & TRN & \\
\hline CHEMBL1532944 & 688267 & 5.95 & 5.0525 & TRN & \\
\hline CHEMBL1350384 & 688267 & 4.3 & 5.0492 & TRN & \\
\hline CHEMBL1556826 & 688267 & 5.35 & 5.041 & TRN & \\
\hline CHEMBL1474124 & 688267 & 6.25 & 5.0282 & TST & \\
\hline CHEMBL1402943 & 688267 & 6.2 & 5.1069 & TST & \\
\hline CHEMBL1331674 & 688267 & 6.25 & 5.0127 & TRN & \\
\hline CHEMBL1551128 & 688267 & 4.9 & 5.0584 & TRN & \\
\hline CHEMBL1321329 & 688267 & 4.75 & 5.0246 & TST & \\
\hline CHEMBL358546 & 688267 & 6.15 & 5.005 & TRN & \\
\hline CHEMBL1536520 & 688267 & 5.35 & 5.0768 & TRN & \\
\hline CHEMBL1611042 & 688267 & 5.75 & 5.032 & TRN & \\
\hline CHEMBL1397122 & 688267 & 6.25 & 5.0753 & TRN & \\
\hline CHEMBL1366895 & 688267 & 4.4 & 5.0651 & TRN & \\
\hline CHEMBL1374081 & 688267 & 4.6 & 5.0325 & TRN & \\
\hline CHEMBL1530249 & 688267 & 6.15 & 4.9819 & TST & \\
\hline CHEMBL1611385 & 688267 & 4.0 & 5.0535 & TRN & \\
\hline CHEMBL1570680 & 688267 & 6.2 & 5.0537 & TRN & \\
\hline CHEMBL1343704 & 688267 & 5.1 & 5.1691 & TRN & \\
\hline CHEMBL1579933 & 688267 & 4.55 & 5.0371 & TST & \\
\hline CHEMBL1480398 & 688267 & 4.35 & 5.0518 & TST & \\
\hline CHEMBL1579035 & 688267 & 5.0 & 5.0668 & TRN & \\
\hline CHEMBL1312072 & 688267 & 4.5 & 5.0678 & TRN & \\
\hline CHEMBL1464961 & 688267 & 4.95 & 5.0137 & TRN & \\
\hline CHEMBL1425390 & 688267 & 4.35 & 5.0681 & TRN & \\
\hline CHEMBL1463010 & 688267 & 5.1 & $5.1080 e$ & 00000000005 & TRN \\
\hline CHEMBL1354208 & 688267 & 5.85 & 5.0968 & TRN & \\
\hline CHEMBL1601822 & 688267 & 4.5 & 5.0201 & TRN & \\
\hline
\end{tabular}




\begin{tabular}{|c|c|c|c|c|}
\hline & & & ipplement & al $\mathrm{Tc}$ \\
\hline CHEMBL1380421 & 688267 & 6.25 & 5.1057 & TRN \\
\hline CHEMBL1395881 & 688267 & 5.45 & 5.0145 & TRN \\
\hline CHEMBL1477304 & 688267 & 6.15 & 5.0028 & TST \\
\hline CHEMBL1299711 & 688267 & 4.55 & 5.1097 & TRN \\
\hline CHEMBL1512588 & 688267 & 3.95 & 5.1422 & TRN \\
\hline CHEMBL1476152 & 688267 & 4.05 & 5.0327 & TRN \\
\hline CHEMBL1330746 & 688267 & 4.05 & 5.0772 & TRN \\
\hline CHEMBL1574813 & 688267 & 5.55 & 5.1301 & TRN \\
\hline CHEMBL1352144 & 688267 & 5.45 & 5.0503 & TRN \\
\hline CHEMBL1415498 & 688267 & 5.4 & 5.0692 & TRN \\
\hline CHEMBL1335160 & 688267 & 5.4 & 5.067 & TRN \\
\hline CHEMBL1407722 & 688267 & 4.0 & 5.1287 & TST \\
\hline CHEMBL3190192 & 688267 & 4.55 & 4.9985 & TST \\
\hline CHEMBL1572712 & 688267 & 4.3 & 5.0034 & TRN \\
\hline CHEMBL1329217 & 688267 & 4.1 & 5.1008 & TRN \\
\hline CHEMBL1350455 & 688267 & 4.35 & 5.0866 & TST \\
\hline CHEMBL1394852 & 688267 & 4.05 & 5.0019 & TRN \\
\hline CHEMBL1611628 & 688267 & 4.05 & 5.1027 & TRN \\
\hline CHEMBL1405030 & 688267 & 4.6 & 5.012 & TST \\
\hline CHEMBL1407006 & 688267 & 3.95 & 5.046 & TST \\
\hline CHEMBL1307014 & 688267 & 5.0 & 5.0419 & TRN \\
\hline CHEMBL1483865 & 688267 & 5.05 & 5.0194 & TRN \\
\hline CHEMBL1312101 & 688267 & 3.95 & 5.0913 & TRN \\
\hline CHEMBL1418270 & 688267 & 6.2 & 5.0209 & TST \\
\hline CHEMBL1471785 & 688267 & 5.3 & 5.0848 & TRN \\
\hline CHEMBL1357599 & 688267 & 3.95 & 5.0018 & TRN \\
\hline CHEMBL1348159 & 688267 & 6.25 & 5.0925 & TST \\
\hline CHEMBL1551522 & 688267 & 5.5 & 5.081 & TRN \\
\hline CHEMBL1385999 & 688267 & 4.4 & 5.0398 & TRN \\
\hline CHEMBL1564860 & 688267 & 6.2 & 5.0808 & TRN \\
\hline CHEMBL1569863 & 688267 & 4.35 & 5.0463 & TRN \\
\hline CHEMBL1514788 & 688267 & 4.05 & 5.0699 & TST \\
\hline CHEMBL1325787 & 688267 & 6.25 & 5.0348 & TRN \\
\hline CHEMBL1549897 & 688267 & 6.2 & 5.0562 & TRN \\
\hline CHEMBL3208849 & 688267 & 5.6 & 5.0207 & TRN \\
\hline CHEMBL1528010 & 688267 & 5.3 & 5.0491 & TST \\
\hline CHEMBL1465851 & 688267 & 5.9 & 5.0711 & TRN \\
\hline CHEMBL1357074 & 688267 & 5.35 & 5.1153 & TRN \\
\hline CHEMBL1586798 & 688267 & 4.5 & 5.0614 & TRN \\
\hline CHEMBL1477433 & 688267 & 6.45 & 5.0962 & TRN \\
\hline CHEMBL1610044 & 688267 & 4.25 & 5.0635 & TST \\
\hline CHEMBL1604717 & 688267 & 5.6 & 5.1097 & TST \\
\hline CHEMBL1416750 & 688267 & 4.6 & 5.1013 & TST \\
\hline CHEMBL1329395 & 688267 & 4.75 & 5.0927 & TRN \\
\hline CHEMBL1414254 & 688267 & 5.75 & 5.0302 & TRN \\
\hline CHEMBL1360267 & 688267 & 6.5 & 5.0609 & TRN \\
\hline CHEMBL1544992 & 688267 & 6.2 & 5.0908 & TRN \\
\hline CHEMBL1540101 & 688267 & 5.35 & 5.0895 & TST \\
\hline
\end{tabular}




\begin{tabular}{|c|c|c|c|c|c|}
\hline \\
\hline CHEMBL1334634 & 688267 & 6.2 & 5.0734 & TRN & \\
\hline CHEMBL1605161 & 688267 & 5.45 & 5.0891 & TRN & \\
\hline CHEMBL1422903 & 688267 & 5.9 & 5.0803 & TRN & \\
\hline CHEMBL1450804 & 688267 & 6.15 & 5.0618 & TRN & \\
\hline CHEMBL1579603 & 688267 & 4.75 & 4.9634 & TRN & \\
\hline CHEMBL3211625 & 688267 & 4.05 & 5.04899 & 99999999995 & TRN \\
\hline CHEMBL1359784 & 688267 & 6.2 & 5.0417 & TST & \\
\hline CHEMBL1427390 & 688267 & 4.45 & 5.0122 & TRN & \\
\hline CHEMBL1440969 & 688267 & 4.65 & 5.0414 & TRN & \\
\hline CHEMBL1397103 & 688267 & 6.0 & 5.0928 & TRN & \\
\hline CHEMBL1454870 & 688267 & 5.15 & 5.155 & TRN & \\
\hline CHEMBL3145108 & 688267 & 5.5 & 5.0115 & TST & \\
\hline CHEMBL1477845 & 688267 & 5.05 & 5.0577 & TRN & \\
\hline CHEMBL1352970 & 688267 & 5.5 & 5.0401 & TRN & \\
\hline CHEMBL1396433 & 688267 & 5.8 & 5.0429 & TRN & \\
\hline CHEMBL1542255 & 688267 & 5.5 & 5.0514 & TRN & \\
\hline CHEMBL1543913 & 688267 & 4.0 & 5.0574 & TRN & \\
\hline CHEMBL1475621 & 688267 & 5.3 & 5.0791 & TRN & \\
\hline CHEMBL1604798 & 688267 & 6.25 & 5.1171 & TRN & \\
\hline CHEMBL1523928 & 688267 & 6.15 & 5.0085 & TRN & \\
\hline CHEMBL1385817 & 688267 & 6.15 & 5.0634 & TRN & \\
\hline CHEMBL1376767 & 688267 & 4.75 & 5.04899 & 99999999995 & TST \\
\hline CHEMBL1435061 & 688267 & 4.55 & 4.9712 & TRN & \\
\hline CHEMBL1375604 & 688267 & 4.3 & 5.0634 & TRN & \\
\hline CHEMBL1374383 & 688267 & 3.95 & 5.0115 & TRN & \\
\hline CHEMBL1581191 & 688267 & 4.85 & 5.0163 & TRN & \\
\hline CHEMBL1403307 & 688267 & 5.2 & 5.0705 & TRN & \\
\hline CHEMBL1409996 & 688267 & 4.3 & 5.0855 & TRN & \\
\hline CHEMBL1469528 & 688267 & 5.7 & 5.0224 & TRN & \\
\hline CHEMBL1498042 & 688267 & 4.8 & 5.1197 & TRN & \\
\hline CHEMBL1424171 & 688267 & 4.9 & 5.1189 & TRN & \\
\hline CHEMBL1347729 & 688267 & 4.55 & 5.0894 & TRN & \\
\hline CHEMBL3209483 & 688267 & 3.95 & 5.03100 & 0000000001 & TRN \\
\hline CHEMBL1431132 & 688267 & 4.9 & 5.0492 & TST & \\
\hline CHEMBL1313704 & 688267 & 4.95 & 5.0637 & TST & \\
\hline CHEMBL1331389 & 688267 & 6.15 & 5.0866 & TRN & \\
\hline CHEMBL1362040 & 688267 & 6.0 & 4.9853 & TRN & \\
\hline CHEMBL1554669 & 688267 & 4.05 & 5.1087 & TRN & \\
\hline CHEMBL1586445 & 688267 & 4.65 & 5.0062 & TRN & \\
\hline CHEMBL1370207 & 688267 & 4.9 & 5.02800 & 00000000005 & TRN \\
\hline CHEMBL1299501 & 688267 & 4.65 & 5.0414 & TST & \\
\hline CHEMBL1510926 & 688267 & 5.25 & 5.0619 & TST & \\
\hline CHEMBL1609362 & 688267 & 4.0 & 5.0617 & TRN & \\
\hline CHEMBL1342330 & 688267 & 6.0 & 5.0281 & TST & \\
\hline CHEMBL1590610 & 688267 & 5.95 & 5.0721 & TRN & \\
\hline CHEMBL1429139 & 688267 & 6.2 & 5.0981 & TRN & \\
\hline CHEMBL1486707 & 688267 & 4.9 & 5.0111 & TST & \\
\hline CHEMBL1360429 & 688267 & 3.95 & 5.0524 & TRN & \\
\hline
\end{tabular}




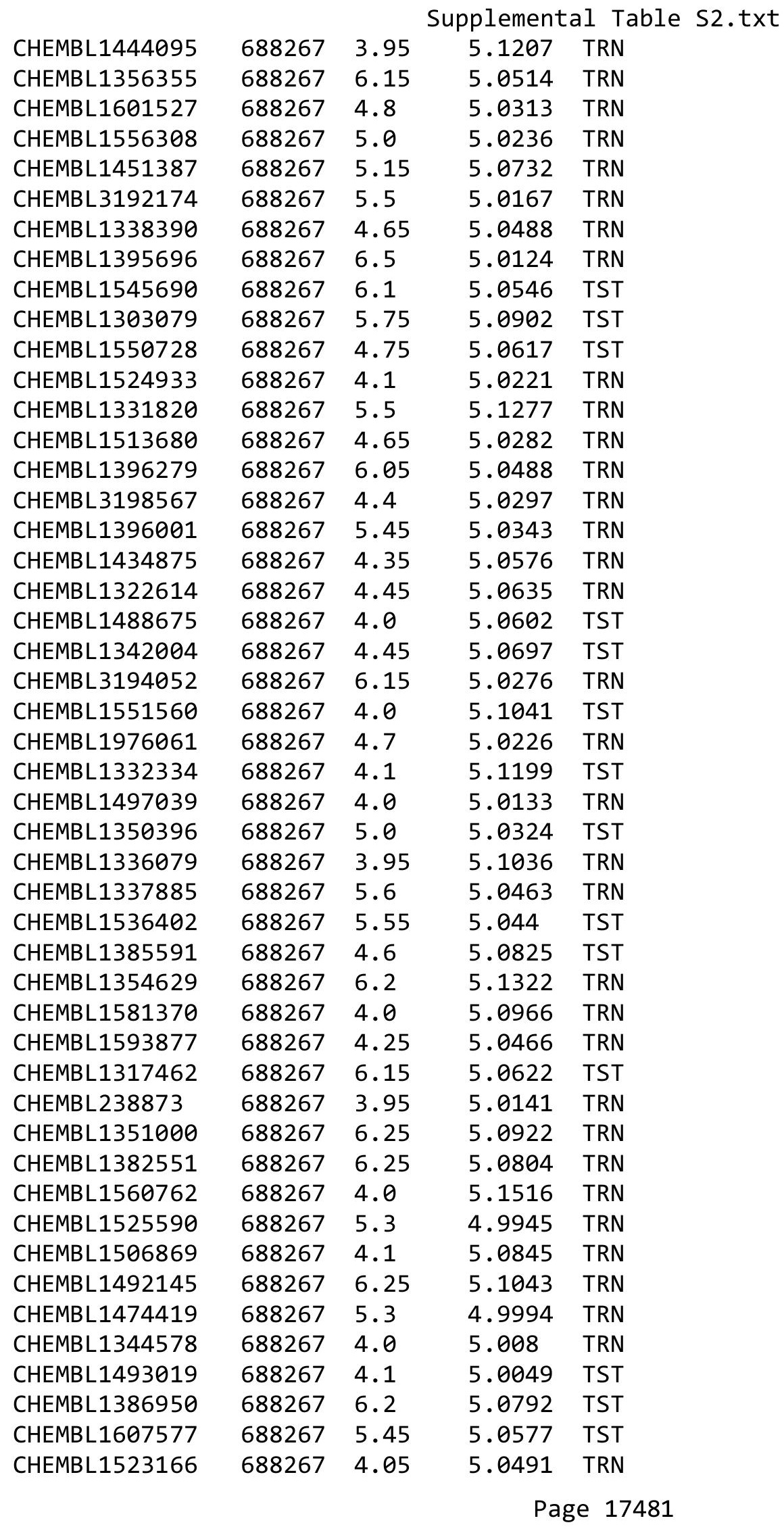




\begin{tabular}{|c|c|c|c|c|c|}
\hline \\
\hline CHEMBL1538226 & 688267 & 6.2 & 5.0698 & TST & \\
\hline CHEMBL1606238 & 688267 & 4.05 & 5.1264 & TST & \\
\hline CHEMBL1491676 & 688267 & 5.8 & 5.0274 & TST & \\
\hline CHEMBL1404151 & 688267 & 5.55 & 5.0028 & TRN & \\
\hline CHEMBL1595200 & 688267 & 4.0 & 5.0272 & TRN & \\
\hline CHEMBL1422552 & 688267 & 4.9 & 5.0391 & TRN & \\
\hline CHEMBL1514138 & 688267 & 4.25 & 5.0868 & TRN & \\
\hline CHEMBL1595565 & 688267 & 4.05 & 5.0499 & TRN & \\
\hline CHEMBL1511141 & 688267 & 4.25 & 5.0445 & TST & \\
\hline CHEMBL1375306 & 688267 & 4.05 & 5.0493 & TRN & \\
\hline CHEMBL1567562 & 688267 & 5.55 & 5.0311 & TRN & \\
\hline CHEMBL1325977 & 688267 & 4.35 & 5.0747 & TRN & \\
\hline CHEMBL1575725 & 688267 & 6.2 & 5.0957 & TRN & \\
\hline CHEMBL1554041 & 688267 & 4.0 & 5.0805 & TRN & \\
\hline CHEMBL1578423 & 688267 & 4.8 & 5.0512 & TST & \\
\hline CHEMBL1394362 & 688267 & 5.15 & 5.0365 & TRN & \\
\hline CHEMBL1452087 & 688267 & 4.6 & 5.0024 & TRN & \\
\hline CHEMBL1335938 & 688267 & 4.0 & 5.0946 & TRN & \\
\hline CHEMBL1605891 & 688267 & 6.15 & 5.0976 & TRN & \\
\hline CHEMBL1479837 & 688267 & 4.6 & 5.0946 & TRN & \\
\hline CHEMBL1368144 & 688267 & 4.3 & 4.9975 & TRN & \\
\hline CHEMBL1561432 & 688267 & 5.55 & 5.0427 & TRN & \\
\hline CHEMBL1452269 & 688267 & 4.05 & 5.0958 & TRN & \\
\hline CHEMBL1478720 & 688267 & 6.2 & 5.0517 & TST & \\
\hline CHEMBL1539074 & 688267 & 5.9 & 5.0573 & TRN & \\
\hline CHEMBL3196083 & 688267 & 4.45 & 4.9788 & TST & \\
\hline CHEMBL1547522 & 688267 & 5.7 & 5.0366 & TRN & \\
\hline CHEMBL1441148 & 688267 & 4.65 & 5.0154 & TRN & \\
\hline CHEMBL1569264 & 688267 & 5.35 & 5.0668 & TRN & \\
\hline CHEMBL1406722 & 688267 & 4.0 & 5.0739 & TRN & \\
\hline CHEMBL1433557 & 688267 & 4.4 & 5.0064 & TRN & \\
\hline CHEMBL1420375 & 688267 & 4.6 & 5.0779 & TRN & \\
\hline CHEMBL1601302 & 688267 & 4.0 & 5.015 & TST & \\
\hline CHEMBL1585183 & 688267 & 4.4 & 5.0523 & TST & \\
\hline CHEMBL1403629 & 688267 & 4.2 & 5.051 & TST & \\
\hline CHEMBL1353626 & 688267 & 5.95 & 5.09699 & 99999999995 & TRN \\
\hline CHEMBL1438312 & 688267 & 4.2 & 5.0005 & TRN & \\
\hline CHEMBL1376660 & 688267 & 4.5 & 5.0468 & TST & \\
\hline CHEMBL1351430 & 688267 & 3.95 & 5.0926 & TRN & \\
\hline CHEMBL1349135 & 688267 & 5.55 & 5.0659 & TST & \\
\hline CHEMBL1435320 & 688267 & 5.3 & 5.0455 & TRN & \\
\hline CHEMBL1330820 & 688267 & 6.2 & 5.0609 & TST & \\
\hline CHEMBL1310256 & 688267 & 5.3 & $5.1110 e$ & 0000000001 & TRN \\
\hline CHEMBL1464390 & 688267 & 6.5 & 5.0211 & TRN & \\
\hline CHEMBL1516799 & 688267 & 4.7 & 5.0575 & TRN & \\
\hline CHEMBL1411625 & 688267 & 3.95 & 5.0616 & TRN & \\
\hline CHEMBL1551860 & 688267 & 4.35 & 5.0218 & TRN & \\
\hline CHEMBL1341543 & 688267 & 5.95 & 5.0513 & TRN & \\
\hline
\end{tabular}




\begin{tabular}{|c|c|c|c|c|}
\hline \multicolumn{5}{|c|}{ Supplemental Table S2.txt } \\
\hline CHEMBL1319846 & 688267 & 4.4 & 5.0919 & TRN \\
\hline CHEMBL1529688 & 688267 & 4.55 & 5.0938 & TRN \\
\hline CHEMBL1346846 & 688267 & 6.2 & 5.0052 & TRN \\
\hline CHEMBL1400770 & 688267 & 5.75 & 5.0658 & TRN \\
\hline CHEMBL1434071 & 688267 & 5.1 & 5.052 & TRN \\
\hline CHEMBL1464809 & 688267 & 5.3 & 5.0875 & TRN \\
\hline CHEMBL1545156 & 688267 & 4.4 & 5.1161 & TST \\
\hline CHEMBL1362576 & 688267 & 6.15 & 5.019 & TRN \\
\hline CHEMBL1376783 & 688267 & 6.2 & 4.9676 & TRN \\
\hline CHEMBL1533901 & 688267 & 6.2 & 5.1198 & TRN \\
\hline CHEMBL1525862 & 688267 & 4.0 & 5.083 & TRN \\
\hline CHEMBL1371793 & 688267 & 4.0 & 5.0743 & TRN \\
\hline CHEMBL1574327 & 688267 & 6.15 & 5.0741 & TRN \\
\hline CHEMBL1352863 & 688267 & 5.65 & 5.0297 & TST \\
\hline CHEMBL1310578 & 688267 & 4.4 & 5.0811 & TRN \\
\hline CHEMBL1494631 & 688267 & 4.3 & 5.0819 & TRN \\
\hline CHEMBL1524295 & 688267 & 4.0 & 4.9895 & TST \\
\hline CHEMBL1527615 & 688267 & 4.05 & 5.1036 & TRN \\
\hline CHEMBL1554698 & 688267 & 5.25 & 5.0615 & TST \\
\hline CHEMBL1320966 & 688267 & 4.05 & 5.0378 & TST \\
\hline CHEMBL1560678 & 688267 & 5.5 & 5.0461 & TST \\
\hline CHEMBL1359942 & 688267 & 4.15 & 5.0067 & TST \\
\hline CHEMBL1573446 & 688267 & 4.75 & 4.9997 & TRN \\
\hline CHEMBL1435483 & 688267 & 3.95 & 5.105 & TRN \\
\hline CHEMBL1466858 & 688267 & 4.0 & 5.0409 & TST \\
\hline CHEMBL1394943 & 688267 & 6.6499 & 5.1133 & TRN \\
\hline CHEMBL1367459 & 688267 & 6.2 & 5.0085 & TRN \\
\hline CHEMBL1368925 & 688267 & 5.95 & 5.0156 & TRN \\
\hline CHEMBL1552559 & 688267 & 4.35 & 5.0296 & TRN \\
\hline CHEMBL1446804 & 688267 & 4.7 & 5.0032 & TST \\
\hline CHEMBL1530155 & 688267 & 5.5 & 5.0697 & TRN \\
\hline CHEMBL1612863 & 688267 & 5.6 & 5.0931 & TRN \\
\hline CHEMBL1559225 & 688267 & 6.15 & 5.0181 & TST \\
\hline CHEMBL1553197 & 688267 & 5.3 & 5.0257 & TRN \\
\hline CHEMBL1489908 & 688267 & 6.15 & 5.0564 & TST \\
\hline CHEMBL1515615 & 688267 & 5.45 & 5.1407 & TRN \\
\hline CHEMBL1323577 & 688267 & 6.0 & 5.0344 & TRN \\
\hline CHEMBL1448332 & 688267 & 5.8 & 5.085 & TRN \\
\hline CHEMBL1567758 & 688267 & 5.55 & 5.0307 & TRN \\
\hline CHEMBL1360086 & 688267 & 4.5 & 5.0609 & TST \\
\hline CHEMBL1487748 & 688267 & 6.0 & 5.0633 & TRN \\
\hline CHEMBL1504798 & 688267 & 4.05 & 5.051 & TRN \\
\hline CHEMBL1588170 & 688267 & 4.55 & 5.0254 & TST \\
\hline CHEMBL1316367 & 688267 & 4.15 & 5.0325 & TRN \\
\hline CHEMBL1554883 & 688267 & 4.3 & 4.9984 & TRN \\
\hline CHEMBL1577439 & 688267 & 5.5 & 5.0884 & TRN \\
\hline CHEMBL1301933 & 688267 & 5.6 & 5.0125 & TRN \\
\hline CHEMBL1358533 & 688267 & 6.15 & 5.1112 & TRN \\
\hline
\end{tabular}




\begin{tabular}{|c|c|c|c|c|c|}
\hline \multicolumn{6}{|c|}{ Supplemental Table S2.txt } \\
\hline CHEMBL1592305 & 688267 & 3.95 & 5.0907 & TRN & \\
\hline CHEMBL1369975 & 688267 & 4.1 & 5.0754 & TST & \\
\hline CHEMBL3211681 & 688267 & 3.95 & 5.0525 & TST & \\
\hline CHEMBL1427980 & 688267 & 6.25 & 5.0509 & TST & \\
\hline CHEMBL1564309 & 688267 & 6.2 & 5.0043 & TRN & \\
\hline CHEMBL1389780 & 688267 & 4.15 & 5.0852 & TRN & \\
\hline CHEMBL1422034 & 688267 & 4.05 & 5.0165 & TRN & \\
\hline CHEMBL1546502 & 688267 & 4.7 & 5.0006 & TRN & \\
\hline CHEMBL1347255 & 688267 & 5.0 & 5.0961 & TRN & \\
\hline CHEMBL1344210 & 688267 & 5.0 & 5.0999 & TRN & \\
\hline CHEMBL1435375 & 688267 & 4.05 & 5.1016 & TRN & \\
\hline CHEMBL1507296 & 688267 & 5.3 & 5.1237 & TRN & \\
\hline CHEMBL1342018 & 688267 & 4.45 & 5.0405 & TRN & \\
\hline CHEMBL1371097 & 688267 & 5.05 & 5.0682 & TST & \\
\hline CHEMBL1405543 & 688267 & 4.35 & 5.0336 & TRN & \\
\hline CHEMBL1424262 & 688267 & 6.5501 & 5.0071 & TST & \\
\hline CHEMBL3213979 & 688267 & 4.5 & 5.0523 & TST & \\
\hline CHEMBL1352230 & 688267 & 6.2 & 5.101 & TST & \\
\hline CHEMBL1576331 & 688267 & 4.45 & 5.0139 & TRN & \\
\hline CHEMBL1526313 & 688267 & 7.3002 & 5.0395 & TRN & \\
\hline CHEMBL1397667 & 688267 & 4.75 & 5.0177 & TRN & \\
\hline CHEMBL1370783 & 688267 & 4.35 & 5.1028 & TRN & \\
\hline CHEMBL1545267 & 688267 & 4.5 & 5.0886 & TST & \\
\hline CHEMBL1361937 & 688267 & 4.25 & 5.0662 & TRN & \\
\hline CHEMBL1368744 & 688267 & 4.7 & 4.9988 & TST & \\
\hline CHEMBL1373766 & 688267 & 4.45 & 5.1098 & TST & \\
\hline CHEMBL1573384 & 688267 & 4.35 & 5.0451 & TRN & \\
\hline CHEMBL1548525 & 688267 & 4.0 & 5.0667 & TRN & \\
\hline CHEMBL1600610 & 688267 & 4.0 & 5.09399 & & TRN \\
\hline CHEMBL1542893 & 688267 & 4.3 & 5.1135 & TRN & \\
\hline CHEMBL1517875 & 688267 & 5.85 & 5.0301 & TST & \\
\hline CHEMBL1416059 & 688267 & 5.85 & 5.0379 & TRN & \\
\hline CHEMBL 231571 & 688267 & 5.1 & 5.0369 & TRN & \\
\hline CHEMBL1474620 & 688267 & 6.5 & 5.0557 & TST & \\
\hline CHEMBL1319707 & 688267 & 4.0 & 5.0185 & TRN & \\
\hline CHEMBL1579861 & 688267 & 5.65 & 5.1266 & TRN & \\
\hline CHEMBL1554178 & 688267 & 4.85 & 5.0316 & TRN & \\
\hline CHEMBL1567698 & 688267 & 6.2 & 5.0176 & TST & \\
\hline CHEMBL1439178 & 688267 & 6.2 & 5.0226 & TRN & \\
\hline CHEMBL1556347 & 688267 & 5.15 & 5.0879 & TRN & \\
\hline CHEMBL1312082 & 688267 & 6.25 & 5.0527 & TRN & \\
\hline CHEMBL1592609 & 688267 & 4.0 & 5.0795 & TRN & \\
\hline CHEMBL1596004 & 688267 & 5.2 & 4.9895 & TRN & \\
\hline CHEMBL1553349 & 688267 & 4.4 & 5.0096 & TRN & \\
\hline CHEMBL1420626 & 688267 & 4.0 & 5.1201 & TRN & \\
\hline CHEMBL1547253 & 688267 & 4.35 & 5.0982 & TST & \\
\hline CHEMBL1328642 & 688267 & 6.2 & 5.0593 & TRN & \\
\hline CHEMBL1344917 & 688267 & 5.5 & 5.131 & TRN & \\
\hline
\end{tabular}




\begin{tabular}{|c|c|c|c|c|c|}
\hline \multicolumn{6}{|c|}{ Supplemental Table S2.txt } \\
\hline CHEMBL1581790 & 688267 & 4.35 & 5.1274 & TRN & \\
\hline CHEMBL1371163 & 688267 & 4.4 & 5.0476 & TRN & \\
\hline CHEMBL1517985 & 688267 & 6.25 & 5.1273 & TRN & \\
\hline CHEMBL1484355 & 688267 & 4.7 & 5.0092 & TRN & \\
\hline CHEMBL1395666 & 688267 & 4.5 & 5.0787 & TRN & \\
\hline CHEMBL1701224 & 688267 & 4.25 & 4.9797 & TST & \\
\hline CHEMBL3213277 & 688267 & 4.05 & 5.0329 & TST & \\
\hline CHEMBL1307538 & 688267 & 6.15 & 5.0348 & TST & \\
\hline CHEMBL1317914 & 688267 & 3.25 & 5.0753 & TRN & \\
\hline CHEMBL1404057 & 688267 & 4.4 & 5.115 & TRN & \\
\hline CHEMBL1565474 & 688267 & 3.95 & 5.0453 & TRN & \\
\hline CHEMBL1329404 & 688267 & 4.0 & 5.0083 & TRN & \\
\hline CHEMBL1430203 & 688267 & 5.75 & 5.1094 & TRN & \\
\hline CHEMBL1516002 & 688267 & 4.05 & 5.0254 & TRN & \\
\hline CHEMBL1570960 & 688267 & 4.35 & 4.9811 & TRN & \\
\hline CHEMBL1446223 & 688267 & 4.0 & 5.0323 & TRN & \\
\hline CHEMBL3212887 & 688267 & 4.05 & 5.0083 & TST & \\
\hline CHEMBL3190077 & 688267 & 4.3 & 5.0448 & TRN & \\
\hline CHEMBL1477967 & 688267 & 4.0 & 5.0469 & TRN & \\
\hline CHEMBL1500968 & 688267 & 5.9 & 5.0264 & TRN & \\
\hline CHEMBL1408744 & 688267 & 4.75 & 5.027 & TRN & \\
\hline CHEMBL1405537 & 688267 & 4.0 & 5.0753 & TRN & \\
\hline CHEMBL1544855 & 688267 & 4.9 & 5.0904 & TRN & \\
\hline CHEMBL1308266 & 688267 & 4.0 & 5.0219 & TST & \\
\hline CHEMBL1407419 & 688267 & 5.9 & 5.1126 & TRN & \\
\hline CHEMBL1469780 & 688267 & 5.1 & 5.0505 & TST & \\
\hline CHEMBL1568939 & 688267 & 4.55 & 5.0669 & TRN & \\
\hline CHEMBL1556391 & 688267 & 4.25 & 5.0787 & TST & \\
\hline CHEMBL1326073 & 688267 & 6.15 & 5.0871 & TST & \\
\hline CHEMBL1559625 & 688267 & 5.05 & 5.1655 & TRN & \\
\hline CHEMBL1404756 & 688267 & 4.3 & 5.0894 & TRN & \\
\hline CHEMBL1362771 & 688267 & 4.6 & 5.0626 & TST & \\
\hline CHEMBL3192144 & 688267 & 5.0 & 5.0045 & TST & \\
\hline CHEMBL1341495 & 688267 & 4.05 & 5.02800 & 00000000005 & TRN \\
\hline CHEMBL1396216 & 688267 & 4.35 & 5.0776 & TRN & \\
\hline CHEMBL1556227 & 688267 & 5.5 & 5.0233 & TRN & \\
\hline CHEMBL41384 & 688267 & 4.05 & 5.041 & TST & \\
\hline CHEMBL1573091 & 688267 & 4.05 & 5.1046 & TST & \\
\hline CHEMBL1493681 & 688267 & 4.05 & 5.0806 & TRN & \\
\hline CHEMBL1611525 & 688267 & 5.85 & 5.0784 & TRN & \\
\hline CHEMBL1445159 & 688267 & 4.5 & 5.1008 & TRN & \\
\hline CHEMBL1474855 & 688267 & 4.85 & 5.1103 & TRN & \\
\hline CHEMBL1328203 & 688267 & 3.95 & 5.1117 & TRN & \\
\hline CHEMBL1571099 & 688267 & 6.0 & 5.0451 & TRN & \\
\hline CHEMBL1495880 & 688267 & 6.2 & 5.0151 & TST & \\
\hline CHEMBL3194718 & 688267 & 4.25 & 5.0189 & TRN & \\
\hline CHEMBL1395749 & 688267 & 4.05 & 5.0421 & TRN & \\
\hline CHEMBL1350843 & 688267 & 6.15 & 5.1604 & TRN & \\
\hline
\end{tabular}




\begin{tabular}{|c|c|c|c|c|c|}
\hline \multicolumn{6}{|c|}{ Supplemental Table s2.txt } \\
\hline CHEMBL1488004 & 688267 & 3.95 & 5.0409 & TRN & \\
\hline CHEMBL1440005 & 688267 & 4.0 & 5.0699 & TRN & \\
\hline CHEMBL1317484 & 688267 & 6.15 & 5.0528 & TRN & \\
\hline CHEMBL1591753 & 688267 & 3.95 & 5.0606 & TRN & \\
\hline CHEMBL1316377 & 688267 & 4.0 & 5.0183 & TRN & \\
\hline CHEMBL1563804 & 688267 & 3.95 & 5.1 & TRN & \\
\hline CHEMBL1596405 & 688267 & 5.6 & 5.0672 & TRN & \\
\hline CHEMBL1497704 & 688267 & 4.25 & 5.0247 & TRN & \\
\hline CHEMBL1403499 & 688267 & 3.95 & 5.04899 & 99999999995 & TST \\
\hline CHEMBL1437479 & 688267 & 5.55 & 5.0457 & TRN & \\
\hline CHEMBL1592280 & 688267 & 4.25 & 5.0864 & TRN & \\
\hline CHEMBL1591479 & 688267 & 5.05 & 5.1189 & TRN & \\
\hline CHEMBL1449760 & 688267 & 3.95 & 4.9979 & TRN & \\
\hline CHEMBL1334399 & 688267 & 4.35 & 5.0344 & TRN & \\
\hline CHEMBL3208776 & 688267 & 4.0 & 5.0009 & TRN & \\
\hline CHEMBL1419069 & 688267 & 4.05 & 5.0402 & TST & \\
\hline CHEMBL1554996 & 688267 & 5.15 & 5.0792 & TST & \\
\hline CHEMBL1433954 & 688267 & 4.0 & 4.9841 & TRN & \\
\hline CHEMBL1400030 & 688267 & 4.3 & 5.0523 & TST & \\
\hline CHEMBL1378064 & 688267 & 5.0 & 5.0073 & TST & \\
\hline CHEMBL1509457 & 688267 & 4.75 & 5.0848 & TRN & \\
\hline CHEMBL1335448 & 688267 & 4.35 & 5.0895 & TRN & \\
\hline CHEMBL1437058 & 688267 & 4.05 & 5.1045 & TST & \\
\hline CHEMBL1367341 & 688267 & 4.1 & 5.0378 & TRN & \\
\hline CHEMBL1350187 & 688267 & 5.9 & 5.1076 & TRN & \\
\hline CHEMBL1470201 & 688267 & 4.3 & 5.0169 & TRN & \\
\hline CHEMBL3190565 & 688267 & 4.65 & 5.0048 & TRN & \\
\hline CHEMBL1511406 & 688267 & 4.55 & 5.0366 & TRN & \\
\hline CHEMBL1350944 & 688267 & 3.95 & 5.0124 & TRN & \\
\hline CHEMBL1316248 & 688267 & 3.95 & 5.0956 & TST & \\
\hline CHEMBL1450323 & 688267 & 5.4 & 5.0973 & TRN & \\
\hline CHEMBL1467947 & 688267 & 5.25 & 5.0548 & TRN & \\
\hline CHEMBL1378977 & 688267 & 5.05 & 5.0516 & TRN & \\
\hline CHEMBL3191798 & 688267 & 6.2 & 5.0812 & TRN & \\
\hline CHEMBL1551747 & 688267 & 6.0 & 5.0782 & TRN & \\
\hline CHEMBL1355306 & 688267 & 4.2 & 5.0571 & TRN & \\
\hline CHEMBL1514792 & 688267 & 4.05 & 5.0688 & TRN & \\
\hline CHEMBL1448520 & 688267 & 6.2 & 5.091 & TRN & \\
\hline CHEMBL1342302 & 688267 & 5.95 & 5.0335 & TRN & \\
\hline CHEMBL1400475 & 688267 & 6.15 & 5.0813 & TRN & \\
\hline CHEMBL1575885 & 688267 & 4.65 & 5.0248 & TRN & \\
\hline CHEMBL1611507 & 688267 & 4.1 & 5.0671 & TRN & \\
\hline CHEMBL1420018 & 688267 & 4.45 & 5.0142 & TRN & \\
\hline CHEMBL1356314 & 688267 & 5.05 & 5.1311 & TRN & \\
\hline CHEMBL1518293 & 688267 & 6.2 & 5.0599 & TRN & \\
\hline CHEMBL1392883 & 688267 & 5.5 & 5.0589 & TRN & \\
\hline CHEMBL1318547 & 688267 & 6.15 & 5.0336 & TST & \\
\hline CHEMBL1420515 & 688267 & 6.25 & 5.0532 & TRN & \\
\hline
\end{tabular}




\begin{tabular}{|c|c|c|c|c|c|}
\hline \multicolumn{6}{|c|}{ Supplemental Table S2.txt } \\
\hline CHEMBL1364610 & 688267 & 4.05 & 5.0458 & TRN & \\
\hline CHEMBL1477366 & 688267 & 4.75 & 5.0759 & TST & \\
\hline CHEMBL 375530 & 688267 & 5.05 & 5.0884 & TRN & \\
\hline CHEMBL1467781 & 688267 & 5.3 & 5.1273 & TST & \\
\hline CHEMBL1592530 & 688267 & 5.45 & 5.0492 & TRN & \\
\hline CHEMBL1535027 & 688267 & 4.3 & 5.1185 & TRN & \\
\hline CHEMBL1507834 & 688267 & 6.2 & 5.0433 & TRN & \\
\hline CHEMBL1417034 & 688267 & 5.5 & 5.1208 & TRN & \\
\hline CHEMBL1580050 & 688267 & 6.2 & 5.0554 & TRN & \\
\hline CHEMBL1399888 & 688267 & 4.05 & 5.0456 & TRN & \\
\hline CHEMBL1360282 & 688267 & 4.05 & 5.0377 & TRN & \\
\hline CHEMBL1308118 & 688267 & 4.0 & 5.0269 & TST & \\
\hline CHEMBL1437887 & 688267 & 5.5 & 5.0118 & TRN & \\
\hline CHEMBL1303651 & 688267 & 4.25 & 4.98600 & 2000000001 & TRN \\
\hline CHEMBL1365626 & 688267 & 4.35 & 5.0386 & TRN & \\
\hline CHEMBL1315237 & 688267 & 4.0 & 5.1238 & TST & \\
\hline CHEMBL1368655 & 688267 & 4.5 & 5.1405 & TST & \\
\hline CHEMBL1551832 & 688267 & 4.15 & 5.1007 & TRN & \\
\hline CHEMBL1401431 & 688267 & 4.35 & 5.0685 & TRN & \\
\hline CHEMBL1585694 & 688267 & 6.2 & 5.1555 & TRN & \\
\hline CHEMBL 2006039 & 688267 & 6.0 & 4.9968 & TST & \\
\hline CHEMBL1346453 & 688267 & 4.0 & 5.0617 & TRN & \\
\hline CHEMBL1555117 & 688267 & 4.1 & 5.0223 & TST & \\
\hline CHEMBL1604492 & 688267 & 5.4 & 5.0792 & TRN & \\
\hline CHEMBL1375875 & 688267 & 4.5 & 5.0134 & TRN & \\
\hline CHEMBL1473617 & 688267 & 5.3 & 5.0543 & TRN & \\
\hline CHEMBL1463236 & 688267 & 6.15 & 5.1342 & TRN & \\
\hline CHEMBL1391387 & 688267 & 4.85 & 5.0976 & TRN & \\
\hline CHEMBL1337230 & 688267 & 4.35 & 5.0222 & TST & \\
\hline CHEMBL1352349 & 688267 & 5.85 & 5.0081 & TST & \\
\hline CHEMBL1529232 & 688267 & 5.5 & 5.0189 & TRN & \\
\hline CHEMBL1357305 & 688267 & 4.05 & 5.0412 & TRN & \\
\hline CHEMBL1586486 & 688267 & 5.5 & 5.0024 & TRN & \\
\hline CHEMBL1377246 & 688267 & 5.5 & 5.0655 & TRN & \\
\hline CHEMBL1594630 & 688267 & 4.05 & 5.1089 & TRN & \\
\hline CHEMBL1571982 & 688267 & 4.85 & 5.0519 & TST & \\
\hline CHEMBL1513200 & 688267 & 4.05 & 5.0317 & TRN & \\
\hline CHEMBL1487673 & 688267 & 4.55 & 5.0088 & TRN & \\
\hline CHEMBL1460359 & 688267 & 4.4 & 5.064 & TRN & \\
\hline CHEMBL1601682 & 688267 & 5.45 & 5.1157 & TRN & \\
\hline CHEMBL1584012 & 688267 & 6.05 & 5.0296 & TRN & \\
\hline CHEMBL3190694 & 688267 & 5.95 & 4.9627 & TRN & \\
\hline CHEMBL1476756 & 688267 & 4.0 & 5.0089 & TRN & \\
\hline CHEMBL1322436 & 688267 & 5.35 & 5.0398 & TRN & \\
\hline CHEMBL1335379 & 688267 & 5.45 & 5.1235 & TRN & \\
\hline CHEMBL1575014 & 688267 & 4.45 & 5.0038 & TRN & \\
\hline CHEMBL 3194734 & 688267 & 3.95 & 5.0244 & TRN & \\
\hline CHEMBL1406640 & 688267 & 4.5 & 5.0175 & TRN & \\
\hline
\end{tabular}




\begin{tabular}{|c|c|c|c|c|}
\hline \multicolumn{5}{|c|}{ Supplemental Table S2.txt } \\
\hline CHEMBL1371429 & 688267 & 6.2 & 5.0525 & TRN \\
\hline CHEMBL1442492 & 688267 & 7.1002 & 5.0593 & TST \\
\hline CHEMBL1446390 & 688267 & 5.4 & 5.0766 & TRN \\
\hline CHEMBL1316018 & 688267 & 5.0 & 5.0398 & TRN \\
\hline CHEMBL1587986 & 688267 & 6.25 & 5.086 & TRN \\
\hline CHEMBL1316012 & 688267 & 6.2 & 5.0878 & TRN \\
\hline CHEMBL1494135 & 688267 & 4.4 & 5.046 & TST \\
\hline CHEMBL1510054 & 688267 & 5.65 & 4.9941 & TST \\
\hline CHEMBL1578806 & 688267 & 5.55 & 5.0259 & TRN \\
\hline CHEMBL1541988 & 688267 & 5.05 & 5.004 & TST \\
\hline CHEMBL1520723 & 688267 & 4.2 & 5.0558 & TRN \\
\hline CHEMBL1355181 & 688267 & 6.0 & 5.0322 & TRN \\
\hline CHEMBL1572630 & 688267 & 5.55 & 5.0557 & TRN \\
\hline CHEMBL1471728 & 688267 & 5.75 & 5.0658 & TRN \\
\hline CHEMBL1414507 & 688267 & 5.45 & 5.0709 & TRN \\
\hline CHEMBL1365124 & 688267 & 5.45 & 5.0733 & TRN \\
\hline CHEMBL1597411 & 688267 & 6.2 & 5.0263 & TST \\
\hline CHEMBL1374668 & 688267 & 6.15 & 5.0983 & TST \\
\hline CHEMBL1384452 & 688267 & 5.25 & 5.0733 & TRN \\
\hline CHEMBL1384476 & 688267 & 6.5 & 5.0875 & TRN \\
\hline CHEMBL1594296 & 688267 & 5.55 & 5.1541 & TRN \\
\hline CHEMBL1345814 & 688267 & 5.9 & 5.1012 & TRN \\
\hline CHEMBL3199773 & 688267 & 4.6 & 5.0313 & TRN \\
\hline CHEMBL1458432 & 688267 & 4.5 & 5.0222 & TST \\
\hline CHEMBL1303216 & 688267 & 5.35 & 5.0725 & TRN \\
\hline CHEMBL1558884 & 688267 & 5.6 & 5.0612 & TRN \\
\hline CHEMBL1528879 & 688267 & 4.0 & 5.0932 & TST \\
\hline CHEMBL1543344 & 688267 & 4.0 & 5.0776 & TRN \\
\hline CHEMBL1536427 & 688267 & 5.45 & 5.0195 & TST \\
\hline CHEMBL3194796 & 688267 & 4.2 & 5.0097 & TRN \\
\hline CHEMBL1492343 & 688267 & 4.9 & 5.0658 & TRN \\
\hline CHEMBL1329528 & 688267 & 4.35 & 5.0142 & TRN \\
\hline CHEMBL1596469 & 688267 & 4.4 & 5.0547 & TRN \\
\hline CHEMBL1548956 & 688267 & 4.0 & 5.073 & TRN \\
\hline CHEMBL1511173 & 688267 & 6.2 & 5.1246 & TST \\
\hline CHEMBL1360138 & 688267 & 4.05 & 5.0084 & TST \\
\hline CHEMBL1530699 & 688267 & 6.25 & 5.0183 & TRN \\
\hline CHEMBL602353 & 688267 & 4.5 & 5.0631 & TRN \\
\hline CHEMBL1437501 & 688267 & 3.95 & 5.0606 & TRN \\
\hline CHEMBL1574445 & 688267 & 4.1 & 5.0751 & TRN \\
\hline CHEMBL1405648 & 688267 & 4.5 & 5.0813 & TRN \\
\hline CHEMBL1468201 & 688267 & 5.5 & 5.1605 & TRN \\
\hline CHEMBL1424907 & 688267 & 5.0 & 4.9665 & TRN \\
\hline CHEMBL1435383 & 688267 & 5.1 & 5.0809 & TRN \\
\hline CHEMBL1536006 & 688267 & 5.95 & 5.0725 & TRN \\
\hline CHEMBL1587924 & 688267 & 4.4 & 5.042 & TRN \\
\hline CHEMBL1459508 & 688267 & 4.35 & 5.03 & TST \\
\hline CHEMBL1361993 & 688267 & 5.2 & 5.039 & TST \\
\hline
\end{tabular}




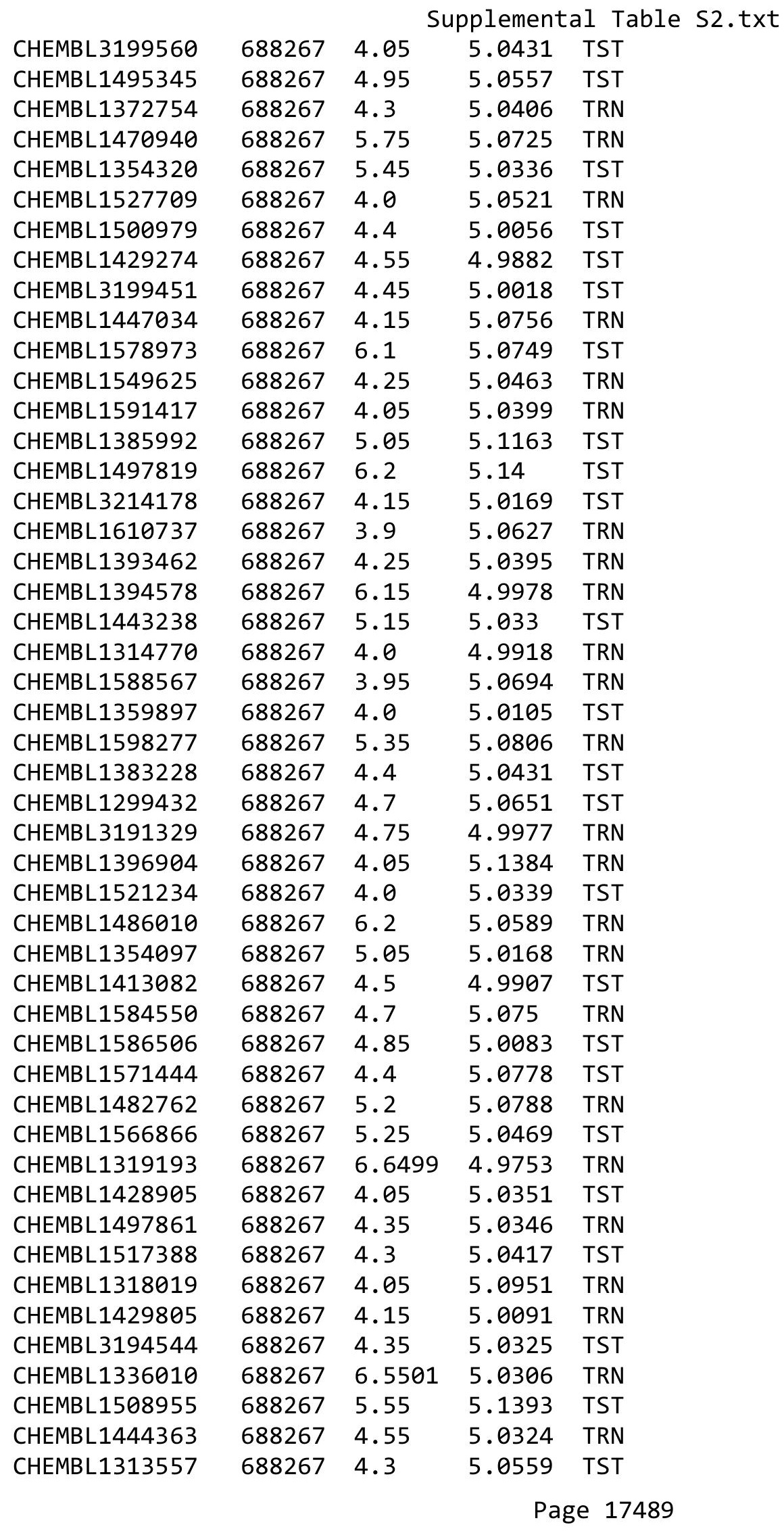




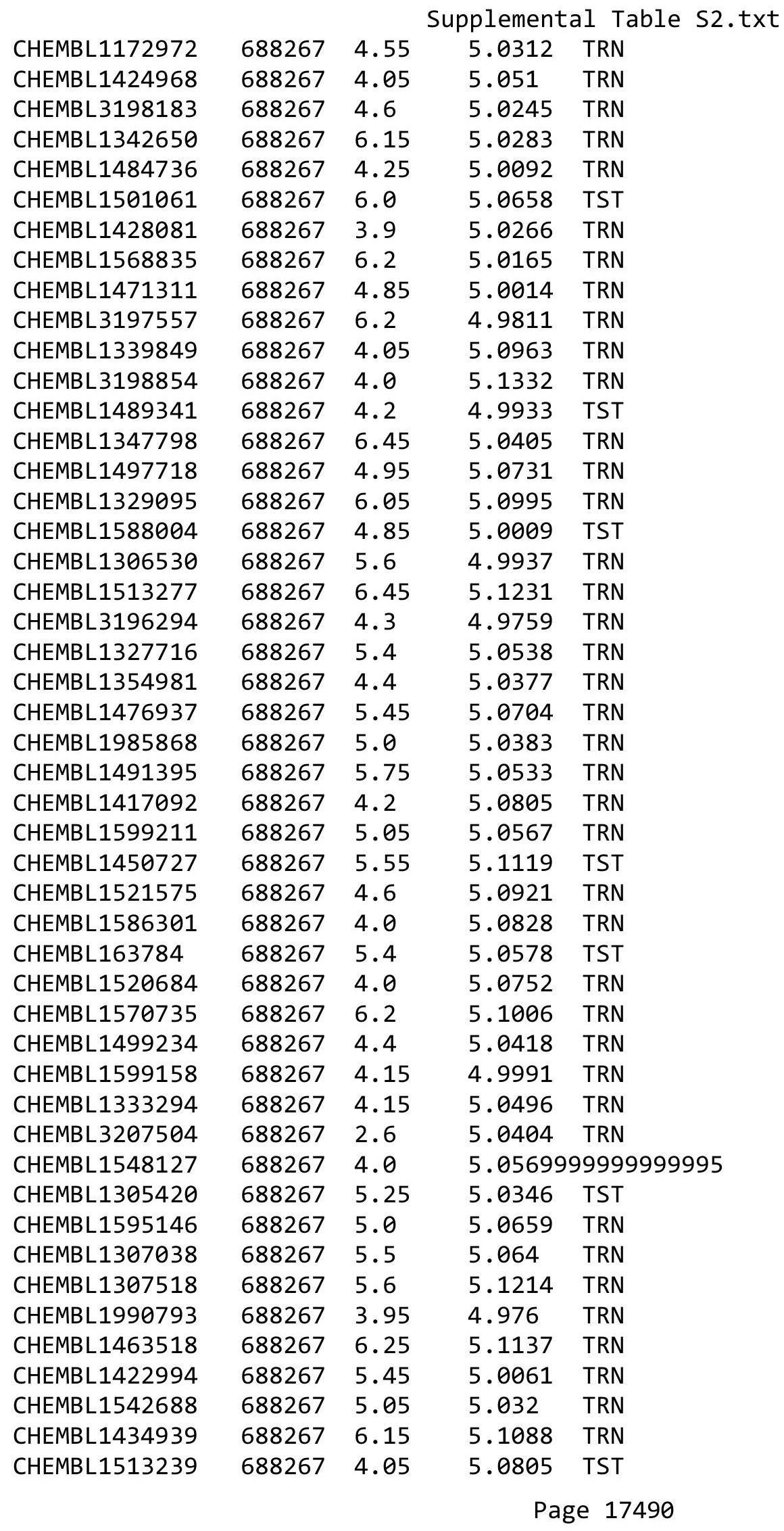




\begin{tabular}{|c|c|c|c|c|c|}
\hline \multicolumn{6}{|c|}{ Supplemental Table S2.txt } \\
\hline CHEMBL1377101 & 688267 & 5.25 & 5.1228 & TRN & \\
\hline CHEMBL1530908 & 688267 & 4.5 & 5.0701 & TRN & \\
\hline CHEMBL1358589 & 688267 & 5.5 & 5.0757 & TRN & \\
\hline CHEMBL1524481 & 688267 & 5.3 & 5.0623 & TRN & \\
\hline CHEMBL3211786 & 688267 & 5.3 & 4.9875 & TRN & \\
\hline CHEMBL1372069 & 688267 & 4.6 & 5.1379 & TRN & \\
\hline CHEMBL1509082 & 688267 & 4.1 & 5.0332 & TRN & \\
\hline CHEMBL1367975 & 688267 & 4.0 & 5.101 & TRN & \\
\hline CHEMBL1379855 & 688267 & 4.7 & 4.9947 & TRN & \\
\hline CHEMBL1522408 & 688267 & 4.2 & 5.0428 & TST & \\
\hline CHEMBL1302938 & 688267 & 5.65 & 5.07600 & 00000000005 & TRN \\
\hline CHEMBL1493569 & 688267 & 4.0 & 5.1364 & TRN & \\
\hline CHEMBL1556822 & 688267 & 4.35 & 5.0439 & TST & \\
\hline CHEMBL1578466 & 688267 & 4.1 & 5.0511 & TRN & \\
\hline CHEMBL1480378 & 688267 & 4.7 & 5.0648 & TRN & \\
\hline CHEMBL1511920 & 688267 & 4.2 & 5.0226 & TRN & \\
\hline CHEMBL1548008 & 688267 & 6.2 & 5.058 & TRN & \\
\hline CHEMBL1542833 & 688267 & 4.3 & 5.03 & TRN & \\
\hline CHEMBL1503744 & 688267 & 5.8 & 5.0495 & TRN & \\
\hline CHEMBL1482449 & 688267 & 6.2 & 5.0172 & TRN & \\
\hline CHEMBL1468597 & 688267 & 5.35 & 5.023 & TST & \\
\hline CHEMBL1508301 & 688267 & 6.2 & 5.1309 & TRN & \\
\hline CHEMBL1405224 & 688267 & 4.1 & 5.1525 & TRN & \\
\hline CHEMBL1476388 & 688267 & 6.2 & 5.0364 & TRN & \\
\hline CHEMBL1590269 & 688267 & 4.05 & 4.9903 & TRN & \\
\hline CHEMBL3193949 & 688267 & 4.1 & 5.011 & TRN & \\
\hline CHEMBL1382575 & 688267 & 4.35 & 5.0867 & TST & \\
\hline CHEMBL1606586 & 688267 & 3.95 & 5.0901 & TRN & \\
\hline CHEMBL1603661 & 688267 & 5.05 & 5.1095 & TRN & \\
\hline CHEMBL1577835 & 688267 & 3.95 & 5.021 & TST & \\
\hline CHEMBL1337728 & 688267 & 6.2 & 5.0112 & TST & \\
\hline CHEMBL1373464 & 688267 & 6.0 & 5.0647 & TRN & \\
\hline CHEMBL1590110 & 688267 & 5.5 & 5.0588 & TRN & \\
\hline CHEMBL1569557 & 688267 & 5.1 & 5.1486 & TRN & \\
\hline CHEMBL1593594 & 688267 & 4.9 & 5.0691 & TRN & \\
\hline CHEMBL3214173 & 688267 & 4.05 & 4.9768 & TRN & \\
\hline CHEMBL1606490 & 688267 & 6.2 & 5.05699 & 99999999995 & TST \\
\hline CHEMBL1547662 & 688267 & 5.3 & 5.0576 & TRN & \\
\hline CHEMBL1408042 & 688267 & 4.35 & 5.1352 & TRN & \\
\hline CHEMBL1392106 & 688267 & 4.2 & 5.0142 & TRN & \\
\hline CHEMBL3209059 & 688267 & 5.7 & 5.0399 & TST & \\
\hline CHEMBL1436404 & 688267 & 4.4 & 5.1325 & TST & \\
\hline CHEMBL1372705 & 688267 & 4.0 & 5.0345 & TRN & \\
\hline CHEMBL1425809 & 688267 & 4.1 & 4.99 & TST & \\
\hline CHEMBL1461540 & 688267 & 5.35 & 5.0336 & TRN & \\
\hline CHEMBL1443016 & 688267 & 4.0 & 5.0229 & TRN & \\
\hline CHEMBL1172020 & 688267 & 5.85 & 4.9863 & TRN & \\
\hline CHEMBL1414265 & 688267 & 5.5 & 5.0049 & TRN & \\
\hline
\end{tabular}




\begin{tabular}{|c|c|c|c|c|}
\hline \multicolumn{5}{|c|}{ Supplemental Table S2.txt } \\
\hline CHEMBL1319333 & 688267 & 4.95 & 5.0365 & TST \\
\hline CHEMBL1516599 & 688267 & 5.2 & 5.0525 & TRN \\
\hline CHEMBL1603360 & 688267 & 5.25 & 5.0979 & TRN \\
\hline CHEMBL1455074 & 688267 & 5.8 & 5.1652 & TRN \\
\hline CHEMBL1556345 & 688267 & 6.6 & 5.0301 & TRN \\
\hline CHEMBL1480982 & 688267 & 6.2 & 5.072 & TRN \\
\hline CHEMBL1546071 & 688267 & 4.05 & 5.0034 & TRN \\
\hline CHEMBL1462424 & 688267 & 5.3 & 5.033 & TRN \\
\hline CHEMBL1438270 & 688267 & 6.2 & 5.0788 & TRN \\
\hline CHEMBL3212102 & 688267 & 5.6 & 5.055 & TRN \\
\hline CHEMBL1533185 & 688267 & 4.05 & 5.08 & TRN \\
\hline CHEMBL1494767 & 688267 & 4.35 & 5.0189 & TST \\
\hline CHEMBL1492265 & 688267 & 5.4 & 5.018 & TRN \\
\hline CHEMBL1415459 & 688267 & 4.05 & 5.0829 & TRN \\
\hline CHEMBL1341259 & 688267 & 6.0 & 5.0723 & TST \\
\hline CHEMBL1392446 & 688267 & 6.25 & 5.0971 & TRN \\
\hline CHEMBL1427345 & 688267 & 4.05 & 5.1283 & TRN \\
\hline CHEMBL1478979 & 688267 & 6.15 & 5.0928 & TRN \\
\hline CHEMBL1984510 & 688267 & 5.95 & 5.0536 & TST \\
\hline CHEMBL1569639 & 688267 & 4.0 & 5.0445 & TRN \\
\hline CHEMBL1498820 & 688267 & 4.25 & 5.0346 & TST \\
\hline CHEMBL1352753 & 688267 & 6.2 & 5.1233 & TST \\
\hline CHEMBL1496977 & 688267 & 5.6 & 5.0299 & TRN \\
\hline CHEMBL1563069 & 688267 & 6.2 & 5.0752 & TST \\
\hline CHEMBL1480229 & 688267 & 5.9 & 5.0976 & TRN \\
\hline CHEMBL1498985 & 688267 & 5.35 & 5.0119 & TRN \\
\hline CHEMBL1596967 & 688267 & 4.05 & 5.0542 & TRN \\
\hline CHEMBL1586020 & 688267 & 5.55 & 5.0951 & TRN \\
\hline CHEMBL1536688 & 688267 & 5.3 & 5.0459 & TRN \\
\hline CHEMBL1356468 & 688267 & 5.05 & 5.0181 & TRN \\
\hline CHEMBL1565540 & 688267 & 4.4 & 4.9728 & TRN \\
\hline CHEMBL1404821 & 688267 & 5.35 & 5.0794 & TRN \\
\hline CHEMBL1506414 & 688267 & 5.8 & 5.0369 & TRN \\
\hline CHEMBL1303933 & 688267 & 4.3 & 5.0768 & TRN \\
\hline CHEMBL1339528 & 688267 & 4.25 & 5.0615 & TRN \\
\hline CHEMBL1440640 & 688267 & 3.95 & 5.1164 & TRN \\
\hline CHEMBL1496479 & 688267 & 5.95 & 5.0462 & TRN \\
\hline CHEMBL1472723 & 688267 & 5.25 & 5.0213 & TRN \\
\hline CHEMBL1412784 & 688267 & 4.45 & 5.0384 & TRN \\
\hline CHEMBL1382833 & 688267 & 5.4 & 5.0865 & TST \\
\hline CHEMBL1582016 & 688267 & 5.25 & 5.0389 & TRN \\
\hline CHEMBL1592814 & 688267 & 5.9 & 5.0176 & TRN \\
\hline CHEMBL1593844 & 688267 & 5.8 & 5.1285 & TST \\
\hline CHEMBL1355188 & 688267 & 6.15 & 5.1724 & TRN \\
\hline CHEMBL1537481 & 688267 & 4.55 & 5.0098 & TST \\
\hline CHEMBL1487313 & 688267 & 6.2 & 5.0517 & TRN \\
\hline CHEMBL1508797 & 688267 & 4.45 & 5.0148 & TRN \\
\hline CHEMBL1568837 & 688267 & 4.1 & 5.1332 & TRN \\
\hline
\end{tabular}




\begin{tabular}{|c|c|c|c|c|}
\hline \multicolumn{5}{|c|}{ Supplemental Table s2.txt } \\
\hline CHEMBL1332127 & 688267 & 6.5501 & 5.117 & TRN \\
\hline CHEMBL1383022 & 688267 & 5.3 & 5.0169 & TRN \\
\hline CHEMBL1411963 & 688267 & 4.25 & 5.0993 & TRN \\
\hline CHEMBL1512017 & 688267 & 6.2 & 5.0718 & TRN \\
\hline CHEMBL1483607 & 688267 & 3.95 & 5.1127 & TST \\
\hline CHEMBL1518119 & 688267 & 4.4 & 5.0616 & TRN \\
\hline CHEMBL1456655 & 688267 & 5.35 & 5.0968 & TRN \\
\hline CHEMBL1505516 & 688267 & 5.0 & 5.0173 & TST \\
\hline CHEMBL1351131 & 688267 & 4.35 & 5.0054 & TRN \\
\hline CHEMBL1367356 & 688267 & 4.05 & 5.0469 & TST \\
\hline CHEMBL1484083 & 688267 & 5.65 & 5.0601 & TRN \\
\hline CHEMBL1594250 & 688267 & 4.1 & 5.0079 & TRN \\
\hline CHEMBL1484983 & 688267 & 4.35 & 5.1047 & TRN \\
\hline CHEMBL1386280 & 688267 & 4.15 & 5.0519 & TST \\
\hline CHEMBL1513697 & 688267 & 4.95 & 5.1051 & TRN \\
\hline CHEMBL1349912 & 688267 & 5.05 & 5.0953 & TST \\
\hline CHEMBL1510261 & 688267 & 4.5 & 5.0396 & TRN \\
\hline CHEMBL1460084 & 688267 & 4.0 & 5.0409 & TRN \\
\hline CHEMBL1546383 & 688267 & 4.05 & 5.0232 & TST \\
\hline CHEMBL1537413 & 688267 & 4.25 & 5.0383 & TST \\
\hline CHEMBL1380939 & 688267 & 6.2 & 5.0119 & TRN \\
\hline CHEMBL1607170 & 688267 & 4.0 & 5.0457 & TST \\
\hline CHEMBL1575120 & 688267 & 4.0 & 5.0886 & TST \\
\hline CHEMBL1444067 & 688267 & 4.35 & 5.0664 & TRN \\
\hline CHEMBL1356365 & 688267 & 6.2 & 5.0849 & TRN \\
\hline CHEMBL1442794 & 688267 & 3.95 & 5.0324 & TST \\
\hline CHEMBL1611719 & 688267 & 5.6 & 5.0275 & TST \\
\hline CHEMBL1524237 & 688267 & 6.0 & 5.0654 & TRN \\
\hline CHEMBL1415491 & 688267 & 5.65 & 5.0634 & TST \\
\hline CHEMBL1466290 & 688267 & 4.6 & 5.0167 & TST \\
\hline CHEMBL1451565 & 688267 & 4.0 & 5.0227 & TRN \\
\hline CHEMBL1477893 & 688267 & 4.05 & 5.1073 & TRN \\
\hline CHEMBL1442991 & 688267 & 4.15 & 5.0149 & TRN \\
\hline CHEMBL1435735 & 688267 & 6.2 & 5.0472 & TRN \\
\hline CHEMBL1430600 & 688267 & 4.8 & 5.0198 & TST \\
\hline CHEMBL1519947 & 688267 & 5.35 & 5.0505 & TST \\
\hline CHEMBL1451451 & 688267 & 5.35 & 5.0564 & TRN \\
\hline CHEMBL1549518 & 688267 & 4.65 & 5.0284 & TRN \\
\hline CHEMBL1461123 & 688267 & 5.6 & 5.0093 & TRN \\
\hline CHEMBL1535801 & 688267 & 6.25 & 5.1306 & TRN \\
\hline CHEMBL1366395 & 688267 & 6.1 & 5.0085 & TST \\
\hline CHEMBL1342013 & 688267 & 5.55 & 5.109 & TST \\
\hline CHEMBL1602649 & 688267 & 4.0 & 5.0939 & TST \\
\hline CHEMBL1522578 & 688267 & 6.9 & 5.0401 & TRN \\
\hline CHEMBL1338533 & 688267 & 6.15 & 5.0206 & TST \\
\hline CHEMBL1535816 & 688267 & 5.2 & 4.9952 & TRN \\
\hline CHEMBL1468925 & 688267 & 6.15 & 5.1015 & TST \\
\hline CHEMBL1511135 & 688267 & 5.45 & 5.1905 & TRN \\
\hline
\end{tabular}




\begin{tabular}{|c|c|c|c|c|}
\hline \multicolumn{5}{|c|}{ Supplemental Table S2.txt } \\
\hline CHEMBL3198549 & 688267 & 5.3 & 5.0489 & TRN \\
\hline CHEMBL1361623 & 688267 & 4.4 & 4.9906 & TRN \\
\hline CHEMBL1517668 & 688267 & 4.0 & 5.0888 & TRN \\
\hline CHEMBL1497201 & 688267 & 5.55 & 4.9831 & TRN \\
\hline CHEMBL1522961 & 688267 & 4.7 & 5.0888 & TRN \\
\hline CHEMBL1335562 & 688267 & 5.3 & 5.1012 & TRN \\
\hline CHEMBL1381330 & 688267 & 4.6 & 5.0357 & TRN \\
\hline CHEMBL1493360 & 688267 & 4.5 & 5.1204 & TRN \\
\hline CHEMBL1436549 & 688267 & 5.9 & 5.1256 & TRN \\
\hline CHEMBL1438240 & 688267 & 5.55 & 5.0949 & TRN \\
\hline CHEMBL1546598 & 688267 & 4.7 & 4.9838 & TST \\
\hline CHEMBL1331444 & 688267 & 6.25 & 5.0562 & TRN \\
\hline CHEMBL1410264 & 688267 & 6.2 & 5.0077 & TST \\
\hline CHEMBL1338419 & 688267 & 6.25 & 5.0629 & TST \\
\hline CHEMBL1487716 & 688267 & 4.0 & 5.1135 & TRN \\
\hline CHEMBL1507075 & 688267 & 3.95 & 5.0205 & TRN \\
\hline CHEMBL1330253 & 688267 & 4.9 & 5.1058 & TRN \\
\hline CHEMBL1994815 & 688267 & 5.55 & 4.9731 & TRN \\
\hline CHEMBL1401925 & 688267 & 5.85 & 5.1146 & TRN \\
\hline CHEMBL1323913 & 688267 & 6.25 & 5.0839 & TRN \\
\hline CHEMBL1608316 & 688267 & 4.65 & 5.0737 & TRN \\
\hline CHEMBL1356281 & 688267 & 4.4 & 5.0833 & TST \\
\hline CHEMBL1360600 & 688267 & 5.35 & 5.1329 & TRN \\
\hline CHEMBL1437626 & 688267 & 4.35 & 5.0989 & TRN \\
\hline CHEMBL1376740 & 688267 & 6.25 & 5.0469 & TRN \\
\hline CHEMBL1420114 & 688267 & 6.2 & 5.0003 & TRN \\
\hline CHEMBL1343465 & 688267 & 5.25 & 5.0701 & TRN \\
\hline CHEMBL1479308 & 688267 & 6.25 & 5.1368 & TRN \\
\hline CHEMBL1595644 & 688267 & 5.15 & 5.0455 & TST \\
\hline CHEMBL1565046 & 688267 & 4.05 & 5.0636 & TST \\
\hline CHEMBL1592583 & 688267 & 5.55 & 5.1135 & TRN \\
\hline CHEMBL1405330 & 688267 & 4.5 & 5.0023 & TRN \\
\hline CHEMBL1474257 & 688267 & 5.85 & 5.095 & TST \\
\hline CHEMBL1520517 & 688267 & 4.4 & 5.0928 & TRN \\
\hline CHEMBL1490394 & 688267 & 6.0 & 5.0744 & TRN \\
\hline CHEMBL1472478 & 688267 & 5.9 & 5.0039 & TRN \\
\hline CHEMBL1496497 & 688267 & 4.0 & 5.1007 & TST \\
\hline CHEMBL1356484 & 688267 & 5.55 & 5.0492 & TST \\
\hline CHEMBL1407620 & 688267 & 6.5501 & 5.0288 & TRN \\
\hline CHEMBL1355530 & 688267 & 5.95 & 5.0036 & TRN \\
\hline CHEMBL1538905 & 688267 & 4.0 & 5.039 & TRN \\
\hline CHEMBL1364190 & 688267 & 4.75 & 5.0681 & TRN \\
\hline CHEMBL1493535 & 688267 & 5.35 & 5.0844 & TRN \\
\hline CHEMBL1559834 & 688267 & 6.15 & 5.1426 & TRN \\
\hline CHEMBL1431869 & 688267 & 4.55 & 5.0377 & TRN \\
\hline CHEMBL3199608 & 688267 & 5.8 & 5.0739 & TRN \\
\hline CHEMBL1355904 & 688267 & 4.05 & 5.1132 & TRN \\
\hline CHEMBL1313142 & 688267 & 4.6 & 5.1061 & TRN \\
\hline
\end{tabular}




\begin{tabular}{|c|c|c|c|c|c|}
\hline & & \multicolumn{4}{|c|}{ Supplemental Table s2.txt } \\
\hline CHEMBL1457562 & 688267 & 4.55 & 5.055 & TST & \\
\hline CHEMBL1572711 & 688267 & 6.2 & 5.044 & TRN & \\
\hline CHEMBL1601225 & 688267 & 6.2 & 5.1418 & TRN & \\
\hline CHEMBL1382567 & 688267 & 4.65 & 5.077 & TRN & \\
\hline CHEMBL1444210 & 688267 & 4.35 & 5.124 & TRN & \\
\hline CHEMBL1510944 & 688267 & 4.6 & 5.0726 & TST & \\
\hline CHEMBL1603155 & 688267 & 6.15 & 5.052 & TRN & \\
\hline CHEMBL1401159 & 688267 & 4.4 & 5.0858 & TRN & \\
\hline CHEMBL179611 & 688267 & 4.0 & 5.0175 & TST & \\
\hline CHEMBL1370020 & 688267 & 4.05 & 5.1216 & TRN & \\
\hline CHEMBL1305148 & 688267 & 4.45 & 5.10800 & 00000000005 & TRN \\
\hline CHEMBL1590924 & 688267 & 5.6 & 5.0906 & TRN & \\
\hline CHEMBL1406663 & 688267 & 4.05 & 4.9936 & TRN & \\
\hline CHEMBL1532570 & 688267 & 4.4 & 5.0323 & TST & \\
\hline CHEMBL1378960 & 688267 & 4.3 & 5.0018 & TRN & \\
\hline CHEMBL1607230 & 688267 & 6.5 & 5.0844 & TRN & \\
\hline CHEMBL1479117 & 688267 & 4.65 & 5.0275 & TRN & \\
\hline CHEMBL1584344 & 688267 & 4.05 & 5.0327 & TST & \\
\hline CHEMBL1257003 & 688267 & 5.1 & 5.0349 & TST & \\
\hline CHEMBL1440200 & 688267 & 5.25 & 5.10800 & 00000000005 & TRN \\
\hline CHEMBL1450527 & 688267 & 4.2 & 5.1021 & TST & \\
\hline CHEMBL1545764 & 688267 & 5.6 & 5.1202 & TRN & \\
\hline CHEMBL1401869 & 688267 & 4.75 & 5.0676 & TRN & \\
\hline CHEMBL3196768 & 688267 & 5.5 & 4.998 & TST & \\
\hline CHEMBL1395582 & 688267 & 5.25 & 5.1364 & TRN & \\
\hline CHEMBL1553561 & 688267 & 5.35 & 5.0301 & TRN & \\
\hline CHEMBL1405847 & 688267 & 4.6 & 5.104 & TST & \\
\hline CHEMBL1330812 & 688267 & 5.35 & 5.0572 & TRN & \\
\hline CHEMBL1378249 & 688267 & 4.65 & 5.0894 & TRN & \\
\hline CHEMBL1433714 & 688267 & 4.0 & 5.0785 & TRN & \\
\hline CHEMBL1586669 & 688267 & 4.0 & 5.084 & TRN & \\
\hline CHEMBL1604589 & 688267 & 4.35 & 5.0888 & TST & \\
\hline CHEMBL1551691 & 688267 & 5.3 & 5.0025 & TRN & \\
\hline CHEMBL1571160 & 688267 & 5.8 & 4.9834 & TRN & \\
\hline CHEMBL1596208 & 688267 & 4.25 & 5.1062 & TRN & \\
\hline CHEMBL1334946 & 688267 & 4.2 & 5.0879 & TST & \\
\hline CHEMBL1368749 & 688267 & 6.15 & 5.0399 & TRN & \\
\hline CHEMBL3195021 & 688267 & 5.25 & 5.0309 & TST & \\
\hline CHEMBL1463142 & 688267 & 5.85 & 5.1008 & TRN & \\
\hline CHEMBL1515113 & 688267 & 4.6 & 5.0403 & TRN & \\
\hline CHEMBL3211976 & 688267 & 5.55 & 5.0156 & TST & \\
\hline CHEMBL1311265 & 688267 & 5.15 & 5.1211 & TST & \\
\hline CHEMBL1594826 & 688267 & 5.6 & 5.0346 & TRN & \\
\hline CHEMBL1538727 & 688267 & 5.45 & 5.0539 & TRN & \\
\hline CHEMBL1599586 & 688267 & 6.25 & 5.0286 & TRN & \\
\hline CHEMBL1575252 & 688267 & 5.6 & 5.0294 & TRN & \\
\hline CHEMBL1412525 & 688267 & 5.3 & 5.044 & TRN & \\
\hline CHEMBL1358360 & 688267 & 6.25 & 5.0199 & TRN & \\
\hline
\end{tabular}




\begin{tabular}{|c|c|c|c|c|}
\hline \multicolumn{5}{|c|}{ Supplemental Table S2.txt } \\
\hline CHEMBL1364964 & 688267 & 4.6 & 5.1413 & TRN \\
\hline CHEMBL1477549 & 688267 & 6.35 & 5.0191 & TRN \\
\hline CHEMBL1474715 & 688267 & 5.35 & 5.0148 & TRN \\
\hline CHEMBL1393128 & 688267 & 5.55 & 5.0997 & TST \\
\hline CHEMBL1583887 & 688267 & 4.55 & 4.9831 & TST \\
\hline CHEMBL1340809 & 688267 & 6.15 & 5.0605 & TRN \\
\hline CHEMBL1566349 & 688267 & 5.5 & 5.0283 & TRN \\
\hline CHEMBL1596975 & 688267 & 4.0 & 5.1444 & TRN \\
\hline CHEMBL1510241 & 688267 & 5.9 & 5.0347 & TRN \\
\hline CHEMBL1364450 & 688267 & 5.75 & 5.0198 & TRN \\
\hline CHEMBL1583480 & 688267 & 4.6 & 5.042 & TST \\
\hline CHEMBL1474051 & 688267 & 5.8 & 5.0324 & TRN \\
\hline CHEMBL1509694 & 688267 & 4.3 & 4.9936 & TST \\
\hline CHEMBL1574721 & 688267 & 4.85 & 4.9828 & TST \\
\hline CHEMBL1507515 & 688267 & 3.95 & 4.9814 & TRN \\
\hline CHEMBL1390822 & 688267 & 5.9 & 5.0286 & TRN \\
\hline CHEMBL1470097 & 688267 & 4.05 & 5.0957 & TRN \\
\hline CHEMBL1524003 & 688267 & 5.85 & 5.0801 & TRN \\
\hline CHEMBL1567621 & 688267 & 4.0 & 5.0425 & TST \\
\hline CHEMBL1499597 & 688267 & 4.4 & 5.0404 & TRN \\
\hline CHEMBL1393289 & 688267 & 4.0 & 5.0788 & TST \\
\hline CHEMBL 366884 & 688267 & 4.95 & 5.0297 & TRN \\
\hline CHEMBL1395293 & 688267 & 3.95 & 5.1081 & TRN \\
\hline CHEMBL1525898 & 688267 & 4.55 & 5.0139 & TST \\
\hline CHEMBL1453599 & 688267 & 4.05 & 5.1083 & TRN \\
\hline CHEMBL1476176 & 688267 & 4.45 & 5.0484 & TST \\
\hline CHEMBL1553616 & 688267 & 4.05 & 5.0424 & TRN \\
\hline CHEMBL1553075 & 688267 & 4.1 & 5.091 & TST \\
\hline CHEMBL1543189 & 688267 & 5.55 & 5.0668 & TRN \\
\hline CHEMBL1430667 & 688267 & 4.25 & 4.9882 & TST \\
\hline CHEMBL532143 & 688267 & 4.65 & 5.0844 & TRN \\
\hline CHEMBL1308577 & 688267 & 5.55 & 5.0455 & TRN \\
\hline CHEMBL1305118 & 688267 & 5.0 & 5.016 & TRN \\
\hline CHEMBL1318001 & 688267 & 3.95 & 5.0814 & TRN \\
\hline CHEMBL1327117 & 688267 & 6.15 & 5.0035 & TRN \\
\hline CHEMBL1619901 & 688267 & 6.15 & 5.0632 & TRN \\
\hline CHEMBL1394813 & 688267 & 4.25 & 5.04 & TRN \\
\hline CHEMBL1333355 & 688267 & 5.5 & 5.0122 & TST \\
\hline CHEMBL1337563 & 688267 & 4.3 & 5.0649 & TST \\
\hline CHEMBL1581538 & 688267 & 4.95 & 5.1087 & TRN \\
\hline CHEMBL1566914 & 688267 & 6.0 & 5.0585 & TRN \\
\hline CHEMBL1412715 & 688267 & 4.25 & 5.0564 & TRN \\
\hline CHEMBL1363670 & 688267 & 5.05 & 5.1045 & TRN \\
\hline CHEMBL1329204 & 688267 & 5.95 & 5.0504 & TRN \\
\hline CHEMBL1326955 & 688267 & 5.4 & 5.0953 & TRN \\
\hline CHEMBL1535342 & 688267 & 6.3 & 5.0517 & TRN \\
\hline CHEMBL1463920 & 688267 & 4.85 & 5.0378 & TRN \\
\hline CHEMBL1344782 & 688267 & 5.3 & 5.166 & TRN \\
\hline
\end{tabular}




\begin{tabular}{|c|c|c|c|c|}
\hline \multicolumn{5}{|c|}{ Supplemental Table S2.txt } \\
\hline CHEMBL1320135 & 688267 & 6.2 & 5.0938 & TRN \\
\hline CHEMBL1470654 & 688267 & 4.05 & 5.0501 & TST \\
\hline CHEMBL1532584 & 688267 & 5.35 & 5.024 & TST \\
\hline CHEMBL1557314 & 688267 & 4.6 & 5.0916 & TST \\
\hline CHEMBL1571544 & 688267 & 6.45 & 5.063 & TRN \\
\hline CHEMBL1432785 & 688267 & 4.0 & 5.121 & TRN \\
\hline CHEMBL1416573 & 688267 & 3.95 & 5.086 & TRN \\
\hline CHEMBL1462131 & 688267 & 4.3 & 5.0754 & TRN \\
\hline CHEMBL1356825 & 688267 & 5.5 & 5.1019 & TRN \\
\hline CHEMBL1401436 & 688267 & 6.4 & 5.0938 & TST \\
\hline CHEMBL1394185 & 688267 & 4.35 & 5.0353 & TST \\
\hline CHEMBL1410005 & 688267 & 6.2 & 5.0435 & TRN \\
\hline CHEMBL1543197 & 688267 & 5.45 & 5.1162 & TRN \\
\hline CHEMBL572576 & 688267 & 4.0 & 5.0728 & TRN \\
\hline CHEMBL1402421 & 688267 & 5.5 & 4.9959 & TRN \\
\hline CHEMBL1381103 & 688267 & 4.65 & 5.0571 & TRN \\
\hline CHEMBL1587879 & 688267 & 5.45 & 5.0577 & TRN \\
\hline CHEMBL1473729 & 688267 & 5.15 & 5.0408 & TRN \\
\hline CHEMBL1350800 & 688267 & 5.3 & 5.0742 & TST \\
\hline CHEMBL1451960 & 688267 & 6.25 & 5.0533 & TST \\
\hline CHEMBL1332123 & 688267 & 4.45 & 5.0063 & TRN \\
\hline CHEMBL1473319 & 688267 & 3.95 & 5.0729 & TRN \\
\hline CHEMBL 2007318 & 688267 & 5.35 & 4.9874 & TST \\
\hline CHEMBL1481997 & 688267 & 4.0 & 4.9863 & TRN \\
\hline CHEMBL1515133 & 688267 & 3.95 & 5.0269 & TRN \\
\hline CHEMBL1573458 & 688267 & 6.2 & 5.0302 & TRN \\
\hline CHEMBL1443078 & 688267 & 4.05 & 5.1159 & TRN \\
\hline CHEMBL1606770 & 688267 & 3.95 & 5.0245 & TRN \\
\hline CHEMBL1374211 & 688267 & 6.2 & 5.0958 & TRN \\
\hline CHEMBL1414577 & 688267 & 6.6 & 4.996 & TRN \\
\hline CHEMBL1407742 & 688267 & 4.5 & 5.0943 & TRN \\
\hline CHEMBL1382878 & 688267 & 6.2 & 5.1001 & TST \\
\hline CHEMBL1446913 & 688267 & 4.0 & 5.0918 & TRN \\
\hline CHEMBL3195996 & 688267 & 5.25 & 5.0004 & TRN \\
\hline CHEMBL1385422 & 688267 & 6.15 & 5.1131 & TRN \\
\hline CHEMBL1376100 & 688267 & 5.55 & 5.1193 & TRN \\
\hline CHEMBL1403000 & 688267 & 5.6 & 5.0193 & TRN \\
\hline CHEMBL1589265 & 688267 & 6.25 & 5.0412 & TRN \\
\hline CHEMBL1485246 & 688267 & 4.7 & 5.0366 & TST \\
\hline CHEMBL1542400 & 688267 & 4.9 & 5.0845 & TRN \\
\hline CHEMBL1379367 & 688267 & 6.25 & 5.0528 & TRN \\
\hline CHEMBL1420086 & 688267 & 4.05 & 5.0013 & TRN \\
\hline CHEMBL1375151 & 688267 & 4.2 & 5.0283 & TRN \\
\hline CHEMBL1320592 & 688267 & 6.2 & 5.0965 & TRN \\
\hline CHEMBL1596989 & 688267 & 4.15 & 5.0761 & TRN \\
\hline CHEMBL1503025 & 688267 & 5.55 & 5.0771 & TRN \\
\hline CHEMBL1433910 & 688267 & 5.9 & 5.0763 & TRN \\
\hline CHEMBL1515561 & 688267 & 4.05 & 5.0645 & TRN \\
\hline
\end{tabular}




\begin{tabular}{|c|c|c|c|c|c|}
\hline \\
\hline CHEMBL1445585 & 688267 & 4.7 & 5.102 & TST & \\
\hline CHEMBL1484339 & 688267 & 4.4 & 5.0706 & TRN & \\
\hline CHEMBL1609526 & 688267 & 4.05 & 5.093 & TRN & \\
\hline CHEMBL1404758 & 688267 & 5.2 & 4.9811 & TRN & \\
\hline CHEMBL1388327 & 688267 & 5.25 & 5.0631 & TRN & \\
\hline CHEMBL1326533 & 688267 & 6.45 & 5.0068 & TST & \\
\hline CHEMBL1330960 & 688267 & 5.75 & 4.979 & TRN & \\
\hline CHEMBL1506062 & 688267 & 4.25 & 5.1399 & TRN & \\
\hline CHEMBL1535099 & 688267 & 4.8 & 5.033 & TST & \\
\hline CHEMBL1333225 & 688267 & 5.85 & 5.0255 & TST & \\
\hline CHEMBL363207 & 688267 & 5.3 & 5.0411 & TST & \\
\hline CHEMBL1507455 & 688267 & 5.55 & 5.064 & TRN & \\
\hline CHEMBL1517463 & 688267 & 5.6 & 5.0784 & TRN & \\
\hline CHEMBL1455891 & 688267 & 6.45 & 5.08899 & 99999999995 & TRN \\
\hline CHEMBL1375246 & 688267 & 4.3 & 5.0383 & TRN & \\
\hline CHEMBL1594123 & 688267 & 4.35 & 5.1172 & TST & \\
\hline CHEMBL1477016 & 688267 & 3.95 & 5.0705 & TRN & \\
\hline CHEMBL1419303 & 688267 & 5.65 & 5.0246 & TST & \\
\hline CHEMBL1477966 & 688267 & 4.8 & 5.081 & TRN & \\
\hline CHEMBL1404458 & 688267 & 6.6 & 5.0251 & TRN & \\
\hline CHEMBL1320716 & 688267 & 4.4 & 5.096 & TRN & \\
\hline CHEMBL1354711 & 688267 & 4.0 & 5.0765 & TRN & \\
\hline CHEMBL1449898 & 688267 & 6.15 & 5.1126 & TRN & \\
\hline CHEMBL1602429 & 688267 & 5.3 & 5.0887 & TRN & \\
\hline CHEMBL1365501 & 688267 & 5.05 & 5.0095 & TST & \\
\hline CHEMBL1433505 & 688267 & 4.0 & 5.0146 & TST & \\
\hline CHEMBL1356195 & 688267 & 5.9 & 5.1103 & TRN & \\
\hline CHEMBL1432228 & 688267 & 3.95 & 5.0066 & TST & \\
\hline CHEMBL1370594 & 688267 & 4.4 & 5.0899 & TST & \\
\hline CHEMBL1397043 & 688267 & 5.35 & 5.0573 & TRN & \\
\hline CHEMBL1507549 & 688267 & 4.35 & 5.0783 & TRN & \\
\hline CHEMBL1396066 & 688267 & 6.1 & 5.1654 & TRN & \\
\hline CHEMBL1486172 & 688267 & 4.75 & 5.0269 & TRN & \\
\hline CHEMBL1574299 & 688267 & 5.9 & 5.0332 & TRN & \\
\hline CHEMBL1529294 & 688267 & 4.05 & 5.0841 & TRN & \\
\hline CHEMBL1601421 & 688267 & 5.55 & 5.0831 & TRN & \\
\hline CHEMBL1418101 & 688267 & 4.15 & 5.0162 & TRN & \\
\hline CHEMBL1580872 & 688267 & 5.0 & 5.0922 & TRN & \\
\hline CHEMBL1343020 & 688267 & 4.25 & 5.0649 & TRN & \\
\hline CHEMBL1373977 & 688267 & 5.35 & 5.0386 & TRN & \\
\hline CHEMBL1391268 & 688267 & 4.75 & 5.121 & TRN & \\
\hline CHEMBL1438933 & 688267 & 4.1 & 4.9906 & TRN & \\
\hline CHEMBL1405957 & 688267 & 5.65 & 5.043 & TST & \\
\hline CHEMBL1336718 & 688267 & 5.85 & 5.0425 & TRN & \\
\hline CHEMBL1566270 & 688267 & 4.0 & 5.0063 & TRN & \\
\hline CHEMBL1535871 & 688267 & 3.95 & 5.1103 & TRN & \\
\hline CHEMBL1453554 & 688267 & 4.0 & 5.0639 & TRN & \\
\hline CHEMBL1375916 & 688267 & 4.0 & 5.0425 & TRN & \\
\hline
\end{tabular}




\begin{tabular}{|c|c|c|c|c|}
\hline \multicolumn{5}{|c|}{ Supplemental Table s2.txt } \\
\hline CHEMBL1372021 & 688267 & 4.2 & 5.0337 & TRN \\
\hline CHEMBL1347621 & 688267 & 5.45 & 5.0991 & TST \\
\hline CHEMBL1334019 & 688267 & 5.55 & 5.1231 & TRN \\
\hline CHEMBL1434545 & 688267 & 6.2 & 5.0868 & TRN \\
\hline CHEMBL1368011 & 688267 & 5.95 & 5.0866 & TRN \\
\hline CHEMBL1412105 & 688267 & 4.0 & 5.0014 & TRN \\
\hline CHEMBL1556799 & 688267 & 5.9 & 5.1273 & TRN \\
\hline CHEMBL1309265 & 688267 & 4.0 & 5.0618 & TRN \\
\hline CHEMBL1327743 & 688267 & 5.3 & 5.0336 & TRN \\
\hline CHEMBL1372312 & 688267 & 4.1 & 5.0666 & TRN \\
\hline CHEMBL1342117 & 688267 & 5.15 & 5.0431 & TRN \\
\hline CHEMBL1438897 & 688267 & 4.6 & 5.0365 & TRN \\
\hline CHEMBL1599533 & 688267 & 4.8 & 5.0399 & TRN \\
\hline CHEMBL1359782 & 688267 & 6.1 & 4.9921 & TRN \\
\hline CHEMBL1437198 & 688267 & 5.05 & 5.1372 & TRN \\
\hline CHEMBL1374546 & 688267 & 4.95 & 5.0121 & TRN \\
\hline CHEMBL1309863 & 688267 & 4.3 & 5.0228 & TRN \\
\hline CHEMBL1424794 & 688267 & 5.35 & 4.994 & TST \\
\hline CHEMBL3191774 & 688267 & 5.25 & 5.044 & TST \\
\hline CHEMBL1525961 & 688267 & 5.9 & 5.0962 & TRN \\
\hline CHEMBL1333180 & 688267 & 4.6 & 5.0686 & TRN \\
\hline CHEMBL1362555 & 688267 & 5.55 & 5.1146 & TRN \\
\hline CHEMBL1387932 & 688267 & 5.95 & 5.0773 & TRN \\
\hline CHEMBL1608083 & 688267 & 6.2 & 5.0031 & TST \\
\hline CHEMBL3145315 & 688267 & 4.0 & 5.0517 & TST \\
\hline CHEMBL1512231 & 688267 & 4.95 & 5.0418 & TRN \\
\hline CHEMBL1604959 & 688267 & 6.15 & 5.102 & TRN \\
\hline CHEMBL1506577 & 688267 & 5.6 & 5.1028 & TRN \\
\hline CHEMBL1318249 & 688267 & 4.0 & 4.9998 & TST \\
\hline CHEMBL1475457 & 688267 & 5.2 & 5.0974 & TRN \\
\hline CHEMBL3193796 & 688267 & 4.95 & 4.9849 & TRN \\
\hline CHEMBL1330631 & 688267 & 5.1 & 5.1154 & TST \\
\hline CHEMBL1394313 & 688267 & 4.3 & 5.026 & TRN \\
\hline CHEMBL1367052 & 688267 & 6.2 & 5.1034 & TRN \\
\hline CHEMBL1387265 & 688267 & 6.45 & 5.0947 & TST \\
\hline CHEMBL1716991 & 688267 & 4.1 & 5.0649 & TST \\
\hline CHEMBL1428776 & 688267 & 6.45 & 5.0302 & TRN \\
\hline CHEMBL1505792 & 688267 & 4.4 & 4.9969 & TRN \\
\hline CHEMBL1496079 & 688267 & 5.5 & 5.0035 & TRN \\
\hline CHEMBL1472928 & 688267 & 4.05 & 5.0216 & TRN \\
\hline CHEMBL1503586 & 688267 & 4.05 & 5.0232 & TRN \\
\hline CHEMBL1580185 & 688267 & 6.2 & 5.0797 & TRN \\
\hline CHEMBL1513351 & 688267 & 4.15 & 5.0087 & TRN \\
\hline CHEMBL1314240 & 688267 & 5.25 & 5.0419 & TRN \\
\hline CHEMBL1535350 & 688267 & 5.55 & 5.0604 & TST \\
\hline CHEMBL1400032 & 688267 & 6.0 & 4.9872 & TRN \\
\hline CHEMBL1438761 & 688267 & 4.3 & 5.0595 & TRN \\
\hline CHEMBL3196063 & 688267 & 4.6 & 5.0089 & TST \\
\hline
\end{tabular}




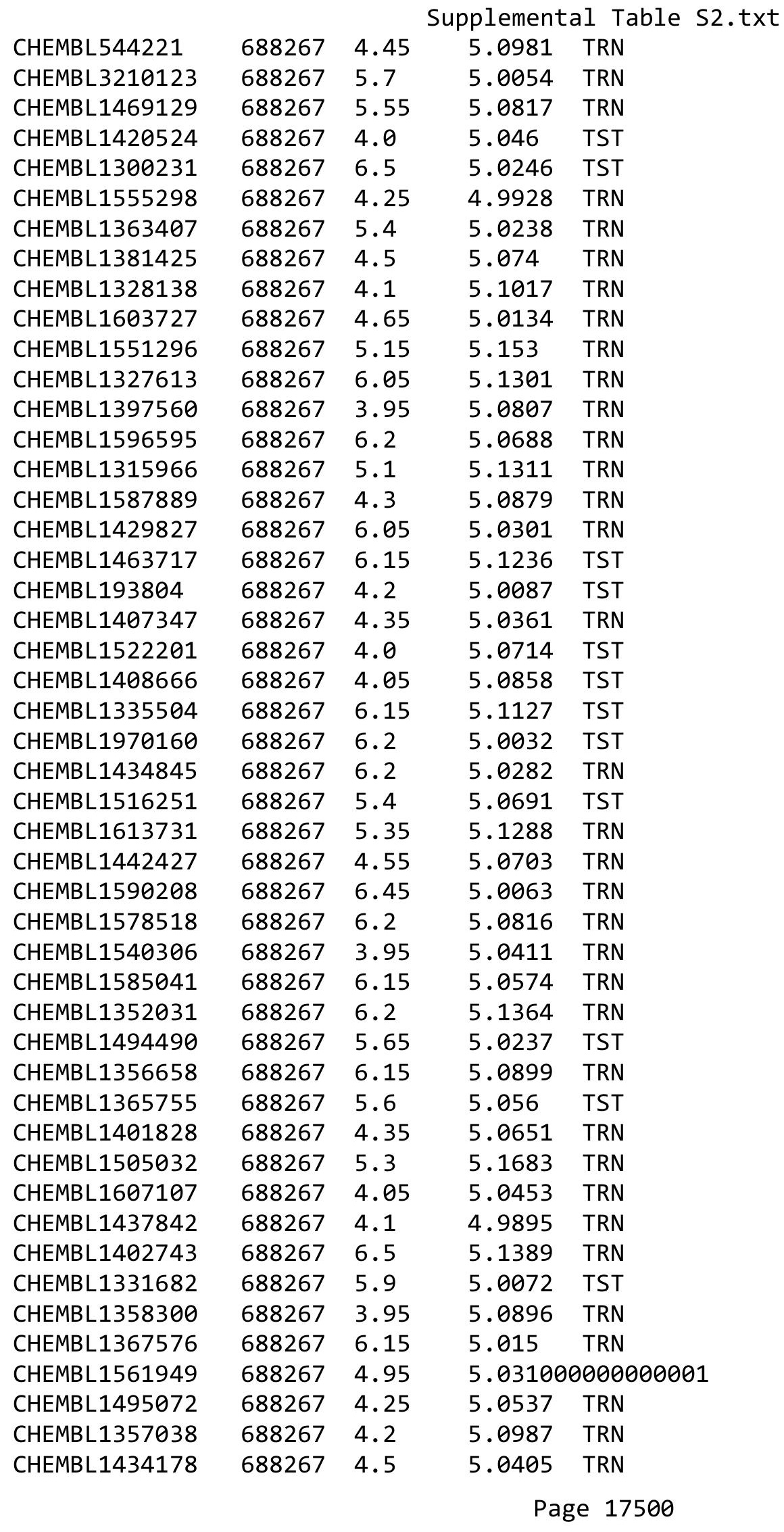




\begin{tabular}{|c|c|c|c|c|}
\hline \multirow[b]{2}{*}{ CHEMBL1347417 } & \multicolumn{4}{|c|}{ Supplemental Table s2.t } \\
\hline & 688267 & 6.2 & 5.0018 & TST \\
\hline CHEMBL1327792 & 688267 & 4.25 & 5.0469 & TRN \\
\hline CHEMBL1552112 & 688267 & 6.0 & 5.0757 & TRN \\
\hline CHEMBL1408865 & 688267 & 4.25 & 5.0975 & TRN \\
\hline CHEMBL1464357 & 688267 & 4.25 & 5.0182 & TST \\
\hline CHEMBL1442758 & 688267 & 4.0 & 5.0233 & TST \\
\hline CHEMBL1400863 & 688267 & 5.5 & 5.0423 & TRN \\
\hline CHEMBL1360687 & 688267 & 4.0 & 5.1102 & TRN \\
\hline CHEMBL1425283 & 688267 & 5.65 & 5.09 & TST \\
\hline CHEMBL1420237 & 688267 & 4.25 & 5.0468 & TRN \\
\hline CHEMBL 1471740 & 688267 & 4.25 & 5.0003 & TST \\
\hline CHEMBL1330121 & 688267 & 6.15 & 4.9974 & TRN \\
\hline CHEMBL1609054 & 688267 & 4.05 & 5.0123 & TST \\
\hline CHEMBL1530721 & 688267 & 4.6 & 5.1017 & TRN \\
\hline CHEMBL1329245 & 688267 & 5.45 & 5.0874 & TRN \\
\hline CHEMBL1325826 & 688267 & 4.35 & 5.0767 & TST \\
\hline CHEMBL1407520 & 688267 & 4.0 & 5.0012 & TRN \\
\hline CHEMBL1588571 & 688267 & 6.5 & 5.0532 & TST \\
\hline CHEMBL1534719 & 688267 & 4.15 & 5.0946 & TST \\
\hline CHEMBL1302170 & 688267 & 5.3 & 5.0619 & TST \\
\hline CHEMBL1488095 & 688267 & 5.35 & 5.0269 & TRN \\
\hline CHEMBL 3212246 & 688267 & 4.0 & 5.0198 & TST \\
\hline CHEMBL1310873 & 688267 & 3.95 & 4.9759 & TRN \\
\hline CHEMBL1434179 & 688267 & 4.4 & 5.0635 & TRN \\
\hline CHEMBL1473164 & 688267 & 4.0 & 5.0139 & TRN \\
\hline CHEMBL1564459 & 688267 & 6.05 & 5.0923 & TST \\
\hline CHEMBL1528573 & 688267 & 6.2 & 5.0371 & TRN \\
\hline CHEMBL1417379 & 688267 & 4.7 & 5.0964 & TST \\
\hline CHEMBL 1492590 & 688267 & 4.6 & 4.9984 & TRN \\
\hline CHEMBL1595390 & 688267 & 6.15 & 5.0785 & TRN \\
\hline CHEMBL1395796 & 688267 & 4.05 & 5.0899 & TRN \\
\hline CHEMBL1376201 & 688267 & 4.35 & 5.0262 & TST \\
\hline CHEMBL1486337 & 688267 & 4.2 & 5.1465 & TRN \\
\hline CHEMBL1580225 & 688267 & 5.3 & 5.0974 & TST \\
\hline CHEMBL1592411 & 688267 & 6.0 & 5.0862 & TRN \\
\hline CHEMBL1459326 & 688267 & 4.5 & 5.0644 & TRN \\
\hline CHEMBL1586902 & 688267 & 5.55 & 5.0679 & TRN \\
\hline CHEMBL1552734 & 688267 & 6.15 & 5.004 & TRN \\
\hline CHEMBL1374059 & 688267 & 5.35 & 5.0292 & TST \\
\hline CHEMBL1457758 & 688267 & 6.25 & 5.0806 & TRN \\
\hline CHEMBL1315843 & 688267 & 5.8 & 5.0692 & TRN \\
\hline CHEMBL1432488 & 688267 & 5.4 & 5.1089 & TRN \\
\hline CHEMBL1411702 & 688267 & 4.65 & 5.0408 & TRN \\
\hline CHEMBL1598391 & 688267 & 4.65 & 5.0068 & TST \\
\hline CHEMBL1575660 & 688267 & 6.25 & 5.0727 & TST \\
\hline CHEMBL3214291 & 688267 & 6.15 & 5.0306 & TST \\
\hline CHEMBL1524813 & 688267 & 5.2 & 5.042 & TRN \\
\hline CHEMBL1541450 & 688267 & 4.35 & 5.0112 & TRN \\
\hline
\end{tabular}




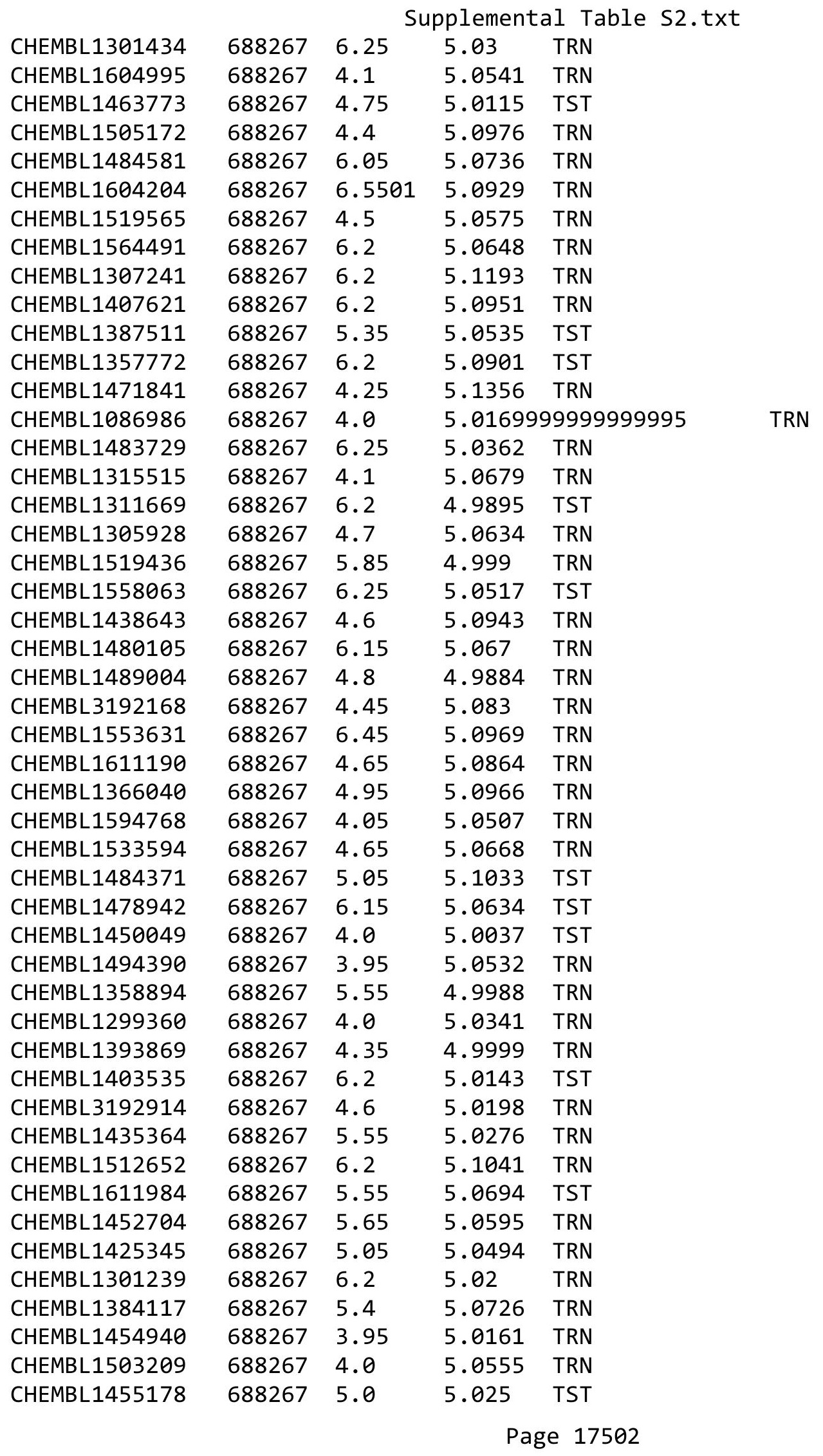




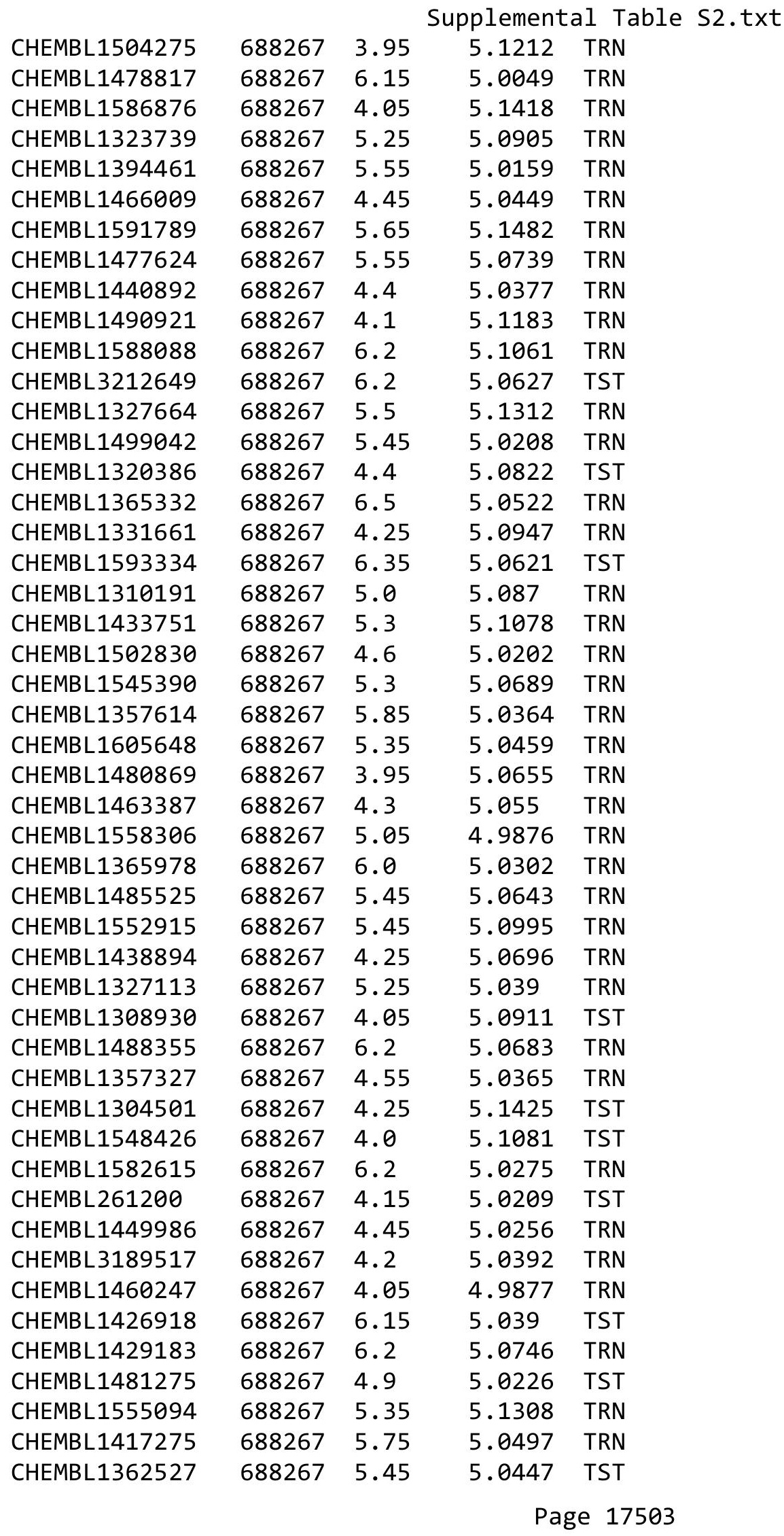




\begin{tabular}{|c|c|c|c|c|}
\hline & & & pplement & al $\mathrm{Ta}$ \\
\hline CHEMBL1456840 & 688267 & 5.3 & 5.1123 & TRN \\
\hline CHEMBL1514477 & 688267 & 6.05 & 5.0966 & TRN \\
\hline CHEMBL1331431 & 688267 & 6.1 & 5.1277 & TRN \\
\hline CHEMBL1395406 & 688267 & 4.05 & 4.9912 & TRN \\
\hline CHEMBL1396340 & 688267 & 5.45 & 4.9749 & TRN \\
\hline CHEMBL1393241 & 688267 & 4.2 & 5.0524 & TRN \\
\hline CHEMBL1362940 & 688267 & 4.6 & 5.0038 & TST \\
\hline CHEMBL1470172 & 688267 & 5.55 & 5.1112 & TRN \\
\hline CHEMBL1474065 & 688267 & 3.9 & 5.0618 & TRN \\
\hline CHEMBL1611271 & 688267 & 4.6 & 5.0346 & TRN \\
\hline CHEMBL1501585 & 688267 & 6.25 & 5.0167 & TST \\
\hline CHEMBL1439819 & 688267 & 5.0 & 5.0796 & TRN \\
\hline CHEMBL1467753 & 688267 & 4.0 & 5.0558 & TST \\
\hline CHEMBL1382258 & 688267 & 6.15 & 5.0832 & TRN \\
\hline CHEMBL1585914 & 688267 & 3.95 & 5.0436 & TRN \\
\hline CHEMBL1578012 & 688267 & 4.05 & 5.0566 & TRN \\
\hline CHEMBL1522478 & 688267 & 4.35 & 5.0189 & TRN \\
\hline CHEMBL1484373 & 688267 & 4.35 & 4.9984 & TRN \\
\hline CHEMBL1602966 & 688267 & 5.45 & 5.0325 & TST \\
\hline CHEMBL1460450 & 688267 & 6.2 & 5.0823 & TST \\
\hline CHEMBL1473439 & 688267 & 4.0 & 5.093 & TRN \\
\hline CHEMBL1965689 & 688267 & 5.85 & 5.0114 & TST \\
\hline CHEMBL1391319 & 688267 & 4.4 & 5.0843 & TRN \\
\hline CHEMBL1463496 & 688267 & 4.05 & 5.0582 & TRN \\
\hline CHEMBL1398207 & 688267 & 5.95 & 5.1327 & TRN \\
\hline CHEMBL 260775 & 688267 & 6.15 & 4.9767 & TRN \\
\hline CHEMBL1459418 & 688267 & 4.35 & 5.0126 & TRN \\
\hline CHEMBL1363596 & 688267 & 6.2 & 5.0244 & TRN \\
\hline CHEMBL1331065 & 688267 & 4.0 & 5.0024 & TRN \\
\hline CHEMBL1381111 & 688267 & 4.75 & 5.0988 & TRN \\
\hline CHEMBL1443657 & 688267 & 3.95 & 4.9889 & TRN \\
\hline CHEMBL3197366 & 688267 & 4.6 & 4.9904 & TRN \\
\hline CHEMBL1448969 & 688267 & 6.2 & 5.0809 & TST \\
\hline CHEMBL1407079 & 688267 & 4.25 & 5.0321 & TRN \\
\hline CHEMBL1409962 & 688267 & 5.2 & 5.0905 & TRN \\
\hline CHEMBL1532634 & 688267 & 4.0 & 5.087 & TRN \\
\hline CHEMBL1383602 & 688267 & 5.4 & 5.1415 & TRN \\
\hline CHEMBL1561901 & 688267 & 5.55 & 5.0245 & TST \\
\hline CHEMBL1504334 & 688267 & 4.0 & 5.0159 & TRN \\
\hline CHEMBL1563222 & 688267 & 5.35 & 5.0922 & TRN \\
\hline CHEMBL1320865 & 688267 & 4.95 & 5.0021 & TRN \\
\hline CHEMBL1336788 & 688267 & 5.0 & 5.0758 & TRN \\
\hline CHEMBL1448535 & 688267 & 4.4 & 5.0527 & TST \\
\hline CHEMBL1385151 & 688267 & 5.55 & 5.0477 & TRN \\
\hline CHEMBL1592678 & 688267 & 5.35 & 4.9815 & TRN \\
\hline CHEMBL1361730 & 688267 & 4.35 & 5.1566 & TRN \\
\hline CHEMBL1515527 & 688267 & 5.55 & 5.0064 & TRN \\
\hline CHEMBL209453 & 688267 & 4.0 & 5.0313 & TRN \\
\hline
\end{tabular}




\begin{tabular}{|c|c|c|c|c|}
\hline & & & pplement & al \\
\hline CHEMBL1307256 & 688267 & 4.9 & 5.0243 & TRN \\
\hline CHEMBL1333208 & 688267 & 6.2 & 5.0108 & TRN \\
\hline CHEMBL1496316 & 688267 & 4.55 & 5.0217 & TRN \\
\hline CHEMBL1357810 & 688267 & 5.55 & 5.0999 & TRN \\
\hline CHEMBL1366885 & 688267 & 4.05 & 5.0156 & TRN \\
\hline CHEMBL1588984 & 688267 & 4.8 & 5.1263 & TRN \\
\hline CHEMBL1308599 & 688267 & 4.25 & 5.0491 & TRN \\
\hline CHEMBL1595378 & 688267 & 5.85 & 5.0866 & TRN \\
\hline CHEMBL1390239 & 688267 & 6.25 & 5.0727 & TRN \\
\hline CHEMBL1505431 & 688267 & 5.05 & 5.0697 & TST \\
\hline CHEMBL1535794 & 688267 & 6.2 & 5.0054 & TRN \\
\hline CHEMBL1418427 & 688267 & 6.1 & 5.0549 & TST \\
\hline CHEMBL1593769 & 688267 & 5.35 & 5.115 & TRN \\
\hline CHEMBL1568504 & 688267 & 4.75 & 5.055 & TRN \\
\hline CHEMBL1519354 & 688267 & 5.3 & 5.0066 & TRN \\
\hline CHEMBL1605435 & 688267 & 5.05 & 4.9878 & TST \\
\hline CHEMBL1316428 & 688267 & 4.3 & 5.1179 & TST \\
\hline CHEMBL1499504 & 688267 & 3.95 & 5.0699 & TRN \\
\hline CHEMBL1318184 & 688267 & 5.2 & 5.018 & TRN \\
\hline CHEMBL1375715 & 688267 & 5.3 & 5.0294 & TRN \\
\hline CHEMBL1331554 & 688267 & 6.1 & 5.0309 & TRN \\
\hline CHEMBL1386967 & 688267 & 4.0 & 5.0227 & TRN \\
\hline CHEMBL1590836 & 688267 & 3.95 & 5.0059 & TRN \\
\hline CHEMBL1506759 & 688267 & 5.5 & 5.0327 & TRN \\
\hline CHEMBL1316375 & 688267 & 4.35 & 5.035 & TRN \\
\hline CHEMBL1455955 & 688267 & 4.25 & 5.0844 & TRN \\
\hline CHEMBL1433077 & 688267 & 4.0 & 5.1256 & TRN \\
\hline CHEMBL1524141 & 688267 & 4.8 & 5.0292 & TRN \\
\hline CHEMBL1412420 & 688267 & 5.55 & 5.0132 & TRN \\
\hline CHEMBL1367687 & 688267 & 6.6 & 5.0151 & TRN \\
\hline CHEMBL1324846 & 688267 & 5.8 & 5.0179 & TRN \\
\hline CHEMBL1440305 & 688267 & 5.05 & 5.1127 & TRN \\
\hline CHEMBL1590303 & 688267 & 5.6 & 5.1364 & TRN \\
\hline CHEMBL1363516 & 688267 & 5.15 & 5.0686 & TRN \\
\hline CHEMBL1376331 & 688267 & 5.4 & 5.0796 & TRN \\
\hline CHEMBL1557803 & 688267 & 5.55 & 5.0865 & TRN \\
\hline CHEMBL3195194 & 688267 & 4.0 & 5.0078 & TST \\
\hline CHEMBL1605506 & 688267 & 6.0 & 5.0664 & TRN \\
\hline CHEMBL1362385 & 688267 & 6.15 & 5.1039 & TRN \\
\hline CHEMBL1556301 & 688267 & 6.2 & 5.0755 & TRN \\
\hline CHEMBL1507546 & 688267 & 4.25 & 5.0998 & TST \\
\hline CHEMBL1509819 & 688267 & 4.75 & 5.0658 & TRN \\
\hline CHEMBL1307493 & 688267 & 5.4 & 5.1264 & TRN \\
\hline CHEMBL1549486 & 688267 & 4.6 & 5.0315 & TRN \\
\hline CHEMBL1553473 & 688267 & 5.1 & 5.0191 & TRN \\
\hline CHEMBL1319936 & 688267 & 4.05 & 5.0966 & TRN \\
\hline CHEMBL1495568 & 688267 & 4.0 & 5.073 & TST \\
\hline CHEMBL1577780 & 688267 & 4.0 & 5.0265 & TRN \\
\hline
\end{tabular}




\begin{tabular}{|c|c|c|c|c|}
\hline \multicolumn{5}{|c|}{ Supplemental Table S2.txt } \\
\hline CHEMBL 3210972 & 688267 & 5.3 & 4.9878 & TRN \\
\hline CHEMBL1360004 & 688267 & 3.95 & 5.0483 & TST \\
\hline CHEMBL1461358 & 688267 & 4.35 & 5.1451 & TRN \\
\hline CHEMBL1405524 & 688267 & 6.25 & 5.1322 & TST \\
\hline CHEMBL1421873 & 688267 & 4.3 & 5.0529 & TRN \\
\hline CHEMBL1384435 & 688267 & 4.95 & 5.0264 & TRN \\
\hline CHEMBL1213834 & 688267 & 4.9 & 5.0025 & TRN \\
\hline CHEMBL1387031 & 688267 & 5.35 & 5.0317 & TRN \\
\hline CHEMBL 3209870 & 688267 & 4.3 & 5.0079 & TRN \\
\hline CHEMBL1565516 & 688267 & 5.0 & 5.1031 & TRN \\
\hline CHEMBL1439109 & 688267 & 4.15 & 5.0994 & TRN \\
\hline CHEMBL1394686 & 688267 & 6.15 & 5.0562 & TRN \\
\hline CHEMBL1513042 & 688267 & 4.85 & 5.1201 & TRN \\
\hline CHEMBL1378703 & 688267 & 3.45 & 5.1208 & TRN \\
\hline CHEMBL1444529 & 688267 & 5.4 & 5.079 & TRN \\
\hline CHEMBL1570404 & 688267 & 4.0 & 5.1478 & TRN \\
\hline CHEMBL1434924 & 688267 & 6.25 & 5.0297 & TRN \\
\hline CHEMBL1372268 & 688267 & 5.85 & 5.1159 & TRN \\
\hline CHEMBL1571609 & 688267 & 6.15 & 5.0068 & TRN \\
\hline CHEMBL1590104 & 688267 & 5.8 & 5.0245 & TRN \\
\hline CHEMBL1376592 & 688267 & 3.95 & 4.982 & TRN \\
\hline CHEMBL1520205 & 688267 & 4.4 & 5.0142 & TST \\
\hline CHEMBL3207357 & 688267 & 4.3 & 5.0852 & TRN \\
\hline CHEMBL1339509 & 688267 & 5.35 & 5.0923 & TRN \\
\hline CHEMBL1336671 & 688267 & 5.1 & 5.0391 & TST \\
\hline CHEMBL1448388 & 688267 & 5.3 & 5.0353 & TRN \\
\hline CHEMBL1364013 & 688267 & 4.05 & 5.1467 & TRN \\
\hline CHEMBL1381032 & 688267 & 4.4 & 5.084 & TRN \\
\hline CHEMBL1449826 & 688267 & 4.65 & 5.0002 & TRN \\
\hline CHEMBL1448633 & 688267 & 4.25 & 5.093 & TRN \\
\hline CHEMBL1592455 & 688267 & 6.15 & 5.0611 & TRN \\
\hline CHEMBL1588756 & 688267 & 5.5 & 5.0765 & TST \\
\hline CHEMBL1473719 & 688267 & 5.95 & 5.0955 & TRN \\
\hline CHEMBL1547742 & 688267 & 6.15 & 5.0701 & TRN \\
\hline CHEMBL1462310 & 688267 & 4.0 & 5.0407 & TST \\
\hline CHEMBL1381076 & 688267 & 5.95 & 5.1061 & TST \\
\hline CHEMBL1333907 & 688267 & 4.0 & 5.0997 & TRN \\
\hline CHEMBL1331076 & 688267 & 6.2 & 5.034 & TRN \\
\hline CHEMBL1443236 & 688267 & 4.05 & 5.0125 & TST \\
\hline CHEMBL1531618 & 688267 & 6.0 & 5.035 & TRN \\
\hline CHEMBL1372648 & 688267 & 4.05 & 5.0817 & TRN \\
\hline CHEMBL1606809 & 688267 & 4.05 & 5.0134 & TST \\
\hline CHEMBL1546102 & 688267 & 4.6 & 4.99100 & 00000000005 \\
\hline CHEMBL1373318 & 688267 & 6.6499 & 5.0611 & TST \\
\hline CHEMBL1447470 & 688267 & 4.35 & 5.0141 & TST \\
\hline CHEMBL1463398 & 688267 & 6.25 & 5.0449 & TST \\
\hline CHEMBL1519161 & 688267 & 5.65 & 4.9975 & TRN \\
\hline CHEMBL1553143 & 688267 & 5.5 & 5.0663 & TRN \\
\hline
\end{tabular}




\begin{tabular}{|c|c|c|c|c|}
\hline \multicolumn{5}{|c|}{ lemental T } \\
\hline CHEMBL1457792 & 688267 & 5.9 & 5.0893 & TRN \\
\hline CHEMBL1533077 & 688267 & 5.9 & 5.0511 & TRN \\
\hline CHEMBL1404886 & 688267 & 4.0 & 5.0466 & TST \\
\hline CHEMBL1341932 & 688267 & 4.0 & 5.0333 & TRN \\
\hline CHEMBL 3211406 & 688267 & 4.1 & 5.0545 & TST \\
\hline CHEMBL1493180 & 688267 & 5.25 & 5.0132 & TRN \\
\hline CHEMBL1381135 & 688267 & 5.9 & 5.0433 & TRN \\
\hline CHEMBL1515666 & 688267 & 4.1 & 5.0391 & TRN \\
\hline CHEMBL1466338 & 688267 & 5.35 & 5.0414 & TST \\
\hline CHEMBL1466832 & 688267 & 5.55 & 5.0713 & TRN \\
\hline CHEMBL 1300253 & 688267 & 6.15 & 5.0145 & TRN \\
\hline CHEMBL1765369 & 688267 & 5.6 & 5.0292 & TST \\
\hline CHEMBL1340113 & 688267 & 4.4 & 5.106 & TRN \\
\hline CHEMBL1556558 & 688267 & 3.95 & 5.091 & TRN \\
\hline CHEMBL1355243 & 688267 & 5.1 & 5.0812 & TRN \\
\hline CHEMBL1307989 & 688267 & 5.1 & 4.9988 & TST \\
\hline CHEMBL1562542 & 688267 & 5.65 & 5.0688 & TRN \\
\hline CHEMBL1516754 & 688267 & 6.2 & 5.0417 & TRN \\
\hline CHEMBL3212325 & 688267 & 5.95 & 5.0731 & TST \\
\hline CHEMBL 250840 & 688267 & 4.35 & 5.0217 & TRN \\
\hline CHEMBL 1485212 & 688267 & 6.5 & 5.0016 & TRN \\
\hline CHEMBL1558082 & 688267 & 6.2 & 5.1449 & TRN \\
\hline CHEMBL1354527 & 688267 & 3.95 & 5.0201 & TST \\
\hline CHEMBL1415302 & 688267 & 4.8 & 5.0461 & TST \\
\hline CHEMBL1359014 & 688267 & 5.25 & 5.048 & TRN \\
\hline CHEMBL3207552 & 688267 & 4.1 & 4.9942 & TRN \\
\hline CHEMBL1430457 & 688267 & 4.0 & 5.0784 & TST \\
\hline CHEMBL1606268 & 688267 & 6.35 & 5.0663 & TRN \\
\hline CHEMBL1311234 & 688267 & 4.4 & 5.0881 & TRN \\
\hline CHEMBL1410255 & 688267 & 6.2 & 5.0973 & TRN \\
\hline CHEMBL1364077 & 688267 & 4.05 & 5.1008 & TRN \\
\hline CHEMBL1399209 & 688267 & 4.4 & 5.0094 & TRN \\
\hline CHEMBL1373929 & 688267 & 6.1 & 5.0558 & TRN \\
\hline CHEMBL1424897 & 688267 & 4.75 & 5.0533 & TRN \\
\hline CHEMBL1334532 & 688267 & 6.25 & 5.0815 & TRN \\
\hline CHEMBL1529718 & 688267 & 5.9 & 5.0089 & TST \\
\hline CHEMBL1980614 & 688267 & 6.25 & 5.0299 & TST \\
\hline CHEMBL 3198988 & 688267 & 6.15 & 4.9711 & TRN \\
\hline CHEMBL1330661 & 688267 & 4.8 & 5.0503 & TRN \\
\hline CHEMBL1446205 & 688267 & 5.55 & 5.0989 & TST \\
\hline CHEMBL1605938 & 688267 & 5.3 & 5.0405 & TRN \\
\hline CHEMBL1494908 & 688267 & 4.95 & 5.0265 & TRN \\
\hline CHEMBL1595150 & 688267 & 4.0 & 5.1652 & TRN \\
\hline CHEMBL1602157 & 688267 & 6.0 & 5.0093 & TRN \\
\hline CHEMBL1367307 & 688267 & 6.25 & 5.0532 & TST \\
\hline CHEMBL1398965 & 688267 & 4.75 & 5.025 & TRN \\
\hline CHEMBL1361672 & 688267 & 4.0 & 5.0243 & TRN \\
\hline CHEMBL1452984 & 688267 & 4.5 & 5.0591 & TRN \\
\hline
\end{tabular}




\begin{tabular}{|c|c|c|c|c|c|}
\hline \multicolumn{6}{|c|}{ Supplemental Table S2.txt } \\
\hline CHEMBL1337064 & 688267 & 4.4 & 5.1164 & TRN & \\
\hline CHEMBL1318286 & 688267 & 6.15 & 5.0555 & TST & \\
\hline CHEMBL1578190 & 688267 & 4.0 & 5.0432 & TRN & \\
\hline CHEMBL1479839 & 688267 & 6.35 & 5.1198 & TRN & \\
\hline CHEMBL1508989 & 688267 & 4.0 & 5.0053 & TRN & \\
\hline CHEMBL1585298 & 688267 & 4.35 & 5.0876 & TRN & \\
\hline CHEMBL1558176 & 688267 & 4.45 & 5.051 & TRN & \\
\hline CHEMBL1354171 & 688267 & 6.2 & $5.0310 e$ & 0000000001 & TRN \\
\hline CHEMBL1224755 & 688267 & 4.05 & 5.1031 & TST & \\
\hline CHEMBL1468491 & 688267 & 6.2 & 5.0587 & TST & \\
\hline CHEMBL1326543 & 688267 & 4.55 & 5.0571 & TRN & \\
\hline CHEMBL1384566 & 688267 & 5.2 & 5.0567 & TRN & \\
\hline CHEMBL1321323 & 688267 & 4.0 & 5.0578 & TRN & \\
\hline CHEMBL1475230 & 688267 & 5.55 & 5.0614 & TRN & \\
\hline CHEMBL1536462 & 688267 & 4.1 & 5.0338 & TST & \\
\hline CHEMBL1369052 & 688267 & 5.4 & 5.0492 & TST & \\
\hline CHEMBL1525845 & 688267 & 5.65 & 5.0025 & TRN & \\
\hline CHEMBL1355499 & 688267 & 6.15 & 5.0975 & TRN & \\
\hline CHEMBL1543322 & 688267 & 5.85 & 5.0883 & TRN & \\
\hline CHEMBL1404905 & 688267 & 5.3 & 5.0643 & TRN & \\
\hline CHEMBL1416806 & 688267 & 4.55 & 5.0108 & TST & \\
\hline CHEMBL1572992 & 688267 & 4.6 & 5.0584 & TRN & \\
\hline CHEMBL1380003 & 688267 & 4.7 & 5.0561 & TST & \\
\hline CHEMBL1541095 & 688267 & 6.2 & 5.0909 & TRN & \\
\hline CHEMBL1423655 & 688267 & 4.0 & 5.0433 & TRN & \\
\hline CHEMBL1566079 & 688267 & 4.05 & 5.0403 & TRN & \\
\hline CHEMBL1491273 & 688267 & 6.25 & 4.9951 & TRN & \\
\hline CHEMBL1552193 & 688267 & 4.5 & 5.0194 & TRN & \\
\hline CHEMBL1538754 & 688267 & 4.05 & 4.9953 & TRN & \\
\hline CHEMBL1392757 & 688267 & 5.4 & 5.0512 & TRN & \\
\hline CHEMBL1561879 & 688267 & 4.25 & 5.1034 & TRN & \\
\hline CHEMBL1408452 & 688267 & 5.9 & 4.9921 & TRN & \\
\hline CHEMBL1360788 & 688267 & 4.0 & 5.0631 & TRN & \\
\hline CHEMBL1494243 & 688267 & 4.35 & 5.0751 & TST & \\
\hline CHEMBL1317351 & 688267 & 6.25 & 5.1376 & TRN & \\
\hline CHEMBL1389633 & 688267 & 3.95 & 5.0346 & TRN & \\
\hline CHEMBL1490482 & 688267 & 5.7 & 5.0667 & TST & \\
\hline CHEMBL1533790 & 688267 & 6.15 & 5.0488 & TRN & \\
\hline CHEMBL1603685 & 688267 & 4.65 & 5.0268 & TRN & \\
\hline CHEMBL1329238 & 688267 & 4.15 & 5.0818 & TRN & \\
\hline CHEMBL1563636 & 688267 & 4.0 & 5.0356 & TRN & \\
\hline CHEMBL1413653 & 688267 & 5.95 & 5.0762 & TRN & \\
\hline CHEMBL1436427 & 688267 & 5.3 & 5.0208 & TRN & \\
\hline CHEMBL1434493 & 688267 & 4.25 & 5.0685 & TRN & \\
\hline CHEMBL1517351 & 688267 & 4.1 & 5.0194 & TRN & \\
\hline CHEMBL3194888 & 688267 & 4.3 & 5.0438 & TRN & \\
\hline CHEMBL1516804 & 688267 & 4.3 & 5.1094 & TRN & \\
\hline CHEMBL1414705 & 688267 & 4.75 & 5.0237 & TRN & \\
\hline
\end{tabular}




\begin{tabular}{|c|c|c|c|c|c|}
\hline \multicolumn{6}{|c|}{ Supplemental Table s2.txt } \\
\hline CHEMBL1384533 & 688267 & 6.15 & 5.069 & TRN & \\
\hline CHEMBL3192839 & 688267 & 4.65 & 5.0724 & TRN & \\
\hline CHEMBL1482465 & 688267 & 6.0 & 5.0328 & TST & \\
\hline CHEMBL1355960 & 688267 & 5.95 & 5.0498 & TRN & \\
\hline CHEMBL1370573 & 688267 & 4.05 & 5.1329 & TRN & \\
\hline CHEMBL1369076 & 688267 & 6.15 & 5.1013 & TRN & \\
\hline CHEMBL1559427 & 688267 & 4.35 & 5.0652 & TST & \\
\hline CHEMBL1503868 & 688267 & 5.25 & 5.0329 & TRN & \\
\hline CHEMBL1583063 & 688267 & 4.7 & 5.0338 & TRN & \\
\hline CHEMBL1575866 & 688267 & 6.2 & 5.1058 & TST & \\
\hline CHEMBL1330457 & 688267 & 4.5 & 5.0525 & TRN & \\
\hline CHEMBL1418404 & 688267 & 4.0 & 5.0047 & TRN & \\
\hline CHEMBL1575617 & 688267 & 4.85 & 5.0661 & TRN & \\
\hline CHEMBL1602416 & 688267 & 5.35 & 5.0479 & TRN & \\
\hline CHEMBL1430535 & 688267 & 4.1 & 5.1018 & TRN & \\
\hline CHEMBL1320414 & 688267 & 5.45 & 4.9978 & TRN & \\
\hline CHEMBL1429358 & 688267 & 5.55 & 5.0881 & TST & \\
\hline CHEMBL1515029 & 688267 & 6.2 & 5.0716 & TRN & \\
\hline CHEMBL1550390 & 688267 & 5.85 & 5.0638 & TRN & \\
\hline CHEMBL1508750 & 688267 & 4.65 & 5.0652 & TRN & \\
\hline CHEMBL1597447 & 688267 & 6.15 & 5.0661 & TST & \\
\hline CHEMBL1520144 & 688267 & 4.8 & 5.0473 & TRN & \\
\hline CHEMBL 37570 & 688267 & 4.1 & 5.0386 & TST & \\
\hline CHEMBL1355205 & 688267 & 5.2 & 5.0124 & TRN & \\
\hline CHEMBL1469926 & 688267 & 5.0 & 5.0745 & TRN & \\
\hline CHEMBL1522354 & 688267 & 4.0 & 5.0505 & TRN & \\
\hline CHEMBL1367749 & 688267 & 4.55 & 5.0329 & TST & \\
\hline CHEMBL1489586 & 688267 & 5.4 & 5.0227 & TRN & \\
\hline CHEMBL1540810 & 688267 & 5.85 & 5.0297 & TST & \\
\hline CHEMBL1357188 & 688267 & 5.55 & 5.0947 & TRN & \\
\hline CHEMBL1423056 & 688267 & 6.2 & 5.0635 & TST & \\
\hline CHEMBL1402462 & 688267 & 4.1 & 5.1277 & TRN & \\
\hline CHEMBL1336205 & 688267 & 6.2 & 5.01699 & 99999999995 & TST \\
\hline CHEMBL1555458 & 688267 & 5.2 & 5.023 & TRN & \\
\hline CHEMBL1488478 & 688267 & 4.05 & 5.1343 & TRN & \\
\hline CHEMBL1415051 & 688267 & 3.95 & 5.1044 & TRN & \\
\hline CHEMBL1538502 & 688267 & 4.95 & 5.0656 & TST & \\
\hline CHEMBL1340453 & 688267 & 5.4 & 5.0249 & TST & \\
\hline CHEMBL1529826 & 688267 & 4.75 & 5.0867 & TRN & \\
\hline CHEMBL1577606 & 688267 & 4.0 & 5.1072 & TRN & \\
\hline CHEMBL1553801 & 688267 & 4.4 & 5.0427 & TRN & \\
\hline CHEMBL3212832 & 688267 & 5.4 & 5.0497 & TRN & \\
\hline CHEMBL1530558 & 688267 & 5.6 & 5.0065 & TRN & \\
\hline CHEMBL3191581 & 688267 & 6.15 & 5.0906 & TST & \\
\hline CHEMBL1987709 & 688267 & 6.25 & 5.0012 & TST & \\
\hline CHEMBL1611619 & 688267 & 6.2 & 5.0552 & TST & \\
\hline CHEMBL1321513 & 688267 & 4.35 & 5.0492 & TST & \\
\hline CHEMBL1406168 & 688267 & 4.1 & 5.0951 & TST & \\
\hline
\end{tabular}




\begin{tabular}{|c|c|c|c|c|}
\hline \multicolumn{5}{|c|}{ Supplemental Table S2.txt } \\
\hline CHEMBL1367443 & 688267 & 4.35 & 5.0458 & TRN \\
\hline CHEMBL1463584 & 688267 & 6.2 & 5.0817 & TRN \\
\hline CHEMBL1342610 & 688267 & 5.45 & 5.0017 & TRN \\
\hline CHEMBL1315629 & 688267 & 5.3 & 5.113 & TRN \\
\hline CHEMBL1554787 & 688267 & 4.45 & 5.1032 & TRN \\
\hline CHEMBL1988416 & 688267 & 6.2 & 5.0618 & TST \\
\hline CHEMBL1590812 & 688267 & 4.0 & 5.0601 & TRN \\
\hline CHEMBL1477510 & 688267 & 4.05 & 5.0785 & TRN \\
\hline CHEMBL1410591 & 688267 & 4.95 & 5.0635 & TRN \\
\hline CHEMBL1574544 & 688267 & 4.35 & 5.1053 & TST \\
\hline CHEMBL1492980 & 688267 & 6.0 & 5.1177 & TRN \\
\hline CHEMBL1429949 & 688267 & 4.55 & 5.0266 & TRN \\
\hline CHEMBL1538536 & 688267 & 4.4 & 5.0347 & TRN \\
\hline CHEMBL1545902 & 688267 & 5.85 & 5.0156 & TST \\
\hline CHEMBL1305738 & 688267 & 4.45 & 5.0272 & TRN \\
\hline CHEMBL1549987 & 688267 & 4.4 & 5.0612 & TST \\
\hline CHEMBL1564908 & 688267 & 4.6 & 5.0429 & TRN \\
\hline CHEMBL1451043 & 688267 & 4.95 & 5.03 & TRN \\
\hline CHEMBL1476193 & 688267 & 5.35 & 5.0391 & TRN \\
\hline CHEMBL1348751 & 688267 & 4.15 & 5.0922 & TRN \\
\hline CHEMBL1567831 & 688267 & 5.55 & 5.0267 & TRN \\
\hline CHEMBL1479162 & 688267 & 6.25 & 5.0562 & TRN \\
\hline CHEMBL1305199 & 688267 & 4.4 & 5.023 & TRN \\
\hline CHEMBL3199203 & 688267 & 6.2 & 5.0613 & TRN \\
\hline CHEMBL1451636 & 688267 & 4.7 & 5.0792 & TRN \\
\hline CHEMBL1486004 & 688267 & 6.2 & 5.0308 & TRN \\
\hline CHEMBL3214580 & 688267 & 4.1 & 5.0435 & TRN \\
\hline CHEMBL1337050 & 688267 & 5.75 & 5.0376 & TRN \\
\hline CHEMBL1378321 & 688267 & 4.0 & 5.0796 & TRN \\
\hline CHEMBL3207476 & 688267 & 6.2 & 5.0542 & TST \\
\hline CHEMBL1546717 & 688267 & 5.85 & 5.0768 & TST \\
\hline CHEMBL1300621 & 688267 & 4.35 & 4.9709 & TRN \\
\hline CHEMBL1552993 & 688267 & 3.95 & 5.0237 & TRN \\
\hline CHEMBL1519377 & 688267 & 6.15 & 5.1064 & TST \\
\hline CHEMBL1469763 & 688267 & 4.0 & 5.0968 & TRN \\
\hline CHEMBL1538843 & 688267 & 5.35 & 5.092 & TST \\
\hline CHEMBL1429006 & 688267 & 5.85 & 5.106 & TRN \\
\hline CHEMBL1409221 & 688267 & 3.95 & 5.1147 & TRN \\
\hline CHEMBL1542811 & 688267 & 4.35 & 5.0123 & TST \\
\hline CHEMBL1400903 & 688267 & 4.1 & 5.0681 & TST \\
\hline CHEMBL1305351 & 688267 & 4.8 & 5.0776 & TRN \\
\hline CHEMBL1427643 & 688267 & 5.4 & 5.0566 & TST \\
\hline CHEMBL1430991 & 688267 & 4.0 & 5.0024 & TST \\
\hline CHEMBL1607018 & 688267 & 5.3 & 5.095 & TRN \\
\hline CHEMBL1396961 & 688267 & 5.9 & 5.1547 & TST \\
\hline CHEMBL1317272 & 688267 & 6.6 & 5.0419 & TRN \\
\hline CHEMBL1494203 & 688267 & 6.2 & 5.1232 & TRN \\
\hline CHEMBL1424927 & 688267 & 4.05 & 5.0662 & TST \\
\hline
\end{tabular}




\begin{tabular}{|c|c|c|c|c|c|}
\hline \multirow[b]{2}{*}{ CHEMBL1511667 } & \multirow[b]{2}{*}{688267} & \\
\hline & & 4.3 & 4.9935 & TST & \\
\hline CHEMBL1532611 & 688267 & 6.2 & 5.0361 & TST & \\
\hline CHEMBL1451948 & 688267 & 5.5 & 5.0813 & TST & \\
\hline CHEMBL1592503 & 688267 & 6.25 & 5.0279 & TRN & \\
\hline CHEMBL1370243 & 688267 & 5.35 & 4.9838 & TRN & \\
\hline CHEMBL1541892 & 688267 & 4.35 & 5.0897 & TRN & \\
\hline CHEMBL1457248 & 688267 & 5.6 & 5.0704 & TRN & \\
\hline CHEMBL1422401 & 688267 & 6.05 & 5.0949 & TRN & \\
\hline CHEMBL1332133 & 688267 & 4.45 & 5.0547 & TRN & \\
\hline CHEMBL1585079 & 688267 & 4.35 & 5.0601 & TRN & \\
\hline CHEMBL1578406 & 688267 & 4.0 & 5.1209 & TST & \\
\hline CHEMBL1444399 & 688267 & 4.4 & 5.0104 & TST & \\
\hline CHEMBL1494148 & 688267 & 5.05 & 5.0896 & TRN & \\
\hline CHEMBL1431065 & 688267 & 6.15 & 5.1615 & TRN & \\
\hline CHEMBL1593777 & 688267 & 5.35 & 5.136 & TRN & \\
\hline CHEMBL1425112 & 688267 & 4.1 & $5.0680 e$ & 00000000005 & TRN \\
\hline CHEMBL3190877 & 688267 & 5.55 & 5.0026 & TRN & \\
\hline CHEMBL 3212072 & 688267 & 4.4 & 5.0538 & TRN & \\
\hline CHEMBL1333584 & 688267 & 5.6 & 5.0716 & TRN & \\
\hline CHEMBL1315831 & 688267 & 6.25 & $5.1610 e$ & 00000000005 & TRN \\
\hline CHEMBL1533858 & 688267 & 5.1 & 5.1006 & TRN & \\
\hline CHEMBL1518753 & 688267 & 5.0 & 5.0513 & TST & \\
\hline CHEMBL1483348 & 688267 & 4.75 & 5.0801 & TRN & \\
\hline CHEMBL1446392 & 688267 & 4.0 & 5.0738 & TRN & \\
\hline CHEMBL1574186 & 688267 & 4.0 & 5.0474 & TRN & \\
\hline CHEMBL1425798 & 688267 & 4.6 & 5.0468 & TRN & \\
\hline CHEMBL1389541 & 688267 & 4.7 & 5.1162 & TRN & \\
\hline CHEMBL1459246 & 688267 & 6.2 & 5.1062 & TST & \\
\hline CHEMBL1373938 & 688267 & 5.45 & 5.0211 & TST & \\
\hline CHEMBL1494936 & 688267 & 5.25 & 5.0258 & TRN & \\
\hline CHEMBL1512429 & 688267 & 4.0 & 5.0777 & TRN & \\
\hline CHEMBL1458332 & 688267 & 4.0 & 5.0427 & TST & \\
\hline CHEMBL1564077 & 688267 & 6.15 & 5.0546 & TRN & \\
\hline CHEMBL1308136 & 688267 & 6.15 & 5.0529 & TRN & \\
\hline CHEMBL1605363 & 688267 & 4.35 & 4.9985 & TRN & \\
\hline CHEMBL3209954 & 688267 & 6.2 & 4.9903 & TRN & \\
\hline CHEMBL1424680 & 688267 & 4.4 & 5.1339 & TRN & \\
\hline CHEMBL1328626 & 688267 & 4.0 & 5.0286 & TST & \\
\hline CHEMBL1517974 & 688267 & 5.4 & 5.0128 & TST & \\
\hline CHEMBL1604427 & 688267 & 5.05 & 5.026 & TRN & \\
\hline CHEMBL1597143 & 688267 & 4.2 & 5.1117 & TRN & \\
\hline CHEMBL1323947 & 688267 & 6.15 & 5.0944 & TRN & \\
\hline CHEMBL1548198 & 688267 & 3.95 & 5.0408 & TRN & \\
\hline CHEMBL1434384 & 688267 & 5.0 & 5.1676 & TRN & \\
\hline CHEMBL1520353 & 688267 & 4.7 & 5.0709 & TRN & \\
\hline CHEMBL1597794 & 688267 & 4.05 & 5.0223 & TST & \\
\hline CHEMBL1338162 & 688267 & 4.85 & 5.0407 & TRN & \\
\hline CHEMBL1517877 & 688267 & 5.75 & 5.075 & TRN & \\
\hline & & & & 7511 & \\
\hline
\end{tabular}




\begin{tabular}{|c|c|c|c|c|}
\hline \multicolumn{5}{|c|}{ Supplemental Table S2.txt } \\
\hline CHEMBL1591861 & 688267 & 4.0 & 5.0145 & TRN \\
\hline CHEMBL1336246 & 688267 & 4.15 & 5.0447 & TRN \\
\hline CHEMBL1563811 & 688267 & 5.35 & 5.0323 & TRN \\
\hline CHEMBL1515031 & 688267 & 5.75 & 5.0429 & TST \\
\hline CHEMBL1335834 & 688267 & 4.8 & 5.0779 & TRN \\
\hline CHEMBL600976 & 688267 & 4.2 & 5.0932 & TRN \\
\hline CHEMBL1407247 & 688267 & 5.55 & 5.0616 & TRN \\
\hline CHEMBL1416849 & 688267 & 5.35 & 5.06 & TRN \\
\hline CHEMBL1547466 & 688267 & 5.95 & 5.0083 & TRN \\
\hline CHEMBL1592494 & 688267 & 4.05 & 5.0997 & TRN \\
\hline CHEMBL1383836 & 688267 & 6.25 & 5.0783 & TST \\
\hline CHEMBL1414896 & 688267 & 6.2 & 5.0587 & TRN \\
\hline CHEMBL1571274 & 688267 & 4.0 & 5.0524 & TRN \\
\hline CHEMBL1318474 & 688267 & 4.0 & 5.0481 & TRN \\
\hline CHEMBL1585807 & 688267 & 6.5501 & 5.0872 & TRN \\
\hline CHEMBL1305822 & 688267 & 3.95 & 5.1262 & TRN \\
\hline CHEMBL1461391 & 688267 & 4.95 & 5.0471 & TRN \\
\hline CHEMBL1585015 & 688267 & 4.05 & 5.0831 & TRN \\
\hline CHEMBL1450928 & 688267 & 4.0 & 5.0537 & TST \\
\hline CHEMBL1399960 & 688267 & 3.95 & 5.1102 & TRN \\
\hline CHEMBL1351940 & 688267 & 4.9 & 5.0292 & TST \\
\hline CHEMBL1363992 & 688267 & 4.4 & 5.0581 & TRN \\
\hline CHEMBL1591578 & 688267 & 4.6 & 5.1081 & TRN \\
\hline CHEMBL1590140 & 688267 & 5.95 & 5.0039 & TRN \\
\hline CHEMBL1442636 & 688267 & 4.0 & 5.043 & TRN \\
\hline CHEMBL1516348 & 688267 & 6.0 & 5.1104 & TST \\
\hline CHEMBL1606681 & 688267 & 4.0 & 5.0126 & TRN \\
\hline CHEMBL1487113 & 688267 & 5.3 & 5.0026 & TRN \\
\hline CHEMBL1453923 & 688267 & 4.05 & 4.999 & TRN \\
\hline CHEMBL1306484 & 688267 & 4.0 & 5.0914 & TST \\
\hline CHEMBL1309583 & 688267 & 4.15 & 5.0978 & TRN \\
\hline CHEMBL1517895 & 688267 & 4.35 & 5.0659 & TRN \\
\hline CHEMBL1317641 & 688267 & 5.35 & 5.0793 & TRN \\
\hline CHEMBL1564455 & 688267 & 6.2 & 5.1514 & TRN \\
\hline CHEMBL1315472 & 688267 & 4.45 & 5.1002 & TRN \\
\hline CHEMBL1503743 & 688267 & 4.5 & 5.0384 & TRN \\
\hline CHEMBL1446609 & 688267 & 5.85 & 5.0144 & TRN \\
\hline CHEMBL1336044 & 688267 & 5.95 & 5.0926 & TST \\
\hline CHEMBL1394063 & 688267 & 4.4 & 5.0366 & TST \\
\hline CHEMBL1610500 & 688267 & 5.55 & 5.0785 & TRN \\
\hline CHEMBL1520334 & 688267 & 5.3 & 5.0623 & TST \\
\hline CHEMBL1567842 & 688267 & 4.35 & 5.083 & TRN \\
\hline CHEMBL1455201 & 688267 & 6.2 & 5.0397 & TRN \\
\hline CHEMBL1420388 & 688267 & 5.05 & 5.0707 & TRN \\
\hline CHEMBL1576109 & 688267 & 6.2 & 5.0147 & TRN \\
\hline CHEMBL1570122 & 688267 & 4.45 & 5.0573 & TST \\
\hline CHEMBL1528779 & 688267 & 4.15 & 5.0734 & TRN \\
\hline CHEMBL1366204 & 688267 & 5.5 & 5.0724 & TRN \\
\hline
\end{tabular}




\begin{tabular}{|c|c|c|c|c|}
\hline \multicolumn{5}{|c|}{ Supplemental Table } \\
\hline CHEMBL1337330 & 688267 & 4.4 & 5.066 & TRN \\
\hline CHEMBL1574175 & 688267 & 4.3 & 5.0357 & TRN \\
\hline CHEMBL1469541 & 688267 & 5.6 & 5.0488 & TRN \\
\hline CHEMBL1366022 & 688267 & 4.05 & 5.1547 & TRN \\
\hline CHEMBL1603025 & 688267 & 6.25 & 5.1312 & TRN \\
\hline CHEMBL1609321 & 688267 & 6.2 & 5.1043 & TRN \\
\hline CHEMBL1477297 & 688267 & 4.05 & 5.0646 & TRN \\
\hline CHEMBL1493416 & 688267 & 5.3 & 5.0344 & TRN \\
\hline CHEMBL1554792 & 688267 & 6.2 & 5.0997 & TRN \\
\hline CHEMBL1574792 & 688267 & 3.95 & 5.0154 & TRN \\
\hline CHEMBL1529799 & 688267 & 5.0 & 5.0386 & TST \\
\hline CHEMBL1399912 & 688267 & 3.95 & 5.0365 & TRN \\
\hline CHEMBL1517990 & 688267 & 6.2 & 5.0439 & TRN \\
\hline CHEMBL1299362 & 688267 & 4.3 & 5.0748 & TRN \\
\hline CHEMBL3199349 & 688267 & 5.0 & 4.9696 & TST \\
\hline CHEMBL1514001 & 688267 & 5.55 & 5.1061 & TRN \\
\hline CHEMBL1328923 & 688267 & 5.1 & 4.9665 & TRN \\
\hline CHEMBL1408060 & 688267 & 5.3 & 5.0803 & TRN \\
\hline CHEMBL1377277 & 688267 & 5.2 & 5.0494 & TRN \\
\hline CHEMBL1537759 & 688267 & 6.15 & 5.0289 & TST \\
\hline CHEMBL1310980 & 688267 & 6.6 & 4.9933 & TRN \\
\hline CHEMBL1493993 & 688267 & 6.05 & 4.9841 & TRN \\
\hline CHEMBL1557008 & 688267 & 6.25 & 5.0607 & TST \\
\hline CHEMBL1384456 & 688267 & 4.0 & 4.9871 & TRN \\
\hline CHEMBL1446824 & 688267 & 6.45 & 5.0206 & TST \\
\hline CHEMBL1452918 & 688267 & 6.0 & 5.0668 & TRN \\
\hline CHEMBL1553131 & 688267 & 4.4 & 5.0348 & TST \\
\hline CHEMBL1510994 & 688267 & 4.7 & 5.0232 & TST \\
\hline CHEMBL1511715 & 688267 & 6.15 & 5.0576 & TRN \\
\hline CHEMBL1348346 & 688267 & 4.3 & 5.0547 & TST \\
\hline CHEMBL1318015 & 688267 & 4.0 & 4.9818 & TRN \\
\hline CHEMBL1301317 & 688267 & 6.2 & 5.0984 & TRN \\
\hline CHEMBL1338965 & 688267 & 4.0 & 5.0557 & TRN \\
\hline CHEMBL1437807 & 688267 & 5.55 & 5.051 & TRN \\
\hline CHEMBL1603271 & 688267 & 5.9 & 5.0926 & TRN \\
\hline CHEMBL1332725 & 688267 & 5.85 & 5.0989 & TST \\
\hline CHEMBL1339794 & 688267 & 5.85 & 5.0078 & TRN \\
\hline CHEMBL1415480 & 688267 & 4.3 & 5.1857 & TST \\
\hline CHEMBL1441273 & 688267 & 4.1 & 5.01 & TRN \\
\hline CHEMBL3191222 & 688267 & 4.1 & 4.9557 & TRN \\
\hline CHEMBL1369460 & 688267 & 6.2 & 5.0451 & TRN \\
\hline CHEMBL1576295 & 688267 & 4.3 & 5.0645 & TRN \\
\hline CHEMBL1409256 & 688267 & 4.6 & 5.0227 & TRN \\
\hline CHEMBL1513021 & 688267 & 6.2 & 5.0213 & TST \\
\hline CHEMBL1306301 & 688267 & 5.3 & 5.1478 & TRN \\
\hline CHEMBL1532072 & 688267 & 6.0 & 5.0016 & TST \\
\hline CHEMBL1609541 & 688267 & 3.9 & 5.0383 & TRN \\
\hline CHEMBL1300964 & 688267 & 5.8 & 5.0595 & TRN \\
\hline
\end{tabular}




\begin{tabular}{|c|c|c|c|c|c|}
\hline \multicolumn{6}{|c|}{ Supplemental Table S2.txt } \\
\hline CHEMBL1445358 & 688267 & 5.55 & 4.9997 & TRN & \\
\hline CHEMBL1349940 & 688267 & 4.05 & 5.0492 & TRN & \\
\hline CHEMBL3196977 & 688267 & 4.7 & 5.0011 & TST & \\
\hline CHEMBL1403126 & 688267 & 3.95 & 5.1079 & TRN & \\
\hline CHEMBL1460472 & 688267 & 4.05 & 5.0313 & TRN & \\
\hline CHEMBL1554267 & 688267 & 6.2 & 5.0175 & TRN & \\
\hline CHEMBL1448500 & 688267 & 4.5 & 5.1054 & TRN & \\
\hline CHEMBL1505570 & 688267 & 6.45 & 5.0377 & TRN & \\
\hline CHEMBL1513545 & 688267 & 5.3 & 5.13899 & 9999999999 & TRN \\
\hline CHEMBL1305103 & 688267 & 5.3 & 5.0805 & TST & \\
\hline CHEMBL1431142 & 688267 & 5.0 & 5.0087 & TRN & \\
\hline CHEMBL1434977 & 688267 & 4.6 & 5.154 & TRN & \\
\hline CHEMBL1403577 & 688267 & 4.25 & 5.0373 & TST & \\
\hline CHEMBL1457908 & 688267 & 4.6 & 5.0091 & TRN & \\
\hline CHEMBL1374128 & 688267 & 5.85 & 5.0849 & TRN & \\
\hline CHEMBL1380322 & 688267 & 4.2 & 5.1246 & TRN & \\
\hline CHEMBL1463716 & 688267 & 6.25 & 5.0045 & TRN & \\
\hline CHEMBL1587264 & 688267 & 4.1 & 5.0857 & TRN & \\
\hline CHEMBL1471221 & 688267 & 5.85 & 5.0944 & TRN & \\
\hline CHEMBL1321692 & 688267 & 4.4 & 5.1259 & TRN & \\
\hline CHEMBL1514429 & 688267 & 3.95 & 5.0122 & TRN & \\
\hline CHEMBL1567897 & 688267 & 5.15 & 4.9774 & TRN & \\
\hline CHEMBL1318093 & 688267 & 6.5 & 5.0975 & TST & \\
\hline CHEMBL1379992 & 688267 & 6.15 & 5.0531 & TRN & \\
\hline CHEMBL1512332 & 688267 & 5.0 & 5.0847 & TRN & \\
\hline CHEMBL1368764 & 688267 & 5.0 & 5.0573 & TRN & \\
\hline CHEMBL1454425 & 688267 & 5.6 & 4.9961 & TRN & \\
\hline CHEMBL1585842 & 688267 & 6.2 & 5.0198 & TST & \\
\hline CHEMBL1321969 & 688267 & 4.7 & 5.0469 & TST & \\
\hline CHEMBL1329880 & 688267 & 4.1 & 5.0096 & TRN & \\
\hline CHEMBL1556491 & 688267 & 5.55 & 5.1297 & TRN & \\
\hline CHEMBL1365409 & 688267 & 4.35 & 5.0567 & TST & \\
\hline CHEMBL1337554 & 688267 & 4.05 & 4.9883 & TRN & \\
\hline CHEMBL1312222 & 688267 & 3.95 & 5.0848 & TST & \\
\hline CHEMBL1992793 & 688267 & 5.35 & 5.0573 & TST & \\
\hline CHEMBL1341110 & 688267 & 4.0 & 5.0916 & TRN & \\
\hline CHEMBL1456119 & 688267 & 6.2 & 5.0949 & TRN & \\
\hline CHEMBL1544843 & 688267 & 5.45 & 5.0627 & TRN & \\
\hline CHEMBL1547003 & 688267 & 5.8 & 5.0612 & TST & \\
\hline CHEMBL1505416 & 688267 & 4.7 & 5.0773 & TST & \\
\hline CHEMBL 3207346 & 688267 & 6.0 & 5.0725 & TRN & \\
\hline CHEMBL1513999 & 688267 & 4.0 & 5.1164 & TRN & \\
\hline CHEMBL1571266 & 688267 & 5.25 & 5.0327 & TST & \\
\hline CHEMBL1454961 & 688267 & 4.35 & 5.0808 & TRN & \\
\hline CHEMBL1578130 & 688267 & 5.75 & 5.0311 & TRN & \\
\hline CHEMBL1371584 & 688267 & 6.2 & 5.0458 & TRN & \\
\hline CHEMBL 1380347 & 688267 & 6.6499 & 5.0452 & TRN & \\
\hline CHEMBL3199685 & 688267 & 4.3 & 5.0349 & TRN & \\
\hline
\end{tabular}




\begin{tabular}{|c|c|c|c|c|c|}
\hline & & & & & \\
\hline CHEMBL1350742 & 688267 & 5.6 & 5.0969 & TRN & \\
\hline CHEMBL3190802 & 688267 & 4.3 & 4.9947 & TST & \\
\hline CHEMBL1315513 & 688267 & 5.85 & 5.0747 & TRN & \\
\hline CHEMBL1534175 & 688267 & 4.45 & 5.0309 & TRN & \\
\hline CHEMBL1550151 & 688267 & 4.35 & 5.0641 & TST & \\
\hline CHEMBL1390458 & 688267 & 3.95 & 5.0621 & TRN & \\
\hline CHEMBL1555815 & 688267 & 4.25 & 5.0198 & TST & \\
\hline CHEMBL1352776 & 688267 & 5.05 & 5.075 & TST & \\
\hline CHEMBL1407029 & 688267 & 3.95 & 5.053 & TST & \\
\hline CHEMBL1308990 & 688267 & 5.3 & 5.0579 & TST & \\
\hline CHEMBL1469425 & 688267 & 6.2 & 5.0495 & TRN & \\
\hline CHEMBL1339816 & 688267 & 4.25 & 5.0611 & TRN & \\
\hline CHEMBL568416 & 688267 & 5.75 & 5.05399 & 9999999999 & TRN \\
\hline CHEMBL1361765 & 688267 & 4.65 & 5.0349 & TST & \\
\hline CHEMBL1436676 & 688267 & 5.55 & 5.0244 & TRN & \\
\hline CHEMBL1328027 & 688267 & 4.55 & 5.019 & TRN & \\
\hline CHEMBL1455587 & 688267 & 6.15 & 5.1085 & TRN & \\
\hline CHEMBL1411042 & 688267 & 5.45 & 5.0819 & TRN & \\
\hline CHEMBL1592445 & 688267 & 5.2 & 5.105 & TRN & \\
\hline CHEMBL1550125 & 688267 & 4.5 & 4.9826 & TRN & \\
\hline CHEMBL1457113 & 688267 & 4.05 & 5.104 & TST & \\
\hline CHEMBL1474590 & 688267 & 5.95 & 5.058 & TRN & \\
\hline CHEMBL3207469 & 688267 & 5.6 & 5.0783 & TRN & \\
\hline CHEMBL1603379 & 688267 & 6.2 & 5.0353 & TRN & \\
\hline CHEMBL1325780 & 688267 & 4.9 & 4.9767 & TRN & \\
\hline CHEMBL1554261 & 688267 & 5.75 & 5.0648 & TST & \\
\hline CHEMBL1397584 & 688267 & 5.8 & 5.0336 & TST & \\
\hline CHEMBL1400836 & 688267 & 4.25 & 5.1188 & TRN & \\
\hline CHEMBL1482712 & 688267 & 4.35 & 5.0177 & TRN & \\
\hline CHEMBL1538687 & 688267 & 4.35 & 5.0871 & TRN & \\
\hline CHEMBL1397844 & 688267 & 6.2 & 5.1177 & TRN & \\
\hline CHEMBL1369642 & 688267 & 5.35 & 5.0477 & TRN & \\
\hline CHEMBL1478258 & 688267 & 5.75 & 5.0111 & TST & \\
\hline CHEMBL 26655 & 688267 & 6.2 & 5.0539 & 9999999999 & TRN \\
\hline CHEMBL1327670 & 688267 & 4.05 & 5.0608 & TRN & \\
\hline CHEMBL1329992 & 688267 & 4.0 & 5.0322 & TRN & \\
\hline CHEMBL1430279 & 688267 & 4.05 & 5.025 & TRN & \\
\hline CHEMBL1366021 & 688267 & 4.15 & 5.0227 & TRN & \\
\hline CHEMBL1484034 & 688267 & 5.5 & 5.0917 & TRN & \\
\hline CHEMBL1388357 & 688267 & 5.85 & 5.0106 & TRN & \\
\hline CHEMBL1392339 & 688267 & 4.65 & 5.0355 & TRN & \\
\hline CHEMBL1538651 & 688267 & 4.6 & 5.0205 & TRN & \\
\hline CHEMBL1450990 & 688267 & 4.45 & 5.0419 & TRN & \\
\hline CHEMBL1322975 & 688267 & 5.9 & 5.1109 & TRN & \\
\hline CHEMBL1609458 & 688267 & 5.2 & 5.1111 & TRN & \\
\hline CHEMBL1600661 & 688267 & 5.65 & 5.0498 & TST & \\
\hline CHEMBL1394363 & 688267 & 6.15 & 5.1513 & TRN & \\
\hline CHEMBL1406813 & 688267 & 5.65 & 5.0123 & TRN & \\
\hline & & & & 17515 & \\
\hline
\end{tabular}




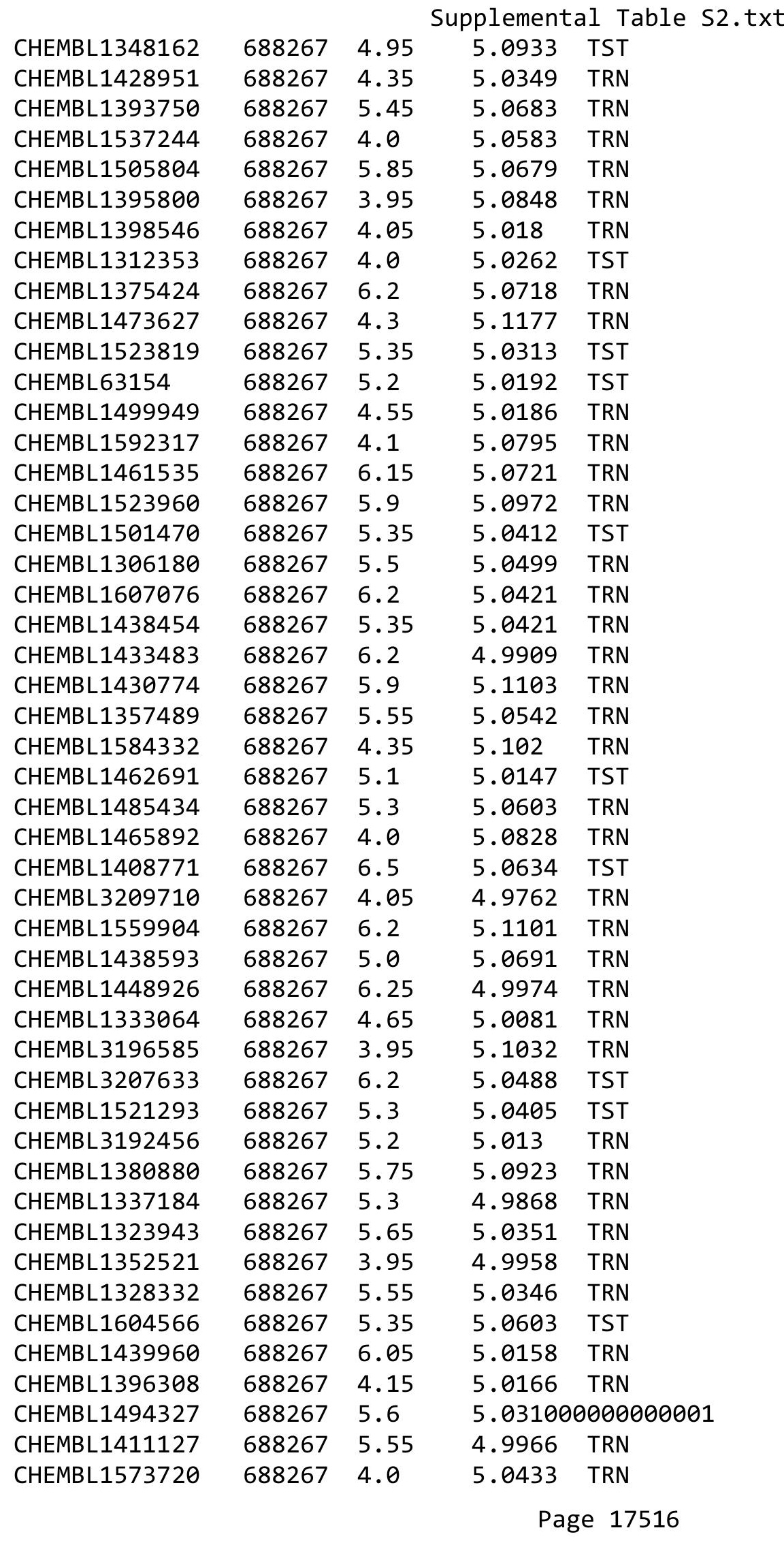




\begin{tabular}{|c|c|c|c|c|c|}
\hline \multicolumn{6}{|c|}{ Supplemental Table S2.txt } \\
\hline CHEMBL1534780 & 688267 & 5.05 & 5.0705 & TRN & \\
\hline CHEMBL1315709 & 688267 & 3.95 & 5.1278 & TRN & \\
\hline CHEMBL1573836 & 688267 & 5.3 & 5.0791 & TRN & \\
\hline CHEMBL1491550 & 688267 & 6.2 & 5.0744 & TST & \\
\hline CHEMBL1376693 & 688267 & 6.2 & 5.0571 & TRN & \\
\hline CHEMBL1436002 & 688267 & 4.5 & 5.0679 & TRN & \\
\hline CHEMBL1386274 & 688267 & 6.2 & 5.0806 & TRN & \\
\hline CHEMBL1587683 & 688267 & 4.25 & 5.0212 & TRN & \\
\hline CHEMBL1328490 & 688267 & 6.2 & 5.0497 & TST & \\
\hline CHEMBL3209312 & 688267 & 5.55 & 5.0471 & TRN & \\
\hline CHEMBL1568424 & 688267 & 4.65 & 5.0907 & TST & \\
\hline CHEMBL 3194938 & 688267 & 5.9 & 5.0271 & TST & \\
\hline CHEMBL1565026 & 688267 & 5.9 & 5.0722 & TRN & \\
\hline CHEMBL1380148 & 688267 & 5.25 & 5.0921 & TRN & \\
\hline CHEMBL1557470 & 688267 & 5.55 & 5.0093 & TRN & \\
\hline CHEMBL1535890 & 688267 & 4.05 & 5.0474 & TRN & \\
\hline CHEMBL1503922 & 688267 & 5.2 & 4.9832 & TST & \\
\hline CHEMBL1450589 & 688267 & 4.0 & 5.0038 & TRN & \\
\hline CHEMBL1457505 & 688267 & 4.0 & 5.0374 & TRN & \\
\hline CHEMBL1330862 & 688267 & 4.1 & 5.0412 & TRN & \\
\hline CHEMBL1609694 & 688267 & 6.2 & 5.0891 & TRN & \\
\hline CHEMBL1255647 & 688267 & 5.3 & 5.0238 & TST & \\
\hline CHEMBL3208807 & 688267 & 5.85 & 4.9783 & TST & \\
\hline CHEMBL1321902 & 688267 & 4.0 & 5.1365 & TRN & \\
\hline CHEMBL1348715 & 688267 & 4.35 & 5.0766 & TRN & \\
\hline CHEMBL1592910 & 688267 & 4.9 & 5.0737 & TRN & \\
\hline CHEMBL1312327 & 688267 & 4.15 & 5.0167 & TRN & \\
\hline CHEMBL1436911 & 688267 & 4.0 & 5.0526 & TRN & \\
\hline CHEMBL1571723 & 688267 & 5.8 & 5.106 & TRN & \\
\hline CHEMBL1546895 & 688267 & 4.1 & 4.9896 & TRN & \\
\hline CHEMBL 2004624 & 688267 & 4.5 & 5.0163 & TRN & \\
\hline CHEMBL1589800 & 688267 & 4.3 & 5.07600 & 00000000005 & TST \\
\hline CHEMBL186124 & 688267 & 5.0 & 5.0278 & TRN & \\
\hline CHEMBL1368248 & 688267 & 4.4 & 5.043 & TST & \\
\hline CHEMBL1385469 & 688267 & 4.0 & 5.0453 & TST & \\
\hline CHEMBL1324271 & 688267 & 4.5 & 5.0901 & TRN & \\
\hline CHEMBL1461377 & 688267 & 4.35 & 5.0879 & TRN & \\
\hline CHEMBL568636 & 688267 & 6.15 & 5.0265 & TRN & \\
\hline CHEMBL 3212308 & 688267 & 3.95 & 5.02800 & 20000000005 & TRN \\
\hline CHEMBL1598945 & 688267 & 4.15 & 5.0209 & TRN & \\
\hline CHEMBL1542697 & 688267 & 6.15 & 5.0981 & TST & \\
\hline CHEMBL1564874 & 688267 & 6.2 & 5.0946 & TRN & \\
\hline CHEMBL1377534 & 688267 & 5.35 & 4.9745 & TRN & \\
\hline CHEMBL1412027 & 688267 & 4.4 & 5.0481 & TST & \\
\hline CHEMBL409315 & 688267 & 4.4 & 5.0041 & TRN & \\
\hline CHEMBL1966612 & 688267 & 5.95 & 5.0329 & TRN & \\
\hline CHEMBL3196597 & 688267 & 6.2 & 5.0208 & TRN & \\
\hline CHEMBL1566406 & 688267 & 5.05 & 5.0263 & TRN & \\
\hline
\end{tabular}




\begin{tabular}{|c|c|c|c|c|c|}
\hline \multicolumn{6}{|c|}{ Supplemental Table S2.txt } \\
\hline CHEMBL1532669 & 688267 & 5.9 & 5.1093 & TRN & \\
\hline CHEMBL1609888 & 688267 & 4.35 & 5.0311 & TRN & \\
\hline CHEMBL1426527 & 688267 & 5.0 & 5.1353 & TRN & \\
\hline CHEMBL1363567 & 688267 & 5.3 & 5.0542 & TST & \\
\hline CHEMBL1537717 & 688267 & 6.15 & 5.0481 & TRN & \\
\hline CHEMBL1344821 & 688267 & 6.15 & 5.063 & TST & \\
\hline CHEMBL1426148 & 688267 & 4.3 & 5.04899 & 99999999995 & TRN \\
\hline CHEMBL3207935 & 688267 & 5.25 & 5.0632 & TRN & \\
\hline CHEMBL1602956 & 688267 & 5.45 & 5.0179 & TRN & \\
\hline CHEMBL1439619 & 688267 & 4.0 & 5.011 & TST & \\
\hline CHEMBL1569925 & 688267 & 4.0 & 5.0667 & TRN & \\
\hline CHEMBL1087885 & 688267 & 5.5 & 5.0784 & TRN & \\
\hline CHEMBL1431558 & 688267 & 5.35 & 5.0272 & TRN & \\
\hline CHEMBL1550593 & 688267 & 5.35 & 5.0049 & TST & \\
\hline CHEMBL1408607 & 688267 & 4.55 & 5.0815 & TRN & \\
\hline CHEMBL1448753 & 688267 & 4.05 & 5.0554 & TRN & \\
\hline CHEMBL1377675 & 688267 & 4.0 & 5.0688 & TRN & \\
\hline CHEMBL1342256 & 688267 & 4.35 & 5.0536 & TRN & \\
\hline CHEMBL1304461 & 688267 & 5.95 & 5.0844 & TRN & \\
\hline CHEMBL 3210727 & 688267 & 4.85 & 4.9943 & TST & \\
\hline CHEMBL1364295 & 688267 & 5.05 & 5.0115 & TRN & \\
\hline CHEMBL1516143 & 688267 & 3.95 & 5.1335 & TRN & \\
\hline CHEMBL1438578 & 688267 & 6.5 & 5.0928 & TST & \\
\hline CHEMBL1985660 & 688267 & 5.4 & 5.0148 & TRN & \\
\hline CHEMBL1359035 & 688267 & 5.3 & 5.0283 & TRN & \\
\hline CHEMBL1402921 & 688267 & 5.4 & 5.053 & TRN & \\
\hline CHEMBL1427601 & 688267 & 6.2 & 5.1144 & TST & \\
\hline CHEMBL1437145 & 688267 & 4.05 & 5.0047 & TRN & \\
\hline CHEMBL1359668 & 688267 & 6.8 & 5.0567 & TST & \\
\hline CHEMBL1319371 & 688267 & 4.0 & 5.0606 & TST & \\
\hline CHEMBL1560719 & 688267 & 6.6499 & 5.1006 & TRN & \\
\hline CHEMBL1532826 & 688267 & 4.6 & 5.0194 & TST & \\
\hline CHEMBL1505202 & 688267 & 4.25 & 5.0511 & TST & \\
\hline CHEMBL1533747 & 688267 & 6.25 & 5.079 & TRN & \\
\hline CHEMBL1431297 & 688267 & 4.4 & 5.0728 & TRN & \\
\hline CHEMBL1445658 & 688267 & 4.0 & 5.0629 & TST & \\
\hline CHEMBL1503829 & 688267 & 4.05 & 5.0969 & TST & \\
\hline CHEMBL1596616 & 688267 & 4.8 & 5.0927 & TST & \\
\hline CHEMBL1316277 & 688267 & 4.15 & 5.1604 & TRN & \\
\hline CHEMBL1425287 & 688267 & 5.3 & 5.0326 & TST & \\
\hline CHEMBL1448492 & 688267 & 4.85 & 5.0288 & TRN & \\
\hline CHEMBL1405153 & 688267 & 5.4 & 5.048 & TRN & \\
\hline CHEMBL1560641 & 688267 & 6.2 & 5.0385 & TST & \\
\hline CHEMBL1355913 & 688267 & 4.0 & 5.0742 & TRN & \\
\hline CHEMBL1421550 & 688267 & 5.55 & 5.0247 & TRN & \\
\hline CHEMBL1326462 & 688267 & 6.15 & 5.142 & TRN & \\
\hline CHEMBL1306383 & 688267 & 6.0 & 5.1095 & TRN & \\
\hline CHEMBL1375441 & 688267 & 4.05 & 5.0378 & TST & \\
\hline
\end{tabular}




\begin{tabular}{|c|c|c|c|c|}
\hline & & & pplement & $\mathrm{a} \perp \mathrm{Ta}$ \\
\hline CHEMBL1383373 & 688267 & 4.0 & 5.0612 & TST \\
\hline CHEMBL1585284 & 688267 & 6.2 & 4.9997 & TRN \\
\hline CHEMBL1302660 & 688267 & 3.9 & 5.0198 & TRN \\
\hline CHEMBL3190711 & 688267 & 5.4 & 5.0536 & TRN \\
\hline CHEMBL1492609 & 688267 & 4.25 & 5.1325 & TST \\
\hline CHEMBL1549175 & 688267 & 4.6 & 5.0333 & TRN \\
\hline CHEMBL1572529 & 688267 & 5.85 & 5.0851 & TST \\
\hline CHEMBL1363818 & 688267 & 4.55 & 5.0502 & TRN \\
\hline CHEMBL1302369 & 688267 & 4.45 & 5.0451 & TST \\
\hline CHEMBL1413388 & 688267 & 4.9 & 5.0441 & TRN \\
\hline CHEMBL1562183 & 688267 & 6.25 & 5.0604 & TRN \\
\hline CHEMBL1439474 & 688267 & 5.75 & 5.0728 & TRN \\
\hline CHEMBL1556130 & 688267 & 5.25 & 5.1198 & TRN \\
\hline CHEMBL1411273 & 688267 & 4.0 & 5.1178 & TRN \\
\hline CHEMBL1414976 & 688267 & 4.05 & 5.0671 & TRN \\
\hline CHEMBL1496234 & 688267 & 4.2 & 5.0556 & TST \\
\hline CHEMBL1558118 & 688267 & 5.8 & 4.9906 & TST \\
\hline CHEMBL347547 & 688267 & 4.3 & 5.0366 & TRN \\
\hline CHEMBL1500881 & 688267 & 3.95 & 5.1324 & TRN \\
\hline CHEMBL3214469 & 688267 & 5.15 & 5.0224 & TRN \\
\hline CHEMBL1582003 & 688267 & 4.65 & 5.0351 & TRN \\
\hline CHEMBL1437220 & 688267 & 3.95 & 5.0103 & TRN \\
\hline CHEMBL3213246 & 688267 & 5.0 & 5.0599 & TRN \\
\hline CHEMBL1566932 & 688267 & 6.2 & 5.0821 & TST \\
\hline CHEMBL1318943 & 688267 & 4.3 & 5.0451 & TST \\
\hline CHEMBL 2003195 & 688267 & 4.1 & 4.9823 & TST \\
\hline CHEMBL1476441 & 688267 & 6.0 & 5.0412 & TRN \\
\hline CHEMBL1301048 & 688267 & 4.35 & 5.0271 & TRN \\
\hline CHEMBL1446251 & 688267 & 4.35 & 5.0164 & TRN \\
\hline CHEMBL1310601 & 688267 & 4.65 & 5.0126 & TRN \\
\hline CHEMBL1317544 & 688267 & 6.2 & 5.0981 & TRN \\
\hline CHEMBL1357881 & 688267 & 6.15 & 5.0993 & TRN \\
\hline CHEMBL1433904 & 688267 & 3.95 & 5.0369 & TRN \\
\hline CHEMBL1380565 & 688267 & 4.65 & 5.0121 & TRN \\
\hline CHEMBL1309173 & 688267 & 4.2 & 5.0806 & TRN \\
\hline CHEMBL1493426 & 688267 & 6.2 & 5.091 & TST \\
\hline CHEMBL1383572 & 688267 & 4.95 & 5.0501 & TST \\
\hline CHEMBL 1355776 & 688267 & 6.05 & 5.0242 & TRN \\
\hline CHEMBL1465374 & 688267 & 5.25 & 4.9923 & TST \\
\hline CHEMBL1507970 & 688267 & 6.25 & 5.037 & TRN \\
\hline CHEMBL1374850 & 688267 & 6.45 & 5.0384 & TRN \\
\hline CHEMBL1585683 & 688267 & 4.8 & 5.073 & TRN \\
\hline CHEMBL1354018 & 688267 & 6.2 & 5.0559 & TRN \\
\hline CHEMBL1525651 & 688267 & 5.3 & 5.0135 & TRN \\
\hline CHEMBL1544004 & 688267 & 4.3 & 5.1132 & TRN \\
\hline CHEMBL1506043 & 688267 & 4.0 & 5.0948 & TRN \\
\hline CHEMBL1547857 & 688267 & 4.6 & 5.0753 & TRN \\
\hline CHEMBL1542901 & 688267 & 4.3 & 5.1274 & TRN \\
\hline
\end{tabular}




\begin{tabular}{|c|c|c|c|c|c|}
\hline \multicolumn{6}{|c|}{ Supplemental Table S2.txt } \\
\hline CHEMBL1500988 & 688267 & 4.05 & 5.0899 & TST & \\
\hline CHEMBL1380060 & 688267 & 6.2 & 5.0925 & TRN & \\
\hline CHEMBL1389534 & 688267 & 5.85 & 5.0182 & TST & \\
\hline CHEMBL1435352 & 688267 & 4.0 & 5.0731 & TRN & \\
\hline CHEMBL1522617 & 688267 & 4.75 & 4.9834 & TRN & \\
\hline CHEMBL1600749 & 688267 & 4.05 & 4.9478 & TRN & \\
\hline CHEMBL1572456 & 688267 & 4.6 & 5.0654 & TRN & \\
\hline CHEMBL1481643 & 688267 & 5.4 & 5.0622 & TRN & \\
\hline CHEMBL1544231 & 688267 & 5.3 & 5.1018 & TRN & \\
\hline CHEMBL1358639 & 688267 & 6.25 & 5.0296 & TRN & \\
\hline CHEMBL1601934 & 688267 & 5.2 & 5.0898 & TRN & \\
\hline CHEMBL1450040 & 688267 & 4.35 & 4.9848 & TRN & \\
\hline CHEMBL1483118 & 688267 & 4.4 & 5.0727 & TRN & \\
\hline CHEMBL1317362 & 688267 & 5.3 & 5.0669 & TRN & \\
\hline CHEMBL1326099 & 688267 & 6.05 & 5.0007 & TRN & \\
\hline CHEMBL3392061 & 688267 & 3.95 & 5.0055 & TST & \\
\hline CHEMBL1515067 & 688267 & 5.3 & 5.0198 & TST & \\
\hline CHEMBL1299193 & 688267 & 5.75 & 5.0352 & TST & \\
\hline CHEMBL1410756 & 688267 & 6.5 & 5.0275 & TRN & \\
\hline CHEMBL1373019 & 688267 & 6.15 & 5.0609 & TST & \\
\hline CHEMBL1341136 & 688267 & 6.2 & 5.0907 & TST & \\
\hline CHEMBL1383711 & 688267 & 4.4 & 5.0194 & TRN & \\
\hline CHEMBL1313257 & 688267 & 5.45 & 5.0507 & TRN & \\
\hline CHEMBL1341432 & 688267 & 5.55 & 5.0575 & TRN & \\
\hline CHEMBL1306658 & 688267 & 4.05 & 5.0015 & TRN & \\
\hline CHEMBL1609554 & 688267 & 6.2 & 5.0559 & TST & \\
\hline CHEMBL1542007 & 688267 & 4.35 & 5.0428 & TRN & \\
\hline CHEMBL1583061 & 688267 & 5.85 & 5.0207 & TST & \\
\hline CHEMBL1591283 & 688267 & 3.95 & 5.0271 & TRN & \\
\hline CHEMBL 3194099 & 688267 & 5.6 & 5.0576 & TRN & \\
\hline CHEMBL1498251 & 688267 & 4.0 & 4.958 & TRN & \\
\hline CHEMBL1518392 & 688267 & 5.85 & 5.0035 & TRN & \\
\hline CHEMBL1514224 & 688267 & 4.0 & 4.97199 & 99999999995 & TRN \\
\hline CHEMBL1482295 & 688267 & 7.4001 & 5.0585 & TRN & \\
\hline CHEMBL1392288 & 688267 & 5.45 & 5.0363 & TRN & \\
\hline CHEMBL1551836 & 688267 & 4.4 & 5.0184 & TRN & \\
\hline CHEMBL1519736 & 688267 & 4.05 & 5.1465 & TRN & \\
\hline CHEMBL1607669 & 688267 & 4.65 & 5.095 & TRN & \\
\hline CHEMBL1477620 & 688267 & 6.2 & 5.0297 & TRN & \\
\hline CHEMBL 3212080 & 688267 & 6.2 & 5.0118 & TRN & \\
\hline CHEMBL1336382 & 688267 & 6.2 & 5.0396 & TRN & \\
\hline CHEMBL1425329 & 688267 & 4.35 & 5.0554 & TRN & \\
\hline CHEMBL1486621 & 688267 & 4.05 & 5.1245 & TRN & \\
\hline CHEMBL3213716 & 688267 & 4.35 & 4.9812 & TST & \\
\hline CHEMBL1360427 & 688267 & 4.45 & 5.1108 & TRN & \\
\hline CHEMBL1487715 & 688267 & 6.0 & 5.0535 & TRN & \\
\hline CHEMBL1313656 & 688267 & 5.05 & 5.1164 & TRN & \\
\hline CHEMBL243089 & 688267 & 5.45 & 4.9941 & TST & \\
\hline
\end{tabular}




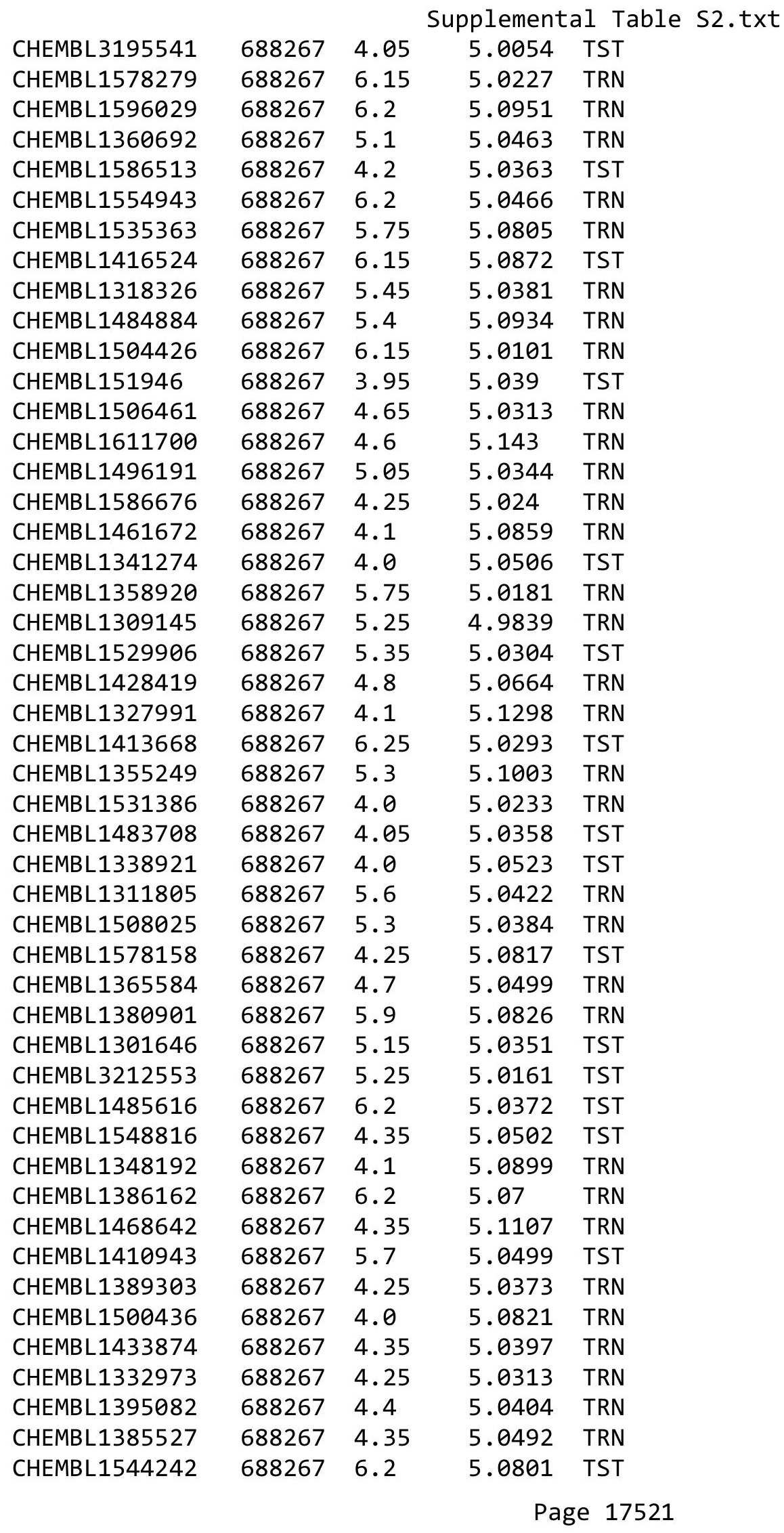




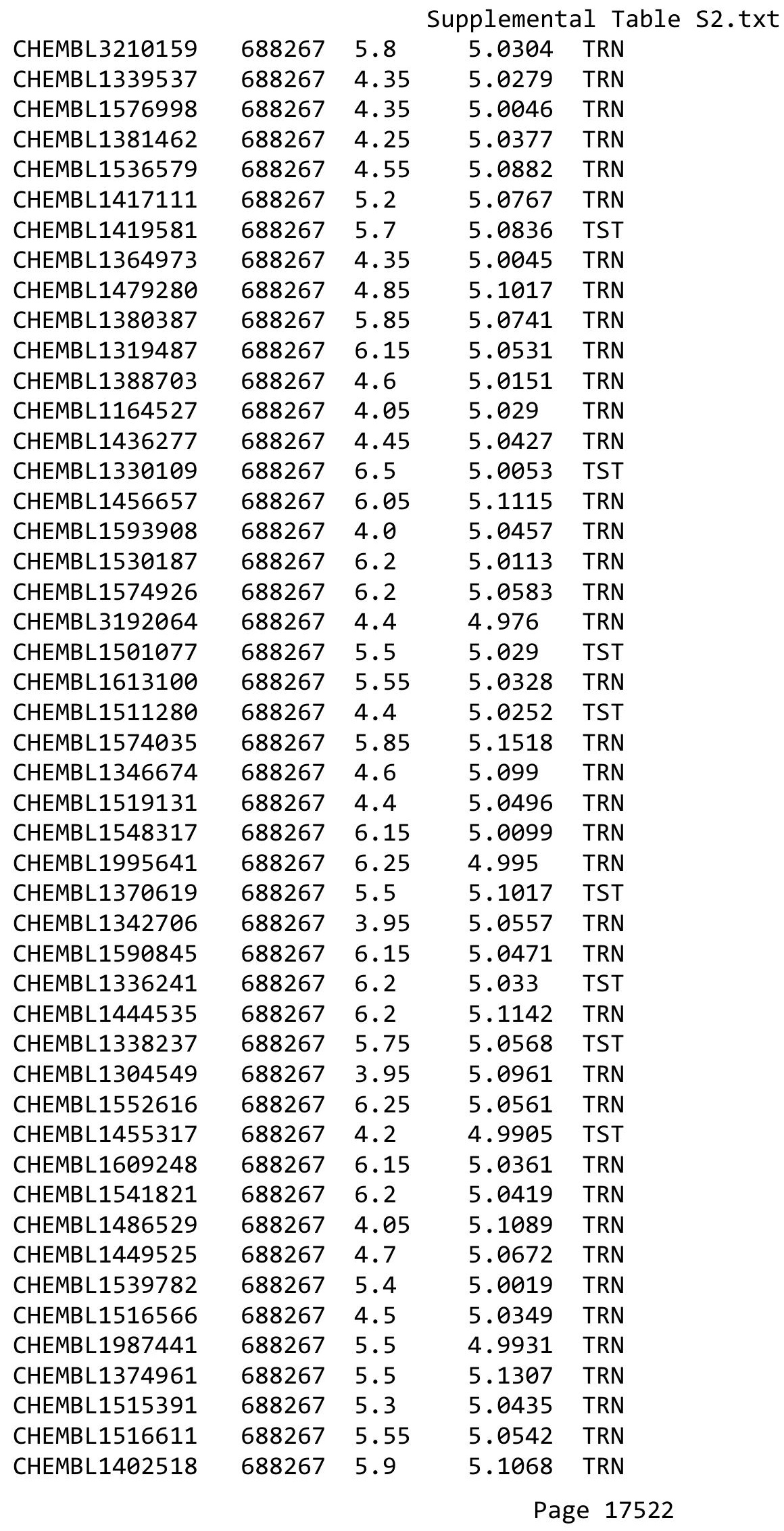




\begin{tabular}{|c|c|c|c|c|c|}
\hline \multicolumn{6}{|c|}{ Supplemental Table S2.txt } \\
\hline CHEMBL1495952 & 688267 & 6.2 & 5.0859 & TRN & \\
\hline CHEMBL1437243 & 688267 & 4.0 & 5.0493 & TRN & \\
\hline CHEMBL1599034 & 688267 & 5.35 & 5.0401 & TRN & \\
\hline CHEMBL1536811 & 688267 & 6.15 & 5.0025 & TRN & \\
\hline CHEMBL1302139 & 688267 & 4.0 & 5.0836 & TRN & \\
\hline CHEMBL1502787 & 688267 & 6.25 & 4.9996 & TRN & \\
\hline CHEMBL1315082 & 688267 & 6.2 & 5.1219 & TRN & \\
\hline CHEMBL1486701 & 688267 & 6.25 & 5.0974 & TRN & \\
\hline CHEMBL1340524 & 688267 & 4.3 & 5.0895 & TST & \\
\hline CHEMBL1450555 & 688267 & 6.2 & 4.9755 & TRN & \\
\hline CHEMBL261185 & 688267 & 6.2 & 4.9843 & TRN & \\
\hline CHEMBL1494472 & 688267 & 4.8 & 5.0292 & TRN & \\
\hline CHEMBL1589594 & 688267 & 6.1 & 5.1161 & TRN & \\
\hline CHEMBL1989210 & 688267 & 4.15 & 5.0433 & TST & \\
\hline CHEMBL1371518 & 688267 & 5.2 & 5.1299 & TRN & \\
\hline CHEMBL1321384 & 688267 & 5.95 & 5.0541 & TRN & \\
\hline CHEMBL1336433 & 688267 & 4.4 & 5.0105 & TST & \\
\hline CHEMBL1460560 & 688267 & 4.15 & 5.0931 & TRN & \\
\hline CHEMBL1416479 & 688267 & 3.95 & 5.1131 & TRN & \\
\hline CHEMBL1325785 & 688267 & 4.4 & 5.0661 & TST & \\
\hline CHEMBL1434808 & 688267 & 4.15 & 5.022 & TRN & \\
\hline CHEMBL1483824 & 688267 & 5.5 & 5.0433 & TRN & \\
\hline CHEMBL1318294 & 688267 & 6.1 & 5.0556 & TRN & \\
\hline CHEMBL1489005 & 688267 & 5.8 & 5.0012 & TRN & \\
\hline CHEMBL1598731 & 688267 & 4.6 & 5.0979 & TRN & \\
\hline CHEMBL1558295 & 688267 & 5.6 & 5.0586 & TRN & \\
\hline CHEMBL1300509 & 688267 & 4.05 & 5.1326 & TST & \\
\hline CHEMBL1549785 & 688267 & 4.6 & 5.0227 & TRN & \\
\hline CHEMBL1400816 & 688267 & 5.45 & 5.0358 & TST & \\
\hline CHEMBL1604625 & 688267 & 4.6 & 5.05399 & 9999999999 & TRN \\
\hline CHEMBL1582389 & 688267 & 5.5 & 5.1419 & TRN & \\
\hline CHEMBL1453793 & 688267 & 4.4 & 5.1248 & TRN & \\
\hline CHEMBL1605085 & 688267 & 6.2 & 5.1419 & TRN & \\
\hline CHEMBL1566477 & 688267 & 5.1 & 5.1086 & TRN & \\
\hline CHEMBL1547259 & 688267 & 6.25 & 5.0642 & TST & \\
\hline CHEMBL1590471 & 688267 & 6.25 & 5.0413 & TRN & \\
\hline CHEMBL1397294 & 688267 & 5.65 & 5.0505 & TRN & \\
\hline CHEMBL1513350 & 688267 & 5.25 & 5.086 & TRN & \\
\hline CHEMBL1602249 & 688267 & 6.15 & 5.0696 & TST & \\
\hline CHEMBL1602191 & 688267 & 4.05 & 5.0816 & TRN & \\
\hline CHEMBL1305919 & 688267 & 4.35 & 5.0251 & TST & \\
\hline CHEMBL1382428 & 688267 & 5.8 & 5.0193 & TRN & \\
\hline CHEMBL1552979 & 688267 & 6.2 & 5.03 & TRN & \\
\hline CHEMBL1608776 & 688267 & 6.2 & 4.9752 & TRN & \\
\hline CHEMBL405072 & 688267 & 4.05 & 4.9836 & TRN & \\
\hline CHEMBL1529860 & 688267 & 6.15 & 5.0346 & TRN & \\
\hline CHEMBL3191598 & 688267 & 5.25 & 4.9654 & TRN & \\
\hline CHEMBL1470856 & 688267 & 5.55 & 5.1088 & TST & \\
\hline
\end{tabular}




\begin{tabular}{|c|c|c|c|c|c|}
\hline \multicolumn{6}{|c|}{ Supplemental Table s2.txt } \\
\hline CHEMBL1523521 & 688267 & 4.0 & 5.0694 & TRN & \\
\hline CHEMBL1550518 & 688267 & 4.35 & 5.0517 & TRN & \\
\hline CHEMBL1965126 & 688267 & 4.0 & 5.0183 & TRN & \\
\hline CHEMBL592123 & 688267 & 6.2 & 5.0863 & TRN & \\
\hline CHEMBL1497171 & 688267 & 5.4 & 5.0759 & TST & \\
\hline CHEMBL1566843 & 688267 & 5.0 & 5.0443 & TST & \\
\hline CHEMBL1434065 & 688267 & 3.95 & 5.0206 & TRN & \\
\hline CHEMBL1465756 & 688267 & 4.0 & 4.9878 & TRN & \\
\hline CHEMBL1532285 & 688267 & 5.75 & 5.0647 & TST & \\
\hline CHEMBL1395466 & 688267 & 4.05 & 5.1333 & TRN & \\
\hline CHEMBL1511809 & 688267 & 4.4 & 4.9981 & TRN & \\
\hline CHEMBL1572270 & 688267 & 4.3 & 5.0548 & TRN & \\
\hline CHEMBL1319824 & 688267 & 4.25 & 5.0631 & TRN & \\
\hline CHEMBL1587836 & 688267 & 4.15 & 5.0173 & TST & \\
\hline CHEMBL1440430 & 688267 & 6.15 & 5.0615 & TRN & \\
\hline CHEMBL1448298 & 688267 & 5.3 & 5.0693 & TST & \\
\hline CHEMBL1560214 & 688267 & 4.1 & 5.0019 & TRN & \\
\hline CHEMBL592588 & 688267 & 6.2 & 5.0263 & TST & \\
\hline CHEMBL410533 & 688267 & 6.2 & 5.0693 & TRN & \\
\hline CHEMBL1345028 & 688267 & 5.05 & 5.0277 & TST & \\
\hline CHEMBL1553695 & 688267 & 4.55 & 5.0831 & TRN & \\
\hline CHEMBL1322978 & 688267 & 4.4 & 5.0159 & TRN & \\
\hline CHEMBL1460494 & 688267 & 4.3 & 5.0715 & TRN & \\
\hline CHEMBL1466527 & 688267 & 5.45 & 5.0218 & TRN & \\
\hline CHEMBL1462220 & 688267 & 4.0 & 5.0305 & TRN & \\
\hline CHEMBL1551452 & 688267 & 5.3 & 5.0214 & TRN & \\
\hline CHEMBL1415430 & 688267 & 4.1 & 5.0331 & TRN & \\
\hline CHEMBL1457155 & 688267 & 4.0 & 5.1162 & TST & \\
\hline CHEMBL1502356 & 688267 & 4.5 & 5.0541 & TRN & \\
\hline CHEMBL1527794 & 688267 & 4.05 & 5.0337 & TST & \\
\hline CHEMBL1304152 & 688267 & 6.2 & 5.0442 & TST & \\
\hline CHEMBL1375964 & 688267 & 4.45 & 5.0413 & TST & \\
\hline CHEMBL1590986 & 688267 & 6.0 & 5.0341 & TST & \\
\hline CHEMBL1462272 & 688267 & 4.05 & 5.0008 & TST & \\
\hline CHEMBL3197145 & 688267 & 5.8 & 4.9975 & TRN & \\
\hline CHEMBL1992283 & 688267 & 5.35 & 5.0366 & TRN & \\
\hline CHEMBL1595816 & 688267 & 5.6 & 5.00899 & 99999999995 & TRN \\
\hline CHEMBL1381853 & 688267 & 5.0 & 5.1082 & TST & \\
\hline CHEMBL1375520 & 688267 & 5.35 & 5.0493 & TRN & \\
\hline CHEMBL1497571 & 688267 & 5.6 & 5.037 & TST & \\
\hline CHEMBL1469092 & 688267 & 4.6 & 5.0556 & TST & \\
\hline CHEMBL1320968 & 688267 & 4.35 & 5.03600 & 00000000005 & TRN \\
\hline CHEMBL1435942 & 688267 & 5.35 & 5.04899 & 99999999995 & TST \\
\hline CHEMBL1304892 & 688267 & 5.8 & 5.0884 & TRN & \\
\hline CHEMBL1448752 & 688267 & 4.6 & 5.1513 & TRN & \\
\hline CHEMBL1437409 & 688267 & 4.2 & 5.1565 & TRN & \\
\hline CHEMBL1591473 & 688267 & 4.05 & 5.0429 & TRN & \\
\hline CHEMBL1382689 & 688267 & 5.35 & 5.0477 & TRN & \\
\hline
\end{tabular}




\begin{tabular}{|c|c|c|c|c|}
\hline \multicolumn{5}{|c|}{ Supplemental Table S2.txt } \\
\hline CHEMBL1557136 & 688267 & 5.1 & 5.0047 & TST \\
\hline CHEMBL1487711 & 688267 & 5.2 & 5.1022 & TRN \\
\hline CHEMBL505863 & 688267 & 6.2 & 5.1053 & TST \\
\hline CHEMBL1339112 & 688267 & 4.05 & 5.1136 & TST \\
\hline CHEMBL1577214 & 688267 & 6.05 & 5.0689 & TST \\
\hline CHEMBL3213316 & 688267 & 4.75 & 5.0481 & TST \\
\hline CHEMBL1460682 & 688267 & 4.2 & 5.0161 & TST \\
\hline CHEMBL1352330 & 688267 & 4.4 & 5.1096 & TRN \\
\hline CHEMBL1486365 & 688267 & 4.1 & 5.0606 & TRN \\
\hline CHEMBL1538596 & 688267 & 4.75 & 5.0151 & TRN \\
\hline CHEMBL1508094 & 688267 & 5.5 & 5.072 & TRN \\
\hline CHEMBL1513109 & 688267 & 5.25 & 5.0723 & TRN \\
\hline CHEMBL1400568 & 688267 & 4.4 & 5.0708 & TST \\
\hline CHEMBL1312267 & 688267 & 5.35 & 5.0514 & TRN \\
\hline CHEMBL1396137 & 688267 & 4.05 & 4.9996 & TRN \\
\hline CHEMBL1299546 & 688267 & 5.65 & 5.0888 & TST \\
\hline CHEMBL3214267 & 688267 & 6.15 & 5.016 & TST \\
\hline CHEMBL1549912 & 688267 & 5.5 & 5.0873 & TRN \\
\hline CHEMBL1353296 & 688267 & 5.4 & 5.0508 & TRN \\
\hline CHEMBL1351302 & 688267 & 4.0 & 5.1234 & TST \\
\hline CHEMBL1567475 & 688267 & 4.6 & 4.9729 & TRN \\
\hline CHEMBL1434077 & 688267 & 6.2 & 5.0668 & TRN \\
\hline CHEMBL1505849 & 688267 & 4.2 & 5.0666 & TRN \\
\hline CHEMBL1580052 & 688267 & 6.25 & 5.0685 & TRN \\
\hline CHEMBL1516659 & 688267 & 4.35 & 5.088 & TRN \\
\hline CHEMBL1601676 & 688267 & 4.35 & 5.0745 & TRN \\
\hline CHEMBL1478021 & 688267 & 5.3 & 5.0591 & TRN \\
\hline CHEMBL1421007 & 688267 & 4.45 & 5.0705 & TRN \\
\hline CHEMBL1542743 & 688267 & 6.2 & 5.0557 & TRN \\
\hline CHEMBL1390084 & 688267 & 4.25 & 5.061 & TRN \\
\hline CHEMBL1356176 & 688267 & 4.0 & 5.0432 & TRN \\
\hline CHEMBL489947 & 688267 & 4.6 & 4.9919 & TRN \\
\hline CHEMBL1561657 & 688267 & 4.6 & 5.05 & TRN \\
\hline CHEMBL1597890 & 688267 & 4.5 & 5.083 & TRN \\
\hline CHEMBL1476473 & 688267 & 4.45 & 5.0673 & TRN \\
\hline CHEMBL1481415 & 688267 & 6.5 & 4.9891 & TRN \\
\hline CHEMBL1341144 & 688267 & 5.5 & 5.0543 & TRN \\
\hline CHEMBL1385800 & 688267 & 5.35 & 5.0325 & TST \\
\hline CHEMBL1442827 & 688267 & 4.05 & 5.0488 & TRN \\
\hline CHEMBL3212823 & 688267 & 4.1 & 5.0849 & TST \\
\hline CHEMBL1575934 & 688267 & 4.0 & 5.0659 & TRN \\
\hline CHEMBL1356338 & 688267 & 4.0 & 5.0113 & TST \\
\hline CHEMBL1317680 & 688267 & 6.0 & 5.0706 & TRN \\
\hline CHEMBL1595199 & 688267 & 3.95 & 5.0894 & TRN \\
\hline CHEMBL1383441 & 688267 & 4.1 & 5.0309 & TST \\
\hline CHEMBL1352041 & 688267 & 4.0 & 5.0952 & TST \\
\hline CHEMBL1385835 & 688267 & 4.7 & 5.0756 & TST \\
\hline CHEMBL1302951 & 688267 & 5.55 & 5.0884 & TRN \\
\hline
\end{tabular}




\begin{tabular}{|c|c|c|c|c|}
\hline \multicolumn{5}{|c|}{ Supplemental Table } \\
\hline CHEMBL1464227 & 688267 & 4.15 & 5.1516 & TRN \\
\hline CHEMBL1593620 & 688267 & 5.4 & 5.1278 & TRN \\
\hline CHEMBL1585944 & 688267 & 5.05 & 5.0619 & TST \\
\hline CHEMBL1315608 & 688267 & 5.7 & 5.0274 & TST \\
\hline CHEMBL1541483 & 688267 & 6.25 & 4.9916 & TST \\
\hline CHEMBL1324045 & 688267 & 5.1 & 5.1395 & TRN \\
\hline CHEMBL1329451 & 688267 & 4.5 & 5.1469 & TRN \\
\hline CHEMBL1534149 & 688267 & 4.25 & 5.0354 & TRN \\
\hline CHEMBL1347646 & 688267 & 4.0 & 5.0317 & TRN \\
\hline CHEMBL1433137 & 688267 & 4.05 & 5.0234 & TRN \\
\hline CHEMBL1557554 & 688267 & 4.65 & 5.037 & TRN \\
\hline CHEMBL1346729 & 688267 & 5.05 & 5.0524 & TRN \\
\hline CHEMBL1595755 & 688267 & 4.0 & 4.9873 & TST \\
\hline CHEMBL1438244 & 688267 & 6.15 & 5.0221 & TRN \\
\hline CHEMBL3213146 & 688267 & 6.2 & 5.0243 & TRN \\
\hline CHEMBL1523203 & 688267 & 4.75 & 5.0365 & TST \\
\hline CHEMBL1467290 & 688267 & 4.25 & 5.0997 & TST \\
\hline CHEMBL1594981 & 688267 & 5.8 & 5.0642 & TST \\
\hline CHEMBL1498052 & 688267 & 5.35 & 5.0171 & TRN \\
\hline CHEMBL1417909 & 688267 & 4.4 & 5.0326 & TRN \\
\hline CHEMBL1553586 & 688267 & 5.3 & 5.0949 & TRN \\
\hline CHEMBL1526009 & 688267 & 5.35 & 5.1166 & TST \\
\hline CHEMBL1380452 & 688267 & 5.05 & 5.0054 & TST \\
\hline CHEMBL1497616 & 688267 & 5.5 & 5.0886 & TST \\
\hline CHEMBL1546771 & 688267 & 3.95 & 5.0415 & TRN \\
\hline CHEMBL1596973 & 688267 & 6.25 & 5.0407 & TRN \\
\hline CHEMBL1434514 & 688267 & 3.95 & 5.0187 & TRN \\
\hline CHEMBL1462618 & 688267 & 4.0 & 5.0233 & TRN \\
\hline CHEMBL1493989 & 688267 & 5.7 & 5.0963 & TRN \\
\hline CHEMBL1373185 & 688267 & 6.25 & 5.1071 & TRN \\
\hline CHEMBL3192815 & 688267 & 6.25 & 5.0181 & TRN \\
\hline CHEMBL1375995 & 688267 & 4.35 & 4.9847 & TRN \\
\hline CHEMBL1506829 & 688267 & 5.0 & 5.0834 & TST \\
\hline CHEMBL1314216 & 688267 & 5.45 & 5.0721 & TRN \\
\hline CHEMBL3210186 & 688267 & 6.25 & 5.0046 & TRN \\
\hline CHEMBL1487411 & 688267 & 6.2 & 5.1033 & TRN \\
\hline CHEMBL 1437252 & 688267 & 6.2 & 5.0539 & TRN \\
\hline CHEMBL1459681 & 688267 & 6.2 & 5.0225 & TRN \\
\hline CHEMBL1443154 & 688267 & 6.25 & 5.0354 & TRN \\
\hline CHEMBL1601297 & 688267 & 6.2 & 4.975 & TRN \\
\hline CHEMBL1461999 & 688267 & 4.7 & 5.0559 & TRN \\
\hline CHEMBL1513879 & 688267 & 4.4 & 5.007 & TRN \\
\hline CHEMBL1307002 & 688267 & 4.0 & 5.0407 & TRN \\
\hline CHEMBL1477101 & 688267 & 4.0 & 4.9891 & TRN \\
\hline CHEMBL1484910 & 688267 & 4.55 & 5.088 & TRN \\
\hline CHEMBL1491254 & 688267 & 4.3 & 5.0745 & TRN \\
\hline CHEMBL1356290 & 688267 & 6.15 & 5.1039 & TRN \\
\hline CHEMBL1489996 & 688267 & 6.15 & 5.0915 & TRN \\
\hline
\end{tabular}




\begin{tabular}{|c|c|c|c|c|}
\hline \multicolumn{5}{|c|}{ Supplemental Table S2.txt } \\
\hline CHEMBL1509198 & 688267 & 4.3 & 5.1169 & TST \\
\hline CHEMBL1494357 & 688267 & 3.95 & 5.1063 & TST \\
\hline CHEMBL1399525 & 688267 & 5.75 & 5.1477 & TST \\
\hline CHEMBL1462686 & 688267 & 5.65 & 5.0187 & TST \\
\hline CHEMBL1378983 & 688267 & 4.05 & 5.0544 & TRN \\
\hline CHEMBL1391585 & 688267 & 5.5 & 5.0186 & TRN \\
\hline CHEMBL453038 & 688267 & 6.0 & 5.0652 & TRN \\
\hline CHEMBL1315903 & 688267 & 6.2 & 5.157 & TRN \\
\hline CHEMBL1415325 & 688267 & 5.3 & 5.0845 & TRN \\
\hline CHEMBL1314269 & 688267 & 5.5 & 5.042 & TRN \\
\hline CHEMBL1410535 & 688267 & 5.35 & 5.0414 & TRN \\
\hline CHEMBL1331560 & 688267 & 4.45 & 5.0499 & TRN \\
\hline CHEMBL1396590 & 688267 & 4.05 & 5.0698 & TST \\
\hline CHEMBL 3193214 & 688267 & 6.15 & 5.0474 & TRN \\
\hline CHEMBL1349586 & 688267 & 4.4 & 5.0338 & TRN \\
\hline CHEMBL1329214 & 688267 & 4.05 & 5.0192 & TRN \\
\hline CHEMBL1551438 & 688267 & 6.2 & 5.1151 & TRN \\
\hline CHEMBL1324329 & 688267 & 5.65 & 5.0378 & TRN \\
\hline CHEMBL1579712 & 688267 & 4.8 & 5.0548 & TRN \\
\hline CHEMBL1337891 & 688267 & 5.7 & 5.0772 & TRN \\
\hline CHEMBL1540584 & 688267 & 4.0 & 5.0197 & TST \\
\hline CHEMBL1602596 & 688267 & 6.2 & 5.0159 & TRN \\
\hline CHEMBL1391421 & 688267 & 3.95 & 5.0748 & TST \\
\hline CHEMBL1602816 & 688267 & 3.95 & 5.0776 & TRN \\
\hline CHEMBL1528411 & 688267 & 4.3 & 5.0335 & TRN \\
\hline CHEMBL1408468 & 688267 & 5.55 & 5.0426 & TST \\
\hline CHEMBL1577186 & 688267 & 6.5501 & 5.0527 & TRN \\
\hline CHEMBL1399176 & 688267 & 4.35 & 5.1039 & TRN \\
\hline CHEMBL1331032 & 688267 & 6.2 & 5.079 & TRN \\
\hline CHEMBL1491033 & 688267 & 6.0 & 5.1211 & TRN \\
\hline CHEMBL1400643 & 688267 & 4.35 & 5.1141 & TST \\
\hline CHEMBL1416614 & 688267 & 4.05 & 5.0112 & TRN \\
\hline CHEMBL1520127 & 688267 & 5.6 & 5.1183 & TRN \\
\hline CHEMBL1365671 & 688267 & 6.45 & 5.0137 & TRN \\
\hline CHEMBL1476062 & 688267 & 5.25 & 5.0287 & TRN \\
\hline CHEMBL1499566 & 688267 & 4.35 & 5.0361 & TRN \\
\hline CHEMBL1558911 & 688267 & 4.55 & 5.1479 & TST \\
\hline CHEMBL1347264 & 688267 & 3.95 & 5.1116 & TRN \\
\hline CHEMBL1495220 & 688267 & 4.0 & 5.0774 & TRN \\
\hline CHEMBL1410375 & 688267 & 5.05 & 5.0623 & TRN \\
\hline CHEMBL1448711 & 688267 & 6.15 & 4.9672 & TRN \\
\hline CHEMBL1545439 & 688267 & 4.3 & 5.1109 & TRN \\
\hline CHEMBL1531470 & 688267 & 5.4 & 5.1207 & TRN \\
\hline CHEMBL1371817 & 688267 & 4.0 & 5.0589 & TRN \\
\hline CHEMBL1541369 & 688267 & 4.0 & 5.0602 & TRN \\
\hline CHEMBL1396044 & 688267 & 4.35 & 5.0534 & TRN \\
\hline CHEMBL1422536 & 688267 & 6.2 & 5.1213 & TRN \\
\hline CHEMBL1608274 & 688267 & 5.85 & 5.1257 & TRN \\
\hline
\end{tabular}




\begin{tabular}{|c|c|c|c|c|}
\hline \multicolumn{5}{|c|}{ Supplemental Table S2.txt } \\
\hline CHEMBL1445644 & 688267 & 4.1 & 5.0201 & TRN \\
\hline CHEMBL1474005 & 688267 & 6.0 & 5.0207 & TRN \\
\hline CHEMBL1303494 & 688267 & 5.35 & 5.0198 & TRN \\
\hline CHEMBL1540526 & 688267 & 5.5 & 5.0548 & TRN \\
\hline CHEMBL1420960 & 688267 & 4.0 & 5.0645 & TRN \\
\hline CHEMBL1450949 & 688267 & 6.1 & 5.1223 & TRN \\
\hline CHEMBL1372642 & 688267 & 3.95 & 5.0746 & TRN \\
\hline CHEMBL1555522 & 688267 & 4.35 & 5.0087 & TST \\
\hline CHEMBL1343575 & 688267 & 4.05 & 5.0352 & TST \\
\hline CHEMBL1552827 & 688267 & 4.05 & 5.1129 & TRN \\
\hline CHEMBL1435333 & 688267 & 4.35 & 5.0358 & TRN \\
\hline CHEMBL1372820 & 688267 & 3.95 & 5.1405 & TRN \\
\hline CHEMBL1564445 & 688267 & 5.5 & 5.0605 & TRN \\
\hline CHEMBL1370427 & 688267 & 4.55 & 5.0548 & TRN \\
\hline CHEMBL1353649 & 688267 & 6.15 & 5.0438 & TRN \\
\hline CHEMBL1543330 & 688267 & 5.3 & 5.0362 & TRN \\
\hline CHEMBL1468567 & 688267 & 5.55 & 4.9685 & TRN \\
\hline CHEMBL1373404 & 688267 & 6.5 & 5.0559 & TRN \\
\hline CHEMBL1324568 & 688267 & 4.1 & 5.064 & TST \\
\hline CHEMBL1405059 & 688267 & 4.55 & 5.0931 & TST \\
\hline CHEMBL1434377 & 688267 & 4.05 & 5.0437 & TRN \\
\hline CHEMBL1465721 & 688267 & 5.9 & 5.0124 & TST \\
\hline CHEMBL1591085 & 688267 & 6.2 & 5.1194 & TRN \\
\hline CHEMBL1342307 & 688267 & 6.2 & 5.0467 & TST \\
\hline CHEMBL1563431 & 688267 & 4.05 & 5.0388 & TST \\
\hline CHEMBL1612701 & 688267 & 4.0 & 5.0932 & TRN \\
\hline CHEMBL1600191 & 688267 & 4.7 & 5.063 & TRN \\
\hline CHEMBL1568318 & 688267 & 5.55 & 5.0436 & TRN \\
\hline CHEMBL1363731 & 688267 & 4.2 & 5.0428 & TRN \\
\hline CHEMBL1345165 & 688267 & 5.4 & 5.0563 & TRN \\
\hline CHEMBL1413647 & 688267 & 5.85 & 5.0946 & TST \\
\hline CHEMBL1346404 & 688267 & 4.55 & 5.073 & TRN \\
\hline CHEMBL1374325 & 688267 & 6.2 & 5.0829 & TRN \\
\hline CHEMBL1606218 & 688267 & 5.35 & 5.0953 & TRN \\
\hline CHEMBL1594301 & 688267 & 3.95 & 5.0265 & TRN \\
\hline CHEMBL1501027 & 688267 & 5.75 & 5.0234 & TRN \\
\hline CHEMBL1408653 & 688267 & 5.3 & 5.0448 & TRN \\
\hline CHEMBL1586805 & 688267 & 6.6 & 5.0311 & TST \\
\hline CHEMBL1378378 & 688267 & 5.2 & 5.0491 & TRN \\
\hline CHEMBL1595408 & 688267 & 4.15 & 5.002 & TRN \\
\hline CHEMBL1327040 & 688267 & 4.95 & 4.9831 & TRN \\
\hline CHEMBL3193792 & 688267 & 4.4 & 5.0315 & TST \\
\hline CHEMBL184238 & 688267 & 4.4 & 5.0894 & TRN \\
\hline CHEMBL1476216 & 688267 & 4.0 & 5.1531 & TRN \\
\hline CHEMBL1565900 & 688267 & 6.15 & 5.0457 & TRN \\
\hline CHEMBL1455403 & 688267 & 4.0 & 5.0826 & TRN \\
\hline CHEMBL608699 & 688267 & 4.35 & 5.0274 & TST \\
\hline CHEMBL1501611 & 688267 & 5.6 & 5.0347 & TRN \\
\hline
\end{tabular}




\begin{tabular}{|c|c|c|c|c|c|}
\hline \\
\hline CHEMBL1302555 & 688267 & 4.3 & 5.07 & TRN & \\
\hline CHEMBL1361432 & 688267 & 5.35 & 5.0345 & TRN & \\
\hline CHEMBL1526804 & 688267 & 4.0 & 5.062 & TRN & \\
\hline CHEMBL1382585 & 688267 & 5.1 & 5.0897 & TRN & \\
\hline CHEMBL1463413 & 688267 & 4.0 & 5.0275 & TRN & \\
\hline CHEMBL3191122 & 688267 & 5.0 & 5.0127 & TRN & \\
\hline CHEMBL1504187 & 688267 & 5.8 & 5.0287 & TST & \\
\hline CHEMBL1583120 & 688267 & 5.55 & 5.0664 & TRN & \\
\hline CHEMBL1561183 & 688267 & 4.0 & 5.0852 & TST & \\
\hline CHEMBL1488908 & 688267 & 4.65 & 5.0494 & TST & \\
\hline CHEMBL1334579 & 688267 & 4.45 & 5.0597 & TST & \\
\hline CHEMBL1565304 & 688267 & 6.2 & 5.07100 & 0000000001 & TRN \\
\hline CHEMBL1581486 & 688267 & 4.6 & 5.0986 & TRN & \\
\hline CHEMBL1589955 & 688267 & 6.15 & 5.1198 & TRN & \\
\hline CHEMBL1303585 & 688267 & 4.0 & 5.0606 & TRN & \\
\hline CHEMBL1431328 & 688267 & 5.4 & 5.062 & TST & \\
\hline CHEMBL1521262 & 688267 & 4.25 & 5.0243 & TRN & \\
\hline CHEMBL3211761 & 688267 & 5.35 & 5.0614 & TST & \\
\hline CHEMBL1508232 & 688267 & 4.55 & 5.0526 & TST & \\
\hline CHEMBL1386930 & 688267 & 5.95 & 5.0678 & TRN & \\
\hline CHEMBL1526566 & 688267 & 6.1 & 5.0372 & TST & \\
\hline CHEMBL1552921 & 688267 & 3.95 & 5.0456 & TRN & \\
\hline CHEMBL1599265 & 688267 & 4.95 & 5.063 & TRN & \\
\hline CHEMBL1427558 & 688267 & 4.0 & 5.0846 & TRN & \\
\hline CHEMBL1518607 & 688267 & 4.0 & 5.1038 & TST & \\
\hline CHEMBL1398078 & 688267 & 5.15 & 5.0617 & TRN & \\
\hline CHEMBL1592955 & 688267 & 4.25 & 5.0252 & TRN & \\
\hline CHEMBL1494808 & 688267 & 3.95 & 5.0007 & TST & \\
\hline CHEMBL3212009 & 688267 & 6.2 & 5.0096 & TRN & \\
\hline CHEMBL1519171 & 688267 & 4.35 & 5.0663 & TRN & \\
\hline CHEMBL 3212742 & 688267 & 4.05 & 5.0617 & TST & \\
\hline CHEMBL1428868 & 688267 & 4.55 & 5.029 & TRN & \\
\hline CHEMBL1429221 & 688267 & 6.45 & 5.0828 & TRN & \\
\hline CHEMBL1590337 & 688267 & 4.55 & 5.0256 & TRN & \\
\hline CHEMBL1594889 & 688267 & 4.15 & 5.1203 & TST & \\
\hline CHEMBL1486766 & 688267 & 4.4 & 4.9518 & TRN & \\
\hline CHEMBL1515703 & 688267 & 4.65 & 5.0558 & TRN & \\
\hline CHEMBL1342543 & 688267 & 4.6 & 4.9959 & TST & \\
\hline CHEMBL1452071 & 688267 & 4.6 & 5.0472 & TRN & \\
\hline CHEMBL1329694 & 688267 & 6.1 & 5.1146 & TRN & \\
\hline CHEMBL1450036 & 688267 & 4.6 & 5.0025 & TRN & \\
\hline CHEMBL1593760 & 688267 & 6.15 & 5.0983 & TRN & \\
\hline CHEMBL1555906 & 688267 & 5.4 & 4.9853 & TRN & \\
\hline CHEMBL1483387 & 688267 & 4.0 & 5.0685 & TRN & \\
\hline CHEMBL1569495 & 688267 & 4.15 & 5.0772 & TST & \\
\hline CHEMBL1584896 & 688267 & 5.1 & 5.1136 & TST & \\
\hline CHEMBL1434738 & 688267 & 6.2 & 5.0419 & TRN & \\
\hline CHEMBL1535283 & 688267 & 4.45 & 5.1509 & TRN & \\
\hline
\end{tabular}




\begin{tabular}{|c|c|c|c|c|}
\hline \multicolumn{5}{|c|}{ Supplemental Table S2.txt } \\
\hline CHEMBL1586933 & 688267 & 5.65 & 5.0732 & TRN \\
\hline CHEMBL1447997 & 688267 & 6.2 & 5.0968 & TRN \\
\hline CHEMBL1376222 & 688267 & 4.2 & 5.0932 & TRN \\
\hline CHEMBL1565824 & 688267 & 4.05 & 5.0467 & TRN \\
\hline CHEMBL1311715 & 688267 & 5.55 & 5.0603 & TRN \\
\hline CHEMBL1377311 & 688267 & 4.1 & 5.032 & TST \\
\hline CHEMBL1579474 & 688267 & 5.35 & 5.0513 & TRN \\
\hline CHEMBL1412923 & 688267 & 6.2 & 5.0924 & TRN \\
\hline CHEMBL1389595 & 688267 & 4.05 & 5.1594 & TRN \\
\hline CHEMBL1351239 & 688267 & 4.3 & 5.0281 & TRN \\
\hline CHEMBL1567586 & 688267 & 4.65 & 5.0574 & TRN \\
\hline CHEMBL1526385 & 688267 & 4.4 & 5.0734 & TST \\
\hline CHEMBL1555330 & 688267 & 6.05 & 5.0578 & TST \\
\hline CHEMBL1341160 & 688267 & 4.3 & 5.0986 & TRN \\
\hline CHEMBL1554045 & 688267 & 6.2 & 5.0328 & TST \\
\hline CHEMBL1304784 & 688267 & 3.95 & 5.0465 & TST \\
\hline CHEMBL1605427 & 688267 & 4.0 & 5.0287 & TRN \\
\hline CHEMBL1311344 & 688267 & 4.15 & 5.1167 & TRN \\
\hline CHEMBL1309505 & 688267 & 4.15 & 5.0144 & TRN \\
\hline CHEMBL1457410 & 688267 & 5.25 & 4.9932 & TST \\
\hline CHEMBL1348720 & 688267 & 6.2 & 5.0332 & TST \\
\hline CHEMBL1404103 & 688267 & 5.35 & 5.1045 & TRN \\
\hline CHEMBL1401224 & 688267 & 6.05 & 5.0528 & TRN \\
\hline CHEMBL1302588 & 688267 & 4.65 & 5.0615 & TST \\
\hline CHEMBL1321798 & 688267 & 4.0 & 5.051 & TRN \\
\hline CHEMBL1484781 & 688267 & 5.45 & 5.0551 & TRN \\
\hline CHEMBL1548619 & 688267 & 5.45 & 5.0639 & TRN \\
\hline CHEMBL1520992 & 688267 & 5.5 & 4.9881 & TRN \\
\hline CHEMBL1428217 & 688267 & 4.25 & 5.0515 & TRN \\
\hline CHEMBL1578473 & 688267 & 3.95 & 5.0213 & TST \\
\hline CHEMBL1575988 & 688267 & 5.35 & 5.0765 & TST \\
\hline CHEMBL1436645 & 688267 & 4.3 & 5.0684 & TRN \\
\hline CHEMBL1346180 & 688267 & 6.45 & 5.0872 & TST \\
\hline CHEMBL3196544 & 688267 & 6.2 & 5.0233 & TST \\
\hline CHEMBL1365094 & 688267 & 6.5 & 5.0563 & TST \\
\hline CHEMBL1490390 & 688267 & 4.0 & 5.0733 & TRN \\
\hline CHEMBL 1453610 & 688267 & 4.4 & 5.1136 & TRN \\
\hline CHEMBL1338691 & 688267 & 4.6 & 5.0247 & TRN \\
\hline CHEMBL1394050 & 688267 & 4.4 & 5.0449 & TRN \\
\hline CHEMBL1573772 & 688267 & 5.4 & 5.0386 & TRN \\
\hline CHEMBL1611095 & 688267 & 4.25 & 5.0133 & TRN \\
\hline CHEMBL1339553 & 688267 & 5.3 & 5.0731 & TRN \\
\hline CHEMBL1484434 & 688267 & 3.95 & 5.0469 & TRN \\
\hline CHEMBL1517041 & 688267 & 4.55 & 5.0511 & TST \\
\hline CHEMBL1345958 & 688267 & 4.85 & 5.0731 & TRN \\
\hline CHEMBL1433615 & 688267 & 5.9 & 5.0582 & TRN \\
\hline CHEMBL1582468 & 688267 & 4.05 & 5.0803 & TRN \\
\hline CHEMBL1432799 & 688267 & 4.25 & 5.0558 & TRN \\
\hline
\end{tabular}




\begin{tabular}{|c|c|c|c|c|c|}
\hline \\
\hline CHEMBL3192745 & 688267 & 5.2 & 5.0209 & TRN & \\
\hline CHEMBL1447693 & 688267 & 6.2 & 5.0879 & TRN & \\
\hline CHEMBL1587989 & 688267 & 4.4 & 5.1631 & TRN & \\
\hline CHEMBL1579762 & 688267 & 5.75 & 5.0879 & TST & \\
\hline CHEMBL1609666 & 688267 & 3.9 & 5.0244 & TRN & \\
\hline CHEMBL1527932 & 688267 & 5.3 & 5.0124 & TRN & \\
\hline CHEMBL1413723 & 688267 & 5.45 & 5.1057 & TRN & \\
\hline CHEMBL1313398 & 688267 & 4.55 & 5.1158 & TRN & \\
\hline CHEMBL1398517 & 688267 & 4.75 & 5.0044 & TRN & \\
\hline CHEMBL1596211 & 688267 & 6.25 & 5.0047 & TRN & \\
\hline CHEMBL1436472 & 688267 & 4.0 & 5.0351 & TRN & \\
\hline CHEMBL1386044 & 688267 & 5.7 & 5.0736 & TRN & \\
\hline CHEMBL1338614 & 688267 & 6.5 & 5.1044 & TRN & \\
\hline CHEMBL1395131 & 688267 & 4.3 & 5.0309 & TRN & \\
\hline CHEMBL1511303 & 688267 & 6.2 & 4.9823 & TRN & \\
\hline CHEMBL1537875 & 688267 & 5.8 & 5.08 & TST & \\
\hline CHEMBL1595754 & 688267 & 5.5 & 5.0506 & TRN & \\
\hline CHEMBL1487388 & 688267 & 6.2 & 5.0733 & TRN & \\
\hline CHEMBL1587674 & 688267 & 4.15 & 5.0234 & TST & \\
\hline CHEMBL1395436 & 688267 & 5.55 & 5.1197 & TRN & \\
\hline CHEMBL1491017 & 688267 & 6.2 & 5.1501 & TRN & \\
\hline CHEMBL1444242 & 688267 & 4.2 & 5.0464 & TRN & \\
\hline CHEMBL1438538 & 688267 & 6.15 & 5.0315 & TRN & \\
\hline CHEMBL1352192 & 688267 & 4.2 & 4.9668 & TRN & \\
\hline CHEMBL1452112 & 688267 & 4.9 & 5.0563 & TRN & \\
\hline CHEMBL1471570 & 688267 & 6.2 & 5.0466 & TST & \\
\hline CHEMBL1343022 & 688267 & 6.15 & 5.012 & TST & \\
\hline CHEMBL1370448 & 688267 & 5.35 & 5.0093 & TRN & \\
\hline CHEMBL1574886 & 688267 & 5.4 & 5.0482 & TRN & \\
\hline CHEMBL1381902 & 688267 & 6.15 & 5.0061 & TST & \\
\hline CHEMBL1395051 & 688267 & 4.5 & 5.0471 & TRN & \\
\hline CHEMBL1590796 & 688267 & 5.55 & 5.0445 & TRN & \\
\hline CHEMBL1344622 & 688267 & 4.05 & 5.0494 & TST & \\
\hline CHEMBL1335045 & 688267 & 6.2 & 5.0547 & TRN & \\
\hline CHEMBL1482012 & 688267 & 5.65 & 5.0369 & TRN & \\
\hline CHEMBL1389009 & 688267 & 4.05 & 5.0895 & TRN & \\
\hline CHEMBL1403883 & 688267 & 3.8 & 5.0074 & TST & \\
\hline CHEMBL1518065 & 688267 & 5.35 & 5.061 & TST & \\
\hline CHEMBL1475127 & 688267 & 4.35 & 5.082 & TRN & \\
\hline CHEMBL1372231 & 688267 & 4.55 & 5.0643 & TRN & \\
\hline CHEMBL1537378 & 688267 & 6.2 & 5.0072 & TST & \\
\hline CHEMBL1505881 & 688267 & 4.05 & 5.0518 & TRN & \\
\hline CHEMBL1338461 & 688267 & 5.5 & 5.062 & TRN & \\
\hline CHEMBL1535735 & 688267 & 4.2 & 5.0598 & TRN & \\
\hline CHEMBL1389301 & 688267 & 4.8 & $5.0280 e$ & 00000000005 & TRN \\
\hline CHEMBL1586248 & 688267 & 4.35 & 5.051 & TST & \\
\hline CHEMBL1334550 & 688267 & 5.25 & 5.0416 & TRN & \\
\hline CHEMBL1397104 & 688267 & 4.05 & 5.0311 & TRN & \\
\hline & & & & 17531 & \\
\hline
\end{tabular}




\begin{tabular}{|c|c|c|c|c|}
\hline & & & pplement & al $\mathrm{T}$ \\
\hline CHEMBL1497364 & 688267 & 4.0 & 5.0544 & TRN \\
\hline CHEMBL1536386 & 688267 & 5.3 & 5.0349 & TRN \\
\hline CHEMBL1481982 & 688267 & 4.5 & 4.997 & TRN \\
\hline CHEMBL1448334 & 688267 & 4.6 & 5.053 & TST \\
\hline CHEMBL1451802 & 688267 & 4.35 & 5.0511 & TRN \\
\hline CHEMBL 1466045 & 688267 & 4.55 & 5.0407 & TRN \\
\hline CHEMBL1525404 & 688267 & 6.05 & 5.0757 & TRN \\
\hline CHEMBL1315276 & 688267 & 4.05 & 5.0982 & TRN \\
\hline CHEMBL1383758 & 688267 & 5.05 & 5.085 & TRN \\
\hline CHEMBL1592263 & 688267 & 4.3 & 5.1649 & TRN \\
\hline CHEMBL1470835 & 688267 & 4.25 & 5.01 & TST \\
\hline CHEMBL1514343 & 688267 & 4.05 & 5.008 & TRN \\
\hline CHEMBL1534602 & 688267 & 6.2 & 5.0234 & TRN \\
\hline CHEMBL1343611 & 688267 & 4.4 & 5.0487 & TST \\
\hline CHEMBL1472347 & 688267 & 5.95 & 5.0154 & TRN \\
\hline CHEMBL1473610 & 688267 & 4.05 & 5.0706 & TRN \\
\hline CHEMBL1568006 & 688267 & 4.0 & 5.0416 & TRN \\
\hline CHEMBL1405869 & 688267 & 5.85 & 5.125 & TRN \\
\hline CHEMBL1569270 & 688267 & 5.75 & 5.0477 & TRN \\
\hline CHEMBL1579607 & 688267 & 6.5501 & 5.0502 & TRN \\
\hline CHEMBL1318191 & 688267 & 6.25 & 5.1406 & TRN \\
\hline CHEMBL1366354 & 688267 & 6.2 & 5.0273 & TRN \\
\hline CHEMBL1526116 & 688267 & 5.45 & 5.0404 & TRN \\
\hline CHEMBL1401471 & 688267 & 6.05 & 5.062 & TRN \\
\hline CHEMBL1398438 & 688267 & 5.45 & 5.1251 & TRN \\
\hline CHEMBL1463833 & 688267 & 4.45 & 5.0561 & TST \\
\hline CHEMBL1389012 & 688267 & 5.65 & 5.0248 & TRN \\
\hline CHEMBL1483807 & 688267 & 6.2 & 5.0033 & TST \\
\hline CHEMBL1313351 & 688267 & 4.0 & 5.0852 & TRN \\
\hline CHEMBL1402222 & 688267 & 4.35 & 5.0732 & TRN \\
\hline CHEMBL1429455 & 688267 & 4.15 & 5.0497 & TRN \\
\hline CHEMBL1572750 & 688267 & 4.0 & 5.1165 & TST \\
\hline CHEMBL1446541 & 688267 & 4.75 & 5.0441 & TRN \\
\hline CHEMBL1475440 & 688267 & 4.0 & 5.039 & TRN \\
\hline CHEMBL1441893 & 688267 & 5.35 & 5.0653 & TST \\
\hline CHEMBL1319020 & 688267 & 6.05 & 5.1098 & TRN \\
\hline CHEMBL 3194522 & 688267 & 4.05 & 5.0121 & TST \\
\hline CHEMBL1399591 & 688267 & 5.55 & 5.0201 & TRN \\
\hline CHEMBL1562940 & 688267 & 5.35 & 5.0356 & TST \\
\hline CHEMBL1596965 & 688267 & 6.15 & 4.9864 & TRN \\
\hline CHEMBL1343668 & 688267 & 5.0 & 5.0368 & TRN \\
\hline CHEMBL1404981 & 688267 & 4.0 & 5.1506 & TRN \\
\hline CHEMBL1469956 & 688267 & 4.4 & 5.0139 & TRN \\
\hline CHEMBL1481362 & 688267 & 5.8 & 5.0841 & TRN \\
\hline CHEMBL262636 & 688267 & 6.45 & 5.013 & TRN \\
\hline CHEMBL1563346 & 688267 & 4.05 & 5.0292 & TRN \\
\hline CHEMBL1355444 & 688267 & 5.05 & 5.1219 & TRN \\
\hline CHEMBL 3194470 & 688267 & 6.2 & 5.0388 & TRN \\
\hline
\end{tabular}




\begin{tabular}{|c|c|c|c|c|}
\hline \multicolumn{5}{|c|}{ Supplemental Table S2.txt } \\
\hline CHEMBL1528527 & 688267 & 4.95 & 5.0665 & TST \\
\hline CHEMBL1372684 & 688267 & 6.5 & 5.0582 & TST \\
\hline CHEMBL1576723 & 688267 & 4.3 & 5.0893 & TRN \\
\hline CHEMBL1487676 & 688267 & 6.25 & 5.0546 & TST \\
\hline CHEMBL1453162 & 688267 & 4.25 & 5.0794 & TRN \\
\hline CHEMBL1611512 & 688267 & 4.35 & 5.0429 & TST \\
\hline CHEMBL3193895 & 688267 & 5.15 & 5.0419 & TRN \\
\hline CHEMBL1308572 & 688267 & 6.2 & 5.0187 & TRN \\
\hline CHEMBL1599790 & 688267 & 6.1 & 5.0435 & TRN \\
\hline CHEMBL1480737 & 688267 & 6.05 & 4.9526 & TRN \\
\hline CHEMBL1581144 & 688267 & 6.2 & 5.0315 & TST \\
\hline CHEMBL1347747 & 688267 & 4.4 & 5.0291 & TRN \\
\hline CHEMBL1367481 & 688267 & 5.9 & 5.0998 & TRN \\
\hline CHEMBL1474539 & 688267 & 5.3 & 5.0384 & TRN \\
\hline CHEMBL1440804 & 688267 & 5.5 & 5.0854 & TRN \\
\hline CHEMBL1596129 & 688267 & 6.2 & 5.0533 & TST \\
\hline CHEMBL1543252 & 688267 & 4.05 & 5.0705 & TRN \\
\hline CHEMBL1578405 & 688267 & 5.8 & 4.9892 & TRN \\
\hline CHEMBL1490079 & 688267 & 4.5 & 5.1188 & TRN \\
\hline CHEMBL1586738 & 688267 & 5.05 & 5.074 & TRN \\
\hline CHEMBL1437566 & 688267 & 4.3 & 5.1477 & TRN \\
\hline CHEMBL1587306 & 688267 & 4.15 & 5.0916 & TRN \\
\hline CHEMBL1475890 & 688267 & 5.35 & 5.0219 & TRN \\
\hline CHEMBL1328825 & 688267 & 5.6 & 5.0766 & TRN \\
\hline CHEMBL1478735 & 688267 & 4.0 & 5.0575 & TRN \\
\hline CHEMBL1302541 & 688267 & 5.75 & 5.0283 & TST \\
\hline CHEMBL1311132 & 688267 & 5.1 & 5.0738 & TST \\
\hline CHEMBL1465583 & 688267 & 6.5 & 5.124 & TRN \\
\hline CHEMBL1377122 & 688267 & 4.4 & 5.0586 & TRN \\
\hline CHEMBL1592390 & 688267 & 4.9 & 5.1058 & TRN \\
\hline CHEMBL1334829 & 688267 & 6.2 & 5.0236 & TRN \\
\hline CHEMBL1580475 & 688267 & 5.05 & 5.1598 & TRN \\
\hline CHEMBL1335552 & 688267 & 4.35 & 5.0544 & TST \\
\hline CHEMBL1353290 & 688267 & 4.55 & 5.0859 & TST \\
\hline CHEMBL1586227 & 688267 & 6.15 & 5.0242 & TRN \\
\hline CHEMBL1569502 & 688267 & 5.4 & 5.1165 & TRN \\
\hline CHEMBL1441440 & 688267 & 4.0 & 5.0486 & TRN \\
\hline CHEMBL1563785 & 688267 & 5.35 & 5.0748 & TRN \\
\hline CHEMBL1472775 & 688267 & 6.15 & 4.9993 & TRN \\
\hline CHEMBL1305667 & 688267 & 4.0 & 5.1014 & TRN \\
\hline CHEMBL1321009 & 688267 & 5.25 & 5.0848 & TRN \\
\hline CHEMBL1573644 & 688267 & 4.3 & 5.0895 & TRN \\
\hline CHEMBL1344093 & 688267 & 6.05 & 5.0256 & TRN \\
\hline CHEMBL1357409 & 688267 & 4.0 & 5.0028 & TST \\
\hline CHEMBL1353538 & 688267 & 4.5 & 4.9979 & TRN \\
\hline CHEMBL1420714 & 688267 & 6.2 & 5.0168 & TST \\
\hline CHEMBL1348091 & 688267 & 4.9 & 5.0012 & TRN \\
\hline CHEMBL1476363 & 688267 & 5.05 & 5.0533 & TRN \\
\hline
\end{tabular}




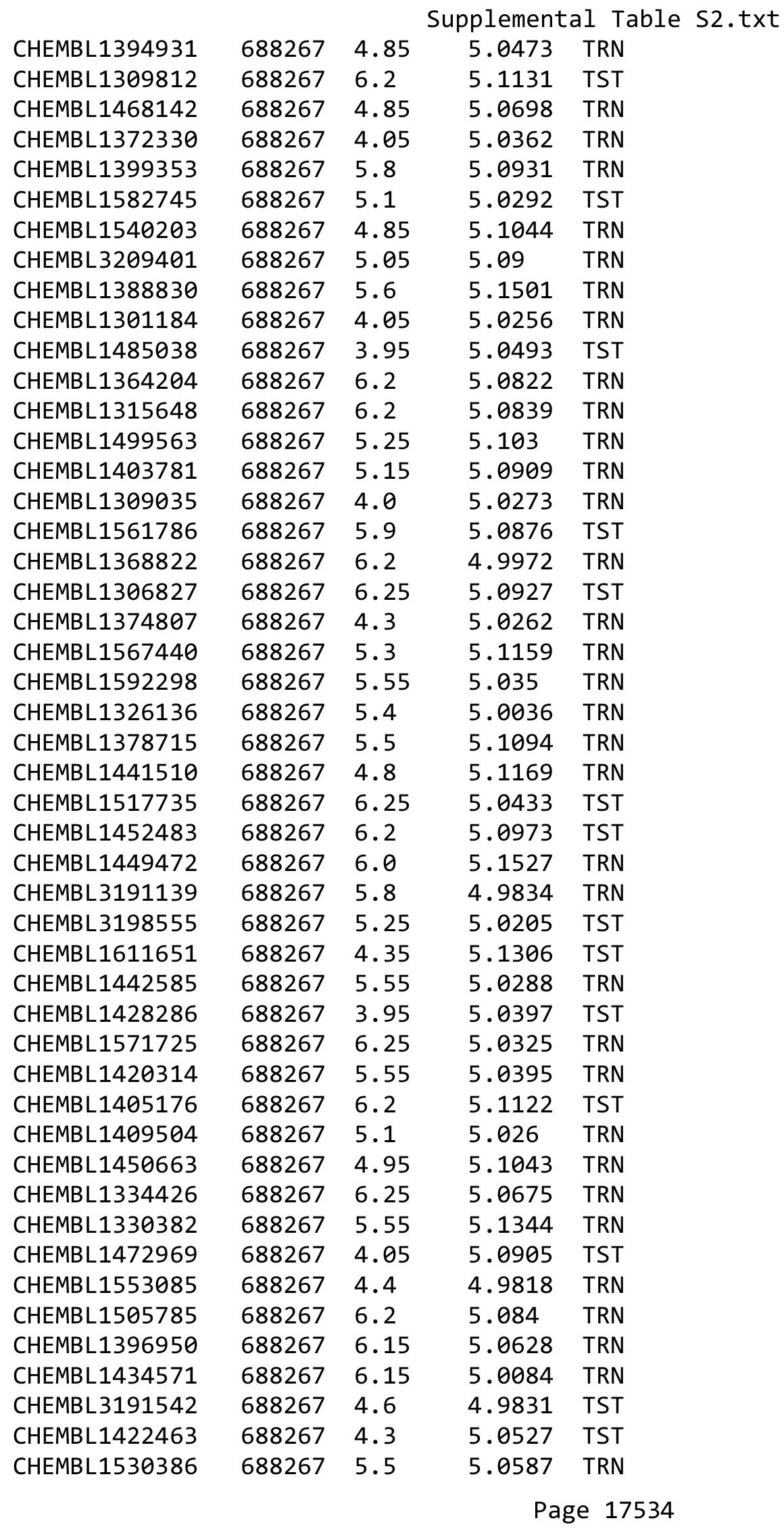




\begin{tabular}{|c|c|c|c|c|c|}
\hline \\
\hline CHEMBL1456971 & 688267 & 4.9 & 5.0778 & TRN & \\
\hline CHEMBL1472174 & 688267 & 4.35 & 5.0549 & TRN & \\
\hline CHEMBL1504140 & 688267 & 5.35 & 5.0685 & TRN & \\
\hline CHEMBL1521314 & 688267 & 6.15 & 5.042 & TST & \\
\hline CHEMBL1564289 & 688267 & 4.6 & 5.1386 & TRN & \\
\hline CHEMBL1352662 & 688267 & 6.2 & 5.0471 & TRN & \\
\hline CHEMBL1364385 & 688267 & 4.05 & 5.0768 & TRN & \\
\hline CHEMBL1433775 & 688267 & 4.05 & 5.0328 & TRN & \\
\hline CHEMBL1407599 & 688267 & 5.9 & 5.0607 & TST & \\
\hline CHEMBL1410076 & 688267 & 4.35 & 5.0411 & TRN & \\
\hline CHEMBL1554377 & 688267 & 4.75 & 5.0868 & TRN & \\
\hline CHEMBL1493551 & 688267 & 6.2 & 5.0833 & TRN & \\
\hline CHEMBL1501765 & 688267 & 4.05 & 5.0185 & TRN & \\
\hline CHEMBL1357571 & 688267 & 4.0 & 5.0981 & TRN & \\
\hline CHEMBL1359001 & 688267 & 4.0 & 5.0426 & TST & \\
\hline CHEMBL1402260 & 688267 & 6.1 & 5.095 & TRN & \\
\hline CHEMBL1356583 & 688267 & 6.25 & 5.0989 & TRN & \\
\hline CHEMBL1444248 & 688267 & 5.3 & 4.9916 & TRN & \\
\hline CHEMBL1458180 & 688267 & 4.55 & 4.9911 & TST & \\
\hline CHEMBL1316536 & 688267 & 5.4 & 5.0345 & TRN & \\
\hline CHEMBL1424017 & 688267 & 4.6 & 4.9715 & TRN & \\
\hline CHEMBL1494385 & 688267 & 5.75 & 5.0036 & TRN & \\
\hline CHEMBL1579038 & 688267 & 5.05 & 5.0736 & TRN & \\
\hline CHEMBL1307159 & 688267 & 4.55 & 5.0841 & TRN & \\
\hline CHEMBL1516131 & 688267 & 6.25 & 5.1528 & TRN & \\
\hline CHEMBL1479660 & 688267 & 5.0 & 5.0733 & TRN & \\
\hline CHEMBL1316313 & 688267 & 4.35 & 5.0839 & TRN & \\
\hline CHEMBL1475898 & 688267 & 6.15 & 5.1103 & TRN & \\
\hline CHEMBL1359313 & 688267 & 4.15 & 5.1369 & TRN & \\
\hline CHEMBL1300468 & 688267 & 4.65 & 5.0228 & TRN & \\
\hline CHEMBL1488436 & 688267 & 5.65 & 5.0768 & TRN & \\
\hline CHEMBL1598597 & 688267 & 5.45 & 5.0681 & TRN & \\
\hline CHEMBL1440691 & 688267 & 6.15 & 5.061 & TRN & \\
\hline CHEMBL1364585 & 688267 & 5.45 & 5.0527 & TRN & \\
\hline CHEMBL1365622 & 688267 & 3.95 & 5.0 & TRN & \\
\hline CHEMBL1368054 & 688267 & 4.55 & 5.0691 & TRN & \\
\hline CHEMBL1576713 & 688267 & 5.15 & 5.0528 & TST & \\
\hline CHEMBL1396564 & 688267 & 4.05 & 5.0063 & TRN & \\
\hline CHEMBL1365554 & 688267 & 4.6 & 5.0928 & TRN & \\
\hline CHEMBL1442423 & 688267 & 5.05 & 5.1045 & TRN & \\
\hline CHEMBL1563049 & 688267 & 6.2 & 5.0973 & TST & \\
\hline CHEMBL1337252 & 688267 & 5.5 & 5.1002 & TRN & \\
\hline CHEMBL1519184 & 688267 & 5.35 & 5.0481 & TRN & \\
\hline CHEMBL1450112 & 688267 & 6.2 & 5.0507 & TRN & \\
\hline CHEMBL1424520 & 688267 & 5.45 & 5.0591 & TRN & \\
\hline CHEMBL1526906 & 688267 & 5.8 & 5.05699 & 99999999995 & TRN \\
\hline CHEMBL1475891 & 688267 & 3.95 & 5.0487 & TRN & \\
\hline CHEMBL1438995 & 688267 & 4.9 & 5.0433 & TST & \\
\hline
\end{tabular}




\begin{tabular}{|c|c|c|c|c|c|}
\hline \multicolumn{6}{|c|}{ Supplemental Table S2.txt } \\
\hline CHEMBL1568708 & 688267 & 3.95 & 5.0515 & TRN & \\
\hline CHEMBL1431171 & 688267 & 4.2 & 5.0126 & TRN & \\
\hline CHEMBL1422689 & 688267 & 6.2 & 5.1319 & TRN & \\
\hline CHEMBL1460163 & 688267 & 4.55 & 5.1112 & TST & \\
\hline CHEMBL1478557 & 688267 & 4.35 & 5.0242 & TRN & \\
\hline CHEMBL1597796 & 688267 & 4.0 & 5.0739 & TST & \\
\hline CHEMBL1565184 & 688267 & 4.3 & 5.0761 & TRN & \\
\hline CHEMBL1484734 & 688267 & 4.65 & 5.0932 & TRN & \\
\hline CHEMBL1349718 & 688267 & 5.85 & 5.0492 & TRN & \\
\hline CHEMBL1599049 & 688267 & 4.05 & 5.0327 & TRN & \\
\hline CHEMBL1604059 & 688267 & 5.25 & 5.0838 & TRN & \\
\hline CHEMBL1402227 & 688267 & 5.45 & 5.04899 & 99999999995 & TST \\
\hline CHEMBL1398302 & 688267 & 3.95 & 5.0068 & TRN & \\
\hline CHEMBL1404777 & 688267 & 6.45 & 5.0671 & TRN & \\
\hline CHEMBL1359805 & 688267 & 4.95 & 5.0859 & TRN & \\
\hline CHEMBL1459870 & 688267 & 4.05 & 5.0906 & TST & \\
\hline CHEMBL1556342 & 688267 & 5.5 & 5.0729 & TRN & \\
\hline CHEMBL1482608 & 688267 & 4.45 & 5.1224 & TST & \\
\hline CHEMBL1591935 & 688267 & 5.4 & 5.0937 & TRN & \\
\hline CHEMBL1492135 & 688267 & 3.95 & 4.9982 & TRN & \\
\hline CHEMBL1512587 & 688267 & 5.9 & 5.0326 & TST & \\
\hline CHEMBL 3198339 & 688267 & 6.15 & 5.0201 & TST & \\
\hline CHEMBL1433439 & 688267 & 4.95 & 4.9967 & TRN & \\
\hline CHEMBL1532472 & 688267 & 4.4 & 5.0061 & TST & \\
\hline CHEMBL1454369 & 688267 & 4.5 & 5.0066 & TRN & \\
\hline CHEMBL1449394 & 688267 & 5.65 & 5.0626 & TRN & \\
\hline CHEMBL1523143 & 688267 & 4.35 & 5.0643 & TRN & \\
\hline CHEMBL3190868 & 688267 & 4.6 & 4.94600 & 0000000001 & TRN \\
\hline CHEMBL1355473 & 688267 & 6.0 & 4.9918 & TRN & \\
\hline CHEMBL1527468 & 688267 & 4.25 & 5.1062 & TRN & \\
\hline CHEMBL1456534 & 688267 & 6.25 & 5.1294 & TRN & \\
\hline CHEMBL1323194 & 688267 & 4.6 & 5.1226 & TRN & \\
\hline CHEMBL1344878 & 688267 & 5.6 & 5.0057 & TRN & \\
\hline CHEMBL1360452 & 688267 & 5.9 & 5.0279 & TRN & \\
\hline CHEMBL1540955 & 688267 & 5.0 & 5.0538 & TRN & \\
\hline CHEMBL1537784 & 688267 & 5.45 & 5.0683 & TRN & \\
\hline CHEMBL 1447347 & 688267 & 6.2 & 5.0219 & TST & \\
\hline CHEMBL1422537 & 688267 & 6.15 & 5.0417 & TRN & \\
\hline CHEMBL1351086 & 688267 & 6.0 & 5.0885 & TRN & \\
\hline CHEMBL1373810 & 688267 & 3.95 & 5.0045 & TRN & \\
\hline CHEMBL1318663 & 688267 & 4.45 & 5.1038 & TST & \\
\hline CHEMBL1318370 & 688267 & 5.55 & 5.1327 & TRN & \\
\hline CHEMBL1587696 & 688267 & 5.6 & 5.1032 & TST & \\
\hline CHEMBL1370961 & 688267 & 4.35 & 5.0563 & TRN & \\
\hline CHEMBL1304561 & 688267 & 6.1 & 5.135 & TRN & \\
\hline CHEMBL1480425 & 688267 & 5.1 & 5.1211 & TRN & \\
\hline CHEMBL1599554 & 688267 & 5.05 & 5.1073 & TRN & \\
\hline CHEMBL1510048 & 688267 & 5.55 & 5.0918 & TST & \\
\hline
\end{tabular}




\begin{tabular}{|c|c|c|c|c|c|}
\hline \multicolumn{6}{|c|}{ Supplemental Table S2.txt } \\
\hline CHEMBL1332065 & 688267 & 5.5 & 5.0366 & TRN & \\
\hline CHEMBL1461324 & 688267 & 4.1 & 5.0126 & TRN & \\
\hline CHEMBL3213390 & 688267 & 3.95 & 5.1286 & TST & \\
\hline CHEMBL1378409 & 688267 & 4.8 & 5.1081 & TST & \\
\hline CHEMBL1477682 & 688267 & 3.95 & 5.067 & TRN & \\
\hline CHEMBL1529272 & 688267 & 4.4 & 5.0922 & TST & \\
\hline CHEMBL1545674 & 688267 & 4.85 & 5.03600 & 00000000005 & TRN \\
\hline CHEMBL1341988 & 688267 & 4.4 & 5.0763 & TRN & \\
\hline CHEMBL1494041 & 688267 & 6.2 & 5.0362 & TRN & \\
\hline CHEMBL1379813 & 688267 & 6.2 & 5.03600 & 00000000005 & TRN \\
\hline CHEMBL1477919 & 688267 & 6.15 & 5.1011 & TRN & \\
\hline CHEMBL1442534 & 688267 & 4.6 & 5.0826 & TRN & \\
\hline CHEMBL1331648 & 688267 & 5.55 & 4.9846 & TRN & \\
\hline CHEMBL1380673 & 688267 & 4.4 & 4.9938 & TRN & \\
\hline CHEMBL1421949 & 688267 & 4.45 & 5.0672 & TRN & \\
\hline CHEMBL1324845 & 688267 & 6.2 & 5.01 & TRN & \\
\hline CHEMBL1572015 & 688267 & 4.9 & 5.0551 & TST & \\
\hline CHEMBL1327055 & 688267 & 4.0 & 5.1077 & TRN & \\
\hline CHEMBL1424909 & 688267 & 4.5 & 5.0889 & TRN & \\
\hline CHEMBL1515533 & 688267 & 4.65 & 5.0535 & TRN & \\
\hline CHEMBL1473596 & 688267 & 6.2 & 5.1101 & TRN & \\
\hline CHEMBL1560119 & 688267 & 5.55 & 5.0093 & TRN & \\
\hline CHEMBL1354720 & 688267 & 5.2 & 5.0411 & TRN & \\
\hline CHEMBL1560867 & 688267 & 6.2 & 5.1317 & TST & \\
\hline CHEMBL1334493 & 688267 & 3.95 & 5.0842 & TRN & \\
\hline CHEMBL1359884 & 688267 & 4.05 & 5.1348 & TRN & \\
\hline CHEMBL1533361 & 688267 & 4.05 & 5.039 & TRN & \\
\hline CHEMBL1513986 & 688267 & 5.15 & 5.0886 & TRN & \\
\hline CHEMBL1394060 & 688267 & 6.2 & 5.0172 & TRN & \\
\hline CHEMBL1584661 & 688267 & 4.6 & 4.9829 & TRN & \\
\hline CHEMBL1299518 & 688267 & 3.95 & 5.1386 & TRN & \\
\hline CHEMBL1574498 & 688267 & 5.15 & 5.0587 & TRN & \\
\hline CHEMBL1438767 & 688267 & 5.55 & 5.0795 & TST & \\
\hline CHEMBL1347235 & 688267 & 5.0 & 5.0593 & TRN & \\
\hline CHEMBL1561445 & 688267 & 4.55 & 5.0419 & TST & \\
\hline CHEMBL1326387 & 688267 & 5.45 & 5.0201 & TST & \\
\hline CHEMBL1401255 & 688267 & 4.4 & 5.0947 & TRN & \\
\hline CHEMBL1478986 & 688267 & 5.75 & 5.0691 & TRN & \\
\hline CHEMBL1340019 & 688267 & 4.55 & 5.1305 & TRN & \\
\hline CHEMBL1467333 & 688267 & 5.55 & 5.0441 & TRN & \\
\hline CHEMBL1336706 & 688267 & 4.4 & 5.0007 & TRN & \\
\hline CHEMBL3193335 & 688267 & 5.35 & 4.9859 & TRN & \\
\hline CHEMBL1346054 & 688267 & 4.25 & 5.0767 & TRN & \\
\hline CHEMBL1303910 & 688267 & 6.2 & 5.0035 & TRN & \\
\hline CHEMBL1448156 & 688267 & 5.85 & 5.0219 & TRN & \\
\hline CHEMBL1394294 & 688267 & 3.95 & 5.0195 & TRN & \\
\hline CHEMBL1441181 & 688267 & 4.45 & 5.0064 & TRN & \\
\hline CHEMBL1558023 & 688267 & 4.25 & 5.0529 & TRN & \\
\hline
\end{tabular}




\begin{tabular}{|c|c|c|c|c|}
\hline & & & pplement & \\
\hline CHEMBL1505825 & 688267 & 4.5 & 5.0635 & TRN \\
\hline CHEMBL1601356 & 688267 & 4.05 & 5.0218 & TRN \\
\hline CHEMBL1437388 & 688267 & 6.0 & 5.0933 & TRN \\
\hline CHEMBL1584736 & 688267 & 4.05 & 5.1539 & TST \\
\hline CHEMBL1395163 & 688267 & 4.05 & 5.0888 & TRN \\
\hline CHEMBL1552471 & 688267 & 3.9 & 5.0332 & TRN \\
\hline CHEMBL1308653 & 688267 & 5.15 & 5.06 & TRN \\
\hline CHEMBL1485289 & 688267 & 6.2 & 5.1061 & TRN \\
\hline CHEMBL1499784 & 688267 & 6.5 & 5.0449 & TRN \\
\hline CHEMBL1369525 & 688267 & 5.95 & 4.979 & TRN \\
\hline CHEMBL1513939 & 688267 & 6.2 & 5.0172 & TST \\
\hline CHEMBL1985696 & 688267 & 5.35 & 4.9819 & TRN \\
\hline CHEMBL1505377 & 688267 & 5.35 & 5.0891 & TRN \\
\hline CHEMBL1388209 & 688267 & 4.6 & 5.1019 & TRN \\
\hline CHEMBL1482269 & 688267 & 4.4 & 5.0419 & TST \\
\hline CHEMBL1460068 & 688267 & 5.45 & 5.1322 & TRN \\
\hline CHEMBL3198547 & 688267 & 4.05 & 5.0787 & TST \\
\hline CHEMBL1420730 & 688267 & 5.55 & 5.0209 & TRN \\
\hline CHEMBL1424896 & 688267 & 4.0 & 5.0429 & TST \\
\hline CHEMBL1588956 & 688267 & 5.85 & 5.0302 & TRN \\
\hline CHEMBL1437209 & 688267 & 6.2 & 5.0263 & TRN \\
\hline CHEMBL1489729 & 688267 & 4.0 & 4.9966 & TRN \\
\hline CHEMBL1554501 & 688267 & 5.3 & 5.0301 & TRN \\
\hline CHEMBL1371615 & 688267 & 5.45 & 5.0661 & TRN \\
\hline CHEMBL1387646 & 688267 & 5.6 & 5.0161 & TRN \\
\hline CHEMBL1520696 & 688267 & 6.5 & 5.0325 & TRN \\
\hline CHEMBL1516328 & 688267 & 6.2 & 5.0072 & TRN \\
\hline CHEMBL1565310 & 688267 & 4.2 & 5.0685 & TRN \\
\hline CHEMBL1595463 & 688267 & 5.4 & 5.0641 & TRN \\
\hline CHEMBL1419595 & 688267 & 5.8 & 5.0588 & TRN \\
\hline CHEMBL1597402 & 688267 & 5.95 & 5.0258 & TRN \\
\hline CHEMBL1467908 & 688267 & 6.15 & 5.0462 & TST \\
\hline CHEMBL1304737 & 688267 & 6.25 & 5.0697 & TST \\
\hline CHEMBL1392946 & 688267 & 6.0 & 5.0277 & TRN \\
\hline CHEMBL1555139 & 688267 & 4.45 & 5.0788 & TST \\
\hline CHEMBL1441942 & 688267 & 5.85 & 5.1023 & TRN \\
\hline CHEMBL1537446 & 688267 & 6.2 & 5.0751 & TRN \\
\hline CHEMBL1525660 & 688267 & 4.0 & 5.0714 & TRN \\
\hline CHEMBL1424662 & 688267 & 5.15 & 5.0779 & TRN \\
\hline CHEMBL1444332 & 688267 & 6.45 & 5.0691 & TRN \\
\hline CHEMBL1302606 & 688267 & 5.0 & 5.1445 & TRN \\
\hline CHEMBL1403679 & 688267 & 4.55 & 5.0229 & TST \\
\hline CHEMBL1349780 & 688267 & 5.35 & 5.081 & TRN \\
\hline CHEMBL1382788 & 688267 & 4.05 & 5.1064 & TRN \\
\hline CHEMBL1348882 & 688267 & 3.95 & 5.0231 & TRN \\
\hline CHEMBL3194859 & 688267 & 3.95 & 5.0561 & TRN \\
\hline CHEMBL1559157 & 688267 & 6.7501 & 5.0925 & TST \\
\hline CHEMBL1452790 & 688267 & 4.35 & 5.0305 & TRN \\
\hline
\end{tabular}




\begin{tabular}{|c|c|c|c|c|c|}
\hline \multicolumn{6}{|c|}{ Supplemental Table S2.txt } \\
\hline CHEMBL1515958 & 688267 & 5.8 & 5.0723 & TRN & \\
\hline CHEMBL1469599 & 688267 & 4.7 & 5.0969 & TRN & \\
\hline CHEMBL1457880 & 688267 & 3.95 & 5.0306 & TST & \\
\hline CHEMBL1588491 & 688267 & 5.5 & 5.0759 & TRN & \\
\hline CHEMBL1316765 & 688267 & 3.95 & 5.0516 & TST & \\
\hline CHEMBL1422443 & 688267 & 3.95 & 5.0269 & TST & \\
\hline CHEMBL1427393 & 688267 & 5.35 & 5.0245 & TRN & \\
\hline CHEMBL1454933 & 688267 & 5.0 & 5.0187 & TRN & \\
\hline CHEMBL1519813 & 688267 & 6.2 & 5.1198 & TRN & \\
\hline CHEMBL1433999 & 688267 & 4.3 & 5.0581 & TRN & \\
\hline CHEMBL1388132 & 688267 & 4.0 & 5.0197 & TST & \\
\hline CHEMBL1342777 & 688267 & 5.0 & 5.1415 & TRN & \\
\hline CHEMBL1403458 & 688267 & 4.4 & 5.0578 & TRN & \\
\hline CHEMBL1524000 & 688267 & 5.25 & 5.0327 & TRN & \\
\hline CHEMBL1407473 & 688267 & 6.5 & 5.0825 & TRN & \\
\hline CHEMBL1360139 & 688267 & 4.35 & 5.1314 & TST & \\
\hline CHEMBL1304112 & 688267 & 4.3 & 5.0516 & TRN & \\
\hline CHEMBL1472862 & 688267 & 5.3 & 5.0224 & TRN & \\
\hline CHEMBL1576113 & 688267 & 6.25 & 5.0747 & TRN & \\
\hline CHEMBL1592783 & 688267 & 6.2 & 5.1566 & TRN & \\
\hline CHEMBL200377 & 688267 & 6.0 & 4.9988 & TRN & \\
\hline CHEMBL1536077 & 688267 & 5.95 & 5.0618 & TRN & \\
\hline CHEMBL1588122 & 688267 & 4.05 & 5.0973 & TST & \\
\hline CHEMBL1504362 & 688267 & 6.2 & 5.0659 & TST & \\
\hline CHEMBL1328531 & 688267 & 6.2 & 5.0989 & TST & \\
\hline CHEMBL1444857 & 688267 & 4.5 & 5.0377 & TRN & \\
\hline CHEMBL1418982 & 688267 & 4.85 & 4.9956 & TST & \\
\hline CHEMBL1512504 & 688267 & 6.5 & 5.0575 & TRN & \\
\hline CHEMBL1421841 & 688267 & 6.2 & 5.0569 & TRN & \\
\hline CHEMBL1394824 & 688267 & 6.2 & 5.0654 & TRN & \\
\hline CHEMBL1551293 & 688267 & 4.95 & 5.1131 & TRN & \\
\hline CHEMBL1320949 & 688267 & 5.65 & 5.11600 & 00000000005 & TRN \\
\hline CHEMBL551600 & 688267 & 6.2 & 5.0156 & TST & \\
\hline CHEMBL1361079 & 688267 & 6.15 & 5.0607 & TST & \\
\hline CHEMBL1576495 & 688267 & 5.9 & 5.0806 & TRN & \\
\hline CHEMBL1591010 & 688267 & 6.15 & 5.0778 & TRN & \\
\hline CHEMBL1361340 & 688267 & 5.2 & 5.0786 & TRN & \\
\hline CHEMBL1585355 & 688267 & 4.7 & 5.0658 & TRN & \\
\hline CHEMBL1310207 & 688267 & 5.5 & 5.1277 & TST & \\
\hline CHEMBL1476153 & 688267 & 5.15 & 5.1023 & TST & \\
\hline CHEMBL1434593 & 688267 & 6.0 & 5.0336 & TRN & \\
\hline CHEMBL1335580 & 688267 & 4.35 & 5.0111 & TRN & \\
\hline CHEMBL1339989 & 688267 & 3.95 & 5.0221 & TST & \\
\hline CHEMBL1387098 & 688267 & 5.05 & 5.0342 & TRN & \\
\hline CHEMBL1549995 & 688267 & 5.05 & 5.0919 & TRN & \\
\hline CHEMBL1316507 & 688267 & 5.85 & 5.1554 & TRN & \\
\hline CHEMBL1439885 & 688267 & 3.9 & 5.0598 & TRN & \\
\hline CHEMBL1597864 & 688267 & 4.35 & 5.0719 & TRN & \\
\hline
\end{tabular}




\begin{tabular}{|c|c|c|c|c|}
\hline & & & pplement & al Ta \\
\hline CHEMBL1386849 & 688267 & 6.15 & 4.9756 & TST \\
\hline CHEMBL1471407 & 688267 & 6.5501 & 5.0725 & TRN \\
\hline CHEMBL1515183 & 688267 & 4.0 & 5.1027 & TRN \\
\hline CHEMBL1524540 & 688267 & 6.45 & 5.0807 & TRN \\
\hline CHEMBL1512710 & 688267 & 4.25 & 5.0773 & TRN \\
\hline CHEMBL1542279 & 688267 & 4.0 & 4.9927 & TST \\
\hline CHEMBL1088577 & 688267 & 4.05 & 5.0369 & TRN \\
\hline CHEMBL1305052 & 688267 & 5.5 & 5.0265 & TST \\
\hline CHEMBL1562190 & 688267 & 4.0 & 5.0207 & TRN \\
\hline CHEMBL3192590 & 688267 & 4.25 & 5.0596 & TST \\
\hline CHEMBL1395631 & 688267 & 6.15 & 5.1351 & TRN \\
\hline CHEMBL1557134 & 688267 & 6.25 & 5.0079 & TRN \\
\hline CHEMBL1457048 & 688267 & 5.45 & 5.0907 & TST \\
\hline CHEMBL1416924 & 688267 & 4.05 & 5.0368 & TRN \\
\hline CHEMBL1535300 & 688267 & 4.0 & 5.0724 & TRN \\
\hline CHEMBL1534190 & 688267 & 4.0 & 5.0801 & TST \\
\hline CHEMBL1481874 & 688267 & 4.15 & 5.0478 & TRN \\
\hline CHEMBL3190113 & 688267 & 4.25 & 5.0551 & TST \\
\hline CHEMBL1605741 & 688267 & 3.95 & 5.0077 & TRN \\
\hline CHEMBL1541189 & 688267 & 5.1 & 5.0339 & TRN \\
\hline CHEMBL1427378 & 688267 & 4.5 & 5.0241 & TRN \\
\hline CHEMBL1446998 & 688267 & 5.85 & 5.0938 & TRN \\
\hline CHEMBL1410124 & 688267 & 4.3 & 4.9919 & TRN \\
\hline CHEMBL1588761 & 688267 & 5.45 & 5.0111 & TST \\
\hline CHEMBL1436019 & 688267 & 4.05 & 5.1168 & TST \\
\hline CHEMBL1367940 & 688267 & 4.2 & 5.0249 & TST \\
\hline CHEMBL1325221 & 688267 & 4.0 & 5.0155 & TRN \\
\hline CHEMBL1532772 & 688267 & 6.0 & 5.0883 & TRN \\
\hline CHEMBL1308461 & 688267 & 5.55 & 5.0708 & TRN \\
\hline CHEMBL3214589 & 688267 & 6.2 & 5.0231 & TST \\
\hline CHEMBL1366400 & 688267 & 4.7 & 5.0032 & TRN \\
\hline CHEMBL1548700 & 688267 & 4.7 & 5.078 & TRN \\
\hline CHEMBL1367085 & 688267 & 4.85 & 5.04 & TST \\
\hline CHEMBL1404786 & 688267 & 4.65 & 5.1153 & TRN \\
\hline CHEMBL1373040 & 688267 & 5.15 & 5.0497 & TRN \\
\hline CHEMBL1499024 & 688267 & 4.65 & 5.0795 & TRN \\
\hline CHEMBL1501386 & 688267 & 4.55 & 5.0752 & TRN \\
\hline CHEMBL1597386 & 688267 & 5.4 & 5.0566 & TRN \\
\hline CHEMBL1571341 & 688267 & 4.75 & 5.065 & TRN \\
\hline CHEMBL1333958 & 688267 & 5.05 & 5.0712 & TST \\
\hline CHEMBL1453488 & 688267 & 5.45 & 5.0579 & TRN \\
\hline CHEMBL1543899 & 688267 & 5.85 & 5.0437 & TST \\
\hline CHEMBL1380799 & 688267 & 4.35 & 5.0778 & TRN \\
\hline CHEMBL1606911 & 688267 & 4.9 & 5.0327 & TRN \\
\hline CHEMBL1330675 & 688267 & 4.95 & 5.1859 & TRN \\
\hline CHEMBL1463536 & 688267 & 5.1 & 5.1076 & TRN \\
\hline CHEMBL1409698 & 688267 & 6.2 & 5.0844 & TST \\
\hline CHEMBL1591951 & 688267 & 5.75 & 5.0223 & TST \\
\hline
\end{tabular}




\begin{tabular}{|c|c|c|c|c|c|}
\hline & & \multicolumn{4}{|c|}{ Supplemental Table s2.txt } \\
\hline CHEMBL1343738 & 688267 & 4.05 & 5.0625 & TST & \\
\hline CHEMBL1446144 & 688267 & 3.95 & 5.0589 & TRN & \\
\hline CHEMBL1500757 & 688267 & 6.2 & 5.0666 & TST & \\
\hline CHEMBL1591990 & 688267 & 5.3 & 5.0321 & TRN & \\
\hline CHEMBL1524246 & 688267 & 6.0 & 5.1364 & TRN & \\
\hline CHEMBL1446667 & 688267 & 5.95 & 5.0496 & TRN & \\
\hline CHEMBL1503771 & 688267 & 5.55 & 5.0177 & TRN & \\
\hline CHEMBL1480860 & 688267 & 4.3 & 5.0181 & TRN & \\
\hline CHEMBL 3193498 & 688267 & 6.45 & 5.1154 & TRN & \\
\hline CHEMBL1410312 & 688267 & 5.05 & 5.0665 & TRN & \\
\hline CHEMBL1345199 & 688267 & 6.2 & 5.0348 & TRN & \\
\hline CHEMBL1526006 & 688267 & 6.2 & 5.026 & TST & \\
\hline CHEMBL3196673 & 688267 & 4.0 & 5.0274 & TRN & \\
\hline CHEMBL1414183 & 688267 & 4.8 & 4.9898 & TST & \\
\hline CHEMBL1556650 & 688267 & 5.9 & 5.0734 & TST & \\
\hline CHEMBL1563909 & 688267 & 5.0 & 5.146 & TRN & \\
\hline CHEMBL1387585 & 688267 & 4.05 & 5.0574 & TST & \\
\hline CHEMBL1435972 & 688267 & 6.2 & 5.0263 & TRN & \\
\hline CHEMBL1419293 & 688267 & 4.15 & 5.0178 & TRN & \\
\hline CHEMBL1388031 & 688267 & 5.35 & 5.0142 & TRN & \\
\hline CHEMBL1551439 & 688267 & 5.25 & 5.075 & TRN & \\
\hline CHEMBL1359420 & 688267 & 4.4 & 5.018 & TRN & \\
\hline CHEMBL1485945 & 688267 & 4.25 & 5.0703 & TRN & \\
\hline CHEMBL1532717 & 688267 & 4.3 & 5.0679 & TST & \\
\hline CHEMBL1419588 & 688267 & 5.15 & 5.0702 & TRN & \\
\hline CHEMBL1572298 & 688267 & 6.2 & 4.999 & TRN & \\
\hline CHEMBL1496226 & 688267 & 5.0 & 5.0459 & TRN & \\
\hline CHEMBL1612898 & 688267 & 5.55 & 5.053 & TRN & \\
\hline CHEMBL1392889 & 688267 & 5.45 & 5.0431 & TRN & \\
\hline CHEMBL1491011 & 688267 & 6.25 & 5.0509 & TST & \\
\hline CHEMBL1314855 & 688267 & 5.2 & 5.0645 & TRN & \\
\hline CHEMBL561936 & 688267 & 3.95 & 4.987 & TRN & \\
\hline CHEMBL1555254 & 688267 & 4.0 & 5.0273 & TRN & \\
\hline CHEMBL3212253 & 688267 & 4.2 & 5.0837 & TRN & \\
\hline CHEMBL3210343 & 688267 & 5.8 & 5.0034 & TRN & \\
\hline CHEMBL1607496 & 688267 & 6.2 & 5.0447 & TRN & \\
\hline CHEMBL3192837 & 688267 & 4.45 & 4.9875 & TRN & \\
\hline CHEMBL1345379 & 688267 & 4.75 & 5.0164 & TRN & \\
\hline CHEMBL3192617 & 688267 & 6.15 & 5.0188 & TRN & \\
\hline CHEMBL1336302 & 688267 & 5.5 & 5.1214 & TRN & \\
\hline CHEMBL1511457 & 688267 & 5.0 & 5.0278 & TRN & \\
\hline CHEMBL1354417 & 688267 & 5.45 & 5.0409 & TRN & \\
\hline CHEMBL1321832 & 688267 & 4.3 & 4.9914 & TRN & \\
\hline CHEMBL1526096 & 688267 & 4.05 & 5.1255 & TST & \\
\hline CHEMBL1592248 & 688267 & 5.05 & 5.0721 & TRN & \\
\hline CHEMBL1369690 & 688267 & 5.85 & 5.1105 & TRN & \\
\hline CHEMBL1527790 & 688267 & 5.55 & 5.1207 & TST & \\
\hline CHEMBL1597633 & 688267 & 5.5 & 5.05399 & 9999999999 & TRN \\
\hline & & & & 1754 & \\
\hline
\end{tabular}




\begin{tabular}{|c|c|c|c|c|c|}
\hline \multicolumn{6}{|c|}{ Supplemental Table S2.txt } \\
\hline CHEMBL1400294 & 688267 & 4.05 & 5.0352 & TRN & \\
\hline CHEMBL1496642 & 688267 & 6.2 & 5.039 & TST & \\
\hline CHEMBL1342401 & 688267 & 6.05 & 5.0414 & TRN & \\
\hline CHEMBL1559917 & 688267 & 4.65 & 5.1388 & TRN & \\
\hline CHEMBL1511900 & 688267 & 6.25 & 4.9934 & TRN & \\
\hline CHEMBL1569222 & 688267 & 4.45 & 4.999 & TRN & \\
\hline CHEMBL1427819 & 688267 & 5.1 & 5.12700 & 0000000001 & TRN \\
\hline CHEMBL1574203 & 688267 & 6.45 & 4.9874 & TRN & \\
\hline CHEMBL1594174 & 688267 & 4.5 & 5.0292 & TST & \\
\hline CHEMBL1439616 & 688267 & 6.5 & 5.1394 & TRN & \\
\hline CHEMBL1564765 & 688267 & 5.65 & 5.0173 & TRN & \\
\hline CHEMBL1529195 & 688267 & 5.75 & 5.1006 & TRN & \\
\hline CHEMBL1355508 & 688267 & 4.1 & 5.105 & TRN & \\
\hline CHEMBL 2374034 & 688267 & 5.8 & 5.0482 & TRN & \\
\hline CHEMBL1393238 & 688267 & 4.9 & 5.0475 & TRN & \\
\hline CHEMBL1978830 & 688267 & 4.2 & 5.0269 & TST & \\
\hline CHEMBL1514130 & 688267 & 5.35 & 5.0122 & TRN & \\
\hline CHEMBL1504433 & 688267 & 5.8 & 5.1007 & TRN & \\
\hline CHEMBL1584916 & 688267 & 6.15 & 5.0183 & TRN & \\
\hline CHEMBL1492832 & 688267 & 6.2 & 5.0532 & TRN & \\
\hline CHEMBL1433957 & 688267 & 4.75 & 5.0257 & TST & \\
\hline CHEMBL1501859 & 688267 & 4.05 & 5.0129 & TST & \\
\hline CHEMBL1440066 & 688267 & 4.55 & 5.0256 & TRN & \\
\hline CHEMBL1337660 & 688267 & 6.2 & 5.0122 & TRN & \\
\hline CHEMBL1551426 & 688267 & 5.3 & 5.1145 & TRN & \\
\hline CHEMBL1362552 & 688267 & 4.25 & 5.0332 & TRN & \\
\hline CHEMBL1347322 & 688267 & 5.55 & 5.1578 & TRN & \\
\hline CHEMBL1374118 & 688267 & 4.4 & 5.0462 & TRN & \\
\hline CHEMBL1430269 & 688267 & 5.55 & 5.0393 & TRN & \\
\hline CHEMBL1434863 & 688267 & 4.95 & 4.9841 & TRN & \\
\hline CHEMBL1563706 & 688267 & 6.2 & 5.0643 & TRN & \\
\hline CHEMBL1604956 & 688267 & 4.35 & 5.0993 & TRN & \\
\hline CHEMBL1449703 & 688267 & 4.4 & 5.0556 & TST & \\
\hline CHEMBL1571164 & 688267 & 6.2 & 5.0192 & TRN & \\
\hline CHEMBL1378659 & 688267 & 5.55 & 5.07 & TST & \\
\hline CHEMBL1313073 & 688267 & 6.1 & 5.1016 & TRN & \\
\hline CHEMBL1360621 & 688267 & 4.05 & 5.0074 & TRN & \\
\hline CHEMBL1412650 & 688267 & 5.65 & 5.0518 & TRN & \\
\hline CHEMBL1393650 & 688267 & 4.05 & 5.081 & TRN & \\
\hline CHEMBL1589802 & 688267 & 5.35 & 5.0834 & TRN & \\
\hline CHEMBL1344791 & 688267 & 5.45 & 5.0629 & TST & \\
\hline CHEMBL1464351 & 688267 & 5.2 & 5.0945 & TRN & \\
\hline CHEMBL1536492 & 688267 & 5.9 & 5.0364 & TRN & \\
\hline CHEMBL 1607742 & 688267 & 5.95 & 5.0865 & TST & \\
\hline CHEMBL1537488 & 688267 & 6.2 & 5.0193 & TRN & \\
\hline CHEMBL1310381 & 688267 & 5.8 & 5.0076 & TRN & \\
\hline CHEMBL1463462 & 688267 & 5.15 & 5.0949 & TST & \\
\hline CHEMBL1475699 & 688267 & 4.05 & 5.0624 & TRN & \\
\hline
\end{tabular}




\begin{tabular}{|c|c|c|c|c|}
\hline \multirow[b]{2}{*}{ CHEMBL1590089 } & \multicolumn{4}{|c|}{ Supplemental Table S2.tx } \\
\hline & 688267 & 5.3 & 5.039 & TRN \\
\hline CHEMBL1581738 & 688267 & 5.65 & 5.0628 & TRN \\
\hline CHEMBL1449600 & 688267 & 5.2 & 5.048 & TST \\
\hline CHEMBL1520221 & 688267 & 3.95 & 5.1028 & TRN \\
\hline CHEMBL1314177 & 688267 & 5.2 & 5.0621 & TRN \\
\hline CHEMBL1535124 & 688267 & 5.5 & 5.0361 & TRN \\
\hline CHEMBL1554916 & 688267 & 4.6 & 5.091 & TRN \\
\hline CHEMBL 3194202 & 688267 & 4.05 & 4.9697 & TST \\
\hline CHEMBL1341213 & 688267 & 4.0 & 5.0263 & TST \\
\hline CHEMBL1521976 & 688267 & 5.8 & 5.0474 & TRN \\
\hline CHEMBL1367841 & 688267 & 6.15 & 5.1105 & TRN \\
\hline CHEMBL1336253 & 688267 & 4.8 & 5.09 & TRN \\
\hline CHEMBL1437594 & 688267 & 4.55 & 5.0327 & TRN \\
\hline CHEMBL1584367 & 688267 & 4.2 & 5.1077 & TST \\
\hline CHEMBL577635 & 688267 & 5.05 & 5.0846 & TST \\
\hline CHEMBL1487264 & 688267 & 5.05 & 5.0372 & TRN \\
\hline CHEMBL1539772 & 688267 & 4.9 & 5.0471 & TST \\
\hline CHEMBL1343365 & 688267 & 5.5 & 5.0163 & TRN \\
\hline CHEMBL1496975 & 688267 & 5.5 & 5.0599 & TST \\
\hline CHEMBL1557393 & 688267 & 5.85 & 5.0506 & TRN \\
\hline CHEMBL1532498 & 688267 & 5.65 & 5.0231 & TRN \\
\hline CHEMBL1434567 & 688267 & 4.05 & 5.0766 & TST \\
\hline CHEMBL1565342 & 688267 & 3.95 & 5.0514 & TRN \\
\hline CHEMBL 3212880 & 688267 & 4.05 & 5.0275 & TRN \\
\hline CHEMBL1413233 & 688267 & 5.8 & 4.9857 & TRN \\
\hline CHEMBL1434185 & 688267 & 4.55 & 5.072 & TST \\
\hline CHEMBL1605341 & 688267 & 4.3 & 5.055 & TRN \\
\hline CHEMBL1613565 & 688267 & 4.4 & 5.0413 & TRN \\
\hline CHEMBL1606787 & 688267 & 5.05 & 5.0282 & TRN \\
\hline CHEMBL1594007 & 688267 & 6.15 & 5.1482 & TRN \\
\hline CHEMBL3195770 & 688267 & 4.1 & 5.0497 & TRN \\
\hline CHEMBL1510122 & 688267 & 6.5 & 5.0733 & TRN \\
\hline CHEMBL1609313 & 688267 & 6.2 & 5.0613 & TRN \\
\hline CHEMBL1326041 & 688267 & 5.0 & 5.0317 & TRN \\
\hline CHEMBL1299669 & 688267 & 6.2 & 5.0897 & TRN \\
\hline CHEMBL1369191 & 688267 & 5.45 & 5.0983 & TRN \\
\hline CHEMBL1451152 & 688267 & 4.15 & 5.0525 & TRN \\
\hline CHEMBL1509538 & 688267 & 6.2 & 5.0236 & TST \\
\hline CHEMBL1610969 & 688267 & 4.7 & 5.0545 & TRN \\
\hline CHEMBL1419434 & 688267 & 4.85 & 5.0111 & TRN \\
\hline CHEMBL1331818 & 688267 & 5.55 & 5.0449 & TRN \\
\hline CHEMBL1597894 & 688267 & 6.25 & 5.037 & TRN \\
\hline CHEMBL1513470 & 688267 & 5.45 & 5.0905 & TRN \\
\hline CHEMBL1520626 & 688267 & 4.05 & 5.0043 & TRN \\
\hline CHEMBL1327272 & 688267 & 5.4 & 5.0229 & TRN \\
\hline CHEMBL1384347 & 688267 & 5.4 & 5.0861 & TRN \\
\hline CHEMBL1361043 & 688267 & 4.1 & 5.0777 & TRN \\
\hline CHEMBL1469676 & 688267 & 4.85 & 5.0398 & TST \\
\hline
\end{tabular}




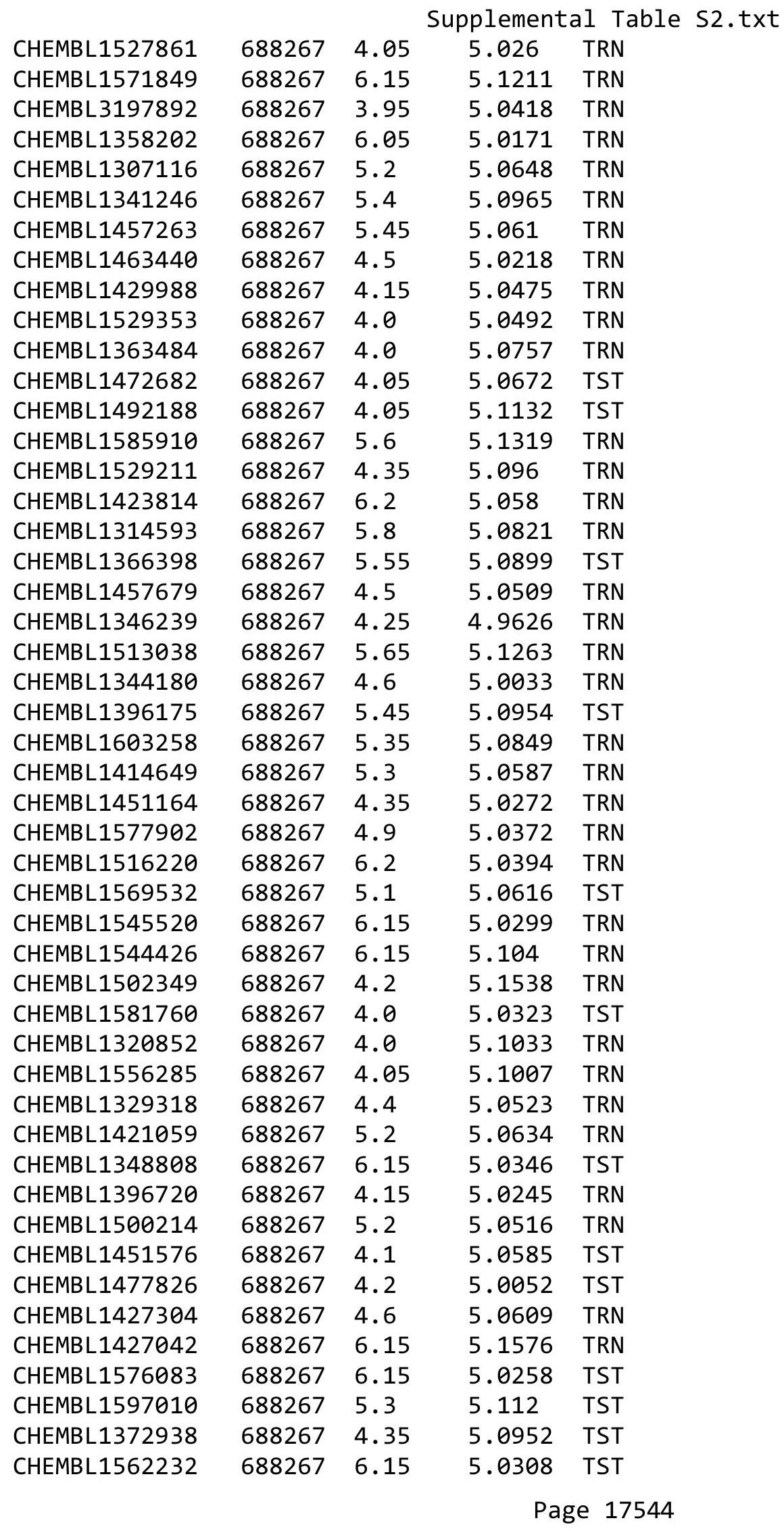




\begin{tabular}{|c|c|c|c|c|}
\hline & & & upplement & al $\mathrm{T}$ \\
\hline CHEMBL1435559 & 688267 & 4.25 & 5.0504 & TST \\
\hline CHEMBL1612413 & 688267 & 5.55 & 4.9984 & TRN \\
\hline CHEMBL1488181 & 688267 & 5.7 & 5.0727 & TRN \\
\hline CHEMBL1536699 & 688267 & 5.35 & 5.0682 & TRN \\
\hline CHEMBL1354935 & 688267 & 6.2 & 5.0857 & TRN \\
\hline CHEMBL1555053 & 688267 & 3.95 & 5.0002 & TRN \\
\hline CHEMBL1495901 & 688267 & 4.45 & 5.1388 & TRN \\
\hline CHEMBL1379099 & 688267 & 4.5 & 5.0584 & TRN \\
\hline CHEMBL1351540 & 688267 & 4.4 & 5.0976 & TRN \\
\hline CHEMBL1572472 & 688267 & 4.4 & 5.1277 & TST \\
\hline CHEMBL1333223 & 688267 & 6.05 & 5.081 & TST \\
\hline CHEMBL1345468 & 688267 & 4.35 & 5.0039 & TST \\
\hline CHEMBL1564453 & 688267 & 4.5 & 5.129 & TRN \\
\hline CHEMBL352865 & 688267 & 5.65 & 5.106 & TST \\
\hline CHEMBL1459347 & 688267 & 6.2 & 5.0864 & TST \\
\hline CHEMBL3210594 & 688267 & 4.0 & 5.0141 & TRN \\
\hline CHEMBL1413658 & 688267 & 4.35 & 5.0984 & TRN \\
\hline CHEMBL3193437 & 688267 & 4.95 & 5.0036 & TRN \\
\hline CHEMBL1417765 & 688267 & 5.6 & 5.0727 & TRN \\
\hline CHEMBL1422172 & 688267 & 5.05 & 5.0157 & TRN \\
\hline CHEMBL1593272 & 688267 & 4.05 & 5.1373 & TRN \\
\hline CHEMBL1500487 & 688267 & 4.2 & 5.0258 & TST \\
\hline CHEMBL3392060 & 688267 & 5.1 & 5.0729 & TST \\
\hline CHEMBL1569504 & 688267 & 4.0 & 5.0522 & TRN \\
\hline CHEMBL1583219 & 688267 & 5.85 & 5.0673 & TRN \\
\hline CHEMBL1320327 & 688267 & 4.95 & 5.0714 & TRN \\
\hline CHEMBL1521826 & 688267 & 6.2 & 5.0141 & TST \\
\hline CHEMBL1417958 & 688267 & 5.55 & 5.033 & TRN \\
\hline CHEMBL1407499 & 688267 & 5.5 & 5.0451 & TRN \\
\hline CHEMBL1531671 & 688267 & 6.2 & 5.0362 & TRN \\
\hline CHEMBL1536654 & 688267 & 5.8 & 5.1025 & TST \\
\hline CHEMBL 1487470 & 688267 & 4.75 & 5.0836 & TRN \\
\hline CHEMBL3189568 & 688267 & 5.6 & 5.0219 & TRN \\
\hline CHEMBL1482189 & 688267 & 4.0 & 4.9882 & TRN \\
\hline CHEMBL1550802 & 688267 & 5.45 & 5.0155 & TRN \\
\hline CHEMBL1319012 & 688267 & 4.65 & 5.0717 & TRN \\
\hline CHEMBL 1407535 & 688267 & 4.6 & 5.0267 & TRN \\
\hline CHEMBL1577403 & 688267 & 5.9 & 5.0975 & TRN \\
\hline CHEMBL1598119 & 688267 & 4.05 & 5.0202 & TST \\
\hline CHEMBL1445134 & 688267 & 4.35 & 5.0717 & TRN \\
\hline CHEMBL1336618 & 688267 & 4.25 & 5.0433 & TRN \\
\hline CHEMBL1413541 & 688267 & 4.5 & 5.0447 & TRN \\
\hline CHEMBL1444130 & 688267 & 4.0 & 5.0029 & TST \\
\hline CHEMBL1350569 & 688267 & 5.55 & 5.166 & TRN \\
\hline CHEMBL1319868 & 688267 & 6.15 & 5.0348 & TRN \\
\hline CHEMBL1469937 & 688267 & 5.25 & 5.0546 & TRN \\
\hline CHEMBL1489283 & 688267 & 5.65 & 4.9738 & TRN \\
\hline CHEMBL1516645 & 688267 & 6.25 & 5.1188 & TRN \\
\hline
\end{tabular}




\begin{tabular}{|c|c|c|c|c|c|}
\hline \\
\hline CHEMBL1518498 & 688267 & 6.45 & 5.0717 & TRN & \\
\hline CHEMBL1554081 & 688267 & 4.35 & 5.0412 & TRN & \\
\hline CHEMBL1514213 & 688267 & 5.55 & 4.9973 & TRN & \\
\hline CHEMBL1391320 & 688267 & 5.5 & 5.078 & TST & \\
\hline CHEMBL1335468 & 688267 & 5.55 & 5.0778 & TST & \\
\hline CHEMBL1366347 & 688267 & 4.45 & 5.0005 & TRN & \\
\hline CHEMBL1493547 & 688267 & 4.05 & 5.0896 & TST & \\
\hline CHEMBL1417777 & 688267 & 4.0 & 5.1203 & TRN & \\
\hline CHEMBL3210009 & 688267 & 4.6 & 4.9633 & TRN & \\
\hline CHEMBL1348119 & 688267 & 6.5 & 4.9423 & TRN & \\
\hline CHEMBL1507290 & 688267 & 5.45 & 5.042 & TRN & \\
\hline CHEMBL1429441 & 688267 & 6.15 & 5.0217 & TST & \\
\hline CHEMBL1515588 & 688267 & 4.0 & 5.0856 & TRN & \\
\hline CHEMBL3191773 & 688267 & 4.95 & 5.0909 & TST & \\
\hline CHEMBL3210416 & 688267 & 4.2 & 5.03600 & 00000000005 & TST \\
\hline CHEMBL1429120 & 688267 & 3.95 & 5.0975 & TRN & \\
\hline CHEMBL1413430 & 688267 & 4.4 & 5.1061 & TRN & \\
\hline CHEMBL1401267 & 688267 & 5.45 & 5.0575 & TRN & \\
\hline CHEMBL1555604 & 688267 & 5.3 & 5.0044 & TST & \\
\hline CHEMBL1510624 & 688267 & 5.25 & 5.15600 & 0000000001 & TRN \\
\hline CHEMBL1566735 & 688267 & 4.35 & 5.0256 & TST & \\
\hline CHEMBL1370881 & 688267 & 5.55 & 5.0856 & TRN & \\
\hline CHEMBL1528929 & 688267 & 5.6 & 5.0356 & TRN & \\
\hline CHEMBL1540525 & 688267 & 4.0 & 4.98 & TRN & \\
\hline CHEMBL1486543 & 688267 & 4.0 & 4.9874 & TRN & \\
\hline CHEMBL1441677 & 688267 & 4.6 & 5.0595 & TST & \\
\hline CHEMBL1549681 & 688267 & 6.15 & 5.1211 & TRN & \\
\hline CHEMBL1486278 & 688267 & 4.05 & 5.0646 & TST & \\
\hline CHEMBL1468823 & 688267 & 4.1 & 5.077 & TRN & \\
\hline CHEMBL1582777 & 688267 & 5.5 & 5.0716 & TST & \\
\hline CHEMBL1425045 & 688267 & 4.55 & 5.077 & TST & \\
\hline CHEMBL 1467351 & 688267 & 3.95 & 5.0075 & TRN & \\
\hline CHEMBL1545010 & 688267 & 4.2 & 5.0997 & TRN & \\
\hline CHEMBL1368654 & 688267 & 5.0 & 5.079 & TRN & \\
\hline CHEMBL1392280 & 688267 & 5.3 & 5.0149 & TRN & \\
\hline CHEMBL1519273 & 688267 & 4.0 & 5.0727 & TRN & \\
\hline CHEMBL 1497816 & 688267 & 4.6 & 5.0178 & TRN & \\
\hline CHEMBL1568948 & 688267 & 5.35 & 5.0852 & TRN & \\
\hline CHEMBL3196731 & 688267 & 4.05 & 5.0414 & TRN & \\
\hline CHEMBL1553932 & 688267 & 6.25 & 4.9995 & TRN & \\
\hline CHEMBL1601236 & 688267 & 4.15 & 5.073 & TRN & \\
\hline CHEMBL1582833 & 688267 & 4.35 & 4.9993 & TRN & \\
\hline CHEMBL1422563 & 688267 & 5.85 & 5.0818 & TRN & \\
\hline CHEMBL1493827 & 688267 & 4.55 & 4.9981 & TRN & \\
\hline CHEMBL1576772 & 688267 & 4.6 & 5.0766 & TST & \\
\hline CHEMBL3212000 & 688267 & 4.0 & 5.0511 & TST & \\
\hline CHEMBL 1489222 & 688267 & 4.1 & 5.0395 & TRN & \\
\hline CHEMBL1602300 & 688267 & 5.25 & 5.0351 & TRN & \\
\hline
\end{tabular}




\begin{tabular}{|c|c|c|c|c|c|}
\hline CHEMBL1322451 & 688267 & 6.2 & \multicolumn{2}{|c|}{5.122000000000001} & \multirow[t]{2}{*}{ TRN } \\
\hline CHEMBL1591975 & 688267 & 6.2 & 5.078 & TST & \\
\hline CHEMBL1438754 & 688267 & 5.75 & 5.0998 & TRN & \\
\hline CHEMBL3209848 & 688267 & 6.2 & 5.0586 & TST & \\
\hline CHEMBL1396514 & 688267 & 4.0 & 5.0151 & TRN & \\
\hline CHEMBL1500595 & 688267 & 5.9 & 5.0948 & TST & \\
\hline CHEMBL1459789 & 688267 & 4.35 & 5.0459 & TST & \\
\hline CHEMBL1527483 & 688267 & 3.95 & 5.0624 & TST & \\
\hline CHEMBL1437247 & 688267 & 4.35 & 5.1331 & TST & \\
\hline CHEMBL1369249 & 688267 & 6.2 & 5.0757 & TST & \\
\hline CHEMBL1368014 & 688267 & 5.65 & 5.0094 & TRN & \\
\hline CHEMBL1613118 & 688267 & 5.8 & 5.0428 & TRN & \\
\hline CHEMBL1415641 & 688267 & 6.25 & 5.0645 & TST & \\
\hline CHEMBL1368906 & 688267 & 4.05 & 5.0784 & TRN & \\
\hline CHEMBL1324254 & 688267 & 4.8 & 5.0283 & TST & \\
\hline CHEMBL1464468 & 688267 & 5.95 & 5.033 & TRN & \\
\hline CHEMBL1329091 & 688267 & 4.0 & 5.0394 & TST & \\
\hline CHEMBL1495820 & 688267 & 5.1 & 5.0773 & TRN & \\
\hline CHEMBL1476903 & 688267 & 4.75 & 5.0663 & TRN & \\
\hline CHEMBL1453029 & 688267 & 4.75 & 5.0017 & TRN & \\
\hline CHEMBL1374833 & 688267 & 4.05 & 5.0834 & TRN & \\
\hline CHEMBL1416855 & 688267 & 5.15 & 5.0347 & TRN & \\
\hline CHEMBL1387009 & 688267 & 4.15 & 5.088 & TRN & \\
\hline CHEMBL1372039 & 688267 & 5.4 & 5.073 & TRN & \\
\hline CHEMBL 324852 & 688267 & 6.15 & 5.0713 & TST & \\
\hline CHEMBL1451322 & 688267 & 5.9 & 5.0158 & TRN & \\
\hline CHEMBL1346256 & 688267 & 5.3 & 5.0705 & TRN & \\
\hline CHEMBL1533461 & 688267 & 4.0 & 5.1137 & TRN & \\
\hline CHEMBL1321248 & 688267 & 4.05 & 5.065 & TRN & \\
\hline CHEMBL1512622 & 688267 & 4.25 & 5.067 & TRN & \\
\hline CHEMBL 383041 & 688267 & 4.35 & 5.0618 & TRN & \\
\hline CHEMBL1375878 & 688267 & 6.15 & 5.1051 & TRN & \\
\hline CHEMBL1340307 & 688267 & 4.75 & 5.0695 & TST & \\
\hline CHEMBL1499044 & 688267 & 4.65 & 5.0154 & TRN & \\
\hline CHEMBL1978608 & 688267 & 6.2 & 4.9474 & TRN & \\
\hline CHEMBL1609077 & 688267 & 5.85 & 5.0206 & TRN & \\
\hline CHEMBL1539973 & 688267 & 4.2 & 5.0612 & TRN & \\
\hline CHEMBL1299683 & 688267 & 6.15 & 5.0551 & TRN & \\
\hline CHEMBL1337817 & 688267 & 4.55 & 5.0412 & TST & \\
\hline CHEMBL1428236 & 688267 & 5.8 & 5.0553 & TRN & \\
\hline CHEMBL1548048 & 688267 & 6.2 & 5.0416 & TRN & \\
\hline CHEMBL1408506 & 688267 & 5.35 & 5.0953 & TRN & \\
\hline CHEMBL3196472 & 688267 & 4.4 & 4.9882 & TST & \\
\hline CHEMBL1424222 & 688267 & 4.0 & 5.0413 & TRN & \\
\hline CHEMBL3197064 & 688267 & 5.5 & 5.0176 & TRN & \\
\hline CHEMBL1504399 & 688267 & 4.45 & 5.05699 & 99999999995 & TRN \\
\hline CHEMBL1428267 & 688267 & 4.05 & 5.0401 & TRN & \\
\hline CHEMBL1460964 & 688267 & 3.95 & 5.0562 & TST & \\
\hline & & & & 17547 & \\
\hline
\end{tabular}




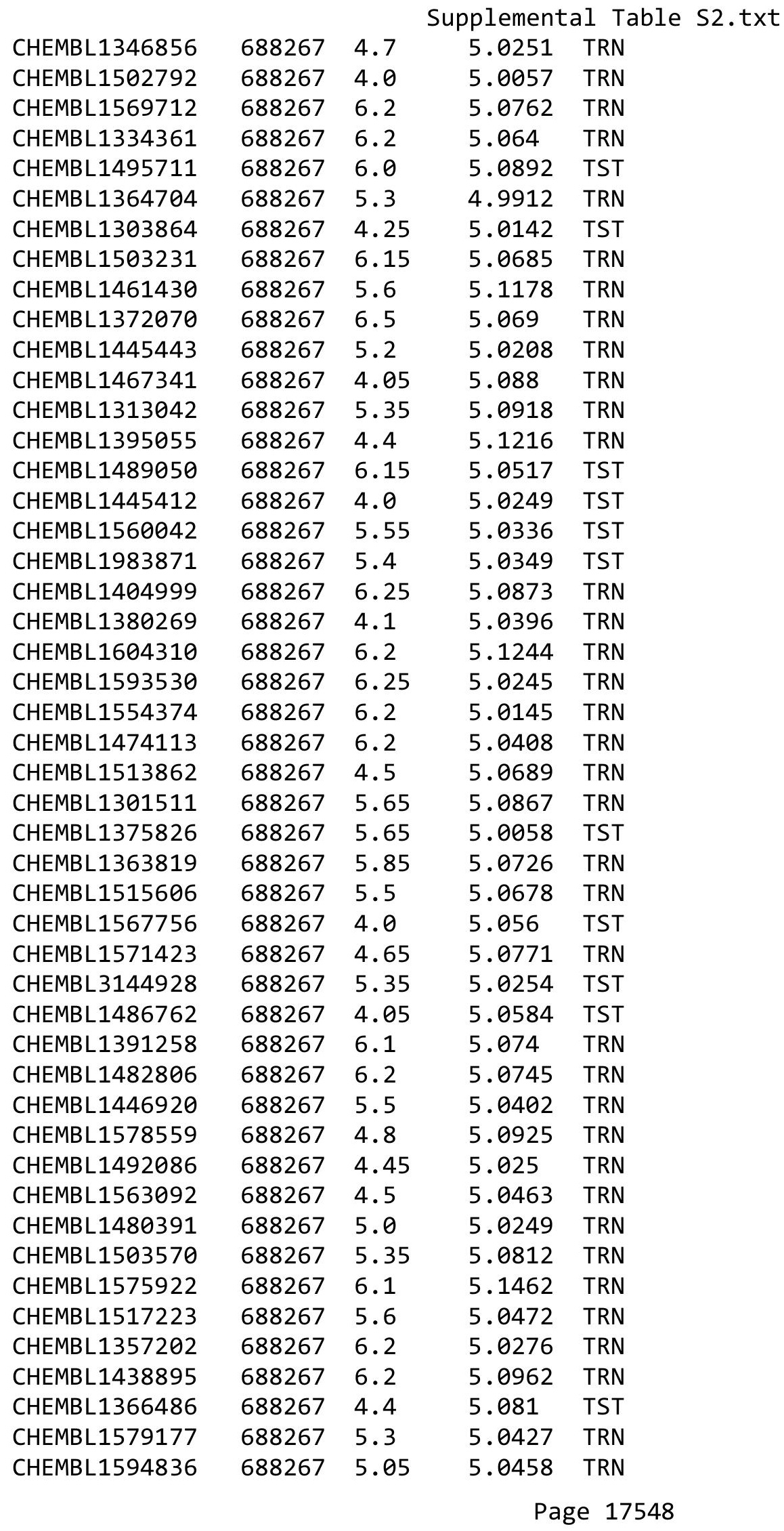




\begin{tabular}{|c|c|c|c|c|}
\hline & & & pplemen & al $\mathrm{T}$ \\
\hline CHEMBL1458598 & 688267 & 4.5 & 5.1558 & TRN \\
\hline CHEMBL1502374 & 688267 & 4.1 & 4.9946 & TRN \\
\hline CHEMBL1330783 & 688267 & 5.9 & 5.0943 & TRN \\
\hline CHEMBL1386356 & 688267 & 4.0 & 5.093 & TRN \\
\hline CHEMBL1322354 & 688267 & 5.15 & 5.0183 & TRN \\
\hline CHEMBL1540859 & 688267 & 6.2 & 5.0706 & TRN \\
\hline CHEMBL1593080 & 688267 & 5.25 & 5.0868 & TRN \\
\hline CHEMBL1320916 & 688267 & 4.0 & 5.0207 & TRN \\
\hline CHEMBL1500807 & 688267 & 5.3 & 5.0773 & TRN \\
\hline CHEMBL1303938 & 688267 & 5.1 & 5.03 & TST \\
\hline CHEMBL1465172 & 688267 & 4.05 & 5.0856 & TRN \\
\hline CHEMBL1355118 & 688267 & 4.05 & 5.0222 & TRN \\
\hline CHEMBL1401439 & 688267 & 5.95 & 5.07 & TST \\
\hline CHEMBL1333841 & 688267 & 6.2 & 4.9876 & TRN \\
\hline CHEMBL1434263 & 688267 & 4.0 & 5.0017 & TRN \\
\hline CHEMBL1540657 & 688267 & 4.35 & 5.0567 & TRN \\
\hline CHEMBL1513702 & 688267 & 3.95 & 5.1308 & TRN \\
\hline CHEMBL1319575 & 688267 & 6.2 & 5.0542 & TST \\
\hline CHEMBL1377052 & 688267 & 5.6 & 5.1411 & TRN \\
\hline CHEMBL1597126 & 688267 & 5.3 & 5.0415 & TRN \\
\hline CHEMBL1472972 & 688267 & 6.2 & 5.0179 & TRN \\
\hline CHEMBL1534637 & 688267 & 5.4 & 5.0585 & TST \\
\hline CHEMBL1474119 & 688267 & 5.7 & 5.0989 & TRN \\
\hline CHEMBL1305293 & 688267 & 4.25 & 5.0591 & TST \\
\hline CHEMBL1511370 & 688267 & 5.4 & 5.0883 & TRN \\
\hline CHEMBL1508512 & 688267 & 4.4 & 5.0537 & TST \\
\hline CHEMBL1455571 & 688267 & 6.25 & 5.0001 & TRN \\
\hline CHEMBL1570634 & 688267 & 4.35 & 5.1363 & TRN \\
\hline CHEMBL1353469 & 688267 & 5.15 & 5.1097 & TRN \\
\hline CHEMBL1531293 & 688267 & 4.75 & 5.1187 & TRN \\
\hline CHEMBL1542351 & 688267 & 4.05 & 5.0682 & TRN \\
\hline CHEMBL1501089 & 688267 & 6.2 & 5.0608 & TST \\
\hline CHEMBL1547272 & 688267 & 4.25 & 5.0545 & TRN \\
\hline CHEMBL1398418 & 688267 & 5.05 & 4.9827 & TRN \\
\hline CHEMBL1416562 & 688267 & 3.95 & 5.0067 & TRN \\
\hline CHEMBL1602387 & 688267 & 5.4 & 5.032 & TRN \\
\hline CHEMBL1330243 & 688267 & 5.25 & 5.0211 & TRN \\
\hline CHEMBL1416795 & 688267 & 4.0 & 5.0845 & TST \\
\hline CHEMBL1496104 & 688267 & 5.45 & 5.0415 & TRN \\
\hline CHEMBL57978 & 688267 & 5.55 & 5.0227 & TRN \\
\hline CHEMBL1567558 & 688267 & 4.05 & 5.1347 & TRN \\
\hline CHEMBL1319958 & 688267 & 6.5 & 4.9945 & TRN \\
\hline CHEMBL3207688 & 688267 & 4.6 & 5.0483 & TRN \\
\hline CHEMBL1464932 & 688267 & 6.15 & 5.0413 & TRN \\
\hline CHEMBL1377756 & 688267 & 5.1 & 5.0087 & TRN \\
\hline CHEMBL1602565 & 688267 & 6.2 & 5.0906 & TRN \\
\hline CHEMBL1349938 & 688267 & 4.0 & 5.0118 & TRN \\
\hline CHEMBL1390875 & 688267 & 5.9 & 5.0323 & TRN \\
\hline
\end{tabular}




\begin{tabular}{|c|c|c|c|c|c|}
\hline \multicolumn{6}{|c|}{ Supplemental Table S2.txt } \\
\hline CHEMBL1347810 & 688267 & 3.95 & 5.0695 & TST & \\
\hline CHEMBL1552489 & 688267 & 6.15 & 5.0953 & TRN & \\
\hline CHEMBL1376113 & 688267 & 4.95 & 5.0042 & TRN & \\
\hline CHEMBL1474054 & 688267 & 5.05 & 5.0811 & TRN & \\
\hline CHEMBL 243216 & 688267 & 4.15 & 5.02800 & 00000000005 & TRN \\
\hline CHEMBL1523335 & 688267 & 4.05 & 5.072 & TST & \\
\hline CHEMBL1571492 & 688267 & 6.1 & 5.0379 & TRN & \\
\hline CHEMBL1559988 & 688267 & 5.65 & 5.0164 & TRN & \\
\hline CHEMBL1385822 & 688267 & 4.0 & 5.0246 & TRN & \\
\hline CHEMBL1588979 & 688267 & 4.9 & 5.1125 & TRN & \\
\hline CHEMBL1485223 & 688267 & 4.1 & 5.0803 & TST & \\
\hline CHEMBL1565492 & 688267 & 5.65 & 5.008 & TRN & \\
\hline CHEMBL1400698 & 688267 & 5.1 & 5.015 & TRN & \\
\hline CHEMBL529939 & 688267 & 4.75 & 5.0816 & TST & \\
\hline CHEMBL1471762 & 688267 & 4.55 & 5.0332 & TRN & \\
\hline CHEMBL1331364 & 688267 & 4.0 & 5.1397 & TRN & \\
\hline CHEMBL1564380 & 688267 & 4.05 & 5.0894 & TRN & \\
\hline CHEMBL3208595 & 688267 & 5.45 & 5.0133 & TRN & \\
\hline CHEMBL1300690 & 688267 & 5.35 & 5.1024 & TRN & \\
\hline CHEMBL1460994 & 688267 & 4.25 & 5.1054 & TST & \\
\hline CHEMBL1517334 & 688267 & 4.35 & 5.0485 & TRN & \\
\hline CHEMBL1482871 & 688267 & 6.2 & 5.1051 & TRN & \\
\hline CHEMBL1579237 & 688267 & 5.6 & 5.003 & TST & \\
\hline CHEMBL1488874 & 688267 & 5.95 & 4.9944 & TRN & \\
\hline CHEMBL1487292 & 688267 & 5.5 & 5.1123 & TRN & \\
\hline CHEMBL1459128 & 688267 & 4.65 & 5.0675 & TST & \\
\hline CHEMBL1395632 & 688267 & 3.95 & 5.115 & TRN & \\
\hline CHEMBL1311302 & 688267 & 5.9 & 5.0209 & TST & \\
\hline CHEMBL3192702 & 688267 & 4.0 & 5.0089 & TRN & \\
\hline CHEMBL1381789 & 688267 & 6.0 & 5.0454 & TST & \\
\hline CHEMBL1428155 & 688267 & 4.9 & 5.084 & TRN & \\
\hline CHEMBL1445661 & 688267 & 4.5 & 5.0563 & TRN & \\
\hline CHEMBL1512453 & 688267 & 4.35 & 5.1216 & TRN & \\
\hline CHEMBL1611472 & 688267 & 6.2 & 4.9855 & TST & \\
\hline CHEMBL1310099 & 688267 & 4.0 & 5.0494 & TRN & \\
\hline CHEMBL1475832 & 688267 & 5.0 & 5.0972 & TRN & \\
\hline CHEMBL1513834 & 688267 & 4.0 & 4.9957 & TRN & \\
\hline CHEMBL1407361 & 688267 & 4.0 & 5.1225 & TRN & \\
\hline CHEMBL1594179 & 688267 & 4.5 & 5.0924 & TRN & \\
\hline CHEMBL1338479 & 688267 & 4.1 & 5.1029 & TRN & \\
\hline CHEMBL1461834 & 688267 & 5.3 & 5.0329 & TRN & \\
\hline CHEMBL1488092 & 688267 & 4.25 & 5.0072 & TRN & \\
\hline CHEMBL1599960 & 688267 & 5.85 & 5.0499 & TRN & \\
\hline CHEMBL1397488 & 688267 & 4.0 & 5.0643 & TRN & \\
\hline CHEMBL1367239 & 688267 & 5.25 & 4.9904 & TRN & \\
\hline CHEMBL1364807 & 688267 & 4.3 & 5.0526 & TST & \\
\hline CHEMBL1310230 & 688267 & 4.6 & 5.0479 & TRN & \\
\hline CHEMBL1513062 & 688267 & 6.25 & 5.0533 & TRN & \\
\hline
\end{tabular}




\begin{tabular}{|c|c|c|c|c|}
\hline \multicolumn{5}{|c|}{ Supplemental Table s2.txt } \\
\hline CHEMBL1381117 & 688267 & 4.85 & 5.029 & TRN \\
\hline CHEMBL1509924 & 688267 & 5.5 & 5.1376 & TRN \\
\hline CHEMBL1539114 & 688267 & 5.55 & 5.0596 & TRN \\
\hline CHEMBL1595604 & 688267 & 6.45 & 5.0011 & TRN \\
\hline CHEMBL1486186 & 688267 & 5.9 & 4.9948 & TRN \\
\hline CHEMBL1413593 & 688267 & 5.8 & 5.0285 & TST \\
\hline CHEMBL1555888 & 688267 & 6.7501 & 5.0599 & TRN \\
\hline CHEMBL1418364 & 688267 & 4.3 & 5.1185 & TST \\
\hline CHEMBL1305073 & 688267 & 4.95 & 5.0263 & TRN \\
\hline CHEMBL1467718 & 688267 & 4.3 & 4.966 & TRN \\
\hline CHEMBL1343907 & 688267 & 5.3 & 5.0312 & TRN \\
\hline CHEMBL1299825 & 688267 & 4.3 & 5.0297 & TRN \\
\hline CHEMBL1478250 & 688267 & 6.2 & 4.9671 & TRN \\
\hline CHEMBL1531454 & 688267 & 4.6 & 4.9969 & TRN \\
\hline CHEMBL1373332 & 688267 & 4.15 & 5.0016 & TST \\
\hline CHEMBL1487547 & 688267 & 6.2 & 5.0472 & TRN \\
\hline CHEMBL1510323 & 688267 & 5.65 & 5.1529 & TRN \\
\hline CHEMBL1424824 & 688267 & 6.15 & 5.0863 & TRN \\
\hline CHEMBL1504274 & 688267 & 5.55 & 5.0125 & TRN \\
\hline CHEMBL1324355 & 688267 & 5.85 & 5.0281 & TRN \\
\hline CHEMBL1338746 & 688267 & 6.45 & 5.0073 & TRN \\
\hline CHEMBL1410295 & 688267 & 4.7 & 5.0857 & TRN \\
\hline CHEMBL1397189 & 688267 & 6.15 & 5.0386 & TRN \\
\hline CHEMBL1353055 & 688267 & 4.4 & 5.0389 & TRN \\
\hline CHEMBL1462218 & 688267 & 5.35 & 5.0456 & TRN \\
\hline CHEMBL1582892 & 688267 & 4.7 & 5.0387 & TRN \\
\hline CHEMBL1430144 & 688267 & 4.25 & 5.0627 & TRN \\
\hline CHEMBL1480306 & 688267 & 6.15 & 5.0699 & TST \\
\hline CHEMBL3199859 & 688267 & 6.1 & 5.0135 & TST \\
\hline CHEMBL1474393 & 688267 & 6.2 & 5.0464 & TRN \\
\hline CHEMBL1405418 & 688267 & 5.4 & 5.1364 & TRN \\
\hline CHEMBL1443289 & 688267 & 4.0 & 5.1184 & TRN \\
\hline CHEMBL1458295 & 688267 & 4.95 & 5.0424 & TST \\
\hline CHEMBL1376579 & 688267 & 4.35 & 5.0435 & TST \\
\hline CHEMBL1519105 & 688267 & 5.8 & 5.1065 & TRN \\
\hline CHEMBL1310912 & 688267 & 5.35 & 5.0183 & TRN \\
\hline CHEMBL1408846 & 688267 & 4.35 & 5.0264 & TRN \\
\hline CHEMBL1470000 & 688267 & 5.3 & 5.0774 & TRN \\
\hline CHEMBL1586877 & 688267 & 5.3 & 5.1617 & TRN \\
\hline CHEMBL1324437 & 688267 & 4.65 & 5.0989 & TRN \\
\hline CHEMBL1374006 & 688267 & 5.65 & 4.9981 & TRN \\
\hline CHEMBL1485518 & 688267 & 4.45 & 5.0463 & TRN \\
\hline CHEMBL1377872 & 688267 & 4.05 & 5.0223 & TRN \\
\hline CHEMBL1571174 & 688267 & 4.3 & 5.0321 & TRN \\
\hline CHEMBL1553874 & 688267 & 5.35 & 5.0265 & TRN \\
\hline CHEMBL1476708 & 688267 & 4.05 & 5.0498 & TST \\
\hline CHEMBL1519735 & 688267 & 5.25 & 5.1283 & TRN \\
\hline CHEMBL1610148 & 688267 & 6.15 & 5.0351 & TST \\
\hline
\end{tabular}




\begin{tabular}{|c|c|c|c|c|}
\hline \multicolumn{5}{|c|}{ Supplemental Tabl } \\
\hline CHEMBL1501830 & 688267 & 6.05 & 5.0663 & TRN \\
\hline CHEMBL1589119 & 688267 & 5.85 & 5.0714 & TRN \\
\hline CHEMBL1412201 & 688267 & 5.75 & 5.0353 & TRN \\
\hline CHEMBL1530508 & 688267 & 6.2 & 5.0187 & TRN \\
\hline CHEMBL1473341 & 688267 & 6.5 & 5.119 & TRN \\
\hline CHEMBL1367398 & 688267 & 5.45 & 5.0178 & TRN \\
\hline CHEMBL3211131 & 688267 & 5.3 & 5.0655 & TRN \\
\hline CHEMBL1458636 & 688267 & 6.2 & 5.0534 & TRN \\
\hline CHEMBL1335919 & 688267 & 4.45 & 5.0525 & TRN \\
\hline CHEMBL1361051 & 688267 & 5.45 & 5.0429 & TRN \\
\hline CHEMBL1526390 & 688267 & 5.3 & 5.0909 & TRN \\
\hline CHEMBL1395454 & 688267 & 5.3 & 5.0105 & TRN \\
\hline CHEMBL1583636 & 688267 & 3.95 & 5.0384 & TRN \\
\hline CHEMBL1365921 & 688267 & 5.4 & 5.1412 & TRN \\
\hline CHEMBL1612924 & 688267 & 5.45 & 5.0968 & TRN \\
\hline CHEMBL1570114 & 688267 & 4.0 & 5.1373 & TRN \\
\hline CHEMBL1312085 & 688267 & 4.25 & 5.0116 & TRN \\
\hline CHEMBL1326555 & 688267 & 4.6 & 5.0894 & TRN \\
\hline CHEMBL1313497 & 688267 & 4.0 & 5.0607 & TRN \\
\hline CHEMBL1607743 & 688267 & 4.1 & 5.0592 & TRN \\
\hline CHEMBL1394286 & 688267 & 4.0 & 5.0263 & TRN \\
\hline CHEMBL1579647 & 688267 & 6.2 & 5.1049 & TRN \\
\hline CHEMBL3211852 & 688267 & 4.0 & 5.0048 & TST \\
\hline CHEMBL 1448430 & 688267 & 4.05 & 5.0798 & TRN \\
\hline CHEMBL1301406 & 688267 & 6.5 & 5.1288 & TRN \\
\hline CHEMBL1316195 & 688267 & 5.1 & 4.9773 & TRN \\
\hline CHEMBL1409857 & 688267 & 5.95 & 5.0839 & TST \\
\hline CHEMBL1502244 & 688267 & 6.2 & 5.0176 & TRN \\
\hline CHEMBL1448946 & 688267 & 6.2 & 5.1072 & TRN \\
\hline CHEMBL1403209 & 688267 & 6.2 & 4.9766 & TST \\
\hline CHEMBL1497070 & 688267 & 6.0 & 5.1047 & TRN \\
\hline CHEMBL1507172 & 688267 & 4.3 & 5.0349 & TRN \\
\hline CHEMBL1317204 & 688267 & 5.5 & 5.0284 & TRN \\
\hline CHEMBL1407162 & 688267 & 4.0 & 5.0696 & TST \\
\hline CHEMBL1344741 & 688267 & 4.4 & 5.1034 & TST \\
\hline CHEMBL1403517 & 688267 & 4.5 & 5.041 & TRN \\
\hline CHEMBL3208173 & 688267 & 5.0 & 4.9952 & TRN \\
\hline CHEMBL1563961 & 688267 & 4.05 & 5.0996 & TRN \\
\hline CHEMBL1319746 & 688267 & 4.3 & 5.0002 & TRN \\
\hline CHEMBL1525483 & 688267 & 4.5 & 5.0072 & TRN \\
\hline CHEMBL1354275 & 688267 & 4.2 & 5.0448 & TRN \\
\hline CHEMBL1484753 & 688267 & 5.3 & 5.1044 & TRN \\
\hline CHEMBL1311711 & 688267 & 6.25 & 5.0855 & TST \\
\hline CHEMBL1526316 & 688267 & 6.25 & 5.0167 & TRN \\
\hline CHEMBL1340728 & 688267 & 6.0 & 5.0447 & TRN \\
\hline CHEMBL1361077 & 688267 & 5.35 & 4.9783 & TRN \\
\hline CHEMBL1423803 & 688267 & 5.65 & 5.1321 & TRN \\
\hline CHEMBL1483488 & 688267 & 5.5 & 5.1499 & TRN \\
\hline
\end{tabular}




\begin{tabular}{|c|c|c|c|c|c|}
\hline \\
\hline CHEMBL1400551 & 688267 & 4.0 & 5.0248 & TRN & \\
\hline CHEMBL1412691 & 688267 & 4.2 & 5.0027 & TRN & \\
\hline CHEMBL1317072 & 688267 & 5.0 & 5.12 & TRN & \\
\hline CHEMBL1408956 & 688267 & 5.1 & 5.0651 & TRN & \\
\hline CHEMBL1519240 & 688267 & 4.4 & 5.0285 & TRN & \\
\hline CHEMBL1585993 & 688267 & 4.5 & 5.0394 & TRN & \\
\hline CHEMBL1490817 & 688267 & 4.25 & 5.0729 & TRN & \\
\hline CHEMBL1426370 & 688267 & 4.0 & 5.0328 & TRN & \\
\hline CHEMBL1438102 & 688267 & 4.0 & 5.098 & TST & \\
\hline CHEMBL1366373 & 688267 & 4.7 & 5.0088 & TST & \\
\hline CHEMBL1516542 & 688267 & 5.05 & 5.0048 & TST & \\
\hline CHEMBL1549774 & 688267 & 5.55 & 5.0912 & TRN & \\
\hline CHEMBL1392664 & 688267 & 4.3 & 5.1195 & TRN & \\
\hline CHEMBL1332726 & 688267 & 5.05 & \multicolumn{2}{|c|}{5.031000000000001} & TST \\
\hline CHEMBL1418437 & 688267 & 5.5 & 5.0768 & TST & \\
\hline CHEMBL1370811 & 688267 & 4.3 & 5.0762 & TRN & \\
\hline CHEMBL1604848 & 688267 & 6.1 & 5.0212 & TRN & \\
\hline CHEMBL1515387 & 688267 & 4.6 & 4.9968 & TST & \\
\hline CHEMBL1338064 & 688267 & 4.0 & 4.9847 & TRN & \\
\hline CHEMBL1499076 & 688267 & 6.25 & 5.0255 & TST & \\
\hline CHEMBL1559152 & 688267 & 5.35 & 5.0466 & TRN & \\
\hline CHEMBL1481905 & 688267 & 5.5 & 5.0587 & TST & \\
\hline CHEMBL1451678 & 688267 & 3.95 & 5.0923 & TRN & \\
\hline CHEMBL1308150 & 688267 & 5.35 & 5.0556 & TRN & \\
\hline CHEMBL1552883 & 688267 & 6.5 & 5.0828 & TRN & \\
\hline CHEMBL1310328 & 688267 & 3.95 & 5.0125 & TST & \\
\hline CHEMBL1591299 & 688267 & 4.2 & 4.997 & TRN & \\
\hline CHEMBL1548740 & 688267 & 4.4 & 5.0098 & TRN & \\
\hline CHEMBL1575600 & 688267 & 4.7 & 5.077 & TST & \\
\hline CHEMBL1336583 & 688267 & 5.85 & 5.0928 & TST & \\
\hline CHEMBL1587331 & 688267 & 3.95 & 5.1293 & TST & \\
\hline CHEMBL1580053 & 688267 & 5.45 & 5.0028 & TRN & \\
\hline CHEMBL1486184 & 688267 & 5.55 & 5.0767 & TST & \\
\hline CHEMBL1319392 & 688267 & 6.25 & \multicolumn{2}{|c|}{5.0760000000000005} & TST \\
\hline CHEMBL1463727 & 688267 & 5.35 & 5.1141 & TRN & \\
\hline CHEMBL1524793 & 688267 & 4.0 & 5.0924 & TRN & \\
\hline CHEMBL1335479 & 688267 & 5.8 & 5.0262 & TRN & \\
\hline CHEMBL1355528 & 688267 & 5.15 & 5.0741 & TRN & \\
\hline CHEMBL1364268 & 688267 & 4.95 & 5.0455 & TST & \\
\hline CHEMBL1521623 & 688267 & 6.25 & 5.0698 & TRN & \\
\hline CHEMBL1561614 & 688267 & 5.25 & 5.0464 & TRN & \\
\hline CHEMBL1433700 & 688267 & 5.15 & 5.0209 & TRN & \\
\hline CHEMBL1604418 & 688267 & 6.05 & 5.1025 & TRN & \\
\hline CHEMBL1396333 & 688267 & 6.2 & 5.0552 & TRN & \\
\hline CHEMBL1999810 & 688267 & 4.45 & 5.0155 & TRN & \\
\hline CHEMBL1604609 & 688267 & 5.35 & 5.0709 & TRN & \\
\hline CHEMBL1429849 & 688267 & 5.9 & 5.0766 & TST & \\
\hline \multirow[t]{2}{*}{ CHEMBL1422847 } & 688267 & 5.0 & \multicolumn{2}{|c|}{5.0680000000000005} & TST \\
\hline & & & & 17553 & \\
\hline
\end{tabular}




\begin{tabular}{|c|c|c|c|c|}
\hline & & & pplement & al $\mathrm{Ta}$ \\
\hline CHEMBL1373407 & 688267 & 5.3 & 5.0261 & TRN \\
\hline CHEMBL3196815 & 688267 & 6.25 & 5.0169 & TRN \\
\hline CHEMBL1486538 & 688267 & 5.0 & 5.0689 & TRN \\
\hline CHEMBL1320976 & 688267 & 4.35 & 5.0668 & TRN \\
\hline CHEMBL1416994 & 688267 & 3.95 & 5.0738 & TST \\
\hline CHEMBL1513627 & 688267 & 5.4 & 5.0626 & TRN \\
\hline CHEMBL1387522 & 688267 & 4.9 & 5.0205 & TRN \\
\hline CHEMBL 3192897 & 688267 & 4.1 & 5.0223 & TST \\
\hline CHEMBL1446585 & 688267 & 5.5 & 5.0013 & TRN \\
\hline CHEMBL1456551 & 688267 & 6.15 & 5.0669 & TRN \\
\hline CHEMBL 1488002 & 688267 & 6.2 & 5.0679 & TRN \\
\hline CHEMBL1502859 & 688267 & 5.35 & 5.0461 & TST \\
\hline CHEMBL1602881 & 688267 & 4.45 & 5.0895 & TRN \\
\hline CHEMBL1384505 & 688267 & 5.3 & 5.0952 & TST \\
\hline CHEMBL1524071 & 688267 & 5.45 & 5.069 & TST \\
\hline CHEMBL1315445 & 688267 & 4.1 & 5.0576 & TRN \\
\hline CHEMBL1557437 & 688267 & 4.6 & 5.0596 & TST \\
\hline CHEMBL1413666 & 688267 & 5.55 & 5.0634 & TST \\
\hline CHEMBL1424260 & 688267 & 5.0 & 5.099 & TRN \\
\hline CHEMBL1514214 & 688267 & 5.35 & 5.0509 & TRN \\
\hline CHEMBL1554152 & 688267 & 5.55 & 5.1128 & TRN \\
\hline CHEMBL1479312 & 688267 & 4.55 & 5.1219 & TRN \\
\hline CHEMBL1318610 & 688267 & 5.55 & 5.0944 & TRN \\
\hline CHEMBL1367179 & 688267 & 4.85 & 5.063 & TRN \\
\hline CHEMBL1374430 & 688267 & 5.3 & 5.0802 & TRN \\
\hline CHEMBL1509317 & 688267 & 4.0 & 5.0512 & TST \\
\hline CHEMBL3197057 & 688267 & 5.85 & 5.0028 & TRN \\
\hline CHEMBL1455931 & 688267 & 4.85 & 5.0174 & TRN \\
\hline CHEMBL1554508 & 688267 & 4.5 & 5.061 & TRN \\
\hline CHEMBL1499167 & 688267 & 6.0 & 5.0243 & TST \\
\hline CHEMBL1594274 & 688267 & 4.05 & 5.0658 & TRN \\
\hline CHEMBL1603464 & 688267 & 4.05 & 5.0924 & TST \\
\hline CHEMBL1408238 & 688267 & 6.2 & 5.032 & TRN \\
\hline CHEMBL1371739 & 688267 & 6.15 & 5.0587 & TRN \\
\hline CHEMBL1433227 & 688267 & 4.05 & 5.0069 & TRN \\
\hline CHEMBL1299308 & 688267 & 4.85 & 5.063 & TRN \\
\hline CHEMBL1540819 & 688267 & 5.05 & 5.0523 & TRN \\
\hline CHEMBL1316487 & 688267 & 4.35 & 5.1026 & TRN \\
\hline CHEMBL1342332 & 688267 & 5.35 & 5.0182 & TRN \\
\hline CHEMBL1460354 & 688267 & 5.25 & 5.1271 & TST \\
\hline CHEMBL1330740 & 688267 & 3.95 & 5.0267 & TST \\
\hline CHEMBL1449789 & 688267 & 4.6 & 5.0586 & TRN \\
\hline CHEMBL1446081 & 688267 & 4.0 & 5.1213 & TRN \\
\hline CHEMBL1511284 & 688267 & 6.15 & 4.9702 & TRN \\
\hline CHEMBL1523792 & 688267 & 6.15 & 5.0144 & TST \\
\hline CHEMBL1374376 & 688267 & 5.45 & 5.1359 & TRN \\
\hline CHEMBL1582474 & 688267 & 4.5 & 5.0055 & TST \\
\hline CHEMBL1321579 & 688267 & 4.7 & 5.0798 & TRN \\
\hline
\end{tabular}




\begin{tabular}{|c|c|c|c|c|}
\hline \multicolumn{5}{|c|}{ Supplemental Table S2.txt } \\
\hline CHEMBL1526497 & 688267 & 4.55 & 5.0166 & TST \\
\hline CHEMBL1566449 & 688267 & 6.2 & 5.0621 & TRN \\
\hline CHEMBL1572138 & 688267 & 4.4 & 5.0499 & TST \\
\hline CHEMBL1349223 & 688267 & 5.3 & 5.006 & TRN \\
\hline CHEMBL1347447 & 688267 & 4.05 & 5.0674 & TST \\
\hline CHEMBL1497742 & 688267 & 6.15 & 5.0269 & TRN \\
\hline CHEMBL1564183 & 688267 & 4.05 & 5.093 & TRN \\
\hline CHEMBL1376281 & 688267 & 4.05 & 5.0829 & TST \\
\hline CHEMBL1396159 & 688267 & 5.45 & 5.0763 & TRN \\
\hline CHEMBL1401635 & 688267 & 4.65 & 5.1 & TRN \\
\hline CHEMBL1979665 & 688267 & 3.95 & 4.9957 & TRN \\
\hline CHEMBL1368393 & 688267 & 5.3 & 5.0308 & TRN \\
\hline CHEMBL1329367 & 688267 & 6.45 & 5.0395 & TST \\
\hline CHEMBL1448884 & 688267 & 5.2 & 5.0962 & TST \\
\hline CHEMBL1609320 & 688267 & 5.85 & 5.12 & TRN \\
\hline CHEMBL1472646 & 688267 & 4.35 & 5.0913 & TRN \\
\hline CHEMBL1527026 & 688267 & 5.5 & 5.0673 & TRN \\
\hline CHEMBL1304155 & 688267 & 6.2 & 5.1208 & TRN \\
\hline CHEMBL1560098 & 688267 & 5.9 & 5.135 & TRN \\
\hline CHEMBL1600383 & 688267 & 5.45 & 5.0251 & TRN \\
\hline CHEMBL1528623 & 688267 & 3.95 & 5.0537 & TRN \\
\hline CHEMBL1424446 & 688267 & 5.45 & 5.0253 & TRN \\
\hline CHEMBL1402947 & 688267 & 3.95 & 5.1187 & TRN \\
\hline CHEMBL1449695 & 688267 & 5.05 & 5.1015 & TRN \\
\hline CHEMBL 3209344 & 688267 & 5.25 & 4.9911 & TRN \\
\hline CHEMBL1568972 & 688267 & 5.95 & 5.0576 & TRN \\
\hline CHEMBL1589817 & 688267 & 4.4 & 5.0007 & TRN \\
\hline CHEMBL1491043 & 688267 & 4.0 & 4.9631 & TRN \\
\hline CHEMBL1445015 & 688267 & 5.5 & 5.0448 & TRN \\
\hline CHEMBL1406501 & 688267 & 4.05 & 5.1372 & TRN \\
\hline CHEMBL1530580 & 688267 & 4.1 & 5.0772 & TRN \\
\hline CHEMBL1476896 & 688267 & 6.2 & 5.0825 & TRN \\
\hline CHEMBL1468794 & 688267 & 4.15 & 5.0422 & TST \\
\hline CHEMBL 3193771 & 688267 & 4.7 & 5.03 & TRN \\
\hline CHEMBL1548785 & 688267 & 5.55 & 5.1055 & TRN \\
\hline CHEMBL1558393 & 688267 & 5.3 & 5.0838 & TRN \\
\hline CHEMBL1397599 & 688267 & 5.3 & 5.0708 & TRN \\
\hline CHEMBL1316587 & 688267 & 5.5 & 4.9911 & TRN \\
\hline CHEMBL1341716 & 688267 & 4.1 & 5.0096 & TST \\
\hline CHEMBL1613626 & 688267 & 6.2 & 5.0732 & TRN \\
\hline CHEMBL1398037 & 688267 & 5.35 & 5.0324 & TRN \\
\hline CHEMBL1361961 & 688267 & 3.95 & 5.0441 & TST \\
\hline CHEMBL1522739 & 688267 & 4.75 & 5.0225 & TRN \\
\hline CHEMBL1480209 & 688267 & 4.0 & 5.0488 & TRN \\
\hline CHEMBL1569516 & 688267 & 4.35 & 5.0708 & TRN \\
\hline CHEMBL1322566 & 688267 & 4.0 & 5.0856 & TRN \\
\hline CHEMBL1466276 & 688267 & 6.2 & 5.0594 & TRN \\
\hline CHEMBL 3210110 & 688267 & 6.2 & 5.0353 & TRN \\
\hline
\end{tabular}




\begin{tabular}{|c|c|c|c|c|c|}
\hline \multicolumn{6}{|c|}{ Supplemental Table S2.txt } \\
\hline CHEMBL1349467 & 688267 & 3.95 & 5.0753 & TST & \\
\hline CHEMBL1307540 & 688267 & 5.6 & 5.0639 & TST & \\
\hline CHEMBL1448385 & 688267 & 5.15 & 5.0675 & TRN & \\
\hline CHEMBL1389056 & 688267 & 6.5 & 5.1434 & TRN & \\
\hline CHEMBL1589615 & 688267 & 4.4 & 5.0058 & TST & \\
\hline CHEMBL1612217 & 688267 & 4.65 & 5.0994 & TRN & \\
\hline CHEMBL3210395 & 688267 & 4.95 & 5.0081 & TRN & \\
\hline CHEMBL1466800 & 688267 & 6.15 & 5.0137 & TST & \\
\hline CHEMBL1584948 & 688267 & 4.8 & 5.1378 & TRN & \\
\hline CHEMBL3199725 & 688267 & 5.05 & 5.0043 & TST & \\
\hline CHEMBL1327551 & 688267 & 5.3 & 5.0755 & TRN & \\
\hline CHEMBL1554404 & 688267 & 3.95 & 5.0137 & TST & \\
\hline CHEMBL1556479 & 688267 & 5.35 & 5.1473 & TRN & \\
\hline CHEMBL1485171 & 688267 & 4.15 & 5.0454 & TST & \\
\hline CHEMBL1398161 & 688267 & 6.2 & 5.0719 & TRN & \\
\hline CHEMBL1445364 & 688267 & 6.2 & 5.1309 & TRN & \\
\hline CHEMBL1368843 & 688267 & 5.0 & 5.0882 & TRN & \\
\hline CHEMBL1469834 & 688267 & 6.2 & 5.0811 & TST & \\
\hline CHEMBL3197851 & 688267 & 4.45 & 5.0313 & TST & \\
\hline CHEMBL1363288 & 688267 & 3.95 & 5.0447 & TRN & \\
\hline CHEMBL1393366 & 688267 & 4.35 & 5.0116 & TRN & \\
\hline CHEMBL1299365 & 688267 & 3.95 & 5.0246 & TST & \\
\hline CHEMBL1599620 & 688267 & 6.25 & 5.1262 & TRN & \\
\hline CHEMBL1572483 & 688267 & 4.7 & 5.0449 & TRN & \\
\hline CHEMBL1588779 & 688267 & 5.55 & 5.0712 & TRN & \\
\hline CHEMBL1519302 & 688267 & 3.95 & 5.065 & TRN & \\
\hline CHEMBL1314728 & 688267 & 5.6 & 5.0572 & TRN & \\
\hline CHEMBL1611892 & 688267 & 6.15 & 5.0544 & TST & \\
\hline CHEMBL1354322 & 688267 & 3.95 & 5.0217 & TRN & \\
\hline CHEMBL1355120 & 688267 & 6.45 & 5.0652 & TRN & \\
\hline CHEMBL1547173 & 688267 & 4.95 & 5.1646 & TRN & \\
\hline CHEMBL1459548 & 688267 & 4.4 & 5.0693 & TST & \\
\hline CHEMBL1399984 & 688267 & 5.2 & 5.0587 & TRN & \\
\hline CHEMBL1448669 & 688267 & 5.0 & 5.16299 & 7999999999 & TRN \\
\hline CHEMBL1378552 & 688267 & 6.0 & 5.0807 & TRN & \\
\hline CHEMBL1564128 & 688267 & 4.05 & 5.0392 & TRN & \\
\hline CHEMBL1394892 & 688267 & 4.05 & 5.0167 & TRN & \\
\hline CHEMBL1457425 & 688267 & 6.2 & 5.0407 & TRN & \\
\hline CHEMBL1398691 & 688267 & 6.5 & 5.0373 & TST & \\
\hline CHEMBL1574368 & 688267 & 5.0 & 5.0822 & TRN & \\
\hline CHEMBL1453499 & 688267 & 4.05 & 5.0671 & TRN & \\
\hline CHEMBL1328435 & 688267 & 5.6 & 5.0349 & TST & \\
\hline CHEMBL1423341 & 688267 & 5.65 & 5.0401 & TRN & \\
\hline CHEMBL1363434 & 688267 & 4.3 & 5.085 & TST & \\
\hline CHEMBL1458889 & 688267 & 3.95 & 5.07100 & 3000000001 & TRN \\
\hline CHEMBL1392511 & 688267 & 6.25 & 5.0266 & TRN & \\
\hline CHEMBL1557292 & 688267 & 3.95 & 5.0677 & TRN & \\
\hline CHEMBL580161 & 688267 & 6.2 & 5.0221 & TRN & \\
\hline
\end{tabular}




\begin{tabular}{|c|c|c|c|c|}
\hline \multicolumn{5}{|c|}{ Supplemental Tabl } \\
\hline CHEMBL1333909 & 688267 & 5.75 & 5.0764 & TRN \\
\hline CHEMBL1427404 & 688267 & 4.3 & 5.044 & TST \\
\hline CHEMBL1339161 & 688267 & 4.0 & 5.0608 & TRN \\
\hline CHEMBL 259474 & 688267 & 4.45 & 5.0081 & TST \\
\hline CHEMBL1591216 & 688267 & 6.1 & 5.157 & TRN \\
\hline CHEMBL1316095 & 688267 & 5.9 & 5.0922 & TRN \\
\hline CHEMBL1353567 & 688267 & 4.4 & 5.0625 & TRN \\
\hline CHEMBL1446699 & 688267 & 4.55 & 5.0729 & TRN \\
\hline CHEMBL1408692 & 688267 & 6.5 & 5.0753 & TRN \\
\hline CHEMBL1551374 & 688267 & 5.75 & 5.026 & TRN \\
\hline CHEMBL1403594 & 688267 & 5.95 & 5.0087 & TRN \\
\hline CHEMBL1364037 & 688267 & 4.05 & 5.0729 & TRN \\
\hline CHEMBL1604826 & 688267 & 6.2 & 5.0897 & TRN \\
\hline CHEMBL1323069 & 688267 & 4.1 & 5.0608 & TST \\
\hline CHEMBL1439567 & 688267 & 6.2 & 5.1618 & TRN \\
\hline CHEMBL1490475 & 688267 & 6.2 & 5.0011 & TST \\
\hline CHEMBL1448595 & 688267 & 4.55 & 5.0423 & TRN \\
\hline CHEMBL1613352 & 688267 & 6.2 & 5.1354 & TST \\
\hline CHEMBL1529385 & 688267 & 6.15 & 5.1167 & TRN \\
\hline CHEMBL1522904 & 688267 & 6.15 & 5.0507 & TRN \\
\hline CHEMBL1462180 & 688267 & 4.4 & 5.0799 & TRN \\
\hline CHEMBL1551903 & 688267 & 4.05 & 5.0537 & TRN \\
\hline CHEMBL1519746 & 688267 & 6.15 & 4.9967 & TRN \\
\hline CHEMBL1332645 & 688267 & 5.6 & 5.0621 & TST \\
\hline CHEMBL1502602 & 688267 & 5.15 & 5.0126 & TST \\
\hline CHEMBL1391143 & 688267 & 6.2 & 5.0132 & TRN \\
\hline CHEMBL1552103 & 688267 & 4.0 & 5.0544 & TRN \\
\hline CHEMBL3199408 & 688267 & 5.75 & 5.0872 & TST \\
\hline CHEMBL1599296 & 688267 & 6.15 & 5.0574 & TRN \\
\hline CHEMBL1422990 & 688267 & 5.15 & 5.0631 & TRN \\
\hline CHEMBL1504879 & 688267 & 4.4 & 5.0344 & TRN \\
\hline CHEMBL1598904 & 688267 & 4.05 & 5.0327 & TST \\
\hline CHEMBL1542312 & 688267 & 4.6 & 5.1113 & TRN \\
\hline CHEMBL1590342 & 688267 & 6.15 & 5.0685 & TRN \\
\hline CHEMBL1315681 & 688267 & 5.0 & 5.0304 & TST \\
\hline CHEMBL1507920 & 688267 & 6.15 & 5.015 & TRN \\
\hline CHEMBL1583016 & 688267 & 5.6 & 5.0803 & TST \\
\hline CHEMBL1550182 & 688267 & 5.3 & 4.9858 & TST \\
\hline CHEMBL1318666 & 688267 & 6.5 & 5.0101 & TRN \\
\hline CHEMBL1496616 & 688267 & 5.55 & 5.0244 & TRN \\
\hline CHEMBL1378807 & 688267 & 6.45 & 5.0721 & TRN \\
\hline CHEMBL1521061 & 688267 & 4.1 & 4.9879 & TRN \\
\hline CHEMBL3209464 & 688267 & 5.95 & 5.0288 & TRN \\
\hline CHEMBL1325128 & 688267 & 5.95 & 5.0743 & TRN \\
\hline CHEMBL1613183 & 688267 & 5.2 & 4.9927 & TRN \\
\hline CHEMBL1494234 & 688267 & 5.0 & 5.0522 & TST \\
\hline CHEMBL1305833 & 688267 & 4.05 & 4.9923 & TRN \\
\hline CHEMBL 2003831 & 688267 & 5.15 & 4.9629 & TST \\
\hline
\end{tabular}




\begin{tabular}{|c|c|c|c|c|c|}
\hline \\
\hline CHEMBL1548915 & 688267 & 5.9 & 5.0683 & TRN & \\
\hline CHEMBL3196519 & 688267 & 4.55 & 5.0265 & TST & \\
\hline CHEMBL1586657 & 688267 & 4.35 & 5.0726 & TRN & \\
\hline CHEMBL1501869 & 688267 & 5.0 & 5.0617 & TST & \\
\hline CHEMBL1344509 & 688267 & 4.0 & 5.0106 & TRN & \\
\hline CHEMBL1401509 & 688267 & 4.9 & 5.0062 & TRN & \\
\hline CHEMBL1407059 & 688267 & 4.05 & 5.0946 & TRN & \\
\hline CHEMBL1496981 & 688267 & 5.05 & 5.0803 & TST & \\
\hline CHEMBL 2000655 & 688267 & 4.4 & 4.9854 & TRN & \\
\hline CHEMBL1466112 & 688267 & 5.4 & 5.1471 & TRN & \\
\hline CHEMBL1441012 & 688267 & 6.2 & 5.0187 & TRN & \\
\hline CHEMBL3196945 & 688267 & 5.6 & 4.9682 & TRN & \\
\hline CHEMBL1439917 & 688267 & 4.25 & 4.9595 & TRN & \\
\hline CHEMBL1396208 & 688267 & 5.65 & 5.0034 & TST & \\
\hline CHEMBL1479591 & 688267 & 4.0 & 5.0491 & TRN & \\
\hline CHEMBL1505379 & 688267 & 3.9 & 5.1084 & TRN & \\
\hline CHEMBL1485363 & 688267 & 4.05 & 5.0398 & TRN & \\
\hline CHEMBL1347309 & 688267 & 5.85 & 5.0139 & TRN & \\
\hline CHEMBL1443296 & 688267 & 5.4 & 5.0461 & TRN & \\
\hline CHEMBL 3214342 & 688267 & 5.9 & 5.0061 & TRN & \\
\hline CHEMBL3194371 & 688267 & 4.05 & 4.9946 & TRN & \\
\hline CHEMBL1522001 & 688267 & 5.9 & 5.0913 & TST & \\
\hline CHEMBL1989853 & 688267 & 6.05 & 5.0719 & TST & \\
\hline CHEMBL1484351 & 688267 & 6.15 & 5.1115 & TRN & \\
\hline CHEMBL1355271 & 688267 & 5.3 & 5.0456 & TRN & \\
\hline CHEMBL3199908 & 688267 & 4.85 & 4.9995 & TST & \\
\hline CHEMBL1518072 & 688267 & 4.0 & 5.1849 & TRN & \\
\hline CHEMBL1553551 & 688267 & 4.05 & 5.0441 & TRN & \\
\hline CHEMBL1570990 & 688267 & 4.45 & 5.048 & TRN & \\
\hline CHEMBL1478114 & 688267 & 5.35 & 5.0751 & TRN & \\
\hline CHEMBL1346649 & 688267 & 5.5 & 5.12700 & 0000000001 & TRN \\
\hline CHEMBL1312194 & 688267 & 4.45 & 5.0852 & TRN & \\
\hline CHEMBL1407443 & 688267 & 6.15 & 5.0553 & TRN & \\
\hline CHEMBL1407221 & 688267 & 5.7 & 5.1 & TRN & \\
\hline CHEMBL1379317 & 688267 & 4.9 & 5.1258 & TRN & \\
\hline CHEMBL1588578 & 688267 & 4.0 & 5.0739 & TRN & \\
\hline CHEMBL1484269 & 688267 & 4.0 & 5.0603 & TST & \\
\hline CHEMBL1476253 & 688267 & 5.9 & 5.0509 & TRN & \\
\hline CHEMBL1449983 & 688267 & 4.7 & 5.0257 & TRN & \\
\hline CHEMBL1451189 & 688267 & 6.2 & 5.0551 & TRN & \\
\hline CHEMBL1414444 & 688267 & 4.55 & 5.0695 & TRN & \\
\hline CHEMBL1397107 & 688267 & 3.95 & 4.9689 & TRN & \\
\hline CHEMBL1481338 & 688267 & 4.05 & 5.0146 & TST & \\
\hline CHEMBL1499189 & 688267 & 5.3 & 5.1014 & TRN & \\
\hline CHEMBL1603566 & 688267 & 3.95 & 5.0204 & TRN & \\
\hline CHEMBL1593458 & 688267 & 4.35 & 5.0245 & TRN & \\
\hline CHEMBL1387223 & 688267 & 5.75 & 5.0681 & TRN & \\
\hline CHEMBL1377019 & 688267 & 4.1 & 5.0276 & TST & \\
\hline
\end{tabular}




\begin{tabular}{|c|c|c|c|c|c|}
\hline \\
\hline CHEMBL1521784 & 688267 & 6.5 & 5.0201 & TRN & \\
\hline CHEMBL1608686 & 688267 & 4.35 & 5.1074 & TST & \\
\hline CHEMBL3190337 & 688267 & 5.35 & 5.0 & TRN & \\
\hline CHEMBL1318903 & 688267 & 3.95 & 5.1126 & TRN & \\
\hline CHEMBL1610867 & 688267 & 5.0 & 5.0316 & TRN & \\
\hline CHEMBL1460588 & 688267 & 4.95 & 5.1506 & TRN & \\
\hline CHEMBL1386424 & 688267 & 4.05 & 5.0376 & TRN & \\
\hline CHEMBL1310573 & 688267 & 4.3 & 5.1307 & TRN & \\
\hline CHEMBL1481061 & 688267 & 6.5 & 5.0925 & TST & \\
\hline CHEMBL1419637 & 688267 & 4.2 & 5.0975 & TRN & \\
\hline CHEMBL1401014 & 688267 & 5.45 & 5.063 & TRN & \\
\hline CHEMBL3189262 & 688267 & 5.1 & 5.0403 & TRN & \\
\hline CHEMBL1484740 & 688267 & 6.15 & 5.0102 & TRN & \\
\hline CHEMBL1446625 & 688267 & 4.35 & 5.0421 & TST & \\
\hline CHEMBL1425974 & 688267 & 4.3 & 5.0371 & TST & \\
\hline CHEMBL1569606 & 688267 & 4.35 & 5.1103 & TRN & \\
\hline CHEMBL1339938 & 688267 & 4.85 & 5.0898 & TRN & \\
\hline CHEMBL1426956 & 688267 & 4.45 & 5.0437 & TST & \\
\hline CHEMBL1525136 & 688267 & 4.5 & 5.0077 & TRN & \\
\hline CHEMBL1425183 & 688267 & 4.95 & 5.0657 & TRN & \\
\hline CHEMBL1506421 & 688267 & 4.3 & 5.0445 & TRN & \\
\hline CHEMBL1322618 & 688267 & 5.9 & 5.1187 & TRN & \\
\hline CHEMBL1389782 & 688267 & 5.35 & 5.0381 & TST & \\
\hline CHEMBL1356317 & 688267 & 4.4 & 5.052 & TRN & \\
\hline CHEMBL1501644 & 688267 & 6.2 & 5.0589 & TRN & \\
\hline CHEMBL1419244 & 688267 & 4.05 & 5.0351 & TRN & \\
\hline CHEMBL1372465 & 688267 & 6.0 & 4.9975 & TRN & \\
\hline CHEMBL1598490 & 688267 & 4.4 & 5.0171 & TRN & \\
\hline CHEMBL1522885 & 688267 & 6.15 & 5.0433 & TRN & \\
\hline CHEMBL3193324 & 688267 & 6.2 & 5.0483 & TRN & \\
\hline CHEMBL1570659 & 688267 & 4.6 & 5.0988 & TRN & \\
\hline CHEMBL1587802 & 688267 & 3.75 & 5.0613 & TRN & \\
\hline CHEMBL1324291 & 688267 & 6.2 & 5.0172 & TST & \\
\hline CHEMBL1586967 & 688267 & 5.7 & 5.0451 & TRN & \\
\hline CHEMBL1499798 & 688267 & 4.35 & 5.048 & TRN & \\
\hline CHEMBL1445245 & 688267 & 6.5 & 5.0917 & TST & \\
\hline CHEMBL1574929 & 688267 & 5.65 & 5.0642 & TST & \\
\hline CHEMBL1589836 & 688267 & 6.2 & 5.0926 & TRN & \\
\hline CHEMBL1441093 & 688267 & 5.75 & 5.1282 & TRN & \\
\hline CHEMBL1557369 & 688267 & 5.3 & 5.0812 & TRN & \\
\hline CHEMBL1586185 & 688267 & 6.0 & 5.0552 & TRN & \\
\hline CHEMBL1423974 & 688267 & 6.2 & 5.0489 & 99999999995 & TRN \\
\hline CHEMBL1574916 & 688267 & 5.6 & 5.0763 & TST & \\
\hline CHEMBL1462443 & 688267 & 4.65 & 5.0847 & TRN & \\
\hline CHEMBL1399934 & 688267 & 5.3 & 5.0409 & TRN & \\
\hline CHEMBL3193505 & 688267 & 4.0 & 5.0233 & TRN & \\
\hline CHEMBL1488429 & 688267 & 6.2 & 5.0671 & TST & \\
\hline CHEMBL1410068 & 688267 & 5.05 & 5.0082 & TST & \\
\hline & & & & 17559 & \\
\hline
\end{tabular}




\begin{tabular}{|c|c|c|c|c|}
\hline \multicolumn{5}{|c|}{ Supplemental Table S2.txt } \\
\hline CHEMBL1386766 & 688267 & 4.05 & 5.0546 & TRN \\
\hline CHEMBL1496489 & 688267 & 3.95 & 5.0369 & TRN \\
\hline CHEMBL1473463 & 688267 & 5.9 & 5.0332 & TRN \\
\hline CHEMBL1377462 & 688267 & 4.6 & 5.0057 & TRN \\
\hline CHEMBL3190449 & 688267 & 4.6 & 5.0546 & TST \\
\hline CHEMBL1323074 & 688267 & 4.0 & 5.0529 & TRN \\
\hline CHEMBL1485221 & 688267 & 3.95 & 5.0169 & TST \\
\hline CHEMBL1415530 & 688267 & 6.15 & 5.0772 & TRN \\
\hline CHEMBL1566297 & 688267 & 6.1 & 4.9735 & TRN \\
\hline CHEMBL1497405 & 688267 & 5.6 & 5.0802 & TRN \\
\hline CHEMBL1556360 & 688267 & 5.15 & 5.0744 & TRN \\
\hline CHEMBL1331998 & 688267 & 3.9 & 5.0329 & TRN \\
\hline CHEMBL1578389 & 688267 & 5.15 & 5.0729 & TRN \\
\hline CHEMBL1540213 & 688267 & 3.95 & 5.0769 & TRN \\
\hline CHEMBL504941 & 688267 & 4.0 & 5.0132 & TST \\
\hline CHEMBL1592917 & 688267 & 4.0 & 5.0757 & TST \\
\hline CHEMBL1590959 & 688267 & 5.95 & 5.1177 & TRN \\
\hline CHEMBL1507176 & 688267 & 5.45 & 5.0771 & TRN \\
\hline CHEMBL1437664 & 688267 & 4.55 & 5.1012 & TRN \\
\hline CHEMBL1476095 & 688267 & 5.45 & 4.9782 & TRN \\
\hline CHEMBL1303094 & 688267 & 3.95 & 5.0089 & TRN \\
\hline CHEMBL1511346 & 688267 & 5.65 & 5.063 & TRN \\
\hline CHEMBL1309469 & 688267 & 5.35 & 5.0744 & TST \\
\hline CHEMBL1535468 & 688267 & 3.95 & 5.0396 & TRN \\
\hline CHEMBL1453909 & 688267 & 4.0 & 5.0357 & TST \\
\hline CHEMBL1415793 & 688267 & 6.5 & 5.007 & TRN \\
\hline CHEMBL1416403 & 688267 & 6.15 & 5.0291 & TST \\
\hline CHEMBL1529552 & 688267 & 5.0 & 5.1083 & TRN \\
\hline CHEMBL1454847 & 688267 & 4.3 & 5.079 & TRN \\
\hline CHEMBL1489655 & 688267 & 4.3 & 5.1214 & TST \\
\hline CHEMBL1552053 & 688267 & 5.55 & 5.0421 & TRN \\
\hline CHEMBL1471493 & 688267 & 5.5 & 5.0477 & TRN \\
\hline CHEMBL1511264 & 688267 & 5.35 & 5.0779 & TRN \\
\hline CHEMBL1554857 & 688267 & 4.05 & 5.1244 & TRN \\
\hline CHEMBL1373045 & 688267 & 6.05 & 5.0628 & TRN \\
\hline CHEMBL1450227 & 688267 & 4.0 & 5.0468 & TRN \\
\hline CHEMBL1461662 & 688267 & 5.1 & 5.0226 & TST \\
\hline CHEMBL1508398 & 688267 & 6.95 & 5.0991 & TRN \\
\hline CHEMBL1596673 & 688267 & 5.2 & 5.0744 & TRN \\
\hline CHEMBL1333184 & 688267 & 3.95 & 4.9914 & TRN \\
\hline CHEMBL1332523 & 688267 & 5.2 & 5.0724 & TST \\
\hline CHEMBL1519104 & 688267 & 4.6 & 5.0814 & TST \\
\hline CHEMBL1459167 & 688267 & 5.8 & 5.0021 & TRN \\
\hline CHEMBL1486634 & 688267 & 4.0 & 5.0341 & TRN \\
\hline CHEMBL3144922 & 688267 & 5.35 & 4.9778 & TST \\
\hline CHEMBL1333830 & 688267 & 5.55 & 5.084 & TST \\
\hline CHEMBL1606434 & 688267 & 6.2 & 5.099 & TRN \\
\hline CHEMBL1468674 & 688267 & 4.6 & 4.9947 & TST \\
\hline
\end{tabular}




\begin{tabular}{|c|c|c|c|c|c|}
\hline \multicolumn{6}{|c|}{ Supplemental Table S2.txt } \\
\hline CHEMBL1461653 & 688267 & 4.2 & 5.0799 & TRN & \\
\hline CHEMBL1437631 & 688267 & 4.05 & 5.0101 & TRN & \\
\hline CHEMBL 3207843 & 688267 & 4.05 & 5.0164 & TRN & \\
\hline CHEMBL1590838 & 688267 & 6.25 & 5.0688 & TRN & \\
\hline CHEMBL1379027 & 688267 & 4.55 & 5.0942 & TRN & \\
\hline CHEMBL1369096 & 688267 & 6.2 & 5.0725 & TRN & \\
\hline CHEMBL1550496 & 688267 & 3.95 & 5.1262 & TST & \\
\hline CHEMBL1581445 & 688267 & 4.35 & 4.9946 & TST & \\
\hline CHEMBL1413642 & 688267 & 5.6 & 5.0364 & TRN & \\
\hline CHEMBL1383479 & 688267 & 6.0 & 5.0545 & TRN & \\
\hline CHEMBL1377593 & 688267 & 4.3 & 5.0065 & TRN & \\
\hline CHEMBL1378878 & 688267 & 6.45 & 5.0815 & TRN & \\
\hline CHEMBL1974737 & 688267 & 5.45 & 5.0954 & TRN & \\
\hline CHEMBL1348518 & 688267 & 5.95 & 5.1416 & TRN & \\
\hline CHEMBL1373860 & 688267 & 6.15 & 5.0749 & TRN & \\
\hline CHEMBL1427376 & 688267 & 4.3 & 5.0029 & TRN & \\
\hline CHEMBL1384838 & 688267 & 5.65 & 5.0948 & TRN & \\
\hline CHEMBL1563208 & 688267 & 5.95 & 5.1005 & TRN & \\
\hline CHEMBL355159 & 688267 & 4.55 & 4.9975 & TRN & \\
\hline CHEMBL1443191 & 688267 & 4.6 & 5.0978 & TRN & \\
\hline CHEMBL1337373 & 688267 & 4.55 & 5.0439 & TRN & \\
\hline CHEMBL1593690 & 688267 & 4.4 & 4.9855 & TRN & \\
\hline CHEMBL1501276 & 688267 & 6.2 & 5.0425 & TST & \\
\hline CHEMBL1471437 & 688267 & 6.2 & 5.1221 & TRN & \\
\hline CHEMBL1599876 & 688267 & 5.7 & 5.0374 & TST & \\
\hline CHEMBL1311183 & 688267 & 4.3 & 5.1325 & TRN & \\
\hline CHEMBL1362127 & 688267 & 4.3 & 5.09699 & 99999999995 & TRN \\
\hline CHEMBL1992925 & 688267 & 4.05 & 5.0153 & TRN & \\
\hline CHEMBL1369087 & 688267 & 6.2 & 5.0928 & TRN & \\
\hline CHEMBL1410235 & 688267 & 5.1 & 5.1204 & TRN & \\
\hline CHEMBL1481400 & 688267 & 6.2 & 5.0552 & TRN & \\
\hline CHEMBL1456581 & 688267 & 4.0 & 5.0473 & TST & \\
\hline CHEMBL1418913 & 688267 & 5.3 & 5.0146 & TRN & \\
\hline CHEMBL1495219 & 688267 & 5.75 & 5.0032 & TST & \\
\hline CHEMBL1595824 & 688267 & 3.95 & 4.9966 & TST & \\
\hline CHEMBL1465854 & 688267 & 6.2 & 5.0448 & TST & \\
\hline CHEMBL1426590 & 688267 & 5.25 & 5.0349 & TRN & \\
\hline CHEMBL1426762 & 688267 & 5.6 & 5.0394 & TST & \\
\hline CHEMBL1434950 & 688267 & 3.95 & 5.1008 & TST & \\
\hline CHEMBL1327674 & 688267 & 6.2 & 5.0114 & TRN & \\
\hline CHEMBL1379851 & 688267 & 4.0 & 5.0163 & TRN & \\
\hline CHEMBL1567784 & 688267 & 5.0 & 5.0898 & TRN & \\
\hline CHEMBL1509573 & 688267 & 4.05 & 5.0084 & TRN & \\
\hline CHEMBL1537661 & 688267 & 4.0 & 5.0989 & TRN & \\
\hline CHEMBL1392210 & 688267 & 6.25 & 5.0306 & TRN & \\
\hline CHEMBL1321006 & 688267 & 4.0 & 5.0774 & TST & \\
\hline CHEMBL1438986 & 688267 & 3.95 & 5.0168 & TRN & \\
\hline CHEMBL1465891 & 688267 & 4.1 & 5.0402 & TRN & \\
\hline
\end{tabular}




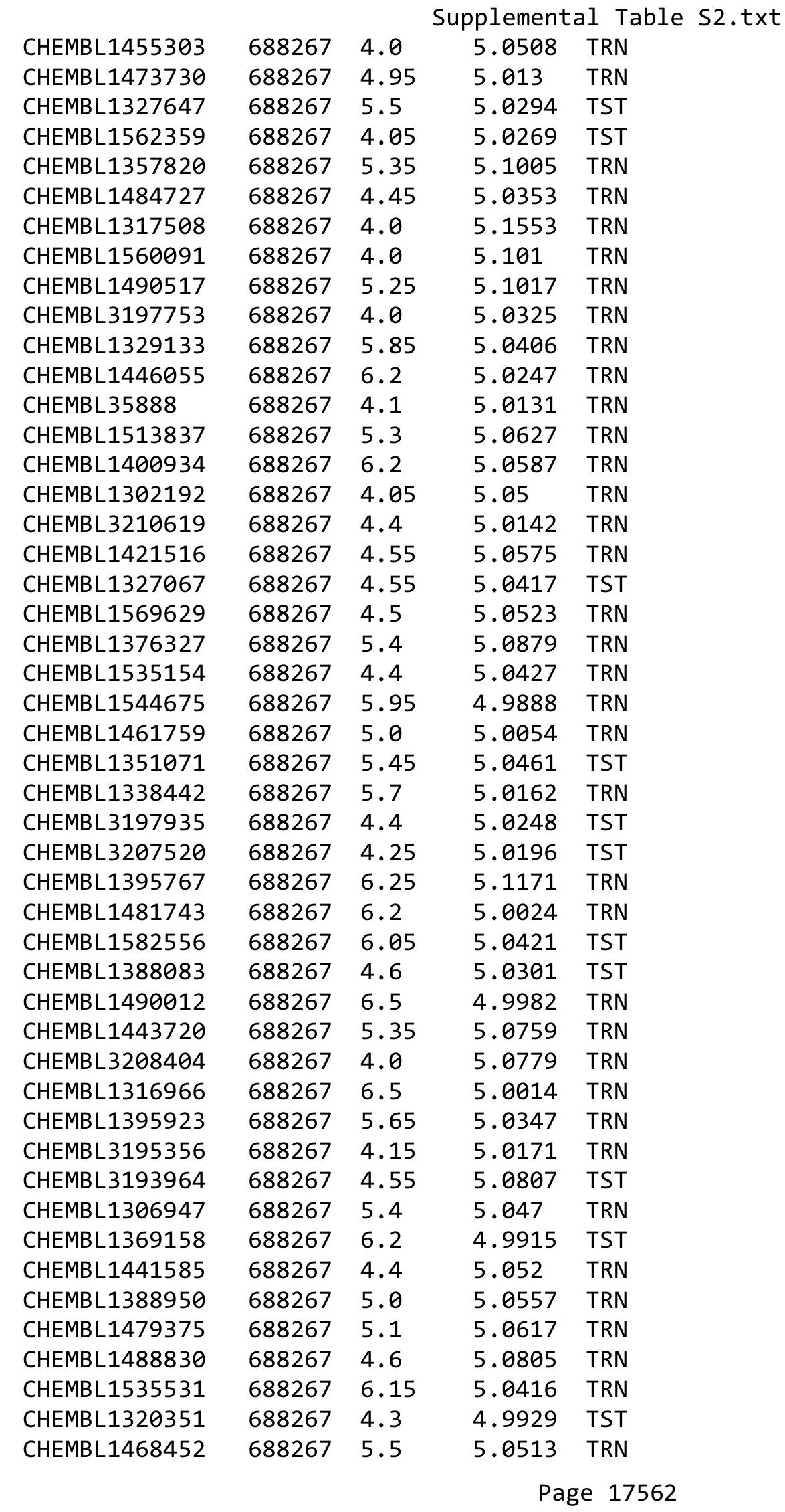




\begin{tabular}{|c|c|c|c|c|}
\hline \multicolumn{5}{|c|}{ Supplemental Table S2.txt } \\
\hline CHEMBL1384754 & 688267 & 4.35 & 5.0475 & TRN \\
\hline CHEMBL569020 & 688267 & 4.35 & 5.0219 & TRN \\
\hline CHEMBL1548451 & 688267 & 6.2 & 5.0129 & TRN \\
\hline CHEMBL1457058 & 688267 & 5.75 & 5.0005 & TRN \\
\hline CHEMBL1309846 & 688267 & 4.05 & 5.0745 & TRN \\
\hline CHEMBL1337446 & 688267 & 4.6 & 5.0944 & TRN \\
\hline CHEMBL1483510 & 688267 & 5.8 & 5.1204 & TRN \\
\hline CHEMBL1323158 & 688267 & 4.5 & 5.0219 & TRN \\
\hline CHEMBL1448750 & 688267 & 4.6 & 4.9942 & TRN \\
\hline CHEMBL1325929 & 688267 & 5.35 & 5.055 & TRN \\
\hline CHEMBL1459262 & 688267 & 4.0 & 5.1449 & TRN \\
\hline CHEMBL1518386 & 688267 & 5.85 & 5.0219 & TRN \\
\hline CHEMBL1566391 & 688267 & 6.15 & 5.0105 & TRN \\
\hline CHEMBL1472947 & 688267 & 4.0 & 5.083 & TRN \\
\hline CHEMBL1591643 & 688267 & 5.35 & 5.0092 & TST \\
\hline CHEMBL1396793 & 688267 & 6.2 & 5.0728 & TRN \\
\hline CHEMBL1475231 & 688267 & 5.55 & 5.1185 & TRN \\
\hline CHEMBL1565957 & 688267 & 5.4 & 5.0462 & TRN \\
\hline CHEMBL1436085 & 688267 & 6.2 & 5.073 & TST \\
\hline CHEMBL1478159 & 688267 & 3.95 & 5.0393 & TRN \\
\hline CHEMBL1532473 & 688267 & 4.75 & 5.1625 & TRN \\
\hline CHEMBL1464079 & 688267 & 5.35 & 5.0794 & TRN \\
\hline CHEMBL1536681 & 688267 & 4.05 & 5.023 & TST \\
\hline CHEMBL3191263 & 688267 & 6.05 & 5.045 & TST \\
\hline CHEMBL1515130 & 688267 & 3.95 & 4.9865 & TRN \\
\hline CHEMBL1384448 & 688267 & 5.9 & 5.0062 & TRN \\
\hline CHEMBL1435591 & 688267 & 4.35 & 4.9985 & TRN \\
\hline CHEMBL1609689 & 688267 & 6.2 & 5.0917 & TRN \\
\hline CHEMBL1540927 & 688267 & 6.15 & 5.0212 & TRN \\
\hline CHEMBL1519781 & 688267 & 5.65 & 5.0841 & TST \\
\hline CHEMBL1340747 & 688267 & 5.25 & 5.0553 & TST \\
\hline CHEMBL1462699 & 688267 & 5.0 & 5.0499 & TST \\
\hline CHEMBL1406237 & 688267 & 4.05 & 5.0135 & TST \\
\hline CHEMBL1488156 & 688267 & 4.05 & 5.079 & TRN \\
\hline CHEMBL1367534 & 688267 & 5.85 & 4.9762 & TRN \\
\hline CHEMBL1361759 & 688267 & 3.95 & 5.061 & TRN \\
\hline CHEMBL3210038 & 688267 & 4.6 & 5.0091 & TST \\
\hline CHEMBL1347712 & 688267 & 4.4 & 5.0539 & TRN \\
\hline CHEMBL1461024 & 688267 & 4.35 & 5.0439 & TRN \\
\hline CHEMBL1524762 & 688267 & 4.9 & 5.0884 & TRN \\
\hline CHEMBL1506360 & 688267 & 4.45 & 5.0701 & TRN \\
\hline CHEMBL1521956 & 688267 & 6.6 & 5.0421 & TRN \\
\hline CHEMBL1380036 & 688267 & 5.1 & 5.1156 & TRN \\
\hline CHEMBL1574761 & 688267 & 4.15 & 5.1109 & TRN \\
\hline CHEMBL1434393 & 688267 & 4.0 & 5.0807 & TRN \\
\hline CHEMBL1509774 & 688267 & 4.0 & 5.0933 & TRN \\
\hline CHEMBL1394954 & 688267 & 4.6 & 5.0212 & TST \\
\hline CHEMBL1355949 & 688267 & 6.2 & 5.0453 & TRN \\
\hline
\end{tabular}




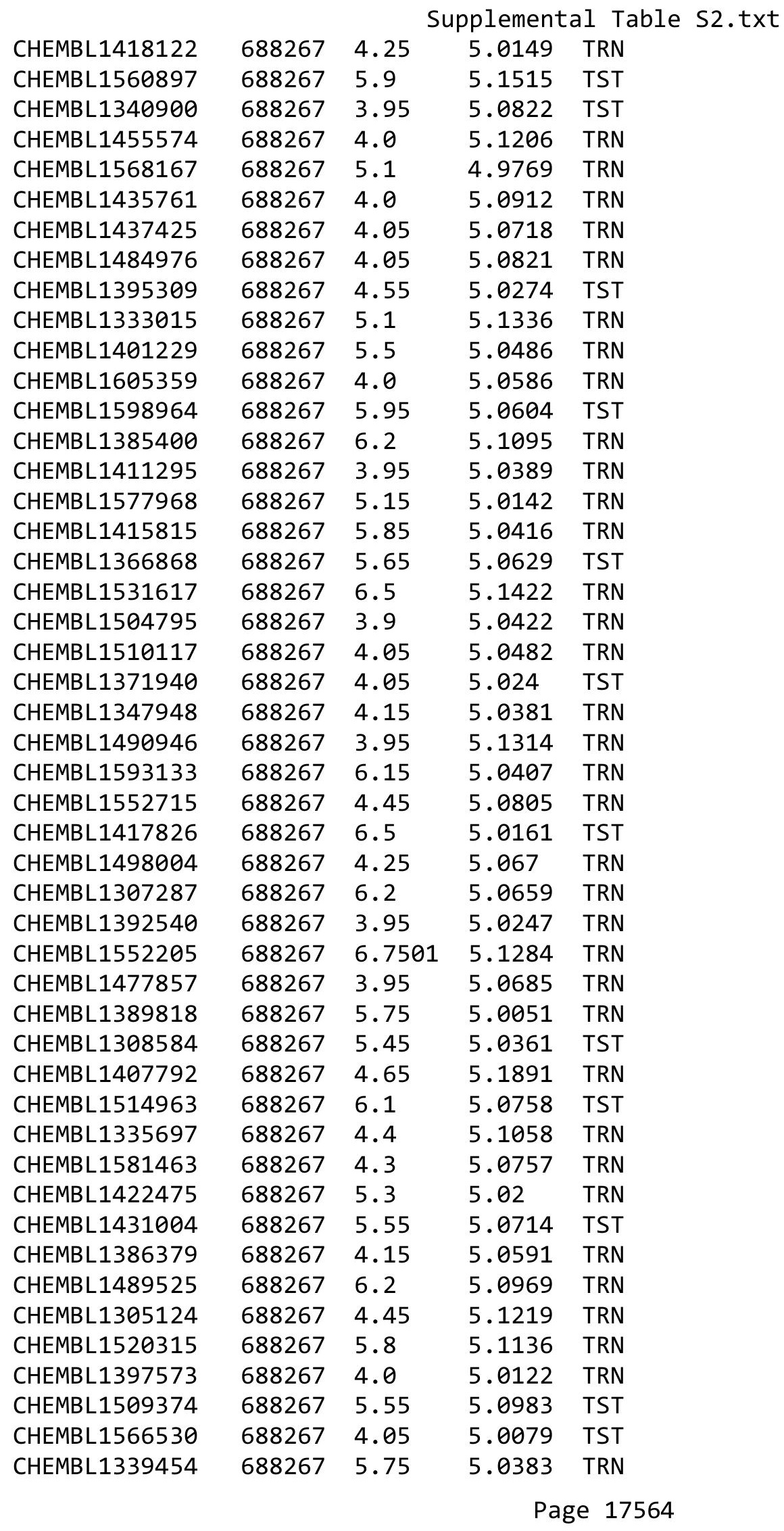




\begin{tabular}{|c|c|c|c|c|c|}
\hline \\
\hline CHEMBL1361250 & 688267 & 4.7 & 5.02 & TRN & \\
\hline CHEMBL1593348 & 688267 & 3.95 & 5.0089 & TRN & \\
\hline CHEMBL1309217 & 688267 & 4.3 & 5.0259 & TRN & \\
\hline CHEMBL1308349 & 688267 & 6.2 & 5.0391 & TRN & \\
\hline CHEMBL1514787 & 688267 & 4.45 & 5.0691 & TRN & \\
\hline CHEMBL1590912 & 688267 & 4.65 & 5.0513 & TRN & \\
\hline CHEMBL1501709 & 688267 & 5.85 & 5.1829 & TRN & \\
\hline CHEMBL1427801 & 688267 & 4.25 & 5.0385 & TST & \\
\hline CHEMBL1387161 & 688267 & 4.55 & 5.0974 & TST & \\
\hline CHEMBL1590254 & 688267 & 4.0 & 5.1364 & TRN & \\
\hline CHEMBL1604869 & 688267 & 5.15 & 4.9647 & TRN & \\
\hline CHEMBL1539947 & 688267 & 5.0 & 5.1729 & TRN & \\
\hline CHEMBL1507331 & 688267 & 5.35 & 5.1022 & TST & \\
\hline CHEMBL1368077 & 688267 & 6.0 & 5.0558 & TRN & \\
\hline CHEMBL1443662 & 688267 & 7.5003 & 5.1099 & TRN & \\
\hline CHEMBL1609279 & 688267 & 5.5 & 5.0303 & TRN & \\
\hline CHEMBL1487840 & 688267 & 5.5 & 5.0879 & TRN & \\
\hline CHEMBL1340007 & 688267 & 5.65 & 5.0987 & TRN & \\
\hline CHEMBL1316266 & 688267 & 4.0 & 5.037 & TRN & \\
\hline CHEMBL3191771 & 688267 & 4.2 & 5.0216 & TST & \\
\hline CHEMBL1427374 & 688267 & 5.35 & 5.0529 & TST & \\
\hline CHEMBL1516895 & 688267 & 6.15 & 5.0827 & TRN & \\
\hline CHEMBL1405489 & 688267 & 4.05 & 5.0611 & TST & \\
\hline CHEMBL1403182 & 688267 & 6.35 & 5.0189 & TRN & \\
\hline CHEMBL1422193 & 688267 & 5.65 & 5.0436 & TRN & \\
\hline CHEMBL1409561 & 688267 & 4.2 & 5.0325 & TRN & \\
\hline CHEMBL1589632 & 688267 & 5.45 & 5.0389 & TRN & \\
\hline CHEMBL1440000 & 688267 & 4.35 & 5.0781 & TRN & \\
\hline CHEMBL1387101 & 688267 & 4.3 & 5.074 & TRN & \\
\hline CHEMBL1586648 & 688267 & 4.0 & 5.0729 & TRN & \\
\hline CHEMBL1591132 & 688267 & 4.25 & 5.0468 & TRN & \\
\hline CHEMBL1513374 & 688267 & 6.25 & 5.0509 & TRN & \\
\hline CHEMBL3198954 & 688267 & 4.45 & 5.1166 & TST & \\
\hline CHEMBL1492782 & 688267 & 5.85 & 5.0932 & TRN & \\
\hline CHEMBL1460076 & 688267 & 4.55 & 5.0667 & TST & \\
\hline CHEMBL1558470 & 688267 & 5.4 & 5.1356 & TRN & \\
\hline CHEMBL1323904 & 688267 & 5.5 & 5.0489 & TST & \\
\hline CHEMBL1360437 & 688267 & 5.15 & 5.1235 & TST & \\
\hline CHEMBL1413522 & 688267 & 6.15 & 5.0305 & TRN & \\
\hline CHEMBL1382514 & 688267 & 4.05 & 5.0496 & TST & \\
\hline CHEMBL1412603 & 688267 & 4.65 & 5.0735 & TST & \\
\hline CHEMBL1502333 & 688267 & 4.65 & 5.0374 & TRN & \\
\hline CHEMBL3211968 & 688267 & 5.85 & 5.05699 & 99999999995 & TST \\
\hline CHEMBL1518304 & 688267 & 6.2 & 5.0345 & TRN & \\
\hline CHEMBL1333686 & 688267 & 5.25 & 5.1294 & TRN & \\
\hline CHEMBL1418123 & 688267 & 5.5 & 5.119 & TRN & \\
\hline CHEMBL1437998 & 688267 & 6.2 & 5.074 & TST & \\
\hline CHEMBL1332261 & 688267 & 4.35 & 5.1001 & TRN & \\
\hline
\end{tabular}




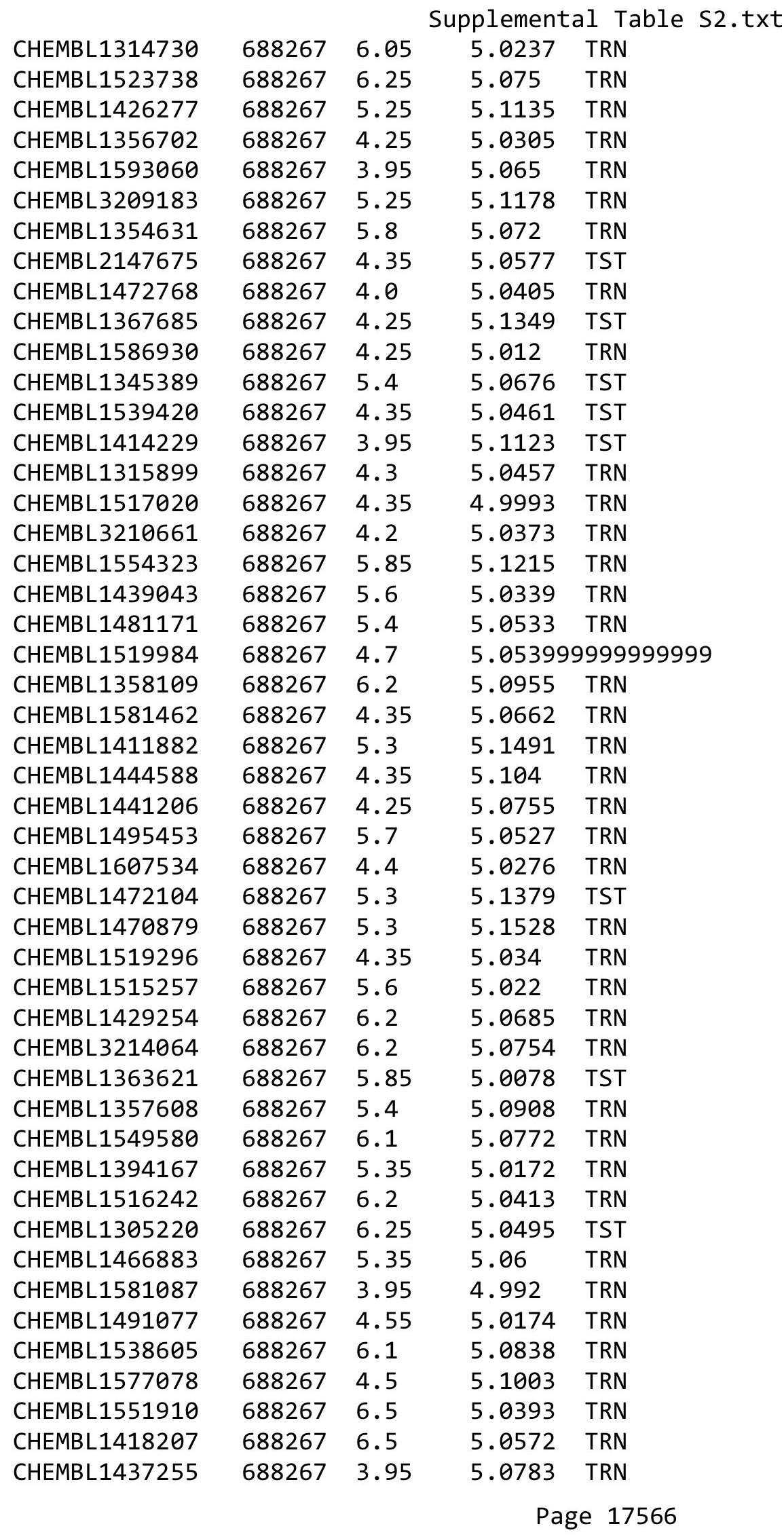




\begin{tabular}{|c|c|c|c|c|c|}
\hline \multicolumn{6}{|c|}{ Supplemental Table S2.txt } \\
\hline CHEMBL1458905 & 688267 & 5.6 & 5.0835 & TRN & \\
\hline CHEMBL1322816 & 688267 & 5.95 & 5.0872 & TRN & \\
\hline CHEMBL1418743 & 688267 & 5.55 & 5.0149 & TRN & \\
\hline CHEMBL1299870 & 688267 & 4.3 & 5.0126 & TRN & \\
\hline CHEMBL1393770 & 688267 & 6.2 & 5.0873 & TRN & \\
\hline CHEMBL1594944 & 688267 & 5.45 & 5.0353 & TRN & \\
\hline CHEMBL1404794 & 688267 & 6.2 & 5.033 & TST & \\
\hline CHEMBL3199706 & 688267 & 5.05 & 4.9865 & TST & \\
\hline CHEMBL1317201 & 688267 & 5.6 & 5.0264 & TRN & \\
\hline CHEMBL1550464 & 688267 & 6.2 & 5.1001 & TRN & \\
\hline CHEMBL1610664 & 688267 & 4.5 & 5.1167 & TRN & \\
\hline CHEMBL1532871 & 688267 & 4.25 & 5.0935 & TRN & \\
\hline CHEMBL1536208 & 688267 & 3.95 & 5.1166 & TST & \\
\hline CHEMBL1515503 & 688267 & 6.2 & 5.0605 & TRN & \\
\hline CHEMBL1592723 & 688267 & 6.25 & 5.0414 & TRN & \\
\hline CHEMBL3207897 & 688267 & 5.5 & 5.0549 & TRN & \\
\hline CHEMBL1304931 & 688267 & 4.85 & 5.0652 & TRN & \\
\hline CHEMBL1353164 & 688267 & 5.85 & 5.1363 & TRN & \\
\hline CHEMBL1495338 & 688267 & 4.3 & 5.0512 & TRN & \\
\hline CHEMBL1565683 & 688267 & 6.2 & 5.0791 & TRN & \\
\hline CHEMBL1417703 & 688267 & 4.65 & 5.0298 & TRN & \\
\hline CHEMBL1454265 & 688267 & 4.0 & 4.9897 & TRN & \\
\hline CHEMBL1312211 & 688267 & 5.8 & 5.0689 & TRN & \\
\hline CHEMBL1467843 & 688267 & 5.1 & 5.0196 & TRN & \\
\hline CHEMBL1313467 & 688267 & 6.2 & 5.0714 & TRN & \\
\hline CHEMBL1492578 & 688267 & 4.0 & 5.0667 & TRN & \\
\hline CHEMBL1536600 & 688267 & 5.35 & 5.0962 & TRN & \\
\hline CHEMBL1509029 & 688267 & 6.2 & 5.08899 & 99999999995 & TRN \\
\hline CHEMBL1373619 & 688267 & 6.05 & 5.0803 & TRN & \\
\hline CHEMBL1488208 & 688267 & 4.0 & 4.9837 & TRN & \\
\hline CHEMBL1412590 & 688267 & 5.05 & 5.0249 & TRN & \\
\hline CHEMBL1522965 & 688267 & 5.5 & 5.013 & TRN & \\
\hline CHEMBL1458329 & 688267 & 6.2 & 5.0514 & TST & \\
\hline CHEMBL1326032 & 688267 & 4.7 & 5.0845 & TST & \\
\hline CHEMBL1506744 & 688267 & 5.75 & 5.0846 & TRN & \\
\hline CHEMBL1459771 & 688267 & 5.3 & 5.0472 & TRN & \\
\hline CHEMBL1590876 & 688267 & 4.15 & 5.008 & TRN & \\
\hline CHEMBL1499163 & 688267 & 5.8 & 5.0611 & TRN & \\
\hline CHEMBL1533618 & 688267 & 6.5 & 5.056 & TRN & \\
\hline CHEMBL1396299 & 688267 & 5.3 & 5.0827 & TRN & \\
\hline CHEMBL1375870 & 688267 & 4.35 & 5.013 & TST & \\
\hline CHEMBL1312433 & 688267 & 4.55 & 5.0241 & TST & \\
\hline CHEMBL1356188 & 688267 & 3.95 & 5.1292 & TRN & \\
\hline CHEMBL1577796 & 688267 & 6.5 & 5.1221 & TRN & \\
\hline CHEMBL1300644 & 688267 & 6.45 & 5.0853 & TRN & \\
\hline CHEMBL1474953 & 688267 & 4.0 & 5.152 & TRN & \\
\hline CHEMBL1382057 & 688267 & 4.35 & 5.0464 & TRN & \\
\hline CHEMBL1611402 & 688267 & 5.15 & 5.0281 & TRN & \\
\hline
\end{tabular}




\begin{tabular}{|c|c|c|c|c|c|}
\hline \multicolumn{6}{|c|}{ Supplemental Table S2.txt } \\
\hline CHEMBL1322817 & 688267 & 6.25 & 5.0225 & TRN & \\
\hline CHEMBL1511814 & 688267 & 5.6 & 5.0944 & TRN & \\
\hline CHEMBL1537306 & 688267 & 4.4 & 5.0568 & TRN & \\
\hline CHEMBL1398076 & 688267 & 6.2 & 5.0887 & TRN & \\
\hline CHEMBL195506 & 688267 & 6.2 & 4.9932 & TST & \\
\hline CHEMBL1306838 & 688267 & 4.3 & 4.96899 & 9999999999 & TRN \\
\hline CHEMBL1423326 & 688267 & 6.25 & 5.0292 & TRN & \\
\hline CHEMBL1568357 & 688267 & 6.2 & 5.0404 & TST & \\
\hline CHEMBL1308247 & 688267 & 5.5 & 5.106 & TRN & \\
\hline CHEMBL1552754 & 688267 & 4.6 & 5.0522 & TRN & \\
\hline CHEMBL600332 & 688267 & 6.5 & 5.0935 & TRN & \\
\hline CHEMBL1496059 & 688267 & 6.2 & 5.0681 & TRN & \\
\hline CHEMBL 3192847 & 688267 & 4.4 & 5.047 & TST & \\
\hline CHEMBL1315635 & 688267 & 3.95 & 5.0564 & TRN & \\
\hline CHEMBL1406603 & 688267 & 4.55 & 5.0769 & TRN & \\
\hline CHEMBL1567648 & 688267 & 4.0 & 5.0691 & TRN & \\
\hline CHEMBL1523222 & 688267 & 5.5 & 5.1246 & TRN & \\
\hline CHEMBL1436800 & 688267 & 6.2 & 5.0743 & TRN & \\
\hline CHEMBL1535708 & 688267 & 6.25 & 5.0979 & TRN & \\
\hline CHEMBL1407050 & 688267 & 6.15 & 5.0776 & TRN & \\
\hline CHEMBL1463046 & 688267 & 5.05 & 5.033 & TRN & \\
\hline CHEMBL1532649 & 688267 & 4.0 & 5.0455 & TRN & \\
\hline CHEMBL1481630 & 688267 & 6.5 & 5.1213 & TRN & \\
\hline CHEMBL1378108 & 688267 & 4.45 & 5.1303 & TRN & \\
\hline CHEMBL1425497 & 688267 & 3.95 & 5.0891 & TRN & \\
\hline CHEMBL1382084 & 688267 & 4.8 & 4.9805 & TRN & \\
\hline CHEMBL1439989 & 688267 & 4.35 & 5.0364 & TRN & \\
\hline CHEMBL1333964 & 688267 & 4.65 & 5.0123 & TRN & \\
\hline CHEMBL1354871 & 688267 & 5.25 & 5.1139 & TST & \\
\hline CHEMBL1477546 & 688267 & 6.2 & 5.0298 & TST & \\
\hline CHEMBL1533883 & 688267 & 3.9 & 5.0688 & TRN & \\
\hline CHEMBL1497713 & 688267 & 5.5 & 4.98300 & 00000000005 & TRN \\
\hline CHEMBL1364177 & 688267 & 4.6 & 5.0492 & TRN & \\
\hline CHEMBL1339128 & 688267 & 5.9 & 5.0756 & TRN & \\
\hline CHEMBL1509428 & 688267 & 4.35 & 5.1164 & TRN & \\
\hline CHEMBL1303986 & 688267 & 4.0 & 5.0297 & TRN & \\
\hline CHEMBL1394074 & 688267 & 4.1 & 5.0263 & TRN & \\
\hline CHEMBL1375267 & 688267 & 6.2 & 5.1399 & TRN & \\
\hline CHEMBL1507638 & 688267 & 4.35 & 5.0542 & TRN & \\
\hline CHEMBL1541084 & 688267 & 5.65 & 5.0283 & TRN & \\
\hline CHEMBL1489681 & 688267 & 4.4 & 5.0943 & TRN & \\
\hline CHEMBL1471277 & 688267 & 4.0 & 4.9941 & TST & \\
\hline CHEMBL1372521 & 688267 & 6.2 & 5.0111 & TRN & \\
\hline CHEMBL1309696 & 688267 & 5.3 & 5.0671 & TRN & \\
\hline CHEMBL1315799 & 688267 & 5.55 & 5.0419 & TRN & \\
\hline CHEMBL3209170 & 688267 & 5.5 & 5.0287 & TST & \\
\hline CHEMBL1580758 & 688267 & 4.65 & 5.0395 & TST & \\
\hline CHEMBL3197171 & 688267 & 4.5 & 5.0141 & TRN & \\
\hline
\end{tabular}




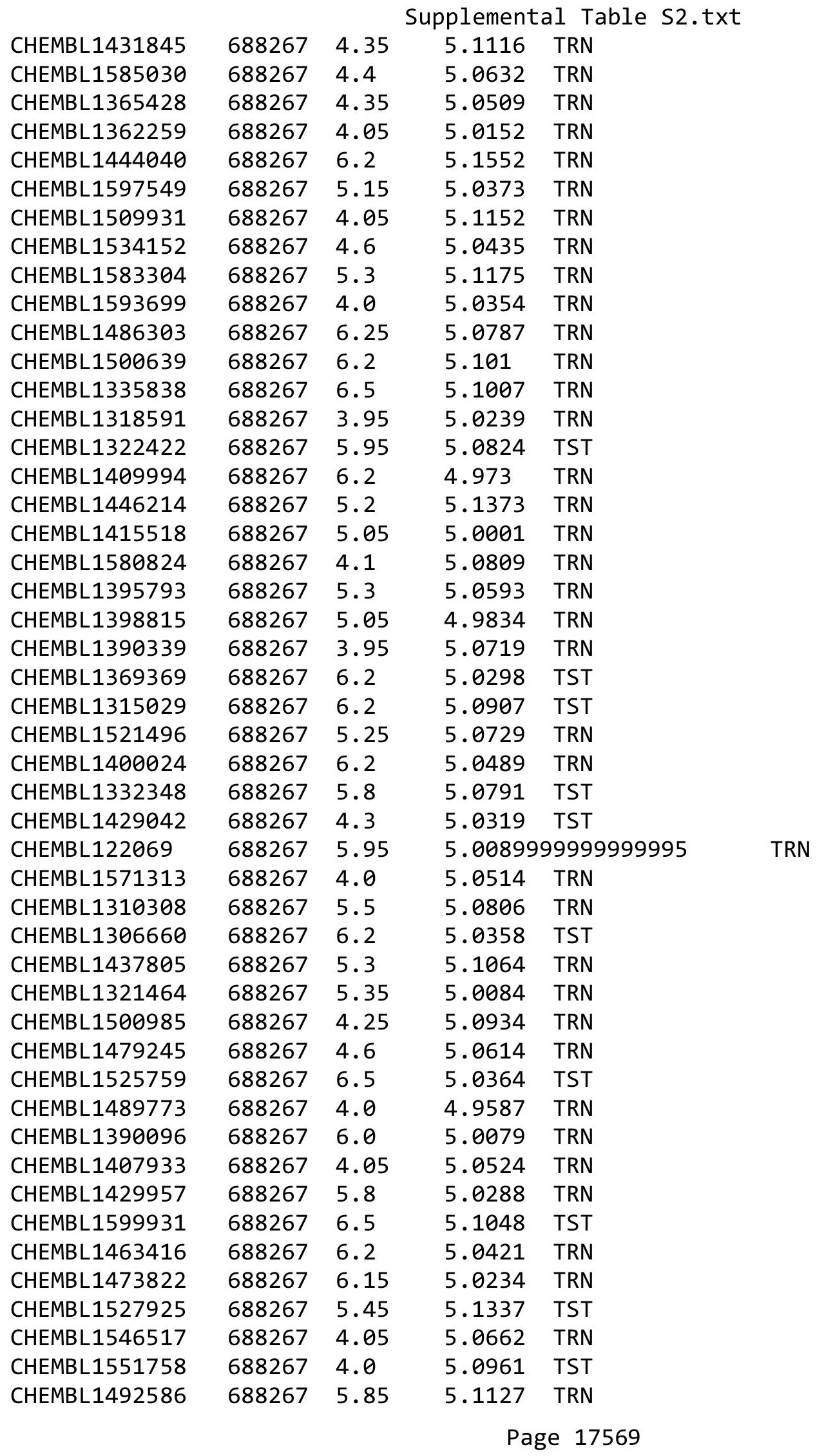




\begin{tabular}{|c|c|c|c|c|}
\hline & & & pplement & al $\mathrm{Ta}$ \\
\hline CHEMBL3190508 & 688267 & 6.2 & 5.021 & TRN \\
\hline CHEMBL1444495 & 688267 & 6.15 & 5.0163 & TRN \\
\hline CHEMBL1465617 & 688267 & 6.15 & 5.1175 & TST \\
\hline CHEMBL1443507 & 688267 & 4.05 & 4.9968 & TRN \\
\hline CHEMBL1532998 & 688267 & 5.75 & 5.0168 & TST \\
\hline CHEMBL1431964 & 688267 & 4.05 & 5.042 & TST \\
\hline CHEMBL292687 & 688267 & 5.25 & 5.0203 & TST \\
\hline CHEMBL1413937 & 688267 & 4.35 & 4.9572 & TRN \\
\hline CHEMBL1516984 & 688267 & 4.65 & 4.9619 & TRN \\
\hline CHEMBL1356653 & 688267 & 5.35 & 5.0981 & TRN \\
\hline CHEMBL1333045 & 688267 & 4.9 & 5.0652 & TRN \\
\hline CHEMBL1557537 & 688267 & 4.55 & 5.0861 & TRN \\
\hline CHEMBL1484200 & 688267 & 6.2 & 5.0512 & TRN \\
\hline CHEMBL1554899 & 688267 & 6.2 & 5.007 & TST \\
\hline CHEMBL1417782 & 688267 & 5.75 & 5.1012 & TRN \\
\hline CHEMBL1609306 & 688267 & 4.35 & 5.0747 & TST \\
\hline CHEMBL1359555 & 688267 & 4.15 & 5.0241 & TRN \\
\hline CHEMBL1577102 & 688267 & 5.3 & 5.1013 & TRN \\
\hline CHEMBL1491752 & 688267 & 6.2 & 5.0855 & TST \\
\hline CHEMBL1328296 & 688267 & 6.2 & 5.0939 & TRN \\
\hline CHEMBL1323667 & 688267 & 4.2 & 5.09 & TRN \\
\hline CHEMBL1552564 & 688267 & 4.0 & 5.0979 & TRN \\
\hline CHEMBL1561552 & 688267 & 4.25 & 5.0153 & TRN \\
\hline CHEMBL1396849 & 688267 & 4.75 & 5.0519 & TRN \\
\hline CHEMBL1462996 & 688267 & 4.0 & 5.0533 & TRN \\
\hline CHEMBL1495200 & 688267 & 6.2 & 5.0669 & TRN \\
\hline CHEMBL1999630 & 688267 & 4.0 & 5.0288 & TST \\
\hline CHEMBL3194919 & 688267 & 4.4 & 5.0455 & TRN \\
\hline CHEMBL1528717 & 688267 & 4.35 & 5.1171 & TST \\
\hline CHEMBL1610798 & 688267 & 5.9 & 5.072 & TRN \\
\hline CHEMBL1305412 & 688267 & 4.5 & 5.0116 & TRN \\
\hline CHEMBL1578581 & 688267 & 4.2 & 5.0958 & TRN \\
\hline CHEMBL3191030 & 688267 & 5.3 & 5.0261 & TST \\
\hline CHEMBL3190137 & 688267 & 5.8 & 5.0569 & TRN \\
\hline CHEMBL1516053 & 688267 & 6.5501 & 4.9949 & TRN \\
\hline CHEMBL1551285 & 688267 & 6.05 & 5.0607 & TRN \\
\hline CHEMBL1456863 & 688267 & 6.25 & 5.0895 & TST \\
\hline CHEMBL1357197 & 688267 & 3.95 & 5.0494 & TRN \\
\hline CHEMBL1542481 & 688267 & 6.25 & 5.0693 & TRN \\
\hline CHEMBL1444098 & 688267 & 6.25 & 5.0712 & TRN \\
\hline CHEMBL1502141 & 688267 & 6.2 & 4.9892 & TRN \\
\hline CHEMBL1413242 & 688267 & 5.95 & 5.0332 & TRN \\
\hline CHEMBL1559600 & 688267 & 5.6 & 4.9931 & TRN \\
\hline CHEMBL1380016 & 688267 & 4.1 & 5.1079 & TRN \\
\hline CHEMBL1387782 & 688267 & 6.15 & 5.0426 & TST \\
\hline CHEMBL1410932 & 688267 & 5.0 & 5.065 & TRN \\
\hline CHEMBL1582660 & 688267 & 5.6 & 5.0503 & TST \\
\hline CHEMBL1400308 & 688267 & 6.2 & 5.0692 & TRN \\
\hline
\end{tabular}




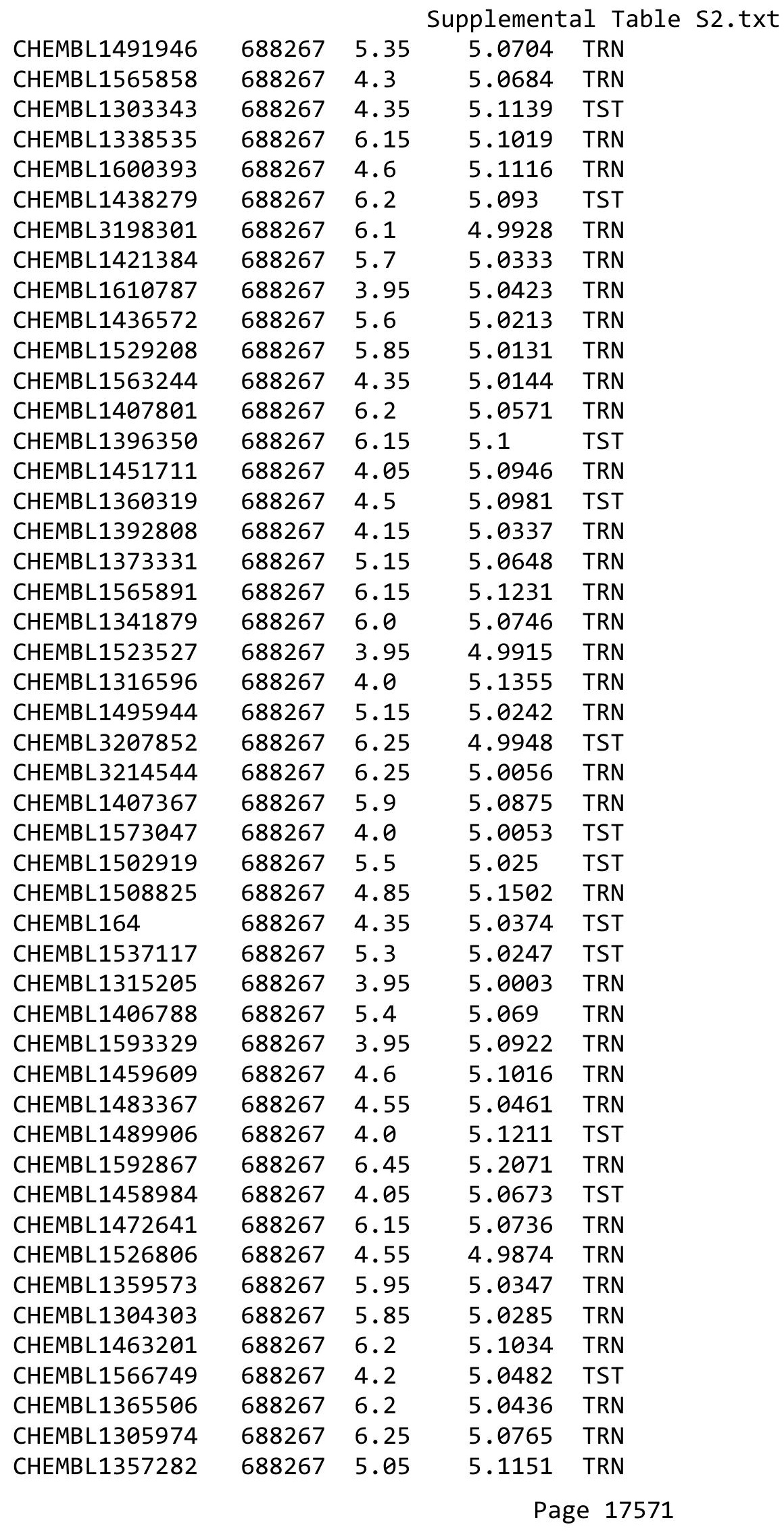




\begin{tabular}{|c|c|c|c|c|}
\hline \multicolumn{5}{|c|}{ Supplemental Table } \\
\hline CHEMBL1329416 & 688267 & 5.45 & 5.0116 & TST \\
\hline CHEMBL1397114 & 688267 & 5.6 & 5.0835 & TRN \\
\hline CHEMBL1591711 & 688267 & 5.5 & 5.0755 & TRN \\
\hline CHEMBL1466975 & 688267 & 4.35 & 5.0597 & TRN \\
\hline CHEMBL1590551 & 688267 & 6.3 & 4.9976 & TST \\
\hline CHEMBL1354289 & 688267 & 6.15 & 5.062 & TRN \\
\hline CHEMBL1367483 & 688267 & 5.3 & 5.0874 & TRN \\
\hline CHEMBL1515921 & 688267 & 5.05 & 5.1614 & TRN \\
\hline CHEMBL1398453 & 688267 & 3.95 & 5.0722 & TRN \\
\hline CHEMBL1464979 & 688267 & 5.0 & 5.0853 & TRN \\
\hline CHEMBL3190812 & 688267 & 4.35 & 5.0239 & TST \\
\hline CHEMBL1426808 & 688267 & 5.5 & 5.1237 & TST \\
\hline CHEMBL1593413 & 688267 & 4.6 & 5.0254 & TRN \\
\hline CHEMBL1516676 & 688267 & 4.35 & 5.0694 & TST \\
\hline CHEMBL1408510 & 688267 & 5.15 & 5.1552 & TRN \\
\hline CHEMBL1547551 & 688267 & 6.2 & 5.0753 & TST \\
\hline CHEMBL1485260 & 688267 & 5.85 & 5.1189 & TRN \\
\hline CHEMBL1311173 & 688267 & 4.65 & 5.0485 & TRN \\
\hline CHEMBL1507260 & 688267 & 6.2 & 5.1412 & TST \\
\hline CHEMBL1374954 & 688267 & 5.35 & 4.9943 & TST \\
\hline CHEMBL1335359 & 688267 & 4.0 & 5.0675 & TRN \\
\hline CHEMBL1563207 & 688267 & 6.2 & 5.0385 & TRN \\
\hline CHEMBL1313694 & 688267 & 4.0 & 5.0269 & TRN \\
\hline CHEMBL1437881 & 688267 & 5.3 & 5.0165 & TRN \\
\hline CHEMBL1789986 & 688267 & 4.95 & 5.0608 & TST \\
\hline CHEMBL1339843 & 688267 & 6.5 & 5.0104 & TRN \\
\hline CHEMBL1505869 & 688267 & 4.3 & 5.0227 & TRN \\
\hline CHEMBL1515252 & 688267 & 3.95 & 5.0707 & TRN \\
\hline CHEMBL1417310 & 688267 & 5.35 & 5.0326 & TRN \\
\hline CHEMBL1403312 & 688267 & 5.55 & 5.0664 & TRN \\
\hline CHEMBL3198969 & 688267 & 4.5 & 5.0284 & TST \\
\hline CHEMBL1561097 & 688267 & 5.6 & 5.0651 & TRN \\
\hline CHEMBL1394755 & 688267 & 6.6499 & 5.0904 & TRN \\
\hline CHEMBL3192792 & 688267 & 4.5 & 5.025 & TST \\
\hline CHEMBL1307987 & 688267 & 4.0 & 5.0843 & TRN \\
\hline CHEMBL1332250 & 688267 & 4.1 & 5.0369 & TRN \\
\hline CHEMBL1306915 & 688267 & 4.1 & 5.046 & TRN \\
\hline CHEMBL1388206 & 688267 & 6.0 & 5.0771 & TRN \\
\hline CHEMBL1350431 & 688267 & 5.5 & 5.045 & TRN \\
\hline CHEMBL1314763 & 688267 & 5.2 & 5.043 & TRN \\
\hline CHEMBL1301931 & 688267 & 5.5 & 5.0717 & TST \\
\hline CHEMBL1432058 & 688267 & 5.05 & 5.0536 & TRN \\
\hline CHEMBL3208401 & 688267 & 5.0 & 4.9952 & TRN \\
\hline CHEMBL1474480 & 688267 & 3.95 & 5.034 & TRN \\
\hline CHEMBL1428018 & 688267 & 4.6 & 5.024 & TRN \\
\hline CHEMBL1562382 & 688267 & 4.4 & 5.0663 & TRN \\
\hline CHEMBL1320240 & 688267 & 6.2 & 5.0945 & TRN \\
\hline CHEMBL1606846 & 688267 & 4.6 & 5.0923 & TRN \\
\hline
\end{tabular}




\begin{tabular}{|c|c|c|c|c|c|}
\hline \multicolumn{6}{|c|}{ Supplemental Table S2.txt } \\
\hline CHEMBL1435074 & 688267 & 5.8 & 5.109 & TRN & \\
\hline CHEMBL1439008 & 688267 & 6.5501 & 5.0804 & TRN & \\
\hline CHEMBL1499872 & 688267 & 5.75 & 5.0457 & TRN & \\
\hline CHEMBL1608339 & 688267 & 4.3 & 5.0466 & TRN & \\
\hline CHEMBL1329097 & 688267 & 5.25 & 5.1105 & TRN & \\
\hline CHEMBL1429328 & 688267 & 4.9 & 5.0986 & TST & \\
\hline CHEMBL1440141 & 688267 & 5.15 & 5.0684 & TST & \\
\hline CHEMBL1559961 & 688267 & 4.65 & 5.0681 & TRN & \\
\hline CHEMBL1324310 & 688267 & 5.35 & 5.0198 & TST & \\
\hline CHEMBL1317185 & 688267 & 4.25 & 4.9729 & TRN & \\
\hline CHEMBL1534161 & 688267 & 4.0 & 5.0602 & TRN & \\
\hline CHEMBL1494869 & 688267 & 5.9 & 5.093 & TRN & \\
\hline CHEMBL1372195 & 688267 & 6.0 & 5.055 & TST & \\
\hline CHEMBL3190798 & 688267 & 5.35 & 5.01 & TRN & \\
\hline CHEMBL1430601 & 688267 & 5.35 & 5.0255 & TST & \\
\hline CHEMBL1377066 & 688267 & 4.6 & 5.06800 & 00000000005 & TRN \\
\hline CHEMBL1413304 & 688267 & 4.55 & 5.0685 & TRN & \\
\hline CHEMBL1423061 & 688267 & 5.05 & 5.0805 & TRN & \\
\hline CHEMBL1304535 & 688267 & 5.75 & 5.0994 & TRN & \\
\hline CHEMBL1407294 & 688267 & 5.95 & 5.0178 & TST & \\
\hline CHEMBL1541123 & 688267 & 6.2 & 5.0524 & TRN & \\
\hline CHEMBL1490983 & 688267 & 4.4 & 5.0233 & TRN & \\
\hline CHEMBL1492074 & 688267 & 4.05 & 5.0148 & TRN & \\
\hline CHEMBL1552363 & 688267 & 6.5 & 5.0745 & TST & \\
\hline CHEMBL1517404 & 688267 & 6.2 & 5.1189 & TRN & \\
\hline CHEMBL1518937 & 688267 & 6.2 & 5.005 & TRN & \\
\hline CHEMBL1486490 & 688267 & 5.95 & 5.0477 & TRN & \\
\hline CHEMBL1501972 & 688267 & 5.8 & 5.119 & TRN & \\
\hline CHEMBL1345409 & 688267 & 4.65 & 5.0581 & TRN & \\
\hline CHEMBL1418518 & 688267 & 4.55 & 5.0439 & TRN & \\
\hline CHEMBL1360602 & 688267 & 5.9 & 5.0607 & TRN & \\
\hline CHEMBL1543776 & 688267 & 5.05 & 5.0251 & TRN & \\
\hline CHEMBL1312713 & 688267 & 4.1 & 5.0516 & TRN & \\
\hline CHEMBL1307542 & 688267 & 6.45 & 5.0511 & TRN & \\
\hline CHEMBL1421566 & 688267 & 5.3 & 5.0942 & TST & \\
\hline CHEMBL579624 & 688267 & 5.55 & 4.9778 & TRN & \\
\hline CHEMBL1341693 & 688267 & 4.75 & 5.064 & TST & \\
\hline CHEMBL3189261 & 688267 & 5.75 & 5.0369 & TRN & \\
\hline CHEMBL1598299 & 688267 & 5.65 & 4.9902 & TST & \\
\hline CHEMBL1442724 & 688267 & 4.3 & 5.0084 & TRN & \\
\hline CHEMBL3197161 & 688267 & 6.25 & 4.9803 & TRN & \\
\hline CHEMBL1360896 & 688267 & 4.05 & 4.99100 & 00000000005 & TRN \\
\hline CHEMBL1513672 & 688267 & 6.0 & 5.1362 & TRN & \\
\hline CHEMBL1364874 & 688267 & 4.05 & 5.0914 & TRN & \\
\hline CHEMBL1445969 & 688267 & 5.15 & 5.0906 & TST & \\
\hline CHEMBL1313369 & 688267 & 5.9 & 5.05 & TRN & \\
\hline CHEMBL547269 & 688267 & 5.0 & 5.0663 & TRN & \\
\hline CHEMBL1315053 & 688267 & 4.1 & 5.0044 & TST & \\
\hline
\end{tabular}




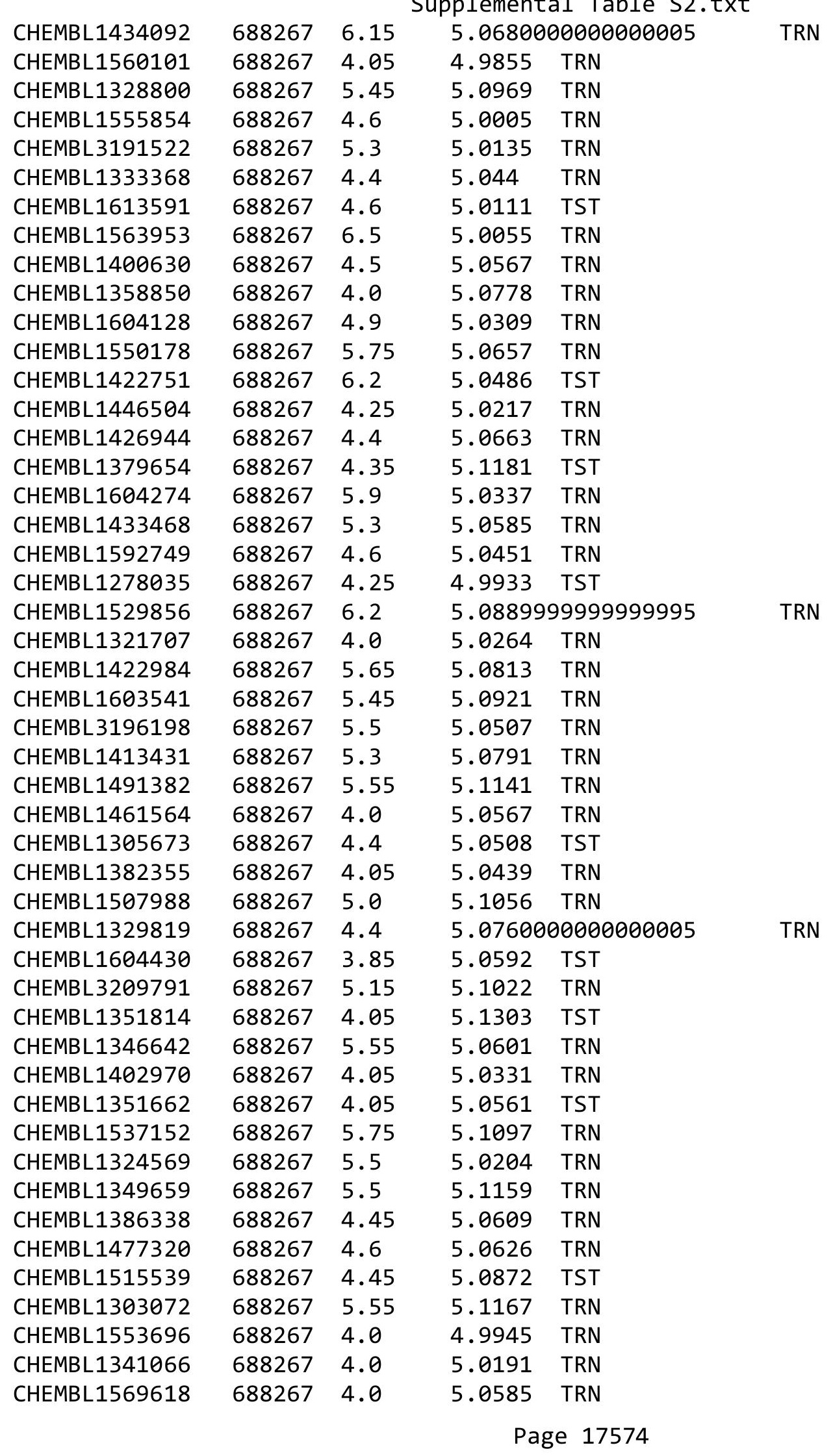




\begin{tabular}{|c|c|c|c|c|c|}
\hline & & \multicolumn{4}{|c|}{ Supplemental Table s2.txt } \\
\hline CHEMBL1613716 & 688267 & 5.75 & 5.0065 & TRN & \\
\hline CHEMBL1527164 & 688267 & 4.0 & 5.0797 & TRN & \\
\hline CHEMBL1435055 & 688267 & 4.35 & 5.0674 & TRN & \\
\hline CHEMBL1325292 & 688267 & 6.1 & 5.0276 & TST & \\
\hline CHEMBL1379254 & 688267 & 6.3 & 5.0127 & TST & \\
\hline CHEMBL1569947 & 688267 & 6.15 & 5.086 & TRN & \\
\hline CHEMBL1514231 & 688267 & 5.45 & 5.1121 & TRN & \\
\hline CHEMBL1544645 & 688267 & 6.15 & 5.0035 & TRN & \\
\hline CHEMBL1321713 & 688267 & 5.85 & 5.0603 & TRN & \\
\hline CHEMBL1390152 & 688267 & 4.05 & 5.0704 & TST & \\
\hline CHEMBL1388312 & 688267 & 5.3 & 5.0367 & TRN & \\
\hline CHEMBL1316904 & 688267 & 6.25 & 5.1014 & TRN & \\
\hline CHEMBL1412034 & 688267 & 6.2 & 5.0527 & TRN & \\
\hline CHEMBL1306968 & 688267 & 4.0 & 5.1037 & TRN & \\
\hline CHEMBL1376781 & 688267 & 5.85 & 5.07600 & 00000000005 & TRN \\
\hline CHEMBL1365976 & 688267 & 6.25 & 5.0867 & TRN & \\
\hline CHEMBL1315090 & 688267 & 5.3 & 5.0699 & TRN & \\
\hline CHEMBL1464818 & 688267 & 4.05 & 5.0415 & TRN & \\
\hline CHEMBL 3208048 & 688267 & 6.2 & 5.0951 & TST & \\
\hline CHEMBL3199453 & 688267 & 5.3 & 4.9781 & TRN & \\
\hline CHEMBL1449428 & 688267 & 6.2 & 5.0342 & TRN & \\
\hline CHEMBL1510720 & 688267 & 5.8 & 5.0482 & TRN & \\
\hline CHEMBL1612542 & 688267 & 4.5 & 4.9707 & TRN & \\
\hline CHEMBL1328077 & 688267 & 4.1 & 5.0418 & TRN & \\
\hline CHEMBL1514520 & 688267 & 5.35 & 5.0562 & TRN & \\
\hline CHEMBL1515386 & 688267 & 6.25 & 5.0182 & TRN & \\
\hline CHEMBL1540983 & 688267 & 6.0 & 5.1344 & TRN & \\
\hline CHEMBL1532012 & 688267 & 6.15 & 5.0085 & TRN & \\
\hline CHEMBL1392671 & 688267 & 4.0 & 5.0855 & TST & \\
\hline CHEMBL1445541 & 688267 & 4.6 & 5.1172 & TRN & \\
\hline CHEMBL1580859 & 688267 & 4.35 & 5.0937 & TRN & \\
\hline CHEMBL1456154 & 688267 & 4.55 & 5.0566 & TRN & \\
\hline CHEMBL1350207 & 688267 & 6.5 & 5.027 & TRN & \\
\hline CHEMBL1362878 & 688267 & 4.05 & 4.9995 & TRN & \\
\hline CHEMBL1496991 & 688267 & 4.35 & 5.044 & TST & \\
\hline CHEMBL1416964 & 688267 & 4.6 & 5.0505 & TRN & \\
\hline CHEMBL1559713 & 688267 & 4.15 & 5.0589 & TRN & \\
\hline CHEMBL1515798 & 688267 & 5.45 & 5.0027 & TRN & \\
\hline CHEMBL1391950 & 688267 & 4.75 & 5.0576 & TRN & \\
\hline CHEMBL1330491 & 688267 & 4.25 & 5.0437 & TRN & \\
\hline CHEMBL1486960 & 688267 & 5.85 & 5.0243 & TRN & \\
\hline CHEMBL1427245 & 688267 & 5.85 & 5.0243 & TRN & \\
\hline CHEMBL1486090 & 688267 & 4.0 & 5.0465 & TRN & \\
\hline CHEMBL1340614 & 688267 & 4.0 & 5.0804 & TRN & \\
\hline CHEMBL1366684 & 688267 & 4.0 & 5.023 & TRN & \\
\hline CHEMBL1448650 & 688267 & 4.6 & 5.0362 & TRN & \\
\hline CHEMBL1450256 & 688267 & 6.25 & 5.1211 & TST & \\
\hline CHEMBL1400535 & 688267 & 6.2 & 5.015 & TRN & \\
\hline
\end{tabular}




\begin{tabular}{|c|c|c|c|c|c|}
\hline \multirow{3}{*}{$\begin{array}{l}\text { CHEMBL1573562 } \\
\text { CHEMBL1512232 }\end{array}$} & \multirow{3}{*}{$\begin{array}{l}688267 \\
688267\end{array}$} & \multicolumn{4}{|c|}{ Supplemental Table S2.txt } \\
\hline & & 6.2 & 5.0489 & 99999999995 & TST \\
\hline & & 4.05 & 5.0764 & TRN & \\
\hline CHEMBL1572258 & 688267 & 4.15 & 5.0858 & TST & \\
\hline CHEMBL3194290 & 688267 & 5.4 & 5.02 & TRN & \\
\hline CHEMBL1451294 & 688267 & 4.05 & 5.0138 & TRN & \\
\hline CHEMBL1574486 & 688267 & 5.05 & 5.0107 & TRN & \\
\hline CHEMBL1316052 & 688267 & 5.35 & 5.0649 & TST & \\
\hline CHEMBL1401718 & 688267 & 3.95 & 5.0247 & TRN & \\
\hline CHEMBL1602070 & 688267 & 5.8 & 5.1232 & TRN & \\
\hline CHEMBL1416357 & 688267 & 4.0 & 5.0522 & TST & \\
\hline CHEMBL1608986 & 688267 & 5.25 & 5.0883 & TRN & \\
\hline CHEMBL1412136 & 688267 & 5.25 & 5.061 & TST & \\
\hline CHEMBL1410985 & 688267 & 6.2 & 5.0697 & TRN & \\
\hline CHEMBL1376577 & 688267 & 5.3 & 5.0114 & TRN & \\
\hline CHEMBL1610903 & 688267 & 6.15 & 5.0542 & TST & \\
\hline CHEMBL1548381 & 688267 & 4.55 & 5.0498 & TST & \\
\hline CHEMBL1495001 & 688267 & 4.85 & 5.0811 & TRN & \\
\hline CHEMBL1350126 & 688267 & 5.5 & 5.0856 & TRN & \\
\hline CHEMBL1324475 & 688267 & 4.05 & 5.0356 & TST & \\
\hline CHEMBL1500558 & 688267 & 6.2 & 5.0414 & TRN & \\
\hline CHEMBL1512198 & 688267 & 5.1 & 5.0564 & TST & \\
\hline CHEMBL1523999 & 688267 & 5.6 & 5.1067 & TRN & \\
\hline CHEMBL1381455 & 688267 & 5.6 & 5.0725 & TRN & \\
\hline CHEMBL1400141 & 688267 & 5.05 & 5.1124 & TRN & \\
\hline CHEMBL1434038 & 688267 & 6.2 & 4.9978 & TRN & \\
\hline CHEMBL1334354 & 688267 & 6.15 & 5.1188 & TRN & \\
\hline CHEMBL1427697 & 688267 & 5.95 & 5.015 & TST & \\
\hline CHEMBL1337356 & 688267 & 4.35 & 5.0203 & TRN & \\
\hline CHEMBL1462451 & 688267 & 6.2 & 5.1178 & TST & \\
\hline CHEMBL1465155 & 688267 & 4.25 & 5.0763 & TRN & \\
\hline CHEMBL1340282 & 688267 & 5.6 & 5.0483 & TRN & \\
\hline CHEMBL1578681 & 688267 & 4.0 & 5.0406 & TST & \\
\hline CHEMBL1606928 & 688267 & 4.7 & 5.0148 & TRN & \\
\hline CHEMBL1998852 & 688267 & 4.35 & 5.0111 & TRN & \\
\hline CHEMBL1491852 & 688267 & 6.2 & 5.0041 & TRN & \\
\hline CHEMBL1400993 & 688267 & 4.15 & 5.093 & TRN & \\
\hline CHEMBL1434436 & 688267 & 5.55 & 5.0924 & TRN & \\
\hline CHEMBL1453777 & 688267 & 5.4 & 5.0634 & TRN & \\
\hline CHEMBL1320440 & 688267 & 6.2 & 5.0184 & TRN & \\
\hline CHEMBL1399352 & 688267 & 4.15 & 5.0928 & TRN & \\
\hline CHEMBL1530027 & 688267 & 5.8 & 5.0015 & TRN & \\
\hline CHEMBL1326381 & 688267 & 4.55 & 5.0576 & TST & \\
\hline CHEMBL1364233 & 688267 & 4.05 & 5.0596 & TRN & \\
\hline CHEMBL1300844 & 688267 & 4.05 & 5.0392 & TST & \\
\hline CHEMBL1539024 & 688267 & 6.15 & 5.0494 & TST & \\
\hline CHEMBL1969987 & 688267 & 4.0 & 5.0532 & TST & \\
\hline CHEMBL1378737 & 688267 & 5.0 & 5.1197 & TRN & \\
\hline CHEMBL1328051 & 688267 & 4.0 & 5.027 & TRN & \\
\hline
\end{tabular}




\begin{tabular}{|c|c|c|c|c|}
\hline \multicolumn{5}{|c|}{ Supplemental Table S2.txt } \\
\hline CHEMBL1451472 & 688267 & 5.5 & 5.0204 & TRN \\
\hline CHEMBL1326623 & 688267 & 4.4 & 5.0906 & TRN \\
\hline CHEMBL1321521 & 688267 & 5.05 & 5.0694 & TRN \\
\hline CHEMBL1565702 & 688267 & 5.3 & 5.0663 & TRN \\
\hline CHEMBL1435395 & 688267 & 6.2 & 5.0932 & TRN \\
\hline CHEMBL1527301 & 688267 & 5.8 & 5.0857 & TRN \\
\hline CHEMBL1393063 & 688267 & 4.85 & 5.0323 & TRN \\
\hline CHEMBL1476246 & 688267 & 4.05 & 5.038 & TRN \\
\hline CHEMBL1394806 & 688267 & 5.3 & 5.0154 & TRN \\
\hline CHEMBL1608553 & 688267 & 4.55 & 5.1196 & TST \\
\hline CHEMBL1402739 & 688267 & 4.6 & 5.0561 & TRN \\
\hline CHEMBL1314563 & 688267 & 6.45 & 5.0435 & TRN \\
\hline CHEMBL1397680 & 688267 & 4.2 & 5.0691 & TRN \\
\hline CHEMBL1482078 & 688267 & 5.65 & 5.1597 & TRN \\
\hline CHEMBL1540154 & 688267 & 4.0 & 5.0381 & TRN \\
\hline CHEMBL1491471 & 688267 & 4.15 & 5.1172 & TRN \\
\hline CHEMBL1390316 & 688267 & 3.95 & 5.0389 & TST \\
\hline CHEMBL1450175 & 688267 & 5.95 & 5.0186 & TST \\
\hline CHEMBL1533277 & 688267 & 3.95 & 5.0144 & TRN \\
\hline CHEMBL1608924 & 688267 & 5.95 & 5.0584 & TST \\
\hline CHEMBL3196782 & 688267 & 4.0 & 5.0609 & TRN \\
\hline CHEMBL3213038 & 688267 & 5.85 & 5.0189 & TRN \\
\hline CHEMBL1321662 & 688267 & 4.05 & 5.0703 & TRN \\
\hline CHEMBL1351208 & 688267 & 6.15 & 5.0748 & TRN \\
\hline CHEMBL1445666 & 688267 & 4.1 & 5.0442 & TRN \\
\hline CHEMBL1489926 & 688267 & 4.9 & 5.0713 & TRN \\
\hline CHEMBL1500037 & 688267 & 6.1 & 5.0046 & TRN \\
\hline CHEMBL1368361 & 688267 & 4.8 & 5.022 & TRN \\
\hline CHEMBL1493556 & 688267 & 5.95 & 5.0346 & TRN \\
\hline CHEMBL1439238 & 688267 & 4.65 & 5.0457 & TRN \\
\hline CHEMBL1517964 & 688267 & 4.15 & 5.1031 & TST \\
\hline CHEMBL1433046 & 688267 & 5.25 & 5.0256 & TST \\
\hline CHEMBL1605750 & 688267 & 6.1 & 5.0349 & TRN \\
\hline CHEMBL1555669 & 688267 & 5.9 & 5.1068 & TRN \\
\hline CHEMBL1577027 & 688267 & 4.6 & 5.0255 & TRN \\
\hline CHEMBL1431731 & 688267 & 4.25 & 5.0449 & TRN \\
\hline CHEMBL1470596 & 688267 & 4.6 & 4.9953 & TRN \\
\hline CHEMBL1516726 & 688267 & 5.55 & 5.0833 & TRN \\
\hline CHEMBL1353114 & 688267 & 4.2 & 5.1404 & TRN \\
\hline CHEMBL1612178 & 688267 & 4.05 & 4.9993 & TRN \\
\hline CHEMBL1434660 & 688267 & 4.0 & 5.0795 & TRN \\
\hline CHEMBL1494582 & 688267 & 5.05 & 5.0992 & TRN \\
\hline CHEMBL1442481 & 688267 & 4.4 & 5.0006 & TRN \\
\hline CHEMBL1426847 & 688267 & 4.4 & 5.1031 & TST \\
\hline CHEMBL1602566 & 688267 & 4.35 & 5.0338 & TST \\
\hline CHEMBL1556710 & 688267 & 4.6 & 5.0515 & TRN \\
\hline CHEMBL1356082 & 688267 & 4.6 & 5.001 & TRN \\
\hline CHEMBL1609757 & 688267 & 5.9 & 5.0306 & TRN \\
\hline
\end{tabular}




\begin{tabular}{|c|c|c|c|c|}
\hline \multicolumn{5}{|c|}{ Supplemental Table S2.txt } \\
\hline CHEMBL3190718 & 688267 & 4.0 & 5.005 & TRN \\
\hline CHEMBL1464650 & 688267 & 5.55 & 5.0812 & TRN \\
\hline CHEMBL1496923 & 688267 & 6.2 & 5.0974 & TST \\
\hline CHEMBL1480683 & 688267 & 6.05 & 5.0483 & TRN \\
\hline CHEMBL1514883 & 688267 & 5.35 & 5.0018 & TRN \\
\hline CHEMBL1388002 & 688267 & 6.2 & 5.0481 & TST \\
\hline CHEMBL1485390 & 688267 & 5.3 & 5.0515 & TRN \\
\hline CHEMBL1411058 & 688267 & 4.75 & 5.0205 & TRN \\
\hline CHEMBL1483225 & 688267 & 5.6 & 5.06 & TST \\
\hline CHEMBL1353159 & 688267 & 4.6 & 5.0796 & TST \\
\hline CHEMBL1549107 & 688267 & 4.95 & 5.0439 & TRN \\
\hline CHEMBL1357863 & 688267 & 5.5 & 5.0991 & TRN \\
\hline CHEMBL1465703 & 688267 & 4.95 & 5.0903 & TRN \\
\hline CHEMBL1442474 & 688267 & 4.4 & 5.1011 & TRN \\
\hline CHEMBL1380158 & 688267 & 4.5 & 4.9963 & TRN \\
\hline CHEMBL1448086 & 688267 & 6.2 & 5.0099 & TRN \\
\hline CHEMBL1497918 & 688267 & 6.15 & 5.0649 & TRN \\
\hline CHEMBL1566904 & 688267 & 6.2 & 5.0131 & TRN \\
\hline CHEMBL1528226 & 688267 & 4.6 & 5.085 & TRN \\
\hline CHEMBL1339042 & 688267 & 4.0 & 5.0329 & TST \\
\hline CHEMBL1324408 & 688267 & 4.55 & 5.008 & TRN \\
\hline CHEMBL1379897 & 688267 & 4.05 & 5.0229 & TRN \\
\hline CHEMBL1497631 & 688267 & 6.2 & 5.0373 & TRN \\
\hline CHEMBL1573147 & 688267 & 4.0 & 5.0621 & TRN \\
\hline CHEMBL1522571 & 688267 & 3.95 & 5.1152 & TRN \\
\hline CHEMBL3194151 & 688267 & 4.6 & 5.0236 & TRN \\
\hline CHEMBL1363334 & 688267 & 4.0 & 5.0569 & TRN \\
\hline CHEMBL1484882 & 688267 & 6.25 & 5.0677 & TST \\
\hline CHEMBL1397164 & 688267 & 5.5 & 5.0671 & TRN \\
\hline CHEMBL1459735 & 688267 & 4.0 & 5.0407 & TRN \\
\hline CHEMBL1402382 & 688267 & 4.0 & 5.0992 & TST \\
\hline CHEMBL1606151 & 688267 & 5.15 & 5.0719 & TRN \\
\hline CHEMBL1404288 & 688267 & 3.95 & 5.0893 & TRN \\
\hline CHEMBL1346053 & 688267 & 4.4 & 5.0206 & TRN \\
\hline CHEMBL1611127 & 688267 & 4.0 & 5.078 & TRN \\
\hline CHEMBL1336599 & 688267 & 4.15 & 5.0759 & TRN \\
\hline CHEMBL1494375 & 688267 & 4.0 & 5.0211 & TRN \\
\hline CHEMBL1496669 & 688267 & 4.25 & 5.0485 & TRN \\
\hline CHEMBL1594515 & 688267 & 5.35 & 5.0093 & TRN \\
\hline CHEMBL1360715 & 688267 & 4.6 & 5.0858 & TRN \\
\hline CHEMBL1443625 & 688267 & 4.35 & 5.0946 & TST \\
\hline CHEMBL3194614 & 688267 & 5.4 & 5.0388 & TRN \\
\hline CHEMBL1528683 & 688267 & 4.7 & 5.0825 & TRN \\
\hline CHEMBL1393307 & 688267 & 5.4 & 5.0591 & TRN \\
\hline CHEMBL1458284 & 688267 & 5.45 & 5.0286 & TST \\
\hline CHEMBL1331347 & 688267 & 5.45 & 5.0701 & TRN \\
\hline CHEMBL1426752 & 688267 & 5.65 & 5.0582 & TRN \\
\hline CHEMBL1407940 & 688267 & 6.1 & 5.0346 & TST \\
\hline
\end{tabular}




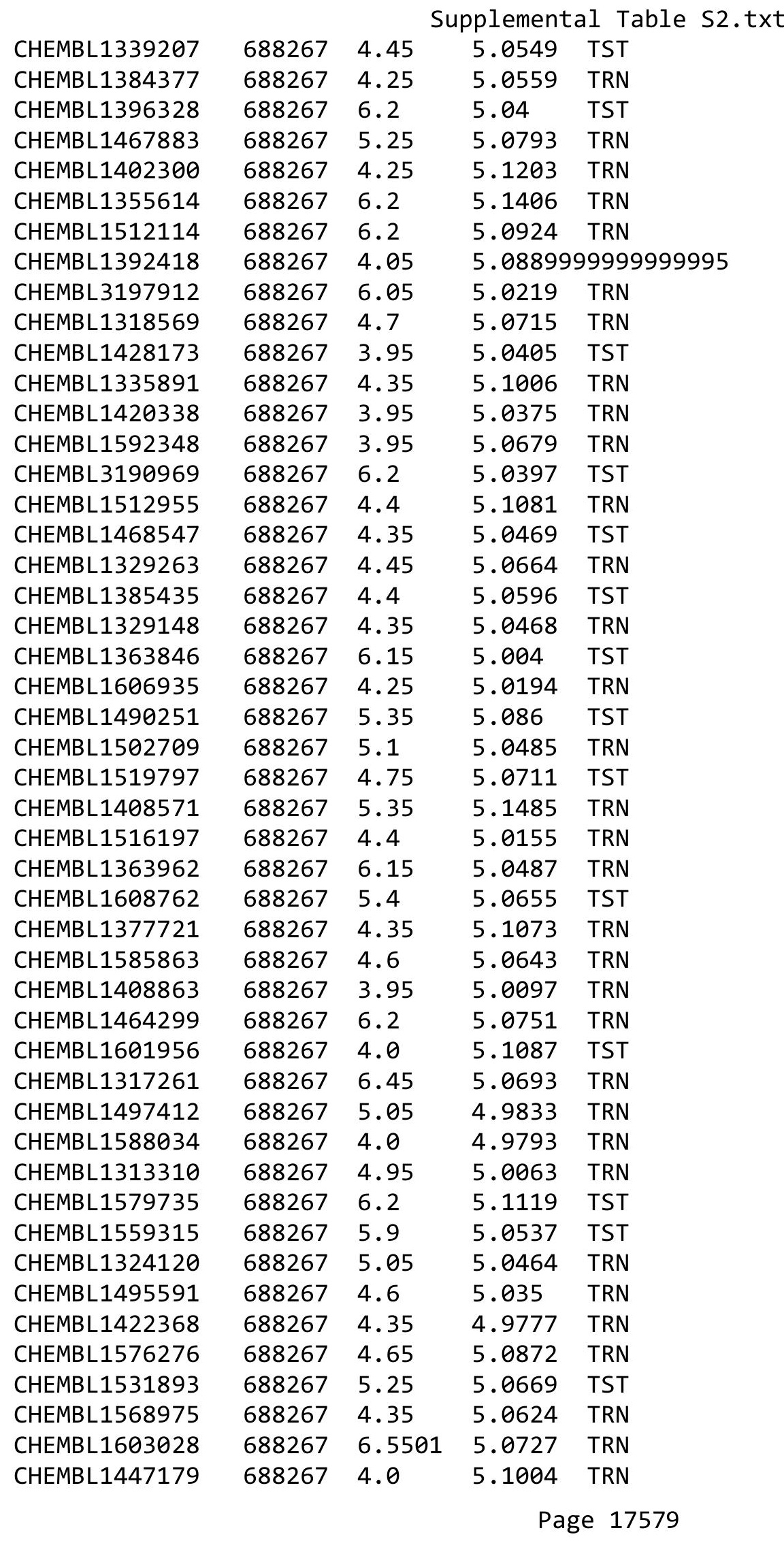




\begin{tabular}{|c|c|c|c|c|}
\hline \multicolumn{5}{|c|}{ Supplemental Table S2.txt } \\
\hline CHEMBL1442711 & 688267 & 4.1 & 5.0475 & TST \\
\hline CHEMBL1475089 & 688267 & 4.1 & 5.0724 & TRN \\
\hline CHEMBL1551756 & 688267 & 5.35 & 5.0456 & TRN \\
\hline CHEMBL1492212 & 688267 & 6.15 & 5.0357 & TST \\
\hline CHEMBL 1477868 & 688267 & 5.45 & 5.0924 & TRN \\
\hline CHEMBL1502074 & 688267 & 6.15 & 5.0772 & TRN \\
\hline CHEMBL1433894 & 688267 & 6.2 & 5.0015 & TRN \\
\hline CHEMBL1436582 & 688267 & 4.0 & 5.0739 & TRN \\
\hline CHEMBL1505934 & 688267 & 4.35 & 5.064 & TST \\
\hline CHEMBL1394120 & 688267 & 4.0 & 5.0242 & TRN \\
\hline CHEMBL1368690 & 688267 & 4.2 & 5.0455 & TST \\
\hline CHEMBL1385220 & 688267 & 5.9 & 5.0496 & TRN \\
\hline CHEMBL297784 & 688267 & 5.25 & 5.0913 & TST \\
\hline CHEMBL1408817 & 688267 & 5.6 & 5.0589 & TRN \\
\hline CHEMBL1553126 & 688267 & 5.05 & 5.0016 & TST \\
\hline CHEMBL1349175 & 688267 & 6.0 & 5.0494 & TRN \\
\hline CHEMBL1303724 & 688267 & 6.2 & 5.0693 & TRN \\
\hline CHEMBL1492956 & 688267 & 5.9 & 5.008 & TRN \\
\hline CHEMBL1471312 & 688267 & 6.2 & 5.1458 & TRN \\
\hline CHEMBL1612627 & 688267 & 4.05 & 5.0041 & TST \\
\hline CHEMBL1319331 & 688267 & 5.3 & 5.0279 & TRN \\
\hline CHEMBL1577946 & 688267 & 5.45 & 5.0663 & TST \\
\hline CHEMBL1436484 & 688267 & 5.1 & 5.0396 & TRN \\
\hline CHEMBL1552722 & 688267 & 4.55 & 5.0356 & TRN \\
\hline CHEMBL1443869 & 688267 & 4.05 & 5.0779 & TRN \\
\hline CHEMBL1591657 & 688267 & 4.0 & 5.1325 & TRN \\
\hline CHEMBL1386512 & 688267 & 4.35 & 5.0737 & TRN \\
\hline CHEMBL1531267 & 688267 & 4.4 & 5.0412 & TRN \\
\hline CHEMBL1415736 & 688267 & 4.7 & 5.0455 & TST \\
\hline CHEMBL1482696 & 688267 & 4.6 & 5.0219 & TRN \\
\hline CHEMBL1348712 & 688267 & 5.55 & 5.0694 & TRN \\
\hline CHEMBL1316100 & 688267 & 4.15 & 5.0242 & TRN \\
\hline CHEMBL1322662 & 688267 & 6.2 & 5.084 & TRN \\
\hline CHEMBL1351372 & 688267 & 4.4 & 5.0949 & TRN \\
\hline CHEMBL1507756 & 688267 & 4.5 & 5.1078 & TRN \\
\hline CHEMBL1548972 & 688267 & 5.55 & 5.0234 & TRN \\
\hline CHEMBL1575203 & 688267 & 5.6 & 5.0961 & TST \\
\hline CHEMBL1408564 & 688267 & 4.5 & 5.0066 & TRN \\
\hline CHEMBL1510519 & 688267 & 6.2 & 5.0822 & TRN \\
\hline CHEMBL1467083 & 688267 & 4.0 & 5.0996 & TRN \\
\hline CHEMBL1361229 & 688267 & 4.25 & 5.0735 & TRN \\
\hline CHEMBL1366918 & 688267 & 5.45 & 5.1153 & TST \\
\hline CHEMBL1303943 & 688267 & 5.35 & 5.0463 & TRN \\
\hline CHEMBL1389910 & 688267 & 4.25 & 5.0516 & TRN \\
\hline CHEMBL1481458 & 688267 & 4.4 & 5.0842 & TST \\
\hline CHEMBL1527351 & 688267 & 5.25 & 5.1088 & TRN \\
\hline CHEMBL1500816 & 688267 & 4.05 & 5.0953 & TST \\
\hline CHEMBL1418531 & 688267 & 6.5 & 5.0083 & TRN \\
\hline
\end{tabular}




\begin{tabular}{|c|c|c|c|c|}
\hline \multicolumn{5}{|c|}{ Supplemental Table S2.txt } \\
\hline CHEMBL1521539 & 688267 & 5.3 & 4.9993 & TRN \\
\hline CHEMBL1396434 & 688267 & 5.2 & 5.0898 & TRN \\
\hline CHEMBL1562730 & 688267 & 4.0 & 5.018 & TRN \\
\hline CHEMBL1409647 & 688267 & 6.45 & 5.0753 & TRN \\
\hline CHEMBL1447499 & 688267 & 4.2 & 4.9802 & TRN \\
\hline CHEMBL1607056 & 688267 & 3.95 & 5.0322 & TRN \\
\hline CHEMBL1497445 & 688267 & 5.35 & 5.1846 & TRN \\
\hline CHEMBL1371110 & 688267 & 7.6003 & 4.9835 & TST \\
\hline CHEMBL1336511 & 688267 & 5.05 & 5.0826 & TRN \\
\hline CHEMBL1409372 & 688267 & 4.3 & 5.0128 & TRN \\
\hline CHEMBL1302720 & 688267 & 5.5 & 5.0744 & TRN \\
\hline CHEMBL1361199 & 688267 & 5.7 & 5.0948 & TST \\
\hline CHEMBL1455223 & 688267 & 6.15 & 5.0349 & TRN \\
\hline CHEMBL1597525 & 688267 & 4.6 & 5.0378 & TRN \\
\hline CHEMBL1335200 & 688267 & 4.0 & 5.0352 & TRN \\
\hline CHEMBL1384287 & 688267 & 6.0 & 5.1061 & TRN \\
\hline CHEMBL1339762 & 688267 & 4.4 & 5.0723 & TST \\
\hline CHEMBL1461200 & 688267 & 6.25 & 5.0431 & TST \\
\hline CHEMBL1482439 & 688267 & 3.95 & 5.0751 & TRN \\
\hline CHEMBL1386629 & 688267 & 5.1 & 5.0613 & TRN \\
\hline CHEMBL1401636 & 688267 & 3.95 & 5.1087 & TRN \\
\hline CHEMBL1383713 & 688267 & 4.25 & 5.0375 & TST \\
\hline CHEMBL1303160 & 688267 & 6.1 & 5.0594 & TRN \\
\hline CHEMBL1355113 & 688267 & 6.0 & 5.0239 & TRN \\
\hline CHEMBL1540555 & 688267 & 4.0 & 5.1051 & TST \\
\hline CHEMBL1454996 & 688267 & 5.65 & 5.0342 & TRN \\
\hline CHEMBL1596815 & 688267 & 6.15 & 5.1294 & TRN \\
\hline CHEMBL1385900 & 688267 & 5.25 & 5.0352 & TRN \\
\hline CHEMBL1326353 & 688267 & 6.25 & 5.0233 & TST \\
\hline CHEMBL1426696 & 688267 & 6.2 & 5.0294 & TST \\
\hline CHEMBL1611165 & 688267 & 5.2 & 5.0293 & TRN \\
\hline CHEMBL1590560 & 688267 & 5.25 & 5.0915 & TRN \\
\hline CHEMBL1399830 & 688267 & 4.05 & 5.1044 & TRN \\
\hline CHEMBL1451407 & 688267 & 4.4 & 5.1302 & TRN \\
\hline CHEMBL1460268 & 688267 & 6.2 & 5.0848 & TRN \\
\hline CHEMBL1436735 & 688267 & 4.65 & 5.0625 & TRN \\
\hline CHEMBL391997 & 688267 & 5.05 & 5.0961 & TST \\
\hline CHEMBL251785 & 688267 & 6.2 & 5.0117 & TRN \\
\hline CHEMBL1476131 & 688267 & 6.2 & 4.9999 & TST \\
\hline CHEMBL 286722 & 688267 & 5.2 & 5.0359 & TRN \\
\hline CHEMBL1413234 & 688267 & 4.7 & 5.0413 & TRN \\
\hline CHEMBL1598546 & 688267 & 5.5 & 5.0532 & TRN \\
\hline CHEMBL1527785 & 688267 & 4.0 & 5.0608 & TST \\
\hline CHEMBL1357821 & 688267 & 4.0 & 5.0011 & TRN \\
\hline CHEMBL1415739 & 688267 & 5.8 & 5.0151 & TST \\
\hline CHEMBL1580705 & 688267 & 4.4 & 5.0272 & TRN \\
\hline CHEMBL1571512 & 688267 & 4.05 & 5.086 & TRN \\
\hline CHEMBL1537164 & 688267 & 5.7 & 5.1163 & TRN \\
\hline
\end{tabular}




\begin{tabular}{|c|c|c|c|c|c|}
\hline \multicolumn{6}{|c|}{ Supplemental Table S2.txt } \\
\hline CHEMBL1464860 & 688267 & 5.35 & 5.0873 & TRN & \\
\hline CHEMBL1589105 & 688267 & 4.05 & 5.0803 & TRN & \\
\hline CHEMBL1545723 & 688267 & 4.05 & 4.9875 & TRN & \\
\hline CHEMBL1365383 & 688267 & 4.5 & 5.0342 & TST & \\
\hline CHEMBL1341990 & 688267 & 4.05 & 5.0347 & TST & \\
\hline CHEMBL1324037 & 688267 & 4.5 & 5.0638 & TST & \\
\hline CHEMBL1347200 & 688267 & 4.35 & 5.0339 & TRN & \\
\hline CHEMBL1508679 & 688267 & 5.9 & 5.0512 & TRN & \\
\hline CHEMBL1450876 & 688267 & 4.2 & 5.107 & TST & \\
\hline CHEMBL3209578 & 688267 & 4.0 & 5.0438 & TST & \\
\hline CHEMBL319931 & 688267 & 6.45 & 5.0337 & TRN & \\
\hline CHEMBL1437927 & 688267 & 5.55 & 5.1261 & TRN & \\
\hline CHEMBL1378146 & 688267 & 4.6 & 5.1078 & TRN & \\
\hline CHEMBL1381555 & 688267 & 5.1 & 5.044 & TRN & \\
\hline CHEMBL1402745 & 688267 & 5.05 & 5.0575 & TRN & \\
\hline CHEMBL1402591 & 688267 & 4.0 & 4.9901 & TRN & \\
\hline CHEMBL1582042 & 688267 & 4.65 & 5.0229 & TRN & \\
\hline CHEMBL1478535 & 688267 & 4.45 & 5.063 & TRN & \\
\hline CHEMBL1523280 & 688267 & 6.2 & 5.1007 & TRN & \\
\hline CHEMBL1597355 & 688267 & 4.3 & 5.0396 & TRN & \\
\hline CHEMBL1512778 & 688267 & 4.95 & 5.0874 & TRN & \\
\hline CHEMBL1429983 & 688267 & 4.45 & 5.0667 & TRN & \\
\hline CHEMBL1586157 & 688267 & 4.45 & 5.0073 & TST & \\
\hline CHEMBL1375977 & 688267 & 5.45 & 5.0563 & TRN & \\
\hline CHEMBL1355858 & 688267 & 4.35 & 5.0248 & TRN & \\
\hline CHEMBL1602281 & 688267 & 4.05 & 5.0041 & TRN & \\
\hline CHEMBL1308773 & 688267 & 4.25 & 5.06800 & 00000000005 & TRN \\
\hline CHEMBL1368754 & 688267 & 5.15 & 5.0391 & TRN & \\
\hline CHEMBL1589858 & 688267 & 5.15 & 5.0131 & TST & \\
\hline CHEMBL1527343 & 688267 & 4.35 & 5.086 & TST & \\
\hline CHEMBL1302990 & 688267 & 6.05 & 5.0915 & TRN & \\
\hline CHEMBL1489947 & 688267 & 4.0 & 5.0986 & TRN & \\
\hline CHEMBL1586260 & 688267 & 5.25 & 5.1204 & TRN & \\
\hline CHEMBL1608982 & 688267 & 4.4 & 5.0208 & TST & \\
\hline CHEMBL1483856 & 688267 & 5.65 & 5.083 & TRN & \\
\hline CHEMBL1520138 & 688267 & 4.4 & 5.0209 & TRN & \\
\hline CHEMBL1364339 & 688267 & 6.2 & 4.9903 & TRN & \\
\hline CHEMBL1612799 & 688267 & 4.9 & 5.0516 & TRN & \\
\hline CHEMBL1357275 & 688267 & 4.4 & 5.09 & TRN & \\
\hline CHEMBL1484225 & 688267 & 4.6 & 5.0052 & TRN & \\
\hline CHEMBL1495102 & 688267 & 5.2 & 5.0676 & TRN & \\
\hline CHEMBL1485464 & 688267 & 4.0 & 5.0846 & TRN & \\
\hline CHEMBL1541908 & 688267 & 5.1 & 5.0371 & TRN & \\
\hline CHEMBL1504065 & 688267 & 4.0 & 5.0673 & TRN & \\
\hline CHEMBL1355435 & 688267 & 6.15 & 5.1118 & TRN & \\
\hline CHEMBL1456303 & 688267 & 6.15 & 5.0567 & TRN & \\
\hline CHEMBL1436565 & 688267 & 4.1 & 5.0175 & TRN & \\
\hline CHEMBL1323350 & 688267 & 6.25 & 5.041 & TRN & \\
\hline
\end{tabular}




\begin{tabular}{|c|c|c|c|c|}
\hline \multicolumn{5}{|c|}{ Supplemental Table } \\
\hline CHEMBL1495642 & 688267 & 3.95 & 5.0085 & TST \\
\hline CHEMBL1576016 & 688267 & 6.1 & 5.1135 & TRN \\
\hline CHEMBL1426463 & 688267 & 5.35 & 5.0418 & TRN \\
\hline CHEMBL1404352 & 688267 & 5.6 & 5.0475 & TRN \\
\hline CHEMBL1377181 & 688267 & 4.55 & 5.0267 & TST \\
\hline CHEMBL1409768 & 688267 & 5.4 & 5.1466 & TRN \\
\hline CHEMBL1455014 & 688267 & 4.0 & 5.0461 & TST \\
\hline CHEMBL1458784 & 688267 & 4.9 & 5.0176 & TRN \\
\hline CHEMBL1447073 & 688267 & 4.75 & 5.0611 & TST \\
\hline CHEMBL1432162 & 688267 & 5.5 & 5.0049 & TRN \\
\hline CHEMBL1506710 & 688267 & 4.6 & 5.0067 & TRN \\
\hline CHEMBL1568039 & 688267 & 5.75 & 5.0345 & TRN \\
\hline CHEMBL1571378 & 688267 & 5.55 & 5.1005 & TRN \\
\hline CHEMBL1551257 & 688267 & 5.65 & 5.1089 & TRN \\
\hline CHEMBL1601162 & 688267 & 5.0 & 5.0159 & TST \\
\hline CHEMBL1527198 & 688267 & 6.2 & 5.0553 & TRN \\
\hline CHEMBL1579625 & 688267 & 4.45 & 5.0245 & TRN \\
\hline CHEMBL1486146 & 688267 & 5.95 & 5.0953 & TRN \\
\hline CHEMBL1480403 & 688267 & 4.6 & 5.129 & TRN \\
\hline CHEMBL1394889 & 688267 & 5.35 & 5.0105 & TRN \\
\hline CHEMBL1379978 & 688267 & 4.0 & 5.1515 & TRN \\
\hline CHEMBL1419046 & 688267 & 4.55 & 5.1031 & TRN \\
\hline CHEMBL321421 & 688267 & 4.8 & 5.062 & TRN \\
\hline CHEMBL1309552 & 688267 & 4.65 & 5.0856 & TST \\
\hline CHEMBL1401280 & 688267 & 5.3 & 5.0225 & TRN \\
\hline CHEMBL1434642 & 688267 & 5.8 & 5.0584 & TRN \\
\hline CHEMBL1548446 & 688267 & 4.5 & 5.1038 & TRN \\
\hline CHEMBL1535439 & 688267 & 4.05 & 4.9909 & TRN \\
\hline CHEMBL1590941 & 688267 & 4.7 & 5.059 & TST \\
\hline CHEMBL1347785 & 688267 & 6.15 & 5.0491 & TRN \\
\hline CHEMBL1485210 & 688267 & 6.45 & 5.0685 & TST \\
\hline CHEMBL1419665 & 688267 & 4.75 & 5.066 & TRN \\
\hline CHEMBL1454834 & 688267 & 4.0 & 5.0799 & TRN \\
\hline CHEMBL1354700 & 688267 & 4.2 & 4.9493 & TRN \\
\hline CHEMBL1449209 & 688267 & 5.9 & 5.0075 & TRN \\
\hline CHEMBL1488222 & 688267 & 6.4 & 5.0169 & TRN \\
\hline CHEMBL1573868 & 688267 & 4.25 & 5.0805 & TRN \\
\hline CHEMBL1332157 & 688267 & 4.8 & 5.1151 & TRN \\
\hline CHEMBL1494281 & 688267 & 4.05 & 5.0966 & TRN \\
\hline CHEMBL1411227 & 688267 & 4.1 & 5.029 & TRN \\
\hline CHEMBL1576625 & 688267 & 3.95 & 5.0555 & TRN \\
\hline CHEMBL1499984 & 688267 & 4.6 & 5.0269 & TRN \\
\hline CHEMBL1325747 & 688267 & 4.1 & 5.0887 & TST \\
\hline CHEMBL3192624 & 688267 & 4.9 & 5.0084 & TRN \\
\hline CHEMBL1520376 & 688267 & 4.55 & 5.0943 & TRN \\
\hline CHEMBL3199887 & 688267 & 4.4 & 5.0657 & TST \\
\hline CHEMBL1356694 & 688267 & 6.5 & 5.0072 & TRN \\
\hline CHEMBL 3214227 & 688267 & 4.2 & 5.0709 & TST \\
\hline
\end{tabular}




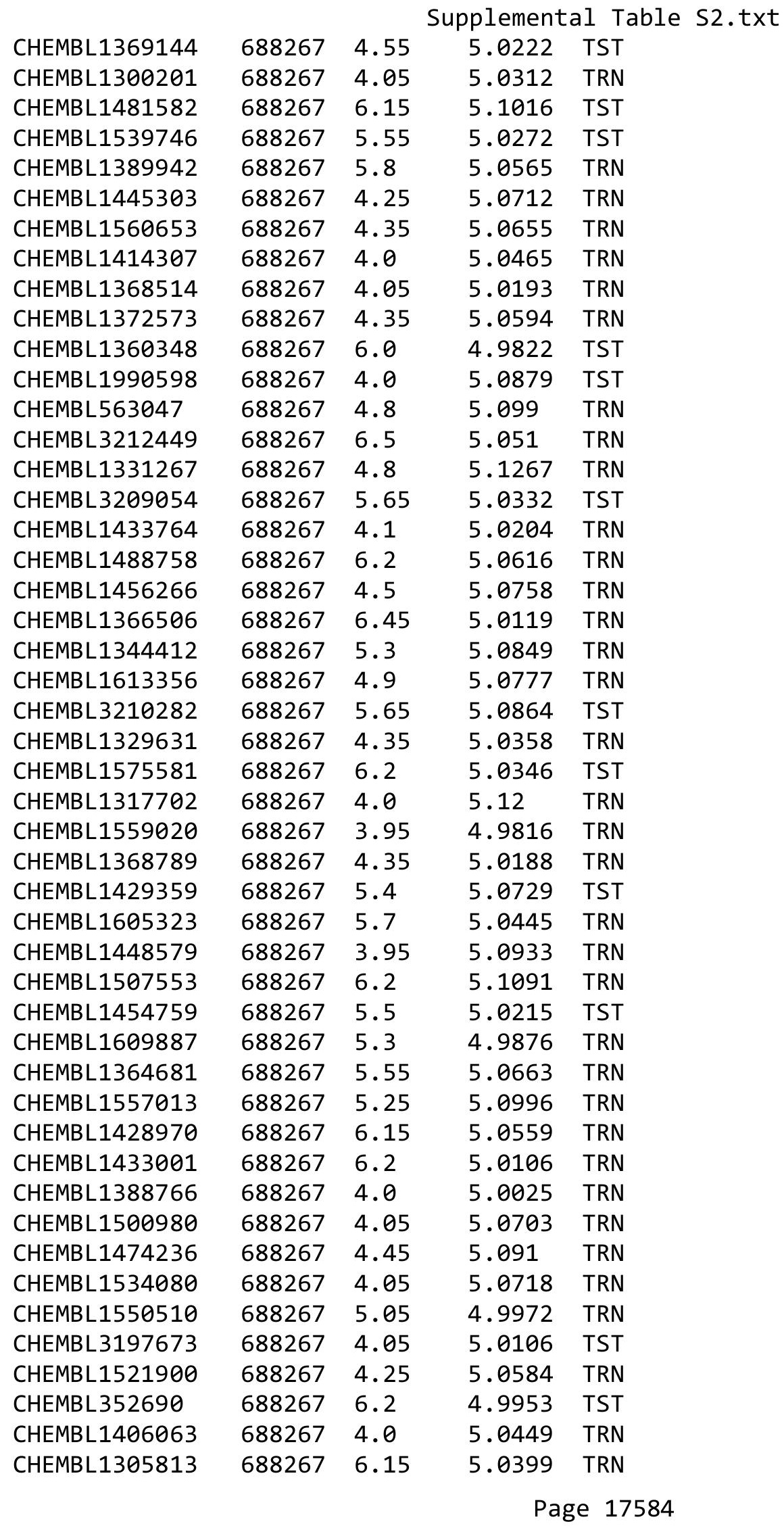




\begin{tabular}{|c|c|c|c|c|}
\hline \multicolumn{5}{|c|}{ Supplemental Table S2.txt } \\
\hline CHEMBL1530307 & 688267 & 5.95 & 5.0609 & TRN \\
\hline CHEMBL1517378 & 688267 & 6.2 & 5.0897 & TST \\
\hline CHEMBL1539133 & 688267 & 6.15 & 5.0543 & TRN \\
\hline CHEMBL1590141 & 688267 & 5.45 & 5.0283 & TRN \\
\hline CHEMBL1323367 & 688267 & 3.95 & 5.1244 & TRN \\
\hline CHEMBL1387785 & 688267 & 6.2 & 5.103 & TRN \\
\hline CHEMBL1436244 & 688267 & 4.15 & 5.0147 & TRN \\
\hline CHEMBL1541269 & 688267 & 4.25 & 5.0525 & TRN \\
\hline CHEMBL1331948 & 688267 & 4.95 & 5.0608 & TST \\
\hline CHEMBL1502036 & 688267 & 4.45 & 5.0122 & TST \\
\hline CHEMBL1593975 & 688267 & 5.35 & 5.0308 & TRN \\
\hline CHEMBL1344728 & 688267 & 5.5 & 5.1367 & TRN \\
\hline CHEMBL1425537 & 688267 & 4.45 & 5.0307 & TRN \\
\hline CHEMBL1592235 & 688267 & 4.3 & 5.0405 & TRN \\
\hline CHEMBL1487471 & 688267 & 4.35 & 5.0229 & TRN \\
\hline CHEMBL1612654 & 688267 & 5.5 & 5.0679 & TRN \\
\hline CHEMBL1537425 & 688267 & 6.2 & 4.9878 & TRN \\
\hline CHEMBL1571579 & 688267 & 4.75 & 5.0508 & TRN \\
\hline CHEMBL1470173 & 688267 & 6.15 & 5.084 & TRN \\
\hline CHEMBL1599804 & 688267 & 4.05 & 5.0777 & TRN \\
\hline CHEMBL1300226 & 688267 & 5.6 & 5.0864 & TRN \\
\hline CHEMBL1435202 & 688267 & 4.05 & 5.0916 & TRN \\
\hline CHEMBL1308592 & 688267 & 6.15 & 5.0469 & TST \\
\hline CHEMBL3210615 & 688267 & 6.2 & 4.9917 & TRN \\
\hline CHEMBL1613407 & 688267 & 6.2 & 5.0905 & TST \\
\hline CHEMBL1514695 & 688267 & 6.5501 & 5.0674 & TST \\
\hline CHEMBL1330979 & 688267 & 4.85 & 5.0804 & TRN \\
\hline CHEMBL1381275 & 688267 & 3.95 & 5.1008 & TRN \\
\hline CHEMBL1531971 & 688267 & 4.0 & 5.0656 & TRN \\
\hline CHEMBL1535116 & 688267 & 5.15 & 5.0622 & TRN \\
\hline CHEMBL1467748 & 688267 & 4.65 & 5.0458 & TRN \\
\hline CHEMBL1498715 & 688267 & 5.1 & 5.0529 & TRN \\
\hline CHEMBL1465195 & 688267 & 5.95 & 5.0114 & TRN \\
\hline CHEMBL1522249 & 688267 & 4.6 & 5.0771 & TRN \\
\hline CHEMBL1446337 & 688267 & 5.85 & 5.064 & TST \\
\hline CHEMBL1572994 & 688267 & 6.1 & 5.0939 & TRN \\
\hline CHEMBL1323555 & 688267 & 6.2 & 5.1001 & TRN \\
\hline CHEMBL1482128 & 688267 & 5.8 & 5.0583 & TST \\
\hline CHEMBL1393383 & 688267 & 5.95 & 5.0783 & TST \\
\hline CHEMBL1513173 & 688267 & 4.05 & 5.0718 & TRN \\
\hline CHEMBL1391682 & 688267 & 6.25 & 5.0073 & TST \\
\hline CHEMBL1586501 & 688267 & 6.0 & 5.0258 & TST \\
\hline CHEMBL1564639 & 688267 & 5.75 & 5.1425 & TRN \\
\hline CHEMBL1589815 & 688267 & 5.8 & 5.0698 & TRN \\
\hline CHEMBL1322587 & 688267 & 4.6 & 5.0315 & TRN \\
\hline CHEMBL1501050 & 688267 & 5.55 & 5.0 & TRN \\
\hline CHEMBL1595832 & 688267 & 4.5 & 5.0306 & TRN \\
\hline CHEMBL1486376 & 688267 & 6.15 & 5.1134 & TRN \\
\hline
\end{tabular}




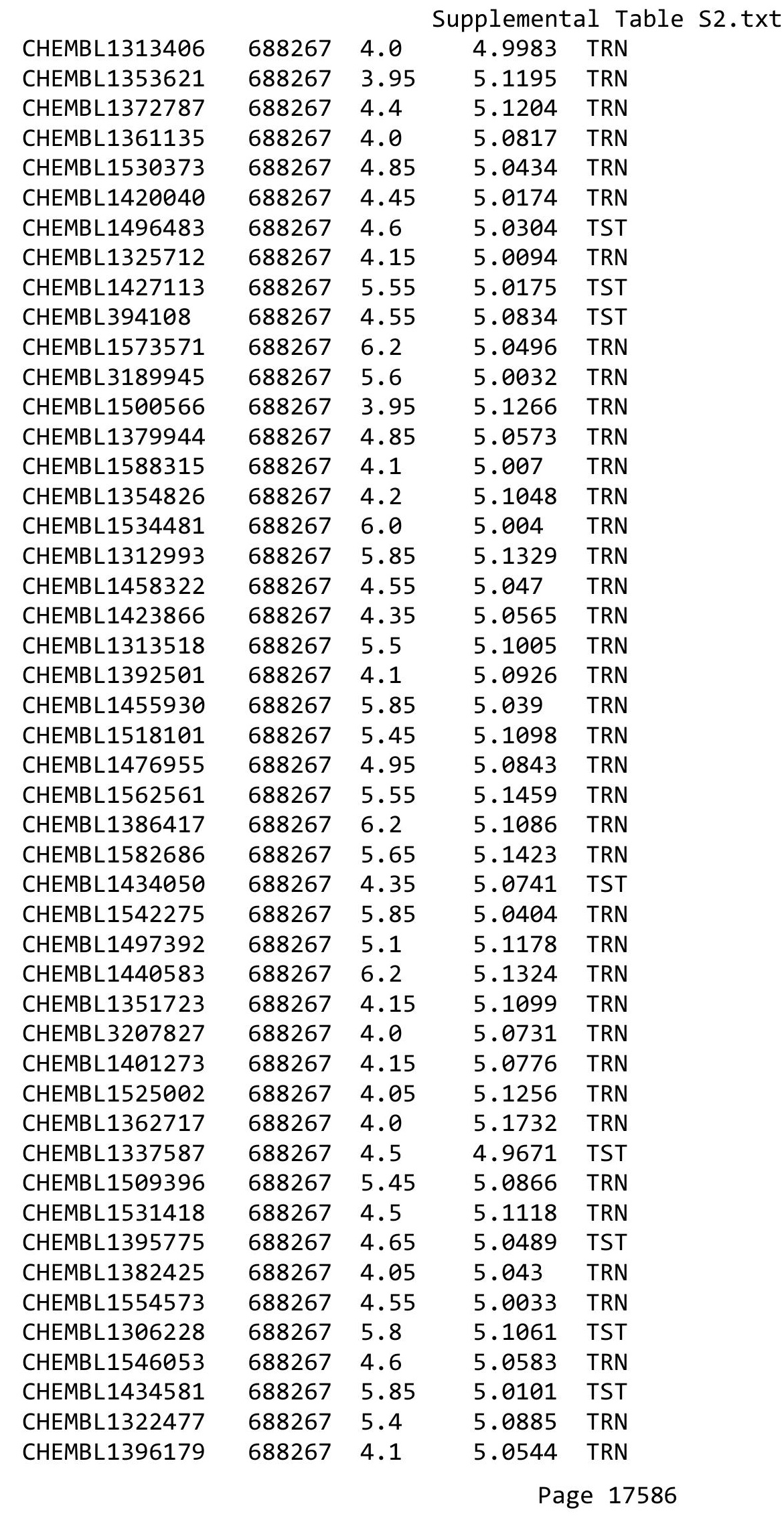




\begin{tabular}{|c|c|c|c|c|}
\hline & & & & 1 Table \\
\hline CHEMBL1530077 & 688267 & 4.0 & 5.0959 & TRN \\
\hline CHEMBL1518729 & 688267 & 4.0 & 5.1231 & TRN \\
\hline CHEMBL1320345 & 688267 & 5.15 & 4.9974 & TRN \\
\hline CHEMBL1359806 & 688267 & 4.75 & 5.0324 & TST \\
\hline CHEMBL1434653 & 688267 & 6.25 & 5.0782 & TST \\
\hline CHEMBL1516691 & 688267 & 4.0 & 5.1274 & TRN \\
\hline CHEMBL1563124 & 688267 & 5.0 & 4.9913 & TRN \\
\hline CHEMBL1335147 & 688267 & 4.9 & 5.1184 & TRN \\
\hline CHEMBL1523802 & 688267 & 6.5 & 5.1342 & TRN \\
\hline CHEMBL1611683 & 688267 & 6.15 & 5.0887 & TRN \\
\hline CHEMBL3209316 & 688267 & 4.05 & 5.0099 & TRN \\
\hline CHEMBL1433740 & 688267 & 6.2 & 5.0738 & TRN \\
\hline CHEMBL1370609 & 688267 & 4.5 & 5.016 & TRN \\
\hline CHEMBL3214521 & 688267 & 5.1 & 5.0372 & TRN \\
\hline CHEMBL1455893 & 688267 & 4.25 & 5.0125 & TRN \\
\hline CHEMBL1314362 & 688267 & 4.05 & 5.1171 & TRN \\
\hline CHEMBL1412912 & 688267 & 4.55 & 5.0323 & TRN \\
\hline CHEMBL1383570 & 688267 & 6.15 & 5.0995 & TST \\
\hline CHEMBL1569995 & 688267 & 6.05 & 5.0525 & TST \\
\hline CHEMBL1435527 & 688267 & 6.5 & 5.0446 & TRN \\
\hline CHEMBL1412868 & 688267 & 6.2 & 5.0586 & TRN \\
\hline CHEMBL1571168 & 688267 & 6.15 & 5.1268 & TRN \\
\hline CHEMBL1391890 & 688267 & 4.05 & 5.05399 & 9999999999 \\
\hline CHEMBL1433879 & 688267 & 6.2 & 5.0813 & TRN \\
\hline CHEMBL1529103 & 688267 & 6.2 & 5.1153 & TRN \\
\hline CHEMBL1340656 & 688267 & 3.95 & 5.1028 & TRN \\
\hline CHEMBL1428677 & 688267 & 4.55 & 5.0941 & TRN \\
\hline CHEMBL1306453 & 688267 & 6.7001 & 5.0767 & TRN \\
\hline CHEMBL1329462 & 688267 & 4.4 & 5.0865 & TRN \\
\hline CHEMBL3195097 & 688267 & 4.2 & 4.9998 & TRN \\
\hline CHEMBL3195111 & 688267 & 4.2 & 5.0266 & TRN \\
\hline CHEMBL1463282 & 688267 & 5.75 & 5.0442 & TST \\
\hline CHEMBL1491302 & 688267 & 5.9 & 5.0369 & TRN \\
\hline CHEMBL1613395 & 688267 & 4.95 & 5.0659 & TRN \\
\hline CHEMBL1461580 & 688267 & 3.9 & 5.0639 & TST \\
\hline CHEMBL1480956 & 688267 & 4.3 & 5.0126 & TST \\
\hline CHEMBL1304627 & 688267 & 4.0 & 5.0474 & TRN \\
\hline CHEMBL1501670 & 688267 & 6.2 & 5.1049 & TRN \\
\hline CHEMBL1382707 & 688267 & 4.4 & 5.012 & TST \\
\hline CHEMBL1335858 & 688267 & 3.95 & 5.0808 & TRN \\
\hline CHEMBL1421473 & 688267 & 5.15 & 5.0496 & TST \\
\hline CHEMBL1480596 & 688267 & 4.65 & 5.04 & TRN \\
\hline CHEMBL1378544 & 688267 & 4.45 & 5.1394 & TRN \\
\hline CHEMBL1339505 & 688267 & 4.7 & 5.018 & TST \\
\hline CHEMBL1372901 & 688267 & 4.05 & 5.0313 & TRN \\
\hline CHEMBL1424345 & 688267 & 5.9 & 5.0773 & TRN \\
\hline CHEMBL1464053 & 688267 & 4.5 & 5.0584 & TRN \\
\hline CHEMBL1331575 & 688267 & 6.5 & 5.0207 & TRN \\
\hline
\end{tabular}




\begin{tabular}{|c|c|c|c|c|c|}
\hline \multicolumn{6}{|c|}{ Supplemental Table S2.txt } \\
\hline CHEMBL1606873 & 688267 & 5.15 & 5.025 & TST & \\
\hline CHEMBL1518977 & 688267 & 3.95 & 5.0004 & TRN & \\
\hline CHEMBL1500269 & 688267 & 4.05 & 5.1097 & TST & \\
\hline CHEMBL1361014 & 688267 & 6.2 & 5.0559 & TRN & \\
\hline CHEMBL1602709 & 688267 & 5.6 & 5.0392 & TRN & \\
\hline CHEMBL1358768 & 688267 & 4.55 & 5.058 & TRN & \\
\hline CHEMBL1368871 & 688267 & 4.05 & 5.074 & TST & \\
\hline CHEMBL1515158 & 688267 & 3.95 & 5.1415 & TRN & \\
\hline CHEMBL1514432 & 688267 & 4.05 & 5.0505 & TRN & \\
\hline CHEMBL1436422 & 688267 & 6.0 & 5.083 & TRN & \\
\hline CHEMBL1441256 & 688267 & 4.0 & 5.0708 & TRN & \\
\hline CHEMBL1318320 & 688267 & 3.95 & 5.0086 & TST & \\
\hline CHEMBL1597629 & 688267 & 5.4 & 5.05699 & 99999999995 & TRN \\
\hline CHEMBL1367970 & 688267 & 6.2 & 5.0089 & TRN & \\
\hline CHEMBL1522879 & 688267 & 4.3 & 5.0948 & TRN & \\
\hline CHEMBL1611930 & 688267 & 4.05 & 5.0738 & TST & \\
\hline CHEMBL1419320 & 688267 & 6.0 & 5.0746 & TST & \\
\hline CHEMBL1567848 & 688267 & 4.35 & 5.0886 & TRN & \\
\hline CHEMBL1444831 & 688267 & 5.35 & 5.0313 & TRN & \\
\hline CHEMBL1400143 & 688267 & 4.65 & 5.0078 & TRN & \\
\hline CHEMBL1455667 & 688267 & 4.6 & 5.0439 & TRN & \\
\hline CHEMBL1554430 & 688267 & 4.5 & 5.0385 & TRN & \\
\hline CHEMBL1526219 & 688267 & 5.6 & 5.029 & TST & \\
\hline CHEMBL 3195438 & 688267 & 5.35 & 5.05 & TRN & \\
\hline CHEMBL1501394 & 688267 & 4.65 & 4.9941 & TRN & \\
\hline CHEMBL528694 & 688267 & 6.15 & 5.011 & TRN & \\
\hline CHEMBL3197859 & 688267 & 5.3 & 5.022 & TRN & \\
\hline CHEMBL1414970 & 688267 & 5.6 & 4.9868 & TRN & \\
\hline CHEMBL1574848 & 688267 & 5.0 & 5.0598 & TRN & \\
\hline CHEMBL1470891 & 688267 & 4.05 & 5.0475 & TRN & \\
\hline CHEMBL1514582 & 688267 & 5.4 & 5.029 & TRN & \\
\hline CHEMBL1398822 & 688267 & 6.25 & 4.9829 & TRN & \\
\hline CHEMBL3207902 & 688267 & 5.95 & 5.0278 & TRN & \\
\hline CHEMBL1346983 & 688267 & 4.7 & 5.0309 & TRN & \\
\hline CHEMBL1483378 & 688267 & 4.5 & 5.0598 & TRN & \\
\hline CHEMBL1459012 & 688267 & 4.45 & 5.1061 & TRN & \\
\hline CHEMBL1520601 & 688267 & 6.2 & 5.0516 & TRN & \\
\hline CHEMBL1328623 & 688267 & 4.35 & 5.0949 & TRN & \\
\hline CHEMBL 3195308 & 688267 & 6.2 & 4.9989 & TRN & \\
\hline CHEMBL1341205 & 688267 & 5.8 & 5.0609 & TST & \\
\hline CHEMBL1437333 & 688267 & 5.85 & 5.1015 & TRN & \\
\hline CHEMBL1437592 & 688267 & 6.15 & 5.0801 & TRN & \\
\hline CHEMBL1398535 & 688267 & 6.2 & 5.0128 & TST & \\
\hline CHEMBL1406823 & 688267 & 6.2 & 5.0557 & TRN & \\
\hline CHEMBL1408717 & 688267 & 4.4 & 4.9904 & TST & \\
\hline CHEMBL1487268 & 688267 & 6.2 & 5.0826 & TRN & \\
\hline CHEMBL1486871 & 688267 & 4.05 & 5.0693 & TST & \\
\hline CHEMBL1440557 & 688267 & 4.6 & 5.0289 & TST & \\
\hline
\end{tabular}




\begin{tabular}{|c|c|c|c|c|c|}
\hline \multicolumn{6}{|c|}{ Supplemental Table S2.txt } \\
\hline CHEMBL1353360 & 688267 & 4.4 & 5.0849 & TRN & \\
\hline CHEMBL1596551 & 688267 & 6.15 & 5.0263 & TRN & \\
\hline CHEMBL1506441 & 688267 & 4.0 & 5.0552 & TRN & \\
\hline CHEMBL1522449 & 688267 & 5.4 & 5.0047 & TRN & \\
\hline CHEMBL1523344 & 688267 & 4.95 & 5.0617 & TRN & \\
\hline CHEMBL1574348 & 688267 & 3.95 & 5.0321 & TRN & \\
\hline CHEMBL1349557 & 688267 & 4.0 & 5.0558 & TRN & \\
\hline CHEMBL3207491 & 688267 & 4.85 & 4.9554 & TRN & \\
\hline CHEMBL1414540 & 688267 & 6.45 & 5.1192 & TRN & \\
\hline CHEMBL1386503 & 688267 & 4.1 & 5.0231 & TRN & \\
\hline CHEMBL1469064 & 688267 & 4.45 & 5.0741 & TRN & \\
\hline CHEMBL1321433 & 688267 & 4.0 & 5.0262 & TRN & \\
\hline CHEMBL1324297 & 688267 & 3.95 & 5.099 & TRN & \\
\hline CHEMBL3194559 & 688267 & 4.0 & 5.0044 & TRN & \\
\hline CHEMBL1500055 & 688267 & 4.15 & 4.9952 & TRN & \\
\hline CHEMBL1598294 & 688267 & 5.85 & 5.1129 & TRN & \\
\hline CHEMBL1431093 & 688267 & 6.2 & 5.0545 & TRN & \\
\hline CHEMBL1580865 & 688267 & 6.2 & 5.0617 & TRN & \\
\hline CHEMBL1591623 & 688267 & 4.05 & 4.9959 & TRN & \\
\hline CHEMBL1391438 & 688267 & 5.35 & 5.0268 & TRN & \\
\hline CHEMBL1451488 & 688267 & 4.55 & 5.0425 & TST & \\
\hline CHEMBL1315500 & 688267 & 6.2 & 5.0586 & TST & \\
\hline CHEMBL1530589 & 688267 & 5.4 & 5.0558 & TST & \\
\hline CHEMBL1348349 & 688267 & 4.1 & 5.0022 & TST & \\
\hline CHEMBL3197445 & 688267 & 4.0 & 5.0641 & TRN & \\
\hline CHEMBL1420781 & 688267 & 6.45 & 5.01399 & 9999999999 & TRN \\
\hline CHEMBL1593349 & 688267 & 5.05 & 5.0348 & TRN & \\
\hline CHEMBL1359857 & 688267 & 4.95 & 5.0373 & TRN & \\
\hline CHEMBL3211461 & 688267 & 6.2 & 5.0543 & TST & \\
\hline CHEMBL1595100 & 688267 & 5.5 & 5.0399 & TRN & \\
\hline CHEMBL1331134 & 688267 & 4.4 & 5.0516 & TST & \\
\hline CHEMBL1341022 & 688267 & 6.25 & 5.0162 & TRN & \\
\hline CHEMBL1306360 & 688267 & 4.35 & 5.0847 & TRN & \\
\hline CHEMBL1590574 & 688267 & 4.9 & 5.1203 & TRN & \\
\hline CHEMBL1371119 & 688267 & 5.35 & 5.0509 & TST & \\
\hline CHEMBL1326095 & 688267 & 4.3 & 5.0926 & TRN & \\
\hline CHEMBL3193232 & 688267 & 3.9 & 4.9932 & TST & \\
\hline CHEMBL1443852 & 688267 & 6.0 & 4.9807 & TRN & \\
\hline CHEMBL1304759 & 688267 & 5.85 & 5.1058 & TRN & \\
\hline CHEMBL1543446 & 688267 & 5.3 & 5.015 & TRN & \\
\hline CHEMBL3207407 & 688267 & 4.65 & 5.1275 & TRN & \\
\hline CHEMBL1390891 & 688267 & 6.2 & 5.0564 & TRN & \\
\hline CHEMBL1427323 & 688267 & 5.2 & 5.07 & TRN & \\
\hline CHEMBL1372286 & 688267 & 6.15 & 5.0443 & TRN & \\
\hline CHEMBL1481459 & 688267 & 4.3 & 5.0673 & TRN & \\
\hline CHEMBL1423809 & 688267 & 6.15 & 5.1023 & TRN & \\
\hline CHEMBL3210597 & 688267 & 6.1 & 5.0488 & TRN & \\
\hline CHEMBL1395717 & 688267 & 5.4 & 5.0165 & TRN & \\
\hline
\end{tabular}




\begin{tabular}{|c|c|c|c|c|}
\hline \multicolumn{5}{|c|}{ Supplemental Table S2.txt } \\
\hline CHEMBL1607638 & 688267 & 4.4 & 5.0124 & TRN \\
\hline CHEMBL1524033 & 688267 & 5.55 & 4.995 & TRN \\
\hline CHEMBL297548 & 688267 & 4.0 & 4.968 & TRN \\
\hline CHEMBL1308918 & 688267 & 5.15 & 5.0255 & TST \\
\hline CHEMBL1361819 & 688267 & 5.9 & 5.0582 & TRN \\
\hline CHEMBL1520990 & 688267 & 4.35 & 5.0941 & TRN \\
\hline CHEMBL1485815 & 688267 & 5.5 & 5.0648 & TRN \\
\hline CHEMBL1545789 & 688267 & 4.9 & 5.0325 & TST \\
\hline CHEMBL1606383 & 688267 & 6.25 & 5.0974 & TRN \\
\hline CHEMBL1596078 & 688267 & 5.3 & 5.0381 & TRN \\
\hline CHEMBL1322412 & 688267 & 4.4 & 5.0731 & TRN \\
\hline CHEMBL1524945 & 688267 & 4.0 & 4.9923 & TRN \\
\hline CHEMBL1403938 & 688267 & 4.6 & 5.024 & TRN \\
\hline CHEMBL1550487 & 688267 & 4.05 & 5.1353 & TRN \\
\hline CHEMBL1322974 & 688267 & 4.0 & 5.1583 & TRN \\
\hline CHEMBL1555220 & 688267 & 4.1 & 5.0437 & TRN \\
\hline CHEMBL1594015 & 688267 & 5.35 & 5.0533 & TRN \\
\hline CHEMBL1560648 & 688267 & 5.05 & 5.0539 & TST \\
\hline CHEMBL1523910 & 688267 & 4.2 & 5.0473 & TRN \\
\hline CHEMBL1554285 & 688267 & 5.4 & 4.9855 & TRN \\
\hline CHEMBL1424560 & 688267 & 4.55 & 5.0268 & TRN \\
\hline CHEMBL 3189987 & 688267 & 5.5 & 5.0709 & TRN \\
\hline CHEMBL1548853 & 688267 & 5.0 & 5.0528 & TST \\
\hline CHEMBL1475326 & 688267 & 4.65 & 5.1304 & TRN \\
\hline CHEMBL1539938 & 688267 & 5.25 & 5.0744 & TRN \\
\hline CHEMBL1508197 & 688267 & 5.6 & 5.0319 & TRN \\
\hline CHEMBL1566606 & 688267 & 5.1 & 5.099 & TST \\
\hline CHEMBL523200 & 688267 & 6.05 & 4.9726 & TST \\
\hline CHEMBL1552665 & 688267 & 5.8 & 5.0745 & TRN \\
\hline CHEMBL1403150 & 688267 & 5.85 & 5.0249 & TRN \\
\hline CHEMBL1483250 & 688267 & 3.95 & 5.1088 & TRN \\
\hline CHEMBL1535370 & 688267 & 5.6 & 5.0563 & TRN \\
\hline CHEMBL1606336 & 688267 & 5.6 & 5.1037 & TRN \\
\hline CHEMBL1487909 & 688267 & 4.0 & 5.0409 & TRN \\
\hline CHEMBL1333392 & 688267 & 4.35 & 5.0189 & TRN \\
\hline CHEMBL1568153 & 688267 & 4.05 & 5.0216 & TRN \\
\hline CHEMBL1476931 & 688267 & 4.55 & 5.0071 & TRN \\
\hline CHEMBL1526843 & 688267 & 4.6 & 5.0507 & TRN \\
\hline CHEMBL1487122 & 688267 & 5.65 & 5.0904 & TRN \\
\hline CHEMBL1433523 & 688267 & 5.4 & 5.0854 & TRN \\
\hline CHEMBL1485478 & 688267 & 6.1 & 5.1112 & TRN \\
\hline CHEMBL1512807 & 688267 & 5.85 & 5.0718 & TRN \\
\hline CHEMBL1451672 & 688267 & 5.0 & 5.0316 & TRN \\
\hline CHEMBL1387696 & 688267 & 4.05 & 5.0842 & TRN \\
\hline CHEMBL1435610 & 688267 & 4.05 & 5.0581 & TRN \\
\hline CHEMBL1382765 & 688267 & 4.6 & 5.1075 & TRN \\
\hline CHEMBL1373716 & 688267 & 6.15 & 5.1203 & TRN \\
\hline CHEMBL1330922 & 688267 & 5.55 & 5.027 & TRN \\
\hline
\end{tabular}




\begin{tabular}{|c|c|c|c|c|c|}
\hline \multicolumn{6}{|c|}{ Supplemental Table S2.txt } \\
\hline CHEMBL 2142970 & 688267 & 5.8 & 5.1238 & TRN & \\
\hline CHEMBL1548907 & 688267 & 5.35 & 5.0255 & TRN & \\
\hline CHEMBL1489884 & 688267 & 4.55 & 5.033 & TRN & \\
\hline CHEMBL1324896 & 688267 & 5.45 & 5.1303 & TRN & \\
\hline CHEMBL1451665 & 688267 & 3.95 & 5.077 & TRN & \\
\hline CHEMBL1381019 & 688267 & 5.15 & \multicolumn{2}{|c|}{5.127000000000001} & TRN \\
\hline CHEMBL1595132 & 688267 & 4.5 & 5.1325 & TRN & \\
\hline CHEMBL1597731 & 688267 & 5.05 & 5.0432 & TRN & \\
\hline CHEMBL1414811 & 688267 & 4.3 & 5.0252 & TRN & \\
\hline CHEMBL1344388 & 688267 & 4.1 & 4.957 & TRN & \\
\hline CHEMBL1434615 & 688267 & 5.65 & 5.0425 & TRN & \\
\hline CHEMBL1594181 & 688267 & 4.0 & 5.0418 & TRN & \\
\hline CHEMBL1088432 & 688267 & 6.2 & 5.1516 & TRN & \\
\hline CHEMBL1447236 & 688267 & 5.25 & 5.0192 & TRN & \\
\hline CHEMBL1394402 & 688267 & 4.0 & 5.0738 & TRN & \\
\hline CHEMBL1335067 & 688267 & 5.8 & 5.0232 & TRN & \\
\hline CHEMBL1378492 & 688267 & 4.55 & 5.0379 & TST & \\
\hline CHEMBL1586748 & 688267 & 6.25 & 5.0113 & TRN & \\
\hline CHEMBL1612398 & 688267 & 4.0 & \multicolumn{2}{|c|}{5.0569999999999995} & TRN \\
\hline CHEMBL1466203 & 688267 & 6.2 & 5.0367 & TST & \\
\hline CHEMBL1501387 & 688267 & 5.55 & 5.0744 & TRN & \\
\hline CHEMBL1358890 & 688267 & 4.7 & 5.0295 & TST & \\
\hline CHEMBL1524853 & 688267 & 6.2 & 5.0753 & TRN & \\
\hline CHEMBL1551659 & 688267 & 4.0 & 5.1139 & TRN & \\
\hline CHEMBL1483818 & 688267 & 5.3 & 5.0378 & TRN & \\
\hline CHEMBL1503720 & 688267 & 5.55 & 5.0047 & TRN & \\
\hline CHEMBL1397618 & 688267 & 5.8 & 5.0338 & TRN & \\
\hline CHEMBL1483616 & 688267 & 4.35 & 5.0069 & TST & \\
\hline CHEMBL1360824 & 688267 & 5.75 & 5.0206 & TRN & \\
\hline CHEMBL1981008 & 688267 & 5.45 & 5.008 & TST & \\
\hline CHEMBL1516725 & 688267 & 6.2 & 5.0833 & TRN & \\
\hline CHEMBL3207722 & 688267 & 5.0 & 5.0402 & TRN & \\
\hline CHEMBL1549569 & 688267 & 6.2 & 5.0483 & TRN & \\
\hline CHEMBL1613178 & 688267 & 5.9 & 5.0855 & TST & \\
\hline CHEMBL1340041 & 688267 & 4.3 & 4.998 & TRN & \\
\hline CHEMBL1555378 & 688267 & 4.4 & 5.0555 & TRN & \\
\hline CHEMBL563919 & 688267 & 5.85 & 5.0029 & TRN & \\
\hline CHEMBL1556173 & 688267 & 5.55 & 5.0492 & TRN & \\
\hline CHEMBL1318404 & 688267 & 5.5 & 5.1166 & TRN & \\
\hline CHEMBL1546730 & 688267 & 4.65 & 5.0336 & TST & \\
\hline CHEMBL1380221 & 688267 & 5.3 & 4.9879 & TRN & \\
\hline CHEMBL1470066 & 688267 & 6.2 & 5.0633 & TST & \\
\hline CHEMBL1376451 & 688267 & 4.6 & 5.0665 & TST & \\
\hline CHEMBL1361704 & 688267 & 4.45 & 5.0178 & TRN & \\
\hline CHEMBL1439255 & 688267 & 6.45 & 4.9875 & TST & \\
\hline CHEMBL1371727 & 688267 & 5.5 & 5.0793 & TRN & \\
\hline CHEMBL1591408 & 688267 & 5.0 & 5.0328 & TST & \\
\hline CHEMBL1574708 & 688267 & 4.0 & 5.0439 & TST & \\
\hline
\end{tabular}




\begin{tabular}{|c|c|c|c|c|c|}
\hline & & \multicolumn{4}{|c|}{ Supplemental Table s2.txt } \\
\hline CHEMBL1484766 & 688267 & 4.35 & 5.0125 & TRN & \\
\hline CHEMBL1536263 & 688267 & 4.4 & 5.0911 & TRN & \\
\hline CHEMBL164791 & 688267 & 6.25 & 5.0256 & TST & \\
\hline CHEMBL1314423 & 688267 & 5.45 & 5.051 & TRN & \\
\hline CHEMBL1418408 & 688267 & 5.3 & 4.9863 & TRN & \\
\hline CHEMBL1334522 & 688267 & 6.15 & 5.0383 & TRN & \\
\hline CHEMBL1344879 & 688267 & 4.05 & 5.0749 & TST & \\
\hline CHEMBL 3196672 & 688267 & 6.45 & 4.9806 & TST & \\
\hline CHEMBL1332658 & 688267 & 5.45 & 5.1492 & TST & \\
\hline CHEMBL1466849 & 688267 & 3.95 & 5.1839 & TRN & \\
\hline CHEMBL1395296 & 688267 & 6.5 & 5.0722 & TRN & \\
\hline CHEMBL1414636 & 688267 & 5.3 & 5.0555 & TRN & \\
\hline CHEMBL1403128 & 688267 & 4.75 & 5.0661 & TST & \\
\hline CHEMBL1437403 & 688267 & 4.6 & 5.048 & TRN & \\
\hline CHEMBL1328744 & 688267 & 5.2 & 5.0776 & TST & \\
\hline CHEMBL1426250 & 688267 & 4.35 & 5.0399 & TST & \\
\hline CHEMBL1480958 & 688267 & 5.65 & 4.9973 & TST & \\
\hline CHEMBL1408667 & 688267 & 4.0 & 5.0335 & TRN & \\
\hline CHEMBL 3210569 & 688267 & 4.3 & 4.9895 & TRN & \\
\hline CHEMBL1370699 & 688267 & 6.05 & 5.1127 & TRN & \\
\hline CHEMBL1529786 & 688267 & 4.5 & 5.0586 & TRN & \\
\hline CHEMBL1529711 & 688267 & 4.15 & 5.0356 & TRN & \\
\hline CHEMBL1495742 & 688267 & 5.85 & 5.1148 & TRN & \\
\hline CHEMBL1553647 & 688267 & 4.0 & 5.07100 & 0000000001 & TRN \\
\hline CHEMBL1573490 & 688267 & 5.75 & 5.02 & TRN & \\
\hline CHEMBL1302542 & 688267 & 5.6 & 5.0842 & TRN & \\
\hline CHEMBL1595488 & 688267 & 4.05 & 4.9693 & TRN & \\
\hline CHEMBL1399541 & 688267 & 5.25 & 5.0981 & TST & \\
\hline CHEMBL1521770 & 688267 & 6.15 & 5.0451 & TRN & \\
\hline CHEMBL77969 & 688267 & 4.05 & 5.058 & TRN & \\
\hline CHEMBL1514803 & 688267 & 4.0 & 5.041 & TRN & \\
\hline CHEMBL1370287 & 688267 & 4.35 & 5.0545 & TRN & \\
\hline CHEMBL1491561 & 688267 & 4.5 & 5.024 & TRN & \\
\hline CHEMBL1452576 & 688267 & 4.25 & 5.0976 & TRN & \\
\hline CHEMBL1591768 & 688267 & 5.1 & 5.0208 & TRN & \\
\hline CHEMBL1475639 & 688267 & 5.45 & 5.0811 & TRN & \\
\hline CHEMBL1479488 & 688267 & 6.5 & 5.0414 & TRN & \\
\hline CHEMBL1519192 & 688267 & 4.3 & 5.1106 & TRN & \\
\hline CHEMBL1559723 & 688267 & 5.35 & 5.0714 & TRN & \\
\hline CHEMBL1401163 & 688267 & 6.2 & 5.0813 & TRN & \\
\hline CHEMBL 3192733 & 688267 & 3.95 & 5.0654 & TRN & \\
\hline CHEMBL3197793 & 688267 & 6.15 & 5.0223 & TST & \\
\hline CHEMBL1585383 & 688267 & 4.1 & 5.0264 & TRN & \\
\hline CHEMBL1610130 & 688267 & 5.2 & 5.0759 & TRN & \\
\hline CHEMBL1357733 & 688267 & 4.0 & 5.0683 & TRN & \\
\hline CHEMBL1585934 & 688267 & 5.65 & 5.0599 & TRN & \\
\hline CHEMBL1305366 & 688267 & 4.3 & 5.1627 & TRN & \\
\hline CHEMBL1372887 & 688267 & 4.05 & 5.02 & TRN & \\
\hline
\end{tabular}




\begin{tabular}{|c|c|c|c|c|}
\hline & & & pplement & al $\mathrm{T}$ \\
\hline CHEMBL1333877 & 688267 & 5.1 & 5.0203 & TST \\
\hline CHEMBL1529392 & 688267 & 5.0 & 5.078 & TRN \\
\hline CHEMBL1369327 & 688267 & 4.3 & 5.0356 & TRN \\
\hline CHEMBL1469703 & 688267 & 4.05 & 5.0855 & TRN \\
\hline CHEMBL1303437 & 688267 & 6.2 & 5.0973 & TRN \\
\hline CHEMBL1567239 & 688267 & 6.15 & 5.0326 & TRN \\
\hline CHEMBL1458082 & 688267 & 5.3 & 5.0497 & TST \\
\hline CHEMBL1437228 & 688267 & 4.45 & 5.0693 & TST \\
\hline CHEMBL1352138 & 688267 & 6.2 & 5.0883 & TRN \\
\hline CHEMBL1350711 & 688267 & 6.0 & 5.0672 & TST \\
\hline CHEMBL1388362 & 688267 & 5.05 & 5.1413 & TRN \\
\hline CHEMBL1382843 & 688267 & 6.5 & 5.0229 & TST \\
\hline CHEMBL1555911 & 688267 & 5.3 & 5.0546 & TST \\
\hline CHEMBL1466049 & 688267 & 6.15 & 5.0888 & TST \\
\hline CHEMBL1325557 & 688267 & 4.0 & 5.0413 & TRN \\
\hline CHEMBL1402118 & 688267 & 5.45 & 5.0678 & TST \\
\hline CHEMBL1599198 & 688267 & 5.45 & 5.0429 & TRN \\
\hline CHEMBL1430715 & 688267 & 4.9 & 5.0858 & TRN \\
\hline CHEMBL1524056 & 688267 & 4.65 & 5.0825 & TRN \\
\hline CHEMBL1602941 & 688267 & 4.6 & 5.1046 & TRN \\
\hline CHEMBL1553008 & 688267 & 5.55 & 5.1177 & TRN \\
\hline CHEMBL1445157 & 688267 & 5.55 & 5.0808 & TRN \\
\hline CHEMBL1607492 & 688267 & 6.15 & 5.029 & TST \\
\hline CHEMBL1541011 & 688267 & 5.3 & 5.0568 & TRN \\
\hline CHEMBL1432469 & 688267 & 5.65 & 5.0647 & TRN \\
\hline CHEMBL1464536 & 688267 & 5.6 & 5.0822 & TST \\
\hline CHEMBL1335521 & 688267 & 5.9 & 5.0141 & TST \\
\hline CHEMBL1550218 & 688267 & 5.4 & 5.0368 & TST \\
\hline CHEMBL1454278 & 688267 & 4.0 & 5.0074 & TST \\
\hline CHEMBL1498409 & 688267 & 4.3 & 5.0153 & TST \\
\hline CHEMBL1360603 & 688267 & 5.0 & 5.0409 & TRN \\
\hline CHEMBL1367662 & 688267 & 5.9 & 4.9967 & TRN \\
\hline CHEMBL1586656 & 688267 & 4.15 & 5.0544 & TST \\
\hline CHEMBL1386480 & 688267 & 4.55 & 5.0838 & TRN \\
\hline CHEMBL1529564 & 688267 & 4.25 & 4.9988 & TRN \\
\hline CHEMBL1608716 & 688267 & 3.95 & 5.1856 & TRN \\
\hline CHEMBL1488742 & 688267 & 4.05 & 5.0834 & TRN \\
\hline CHEMBL1602236 & 688267 & 5.3 & 5.0567 & TRN \\
\hline CHEMBL1305924 & 688267 & 4.4 & 5.0109 & TST \\
\hline CHEMBL1530887 & 688267 & 5.55 & 5.1547 & TRN \\
\hline CHEMBL1520625 & 688267 & 5.55 & 5.1352 & TRN \\
\hline CHEMBL1501692 & 688267 & 5.8 & 5.0748 & TRN \\
\hline CHEMBL1561787 & 688267 & 5.6 & 5.0321 & TRN \\
\hline CHEMBL1554822 & 688267 & 5.3 & 5.0957 & TRN \\
\hline CHEMBL1416478 & 688267 & 4.0 & 5.0614 & TRN \\
\hline CHEMBL1446128 & 688267 & 4.4 & 4.9912 & TRN \\
\hline CHEMBL1361191 & 688267 & 4.35 & 5.0182 & TRN \\
\hline CHEMBL1424562 & 688267 & 4.1 & 4.9898 & TRN \\
\hline
\end{tabular}




\begin{tabular}{|c|c|c|c|c|}
\hline & & & pplement & al $\mathrm{Ta}$ \\
\hline CHEMBL1314569 & 688267 & 4.0 & 5.0285 & TRN \\
\hline CHEMBL1607834 & 688267 & 4.0 & 5.0234 & TRN \\
\hline CHEMBL1533543 & 688267 & 4.1 & 5.0362 & TRN \\
\hline CHEMBL1415454 & 688267 & 4.3 & 5.0184 & TST \\
\hline CHEMBL1532004 & 688267 & 5.9 & 5.0461 & TRN \\
\hline CHEMBL1538372 & 688267 & 5.5 & 5.0599 & TST \\
\hline CHEMBL1321856 & 688267 & 4.45 & 5.0386 & TST \\
\hline CHEMBL 3214284 & 688267 & 4.05 & 5.0713 & TST \\
\hline CHEMBL1354602 & 688267 & 5.3 & 5.0854 & TRN \\
\hline CHEMBL1440530 & 688267 & 5.25 & 5.0754 & TRN \\
\hline CHEMBL1404701 & 688267 & 4.3 & 5.0132 & TST \\
\hline CHEMBL1530467 & 688267 & 4.15 & 5.0016 & TRN \\
\hline CHEMBL1570067 & 688267 & 4.3 & 5.078 & TRN \\
\hline CHEMBL1612380 & 688267 & 4.3 & 4.9877 & TRN \\
\hline CHEMBL1445702 & 688267 & 4.4 & 5.0553 & TRN \\
\hline CHEMBL1571129 & 688267 & 4.55 & 5.0651 & TST \\
\hline CHEMBL1560008 & 688267 & 6.25 & 5.0884 & TRN \\
\hline CHEMBL1535624 & 688267 & 4.5 & 5.1267 & TRN \\
\hline CHEMBL1527876 & 688267 & 5.4 & 5.0592 & TRN \\
\hline CHEMBL1566463 & 688267 & 5.1 & 5.1063 & TRN \\
\hline CHEMBL1348842 & 688267 & 6.5 & 5.0248 & TRN \\
\hline CHEMBL1361709 & 688267 & 4.15 & 5.0135 & TST \\
\hline CHEMBL1448801 & 688267 & 4.65 & 5.0187 & TRN \\
\hline CHEMBL1384172 & 688267 & 4.55 & 5.0105 & TST \\
\hline CHEMBL1317501 & 688267 & 4.3 & 5.0641 & TRN \\
\hline CHEMBL1611149 & 688267 & 4.9 & 5.0028 & TRN \\
\hline CHEMBL1570218 & 688267 & 5.9 & 5.0668 & TST \\
\hline CHEMBL1308267 & 688267 & 5.2 & 5.0505 & TST \\
\hline CHEMBL3214018 & 688267 & 4.5 & 5.0207 & TRN \\
\hline CHEMBL1473631 & 688267 & 3.9 & 5.0191 & TRN \\
\hline CHEMBL1314034 & 688267 & 5.65 & 5.1008 & TRN \\
\hline CHEMBL1385739 & 688267 & 5.1 & 5.0439 & TRN \\
\hline CHEMBL1556785 & 688267 & 4.05 & 5.0532 & TRN \\
\hline CHEMBL1481336 & 688267 & 6.25 & 5.056 & TRN \\
\hline CHEMBL1369069 & 688267 & 4.4 & 5.0468 & TRN \\
\hline CHEMBL1552141 & 688267 & 4.05 & 5.0759 & TRN \\
\hline CHEMBL1332632 & 688267 & 4.05 & 5.1117 & TST \\
\hline CHEMBL1448432 & 688267 & 5.2 & 5.0538 & TRN \\
\hline CHEMBL1566702 & 688267 & 4.05 & 5.0322 & TRN \\
\hline CHEMBL1453461 & 688267 & 4.85 & 5.0174 & TRN \\
\hline CHEMBL1443098 & 688267 & 5.6 & 5.0556 & TRN \\
\hline CHEMBL1600640 & 688267 & 4.35 & 5.0167 & TRN \\
\hline CHEMBL1311441 & 688267 & 4.0 & 5.102 & TST \\
\hline CHEMBL1519149 & 688267 & 3.95 & 4.9776 & TST \\
\hline CHEMBL1484708 & 688267 & 4.85 & 5.0616 & TRN \\
\hline CHEMBL1573688 & 688267 & 4.0 & 5.0493 & TRN \\
\hline CHEMBL1613430 & 688267 & 4.1 & 5.0135 & TST \\
\hline CHEMBL1591746 & 688267 & 6.2 & 5.0876 & TRN \\
\hline
\end{tabular}




\begin{tabular}{|c|c|c|c|c|}
\hline & & & pplement & $\mathrm{T}$ \\
\hline CHEMBL3208493 & 688267 & 6.2 & 5.0013 & TST \\
\hline CHEMBL1505854 & 688267 & 4.05 & 5.1145 & TRN \\
\hline CHEMBL1599179 & 688267 & 5.45 & 5.0238 & TRN \\
\hline CHEMBL1553032 & 688267 & 6.25 & 5.0338 & TRN \\
\hline CHEMBL1316744 & 688267 & 6.25 & 5.0461 & TRN \\
\hline CHEMBL1341394 & 688267 & 4.6 & 5.0865 & TRN \\
\hline CHEMBL1470562 & 688267 & 6.15 & 5.0401 & TRN \\
\hline CHEMBL1440615 & 688267 & 3.95 & 5.1367 & TRN \\
\hline CHEMBL1351355 & 688267 & 4.0 & 5.1047 & TRN \\
\hline CHEMBL1478523 & 688267 & 6.2 & 5.0497 & TRN \\
\hline CHEMBL1481366 & 688267 & 4.0 & 5.0404 & TRN \\
\hline CHEMBL1437688 & 688267 & 3.95 & 5.0067 & TRN \\
\hline CHEMBL1473264 & 688267 & 6.1 & 5.0507 & TST \\
\hline CHEMBL1377711 & 688267 & 5.85 & 5.0692 & TRN \\
\hline CHEMBL1473624 & 688267 & 4.55 & 5.0299 & TRN \\
\hline CHEMBL1560539 & 688267 & 5.9 & 5.0846 & TRN \\
\hline CHEMBL1486775 & 688267 & 5.3 & 5.0195 & TST \\
\hline CHEMBL1472108 & 688267 & 6.5 & 5.0188 & TRN \\
\hline CHEMBL1372504 & 688267 & 4.1 & 5.0679 & TRN \\
\hline CHEMBL1378513 & 688267 & 4.65 & 5.0162 & TST \\
\hline CHEMBL1593964 & 688267 & 6.2 & 5.0295 & TRN \\
\hline CHEMBL1432145 & 688267 & 4.25 & 5.072 & TRN \\
\hline CHEMBL1458776 & 688267 & 3.95 & 5.0358 & TRN \\
\hline CHEMBL1438614 & 688267 & 4.1 & 5.0296 & TST \\
\hline CHEMBL1517695 & 688267 & 5.45 & 5.0458 & TRN \\
\hline CHEMBL1541658 & 688267 & 5.4 & 5.1012 & TRN \\
\hline CHEMBL586029 & 688267 & 4.35 & 5.1074 & TRN \\
\hline CHEMBL1604350 & 688267 & 4.3 & 5.0311 & TRN \\
\hline CHEMBL1424254 & 688267 & 4.0 & 5.1095 & TST \\
\hline CHEMBL1583701 & 688267 & 4.05 & 5.0617 & TST \\
\hline CHEMBL1342413 & 688267 & 6.2 & 5.0329 & TST \\
\hline CHEMBL1355116 & 688267 & 6.2 & 5.0852 & TRN \\
\hline CHEMBL1499584 & 688267 & 4.25 & 5.0345 & TST \\
\hline CHEMBL1416896 & 688267 & 6.2 & 5.0939 & TRN \\
\hline CHEMBL1357792 & 688267 & 6.15 & 5.0571 & TRN \\
\hline CHEMBL1312539 & 688267 & 4.0 & 5.0412 & TST \\
\hline CHEMBL1416023 & 688267 & 4.4 & 5.0408 & TST \\
\hline CHEMBL1476809 & 688267 & 4.3 & 4.9798 & TRN \\
\hline CHEMBL1388103 & 688267 & 4.75 & 5.0695 & TRN \\
\hline CHEMBL1488893 & 688267 & 4.1 & 5.0495 & TRN \\
\hline CHEMBL1547241 & 688267 & 5.6 & 5.0146 & TRN \\
\hline CHEMBL1377336 & 688267 & 4.55 & 4.9878 & TRN \\
\hline CHEMBL1373105 & 688267 & 4.4 & 5.113 & TRN \\
\hline CHEMBL1575931 & 688267 & 4.0 & 5.0682 & TRN \\
\hline CHEMBL1569549 & 688267 & 5.45 & 5.0537 & TRN \\
\hline CHEMBL 309176 & 688267 & 5.5 & 5.0831 & TRN \\
\hline CHEMBL1582996 & 688267 & 5.55 & 4.9962 & TRN \\
\hline CHEMBL1436632 & 688267 & 4.55 & 5.1349 & TRN \\
\hline
\end{tabular}




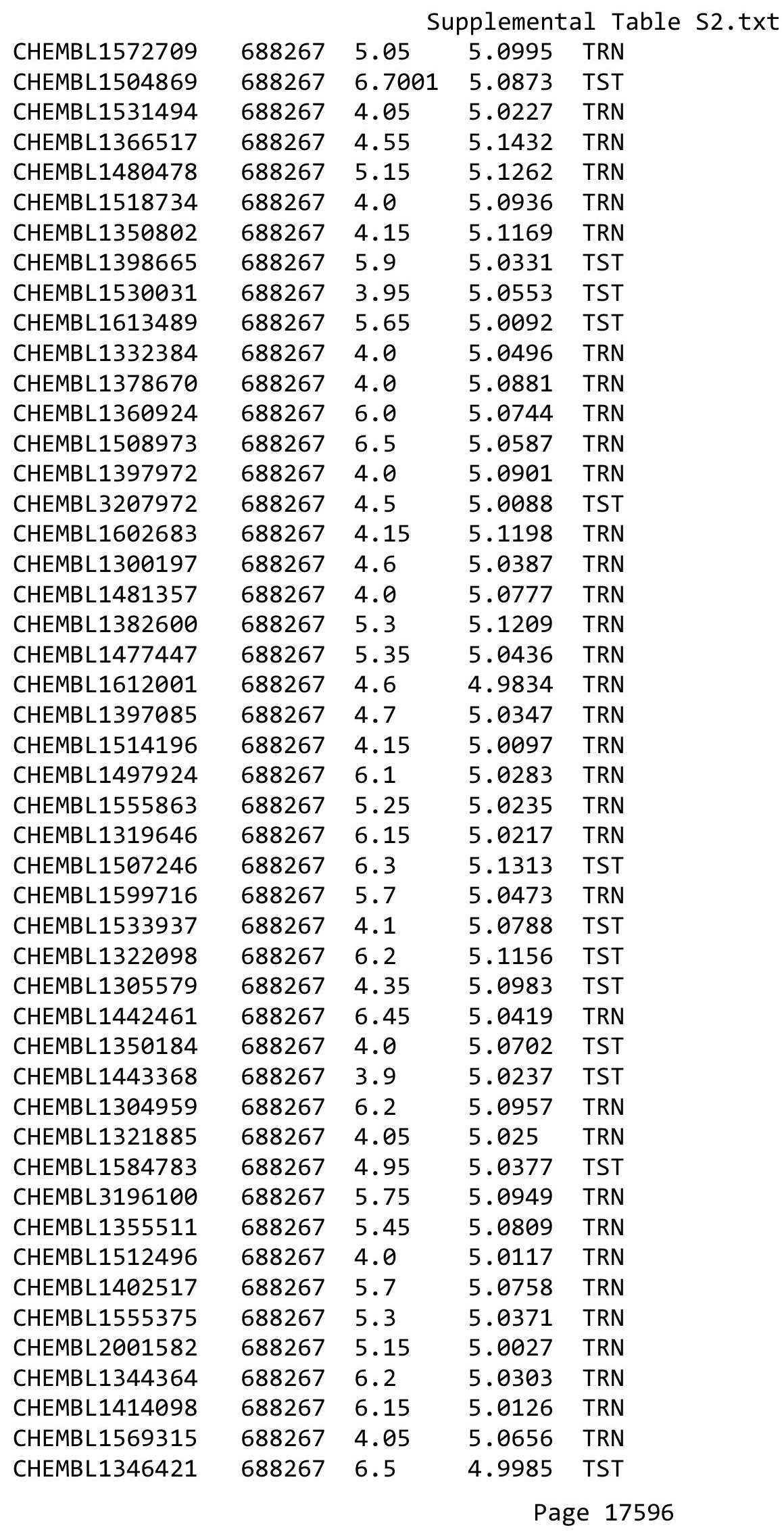




\begin{tabular}{|c|c|c|c|c|}
\hline & & & pplement & al $\mathrm{Tc}$ \\
\hline CHEMBL1434143 & 688267 & 6.15 & 5.0823 & TRN \\
\hline CHEMBL1611125 & 688267 & 4.6 & 5.0352 & TRN \\
\hline CHEMBL1376986 & 688267 & 4.05 & 5.1374 & TRN \\
\hline CHEMBL1356221 & 688267 & 5.5 & 5.0911 & TRN \\
\hline CHEMBL1429135 & 688267 & 6.2 & 5.0949 & TRN \\
\hline CHEMBL1538025 & 688267 & 4.7 & 5.0503 & TST \\
\hline CHEMBL1563567 & 688267 & 4.05 & 5.0949 & TRN \\
\hline CHEMBL1380085 & 688267 & 5.9 & 4.9972 & TRN \\
\hline CHEMBL1475227 & 688267 & 5.25 & 5.1404 & TRN \\
\hline CHEMBL1482867 & 688267 & 4.1 & 5.0461 & TRN \\
\hline CHEMBL1349575 & 688267 & 4.6 & 5.1042 & TRN \\
\hline CHEMBL1976499 & 688267 & 4.35 & 5.0012 & TRN \\
\hline CHEMBL1316977 & 688267 & 4.0 & 5.0401 & TRN \\
\hline CHEMBL1428629 & 688267 & 4.05 & 4.963 & TST \\
\hline CHEMBL1587535 & 688267 & 4.35 & 5.0237 & TRN \\
\hline CHEMBL1538147 & 688267 & 5.5 & 5.0228 & TRN \\
\hline CHEMBL1450563 & 688267 & 5.25 & 5.0862 & TRN \\
\hline CHEMBL1391933 & 688267 & 4.0 & 5.0431 & TST \\
\hline CHEMBL1404321 & 688267 & 6.25 & 5.0596 & TRN \\
\hline CHEMBL1605679 & 688267 & 4.0 & 5.0573 & TST \\
\hline CHEMBL1492548 & 688267 & 5.8 & 5.0994 & TRN \\
\hline CHEMBL 3213222 & 688267 & 4.8 & 4.9941 & TRN \\
\hline CHEMBL1495123 & 688267 & 5.6 & 5.1338 & TRN \\
\hline CHEMBL1456250 & 688267 & 6.2 & 5.1373 & TRN \\
\hline CHEMBL1479855 & 688267 & 4.45 & 5.0399 & TRN \\
\hline CHEMBL1382414 & 688267 & 4.95 & 5.0448 & TRN \\
\hline CHEMBL3210546 & 688267 & 4.45 & 5.0494 & TRN \\
\hline CHEMBL1545375 & 688267 & 6.15 & 5.0859 & TRN \\
\hline CHEMBL1310408 & 688267 & 4.35 & 5.0724 & TST \\
\hline CHEMBL1457894 & 688267 & 5.3 & 5.041 & TRN \\
\hline CHEMBL1479967 & 688267 & 4.4 & 5.0586 & TST \\
\hline CHEMBL1566004 & 688267 & 4.05 & 5.1 & TRN \\
\hline CHEMBL1518435 & 688267 & 4.05 & 5.0273 & TRN \\
\hline CHEMBL1339011 & 688267 & 5.35 & 5.1329 & TRN \\
\hline CHEMBL1608850 & 688267 & 6.2 & 5.0627 & TRN \\
\hline CHEMBL1538793 & 688267 & 5.9 & 5.0692 & TRN \\
\hline CHEMBL197014 & 688267 & 6.2 & 5.0541 & TST \\
\hline CHEMBL1509359 & 688267 & 6.0 & 4.9989 & TRN \\
\hline CHEMBL1318537 & 688267 & 4.0 & 5.0012 & TRN \\
\hline CHEMBL1468479 & 688267 & 5.2 & 5.0585 & TRN \\
\hline CHEMBL1546358 & 688267 & 5.3 & 5.0663 & TRN \\
\hline CHEMBL1495932 & 688267 & 4.35 & 5.0342 & TRN \\
\hline CHEMBL1427410 & 688267 & 3.95 & 5.0846 & TRN \\
\hline CHEMBL1316481 & 688267 & 5.45 & 5.0554 & TRN \\
\hline CHEMBL1447116 & 688267 & 6.2 & 5.0635 & TRN \\
\hline CHEMBL1499502 & 688267 & 4.15 & 5.1009 & TRN \\
\hline CHEMBL1565742 & 688267 & 5.6 & 5.0637 & TRN \\
\hline CHEMBL1356209 & 688267 & 5.4 & 5.0694 & TRN \\
\hline
\end{tabular}




\begin{tabular}{|c|c|c|c|c|}
\hline \multicolumn{5}{|c|}{ Supplemental Table S2.txt } \\
\hline CHEMBL1395084 & 688267 & 6.6 & 5.0291 & TRN \\
\hline CHEMBL1407107 & 688267 & 5.55 & 5.0304 & TRN \\
\hline CHEMBL1304563 & 688267 & 4.6 & 5.0068 & TRN \\
\hline CHEMBL1533947 & 688267 & 5.55 & 5.0272 & TRN \\
\hline CHEMBL1441645 & 688267 & 5.15 & 5.0298 & TRN \\
\hline CHEMBL1305950 & 688267 & 3.95 & 5.1408 & TRN \\
\hline CHEMBL1360556 & 688267 & 5.95 & 5.0696 & TRN \\
\hline CHEMBL1324387 & 688267 & 5.15 & 5.0097 & TRN \\
\hline CHEMBL1394816 & 688267 & 6.2 & 5.0467 & TRN \\
\hline CHEMBL1351545 & 688267 & 5.25 & 5.1127 & TRN \\
\hline CHEMBL1255655 & 688267 & 6.25 & 5.0722 & TST \\
\hline CHEMBL1580170 & 688267 & 5.35 & 5.0495 & TST \\
\hline CHEMBL1598267 & 688267 & 6.5 & 5.0566 & TRN \\
\hline CHEMBL 305978 & 688267 & 5.25 & 4.9792 & TST \\
\hline CHEMBL1434409 & 688267 & 4.4 & 5.0152 & TRN \\
\hline CHEMBL1567833 & 688267 & 5.3 & 5.1337 & TST \\
\hline CHEMBL1593933 & 688267 & 5.35 & 5.0621 & TRN \\
\hline CHEMBL1553217 & 688267 & 6.15 & 5.0872 & TRN \\
\hline CHEMBL1576485 & 688267 & 6.5501 & 5.1152 & TST \\
\hline CHEMBL1477154 & 688267 & 5.1 & 5.0143 & TST \\
\hline CHEMBL3196582 & 688267 & 4.0 & 5.05399 & 9999999999 \\
\hline CHEMBL1321767 & 688267 & 4.0 & 5.1222 & TRN \\
\hline CHEMBL1426764 & 688267 & 4.05 & 5.0985 & TST \\
\hline CHEMBL1545106 & 688267 & 4.95 & 5.0656 & TST \\
\hline CHEMBL1494250 & 688267 & 4.0 & 5.0227 & TRN \\
\hline CHEMBL1586804 & 688267 & 4.25 & 5.0776 & TRN \\
\hline CHEMBL1602017 & 688267 & 6.2 & 5.1191 & TRN \\
\hline CHEMBL1598850 & 688267 & 4.75 & 5.1474 & TRN \\
\hline CHEMBL1501433 & 688267 & 4.75 & 5.1447 & TRN \\
\hline CHEMBL1612726 & 688267 & 4.2 & 5.0788 & TST \\
\hline CHEMBL1327378 & 688267 & 4.1 & 4.9739 & TRN \\
\hline CHEMBL1571441 & 688267 & 6.15 & 5.0307 & TST \\
\hline CHEMBL1379570 & 688267 & 5.4 & 5.0617 & TRN \\
\hline CHEMBL1416625 & 688267 & 5.0 & 5.1037 & TRN \\
\hline CHEMBL1302093 & 688267 & 4.3 & 5.135 & TRN \\
\hline CHEMBL1474772 & 688267 & 6.1 & 5.0382 & TRN \\
\hline CHEMBL1444907 & 688267 & 5.65 & 5.08 & TRN \\
\hline CHEMBL1530185 & 688267 & 6.2 & 5.0535 & TRN \\
\hline CHEMBL1597997 & 688267 & 5.4 & 5.0529 & TRN \\
\hline CHEMBL1348319 & 688267 & 5.3 & 5.0964 & TRN \\
\hline CHEMBL1547669 & 688267 & 4.05 & 5.1047 & TST \\
\hline CHEMBL1307971 & 688267 & 5.1 & 5.0258 & TST \\
\hline CHEMBL1307358 & 688267 & 5.25 & 5.0614 & TRN \\
\hline CHEMBL1437621 & 688267 & 4.05 & 5.0007 & TRN \\
\hline CHEMBL1495630 & 688267 & 4.25 & 5.0455 & TST \\
\hline CHEMBL1392294 & 688267 & 5.35 & 5.0839 & TRN \\
\hline CHEMBL1578127 & 688267 & 4.05 & 5.0122 & TST \\
\hline CHEMBL1596582 & 688267 & 4.35 & 5.083 & TRN \\
\hline
\end{tabular}




\begin{tabular}{|c|c|c|c|c|}
\hline & & & 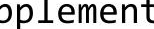 & \\
\hline CHEMBL1441024 & 688267 & 4.6 & 5.0077 & TST \\
\hline CHEMBL1483861 & 688267 & 5.6 & 5.0449 & TRN \\
\hline CHEMBL1327498 & 688267 & 3.95 & 5.0636 & TRN \\
\hline CHEMBL1573229 & 688267 & 5.9 & 5.033 & TRN \\
\hline CHEMBL1356491 & 688267 & 5.45 & 5.0963 & TST \\
\hline CHEMBL1324298 & 688267 & 4.5 & 5.0398 & TST \\
\hline CHEMBL1310854 & 688267 & 4.1 & 5.0569 & TRN \\
\hline CHEMBL1531825 & 688267 & 5.65 & 5.0522 & TRN \\
\hline CHEMBL1303206 & 688267 & 6.15 & 5.1437 & TRN \\
\hline CHEMBL1474239 & 688267 & 4.0 & 5.1192 & TST \\
\hline CHEMBL1303914 & 688267 & 4.6 & \multicolumn{2}{|c|}{4.9830000000000005} \\
\hline CHEMBL1458441 & 688267 & 3.95 & 5.0017 & TRN \\
\hline CHEMBL1439517 & 688267 & 6.5 & 5.1094 & TRN \\
\hline CHEMBL3211033 & 688267 & 4.25 & 5.0655 & TRN \\
\hline CHEMBL1317738 & 688267 & 4.0 & 5.0674 & TST \\
\hline CHEMBL1534143 & 688267 & 4.0 & 4.9875 & TRN \\
\hline CHEMBL1389570 & 688267 & 4.1 & 5.0188 & TRN \\
\hline CHEMBL1383137 & 688267 & 4.5 & 4.9886 & TRN \\
\hline CHEMBL1421962 & 688267 & 4.35 & 5.0461 & TST \\
\hline CHEMBL1447709 & 688267 & 4.3 & 4.9874 & TST \\
\hline CHEMBL1518975 & 688267 & 5.85 & 5.0559 & TRN \\
\hline CHEMBL1572541 & 688267 & 5.6 & 5.0883 & TRN \\
\hline CHEMBL1406864 & 688267 & 4.0 & 5.0297 & TRN \\
\hline CHEMBL1383061 & 688267 & 5.55 & 5.058 & TST \\
\hline CHEMBL1490004 & 688267 & 5.1 & 5.1092 & TRN \\
\hline CHEMBL1324953 & 688267 & 5.45 & 5.1614 & TRN \\
\hline CHEMBL1587641 & 688267 & 4.95 & 5.0317 & TST \\
\hline CHEMBL1610270 & 688267 & 6.2 & 5.0692 & TRN \\
\hline CHEMBL1484236 & 688267 & 5.55 & 5.0349 & TRN \\
\hline CHEMBL1559350 & 688267 & 4.6 & 5.0475 & TRN \\
\hline CHEMBL1596619 & 688267 & 6.2 & 5.0574 & TRN \\
\hline CHEMBL1391846 & 688267 & 3.95 & 5.0915 & TRN \\
\hline CHEMBL1436595 & 688267 & 5.8 & 5.0611 & TST \\
\hline CHEMBL1600257 & 688267 & 4.35 & 5.0597 & TST \\
\hline CHEMBL 1377110 & 688267 & 5.45 & 5.0671 & TRN \\
\hline CHEMBL1306899 & 688267 & 3.95 & 5.0031 & TRN \\
\hline CHEMBL1372928 & 688267 & 4.75 & 5.0117 & TRN \\
\hline CHEMBL1433743 & 688267 & 6.2 & 5.0232 & TST \\
\hline CHEMBL3213624 & 688267 & 4.3 & 5.1107 & TRN \\
\hline CHEMBL1463934 & 688267 & 4.0 & 5.0102 & TRN \\
\hline CHEMBL1343371 & 688267 & 3.95 & 5.1046 & TRN \\
\hline CHEMBL1460717 & 688267 & 5.35 & 5.0648 & TRN \\
\hline CHEMBL1434790 & 688267 & 4.05 & 5.1251 & TRN \\
\hline CHEMBL1487943 & 688267 & 4.25 & 5.0351 & TRN \\
\hline CHEMBL 2007390 & 688267 & 4.2 & 5.0067 & TST \\
\hline CHEMBL1506079 & 688267 & 4.35 & 5.0324 & TST \\
\hline CHEMBL1966108 & 688267 & 5.3 & 4.9921 & TRN \\
\hline CHEMBL1327280 & 688267 & 5.35 & 5.1068 & TRN \\
\hline
\end{tabular}




\begin{tabular}{|c|c|c|c|c|}
\hline \multicolumn{5}{|c|}{ Supplemental Table S2.txt } \\
\hline CHEMBL1363187 & 688267 & 4.05 & 5.0564 & TRN \\
\hline CHEMBL1591316 & 688267 & 4.05 & 5.0693 & TRN \\
\hline CHEMBL1463766 & 688267 & 6.2 & 5.0875 & TRN \\
\hline CHEMBL1366712 & 688267 & 5.2 & 5.0029 & TRN \\
\hline CHEMBL1598206 & 688267 & 4.45 & 5.0148 & TRN \\
\hline CHEMBL1327578 & 688267 & 4.0 & 5.0681 & TRN \\
\hline CHEMBL1536294 & 688267 & 4.7 & 5.0892 & TRN \\
\hline CHEMBL1358568 & 688267 & 5.9 & 5.0603 & TRN \\
\hline CHEMBL1436863 & 688267 & 5.8 & 5.0526 & TRN \\
\hline CHEMBL1518653 & 688267 & 5.25 & 5.0481 & TST \\
\hline CHEMBL3198502 & 688267 & 4.0 & 4.9908 & TRN \\
\hline CHEMBL1465427 & 688267 & 4.35 & 5.0819 & TST \\
\hline CHEMBL1493896 & 688267 & 6.2 & 4.9933 & TRN \\
\hline CHEMBL1570037 & 688267 & 3.95 & 5.0297 & TRN \\
\hline CHEMBL3198699 & 688267 & 4.45 & 5.0294 & TRN \\
\hline CHEMBL1336412 & 688267 & 5.1 & 5.019 & TST \\
\hline CHEMBL1402454 & 688267 & 3.95 & 5.0759 & TST \\
\hline CHEMBL1453297 & 688267 & 6.25 & 5.0352 & TRN \\
\hline CHEMBL1613718 & 688267 & 4.0 & 5.0617 & TST \\
\hline CHEMBL3191791 & 688267 & 4.15 & 5.0342 & TRN \\
\hline CHEMBL1377174 & 688267 & 6.2 & 5.0742 & TRN \\
\hline CHEMBL1476978 & 688267 & 3.95 & 5.1388 & TRN \\
\hline CHEMBL1339024 & 688267 & 4.0 & 5.0376 & TRN \\
\hline CHEMBL1574412 & 688267 & 5.0 & 5.0879 & TRN \\
\hline CHEMBL1591567 & 688267 & 4.0 & 5.0261 & TRN \\
\hline CHEMBL1306395 & 688267 & 6.5 & 5.0443 & TRN \\
\hline CHEMBL1310296 & 688267 & 4.0 & 5.0257 & TST \\
\hline CHEMBL1570464 & 688267 & 5.7 & 4.9941 & TST \\
\hline CHEMBL1451958 & 688267 & 5.15 & 5.0449 & TST \\
\hline CHEMBL1599305 & 688267 & 4.4 & 4.9906 & TST \\
\hline CHEMBL1526680 & 688267 & 5.5 & 5.0401 & TRN \\
\hline CHEMBL1318524 & 688267 & 3.95 & 4.992 & TRN \\
\hline CHEMBL1545796 & 688267 & 5.25 & 5.0954 & TRN \\
\hline CHEMBL1392628 & 688267 & 6.25 & 5.0494 & TRN \\
\hline CHEMBL1354258 & 688267 & 4.15 & 5.0837 & TST \\
\hline CHEMBL541974 & 688267 & 3.95 & 5.0115 & TST \\
\hline CHEMBL1324338 & 688267 & 5.95 & 5.1598 & TRN \\
\hline CHEMBL1391613 & 688267 & 6.25 & 5.0923 & TST \\
\hline CHEMBL1496265 & 688267 & 4.2 & 5.1322 & TRN \\
\hline CHEMBL1533385 & 688267 & 5.55 & 5.0997 & TRN \\
\hline CHEMBL1602918 & 688267 & 5.55 & 5.0384 & TRN \\
\hline CHEMBL1332663 & 688267 & 4.3 & 5.0815 & TRN \\
\hline CHEMBL1317311 & 688267 & 5.35 & 5.0488 & TRN \\
\hline CHEMBL1606598 & 688267 & 6.5 & 5.0167 & TRN \\
\hline CHEMBL1527380 & 688267 & 5.35 & 5.1184 & TRN \\
\hline CHEMBL1368571 & 688267 & 5.8 & 5.044 & TRN \\
\hline CHEMBL1456125 & 688267 & 6.2 & 5.0743 & TRN \\
\hline CHEMBL1314137 & 688267 & 5.5 & 5.0485 & TRN \\
\hline
\end{tabular}




\begin{tabular}{|c|c|c|c|c|c|}
\hline \multicolumn{6}{|c|}{ pplemental } \\
\hline CHEMBL1491697 & 688267 & 6.2 & 5.0893 & TRN & \\
\hline CHEMBL1479063 & 688267 & 4.25 & 5.0238 & TRN & \\
\hline CHEMBL1485101 & 688267 & 6.1 & 5.0144 & TRN & \\
\hline CHEMBL1341415 & 688267 & 4.85 & 5.0233 & TRN & \\
\hline CHEMBL1442863 & 688267 & 4.4 & 5.0486 & TRN & \\
\hline CHEMBL1344377 & 688267 & 4.35 & 5.0668 & TRN & \\
\hline CHEMBL1516219 & 688267 & 4.5 & 5.0433 & TRN & \\
\hline CHEMBL1352387 & 688267 & 4.0 & 5.0377 & TST & \\
\hline CHEMBL1301005 & 688267 & 4.3 & 5.0369 & TST & \\
\hline CHEMBL1456843 & 688267 & 5.75 & 4.9929 & TRN & \\
\hline CHEMBL1480684 & 688267 & 4.25 & 5.0234 & TRN & \\
\hline CHEMBL1387658 & 688267 & 5.75 & 5.1187 & TRN & \\
\hline CHEMBL1471825 & 688267 & 4.05 & 5.1286 & TRN & \\
\hline CHEMBL1463316 & 688267 & 4.7 & 5.092 & TST & \\
\hline CHEMBL1299906 & 688267 & 4.3 & 5.033 & TRN & \\
\hline CHEMBL1457193 & 688267 & 3.95 & 5.0655 & TST & \\
\hline CHEMBL1354350 & 688267 & 5.6 & 5.0353 & TRN & \\
\hline CHEMBL1356095 & 688267 & 4.0 & 5.0384 & TRN & \\
\hline CHEMBL1323721 & 688267 & 5.0 & 5.09399 & 9999999999 & TST \\
\hline CHEMBL1323849 & 688267 & 4.0 & 5.0438 & TRN & \\
\hline CHEMBL1318438 & 688267 & 6.25 & 5.0767 & TRN & \\
\hline CHEMBL1561463 & 688267 & 5.6 & 5.0736 & TRN & \\
\hline CHEMBL1503081 & 688267 & 4.4 & 5.0082 & TRN & \\
\hline CHEMBL465843 & 688267 & 5.4 & 5.1045 & TST & \\
\hline CHEMBL1589395 & 688267 & 4.4 & 5.0372 & TST & \\
\hline CHEMBL1426961 & 688267 & 4.25 & 5.07 & TST & \\
\hline CHEMBL1352549 & 688267 & 6.2 & 5.0316 & TRN & \\
\hline CHEMBL1519970 & 688267 & 5.25 & 5.164 & TRN & \\
\hline CHEMBL1469687 & 688267 & 4.2 & 5.0474 & TST & \\
\hline CHEMBL1366859 & 688267 & 4.4 & 5.0432 & TRN & \\
\hline CHEMBL1494320 & 688267 & 5.95 & 5.0162 & TRN & \\
\hline CHEMBL1559980 & 688267 & 5.15 & 5.0813 & TST & \\
\hline CHEMBL1340173 & 688267 & 5.8 & 5.0419 & TST & \\
\hline CHEMBL1335460 & 688267 & 4.4 & 5.0806 & TRN & \\
\hline CHEMBL1443056 & 688267 & 4.4 & 5.0948 & TRN & \\
\hline CHEMBL1424193 & 688267 & 4.6 & 5.0745 & TRN & \\
\hline CHEMBL1506890 & 688267 & 5.3 & 5.0872 & TRN & \\
\hline CHEMBL1399617 & 688267 & 4.25 & 5.04899 & 99999999995 & TRN \\
\hline CHEMBL1375207 & 688267 & 6.2 & 5.0289 & TST & \\
\hline CHEMBL1559850 & 688267 & 4.65 & 5.0822 & TRN & \\
\hline CHEMBL1467594 & 688267 & 4.05 & 5.0541 & TRN & \\
\hline CHEMBL1474604 & 688267 & 4.9 & 5.0375 & TRN & \\
\hline CHEMBL1517634 & 688267 & 4.85 & 5.0095 & TRN & \\
\hline CHEMBL1173672 & 688267 & 4.35 & 5.0093 & TRN & \\
\hline CHEMBL1568400 & 688267 & 4.05 & 5.0651 & TRN & \\
\hline CHEMBL1591883 & 688267 & 6.25 & 5.1658 & TRN & \\
\hline CHEMBL1362638 & 688267 & 5.2 & 5.0365 & TRN & \\
\hline CHEMBL1532022 & 688267 & 4.3 & 5.0708 & TRN & \\
\hline
\end{tabular}




\begin{tabular}{|c|c|c|c|c|c|}
\hline \multicolumn{6}{|c|}{ Supplemental Table S2.txt } \\
\hline CHEMBL1998979 & 688267 & 4.0 & 4.9968 & TRN & \\
\hline CHEMBL1397176 & 688267 & 4.0 & 5.0995 & TST & \\
\hline CHEMBL1332728 & 688267 & 4.25 & 5.0264 & TRN & \\
\hline CHEMBL1407602 & 688267 & 5.25 & 5.1304 & TRN & \\
\hline CHEMBL1417093 & 688267 & 5.6 & 5.0895 & TRN & \\
\hline CHEMBL1323598 & 688267 & 5.55 & 5.0371 & TRN & \\
\hline CHEMBL1582684 & 688267 & 5.65 & 4.99100 & 00000000005 & TRN \\
\hline CHEMBL1436106 & 688267 & 5.3 & 5.0369 & TRN & \\
\hline CHEMBL1575605 & 688267 & 4.0 & 5.0743 & TRN & \\
\hline CHEMBL1453710 & 688267 & 4.5 & 5.066 & TRN & \\
\hline CHEMBL1398961 & 688267 & 6.15 & 5.0502 & TRN & \\
\hline CHEMBL1481530 & 688267 & 5.3 & 5.0519 & TST & \\
\hline CHEMBL1434770 & 688267 & 6.15 & 5.0804 & TRN & \\
\hline CHEMBL 3192455 & 688267 & 6.7501 & 5.062 & TST & \\
\hline CHEMBL1370159 & 688267 & 6.2 & 5.0488 & TRN & \\
\hline CHEMBL1403538 & 688267 & 4.0 & 5.0751 & TRN & \\
\hline CHEMBL1397284 & 688267 & 6.25 & 4.9935 & TRN & \\
\hline CHEMBL1333238 & 688267 & 4.45 & 5.0045 & TST & \\
\hline CHEMBL1586357 & 688267 & 4.4 & 5.0714 & TRN & \\
\hline CHEMBL1440297 & 688267 & 6.5 & 5.1049 & TRN & \\
\hline CHEMBL1515767 & 688267 & 6.2 & 5.0712 & TST & \\
\hline CHEMBL3213447 & 688267 & 6.25 & 5.0125 & TRN & \\
\hline CHEMBL1574280 & 688267 & 4.9 & 4.9834 & TST & \\
\hline CHEMBL1388953 & 688267 & 6.2 & 5.0678 & TST & \\
\hline CHEMBL1489099 & 688267 & 4.25 & 5.0568 & TST & \\
\hline CHEMBL1337042 & 688267 & 5.45 & 4.9796 & TRN & \\
\hline CHEMBL1439506 & 688267 & 5.75 & 5.0581 & TRN & \\
\hline CHEMBL1455914 & 688267 & 5.85 & 5.0445 & TST & \\
\hline CHEMBL1455099 & 688267 & 6.5501 & 5.07 & TRN & \\
\hline CHEMBL1480499 & 688267 & 6.5 & 5.1075 & TRN & \\
\hline CHEMBL1313971 & 688267 & 6.25 & 5.0367 & TRN & \\
\hline CHEMBL1473667 & 688267 & 4.3 & 5.1353 & TRN & \\
\hline CHEMBL1604269 & 688267 & 4.75 & 5.114 & TRN & \\
\hline CHEMBL1350631 & 688267 & 4.7 & 5.0689 & TRN & \\
\hline CHEMBL1396984 & 688267 & 5.65 & 4.979 & TRN & \\
\hline CHEMBL1415682 & 688267 & 5.85 & 4.9933 & TRN & \\
\hline CHEMBL1334747 & 688267 & 6.0 & 5.0764 & TRN & \\
\hline CHEMBL1589823 & 688267 & 6.2 & 5.0491 & TST & \\
\hline CHEMBL1581924 & 688267 & 6.2 & 5.1038 & TST & \\
\hline CHEMBL1302067 & 688267 & 4.1 & 5.0031 & TRN & \\
\hline CHEMBL3211207 & 688267 & 5.8 & 5.0527 & TST & \\
\hline CHEMBL1417493 & 688267 & 4.05 & 5.0462 & TRN & \\
\hline CHEMBL1549269 & 688267 & 5.55 & 5.0542 & TST & \\
\hline CHEMBL1491783 & 688267 & 5.3 & 5.0867 & TRN & \\
\hline CHEMBL1555443 & 688267 & 4.4 & 5.0032 & TRN & \\
\hline CHEMBL1365542 & 688267 & 4.35 & 5.1062 & TRN & \\
\hline CHEMBL1473556 & 688267 & 5.85 & 5.0002 & TRN & \\
\hline CHEMBL3213254 & 688267 & 6.45 & 5.0456 & TST & \\
\hline
\end{tabular}




\begin{tabular}{|c|c|c|c|c|c|}
\hline \multicolumn{6}{|c|}{ Supplemental Table S2.txt } \\
\hline CHEMBL1440644 & 688267 & 4.0 & 5.0611 & TRN & \\
\hline CHEMBL1534829 & 688267 & 6.15 & 5.0249 & TRN & \\
\hline CHEMBL1607343 & 688267 & 5.65 & 5.1223 & TRN & \\
\hline CHEMBL1438652 & 688267 & 5.0 & 5.1216 & TRN & \\
\hline CHEMBL1382649 & 688267 & 6.2 & 5.0355 & TRN & \\
\hline CHEMBL1484454 & 688267 & 4.65 & 4.9806 & TRN & \\
\hline CHEMBL1531243 & 688267 & 6.15 & 5.0619 & TRN & \\
\hline CHEMBL3209110 & 688267 & 6.2 & 5.0582 & TRN & \\
\hline CHEMBL3190052 & 688267 & 4.5 & 4.9933 & TRN & \\
\hline CHEMBL1302394 & 688267 & 4.0 & 5.0035 & TRN & \\
\hline CHEMBL1447315 & 688267 & 4.05 & 5.0122 & TST & \\
\hline CHEMBL1420473 & 688267 & 4.4 & 5.0862 & TST & \\
\hline CHEMBL1389470 & 688267 & 6.1 & 5.06800 & 00000000005 & TST \\
\hline CHEMBL1494326 & 688267 & 5.3 & 5.1393 & TRN & \\
\hline CHEMBL1564301 & 688267 & 4.6 & 5.038 & TRN & \\
\hline CHEMBL1523096 & 688267 & 6.2 & 5.0766 & TRN & \\
\hline CHEMBL1611007 & 688267 & 6.25 & 5.0796 & TRN & \\
\hline CHEMBL3196376 & 688267 & 4.0 & 5.0226 & TST & \\
\hline CHEMBL3210122 & 688267 & 4.4 & 5.0673 & TRN & \\
\hline CHEMBL1368972 & 688267 & 4.5 & 5.1144 & TRN & \\
\hline CHEMBL1357269 & 688267 & 5.1 & 5.0076 & TRN & \\
\hline CHEMBL1458678 & 688267 & 5.0 & 5.1196 & TST & \\
\hline CHEMBL1365706 & 688267 & 4.05 & 5.0454 & TRN & \\
\hline CHEMBL1522702 & 688267 & 5.5 & 5.0554 & TRN & \\
\hline CHEMBL1341714 & 688267 & 6.5 & 5.1257 & TRN & \\
\hline CHEMBL1437619 & 688267 & 6.15 & 5.0606 & TST & \\
\hline CHEMBL1576301 & 688267 & 4.65 & 5.1232 & TRN & \\
\hline CHEMBL1494075 & 688267 & 4.65 & 5.1121 & TRN & \\
\hline CHEMBL1364061 & 688267 & 5.3 & 5.037 & TRN & \\
\hline CHEMBL1553714 & 688267 & 5.15 & 5.0268 & TRN & \\
\hline CHEMBL1400550 & 688267 & 6.2 & 5.098 & TRN & \\
\hline CHEMBL1342378 & 688267 & 4.35 & 5.0997 & TRN & \\
\hline CHEMBL1447213 & 688267 & 6.0 & 5.0502 & TRN & \\
\hline CHEMBL1584265 & 688267 & 5.2 & 5.118 & TRN & \\
\hline CHEMBL1405354 & 688267 & 4.45 & 5.0938 & TRN & \\
\hline CHEMBL3197329 & 688267 & 3.95 & 5.0274 & TRN & \\
\hline CHEMBL1511000 & 688267 & 4.85 & 5.1128 & TRN & \\
\hline CHEMBL1551626 & 688267 & 6.2 & 5.0007 & TRN & \\
\hline CHEMBL1607865 & 688267 & 4.0 & 4.9743 & TRN & \\
\hline CHEMBL1372008 & 688267 & 5.9 & 5.0229 & TST & \\
\hline CHEMBL1580418 & 688267 & 5.3 & 5.0273 & TRN & \\
\hline CHEMBL1427388 & 688267 & 5.3 & 5.0404 & TRN & \\
\hline CHEMBL1329139 & 688267 & 4.55 & 5.1729 & TRN & \\
\hline CHEMBL3199553 & 688267 & 4.05 & 5.023 & TST & \\
\hline CHEMBL1323617 & 688267 & 4.35 & 5.01699 & 99999999995 & TRN \\
\hline CHEMBL1474595 & 688267 & 4.45 & 5.1097 & TRN & \\
\hline CHEMBL1498197 & 688267 & 5.1 & 5.069 & TRN & \\
\hline CHEMBL1314578 & 688267 & 5.6 & 5.0733 & TST & \\
\hline
\end{tabular}




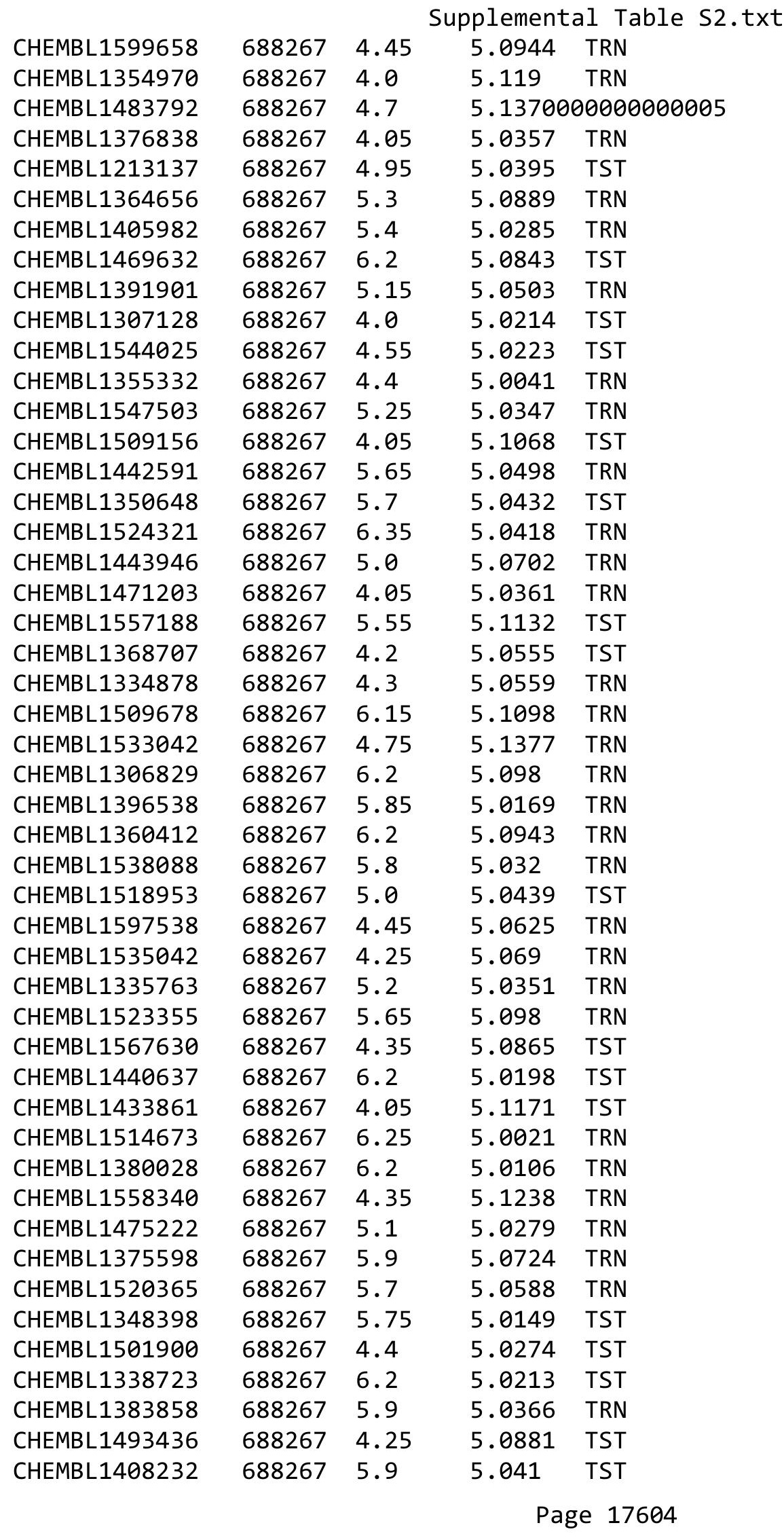

TRN 


\begin{tabular}{|c|c|c|c|c|}
\hline \multicolumn{5}{|c|}{ Supplemental Table S2.txt } \\
\hline CHEMBL1581255 & 688267 & 5.6 & 5.0167 & TST \\
\hline CHEMBL1424015 & 688267 & 4.8 & 5.067 & TST \\
\hline CHEMBL1562011 & 688267 & 5.45 & 5.1258 & TRN \\
\hline CHEMBL1361995 & 688267 & 5.5 & 5.0387 & TRN \\
\hline CHEMBL1581914 & 688267 & 5.3 & 5.0233 & TRN \\
\hline CHEMBL1591605 & 688267 & 6.2 & 5.086 & TRN \\
\hline CHEMBL1427680 & 688267 & 4.65 & 5.098 & TRN \\
\hline CHEMBL1393927 & 688267 & 5.75 & 5.0451 & TST \\
\hline CHEMBL1495178 & 688267 & 3.95 & 5.0553 & TST \\
\hline CHEMBL1314143 & 688267 & 5.8 & 5.0724 & TRN \\
\hline CHEMBL1502271 & 688267 & 5.5 & 5.0283 & TRN \\
\hline CHEMBL1487655 & 688267 & 5.2 & 5.1261 & TRN \\
\hline CHEMBL1562910 & 688267 & 4.5 & 5.0168 & TRN \\
\hline CHEMBL1434008 & 688267 & 5.3 & 5.09 & TRN \\
\hline CHEMBL1336375 & 688267 & 6.25 & 5.0921 & TRN \\
\hline CHEMBL1612517 & 688267 & 6.0 & 5.0373 & TRN \\
\hline CHEMBL1540602 & 688267 & 4.2 & 5.0516 & TST \\
\hline CHEMBL1360063 & 688267 & 4.25 & 5.1014 & TRN \\
\hline CHEMBL1378169 & 688267 & 4.55 & 5.0185 & TRN \\
\hline CHEMBL1400635 & 688267 & 4.1 & 4.9993 & TST \\
\hline CHEMBL1562200 & 688267 & 4.3 & 5.0777 & TRN \\
\hline CHEMBL1391204 & 688267 & 4.0 & 5.0982 & TRN \\
\hline CHEMBL1427708 & 688267 & 4.0 & 5.0819 & TRN \\
\hline CHEMBL1331561 & 688267 & 4.35 & 5.0502 & TRN \\
\hline CHEMBL1435988 & 688267 & 3.95 & 5.0792 & TRN \\
\hline CHEMBL1513301 & 688267 & 4.0 & 5.0034 & TRN \\
\hline CHEMBL1560617 & 688267 & 3.95 & 5.0448 & TRN \\
\hline CHEMBL1303219 & 688267 & 4.3 & 5.0606 & TST \\
\hline CHEMBL1324469 & 688267 & 4.0 & 5.1277 & TST \\
\hline CHEMBL1437551 & 688267 & 4.0 & 5.0993 & TRN \\
\hline CHEMBL1458153 & 688267 & 4.0 & 5.0621 & TRN \\
\hline CHEMBL1485495 & 688267 & 4.55 & 5.0408 & TRN \\
\hline CHEMBL1492599 & 688267 & 5.5 & 5.0806 & TRN \\
\hline CHEMBL1416991 & 688267 & 5.7 & 5.1038 & TRN \\
\hline CHEMBL1336271 & 688267 & 6.25 & 5.0141 & TRN \\
\hline CHEMBL1494642 & 688267 & 4.35 & 5.0177 & TST \\
\hline CHEMBL1441100 & 688267 & 5.35 & 5.0775 & TST \\
\hline CHEMBL1370867 & 688267 & 5.05 & 5.1236 & TRN \\
\hline CHEMBL1512533 & 688267 & 4.45 & 5.0582 & TRN \\
\hline CHEMBL1531581 & 688267 & 5.85 & 5.1483 & TRN \\
\hline CHEMBL1417043 & 688267 & 6.2 & 5.0578 & TRN \\
\hline CHEMBL3194695 & 688267 & 5.45 & 5.1079 & TRN \\
\hline CHEMBL1354613 & 688267 & 5.2 & 5.1315 & TRN \\
\hline CHEMBL1327840 & 688267 & 6.2 & 5.0595 & TST \\
\hline CHEMBL1305681 & 688267 & 4.55 & 5.0018 & TRN \\
\hline CHEMBL1612136 & 688267 & 4.05 & 5.1191 & TST \\
\hline CHEMBL1493173 & 688267 & 5.4 & 5.1501 & TRN \\
\hline CHEMBL1428706 & 688267 & 4.7 & 5.1016 & TRN \\
\hline
\end{tabular}




\begin{tabular}{|c|c|c|c|c|}
\hline \multicolumn{5}{|c|}{ Supplemental Table s2.txt } \\
\hline CHEMBL1516334 & 688267 & 4.1 & 4.9808 & TRN \\
\hline CHEMBL 3210818 & 688267 & 4.7 & 5.1257 & TST \\
\hline CHEMBL1452299 & 688267 & 4.0 & 5.1472 & TRN \\
\hline CHEMBL1256616 & 688267 & 4.95 & 5.0823 & TST \\
\hline CHEMBL1380740 & 688267 & 6.2 & 5.0312 & TRN \\
\hline CHEMBL1418665 & 688267 & 4.3 & 5.0643 & TRN \\
\hline CHEMBL3145299 & 688267 & 6.2 & 4.9758 & TST \\
\hline CHEMBL1380342 & 688267 & 4.0 & 5.1289 & TRN \\
\hline CHEMBL1553831 & 688267 & 5.0 & 5.055 & TRN \\
\hline CHEMBL1367079 & 688267 & 5.9 & 5.0374 & TRN \\
\hline CHEMBL1426542 & 688267 & 5.05 & 5.075 & TRN \\
\hline CHEMBL1335750 & 688267 & 5.95 & 5.0336 & TRN \\
\hline CHEMBL3198694 & 688267 & 4.4 & 5.0372 & TST \\
\hline CHEMBL1350017 & 688267 & 5.25 & 5.0516 & TRN \\
\hline CHEMBL1490790 & 688267 & 4.3 & 5.0422 & TRN \\
\hline CHEMBL1381644 & 688267 & 3.95 & 5.0501 & TST \\
\hline CHEMBL1444173 & 688267 & 4.6 & 5.1163 & TRN \\
\hline CHEMBL1334068 & 688267 & 4.0 & 5.1036 & TRN \\
\hline CHEMBL1516272 & 688267 & 4.1 & 5.0399 & TRN \\
\hline CHEMBL1353132 & 688267 & 5.0 & 5.051 & TRN \\
\hline CHEMBL1478109 & 688267 & 6.2 & 5.0525 & TRN \\
\hline CHEMBL3198170 & 688267 & 4.55 & 5.0319 & TST \\
\hline CHEMBL1534381 & 688267 & 5.75 & 5.0277 & TST \\
\hline CHEMBL1509929 & 688267 & 6.2 & 4.9724 & TRN \\
\hline CHEMBL1445335 & 688267 & 5.3 & 5.0458 & TRN \\
\hline CHEMBL1505649 & 688267 & 4.45 & 5.0785 & TRN \\
\hline CHEMBL1351161 & 688267 & 5.8 & 4.9944 & TRN \\
\hline CHEMBL1417948 & 688267 & 4.6 & 5.1521 & TRN \\
\hline CHEMBL1376581 & 688267 & 4.0 & 5.0612 & TRN \\
\hline CHEMBL1448723 & 688267 & 5.55 & 5.079 & TRN \\
\hline CHEMBL1515041 & 688267 & 6.25 & 5.0861 & TRN \\
\hline CHEMBL1328211 & 688267 & 4.4 & 5.1269 & TRN \\
\hline CHEMBL1603733 & 688267 & 3.95 & 5.0524 & TRN \\
\hline CHEMBL1588107 & 688267 & 4.2 & 5.0367 & TRN \\
\hline CHEMBL1366705 & 688267 & 4.45 & 5.0771 & TRN \\
\hline CHEMBL1533504 & 688267 & 4.0 & 5.0089 & TRN \\
\hline CHEMBL3194889 & 688267 & 6.15 & 5.0665 & TRN \\
\hline CHEMBL1411665 & 688267 & 4.05 & 5.0233 & TST \\
\hline CHEMBL1442900 & 688267 & 4.2 & $5.1220 e$ & 0000000001 \\
\hline CHEMBL1388698 & 688267 & 5.0 & 5.0579 & TST \\
\hline CHEMBL1595916 & 688267 & 4.6 & 5.0314 & TRN \\
\hline CHEMBL1408714 & 688267 & 4.95 & 5.0884 & TRN \\
\hline CHEMBL1384828 & 688267 & 4.5 & 5.0536 & TRN \\
\hline CHEMBL1576622 & 688267 & 5.5 & 5.0326 & TRN \\
\hline CHEMBL1516411 & 688267 & 5.8 & 5.0543 & TRN \\
\hline CHEMBL1482057 & 688267 & 5.7 & 5.0987 & TRN \\
\hline CHEMBL1332009 & 688267 & 5.25 & 5.0629 & TRN \\
\hline CHEMBL1560138 & 688267 & 6.2 & 5.0741 & TRN \\
\hline
\end{tabular}

TRN 


\begin{tabular}{|c|c|c|c|c|}
\hline & & & pplement & al $\mathrm{Ta}$ \\
\hline CHEMBL1440611 & 688267 & 6.0 & 5.1177 & TRN \\
\hline CHEMBL1415795 & 688267 & 6.2 & 5.0305 & TRN \\
\hline CHEMBL1569693 & 688267 & 4.1 & 5.0123 & TRN \\
\hline CHEMBL85233 & 688267 & 4.3 & 5.0296 & TRN \\
\hline CHEMBL1517897 & 688267 & 5.2 & 5.1091 & TRN \\
\hline CHEMBL1320818 & 688267 & 4.05 & 5.0698 & TRN \\
\hline CHEMBL1301691 & 688267 & 5.3 & 5.0704 & TRN \\
\hline CHEMBL1304051 & 688267 & 4.15 & 5.0164 & TRN \\
\hline CHEMBL1305538 & 688267 & 6.45 & 5.0718 & TST \\
\hline CHEMBL1397837 & 688267 & 5.35 & 5.0688 & TRN \\
\hline CHEMBL1575669 & 688267 & 6.2 & 5.0056 & TST \\
\hline CHEMBL1601057 & 688267 & 4.05 & 5.0487 & TRN \\
\hline CHEMBL1387740 & 688267 & 4.35 & 5.0465 & TRN \\
\hline CHEMBL1494204 & 688267 & 4.35 & 5.0912 & TST \\
\hline CHEMBL1592729 & 688267 & 3.95 & 5.0739 & TST \\
\hline CHEMBL1493381 & 688267 & 5.4 & 5.1016 & TRN \\
\hline CHEMBL1522049 & 688267 & 5.5 & 4.9974 & TRN \\
\hline CHEMBL1582213 & 688267 & 6.2 & 5.086 & TRN \\
\hline CHEMBL1369798 & 688267 & 4.5 & 4.9909 & TRN \\
\hline CHEMBL1610809 & 688267 & 6.2 & 5.0671 & TRN \\
\hline CHEMBL1448959 & 688267 & 4.1 & 5.115 & TST \\
\hline CHEMBL1461633 & 688267 & 4.35 & 5.0771 & TST \\
\hline CHEMBL1334083 & 688267 & 6.0 & 5.088 & TRN \\
\hline CHEMBL1509216 & 688267 & 4.2 & 5.0572 & TST \\
\hline CHEMBL1344942 & 688267 & 4.0 & 5.0696 & TST \\
\hline CHEMBL1375999 & 688267 & 4.35 & 5.0626 & TST \\
\hline CHEMBL1504634 & 688267 & 4.35 & 5.1377 & TRN \\
\hline CHEMBL1426070 & 688267 & 5.5 & 5.0942 & TRN \\
\hline CHEMBL1423516 & 688267 & 5.95 & 5.0494 & TST \\
\hline CHEMBL1497139 & 688267 & 5.45 & 4.9992 & TST \\
\hline CHEMBL1540016 & 688267 & 5.25 & 5.0172 & TST \\
\hline CHEMBL1335868 & 688267 & 4.0 & 5.1378 & TST \\
\hline CHEMBL1611863 & 688267 & 5.5 & 5.0865 & TST \\
\hline CHEMBL3198385 & 688267 & 4.45 & 4.9986 & TRN \\
\hline CHEMBL1549368 & 688267 & 5.95 & 5.0556 & TRN \\
\hline CHEMBL1553332 & 688267 & 5.9 & 5.0672 & TRN \\
\hline CHEMBL1414656 & 688267 & 4.1 & 5.078 & TST \\
\hline CHEMBL1350785 & 688267 & 5.8 & 5.0239 & TST \\
\hline CHEMBL1418757 & 688267 & 5.3 & 5.0959 & TRN \\
\hline CHEMBL1503831 & 688267 & 4.05 & 4.9826 & TST \\
\hline CHEMBL1609310 & 688267 & 4.05 & 5.0584 & TST \\
\hline CHEMBL1330206 & 688267 & 4.0 & 5.0201 & TRN \\
\hline CHEMBL1459083 & 688267 & 4.2 & 5.0128 & TST \\
\hline CHEMBL1486564 & 688267 & 4.05 & 5.0528 & TRN \\
\hline CHEMBL1612439 & 688267 & 3.95 & 5.0287 & TRN \\
\hline CHEMBL1444228 & 688267 & 5.4 & 5.0507 & TRN \\
\hline CHEMBL1606516 & 688267 & 4.3 & 4.985 & TRN \\
\hline CHEMBL1561953 & 688267 & 5.05 & 5.1254 & TRN \\
\hline
\end{tabular}




\begin{tabular}{|c|c|c|c|c|}
\hline & & & pplemen & al $\mathrm{T}$ \\
\hline CHEMBL1593764 & 688267 & 6.2 & 5.1166 & TRN \\
\hline CHEMBL1349323 & 688267 & 6.2 & 5.0906 & TRN \\
\hline CHEMBL3208854 & 688267 & 6.25 & 5.0525 & TRN \\
\hline CHEMBL1492064 & 688267 & 6.2 & 5.0799 & TRN \\
\hline CHEMBL1553725 & 688267 & 3.95 & 4.9981 & TRN \\
\hline CHEMBL1336387 & 688267 & 5.95 & 5.1287 & TRN \\
\hline CHEMBL1424112 & 688267 & 4.0 & 5.0306 & TRN \\
\hline CHEMBL1584606 & 688267 & 4.0 & 5.0786 & TRN \\
\hline CHEMBL1308604 & 688267 & 5.85 & 5.0515 & TRN \\
\hline CHEMBL1384719 & 688267 & 4.95 & 5.0888 & TRN \\
\hline CHEMBL1442837 & 688267 & 3.9 & 5.0659 & TRN \\
\hline CHEMBL1570176 & 688267 & 6.1 & 5.0967 & TST \\
\hline CHEMBL1348894 & 688267 & 5.1 & 5.1171 & TRN \\
\hline CHEMBL1310847 & 688267 & 3.95 & 5.1086 & TRN \\
\hline CHEMBL1448402 & 688267 & 4.4 & 5.0604 & TRN \\
\hline CHEMBL1564352 & 688267 & 6.25 & 5.0293 & TRN \\
\hline CHEMBL1351645 & 688267 & 5.55 & 5.029 & TST \\
\hline CHEMBL1476195 & 688267 & 6.2 & 5.0837 & TRN \\
\hline CHEMBL1462263 & 688267 & 5.4 & 5.1446 & TST \\
\hline CHEMBL1438919 & 688267 & 5.5 & 5.0373 & TST \\
\hline CHEMBL1608032 & 688267 & 4.05 & 5.0391 & TRN \\
\hline CHEMBL1492813 & 688267 & 5.25 & 5.0315 & TST \\
\hline CHEMBL1542508 & 688267 & 6.2 & 5.0508 & TST \\
\hline CHEMBL1517567 & 688267 & 4.35 & 5.0305 & TRN \\
\hline CHEMBL1348858 & 688267 & 4.35 & 5.0439 & TRN \\
\hline CHEMBL1538233 & 688267 & 5.85 & 5.1077 & TRN \\
\hline CHEMBL1430941 & 688267 & 4.35 & 5.0078 & TRN \\
\hline CHEMBL1541429 & 688267 & 6.1 & 5.0791 & TRN \\
\hline CHEMBL1580710 & 688267 & 4.5 & 5.0491 & TST \\
\hline CHEMBL1604720 & 688267 & 6.1 & 5.0474 & TRN \\
\hline CHEMBL1485966 & 688267 & 6.1 & 5.0504 & TST \\
\hline CHEMBL1503655 & 688267 & 6.2 & 5.107 & TRN \\
\hline CHEMBL3191088 & 688267 & 4.15 & 5.0597 & TST \\
\hline CHEMBL1328648 & 688267 & 3.95 & 5.001 & TST \\
\hline CHEMBL1255934 & 688267 & 4.35 & 5.0564 & TST \\
\hline CHEMBL1477390 & 688267 & 4.05 & 5.1071 & TRN \\
\hline CHEMBL1593419 & 688267 & 6.2 & 5.0098 & TRN \\
\hline CHEMBL1477994 & 688267 & 6.15 & 5.0546 & TRN \\
\hline CHEMBL1580311 & 688267 & 5.0 & 5.0254 & TST \\
\hline CHEMBL1355817 & 688267 & 6.2 & 5.0356 & TST \\
\hline CHEMBL1540541 & 688267 & 5.0 & 5.0589 & TRN \\
\hline CHEMBL1553100 & 688267 & 4.0 & 5.0848 & TRN \\
\hline CHEMBL1500106 & 688267 & 4.95 & 4.9954 & TRN \\
\hline CHEMBL1463052 & 688267 & 4.05 & 5.0232 & TRN \\
\hline CHEMBL1501831 & 688267 & 5.25 & 5.016 & TRN \\
\hline CHEMBL1368727 & 688267 & 5.55 & 5.0456 & TRN \\
\hline CHEMBL 3214224 & 688267 & 6.2 & 5.0435 & TST \\
\hline CHEMBL1587385 & 688267 & 6.15 & 4.9971 & TRN \\
\hline
\end{tabular}




\begin{tabular}{|c|c|c|c|c|c|}
\hline \\
\hline CHEMBL1443146 & 688267 & 4.1 & 5.0415 & TRN & \\
\hline CHEMBL1418647 & 688267 & 4.3 & 4.9968 & TST & \\
\hline CHEMBL1341414 & 688267 & 5.9 & 5.0515 & TRN & \\
\hline CHEMBL1476277 & 688267 & 6.2 & 5.0997 & TRN & \\
\hline CHEMBL1504537 & 688267 & 5.6 & 5.1475 & TRN & \\
\hline CHEMBL1452856 & 688267 & 6.2 & 5.1509 & TRN & \\
\hline CHEMBL1304264 & 688267 & 5.6 & 5.0352 & TST & \\
\hline CHEMBL1341057 & 688267 & 4.4 & 5.0563 & TRN & \\
\hline CHEMBL1473072 & 688267 & 4.0 & \multicolumn{2}{|c|}{5.132999999999999} & TRN \\
\hline CHEMBL3207531 & 688267 & 5.8 & 5.0124 & TRN & \\
\hline CHEMBL1209370 & 688267 & 6.45 & 5.0496 & TRN & \\
\hline CHEMBL1323692 & 688267 & 4.2 & 5.0646 & TRN & \\
\hline CHEMBL1527827 & 688267 & 4.0 & 5.0249 & TRN & \\
\hline CHEMBL1501257 & 688267 & 6.25 & 5.0936 & TRN & \\
\hline CHEMBL1508997 & 688267 & 4.1 & 5.0268 & TRN & \\
\hline CHEMBL1365168 & 688267 & 4.0 & 5.0225 & TST & \\
\hline CHEMBL3195092 & 688267 & 5.55 & 5.0809 & TRN & \\
\hline CHEMBL1443917 & 688267 & 4.4 & 5.0691 & TRN & \\
\hline CHEMBL1510656 & 688267 & 4.95 & 5.1325 & TRN & \\
\hline CHEMBL1598000 & 688267 & 5.4 & 5.0799 & TRN & \\
\hline CHEMBL1395464 & 688267 & 6.15 & 5.0737 & TST & \\
\hline CHEMBL1301867 & 688267 & 5.8 & 5.0544 & TRN & \\
\hline CHEMBL1534492 & 688267 & 6.2 & 4.9889 & TRN & \\
\hline CHEMBL1458490 & 688267 & 3.95 & 5.0101 & TRN & \\
\hline CHEMBL1436747 & 688267 & 5.55 & 5.0444 & TRN & \\
\hline CHEMBL3212317 & 688267 & 6.2 & 5.0399 & TRN & \\
\hline CHEMBL1580674 & 688267 & 4.3 & 5.0845 & TRN & \\
\hline CHEMBL1460752 & 688267 & 4.25 & 5.1388 & TRN & \\
\hline CHEMBL1584815 & 688267 & 4.0 & 5.1155 & TST & \\
\hline CHEMBL1326116 & 688267 & 4.2 & 5.0202 & TST & \\
\hline CHEMBL1537228 & 688267 & 6.05 & 5.0829 & TST & \\
\hline CHEMBL1453127 & 688267 & 4.05 & 5.0561 & TRN & \\
\hline CHEMBL1372854 & 688267 & 4.0 & 5.0827 & TST & \\
\hline CHEMBL1345344 & 688267 & 6.2 & 5.052 & TRN & \\
\hline CHEMBL1407151 & 688267 & 6.5 & 5.0271 & TST & \\
\hline CHEMBL1417678 & 688267 & 6.2 & 5.0307 & TRN & \\
\hline CHEMBL1391008 & 688267 & 5.4 & 5.1096 & TRN & \\
\hline CHEMBL1557176 & 688267 & 4.0 & 5.0547 & TRN & \\
\hline CHEMBL1565164 & 688267 & 4.1 & 5.0056 & TST & \\
\hline CHEMBL1407186 & 688267 & 5.05 & 5.1093 & TRN & \\
\hline CHEMBL1603741 & 688267 & 4.75 & 5.1453 & TRN & \\
\hline CHEMBL1508061 & 688267 & 5.8 & 5.0162 & TRN & \\
\hline CHEMBL1401600 & 688267 & 6.2 & 5.0458 & TRN & \\
\hline CHEMBL1358897 & 688267 & 4.0 & 5.087 & TRN & \\
\hline CHEMBL1342567 & 688267 & 4.15 & 5.092 & TRN & \\
\hline CHEMBL1374114 & 688267 & 5.15 & 5.0587 & TST & \\
\hline CHEMBL1443549 & 688267 & 4.1 & 5.0448 & TRN & \\
\hline CHEMBL589461 & 688267 & 5.3 & 4.9665 & TRN & \\
\hline & & & & 1766 & \\
\hline
\end{tabular}




\begin{tabular}{|c|c|c|c|c|}
\hline & & & pplement & al $\mathrm{Ta}$ \\
\hline CHEMBL1574107 & 688267 & 6.2 & 5.1028 & TST \\
\hline CHEMBL1396851 & 688267 & 5.75 & 5.0842 & TRN \\
\hline CHEMBL1557991 & 688267 & 5.25 & 5.0222 & TRN \\
\hline CHEMBL1321321 & 688267 & 6.1 & 5.0175 & TRN \\
\hline CHEMBL120568 & 688267 & 4.6 & 5.0485 & TRN \\
\hline CHEMBL1476485 & 688267 & 4.25 & 5.0146 & TRN \\
\hline CHEMBL1556635 & 688267 & 6.15 & 5.1104 & TRN \\
\hline CHEMBL1556743 & 688267 & 6.2 & 5.0135 & TST \\
\hline CHEMBL1559115 & 688267 & 4.8 & 5.0433 & TST \\
\hline CHEMBL1384631 & 688267 & 4.3 & 5.0605 & TRN \\
\hline CHEMBL1486705 & 688267 & 5.55 & 5.0637 & TST \\
\hline CHEMBL1425761 & 688267 & 4.35 & 4.9994 & TST \\
\hline CHEMBL1531226 & 688267 & 5.4 & 5.1295 & TRN \\
\hline CHEMBL1445735 & 688267 & 6.2 & 5.0759 & TST \\
\hline CHEMBL1315556 & 688267 & 4.05 & 5.03 & TRN \\
\hline CHEMBL1567627 & 688267 & 5.6 & 5.103 & TRN \\
\hline CHEMBL1256576 & 688267 & 5.2 & 5.0798 & TST \\
\hline CHEMBL1371341 & 688267 & 5.3 & 5.062 & TRN \\
\hline CHEMBL239322 & 688267 & 5.1 & 5.0263 & TST \\
\hline CHEMBL1439188 & 688267 & 4.05 & 5.0631 & TRN \\
\hline CHEMBL3192575 & 688267 & 5.9 & 5.0529 & TRN \\
\hline CHEMBL1479023 & 688267 & 5.45 & 5.0618 & TRN \\
\hline CHEMBL1455222 & 688267 & 4.0 & 5.0347 & TRN \\
\hline CHEMBL260560 & 688267 & 4.0 & 4.9779 & TRN \\
\hline CHEMBL1596969 & 688267 & 3.95 & 5.0151 & TRN \\
\hline CHEMBL1331617 & 688267 & 4.2 & 5.084 & TRN \\
\hline CHEMBL1578500 & 688267 & 4.4 & 5.0319 & TRN \\
\hline CHEMBL1602366 & 688267 & 5.0 & 5.0508 & TST \\
\hline CHEMBL1968327 & 688267 & 4.65 & 5.0211 & TRN \\
\hline CHEMBL1604151 & 688267 & 4.6 & 5.0226 & TST \\
\hline CHEMBL1434386 & 688267 & 6.1 & 5.0929 & TRN \\
\hline CHEMBL1556738 & 688267 & 3.9 & 5.0554 & TRN \\
\hline CHEMBL1348199 & 688267 & 4.1 & 5.0902 & TRN \\
\hline CHEMBL1509090 & 688267 & 5.15 & 5.0655 & TRN \\
\hline CHEMBL1357152 & 688267 & 4.35 & 5.0398 & TST \\
\hline CHEMBL1459703 & 688267 & 4.1 & 5.1136 & TRN \\
\hline CHEMBL1376906 & 688267 & 4.1 & 5.0916 & TST \\
\hline CHEMBL1424220 & 688267 & 4.45 & 5.0487 & TRN \\
\hline CHEMBL1337960 & 688267 & 5.55 & 5.0169 & TRN \\
\hline CHEMBL1565522 & 688267 & 4.5 & 5.0867 & TRN \\
\hline CHEMBL1447856 & 688267 & 4.0 & 5.0365 & TRN \\
\hline CHEMBL1506653 & 688267 & 4.6 & 5.0565 & TST \\
\hline CHEMBL1516677 & 688267 & 4.0 & 5.0636 & TRN \\
\hline CHEMBL1498652 & 688267 & 5.3 & 5.0222 & TST \\
\hline CHEMBL3190491 & 688267 & 6.2 & 4.9808 & TRN \\
\hline CHEMBL1451873 & 688267 & 5.45 & 5.0693 & TST \\
\hline CHEMBL1596024 & 688267 & 5.55 & 4.9861 & TRN \\
\hline CHEMBL1493502 & 688267 & 4.65 & 4.9966 & TST \\
\hline
\end{tabular}




\begin{tabular}{|c|c|c|c|c|c|}
\hline \multicolumn{6}{|c|}{ Supplemental Table S2.txt } \\
\hline CHEMBL1511455 & 688267 & 5.95 & 5.1011 & TRN & \\
\hline CHEMBL1489162 & 688267 & 4.45 & 5.1117 & TRN & \\
\hline CHEMBL1613512 & 688267 & 4.05 & 5.0557 & TRN & \\
\hline CHEMBL1444018 & 688267 & 6.5 & 4.9858 & TRN & \\
\hline CHEMBL1385326 & 688267 & 4.45 & 5.0282 & TRN & \\
\hline CHEMBL1359091 & 688267 & 6.5 & 5.0311 & TRN & \\
\hline CHEMBL1543166 & 688267 & 5.8 & 5.1288 & TRN & \\
\hline CHEMBL1526891 & 688267 & 5.3 & 5.0581 & TRN & \\
\hline CHEMBL1521127 & 688267 & 4.6 & 5.0467 & TRN & \\
\hline CHEMBL1593559 & 688267 & 4.5 & 5.0642 & TRN & \\
\hline CHEMBL1483080 & 688267 & 4.55 & 4.9987 & TST & \\
\hline CHEMBL1576676 & 688267 & 4.55 & 5.073 & TST & \\
\hline CHEMBL1589613 & 688267 & 4.05 & 5.0665 & TRN & \\
\hline CHEMBL1603351 & 688267 & 5.05 & 5.0507 & TRN & \\
\hline CHEMBL1555674 & 688267 & 6.25 & 5.091 & TRN & \\
\hline CHEMBL3213392 & 688267 & 4.25 & 5.0721 & TST & \\
\hline CHEMBL3198425 & 688267 & 4.1 & 5.0278 & TRN & \\
\hline CHEMBL1543445 & 688267 & 4.5 & 5.0358 & TRN & \\
\hline CHEMBL1595376 & 688267 & 5.65 & 5.0183 & TST & \\
\hline CHEMBL1577246 & 688267 & 4.0 & 5.0269 & TRN & \\
\hline CHEMBL1526840 & 688267 & 6.2 & 5.0272 & TRN & \\
\hline CHEMBL1489408 & 688267 & 4.45 & 5.03600 & 00000000005 & TRN \\
\hline CHEMBL1344153 & 688267 & 4.95 & 5.0499 & TRN & \\
\hline CHEMBL1359111 & 688267 & 5.35 & 5.0404 & TST & \\
\hline CHEMBL1356671 & 688267 & 4.45 & 5.0344 & TRN & \\
\hline CHEMBL1377972 & 688267 & 4.5 & 5.0169 & TST & \\
\hline CHEMBL1425314 & 688267 & 5.4 & 4.9929 & TST & \\
\hline CHEMBL1473874 & 688267 & 6.45 & 5.0353 & TST & \\
\hline CHEMBL1341015 & 688267 & 6.15 & 4.9908 & TRN & \\
\hline CHEMBL3191119 & 688267 & 6.15 & 5.0384 & TST & \\
\hline CHEMBL1466919 & 688267 & 4.85 & 5.0636 & TRN & \\
\hline CHEMBL1476886 & 688267 & 6.2 & 5.08 & TRN & \\
\hline CHEMBL1389583 & 688267 & 5.2 & 5.0546 & TST & \\
\hline CHEMBL1309092 & 688267 & 3.95 & 5.0638 & TST & \\
\hline CHEMBL1536815 & 688267 & 6.2 & 5.0396 & TST & \\
\hline CHEMBL1306230 & 688267 & 4.0 & 4.9927 & TST & \\
\hline CHEMBL1591984 & 688267 & 5.3 & 5.0319 & TRN & \\
\hline CHEMBL1565183 & 688267 & 5.45 & 5.0441 & TST & \\
\hline CHEMBL1356674 & 688267 & 4.2 & 5.0257 & TRN & \\
\hline CHEMBL1325338 & 688267 & 4.55 & 5.1194 & TST & \\
\hline CHEMBL1561413 & 688267 & 6.2 & 5.0427 & TRN & \\
\hline CHEMBL1335958 & 688267 & 5.25 & 5.044 & TRN & \\
\hline CHEMBL3208044 & 688267 & 5.3 & 5.0756 & TRN & \\
\hline CHEMBL1400177 & 688267 & 6.2 & 5.0555 & TRN & \\
\hline CHEMBL1592019 & 688267 & 4.25 & 5.1406 & TRN & \\
\hline CHEMBL1554386 & 688267 & 5.45 & 5.0982 & TRN & \\
\hline CHEMBL1496939 & 688267 & 4.3 & 5.0438 & TRN & \\
\hline CHEMBL1602431 & 688267 & 6.0 & 5.0937 & TRN & \\
\hline
\end{tabular}




\begin{tabular}{|c|c|c|c|c|}
\hline \multicolumn{5}{|c|}{ Supplemental Table S2.txt } \\
\hline CHEMBL1377318 & 688267 & 4.0 & 5.0828 & TST \\
\hline CHEMBL1441466 & 688267 & 4.05 & 5.0305 & TRN \\
\hline CHEMBL1430932 & 688267 & 5.35 & 5.0259 & TST \\
\hline CHEMBL1349016 & 688267 & 5.65 & 5.0099 & TRN \\
\hline CHEMBL1429439 & 688267 & 4.0 & 5.0482 & TST \\
\hline CHEMBL1448929 & 688267 & 6.25 & 5.0447 & TRN \\
\hline CHEMBL1302528 & 688267 & 4.1 & 5.0181 & TRN \\
\hline CHEMBL1608976 & 688267 & 4.6 & 5.0137 & TRN \\
\hline CHEMBL1979360 & 688267 & 6.2 & 5.0277 & TRN \\
\hline CHEMBL1598133 & 688267 & 4.5 & 5.0637 & TRN \\
\hline CHEMBL1578259 & 688267 & 4.4 & 5.0437 & TRN \\
\hline CHEMBL1374924 & 688267 & 6.5 & 5.0428 & TRN \\
\hline CHEMBL1567836 & 688267 & 4.15 & 5.0423 & TRN \\
\hline CHEMBL1413154 & 688267 & 4.25 & 5.0085 & TST \\
\hline CHEMBL1598773 & 688267 & 4.95 & 5.0809 & TRN \\
\hline CHEMBL1350007 & 688267 & 4.15 & 5.0787 & TRN \\
\hline CHEMBL1489723 & 688267 & 4.0 & 5.0718 & TRN \\
\hline CHEMBL1483817 & 688267 & 5.85 & 5.0156 & TST \\
\hline CHEMBL1438327 & 688267 & 4.8 & 5.0797 & TRN \\
\hline CHEMBL1496357 & 688267 & 4.95 & 5.0873 & TRN \\
\hline CHEMBL1400878 & 688267 & 4.8 & 5.0407 & TRN \\
\hline CHEMBL1311047 & 688267 & 4.65 & 5.0971 & TST \\
\hline CHEMBL1453725 & 688267 & 5.45 & 5.115 & TRN \\
\hline CHEMBL1611895 & 688267 & 4.35 & 5.0791 & TST \\
\hline CHEMBL3189349 & 688267 & 4.35 & 5.0372 & TRN \\
\hline CHEMBL1536903 & 688267 & 4.95 & 5.0858 & TRN \\
\hline CHEMBL1335161 & 688267 & 4.4 & 5.0102 & TST \\
\hline CHEMBL3194126 & 688267 & 5.75 & 5.0463 & TST \\
\hline CHEMBL1552809 & 688267 & 4.45 & 5.0525 & TRN \\
\hline CHEMBL1341364 & 688267 & 4.2 & 5.0426 & TRN \\
\hline CHEMBL1535269 & 688267 & 5.55 & 5.0922 & TRN \\
\hline CHEMBL1522175 & 688267 & 5.8 & 4.9839 & TST \\
\hline CHEMBL1597521 & 688267 & 4.6 & 5.0621 & TRN \\
\hline CHEMBL1398548 & 688267 & 6.45 & 5.0626 & TRN \\
\hline CHEMBL3210662 & 688267 & 5.5 & 5.0081 & TRN \\
\hline CHEMBL1446414 & 688267 & 6.15 & 5.0625 & TRN \\
\hline CHEMBL1561849 & 688267 & 4.6 & 5.0519 & TRN \\
\hline CHEMBL1346504 & 688267 & 4.65 & 5.0618 & TRN \\
\hline CHEMBL1434674 & 688267 & 6.0 & 5.026 & TRN \\
\hline CHEMBL1516037 & 688267 & 5.8 & 5.083 & TRN \\
\hline CHEMBL3212728 & 688267 & 5.35 & 5.0341 & TST \\
\hline CHEMBL1372324 & 688267 & 4.45 & 5.0288 & TRN \\
\hline CHEMBL1613713 & 688267 & 3.95 & 5.0631 & TST \\
\hline CHEMBL1379059 & 688267 & 5.4 & 5.0674 & TRN \\
\hline CHEMBL1550257 & 688267 & 6.0 & 5.1468 & TRN \\
\hline CHEMBL1509427 & 688267 & 5.75 & 5.1356 & TRN \\
\hline CHEMBL1548412 & 688267 & 6.15 & 5.0844 & TRN \\
\hline CHEMBL1453251 & 688267 & 5.6 & 5.1073 & TRN \\
\hline
\end{tabular}




\begin{tabular}{|c|c|c|c|c|}
\hline & & & upplement & \\
\hline CHEMBL 3208924 & 688267 & 5.9 & 5.0724 & TST \\
\hline CHEMBL1356818 & 688267 & 6.2 & 4.9963 & TRN \\
\hline CHEMBL 3191095 & 688267 & 4.55 & 5.0024 & TST \\
\hline CHEMBL1485955 & 688267 & 5.3 & 5.0336 & TRN \\
\hline CHEMBL1353247 & 688267 & 6.2 & 5.005 & TRN \\
\hline CHEMBL1345554 & 688267 & 5.3 & 5.0566 & TRN \\
\hline CHEMBL1448830 & 688267 & 4.4 & 5.0469 & TRN \\
\hline CHEMBL1330976 & 688267 & 4.45 & 5.0308 & TST \\
\hline CHEMBL1357714 & 688267 & 4.05 & 5.1251 & TRN \\
\hline CHEMBL1352621 & 688267 & 6.25 & 5.0565 & TRN \\
\hline CHEMBL1538436 & 688267 & 5.85 & 5.0956 & TRN \\
\hline CHEMBL1470534 & 688267 & 4.1 & 5.0648 & TRN \\
\hline CHEMBL1334960 & 688267 & 5.5 & 5.1213 & TRN \\
\hline CHEMBL1310989 & 688267 & 3.95 & 5.0924 & TRN \\
\hline CHEMBL1590228 & 688267 & 5.25 & 5.0954 & TRN \\
\hline CHEMBL1405248 & 688267 & 4.65 & 5.0572 & TRN \\
\hline CHEMBL1495772 & 688267 & 4.35 & 5.0889 & TRN \\
\hline CHEMBL1404845 & 688267 & 4.0 & 5.0425 & TRN \\
\hline CHEMBL1536631 & 688267 & 5.3 & 5.1068 & TRN \\
\hline CHEMBL1375682 & 688267 & 4.6 & 5.0757 & TST \\
\hline CHEMBL1314392 & 688267 & 5.65 & 5.0699 & TRN \\
\hline CHEMBL1510186 & 688267 & 4.15 & 5.0537 & TST \\
\hline CHEMBL1599008 & 688267 & 6.2 & 4.989 & TRN \\
\hline CHEMBL1450382 & 688267 & 4.4 & 5.0568 & TRN \\
\hline CHEMBL1496591 & 688267 & 6.45 & 5.0986 & TRN \\
\hline CHEMBL1567051 & 688267 & 4.0 & 5.1477 & TRN \\
\hline CHEMBL1522647 & 688267 & 4.25 & 4.9966 & TRN \\
\hline CHEMBL1558558 & 688267 & 4.7 & 5.1532 & TRN \\
\hline CHEMBL 3193170 & 688267 & 5.4 & 5.0009 & TST \\
\hline CHEMBL1388147 & 688267 & 6.15 & 5.0328 & TST \\
\hline CHEMBL1438639 & 688267 & 3.95 & 5.0043 & TST \\
\hline CHEMBL1552928 & 688267 & 4.25 & 5.0828 & TRN \\
\hline CHEMBL1320859 & 688267 & 6.25 & 5.0596 & TRN \\
\hline CHEMBL1339032 & 688267 & 4.5 & 5.1081 & TRN \\
\hline CHEMBL1471262 & 688267 & 6.0 & 4.9997 & TRN \\
\hline CHEMBL1361412 & 688267 & 6.2 & 5.1063 & TRN \\
\hline CHEMBL551294 & 688267 & 5.75 & 5.0476 & TST \\
\hline CHEMBL1554891 & 688267 & 5.2 & 5.0902 & TRN \\
\hline CHEMBL1546451 & 688267 & 6.15 & 5.1363 & TRN \\
\hline CHEMBL1533637 & 688267 & 4.05 & 5.1107 & TST \\
\hline CHEMBL1580982 & 688267 & 6.15 & 5.0029 & TRN \\
\hline CHEMBL1401911 & 688267 & 6.25 & 5.0367 & TRN \\
\hline CHEMBL1367422 & 688267 & 6.2 & 5.0829 & TST \\
\hline CHEMBL1431733 & 688267 & 4.55 & 5.0706 & TST \\
\hline CHEMBL1377463 & 688267 & 5.05 & 4.996 & TRN \\
\hline CHEMBL1499381 & 688267 & 6.15 & 5.0335 & TRN \\
\hline CHEMBL1475881 & 688267 & 4.0 & 5.0233 & TRN \\
\hline CHEMBL1335305 & 688267 & 4.05 & 5.0064 & TRN \\
\hline
\end{tabular}




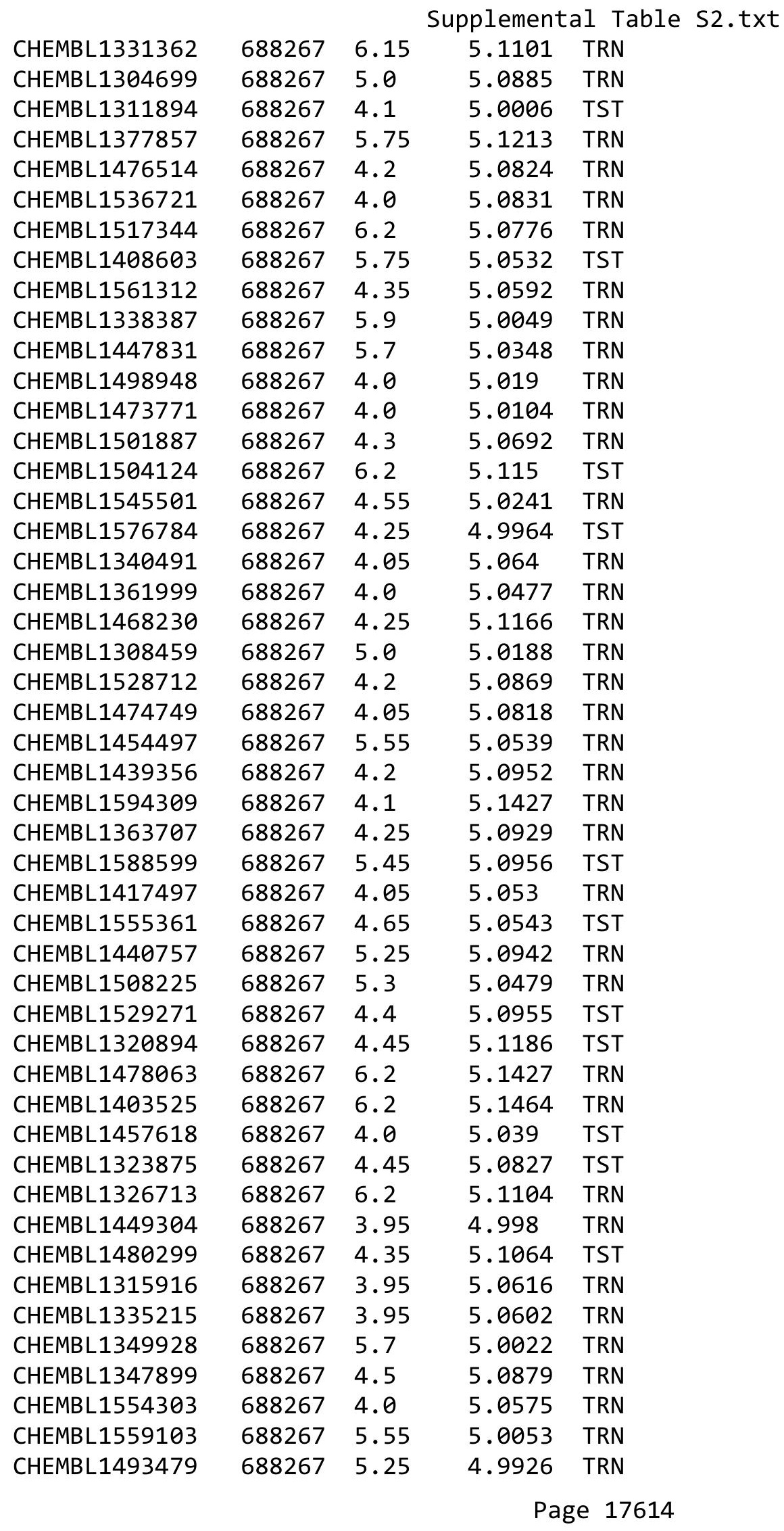




\begin{tabular}{|c|c|c|c|c|c|}
\hline & & & & & \\
\hline CHEMBL1376529 & 688267 & 4.5 & 5.0783 & TRN & \\
\hline CHEMBL1600077 & 688267 & 6.15 & 5.0514 & TRN & \\
\hline CHEMBL1319234 & 688267 & 4.35 & 5.1563 & TRN & \\
\hline CHEMBL1462484 & 688267 & 4.05 & 5.0859 & TRN & \\
\hline CHEMBL1452170 & 688267 & 5.0 & 5.0646 & TRN & \\
\hline CHEMBL1419290 & 688267 & 4.05 & 5.0462 & TRN & \\
\hline CHEMBL1556254 & 688267 & 4.25 & 4.9982 & TRN & \\
\hline CHEMBL1596322 & 688267 & 5.3 & 5.1045 & TST & \\
\hline CHEMBL1458238 & 688267 & 5.8 & $5.0710 e$ & 0000000001 & TRN \\
\hline CHEMBL1536577 & 688267 & 5.6 & 5.0559 & TRN & \\
\hline CHEMBL1365695 & 688267 & 4.05 & 5.0251 & TRN & \\
\hline CHEMBL1371065 & 688267 & 4.05 & 5.0408 & TST & \\
\hline CHEMBL1454243 & 688267 & 4.0 & 5.0264 & TRN & \\
\hline CHEMBL1417378 & 688267 & 4.3 & 5.0574 & TRN & \\
\hline CHEMBL1318731 & 688267 & 3.95 & 5.0947 & TRN & \\
\hline CHEMBL3192782 & 688267 & 5.45 & 5.0858 & TST & \\
\hline CHEMBL1375653 & 688267 & 6.2 & 5.0559 & TRN & \\
\hline CHEMBL1411437 & 688267 & 4.0 & 5.1034 & TRN & \\
\hline CHEMBL1707406 & 688267 & 4.45 & 5.0231 & TST & \\
\hline CHEMBL1474243 & 688267 & 4.05 & 5.1179 & TRN & \\
\hline CHEMBL1481841 & 688267 & 4.4 & 5.0081 & TRN & \\
\hline CHEMBL 3213176 & 688267 & 6.2 & 5.0125 & TRN & \\
\hline CHEMBL1331668 & 688267 & 5.55 & 5.0165 & TRN & \\
\hline CHEMBL1485695 & 688267 & 4.0 & 5.1387 & TRN & \\
\hline CHEMBL1325259 & 688267 & 5.1 & 5.0769 & TRN & \\
\hline CHEMBL1476854 & 688267 & 5.75 & 5.1037 & TRN & \\
\hline CHEMBL1339465 & 688267 & 3.95 & 5.0267 & TRN & \\
\hline CHEMBL1447383 & 688267 & 6.2 & 5.0497 & TST & \\
\hline CHEMBL1411444 & 688267 & 5.4 & 5.135 & TRN & \\
\hline CHEMBL3211676 & 688267 & 6.0 & 5.0528 & TST & \\
\hline CHEMBL1536143 & 688267 & 5.25 & 5.0848 & TRN & \\
\hline CHEMBL1323610 & 688267 & 6.2 & 5.0354 & TST & \\
\hline CHEMBL1569444 & 688267 & 5.15 & 5.0469 & TRN & \\
\hline CHEMBL1512000 & 688267 & 6.0 & 5.0495 & TRN & \\
\hline CHEMBL1539988 & 688267 & 5.75 & 5.0207 & TRN & \\
\hline CHEMBL1396440 & 688267 & 5.35 & 4.9754 & TST & \\
\hline CHEMBL182350 & 688267 & 4.0 & 5.0498 & TST & \\
\hline CHEMBL1551250 & 688267 & 6.2 & 5.0664 & TRN & \\
\hline CHEMBL3208040 & 688267 & 6.25 & 5.0099 & TRN & \\
\hline CHEMBL1336855 & 688267 & 4.4 & 5.0649 & TRN & \\
\hline CHEMBL1475930 & 688267 & 4.0 & 5.1091 & TRN & \\
\hline CHEMBL1339066 & 688267 & 4.65 & 5.0399 & TST & \\
\hline CHEMBL1425461 & 688267 & 6.2 & 5.099 & TRN & \\
\hline CHEMBL1334758 & 688267 & 6.2 & 5.048 & TRN & \\
\hline CHEMBL1418924 & 688267 & 5.55 & 5.0563 & TRN & \\
\hline CHEMBL1528692 & 688267 & 4.2 & 5.096 & TRN & \\
\hline CHEMBL1479231 & 688267 & 5.5 & 4.9955 & TST & \\
\hline CHEMBL1441190 & 688267 & 4.65 & 5.0388 & TRN & \\
\hline & & & & 1761 & \\
\hline
\end{tabular}




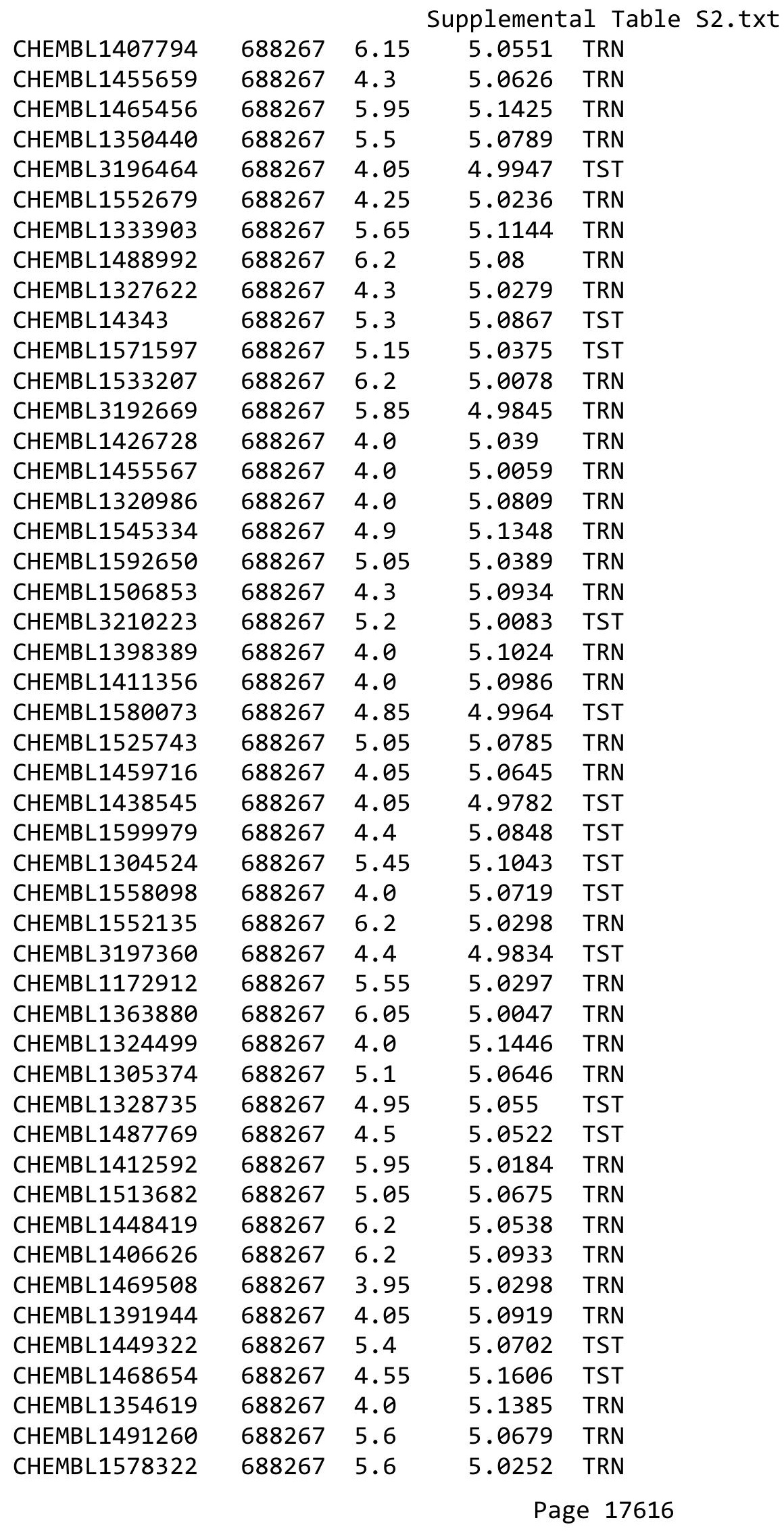




\begin{tabular}{|c|c|c|c|c|c|}
\hline \\
\hline CHEMBL1359707 & 688267 & 5.1 & 5.0865 & TST & \\
\hline CHEMBL1488906 & 688267 & 4.0 & 5.0598 & TRN & \\
\hline CHEMBL1356860 & 688267 & 4.0 & 4.9942 & TRN & \\
\hline CHEMBL1486656 & 688267 & 6.15 & 5.1227 & TST & \\
\hline CHEMBL1587105 & 688267 & 5.35 & 5.0615 & TRN & \\
\hline CHEMBL1607768 & 688267 & 4.3 & 5.0283 & TRN & \\
\hline CHEMBL1418386 & 688267 & 4.6 & 5.092 & TST & \\
\hline CHEMBL1513546 & 688267 & 6.2 & 5.0626 & TRN & \\
\hline CHEMBL1505089 & 688267 & 3.9 & 4.9993 & TRN & \\
\hline CHEMBL1460733 & 688267 & 4.0 & 5.0546 & TST & \\
\hline CHEMBL1363273 & 688267 & 6.2 & 5.1067 & TRN & \\
\hline CHEMBL1496209 & 688267 & 4.35 & 5.0477 & TRN & \\
\hline CHEMBL1497893 & 688267 & 4.4 & 5.0161 & TRN & \\
\hline CHEMBL1502950 & 688267 & 4.0 & 5.035 & TST & \\
\hline CHEMBL1560018 & 688267 & 4.05 & 5.0678 & TRN & \\
\hline CHEMBL1347084 & 688267 & 4.05 & 5.0747 & TST & \\
\hline CHEMBL1502402 & 688267 & 5.55 & 5.0415 & TRN & \\
\hline CHEMBL1322481 & 688267 & 4.3 & 5.0917 & TRN & \\
\hline CHEMBL1533933 & 688267 & 3.95 & 5.0719 & TRN & \\
\hline CHEMBL 2361495 & 688267 & 4.35 & 4.9656 & TST & \\
\hline CHEMBL1341999 & 688267 & 4.3 & 5.0852 & TRN & \\
\hline CHEMBL1449332 & 688267 & 6.2 & 5.0879 & TST & \\
\hline CHEMBL1567813 & 688267 & 5.95 & 5.0572 & TRN & \\
\hline CHEMBL1440834 & 688267 & 5.9 & 5.0802 & TRN & \\
\hline CHEMBL1397679 & 688267 & 4.0 & 5.0021 & TRN & \\
\hline CHEMBL1441010 & 688267 & 5.0 & 5.0716 & TST & \\
\hline CHEMBL1601896 & 688267 & 6.15 & 5.0532 & TST & \\
\hline CHEMBL1444260 & 688267 & 5.5 & 5.0884 & TST & \\
\hline CHEMBL3199537 & 688267 & 6.2 & 5.0343 & TST & \\
\hline CHEMBL1509863 & 688267 & 4.6 & 5.0932 & TST & \\
\hline CHEMBL1559724 & 688267 & 5.5 & 5.0944 & TRN & \\
\hline CHEMBL1405102 & 688267 & 5.3 & 5.0157 & TRN & \\
\hline CHEMBL1579373 & 688267 & 3.95 & 5.1652 & TRN & \\
\hline CHEMBL1574764 & 688267 & 4.1 & 5.0588 & TST & \\
\hline CHEMBL1425532 & 688267 & 5.15 & 5.0352 & TRN & \\
\hline CHEMBL1490993 & 688267 & 5.05 & 5.0935 & TRN & \\
\hline CHEMBL1449429 & 688267 & 3.95 & 5.1127 & TRN & \\
\hline CHEMBL1418715 & 688267 & 5.85 & 5.1269 & TST & \\
\hline CHEMBL1545895 & 688267 & 4.6 & 5.06800 & 00000000005 & TRN \\
\hline CHEMBL1504909 & 688267 & 4.6 & 5.04 & TRN & \\
\hline CHEMBL1558562 & 688267 & 4.3 & 5.0431 & TST & \\
\hline CHEMBL1515884 & 688267 & 5.15 & 5.1075 & TRN & \\
\hline CHEMBL1407399 & 688267 & 4.4 & 5.0847 & TST & \\
\hline CHEMBL1440448 & 688267 & 4.35 & 5.126 & TRN & \\
\hline CHEMBL1461461 & 688267 & 4.4 & 5.0119 & TRN & \\
\hline CHEMBL1428624 & 688267 & 4.05 & 5.0772 & TST & \\
\hline CHEMBL1519459 & 688267 & 6.2 & 5.1381 & TRN & \\
\hline CHEMBL1485442 & 688267 & 5.0 & 5.046 & TST & \\
\hline
\end{tabular}




\begin{tabular}{|c|c|c|c|c|c|}
\hline \multicolumn{6}{|c|}{ Supplemental Table s2.txt } \\
\hline CHEMBL1497274 & 688267 & 5.25 & 5.0023 & TRN & \\
\hline CHEMBL1438823 & 688267 & 4.4 & 5.0476 & TRN & \\
\hline CHEMBL1475320 & 688267 & 4.0 & 5.0733 & TRN & \\
\hline CHEMBL1537415 & 688267 & 5.95 & 5.0311 & TST & \\
\hline CHEMBL1554219 & 688267 & 5.05 & 5.1155 & TRN & \\
\hline CHEMBL1356754 & 688267 & 6.5 & 5.1765 & TRN & \\
\hline CHEMBL1475419 & 688267 & 6.2 & 5.0484 & TRN & \\
\hline CHEMBL1449678 & 688267 & 4.0 & 5.0275 & TRN & \\
\hline CHEMBL1363667 & 688267 & 4.6 & 5.1436 & TRN & \\
\hline CHEMBL1440703 & 688267 & 4.0 & 5.0446 & TST & \\
\hline CHEMBL1386640 & 688267 & 6.0 & 5.0124 & TST & \\
\hline CHEMBL1417622 & 688267 & 5.3 & 4.9994 & TRN & \\
\hline CHEMBL1316261 & 688267 & 6.25 & 4.9591 & TST & \\
\hline CHEMBL1512826 & 688267 & 6.0 & 5.0563 & TRN & \\
\hline CHEMBL1598859 & 688267 & 6.0 & 5.1023 & TRN & \\
\hline CHEMBL1612877 & 688267 & 4.6 & 5.0844 & TRN & \\
\hline CHEMBL1485418 & 688267 & 5.3 & 5.0285 & TST & \\
\hline CHEMBL1337041 & 688267 & 5.1 & 5.0216 & TST & \\
\hline CHEMBL1357323 & 688267 & 5.45 & 5.1362 & TRN & \\
\hline CHEMBL1492337 & 688267 & 6.2 & 5.0402 & TRN & \\
\hline CHEMBL1592851 & 688267 & 3.95 & 4.9982 & TRN & \\
\hline CHEMBL1318636 & 688267 & 4.7 & 5.0851 & TRN & \\
\hline CHEMBL1566048 & 688267 & 4.35 & 5.0465 & TRN & \\
\hline CHEMBL1530472 & 688267 & 5.0 & 5.098 & TRN & \\
\hline CHEMBL1996757 & 688267 & 4.8 & 5.06800 & 00000000005 & TST \\
\hline CHEMBL1326511 & 688267 & 4.45 & 4.9877 & TRN & \\
\hline CHEMBL1494009 & 688267 & 6.25 & 5.0068 & TRN & \\
\hline CHEMBL3191446 & 688267 & 4.55 & 5.0496 & TST & \\
\hline CHEMBL1485755 & 688267 & 4.95 & 5.0546 & TRN & \\
\hline CHEMBL1551094 & 688267 & 4.85 & 5.0689 & TRN & \\
\hline CHEMBL1523240 & 688267 & 5.5 & 5.0581 & TST & \\
\hline CHEMBL1514115 & 688267 & 5.65 & 5.0998 & TRN & \\
\hline CHEMBL1358435 & 688267 & 5.8 & 5.0178 & TRN & \\
\hline CHEMBL1577583 & 688267 & 6.15 & 5.0312 & TRN & \\
\hline CHEMBL1383717 & 688267 & 5.0 & 5.0347 & TRN & \\
\hline CHEMBL1384351 & 688267 & 5.55 & 5.0852 & TST & \\
\hline CHEMBL1545908 & 688267 & 5.8 & 5.0491 & TRN & \\
\hline CHEMBL1541479 & 688267 & 4.15 & 5.1226 & TRN & \\
\hline CHEMBL1373629 & 688267 & 4.25 & 5.0728 & TRN & \\
\hline CHEMBL1484620 & 688267 & 6.15 & 5.1075 & TRN & \\
\hline CHEMBL1407384 & 688267 & 4.1 & 5.059 & TST & \\
\hline CHEMBL1524968 & 688267 & 4.6 & 5.1142 & TRN & \\
\hline CHEMBL1354418 & 688267 & 5.7 & 5.0159 & TRN & \\
\hline CHEMBL1303667 & 688267 & 4.05 & 5.0429 & TST & \\
\hline CHEMBL1357944 & 688267 & 4.45 & 5.0691 & TRN & \\
\hline CHEMBL1440135 & 688267 & 4.0 & 5.0737 & TRN & \\
\hline CHEMBL1368504 & 688267 & 4.25 & 5.0218 & TST & \\
\hline CHEMBL1452344 & 688267 & 4.6 & 5.0869 & TRN & \\
\hline
\end{tabular}




\begin{tabular}{|c|c|c|c|c|c|}
\hline & & \multicolumn{4}{|c|}{ Supplemental Table S2.txt } \\
\hline CHEMBL1439834 & 688267 & 4.4 & 5.0299 & TST & \\
\hline CHEMBL1459358 & 688267 & 4.65 & 5.101 & TRN & \\
\hline CHEMBL1436233 & 688267 & 4.4 & 5.1027 & TRN & \\
\hline CHEMBL1528049 & 688267 & 4.05 & 4.9874 & TRN & \\
\hline CHEMBL3207317 & 688267 & 4.4 & 5.0447 & TST & \\
\hline CHEMBL1353122 & 688267 & 4.35 & $5.0280 e$ & 00000000005 & TRN \\
\hline CHEMBL1377257 & 688267 & 6.25 & 5.0421 & TRN & \\
\hline CHEMBL1457072 & 688267 & 6.2 & 5.0958 & TST & \\
\hline CHEMBL1306131 & 688267 & 6.15 & 5.0432 & TST & \\
\hline CHEMBL1324973 & 688267 & 5.55 & 5.1276 & TRN & \\
\hline CHEMBL1412322 & 688267 & 5.9 & 5.0629 & TST & \\
\hline CHEMBL1440106 & 688267 & 4.3 & 5.0217 & TST & \\
\hline CHEMBL1566240 & 688267 & 5.4 & 5.0188 & TRN & \\
\hline CHEMBL1319542 & 688267 & 4.05 & 5.0464 & TRN & \\
\hline CHEMBL1471062 & 688267 & 5.9 & 5.0245 & TRN & \\
\hline CHEMBL1552095 & 688267 & 5.3 & 5.0694 & TST & \\
\hline CHEMBL1382678 & 688267 & 6.2 & 5.0362 & TRN & \\
\hline CHEMBL1439022 & 688267 & 4.3 & 5.0475 & TST & \\
\hline CHEMBL1316499 & 688267 & 5.85 & 5.0027 & TRN & \\
\hline CHEMBL3192358 & 688267 & 6.2 & 5.1112 & TRN & \\
\hline CHEMBL1473788 & 688267 & 5.25 & 5.0569 & TRN & \\
\hline CHEMBL1548152 & 688267 & 4.35 & 5.0512 & TRN & \\
\hline CHEMBL1515250 & 688267 & 5.1 & 5.0627 & TRN & \\
\hline CHEMBL582259 & 688267 & 5.4 & 5.035 & TST & \\
\hline CHEMBL3211392 & 688267 & 4.85 & 5.0924 & TRN & \\
\hline CHEMBL1584114 & 688267 & 5.3 & 5.0309 & TST & \\
\hline CHEMBL223179 & 688267 & 4.7 & 5.0448 & TST & \\
\hline CHEMBL1501412 & 688267 & 3.95 & 5.032 & TRN & \\
\hline CHEMBL1534970 & 688267 & 5.65 & 5.1093 & TRN & \\
\hline CHEMBL1610599 & 688267 & 4.3 & 5.091 & TRN & \\
\hline CHEMBL1339774 & 688267 & 4.3 & 5.0545 & TRN & \\
\hline CHEMBL1431538 & 688267 & 6.25 & 5.0973 & TRN & \\
\hline CHEMBL1570911 & 688267 & 4.0 & 5.1175 & TST & \\
\hline CHEMBL1459338 & 688267 & 4.15 & 5.1221 & TRN & \\
\hline CHEMBL1434647 & 688267 & 4.0 & 5.0148 & TRN & \\
\hline CHEMBL1533339 & 688267 & 5.9 & 5.0057 & TRN & \\
\hline CHEMBL1319599 & 688267 & 5.1 & 5.0397 & TRN & \\
\hline CHEMBL1404748 & 688267 & 5.05 & 5.0478 & TST & \\
\hline CHEMBL1513826 & 688267 & 5.35 & 5.0805 & TRN & \\
\hline CHEMBL1609469 & 688267 & 6.15 & 5.0972 & TRN & \\
\hline CHEMBL1335373 & 688267 & 3.95 & 5.0546 & TST & \\
\hline CHEMBL1524723 & 688267 & 4.3 & 5.1691 & TRN & \\
\hline CHEMBL1376550 & 688267 & 6.2 & 5.0474 & TRN & \\
\hline CHEMBL1586193 & 688267 & 5.0 & 5.0386 & TRN & \\
\hline CHEMBL1562423 & 688267 & 4.0 & 5.0684 & TRN & \\
\hline CHEMBL1436402 & 688267 & 4.85 & 5.1264 & TRN & \\
\hline CHEMBL1303250 & 688267 & 4.95 & 5.0413 & TRN & \\
\hline CHEMBL1322147 & 688267 & 5.3 & 5.015 & TST & \\
\hline
\end{tabular}




\begin{tabular}{|c|c|c|c|c|c|}
\hline \\
\hline CHEMBL1442877 & 688267 & 5.8 & 5.0324 & TST & \\
\hline CHEMBL1551197 & 688267 & 4.1 & 5.0394 & TRN & \\
\hline CHEMBL1364553 & 688267 & 4.0 & 5.0463 & TST & \\
\hline CHEMBL1538940 & 688267 & 5.5 & 5.0735 & TRN & \\
\hline CHEMBL1349451 & 688267 & 4.35 & 4.9984 & TST & \\
\hline CHEMBL1373720 & 688267 & 5.55 & 5.0914 & TRN & \\
\hline CHEMBL1406372 & 688267 & 6.2 & 5.0174 & TRN & \\
\hline CHEMBL1385697 & 688267 & 5.15 & 5.1068 & TST & \\
\hline CHEMBL1463864 & 688267 & 5.75 & 5.1356 & TRN & \\
\hline CHEMBL1550255 & 688267 & 6.0 & 5.0487 & TRN & \\
\hline CHEMBL3193422 & 688267 & 6.05 & 5.0295 & TRN & \\
\hline CHEMBL1537623 & 688267 & 4.0 & 5.074 & TRN & \\
\hline CHEMBL1440077 & 688267 & 5.3 & 5.0951 & TRN & \\
\hline CHEMBL3211506 & 688267 & 5.35 & 5.0041 & TRN & \\
\hline CHEMBL1411761 & 688267 & 5.45 & 5.0141 & TST & \\
\hline CHEMBL1480166 & 688267 & 4.05 & 5.0536 & TST & \\
\hline CHEMBL1415122 & 688267 & 5.8 & 5.1197 & TST & \\
\hline CHEMBL1604404 & 688267 & 4.0 & 5.1192 & TRN & \\
\hline CHEMBL1391847 & 688267 & 6.1 & 5.0752 & TRN & \\
\hline CHEMBL1349806 & 688267 & 5.3 & 5.0142 & TRN & \\
\hline CHEMBL1602685 & 688267 & 6.2 & 5.0161 & TRN & \\
\hline CHEMBL1425518 & 688267 & 6.2 & 5.0633 & TRN & \\
\hline CHEMBL1587963 & 688267 & 4.0 & 5.0563 & TRN & \\
\hline CHEMBL1315125 & 688267 & 4.0 & 5.0944 & TRN & \\
\hline CHEMBL1437532 & 688267 & 5.8 & 5.07100 & 0000000001 & TRN \\
\hline CHEMBL1398018 & 688267 & 4.05 & 5.0806 & TRN & \\
\hline CHEMBL1435751 & 688267 & 4.35 & 4.9703 & TRN & \\
\hline CHEMBL1588461 & 688267 & 6.15 & 5.0766 & TRN & \\
\hline CHEMBL1564676 & 688267 & 4.5 & 5.0165 & TRN & \\
\hline CHEMBL1371951 & 688267 & 4.1 & 5.0521 & TRN & \\
\hline CHEMBL1429964 & 688267 & 3.95 & 5.0675 & TRN & \\
\hline CHEMBL1353426 & 688267 & 5.55 & 5.0297 & TRN & \\
\hline CHEMBL1380769 & 688267 & 4.0 & 5.0228 & TRN & \\
\hline CHEMBL3212135 & 688267 & 4.3 & 5.0035 & TRN & \\
\hline CHEMBL1413521 & 688267 & 5.0 & 5.0174 & TRN & \\
\hline CHEMBL1316689 & 688267 & 4.05 & 5.0924 & TRN & \\
\hline CHEMBL1423085 & 688267 & 6.2 & 4.9951 & TRN & \\
\hline CHEMBL1502533 & 688267 & 6.5 & 5.1629 & TRN & \\
\hline CHEMBL1348661 & 688267 & 4.15 & 5.0848 & TST & \\
\hline CHEMBL1581308 & 688267 & 4.8 & 5.0304 & TST & \\
\hline CHEMBL1303935 & 688267 & 5.05 & 5.0394 & TRN & \\
\hline CHEMBL1522543 & 688267 & 5.25 & 5.0076 & TRN & \\
\hline CHEMBL1571912 & 688267 & 4.05 & 5.0169 & TRN & \\
\hline CHEMBL1585632 & 688267 & 4.0 & 5.0021 & TRN & \\
\hline CHEMBL1318363 & 688267 & 5.15 & 5.1064 & TRN & \\
\hline CHEMBL1325391 & 688267 & 5.95 & 5.0648 & TRN & \\
\hline CHEMBL1530423 & 688267 & 6.25 & 4.9843 & TRN & \\
\hline CHEMBL1343554 & 688267 & 5.55 & 5.1012 & TRN & \\
\hline & & & & 7620 & \\
\hline
\end{tabular}




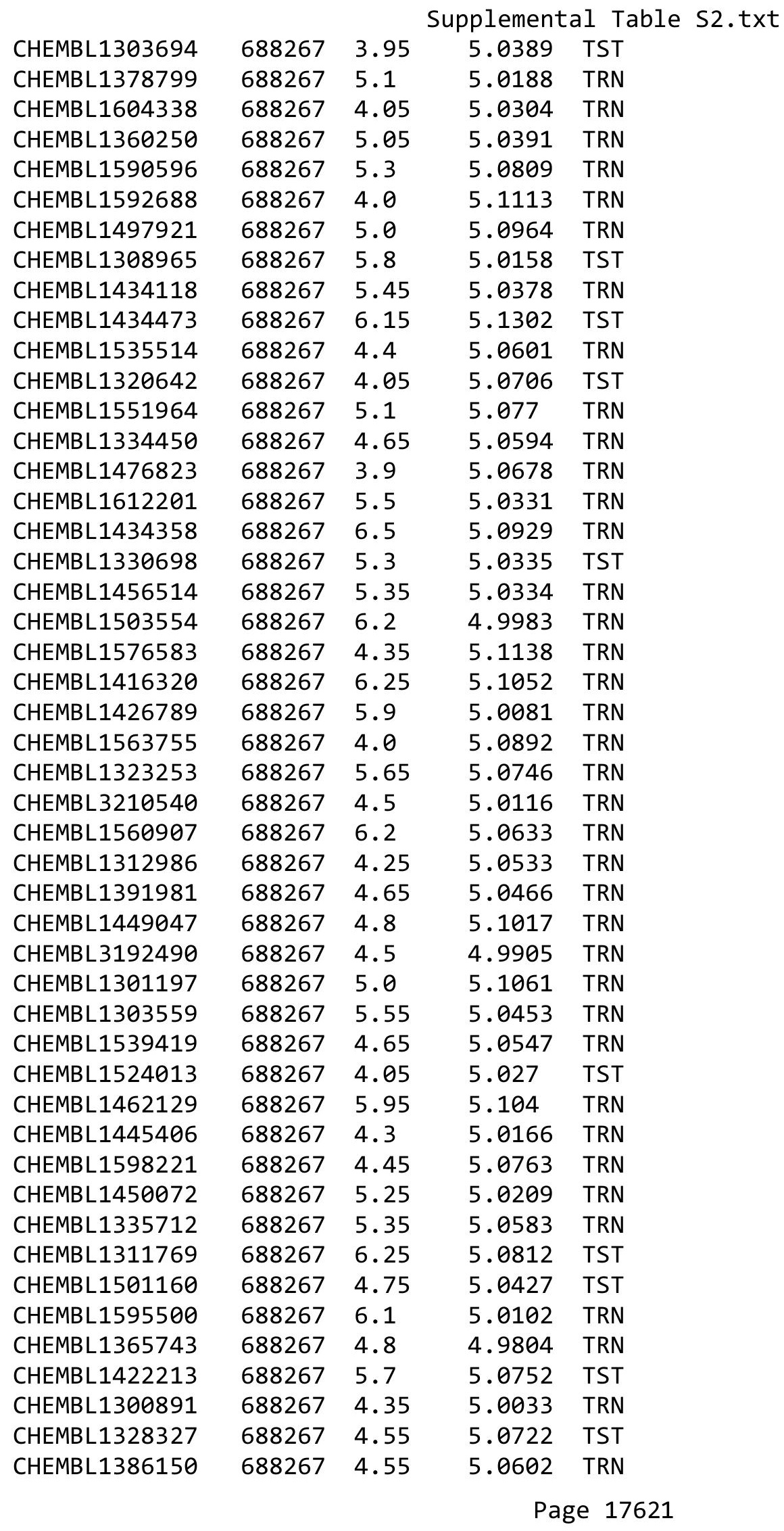




\begin{tabular}{|c|c|c|c|c|c|}
\hline \\
\hline CHEMBL1503444 & 688267 & 5.3 & 5.084 & TRN & \\
\hline CHEMBL1406692 & 688267 & 5.8 & 5.0805 & TRN & \\
\hline CHEMBL1472077 & 688267 & 6.2 & 5.0415 & TST & \\
\hline CHEMBL1377699 & 688267 & 5.4 & 5.0158 & TRN & \\
\hline CHEMBL1574780 & 688267 & 5.3 & 5.1319 & TST & \\
\hline CHEMBL1325470 & 688267 & 3.95 & 5.0507 & TRN & \\
\hline CHEMBL1464477 & 688267 & 6.1 & 5.0081 & TST & \\
\hline CHEMBL1346629 & 688267 & 5.5 & 5.0353 & TRN & \\
\hline CHEMBL1549363 & 688267 & 5.8 & 5.0705 & TST & \\
\hline CHEMBL1320146 & 688267 & 6.15 & 5.1174 & TRN & \\
\hline CHEMBL1580490 & 688267 & 4.5 & 5.0193 & TRN & \\
\hline CHEMBL1406245 & 688267 & 4.35 & 5.1484 & TRN & \\
\hline CHEMBL1379967 & 688267 & 5.7 & 4.9842 & TRN & \\
\hline CHEMBL1460652 & 688267 & 4.3 & 5.0067 & TRN & \\
\hline CHEMBL1590856 & 688267 & 5.85 & 5.05399 & 9999999999 & TRN \\
\hline CHEMBL1552417 & 688267 & 4.05 & 5.0117 & TST & \\
\hline CHEMBL3191972 & 688267 & 4.1 & 4.9748 & TRN & \\
\hline CHEMBL1505313 & 688267 & 4.95 & 5.0791 & TST & \\
\hline CHEMBL2373689 & 688267 & 5.1 & 5.0842 & TRN & \\
\hline CHEMBL1457214 & 688267 & 4.55 & 5.0767 & TST & \\
\hline CHEMBL1356408 & 688267 & 3.95 & 5.0064 & TRN & \\
\hline CHEMBL1506196 & 688267 & 5.75 & 5.039 & TRN & \\
\hline CHEMBL1593149 & 688267 & 6.2 & 5.1408 & TRN & \\
\hline CHEMBL1602914 & 688267 & 5.25 & 5.0266 & TST & \\
\hline CHEMBL1299757 & 688267 & 5.25 & 5.0186 & TST & \\
\hline CHEMBL1417734 & 688267 & 6.15 & 5.1212 & TRN & \\
\hline CHEMBL1535255 & 688267 & 6.2 & 5.1132 & TRN & \\
\hline CHEMBL1364469 & 688267 & 6.2 & 5.0445 & TRN & \\
\hline CHEMBL1965155 & 688267 & 4.05 & 4.9937 & TRN & \\
\hline CHEMBL1582845 & 688267 & 4.25 & 5.0889 & TST & \\
\hline CHEMBL1474807 & 688267 & 5.2 & 5.1014 & TRN & \\
\hline CHEMBL1402584 & 688267 & 5.85 & 4.9967 & TRN & \\
\hline CHEMBL1498344 & 688267 & 4.0 & 5.0983 & TST & \\
\hline CHEMBL1309264 & 688267 & 4.35 & 5.0361 & TRN & \\
\hline CHEMBL1432072 & 688267 & 4.4 & 5.0824 & TST & \\
\hline CHEMBL1377176 & 688267 & 5.45 & 5.044 & TST & \\
\hline CHEMBL1323462 & 688267 & 6.2 & 5.025 & TRN & \\
\hline CHEMBL1428562 & 688267 & 4.3 & 4.9806 & TST & \\
\hline CHEMBL1368064 & 688267 & 6.15 & 5.142 & TRN & \\
\hline CHEMBL1408107 & 688267 & 4.8 & 5.0079 & TST & \\
\hline CHEMBL1518990 & 688267 & 5.7 & 5.0268 & TRN & \\
\hline CHEMBL1377355 & 688267 & 6.15 & 5.0302 & TRN & \\
\hline CHEMBL1588626 & 688267 & 4.0 & 5.0143 & TRN & \\
\hline CHEMBL1480079 & 688267 & 5.35 & 4.9911 & TRN & \\
\hline CHEMBL1582574 & 688267 & 4.05 & 5.0821 & TRN & \\
\hline CHEMBL1592194 & 688267 & 5.45 & 5.0725 & TRN & \\
\hline CHEMBL1507171 & 688267 & 4.45 & 5.0565 & TST & \\
\hline CHEMBL1588191 & 688267 & 5.3 & 5.0656 & TRN & \\
\hline
\end{tabular}




\begin{tabular}{|c|c|c|c|c|}
\hline \multicolumn{5}{|c|}{ Supplemental Table S2.txt } \\
\hline CHEMBL1328818 & 688267 & 4.45 & 5.0783 & TRN \\
\hline CHEMBL1336367 & 688267 & 5.95 & 5.1119 & TRN \\
\hline CHEMBL1299402 & 688267 & 5.55 & 5.0211 & TRN \\
\hline CHEMBL1457952 & 688267 & 4.3 & 5.0852 & TST \\
\hline CHEMBL1538747 & 688267 & 4.05 & 4.9979 & TRN \\
\hline CHEMBL1404457 & 688267 & 4.0 & 5.0054 & TRN \\
\hline CHEMBL1462223 & 688267 & 4.85 & 5.0917 & TST \\
\hline CHEMBL1398785 & 688267 & 6.1 & 5.0504 & TST \\
\hline CHEMBL1425265 & 688267 & 5.75 & 5.0193 & TRN \\
\hline CHEMBL 1358670 & 688267 & 3.95 & 5.0431 & TRN \\
\hline CHEMBL1417183 & 688267 & 4.0 & 5.051 & TST \\
\hline CHEMBL1351526 & 688267 & 4.8 & 5.0399 & TRN \\
\hline CHEMBL1469778 & 688267 & 5.6 & 5.082 & TRN \\
\hline CHEMBL1516427 & 688267 & 6.2 & 5.0091 & TRN \\
\hline CHEMBL1596614 & 688267 & 6.5 & 5.0972 & TRN \\
\hline CHEMBL1352911 & 688267 & 4.4 & 5.0294 & TRN \\
\hline CHEMBL1502763 & 688267 & 6.5 & 5.1312 & TRN \\
\hline CHEMBL1600993 & 688267 & 6.15 & 5.041 & TRN \\
\hline CHEMBL1371014 & 688267 & 5.75 & 5.0127 & TRN \\
\hline CHEMBL1359580 & 688267 & 3.95 & 5.033 & TRN \\
\hline CHEMBL1447260 & 688267 & 5.45 & 5.0787 & TRN \\
\hline CHEMBL3211515 & 688267 & 4.0 & 4.9739 & TRN \\
\hline CHEMBL1473294 & 688267 & 6.2 & 5.0303 & TST \\
\hline CHEMBL1318385 & 688267 & 5.25 & 5.0286 & TRN \\
\hline CHEMBL1458910 & 688267 & 4.1 & 5.0101 & TST \\
\hline CHEMBL 2006780 & 688267 & 6.2 & 5.0663 & TST \\
\hline CHEMBL1429212 & 688267 & 5.05 & 5.0603 & TRN \\
\hline CHEMBL1480404 & 688267 & 4.1 & 5.0399 & TRN \\
\hline CHEMBL1424127 & 688267 & 6.2 & 5.0668 & TRN \\
\hline CHEMBL1322594 & 688267 & 6.05 & 5.0791 & TRN \\
\hline CHEMBL1318103 & 688267 & 4.0 & 4.9983 & TST \\
\hline CHEMBL1373628 & 688267 & 6.2 & 5.0094 & TRN \\
\hline CHEMBL1394397 & 688267 & 5.85 & 5.0482 & TRN \\
\hline CHEMBL1376520 & 688267 & 6.2 & 5.0246 & TRN \\
\hline CHEMBL1461528 & 688267 & 5.0 & 5.0735 & TRN \\
\hline CHEMBL1540347 & 688267 & 6.15 & 5.0137 & TRN \\
\hline CHEMBL1356665 & 688267 & 4.9 & 5.1092 & TRN \\
\hline CHEMBL1380959 & 688267 & 6.2 & 5.0215 & TRN \\
\hline CHEMBL3189562 & 688267 & 4.05 & 4.9985 & TST \\
\hline CHEMBL1575721 & 688267 & 5.85 & 5.1103 & TRN \\
\hline CHEMBL1435992 & 688267 & 4.35 & 5.0659 & TST \\
\hline CHEMBL1349862 & 688267 & 4.2 & 5.08 & TRN \\
\hline CHEMBL1435915 & 688267 & 4.15 & 5.0983 & TRN \\
\hline CHEMBL1363564 & 688267 & 4.6 & 5.0349 & TST \\
\hline CHEMBL585594 & 688267 & 4.8 & 5.0546 & TRN \\
\hline CHEMBL1381040 & 688267 & 4.4 & 5.1164 & TRN \\
\hline CHEMBL1388015 & 688267 & 3.95 & 5.0125 & TRN \\
\hline CHEMBL1598138 & 688267 & 4.35 & 5.0753 & TRN \\
\hline
\end{tabular}




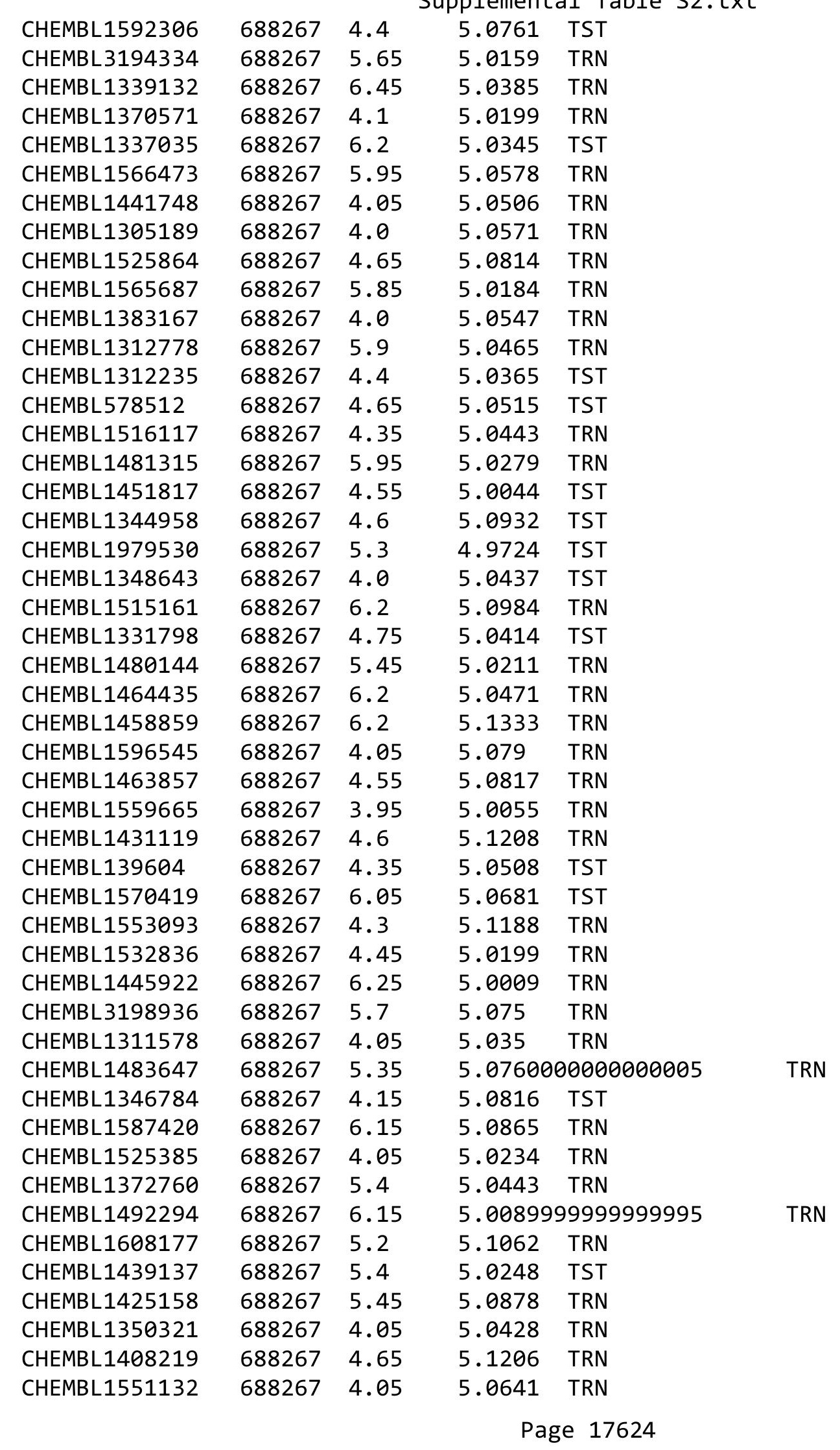




\begin{tabular}{|c|c|c|c|c|c|}
\hline & & \multicolumn{4}{|c|}{ Supplemental Table s2.txt } \\
\hline CHEMBL1612751 & 688267 & 4.55 & 5.0706 & TRN & \\
\hline CHEMBL1594903 & 688267 & 4.4 & 5.0797 & TRN & \\
\hline CHEMBL1516684 & 688267 & 4.0 & 5.072 & TRN & \\
\hline CHEMBL1306120 & 688267 & 4.35 & 5.0916 & TRN & \\
\hline CHEMBL1570431 & 688267 & 4.0 & 5.1359 & TRN & \\
\hline CHEMBL1314520 & 688267 & 4.0 & 5.1017 & TRN & \\
\hline CHEMBL1312832 & 688267 & 4.05 & 5.0876 & TRN & \\
\hline CHEMBL1395367 & 688267 & 5.9 & 5.0966 & TRN & \\
\hline CHEMBL1362841 & 688267 & 5.65 & 5.0179 & TRN & \\
\hline CHEMBL1578676 & 688267 & 4.5 & 4.987 & TST & \\
\hline CHEMBL1606424 & 688267 & 4.35 & 5.0018 & TRN & \\
\hline CHEMBL1364786 & 688267 & 6.2 & 5.1119 & TST & \\
\hline CHEMBL69880 & 688267 & 5.3 & 5.0486 & TRN & \\
\hline CHEMBL1570039 & 688267 & 6.2 & 5.0807 & TRN & \\
\hline CHEMBL1458665 & 688267 & 5.55 & 5.0395 & TST & \\
\hline CHEMBL1336605 & 688267 & 5.35 & 5.0377 & TRN & \\
\hline CHEMBL1557381 & 688267 & 4.25 & 5.0389 & TST & \\
\hline CHEMBL1408248 & 688267 & 4.35 & 5.022 & TRN & \\
\hline CHEMBL1373961 & 688267 & 5.3 & 5.0895 & TRN & \\
\hline CHEMBL1474942 & 688267 & 6.2 & 5.0513 & TRN & \\
\hline CHEMBL1609102 & 688267 & 4.1 & 4.9928 & TRN & \\
\hline CHEMBL1520132 & 688267 & 6.0 & 5.11600 & 00000000005 & TRN \\
\hline CHEMBL1524996 & 688267 & 4.5 & 5.0652 & TRN & \\
\hline CHEMBL569708 & 688267 & 3.95 & 5.0669 & TRN & \\
\hline CHEMBL1325308 & 688267 & 5.3 & 5.0735 & TRN & \\
\hline CHEMBL1595551 & 688267 & 5.3 & 5.0732 & TRN & \\
\hline CHEMBL1539876 & 688267 & 6.2 & 4.9983 & TST & \\
\hline CHEMBL1496011 & 688267 & 5.85 & 5.0056 & TRN & \\
\hline CHEMBL3192939 & 688267 & 6.2 & 5.0122 & TST & \\
\hline CHEMBL1463968 & 688267 & 4.4 & 4.9918 & TST & \\
\hline CHEMBL1498640 & 688267 & 5.35 & 5.1046 & TRN & \\
\hline CHEMBL1320514 & 688267 & 5.45 & 4.9954 & TRN & \\
\hline CHEMBL1578254 & 688267 & 5.6 & 5.0913 & TRN & \\
\hline CHEMBL1312888 & 688267 & 5.0 & 4.9844 & TRN & \\
\hline CHEMBL1605477 & 688267 & 4.0 & 5.0496 & TST & \\
\hline CHEMBL1421030 & 688267 & 4.0 & 5.0615 & TRN & \\
\hline CHEMBL1605772 & 688267 & 5.85 & 5.0974 & TST & \\
\hline CHEMBL1498366 & 688267 & 4.35 & 5.09 & TRN & \\
\hline CHEMBL1392933 & 688267 & 5.4 & 5.1375 & TRN & \\
\hline CHEMBL1350845 & 688267 & 4.3 & 5.0203 & TST & \\
\hline CHEMBL1471573 & 688267 & 5.35 & 5.0983 & TRN & \\
\hline CHEMBL1338894 & 688267 & 6.5 & 5.0458 & TRN & \\
\hline CHEMBL1461976 & 688267 & 4.05 & 5.0 & TRN & \\
\hline CHEMBL1390056 & 688267 & 4.3 & 5.0038 & TRN & \\
\hline CHEMBL1321097 & 688267 & 5.55 & 5.0049 & TRN & \\
\hline CHEMBL1527570 & 688267 & 4.05 & 4.9875 & TRN & \\
\hline CHEMBL1593884 & 688267 & 3.95 & 5.1072 & TRN & \\
\hline CHEMBL1377935 & 688267 & 6.2 & 5.0464 & TRN & \\
\hline
\end{tabular}




\begin{tabular}{|c|c|c|c|c|c|}
\hline \\
\hline CHEMBL1332246 & 688267 & 4.0 & 5.0194 & TRN & \\
\hline CHEMBL1478877 & 688267 & 5.3 & 5.1255 & TST & \\
\hline CHEMBL1475771 & 688267 & 5.05 & 5.0612 & TRN & \\
\hline CHEMBL1606650 & 688267 & 4.65 & 5.0602 & TST & \\
\hline CHEMBL1550149 & 688267 & 4.55 & 5.0867 & TRN & \\
\hline CHEMBL1522852 & 688267 & 4.7 & 5.0736 & TRN & \\
\hline CHEMBL1529414 & 688267 & 5.6 & 5.0409 & TRN & \\
\hline CHEMBL1319578 & 688267 & 4.05 & 5.0563 & TRN & \\
\hline CHEMBL1504050 & 688267 & 6.2 & 5.0298 & TRN & \\
\hline CHEMBL1479953 & 688267 & 6.15 & 5.0471 & TRN & \\
\hline CHEMBL1396952 & 688267 & 4.05 & 5.0705 & TRN & \\
\hline CHEMBL1350234 & 688267 & 6.15 & 5.0061 & TST & \\
\hline CHEMBL1416654 & 688267 & 3.95 & 5.0323 & TRN & \\
\hline CHEMBL1555656 & 688267 & 6.2 & 5.1526 & TRN & \\
\hline CHEMBL1488781 & 688267 & 6.2 & 5.0002 & TRN & \\
\hline CHEMBL1593960 & 688267 & 6.2 & 5.0542 & TST & \\
\hline CHEMBL1438005 & 688267 & 5.3 & 5.0488 & TST & \\
\hline CHEMBL1606147 & 688267 & 6.05 & 5.0903 & TST & \\
\hline CHEMBL1578028 & 688267 & 4.85 & 5.0647 & TST & \\
\hline CHEMBL1581053 & 688267 & 5.0 & 5.046 & TRN & \\
\hline CHEMBL1393439 & 688267 & 4.45 & 5.0811 & TRN & \\
\hline CHEMBL1375334 & 688267 & 4.65 & 5.0379 & TRN & \\
\hline CHEMBL1431870 & 688267 & 6.15 & 5.0887 & TRN & \\
\hline CHEMBL1608619 & 688267 & 4.0 & 5.021 & TRN & \\
\hline CHEMBL1572140 & 688267 & 4.95 & 5.0236 & TRN & \\
\hline CHEMBL1394076 & 688267 & 5.55 & 5.0706 & TRN & \\
\hline CHEMBL1451846 & 688267 & 5.5 & 5.1215 & TRN & \\
\hline CHEMBL1518090 & 688267 & 5.95 & 5.0812 & TRN & \\
\hline CHEMBL1553810 & 688267 & 5.95 & 5.0464 & TRN & \\
\hline CHEMBL1444841 & 688267 & 6.15 & 5.0657 & TRN & \\
\hline CHEMBL1438359 & 688267 & 4.5 & 5.0596 & TST & \\
\hline CHEMBL1386609 & 688267 & 3.95 & 5.0371 & TRN & \\
\hline CHEMBL1395270 & 688267 & 3.95 & 5.0653 & TRN & \\
\hline CHEMBL1452018 & 688267 & 3.95 & 5.0581 & TRN & \\
\hline CHEMBL1603895 & 688267 & 4.95 & 5.0939 & TRN & \\
\hline CHEMBL1490381 & 688267 & 5.5 & 5.04899 & 99999999995 & TST \\
\hline CHEMBL1388191 & 688267 & 5.4 & 5.0499 & TST & \\
\hline CHEMBL1423150 & 688267 & 4.35 & 5.0502 & TRN & \\
\hline CHEMBL1383725 & 688267 & 6.2 & 5.0218 & TRN & \\
\hline CHEMBL1493696 & 688267 & 5.9 & 5.0604 & TRN & \\
\hline CHEMBL1562405 & 688267 & 4.9 & 5.0275 & TST & \\
\hline CHEMBL1582520 & 688267 & 5.1 & 5.0623 & TST & \\
\hline CHEMBL1522946 & 688267 & 5.8 & 5.1165 & TRN & \\
\hline CHEMBL1468545 & 688267 & 3.95 & $5.1220 e$ & 0000000001 & TRN \\
\hline CHEMBL1608359 & 688267 & 5.3 & 5.1216 & TRN & \\
\hline CHEMBL1432443 & 688267 & 5.45 & 4.9741 & TRN & \\
\hline CHEMBL1420774 & 688267 & 6.25 & 5.1085 & TRN & \\
\hline CHEMBL1530280 & 688267 & 6.45 & 5.0006 & TRN & \\
\hline
\end{tabular}




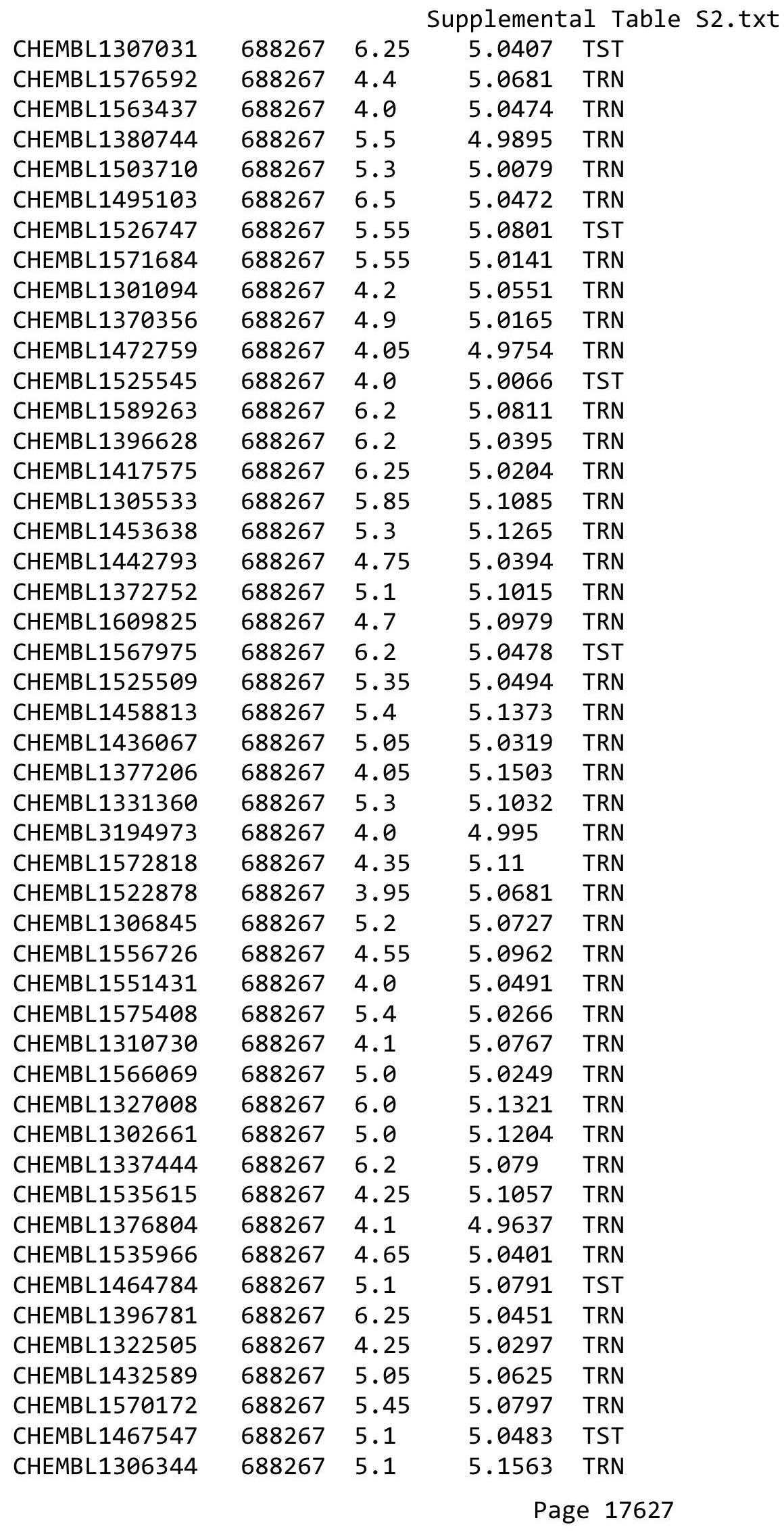




\begin{tabular}{|c|c|c|c|c|}
\hline & & & ipplement & al Table S2 \\
\hline CHEMBL1544100 & 688267 & 5.7 & 5.0617 & TRN \\
\hline CHEMBL1478281 & 688267 & 5.95 & 5.118 & TRN \\
\hline CHEMBL1595364 & 688267 & 5.65 & 5.0374 & TRN \\
\hline CHEMBL1301055 & 688267 & 4.8 & 5.0095 & TRN \\
\hline CHEMBL3192005 & 688267 & 5.5 & 5.0287 & TST \\
\hline CHEMBL1324877 & 688267 & 5.25 & 5.06 & TST \\
\hline CHEMBL1599839 & 688267 & 6.1 & 4.9926 & TST \\
\hline CHEMBL1463155 & 688267 & 4.05 & 5.1282 & TRN \\
\hline CHEMBL1326339 & 688267 & 3.95 & 5.1395 & TRN \\
\hline CHEMBL1397026 & 688267 & 5.45 & 5.034 & TRN \\
\hline CHEMBL1509403 & 688267 & 4.35 & 5.0122 & TRN \\
\hline CHEMBL1524158 & 688267 & 5.8 & 5.045 & TST \\
\hline CHEMBL1445985 & 688267 & 5.4 & 5.1406 & TRN \\
\hline CHEMBL1460364 & 688267 & 4.75 & 5.1512 & TRN \\
\hline CHEMBL1505062 & 688267 & 4.8 & 5.0192 & TST \\
\hline CHEMBL1571507 & 688267 & 4.55 & 5.03 & TRN \\
\hline CHEMBL1436609 & 688267 & 3.95 & 5.0452 & TRN \\
\hline CHEMBL1466183 & 688267 & 4.4 & 5.066 & TRN \\
\hline CHEMBL1595877 & 688267 & 5.25 & 5.0132 & TRN \\
\hline CHEMBL1435513 & 688267 & 5.3 & 5.0856 & TRN \\
\hline CHEMBL1309195 & 688267 & 4.2 & 5.016 & TST \\
\hline CHEMBL1310098 & 688267 & 4.0 & 5.0574 & TST \\
\hline CHEMBL1356204 & 688267 & 6.1 & 5.0494 & TRN \\
\hline CHEMBL1591379 & 688267 & 3.95 & 5.0142 & TRN \\
\hline CHEMBL1328604 & 688267 & 4.05 & 5.1425 & TST \\
\hline CHEMBL1335591 & 688267 & 4.05 & 5.0418 & TRN \\
\hline CHEMBL1362967 & 688267 & 4.45 & 5.0565 & TRN \\
\hline CHEMBL1478963 & 688267 & 4.35 & 5.0764 & TRN \\
\hline CHEMBL1543403 & 688267 & 4.3 & 5.1208 & TRN \\
\hline CHEMBL1610636 & 688267 & 4.25 & 5.0295 & TRN \\
\hline CHEMBL1482284 & 688267 & 6.0 & 5.0737 & TRN \\
\hline CHEMBL1595393 & 688267 & 6.05 & 5.1005 & TRN \\
\hline CHEMBL1373096 & 688267 & 6.2 & 5.04 & TRN \\
\hline CHEMBL1376438 & 688267 & 5.45 & 5.01 & TRN \\
\hline CHEMBL1571216 & 688267 & 4.35 & 5.0164 & TRN \\
\hline CHEMBL1453795 & 688267 & 4.05 & 5.1518 & TRN \\
\hline CHEMBL1607049 & 688267 & 4.6 & 5.0741 & TRN \\
\hline CHEMBL1301660 & 688267 & 4.0 & 5.05 & TRN \\
\hline CHEMBL1604730 & 688267 & 4.3 & 5.069 & TRN \\
\hline CHEMBL1334016 & 688267 & 6.2 & 5.0432 & TRN \\
\hline CHEMBL1526524 & 688267 & 4.45 & 5.0732 & TRN \\
\hline CHEMBL1469492 & 688267 & 4.6 & 5.0212 & TRN \\
\hline CHEMBL1364499 & 688267 & 4.6 & 5.059 & TST \\
\hline CHEMBL1560278 & 688267 & 4.4 & 5.0659 & TST \\
\hline CHEMBL1502166 & 688267 & 4.45 & 5.0805 & TRN \\
\hline CHEMBL1450873 & 688267 & 4.0 & 5.07600 & 00000000005 \\
\hline CHEMBL1391702 & 688267 & 4.2 & 5.0148 & TST \\
\hline CHEMBL3209404 & 688267 & 4.0 & 5.0407 & TRN \\
\hline
\end{tabular}




\begin{tabular}{|c|c|c|c|c|}
\hline \multicolumn{5}{|c|}{ Supplemental Table S2.txt } \\
\hline CHEMBL1394196 & 688267 & 3.95 & 5.0756 & TRN \\
\hline CHEMBL1507238 & 688267 & 4.0 & 5.0531 & TST \\
\hline CHEMBL1378716 & 688267 & 6.2 & 5.1212 & TST \\
\hline CHEMBL1497426 & 688267 & 5.05 & 5.0949 & TRN \\
\hline CHEMBL1986504 & 688267 & 5.2 & 5.0001 & TRN \\
\hline CHEMBL1607320 & 688267 & 6.0 & 5.0867 & TRN \\
\hline CHEMBL1433516 & 688267 & 4.0 & 5.0414 & TST \\
\hline CHEMBL1513654 & 688267 & 4.8 & 5.0759 & TST \\
\hline CHEMBL1328784 & 688267 & 7.0 & 5.0505 & TRN \\
\hline CHEMBL1480369 & 688267 & 4.55 & 5.0086 & TST \\
\hline CHEMBL 3199429 & 688267 & 5.65 & 5.0046 & TRN \\
\hline CHEMBL1327327 & 688267 & 6.2 & 5.0971 & TRN \\
\hline CHEMBL1609492 & 688267 & 5.75 & 5.1016 & TRN \\
\hline CHEMBL1407078 & 688267 & 4.45 & 5.0649 & TST \\
\hline CHEMBL1592738 & 688267 & 4.75 & 5.0605 & TRN \\
\hline CHEMBL1610625 & 688267 & 6.2 & 5.0724 & TRN \\
\hline CHEMBL1458433 & 688267 & 5.15 & 5.0797 & TRN \\
\hline CHEMBL1575088 & 688267 & 4.5 & 5.0933 & TRN \\
\hline CHEMBL1609556 & 688267 & 4.05 & 5.0504 & TST \\
\hline CHEMBL1543816 & 688267 & 3.85 & 5.0904 & TRN \\
\hline CHEMBL1548002 & 688267 & 4.05 & 5.1012 & TRN \\
\hline CHEMBL177987 & 688267 & 4.9 & 5.0485 & TST \\
\hline CHEMBL1596190 & 688267 & 6.5501 & 5.0617 & TRN \\
\hline CHEMBL1536830 & 688267 & 6.25 & 5.0692 & TRN \\
\hline CHEMBL1611141 & 688267 & 5.15 & 4.9714 & TST \\
\hline CHEMBL1516088 & 688267 & 4.05 & 5.1322 & TRN \\
\hline CHEMBL1495055 & 688267 & 4.35 & 5.0376 & TRN \\
\hline CHEMBL1516315 & 688267 & 3.95 & 5.0336 & TRN \\
\hline CHEMBL 3213992 & 688267 & 5.0 & 5.0568 & TST \\
\hline CHEMBL1517528 & 688267 & 5.45 & 5.0497 & TRN \\
\hline CHEMBL1583989 & 688267 & 4.4 & 5.0046 & TST \\
\hline CHEMBL1504792 & 688267 & 4.05 & 5.0726 & TST \\
\hline CHEMBL1576278 & 688267 & 4.0 & 5.0247 & TRN \\
\hline CHEMBL1529706 & 688267 & 4.35 & 5.0296 & TRN \\
\hline CHEMBL1328881 & 688267 & 4.0 & 5.0409 & TRN \\
\hline CHEMBL1327865 & 688267 & 5.3 & 5.0301 & TRN \\
\hline CHEMBL3198987 & 688267 & 6.2 & 5.0071 & TST \\
\hline CHEMBL1311530 & 688267 & 4.2 & 5.0708 & TST \\
\hline CHEMBL1506953 & 688267 & 4.55 & 5.0751 & TST \\
\hline CHEMBL1512843 & 688267 & 5.4 & 5.0926 & TST \\
\hline CHEMBL1517159 & 688267 & 4.0 & 5.0436 & TRN \\
\hline CHEMBL1468867 & 688267 & 5.65 & 5.1019 & TST \\
\hline CHEMBL16425 & 688267 & 4.9 & 5.0411 & TRN \\
\hline CHEMBL1322085 & 688267 & 6.25 & 5.0493 & TRN \\
\hline CHEMBL1553907 & 688267 & 5.15 & 5.0245 & TRN \\
\hline CHEMBL1464755 & 688267 & 5.4 & 5.0765 & TRN \\
\hline CHEMBL3210780 & 688267 & 5.6 & 5.0578 & TST \\
\hline CHEMBL1449593 & 688267 & 4.85 & 5.0446 & TRN \\
\hline
\end{tabular}




\begin{tabular}{|c|c|c|c|c|c|}
\hline \multicolumn{6}{|c|}{ Supplemental Table S2.txt } \\
\hline CHEMBL1422096 & 688267 & 5.45 & 4.9867 & TRN & \\
\hline CHEMBL349605 & 688267 & 6.5501 & 5.0703 & TST & \\
\hline CHEMBL3210173 & 688267 & 5.0 & 5.0334 & TST & \\
\hline CHEMBL1316180 & 688267 & 6.2 & 5.0917 & TRN & \\
\hline CHEMBL1453799 & 688267 & 4.9 & 5.0601 & TRN & \\
\hline CHEMBL1565065 & 688267 & 4.4 & 5.1461 & TRN & \\
\hline CHEMBL1470865 & 688267 & 6.0 & 5.0793 & TRN & \\
\hline CHEMBL1492585 & 688267 & 5.85 & 5.0219 & TST & \\
\hline CHEMBL1512170 & 688267 & 5.95 & 5.037 & TRN & \\
\hline CHEMBL1583805 & 688267 & 5.35 & 5.0217 & TRN & \\
\hline CHEMBL1349799 & 688267 & 5.55 & 5.0728 & TRN & \\
\hline CHEMBL1607760 & 688267 & 4.4 & 5.0982 & TRN & \\
\hline CHEMBL1458327 & 688267 & 5.75 & 5.0306 & TRN & \\
\hline CHEMBL1299539 & 688267 & 5.5 & 5.1081 & TRN & \\
\hline CHEMBL1423643 & 688267 & 5.65 & 5.1032 & TRN & \\
\hline CHEMBL1372506 & 688267 & 4.65 & 5.0591 & TST & \\
\hline CHEMBL1488132 & 688267 & 5.55 & 5.0451 & TRN & \\
\hline CHEMBL1337091 & 688267 & 4.45 & 5.0993 & TRN & \\
\hline CHEMBL1490312 & 688267 & 5.95 & 5.0507 & TST & \\
\hline CHEMBL1525591 & 688267 & 6.25 & 5.0449 & TRN & \\
\hline CHEMBL3199817 & 688267 & 6.15 & 5.0251 & TRN & \\
\hline CHEMBL1317310 & 688267 & 6.2 & 5.1107 & TRN & \\
\hline CHEMBL1562457 & 688267 & 4.05 & 4.99 & TRN & \\
\hline CHEMBL1338986 & 688267 & 5.25 & 5.1155 & TRN & \\
\hline CHEMBL1326224 & 688267 & 4.0 & 5.1336 & TRN & \\
\hline CHEMBL1526046 & 688267 & 5.75 & 5.0858 & TST & \\
\hline CHEMBL1442195 & 688267 & 5.3 & 5.0582 & TRN & \\
\hline CHEMBL1523352 & 688267 & 6.2 & 5.082 & TRN & \\
\hline CHEMBL3189818 & 688267 & 5.45 & 5.0734 & TST & \\
\hline CHEMBL1514331 & 688267 & 6.45 & 5.107 & TRN & \\
\hline CHEMBL1522548 & 688267 & 4.05 & 4.9987 & TRN & \\
\hline CHEMBL1428552 & 688267 & 6.2 & 5.0661 & TRN & \\
\hline CHEMBL1475926 & 688267 & 5.65 & 5.1367 & TRN & \\
\hline CHEMBL1407181 & 688267 & 4.4 & 5.05399 & 9999999999 & TST \\
\hline CHEMBL3196966 & 688267 & 6.2 & 5.0392 & TRN & \\
\hline CHEMBL1541509 & 688267 & 6.2 & 5.1456 & TRN & \\
\hline CHEMBL1515547 & 688267 & 6.2 & 5.0677 & TRN & \\
\hline CHEMBL1609096 & 688267 & 4.0 & 5.119 & TST & \\
\hline CHEMBL1407774 & 688267 & 5.4 & 5.0286 & TRN & \\
\hline CHEMBL1599618 & 688267 & 5.85 & 5.0728 & TRN & \\
\hline CHEMBL1523438 & 688267 & 4.4 & 5.003 & TST & \\
\hline CHEMBL1351894 & 688267 & 5.6 & 5.0807 & TRN & \\
\hline CHEMBL1477518 & 688267 & 6.15 & 5.0497 & TRN & \\
\hline CHEMBL1609039 & 688267 & 5.15 & 5.1526 & TRN & \\
\hline CHEMBL1416558 & 688267 & 4.3 & 4.997 & TRN & \\
\hline CHEMBL1510981 & 688267 & 4.5 & 5.0939 & TRN & \\
\hline CHEMBL1467342 & 688267 & 4.65 & 5.029 & TRN & \\
\hline CHEMBL1395550 & 688267 & 6.45 & 5.035 & TRN & \\
\hline
\end{tabular}




\begin{tabular}{|c|c|c|c|c|}
\hline & & & ipplement & al $\mathrm{Tc}$ \\
\hline CHEMBL1314610 & 688267 & 4.05 & 5.1353 & TRN \\
\hline CHEMBL1537664 & 688267 & 5.65 & 5.0296 & TST \\
\hline CHEMBL1362063 & 688267 & 6.5 & 5.0266 & TRN \\
\hline CHEMBL1300397 & 688267 & 6.2 & 4.9919 & TST \\
\hline CHEMBL1533082 & 688267 & 4.9 & 5.1475 & TRN \\
\hline CHEMBL1591687 & 688267 & 4.05 & 5.0524 & TRN \\
\hline CHEMBL1435349 & 688267 & 4.7 & 5.1096 & TRN \\
\hline CHEMBL1355300 & 688267 & 6.2 & 5.1168 & TRN \\
\hline CHEMBL1395601 & 688267 & 5.8 & 5.0621 & TRN \\
\hline CHEMBL1583553 & 688267 & 4.05 & 5.0195 & TST \\
\hline CHEMBL1471520 & 688267 & 6.5 & 5.1 & TST \\
\hline CHEMBL1428818 & 688267 & 5.9 & 5.1481 & TST \\
\hline CHEMBL1522765 & 688267 & 6.15 & 5.011 & TST \\
\hline CHEMBL1524822 & 688267 & 3.95 & 5.1052 & TRN \\
\hline CHEMBL1520329 & 688267 & 4.4 & 5.1428 & TRN \\
\hline CHEMBL232714 & 688267 & 5.15 & 5.0175 & TST \\
\hline CHEMBL 3214444 & 688267 & 5.9 & 5.02 & TST \\
\hline CHEMBL1309423 & 688267 & 5.3 & 5.0771 & TST \\
\hline CHEMBL1447015 & 688267 & 5.55 & 5.0335 & TRN \\
\hline CHEMBL1493941 & 688267 & 4.35 & 5.0696 & TRN \\
\hline CHEMBL1319325 & 688267 & 4.65 & 5.0821 & TRN \\
\hline CHEMBL1535202 & 688267 & 4.05 & 5.0259 & TST \\
\hline CHEMBL1411397 & 688267 & 4.05 & 5.0102 & TST \\
\hline CHEMBL1435609 & 688267 & 4.0 & 5.0385 & TRN \\
\hline CHEMBL1431975 & 688267 & 4.0 & 4.9677 & TRN \\
\hline CHEMBL1533728 & 688267 & 5.9 & 4.9789 & TRN \\
\hline CHEMBL1546549 & 688267 & 5.9 & 5.1383 & TRN \\
\hline CHEMBL1562947 & 688267 & 5.55 & 5.0997 & TRN \\
\hline CHEMBL1319998 & 688267 & 5.5 & 5.0399 & TRN \\
\hline CHEMBL1595631 & 688267 & 5.6 & 5.0657 & TRN \\
\hline CHEMBL1315289 & 688267 & 6.25 & 5.0445 & TRN \\
\hline CHEMBL1315591 & 688267 & 4.05 & 5.0443 & TST \\
\hline CHEMBL1513363 & 688267 & 5.9 & 5.0761 & TRN \\
\hline CHEMBL1409627 & 688267 & 5.4 & 5.0297 & TRN \\
\hline CHEMBL1579418 & 688267 & 5.3 & 5.0814 & TRN \\
\hline CHEMBL1372249 & 688267 & 4.0 & 5.0432 & TST \\
\hline CHEMBL1584666 & 688267 & 4.55 & 5.0391 & TST \\
\hline CHEMBL1562111 & 688267 & 5.15 & 5.0893 & TST \\
\hline CHEMBL1612567 & 688267 & 5.0 & 5.0173 & TRN \\
\hline CHEMBL1524349 & 688267 & 6.15 & 4.9853 & TRN \\
\hline CHEMBL1426812 & 688267 & 5.7 & 5.0418 & TRN \\
\hline CHEMBL1608229 & 688267 & 4.55 & 5.0867 & TRN \\
\hline CHEMBL1442494 & 688267 & 4.0 & 5.0671 & TRN \\
\hline CHEMBL1504357 & 688267 & 5.85 & 4.9978 & TRN \\
\hline CHEMBL1598307 & 688267 & 5.05 & 5.0727 & TST \\
\hline CHEMBL1365400 & 688267 & 5.35 & 5.0292 & TST \\
\hline CHEMBL1419902 & 688267 & 6.2 & 5.0758 & TRN \\
\hline CHEMBL1321363 & 688267 & 4.45 & 5.0991 & TST \\
\hline
\end{tabular}




\begin{tabular}{|c|c|c|c|c|}
\hline \multicolumn{5}{|c|}{ Supplemental Table S2.txt } \\
\hline CHEMBL1412438 & 688267 & 5.45 & 5.0663 & TRN \\
\hline CHEMBL1316220 & 688267 & 5.3 & 5.0065 & TRN \\
\hline CHEMBL1479322 & 688267 & 4.7 & 5.1081 & TRN \\
\hline CHEMBL1351451 & 688267 & 5.85 & 5.0664 & TST \\
\hline CHEMBL1502717 & 688267 & 4.25 & 5.0353 & TRN \\
\hline CHEMBL1588985 & 688267 & 6.6 & 5.1254 & TRN \\
\hline CHEMBL1518345 & 688267 & 5.35 & 5.0363 & TRN \\
\hline CHEMBL1399484 & 688267 & 6.15 & 5.0721 & TRN \\
\hline CHEMBL1487215 & 688267 & 4.0 & 5.0007 & TRN \\
\hline CHEMBL1394637 & 688267 & 6.0 & 5.0627 & TRN \\
\hline CHEMBL1508447 & 688267 & 6.2 & 5.1379 & TRN \\
\hline CHEMBL1319618 & 688267 & 5.6 & 5.0351 & TST \\
\hline CHEMBL1418677 & 688267 & 5.0 & 5.0738 & TST \\
\hline CHEMBL1554913 & 688267 & 6.0 & 5.1193 & TRN \\
\hline CHEMBL1541102 & 688267 & 5.3 & 5.056 & TRN \\
\hline CHEMBL1501728 & 688267 & 4.1 & 5.0948 & TRN \\
\hline CHEMBL1392845 & 688267 & 5.3 & 5.022 & TRN \\
\hline CHEMBL1462372 & 688267 & 6.45 & 5.0877 & TRN \\
\hline CHEMBL1513429 & 688267 & 4.05 & 5.1107 & TRN \\
\hline CHEMBL548426 & 688267 & 4.6 & 5.0924 & TST \\
\hline CHEMBL1434952 & 688267 & 5.4 & 5.0464 & TRN \\
\hline CHEMBL502936 & 688267 & 4.45 & 5.0226 & TRN \\
\hline CHEMBL1357452 & 688267 & 5.3 & 5.0716 & TST \\
\hline CHEMBL1593465 & 688267 & 4.0 & 5.1071 & TRN \\
\hline CHEMBL1610951 & 688267 & 4.6 & 5.0638 & TRN \\
\hline CHEMBL 278041 & 688267 & 5.15 & 5.0311 & TST \\
\hline CHEMBL1525469 & 688267 & 4.4 & 5.0843 & TST \\
\hline CHEMBL1411942 & 688267 & 3.95 & 5.0175 & TST \\
\hline CHEMBL1330824 & 688267 & 4.35 & 5.063 & TRN \\
\hline CHEMBL1344611 & 688267 & 5.0 & 5.0154 & TRN \\
\hline CHEMBL1429272 & 688267 & 4.6 & 4.9932 & TRN \\
\hline CHEMBL1391408 & 688267 & 6.45 & 5.0699 & TST \\
\hline CHEMBL1566933 & 688267 & 3.9 & 5.05 & TRN \\
\hline CHEMBL1488183 & 688267 & 5.6 & 5.0266 & TRN \\
\hline CHEMBL1335557 & 688267 & 6.2 & 5.0164 & TRN \\
\hline CHEMBL1437277 & 688267 & 5.35 & 5.0384 & TRN \\
\hline CHEMBL1445628 & 688267 & 5.45 & 5.0667 & TRN \\
\hline CHEMBL1496920 & 688267 & 4.4 & 5.0714 & TRN \\
\hline CHEMBL1566873 & 688267 & 4.2 & 5.0681 & TRN \\
\hline CHEMBL1486934 & 688267 & 5.5 & 5.0905 & TST \\
\hline CHEMBL1572095 & 688267 & 4.6 & 5.0334 & TRN \\
\hline CHEMBL1436356 & 688267 & 4.95 & 5.0664 & TRN \\
\hline CHEMBL1528158 & 688267 & 5.4 & 5.0031 & TRN \\
\hline CHEMBL1324372 & 688267 & 4.0 & 5.0145 & TRN \\
\hline CHEMBL1443893 & 688267 & 5.75 & 5.1593 & TRN \\
\hline CHEMBL1430644 & 688267 & 5.45 & 5.1071 & TRN \\
\hline CHEMBL1349567 & 688267 & 5.95 & 5.007 & TST \\
\hline CHEMBL579105 & 688267 & 4.4 & 5.0016 & TRN \\
\hline
\end{tabular}




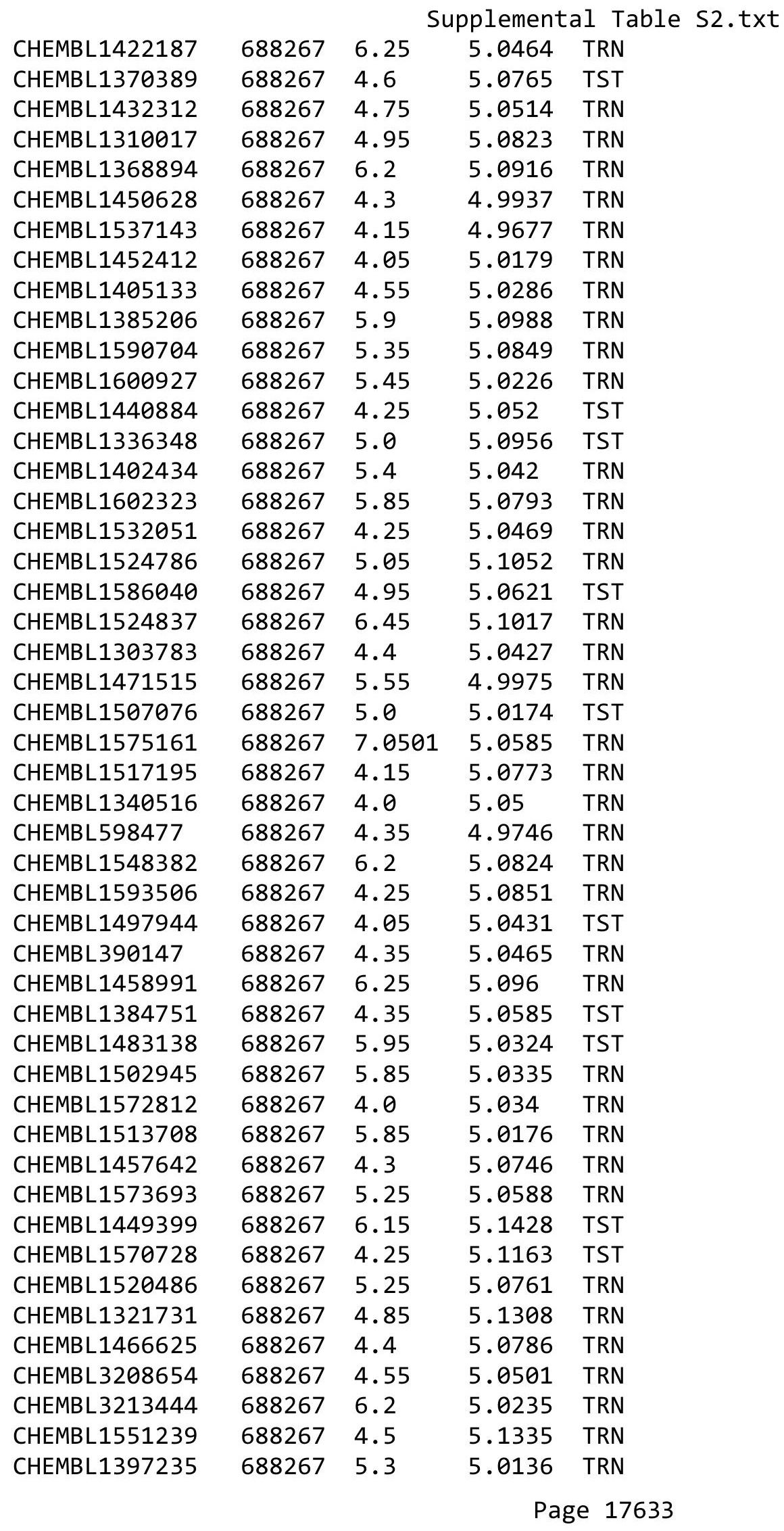




\begin{tabular}{|c|c|c|c|c|}
\hline & & & pplement & al Ta \\
\hline CHEMBL1559644 & 688267 & 5.5 & 5.0305 & TST \\
\hline CHEMBL416874 & 688267 & 4.1 & 4.9906 & TRN \\
\hline CHEMBL1395001 & 688267 & 5.85 & 5.034 & TRN \\
\hline CHEMBL1364841 & 688267 & 5.5 & 5.0154 & TRN \\
\hline CHEMBL1395964 & 688267 & 6.2 & 5.0585 & TRN \\
\hline CHEMBL1336748 & 688267 & 4.95 & 5.035 & TRN \\
\hline CHEMBL1541512 & 688267 & 5.4 & 5.0489 & TRN \\
\hline CHEMBL1408461 & 688267 & 4.2 & 5.0126 & TRN \\
\hline CHEMBL1344283 & 688267 & 5.55 & 5.0939 & TRN \\
\hline CHEMBL1325336 & 688267 & 4.9 & 5.0153 & TRN \\
\hline CHEMBL1486405 & 688267 & 5.25 & 5.0181 & TST \\
\hline CHEMBL1413662 & 688267 & 4.05 & 5.0197 & TRN \\
\hline CHEMBL1391233 & 688267 & 4.0 & 5.0024 & TRN \\
\hline CHEMBL1382696 & 688267 & 6.0 & 5.0813 & TRN \\
\hline CHEMBL1470408 & 688267 & 4.0 & 5.0279 & TRN \\
\hline CHEMBL1418020 & 688267 & 5.7 & 5.0022 & TRN \\
\hline CHEMBL1585334 & 688267 & 5.3 & 5.0345 & TRN \\
\hline CHEMBL1307379 & 688267 & 4.4 & 5.0781 & TRN \\
\hline CHEMBL1387675 & 688267 & 6.2 & 5.0509 & TRN \\
\hline CHEMBL1427687 & 688267 & 4.6 & 5.0143 & TRN \\
\hline CHEMBL1531894 & 688267 & 4.15 & 5.1321 & TRN \\
\hline CHEMBL1367719 & 688267 & 5.45 & 5.0646 & TRN \\
\hline CHEMBL1436442 & 688267 & 5.1 & 5.0753 & TRN \\
\hline CHEMBL1299955 & 688267 & 6.1 & 5.0355 & TRN \\
\hline CHEMBL1488381 & 688267 & 6.05 & 5.1046 & TRN \\
\hline CHEMBL1364273 & 688267 & 6.25 & 5.0191 & TRN \\
\hline CHEMBL3207598 & 688267 & 4.1 & 5.0522 & TRN \\
\hline CHEMBL1476993 & 688267 & 6.2 & 5.0423 & TRN \\
\hline CHEMBL1509089 & 688267 & 5.3 & 5.1111 & TRN \\
\hline CHEMBL1369398 & 688267 & 6.2 & 5.0171 & TST \\
\hline CHEMBL1377006 & 688267 & 4.4 & 5.0632 & TRN \\
\hline CHEMBL1426063 & 688267 & 6.2 & 5.0515 & TST \\
\hline CHEMBL1373392 & 688267 & 6.2 & 5.0853 & TRN \\
\hline CHEMBL1593972 & 688267 & 4.65 & 5.0304 & TST \\
\hline CHEMBL1414745 & 688267 & 5.1 & 5.069 & TRN \\
\hline CHEMBL1494035 & 688267 & 4.55 & 5.1032 & TRN \\
\hline CHEMBL1503527 & 688267 & 5.3 & 5.1194 & TRN \\
\hline CHEMBL1410942 & 688267 & 4.95 & 5.0214 & TRN \\
\hline CHEMBL1475285 & 688267 & 4.05 & 5.0123 & TRN \\
\hline CHEMBL1332941 & 688267 & 6.5 & 5.0341 & TST \\
\hline CHEMBL1568143 & 688267 & 3.95 & 5.0935 & TRN \\
\hline CHEMBL1380068 & 688267 & 4.15 & 5.0395 & TRN \\
\hline CHEMBL1531619 & 688267 & 4.05 & 4.9998 & TRN \\
\hline CHEMBL1535298 & 688267 & 5.0 & 5.0707 & TRN \\
\hline CHEMBL1352023 & 688267 & 4.0 & 5.0466 & TRN \\
\hline CHEMBL1319466 & 688267 & 5.35 & 5.025 & TRN \\
\hline CHEMBL1353747 & 688267 & 6.1 & 5.0241 & TRN \\
\hline CHEMBL1548893 & 688267 & 4.0 & 5.0961 & TST \\
\hline
\end{tabular}




\begin{tabular}{|c|c|c|c|c|c|}
\hline & & \multicolumn{4}{|c|}{ Supplemental Table S2.txt } \\
\hline CHEMBL3213751 & 688267 & 5.45 & 4.9886 & TRN & \\
\hline CHEMBL1449633 & 688267 & 4.9 & 5.105 & TRN & \\
\hline CHEMBL1445961 & 688267 & 6.2 & 5.045 & TRN & \\
\hline CHEMBL1302869 & 688267 & 4.0 & 5.0314 & TRN & \\
\hline CHEMBL206595 & 688267 & 5.95 & 5.0502 & TRN & \\
\hline CHEMBL1579856 & 688267 & 6.0 & 5.0526 & TRN & \\
\hline CHEMBL1350729 & 688267 & 5.35 & 5.1691 & TRN & \\
\hline CHEMBL1506107 & 688267 & 4.45 & 5.0222 & TRN & \\
\hline CHEMBL1575755 & 688267 & 5.6 & 5.1107 & TRN & \\
\hline CHEMBL1321505 & 688267 & 4.35 & 5.0624 & TRN & \\
\hline CHEMBL1363084 & 688267 & 5.9 & 5.0277 & TRN & \\
\hline CHEMBL1418496 & 688267 & 5.5 & 5.0522 & TRN & \\
\hline CHEMBL1397741 & 688267 & 4.0 & 5.033 & TST & \\
\hline CHEMBL1604577 & 688267 & 5.55 & 5.001 & TRN & \\
\hline CHEMBL1307314 & 688267 & 4.35 & 5.09399 & 9999999999 & TRN \\
\hline CHEMBL1542898 & 688267 & 5.3 & 5.0856 & TRN & \\
\hline CHEMBL1603376 & 688267 & 4.0 & 5.0643 & TRN & \\
\hline CHEMBL1555830 & 688267 & 4.4 & 5.1474 & TRN & \\
\hline CHEMBL1547316 & 688267 & 5.6 & 5.0999 & TRN & \\
\hline CHEMBL1333438 & 688267 & 4.0 & 5.1386 & TRN & \\
\hline CHEMBL1564414 & 688267 & 4.35 & 5.1031 & TRN & \\
\hline CHEMBL1330981 & 688267 & 4.4 & 5.1052 & TRN & \\
\hline CHEMBL1457236 & 688267 & 4.3 & 5.1007 & TST & \\
\hline CHEMBL1390867 & 688267 & 5.85 & 5.1181 & TRN & \\
\hline CHEMBL1472195 & 688267 & 5.3 & 5.1671 & TRN & \\
\hline CHEMBL1326603 & 688267 & 6.2 & 5.0775 & TRN & \\
\hline CHEMBL1367700 & 688267 & 4.05 & 5.1149 & TRN & \\
\hline CHEMBL1311130 & 688267 & 4.0 & 5.0835 & TST & \\
\hline CHEMBL1415227 & 688267 & 6.5 & 5.0993 & TRN & \\
\hline CHEMBL1600398 & 688267 & 5.55 & 5.0915 & TRN & \\
\hline CHEMBL1437411 & 688267 & 6.15 & 4.9792 & TST & \\
\hline CHEMBL1392361 & 688267 & 4.0 & 5.0391 & TRN & \\
\hline CHEMBL1359265 & 688267 & 6.5501 & 5.0246 & TRN & \\
\hline CHEMBL3199934 & 688267 & 6.2 & 4.9984 & TRN & \\
\hline CHEMBL1578503 & 688267 & 4.4 & 5.043 & TST & \\
\hline CHEMBL1577812 & 688267 & 5.55 & 5.0179 & TRN & \\
\hline CHEMBL1312714 & 688267 & 4.25 & 5.0637 & TST & \\
\hline CHEMBL1508018 & 688267 & 6.2 & 5.0555 & TRN & \\
\hline CHEMBL1562931 & 688267 & 5.6 & 5.0986 & TRN & \\
\hline CHEMBL1387143 & 688267 & 4.1 & 5.0907 & TRN & \\
\hline CHEMBL1433470 & 688267 & 3.95 & 5.0441 & TRN & \\
\hline CHEMBL1572357 & 688267 & 3.95 & 5.0614 & TRN & \\
\hline CHEMBL1552168 & 688267 & 5.2 & 5.0293 & TRN & \\
\hline CHEMBL1433825 & 688267 & 6.45 & 5.0623 & TRN & \\
\hline CHEMBL1485283 & 688267 & 5.35 & 5.0146 & TRN & \\
\hline CHEMBL1437168 & 688267 & 4.35 & 5.0473 & TRN & \\
\hline CHEMBL1318055 & 688267 & 4.15 & 5.0685 & TRN & \\
\hline CHEMBL1314908 & 688267 & 5.3 & 5.055 & TRN & \\
\hline
\end{tabular}




\begin{tabular}{|c|c|c|c|c|c|}
\hline \multicolumn{6}{|c|}{ Supplemental Table S2.txt } \\
\hline CHEMBL1385001 & 688267 & 4.0 & 5.0137 & TRN & \\
\hline CHEMBL1493597 & 688267 & 5.1 & 5.0887 & TST & \\
\hline CHEMBL1459112 & 688267 & 5.45 & 5.0614 & TST & \\
\hline CHEMBL1342613 & 688267 & 6.2 & 5.0189 & TRN & \\
\hline CHEMBL1499884 & 688267 & 5.75 & 5.1055 & TST & \\
\hline CHEMBL1573041 & 688267 & 5.4 & 4.9985 & TST & \\
\hline CHEMBL1447822 & 688267 & 4.0 & 5.056 & TST & \\
\hline CHEMBL1306010 & 688267 & 3.95 & 5.0927 & TRN & \\
\hline CHEMBL1338967 & 688267 & 4.4 & 5.0264 & TST & \\
\hline CHEMBL1303758 & 688267 & 4.05 & 5.0175 & TRN & \\
\hline CHEMBL1575443 & 688267 & 6.2 & 5.0952 & TRN & \\
\hline CHEMBL1588927 & 688267 & 5.85 & 5.0513 & TRN & \\
\hline CHEMBL1331604 & 688267 & 4.3 & 5.0606 & TRN & \\
\hline CHEMBL1481072 & 688267 & 5.85 & 5.0847 & TST & \\
\hline CHEMBL1605878 & 688267 & 4.65 & 5.0423 & TRN & \\
\hline CHEMBL1443995 & 688267 & 4.0 & 5.0862 & TST & \\
\hline CHEMBL1323868 & 688267 & 5.4 & 5.0416 & TRN & \\
\hline CHEMBL80799 & 688267 & 4.7 & 5.0428 & TRN & \\
\hline CHEMBL1305690 & 688267 & 6.15 & 5.1134 & TRN & \\
\hline CHEMBL1416197 & 688267 & 4.05 & 5.1349 & TRN & \\
\hline CHEMBL1337272 & 688267 & 4.25 & 5.0533 & TST & \\
\hline CHEMBL1402834 & 688267 & 5.3 & 4.9997 & TRN & \\
\hline CHEMBL1432264 & 688267 & 5.55 & 5.0494 & TST & \\
\hline CHEMBL1457619 & 688267 & 5.3 & 5.0695 & TRN & \\
\hline CHEMBL1348850 & 688267 & 4.0 & 5.0516 & TST & \\
\hline CHEMBL1552617 & 688267 & 4.0 & 5.0221 & TRN & \\
\hline CHEMBL1440182 & 688267 & 4.0 & 5.0948 & TRN & \\
\hline CHEMBL1363659 & 688267 & 6.2 & 5.1403 & TRN & \\
\hline CHEMBL1567787 & 688267 & 5.3 & 5.0577 & TRN & \\
\hline CHEMBL1611593 & 688267 & 4.05 & 5.0654 & TRN & \\
\hline CHEMBL1549767 & 688267 & 4.5 & 5.0499 & TRN & \\
\hline CHEMBL1385771 & 688267 & 4.2 & 5.0579 & TRN & \\
\hline CHEMBL1353430 & 688267 & 4.75 & 5.0717 & TRN & \\
\hline CHEMBL1394804 & 688267 & 4.0 & 5.0881 & TRN & \\
\hline CHEMBL1569152 & 688267 & 4.9 & 5.0666 & TST & \\
\hline CHEMBL1353444 & 688267 & 6.2 & 5.05699 & 99999999995 & TRN \\
\hline CHEMBL1418360 & 688267 & 4.7 & 5.043 & TRN & \\
\hline CHEMBL1520260 & 688267 & 5.75 & 5.1322 & TRN & \\
\hline CHEMBL504665 & 688267 & 4.05 & 5.0402 & TRN & \\
\hline CHEMBL1452766 & 688267 & 4.45 & 4.9889 & TRN & \\
\hline CHEMBL1379198 & 688267 & 5.0 & 5.0262 & TRN & \\
\hline CHEMBL1327435 & 688267 & 6.15 & 5.1051 & TST & \\
\hline CHEMBL1591410 & 688267 & 4.0 & 5.0734 & TST & \\
\hline CHEMBL1512003 & 688267 & 5.6 & 5.0387 & TST & \\
\hline CHEMBL 3211401 & 688267 & 4.4 & 5.0266 & TST & \\
\hline CHEMBL1376807 & 688267 & 4.75 & 5.0357 & TRN & \\
\hline CHEMBL1526517 & 688267 & 6.15 & 5.1042 & TST & \\
\hline CHEMBL1437120 & 688267 & 5.65 & 5.0502 & TRN & \\
\hline
\end{tabular}




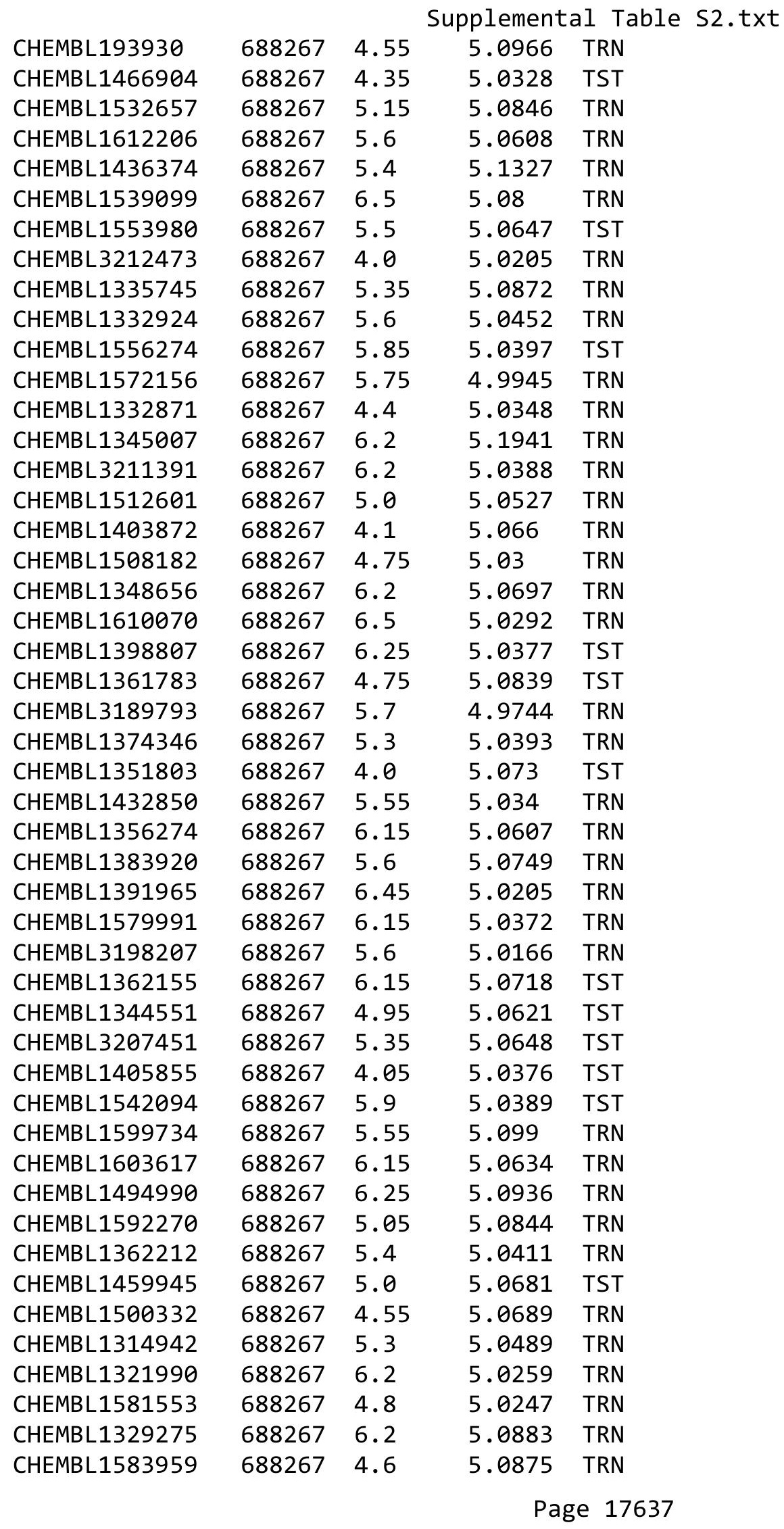




\begin{tabular}{|c|c|c|c|c|}
\hline & & & pplemen & al $\mathrm{T}$ \\
\hline CHEMBL1398817 & 688267 & 4.45 & 5.0782 & TST \\
\hline CHEMBL1601435 & 688267 & 5.8 & 5.0614 & TRN \\
\hline CHEMBL1499261 & 688267 & 4.0 & 5.0404 & TRN \\
\hline CHEMBL1517914 & 688267 & 4.1 & 5.1446 & TRN \\
\hline CHEMBL1299762 & 688267 & 5.9 & 5.0595 & TST \\
\hline CHEMBL3212483 & 688267 & 4.1 & 5.0984 & TST \\
\hline CHEMBL3190099 & 688267 & 4.3 & 5.0205 & TST \\
\hline CHEMBL3214568 & 688267 & 6.2 & 5.0468 & TST \\
\hline CHEMBL1363948 & 688267 & 5.25 & 5.0787 & TRN \\
\hline CHEMBL1566323 & 688267 & 5.4 & 5.091 & TST \\
\hline CHEMBL1406268 & 688267 & 4.1 & 5.0552 & TRN \\
\hline CHEMBL1315122 & 688267 & 5.35 & 5.0578 & TST \\
\hline CHEMBL1555706 & 688267 & 5.4 & 5.0415 & TRN \\
\hline CHEMBL1390570 & 688267 & 4.25 & 5.0271 & TRN \\
\hline CHEMBL1546135 & 688267 & 4.0 & 5.0824 & TRN \\
\hline CHEMBL1321726 & 688267 & 4.0 & 5.1305 & TST \\
\hline CHEMBL1462536 & 688267 & 6.2 & 5.0356 & TRN \\
\hline CHEMBL3196375 & 688267 & 4.55 & 5.0168 & TST \\
\hline CHEMBL1353389 & 688267 & 5.25 & 5.0723 & TRN \\
\hline CHEMBL1487961 & 688267 & 4.25 & 5.1119 & TST \\
\hline CHEMBL1488934 & 688267 & 4.2 & 5.0738 & TST \\
\hline CHEMBL1586425 & 688267 & 4.2 & 5.0775 & TST \\
\hline CHEMBL1507148 & 688267 & 4.75 & 5.0797 & TST \\
\hline CHEMBL1529307 & 688267 & 4.05 & 5.062 & TST \\
\hline CHEMBL1480362 & 688267 & 3.3 & 5.0234 & TRN \\
\hline CHEMBL1387167 & 688267 & 6.2 & 5.1305 & TRN \\
\hline CHEMBL1530191 & 688267 & 4.3 & 5.0505 & TRN \\
\hline CHEMBL1539002 & 688267 & 5.05 & 5.0191 & TRN \\
\hline CHEMBL1346245 & 688267 & 4.35 & 5.1147 & TST \\
\hline CHEMBL1589996 & 688267 & 5.55 & 5.0934 & TRN \\
\hline CHEMBL1481183 & 688267 & 3.9 & 5.0506 & TRN \\
\hline CHEMBL1471783 & 688267 & 6.15 & 5.0655 & TRN \\
\hline CHEMBL1460206 & 688267 & 5.0 & 5.0374 & TRN \\
\hline CHEMBL1475063 & 688267 & 6.2 & 5.0703 & TRN \\
\hline CHEMBL1437820 & 688267 & 4.8 & 5.1103 & TST \\
\hline CHEMBL1469870 & 688267 & 4.45 & 5.0115 & TRN \\
\hline CHEMBL1597939 & 688267 & 5.1 & 5.0639 & TST \\
\hline CHEMBL1473321 & 688267 & 5.25 & 5.0354 & TRN \\
\hline CHEMBL1547229 & 688267 & 6.2 & 5.0318 & TST \\
\hline CHEMBL1363655 & 688267 & 4.65 & 5.0707 & TST \\
\hline CHEMBL1321991 & 688267 & 5.2 & 4.9934 & TRN \\
\hline CHEMBL1423891 & 688267 & 4.35 & 5.0455 & TST \\
\hline CHEMBL1389831 & 688267 & 4.0 & 5.0543 & TRN \\
\hline CHEMBL1502665 & 688267 & 5.55 & 5.0106 & TST \\
\hline CHEMBL1578456 & 688267 & 5.05 & 5.0786 & TRN \\
\hline CHEMBL1355295 & 688267 & 6.2 & 5.0041 & TRN \\
\hline CHEMBL127729 & 688267 & 4.65 & 5.1136 & TRN \\
\hline CHEMBL1488899 & 688267 & 6.1 & 5.0781 & TRN \\
\hline
\end{tabular}




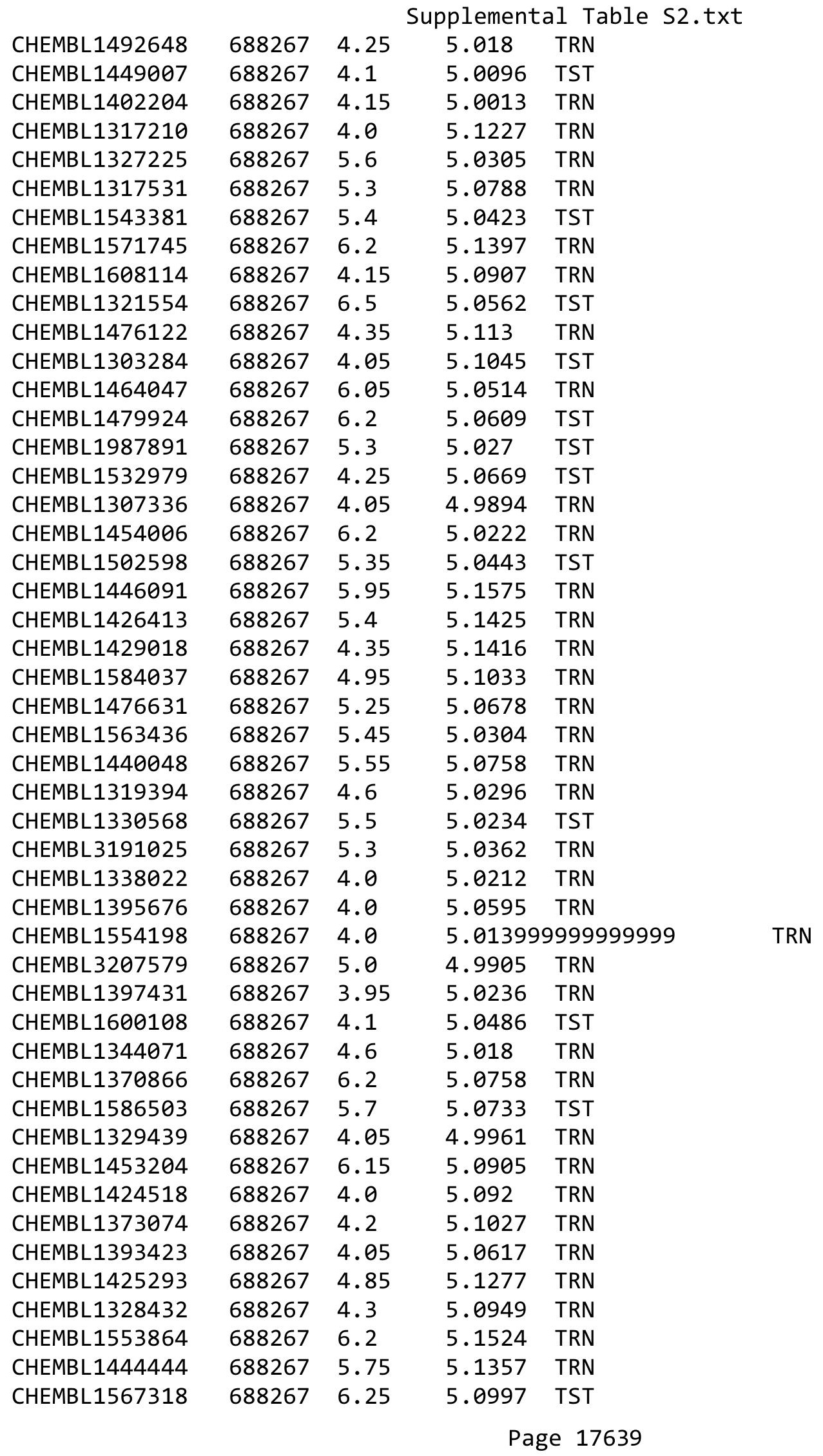




\begin{tabular}{|c|c|c|c|c|c|}
\hline \\
\hline CHEMBL1580603 & 688267 & 4.0 & 5.0166 & TST & \\
\hline CHEMBL1435073 & 688267 & 5.4 & 5.0744 & TRN & \\
\hline CHEMBL1392038 & 688267 & 4.5 & 5.0609 & TRN & \\
\hline CHEMBL1539272 & 688267 & 5.0 & 5.124 & TRN & \\
\hline CHEMBL3213622 & 688267 & 5.45 & 5.0144 & TRN & \\
\hline CHEMBL1429092 & 688267 & 4.4 & 5.0203 & TRN & \\
\hline CHEMBL1434719 & 688267 & 4.05 & 5.0443 & TRN & \\
\hline CHEMBL1324721 & 688267 & 4.05 & 5.0991 & TRN & \\
\hline CHEMBL1501141 & 688267 & 5.3 & 5.0206 & TRN & \\
\hline CHEMBL1566853 & 688267 & 4.95 & 5.0417 & TRN & \\
\hline CHEMBL1362983 & 688267 & 6.1 & 5.0772 & TRN & \\
\hline CHEMBL1548888 & 688267 & 5.2 & 5.0412 & TST & \\
\hline CHEMBL1404492 & 688267 & 4.0 & 5.0648 & TST & \\
\hline CHEMBL1313322 & 688267 & 6.1 & 5.1036 & TRN & \\
\hline CHEMBL1555506 & 688267 & 6.2 & 5.0643 & TST & \\
\hline CHEMBL1417447 & 688267 & 4.6 & 5.0156 & TRN & \\
\hline CHEMBL1407922 & 688267 & 5.8 & 5.0466 & TST & \\
\hline CHEMBL1080549 & 688267 & 6.15 & 5.13899 & 9999999999 & TRN \\
\hline CHEMBL1400339 & 688267 & 4.3 & 5.1033 & TRN & \\
\hline CHEMBL1578257 & 688267 & 4.0 & 5.1131 & TRN & \\
\hline CHEMBL1531594 & 688267 & 4.5 & 5.0535 & TST & \\
\hline CHEMBL1533083 & 688267 & 5.5 & 5.008 & TRN & \\
\hline CHEMBL1448210 & 688267 & 4.2 & 5.1045 & TST & \\
\hline CHEMBL1464059 & 688267 & 4.35 & 5.0564 & TRN & \\
\hline CHEMBL1520562 & 688267 & 4.4 & 5.0735 & TST & \\
\hline CHEMBL1337243 & 688267 & 4.05 & 5.0639 & TRN & \\
\hline CHEMBL1385690 & 688267 & 4.05 & 5.06 & TRN & \\
\hline CHEMBL1471888 & 688267 & 6.2 & 5.013 & TRN & \\
\hline CHEMBL1460011 & 688267 & 4.05 & 5.0765 & TST & \\
\hline CHEMBL1356543 & 688267 & 6.2 & 5.0709 & TRN & \\
\hline CHEMBL1370644 & 688267 & 6.15 & 5.0947 & TST & \\
\hline CHEMBL3194235 & 688267 & 6.15 & 4.9849 & TST & \\
\hline CHEMBL1542671 & 688267 & 4.35 & 5.0967 & TRN & \\
\hline CHEMBL1401608 & 688267 & 5.45 & 5.1653 & TRN & \\
\hline CHEMBL1413002 & 688267 & 5.2 & 5.0191 & TRN & \\
\hline CHEMBL1359002 & 688267 & 4.25 & 5.0312 & TST & \\
\hline CHEMBL1371154 & 688267 & 4.0 & 5.0996 & TRN & \\
\hline CHEMBL1386648 & 688267 & 5.25 & 5.0228 & TRN & \\
\hline CHEMBL1553624 & 688267 & 6.2 & 5.0716 & TRN & \\
\hline CHEMBL1414388 & 688267 & 5.3 & 4.9851 & TST & \\
\hline CHEMBL1438662 & 688267 & 6.2 & 5.0339 & TRN & \\
\hline CHEMBL1479041 & 688267 & 5.65 & 5.0517 & TRN & \\
\hline CHEMBL1528754 & 688267 & 6.2 & 5.0318 & TRN & \\
\hline CHEMBL1443955 & 688267 & 3.95 & 5.0172 & TST & \\
\hline CHEMBL1453839 & 688267 & 3.95 & 5.0439 & TRN & \\
\hline CHEMBL1436074 & 688267 & 5.55 & 5.0395 & TRN & \\
\hline CHEMBL1365017 & 688267 & 4.1 & 5.1463 & TRN & \\
\hline CHEMBL1974081 & 688267 & 6.2 & 5.0143 & TST & \\
\hline
\end{tabular}




\begin{tabular}{|c|c|c|c|c|}
\hline \multicolumn{5}{|c|}{ Supplemental Table S2.txt } \\
\hline CHEMBL1405834 & 688267 & 4.5 & 5.0075 & TST \\
\hline CHEMBL1363776 & 688267 & 4.1 & 5.0558 & TRN \\
\hline CHEMBL1459801 & 688267 & 6.2 & 5.0371 & TRN \\
\hline CHEMBL1435843 & 688267 & 6.2 & 5.1042 & TRN \\
\hline CHEMBL1493521 & 688267 & 6.15 & 5.0369 & TRN \\
\hline CHEMBL1564619 & 688267 & 6.25 & 5.0114 & TRN \\
\hline CHEMBL1553904 & 688267 & 6.5 & 5.0641 & TRN \\
\hline CHEMBL3199010 & 688267 & 4.4 & 5.0205 & TST \\
\hline CHEMBL1318528 & 688267 & 6.5 & 5.0888 & TRN \\
\hline CHEMBL125044 & 688267 & 5.6 & 4.9979 & TRN \\
\hline CHEMBL1401826 & 688267 & 4.05 & 5.0193 & TST \\
\hline CHEMBL1562195 & 688267 & 5.95 & 4.9422 & TRN \\
\hline CHEMBL1315539 & 688267 & 5.1 & 5.0381 & TRN \\
\hline CHEMBL1444860 & 688267 & 4.35 & 5.1293 & TRN \\
\hline CHEMBL1425920 & 688267 & 4.45 & 5.0372 & TRN \\
\hline CHEMBL1345056 & 688267 & 5.85 & 5.0326 & TST \\
\hline CHEMBL1567656 & 688267 & 4.6 & 5.033 & TST \\
\hline CHEMBL1537416 & 688267 & 6.2 & 5.0342 & TRN \\
\hline CHEMBL1575331 & 688267 & 4.35 & 4.9848 & TRN \\
\hline CHEMBL1377013 & 688267 & 6.45 & 5.0494 & TRN \\
\hline CHEMBL1240755 & 688267 & 4.2 & 5.0676 & TRN \\
\hline CHEMBL1497043 & 688267 & 5.2 & 5.1271 & TRN \\
\hline CHEMBL1433713 & 688267 & 4.05 & 5.0614 & TRN \\
\hline CHEMBL1553652 & 688267 & 5.6 & 5.0497 & TST \\
\hline CHEMBL3208813 & 688267 & 4.6 & 5.0327 & TRN \\
\hline CHEMBL1524325 & 688267 & 5.4 & 5.0664 & TRN \\
\hline CHEMBL1299897 & 688267 & 6.2 & 5.1184 & TRN \\
\hline CHEMBL 3145283 & 688267 & 4.3 & 5.0321 & TST \\
\hline CHEMBL1379437 & 688267 & 4.0 & 5.1006 & TRN \\
\hline CHEMBL1577939 & 688267 & 4.35 & 5.056 & TRN \\
\hline CHEMBL1312135 & 688267 & 5.9 & 5.0376 & TRN \\
\hline CHEMBL1546182 & 688267 & 4.4 & 5.0676 & TST \\
\hline CHEMBL1315951 & 688267 & 3.95 & 5.0136 & TRN \\
\hline CHEMBL1340666 & 688267 & 6.25 & 5.1052 & TST \\
\hline CHEMBL1327140 & 688267 & 5.55 & 5.0591 & TRN \\
\hline CHEMBL1529090 & 688267 & 5.35 & 4.9796 & TST \\
\hline CHEMBL1361985 & 688267 & 4.25 & 5.0718 & TRN \\
\hline CHEMBL1555182 & 688267 & 5.2 & 5.0707 & TRN \\
\hline CHEMBL1420847 & 688267 & 4.1 & 5.0967 & TRN \\
\hline CHEMBL1323831 & 688267 & 5.4 & 5.029 & TST \\
\hline CHEMBL1425019 & 688267 & 5.5 & 4.9822 & TRN \\
\hline CHEMBL1363085 & 688267 & 4.4 & 5.1179 & TRN \\
\hline CHEMBL1543258 & 688267 & 6.2 & 5.0843 & TST \\
\hline CHEMBL1516104 & 688267 & 5.05 & 5.0778 & TRN \\
\hline CHEMBL1452026 & 688267 & 4.7 & 5.0271 & TRN \\
\hline CHEMBL1433774 & 688267 & 6.15 & 5.0856 & TRN \\
\hline CHEMBL1493288 & 688267 & 4.2 & 5.0668 & TRN \\
\hline CHEMBL1430325 & 688267 & 5.75 & 5.0187 & TRN \\
\hline
\end{tabular}




\begin{tabular}{|c|c|c|c|c|c|}
\hline & & & & & \\
\hline CHEMBL1318250 & 688267 & 4.8 & 5.0756 & TST & \\
\hline CHEMBL1430311 & 688267 & 4.65 & 5.0417 & TRN & \\
\hline CHEMBL1326206 & 688267 & 5.45 & 5.0316 & TST & \\
\hline CHEMBL1317766 & 688267 & 5.4 & 5.142 & TRN & \\
\hline CHEMBL1483962 & 688267 & 4.55 & 5.15600 & 2000000001 & TST \\
\hline CHEMBL1558852 & 688267 & 6.15 & 5.0875 & TRN & \\
\hline CHEMBL3194241 & 688267 & 5.35 & 5.0211 & TRN & \\
\hline CHEMBL1427060 & 688267 & 6.2 & 5.0503 & TST & \\
\hline CHEMBL1446944 & 688267 & 5.05 & 5.1256 & TRN & \\
\hline CHEMBL1559056 & 688267 & 6.2 & 5.0527 & TRN & \\
\hline CHEMBL1471561 & 688267 & 6.45 & 5.0394 & TST & \\
\hline CHEMBL1613088 & 688267 & 4.15 & 5.0649 & TRN & \\
\hline CHEMBL1511842 & 688267 & 5.85 & 5.0458 & TST & \\
\hline CHEMBL1580821 & 688267 & 4.6 & 5.0432 & TST & \\
\hline CHEMBL1468988 & 688267 & 5.55 & 5.1332 & TRN & \\
\hline CHEMBL1320151 & 688267 & 3.95 & 5.0155 & TST & \\
\hline CHEMBL1483215 & 688267 & 5.5 & 5.0531 & TRN & \\
\hline CHEMBL1519922 & 688267 & 4.0 & 5.0083 & TRN & \\
\hline CHEMBL1534323 & 688267 & 4.05 & 5.0637 & TST & \\
\hline CHEMBL1424960 & 688267 & 4.05 & 5.0026 & TRN & \\
\hline CHEMBL1360416 & 688267 & 6.1 & 4.9737 & TRN & \\
\hline CHEMBL1607861 & 688267 & 4.2 & 5.0734 & TRN & \\
\hline CHEMBL1334578 & 688267 & 5.6 & 5.0408 & TRN & \\
\hline CHEMBL1476767 & 688267 & 5.0 & 5.0305 & TRN & \\
\hline CHEMBL1340831 & 688267 & 3.95 & 5.0591 & TST & \\
\hline CHEMBL1390333 & 688267 & 6.3 & 4.9994 & TRN & \\
\hline CHEMBL1445992 & 688267 & 5.0 & 5.1221 & TRN & \\
\hline CHEMBL1377356 & 688267 & 5.55 & 5.0497 & TST & \\
\hline CHEMBL1555902 & 688267 & 4.4 & 5.0794 & TRN & \\
\hline CHEMBL1545736 & 688267 & 4.6 & 5.00899 & 99999999995 & TST \\
\hline CHEMBL1303210 & 688267 & 5.85 & 5.0829 & TRN & \\
\hline CHEMBL1416086 & 688267 & 4.7 & 4.9903 & TRN & \\
\hline CHEMBL278755 & 688267 & 5.0 & 5.0227 & TST & \\
\hline CHEMBL1388904 & 688267 & 5.85 & 5.0422 & TST & \\
\hline CHEMBL1542785 & 688267 & 6.2 & 5.0634 & TRN & \\
\hline CHEMBL1327342 & 688267 & 5.6 & 5.0106 & TRN & \\
\hline CHEMBL1587148 & 688267 & 3.95 & 5.1592 & TRN & \\
\hline CHEMBL1376769 & 688267 & 5.35 & 5.0386 & TRN & \\
\hline CHEMBL1304099 & 688267 & 4.7 & 5.0901 & TRN & \\
\hline CHEMBL1397393 & 688267 & 5.9 & 5.1165 & TST & \\
\hline CHEMBL1468391 & 688267 & 5.8 & 5.0492 & TRN & \\
\hline CHEMBL1526103 & 688267 & 6.15 & 5.078 & TRN & \\
\hline CHEMBL1300788 & 688267 & 4.05 & 5.0139 & TRN & \\
\hline CHEMBL1514689 & 688267 & 4.05 & 5.0225 & TRN & \\
\hline CHEMBL1331006 & 688267 & 4.0 & 5.044 & TST & \\
\hline CHEMBL1575565 & 688267 & 5.3 & 5.0678 & TRN & \\
\hline CHEMBL1483630 & 688267 & 4.6 & 5.0656 & TST & \\
\hline CHEMBL1420583 & 688267 & 6.2 & 5.1087 & TRN & \\
\hline
\end{tabular}




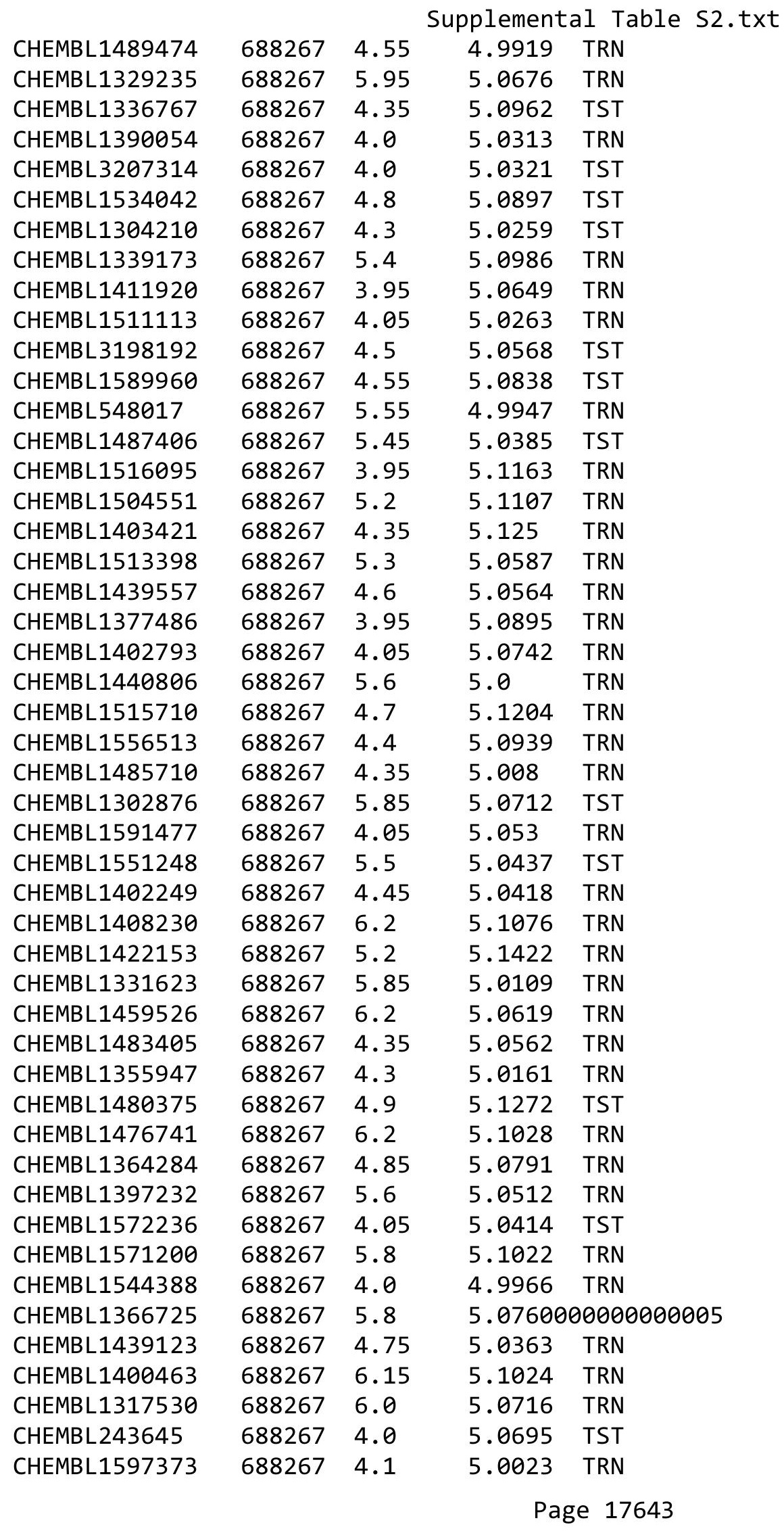




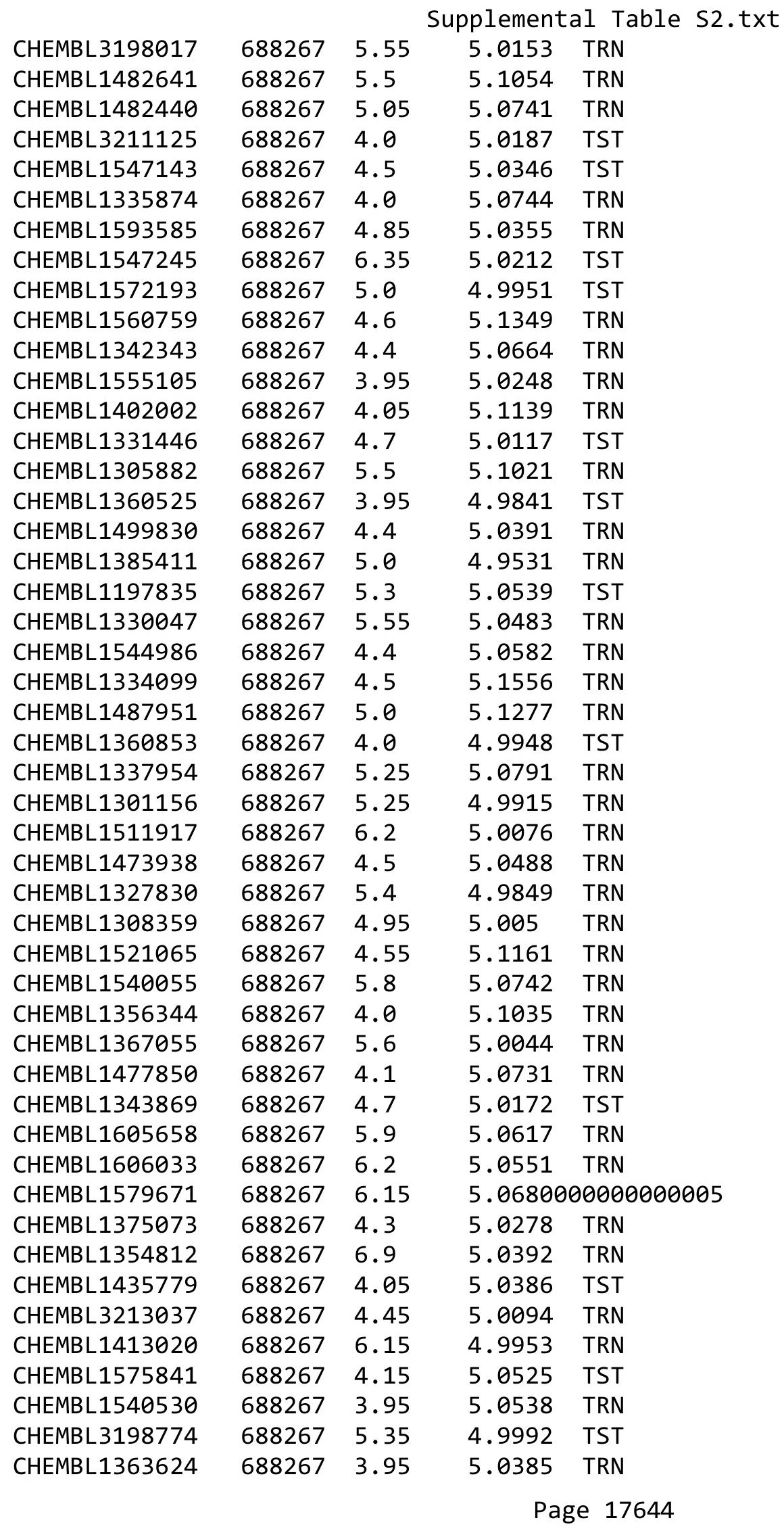




\begin{tabular}{|c|c|c|c|c|}
\hline & & & upplement & \\
\hline CHEMBL1607736 & 688267 & 5.5 & 5.0506 & TST \\
\hline CHEMBL1559968 & 688267 & 4.05 & 5.0189 & TRN \\
\hline CHEMBL1306668 & 688267 & 4.05 & 5.0008 & TRN \\
\hline CHEMBL1367015 & 688267 & 4.75 & 4.9923 & TST \\
\hline CHEMBL1528875 & 688267 & 4.95 & 5.0534 & TST \\
\hline CHEMBL1425020 & 688267 & 4.05 & 5.041 & TST \\
\hline CHEMBL1504020 & 688267 & 4.0 & 5.0014 & TRN \\
\hline CHEMBL1356830 & 688267 & 6.2 & 4.9859 & TRN \\
\hline CHEMBL 3212807 & 688267 & 4.6 & 4.9851 & TST \\
\hline CHEMBL1398385 & 688267 & 4.0 & 5.1672 & TRN \\
\hline CHEMBL1530733 & 688267 & 4.0 & 5.055 & TST \\
\hline CHEMBL1551995 & 688267 & 4.95 & 5.0766 & TRN \\
\hline CHEMBL1402059 & 688267 & 5.6 & 5.0444 & TST \\
\hline CHEMBL1415165 & 688267 & 5.9 & 5.0404 & TST \\
\hline CHEMBL3199350 & 688267 & 4.35 & 5.0047 & TRN \\
\hline CHEMBL1342114 & 688267 & 4.8 & 5.0374 & TRN \\
\hline CHEMBL1498412 & 688267 & 5.35 & 5.088 & TRN \\
\hline CHEMBL1484365 & 688267 & 3.95 & 5.0599 & TRN \\
\hline CHEMBL1476375 & 688267 & 6.25 & 5.0053 & TRN \\
\hline CHEMBL3211204 & 688267 & 6.2 & 5.0008 & TST \\
\hline CHEMBL1594633 & 688267 & 4.15 & 5.1081 & TRN \\
\hline CHEMBL3190242 & 688267 & 6.2 & 5.0306 & TRN \\
\hline CHEMBL3212737 & 688267 & 5.05 & 5.0028 & TRN \\
\hline CHEMBL1542540 & 688267 & 5.65 & 5.0573 & TST \\
\hline CHEMBL1524597 & 688267 & 4.55 & 5.1122 & TRN \\
\hline CHEMBL1545979 & 688267 & 5.6 & 5.0766 & TRN \\
\hline CHEMBL1543562 & 688267 & 4.0 & 5.1557 & TRN \\
\hline CHEMBL1348232 & 688267 & 4.55 & 5.0506 & TRN \\
\hline CHEMBL1303713 & 688267 & 4.6 & 5.1261 & TRN \\
\hline CHEMBL1568729 & 688267 & 4.0 & 5.0564 & TRN \\
\hline CHEMBL3192366 & 688267 & 4.25 & 5.0542 & TST \\
\hline CHEMBL1514248 & 688267 & 5.6 & 5.1011 & TRN \\
\hline CHEMBL1582787 & 688267 & 4.5 & 5.0431 & TST \\
\hline CHEMBL1353057 & 688267 & 5.15 & 5.1247 & TRN \\
\hline CHEMBL1330471 & 688267 & 3.95 & 5.0469 & TRN \\
\hline CHEMBL1409806 & 688267 & 5.25 & 5.1235 & TRN \\
\hline CHEMBL1500847 & 688267 & 5.4 & 5.1217 & TRN \\
\hline CHEMBL1554480 & 688267 & 3.95 & 5.0435 & TRN \\
\hline CHEMBL1459717 & 688267 & 3.95 & 5.0519 & TRN \\
\hline CHEMBL1329588 & 688267 & 6.0 & 5.0984 & TRN \\
\hline CHEMBL1459321 & 688267 & 4.25 & 5.0577 & TRN \\
\hline CHEMBL1322111 & 688267 & 5.35 & 5.0923 & TRN \\
\hline CHEMBL1570029 & 688267 & 6.15 & 5.0422 & TRN \\
\hline CHEMBL1495449 & 688267 & 6.0 & 4.995 & TRN \\
\hline CHEMBL1553159 & 688267 & 6.15 & 5.0477 & TRN \\
\hline CHEMBL1468332 & 688267 & 5.75 & 5.0394 & TRN \\
\hline CHEMBL1331756 & 688267 & 5.35 & 5.1039 & TRN \\
\hline CHEMBL1574411 & 688267 & 4.55 & 5.101 & TRN \\
\hline
\end{tabular}




\begin{tabular}{|c|c|c|c|c|c|}
\hline CHEMBL1336964 & 688267 & 4.0 & \multicolumn{2}{|c|}{5.0280000000000005} & TRN \\
\hline CHEMBL1314504 & 688267 & 6.2 & 5.0408 & TRN & \\
\hline CHEMBL1322540 & 688267 & 4.35 & 5.1396 & TST & \\
\hline CHEMBL1494872 & 688267 & 6.2 & 5.0725 & TRN & \\
\hline CHEMBL1323037 & 688267 & 4.0 & 5.0814 & TST & \\
\hline CHEMBL1581487 & 688267 & 5.75 & 5.0005 & TRN & \\
\hline CHEMBL1456674 & 688267 & 3.95 & 5.0341 & TRN & \\
\hline CHEMBL1509391 & 688267 & 4.3 & 5.073 & TST & \\
\hline CHEMBL3213195 & 688267 & 5.75 & 5.0313 & TRN & \\
\hline CHEMBL1385915 & 688267 & 4.85 & 5.0454 & TRN & \\
\hline CHEMBL1376377 & 688267 & 4.8 & 5.0784 & TST & \\
\hline CHEMBL3196177 & 688267 & 5.3 & 5.0075 & TRN & \\
\hline CHEMBL1576840 & 688267 & 4.0 & 5.0448 & TRN & \\
\hline CHEMBL1478865 & 688267 & 5.4 & 5.0658 & TRN & \\
\hline CHEMBL1443223 & 688267 & 4.35 & 5.0082 & TST & \\
\hline CHEMBL566687 & 688267 & 6.25 & 5.0247 & TRN & \\
\hline CHEMBL1334575 & 688267 & 4.05 & 5.0567 & TST & \\
\hline CHEMBL1414461 & 688267 & 5.75 & 5.0689 & TST & \\
\hline CHEMBL3199720 & 688267 & 6.2 & 5.0145 & TST & \\
\hline CHEMBL1485118 & 688267 & 4.65 & 5.0464 & TST & \\
\hline CHEMBL1379015 & 688267 & 4.55 & 5.0828 & TRN & \\
\hline CHEMBL1353069 & 688267 & 5.35 & 5.0444 & TRN & \\
\hline CHEMBL1436705 & 688267 & 4.0 & 5.0742 & TRN & \\
\hline CHEMBL1495143 & 688267 & 5.9 & 5.0365 & TRN & \\
\hline CHEMBL1385508 & 688267 & 4.0 & 5.0516 & TRN & \\
\hline CHEMBL1612982 & 688267 & 4.25 & 5.0679 & TRN & \\
\hline CHEMBL1493838 & 688267 & 4.3 & 5.0306 & TRN & \\
\hline CHEMBL1530826 & 688267 & 6.2 & 5.053 & TRN & \\
\hline CHEMBL1410108 & 688267 & 3.95 & 5.015 & TST & \\
\hline CHEMBL1987938 & 688267 & 6.1 & 5.0253 & TRN & \\
\hline CHEMBL1465546 & 688267 & 5.0 & 5.086 & TRN & \\
\hline CHEMBL1398988 & 688267 & 5.1 & 5.0859 & TST & \\
\hline CHEMBL1422013 & 688267 & 4.05 & 5.0932 & TRN & \\
\hline CHEMBL1333749 & 688267 & 4.4 & 5.0837 & TRN & \\
\hline CHEMBL1357784 & 688267 & 6.4 & 5.0969 & TRN & \\
\hline CHEMBL1377037 & 688267 & 6.0 & 5.0163 & TRN & \\
\hline CHEMBL3208558 & 688267 & 6.7501 & 5.0376 & TST & \\
\hline CHEMBL1376288 & 688267 & 5.35 & 5.0274 & TST & \\
\hline CHEMBL1425082 & 688267 & 4.35 & 5.0708 & TRN & \\
\hline CHEMBL1441782 & 688267 & 4.9 & 5.0361 & TRN & \\
\hline CHEMBL1410698 & 688267 & 6.15 & 5.1199 & TRN & \\
\hline CHEMBL1585453 & 688267 & 4.45 & 5.0601 & TRN & \\
\hline CHEMBL1582559 & 688267 & 4.0 & 5.0742 & TRN & \\
\hline CHEMBL1396712 & 688267 & 4.05 & 5.053 & TRN & \\
\hline CHEMBL1541115 & 688267 & 4.3 & 5.1084 & TRN & \\
\hline CHEMBL3195830 & 688267 & 4.0 & 5.0333 & TST & \\
\hline CHEMBL1551463 & 688267 & 5.6 & 5.0334 & TRN & \\
\hline CHEMBL1454731 & 688267 & 4.05 & 5.141 & TRN & \\
\hline
\end{tabular}




\begin{tabular}{|c|c|c|c|c|}
\hline & & & pplement & al $\mathrm{Ta}$ \\
\hline CHEMBL1414757 & 688267 & 5.3 & 5.1099 & TRN \\
\hline CHEMBL1524271 & 688267 & 6.5 & 5.0513 & TRN \\
\hline CHEMBL1371025 & 688267 & 6.2 & 5.1402 & TRN \\
\hline CHEMBL1431444 & 688267 & 5.35 & 4.9993 & TRN \\
\hline CHEMBL1483092 & 688267 & 4.5 & 5.1027 & TRN \\
\hline CHEMBL1578104 & 688267 & 5.25 & 5.0514 & TRN \\
\hline CHEMBL1453681 & 688267 & 5.1 & 4.9972 & TST \\
\hline CHEMBL1362073 & 688267 & 4.25 & 5.0488 & TST \\
\hline CHEMBL1569181 & 688267 & 5.4 & 5.0616 & TRN \\
\hline CHEMBL1400646 & 688267 & 6.5 & 5.0215 & TRN \\
\hline CHEMBL1464129 & 688267 & 5.25 & 4.9906 & TRN \\
\hline CHEMBL1425081 & 688267 & 5.5 & 5.0917 & TRN \\
\hline CHEMBL1360548 & 688267 & 4.35 & 5.0107 & TRN \\
\hline CHEMBL 3211844 & 688267 & 6.15 & 5.0345 & TST \\
\hline CHEMBL1428861 & 688267 & 6.2 & 4.9942 & TRN \\
\hline CHEMBL1453955 & 688267 & 6.5 & 5.1394 & TRN \\
\hline CHEMBL1520382 & 688267 & 5.9 & 5.0822 & TRN \\
\hline CHEMBL1428223 & 688267 & 4.1 & 5.0335 & TRN \\
\hline CHEMBL1495026 & 688267 & 6.2 & 5.1065 & TRN \\
\hline CHEMBL1364310 & 688267 & 4.4 & 5.0695 & TRN \\
\hline CHEMBL1593771 & 688267 & 5.5 & 5.0975 & TRN \\
\hline CHEMBL1536382 & 688267 & 5.5 & 5.062 & TRN \\
\hline CHEMBL1974859 & 688267 & 5.65 & 5.0499 & TST \\
\hline CHEMBL1491831 & 688267 & 5.9 & 5.1017 & TST \\
\hline CHEMBL1560829 & 688267 & 5.6 & 5.0255 & TRN \\
\hline CHEMBL1378155 & 688267 & 6.2 & 5.012 & TST \\
\hline CHEMBL1480365 & 688267 & 6.5 & 5.1143 & TST \\
\hline CHEMBL1585967 & 688267 & 6.15 & 5.1337 & TRN \\
\hline CHEMBL1472803 & 688267 & 4.1 & 5.0758 & TRN \\
\hline CHEMBL1454905 & 688267 & 4.7 & 5.0406 & TRN \\
\hline CHEMBL1334598 & 688267 & 5.8 & 5.056 & TRN \\
\hline CHEMBL1518437 & 688267 & 6.25 & 5.0097 & TRN \\
\hline CHEMBL1543998 & 688267 & 6.2 & 5.074 & TRN \\
\hline CHEMBL1492684 & 688267 & 5.3 & 5.0609 & TRN \\
\hline CHEMBL1435554 & 688267 & 5.85 & 5.0967 & TRN \\
\hline CHEMBL1445197 & 688267 & 4.9 & 5.119 & TRN \\
\hline CHEMBL1374417 & 688267 & 5.4 & 5.0224 & TRN \\
\hline CHEMBL1580532 & 688267 & 4.0 & 4.9937 & TRN \\
\hline CHEMBL1312551 & 688267 & 5.95 & 5.0282 & TRN \\
\hline CHEMBL1557120 & 688267 & 4.65 & 5.0159 & TRN \\
\hline CHEMBL1567308 & 688267 & 5.65 & 5.0578 & TST \\
\hline CHEMBL1318380 & 688267 & 5.9 & 5.1075 & TRN \\
\hline CHEMBL1604010 & 688267 & 5.25 & 5.0589 & TRN \\
\hline CHEMBL1394435 & 688267 & 3.95 & 5.0652 & TST \\
\hline CHEMBL1541814 & 688267 & 6.2 & 5.1305 & TRN \\
\hline CHEMBL1536598 & 688267 & 4.05 & 4.9801 & TRN \\
\hline CHEMBL1514913 & 688267 & 5.0 & 5.0364 & TRN \\
\hline CHEMBL1378276 & 688267 & 4.6 & 5.1066 & TST \\
\hline
\end{tabular}




\begin{tabular}{|c|c|c|c|c|c|}
\hline \\
\hline CHEMBL1573915 & 688267 & 6.2 & 5.0255 & TRN & \\
\hline CHEMBL1587630 & 688267 & 4.9 & 5.0143 & TRN & \\
\hline CHEMBL1339739 & 688267 & 5.05 & 5.1171 & TRN & \\
\hline CHEMBL1354873 & 688267 & 4.0 & 5.07 & TRN & \\
\hline CHEMBL1486454 & 688267 & 4.4 & 5.1561 & TRN & \\
\hline CHEMBL1430079 & 688267 & 5.6 & 5.1459 & TRN & \\
\hline CHEMBL1376506 & 688267 & 4.25 & 5.1246 & TRN & \\
\hline CHEMBL1406675 & 688267 & 5.25 & 5.0147 & TST & \\
\hline CHEMBL1367336 & 688267 & 4.4 & 5.0142 & TST & \\
\hline CHEMBL1588665 & 688267 & 6.15 & 5.0379 & TRN & \\
\hline CHEMBL1590475 & 688267 & 4.45 & 5.1504 & TRN & \\
\hline CHEMBL1302228 & 688267 & 5.4 & 5.0407 & TRN & \\
\hline CHEMBL1366717 & 688267 & 6.3 & 5.0559 & TRN & \\
\hline CHEMBL1315428 & 688267 & 5.75 & 5.0421 & TRN & \\
\hline CHEMBL1435870 & 688267 & 5.3 & 5.0811 & TRN & \\
\hline CHEMBL1401265 & 688267 & 4.1 & 5.008 & TST & \\
\hline CHEMBL1432867 & 688267 & 4.0 & 4.9616 & TRN & \\
\hline CHEMBL1434718 & 688267 & 4.05 & 5.0988 & TRN & \\
\hline CHEMBL1310014 & 688267 & 5.1 & 5.1125 & TRN & \\
\hline CHEMBL1325089 & 688267 & 4.2 & 4.9922 & TRN & \\
\hline CHEMBL1372127 & 688267 & 4.05 & 5.0027 & TST & \\
\hline CHEMBL1602505 & 688267 & 5.5 & 5.0229 & TRN & \\
\hline CHEMBL1549332 & 688267 & 6.2 & 5.0808 & TST & \\
\hline CHEMBL1583948 & 688267 & 5.65 & 5.05 & TRN & \\
\hline CHEMBL1605160 & 688267 & 5.05 & 5.0208 & TRN & \\
\hline CHEMBL1420788 & 688267 & 4.6 & 4.9997 & TRN & \\
\hline CHEMBL1549687 & 688267 & 4.5 & 5.0759 & TST & \\
\hline CHEMBL1597480 & 688267 & 4.4 & 5.0616 & TRN & \\
\hline CHEMBL1327601 & 688267 & 5.45 & 5.0595 & TRN & \\
\hline CHEMBL1410917 & 688267 & 6.05 & 5.0726 & TRN & \\
\hline CHEMBL1303915 & 688267 & 4.35 & 5.0873 & TRN & \\
\hline CHEMBL1567560 & 688267 & 3.95 & 4.9993 & TRN & \\
\hline CHEMBL1488822 & 688267 & 4.4 & 5.0432 & TRN & \\
\hline CHEMBL1563839 & 688267 & 4.05 & 5.0464 & TRN & \\
\hline CHEMBL1366220 & 688267 & 4.35 & 5.0381 & TRN & \\
\hline CHEMBL1475011 & 688267 & 4.1 & 5.0435 & TRN & \\
\hline CHEMBL1404803 & 688267 & 3.95 & 5.0542 & TRN & \\
\hline CHEMBL1583886 & 688267 & 6.2 & 5.0361 & TRN & \\
\hline CHEMBL1608875 & 688267 & 6.25 & 5.0568 & TST & \\
\hline CHEMBL1450824 & 688267 & 4.85 & 5.0468 & TRN & \\
\hline CHEMBL1337953 & 688267 & 4.0 & 5.0106 & TRN & \\
\hline CHEMBL1545610 & 688267 & 5.95 & 5.0209 & TRN & \\
\hline CHEMBL1535596 & 688267 & 5.3 & 5.0826 & TRN & \\
\hline CHEMBL1607435 & 688267 & 5.8 & 5.04899 & 99999999995 & TRN \\
\hline CHEMBL1319367 & 688267 & 4.05 & 5.0624 & TST & \\
\hline CHEMBL1501211 & 688267 & 5.0 & 5.0842 & TST & \\
\hline CHEMBL1532177 & 688267 & 3.95 & 5.0174 & TRN & \\
\hline CHEMBL1400559 & 688267 & 6.15 & 5.0607 & TRN & \\
\hline
\end{tabular}




\begin{tabular}{|c|c|c|c|c|}
\hline & & & upplement & al $\mathrm{T}$ \\
\hline CHEMBL1572939 & 688267 & 4.9 & 5.0164 & TRN \\
\hline CHEMBL1582482 & 688267 & 5.0 & 5.0944 & TRN \\
\hline CHEMBL1475772 & 688267 & 6.3 & 5.0696 & TST \\
\hline CHEMBL 3197490 & 688267 & 5.1 & 5.0827 & TST \\
\hline CHEMBL1309263 & 688267 & 5.75 & 5.1277 & TRN \\
\hline CHEMBL1476223 & 688267 & 5.75 & 5.0147 & TRN \\
\hline CHEMBL1446315 & 688267 & 5.2 & 5.084 & TRN \\
\hline CHEMBL1467822 & 688267 & 5.8 & 5.0562 & TRN \\
\hline CHEMBL1612746 & 688267 & 5.5 & 5.1145 & TRN \\
\hline CHEMBL1349194 & 688267 & 4.8 & 5.0461 & TRN \\
\hline CHEMBL1438765 & 688267 & 4.35 & 5.0113 & TST \\
\hline CHEMBL1367842 & 688267 & 4.55 & 5.034 & TST \\
\hline CHEMBL1512611 & 688267 & 4.0 & 5.0387 & TRN \\
\hline CHEMBL1493962 & 688267 & 4.4 & 5.0253 & TRN \\
\hline CHEMBL1309524 & 688267 & 4.9 & 5.0864 & TST \\
\hline CHEMBL1499743 & 688267 & 5.3 & 4.9878 & TRN \\
\hline CHEMBL1540536 & 688267 & 5.3 & 5.0122 & TRN \\
\hline CHEMBL1320873 & 688267 & 4.05 & 5.0724 & TRN \\
\hline CHEMBL1415274 & 688267 & 4.05 & 5.0433 & TRN \\
\hline CHEMBL1367190 & 688267 & 6.25 & 5.047 & TRN \\
\hline CHEMBL1396357 & 688267 & 6.5 & 5.0731 & TRN \\
\hline CHEMBL1348154 & 688267 & 4.35 & 5.0391 & TRN \\
\hline CHEMBL1523765 & 688267 & 5.1 & 5.0351 & TRN \\
\hline CHEMBL1418022 & 688267 & 5.35 & 5.1072 & TST \\
\hline CHEMBL1306587 & 688267 & 5.45 & 5.1092 & TRN \\
\hline CHEMBL1547917 & 688267 & 4.9 & 5.0192 & TRN \\
\hline CHEMBL1368811 & 688267 & 4.65 & 5.0823 & TST \\
\hline CHEMBL1547638 & 688267 & 4.0 & 4.9875 & TRN \\
\hline CHEMBL1435004 & 688267 & 6.0 & 5.0713 & TRN \\
\hline CHEMBL1457916 & 688267 & 4.35 & 5.0985 & TRN \\
\hline CHEMBL3191383 & 688267 & 6.2 & 5.0662 & TST \\
\hline CHEMBL1340324 & 688267 & 4.7 & 5.0934 & TRN \\
\hline CHEMBL1582354 & 688267 & 5.55 & 5.1285 & TST \\
\hline CHEMBL1378444 & 688267 & 6.3 & 5.0948 & TRN \\
\hline CHEMBL1356472 & 688267 & 4.3 & 4.9936 & TST \\
\hline CHEMBL1533983 & 688267 & 5.55 & 5.1508 & TRN \\
\hline CHEMBL1555525 & 688267 & 5.95 & 5.0535 & TST \\
\hline CHEMBL1434634 & 688267 & 5.55 & 5.0086 & TRN \\
\hline CHEMBL 3197464 & 688267 & 4.4 & 5.0256 & TRN \\
\hline CHEMBL 1403848 & 688267 & 4.6 & 5.0975 & TST \\
\hline CHEMBL1441945 & 688267 & 4.4 & 5.0455 & TRN \\
\hline CHEMBL3198916 & 688267 & 6.2 & 5.0161 & TRN \\
\hline CHEMBL1535632 & 688267 & 4.4 & 5.1161 & TRN \\
\hline CHEMBL1426117 & 688267 & 4.65 & 5.0736 & TRN \\
\hline CHEMBL1520813 & 688267 & 5.9 & 5.0478 & TRN \\
\hline CHEMBL1430473 & 688267 & 4.4 & 5.0535 & TST \\
\hline CHEMBL1357912 & 688267 & 4.25 & 5.0112 & TRN \\
\hline CHEMBL1449320 & 688267 & 6.1 & 5.0435 & TRN \\
\hline
\end{tabular}




\begin{tabular}{|c|c|c|c|c|c|}
\hline \\
\hline CHEMBL1436087 & 688267 & 6.2 & 5.0636 & TRN & \\
\hline CHEMBL1568885 & 688267 & 4.3 & 4.9665 & TRN & \\
\hline CHEMBL1590656 & 688267 & 5.15 & 4.997 & TRN & \\
\hline CHEMBL1417149 & 688267 & 5.45 & 5.0332 & TST & \\
\hline CHEMBL1984796 & 688267 & 5.65 & 5.0162 & TST & \\
\hline CHEMBL1416724 & 688267 & 4.0 & 5.0099 & TRN & \\
\hline CHEMBL1469239 & 688267 & 4.0 & 5.1489 & TRN & \\
\hline CHEMBL1606685 & 688267 & 4.3 & 5.0383 & TST & \\
\hline CHEMBL1551804 & 688267 & 4.35 & 5.1467 & TRN & \\
\hline CHEMBL1561382 & 688267 & 4.05 & 5.0692 & TST & \\
\hline CHEMBL1454338 & 688267 & 4.1 & 5.0768 & TRN & \\
\hline CHEMBL1352248 & 688267 & 5.9 & 5.0115 & TRN & \\
\hline CHEMBL1592600 & 688267 & 5.65 & 5.112 & TRN & \\
\hline CHEMBL1502014 & 688267 & 6.05 & 4.98300 & 00000000005 & TST \\
\hline CHEMBL1400092 & 688267 & 5.95 & 5.0732 & TRN & \\
\hline CHEMBL1406651 & 688267 & 4.1 & 5.0826 & TRN & \\
\hline CHEMBL1453066 & 688267 & 6.2 & 5.0576 & TRN & \\
\hline CHEMBL1591317 & 688267 & 4.15 & 5.0904 & TRN & \\
\hline CHEMBL1593460 & 688267 & 4.85 & 5.0018 & TST & \\
\hline CHEMBL1516159 & 688267 & 4.2 & 5.0423 & TRN & \\
\hline CHEMBL1310477 & 688267 & 4.4 & 5.0083 & TRN & \\
\hline CHEMBL1328817 & 688267 & 4.15 & 5.0264 & TRN & \\
\hline CHEMBL1499148 & 688267 & 5.3 & 5.0098 & TRN & \\
\hline CHEMBL1439234 & 688267 & 6.45 & 5.0276 & TRN & \\
\hline CHEMBL1554695 & 688267 & 4.1 & 5.1064 & TRN & \\
\hline CHEMBL1598306 & 688267 & 5.5 & 5.1097 & TST & \\
\hline CHEMBL1363327 & 688267 & 5.85 & 5.0539 & TRN & \\
\hline CHEMBL1375702 & 688267 & 5.55 & 5.0683 & TST & \\
\hline CHEMBL1435573 & 688267 & 4.9 & 5.0791 & TST & \\
\hline CHEMBL1379785 & 688267 & 6.2 & 5.082 & TRN & \\
\hline CHEMBL1462037 & 688267 & 5.3 & 5.0559 & TRN & \\
\hline CHEMBL1377734 & 688267 & 5.65 & 5.05699 & 99999999995 & TRN \\
\hline CHEMBL1406971 & 688267 & 6.2 & 5.0448 & TST & \\
\hline CHEMBL3190335 & 688267 & 6.15 & 5.0456 & TRN & \\
\hline CHEMBL1610846 & 688267 & 5.75 & 5.0252 & TRN & \\
\hline CHEMBL1437398 & 688267 & 5.5 & 5.0779 & TRN & \\
\hline CHEMBL1526969 & 688267 & 3.95 & 5.0733 & TRN & \\
\hline CHEMBL1464178 & 688267 & 4.8 & 5.0988 & TRN & \\
\hline CHEMBL1507211 & 688267 & 5.5 & 5.0778 & TRN & \\
\hline CHEMBL1510861 & 688267 & 6.0 & 5.1683 & TRN & \\
\hline CHEMBL1463493 & 688267 & 5.35 & 5.0529 & TRN & \\
\hline CHEMBL 3195228 & 688267 & 6.6 & 5.0043 & TRN & \\
\hline CHEMBL1494314 & 688267 & 6.2 & 5.0749 & TRN & \\
\hline CHEMBL1503723 & 688267 & 5.8 & 5.0162 & TRN & \\
\hline CHEMBL1319250 & 688267 & 5.8 & 4.9975 & TRN & \\
\hline CHEMBL 3190064 & 688267 & 4.35 & 5.0062 & TRN & \\
\hline CHEMBL1527694 & 688267 & 6.2 & 5.0391 & TRN & \\
\hline CHEMBL1468593 & 688267 & 4.3 & 5.0334 & TRN & \\
\hline
\end{tabular}




\begin{tabular}{|c|c|c|c|c|c|}
\hline \\
\hline CHEMBL1470609 & 688267 & 4.2 & 5.0619 & TRN & \\
\hline CHEMBL1569754 & 688267 & 4.3 & 4.9973 & TST & \\
\hline CHEMBL1434526 & 688267 & 6.0 & 5.0425 & TST & \\
\hline CHEMBL1369926 & 688267 & 3.95 & 4.9866 & TRN & \\
\hline CHEMBL1516151 & 688267 & 5.6 & 4.9888 & TRN & \\
\hline CHEMBL1529427 & 688267 & 4.85 & 4.9931 & TRN & \\
\hline CHEMBL1478428 & 688267 & 5.35 & 5.0937 & TRN & \\
\hline CHEMBL1599199 & 688267 & 5.3 & 5.0325 & TST & \\
\hline CHEMBL1593800 & 688267 & 5.3 & 5.0613 & TRN & \\
\hline CHEMBL1330037 & 688267 & 6.2 & 5.0315 & TRN & \\
\hline CHEMBL1382883 & 688267 & 5.55 & 5.0332 & TRN & \\
\hline CHEMBL1454178 & 688267 & 5.5 & 5.11 & TRN & \\
\hline CHEMBL1613379 & 688267 & 4.6 & 5.0483 & TRN & \\
\hline CHEMBL1436879 & 688267 & 4.05 & 5.0274 & TST & \\
\hline CHEMBL1467663 & 688267 & 4.6 & 5.0756 & TRN & \\
\hline CHEMBL1572746 & 688267 & 6.05 & 5.0624 & TRN & \\
\hline CHEMBL1423939 & 688267 & 5.4 & 5.099 & TRN & \\
\hline CHEMBL1363302 & 688267 & 5.3 & 5.0412 & TST & \\
\hline CHEMBL1559873 & 688267 & 4.95 & 5.0637 & TRN & \\
\hline CHEMBL1558008 & 688267 & 4.55 & 5.0432 & TRN & \\
\hline CHEMBL1423975 & 688267 & 6.5 & 5.0874 & TST & \\
\hline CHEMBL1564539 & 688267 & 6.2 & 5.1091 & TRN & \\
\hline CHEMBL1439829 & 688267 & 5.4 & 5.0362 & TRN & \\
\hline CHEMBL1609617 & 688267 & 4.15 & 5.0369 & TRN & \\
\hline CHEMBL1448043 & 688267 & 6.2 & 5.0238 & TRN & \\
\hline CHEMBL1420353 & 688267 & 5.8 & 5.129 & TRN & \\
\hline CHEMBL3193946 & 688267 & 4.05 & 5.0235 & TST & \\
\hline CHEMBL1331070 & 688267 & 5.95 & 5.1509 & TRN & \\
\hline CHEMBL1439120 & 688267 & 6.1 & 5.0301 & TRN & \\
\hline CHEMBL1532733 & 688267 & 5.55 & 5.0439 & TRN & \\
\hline CHEMBL1406917 & 688267 & 4.25 & 5.0353 & TST & \\
\hline CHEMBL1502030 & 688267 & 4.35 & 5.0552 & TST & \\
\hline CHEMBL1550115 & 688267 & 5.1 & 5.0232 & TRN & \\
\hline CHEMBL1401291 & 688267 & 6.2 & 5.0622 & TRN & \\
\hline CHEMBL1454773 & 688267 & 5.8 & 5.0539 & TRN & \\
\hline CHEMBL1430210 & 688267 & 5.35 & 5.1035 & TRN & \\
\hline CHEMBL1584282 & 688267 & 5.25 & 5.1022 & TST & \\
\hline CHEMBL1979293 & 688267 & 4.9 & 5.0631 & TST & \\
\hline CHEMBL1353283 & 688267 & 4.6 & 5.0146 & TRN & \\
\hline CHEMBL1365902 & 688267 & 6.25 & 4.9766 & TRN & \\
\hline CHEMBL1525350 & 688267 & 6.2 & 5.0923 & TRN & \\
\hline CHEMBL1507576 & 688267 & 6.2 & 5.1841 & TRN & \\
\hline CHEMBL1533403 & 688267 & 4.0 & 5.0969 & TRN & \\
\hline CHEMBL1372906 & 688267 & 4.05 & 5.07600 & 00000000005 & TRN \\
\hline CHEMBL1467012 & 688267 & 3.95 & 5.0317 & TST & \\
\hline CHEMBL 2374035 & 688267 & 5.45 & 5.0484 & TRN & \\
\hline CHEMBL1569547 & 688267 & 5.3 & 5.0403 & TRN & \\
\hline CHEMBL1415452 & 688267 & 4.35 & 5.1031 & TRN & \\
\hline
\end{tabular}




\begin{tabular}{|c|c|c|c|c|c|}
\hline \multicolumn{6}{|c|}{ Supplemental Table S2.txt } \\
\hline CHEMBL1358517 & 688267 & 4.85 & 5.1259 & TRN & \\
\hline CHEMBL1442158 & 688267 & 6.05 & 5.0036 & TRN & \\
\hline CHEMBL1306965 & 688267 & 4.25 & 5.0777 & TRN & \\
\hline CHEMBL1301826 & 688267 & 6.2 & 5.0225 & TRN & \\
\hline CHEMBL1333394 & 688267 & 6.1 & 5.0904 & TRN & \\
\hline CHEMBL1515211 & 688267 & 6.2 & 5.0194 & TRN & \\
\hline CHEMBL1584232 & 688267 & 4.55 & 5.0453 & TRN & \\
\hline CHEMBL1436178 & 688267 & 6.2 & 5.0626 & TRN & \\
\hline CHEMBL1433889 & 688267 & 4.0 & 5.0563 & TRN & \\
\hline CHEMBL1549273 & 688267 & 5.35 & 5.0498 & TST & \\
\hline CHEMBL1384333 & 688267 & 5.4 & 5.0264 & TST & \\
\hline CHEMBL1597025 & 688267 & 4.3 & 5.1093 & TRN & \\
\hline CHEMBL1570065 & 688267 & 5.05 & 5.1346 & TRN & \\
\hline CHEMBL3207706 & 688267 & 3.95 & 5.0059 & TRN & \\
\hline CHEMBL1379928 & 688267 & 5.95 & 5.1147 & TRN & \\
\hline CHEMBL1381261 & 688267 & 4.95 & 5.03100 & 0000000001 & TRN \\
\hline CHEMBL1544198 & 688267 & 4.5 & 5.0225 & TST & \\
\hline CHEMBL1330403 & 688267 & 5.9 & 5.1219 & TRN & \\
\hline CHEMBL1480178 & 688267 & 5.85 & 5.0104 & TST & \\
\hline CHEMBL1482091 & 688267 & 4.55 & 5.0647 & TST & \\
\hline CHEMBL1353328 & 688267 & 4.1 & 5.0638 & TST & \\
\hline CHEMBL1441948 & 688267 & 3.85 & 5.0552 & TRN & \\
\hline CHEMBL1466715 & 688267 & 6.1 & 5.0235 & TRN & \\
\hline CHEMBL1441852 & 688267 & 6.25 & 5.0688 & TRN & \\
\hline CHEMBL1533098 & 688267 & 4.35 & 5.0872 & TST & \\
\hline CHEMBL1304653 & 688267 & 4.3 & 5.093 & TRN & \\
\hline CHEMBL1547822 & 688267 & 3.95 & 5.0171 & TRN & \\
\hline CHEMBL1612286 & 688267 & 4.3 & 5.0726 & TRN & \\
\hline CHEMBL1368087 & 688267 & 6.2 & 4.9654 & TRN & \\
\hline CHEMBL1309615 & 688267 & 4.15 & 5.0896 & TRN & \\
\hline CHEMBL1407112 & 688267 & 5.5 & 5.0757 & TRN & \\
\hline CHEMBL1358441 & 688267 & 6.2 & 5.0227 & TRN & \\
\hline CHEMBL1597515 & 688267 & 5.45 & 5.058 & TST & \\
\hline CHEMBL1478284 & 688267 & 5.8 & 5.1517 & TRN & \\
\hline CHEMBL1428465 & 688267 & 6.25 & 5.0899 & TRN & \\
\hline CHEMBL1382837 & 688267 & 3.95 & 5.0544 & TRN & \\
\hline CHEMBL1536345 & 688267 & 6.2 & 5.025 & TRN & \\
\hline CHEMBL1551076 & 688267 & 3.95 & 5.1026 & TST & \\
\hline CHEMBL3195869 & 688267 & 4.6 & 4.9935 & TST & \\
\hline CHEMBL1448873 & 688267 & 5.4 & 5.0575 & TRN & \\
\hline CHEMBL1427131 & 688267 & 5.3 & 5.1255 & TRN & \\
\hline CHEMBL1543122 & 688267 & 4.05 & 5.0067 & TRN & \\
\hline CHEMBL1513469 & 688267 & 5.75 & 5.0397 & TRN & \\
\hline CHEMBL1594168 & 688267 & 4.05 & 5.0794 & TRN & \\
\hline CHEMBL1451757 & 688267 & 4.0 & 5.0832 & TRN & \\
\hline CHEMBL1492846 & 688267 & 5.05 & 5.0034 & TST & \\
\hline CHEMBL1517719 & 688267 & 5.65 & 5.0888 & TRN & \\
\hline CHEMBL1545975 & 688267 & 6.2 & 5.0341 & TRN & \\
\hline
\end{tabular}




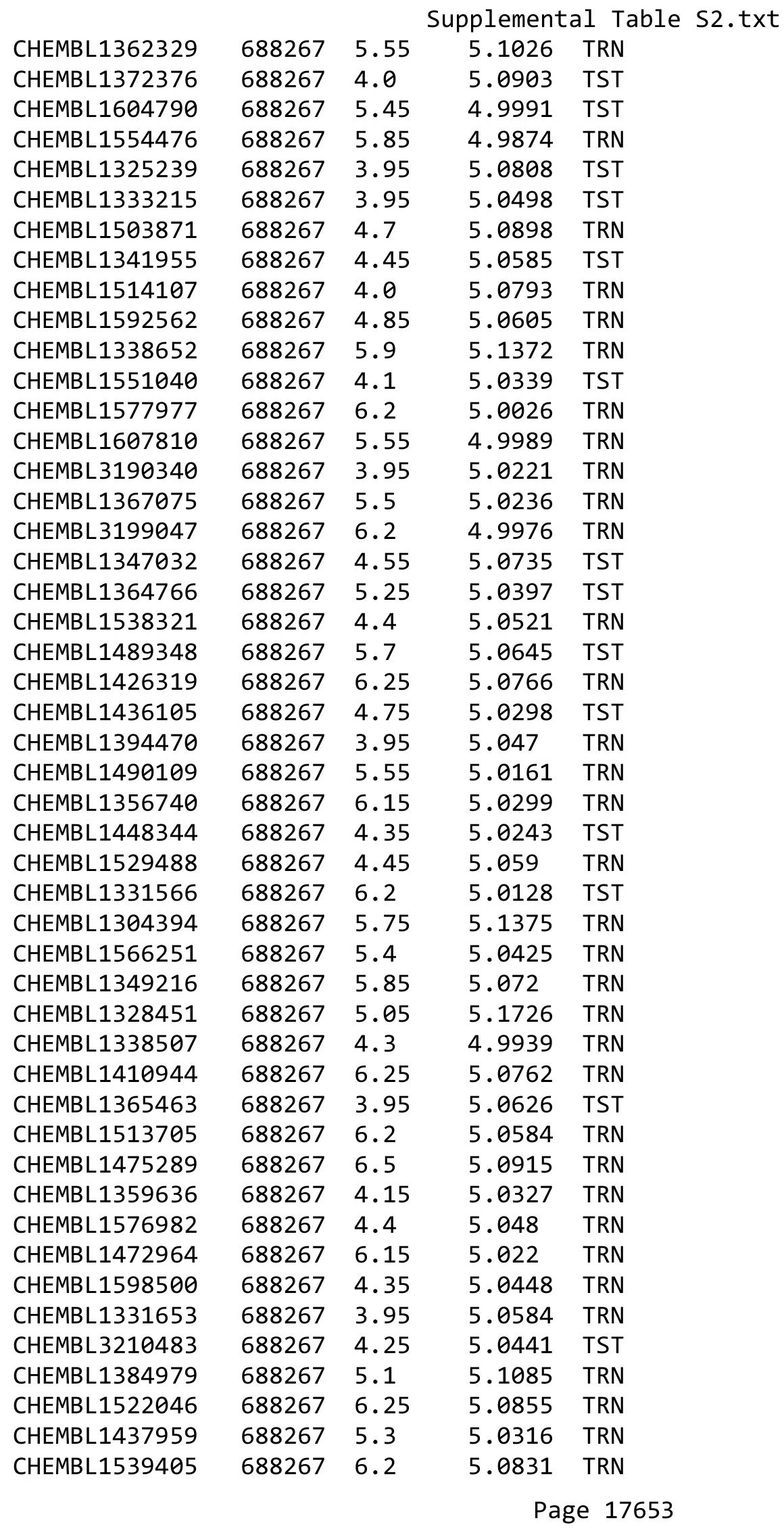




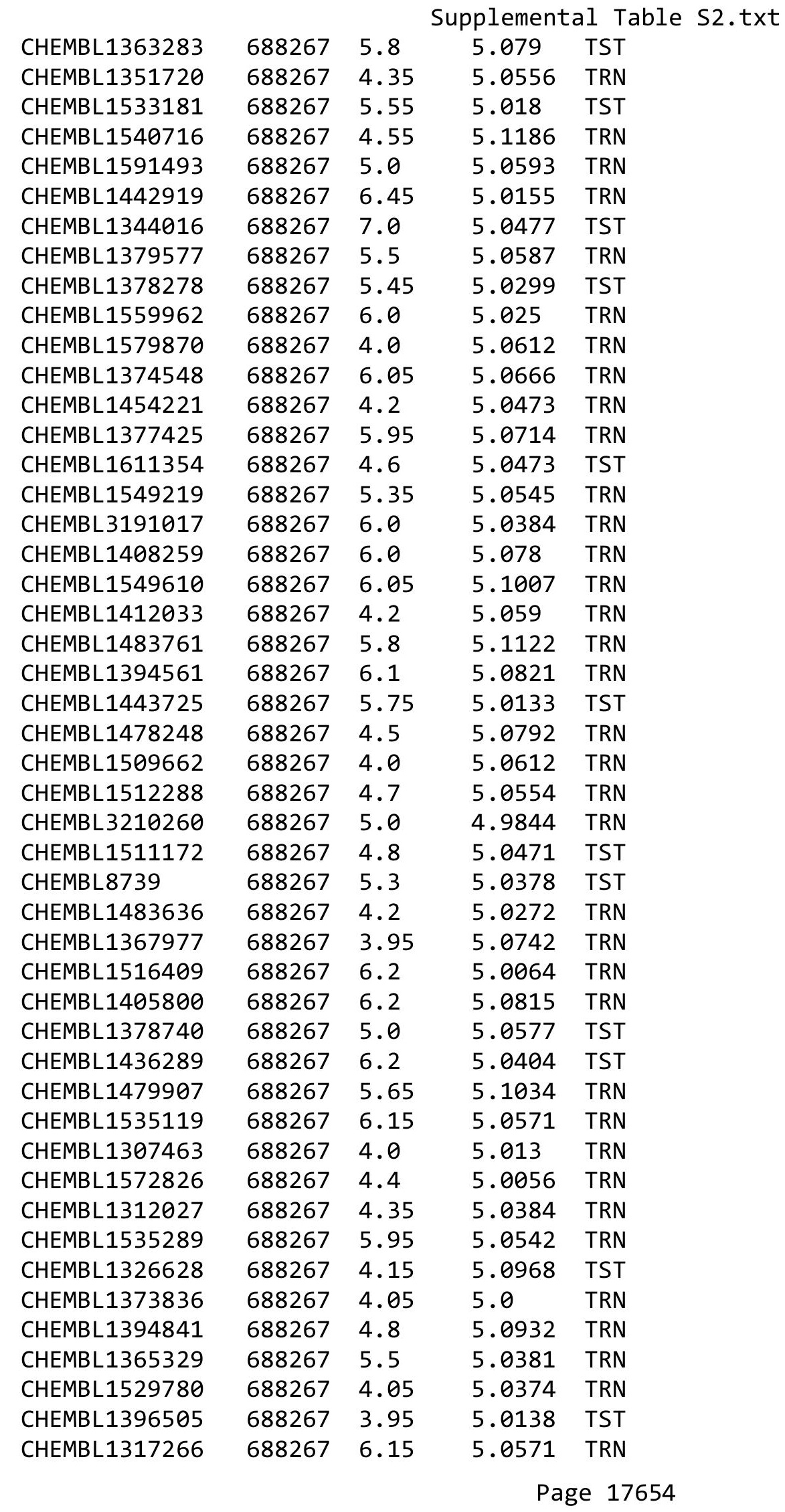




\begin{tabular}{|c|c|c|c|c|c|}
\hline & & & & & \\
\hline CHEMBL1560996 & 688267 & 5.6 & 5.0576 & TST & \\
\hline CHEMBL1316325 & 688267 & 6.4 & 5.0858 & TRN & \\
\hline CHEMBL1466636 & 688267 & 5.9 & 5.0326 & TST & \\
\hline CHEMBL1406518 & 688267 & 4.15 & 5.0379 & TRN & \\
\hline CHEMBL1570947 & 688267 & 4.25 & 5.0855 & TRN & \\
\hline CHEMBL3211850 & 688267 & 5.3 & 5.0728 & TST & \\
\hline CHEMBL1311820 & 688267 & 5.3 & 5.0194 & TST & \\
\hline CHEMBL1526427 & 688267 & 4.4 & 5.0733 & TRN & \\
\hline CHEMBL1527325 & 688267 & 6.15 & 5.1031 & TRN & \\
\hline CHEMBL1414311 & 688267 & 6.15 & 5.025 & TST & \\
\hline CHEMBL1531275 & 688267 & 5.55 & 5.0726 & TRN & \\
\hline CHEMBL1475588 & 688267 & 5.8 & 5.0823 & TRN & \\
\hline CHEMBL1373284 & 688267 & 6.2 & 5.0893 & TRN & \\
\hline CHEMBL1385368 & 688267 & 4.35 & 5.0174 & TST & \\
\hline CHEMBL1495197 & 688267 & 6.95 & 5.043 & TRN & \\
\hline CHEMBL1490295 & 688267 & 4.3 & 5.05399 & 9999999999 & TRN \\
\hline CHEMBL1301575 & 688267 & 4.05 & 5.0648 & TST & \\
\hline CHEMBL1455634 & 688267 & 6.2 & 5.0271 & TRN & \\
\hline CHEMBL1609020 & 688267 & 4.4 & 5.0652 & TRN & \\
\hline CHEMBL1574407 & 688267 & 6.15 & 5.0983 & TRN & \\
\hline CHEMBL1454181 & 688267 & 5.2 & 5.0661 & TRN & \\
\hline CHEMBL1607219 & 688267 & 4.65 & 5.0289 & TRN & \\
\hline CHEMBL1395396 & 688267 & 5.3 & 5.0458 & TRN & \\
\hline CHEMBL1397365 & 688267 & 4.0 & 5.1027 & TRN & \\
\hline CHEMBL1554610 & 688267 & 4.4 & 5.044 & TRN & \\
\hline CHEMBL1409966 & 688267 & 6.5 & 5.09699 & 99999999995 & TRN \\
\hline CHEMBL1408778 & 688267 & 4.9 & 5.0413 & TST & \\
\hline CHEMBL1511040 & 688267 & 4.4 & 5.02 & TRN & \\
\hline CHEMBL1485553 & 688267 & 5.4 & 5.0695 & TRN & \\
\hline CHEMBL1524852 & 688267 & 4.25 & 5.1163 & TRN & \\
\hline CHEMBL1458348 & 688267 & 4.1 & 5.1527 & TRN & \\
\hline CHEMBL1474830 & 688267 & 6.5 & 5.0214 & TRN & \\
\hline CHEMBL1341953 & 688267 & 4.3 & 5.1119 & TRN & \\
\hline CHEMBL1369344 & 688267 & 4.5 & 4.9875 & TRN & \\
\hline CHEMBL1441892 & 688267 & 4.2 & 5.0375 & TRN & \\
\hline CHEMBL1425526 & 688267 & 5.5 & 5.0856 & TRN & \\
\hline CHEMBL1319104 & 688267 & 4.5 & 5.0087 & TST & \\
\hline CHEMBL1601157 & 688267 & 5.3 & 5.1159 & TRN & \\
\hline CHEMBL1434944 & 688267 & 4.0 & 5.0312 & TRN & \\
\hline CHEMBL1597609 & 688267 & 6.1 & 5.0804 & TRN & \\
\hline CHEMBL3213952 & 688267 & 4.35 & 5.0033 & TRN & \\
\hline CHEMBL1549403 & 688267 & 5.35 & 5.0547 & TST & \\
\hline CHEMBL1433109 & 688267 & 6.7001 & 5.0423 & TST & \\
\hline CHEMBL1498203 & 688267 & 5.8 & 5.0534 & TST & \\
\hline CHEMBL1362752 & 688267 & 4.95 & 5.0869 & TRN & \\
\hline CHEMBL1347018 & 688267 & 4.75 & 5.0908 & TRN & \\
\hline CHEMBL1539025 & 688267 & 5.75 & 5.062 & TRN & \\
\hline CHEMBL1587092 & 688267 & 4.6 & 5.0908 & TRN & \\
\hline
\end{tabular}




\begin{tabular}{|c|c|c|c|c|}
\hline \multicolumn{5}{|c|}{ Supplemental Table S2.txt } \\
\hline CHEMBL1328505 & 688267 & 4.05 & 5.001 & TST \\
\hline CHEMBL1481450 & 688267 & 5.45 & 5.0604 & TRN \\
\hline CHEMBL1592946 & 688267 & 5.9 & 5.0026 & TRN \\
\hline CHEMBL1375699 & 688267 & 5.75 & 5.0124 & TST \\
\hline CHEMBL1526251 & 688267 & 6.15 & 5.062 & TST \\
\hline CHEMBL1450201 & 688267 & 4.4 & 5.1012 & TRN \\
\hline CHEMBL3193539 & 688267 & 5.35 & 5.0029 & TRN \\
\hline CHEMBL1400670 & 688267 & 4.0 & 5.0438 & TRN \\
\hline CHEMBL1609847 & 688267 & 4.0 & 5.0406 & TST \\
\hline CHEMBL1395274 & 688267 & 6.5501 & 5.0453 & TRN \\
\hline CHEMBL1612167 & 688267 & 4.05 & 5.0767 & TST \\
\hline CHEMBL1311090 & 688267 & 6.2 & 5.0422 & TST \\
\hline CHEMBL1574371 & 688267 & 5.05 & 5.0755 & TST \\
\hline CHEMBL1448594 & 688267 & 5.4 & 5.0425 & TRN \\
\hline CHEMBL1537102 & 688267 & 5.25 & 5.015 & TRN \\
\hline CHEMBL1450397 & 688267 & 5.3 & 5.0724 & TRN \\
\hline CHEMBL1443692 & 688267 & 5.0 & 5.0405 & TRN \\
\hline CHEMBL1499909 & 688267 & 4.85 & 5.1019 & TRN \\
\hline CHEMBL1545255 & 688267 & 6.15 & 5.0169 & TRN \\
\hline CHEMBL1336391 & 688267 & 4.55 & 5.1178 & TRN \\
\hline CHEMBL1525083 & 688267 & 3.95 & 5.0383 & TRN \\
\hline CHEMBL1499893 & 688267 & 6.15 & 5.0488 & TST \\
\hline CHEMBL1433171 & 688267 & 5.6 & 5.0534 & TRN \\
\hline CHEMBL1555614 & 688267 & 4.35 & 5.0898 & TRN \\
\hline CHEMBL1612275 & 688267 & 4.9 & 5.1159 & TRN \\
\hline CHEMBL1322146 & 688267 & 5.45 & 5.0751 & TST \\
\hline CHEMBL1536048 & 688267 & 5.6 & 4.9798 & TRN \\
\hline CHEMBL1582500 & 688267 & 5.1 & 5.0697 & TRN \\
\hline CHEMBL1327259 & 688267 & 5.55 & 5.1113 & TRN \\
\hline CHEMBL1519994 & 688267 & 6.2 & 5.0174 & TST \\
\hline CHEMBL1443402 & 688267 & 4.3 & 5.0198 & TRN \\
\hline CHEMBL1502160 & 688267 & 4.05 & 5.0576 & TRN \\
\hline CHEMBL3211664 & 688267 & 4.85 & 5.0224 & TST \\
\hline CHEMBL1483049 & 688267 & 6.2 & 5.0419 & TRN \\
\hline CHEMBL1319814 & 688267 & 6.05 & 4.9975 & TRN \\
\hline CHEMBL1545748 & 688267 & 4.7 & 5.107 & TRN \\
\hline CHEMBL1537104 & 688267 & 4.05 & 5.0612 & TRN \\
\hline CHEMBL1495375 & 688267 & 4.35 & 5.0305 & TST \\
\hline CHEMBL1563653 & 688267 & 5.7 & 4.9941 & TRN \\
\hline CHEMBL1432758 & 688267 & 4.35 & 5.0869 & TRN \\
\hline CHEMBL1335231 & 688267 & 6.2 & 5.0435 & TRN \\
\hline CHEMBL1511978 & 688267 & 4.0 & 5.0408 & TRN \\
\hline CHEMBL1596504 & 688267 & 5.9 & 5.0468 & TST \\
\hline CHEMBL1493697 & 688267 & 5.35 & 5.0504 & TST \\
\hline CHEMBL1554010 & 688267 & 4.0 & 5.0415 & TRN \\
\hline CHEMBL1403684 & 688267 & 5.35 & 5.0257 & TST \\
\hline CHEMBL1312634 & 688267 & 4.35 & 5.0602 & TRN \\
\hline CHEMBL3208795 & 688267 & 6.45 & 4.9658 & TST \\
\hline
\end{tabular}




\begin{tabular}{|c|c|c|c|c|}
\hline \multicolumn{5}{|c|}{ Supplemental Table S2.txt } \\
\hline CHEMBL1585392 & 688267 & 3.95 & 5.0524 & TRN \\
\hline CHEMBL1492708 & 688267 & 5.65 & 5.0479 & TRN \\
\hline CHEMBL1589579 & 688267 & 4.3 & 5.1255 & TST \\
\hline CHEMBL1561458 & 688267 & 5.6 & 5.1006 & TRN \\
\hline CHEMBL1345734 & 688267 & 5.5 & 5.0744 & TRN \\
\hline CHEMBL1532486 & 688267 & 4.5 & 5.0734 & TRN \\
\hline CHEMBL1358056 & 688267 & 6.15 & 5.034 & TRN \\
\hline CHEMBL1595811 & 688267 & 3.95 & 5.0787 & TRN \\
\hline CHEMBL3207938 & 688267 & 5.3 & 5.1398 & TRN \\
\hline CHEMBL1424628 & 688267 & 4.35 & 5.0537 & TST \\
\hline CHEMBL1511454 & 688267 & 4.05 & 5.1355 & TST \\
\hline CHEMBL1316913 & 688267 & 4.5 & 5.0917 & TRN \\
\hline CHEMBL1539867 & 688267 & 4.35 & 5.0617 & TRN \\
\hline CHEMBL1321074 & 688267 & 4.5 & 5.0956 & TST \\
\hline CHEMBL1415142 & 688267 & 4.35 & 5.0765 & TRN \\
\hline CHEMBL1356153 & 688267 & 5.4 & 5.0242 & TRN \\
\hline CHEMBL1603808 & 688267 & 4.55 & 5.11 & TRN \\
\hline CHEMBL1425669 & 688267 & 5.4 & 5.058 & TRN \\
\hline CHEMBL1503147 & 688267 & 5.85 & 5.0143 & TRN \\
\hline CHEMBL1529100 & 688267 & 6.15 & 5.0311 & TRN \\
\hline CHEMBL1497542 & 688267 & 5.0 & 5.0607 & TRN \\
\hline CHEMBL1393655 & 688267 & 5.55 & 4.994 & TRN \\
\hline CHEMBL1349995 & 688267 & 6.15 & 5.042 & TRN \\
\hline CHEMBL1342590 & 688267 & 4.4 & 5.0266 & TRN \\
\hline CHEMBL1559719 & 688267 & 4.2 & 5.0424 & TRN \\
\hline CHEMBL1377475 & 688267 & 4.95 & 5.0437 & TRN \\
\hline CHEMBL1558755 & 688267 & 5.0 & 5.1458 & TRN \\
\hline CHEMBL3199277 & 688267 & 6.15 & 4.9612 & TRN \\
\hline CHEMBL1435567 & 688267 & 6.25 & 5.0416 & TRN \\
\hline CHEMBL1549917 & 688267 & 4.65 & 5.0222 & TRN \\
\hline CHEMBL1405440 & 688267 & 6.05 & 5.1058 & TRN \\
\hline CHEMBL1398195 & 688267 & 6.2 & 5.0455 & TST \\
\hline CHEMBL1473568 & 688267 & 4.3 & 5.0723 & TST \\
\hline CHEMBL1527530 & 688267 & 4.1 & 5.0461 & TRN \\
\hline CHEMBL1369121 & 688267 & 5.3 & 5.101 & TRN \\
\hline CHEMBL1309774 & 688267 & 5.3 & 5.0459 & TST \\
\hline CHEMBL 280065 & 688267 & 4.3 & 5.0693 & TST \\
\hline CHEMBL1543078 & 688267 & 6.15 & 5.0247 & TRN \\
\hline CHEMBL1605203 & 688267 & 3.95 & 5.0315 & TRN \\
\hline CHEMBL3195761 & 688267 & 5.4 & 5.0069 & TST \\
\hline CHEMBL1314685 & 688267 & 6.2 & 5.0814 & TRN \\
\hline CHEMBL1539995 & 688267 & 4.35 & 5.0616 & TRN \\
\hline CHEMBL1516660 & 688267 & 4.1 & 5.0425 & TRN \\
\hline CHEMBL1551932 & 688267 & 4.0 & 4.9744 & TRN \\
\hline CHEMBL1455621 & 688267 & 4.55 & 5.0093 & TST \\
\hline CHEMBL1503005 & 688267 & 6.2 & 5.0999 & TRN \\
\hline CHEMBL1435354 & 688267 & 3.5 & 5.1001 & TRN \\
\hline CHEMBL1355123 & 688267 & 5.4 & 5.0031 & TRN \\
\hline
\end{tabular}




\begin{tabular}{|c|c|c|c|c|c|}
\hline \multicolumn{6}{|c|}{ plemental } \\
\hline CHEMBL1435424 & 688267 & 4.35 & 5.1208 & TST & \\
\hline CHEMBL1419131 & 688267 & 5.55 & 5.0543 & TRN & \\
\hline CHEMBL1393067 & 688267 & 4.0 & 5.0942 & TRN & \\
\hline CHEMBL1367005 & 688267 & 6.5 & 5.1297 & TST & \\
\hline CHEMBL1397118 & 688267 & 4.1 & 5.1226 & TRN & \\
\hline CHEMBL1323570 & 688267 & 3.95 & 5.0602 & TST & \\
\hline CHEMBL1383447 & 688267 & 6.2 & 5.024 & TST & \\
\hline CHEMBL1434865 & 688267 & 4.35 & 5.1517 & TRN & \\
\hline CHEMBL1428395 & 688267 & 4.0 & 5.0595 & TRN & \\
\hline CHEMBL1493868 & 688267 & 4.15 & 5.064 & TRN & \\
\hline CHEMBL1544301 & 688267 & 4.65 & 5.0984 & TST & \\
\hline CHEMBL1510502 & 688267 & 4.0 & $5.0360 e$ & 00000000005 & TST \\
\hline CHEMBL1492873 & 688267 & 4.0 & 5.0754 & TRN & \\
\hline CHEMBL1437530 & 688267 & 4.35 & 5.0729 & TRN & \\
\hline CHEMBL1573251 & 688267 & 4.65 & 5.0577 & TRN & \\
\hline CHEMBL1413003 & 688267 & 4.25 & 5.0905 & TRN & \\
\hline CHEMBL1471929 & 688267 & 6.15 & 5.0977 & TRN & \\
\hline CHEMBL1527683 & 688267 & 3.95 & 5.0906 & TST & \\
\hline CHEMBL1407100 & 688267 & 5.75 & 4.9696 & TRN & \\
\hline CHEMBL1310493 & 688267 & 5.55 & 5.0579 & TRN & \\
\hline CHEMBL1315737 & 688267 & 5.6 & 4.9853 & TRN & \\
\hline CHEMBL1537390 & 688267 & 4.65 & 5.0267 & TRN & \\
\hline CHEMBL3213043 & 688267 & 3.95 & 5.0713 & TST & \\
\hline CHEMBL1305500 & 688267 & 5.45 & 5.0563 & TRN & \\
\hline CHEMBL1443354 & 688267 & 4.05 & 5.0772 & TST & \\
\hline CHEMBL1488425 & 688267 & 5.1 & 5.0231 & TRN & \\
\hline CHEMBL1387348 & 688267 & 4.15 & 5.0354 & TST & \\
\hline CHEMBL1462962 & 688267 & 5.2 & 5.0842 & TST & \\
\hline CHEMBL3197501 & 688267 & 6.2 & 5.0146 & TRN & \\
\hline CHEMBL1255778 & 688267 & 4.4 & 5.0434 & TST & \\
\hline CHEMBL1382598 & 688267 & 5.6 & 5.0441 & TRN & \\
\hline CHEMBL1577326 & 688267 & 4.35 & 5.1218 & TRN & \\
\hline CHEMBL1314503 & 688267 & 5.8 & 5.0559 & TRN & \\
\hline CHEMBL1612904 & 688267 & 4.9 & 5.0697 & TRN & \\
\hline CHEMBL153535 & 688267 & 4.4 & 4.9781 & TRN & \\
\hline CHEMBL1525066 & 688267 & 4.0 & 5.0226 & TRN & \\
\hline CHEMBL1598761 & 688267 & 4.0 & 5.1285 & TST & \\
\hline CHEMBL1387034 & 688267 & 4.4 & 5.0727 & TRN & \\
\hline CHEMBL3194233 & 688267 & 4.3 & 4.9759 & TRN & \\
\hline CHEMBL1516877 & 688267 & 5.65 & 4.9949 & TST & \\
\hline CHEMBL1363148 & 688267 & 4.05 & 5.0778 & TST & \\
\hline CHEMBL1584122 & 688267 & 6.15 & 5.0408 & TRN & \\
\hline CHEMBL1604381 & 688267 & 3.95 & 5.1252 & TRN & \\
\hline CHEMBL1601571 & 688267 & 4.0 & 5.0527 & TRN & \\
\hline CHEMBL1437260 & 688267 & 4.1 & 5.013 & TRN & \\
\hline CHEMBL1534915 & 688267 & 6.2 & 5.0911 & TRN & \\
\hline CHEMBL1589450 & 688267 & 3.95 & 4.9962 & TRN & \\
\hline CHEMBL1473830 & 688267 & 6.3 & 5.085 & TRN & \\
\hline
\end{tabular}




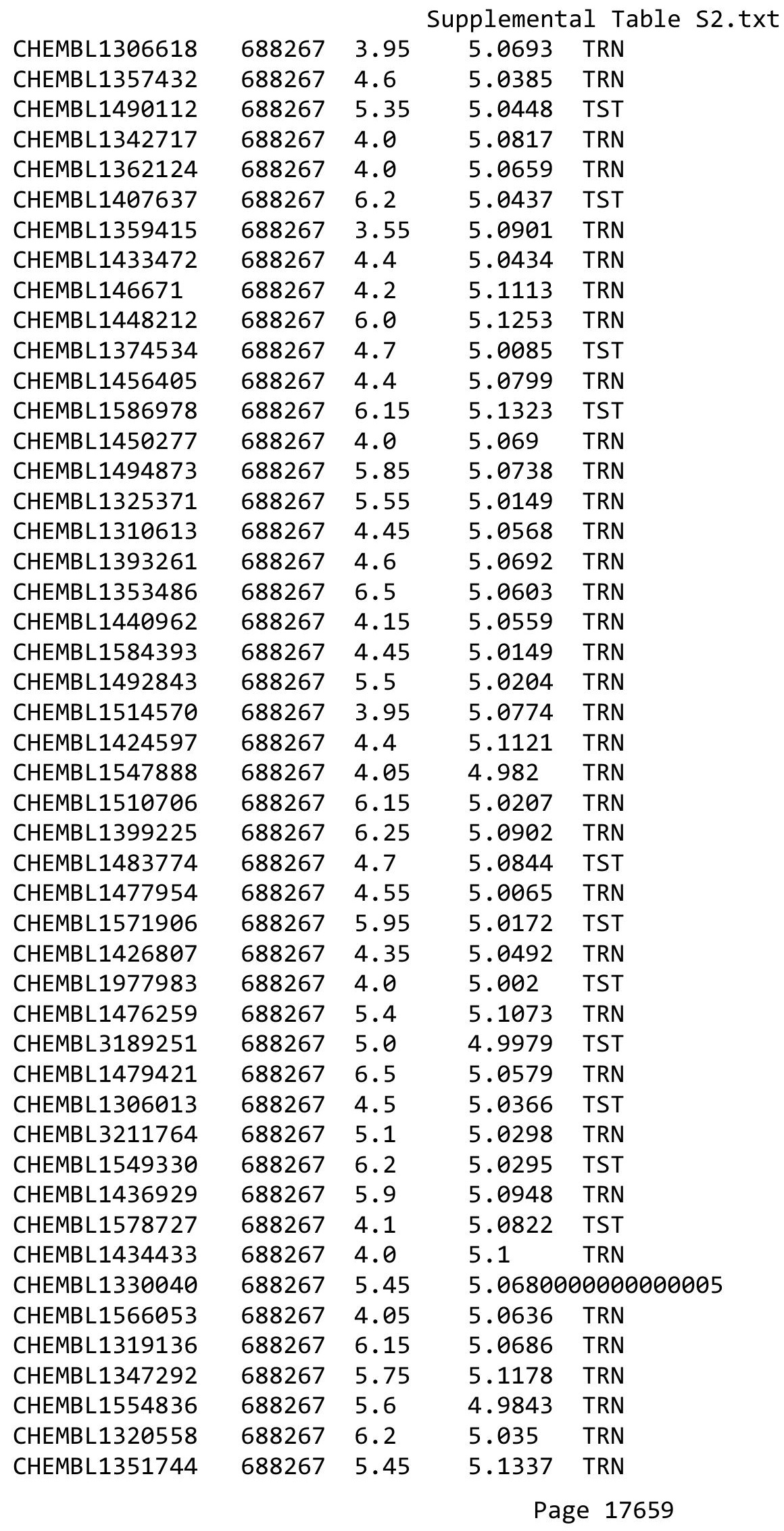

TRN 


\begin{tabular}{|c|c|c|c|c|c|}
\hline & & \multicolumn{4}{|c|}{ Supplemental Table S2.txt } \\
\hline CHEMBL1299787 & 688267 & 5.4 & 5.0329 & TRN & \\
\hline CHEMBL1318258 & 688267 & 5.25 & 5.0262 & TRN & \\
\hline CHEMBL1327246 & 688267 & 4.9 & 5.066 & TRN & \\
\hline CHEMBL1603428 & 688267 & 4.4 & 5.0905 & TRN & \\
\hline CHEMBL1602145 & 688267 & 4.0 & 5.0324 & TRN & \\
\hline CHEMBL1576709 & 688267 & 4.9 & 5.0368 & TRN & \\
\hline CHEMBL1366047 & 688267 & 6.0 & 5.06 & TRN & \\
\hline CHEMBL1588952 & 688267 & 5.25 & 5.0605 & TRN & \\
\hline CHEMBL1578055 & 688267 & 5.85 & 5.0456 & TRN & \\
\hline CHEMBL1495673 & 688267 & 6.15 & 5.0753 & TRN & \\
\hline CHEMBL1572791 & 688267 & 5.35 & $5.0710 e$ & 0000000001 & TRN \\
\hline CHEMBL1395227 & 688267 & 5.75 & 5.0461 & TRN & \\
\hline CHEMBL1456846 & 688267 & 6.2 & 5.0336 & TRN & \\
\hline CHEMBL1484065 & 688267 & 3.95 & 5.0147 & TST & \\
\hline CHEMBL1603767 & 688267 & 4.0 & 5.0587 & TST & \\
\hline CHEMBL1606840 & 688267 & 4.0 & 5.0678 & TRN & \\
\hline CHEMBL1533140 & 688267 & 4.4 & 5.0117 & TRN & \\
\hline CHEMBL1536988 & 688267 & 4.2 & 5.0746 & TRN & \\
\hline CHEMBL1301217 & 688267 & 6.2 & 5.0626 & TRN & \\
\hline CHEMBL1593542 & 688267 & 3.95 & 5.0371 & TRN & \\
\hline CHEMBL1464039 & 688267 & 4.0 & 5.0197 & TRN & \\
\hline CHEMBL1410776 & 688267 & 6.15 & 5.0109 & TST & \\
\hline CHEMBL1366140 & 688267 & 4.3 & 5.0952 & TRN & \\
\hline CHEMBL1551328 & 688267 & 3.95 & 5.0237 & TRN & \\
\hline CHEMBL1577873 & 688267 & 5.9 & 5.0281 & TRN & \\
\hline CHEMBL1972519 & 688267 & 4.0 & 5.0133 & TST & \\
\hline CHEMBL1400963 & 688267 & 5.25 & 5.0478 & TRN & \\
\hline CHEMBL1432007 & 688267 & 5.55 & 4.9661 & TST & \\
\hline CHEMBL1996749 & 688267 & 5.75 & 4.985 & TRN & \\
\hline CHEMBL1554956 & 688267 & 4.1 & 5.1592 & TRN & \\
\hline CHEMBL1430844 & 688267 & 4.0 & 5.065 & TST & \\
\hline CHEMBL1610077 & 688267 & 5.15 & 5.0852 & TST & \\
\hline CHEMBL1373791 & 688267 & 5.35 & 5.0912 & TRN & \\
\hline CHEMBL1345258 & 688267 & 5.8 & 5.0357 & TRN & \\
\hline CHEMBL1425786 & 688267 & 5.4 & 5.0314 & TST & \\
\hline CHEMBL1347981 & 688267 & 6.25 & 5.0614 & TRN & \\
\hline CHEMBL1524152 & 688267 & 4.0 & 5.0243 & TRN & \\
\hline CHEMBL1382310 & 688267 & 4.6 & 5.0213 & TRN & \\
\hline CHEMBL1382582 & 688267 & 6.2 & 5.0707 & TRN & \\
\hline CHEMBL1549079 & 688267 & 6.2 & 5.022 & TRN & \\
\hline CHEMBL1432722 & 688267 & 3.95 & 5.0361 & TRN & \\
\hline CHEMBL1547335 & 688267 & 6.15 & 5.0831 & TRN & \\
\hline CHEMBL1462357 & 688267 & 5.85 & 5.1148 & TRN & \\
\hline CHEMBL1395904 & 688267 & 4.3 & 5.1124 & TST & \\
\hline CHEMBL1600066 & 688267 & 6.25 & 5.0963 & TST & \\
\hline CHEMBL1465269 & 688267 & 4.3 & 5.0325 & TRN & \\
\hline CHEMBL1350823 & 688267 & 4.2 & 5.1101 & TST & \\
\hline CHEMBL1383077 & 688267 & 4.05 & 5.0885 & TRN & \\
\hline
\end{tabular}




\begin{tabular}{|c|c|c|c|c|c|}
\hline \multicolumn{6}{|c|}{ oplemental İ } \\
\hline CHEMBL1513210 & 688267 & 4.9 & 5.1408 & TRN & \\
\hline CHEMBL1536281 & 688267 & 5.55 & 5.0383 & TRN & \\
\hline CHEMBL1357550 & 688267 & 4.2 & 5.0054 & TRN & \\
\hline CHEMBL602722 & 688267 & 5.4 & 4.9821 & TST & \\
\hline CHEMBL1604049 & 688267 & 4.0 & 5.052 & TRN & \\
\hline CHEMBL1321472 & 688267 & 6.2 & 5.0513 & TST & \\
\hline CHEMBL1459350 & 688267 & 4.0 & 5.01 & TST & \\
\hline CHEMBL1441556 & 688267 & 6.15 & 5.1072 & TRN & \\
\hline CHEMBL1371290 & 688267 & 6.2 & 5.0788 & TRN & \\
\hline CHEMBL1413001 & 688267 & 4.6 & 5.0279 & TRN & \\
\hline CHEMBL1312394 & 688267 & 4.6 & 5.0526 & TRN & \\
\hline CHEMBL3192844 & 688267 & 4.2 & 4.9937 & TST & \\
\hline CHEMBL1327841 & 688267 & 6.5 & 5.0297 & TRN & \\
\hline CHEMBL1579120 & 688267 & 4.4 & 5.0462 & TRN & \\
\hline CHEMBL1395136 & 688267 & 4.2 & 5.0911 & TRN & \\
\hline CHEMBL1492891 & 688267 & 4.75 & 5.0661 & TRN & \\
\hline CHEMBL1449655 & 688267 & 4.0 & 5.0004 & TRN & \\
\hline CHEMBL1404808 & 688267 & 4.1 & 5.0155 & TRN & \\
\hline CHEMBL1342377 & 688267 & 3.95 & 5.05 & TRN & \\
\hline CHEMBL1389991 & 688267 & 5.7 & 5.1119 & TRN & \\
\hline CHEMBL1430763 & 688267 & 5.85 & 5.0486 & TRN & \\
\hline CHEMBL1595188 & 688267 & 3.95 & 5.0307 & TRN & \\
\hline CHEMBL1395358 & 688267 & 4.15 & 5.0488 & TRN & \\
\hline CHEMBL1383585 & 688267 & 4.35 & 5.0743 & TST & \\
\hline CHEMBL1483200 & 688267 & 4.05 & 5.1496 & TRN & \\
\hline CHEMBL1589419 & 688267 & 4.3 & 5.1301 & TRN & \\
\hline CHEMBL1586652 & 688267 & 4.15 & 4.9862 & TST & \\
\hline CHEMBL1309449 & 688267 & 5.25 & 5.0833 & TRN & \\
\hline CHEMBL1473209 & 688267 & 6.2 & 5.0281 & TRN & \\
\hline CHEMBL1535086 & 688267 & 4.35 & 5.0624 & TST & \\
\hline CHEMBL1475938 & 688267 & 4.45 & 5.0479 & TRN & \\
\hline CHEMBL1466885 & 688267 & 5.65 & 5.0715 & TST & \\
\hline CHEMBL1479981 & 688267 & 5.45 & 5.08899 & 99999999995 & TRN \\
\hline CHEMBL1465278 & 688267 & 6.45 & 5.0485 & TRN & \\
\hline CHEMBL1395754 & 688267 & 4.0 & 5.0128 & TRN & \\
\hline CHEMBL1448461 & 688267 & 4.3 & 5.0804 & TST & \\
\hline CHEMBL3195015 & 688267 & 5.45 & 5.0315 & TST & \\
\hline CHEMBL1400109 & 688267 & 4.2 & 5.1066 & TRN & \\
\hline CHEMBL1377330 & 688267 & 6.1 & 5.0387 & TST & \\
\hline CHEMBL3195978 & 688267 & 4.0 & 5.0566 & TRN & \\
\hline CHEMBL1315649 & 688267 & 5.9 & 5.0425 & TRN & \\
\hline CHEMBL1362535 & 688267 & 5.5 & 5.0835 & TST & \\
\hline CHEMBL1513481 & 688267 & 6.15 & 5.0007 & TRN & \\
\hline CHEMBL1499663 & 688267 & 4.1 & 5.0464 & TST & \\
\hline CHEMBL1528815 & 688267 & 5.5 & 5.0475 & TRN & \\
\hline CHEMBL3199816 & 688267 & 4.05 & 5.0187 & TRN & \\
\hline CHEMBL1421515 & 688267 & 5.6 & 5.1273 & TRN & \\
\hline CHEMBL1534470 & 688267 & 5.9 & 5.0127 & TST & \\
\hline
\end{tabular}




\begin{tabular}{|c|c|c|c|c|c|}
\hline & & & & & \\
\hline CHEMBL1504508 & 688267 & 5.6 & 5.085 & TST & \\
\hline CHEMBL1443173 & 688267 & 6.0 & 5.0087 & TRN & \\
\hline CHEMBL1352974 & 688267 & 5.4 & 4.9987 & TRN & \\
\hline CHEMBL1440267 & 688267 & 4.0 & 5.0838 & TST & \\
\hline CHEMBL1358382 & 688267 & 5.45 & 5.078 & TRN & \\
\hline CHEMBL1388436 & 688267 & 4.3 & 5.099 & TRN & \\
\hline CHEMBL1331990 & 688267 & 4.0 & 5.0919 & TST & \\
\hline CHEMBL1451902 & 688267 & 4.5 & 5.0667 & TRN & \\
\hline CHEMBL1353670 & 688267 & 6.0 & 5.0651 & TST & \\
\hline CHEMBL1579811 & 688267 & 4.05 & 5.09399 & & TRN \\
\hline CHEMBL1552424 & 688267 & 6.25 & 5.0282 & TRN & \\
\hline CHEMBL1464839 & 688267 & 4.55 & 5.058 & TRN & \\
\hline CHEMBL1584316 & 688267 & 6.5 & 5.0055 & TRN & \\
\hline CHEMBL1478500 & 688267 & 5.05 & 5.0774 & TRN & \\
\hline CHEMBL1477907 & 688267 & 4.6 & 5.0631 & TRN & \\
\hline CHEMBL1518353 & 688267 & 5.4 & 5.0868 & TRN & \\
\hline CHEMBL1606529 & 688267 & 4.6 & 5.0815 & TRN & \\
\hline CHEMBL1425745 & 688267 & 4.05 & 5.0567 & TRN & \\
\hline CHEMBL1565259 & 688267 & 4.85 & 5.1137 & TRN & \\
\hline CHEMBL1421760 & 688267 & 4.5 & 5.0354 & TRN & \\
\hline CHEMBL1496182 & 688267 & 5.3 & 4.9962 & TST & \\
\hline CHEMBL1448074 & 688267 & 5.4 & 5.106 & TRN & \\
\hline CHEMBL1511205 & 688267 & 5.7 & 5.1208 & TST & \\
\hline CHEMBL1315061 & 688267 & 4.7 & 5.0669 & TRN & \\
\hline CHEMBL1416373 & 688267 & 4.0 & 5.0639 & TRN & \\
\hline CHEMBL1381778 & 688267 & 4.25 & 5.0284 & TRN & \\
\hline CHEMBL1559976 & 688267 & 4.0 & 5.1851 & TRN & \\
\hline CHEMBL1610965 & 688267 & 4.05 & 5.0592 & TST & \\
\hline CHEMBL1529730 & 688267 & 4.05 & 5.0393 & TRN & \\
\hline CHEMBL1341505 & 688267 & 6.15 & 4.9729 & TST & \\
\hline CHEMBL1319298 & 688267 & 5.5 & 5.0114 & TRN & \\
\hline CHEMBL1344237 & 688267 & 4.0 & 5.0856 & TRN & \\
\hline CHEMBL1530294 & 688267 & 4.0 & 4.989 & TST & \\
\hline CHEMBL1550636 & 688267 & 4.25 & 5.0646 & TRN & \\
\hline CHEMBL1344134 & 688267 & 4.3 & 5.0608 & TST & \\
\hline CHEMBL1599685 & 688267 & 5.4 & 5.09699 & 99999999995 & TRN \\
\hline CHEMBL1403311 & 688267 & 4.8 & 5.0526 & TST & \\
\hline CHEMBL1365869 & 688267 & 4.8 & 5.0736 & TRN & \\
\hline CHEMBL3191505 & 688267 & 6.6499 & 5.0904 & TRN & \\
\hline CHEMBL1494067 & 688267 & 4.55 & 5.0502 & TRN & \\
\hline CHEMBL1449630 & 688267 & 4.35 & 5.0448 & TRN & \\
\hline CHEMBL1565939 & 688267 & 4.65 & 5.0073 & TRN & \\
\hline CHEMBL1495842 & 688267 & 5.4 & 5.0652 & TRN & \\
\hline CHEMBL1430908 & 688267 & 5.2 & 5.0245 & TRN & \\
\hline CHEMBL1543963 & 688267 & 4.75 & 4.9827 & TRN & \\
\hline CHEMBL1482227 & 688267 & 5.45 & 5.0541 & TST & \\
\hline CHEMBL1603569 & 688267 & 4.3 & 5.0503 & TRN & \\
\hline CHEMBL1466712 & 688267 & 4.25 & 4.9964 & TRN & \\
\hline & & & & 17662 & \\
\hline
\end{tabular}




\begin{tabular}{|c|c|c|c|c|}
\hline & & & CI & al Ta \\
\hline CHEMBL1593187 & 688267 & 4.0 & 4.9815 & TRN \\
\hline CHEMBL1301125 & 688267 & 4.0 & 5.0443 & TST \\
\hline CHEMBL1326242 & 688267 & 5.8 & 5.0366 & TRN \\
\hline CHEMBL1391878 & 688267 & 4.4 & 5.0963 & TRN \\
\hline CHEMBL1430646 & 688267 & 6.2 & 5.1012 & TRN \\
\hline CHEMBL1368297 & 688267 & 5.0 & 5.0799 & TRN \\
\hline CHEMBL1310909 & 688267 & 4.3 & 5.0604 & TST \\
\hline CHEMBL1313280 & 688267 & 5.8 & 4.9874 & TST \\
\hline CHEMBL1300261 & 688267 & 5.3 & 5.0991 & TRN \\
\hline CHEMBL1436329 & 688267 & 6.35 & 5.0236 & TRN \\
\hline CHEMBL1603997 & 688267 & 5.85 & 5.0384 & TST \\
\hline CHEMBL1400866 & 688267 & 5.35 & 5.0686 & TRN \\
\hline CHEMBL1336543 & 688267 & 4.6 & 5.0804 & TRN \\
\hline CHEMBL3190698 & 688267 & 4.0 & 5.1215 & TRN \\
\hline CHEMBL1497287 & 688267 & 6.0 & 5.0262 & TST \\
\hline CHEMBL1503891 & 688267 & 5.25 & 5.1475 & TRN \\
\hline CHEMBL1369473 & 688267 & 5.3 & 5.0217 & TRN \\
\hline CHEMBL1377825 & 688267 & 4.9 & 5.0713 & TRN \\
\hline CHEMBL1474729 & 688267 & 5.2 & 5.0381 & TRN \\
\hline CHEMBL1578755 & 688267 & 5.8 & 5.0495 & TRN \\
\hline CHEMBL1445029 & 688267 & 6.2 & 5.0258 & TRN \\
\hline CHEMBL 367093 & 688267 & 5.45 & 5.0579 & TST \\
\hline CHEMBL1523003 & 688267 & 4.0 & 5.0281 & TRN \\
\hline CHEMBL1556421 & 688267 & 5.25 & 5.0291 & TRN \\
\hline CHEMBL1384509 & 688267 & 5.9 & 5.1209 & TRN \\
\hline CHEMBL1354441 & 688267 & 5.55 & 4.9866 & TRN \\
\hline CHEMBL3213431 & 688267 & 5.65 & 5.0017 & TRN \\
\hline CHEMBL3191804 & 688267 & 5.75 & 5.0198 & TST \\
\hline CHEMBL1539175 & 688267 & 6.2 & 5.1068 & TRN \\
\hline CHEMBL1594201 & 688267 & 5.45 & 4.9901 & TRN \\
\hline CHEMBL1470655 & 688267 & 4.5 & 5.0271 & TST \\
\hline CHEMBL3210218 & 688267 & 5.55 & 5.0446 & TRN \\
\hline CHEMBL1548952 & 688267 & 6.2 & 5.0446 & TRN \\
\hline CHEMBL1592552 & 688267 & 5.35 & 5.0915 & TRN \\
\hline CHEMBL1410579 & 688267 & 6.15 & 5.1331 & TRN \\
\hline CHEMBL1314158 & 688267 & 5.4 & 5.1285 & TRN \\
\hline CHEMBL1447581 & 688267 & 6.45 & 5.0063 & TRN \\
\hline CHEMBL1472617 & 688267 & 6.2 & 5.0685 & TRN \\
\hline CHEMBL1553967 & 688267 & 4.9 & 5.0743 & TRN \\
\hline CHEMBL1515676 & 688267 & 5.45 & 5.0858 & TRN \\
\hline CHEMBL1510469 & 688267 & 4.55 & 4.9881 & TRN \\
\hline CHEMBL1432895 & 688267 & 4.25 & 5.0304 & TST \\
\hline CHEMBL1487386 & 688267 & 5.35 & 5.0611 & TST \\
\hline CHEMBL1477875 & 688267 & 5.6 & 5.029 & TST \\
\hline CHEMBL1456223 & 688267 & 4.55 & 5.0668 & TST \\
\hline CHEMBL1302741 & 688267 & 5.95 & 5.0307 & TRN \\
\hline CHEMBL1509738 & 688267 & 4.3 & 5.0123 & TRN \\
\hline CHEMBL1421132 & 688267 & 5.0 & 5.0258 & TRN \\
\hline
\end{tabular}




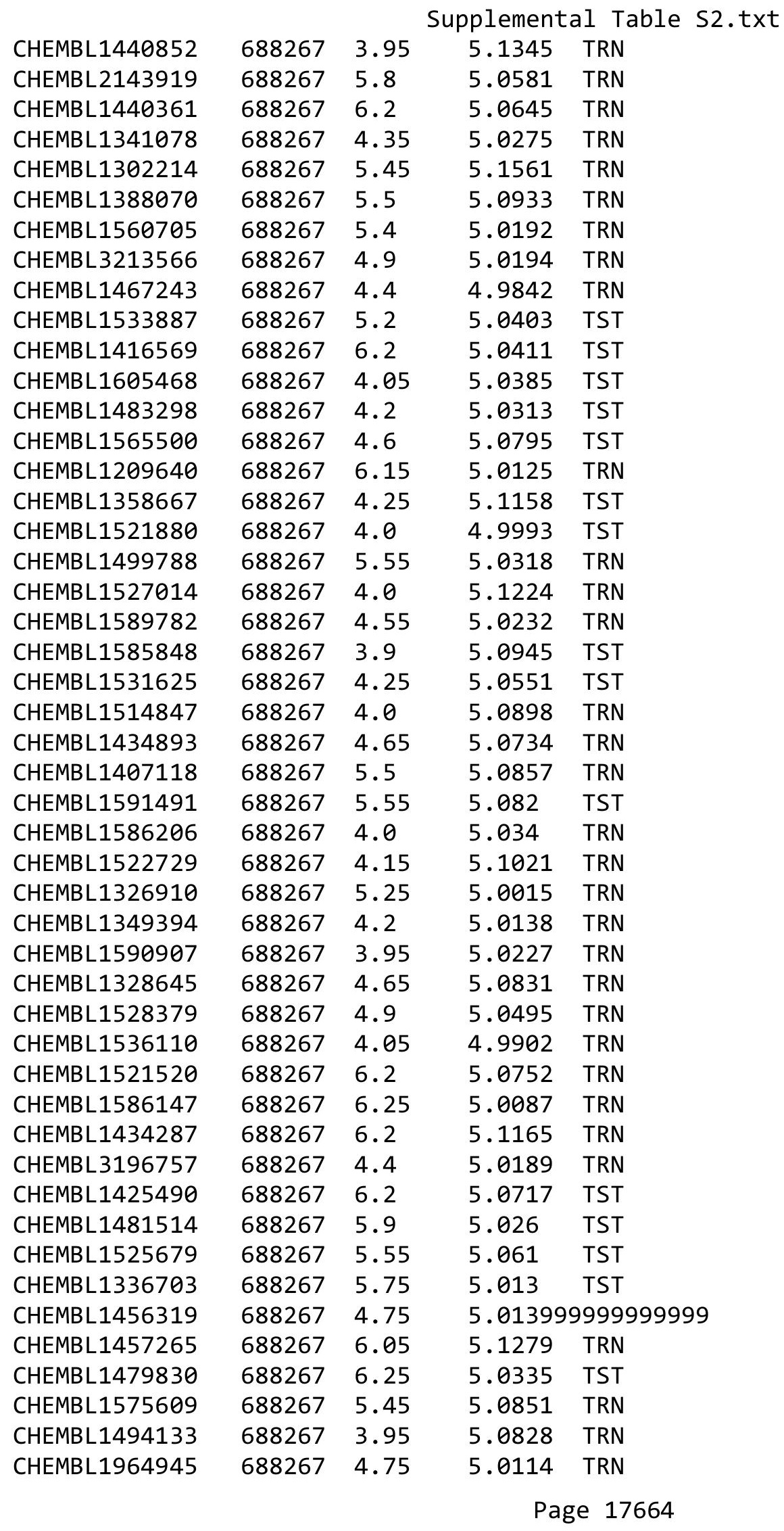

TRN 


\begin{tabular}{|c|c|c|c|c|}
\hline \multicolumn{5}{|c|}{ Supplemental Table S2.txt } \\
\hline CHEMBL1981538 & 688267 & 4.25 & 4.9994 & TRN \\
\hline CHEMBL1592334 & 688267 & 5.05 & 4.9861 & TRN \\
\hline CHEMBL1415963 & 688267 & 4.4 & 5.1101 & TRN \\
\hline CHEMBL1310792 & 688267 & 4.65 & 4.9921 & TRN \\
\hline CHEMBL1349140 & 688267 & 5.45 & 5.0238 & TRN \\
\hline CHEMBL1362682 & 688267 & 5.5 & 5.0699 & TRN \\
\hline CHEMBL1425062 & 688267 & 4.25 & 5.0702 & TRN \\
\hline CHEMBL1330841 & 688267 & 4.95 & 5.1154 & TRN \\
\hline CHEMBL1388459 & 688267 & 5.25 & 5.0032 & TST \\
\hline CHEMBL1530646 & 688267 & 5.6 & 5.0858 & TRN \\
\hline CHEMBL1547895 & 688267 & 4.0 & 5.106 & TRN \\
\hline CHEMBL1558648 & 688267 & 4.25 & 5.0946 & TRN \\
\hline CHEMBL1480406 & 688267 & 4.4 & 5.0629 & TST \\
\hline CHEMBL1328500 & 688267 & 4.1 & 5.0623 & TRN \\
\hline CHEMBL 3207700 & 688267 & 5.6 & 5.0489 & TST \\
\hline CHEMBL1541473 & 688267 & 6.5 & 5.1326 & TRN \\
\hline CHEMBL1382655 & 688267 & 5.3 & 5.0001 & TRN \\
\hline CHEMBL1564103 & 688267 & 4.1 & 5.0012 & TST \\
\hline CHEMBL1468838 & 688267 & 4.8 & 5.0042 & TST \\
\hline CHEMBL1517963 & 688267 & 4.35 & 4.9455 & TRN \\
\hline CHEMBL1302687 & 688267 & 6.15 & 5.0817 & TRN \\
\hline CHEMBL1384549 & 688267 & 4.55 & 5.1859 & TRN \\
\hline CHEMBL1395072 & 688267 & 3.95 & 5.138 & TRN \\
\hline CHEMBL1481620 & 688267 & 5.45 & 5.0552 & TRN \\
\hline CHEMBL1444980 & 688267 & 6.2 & 4.9652 & TRN \\
\hline CHEMBL596028 & 688267 & 5.35 & 5.0122 & TRN \\
\hline CHEMBL1363969 & 688267 & 4.9 & 5.1002 & TRN \\
\hline CHEMBL1528960 & 688267 & 6.25 & 5.0296 & TRN \\
\hline CHEMBL1498207 & 688267 & 4.9 & 5.0304 & TRN \\
\hline CHEMBL1596833 & 688267 & 4.1 & 5.0828 & TRN \\
\hline CHEMBL1513406 & 688267 & 3.95 & 4.9936 & TRN \\
\hline CHEMBL1491270 & 688267 & 5.55 & 5.0818 & TRN \\
\hline CHEMBL1494975 & 688267 & 5.65 & 5.0171 & TRN \\
\hline CHEMBL1443667 & 688267 & 5.3 & 5.0402 & TST \\
\hline CHEMBL1357999 & 688267 & 4.45 & 5.0193 & TST \\
\hline CHEMBL1587569 & 688267 & 4.35 & 5.0578 & TRN \\
\hline CHEMBL1436208 & 688267 & 6.2 & 5.1465 & TRN \\
\hline CHEMBL1453185 & 688267 & 4.4 & 5.1427 & TRN \\
\hline CHEMBL1314785 & 688267 & 5.8 & 5.1082 & TRN \\
\hline CHEMBL1396839 & 688267 & 4.05 & 5.0386 & TRN \\
\hline CHEMBL1459382 & 688267 & 6.2 & 5.1063 & TRN \\
\hline CHEMBL1328000 & 688267 & 4.95 & 5.0861 & TRN \\
\hline CHEMBL1473403 & 688267 & 6.5 & 5.0109 & TRN \\
\hline CHEMBL1362404 & 688267 & 5.45 & 5.0911 & TRN \\
\hline CHEMBL1514528 & 688267 & 4.2 & 5.0453 & TRN \\
\hline CHEMBL1399253 & 688267 & 6.2 & 5.0847 & TRN \\
\hline CHEMBL1349518 & 688267 & 4.45 & 5.0401 & TST \\
\hline CHEMBL1490679 & 688267 & 5.35 & 5.0528 & TRN \\
\hline
\end{tabular}




\begin{tabular}{|c|c|c|c|c|}
\hline & & & & al T \\
\hline CHEMBL1170688 & 688267 & 4.0 & 5.0539 & TST \\
\hline CHEMBL1335189 & 688267 & 4.4 & 5.1082 & TRN \\
\hline CHEMBL1367401 & 688267 & 4.5 & 5.0268 & TRN \\
\hline CHEMBL1423729 & 688267 & 4.35 & 4.9992 & TRN \\
\hline CHEMBL1372699 & 688267 & 6.5 & 5.096 & TRN \\
\hline CHEMBL1532598 & 688267 & 3.95 & 5.0446 & TST \\
\hline CHEMBL3207899 & 688267 & 3.95 & 5.0341 & TRN \\
\hline CHEMBL1381634 & 688267 & 5.75 & 5.0133 & TRN \\
\hline CHEMBL1326576 & 688267 & 5.6 & 5.0607 & TST \\
\hline CHEMBL1511076 & 688267 & 6.2 & 5.0513 & TST \\
\hline CHEMBL1557346 & 688267 & 4.2 & 5.0435 & TRN \\
\hline CHEMBL1592698 & 688267 & 6.15 & 5.0517 & TRN \\
\hline CHEMBL1311648 & 688267 & 4.05 & 5.0741 & TST \\
\hline CHEMBL1431348 & 688267 & 4.35 & 5.0659 & TRN \\
\hline CHEMBL1529190 & 688267 & 5.25 & 5.0503 & TRN \\
\hline CHEMBL1405245 & 688267 & 3.95 & 5.0236 & TRN \\
\hline CHEMBL251999 & 688267 & 6.2 & 5.0446 & TRN \\
\hline CHEMBL 3212526 & 688267 & 4.4 & 5.0085 & TRN \\
\hline CHEMBL1608066 & 688267 & 4.05 & 5.0374 & TRN \\
\hline CHEMBL1383525 & 688267 & 5.1 & 5.0494 & TRN \\
\hline CHEMBL1440840 & 688267 & 4.95 & 5.0312 & TST \\
\hline CHEMBL1341085 & 688267 & 5.3 & 5.0034 & TRN \\
\hline CHEMBL1336263 & 688267 & 4.95 & 5.0498 & TRN \\
\hline CHEMBL1520664 & 688267 & 6.15 & 5.0965 & TRN \\
\hline CHEMBL1317081 & 688267 & 4.2 & 4.9941 & TRN \\
\hline CHEMBL1608320 & 688267 & 6.2 & 5.024 & TRN \\
\hline CHEMBL1610862 & 688267 & 4.25 & 5.0631 & TRN \\
\hline CHEMBL1485362 & 688267 & 4.5 & 5.1213 & TRN \\
\hline CHEMBL1537985 & 688267 & 5.3 & 5.0656 & TRN \\
\hline CHEMBL1332249 & 688267 & 4.35 & 5.1351 & TRN \\
\hline CHEMBL 1451250 & 688267 & 5.2 & 5.148 & TRN \\
\hline CHEMBL1327066 & 688267 & 6.15 & 5.0465 & TST \\
\hline CHEMBL1314325 & 688267 & 4.05 & 5.0441 & TRN \\
\hline CHEMBL1464156 & 688267 & 4.25 & 4.9901 & TRN \\
\hline CHEMBL1548318 & 688267 & 4.8 & 5.0603 & TRN \\
\hline CHEMBL3198649 & 688267 & 4.1 & 5.0125 & TRN \\
\hline CHEMBL1414244 & 688267 & 5.95 & 5.1038 & TRN \\
\hline CHEMBL1422397 & 688267 & 5.45 & 5.02 & TRN \\
\hline CHEMBL1513091 & 688267 & 4.05 & 5.0882 & TRN \\
\hline CHEMBL1388245 & 688267 & 4.35 & 5.0711 & TRN \\
\hline CHEMBL1550444 & 688267 & 5.3 & 5.0809 & TRN \\
\hline CHEMBL1497349 & 688267 & 4.25 & 5.0523 & TRN \\
\hline CHEMBL1487941 & 688267 & 5.15 & 5.0929 & TRN \\
\hline CHEMBL3199569 & 688267 & 4.85 & 5.099 & TRN \\
\hline CHEMBL1515511 & 688267 & 4.15 & 5.0507 & TRN \\
\hline CHEMBL1353623 & 688267 & 4.35 & 5.0592 & TRN \\
\hline CHEMBL1520410 & 688267 & 4.3 & 5.1092 & TRN \\
\hline CHEMBL1362986 & 688267 & 4.65 & 4.9853 & TST \\
\hline
\end{tabular}




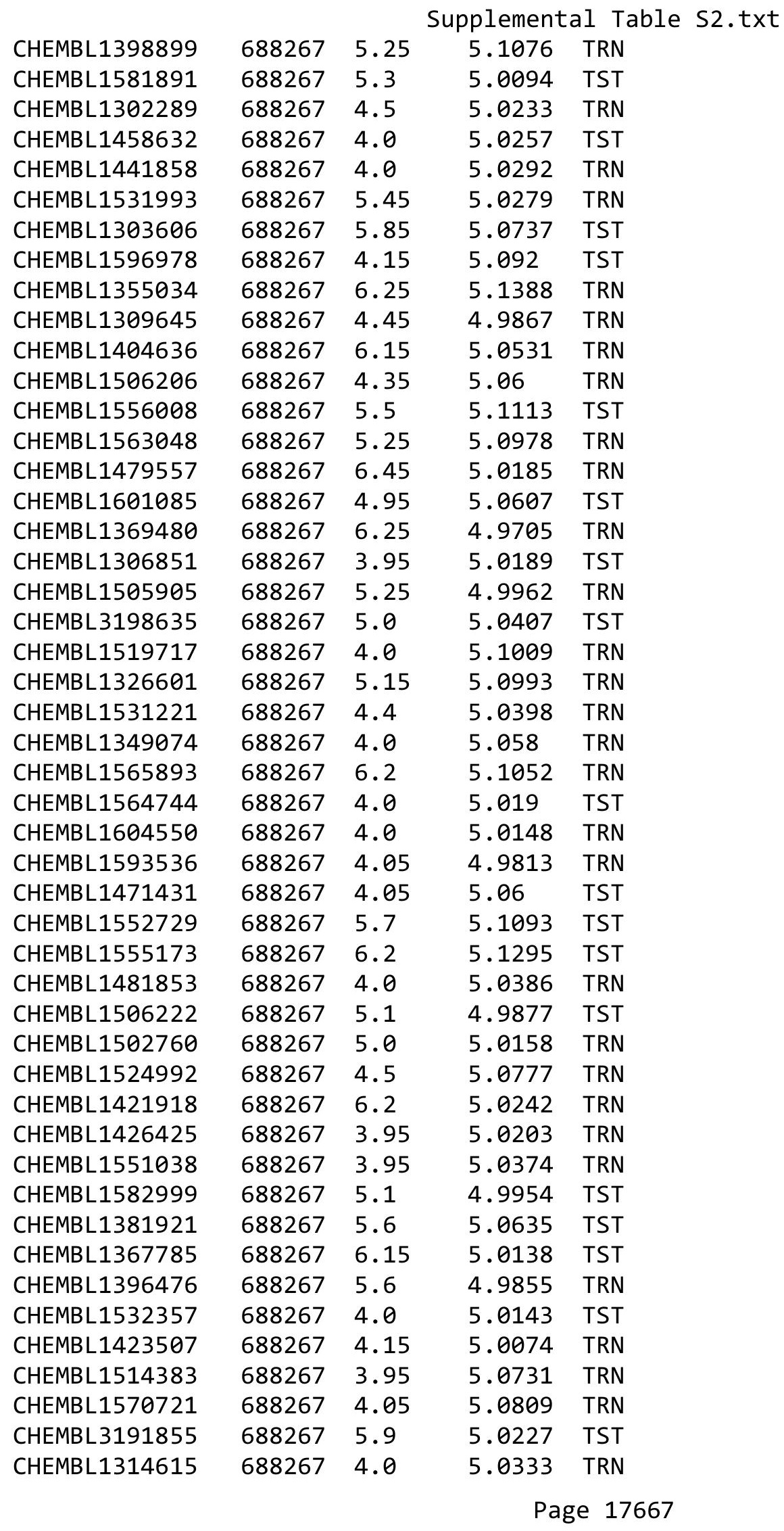




\begin{tabular}{|c|c|c|c|c|c|}
\hline \\
\hline CHEMBL1407811 & 688267 & 6.2 & 5.0316 & TST & \\
\hline CHEMBL1418314 & 688267 & 5.5 & 5.0008 & TRN & \\
\hline CHEMBL1408275 & 688267 & 4.7 & 5.1293 & TRN & \\
\hline CHEMBL1305440 & 688267 & 4.7 & 4.9987 & TRN & \\
\hline CHEMBL1453050 & 688267 & 6.15 & 5.0364 & TRN & \\
\hline CHEMBL1339005 & 688267 & 5.55 & 5.0841 & TST & \\
\hline CHEMBL1506299 & 688267 & 4.2 & 5.1156 & TST & \\
\hline CHEMBL1402117 & 688267 & 4.3 & 5.048 & TST & \\
\hline CHEMBL1511939 & 688267 & 5.8 & 5.0856 & TRN & \\
\hline CHEMBL1355502 & 688267 & 4.0 & 5.1149 & TRN & \\
\hline CHEMBL1967062 & 688267 & 4.0 & 5.0099 & TRN & \\
\hline CHEMBL1454852 & 688267 & 5.1 & 5.0576 & TRN & \\
\hline CHEMBL1431593 & 688267 & 4.4 & 5.0736 & TST & \\
\hline CHEMBL1514568 & 688267 & 5.55 & 5.0298 & TRN & \\
\hline CHEMBL1456706 & 688267 & 5.55 & 5.0554 & TRN & \\
\hline CHEMBL1386161 & 688267 & 6.05 & 5.0354 & TRN & \\
\hline CHEMBL1503466 & 688267 & 4.55 & 5.0337 & TRN & \\
\hline CHEMBL1383808 & 688267 & 4.35 & 5.0421 & TRN & \\
\hline CHEMBL1578925 & 688267 & 5.3 & 5.0274 & TST & \\
\hline CHEMBL1427062 & 688267 & 5.65 & 5.029 & TRN & \\
\hline CHEMBL1437904 & 688267 & 6.45 & 5.0783 & TRN & \\
\hline CHEMBL3192577 & 688267 & 6.2 & 5.0876 & TRN & \\
\hline CHEMBL1489997 & 688267 & 5.8 & 5.0365 & TRN & \\
\hline CHEMBL1374496 & 688267 & 4.1 & 5.0654 & TRN & \\
\hline CHEMBL1543182 & 688267 & 5.9 & 5.0764 & TST & \\
\hline CHEMBL1582642 & 688267 & 5.85 & 5.0249 & TRN & \\
\hline CHEMBL1437399 & 688267 & 5.95 & 5.1048 & TRN & \\
\hline CHEMBL1457363 & 688267 & 6.2 & 5.0421 & TRN & \\
\hline CHEMBL1465961 & 688267 & 4.4 & 5.0695 & TST & \\
\hline CHEMBL1334287 & 688267 & 5.55 & 5.1221 & TST & \\
\hline CHEMBL1566547 & 688267 & 5.95 & 5.1259 & TRN & \\
\hline CHEMBL1611903 & 688267 & 4.65 & 5.07100 & 2000000001 & TRN \\
\hline CHEMBL1324782 & 688267 & 4.2 & 5.0463 & TRN & \\
\hline CHEMBL1432407 & 688267 & 4.05 & 5.05699 & 99999999995 & TRN \\
\hline CHEMBL1350974 & 688267 & 3.95 & 5.0768 & TST & \\
\hline CHEMBL1434769 & 688267 & 4.1 & 5.1147 & TRN & \\
\hline CHEMBL1567454 & 688267 & 4.1 & 5.0869 & TRN & \\
\hline CHEMBL1434132 & 688267 & 5.3 & 5.035 & TRN & \\
\hline CHEMBL1535287 & 688267 & 6.2 & 5.1126 & TRN & \\
\hline CHEMBL1415360 & 688267 & 4.05 & 5.0506 & TRN & \\
\hline CHEMBL1591137 & 688267 & 6.25 & 5.0628 & TRN & \\
\hline CHEMBL1427602 & 688267 & 5.0 & 5.0715 & TST & \\
\hline CHEMBL1386751 & 688267 & 4.25 & 5.0777 & TRN & \\
\hline CHEMBL1516429 & 688267 & 4.35 & 5.0265 & TRN & \\
\hline CHEMBL1462089 & 688267 & 4.55 & 5.0619 & TST & \\
\hline CHEMBL1303808 & 688267 & 5.75 & 5.1001 & TST & \\
\hline CHEMBL1429539 & 688267 & 5.6 & 5.0621 & TRN & \\
\hline CHEMBL1518769 & 688267 & 6.0 & 5.0894 & TRN & \\
\hline & & & & 17668 & \\
\hline
\end{tabular}




\begin{tabular}{|c|c|c|c|c|}
\hline \multicolumn{5}{|c|}{ Supplement } \\
\hline CHEMBL1311295 & 688267 & 6.5 & 5.1392 & TRN \\
\hline CHEMBL1363895 & 688267 & 5.3 & 5.0819 & TRN \\
\hline CHEMBL1587892 & 688267 & 4.05 & 5.1171 & TRN \\
\hline CHEMBL1429478 & 688267 & 4.0 & 5.1077 & TST \\
\hline CHEMBL1302035 & 688267 & 5.0 & 5.0371 & TRN \\
\hline CHEMBL1531542 & 688267 & 5.55 & 5.0733 & TRN \\
\hline CHEMBL1568412 & 688267 & 4.05 & 5.0379 & TRN \\
\hline CHEMBL1550733 & 688267 & 6.15 & 5.1719 & TST \\
\hline CHEMBL1496014 & 688267 & 4.65 & 5.0785 & TST \\
\hline CHEMBL1340697 & 688267 & 4.3 & 5.0468 & TST \\
\hline CHEMBL1342957 & 688267 & 5.8 & 5.0449 & TRN \\
\hline CHEMBL1354918 & 688267 & 4.4 & 5.1653 & TST \\
\hline CHEMBL1413198 & 688267 & 4.1 & 5.0265 & TRN \\
\hline CHEMBL1484421 & 688267 & 4.8 & 5.0562 & TST \\
\hline CHEMBL1396732 & 688267 & 4.05 & 5.1001 & TRN \\
\hline CHEMBL1400438 & 688267 & 4.15 & 5.0383 & TRN \\
\hline CHEMBL1321683 & 688267 & 4.05 & 5.1343 & TRN \\
\hline CHEMBL1409125 & 688267 & 4.05 & 5.05 & TST \\
\hline CHEMBL1325447 & 688267 & 5.35 & 5.098 & TRN \\
\hline CHEMBL1382700 & 688267 & 6.15 & 5.0302 & TST \\
\hline CHEMBL1371079 & 688267 & 4.35 & 5.0658 & TRN \\
\hline CHEMBL1393641 & 688267 & 6.15 & 5.05399 & 9999999999 \\
\hline CHEMBL1355401 & 688267 & 4.6 & 5.0084 & TRN \\
\hline CHEMBL1600041 & 688267 & 4.2 & 5.1105 & TST \\
\hline CHEMBL1334032 & 688267 & 4.3 & 5.034 & TRN \\
\hline CHEMBL1315436 & 688267 & 6.2 & 5.0219 & TST \\
\hline CHEMBL1590723 & 688267 & 7.6498 & 5.1923 & TRN \\
\hline CHEMBL1607171 & 688267 & 5.6 & 5.0586 & TRN \\
\hline CHEMBL1438884 & 688267 & 3.95 & 5.0964 & TRN \\
\hline CHEMBL1574236 & 688267 & 6.0 & 5.1246 & TRN \\
\hline CHEMBL1543698 & 688267 & 6.2 & 5.0414 & TRN \\
\hline CHEMBL1534579 & 688267 & 5.6 & 5.0301 & TRN \\
\hline CHEMBL1609777 & 688267 & 4.35 & 5.0413 & TST \\
\hline CHEMBL1394179 & 688267 & 4.0 & 5.0291 & TST \\
\hline CHEMBL1449684 & 688267 & 6.15 & 5.0603 & TRN \\
\hline CHEMBL1328030 & 688267 & 4.35 & 5.053 & TRN \\
\hline CHEMBL1564400 & 688267 & 4.3 & 5.0381 & TRN \\
\hline CHEMBL1437633 & 688267 & 3.95 & 5.0699 & TST \\
\hline CHEMBL1569687 & 688267 & 6.5 & 5.0459 & TRN \\
\hline CHEMBL3211611 & 688267 & 5.25 & 5.0604 & TRN \\
\hline CHEMBL1540023 & 688267 & 5.8 & 5.0602 & TST \\
\hline CHEMBL1309910 & 688267 & 4.1 & 5.0576 & TRN \\
\hline CHEMBL1452644 & 688267 & 6.45 & 4.9837 & TRN \\
\hline CHEMBL1369930 & 688267 & 5.4 & 5.0695 & TRN \\
\hline CHEMBL1521755 & 688267 & 6.2 & 4.9624 & TRN \\
\hline CHEMBL1455937 & 688267 & 6.25 & 5.0316 & TST \\
\hline CHEMBL1556075 & 688267 & 4.05 & 5.1616 & TST \\
\hline CHEMBL1506401 & 688267 & 4.0 & 5.0695 & TST \\
\hline
\end{tabular}




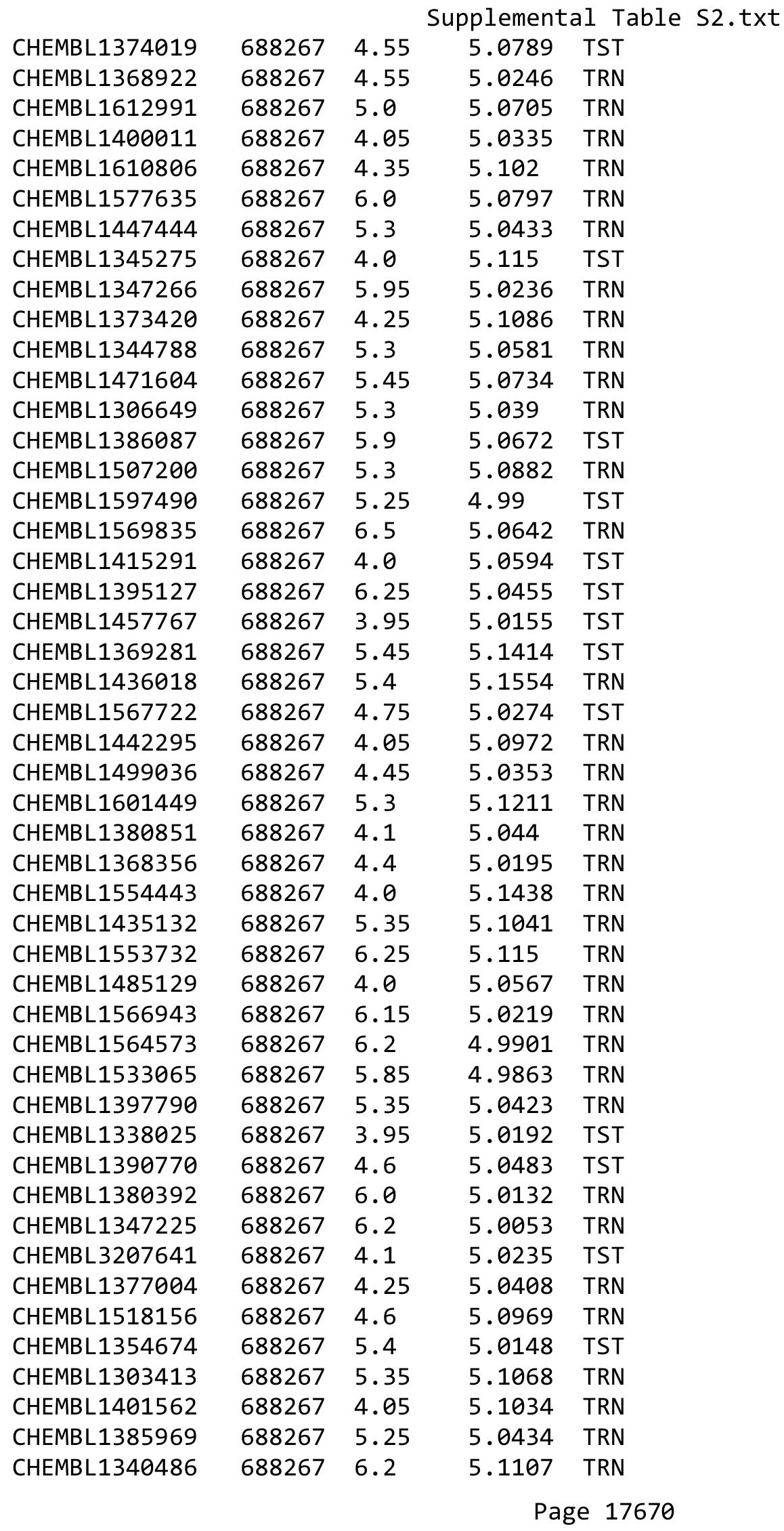




\begin{tabular}{|c|c|c|c|c|c|}
\hline \\
\hline CHEMBL1356227 & 688267 & 5.3 & 5.0022 & TRN & \\
\hline CHEMBL1343082 & 688267 & 6.5 & 5.0462 & TST & \\
\hline CHEMBL1435876 & 688267 & 3.95 & 5.0358 & TRN & \\
\hline CHEMBL1394422 & 688267 & 3.95 & 5.1694 & TRN & \\
\hline CHEMBL1588968 & 688267 & 4.35 & 5.0666 & TST & \\
\hline CHEMBL1382255 & 688267 & 6.25 & 5.0917 & TRN & \\
\hline CHEMBL1505083 & 688267 & 5.8 & 5.0414 & TRN & \\
\hline CHEMBL1433270 & 688267 & 5.0 & 5.0671 & TST & \\
\hline CHEMBL1582849 & 688267 & 4.65 & 5.0296 & TST & \\
\hline CHEMBL3190140 & 688267 & 5.2 & 5.0042 & TRN & \\
\hline CHEMBL1302596 & 688267 & 4.5 & 5.0407 & TST & \\
\hline CHEMBL1348158 & 688267 & 3.95 & 5.0518 & TRN & \\
\hline CHEMBL1610432 & 688267 & 4.1 & 5.0396 & TRN & \\
\hline CHEMBL1409245 & 688267 & 4.55 & 5.1075 & TRN & \\
\hline CHEMBL1326246 & 688267 & 5.75 & 4.9922 & TST & \\
\hline CHEMBL1435531 & 688267 & 4.55 & 5.0524 & TRN & \\
\hline CHEMBL1385352 & 688267 & 5.45 & 5.0212 & TST & \\
\hline CHEMBL1302663 & 688267 & 6.15 & 5.12200 & 2000000001 & TRN \\
\hline CHEMBL 2004059 & 688267 & 5.65 & 5.0249 & TST & \\
\hline CHEMBL1502605 & 688267 & 4.05 & 5.0836 & TRN & \\
\hline CHEMBL1443985 & 688267 & 5.35 & 5.0148 & TRN & \\
\hline CHEMBL1509986 & 688267 & 5.5 & 5.0632 & TRN & \\
\hline CHEMBL1326358 & 688267 & 4.05 & 5.1006 & TRN & \\
\hline CHEMBL3209065 & 688267 & 5.15 & 5.0459 & TRN & \\
\hline CHEMBL1411363 & 688267 & 4.55 & 5.0277 & TST & \\
\hline CHEMBL1512954 & 688267 & 4.05 & 5.1222 & TRN & \\
\hline CHEMBL1425675 & 688267 & 6.45 & 5.0535 & TST & \\
\hline CHEMBL1736377 & 688267 & 6.2 & 5.0329 & TRN & \\
\hline CHEMBL1610526 & 688267 & 4.05 & 5.0875 & TRN & \\
\hline CHEMBL1464015 & 688267 & 5.8 & 5.1044 & TST & \\
\hline CHEMBL1500105 & 688267 & 4.55 & 5.0794 & TRN & \\
\hline CHEMBL3190520 & 688267 & 4.05 & 4.9897 & TST & \\
\hline CHEMBL1480735 & 688267 & 4.0 & 5.0423 & TRN & \\
\hline CHEMBL1329057 & 688267 & 5.4 & 5.037 & TRN & \\
\hline CHEMBL1519987 & 688267 & 4.0 & 4.9894 & TRN & \\
\hline CHEMBL1513256 & 688267 & 6.25 & 5.0408 & TRN & \\
\hline CHEMBL3211121 & 688267 & 4.7 & 5.0643 & TST & \\
\hline CHEMBL1416209 & 688267 & 6.3 & 5.0102 & TRN & \\
\hline CHEMBL1401101 & 688267 & 4.3 & 5.0173 & TST & \\
\hline CHEMBL1515605 & 688267 & 5.65 & 5.0366 & TRN & \\
\hline CHEMBL1318493 & 688267 & 6.2 & 5.0201 & TRN & \\
\hline CHEMBL1407036 & 688267 & 4.1 & 5.1013 & TRN & \\
\hline CHEMBL1445543 & 688267 & 6.0 & 5.0233 & TRN & \\
\hline CHEMBL1380376 & 688267 & 5.4 & 5.0127 & TRN & \\
\hline CHEMBL1303272 & 688267 & 5.5 & 5.0477 & TST & \\
\hline CHEMBL1579449 & 688267 & 6.45 & 5.1055 & TRN & \\
\hline CHEMBL1585530 & 688267 & 4.3 & 5.0722 & TST & \\
\hline CHEMBL1584850 & 688267 & 4.4 & 5.0597 & TST & \\
\hline
\end{tabular}




\begin{tabular}{|c|c|c|c|c|}
\hline \multicolumn{5}{|c|}{ Supplemental Table S2.txt } \\
\hline CHEMBL1433040 & 688267 & 6.2 & 5.0166 & TRN \\
\hline CHEMBL1315836 & 688267 & 6.1 & 5.1339 & TRN \\
\hline CHEMBL1560216 & 688267 & 4.25 & 5.0208 & TRN \\
\hline CHEMBL1598780 & 688267 & 4.55 & 5.0097 & TRN \\
\hline CHEMBL1366899 & 688267 & 6.15 & 5.0385 & TRN \\
\hline CHEMBL1563469 & 688267 & 4.25 & 5.0753 & TRN \\
\hline CHEMBL1602221 & 688267 & 5.6 & 5.15 & TST \\
\hline CHEMBL1470252 & 688267 & 4.35 & 5.1214 & TST \\
\hline CHEMBL1407414 & 688267 & 5.2 & 5.0636 & TRN \\
\hline CHEMBL1300013 & 688267 & 4.0 & 5.0966 & TRN \\
\hline CHEMBL1353422 & 688267 & 4.95 & 5.1164 & TRN \\
\hline CHEMBL1452626 & 688267 & 4.25 & 5.0413 & TRN \\
\hline CHEMBL1453382 & 688267 & 4.3 & 5.1154 & TST \\
\hline CHEMBL1547319 & 688267 & 6.2 & 5.0795 & TRN \\
\hline CHEMBL1505096 & 688267 & 4.15 & 5.1189 & TRN \\
\hline CHEMBL1557876 & 688267 & 4.35 & 5.026 & TST \\
\hline CHEMBL1308524 & 688267 & 5.7 & 5.1118 & TRN \\
\hline CHEMBL1589475 & 688267 & 5.1 & 5.0234 & TRN \\
\hline CHEMBL1534385 & 688267 & 4.6 & 5.011 & TRN \\
\hline CHEMBL1467437 & 688267 & 4.0 & 5.1284 & TRN \\
\hline CHEMBL11945 & 688267 & 6.2 & 5.0418 & TRN \\
\hline CHEMBL1084441 & 688267 & 5.65 & 5.0161 & TRN \\
\hline CHEMBL1585612 & 688267 & 6.05 & 5.0452 & TST \\
\hline CHEMBL1472843 & 688267 & 4.6 & 5.0755 & TRN \\
\hline CHEMBL1358282 & 688267 & 6.2 & 4.9773 & TRN \\
\hline CHEMBL3145098 & 688267 & 5.5 & 4.9928 & TST \\
\hline CHEMBL1559538 & 688267 & 5.8 & 5.0003 & TRN \\
\hline CHEMBL499296 & 688267 & 6.2 & 5.0494 & TRN \\
\hline CHEMBL1494792 & 688267 & 4.6 & 5.006 & TRN \\
\hline CHEMBL1518091 & 688267 & 6.2 & 5.0463 & TRN \\
\hline CHEMBL1334728 & 688267 & 4.35 & 5.1038 & TRN \\
\hline CHEMBL1326853 & 688267 & 6.0 & 5.0024 & TRN \\
\hline CHEMBL1607660 & 688267 & 4.65 & 5.0507 & TRN \\
\hline CHEMBL1311096 & 688267 & 4.4 & 5.0036 & TRN \\
\hline CHEMBL1465186 & 688267 & 6.6499 & 5.0202 & TST \\
\hline CHEMBL1337151 & 688267 & 4.05 & 5.0809 & TRN \\
\hline CHEMBL1553870 & 688267 & 4.1 & 5.1166 & TRN \\
\hline CHEMBL3196372 & 688267 & 4.35 & 5.0736 & TRN \\
\hline CHEMBL1507851 & 688267 & 6.2 & 5.0405 & TST \\
\hline CHEMBL1320930 & 688267 & 6.25 & 5.0152 & TRN \\
\hline CHEMBL1570864 & 688267 & 5.05 & 5.09 & TRN \\
\hline CHEMBL1402692 & 688267 & 3.95 & 5.0107 & TRN \\
\hline CHEMBL1364389 & 688267 & 5.45 & 5.0725 & TST \\
\hline CHEMBL1360562 & 688267 & 6.2 & 4.9835 & TRN \\
\hline CHEMBL1590118 & 688267 & 6.0 & 5.0957 & TST \\
\hline CHEMBL1308488 & 688267 & 4.0 & 5.0567 & TST \\
\hline CHEMBL1426587 & 688267 & 5.45 & 5.0869 & TRN \\
\hline CHEMBL1300429 & 688267 & 6.2 & 5.0255 & TRN \\
\hline
\end{tabular}




\begin{tabular}{|c|c|c|c|c|}
\hline \multicolumn{5}{|c|}{ Supplemental Table S2.txt } \\
\hline CHEMBL1569230 & 688267 & 4.65 & 5.0099 & TRN \\
\hline CHEMBL1453178 & 688267 & 5.8 & 5.1154 & TRN \\
\hline CHEMBL1344417 & 688267 & 4.5 & 5.0983 & TRN \\
\hline CHEMBL1372670 & 688267 & 4.05 & 5.1041 & TRN \\
\hline CHEMBL1380607 & 688267 & 4.2 & 5.0441 & TST \\
\hline CHEMBL1488604 & 688267 & 6.0 & 5.1283 & TRN \\
\hline CHEMBL1586527 & 688267 & 5.25 & 5.0899 & TRN \\
\hline CHEMBL1556797 & 688267 & 6.4 & 5.0797 & TRN \\
\hline CHEMBL1358802 & 688267 & 4.35 & 5.0671 & TRN \\
\hline CHEMBL1596958 & 688267 & 5.4 & 5.1122 & TRN \\
\hline CHEMBL1440250 & 688267 & 4.0 & 5.0457 & TRN \\
\hline CHEMBL1522323 & 688267 & 4.35 & 5.0509 & TST \\
\hline CHEMBL1580921 & 688267 & 4.5 & 5.129 & TST \\
\hline CHEMBL1532971 & 688267 & 6.2 & 5.1085 & TRN \\
\hline CHEMBL1593181 & 688267 & 4.45 & 5.0182 & TRN \\
\hline CHEMBL1390497 & 688267 & 4.4 & 5.0301 & TST \\
\hline CHEMBL1483163 & 688267 & 4.05 & 4.9816 & TRN \\
\hline CHEMBL1309852 & 688267 & 4.25 & 5.1494 & TRN \\
\hline CHEMBL1354745 & 688267 & 5.55 & 5.042 & TRN \\
\hline CHEMBL1485350 & 688267 & 6.25 & 5.0412 & TRN \\
\hline CHEMBL1460612 & 688267 & 7.0501 & 5.0338 & TST \\
\hline CHEMBL1341234 & 688267 & 6.15 & 5.0487 & TRN \\
\hline CHEMBL1535734 & 688267 & 5.75 & 5.0614 & TRN \\
\hline CHEMBL1598437 & 688267 & 5.6 & 5.1027 & TRN \\
\hline CHEMBL585071 & 688267 & 4.0 & 5.1084 & TST \\
\hline CHEMBL1386843 & 688267 & 5.4 & 5.0297 & TST \\
\hline CHEMBL1574237 & 688267 & 6.2 & 4.9884 & TRN \\
\hline CHEMBL1601743 & 688267 & 4.3 & 5.1562 & TST \\
\hline CHEMBL1375377 & 688267 & 4.4 & 5.1255 & TRN \\
\hline CHEMBL1574111 & 688267 & 4.95 & 4.9928 & TST \\
\hline CHEMBL1435798 & 688267 & 4.0 & 5.0759 & TRN \\
\hline CHEMBL1457240 & 688267 & 6.1 & 5.033 & TRN \\
\hline CHEMBL1511909 & 688267 & 5.55 & 5.0384 & TRN \\
\hline CHEMBL1338045 & 688267 & 4.8 & 4.9807 & TRN \\
\hline CHEMBL1524083 & 688267 & 5.3 & 5.0952 & TRN \\
\hline CHEMBL1353409 & 688267 & 5.3 & 5.0043 & TST \\
\hline CHEMBL1594386 & 688267 & 4.6 & 5.0505 & TRN \\
\hline CHEMBL1466233 & 688267 & 5.6 & 5.1187 & TRN \\
\hline CHEMBL1510755 & 688267 & 5.8 & 5.0649 & TRN \\
\hline CHEMBL1330579 & 688267 & 4.0 & 5.0257 & TRN \\
\hline CHEMBL1472049 & 688267 & 6.2 & 5.0514 & TRN \\
\hline CHEMBL1527237 & 688267 & 4.9 & 5.0264 & TRN \\
\hline CHEMBL1452375 & 688267 & 5.35 & 5.0098 & TRN \\
\hline CHEMBL1998304 & 688267 & 6.2 & 4.9971 & TST \\
\hline CHEMBL1421895 & 688267 & 4.45 & 5.0756 & TRN \\
\hline CHEMBL1492768 & 688267 & 6.15 & 5.0377 & TRN \\
\hline CHEMBL1387250 & 688267 & 6.05 & 5.0803 & TRN \\
\hline CHEMBL1564780 & 688267 & 6.25 & 5.0693 & TRN \\
\hline
\end{tabular}




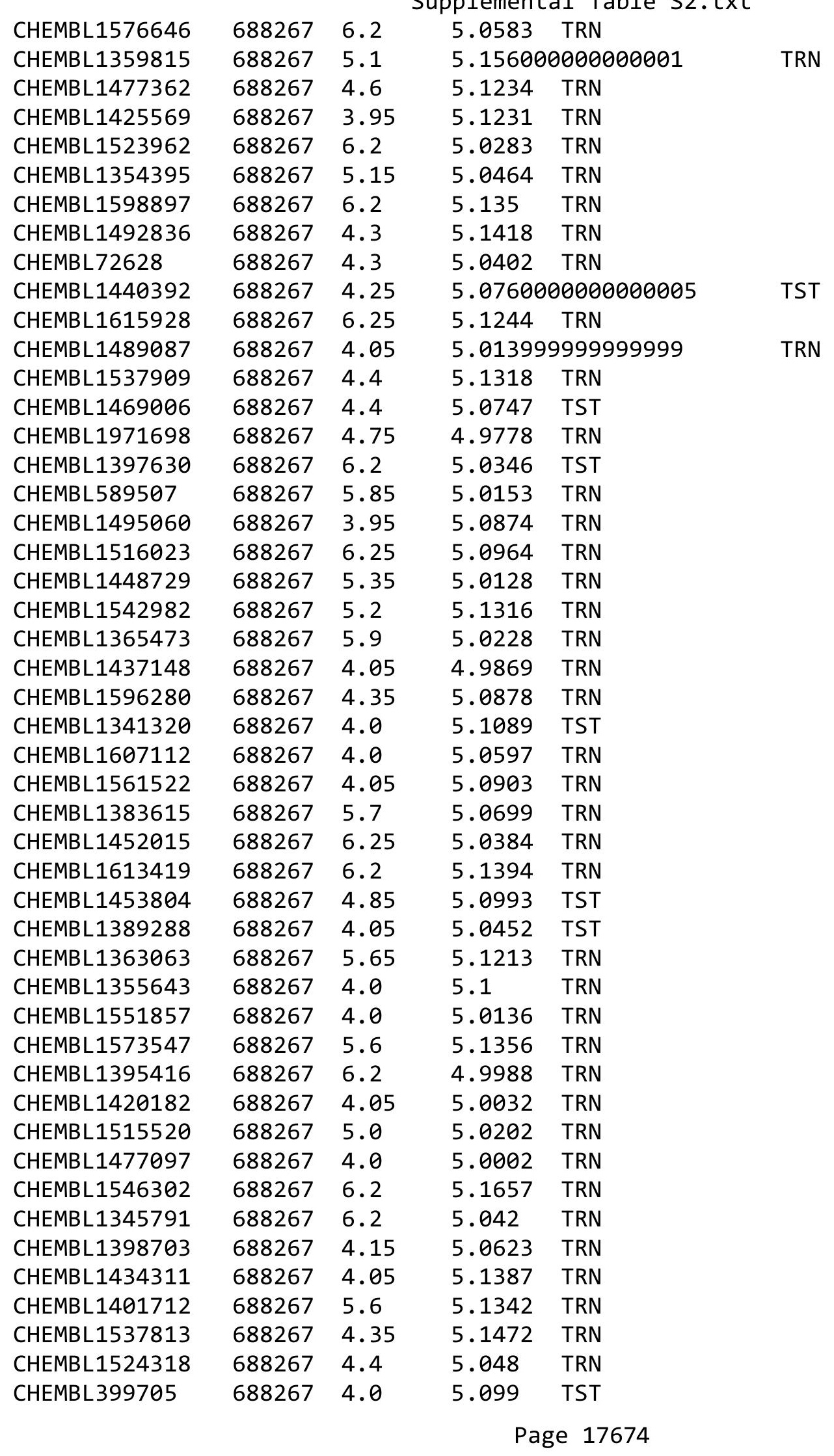




\begin{tabular}{|c|c|c|c|c|c|}
\hline \\
\hline CHEMBL1591147 & 688267 & 6.2 & 5.0987 & TRN & \\
\hline CHEMBL1420176 & 688267 & 4.35 & 5.0204 & TRN & \\
\hline CHEMBL1394699 & 688267 & 6.1 & 5.0812 & TRN & \\
\hline CHEMBL1355504 & 688267 & 5.45 & 5.0561 & TRN & \\
\hline CHEMBL3198370 & 688267 & 4.35 & 5.0263 & TST & \\
\hline CHEMBL1368597 & 688267 & 6.15 & 5.0443 & TST & \\
\hline CHEMBL1301394 & 688267 & 5.05 & 5.0841 & TST & \\
\hline CHEMBL1300634 & 688267 & 4.35 & 5.0595 & TRN & \\
\hline CHEMBL1546663 & 688267 & 4.6 & 5.0263 & TRN & \\
\hline CHEMBL1334331 & 688267 & 6.2 & 5.1095 & TRN & \\
\hline CHEMBL1313679 & 688267 & 5.85 & 5.0638 & TRN & \\
\hline CHEMBL1567512 & 688267 & 4.35 & 5.0455 & TRN & \\
\hline CHEMBL1444735 & 688267 & 5.5 & 5.0998 & TRN & \\
\hline CHEMBL3190838 & 688267 & 5.45 & 5.0025 & TRN & \\
\hline CHEMBL1486812 & 688267 & 4.75 & 5.0226 & TRN & \\
\hline CHEMBL 3198543 & 688267 & 4.1 & 5.0008 & TRN & \\
\hline CHEMBL1455154 & 688267 & 6.25 & 5.027 & TST & \\
\hline CHEMBL1570111 & 688267 & 5.45 & 5.0767 & TRN & \\
\hline CHEMBL1500111 & 688267 & 4.0 & 5.0293 & TRN & \\
\hline CHEMBL1582039 & 688267 & 5.7 & 5.118 & TRN & \\
\hline CHEMBL1587176 & 688267 & 5.75 & 5.114 & TST & \\
\hline CHEMBL1590861 & 688267 & 3.95 & 5.0812 & TRN & \\
\hline CHEMBL1981200 & 688267 & 4.1 & 4.9625 & TRN & \\
\hline CHEMBL1346892 & 688267 & 6.15 & 5.0014 & TST & \\
\hline CHEMBL 3210515 & 688267 & 5.55 & 5.0287 & TRN & \\
\hline CHEMBL1562920 & 688267 & 6.2 & 5.0449 & TRN & \\
\hline CHEMBL1576849 & 688267 & 3.95 & 5.0143 & TST & \\
\hline CHEMBL1546758 & 688267 & 4.05 & 5.115 & TST & \\
\hline CHEMBL1379588 & 688267 & 5.05 & 5.0626 & TRN & \\
\hline CHEMBL1337876 & 688267 & 4.35 & 5.126 & TRN & \\
\hline CHEMBL1533441 & 688267 & 4.3 & 5.0475 & TRN & \\
\hline CHEMBL1367592 & 688267 & 5.9 & 5.1286 & TST & \\
\hline CHEMBL1531997 & 688267 & 4.3 & 5.004 & TRN & \\
\hline CHEMBL1314599 & 688267 & 3.95 & 5.0868 & TRN & \\
\hline CHEMBL1351745 & 688267 & 5.25 & 5.0642 & TST & \\
\hline CHEMBL1445815 & 688267 & 4.4 & 5.098 & TRN & \\
\hline CHEMBL1514929 & 688267 & 5.45 & 5.1049 & TRN & \\
\hline CHEMBL1465098 & 688267 & 5.1 & 5.06800 & 00000000005 & TRN \\
\hline CHEMBL1322095 & 688267 & 5.9 & 5.0109 & TRN & \\
\hline CHEMBL1516747 & 688267 & 5.8 & 5.0474 & TST & \\
\hline CHEMBL1382427 & 688267 & 5.05 & 5.0457 & TRN & \\
\hline CHEMBL3194376 & 688267 & 4.6 & 5.0157 & TRN & \\
\hline CHEMBL1566667 & 688267 & 4.25 & 5.0225 & TRN & \\
\hline CHEMBL1516316 & 688267 & 4.5 & 5.0958 & TRN & \\
\hline CHEMBL1317345 & 688267 & 5.3 & 5.0529 & TRN & \\
\hline CHEMBL1606623 & 688267 & 5.35 & 5.0558 & TRN & \\
\hline CHEMBL1362751 & 688267 & 5.4 & 5.1062 & TRN & \\
\hline CHEMBL1533597 & 688267 & 3.95 & 5.0224 & TST & \\
\hline
\end{tabular}




\begin{tabular}{|c|c|c|c|c|c|}
\hline & & & & & \\
\hline CHEMBL1359437 & 688267 & 6.2 & 5.0621 & TRN & \\
\hline CHEMBL1567679 & 688267 & 6.2 & 5.0863 & TRN & \\
\hline CHEMBL1583912 & 688267 & 6.0 & 5.0259 & TRN & \\
\hline CHEMBL1379001 & 688267 & 5.05 & 5.0055 & TRN & \\
\hline CHEMBL1537965 & 688267 & 4.45 & $5.1080 e$ & 30000000005 & TRN \\
\hline CHEMBL1553707 & 688267 & 4.35 & 5.0752 & TRN & \\
\hline CHEMBL1485209 & 688267 & 3.95 & 5.0452 & TRN & \\
\hline CHEMBL1584057 & 688267 & 4.35 & 5.0719 & TST & \\
\hline CHEMBL1511351 & 688267 & 5.85 & 5.1064 & TST & \\
\hline CHEMBL1320674 & 688267 & 6.2 & 5.0347 & TST & \\
\hline CHEMBL1387290 & 688267 & 4.5 & 5.0833 & TRN & \\
\hline CHEMBL1447873 & 688267 & 4.75 & 5.0677 & TRN & \\
\hline CHEMBL1566412 & 688267 & 6.25 & 5.0915 & TRN & \\
\hline CHEMBL1588040 & 688267 & 4.4 & 5.0233 & TRN & \\
\hline CHEMBL1598878 & 688267 & 5.1 & 5.0281 & TST & \\
\hline CHEMBL1302082 & 688267 & 4.55 & 5.0208 & TRN & \\
\hline CHEMBL1441076 & 688267 & 5.5 & 5.0915 & TRN & \\
\hline CHEMBL1468076 & 688267 & 4.1 & 5.0856 & TRN & \\
\hline CHEMBL1578689 & 688267 & 4.3 & 5.0054 & TRN & \\
\hline CHEMBL1350614 & 688267 & 4.95 & 5.1425 & TRN & \\
\hline CHEMBL1597005 & 688267 & 4.4 & 5.0788 & TRN & \\
\hline CHEMBL1515602 & 688267 & 4.2 & 5.0038 & TRN & \\
\hline CHEMBL1385796 & 688267 & 6.25 & 5.0191 & TRN & \\
\hline CHEMBL1472603 & 688267 & 5.1 & 5.0479 & TRN & \\
\hline CHEMBL1320611 & 688267 & 5.75 & 5.0246 & TRN & \\
\hline CHEMBL1565908 & 688267 & 3.95 & 5.0326 & TRN & \\
\hline CHEMBL1517663 & 688267 & 4.55 & 4.9837 & TRN & \\
\hline CHEMBL1324134 & 688267 & 3.95 & 5.0799 & TRN & \\
\hline CHEMBL1544600 & 688267 & 5.05 & 5.1299 & TRN & \\
\hline CHEMBL1606739 & 688267 & 5.0 & 5.1154 & TRN & \\
\hline CHEMBL1548756 & 688267 & 3.95 & 5.1085 & TRN & \\
\hline CHEMBL1449501 & 688267 & 4.45 & 5.0577 & TRN & \\
\hline CHEMBL1368119 & 688267 & 6.05 & 5.0699 & TRN & \\
\hline CHEMBL1581953 & 688267 & 6.2 & 5.0634 & TRN & \\
\hline CHEMBL1372467 & 688267 & 4.35 & 5.0004 & TST & \\
\hline CHEMBL1401428 & 688267 & 4.7 & 4.9816 & TRN & \\
\hline CHEMBL1517856 & 688267 & 4.05 & 5.0099 & TST & \\
\hline CHEMBL1570213 & 688267 & 4.0 & 5.0029 & TRN & \\
\hline CHEMBL1500376 & 688267 & 6.15 & 5.0344 & TRN & \\
\hline CHEMBL1412028 & 688267 & 5.65 & 5.0682 & TRN & \\
\hline CHEMBL1341203 & 688267 & 6.15 & 5.0226 & TRN & \\
\hline CHEMBL1435176 & 688267 & 6.15 & 5.0275 & TRN & \\
\hline CHEMBL1549700 & 688267 & 4.35 & 5.0449 & TST & \\
\hline CHEMBL1554262 & 688267 & 4.15 & 5.0324 & TRN & \\
\hline CHEMBL1458342 & 688267 & 4.0 & 5.0505 & TRN & \\
\hline CHEMBL1405138 & 688267 & 4.6 & 5.027 & TST & \\
\hline CHEMBL3199714 & 688267 & 4.05 & 4.9709 & TRN & \\
\hline CHEMBL1465075 & 688267 & 4.0 & 5.0577 & TRN & \\
\hline & & & & 17676 & \\
\hline
\end{tabular}




\begin{tabular}{|c|c|c|c|c|c|}
\hline \multirow{2}{*}{\multicolumn{2}{|c|}{ CHEMBL1484840 }} & \\
\hline & & 5.9 & 4.9893 & TRN & \\
\hline CHEMBL1557956 & 688267 & 5.3 & 5.0755 & TRN & \\
\hline CHEMBL3213507 & 688267 & 5.55 & 4.9946 & TRN & \\
\hline CHEMBL1372975 & 688267 & 6.5 & 5.0944 & TST & \\
\hline CHEMBL1523255 & 688267 & 4.05 & 5.0542 & TRN & \\
\hline CHEMBL1332736 & 688267 & 4.1 & 5.0714 & TRN & \\
\hline CHEMBL1329135 & 688267 & 4.1 & 5.1 & TRN & \\
\hline CHEMBL1404034 & 688267 & 4.65 & 5.0394 & TRN & \\
\hline CHEMBL1461227 & 688267 & 4.3 & 5.0625 & TRN & \\
\hline CHEMBL1377095 & 688267 & 6.2 & 5.0481 & TRN & \\
\hline CHEMBL1579786 & 688267 & 4.5 & 5.0648 & TST & \\
\hline CHEMBL1310649 & 688267 & 4.4 & 5.1298 & TRN & \\
\hline CHEMBL1405602 & 688267 & 5.8 & 5.0173 & TST & \\
\hline CHEMBL1393038 & 688267 & 4.15 & 5.0835 & TST & \\
\hline CHEMBL1334871 & 688267 & 4.2 & 4.9823 & TRN & \\
\hline CHEMBL3193227 & 688267 & 4.0 & 5.0149 & TST & \\
\hline CHEMBL1546650 & 688267 & 4.35 & 5.0483 & TRN & \\
\hline CHEMBL1399971 & 688267 & 5.95 & 5.0549 & TST & \\
\hline CHEMBL1421946 & 688267 & 4.65 & 5.0437 & TRN & \\
\hline CHEMBL1349603 & 688267 & 4.2 & 5.1339 & TRN & \\
\hline CHEMBL1579013 & 688267 & 5.6 & 5.066 & TRN & \\
\hline CHEMBL1408886 & 688267 & 6.2 & 5.0061 & TRN & \\
\hline CHEMBL1438921 & 688267 & 6.2 & 5.0396 & TRN & \\
\hline CHEMBL1600846 & 688267 & 5.15 & 5.0112 & TST & \\
\hline CHEMBL1510266 & 688267 & 4.0 & 4.9901 & TRN & \\
\hline CHEMBL1480843 & 688267 & 4.4 & 5.0372 & TRN & \\
\hline CHEMBL1317844 & 688267 & 4.05 & 5.1186 & TRN & \\
\hline CHEMBL1609992 & 688267 & 5.0 & 5.17399 & 99999999995 & TRN \\
\hline CHEMBL 254530 & 688267 & 5.4 & 5.1743 & TRN & \\
\hline CHEMBL1532352 & 688267 & 6.2 & 5.0407 & TRN & \\
\hline CHEMBL1406310 & 688267 & 4.4 & 5.0899 & TRN & \\
\hline CHEMBL1318224 & 688267 & 5.55 & 5.0403 & TRN & \\
\hline CHEMBL1593273 & 688267 & 4.0 & 5.0627 & TRN & \\
\hline CHEMBL1310738 & 688267 & 6.3 & 5.0673 & TRN & \\
\hline CHEMBL1586150 & 688267 & 5.8 & 5.0856 & TRN & \\
\hline CHEMBL1347598 & 688267 & 4.8 & 5.0535 & TRN & \\
\hline CHEMBL1325246 & 688267 & 4.4 & 5.1272 & TRN & \\
\hline CHEMBL1602172 & 688267 & 5.9 & 5.0074 & TRN & \\
\hline CHEMBL1405589 & 688267 & 5.5 & 5.0129 & TST & \\
\hline CHEMBL1545701 & 688267 & 4.05 & 5.0316 & TST & \\
\hline CHEMBL1464942 & 688267 & 3.95 & 5.0287 & TST & \\
\hline CHEMBL1531689 & 688267 & 4.35 & 5.0934 & TRN & \\
\hline CHEMBL1585413 & 688267 & 4.35 & 5.0608 & TRN & \\
\hline CHEMBL1586228 & 688267 & 6.15 & 5.0117 & TRN & \\
\hline CHEMBL1332560 & 688267 & 4.8 & 5.1267 & TST & \\
\hline CHEMBL1396043 & 688267 & 5.3 & 5.0192 & TRN & \\
\hline CHEMBL1446684 & 688267 & 5.05 & 5.0803 & TRN & \\
\hline CHEMBL1463261 & 688267 & 4.0 & 5.0264 & TRN & \\
\hline & & & & 17677 & \\
\hline
\end{tabular}




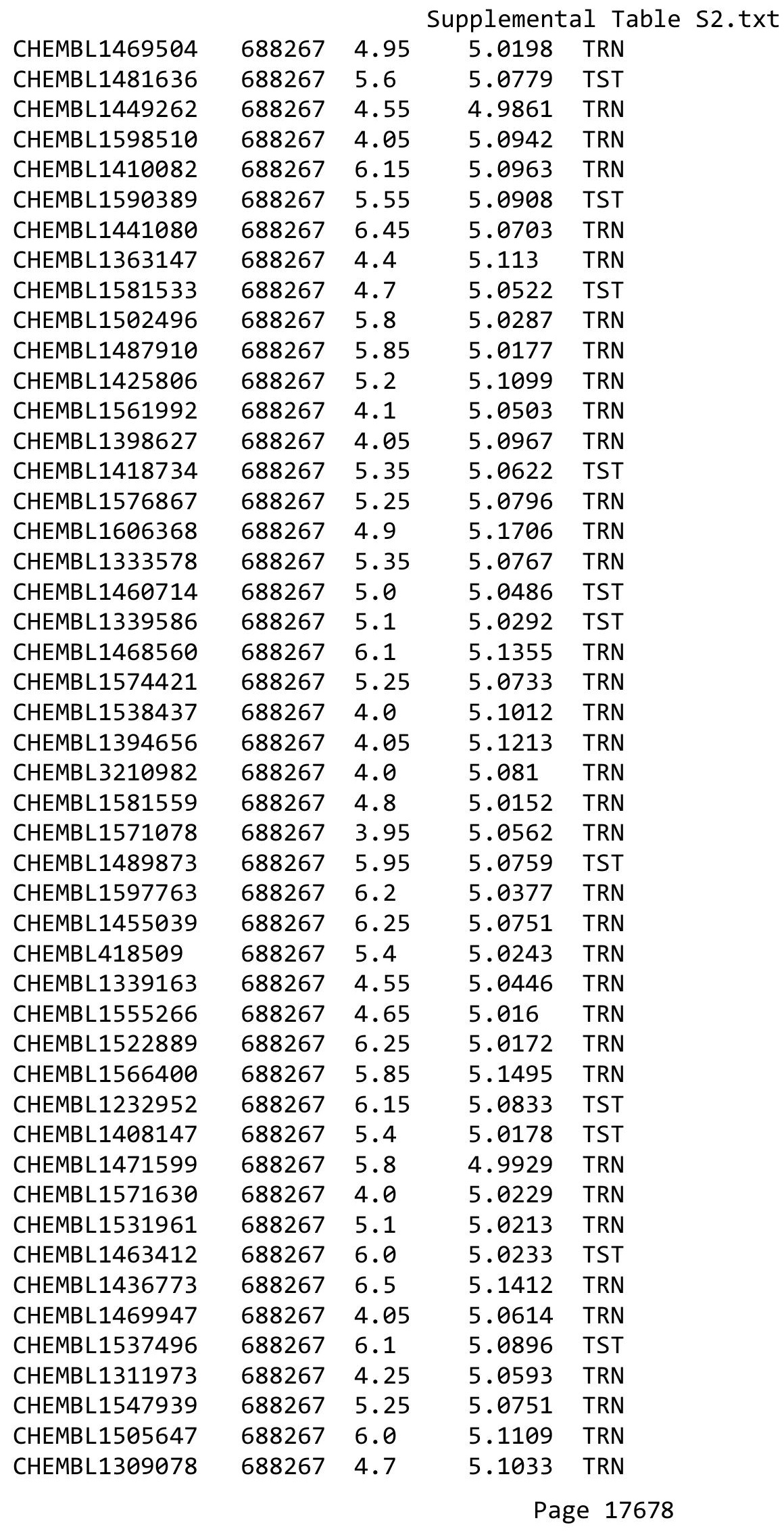




\begin{tabular}{|c|c|c|c|c|c|}
\hline \multicolumn{6}{|c|}{ Supplemental Table S2.txt } \\
\hline CHEMBL1405824 & 688267 & 5.85 & 5.04 & TRN & \\
\hline CHEMBL1387852 & 688267 & 5.55 & 5.1226 & TRN & \\
\hline CHEMBL1545463 & 688267 & 6.0 & 5.1211 & TST & \\
\hline CHEMBL1490804 & 688267 & 4.7 & 4.9977 & TRN & \\
\hline CHEMBL1432255 & 688267 & 6.5 & 5.0259 & TRN & \\
\hline CHEMBL1440952 & 688267 & 6.45 & 5.0815 & TRN & \\
\hline CHEMBL1421577 & 688267 & 4.55 & 5.0447 & TST & \\
\hline CHEMBL1556077 & 688267 & 4.45 & 5.0968 & TRN & \\
\hline CHEMBL1352786 & 688267 & 6.2 & 5.1056 & TST & \\
\hline CHEMBL1422469 & 688267 & 3.95 & 5.1057 & TRN & \\
\hline CHEMBL1578206 & 688267 & 4.25 & 5.0504 & TRN & \\
\hline CHEMBL1314372 & 688267 & 4.4 & 5.1668 & TRN & \\
\hline CHEMBL1531227 & 688267 & 5.75 & 5.0618 & TRN & \\
\hline CHEMBL 74384 & 688267 & 6.05 & 5.0561 & TST & \\
\hline CHEMBL1584108 & 688267 & 4.75 & 5.0376 & TRN & \\
\hline CHEMBL1503578 & 688267 & 4.0 & 5.1532 & TRN & \\
\hline CHEMBL3211339 & 688267 & 4.05 & 5.0142 & TST & \\
\hline CHEMBL1325740 & 688267 & 5.75 & 5.039 & TRN & \\
\hline CHEMBL1310358 & 688267 & 6.0 & 5.0447 & TRN & \\
\hline CHEMBL1526451 & 688267 & 6.2 & 5.0649 & TRN & \\
\hline CHEMBL1487491 & 688267 & 5.55 & 5.0417 & TRN & \\
\hline CHEMBL1439575 & 688267 & 4.0 & 5.17399 & 99999999995 & TST \\
\hline CHEMBL1389035 & 688267 & 5.55 & 5.0844 & TST & \\
\hline CHEMBL1361861 & 688267 & 4.8 & 5.1236 & TRN & \\
\hline CHEMBL1342275 & 688267 & 5.2 & 5.1309 & TRN & \\
\hline CHEMBL1362843 & 688267 & 4.35 & 5.096 & TRN & \\
\hline CHEMBL1363189 & 688267 & 3.95 & 5.0628 & TRN & \\
\hline CHEMBL1479718 & 688267 & 4.25 & 5.0345 & TRN & \\
\hline CHEMBL1414250 & 688267 & 5.35 & 5.0621 & TRN & \\
\hline CHEMBL1387509 & 688267 & 5.6 & 5.115 & TRN & \\
\hline CHEMBL1736239 & 688267 & 3.95 & 5.0138 & TRN & \\
\hline CHEMBL1437122 & 688267 & 4.3 & 5.0263 & TRN & \\
\hline CHEMBL1606254 & 688267 & 5.35 & 5.0669 & TRN & \\
\hline CHEMBL1441168 & 688267 & 4.4 & 5.029 & TRN & \\
\hline CHEMBL1558606 & 688267 & 3.95 & 5.0399 & TST & \\
\hline CHEMBL1418163 & 688267 & 4.3 & 5.0322 & TRN & \\
\hline CHEMBL1390962 & 688267 & 5.0 & 5.0858 & TST & \\
\hline CHEMBL1375332 & 688267 & 4.4 & 5.0192 & TRN & \\
\hline CHEMBL1576890 & 688267 & 5.5 & 5.0471 & TRN & \\
\hline CHEMBL1390989 & 688267 & 4.05 & 5.0135 & TST & \\
\hline CHEMBL1518208 & 688267 & 5.4 & 5.0052 & TRN & \\
\hline CHEMBL1557020 & 688267 & 4.55 & 5.1128 & TRN & \\
\hline CHEMBL1328713 & 688267 & 5.3 & 5.0096 & TRN & \\
\hline CHEMBL1307357 & 688267 & 6.2 & 5.0468 & TST & \\
\hline CHEMBL1511111 & 688267 & 4.05 & 5.0536 & TRN & \\
\hline CHEMBL1462993 & 688267 & 6.45 & 5.0084 & TRN & \\
\hline CHEMBL1374392 & 688267 & 5.85 & 5.0329 & TRN & \\
\hline CHEMBL1568532 & 688267 & 4.75 & 5.0337 & TRN & \\
\hline
\end{tabular}




\begin{tabular}{|c|c|c|c|c|}
\hline \multicolumn{5}{|c|}{ Supplemental Table S2.txt } \\
\hline CHEMBL1081471 & 688267 & 5.65 & 5.0377 & TRN \\
\hline CHEMBL1518807 & 688267 & 5.1 & 5.0483 & TRN \\
\hline CHEMBL1586195 & 688267 & 5.8 & 5.0986 & TRN \\
\hline CHEMBL1508502 & 688267 & 4.4 & 5.0688 & TRN \\
\hline CHEMBL3210858 & 688267 & 4.05 & 5.0071 & TRN \\
\hline CHEMBL1334496 & 688267 & 4.35 & 5.1047 & TRN \\
\hline CHEMBL1531623 & 688267 & 6.15 & 5.0039 & TRN \\
\hline CHEMBL1396091 & 688267 & 4.05 & 5.0783 & TST \\
\hline CHEMBL1406336 & 688267 & 5.55 & 5.1485 & TRN \\
\hline CHEMBL1401329 & 688267 & 4.05 & 5.0106 & TRN \\
\hline CHEMBL1478792 & 688267 & 5.4 & 5.0895 & TRN \\
\hline CHEMBL1493251 & 688267 & 5.35 & 5.0503 & TST \\
\hline CHEMBL1435237 & 688267 & 5.25 & 5.0287 & TRN \\
\hline CHEMBL1305023 & 688267 & 5.5 & 5.144 & TRN \\
\hline CHEMBL1552674 & 688267 & 4.35 & 5.0761 & TRN \\
\hline CHEMBL490550 & 688267 & 4.05 & 4.9932 & TRN \\
\hline CHEMBL1378439 & 688267 & 5.45 & 5.0639 & TST \\
\hline CHEMBL1445680 & 688267 & 6.4 & 5.0133 & TRN \\
\hline CHEMBL1395675 & 688267 & 6.1 & 4.994 & TRN \\
\hline CHEMBL1526426 & 688267 & 4.5 & 5.0561 & TRN \\
\hline CHEMBL1375642 & 688267 & 4.4 & 5.0475 & TRN \\
\hline CHEMBL1578194 & 688267 & 6.5 & 5.0532 & TRN \\
\hline CHEMBL3209503 & 688267 & 4.55 & 5.1297 & TRN \\
\hline CHEMBL1373605 & 688267 & 4.1 & 5.0812 & TRN \\
\hline CHEMBL1486342 & 688267 & 6.1 & 5.0269 & TRN \\
\hline CHEMBL1385176 & 688267 & 5.7 & 5.0225 & TRN \\
\hline CHEMBL1317899 & 688267 & 6.2 & 5.1181 & TRN \\
\hline CHEMBL3191660 & 688267 & 4.2 & 5.0677 & TST \\
\hline CHEMBL1535306 & 688267 & 4.2 & 5.0389 & TRN \\
\hline CHEMBL3208406 & 688267 & 4.55 & 5.0241 & TRN \\
\hline CHEMBL1335082 & 688267 & 6.2 & 5.074 & TRN \\
\hline CHEMBL1332469 & 688267 & 5.05 & 5.0812 & TRN \\
\hline CHEMBL1421273 & 688267 & 4.35 & 5.0398 & TRN \\
\hline CHEMBL1470765 & 688267 & 5.6 & 5.0943 & TRN \\
\hline CHEMBL1552630 & 688267 & 5.55 & 5.0455 & TRN \\
\hline CHEMBL1420358 & 688267 & 4.6 & 5.0752 & TRN \\
\hline CHEMBL1344087 & 688267 & 5.2 & 5.0802 & TST \\
\hline CHEMBL1382845 & 688267 & 5.5 & 5.0369 & TRN \\
\hline CHEMBL1494550 & 688267 & 5.5 & 5.1304 & TRN \\
\hline CHEMBL1345316 & 688267 & 5.55 & 5.0632 & TRN \\
\hline CHEMBL1383662 & 688267 & 6.2 & 5.1886 & TRN \\
\hline CHEMBL579498 & 688267 & 4.0 & 5.0366 & TRN \\
\hline CHEMBL1319281 & 688267 & 6.25 & 5.0361 & TRN \\
\hline CHEMBL1518596 & 688267 & 5.3 & 5.0684 & TST \\
\hline CHEMBL1421883 & 688267 & 6.2 & 5.042 & TRN \\
\hline CHEMBL1317436 & 688267 & 4.8 & 5.01 & TRN \\
\hline CHEMBL1392093 & 688267 & 4.0 & 5.0461 & TST \\
\hline CHEMBL3207824 & 688267 & 5.45 & 5.0811 & TST \\
\hline
\end{tabular}




\begin{tabular}{|c|c|c|c|c|}
\hline & & & pplement & al Table S \\
\hline CHEMBL1580768 & 688267 & 4.4 & 5.0506 & TRN \\
\hline CHEMBL1448292 & 688267 & 4.05 & 5.0052 & TRN \\
\hline CHEMBL1301020 & 688267 & 5.35 & 5.0516 & TST \\
\hline CHEMBL1434203 & 688267 & 5.45 & 5.1012 & TRN \\
\hline CHEMBL1323493 & 688267 & 5.45 & 5.0969 & TRN \\
\hline CHEMBL1529511 & 688267 & 4.05 & 5.008 & TRN \\
\hline CHEMBL1349662 & 688267 & 4.3 & 5.0316 & TST \\
\hline CHEMBL1420343 & 688267 & 4.05 & 5.0101 & TST \\
\hline CHEMBL1300853 & 688267 & 5.4 & 5.088 & TRN \\
\hline CHEMBL1313533 & 688267 & 4.0 & 5.0351 & TST \\
\hline CHEMBL1465105 & 688267 & 4.0 & 5.0496 & TST \\
\hline CHEMBL1440007 & 688267 & 3.95 & 5.0773 & TRN \\
\hline CHEMBL1520575 & 688267 & 3.95 & 5.1524 & TRN \\
\hline CHEMBL1593951 & 688267 & 4.05 & 5.1008 & TST \\
\hline CHEMBL1374666 & 688267 & 4.0 & 5.0155 & TRN \\
\hline CHEMBL1344513 & 688267 & 4.0 & 5.0357 & TRN \\
\hline CHEMBL3193798 & 688267 & 4.05 & 5.0517 & TRN \\
\hline CHEMBL1522520 & 688267 & 3.95 & 5.0359 & TRN \\
\hline CHEMBL1423761 & 688267 & 4.5 & $5.0710 e$ & 0000000001 \\
\hline CHEMBL1310870 & 688267 & 4.2 & 5.0301 & TRN \\
\hline CHEMBL1351076 & 688267 & 4.45 & 5.0487 & TST \\
\hline CHEMBL1407974 & 688267 & 5.55 & 5.0567 & TRN \\
\hline CHEMBL1597061 & 688267 & 4.55 & 4.9825 & TRN \\
\hline CHEMBL1459781 & 688267 & 5.2 & 5.006 & TRN \\
\hline CHEMBL1495656 & 688267 & 5.35 & 5.091 & TRN \\
\hline CHEMBL1335803 & 688267 & 5.3 & 5.0697 & TRN \\
\hline CHEMBL1345036 & 688267 & 6.45 & 5.0393 & TRN \\
\hline CHEMBL3212690 & 688267 & 4.6 & 5.0379 & TST \\
\hline CHEMBL1324168 & 688267 & 6.0 & 5.063 & TRN \\
\hline CHEMBL1548119 & 688267 & 4.6 & 5.0323 & TRN \\
\hline CHEMBL1429746 & 688267 & 4.4 & 5.0921 & TST \\
\hline CHEMBL1441701 & 688267 & 5.3 & 5.0991 & TRN \\
\hline CHEMBL1359244 & 688267 & 5.1 & 5.025 & TRN \\
\hline CHEMBL1474423 & 688267 & 5.75 & 5.06 & TRN \\
\hline CHEMBL1414535 & 688267 & 4.9 & 5.053 & TRN \\
\hline CHEMBL1314444 & 688267 & 5.35 & 5.0008 & TRN \\
\hline CHEMBL1580183 & 688267 & 3.95 & 5.1407 & TRN \\
\hline CHEMBL1543367 & 688267 & 5.4 & 5.0293 & TRN \\
\hline CHEMBL1425622 & 688267 & 5.6 & 5.05 & TRN \\
\hline CHEMBL1539046 & 688267 & 5.25 & 5.0382 & TRN \\
\hline CHEMBL1580460 & 688267 & 5.05 & 5.0192 & TST \\
\hline CHEMBL1402401 & 688267 & 5.3 & 5.0552 & TST \\
\hline CHEMBL1528068 & 688267 & 6.2 & 5.1046 & TRN \\
\hline CHEMBL1478047 & 688267 & 3.95 & 5.0378 & TRN \\
\hline CHEMBL1560389 & 688267 & 6.1 & 5.1158 & TRN \\
\hline CHEMBL1530092 & 688267 & 5.45 & 5.0627 & TST \\
\hline CHEMBL1498631 & 688267 & 6.2 & 5.1031 & TRN \\
\hline CHEMBL3199503 & 688267 & 5.5 & 5.0333 & TRN \\
\hline
\end{tabular}




\begin{tabular}{|c|c|c|c|c|c|}
\hline \multicolumn{6}{|c|}{ Supplemental Table s2.txt } \\
\hline CHEMBL1371769 & 688267 & 5.25 & 5.021 & TRN & \\
\hline CHEMBL1340201 & 688267 & 4.2 & 5.0875 & TRN & \\
\hline CHEMBL1309172 & 688267 & 3.95 & 5.0878 & TST & \\
\hline CHEMBL1564733 & 688267 & 4.75 & 5.0644 & TST & \\
\hline CHEMBL1351706 & 688267 & 6.1 & 5.0513 & TRN & \\
\hline CHEMBL 3199234 & 688267 & 6.2 & 5.0325 & TST & \\
\hline CHEMBL1434870 & 688267 & 6.05 & 5.0012 & TRN & \\
\hline CHEMBL1320223 & 688267 & 4.3 & 5.0538 & TRN & \\
\hline CHEMBL1605290 & 688267 & 4.05 & 5.016 & TRN & \\
\hline CHEMBL1558651 & 688267 & 5.6 & 5.0761 & TRN & \\
\hline CHEMBL1566934 & 688267 & 4.7 & 5.1112 & TRN & \\
\hline CHEMBL1550077 & 688267 & 6.2 & 5.0824 & TRN & \\
\hline CHEMBL1429614 & 688267 & 5.4 & 5.0028 & TRN & \\
\hline CHEMBL1497176 & 688267 & 4.65 & 5.0267 & TRN & \\
\hline CHEMBL1471623 & 688267 & 4.15 & 5.0488 & TST & \\
\hline CHEMBL1565746 & 688267 & 5.3 & 5.0737 & TRN & \\
\hline CHEMBL1360940 & 688267 & 5.25 & 5.0264 & TRN & \\
\hline CHEMBL1527912 & 688267 & 4.25 & 5.0386 & TRN & \\
\hline CHEMBL1505616 & 688267 & 6.2 & 5.0428 & TST & \\
\hline CHEMBL1339235 & 688267 & 5.85 & 5.0419 & TRN & \\
\hline CHEMBL1309237 & 688267 & 6.25 & 5.0524 & TST & \\
\hline CHEMBL1460707 & 688267 & 5.0 & 5.0026 & TST & \\
\hline CHEMBL1363687 & 688267 & 6.15 & 5.0814 & TRN & \\
\hline CHEMBL1462923 & 688267 & 5.85 & 5.0827 & TRN & \\
\hline CHEMBL1477267 & 688267 & 5.3 & 5.0381 & TRN & \\
\hline CHEMBL1393368 & 688267 & 4.3 & 5.0612 & TRN & \\
\hline CHEMBL1507620 & 688267 & 4.35 & 5.0145 & TRN & \\
\hline CHEMBL1544798 & 688267 & 5.1 & 5.0207 & TST & \\
\hline CHEMBL1589933 & 688267 & 5.25 & 5.0378 & TST & \\
\hline CHEMBL1438983 & 688267 & 4.0 & 5.0135 & TST & \\
\hline CHEMBL1521525 & 688267 & 4.4 & 5.0493 & TRN & \\
\hline CHEMBL1565196 & 688267 & 6.25 & 5.1345 & TRN & \\
\hline CHEMBL1434078 & 688267 & 6.0 & 5.1198 & TRN & \\
\hline CHEMBL1469811 & 688267 & 5.1 & 5.0351 & TRN & \\
\hline CHEMBL1509302 & 688267 & 5.4 & 5.106 & TST & \\
\hline CHEMBL1543502 & 688267 & 3.95 & 5.05699 & 99999999995 & TRN \\
\hline CHEMBL1455375 & 688267 & 5.85 & 5.0214 & TRN & \\
\hline CHEMBL1589157 & 688267 & 4.05 & 5.0531 & TRN & \\
\hline CHEMBL1446306 & 688267 & 4.05 & 5.0817 & TRN & \\
\hline CHEMBL1568145 & 688267 & 5.3 & 4.9947 & TRN & \\
\hline CHEMBL1975660 & 688267 & 4.0 & 4.975 & TST & \\
\hline CHEMBL1520482 & 688267 & 5.45 & 5.0163 & TST & \\
\hline CHEMBL1556393 & 688267 & 4.15 & 5.0711 & TRN & \\
\hline CHEMBL1396723 & 688267 & 5.65 & 5.0166 & TRN & \\
\hline CHEMBL1501133 & 688267 & 6.1 & 5.0088 & TST & \\
\hline CHEMBL1480124 & 688267 & 5.45 & 5.0914 & TRN & \\
\hline CHEMBL1423569 & 688267 & 6.2 & 5.0563 & TRN & \\
\hline CHEMBL1370681 & 688267 & 4.0 & 5.0169 & TST & \\
\hline
\end{tabular}




\begin{tabular}{|c|c|c|c|c|}
\hline & & & upplement & al $\mathrm{T}$ \\
\hline CHEMBL1380057 & 688267 & 4.05 & 5.0053 & TST \\
\hline CHEMBL1385595 & 688267 & 4.0 & 5.0699 & TST \\
\hline CHEMBL1319388 & 688267 & 5.3 & 5.075 & TRN \\
\hline CHEMBL1499260 & 688267 & 6.25 & 5.0668 & TST \\
\hline CHEMBL1389222 & 688267 & 4.4 & 5.096 & TRN \\
\hline CHEMBL1581165 & 688267 & 4.0 & 5.0344 & TST \\
\hline CHEMBL1417556 & 688267 & 5.4 & 5.0645 & TRN \\
\hline CHEMBL1479274 & 688267 & 4.1 & 5.0985 & TRN \\
\hline CHEMBL1548403 & 688267 & 4.15 & 5.0387 & TRN \\
\hline CHEMBL1557089 & 688267 & 5.65 & 4.9926 & TRN \\
\hline CHEMBL1992197 & 688267 & 5.1 & 5.0299 & TST \\
\hline CHEMBL1301490 & 688267 & 3.95 & 5.0861 & TST \\
\hline CHEMBL1465910 & 688267 & 5.4 & 5.0738 & TST \\
\hline CHEMBL1441599 & 688267 & 5.35 & 5.0507 & TRN \\
\hline CHEMBL 2000517 & 688267 & 4.35 & 5.0025 & TST \\
\hline CHEMBL1425989 & 688267 & 4.2 & 5.0994 & TRN \\
\hline CHEMBL1334609 & 688267 & 6.0 & 5.0955 & TRN \\
\hline CHEMBL1445559 & 688267 & 4.05 & 5.0538 & TRN \\
\hline CHEMBL1420068 & 688267 & 5.15 & 5.0256 & TRN \\
\hline CHEMBL1492929 & 688267 & 5.95 & 5.0759 & TRN \\
\hline CHEMBL1378929 & 688267 & 4.8 & 5.0913 & TRN \\
\hline CHEMBL1317798 & 688267 & 6.6 & 5.113 & TST \\
\hline CHEMBL1349883 & 688267 & 5.4 & 4.99 & TRN \\
\hline CHEMBL1475133 & 688267 & 4.5 & 5.0827 & TST \\
\hline CHEMBL1316025 & 688267 & 4.3 & 5.0765 & TST \\
\hline CHEMBL1435391 & 688267 & 4.1 & 5.02 & TRN \\
\hline CHEMBL1553800 & 688267 & 3.95 & 5.0387 & TRN \\
\hline CHEMBL1487087 & 688267 & 5.95 & 5.0698 & TRN \\
\hline CHEMBL602837 & 688267 & 5.65 & 5.0267 & TRN \\
\hline CHEMBL1439447 & 688267 & 4.85 & 5.0106 & TRN \\
\hline CHEMBL1416299 & 688267 & 5.05 & 5.0268 & TST \\
\hline CHEMBL1303109 & 688267 & 4.0 & 5.0547 & TRN \\
\hline CHEMBL1327060 & 688267 & 6.15 & 5.0651 & TRN \\
\hline CHEMBL1492123 & 688267 & 4.5 & 5.0968 & TRN \\
\hline CHEMBL1466937 & 688267 & 5.5 & 5.0318 & TST \\
\hline CHEMBL1340514 & 688267 & 5.35 & 5.03 & TST \\
\hline CHEMBL1360475 & 688267 & 4.6 & 5.0096 & TRN \\
\hline CHEMBL1495482 & 688267 & 5.45 & 5.0421 & TST \\
\hline CHEMBL1531298 & 688267 & 4.3 & 5.0625 & TST \\
\hline CHEMBL1300496 & 688267 & 4.2 & 5.0538 & TRN \\
\hline CHEMBL1567768 & 688267 & 4.05 & 5.0254 & TRN \\
\hline CHEMBL1402333 & 688267 & 5.5 & 5.0461 & TRN \\
\hline CHEMBL1554938 & 688267 & 6.05 & 5.0463 & TRN \\
\hline CHEMBL1383868 & 688267 & 6.2 & 5.048 & TRN \\
\hline CHEMBL1352936 & 688267 & 4.85 & 5.0177 & TST \\
\hline CHEMBL1506320 & 688267 & 5.3 & 5.0554 & TST \\
\hline CHEMBL1371834 & 688267 & 5.1 & 5.0694 & TRN \\
\hline CHEMBL1551048 & 688267 & 3.95 & 5.0225 & TRN \\
\hline
\end{tabular}




\begin{tabular}{|c|c|c|c|c|}
\hline \multicolumn{5}{|c|}{ Supplemental Table S2.txt } \\
\hline CHEMBL1524548 & 688267 & 5.05 & 5.0119 & TRN \\
\hline CHEMBL1465796 & 688267 & 5.25 & 4.9757 & TRN \\
\hline CHEMBL1552631 & 688267 & 3.95 & 5.0238 & TRN \\
\hline CHEMBL1369860 & 688267 & 4.05 & 5.0839 & TST \\
\hline CHEMBL1488125 & 688267 & 6.2 & 5.1184 & TST \\
\hline CHEMBL1550329 & 688267 & 5.3 & 5.0645 & TRN \\
\hline CHEMBL1492819 & 688267 & 5.8 & 5.0008 & TRN \\
\hline CHEMBL1413838 & 688267 & 6.05 & 5.0348 & TST \\
\hline CHEMBL1344501 & 688267 & 5.15 & 5.0368 & TRN \\
\hline CHEMBL1541567 & 688267 & 5.35 & 5.0387 & TRN \\
\hline CHEMBL1525362 & 688267 & 4.2 & 5.0698 & TST \\
\hline CHEMBL1451089 & 688267 & 4.85 & 5.0509 & TRN \\
\hline CHEMBL1482349 & 688267 & 4.85 & 5.0752 & TRN \\
\hline CHEMBL1483059 & 688267 & 4.05 & 5.0346 & TRN \\
\hline CHEMBL1518436 & 688267 & 6.6499 & 5.0082 & TRN \\
\hline CHEMBL1597176 & 688267 & 6.2 & 5.0577 & TST \\
\hline CHEMBL1466488 & 688267 & 4.25 & 5.0474 & TRN \\
\hline CHEMBL1561234 & 688267 & 3.95 & 5.0316 & TRN \\
\hline CHEMBL1579847 & 688267 & 4.0 & 5.1125 & TRN \\
\hline CHEMBL1577392 & 688267 & 5.35 & 5.0282 & TRN \\
\hline CHEMBL3211189 & 688267 & 4.3 & 5.0823 & TRN \\
\hline CHEMBL1365569 & 688267 & 5.35 & 5.0401 & TST \\
\hline CHEMBL1378199 & 688267 & 4.8 & 5.07 & TRN \\
\hline CHEMBL1480027 & 688267 & 3.95 & 5.0879 & TRN \\
\hline CHEMBL1477741 & 688267 & 4.35 & 5.0587 & TRN \\
\hline CHEMBL3195567 & 688267 & 5.85 & 5.0673 & TRN \\
\hline CHEMBL1405986 & 688267 & 4.7 & 5.0637 & TST \\
\hline CHEMBL1526511 & 688267 & 4.3 & 5.0498 & TRN \\
\hline CHEMBL1553094 & 688267 & 4.7 & 5.1505 & TRN \\
\hline CHEMBL1418737 & 688267 & 6.25 & 5.0364 & TRN \\
\hline CHEMBL1570226 & 688267 & 6.2 & 5.0379 & TST \\
\hline CHEMBL1327295 & 688267 & 5.35 & 5.0647 & TRN \\
\hline CHEMBL1601447 & 688267 & 4.0 & 4.9937 & TST \\
\hline CHEMBL1569985 & 688267 & 4.55 & 5.0242 & TST \\
\hline CHEMBL1361743 & 688267 & 6.05 & 5.0197 & TRN \\
\hline CHEMBL1384010 & 688267 & 6.2 & 5.0311 & TRN \\
\hline CHEMBL1573946 & 688267 & 4.45 & 5.1154 & TRN \\
\hline CHEMBL1547431 & 688267 & 4.05 & 5.0215 & TRN \\
\hline CHEMBL1394234 & 688267 & 6.45 & 5.109 & TRN \\
\hline CHEMBL1313607 & 688267 & 5.2 & 5.0512 & TRN \\
\hline CHEMBL1435081 & 688267 & 4.0 & 4.9985 & TRN \\
\hline CHEMBL1389034 & 688267 & 6.2 & 5.0384 & TRN \\
\hline CHEMBL1339679 & 688267 & 5.25 & 5.0759 & TRN \\
\hline CHEMBL1424504 & 688267 & 3.95 & 5.0347 & TRN \\
\hline CHEMBL1966867 & 688267 & 4.3 & 5.0051 & TST \\
\hline CHEMBL1609323 & 688267 & 4.0 & 5.0299 & TST \\
\hline CHEMBL1557660 & 688267 & 4.85 & 5.0849 & TST \\
\hline CHEMBL1476733 & 688267 & 4.0 & 5.0133 & TRN \\
\hline
\end{tabular}




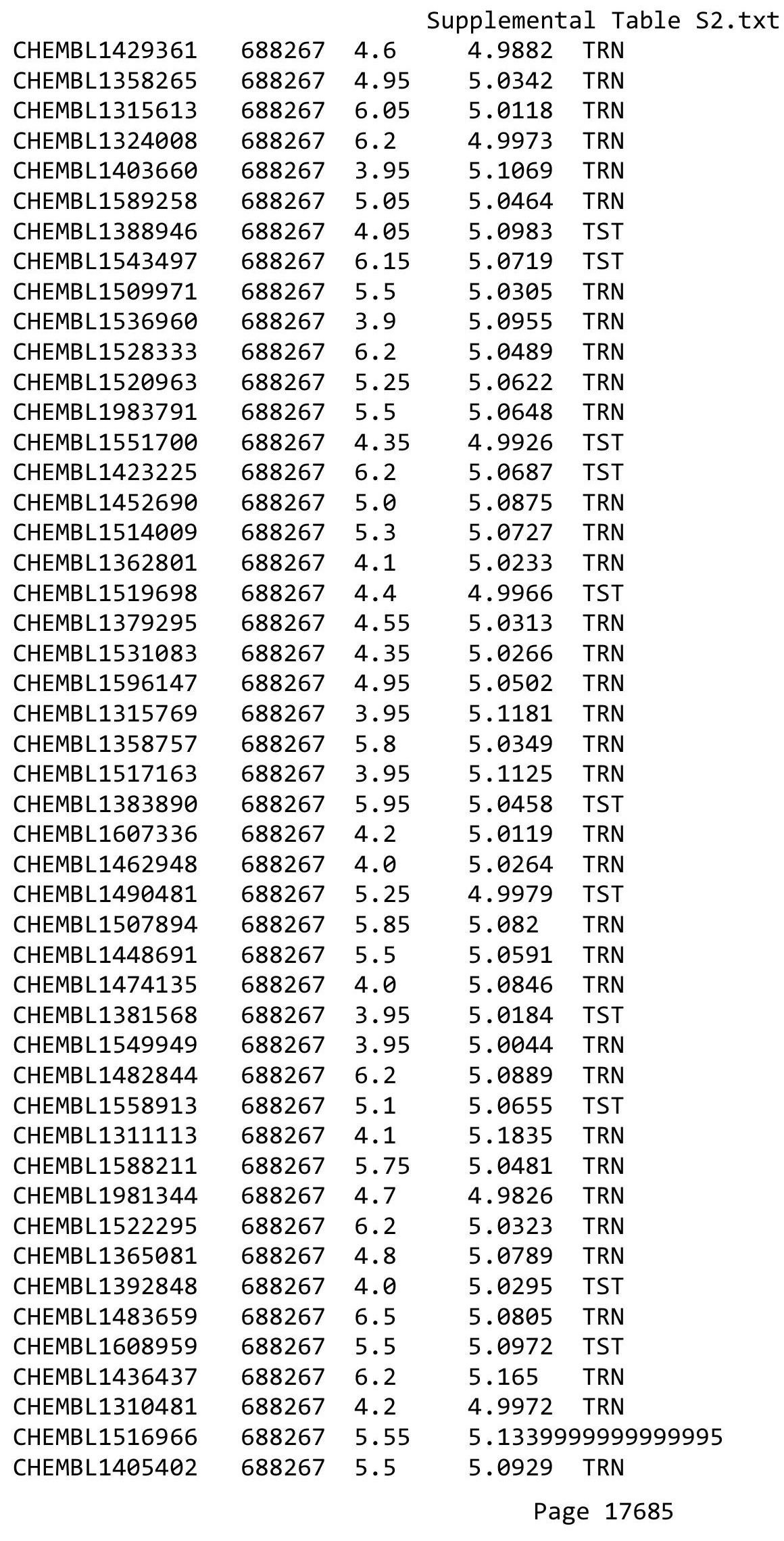




\begin{tabular}{|c|c|c|c|c|c|}
\hline \multicolumn{6}{|c|}{ oplemental Table } \\
\hline CHEMBL1587820 & 688267 & 4.35 & 5.0246 & TRN & \\
\hline CHEMBL1461382 & 688267 & 5.95 & 5.0588 & TRN & \\
\hline CHEMBL1330751 & 688267 & 5.25 & 5.059 & TRN & \\
\hline CHEMBL1585933 & 688267 & 5.55 & 5.1513 & TRN & \\
\hline CHEMBL1435089 & 688267 & 4.55 & 5.0707 & TRN & \\
\hline CHEMBL1490774 & 688267 & 4.0 & 5.0329 & TRN & \\
\hline CHEMBL 2004978 & 688267 & 4.0 & 5.0065 & TST & \\
\hline CHEMBL1967040 & 688267 & 4.6 & 5.0083 & TRN & \\
\hline CHEMBL1492053 & 688267 & 4.4 & 4.9959 & TRN & \\
\hline CHEMBL1358887 & 688267 & 5.35 & 5.0584 & TRN & \\
\hline CHEMBL1300714 & 688267 & 4.55 & 5.0326 & TRN & \\
\hline CHEMBL1402934 & 688267 & 4.35 & 5.0217 & TRN & \\
\hline CHEMBL1339608 & 688267 & 4.0 & 5.143 & TRN & \\
\hline CHEMBL1443959 & 688267 & 4.2 & 5.0696 & TST & \\
\hline CHEMBL1474917 & 688267 & 6.0 & 5.1461 & TRN & \\
\hline CHEMBL1306955 & 688267 & 6.45 & 5.0463 & TRN & \\
\hline CHEMBL1314690 & 688267 & 5.5 & 5.0713 & TRN & \\
\hline CHEMBL 3209056 & 688267 & 3.95 & 5.056 & TST & \\
\hline CHEMBL1389168 & 688267 & 3.9 & 5.1118 & TRN & \\
\hline CHEMBL1526360 & 688267 & 4.05 & 5.0058 & TRN & \\
\hline CHEMBL1606116 & 688267 & 6.0 & 5.1037 & TRN & \\
\hline CHEMBL1466536 & 688267 & 4.6 & 5.0582 & TRN & \\
\hline CHEMBL1484912 & 688267 & 4.1 & 5.0663 & TRN & \\
\hline CHEMBL1440529 & 688267 & 5.3 & 5.0015 & TRN & \\
\hline CHEMBL1609352 & 688267 & 5.75 & 5.0732 & TRN & \\
\hline CHEMBL1326237 & 688267 & 5.85 & 5.0968 & TRN & \\
\hline CHEMBL1601898 & 688267 & 5.3 & 5.0895 & TST & \\
\hline CHEMBL1593200 & 688267 & 6.2 & 5.0263 & TST & \\
\hline CHEMBL1476190 & 688267 & 3.95 & 5.075 & TRN & \\
\hline CHEMBL81935 & 688267 & 5.9 & 4.9841 & TST & \\
\hline CHEMBL1445300 & 688267 & 5.35 & 5.0369 & TST & \\
\hline CHEMBL 3191406 & 688267 & 4.95 & 5.01399 & 7999999999 & TRN \\
\hline CHEMBL1491508 & 688267 & 6.2 & 5.1603 & TRN & \\
\hline CHEMBL3196435 & 688267 & 4.5 & 5.0195 & TRN & \\
\hline CHEMBL1569353 & 688267 & 5.1 & 5.0335 & TST & \\
\hline CHEMBL1349890 & 688267 & 4.05 & 4.9868 & TST & \\
\hline CHEMBL1595010 & 688267 & 6.0 & 5.0762 & TRN & \\
\hline CHEMBL1442942 & 688267 & 6.2 & 5.1382 & TRN & \\
\hline CHEMBL1338725 & 688267 & 4.05 & 5.0405 & TRN & \\
\hline CHEMBL1488366 & 688267 & 5.45 & 4.9883 & TRN & \\
\hline CHEMBL1581136 & 688267 & 4.45 & 5.1107 & TST & \\
\hline CHEMBL1413083 & 688267 & 4.6 & 5.0466 & TST & \\
\hline CHEMBL 1458025 & 688267 & 4.3 & 5.0753 & TRN & \\
\hline CHEMBL1361005 & 688267 & 5.5 & 5.0102 & TRN & \\
\hline CHEMBL1443341 & 688267 & 4.2 & 5.11 & TRN & \\
\hline CHEMBL1565737 & 688267 & 4.0 & 5.0214 & TST & \\
\hline CHEMBL1418453 & 688267 & 4.1 & 5.0727 & TRN & \\
\hline CHEMBL1371201 & 688267 & 4.35 & 5.0318 & TST & \\
\hline
\end{tabular}




\begin{tabular}{|c|c|c|c|c|}
\hline & & & pplement & al $\mathrm{Ta}$ \\
\hline CHEMBL1304672 & 688267 & 6.2 & 5.0378 & TRN \\
\hline CHEMBL1350137 & 688267 & 3.95 & 5.1281 & TRN \\
\hline CHEMBL3192959 & 688267 & 5.3 & 5.0391 & TRN \\
\hline CHEMBL1553959 & 688267 & 5.75 & 5.1411 & TRN \\
\hline CHEMBL1610373 & 688267 & 5.8 & 5.0532 & TRN \\
\hline CHEMBL1413862 & 688267 & 6.45 & 5.0229 & TRN \\
\hline CHEMBL1342374 & 688267 & 4.45 & 5.0528 & TRN \\
\hline CHEMBL1580513 & 688267 & 4.05 & 4.9779 & TRN \\
\hline CHEMBL1394618 & 688267 & 3.95 & 5.0192 & TRN \\
\hline CHEMBL1593473 & 688267 & 4.0 & 5.0482 & TRN \\
\hline CHEMBL1384806 & 688267 & 4.0 & 5.0523 & TST \\
\hline CHEMBL1477789 & 688267 & 5.05 & 5.117 & TRN \\
\hline CHEMBL1522881 & 688267 & 5.3 & 5.0891 & TRN \\
\hline CHEMBL1564726 & 688267 & 5.4 & 5.0526 & TRN \\
\hline CHEMBL1372974 & 688267 & 6.15 & 5.0781 & TRN \\
\hline CHEMBL1572157 & 688267 & 6.45 & 5.0666 & TRN \\
\hline CHEMBL1554288 & 688267 & 3.95 & 5.0623 & TRN \\
\hline CHEMBL1428517 & 688267 & 3.95 & 5.0793 & TST \\
\hline CHEMBL1400756 & 688267 & 5.2 & 5.0567 & TRN \\
\hline CHEMBL1449010 & 688267 & 5.75 & 5.0932 & TRN \\
\hline CHEMBL1517077 & 688267 & 5.45 & 5.0159 & TRN \\
\hline CHEMBL1540717 & 688267 & 4.25 & 5.0695 & TST \\
\hline CHEMBL1608650 & 688267 & 5.3 & 5.0809 & TRN \\
\hline CHEMBL1375017 & 688267 & 4.65 & 5.0314 & TRN \\
\hline CHEMBL1459873 & 688267 & 6.2 & 5.0627 & TRN \\
\hline CHEMBL1390343 & 688267 & 4.65 & 5.0185 & TST \\
\hline CHEMBL1363460 & 688267 & 5.7 & 5.1059 & TRN \\
\hline CHEMBL3191920 & 688267 & 6.15 & 5.0086 & TRN \\
\hline CHEMBL1538415 & 688267 & 5.0 & 5.0959 & TRN \\
\hline CHEMBL1575108 & 688267 & 4.5 & 5.0852 & TRN \\
\hline CHEMBL1383620 & 688267 & 6.2 & 5.0575 & TRN \\
\hline CHEMBL1523421 & 688267 & 4.6 & 4.9777 & TRN \\
\hline CHEMBL1336097 & 688267 & 5.5 & 4.9868 & TST \\
\hline CHEMBL1415925 & 688267 & 4.05 & 5.0136 & TRN \\
\hline CHEMBL1587355 & 688267 & 4.0 & 5.0227 & TRN \\
\hline CHEMBL1370521 & 688267 & 6.2 & 5.0522 & TRN \\
\hline CHEMBL1410616 & 688267 & 4.1 & 4.9602 & TST \\
\hline CHEMBL1554007 & 688267 & 6.05 & 5.0217 & TRN \\
\hline CHEMBL1588639 & 688267 & 4.7 & 5.0488 & TRN \\
\hline CHEMBL1329891 & 688267 & 4.0 & 5.1172 & TST \\
\hline CHEMBL1326860 & 688267 & 5.2 & 5.1396 & TRN \\
\hline CHEMBL1491923 & 688267 & 6.2 & 5.0555 & TST \\
\hline CHEMBL1601825 & 688267 & 6.15 & 5.063 & TRN \\
\hline CHEMBL1418906 & 688267 & 4.25 & 5.0803 & TRN \\
\hline CHEMBL1357290 & 688267 & 5.8 & 5.0015 & TRN \\
\hline CHEMBL1338498 & 688267 & 4.0 & 5.0085 & TRN \\
\hline CHEMBL1605155 & 688267 & 5.55 & 5.109 & TRN \\
\hline CHEMBL1307728 & 688267 & 4.4 & 4.9981 & TST \\
\hline
\end{tabular}




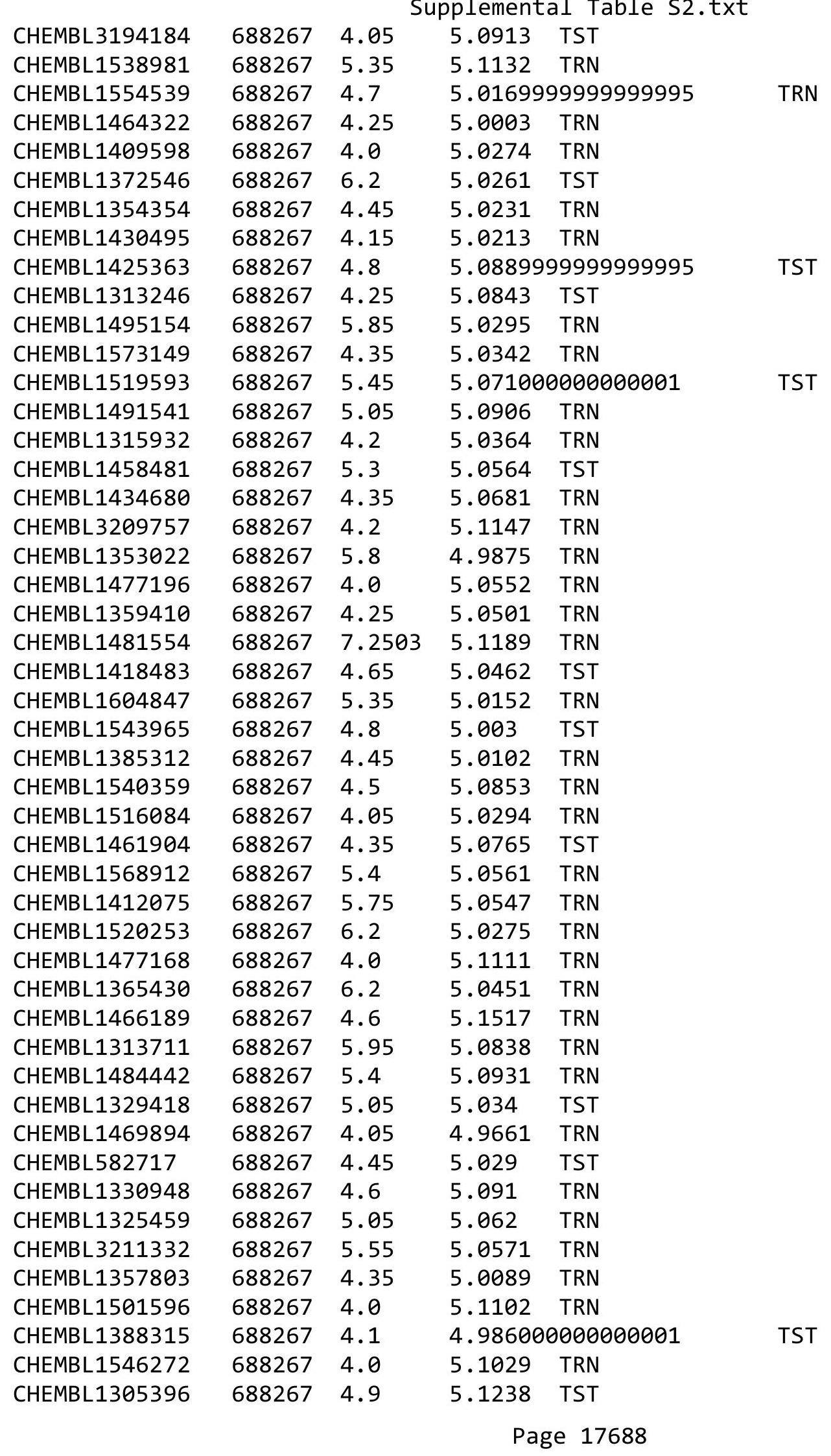




\begin{tabular}{|c|c|c|c|c|}
\hline & & & pplement & al Tá \\
\hline CHEMBL1355099 & 688267 & 4.15 & 5.1277 & TRN \\
\hline CHEMBL1329674 & 688267 & 5.25 & 5.0471 & TRN \\
\hline CHEMBL1512019 & 688267 & 4.0 & 5.048 & TRN \\
\hline CHEMBL1533050 & 688267 & 6.25 & 5.0308 & TRN \\
\hline CHEMBL1540394 & 688267 & 4.0 & 5.0242 & TRN \\
\hline CHEMBL1434781 & 688267 & 4.3 & 5.0636 & TRN \\
\hline CHEMBL1468775 & 688267 & 3.95 & 5.0647 & TRN \\
\hline CHEMBL1571826 & 688267 & 5.6 & 5.0398 & TST \\
\hline CHEMBL1564481 & 688267 & 5.35 & 5.0188 & TST \\
\hline CHEMBL1472910 & 688267 & 4.45 & 5.0658 & TRN \\
\hline CHEMBL1348127 & 688267 & 6.45 & 5.0354 & TRN \\
\hline CHEMBL1317120 & 688267 & 6.2 & 5.0293 & TRN \\
\hline CHEMBL1533721 & 688267 & 5.1 & 5.0828 & TRN \\
\hline CHEMBL1507582 & 688267 & 4.0 & 5.0877 & TRN \\
\hline CHEMBL1386223 & 688267 & 5.0 & 5.1378 & TRN \\
\hline CHEMBL1505433 & 688267 & 5.55 & 5.0405 & TRN \\
\hline CHEMBL1571749 & 688267 & 4.45 & 5.1874 & TRN \\
\hline CHEMBL1526738 & 688267 & 5.35 & 5.0158 & TRN \\
\hline CHEMBL1489063 & 688267 & 4.35 & 5.0387 & TRN \\
\hline CHEMBL1477663 & 688267 & 4.0 & 5.0104 & TRN \\
\hline CHEMBL1356340 & 688267 & 5.95 & 5.0988 & TRN \\
\hline CHEMBL1553604 & 688267 & 6.2 & 4.9886 & TST \\
\hline CHEMBL1307857 & 688267 & 5.8 & 5.0583 & TRN \\
\hline CHEMBL1397265 & 688267 & 6.25 & 5.026 & TRN \\
\hline CHEMBL1392239 & 688267 & 6.25 & 4.9975 & TRN \\
\hline CHEMBL1372713 & 688267 & 5.1 & 5.0375 & TRN \\
\hline CHEMBL1516115 & 688267 & 4.05 & 5.0294 & TRN \\
\hline CHEMBL1372751 & 688267 & 5.0 & 5.03 & TRN \\
\hline CHEMBL3196076 & 688267 & 4.0 & 5.0112 & TST \\
\hline CHEMBL1386739 & 688267 & 4.35 & 5.027 & TST \\
\hline CHEMBL1597660 & 688267 & 5.75 & 5.0261 & TRN \\
\hline CHEMBL1569601 & 688267 & 4.05 & 5.0949 & TRN \\
\hline CHEMBL1394511 & 688267 & 6.2 & 5.0225 & TRN \\
\hline CHEMBL1557488 & 688267 & 3.95 & 5.0383 & TRN \\
\hline CHEMBL1333734 & 688267 & 5.75 & 5.0452 & TST \\
\hline CHEMBL1422595 & 688267 & 5.65 & 5.0533 & TRN \\
\hline CHEMBL1412224 & 688267 & 3.9 & 5.0297 & TST \\
\hline CHEMBL1445719 & 688267 & 4.4 & 5.1717 & TRN \\
\hline CHEMBL1613695 & 688267 & 4.05 & 5.0299 & TRN \\
\hline CHEMBL1449549 & 688267 & 4.45 & 5.0373 & TRN \\
\hline CHEMBL1412159 & 688267 & 4.95 & 5.066 & TST \\
\hline CHEMBL3199766 & 688267 & 4.3 & 5.0113 & TRN \\
\hline CHEMBL1494104 & 688267 & 4.35 & 5.1487 & TRN \\
\hline CHEMBL1531981 & 688267 & 4.05 & 4.9928 & TRN \\
\hline CHEMBL1352016 & 688267 & 4.05 & 4.9971 & TRN \\
\hline CHEMBL 3189948 & 688267 & 4.55 & 5.0275 & TST \\
\hline CHEMBL1497357 & 688267 & 5.45 & 5.0977 & TRN \\
\hline CHEMBL1510664 & 688267 & 4.55 & 5.0115 & TRN \\
\hline
\end{tabular}




\begin{tabular}{|c|c|c|c|c|c|}
\hline \multicolumn{6}{|c|}{ Supplemental Table S2.txt } \\
\hline CHEMBL1402891 & 688267 & 5.0 & 5.026 & TRN & \\
\hline CHEMBL1427753 & 688267 & 5.85 & 5.0814 & TRN & \\
\hline CHEMBL1552925 & 688267 & 5.25 & 5.1094 & TRN & \\
\hline CHEMBL1583901 & 688267 & 5.5 & 5.0003 & TRN & \\
\hline CHEMBL1386414 & 688267 & 5.4 & 5.1264 & TRN & \\
\hline CHEMBL1586617 & 688267 & 5.0 & 5.0725 & TRN & \\
\hline CHEMBL1305628 & 688267 & 4.85 & 5.0539 & TRN & \\
\hline CHEMBL1339807 & 688267 & 5.1 & 5.0572 & TST & \\
\hline CHEMBL1596824 & 688267 & 5.8 & 5.0225 & TRN & \\
\hline CHEMBL1487226 & 688267 & 5.15 & 5.1182 & TRN & \\
\hline CHEMBL1427364 & 688267 & 4.05 & 5.087 & TST & \\
\hline CHEMBL1397049 & 688267 & 5.25 & 4.9839 & TRN & \\
\hline CHEMBL1450528 & 688267 & 4.0 & 5.0544 & TST & \\
\hline CHEMBL1569591 & 688267 & 4.4 & 5.0541 & TRN & \\
\hline CHEMBL1574313 & 688267 & 3.95 & 5.0568 & TST & \\
\hline CHEMBL1542159 & 688267 & 5.1 & 4.977 & TRN & \\
\hline CHEMBL1607720 & 688267 & 6.15 & 5.0343 & TRN & \\
\hline CHEMBL1605848 & 688267 & 4.4 & 4.9746 & TST & \\
\hline CHEMBL1498792 & 688267 & 5.1 & 5.0934 & TST & \\
\hline CHEMBL1475232 & 688267 & 4.7 & 4.9828 & TRN & \\
\hline CHEMBL1407925 & 688267 & 4.4 & 5.0697 & TRN & \\
\hline CHEMBL1489832 & 688267 & 4.1 & 5.0812 & TRN & \\
\hline CHEMBL1384319 & 688267 & 4.4 & 5.0853 & TRN & \\
\hline CHEMBL1416348 & 688267 & 3.8 & 5.0248 & TST & \\
\hline CHEMBL1604641 & 688267 & 5.5 & 5.0767 & TRN & \\
\hline CHEMBL1478227 & 688267 & 5.55 & 5.0472 & TST & \\
\hline CHEMBL1340176 & 688267 & 4.35 & 5.0253 & TST & \\
\hline CHEMBL1431261 & 688267 & 6.25 & 5.0452 & TST & \\
\hline CHEMBL1451694 & 688267 & 4.75 & 5.0454 & TRN & \\
\hline CHEMBL1358526 & 688267 & 4.05 & 5.0386 & TRN & \\
\hline CHEMBL1303087 & 688267 & 6.2 & 5.0947 & TRN & \\
\hline CHEMBL1510487 & 688267 & 4.0 & 5.043 & TST & \\
\hline CHEMBL1607913 & 688267 & 5.2 & 5.0115 & TRN & \\
\hline CHEMBL1476985 & 688267 & 6.15 & 5.0746 & TRN & \\
\hline CHEMBL1400368 & 688267 & 4.45 & 5.0244 & TRN & \\
\hline CHEMBL1410597 & 688267 & 6.2 & 5.0387 & TRN & \\
\hline CHEMBL1406160 & 688267 & 6.2 & 5.121 & TST & \\
\hline CHEMBL1314553 & 688267 & 4.05 & 5.0962 & TRN & \\
\hline CHEMBL1484143 & 688267 & 4.45 & 5.0559 & TRN & \\
\hline CHEMBL1322909 & 688267 & 5.35 & 5.07 & TRN & \\
\hline CHEMBL1486881 & 688267 & 4.0 & 5.0218 & TRN & \\
\hline CHEMBL1525429 & 688267 & 5.1 & 5.0509 & TRN & \\
\hline CHEMBL1601610 & 688267 & 4.0 & 4.9968 & TRN & \\
\hline CHEMBL1514525 & 688267 & 4.3 & 5.0324 & TRN & \\
\hline CHEMBL1402911 & 688267 & 4.65 & 5.1037 & TRN & \\
\hline CHEMBL1439748 & 688267 & 4.05 & 5.0381 & TRN & \\
\hline CHEMBL1540957 & 688267 & 6.2 & 5.0809 & TRN & \\
\hline CHEMBL3212202 & 688267 & 5.35 & $5.0280 e$ & 00000000005 & TST \\
\hline & & & & 17690 & \\
\hline
\end{tabular}




\begin{tabular}{|c|c|c|c|c|c|}
\hline \\
\hline CHEMBL1367282 & 688267 & 4.0 & 5.0707 & TST & \\
\hline CHEMBL1381323 & 688267 & 6.2 & 5.0856 & TRN & \\
\hline CHEMBL548681 & 688267 & 4.3 & 5.0325 & TRN & \\
\hline CHEMBL1974800 & 688267 & 5.9 & 5.0066 & TRN & \\
\hline CHEMBL1466522 & 688267 & 4.5 & 5.0653 & TRN & \\
\hline CHEMBL1419477 & 688267 & 5.3 & 5.1062 & TRN & \\
\hline CHEMBL1366214 & 688267 & 4.55 & 5.0397 & TRN & \\
\hline CHEMBL1438178 & 688267 & 4.8 & 5.0373 & TRN & \\
\hline CHEMBL1567409 & 688267 & 3.95 & 5.0703 & TRN & \\
\hline CHEMBL3194243 & 688267 & 4.55 & 5.0789 & TST & \\
\hline CHEMBL1317321 & 688267 & 4.05 & 5.0527 & TST & \\
\hline CHEMBL1608087 & 688267 & 6.2 & 5.1025 & TRN & \\
\hline CHEMBL1507683 & 688267 & 5.0 & 4.9854 & TRN & \\
\hline CHEMBL1535580 & 688267 & 4.15 & 5.0876 & TST & \\
\hline CHEMBL1335879 & 688267 & 4.7 & 4.9908 & TST & \\
\hline CHEMBL1521306 & 688267 & 6.2 & 5.1083 & TST & \\
\hline CHEMBL1378501 & 688267 & 5.55 & 5.0349 & TRN & \\
\hline CHEMBL1591351 & 688267 & 6.2 & 5.0875 & TRN & \\
\hline CHEMBL1555061 & 688267 & 5.45 & 5.0 & TRN & \\
\hline CHEMBL 3210720 & 688267 & 4.3 & 5.0373 & TST & \\
\hline CHEMBL1594792 & 688267 & 4.05 & 5.1406 & TRN & \\
\hline CHEMBL1550421 & 688267 & 4.35 & 5.0083 & TRN & \\
\hline CHEMBL1368021 & 688267 & 6.1 & 5.0222 & TRN & \\
\hline CHEMBL1518387 & 688267 & 5.0 & 5.0306 & TRN & \\
\hline CHEMBL1307812 & 688267 & 5.4 & 5.0311 & TST & \\
\hline CHEMBL1476381 & 688267 & 6.05 & 5.0135 & TRN & \\
\hline CHEMBL1487091 & 688267 & 5.3 & 5.0553 & TRN & \\
\hline CHEMBL1495163 & 688267 & 4.4 & 5.0704 & TRN & \\
\hline CHEMBL1389182 & 688267 & 5.8 & 5.0962 & TST & \\
\hline CHEMBL1554271 & 688267 & 4.4 & 5.07100 & $\partial 000000001$ & TRN \\
\hline CHEMBL1435407 & 688267 & 4.85 & 5.0538 & TRN & \\
\hline CHEMBL1488124 & 688267 & 6.2 & 5.0292 & TST & \\
\hline CHEMBL1314468 & 688267 & 4.0 & 5.0842 & TRN & \\
\hline CHEMBL1331776 & 688267 & 6.25 & 5.0145 & TRN & \\
\hline CHEMBL1480630 & 688267 & 3.95 & 5.0797 & TRN & \\
\hline CHEMBL1581927 & 688267 & 5.2 & 5.0658 & TRN & \\
\hline CHEMBL1570486 & 688267 & 6.45 & 5.0586 & TRN & \\
\hline CHEMBL1313048 & 688267 & 3.95 & 5.08 & TRN & \\
\hline CHEMBL1353545 & 688267 & 5.3 & 5.0882 & TRN & \\
\hline CHEMBL1548912 & 688267 & 4.35 & 5.0539 & TRN & \\
\hline CHEMBL3195331 & 688267 & 4.05 & 5.0307 & TRN & \\
\hline CHEMBL1307167 & 688267 & 4.05 & 5.0544 & TST & \\
\hline CHEMBL3208821 & 688267 & 4.05 & 5.0127 & TST & \\
\hline CHEMBL1384293 & 688267 & 5.25 & 5.0068 & TRN & \\
\hline CHEMBL1433773 & 688267 & 4.35 & 5.1688 & TRN & \\
\hline CHEMBL1489509 & 688267 & 5.35 & 5.0843 & TRN & \\
\hline CHEMBL1352691 & 688267 & 4.1 & 4.9896 & TRN & \\
\hline CHEMBL3210940 & 688267 & 4.35 & 5.0685 & TST & \\
\hline
\end{tabular}




\begin{tabular}{|c|c|c|c|c|}
\hline \multicolumn{5}{|c|}{ Supplemental Table S2.txt } \\
\hline CHEMBL1582769 & 688267 & 4.05 & 5.0391 & TRN \\
\hline CHEMBL1358165 & 688267 & 4.0 & 5.0052 & TRN \\
\hline CHEMBL1418194 & 688267 & 5.45 & 5.0616 & TRN \\
\hline CHEMBL1331764 & 688267 & 4.2 & 5.0566 & TRN \\
\hline CHEMBL1469680 & 688267 & 4.4 & 5.037 & TRN \\
\hline CHEMBL1490735 & 688267 & 5.8 & 5.0359 & TST \\
\hline CHEMBL1531547 & 688267 & 5.05 & 5.0911 & TRN \\
\hline CHEMBL1492625 & 688267 & 4.3 & 5.0618 & TST \\
\hline CHEMBL1580488 & 688267 & 6.2 & 5.0735 & TST \\
\hline CHEMBL1517997 & 688267 & 6.25 & 5.1256 & TRN \\
\hline CHEMBL1554602 & 688267 & 4.9 & 5.1032 & TRN \\
\hline CHEMBL1490837 & 688267 & 5.6 & 5.1683 & TRN \\
\hline CHEMBL1336114 & 688267 & 6.2 & 5.0294 & TRN \\
\hline CHEMBL1305261 & 688267 & 6.25 & 5.0208 & TRN \\
\hline CHEMBL597452 & 688267 & 5.35 & 5.0317 & TRN \\
\hline CHEMBL1482749 & 688267 & 6.2 & 5.0332 & TRN \\
\hline CHEMBL1352091 & 688267 & 4.1 & 5.1266 & TRN \\
\hline CHEMBL1547019 & 688267 & 5.25 & 5.0877 & TST \\
\hline CHEMBL1436892 & 688267 & 4.0 & 5.0552 & TRN \\
\hline CHEMBL1354735 & 688267 & 4.35 & 5.1073 & TRN \\
\hline CHEMBL1328994 & 688267 & 4.05 & 5.01 & TST \\
\hline CHEMBL1484876 & 688267 & 4.4 & 5.0976 & TRN \\
\hline CHEMBL1329853 & 688267 & 6.2 & 5.0199 & TRN \\
\hline CHEMBL1433916 & 688267 & 6.2 & 5.1107 & TRN \\
\hline CHEMBL1543213 & 688267 & 5.4 & 5.1569 & TRN \\
\hline CHEMBL1537955 & 688267 & 5.5 & 5.0877 & TRN \\
\hline CHEMBL1554834 & 688267 & 5.4 & 5.0684 & TRN \\
\hline CHEMBL 8883 & 688267 & 4.35 & 5.0733 & TRN \\
\hline CHEMBL1407987 & 688267 & 4.05 & 4.9946 & TRN \\
\hline CHEMBL3209339 & 688267 & 5.75 & 5.0397 & TST \\
\hline CHEMBL1312704 & 688267 & 4.5 & 5.0532 & TRN \\
\hline CHEMBL1431848 & 688267 & 5.35 & 5.0693 & TRN \\
\hline CHEMBL1568087 & 688267 & 6.15 & 5.0069 & TRN \\
\hline CHEMBL1506437 & 688267 & 4.55 & 5.0411 & TRN \\
\hline CHEMBL1500497 & 688267 & 5.7 & 5.064 & TRN \\
\hline CHEMBL1443411 & 688267 & 5.9 & 5.0968 & TRN \\
\hline CHEMBL 1496746 & 688267 & 4.3 & 5.048 & TRN \\
\hline CHEMBL1506190 & 688267 & 5.2 & 5.0667 & TST \\
\hline CHEMBL1446276 & 688267 & 4.3 & 5.0448 & TST \\
\hline CHEMBL1410200 & 688267 & 4.05 & 5.0049 & TRN \\
\hline CHEMBL1527896 & 688267 & 4.4 & 5.0934 & TST \\
\hline CHEMBL1464195 & 688267 & 4.5 & 5.0276 & TRN \\
\hline CHEMBL1553521 & 688267 & 5.2 & 5.07 & TRN \\
\hline CHEMBL1448047 & 688267 & 4.3 & 5.0608 & TRN \\
\hline CHEMBL3192712 & 688267 & 4.6 & 5.0279 & TRN \\
\hline CHEMBL1348658 & 688267 & 4.35 & 5.0422 & TRN \\
\hline CHEMBL1605689 & 688267 & 6.25 & 5.015 & TRN \\
\hline CHEMBL1591279 & 688267 & 4.4 & 5.1219 & TRN \\
\hline
\end{tabular}




\begin{tabular}{|c|c|c|c|c|c|}
\hline \\
\hline CHEMBL1568433 & 688267 & 4.2 & 5.0631 & TST & \\
\hline CHEMBL242149 & 688267 & 4.05 & 5.1144 & TST & \\
\hline CHEMBL1582722 & 688267 & 5.0 & 5.1489 & TRN & \\
\hline CHEMBL1437500 & 688267 & 5.4 & 5.0033 & TRN & \\
\hline CHEMBL 249032 & 688267 & 5.35 & 5.0719 & TRN & \\
\hline CHEMBL1560016 & 688267 & 6.2 & 5.0868 & TRN & \\
\hline CHEMBL1541465 & 688267 & 5.4 & 5.063 & TRN & \\
\hline CHEMBL1319695 & 688267 & 4.35 & 5.1251 & TRN & \\
\hline CHEMBL1452574 & 688267 & 4.45 & 5.0604 & TRN & \\
\hline CHEMBL1434608 & 688267 & 5.85 & 5.101 & TRN & \\
\hline CHEMBL1345570 & 688267 & 4.05 & 5.0469 & TRN & \\
\hline CHEMBL1336168 & 688267 & 3.95 & 5.0708 & TRN & \\
\hline CHEMBL1575693 & 688267 & 4.05 & 5.0792 & TST & \\
\hline CHEMBL1323397 & 688267 & 5.35 & 5.0494 & TST & \\
\hline CHEMBL1613305 & 688267 & 5.8 & 5.0752 & TRN & \\
\hline CHEMBL1598126 & 688267 & 5.85 & 5.0383 & TST & \\
\hline CHEMBL3199083 & 688267 & 4.0 & 5.0365 & TRN & \\
\hline CHEMBL1545259 & 688267 & 5.8 & 5.0111 & TRN & \\
\hline CHEMBL1406331 & 688267 & 4.55 & 5.0762 & TST & \\
\hline CHEMBL1592762 & 688267 & 6.25 & 5.0353 & TRN & \\
\hline CHEMBL1532641 & 688267 & 6.2 & 5.0581 & TST & \\
\hline CHEMBL1317973 & 688267 & 6.15 & 5.11100 & 0000000001 & TRN \\
\hline CHEMBL1975767 & 688267 & 4.4 & 5.0358 & TST & \\
\hline CHEMBL1371242 & 688267 & 6.0 & 5.1272 & TRN & \\
\hline CHEMBL1524939 & 688267 & 4.3 & 4.977 & TRN & \\
\hline CHEMBL1318723 & 688267 & 5.8 & 5.0587 & TRN & \\
\hline CHEMBL1364487 & 688267 & 6.15 & 5.0774 & TRN & \\
\hline CHEMBL1473786 & 688267 & 6.15 & 5.0499 & TRN & \\
\hline CHEMBL1406493 & 688267 & 4.25 & 5.0366 & TST & \\
\hline CHEMBL1468086 & 688267 & 6.2 & 5.0354 & TRN & \\
\hline CHEMBL1475343 & 688267 & 5.85 & 5.0753 & TRN & \\
\hline CHEMBL1513563 & 688267 & 4.1 & 5.0523 & TST & \\
\hline CHEMBL1610405 & 688267 & 5.45 & 5.05699 & 99999999995 & TST \\
\hline CHEMBL1338803 & 688267 & 6.2 & 5.0125 & TRN & \\
\hline CHEMBL3199846 & 688267 & 5.0 & 5.0244 & TRN & \\
\hline CHEMBL1555415 & 688267 & 4.05 & 5.0739 & TRN & \\
\hline CHEMBL3392417 & 688267 & 6.0 & 5.0807 & TRN & \\
\hline CHEMBL1479815 & 688267 & 5.3 & 5.0689 & TRN & \\
\hline CHEMBL1530543 & 688267 & 5.75 & 5.0301 & TRN & \\
\hline CHEMBL1511437 & 688267 & 5.75 & 5.0705 & TRN & \\
\hline CHEMBL1574201 & 688267 & 4.55 & 5.0775 & TST & \\
\hline CHEMBL1473512 & 688267 & 3.95 & 5.0459 & TRN & \\
\hline CHEMBL1550099 & 688267 & 5.4 & 5.0825 & TST & \\
\hline CHEMBL1508216 & 688267 & 4.45 & 5.0373 & TRN & \\
\hline CHEMBL1393730 & 688267 & 6.25 & 5.0624 & TRN & \\
\hline CHEMBL1477455 & 688267 & 5.75 & 5.0197 & TRN & \\
\hline CHEMBL1442047 & 688267 & 6.5 & 5.0463 & TRN & \\
\hline CHEMBL1365003 & 688267 & 4.05 & 5.0685 & TST & \\
\hline
\end{tabular}




\begin{tabular}{|c|c|c|c|c|c|}
\hline \multicolumn{6}{|c|}{ Supplemental Table S2.txt } \\
\hline CHEMBL1437498 & 688267 & 5.25 & 5.0612 & TRN & \\
\hline CHEMBL1588500 & 688267 & 6.5 & 5.0457 & TST & \\
\hline CHEMBL1469750 & 688267 & 5.1 & 5.0524 & TRN & \\
\hline CHEMBL1334523 & 688267 & 5.35 & 5.0549 & TRN & \\
\hline CHEMBL1446810 & 688267 & 4.05 & 5.0788 & TRN & \\
\hline CHEMBL1513987 & 688267 & 3.95 & 5.0659 & TRN & \\
\hline CHEMBL1534274 & 688267 & 5.85 & 5.0626 & TRN & \\
\hline CHEMBL1539651 & 688267 & 5.8 & 5.0594 & TRN & \\
\hline CHEMBL1423073 & 688267 & 5.25 & 5.1623 & TST & \\
\hline CHEMBL1986392 & 688267 & 4.25 & 5.00899 & 99999999995 & TRN \\
\hline CHEMBL1554528 & 688267 & 3.95 & 5.1113 & TRN & \\
\hline CHEMBL1557467 & 688267 & 4.4 & 5.1454 & TRN & \\
\hline CHEMBL1339829 & 688267 & 5.45 & 5.12799 & 9999999999 & TRN \\
\hline CHEMBL1350528 & 688267 & 5.9 & 5.062 & TRN & \\
\hline CHEMBL1322286 & 688267 & 6.15 & 5.1076 & TRN & \\
\hline CHEMBL1610132 & 688267 & 6.25 & 5.0365 & TRN & \\
\hline CHEMBL1491430 & 688267 & 4.1 & 5.0268 & TRN & \\
\hline CHEMBL1316301 & 688267 & 6.25 & 5.0861 & TRN & \\
\hline CHEMBL1351252 & 688267 & 5.45 & 5.0253 & TRN & \\
\hline CHEMBL1407653 & 688267 & 5.55 & 5.0103 & TRN & \\
\hline CHEMBL1390307 & 688267 & 5.5 & 5.142 & TRN & \\
\hline CHEMBL1523709 & 688267 & 4.05 & 5.03600 & 00000000005 & TRN \\
\hline CHEMBL1354853 & 688267 & 6.2 & 5.0956 & TRN & \\
\hline CHEMBL1349253 & 688267 & 4.25 & 5.0363 & TST & \\
\hline CHEMBL1598931 & 688267 & 4.2 & 5.0405 & TST & \\
\hline CHEMBL1541595 & 688267 & 4.0 & 5.0183 & TST & \\
\hline CHEMBL1556224 & 688267 & 4.35 & 5.0759 & TRN & \\
\hline CHEMBL1432024 & 688267 & 4.35 & 5.1132 & TRN & \\
\hline CHEMBL1506168 & 688267 & 4.0 & 5.0915 & TRN & \\
\hline CHEMBL1447377 & 688267 & 4.55 & 5.1011 & TRN & \\
\hline CHEMBL1430297 & 688267 & 6.2 & 5.0824 & TST & \\
\hline CHEMBL1601771 & 688267 & 4.1 & 5.0394 & TRN & \\
\hline CHEMBL1580646 & 688267 & 5.1 & 5.0797 & TRN & \\
\hline CHEMBL1492515 & 688267 & 5.0 & 5.1269 & TRN & \\
\hline CHEMBL1394909 & 688267 & 4.35 & 5.0871 & TRN & \\
\hline CHEMBL1547594 & 688267 & 4.3 & 5.0331 & TRN & \\
\hline CHEMBL1577117 & 688267 & 4.25 & 4.9879 & TRN & \\
\hline CHEMBL1571672 & 688267 & 4.0 & 5.077 & TRN & \\
\hline CHEMBL1356567 & 688267 & 5.85 & 5.1336 & TRN & \\
\hline CHEMBL1578546 & 688267 & 4.6 & 5.0263 & TRN & \\
\hline CHEMBL1401992 & 688267 & 6.1 & 5.0255 & TRN & \\
\hline CHEMBL1417370 & 688267 & 5.3 & 5.0537 & TRN & \\
\hline CHEMBL3210738 & 688267 & 5.4 & 5.042 & TST & \\
\hline CHEMBL1600375 & 688267 & 4.45 & 5.0095 & TST & \\
\hline CHEMBL1597897 & 688267 & 4.4 & 5.0062 & TRN & \\
\hline CHEMBL1380309 & 688267 & 5.15 & 5.0746 & TST & \\
\hline CHEMBL1506998 & 688267 & 4.8 & 5.0117 & TRN & \\
\hline CHEMBL1596786 & 688267 & 4.15 & 5.1564 & TRN & \\
\hline
\end{tabular}




\begin{tabular}{|c|c|c|c|c|c|}
\hline \multicolumn{6}{|c|}{ Supplemental Table S2.txt } \\
\hline CHEMBL1524621 & 688267 & 6.15 & 5.0274 & TRN & \\
\hline CHEMBL1585669 & 688267 & 6.05 & 5.0242 & TRN & \\
\hline CHEMBL1348164 & 688267 & 3.95 & 5.1105 & TRN & \\
\hline CHEMBL1560395 & 688267 & 4.0 & 5.0372 & TRN & \\
\hline CHEMBL3208934 & 688267 & 4.6 & 5.0234 & TRN & \\
\hline CHEMBL1465077 & 688267 & 4.05 & 5.0017 & TST & \\
\hline CHEMBL1613213 & 688267 & 4.4 & 4.985 & TRN & \\
\hline CHEMBL1347190 & 688267 & 5.35 & 5.0687 & TRN & \\
\hline CHEMBL1423560 & 688267 & 5.35 & 5.0838 & TST & \\
\hline CHEMBL1435523 & 688267 & 6.25 & 5.0313 & TRN & \\
\hline CHEMBL1429916 & 688267 & 5.55 & 5.0401 & TRN & \\
\hline CHEMBL1441258 & 688267 & 4.3 & 5.0245 & TRN & \\
\hline CHEMBL1526739 & 688267 & 5.65 & 5.0674 & TST & \\
\hline CHEMBL1493515 & 688267 & 6.2 & 5.1056 & TRN & \\
\hline CHEMBL1367505 & 688267 & 4.25 & 5.1092 & TST & \\
\hline CHEMBL1356284 & 688267 & 5.55 & 5.0383 & TRN & \\
\hline CHEMBL1510842 & 688267 & 4.25 & 5.12200 & 0000000001 & TRN \\
\hline CHEMBL1467952 & 688267 & 4.5 & 5.0929 & TRN & \\
\hline CHEMBL1591606 & 688267 & 4.85 & 5.0012 & TRN & \\
\hline CHEMBL1596043 & 688267 & 4.25 & 5.0098 & TST & \\
\hline CHEMBL1368624 & 688267 & 4.4 & 5.1379 & TRN & \\
\hline CHEMBL1365346 & 688267 & 5.35 & 5.0509 & TRN & \\
\hline CHEMBL1440222 & 688267 & 4.15 & 5.1274 & TST & \\
\hline CHEMBL1324304 & 688267 & 6.2 & 5.0606 & TRN & \\
\hline CHEMBL1533916 & 688267 & 4.35 & 5.0177 & TRN & \\
\hline CHEMBL1423980 & 688267 & 5.4 & 5.0637 & TRN & \\
\hline CHEMBL1541609 & 688267 & 6.2 & 5.0881 & TRN & \\
\hline CHEMBL1598254 & 688267 & 4.15 & 5.1128 & TRN & \\
\hline CHEMBL1478336 & 688267 & 5.0 & 5.0 & TRN & \\
\hline CHEMBL1529005 & 688267 & 6.45 & 5.0195 & TRN & \\
\hline CHEMBL1994094 & 688267 & 4.0 & 5.0081 & TRN & \\
\hline CHEMBL1539869 & 688267 & 5.35 & 5.1407 & TRN & \\
\hline CHEMBL1577543 & 688267 & 5.8 & 5.0658 & TST & \\
\hline CHEMBL1539617 & 688267 & 4.9 & 5.0519 & TRN & \\
\hline CHEMBL1391441 & 688267 & 4.0 & 5.0397 & TST & \\
\hline CHEMBL1518808 & 688267 & 4.85 & 5.0334 & TRN & \\
\hline CHEMBL1514370 & 688267 & 6.15 & 5.1155 & TST & \\
\hline CHEMBL1382581 & 688267 & 4.6 & 5.0573 & TRN & \\
\hline CHEMBL1515778 & 688267 & 6.25 & 5.0931 & TRN & \\
\hline CHEMBL1383983 & 688267 & 4.9 & 5.109 & TRN & \\
\hline CHEMBL1384376 & 688267 & 4.55 & 5.0336 & TRN & \\
\hline CHEMBL1511106 & 688267 & 5.6 & 5.0138 & TST & \\
\hline CHEMBL1411156 & 688267 & 4.6 & 4.9867 & TST & \\
\hline CHEMBL1596873 & 688267 & 6.0 & 5.0164 & TRN & \\
\hline CHEMBL1490354 & 688267 & 5.45 & 5.0862 & TRN & \\
\hline CHEMBL1315680 & 688267 & 4.3 & 5.1118 & TRN & \\
\hline CHEMBL1598865 & 688267 & 5.55 & 5.0377 & TRN & \\
\hline CHEMBL1527042 & 688267 & 4.7 & 5.007 & TST & \\
\hline
\end{tabular}




\begin{tabular}{|c|c|c|c|c|c|}
\hline \multicolumn{6}{|c|}{ oplemental Table sa } \\
\hline CHEMBL1575938 & 688267 & 4.4 & 5.0227 & TST & \\
\hline CHEMBL1493606 & 688267 & 6.2 & 5.0081 & TRN & \\
\hline CHEMBL1594112 & 688267 & 4.0 & 5.0877 & TRN & \\
\hline CHEMBL1429137 & 688267 & 6.5 & 5.0224 & TRN & \\
\hline CHEMBL1329177 & 688267 & 6.45 & 5.079 & TRN & \\
\hline CHEMBL1395530 & 688267 & 6.4 & 5.0619 & TRN & \\
\hline CHEMBL1506431 & 688267 & 4.35 & 5.0682 & TRN & \\
\hline CHEMBL1415929 & 688267 & 6.15 & 5.053 & TST & \\
\hline CHEMBL1596748 & 688267 & 4.65 & 5.0776 & TRN & \\
\hline CHEMBL565118 & 688267 & 6.2 & 5.0548 & TRN & \\
\hline CHEMBL1509595 & 688267 & 4.25 & 5.0214 & TRN & \\
\hline CHEMBL1351249 & 688267 & 4.0 & 5.06 & TRN & \\
\hline CHEMBL1307960 & 688267 & 4.05 & 5.1114 & TRN & \\
\hline CHEMBL1523232 & 688267 & 4.0 & 5.0051 & TST & \\
\hline CHEMBL1347837 & 688267 & 6.5 & 5.0749 & TST & \\
\hline CHEMBL1536430 & 688267 & 4.8 & 5.1981 & TRN & \\
\hline CHEMBL1552733 & 688267 & 6.25 & 5.0842 & TRN & \\
\hline CHEMBL1597027 & 688267 & 4.05 & 5.0805 & TST & \\
\hline CHEMBL1472076 & 688267 & 4.6 & 5.0622 & TRN & \\
\hline CHEMBL1299393 & 688267 & 5.2 & 5.0633 & TST & \\
\hline CHEMBL1607284 & 688267 & 4.3 & 5.0174 & TRN & \\
\hline CHEMBL1488846 & 688267 & 4.95 & 5.0648 & TRN & \\
\hline CHEMBL1334384 & 688267 & 6.2 & 4.9949 & TST & \\
\hline CHEMBL1313199 & 688267 & 5.2 & 5.0722 & TRN & \\
\hline CHEMBL1334880 & 688267 & 6.2 & 5.0182 & TRN & \\
\hline CHEMBL1330564 & 688267 & 4.45 & 5.0477 & TRN & \\
\hline CHEMBL1531394 & 688267 & 5.85 & 5.0383 & TST & \\
\hline CHEMBL1522318 & 688267 & 4.5 & 5.0708 & TRN & \\
\hline CHEMBL1475210 & 688267 & 5.95 & 4.9957 & TST & \\
\hline CHEMBL1539255 & 688267 & 6.2 & 5.0946 & TST & \\
\hline CHEMBL1405065 & 688267 & 3.95 & 5.0786 & TST & \\
\hline CHEMBL1528664 & 688267 & 4.0 & 5.0951 & TST & \\
\hline CHEMBL3191706 & 688267 & 4.55 & 4.99106 & 20000000005 & TST \\
\hline CHEMBL1485820 & 688267 & 5.9 & 5.1157 & TRN & \\
\hline CHEMBL1553148 & 688267 & 6.5 & 4.9888 & TST & \\
\hline CHEMBL1562345 & 688267 & 6.0 & $5.1370 €$ & 00000000005 & TRN \\
\hline CHEMBL1450310 & 688267 & 6.2 & 5.0898 & TRN & \\
\hline CHEMBL1598846 & 688267 & 4.7 & 5.0269 & TRN & \\
\hline CHEMBL1538339 & 688267 & 4.0 & 4.9987 & TST & \\
\hline CHEMBL1489002 & 688267 & 5.8 & 5.0461 & TST & \\
\hline CHEMBL1573143 & 688267 & 6.25 & 4.9904 & TRN & \\
\hline CHEMBL1363951 & 688267 & 5.05 & 5.016 & TRN & \\
\hline CHEMBL1534061 & 688267 & 4.0 & 5.0564 & TST & \\
\hline CHEMBL1524093 & 688267 & 5.1 & 5.0388 & TRN & \\
\hline CHEMBL1557729 & 688267 & 5.05 & 5.0303 & TRN & \\
\hline CHEMBL1561322 & 688267 & 5.35 & 5.0147 & TRN & \\
\hline CHEMBL1590358 & 688267 & 6.2 & 4.9856 & TRN & \\
\hline CHEMBL1571062 & 688267 & 5.7 & 5.0103 & TST & \\
\hline
\end{tabular}




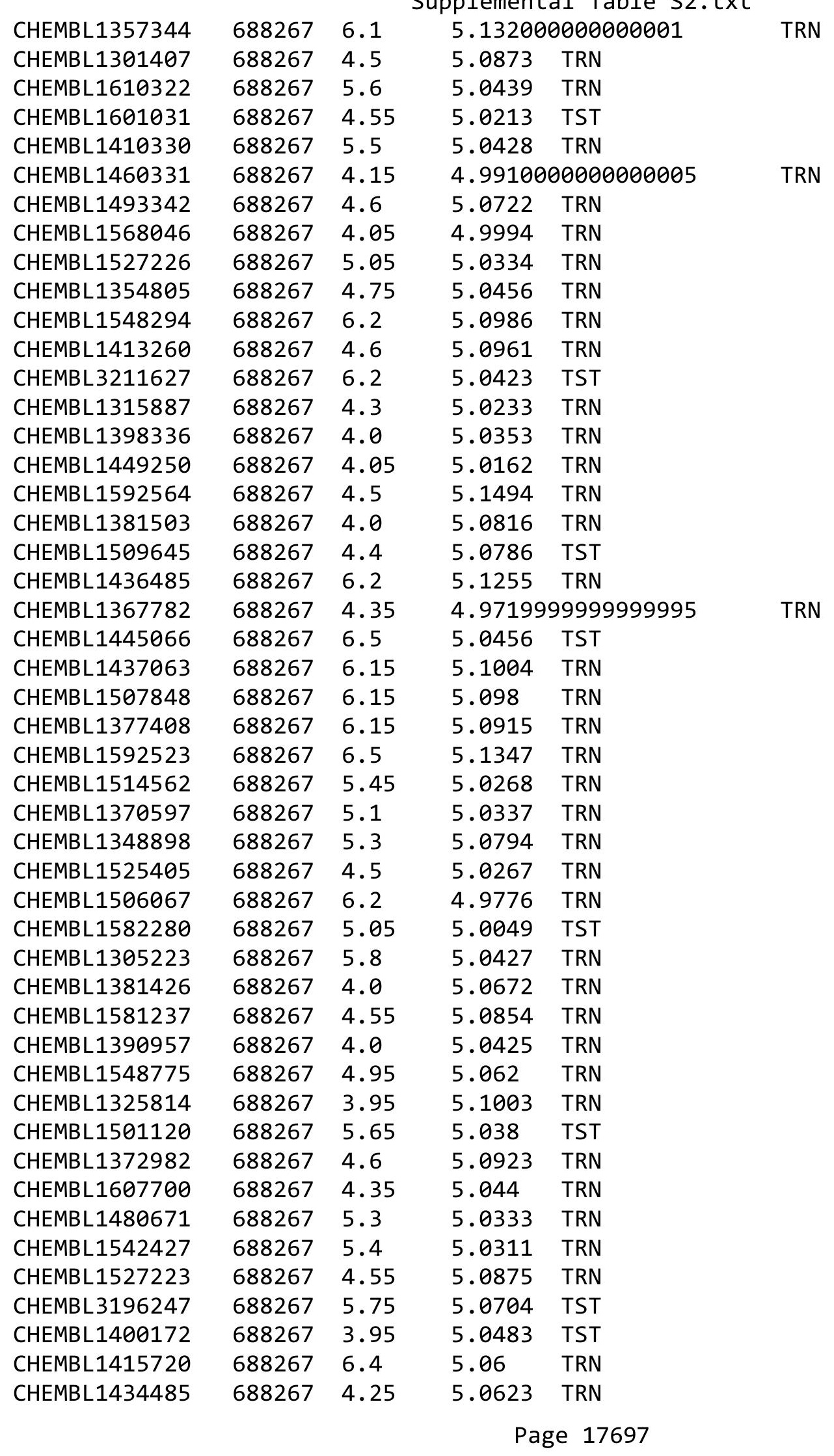




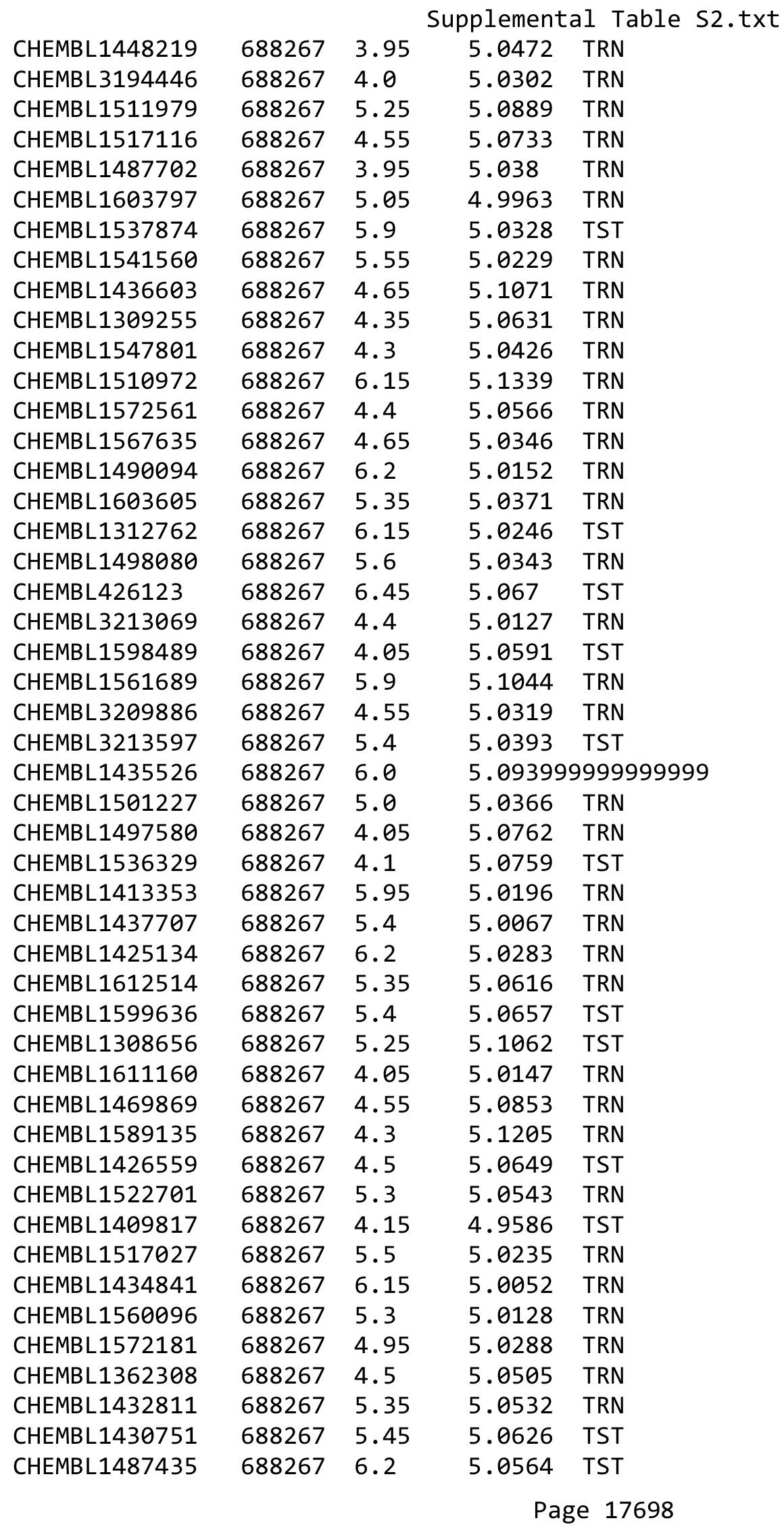




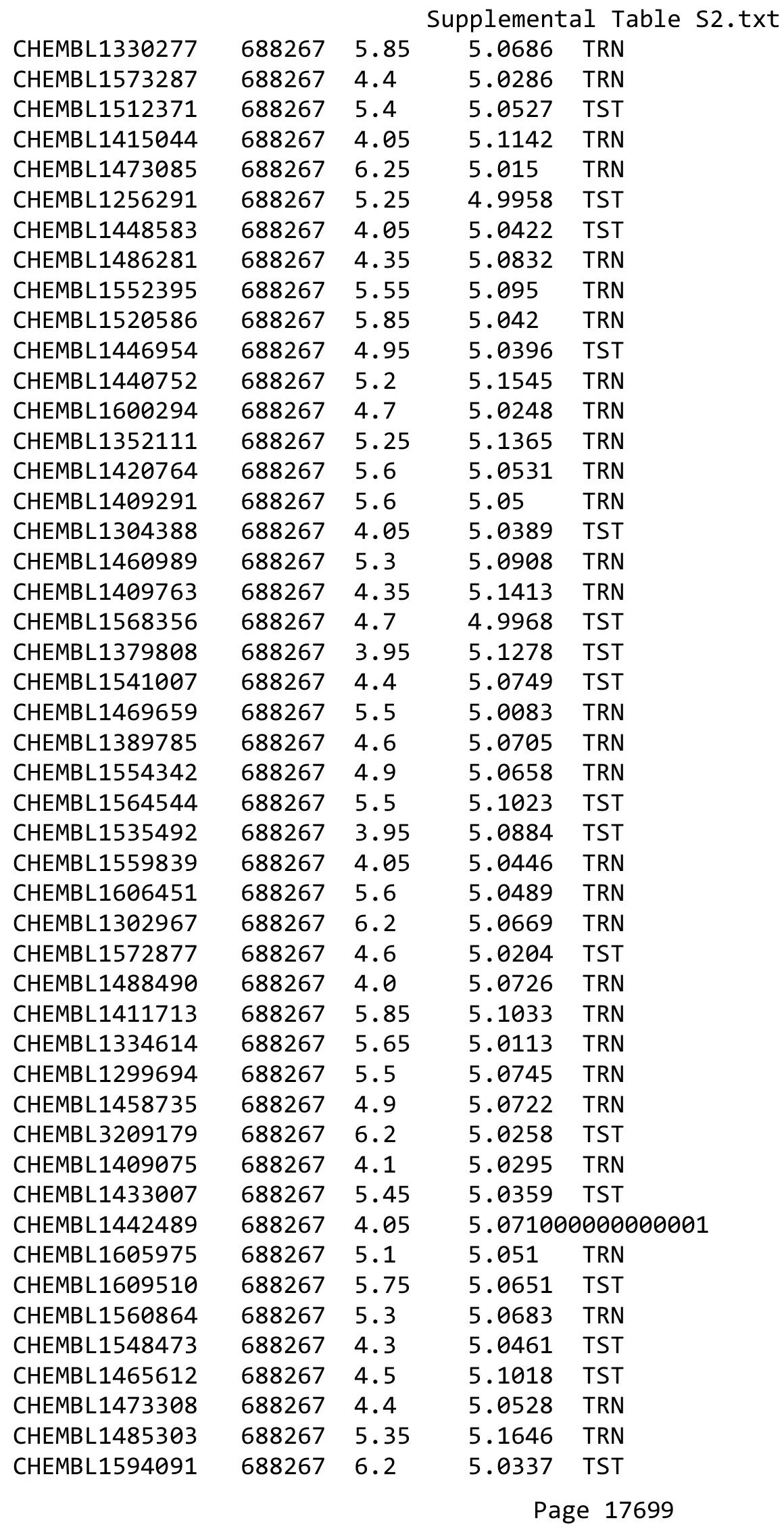




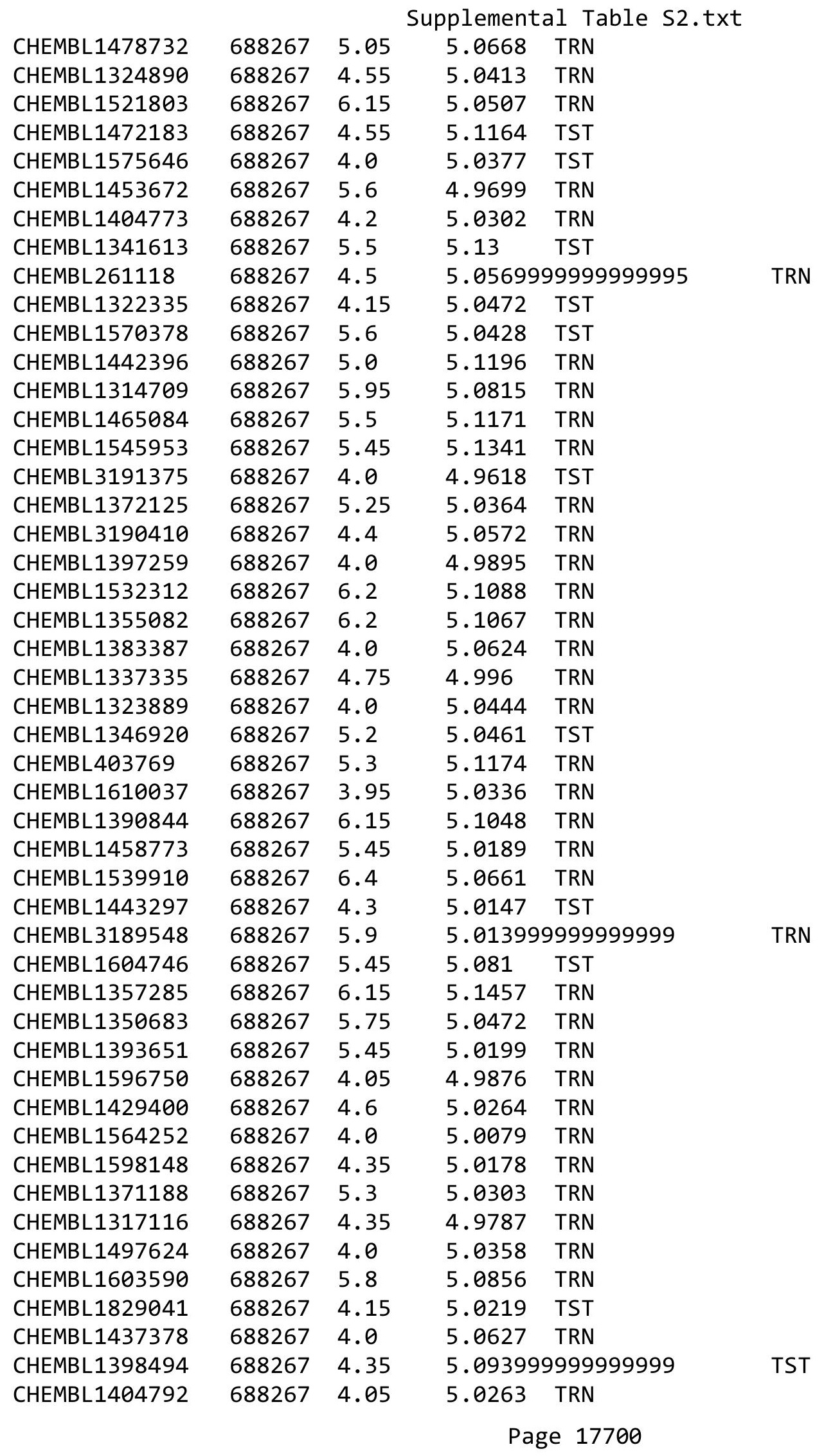




\begin{tabular}{|c|c|c|c|c|c|}
\hline \\
\hline CHEMBL1590815 & 688267 & 6.2 & 5.0593 & TRN & \\
\hline CHEMBL1977301 & 688267 & 4.0 & 4.9887 & TRN & \\
\hline CHEMBL1481579 & 688267 & 4.9 & 5.0784 & TRN & \\
\hline CHEMBL1600425 & 688267 & 4.25 & 5.0405 & TRN & \\
\hline CHEMBL1370790 & 688267 & 5.25 & 5.0869 & TRN & \\
\hline CHEMBL1436791 & 688267 & 4.1 & 5.0635 & TRN & \\
\hline CHEMBL1436089 & 688267 & 5.9 & 5.078 & TST & \\
\hline CHEMBL1393399 & 688267 & 4.35 & 5.0782 & TST & \\
\hline CHEMBL1304696 & 688267 & 4.3 & 5.0208 & TRN & \\
\hline CHEMBL1312103 & 688267 & 4.75 & 5.0426 & TST & \\
\hline CHEMBL1386443 & 688267 & 6.2 & 5.05399 & 9999999999 & TST \\
\hline CHEMBL1450171 & 688267 & 6.15 & 5.1265 & TRN & \\
\hline CHEMBL1431660 & 688267 & 5.25 & 5.0384 & TRN & \\
\hline CHEMBL1423630 & 688267 & 4.05 & 5.0953 & TRN & \\
\hline CHEMBL1522444 & 688267 & 3.9 & 4.9863 & TRN & \\
\hline CHEMBL1545147 & 688267 & 6.2 & 5.0927 & TST & \\
\hline CHEMBL1538018 & 688267 & 4.05 & 5.0586 & TRN & \\
\hline CHEMBL1545452 & 688267 & 5.05 & 4.984 & TRN & \\
\hline CHEMBL1314941 & 688267 & 6.15 & 5.0741 & TRN & \\
\hline CHEMBL1411725 & 688267 & 3.95 & 5.0263 & TRN & \\
\hline CHEMBL1385375 & 688267 & 4.7 & 5.0647 & TST & \\
\hline CHEMBL1467281 & 688267 & 5.3 & 5.0414 & TST & \\
\hline CHEMBL1348784 & 688267 & 4.6 & 4.9938 & TRN & \\
\hline CHEMBL1356293 & 688267 & 5.8 & 4.9889 & TRN & \\
\hline CHEMBL1362140 & 688267 & 6.1 & 5.0744 & TRN & \\
\hline CHEMBL1355658 & 688267 & 3.95 & 5.0684 & TRN & \\
\hline CHEMBL1420831 & 688267 & 5.6 & 5.1199 & TRN & \\
\hline CHEMBL1321652 & 688267 & 4.0 & 5.1231 & TRN & \\
\hline CHEMBL3212788 & 688267 & 4.0 & 4.9635 & TRN & \\
\hline CHEMBL 1446738 & 688267 & 4.5 & 5.1283 & TRN & \\
\hline CHEMBL1445200 & 688267 & 4.6 & 5.0105 & TRN & \\
\hline CHEMBL1523869 & 688267 & 6.2 & 5.0743 & TST & \\
\hline CHEMBL1994279 & 688267 & 6.45 & 5.0134 & TST & \\
\hline CHEMBL 2007354 & 688267 & 5.35 & 4.9838 & TRN & \\
\hline CHEMBL1419928 & 688267 & 3.95 & 5.0591 & TRN & \\
\hline CHEMBL1311136 & 688267 & 4.0 & 5.0635 & TRN & \\
\hline CHEMBL1306887 & 688267 & 4.4 & 5.00899 & 99999999995 & TRN \\
\hline CHEMBL1457523 & 688267 & 4.95 & 5.0434 & TST & \\
\hline CHEMBL1604275 & 688267 & 6.15 & 5.1456 & TRN & \\
\hline CHEMBL1351211 & 688267 & 5.0 & 5.06 & TRN & \\
\hline CHEMBL1455920 & 688267 & 4.45 & 5.0596 & TRN & \\
\hline CHEMBL1571779 & 688267 & 5.35 & 4.9986 & TRN & \\
\hline CHEMBL1406479 & 688267 & 6.2 & 4.9918 & TRN & \\
\hline CHEMBL1341360 & 688267 & 4.2 & 5.079 & TST & \\
\hline CHEMBL1522721 & 688267 & 6.0 & 5.159 & TRN & \\
\hline CHEMBL1521082 & 688267 & 4.35 & 5.0249 & TST & \\
\hline CHEMBL1567801 & 688267 & 5.9 & 4.9909 & TRN & \\
\hline CHEMBL1506012 & 688267 & 5.45 & 5.0257 & TST & \\
\hline
\end{tabular}




\begin{tabular}{|c|c|c|c|c|c|}
\hline \\
\hline CHEMBL1473178 & 688267 & 6.2 & 5.131 & TRN & \\
\hline CHEMBL1356988 & 688267 & 5.7 & 5.0203 & TRN & \\
\hline CHEMBL1414199 & 688267 & 4.7 & 5.0367 & TST & \\
\hline CHEMBL1416634 & 688267 & 4.45 & 5.0049 & TRN & \\
\hline CHEMBL524603 & 688267 & 5.25 & 5.0403 & TRN & \\
\hline CHEMBL3194486 & 688267 & 4.05 & 5.0055 & TST & \\
\hline CHEMBL1363385 & 688267 & 4.6 & 5.0312 & TRN & \\
\hline CHEMBL1418246 & 688267 & 4.0 & 5.0028 & TRN & \\
\hline CHEMBL1555413 & 688267 & 6.2 & 5.0333 & TRN & \\
\hline CHEMBL1587042 & 688267 & 5.85 & 5.0826 & TRN & \\
\hline CHEMBL1307776 & 688267 & 6.2 & 4.9991 & TST & \\
\hline CHEMBL1472773 & 688267 & 5.05 & 5.012 & TST & \\
\hline CHEMBL1549590 & 688267 & 4.3 & 5.0741 & TST & \\
\hline CHEMBL1394802 & 688267 & 5.45 & 5.1294 & TRN & \\
\hline CHEMBL448847 & 688267 & 4.6 & 5.1 & TRN & \\
\hline CHEMBL3195603 & 688267 & 3.95 & 5.0187 & TRN & \\
\hline CHEMBL1480858 & 688267 & 4.75 & 5.05399 & 9999999999 & TRN \\
\hline CHEMBL1447050 & 688267 & 5.1 & 5.0925 & TRN & \\
\hline CHEMBL1336759 & 688267 & 6.2 & 5.0381 & TRN & \\
\hline CHEMBL1366750 & 688267 & 6.15 & 5.0429 & TRN & \\
\hline CHEMBL1377677 & 688267 & 5.3 & 5.0478 & TST & \\
\hline CHEMBL1532076 & 688267 & 4.55 & 5.1276 & TRN & \\
\hline CHEMBL1497977 & 688267 & 6.2 & 5.126 & TRN & \\
\hline CHEMBL1332754 & 688267 & 6.2 & 5.0475 & TRN & \\
\hline CHEMBL1354434 & 688267 & 4.0 & 5.0592 & TRN & \\
\hline CHEMBL1391752 & 688267 & 4.65 & 5.0667 & TRN & \\
\hline CHEMBL1512099 & 688267 & 4.85 & 5.0862 & TRN & \\
\hline CHEMBL1372560 & 688267 & 5.55 & 5.1022 & TRN & \\
\hline CHEMBL1377139 & 688267 & 5.15 & 5.0777 & TRN & \\
\hline CHEMBL1415946 & 688267 & 3.95 & 5.0467 & TRN & \\
\hline CHEMBL1611002 & 688267 & 4.0 & 5.0077 & TRN & \\
\hline CHEMBL1416192 & 688267 & 4.8 & 5.018 & TRN & \\
\hline CHEMBL1537284 & 688267 & 6.2 & 5.0771 & TST & \\
\hline CHEMBL1472890 & 688267 & 4.05 & 5.0127 & TRN & \\
\hline CHEMBL1515368 & 688267 & 6.2 & 5.1026 & TRN & \\
\hline CHEMBL1593761 & 688267 & 5.8 & 5.0665 & TRN & \\
\hline CHEMBL1499617 & 688267 & 4.05 & 5.0746 & TST & \\
\hline CHEMBL1340855 & 688267 & 6.1 & 5.0106 & TRN & \\
\hline CHEMBL1343614 & 688267 & 6.5 & 5.1061 & TRN & \\
\hline CHEMBL 1436570 & 688267 & 4.05 & 5.0115 & TRN & \\
\hline CHEMBL1533976 & 688267 & 5.95 & 5.1314 & TRN & \\
\hline CHEMBL1490589 & 688267 & 5.3 & 5.0381 & TRN & \\
\hline CHEMBL1484172 & 688267 & 4.4 & 5.0118 & TRN & \\
\hline CHEMBL1415537 & 688267 & 4.0 & 5.074 & TRN & \\
\hline CHEMBL1527296 & 688267 & 4.6 & 5.0453 & TRN & \\
\hline CHEMBL1435855 & 688267 & 4.0 & 5.1004 & TRN & \\
\hline CHEMBL1418956 & 688267 & 4.2 & 5.1184 & TRN & \\
\hline CHEMBL1534162 & 688267 & 4.4 & 4.9773 & TRN & \\
\hline
\end{tabular}




\begin{tabular}{|c|c|c|c|c|c|}
\hline \\
\hline CHEMBL1468749 & 688267 & 4.45 & 5.011 & TST & \\
\hline CHEMBL1529533 & 688267 & 5.9 & 5.0522 & TST & \\
\hline CHEMBL1589142 & 688267 & 4.45 & 5.0881 & TRN & \\
\hline CHEMBL1388663 & 688267 & 4.55 & 5.0124 & TST & \\
\hline CHEMBL1337621 & 688267 & 6.45 & 5.0989 & TST & \\
\hline CHEMBL1469530 & 688267 & 6.45 & 5.0644 & TST & \\
\hline CHEMBL1333113 & 688267 & 6.45 & 5.1179 & TRN & \\
\hline CHEMBL1542377 & 688267 & 5.25 & 5.1089 & TST & \\
\hline CHEMBL1442062 & 688267 & 4.45 & 4.9849 & TRN & \\
\hline CHEMBL1390112 & 688267 & 4.8 & 5.0538 & TRN & \\
\hline CHEMBL1596552 & 688267 & 4.85 & 5.04899 & 99999999995 & TRN \\
\hline CHEMBL1529285 & 688267 & 4.25 & 5.09399 & 9999999999 & TST \\
\hline CHEMBL1314171 & 688267 & 5.5 & 5.0901 & TRN & \\
\hline CHEMBL1604354 & 688267 & 6.2 & 4.9724 & TRN & \\
\hline CHEMBL1498200 & 688267 & 4.0 & 5.0944 & TST & \\
\hline CHEMBL1528247 & 688267 & 4.15 & 4.9782 & TST & \\
\hline CHEMBL1355768 & 688267 & 4.95 & 5.0812 & TST & \\
\hline CHEMBL1504757 & 688267 & 4.0 & 5.0702 & TRN & \\
\hline CHEMBL1551494 & 688267 & 5.3 & 5.027 & TRN & \\
\hline CHEMBL1488219 & 688267 & 5.9 & 5.0156 & TST & \\
\hline CHEMBL1605053 & 688267 & 5.05 & 5.0315 & TRN & \\
\hline CHEMBL1471138 & 688267 & 4.0 & 5.0153 & TRN & \\
\hline CHEMBL1569097 & 688267 & 4.05 & 5.0486 & TRN & \\
\hline CHEMBL1397439 & 688267 & 5.4 & 5.0638 & TRN & \\
\hline CHEMBL1606775 & 688267 & 4.75 & 5.1064 & TRN & \\
\hline CHEMBL1597138 & 688267 & 4.0 & 5.064 & TRN & \\
\hline CHEMBL1340336 & 688267 & 6.15 & 5.0346 & TRN & \\
\hline CHEMBL1409757 & 688267 & 3.95 & 5.1633 & TRN & \\
\hline CHEMBL1416243 & 688267 & 4.2 & 5.0296 & TRN & \\
\hline CHEMBL1329990 & 688267 & 5.4 & 5.0834 & TST & \\
\hline CHEMBL1420389 & 688267 & 6.1 & 5.1252 & TRN & \\
\hline CHEMBL1486265 & 688267 & 4.9 & 5.0442 & TST & \\
\hline CHEMBL1368063 & 688267 & 5.3 & 5.0157 & TST & \\
\hline CHEMBL1344593 & 688267 & 4.35 & 4.9977 & TRN & \\
\hline CHEMBL1354968 & 688267 & 6.1 & 5.1436 & TRN & \\
\hline CHEMBL1476252 & 688267 & 6.2 & 5.0878 & TST & \\
\hline CHEMBL3190428 & 688267 & 4.4 & 5.0415 & TRN & \\
\hline CHEMBL1547256 & 688267 & 6.1 & 5.1018 & TRN & \\
\hline CHEMBL1480177 & 688267 & 4.05 & 5.0301 & TRN & \\
\hline CHEMBL1473271 & 688267 & 5.35 & 5.1053 & TRN & \\
\hline CHEMBL1355656 & 688267 & 5.3 & 5.0419 & TRN & \\
\hline CHEMBL3190067 & 688267 & 6.15 & 5.0049 & TRN & \\
\hline CHEMBL1375929 & 688267 & 4.0 & 5.095 & TRN & \\
\hline CHEMBL1411231 & 688267 & 5.25 & 5.0636 & TRN & \\
\hline CHEMBL1394452 & 688267 & 4.05 & 5.1544 & TRN & \\
\hline CHEMBL1562809 & 688267 & 6.05 & 5.0826 & TRN & \\
\hline CHEMBL1366330 & 688267 & 4.2 & 5.084 & TRN & \\
\hline CHEMBL1407506 & 688267 & 5.5 & 5.0859 & TRN & \\
\hline
\end{tabular}




\begin{tabular}{|c|c|c|c|c|c|}
\hline \multicolumn{6}{|c|}{ Supplemental Table s2.txt } \\
\hline CHEMBL1495279 & 688267 & 5.25 & 5.0632 & TRN & \\
\hline CHEMBL1492015 & 688267 & 4.35 & 5.0941 & TST & \\
\hline CHEMBL1330392 & 688267 & 5.85 & 5.0085 & TRN & \\
\hline CHEMBL1364691 & 688267 & 6.2 & 5.0392 & TRN & \\
\hline CHEMBL1505614 & 688267 & 5.9 & 5.0369 & TRN & \\
\hline CHEMBL1521751 & 688267 & 6.4 & 5.0441 & TRN & \\
\hline CHEMBL1334506 & 688267 & 4.0 & 4.9982 & TRN & \\
\hline CHEMBL1391795 & 688267 & 5.75 & 5.0402 & TRN & \\
\hline CHEMBL1557138 & 688267 & 5.05 & 5.0292 & TRN & \\
\hline CHEMBL1607951 & 688267 & 6.2 & 5.0676 & TRN & \\
\hline CHEMBL1479302 & 688267 & 4.05 & 5.0319 & TST & \\
\hline CHEMBL1399307 & 688267 & 5.85 & 5.1282 & TST & \\
\hline CHEMBL1412768 & 688267 & 4.7 & 5.0863 & TRN & \\
\hline CHEMBL1357481 & 688267 & 5.7 & 4.9977 & TRN & \\
\hline CHEMBL1510785 & 688267 & 5.3 & 5.1019 & TRN & \\
\hline CHEMBL1372881 & 688267 & 5.55 & 5.1004 & TRN & \\
\hline CHEMBL1552596 & 688267 & 5.05 & 5.0318 & TRN & \\
\hline CHEMBL1539455 & 688267 & 4.3 & 5.1035 & TRN & \\
\hline CHEMBL1360387 & 688267 & 5.35 & 5.016 & TRN & \\
\hline CHEMBL1372922 & 688267 & 4.3 & 5.008 & TST & \\
\hline CHEMBL1527691 & 688267 & 5.35 & 5.0249 & TST & \\
\hline CHEMBL1529369 & 688267 & 4.3 & 5.0321 & TRN & \\
\hline CHEMBL1421981 & 688267 & 4.5 & 4.9818 & TST & \\
\hline CHEMBL1455405 & 688267 & 5.9 & 4.9998 & TRN & \\
\hline CHEMBL1424190 & 688267 & 4.1 & 5.0729 & TST & \\
\hline CHEMBL1596277 & 688267 & 4.3 & 5.0622 & TST & \\
\hline CHEMBL1358563 & 688267 & 5.8 & 5.0529 & TRN & \\
\hline CHEMBL1549329 & 688267 & 3.95 & 5.0479 & TRN & \\
\hline CHEMBL1328636 & 688267 & 5.55 & 5.1378 & TRN & \\
\hline CHEMBL1501593 & 688267 & 4.0 & 5.0881 & TRN & \\
\hline CHEMBL1412875 & 688267 & 5.85 & 5.0069 & TRN & \\
\hline CHEMBL1517950 & 688267 & 5.3 & 5.0571 & TRN & \\
\hline CHEMBL1611112 & 688267 & 5.05 & 5.053 & TRN & \\
\hline CHEMBL1302497 & 688267 & 5.4 & 5.0729 & TRN & \\
\hline CHEMBL1433281 & 688267 & 6.15 & 5.0504 & TRN & \\
\hline CHEMBL1351955 & 688267 & 5.4 & 5.0402 & TRN & \\
\hline CHEMBL1585208 & 688267 & 5.4 & 5.0559 & TST & \\
\hline CHEMBL1507691 & 688267 & 6.2 & 5.1208 & TRN & \\
\hline CHEMBL1590335 & 688267 & 5.55 & 5.09399 & 7999999999 & TRN \\
\hline CHEMBL3207850 & 688267 & 5.55 & 5.0131 & TRN & \\
\hline CHEMBL1484619 & 688267 & 4.35 & 4.9757 & TRN & \\
\hline CHEMBL1513052 & 688267 & 5.85 & 5.0242 & TRN & \\
\hline CHEMBL1543422 & 688267 & 4.05 & 5.0839 & TRN & \\
\hline CHEMBL1396280 & 688267 & 6.35 & 5.0263 & TRN & \\
\hline CHEMBL1337205 & 688267 & 5.6 & 5.1565 & TRN & \\
\hline CHEMBL1314949 & 688267 & 5.1 & 5.0816 & TRN & \\
\hline CHEMBL1317221 & 688267 & 6.2 & 5.0908 & TRN & \\
\hline CHEMBL1379968 & 688267 & 5.4 & 5.0823 & TRN & \\
\hline
\end{tabular}




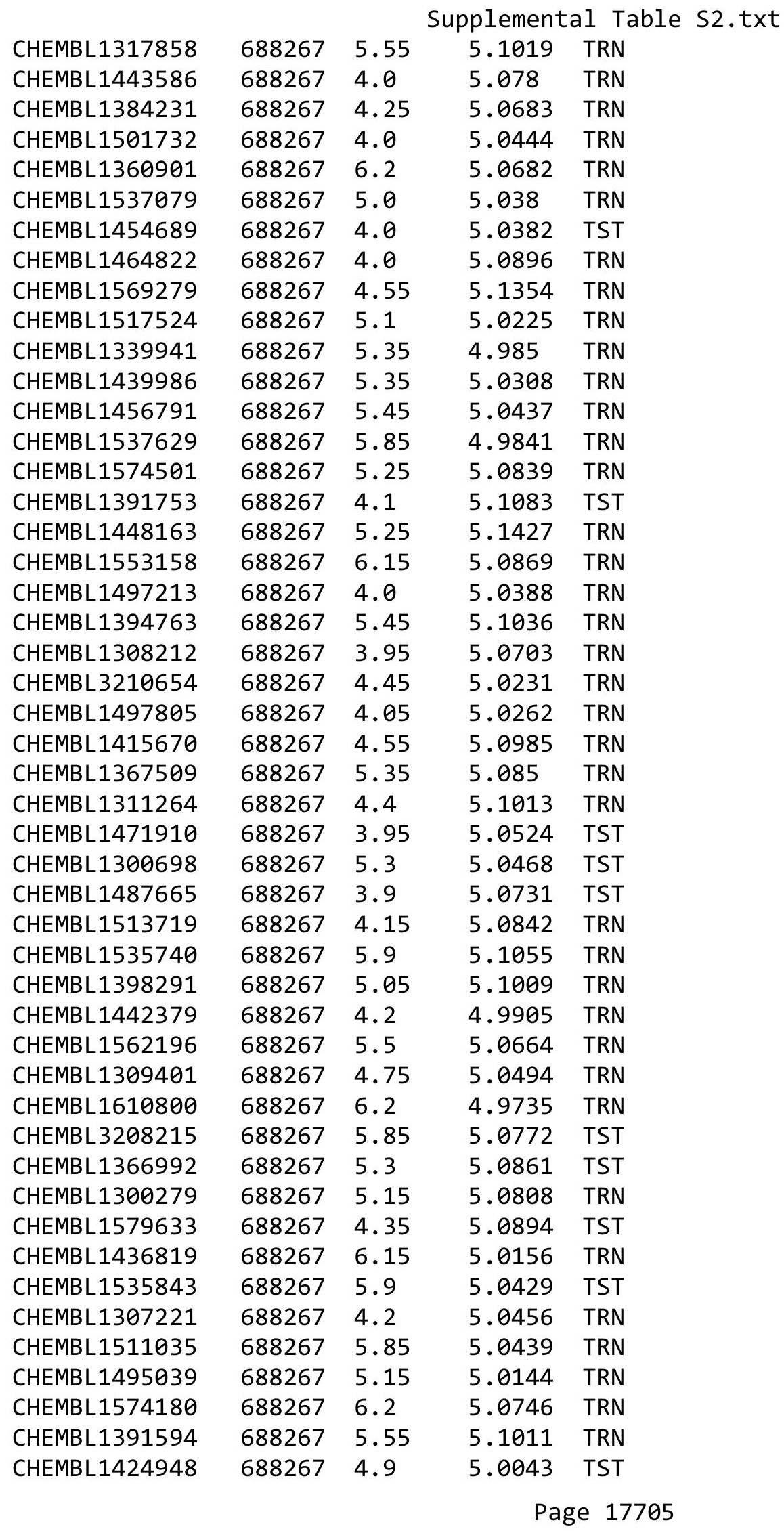




\begin{tabular}{|c|c|c|c|c|}
\hline & & & pplement & al Ta \\
\hline CHEMBL1599308 & 688267 & 6.15 & 5.0198 & TST \\
\hline CHEMBL1362482 & 688267 & 4.05 & 5.0318 & TRN \\
\hline CHEMBL1402580 & 688267 & 5.5 & 5.0606 & TRN \\
\hline CHEMBL1508255 & 688267 & 4.4 & 5.0466 & TRN \\
\hline CHEMBL1452453 & 688267 & 4.1 & 5.0433 & TRN \\
\hline CHEMBL1593647 & 688267 & 4.7 & 5.1272 & TRN \\
\hline CHEMBL1496339 & 688267 & 6.2 & 5.0823 & TST \\
\hline CHEMBL1350680 & 688267 & 5.35 & 5.0297 & TST \\
\hline CHEMBL1515525 & 688267 & 5.6 & 5.0534 & TST \\
\hline CHEMBL1454923 & 688267 & 6.2 & 5.0778 & TST \\
\hline CHEMBL1470999 & 688267 & 5.4 & 4.9867 & TST \\
\hline CHEMBL1511612 & 688267 & 5.0 & 4.9887 & TRN \\
\hline CHEMBL1383145 & 688267 & 5.3 & 5.1001 & TRN \\
\hline CHEMBL1302766 & 688267 & 4.0 & 5.1387 & TRN \\
\hline CHEMBL1455321 & 688267 & 4.5 & 5.0138 & TRN \\
\hline CHEMBL1435060 & 688267 & 6.2 & 5.0854 & TRN \\
\hline CHEMBL1403360 & 688267 & 6.2 & 5.0907 & TST \\
\hline CHEMBL1516812 & 688267 & 4.05 & 5.0103 & TRN \\
\hline CHEMBL1542557 & 688267 & 5.8 & 4.9948 & TRN \\
\hline CHEMBL1352431 & 688267 & 4.05 & 5.0093 & TST \\
\hline CHEMBL1340311 & 688267 & 5.5 & 5.0187 & TST \\
\hline CHEMBL1519823 & 688267 & 4.05 & 5.0445 & TST \\
\hline CHEMBL1521816 & 688267 & 4.5 & 5.0204 & TRN \\
\hline CHEMBL1468653 & 688267 & 5.7 & 5.1099 & TRN \\
\hline CHEMBL 3197308 & 688267 & 4.35 & 5.0356 & TRN \\
\hline CHEMBL1464220 & 688267 & 3.95 & 5.0146 & TRN \\
\hline CHEMBL1477038 & 688267 & 6.2 & 5.0951 & TRN \\
\hline CHEMBL1320711 & 688267 & 4.45 & 4.9977 & TRN \\
\hline CHEMBL3196684 & 688267 & 4.05 & 4.994 & TST \\
\hline CHEMBL1457921 & 688267 & 5.45 & 5.0874 & TRN \\
\hline CHEMBL1372732 & 688267 & 4.0 & 4.9926 & TST \\
\hline CHEMBL1325113 & 688267 & 4.0 & 5.1315 & TRN \\
\hline CHEMBL1553061 & 688267 & 5.6 & 5.0464 & TRN \\
\hline CHEMBL1368713 & 688267 & 5.85 & 5.1107 & TRN \\
\hline CHEMBL1529868 & 688267 & 5.25 & 5.0081 & TST \\
\hline CHEMBL1603168 & 688267 & 3.9 & 5.0387 & TRN \\
\hline CHEMBL1484276 & 688267 & 5.9 & 5.055 & TRN \\
\hline CHEMBL1315919 & 688267 & 4.0 & 5.0455 & TRN \\
\hline CHEMBL1333716 & 688267 & 4.0 & 5.0464 & TST \\
\hline CHEMBL1385311 & 688267 & 4.05 & 5.0183 & TST \\
\hline CHEMBL1400131 & 688267 & 5.4 & 5.0055 & TRN \\
\hline CHEMBL1349090 & 688267 & 4.5 & 5.0436 & TRN \\
\hline CHEMBL1405674 & 688267 & 5.05 & 5.1157 & TRN \\
\hline CHEMBL1481516 & 688267 & 5.5 & 5.1262 & TRN \\
\hline CHEMBL1455889 & 688267 & 6.2 & 5.074 & TRN \\
\hline CHEMBL1458155 & 688267 & 5.3 & 5.1746 & TST \\
\hline CHEMBL1364229 & 688267 & 6.2 & 5.0926 & TRN \\
\hline CHEMBL1362251 & 688267 & 4.1 & 5.0309 & TRN \\
\hline
\end{tabular}




\begin{tabular}{|c|c|c|c|c|}
\hline \multirow[b]{2}{*}{ CHEMBL1400114 } & \multicolumn{4}{|c|}{ Supplemental Table s2.t } \\
\hline & 688267 & 6.2 & 5.0198 & TRN \\
\hline CHEMBL1479385 & 688267 & 6.25 & 5.0812 & TRN \\
\hline CHEMBL1487314 & 688267 & 4.3 & 5.0161 & TRN \\
\hline CHEMBL1363930 & 688267 & 4.55 & 5.0987 & TRN \\
\hline CHEMBL1520861 & 688267 & 6.2 & 5.0665 & TRN \\
\hline CHEMBL1514791 & 688267 & 5.2 & 5.0227 & TRN \\
\hline CHEMBL1363478 & 688267 & 4.05 & 5.0445 & TRN \\
\hline CHEMBL1467315 & 688267 & 4.0 & 5.1529 & TST \\
\hline CHEMBL1534644 & 688267 & 4.35 & 5.0318 & TRN \\
\hline CHEMBL1312339 & 688267 & 5.35 & 5.0835 & TST \\
\hline CHEMBL1520359 & 688267 & 5.8 & 5.0483 & TRN \\
\hline CHEMBL1332634 & 688267 & 4.7 & 5.0529 & TRN \\
\hline CHEMBL1556719 & 688267 & 4.55 & 5.0951 & TRN \\
\hline CHEMBL1586710 & 688267 & 4.2 & 5.0021 & TRN \\
\hline CHEMBL3199362 & 688267 & 5.4 & 5.0324 & TRN \\
\hline CHEMBL1526686 & 688267 & 4.75 & 5.0579 & TRN \\
\hline CHEMBL1352426 & 688267 & 6.2 & 5.0797 & TRN \\
\hline CHEMBL1512543 & 688267 & 5.6 & 5.1207 & TRN \\
\hline CHEMBL1491366 & 688267 & 3.95 & 5.074 & TRN \\
\hline CHEMBL1534102 & 688267 & 4.4 & 5.088 & TST \\
\hline CHEMBL1511693 & 688267 & 4.0 & 5.0752 & TRN \\
\hline CHEMBL1571157 & 688267 & 4.55 & 5.0776 & TST \\
\hline CHEMBL1419043 & 688267 & 4.0 & 5.1111 & TRN \\
\hline CHEMBL 2261860 & 688267 & 6.2 & 4.994 & TRN \\
\hline CHEMBL1358495 & 688267 & 6.2 & 5.0276 & TRN \\
\hline CHEMBL1530563 & 688267 & 6.2 & 5.0497 & TRN \\
\hline CHEMBL1426763 & 688267 & 4.9 & 4.9994 & TRN \\
\hline CHEMBL 3145092 & 688267 & 4.05 & 5.0317 & TST \\
\hline CHEMBL1432270 & 688267 & 4.0 & 5.0102 & TRN \\
\hline CHEMBL1563050 & 688267 & 5.05 & 5.0731 & TST \\
\hline CHEMBL1485810 & 688267 & 6.5 & 5.0646 & TRN \\
\hline CHEMBL1533885 & 688267 & 5.4 & 5.0338 & TRN \\
\hline CHEMBL1374277 & 688267 & 5.45 & 5.0285 & TRN \\
\hline CHEMBL1336294 & 688267 & 6.2 & 5.0454 & TRN \\
\hline CHEMBL1427046 & 688267 & 4.25 & 5.0745 & TRN \\
\hline CHEMBL1467627 & 688267 & 5.4 & 5.0345 & TRN \\
\hline CHEMBL 3197420 & 688267 & 4.25 & 5.0719 & TRN \\
\hline CHEMBL1380748 & 688267 & 4.35 & 5.0329 & TRN \\
\hline CHEMBL1418792 & 688267 & 5.9 & 5.0816 & TRN \\
\hline CHEMBL1593394 & 688267 & 4.05 & 5.0747 & TST \\
\hline CHEMBL1487586 & 688267 & 4.95 & 5.0757 & TST \\
\hline CHEMBL1571847 & 688267 & 3.95 & 5.0302 & TRN \\
\hline CHEMBL1455512 & 688267 & 4.25 & 5.0894 & TRN \\
\hline CHEMBL1453231 & 688267 & 4.3 & 5.0666 & TRN \\
\hline CHEMBL1555305 & 688267 & 5.15 & 5.1143 & TRN \\
\hline CHEMBL3213658 & 688267 & 4.65 & 5.0997 & TST \\
\hline CHEMBL1408069 & 688267 & 5.05 & 5.0906 & TRN \\
\hline CHEMBL1320245 & 688267 & 6.2 & 5.0232 & TRN \\
\hline
\end{tabular}




\begin{tabular}{|c|c|c|c|c|}
\hline \multicolumn{5}{|c|}{ Supplemental Table } \\
\hline CHEMBL1332013 & 688267 & 5.45 & 5.0219 & TST \\
\hline CHEMBL1567149 & 688267 & 4.5 & 5.1186 & TRN \\
\hline CHEMBL1360722 & 688267 & 3.95 & 5.0167 & TST \\
\hline CHEMBL1405392 & 688267 & 4.05 & 5.0719 & TRN \\
\hline CHEMBL1341090 & 688267 & 4.45 & 5.0711 & TST \\
\hline CHEMBL1593021 & 688267 & 5.6 & 5.0597 & TRN \\
\hline CHEMBL1316293 & 688267 & 5.4 & 5.0377 & TST \\
\hline CHEMBL1566520 & 688267 & 4.0 & 5.0989 & TRN \\
\hline CHEMBL1473416 & 688267 & 5.0 & 5.0527 & TRN \\
\hline CHEMBL1521282 & 688267 & 4.4 & 5.1108 & TRN \\
\hline CHEMBL1469761 & 688267 & 5.85 & 5.0852 & TRN \\
\hline CHEMBL 3214134 & 688267 & 6.2 & 5.0503 & TRN \\
\hline CHEMBL1553515 & 688267 & 6.2 & 5.0771 & TRN \\
\hline CHEMBL1475725 & 688267 & 6.7501 & 5.0381 & TRN \\
\hline CHEMBL1443438 & 688267 & 6.5 & 5.0019 & TST \\
\hline CHEMBL1455262 & 688267 & 5.1 & 5.0626 & TRN \\
\hline CHEMBL1359253 & 688267 & 5.8 & 5.0836 & TRN \\
\hline CHEMBL1457189 & 688267 & 5.9 & 5.0389 & TRN \\
\hline CHEMBL1452256 & 688267 & 4.15 & 5.0734 & TST \\
\hline CHEMBL1318919 & 688267 & 4.05 & 5.0449 & TST \\
\hline CHEMBL1434570 & 688267 & 4.0 & 5.1433 & TRN \\
\hline CHEMBL1362003 & 688267 & 6.2 & 5.114 & TRN \\
\hline CHEMBL1460804 & 688267 & 5.55 & 5.1464 & TRN \\
\hline CHEMBL1309008 & 688267 & 4.4 & 5.0614 & TST \\
\hline CHEMBL1255656 & 688267 & 6.2 & 5.1077 & TST \\
\hline CHEMBL1419962 & 688267 & 4.95 & 5.0214 & TST \\
\hline CHEMBL1377015 & 688267 & 4.3 & 5.0269 & TRN \\
\hline CHEMBL1986232 & 688267 & 6.2 & 5.0053 & TRN \\
\hline CHEMBL1436065 & 688267 & 4.4 & 5.0345 & TRN \\
\hline CHEMBL1356642 & 688267 & 6.15 & 5.0584 & TRN \\
\hline CHEMBL1463994 & 688267 & 5.5 & 5.11 & TRN \\
\hline CHEMBL1569721 & 688267 & 7.4498 & 5.1033 & TST \\
\hline CHEMBL1482609 & 688267 & 6.2 & 5.04 & TRN \\
\hline CHEMBL1443192 & 688267 & 4.05 & 5.0546 & TST \\
\hline CHEMBL1605405 & 688267 & 4.35 & 5.0929 & TRN \\
\hline CHEMBL1412231 & 688267 & 4.4 & 5.1103 & TRN \\
\hline CHEMBL1401289 & 688267 & 4.25 & 5.0532 & TST \\
\hline CHEMBL1422669 & 688267 & 5.95 & 5.0556 & TRN \\
\hline CHEMBL1393179 & 688267 & 5.1 & 5.0362 & TRN \\
\hline CHEMBL1557356 & 688267 & 5.1 & 5.0103 & TRN \\
\hline CHEMBL1345053 & 688267 & 6.2 & 5.0614 & TST \\
\hline CHEMBL1407411 & 688267 & 5.15 & 5.1033 & TRN \\
\hline CHEMBL1363531 & 688267 & 4.4 & 4.9744 & TRN \\
\hline CHEMBL1509048 & 688267 & 4.3 & 5.0597 & TRN \\
\hline CHEMBL1449066 & 688267 & 4.6 & 5.0678 & TRN \\
\hline CHEMBL1341580 & 688267 & 6.5 & 5.0517 & TRN \\
\hline CHEMBL1310885 & 688267 & 5.4 & 5.0625 & TRN \\
\hline CHEMBL1327585 & 688267 & 6.25 & 5.1289 & TRN \\
\hline
\end{tabular}




\begin{tabular}{|c|c|c|c|c|c|}
\hline \\
\hline CHEMBL1580497 & 688267 & 5.0 & 5.0171 & TRN & \\
\hline CHEMBL1417443 & 688267 & 5.1 & 5.0884 & TRN & \\
\hline CHEMBL1516209 & 688267 & 5.55 & 5.0509 & TRN & \\
\hline CHEMBL1531818 & 688267 & 4.2 & 5.0988 & TRN & \\
\hline CHEMBL1529177 & 688267 & 4.55 & 5.061 & TST & \\
\hline CHEMBL1490436 & 688267 & 5.85 & 5.1271 & TST & \\
\hline CHEMBL1321287 & 688267 & 4.6 & 5.0655 & TRN & \\
\hline CHEMBL1348621 & 688267 & 4.75 & 5.0518 & TRN & \\
\hline CHEMBL1484813 & 688267 & 4.05 & 5.0273 & TST & \\
\hline CHEMBL1349388 & 688267 & 4.05 & 5.0665 & TRN & \\
\hline CHEMBL1342323 & 688267 & 5.8 & 5.0869 & TRN & \\
\hline CHEMBL1486581 & 688267 & 6.2 & 5.0081 & TRN & \\
\hline CHEMBL1456798 & 688267 & 5.3 & 5.0816 & TRN & \\
\hline CHEMBL1356213 & 688267 & 6.2 & 5.0691 & TRN & \\
\hline CHEMBL1450250 & 688267 & 4.0 & 5.0629 & TRN & \\
\hline CHEMBL1511361 & 688267 & 4.05 & 5.0998 & TRN & \\
\hline CHEMBL1321978 & 688267 & 3.95 & 5.1132 & TRN & \\
\hline CHEMBL1399530 & 688267 & 4.95 & 5.0372 & TRN & \\
\hline CHEMBL1538644 & 688267 & 5.05 & 5.0012 & TST & \\
\hline CHEMBL1477623 & 688267 & 4.55 & 5.091 & TRN & \\
\hline CHEMBL1456160 & 688267 & 6.45 & 5.1001 & TRN & \\
\hline CHEMBL1524874 & 688267 & 5.3 & 5.0368 & TRN & \\
\hline CHEMBL1537272 & 688267 & 6.15 & 5.0598 & TRN & \\
\hline CHEMBL1557140 & 688267 & 4.35 & 5.0334 & TRN & \\
\hline CHEMBL1533158 & 688267 & 4.5 & 5.0736 & TRN & \\
\hline CHEMBL3209763 & 688267 & 4.35 & 5.0013 & TRN & \\
\hline CHEMBL1357304 & 688267 & 3.95 & 5.001 & TRN & \\
\hline CHEMBL1446642 & 688267 & 5.35 & 5.0766 & TRN & \\
\hline CHEMBL1400578 & 688267 & 6.2 & 5.022 & TRN & \\
\hline CHEMBL1375316 & 688267 & 5.35 & 5.0298 & TRN & \\
\hline CHEMBL1534432 & 688267 & 4.7 & 5.0981 & TRN & \\
\hline CHEMBL1506370 & 688267 & 4.95 & 5.0576 & TST & \\
\hline CHEMBL1545103 & 688267 & 6.15 & 5.0203 & TST & \\
\hline CHEMBL1368705 & 688267 & 3.95 & 5.1815 & TRN & \\
\hline CHEMBL1492950 & 688267 & 4.1 & 5.04899 & 99999999995 & TRN \\
\hline CHEMBL1393173 & 688267 & 6.05 & 5.0636 & TST & \\
\hline CHEMBL1591627 & 688267 & 4.0 & 5.0774 & TRN & \\
\hline CHEMBL1400549 & 688267 & 4.45 & 5.0698 & TST & \\
\hline CHEMBL1450479 & 688267 & 5.8 & 5.0817 & TRN & \\
\hline CHEMBL1484605 & 688267 & 4.05 & 5.104 & TRN & \\
\hline CHEMBL1360125 & 688267 & 5.5 & 4.9994 & TRN & \\
\hline CHEMBL 260326 & 688267 & 6.2 & 4.9955 & TRN & \\
\hline CHEMBL3210960 & 688267 & 4.05 & 5.059 & TRN & \\
\hline CHEMBL1353986 & 688267 & 5.15 & 5.1376 & TST & \\
\hline CHEMBL1397793 & 688267 & 3.95 & 4.9754 & TRN & \\
\hline CHEMBL1578354 & 688267 & 4.55 & 5.046 & TRN & \\
\hline CHEMBL1613526 & 688267 & 4.8 & 5.1258 & TRN & \\
\hline CHEMBL1303198 & 688267 & 5.5 & 5.0856 & TRN & \\
\hline
\end{tabular}




\begin{tabular}{|c|c|c|c|c|c|}
\hline \\
\hline CHEMBL1550545 & 688267 & 6.2 & 5.1307 & TST & \\
\hline CHEMBL1350310 & 688267 & 4.25 & 5.0338 & TRN & \\
\hline CHEMBL1301167 & 688267 & 5.45 & 5.0763 & TST & \\
\hline CHEMBL1305150 & 688267 & 4.6 & 5.0567 & TRN & \\
\hline CHEMBL1539605 & 688267 & 5.3 & 5.0976 & TST & \\
\hline CHEMBL1361125 & 688267 & 4.2 & 5.0059 & TRN & \\
\hline CHEMBL1472135 & 688267 & 4.3 & 5.0652 & TRN & \\
\hline CHEMBL1421965 & 688267 & 3.95 & 5.1034 & TRN & \\
\hline CHEMBL1408901 & 688267 & 6.1 & 5.0553 & TST & \\
\hline CHEMBL1448551 & 688267 & 5.3 & 5.0723 & TRN & \\
\hline CHEMBL1558740 & 688267 & 6.2 & 5.0662 & TRN & \\
\hline CHEMBL1499527 & 688267 & 4.0 & 5.0335 & TST & \\
\hline CHEMBL1515967 & 688267 & 4.8 & 5.1291 & TST & \\
\hline CHEMBL1385732 & 688267 & 5.55 & 4.9958 & TRN & \\
\hline CHEMBL1473042 & 688267 & 6.15 & 5.1042 & TRN & \\
\hline CHEMBL1357669 & 688267 & 6.05 & 5.0127 & TRN & \\
\hline CHEMBL1363931 & 688267 & 4.2 & 5.0371 & TRN & \\
\hline CHEMBL1417597 & 688267 & 6.15 & 4.9904 & TRN & \\
\hline CHEMBL1358214 & 688267 & 6.2 & 5.0639 & TRN & \\
\hline CHEMBL1471912 & 688267 & 4.0 & 5.0273 & TRN & \\
\hline CHEMBL1602690 & 688267 & 5.7 & 5.0773 & TRN & \\
\hline CHEMBL1344814 & 688267 & 4.35 & 5.0525 & TRN & \\
\hline CHEMBL1464976 & 688267 & 5.55 & 5.0476 & TST & \\
\hline CHEMBL1518694 & 688267 & 5.6 & 5.0362 & TRN & \\
\hline CHEMBL1319803 & 688267 & 4.05 & 5.0421 & TRN & \\
\hline CHEMBL1425674 & 688267 & 4.4 & 4.99100 & 30000000005 & TRN \\
\hline CHEMBL1437313 & 688267 & 6.15 & 5.05699 & 99999999995 & TRN \\
\hline CHEMBL1479719 & 688267 & 5.25 & 5.0602 & TRN & \\
\hline CHEMBL1301837 & 688267 & 4.1 & 5.0881 & TRN & \\
\hline CHEMBL1397768 & 688267 & 4.15 & 5.0836 & TRN & \\
\hline CHEMBL1609727 & 688267 & 5.85 & 5.0552 & TRN & \\
\hline CHEMBL1390863 & 688267 & 4.35 & 5.032 & TRN & \\
\hline CHEMBL1608623 & 688267 & 4.7 & 5.1088 & TRN & \\
\hline CHEMBL1498645 & 688267 & 4.4 & 5.05 & TRN & \\
\hline CHEMBL1447779 & 688267 & 5.3 & 5.0942 & TRN & \\
\hline CHEMBL1423412 & 688267 & 3.95 & 5.0865 & TRN & \\
\hline CHEMBL1395467 & 688267 & 6.0 & 5.1319 & TRN & \\
\hline CHEMBL 1605340 & 688267 & 3.95 & 5.0068 & TST & \\
\hline CHEMBL1312440 & 688267 & 5.3 & 5.0528 & TRN & \\
\hline CHEMBL1357945 & 688267 & 4.6 & 5.0581 & TRN & \\
\hline CHEMBL1522917 & 688267 & 5.35 & 5.1151 & TST & \\
\hline CHEMBL1460725 & 688267 & 5.85 & 5.1051 & TRN & \\
\hline CHEMBL1339486 & 688267 & 3.95 & 5.1268 & TST & \\
\hline CHEMBL1487365 & 688267 & 4.5 & 5.044 & TRN & \\
\hline CHEMBL1351954 & 688267 & 5.95 & 5.0227 & TRN & \\
\hline CHEMBL1590144 & 688267 & 4.5 & 5.0622 & TRN & \\
\hline CHEMBL1550363 & 688267 & 5.4 & 5.0396 & TRN & \\
\hline CHEMBL1555774 & 688267 & 4.0 & 5.0039 & TRN & \\
\hline
\end{tabular}




\begin{tabular}{|c|c|c|c|c|}
\hline \multicolumn{5}{|c|}{ Supplemental Table S2.txt } \\
\hline CHEMBL1319562 & 688267 & 4.4 & 5.1021 & TRN \\
\hline CHEMBL1457869 & 688267 & 4.35 & 5.0979 & TRN \\
\hline CHEMBL1445266 & 688267 & 6.2 & 5.0713 & TRN \\
\hline CHEMBL1312653 & 688267 & 4.35 & 5.0615 & TRN \\
\hline CHEMBL1445103 & 688267 & 5.65 & 5.0307 & TRN \\
\hline CHEMBL3209473 & 688267 & 4.85 & 5.064 & TST \\
\hline CHEMBL1389128 & 688267 & 4.9 & 5.0047 & TST \\
\hline CHEMBL1316330 & 688267 & 4.0 & 5.0941 & TRN \\
\hline CHEMBL1441371 & 688267 & 5.05 & 5.0677 & TRN \\
\hline CHEMBL1387898 & 688267 & 4.0 & 5.041 & TRN \\
\hline CHEMBL1455371 & 688267 & 5.45 & 5.0769 & TST \\
\hline CHEMBL1360970 & 688267 & 4.9 & 5.0966 & TRN \\
\hline CHEMBL1488276 & 688267 & 4.65 & 5.0617 & TRN \\
\hline CHEMBL430193 & 688267 & 5.95 & 5.0715 & TRN \\
\hline CHEMBL1435243 & 688267 & 6.25 & 5.0564 & TRN \\
\hline CHEMBL1323554 & 688267 & 5.6 & 5.0521 & TST \\
\hline CHEMBL3191494 & 688267 & 4.5 & 4.9922 & TRN \\
\hline CHEMBL 3195662 & 688267 & 4.4 & 5.032 & TST \\
\hline CHEMBL1445776 & 688267 & 4.55 & 5.0709 & TST \\
\hline CHEMBL1385746 & 688267 & 3.95 & 5.0688 & TRN \\
\hline CHEMBL1431468 & 688267 & 6.15 & 5.0142 & TRN \\
\hline CHEMBL1457076 & 688267 & 5.0 & 5.0807 & TST \\
\hline CHEMBL1310290 & 688267 & 4.2 & 5.0068 & TST \\
\hline CHEMBL1422728 & 688267 & 5.15 & 5.1497 & TRN \\
\hline CHEMBL1549349 & 688267 & 5.1 & 5.0424 & TRN \\
\hline CHEMBL1529045 & 688267 & 4.0 & 5.0681 & TRN \\
\hline CHEMBL1393217 & 688267 & 4.05 & 5.1163 & TRN \\
\hline CHEMBL1436254 & 688267 & 4.4 & 5.1245 & TRN \\
\hline CHEMBL568169 & 688267 & 5.8 & 5.0191 & TRN \\
\hline CHEMBL1460867 & 688267 & 5.35 & 5.0953 & TRN \\
\hline CHEMBL1390033 & 688267 & 4.35 & 5.0132 & TRN \\
\hline CHEMBL1343468 & 688267 & 4.3 & 5.0752 & TRN \\
\hline CHEMBL1509459 & 688267 & 5.9 & 5.0183 & TST \\
\hline CHEMBL1307530 & 688267 & 6.2 & 5.0559 & TRN \\
\hline CHEMBL1422068 & 688267 & 6.2 & 5.0399 & TRN \\
\hline CHEMBL577595 & 688267 & 4.0 & 5.0505 & TST \\
\hline CHEMBL1320244 & 688267 & 4.05 & 5.1016 & TST \\
\hline CHEMBL1455347 & 688267 & 4.1 & 5.0926 & TRN \\
\hline CHEMBL1510076 & 688267 & 5.05 & 5.0581 & TRN \\
\hline CHEMBL1440666 & 688267 & 4.0 & 5.0174 & TRN \\
\hline CHEMBL1593352 & 688267 & 6.5 & 5.0608 & TRN \\
\hline CHEMBL3198786 & 688267 & 5.05 & 4.954 & TRN \\
\hline CHEMBL1481702 & 688267 & 4.05 & 5.1427 & TRN \\
\hline CHEMBL1578156 & 688267 & 4.2 & 5.0594 & TRN \\
\hline CHEMBL1602512 & 688267 & 4.0 & 5.0532 & TRN \\
\hline CHEMBL1331685 & 688267 & 6.2 & 5.0171 & TRN \\
\hline CHEMBL1593402 & 688267 & 6.2 & 5.0673 & TRN \\
\hline CHEMBL1312355 & 688267 & 5.5 & 5.0477 & TRN \\
\hline
\end{tabular}




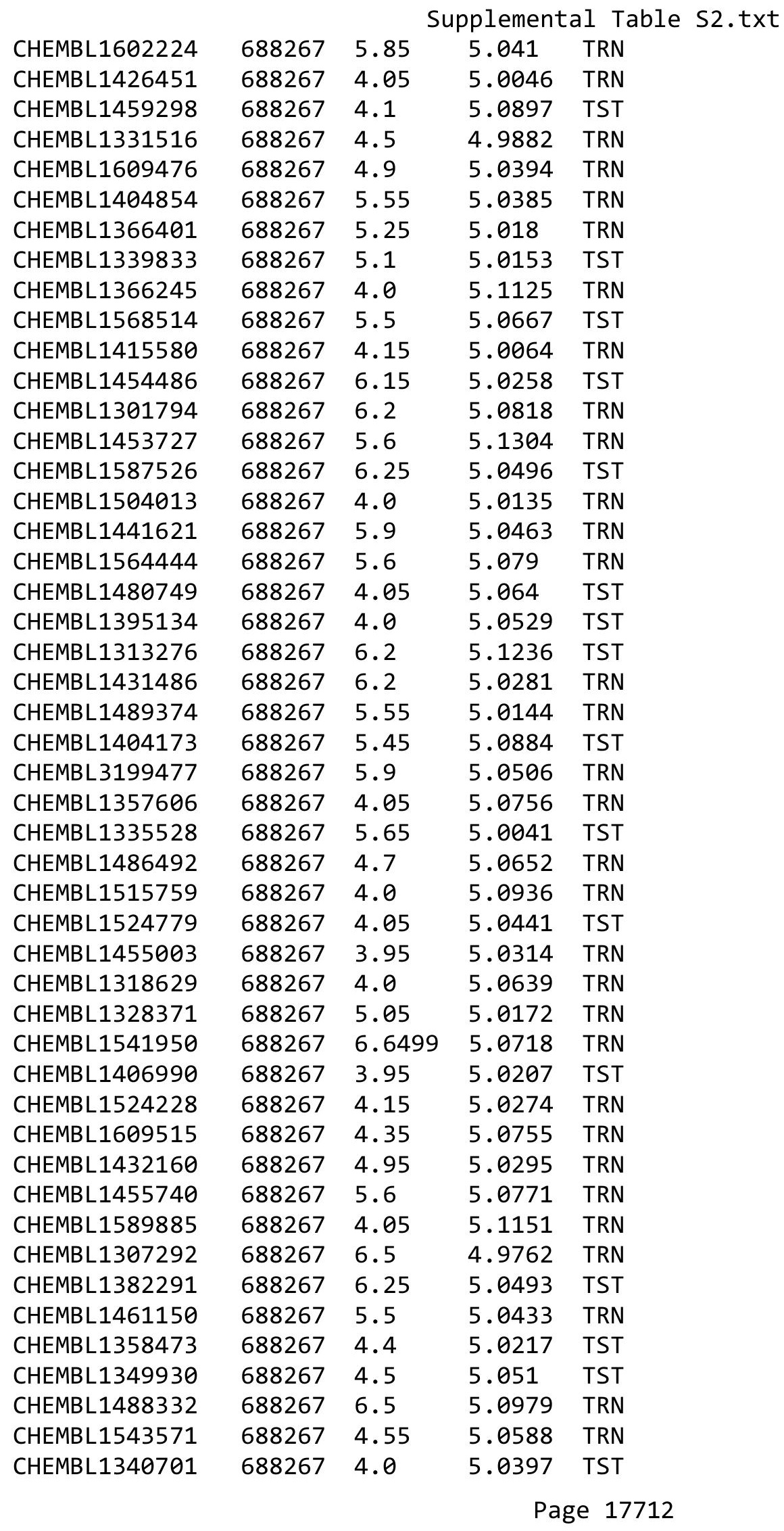




\begin{tabular}{|c|c|c|c|c|}
\hline & & & pplement & al $\mathrm{Ta}$ \\
\hline CHEMBL1431248 & 688267 & 6.2 & 5.1104 & TRN \\
\hline CHEMBL1518915 & 688267 & 4.95 & 5.0221 & TRN \\
\hline CHEMBL1388674 & 688267 & 4.35 & 5.0264 & TRN \\
\hline CHEMBL 3197876 & 688267 & 5.5 & 4.9985 & TRN \\
\hline CHEMBL1548013 & 688267 & 5.25 & 5.0137 & TRN \\
\hline CHEMBL1338384 & 688267 & 5.1 & 4.9979 & TRN \\
\hline CHEMBL1559400 & 688267 & 4.35 & 5.0347 & TRN \\
\hline CHEMBL1394670 & 688267 & 4.35 & 5.0279 & TRN \\
\hline CHEMBL1363886 & 688267 & 6.5 & 5.0644 & TRN \\
\hline CHEMBL1405552 & 688267 & 4.05 & 5.0206 & TRN \\
\hline CHEMBL1467013 & 688267 & 4.35 & 5.112 & TRN \\
\hline CHEMBL1349500 & 688267 & 6.5 & 5.0151 & TRN \\
\hline CHEMBL1409099 & 688267 & 4.35 & 5.1043 & TRN \\
\hline CHEMBL1367865 & 688267 & 4.65 & 5.1229 & TRN \\
\hline CHEMBL1358396 & 688267 & 4.05 & 5.0117 & TRN \\
\hline CHEMBL1443649 & 688267 & 5.2 & 5.0381 & TRN \\
\hline CHEMBL1519921 & 688267 & 6.2 & 4.9921 & TRN \\
\hline CHEMBL1476212 & 688267 & 3.95 & 5.1201 & TRN \\
\hline CHEMBL1311779 & 688267 & 4.3 & 5.0684 & TRN \\
\hline CHEMBL175434 & 688267 & 3.95 & 5.0406 & TST \\
\hline CHEMBL1436041 & 688267 & 6.2 & 5.0737 & TRN \\
\hline CHEMBL1300575 & 688267 & 4.3 & 5.0069 & TRN \\
\hline CHEMBL1461961 & 688267 & 4.0 & 5.0504 & TRN \\
\hline CHEMBL1516745 & 688267 & 5.5 & 5.0882 & TRN \\
\hline CHEMBL1482724 & 688267 & 6.2 & 5.0612 & TST \\
\hline CHEMBL1481656 & 688267 & 4.0 & 5.0388 & TRN \\
\hline CHEMBL1493832 & 688267 & 4.5 & 5.0877 & TST \\
\hline CHEMBL1564884 & 688267 & 5.1 & 5.0436 & TST \\
\hline CHEMBL1455409 & 688267 & 5.8 & 5.007 & TRN \\
\hline CHEMBL1510779 & 688267 & 5.05 & 5.0741 & TRN \\
\hline CHEMBL1491004 & 688267 & 4.95 & 5.0159 & TRN \\
\hline CHEMBL1558451 & 688267 & 6.2 & 5.0537 & TRN \\
\hline CHEMBL1319181 & 688267 & 4.05 & 5.124 & TRN \\
\hline CHEMBL1532599 & 688267 & 4.55 & 5.0231 & TRN \\
\hline CHEMBL1534836 & 688267 & 6.2 & 5.1089 & TST \\
\hline CHEMBL1441152 & 688267 & 5.6 & 5.0562 & TRN \\
\hline CHEMBL1584862 & 688267 & 5.45 & 5.0375 & TRN \\
\hline CHEMBL1330009 & 688267 & 4.0 & 5.067 & TRN \\
\hline CHEMBL1554711 & 688267 & 5.35 & 5.0868 & TST \\
\hline CHEMBL 2003153 & 688267 & 5.2 & 5.0125 & TRN \\
\hline CHEMBL3209957 & 688267 & 6.25 & 5.091 & TST \\
\hline CHEMBL1485258 & 688267 & 5.5 & 5.0657 & TST \\
\hline CHEMBL1511966 & 688267 & 4.1 & 5.0283 & TRN \\
\hline CHEMBL1391340 & 688267 & 4.75 & 5.069 & TST \\
\hline CHEMBL1355588 & 688267 & 6.0 & 5.1064 & TRN \\
\hline CHEMBL1590597 & 688267 & 6.2 & 5.0887 & TRN \\
\hline CHEMBL1984338 & 688267 & 4.8 & 4.9637 & TRN \\
\hline CHEMBL1351754 & 688267 & 5.55 & 5.0912 & TRN \\
\hline
\end{tabular}




\begin{tabular}{|c|c|c|c|c|c|}
\hline \multicolumn{6}{|c|}{ plemental } \\
\hline CHEMBL1364770 & 688267 & 4.4 & 5.1234 & TST & \\
\hline CHEMBL402477 & 688267 & 6.15 & 5.0709 & TRN & \\
\hline CHEMBL1366075 & 688267 & 4.6 & 5.0353 & TRN & \\
\hline CHEMBL1537074 & 688267 & 4.6 & 5.0915 & TRN & \\
\hline CHEMBL1488302 & 688267 & 6.2 & 5.0638 & TRN & \\
\hline CHEMBL1436674 & 688267 & 4.0 & 5.0913 & TRN & \\
\hline CHEMBL1532544 & 688267 & 5.2 & 5.1112 & TST & \\
\hline CHEMBL1452417 & 688267 & 5.55 & 5.0039 & TRN & \\
\hline CHEMBL1358668 & 688267 & 5.3 & 5.0591 & TRN & \\
\hline CHEMBL1550525 & 688267 & 5.85 & 5.1042 & TST & \\
\hline CHEMBL1456421 & 688267 & 4.05 & 5.0571 & TRN & \\
\hline CHEMBL1305454 & 688267 & 4.35 & 5.0203 & TRN & \\
\hline CHEMBL1412049 & 688267 & 5.4 & 5.1276 & TRN & \\
\hline CHEMBL1527123 & 688267 & 5.8 & 5.0445 & TRN & \\
\hline CHEMBL1399447 & 688267 & 4.85 & 5.0226 & TRN & \\
\hline CHEMBL1606737 & 688267 & 5.8 & 5.0794 & TRN & \\
\hline CHEMBL1531114 & 688267 & 5.3 & 5.1319 & TRN & \\
\hline CHEMBL1552009 & 688267 & 4.35 & 5.17299 & 9999999999 & TRN \\
\hline CHEMBL1608552 & 688267 & 6.15 & 5.0756 & TRN & \\
\hline CHEMBL1520838 & 688267 & 4.2 & 5.1096 & TRN & \\
\hline CHEMBL1436202 & 688267 & 5.9 & 5.0106 & TST & \\
\hline CHEMBL589458 & 688267 & 6.15 & 5.0848 & TST & \\
\hline CHEMBL1395742 & 688267 & 5.3 & 4.9776 & TST & \\
\hline CHEMBL1332812 & 688267 & 4.95 & 5.0162 & TRN & \\
\hline CHEMBL1357509 & 688267 & 5.0 & 5.0348 & TRN & \\
\hline CHEMBL1471791 & 688267 & 5.5 & 5.0872 & TRN & \\
\hline CHEMBL1430852 & 688267 & 4.1 & 5.0573 & TST & \\
\hline CHEMBL1585100 & 688267 & 4.0 & 5.1051 & TRN & \\
\hline CHEMBL1448862 & 688267 & 4.6 & 5.0303 & TRN & \\
\hline CHEMBL1467370 & 688267 & 4.0 & 5.0918 & TST & \\
\hline CHEMBL3191948 & 688267 & 4.6 & 5.0116 & TST & \\
\hline CHEMBL1320915 & 688267 & 6.2 & 5.0012 & TRN & \\
\hline CHEMBL3190561 & 688267 & 4.05 & 5.0404 & TRN & \\
\hline CHEMBL1482743 & 688267 & 4.9 & 5.0776 & TRN & \\
\hline CHEMBL1309938 & 688267 & 4.45 & 5.0796 & TST & \\
\hline CHEMBL1398708 & 688267 & 4.6 & 5.1134 & TRN & \\
\hline CHEMBL1530969 & 688267 & 4.05 & 5.0327 & TST & \\
\hline CHEMBL1397915 & 688267 & 6.15 & 5.0703 & TRN & \\
\hline CHEMBL1327767 & 688267 & 4.65 & 5.0481 & TRN & \\
\hline CHEMBL 3213188 & 688267 & 5.75 & 5.0219 & TST & \\
\hline CHEMBL1480235 & 688267 & 5.55 & 5.0653 & TST & \\
\hline CHEMBL399121 & 688267 & 5.25 & 5.075 & TST & \\
\hline CHEMBL1422869 & 688267 & 4.4 & 5.03100 & 0000000001 & TRN \\
\hline CHEMBL1544181 & 688267 & 6.2 & 5.0481 & TST & \\
\hline CHEMBL1474064 & 688267 & 6.2 & 5.1178 & TST & \\
\hline CHEMBL1514451 & 688267 & 4.8 & 5.0625 & TRN & \\
\hline CHEMBL1387313 & 688267 & 4.75 & 5.0 & TRN & \\
\hline CHEMBL1446070 & 688267 & 5.65 & 4.9834 & TRN & \\
\hline
\end{tabular}




\begin{tabular}{|c|c|c|c|c|}
\hline \multicolumn{5}{|c|}{ Supplemental Table S2.txt } \\
\hline CHEMBL1397193 & 688267 & 4.2 & 5.037 & TRN \\
\hline CHEMBL1492841 & 688267 & 5.6 & 5.0361 & TST \\
\hline CHEMBL1300741 & 688267 & 4.05 & 5.001 & TRN \\
\hline CHEMBL1592659 & 688267 & 5.4 & 5.0177 & TRN \\
\hline CHEMBL1399354 & 688267 & 5.55 & 5.0187 & TRN \\
\hline CHEMBL1602503 & 688267 & 6.25 & 5.1035 & TRN \\
\hline CHEMBL1490902 & 688267 & 5.8 & 5.0262 & TRN \\
\hline CHEMBL1383472 & 688267 & 6.2 & 5.0277 & TRN \\
\hline CHEMBL1399857 & 688267 & 6.2 & 5.0824 & TST \\
\hline CHEMBL1322109 & 688267 & 3.95 & 5.0089 & TRN \\
\hline CHEMBL1600227 & 688267 & 6.5 & 5.067 & TRN \\
\hline CHEMBL1440554 & 688267 & 6.15 & 5.0313 & TRN \\
\hline CHEMBL1310180 & 688267 & 5.1 & 5.0885 & TRN \\
\hline CHEMBL1502175 & 688267 & 4.75 & 5.0063 & TRN \\
\hline CHEMBL1395423 & 688267 & 4.1 & 5.0211 & TRN \\
\hline CHEMBL1577524 & 688267 & 4.3 & 5.0859 & TST \\
\hline CHEMBL1474643 & 688267 & 4.35 & 5.0184 & TRN \\
\hline CHEMBL1514037 & 688267 & 4.05 & 5.0507 & TRN \\
\hline CHEMBL1406095 & 688267 & 6.45 & 5.039 & TRN \\
\hline CHEMBL1428547 & 688267 & 5.75 & 5.0762 & TST \\
\hline CHEMBL1474809 & 688267 & 5.1 & 5.0767 & TRN \\
\hline CHEMBL1532737 & 688267 & 4.05 & 5.0601 & TRN \\
\hline CHEMBL1374090 & 688267 & 5.6 & 4.9991 & TRN \\
\hline CHEMBL1527520 & 688267 & 4.15 & 5.0588 & TRN \\
\hline CHEMBL1538917 & 688267 & 6.15 & 5.0409 & TST \\
\hline CHEMBL1434804 & 688267 & 4.05 & 5.0463 & TRN \\
\hline CHEMBL1482198 & 688267 & 5.55 & 5.0298 & TST \\
\hline CHEMBL1342116 & 688267 & 4.4 & 5.0139 & TRN \\
\hline CHEMBL1514634 & 688267 & 6.45 & 5.0978 & TST \\
\hline CHEMBL1559667 & 688267 & 5.65 & 5.0805 & TST \\
\hline CHEMBL1324287 & 688267 & 5.35 & 5.0879 & TRN \\
\hline CHEMBL1589846 & 688267 & 6.2 & 5.0147 & TRN \\
\hline CHEMBL1553345 & 688267 & 4.0 & 5.0453 & TRN \\
\hline CHEMBL1510855 & 688267 & 4.0 & 5.1115 & TRN \\
\hline CHEMBL1336738 & 688267 & 5.6 & 5.0149 & TRN \\
\hline CHEMBL1481290 & 688267 & 5.3 & 5.0953 & TRN \\
\hline CHEMBL1393485 & 688267 & 4.1 & 5.0121 & TST \\
\hline CHEMBL1571328 & 688267 & 5.8 & 5.0352 & TRN \\
\hline CHEMBL1482278 & 688267 & 5.8 & 5.0353 & TRN \\
\hline CHEMBL1538471 & 688267 & 4.95 & 5.0678 & TRN \\
\hline CHEMBL1317770 & 688267 & 5.4 & 5.0101 & TRN \\
\hline CHEMBL1508578 & 688267 & 6.0 & 5.0207 & TST \\
\hline CHEMBL1498274 & 688267 & 4.05 & 5.0997 & TRN \\
\hline CHEMBL1376013 & 688267 & 4.25 & 5.1029 & TRN \\
\hline CHEMBL1565612 & 688267 & 3.95 & 5.0709 & TRN \\
\hline CHEMBL1314263 & 688267 & 6.25 & 5.0674 & TRN \\
\hline CHEMBL1540613 & 688267 & 4.25 & 5.1166 & TRN \\
\hline CHEMBL1401093 & 688267 & 4.25 & 5.0488 & TST \\
\hline
\end{tabular}




\begin{tabular}{|c|c|c|c|c|}
\hline \multicolumn{5}{|c|}{ Supplemental Table S2.txt } \\
\hline CHEMBL1409225 & 688267 & 6.15 & 5.1229 & TRN \\
\hline CHEMBL1431255 & 688267 & 5.75 & 5.0511 & TRN \\
\hline CHEMBL1535171 & 688267 & 3.95 & 5.0161 & TRN \\
\hline CHEMBL1440393 & 688267 & 4.25 & 5.0389 & TST \\
\hline CHEMBL1365578 & 688267 & 6.2 & 5.0022 & TRN \\
\hline CHEMBL1540880 & 688267 & 6.2 & 5.0455 & TRN \\
\hline CHEMBL1334062 & 688267 & 4.25 & 5.0223 & TST \\
\hline CHEMBL1329180 & 688267 & 3.95 & 5.1291 & TRN \\
\hline CHEMBL1474520 & 688267 & 5.55 & 5.0167 & TRN \\
\hline CHEMBL1482105 & 688267 & 6.5 & 4.9906 & TRN \\
\hline CHEMBL1508473 & 688267 & 7.4001 & 5.0101 & TRN \\
\hline CHEMBL1509979 & 688267 & 4.65 & 4.9955 & TRN \\
\hline CHEMBL1358169 & 688267 & 5.9 & 5.0352 & TRN \\
\hline CHEMBL1482889 & 688267 & 6.2 & 5.0699 & TRN \\
\hline CHEMBL1409299 & 688267 & 5.35 & 5.1235 & TRN \\
\hline CHEMBL1370746 & 688267 & 4.25 & 5.052 & TRN \\
\hline CHEMBL1338979 & 688267 & 5.25 & 5.1141 & TRN \\
\hline CHEMBL1401331 & 688267 & 5.9 & 4.9987 & TRN \\
\hline CHEMBL1415397 & 688267 & 4.65 & 5.0189 & TRN \\
\hline CHEMBL1342894 & 688267 & 4.1 & 5.0215 & TST \\
\hline CHEMBL1435848 & 688267 & 5.25 & 5.1278 & TRN \\
\hline CHEMBL1473879 & 688267 & 6.6 & 5.0265 & TRN \\
\hline CHEMBL1516423 & 688267 & 4.05 & 5.0304 & TRN \\
\hline CHEMBL1595785 & 688267 & 6.2 & 5.0705 & TST \\
\hline CHEMBL1493240 & 688267 & 4.3 & 5.0121 & TRN \\
\hline CHEMBL1364350 & 688267 & 4.6 & 5.0687 & TST \\
\hline CHEMBL1357885 & 688267 & 4.05 & 5.0796 & TRN \\
\hline CHEMBL3190380 & 688267 & 4.95 & 4.9991 & TRN \\
\hline CHEMBL1572889 & 688267 & 5.05 & 5.0675 & TRN \\
\hline CHEMBL1546498 & 688267 & 4.35 & 5.0464 & TRN \\
\hline CHEMBL1563315 & 688267 & 4.05 & 5.1118 & TRN \\
\hline CHEMBL1555622 & 688267 & 4.0 & 5.0768 & TRN \\
\hline CHEMBL3197958 & 688267 & 4.1 & 4.975 & TRN \\
\hline CHEMBL1368763 & 688267 & 4.0 & 5.0165 & TRN \\
\hline CHEMBL1395570 & 688267 & 4.4 & 5.0155 & TRN \\
\hline CHEMBL1548723 & 688267 & 5.75 & 5.0829 & TST \\
\hline CHEMBL 304383 & 688267 & 4.0 & 5.0635 & TST \\
\hline CHEMBL3212383 & 688267 & 6.05 & 5.0178 & TST \\
\hline CHEMBL1567468 & 688267 & 4.35 & 5.0336 & TRN \\
\hline CHEMBL2369312 & 688267 & 4.0 & 5.0299 & TST \\
\hline CHEMBL1527875 & 688267 & 6.2 & 5.0903 & TRN \\
\hline CHEMBL1589864 & 688267 & 4.75 & 5.0913 & TRN \\
\hline CHEMBL1366217 & 688267 & 4.35 & 5.1087 & TST \\
\hline CHEMBL3211186 & 688267 & 6.15 & 5.0953 & TRN \\
\hline CHEMBL1397923 & 688267 & 5.75 & 5.0462 & TRN \\
\hline CHEMBL1465585 & 688267 & 4.0 & 5.0573 & TST \\
\hline CHEMBL1505655 & 688267 & 6.25 & 5.1104 & TST \\
\hline CHEMBL1347379 & 688267 & 6.2 & 5.1034 & TRN \\
\hline
\end{tabular}




\begin{tabular}{|c|c|c|c|c|c|}
\hline \multicolumn{6}{|c|}{ Supplemental Table S2.txt } \\
\hline CHEMBL1521047 & 688267 & 4.05 & 5.0333 & TRN & \\
\hline CHEMBL1359788 & 688267 & 4.4 & 5.0146 & TRN & \\
\hline CHEMBL1473992 & 688267 & 4.0 & 5.101 & TRN & \\
\hline CHEMBL1600739 & 688267 & 5.45 & 5.0057 & TRN & \\
\hline CHEMBL1609480 & 688267 & 6.6499 & 5.0511 & TRN & \\
\hline CHEMBL1438865 & 688267 & 4.55 & 5.1297 & TRN & \\
\hline CHEMBL1495530 & 688267 & 4.5 & 5.1208 & TST & \\
\hline CHEMBL1563202 & 688267 & 6.15 & 5.0223 & TST & \\
\hline CHEMBL1318063 & 688267 & 4.95 & 5.1027 & TRN & \\
\hline CHEMBL1531903 & 688267 & 4.0 & 5.0921 & TST & \\
\hline CHEMBL1492687 & 688267 & 6.1 & 5.0322 & TRN & \\
\hline CHEMBL1550284 & 688267 & 5.45 & 5.0474 & TST & \\
\hline CHEMBL1372788 & 688267 & 4.6 & 5.0543 & TST & \\
\hline CHEMBL1474184 & 688267 & 6.2 & 5.0656 & TRN & \\
\hline CHEMBL1465646 & 688267 & 4.0 & 5.1011 & TRN & \\
\hline CHEMBL3196450 & 688267 & 4.65 & 5.0282 & TRN & \\
\hline CHEMBL1567748 & 688267 & 4.0 & 4.9882 & TRN & \\
\hline CHEMBL1552494 & 688267 & 5.3 & 4.96899 & 9999999999 & TRN \\
\hline CHEMBL1408501 & 688267 & 6.2 & 5.1185 & TRN & \\
\hline CHEMBL1519913 & 688267 & 6.5 & 5.1431 & TST & \\
\hline CHEMBL1474919 & 688267 & 5.55 & 5.0729 & TRN & \\
\hline CHEMBL1468580 & 688267 & 4.35 & 4.9687 & TRN & \\
\hline CHEMBL1359232 & 688267 & 5.05 & 5.0783 & TST & \\
\hline CHEMBL1450379 & 688267 & 4.5 & 5.074 & TRN & \\
\hline CHEMBL1495193 & 688267 & 4.05 & 5.0188 & TRN & \\
\hline CHEMBL1571925 & 688267 & 4.35 & 5.0566 & TRN & \\
\hline CHEMBL1571548 & 688267 & 6.2 & 5.0124 & TRN & \\
\hline CHEMBL1992164 & 688267 & 6.2 & 4.9807 & TRN & \\
\hline CHEMBL1455168 & 688267 & 5.75 & 5.091 & TRN & \\
\hline CHEMBL1335202 & 688267 & 5.8 & 5.0505 & TRN & \\
\hline CHEMBL1555965 & 688267 & 6.25 & 5.1065 & TST & \\
\hline CHEMBL1602734 & 688267 & 6.25 & 5.073 & TRN & \\
\hline CHEMBL1485911 & 688267 & 5.4 & 5.0608 & TST & \\
\hline CHEMBL1405535 & 688267 & 5.5 & 5.1155 & TRN & \\
\hline CHEMBL1547795 & 688267 & 3.95 & 5.0152 & TRN & \\
\hline CHEMBL1428520 & 688267 & 3.95 & 5.0753 & TRN & \\
\hline CHEMBL1979550 & 688267 & 4.75 & 5.0519 & TRN & \\
\hline CHEMBL1350031 & 688267 & 4.4 & 5.0782 & TRN & \\
\hline CHEMBL1362077 & 688267 & 6.2 & 5.0116 & TRN & \\
\hline CHEMBL1394424 & 688267 & 6.2 & 5.0284 & TST & \\
\hline CHEMBL 1408660 & 688267 & 6.2 & 5.074 & TRN & \\
\hline CHEMBL1407060 & 688267 & 4.3 & 5.0839 & TST & \\
\hline CHEMBL1420493 & 688267 & 4.0 & 5.0754 & TST & \\
\hline CHEMBL1564906 & 688267 & 6.2 & 5.141 & TRN & \\
\hline CHEMBL1565696 & 688267 & 4.1 & 5.0489 & TRN & \\
\hline CHEMBL1557010 & 688267 & 5.1 & 5.0247 & TST & \\
\hline CHEMBL1355785 & 688267 & 5.85 & 5.0922 & TRN & \\
\hline CHEMBL1386937 & 688267 & 4.0 & 5.0413 & TRN & \\
\hline
\end{tabular}




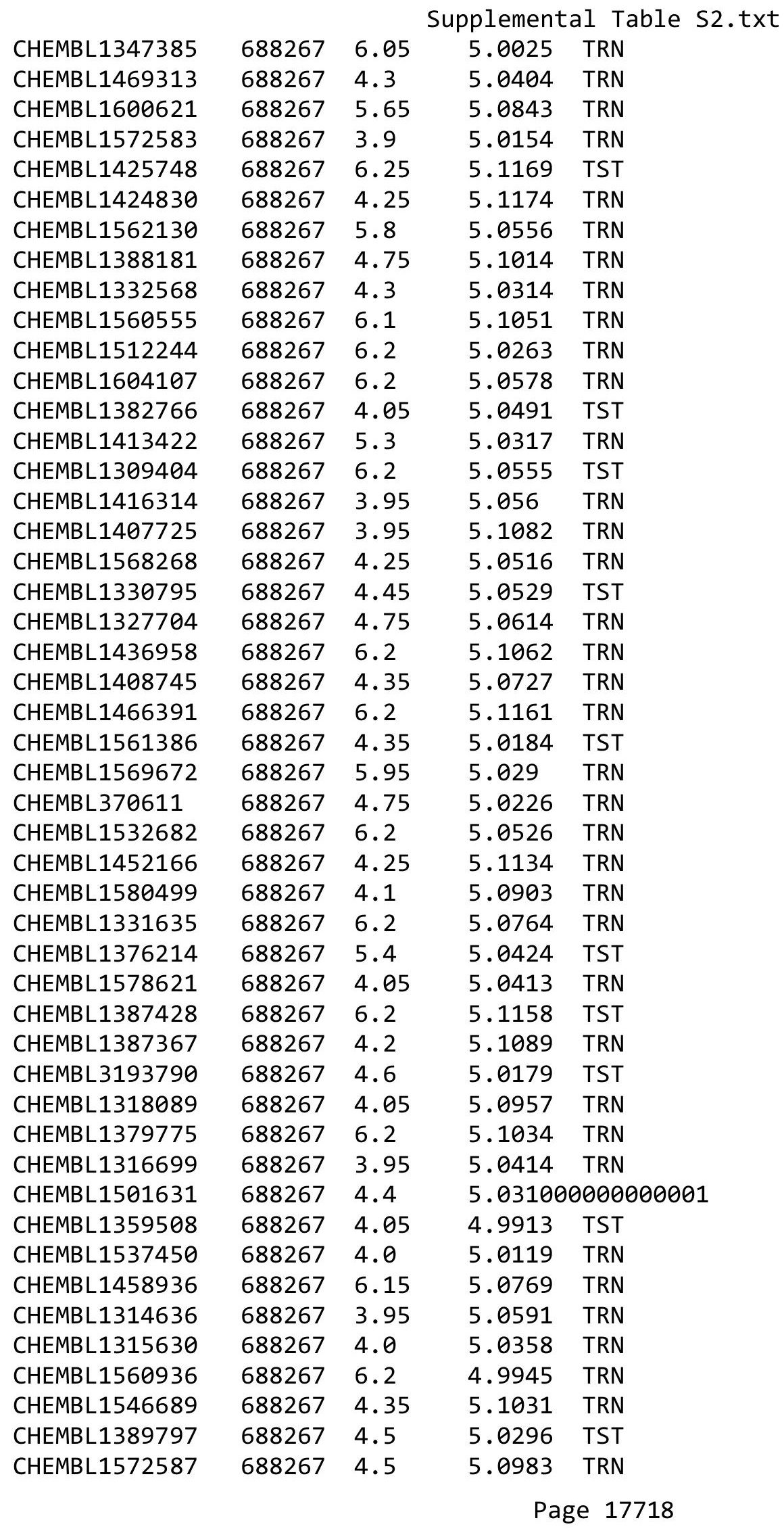




\begin{tabular}{|c|c|c|c|c|}
\hline \multicolumn{5}{|c|}{ Supplemental Table S2.txt } \\
\hline CHEMBL1524055 & 688267 & 5.9 & 5.1387 & TRN \\
\hline CHEMBL1364455 & 688267 & 5.95 & 5.0718 & TRN \\
\hline CHEMBL1509328 & 688267 & 5.6 & 5.1118 & TRN \\
\hline CHEMBL1433526 & 688267 & 6.15 & 5.1095 & TRN \\
\hline CHEMBL1559507 & 688267 & 5.6 & 5.0524 & TRN \\
\hline CHEMBL1516204 & 688267 & 4.05 & 5.0182 & TRN \\
\hline CHEMBL1328869 & 688267 & 5.8 & 5.035 & TST \\
\hline CHEMBL1315884 & 688267 & 4.0 & 5.0125 & TRN \\
\hline CHEMBL1518656 & 688267 & 5.0 & 5.0852 & TRN \\
\hline CHEMBL3212700 & 688267 & 5.75 & 5.0324 & TST \\
\hline CHEMBL3194746 & 688267 & 4.0 & 5.0525 & TST \\
\hline CHEMBL1560305 & 688267 & 4.3 & 4.9883 & TRN \\
\hline CHEMBL1474874 & 688267 & 3.95 & 5.012 & TRN \\
\hline CHEMBL1439683 & 688267 & 4.0 & 5.1197 & TRN \\
\hline CHEMBL3210640 & 688267 & 4.95 & 4.9744 & TRN \\
\hline CHEMBL1362475 & 688267 & 5.4 & 5.0351 & TRN \\
\hline CHEMBL1435096 & 688267 & 5.1 & 5.081 & TRN \\
\hline CHEMBL1612002 & 688267 & 4.35 & 5.0591 & TRN \\
\hline CHEMBL1411945 & 688267 & 4.75 & 5.0494 & TRN \\
\hline CHEMBL1301361 & 688267 & 4.05 & 5.0118 & TRN \\
\hline CHEMBL1371559 & 688267 & 6.5 & 5.1129 & TST \\
\hline CHEMBL1596770 & 688267 & 5.45 & 5.1335 & TST \\
\hline CHEMBL1521920 & 688267 & 6.2 & 5.0649 & TRN \\
\hline CHEMBL1314993 & 688267 & 4.05 & 5.018 & TST \\
\hline CHEMBL1560378 & 688267 & 4.0 & 5.0188 & TRN \\
\hline CHEMBL1370757 & 688267 & 4.35 & 5.0969 & TST \\
\hline CHEMBL1604195 & 688267 & 4.0 & 5.0619 & TRN \\
\hline CHEMBL1339009 & 688267 & 6.0 & 5.0786 & TRN \\
\hline CHEMBL1507618 & 688267 & 5.35 & 5.0293 & TRN \\
\hline CHEMBL1603834 & 688267 & 4.05 & 5.0169 & TRN \\
\hline CHEMBL3211386 & 688267 & 5.05 & 5.062 & TRN \\
\hline CHEMBL1551208 & 688267 & 5.0 & 5.0495 & TST \\
\hline CHEMBL1609662 & 688267 & 5.5 & 5.0677 & TRN \\
\hline CHEMBL1564207 & 688267 & 6.0 & 5.0978 & TST \\
\hline CHEMBL1337823 & 688267 & 4.0 & 5.0696 & TRN \\
\hline CHEMBL1364828 & 688267 & 6.2 & 5.0445 & TRN \\
\hline CHEMBL234978 & 688267 & 5.85 & 4.9887 & TRN \\
\hline CHEMBL1495715 & 688267 & 5.4 & 5.043 & TRN \\
\hline CHEMBL1338270 & 688267 & 5.95 & 5.0911 & TST \\
\hline CHEMBL1486653 & 688267 & 6.5 & 5.1088 & TST \\
\hline CHEMBL1406219 & 688267 & 4.1 & 5.0168 & TRN \\
\hline CHEMBL1527633 & 688267 & 6.2 & 5.0778 & TST \\
\hline CHEMBL1317330 & 688267 & 6.15 & 5.0738 & TRN \\
\hline CHEMBL1405767 & 688267 & 6.2 & 5.0606 & TRN \\
\hline CHEMBL1391853 & 688267 & 4.5 & 5.1017 & TRN \\
\hline CHEMBL1424238 & 688267 & 6.5 & 5.011 & TRN \\
\hline CHEMBL1335676 & 688267 & 4.35 & 5.0461 & TRN \\
\hline CHEMBL1415772 & 688267 & 4.5 & 5.0377 & TRN \\
\hline
\end{tabular}




\begin{tabular}{|c|c|c|c|c|c|}
\hline \\
\hline CHEMBL1575764 & 688267 & 4.0 & 5.0801 & TRN & \\
\hline CHEMBL1305803 & 688267 & 5.0 & 5.0244 & TRN & \\
\hline CHEMBL1343252 & 688267 & 5.25 & 5.0199 & TRN & \\
\hline CHEMBL1545294 & 688267 & 4.3 & 5.1036 & TST & \\
\hline CHEMBL1604668 & 688267 & 5.3 & 5.0396 & TRN & \\
\hline CHEMBL1606004 & 688267 & 4.35 & 5.0362 & TRN & \\
\hline CHEMBL1355471 & 688267 & 5.35 & 5.0992 & TRN & \\
\hline CHEMBL1568425 & 688267 & 5.3 & 4.9869 & TRN & \\
\hline CHEMBL1473609 & 688267 & 4.05 & 5.0206 & TRN & \\
\hline CHEMBL1481213 & 688267 & 4.6 & 5.0642 & TRN & \\
\hline CHEMBL1255870 & 688267 & 5.3 & 5.0931 & TST & \\
\hline CHEMBL1594272 & 688267 & 4.3 & 5.1106 & TST & \\
\hline CHEMBL1511255 & 688267 & 6.2 & 5.0222 & TRN & \\
\hline CHEMBL1439849 & 688267 & 3.95 & 5.1174 & TRN & \\
\hline CHEMBL1362201 & 688267 & 4.5 & 5.0777 & TST & \\
\hline CHEMBL1386972 & 688267 & 5.5 & 5.0288 & TRN & \\
\hline CHEMBL1352123 & 688267 & 6.2 & 5.0453 & TRN & \\
\hline CHEMBL1554597 & 688267 & 5.15 & 5.0376 & TRN & \\
\hline CHEMBL3191345 & 688267 & 4.8 & 5.0152 & TST & \\
\hline CHEMBL1553407 & 688267 & 4.1 & 5.1304 & TRN & \\
\hline CHEMBL1407404 & 688267 & 4.6 & 5.019 & TRN & \\
\hline CHEMBL1458885 & 688267 & 4.35 & 5.0863 & TRN & \\
\hline CHEMBL1427613 & 688267 & 6.15 & 5.0614 & TRN & \\
\hline CHEMBL3195520 & 688267 & 6.2 & 5.0661 & TRN & \\
\hline CHEMBL1539894 & 688267 & 4.05 & 5.0155 & TST & \\
\hline CHEMBL1404373 & 688267 & 4.0 & 5.0471 & TST & \\
\hline CHEMBL1438704 & 688267 & 4.35 & 5.0808 & TRN & \\
\hline CHEMBL1452484 & 688267 & 5.0 & 5.0469 & TRN & \\
\hline CHEMBL1372519 & 688267 & 4.65 & 5.0403 & TRN & \\
\hline CHEMBL1594780 & 688267 & 4.0 & 5.0095 & TRN & \\
\hline CHEMBL1418723 & 688267 & 4.0 & 5.0499 & TST & \\
\hline CHEMBL1402695 & 688267 & 4.0 & 5.082 & TRN & \\
\hline CHEMBL1520646 & 688267 & 4.1 & 5.0738 & TRN & \\
\hline CHEMBL1510019 & 688267 & 4.05 & 5.0821 & TST & \\
\hline CHEMBL1567381 & 688267 & 4.25 & 5.0774 & TRN & \\
\hline CHEMBL1514630 & 688267 & 5.5 & 5.0762 & TST & \\
\hline CHEMBL1505394 & 688267 & 6.45 & 5.1324 & TRN & \\
\hline CHEMBL1316333 & 688267 & 5.0 & 5.0581 & TRN & \\
\hline CHEMBL1537126 & 688267 & 4.45 & 5.00899 & 99999999995 & TRN \\
\hline CHEMBL1575573 & 688267 & 4.5 & 5.1401 & TST & \\
\hline CHEMBL1499391 & 688267 & 4.1 & 5.0347 & TRN & \\
\hline CHEMBL3209298 & 688267 & 6.2 & 5.0348 & TST & \\
\hline CHEMBL1375880 & 688267 & 4.9 & 5.1019 & TRN & \\
\hline CHEMBL1538291 & 688267 & 6.2 & 5.12 & TRN & \\
\hline CHEMBL 1421420 & 688267 & 4.0 & 5.0445 & TST & \\
\hline CHEMBL1385404 & 688267 & 5.05 & 5.0337 & TRN & \\
\hline CHEMBL1454073 & 688267 & 4.0 & 5.0473 & TRN & \\
\hline CHEMBL1441098 & 688267 & 3.95 & 4.9874 & TRN & \\
\hline
\end{tabular}




\begin{tabular}{|c|c|c|c|c|c|}
\hline & & \multicolumn{4}{|c|}{ Supplemental Table s2.txt } \\
\hline CHEMBL1401818 & 688267 & 3.95 & 4.9758 & TRN & \\
\hline CHEMBL1979018 & 688267 & 4.75 & 5.011 & TRN & \\
\hline CHEMBL1348223 & 688267 & 6.45 & 5.0278 & TRN & \\
\hline CHEMBL1564950 & 688267 & 4.55 & 5.0134 & TRN & \\
\hline CHEMBL1526015 & 688267 & 4.1 & 5.0827 & TRN & \\
\hline CHEMBL1385124 & 688267 & 4.4 & 5.0777 & TRN & \\
\hline CHEMBL1600389 & 688267 & 4.7 & 5.0677 & TRN & \\
\hline CHEMBL1372260 & 688267 & 4.35 & 5.0775 & TRN & \\
\hline CHEMBL1597996 & 688267 & 4.05 & 4.9687 & TRN & \\
\hline CHEMBL1446628 & 688267 & 4.9 & 5.0569 & TRN & \\
\hline CHEMBL1403743 & 688267 & 5.55 & 5.1212 & TRN & \\
\hline CHEMBL1589843 & 688267 & 4.25 & 5.0063 & TRN & \\
\hline CHEMBL1376977 & 688267 & 4.35 & 5.079 & TRN & \\
\hline CHEMBL1436835 & 688267 & 4.35 & 5.0148 & TRN & \\
\hline CHEMBL1456311 & 688267 & 4.6 & 5.0397 & TRN & \\
\hline CHEMBL1402073 & 688267 & 6.15 & 5.1663 & TST & \\
\hline CHEMBL1584591 & 688267 & 6.5 & 5.0407 & TST & \\
\hline CHEMBL1414051 & 688267 & 6.2 & 5.0612 & TRN & \\
\hline CHEMBL1412283 & 688267 & 5.5 & 5.0661 & TRN & \\
\hline CHEMBL1569711 & 688267 & 4.25 & 4.994 & TST & \\
\hline CHEMBL1387949 & 688267 & 5.55 & 5.0229 & TST & \\
\hline CHEMBL1450340 & 688267 & 6.2 & 5.0163 & TRN & \\
\hline CHEMBL1572973 & 688267 & 4.5 & 5.0286 & TRN & \\
\hline CHEMBL1332252 & 688267 & 6.25 & 5.1583 & TRN & \\
\hline CHEMBL1430963 & 688267 & 4.0 & 5.1518 & TRN & \\
\hline CHEMBL1432379 & 688267 & 5.9 & 5.1198 & TRN & \\
\hline CHEMBL1458914 & 688267 & 5.65 & 5.0348 & TRN & \\
\hline CHEMBL1413973 & 688267 & 5.45 & 5.0203 & TRN & \\
\hline CHEMBL1500959 & 688267 & 4.2 & 4.9909 & TRN & \\
\hline CHEMBL1353217 & 688267 & 5.65 & 5.069 & TST & \\
\hline CHEMBL1425756 & 688267 & 3.95 & 5.038 & TST & \\
\hline CHEMBL1318244 & 688267 & 5.4 & 5.0596 & TRN & \\
\hline CHEMBL1553241 & 688267 & 6.2 & 5.1163 & TRN & \\
\hline CHEMBL1324602 & 688267 & 6.2 & 5.07 & TRN & \\
\hline CHEMBL1560110 & 688267 & 5.15 & 5.1181 & TRN & \\
\hline CHEMBL396323 & 688267 & 5.5 & 5.0973 & TRN & \\
\hline CHEMBL1402795 & 688267 & 5.85 & 5.0741 & TRN & \\
\hline CHEMBL1433809 & 688267 & 5.3 & 5.15600 & 0000000001 & TRN \\
\hline CHEMBL1317359 & 688267 & 6.25 & 5.0788 & TRN & \\
\hline CHEMBL1588155 & 688267 & 5.1 & 5.0375 & TRN & \\
\hline CHEMBL1420517 & 688267 & 4.45 & 5.0063 & TRN & \\
\hline CHEMBL1552050 & 688267 & 6.2 & 5.041 & TRN & \\
\hline CHEMBL1402821 & 688267 & 4.05 & 5.0673 & TRN & \\
\hline CHEMBL1386728 & 688267 & 6.3 & 5.0303 & TRN & \\
\hline CHEMBL1316653 & 688267 & 6.5 & 5.0384 & TRN & \\
\hline CHEMBL1579077 & 688267 & 4.0 & 5.0403 & TRN & \\
\hline CHEMBL1536322 & 688267 & 6.15 & 5.0138 & TRN & \\
\hline CHEMBL1329535 & 688267 & 4.05 & 5.0666 & TRN & \\
\hline
\end{tabular}




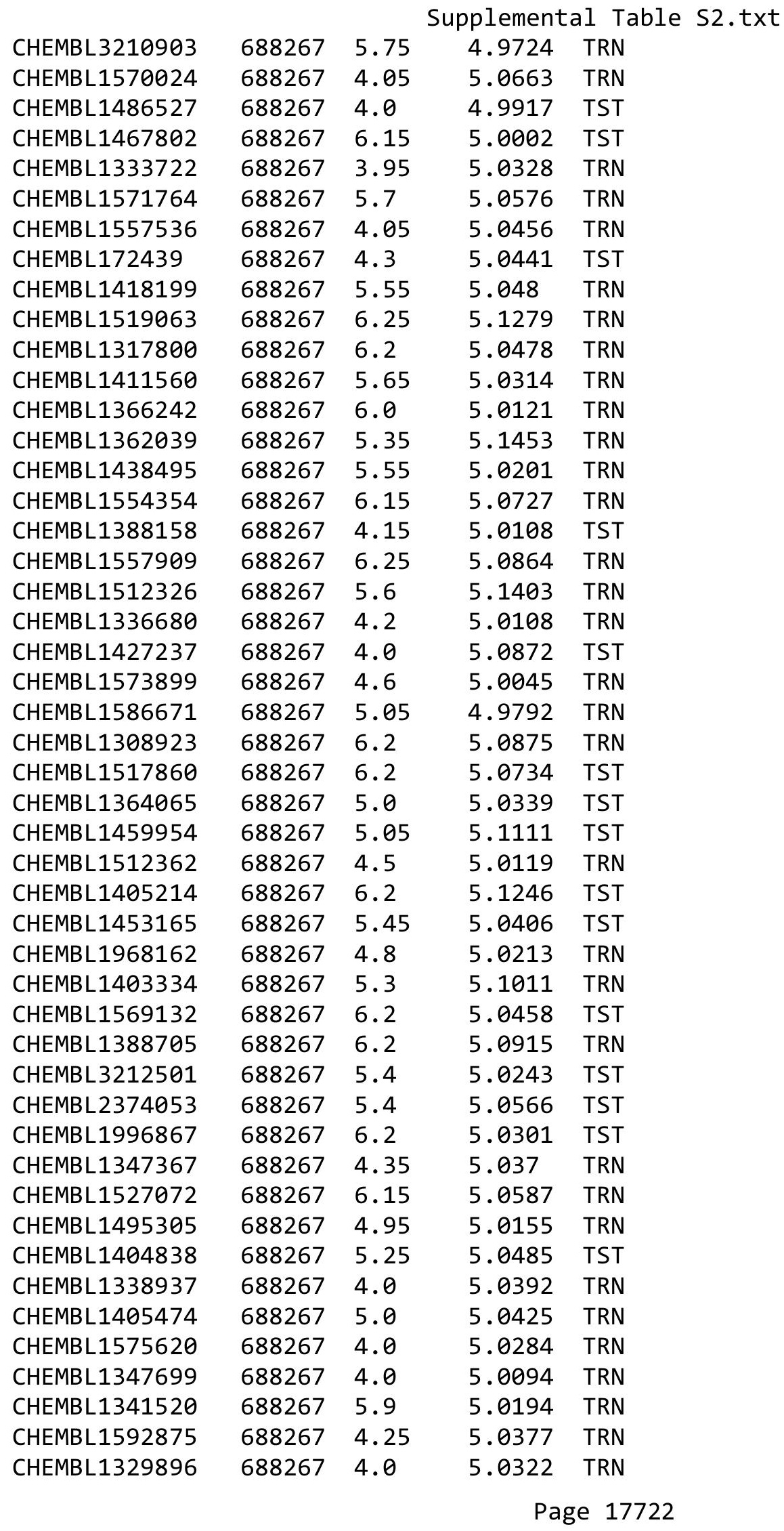




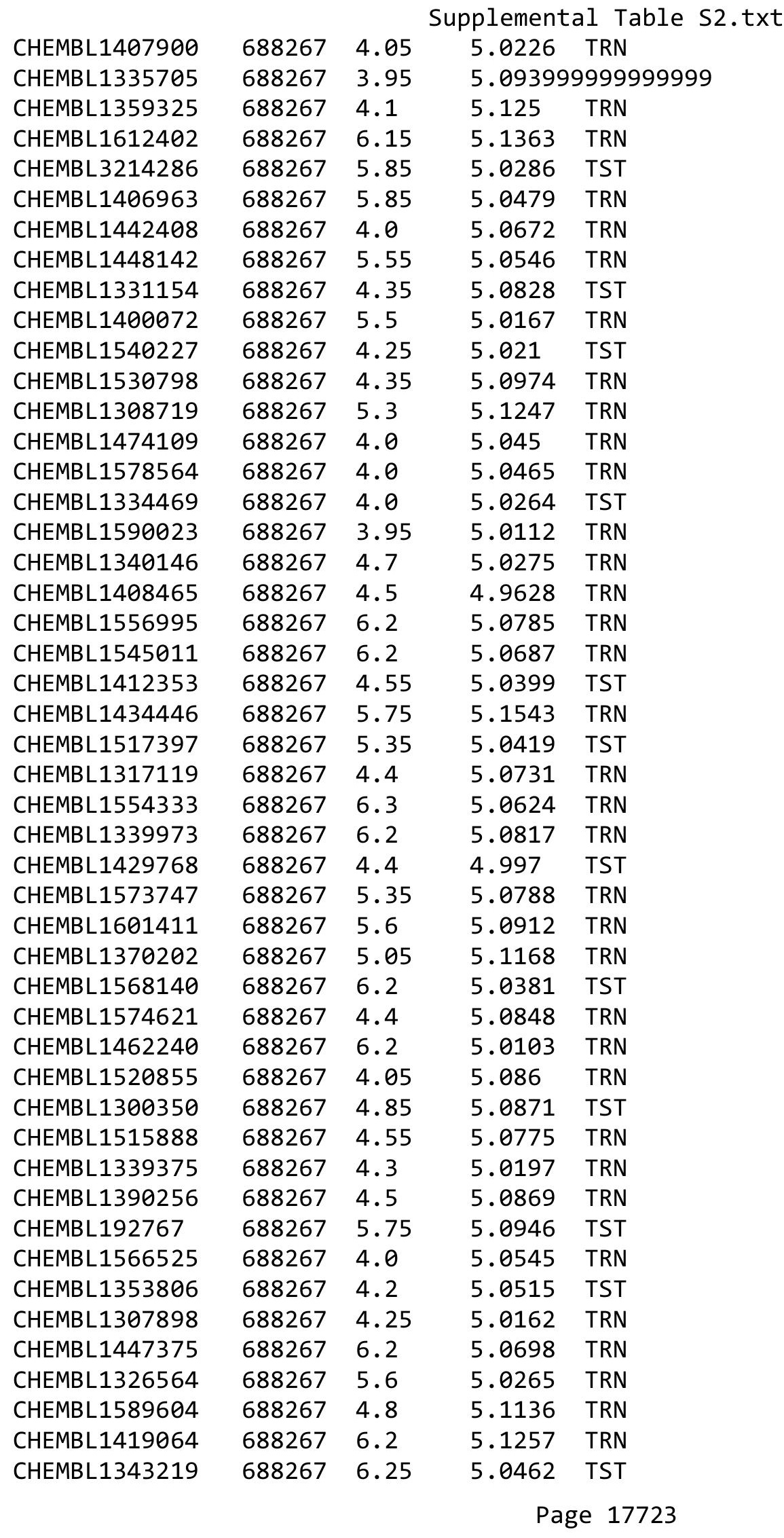

TRN 


\begin{tabular}{|c|c|c|c|c|c|}
\hline \\
\hline CHEMBL1568883 & 688267 & 5.1 & 5.1322 & TRN & \\
\hline CHEMBL1488594 & 688267 & 5.25 & 5.0674 & TST & \\
\hline CHEMBL1495925 & 688267 & 4.35 & 5.0736 & TRN & \\
\hline CHEMBL1422050 & 688267 & 5.6 & 5.0985 & TRN & \\
\hline CHEMBL1597631 & 688267 & 4.0 & 5.0283 & TRN & \\
\hline CHEMBL1440368 & 688267 & 6.2 & 4.9943 & TRN & \\
\hline CHEMBL1594023 & 688267 & 5.6 & 5.0448 & TST & \\
\hline CHEMBL1399344 & 688267 & 4.25 & 5.1439 & TRN & \\
\hline CHEMBL1444713 & 688267 & 4.3 & 5.0916 & TRN & \\
\hline CHEMBL1596091 & 688267 & 5.85 & 5.1226 & TRN & \\
\hline CHEMBL1494233 & 688267 & 4.0 & 5.0098 & TRN & \\
\hline CHEMBL1344147 & 688267 & 4.35 & 5.1329 & TST & \\
\hline CHEMBL1437639 & 688267 & 7.699 & 5.0396 & TRN & \\
\hline CHEMBL1592535 & 688267 & 4.45 & 5.0902 & TRN & \\
\hline CHEMBL1400142 & 688267 & 5.45 & 5.02800 & 00000000005 & TST \\
\hline CHEMBL1572668 & 688267 & 5.95 & 5.0665 & TRN & \\
\hline CHEMBL1587399 & 688267 & 5.3 & 5.0221 & TRN & \\
\hline CHEMBL1547072 & 688267 & 5.4 & 5.1425 & TRN & \\
\hline CHEMBL1566602 & 688267 & 4.1 & 5.075 & TRN & \\
\hline CHEMBL1326113 & 688267 & 4.3 & 5.0477 & TRN & \\
\hline CHEMBL1475007 & 688267 & 4.95 & 5.0747 & TRN & \\
\hline CHEMBL1417719 & 688267 & 4.05 & 5.0772 & TST & \\
\hline CHEMBL1534353 & 688267 & 4.3 & 5.1014 & TRN & \\
\hline CHEMBL1560354 & 688267 & 5.3 & 5.0661 & TRN & \\
\hline CHEMBL1443654 & 688267 & 4.35 & 5.0503 & TRN & \\
\hline CHEMBL1426602 & 688267 & 6.2 & 5.0202 & TRN & \\
\hline CHEMBL1432129 & 688267 & 6.25 & 5.0881 & TRN & \\
\hline CHEMBL1425790 & 688267 & 4.05 & 5.1264 & TRN & \\
\hline CHEMBL1338481 & 688267 & 4.05 & 5.09 & TRN & \\
\hline CHEMBL3210418 & 688267 & 4.4 & 5.0545 & TRN & \\
\hline CHEMBL1336565 & 688267 & 3.95 & 5.0554 & TRN & \\
\hline CHEMBL1320690 & 688267 & 5.7 & 5.0962 & TST & \\
\hline CHEMBL1601285 & 688267 & 4.15 & 4.9987 & TRN & \\
\hline CHEMBL1499516 & 688267 & 5.1 & 5.0752 & TRN & \\
\hline CHEMBL1548109 & 688267 & 4.05 & 5.0161 & TST & \\
\hline CHEMBL63354 & 688267 & 4.65 & 5.0099 & TST & \\
\hline CHEMBL1360359 & 688267 & 5.35 & 5.1032 & TRN & \\
\hline CHEMBL1347581 & 688267 & 4.4 & 5.0424 & TRN & \\
\hline CHEMBL1356342 & 688267 & 5.25 & 5.0599 & TST & \\
\hline CHEMBL1398255 & 688267 & 6.2 & 5.0476 & TRN & \\
\hline CHEMBL1451255 & 688267 & 5.2 & 5.0473 & TRN & \\
\hline CHEMBL1543793 & 688267 & 5.05 & 5.0308 & TRN & \\
\hline CHEMBL1313785 & 688267 & 4.35 & 5.0588 & TST & \\
\hline CHEMBL3195838 & 688267 & 4.8 & 4.9992 & TST & \\
\hline CHEMBL1591846 & 688267 & 5.15 & 5.0323 & TRN & \\
\hline CHEMBL1549463 & 688267 & 6.2 & 5.0645 & TST & \\
\hline CHEMBL1467881 & 688267 & 6.15 & 5.0327 & TST & \\
\hline CHEMBL1322369 & 688267 & 5.65 & 5.0286 & TRN & \\
\hline
\end{tabular}




\begin{tabular}{|c|c|c|c|c|c|}
\hline \multicolumn{6}{|c|}{ Supplemental Table S2.txt } \\
\hline CHEMBL1340210 & 688267 & 5.6 & 5.0647 & TRN & \\
\hline CHEMBL 2005238 & 688267 & 4.45 & 5.0406 & TRN & \\
\hline CHEMBL3208359 & 688267 & 4.05 & 5.0554 & TST & \\
\hline CHEMBL1558464 & 688267 & 6.15 & 5.0295 & TST & \\
\hline CHEMBL1541222 & 688267 & 6.2 & 5.0881 & TRN & \\
\hline CHEMBL1568830 & 688267 & 5.5 & 5.0235 & TRN & \\
\hline CHEMBL1605019 & 688267 & 6.2 & 5.0962 & TRN & \\
\hline CHEMBL1404383 & 688267 & 6.25 & 5.0365 & TRN & \\
\hline CHEMBL1613389 & 688267 & 5.25 & 5.0592 & TRN & \\
\hline CHEMBL1357189 & 688267 & 6.2 & 5.0773 & TRN & \\
\hline CHEMBL1440494 & 688267 & 3.95 & 5.0581 & TRN & \\
\hline CHEMBL1455712 & 688267 & 6.25 & 5.0946 & TRN & \\
\hline CHEMBL1497267 & 688267 & 5.35 & 4.9966 & TST & \\
\hline CHEMBL1478675 & 688267 & 4.2 & 5.065 & TRN & \\
\hline CHEMBL1368422 & 688267 & 5.85 & 5.0537 & TRN & \\
\hline CHEMBL1508794 & 688267 & 5.6 & 5.0474 & TRN & \\
\hline CHEMBL1475461 & 688267 & 4.45 & 5.0766 & TRN & \\
\hline CHEMBL1377606 & 688267 & 4.2 & 5.005 & TRN & \\
\hline CHEMBL1454769 & 688267 & 3.95 & 5.0813 & TRN & \\
\hline CHEMBL1361538 & 688267 & 4.45 & 5.0983 & TRN & \\
\hline CHEMBL1301938 & 688267 & 5.05 & 5.1176 & TRN & \\
\hline CHEMBL1503270 & 688267 & 5.8 & 5.1134 & TRN & \\
\hline CHEMBL1612706 & 688267 & 4.65 & 5.0165 & TST & \\
\hline CHEMBL1483942 & 688267 & 4.35 & 5.0175 & TST & \\
\hline CHEMBL1403520 & 688267 & 5.35 & 5.039 & TRN & \\
\hline CHEMBL1370130 & 688267 & 5.6 & 5.0498 & TRN & \\
\hline CHEMBL1311565 & 688267 & 4.4 & 5.1485 & TRN & \\
\hline CHEMBL1399747 & 688267 & 5.6 & 5.0215 & TST & \\
\hline CHEMBL1547451 & 688267 & 4.6 & 5.0574 & TRN & \\
\hline CHEMBL1591568 & 688267 & 4.0 & 5.0642 & TST & \\
\hline CHEMBL1396762 & 688267 & 6.1 & 5.022 & TST & \\
\hline CHEMBL1558819 & 688267 & 6.2 & 5.1014 & TST & \\
\hline CHEMBL1380890 & 688267 & 4.05 & 5.0331 & TST & \\
\hline CHEMBL1376753 & 688267 & 4.7 & 5.0131 & TST & \\
\hline CHEMBL1327528 & 688267 & 5.85 & 5.0792 & TRN & \\
\hline CHEMBL1611559 & 688267 & 4.0 & 5.0310 & 0000000001 & TRN \\
\hline CHEMBL1502711 & 688267 & 5.0 & 5.0301 & TRN & \\
\hline CHEMBL1352609 & 688267 & 6.2 & 5.0596 & TST & \\
\hline CHEMBL1466741 & 688267 & 4.15 & 5.0262 & TRN & \\
\hline CHEMBL1432089 & 688267 & 5.1 & 5.0735 & TRN & \\
\hline CHEMBL1379896 & 688267 & 5.85 & 5.0645 & TRN & \\
\hline CHEMBL1608381 & 688267 & 4.55 & 5.1254 & TRN & \\
\hline CHEMBL1440539 & 688267 & 4.0 & 5.035 & TRN & \\
\hline CHEMBL1423799 & 688267 & 4.6 & 5.0276 & TRN & \\
\hline CHEMBL3195187 & 688267 & 5.85 & 5.0275 & TRN & \\
\hline CHEMBL1513666 & 688267 & 4.0 & 5.0797 & TRN & \\
\hline CHEMBL1599783 & 688267 & 4.0 & 5.0232 & TST & \\
\hline CHEMBL1325240 & 688267 & 4.1 & 5.0625 & TRN & \\
\hline
\end{tabular}




\begin{tabular}{|c|c|c|c|c|}
\hline \multicolumn{5}{|c|}{ Supplemental Table S2.txt } \\
\hline CHEMBL1333723 & 688267 & 6.2 & 5.1165 & TST \\
\hline CHEMBL1569563 & 688267 & 4.35 & 5.0788 & TRN \\
\hline CHEMBL1472170 & 688267 & 4.3 & 5.0427 & TRN \\
\hline CHEMBL1323673 & 688267 & 4.3 & 5.0486 & TRN \\
\hline CHEMBL1522351 & 688267 & 4.55 & 4.9826 & TRN \\
\hline CHEMBL1561650 & 688267 & 4.3 & 5.0139 & TRN \\
\hline CHEMBL1501430 & 688267 & 5.45 & 5.0364 & TST \\
\hline CHEMBL1569792 & 688267 & 5.55 & 5.0708 & TRN \\
\hline CHEMBL1426589 & 688267 & 4.7 & 5.1353 & TST \\
\hline CHEMBL1334671 & 688267 & 5.35 & 5.0297 & TST \\
\hline CHEMBL1373959 & 688267 & 4.85 & 4.9819 & TRN \\
\hline CHEMBL1367348 & 688267 & 5.6 & 5.0 & TRN \\
\hline CHEMBL1582983 & 688267 & 6.25 & 5.1011 & TRN \\
\hline CHEMBL1582091 & 688267 & 4.5 & 5.0324 & TST \\
\hline CHEMBL1351722 & 688267 & 4.3 & 5.0704 & TRN \\
\hline CHEMBL1452064 & 688267 & 5.05 & 5.0516 & TST \\
\hline CHEMBL1418232 & 688267 & 5.3 & 5.0131 & TRN \\
\hline CHEMBL1417662 & 688267 & 4.3 & 5.109 & TRN \\
\hline CHEMBL1418413 & 688267 & 4.35 & 5.0966 & TRN \\
\hline CHEMBL1344566 & 688267 & 5.9 & 5.0363 & TST \\
\hline CHEMBL1351185 & 688267 & 6.25 & 5.1355 & TST \\
\hline CHEMBL1355737 & 688267 & 5.85 & 5.0715 & TRN \\
\hline CHEMBL1315841 & 688267 & 4.75 & 5.0643 & TRN \\
\hline CHEMBL1318158 & 688267 & 6.2 & 5.1086 & TRN \\
\hline CHEMBL1413948 & 688267 & 5.3 & 5.0565 & TRN \\
\hline CHEMBL1475701 & 688267 & 3.95 & 5.0051 & TRN \\
\hline CHEMBL1446582 & 688267 & 5.85 & 5.0716 & TST \\
\hline CHEMBL1563358 & 688267 & 4.8 & 5.0561 & TST \\
\hline CHEMBL1401189 & 688267 & 6.8499 & 5.0939 & TRN \\
\hline CHEMBL1358821 & 688267 & 6.15 & 5.088 & TRN \\
\hline CHEMBL1579665 & 688267 & 3.95 & 5.0504 & TST \\
\hline CHEMBL1542260 & 688267 & 4.25 & 5.0603 & TST \\
\hline CHEMBL1528769 & 688267 & 4.4 & 5.0298 & TRN \\
\hline CHEMBL1318631 & 688267 & 4.95 & 5.1088 & TRN \\
\hline CHEMBL1380283 & 688267 & 6.2 & 5.0388 & TST \\
\hline CHEMBL1611024 & 688267 & 4.65 & 5.035 & TRN \\
\hline CHEMBL1488434 & 688267 & 4.45 & 5.0498 & TRN \\
\hline CHEMBL1461803 & 688267 & 4.4 & 5.0553 & TST \\
\hline CHEMBL1334641 & 688267 & 5.25 & 5.0555 & TRN \\
\hline CHEMBL1549903 & 688267 & 5.05 & 5.0696 & TST \\
\hline CHEMBL1453358 & 688267 & 3.95 & 5.0546 & TRN \\
\hline CHEMBL1511354 & 688267 & 5.9 & 5.045 & TRN \\
\hline CHEMBL1606505 & 688267 & 6.5501 & 5.0496 & TRN \\
\hline CHEMBL1342892 & 688267 & 4.9 & 5.0258 & TRN \\
\hline CHEMBL1540147 & 688267 & 5.2 & 5.1077 & TRN \\
\hline CHEMBL1488101 & 688267 & 4.1 & 5.056 & TRN \\
\hline CHEMBL1451177 & 688267 & 6.2 & 5.1001 & TRN \\
\hline CHEMBL1551558 & 688267 & 4.05 & 5.0568 & TST \\
\hline
\end{tabular}




\begin{tabular}{|c|c|c|c|c|c|}
\hline \\
\hline CHEMBL1542064 & 688267 & 4.0 & 5.023 & TST & \\
\hline CHEMBL1307576 & 688267 & 5.1 & 5.0626 & TST & \\
\hline CHEMBL3195856 & 688267 & 5.8 & 5.0226 & TST & \\
\hline CHEMBL1596924 & 688267 & 6.2 & 5.0638 & TRN & \\
\hline CHEMBL1399187 & 688267 & 6.2 & 5.1513 & TRN & \\
\hline CHEMBL1522169 & 688267 & 4.0 & 5.02 & TST & \\
\hline CHEMBL1503903 & 688267 & 6.2 & 5.079 & TST & \\
\hline CHEMBL1460161 & 688267 & 4.75 & 5.0428 & TST & \\
\hline CHEMBL1315264 & 688267 & 5.95 & 5.0239 & TRN & \\
\hline CHEMBL1565726 & 688267 & 4.6 & 5.0805 & TRN & \\
\hline CHEMBL1600974 & 688267 & 4.35 & 5.0288 & TST & \\
\hline CHEMBL1966406 & 688267 & 5.05 & 5.0457 & TRN & \\
\hline CHEMBL1555445 & 688267 & 4.9 & 5.0656 & TRN & \\
\hline CHEMBL1452303 & 688267 & 6.2 & 5.0876 & TST & \\
\hline CHEMBL1337255 & 688267 & 4.3 & 5.0823 & TRN & \\
\hline CHEMBL1409284 & 688267 & 6.15 & 5.0394 & TST & \\
\hline CHEMBL 3207788 & 688267 & 5.9 & 5.1034 & TRN & \\
\hline CHEMBL602209 & 688267 & 5.45 & 5.0373 & TRN & \\
\hline CHEMBL1345318 & 688267 & 4.05 & 5.0515 & TST & \\
\hline CHEMBL1397478 & 688267 & 6.15 & 5.0511 & TRN & \\
\hline CHEMBL1567972 & 688267 & 4.6 & 4.9946 & TST & \\
\hline CHEMBL1383968 & 688267 & 5.35 & 5.048 & TST & \\
\hline CHEMBL1500593 & 688267 & 5.3 & 5.0969 & 99999999995 & TRN \\
\hline CHEMBL1308365 & 688267 & 6.2 & 5.0434 & TRN & \\
\hline CHEMBL1357525 & 688267 & 4.1 & 5.0096 & TRN & \\
\hline CHEMBL1428784 & 688267 & 5.0 & 5.1059 & TRN & \\
\hline CHEMBL1571140 & 688267 & 6.2 & 5.0211 & TRN & \\
\hline CHEMBL1310956 & 688267 & 5.35 & 5.0203 & TRN & \\
\hline CHEMBL1318037 & 688267 & 6.15 & 5.0385 & TRN & \\
\hline CHEMBL 1449000 & 688267 & 5.3 & 5.0143 & TST & \\
\hline CHEMBL1515647 & 688267 & 6.2 & 5.0402 & TRN & \\
\hline CHEMBL1353230 & 688267 & 4.35 & 5.092 & TRN & \\
\hline CHEMBL1345396 & 688267 & 6.2 & 5.0822 & TRN & \\
\hline CHEMBL1317687 & 688267 & 4.55 & 5.1353 & TRN & \\
\hline CHEMBL1600987 & 688267 & 5.45 & 5.0601 & TRN & \\
\hline CHEMBL1409622 & 688267 & 5.0 & 5.0681 & TRN & \\
\hline CHEMBL1612291 & 688267 & 4.25 & 5.0748 & TRN & \\
\hline CHEMBL1401285 & 688267 & 5.3 & 5.0266 & TRN & \\
\hline CHEMBL3210091 & 688267 & 4.1 & 4.9912 & TST & \\
\hline CHEMBL1455164 & 688267 & 5.35 & 5.0286 & TRN & \\
\hline CHEMBL1506846 & 688267 & 4.6 & 5.1517 & TRN & \\
\hline CHEMBL1500721 & 688267 & 4.15 & 5.0831 & TRN & \\
\hline CHEMBL3197106 & 688267 & 4.4 & 4.9787 & TRN & \\
\hline CHEMBL1378071 & 688267 & 4.65 & 5.0846 & TRN & \\
\hline CHEMBL1428042 & 688267 & 4.5 & 5.0856 & TST & \\
\hline CHEMBL1566996 & 688267 & 6.15 & 5.0364 & TRN & \\
\hline CHEMBL1544295 & 688267 & 4.35 & 5.0452 & TRN & \\
\hline CHEMBL1475292 & 688267 & 4.05 & 5.0317 & TRN & \\
\hline
\end{tabular}




\begin{tabular}{|c|c|c|c|c|c|}
\hline \multirow[b]{2}{*}{ CHEMBL1515549 } & \multirow[b]{2}{*}{688267} & \multicolumn{4}{|c|}{ oplemental Table S } \\
\hline & & 6.25 & 5.0786 & TST & \\
\hline CHEMBL1475975 & 688267 & 6.2 & 5.1389 & 9999999999 & TRN \\
\hline CHEMBL1579519 & 688267 & 4.55 & 5.0345 & TRN & \\
\hline CHEMBL1342457 & 688267 & 4.85 & 5.1972 & TRN & \\
\hline CHEMBL1515400 & 688267 & 4.0 & 5.0047 & TRN & \\
\hline CHEMBL1507313 & 688267 & 5.8 & 5.0531 & TRN & \\
\hline CHEMBL1531611 & 688267 & 5.5 & 5.0462 & TST & \\
\hline CHEMBL1484777 & 688267 & 5.65 & 5.0272 & TST & \\
\hline CHEMBL1357027 & 688267 & 5.05 & 5.0436 & TRN & \\
\hline CHEMBL1480430 & 688267 & 6.25 & 5.0355 & TRN & \\
\hline CHEMBL1490428 & 688267 & 4.65 & 5.0284 & TRN & \\
\hline CHEMBL1454822 & 688267 & 5.25 & 5.1276 & TRN & \\
\hline CHEMBL1484657 & 688267 & 6.2 & 5.0546 & TRN & \\
\hline CHEMBL529675 & 688267 & 4.05 & 5.0269 & TST & \\
\hline CHEMBL1416818 & 688267 & 6.2 & 5.0471 & TRN & \\
\hline CHEMBL1389892 & 688267 & 4.65 & 5.1202 & TRN & \\
\hline CHEMBL1531279 & 688267 & 5.35 & 5.073 & TRN & \\
\hline CHEMBL1596012 & 688267 & 5.25 & 5.0679 & TRN & \\
\hline CHEMBL1535553 & 688267 & 4.0 & 5.0251 & TST & \\
\hline CHEMBL1379734 & 688267 & 6.15 & 5.0912 & TRN & \\
\hline CHEMBL1415097 & 688267 & 5.6 & 5.0228 & TRN & \\
\hline CHEMBL1502454 & 688267 & 6.25 & 5.1321 & TRN & \\
\hline CHEMBL 3212647 & 688267 & 6.2 & 5.0423 & TRN & \\
\hline CHEMBL1506811 & 688267 & 5.9 & 5.0707 & TRN & \\
\hline CHEMBL1561732 & 688267 & 6.25 & 5.0425 & TRN & \\
\hline CHEMBL1426749 & 688267 & 4.25 & 5.0214 & TRN & \\
\hline CHEMBL1404963 & 688267 & 4.0 & 4.9939 & TRN & \\
\hline CHEMBL1487035 & 688267 & 3.95 & 5.0819 & TRN & \\
\hline CHEMBL1493543 & 688267 & 4.0 & 5.121 & TRN & \\
\hline CHEMBL1513913 & 688267 & 5.5 & 5.0807 & TRN & \\
\hline CHEMBL1301904 & 688267 & 4.25 & 5.0509 & TRN & \\
\hline CHEMBL1567817 & 688267 & 5.5 & 5.0709 & TST & \\
\hline CHEMBL1417458 & 688267 & 5.95 & 5.0556 & TST & \\
\hline CHEMBL1340945 & 688267 & 5.0 & 5.0369 & TRN & \\
\hline CHEMBL2369160 & 688267 & 4.3 & 4.992 & TRN & \\
\hline CHEMBL1370984 & 688267 & 6.1 & 5.0916 & TRN & \\
\hline CHEMBL1435185 & 688267 & 5.65 & 5.0606 & TRN & \\
\hline CHEMBL1571644 & 688267 & 5.35 & 5.0571 & TRN & \\
\hline CHEMBL1300266 & 688267 & 5.35 & 5.0601 & TST & \\
\hline CHEMBL1476067 & 688267 & 4.05 & 5.0059 & TRN & \\
\hline CHEMBL1531925 & 688267 & 4.0 & 5.0256 & TST & \\
\hline CHEMBL1559609 & 688267 & 6.25 & 5.0088 & TST & \\
\hline CHEMBL1380990 & 688267 & 4.5 & 5.13 & TST & \\
\hline CHEMBL1610718 & 688267 & 4.55 & 5.0912 & TRN & \\
\hline CHEMBL1493913 & 688267 & 4.65 & 4.9894 & TRN & \\
\hline CHEMBL1331782 & 688267 & 6.25 & 5.0558 & TRN & \\
\hline CHEMBL1427302 & 688267 & 4.0 & 4.9783 & TRN & \\
\hline CHEMBL1321281 & 688267 & 4.6 & 5.1041 & TRN & \\
\hline
\end{tabular}




\begin{tabular}{|c|c|c|c|c|c|}
\hline & & & & & \\
\hline CHEMBL1986922 & 688267 & 6.5 & 5.0105 & TRN & \\
\hline CHEMBL1401923 & 688267 & 5.45 & 5.032 & TRN & \\
\hline CHEMBL3192518 & 688267 & 6.6499 & 5.0632 & TRN & \\
\hline CHEMBL1559967 & 688267 & 5.0 & 5.1123 & TRN & \\
\hline CHEMBL1338554 & 688267 & 6.15 & 5.0546 & TRN & \\
\hline CHEMBL1334928 & 688267 & 5.35 & 5.0061 & TST & \\
\hline CHEMBL1573416 & 688267 & 6.2 & 5.0574 & TRN & \\
\hline CHEMBL1558742 & 688267 & 6.25 & 5.0408 & TRN & \\
\hline CHEMBL1594412 & 688267 & 5.6 & 5.05699 & 99999999995 & TRN \\
\hline CHEMBL1473666 & 688267 & 4.05 & 5.1026 & TRN & \\
\hline CHEMBL1518351 & 688267 & 6.25 & 5.0655 & TRN & \\
\hline CHEMBL1353358 & 688267 & 4.3 & 5.0085 & TRN & \\
\hline CHEMBL1340933 & 688267 & 4.5 & 5.1427 & TRN & \\
\hline CHEMBL1604652 & 688267 & 3.95 & 5.1255 & TRN & \\
\hline CHEMBL1486574 & 688267 & 4.25 & 5.0444 & TRN & \\
\hline CHEMBL1425228 & 688267 & 4.4 & 5.0765 & TRN & \\
\hline CHEMBL1383149 & 688267 & 4.05 & 4.9994 & TST & \\
\hline CHEMBL1553377 & 688267 & 5.0 & 5.01 & TRN & \\
\hline CHEMBL1476740 & 688267 & 4.05 & 5.08899 & 99999999995 & TRN \\
\hline CHEMBL1515990 & 688267 & 5.8 & 5.0409 & TST & \\
\hline CHEMBL1521937 & 688267 & 5.6 & 5.075 & TRN & \\
\hline CHEMBL1406654 & 688267 & 3.95 & 5.0665 & TRN & \\
\hline CHEMBL1491947 & 688267 & 5.5 & 5.0241 & TST & \\
\hline CHEMBL1456155 & 688267 & 6.2 & 4.9959 & TRN & \\
\hline CHEMBL1361238 & 688267 & 4.4 & 5.0716 & TRN & \\
\hline CHEMBL1394153 & 688267 & 5.8 & 5.1053 & TST & \\
\hline CHEMBL1358307 & 688267 & 5.25 & 5.0778 & TRN & \\
\hline CHEMBL1309358 & 688267 & 4.95 & 5.0426 & TST & \\
\hline CHEMBL1576924 & 688267 & 6.2 & 5.0586 & TRN & \\
\hline CHEMBL539313 & 688267 & 5.2 & 5.0568 & TST & \\
\hline CHEMBL1415962 & 688267 & 4.05 & 5.0387 & TRN & \\
\hline CHEMBL1332724 & 688267 & 4.8 & 5.0142 & TRN & \\
\hline CHEMBL1457409 & 688267 & 5.1 & 5.1096 & TRN & \\
\hline CHEMBL1328725 & 688267 & 4.2 & 5.0328 & TST & \\
\hline CHEMBL3191377 & 688267 & 4.4 & 5.0882 & TRN & \\
\hline CHEMBL2005770 & 688267 & 5.5 & 5.0299 & TST & \\
\hline CHEMBL1515079 & 688267 & 4.4 & 5.0719 & TST & \\
\hline CHEMBL1353557 & 688267 & 4.0 & 5.034 & TRN & \\
\hline CHEMBL1395352 & 688267 & 5.6 & 5.0634 & TRN & \\
\hline CHEMBL1325485 & 688267 & 5.5 & 5.0699 & TRN & \\
\hline CHEMBL1399179 & 688267 & 6.2 & 5.1277 & TRN & \\
\hline CHEMBL1410595 & 688267 & 6.2 & 5.1079 & TRN & \\
\hline CHEMBL1319629 & 688267 & 5.95 & 5.0063 & TRN & \\
\hline CHEMBL 2170103 & 688267 & 4.6 & 4.989 & TST & \\
\hline CHEMBL1439350 & 688267 & 4.0 & 5.0685 & TST & \\
\hline CHEMBL1525371 & 688267 & 5.0 & 5.0002 & TRN & \\
\hline CHEMBL1436003 & 688267 & 6.5 & 5.0275 & TRN & \\
\hline CHEMBL1613082 & 688267 & 5.15 & 5.05 & TRN & \\
\hline & & & & 1772 & \\
\hline
\end{tabular}




\begin{tabular}{|c|c|c|c|c|c|}
\hline \multicolumn{6}{|c|}{ Supplemental Table S2.txt } \\
\hline CHEMBL1536235 & 688267 & 5.35 & 5.0955 & TST & \\
\hline CHEMBL1364870 & 688267 & 5.0 & 5.0416 & TRN & \\
\hline CHEMBL1387046 & 688267 & 5.4 & 5.0795 & TRN & \\
\hline CHEMBL1343578 & 688267 & 6.3 & 5.1476 & TRN & \\
\hline CHEMBL1528364 & 688267 & 6.2 & 5.083 & TRN & \\
\hline CHEMBL1491085 & 688267 & 4.05 & 5.0481 & TRN & \\
\hline CHEMBL1351891 & 688267 & 4.65 & 5.1324 & TRN & \\
\hline CHEMBL1457917 & 688267 & 6.2 & 5.1304 & TRN & \\
\hline CHEMBL1563641 & 688267 & 4.35 & 5.0311 & TRN & \\
\hline CHEMBL1370824 & 688267 & 3.95 & 5.0853 & TRN & \\
\hline CHEMBL1452709 & 688267 & 4.7 & 5.0925 & TRN & \\
\hline CHEMBL1232076 & 688267 & 4.05 & 5.0744 & TST & \\
\hline CHEMBL1523071 & 688267 & 4.45 & 5.06 & TST & \\
\hline CHEMBL1611377 & 688267 & 4.65 & 5.043 & TRN & \\
\hline CHEMBL3190197 & 688267 & 4.75 & 5.0088 & TRN & \\
\hline CHEMBL1547617 & 688267 & 4.4 & 5.0629 & TRN & \\
\hline CHEMBL1382025 & 688267 & 5.85 & 5.0344 & TRN & \\
\hline CHEMBL1472684 & 688267 & 6.45 & 5.1524 & TRN & \\
\hline CHEMBL1340792 & 688267 & 4.3 & 5.0574 & TST & \\
\hline CHEMBL1498874 & 688267 & 6.2 & 5.0787 & TRN & \\
\hline CHEMBL1336730 & 688267 & 3.95 & 5.0708 & TRN & \\
\hline CHEMBL1531600 & 688267 & 4.0 & 5.0488 & TRN & \\
\hline CHEMBL1425838 & 688267 & 5.55 & 5.0309 & TRN & \\
\hline CHEMBL1361729 & 688267 & 6.2 & 5.0481 & TST & \\
\hline CHEMBL1317614 & 688267 & 6.2 & 5.0688 & TST & \\
\hline CHEMBL1476927 & 688267 & 6.8 & 5.0679 & TRN & \\
\hline CHEMBL1304464 & 688267 & 4.35 & 5.0805 & TRN & \\
\hline CHEMBL1415912 & 688267 & 5.1 & 5.022 & TRN & \\
\hline CHEMBL1537080 & 688267 & 3.95 & 4.9974 & TRN & \\
\hline CHEMBL1359649 & 688267 & 4.3 & 5.0437 & TRN & \\
\hline CHEMBL1612199 & 688267 & 5.3 & 5.0498 & TRN & \\
\hline CHEMBL1492818 & 688267 & 6.1 & 5.08899 & 99999999995 & TRN \\
\hline CHEMBL1339346 & 688267 & 5.0 & 5.0207 & TRN & \\
\hline CHEMBL1606605 & 688267 & 3.95 & 5.0509 & TST & \\
\hline CHEMBL1319698 & 688267 & 5.1 & 5.0669 & TRN & \\
\hline CHEMBL1501261 & 688267 & 4.4 & 5.1019 & TRN & \\
\hline CHEMBL1465950 & 688267 & 4.0 & 5.0963 & TRN & \\
\hline CHEMBL1505477 & 688267 & 5.55 & 5.0221 & TRN & \\
\hline CHEMBL1566963 & 688267 & 4.05 & 5.1474 & TRN & \\
\hline CHEMBL1506466 & 688267 & 4.25 & 5.0038 & TRN & \\
\hline CHEMBL1336243 & 688267 & 5.3 & 5.0538 & TRN & \\
\hline CHEMBL1413793 & 688267 & 5.55 & 5.0012 & TRN & \\
\hline CHEMBL1462191 & 688267 & 4.85 & 5.0196 & TRN & \\
\hline CHEMBL1498054 & 688267 & 5.35 & 5.0117 & TRN & \\
\hline CHEMBL1466406 & 688267 & 6.2 & 5.023 & TST & \\
\hline CHEMBL1308447 & 688267 & 5.3 & 5.0901 & TST & \\
\hline CHEMBL1385973 & 688267 & 6.25 & 5.0513 & TRN & \\
\hline CHEMBL1323982 & 688267 & 4.0 & 5.0861 & TRN & \\
\hline
\end{tabular}




\begin{tabular}{|c|c|c|c|c|c|}
\hline \multicolumn{6}{|c|}{ Supplemental Table S2.txt } \\
\hline CHEMBL1308793 & 688267 & 5.95 & 5.027 & TRN & \\
\hline CHEMBL1421401 & 688267 & 4.0 & 4.9915 & TST & \\
\hline CHEMBL1310136 & 688267 & 4.35 & 5.0052 & TRN & \\
\hline CHEMBL1432590 & 688267 & 6.2 & 4.999 & TST & \\
\hline CHEMBL1504383 & 688267 & 6.5 & 5.0901 & TRN & \\
\hline CHEMBL1576789 & 688267 & 5.85 & 5.0429 & TRN & \\
\hline CHEMBL1526617 & 688267 & 5.6 & 5.0804 & TRN & \\
\hline CHEMBL1598135 & 688267 & 4.0 & 5.0816 & TRN & \\
\hline CHEMBL1495800 & 688267 & 4.4 & 5.0588 & TRN & \\
\hline CHEMBL1449024 & 688267 & 4.85 & 5.0493 & TRN & \\
\hline CHEMBL1326216 & 688267 & 6.2 & 5.0421 & TRN & \\
\hline CHEMBL1256750 & 688267 & 5.3 & 5.1075 & TST & \\
\hline CHEMBL1361265 & 688267 & 6.15 & 5.0961 & TST & \\
\hline CHEMBL1601235 & 688267 & 4.0 & 5.0368 & TRN & \\
\hline CHEMBL1518772 & 688267 & 4.05 & 5.0337 & TST & \\
\hline CHEMBL1592243 & 688267 & 4.7 & 5.0494 & TRN & \\
\hline CHEMBL1344196 & 688267 & 5.55 & 5.0101 & TRN & \\
\hline CHEMBL1458639 & 688267 & 5.9 & 5.0254 & TST & \\
\hline CHEMBL1402883 & 688267 & 4.2 & 5.0077 & TRN & \\
\hline CHEMBL1375019 & 688267 & 4.6 & 5.0119 & TST & \\
\hline CHEMBL1442016 & 688267 & 4.0 & 5.0391 & TRN & \\
\hline CHEMBL1530115 & 688267 & 4.4 & 5.0143 & TRN & \\
\hline CHEMBL1510521 & 688267 & 5.15 & 4.9887 & TST & \\
\hline CHEMBL1418451 & 688267 & 4.0 & 5.0484 & TRN & \\
\hline CHEMBL1336926 & 688267 & 6.2 & 5.0348 & TRN & \\
\hline CHEMBL1525150 & 688267 & 4.15 & 5.046 & TRN & \\
\hline CHEMBL1434211 & 688267 & 6.15 & 5.0061 & TRN & \\
\hline CHEMBL1423785 & 688267 & 4.35 & 5.0519 & TRN & \\
\hline CHEMBL1605558 & 688267 & 6.45 & 5.0854 & TST & \\
\hline CHEMBL1399801 & 688267 & 4.35 & 5.082 & TST & \\
\hline CHEMBL1528237 & 688267 & 5.9 & 5.0191 & TST & \\
\hline CHEMBL1576262 & 688267 & 5.35 & 5.10800 & 00000000005 & TRN \\
\hline CHEMBL1444011 & 688267 & 6.2 & 5.0496 & TRN & \\
\hline CHEMBL1347497 & 688267 & 4.1 & 5.0957 & TST & \\
\hline CHEMBL1314994 & 688267 & 5.15 & 5.0373 & TRN & \\
\hline CHEMBL1389057 & 688267 & 5.35 & 5.0302 & TRN & \\
\hline CHEMBL1343691 & 688267 & 4.4 & 5.0202 & TST & \\
\hline CHEMBL1598398 & 688267 & 4.2 & 5.1124 & TRN & \\
\hline CHEMBL 3214618 & 688267 & 4.35 & 4.9756 & TRN & \\
\hline CHEMBL1387014 & 688267 & 4.2 & 5.0082 & TRN & \\
\hline CHEMBL1534070 & 688267 & 6.0 & 5.0588 & TRN & \\
\hline CHEMBL1589591 & 688267 & 4.2 & 5.0548 & TST & \\
\hline CHEMBL1501073 & 688267 & 6.5 & 5.0273 & TRN & \\
\hline CHEMBL1357693 & 688267 & 5.95 & 5.1297 & TRN & \\
\hline CHEMBL1420412 & 688267 & 4.3 & 5.0401 & TRN & \\
\hline CHEMBL1396846 & 688267 & 5.9 & 5.1358 & TRN & \\
\hline CHEMBL1422075 & 688267 & 6.25 & 5.0341 & TRN & \\
\hline CHEMBL1545195 & 688267 & 6.5 & 5.0783 & TST & \\
\hline
\end{tabular}




\begin{tabular}{|c|c|c|c|c|c|}
\hline & & & & & \\
\hline CHEMBL1393333 & 688267 & 5.3 & 5.0788 & TRN & \\
\hline CHEMBL1514766 & 688267 & 5.8 & 5.0389 & TRN & \\
\hline CHEMBL1479541 & 688267 & 5.9 & 5.0044 & TRN & \\
\hline CHEMBL1381313 & 688267 & 4.25 & 5.0562 & TST & \\
\hline CHEMBL1497341 & 688267 & 4.0 & 5.0779 & TRN & \\
\hline CHEMBL1393543 & 688267 & 4.95 & 5.0001 & TRN & \\
\hline CHEMBL1545740 & 688267 & 4.35 & 5.074 & TST & \\
\hline CHEMBL1549779 & 688267 & 4.6 & 5.0794 & TRN & \\
\hline CHEMBL1576349 & 688267 & 5.2 & $5.0280 e$ & 00000000005 & TRN \\
\hline CHEMBL1323482 & 688267 & 5.55 & 5.0954 & TRN & \\
\hline CHEMBL1613429 & 688267 & 6.15 & 5.0626 & TRN & \\
\hline CHEMBL1525361 & 688267 & 6.2 & 5.0806 & TRN & \\
\hline CHEMBL1443490 & 688267 & 6.15 & 5.0378 & TRN & \\
\hline CHEMBL1588251 & 688267 & 6.2 & 5.1201 & TRN & \\
\hline CHEMBL1386240 & 688267 & 4.05 & 5.0728 & TRN & \\
\hline CHEMBL1365475 & 688267 & 4.4 & 5.0287 & TST & \\
\hline CHEMBL1549291 & 688267 & 4.1 & 5.1264 & TRN & \\
\hline CHEMBL1361009 & 688267 & 4.0 & 5.1187 & TST & \\
\hline CHEMBL1479257 & 688267 & 4.25 & 5.0351 & TST & \\
\hline CHEMBL1575320 & 688267 & 6.2 & 4.9993 & TST & \\
\hline CHEMBL1383960 & 688267 & 5.7 & 5.0913 & TRN & \\
\hline CHEMBL1394496 & 688267 & 5.3 & 5.1161 & TRN & \\
\hline CHEMBL1376544 & 688267 & 5.3 & $5.1160 e$ & j0000000005 & TRN \\
\hline CHEMBL1479528 & 688267 & 4.2 & 5.0134 & TST & \\
\hline CHEMBL1536859 & 688267 & 5.95 & 5.0784 & TRN & \\
\hline CHEMBL1348044 & 688267 & 5.55 & 5.0623 & TRN & \\
\hline CHEMBL3214257 & 688267 & 4.0 & 5.023 & TRN & \\
\hline CHEMBL1455819 & 688267 & 6.2 & 5.0388 & TRN & \\
\hline CHEMBL1611834 & 688267 & 5.3 & 5.1234 & TRN & \\
\hline CHEMBL1357892 & 688267 & 6.2 & 5.0008 & TRN & \\
\hline CHEMBL1557027 & 688267 & 4.25 & 5.044 & TST & \\
\hline CHEMBL1437347 & 688267 & 4.05 & 5.0286 & TRN & \\
\hline CHEMBL1395542 & 688267 & 4.4 & 5.0762 & TRN & \\
\hline CHEMBL1551108 & 688267 & 5.25 & 5.1158 & TRN & \\
\hline CHEMBL1393836 & 688267 & 6.2 & 5.0752 & TRN & \\
\hline CHEMBL1516090 & 688267 & 5.55 & 5.1424 & TRN & \\
\hline CHEMBL1395546 & 688267 & 3.95 & 5.0073 & TRN & \\
\hline CHEMBL1454350 & 688267 & 4.95 & 5.143 & TRN & \\
\hline CHEMBL1468015 & 688267 & 6.2 & 5.1076 & TRN & \\
\hline CHEMBL1471153 & 688267 & 4.35 & 5.0307 & TRN & \\
\hline CHEMBL1089894 & 688267 & 4.1 & 5.0704 & TRN & \\
\hline CHEMBL1471738 & 688267 & 4.35 & $5.0680 e$ & 00000000005 & TRN \\
\hline CHEMBL1442057 & 688267 & 5.55 & 5.1034 & TRN & \\
\hline CHEMBL1458643 & 688267 & 4.0 & 5.0575 & TRN & \\
\hline CHEMBL1344826 & 688267 & 6.2 & 4.9902 & TRN & \\
\hline CHEMBL1422532 & 688267 & 4.0 & 5.0856 & TST & \\
\hline CHEMBL1603284 & 688267 & 4.0 & 5.1442 & TRN & \\
\hline CHEMBL1965975 & 688267 & 4.35 & 5.0315 & TRN & \\
\hline & & & & 17732 & \\
\hline
\end{tabular}




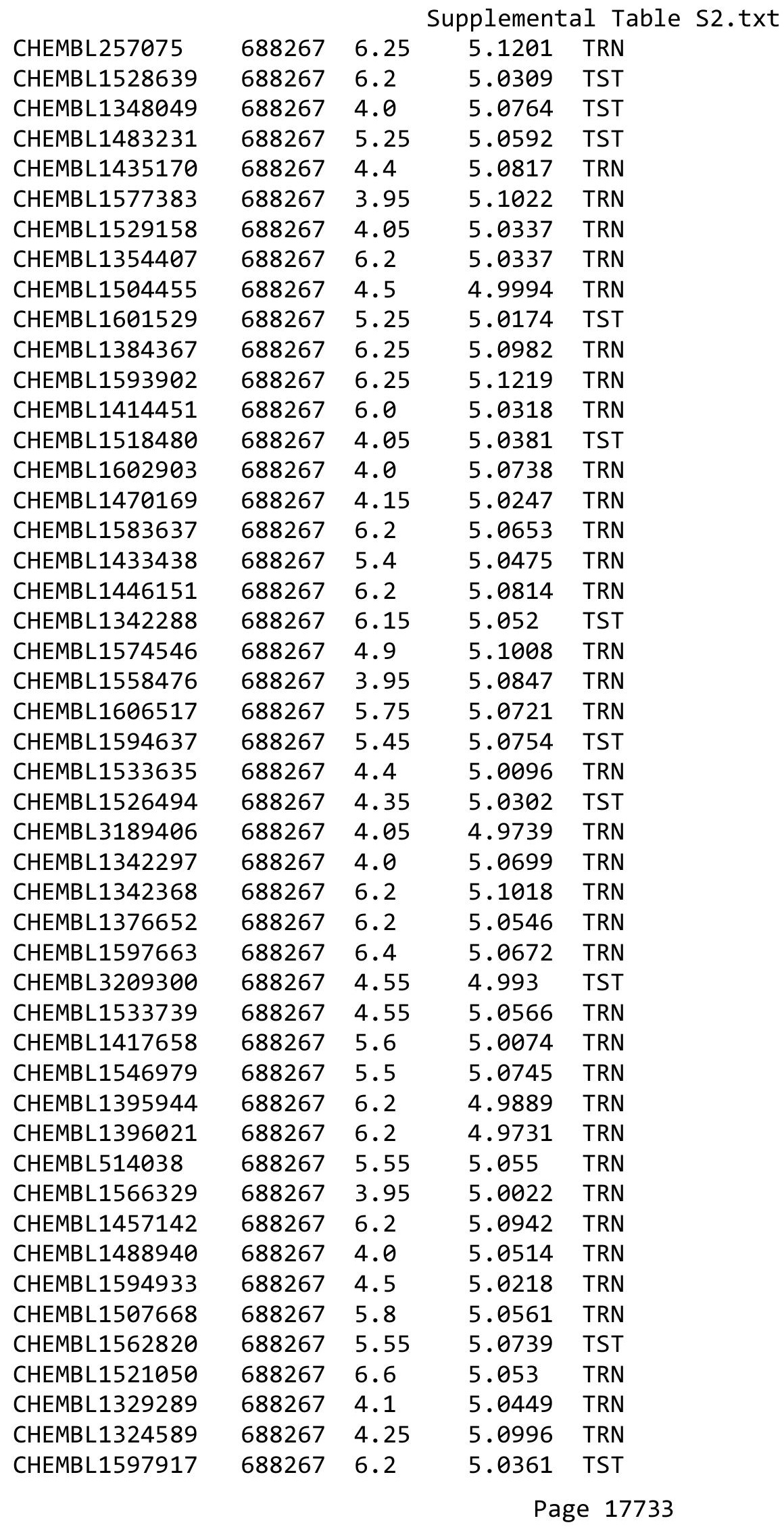




\begin{tabular}{|c|c|c|c|c|}
\hline & & & pplement & al $\mathrm{Ta}$ \\
\hline CHEMBL1497970 & 688267 & 4.35 & 5.0644 & TRN \\
\hline CHEMBL1436384 & 688267 & 6.05 & 5.1085 & TRN \\
\hline CHEMBL3211878 & 688267 & 4.4 & 4.9953 & TST \\
\hline CHEMBL1436944 & 688267 & 4.0 & 5.0078 & TRN \\
\hline CHEMBL1522388 & 688267 & 4.0 & 5.084 & TRN \\
\hline CHEMBL1375231 & 688267 & 4.3 & 5.0363 & TRN \\
\hline CHEMBL1370693 & 688267 & 4.45 & 5.1339 & TST \\
\hline CHEMBL1479381 & 688267 & 4.95 & 5.1138 & TRN \\
\hline CHEMBL1998092 & 688267 & 4.45 & 5.0225 & TST \\
\hline CHEMBL1514833 & 688267 & 6.2 & 5.0298 & TST \\
\hline CHEMBL1604935 & 688267 & 4.7 & 5.0791 & TRN \\
\hline CHEMBL1340953 & 688267 & 5.35 & 5.0229 & TRN \\
\hline CHEMBL1342820 & 688267 & 6.2 & 5.1123 & TRN \\
\hline CHEMBL1410737 & 688267 & 5.1 & 5.0785 & TRN \\
\hline CHEMBL1333242 & 688267 & 6.25 & 5.109 & TST \\
\hline CHEMBL1318253 & 688267 & 5.1 & 5.0697 & TRN \\
\hline CHEMBL1327083 & 688267 & 4.35 & 5.1649 & TRN \\
\hline CHEMBL1542992 & 688267 & 4.8 & 5.0625 & TST \\
\hline CHEMBL1575497 & 688267 & 4.5 & 5.0646 & TST \\
\hline CHEMBL1507915 & 688267 & 5.45 & 5.0854 & TRN \\
\hline CHEMBL1408629 & 688267 & 5.25 & 4.9751 & TRN \\
\hline CHEMBL1308486 & 688267 & 6.15 & 5.0486 & TRN \\
\hline CHEMBL1382152 & 688267 & 4.4 & 5.0979 & TST \\
\hline CHEMBL1464938 & 688267 & 5.3 & 5.0182 & TRN \\
\hline CHEMBL1315503 & 688267 & 4.85 & 5.0797 & TRN \\
\hline CHEMBL1606953 & 688267 & 5.85 & 5.1289 & TRN \\
\hline CHEMBL1551252 & 688267 & 4.65 & 5.0083 & TRN \\
\hline CHEMBL1597251 & 688267 & 5.55 & 5.0414 & TRN \\
\hline CHEMBL1497032 & 688267 & 5.25 & 5.0453 & TRN \\
\hline CHEMBL1460195 & 688267 & 4.55 & 5.0989 & TRN \\
\hline CHEMBL1585976 & 688267 & 5.95 & 5.1301 & TST \\
\hline CHEMBL1548495 & 688267 & 5.45 & 4.996 & TRN \\
\hline CHEMBL1568212 & 688267 & 5.55 & 4.9968 & TRN \\
\hline CHEMBL1370564 & 688267 & 4.65 & 5.0329 & TST \\
\hline CHEMBL1351788 & 688267 & 6.25 & 5.1102 & TRN \\
\hline CHEMBL1379246 & 688267 & 6.2 & 5.0871 & TRN \\
\hline CHEMBL1532153 & 688267 & 5.0 & 5.0216 & TRN \\
\hline CHEMBL1433491 & 688267 & 5.5 & 5.0973 & TST \\
\hline CHEMBL1605170 & 688267 & 4.4 & 5.0734 & TRN \\
\hline CHEMBL1428159 & 688267 & 5.55 & 5.0825 & TRN \\
\hline CHEMBL1411878 & 688267 & 5.1 & 5.0317 & TRN \\
\hline CHEMBL1493245 & 688267 & 6.2 & 5.1102 & TRN \\
\hline CHEMBL1591979 & 688267 & 5.95 & 5.0603 & TRN \\
\hline CHEMBL1582981 & 688267 & 4.25 & 5.0849 & TST \\
\hline CHEMBL 3214065 & 688267 & 6.2 & 5.0679 & TST \\
\hline CHEMBL1395441 & 688267 & 6.0 & 5.1108 & TRN \\
\hline CHEMBL1509071 & 688267 & 4.0 & 5.0064 & TST \\
\hline CHEMBL1455609 & 688267 & 5.35 & 5.0731 & TRN \\
\hline
\end{tabular}




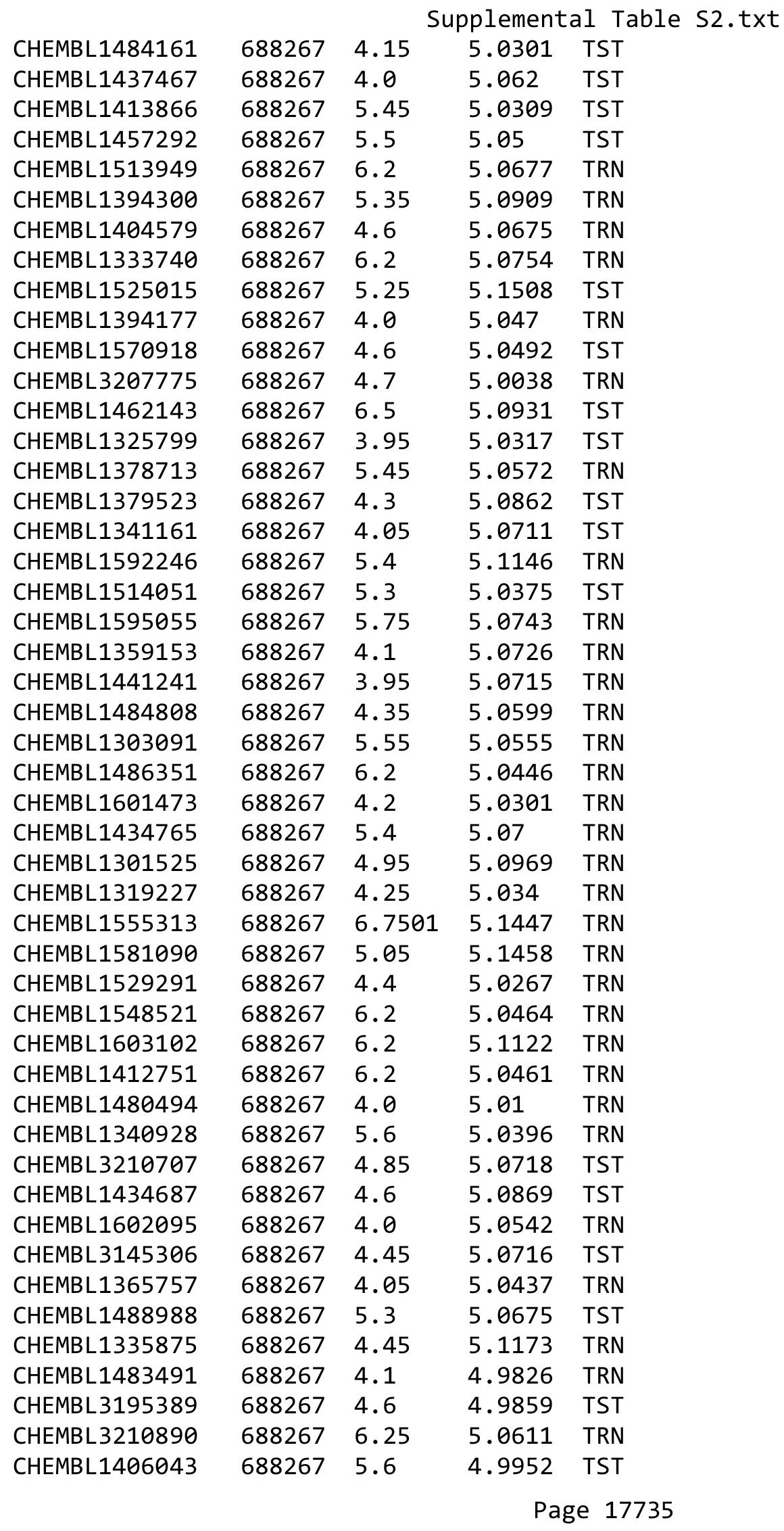




\begin{tabular}{|c|c|c|c|c|c|}
\hline \\
\hline CHEMBL1506294 & 688267 & 4.4 & 5.0534 & TRN & \\
\hline CHEMBL1323648 & 688267 & 5.9 & 5.0202 & TRN & \\
\hline CHEMBL1406698 & 688267 & 4.0 & 5.0017 & TST & \\
\hline CHEMBL1550079 & 688267 & 4.9 & 5.1601 & TRN & \\
\hline CHEMBL1439738 & 688267 & 4.15 & 5.0788 & TST & \\
\hline CHEMBL1376001 & 688267 & 3.95 & 5.0816 & TRN & \\
\hline CHEMBL1355050 & 688267 & 4.1 & 5.0788 & TRN & \\
\hline CHEMBL1602705 & 688267 & 5.85 & 5.1615 & TRN & \\
\hline CHEMBL1573917 & 688267 & 6.0 & 5.0334 & TST & \\
\hline CHEMBL3191010 & 688267 & 4.5 & 4.9835 & TRN & \\
\hline CHEMBL1397363 & 688267 & 4.05 & 5.0522 & TRN & \\
\hline CHEMBL1354304 & 688267 & 4.75 & 5.0502 & TRN & \\
\hline CHEMBL1538723 & 688267 & 4.4 & 5.1061 & TRN & \\
\hline CHEMBL1501290 & 688267 & 4.75 & 5.0077 & TRN & \\
\hline CHEMBL1355820 & 688267 & 6.2 & 5.1674 & TRN & \\
\hline CHEMBL1521378 & 688267 & 4.9 & 5.0909 & TRN & \\
\hline CHEMBL1500088 & 688267 & 4.75 & 5.0081 & TRN & \\
\hline CHEMBL1469908 & 688267 & 5.05 & 5.0145 & TRN & \\
\hline CHEMBL1580985 & 688267 & 5.25 & 5.0684 & TST & \\
\hline CHEMBL1555260 & 688267 & 6.2 & 4.9896 & TST & \\
\hline CHEMBL1434867 & 688267 & 4.35 & 5.144 & TRN & \\
\hline CHEMBL1502219 & 688267 & 5.55 & 5.1014 & TRN & \\
\hline CHEMBL1398039 & 688267 & 6.25 & 5.1613 & TRN & \\
\hline CHEMBL1582276 & 688267 & 5.45 & 5.1001 & TRN & \\
\hline CHEMBL1306128 & 688267 & 4.1 & 5.0374 & TRN & \\
\hline CHEMBL1514024 & 688267 & 4.0 & 4.9863 & TRN & \\
\hline CHEMBL1493828 & 688267 & 4.2 & 5.1102 & TRN & \\
\hline CHEMBL1425230 & 688267 & 4.4 & 5.0929 & TRN & \\
\hline CHEMBL1485331 & 688267 & 6.25 & 5.0944 & TST & \\
\hline CHEMBL1425831 & 688267 & 4.25 & 5.0268 & TST & \\
\hline CHEMBL1299596 & 688267 & 4.5 & 5.1003 & TRN & \\
\hline CHEMBL1476943 & 688267 & 4.4 & 5.0927 & TRN & \\
\hline CHEMBL1474091 & 688267 & 6.25 & 5.1007 & TRN & \\
\hline CHEMBL1511138 & 688267 & 6.1 & 5.0053 & TST & \\
\hline CHEMBL1406459 & 688267 & 5.85 & 4.9865 & TRN & \\
\hline CHEMBL1585393 & 688267 & 4.25 & 5.0569 & TRN & \\
\hline CHEMBL1435535 & 688267 & 4.0 & 5.0873 & TRN & \\
\hline CHEMBL1452363 & 688267 & 5.15 & 5.0685 & TRN & \\
\hline CHEMBL1387796 & 688267 & 4.0 & 5.0337 & TRN & \\
\hline CHEMBL1356145 & 688267 & 6.25 & 5.0583 & TRN & \\
\hline CHEMBL1490441 & 688267 & 5.45 & 5.0432 & TRN & \\
\hline CHEMBL 3210778 & 688267 & 4.1 & 5.0887 & TRN & \\
\hline CHEMBL1413133 & 688267 & 4.0 & 5.0603 & TRN & \\
\hline CHEMBL1582576 & 688267 & 6.2 & 5.17200 & 0000000001 & TRN \\
\hline CHEMBL1523176 & 688267 & 3.95 & 5.0456 & TRN & \\
\hline CHEMBL1332814 & 688267 & 5.6 & 5.0849 & TRN & \\
\hline CHEMBL1319268 & 688267 & 5.75 & 5.0586 & TST & \\
\hline CHEMBL1399472 & 688267 & 5.45 & 5.0122 & TRN & \\
\hline
\end{tabular}




\begin{tabular}{|c|c|c|c|c|}
\hline \multicolumn{5}{|c|}{ Supplemental Table S2.txt } \\
\hline CHEMBL1423054 & 688267 & 4.05 & 4.9926 & TRN \\
\hline CHEMBL1501520 & 688267 & 4.0 & 5.0901 & TRN \\
\hline CHEMBL1456844 & 688267 & 4.3 & 5.0651 & TRN \\
\hline CHEMBL1431618 & 688267 & 4.05 & 5.0681 & TRN \\
\hline CHEMBL1359170 & 688267 & 4.05 & 5.0662 & TST \\
\hline CHEMBL1505223 & 688267 & 4.1 & 5.0269 & TRN \\
\hline CHEMBL3199118 & 688267 & 4.05 & 5.0007 & TST \\
\hline CHEMBL1376298 & 688267 & 4.0 & 5.0015 & TRN \\
\hline CHEMBL1307893 & 688267 & 5.75 & 5.0487 & TRN \\
\hline CHEMBL1430550 & 688267 & 4.25 & 5.05699 & 99999999995 \\
\hline CHEMBL1581285 & 688267 & 4.5 & 5.0114 & TRN \\
\hline CHEMBL1488903 & 688267 & 5.35 & 5.0664 & TST \\
\hline CHEMBL1493325 & 688267 & 5.75 & 5.0351 & TRN \\
\hline CHEMBL1473534 & 688267 & 4.0 & 5.0388 & TRN \\
\hline CHEMBL1310899 & 688267 & 5.5 & 5.0694 & TRN \\
\hline CHEMBL1364607 & 688267 & 4.1 & 5.0677 & TRN \\
\hline CHEMBL1603491 & 688267 & 6.25 & 5.1044 & TRN \\
\hline CHEMBL1512034 & 688267 & 6.2 & 5.0667 & TRN \\
\hline CHEMBL1419083 & 688267 & 5.05 & 5.0272 & TRN \\
\hline CHEMBL1562178 & 688267 & 6.15 & 5.0738 & TST \\
\hline CHEMBL1580171 & 688267 & 5.45 & 5.0975 & TRN \\
\hline CHEMBL1302075 & 688267 & 4.55 & 5.023 & TST \\
\hline CHEMBL1597772 & 688267 & 4.4 & 5.0314 & TST \\
\hline CHEMBL1376510 & 688267 & 6.2 & 5.0614 & TRN \\
\hline CHEMBL1414806 & 688267 & 6.45 & 5.0071 & TRN \\
\hline CHEMBL1466518 & 688267 & 4.0 & 4.9635 & TRN \\
\hline CHEMBL1529316 & 688267 & 4.0 & 5.0261 & TST \\
\hline CHEMBL1556942 & 688267 & 6.0 & 5.0342 & TRN \\
\hline CHEMBL 1366350 & 688267 & 6.0 & 5.0438 & TRN \\
\hline CHEMBL1539052 & 688267 & 4.0 & 5.13 & TRN \\
\hline CHEMBL1434195 & 688267 & 6.15 & 5.0391 & TRN \\
\hline CHEMBL1310646 & 688267 & 4.7 & 4.9995 & TRN \\
\hline CHEMBL1563012 & 688267 & 4.05 & 5.0094 & TRN \\
\hline CHEMBL1334762 & 688267 & 3.95 & 5.0181 & TRN \\
\hline CHEMBL1323125 & 688267 & 5.6 & 5.0299 & TST \\
\hline CHEMBL1424317 & 688267 & 4.3 & 5.118 & TST \\
\hline CHEMBL1524342 & 688267 & 5.15 & 5.0018 & TRN \\
\hline CHEMBL1498133 & 688267 & 4.15 & 5.0037 & TST \\
\hline CHEMBL1564357 & 688267 & 6.2 & 4.9944 & TRN \\
\hline CHEMBL1382922 & 688267 & 4.0 & 5.047 & TRN \\
\hline CHEMBL1498712 & 688267 & 4.05 & 5.008 & TRN \\
\hline CHEMBL1364440 & 688267 & 4.35 & 5.04 & TRN \\
\hline CHEMBL1492724 & 688267 & 4.0 & 5.0976 & TRN \\
\hline CHEMBL1445232 & 688267 & 5.75 & 5.029 & TRN \\
\hline CHEMBL1315290 & 688267 & 5.55 & 5.0191 & TRN \\
\hline CHEMBL1476081 & 688267 & 6.15 & 5.1543 & TRN \\
\hline CHEMBL1367738 & 688267 & 5.4 & 5.0732 & TRN \\
\hline CHEMBL1482511 & 688267 & 4.25 & 5.0302 & TRN \\
\hline
\end{tabular}




\begin{tabular}{|c|c|c|c|c|}
\hline \multicolumn{5}{|c|}{ Supplemental Tabl } \\
\hline CHEMBL1335979 & 688267 & 5.55 & 5.0668 & TRN \\
\hline CHEMBL582073 & 688267 & 5.0 & 5.033 & TST \\
\hline CHEMBL1496084 & 688267 & 6.8 & 5.1086 & TRN \\
\hline CHEMBL1348434 & 688267 & 5.25 & 5.0729 & TRN \\
\hline CHEMBL1322853 & 688267 & 5.8 & 5.1017 & TRN \\
\hline CHEMBL1487517 & 688267 & 5.05 & 5.039 & TRN \\
\hline CHEMBL1368349 & 688267 & 5.0 & 5.0273 & TRN \\
\hline CHEMBL1343044 & 688267 & 6.25 & 5.0242 & TST \\
\hline CHEMBL1595470 & 688267 & 6.2 & 5.0726 & TST \\
\hline CHEMBL1585371 & 688267 & 4.05 & 5.004 & TRN \\
\hline CHEMBL3196362 & 688267 & 4.05 & 4.9699 & TRN \\
\hline CHEMBL1470976 & 688267 & 5.4 & 5.0351 & TRN \\
\hline CHEMBL1573813 & 688267 & 4.4 & 4.9777 & TRN \\
\hline CHEMBL1435082 & 688267 & 3.95 & 5.166 & TRN \\
\hline CHEMBL1512159 & 688267 & 5.6 & 5.0225 & TST \\
\hline CHEMBL1587199 & 688267 & 4.35 & 5.0319 & TRN \\
\hline CHEMBL1384774 & 688267 & 4.6 & 5.1028 & TRN \\
\hline CHEMBL1314639 & 688267 & 4.8 & 5.1235 & TRN \\
\hline CHEMBL1308210 & 688267 & 4.4 & 5.0079 & TST \\
\hline CHEMBL1331861 & 688267 & 4.05 & 5.0962 & TRN \\
\hline CHEMBL1517857 & 688267 & 5.9 & 4.998 & TST \\
\hline CHEMBL1332077 & 688267 & 4.35 & 5.1209 & TST \\
\hline CHEMBL1402466 & 688267 & 4.0 & 5.0083 & TRN \\
\hline CHEMBL1084643 & 688267 & 4.85 & 5.0604 & TST \\
\hline CHEMBL1533424 & 688267 & 6.0 & 5.0234 & TST \\
\hline CHEMBL1569051 & 688267 & 6.2 & 5.0495 & TRN \\
\hline CHEMBL1355285 & 688267 & 4.0 & 5.0344 & TST \\
\hline CHEMBL1548789 & 688267 & 4.55 & 5.0256 & TRN \\
\hline CHEMBL1348502 & 688267 & 5.45 & 5.0549 & TRN \\
\hline CHEMBL1539656 & 688267 & 6.2 & 5.0076 & TRN \\
\hline CHEMBL1528387 & 688267 & 6.2 & 4.992 & TRN \\
\hline CHEMBL1326539 & 688267 & 6.2 & 5.0738 & TRN \\
\hline CHEMBL1309507 & 688267 & 4.7 & 5.0324 & TRN \\
\hline CHEMBL1394146 & 688267 & 4.05 & 5.0231 & TRN \\
\hline CHEMBL1546727 & 688267 & 4.0 & 5.1012 & TST \\
\hline CHEMBL1593058 & 688267 & 5.4 & 5.0539 & TRN \\
\hline CHEMBL1555756 & 688267 & 4.0 & 5.0787 & TST \\
\hline CHEMBL1413680 & 688267 & 4.05 & 5.0324 & TST \\
\hline CHEMBL1404621 & 688267 & 6.2 & 5.0806 & TRN \\
\hline CHEMBL1430007 & 688267 & 6.2 & 5.1044 & TRN \\
\hline CHEMBL1611126 & 688267 & 4.65 & 5.0084 & TRN \\
\hline CHEMBL1411009 & 688267 & 4.4 & 5.0147 & TRN \\
\hline CHEMBL1341516 & 688267 & 4.35 & 5.0365 & TRN \\
\hline CHEMBL1331340 & 688267 & 4.25 & 5.0625 & TRN \\
\hline CHEMBL1487560 & 688267 & 3.95 & 5.1133 & TRN \\
\hline CHEMBL1581188 & 688267 & 6.2 & 4.9894 & TRN \\
\hline CHEMBL1444122 & 688267 & 5.2 & 5.0252 & TRN \\
\hline CHEMBL1348445 & 688267 & 4.3 & 5.0032 & TRN \\
\hline
\end{tabular}




\begin{tabular}{|c|c|c|c|c|c|}
\hline & & \multicolumn{4}{|c|}{ Supplemental Table s2.txt } \\
\hline CHEMBL1490432 & 688267 & 3.95 & 5.1139 & TRN & \\
\hline CHEMBL1471831 & 688267 & 6.2 & 5.0278 & TRN & \\
\hline CHEMBL1430710 & 688267 & 3.95 & 5.1513 & TRN & \\
\hline CHEMBL1547698 & 688267 & 4.25 & 5.1489 & TRN & \\
\hline CHEMBL1475070 & 688267 & 4.95 & 5.0376 & TRN & \\
\hline CHEMBL1559519 & 688267 & 5.55 & 5.083 & TRN & \\
\hline CHEMBL1542395 & 688267 & 4.2 & 5.1102 & TST & \\
\hline CHEMBL1968355 & 688267 & 3.95 & 5.0235 & TRN & \\
\hline CHEMBL1348573 & 688267 & 6.2 & 5.0837 & TST & \\
\hline CHEMBL1597588 & 688267 & 5.5 & 5.0164 & TRN & \\
\hline CHEMBL579956 & 688267 & 6.2 & 5.0491 & TST & \\
\hline CHEMBL1471018 & 688267 & 5.4 & 5.0451 & TRN & \\
\hline CHEMBL1560414 & 688267 & 5.7 & 5.0747 & TRN & \\
\hline CHEMBL1400935 & 688267 & 4.55 & 4.9794 & TST & \\
\hline CHEMBL1432773 & 688267 & 5.55 & 5.0605 & TST & \\
\hline CHEMBL1464653 & 688267 & 5.8 & 5.0491 & TST & \\
\hline CHEMBL1460447 & 688267 & 3.95 & 5.0937 & TRN & \\
\hline CHEMBL1422651 & 688267 & 4.4 & 5.0944 & TRN & \\
\hline CHEMBL1433908 & 688267 & 6.2 & 5.0796 & TRN & \\
\hline CHEMBL1424998 & 688267 & 5.05 & 5.0824 & TRN & \\
\hline CHEMBL1543241 & 688267 & 6.15 & 5.0356 & TST & \\
\hline CHEMBL3193278 & 688267 & 5.75 & 5.025 & TRN & \\
\hline CHEMBL3193883 & 688267 & 6.0 & 5.0411 & TST & \\
\hline CHEMBL1402322 & 688267 & 3.9 & 5.0337 & TRN & \\
\hline CHEMBL1305958 & 688267 & 4.05 & 5.033 & TRN & \\
\hline CHEMBL1393198 & 688267 & 4.45 & 5.0325 & TRN & \\
\hline CHEMBL1525222 & 688267 & 4.25 & 5.0475 & TRN & \\
\hline CHEMBL1551464 & 688267 & 5.35 & 4.9977 & TRN & \\
\hline CHEMBL1544070 & 688267 & 4.1 & 5.0415 & TRN & \\
\hline CHEMBL1458833 & 688267 & 4.55 & 5.0341 & TRN & \\
\hline CHEMBL3195954 & 688267 & 4.35 & 5.0553 & TRN & \\
\hline CHEMBL1305921 & 688267 & 4.9 & 5.0071 & TRN & \\
\hline CHEMBL1390952 & 688267 & 4.1 & 5.0309 & TRN & \\
\hline CHEMBL1484162 & 688267 & 4.05 & 5.1247 & TRN & \\
\hline CHEMBL1421526 & 688267 & 4.15 & 5.12700 & 0000000001 & TST \\
\hline CHEMBL1564152 & 688267 & 5.55 & 5.0389 & TRN & \\
\hline CHEMBL1466938 & 688267 & 4.0 & 5.0584 & TRN & \\
\hline CHEMBL1509558 & 688267 & 6.15 & 5.0426 & TRN & \\
\hline CHEMBL1331453 & 688267 & 4.25 & 5.1144 & TRN & \\
\hline CHEMBL1409878 & 688267 & 6.2 & 5.0076 & TST & \\
\hline CHEMBL1510174 & 688267 & 4.2 & 4.9894 & TST & \\
\hline CHEMBL1332818 & 688267 & 4.45 & 5.09699 & 99999999995 & TRN \\
\hline CHEMBL1304592 & 688267 & 4.7 & 5.0605 & TRN & \\
\hline CHEMBL1481146 & 688267 & 4.65 & 5.0398 & TST & \\
\hline CHEMBL1493805 & 688267 & 3.9 & 5.0736 & TRN & \\
\hline CHEMBL1357584 & 688267 & 3.95 & 5.1035 & TRN & \\
\hline CHEMBL1301717 & 688267 & 5.55 & 5.1265 & TST & \\
\hline CHEMBL1377444 & 688267 & 4.4 & 5.1499 & TRN & \\
\hline
\end{tabular}




\begin{tabular}{|c|c|c|c|c|}
\hline \multicolumn{5}{|c|}{ Supplemental Table S2.txt } \\
\hline CHEMBL1455038 & 688267 & 6.2 & 5.0184 & TRN \\
\hline CHEMBL1301954 & 688267 & 6.2 & 5.101 & TRN \\
\hline CHEMBL1446773 & 688267 & 6.25 & 5.0201 & TRN \\
\hline CHEMBL1380181 & 688267 & 5.05 & 5.2064 & TRN \\
\hline CHEMBL1332433 & 688267 & 3.95 & 5.0968 & TRN \\
\hline CHEMBL1416145 & 688267 & 4.35 & 5.0534 & TRN \\
\hline CHEMBL3190439 & 688267 & 4.05 & 5.0674 & TST \\
\hline CHEMBL1495672 & 688267 & 5.0 & 5.1051 & TRN \\
\hline CHEMBL1546711 & 688267 & 6.25 & 5.0846 & TRN \\
\hline CHEMBL1607247 & 688267 & 5.75 & 5.051 & TRN \\
\hline CHEMBL1594849 & 688267 & 6.2 & 5.043 & TST \\
\hline CHEMBL1582286 & 688267 & 4.4 & 5.0872 & TST \\
\hline CHEMBL1473025 & 688267 & 4.1 & 5.1026 & TRN \\
\hline CHEMBL1583986 & 688267 & 5.55 & 5.1028 & TRN \\
\hline CHEMBL3193733 & 688267 & 4.05 & 4.9643 & TRN \\
\hline CHEMBL1586234 & 688267 & 4.95 & 4.9621 & TRN \\
\hline CHEMBL1411767 & 688267 & 5.0 & 5.1285 & TRN \\
\hline CHEMBL1612086 & 688267 & 4.3 & 5.0226 & TRN \\
\hline CHEMBL1357802 & 688267 & 5.25 & 5.0306 & TST \\
\hline CHEMBL1575906 & 688267 & 5.35 & 5.1314 & TRN \\
\hline CHEMBL1557924 & 688267 & 4.35 & 5.0613 & TRN \\
\hline CHEMBL1321483 & 688267 & 4.35 & 5.1311 & TRN \\
\hline CHEMBL1566197 & 688267 & 4.1 & 5.0229 & TRN \\
\hline CHEMBL1331993 & 688267 & 6.2 & 5.1105 & TST \\
\hline CHEMBL1589956 & 688267 & 4.85 & 5.0415 & TRN \\
\hline CHEMBL1358451 & 688267 & 6.25 & 5.0577 & TRN \\
\hline CHEMBL1367095 & 688267 & 4.55 & 5.0125 & TRN \\
\hline CHEMBL1376908 & 688267 & 4.05 & 5.027 & TST \\
\hline CHEMBL1581773 & 688267 & 4.55 & 5.0055 & TRN \\
\hline CHEMBL1334617 & 688267 & 4.4 & 5.0114 & TRN \\
\hline CHEMBL1370134 & 688267 & 5.75 & 5.0631 & TST \\
\hline CHEMBL1424967 & 688267 & 4.9 & 5.0333 & TRN \\
\hline CHEMBL1309184 & 688267 & 6.05 & 5.0107 & TST \\
\hline CHEMBL1606286 & 688267 & 5.15 & 5.0583 & TRN \\
\hline CHEMBL1322814 & 688267 & 5.3 & 5.0199 & TRN \\
\hline CHEMBL1495668 & 688267 & 5.55 & 5.0887 & TST \\
\hline CHEMBL1517181 & 688267 & 6.1 & 5.0048 & TRN \\
\hline CHEMBL1346507 & 688267 & 6.6499 & 5.0373 & TRN \\
\hline CHEMBL1500464 & 688267 & 5.05 & 5.0767 & TRN \\
\hline CHEMBL1407230 & 688267 & 4.0 & 5.1169 & TRN \\
\hline CHEMBL1583272 & 688267 & 5.25 & 5.0495 & TRN \\
\hline CHEMBL1604833 & 688267 & 6.2 & 5.0034 & TRN \\
\hline CHEMBL1369074 & 688267 & 4.8 & 5.0536 & TRN \\
\hline CHEMBL1520584 & 688267 & 5.05 & 5.1331 & TRN \\
\hline CHEMBL1489322 & 688267 & 4.3 & 5.1051 & TRN \\
\hline CHEMBL1350544 & 688267 & 4.55 & 5.0704 & TST \\
\hline CHEMBL1307214 & 688267 & 5.55 & 5.1026 & TRN \\
\hline CHEMBL1394672 & 688267 & 6.15 & 5.0403 & TRN \\
\hline
\end{tabular}




\begin{tabular}{|c|c|c|c|c|c|}
\hline \multicolumn{6}{|c|}{ Supplemental Table S2.txt } \\
\hline CHEMBL1407594 & 688267 & 4.35 & 5.0599 & TRN & \\
\hline CHEMBL1598059 & 688267 & 4.05 & 5.0468 & TRN & \\
\hline CHEMBL1332621 & 688267 & 6.5 & 5.0834 & TST & \\
\hline CHEMBL1606340 & 688267 & 5.4 & 5.0435 & TRN & \\
\hline CHEMBL1397824 & 688267 & 4.05 & 5.0487 & TRN & \\
\hline CHEMBL1306944 & 688267 & 4.7 & 5.0732 & TRN & \\
\hline CHEMBL1590501 & 688267 & 4.15 & 5.1227 & TRN & \\
\hline CHEMBL1347634 & 688267 & 5.6 & 5.038 & TRN & \\
\hline CHEMBL1325217 & 688267 & 5.5 & 5.0191 & TRN & \\
\hline CHEMBL1320256 & 688267 & 4.65 & 5.0147 & TRN & \\
\hline CHEMBL1546318 & 688267 & 4.8 & 5.1173 & TRN & \\
\hline CHEMBL1370900 & 688267 & 5.5 & 5.07100 & 0000000001 & TRN \\
\hline CHEMBL1572089 & 688267 & 4.65 & 5.0141 & TRN & \\
\hline CHEMBL1408035 & 688267 & 4.2 & 5.0335 & TRN & \\
\hline CHEMBL1391056 & 688267 & 5.45 & 5.0947 & TRN & \\
\hline CHEMBL1488738 & 688267 & 6.15 & 5.038 & TRN & \\
\hline CHEMBL1441368 & 688267 & 4.3 & 5.121 & TRN & \\
\hline CHEMBL1337393 & 688267 & 6.05 & 5.0066 & TRN & \\
\hline CHEMBL1580881 & 688267 & 4.4 & 5.0251 & TRN & \\
\hline CHEMBL1314842 & 688267 & 6.2 & 5.0282 & TST & \\
\hline CHEMBL1339172 & 688267 & 5.0 & 5.0325 & TST & \\
\hline CHEMBL1984001 & 688267 & 4.25 & 4.9964 & TST & \\
\hline CHEMBL1422824 & 688267 & 6.2 & 4.9981 & TRN & \\
\hline CHEMBL1503665 & 688267 & 5.15 & 5.0716 & TRN & \\
\hline CHEMBL1534014 & 688267 & 5.05 & 5.0273 & TRN & \\
\hline CHEMBL1308876 & 688267 & 5.3 & 5.0392 & TRN & \\
\hline CHEMBL1468937 & 688267 & 5.9 & 5.0225 & TRN & \\
\hline CHEMBL1573661 & 688267 & 6.0 & 4.9969 & TRN & \\
\hline CHEMBL1475503 & 688267 & 4.0 & 5.0329 & TRN & \\
\hline CHEMBL3191725 & 688267 & 4.95 & 5.0253 & TRN & \\
\hline CHEMBL1441153 & 688267 & 6.2 & 5.0115 & TRN & \\
\hline CHEMBL1277546 & 688267 & 6.2 & 5.0103 & TST & \\
\hline CHEMBL1506417 & 688267 & 4.05 & 5.0125 & TST & \\
\hline CHEMBL1423301 & 688267 & 5.25 & 5.0584 & TST & \\
\hline CHEMBL1549825 & 688267 & 3.95 & 5.08899 & 99999999995 & TRN \\
\hline CHEMBL1472023 & 688267 & 5.5 & 5.1091 & TST & \\
\hline CHEMBL169520 & 688267 & 5.1 & 5.0278 & TRN & \\
\hline CHEMBL1415371 & 688267 & 4.75 & 5.07100 & 0000000001 & TRN \\
\hline CHEMBL1431091 & 688267 & 3.95 & 5.0839 & TRN & \\
\hline CHEMBL1538743 & 688267 & 6.15 & 5.0641 & TST & \\
\hline CHEMBL1490573 & 688267 & 5.4 & 5.0401 & TRN & \\
\hline CHEMBL1405792 & 688267 & 5.05 & 5.1258 & TRN & \\
\hline CHEMBL1553341 & 688267 & 4.0 & 4.9998 & TRN & \\
\hline CHEMBL 3145380 & 688267 & 4.4 & 5.01 & TRN & \\
\hline CHEMBL1412218 & 688267 & 4.3 & 5.0729 & TST & \\
\hline CHEMBL1565085 & 688267 & 4.4 & 5.1268 & TST & \\
\hline CHEMBL1551089 & 688267 & 5.0 & 5.091 & TRN & \\
\hline CHEMBL1384217 & 688267 & 4.0 & 4.9898 & TST & \\
\hline
\end{tabular}




\begin{tabular}{|c|c|c|c|c|}
\hline \multicolumn{5}{|c|}{ Supplemental Tabl } \\
\hline CHEMBL1564693 & 688267 & 6.25 & 5.0562 & TRN \\
\hline CHEMBL1553280 & 688267 & 4.4 & 5.088 & TRN \\
\hline CHEMBL3210524 & 688267 & 4.65 & 5.0036 & TST \\
\hline CHEMBL1505662 & 688267 & 5.3 & 5.0751 & TRN \\
\hline CHEMBL1534272 & 688267 & 3.95 & 5.0335 & TRN \\
\hline CHEMBL1360081 & 688267 & 4.35 & 5.0121 & TRN \\
\hline CHEMBL1481182 & 688267 & 3.95 & 5.0524 & TRN \\
\hline CHEMBL1476247 & 688267 & 5.35 & 5.106 & TRN \\
\hline CHEMBL1580220 & 688267 & 5.6 & 5.1572 & TRN \\
\hline CHEMBL1407452 & 688267 & 4.5 & 5.0254 & TRN \\
\hline CHEMBL1447338 & 688267 & 5.7 & 5.0167 & TST \\
\hline CHEMBL1519546 & 688267 & 4.05 & 4.9935 & TRN \\
\hline CHEMBL1364332 & 688267 & 4.0 & 5.077 & TRN \\
\hline CHEMBL1449343 & 688267 & 5.55 & 5.0797 & TST \\
\hline CHEMBL3198897 & 688267 & 6.05 & 5.0918 & TRN \\
\hline CHEMBL1330790 & 688267 & 5.25 & 5.0824 & TRN \\
\hline CHEMBL1382564 & 688267 & 4.1 & 5.0446 & TRN \\
\hline CHEMBL1531315 & 688267 & 6.2 & 5.0348 & TRN \\
\hline CHEMBL1320376 & 688267 & 4.05 & 5.0185 & TRN \\
\hline CHEMBL1571695 & 688267 & 6.2 & 5.0611 & TRN \\
\hline CHEMBL1610498 & 688267 & 6.0 & 5.0419 & TRN \\
\hline CHEMBL1390440 & 688267 & 4.0 & 5.1238 & TRN \\
\hline CHEMBL1555762 & 688267 & 6.5 & 5.1203 & TRN \\
\hline CHEMBL1437068 & 688267 & 4.05 & 5.1478 & TRN \\
\hline CHEMBL1485674 & 688267 & 4.05 & 5.0184 & TRN \\
\hline CHEMBL1531937 & 688267 & 5.75 & 4.9909 & TRN \\
\hline CHEMBL1485985 & 688267 & 6.2 & 5.0885 & TRN \\
\hline CHEMBL3208037 & 688267 & 4.0 & 5.0468 & TST \\
\hline CHEMBL1395486 & 688267 & 6.5 & 4.9957 & TRN \\
\hline CHEMBL1569058 & 688267 & 4.0 & 5.0685 & TRN \\
\hline CHEMBL1395512 & 688267 & 4.1 & 5.092 & TRN \\
\hline CHEMBL1592127 & 688267 & 6.0 & 5.0501 & TRN \\
\hline CHEMBL1306288 & 688267 & 5.5 & 5.0909 & TRN \\
\hline CHEMBL1516244 & 688267 & 4.35 & 5.0648 & TRN \\
\hline CHEMBL1424818 & 688267 & 6.15 & 5.0355 & TST \\
\hline CHEMBL1504664 & 688267 & 5.2 & 5.1301 & TRN \\
\hline CHEMBL1539289 & 688267 & 5.25 & 5.1289 & TRN \\
\hline CHEMBL1406315 & 688267 & 4.85 & 5.0933 & TST \\
\hline CHEMBL1356453 & 688267 & 5.45 & 5.0673 & TRN \\
\hline CHEMBL1545537 & 688267 & 6.2 & 5.0537 & TST \\
\hline CHEMBL1521046 & 688267 & 4.7 & 5.0335 & TST \\
\hline CHEMBL1594931 & 688267 & 4.0 & 5.0531 & TRN \\
\hline CHEMBL3196833 & 688267 & 6.9 & 4.9906 & TRN \\
\hline CHEMBL1476675 & 688267 & 5.85 & 5.0813 & TRN \\
\hline CHEMBL1571422 & 688267 & 4.1 & 5.0155 & TRN \\
\hline CHEMBL1358725 & 688267 & 4.35 & 5.0595 & TST \\
\hline CHEMBL1420641 & 688267 & 5.25 & 5.0549 & TRN \\
\hline CHEMBL1400676 & 688267 & 5.8 & 5.077 & TRN \\
\hline
\end{tabular}




\begin{tabular}{|c|c|c|c|c|c|}
\hline \multicolumn{6}{|c|}{ Supplemental Table S2.txt } \\
\hline CHEMBL1556917 & 688267 & 4.0 & 5.0478 & TST & \\
\hline CHEMBL1534517 & 688267 & 5.45 & 5.0952 & TRN & \\
\hline CHEMBL1493412 & 688267 & 4.55 & 5.0788 & TRN & \\
\hline CHEMBL75913 & 688267 & 4.2 & 5.0462 & TRN & \\
\hline CHEMBL1469268 & 688267 & 4.6 & 5.0191 & TST & \\
\hline CHEMBL3210161 & 688267 & 4.0 & 5.0277 & TRN & \\
\hline CHEMBL1480979 & 688267 & 4.3 & 5.0298 & TRN & \\
\hline CHEMBL1475925 & 688267 & 6.2 & 5.0821 & TST & \\
\hline CHEMBL1387453 & 688267 & 6.15 & 5.0252 & TRN & \\
\hline CHEMBL1416453 & 688267 & 5.2 & 5.1052 & TRN & \\
\hline CHEMBL1451301 & 688267 & 4.1 & 5.12700 & 0000000001 & TRN \\
\hline CHEMBL1497506 & 688267 & 6.2 & 5.0921 & TRN & \\
\hline CHEMBL1406422 & 688267 & 6.2 & 5.0439 & TRN & \\
\hline CHEMBL1536154 & 688267 & 5.0 & 5.0295 & TST & \\
\hline CHEMBL1426127 & 688267 & 4.1 & 5.0264 & TST & \\
\hline CHEMBL1357007 & 688267 & 4.0 & 5.1496 & TRN & \\
\hline CHEMBL1537690 & 688267 & 4.3 & 5.001 & TRN & \\
\hline CHEMBL1985530 & 688267 & 5.0 & 5.029 & TST & \\
\hline CHEMBL1428037 & 688267 & 6.15 & 5.0307 & TRN & \\
\hline CHEMBL1429950 & 688267 & 6.25 & 5.1048 & TRN & \\
\hline CHEMBL1347212 & 688267 & 4.6 & 5.1159 & TST & \\
\hline CHEMBL1568384 & 688267 & 5.5 & 5.0711 & TRN & \\
\hline CHEMBL1376221 & 688267 & 4.4 & 5.0438 & TRN & \\
\hline CHEMBL3197355 & 688267 & 4.5 & 5.037 & TRN & \\
\hline CHEMBL1977524 & 688267 & 4.2 & 5.0115 & TRN & \\
\hline CHEMBL1430288 & 688267 & 4.4 & 5.1138 & TRN & \\
\hline CHEMBL1576076 & 688267 & 5.85 & 5.0759 & TRN & \\
\hline CHEMBL1405097 & 688267 & 4.4 & 5.0344 & TRN & \\
\hline CHEMBL1357425 & 688267 & 4.0 & 5.1128 & TRN & \\
\hline CHEMBL3192417 & 688267 & 5.4 & 4.9923 & TRN & \\
\hline CHEMBL1460519 & 688267 & 4.1 & 5.065 & TRN & \\
\hline CHEMBL586628 & 688267 & 4.05 & 5.0509 & TST & \\
\hline CHEMBL1326290 & 688267 & 6.45 & 5.0592 & TRN & \\
\hline CHEMBL1302939 & 688267 & 6.2 & 5.0856 & TRN & \\
\hline CHEMBL1543412 & 688267 & 3.95 & 5.0764 & TRN & \\
\hline CHEMBL1370518 & 688267 & 6.05 & 5.0355 & TRN & \\
\hline CHEMBL1307586 & 688267 & 6.25 & 5.1296 & TRN & \\
\hline CHEMBL1501832 & 688267 & 5.5 & 5.0757 & TST & \\
\hline CHEMBL1520107 & 688267 & 4.55 & 5.0181 & TRN & \\
\hline CHEMBL1586063 & 688267 & 5.3 & 5.1076 & TRN & \\
\hline CHEMBL1425557 & 688267 & 4.35 & 5.0019 & TRN & \\
\hline CHEMBL1479395 & 688267 & 6.05 & 5.0842 & TRN & \\
\hline CHEMBL1323176 & 688267 & 4.05 & 5.0455 & TRN & \\
\hline CHEMBL1371051 & 688267 & 5.6 & 5.1668 & TRN & \\
\hline CHEMBL1612788 & 688267 & 4.65 & 5.1025 & TRN & \\
\hline CHEMBL1409173 & 688267 & 6.2 & 5.0317 & TRN & \\
\hline CHEMBL567735 & 688267 & 4.05 & 5.0263 & TST & \\
\hline CHEMBL1604732 & 688267 & 3.95 & 5.0777 & TRN & \\
\hline
\end{tabular}




\begin{tabular}{|c|c|c|c|c|}
\hline \multicolumn{5}{|c|}{ Supplemental Tabl } \\
\hline CHEMBL1540554 & 688267 & 6.15 & 5.0817 & TRN \\
\hline CHEMBL1394287 & 688267 & 4.0 & 4.9368 & TRN \\
\hline CHEMBL1543853 & 688267 & 6.2 & 5.0489 & TRN \\
\hline CHEMBL1447513 & 688267 & 6.1 & 5.0288 & TST \\
\hline CHEMBL1373455 & 688267 & 6.05 & 5.0819 & TRN \\
\hline CHEMBL1534725 & 688267 & 6.2 & 5.0606 & TRN \\
\hline CHEMBL1334060 & 688267 & 4.25 & 5.0153 & TRN \\
\hline CHEMBL1367488 & 688267 & 4.95 & 5.0502 & TRN \\
\hline CHEMBL1331183 & 688267 & 4.0 & 5.0767 & TRN \\
\hline CHEMBL1604248 & 688267 & 4.45 & 5.092 & TRN \\
\hline CHEMBL1358217 & 688267 & 4.55 & 5.0621 & TRN \\
\hline CHEMBL1452313 & 688267 & 4.05 & 5.0819 & TRN \\
\hline CHEMBL1495625 & 688267 & 4.05 & 4.9693 & TRN \\
\hline CHEMBL1405952 & 688267 & 6.2 & 5.0283 & TRN \\
\hline CHEMBL1343844 & 688267 & 5.5 & 5.0402 & TRN \\
\hline CHEMBL1486526 & 688267 & 6.2 & 5.1457 & TRN \\
\hline CHEMBL1305642 & 688267 & 4.0 & 5.0281 & TST \\
\hline CHEMBL1391758 & 688267 & 5.25 & 5.0626 & TRN \\
\hline CHEMBL1436534 & 688267 & 5.15 & 5.0721 & TRN \\
\hline CHEMBL1316194 & 688267 & 5.6 & 5.0337 & TRN \\
\hline CHEMBL1591705 & 688267 & 6.05 & 5.1027 & TST \\
\hline CHEMBL1428589 & 688267 & 5.3 & 5.1028 & TRN \\
\hline CHEMBL1325968 & 688267 & 5.85 & 5.0221 & TRN \\
\hline CHEMBL1361887 & 688267 & 5.3 & 5.0397 & TST \\
\hline CHEMBL1529216 & 688267 & 5.45 & 5.0617 & TRN \\
\hline CHEMBL1519556 & 688267 & 6.15 & 5.1125 & TRN \\
\hline CHEMBL1344393 & 688267 & 5.5 & 5.0983 & TST \\
\hline CHEMBL1382855 & 688267 & 5.35 & 5.0766 & TRN \\
\hline CHEMBL1603150 & 688267 & 5.35 & 5.0331 & TRN \\
\hline CHEMBL 1445660 & 688267 & 4.7 & 5.0119 & TRN \\
\hline CHEMBL1411537 & 688267 & 4.55 & 5.0449 & TRN \\
\hline CHEMBL1544207 & 688267 & 4.35 & 5.0489 & TRN \\
\hline CHEMBL1380464 & 688267 & 5.3 & 5.1165 & TST \\
\hline CHEMBL1547175 & 688267 & 4.0 & 5.0701 & TST \\
\hline CHEMBL1340494 & 688267 & 6.45 & 5.0342 & TST \\
\hline CHEMBL1473718 & 688267 & 6.25 & 5.0687 & TRN \\
\hline CHEMBL1406377 & 688267 & 5.4 & 5.1761 & TRN \\
\hline CHEMBL1495562 & 688267 & 4.15 & 5.0562 & TST \\
\hline CHEMBL1423549 & 688267 & 4.85 & 5.0508 & TST \\
\hline CHEMBL 1475378 & 688267 & 4.95 & 5.0389 & TRN \\
\hline CHEMBL1361913 & 688267 & 4.0 & 5.0031 & TST \\
\hline CHEMBL1445075 & 688267 & 6.25 & 5.0483 & TST \\
\hline CHEMBL1607787 & 688267 & 5.65 & 5.0414 & TST \\
\hline CHEMBL1523754 & 688267 & 4.1 & 5.1616 & TRN \\
\hline CHEMBL 1385342 & 688267 & 5.25 & 5.0576 & TRN \\
\hline CHEMBL1317979 & 688267 & 6.2 & 5.0874 & TRN \\
\hline CHEMBL1539921 & 688267 & 5.8 & 5.1336 & TRN \\
\hline CHEMBL1406707 & 688267 & 5.15 & 5.0635 & TRN \\
\hline
\end{tabular}




\begin{tabular}{|c|c|c|c|c|}
\hline \multicolumn{5}{|c|}{ Supplemental Table S2.txt } \\
\hline CHEMBL1385619 & 688267 & 4.3 & 5.0216 & TRN \\
\hline CHEMBL1312501 & 688267 & 4.1 & 5.0686 & TRN \\
\hline CHEMBL1517282 & 688267 & 5.55 & 5.0441 & TRN \\
\hline CHEMBL2001936 & 688267 & 4.85 & 5.0083 & TRN \\
\hline CHEMBL3192197 & 688267 & 4.0 & 4.9968 & TRN \\
\hline CHEMBL1442146 & 688267 & 3.95 & 5.0584 & TRN \\
\hline CHEMBL1346515 & 688267 & 6.15 & 5.0085 & TRN \\
\hline CHEMBL1504205 & 688267 & 4.05 & 5.0672 & TRN \\
\hline CHEMBL1333396 & 688267 & 6.5 & 4.996 & TRN \\
\hline CHEMBL1396838 & 688267 & 5.9 & 5.0467 & TRN \\
\hline CHEMBL1355158 & 688267 & 6.2 & 5.0813 & TRN \\
\hline CHEMBL1449410 & 688267 & 6.25 & 5.0336 & TST \\
\hline CHEMBL1517616 & 688267 & 6.2 & 5.0709 & TRN \\
\hline CHEMBL1458127 & 688267 & 4.75 & 5.0117 & TRN \\
\hline CHEMBL1600046 & 688267 & 4.0 & 5.1037 & TRN \\
\hline CHEMBL596847 & 688267 & 4.05 & 5.0686 & TRN \\
\hline CHEMBL1372419 & 688267 & 4.4 & 5.0521 & TST \\
\hline CHEMBL1454362 & 688267 & 6.15 & 5.0942 & TRN \\
\hline CHEMBL3197314 & 688267 & 4.55 & 4.9843 & TST \\
\hline CHEMBL1466843 & 688267 & 4.65 & 5.0512 & TRN \\
\hline CHEMBL1604414 & 688267 & 5.0 & 5.1072 & TST \\
\hline CHEMBL1553142 & 688267 & 5.4 & 5.0865 & TRN \\
\hline CHEMBL1564237 & 688267 & 5.95 & 5.0392 & TST \\
\hline CHEMBL1488005 & 688267 & 6.2 & 4.9932 & TRN \\
\hline CHEMBL1389446 & 688267 & 4.6 & 4.9894 & TRN \\
\hline CHEMBL1578092 & 688267 & 5.0 & 5.1006 & TRN \\
\hline CHEMBL1404119 & 688267 & 3.95 & 5.0762 & TRN \\
\hline CHEMBL1555327 & 688267 & 4.35 & 5.1256 & TRN \\
\hline CHEMBL1579118 & 688267 & 4.6 & 5.0467 & TST \\
\hline CHEMBL1402184 & 688267 & 4.3 & 5.0067 & TRN \\
\hline CHEMBL1484572 & 688267 & 5.25 & 5.0975 & TST \\
\hline CHEMBL1521909 & 688267 & 5.0 & 5.0139 & TST \\
\hline CHEMBL1377684 & 688267 & 4.45 & 5.0313 & TST \\
\hline CHEMBL1568674 & 688267 & 6.5 & 4.9738 & TRN \\
\hline CHEMBL1454663 & 688267 & 5.1 & 5.0335 & TRN \\
\hline CHEMBL1315809 & 688267 & 4.05 & 5.0546 & TRN \\
\hline CHEMBL1594715 & 688267 & 5.25 & 5.0593 & TST \\
\hline CHEMBL1388107 & 688267 & 5.35 & 5.0648 & TRN \\
\hline CHEMBL1498269 & 688267 & 3.95 & 5.0326 & TRN \\
\hline CHEMBL1402100 & 688267 & 6.45 & 5.0425 & TRN \\
\hline CHEMBL1590759 & 688267 & 6.45 & 5.0582 & TRN \\
\hline CHEMBL1348855 & 688267 & 5.35 & 5.0593 & TRN \\
\hline CHEMBL1485502 & 688267 & 4.25 & 5.0502 & TST \\
\hline CHEMBL1416270 & 688267 & 6.0 & 5.0827 & TRN \\
\hline CHEMBL1513745 & 688267 & 4.6 & 5.102 & TRN \\
\hline CHEMBL1463449 & 688267 & 4.6 & 5.0547 & TST \\
\hline CHEMBL544752 & 688267 & 4.05 & 4.9887 & TST \\
\hline CHEMBL 2373660 & 688267 & 4.0 & 5.0833 & TRN \\
\hline
\end{tabular}




\begin{tabular}{|c|c|c|c|c|}
\hline & & & upplement & al $\mathrm{T}$ \\
\hline CHEMBL1332169 & 688267 & 5.85 & 5.0514 & TST \\
\hline CHEMBL1480427 & 688267 & 5.0 & 5.1434 & TST \\
\hline CHEMBL1346925 & 688267 & 4.55 & 5.0107 & TST \\
\hline CHEMBL1352993 & 688267 & 4.55 & 5.0622 & TRN \\
\hline CHEMBL1456203 & 688267 & 4.0 & 5.087 & TRN \\
\hline CHEMBL1419780 & 688267 & 4.05 & 5.0557 & TRN \\
\hline CHEMBL1455949 & 688267 & 4.0 & 5.0575 & TST \\
\hline CHEMBL1463602 & 688267 & 5.4 & 4.9829 & TST \\
\hline CHEMBL1514852 & 688267 & 5.6 & 5.0773 & TRN \\
\hline CHEMBL1397645 & 688267 & 5.3 & 5.0825 & TRN \\
\hline CHEMBL1344921 & 688267 & 4.35 & 5.0055 & TST \\
\hline CHEMBL1406821 & 688267 & 5.3 & 5.0491 & TRN \\
\hline CHEMBL1303357 & 688267 & 4.2 & 4.9771 & TRN \\
\hline CHEMBL1510884 & 688267 & 4.5 & 5.0014 & TRN \\
\hline CHEMBL1602957 & 688267 & 4.35 & 5.0488 & TRN \\
\hline CHEMBL1610966 & 688267 & 5.55 & 5.1486 & TRN \\
\hline CHEMBL1448634 & 688267 & 5.35 & 5.1171 & TRN \\
\hline CHEMBL1603635 & 688267 & 5.05 & 5.061 & TST \\
\hline CHEMBL1411021 & 688267 & 4.4 & 5.0833 & TRN \\
\hline CHEMBL1411494 & 688267 & 5.6 & 5.0464 & TRN \\
\hline CHEMBL1353149 & 688267 & 5.65 & 5.0512 & TRN \\
\hline CHEMBL1328262 & 688267 & 4.3 & 5.0222 & TRN \\
\hline CHEMBL1359951 & 688267 & 5.55 & 5.0353 & TRN \\
\hline CHEMBL2374032 & 688267 & 4.85 & 5.0497 & TRN \\
\hline CHEMBL1546220 & 688267 & 4.05 & 5.0713 & TST \\
\hline CHEMBL1378916 & 688267 & 5.35 & 5.1223 & TRN \\
\hline CHEMBL1468761 & 688267 & 4.1 & 5.0014 & TRN \\
\hline CHEMBL1327846 & 688267 & 4.4 & 5.0889 & TRN \\
\hline CHEMBL405081 & 688267 & 4.15 & 5.0402 & TST \\
\hline CHEMBL1380377 & 688267 & 4.5 & 5.1186 & TST \\
\hline CHEMBL1350381 & 688267 & 6.15 & 5.0662 & TST \\
\hline CHEMBL1574414 & 688267 & 5.15 & 5.0735 & TRN \\
\hline CHEMBL1431384 & 688267 & 5.55 & 5.0919 & TRN \\
\hline CHEMBL1481165 & 688267 & 4.0 & 5.008 & TRN \\
\hline CHEMBL1521053 & 688267 & 5.6 & 5.1023 & TRN \\
\hline CHEMBL1587849 & 688267 & 6.45 & 5.055 & TST \\
\hline CHEMBL 1607100 & 688267 & 5.25 & 5.012 & TST \\
\hline CHEMBL1521568 & 688267 & 7.15 & 5.0925 & TRN \\
\hline CHEMBL1568659 & 688267 & 5.55 & 5.0527 & TST \\
\hline CHEMBL1450738 & 688267 & 5.4 & 5.0466 & TRN \\
\hline CHEMBL 251963 & 688267 & 5.4 & 5.01 & TST \\
\hline CHEMBL1438070 & 688267 & 4.4 & 5.0759 & TST \\
\hline CHEMBL1502969 & 688267 & 4.45 & 5.1374 & TST \\
\hline CHEMBL1387691 & 688267 & 5.25 & 5.1139 & TRN \\
\hline CHEMBL1354495 & 688267 & 4.05 & 5.044 & TRN \\
\hline CHEMBL1392136 & 688267 & 6.25 & 5.1134 & TRN \\
\hline CHEMBL1433476 & 688267 & 4.05 & 5.0225 & TRN \\
\hline CHEMBL1553116 & 688267 & 4.2 & 5.0172 & TRN \\
\hline
\end{tabular}




\begin{tabular}{|c|c|c|c|c|c|}
\hline \\
\hline CHEMBL3191448 & 688267 & 5.7 & 5.0007 & TST & \\
\hline CHEMBL1414226 & 688267 & 4.55 & 4.9998 & TRN & \\
\hline CHEMBL1430587 & 688267 & 6.7001 & 5.1799 & TRN & \\
\hline CHEMBL1444903 & 688267 & 4.35 & 5.1093 & TRN & \\
\hline CHEMBL1607158 & 688267 & 4.45 & 5.0585 & TST & \\
\hline CHEMBL1454498 & 688267 & 5.9 & 5.1143 & TRN & \\
\hline CHEMBL1461277 & 688267 & 4.55 & 5.006 & TRN & \\
\hline CHEMBL3193984 & 688267 & 4.4 & 5.0881 & TRN & \\
\hline CHEMBL1491287 & 688267 & 4.95 & 5.018 & TRN & \\
\hline CHEMBL1553071 & 688267 & 4.75 & 5.1045 & TRN & \\
\hline CHEMBL1524095 & 688267 & 4.55 & 5.0368 & TRN & \\
\hline CHEMBL1608379 & 688267 & 4.45 & 5.0483 & TRN & \\
\hline CHEMBL1529319 & 688267 & 4.25 & 5.113 & TRN & \\
\hline CHEMBL1381532 & 688267 & 4.85 & 5.0679 & TST & \\
\hline CHEMBL1466860 & 688267 & 3.95 & 5.0411 & TRN & \\
\hline CHEMBL1522246 & 688267 & 5.35 & 5.0342 & TRN & \\
\hline CHEMBL1369304 & 688267 & 6.2 & 5.1068 & TRN & \\
\hline CHEMBL1426255 & 688267 & 4.35 & 5.0312 & TRN & \\
\hline CHEMBL1593919 & 688267 & 4.0 & 5.0305 & TRN & \\
\hline CHEMBL1521321 & 688267 & 4.4 & 5.13299 & & TRN \\
\hline CHEMBL1305732 & 688267 & 4.05 & 5.0805 & TRN & \\
\hline CHEMBL1335280 & 688267 & 5.95 & 5.0422 & TRN & \\
\hline CHEMBL1581311 & 688267 & 6.2 & 4.9639 & TRN & \\
\hline CHEMBL1314565 & 688267 & 4.05 & 5.0476 & TRN & \\
\hline CHEMBL1389375 & 688267 & 6.15 & 5.1312 & TST & \\
\hline CHEMBL1505147 & 688267 & 5.35 & 5.0622 & TRN & \\
\hline CHEMBL1547265 & 688267 & 5.45 & 5.0572 & TST & \\
\hline CHEMBL1508570 & 688267 & 5.3 & 5.0849 & TRN & \\
\hline CHEMBL1202936 & 688267 & 5.25 & 5.0752 & TST & \\
\hline CHEMBL1344696 & 688267 & 5.95 & 5.0236 & TRN & \\
\hline CHEMBL1474017 & 688267 & 5.8 & 5.0756 & TRN & \\
\hline CHEMBL1387331 & 688267 & 4.65 & 5.0089 & TRN & \\
\hline CHEMBL1523657 & 688267 & 4.55 & 5.0913 & TRN & \\
\hline CHEMBL1403040 & 688267 & 4.65 & 5.0915 & TRN & \\
\hline CHEMBL1396218 & 688267 & 4.0 & 5.1199 & TRN & \\
\hline CHEMBL1580615 & 688267 & 6.25 & 5.0725 & TRN & \\
\hline CHEMBL1560558 & 688267 & 5.1 & 5.1897 & TRN & \\
\hline CHEMBL1595077 & 688267 & 4.4 & 5.0621 & TRN & \\
\hline CHEMBL1358147 & 688267 & 4.7 & 5.1142 & TRN & \\
\hline CHEMBL1457126 & 688267 & 6.2 & 5.0759 & TRN & \\
\hline CHEMBL1499880 & 688267 & 4.4 & 5.1037 & TRN & \\
\hline CHEMBL1418893 & 688267 & 4.25 & 5.1106 & TRN & \\
\hline CHEMBL1334672 & 688267 & 5.8 & 5.0894 & TRN & \\
\hline CHEMBL1359370 & 688267 & 3.85 & 5.0044 & TRN & \\
\hline CHEMBL1337616 & 688267 & 4.65 & 5.0064 & TRN & \\
\hline CHEMBL1520348 & 688267 & 5.6 & 5.0535 & TRN & \\
\hline CHEMBL1368295 & 688267 & 4.05 & 5.0572 & TRN & \\
\hline CHEMBL1565404 & 688267 & 6.15 & 5.022 & TRN & \\
\hline
\end{tabular}




\begin{tabular}{|c|c|c|c|c|c|}
\hline \\
\hline CHEMBL1319368 & 688267 & 5.1 & 5.0253 & TRN & \\
\hline CHEMBL1472093 & 688267 & 5.55 & 5.011 & TRN & \\
\hline CHEMBL1395623 & 688267 & 7.9508 & 5.0784 & TRN & \\
\hline CHEMBL1586846 & 688267 & 4.0 & 5.0265 & TRN & \\
\hline CHEMBL1434307 & 688267 & 4.0 & 5.12799 & 9999999999 & TRN \\
\hline CHEMBL1344273 & 688267 & 5.8 & 5.0863 & TRN & \\
\hline CHEMBL1373630 & 688267 & 3.95 & 5.0847 & TRN & \\
\hline CHEMBL1532591 & 688267 & 4.05 & 5.0071 & TRN & \\
\hline CHEMBL1510295 & 688267 & 4.05 & 5.0753 & TST & \\
\hline CHEMBL1584169 & 688267 & 5.85 & 5.0554 & TRN & \\
\hline CHEMBL1302972 & 688267 & 4.4 & 5.0397 & TRN & \\
\hline CHEMBL1384724 & 688267 & 4.15 & 5.0805 & TRN & \\
\hline CHEMBL1524757 & 688267 & 5.6 & 5.0254 & TRN & \\
\hline CHEMBL1375521 & 688267 & 4.05 & 5.0008 & TST & \\
\hline CHEMBL1610961 & 688267 & 4.5 & 5.0741 & TST & \\
\hline CHEMBL1565836 & 688267 & 4.05 & 5.0748 & TRN & \\
\hline CHEMBL1438566 & 688267 & 6.0 & 5.0441 & TRN & \\
\hline CHEMBL1491794 & 688267 & 5.3 & 5.1626 & TST & \\
\hline CHEMBL1310222 & 688267 & 5.1 & 5.1375 & TRN & \\
\hline CHEMBL1408509 & 688267 & 6.2 & 5.08899 & 999999999995 & TRN \\
\hline CHEMBL1348645 & 688267 & 4.5 & 5.0507 & TST & \\
\hline CHEMBL1470306 & 688267 & 4.95 & 5.0842 & TRN & \\
\hline CHEMBL1438351 & 688267 & 3.95 & 5.0187 & TRN & \\
\hline CHEMBL1457925 & 688267 & 6.5 & 5.0722 & TST & \\
\hline CHEMBL1411361 & 688267 & 4.6 & 5.0119 & TRN & \\
\hline CHEMBL1307845 & 688267 & 4.55 & 5.0527 & TRN & \\
\hline CHEMBL1485671 & 688267 & 6.2 & 5.0226 & TRN & \\
\hline CHEMBL1403637 & 688267 & 4.0 & 5.0501 & TST & \\
\hline CHEMBL1604944 & 688267 & 4.0 & 5.0078 & TRN & \\
\hline CHEMBL1469883 & 688267 & 4.4 & 4.9993 & TRN & \\
\hline CHEMBL1454314 & 688267 & 4.4 & 5.0883 & TST & \\
\hline CHEMBL1557193 & 688267 & 4.35 & 5.0533 & TRN & \\
\hline CHEMBL1567766 & 688267 & 5.55 & 4.9588 & TRN & \\
\hline CHEMBL1371153 & 688267 & 5.85 & 5.0671 & TRN & \\
\hline CHEMBL1582669 & 688267 & 5.1 & 5.0654 & TRN & \\
\hline CHEMBL1516664 & 688267 & 4.2 & 5.0494 & TST & \\
\hline CHEMBL1379902 & 688267 & 4.6 & 5.034 & TRN & \\
\hline CHEMBL1376217 & 688267 & 5.65 & 5.1137 & TRN & \\
\hline CHEMBL1327402 & 688267 & 6.15 & 5.1004 & TRN & \\
\hline CHEMBL1304105 & 688267 & 5.6 & 5.0652 & TRN & \\
\hline CHEMBL1412121 & 688267 & 4.05 & 5.0356 & TRN & \\
\hline CHEMBL1448071 & 688267 & 5.7 & 5.0708 & TST & \\
\hline CHEMBL1495113 & 688267 & 5.0 & 5.0146 & TRN & \\
\hline CHEMBL1434376 & 688267 & 6.25 & 5.0244 & TST & \\
\hline CHEMBL1567182 & 688267 & 6.2 & 5.0372 & TST & \\
\hline CHEMBL1339347 & 688267 & 6.2 & 5.0135 & TRN & \\
\hline CHEMBL1453202 & 688267 & 5.0 & 5.0167 & TRN & \\
\hline CHEMBL1314363 & 688267 & 4.05 & 5.0903 & TRN & \\
\hline
\end{tabular}




\begin{tabular}{|c|c|c|c|c|}
\hline \multicolumn{5}{|c|}{ Supplemental Table S2.txt } \\
\hline CHEMBL1333235 & 688267 & 5.3 & 5.0308 & TRN \\
\hline CHEMBL1583171 & 688267 & 4.05 & 5.0508 & TRN \\
\hline CHEMBL1542987 & 688267 & 4.1 & 5.0716 & TST \\
\hline CHEMBL1479876 & 688267 & 4.85 & 5.0307 & TST \\
\hline CHEMBL1552766 & 688267 & 4.05 & 5.0308 & TRN \\
\hline CHEMBL1313233 & 688267 & 5.85 & 5.1251 & TRN \\
\hline CHEMBL1440258 & 688267 & 5.35 & 5.0347 & TRN \\
\hline CHEMBL3210881 & 688267 & 6.0 & 5.0394 & TRN \\
\hline CHEMBL1384192 & 688267 & 6.2 & 5.0983 & TST \\
\hline CHEMBL1427036 & 688267 & 4.05 & 5.0534 & TRN \\
\hline CHEMBL1518709 & 688267 & 4.85 & 5.0411 & TST \\
\hline CHEMBL1459826 & 688267 & 4.35 & 4.9898 & TST \\
\hline CHEMBL1403212 & 688267 & 4.8 & 5.1258 & TRN \\
\hline CHEMBL1441693 & 688267 & 6.2 & 5.0068 & TRN \\
\hline CHEMBL1311929 & 688267 & 5.6 & 5.0461 & TRN \\
\hline CHEMBL1523322 & 688267 & 3.95 & 5.1186 & TST \\
\hline CHEMBL1429030 & 688267 & 4.25 & 5.0889 & TRN \\
\hline CHEMBL1343571 & 688267 & 6.2 & 4.9969 & TRN \\
\hline CHEMBL2373675 & 688267 & 4.8 & 5.0567 & TRN \\
\hline CHEMBL1517410 & 688267 & 5.55 & 5.1005 & TRN \\
\hline CHEMBL1453915 & 688267 & 4.5 & 5.0579 & TST \\
\hline CHEMBL1422725 & 688267 & 5.0 & 5.0947 & TRN \\
\hline CHEMBL1500561 & 688267 & 4.35 & 5.0796 & TRN \\
\hline CHEMBL1420465 & 688267 & 4.9 & 5.0711 & TST \\
\hline CHEMBL1503854 & 688267 & 4.0 & 5.0028 & TST \\
\hline CHEMBL1432062 & 688267 & 3.85 & 5.102 & TRN \\
\hline CHEMBL1475097 & 688267 & 4.0 & 5.0912 & TRN \\
\hline CHEMBL1555049 & 688267 & 4.0 & 5.0223 & TRN \\
\hline CHEMBL1344965 & 688267 & 4.35 & 5.0241 & TRN \\
\hline CHEMBL1518722 & 688267 & 4.6 & 5.0064 & TRN \\
\hline CHEMBL1551859 & 688267 & 4.05 & 5.019 & TRN \\
\hline CHEMBL1571034 & 688267 & 5.05 & 5.0473 & TST \\
\hline CHEMBL1493439 & 688267 & 6.5501 & 5.0437 & TRN \\
\hline CHEMBL1484859 & 688267 & 4.45 & 5.0008 & TRN \\
\hline CHEMBL1566157 & 688267 & 4.0 & 5.0168 & TRN \\
\hline CHEMBL1565616 & 688267 & 5.05 & 5.0128 & TRN \\
\hline CHEMBL1527493 & 688267 & 6.2 & 5.0711 & TRN \\
\hline CHEMBL1332636 & 688267 & 4.75 & 5.0662 & TRN \\
\hline CHEMBL1565459 & 688267 & 5.35 & 5.0617 & TRN \\
\hline CHEMBL1417185 & 688267 & 4.1 & 5.0854 & TRN \\
\hline CHEMBL1576146 & 688267 & 5.7 & 5.0505 & TST \\
\hline CHEMBL1300372 & 688267 & 6.15 & 4.9819 & TRN \\
\hline CHEMBL1300973 & 688267 & 4.05 & 5.0671 & TRN \\
\hline CHEMBL1411546 & 688267 & 6.15 & 5.0757 & TRN \\
\hline CHEMBL1445967 & 688267 & 6.2 & 5.1048 & TRN \\
\hline CHEMBL1517741 & 688267 & 3.95 & 5.0233 & TST \\
\hline CHEMBL1378267 & 688267 & 5.65 & 5.0476 & TRN \\
\hline CHEMBL1449292 & 688267 & 4.05 & 5.0569 & TRN \\
\hline
\end{tabular}




\begin{tabular}{|c|c|c|c|c|c|}
\hline & & \multicolumn{4}{|c|}{ Supplemental Table s2.txt } \\
\hline CHEMBL1481756 & 688267 & 5.55 & 5.0355 & TST & \\
\hline CHEMBL1573777 & 688267 & 6.2 & 5.1617 & TRN & \\
\hline CHEMBL1490216 & 688267 & 6.2 & 5.0502 & TRN & \\
\hline CHEMBL1326708 & 688267 & 3.95 & 5.0922 & TRN & \\
\hline CHEMBL1484967 & 688267 & 6.2 & 5.0282 & TRN & \\
\hline CHEMBL1415363 & 688267 & 6.15 & 5.0553 & TRN & \\
\hline CHEMBL1497596 & 688267 & 4.55 & 5.0501 & TRN & \\
\hline CHEMBL1511197 & 688267 & 4.95 & 5.0409 & TRN & \\
\hline CHEMBL1338314 & 688267 & 6.5 & 5.1092 & TRN & \\
\hline CHEMBL1492666 & 688267 & 5.3 & 5.1016 & TST & \\
\hline CHEMBL1356164 & 688267 & 4.0 & 5.0391 & TRN & \\
\hline CHEMBL1550696 & 688267 & 5.35 & 5.0366 & TRN & \\
\hline CHEMBL1365904 & 688267 & 6.2 & 5.1308 & TRN & \\
\hline CHEMBL1519682 & 688267 & 6.2 & 5.1448 & TRN & \\
\hline CHEMBL1386479 & 688267 & 4.25 & 5.0699 & TRN & \\
\hline CHEMBL1478167 & 688267 & 6.15 & 5.13 & TRN & \\
\hline CHEMBL 75412 & 688267 & 4.5 & 5.02800 & 00000000005 & TRN \\
\hline CHEMBL1604926 & 688267 & 5.35 & 5.0705 & TRN & \\
\hline CHEMBL1560059 & 688267 & 4.3 & 5.0596 & TRN & \\
\hline CHEMBL1975289 & 688267 & 4.35 & 5.0216 & TRN & \\
\hline CHEMBL1475154 & 688267 & 5.95 & 5.1221 & TRN & \\
\hline CHEMBL1464964 & 688267 & 5.65 & 5.0249 & TRN & \\
\hline CHEMBL1483009 & 688267 & 6.5 & 5.1246 & TRN & \\
\hline CHEMBL1598156 & 688267 & 5.05 & 5.0509 & TRN & \\
\hline CHEMBL1464319 & 688267 & 5.35 & 5.1262 & TST & \\
\hline CHEMBL1465902 & 688267 & 4.45 & 5.0305 & TRN & \\
\hline CHEMBL1428898 & 688267 & 4.3 & 5.0315 & TRN & \\
\hline CHEMBL1450911 & 688267 & 5.55 & 5.0595 & TRN & \\
\hline CHEMBL1507640 & 688267 & 5.35 & 5.0035 & TRN & \\
\hline CHEMBL1557781 & 688267 & 5.5 & 5.0389 & TST & \\
\hline CHEMBL1579007 & 688267 & 6.2 & 5.1287 & TRN & \\
\hline CHEMBL1380528 & 688267 & 6.15 & 5.0985 & TRN & \\
\hline CHEMBL1445146 & 688267 & 4.35 & 5.0329 & TST & \\
\hline CHEMBL1590071 & 688267 & 5.3 & 4.9996 & TRN & \\
\hline CHEMBL1334012 & 688267 & 6.2 & 5.0523 & TRN & \\
\hline CHEMBL1433251 & 688267 & 5.5 & 5.0389 & TST & \\
\hline CHEMBL1332549 & 688267 & 5.15 & 5.0332 & TRN & \\
\hline CHEMBL3210152 & 688267 & 4.5 & 5.0648 & TRN & \\
\hline CHEMBL1378263 & 688267 & 5.2 & 5.053 & TRN & \\
\hline CHEMBL1361295 & 688267 & 5.55 & 5.0493 & TST & \\
\hline CHEMBL1492204 & 688267 & 5.3 & 5.1087 & TRN & \\
\hline CHEMBL1448429 & 688267 & 4.0 & 5.018 & TST & \\
\hline CHEMBL1528995 & 688267 & 5.55 & 5.1299 & TRN & \\
\hline CHEMBL1534060 & 688267 & 6.2 & 5.0531 & TRN & \\
\hline CHEMBL1529790 & 688267 & 6.2 & 5.0524 & TRN & \\
\hline CHEMBL1368244 & 688267 & 4.5 & 5.0647 & TST & \\
\hline CHEMBL1458362 & 688267 & 6.2 & 5.0428 & TRN & \\
\hline CHEMBL1604784 & 688267 & 6.15 & 5.0682 & TRN & \\
\hline
\end{tabular}




\begin{tabular}{|c|c|c|c|c|c|}
\hline \multicolumn{6}{|c|}{ Supplemental Table S2.txt } \\
\hline CHEMBL1495475 & 688267 & 6.15 & 5.1005 & TST & \\
\hline CHEMBL1354379 & 688267 & 5.05 & 5.0795 & TRN & \\
\hline CHEMBL1411681 & 688267 & 4.65 & 4.9859 & TRN & \\
\hline CHEMBL1546736 & 688267 & 4.1 & 5.1335 & TRN & \\
\hline CHEMBL1586844 & 688267 & 4.2 & 5.0652 & TRN & \\
\hline CHEMBL1536947 & 688267 & 6.2 & 5.1288 & TRN & \\
\hline CHEMBL1307947 & 688267 & 6.15 & 5.0524 & TRN & \\
\hline CHEMBL1489052 & 688267 & 4.0 & 5.0189 & TRN & \\
\hline CHEMBL1566056 & 688267 & 5.45 & 5.0136 & TRN & \\
\hline CHEMBL1583802 & 688267 & 4.0 & 5.0595 & TRN & \\
\hline CHEMBL1453141 & 688267 & 5.6 & 5.0306 & TRN & \\
\hline CHEMBL1458178 & 688267 & 5.85 & 5.0192 & TST & \\
\hline CHEMBL1354342 & 688267 & 4.0 & 5.0306 & TRN & \\
\hline CHEMBL1553340 & 688267 & 5.3 & 5.099 & TST & \\
\hline CHEMBL1404186 & 688267 & 5.5 & 5.0436 & TRN & \\
\hline CHEMBL1564499 & 688267 & 4.6 & 5.0061 & TRN & \\
\hline CHEMBL1318602 & 688267 & 4.0 & 5.0578 & TRN & \\
\hline CHEMBL1533722 & 688267 & 4.55 & 5.0055 & TRN & \\
\hline CHEMBL1344120 & 688267 & 5.95 & 5.0927 & TRN & \\
\hline CHEMBL1346455 & 688267 & 5.55 & 5.1392 & TST & \\
\hline CHEMBL1589602 & 688267 & 4.5 & 5.1136 & TRN & \\
\hline CHEMBL1528649 & 688267 & 5.15 & 5.0357 & TRN & \\
\hline CHEMBL1460306 & 688267 & 6.2 & 5.0051 & TRN & \\
\hline CHEMBL1589248 & 688267 & 4.35 & 5.0335 & TST & \\
\hline CHEMBL1597908 & 688267 & 4.5 & 5.0418 & TRN & \\
\hline CHEMBL1583027 & 688267 & 6.4 & 5.0498 & TRN & \\
\hline CHEMBL1346094 & 688267 & 4.95 & 5.0229 & TST & \\
\hline CHEMBL1612203 & 688267 & 6.0 & 5.026 & TRN & \\
\hline CHEMBL1532133 & 688267 & 6.2 & 5.0701 & TRN & \\
\hline CHEMBL1351610 & 688267 & 4.35 & 5.0724 & TST & \\
\hline CHEMBL1597255 & 688267 & 4.0 & 5.09 & TST & \\
\hline CHEMBL1314187 & 688267 & 6.15 & 5.0657 & TRN & \\
\hline CHEMBL1522364 & 688267 & 5.6 & 4.9947 & TRN & \\
\hline CHEMBL1332584 & 688267 & 5.85 & 5.0545 & TRN & \\
\hline CHEMBL1378635 & 688267 & 4.65 & 5.08 & TRN & \\
\hline CHEMBL1575246 & 688267 & 5.35 & 4.99100 & 00000000005 & TRN \\
\hline CHEMBL1318126 & 688267 & 6.2 & 5.0661 & TRN & \\
\hline CHEMBL1551667 & 688267 & 5.3 & 5.1336 & TRN & \\
\hline CHEMBL1357406 & 688267 & 4.2 & 5.039 & TRN & \\
\hline CHEMBL1564849 & 688267 & 4.9 & 5.0203 & TRN & \\
\hline CHEMBL1430781 & 688267 & 5.1 & 5.1012 & TRN & \\
\hline CHEMBL1481333 & 688267 & 4.05 & 5.0863 & TST & \\
\hline CHEMBL1532764 & 688267 & 4.05 & 5.0725 & TRN & \\
\hline CHEMBL1512367 & 688267 & 4.55 & 5.1075 & TRN & \\
\hline CHEMBL1518842 & 688267 & 6.25 & 5.052 & TRN & \\
\hline CHEMBL1530641 & 688267 & 5.75 & 5.0419 & TRN & \\
\hline CHEMBL1377932 & 688267 & 6.2 & 5.115 & TRN & \\
\hline CHEMBL1572302 & 688267 & 5.3 & 5.0752 & TST & \\
\hline
\end{tabular}




\begin{tabular}{|c|c|c|c|c|}
\hline & & & pplement & al $\mathrm{Ta}$ \\
\hline CHEMBL1486084 & 688267 & 6.2 & 5.1153 & TRN \\
\hline CHEMBL1565134 & 688267 & 5.35 & 5.0607 & TRN \\
\hline CHEMBL1535221 & 688267 & 6.0 & 5.0823 & TRN \\
\hline CHEMBL1582911 & 688267 & 6.2 & 5.0949 & TST \\
\hline CHEMBL1438834 & 688267 & 4.9 & 5.0336 & TRN \\
\hline CHEMBL1331551 & 688267 & 4.0 & 5.0692 & TRN \\
\hline CHEMBL1453010 & 688267 & 5.9 & 5.0899 & TRN \\
\hline CHEMBL1492674 & 688267 & 5.85 & 5.0409 & TST \\
\hline CHEMBL1603183 & 688267 & 6.1 & 5.0721 & TRN \\
\hline CHEMBL1454926 & 688267 & 4.45 & 5.0197 & TRN \\
\hline CHEMBL2002565 & 688267 & 6.2 & 4.9858 & TRN \\
\hline CHEMBL1477238 & 688267 & 4.15 & 5.0273 & TST \\
\hline CHEMBL1353504 & 688267 & 6.15 & 5.0173 & TST \\
\hline CHEMBL1313344 & 688267 & 4.7 & 5.106 & TRN \\
\hline CHEMBL1364927 & 688267 & 6.25 & 5.0746 & TRN \\
\hline CHEMBL1523788 & 688267 & 6.2 & 5.0513 & TST \\
\hline CHEMBL1547475 & 688267 & 5.55 & 5.0869 & TST \\
\hline CHEMBL1523199 & 688267 & 5.55 & 5.0445 & TRN \\
\hline CHEMBL1602504 & 688267 & 4.85 & 5.0511 & TST \\
\hline CHEMBL1497416 & 688267 & 6.15 & 5.0031 & TST \\
\hline CHEMBL1612281 & 688267 & 5.35 & 5.0331 & TRN \\
\hline CHEMBL1410580 & 688267 & 4.05 & 5.0961 & TRN \\
\hline CHEMBL1588828 & 688267 & 5.65 & 5.0592 & TRN \\
\hline CHEMBL1488861 & 688267 & 4.7 & 5.1073 & TRN \\
\hline CHEMBL1480349 & 688267 & 4.05 & 5.0891 & TRN \\
\hline CHEMBL1393457 & 688267 & 4.4 & 5.0924 & TRN \\
\hline CHEMBL1388169 & 688267 & 4.1 & 4.9738 & TRN \\
\hline CHEMBL1508551 & 688267 & 4.25 & 5.066 & TRN \\
\hline CHEMBL36641 & 688267 & 6.2 & 4.9926 & TRN \\
\hline CHEMBL1316427 & 688267 & 4.05 & 5.0092 & TRN \\
\hline CHEMBL1579996 & 688267 & 6.2 & 5.0215 & TRN \\
\hline CHEMBL1497180 & 688267 & 4.8 & 5.1356 & TRN \\
\hline CHEMBL1448457 & 688267 & 5.5 & 5.0696 & TRN \\
\hline CHEMBL1606007 & 688267 & 4.2 & 5.0078 & TST \\
\hline CHEMBL1404467 & 688267 & 6.05 & 5.084 & TRN \\
\hline CHEMBL1460758 & 688267 & 6.2 & 5.0345 & TRN \\
\hline CHEMBL1488352 & 688267 & 4.45 & 5.0815 & TRN \\
\hline CHEMBL1591700 & 688267 & 4.05 & 5.0854 & TRN \\
\hline CHEMBL1420741 & 688267 & 6.2 & 5.043 & TRN \\
\hline CHEMBL1560103 & 688267 & 5.25 & 5.0362 & TST \\
\hline CHEMBL1592485 & 688267 & 5.8 & 5.1248 & TRN \\
\hline CHEMBL1512981 & 688267 & 6.25 & 5.0255 & TRN \\
\hline CHEMBL1523761 & 688267 & 5.45 & 5.0285 & TST \\
\hline CHEMBL1373705 & 688267 & 4.6 & 5.0409 & TST \\
\hline CHEMBL1376442 & 688267 & 5.9 & 5.0129 & TRN \\
\hline CHEMBL1458304 & 688267 & 4.0 & 5.0759 & TST \\
\hline CHEMBL1461182 & 688267 & 6.5 & 4.9916 & TST \\
\hline CHEMBL1485198 & 688267 & 4.05 & 5.0031 & TST \\
\hline
\end{tabular}




\begin{tabular}{|c|c|c|c|c|c|}
\hline \\
\hline CHEMBL1319440 & 688267 & 4.6 & 5.035 & TRN & \\
\hline CHEMBL1467981 & 688267 & 3.95 & 5.0326 & TRN & \\
\hline CHEMBL1420077 & 688267 & 6.2 & 4.9661 & TRN & \\
\hline CHEMBL1502098 & 688267 & 4.55 & 4.9803 & TRN & \\
\hline CHEMBL1552524 & 688267 & 5.6 & 5.1088 & TRN & \\
\hline CHEMBL1534702 & 688267 & 3.95 & 5.0883 & TRN & \\
\hline CHEMBL1495928 & 688267 & 5.8 & 5.1007 & TST & \\
\hline CHEMBL1485855 & 688267 & 4.6 & 5.081 & TRN & \\
\hline CHEMBL1318371 & 688267 & 5.35 & 5.0089 & TRN & \\
\hline CHEMBL1310552 & 688267 & 5.6 & 4.9883 & TST & \\
\hline CHEMBL1374183 & 688267 & 5.45 & 4.9442 & TRN & \\
\hline CHEMBL1512781 & 688267 & 4.05 & 5.0287 & TRN & \\
\hline CHEMBL1433094 & 688267 & 4.8 & 5.0502 & TRN & \\
\hline CHEMBL1320745 & 688267 & 6.15 & 5.05399 & 9999999999 & TRN \\
\hline CHEMBL1460377 & 688267 & 4.65 & 5.1088 & TRN & \\
\hline CHEMBL1499763 & 688267 & 5.8 & 5.1676 & TRN & \\
\hline CHEMBL531709 & 688267 & 4.25 & 5.0573 & TRN & \\
\hline CHEMBL1560667 & 688267 & 5.85 & 5.0203 & TRN & \\
\hline CHEMBL1588345 & 688267 & 5.85 & 5.0741 & TRN & \\
\hline CHEMBL1545041 & 688267 & 4.4 & 5.0649 & TST & \\
\hline CHEMBL1493917 & 688267 & 5.5 & 5.0353 & TRN & \\
\hline CHEMBL1507815 & 688267 & 4.0 & 5.0033 & TRN & \\
\hline CHEMBL3198621 & 688267 & 6.2 & 5.0086 & TST & \\
\hline CHEMBL1359197 & 688267 & 5.95 & 5.0932 & TRN & \\
\hline CHEMBL1385903 & 688267 & 4.7 & 5.0277 & TRN & \\
\hline CHEMBL1420229 & 688267 & 5.55 & 5.0657 & TST & \\
\hline CHEMBL1538204 & 688267 & 4.05 & 5.0909 & TRN & \\
\hline CHEMBL1542315 & 688267 & 5.3 & 5.0405 & TRN & \\
\hline CHEMBL1527517 & 688267 & 6.2 & 5.0558 & TRN & \\
\hline CHEMBL1454351 & 688267 & 4.55 & 5.0157 & TST & \\
\hline CHEMBL1470618 & 688267 & 4.05 & 5.0544 & TST & \\
\hline CHEMBL1611233 & 688267 & 6.1 & 5.053 & TRN & \\
\hline CHEMBL1386509 & 688267 & 5.65 & 5.0231 & TRN & \\
\hline CHEMBL1375593 & 688267 & 4.4 & 5.0567 & TST & \\
\hline CHEMBL1346758 & 688267 & 6.5 & 5.0723 & TRN & \\
\hline CHEMBL1382730 & 688267 & 4.05 & 5.0588 & TRN & \\
\hline CHEMBL1542493 & 688267 & 5.4 & 5.0409 & TST & \\
\hline CHEMBL1536161 & 688267 & 4.25 & 5.0036 & TST & \\
\hline CHEMBL1321438 & 688267 & 6.2 & 5.0908 & TRN & \\
\hline CHEMBL1554964 & 688267 & 4.0 & 4.9627 & TRN & \\
\hline CHEMBL1390964 & 688267 & 6.15 & 5.0103 & TST & \\
\hline CHEMBL1379391 & 688267 & 4.25 & 5.0145 & TRN & \\
\hline CHEMBL1579469 & 688267 & 4.1 & 5.0761 & TRN & \\
\hline CHEMBL1606588 & 688267 & 5.0 & 5.0795 & TRN & \\
\hline CHEMBL1570504 & 688267 & 4.35 & 5.0238 & TST & \\
\hline CHEMBL1498774 & 688267 & 6.45 & 5.0673 & TRN & \\
\hline CHEMBL1350516 & 688267 & 5.95 & 5.0913 & TRN & \\
\hline CHEMBL1436314 & 688267 & 3.95 & 5.092 & TRN & \\
\hline
\end{tabular}




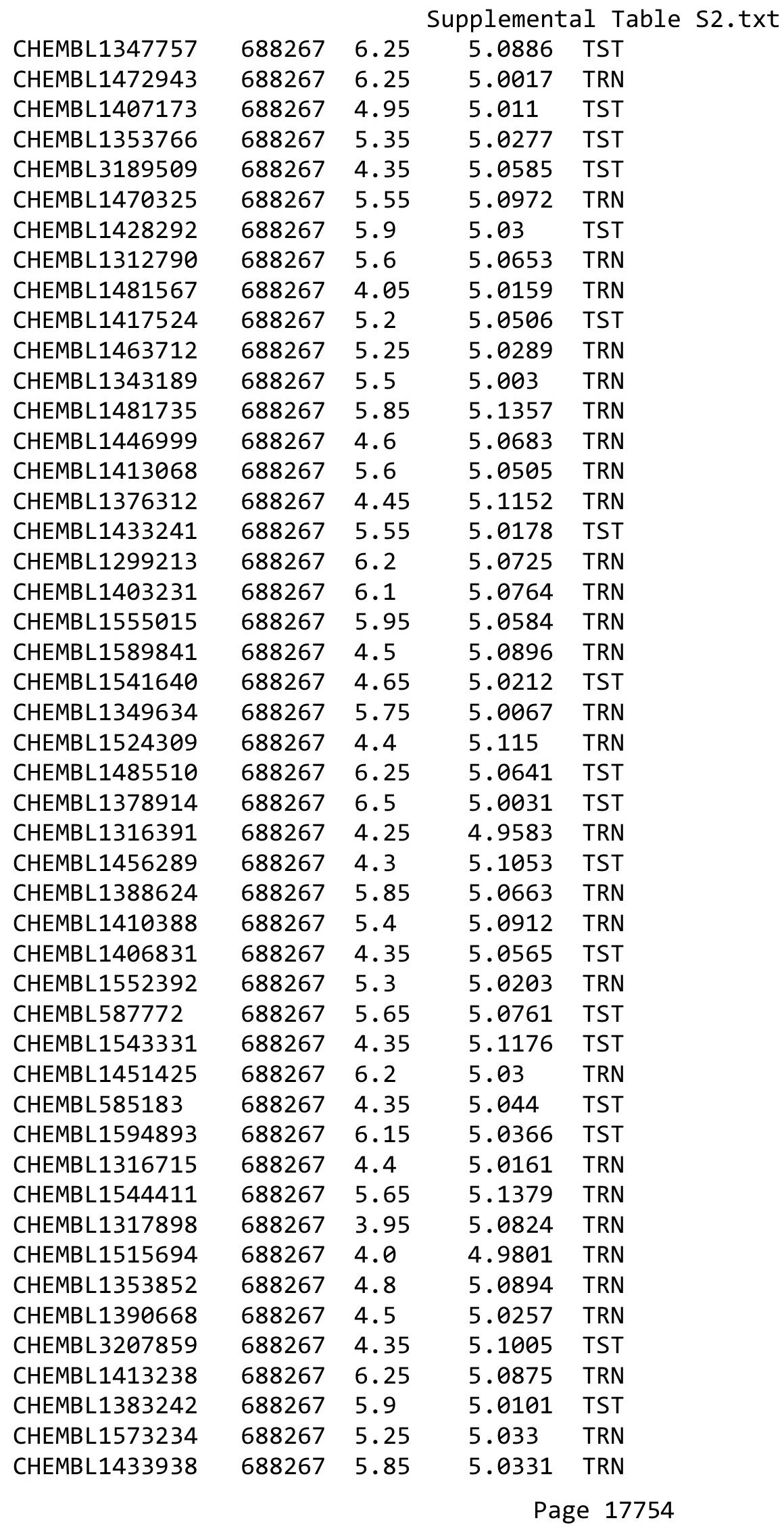




\begin{tabular}{|c|c|c|c|c|c|}
\hline \multicolumn{6}{|c|}{ Supplemental Table S2.txt } \\
\hline CHEMBL1597596 & 688267 & 4.25 & 5.1589 & TRN & \\
\hline CHEMBL1503354 & 688267 & 3.95 & 5.0913 & TST & \\
\hline CHEMBL1422161 & 688267 & 6.2 & 5.0273 & TST & \\
\hline CHEMBL1532516 & 688267 & 5.05 & 5.0521 & TRN & \\
\hline CHEMBL1557983 & 688267 & 3.95 & 5.0631 & TST & \\
\hline CHEMBL1372056 & 688267 & 4.05 & 5.0991 & TRN & \\
\hline CHEMBL1527977 & 688267 & 5.15 & 5.0776 & TRN & \\
\hline CHEMBL1368656 & 688267 & 6.6 & 5.0292 & TRN & \\
\hline CHEMBL1557060 & 688267 & 4.25 & 5.0322 & TRN & \\
\hline CHEMBL1484502 & 688267 & 4.3 & 5.0286 & TST & \\
\hline CHEMBL1578917 & 688267 & 4.0 & 5.0908 & TRN & \\
\hline CHEMBL1536085 & 688267 & 4.9 & 5.0765 & TST & \\
\hline CHEMBL1449168 & 688267 & 4.0 & 5.0112 & TRN & \\
\hline CHEMBL1548794 & 688267 & 4.1 & 5.0484 & TST & \\
\hline CHEMBL1442737 & 688267 & 4.1 & 5.0799 & TRN & \\
\hline CHEMBL1427043 & 688267 & 3.95 & 5.0569 & TST & \\
\hline CHEMBL1539572 & 688267 & 3.9 & 5.0848 & TRN & \\
\hline CHEMBL1332290 & 688267 & 5.9 & 5.0014 & TRN & \\
\hline CHEMBL1571957 & 688267 & 4.45 & 5.01399 & 7999999999 & TRN \\
\hline CHEMBL1347400 & 688267 & 4.3 & 5.0055 & TRN & \\
\hline CHEMBL1473766 & 688267 & 4.25 & 5.0481 & TRN & \\
\hline CHEMBL1565558 & 688267 & 5.5 & 5.0302 & TST & \\
\hline CHEMBL1543101 & 688267 & 5.0 & 5.042 & TRN & \\
\hline CHEMBL1449571 & 688267 & 6.2 & 5.0182 & TRN & \\
\hline CHEMBL1430702 & 688267 & 4.65 & 5.0293 & TRN & \\
\hline CHEMBL3199543 & 688267 & 6.25 & 5.0103 & TRN & \\
\hline CHEMBL1362107 & 688267 & 5.35 & 5.0196 & TST & \\
\hline CHEMBL1446970 & 688267 & 4.65 & 5.0822 & TST & \\
\hline CHEMBL3212307 & 688267 & 4.65 & 5.0056 & TRN & \\
\hline CHEMBL3191502 & 688267 & 5.9 & 5.0359 & TST & \\
\hline CHEMBL1471126 & 688267 & 5.8 & 4.9635 & TRN & \\
\hline CHEMBL1556119 & 688267 & 4.25 & 5.0256 & TRN & \\
\hline CHEMBL580819 & 688267 & 4.4 & 4.9533 & TRN & \\
\hline CHEMBL1412114 & 688267 & 4.05 & 5.0526 & TST & \\
\hline CHEMBL1528795 & 688267 & 5.45 & 4.9999 & TST & \\
\hline CHEMBL1468991 & 688267 & 6.5 & 5.1243 & TRN & \\
\hline CHEMBL1452882 & 688267 & 5.55 & 5.0755 & TST & \\
\hline CHEMBL1423277 & 688267 & 5.05 & 5.0715 & TRN & \\
\hline CHEMBL1407025 & 688267 & 5.25 & 5.0356 & TRN & \\
\hline CHEMBL1515393 & 688267 & 6.2 & 5.0271 & TRN & \\
\hline CHEMBL1326898 & 688267 & 6.15 & 5.0013 & TRN & \\
\hline CHEMBL1497885 & 688267 & 4.0 & 5.0964 & TRN & \\
\hline CHEMBL3190777 & 688267 & 4.1 & 5.0634 & TRN & \\
\hline CHEMBL1350810 & 688267 & 4.75 & 5.1539 & TRN & \\
\hline CHEMBL1299969 & 688267 & 3.95 & 5.1103 & TRN & \\
\hline CHEMBL1522863 & 688267 & 3.9 & 5.0373 & TRN & \\
\hline CHEMBL1430748 & 688267 & 4.4 & 5.0603 & TRN & \\
\hline CHEMBL1455641 & 688267 & 4.25 & 5.0331 & TST & \\
\hline
\end{tabular}




\begin{tabular}{|c|c|c|c|c|c|}
\hline \multicolumn{6}{|c|}{ Supplemental Table S2.txt } \\
\hline CHEMBL1454659 & 688267 & 4.0 & 5.0848 & TRN & \\
\hline CHEMBL1453332 & 688267 & 6.15 & 5.0125 & TRN & \\
\hline CHEMBL1497011 & 688267 & 4.45 & 5.0153 & TST & \\
\hline CHEMBL1338877 & 688267 & 5.8 & 5.0549 & TRN & \\
\hline CHEMBL1303999 & 688267 & 5.25 & 5.0989 & TRN & \\
\hline CHEMBL1485112 & 688267 & 4.05 & 5.0167 & TRN & \\
\hline CHEMBL1454458 & 688267 & 6.15 & 5.0509 & TRN & \\
\hline CHEMBL1426369 & 688267 & 6.5 & 5.0706 & TRN & \\
\hline CHEMBL1401149 & 688267 & 4.0 & 5.0977 & TST & \\
\hline CHEMBL1541047 & 688267 & 4.4 & 5.117 & TRN & \\
\hline CHEMBL1490286 & 688267 & 6.1 & 5.0596 & TST & \\
\hline CHEMBL1473640 & 688267 & 5.5 & 5.0914 & TRN & \\
\hline CHEMBL1604676 & 688267 & 5.3 & 5.1215 & TRN & \\
\hline CHEMBL1352617 & 688267 & 4.25 & 5.063 & TRN & \\
\hline CHEMBL1380289 & 688267 & 4.0 & 5.11100 & 0000000001 & TRN \\
\hline CHEMBL1484094 & 688267 & 5.15 & 5.02800 & 00000000005 & TRN \\
\hline CHEMBL1542808 & 688267 & 6.05 & 5.1189 & TRN & \\
\hline CHEMBL1545112 & 688267 & 4.0 & 5.0437 & TST & \\
\hline CHEMBL1367951 & 688267 & 5.2 & 5.0033 & TRN & \\
\hline CHEMBL1333719 & 688267 & 4.7 & 5.0166 & TRN & \\
\hline CHEMBL1385994 & 688267 & 4.1 & 5.0637 & TST & \\
\hline CHEMBL1491560 & 688267 & 6.2 & 5.0749 & TRN & \\
\hline CHEMBL1525936 & 688267 & 5.6 & 5.0271 & TST & \\
\hline CHEMBL1591141 & 688267 & 5.6 & 5.0116 & TRN & \\
\hline CHEMBL1355784 & 688267 & 6.15 & 5.0707 & TRN & \\
\hline CHEMBL3191942 & 688267 & 4.4 & 5.0041 & TRN & \\
\hline CHEMBL1391779 & 688267 & 4.25 & 5.0893 & TST & \\
\hline CHEMBL1609183 & 688267 & 4.0 & 5.1238 & TRN & \\
\hline CHEMBL1432936 & 688267 & 6.2 & 5.0368 & TST & \\
\hline CHEMBL1564199 & 688267 & 4.35 & 5.1285 & TRN & \\
\hline CHEMBL1353730 & 688267 & 6.25 & 5.0658 & TRN & \\
\hline CHEMBL3145028 & 688267 & 5.55 & 5.0106 & TST & \\
\hline CHEMBL1415618 & 688267 & 3.95 & 5.0326 & TRN & \\
\hline CHEMBL1599071 & 688267 & 3.95 & 5.0465 & TRN & \\
\hline CHEMBL3210271 & 688267 & 6.2 & 5.0749 & TST & \\
\hline CHEMBL1471729 & 688267 & 4.55 & 5.0182 & TRN & \\
\hline CHEMBL1511790 & 688267 & 5.35 & 5.0719 & TST & \\
\hline CHEMBL1393020 & 688267 & 5.8 & 5.0105 & TRN & \\
\hline CHEMBL1317489 & 688267 & 5.3 & 5.0778 & TRN & \\
\hline CHEMBL1559468 & 688267 & 5.25 & 5.0555 & TRN & \\
\hline CHEMBL1320657 & 688267 & 4.05 & 5.0461 & TRN & \\
\hline CHEMBL1598568 & 688267 & 6.2 & 5.0499 & TST & \\
\hline CHEMBL1488328 & 688267 & 4.4 & 5.0075 & TRN & \\
\hline CHEMBL1417828 & 688267 & 4.5 & 5.0512 & TST & \\
\hline CHEMBL1411269 & 688267 & 6.2 & 5.0447 & TRN & \\
\hline CHEMBL1470372 & 688267 & 5.35 & 5.1128 & TRN & \\
\hline CHEMBL1474600 & 688267 & 5.15 & 5.016 & TRN & \\
\hline CHEMBL1331557 & 688267 & 4.05 & 5.0206 & TRN & \\
\hline
\end{tabular}




\begin{tabular}{|c|c|c|c|c|}
\hline & & & pplemen & al $\mathrm{T}$ \\
\hline CHEMBL1322016 & 688267 & 4.8 & 5.1072 & TRN \\
\hline CHEMBL1571085 & 688267 & 5.5 & 5.0584 & TRN \\
\hline CHEMBL327209 & 688267 & 5.0 & 4.9965 & TST \\
\hline CHEMBL1384954 & 688267 & 4.55 & 5.0097 & TRN \\
\hline CHEMBL1612129 & 688267 & 5.15 & 5.1541 & TRN \\
\hline CHEMBL1363842 & 688267 & 4.15 & 5.0325 & TRN \\
\hline CHEMBL1323475 & 688267 & 4.6 & 5.0567 & TRN \\
\hline CHEMBL1437284 & 688267 & 6.15 & 5.0802 & TRN \\
\hline CHEMBL1598929 & 688267 & 4.95 & 5.1375 & TRN \\
\hline CHEMBL1380487 & 688267 & 4.45 & 5.043 & TST \\
\hline CHEMBL1415605 & 688267 & 4.35 & 5.106 & TST \\
\hline CHEMBL1370502 & 688267 & 4.05 & 4.981 & TST \\
\hline CHEMBL1415743 & 688267 & 4.4 & 5.0483 & TRN \\
\hline CHEMBL1402175 & 688267 & 4.75 & 5.0262 & TRN \\
\hline CHEMBL1540070 & 688267 & 4.95 & 5.0831 & TRN \\
\hline CHEMBL1593852 & 688267 & 4.05 & 5.0096 & TRN \\
\hline CHEMBL1410662 & 688267 & 4.4 & 5.0305 & TST \\
\hline CHEMBL1602759 & 688267 & 4.0 & 4.9815 & TST \\
\hline CHEMBL1417843 & 688267 & 5.6 & 5.1425 & TRN \\
\hline CHEMBL1324204 & 688267 & 4.7 & 5.026 & TRN \\
\hline CHEMBL1318570 & 688267 & 6.2 & 5.119 & TRN \\
\hline CHEMBL1528328 & 688267 & 6.2 & 5.0795 & TRN \\
\hline CHEMBL1497843 & 688267 & 4.5 & 5.0358 & TRN \\
\hline CHEMBL1538814 & 688267 & 4.35 & 5.0536 & TRN \\
\hline CHEMBL1570814 & 688267 & 4.45 & 5.033 & TRN \\
\hline CHEMBL1403850 & 688267 & 6.2 & 5.0188 & TST \\
\hline CHEMBL1318178 & 688267 & 5.85 & 5.0166 & TRN \\
\hline CHEMBL1362237 & 688267 & 4.55 & 5.0708 & TRN \\
\hline CHEMBL1460178 & 688267 & 6.2 & 5.1041 & TRN \\
\hline CHEMBL1496871 & 688267 & 5.3 & 5.0919 & TRN \\
\hline CHEMBL1577451 & 688267 & 3.95 & 5.1343 & TST \\
\hline CHEMBL1588606 & 688267 & 6.2 & 5.0627 & TRN \\
\hline CHEMBL1320422 & 688267 & 5.05 & 5.101 & TRN \\
\hline CHEMBL1334194 & 688267 & 6.2 & 5.1808 & TRN \\
\hline CHEMBL1540430 & 688267 & 4.45 & 5.0566 & TST \\
\hline CHEMBL1452113 & 688267 & 4.0 & 5.0617 & TRN \\
\hline CHEMBL1558530 & 688267 & 4.95 & 5.0878 & TST \\
\hline CHEMBL1363754 & 688267 & 6.15 & 5.0298 & TRN \\
\hline CHEMBL1404293 & 688267 & 5.35 & 5.1149 & TRN \\
\hline CHEMBL1566127 & 688267 & 4.0 & 5.1337 & TRN \\
\hline CHEMBL1554998 & 688267 & 6.5 & 4.9855 & TRN \\
\hline CHEMBL1434984 & 688267 & 4.05 & 5.0624 & TRN \\
\hline CHEMBL1324235 & 688267 & 5.35 & 5.1355 & TST \\
\hline CHEMBL1465808 & 688267 & 4.9 & 5.0203 & TST \\
\hline CHEMBL1436847 & 688267 & 6.2 & 5.0392 & TRN \\
\hline CHEMBL1487570 & 688267 & 5.2 & 4.9894 & TST \\
\hline CHEMBL1520052 & 688267 & 5.5 & 5.0463 & TRN \\
\hline CHEMBL1346959 & 688267 & 5.6 & 5.0572 & TST \\
\hline
\end{tabular}




\begin{tabular}{|c|c|c|c|c|}
\hline & & & pplement & al $\mathrm{Ta}$ \\
\hline CHEMBL1611490 & 688267 & 4.15 & 5.0421 & TRN \\
\hline CHEMBL1336535 & 688267 & 5.7 & 4.9883 & TRN \\
\hline CHEMBL1459134 & 688267 & 4.3 & 5.1049 & TRN \\
\hline CHEMBL 1467968 & 688267 & 4.25 & 4.9736 & TRN \\
\hline CHEMBL1531130 & 688267 & 4.05 & 5.0975 & TRN \\
\hline CHEMBL1558955 & 688267 & 5.05 & 5.0823 & TRN \\
\hline CHEMBL1484508 & 688267 & 4.6 & 5.0472 & TST \\
\hline CHEMBL1450069 & 688267 & 4.7 & 5.0842 & TRN \\
\hline CHEMBL1434041 & 688267 & 5.8 & 4.9961 & TST \\
\hline CHEMBL1377320 & 688267 & 4.45 & 4.9886 & TRN \\
\hline CHEMBL498373 & 688267 & 5.2 & 5.0698 & TRN \\
\hline CHEMBL1577554 & 688267 & 6.1 & 5.1182 & TRN \\
\hline CHEMBL1564757 & 688267 & 4.4 & 5.1376 & TRN \\
\hline CHEMBL 1463460 & 688267 & 4.55 & 5.0629 & TRN \\
\hline CHEMBL1557668 & 688267 & 5.5 & 5.0812 & TRN \\
\hline CHEMBL1569475 & 688267 & 3.95 & 5.0664 & TRN \\
\hline CHEMBL1568173 & 688267 & 5.8 & 5.0441 & TRN \\
\hline CHEMBL1546646 & 688267 & 5.5 & 5.1035 & TRN \\
\hline CHEMBL1520972 & 688267 & 5.4 & 5.0793 & TRN \\
\hline CHEMBL1448510 & 688267 & 6.15 & 5.0166 & TST \\
\hline CHEMBL1447685 & 688267 & 6.1 & 5.0634 & TRN \\
\hline CHEMBL1452082 & 688267 & 5.6 & 5.0692 & TRN \\
\hline CHEMBL 1480526 & 688267 & 3.85 & 5.0374 & TRN \\
\hline CHEMBL1477122 & 688267 & 6.5 & 5.0202 & TST \\
\hline CHEMBL1423355 & 688267 & 6.25 & 5.0961 & TRN \\
\hline CHEMBL1384741 & 688267 & 4.05 & 5.1247 & TRN \\
\hline CHEMBL1362889 & 688267 & 4.2 & 5.0505 & TST \\
\hline CHEMBL1600494 & 688267 & 6.2 & 4.9924 & TRN \\
\hline CHEMBL1524504 & 688267 & 3.95 & 5.0292 & TRN \\
\hline CHEMBL1428887 & 688267 & 6.15 & 5.0545 & TRN \\
\hline CHEMBL1401343 & 688267 & 4.55 & 5.0937 & TST \\
\hline CHEMBL1442238 & 688267 & 6.45 & 5.064 & TRN \\
\hline CHEMBL1560193 & 688267 & 5.3 & 5.0696 & TRN \\
\hline CHEMBL1498907 & 688267 & 6.45 & 5.0167 & TRN \\
\hline CHEMBL1532168 & 688267 & 2.95 & 5.1006 & TRN \\
\hline CHEMBL1492485 & 688267 & 5.35 & 5.0066 & TRN \\
\hline CHEMBL1383187 & 688267 & 4.0 & 5.0918 & TRN \\
\hline CHEMBL1367728 & 688267 & 5.65 & 5.0815 & TRN \\
\hline CHEMBL1527377 & 688267 & 5.05 & 5.0241 & TRN \\
\hline CHEMBL1493901 & 688267 & 4.05 & 5.0584 & TRN \\
\hline CHEMBL1499089 & 688267 & 4.0 & 5.0618 & TRN \\
\hline CHEMBL3191956 & 688267 & 5.85 & 5.0269 & TRN \\
\hline CHEMBL1576205 & 688267 & 6.2 & 4.9515 & TST \\
\hline CHEMBL1592498 & 688267 & 4.05 & 5.0184 & TRN \\
\hline CHEMBL1323057 & 688267 & 5.95 & 5.0205 & TRN \\
\hline CHEMBL1449917 & 688267 & 3.95 & 5.0409 & TRN \\
\hline CHEMBL1373159 & 688267 & 5.15 & 5.0287 & TRN \\
\hline CHEMBL1448225 & 688267 & 5.5 & 5.1344 & TRN \\
\hline
\end{tabular}




\begin{tabular}{|c|c|c|c|c|}
\hline \multicolumn{5}{|c|}{ Supplemental Table S2.txt } \\
\hline CHEMBL1531764 & 688267 & 5.85 & 5.0161 & TRN \\
\hline CHEMBL1474500 & 688267 & 5.4 & 4.9866 & TRN \\
\hline CHEMBL1302702 & 688267 & 3.95 & 5.0758 & TRN \\
\hline CHEMBL1309824 & 688267 & 6.15 & 5.0898 & TRN \\
\hline CHEMBL1582002 & 688267 & 6.15 & 5.0013 & TRN \\
\hline CHEMBL1476585 & 688267 & 5.75 & 5.0818 & TRN \\
\hline CHEMBL1424541 & 688267 & 3.95 & 5.0595 & TRN \\
\hline CHEMBL1336109 & 688267 & 3.95 & 5.1605 & TRN \\
\hline CHEMBL1329162 & 688267 & 5.6 & 5.0984 & TRN \\
\hline CHEMBL1363590 & 688267 & 4.05 & 5.0536 & TST \\
\hline CHEMBL1476997 & 688267 & 5.0 & 5.1516 & TRN \\
\hline CHEMBL 3193226 & 688267 & 6.0 & 5.0524 & TST \\
\hline CHEMBL1364260 & 688267 & 4.1 & 5.0374 & TRN \\
\hline CHEMBL1580624 & 688267 & 4.5 & 5.0973 & TRN \\
\hline CHEMBL1485747 & 688267 & 6.25 & 5.0482 & TST \\
\hline CHEMBL1584686 & 688267 & 5.75 & 5.0382 & TST \\
\hline CHEMBL1399370 & 688267 & 5.7 & 4.9952 & TRN \\
\hline CHEMBL1530370 & 688267 & 4.35 & 5.0217 & TST \\
\hline CHEMBL1558975 & 688267 & 5.55 & 5.0602 & TRN \\
\hline CHEMBL1550882 & 688267 & 5.0 & 5.0987 & TRN \\
\hline CHEMBL1479369 & 688267 & 5.55 & 5.0571 & TRN \\
\hline CHEMBL1495241 & 688267 & 4.0 & 5.0068 & TRN \\
\hline CHEMBL1321586 & 688267 & 4.6 & 5.0653 & TRN \\
\hline CHEMBL1528287 & 688267 & 6.2 & 5.0982 & TST \\
\hline CHEMBL1376478 & 688267 & 5.8 & 5.0972 & TRN \\
\hline CHEMBL1423156 & 688267 & 6.15 & 5.059 & TRN \\
\hline CHEMBL1447878 & 688267 & 5.8 & 5.0697 & TST \\
\hline CHEMBL1568244 & 688267 & 4.4 & 5.1637 & TST \\
\hline CHEMBL1545208 & 688267 & 4.2 & 5.0411 & TRN \\
\hline CHEMBL1593702 & 688267 & 6.2 & 5.0568 & TRN \\
\hline CHEMBL1357572 & 688267 & 6.25 & 5.0249 & TRN \\
\hline CHEMBL 2373627 & 688267 & 5.65 & 5.0428 & TRN \\
\hline CHEMBL1479937 & 688267 & 4.25 & 5.0973 & TRN \\
\hline CHEMBL1443197 & 688267 & 4.35 & 5.1051 & TRN \\
\hline CHEMBL1448683 & 688267 & 4.15 & 5.0222 & TRN \\
\hline CHEMBL1533078 & 688267 & 4.25 & 5.0257 & TST \\
\hline CHEMBL1335002 & 688267 & 4.05 & 5.0105 & TST \\
\hline CHEMBL1315163 & 688267 & 4.4 & 5.0989 & TRN \\
\hline CHEMBL1452335 & 688267 & 4.05 & 5.1078 & TRN \\
\hline CHEMBL1310580 & 688267 & 6.2 & 5.0277 & TRN \\
\hline CHEMBL1324179 & 688267 & 5.3 & 5.0775 & TST \\
\hline CHEMBL1305511 & 688267 & 6.25 & 5.0153 & TST \\
\hline CHEMBL1407625 & 688267 & 6.15 & 5.0448 & TRN \\
\hline CHEMBL1457627 & 688267 & 4.3 & 5.0916 & TRN \\
\hline CHEMBL3209200 & 688267 & 6.45 & 5.0161 & TRN \\
\hline CHEMBL1501234 & 688267 & 4.05 & 5.1189 & TST \\
\hline CHEMBL1332881 & 688267 & 4.0 & 5.0686 & TRN \\
\hline CHEMBL1507875 & 688267 & 4.3 & 5.0333 & TRN \\
\hline
\end{tabular}




\begin{tabular}{|c|c|c|c|c|c|}
\hline CHEMBL1510464 & 688267 & $5.1^{\mathrm{S}}$ & \multicolumn{2}{|c|}{ supplemental lable sz.txt } & TRN \\
\hline CHEMBL1327420 & 688267 & 6.15 & 5.0887 & TRN & \\
\hline CHEMBL1512109 & 688267 & 4.6 & 5.0204 & TRN & \\
\hline CHEMBL1456390 & 688267 & 5.3 & 5.0396 & TST & \\
\hline CHEMBL1591156 & 688267 & 4.55 & 5.1075 & TRN & \\
\hline CHEMBL1384108 & 688267 & 6.2 & 5.0479 & TRN & \\
\hline CHEMBL1313688 & 688267 & 4.6 & 5.0511 & TST & \\
\hline CHEMBL1504238 & 688267 & 3.9 & 5.0951 & TRN & \\
\hline CHEMBL1427812 & 688267 & 6.7001 & 5.1157 & TRN & \\
\hline CHEMBL1416161 & 688267 & 5.15 & 5.0227 & TRN & \\
\hline CHEMBL1507700 & 688267 & 5.3 & 5.0085 & TRN & \\
\hline CHEMBL1579226 & 688267 & 4.0 & 5.0316 & TST & \\
\hline CHEMBL1578776 & 688267 & 5.5 & 5.0018 & TRN & \\
\hline CHEMBL1393113 & 688267 & 5.5 & 5.1893 & TRN & \\
\hline CHEMBL1404141 & 688267 & 4.85 & 5.0551 & TRN & \\
\hline CHEMBL1495953 & 688267 & 5.3 & 5.0349 & TRN & \\
\hline CHEMBL1517582 & 688267 & 5.35 & 5.0694 & TRN & \\
\hline CHEMBL1435707 & 688267 & 4.45 & 5.0839 & TRN & \\
\hline CHEMBL1577889 & 688267 & 4.35 & 5.0495 & TRN & \\
\hline CHEMBL1473737 & 688267 & 4.25 & 5.0619 & TST & \\
\hline CHEMBL1312350 & 688267 & 5.0 & 5.1228 & TST & \\
\hline CHEMBL1304157 & 688267 & 5.3 & 5.055 & TRN & \\
\hline CHEMBL1507776 & 688267 & 6.5 & 5.0414 & TRN & \\
\hline CHEMBL600736 & 688267 & 6.5501 & 5.0288 & TRN & \\
\hline CHEMBL1524558 & 688267 & 4.55 & 5.0415 & TRN & \\
\hline CHEMBL1409377 & 688267 & 5.6 & 5.0904 & TRN & \\
\hline CHEMBL1322027 & 688267 & 4.0 & 5.0261 & TRN & \\
\hline CHEMBL1307416 & 688267 & 6.45 & 5.0641 & TST & \\
\hline CHEMBL1525878 & 688267 & 3.95 & 5.0364 & TRN & \\
\hline CHEMBL1510296 & 688267 & 5.1 & 5.0878 & TRN & \\
\hline CHEMBL1479401 & 688267 & 4.45 & 5.1128 & TRN & \\
\hline CHEMBL1510887 & 688267 & 6.2 & 5.0624 & TRN & \\
\hline CHEMBL1497470 & 688267 & 4.55 & 5.0554 & TRN & \\
\hline CHEMBL1311887 & 688267 & 5.3 & 5.0368 & TRN & \\
\hline CHEMBL1593685 & 688267 & 4.35 & 5.1063 & TRN & \\
\hline CHEMBL269881 & 688267 & 4.4 & 5.1234 & TST & \\
\hline CHEMBL1518764 & 688267 & 4.0 & 5.093 & TRN & \\
\hline CHEMBL1597262 & 688267 & 4.6 & 5.0439 & TRN & \\
\hline CHEMBL1433582 & 688267 & 5.1 & 5.0923 & TST & \\
\hline CHEMBL1463810 & 688267 & 6.2 & 5.1067 & TRN & \\
\hline CHEMBL3192389 & 688267 & 4.2 & 4.9958 & TST & \\
\hline CHEMBL1421987 & 688267 & 6.2 & 5.0584 & TST & \\
\hline CHEMBL1498117 & 688267 & 4.55 & 5.0669 & TRN & \\
\hline CHEMBL3189231 & 688267 & 5.55 & 5.02800 & 00000000005 & TRN \\
\hline CHEMBL1471482 & 688267 & 4.05 & 5.01699 & 99999999995 & TRN \\
\hline CHEMBL1324315 & 688267 & 3.95 & 5.1127 & TRN & \\
\hline CHEMBL1372757 & 688267 & 4.35 & 5.0625 & TST & \\
\hline CHEMBL1325638 & 688267 & 6.25 & 5.0487 & TST & \\
\hline
\end{tabular}




\begin{tabular}{|c|c|c|c|c|}
\hline \multicolumn{5}{|c|}{ Supplemental Table S2.txt } \\
\hline CHEMBL1411006 & 688267 & 3.95 & 5.0619 & TRN \\
\hline CHEMBL1446015 & 688267 & 6.2 & 5.1203 & TRN \\
\hline CHEMBL1552086 & 688267 & 4.05 & 5.0404 & TRN \\
\hline CHEMBL1306987 & 688267 & 3.95 & 5.1094 & TRN \\
\hline CHEMBL1479264 & 688267 & 5.05 & 5.0939 & TRN \\
\hline CHEMBL1383599 & 688267 & 4.0 & 5.1208 & TRN \\
\hline CHEMBL1518502 & 688267 & 5.5 & 5.1069 & TST \\
\hline CHEMBL1390015 & 688267 & 6.2 & 5.0086 & TST \\
\hline CHEMBL1394664 & 688267 & 5.8 & 5.0329 & TRN \\
\hline CHEMBL1365405 & 688267 & 4.6 & 5.0426 & TRN \\
\hline CHEMBL1381760 & 688267 & 4.0 & 5.0493 & TST \\
\hline CHEMBL1528182 & 688267 & 4.0 & 5.0149 & TRN \\
\hline CHEMBL1506750 & 688267 & 5.3 & 5.0349 & TRN \\
\hline CHEMBL1427862 & 688267 & 4.05 & 5.0853 & TST \\
\hline CHEMBL1317737 & 688267 & 6.45 & 5.0699 & TRN \\
\hline CHEMBL1562769 & 688267 & 5.3 & 5.0144 & TST \\
\hline CHEMBL1603557 & 688267 & 5.6 & 5.0564 & TRN \\
\hline CHEMBL1346510 & 688267 & 4.3 & 5.0139 & TRN \\
\hline CHEMBL1525805 & 688267 & 5.2 & 5.042 & TRN \\
\hline CHEMBL1365739 & 688267 & 5.05 & 5.0388 & TRN \\
\hline CHEMBL1518680 & 688267 & 4.05 & 5.0519 & TST \\
\hline CHEMBL1485430 & 688267 & 5.55 & 5.0204 & TRN \\
\hline CHEMBL1491329 & 688267 & 6.15 & 5.0437 & TST \\
\hline CHEMBL1342652 & 688267 & 4.3 & 5.0306 & TRN \\
\hline CHEMBL1410052 & 688267 & 4.05 & 5.0577 & TRN \\
\hline CHEMBL3210454 & 688267 & 4.35 & 5.0096 & TST \\
\hline CHEMBL1547434 & 688267 & 6.2 & 5.1315 & TRN \\
\hline CHEMBL1299295 & 688267 & 4.7 & 5.0612 & TST \\
\hline CHEMBL1603587 & 688267 & 5.15 & 5.0371 & TST \\
\hline CHEMBL1556910 & 688267 & 4.0 & 5.0421 & TRN \\
\hline CHEMBL1411487 & 688267 & 6.2 & 5.0517 & TST \\
\hline CHEMBL1576056 & 688267 & 5.3 & 5.0666 & TRN \\
\hline CHEMBL1578072 & 688267 & 6.2 & 5.0691 & TST \\
\hline CHEMBL3198210 & 688267 & 4.4 & 4.9995 & TRN \\
\hline CHEMBL1580090 & 688267 & 5.4 & 5.0655 & TRN \\
\hline CHEMBL1487950 & 688267 & 4.5 & 5.0909 & TRN \\
\hline CHEMBL1308244 & 688267 & 4.65 & 5.0048 & TRN \\
\hline CHEMBL1459004 & 688267 & 6.2 & 5.0238 & TRN \\
\hline CHEMBL1394873 & 688267 & 4.05 & 5.0262 & TRN \\
\hline CHEMBL1327662 & 688267 & 4.05 & 5.0773 & TRN \\
\hline CHEMBL395805 & 688267 & 4.2 & 5.0349 & TRN \\
\hline CHEMBL 1607141 & 688267 & 4.25 & 5.1449 & TST \\
\hline CHEMBL1590042 & 688267 & 4.9 & 5.169 & TRN \\
\hline CHEMBL1464840 & 688267 & 4.25 & 5.0762 & TRN \\
\hline CHEMBL1601811 & 688267 & 4.4 & 5.075 & TRN \\
\hline CHEMBL1577120 & 688267 & 5.3 & 5.1044 & TRN \\
\hline CHEMBL 1404744 & 688267 & 4.2 & 5.0452 & TRN \\
\hline CHEMBL1409027 & 688267 & 4.05 & 5.1351 & TRN \\
\hline
\end{tabular}




\begin{tabular}{|c|c|c|c|c|}
\hline & & & pplement & al $\mathrm{Ta}$ \\
\hline CHEMBL1382957 & 688267 & 6.1 & 5.0849 & TST \\
\hline CHEMBL3208702 & 688267 & 4.55 & 4.9995 & TRN \\
\hline CHEMBL1451272 & 688267 & 5.6 & 5.0354 & TRN \\
\hline CHEMBL1317754 & 688267 & 3.95 & 5.0821 & TRN \\
\hline CHEMBL1364153 & 688267 & 4.0 & 5.042 & TRN \\
\hline CHEMBL1452853 & 688267 & 4.05 & 5.0927 & TRN \\
\hline CHEMBL1412284 & 688267 & 4.1 & 5.0512 & TST \\
\hline CHEMBL1591936 & 688267 & 5.6 & 5.0824 & TRN \\
\hline CHEMBL1399111 & 688267 & 4.2 & 5.0435 & TST \\
\hline CHEMBL1330307 & 688267 & 6.6 & 5.0229 & TRN \\
\hline CHEMBL1470284 & 688267 & 3.95 & 5.0223 & TRN \\
\hline CHEMBL1408979 & 688267 & 6.2 & 5.07 & TST \\
\hline CHEMBL1485276 & 688267 & 6.45 & 5.0407 & TRN \\
\hline CHEMBL1348262 & 688267 & 5.7 & 5.0719 & TRN \\
\hline CHEMBL1565518 & 688267 & 5.1 & 5.026 & TRN \\
\hline CHEMBL1322138 & 688267 & 4.25 & 5.1133 & TST \\
\hline CHEMBL1594626 & 688267 & 4.7 & 5.1374 & TST \\
\hline CHEMBL1528344 & 688267 & 5.3 & 5.0988 & TST \\
\hline CHEMBL1945274 & 688267 & 5.35 & 5.0035 & TRN \\
\hline CHEMBL1613665 & 688267 & 4.3 & 5.037 & TST \\
\hline CHEMBL1538516 & 688267 & 5.3 & 5.0702 & TRN \\
\hline CHEMBL1403188 & 688267 & 5.3 & 5.0536 & TRN \\
\hline CHEMBL1593275 & 688267 & 5.55 & 5.1113 & TRN \\
\hline CHEMBL1345630 & 688267 & 3.95 & 5.0422 & TST \\
\hline CHEMBL1560882 & 688267 & 5.2 & 5.0379 & TRN \\
\hline CHEMBL1475599 & 688267 & 5.9 & 5.0568 & TRN \\
\hline CHEMBL1561221 & 688267 & 6.0 & 5.0528 & TRN \\
\hline CHEMBL1341531 & 688267 & 5.8 & 5.0222 & TST \\
\hline CHEMBL1517284 & 688267 & 5.35 & 5.0088 & TRN \\
\hline CHEMBL1602748 & 688267 & 4.4 & 5.0851 & TRN \\
\hline CHEMBL1318029 & 688267 & 6.15 & 5.0532 & TRN \\
\hline CHEMBL1524610 & 688267 & 6.15 & 5.0565 & TRN \\
\hline CHEMBL1206239 & 688267 & 6.25 & 5.1091 & TRN \\
\hline CHEMBL1565203 & 688267 & 4.0 & 5.0988 & TRN \\
\hline CHEMBL1398926 & 688267 & 4.3 & 5.0499 & TST \\
\hline CHEMBL1442539 & 688267 & 5.05 & 5.0351 & TRN \\
\hline CHEMBL1488640 & 688267 & 3.95 & 5.1056 & TRN \\
\hline CHEMBL1582991 & 688267 & 4.2 & 5.1097 & TST \\
\hline CHEMBL1339968 & 688267 & 4.95 & 5.0194 & TST \\
\hline CHEMBL1367433 & 688267 & 4.35 & 5.0621 & TRN \\
\hline CHEMBL1425863 & 688267 & 5.45 & 5.0403 & TST \\
\hline CHEMBL1322420 & 688267 & 5.3 & 5.0144 & TRN \\
\hline CHEMBL1496929 & 688267 & 6.2 & 5.0918 & TRN \\
\hline CHEMBL3194962 & 688267 & 5.0 & 5.0412 & TRN \\
\hline CHEMBL1478559 & 688267 & 4.95 & 5.0375 & TRN \\
\hline CHEMBL1371463 & 688267 & 4.4 & 5.1704 & TRN \\
\hline CHEMBL1505301 & 688267 & 4.4 & 5.1444 & TRN \\
\hline CHEMBL1586939 & 688267 & 5.35 & 5.0212 & TRN \\
\hline
\end{tabular}




\begin{tabular}{|c|c|c|c|c|}
\hline \multicolumn{5}{|c|}{ Supplemental Table S2.txt } \\
\hline CHEMBL1554632 & 688267 & 6.2 & 5.0561 & TRN \\
\hline CHEMBL1485134 & 688267 & 4.25 & 5.0198 & TRN \\
\hline CHEMBL1517349 & 688267 & 5.35 & 5.1075 & TRN \\
\hline CHEMBL1380175 & 688267 & 5.6 & 5.1134 & TRN \\
\hline CHEMBL1557580 & 688267 & 3.95 & 5.0901 & TRN \\
\hline CHEMBL1550251 & 688267 & 3.95 & 5.0231 & TRN \\
\hline CHEMBL1530177 & 688267 & 4.05 & 5.0601 & TRN \\
\hline CHEMBL1564163 & 688267 & 4.5 & 5.0265 & TRN \\
\hline CHEMBL1380903 & 688267 & 3.95 & 5.1452 & TRN \\
\hline CHEMBL1418558 & 688267 & 5.95 & 5.0419 & TRN \\
\hline CHEMBL1589120 & 688267 & 4.75 & 5.0351 & TRN \\
\hline CHEMBL1599797 & 688267 & 5.45 & 5.1778 & TRN \\
\hline CHEMBL1350997 & 688267 & 4.35 & 5.0515 & TST \\
\hline CHEMBL1372477 & 688267 & 4.05 & 5.1111 & TST \\
\hline CHEMBL1558691 & 688267 & 4.0 & 5.0511 & TRN \\
\hline CHEMBL1446518 & 688267 & 5.45 & 5.0648 & TST \\
\hline CHEMBL1421066 & 688267 & 6.2 & 5.0108 & TRN \\
\hline CHEMBL1570821 & 688267 & 5.55 & 5.1269 & TRN \\
\hline CHEMBL1458071 & 688267 & 4.1 & 5.0918 & TST \\
\hline CHEMBL1408043 & 688267 & 3.95 & 5.0319 & TRN \\
\hline CHEMBL1504459 & 688267 & 6.2 & 5.0745 & TRN \\
\hline CHEMBL1539843 & 688267 & 4.4 & 5.0196 & TRN \\
\hline CHEMBL1451830 & 688267 & 5.8 & 5.1113 & TRN \\
\hline CHEMBL1588559 & 688267 & 4.0 & 5.0915 & TRN \\
\hline CHEMBL1505661 & 688267 & 4.7 & 4.9819 & TRN \\
\hline CHEMBL1518957 & 688267 & 6.2 & 5.0434 & TRN \\
\hline CHEMBL1495215 & 688267 & 5.4 & 5.1038 & TRN \\
\hline CHEMBL1307659 & 688267 & 4.55 & 5.0709 & TRN \\
\hline CHEMBL1493179 & 688267 & 4.6 & 5.0278 & TRN \\
\hline CHEMBL1394857 & 688267 & 5.25 & 5.0651 & TRN \\
\hline CHEMBL1512172 & 688267 & 5.45 & 5.0549 & TST \\
\hline CHEMBL1550965 & 688267 & 3.95 & 5.0073 & TRN \\
\hline CHEMBL1527801 & 688267 & 5.8 & 5.1512 & TRN \\
\hline CHEMBL1475760 & 688267 & 3.95 & 4.9903 & TRN \\
\hline CHEMBL1515719 & 688267 & 5.45 & 5.1221 & TRN \\
\hline CHEMBL1383368 & 688267 & 5.35 & 5.06 & TST \\
\hline CHEMBL1368201 & 688267 & 4.4 & 5.0481 & TRN \\
\hline CHEMBL1581419 & 688267 & 5.5 & 5.0793 & TST \\
\hline CHEMBL1317385 & 688267 & 5.1 & 5.0191 & TRN \\
\hline CHEMBL3196207 & 688267 & 4.0 & 4.9695 & TRN \\
\hline CHEMBL1486298 & 688267 & 4.1 & 5.0047 & TRN \\
\hline CHEMBL1491041 & 688267 & 4.55 & 5.0522 & TRN \\
\hline CHEMBL1395199 & 688267 & 6.1 & 5.0511 & TST \\
\hline CHEMBL1582185 & 688267 & 6.2 & 5.106 & TRN \\
\hline CHEMBL1409151 & 688267 & 5.4 & 5.052 & TRN \\
\hline CHEMBL1375519 & 688267 & 4.5 & 5.1046 & TRN \\
\hline CHEMBL1519437 & 688267 & 5.1 & 5.0821 & TRN \\
\hline CHEMBL1474569 & 688267 & 4.05 & 5.0513 & TST \\
\hline
\end{tabular}




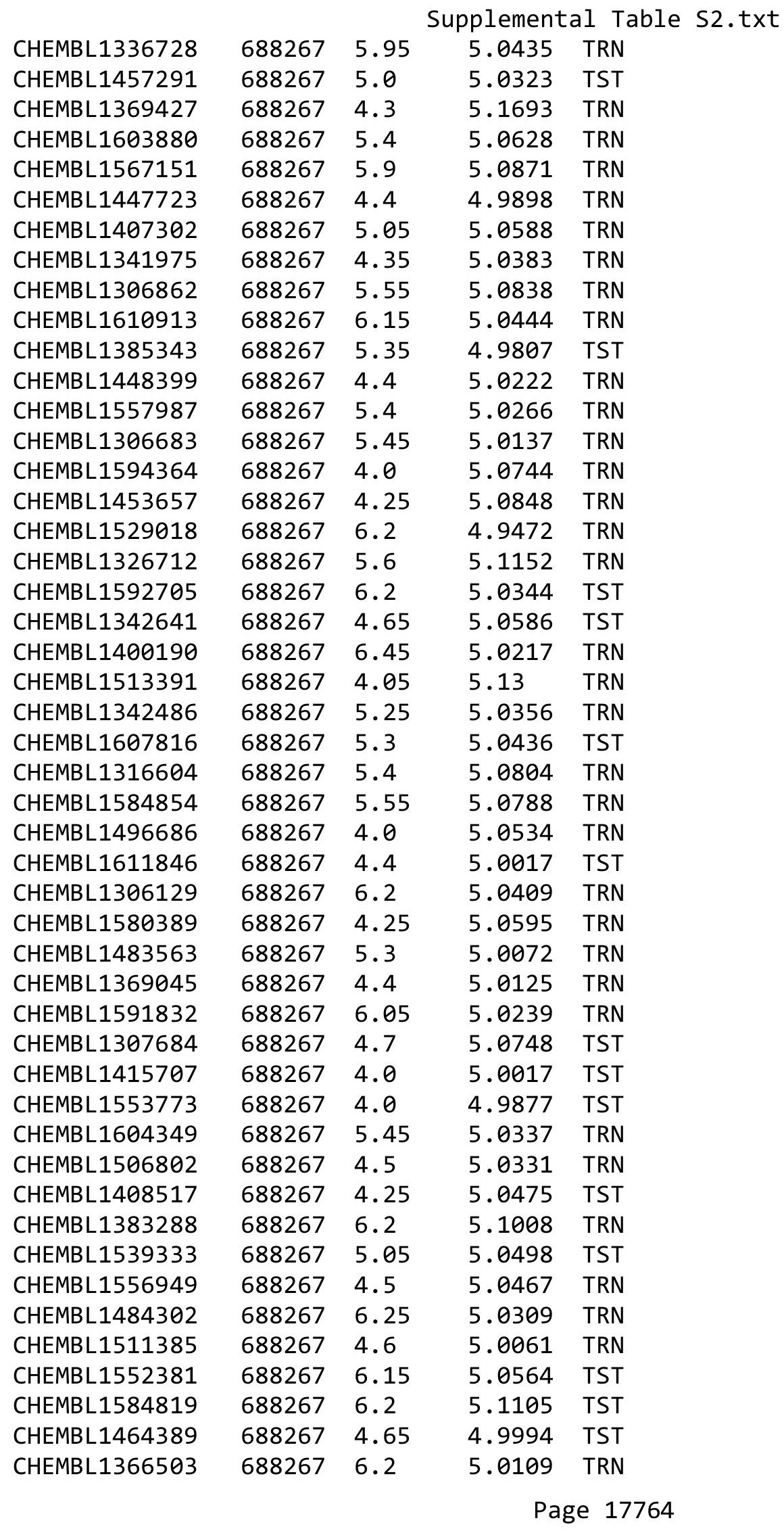




\begin{tabular}{|c|c|c|c|c|}
\hline \multicolumn{5}{|c|}{ Supplemental Table S2.txt } \\
\hline CHEMBL1591035 & 688267 & 6.5 & 5.0191 & TRN \\
\hline CHEMBL1489892 & 688267 & 6.15 & 5.0093 & TRN \\
\hline CHEMBL1584029 & 688267 & 4.05 & 5.0124 & TRN \\
\hline CHEMBL1414278 & 688267 & 6.1 & 5.067 & TRN \\
\hline CHEMBL1478234 & 688267 & 4.05 & 5.048 & TRN \\
\hline CHEMBL1343886 & 688267 & 4.0 & 5.0539 & TST \\
\hline CHEMBL1314948 & 688267 & 4.35 & 5.1294 & TRN \\
\hline CHEMBL1324944 & 688267 & 4.05 & 5.1135 & TST \\
\hline CHEMBL1414695 & 688267 & 4.05 & 5.0982 & TRN \\
\hline CHEMBL1599584 & 688267 & 5.65 & 5.0758 & TRN \\
\hline CHEMBL1592436 & 688267 & 3.95 & 5.0386 & TRN \\
\hline CHEMBL1410980 & 688267 & 5.95 & 5.0911 & TRN \\
\hline CHEMBL1418261 & 688267 & 3.9 & 5.085 & TRN \\
\hline CHEMBL1328363 & 688267 & 6.2 & 5.0191 & TRN \\
\hline CHEMBL1506601 & 688267 & 4.3 & 5.0672 & TRN \\
\hline CHEMBL1612638 & 688267 & 5.2 & 5.1535 & TST \\
\hline CHEMBL3212344 & 688267 & 6.5 & 5.0286 & TRN \\
\hline CHEMBL1541430 & 688267 & 5.45 & 4.9964 & TRN \\
\hline CHEMBL1551256 & 688267 & 4.35 & 5.0898 & TRN \\
\hline CHEMBL204595 & 688267 & 6.15 & 5.0569 & TRN \\
\hline CHEMBL1359695 & 688267 & 4.55 & 5.1044 & TRN \\
\hline CHEMBL1462475 & 688267 & 4.55 & 5.0422 & TST \\
\hline CHEMBL1397484 & 688267 & 4.4 & 5.0232 & TRN \\
\hline CHEMBL1521876 & 688267 & 5.5 & 5.0901 & TRN \\
\hline CHEMBL1574665 & 688267 & 6.15 & 5.0694 & TRN \\
\hline CHEMBL1602623 & 688267 & 3.95 & 5.0302 & TRN \\
\hline CHEMBL1433865 & 688267 & 4.0 & 5.0522 & TRN \\
\hline CHEMBL3207359 & 688267 & 5.35 & 5.0051 & TRN \\
\hline CHEMBL1529762 & 688267 & 6.2 & 5.0647 & TST \\
\hline CHEMBL1535589 & 688267 & 4.4 & 5.1102 & TST \\
\hline CHEMBL1530874 & 688267 & 4.5 & 5.0861 & TRN \\
\hline CHEMBL1520651 & 688267 & 5.3 & 5.0615 & TRN \\
\hline CHEMBL1357762 & 688267 & 4.7 & 5.0747 & TRN \\
\hline CHEMBL1459888 & 688267 & 4.05 & 5.0448 & TRN \\
\hline CHEMBL1582339 & 688267 & 6.2 & 5.0333 & TST \\
\hline CHEMBL3190475 & 688267 & 4.85 & 4.99 & TST \\
\hline CHEMBL1331320 & 688267 & 4.6 & 5.0543 & TRN \\
\hline CHEMBL1541940 & 688267 & 4.85 & 5.027 & TST \\
\hline CHEMBL1597058 & 688267 & 4.55 & 5.0825 & TRN \\
\hline CHEMBL1396799 & 688267 & 6.2 & 5.065 & TRN \\
\hline CHEMBL1560423 & 688267 & 4.1 & 4.9791 & TST \\
\hline CHEMBL1558011 & 688267 & 4.05 & 4.9966 & TST \\
\hline CHEMBL1386797 & 688267 & 4.25 & 5.0631 & TRN \\
\hline CHEMBL1439097 & 688267 & 5.45 & 5.1861 & TRN \\
\hline CHEMBL1490320 & 688267 & 5.55 & 5.0644 & TRN \\
\hline CHEMBL1589408 & 688267 & 5.2 & 5.0543 & TST \\
\hline CHEMBL1563762 & 688267 & 6.2 & 5.0494 & TRN \\
\hline CHEMBL1569854 & 688267 & 5.9 & 5.0382 & TRN \\
\hline
\end{tabular}




\begin{tabular}{|c|c|c|c|c|}
\hline & & & pplement & $d \pm$ \\
\hline CHEMBL1431052 & 688267 & 6.2 & 5.0605 & TST \\
\hline CHEMBL3192391 & 688267 & 5.4 & 4.984 & TRN \\
\hline CHEMBL1372790 & 688267 & 5.85 & 5.0269 & TRN \\
\hline CHEMBL1401654 & 688267 & 5.45 & 5.0742 & TST \\
\hline CHEMBL1308393 & 688267 & 4.9 & 5.0048 & TRN \\
\hline CHEMBL1443295 & 688267 & 4.0 & 5.0698 & TRN \\
\hline CHEMBL1429397 & 688267 & 6.05 & 4.9939 & TRN \\
\hline CHEMBL1316936 & 688267 & 4.35 & 5.1191 & TRN \\
\hline CHEMBL1437379 & 688267 & 6.2 & 5.0711 & TST \\
\hline CHEMBL1361998 & 688267 & 4.35 & 5.0489 & TRN \\
\hline CHEMBL1541655 & 688267 & 6.2 & 5.0314 & TST \\
\hline CHEMBL1440303 & 688267 & 4.25 & 5.0422 & TRN \\
\hline CHEMBL1550803 & 688267 & 4.55 & 5.0377 & TRN \\
\hline CHEMBL1522869 & 688267 & 6.15 & 5.0504 & TST \\
\hline CHEMBL1347140 & 688267 & 4.05 & 4.9758 & TRN \\
\hline CHEMBL1568892 & 688267 & 4.65 & 5.0325 & TST \\
\hline CHEMBL1332512 & 688267 & 5.65 & 5.0183 & TRN \\
\hline CHEMBL1411306 & 688267 & 4.0 & 5.0428 & TRN \\
\hline CHEMBL1592443 & 688267 & 5.0 & 5.0165 & TRN \\
\hline CHEMBL1316666 & 688267 & 4.0 & 5.0225 & TRN \\
\hline CHEMBL1329463 & 688267 & 3.95 & 5.0637 & TRN \\
\hline CHEMBL1463642 & 688267 & 5.5 & 5.034 & TRN \\
\hline CHEMBL1321465 & 688267 & 4.55 & 5.0741 & TRN \\
\hline CHEMBL1558921 & 688267 & 6.2 & 5.0626 & TRN \\
\hline CHEMBL1406648 & 688267 & 6.05 & 5.0296 & TRN \\
\hline CHEMBL1419335 & 688267 & 6.2 & 5.006 & TRN \\
\hline CHEMBL1586862 & 688267 & 4.05 & 5.0155 & TRN \\
\hline CHEMBL1448072 & 688267 & 4.35 & 5.0153 & TST \\
\hline CHEMBL 1485355 & 688267 & 4.05 & 5.0616 & TRN \\
\hline CHEMBL1316696 & 688267 & 4.35 & 5.0216 & TRN \\
\hline CHEMBL1546907 & 688267 & 5.55 & 5.0271 & TRN \\
\hline CHEMBL1314425 & 688267 & 5.5 & 5.018 & TRN \\
\hline CHEMBL 2373563 & 688267 & 5.4 & 5.0787 & TRN \\
\hline CHEMBL1327803 & 688267 & 4.45 & 5.0288 & TRN \\
\hline CHEMBL1389329 & 688267 & 5.35 & 5.0387 & TRN \\
\hline CHEMBL1595768 & 688267 & 4.4 & 5.0383 & TRN \\
\hline CHEMBL1481959 & 688267 & 5.3 & 5.0789 & TRN \\
\hline CHEMBL1415481 & 688267 & 5.1 & 5.1198 & TRN \\
\hline CHEMBL1491480 & 688267 & 4.15 & 5.032 & TRN \\
\hline CHEMBL1392794 & 688267 & 4.25 & 5.0191 & TRN \\
\hline CHEMBL1363413 & 688267 & 3.9 & 5.0491 & TRN \\
\hline CHEMBL1511712 & 688267 & 3.95 & 5.1311 & TRN \\
\hline CHEMBL1555511 & 688267 & 4.25 & 4.9965 & TST \\
\hline CHEMBL1425624 & 688267 & 6.45 & 5.0115 & TRN \\
\hline CHEMBL1436413 & 688267 & 4.05 & 5.0169 & TRN \\
\hline CHEMBL1307111 & 688267 & 4.0 & 5.0449 & TST \\
\hline CHEMBL1453110 & 688267 & 4.0 & 4.9868 & TST \\
\hline CHEMBL1080867 & 688267 & 4.45 & 5.0926 & TRN \\
\hline
\end{tabular}




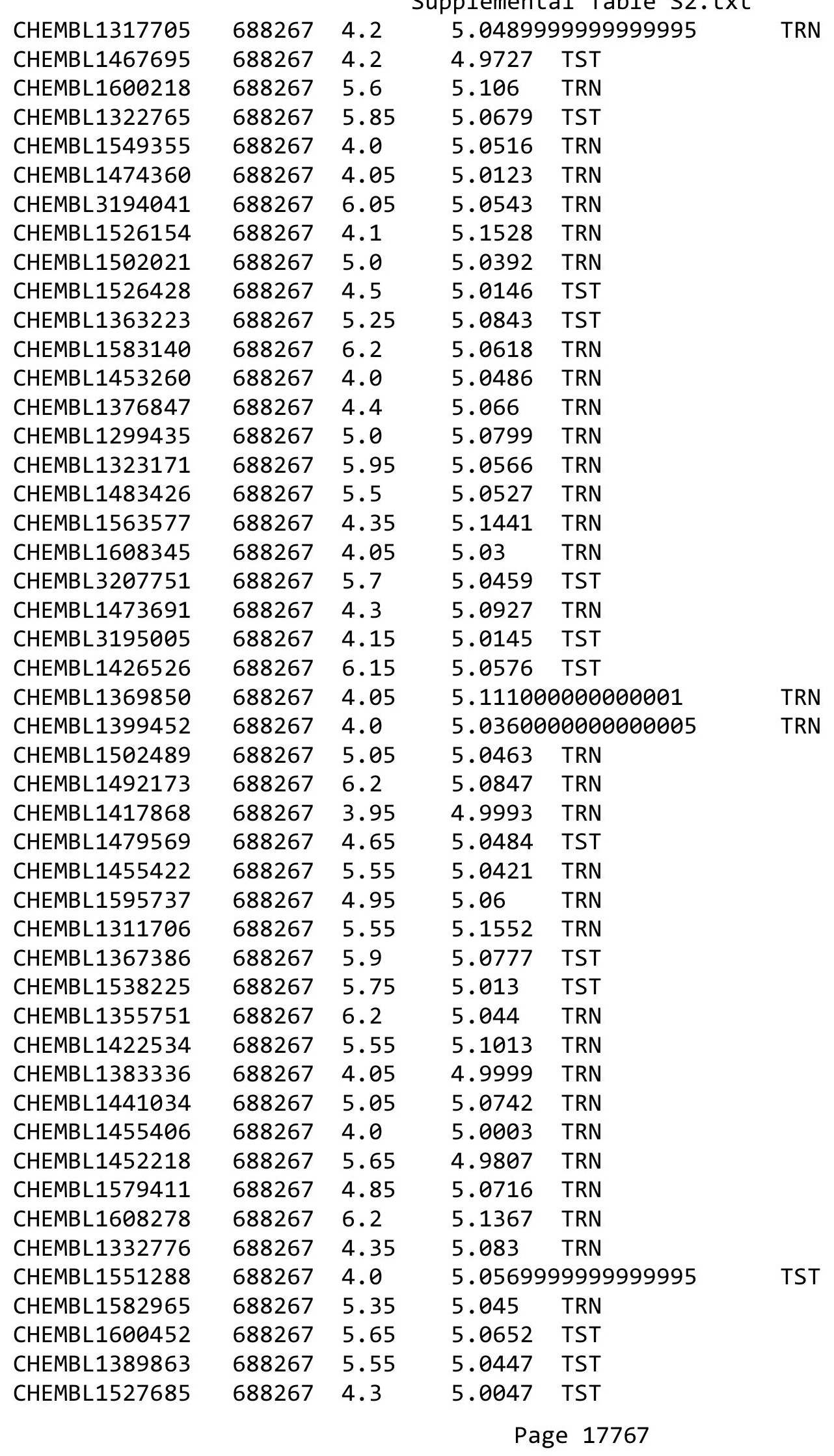




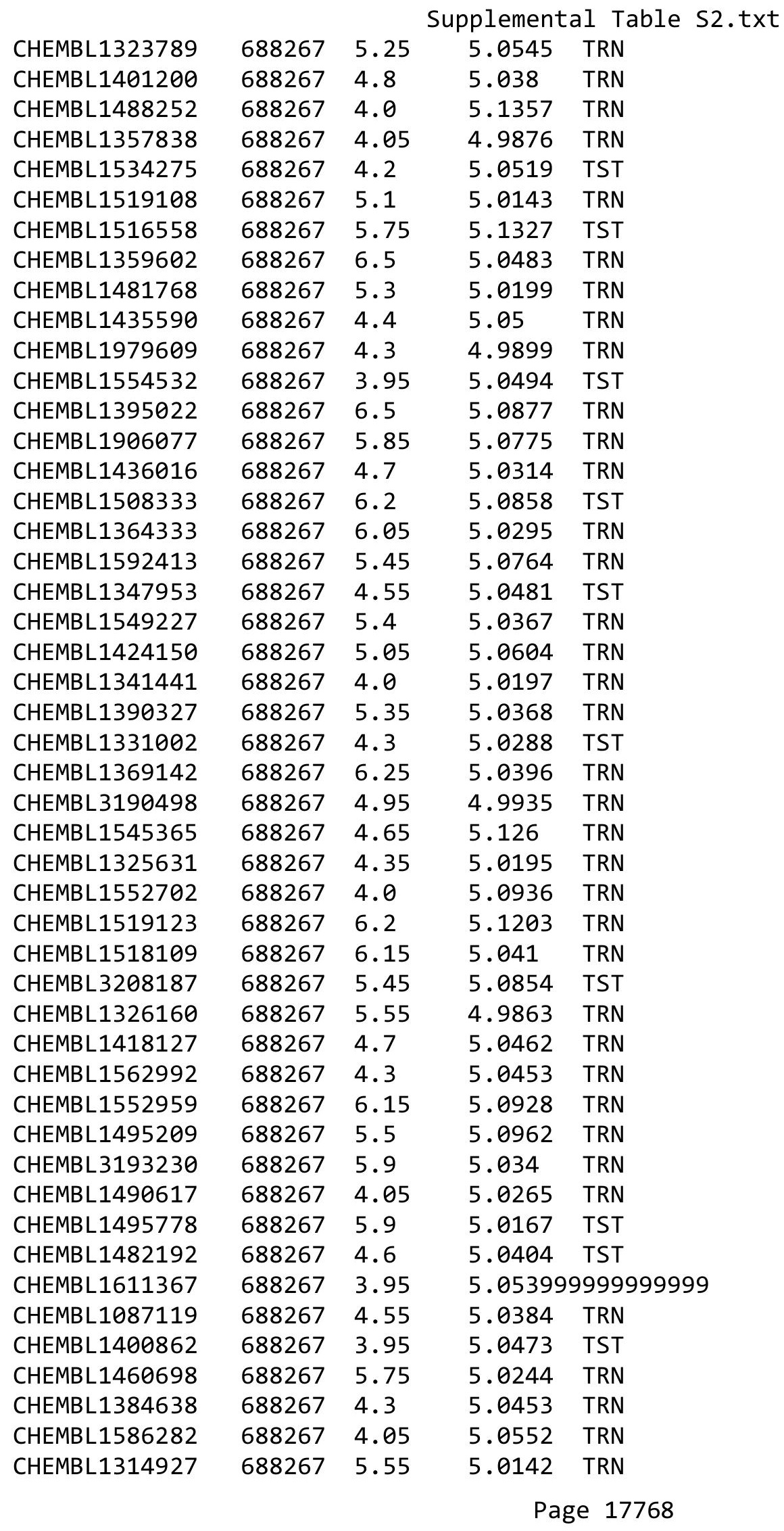

TRN 


\begin{tabular}{|c|c|c|c|c|}
\hline \multicolumn{5}{|c|}{ Supplemental Table S2.txt } \\
\hline CHEMBL1319630 & 688267 & 4.2 & 5.0247 & TRN \\
\hline CHEMBL1595272 & 688267 & 4.55 & 5.0484 & TRN \\
\hline CHEMBL1454669 & 688267 & 5.55 & 5.1185 & TST \\
\hline CHEMBL1559915 & 688267 & 6.05 & 5.1059 & TRN \\
\hline CHEMBL1574272 & 688267 & 4.1 & 5.0079 & TST \\
\hline CHEMBL1520028 & 688267 & 5.6 & 5.1175 & TRN \\
\hline CHEMBL1560589 & 688267 & 4.4 & 5.0459 & TRN \\
\hline CHEMBL1582588 & 688267 & 5.45 & 5.0854 & TRN \\
\hline CHEMBL1523983 & 688267 & 5.45 & 5.0676 & TRN \\
\hline CHEMBL1607469 & 688267 & 4.0 & 5.0933 & TRN \\
\hline CHEMBL1393017 & 688267 & 4.0 & 4.9846 & TRN \\
\hline CHEMBL1497381 & 688267 & 3.95 & 5.011 & TRN \\
\hline CHEMBL1385951 & 688267 & 3.95 & 4.9895 & TRN \\
\hline CHEMBL1560123 & 688267 & 4.0 & 5.0235 & TST \\
\hline CHEMBL1454838 & 688267 & 4.9 & 5.062 & TRN \\
\hline CHEMBL1548319 & 688267 & 4.3 & 5.0404 & TST \\
\hline CHEMBL1344420 & 688267 & 5.8 & 5.0486 & TRN \\
\hline CHEMBL1386434 & 688267 & 6.2 & 5.1035 & TRN \\
\hline CHEMBL1523026 & 688267 & 5.95 & 5.1184 & TRN \\
\hline CHEMBL1531973 & 688267 & 4.1 & 5.0036 & TRN \\
\hline CHEMBL1485003 & 688267 & 6.2 & 5.0487 & TRN \\
\hline CHEMBL1385501 & 688267 & 5.9 & 4.9843 & TRN \\
\hline CHEMBL1524901 & 688267 & 5.3 & 5.0237 & TRN \\
\hline CHEMBL1305265 & 688267 & 4.5 & 5.1315 & TRN \\
\hline CHEMBL1604855 & 688267 & 3.95 & 5.1251 & TST \\
\hline CHEMBL1397142 & 688267 & 4.15 & 5.1078 & TRN \\
\hline CHEMBL1585697 & 688267 & 4.15 & 5.1562 & TRN \\
\hline CHEMBL1537013 & 688267 & 4.05 & 5.0293 & TST \\
\hline CHEMBL1391475 & 688267 & 5.8 & 5.0045 & TST \\
\hline CHEMBL1528373 & 688267 & 5.05 & 5.015 & TRN \\
\hline CHEMBL1327615 & 688267 & 5.05 & 5.0592 & TRN \\
\hline CHEMBL1311871 & 688267 & 5.35 & 5.0809 & TRN \\
\hline CHEMBL1398960 & 688267 & 4.05 & 5.0413 & TST \\
\hline CHEMBL1380830 & 688267 & 6.5 & 5.0873 & TRN \\
\hline CHEMBL1338376 & 688267 & 4.05 & 5.0369 & TST \\
\hline CHEMBL1537753 & 688267 & 4.0 & 5.0489 & TRN \\
\hline CHEMBL3145102 & 688267 & 4.05 & 5.0292 & TST \\
\hline CHEMBL1485916 & 688267 & 4.4 & 5.0509 & TRN \\
\hline CHEMBL1589980 & 688267 & 6.5501 & 4.9952 & TRN \\
\hline CHEMBL1381674 & 688267 & 4.2 & 5.0161 & TST \\
\hline CHEMBL1542747 & 688267 & 6.25 & 5.0857 & TRN \\
\hline CHEMBL1494074 & 688267 & 6.45 & 5.0223 & TRN \\
\hline CHEMBL1403803 & 688267 & 5.4 & 5.063 & TRN \\
\hline CHEMBL1376177 & 688267 & 4.35 & 5.1144 & TRN \\
\hline CHEMBL1463581 & 688267 & 4.0 & 5.0081 & TRN \\
\hline CHEMBL1468417 & 688267 & 5.3 & 5.0486 & TRN \\
\hline CHEMBL1457381 & 688267 & 6.2 & 5.0986 & TST \\
\hline CHEMBL1444819 & 688267 & 3.95 & 5.1136 & TRN \\
\hline
\end{tabular}




\begin{tabular}{|c|c|c|c|c|}
\hline & & & pplement & al $\mathrm{Ta}$ \\
\hline CHEMBL1600933 & 688267 & 5.5 & 5.0499 & TRN \\
\hline CHEMBL1357411 & 688267 & 4.5 & 5.1194 & TRN \\
\hline CHEMBL1447005 & 688267 & 4.0 & 5.0526 & TRN \\
\hline CHEMBL1329364 & 688267 & 5.9 & 4.9946 & TRN \\
\hline CHEMBL1476384 & 688267 & 4.05 & 5.1613 & TRN \\
\hline CHEMBL1976631 & 688267 & 4.45 & 5.0235 & TRN \\
\hline CHEMBL1541900 & 688267 & 4.65 & 5.0563 & TST \\
\hline CHEMBL3199199 & 688267 & 6.0 & 5.0169 & TST \\
\hline CHEMBL1465667 & 688267 & 4.05 & 5.0545 & TRN \\
\hline CHEMBL1465356 & 688267 & 4.3 & 5.0583 & TRN \\
\hline CHEMBL1372480 & 688267 & 3.95 & 5.0168 & TRN \\
\hline CHEMBL1443189 & 688267 & 6.2 & 5.0264 & TRN \\
\hline CHEMBL1382664 & 688267 & 5.35 & 5.0105 & TRN \\
\hline CHEMBL1430030 & 688267 & 6.0 & 5.1282 & TRN \\
\hline CHEMBL1448008 & 688267 & 4.0 & 5.0313 & TRN \\
\hline CHEMBL1500326 & 688267 & 6.15 & 5.1182 & TRN \\
\hline CHEMBL1549328 & 688267 & 6.25 & 5.1051 & TRN \\
\hline CHEMBL1588835 & 688267 & 5.7 & 5.0183 & TRN \\
\hline CHEMBL 3195423 & 688267 & 4.05 & 5.0336 & TRN \\
\hline CHEMBL 3213837 & 688267 & 6.45 & 5.0772 & TRN \\
\hline CHEMBL1559139 & 688267 & 4.05 & 5.1042 & TST \\
\hline CHEMBL1325670 & 688267 & 4.95 & 5.0157 & TST \\
\hline CHEMBL1366842 & 688267 & 6.2 & 5.0513 & TST \\
\hline CHEMBL1475035 & 688267 & 4.15 & 5.1086 & TRN \\
\hline CHEMBL1444166 & 688267 & 4.05 & 5.0253 & TRN \\
\hline CHEMBL1448816 & 688267 & 3.95 & 5.1095 & TRN \\
\hline CHEMBL1571531 & 688267 & 5.3 & 5.0323 & TRN \\
\hline CHEMBL1443302 & 688267 & 5.5 & 5.0477 & TRN \\
\hline CHEMBL1329468 & 688267 & 6.2 & 5.1128 & TST \\
\hline CHEMBL 3214333 & 688267 & 4.05 & 5.0263 & TRN \\
\hline CHEMBL1531975 & 688267 & 4.55 & 5.0845 & TRN \\
\hline CHEMBL1560450 & 688267 & 4.3 & 5.0269 & TRN \\
\hline CHEMBL1599886 & 688267 & 5.35 & 4.9755 & TST \\
\hline CHEMBL1327981 & 688267 & 5.45 & 5.0612 & TRN \\
\hline CHEMBL1498055 & 688267 & 6.15 & 5.0169 & TRN \\
\hline CHEMBL1450909 & 688267 & 5.8 & 5.0596 & TST \\
\hline CHEMBL1530928 & 688267 & 6.2 & 4.9932 & TRN \\
\hline CHEMBL1407759 & 688267 & 4.0 & 5.0297 & TRN \\
\hline CHEMBL1523985 & 688267 & 4.45 & 5.1359 & TRN \\
\hline CHEMBL1332323 & 688267 & 6.2 & 4.9943 & TRN \\
\hline CHEMBL1422003 & 688267 & 4.1 & 5.0802 & TRN \\
\hline CHEMBL1389593 & 688267 & 4.05 & 5.0338 & TRN \\
\hline CHEMBL1384382 & 688267 & 5.3 & 5.0395 & TRN \\
\hline CHEMBL1394771 & 688267 & 5.85 & 5.0437 & TRN \\
\hline CHEMBL1476623 & 688267 & 4.2 & 5.0346 & TRN \\
\hline CHEMBL1586918 & 688267 & 4.35 & 5.0031 & TRN \\
\hline CHEMBL1317601 & 688267 & 3.95 & 5.0264 & TRN \\
\hline CHEMBL1441651 & 688267 & 4.1 & 5.0731 & TRN \\
\hline
\end{tabular}




\begin{tabular}{|c|c|c|c|c|c|}
\hline \multicolumn{6}{|c|}{ Supplemental Table S2.txt } \\
\hline CHEMBL3214030 & 688267 & 4.25 & 5.0085 & TRN & \\
\hline CHEMBL1576473 & 688267 & 5.4 & 5.0836 & TRN & \\
\hline CHEMBL1452330 & 688267 & 4.4 & 4.9708 & TRN & \\
\hline CHEMBL1497150 & 688267 & 4.45 & 5.0092 & TRN & \\
\hline CHEMBL1346614 & 688267 & 4.4 & 5.0403 & TRN & \\
\hline CHEMBL1361220 & 688267 & 5.5 & 5.1306 & TST & \\
\hline CHEMBL1515935 & 688267 & 6.2 & 5.1379 & TRN & \\
\hline CHEMBL1324380 & 688267 & 6.1 & 5.0899 & TRN & \\
\hline CHEMBL1302916 & 688267 & 5.3 & 4.9964 & TRN & \\
\hline CHEMBL1552789 & 688267 & 5.3 & 5.0789 & TST & \\
\hline CHEMBL1350446 & 688267 & 6.2 & 5.0231 & TRN & \\
\hline CHEMBL1318439 & 688267 & 5.85 & 5.0256 & TRN & \\
\hline CHEMBL1436072 & 688267 & 4.0 & 5.0238 & TRN & \\
\hline CHEMBL1613126 & 688267 & 5.35 & 5.0073 & TRN & \\
\hline CHEMBL1431492 & 688267 & 5.5 & 5.0994 & TRN & \\
\hline CHEMBL1560963 & 688267 & 4.0 & 5.0591 & TST & \\
\hline CHEMBL1358028 & 688267 & 4.3 & 5.0075 & TRN & \\
\hline CHEMBL1532951 & 688267 & 4.55 & 5.0958 & TRN & \\
\hline CHEMBL 3211588 & 688267 & 3.95 & 5.0156 & TRN & \\
\hline CHEMBL443510 & 688267 & 6.2 & 5.001 & TST & \\
\hline CHEMBL1331883 & 688267 & 4.3 & 5.0716 & TRN & \\
\hline CHEMBL1382820 & 688267 & 4.6 & 5.0408 & TRN & \\
\hline CHEMBL1453101 & 688267 & 5.55 & 5.1137 & TRN & \\
\hline CHEMBL1611048 & 688267 & 6.2 & 5.016 & TRN & \\
\hline CHEMBL1591794 & 688267 & 5.45 & 5.1063 & TRN & \\
\hline CHEMBL1480618 & 688267 & 4.65 & 5.0491 & TST & \\
\hline CHEMBL3196532 & 688267 & 5.45 & 5.0393 & TST & \\
\hline CHEMBL1523392 & 688267 & 4.25 & 5.0974 & TST & \\
\hline CHEMBL1402332 & 688267 & 6.15 & 5.0444 & TRN & \\
\hline CHEMBL1342646 & 688267 & 5.35 & 5.056 & TRN & \\
\hline CHEMBL1394413 & 688267 & 5.6 & 5.0635 & TRN & \\
\hline CHEMBL1384482 & 688267 & 4.4 & 5.0715 & TST & \\
\hline CHEMBL1402017 & 688267 & 5.4 & 5.1365 & TRN & \\
\hline CHEMBL1584574 & 688267 & 4.45 & 5.0579 & TRN & \\
\hline CHEMBL1555111 & 688267 & 4.05 & 5.0332 & TRN & \\
\hline CHEMBL1521932 & 688267 & 4.3 & 5.0085 & TRN & \\
\hline CHEMBL1363272 & 688267 & 6.15 & 5.0881 & TST & \\
\hline CHEMBL1446821 & 688267 & 6.15 & 5.0348 & TRN & \\
\hline CHEMBL1556735 & 688267 & 5.45 & 5.0229 & TRN & \\
\hline CHEMBL 3196008 & 688267 & 5.95 & 5.003 & TST & \\
\hline CHEMBL1576491 & 688267 & 5.6 & 5.0628 & TRN & \\
\hline CHEMBL1417569 & 688267 & 4.3 & 5.10800 & 00000000005 & TRN \\
\hline CHEMBL1351636 & 688267 & 4.95 & 5.0991 & TRN & \\
\hline CHEMBL1334888 & 688267 & 5.3 & 5.0298 & TRN & \\
\hline CHEMBL1370517 & 688267 & 5.95 & 5.1179 & TRN & \\
\hline CHEMBL1365035 & 688267 & 4.5 & 5.0425 & TRN & \\
\hline CHEMBL1538833 & 688267 & 4.1 & 5.1311 & TST & \\
\hline CHEMBL1470625 & 688267 & 5.0 & 5.0603 & TST & \\
\hline
\end{tabular}




\begin{tabular}{|c|c|c|c|c|c|}
\hline \multicolumn{6}{|c|}{ Supplemental Table S2.txt } \\
\hline CHEMBL1425347 & 688267 & 4.6 & 5.001 & TRN & \\
\hline CHEMBL1344284 & 688267 & 4.35 & 5.064 & TRN & \\
\hline CHEMBL1470647 & 688267 & 4.05 & 5.0399 & TRN & \\
\hline CHEMBL1376762 & 688267 & 4.35 & 5.0705 & TST & \\
\hline CHEMBL1535250 & 688267 & 6.5 & 5.0922 & TRN & \\
\hline CHEMBL1580558 & 688267 & 4.0 & 5.0873 & TST & \\
\hline CHEMBL1370503 & 688267 & 6.5 & 5.1614 & TRN & \\
\hline CHEMBL1330525 & 688267 & 5.3 & 5.0575 & TRN & \\
\hline CHEMBL1365189 & 688267 & 4.55 & 5.0753 & TST & \\
\hline CHEMBL1309655 & 688267 & 6.15 & 5.07100 & 0000000001 & TRN \\
\hline CHEMBL1326078 & 688267 & 5.8 & 5.0474 & TRN & \\
\hline CHEMBL1586145 & 688267 & 5.3 & 5.0274 & TST & \\
\hline CHEMBL1377974 & 688267 & 4.3 & 5.1011 & TRN & \\
\hline CHEMBL1386012 & 688267 & 4.0 & 5.039 & TRN & \\
\hline CHEMBL3195283 & 688267 & 4.6 & 5.0696 & TRN & \\
\hline CHEMBL1476471 & 688267 & 5.9 & 5.0512 & TRN & \\
\hline CHEMBL1385019 & 688267 & 4.5 & 5.0417 & TRN & \\
\hline CHEMBL1334380 & 688267 & 6.5 & 5.1451 & TRN & \\
\hline CHEMBL1430998 & 688267 & 5.05 & 5.0387 & TST & \\
\hline CHEMBL1327072 & 688267 & 5.95 & 5.0936 & TRN & \\
\hline CHEMBL1358590 & 688267 & 3.95 & 5.053 & TRN & \\
\hline CHEMBL1445008 & 688267 & 6.15 & 5.0428 & TST & \\
\hline CHEMBL1354217 & 688267 & 5.6 & 5.1127 & TRN & \\
\hline CHEMBL1608895 & 688267 & 5.7 & 5.0523 & TRN & \\
\hline CHEMBL1606730 & 688267 & 4.55 & 5.056 & TRN & \\
\hline CHEMBL1548421 & 688267 & 5.45 & 5.117 & TRN & \\
\hline CHEMBL1545296 & 688267 & 4.15 & 5.0413 & TRN & \\
\hline CHEMBL1996020 & 688267 & 4.15 & 5.0056 & TRN & \\
\hline CHEMBL1480886 & 688267 & 5.5 & 5.0952 & TST & \\
\hline CHEMBL1373693 & 688267 & 5.05 & 5.0702 & TRN & \\
\hline CHEMBL1532627 & 688267 & 5.15 & 5.1502 & TRN & \\
\hline CHEMBL1309795 & 688267 & 5.3 & 5.145 & TRN & \\
\hline CHEMBL1543824 & 688267 & 5.25 & 5.0403 & TST & \\
\hline CHEMBL1572011 & 688267 & 5.2 & 5.0838 & TST & \\
\hline CHEMBL1363887 & 688267 & 4.0 & 5.1505 & TRN & \\
\hline CHEMBL1540191 & 688267 & 5.4 & 5.012 & TRN & \\
\hline CHEMBL3192721 & 688267 & 4.7 & 5.0204 & TRN & \\
\hline CHEMBL1585755 & 688267 & 4.6 & 5.0997 & TRN & \\
\hline CHEMBL1538851 & 688267 & 6.2 & 5.1117 & TRN & \\
\hline CHEMBL1519544 & 688267 & 4.15 & 5.0286 & TRN & \\
\hline CHEMBL1517249 & 688267 & 4.0 & 5.0516 & TST & \\
\hline CHEMBL1337015 & 688267 & 6.2 & 5.035 & TST & \\
\hline CHEMBL1516358 & 688267 & 5.1 & 5.063 & TST & \\
\hline CHEMBL1528634 & 688267 & 5.15 & 5.0133 & TRN & \\
\hline CHEMBL1564372 & 688267 & 4.55 & 5.1293 & TRN & \\
\hline CHEMBL3214067 & 688267 & 6.2 & 5.047 & TST & \\
\hline CHEMBL1576018 & 688267 & 4.4 & 5.0289 & TRN & \\
\hline CHEMBL1450837 & 688267 & 5.3 & 5.0288 & TST & \\
\hline
\end{tabular}




\begin{tabular}{|c|c|c|c|c|c|}
\hline CHEMBL1541445 & 688267 & 4.5 & \multicolumn{2}{|c|}{5.122999999999999} & \multirow[t]{2}{*}{ TRN } \\
\hline CHEMBL1354308 & 688267 & 5.45 & 5.0314 & TRN & \\
\hline CHEMBL1299621 & 688267 & 5.3 & 5.0905 & TRN & \\
\hline CHEMBL1607330 & 688267 & 4.4 & 5.0683 & TRN & \\
\hline CHEMBL1364987 & 688267 & 5.55 & 5.0356 & TRN & \\
\hline CHEMBL1603478 & 688267 & 4.05 & 4.9812 & TRN & \\
\hline CHEMBL1419693 & 688267 & 4.35 & 5.0036 & TRN & \\
\hline CHEMBL1359719 & 688267 & 3.9 & 5.1406 & TRN & \\
\hline CHEMBL1504587 & 688267 & 4.4 & 5.0471 & TST & \\
\hline CHEMBL1507832 & 688267 & 4.5 & 5.0884 & TRN & \\
\hline CHEMBL1345448 & 688267 & 5.15 & 5.0581 & TRN & \\
\hline CHEMBL1399902 & 688267 & 5.4 & 5.0144 & TRN & \\
\hline CHEMBL1521700 & 688267 & 4.05 & 5.0744 & TRN & \\
\hline CHEMBL1608942 & 688267 & 4.35 & 5.1705 & TST & \\
\hline CHEMBL1995365 & 688267 & 5.0 & 5.0196 & TRN & \\
\hline CHEMBL1422496 & 688267 & 4.85 & 5.1103 & TRN & \\
\hline CHEMBL1480908 & 688267 & 5.35 & 5.0706 & TST & \\
\hline CHEMBL3193416 & 688267 & 5.85 & 5.0392 & TST & \\
\hline CHEMBL1351759 & 688267 & 4.0 & 5.0319 & TST & \\
\hline CHEMBL1451147 & 688267 & 4.55 & 5.0352 & TRN & \\
\hline CHEMBL1521006 & 688267 & 6.2 & 5.0252 & TRN & \\
\hline CHEMBL1340790 & 688267 & 6.2 & 5.0586 & TRN & \\
\hline CHEMBL1540825 & 688267 & 5.6 & 5.0829 & TST & \\
\hline CHEMBL1316208 & 688267 & 4.15 & 5.0356 & TST & \\
\hline CHEMBL3198376 & 688267 & 5.8 & 5.0224 & TRN & \\
\hline CHEMBL1362491 & 688267 & 5.6 & 5.0992 & TRN & \\
\hline CHEMBL1357886 & 688267 & 5.4 & 5.15799 & 99999999995 & TRN \\
\hline CHEMBL33171 & 688267 & 6.6499 & 5.0293 & TRN & \\
\hline CHEMBL1547975 & 688267 & 4.7 & 5.0404 & TRN & \\
\hline CHEMBL1593049 & 688267 & 6.15 & 4.9903 & TRN & \\
\hline CHEMBL1345782 & 688267 & 4.0 & 5.0742 & TRN & \\
\hline CHEMBL1421632 & 688267 & 4.05 & 5.0875 & TRN & \\
\hline CHEMBL1384757 & 688267 & 5.1 & 5.0953 & TRN & \\
\hline CHEMBL1484230 & 688267 & 5.55 & 5.0885 & TRN & \\
\hline CHEMBL3196587 & 688267 & 4.0 & 5.0275 & TST & \\
\hline CHEMBL1445211 & 688267 & 5.4 & 5.0302 & TST & \\
\hline CHEMBL1502876 & 688267 & 4.25 & 5.0226 & TRN & \\
\hline CHEMBL1587208 & 688267 & 5.0 & 5.0556 & TST & \\
\hline CHEMBL1357312 & 688267 & 4.45 & 5.1084 & TRN & \\
\hline CHEMBL1387705 & 688267 & 4.5 & 5.0547 & TST & \\
\hline CHEMBL1340417 & 688267 & 6.15 & 4.9834 & TRN & \\
\hline CHEMBL1531485 & 688267 & 5.9 & 5.1135 & TRN & \\
\hline CHEMBL1330102 & 688267 & 5.55 & 5.0955 & TRN & \\
\hline CHEMBL1598038 & 688267 & 6.25 & 5.0805 & TRN & \\
\hline CHEMBL1561347 & 688267 & 5.6 & 5.0208 & TRN & \\
\hline CHEMBL531079 & 688267 & 6.0 & 5.0481 & TRN & \\
\hline CHEMBL1343764 & 688267 & 5.75 & 5.0288 & TRN & \\
\hline CHEMBL1596337 & 688267 & 4.4 & 5.0581 & TRN & \\
\hline & & & & 17773 & \\
\hline
\end{tabular}




\begin{tabular}{|c|c|c|c|c|c|}
\hline \\
\hline CHEMBL1515803 & 688267 & 6.2 & 5.0397 & TRN & \\
\hline CHEMBL609604 & 688267 & 4.45 & 5.0781 & TRN & \\
\hline CHEMBL1488578 & 688267 & 6.9 & 5.0558 & TST & \\
\hline CHEMBL1494545 & 688267 & 4.0 & 5.0659 & TRN & \\
\hline CHEMBL1392697 & 688267 & 4.15 & 5.0654 & TRN & \\
\hline CHEMBL1584189 & 688267 & 3.95 & 5.0153 & TRN & \\
\hline CHEMBL1434628 & 688267 & 5.35 & 5.1389 & TRN & \\
\hline CHEMBL1405568 & 688267 & 6.15 & 5.1359 & TRN & \\
\hline CHEMBL1369488 & 688267 & 4.45 & 5.0175 & TRN & \\
\hline CHEMBL1426831 & 688267 & 3.95 & 5.0945 & TST & \\
\hline CHEMBL1539953 & 688267 & 4.3 & 5.019 & TRN & \\
\hline CHEMBL1353841 & 688267 & 4.8 & 5.0973 & TRN & \\
\hline CHEMBL1529955 & 688267 & 5.5 & 5.1168 & TST & \\
\hline CHEMBL1453593 & 688267 & 5.45 & 5.0502 & TRN & \\
\hline CHEMBL1367197 & 688267 & 5.8 & 4.9985 & TRN & \\
\hline CHEMBL1597937 & 688267 & 6.45 & 5.0146 & TRN & \\
\hline CHEMBL1370685 & 688267 & 3.9 & 5.00899 & 99999999995 & TRN \\
\hline CHEMBL1572098 & 688267 & 6.25 & 5.1076 & TRN & \\
\hline CHEMBL1507267 & 688267 & 5.65 & 5.0974 & TRN & \\
\hline CHEMBL1404887 & 688267 & 4.5 & 5.0105 & TRN & \\
\hline CHEMBL1601755 & 688267 & 5.3 & 5.1997 & TRN & \\
\hline CHEMBL1543683 & 688267 & 5.2 & 5.113 & TRN & \\
\hline CHEMBL1563227 & 688267 & 6.25 & 4.9717 & TRN & \\
\hline CHEMBL3195359 & 688267 & 4.2 & 5.0279 & TRN & \\
\hline CHEMBL1343010 & 688267 & 5.25 & 5.0422 & TRN & \\
\hline CHEMBL1607977 & 688267 & 6.2 & 5.0578 & TRN & \\
\hline CHEMBL1335945 & 688267 & 4.05 & 5.0334 & TST & \\
\hline CHEMBL1376069 & 688267 & 4.35 & 5.0647 & TST & \\
\hline CHEMBL1599444 & 688267 & 4.2 & 5.0252 & TRN & \\
\hline CHEMBL1513208 & 688267 & 6.25 & 5.0014 & TRN & \\
\hline CHEMBL1551885 & 688267 & 5.1 & 5.0697 & TRN & \\
\hline CHEMBL1444955 & 688267 & 5.3 & 5.043 & TRN & \\
\hline CHEMBL1344649 & 688267 & 4.35 & 5.1418 & TRN & \\
\hline CHEMBL1326895 & 688267 & 3.95 & 5.0512 & TRN & \\
\hline CHEMBL1515978 & 688267 & 3.95 & 5.051 & TST & \\
\hline CHEMBL1493948 & 688267 & 4.4 & 5.0608 & TST & \\
\hline CHEMBL1571042 & 688267 & 5.85 & 5.0425 & TST & \\
\hline CHEMBL1555615 & 688267 & 5.3 & 5.1668 & TRN & \\
\hline CHEMBL1413246 & 688267 & 5.85 & 5.0506 & TRN & \\
\hline CHEMBL1318888 & 688267 & 4.55 & 5.0236 & TRN & \\
\hline CHEMBL1570832 & 688267 & 4.7 & 5.0596 & TRN & \\
\hline CHEMBL1329994 & 688267 & 4.25 & 5.0098 & TST & \\
\hline CHEMBL1302908 & 688267 & 4.35 & 5.063 & TRN & \\
\hline CHEMBL1603705 & 688267 & 6.45 & 5.0597 & TRN & \\
\hline CHEMBL1539123 & 688267 & 6.15 & 5.0028 & TRN & \\
\hline CHEMBL1552047 & 688267 & 3.95 & 5.0269 & TRN & \\
\hline CHEMBL1426576 & 688267 & 6.05 & 5.0024 & TST & \\
\hline CHEMBL1338432 & 688267 & 5.35 & 5.0701 & TST & \\
\hline
\end{tabular}




\begin{tabular}{|c|c|c|c|c|}
\hline \multicolumn{5}{|c|}{ Supplemental Table s2.txt } \\
\hline CHEMBL1354761 & 688267 & 4.0 & 5.0859 & TRN \\
\hline CHEMBL1572838 & 688267 & 4.35 & 4.9707 & TST \\
\hline CHEMBL1320613 & 688267 & 4.5 & 5.0343 & TRN \\
\hline CHEMBL1484412 & 688267 & 6.2 & 5.0217 & TST \\
\hline CHEMBL1597306 & 688267 & 5.05 & 5.0214 & TST \\
\hline CHEMBL1330626 & 688267 & 5.3 & 5.041 & TST \\
\hline CHEMBL1459595 & 688267 & 5.05 & 5.0652 & TRN \\
\hline CHEMBL1417475 & 688267 & 4.1 & 5.0395 & TRN \\
\hline CHEMBL3199444 & 688267 & 6.2 & 5.0334 & TST \\
\hline CHEMBL1456416 & 688267 & 6.05 & 5.1202 & TRN \\
\hline CHEMBL1352566 & 688267 & 4.75 & 5.0054 & TRN \\
\hline CHEMBL1428690 & 688267 & 4.0 & 4.9993 & TRN \\
\hline CHEMBL1423436 & 688267 & 6.2 & 5.1095 & TRN \\
\hline CHEMBL1494958 & 688267 & 4.35 & 5.0138 & TRN \\
\hline CHEMBL3189805 & 688267 & 5.55 & 5.0592 & TST \\
\hline CHEMBL1339685 & 688267 & 4.8 & 5.1043 & TRN \\
\hline CHEMBL1376262 & 688267 & 6.2 & 5.0804 & TRN \\
\hline CHEMBL1546797 & 688267 & 6.15 & 4.9868 & TRN \\
\hline CHEMBL1588134 & 688267 & 5.35 & 5.1216 & TRN \\
\hline CHEMBL1334789 & 688267 & 4.9 & 5.0458 & TST \\
\hline CHEMBL1422010 & 688267 & 5.85 & 5.0244 & TST \\
\hline CHEMBL1510603 & 688267 & 4.15 & 5.0075 & TRN \\
\hline CHEMBL3209100 & 688267 & 4.05 & 4.9982 & TRN \\
\hline CHEMBL1529509 & 688267 & 4.0 & 5.0189 & TRN \\
\hline CHEMBL1335100 & 688267 & 4.55 & 4.9842 & TRN \\
\hline CHEMBL1436942 & 688267 & 5.35 & 5.0973 & TRN \\
\hline CHEMBL1559373 & 688267 & 4.0 & 5.0244 & TRN \\
\hline CHEMBL1368067 & 688267 & 5.65 & 5.0352 & TRN \\
\hline CHEMBL1435065 & 688267 & 4.0 & 5.0154 & TRN \\
\hline CHEMBL1447069 & 688267 & 4.1 & 5.0544 & TRN \\
\hline CHEMBL1396662 & 688267 & 4.7 & 5.0294 & TRN \\
\hline CHEMBL1600070 & 688267 & 6.05 & 5.0272 & TRN \\
\hline CHEMBL1534640 & 688267 & 4.35 & 5.1154 & TRN \\
\hline CHEMBL1460187 & 688267 & 5.15 & 5.1351 & TRN \\
\hline CHEMBL1482825 & 688267 & 6.05 & 5.0913 & TST \\
\hline CHEMBL1302458 & 688267 & 4.55 & 5.1217 & TRN \\
\hline CHEMBL1328870 & 688267 & 4.55 & 5.1245 & TRN \\
\hline CHEMBL1593426 & 688267 & 6.2 & 4.982 & TRN \\
\hline CHEMBL 1607790 & 688267 & 6.1 & 5.0735 & TRN \\
\hline CHEMBL 1605350 & 688267 & 5.9 & 5.0213 & TST \\
\hline CHEMBL1508858 & 688267 & 4.05 & 5.0743 & TRN \\
\hline CHEMBL1578991 & 688267 & 4.05 & $5.0680 e$ & 00000000005 \\
\hline CHEMBL1381437 & 688267 & 4.05 & 5.0864 & TRN \\
\hline CHEMBL 3207465 & 688267 & 4.55 & 4.9948 & TRN \\
\hline CHEMBL1455330 & 688267 & 5.45 & 5.0885 & TRN \\
\hline CHEMBL1329554 & 688267 & 5.55 & 5.0378 & TRN \\
\hline CHEMBL1546402 & 688267 & 4.05 & 5.0112 & TRN \\
\hline CHEMBL1394572 & 688267 & 4.1 & 5.008 & TRN \\
\hline
\end{tabular}




\begin{tabular}{|c|c|c|c|c|}
\hline \multicolumn{5}{|c|}{ Supplemental Table S2.txt } \\
\hline CHEMBL1357003 & 688267 & 4.35 & 5.0264 & TRN \\
\hline CHEMBL1572149 & 688267 & 3.95 & 5.0199 & TRN \\
\hline CHEMBL1345508 & 688267 & 4.1 & 5.0351 & TRN \\
\hline CHEMBL1522874 & 688267 & 5.5 & 5.086 & TRN \\
\hline CHEMBL1300511 & 688267 & 5.2 & 5.0595 & TRN \\
\hline CHEMBL1361337 & 688267 & 4.0 & 5.0799 & TRN \\
\hline CHEMBL1538376 & 688267 & 5.55 & 5.0234 & TRN \\
\hline CHEMBL1327947 & 688267 & 4.4 & 5.1018 & TRN \\
\hline CHEMBL1389773 & 688267 & 4.75 & 5.0591 & TRN \\
\hline CHEMBL1338818 & 688267 & 4.3 & 5.0204 & TRN \\
\hline CHEMBL1523503 & 688267 & 4.4 & 5.0453 & TRN \\
\hline CHEMBL 3194187 & 688267 & 5.65 & 5.0082 & TRN \\
\hline CHEMBL1494902 & 688267 & 6.2 & 5.1251 & TRN \\
\hline CHEMBL1435861 & 688267 & 4.6 & 5.0153 & TRN \\
\hline CHEMBL1326349 & 688267 & 4.5 & 4.9988 & TST \\
\hline CHEMBL1530770 & 688267 & 4.45 & 4.9933 & TRN \\
\hline CHEMBL1367025 & 688267 & 5.5 & 5.0291 & TRN \\
\hline CHEMBL1322271 & 688267 & 4.35 & 5.1137 & TRN \\
\hline CHEMBL1469840 & 688267 & 5.05 & 5.0683 & TRN \\
\hline CHEMBL1399217 & 688267 & 5.65 & 5.0933 & TRN \\
\hline CHEMBL1714915 & 688267 & 4.45 & 5.0242 & TST \\
\hline CHEMBL1375937 & 688267 & 6.1 & 5.0269 & TRN \\
\hline CHEMBL1391330 & 688267 & 4.0 & 5.0569 & TST \\
\hline CHEMBL1496047 & 688267 & 6.0 & 5.0639 & TRN \\
\hline CHEMBL1340131 & 688267 & 6.3 & 5.1126 & TRN \\
\hline CHEMBL1577301 & 688267 & 4.4 & 5.0618 & TST \\
\hline CHEMBL1465565 & 688267 & 5.9 & 5.0159 & TST \\
\hline CHEMBL1305632 & 688267 & 5.5 & 5.0219 & TRN \\
\hline CHEMBL 3193446 & 688267 & 6.8499 & 5.0658 & TRN \\
\hline CHEMBL1499808 & 688267 & 6.2 & 5.0256 & TST \\
\hline CHEMBL1377588 & 688267 & 6.25 & 5.0546 & TST \\
\hline CHEMBL1573799 & 688267 & 4.4 & 5.0243 & TRN \\
\hline CHEMBL1515380 & 688267 & 4.05 & 5.0845 & TRN \\
\hline CHEMBL1521382 & 688267 & 4.1 & 5.048 & TRN \\
\hline CHEMBL1485685 & 688267 & 6.2 & 5.0507 & TRN \\
\hline CHEMBL1458172 & 688267 & 6.1 & 5.0797 & TRN \\
\hline CHEMBL1332511 & 688267 & 4.6 & 5.0523 & TRN \\
\hline CHEMBL1324017 & 688267 & 4.0 & 5.0732 & TRN \\
\hline CHEMBL1479345 & 688267 & 5.3 & 5.0147 & TRN \\
\hline CHEMBL1442496 & 688267 & 5.9 & 5.0766 & TRN \\
\hline CHEMBL1613015 & 688267 & 4.75 & 4.9947 & TRN \\
\hline CHEMBL1398381 & 688267 & 6.2 & 5.1027 & TRN \\
\hline CHEMBL1305328 & 688267 & 5.05 & 5.1696 & TRN \\
\hline CHEMBL3211635 & 688267 & 4.05 & 5.0916 & TST \\
\hline CHEMBL1500766 & 688267 & 5.95 & 5.045 & TRN \\
\hline CHEMBL389516 & 688267 & 6.15 & 5.0789 & TST \\
\hline CHEMBL1450970 & 688267 & 5.5 & 5.0713 & TRN \\
\hline CHEMBL1524964 & 688267 & 5.2 & 5.0625 & TRN \\
\hline
\end{tabular}




\begin{tabular}{|c|c|c|c|c|}
\hline \multicolumn{5}{|c|}{ Supplemental Table S2.txt } \\
\hline CHEMBL1311124 & 688267 & 4.15 & 5.0377 & TRN \\
\hline CHEMBL1485811 & 688267 & 4.7 & 5.1223 & TRN \\
\hline CHEMBL1448336 & 688267 & 6.1 & 5.0474 & TRN \\
\hline CHEMBL1352167 & 688267 & 5.3 & 5.0743 & TRN \\
\hline CHEMBL1469613 & 688267 & 4.75 & 5.141 & TRN \\
\hline CHEMBL1503523 & 688267 & 4.85 & 5.0003 & TRN \\
\hline CHEMBL1352879 & 688267 & 5.0 & 5.0394 & TST \\
\hline CHEMBL1089451 & 688267 & 6.2 & 5.1346 & TRN \\
\hline CHEMBL1493209 & 688267 & 5.95 & 5.0158 & TRN \\
\hline CHEMBL1476667 & 688267 & 4.0 & 5.0439 & TRN \\
\hline CHEMBL1450281 & 688267 & 6.2 & 4.9756 & TRN \\
\hline CHEMBL1375164 & 688267 & 4.9 & 5.0188 & TRN \\
\hline CHEMBL1445179 & 688267 & 4.25 & 5.1256 & TRN \\
\hline CHEMBL1420628 & 688267 & 4.35 & 4.9888 & TRN \\
\hline CHEMBL1441013 & 688267 & 6.2 & 5.1062 & TRN \\
\hline CHEMBL1392118 & 688267 & 6.15 & 5.0158 & TRN \\
\hline CHEMBL1401571 & 688267 & 5.9 & 5.0165 & TST \\
\hline CHEMBL1333575 & 688267 & 5.95 & 5.1253 & TRN \\
\hline CHEMBL1486335 & 688267 & 5.3 & 5.0041 & TST \\
\hline CHEMBL1396650 & 688267 & 4.35 & 5.0912 & TRN \\
\hline CHEMBL3192793 & 688267 & 6.2 & 4.9778 & TRN \\
\hline CHEMBL1333943 & 688267 & 6.15 & 5.0683 & TRN \\
\hline CHEMBL1383033 & 688267 & 4.0 & 5.0773 & TRN \\
\hline CHEMBL1547136 & 688267 & 5.45 & 5.0268 & TRN \\
\hline CHEMBL3198305 & 688267 & 6.15 & 5.0217 & TRN \\
\hline CHEMBL1316031 & 688267 & 4.2 & 5.099 & TRN \\
\hline CHEMBL1416262 & 688267 & 4.0 & 5.0301 & TST \\
\hline CHEMBL1370157 & 688267 & 6.0 & 5.0543 & TRN \\
\hline CHEMBL1447363 & 688267 & 6.2 & 5.0452 & TRN \\
\hline CHEMBL1395836 & 688267 & 4.55 & 5.0084 & TRN \\
\hline CHEMBL1411741 & 688267 & 5.3 & 5.0579 & TST \\
\hline CHEMBL1350585 & 688267 & 4.15 & 5.1032 & TRN \\
\hline CHEMBL 277525 & 688267 & 4.95 & 5.0252 & TST \\
\hline CHEMBL162783 & 688267 & 4.0 & 5.072 & TST \\
\hline CHEMBL1365165 & 688267 & 4.05 & 5.0512 & TRN \\
\hline CHEMBL1371183 & 688267 & 5.6 & 5.061 & TRN \\
\hline CHEMBL1399873 & 688267 & 4.75 & 5.0509 & TRN \\
\hline CHEMBL1404012 & 688267 & 4.5 & 5.0539 & TRN \\
\hline CHEMBL1604545 & 688267 & 5.05 & 5.0288 & TRN \\
\hline CHEMBL1519822 & 688267 & 5.6 & 5.0618 & TRN \\
\hline CHEMBL1516874 & 688267 & 4.55 & 5.0761 & TST \\
\hline CHEMBL1431804 & 688267 & 4.35 & 5.0929 & TST \\
\hline CHEMBL1339779 & 688267 & 5.45 & 5.0997 & TRN \\
\hline CHEMBL1434522 & 688267 & 6.2 & 5.1737 & TST \\
\hline CHEMBL1437289 & 688267 & 5.45 & 5.0258 & TRN \\
\hline CHEMBL1368768 & 688267 & 6.25 & 5.0673 & TRN \\
\hline CHEMBL1496776 & 688267 & 5.55 & 5.1035 & TST \\
\hline CHEMBL1449556 & 688267 & 4.25 & 5.0819 & TRN \\
\hline
\end{tabular}




\begin{tabular}{|c|c|c|c|c|}
\hline \multicolumn{5}{|c|}{ Supplemental Table S2.txt } \\
\hline CHEMBL1375564 & 688267 & 5.3 & 5.0994 & TRN \\
\hline CHEMBL1525256 & 688267 & 4.35 & 5.0907 & TRN \\
\hline CHEMBL84010 & 688267 & 5.5 & 5.0038 & TST \\
\hline CHEMBL1527800 & 688267 & 4.2 & 5.0405 & TRN \\
\hline CHEMBL1475798 & 688267 & 5.45 & 5.0151 & TRN \\
\hline CHEMBL1430041 & 688267 & 4.7 & 5.0114 & TRN \\
\hline CHEMBL1564430 & 688267 & 4.4 & 5.1098 & TST \\
\hline CHEMBL1562698 & 688267 & 4.5 & 5.0522 & TST \\
\hline CHEMBL1372942 & 688267 & 4.05 & 5.0433 & TRN \\
\hline CHEMBL1511526 & 688267 & 5.15 & 5.0275 & TST \\
\hline CHEMBL1593597 & 688267 & 4.0 & 5.0435 & TST \\
\hline CHEMBL1359178 & 688267 & 6.15 & 5.0506 & TRN \\
\hline CHEMBL1444380 & 688267 & 5.75 & 5.0709 & TRN \\
\hline CHEMBL1405054 & 688267 & 5.35 & 4.9888 & TRN \\
\hline CHEMBL1481431 & 688267 & 4.0 & 5.0383 & TRN \\
\hline CHEMBL1502406 & 688267 & 4.4 & 5.0321 & TRN \\
\hline CHEMBL1501336 & 688267 & 6.2 & 5.1075 & TST \\
\hline CHEMBL1316490 & 688267 & 4.6 & 5.0807 & TRN \\
\hline CHEMBL1368482 & 688267 & 4.05 & 5.0534 & TST \\
\hline CHEMBL1337780 & 688267 & 4.3 & 5.1207 & TST \\
\hline CHEMBL1475409 & 688267 & 4.55 & 5.0845 & TRN \\
\hline CHEMBL1303459 & 688267 & 6.25 & 5.0821 & TRN \\
\hline CHEMBL1593362 & 688267 & 4.3 & 5.0928 & TRN \\
\hline CHEMBL1388127 & 688267 & 5.05 & 5.0077 & TST \\
\hline CHEMBL484385 & 688267 & 4.75 & 5.0408 & TRN \\
\hline CHEMBL1559016 & 688267 & 4.35 & 4.9821 & TRN \\
\hline CHEMBL1533805 & 688267 & 6.2 & 5.072 & TRN \\
\hline CHEMBL1375833 & 688267 & 5.85 & 5.0099 & TRN \\
\hline CHEMBL1163764 & 688267 & 6.6499 & 5.0893 & TRN \\
\hline CHEMBL1606185 & 688267 & 4.25 & 5.0233 & TRN \\
\hline CHEMBL1357133 & 688267 & 4.05 & 5.0234 & TRN \\
\hline CHEMBL1403833 & 688267 & 6.15 & 5.1159 & TRN \\
\hline CHEMBL1455985 & 688267 & 4.5 & 5.0948 & TRN \\
\hline CHEMBL1524473 & 688267 & 5.3 & 5.0894 & TRN \\
\hline CHEMBL1609676 & 688267 & 6.2 & 4.9857 & TRN \\
\hline CHEMBL220287 & 688267 & 5.5 & 5.006 & TRN \\
\hline CHEMBL1401547 & 688267 & 5.25 & 5.0482 & TRN \\
\hline CHEMBL1447627 & 688267 & 4.35 & 5.1125 & TRN \\
\hline CHEMBL1318034 & 688267 & 3.95 & 5.0609 & TRN \\
\hline CHEMBL1485956 & 688267 & 5.0 & 5.0376 & TST \\
\hline CHEMBL1465231 & 688267 & 4.1 & 5.0129 & TST \\
\hline CHEMBL1549607 & 688267 & 4.0 & 5.0477 & TRN \\
\hline CHEMBL1503083 & 688267 & 4.75 & 5.0728 & TRN \\
\hline CHEMBL1564476 & 688267 & 6.15 & 5.0994 & TRN \\
\hline CHEMBL1332096 & 688267 & 4.15 & 5.0838 & TRN \\
\hline CHEMBL1393661 & 688267 & 5.15 & 5.0823 & TRN \\
\hline CHEMBL1394099 & 688267 & 5.05 & 5.0152 & TRN \\
\hline CHEMBL1414916 & 688267 & 6.25 & 5.0621 & TRN \\
\hline
\end{tabular}




\begin{tabular}{|c|c|c|c|c|c|}
\hline \multicolumn{6}{|c|}{ Supplemental Table S2.txt } \\
\hline CHEMBL1378975 & 688267 & 5.25 & 5.0787 & TST & \\
\hline CHEMBL1403661 & 688267 & 4.55 & 5.1546 & TRN & \\
\hline CHEMBL1585896 & 688267 & 3.9 & 5.104 & TRN & \\
\hline CHEMBL1543628 & 688267 & 6.15 & 5.0344 & TRN & \\
\hline CHEMBL1519704 & 688267 & 4.45 & 5.0164 & TRN & \\
\hline CHEMBL1576214 & 688267 & 5.65 & 5.0833 & TST & \\
\hline CHEMBL1311310 & 688267 & 5.55 & 5.0552 & TST & \\
\hline CHEMBL1592799 & 688267 & 5.3 & 5.0159 & TRN & \\
\hline CHEMBL1418219 & 688267 & 6.5 & 5.0948 & TRN & \\
\hline CHEMBL1520219 & 688267 & 6.2 & 5.0636 & TRN & \\
\hline CHEMBL1356322 & 688267 & 6.2 & 5.0407 & TRN & \\
\hline CHEMBL1599787 & 688267 & 5.0 & 5.0277 & TST & \\
\hline CHEMBL1305450 & 688267 & 5.5 & 5.01 & TST & \\
\hline CHEMBL1341664 & 688267 & 4.5 & 5.0532 & TRN & \\
\hline CHEMBL1360705 & 688267 & 6.15 & 5.1204 & TRN & \\
\hline CHEMBL1515754 & 688267 & 5.85 & 5.1305 & TRN & \\
\hline CHEMBL1508523 & 688267 & 6.15 & 4.9856 & TRN & \\
\hline CHEMBL1331174 & 688267 & 4.4 & 5.022 & TRN & \\
\hline CHEMBL1305306 & 688267 & 6.25 & 5.0571 & TRN & \\
\hline CHEMBL1536267 & 688267 & 4.3 & 5.0672 & TRN & \\
\hline CHEMBL1985295 & 688267 & 6.05 & 5.0749 & TRN & \\
\hline CHEMBL1483026 & 688267 & 5.35 & 5.0139 & TRN & \\
\hline CHEMBL1495616 & 688267 & 5.3 & 5.0327 & TRN & \\
\hline CHEMBL1437583 & 688267 & 6.2 & 5.08899 & 99999999995 & TRN \\
\hline CHEMBL1549589 & 688267 & 4.25 & 5.006 & TRN & \\
\hline CHEMBL1318235 & 688267 & 6.1 & 5.0587 & TRN & \\
\hline CHEMBL1610910 & 688267 & 4.05 & 5.0391 & TRN & \\
\hline CHEMBL1497143 & 688267 & 5.65 & 5.0726 & TST & \\
\hline CHEMBL1304676 & 688267 & 5.8 & 5.029 & TRN & \\
\hline CHEMBL1408806 & 688267 & 5.1 & 5.0402 & TRN & \\
\hline CHEMBL1611740 & 688267 & 5.3 & 5.0321 & TRN & \\
\hline CHEMBL1361058 & 688267 & 4.4 & 5.0016 & TRN & \\
\hline CHEMBL1541587 & 688267 & 4.0 & 5.0804 & TRN & \\
\hline CHEMBL1500801 & 688267 & 5.45 & 5.0033 & TST & \\
\hline CHEMBL1426564 & 688267 & 6.2 & 5.1242 & TRN & \\
\hline CHEMBL1393946 & 688267 & 4.95 & 5.0469 & TRN & \\
\hline CHEMBL1475753 & 688267 & 4.0 & 5.0434 & TRN & \\
\hline CHEMBL 3194010 & 688267 & 4.05 & 4.9938 & TRN & \\
\hline CHEMBL1392315 & 688267 & 4.4 & 5.1071 & TRN & \\
\hline CHEMBL1383484 & 688267 & 4.0 & 5.0424 & TST & \\
\hline CHEMBL1536993 & 688267 & 4.6 & 5.1073 & TRN & \\
\hline CHEMBL1382261 & 688267 & 4.35 & 5.0699 & TST & \\
\hline CHEMBL1309208 & 688267 & 6.1 & 5.038 & TRN & \\
\hline CHEMBL1347052 & 688267 & 4.55 & 5.0963 & TRN & \\
\hline CHEMBL1357100 & 688267 & 5.55 & 4.994 & TRN & \\
\hline CHEMBL1484942 & 688267 & 5.35 & 5.1029 & TST & \\
\hline CHEMBL 3213688 & 688267 & 5.7 & 5.0671 & TRN & \\
\hline CHEMBL3197116 & 688267 & 5.6 & 5.0278 & TRN & \\
\hline
\end{tabular}




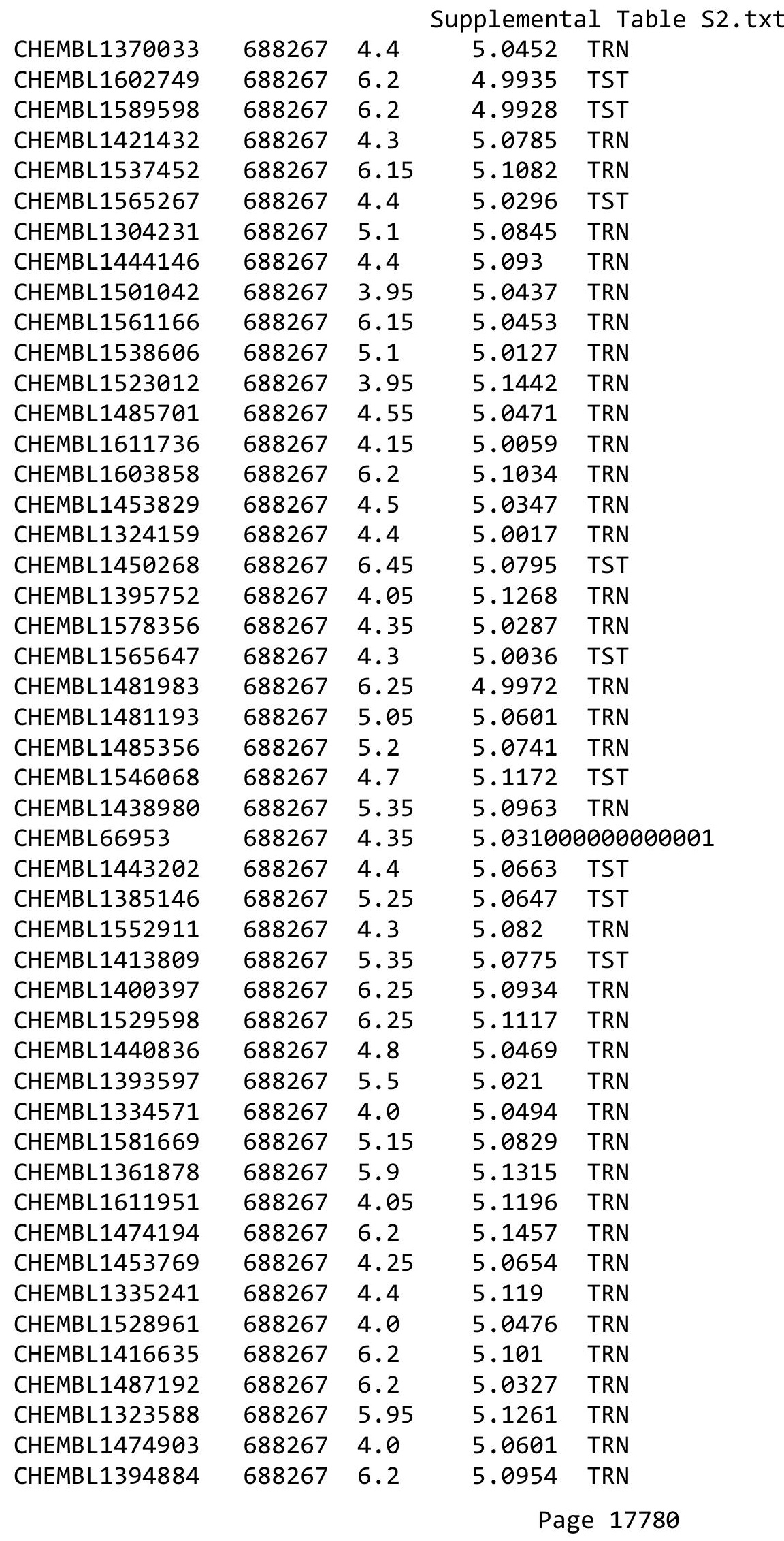




\begin{tabular}{|c|c|c|c|c|c|}
\hline \\
\hline CHEMBL1363100 & 688267 & 5.3 & 5.0137 & TRN & \\
\hline CHEMBL1480525 & 688267 & 6.15 & 5.0758 & TRN & \\
\hline CHEMBL3197849 & 688267 & 4.35 & 4.9873 & TRN & \\
\hline CHEMBL1316578 & 688267 & 5.35 & 5.1318 & TRN & \\
\hline CHEMBL1354556 & 688267 & 6.1 & 5.0729 & TRN & \\
\hline CHEMBL1494044 & 688267 & 6.2 & 5.0022 & TRN & \\
\hline CHEMBL1536145 & 688267 & 4.35 & 5.0417 & TRN & \\
\hline CHEMBL1510341 & 688267 & 4.55 & 5.0301 & TST & \\
\hline CHEMBL1604789 & 688267 & 4.35 & 5.0863 & TRN & \\
\hline CHEMBL1556204 & 688267 & 5.55 & 5.0394 & TRN & \\
\hline CHEMBL1495582 & 688267 & 5.85 & 5.1569 & TRN & \\
\hline CHEMBL1594213 & 688267 & 5.45 & 5.0337 & TST & \\
\hline CHEMBL1605396 & 688267 & 4.0 & 5.0404 & TST & \\
\hline CHEMBL1508613 & 688267 & 4.35 & 5.0687 & TST & \\
\hline CHEMBL1472141 & 688267 & 4.3 & 5.1014 & TRN & \\
\hline CHEMBL1462396 & 688267 & 4.85 & 5.0885 & TRN & \\
\hline CHEMBL1457356 & 688267 & 4.7 & 4.9919 & TRN & \\
\hline CHEMBL465909 & 688267 & 6.5 & 4.9808 & TRN & \\
\hline CHEMBL1356189 & 688267 & 4.05 & 5.1106 & TRN & \\
\hline CHEMBL1312038 & 688267 & 6.2 & 5.0469 & TRN & \\
\hline CHEMBL1450146 & 688267 & 4.05 & 5.0972 & TST & \\
\hline CHEMBL1516263 & 688267 & 4.2 & 5.0864 & TRN & \\
\hline CHEMBL3208147 & 688267 & 5.55 & 5.0064 & TST & \\
\hline CHEMBL1337925 & 688267 & 4.15 & 5.0629 & TST & \\
\hline CHEMBL1476965 & 688267 & 4.4 & 5.0421 & TRN & \\
\hline CHEMBL1611778 & 688267 & 6.15 & 5.0133 & TRN & \\
\hline CHEMBL1528353 & 688267 & 6.15 & 5.0205 & TRN & \\
\hline CHEMBL1573332 & 688267 & 3.95 & 5.1229 & TST & \\
\hline CHEMBL1594530 & 688267 & 5.9 & 5.0374 & TRN & \\
\hline CHEMBL1395079 & 688267 & 5.6 & 5.0878 & TRN & \\
\hline CHEMBL1584266 & 688267 & 5.05 & 5.0345 & TRN & \\
\hline CHEMBL1329401 & 688267 & 5.05 & 5.0652 & TRN & \\
\hline CHEMBL1492158 & 688267 & 5.6 & $5.0280 e$ & 20000000005 & TRN \\
\hline CHEMBL1437663 & 688267 & 5.3 & 5.0208 & TRN & \\
\hline CHEMBL1508771 & 688267 & 6.25 & $5.0280 e$ & 00000000005 & TST \\
\hline CHEMBL1529518 & 688267 & 5.45 & 5.0445 & TST & \\
\hline CHEMBL1484227 & 688267 & 6.5 & 5.0807 & TST & \\
\hline CHEMBL1610932 & 688267 & 4.55 & 5.0337 & TRN & \\
\hline CHEMBL1487242 & 688267 & 6.2 & 5.1094 & TST & \\
\hline CHEMBL1543382 & 688267 & 5.3 & 5.0688 & TRN & \\
\hline CHEMBL1463499 & 688267 & 4.0 & 5.0521 & TST & \\
\hline CHEMBL1994460 & 688267 & 6.25 & 5.0437 & TST & \\
\hline CHEMBL1555306 & 688267 & 4.75 & 5.0899 & TRN & \\
\hline CHEMBL1478809 & 688267 & 4.4 & 5.0225 & TRN & \\
\hline CHEMBL1543830 & 688267 & 4.0 & 5.0182 & TRN & \\
\hline CHEMBL1598803 & 688267 & 4.1 & 5.0653 & TRN & \\
\hline CHEMBL1427934 & 688267 & 4.0 & 5.0909 & TRN & \\
\hline CHEMBL1397371 & 688267 & 5.4 & 5.0095 & TRN & \\
\hline
\end{tabular}




\begin{tabular}{|c|c|c|c|c|}
\hline \multicolumn{5}{|c|}{ Supplemental Table S2.txt } \\
\hline CHEMBL 3195088 & 688267 & 4.25 & 5.0102 & TST \\
\hline CHEMBL1414252 & 688267 & 5.6 & 5.0525 & TST \\
\hline CHEMBL1417930 & 688267 & 6.25 & 4.9872 & TRN \\
\hline CHEMBL1369749 & 688267 & 4.3 & 4.9957 & TST \\
\hline CHEMBL1427901 & 688267 & 5.05 & 5.1218 & TRN \\
\hline CHEMBL1475233 & 688267 & 6.05 & 5.0533 & TRN \\
\hline CHEMBL1398850 & 688267 & 4.5 & 5.026 & TST \\
\hline CHEMBL1552289 & 688267 & 4.35 & 5.0615 & TRN \\
\hline CHEMBL1602666 & 688267 & 5.3 & 5.0073 & TRN \\
\hline CHEMBL1397495 & 688267 & 4.4 & 5.1017 & TRN \\
\hline CHEMBL1555940 & 688267 & 5.65 & 5.0698 & TRN \\
\hline CHEMBL1470448 & 688267 & 6.2 & 5.0093 & TRN \\
\hline CHEMBL1523769 & 688267 & 6.15 & 5.0842 & TRN \\
\hline CHEMBL1439853 & 688267 & 5.5 & 5.0996 & TRN \\
\hline CHEMBL1404080 & 688267 & 4.35 & 5.0724 & TRN \\
\hline CHEMBL1547295 & 688267 & 6.5501 & 5.0762 & TRN \\
\hline CHEMBL1493718 & 688267 & 4.45 & 5.0029 & TRN \\
\hline CHEMBL1313445 & 688267 & 5.9 & 5.0568 & TRN \\
\hline CHEMBL251670 & 688267 & 6.45 & 5.1121 & TST \\
\hline CHEMBL1561107 & 688267 & 6.2 & 5.0321 & TRN \\
\hline CHEMBL1555109 & 688267 & 3.95 & 5.0672 & TRN \\
\hline CHEMBL1331387 & 688267 & 4.4 & 5.0415 & TRN \\
\hline CHEMBL1611260 & 688267 & 4.2 & 5.1118 & TRN \\
\hline CHEMBL1313923 & 688267 & 4.8 & 5.0126 & TRN \\
\hline CHEMBL1533106 & 688267 & 5.05 & 5.1303 & TRN \\
\hline CHEMBL1520947 & 688267 & 6.2 & 5.1083 & TRN \\
\hline CHEMBL528724 & 688267 & 4.8 & 5.0419 & TST \\
\hline CHEMBL1560036 & 688267 & 6.2 & 5.0147 & TRN \\
\hline CHEMBL1314236 & 688267 & 5.35 & 5.0871 & TRN \\
\hline CHEMBL1488767 & 688267 & 6.15 & 5.0632 & TST \\
\hline CHEMBL1513856 & 688267 & 6.25 & 5.0654 & TST \\
\hline CHEMBL1561536 & 688267 & 6.05 & 5.0752 & TRN \\
\hline CHEMBL1552620 & 688267 & 5.2 & 4.9869 & TRN \\
\hline CHEMBL1315961 & 688267 & 5.55 & 5.0813 & TRN \\
\hline CHEMBL1395446 & 688267 & 4.6 & 5.0326 & TRN \\
\hline CHEMBL1490670 & 688267 & 5.15 & 5.053 & TRN \\
\hline CHEMBL1540624 & 688267 & 4.05 & 5.0932 & TRN \\
\hline CHEMBL1569382 & 688267 & 6.45 & 5.0114 & TRN \\
\hline CHEMBL1541334 & 688267 & 5.0 & 4.9708 & TRN \\
\hline CHEMBL1413597 & 688267 & 5.95 & 5.129 & TST \\
\hline CHEMBL1377276 & 688267 & 6.2 & 5.1229 & TRN \\
\hline CHEMBL1527219 & 688267 & 5.85 & 5.0307 & TRN \\
\hline CHEMBL1408070 & 688267 & 4.95 & 5.0835 & TRN \\
\hline CHEMBL1512906 & 688267 & 5.45 & 5.0046 & TRN \\
\hline CHEMBL1611741 & 688267 & 4.75 & 5.0581 & TST \\
\hline CHEMBL 2297588 & 688267 & 4.35 & 5.0588 & TST \\
\hline CHEMBL1473747 & 688267 & 4.3 & 5.0222 & TRN \\
\hline CHEMBL1580807 & 688267 & 5.15 & 5.0498 & TST \\
\hline
\end{tabular}




\begin{tabular}{|c|c|c|c|c|c|}
\hline \multicolumn{6}{|c|}{ Supplemental Table S2.txt } \\
\hline CHEMBL1323183 & 688267 & 5.55 & 5.0008 & TRN & \\
\hline CHEMBL1394257 & 688267 & 5.3 & 5.0499 & TRN & \\
\hline CHEMBL1613174 & 688267 & 6.2 & 5.0865 & TRN & \\
\hline CHEMBL1546849 & 688267 & 5.8 & 5.1033 & TRN & \\
\hline CHEMBL1575942 & 688267 & 4.0 & 5.0896 & TST & \\
\hline CHEMBL513436 & 688267 & 4.0 & 4.97199 & 99999999995 & TRN \\
\hline CHEMBL1362687 & 688267 & 4.4 & 5.0005 & TST & \\
\hline CHEMBL1499592 & 688267 & 5.4 & 5.0058 & TRN & \\
\hline CHEMBL1452085 & 688267 & 4.05 & 5.0928 & TRN & \\
\hline CHEMBL1369273 & 688267 & 5.5 & 5.0902 & TST & \\
\hline CHEMBL1547984 & 688267 & 6.25 & 5.0178 & TRN & \\
\hline CHEMBL1517319 & 688267 & 4.25 & 5.056 & TRN & \\
\hline CHEMBL600060 & 688267 & 4.25 & 5.0635 & TRN & \\
\hline CHEMBL1589959 & 688267 & 5.55 & 4.9851 & TRN & \\
\hline CHEMBL1567019 & 688267 & 5.85 & 5.0299 & TST & \\
\hline CHEMBL1588997 & 688267 & 4.05 & 5.025 & TRN & \\
\hline CHEMBL3194135 & 688267 & 4.35 & 5.022 & TRN & \\
\hline CHEMBL1435100 & 688267 & 5.05 & 4.9996 & TRN & \\
\hline CHEMBL1351708 & 688267 & 6.25 & 5.0012 & TRN & \\
\hline CHEMBL1330864 & 688267 & 5.3 & 5.0382 & TRN & \\
\hline CHEMBL1523668 & 688267 & 5.4 & 5.1002 & TST & \\
\hline CHEMBL1467160 & 688267 & 3.95 & 5.0508 & TRN & \\
\hline CHEMBL1449220 & 688267 & 5.75 & 5.03600 & 00000000005 & TST \\
\hline CHEMBL1314478 & 688267 & 6.2 & 5.0142 & TRN & \\
\hline CHEMBL394930 & 688267 & 4.35 & 5.0775 & TRN & \\
\hline CHEMBL1406852 & 688267 & 6.0 & 5.0546 & TRN & \\
\hline CHEMBL1370951 & 688267 & 4.25 & 5.0701 & TRN & \\
\hline CHEMBL1554009 & 688267 & 4.55 & 5.0653 & TRN & \\
\hline CHEMBL1607611 & 688267 & 4.2 & 5.0258 & TRN & \\
\hline CHEMBL1610008 & 688267 & 4.0 & 4.9584 & TRN & \\
\hline CHEMBL1369130 & 688267 & 4.4 & 4.9832 & TRN & \\
\hline CHEMBL1596951 & 688267 & 4.05 & 5.1122 & TRN & \\
\hline CHEMBL1477018 & 688267 & 4.5 & 5.0546 & TRN & \\
\hline CHEMBL 3208878 & 688267 & 6.35 & 5.0529 & TRN & \\
\hline CHEMBL567130 & 688267 & 5.1 & 5.019 & TRN & \\
\hline CHEMBL1552077 & 688267 & 5.5 & 5.0317 & TRN & \\
\hline CHEMBL1538763 & 688267 & 4.3 & 5.0332 & TRN & \\
\hline CHEMBL1405019 & 688267 & 4.8 & 5.1268 & TRN & \\
\hline CHEMBL1444180 & 688267 & 5.55 & 5.0117 & TRN & \\
\hline CHEMBL1500627 & 688267 & 4.35 & 5.0921 & TRN & \\
\hline CHEMBL1321410 & 688267 & 5.85 & 5.0376 & TRN & \\
\hline CHEMBL1482264 & 688267 & 6.2 & 5.0203 & TST & \\
\hline CHEMBL1576697 & 688267 & 5.05 & 5.0711 & TRN & \\
\hline CHEMBL1363486 & 688267 & 4.0 & 5.0253 & TRN & \\
\hline CHEMBL1445488 & 688267 & 4.6 & 5.0057 & TST & \\
\hline CHEMBL1309452 & 688267 & 5.0 & 5.0789 & TRN & \\
\hline CHEMBL3193100 & 688267 & 5.65 & 5.0996 & TST & \\
\hline CHEMBL1417463 & 688267 & 4.35 & 5.0023 & TST & \\
\hline
\end{tabular}




\begin{tabular}{|c|c|c|c|c|}
\hline & & & pplement & al $\mathrm{Ta}$ \\
\hline CHEMBL1404881 & 688267 & 4.1 & 5.0575 & TST \\
\hline CHEMBL1506082 & 688267 & 4.35 & 5.0158 & TRN \\
\hline CHEMBL1360117 & 688267 & 4.35 & 5.0028 & TST \\
\hline CHEMBL1502456 & 688267 & 5.05 & 5.082 & TRN \\
\hline CHEMBL1554627 & 688267 & 5.55 & 5.0603 & TST \\
\hline CHEMBL1308097 & 688267 & 6.2 & 5.0702 & TST \\
\hline CHEMBL3189518 & 688267 & 5.4 & 5.0925 & TST \\
\hline CHEMBL1372049 & 688267 & 6.2 & 5.0278 & TRN \\
\hline CHEMBL1596746 & 688267 & 5.0 & 5.0358 & TST \\
\hline CHEMBL1502343 & 688267 & 6.05 & 5.1389 & TRN \\
\hline CHEMBL 2006764 & 688267 & 6.35 & 5.0268 & TRN \\
\hline CHEMBL1540559 & 688267 & 4.35 & 5.13 & TRN \\
\hline CHEMBL1515528 & 688267 & 4.6 & 5.082 & TST \\
\hline CHEMBL1314859 & 688267 & 5.25 & 5.0764 & TRN \\
\hline CHEMBL1532287 & 688267 & 6.2 & 5.0377 & TRN \\
\hline CHEMBL1572898 & 688267 & 5.95 & 5.1345 & TRN \\
\hline CHEMBL1498553 & 688267 & 4.0 & 4.9986 & TRN \\
\hline CHEMBL1586050 & 688267 & 4.65 & 5.0535 & TRN \\
\hline CHEMBL1490003 & 688267 & 5.3 & 5.0813 & TRN \\
\hline CHEMBL1363468 & 688267 & 4.05 & 5.1199 & TRN \\
\hline CHEMBL1354155 & 688267 & 4.4 & 5.0152 & TRN \\
\hline CHEMBL1479959 & 688267 & 5.3 & 5.0539 & TST \\
\hline CHEMBL1554779 & 688267 & 6.2 & 5.1233 & TRN \\
\hline CHEMBL1484035 & 688267 & 5.35 & 5.0276 & TRN \\
\hline CHEMBL1579707 & 688267 & 4.8 & 5.0199 & TRN \\
\hline CHEMBL1399894 & 688267 & 5.3 & 5.1443 & TRN \\
\hline CHEMBL1583865 & 688267 & 4.4 & 5.0783 & TRN \\
\hline CHEMBL1437670 & 688267 & 6.25 & 4.9965 & TRN \\
\hline CHEMBL1589529 & 688267 & 4.35 & 5.0704 & TRN \\
\hline CHEMBL1356025 & 688267 & 4.95 & 5.0372 & TST \\
\hline CHEMBL85139 & 688267 & 5.2 & 5.0254 & TRN \\
\hline CHEMBL1529787 & 688267 & 4.65 & 5.1266 & TRN \\
\hline CHEMBL1559884 & 688267 & 3.95 & 5.0369 & TST \\
\hline CHEMBL1575751 & 688267 & 4.3 & 5.0351 & TRN \\
\hline CHEMBL1978894 & 688267 & 4.25 & 5.0024 & TRN \\
\hline CHEMBL1443822 & 688267 & 6.2 & 4.9992 & TRN \\
\hline CHEMBL1329158 & 688267 & 4.2 & 5.0471 & TST \\
\hline CHEMBL1495290 & 688267 & 4.1 & 5.029 & TST \\
\hline CHEMBL1557001 & 688267 & 4.65 & 5.0947 & TRN \\
\hline CHEMBL1394925 & 688267 & 5.4 & 5.0725 & TRN \\
\hline CHEMBL1391050 & 688267 & 4.35 & 5.1262 & TST \\
\hline CHEMBL1438927 & 688267 & 5.3 & 5.0186 & TST \\
\hline CHEMBL1313486 & 688267 & 5.65 & 5.0779 & TRN \\
\hline CHEMBL1348265 & 688267 & 4.5 & 5.0306 & TST \\
\hline CHEMBL1471042 & 688267 & 6.2 & 5.1672 & TRN \\
\hline CHEMBL1581244 & 688267 & 5.8 & 5.0147 & TST \\
\hline CHEMBL1576461 & 688267 & 5.55 & 5.0464 & TRN \\
\hline CHEMBL1545175 & 688267 & 3.75 & 5.0826 & TST \\
\hline
\end{tabular}




\begin{tabular}{|c|c|c|c|c|}
\hline \multicolumn{5}{|c|}{ Supplemental Table S2.txt } \\
\hline CHEMBL1322015 & 688267 & 4.45 & 5.0417 & TRN \\
\hline CHEMBL1572080 & 688267 & 4.0 & 5.0571 & TRN \\
\hline CHEMBL1530607 & 688267 & 4.9 & 5.0766 & TST \\
\hline CHEMBL1597829 & 688267 & 5.9 & 5.0294 & TST \\
\hline CHEMBL1336442 & 688267 & 5.4 & 5.0108 & TRN \\
\hline CHEMBL1478522 & 688267 & 5.8 & 5.0061 & TST \\
\hline CHEMBL1443939 & 688267 & 4.6 & 5.0642 & TRN \\
\hline CHEMBL1519375 & 688267 & 5.1 & 5.0213 & TRN \\
\hline CHEMBL1413811 & 688267 & 5.2 & 5.0511 & TRN \\
\hline CHEMBL1309001 & 688267 & 4.4 & 5.0038 & TRN \\
\hline CHEMBL3189512 & 688267 & 5.1 & 5.0175 & TST \\
\hline CHEMBL1525785 & 688267 & 4.05 & 5.1295 & TST \\
\hline CHEMBL3189327 & 688267 & 5.15 & 4.9679 & TST \\
\hline CHEMBL1410110 & 688267 & 4.05 & 5.0181 & TRN \\
\hline CHEMBL1404961 & 688267 & 5.05 & 5.0644 & TRN \\
\hline CHEMBL1529620 & 688267 & 4.75 & 5.0361 & TST \\
\hline CHEMBL1436321 & 688267 & 4.4 & 5.0234 & TRN \\
\hline CHEMBL1363541 & 688267 & 6.25 & 5.072 & TRN \\
\hline CHEMBL1464246 & 688267 & 5.3 & 5.0791 & TST \\
\hline CHEMBL1570143 & 688267 & 4.8 & 5.1141 & TST \\
\hline CHEMBL1428153 & 688267 & 5.85 & 4.9946 & TST \\
\hline CHEMBL1306685 & 688267 & 6.2 & 5.125 & TRN \\
\hline CHEMBL1520097 & 688267 & 3.8 & 5.1314 & TRN \\
\hline CHEMBL1412411 & 688267 & 6.15 & 4.9922 & TRN \\
\hline CHEMBL1383106 & 688267 & 6.25 & 5.0699 & TRN \\
\hline CHEMBL1351796 & 688267 & 5.35 & 5.1196 & TRN \\
\hline CHEMBL1438369 & 688267 & 5.9 & 5.0611 & TRN \\
\hline CHEMBL1595788 & 688267 & 5.75 & 5.0699 & TRN \\
\hline CHEMBL1392517 & 688267 & 4.75 & 5.0061 & TRN \\
\hline CHEMBL1434059 & 688267 & 5.6 & 5.0198 & TRN \\
\hline CHEMBL1439926 & 688267 & 5.05 & 5.0355 & TRN \\
\hline CHEMBL3196099 & 688267 & 4.25 & 5.0116 & TRN \\
\hline CHEMBL1535725 & 688267 & 5.1 & 5.0641 & TRN \\
\hline CHEMBL1506369 & 688267 & 5.0 & 5.0622 & TRN \\
\hline CHEMBL1488134 & 688267 & 4.25 & 5.102 & TRN \\
\hline CHEMBL1502026 & 688267 & 3.95 & 5.058 & TRN \\
\hline CHEMBL1524629 & 688267 & 5.3 & 5.0198 & TST \\
\hline CHEMBL1582392 & 688267 & 4.0 & 5.106 & TRN \\
\hline CHEMBL221219 & 688267 & 4.05 & 4.977 & TRN \\
\hline CHEMBL 3214020 & 688267 & 6.25 & 5.0744 & TRN \\
\hline CHEMBL1514293 & 688267 & 5.45 & 5.0275 & TRN \\
\hline CHEMBL1562981 & 688267 & 4.4 & 5.0626 & TRN \\
\hline CHEMBL1531842 & 688267 & 4.4 & 4.994 & TST \\
\hline CHEMBL1339323 & 688267 & 5.8 & 5.0555 & TRN \\
\hline CHEMBL1419835 & 688267 & 4.4 & 4.9977 & TST \\
\hline CHEMBL1599995 & 688267 & 5.65 & 5.0135 & TRN \\
\hline CHEMBL 1474825 & 688267 & 5.55 & 5.0182 & TST \\
\hline CHEMBL1357730 & 688267 & 4.05 & 5.1285 & TRN \\
\hline
\end{tabular}




\begin{tabular}{|c|c|c|c|c|}
\hline \multicolumn{5}{|c|}{ mental T } \\
\hline CHEMBL1368562 & 688267 & 4.0 & 4.9946 & TRN \\
\hline CHEMBL1361062 & 688267 & 6.2 & 5.0271 & TRN \\
\hline CHEMBL1490684 & 688267 & 5.1 & 5.0692 & TRN \\
\hline CHEMBL1503564 & 688267 & 4.5 & 5.0446 & TRN \\
\hline CHEMBL1531824 & 688267 & 5.5 & 5.0238 & TST \\
\hline CHEMBL1444669 & 688267 & 6.0 & 5.0387 & TRN \\
\hline CHEMBL3194665 & 688267 & 4.1 & 5.0125 & TRN \\
\hline CHEMBL1522913 & 688267 & 6.0 & 5.0153 & TRN \\
\hline CHEMBL1556260 & 688267 & 4.0 & 5.0965 & TRN \\
\hline CHEMBL1434505 & 688267 & 3.95 & 5.0956 & TRN \\
\hline CHEMBL1464069 & 688267 & 4.95 & 5.0899 & TRN \\
\hline CHEMBL1318531 & 688267 & 6.2 & 5.1097 & TRN \\
\hline CHEMBL1449454 & 688267 & 4.65 & 5.0402 & TRN \\
\hline CHEMBL1565656 & 688267 & 4.2 & 5.0654 & TRN \\
\hline CHEMBL1359016 & 688267 & 4.0 & 5.0207 & TRN \\
\hline CHEMBL1547292 & 688267 & 5.4 & 5.0694 & TRN \\
\hline CHEMBL1525692 & 688267 & 4.05 & 5.1004 & TRN \\
\hline CHEMBL1475779 & 688267 & 5.05 & 5.0323 & TRN \\
\hline CHEMBL1314758 & 688267 & 6.05 & 5.0438 & TRN \\
\hline CHEMBL1486745 & 688267 & 3.95 & 5.1236 & TST \\
\hline CHEMBL1392503 & 688267 & 4.55 & 5.0759 & TRN \\
\hline CHEMBL1319872 & 688267 & 6.0 & 5.0509 & TRN \\
\hline CHEMBL1345521 & 688267 & 5.5 & 5.0685 & TRN \\
\hline CHEMBL1448353 & 688267 & 5.3 & 5.061 & TRN \\
\hline CHEMBL1358434 & 688267 & 4.35 & 5.0286 & TRN \\
\hline CHEMBL1474098 & 688267 & 4.0 & 5.0838 & TST \\
\hline CHEMBL1427933 & 688267 & 4.55 & 5.0586 & TRN \\
\hline CHEMBL1385683 & 688267 & 4.05 & 5.0799 & TRN \\
\hline CHEMBL1397417 & 688267 & 5.9 & 5.0995 & TST \\
\hline CHEMBL3189930 & 688267 & 4.55 & 4.9747 & TST \\
\hline CHEMBL1475981 & 688267 & 5.35 & 5.0424 & TRN \\
\hline CHEMBL1479621 & 688267 & 4.65 & 5.0594 & TST \\
\hline CHEMBL1381326 & 688267 & 4.0 & 5.0021 & TRN \\
\hline CHEMBL1315776 & 688267 & 5.9 & 5.0882 & TRN \\
\hline CHEMBL1471272 & 688267 & 4.4 & 5.0005 & TST \\
\hline CHEMBL1352805 & 688267 & 6.4 & 5.04 & TRN \\
\hline CHEMBL1538582 & 688267 & 4.9 & 5.1085 & TST \\
\hline CHEMBL1365498 & 688267 & 5.3 & 5.0671 & TRN \\
\hline CHEMBL1496789 & 688267 & 4.4 & 5.1079 & TST \\
\hline CHEMBL1593003 & 688267 & 4.15 & 5.0403 & TRN \\
\hline CHEMBL1577272 & 688267 & 5.8 & 5.0129 & TST \\
\hline CHEMBL3213631 & 688267 & 6.2 & 5.0131 & TRN \\
\hline CHEMBL1583655 & 688267 & 5.6 & 5.0511 & TRN \\
\hline CHEMBL1460767 & 688267 & 6.15 & 5.0129 & TST \\
\hline CHEMBL1329346 & 688267 & 4.05 & 5.1025 & TRN \\
\hline CHEMBL1499785 & 688267 & 3.95 & 5.0245 & TST \\
\hline CHEMBL1532386 & 688267 & 4.5 & 5.0126 & TRN \\
\hline CHEMBL1603991 & 688267 & 4.0 & 5.0497 & TRN \\
\hline
\end{tabular}




\begin{tabular}{|c|c|c|c|c|c|}
\hline \\
\hline CHEMBL1334757 & 688267 & 5.9 & 4.9795 & TRN & \\
\hline CHEMBL1481912 & 688267 & 5.25 & 5.0169 & TRN & \\
\hline CHEMBL1557504 & 688267 & 4.35 & 5.1652 & TRN & \\
\hline CHEMBL1444023 & 688267 & 6.25 & 5.0046 & TRN & \\
\hline CHEMBL1545050 & 688267 & 5.3 & 5.0955 & TRN & \\
\hline CHEMBL1343072 & 688267 & 5.4 & 5.0046 & TST & \\
\hline CHEMBL1479970 & 688267 & 4.2 & 5.0252 & TST & \\
\hline CHEMBL1583206 & 688267 & 5.2 & 5.0195 & TRN & \\
\hline CHEMBL1333737 & 688267 & 3.95 & 4.9972 & TST & \\
\hline CHEMBL1389713 & 688267 & 4.05 & 5.0353 & TRN & \\
\hline CHEMBL589915 & 688267 & 3.95 & 5.0755 & TRN & \\
\hline CHEMBL1587378 & 688267 & 4.35 & 5.0844 & TST & \\
\hline CHEMBL1603148 & 688267 & 5.3 & 5.1033 & TRN & \\
\hline CHEMBL1485245 & 688267 & 4.95 & 5.1308 & TRN & \\
\hline CHEMBL1490363 & 688267 & 4.35 & 5.1292 & TST & \\
\hline CHEMBL6705 & 688267 & 5.4 & 5.0356 & TST & \\
\hline CHEMBL1522846 & 688267 & 4.2 & 5.0511 & TST & \\
\hline CHEMBL1447787 & 688267 & 4.55 & 5.1543 & TRN & \\
\hline CHEMBL1314381 & 688267 & 4.85 & 5.0574 & TRN & \\
\hline CHEMBL1375599 & 688267 & 5.8 & 5.1125 & TRN & \\
\hline CHEMBL1552425 & 688267 & 4.95 & 5.0846 & TRN & \\
\hline CHEMBL1461063 & 688267 & 4.4 & 5.0676 & TST & \\
\hline CHEMBL1496290 & 688267 & 4.1 & 5.05399 & 9999999999 & TRN \\
\hline CHEMBL1314017 & 688267 & 5.35 & 5.0817 & TRN & \\
\hline CHEMBL1516259 & 688267 & 6.2 & 5.1397 & TRN & \\
\hline CHEMBL1513008 & 688267 & 5.85 & 5.0224 & TST & \\
\hline CHEMBL1419490 & 688267 & 6.2 & 5.0665 & TRN & \\
\hline CHEMBL1368518 & 688267 & 4.85 & 5.1079 & TRN & \\
\hline CHEMBL1335271 & 688267 & 4.05 & 5.0112 & TRN & \\
\hline CHEMBL1371676 & 688267 & 6.25 & 5.085 & TRN & \\
\hline CHEMBL1388243 & 688267 & 4.3 & 5.0624 & TRN & \\
\hline CHEMBL1507191 & 688267 & 4.5 & 5.0414 & TRN & \\
\hline CHEMBL1399900 & 688267 & 4.65 & 5.1062 & TRN & \\
\hline CHEMBL1347358 & 688267 & 5.2 & 5.0458 & TRN & \\
\hline CHEMBL174231 & 688267 & 6.25 & 5.0634 & TST & \\
\hline CHEMBL1502060 & 688267 & 4.2 & 5.0241 & TST & \\
\hline CHEMBL1454468 & 688267 & 6.0 & 5.0181 & TST & \\
\hline CHEMBL1552714 & 688267 & 5.05 & 4.9771 & TRN & \\
\hline CHEMBL1593843 & 688267 & 4.4 & 5.0554 & TRN & \\
\hline CHEMBL1344996 & 688267 & 4.35 & 5.0592 & TRN & \\
\hline CHEMBL1321639 & 688267 & 5.45 & 5.0195 & TRN & \\
\hline CHEMBL1580334 & 688267 & 4.05 & 5.0449 & TST & \\
\hline CHEMBL1339152 & 688267 & 6.5 & 5.115 & TRN & \\
\hline CHEMBL1438349 & 688267 & 3.9 & 5.1309 & TST & \\
\hline CHEMBL1526005 & 688267 & 4.0 & 5.0184 & TRN & \\
\hline CHEMBL1434034 & 688267 & 4.05 & 5.0471 & TRN & \\
\hline CHEMBL1610902 & 688267 & 5.2 & 5.0162 & TRN & \\
\hline CHEMBL1471359 & 688267 & 5.15 & 5.0245 & TRN & \\
\hline
\end{tabular}




\begin{tabular}{|c|c|c|c|c|}
\hline & & & pplement & al $\mathrm{Ta}$ \\
\hline CHEMBL1405443 & 688267 & 4.2 & 5.0891 & TRN \\
\hline CHEMBL1380088 & 688267 & 6.2 & 5.0366 & TST \\
\hline CHEMBL1382934 & 688267 & 4.1 & 5.0726 & TRN \\
\hline CHEMBL1564320 & 688267 & 4.65 & 5.0575 & TRN \\
\hline CHEMBL3214432 & 688267 & 5.35 & 5.0483 & TRN \\
\hline CHEMBL1965165 & 688267 & 4.05 & 5.0195 & TRN \\
\hline CHEMBL1371567 & 688267 & 5.25 & 5.0797 & TRN \\
\hline CHEMBL1597938 & 688267 & 4.25 & 5.0713 & TST \\
\hline CHEMBL1317026 & 688267 & 5.9 & 5.0239 & TST \\
\hline CHEMBL1362694 & 688267 & 5.95 & 5.1217 & TRN \\
\hline CHEMBL1338447 & 688267 & 5.0 & 5.0789 & TST \\
\hline CHEMBL1546915 & 688267 & 6.25 & 5.0834 & TST \\
\hline CHEMBL1403590 & 688267 & 5.35 & 5.0878 & TRN \\
\hline CHEMBL1480304 & 688267 & 4.05 & 5.0251 & TST \\
\hline CHEMBL1363640 & 688267 & 5.3 & 5.0602 & TRN \\
\hline CHEMBL1453894 & 688267 & 6.15 & 5.0504 & TRN \\
\hline CHEMBL1481300 & 688267 & 4.05 & 5.1155 & TRN \\
\hline CHEMBL1528303 & 688267 & 4.65 & 5.0376 & TST \\
\hline CHEMBL1434174 & 688267 & 6.2 & 4.9921 & TRN \\
\hline CHEMBL1463790 & 688267 & 3.95 & 5.0633 & TRN \\
\hline CHEMBL1560149 & 688267 & 6.2 & 5.0814 & TST \\
\hline CHEMBL1318171 & 688267 & 6.2 & 5.011 & TRN \\
\hline CHEMBL1557552 & 688267 & 4.0 & 5.074 & TST \\
\hline CHEMBL3213271 & 688267 & 4.6 & 5.0285 & TRN \\
\hline CHEMBL1501377 & 688267 & 5.55 & 5.012 & TRN \\
\hline CHEMBL1450200 & 688267 & 4.15 & 5.1165 & TRN \\
\hline CHEMBL1438337 & 688267 & 5.3 & 5.0146 & TST \\
\hline CHEMBL1459346 & 688267 & 3.95 & 5.0351 & TRN \\
\hline CHEMBL1448394 & 688267 & 6.1 & 5.0399 & TRN \\
\hline CHEMBL1308005 & 688267 & 5.4 & 5.0334 & TRN \\
\hline CHEMBL1492107 & 688267 & 4.45 & 5.0066 & TRN \\
\hline CHEMBL1561138 & 688267 & 5.6 & 5.0536 & TRN \\
\hline CHEMBL1593319 & 688267 & 6.2 & 5.0575 & TRN \\
\hline CHEMBL1606684 & 688267 & 5.8 & 5.0493 & TRN \\
\hline CHEMBL1374243 & 688267 & 6.15 & 5.0085 & TRN \\
\hline CHEMBL1372984 & 688267 & 5.75 & 4.9986 & TRN \\
\hline CHEMBL1358973 & 688267 & 6.15 & 5.0482 & TRN \\
\hline CHEMBL1579777 & 688267 & 4.15 & 4.9974 & TST \\
\hline CHEMBL1391860 & 688267 & 4.5 & 5.0671 & TST \\
\hline CHEMBL1530668 & 688267 & 4.35 & 5.0608 & TRN \\
\hline CHEMBL1476039 & 688267 & 6.15 & 5.0476 & TRN \\
\hline CHEMBL1328452 & 688267 & 4.0 & 5.1265 & TRN \\
\hline CHEMBL1320898 & 688267 & 4.2 & 5.0278 & TRN \\
\hline CHEMBL3209978 & 688267 & 5.55 & 5.0325 & TRN \\
\hline CHEMBL1318073 & 688267 & 6.15 & 5.0138 & TRN \\
\hline CHEMBL1524766 & 688267 & 4.4 & 5.0557 & TRN \\
\hline CHEMBL1979306 & 688267 & 5.25 & 5.1101 & TST \\
\hline CHEMBL1410653 & 688267 & 3.95 & 5.0359 & TRN \\
\hline
\end{tabular}




\begin{tabular}{|c|c|c|c|c|c|}
\hline \multicolumn{6}{|c|}{ Supplemental Table S2.txt } \\
\hline CHEMBL1594334 & 688267 & 4.05 & 5.0928 & TRN & \\
\hline CHEMBL1391087 & 688267 & 4.05 & 5.0596 & TST & \\
\hline CHEMBL1319025 & 688267 & 4.2 & 5.0563 & TRN & \\
\hline CHEMBL1481730 & 688267 & 5.5 & 5.07100 & 0000000001 & TRN \\
\hline CHEMBL1524372 & 688267 & 4.1 & 5.0109 & TRN & \\
\hline CHEMBL1570013 & 688267 & 4.0 & 5.0017 & TRN & \\
\hline CHEMBL1473986 & 688267 & 4.9 & 5.1021 & TST & \\
\hline CHEMBL3194995 & 688267 & 4.3 & 5.0153 & TST & \\
\hline CHEMBL1393759 & 688267 & 4.05 & 5.1246 & TRN & \\
\hline CHEMBL1481102 & 688267 & 5.3 & 5.0598 & TRN & \\
\hline CHEMBL1587486 & 688267 & 4.7 & 5.1103 & TST & \\
\hline CHEMBL1342856 & 688267 & 4.0 & 5.0671 & TST & \\
\hline CHEMBL1476310 & 688267 & 5.3 & 5.0763 & TRN & \\
\hline CHEMBL1564557 & 688267 & 6.2 & 5.1184 & TRN & \\
\hline CHEMBL1567786 & 688267 & 4.25 & 5.1547 & TRN & \\
\hline CHEMBL1401961 & 688267 & 5.25 & 4.9853 & TRN & \\
\hline CHEMBL3191286 & 688267 & 6.45 & 5.0436 & TST & \\
\hline CHEMBL1455075 & 688267 & 5.4 & 5.0775 & TRN & \\
\hline CHEMBL1542252 & 688267 & 5.4 & 5.066 & TRN & \\
\hline CHEMBL1305107 & 688267 & 5.6 & 5.1162 & TRN & \\
\hline CHEMBL1301065 & 688267 & 4.5 & 5.0954 & TRN & \\
\hline CHEMBL1590800 & 688267 & 4.35 & 5.0723 & TRN & \\
\hline CHEMBL1610380 & 688267 & 4.9 & 5.1439 & TST & \\
\hline CHEMBL1437991 & 688267 & 3.95 & 4.9984 & TST & \\
\hline CHEMBL1997052 & 688267 & 4.1 & 5.0096 & TRN & \\
\hline CHEMBL1550638 & 688267 & 4.25 & 5.0166 & TRN & \\
\hline CHEMBL1482855 & 688267 & 6.45 & 5.0688 & TRN & \\
\hline CHEMBL1482123 & 688267 & 6.2 & 5.09699 & 99999999995 & TST \\
\hline CHEMBL1333098 & 688267 & 4.3 & 5.0497 & TRN & \\
\hline CHEMBL1584588 & 688267 & 4.1 & 5.1012 & TRN & \\
\hline CHEMBL1434270 & 688267 & 6.15 & 5.1013 & TRN & \\
\hline CHEMBL3189691 & 688267 & 4.0 & 4.9946 & TRN & \\
\hline CHEMBL1455053 & 688267 & 3.9 & 5.0518 & TST & \\
\hline CHEMBL1495893 & 688267 & 3.95 & 5.02 & TST & \\
\hline CHEMBL1448311 & 688267 & 6.2 & 5.0269 & TST & \\
\hline CHEMBL1343418 & 688267 & 4.55 & 5.0804 & TST & \\
\hline CHEMBL1476136 & 688267 & 5.8 & 5.0567 & TRN & \\
\hline CHEMBL1577794 & 688267 & 5.9 & 5.0385 & TRN & \\
\hline CHEMBL1381882 & 688267 & 4.25 & 5.0183 & TRN & \\
\hline CHEMBL1404920 & 688267 & 6.25 & 5.0426 & TRN & \\
\hline CHEMBL1556918 & 688267 & 5.1 & 5.038 & TST & \\
\hline CHEMBL1311206 & 688267 & 6.0 & 4.9988 & TST & \\
\hline CHEMBL1613130 & 688267 & 6.15 & 5.0338 & TRN & \\
\hline CHEMBL1371844 & 688267 & 4.05 & 5.0615 & TRN & \\
\hline CHEMBL1537344 & 688267 & 4.0 & 5.0746 & TRN & \\
\hline CHEMBL1427794 & 688267 & 4.75 & 5.0463 & TRN & \\
\hline CHEMBL1534264 & 688267 & 6.15 & 5.0785 & TRN & \\
\hline CHEMBL3196744 & 688267 & 4.3 & 5.0394 & TST & \\
\hline
\end{tabular}




\begin{tabular}{|c|c|c|c|c|c|}
\hline \\
\hline CHEMBL1494008 & 688267 & 6.2 & 5.0786 & TRN & \\
\hline CHEMBL1485960 & 688267 & 4.45 & 5.0616 & TRN & \\
\hline CHEMBL1522274 & 688267 & 5.45 & 5.0304 & TRN & \\
\hline CHEMBL1355915 & 688267 & 4.05 & 5.08 & TRN & \\
\hline CHEMBL1606348 & 688267 & 3.95 & 5.093 & TRN & \\
\hline CHEMBL1460856 & 688267 & 4.8 & 5.0388 & TST & \\
\hline CHEMBL1579570 & 688267 & 5.85 & 5.0682 & TRN & \\
\hline CHEMBL1507717 & 688267 & 3.95 & 5.1223 & TRN & \\
\hline CHEMBL1569867 & 688267 & 4.0 & 5.0683 & TRN & \\
\hline CHEMBL1362014 & 688267 & 5.9 & 5.0577 & TST & \\
\hline CHEMBL1504831 & 688267 & 3.95 & 5.0848 & TRN & \\
\hline CHEMBL1581028 & 688267 & 5.6 & 5.1405 & TRN & \\
\hline CHEMBL1415635 & 688267 & 4.35 & 5.0106 & TST & \\
\hline CHEMBL1376531 & 688267 & 4.95 & 5.0535 & TST & \\
\hline CHEMBL1441315 & 688267 & 4.35 & 5.0541 & TRN & \\
\hline CHEMBL1595071 & 688267 & 5.25 & 5.0435 & TRN & \\
\hline CHEMBL1359194 & 688267 & 3.95 & 5.1113 & TRN & \\
\hline CHEMBL1409636 & 688267 & 3.95 & 5.05399 & 9999999999 & TST \\
\hline CHEMBL1488159 & 688267 & 4.55 & 5.0348 & TRN & \\
\hline CHEMBL1405397 & 688267 & 6.15 & 5.1052 & TST & \\
\hline CHEMBL1445097 & 688267 & 5.8 & 5.029 & TRN & \\
\hline CHEMBL1513014 & 688267 & 5.55 & 5.1134 & TRN & \\
\hline CHEMBL1534473 & 688267 & 4.0 & 5.0697 & TRN & \\
\hline CHEMBL1555250 & 688267 & 5.5 & 4.9948 & TRN & \\
\hline CHEMBL1408433 & 688267 & 5.55 & 5.0497 & TST & \\
\hline CHEMBL1522638 & 688267 & 5.25 & $5.1320 e$ & $\partial 000000001$ & TRN \\
\hline CHEMBL1416609 & 688267 & 4.25 & 5.018 & TRN & \\
\hline CHEMBL1492440 & 688267 & 5.45 & 5.0871 & TRN & \\
\hline CHEMBL1443561 & 688267 & 5.0 & 5.0336 & TRN & \\
\hline CHEMBL1379505 & 688267 & 5.6 & 5.0657 & TST & \\
\hline CHEMBL501701 & 688267 & 3.95 & 5.1148 & TST & \\
\hline CHEMBL1508134 & 688267 & 4.55 & 5.0681 & TRN & \\
\hline CHEMBL1317019 & 688267 & 6.2 & 5.0578 & TRN & \\
\hline CHEMBL1425840 & 688267 & 4.75 & 5.0118 & TRN & \\
\hline CHEMBL 1433632 & 688267 & 5.5 & 5.0554 & TRN & \\
\hline CHEMBL1345501 & 688267 & 6.2 & 5.1149 & TRN & \\
\hline CHEMBL1470485 & 688267 & 4.0 & 5.0059 & TRN & \\
\hline CHEMBL1445982 & 688267 & 5.5 & 5.0258 & TRN & \\
\hline CHEMBL 3190245 & 688267 & 5.25 & 5.0894 & TRN & \\
\hline CHEMBL1349896 & 688267 & 3.95 & 5.1193 & TRN & \\
\hline CHEMBL1567256 & 688267 & 5.65 & 5.0046 & TRN & \\
\hline CHEMBL1380761 & 688267 & 5.3 & 5.0783 & TRN & \\
\hline CHEMBL1580179 & 688267 & 4.05 & 5.061 & TST & \\
\hline CHEMBL1436300 & 688267 & 4.3 & 5.079 & TRN & \\
\hline CHEMBL592363 & 688267 & 4.0 & 5.0093 & TST & \\
\hline CHEMBL1387273 & 688267 & 6.2 & 5.0408 & TRN & \\
\hline CHEMBL1346825 & 688267 & 5.3 & 5.0818 & TRN & \\
\hline CHEMBL1527589 & 688267 & 6.05 & 5.1446 & TRN & \\
\hline
\end{tabular}




\begin{tabular}{|c|c|c|c|c|c|}
\hline \multicolumn{6}{|c|}{ Supplemental Table S2.txt } \\
\hline CHEMBL271139 & 688267 & 5.6 & 5.1164 & TST & \\
\hline CHEMBL1337471 & 688267 & 5.5 & 5.0554 & TRN & \\
\hline CHEMBL1468309 & 688267 & 4.75 & 5.0578 & TRN & \\
\hline CHEMBL1582372 & 688267 & 4.4 & 5.0687 & TRN & \\
\hline CHEMBL1353714 & 688267 & 6.15 & 5.0291 & TST & \\
\hline CHEMBL1595948 & 688267 & 4.5 & 5.0064 & TST & \\
\hline CHEMBL1460818 & 688267 & 3.95 & 5.045 & TST & \\
\hline CHEMBL3210334 & 688267 & 4.3 & 5.0431 & TST & \\
\hline CHEMBL1446277 & 688267 & 4.1 & 4.993 & TRN & \\
\hline CHEMBL1584679 & 688267 & 6.15 & 5.1038 & TRN & \\
\hline CHEMBL1610287 & 688267 & 4.05 & 5.0113 & TST & \\
\hline CHEMBL1558784 & 688267 & 5.65 & 5.0088 & TRN & \\
\hline CHEMBL1427504 & 688267 & 6.2 & 5.01399 & э999999999 & TRN \\
\hline CHEMBL1455295 & 688267 & 6.25 & 5.1356 & TRN & \\
\hline CHEMBL1395978 & 688267 & 4.35 & 5.0372 & TRN & \\
\hline CHEMBL1588326 & 688267 & 4.25 & 5.1016 & TRN & \\
\hline CHEMBL1402868 & 688267 & 6.15 & 5.0294 & TST & \\
\hline CHEMBL1583946 & 688267 & 4.85 & 5.0333 & TRN & \\
\hline CHEMBL1386873 & 688267 & 5.05 & 5.0143 & TST & \\
\hline CHEMBL1336813 & 688267 & 4.3 & 5.0414 & TRN & \\
\hline CHEMBL1392054 & 688267 & 4.15 & 5.0284 & TRN & \\
\hline CHEMBL1570624 & 688267 & 4.85 & 5.0554 & TRN & \\
\hline CHEMBL1551851 & 688267 & 6.2 & 5.1136 & TRN & \\
\hline CHEMBL1368595 & 688267 & 5.85 & 5.0894 & TRN & \\
\hline CHEMBL1311905 & 688267 & 4.35 & 5.1529 & TRN & \\
\hline CHEMBL1564542 & 688267 & 4.6 & 5.0173 & TST & \\
\hline CHEMBL1573035 & 688267 & 5.8 & 5.0678 & TRN & \\
\hline CHEMBL1543247 & 688267 & 4.4 & 5.0885 & TRN & \\
\hline CHEMBL1325123 & 688267 & 5.7 & 5.0873 & TRN & \\
\hline CHEMBL1541237 & 688267 & 6.25 & 5.1061 & TRN & \\
\hline CHEMBL1440797 & 688267 & 4.05 & 5.0905 & TST & \\
\hline CHEMBL1609682 & 688267 & 6.15 & 5.0921 & TRN & \\
\hline CHEMBL1613071 & 688267 & 5.3 & 5.056 & TRN & \\
\hline CHEMBL1368426 & 688267 & 5.65 & 5.018 & TRN & \\
\hline CHEMBL1611199 & 688267 & 4.25 & 4.9815 & TRN & \\
\hline CHEMBL1500553 & 688267 & 6.0 & 5.0067 & TRN & \\
\hline CHEMBL1336870 & 688267 & 6.2 & 5.0669 & TRN & \\
\hline CHEMBL1398301 & 688267 & 6.25 & 5.0923 & TRN & \\
\hline CHEMBL3197818 & 688267 & 5.2 & 5.0246 & TST & \\
\hline CHEMBL1520669 & 688267 & 4.0 & 5.0178 & TST & \\
\hline CHEMBL3212320 & 688267 & 5.15 & 5.0957 & TRN & \\
\hline CHEMBL1524719 & 688267 & 4.55 & 5.0972 & TST & \\
\hline CHEMBL1557954 & 688267 & 5.35 & 5.0066 & TRN & \\
\hline CHEMBL1307385 & 688267 & 5.85 & 5.0833 & TST & \\
\hline CHEMBL1323594 & 688267 & 4.4 & 5.0655 & TRN & \\
\hline CHEMBL1505927 & 688267 & 6.2 & 5.1288 & TRN & \\
\hline CHEMBL1492197 & 688267 & 4.55 & 5.0033 & TRN & \\
\hline CHEMBL1514536 & 688267 & 5.3 & 5.1008 & TRN & \\
\hline
\end{tabular}




\begin{tabular}{|c|c|c|c|c|}
\hline \multicolumn{5}{|c|}{ Supplemental Tabl } \\
\hline CHEMBL1325306 & 688267 & 5.65 & 5.0933 & TRN \\
\hline CHEMBL3212706 & 688267 & 5.6 & 4.9701 & TST \\
\hline CHEMBL1564661 & 688267 & 5.8 & 5.0691 & TRN \\
\hline CHEMBL1335678 & 688267 & 4.5 & 5.0102 & TRN \\
\hline CHEMBL1577238 & 688267 & 4.35 & 5.0217 & TRN \\
\hline CHEMBL1347916 & 688267 & 4.25 & 5.1061 & TRN \\
\hline CHEMBL1598942 & 688267 & 5.55 & 5.0948 & TRN \\
\hline CHEMBL1507946 & 688267 & 4.1 & 5.0088 & TST \\
\hline CHEMBL1381368 & 688267 & 6.25 & 5.0989 & TRN \\
\hline CHEMBL38326 & 688267 & 6.25 & 4.9986 & TRN \\
\hline CHEMBL1516854 & 688267 & 5.4 & 5.0748 & TRN \\
\hline CHEMBL1317893 & 688267 & 3.95 & 5.0856 & TRN \\
\hline CHEMBL1604486 & 688267 & 5.7 & 5.0242 & TRN \\
\hline CHEMBL1315756 & 688267 & 6.2 & 5.0682 & TRN \\
\hline CHEMBL1474935 & 688267 & 5.15 & 5.0101 & TRN \\
\hline CHEMBL1439283 & 688267 & 4.25 & 5.0442 & TST \\
\hline CHEMBL1361428 & 688267 & 5.5 & 5.0621 & TRN \\
\hline CHEMBL1531297 & 688267 & 6.45 & 5.077 & TST \\
\hline CHEMBL1477144 & 688267 & 4.0 & 5.0396 & TRN \\
\hline CHEMBL1459315 & 688267 & 4.75 & 5.0631 & TST \\
\hline CHEMBL1329242 & 688267 & 4.55 & 5.0704 & TRN \\
\hline CHEMBL1494734 & 688267 & 6.15 & 5.0464 & TRN \\
\hline CHEMBL1500019 & 688267 & 5.6 & 5.0446 & TST \\
\hline CHEMBL1576855 & 688267 & 5.25 & 5.0725 & TRN \\
\hline CHEMBL1561002 & 688267 & 6.0 & 5.1004 & TRN \\
\hline CHEMBL 2003587 & 688267 & 4.25 & 5.0525 & TRN \\
\hline CHEMBL1509603 & 688267 & 5.95 & 5.0687 & TRN \\
\hline CHEMBL1329094 & 688267 & 6.2 & 5.0267 & TST \\
\hline CHEMBL1590036 & 688267 & 4.3 & 4.9921 & TRN \\
\hline CHEMBL1395586 & 688267 & 5.45 & 5.0149 & TRN \\
\hline CHEMBL1449199 & 688267 & 6.2 & 5.0753 & TRN \\
\hline CHEMBL1479784 & 688267 & 3.95 & 5.0432 & TRN \\
\hline CHEMBL1507741 & 688267 & 5.0 & 5.0599 & TRN \\
\hline CHEMBL1362244 & 688267 & 4.2 & 4.9866 & TRN \\
\hline CHEMBL1498423 & 688267 & 5.3 & 5.1121 & TRN \\
\hline CHEMBL3191676 & 688267 & 6.05 & 5.0274 & TRN \\
\hline CHEMBL1500958 & 688267 & 6.25 & 5.0287 & TST \\
\hline CHEMBL1516601 & 688267 & 4.0 & 5.0095 & TRN \\
\hline CHEMBL1320088 & 688267 & 4.4 & 5.1389 & TST \\
\hline CHEMBL1457428 & 688267 & 4.0 & 5.1208 & TRN \\
\hline CHEMBL1475288 & 688267 & 6.2 & 5.0607 & TST \\
\hline CHEMBL1584855 & 688267 & 5.7 & 5.0764 & TST \\
\hline CHEMBL1591571 & 688267 & 5.35 & 5.0209 & TRN \\
\hline CHEMBL1450600 & 688267 & 4.05 & 5.0704 & TRN \\
\hline CHEMBL1458439 & 688267 & 6.15 & 5.0156 & TRN \\
\hline CHEMBL1357363 & 688267 & 5.9 & 5.0473 & TRN \\
\hline CHEMBL1410458 & 688267 & 4.3 & 5.029 & TST \\
\hline CHEMBL1364753 & 688267 & 6.25 & 5.0527 & TST \\
\hline
\end{tabular}




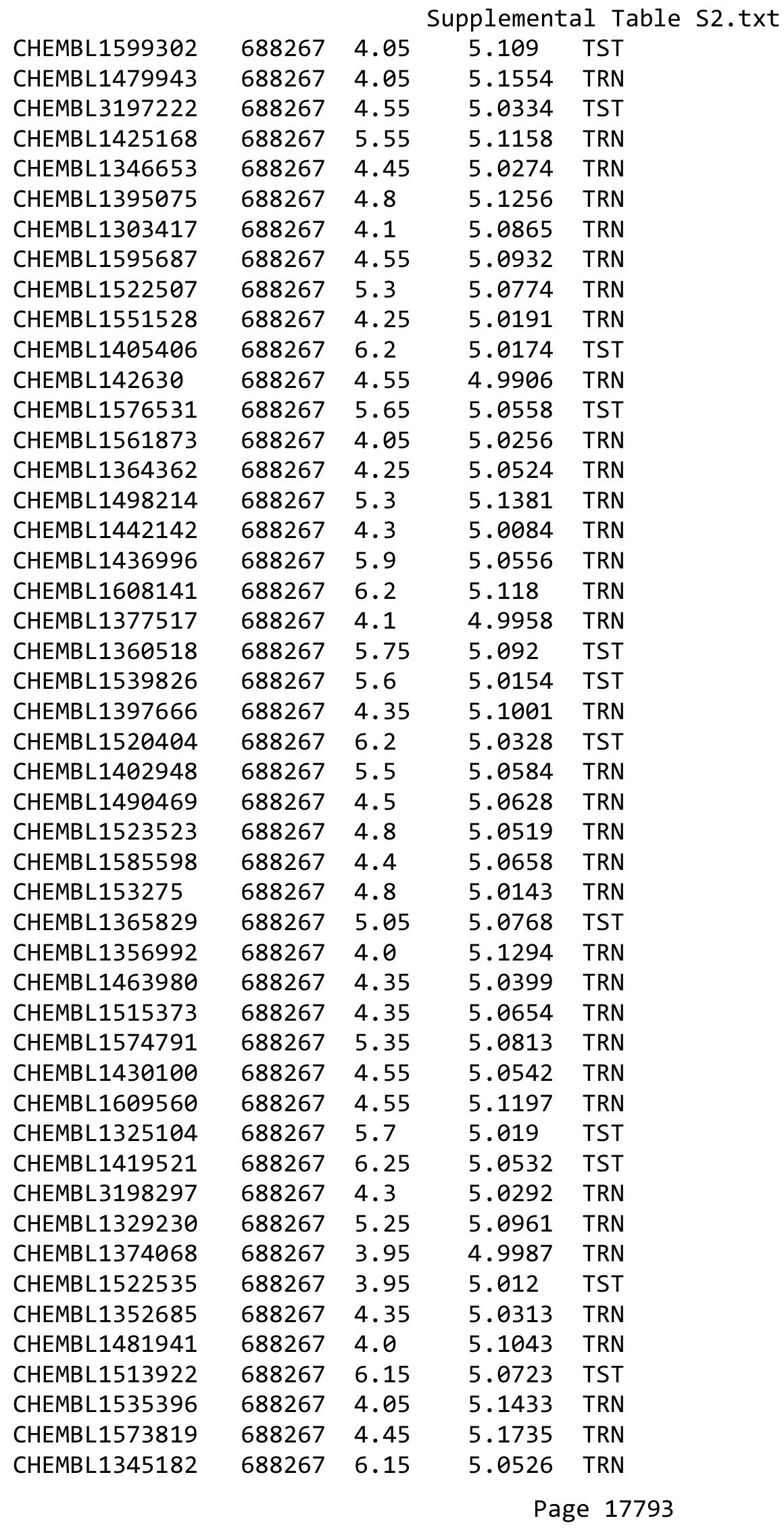




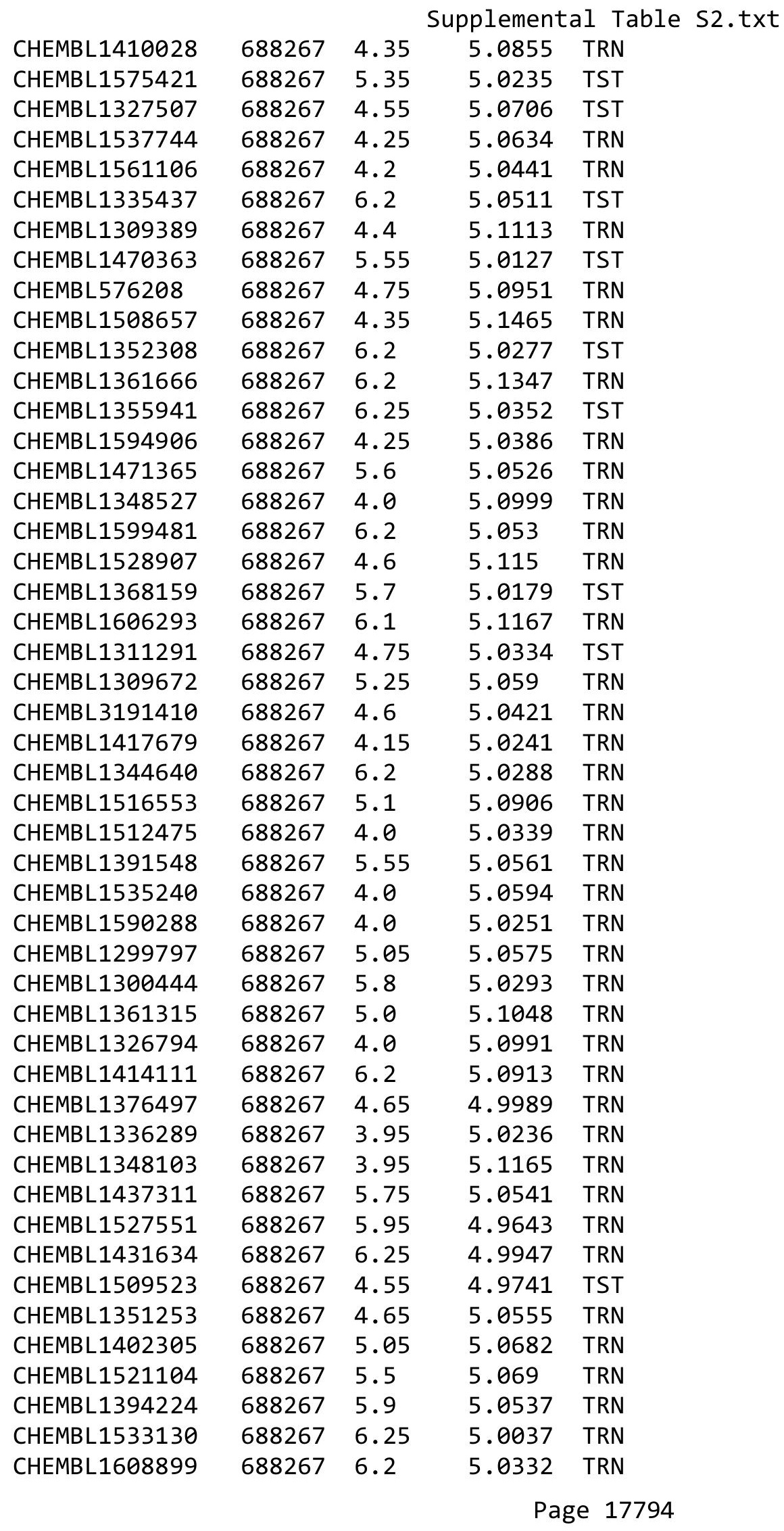




\begin{tabular}{|c|c|c|c|c|c|}
\hline \multicolumn{6}{|c|}{ Supplemental Table S2.txt } \\
\hline CHEMBL1522160 & 688267 & 6.15 & 5.0742 & TRN & \\
\hline CHEMBL1349649 & 688267 & 5.6 & 5.1117 & TRN & \\
\hline CHEMBL1426164 & 688267 & 5.6 & 5.1489 & TRN & \\
\hline CHEMBL1391406 & 688267 & 4.95 & 5.0204 & TST & \\
\hline CHEMBL1564270 & 688267 & 3.95 & 5.0537 & TRN & \\
\hline CHEMBL1400687 & 688267 & 6.0 & 5.0824 & TRN & \\
\hline CHEMBL1474446 & 688267 & 5.25 & 5.0287 & TRN & \\
\hline CHEMBL1478068 & 688267 & 4.0 & 5.059 & TRN & \\
\hline CHEMBL1320147 & 688267 & 4.0 & 5.0422 & TST & \\
\hline CHEMBL1329985 & 688267 & 6.2 & 5.0557 & TRN & \\
\hline CHEMBL1468164 & 688267 & 5.05 & 5.0713 & TST & \\
\hline CHEMBL1515463 & 688267 & 4.1 & 5.0655 & TRN & \\
\hline CHEMBL1544143 & 688267 & 5.7 & 5.0581 & TRN & \\
\hline CHEMBL1596401 & 688267 & 4.05 & 5.0482 & TST & \\
\hline CHEMBL1356385 & 688267 & 4.25 & 5.0904 & TRN & \\
\hline CHEMBL1513947 & 688267 & 6.3 & 5.0373 & TRN & \\
\hline CHEMBL3191564 & 688267 & 3.95 & 4.9752 & TRN & \\
\hline CHEMBL375966 & 688267 & 4.0 & 4.9978 & TRN & \\
\hline CHEMBL1355003 & 688267 & 5.6 & 5.062 & TST & \\
\hline CHEMBL1465819 & 688267 & 5.5 & 5.0682 & TRN & \\
\hline CHEMBL1470758 & 688267 & 5.4 & 4.9746 & TST & \\
\hline CHEMBL1548085 & 688267 & 5.8 & 5.0454 & TST & \\
\hline CHEMBL1567665 & 688267 & 3.95 & 5.0859 & TRN & \\
\hline CHEMBL1603421 & 688267 & 4.05 & 5.1275 & TRN & \\
\hline CHEMBL1411420 & 688267 & 6.2 & 5.02 & TRN & \\
\hline CHEMBL1435924 & 688267 & 5.3 & 5.0112 & TRN & \\
\hline CHEMBL1313713 & 688267 & 4.95 & 5.0899 & TRN & \\
\hline CHEMBL1333084 & 688267 & 6.5 & 5.0655 & TST & \\
\hline CHEMBL1523695 & 688267 & 6.2 & 5.1096 & TRN & \\
\hline CHEMBL1606048 & 688267 & 5.0 & 5.1243 & TRN & \\
\hline CHEMBL1354380 & 688267 & 6.15 & 4.9944 & TRN & \\
\hline CHEMBL1611979 & 688267 & 4.05 & 5.1054 & TRN & \\
\hline CHEMBL1535232 & 688267 & 5.3 & 5.00899 & 99999999995 & TRN \\
\hline CHEMBL1572997 & 688267 & 4.15 & 5.0714 & TRN & \\
\hline CHEMBL1535450 & 688267 & 5.45 & 5.0321 & TRN & \\
\hline CHEMBL1399641 & 688267 & 6.15 & 5.1424 & TRN & \\
\hline CHEMBL1365027 & 688267 & 5.05 & 5.1298 & TRN & \\
\hline CHEMBL3210584 & 688267 & 6.15 & 5.0221 & TST & \\
\hline CHEMBL1580847 & 688267 & 6.15 & 5.073 & TRN & \\
\hline CHEMBL1533854 & 688267 & 4.0 & 5.0421 & TRN & \\
\hline CHEMBL1355859 & 688267 & 6.15 & 5.0763 & TRN & \\
\hline CHEMBL1322961 & 688267 & 4.1 & 5.04899 & 99999999995 & TST \\
\hline CHEMBL1345678 & 688267 & 6.2 & 5.0303 & TRN & \\
\hline CHEMBL1546858 & 688267 & 4.0 & 5.1154 & TRN & \\
\hline CHEMBL1463051 & 688267 & 4.3 & 4.9543 & TRN & \\
\hline CHEMBL1352121 & 688267 & 5.15 & 5.0161 & TRN & \\
\hline CHEMBL1301991 & 688267 & 6.15 & 5.1043 & TRN & \\
\hline CHEMBL1488533 & 688267 & 5.3 & 5.0588 & TST & \\
\hline
\end{tabular}




\begin{tabular}{|c|c|c|c|c|c|}
\hline \multicolumn{6}{|c|}{ } \\
\hline CHEMBL1398808 & 688267 & 5.3 & 5.0333 & TRN & \\
\hline CHEMBL1363520 & 688267 & 4.0 & 5.1434 & TRN & \\
\hline CHEMBL1395064 & 688267 & 4.25 & 4.9743 & TRN & \\
\hline CHEMBL1351531 & 688267 & 6.2 & 5.0173 & TRN & \\
\hline CHEMBL1501025 & 688267 & 4.35 & 5.0548 & TRN & \\
\hline CHEMBL1581868 & 688267 & 5.3 & 5.0647 & TRN & \\
\hline CHEMBL1593471 & 688267 & 5.0 & 5.0975 & TRN & \\
\hline CHEMBL1576246 & 688267 & 5.55 & 4.9937 & TST & \\
\hline CHEMBL1396717 & 688267 & 3.95 & 5.0636 & TRN & \\
\hline CHEMBL1498379 & 688267 & 5.1 & 5.0659 & TST & \\
\hline CHEMBL1557379 & 688267 & 4.1 & 5.0876 & TST & \\
\hline CHEMBL1509712 & 688267 & 6.2 & 5.0629 & TRN & \\
\hline CHEMBL1542721 & 688267 & 6.2 & 5.0403 & TRN & \\
\hline CHEMBL1370232 & 688267 & 5.5 & 5.0666 & TRN & \\
\hline CHEMBL1386321 & 688267 & 4.2 & 5.072 & TST & \\
\hline CHEMBL1399068 & 688267 & 5.45 & 5.0144 & TRN & \\
\hline CHEMBL1476112 & 688267 & 6.15 & 5.1026 & TRN & \\
\hline CHEMBL1322653 & 688267 & 4.7 & 5.1012 & TRN & \\
\hline CHEMBL1430979 & 688267 & 5.6 & 5.0155 & TRN & \\
\hline CHEMBL1480429 & 688267 & 4.6 & 5.0845 & TRN & \\
\hline CHEMBL1606927 & 688267 & 4.15 & 5.1015 & TRN & \\
\hline CHEMBL1455987 & 688267 & 4.5 & 5.0597 & TRN & \\
\hline CHEMBL1473843 & 688267 & 6.15 & 5.0284 & TRN & \\
\hline CHEMBL1463211 & 688267 & 4.35 & 5.0976 & TST & \\
\hline CHEMBL1535601 & 688267 & 4.35 & 5.0039 & TRN & \\
\hline CHEMBL1609138 & 688267 & 5.15 & 5.0878 & TRN & \\
\hline CHEMBL1438559 & 688267 & 5.9 & 5.0824 & TRN & \\
\hline CHEMBL1364186 & 688267 & 4.85 & 5.1391 & TRN & \\
\hline CHEMBL1527005 & 688267 & 4.3 & 5.047 & TRN & \\
\hline CHEMBL1612166 & 688267 & 6.2 & 5.0441 & TRN & \\
\hline CHEMBL1416466 & 688267 & 4.9 & 5.1136 & TRN & \\
\hline CHEMBL1335186 & 688267 & 5.5 & 4.9994 & TRN & \\
\hline CHEMBL1441350 & 688267 & 4.65 & 5.0185 & TRN & \\
\hline CHEMBL1509507 & 688267 & 6.2 & 5.03600 & 00000000005 & TRN \\
\hline CHEMBL1384313 & 688267 & 5.95 & 5.059 & TST & \\
\hline CHEMBL1575787 & 688267 & 4.1 & 5.0848 & TRN & \\
\hline CHEMBL1511306 & 688267 & 6.25 & 5.0248 & TST & \\
\hline CHEMBL1510221 & 688267 & 4.35 & 5.1191 & TRN & \\
\hline CHEMBL1555191 & 688267 & 5.55 & 5.0595 & TRN & \\
\hline CHEMBL1303892 & 688267 & 5.35 & 5.0339 & TRN & \\
\hline CHEMBL1313033 & 688267 & 4.35 & 5.0432 & TST & \\
\hline CHEMBL1982539 & 688267 & 6.1 & 5.0015 & TST & \\
\hline CHEMBL1474066 & 688267 & 4.45 & 5.0863 & TRN & \\
\hline CHEMBL1514249 & 688267 & 4.0 & 5.0512 & TRN & \\
\hline CHEMBL1593734 & 688267 & 5.6 & 5.0345 & TST & \\
\hline CHEMBL1493160 & 688267 & 4.05 & 5.0176 & TST & \\
\hline CHEMBL1459366 & 688267 & 5.75 & 5.0873 & TRN & \\
\hline CHEMBL1399361 & 688267 & 3.95 & 5.044 & TRN & \\
\hline
\end{tabular}




\begin{tabular}{|c|c|c|c|c|c|}
\hline \\
\hline CHEMBL2163817 & 688267 & 5.3 & 4.989 & TRN & \\
\hline CHEMBL1493000 & 688267 & 4.95 & 5.0657 & TST & \\
\hline CHEMBL1498578 & 688267 & 4.0 & 5.0669 & TRN & \\
\hline CHEMBL1588457 & 688267 & 5.3 & 5.0939 & TST & \\
\hline CHEMBL1471797 & 688267 & 4.85 & 5.0245 & TRN & \\
\hline CHEMBL1513832 & 688267 & 4.35 & 5.1344 & TRN & \\
\hline CHEMBL1524818 & 688267 & 6.0 & 5.0351 & TRN & \\
\hline CHEMBL1316880 & 688267 & 5.2 & 5.1469 & TRN & \\
\hline CHEMBL1445604 & 688267 & 4.9 & 5.0704 & TST & \\
\hline CHEMBL1397919 & 688267 & 6.0 & 5.1001 & TRN & \\
\hline CHEMBL1374254 & 688267 & 5.1 & 5.0058 & TRN & \\
\hline CHEMBL1592724 & 688267 & 5.65 & 5.0893 & TRN & \\
\hline CHEMBL1432073 & 688267 & 4.6 & 5.124 & TRN & \\
\hline CHEMBL1393692 & 688267 & 5.9 & 5.0766 & TRN & \\
\hline CHEMBL1364754 & 688267 & 4.35 & 5.0487 & TRN & \\
\hline CHEMBL1315140 & 688267 & 4.55 & 5.0838 & TRN & \\
\hline CHEMBL1471151 & 688267 & 5.3 & 5.0559 & TRN & \\
\hline CHEMBL1571411 & 688267 & 5.4 & 5.0886 & TRN & \\
\hline CHEMBL1559262 & 688267 & 6.15 & 5.0586 & TRN & \\
\hline CHEMBL1436495 & 688267 & 5.45 & 4.9978 & TRN & \\
\hline CHEMBL1486438 & 688267 & 4.4 & 5.0378 & TST & \\
\hline CHEMBL3192819 & 688267 & 4.05 & 5.0131 & TRN & \\
\hline CHEMBL1403662 & 688267 & 5.0 & 5.1082 & TRN & \\
\hline CHEMBL1531346 & 688267 & 5.0 & 4.9855 & TRN & \\
\hline CHEMBL1426645 & 688267 & 4.4 & 5.0974 & TRN & \\
\hline CHEMBL1299571 & 688267 & 5.0 & 5.0645 & TRN & \\
\hline CHEMBL1570025 & 688267 & 4.05 & 5.0551 & TRN & \\
\hline CHEMBL1566150 & 688267 & 4.0 & 5.0614 & TRN & \\
\hline CHEMBL1594127 & 688267 & 6.2 & 5.0454 & TRN & \\
\hline CHEMBL1372811 & 688267 & 4.65 & 5.0817 & TRN & \\
\hline CHEMBL1428215 & 688267 & 5.85 & 5.073 & TST & \\
\hline CHEMBL1394150 & 688267 & 4.6 & 5.0729 & TRN & \\
\hline CHEMBL1346469 & 688267 & 5.35 & 5.1517 & TRN & \\
\hline CHEMBL1477324 & 688267 & 4.4 & 5.0253 & TRN & \\
\hline CHEMBL1392132 & 688267 & 5.05 & 5.0153 & TRN & \\
\hline CHEMBL1451842 & 688267 & 4.5 & 5.0345 & TRN & \\
\hline CHEMBL1513510 & 688267 & 6.5501 & 5.11600 & 30000000005 & TRN \\
\hline CHEMBL1494671 & 688267 & 6.05 & 5.0705 & TRN & \\
\hline CHEMBL1531929 & 688267 & 5.9 & 5.0279 & TRN & \\
\hline CHEMBL1572200 & 688267 & 4.05 & 5.1096 & TRN & \\
\hline CHEMBL1319780 & 688267 & 4.05 & 5.0428 & TRN & \\
\hline CHEMBL1461806 & 688267 & 4.05 & 5.0058 & TST & \\
\hline CHEMBL1462939 & 688267 & 5.35 & 5.09399 & 9999999999 & TRN \\
\hline CHEMBL1480009 & 688267 & 4.0 & 5.0522 & TRN & \\
\hline CHEMBL1399210 & 688267 & 6.2 & 5.1232 & TST & \\
\hline CHEMBL1588525 & 688267 & 5.05 & 5.1618 & TRN & \\
\hline CHEMBL1544822 & 688267 & 6.2 & 5.112 & TRN & \\
\hline CHEMBL1541641 & 688267 & 4.85 & 5.13 & TRN & \\
\hline
\end{tabular}




\begin{tabular}{|c|c|c|c|c|c|}
\hline \multicolumn{6}{|c|}{ Supplemental Table S2.txt } \\
\hline CHEMBL1473122 & 688267 & 5.6 & 5.1098 & TRN & \\
\hline CHEMBL1410393 & 688267 & 3.95 & 5.0001 & TRN & \\
\hline CHEMBL1403027 & 688267 & 4.0 & 5.0527 & TST & \\
\hline CHEMBL1488506 & 688267 & 5.65 & 5.1261 & TRN & \\
\hline CHEMBL1512767 & 688267 & 4.6 & 5.0166 & TRN & \\
\hline CHEMBL1489639 & 688267 & 4.05 & 4.9907 & TRN & \\
\hline CHEMBL1333682 & 688267 & 6.2 & 5.0323 & TST & \\
\hline CHEMBL1437339 & 688267 & 3.95 & 5.0484 & TST & \\
\hline CHEMBL1548839 & 688267 & 4.05 & 5.0109 & TRN & \\
\hline CHEMBL1410206 & 688267 & 5.5 & 5.098 & TRN & \\
\hline CHEMBL1375627 & 688267 & 5.8 & 5.0561 & TST & \\
\hline CHEMBL3193931 & 688267 & 4.05 & 5.024 & TST & \\
\hline CHEMBL1313124 & 688267 & 4.0 & 5.0319 & TST & \\
\hline CHEMBL1351389 & 688267 & 6.25 & 5.0063 & TST & \\
\hline CHEMBL1343539 & 688267 & 5.5 & 5.0372 & TST & \\
\hline CHEMBL1544339 & 688267 & 4.05 & 5.0367 & TRN & \\
\hline CHEMBL1310272 & 688267 & 4.55 & 5.0979 & TRN & \\
\hline CHEMBL490552 & 688267 & 6.15 & 5.0052 & TRN & \\
\hline CHEMBL1365445 & 688267 & 5.55 & 5.0479 & TRN & \\
\hline CHEMBL1552338 & 688267 & 6.2 & 5.0873 & TRN & \\
\hline CHEMBL1396554 & 688267 & 3.95 & 5.0225 & TRN & \\
\hline CHEMBL1452317 & 688267 & 5.0 & 5.1175 & TST & \\
\hline CHEMBL1553245 & 688267 & 6.0 & 5.0451 & TRN & \\
\hline CHEMBL1366631 & 688267 & 5.55 & 5.0644 & TST & \\
\hline CHEMBL1472007 & 688267 & 6.15 & 5.1127 & TRN & \\
\hline CHEMBL1457386 & 688267 & 5.3 & 5.0637 & TRN & \\
\hline CHEMBL367971 & 688267 & 5.05 & 4.9994 & TRN & \\
\hline CHEMBL3199239 & 688267 & 4.95 & 5.0904 & TRN & \\
\hline CHEMBL1589918 & 688267 & 4.25 & 5.0172 & TRN & \\
\hline CHEMBL1333796 & 688267 & 5.55 & 5.1253 & TST & \\
\hline CHEMBL1356800 & 688267 & 4.35 & 5.1254 & TRN & \\
\hline CHEMBL1307950 & 688267 & 5.75 & 5.0375 & TST & \\
\hline CHEMBL1369170 & 688267 & 5.05 & 5.1145 & TRN & \\
\hline CHEMBL3193740 & 688267 & 5.35 & 5.00899 & 99999999995 & TRN \\
\hline CHEMBL2369219 & 688267 & 5.8 & 5.0551 & TST & \\
\hline CHEMBL1612804 & 688267 & 4.5 & 4.9985 & TRN & \\
\hline CHEMBL1549711 & 688267 & 4.1 & 5.0683 & TRN & \\
\hline CHEMBL1331162 & 688267 & 5.6 & 5.0077 & TRN & \\
\hline CHEMBL1572880 & 688267 & 4.55 & 5.09399 & 9999999999 & TRN \\
\hline CHEMBL1353777 & 688267 & 5.3 & 4.9746 & TRN & \\
\hline CHEMBL1607311 & 688267 & 4.55 & 5.0901 & TRN & \\
\hline CHEMBL1310831 & 688267 & 5.3 & 5.083 & TST & \\
\hline CHEMBL1383563 & 688267 & 6.0 & 5.0268 & TRN & \\
\hline CHEMBL1350864 & 688267 & 5.65 & 5.0433 & TRN & \\
\hline CHEMBL3197549 & 688267 & 4.6 & 5.0026 & TST & \\
\hline CHEMBL1358296 & 688267 & 3.95 & 5.1008 & TRN & \\
\hline CHEMBL1362100 & 688267 & 6.15 & 5.0639 & TRN & \\
\hline CHEMBL1543711 & 688267 & 5.35 & 5.1468 & TRN & \\
\hline
\end{tabular}




\begin{tabular}{|c|c|c|c|c|}
\hline \multicolumn{5}{|c|}{ Supplemental Table S2.txt } \\
\hline CHEMBL1318593 & 688267 & 5.8 & 5.0313 & TRN \\
\hline CHEMBL1353410 & 688267 & 6.25 & 5.0194 & TRN \\
\hline CHEMBL1415241 & 688267 & 4.35 & 5.0085 & TRN \\
\hline CHEMBL1359274 & 688267 & 6.2 & 5.0559 & TRN \\
\hline CHEMBL1507746 & 688267 & 4.0 & 5.0285 & TRN \\
\hline CHEMBL1476971 & 688267 & 4.05 & 5.086 & TST \\
\hline CHEMBL1519168 & 688267 & 6.0 & 5.1282 & TST \\
\hline CHEMBL1488749 & 688267 & 4.75 & 5.0532 & TST \\
\hline CHEMBL1340301 & 688267 & 4.45 & 5.0183 & TST \\
\hline CHEMBL1309816 & 688267 & 5.7 & 5.0503 & TST \\
\hline CHEMBL1428178 & 688267 & 5.9 & 5.0667 & TST \\
\hline CHEMBL1394904 & 688267 & 4.0 & 5.0458 & TRN \\
\hline CHEMBL1537018 & 688267 & 6.2 & 5.0322 & TRN \\
\hline CHEMBL1302322 & 688267 & 5.35 & 5.0491 & TST \\
\hline CHEMBL1442607 & 688267 & 5.55 & 5.0434 & TRN \\
\hline CHEMBL1519712 & 688267 & 4.05 & 5.0416 & TRN \\
\hline CHEMBL1594430 & 688267 & 6.15 & 5.032 & TST \\
\hline CHEMBL1527774 & 688267 & 4.6 & 5.1012 & TST \\
\hline CHEMBL1492348 & 688267 & 4.25 & 5.0401 & TST \\
\hline CHEMBL3208198 & 688267 & 4.85 & 5.0545 & TST \\
\hline CHEMBL1332206 & 688267 & 4.0 & 5.0648 & TRN \\
\hline CHEMBL1987579 & 688267 & 3.95 & 4.9633 & TRN \\
\hline CHEMBL1334701 & 688267 & 4.3 & 5.0206 & TRN \\
\hline CHEMBL1510446 & 688267 & 6.2 & 5.0251 & TST \\
\hline CHEMBL1390619 & 688267 & 4.4 & 5.0077 & TST \\
\hline CHEMBL 3192848 & 688267 & 6.15 & 5.0098 & TRN \\
\hline CHEMBL1424675 & 688267 & 4.3 & 5.0617 & TRN \\
\hline CHEMBL1610437 & 688267 & 5.1 & 5.0496 & TRN \\
\hline CHEMBL1300359 & 688267 & 6.25 & 4.9855 & TRN \\
\hline CHEMBL1504679 & 688267 & 4.65 & 4.9956 & TST \\
\hline CHEMBL376426 & 688267 & 5.25 & 4.9973 & TST \\
\hline CHEMBL1469592 & 688267 & 4.35 & 5.0232 & TST \\
\hline CHEMBL1419350 & 688267 & 4.0 & 5.0717 & TRN \\
\hline CHEMBL1335451 & 688267 & 4.6 & 5.0982 & TST \\
\hline CHEMBL1457594 & 688267 & 4.7 & 5.0005 & TRN \\
\hline CHEMBL1469838 & 688267 & 4.85 & 4.9957 & TRN \\
\hline CHEMBL1526879 & 688267 & 4.55 & 5.0861 & TRN \\
\hline CHEMBL1430841 & 688267 & 4.8 & 5.1365 & TRN \\
\hline CHEMBL1411318 & 688267 & 6.2 & 5.0656 & TRN \\
\hline CHEMBL1392792 & 688267 & 3.95 & 5.0405 & TRN \\
\hline CHEMBL1511547 & 688267 & 6.2 & 5.0502 & TRN \\
\hline CHEMBL1544084 & 688267 & 4.45 & 5.1213 & TST \\
\hline CHEMBL1326483 & 688267 & 5.6 & 5.0416 & TRN \\
\hline CHEMBL1309227 & 688267 & 4.6 & 5.0995 & TRN \\
\hline CHEMBL1439647 & 688267 & 6.2 & 5.0422 & TRN \\
\hline CHEMBL1498084 & 688267 & 4.1 & 5.0709 & TRN \\
\hline CHEMBL1581057 & 688267 & 4.05 & 5.0779 & TRN \\
\hline CHEMBL1566700 & 688267 & 3.95 & 4.989 & TRN \\
\hline
\end{tabular}




\begin{tabular}{|c|c|c|c|c|c|}
\hline \multicolumn{6}{|c|}{ Supplemental Table S2.txt } \\
\hline CHEMBL 3192789 & 688267 & 4.35 & 5.0436 & TST & \\
\hline CHEMBL1309339 & 688267 & 4.4 & 5.0235 & TRN & \\
\hline CHEMBL1490074 & 688267 & 6.25 & 5.0335 & TRN & \\
\hline CHEMBL1559107 & 688267 & 5.85 & 5.0285 & TRN & \\
\hline CHEMBL1601217 & 688267 & 4.45 & 4.9964 & TRN & \\
\hline CHEMBL1514030 & 688267 & 4.45 & 5.1082 & TRN & \\
\hline CHEMBL1365244 & 688267 & 4.25 & 5.1109 & TRN & \\
\hline CHEMBL1548077 & 688267 & 5.5 & 5.0959 & TST & \\
\hline CHEMBL1360813 & 688267 & 6.2 & 5.1038 & TRN & \\
\hline CHEMBL1547216 & 688267 & 4.6 & 5.1146 & TST & \\
\hline CHEMBL1589042 & 688267 & 4.0 & 5.0444 & TRN & \\
\hline CHEMBL1397873 & 688267 & 5.45 & 5.1078 & TRN & \\
\hline CHEMBL 3214533 & 688267 & 6.2 & 5.1329 & TST & \\
\hline CHEMBL1553391 & 688267 & 3.95 & 4.9753 & TRN & \\
\hline CHEMBL1400016 & 688267 & 4.0 & 5.1086 & TRN & \\
\hline CHEMBL1422663 & 688267 & 5.55 & 5.0616 & TRN & \\
\hline CHEMBL1561891 & 688267 & 5.6 & 5.0761 & TST & \\
\hline CHEMBL1515839 & 688267 & 5.15 & 5.0413 & TRN & \\
\hline CHEMBL1591166 & 688267 & 6.1 & 5.0819 & TRN & \\
\hline CHEMBL1592779 & 688267 & 4.35 & 5.0401 & TRN & \\
\hline CHEMBL1400343 & 688267 & 5.1 & 5.0001 & TRN & \\
\hline CHEMBL1503407 & 688267 & 5.55 & 5.0295 & TST & \\
\hline CHEMBL1537045 & 688267 & 4.0 & 5.0562 & TST & \\
\hline CHEMBL1374102 & 688267 & 6.5501 & 5.1096 & TRN & \\
\hline CHEMBL1537368 & 688267 & 4.65 & 5.0298 & TRN & \\
\hline CHEMBL1393530 & 688267 & 5.55 & 5.0717 & TRN & \\
\hline CHEMBL1520420 & 688267 & 4.0 & 5.0598 & TRN & \\
\hline CHEMBL1518483 & 688267 & 4.4 & 4.9918 & TRN & \\
\hline CHEMBL1439375 & 688267 & 4.0 & 5.0427 & TRN & \\
\hline CHEMBL1398244 & 688267 & 5.2 & 5.023 & TRN & \\
\hline CHEMBL1352375 & 688267 & 6.25 & 5.06800 & 00000000005 & TRN \\
\hline CHEMBL1450934 & 688267 & 4.6 & 5.0263 & TST & \\
\hline CHEMBL1406125 & 688267 & 4.0 & 5.0597 & TRN & \\
\hline CHEMBL1357153 & 688267 & 4.55 & 5.1032 & TRN & \\
\hline CHEMBL3190384 & 688267 & 4.15 & 5.0304 & TRN & \\
\hline CHEMBL1544213 & 688267 & 5.4 & 5.0397 & TRN & \\
\hline CHEMBL1531495 & 688267 & 3.95 & 4.9866 & TRN & \\
\hline CHEMBL1318871 & 688267 & 5.0 & 5.0731 & TRN & \\
\hline CHEMBL1604222 & 688267 & 4.4 & 5.0268 & TRN & \\
\hline CHEMBL1397182 & 688267 & 4.25 & 5.1333 & TRN & \\
\hline CHEMBL1311117 & 688267 & 4.05 & 5.0786 & TST & \\
\hline CHEMBL1413950 & 688267 & 4.05 & 5.0333 & TRN & \\
\hline CHEMBL1563894 & 688267 & 3.95 & 5.0112 & TRN & \\
\hline CHEMBL1507938 & 688267 & 6.45 & 5.0284 & TRN & \\
\hline CHEMBL1415388 & 688267 & 6.2 & 5.0507 & TRN & \\
\hline CHEMBL1301940 & 688267 & 4.75 & 5.083 & TRN & \\
\hline CHEMBL1517243 & 688267 & 5.35 & 5.0845 & TRN & \\
\hline CHEMBL1403130 & 688267 & 4.0 & 5.0676 & TRN & \\
\hline
\end{tabular}




\begin{tabular}{|c|c|c|c|c|c|}
\hline \\
\hline CHEMBL1441887 & 688267 & 4.35 & 5.0437 & TST & \\
\hline CHEMBL1322082 & 688267 & 6.2 & 4.9962 & TRN & \\
\hline CHEMBL1446248 & 688267 & 5.4 & 5.0824 & TST & \\
\hline CHEMBL1506458 & 688267 & 4.0 & 5.0735 & TRN & \\
\hline CHEMBL1321657 & 688267 & 4.35 & 5.0004 & TRN & \\
\hline CHEMBL3214556 & 688267 & 3.95 & 5.0184 & TRN & \\
\hline CHEMBL3197559 & 688267 & 5.35 & 5.0636 & TST & \\
\hline CHEMBL1327531 & 688267 & 4.05 & 4.9987 & TST & \\
\hline CHEMBL1321095 & 688267 & 5.5 & 5.1129 & TRN & \\
\hline CHEMBL1389513 & 688267 & 6.2 & 5.1252 & TRN & \\
\hline CHEMBL1382891 & 688267 & 4.25 & 5.0239 & TRN & \\
\hline CHEMBL1516355 & 688267 & 4.0 & 5.0412 & TRN & \\
\hline CHEMBL1481712 & 688267 & 5.45 & 5.1221 & TRN & \\
\hline CHEMBL1484827 & 688267 & 6.2 & 5.1479 & TRN & \\
\hline CHEMBL1531563 & 688267 & 6.2 & 5.0202 & TRN & \\
\hline CHEMBL1422233 & 688267 & 4.0 & 5.0389 & TST & \\
\hline CHEMBL1457175 & 688267 & 4.35 & 5.0428 & TRN & \\
\hline CHEMBL1469852 & 688267 & 5.5 & 5.1847 & TRN & \\
\hline CHEMBL1522957 & 688267 & 4.1 & 5.0266 & TRN & \\
\hline CHEMBL1314412 & 688267 & 4.0 & 5.0557 & TRN & \\
\hline CHEMBL1590507 & 688267 & 6.2 & 5.0923 & TST & \\
\hline CHEMBL604116 & 688267 & 5.85 & 5.074 & TRN & \\
\hline CHEMBL1323134 & 688267 & 6.45 & 5.0246 & TRN & \\
\hline CHEMBL1455552 & 688267 & 6.2 & 5.1039 & TRN & \\
\hline CHEMBL1394253 & 688267 & 4.4 & 4.9977 & TRN & \\
\hline CHEMBL1452980 & 688267 & 5.45 & 4.9991 & TRN & \\
\hline CHEMBL600960 & 688267 & 5.35 & 5.0962 & TRN & \\
\hline CHEMBL1483055 & 688267 & 3.95 & 5.0539 & TRN & \\
\hline CHEMBL1517191 & 688267 & 5.55 & 5.0198 & TRN & \\
\hline CHEMBL1574594 & 688267 & 4.3 & 5.0521 & TRN & \\
\hline CHEMBL1414036 & 688267 & 4.45 & 5.0781 & TRN & \\
\hline CHEMBL1391231 & 688267 & 4.35 & 5.0908 & TRN & \\
\hline CHEMBL1374386 & 688267 & 5.35 & 5.0067 & TRN & \\
\hline CHEMBL1566057 & 688267 & 5.0 & 5.0828 & TST & \\
\hline CHEMBL1331390 & 688267 & 5.95 & 5.0745 & TRN & \\
\hline CHEMBL1366013 & 688267 & 6.15 & 5.0762 & TST & \\
\hline CHEMBL1333330 & 688267 & 5.45 & 5.0533 & TRN & \\
\hline CHEMBL1318538 & 688267 & 4.9 & 5.0596 & TRN & \\
\hline CHEMBL1586499 & 688267 & 6.05 & 5.104 & TRN & \\
\hline CHEMBL1596674 & 688267 & 5.3 & 5.0351 & TRN & \\
\hline CHEMBL1302970 & 688267 & 4.05 & 5.0908 & TST & \\
\hline CHEMBL1456300 & 688267 & 5.65 & 5.0063 & TRN & \\
\hline CHEMBL1540335 & 688267 & 4.0 & 5.0346 & TRN & \\
\hline CHEMBL1430793 & 688267 & 5.3 & 5.0516 & TRN & \\
\hline CHEMBL1599903 & 688267 & 4.0 & 5.0909 & TRN & \\
\hline CHEMBL1585119 & 688267 & 6.2 & 5.0718 & TST & \\
\hline CHEMBL1599469 & 688267 & 6.45 & 5.0938 & TST & \\
\hline CHEMBL1595180 & 688267 & 6.2 & 5.00899 & 99999999995 & TRN \\
\hline & & & & 7801 & \\
\hline
\end{tabular}




\begin{tabular}{|c|c|c|c|c|}
\hline & & \multicolumn{3}{|c|}{ Supplemental Table S2.txt } \\
\hline CHEMBL1517202 & 688267 & 5.85 & 5.1552 & TRN \\
\hline CHEMBL1599088 & 688267 & 6.0 & 5.0947 & TRN \\
\hline CHEMBL1453449 & 688267 & 5.3 & 5.112 & TRN \\
\hline CHEMBL1600435 & 688267 & 4.35 & 5.0727 & TRN \\
\hline CHEMBL1358531 & 688267 & 5.2 & 5.0728 & TST \\
\hline CHEMBL1493483 & 688267 & 5.4 & 5.0598 & TST \\
\hline CHEMBL1594343 & 688267 & 4.8 & 5.0892 & TRN \\
\hline CHEMBL1419004 & 688267 & 5.3 & 5.1446 & TRN \\
\hline CHEMBL1530281 & 688267 & 4.0 & 5.0128 & TRN \\
\hline CHEMBL1607702 & 688267 & 6.15 & 5.1147 & TRN \\
\hline CHEMBL1443604 & 688267 & 4.9 & 5.1249 & TRN \\
\hline CHEMBL1526261 & 688267 & 6.15 & 5.0974 & TRN \\
\hline CHEMBL1593836 & 688267 & 4.4 & 5.0818 & TRN \\
\hline CHEMBL1450287 & 688267 & 4.2 & 5.0218 & TST \\
\hline CHEMBL222660 & 688267 & 4.35 & 5.0672 & TST \\
\hline CHEMBL1538849 & 688267 & 3.95 & 5.0589 & TST \\
\hline CHEMBL1444091 & 688267 & 5.6 & 5.0771 & TST \\
\hline CHEMBL3189487 & 688267 & 5.8 & 5.0269 & TST \\
\hline CHEMBL1411458 & 688267 & 4.0 & 5.0342 & TRN \\
\hline CHEMBL1571267 & 688267 & 4.15 & 5.0209 & TRN \\
\hline CHEMBL1327728 & 688267 & 5.55 & 5.0185 & TRN \\
\hline CHEMBL1602940 & 688267 & 4.55 & 5.1166 & TST \\
\hline CHEMBL1335012 & 688267 & 5.95 & 5.0967 & TRN \\
\hline CHEMBL1322874 & 688267 & 5.35 & 5.0377 & TRN \\
\hline CHEMBL1548087 & 688267 & 4.35 & 5.0852 & TRN \\
\hline CHEMBL1540172 & 688267 & 4.3 & 5.0358 & TST \\
\hline CHEMBL1418494 & 688267 & 5.6 & 5.0406 & TRN \\
\hline CHEMBL1517134 & 688267 & 5.4 & 5.0852 & TRN \\
\hline CHEMBL1591007 & 688267 & 5.2 & 5.1372 & TRN \\
\hline CHEMBL1485376 & 688267 & 6.15 & 5.0335 & TRN \\
\hline CHEMBL3199450 & 688267 & 5.55 & 5.0224 & TST \\
\hline CHEMBL1330575 & 688267 & 4.05 & 5.0555 & TST \\
\hline CHEMBL1346277 & 688267 & 6.0 & 4.9751 & TRN \\
\hline CHEMBL1387822 & 688267 & 4.1 & 5.0657 & TRN \\
\hline CHEMBL1401150 & 688267 & 4.55 & 5.0506 & TRN \\
\hline CHEMBL1531904 & 688267 & 6.2 & 5.0457 & TST \\
\hline CHEMBL1369943 & 688267 & 4.3 & 5.0813 & TRN \\
\hline CHEMBL1554003 & 688267 & 4.65 & 5.1083 & TRN \\
\hline CHEMBL1322759 & 688267 & 4.0 & 5.1213 & TST \\
\hline CHEMBL1968039 & 688267 & 6.5 & 4.9809 & TST \\
\hline CHEMBL1344434 & 688267 & 5.4 & 5.1023 & TRN \\
\hline CHEMBL1462743 & 688267 & 6.2 & 5.0533 & TST \\
\hline CHEMBL1531644 & 688267 & 5.5 & 5.1167 & TRN \\
\hline CHEMBL1435083 & 688267 & 4.3 & 5.1056 & TRN \\
\hline CHEMBL1410201 & 688267 & 5.25 & 5.0716 & TRN \\
\hline CHEMBL1534667 & 688267 & 4.7 & 5.0924 & TRN \\
\hline CHEMBL1520391 & 688267 & 5.35 & 5.05399 & 9999999999 \\
\hline CHEMBL1467059 & 688267 & 6.15 & 5.0681 & TRN \\
\hline
\end{tabular}




\begin{tabular}{|c|c|c|c|c|c|}
\hline \multicolumn{6}{|c|}{ Supplemental Table S2.txt } \\
\hline CHEMBL1299849 & 688267 & 5.35 & 5.0452 & TST & \\
\hline CHEMBL1608003 & 688267 & 6.2 & 5.0504 & TRN & \\
\hline CHEMBL1584572 & 688267 & 5.25 & 5.0746 & TRN & \\
\hline CHEMBL1433754 & 688267 & 6.25 & 5.0189 & TRN & \\
\hline CHEMBL1437236 & 688267 & 5.35 & 5.0734 & TRN & \\
\hline CHEMBL1453419 & 688267 & 4.4 & 5.045 & TRN & \\
\hline CHEMBL 3193603 & 688267 & 4.05 & 5.0574 & TST & \\
\hline CHEMBL1474469 & 688267 & 5.8 & 5.0532 & TRN & \\
\hline CHEMBL1357925 & 688267 & 5.8 & 5.0051 & TRN & \\
\hline CHEMBL1576239 & 688267 & 5.8 & 5.0262 & TRN & \\
\hline CHEMBL1376967 & 688267 & 4.05 & 5.0508 & TRN & \\
\hline CHEMBL1455624 & 688267 & 5.45 & 5.0264 & TST & \\
\hline CHEMBL1431303 & 688267 & 5.25 & 5.0229 & TRN & \\
\hline CHEMBL1324024 & 688267 & 4.95 & 5.1101 & TRN & \\
\hline CHEMBL1495393 & 688267 & 6.25 & 5.0481 & TRN & \\
\hline CHEMBL1402446 & 688267 & 4.6 & 5.0396 & TRN & \\
\hline CHEMBL 2172255 & 688267 & 4.25 & 5.0411 & TRN & \\
\hline CHEMBL1476590 & 688267 & 4.0 & 5.0195 & TRN & \\
\hline CHEMBL1432896 & 688267 & 4.45 & 5.141 & TRN & \\
\hline CHEMBL1467634 & 688267 & 6.1 & 5.1542 & TRN & \\
\hline CHEMBL1564231 & 688267 & 4.0 & 5.0972 & TRN & \\
\hline CHEMBL1397162 & 688267 & 4.0 & 5.0284 & TRN & \\
\hline CHEMBL1553108 & 688267 & 4.35 & 5.0774 & TRN & \\
\hline CHEMBL1512530 & 688267 & 6.2 & 5.0011 & TRN & \\
\hline CHEMBL1335183 & 688267 & 4.65 & 5.0719 & TRN & \\
\hline CHEMBL610508 & 688267 & 4.45 & 5.0431 & TRN & \\
\hline CHEMBL1400474 & 688267 & 5.85 & 5.0561 & TRN & \\
\hline CHEMBL1551236 & 688267 & 4.9 & 5.07600 & 00000000005 & TRN \\
\hline CHEMBL1324259 & 688267 & 3.95 & 5.0985 & TRN & \\
\hline CHEMBL1328613 & 688267 & 5.0 & 5.0434 & TRN & \\
\hline CHEMBL1493721 & 688267 & 5.35 & 5.1393 & TRN & \\
\hline CHEMBL1319469 & 688267 & 6.0 & 5.0608 & TST & \\
\hline CHEMBL1495416 & 688267 & 6.15 & 5.0102 & TRN & \\
\hline CHEMBL1513549 & 688267 & 4.35 & 5.0975 & TRN & \\
\hline CHEMBL1436199 & 688267 & 6.25 & 5.1187 & TRN & \\
\hline CHEMBL1318566 & 688267 & 5.55 & 4.9779 & TRN & \\
\hline CHEMBL1579084 & 688267 & 4.3 & 5.0458 & TST & \\
\hline CHEMBL1308444 & 688267 & 5.15 & 5.045 & TRN & \\
\hline CHEMBL1311277 & 688267 & 6.2 & 4.9987 & TRN & \\
\hline CHEMBL1511131 & 688267 & 4.95 & 5.0256 & TRN & \\
\hline CHEMBL1596124 & 688267 & 4.55 & 5.0756 & TRN & \\
\hline CHEMBL 1483585 & 688267 & 4.0 & 5.0348 & TRN & \\
\hline CHEMBL1473638 & 688267 & 3.95 & 5.0977 & TRN & \\
\hline CHEMBL1536215 & 688267 & 4.2 & 5.0399 & TST & \\
\hline CHEMBL1369143 & 688267 & 3.95 & 4.9878 & TRN & \\
\hline CHEMBL1347197 & 688267 & 4.15 & 5.1012 & TRN & \\
\hline CHEMBL1448164 & 688267 & 4.3 & 5.0657 & TST & \\
\hline CHEMBL1610922 & 688267 & 4.95 & 5.0324 & TRN & \\
\hline
\end{tabular}




\begin{tabular}{|c|c|c|c|c|}
\hline \multicolumn{5}{|c|}{ Supplemental Table S2.txt } \\
\hline CHEMBL1524957 & 688267 & 3.95 & 5.0563 & TRN \\
\hline CHEMBL1330000 & 688267 & 4.6 & 4.9966 & TRN \\
\hline CHEMBL1526938 & 688267 & 4.05 & 4.9823 & TRN \\
\hline CHEMBL1481572 & 688267 & 4.35 & 5.0251 & TST \\
\hline CHEMBL1389233 & 688267 & 5.95 & 5.0366 & TRN \\
\hline CHEMBL1374323 & 688267 & 4.25 & 4.9954 & TRN \\
\hline CHEMBL1567040 & 688267 & 5.2 & 5.0351 & TRN \\
\hline CHEMBL1579567 & 688267 & 6.45 & 5.1234 & TRN \\
\hline CHEMBL1466418 & 688267 & 6.1 & 5.0232 & TRN \\
\hline CHEMBL3209620 & 688267 & 4.95 & 5.0426 & TST \\
\hline CHEMBL1311215 & 688267 & 5.7 & 5.1373 & TRN \\
\hline CHEMBL1407159 & 688267 & 4.0 & 5.0876 & TST \\
\hline CHEMBL1584381 & 688267 & 4.05 & 5.0742 & TST \\
\hline CHEMBL1531096 & 688267 & 5.6 & 5.0851 & TRN \\
\hline CHEMBL1595249 & 688267 & 4.0 & 5.0588 & TRN \\
\hline CHEMBL1370280 & 688267 & 4.5 & 5.1183 & TRN \\
\hline CHEMBL1376663 & 688267 & 4.4 & 5.0308 & TRN \\
\hline CHEMBL1577067 & 688267 & 4.4 & 5.1095 & TST \\
\hline CHEMBL1610470 & 688267 & 4.95 & 5.0485 & TRN \\
\hline CHEMBL1475540 & 688267 & 4.65 & 5.1142 & TRN \\
\hline CHEMBL1398997 & 688267 & 5.0 & 5.0719 & TRN \\
\hline CHEMBL1558633 & 688267 & 5.05 & 5.0556 & TST \\
\hline CHEMBL599102 & 688267 & 5.5 & 5.0442 & TST \\
\hline CHEMBL1342065 & 688267 & 5.95 & 5.0814 & TRN \\
\hline CHEMBL1455706 & 688267 & 4.35 & 5.0636 & TRN \\
\hline CHEMBL1323912 & 688267 & 4.45 & 5.0966 & TRN \\
\hline CHEMBL1495982 & 688267 & 5.55 & 5.0521 & TRN \\
\hline CHEMBL1554209 & 688267 & 4.05 & 5.0969 & TRN \\
\hline CHEMBL1351114 & 688267 & 4.35 & 5.0807 & TST \\
\hline CHEMBL1569527 & 688267 & 4.8 & 5.0268 & TRN \\
\hline CHEMBL1480531 & 688267 & 4.95 & 5.0948 & TRN \\
\hline CHEMBL1427526 & 688267 & 4.0 & 5.0989 & TST \\
\hline CHEMBL1503406 & 688267 & 4.05 & 5.0322 & TRN \\
\hline CHEMBL1325963 & 688267 & 6.2 & 5.0529 & TST \\
\hline CHEMBL1424613 & 688267 & 3.95 & 5.0358 & TRN \\
\hline CHEMBL1585127 & 688267 & 6.15 & 5.0189 & TST \\
\hline CHEMBL1397346 & 688267 & 5.45 & 5.0787 & TRN \\
\hline CHEMBL1456396 & 688267 & 4.3 & 5.0528 & TST \\
\hline CHEMBL1314179 & 688267 & 5.05 & 5.0137 & TRN \\
\hline CHEMBL 3193755 & 688267 & 4.3 & 5.0118 & TRN \\
\hline CHEMBL1599898 & 688267 & 4.4 & 5.0385 & TST \\
\hline CHEMBL1377219 & 688267 & 6.05 & 5.0234 & TRN \\
\hline CHEMBL1537663 & 688267 & 6.5 & 5.0991 & TST \\
\hline CHEMBL1326441 & 688267 & 5.15 & 5.033 & TST \\
\hline CHEMBL1479004 & 688267 & 5.3 & 5.0903 & TRN \\
\hline CHEMBL1442521 & 688267 & 4.05 & 5.0312 & TRN \\
\hline CHEMBL1502279 & 688267 & 5.15 & 5.0545 & TRN \\
\hline CHEMBL1606077 & 688267 & 5.9 & 5.0933 & TST \\
\hline
\end{tabular}




\begin{tabular}{|c|c|c|c|c|c|}
\hline \multirow[b]{2}{*}{ CHEMBL1515679 } & \multicolumn{5}{|c|}{ lemental Table S2 } \\
\hline & 688267 & 4.35 & 5.0545 & TRN & \multirow[b]{2}{*}{ TRN } \\
\hline CHEMBL1369753 & 688267 & 5.4 & \multicolumn{2}{|c|}{5.138999999999999} & \\
\hline CHEMBL1429140 & 688267 & 5.0 & 5.078 & TST & \\
\hline CHEMBL1591692 & 688267 & 6.2 & 5.0244 & TRN & \\
\hline CHEMBL1558192 & 688267 & 4.25 & 5.0074 & TRN & \\
\hline CHEMBL1401708 & 688267 & 6.2 & 5.0534 & TRN & \\
\hline CHEMBL1468780 & 688267 & 5.1 & 5.1204 & TST & \\
\hline CHEMBL1379162 & 688267 & 6.2 & 5.0643 & TST & \\
\hline CHEMBL3212685 & 688267 & 5.55 & 5.0382 & TRN & \\
\hline CHEMBL1362711 & 688267 & 4.45 & 5.0741 & TRN & \\
\hline CHEMBL1387349 & 688267 & 3.95 & 5.0342 & TRN & \\
\hline CHEMBL1408554 & 688267 & 5.4 & 5.0509 & TRN & \\
\hline CHEMBL1348399 & 688267 & 4.95 & 5.0262 & TRN & \\
\hline CHEMBL1378662 & 688267 & 6.15 & 5.0537 & TST & \\
\hline CHEMBL1451805 & 688267 & 4.2 & 5.0701 & TRN & \\
\hline CHEMBL1495465 & 688267 & 4.0 & 5.106 & TRN & \\
\hline CHEMBL1373922 & 688267 & 5.9 & 5.0728 & TRN & \\
\hline CHEMBL1433811 & 688267 & 6.5 & 5.0542 & TRN & \\
\hline CHEMBL1424468 & 688267 & 5.55 & 5.0497 & TRN & \\
\hline CHEMBL1325925 & 688267 & 5.45 & 5.1188 & TRN & \\
\hline CHEMBL1545060 & 688267 & 5.3 & 5.0364 & TRN & \\
\hline CHEMBL1496117 & 688267 & 6.2 & 5.0422 & TRN & \\
\hline CHEMBL1345193 & 688267 & 5.3 & 5.0851 & TRN & \\
\hline CHEMBL3191171 & 688267 & 4.0 & 5.0214 & TRN & \\
\hline CHEMBL1330437 & 688267 & 6.25 & 5.0724 & TST & \\
\hline CHEMBL 1455856 & 688267 & 6.15 & 5.0552 & TRN & \\
\hline CHEMBL1610836 & 688267 & 6.0 & 4.9751 & TST & \\
\hline CHEMBL1482535 & 688267 & 5.2 & 5.0704 & TRN & \\
\hline CHEMBL1389205 & 688267 & 6.2 & 5.0111 & TRN & \\
\hline CHEMBL1400423 & 688267 & 5.5 & 5.0659 & TRN & \\
\hline CHEMBL1496764 & 688267 & 7.4498 & 5.1265 & TRN & \\
\hline CHEMBL1415101 & 688267 & 4.15 & 5.07600 & 00000000005 & TRN \\
\hline CHEMBL1404036 & 688267 & 6.2 & 4.9983 & TRN & \\
\hline CHEMBL1321618 & 688267 & 4.45 & 5.0133 & TRN & \\
\hline CHEMBL1435281 & 688267 & 4.05 & 5.08 & TRN & \\
\hline CHEMBL1436653 & 688267 & 5.5 & 4.999 & TRN & \\
\hline CHEMBL1603818 & 688267 & 4.6 & 5.171 & TRN & \\
\hline CHEMBL1567002 & 688267 & 6.15 & 5.0859 & TRN & \\
\hline CHEMBL1560887 & 688267 & 4.0 & 5.0396 & TRN & \\
\hline CHEMBL1449117 & 688267 & 4.35 & 5.0337 & TRN & \\
\hline CHEMBL 313833 & 688267 & 4.95 & 5.05 & TST & \\
\hline CHEMBL1460548 & 688267 & 4.05 & 5.0376 & TST & \\
\hline CHEMBL1380755 & 688267 & 5.55 & 5.0157 & TRN & \\
\hline CHEMBL1342962 & 688267 & 5.1 & 5.145 & TRN & \\
\hline CHEMBL1488602 & 688267 & 6.15 & 5.0427 & TRN & \\
\hline CHEMBL1428189 & 688267 & 4.3 & 5.0986 & TRN & \\
\hline CHEMBL1495962 & 688267 & 5.7 & 5.1082 & TRN & \\
\hline CHEMBL3211931 & 688267 & 6.2 & 5.0446 & TST & \\
\hline & & & & 17805 & \\
\hline
\end{tabular}




\begin{tabular}{|c|c|c|c|c|c|}
\hline \\
\hline CHEMBL1354160 & 688267 & 5.9 & 5.0848 & TST & \\
\hline CHEMBL1447332 & 688267 & 4.05 & 4.9877 & TRN & \\
\hline CHEMBL1371333 & 688267 & 4.0 & 5.0415 & TRN & \\
\hline CHEMBL1399222 & 688267 & 4.45 & 5.0672 & TRN & \\
\hline CHEMBL1496545 & 688267 & 4.0 & 5.0123 & TRN & \\
\hline CHEMBL1338167 & 688267 & 4.65 & 5.0322 & TRN & \\
\hline CHEMBL1602089 & 688267 & 6.2 & 5.037 & TRN & \\
\hline CHEMBL1539423 & 688267 & 4.05 & 5.0858 & TRN & \\
\hline CHEMBL1384306 & 688267 & 4.55 & 5.0475 & TRN & \\
\hline CHEMBL1478811 & 688267 & 3.95 & 5.1065 & TRN & \\
\hline CHEMBL1473084 & 688267 & 5.6 & 5.0071 & TRN & \\
\hline CHEMBL3207665 & 688267 & 4.35 & 5.0465 & TST & \\
\hline CHEMBL1552251 & 688267 & 6.25 & 5.0523 & TRN & \\
\hline CHEMBL1554179 & 688267 & 4.0 & 5.1389 & TST & \\
\hline CHEMBL1486099 & 688267 & 5.8 & 5.0446 & TRN & \\
\hline CHEMBL1315541 & 688267 & 5.35 & 5.0817 & TRN & \\
\hline CHEMBL1340883 & 688267 & 4.4 & 5.046 & TRN & \\
\hline CHEMBL1483527 & 688267 & 5.2 & 5.0464 & TST & \\
\hline CHEMBL1301246 & 688267 & 5.55 & 5.0462 & TRN & \\
\hline CHEMBL1364547 & 688267 & 4.55 & 5.0203 & TRN & \\
\hline CHEMBL1377664 & 688267 & 5.15 & 5.0105 & TRN & \\
\hline CHEMBL1591069 & 688267 & 4.7 & 5.0867 & TRN & \\
\hline CHEMBL1542938 & 688267 & 4.3 & 5.0766 & TRN & \\
\hline CHEMBL1603942 & 688267 & 5.1 & 5.0018 & TRN & \\
\hline CHEMBL1500551 & 688267 & 5.6 & 5.041 & TST & \\
\hline CHEMBL1444895 & 688267 & 6.2 & 5.0255 & TST & \\
\hline CHEMBL1607902 & 688267 & 5.3 & 5.0757 & TRN & \\
\hline CHEMBL1367230 & 688267 & 3.95 & 5.1282 & TRN & \\
\hline CHEMBL1333146 & 688267 & 4.0 & 5.0696 & TST & \\
\hline CHEMBL1417737 & 688267 & 4.0 & 5.062 & TRN & \\
\hline CHEMBL1317140 & 688267 & 4.5 & 5.0226 & TRN & \\
\hline CHEMBL1437424 & 688267 & 5.55 & 4.9652 & TRN & \\
\hline CHEMBL1479065 & 688267 & 6.2 & 5.0334 & TST & \\
\hline CHEMBL 3212750 & 688267 & 6.2 & 4.9858 & TRN & \\
\hline CHEMBL1425874 & 688267 & 5.45 & 5.1033 & TRN & \\
\hline CHEMBL1493627 & 688267 & 6.2 & 5.0657 & TRN & \\
\hline CHEMBL1435054 & 688267 & 4.05 & 5.1138 & TRN & \\
\hline CHEMBL3207447 & 688267 & 4.35 & 5.0303 & TRN & \\
\hline CHEMBL1369621 & 688267 & 4.25 & 5.04899 & 99999999995 & TST \\
\hline CHEMBL1593216 & 688267 & 5.9 & 5.0693 & TST & \\
\hline CHEMBL1359353 & 688267 & 4.35 & 5.0914 & TRN & \\
\hline CHEMBL1374043 & 688267 & 5.55 & 5.1139 & TRN & \\
\hline CHEMBL1591036 & 688267 & 6.2 & 5.0585 & TRN & \\
\hline CHEMBL1552872 & 688267 & 6.45 & 5.1542 & TRN & \\
\hline CHEMBL1407755 & 688267 & 6.25 & 5.0593 & TRN & \\
\hline CHEMBL1328466 & 688267 & 4.9 & 5.0567 & TRN & \\
\hline CHEMBL1568437 & 688267 & 4.4 & 5.0419 & TST & \\
\hline CHEMBL1510978 & 688267 & 5.55 & 5.1018 & TRN & \\
\hline
\end{tabular}




\begin{tabular}{|c|c|c|c|c|c|}
\hline \multicolumn{6}{|c|}{ Supplemental Table S2.txt } \\
\hline CHEMBL1363781 & 688267 & 4.15 & 5.1508 & TST & \\
\hline CHEMBL1585111 & 688267 & 6.1 & 5.022 & TRN & \\
\hline CHEMBL1342407 & 688267 & 4.8 & 5.0013 & TRN & \\
\hline CHEMBL1415295 & 688267 & 5.3 & 5.0647 & TST & \\
\hline CHEMBL1468297 & 688267 & 5.35 & 5.0581 & TRN & \\
\hline CHEMBL1461245 & 688267 & 6.2 & 5.1576 & TRN & \\
\hline CHEMBL1320675 & 688267 & 5.25 & 5.053 & TRN & \\
\hline CHEMBL1372817 & 688267 & 6.2 & 5.0352 & TRN & \\
\hline CHEMBL109866 & 688267 & 5.65 & 5.1067 & TST & \\
\hline CHEMBL1547626 & 688267 & 5.35 & 5.0523 & TST & \\
\hline CHEMBL1475797 & 688267 & 5.8 & 5.0771 & TRN & \\
\hline CHEMBL1500947 & 688267 & 5.1 & 5.1309 & TRN & \\
\hline CHEMBL1494672 & 688267 & 4.25 & 5.04 & TST & \\
\hline CHEMBL1435223 & 688267 & 4.0 & 4.99100 & 00000000005 & TRN \\
\hline CHEMBL1458366 & 688267 & 4.5 & 5.0165 & TRN & \\
\hline CHEMBL1427597 & 688267 & 4.05 & 5.0434 & TRN & \\
\hline CHEMBL1495595 & 688267 & 6.2 & 5.0137 & TRN & \\
\hline CHEMBL1587874 & 688267 & 3.95 & 5.1517 & TRN & \\
\hline CHEMBL1382284 & 688267 & 4.8 & 5.0113 & TRN & \\
\hline CHEMBL1451920 & 688267 & 3.95 & 5.0492 & TRN & \\
\hline CHEMBL1592252 & 688267 & 5.4 & 5.1225 & TRN & \\
\hline CHEMBL1497497 & 688267 & 6.15 & 5.0865 & TRN & \\
\hline CHEMBL1347626 & 688267 & 4.35 & 5.0246 & TST & \\
\hline CHEMBL1557319 & 688267 & 4.0 & 5.062 & TRN & \\
\hline CHEMBL1306224 & 688267 & 4.6 & 5.1217 & TRN & \\
\hline CHEMBL1467418 & 688267 & 4.3 & 4.9809 & TRN & \\
\hline CHEMBL1313075 & 688267 & 4.1 & 5.0965 & TST & \\
\hline CHEMBL1332784 & 688267 & 4.65 & 5.1198 & TRN & \\
\hline CHEMBL1441475 & 688267 & 4.35 & 5.1225 & TRN & \\
\hline CHEMBL1574485 & 688267 & 4.1 & 5.0877 & TST & \\
\hline CHEMBL1315032 & 688267 & 6.2 & 5.0878 & TST & \\
\hline CHEMBL1483687 & 688267 & 5.0 & 5.118 & TRN & \\
\hline CHEMBL1332692 & 688267 & 4.25 & 5.0782 & TRN & \\
\hline CHEMBL1414040 & 688267 & 6.05 & 5.0831 & TRN & \\
\hline CHEMBL1343212 & 688267 & 5.5 & 4.9834 & TRN & \\
\hline CHEMBL1400851 & 688267 & 4.25 & 5.0524 & TRN & \\
\hline CHEMBL1582310 & 688267 & 4.95 & 5.0113 & TST & \\
\hline CHEMBL1443902 & 688267 & 4.4 & 5.0633 & TRN & \\
\hline CHEMBL1373471 & 688267 & 5.85 & 5.0412 & TRN & \\
\hline CHEMBL1313110 & 688267 & 4.6 & 5.0771 & TRN & \\
\hline CHEMBL1344157 & 688267 & 5.8 & 5.0402 & TST & \\
\hline CHEMBL1441000 & 688267 & 5.3 & 5.024 & TRN & \\
\hline CHEMBL1612634 & 688267 & 5.15 & 5.0466 & TST & \\
\hline CHEMBL1354844 & 688267 & 5.85 & 5.1112 & TRN & \\
\hline CHEMBL1365814 & 688267 & 5.0 & 4.9918 & TRN & \\
\hline CHEMBL1359679 & 688267 & 4.55 & 5.0393 & TST & \\
\hline CHEMBL1437183 & 688267 & 4.0 & 5.0747 & TRN & \\
\hline CHEMBL1347487 & 688267 & 6.2 & 4.9898 & TST & \\
\hline
\end{tabular}




\begin{tabular}{|c|c|c|c|c|c|}
\hline \multicolumn{6}{|c|}{ plemental } \\
\hline CHEMBL1448382 & 688267 & 4.3 & 5.0248 & TRN & \\
\hline CHEMBL1338400 & 688267 & 4.55 & 5.1005 & TST & \\
\hline CHEMBL1604384 & 688267 & 5.0 & 5.0948 & TRN & \\
\hline CHEMBL1594039 & 688267 & 4.4 & 5.03100 & 0000000001 & TRN \\
\hline CHEMBL1346836 & 688267 & 4.0 & 5.0496 & TRN & \\
\hline CHEMBL1555855 & 688267 & 6.0 & 5.0785 & TRN & \\
\hline CHEMBL405886 & 688267 & 4.5 & 5.0248 & TRN & \\
\hline CHEMBL1609050 & 688267 & 5.95 & 5.0803 & TRN & \\
\hline CHEMBL1450403 & 688267 & 4.05 & 5.0015 & TRN & \\
\hline CHEMBL1513044 & 688267 & 4.55 & 5.0756 & TRN & \\
\hline CHEMBL1434099 & 688267 & 6.1 & 5.0398 & TRN & \\
\hline CHEMBL1358764 & 688267 & 5.05 & 5.0152 & TRN & \\
\hline CHEMBL1553589 & 688267 & 5.7 & 5.0872 & TRN & \\
\hline CHEMBL1330982 & 688267 & 4.0 & 5.0233 & TRN & \\
\hline CHEMBL1475777 & 688267 & 5.3 & 5.0459 & TRN & \\
\hline CHEMBL 2358182 & 688267 & 6.2 & 5.0318 & TRN & \\
\hline CHEMBL1366348 & 688267 & 5.1 & 5.0793 & TRN & \\
\hline CHEMBL1443012 & 688267 & 4.45 & 5.0831 & TST & \\
\hline CHEMBL1545512 & 688267 & 6.2 & 5.0051 & TRN & \\
\hline CHEMBL1378622 & 688267 & 5.05 & 5.0452 & TRN & \\
\hline CHEMBL1383977 & 688267 & 4.6 & 5.1107 & TRN & \\
\hline CHEMBL1419979 & 688267 & 4.25 & 5.0462 & TRN & \\
\hline CHEMBL1583286 & 688267 & 5.3 & 5.0938 & TRN & \\
\hline CHEMBL1444758 & 688267 & 4.45 & 5.019 & TRN & \\
\hline CHEMBL1591816 & 688267 & 5.8 & 5.0733 & TRN & \\
\hline CHEMBL1491738 & 688267 & 4.35 & 5.0432 & TRN & \\
\hline CHEMBL1480078 & 688267 & 4.4 & 5.0657 & TRN & \\
\hline CHEMBL1609065 & 688267 & 4.0 & 5.0814 & TRN & \\
\hline CHEMBL1553558 & 688267 & 6.1 & 5.0468 & TRN & \\
\hline CHEMBL1381944 & 688267 & 5.75 & 5.0604 & TST & \\
\hline CHEMBL1306072 & 688267 & 5.2 & 5.0637 & TRN & \\
\hline CHEMBL1599127 & 688267 & 3.95 & 5.0191 & TST & \\
\hline CHEMBL3210446 & 688267 & 6.0 & 5.0738 & TRN & \\
\hline CHEMBL1367148 & 688267 & 4.0 & 5.0315 & TRN & \\
\hline CHEMBL1375458 & 688267 & 4.0 & 4.9835 & TRN & \\
\hline CHEMBL1302684 & 688267 & 6.2 & 5.0987 & TRN & \\
\hline CHEMBL1606697 & 688267 & 3.95 & 5.0541 & TRN & \\
\hline CHEMBL1493653 & 688267 & 4.25 & 5.0972 & TST & \\
\hline CHEMBL1313019 & 688267 & 3.95 & 5.0913 & TST & \\
\hline CHEMBL1409040 & 688267 & 4.1 & 5.0601 & TRN & \\
\hline CHEMBL1419217 & 688267 & 4.5 & 5.0727 & TST & \\
\hline CHEMBL1559682 & 688267 & 3.95 & 5.16200 & $\partial 000000001$ & TRN \\
\hline CHEMBL1558316 & 688267 & 4.3 & 5.0283 & TST & \\
\hline CHEMBL1308200 & 688267 & 4.75 & 5.06800 & 00000000005 & TRN \\
\hline CHEMBL1496654 & 688267 & 5.7 & 5.016 & TRN & \\
\hline CHEMBL1606768 & 688267 & 5.9 & 5.119 & TRN & \\
\hline CHEMBL1462999 & 688267 & 6.2 & 5.0144 & TST & \\
\hline CHEMBL1511843 & 688267 & 5.9 & 5.0146 & TRN & \\
\hline
\end{tabular}




\begin{tabular}{|c|c|c|c|c|}
\hline \multicolumn{5}{|c|}{ Supplemental Table } \\
\hline CHEMBL1597331 & 688267 & 6.2 & 5.0112 & TST \\
\hline CHEMBL1346650 & 688267 & 4.0 & 5.0222 & TRN \\
\hline CHEMBL1364976 & 688267 & 4.0 & 5.0698 & TST \\
\hline CHEMBL1574289 & 688267 & 3.95 & 5.0555 & TRN \\
\hline CHEMBL1546261 & 688267 & 5.65 & 5.0595 & TRN \\
\hline CHEMBL1559450 & 688267 & 6.45 & 5.1068 & TRN \\
\hline CHEMBL1517464 & 688267 & 3.95 & 5.0747 & TRN \\
\hline CHEMBL1606483 & 688267 & 5.55 & 5.0253 & TRN \\
\hline CHEMBL1326458 & 688267 & 5.35 & 5.1256 & TRN \\
\hline CHEMBL1605339 & 688267 & 6.15 & 5.0635 & TRN \\
\hline CHEMBL1398296 & 688267 & 6.2 & 5.0694 & TRN \\
\hline CHEMBL1391471 & 688267 & 5.1 & 5.0731 & TRN \\
\hline CHEMBL1567948 & 688267 & 4.25 & 5.0815 & TRN \\
\hline CHEMBL 3212503 & 688267 & 4.85 & 5.0144 & TRN \\
\hline CHEMBL1376419 & 688267 & 4.5 & 5.0207 & TRN \\
\hline CHEMBL1475506 & 688267 & 6.15 & 5.0231 & TST \\
\hline CHEMBL1523636 & 688267 & 6.2 & 5.1016 & TST \\
\hline CHEMBL1603135 & 688267 & 5.95 & 5.0826 & TRN \\
\hline CHEMBL1416002 & 688267 & 4.9 & 5.0858 & TST \\
\hline CHEMBL1601364 & 688267 & 6.2 & 5.0353 & TRN \\
\hline CHEMBL1447114 & 688267 & 4.05 & 5.0663 & TRN \\
\hline CHEMBL1305850 & 688267 & 6.45 & 5.0147 & TST \\
\hline CHEMBL1590401 & 688267 & 6.15 & 5.1399 & TRN \\
\hline CHEMBL1541443 & 688267 & 5.85 & 5.047 & TRN \\
\hline CHEMBL1518433 & 688267 & 5.4 & 5.1413 & TRN \\
\hline CHEMBL1409271 & 688267 & 6.2 & 5.0186 & TRN \\
\hline CHEMBL1368367 & 688267 & 5.6 & 5.1109 & TRN \\
\hline CHEMBL1326597 & 688267 & 5.0 & 5.0662 & TST \\
\hline CHEMBL1357070 & 688267 & 4.3 & 5.0503 & TRN \\
\hline CHEMBL1388344 & 688267 & 4.4 & 4.9993 & TST \\
\hline CHEMBL1495874 & 688267 & 4.0 & 5.0324 & TRN \\
\hline CHEMBL1405240 & 688267 & 4.4 & 5.0478 & TRN \\
\hline CHEMBL1558865 & 688267 & 6.15 & 5.0597 & TRN \\
\hline CHEMBL1425659 & 688267 & 4.75 & 4.9834 & TRN \\
\hline CHEMBL1576642 & 688267 & 5.9 & 5.0493 & TRN \\
\hline CHEMBL1499067 & 688267 & 6.25 & 5.0446 & TRN \\
\hline CHEMBL1569653 & 688267 & 4.35 & 5.0192 & TRN \\
\hline CHEMBL1603374 & 688267 & 4.0 & 5.0913 & TRN \\
\hline CHEMBL1307803 & 688267 & 4.4 & 5.0586 & TRN \\
\hline CHEMBL1570443 & 688267 & 6.2 & 5.0625 & TST \\
\hline CHEMBL1586178 & 688267 & 5.9 & 5.1095 & TRN \\
\hline CHEMBL1606284 & 688267 & 4.8 & 5.0154 & TRN \\
\hline CHEMBL586937 & 688267 & 5.1 & 5.0516 & TST \\
\hline CHEMBL1390145 & 688267 & 4.05 & 5.0387 & TRN \\
\hline CHEMBL1427032 & 688267 & 4.15 & 5.1134 & TRN \\
\hline CHEMBL1591482 & 688267 & 6.15 & 5.0913 & TRN \\
\hline CHEMBL1607930 & 688267 & 4.0 & 4.9959 & TRN \\
\hline CHEMBL1532224 & 688267 & 4.55 & 5.1628 & TST \\
\hline
\end{tabular}




\begin{tabular}{|c|c|c|c|c|c|}
\hline \multirow{3}{*}{$\begin{array}{l}\text { CHEMBL1343403 } \\
\text { CHEMBL } 1613370\end{array}$} & \multirow{3}{*}{$\begin{array}{l}688267 \\
688267\end{array}$} & \multicolumn{4}{|c|}{ Supplemental Table s2.txt } \\
\hline & & 5.25 & \multicolumn{2}{|c|}{5.122999999999999} & TRN \\
\hline & & 5.4 & 5.044 & TST & \\
\hline CHEMBL1520759 & 688267 & 5.3 & 5.149 & TRN & \\
\hline CHEMBL1437677 & 688267 & 6.0 & 5.1044 & TRN & \\
\hline CHEMBL1380295 & 688267 & 5.3 & 5.07600 & 00000000005 & TST \\
\hline CHEMBL1399076 & 688267 & 4.4 & 5.1165 & TRN & \\
\hline CHEMBL1559122 & 688267 & 4.35 & 5.1224 & TST & \\
\hline CHEMBL1515445 & 688267 & 6.2 & 5.0531 & TST & \\
\hline CHEMBL1463772 & 688267 & 5.75 & 5.0423 & TRN & \\
\hline CHEMBL1360329 & 688267 & 4.05 & 5.1205 & TST & \\
\hline CHEMBL1475522 & 688267 & 4.35 & 5.0014 & TST & \\
\hline CHEMBL1241452 & 688267 & 5.9 & 5.0322 & TRN & \\
\hline CHEMBL1320670 & 688267 & 5.4 & 5.0087 & TRN & \\
\hline CHEMBL1357355 & 688267 & 5.15 & 5.0448 & TRN & \\
\hline CHEMBL1556755 & 688267 & 6.4 & 5.0416 & TST & \\
\hline CHEMBL1399445 & 688267 & 4.35 & 5.0162 & TRN & \\
\hline CHEMBL1375587 & 688267 & 5.5 & 5.0802 & TRN & \\
\hline CHEMBL1435514 & 688267 & 3.95 & 5.0512 & TRN & \\
\hline CHEMBL1498937 & 688267 & 4.45 & 4.9991 & TRN & \\
\hline CHEMBL1509443 & 688267 & 4.05 & 5.0872 & TST & \\
\hline CHEMBL1482218 & 688267 & 6.2 & 5.0058 & TRN & \\
\hline CHEMBL1421042 & 688267 & 4.5 & 5.0492 & TRN & \\
\hline CHEMBL1329038 & 688267 & 4.05 & 5.0283 & TRN & \\
\hline CHEMBL1369528 & 688267 & 4.0 & 5.0418 & TRN & \\
\hline CHEMBL1489448 & 688267 & 4.4 & 5.0338 & TRN & \\
\hline CHEMBL1551233 & 688267 & 5.3 & 5.0982 & TRN & \\
\hline CHEMBL1387134 & 688267 & 4.05 & 5.0615 & TRN & \\
\hline CHEMBL1331813 & 688267 & 4.4 & 5.0118 & TST & \\
\hline CHEMBL1412805 & 688267 & 4.0 & 5.0649 & TRN & \\
\hline CHEMBL1605044 & 688267 & 6.2 & 4.9966 & TRN & \\
\hline CHEMBL1376322 & 688267 & 6.2 & 5.0498 & TRN & \\
\hline CHEMBL1607365 & 688267 & 6.15 & 5.1283 & TRN & \\
\hline CHEMBL1406080 & 688267 & 5.6 & 5.0925 & TRN & \\
\hline CHEMBL1557082 & 688267 & 4.3 & 5.1106 & TST & \\
\hline CHEMBL1538846 & 688267 & 4.45 & 5.0161 & TST & \\
\hline CHEMBL1315761 & 688267 & 6.15 & 5.0248 & TRN & \\
\hline CHEMBL1569512 & 688267 & 5.65 & 5.0556 & TST & \\
\hline CHEMBL1418463 & 688267 & 4.0 & 5.0329 & TRN & \\
\hline CHEMBL1372013 & 688267 & 5.5 & 5.0481 & TST & \\
\hline CHEMBL1361033 & 688267 & 6.25 & 4.9957 & TRN & \\
\hline CHEMBL1554403 & 688267 & 5.6 & 5.0917 & TRN & \\
\hline CHEMBL1549051 & 688267 & 4.1 & 5.0076 & TRN & \\
\hline CHEMBL1455398 & 688267 & 6.2 & 5.058 & TRN & \\
\hline CHEMBL1323696 & 688267 & 4.3 & 4.985 & TST & \\
\hline CHEMBL1469741 & 688267 & 4.35 & 5.0967 & TRN & \\
\hline CHEMBL1366600 & 688267 & 4.0 & 5.052 & TRN & \\
\hline CHEMBL1562218 & 688267 & 5.2 & 5.081 & TRN & \\
\hline CHEMBL1369866 & 688267 & 6.3 & 5.1043 & TRN & \\
\hline
\end{tabular}




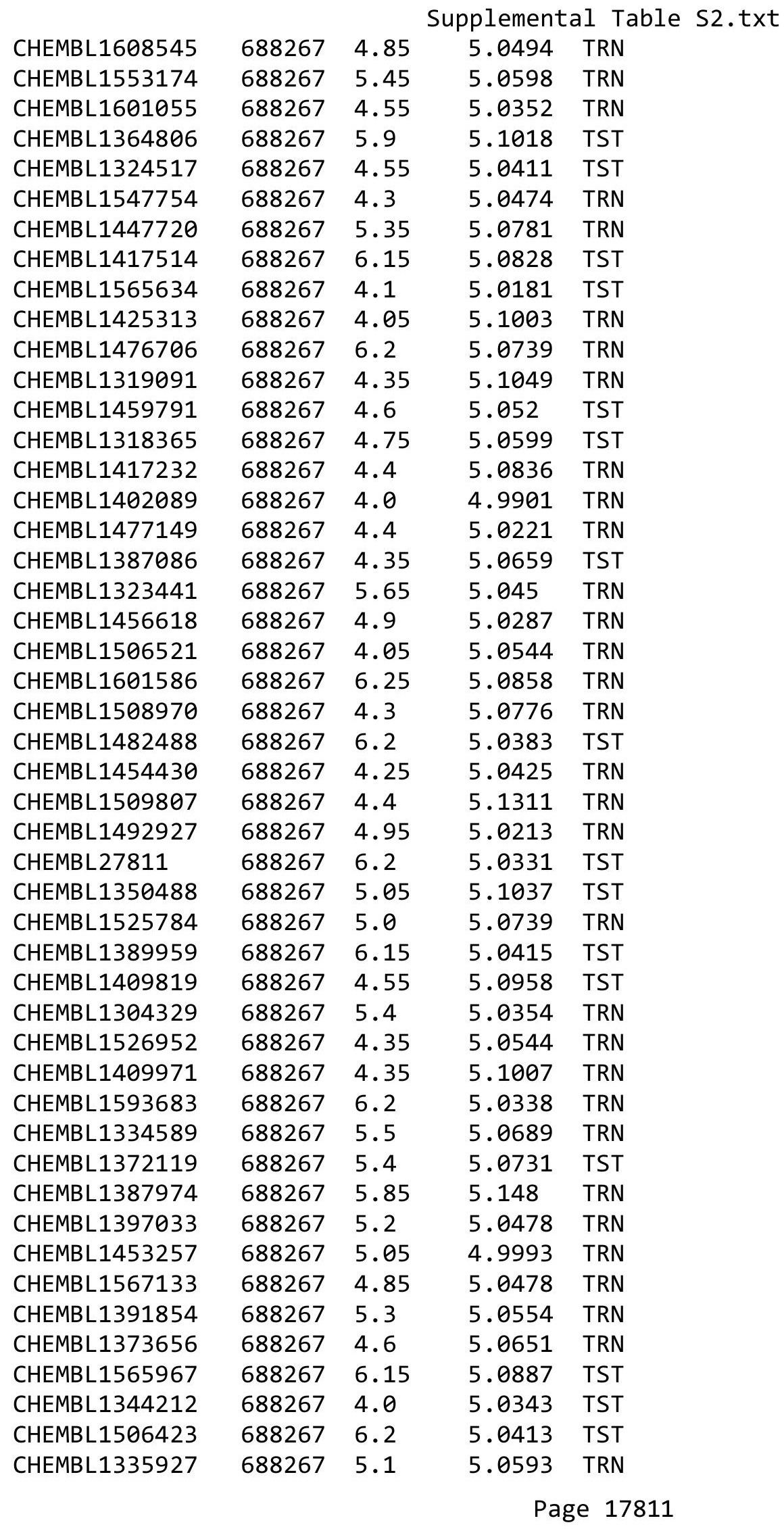




\begin{tabular}{|c|c|c|c|c|}
\hline \multicolumn{5}{|c|}{ Supplemental Table S2.txt } \\
\hline CHEMBL1324288 & 688267 & 5.45 & 5.1562 & TRN \\
\hline CHEMBL1452839 & 688267 & 5.0 & 5.0008 & TRN \\
\hline CHEMBL1304242 & 688267 & 5.05 & 5.0932 & TST \\
\hline CHEMBL1527264 & 688267 & 5.35 & 5.0984 & TRN \\
\hline CHEMBL1358609 & 688267 & 4.05 & 5.0671 & TRN \\
\hline CHEMBL1347460 & 688267 & 4.0 & 5.0273 & TST \\
\hline CHEMBL1533429 & 688267 & 4.6 & 5.0944 & TRN \\
\hline CHEMBL1451905 & 688267 & 5.35 & 5.0608 & TST \\
\hline CHEMBL1570901 & 688267 & 3.95 & 5.0385 & TST \\
\hline CHEMBL1601084 & 688267 & 3.95 & 5.1431 & TRN \\
\hline CHEMBL1548102 & 688267 & 4.65 & 5.0554 & TST \\
\hline CHEMBL1493057 & 688267 & 5.35 & 5.01 & TRN \\
\hline CHEMBL1443534 & 688267 & 4.0 & 5.0498 & TST \\
\hline CHEMBL1305172 & 688267 & 5.2 & 5.1329 & TRN \\
\hline CHEMBL1439110 & 688267 & 5.55 & 5.0751 & TRN \\
\hline CHEMBL1400130 & 688267 & 4.0 & 5.0564 & TST \\
\hline CHEMBL1613491 & 688267 & 4.3 & 5.1158 & TST \\
\hline CHEMBL3193111 & 688267 & 5.9 & 4.9776 & TRN \\
\hline CHEMBL1488711 & 688267 & 6.25 & 5.056 & TST \\
\hline CHEMBL1522559 & 688267 & 4.8 & 5.0807 & TRN \\
\hline CHEMBL1578085 & 688267 & 5.0 & 5.0928 & TRN \\
\hline CHEMBL1479074 & 688267 & 4.85 & 5.0343 & TRN \\
\hline CHEMBL1596647 & 688267 & 4.1 & 5.0051 & TRN \\
\hline CHEMBL1457979 & 688267 & 4.0 & 5.0481 & TRN \\
\hline CHEMBL1503395 & 688267 & 4.0 & 5.0336 & TRN \\
\hline CHEMBL1360376 & 688267 & 6.15 & 5.0427 & TRN \\
\hline CHEMBL1540822 & 688267 & 4.05 & 5.0095 & TST \\
\hline CHEMBL3196297 & 688267 & 4.05 & 4.995 & TST \\
\hline CHEMBL1523798 & 688267 & 6.2 & 5.0475 & TRN \\
\hline CHEMBL1424664 & 688267 & 4.05 & 5.0374 & TST \\
\hline CHEMBL1441074 & 688267 & 5.9 & 5.0112 & TRN \\
\hline CHEMBL1330528 & 688267 & 4.1 & 5.0821 & TRN \\
\hline CHEMBL1340248 & 688267 & 6.2 & 5.0498 & TRN \\
\hline CHEMBL1450390 & 688267 & 4.0 & 5.0358 & TST \\
\hline CHEMBL1353691 & 688267 & 5.4 & 5.0573 & TRN \\
\hline CHEMBL1508895 & 688267 & 4.5 & 5.1042 & TRN \\
\hline CHEMBL1505116 & 688267 & 4.7 & 5.0645 & TST \\
\hline CHEMBL1441584 & 688267 & 6.1 & 5.0453 & TRN \\
\hline CHEMBL1432677 & 688267 & 5.45 & 5.1359 & TRN \\
\hline CHEMBL1501209 & 688267 & 5.4 & 5.0259 & TST \\
\hline CHEMBL3193689 & 688267 & 5.2 & 5.0183 & TRN \\
\hline CHEMBL1318964 & 688267 & 4.3 & 5.0305 & TRN \\
\hline CHEMBL1318761 & 688267 & 4.25 & 5.0791 & TRN \\
\hline CHEMBL1500578 & 688267 & 6.5 & 5.052 & TRN \\
\hline CHEMBL1393725 & 688267 & 4.25 & 5.0978 & TST \\
\hline CHEMBL 2374093 & 688267 & 6.25 & 5.0476 & TRN \\
\hline CHEMBL1496415 & 688267 & 4.15 & 5.0879 & TRN \\
\hline CHEMBL1374472 & 688267 & 6.5 & 5.0923 & TRN \\
\hline
\end{tabular}




\begin{tabular}{|c|c|c|c|c|c|}
\hline \multicolumn{6}{|c|}{ Supplemental Table S2.txt } \\
\hline CHEMBL1386935 & 688267 & 4.55 & 5.0175 & TRN & \\
\hline CHEMBL1397585 & 688267 & 3.9 & 5.1592 & TRN & \\
\hline CHEMBL1432384 & 688267 & 4.0 & 5.0108 & TST & \\
\hline CHEMBL1389661 & 688267 & 4.55 & 5.0965 & TST & \\
\hline CHEMBL1448795 & 688267 & 4.25 & 5.0968 & TST & \\
\hline CHEMBL1477179 & 688267 & 4.7 & 5.0013 & TRN & \\
\hline CHEMBL1567080 & 688267 & 5.65 & 5.0804 & TRN & \\
\hline CHEMBL 3199117 & 688267 & 3.95 & 5.0215 & TRN & \\
\hline CHEMBL1570672 & 688267 & 4.2 & 5.0064 & TRN & \\
\hline CHEMBL1564513 & 688267 & 5.45 & 5.1403 & TRN & \\
\hline CHEMBL1494338 & 688267 & 6.1 & 5.0304 & TRN & \\
\hline CHEMBL1368345 & 688267 & 6.2 & 5.0287 & TRN & \\
\hline CHEMBL1506980 & 688267 & 4.05 & 5.0906 & TRN & \\
\hline CHEMBL1604245 & 688267 & 5.4 & 4.9808 & TRN & \\
\hline CHEMBL1569465 & 688267 & 3.95 & 5.0392 & TRN & \\
\hline CHEMBL1494980 & 688267 & 4.0 & 5.0111 & TST & \\
\hline CHEMBL1474783 & 688267 & 5.15 & 5.1491 & TRN & \\
\hline CHEMBL1431307 & 688267 & 5.8 & 5.0328 & TRN & \\
\hline CHEMBL1604707 & 688267 & 4.65 & 5.0126 & TRN & \\
\hline CHEMBL1584511 & 688267 & 4.0 & 5.087 & TRN & \\
\hline CHEMBL1555234 & 688267 & 5.85 & 5.1139 & TRN & \\
\hline CHEMBL1429126 & 688267 & 5.15 & 5.0413 & TST & \\
\hline CHEMBL1489393 & 688267 & 6.2 & 5.0424 & TRN & \\
\hline CHEMBL1322834 & 688267 & 4.0 & 5.018 & TRN & \\
\hline CHEMBL1556087 & 688267 & 5.05 & 5.027 & TRN & \\
\hline CHEMBL1995605 & 688267 & 5.3 & 5.0059 & TRN & \\
\hline CHEMBL1398501 & 688267 & 6.15 & 5.0493 & TRN & \\
\hline CHEMBL1966283 & 688267 & 5.1 & 5.0609 & TST & \\
\hline CHEMBL1494580 & 688267 & 4.75 & 5.0609 & TRN & \\
\hline CHEMBL1546919 & 688267 & 5.1 & 5.04899 & 99999999995 & TRN \\
\hline CHEMBL1566280 & 688267 & 5.85 & 5.0158 & TST & \\
\hline CHEMBL1586093 & 688267 & 4.0 & 5.067 & TRN & \\
\hline CHEMBL1451081 & 688267 & 4.85 & 5.084 & TRN & \\
\hline CHEMBL1306281 & 688267 & 4.7 & 5.1202 & TRN & \\
\hline CHEMBL1476209 & 688267 & 4.8 & 4.9983 & TRN & \\
\hline CHEMBL1446726 & 688267 & 6.2 & 5.064 & TST & \\
\hline CHEMBL1522992 & 688267 & 4.0 & 5.0951 & TRN & \\
\hline CHEMBL1378123 & 688267 & 5.35 & 5.101 & TRN & \\
\hline CHEMBL1385331 & 688267 & 5.6 & 5.0586 & TST & \\
\hline CHEMBL1340127 & 688267 & 4.0 & 5.0517 & TRN & \\
\hline CHEMBL1603902 & 688267 & 4.6 & 5.0505 & TRN & \\
\hline CHEMBL1345486 & 688267 & 5.45 & 5.0346 & TST & \\
\hline CHEMBL1311404 & 688267 & 4.05 & 5.0395 & TRN & \\
\hline CHEMBL1594829 & 688267 & 5.65 & 5.0619 & TRN & \\
\hline CHEMBL1371232 & 688267 & 5.05 & 5.1114 & TRN & \\
\hline CHEMBL1382975 & 688267 & 5.05 & 5.0972 & TST & \\
\hline CHEMBL1582464 & 688267 & 4.0 & 5.0108 & TRN & \\
\hline CHEMBL1554196 & 688267 & 4.1 & 5.1241 & TRN & \\
\hline
\end{tabular}




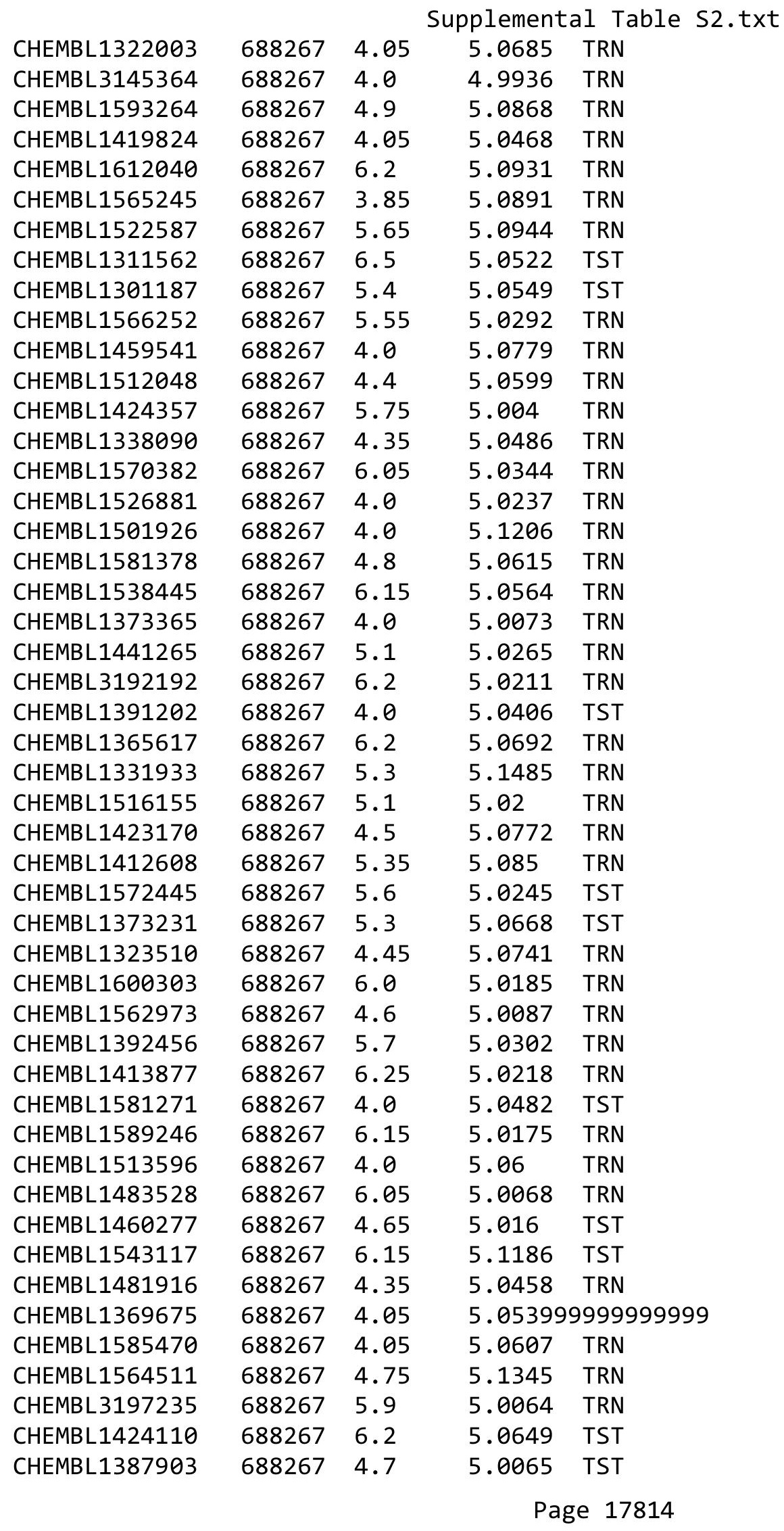

TRN 


\begin{tabular}{|c|c|c|c|c|}
\hline & & & upplement & $\mathrm{T}$ \\
\hline CHEMBL1545853 & 688267 & 4.45 & 5.0182 & TRN \\
\hline CHEMBL1427210 & 688267 & 4.0 & 5.0353 & TST \\
\hline CHEMBL1587170 & 688267 & 5.9 & 5.1239 & TRN \\
\hline CHEMBL1406786 & 688267 & 4.0 & 5.1243 & TRN \\
\hline CHEMBL1545019 & 688267 & 4.05 & 5.0627 & TRN \\
\hline CHEMBL1361498 & 688267 & 6.45 & 5.0371 & TRN \\
\hline CHEMBL1528455 & 688267 & 6.2 & 5.0341 & TRN \\
\hline CHEMBL1376145 & 688267 & 4.0 & 5.0319 & TRN \\
\hline CHEMBL1333836 & 688267 & 4.05 & 5.0603 & TRN \\
\hline CHEMBL1434599 & 688267 & 4.4 & 5.0088 & TST \\
\hline CHEMBL1324591 & 688267 & 5.8 & 5.1427 & TRN \\
\hline CHEMBL1559638 & 688267 & 5.35 & 5.0408 & TRN \\
\hline CHEMBL1491833 & 688267 & 5.0 & 5.0119 & TRN \\
\hline CHEMBL1504172 & 688267 & 5.35 & 5.0598 & TRN \\
\hline CHEMBL1343165 & 688267 & 4.5 & 5.0976 & TRN \\
\hline CHEMBL1433943 & 688267 & 4.2 & 5.1136 & TRN \\
\hline CHEMBL 2000222 & 688267 & 4.55 & 4.996 & TST \\
\hline CHEMBL1428427 & 688267 & 6.5 & 5.1021 & TRN \\
\hline CHEMBL1567088 & 688267 & 4.6 & 5.1691 & TRN \\
\hline CHEMBL1367474 & 688267 & 5.05 & 5.0254 & TST \\
\hline CHEMBL1509346 & 688267 & 6.2 & 5.1102 & TRN \\
\hline CHEMBL1553703 & 688267 & 6.2 & 4.99 & TRN \\
\hline CHEMBL1474029 & 688267 & 4.3 & 5.0452 & TRN \\
\hline CHEMBL1306512 & 688267 & 5.45 & 5.0737 & TRN \\
\hline CHEMBL1301847 & 688267 & 5.55 & 5.074 & TRN \\
\hline CHEMBL1543010 & 688267 & 4.1 & 5.0297 & TRN \\
\hline CHEMBL1359916 & 688267 & 4.65 & 5.032 & TST \\
\hline CHEMBL1463950 & 688267 & 3.95 & 5.0005 & TST \\
\hline CHEMBL1498247 & 688267 & 3.95 & 5.0219 & TRN \\
\hline CHEMBL1599329 & 688267 & 5.35 & 5.0141 & TRN \\
\hline CHEMBL1551760 & 688267 & 5.5 & 5.0619 & TRN \\
\hline CHEMBL1574002 & 688267 & 5.3 & 5.0129 & TRN \\
\hline CHEMBL1350513 & 688267 & 4.05 & 5.0253 & TST \\
\hline CHEMBL1609720 & 688267 & 5.15 & 5.0854 & TRN \\
\hline CHEMBL1335715 & 688267 & 5.1 & 5.075 & TRN \\
\hline CHEMBL565359 & 688267 & 5.8 & 5.0562 & TRN \\
\hline CHEMBL 1405569 & 688267 & 5.5 & 5.0602 & TRN \\
\hline CHEMBL1333110 & 688267 & 5.7 & 4.9968 & TRN \\
\hline CHEMBL1341962 & 688267 & 4.4 & 5.0223 & TRN \\
\hline CHEMBL1552746 & 688267 & 4.05 & 5.0946 & TRN \\
\hline CHEMBL1422899 & 688267 & 5.8 & 5.0312 & TRN \\
\hline CHEMBL1422590 & 688267 & 4.05 & 5.0889 & TST \\
\hline CHEMBL1445088 & 688267 & 4.4 & 5.0676 & TRN \\
\hline CHEMBL1554034 & 688267 & 6.05 & 5.0505 & TRN \\
\hline CHEMBL1596472 & 688267 & 4.05 & 5.0502 & TRN \\
\hline CHEMBL1503316 & 688267 & 4.05 & 5.0757 & TST \\
\hline CHEMBL1574854 & 688267 & 5.35 & 5.0463 & TRN \\
\hline CHEMBL1393953 & 688267 & 5.1 & 5.0485 & TRN \\
\hline
\end{tabular}




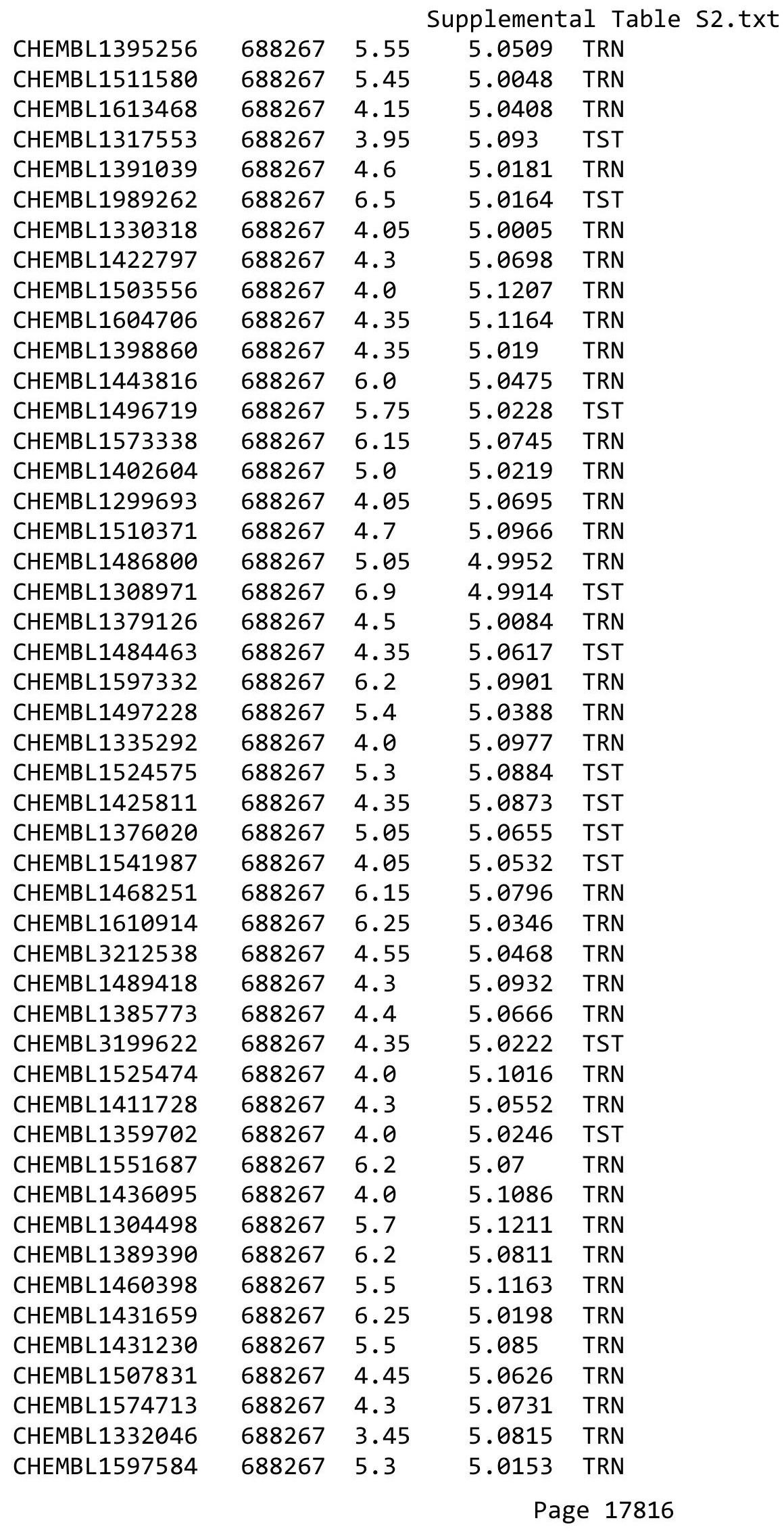




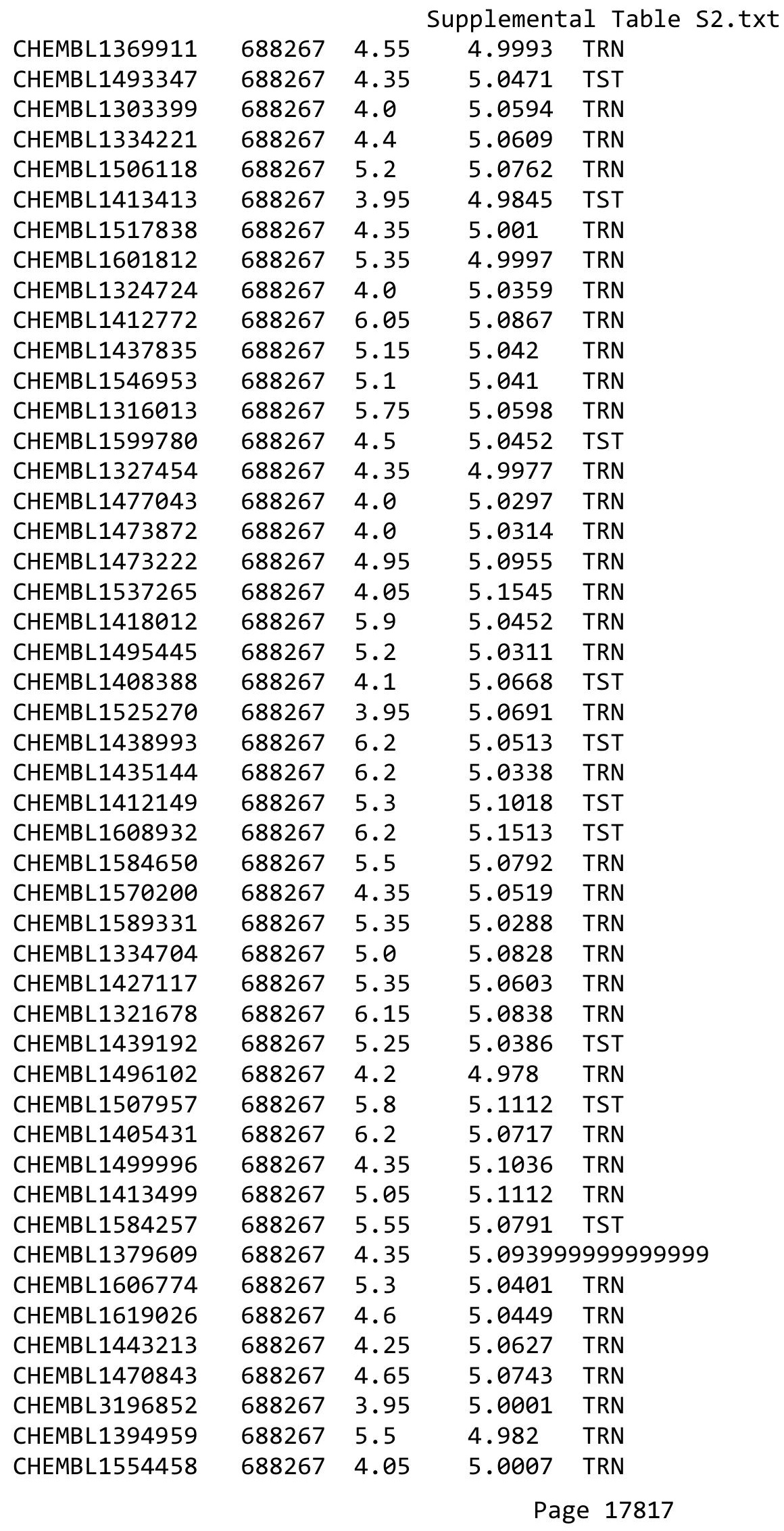




\begin{tabular}{|c|c|c|c|c|}
\hline \multicolumn{5}{|c|}{ Supplemental Table S2.txt } \\
\hline CHEMBL1409055 & 688267 & 4.35 & 5.0831 & TST \\
\hline CHEMBL1428263 & 688267 & 4.0 & 5.1075 & TRN \\
\hline CHEMBL1397891 & 688267 & 5.4 & 5.1231 & TRN \\
\hline CHEMBL1529997 & 688267 & 4.55 & 5.0741 & TRN \\
\hline CHEMBL1606898 & 688267 & 7.5003 & 5.0147 & TST \\
\hline CHEMBL1460956 & 688267 & 6.2 & 5.0204 & TRN \\
\hline CHEMBL378434 & 688267 & 4.3 & 4.9759 & TRN \\
\hline CHEMBL1533155 & 688267 & 5.3 & 5.0463 & TRN \\
\hline CHEMBL1596385 & 688267 & 4.5 & 5.0416 & TRN \\
\hline CHEMBL1304736 & 688267 & 6.15 & 5.0668 & TST \\
\hline CHEMBL3199746 & 688267 & 4.4 & 5.0275 & TRN \\
\hline CHEMBL3210125 & 688267 & 5.95 & 4.9801 & TRN \\
\hline CHEMBL 3190083 & 688267 & 4.65 & 5.0412 & TST \\
\hline CHEMBL1606070 & 688267 & 5.9 & 5.0569 & TST \\
\hline CHEMBL1309087 & 688267 & 4.95 & 5.0277 & TRN \\
\hline CHEMBL1435811 & 688267 & 4.35 & 5.0966 & TRN \\
\hline CHEMBL1569123 & 688267 & 4.25 & 5.1277 & TST \\
\hline CHEMBL1489019 & 688267 & 4.7 & 5.0767 & TRN \\
\hline CHEMBL1418021 & 688267 & 4.15 & 5.0692 & TRN \\
\hline CHEMBL1398058 & 688267 & 5.8 & 5.1291 & TRN \\
\hline CHEMBL1381861 & 688267 & 5.8 & 5.0751 & TRN \\
\hline CHEMBL1612713 & 688267 & 6.05 & 5.0722 & TST \\
\hline CHEMBL1424039 & 688267 & 6.15 & 5.1153 & TRN \\
\hline CHEMBL1448442 & 688267 & 4.05 & 4.9952 & TST \\
\hline CHEMBL1518030 & 688267 & 4.35 & 5.0362 & TRN \\
\hline CHEMBL1395282 & 688267 & 4.0 & 5.1514 & TRN \\
\hline CHEMBL 2003688 & 688267 & 4.0 & 5.0064 & TRN \\
\hline CHEMBL1559582 & 688267 & 6.0 & 5.1433 & TRN \\
\hline CHEMBL1423773 & 688267 & 4.7 & 5.0672 & TRN \\
\hline CHEMBL1394652 & 688267 & 5.8 & 5.0805 & TRN \\
\hline CHEMBL3192186 & 688267 & 6.2 & 5.0762 & TST \\
\hline CHEMBL1398106 & 688267 & 6.15 & 5.0468 & TRN \\
\hline CHEMBL1412690 & 688267 & 4.6 & 5.1606 & TRN \\
\hline CHEMBL1456903 & 688267 & 4.05 & 5.0258 & TRN \\
\hline CHEMBL1379230 & 688267 & 4.45 & 5.0463 & TRN \\
\hline CHEMBL1420216 & 688267 & 4.05 & 5.0881 & TRN \\
\hline CHEMBL1435453 & 688267 & 6.25 & 5.0654 & TRN \\
\hline CHEMBL1356465 & 688267 & 5.7 & 5.0837 & TRN \\
\hline CHEMBL1313529 & 688267 & 4.25 & 5.0137 & TRN \\
\hline CHEMBL1515418 & 688267 & 4.5 & 5.0307 & TRN \\
\hline CHEMBL1299581 & 688267 & 4.6 & 5.051 & TST \\
\hline CHEMBL1421364 & 688267 & 6.15 & 5.1139 & TST \\
\hline CHEMBL1343126 & 688267 & 4.0 & 5.0448 & TRN \\
\hline CHEMBL1447019 & 688267 & 5.35 & 5.069 & TRN \\
\hline CHEMBL1585764 & 688267 & 5.3 & 4.9967 & TST \\
\hline CHEMBL1586885 & 688267 & 4.35 & 5.0751 & TST \\
\hline CHEMBL1605647 & 688267 & 6.25 & 5.1213 & TRN \\
\hline CHEMBL1481448 & 688267 & 3.95 & 5.0549 & TRN \\
\hline
\end{tabular}




\begin{tabular}{|c|c|c|c|c|}
\hline \multicolumn{5}{|c|}{ Supplemental Table S2.txt } \\
\hline CHEMBL1327376 & 688267 & 4.55 & 5.1052 & TRN \\
\hline CHEMBL1971532 & 688267 & 4.3 & 4.9539 & TRN \\
\hline CHEMBL1472829 & 688267 & 7.4001 & 5.01399 & 9999999999 \\
\hline CHEMBL1309713 & 688267 & 4.0 & 5.0443 & TST \\
\hline CHEMBL1364600 & 688267 & 6.1 & 5.033 & TST \\
\hline CHEMBL1388597 & 688267 & 6.2 & 5.0493 & TRN \\
\hline CHEMBL1321842 & 688267 & 4.25 & 5.0435 & TST \\
\hline CHEMBL1528191 & 688267 & 4.0 & 5.0643 & TRN \\
\hline CHEMBL1537039 & 688267 & 6.2 & 5.0643 & TRN \\
\hline CHEMBL1355537 & 688267 & 5.5 & 4.9953 & TST \\
\hline CHEMBL1327646 & 688267 & 6.45 & 5.0668 & TRN \\
\hline CHEMBL1356139 & 688267 & 5.6 & 5.098 & TRN \\
\hline CHEMBL1401423 & 688267 & 5.15 & 5.0971 & TRN \\
\hline CHEMBL1477563 & 688267 & 6.25 & 5.0989 & TRN \\
\hline CHEMBL1370341 & 688267 & 5.05 & 5.1605 & TRN \\
\hline CHEMBL 3214530 & 688267 & 4.1 & 5.0197 & TST \\
\hline CHEMBL1493143 & 688267 & 4.55 & 5.1078 & TRN \\
\hline CHEMBL1464207 & 688267 & 5.8 & 5.1042 & TRN \\
\hline CHEMBL1359848 & 688267 & 6.5 & 5.1152 & TRN \\
\hline CHEMBL1356588 & 688267 & 5.3 & 5.1133 & TRN \\
\hline CHEMBL1461995 & 688267 & 4.75 & 5.0766 & TRN \\
\hline CHEMBL1330203 & 688267 & 4.0 & 5.101 & TST \\
\hline CHEMBL1404040 & 688267 & 4.4 & 5.0975 & TRN \\
\hline CHEMBL1304075 & 688267 & 5.55 & 5.0665 & TRN \\
\hline CHEMBL1563914 & 688267 & 6.2 & 5.0541 & TRN \\
\hline CHEMBL 3196574 & 688267 & 5.4 & 5.063 & TRN \\
\hline CHEMBL1299342 & 688267 & 4.65 & 5.007 & TST \\
\hline CHEMBL1544292 & 688267 & 6.25 & 5.0104 & TST \\
\hline CHEMBL1410341 & 688267 & 6.15 & 5.0331 & TRN \\
\hline CHEMBL1506230 & 688267 & 5.6 & 5.0942 & TST \\
\hline CHEMBL1380984 & 688267 & 4.7 & 5.0406 & TRN \\
\hline CHEMBL1568112 & 688267 & 6.15 & 5.1132 & TST \\
\hline CHEMBL1401260 & 688267 & 5.2 & 5.0368 & TRN \\
\hline CHEMBL1424620 & 688267 & 5.3 & 5.0863 & TRN \\
\hline CHEMBL1437028 & 688267 & 4.55 & 5.063 & TRN \\
\hline CHEMBL1505179 & 688267 & 4.5 & 5.0408 & TST \\
\hline CHEMBL1507454 & 688267 & 6.5 & 5.1323 & TST \\
\hline CHEMBL1469518 & 688267 & 5.1 & 5.0383 & TRN \\
\hline CHEMBL1344544 & 688267 & 4.0 & 5.0817 & TST \\
\hline CHEMBL1351984 & 688267 & 6.15 & 5.1271 & TRN \\
\hline CHEMBL1518786 & 688267 & 4.95 & 5.0017 & TRN \\
\hline CHEMBL1405452 & 688267 & 4.05 & 5.0542 & TST \\
\hline CHEMBL1413175 & 688267 & 5.05 & 5.0053 & TST \\
\hline CHEMBL1573748 & 688267 & 5.6 & 5.003 & TST \\
\hline CHEMBL1542241 & 688267 & 5.35 & 5.109 & TRN \\
\hline CHEMBL1437627 & 688267 & 4.05 & 5.0061 & TRN \\
\hline CHEMBL1306234 & 688267 & 4.0 & 5.0123 & TRN \\
\hline CHEMBL1523724 & 688267 & 6.2 & 5.0689 & TRN \\
\hline
\end{tabular}

TRN 


\begin{tabular}{|c|c|c|c|c|c|}
\hline \multicolumn{6}{|c|}{ Supplemental Table S2.txt } \\
\hline CHEMBL1325821 & 688267 & 4.05 & 5.0922 & TRN & \\
\hline CHEMBL1338069 & 688267 & 6.15 & 5.1052 & TRN & \\
\hline CHEMBL1426885 & 688267 & 6.05 & 5.1005 & TRN & \\
\hline CHEMBL3145191 & 688267 & 3.95 & 5.0294 & TST & \\
\hline CHEMBL1362159 & 688267 & 4.0 & 5.0575 & TRN & \\
\hline CHEMBL1530878 & 688267 & 4.1 & 5.04899 & 99999999995 & TRN \\
\hline CHEMBL1438205 & 688267 & 5.3 & 5.0224 & TST & \\
\hline CHEMBL1383693 & 688267 & 5.25 & 5.0853 & TRN & \\
\hline CHEMBL1468468 & 688267 & 4.45 & 5.0711 & TRN & \\
\hline CHEMBL1455120 & 688267 & 5.25 & 5.01399 & 9999999999 & TRN \\
\hline CHEMBL1476938 & 688267 & 5.35 & 5.0831 & TST & \\
\hline CHEMBL1319271 & 688267 & 6.15 & 5.0928 & TRN & \\
\hline CHEMBL1570299 & 688267 & 5.55 & 5.0277 & TRN & \\
\hline CHEMBL1378099 & 688267 & 4.1 & 5.0305 & TRN & \\
\hline CHEMBL1416995 & 688267 & 5.8 & 5.0568 & TRN & \\
\hline CHEMBL1480794 & 688267 & 4.65 & 5.1142 & TRN & \\
\hline CHEMBL1468124 & 688267 & 4.3 & 5.033 & TRN & \\
\hline CHEMBL1473736 & 688267 & 5.45 & 5.095 & TRN & \\
\hline CHEMBL1567220 & 688267 & 6.0 & 5.0797 & TRN & \\
\hline CHEMBL1328357 & 688267 & 4.75 & 4.995 & TST & \\
\hline CHEMBL1306511 & 688267 & 5.5 & 5.0304 & TRN & \\
\hline CHEMBL1595991 & 688267 & 5.0 & 5.1612 & TRN & \\
\hline CHEMBL1308196 & 688267 & 4.6 & 5.0379 & TRN & \\
\hline CHEMBL1305603 & 688267 & 6.5 & 5.05 & TRN & \\
\hline CHEMBL1535610 & 688267 & 5.45 & 5.0061 & TRN & \\
\hline CHEMBL1421236 & 688267 & 4.4 & 5.0776 & TST & \\
\hline CHEMBL1543496 & 688267 & 5.35 & 5.0428 & TRN & \\
\hline CHEMBL1344753 & 688267 & 6.2 & 5.0716 & TRN & \\
\hline CHEMBL1350028 & 688267 & 5.15 & 5.0493 & TRN & \\
\hline CHEMBL1314472 & 688267 & 4.05 & 4.9708 & TRN & \\
\hline CHEMBL3213307 & 688267 & 4.05 & 5.0708 & TST & \\
\hline CHEMBL1531182 & 688267 & 6.2 & 5.092 & TRN & \\
\hline CHEMBL3196026 & 688267 & 4.95 & 4.9919 & TRN & \\
\hline CHEMBL1316851 & 688267 & 5.7 & 5.1101 & TRN & \\
\hline CHEMBL1525959 & 688267 & 4.55 & 5.0924 & TST & \\
\hline CHEMBL1583673 & 688267 & 6.2 & 5.0308 & TST & \\
\hline CHEMBL1472625 & 688267 & 5.25 & 5.1205 & TRN & \\
\hline CHEMBL1600144 & 688267 & 5.8 & 5.0732 & TRN & \\
\hline CHEMBL1371556 & 688267 & 5.45 & 4.9887 & TST & \\
\hline CHEMBL1356675 & 688267 & 4.3 & 5.1004 & TRN & \\
\hline CHEMBL1515924 & 688267 & 4.0 & 5.0523 & TRN & \\
\hline CHEMBL1401872 & 688267 & 6.45 & 5.0123 & TRN & \\
\hline CHEMBL1508412 & 688267 & 6.2 & 5.067 & TRN & \\
\hline CHEMBL1309319 & 688267 & 4.3 & 5.035 & TRN & \\
\hline CHEMBL1349203 & 688267 & 6.25 & 5.0434 & TRN & \\
\hline CHEMBL1598746 & 688267 & 6.0 & 5.0555 & TRN & \\
\hline CHEMBL1335307 & 688267 & 4.4 & 5.0019 & TRN & \\
\hline CHEMBL1373634 & 688267 & 4.4 & 5.0489 & TRN & \\
\hline
\end{tabular}




\begin{tabular}{|c|c|c|c|c|}
\hline \multicolumn{5}{|c|}{ Supplemental Table S2.txt } \\
\hline CHEMBL1319445 & 688267 & 5.85 & 5.1304 & TRN \\
\hline CHEMBL1486253 & 688267 & 5.0 & 5.07 & TRN \\
\hline CHEMBL1458378 & 688267 & 5.85 & 5.0289 & TRN \\
\hline CHEMBL1433787 & 688267 & 5.35 & 5.0638 & TRN \\
\hline CHEMBL1964512 & 688267 & 4.45 & 4.9799 & TRN \\
\hline CHEMBL1535447 & 688267 & 5.5 & 5.0341 & TRN \\
\hline CHEMBL1382769 & 688267 & 4.05 & 5.0256 & TRN \\
\hline CHEMBL1329689 & 688267 & 4.4 & 4.9972 & TRN \\
\hline CHEMBL1383082 & 688267 & 6.15 & 5.0121 & TRN \\
\hline CHEMBL1379365 & 688267 & 4.4 & 5.0185 & TRN \\
\hline CHEMBL1463338 & 688267 & 3.95 & 5.078 & TRN \\
\hline CHEMBL1475406 & 688267 & 5.05 & 4.9776 & TRN \\
\hline CHEMBL1355159 & 688267 & 3.95 & 5.0356 & TRN \\
\hline CHEMBL1529431 & 688267 & 4.35 & 5.0369 & TST \\
\hline CHEMBL1425159 & 688267 & 4.4 & 5.0139 & TRN \\
\hline CHEMBL1551839 & 688267 & 6.0 & 4.9887 & TST \\
\hline CHEMBL1330654 & 688267 & 4.75 & 5.0613 & TRN \\
\hline CHEMBL1521807 & 688267 & 3.95 & 5.1199 & TRN \\
\hline CHEMBL1477528 & 688267 & 4.45 & 5.0301 & TRN \\
\hline CHEMBL3209173 & 688267 & 4.0 & 5.0047 & TST \\
\hline CHEMBL1319994 & 688267 & 4.1 & 5.0199 & TRN \\
\hline CHEMBL1576716 & 688267 & 5.5 & 5.0723 & TRN \\
\hline CHEMBL1375868 & 688267 & 5.2 & 5.0636 & TRN \\
\hline CHEMBL1576756 & 688267 & 4.95 & 5.0495 & TRN \\
\hline CHEMBL1394248 & 688267 & 5.35 & 5.0639 & TRN \\
\hline CHEMBL1455036 & 688267 & 4.4 & 5.0246 & TRN \\
\hline CHEMBL1546753 & 688267 & 4.05 & 5.0873 & TST \\
\hline CHEMBL1450603 & 688267 & 4.0 & 5.1308 & TRN \\
\hline CHEMBL1441816 & 688267 & 6.5 & 5.0992 & TRN \\
\hline CHEMBL1406157 & 688267 & 5.3 & 5.0059 & TRN \\
\hline CHEMBL1479880 & 688267 & 4.35 & 5.0232 & TRN \\
\hline CHEMBL1606924 & 688267 & 4.4 & 5.0299 & TST \\
\hline CHEMBL1429887 & 688267 & 4.0 & 5.0168 & TRN \\
\hline CHEMBL1364263 & 688267 & 5.85 & 5.1046 & TRN \\
\hline CHEMBL1386363 & 688267 & 4.0 & 5.0871 & TRN \\
\hline CHEMBL1522457 & 688267 & 4.05 & 5.0478 & TRN \\
\hline CHEMBL1608246 & 688267 & 4.0 & 5.1033 & TST \\
\hline CHEMBL1368025 & 688267 & 3.95 & 5.0756 & TRN \\
\hline CHEMBL3208208 & 688267 & 5.55 & 4.9837 & TST \\
\hline CHEMBL1490485 & 688267 & 6.25 & 5.0368 & TST \\
\hline CHEMBL1418289 & 688267 & 6.1 & 5.062 & TRN \\
\hline CHEMBL1601821 & 688267 & 5.9 & 5.0053 & TRN \\
\hline CHEMBL1405713 & 688267 & 4.35 & 5.0549 & TRN \\
\hline CHEMBL1563116 & 688267 & 4.0 & 5.032 & TRN \\
\hline CHEMBL1572422 & 688267 & 4.8 & 5.0153 & TST \\
\hline CHEMBL1496273 & 688267 & 4.75 & 5.0465 & TRN \\
\hline CHEMBL1462117 & 688267 & 4.05 & 4.9517 & TRN \\
\hline CHEMBL1477364 & 688267 & 6.45 & 5.0547 & TRN \\
\hline
\end{tabular}




\begin{tabular}{|c|c|c|c|c|c|}
\hline \multicolumn{6}{|c|}{ Supplemental Table S2.txt } \\
\hline CHEMBL1446607 & 688267 & 5.25 & 5.0699 & TRN & \\
\hline CHEMBL1319169 & 688267 & 5.25 & 5.0312 & TRN & \\
\hline CHEMBL1561391 & 688267 & 4.05 & 5.088 & TRN & \\
\hline CHEMBL1435932 & 688267 & 4.35 & 4.9599 & TRN & \\
\hline CHEMBL1489860 & 688267 & 5.3 & 5.103 & TRN & \\
\hline CHEMBL1553196 & 688267 & 3.95 & 5.0303 & TRN & \\
\hline CHEMBL3196713 & 688267 & 3.95 & 5.0125 & TST & \\
\hline CHEMBL1317965 & 688267 & 5.3 & 5.0425 & TRN & \\
\hline CHEMBL1604756 & 688267 & 6.2 & 5.1211 & TRN & \\
\hline CHEMBL1509746 & 688267 & 5.85 & 5.0503 & TST & \\
\hline CHEMBL1479459 & 688267 & 4.4 & 5.0508 & TRN & \\
\hline CHEMBL1570169 & 688267 & 4.35 & 5.0745 & TRN & \\
\hline CHEMBL1585093 & 688267 & 5.75 & 5.0556 & TRN & \\
\hline CHEMBL1520133 & 688267 & 3.95 & 4.9847 & TST & \\
\hline CHEMBL1418228 & 688267 & 6.25 & 5.151 & TRN & \\
\hline CHEMBL1406252 & 688267 & 6.2 & 5.0031 & TRN & \\
\hline CHEMBL1559415 & 688267 & 4.15 & 5.0408 & TRN & \\
\hline CHEMBL3197185 & 688267 & 4.0 & 5.0797 & TRN & \\
\hline CHEMBL1367200 & 688267 & 4.0 & 5.01399 & 9999999999 & TRN \\
\hline CHEMBL1456153 & 688267 & 4.2 & 5.0504 & TRN & \\
\hline CHEMBL1539783 & 688267 & 4.8 & 5.0438 & TRN & \\
\hline CHEMBL1482812 & 688267 & 5.5 & 5.0862 & TRN & \\
\hline CHEMBL1338206 & 688267 & 5.45 & 5.0991 & TRN & \\
\hline CHEMBL1329050 & 688267 & 4.45 & 5.1376 & TRN & \\
\hline CHEMBL1448453 & 688267 & 6.15 & 5.0019 & TRN & \\
\hline CHEMBL1347045 & 688267 & 5.4 & 5.0329 & TST & \\
\hline CHEMBL3212909 & 688267 & 5.25 & 5.0527 & TST & \\
\hline CHEMBL1438094 & 688267 & 5.8 & 5.0011 & TRN & \\
\hline CHEMBL1426754 & 688267 & 6.25 & 5.0161 & TST & \\
\hline CHEMBL1522042 & 688267 & 5.5 & 5.019 & TRN & \\
\hline CHEMBL1435400 & 688267 & 6.15 & 4.98600 & 0000000001 & TRN \\
\hline CHEMBL1596972 & 688267 & 5.5 & 5.0343 & TST & \\
\hline CHEMBL1521155 & 688267 & 5.05 & 5.0956 & TRN & \\
\hline CHEMBL1476337 & 688267 & 5.05 & 5.1122 & TRN & \\
\hline CHEMBL1473603 & 688267 & 6.2 & 5.0969 & TRN & \\
\hline CHEMBL1535375 & 688267 & 5.9 & 5.0623 & TRN & \\
\hline CHEMBL 3194225 & 688267 & 5.1 & 5.0179 & TRN & \\
\hline CHEMBL1441594 & 688267 & 4.6 & 5.084 & TRN & \\
\hline CHEMBL1604374 & 688267 & 5.35 & 5.1051 & TST & \\
\hline CHEMBL1457250 & 688267 & 6.15 & 5.0845 & TRN & \\
\hline CHEMBL1393053 & 688267 & 5.95 & 5.0202 & TST & \\
\hline CHEMBL1397047 & 688267 & 5.35 & 5.0257 & TRN & \\
\hline CHEMBL1500027 & 688267 & 3.5 & 5.1195 & TST & \\
\hline CHEMBL1481142 & 688267 & 4.95 & 5.1043 & TRN & \\
\hline CHEMBL1449865 & 688267 & 6.15 & 5.056 & TRN & \\
\hline CHEMBL1390644 & 688267 & 3.95 & 5.0027 & TRN & \\
\hline CHEMBL 3213193 & 688267 & 5.95 & 5.069 & TRN & \\
\hline CHEMBL1454710 & 688267 & 3.95 & 5.0109 & TRN & \\
\hline
\end{tabular}




\begin{tabular}{|c|c|c|c|c|}
\hline & & & pplement & al $\mathrm{Ta}$ \\
\hline CHEMBL1605795 & 688267 & 4.3 & 5.0637 & TRN \\
\hline CHEMBL1543951 & 688267 & 5.6 & 5.0128 & TRN \\
\hline CHEMBL1511379 & 688267 & 5.75 & 5.0456 & TST \\
\hline CHEMBL1299707 & 688267 & 6.5 & 5.0393 & TST \\
\hline CHEMBL1564277 & 688267 & 6.2 & 5.0648 & TRN \\
\hline CHEMBL1389546 & 688267 & 4.05 & 5.1165 & TRN \\
\hline CHEMBL112597 & 688267 & 4.65 & 5.0191 & TST \\
\hline CHEMBL1383873 & 688267 & 4.15 & 5.0602 & TST \\
\hline CHEMBL1414046 & 688267 & 3.95 & 4.9927 & TRN \\
\hline CHEMBL1605216 & 688267 & 4.85 & 5.0802 & TST \\
\hline CHEMBL1341451 & 688267 & 5.55 & 5.0471 & TST \\
\hline CHEMBL1499199 & 688267 & 5.5 & 5.1406 & TRN \\
\hline CHEMBL1432916 & 688267 & 4.0 & 5.1164 & TRN \\
\hline CHEMBL1437767 & 688267 & 4.35 & 5.0727 & TRN \\
\hline CHEMBL1336630 & 688267 & 4.0 & 5.0744 & TRN \\
\hline CHEMBL1475533 & 688267 & 4.0 & 4.9948 & TRN \\
\hline CHEMBL3213593 & 688267 & 4.0 & 5.0178 & TST \\
\hline CHEMBL1391296 & 688267 & 3.95 & 5.0432 & TRN \\
\hline CHEMBL1498592 & 688267 & 5.45 & 5.131 & TRN \\
\hline CHEMBL1326101 & 688267 & 4.65 & 5.0228 & TRN \\
\hline CHEMBL1457521 & 688267 & 4.85 & 5.0137 & TST \\
\hline CHEMBL3207704 & 688267 & 6.05 & 5.1048 & TRN \\
\hline CHEMBL1329601 & 688267 & 6.5 & 5.0634 & TRN \\
\hline CHEMBL1325278 & 688267 & 4.0 & 5.0515 & TRN \\
\hline CHEMBL1521735 & 688267 & 4.4 & 5.1002 & TRN \\
\hline CHEMBL1427968 & 688267 & 4.0 & 5.0833 & TRN \\
\hline CHEMBL1533036 & 688267 & 4.7 & 5.0315 & TST \\
\hline CHEMBL1559619 & 688267 & 6.2 & 5.1194 & TRN \\
\hline CHEMBL1520332 & 688267 & 4.35 & 5.0017 & TRN \\
\hline CHEMBL1392506 & 688267 & 6.5 & 5.0437 & TRN \\
\hline CHEMBL1333361 & 688267 & 5.35 & 5.024 & TST \\
\hline CHEMBL1475849 & 688267 & 5.15 & 5.0241 & TRN \\
\hline CHEMBL460347 & 688267 & 4.3 & 5.084 & TST \\
\hline CHEMBL1408197 & 688267 & 5.75 & 5.0811 & TRN \\
\hline CHEMBL1356600 & 688267 & 6.25 & 5.1316 & TRN \\
\hline CHEMBL1563963 & 688267 & 6.25 & 5.0492 & TRN \\
\hline CHEMBL1445373 & 688267 & 6.2 & 5.0527 & TRN \\
\hline CHEMBL1433536 & 688267 & 6.1 & 5.1325 & TRN \\
\hline CHEMBL1575965 & 688267 & 4.25 & 5.1029 & TRN \\
\hline CHEMBL1356579 & 688267 & 3.95 & 5.0144 & TRN \\
\hline CHEMBL1323291 & 688267 & 5.4 & 5.1419 & TRN \\
\hline CHEMBL1337408 & 688267 & 6.2 & 5.0391 & TRN \\
\hline CHEMBL1398411 & 688267 & 4.0 & 5.0331 & TRN \\
\hline CHEMBL1359909 & 688267 & 4.1 & 5.0679 & TRN \\
\hline CHEMBL1320741 & 688267 & 4.95 & 5.0161 & TRN \\
\hline CHEMBL1487494 & 688267 & 5.4 & 5.0423 & TRN \\
\hline CHEMBL1432889 & 688267 & 5.45 & 5.0443 & TST \\
\hline CHEMBL1488802 & 688267 & 4.9 & 5.0078 & TRN \\
\hline
\end{tabular}




\begin{tabular}{|c|c|c|c|c|c|}
\hline \multicolumn{6}{|c|}{ Supplemental Table S2.txt } \\
\hline CHEMBL1456355 & 688267 & 5.35 & 5.0197 & TST & \\
\hline CHEMBL1508986 & 688267 & 4.75 & 5.091 & TRN & \\
\hline CHEMBL1503598 & 688267 & 5.5 & 5.055 & TRN & \\
\hline CHEMBL1580560 & 688267 & 5.4 & 5.0494 & TRN & \\
\hline CHEMBL1453008 & 688267 & 6.05 & 5.011 & TRN & \\
\hline CHEMBL1541573 & 688267 & 4.4 & 5.0869 & TRN & \\
\hline CHEMBL1574383 & 688267 & 4.0 & 4.9842 & TST & \\
\hline CHEMBL1366072 & 688267 & 4.3 & 5.1356 & TRN & \\
\hline CHEMBL1423861 & 688267 & 4.1 & 5.0517 & TST & \\
\hline CHEMBL1515205 & 688267 & 6.05 & 5.0399 & TRN & \\
\hline CHEMBL1428011 & 688267 & 6.2 & 5.1029 & TRN & \\
\hline CHEMBL1404138 & 688267 & 6.2 & 5.0943 & TST & \\
\hline CHEMBL1402093 & 688267 & 6.5 & 5.0793 & TST & \\
\hline CHEMBL1602586 & 688267 & 4.0 & 5.0626 & TRN & \\
\hline CHEMBL1550354 & 688267 & 5.5 & 5.1343 & TRN & \\
\hline CHEMBL1419766 & 688267 & 6.15 & 5.0431 & TST & \\
\hline CHEMBL1319631 & 688267 & 5.05 & 5.0763 & TST & \\
\hline CHEMBL1321854 & 688267 & 5.9 & 5.0688 & TRN & \\
\hline CHEMBL3210613 & 688267 & 4.3 & 5.0383 & TST & \\
\hline CHEMBL1473819 & 688267 & 4.0 & 4.9874 & TST & \\
\hline CHEMBL1524346 & 688267 & 5.25 & 5.0961 & TRN & \\
\hline CHEMBL1433845 & 688267 & 4.75 & 5.0903 & TRN & \\
\hline CHEMBL1497706 & 688267 & 6.0 & 5.0571 & TST & \\
\hline CHEMBL1513560 & 688267 & 5.9 & 5.0276 & TRN & \\
\hline CHEMBL1413906 & 688267 & 4.0 & 5.0474 & TRN & \\
\hline CHEMBL1609919 & 688267 & 5.6 & 5.0239 & TRN & \\
\hline CHEMBL1547052 & 688267 & 4.0 & 5.1004 & TST & \\
\hline CHEMBL1522041 & 688267 & 5.6 & 5.0662 & TRN & \\
\hline CHEMBL1571651 & 688267 & 4.85 & 5.0535 & TRN & \\
\hline CHEMBL1473765 & 688267 & 3.95 & 5.0748 & TRN & \\
\hline CHEMBL407242 & 688267 & 6.15 & 5.119 & TRN & \\
\hline CHEMBL1445671 & 688267 & 4.7 & 5.0652 & TST & \\
\hline CHEMBL1374450 & 688267 & 5.85 & 5.0941 & TST & \\
\hline CHEMBL1588337 & 688267 & 4.0 & 5.0432 & TRN & \\
\hline CHEMBL1477685 & 688267 & 4.4 & 4.99 & TST & \\
\hline CHEMBL1299418 & 688267 & 5.4 & 5.03100 & 0000000001 & TRN \\
\hline CHEMBL1434605 & 688267 & 6.2 & 5.0142 & TRN & \\
\hline CHEMBL1322813 & 688267 & 5.8 & 5.0894 & TST & \\
\hline CHEMBL1390979 & 688267 & 4.0 & 5.0101 & TST & \\
\hline CHEMBL3209273 & 688267 & 5.8 & 5.04 & TRN & \\
\hline CHEMBL1450686 & 688267 & 5.85 & 5.0299 & TRN & \\
\hline CHEMBL1490353 & 688267 & 6.0 & 5.0552 & TRN & \\
\hline CHEMBL3211922 & 688267 & 5.95 & 5.1261 & TRN & \\
\hline CHEMBL1595248 & 688267 & 6.25 & 5.0088 & TRN & \\
\hline CHEMBL1404334 & 688267 & 4.05 & 5.0274 & TRN & \\
\hline CHEMBL1451513 & 688267 & 4.15 & 5.1007 & TRN & \\
\hline CHEMBL1302364 & 688267 & 6.2 & 5.1083 & TST & \\
\hline CHEMBL1478691 & 688267 & 6.1 & 4.9891 & TRN & \\
\hline
\end{tabular}




\begin{tabular}{|c|c|c|c|c|c|}
\hline \multirow[b]{2}{*}{ CHEMBL1550481 } & \multirow[b]{2}{*}{688267} & \multicolumn{4}{|c|}{ Supplemental Table s2.txt } \\
\hline & & 5.85 & 4.9992 & TST & \\
\hline CHEMBL1986081 & 688267 & 4.0 & 5.0503 & TST & \\
\hline CHEMBL1540809 & 688267 & 3.95 & 5.07600 & 00000000005 & TST \\
\hline CHEMBL1318850 & 688267 & 6.2 & 5.0521 & TRN & \\
\hline CHEMBL1407090 & 688267 & 6.15 & 5.045 & TST & \\
\hline CHEMBL1356121 & 688267 & 4.45 & 5.0624 & TRN & \\
\hline CHEMBL1397574 & 688267 & 4.6 & 5.1324 & TRN & \\
\hline CHEMBL1323574 & 688267 & 4.0 & 5.0115 & TRN & \\
\hline CHEMBL1491301 & 688267 & 5.75 & 5.1835 & TRN & \\
\hline CHEMBL1598263 & 688267 & 6.2 & 5.0348 & TRN & \\
\hline CHEMBL1536546 & 688267 & 4.0 & 5.1027 & TRN & \\
\hline CHEMBL1574326 & 688267 & 6.25 & 5.0262 & TST & \\
\hline CHEMBL1434671 & 688267 & 4.05 & 5.0627 & TRN & \\
\hline CHEMBL1476175 & 688267 & 5.5 & 5.0781 & TRN & \\
\hline CHEMBL1589995 & 688267 & 5.95 & 5.1039 & TRN & \\
\hline CHEMBL1390696 & 688267 & 4.0 & 5.0025 & TRN & \\
\hline CHEMBL1395701 & 688267 & 5.6 & 5.0487 & TRN & \\
\hline CHEMBL1485194 & 688267 & 6.45 & 5.1245 & TRN & \\
\hline CHEMBL3199108 & 688267 & 6.1 & 5.0346 & TST & \\
\hline CHEMBL1563242 & 688267 & 6.2 & 5.1127 & TST & \\
\hline CHEMBL1364034 & 688267 & 5.8 & 5.1127 & TRN & \\
\hline CHEMBL1486105 & 688267 & 4.45 & 5.09399 & 9999999999 & TST \\
\hline CHEMBL1537362 & 688267 & 4.4 & 5.0454 & TRN & \\
\hline CHEMBL1451170 & 688267 & 5.55 & 5.0155 & TST & \\
\hline CHEMBL1458958 & 688267 & 5.3 & 5.1135 & TRN & \\
\hline CHEMBL1438460 & 688267 & 3.95 & 5.0537 & TRN & \\
\hline CHEMBL1371855 & 688267 & 4.35 & 5.0794 & TST & \\
\hline CHEMBL1525479 & 688267 & 4.0 & 5.0434 & TRN & \\
\hline CHEMBL1472879 & 688267 & 4.8 & 5.0927 & TST & \\
\hline CHEMBL1377632 & 688267 & 4.4 & 5.0069 & TST & \\
\hline CHEMBL1438493 & 688267 & 5.0 & 5.1086 & TRN & \\
\hline CHEMBL1353572 & 688267 & 5.05 & 5.0333 & TRN & \\
\hline CHEMBL1479918 & 688267 & 5.55 & 5.1369 & TRN & \\
\hline CHEMBL1557039 & 688267 & 5.5 & 5.0287 & TRN & \\
\hline CHEMBL1390444 & 688267 & 5.9 & 5.0179 & TST & \\
\hline CHEMBL1603603 & 688267 & 6.25 & 5.0851 & TRN & \\
\hline CHEMBL1475816 & 688267 & 5.95 & 5.0252 & TRN & \\
\hline CHEMBL1359296 & 688267 & 4.3 & 5.0653 & TRN & \\
\hline CHEMBL1578602 & 688267 & 6.2 & 5.0243 & TRN & \\
\hline CHEMBL3211491 & 688267 & 4.1 & 4.9792 & TST & \\
\hline CHEMBL1414863 & 688267 & 4.65 & 5.0609 & TST & \\
\hline CHEMBL1470155 & 688267 & 5.45 & 5.1282 & TRN & \\
\hline CHEMBL1597155 & 688267 & 4.6 & 5.0573 & TRN & \\
\hline CHEMBL1407961 & 688267 & 4.2 & 5.143 & TST & \\
\hline CHEMBL1379692 & 688267 & 5.75 & 5.1371 & TST & \\
\hline CHEMBL3193799 & 688267 & 5.0 & 5.0404 & TRN & \\
\hline CHEMBL108014 & 688267 & 4.7 & 5.0575 & TST & \\
\hline CHEMBL1607287 & 688267 & 4.45 & 5.1029 & TRN & \\
\hline
\end{tabular}




\begin{tabular}{|c|c|c|c|c|c|}
\hline \multicolumn{6}{|c|}{ Supplemental Table S2.txt } \\
\hline CHEMBL1474964 & 688267 & 6.05 & 5.1445 & TRN & \\
\hline CHEMBL1507491 & 688267 & 4.4 & 5.0387 & TST & \\
\hline CHEMBL3209747 & 688267 & 6.5 & 5.0882 & TRN & \\
\hline CHEMBL1579106 & 688267 & 4.15 & 5.0983 & TRN & \\
\hline CHEMBL1461093 & 688267 & 6.1 & 5.0535 & TRN & \\
\hline CHEMBL1602332 & 688267 & 5.5 & 5.0684 & TRN & \\
\hline CHEMBL1607359 & 688267 & 4.3 & 5.065 & TRN & \\
\hline CHEMBL1476296 & 688267 & 5.0 & 5.1491 & TRN & \\
\hline CHEMBL1594924 & 688267 & 4.9 & 5.0092 & TST & \\
\hline CHEMBL1313374 & 688267 & 4.0 & 5.0724 & TRN & \\
\hline CHEMBL1610110 & 688267 & 6.2 & 5.1391 & TRN & \\
\hline CHEMBL1536698 & 688267 & 4.6 & 5.066 & TST & \\
\hline CHEMBL1399596 & 688267 & 5.55 & 5.1251 & TRN & \\
\hline CHEMBL1571205 & 688267 & 5.5 & 5.1485 & TRN & \\
\hline CHEMBL1516267 & 688267 & 5.0 & 5.0588 & TRN & \\
\hline CHEMBL1568247 & 688267 & 4.45 & 5.12700 & 0000000001 & TRN \\
\hline CHEMBL1450386 & 688267 & 5.45 & 5.0339 & TRN & \\
\hline CHEMBL1604426 & 688267 & 6.15 & 5.0536 & TRN & \\
\hline CHEMBL 3195244 & 688267 & 5.5 & 5.1014 & TRN & \\
\hline CHEMBL1528200 & 688267 & 4.25 & 5.0219 & TRN & \\
\hline CHEMBL1343910 & 688267 & 4.4 & 5.0545 & TRN & \\
\hline CHEMBL1209360 & 688267 & 4.95 & 5.1056 & TRN & \\
\hline CHEMBL1554749 & 688267 & 4.3 & 5.0195 & TRN & \\
\hline CHEMBL1397105 & 688267 & 4.3 & 5.10800 & 00000000005 & TRN \\
\hline CHEMBL1387182 & 688267 & 6.2 & 5.0391 & TRN & \\
\hline CHEMBL1513333 & 688267 & 5.45 & 5.0144 & TRN & \\
\hline CHEMBL1586975 & 688267 & 6.15 & 5.0815 & TST & \\
\hline CHEMBL1521322 & 688267 & 5.55 & 5.0875 & TRN & \\
\hline CHEMBL1310331 & 688267 & 4.55 & 5.0764 & TRN & \\
\hline CHEMBL1534065 & 688267 & 5.55 & 5.0669 & TRN & \\
\hline CHEMBL1449512 & 688267 & 4.3 & 5.0977 & TST & \\
\hline CHEMBL1536306 & 688267 & 4.6 & 5.1155 & TRN & \\
\hline CHEMBL1532452 & 688267 & 4.85 & 5.0311 & TST & \\
\hline CHEMBL3193962 & 688267 & 5.25 & 5.013 & TST & \\
\hline CHEMBL1475237 & 688267 & 3.9 & 5.0251 & TRN & \\
\hline CHEMBL1556692 & 688267 & 5.4 & 5.0278 & TRN & \\
\hline CHEMBL1604129 & 688267 & 5.4 & 4.9975 & TRN & \\
\hline CHEMBL1569437 & 688267 & 4.0 & 5.1527 & TRN & \\
\hline CHEMBL1412280 & 688267 & 4.25 & 5.0424 & TRN & \\
\hline CHEMBL1317485 & 688267 & 5.0 & 5.0455 & TRN & \\
\hline CHEMBL1312898 & 688267 & 5.05 & 5.0808 & TRN & \\
\hline CHEMBL1517758 & 688267 & 6.2 & 5.0907 & TRN & \\
\hline CHEMBL1599882 & 688267 & 4.0 & 5.0597 & TRN & \\
\hline CHEMBL1443912 & 688267 & 6.1 & 5.0592 & TRN & \\
\hline CHEMBL1307020 & 688267 & 5.55 & 5.1058 & TST & \\
\hline CHEMBL1376664 & 688267 & 5.8 & 5.0419 & TST & \\
\hline CHEMBL1393162 & 688267 & 4.6 & 5.0247 & TRN & \\
\hline CHEMBL3213538 & 688267 & 5.8 & 5.0565 & TST & \\
\hline
\end{tabular}




\begin{tabular}{|c|c|c|c|c|}
\hline \multicolumn{5}{|c|}{ Supplemental Table S2.txt } \\
\hline CHEMBL1502536 & 688267 & 6.15 & 4.9906 & TRN \\
\hline CHEMBL1412057 & 688267 & 4.6 & 5.0599 & TST \\
\hline CHEMBL1507051 & 688267 & 4.55 & 4.9997 & TST \\
\hline CHEMBL1600009 & 688267 & 6.2 & 5.0729 & TRN \\
\hline CHEMBL1531750 & 688267 & 5.0 & 5.102 & TRN \\
\hline CHEMBL1421360 & 688267 & 4.05 & 5.0611 & TRN \\
\hline CHEMBL1518003 & 688267 & 4.55 & 5.0175 & TRN \\
\hline CHEMBL1333506 & 688267 & 4.0 & 5.1264 & TRN \\
\hline CHEMBL3211939 & 688267 & 3.95 & 5.0629 & TRN \\
\hline CHEMBL1539834 & 688267 & 4.0 & 5.0189 & TRN \\
\hline CHEMBL1313659 & 688267 & 6.2 & 5.0781 & TRN \\
\hline CHEMBL1427730 & 688267 & 6.2 & 5.0131 & TRN \\
\hline CHEMBL1581155 & 688267 & 4.9 & 5.0113 & TST \\
\hline CHEMBL1414280 & 688267 & 6.0 & 5.0528 & TRN \\
\hline CHEMBL1327252 & 688267 & 4.25 & 5.0713 & TRN \\
\hline CHEMBL1399428 & 688267 & 6.15 & 5.0717 & TST \\
\hline CHEMBL1490694 & 688267 & 5.3 & 5.0465 & TRN \\
\hline CHEMBL1505460 & 688267 & 4.45 & 5.0604 & TST \\
\hline CHEMBL1342084 & 688267 & 5.0 & 5.0845 & TRN \\
\hline CHEMBL 3207445 & 688267 & 5.0 & 5.0656 & TST \\
\hline CHEMBL1328303 & 688267 & 4.0 & 5.0405 & TRN \\
\hline CHEMBL1551893 & 688267 & 5.1 & 5.1346 & TRN \\
\hline CHEMBL1394990 & 688267 & 5.0 & 5.0747 & TRN \\
\hline CHEMBL1527899 & 688267 & 5.8 & 5.0077 & TRN \\
\hline CHEMBL1352821 & 688267 & 5.45 & 5.0186 & TRN \\
\hline CHEMBL3196735 & 688267 & 4.65 & 5.0603 & TRN \\
\hline CHEMBL1513613 & 688267 & 3.95 & 5.0707 & TRN \\
\hline CHEMBL1499524 & 688267 & 4.15 & 5.0651 & TRN \\
\hline CHEMBL1467877 & 688267 & 4.4 & 5.0559 & TST \\
\hline CHEMBL1408402 & 688267 & 5.05 & 5.0368 & TST \\
\hline CHEMBL1358146 & 688267 & 4.3 & 5.046 & TRN \\
\hline CHEMBL1404878 & 688267 & 5.8 & 5.1258 & TRN \\
\hline CHEMBL1420510 & 688267 & 5.7 & 5.0654 & TRN \\
\hline CHEMBL1480232 & 688267 & 5.9 & 5.0591 & TRN \\
\hline CHEMBL1432551 & 688267 & 4.95 & 5.0149 & TRN \\
\hline CHEMBL1313797 & 688267 & 5.75 & 5.0693 & TST \\
\hline CHEMBL1496332 & 688267 & 5.55 & 5.0218 & TRN \\
\hline CHEMBL1514422 & 688267 & 6.15 & 5.1241 & TST \\
\hline CHEMBL1508618 & 688267 & 5.3 & 5.0093 & TRN \\
\hline CHEMBL1461188 & 688267 & 6.2 & 5.0182 & TRN \\
\hline CHEMBL1609811 & 688267 & 5.3 & 5.0311 & TRN \\
\hline CHEMBL1460461 & 688267 & 6.2 & 5.045 & TST \\
\hline CHEMBL1586741 & 688267 & 4.05 & 5.0596 & TRN \\
\hline CHEMBL1442302 & 688267 & 5.55 & 5.1535 & TRN \\
\hline CHEMBL1523270 & 688267 & 6.25 & 4.994 & TST \\
\hline CHEMBL25280 & 688267 & 5.4 & 5.0281 & TST \\
\hline CHEMBL1417269 & 688267 & 4.05 & 5.0469 & TRN \\
\hline CHEMBL1504087 & 688267 & 4.0 & 4.9987 & TRN \\
\hline
\end{tabular}




\begin{tabular}{|c|c|c|c|c|}
\hline & & & pplement & al $\mathrm{Ta}$ \\
\hline CHEMBL1445588 & 688267 & 4.75 & 5.1071 & TRN \\
\hline CHEMBL1317276 & 688267 & 5.35 & 5.1197 & TRN \\
\hline CHEMBL1475560 & 688267 & 5.45 & 5.1502 & TRN \\
\hline CHEMBL1473094 & 688267 & 4.1 & 4.998 & TRN \\
\hline CHEMBL1425833 & 688267 & 5.55 & 5.0791 & TST \\
\hline CHEMBL1486155 & 688267 & 5.25 & 5.1419 & TRN \\
\hline CHEMBL1494585 & 688267 & 3.95 & 5.0285 & TRN \\
\hline CHEMBL1590164 & 688267 & 4.0 & 5.032 & TRN \\
\hline CHEMBL1579045 & 688267 & 6.2 & 5.0702 & TRN \\
\hline CHEMBL1487565 & 688267 & 5.8 & 5.0585 & TRN \\
\hline CHEMBL1556751 & 688267 & 5.9 & 5.1079 & TRN \\
\hline CHEMBL1542798 & 688267 & 5.6 & 5.0311 & TST \\
\hline CHEMBL1349464 & 688267 & 4.35 & 5.1169 & TRN \\
\hline CHEMBL1395195 & 688267 & 4.7 & 5.0479 & TRN \\
\hline CHEMBL1611406 & 688267 & 3.95 & 5.0246 & TRN \\
\hline CHEMBL1982028 & 688267 & 5.0 & 5.0308 & TST \\
\hline CHEMBL1320616 & 688267 & 4.25 & 5.1045 & TRN \\
\hline CHEMBL1433953 & 688267 & 6.15 & 5.008 & TST \\
\hline CHEMBL1397430 & 688267 & 4.05 & 5.0634 & TRN \\
\hline CHEMBL1337484 & 688267 & 4.3 & 5.0422 & TRN \\
\hline CHEMBL1318061 & 688267 & 4.4 & 5.0563 & TRN \\
\hline CHEMBL1351080 & 688267 & 4.8 & 5.0799 & TRN \\
\hline CHEMBL1475991 & 688267 & 4.2 & 5.0718 & TST \\
\hline CHEMBL1427261 & 688267 & 6.15 & 5.0924 & TST \\
\hline CHEMBL1486777 & 688267 & 6.5 & 5.1015 & TRN \\
\hline CHEMBL1606968 & 688267 & 5.3 & 4.9796 & TRN \\
\hline CHEMBL1521311 & 688267 & 6.5 & 5.0321 & TRN \\
\hline CHEMBL1303675 & 688267 & 4.4 & 4.9826 & TRN \\
\hline CHEMBL1445285 & 688267 & 5.05 & 5.0576 & TRN \\
\hline CHEMBL1535642 & 688267 & 4.0 & 5.1141 & TST \\
\hline CHEMBL1308105 & 688267 & 5.75 & 5.0816 & TRN \\
\hline CHEMBL1329960 & 688267 & 4.1 & 5.0327 & TRN \\
\hline CHEMBL1356547 & 688267 & 4.0 & 5.042 & TRN \\
\hline CHEMBL1353854 & 688267 & 6.15 & 5.0136 & TST \\
\hline CHEMBL1587544 & 688267 & 4.4 & 5.0645 & TRN \\
\hline CHEMBL1309909 & 688267 & 4.25 & 5.0619 & TST \\
\hline CHEMBL3198213 & 688267 & 4.35 & 5.0332 & TST \\
\hline CHEMBL1563622 & 688267 & 5.3 & 5.1376 & TRN \\
\hline CHEMBL1514778 & 688267 & 4.5 & 4.9958 & TRN \\
\hline CHEMBL1395931 & 688267 & 4.4 & 5.0967 & TRN \\
\hline CHEMBL1488210 & 688267 & 5.0 & 5.0648 & TRN \\
\hline CHEMBL1336349 & 688267 & 5.35 & 5.1687 & TRN \\
\hline CHEMBL1612449 & 688267 & 6.2 & 5.1042 & TRN \\
\hline CHEMBL1493971 & 688267 & 5.05 & 5.125 & TRN \\
\hline CHEMBL1414833 & 688267 & 6.2 & 5.0498 & TRN \\
\hline CHEMBL1369338 & 688267 & 5.85 & 5.0308 & TRN \\
\hline CHEMBL1604405 & 688267 & 4.0 & 5.0148 & TRN \\
\hline CHEMBL1489605 & 688267 & 4.55 & 5.0005 & TRN \\
\hline
\end{tabular}




\begin{tabular}{|c|c|c|c|c|c|}
\hline \\
\hline CHEMBL1339987 & 688267 & 6.2 & 5.0278 & TRN & \\
\hline CHEMBL1337329 & 688267 & 4.4 & 4.9882 & TRN & \\
\hline CHEMBL1416648 & 688267 & 5.9 & 5.0394 & TRN & \\
\hline CHEMBL1552015 & 688267 & 5.0 & 5.0431 & TRN & \\
\hline CHEMBL1319636 & 688267 & 4.25 & 4.9726 & TRN & \\
\hline CHEMBL1467282 & 688267 & 4.8 & 5.086 & TST & \\
\hline CHEMBL3197059 & 688267 & 4.85 & 5.058 & TRN & \\
\hline CHEMBL1347089 & 688267 & 4.0 & 4.9971 & TRN & \\
\hline CHEMBL1514410 & 688267 & 4.95 & 5.0598 & TRN & \\
\hline CHEMBL1407261 & 688267 & 4.4 & 5.0651 & TRN & \\
\hline CHEMBL1471273 & 688267 & 5.9 & $5.0310 e$ & 2000000001 & TRN \\
\hline CHEMBL1458887 & 688267 & 4.05 & 5.1052 & TST & \\
\hline CHEMBL1350928 & 688267 & 4.1 & 5.0726 & TST & \\
\hline CHEMBL1556273 & 688267 & 6.2 & 5.0102 & TST & \\
\hline CHEMBL1481110 & 688267 & 3.95 & 5.0195 & TST & \\
\hline CHEMBL1339063 & 688267 & 4.95 & 5.0549 & TRN & \\
\hline CHEMBL1603844 & 688267 & 5.85 & 4.9902 & TST & \\
\hline CHEMBL1387327 & 688267 & 6.2 & 5.0799 & TRN & \\
\hline CHEMBL3197014 & 688267 & 4.05 & 5.0085 & TST & \\
\hline CHEMBL1535663 & 688267 & 4.6 & 5.0431 & TST & \\
\hline CHEMBL1435858 & 688267 & 5.15 & 5.0091 & TRN & \\
\hline CHEMBL1590775 & 688267 & 4.75 & 5.102 & TRN & \\
\hline CHEMBL3196382 & 688267 & 4.35 & 5.0956 & TRN & \\
\hline CHEMBL1310801 & 688267 & 4.0 & 5.0651 & TRN & \\
\hline CHEMBL1379960 & 688267 & 4.7 & 5.0484 & TRN & \\
\hline CHEMBL1419744 & 688267 & 4.25 & 5.0366 & TRN & \\
\hline CHEMBL1367835 & 688267 & 4.9 & 5.1408 & TRN & \\
\hline CHEMBL1382948 & 688267 & 3.95 & 5.0261 & TRN & \\
\hline CHEMBL1612767 & 688267 & 6.45 & 5.1096 & TRN & \\
\hline CHEMBL1606089 & 688267 & 4.25 & 5.0835 & TRN & \\
\hline CHEMBL1511277 & 688267 & 5.0 & 5.0729 & TRN & \\
\hline CHEMBL225852 & 688267 & 4.95 & 5.0886 & TST & \\
\hline CHEMBL1326535 & 688267 & 4.35 & 5.0786 & TRN & \\
\hline CHEMBL1592785 & 688267 & 4.1 & 5.0371 & TRN & \\
\hline CHEMBL1378381 & 688267 & 4.4 & 5.0381 & TRN & \\
\hline CHEMBL1592617 & 688267 & 4.35 & 5.0619 & TRN & \\
\hline CHEMBL1481231 & 688267 & 4.35 & 5.0322 & TRN & \\
\hline CHEMBL1309640 & 688267 & 4.4 & 5.0318 & TST & \\
\hline CHEMBL1373191 & 688267 & 4.35 & 5.0862 & TRN & \\
\hline CHEMBL1581749 & 688267 & 5.55 & 5.0248 & TRN & \\
\hline CHEMBL1319319 & 688267 & 4.6 & 4.9681 & TRN & \\
\hline CHEMBL1513585 & 688267 & 6.05 & 5.0318 & TRN & \\
\hline CHEMBL1567574 & 688267 & 4.0 & 5.0341 & TRN & \\
\hline CHEMBL1600981 & 688267 & 5.9 & 5.0288 & TST & \\
\hline CHEMBL1378844 & 688267 & 6.2 & 5.1235 & TRN & \\
\hline CHEMBL1340604 & 688267 & 4.25 & 5.0298 & TRN & \\
\hline CHEMBL1539860 & 688267 & 4.25 & 4.9802 & TST & \\
\hline CHEMBL1587896 & 688267 & 5.75 & 5.1209 & TRN & \\
\hline
\end{tabular}




\begin{tabular}{|c|c|c|c|c|c|}
\hline \multicolumn{6}{|c|}{ supplementa } \\
\hline CHEMBL1461312 & 688267 & 6.7001 & 5.0621 & TST & \\
\hline CHEMBL1551665 & 688267 & 5.95 & 5.0929 & TRN & \\
\hline CHEMBL1407819 & 688267 & 6.25 & 5.0065 & TST & \\
\hline CHEMBL1361986 & 688267 & 5.85 & 5.015 & TST & \\
\hline CHEMBL1369974 & 688267 & 6.1 & 5.0474 & TRN & \\
\hline CHEMBL1593549 & 688267 & 4.35 & 5.0472 & TRN & \\
\hline CHEMBL1401230 & 688267 & 4.05 & 5.1036 & TRN & \\
\hline CHEMBL1474858 & 688267 & 5.35 & 5.1062 & TRN & \\
\hline CHEMBL1314705 & 688267 & 4.1 & 5.0304 & TRN & \\
\hline CHEMBL1514134 & 688267 & 4.55 & 5.0903 & TRN & \\
\hline CHEMBL1474086 & 688267 & 5.4 & 5.0693 & TST & \\
\hline CHEMBL1441065 & 688267 & 5.6 & 5.0476 & TRN & \\
\hline CHEMBL1336237 & 688267 & 3.95 & 5.0385 & TST & \\
\hline CHEMBL1565080 & 688267 & 5.55 & 5.0707 & TRN & \\
\hline CHEMBL1457820 & 688267 & 5.05 & 5.0623 & TRN & \\
\hline CHEMBL1492622 & 688267 & 5.35 & 4.9981 & TRN & \\
\hline CHEMBL1255646 & 688267 & 4.1 & 5.0851 & TST & \\
\hline CHEMBL1531552 & 688267 & 5.55 & 5.0075 & TRN & \\
\hline CHEMBL1477777 & 688267 & 6.2 & 5.099 & TST & \\
\hline CHEMBL1467690 & 688267 & 6.5 & 5.0106 & TRN & \\
\hline CHEMBL1362270 & 688267 & 4.1 & 5.1283 & TRN & \\
\hline CHEMBL1333550 & 688267 & 4.6 & 5.1399 & TRN & \\
\hline CHEMBL1472003 & 688267 & 6.15 & 5.092 & TRN & \\
\hline CHEMBL1368224 & 688267 & 5.85 & 5.1241 & TRN & \\
\hline CHEMBL1311585 & 688267 & 4.25 & 5.0082 & TST & \\
\hline CHEMBL1569619 & 688267 & 4.45 & 5.0667 & TST & \\
\hline CHEMBL1375258 & 688267 & 4.3 & 5.0568 & TRN & \\
\hline CHEMBL1411997 & 688267 & 6.2 & 5.0385 & TRN & \\
\hline CHEMBL1487187 & 688267 & 6.2 & 5.0933 & TST & \\
\hline CHEMBL1591270 & 688267 & 5.7 & 5.0516 & TRN & \\
\hline CHEMBL1311876 & 688267 & 6.2 & 5.0388 & TST & \\
\hline CHEMBL1346078 & 688267 & 4.9 & 5.0395 & TST & \\
\hline CHEMBL1610285 & 688267 & 4.0 & 5.118 & TRN & \\
\hline CHEMBL1533375 & 688267 & 4.8 & 5.05699 & 99999999995 & TRN \\
\hline CHEMBL1387280 & 688267 & 6.3 & 5.1134 & TRN & \\
\hline CHEMBL1402708 & 688267 & 5.5 & 5.0119 & TRN & \\
\hline CHEMBL3192201 & 688267 & 4.25 & 5.0393 & TRN & \\
\hline CHEMBL1321694 & 688267 & 4.35 & 5.0917 & TRN & \\
\hline CHEMBL1433024 & 688267 & 6.25 & 5.0456 & TRN & \\
\hline CHEMBL1525705 & 688267 & 5.55 & 5.0249 & TRN & \\
\hline CHEMBL1462908 & 688267 & 6.1 & 5.0995 & TRN & \\
\hline CHEMBL1356356 & 688267 & 4.3 & 5.0542 & TST & \\
\hline CHEMBL1434348 & 688267 & 4.1 & 5.1372 & TRN & \\
\hline CHEMBL1361284 & 688267 & 5.5 & 5.0823 & TST & \\
\hline CHEMBL1462378 & 688267 & 5.05 & 5.0521 & TRN & \\
\hline CHEMBL1574291 & 688267 & 5.15 & 5.067 & TRN & \\
\hline CHEMBL1474189 & 688267 & 4.05 & 4.9839 & TRN & \\
\hline CHEMBL1398802 & 688267 & 5.85 & 5.0557 & TRN & \\
\hline
\end{tabular}




\begin{tabular}{|c|c|c|c|c|}
\hline & & & pplement & al $\mathrm{Ta}$ \\
\hline CHEMBL1546164 & 688267 & 5.15 & 5.0269 & TRN \\
\hline CHEMBL1449118 & 688267 & 4.6 & 4.9955 & TRN \\
\hline CHEMBL1487013 & 688267 & 4.4 & 5.078 & TST \\
\hline CHEMBL1571898 & 688267 & 5.2 & 5.0012 & TRN \\
\hline CHEMBL1458299 & 688267 & 4.4 & 5.0575 & TST \\
\hline CHEMBL1490746 & 688267 & 4.05 & 5.0724 & TRN \\
\hline CHEMBL1503421 & 688267 & 4.05 & 5.098 & TRN \\
\hline CHEMBL1556154 & 688267 & 4.3 & 4.9966 & TST \\
\hline CHEMBL1582198 & 688267 & 5.0 & 5.0057 & TRN \\
\hline CHEMBL1560485 & 688267 & 4.0 & 5.01 & TRN \\
\hline CHEMBL1516319 & 688267 & 6.2 & 5.1262 & TRN \\
\hline CHEMBL1448821 & 688267 & 4.35 & 5.1217 & TRN \\
\hline CHEMBL1492045 & 688267 & 5.95 & 5.0041 & TRN \\
\hline CHEMBL1360589 & 688267 & 4.45 & 5.1108 & TRN \\
\hline CHEMBL1392180 & 688267 & 5.95 & 5.075 & TRN \\
\hline CHEMBL1356945 & 688267 & 4.05 & 4.9927 & TRN \\
\hline CHEMBL1400826 & 688267 & 5.75 & 5.0444 & TRN \\
\hline CHEMBL1438882 & 688267 & 6.2 & 5.0164 & TST \\
\hline CHEMBL1536327 & 688267 & 4.75 & 5.1223 & TRN \\
\hline CHEMBL1368719 & 688267 & 3.95 & 5.0433 & TRN \\
\hline CHEMBL1552297 & 688267 & 5.3 & 5.09 & TRN \\
\hline CHEMBL1431700 & 688267 & 6.2 & 5.0693 & TRN \\
\hline CHEMBL1535163 & 688267 & 4.35 & 5.1057 & TRN \\
\hline CHEMBL1483281 & 688267 & 4.05 & 5.0399 & TRN \\
\hline CHEMBL1575849 & 688267 & 4.35 & 5.0613 & TRN \\
\hline CHEMBL1302474 & 688267 & 5.55 & 5.0328 & TRN \\
\hline CHEMBL1472725 & 688267 & 6.05 & 5.0791 & TST \\
\hline CHEMBL1483921 & 688267 & 5.35 & 5.0965 & TRN \\
\hline CHEMBL1512071 & 688267 & 5.95 & 5.0154 & TST \\
\hline CHEMBL1512535 & 688267 & 4.35 & 5.018 & TRN \\
\hline CHEMBL1310697 & 688267 & 6.5 & 5.0729 & TRN \\
\hline CHEMBL1509730 & 688267 & 6.2 & 5.002 & TST \\
\hline CHEMBL1323703 & 688267 & 6.3 & 5.0718 & TST \\
\hline CHEMBL1317459 & 688267 & 4.0 & 5.0579 & TRN \\
\hline CHEMBL1378647 & 688267 & 4.0 & 5.0282 & TRN \\
\hline CHEMBL1444668 & 688267 & 5.4 & 5.1088 & TRN \\
\hline CHEMBL1527355 & 688267 & 4.05 & 5.0949 & TST \\
\hline CHEMBL1500290 & 688267 & 4.6 & 5.06 & TRN \\
\hline CHEMBL1313446 & 688267 & 4.0 & 5.044 & TST \\
\hline CHEMBL1379029 & 688267 & 5.6 & 5.0275 & TRN \\
\hline CHEMBL1410251 & 688267 & 4.7 & 5.0018 & TST \\
\hline CHEMBL1420052 & 688267 & 6.25 & 5.1029 & TRN \\
\hline CHEMBL1578145 & 688267 & 5.45 & 4.961 & TRN \\
\hline CHEMBL1322336 & 688267 & 5.3 & 5.0266 & TRN \\
\hline CHEMBL1491588 & 688267 & 4.9 & 5.0755 & TST \\
\hline CHEMBL1302931 & 688267 & 5.55 & 5.1422 & TRN \\
\hline CHEMBL1456387 & 688267 & 3.85 & 5.0927 & TRN \\
\hline CHEMBL1456418 & 688267 & 4.0 & 5.0774 & TRN \\
\hline
\end{tabular}




\begin{tabular}{|c|c|c|c|c|c|}
\hline \multicolumn{6}{|c|}{ 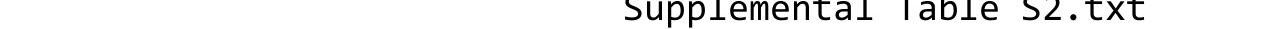 } \\
\hline CHEMBL1467467 & 688267 & 6.2 & 5.1032 & TRN & \\
\hline CHEMBL418661 & 688267 & 6.1 & 5.0738 & TST & \\
\hline CHEMBL1363224 & 688267 & 4.5 & 5.0237 & TRN & \\
\hline CHEMBL1404221 & 688267 & 4.55 & 5.013 & TRN & \\
\hline CHEMBL1536909 & 688267 & 5.65 & 5.0628 & TRN & \\
\hline CHEMBL1550945 & 688267 & 5.5 & 5.0762 & TRN & \\
\hline CHEMBL10347 & 688267 & 4.85 & 5.0813 & TST & \\
\hline CHEMBL1486174 & 688267 & 5.95 & 5.0419 & TRN & \\
\hline CHEMBL1462734 & 688267 & 5.65 & 5.0644 & TST & \\
\hline CHEMBL3196208 & 688267 & 6.0 & 5.0577 & TST & \\
\hline CHEMBL1502432 & 688267 & 4.5 & 5.0902 & TST & \\
\hline CHEMBL1567331 & 688267 & 4.4 & 5.0768 & TRN & \\
\hline CHEMBL1356635 & 688267 & 6.15 & 5.0831 & TRN & \\
\hline CHEMBL1413798 & 688267 & 6.2 & 5.0643 & TRN & \\
\hline CHEMBL1357247 & 688267 & 5.55 & 5.0387 & TST & \\
\hline CHEMBL1385583 & 688267 & 4.75 & 5.1256 & TRN & \\
\hline CHEMBL3197647 & 688267 & 4.45 & 5.0209 & TRN & \\
\hline CHEMBL1504411 & 688267 & 4.6 & 5.1159 & TRN & \\
\hline CHEMBL1986183 & 688267 & 5.5 & 5.1105 & TRN & \\
\hline CHEMBL1363387 & 688267 & 4.0 & 5.0986 & TRN & \\
\hline CHEMBL1449200 & 688267 & 5.8 & 5.0719 & TRN & \\
\hline CHEMBL3145193 & 688267 & 5.55 & 4.9947 & TRN & \\
\hline CHEMBL1365828 & 688267 & 5.35 & 5.0872 & TST & \\
\hline CHEMBL1509578 & 688267 & 5.85 & 5.1028 & TRN & \\
\hline CHEMBL1406192 & 688267 & 6.7001 & 5.0757 & TRN & \\
\hline CHEMBL1352957 & 688267 & 6.5 & 5.0283 & TST & \\
\hline CHEMBL1471373 & 688267 & 6.6 & 5.0926 & TRN & \\
\hline CHEMBL1430259 & 688267 & 4.4 & 5.1059 & TST & \\
\hline CHEMBL1533785 & 688267 & 5.35 & 5.0222 & TST & \\
\hline CHEMBL1377306 & 688267 & 5.5 & 5.038 & TRN & \\
\hline CHEMBL1487754 & 688267 & 5.35 & 5.08899 & 99999999995 & TRN \\
\hline CHEMBL1464258 & 688267 & 4.45 & 5.0119 & TST & \\
\hline CHEMBL1521071 & 688267 & 5.6 & 5.0394 & TST & \\
\hline CHEMBL1594742 & 688267 & 6.1 & 5.0851 & TST & \\
\hline CHEMBL581196 & 688267 & 5.3 & 5.0527 & TRN & \\
\hline CHEMBL1369189 & 688267 & 5.9 & 5.042 & TRN & \\
\hline CHEMBL1347934 & 688267 & 5.15 & 5.0687 & TRN & \\
\hline CHEMBL1354601 & 688267 & 4.05 & 5.05 & TRN & \\
\hline CHEMBL1557898 & 688267 & 4.05 & 5.0316 & TRN & \\
\hline CHEMBL1598144 & 688267 & 4.0 & 5.0554 & TRN & \\
\hline CHEMBL1537337 & 688267 & 5.8 & 5.0276 & TRN & \\
\hline CHEMBL3210361 & 688267 & 6.2 & 5.0305 & TRN & \\
\hline CHEMBL1423536 & 688267 & 4.15 & 5.0052 & TRN & \\
\hline CHEMBL1425419 & 688267 & 6.15 & 4.977 & TRN & \\
\hline CHEMBL1535842 & 688267 & 6.25 & 5.0331 & TRN & \\
\hline CHEMBL1560749 & 688267 & 6.2 & 5.0808 & TST & \\
\hline CHEMBL1352870 & 688267 & 4.25 & 5.0417 & TST & \\
\hline CHEMBL1367096 & 688267 & 5.4 & 5.0174 & TST & \\
\hline
\end{tabular}




\begin{tabular}{|c|c|c|c|c|c|}
\hline \multicolumn{6}{|c|}{ Supplemental Table S2.txt } \\
\hline CHEMBL1432796 & 688267 & 5.9 & 5.0126 & TST & \\
\hline CHEMBL1466630 & 688267 & 4.85 & 4.98 & TST & \\
\hline CHEMBL3208293 & 688267 & 4.05 & 5.0242 & TRN & \\
\hline CHEMBL1490785 & 688267 & 4.85 & 5.0797 & TRN & \\
\hline CHEMBL1509708 & 688267 & 5.3 & 5.0607 & TST & \\
\hline CHEMBL1384768 & 688267 & 4.3 & 5.1463 & TRN & \\
\hline CHEMBL1497465 & 688267 & 4.35 & 5.06 & TRN & \\
\hline CHEMBL1437697 & 688267 & 5.95 & 5.0827 & TRN & \\
\hline CHEMBL1370777 & 688267 & 4.0 & 5.0763 & TST & \\
\hline CHEMBL1369768 & 688267 & 5.5 & 5.0671 & TRN & \\
\hline CHEMBL1501977 & 688267 & 4.05 & 5.0444 & TRN & \\
\hline CHEMBL1603277 & 688267 & 4.05 & 5.0493 & TST & \\
\hline CHEMBL1555446 & 688267 & 6.2 & 5.0913 & TRN & \\
\hline CHEMBL1481349 & 688267 & 5.3 & 5.0254 & TST & \\
\hline CHEMBL1517858 & 688267 & 4.1 & 5.0609 & TRN & \\
\hline CHEMBL1389024 & 688267 & 5.05 & 5.027 & TST & \\
\hline CHEMBL1519705 & 688267 & 6.05 & 5.0542 & TST & \\
\hline CHEMBL1570958 & 688267 & 4.6 & 5.0617 & TRN & \\
\hline CHEMBL1335297 & 688267 & 4.4 & 5.0045 & TRN & \\
\hline CHEMBL1495812 & 688267 & 4.25 & 5.0594 & TST & \\
\hline CHEMBL1571081 & 688267 & 5.6 & 5.0579 & TST & \\
\hline CHEMBL1574017 & 688267 & 4.35 & 5.0364 & TRN & \\
\hline CHEMBL1605615 & 688267 & 4.3 & 5.0393 & TRN & \\
\hline CHEMBL1304426 & 688267 & 5.0 & 5.1079 & TRN & \\
\hline CHEMBL1431319 & 688267 & 4.8 & 5.1287 & TRN & \\
\hline CHEMBL1573586 & 688267 & 4.15 & 5.0322 & TST & \\
\hline CHEMBL1481101 & 688267 & 4.7 & 5.0299 & TRN & \\
\hline CHEMBL1256360 & 688267 & 5.3 & 5.0691 & TST & \\
\hline CHEMBL1609638 & 688267 & 4.05 & 5.0622 & TST & \\
\hline CHEMBL1469229 & 688267 & 4.0 & 5.0319 & TRN & \\
\hline CHEMBL1315785 & 688267 & 4.0 & 5.0282 & TRN & \\
\hline CHEMBL1397141 & 688267 & 4.0 & 5.1471 & TRN & \\
\hline CHEMBL1457994 & 688267 & 4.0 & 5.085 & TRN & \\
\hline CHEMBL1411855 & 688267 & 4.4 & 5.1045 & TRN & \\
\hline CHEMBL1583846 & 688267 & 4.3 & 5.0158 & TST & \\
\hline CHEMBL1421789 & 688267 & 4.05 & 5.0088 & TRN & \\
\hline CHEMBL1481996 & 688267 & 5.1 & 5.0688 & TRN & \\
\hline CHEMBL1474606 & 688267 & 6.25 & 5.1304 & TRN & \\
\hline CHEMBL2005959 & 688267 & 4.35 & 5.0731 & TST & \\
\hline CHEMBL1526890 & 688267 & 6.2 & 5.05399 & 9999999999 & TRN \\
\hline CHEMBL1583188 & 688267 & 4.3 & 5.0624 & TST & \\
\hline CHEMBL3212853 & 688267 & 5.85 & 5.0229 & TST & \\
\hline CHEMBL1380369 & 688267 & 6.9 & 5.0962 & TRN & \\
\hline CHEMBL1333205 & 688267 & 5.65 & 5.0768 & TRN & \\
\hline CHEMBL3192227 & 688267 & 4.4 & 5.005 & TRN & \\
\hline CHEMBL1309453 & 688267 & 5.4 & 5.1236 & TST & \\
\hline CHEMBL1428919 & 688267 & 6.25 & 5.1574 & TST & \\
\hline CHEMBL1422489 & 688267 & 5.0 & 5.0441 & TRN & \\
\hline
\end{tabular}




\begin{tabular}{|c|c|c|c|c|c|}
\hline \multicolumn{6}{|c|}{ Supplemental Table S2.txt } \\
\hline CHEMBL1611469 & 688267 & 6.05 & 5.104 & TRN & \\
\hline CHEMBL1504502 & 688267 & 5.6 & 5.0893 & TRN & \\
\hline CHEMBL1558812 & 688267 & 4.3 & 5.0583 & TRN & \\
\hline CHEMBL1318209 & 688267 & 5.4 & 5.0342 & TRN & \\
\hline CHEMBL1357946 & 688267 & 4.1 & 5.0136 & TRN & \\
\hline CHEMBL1310985 & 688267 & 5.55 & 5.0954 & TRN & \\
\hline CHEMBL1393062 & 688267 & 4.5 & 5.0753 & TST & \\
\hline CHEMBL1470364 & 688267 & 3.95 & 5.0636 & TRN & \\
\hline CHEMBL1372168 & 688267 & 6.0 & 5.1172 & TRN & \\
\hline CHEMBL1596817 & 688267 & 4.95 & 5.025 & TST & \\
\hline CHEMBL1541481 & 688267 & 6.2 & 5.0891 & TRN & \\
\hline CHEMBL1405598 & 688267 & 5.35 & 5.0551 & TRN & \\
\hline CHEMBL1307490 & 688267 & 4.4 & 5.1679 & TRN & \\
\hline CHEMBL1375353 & 688267 & 5.95 & 5.0389 & TST & \\
\hline CHEMBL1585233 & 688267 & 4.6 & 5.039 & TRN & \\
\hline CHEMBL1613683 & 688267 & 3.95 & 5.1039 & TRN & \\
\hline CHEMBL1360283 & 688267 & 4.0 & 5.019 & TRN & \\
\hline CHEMBL1398953 & 688267 & 4.0 & 5.0059 & TRN & \\
\hline CHEMBL1501299 & 688267 & 6.2 & 5.0312 & TRN & \\
\hline CHEMBL1395681 & 688267 & 3.95 & 5.0425 & TST & \\
\hline CHEMBL1531582 & 688267 & 4.8 & 5.0354 & TRN & \\
\hline CHEMBL1591465 & 688267 & 5.3 & 5.0217 & TRN & \\
\hline CHEMBL193585 & 688267 & 6.0 & 5.04899 & 99999999995 & TRN \\
\hline CHEMBL1420363 & 688267 & 5.6 & 5.0697 & TRN & \\
\hline CHEMBL1419560 & 688267 & 5.55 & 5.1097 & TRN & \\
\hline CHEMBL1393879 & 688267 & 4.65 & 5.0291 & TRN & \\
\hline CHEMBL1356343 & 688267 & 5.45 & 5.0392 & TST & \\
\hline CHEMBL3193023 & 688267 & 6.2 & 5.0157 & TRN & \\
\hline CHEMBL1320653 & 688267 & 6.0 & 5.0218 & TRN & \\
\hline CHEMBL1396574 & 688267 & 5.0 & 5.0561 & TRN & \\
\hline CHEMBL1302084 & 688267 & 4.35 & 5.0658 & TST & \\
\hline CHEMBL1511288 & 688267 & 6.2 & 5.0362 & TST & \\
\hline CHEMBL1460813 & 688267 & 6.5 & 5.0876 & TRN & \\
\hline CHEMBL1580141 & 688267 & 3.95 & 5.0644 & TRN & \\
\hline CHEMBL1316310 & 688267 & 6.2 & 5.0519 & TRN & \\
\hline CHEMBL1470498 & 688267 & 6.2 & 5.1007 & TRN & \\
\hline CHEMBL1561224 & 688267 & 5.8 & 5.0752 & TST & \\
\hline CHEMBL1436443 & 688267 & 3.95 & 5.0812 & TRN & \\
\hline CHEMBL1447099 & 688267 & 6.5 & 4.9999 & TRN & \\
\hline CHEMBL1361712 & 688267 & 4.25 & 5.0683 & TRN & \\
\hline CHEMBL1600226 & 688267 & 4.55 & 5.0008 & TRN & \\
\hline CHEMBL1446852 & 688267 & 5.55 & 5.043 & TST & \\
\hline CHEMBL1452987 & 688267 & 5.15 & 5.0583 & TRN & \\
\hline CHEMBL1551230 & 688267 & 6.2 & 5.129 & TRN & \\
\hline CHEMBL1554017 & 688267 & 5.2 & 5.024 & TRN & \\
\hline CHEMBL1375782 & 688267 & 4.8 & 5.0911 & TST & \\
\hline CHEMBL1492300 & 688267 & 5.8 & 5.1819 & TRN & \\
\hline CHEMBL1528859 & 688267 & 5.8 & 5.0082 & TRN & \\
\hline
\end{tabular}




\begin{tabular}{|c|c|c|c|c|}
\hline \multicolumn{5}{|c|}{ Supplemental Table S2.txt } \\
\hline CHEMBL1579492 & 688267 & 6.0 & 5.0103 & TST \\
\hline CHEMBL1553698 & 688267 & 4.3 & 5.0813 & TRN \\
\hline CHEMBL1500555 & 688267 & 5.85 & 5.1363 & TST \\
\hline CHEMBL1324853 & 688267 & 5.2 & 5.0749 & TRN \\
\hline CHEMBL1363383 & 688267 & 4.0 & 5.0178 & TRN \\
\hline CHEMBL1344014 & 688267 & 6.15 & 5.1001 & TRN \\
\hline CHEMBL1306068 & 688267 & 4.35 & 4.9996 & TRN \\
\hline CHEMBL1299968 & 688267 & 5.65 & 4.9979 & TRN \\
\hline CHEMBL1580575 & 688267 & 5.85 & 5.0229 & TRN \\
\hline CHEMBL1474368 & 688267 & 4.05 & 5.0391 & TRN \\
\hline CHEMBL1454678 & 688267 & 5.3 & 5.0458 & TRN \\
\hline CHEMBL1592892 & 688267 & 3.95 & 5.0661 & TRN \\
\hline CHEMBL1500726 & 688267 & 4.7 & 5.0577 & TST \\
\hline CHEMBL1376621 & 688267 & 6.5 & 5.0943 & TRN \\
\hline CHEMBL1402951 & 688267 & 6.2 & 5.0721 & TRN \\
\hline CHEMBL1550729 & 688267 & 3.95 & 5.0818 & TRN \\
\hline CHEMBL1404054 & 688267 & 6.15 & 5.016 & TST \\
\hline CHEMBL1475679 & 688267 & 4.0 & 5.0626 & TRN \\
\hline CHEMBL1525406 & 688267 & 5.35 & 5.1094 & TST \\
\hline CHEMBL1588254 & 688267 & 5.65 & 5.0539 & TRN \\
\hline CHEMBL3195713 & 688267 & 4.65 & 4.9984 & TRN \\
\hline CHEMBL3195693 & 688267 & 5.35 & 5.0309 & TST \\
\hline CHEMBL1555492 & 688267 & 4.25 & 5.034 & TRN \\
\hline CHEMBL1428502 & 688267 & 5.85 & 5.1305 & TRN \\
\hline CHEMBL1465307 & 688267 & 4.05 & 5.1127 & TRN \\
\hline CHEMBL1469357 & 688267 & 5.55 & 4.9994 & TRN \\
\hline CHEMBL1531700 & 688267 & 5.25 & 5.1159 & TRN \\
\hline CHEMBL1529235 & 688267 & 5.45 & 5.0959 & TRN \\
\hline CHEMBL1412742 & 688267 & 6.2 & 5.0727 & TRN \\
\hline CHEMBL1591022 & 688267 & 6.2 & 5.0318 & TRN \\
\hline CHEMBL1434056 & 688267 & 4.25 & 5.1194 & TRN \\
\hline CHEMBL1517531 & 688267 & 6.2 & 5.079 & TRN \\
\hline CHEMBL1426220 & 688267 & 4.6 & 5.0487 & TST \\
\hline CHEMBL1330785 & 688267 & 5.7 & 5.1382 & TST \\
\hline CHEMBL1429875 & 688267 & 4.0 & 5.0653 & TRN \\
\hline CHEMBL1419548 & 688267 & 3.95 & 5.0949 & TRN \\
\hline CHEMBL1566895 & 688267 & 4.6 & 5.0902 & TST \\
\hline CHEMBL1415998 & 688267 & 6.45 & 5.0933 & TRN \\
\hline CHEMBL1339582 & 688267 & 6.2 & 5.0362 & TRN \\
\hline CHEMBL1336783 & 688267 & 5.6 & 5.1645 & TRN \\
\hline CHEMBL1580287 & 688267 & 4.0 & 5.081 & TST \\
\hline CHEMBL 3211400 & 688267 & 6.2 & 5.0229 & TST \\
\hline CHEMBL1433718 & 688267 & 5.95 & 4.9929 & TST \\
\hline CHEMBL1484885 & 688267 & 5.45 & 5.0276 & TRN \\
\hline CHEMBL1587536 & 688267 & 4.05 & 5.0054 & TST \\
\hline CHEMBL1601819 & 688267 & 4.1 & 5.0815 & TRN \\
\hline CHEMBL1442483 & 688267 & 4.9 & 5.0358 & TRN \\
\hline CHEMBL1569922 & 688267 & 6.1 & 5.1097 & TRN \\
\hline
\end{tabular}




\begin{tabular}{|c|c|c|c|c|}
\hline \multicolumn{5}{|c|}{ Supplemental Table } \\
\hline CHEMBL1451367 & 688267 & 5.0 & 5.1119 & TST \\
\hline CHEMBL3190180 & 688267 & 6.2 & 5.0135 & TRN \\
\hline CHEMBL1498455 & 688267 & 4.05 & 4.9935 & TRN \\
\hline CHEMBL1385749 & 688267 & 6.25 & 5.0462 & TST \\
\hline CHEMBL1527501 & 688267 & 6.2 & 5.0508 & TRN \\
\hline CHEMBL1469828 & 688267 & 4.05 & 5.1253 & TRN \\
\hline CHEMBL1524534 & 688267 & 5.8 & 5.0337 & TRN \\
\hline CHEMBL1472944 & 688267 & 4.4 & 5.0578 & TRN \\
\hline CHEMBL1325353 & 688267 & 3.9 & 5.1189 & TRN \\
\hline CHEMBL1586558 & 688267 & 5.0 & 5.0006 & TRN \\
\hline CHEMBL1329701 & 688267 & 6.5 & 5.0062 & TRN \\
\hline CHEMBL1479000 & 688267 & 5.35 & 5.0789 & TRN \\
\hline CHEMBL1358955 & 688267 & 4.95 & 5.0305 & TRN \\
\hline CHEMBL1469283 & 688267 & 3.8 & 5.0179 & TRN \\
\hline CHEMBL1495894 & 688267 & 4.55 & 5.037 & TRN \\
\hline CHEMBL1436786 & 688267 & 5.25 & 4.9832 & TRN \\
\hline CHEMBL1310333 & 688267 & 6.2 & 5.1122 & TRN \\
\hline CHEMBL1314475 & 688267 & 6.2 & 5.1136 & TRN \\
\hline CHEMBL1409319 & 688267 & 5.2 & 5.0241 & TRN \\
\hline CHEMBL1564047 & 688267 & 4.25 & 5.0212 & TST \\
\hline CHEMBL1503418 & 688267 & 6.15 & 5.0263 & TRN \\
\hline CHEMBL1497618 & 688267 & 5.1 & 5.0551 & TRN \\
\hline CHEMBL1607645 & 688267 & 4.25 & 5.0802 & TRN \\
\hline CHEMBL1355230 & 688267 & 4.05 & 5.0012 & TST \\
\hline CHEMBL1568630 & 688267 & 5.5 & 5.0237 & TRN \\
\hline CHEMBL3192098 & 688267 & 4.35 & 5.0228 & TRN \\
\hline CHEMBL1474968 & 688267 & 4.2 & 5.0803 & TST \\
\hline CHEMBL1366248 & 688267 & 6.2 & 5.0705 & TRN \\
\hline CHEMBL1474087 & 688267 & 6.2 & 5.0332 & TRN \\
\hline CHEMBL1334053 & 688267 & 4.05 & 5.0163 & TRN \\
\hline CHEMBL1595153 & 688267 & 4.7 & 5.0272 & TST \\
\hline CHEMBL1480476 & 688267 & 6.35 & 5.0647 & TRN \\
\hline CHEMBL1473118 & 688267 & 6.2 & 5.0403 & TRN \\
\hline CHEMBL1411981 & 688267 & 4.95 & 5.0999 & TRN \\
\hline CHEMBL1512304 & 688267 & 6.2 & 5.0803 & TRN \\
\hline CHEMBL1370186 & 688267 & 5.1 & 5.043 & TRN \\
\hline CHEMBL1476396 & 688267 & 6.2 & 5.1571 & TRN \\
\hline CHEMBL1389498 & 688267 & 4.05 & 5.1038 & TRN \\
\hline CHEMBL1308931 & 688267 & 4.05 & 5.0833 & TRN \\
\hline CHEMBL3191230 & 688267 & 4.25 & 4.9857 & TRN \\
\hline CHEMBL1495263 & 688267 & 4.3 & 5.0223 & TRN \\
\hline CHEMBL1593340 & 688267 & 5.55 & 5.1519 & TRN \\
\hline CHEMBL1586041 & 688267 & 5.15 & 5.0716 & TRN \\
\hline CHEMBL1403955 & 688267 & 5.25 & 5.1046 & TST \\
\hline CHEMBL1499086 & 688267 & 4.95 & 5.0392 & TST \\
\hline CHEMBL1434233 & 688267 & 6.2 & 5.0933 & TRN \\
\hline CHEMBL1360180 & 688267 & 5.35 & 5.0395 & TST \\
\hline CHEMBL1400730 & 688267 & 5.0 & 5.0953 & TST \\
\hline
\end{tabular}




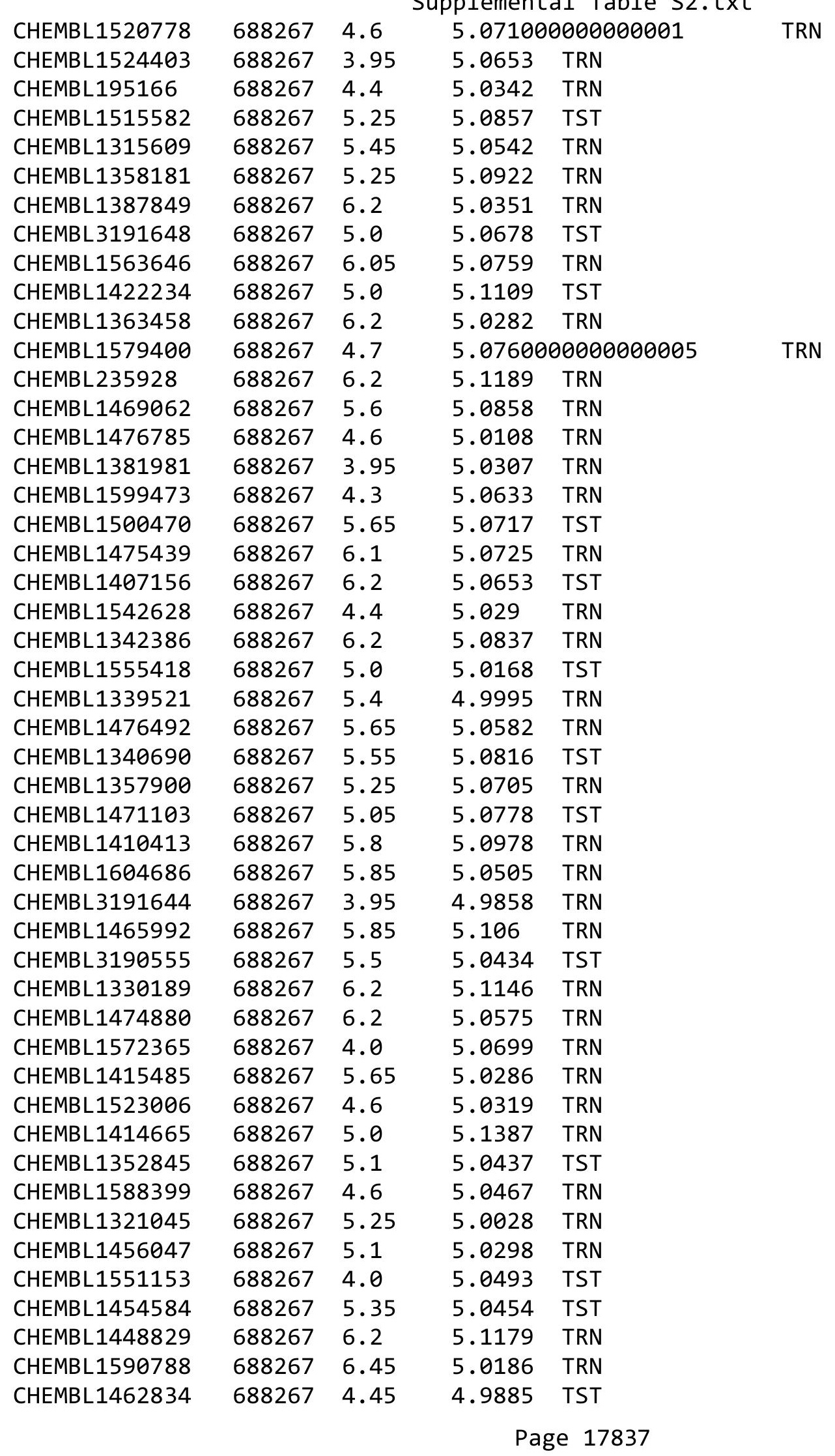




\begin{tabular}{|c|c|c|c|c|c|}
\hline & & \multicolumn{4}{|c|}{ Supplemental Table S2.txt } \\
\hline CHEMBL1532281 & 688267 & 6.15 & 5.0504 & TRN & \\
\hline CHEMBL1301682 & 688267 & 4.35 & 5.0755 & TRN & \\
\hline CHEMBL1519255 & 688267 & 5.85 & 5.0178 & TRN & \\
\hline CHEMBL1531288 & 688267 & 4.4 & 5.0831 & TRN & \\
\hline CHEMBL1489795 & 688267 & 3.95 & 5.1059 & TRN & \\
\hline CHEMBL1477057 & 688267 & 4.0 & 5.0167 & TST & \\
\hline CHEMBL1565314 & 688267 & 4.0 & 5.0298 & TRN & \\
\hline CHEMBL1338160 & 688267 & 5.9 & 5.0408 & TRN & \\
\hline CHEMBL1368460 & 688267 & 4.0 & 5.0728 & TRN & \\
\hline CHEMBL1549714 & 688267 & 4.35 & 5.0078 & TST & \\
\hline CHEMBL1464827 & 688267 & 4.75 & 5.0271 & TRN & \\
\hline CHEMBL1571215 & 688267 & 6.15 & 5.0342 & TRN & \\
\hline CHEMBL1485822 & 688267 & 6.25 & 5.0872 & TRN & \\
\hline CHEMBL1541367 & 688267 & 6.5 & 5.0723 & TST & \\
\hline CHEMBL216887 & 688267 & 5.45 & 5.0947 & TRN & \\
\hline CHEMBL1591546 & 688267 & 4.0 & 5.0744 & TRN & \\
\hline CHEMBL1542657 & 688267 & 6.05 & 5.0281 & TST & \\
\hline CHEMBL1502029 & 688267 & 5.15 & 5.1363 & TST & \\
\hline CHEMBL1613201 & 688267 & 4.05 & 5.0258 & TRN & \\
\hline CHEMBL1426983 & 688267 & 6.2 & 5.0777 & TST & \\
\hline CHEMBL1317222 & 688267 & 5.35 & 5.0485 & TRN & \\
\hline CHEMBL1482416 & 688267 & 6.2 & 5.0693 & TRN & \\
\hline CHEMBL1430724 & 688267 & 6.6 & 5.1014 & TST & \\
\hline CHEMBL1403507 & 688267 & 6.2 & 5.0037 & TRN & \\
\hline CHEMBL1406266 & 688267 & 5.55 & 5.0852 & TRN & \\
\hline CHEMBL1494966 & 688267 & 5.25 & 5.0461 & TRN & \\
\hline CHEMBL1312560 & 688267 & 4.4 & 5.0535 & TRN & \\
\hline CHEMBL1494487 & 688267 & 5.45 & 5.0303 & TST & \\
\hline CHEMBL1322730 & 688267 & 4.0 & 5.0449 & TRN & \\
\hline CHEMBL1487418 & 688267 & 4.95 & 5.0978 & TST & \\
\hline CHEMBL1350717 & 688267 & 4.65 & 5.1484 & TST & \\
\hline CHEMBL1585222 & 688267 & 5.4 & 5.1051 & TRN & \\
\hline CHEMBL1531417 & 688267 & 5.0 & 5.0601 & TRN & \\
\hline CHEMBL1561397 & 688267 & 4.05 & 5.082 & TRN & \\
\hline CHEMBL1543036 & 688267 & 4.4 & 5.0867 & TRN & \\
\hline CHEMBL1574991 & 688267 & 4.8 & 5.0116 & TST & \\
\hline CHEMBL1518543 & 688267 & 4.35 & 5.0593 & TST & \\
\hline CHEMBL1529644 & 688267 & 4.65 & 4.9907 & TRN & \\
\hline CHEMBL1510948 & 688267 & 4.45 & 5.0765 & TST & \\
\hline CHEMBL1491610 & 688267 & 4.45 & 5.0309 & TRN & \\
\hline CHEMBL1359007 & 688267 & 4.85 & 5.0629 & TRN & \\
\hline CHEMBL1354076 & 688267 & 4.2 & 5.0188 & TRN & \\
\hline CHEMBL1502923 & 688267 & 6.2 & 5.0571 & TRN & \\
\hline CHEMBL1532265 & 688267 & 6.2 & 5.0343 & TST & \\
\hline CHEMBL1458782 & 688267 & 4.4 & 5.056 & TRN & \\
\hline CHEMBL1399521 & 688267 & 6.2 & 5.04899 & 99999999995 & TRN \\
\hline CHEMBL1454159 & 688267 & 5.45 & 5.0561 & TRN & \\
\hline CHEMBL1531875 & 688267 & 4.4 & 5.0496 & TST & \\
\hline
\end{tabular}




\begin{tabular}{|c|c|c|c|c|c|}
\hline & & \multicolumn{4}{|c|}{ Supplemental Table s2.txt } \\
\hline CHEMBL1353904 & 688267 & 4.55 & 5.0635 & TRN & \\
\hline CHEMBL1332905 & 688267 & 4.25 & 5.0461 & TRN & \\
\hline CHEMBL1593893 & 688267 & 6.5 & 5.032 & TRN & \\
\hline CHEMBL1391278 & 688267 & 4.0 & 5.02800 & 00000000005 & TRN \\
\hline CHEMBL1302255 & 688267 & 5.9 & 5.0766 & TRN & \\
\hline CHEMBL1418131 & 688267 & 5.45 & 5.0708 & TRN & \\
\hline CHEMBL1353591 & 688267 & 4.4 & 5.0288 & TRN & \\
\hline CHEMBL1460210 & 688267 & 6.15 & 5.0774 & TRN & \\
\hline CHEMBL1486518 & 688267 & 5.3 & 5.0849 & TRN & \\
\hline CHEMBL1552829 & 688267 & 4.05 & 5.0488 & TRN & \\
\hline CHEMBL1556186 & 688267 & 5.25 & 5.0353 & TST & \\
\hline CHEMBL1506149 & 688267 & 5.6 & 5.1271 & TRN & \\
\hline CHEMBL1546833 & 688267 & 4.0 & 5.0481 & TRN & \\
\hline CHEMBL1566792 & 688267 & 5.35 & 5.0256 & TRN & \\
\hline CHEMBL3192026 & 688267 & 6.1 & 5.02 & TRN & \\
\hline CHEMBL1335342 & 688267 & 4.0 & 5.0441 & TRN & \\
\hline CHEMBL1605382 & 688267 & 4.35 & 5.0361 & TRN & \\
\hline CHEMBL 1608710 & 688267 & 6.2 & 4.9789 & TRN & \\
\hline CHEMBL1572793 & 688267 & 4.5 & 5.0558 & TST & \\
\hline CHEMBL1385495 & 688267 & 4.35 & 5.0459 & TRN & \\
\hline CHEMBL1553318 & 688267 & 6.2 & 4.9819 & TRN & \\
\hline CHEMBL1406122 & 688267 & 4.5 & 5.0834 & TRN & \\
\hline CHEMBL1530522 & 688267 & 6.2 & 5.066 & TRN & \\
\hline CHEMBL1403856 & 688267 & 4.15 & 4.9981 & TRN & \\
\hline CHEMBL1336617 & 688267 & 4.0 & 5.0222 & TRN & \\
\hline CHEMBL1404937 & 688267 & 4.8 & 5.0586 & TRN & \\
\hline CHEMBL1568834 & 688267 & 4.05 & 5.0588 & TST & \\
\hline CHEMBL1578644 & 688267 & 5.4 & 5.0347 & TRN & \\
\hline CHEMBL1470598 & 688267 & 4.45 & 5.0111 & TRN & \\
\hline CHEMBL1323458 & 688267 & 4.05 & 5.0142 & TST & \\
\hline CHEMBL1475662 & 688267 & 5.75 & 4.9972 & TRN & \\
\hline CHEMBL1437763 & 688267 & 6.25 & 5.0752 & TRN & \\
\hline CHEMBL1317793 & 688267 & 5.15 & 5.0272 & TST & \\
\hline CHEMBL1527773 & 688267 & 5.65 & 5.0423 & TST & \\
\hline CHEMBL1612842 & 688267 & 5.5 & 5.0563 & TRN & \\
\hline CHEMBL1400425 & 688267 & 3.95 & 5.0053 & TRN & \\
\hline CHEMBL1342234 & 688267 & 6.2 & 4.9785 & TRN & \\
\hline CHEMBL1304431 & 688267 & 4.4 & 5.0149 & TRN & \\
\hline CHEMBL1608285 & 688267 & 5.25 & 5.0788 & TRN & \\
\hline CHEMBL1551773 & 688267 & 4.05 & 5.0491 & TRN & \\
\hline CHEMBL1353014 & 688267 & 6.2 & 5.019 & TRN & \\
\hline CHEMBL1350202 & 688267 & 4.05 & 5.0753 & TRN & \\
\hline CHEMBL1414426 & 688267 & 4.95 & 5.0847 & TRN & \\
\hline CHEMBL1491143 & 688267 & 5.6 & 5.0304 & TRN & \\
\hline CHEMBL1475026 & 688267 & 5.4 & 5.1091 & TRN & \\
\hline CHEMBL1302298 & 688267 & 5.2 & 5.0607 & TRN & \\
\hline CHEMBL1513774 & 688267 & 4.45 & 5.0198 & TST & \\
\hline CHEMBL1980827 & 688267 & 4.85 & 5.0174 & TST & \\
\hline
\end{tabular}




\begin{tabular}{|c|c|c|c|c|}
\hline \multicolumn{5}{|c|}{ Supplemental Table S2.txt } \\
\hline CHEMBL1332194 & 688267 & 3.95 & 5.0322 & TST \\
\hline CHEMBL1371480 & 688267 & 5.7 & 5.0313 & TRN \\
\hline CHEMBL1361301 & 688267 & 6.2 & 5.0972 & TST \\
\hline CHEMBL1591788 & 688267 & 4.0 & 5.0904 & TRN \\
\hline CHEMBL1547388 & 688267 & 6.15 & 5.0498 & TRN \\
\hline CHEMBL1449569 & 688267 & 5.55 & 5.04 & TRN \\
\hline CHEMBL1431996 & 688267 & 4.65 & 5.0472 & TST \\
\hline CHEMBL1590218 & 688267 & 4.45 & 5.052 & TRN \\
\hline CHEMBL1328903 & 688267 & 6.2 & 5.003 & TRN \\
\hline CHEMBL1440744 & 688267 & 5.55 & 5.0717 & TRN \\
\hline CHEMBL 3210138 & 688267 & 4.0 & 5.1318 & TRN \\
\hline CHEMBL1510503 & 688267 & 5.25 & 5.0339 & TRN \\
\hline CHEMBL1475648 & 688267 & 6.2 & 5.0666 & TRN \\
\hline CHEMBL1611607 & 688267 & 6.2 & 5.051 & TRN \\
\hline CHEMBL1522107 & 688267 & 6.2 & 4.9863 & TST \\
\hline CHEMBL1518858 & 688267 & 4.7 & 5.0214 & TRN \\
\hline CHEMBL1435747 & 688267 & 5.6 & 5.0443 & TRN \\
\hline CHEMBL1571742 & 688267 & 4.55 & 5.0435 & TRN \\
\hline CHEMBL1434363 & 688267 & 6.3 & 5.0536 & TRN \\
\hline CHEMBL3212962 & 688267 & 4.1 & 5.0353 & TST \\
\hline CHEMBL1458169 & 688267 & 4.9 & 5.0995 & TST \\
\hline CHEMBL1323945 & 688267 & 6.15 & 5.0784 & TRN \\
\hline CHEMBL1333745 & 688267 & 7.4001 & 5.0654 & TRN \\
\hline CHEMBL1427775 & 688267 & 4.2 & 4.9885 & TRN \\
\hline CHEMBL1356619 & 688267 & 5.55 & 5.0733 & TRN \\
\hline CHEMBL1498806 & 688267 & 6.9 & 5.074 & TRN \\
\hline CHEMBL1441250 & 688267 & 5.9 & 5.0413 & TST \\
\hline CHEMBL1498666 & 688267 & 5.1 & 5.0334 & TRN \\
\hline CHEMBL1339893 & 688267 & 5.95 & 5.0871 & TRN \\
\hline CHEMBL1403163 & 688267 & 6.2 & 5.0446 & TRN \\
\hline CHEMBL1477029 & 688267 & 6.15 & 5.0023 & TRN \\
\hline CHEMBL1609456 & 688267 & 4.0 & 5.0492 & TST \\
\hline CHEMBL1392457 & 688267 & 5.55 & 5.0808 & TRN \\
\hline CHEMBL1604576 & 688267 & 5.3 & 5.0501 & TST \\
\hline CHEMBL1479358 & 688267 & 6.2 & 5.08 & TRN \\
\hline CHEMBL1436282 & 688267 & 4.0 & 4.9934 & TRN \\
\hline CHEMBL1611422 & 688267 & 6.15 & 5.0369 & TRN \\
\hline CHEMBL1567335 & 688267 & 4.9 & 5.047 & TRN \\
\hline CHEMBL1416637 & 688267 & 6.25 & 5.0586 & TST \\
\hline CHEMBL1545362 & 688267 & 4.9 & 5.1499 & TRN \\
\hline CHEMBL1417314 & 688267 & 4.15 & 5.0199 & TRN \\
\hline CHEMBL3194295 & 688267 & 4.85 & 5.0662 & TST \\
\hline CHEMBL1362605 & 688267 & 4.0 & 5.0713 & TRN \\
\hline CHEMBL1376822 & 688267 & 5.0 & 5.0774 & TRN \\
\hline CHEMBL1377063 & 688267 & 5.85 & 5.0409 & TRN \\
\hline CHEMBL1305498 & 688267 & 5.6 & 5.1177 & TST \\
\hline CHEMBL1501185 & 688267 & 6.2 & 5.0298 & TST \\
\hline CHEMBL1560725 & 688267 & 6.25 & 5.0269 & TRN \\
\hline
\end{tabular}




\begin{tabular}{|c|c|c|c|c|c|}
\hline \multirow[b]{2}{*}{ CHEMBL1462409 } & \multirow[b]{2}{*}{688267} & \multicolumn{4}{|c|}{ Supplemental Table S2.txt } \\
\hline & & 5.45 & 5.0907 & TST & \\
\hline CHEMBL1533961 & 688267 & 4.65 & 5.0233 & TRN & \\
\hline CHEMBL1594349 & 688267 & 4.05 & 5.0812 & TRN & \\
\hline CHEMBL1495865 & 688267 & 5.5 & 5.0741 & TST & \\
\hline CHEMBL1585758 & 688267 & 6.2 & 5.0511 & TST & \\
\hline CHEMBL1417806 & 688267 & 5.75 & 5.0558 & TRN & \\
\hline CHEMBL1543481 & 688267 & 4.25 & 4.9709 & TRN & \\
\hline CHEMBL1402388 & 688267 & 5.85 & 5.0505 & TRN & \\
\hline CHEMBL1315089 & 688267 & 5.45 & 5.0162 & TRN & \\
\hline CHEMBL1320253 & 688267 & 3.95 & 5.1422 & TRN & \\
\hline CHEMBL1468233 & 688267 & 4.55 & 5.0421 & TRN & \\
\hline CHEMBL1445569 & 688267 & 4.65 & 5.0396 & TRN & \\
\hline CHEMBL1450384 & 688267 & 5.85 & 5.048 & TRN & \\
\hline CHEMBL1428059 & 688267 & 4.85 & 5.0871 & TRN & \\
\hline CHEMBL1337438 & 688267 & 5.3 & 5.0408 & TRN & \\
\hline CHEMBL1493220 & 688267 & 5.4 & 5.1013 & TST & \\
\hline CHEMBL3193982 & 688267 & 5.9 & 5.0527 & TRN & \\
\hline CHEMBL1569309 & 688267 & 6.25 & 5.0674 & TRN & \\
\hline CHEMBL1550517 & 688267 & 4.6 & 5.0866 & TST & \\
\hline CHEMBL1506757 & 688267 & 4.05 & 5.0247 & TST & \\
\hline CHEMBL1341156 & 688267 & 4.4 & 5.0697 & TRN & \\
\hline CHEMBL1372688 & 688267 & 5.9 & 5.0134 & TST & \\
\hline CHEMBL1611187 & 688267 & 5.5 & 5.0267 & TRN & \\
\hline CHEMBL3212206 & 688267 & 4.3 & 5.0131 & TRN & \\
\hline CHEMBL1391767 & 688267 & 5.45 & 5.0353 & TRN & \\
\hline CHEMBL1355617 & 688267 & 6.7001 & 5.0005 & TRN & \\
\hline CHEMBL1476636 & 688267 & 5.0 & 5.0026 & TST & \\
\hline CHEMBL1403054 & 688267 & 4.7 & 5.0625 & TRN & \\
\hline CHEMBL1333346 & 688267 & 5.9 & 5.0595 & TRN & \\
\hline CHEMBL1381060 & 688267 & 5.45 & 5.00899 & 99999999995 & TRN \\
\hline CHEMBL1501140 & 688267 & 5.0 & 5.0823 & TRN & \\
\hline CHEMBL1352717 & 688267 & 4.0 & 5.0286 & TRN & \\
\hline CHEMBL1466034 & 688267 & 6.1 & 5.0517 & TRN & \\
\hline CHEMBL3197965 & 688267 & 5.95 & 5.01699 & 99999999995 & TST \\
\hline CHEMBL1337482 & 688267 & 5.1 & 5.0565 & TRN & \\
\hline CHEMBL1601274 & 688267 & 4.25 & 5.1033 & TRN & \\
\hline CHEMBL1452039 & 688267 & 4.0 & 5.0404 & TST & \\
\hline CHEMBL1461686 & 688267 & 4.3 & 5.0231 & TRN & \\
\hline CHEMBL1601627 & 688267 & 6.2 & 5.0011 & TRN & \\
\hline CHEMBL1476273 & 688267 & 4.35 & 5.0284 & TRN & \\
\hline CHEMBL1331113 & 688267 & 4.75 & 5.1656 & TRN & \\
\hline CHEMBL1483006 & 688267 & 5.4 & 5.1082 & TRN & \\
\hline CHEMBL1319840 & 688267 & 6.2 & 5.0306 & TRN & \\
\hline CHEMBL1520521 & 688267 & 4.55 & 5.1018 & TST & \\
\hline CHEMBL1357030 & 688267 & 4.4 & 5.1216 & TRN & \\
\hline CHEMBL1320231 & 688267 & 4.0 & 5.0474 & TRN & \\
\hline CHEMBL1394911 & 688267 & 4.35 & 5.0613 & TRN & \\
\hline CHEMBL1324645 & 688267 & 5.5 & 5.09699 & 99999999995 & TST \\
\hline & & & & 17841 & \\
\hline
\end{tabular}




\begin{tabular}{|c|c|c|c|c|c|}
\hline \multicolumn{6}{|c|}{ Supplemental Table S2.txt } \\
\hline CHEMBL1475796 & 688267 & 4.7 & 5.0152 & TST & \\
\hline CHEMBL1363450 & 688267 & 4.4 & 5.1181 & TRN & \\
\hline CHEMBL1503460 & 688267 & 5.45 & 5.0582 & TST & \\
\hline CHEMBL1535567 & 688267 & 5.65 & 5.0873 & TST & \\
\hline CHEMBL1593794 & 688267 & 4.05 & 5.0488 & TRN & \\
\hline CHEMBL1550116 & 688267 & 4.55 & 5.0795 & TST & \\
\hline CHEMBL1608413 & 688267 & 6.05 & 5.1032 & TRN & \\
\hline CHEMBL1505138 & 688267 & 5.4 & 5.0843 & TRN & \\
\hline CHEMBL1314186 & 688267 & 5.2 & 5.0896 & TST & \\
\hline CHEMBL1372863 & 688267 & 5.0 & 4.9943 & TRN & \\
\hline CHEMBL1421775 & 688267 & 6.2 & 5.1259 & TRN & \\
\hline CHEMBL1466909 & 688267 & 4.35 & 5.0616 & TRN & \\
\hline CHEMBL1400468 & 688267 & 4.0 & 5.0588 & TST & \\
\hline CHEMBL1408102 & 688267 & 4.6 & 5.0101 & TST & \\
\hline CHEMBL1512572 & 688267 & 4.05 & 5.0589 & TRN & \\
\hline CHEMBL1362958 & 688267 & 3.95 & 5.0947 & TST & \\
\hline CHEMBL1438300 & 688267 & 4.6 & 5.0543 & TRN & \\
\hline CHEMBL1438743 & 688267 & 4.0 & 5.0068 & TST & \\
\hline CHEMBL1398955 & 688267 & 6.2 & 5.1013 & TRN & \\
\hline CHEMBL1471645 & 688267 & 4.7 & 5.0604 & TST & \\
\hline CHEMBL1578517 & 688267 & 5.5 & 5.0393 & TRN & \\
\hline CHEMBL1579155 & 688267 & 4.75 & 5.051 & TST & \\
\hline CHEMBL1460712 & 688267 & 5.55 & 5.1302 & TRN & \\
\hline CHEMBL1451992 & 688267 & 5.9 & 5.0523 & TST & \\
\hline CHEMBL1470021 & 688267 & 4.25 & 5.0385 & TRN & \\
\hline CHEMBL1397275 & 688267 & 5.35 & 5.0286 & TRN & \\
\hline CHEMBL1893861 & 688267 & 4.25 & 4.984 & TRN & \\
\hline CHEMBL1470107 & 688267 & 4.8 & 5.1131 & TST & \\
\hline CHEMBL1432759 & 688267 & 6.2 & 5.0222 & TRN & \\
\hline CHEMBL1368554 & 688267 & 4.35 & 5.1397 & TRN & \\
\hline CHEMBL1608031 & 688267 & 4.25 & 5.0279 & TRN & \\
\hline CHEMBL1356939 & 688267 & 3.95 & 5.0222 & TRN & \\
\hline CHEMBL1404578 & 688267 & 6.1 & 5.0337 & TRN & \\
\hline CHEMBL1326928 & 688267 & 4.65 & 5.0253 & TST & \\
\hline CHEMBL1547900 & 688267 & 4.2 & 5.1437 & TRN & \\
\hline CHEMBL1538191 & 688267 & 5.0 & 5.0856 & TST & \\
\hline CHEMBL1474870 & 688267 & 5.9 & 5.0864 & TST & \\
\hline CHEMBL1489082 & 688267 & 6.1 & 5.0272 & TRN & \\
\hline CHEMBL 3213770 & 688267 & 4.05 & 5.0232 & TST & \\
\hline CHEMBL1415354 & 688267 & 4.0 & 5.0165 & TST & \\
\hline CHEMBL1450973 & 688267 & 6.15 & 5.0493 & TRN & \\
\hline CHEMBL1570370 & 688267 & 5.3 & 5.13399 & 99999999995 & TRN \\
\hline CHEMBL1461963 & 688267 & 4.45 & 5.0184 & TRN & \\
\hline CHEMBL1609076 & 688267 & 4.5 & 5.0514 & TRN & \\
\hline CHEMBL1411178 & 688267 & 4.85 & 4.982 & TRN & \\
\hline CHEMBL1607448 & 688267 & 5.6 & 5.0626 & TRN & \\
\hline CHEMBL1601034 & 688267 & 4.0 & 5.1263 & TRN & \\
\hline CHEMBL1457840 & 688267 & 4.4 & 5.095 & TST & \\
\hline
\end{tabular}




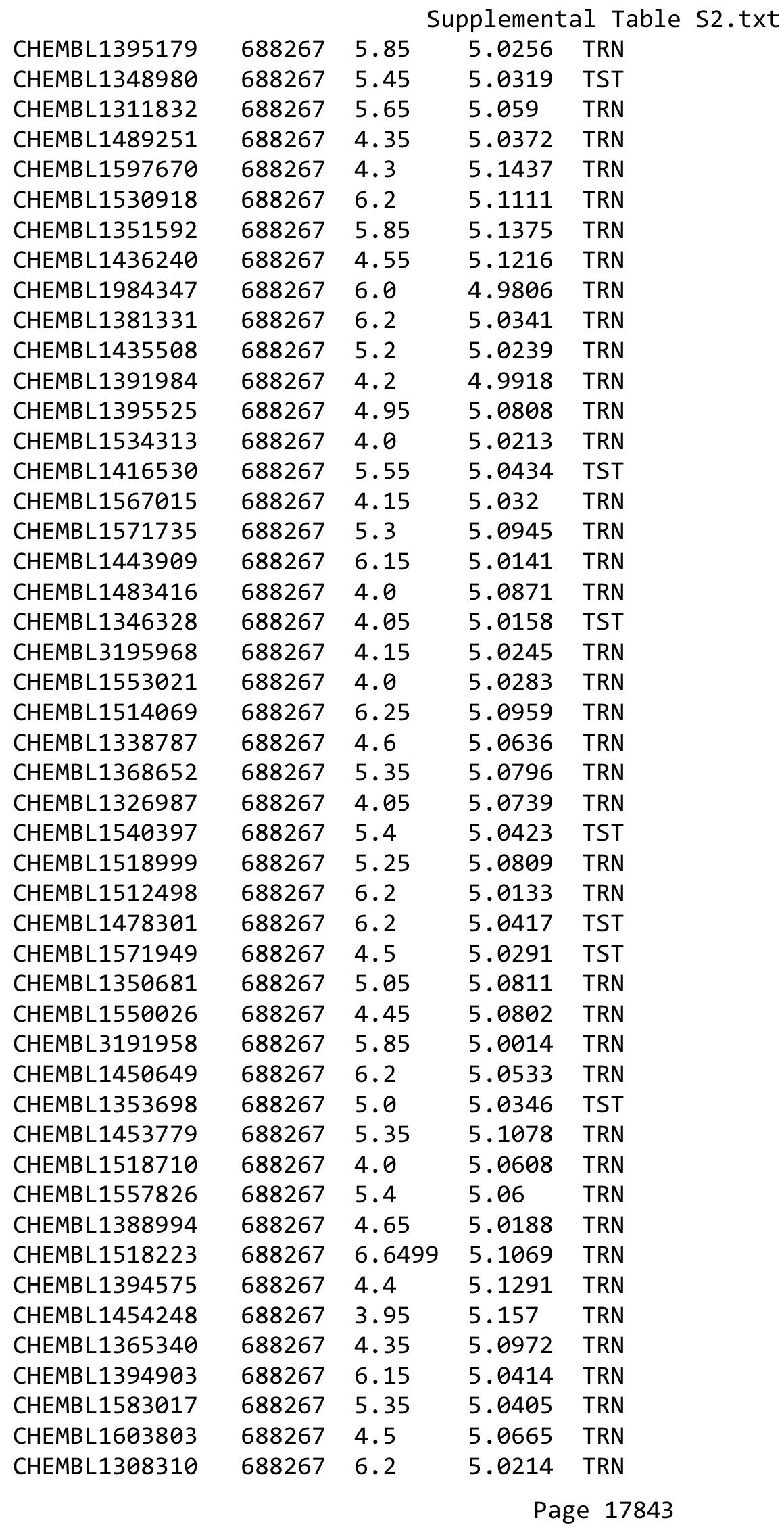




\begin{tabular}{|c|c|c|c|c|c|}
\hline \\
\hline CHEMBL1376637 & 688267 & 4.3 & 5.0961 & TRN & \\
\hline CHEMBL1533759 & 688267 & 4.25 & 5.0117 & TST & \\
\hline CHEMBL1401938 & 688267 & 4.0 & 5.0019 & TST & \\
\hline CHEMBL1608367 & 688267 & 4.1 & 5.0156 & TST & \\
\hline CHEMBL1475854 & 688267 & 6.5 & 4.98300 & 00000000005 & TRN \\
\hline CHEMBL1543935 & 688267 & 6.05 & 5.0609 & TRN & \\
\hline CHEMBL1589121 & 688267 & 6.25 & 5.026 & TRN & \\
\hline CHEMBL1567003 & 688267 & 6.2 & 5.0483 & TRN & \\
\hline CHEMBL412059 & 688267 & 4.25 & 5.0616 & TRN & \\
\hline CHEMBL1407288 & 688267 & 5.5 & 5.1015 & TRN & \\
\hline CHEMBL1612753 & 688267 & 5.9 & 5.0839 & TST & \\
\hline CHEMBL1582069 & 688267 & 4.05 & 5.0602 & TRN & \\
\hline CHEMBL1421266 & 688267 & 6.15 & 5.1273 & TRN & \\
\hline CHEMBL1354696 & 688267 & 6.15 & 5.1731 & TRN & \\
\hline CHEMBL1338675 & 688267 & 6.25 & 4.9876 & TRN & \\
\hline CHEMBL1404990 & 688267 & 4.4 & 5.0659 & TRN & \\
\hline CHEMBL1377328 & 688267 & 5.5 & 5.0967 & TRN & \\
\hline CHEMBL1440074 & 688267 & 4.0 & 5.006 & TRN & \\
\hline CHEMBL1595852 & 688267 & 6.25 & 5.1103 & TRN & \\
\hline CHEMBL1613089 & 688267 & 5.55 & 4.9944 & TRN & \\
\hline CHEMBL1561289 & 688267 & 5.9 & 5.0914 & TRN & \\
\hline CHEMBL1519794 & 688267 & 5.6 & 5.1047 & TST & \\
\hline CHEMBL1538367 & 688267 & 5.05 & 5.0298 & TST & \\
\hline CHEMBL1605625 & 688267 & 5.3 & 5.1283 & TRN & \\
\hline CHEMBL1475187 & 688267 & 5.25 & 5.0168 & TRN & \\
\hline CHEMBL3210485 & 688267 & 5.1 & 5.0766 & TRN & \\
\hline CHEMBL1384945 & 688267 & 5.3 & 5.095 & TRN & \\
\hline CHEMBL1513902 & 688267 & 5.35 & 5.0272 & TRN & \\
\hline CHEMBL1535266 & 688267 & 5.9 & 5.0998 & TRN & \\
\hline CHEMBL1417368 & 688267 & 6.35 & 5.0315 & TRN & \\
\hline CHEMBL1467710 & 688267 & 4.55 & 5.084 & TRN & \\
\hline CHEMBL1410284 & 688267 & 4.65 & 5.1384 & TRN & \\
\hline CHEMBL1331603 & 688267 & 4.4 & 5.0408 & TRN & \\
\hline CHEMBL1350493 & 688267 & 4.55 & 5.0676 & TRN & \\
\hline CHEMBL1380035 & 688267 & 6.25 & 4.9619 & TRN & \\
\hline CHEMBL1420544 & 688267 & 4.0 & 5.0251 & TRN & \\
\hline CHEMBL1538178 & 688267 & 6.25 & 5.0555 & TRN & \\
\hline CHEMBL1380161 & 688267 & 5.65 & 5.019 & TRN & \\
\hline CHEMBL1314712 & 688267 & 4.25 & 5.0725 & TRN & \\
\hline CHEMBL1401089 & 688267 & 6.5 & 4.9964 & TRN & \\
\hline CHEMBL1361679 & 688267 & 6.05 & 5.1103 & TRN & \\
\hline CHEMBL1472610 & 688267 & 4.85 & 5.1191 & TRN & \\
\hline CHEMBL3191020 & 688267 & 4.0 & 5.035 & TRN & \\
\hline CHEMBL1515198 & 688267 & 5.45 & 4.9905 & TRN & \\
\hline CHEMBL1367436 & 688267 & 4.6 & 5.0618 & TRN & \\
\hline CHEMBL1498905 & 688267 & 5.3 & 5.1001 & TRN & \\
\hline CHEMBL1427365 & 688267 & 4.8 & 5.0771 & TST & \\
\hline CHEMBL1552110 & 688267 & 4.6 & 5.0796 & TRN & \\
\hline & & & & 784 & \\
\hline
\end{tabular}




\begin{tabular}{|c|c|c|c|c|c|}
\hline \multicolumn{6}{|c|}{ Supplemental Table S2.txt } \\
\hline CHEMBL1321234 & 688267 & 5.5 & 5.073 & TRN & \\
\hline CHEMBL1524859 & 688267 & 3.95 & 5.0537 & TRN & \\
\hline CHEMBL1317139 & 688267 & 4.6 & 5.0147 & TRN & \\
\hline CHEMBL1330257 & 688267 & 6.2 & 5.0031 & TRN & \\
\hline CHEMBL1427168 & 688267 & 5.85 & 5.16200 & 0000000001 & TRN \\
\hline CHEMBL1499043 & 688267 & 5.35 & 5.0553 & TRN & \\
\hline CHEMBL1529514 & 688267 & 6.15 & 5.0301 & TRN & \\
\hline CHEMBL1534171 & 688267 & 4.3 & 4.9922 & TRN & \\
\hline CHEMBL1302609 & 688267 & 5.6 & 5.0439 & TST & \\
\hline CHEMBL1601354 & 688267 & 6.2 & 5.1214 & TRN & \\
\hline CHEMBL1552891 & 688267 & 3.95 & 5.0083 & TRN & \\
\hline CHEMBL1516026 & 688267 & 4.0 & 5.0735 & TRN & \\
\hline CHEMBL1480939 & 688267 & 5.95 & 5.0573 & TRN & \\
\hline CHEMBL1535747 & 688267 & 6.2 & 4.9861 & TRN & \\
\hline CHEMBL1476302 & 688267 & 5.95 & 5.0498 & TRN & \\
\hline CHEMBL1557933 & 688267 & 4.1 & 5.0214 & TRN & \\
\hline CHEMBL1590563 & 688267 & 6.2 & 5.1003 & TST & \\
\hline CHEMBL1446113 & 688267 & 5.3 & 5.0278 & TRN & \\
\hline CHEMBL1559693 & 688267 & 5.55 & 5.1112 & TRN & \\
\hline CHEMBL1430985 & 688267 & 4.1 & 5.0316 & TST & \\
\hline CHEMBL1478425 & 688267 & 4.85 & 5.0969 & TRN & \\
\hline CHEMBL1373841 & 688267 & 5.6 & 5.0421 & TST & \\
\hline CHEMBL1593888 & 688267 & 4.4 & 5.0239 & TRN & \\
\hline CHEMBL1550790 & 688267 & 6.2 & 5.0272 & TRN & \\
\hline CHEMBL1328242 & 688267 & 5.3 & 5.0846 & TRN & \\
\hline CHEMBL1466328 & 688267 & 5.05 & 5.1144 & TRN & \\
\hline CHEMBL1537281 & 688267 & 4.45 & 5.0593 & TRN & \\
\hline CHEMBL1412048 & 688267 & 5.3 & 4.9998 & TRN & \\
\hline CHEMBL1375262 & 688267 & 5.85 & 5.0782 & TRN & \\
\hline CHEMBL1600629 & 688267 & 4.0 & 5.0358 & TRN & \\
\hline CHEMBL1535964 & 688267 & 4.35 & 5.0018 & TRN & \\
\hline CHEMBL1511376 & 688267 & 4.75 & 5.1227 & TRN & \\
\hline CHEMBL1375781 & 688267 & 4.7 & 5.0376 & TST & \\
\hline CHEMBL1561781 & 688267 & 6.15 & 5.1436 & TRN & \\
\hline CHEMBL1389228 & 688267 & 5.95 & 5.0553 & TRN & \\
\hline CHEMBL1373865 & 688267 & 4.3 & 5.0233 & TRN & \\
\hline CHEMBL1555685 & 688267 & 5.8 & 5.03100 & 0000000001 & TRN \\
\hline CHEMBL1572933 & 688267 & 4.0 & 5.1017 & TRN & \\
\hline CHEMBL1506508 & 688267 & 5.35 & 5.0645 & TST & \\
\hline CHEMBL1602407 & 688267 & 4.6 & 4.9803 & TRN & \\
\hline CHEMBL1559190 & 688267 & 5.75 & 5.1048 & TRN & \\
\hline CHEMBL1514199 & 688267 & 4.6 & 5.1379 & TRN & \\
\hline CHEMBL1364311 & 688267 & 4.0 & 5.0597 & TRN & \\
\hline CHEMBL1463020 & 688267 & 6.2 & 5.0582 & TST & \\
\hline CHEMBL1341632 & 688267 & 5.95 & 5.0434 & TRN & \\
\hline CHEMBL1610465 & 688267 & 4.45 & 5.0739 & TST & \\
\hline CHEMBL1553839 & 688267 & 5.55 & 5.0399 & TRN & \\
\hline CHEMBL1340334 & 688267 & 6.0 & 5.0576 & TRN & \\
\hline
\end{tabular}




\begin{tabular}{|c|c|c|c|c|}
\hline & & & pplement & al $\mathrm{Ta}$ \\
\hline CHEMBL1335146 & 688267 & 4.0 & 5.0027 & TRN \\
\hline CHEMBL1475149 & 688267 & 4.1 & 5.0778 & TRN \\
\hline CHEMBL1565535 & 688267 & 4.0 & 5.0267 & TST \\
\hline CHEMBL1318268 & 688267 & 5.65 & 5.091 & TST \\
\hline CHEMBL1377788 & 688267 & 5.4 & 5.0929 & TST \\
\hline CHEMBL 3208842 & 688267 & 5.2 & 4.9851 & TST \\
\hline CHEMBL1333579 & 688267 & 5.55 & 5.038 & TRN \\
\hline CHEMBL1515753 & 688267 & 4.4 & 5.0838 & TRN \\
\hline CHEMBL3197953 & 688267 & 5.4 & 5.0463 & TRN \\
\hline CHEMBL1472375 & 688267 & 4.05 & 5.1078 & TRN \\
\hline CHEMBL1551822 & 688267 & 4.0 & 5.1538 & TRN \\
\hline CHEMBL3213956 & 688267 & 4.05 & 5.0164 & TST \\
\hline CHEMBL1507339 & 688267 & 5.1 & 5.0952 & TRN \\
\hline CHEMBL1529745 & 688267 & 5.55 & 5.0918 & TST \\
\hline CHEMBL1422874 & 688267 & 5.65 & 5.0511 & TRN \\
\hline CHEMBL1386447 & 688267 & 4.95 & 5.0774 & TST \\
\hline CHEMBL1383675 & 688267 & 6.2 & 5.0797 & TST \\
\hline CHEMBL1599740 & 688267 & 4.4 & 5.0715 & TRN \\
\hline CHEMBL1330870 & 688267 & 4.5 & 5.0909 & TRN \\
\hline CHEMBL1426137 & 688267 & 4.35 & 5.0543 & TST \\
\hline CHEMBL1315946 & 688267 & 4.0 & 5.0623 & TRN \\
\hline CHEMBL1395494 & 688267 & 4.25 & 5.0282 & TRN \\
\hline CHEMBL1562531 & 688267 & 4.0 & 5.0263 & TST \\
\hline CHEMBL1316434 & 688267 & 6.5 & 5.1082 & TRN \\
\hline CHEMBL1558177 & 688267 & 6.2 & 5.0735 & TRN \\
\hline CHEMBL1327709 & 688267 & 4.55 & 4.9884 & TST \\
\hline CHEMBL1455771 & 688267 & 5.85 & 5.0043 & TRN \\
\hline CHEMBL1393785 & 688267 & 6.2 & 5.0213 & TRN \\
\hline CHEMBL1376488 & 688267 & 6.15 & 5.0236 & TRN \\
\hline CHEMBL1453535 & 688267 & 6.2 & 5.0443 & TRN \\
\hline CHEMBL1385744 & 688267 & 4.5 & 5.1204 & TRN \\
\hline CHEMBL1342224 & 688267 & 4.05 & 5.0359 & TRN \\
\hline CHEMBL1420442 & 688267 & 4.0 & 5.0064 & TRN \\
\hline CHEMBL1435478 & 688267 & 4.7 & 5.0922 & TRN \\
\hline CHEMBL 3199154 & 688267 & 4.7 & 4.9992 & TST \\
\hline CHEMBL1454531 & 688267 & 5.3 & 5.0478 & TST \\
\hline CHEMBL1524030 & 688267 & 4.25 & 5.0945 & TST \\
\hline CHEMBL1377956 & 688267 & 6.15 & 4.9923 & TRN \\
\hline CHEMBL1469969 & 688267 & 4.35 & 5.0676 & TRN \\
\hline CHEMBL1389783 & 688267 & 6.15 & 4.9916 & TRN \\
\hline CHEMBL1355579 & 688267 & 5.45 & 5.0777 & TRN \\
\hline CHEMBL1563374 & 688267 & 6.25 & 5.077 & TST \\
\hline CHEMBL1606549 & 688267 & 5.3 & 5.0317 & TRN \\
\hline CHEMBL1385981 & 688267 & 6.2 & 5.1068 & TRN \\
\hline CHEMBL1512354 & 688267 & 5.5 & 5.0133 & TRN \\
\hline CHEMBL1304746 & 688267 & 3.95 & 5.0731 & TRN \\
\hline CHEMBL1507153 & 688267 & 6.0 & 5.0206 & TRN \\
\hline CHEMBL1336118 & 688267 & 4.9 & 5.1439 & TST \\
\hline
\end{tabular}




\begin{tabular}{|c|c|c|c|c|c|}
\hline \multicolumn{6}{|c|}{ Supplemental Table S2.txt } \\
\hline CHEMBL1358211 & 688267 & 6.2 & 4.9661 & TRN & \\
\hline CHEMBL1561416 & 688267 & 4.0 & 4.9995 & TRN & \\
\hline CHEMBL1355171 & 688267 & 4.05 & 5.0165 & TRN & \\
\hline CHEMBL1329130 & 688267 & 5.05 & 5.0851 & TRN & \\
\hline CHEMBL1311829 & 688267 & 6.2 & 5.129 & TRN & \\
\hline CHEMBL1452519 & 688267 & 5.4 & 5.0454 & TRN & \\
\hline CHEMBL1505904 & 688267 & 4.4 & 5.0816 & TRN & \\
\hline CHEMBL1385651 & 688267 & 6.1 & 5.1258 & TST & \\
\hline CHEMBL1344167 & 688267 & 4.05 & 5.039 & TRN & \\
\hline CHEMBL1380211 & 688267 & 5.3 & 5.0507 & TRN & \\
\hline CHEMBL1320066 & 688267 & 5.55 & 5.0923 & TRN & \\
\hline CHEMBL1529030 & 688267 & 4.2 & 5.0594 & TRN & \\
\hline CHEMBL1526101 & 688267 & 5.95 & 5.1006 & TRN & \\
\hline CHEMBL1496016 & 688267 & 4.05 & 5.0472 & TST & \\
\hline CHEMBL1371757 & 688267 & 6.45 & 5.1003 & TRN & \\
\hline CHEMBL1431672 & 688267 & 3.95 & 4.9896 & TST & \\
\hline CHEMBL1339546 & 688267 & 6.2 & 5.0765 & TRN & \\
\hline CHEMBL1303456 & 688267 & 4.4 & 5.0445 & TST & \\
\hline CHEMBL1411754 & 688267 & 4.15 & 5.0246 & TRN & \\
\hline CHEMBL1569474 & 688267 & 6.2 & 5.1153 & TST & \\
\hline CHEMBL1445198 & 688267 & 6.2 & 5.0534 & TRN & \\
\hline CHEMBL1553922 & 688267 & 4.05 & 5.0538 & TST & \\
\hline CHEMBL1377864 & 688267 & 4.0 & 5.0 & TRN & \\
\hline CHEMBL1494971 & 688267 & 6.15 & 5.0511 & TST & \\
\hline CHEMBL1409442 & 688267 & 5.8 & 5.0274 & TRN & \\
\hline CHEMBL1562145 & 688267 & 4.55 & $5.1080 e$ & 00000000005 & TRN \\
\hline CHEMBL1592999 & 688267 & 5.3 & 5.0411 & TRN & \\
\hline CHEMBL1450476 & 688267 & 6.2 & 5.0123 & TST & \\
\hline CHEMBL1386182 & 688267 & 5.15 & 5.0448 & TRN & \\
\hline CHEMBL1559787 & 688267 & 5.45 & 5.079 & TRN & \\
\hline CHEMBL1447488 & 688267 & 4.65 & 5.0163 & TRN & \\
\hline CHEMBL1349385 & 688267 & 4.4 & 5.0526 & TST & \\
\hline CHEMBL1438227 & 688267 & 4.05 & 5.1092 & TRN & \\
\hline CHEMBL1584653 & 688267 & 4.0 & 5.0504 & TST & \\
\hline CHEMBL1345220 & 688267 & 6.2 & 5.0044 & TST & \\
\hline CHEMBL1603229 & 688267 & 4.8 & 5.0676 & TST & \\
\hline CHEMBL1407938 & 688267 & 4.35 & 5.048 & TRN & \\
\hline CHEMBL1329966 & 688267 & 4.4 & 5.0503 & TRN & \\
\hline CHEMBL1482188 & 688267 & 5.1 & 5.0576 & TRN & \\
\hline CHEMBL1554880 & 688267 & 4.15 & 5.0536 & TRN & \\
\hline CHEMBL1515411 & 688267 & 5.65 & 5.0425 & TRN & \\
\hline CHEMBL1385788 & 688267 & 6.2 & 5.1119 & TRN & \\
\hline CHEMBL1417118 & 688267 & 5.85 & 5.0686 & TRN & \\
\hline CHEMBL1591392 & 688267 & 4.5 & 5.1179 & TRN & \\
\hline CHEMBL1549583 & 688267 & 5.35 & 5.0476 & TRN & \\
\hline CHEMBL1525148 & 688267 & 6.15 & 5.0143 & TRN & \\
\hline CHEMBL1375256 & 688267 & 4.0 & 5.0957 & TRN & \\
\hline CHEMBL1386827 & 688267 & 4.95 & 5.08 & TRN & \\
\hline
\end{tabular}




\begin{tabular}{|c|c|c|c|c|c|}
\hline & & \multicolumn{4}{|c|}{ Supplemental Table S2.txt } \\
\hline CHEMBL1327354 & 688267 & 4.25 & 5.0428 & TST & \\
\hline CHEMBL1457195 & 688267 & 5.35 & 5.0257 & TRN & \\
\hline CHEMBL1372435 & 688267 & 6.2 & 5.062 & TRN & \\
\hline CHEMBL1405748 & 688267 & 5.9 & 5.0733 & TST & \\
\hline CHEMBL1489156 & 688267 & 5.35 & 5.0539 & TST & \\
\hline CHEMBL1605862 & 688267 & 5.8 & 5.0674 & TRN & \\
\hline CHEMBL1398311 & 688267 & 4.35 & 5.1218 & TRN & \\
\hline CHEMBL1596604 & 688267 & 4.0 & 5.1032 & TRN & \\
\hline CHEMBL1434074 & 688267 & 6.05 & 5.046 & TRN & \\
\hline CHEMBL1542613 & 688267 & 4.15 & 5.0629 & TRN & \\
\hline CHEMBL1436985 & 688267 & 6.2 & 5.0943 & TRN & \\
\hline CHEMBL1517583 & 688267 & 5.3 & 5.0989 & TST & \\
\hline CHEMBL1486475 & 688267 & 5.15 & 5.0474 & TST & \\
\hline CHEMBL1376813 & 688267 & 4.55 & 5.1206 & TRN & \\
\hline CHEMBL1346827 & 688267 & 4.05 & 5.0199 & TRN & \\
\hline CHEMBL3197058 & 688267 & 4.4 & 5.0538 & TST & \\
\hline CHEMBL1569360 & 688267 & 4.25 & 4.9922 & TRN & \\
\hline CHEMBL1386146 & 688267 & 4.5 & 5.0447 & TST & \\
\hline CHEMBL1598011 & 688267 & 4.55 & 5.0059 & TST & \\
\hline CHEMBL1473769 & 688267 & 5.5 & 5.0676 & TRN & \\
\hline CHEMBL1399267 & 688267 & 5.15 & 5.1022 & TRN & \\
\hline CHEMBL1330754 & 688267 & 4.4 & 5.1067 & TRN & \\
\hline CHEMBL1579213 & 688267 & 5.3 & 5.0528 & TRN & \\
\hline CHEMBL1344784 & 688267 & 4.0 & 5.061 & TRN & \\
\hline CHEMBL1593345 & 688267 & 6.25 & 5.0126 & TRN & \\
\hline CHEMBL1454272 & 688267 & 5.3 & 5.043 & TRN & \\
\hline CHEMBL3194716 & 688267 & 6.15 & 5.0426 & TST & \\
\hline CHEMBL 2004449 & 688267 & 4.0 & 4.9614 & TRN & \\
\hline CHEMBL1372411 & 688267 & 4.0 & 5.0601 & TRN & \\
\hline CHEMBL1373699 & 688267 & 4.4 & 5.0114 & TRN & \\
\hline CHEMBL1303503 & 688267 & 5.5 & 4.9945 & TRN & \\
\hline CHEMBL1409516 & 688267 & 4.0 & 5.0183 & TRN & \\
\hline CHEMBL1546179 & 688267 & 5.05 & 5.13700 & 00000000005 & TRN \\
\hline CHEMBL1371356 & 688267 & 5.45 & 5.0786 & TRN & \\
\hline CHEMBL1512197 & 688267 & 4.1 & 5.0853 & TRN & \\
\hline CHEMBL1393313 & 688267 & 6.15 & 5.023 & TST & \\
\hline CHEMBL1605298 & 688267 & 4.0 & 5.0613 & TRN & \\
\hline CHEMBL1416975 & 688267 & 4.6 & 5.079 & TRN & \\
\hline CHEMBL1500258 & 688267 & 4.05 & 5.0452 & TRN & \\
\hline CHEMBL1329889 & 688267 & 5.35 & 5.0286 & TRN & \\
\hline CHEMBL1374611 & 688267 & 4.9 & 5.0777 & TRN & \\
\hline CHEMBL1612272 & 688267 & 5.15 & 5.0619 & TRN & \\
\hline CHEMBL1559621 & 688267 & 4.1 & 5.0333 & TST & \\
\hline CHEMBL1304201 & 688267 & 6.5 & 5.0589 & TRN & \\
\hline CHEMBL1504105 & 688267 & 4.0 & 5.0472 & TRN & \\
\hline CHEMBL1230004 & 688267 & 3.95 & 5.0723 & TST & \\
\hline CHEMBL1534358 & 688267 & 4.05 & 4.9972 & TST & \\
\hline CHEMBL1535406 & 688267 & 6.5 & 5.0406 & TRN & \\
\hline
\end{tabular}




\begin{tabular}{|c|c|c|c|c|}
\hline & & & pplement & al $\mathrm{T}$ \\
\hline CHEMBL1344278 & 688267 & 4.3 & 4.9792 & TST \\
\hline CHEMBL1501491 & 688267 & 4.25 & 5.1505 & TRN \\
\hline CHEMBL1600536 & 688267 & 5.65 & 5.0648 & TST \\
\hline CHEMBL1571703 & 688267 & 4.2 & 5.0928 & TRN \\
\hline CHEMBL1312260 & 688267 & 4.9 & 5.0804 & TST \\
\hline CHEMBL1319957 & 688267 & 3.95 & 5.0066 & TRN \\
\hline CHEMBL1480174 & 688267 & 4.2 & 5.1181 & TRN \\
\hline CHEMBL3198063 & 688267 & 3.95 & 5.0371 & TST \\
\hline CHEMBL2369162 & 688267 & 5.0 & 5.01 & TRN \\
\hline CHEMBL1542587 & 688267 & 5.95 & 5.0046 & TRN \\
\hline CHEMBL1310908 & 688267 & 4.0 & 5.0331 & TST \\
\hline CHEMBL1085649 & 688267 & 5.55 & 5.0535 & TRN \\
\hline CHEMBL1463301 & 688267 & 4.35 & 5.039 & TRN \\
\hline CHEMBL1414868 & 688267 & 6.05 & 5.0314 & TRN \\
\hline CHEMBL1315958 & 688267 & 4.9 & 5.1396 & TRN \\
\hline CHEMBL1432580 & 688267 & 4.7 & 5.0462 & TRN \\
\hline CHEMBL1509108 & 688267 & 6.2 & 5.0367 & TRN \\
\hline CHEMBL1519956 & 688267 & 6.05 & 5.066 & TRN \\
\hline CHEMBL1321865 & 688267 & 4.95 & 5.1509 & TRN \\
\hline CHEMBL1455688 & 688267 & 6.2 & 5.0143 & TST \\
\hline CHEMBL1583299 & 688267 & 4.3 & 5.1372 & TRN \\
\hline CHEMBL1427063 & 688267 & 5.0 & 5.1052 & TRN \\
\hline CHEMBL1552512 & 688267 & 5.55 & 5.0642 & TRN \\
\hline CHEMBL1384881 & 688267 & 5.85 & 5.047 & TRN \\
\hline CHEMBL1498638 & 688267 & 5.1 & 5.0875 & TRN \\
\hline CHEMBL1308995 & 688267 & 4.25 & 5.0435 & TST \\
\hline CHEMBL1435504 & 688267 & 5.95 & 5.0114 & TRN \\
\hline CHEMBL1549739 & 688267 & 5.95 & 5.0252 & TRN \\
\hline CHEMBL1355119 & 688267 & 4.55 & 5.0276 & TRN \\
\hline CHEMBL1451764 & 688267 & 4.4 & 5.1288 & TRN \\
\hline CHEMBL1571158 & 688267 & 4.8 & 5.1818 & TRN \\
\hline CHEMBL1601465 & 688267 & 4.4 & 5.0853 & TST \\
\hline CHEMBL1523061 & 688267 & 6.15 & 5.0523 & TRN \\
\hline CHEMBL1349618 & 688267 & 4.4 & 5.0184 & TRN \\
\hline CHEMBL1555482 & 688267 & 4.0 & 5.0167 & TST \\
\hline CHEMBL1512720 & 688267 & 6.25 & 5.0691 & TST \\
\hline CHEMBL1471231 & 688267 & 4.6 & 5.0856 & TRN \\
\hline CHEMBL1561117 & 688267 & 4.0 & 5.0353 & TRN \\
\hline CHEMBL3214213 & 688267 & 3.9 & 5.0662 & TST \\
\hline CHEMBL1601791 & 688267 & 4.0 & 5.0101 & TRN \\
\hline CHEMBL1568749 & 688267 & 5.25 & 5.0347 & TRN \\
\hline CHEMBL1377874 & 688267 & 4.55 & 5.0537 & TRN \\
\hline CHEMBL3199006 & 688267 & 6.25 & 5.0429 & TRN \\
\hline CHEMBL1364897 & 688267 & 4.4 & 5.0698 & TRN \\
\hline CHEMBL1349438 & 688267 & 5.5 & 5.0364 & TRN \\
\hline CHEMBL1420475 & 688267 & 5.4 & 5.0316 & TST \\
\hline CHEMBL1388911 & 688267 & 4.9 & 5.1245 & TST \\
\hline CHEMBL1417547 & 688267 & 4.4 & 5.0551 & TST \\
\hline
\end{tabular}




\begin{tabular}{|c|c|c|c|c|}
\hline \multirow[b]{2}{*}{ CHEMBL1469606 } & \multicolumn{4}{|c|}{ Supplemental Table s2.t } \\
\hline & 688267 & 4.3 & 5.064 & TST \\
\hline CHEMBL1373425 & 688267 & 5.35 & 5.043 & TRN \\
\hline CHEMBL1515718 & 688267 & 5.5 & 5.0749 & TRN \\
\hline CHEMBL1570152 & 688267 & 4.0 & 5.0588 & TRN \\
\hline CHEMBL1583779 & 688267 & 4.7 & 5.0935 & TRN \\
\hline CHEMBL1589661 & 688267 & 6.25 & 5.1231 & TRN \\
\hline CHEMBL1551466 & 688267 & 5.35 & 4.9918 & TST \\
\hline CHEMBL1445577 & 688267 & 4.0 & 5.0214 & TRN \\
\hline CHEMBL1324176 & 688267 & 6.15 & 4.987 & TRN \\
\hline CHEMBL1410348 & 688267 & 4.55 & 4.9964 & TRN \\
\hline CHEMBL1359360 & 688267 & 5.6 & 5.1585 & TRN \\
\hline CHEMBL1573606 & 688267 & 3.95 & 5.0261 & TST \\
\hline CHEMBL1338487 & 688267 & 5.3 & 5.0557 & TRN \\
\hline CHEMBL1552035 & 688267 & 4.45 & 5.0153 & TRN \\
\hline CHEMBL1600166 & 688267 & 6.45 & 5.0692 & TRN \\
\hline CHEMBL1519387 & 688267 & 4.45 & 5.0213 & TRN \\
\hline CHEMBL1545413 & 688267 & 6.2 & 5.0905 & TRN \\
\hline CHEMBL1351273 & 688267 & 5.85 & 5.1112 & TRN \\
\hline CHEMBL1468212 & 688267 & 5.55 & 5.0243 & TST \\
\hline CHEMBL1331629 & 688267 & 4.05 & 4.9966 & TRN \\
\hline CHEMBL1364834 & 688267 & 4.0 & 5.0929 & TST \\
\hline CHEMBL1440638 & 688267 & 4.6 & 5.0696 & TRN \\
\hline CHEMBL1465041 & 688267 & 6.1 & 5.0312 & TRN \\
\hline CHEMBL1513101 & 688267 & 4.0 & 5.032 & TRN \\
\hline CHEMBL 1475840 & 688267 & 6.15 & 5.0815 & TRN \\
\hline CHEMBL1488414 & 688267 & 4.0 & 5.0708 & TRN \\
\hline CHEMBL1503729 & 688267 & 6.2 & 5.0875 & TST \\
\hline CHEMBL1432873 & 688267 & 5.55 & 5.1159 & TRN \\
\hline CHEMBL1315280 & 688267 & 4.25 & 5.0965 & TRN \\
\hline CHEMBL1324557 & 688267 & 4.1 & 5.0618 & TRN \\
\hline CHEMBL1388999 & 688267 & 4.9 & 5.1014 & TRN \\
\hline CHEMBL1428431 & 688267 & 6.15 & 5.0478 & TRN \\
\hline CHEMBL1460028 & 688267 & 4.0 & 5.0096 & TRN \\
\hline CHEMBL1402259 & 688267 & 4.0 & 5.0594 & TRN \\
\hline CHEMBL1351908 & 688267 & 3.95 & 4.9717 & TRN \\
\hline CHEMBL1486600 & 688267 & 4.0 & 5.0303 & TST \\
\hline CHEMBL1511989 & 688267 & 4.0 & 5.1097 & TRN \\
\hline CHEMBL1344224 & 688267 & 4.45 & 4.9937 & TRN \\
\hline CHEMBL1499580 & 688267 & 5.55 & 5.1728 & TRN \\
\hline CHEMBL1395246 & 688267 & 3.95 & 5.1133 & TRN \\
\hline CHEMBL1318700 & 688267 & 5.2 & 5.0415 & TST \\
\hline CHEMBL1442765 & 688267 & 6.2 & 5.0742 & TRN \\
\hline CHEMBL1328338 & 688267 & 6.2 & 5.0962 & TRN \\
\hline CHEMBL1432681 & 688267 & 5.75 & 5.0827 & TST \\
\hline CHEMBL1597501 & 688267 & 6.2 & 5.1107 & TRN \\
\hline CHEMBL1577926 & 688267 & 5.25 & 5.0221 & TRN \\
\hline CHEMBL1307846 & 688267 & 3.95 & 5.0529 & TRN \\
\hline CHEMBL 3189841 & 688267 & 5.55 & 5.0229 & TST \\
\hline
\end{tabular}




\begin{tabular}{|c|c|c|c|c|}
\hline & & & pplement & al $\mathrm{Ta}$ \\
\hline CHEMBL1478408 & 688267 & 5.25 & 5.0453 & TST \\
\hline CHEMBL1545666 & 688267 & 5.65 & 5.0597 & TRN \\
\hline CHEMBL1348752 & 688267 & 4.7 & 5.0937 & TRN \\
\hline CHEMBL1475464 & 688267 & 4.25 & 5.0491 & TRN \\
\hline CHEMBL1399061 & 688267 & 4.0 & 5.1025 & TRN \\
\hline CHEMBL1531665 & 688267 & 4.9 & 5.0181 & TRN \\
\hline CHEMBL1448055 & 688267 & 5.25 & 5.0533 & TRN \\
\hline CHEMBL1459181 & 688267 & 5.1 & 5.0835 & TRN \\
\hline CHEMBL1407086 & 688267 & 5.15 & 5.0763 & TRN \\
\hline CHEMBL1302200 & 688267 & 4.35 & 5.1017 & TRN \\
\hline CHEMBL1399027 & 688267 & 6.25 & 5.0092 & TST \\
\hline CHEMBL1421208 & 688267 & 6.2 & 5.0544 & TRN \\
\hline CHEMBL1441821 & 688267 & 4.95 & 5.0897 & TRN \\
\hline CHEMBL1473205 & 688267 & 5.05 & 5.0592 & TRN \\
\hline CHEMBL1330942 & 688267 & 4.65 & 5.103 & TRN \\
\hline CHEMBL3193259 & 688267 & 6.2 & 5.0107 & TST \\
\hline CHEMBL1537456 & 688267 & 4.05 & 5.038 & TST \\
\hline CHEMBL1518578 & 688267 & 4.5 & 5.0613 & TRN \\
\hline CHEMBL1410019 & 688267 & 4.0 & 5.0877 & TRN \\
\hline CHEMBL1610639 & 688267 & 6.25 & 5.1454 & TRN \\
\hline CHEMBL1433191 & 688267 & 6.1 & 5.0792 & TRN \\
\hline CHEMBL1393012 & 688267 & 5.35 & 5.1206 & TRN \\
\hline CHEMBL1455387 & 688267 & 4.55 & 5.0436 & TRN \\
\hline CHEMBL1567559 & 688267 & 5.3 & 5.0834 & TRN \\
\hline CHEMBL1534823 & 688267 & 5.6 & 5.0445 & TRN \\
\hline CHEMBL1492602 & 688267 & 6.15 & 5.085 & TRN \\
\hline CHEMBL1341870 & 688267 & 6.25 & 5.0281 & TRN \\
\hline CHEMBL1314605 & 688267 & 6.2 & 5.0668 & TRN \\
\hline CHEMBL1570246 & 688267 & 5.2 & 5.0773 & TRN \\
\hline CHEMBL1460352 & 688267 & 4.6 & 4.9809 & TST \\
\hline CHEMBL1588066 & 688267 & 5.5 & 5.0126 & TRN \\
\hline CHEMBL1383742 & 688267 & 5.85 & 5.0548 & TRN \\
\hline CHEMBL1517775 & 688267 & 5.2 & 5.0492 & TRN \\
\hline CHEMBL1465671 & 688267 & 6.0 & 5.0615 & TRN \\
\hline CHEMBL1597360 & 688267 & 5.95 & 5.0668 & TRN \\
\hline CHEMBL1369231 & 688267 & 4.8 & 5.0264 & TST \\
\hline CHEMBL3189739 & 688267 & 4.0 & 4.9707 & TRN \\
\hline CHEMBL1330722 & 688267 & 6.0 & 5.0709 & TRN \\
\hline CHEMBL1389734 & 688267 & 4.85 & 5.0489 & TRN \\
\hline CHEMBL1603841 & 688267 & 5.3 & 5.0357 & TRN \\
\hline CHEMBL1544002 & 688267 & 4.3 & 5.0544 & TST \\
\hline CHEMBL1322011 & 688267 & 4.0 & 5.0704 & TST \\
\hline CHEMBL1511498 & 688267 & 5.6 & 5.0412 & TRN \\
\hline CHEMBL1356737 & 688267 & 6.45 & 5.0317 & TRN \\
\hline CHEMBL1479495 & 688267 & 4.65 & 5.1086 & TRN \\
\hline CHEMBL1435164 & 688267 & 5.4 & 5.1147 & TRN \\
\hline CHEMBL1334885 & 688267 & 4.4 & 5.1353 & TRN \\
\hline CHEMBL1360965 & 688267 & 4.3 & 5.0366 & TST \\
\hline
\end{tabular}




\begin{tabular}{|c|c|c|c|c|}
\hline & & & pplement & al $\mathrm{Ta}$ \\
\hline CHEMBL271958 & 688267 & 4.0 & 5.0701 & TST \\
\hline CHEMBL1380381 & 688267 & 5.3 & 5.0883 & TRN \\
\hline CHEMBL1513407 & 688267 & 4.0 & 4.9856 & TRN \\
\hline CHEMBL1398599 & 688267 & 5.3 & 5.0528 & TRN \\
\hline CHEMBL1436469 & 688267 & 6.95 & 5.1593 & TRN \\
\hline CHEMBL106354 & 688267 & 4.0 & 5.0431 & TST \\
\hline CHEMBL1367934 & 688267 & 4.2 & 5.1202 & TST \\
\hline CHEMBL 3190404 & 688267 & 4.05 & 5.0674 & TST \\
\hline CHEMBL1356236 & 688267 & 5.85 & 5.0445 & TRN \\
\hline CHEMBL1604031 & 688267 & 6.2 & 5.1041 & TRN \\
\hline CHEMBL1433228 & 688267 & 6.2 & 5.0084 & TRN \\
\hline CHEMBL1430134 & 688267 & 4.65 & 4.9985 & TRN \\
\hline CHEMBL1591561 & 688267 & 5.85 & 5.0279 & TRN \\
\hline CHEMBL1365942 & 688267 & 5.8 & 5.0571 & TRN \\
\hline CHEMBL1520706 & 688267 & 4.6 & 5.0368 & TRN \\
\hline CHEMBL1333491 & 688267 & 4.5 & 5.0791 & TRN \\
\hline CHEMBL1450992 & 688267 & 4.4 & 5.0973 & TST \\
\hline CHEMBL1306088 & 688267 & 3.95 & 5.0466 & TRN \\
\hline CHEMBL1502091 & 688267 & 4.05 & 5.0871 & TRN \\
\hline CHEMBL1475393 & 688267 & 5.35 & 5.0094 & TST \\
\hline CHEMBL1970265 & 688267 & 5.25 & 5.0366 & TST \\
\hline CHEMBL1608065 & 688267 & 5.6 & 5.1022 & TRN \\
\hline CHEMBL 3191879 & 688267 & 4.0 & 4.9963 & TRN \\
\hline CHEMBL1579256 & 688267 & 5.6 & 5.0068 & TST \\
\hline CHEMBL1385232 & 688267 & 5.55 & 5.0249 & TRN \\
\hline CHEMBL1389216 & 688267 & 4.55 & 5.0407 & TST \\
\hline CHEMBL1406696 & 688267 & 6.15 & 5.0023 & TST \\
\hline CHEMBL1519490 & 688267 & 3.95 & 5.0893 & TRN \\
\hline CHEMBL1390733 & 688267 & 6.2 & 5.0805 & TST \\
\hline CHEMBL1335845 & 688267 & 4.9 & 5.0688 & TRN \\
\hline CHEMBL1367275 & 688267 & 4.95 & 5.0769 & TRN \\
\hline CHEMBL1497522 & 688267 & 5.95 & 5.1262 & TST \\
\hline CHEMBL1446032 & 688267 & 5.9 & 5.0201 & TST \\
\hline CHEMBL1611060 & 688267 & 4.35 & 5.0796 & TRN \\
\hline CHEMBL1301518 & 688267 & 4.35 & 5.0239 & TRN \\
\hline CHEMBL1533395 & 688267 & 5.35 & 5.1418 & TRN \\
\hline CHEMBL3209688 & 688267 & 5.35 & 5.0005 & TRN \\
\hline CHEMBL1331836 & 688267 & 4.25 & 5.0601 & TRN \\
\hline CHEMBL1585629 & 688267 & 5.85 & 5.0853 & TRN \\
\hline CHEMBL1353384 & 688267 & 6.05 & 5.0553 & TRN \\
\hline CHEMBL1561168 & 688267 & 5.1 & 5.0721 & TRN \\
\hline CHEMBL1460792 & 688267 & 4.05 & 5.0676 & TRN \\
\hline CHEMBL1458258 & 688267 & 4.55 & 5.0975 & TRN \\
\hline CHEMBL1483381 & 688267 & 4.0 & 5.077 & TRN \\
\hline CHEMBL1578493 & 688267 & 4.0 & 5.0265 & TRN \\
\hline CHEMBL1482169 & 688267 & 5.0 & 5.0922 & TRN \\
\hline CHEMBL1329216 & 688267 & 5.35 & 5.0225 & TRN \\
\hline CHEMBL3199165 & 688267 & 4.3 & 4.9932 & TRN \\
\hline
\end{tabular}




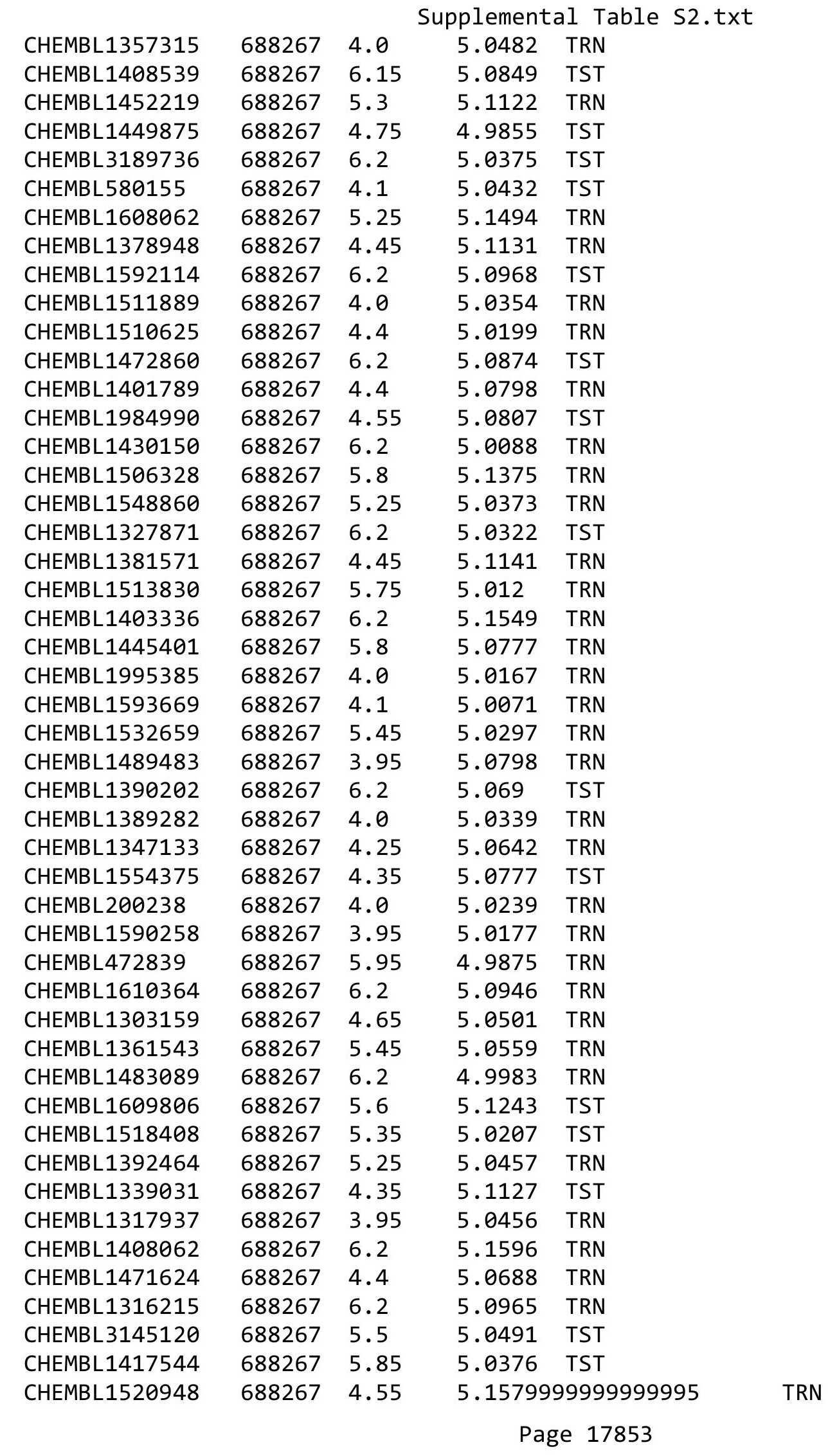




\begin{tabular}{|c|c|c|c|c|}
\hline & & & upplement & $\mathrm{T}$ \\
\hline CHEMBL1469954 & 688267 & 4.75 & 4.9901 & TRN \\
\hline CHEMBL1547387 & 688267 & 4.4 & 5.0315 & TRN \\
\hline CHEMBL1606852 & 688267 & 6.2 & 5.0701 & TRN \\
\hline CHEMBL1600563 & 688267 & 5.6 & 5.1249 & TRN \\
\hline CHEMBL1343984 & 688267 & 5.85 & 5.0417 & TRN \\
\hline CHEMBL1508312 & 688267 & 4.35 & 5.0927 & TST \\
\hline CHEMBL1498172 & 688267 & 5.9 & 5.078 & TRN \\
\hline CHEMBL1385318 & 688267 & 5.85 & 5.0709 & TRN \\
\hline CHEMBL1324648 & 688267 & 5.45 & 5.0627 & TST \\
\hline CHEMBL1574457 & 688267 & 4.4 & 5.1214 & TST \\
\hline CHEMBL1334247 & 688267 & 4.55 & 5.0531 & TRN \\
\hline CHEMBL1401321 & 688267 & 4.35 & 5.0684 & TST \\
\hline CHEMBL1582665 & 688267 & 5.1 & 5.029 & TRN \\
\hline CHEMBL1418930 & 688267 & 3.95 & 4.9827 & TRN \\
\hline CHEMBL1430547 & 688267 & 5.8 & 5.0615 & TRN \\
\hline CHEMBL1464851 & 688267 & 4.05 & 5.1011 & TRN \\
\hline CHEMBL1365093 & 688267 & 5.9 & 5.0203 & TRN \\
\hline CHEMBL1369233 & 688267 & 6.5 & 5.0717 & TST \\
\hline CHEMBL1358326 & 688267 & 5.9 & 5.034 & TRN \\
\hline CHEMBL1507326 & 688267 & 5.6 & 5.0886 & TST \\
\hline CHEMBL1592907 & 688267 & 6.05 & 4.9756 & TRN \\
\hline CHEMBL1570621 & 688267 & 4.5 & 5.003 & TRN \\
\hline CHEMBL1358063 & 688267 & 5.5 & 5.0972 & TRN \\
\hline CHEMBL1539770 & 688267 & 4.55 & 5.0113 & TST \\
\hline CHEMBL1572227 & 688267 & 5.55 & 5.0452 & TRN \\
\hline CHEMBL1435109 & 688267 & 4.0 & 4.9929 & TRN \\
\hline CHEMBL1605265 & 688267 & 4.05 & 5.0713 & TRN \\
\hline CHEMBL1329817 & 688267 & 5.5 & 5.062 & TRN \\
\hline CHEMBL1369945 & 688267 & 4.05 & 5.0006 & TRN \\
\hline CHEMBL1515546 & 688267 & 6.2 & 5.0876 & TRN \\
\hline CHEMBL1353232 & 688267 & 4.05 & 5.0465 & TRN \\
\hline CHEMBL1576013 & 688267 & 5.85 & 5.0199 & TRN \\
\hline CHEMBL1368979 & 688267 & 4.2 & 5.0569 & TRN \\
\hline CHEMBL1585077 & 688267 & 3.95 & 5.0901 & TRN \\
\hline CHEMBL1329632 & 688267 & 5.55 & 5.0217 & TRN \\
\hline CHEMBL1583012 & 688267 & 4.0 & 5.0976 & TRN \\
\hline CHEMBL1439464 & 688267 & 4.05 & 5.0374 & TRN \\
\hline CHEMBL1304396 & 688267 & 4.35 & 5.0148 & TST \\
\hline CHEMBL1516049 & 688267 & 3.95 & 5.0275 & TST \\
\hline CHEMBL1514320 & 688267 & 4.95 & 5.0298 & TST \\
\hline CHEMBL1598685 & 688267 & 6.2 & 5.041 & TRN \\
\hline CHEMBL1374445 & 688267 & 4.55 & 5.0508 & TRN \\
\hline CHEMBL1970872 & 688267 & 6.2 & 4.9508 & TST \\
\hline CHEMBL1597359 & 688267 & 4.35 & 5.0514 & TST \\
\hline CHEMBL1313118 & 688267 & 4.95 & 5.0986 & TST \\
\hline CHEMBL1560220 & 688267 & 5.2 & 5.0716 & TRN \\
\hline CHEMBL1335159 & 688267 & 6.25 & 5.1063 & TRN \\
\hline CHEMBL1369661 & 688267 & 5.6 & 5.0409 & TRN \\
\hline
\end{tabular}




\begin{tabular}{|c|c|c|c|c|}
\hline & & & pplement & al $\mathrm{T}$ \\
\hline CHEMBL1442958 & 688267 & 4.0 & 5.022 & TST \\
\hline CHEMBL1314237 & 688267 & 6.25 & 5.0953 & TRN \\
\hline CHEMBL3214373 & 688267 & 4.75 & 4.9912 & TRN \\
\hline CHEMBL1316532 & 688267 & 5.55 & 5.0124 & TRN \\
\hline CHEMBL1531770 & 688267 & 5.9 & 5.0228 & TRN \\
\hline CHEMBL1329612 & 688267 & 6.2 & 5.1364 & TST \\
\hline CHEMBL1561149 & 688267 & 4.0 & 4.9934 & TRN \\
\hline CHEMBL1370680 & 688267 & 4.4 & 5.0678 & TRN \\
\hline CHEMBL1325397 & 688267 & 3.95 & 5.0256 & TRN \\
\hline CHEMBL1530940 & 688267 & 4.3 & 5.0611 & TRN \\
\hline CHEMBL1320784 & 688267 & 5.0 & 5.0712 & TST \\
\hline CHEMBL1437624 & 688267 & 5.45 & 5.0292 & TRN \\
\hline CHEMBL 600107 & 688267 & 3.95 & 5.018 & TRN \\
\hline CHEMBL1395489 & 688267 & 4.05 & 5.1046 & TST \\
\hline CHEMBL1466414 & 688267 & 4.45 & 5.1148 & TRN \\
\hline CHEMBL1499513 & 688267 & 4.3 & 5.1521 & TRN \\
\hline CHEMBL1369506 & 688267 & 4.0 & 5.0064 & TRN \\
\hline CHEMBL1535041 & 688267 & 4.8 & 4.9952 & TRN \\
\hline CHEMBL1552874 & 688267 & 4.0 & 5.0163 & TRN \\
\hline CHEMBL1574965 & 688267 & 4.15 & 5.0018 & TRN \\
\hline CHEMBL1475940 & 688267 & 4.35 & 5.0744 & TST \\
\hline CHEMBL1422360 & 688267 & 6.5 & 5.0413 & TST \\
\hline CHEMBL1347440 & 688267 & 4.55 & 5.0502 & TRN \\
\hline CHEMBL1488502 & 688267 & 4.6 & 5.063 & TRN \\
\hline CHEMBL1365040 & 688267 & 4.0 & 5.0759 & TRN \\
\hline CHEMBL1329693 & 688267 & 6.2 & 5.0803 & TRN \\
\hline CHEMBL1612548 & 688267 & 4.65 & 5.027 & TRN \\
\hline CHEMBL3213974 & 688267 & 4.35 & 5.0755 & TRN \\
\hline CHEMBL1518234 & 688267 & 6.15 & 4.9668 & TRN \\
\hline CHEMBL1305663 & 688267 & 6.15 & 5.0217 & TST \\
\hline CHEMBL1604897 & 688267 & 4.2 & 5.0862 & TRN \\
\hline CHEMBL1509953 & 688267 & 5.25 & 5.0932 & TRN \\
\hline CHEMBL1385358 & 688267 & 5.25 & 5.0503 & TRN \\
\hline CHEMBL1473421 & 688267 & 5.05 & 5.0043 & TRN \\
\hline CHEMBL1604109 & 688267 & 3.95 & 5.0343 & TRN \\
\hline CHEMBL1466814 & 688267 & 3.95 & 5.0794 & TRN \\
\hline CHEMBL1323731 & 688267 & 6.1 & 5.0809 & TRN \\
\hline CHEMBL1372206 & 688267 & 6.2 & 5.1147 & TRN \\
\hline CHEMBL1541653 & 688267 & 4.65 & 5.0262 & TRN \\
\hline CHEMBL1450957 & 688267 & 5.85 & 5.0514 & TRN \\
\hline CHEMBL1333627 & 688267 & 5.5 & 5.0607 & TRN \\
\hline CHEMBL1569906 & 688267 & 5.8 & 5.1271 & TST \\
\hline CHEMBL1400669 & 688267 & 6.15 & 5.0899 & TRN \\
\hline CHEMBL1558776 & 688267 & 5.1 & 5.0515 & TRN \\
\hline CHEMBL1538212 & 688267 & 4.3 & 5.0345 & TRN \\
\hline CHEMBL1362342 & 688267 & 4.0 & 4.9952 & TRN \\
\hline CHEMBL1432345 & 688267 & 6.2 & 5.079 & TRN \\
\hline CHEMBL1344198 & 688267 & 4.8 & 5.0871 & TRN \\
\hline
\end{tabular}




\begin{tabular}{|c|c|c|c|c|c|}
\hline \multicolumn{6}{|c|}{ Supplemental Table S2.txt } \\
\hline CHEMBL1348096 & 688267 & 5.85 & 5.0207 & TRN & \\
\hline CHEMBL1341774 & 688267 & 4.0 & 5.1086 & TRN & \\
\hline CHEMBL1508828 & 688267 & 4.65 & 5.1089 & TRN & \\
\hline CHEMBL1313044 & 688267 & 5.5 & 5.0278 & TRN & \\
\hline CHEMBL1374201 & 688267 & 4.4 & 5.0641 & TRN & \\
\hline CHEMBL1488415 & 688267 & 6.25 & 4.9984 & TRN & \\
\hline CHEMBL1582499 & 688267 & 6.15 & 5.0255 & TRN & \\
\hline CHEMBL1442207 & 688267 & 4.4 & 5.0703 & TST & \\
\hline CHEMBL1521954 & 688267 & 6.2 & 5.0609 & TRN & \\
\hline CHEMBL1995825 & 688267 & 5.65 & 5.0385 & TST & \\
\hline CHEMBL1436764 & 688267 & 6.2 & 4.9642 & TRN & \\
\hline CHEMBL1322535 & 688267 & 4.5 & 5.0846 & TRN & \\
\hline CHEMBL1347778 & 688267 & 4.0 & 5.07100 & 3000000001 & TRN \\
\hline CHEMBL1495418 & 688267 & 4.35 & 5.0614 & TRN & \\
\hline CHEMBL1501403 & 688267 & 5.45 & 5.082 & TRN & \\
\hline CHEMBL1325125 & 688267 & 5.8 & 5.0209 & TRN & \\
\hline CHEMBL1369217 & 688267 & 6.0 & 5.0181 & TRN & \\
\hline CHEMBL1356018 & 688267 & 4.1 & 5.0746 & TRN & \\
\hline CHEMBL1497949 & 688267 & 4.45 & 5.0909 & TRN & \\
\hline CHEMBL1478813 & 688267 & 4.35 & 5.0667 & TRN & \\
\hline CHEMBL1592277 & 688267 & 4.05 & 5.0561 & TRN & \\
\hline CHEMBL1509766 & 688267 & 5.35 & 5.0694 & TRN & \\
\hline CHEMBL1462055 & 688267 & 4.3 & 5.0451 & TRN & \\
\hline CHEMBL1425613 & 688267 & 6.5 & 5.0094 & TST & \\
\hline CHEMBL1475342 & 688267 & 5.2 & 5.0261 & TRN & \\
\hline CHEMBL1404076 & 688267 & 6.5 & 5.0423 & TRN & \\
\hline CHEMBL1442468 & 688267 & 6.0 & 5.1533 & TRN & \\
\hline CHEMBL1333129 & 688267 & 4.0 & 5.1091 & TRN & \\
\hline CHEMBL1565623 & 688267 & 5.45 & 5.0115 & TST & \\
\hline CHEMBL1363097 & 688267 & 4.4 & 4.9863 & TRN & \\
\hline CHEMBL1490675 & 688267 & 3.95 & 4.9802 & TRN & \\
\hline CHEMBL1457882 & 688267 & 5.45 & 5.131 & TRN & \\
\hline CHEMBL1299217 & 688267 & 5.2 & 4.9985 & TST & \\
\hline CHEMBL1386042 & 688267 & 4.0 & 5.0422 & TST & \\
\hline CHEMBL1360748 & 688267 & 5.0 & 5.0214 & TST & \\
\hline CHEMBL1450740 & 688267 & 5.85 & 5.1066 & TRN & \\
\hline CHEMBL1343732 & 688267 & 5.6 & 5.0407 & TRN & \\
\hline CHEMBL1571688 & 688267 & 5.85 & 5.0289 & TRN & \\
\hline CHEMBL1596844 & 688267 & 5.75 & 5.1065 & TRN & \\
\hline CHEMBL1432504 & 688267 & 4.1 & 5.0253 & TRN & \\
\hline CHEMBL1402445 & 688267 & 5.35 & 5.0939 & TRN & \\
\hline CHEMBL1530371 & 688267 & 4.0 & 5.05699 & 99999999995 & TRN \\
\hline CHEMBL1365295 & 688267 & 4.85 & 5.0412 & TST & \\
\hline CHEMBL1573172 & 688267 & 4.05 & 5.0571 & TRN & \\
\hline CHEMBL1402226 & 688267 & 4.75 & 5.0203 & TRN & \\
\hline CHEMBL1564364 & 688267 & 4.0 & 5.1594 & TRN & \\
\hline CHEMBL1453311 & 688267 & 5.85 & 5.0405 & TRN & \\
\hline CHEMBL1610627 & 688267 & 5.35 & 5.0547 & TRN & \\
\hline
\end{tabular}




\begin{tabular}{|c|c|c|c|c|c|}
\hline \multicolumn{6}{|c|}{ Supplemental Table S2.txt } \\
\hline CHEMBL1384763 & 688267 & 4.0 & 5.0516 & TRN & \\
\hline CHEMBL1388945 & 688267 & 5.0 & 5.0464 & TST & \\
\hline CHEMBL1504816 & 688267 & 4.5 & 5.0768 & TRN & \\
\hline CHEMBL1574346 & 688267 & 5.1 & 5.1241 & TRN & \\
\hline CHEMBL1332694 & 688267 & 6.2 & 5.1141 & TRN & \\
\hline CHEMBL1579319 & 688267 & 6.0 & 5.0454 & TRN & \\
\hline CHEMBL3190033 & 688267 & 6.15 & 5.0013 & TRN & \\
\hline CHEMBL1347128 & 688267 & 5.55 & 5.0252 & TST & \\
\hline CHEMBL1509544 & 688267 & 4.0 & 5.0441 & TST & \\
\hline CHEMBL1370595 & 688267 & 6.25 & 5.0357 & TRN & \\
\hline CHEMBL1547333 & 688267 & 5.0 & 5.1553 & TRN & \\
\hline CHEMBL1386969 & 688267 & 4.05 & 4.9991 & TRN & \\
\hline CHEMBL1350596 & 688267 & 4.5 & 5.0248 & TRN & \\
\hline CHEMBL1392675 & 688267 & 6.2 & 5.0219 & TRN & \\
\hline CHEMBL1339984 & 688267 & 4.35 & 5.0308 & TRN & \\
\hline CHEMBL1317755 & 688267 & 5.4 & 5.0887 & TRN & \\
\hline CHEMBL312858 & 688267 & 5.8 & 5.0215 & TRN & \\
\hline CHEMBL1483816 & 688267 & 4.55 & 5.0187 & TRN & \\
\hline CHEMBL3199600 & 688267 & 5.8 & 5.0395 & TST & \\
\hline CHEMBL1312478 & 688267 & 6.15 & 5.1438 & TRN & \\
\hline CHEMBL1448625 & 688267 & 4.75 & 5.0361 & TRN & \\
\hline CHEMBL1464277 & 688267 & 4.0 & 5.079 & TRN & \\
\hline CHEMBL1436438 & 688267 & 4.0 & 5.11600 & 00000000005 & TRN \\
\hline CHEMBL1465066 & 688267 & 5.15 & 5.0994 & TRN & \\
\hline CHEMBL1560631 & 688267 & 6.05 & 5.0475 & TRN & \\
\hline CHEMBL1481674 & 688267 & 5.25 & 5.0191 & TRN & \\
\hline CHEMBL1364480 & 688267 & 4.4 & 5.0839 & TST & \\
\hline CHEMBL1329325 & 688267 & 4.7 & 5.0567 & TST & \\
\hline CHEMBL1331225 & 688267 & 5.95 & 5.0416 & TRN & \\
\hline CHEMBL1372749 & 688267 & 4.05 & 5.0555 & TST & \\
\hline CHEMBL1431510 & 688267 & 5.85 & 5.0856 & TRN & \\
\hline CHEMBL1582418 & 688267 & 4.35 & 5.1042 & TRN & \\
\hline CHEMBL1306672 & 688267 & 4.75 & 5.0727 & TRN & \\
\hline CHEMBL1541096 & 688267 & 6.15 & 5.0583 & TST & \\
\hline CHEMBL1511292 & 688267 & 6.15 & 5.1144 & TRN & \\
\hline CHEMBL1372885 & 688267 & 6.2 & 5.0669 & TRN & \\
\hline CHEMBL1333528 & 688267 & 4.55 & 5.0679 & TRN & \\
\hline CHEMBL1472894 & 688267 & 4.05 & 5.0763 & TRN & \\
\hline CHEMBL1330049 & 688267 & 4.1 & 5.105 & TST & \\
\hline CHEMBL1354381 & 688267 & 3.95 & 5.0078 & TRN & \\
\hline CHEMBL1997059 & 688267 & 5.3 & 5.0338 & TST & \\
\hline CHEMBL1471484 & 688267 & 5.85 & 5.0113 & TST & \\
\hline CHEMBL1601804 & 688267 & 4.3 & 5.0861 & TRN & \\
\hline CHEMBL1364386 & 688267 & 6.1 & 5.0198 & TRN & \\
\hline CHEMBL1435146 & 688267 & 6.6499 & 5.0284 & TRN & \\
\hline CHEMBL1482769 & 688267 & 4.0 & 5.1249 & TRN & \\
\hline CHEMBL1491195 & 688267 & 6.15 & 5.0912 & TRN & \\
\hline CHEMBL1482131 & 688267 & 5.15 & 5.0589 & TST & \\
\hline
\end{tabular}




\begin{tabular}{|c|c|c|c|c|c|}
\hline \\
\hline CHEMBL1504989 & 688267 & 4.0 & 5.0672 & TST & \\
\hline CHEMBL1560245 & 688267 & 5.6 & 5.0364 & TRN & \\
\hline CHEMBL1421493 & 688267 & 6.25 & 4.9879 & TRN & \\
\hline CHEMBL1427160 & 688267 & 4.05 & 5.0225 & TRN & \\
\hline CHEMBL1480847 & 688267 & 5.3 & 4.988 & TRN & \\
\hline CHEMBL1564658 & 688267 & 4.3 & 5.0112 & TST & \\
\hline CHEMBL1590448 & 688267 & 5.15 & 5.0425 & TRN & \\
\hline CHEMBL3210488 & 688267 & 4.5 & 4.9928 & TRN & \\
\hline CHEMBL1555410 & 688267 & 3.95 & 5.0932 & TRN & \\
\hline CHEMBL1326737 & 688267 & 4.35 & 5.0088 & TRN & \\
\hline CHEMBL1315668 & 688267 & 6.15 & 5.0663 & TRN & \\
\hline CHEMBL1388717 & 688267 & 5.5 & 5.1364 & TRN & \\
\hline CHEMBL1609012 & 688267 & 4.55 & 5.047 & TRN & \\
\hline CHEMBL1527918 & 688267 & 4.35 & 5.0331 & TRN & \\
\hline CHEMBL1459531 & 688267 & 5.0 & 5.06800 & 00000000005 & TRN \\
\hline CHEMBL1560222 & 688267 & 4.25 & 5.0789 & TRN & \\
\hline CHEMBL1321616 & 688267 & 3.95 & 5.0588 & TRN & \\
\hline CHEMBL3208286 & 688267 & 5.95 & 5.0302 & TRN & \\
\hline CHEMBL1393801 & 688267 & 3.95 & 5.0404 & TST & \\
\hline CHEMBL1448155 & 688267 & 4.05 & 5.1232 & TRN & \\
\hline CHEMBL3198194 & 688267 & 4.0 & 5.0048 & TRN & \\
\hline CHEMBL1393382 & 688267 & 5.0 & 5.1245 & TRN & \\
\hline CHEMBL1430933 & 688267 & 5.25 & 5.0841 & TRN & \\
\hline CHEMBL1338863 & 688267 & 5.9 & 5.1063 & TRN & \\
\hline CHEMBL1499616 & 688267 & 6.15 & 5.1062 & TRN & \\
\hline CHEMBL1334962 & 688267 & 4.15 & 5.0693 & TST & \\
\hline CHEMBL1336496 & 688267 & 5.55 & 5.0314 & TRN & \\
\hline CHEMBL1328469 & 688267 & 5.7 & 5.0647 & TRN & \\
\hline CHEMBL1420220 & 688267 & 4.35 & 5.0163 & TRN & \\
\hline CHEMBL1553466 & 688267 & 6.2 & 5.0484 & TRN & \\
\hline CHEMBL1388468 & 688267 & 5.1 & 5.0147 & TRN & \\
\hline CHEMBL1361824 & 688267 & 4.85 & 5.0955 & TRN & \\
\hline CHEMBL1357439 & 688267 & 4.35 & 5.0533 & TRN & \\
\hline CHEMBL1392992 & 688267 & 4.4 & 5.0164 & TST & \\
\hline CHEMBL1370347 & 688267 & 5.15 & 5.1261 & TRN & \\
\hline CHEMBL1484735 & 688267 & 6.2 & 5.0937 & TST & \\
\hline CHEMBL3190849 & 688267 & 4.7 & 4.9706 & TRN & \\
\hline CHEMBL1381500 & 688267 & 6.5 & 5.06 & TRN & \\
\hline CHEMBL1508743 & 688267 & 3.95 & 5.1003 & TRN & \\
\hline CHEMBL1568755 & 688267 & 4.15 & 5.0046 & TST & \\
\hline CHEMBL 235672 & 688267 & 4.65 & 5.0542 & TST & \\
\hline CHEMBL1524340 & 688267 & 6.15 & 5.0263 & TRN & \\
\hline CHEMBL1567060 & 688267 & 5.55 & 5.1048 & TST & \\
\hline CHEMBL1472227 & 688267 & 5.4 & 5.0421 & TST & \\
\hline CHEMBL1533900 & 688267 & 5.4 & 5.1326 & TRN & \\
\hline CHEMBL1322362 & 688267 & 5.9 & 5.1173 & TRN & \\
\hline CHEMBL1470130 & 688267 & 6.5 & 5.1744 & TST & \\
\hline CHEMBL1300945 & 688267 & 5.45 & 5.1242 & TRN & \\
\hline
\end{tabular}




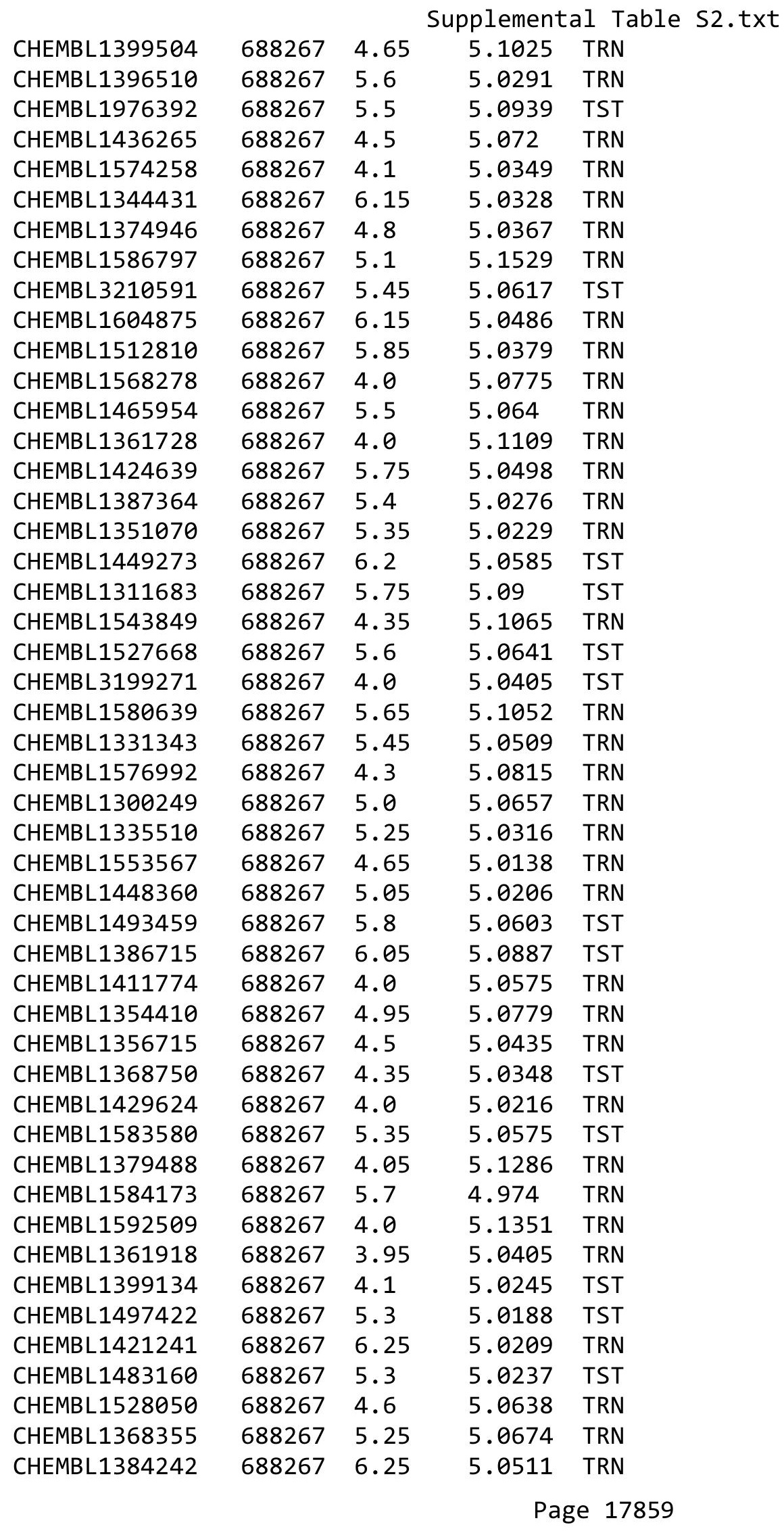




\begin{tabular}{|c|c|c|c|c|}
\hline \multicolumn{5}{|c|}{ Supplemental Table S2.txt } \\
\hline CHEMBL1474193 & 688267 & 4.5 & 5.1528 & TRN \\
\hline CHEMBL1405236 & 688267 & 5.75 & 5.0579 & TRN \\
\hline CHEMBL1333720 & 688267 & 6.2 & 5.1308 & TRN \\
\hline CHEMBL1437076 & 688267 & 5.2 & 5.04 & TRN \\
\hline CHEMBL1462156 & 688267 & 4.0 & 5.0694 & TRN \\
\hline CHEMBL1527751 & 688267 & 6.2 & 5.0389 & TRN \\
\hline CHEMBL1473782 & 688267 & 4.35 & 5.0006 & TRN \\
\hline CHEMBL1516147 & 688267 & 4.0 & 5.0194 & TST \\
\hline CHEMBL1376857 & 688267 & 5.1 & 5.0952 & TRN \\
\hline CHEMBL1436014 & 688267 & 6.25 & 5.1062 & TRN \\
\hline CHEMBL1312797 & 688267 & 5.1 & 5.073 & TST \\
\hline CHEMBL1353674 & 688267 & 4.25 & 5.1479 & TRN \\
\hline CHEMBL1610289 & 688267 & 4.0 & 5.0422 & TRN \\
\hline CHEMBL1343887 & 688267 & 4.4 & 5.0995 & TRN \\
\hline CHEMBL1993612 & 688267 & 4.5 & 4.967 & TRN \\
\hline CHEMBL1601989 & 688267 & 5.0 & 5.0088 & TRN \\
\hline CHEMBL1409002 & 688267 & 6.2 & 5.0481 & TRN \\
\hline CHEMBL1326740 & 688267 & 6.2 & 5.1124 & TRN \\
\hline CHEMBL1516009 & 688267 & 5.3 & 5.0282 & TRN \\
\hline CHEMBL1592017 & 688267 & 4.25 & 5.0139 & TRN \\
\hline CHEMBL1613654 & 688267 & 6.5 & 5.072 & TRN \\
\hline CHEMBL1359864 & 688267 & 4.15 & 5.0791 & TRN \\
\hline CHEMBL1421344 & 688267 & 4.25 & 5.0115 & TRN \\
\hline CHEMBL1584120 & 688267 & 5.3 & 5.0923 & TST \\
\hline CHEMBL1363269 & 688267 & 4.6 & 5.0712 & TRN \\
\hline CHEMBL1581431 & 688267 & 4.05 & 5.0642 & TRN \\
\hline CHEMBL1560052 & 688267 & 4.4 & 5.0768 & TRN \\
\hline CHEMBL567508 & 688267 & 5.5 & 5.0691 & TRN \\
\hline CHEMBL3193427 & 688267 & 4.3 & 4.9715 & TRN \\
\hline CHEMBL1612055 & 688267 & 6.2 & 5.0641 & TST \\
\hline CHEMBL1559421 & 688267 & 5.35 & 5.0227 & TRN \\
\hline CHEMBL1577995 & 688267 & 5.55 & 5.0073 & TST \\
\hline CHEMBL1571757 & 688267 & 4.15 & 5.0181 & TRN \\
\hline CHEMBL1506303 & 688267 & 4.9 & 5.0544 & TRN \\
\hline CHEMBL1322171 & 688267 & 4.35 & 5.1317 & TRN \\
\hline CHEMBL1570372 & 688267 & 4.4 & 5.0433 & TRN \\
\hline CHEMBL1537595 & 688267 & 6.2 & 5.0474 & TRN \\
\hline CHEMBL1612816 & 688267 & 4.8 & 5.0921 & TRN \\
\hline CHEMBL1598520 & 688267 & 4.05 & 5.0413 & TRN \\
\hline CHEMBL 3214270 & 688267 & 5.85 & 5.0457 & TST \\
\hline CHEMBL1550716 & 688267 & 4.25 & 5.0593 & TRN \\
\hline CHEMBL1593248 & 688267 & 4.55 & 5.0634 & TRN \\
\hline CHEMBL1544864 & 688267 & 5.65 & 5.0546 & TRN \\
\hline CHEMBL1438275 & 688267 & 3.95 & 5.1306 & TRN \\
\hline CHEMBL1344199 & 688267 & 4.0 & 5.1839 & TRN \\
\hline CHEMBL1524609 & 688267 & 4.25 & 5.0256 & TST \\
\hline CHEMBL1325878 & 688267 & 4.7 & 5.0283 & TRN \\
\hline CHEMBL467705 & 688267 & 4.2 & 5.0467 & TST \\
\hline
\end{tabular}




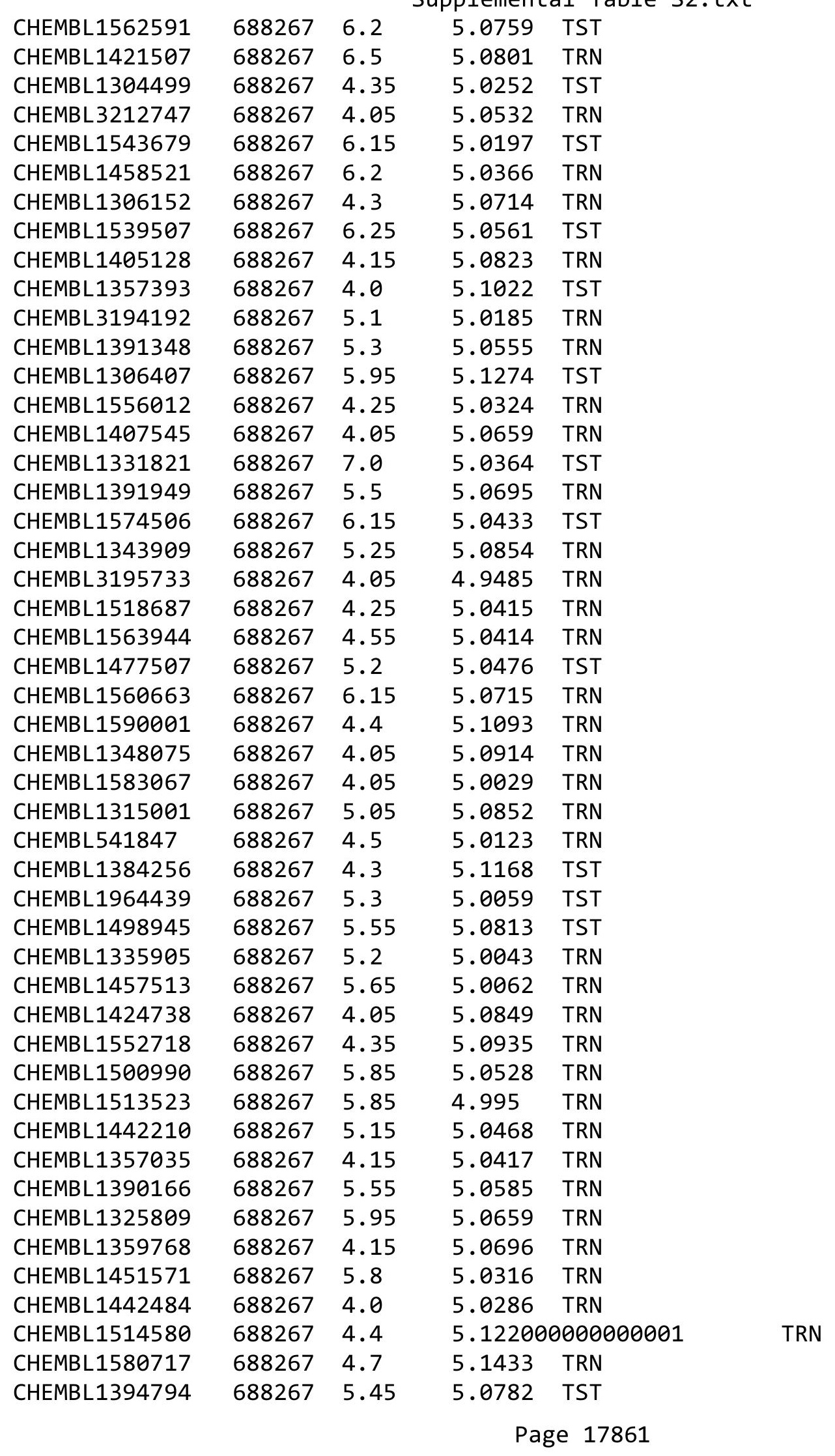




\begin{tabular}{|c|c|c|c|c|}
\hline \multicolumn{5}{|c|}{ Supplemental Table S2.txt } \\
\hline CHEMBL1379255 & 688267 & 4.2 & 5.0568 & TRN \\
\hline CHEMBL1583641 & 688267 & 4.0 & 5.0466 & TRN \\
\hline CHEMBL1453959 & 688267 & 4.05 & 5.0332 & TRN \\
\hline CHEMBL1528401 & 688267 & 4.45 & 5.0681 & TST \\
\hline CHEMBL1543395 & 688267 & 5.25 & 5.0454 & TRN \\
\hline CHEMBL1593147 & 688267 & 5.85 & 5.0312 & TRN \\
\hline CHEMBL3192608 & 688267 & 5.3 & 5.0458 & TRN \\
\hline CHEMBL1584522 & 688267 & 5.3 & 5.0622 & TRN \\
\hline CHEMBL1322306 & 688267 & 4.35 & 5.0564 & TST \\
\hline CHEMBL1397323 & 688267 & 4.7 & 5.0522 & TRN \\
\hline CHEMBL1323119 & 688267 & 4.15 & 5.0689 & TRN \\
\hline CHEMBL1543979 & 688267 & 6.25 & 5.0752 & TRN \\
\hline CHEMBL1513631 & 688267 & 6.15 & 4.99 & TRN \\
\hline CHEMBL1386144 & 688267 & 5.35 & 5.1571 & TRN \\
\hline CHEMBL 2110291 & 688267 & 5.55 & 5.0558 & TRN \\
\hline CHEMBL1412320 & 688267 & 6.5 & 5.0832 & TST \\
\hline CHEMBL1351236 & 688267 & 5.0 & 5.0596 & TST \\
\hline CHEMBL1445220 & 688267 & 5.95 & 5.0959 & TRN \\
\hline CHEMBL1493633 & 688267 & 5.3 & 5.0717 & TST \\
\hline CHEMBL1345200 & 688267 & 5.8 & 5.0672 & TST \\
\hline CHEMBL3209535 & 688267 & 6.25 & 5.0102 & TRN \\
\hline CHEMBL1520951 & 688267 & 6.2 & 5.0203 & TRN \\
\hline CHEMBL1573613 & 688267 & 6.15 & 5.0156 & TRN \\
\hline CHEMBL1483956 & 688267 & 6.5501 & 5.0423 & TRN \\
\hline CHEMBL1402902 & 688267 & 4.4 & 4.9932 & TRN \\
\hline CHEMBL1551214 & 688267 & 6.2 & 5.1493 & TRN \\
\hline CHEMBL1420977 & 688267 & 4.1 & 5.0661 & TRN \\
\hline CHEMBL1425475 & 688267 & 6.2 & 5.0726 & TRN \\
\hline CHEMBL1509349 & 688267 & 5.55 & 5.0882 & TST \\
\hline CHEMBL1309191 & 688267 & 4.05 & 5.0006 & TST \\
\hline CHEMBL1503320 & 688267 & 4.0 & 5.0245 & TRN \\
\hline CHEMBL1441668 & 688267 & 6.1 & 4.9843 & TRN \\
\hline CHEMBL1480114 & 688267 & 4.35 & 5.0291 & TRN \\
\hline CHEMBL1321710 & 688267 & 6.2 & 4.9886 & TRN \\
\hline CHEMBL1431900 & 688267 & 6.2 & 5.0198 & TRN \\
\hline CHEMBL1315434 & 688267 & 6.15 & 5.0768 & TRN \\
\hline CHEMBL1368999 & 688267 & 5.6 & 5.0092 & TRN \\
\hline CHEMBL1400800 & 688267 & 4.55 & 5.0676 & TST \\
\hline CHEMBL3196411 & 688267 & 5.3 & 5.0071 & TRN \\
\hline CHEMBL1317284 & 688267 & 6.1 & 5.0528 & TRN \\
\hline CHEMBL1444952 & 688267 & 4.6 & 5.1185 & TRN \\
\hline CHEMBL1573726 & 688267 & 4.2 & 5.0452 & TRN \\
\hline CHEMBL1342063 & 688267 & 4.6 & 5.0455 & TRN \\
\hline CHEMBL1449651 & 688267 & 4.9 & 5.1283 & TST \\
\hline CHEMBL1548787 & 688267 & 4.05 & 5.1312 & TRN \\
\hline CHEMBL1524140 & 688267 & 6.2 & 5.0504 & TST \\
\hline CHEMBL1436567 & 688267 & 5.5 & 5.0148 & TRN \\
\hline CHEMBL1387977 & 688267 & 4.6 & 5.0787 & TST \\
\hline
\end{tabular}




\begin{tabular}{|c|c|c|c|c|c|}
\hline \\
\hline CHEMBL1494370 & 688267 & 5.2 & 5.0133 & TST & \\
\hline CHEMBL1440614 & 688267 & 4.35 & 5.004 & TRN & \\
\hline CHEMBL1393060 & 688267 & 5.85 & 5.0445 & TST & \\
\hline CHEMBL1469813 & 688267 & 5.4 & 5.0517 & TRN & \\
\hline CHEMBL1399816 & 688267 & 5.2 & 5.0349 & TRN & \\
\hline CHEMBL1492533 & 688267 & 5.85 & 5.0299 & TRN & \\
\hline CHEMBL1535726 & 688267 & 4.45 & 5.0866 & TST & \\
\hline CHEMBL1592880 & 688267 & 3.95 & 5.0093 & TRN & \\
\hline CHEMBL1390744 & 688267 & 5.35 & 5.0873 & TRN & \\
\hline CHEMBL1449205 & 688267 & 6.45 & 5.0998 & TST & \\
\hline CHEMBL1305484 & 688267 & 6.25 & 4.9881 & TRN & \\
\hline CHEMBL1440401 & 688267 & 4.6 & $5.0360 e$ & 30000000005 & TST \\
\hline CHEMBL1316320 & 688267 & 4.0 & 5.0283 & TRN & \\
\hline CHEMBL3392039 & 688267 & 6.25 & 5.0488 & TST & \\
\hline CHEMBL1529350 & 688267 & 4.0 & 5.0064 & TRN & \\
\hline CHEMBL1356245 & 688267 & 4.65 & 5.0792 & TRN & \\
\hline CHEMBL1602168 & 688267 & 4.0 & 5.0429 & TST & \\
\hline CHEMBL1541632 & 688267 & 4.5 & 5.0389 & TST & \\
\hline CHEMBL1566683 & 688267 & 5.05 & 5.0467 & TRN & \\
\hline CHEMBL1413439 & 688267 & 5.25 & 5.1004 & TRN & \\
\hline CHEMBL1531525 & 688267 & 4.05 & 5.107 & TRN & \\
\hline CHEMBL552272 & 688267 & 4.05 & 5.0417 & TRN & \\
\hline CHEMBL1576563 & 688267 & 4.95 & 5.043 & TRN & \\
\hline CHEMBL1413557 & 688267 & 4.55 & 4.9857 & TRN & \\
\hline CHEMBL1428906 & 688267 & 5.45 & 5.0853 & TRN & \\
\hline CHEMBL1390657 & 688267 & 6.15 & 4.9746 & TRN & \\
\hline CHEMBL1452259 & 688267 & 4.05 & 5.194 & TST & \\
\hline CHEMBL1480559 & 688267 & 3.95 & 5.0531 & TRN & \\
\hline CHEMBL1450718 & 688267 & 3.95 & 4.984 & TRN & \\
\hline CHEMBL1404715 & 688267 & 3.95 & 5.0282 & TRN & \\
\hline CHEMBL1514676 & 688267 & 4.35 & 5.0575 & TRN & \\
\hline CHEMBL3211954 & 688267 & 6.2 & 5.0871 & TST & \\
\hline CHEMBL1536841 & 688267 & 5.25 & 5.1565 & TRN & \\
\hline CHEMBL1402681 & 688267 & 6.5 & 5.0508 & TRN & \\
\hline CHEMBL1302356 & 688267 & 4.1 & 4.9845 & TST & \\
\hline CHEMBL1372425 & 688267 & 4.05 & 5.1386 & TRN & \\
\hline CHEMBL1350906 & 688267 & 5.35 & 5.0458 & TRN & \\
\hline CHEMBL1477163 & 688267 & 5.1 & 5.0196 & TRN & \\
\hline CHEMBL1574037 & 688267 & 4.1 & 5.0676 & TST & \\
\hline CHEMBL1409053 & 688267 & 4.6 & 4.9921 & TST & \\
\hline CHEMBL1570953 & 688267 & 4.65 & 5.1359 & TRN & \\
\hline CHEMBL1311704 & 688267 & 6.15 & 5.0846 & TST & \\
\hline CHEMBL1447789 & 688267 & 3.95 & 5.0533 & TRN & \\
\hline CHEMBL1321068 & 688267 & 4.45 & 5.0526 & TRN & \\
\hline CHEMBL1472713 & 688267 & 3.9 & 5.0463 & TRN & \\
\hline CHEMBL1443228 & 688267 & 5.55 & 5.0384 & TRN & \\
\hline CHEMBL1312375 & 688267 & 4.95 & 5.0359 & TST & \\
\hline CHEMBL1551099 & 688267 & 5.95 & 5.0363 & TRN & \\
\hline
\end{tabular}




\begin{tabular}{|c|c|c|c|c|}
\hline \multicolumn{5}{|c|}{ Supplemental Table S2.txt } \\
\hline CHEMBL1316331 & 688267 & 5.5 & 5.0605 & TRN \\
\hline CHEMBL1597046 & 688267 & 6.5 & 5.0377 & TRN \\
\hline CHEMBL1422593 & 688267 & 3.95 & 5.1274 & TRN \\
\hline CHEMBL1577330 & 688267 & 5.55 & 5.1269 & TRN \\
\hline CHEMBL1453290 & 688267 & 6.1 & 5.0291 & TST \\
\hline CHEMBL1510829 & 688267 & 4.35 & 5.1389 & TRN \\
\hline CHEMBL1398813 & 688267 & 6.25 & 5.0487 & TRN \\
\hline CHEMBL1535575 & 688267 & 5.85 & 5.0958 & TRN \\
\hline CHEMBL1608996 & 688267 & 4.4 & 5.0662 & TST \\
\hline CHEMBL1385091 & 688267 & 4.65 & 5.1017 & TST \\
\hline CHEMBL1441833 & 688267 & 6.2 & 5.0318 & TRN \\
\hline CHEMBL 3190834 & 688267 & 4.6 & 4.9824 & TST \\
\hline CHEMBL1585548 & 688267 & 4.1 & 5.0535 & TRN \\
\hline CHEMBL1371459 & 688267 & 4.4 & 5.0649 & TRN \\
\hline CHEMBL1473125 & 688267 & 4.3 & 5.0128 & TST \\
\hline CHEMBL1402285 & 688267 & 5.1 & 4.9928 & TRN \\
\hline CHEMBL1998627 & 688267 & 4.6 & 5.0617 & TST \\
\hline CHEMBL1343593 & 688267 & 4.8 & 5.0185 & TRN \\
\hline CHEMBL1372513 & 688267 & 3.95 & 5.0592 & TRN \\
\hline CHEMBL1401602 & 688267 & 6.2 & 5.1492 & TST \\
\hline CHEMBL1430543 & 688267 & 5.5 & 5.0357 & TRN \\
\hline CHEMBL1316218 & 688267 & 6.25 & 5.0438 & TST \\
\hline CHEMBL1532880 & 688267 & 4.7 & 5.0174 & TRN \\
\hline CHEMBL1494923 & 688267 & 4.05 & 5.1362 & TRN \\
\hline CHEMBL1355722 & 688267 & 4.55 & 5.0884 & TRN \\
\hline CHEMBL1350869 & 688267 & 5.4 & 5.0173 & TST \\
\hline CHEMBL 3194481 & 688267 & 5.55 & 5.0134 & TST \\
\hline CHEMBL1577754 & 688267 & 4.1 & 5.079 & TRN \\
\hline CHEMBL1466171 & 688267 & 4.05 & 5.0331 & TRN \\
\hline CHEMBL1573444 & 688267 & 4.8 & 5.0466 & TST \\
\hline CHEMBL1553712 & 688267 & 5.4 & 5.1037 & TRN \\
\hline CHEMBL1601564 & 688267 & 5.6 & 5.0416 & TRN \\
\hline CHEMBL3210836 & 688267 & 6.2 & 5.0382 & TST \\
\hline CHEMBL1319015 & 688267 & 6.0 & 5.0091 & TRN \\
\hline CHEMBL1556450 & 688267 & 5.4 & 5.1272 & TRN \\
\hline CHEMBL1513581 & 688267 & 5.9 & 5.0852 & TRN \\
\hline CHEMBL1299533 & 688267 & 6.0 & 5.0999 & TRN \\
\hline CHEMBL1354348 & 688267 & 4.05 & 5.1448 & TRN \\
\hline CHEMBL1432698 & 688267 & 4.1 & 5.0955 & TRN \\
\hline CHEMBL1319513 & 688267 & 4.4 & 4.9878 & TRN \\
\hline CHEMBL1538848 & 688267 & 6.5501 & 5.0203 & TRN \\
\hline CHEMBL1599155 & 688267 & 4.0 & 5.0099 & TRN \\
\hline CHEMBL1599933 & 688267 & 6.2 & 5.0311 & TRN \\
\hline CHEMBL150809 & 688267 & 6.2 & 5.0093 & TRN \\
\hline CHEMBL1402671 & 688267 & 6.45 & 5.0305 & TRN \\
\hline CHEMBL1318160 & 688267 & 5.6 & 5.0628 & TRN \\
\hline CHEMBL1431393 & 688267 & 4.0 & 5.0096 & TRN \\
\hline CHEMBL1543370 & 688267 & 5.85 & 4.9925 & TRN \\
\hline
\end{tabular}




\begin{tabular}{|c|c|c|c|c|c|}
\hline \multicolumn{6}{|c|}{ Supplemental Table S2.txt } \\
\hline CHEMBL1539687 & 688267 & 3.95 & 5.0957 & TST & \\
\hline CHEMBL1336762 & 688267 & 5.5 & 5.0944 & TRN & \\
\hline CHEMBL1355790 & 688267 & 4.0 & 5.0291 & TRN & \\
\hline CHEMBL1474879 & 688267 & 6.5 & 5.0941 & TRN & \\
\hline CHEMBL3209796 & 688267 & 5.0 & 5.0305 & TRN & \\
\hline CHEMBL1575852 & 688267 & 6.15 & 5.0377 & TST & \\
\hline CHEMBL1365286 & 688267 & 5.45 & 5.025 & TRN & \\
\hline CHEMBL1305889 & 688267 & 5.0 & 5.0638 & TRN & \\
\hline CHEMBL1584004 & 688267 & 5.6 & 5.0124 & TST & \\
\hline CHEMBL3213683 & 688267 & 5.35 & 5.0053 & TRN & \\
\hline CHEMBL1514772 & 688267 & 5.9 & 4.988 & TRN & \\
\hline CHEMBL1277809 & 688267 & 5.5 & 5.0 & TRN & \\
\hline CHEMBL1314205 & 688267 & 5.35 & 5.1201 & TST & \\
\hline CHEMBL1587294 & 688267 & 6.45 & 5.1736 & TRN & \\
\hline CHEMBL1393043 & 688267 & 4.25 & 5.0594 & TST & \\
\hline CHEMBL1514783 & 688267 & 5.6 & 5.0246 & TRN & \\
\hline CHEMBL1481259 & 688267 & 6.25 & 5.0374 & TRN & \\
\hline CHEMBL1444235 & 688267 & 4.4 & 5.0982 & TRN & \\
\hline CHEMBL1452103 & 688267 & 5.05 & 5.0823 & TRN & \\
\hline CHEMBL1417812 & 688267 & 5.25 & 5.0992 & TRN & \\
\hline CHEMBL1316573 & 688267 & 4.1 & 5.0277 & TRN & \\
\hline CHEMBL1517395 & 688267 & 4.05 & 5.059 & TST & \\
\hline CHEMBL1314559 & 688267 & 4.05 & 5.0592 & TRN & \\
\hline CHEMBL1405218 & 688267 & 5.3 & 5.0575 & TRN & \\
\hline CHEMBL1347935 & 688267 & 6.2 & 5.0304 & TRN & \\
\hline CHEMBL1401699 & 688267 & 4.5 & 5.0017 & TRN & \\
\hline CHEMBL1410525 & 688267 & 6.2 & 5.1466 & TST & \\
\hline CHEMBL1448561 & 688267 & 4.05 & 5.1147 & TST & \\
\hline CHEMBL1451431 & 688267 & 6.0 & 5.05399 & 9999999999 & TRN \\
\hline CHEMBL1495056 & 688267 & 4.6 & 5.1548 & TRN & \\
\hline CHEMBL1447989 & 688267 & 6.0 & 5.008 & TRN & \\
\hline CHEMBL1536561 & 688267 & 5.1 & 5.0403 & TST & \\
\hline CHEMBL1432776 & 688267 & 5.35 & 5.0341 & TST & \\
\hline CHEMBL1498426 & 688267 & 6.25 & 5.092 & TRN & \\
\hline CHEMBL1377474 & 688267 & 6.3 & 5.03600 & 00000000005 & TRN \\
\hline CHEMBL1568462 & 688267 & 6.25 & 5.0677 & TRN & \\
\hline CHEMBL1602836 & 688267 & 4.05 & 4.9961 & TRN & \\
\hline CHEMBL1303512 & 688267 & 6.2 & 5.0666 & TRN & \\
\hline CHEMBL1346050 & 688267 & 5.35 & 5.1077 & TRN & \\
\hline CHEMBL1493163 & 688267 & 4.35 & 5.0551 & TRN & \\
\hline CHEMBL3214456 & 688267 & 4.2 & 5.0333 & TRN & \\
\hline CHEMBL1422474 & 688267 & 5.6 & 5.1423 & TST & \\
\hline CHEMBL1392916 & 688267 & 4.85 & 5.0541 & TRN & \\
\hline CHEMBL1428269 & 688267 & 4.5 & 5.0522 & TST & \\
\hline CHEMBL1336021 & 688267 & 4.05 & 5.0717 & TRN & \\
\hline CHEMBL1483941 & 688267 & 4.45 & 5.0181 & TST & \\
\hline CHEMBL1532261 & 688267 & 5.55 & 4.9962 & TRN & \\
\hline CHEMBL1432155 & 688267 & 4.3 & 5.0039 & TRN & \\
\hline
\end{tabular}




\begin{tabular}{|c|c|c|c|c|}
\hline \multicolumn{5}{|c|}{ Supplemental Table S2.txt } \\
\hline CHEMBL1539125 & 688267 & 4.0 & 5.0354 & TRN \\
\hline CHEMBL1584791 & 688267 & 3.85 & 5.0303 & TRN \\
\hline CHEMBL1331435 & 688267 & 5.8 & 5.03100 & 0000000001 \\
\hline CHEMBL1456955 & 688267 & 3.95 & 5.0904 & TST \\
\hline CHEMBL1440034 & 688267 & 4.1 & 4.9803 & TRN \\
\hline CHEMBL1321357 & 688267 & 4.9 & 5.0316 & TRN \\
\hline CHEMBL1609804 & 688267 & 6.15 & 5.0756 & TRN \\
\hline CHEMBL1520201 & 688267 & 6.25 & 5.0427 & TRN \\
\hline CHEMBL1386660 & 688267 & 4.35 & 5.0261 & TRN \\
\hline CHEMBL1562053 & 688267 & 5.9 & 5.051 & TST \\
\hline CHEMBL1514699 & 688267 & 5.3 & 5.0958 & TRN \\
\hline CHEMBL3191241 & 688267 & 5.5 & 4.9976 & TRN \\
\hline CHEMBL1446203 & 688267 & 4.05 & 5.0279 & TST \\
\hline CHEMBL1315055 & 688267 & 4.05 & 5.0318 & TST \\
\hline CHEMBL1306640 & 688267 & 5.4 & 5.0174 & TRN \\
\hline CHEMBL1315564 & 688267 & 4.55 & 5.0228 & TST \\
\hline CHEMBL1386928 & 688267 & 5.35 & 5.0008 & TRN \\
\hline CHEMBL1416187 & 688267 & 5.4 & 5.0813 & TRN \\
\hline CHEMBL1527240 & 688267 & 5.25 & 5.1204 & TRN \\
\hline CHEMBL1562013 & 688267 & 4.45 & 5.0898 & TRN \\
\hline CHEMBL1483860 & 688267 & 4.6 & 5.0451 & TST \\
\hline CHEMBL1429088 & 688267 & 6.5 & 4.9998 & TRN \\
\hline CHEMBL1550135 & 688267 & 4.5 & 4.9776 & TRN \\
\hline CHEMBL1457342 & 688267 & 5.05 & 5.1062 & TRN \\
\hline CHEMBL 3191755 & 688267 & 5.25 & 5.0382 & TRN \\
\hline CHEMBL1506655 & 688267 & 4.55 & 5.0239 & TRN \\
\hline CHEMBL48449 & 688267 & 5.2 & 5.0949 & TST \\
\hline CHEMBL1372935 & 688267 & 5.85 & 5.1413 & TST \\
\hline CHEMBL1449464 & 688267 & 4.7 & 5.0872 & TST \\
\hline CHEMBL1390739 & 688267 & 4.35 & 5.1087 & TRN \\
\hline CHEMBL1360672 & 688267 & 4.85 & 5.0139 & TRN \\
\hline CHEMBL1496228 & 688267 & 4.05 & 5.0054 & TRN \\
\hline CHEMBL1521860 & 688267 & 5.45 & 5.0188 & TRN \\
\hline CHEMBL1474228 & 688267 & 6.2 & 5.1114 & TRN \\
\hline CHEMBL1360948 & 688267 & 4.3 & 5.0621 & TST \\
\hline CHEMBL1372162 & 688267 & 5.85 & 5.0413 & TRN \\
\hline CHEMBL1527699 & 688267 & 4.3 & 5.0231 & TRN \\
\hline CHEMBL1463506 & 688267 & 4.45 & 5.0608 & TRN \\
\hline CHEMBL1437203 & 688267 & 5.0 & 5.0181 & TRN \\
\hline CHEMBL1497235 & 688267 & 4.75 & 5.0857 & TRN \\
\hline CHEMBL1314973 & 688267 & 4.4 & 5.1021 & TRN \\
\hline CHEMBL1592006 & 688267 & 4.95 & 5.0391 & TRN \\
\hline CHEMBL3211060 & 688267 & 4.45 & 5.046 & TRN \\
\hline CHEMBL1310091 & 688267 & 4.35 & 5.0292 & TST \\
\hline CHEMBL1541830 & 688267 & 6.2 & 5.0865 & TST \\
\hline CHEMBL1993401 & 688267 & 5.35 & 5.0052 & TST \\
\hline CHEMBL1329257 & 688267 & 5.55 & 5.0394 & TRN \\
\hline CHEMBL1413329 & 688267 & 5.3 & 5.0522 & TST \\
\hline
\end{tabular}

TRN 


\begin{tabular}{|c|c|c|c|c|}
\hline & & & pplement & al $\mathrm{Ta}$ \\
\hline CHEMBL1990214 & 688267 & 5.8 & 4.9884 & TST \\
\hline CHEMBL1338654 & 688267 & 5.85 & 5.1165 & TRN \\
\hline CHEMBL1605127 & 688267 & 4.0 & 5.0407 & TRN \\
\hline CHEMBL1530643 & 688267 & 5.55 & 5.0298 & TRN \\
\hline CHEMBL1335809 & 688267 & 6.95 & 5.0487 & TRN \\
\hline CHEMBL1602413 & 688267 & 4.6 & 5.0433 & TRN \\
\hline CHEMBL1353606 & 688267 & 4.4 & 5.0717 & TRN \\
\hline CHEMBL1366679 & 688267 & 4.0 & 5.0109 & TRN \\
\hline CHEMBL1393392 & 688267 & 4.3 & 5.0872 & TRN \\
\hline CHEMBL1573226 & 688267 & 3.95 & 5.1142 & TRN \\
\hline CHEMBL1611989 & 688267 & 5.45 & 5.0689 & TRN \\
\hline CHEMBL1357470 & 688267 & 6.15 & 5.0465 & TRN \\
\hline CHEMBL1518853 & 688267 & 4.35 & 5.1627 & TRN \\
\hline CHEMBL1555494 & 688267 & 5.75 & 5.0267 & TRN \\
\hline CHEMBL1386040 & 688267 & 6.2 & 5.0583 & TRN \\
\hline CHEMBL1367955 & 688267 & 4.35 & 5.0781 & TRN \\
\hline CHEMBL1308837 & 688267 & 4.35 & 5.1453 & TRN \\
\hline CHEMBL1558974 & 688267 & 5.65 & 5.0668 & TRN \\
\hline CHEMBL1341894 & 688267 & 5.5 & 5.0802 & TRN \\
\hline CHEMBL1449226 & 688267 & 6.15 & 5.0244 & TRN \\
\hline CHEMBL1602635 & 688267 & 4.35 & 5.0324 & TRN \\
\hline CHEMBL1609045 & 688267 & 6.5 & 5.1266 & TRN \\
\hline CHEMBL1309338 & 688267 & 4.45 & 5.0629 & TRN \\
\hline CHEMBL1526913 & 688267 & 6.25 & 5.0185 & TRN \\
\hline CHEMBL1573294 & 688267 & 4.3 & 5.0143 & TRN \\
\hline CHEMBL1505027 & 688267 & 5.6 & 5.0495 & TRN \\
\hline CHEMBL1320975 & 688267 & 6.2 & 5.0287 & TST \\
\hline CHEMBL1345386 & 688267 & 4.55 & 5.0603 & TRN \\
\hline CHEMBL1609437 & 688267 & 5.85 & 5.0204 & TRN \\
\hline CHEMBL1557661 & 688267 & 5.55 & 5.0867 & TRN \\
\hline CHEMBL1381269 & 688267 & 6.2 & 5.0262 & TRN \\
\hline CHEMBL1327163 & 688267 & 4.3 & 5.0169 & TRN \\
\hline CHEMBL1572218 & 688267 & 4.5 & 5.1399 & TRN \\
\hline CHEMBL1359226 & 688267 & 4.35 & 5.1034 & TST \\
\hline CHEMBL1499878 & 688267 & 5.85 & 5.1037 & TRN \\
\hline CHEMBL3190918 & 688267 & 5.3 & 5.0176 & TRN \\
\hline CHEMBL1359051 & 688267 & 6.2 & 5.0722 & TRN \\
\hline CHEMBL1353633 & 688267 & 6.1 & 5.0517 & TST \\
\hline CHEMBL1537360 & 688267 & 5.95 & 5.1475 & TRN \\
\hline CHEMBL1491868 & 688267 & 3.95 & 5.0647 & TRN \\
\hline CHEMBL1378836 & 688267 & 5.6 & 5.0132 & TRN \\
\hline CHEMBL1420522 & 688267 & 4.7 & 5.0708 & TST \\
\hline CHEMBL1257106 & 688267 & 5.55 & 5.1202 & TST \\
\hline CHEMBL1552300 & 688267 & 5.0 & 4.9756 & TRN \\
\hline CHEMBL1342259 & 688267 & 5.6 & 5.0357 & TRN \\
\hline CHEMBL1515427 & 688267 & 5.15 & 5.0699 & TRN \\
\hline CHEMBL 387762 & 688267 & 5.25 & 5.0655 & TST \\
\hline CHEMBL1537297 & 688267 & 6.15 & 5.1189 & TRN \\
\hline
\end{tabular}




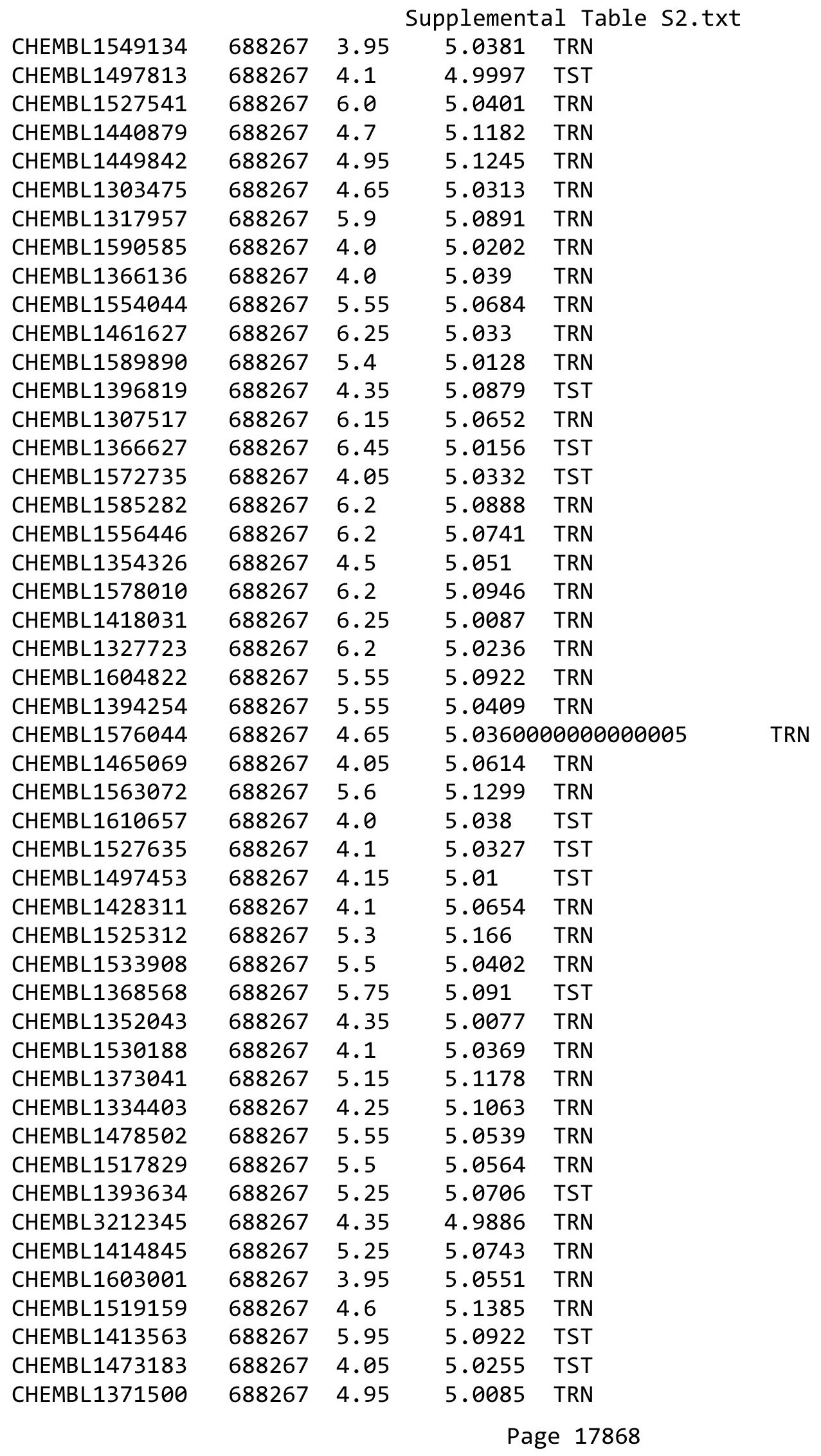




\begin{tabular}{|c|c|c|c|c|c|}
\hline \multicolumn{6}{|c|}{ Supplemental Table S2.txt } \\
\hline CHEMBL1602612 & 688267 & 5.95 & 5.0196 & TRN & \\
\hline CHEMBL1519664 & 688267 & 4.1 & 5.0223 & TRN & \\
\hline CHEMBL1490862 & 688267 & 5.6 & 5.0176 & TRN & \\
\hline CHEMBL1538664 & 688267 & 6.2 & 4.9949 & TRN & \\
\hline CHEMBL1398220 & 688267 & 5.2 & 5.1253 & TRN & \\
\hline CHEMBL1382735 & 688267 & 5.35 & 5.0534 & TST & \\
\hline CHEMBL1517972 & 688267 & 4.25 & 5.0897 & TRN & \\
\hline CHEMBL1532350 & 688267 & 5.05 & 5.0803 & TRN & \\
\hline CHEMBL1444915 & 688267 & 5.35 & 5.0808 & TST & \\
\hline CHEMBL1373632 & 688267 & 6.15 & 5.0754 & TRN & \\
\hline CHEMBL1550343 & 688267 & 4.2 & 5.0945 & TST & \\
\hline CHEMBL1578817 & 688267 & 6.2 & 5.046 & TRN & \\
\hline CHEMBL1490152 & 688267 & 5.35 & 4.9994 & TRN & \\
\hline CHEMBL1578570 & 688267 & 6.2 & 5.03600 & 00000000005 & TRN \\
\hline CHEMBL1528184 & 688267 & 5.35 & 5.0245 & TRN & \\
\hline CHEMBL1606465 & 688267 & 4.05 & 5.0718 & TRN & \\
\hline CHEMBL1483874 & 688267 & 4.55 & 5.0028 & TRN & \\
\hline CHEMBL1993826 & 688267 & 5.35 & 5.041 & TST & \\
\hline CHEMBL1519773 & 688267 & 5.4 & 5.1179 & TRN & \\
\hline CHEMBL1299530 & 688267 & 5.5 & 5.04899 & 99999999995 & TRN \\
\hline CHEMBL1371608 & 688267 & 4.45 & 5.0729 & TST & \\
\hline CHEMBL1479160 & 688267 & 4.3 & 5.1109 & TRN & \\
\hline CHEMBL1438325 & 688267 & 6.2 & 5.1458 & TRN & \\
\hline CHEMBL1439836 & 688267 & 4.0 & 5.0595 & TRN & \\
\hline CHEMBL1371366 & 688267 & 4.65 & 5.0742 & TRN & \\
\hline CHEMBL1316356 & 688267 & 3.95 & 5.048 & TRN & \\
\hline CHEMBL1544155 & 688267 & 6.5 & 5.0364 & TST & \\
\hline CHEMBL1395955 & 688267 & 5.2 & 5.0703 & TRN & \\
\hline CHEMBL1328885 & 688267 & 6.0 & 5.1227 & TRN & \\
\hline CHEMBL1483568 & 688267 & 4.0 & 5.1266 & TST & \\
\hline CHEMBL1971015 & 688267 & 4.3 & 5.0332 & TST & \\
\hline CHEMBL1485980 & 688267 & 5.65 & 4.9987 & TRN & \\
\hline CHEMBL1568000 & 688267 & 4.0 & 5.0504 & TRN & \\
\hline CHEMBL1409834 & 688267 & 5.3 & 5.0609 & TRN & \\
\hline CHEMBL1584598 & 688267 & 6.15 & 4.9943 & TRN & \\
\hline CHEMBL1517518 & 688267 & 3.95 & 5.0484 & TRN & \\
\hline CHEMBL1548507 & 688267 & 4.1 & 5.0443 & TST & \\
\hline CHEMBL1557409 & 688267 & 4.0 & 5.0923 & TRN & \\
\hline CHEMBL1511312 & 688267 & 4.25 & 5.015 & TRN & \\
\hline CHEMBL1537917 & 688267 & 4.35 & 5.0811 & TRN & \\
\hline CHEMBL1487525 & 688267 & 5.55 & 5.1023 & TRN & \\
\hline CHEMBL1428099 & 688267 & 4.85 & 5.1189 & TRN & \\
\hline CHEMBL1427189 & 688267 & 4.35 & 5.0926 & TST & \\
\hline CHEMBL1513664 & 688267 & 5.25 & 5.0381 & TRN & \\
\hline CHEMBL1535803 & 688267 & 5.5 & 5.0665 & TRN & \\
\hline CHEMBL1525104 & 688267 & 6.7001 & 5.0221 & TST & \\
\hline CHEMBL1455308 & 688267 & 6.2 & 5.0604 & TST & \\
\hline CHEMBL1426134 & 688267 & 4.3 & 5.0685 & TRN & \\
\hline
\end{tabular}




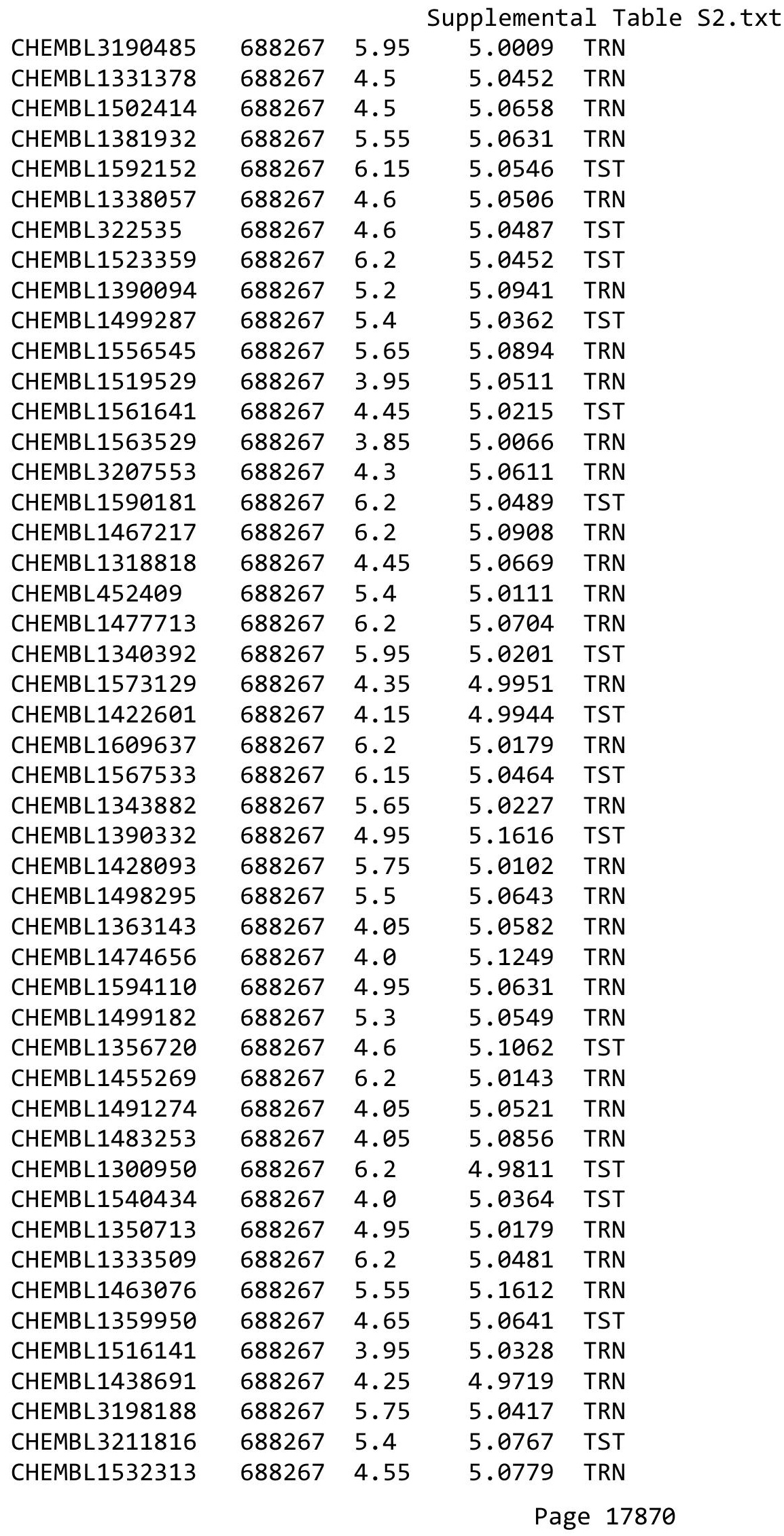




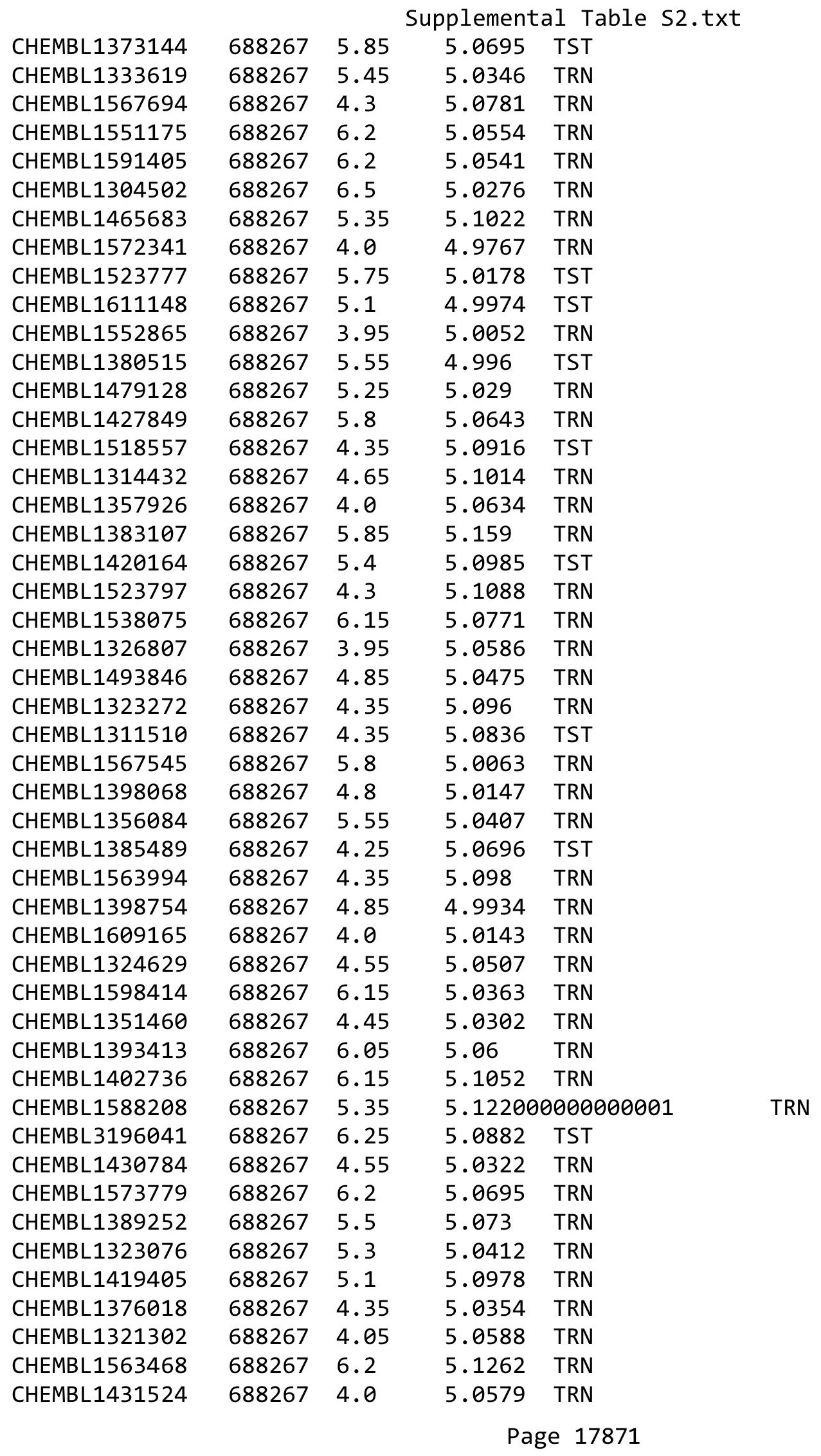




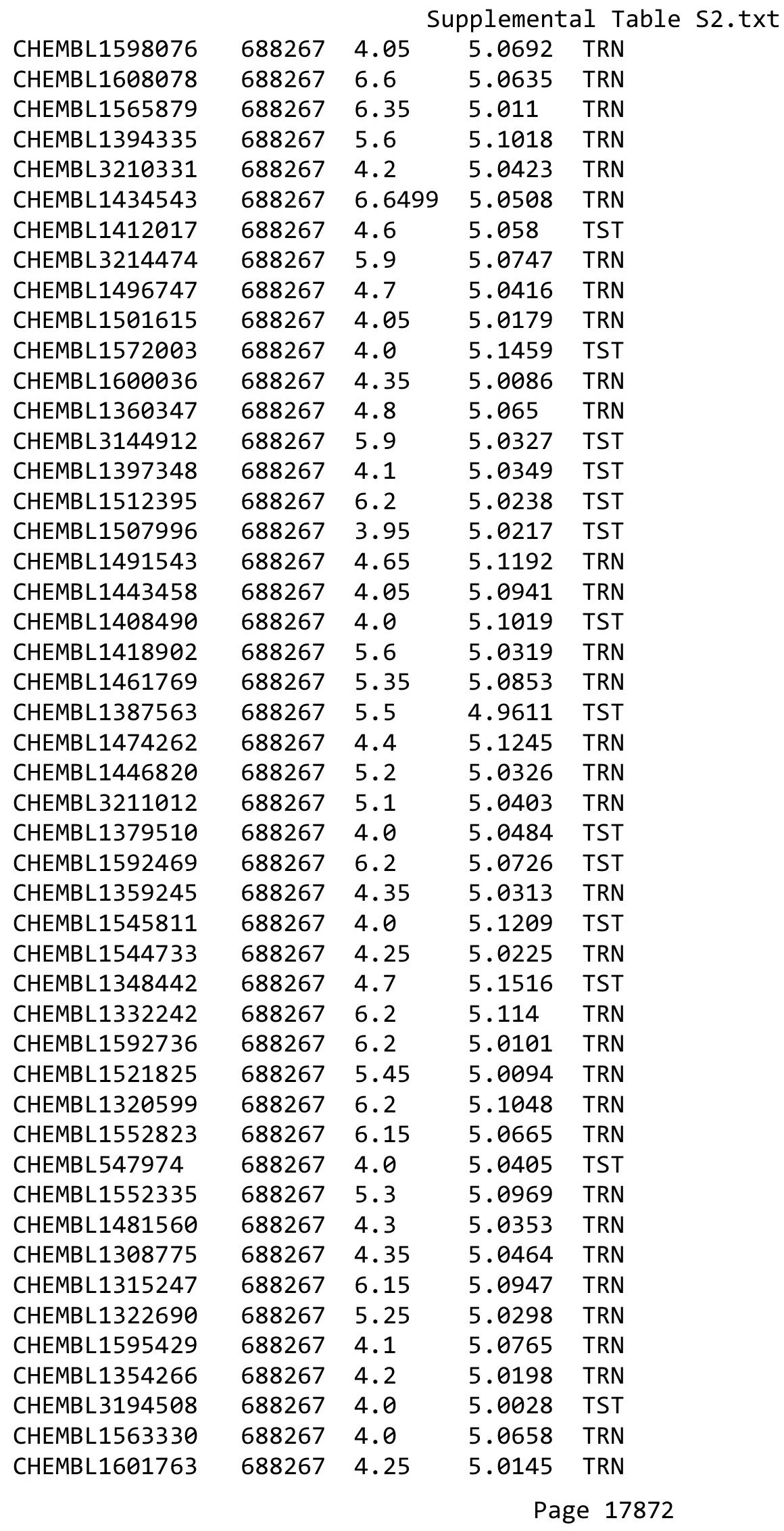




\begin{tabular}{|c|c|c|c|c|}
\hline & & & pplement & al $\mathrm{Ta}$ \\
\hline CHEMBL1380997 & 688267 & 6.2 & 5.0806 & TRN \\
\hline CHEMBL1456694 & 688267 & 4.15 & 4.9946 & TRN \\
\hline CHEMBL1603372 & 688267 & 5.5 & 5.1297 & TRN \\
\hline CHEMBL1519884 & 688267 & 6.05 & 5.0752 & TST \\
\hline CHEMBL1546741 & 688267 & 5.0 & 5.0427 & TRN \\
\hline CHEMBL 3211427 & 688267 & 5.95 & 5.0021 & TRN \\
\hline CHEMBL1356985 & 688267 & 4.5 & 5.0234 & TRN \\
\hline CHEMBL1603439 & 688267 & 6.2 & 5.0666 & TRN \\
\hline CHEMBL1387984 & 688267 & 4.0 & 5.1232 & TRN \\
\hline CHEMBL1474716 & 688267 & 5.75 & 5.0583 & TRN \\
\hline CHEMBL1363049 & 688267 & 4.8 & 5.1825 & TRN \\
\hline CHEMBL1497319 & 688267 & 4.0 & 5.1087 & TST \\
\hline CHEMBL444125 & 688267 & 5.25 & 5.0815 & TRN \\
\hline CHEMBL1604351 & 688267 & 5.55 & 5.0946 & TRN \\
\hline CHEMBL3191455 & 688267 & 4.05 & 5.0425 & TRN \\
\hline CHEMBL1567113 & 688267 & 4.05 & 5.0979 & TRN \\
\hline CHEMBL1522973 & 688267 & 5.75 & 5.098 & TRN \\
\hline CHEMBL3212927 & 688267 & 4.0 & 4.9765 & TRN \\
\hline CHEMBL1579030 & 688267 & 6.5 & 5.0938 & TST \\
\hline CHEMBL1573191 & 688267 & 4.7 & 5.0267 & TST \\
\hline CHEMBL567132 & 688267 & 4.2 & 5.0195 & TST \\
\hline CHEMBL1394121 & 688267 & 4.5 & 5.0392 & TST \\
\hline CHEMBL1395379 & 688267 & 4.3 & 5.0083 & TRN \\
\hline CHEMBL1463918 & 688267 & 5.1 & 5.0578 & TRN \\
\hline CHEMBL1572493 & 688267 & 4.05 & 5.0054 & TRN \\
\hline CHEMBL1565946 & 688267 & 5.55 & 5.0278 & TRN \\
\hline CHEMBL1481278 & 688267 & 5.55 & 5.087 & TRN \\
\hline CHEMBL1535029 & 688267 & 4.45 & 5.1181 & TRN \\
\hline CHEMBL1365794 & 688267 & 4.35 & 5.0545 & TRN \\
\hline CHEMBL1462742 & 688267 & 5.25 & 5.1057 & TRN \\
\hline CHEMBL1433576 & 688267 & 3.95 & 5.0436 & TST \\
\hline CHEMBL1436494 & 688267 & 6.1 & 5.0572 & TRN \\
\hline CHEMBL1361138 & 688267 & 5.35 & 5.0795 & TRN \\
\hline CHEMBL1408457 & 688267 & 5.75 & 5.1065 & TRN \\
\hline CHEMBL1575101 & 688267 & 4.25 & 5.0315 & TRN \\
\hline CHEMBL1607384 & 688267 & 5.15 & 5.0584 & TRN \\
\hline CHEMBL1500359 & 688267 & 5.45 & 5.0472 & TRN \\
\hline CHEMBL1346415 & 688267 & 5.45 & 5.0354 & TRN \\
\hline CHEMBL1091556 & 688267 & 4.8 & 4.9874 & TRN \\
\hline CHEMBL1431798 & 688267 & 5.5 & 4.9844 & TST \\
\hline CHEMBL1391959 & 688267 & 4.6 & 5.1229 & TRN \\
\hline CHEMBL1333747 & 688267 & 4.7 & 5.0803 & TRN \\
\hline CHEMBL1365342 & 688267 & 5.15 & 5.0509 & TST \\
\hline CHEMBL1555299 & 688267 & 6.5 & 5.1173 & TRN \\
\hline CHEMBL1449353 & 688267 & 4.1 & 5.024 & TRN \\
\hline CHEMBL1432802 & 688267 & 4.75 & 5.0476 & TRN \\
\hline CHEMBL1444182 & 688267 & 4.0 & 5.117 & TRN \\
\hline CHEMBL1580914 & 688267 & 5.3 & 5.0381 & TST \\
\hline
\end{tabular}




\begin{tabular}{|c|c|c|c|c|}
\hline \multicolumn{5}{|c|}{ Supplemental Table S2.txt } \\
\hline CHEMBL1374552 & 688267 & 4.05 & 5.0129 & TST \\
\hline CHEMBL1525461 & 688267 & 6.15 & 5.1446 & TST \\
\hline CHEMBL1608550 & 688267 & 4.0 & 5.0891 & TRN \\
\hline CHEMBL1539008 & 688267 & 4.35 & 5.0525 & TRN \\
\hline CHEMBL1556394 & 688267 & 6.2 & 5.0364 & TRN \\
\hline CHEMBL1361634 & 688267 & 5.1 & 5.0316 & TRN \\
\hline CHEMBL1610065 & 688267 & 4.05 & 5.1338 & TRN \\
\hline CHEMBL1416108 & 688267 & 5.0 & 5.0967 & TST \\
\hline CHEMBL1584665 & 688267 & 5.25 & 5.1677 & TRN \\
\hline CHEMBL1355488 & 688267 & 5.5 & 5.0312 & TRN \\
\hline CHEMBL1368448 & 688267 & 4.0 & 5.0241 & TST \\
\hline CHEMBL1593985 & 688267 & 4.0 & 5.0753 & TST \\
\hline CHEMBL1390 & 688267 & 3.95 & 5.0865 & TST \\
\hline CHEMBL1310800 & 688267 & 6.2 & 5.1357 & TRN \\
\hline CHEMBL1356276 & 688267 & 6.15 & 5.1104 & TRN \\
\hline CHEMBL1563460 & 688267 & 4.05 & 5.1314 & TRN \\
\hline CHEMBL1475277 & 688267 & 5.3 & 5.1506 & TRN \\
\hline CHEMBL1534572 & 688267 & 4.15 & 5.0621 & TRN \\
\hline CHEMBL1403155 & 688267 & 4.25 & 5.064 & TRN \\
\hline CHEMBL1354944 & 688267 & 6.2 & 5.0555 & TST \\
\hline CHEMBL1364346 & 688267 & 5.5 & 5.0443 & TRN \\
\hline CHEMBL1304842 & 688267 & 4.05 & 5.0418 & TST \\
\hline CHEMBL1378556 & 688267 & 5.45 & 5.0274 & TRN \\
\hline CHEMBL1530096 & 688267 & 4.0 & 5.1102 & TRN \\
\hline CHEMBL1400846 & 688267 & 5.55 & 5.042 & TST \\
\hline CHEMBL1601450 & 688267 & 4.05 & 5.1088 & TRN \\
\hline CHEMBL1599424 & 688267 & 5.3 & 5.1184 & TRN \\
\hline CHEMBL1459179 & 688267 & 4.3 & 5.1358 & TRN \\
\hline CHEMBL1525226 & 688267 & 3.95 & 5.0353 & TST \\
\hline CHEMBL3211178 & 688267 & 4.4 & 5.011 & TST \\
\hline CHEMBL1461217 & 688267 & 5.6 & 5.0786 & TST \\
\hline CHEMBL1568508 & 688267 & 6.2 & 5.0283 & TRN \\
\hline CHEMBL1529847 & 688267 & 4.0 & 5.0669 & TRN \\
\hline CHEMBL1405285 & 688267 & 6.15 & 5.0153 & TRN \\
\hline CHEMBL3199459 & 688267 & 5.8 & 4.9862 & TRN \\
\hline CHEMBL1436278 & 688267 & 4.0 & 5.0085 & TRN \\
\hline CHEMBL1605107 & 688267 & 5.8 & 5.011 & TRN \\
\hline CHEMBL1398273 & 688267 & 6.45 & 5.0628 & TRN \\
\hline CHEMBL1359141 & 688267 & 6.25 & 5.0554 & TRN \\
\hline CHEMBL1351651 & 688267 & 5.3 & 5.0372 & TRN \\
\hline CHEMBL1524949 & 688267 & 5.55 & 5.0148 & TRN \\
\hline CHEMBL1522732 & 688267 & 4.05 & 5.0892 & TRN \\
\hline CHEMBL1441359 & 688267 & 4.0 & 5.007 & TRN \\
\hline CHEMBL1326761 & 688267 & 4.05 & 5.0877 & TRN \\
\hline CHEMBL1466453 & 688267 & 3.95 & 5.0318 & TST \\
\hline CHEMBL1512348 & 688267 & 3.95 & 5.1238 & TRN \\
\hline CHEMBL1412413 & 688267 & 5.4 & 4.9893 & TST \\
\hline CHEMBL3213894 & 688267 & 7.8996 & 5.0641 & TST \\
\hline
\end{tabular}




\begin{tabular}{|c|c|c|c|c|c|}
\hline \multicolumn{6}{|c|}{ Supplemental Table S2.txt } \\
\hline CHEMBL1321333 & 688267 & 4.1 & 5.026 & TST & \\
\hline CHEMBL1321306 & 688267 & 6.2 & 5.1032 & TRN & \\
\hline CHEMBL1461892 & 688267 & 3.95 & 5.1447 & TRN & \\
\hline CHEMBL1352637 & 688267 & 4.0 & 5.1375 & TRN & \\
\hline CHEMBL1562374 & 688267 & 6.05 & 5.0225 & TRN & \\
\hline CHEMBL1222145 & 688267 & 5.3 & 4.9598 & TRN & \\
\hline CHEMBL1366555 & 688267 & 4.7 & 5.0459 & TRN & \\
\hline CHEMBL1566107 & 688267 & 4.3 & 5.1086 & TRN & \\
\hline CHEMBL3197226 & 688267 & 5.8 & $5.0280 e$ & 00000000005 & TST \\
\hline CHEMBL1394341 & 688267 & 5.45 & 5.0805 & TRN & \\
\hline CHEMBL3196793 & 688267 & 4.4 & 4.9989 & TST & \\
\hline CHEMBL3213196 & 688267 & 4.95 & 5.0672 & TST & \\
\hline CHEMBL1467056 & 688267 & 5.35 & 5.1302 & TRN & \\
\hline CHEMBL1599010 & 688267 & 4.65 & 5.0426 & TRN & \\
\hline CHEMBL1510654 & 688267 & 4.35 & 5.0004 & TRN & \\
\hline CHEMBL1459332 & 688267 & 4.3 & 5.0001 & TST & \\
\hline CHEMBL1403773 & 688267 & 6.15 & 5.121 & TRN & \\
\hline CHEMBL1453402 & 688267 & 5.0 & 5.0577 & TRN & \\
\hline CHEMBL1418487 & 688267 & 4.35 & 5.0421 & TRN & \\
\hline CHEMBL3210575 & 688267 & 4.05 & 4.9919 & TRN & \\
\hline CHEMBL1333717 & 688267 & 4.35 & 4.9516 & TRN & \\
\hline CHEMBL1357501 & 688267 & 5.25 & 5.1195 & TRN & \\
\hline CHEMBL1463332 & 688267 & 5.55 & 5.044 & TST & \\
\hline CHEMBL1465713 & 688267 & 5.0 & 5.1051 & TRN & \\
\hline CHEMBL3210493 & 688267 & 6.2 & 5.041 & TRN & \\
\hline CHEMBL1569419 & 688267 & 4.4 & 5.1562 & TRN & \\
\hline CHEMBL1585330 & 688267 & 5.65 & 5.0238 & TST & \\
\hline CHEMBL1603014 & 688267 & 6.25 & 5.1339 & TRN & \\
\hline CHEMBL1528999 & 688267 & 5.4 & 5.0674 & TRN & \\
\hline CHEMBL567422 & 688267 & 4.3 & 5.0744 & TST & \\
\hline CHEMBL1541977 & 688267 & 4.1 & 5.0426 & TST & \\
\hline CHEMBL1579785 & 688267 & 5.0 & 4.9986 & TRN & \\
\hline CHEMBL1434610 & 688267 & 3.95 & 5.0543 & TRN & \\
\hline CHEMBL1348674 & 688267 & 5.85 & $5.0680 e$ & 00000000005 & TRN \\
\hline CHEMBL1489220 & 688267 & 4.3 & 5.0292 & TRN & \\
\hline CHEMBL1435558 & 688267 & 5.3 & 5.0856 & TST & \\
\hline CHEMBL1479685 & 688267 & 4.4 & 5.0297 & TRN & \\
\hline CHEMBL1447562 & 688267 & 6.45 & 5.0502 & TRN & \\
\hline CHEMBL1505465 & 688267 & 5.25 & 5.0437 & TRN & \\
\hline CHEMBL1378206 & 688267 & 4.25 & 4.9857 & TRN & \\
\hline CHEMBL1310205 & 688267 & 5.3 & 5.0793 & TRN & \\
\hline CHEMBL1543279 & 688267 & 5.55 & 5.0252 & TRN & \\
\hline CHEMBL1402876 & 688267 & 6.2 & 5.0419 & TST & \\
\hline CHEMBL1369645 & 688267 & 4.5 & 5.013 & TRN & \\
\hline CHEMBL1350895 & 688267 & 5.3 & 5.0198 & TRN & \\
\hline CHEMBL1478634 & 688267 & 4.35 & 5.0349 & TST & \\
\hline CHEMBL1309342 & 688267 & 4.3 & 5.0885 & TRN & \\
\hline CHEMBL1568456 & 688267 & 6.25 & 5.1016 & TRN & \\
\hline
\end{tabular}




\begin{tabular}{|c|c|c|c|c|}
\hline & & & pplemen & al $\mathrm{T}$ \\
\hline CHEMBL1387244 & 688267 & 4.6 & 5.1296 & TST \\
\hline CHEMBL1459360 & 688267 & 6.2 & 5.0123 & TST \\
\hline CHEMBL1561220 & 688267 & 5.55 & 5.129 & TRN \\
\hline CHEMBL1407816 & 688267 & 4.0 & 5.0324 & TST \\
\hline CHEMBL1410080 & 688267 & 4.75 & 5.0638 & TRN \\
\hline CHEMBL1303440 & 688267 & 4.4 & 5.0222 & TRN \\
\hline CHEMBL1574347 & 688267 & 4.6 & 5.0649 & TST \\
\hline CHEMBL1384397 & 688267 & 5.4 & 5.0237 & TRN \\
\hline CHEMBL1409586 & 688267 & 3.95 & 5.0814 & TRN \\
\hline CHEMBL1301535 & 688267 & 5.25 & 5.1663 & TST \\
\hline CHEMBL 1478280 & 688267 & 5.6 & 5.0568 & TRN \\
\hline CHEMBL1430510 & 688267 & 5.05 & 5.0446 & TRN \\
\hline CHEMBL1551524 & 688267 & 5.0 & 5.0293 & TRN \\
\hline CHEMBL1355365 & 688267 & 6.2 & 5.0496 & TRN \\
\hline CHEMBL1325396 & 688267 & 4.05 & 5.0976 & TRN \\
\hline CHEMBL1460859 & 688267 & 6.25 & 5.0913 & TRN \\
\hline CHEMBL1607557 & 688267 & 4.25 & 5.0379 & TRN \\
\hline CHEMBL1410480 & 688267 & 4.65 & 5.0242 & TRN \\
\hline CHEMBL1566585 & 688267 & 4.25 & 5.0647 & TST \\
\hline CHEMBL1612705 & 688267 & 6.3 & 5.1169 & TST \\
\hline CHEMBL3192392 & 688267 & 4.0 & 5.0441 & TST \\
\hline CHEMBL1533827 & 688267 & 4.4 & 5.1099 & TRN \\
\hline CHEMBL1336182 & 688267 & 4.05 & 5.0627 & TST \\
\hline CHEMBL1419579 & 688267 & 5.2 & 4.993 & TRN \\
\hline CHEMBL1432097 & 688267 & 4.1 & 4.9948 & TRN \\
\hline CHEMBL1501935 & 688267 & 5.25 & 5.0564 & TRN \\
\hline CHEMBL1394277 & 688267 & 4.1 & 5.0122 & TRN \\
\hline CHEMBL1515728 & 688267 & 4.0 & 5.12 & TST \\
\hline CHEMBL1317113 & 688267 & 4.05 & 5.1188 & TRN \\
\hline CHEMBL 1485848 & 688267 & 4.6 & 5.0738 & TRN \\
\hline CHEMBL1493876 & 688267 & 4.05 & 5.0712 & TRN \\
\hline CHEMBL1475904 & 688267 & 6.2 & 5.0693 & TRN \\
\hline CHEMBL1544841 & 688267 & 6.15 & 5.0567 & TRN \\
\hline CHEMBL1374662 & 688267 & 6.15 & 5.0798 & TRN \\
\hline CHEMBL1404209 & 688267 & 6.25 & 5.0396 & TST \\
\hline CHEMBL1477226 & 688267 & 4.0 & 5.084 & TRN \\
\hline CHEMBL1511490 & 688267 & 4.3 & 5.0999 & TRN \\
\hline CHEMBL1609048 & 688267 & 4.75 & 5.0556 & TRN \\
\hline CHEMBL1481484 & 688267 & 5.55 & 5.0803 & TRN \\
\hline CHEMBL1324294 & 688267 & 4.3 & 5.0202 & TST \\
\hline CHEMBL3195101 & 688267 & 5.8 & 5.0033 & TRN \\
\hline CHEMBL1309016 & 688267 & 5.65 & 5.0214 & TST \\
\hline CHEMBL1358543 & 688267 & 3.95 & 5.072 & TRN \\
\hline CHEMBL1459523 & 688267 & 4.25 & 5.0292 & TRN \\
\hline CHEMBL1470243 & 688267 & 5.5 & 5.1117 & TST \\
\hline CHEMBL1568993 & 688267 & 5.6 & 5.0363 & TRN \\
\hline CHEMBL1372700 & 688267 & 5.95 & 5.0636 & TRN \\
\hline CHEMBL 3193148 & 688267 & 5.15 & 5.0359 & TRN \\
\hline
\end{tabular}




\begin{tabular}{|c|c|c|c|c|}
\hline \multicolumn{5}{|c|}{ Supplemental Table S2.txt } \\
\hline CHEMBL1483832 & 688267 & 4.6 & 5.103 & TRN \\
\hline CHEMBL1303942 & 688267 & 4.0 & 5.0985 & TST \\
\hline CHEMBL1478482 & 688267 & 4.0 & 5.0199 & TRN \\
\hline CHEMBL1449645 & 688267 & 5.15 & 5.012 & TRN \\
\hline CHEMBL1560334 & 688267 & 5.8 & 5.1167 & TST \\
\hline CHEMBL1444799 & 688267 & 6.2 & 5.0789 & TRN \\
\hline CHEMBL1330348 & 688267 & 6.0 & 5.0011 & TRN \\
\hline CHEMBL1493598 & 688267 & 4.55 & 5.0665 & TRN \\
\hline CHEMBL1607153 & 688267 & 6.3 & 5.1506 & TRN \\
\hline CHEMBL1593456 & 688267 & 5.6 & 5.0194 & TRN \\
\hline CHEMBL1498066 & 688267 & 5.3 & 5.0572 & TRN \\
\hline CHEMBL1531847 & 688267 & 4.05 & 5.0659 & TRN \\
\hline CHEMBL3213526 & 688267 & 4.6 & 5.0332 & TRN \\
\hline CHEMBL1395236 & 688267 & 6.2 & 5.0728 & TRN \\
\hline CHEMBL1408508 & 688267 & 4.0 & 5.0317 & TRN \\
\hline CHEMBL1364122 & 688267 & 4.1 & 5.0431 & TRN \\
\hline CHEMBL1448950 & 688267 & 4.55 & 5.0697 & TRN \\
\hline CHEMBL1334112 & 688267 & 5.4 & 5.0788 & TST \\
\hline CHEMBL1367029 & 688267 & 4.4 & 5.0814 & TST \\
\hline CHEMBL1547752 & 688267 & 4.9 & 5.0656 & TST \\
\hline CHEMBL1313579 & 688267 & 5.2 & 5.0639 & TST \\
\hline CHEMBL1555003 & 688267 & 4.05 & 5.1054 & TRN \\
\hline CHEMBL1585247 & 688267 & 6.25 & 5.0423 & TRN \\
\hline CHEMBL1356494 & 688267 & 4.95 & 5.1132 & TRN \\
\hline CHEMBL1354750 & 688267 & 4.05 & 5.0214 & TRN \\
\hline CHEMBL1485845 & 688267 & 4.4 & 5.0837 & TRN \\
\hline CHEMBL1600909 & 688267 & 6.2 & 5.1275 & TRN \\
\hline CHEMBL1502072 & 688267 & 4.2 & 5.0182 & TRN \\
\hline CHEMBL1355926 & 688267 & 5.25 & 5.0298 & TRN \\
\hline CHEMBL597449 & 688267 & 4.65 & 5.0537 & TRN \\
\hline CHEMBL1502804 & 688267 & 6.6499 & 5.0524 & TRN \\
\hline CHEMBL507603 & 688267 & 6.25 & 5.0732 & TRN \\
\hline CHEMBL1523173 & 688267 & 5.1 & 5.0372 & TRN \\
\hline CHEMBL1514121 & 688267 & 5.5 & 5.0119 & TRN \\
\hline CHEMBL1550051 & 688267 & 6.2 & 5.0663 & TRN \\
\hline CHEMBL1543212 & 688267 & 5.35 & 5.0777 & TRN \\
\hline CHEMBL1562441 & 688267 & 6.15 & 5.0173 & TRN \\
\hline CHEMBL1544917 & 688267 & 5.0 & 5.0194 & TST \\
\hline CHEMBL1426064 & 688267 & 6.2 & 5.0539 & TRN \\
\hline CHEMBL1532529 & 688267 & 6.2 & 5.0742 & TRN \\
\hline CHEMBL1527717 & 688267 & 5.35 & 5.0354 & TRN \\
\hline CHEMBL1313837 & 688267 & 5.35 & 5.0529 & TST \\
\hline CHEMBL1550372 & 688267 & 6.2 & 5.0916 & TRN \\
\hline CHEMBL1569048 & 688267 & 4.3 & 5.038 & TRN \\
\hline CHEMBL1319294 & 688267 & 4.0 & 5.0901 & TRN \\
\hline CHEMBL1484319 & 688267 & 4.05 & 5.0328 & TRN \\
\hline CHEMBL1464707 & 688267 & 5.85 & 5.0125 & TST \\
\hline CHEMBL1383068 & 688267 & 4.65 & 5.0205 & TRN \\
\hline
\end{tabular}




\begin{tabular}{|c|c|c|c|c|}
\hline & & & pplement & \\
\hline CHEMBL1375971 & 688267 & 6.2 & 5.0841 & TRN \\
\hline CHEMBL3193592 & 688267 & 4.05 & 4.9994 & TRN \\
\hline CHEMBL1567473 & 688267 & 6.2 & 5.0238 & TRN \\
\hline CHEMBL1338342 & 688267 & 5.05 & 5.069 & TRN \\
\hline CHEMBL1338955 & 688267 & 6.15 & 5.0651 & TRN \\
\hline CHEMBL1342441 & 688267 & 5.4 & 5.0532 & TRN \\
\hline CHEMBL1512370 & 688267 & 5.9 & 5.0833 & TRN \\
\hline CHEMBL1502818 & 688267 & 5.8 & 5.0269 & TST \\
\hline CHEMBL1316099 & 688267 & 5.85 & 5.0667 & TRN \\
\hline CHEMBL1360463 & 688267 & 4.55 & 5.0935 & TRN \\
\hline CHEMBL1521478 & 688267 & 5.4 & 5.006 & TRN \\
\hline CHEMBL1396707 & 688267 & 4.8 & 5.0923 & TST \\
\hline CHEMBL1612699 & 688267 & 4.05 & 5.0478 & TRN \\
\hline CHEMBL1483704 & 688267 & 4.95 & 5.0107 & TST \\
\hline CHEMBL1395647 & 688267 & 4.8 & 5.0423 & TRN \\
\hline CHEMBL1573356 & 688267 & 6.2 & 5.0396 & TRN \\
\hline CHEMBL1396102 & 688267 & 3.95 & 4.9974 & TRN \\
\hline CHEMBL1563271 & 688267 & 4.0 & 5.0691 & TRN \\
\hline CHEMBL1397091 & 688267 & 4.05 & 4.9839 & TRN \\
\hline CHEMBL1605782 & 688267 & 5.55 & 5.0412 & TST \\
\hline CHEMBL404584 & 688267 & 4.0 & 5.0619 & TRN \\
\hline CHEMBL1559493 & 688267 & 4.75 & 5.0339 & TRN \\
\hline CHEMBL1481925 & 688267 & 6.15 & 5.1327 & TRN \\
\hline CHEMBL1497499 & 688267 & 3.9 & 5.1724 & TRN \\
\hline CHEMBL1411482 & 688267 & 5.45 & 4.9818 & TST \\
\hline CHEMBL1573401 & 688267 & 5.35 & 5.0242 & TRN \\
\hline CHEMBL1538571 & 688267 & 5.3 & 5.0377 & TRN \\
\hline CHEMBL1554830 & 688267 & 4.25 & 5.146 & TRN \\
\hline CHEMBL1358650 & 688267 & 6.7001 & 5.047 & TRN \\
\hline CHEMBL 1440327 & 688267 & 4.0 & 5.1246 & TRN \\
\hline CHEMBL1541071 & 688267 & 3.95 & 4.9987 & TRN \\
\hline CHEMBL1610025 & 688267 & 5.85 & 4.9827 & TST \\
\hline CHEMBL1461207 & 688267 & 5.9 & 5.0599 & TST \\
\hline CHEMBL1553096 & 688267 & 4.0 & 5.053 & TRN \\
\hline CHEMBL1340372 & 688267 & 5.9 & 5.0606 & TRN \\
\hline CHEMBL1322981 & 688267 & 5.35 & 5.073 & TRN \\
\hline CHEMBL1395808 & 688267 & 5.6 & 5.0955 & TRN \\
\hline CHEMBL1457288 & 688267 & 4.05 & 5.0962 & TRN \\
\hline CHEMBL1532349 & 688267 & 6.5 & 5.0112 & TST \\
\hline CHEMBL1359305 & 688267 & 6.5 & 5.1114 & TRN \\
\hline CHEMBL1421158 & 688267 & 5.2 & 5.1039 & TRN \\
\hline CHEMBL1519082 & 688267 & 6.2 & 5.0677 & TRN \\
\hline CHEMBL1465944 & 688267 & 6.2 & 5.0893 & TST \\
\hline CHEMBL1580733 & 688267 & 5.1 & 5.0624 & TRN \\
\hline CHEMBL1347252 & 688267 & 4.4 & 5.0443 & TST \\
\hline CHEMBL1405276 & 688267 & 4.0 & 5.1094 & TRN \\
\hline CHEMBL1610221 & 688267 & 5.3 & 5.0383 & TRN \\
\hline CHEMBL1610460 & 688267 & 3.95 & 5.0318 & TRN \\
\hline
\end{tabular}




\begin{tabular}{|c|c|c|c|c|c|}
\hline \\
\hline CHEMBL1443047 & 688267 & 6.2 & 5.0343 & TRN & \\
\hline CHEMBL1589603 & 688267 & 6.2 & 5.0049 & TRN & \\
\hline CHEMBL1463710 & 688267 & 6.0 & 5.0997 & TRN & \\
\hline CHEMBL1357957 & 688267 & 6.15 & 5.0998 & TRN & \\
\hline CHEMBL1513514 & 688267 & 5.45 & 5.0182 & TRN & \\
\hline CHEMBL1593282 & 688267 & 4.25 & \multicolumn{2}{|c|}{5.1080000000000005} & TRN \\
\hline CHEMBL1579175 & 688267 & 4.4 & 5.0172 & TRN & \\
\hline CHEMBL1375639 & 688267 & 4.9 & 5.043 & TRN & \\
\hline CHEMBL1080566 & 688267 & 5.05 & 5.0641 & TRN & \\
\hline CHEMBL1483024 & 688267 & 4.8 & 5.0824 & TRN & \\
\hline CHEMBL1577180 & 688267 & 5.35 & 5.0911 & TRN & \\
\hline CHEMBL1552290 & 688267 & 4.0 & 5.092 & TRN & \\
\hline CHEMBL1347204 & 688267 & 5.35 & 4.9572 & TRN & \\
\hline CHEMBL1487297 & 688267 & 5.4 & 5.1059 & TRN & \\
\hline CHEMBL1413345 & 688267 & 5.9 & 5.0393 & TRN & \\
\hline CHEMBL1544884 & 688267 & 6.05 & 5.0737 & TST & \\
\hline CHEMBL1417297 & 688267 & 5.95 & 5.0897 & TRN & \\
\hline CHEMBL1341903 & 688267 & 4.05 & 5.0448 & TRN & \\
\hline CHEMBL1581548 & 688267 & 6.05 & 5.0275 & TRN & \\
\hline CHEMBL1470024 & 688267 & 5.45 & 5.1024 & TRN & \\
\hline CHEMBL1558017 & 688267 & 6.2 & 5.0606 & TRN & \\
\hline CHEMBL1459406 & 688267 & 4.0 & 5.0269 & TRN & \\
\hline CHEMBL1563613 & 688267 & 4.4 & 5.0708 & TRN & \\
\hline CHEMBL1348068 & 688267 & 6.25 & 5.0717 & TRN & \\
\hline CHEMBL1454066 & 688267 & 4.0 & 5.0786 & TRN & \\
\hline CHEMBL1525369 & 688267 & 6.2 & 5.0223 & TST & \\
\hline CHEMBL1613122 & 688267 & 4.0 & 5.0416 & TRN & \\
\hline CHEMBL1547806 & 688267 & 6.1 & 5.0527 & TRN & \\
\hline CHEMBL1586327 & 688267 & 4.4 & 5.0431 & TST & \\
\hline CHEMBL1474611 & 688267 & 3.95 & 5.0189 & TRN & \\
\hline CHEMBL1476217 & 688267 & 4.3 & 5.1047 & TRN & \\
\hline CHEMBL1591455 & 688267 & 5.45 & 5.0105 & TRN & \\
\hline CHEMBL1389591 & 688267 & 5.3 & 5.0901 & TRN & \\
\hline CHEMBL1354682 & 688267 & 4.4 & 5.0212 & TRN & \\
\hline CHEMBL1508529 & 688267 & 5.4 & 5.0963 & TRN & \\
\hline CHEMBL1371082 & 688267 & 5.55 & 5.1267 & TRN & \\
\hline CHEMBL1545945 & 688267 & 5.35 & 5.0592 & TRN & \\
\hline CHEMBL1404678 & 688267 & 5.55 & 5.039 & TRN & \\
\hline CHEMBL1548967 & 688267 & 5.45 & 5.0428 & TST & \\
\hline CHEMBL1576880 & 688267 & 6.2 & 5.1034 & TST & \\
\hline CHEMBL1606936 & 688267 & 4.0 & 5.0722 & TRN & \\
\hline CHEMBL1609759 & 688267 & 3.95 & 5.0579 & TRN & \\
\hline CHEMBL1514437 & 688267 & 5.25 & 5.1052 & TRN & \\
\hline CHEMBL1416060 & 688267 & 6.25 & 5.0409 & TRN & \\
\hline CHEMBL1300763 & 688267 & 5.4 & 5.0597 & TRN & \\
\hline CHEMBL1335744 & 688267 & 6.25 & 5.1042 & TRN & \\
\hline CHEMBL1552587 & 688267 & 6.1 & 5.0415 & TRN & \\
\hline CHEMBL1321716 & 688267 & 5.6 & 5.0075 & TRN & \\
\hline & & & & 1787 & \\
\hline
\end{tabular}




\begin{tabular}{|c|c|c|c|c|c|}
\hline \multicolumn{6}{|c|}{ Supplemental Table S2.txt } \\
\hline CHEMBL1301421 & 688267 & 4.0 & 5.0432 & TRN & \\
\hline CHEMBL1555783 & 688267 & 6.2 & 5.0721 & TRN & \\
\hline CHEMBL1357306 & 688267 & 6.45 & 5.0759 & TRN & \\
\hline CHEMBL1442100 & 688267 & 5.5 & 5.0493 & TST & \\
\hline CHEMBL1551054 & 688267 & 4.1 & 5.1171 & TRN & \\
\hline CHEMBL1572642 & 688267 & 5.5 & 5.0622 & TRN & \\
\hline CHEMBL1365701 & 688267 & 5.2 & 5.0381 & TST & \\
\hline CHEMBL1565401 & 688267 & 6.5 & 4.99 & TRN & \\
\hline CHEMBL1475877 & 688267 & 5.3 & 5.0469 & TRN & \\
\hline CHEMBL1533519 & 688267 & 5.55 & 5.0532 & TRN & \\
\hline CHEMBL1442152 & 688267 & 5.85 & 5.0583 & TRN & \\
\hline CHEMBL1504332 & 688267 & 5.3 & 5.0135 & TST & \\
\hline CHEMBL1519791 & 688267 & 4.05 & 5.0531 & TRN & \\
\hline CHEMBL3211003 & 688267 & 4.6 & 5.0034 & TRN & \\
\hline CHEMBL1463148 & 688267 & 5.05 & 5.1231 & TRN & \\
\hline CHEMBL1551098 & 688267 & 5.8 & 5.11 & TRN & \\
\hline CHEMBL3190311 & 688267 & 4.2 & 5.0191 & TRN & \\
\hline CHEMBL1503196 & 688267 & 4.0 & 5.09399 & 9999999999 & TST \\
\hline CHEMBL296536 & 688267 & 4.6 & 5.0737 & TRN & \\
\hline CHEMBL1601264 & 688267 & 6.2 & 5.0904 & TRN & \\
\hline CHEMBL1369895 & 688267 & 5.85 & 5.0925 & TRN & \\
\hline CHEMBL1586763 & 688267 & 4.35 & 5.0546 & TRN & \\
\hline CHEMBL1475479 & 688267 & 4.4 & 5.0331 & TRN & \\
\hline CHEMBL1464861 & 688267 & 6.1 & 5.1079 & TRN & \\
\hline CHEMBL1331143 & 688267 & 6.25 & 5.0741 & TRN & \\
\hline CHEMBL1300177 & 688267 & 5.25 & $5.0710 e$ & 0000000001 & TRN \\
\hline CHEMBL1554382 & 688267 & 6.2 & 5.0627 & TRN & \\
\hline CHEMBL1587127 & 688267 & 4.0 & 5.0808 & TRN & \\
\hline CHEMBL1428604 & 688267 & 6.1 & 5.1289 & TRN & \\
\hline CHEMBL1317483 & 688267 & 3.95 & 5.0557 & TRN & \\
\hline CHEMBL1584610 & 688267 & 3.95 & 5.0157 & TRN & \\
\hline CHEMBL1451109 & 688267 & 4.95 & 5.1014 & TRN & \\
\hline CHEMBL1472716 & 688267 & 6.2 & 5.0577 & TRN & \\
\hline CHEMBL1307631 & 688267 & 5.6 & 5.0984 & TRN & \\
\hline CHEMBL1399715 & 688267 & 5.45 & 5.0677 & TRN & \\
\hline CHEMBL1349990 & 688267 & 5.05 & 5.0805 & TST & \\
\hline CHEMBL1489066 & 688267 & 6.15 & 5.1089 & TRN & \\
\hline CHEMBL1368963 & 688267 & 4.0 & 5.0993 & TRN & \\
\hline CHEMBL1321563 & 688267 & 6.2 & 5.0559 & TRN & \\
\hline CHEMBL1610896 & 688267 & 5.8 & 5.1114 & TRN & \\
\hline CHEMBL1329864 & 688267 & 5.0 & 5.039 & TRN & \\
\hline CHEMBL1393933 & 688267 & 4.25 & 5.0242 & TRN & \\
\hline CHEMBL1337190 & 688267 & 5.4 & 5.0664 & TST & \\
\hline CHEMBL1349134 & 688267 & 4.8 & 5.1295 & TRN & \\
\hline CHEMBL1462763 & 688267 & 6.15 & 5.0231 & TRN & \\
\hline CHEMBL1444847 & 688267 & 5.35 & 5.034 & TRN & \\
\hline CHEMBL1320724 & 688267 & 6.2 & 5.0733 & TRN & \\
\hline CHEMBL1335964 & 688267 & 4.3 & 5.0545 & TRN & \\
\hline
\end{tabular}




\begin{tabular}{|c|c|c|c|c|}
\hline \multicolumn{5}{|c|}{ Supplemental Table } \\
\hline CHEMBL1546933 & 688267 & 6.2 & 5.0576 & TST \\
\hline CHEMBL1585335 & 688267 & 4.5 & 5.0465 & TRN \\
\hline CHEMBL1558649 & 688267 & 4.3 & 5.1129 & TRN \\
\hline CHEMBL1539977 & 688267 & 6.2 & 5.1285 & TST \\
\hline CHEMBL1327982 & 688267 & 4.45 & 5.0676 & TRN \\
\hline CHEMBL1493925 & 688267 & 4.1 & 5.0375 & TST \\
\hline CHEMBL1506282 & 688267 & 5.5 & 5.0884 & TST \\
\hline CHEMBL1397909 & 688267 & 5.35 & 5.0494 & TRN \\
\hline CHEMBL1376032 & 688267 & 5.45 & 5.0836 & TRN \\
\hline CHEMBL1493663 & 688267 & 4.3 & 5.1039 & TRN \\
\hline CHEMBL1583302 & 688267 & 6.25 & 5.1138 & TRN \\
\hline CHEMBL1526692 & 688267 & 5.35 & 5.0744 & TRN \\
\hline CHEMBL1979849 & 688267 & 4.4 & 5.0034 & TRN \\
\hline CHEMBL1321591 & 688267 & 5.0 & 5.0319 & TRN \\
\hline CHEMBL1465191 & 688267 & 4.35 & 5.0065 & TST \\
\hline CHEMBL1384660 & 688267 & 5.3 & 5.09 & TRN \\
\hline CHEMBL1328867 & 688267 & 5.8 & 5.0817 & TRN \\
\hline CHEMBL1506155 & 688267 & 3.95 & 5.1276 & TRN \\
\hline CHEMBL1516150 & 688267 & 5.95 & 5.0587 & TRN \\
\hline CHEMBL1521561 & 688267 & 5.9 & 5.1096 & TRN \\
\hline CHEMBL1562745 & 688267 & 6.0 & 5.0037 & TRN \\
\hline CHEMBL1565397 & 688267 & 4.4 & 5.0864 & TRN \\
\hline CHEMBL1484082 & 688267 & 4.55 & 5.023 & TRN \\
\hline CHEMBL1340139 & 688267 & 5.0 & 5.0506 & TRN \\
\hline CHEMBL1372897 & 688267 & 5.2 & 5.099 & TST \\
\hline CHEMBL1582378 & 688267 & 4.9 & 5.0573 & TRN \\
\hline CHEMBL1519532 & 688267 & 4.6 & 5.0767 & TRN \\
\hline CHEMBL1421922 & 688267 & 5.6 & 5.1115 & TRN \\
\hline CHEMBL1314129 & 688267 & 4.6 & 5.1354 & TRN \\
\hline CHEMBL 1472394 & 688267 & 4.5 & 5.0518 & TRN \\
\hline CHEMBL1585083 & 688267 & 5.55 & 5.0587 & TRN \\
\hline CHEMBL1393425 & 688267 & 5.4 & 5.1396 & TRN \\
\hline CHEMBL1359171 & 688267 & 4.15 & 5.059 & TRN \\
\hline CHEMBL 303425 & 688267 & 5.15 & 5.058 & TST \\
\hline CHEMBL1478265 & 688267 & 4.0 & 5.1504 & TRN \\
\hline CHEMBL568420 & 688267 & 6.5 & 5.0768 & TRN \\
\hline CHEMBL1369921 & 688267 & 4.25 & 5.0609 & TST \\
\hline CHEMBL1367228 & 688267 & 5.05 & 5.0254 & TST \\
\hline CHEMBL1433454 & 688267 & 4.05 & 4.9767 & TRN \\
\hline CHEMBL1366619 & 688267 & 4.0 & 5.0623 & TRN \\
\hline CHEMBL 2369280 & 688267 & 4.0 & 4.9683 & TST \\
\hline CHEMBL1533832 & 688267 & 4.5 & 5.0217 & TST \\
\hline CHEMBL1314534 & 688267 & 5.6 & 5.033 & TRN \\
\hline CHEMBL1552069 & 688267 & 3.95 & 5.0417 & TRN \\
\hline CHEMBL 1575530 & 688267 & 4.5 & 4.9995 & TRN \\
\hline CHEMBL1595608 & 688267 & 5.55 & 5.0715 & TRN \\
\hline CHEMBL1541637 & 688267 & 6.25 & 4.9968 & TST \\
\hline CHEMBL1315593 & 688267 & 6.3 & 5.048 & TST \\
\hline
\end{tabular}




\begin{tabular}{|c|c|c|c|c|}
\hline & & & pplement & al $\mathrm{Ta}$ \\
\hline CHEMBL1562155 & 688267 & 6.2 & 5.0984 & TRN \\
\hline CHEMBL1494944 & 688267 & 4.0 & 5.1584 & TRN \\
\hline CHEMBL1481191 & 688267 & 3.95 & 5.0151 & TRN \\
\hline CHEMBL1409100 & 688267 & 4.0 & 5.0047 & TRN \\
\hline CHEMBL3211513 & 688267 & 5.65 & 4.9647 & TRN \\
\hline CHEMBL1489367 & 688267 & 5.0 & 5.0767 & TRN \\
\hline CHEMBL1519610 & 688267 & 6.2 & 5.0525 & TST \\
\hline CHEMBL1359981 & 688267 & 5.15 & 5.0619 & TRN \\
\hline CHEMBL1307325 & 688267 & 4.15 & 5.0392 & TRN \\
\hline CHEMBL3192471 & 688267 & 5.35 & 5.0344 & TST \\
\hline CHEMBL1459281 & 688267 & 4.35 & 5.0919 & TRN \\
\hline CHEMBL1308223 & 688267 & 4.8 & 5.0369 & TRN \\
\hline CHEMBL1503706 & 688267 & 4.55 & 5.0982 & TRN \\
\hline CHEMBL1999835 & 688267 & 4.0 & 5.0242 & TRN \\
\hline CHEMBL1533338 & 688267 & 5.5 & 5.1112 & TST \\
\hline CHEMBL1449303 & 688267 & 4.2 & 5.0107 & TRN \\
\hline CHEMBL1396794 & 688267 & 4.95 & 5.0274 & TRN \\
\hline CHEMBL1299731 & 688267 & 4.05 & 5.0032 & TRN \\
\hline CHEMBL1613651 & 688267 & 4.8 & 5.0776 & TRN \\
\hline CHEMBL1358193 & 688267 & 5.15 & 5.1295 & TST \\
\hline CHEMBL1542610 & 688267 & 6.2 & 5.1154 & TRN \\
\hline CHEMBL1564379 & 688267 & 5.65 & 5.0259 & TRN \\
\hline CHEMBL1439353 & 688267 & 4.35 & 5.0673 & TRN \\
\hline CHEMBL1464604 & 688267 & 4.6 & 5.0217 & TST \\
\hline CHEMBL1449327 & 688267 & 4.0 & 5.0302 & TRN \\
\hline CHEMBL1391316 & 688267 & 4.6 & 5.0352 & TRN \\
\hline CHEMBL3207981 & 688267 & 5.3 & 5.0136 & TST \\
\hline CHEMBL1525563 & 688267 & 5.65 & 5.1162 & TST \\
\hline CHEMBL1318633 & 688267 & 3.9 & 5.0632 & TRN \\
\hline CHEMBL1611707 & 688267 & 4.6 & 5.0515 & TRN \\
\hline CHEMBL1575183 & 688267 & 6.45 & 5.0026 & TRN \\
\hline CHEMBL1571295 & 688267 & 6.2 & 5.0713 & TST \\
\hline CHEMBL1495813 & 688267 & 4.05 & 5.0732 & TRN \\
\hline CHEMBL1300202 & 688267 & 5.5 & 5.0851 & TRN \\
\hline CHEMBL1320462 & 688267 & 5.85 & 5.0805 & TRN \\
\hline CHEMBL1606510 & 688267 & 6.45 & 5.0184 & TRN \\
\hline CHEMBL1400239 & 688267 & 4.4 & 5.0094 & TRN \\
\hline CHEMBL1521637 & 688267 & 4.0 & 5.0451 & TST \\
\hline CHEMBL1520012 & 688267 & 5.8 & 5.0855 & TST \\
\hline CHEMBL 3209048 & 688267 & 5.0 & 5.0263 & TRN \\
\hline CHEMBL1455814 & 688267 & 4.1 & 4.9951 & TST \\
\hline CHEMBL1529163 & 688267 & 4.25 & 5.0056 & TST \\
\hline CHEMBL1556247 & 688267 & 4.35 & 5.0167 & TST \\
\hline CHEMBL1584362 & 688267 & 5.75 & 5.0536 & TRN \\
\hline CHEMBL1317525 & 688267 & 6.2 & 5.0656 & TRN \\
\hline CHEMBL1451485 & 688267 & 5.4 & 5.0343 & TST \\
\hline CHEMBL1459258 & 688267 & 6.15 & 5.0824 & TRN \\
\hline CHEMBL1583218 & 688267 & 5.45 & 5.1444 & TRN \\
\hline
\end{tabular}




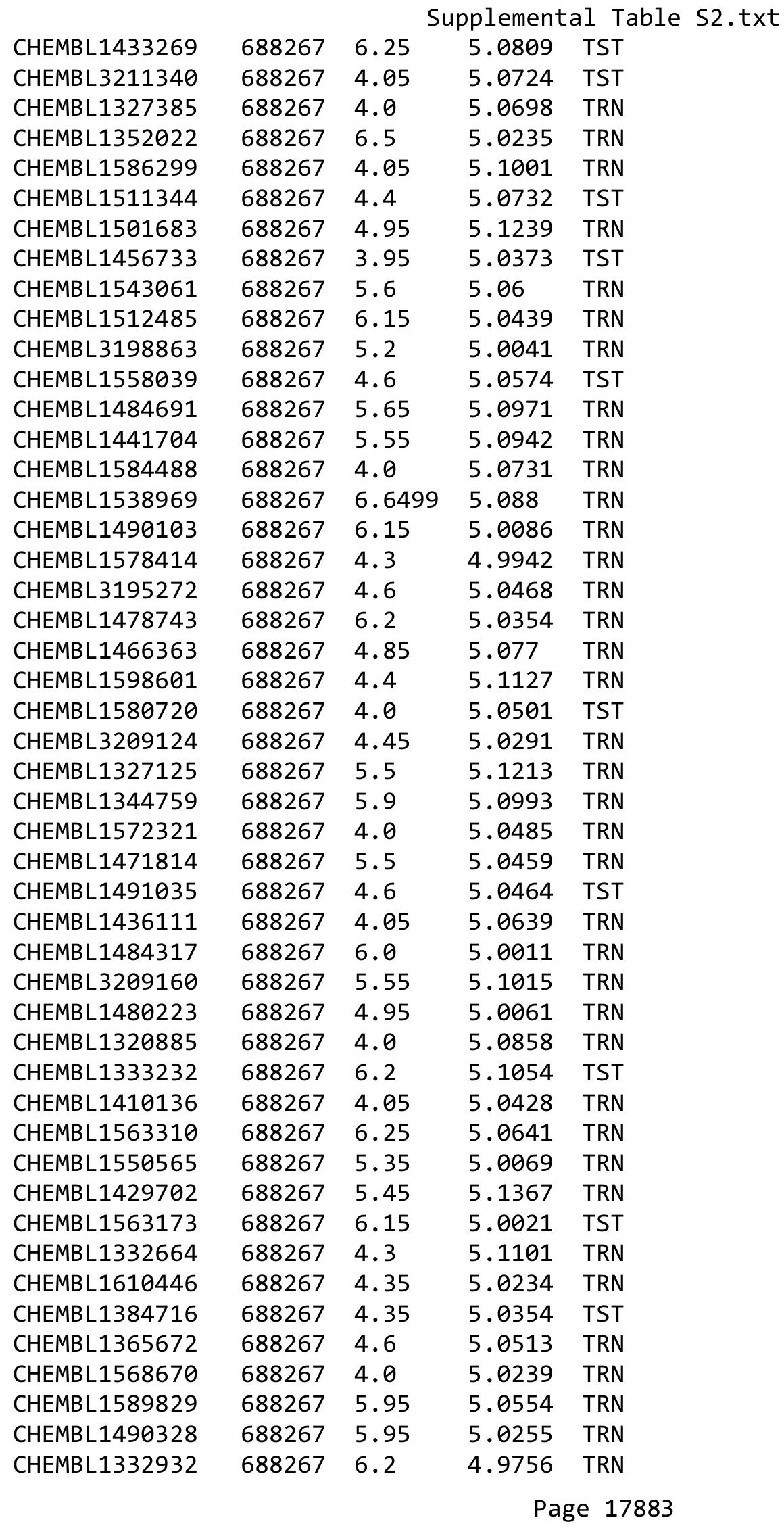




\begin{tabular}{|c|c|c|c|c|c|}
\hline \multirow{3}{*}{$\begin{array}{l}\text { CHEMBL } 3208268 \\
\text { CHEMBL1586702 }\end{array}$} & \multirow{3}{*}{$\begin{array}{l}688267 \\
688267\end{array}$} & \multicolumn{4}{|c|}{ Supplemental Table S2.txt } \\
\hline & & 4.85 & 5.1279 & 9999999999 & TRN \\
\hline & & 4.65 & 5.0778 & TRN & \\
\hline CHEMBL460366 & 688267 & 6.5 & 5.0624 & TRN & \\
\hline CHEMBL1507836 & 688267 & 5.05 & 5.0802 & TRN & \\
\hline CHEMBL1544397 & 688267 & 5.3 & 4.9899 & TRN & \\
\hline CHEMBL1313469 & 688267 & 5.05 & 5.0735 & TRN & \\
\hline CHEMBL3196994 & 688267 & 5.0 & 5.0218 & TST & \\
\hline CHEMBL1396210 & 688267 & 5.05 & 5.0059 & TRN & \\
\hline CHEMBL1308693 & 688267 & 5.75 & 5.0962 & TRN & \\
\hline CHEMBL3211220 & 688267 & 5.0 & 5.0698 & TST & \\
\hline CHEMBL1535245 & 688267 & 4.1 & 4.9999 & TRN & \\
\hline CHEMBL1363174 & 688267 & 5.8 & 5.0339 & TST & \\
\hline CHEMBL3211283 & 688267 & 4.35 & 5.0272 & TST & \\
\hline CHEMBL1539557 & 688267 & 6.2 & 5.0223 & TST & \\
\hline CHEMBL1477855 & 688267 & 4.0 & 5.0941 & TRN & \\
\hline CHEMBL1465450 & 688267 & 3.95 & 5.0505 & TST & \\
\hline CHEMBL3199048 & 688267 & 5.05 & 5.0221 & TRN & \\
\hline CHEMBL1449961 & 688267 & 5.2 & 5.0713 & TRN & \\
\hline CHEMBL1528806 & 688267 & 6.25 & 5.0393 & TRN & \\
\hline CHEMBL3189619 & 688267 & 4.25 & 5.0733 & TST & \\
\hline CHEMBL98406 & 688267 & 4.2 & 5.0257 & TST & \\
\hline CHEMBL1573179 & 688267 & 5.6 & 5.1284 & TRN & \\
\hline CHEMBL1317053 & 688267 & 3.95 & 5.109 & TRN & \\
\hline CHEMBL1427111 & 688267 & 4.05 & 5.0516 & TRN & \\
\hline CHEMBL1510410 & 688267 & 5.55 & 5.0925 & TRN & \\
\hline CHEMBL1552994 & 688267 & 5.05 & 5.0464 & TRN & \\
\hline CHEMBL1358384 & 688267 & 5.2 & 5.0521 & TST & \\
\hline CHEMBL1311726 & 688267 & 4.95 & 5.1281 & TST & \\
\hline CHEMBL1563221 & 688267 & 4.75 & 5.0154 & TRN & \\
\hline CHEMBL1566363 & 688267 & 4.0 & 5.0469 & TRN & \\
\hline CHEMBL1418395 & 688267 & 4.3 & 5.0246 & TRN & \\
\hline CHEMBL1396740 & 688267 & 4.05 & 5.1136 & TRN & \\
\hline CHEMBL1602542 & 688267 & 4.95 & 5.0112 & TRN & \\
\hline CHEMBL1397528 & 688267 & 6.2 & 5.0027 & TRN & \\
\hline CHEMBL1544554 & 688267 & 5.3 & 5.0538 & TRN & \\
\hline CHEMBL1461563 & 688267 & 5.6 & 5.0289 & TRN & \\
\hline CHEMBL1466084 & 688267 & 4.0 & 5.0237 & TST & \\
\hline CHEMBL1369533 & 688267 & 6.2 & 5.0018 & TRN & \\
\hline CHEMBL1413949 & 688267 & 4.4 & 5.0583 & TST & \\
\hline CHEMBL1537537 & 688267 & 5.8 & 5.0346 & TRN & \\
\hline CHEMBL1438977 & 688267 & 4.25 & 5.12 & TRN & \\
\hline CHEMBL1606350 & 688267 & 6.2 & 5.0763 & TRN & \\
\hline CHEMBL1574620 & 688267 & 5.8 & 5.0352 & TRN & \\
\hline CHEMBL1391460 & 688267 & 6.0 & 5.0484 & TRN & \\
\hline CHEMBL1554665 & 688267 & 5.3 & 5.0968 & TRN & \\
\hline CHEMBL1416710 & 688267 & 4.6 & 4.9795 & TRN & \\
\hline CHEMBL1381923 & 688267 & 5.25 & 5.0631 & TST & \\
\hline CHEMBL1422327 & 688267 & 5.8 & 5.0578 & TRN & \\
\hline
\end{tabular}




\begin{tabular}{|c|c|c|c|c|c|}
\hline \multicolumn{6}{|c|}{ Supplemental Table S2.txt } \\
\hline CHEMBL1381649 & 688267 & 4.05 & 5.0395 & TRN & \\
\hline CHEMBL1472438 & 688267 & 5.3 & 5.1519 & TRN & \\
\hline CHEMBL1427520 & 688267 & 5.8 & 5.0729 & TRN & \\
\hline CHEMBL1318519 & 688267 & 4.95 & 5.1144 & TRN & \\
\hline CHEMBL1410531 & 688267 & 4.5 & 5.1692 & TRN & \\
\hline CHEMBL1303499 & 688267 & 4.6 & 4.9847 & TRN & \\
\hline CHEMBL1477483 & 688267 & 5.45 & 5.088 & TRN & \\
\hline CHEMBL1366584 & 688267 & 5.5 & 5.0786 & TRN & \\
\hline CHEMBL1581173 & 688267 & 5.0 & 5.0413 & TST & \\
\hline CHEMBL1473144 & 688267 & 5.85 & 5.0393 & TRN & \\
\hline CHEMBL3208485 & 688267 & 4.0 & 4.9898 & TRN & \\
\hline CHEMBL1583679 & 688267 & 4.2 & 5.0436 & TST & \\
\hline CHEMBL1480245 & 688267 & 5.65 & 5.0911 & TRN & \\
\hline CHEMBL1584716 & 688267 & 5.1 & 5.0336 & TRN & \\
\hline CHEMBL1519419 & 688267 & 4.3 & 5.1011 & TRN & \\
\hline CHEMBL1367330 & 688267 & 4.85 & 5.11600 & 00000000005 & TRN \\
\hline CHEMBL1541965 & 688267 & 5.3 & 5.0643 & TRN & \\
\hline CHEMBL1556866 & 688267 & 4.0 & 5.1417 & TST & \\
\hline CHEMBL1561566 & 688267 & 3.95 & 5.0346 & TRN & \\
\hline CHEMBL1499886 & 688267 & 6.25 & 5.1443 & TRN & \\
\hline CHEMBL1374475 & 688267 & 5.4 & 4.9979 & TRN & \\
\hline CHEMBL1400615 & 688267 & 5.95 & 5.0693 & TRN & \\
\hline CHEMBL1382331 & 688267 & 5.8 & 5.0557 & TST & \\
\hline CHEMBL3212686 & 688267 & 4.65 & 5.023 & TRN & \\
\hline CHEMBL1320982 & 688267 & 4.4 & 5.0434 & TRN & \\
\hline CHEMBL1375237 & 688267 & 4.1 & 5.0248 & TRN & \\
\hline CHEMBL1574473 & 688267 & 4.05 & 5.0731 & TRN & \\
\hline CHEMBL1367714 & 688267 & 5.2 & 5.0631 & TST & \\
\hline CHEMBL1466619 & 688267 & 3.95 & 5.0471 & TRN & \\
\hline CHEMBL1577706 & 688267 & 6.2 & 5.0649 & TST & \\
\hline CHEMBL1439416 & 688267 & 5.25 & 5.1088 & TRN & \\
\hline CHEMBL1326348 & 688267 & 5.3 & 5.1307 & TRN & \\
\hline CHEMBL1472785 & 688267 & 4.05 & 5.0482 & TRN & \\
\hline CHEMBL1576684 & 688267 & 6.2 & 5.1146 & TRN & \\
\hline CHEMBL1557035 & 688267 & 5.25 & 4.9746 & TRN & \\
\hline CHEMBL3214511 & 688267 & 4.5 & 5.0602 & TST & \\
\hline CHEMBL1424133 & 688267 & 5.85 & 5.0191 & TRN & \\
\hline CHEMBL1399870 & 688267 & 6.15 & 5.1013 & TRN & \\
\hline CHEMBL1449264 & 688267 & 5.35 & 5.0147 & TRN & \\
\hline CHEMBL1505449 & 688267 & 5.8 & 5.0632 & TRN & \\
\hline CHEMBL1405702 & 688267 & 5.35 & 5.1233 & TRN & \\
\hline CHEMBL1574243 & 688267 & 5.25 & 5.09 & TRN & \\
\hline CHEMBL1575458 & 688267 & 4.35 & 5.0252 & TRN & \\
\hline CHEMBL1310190 & 688267 & 4.95 & 5.0407 & TRN & \\
\hline CHEMBL1347039 & 688267 & 4.65 & 4.989 & TRN & \\
\hline CHEMBL1331275 & 688267 & 5.4 & 5.0672 & TRN & \\
\hline CHEMBL1558320 & 688267 & 6.25 & 5.0378 & TRN & \\
\hline CHEMBL1599668 & 688267 & 5.55 & 5.0345 & TST & \\
\hline
\end{tabular}




\begin{tabular}{|c|c|c|c|c|}
\hline \multicolumn{5}{|c|}{ Supplemental Table S2.txt } \\
\hline CHEMBL1339021 & 688267 & 4.0 & 5.0874 & TST \\
\hline CHEMBL1525804 & 688267 & 4.0 & 5.0235 & TRN \\
\hline CHEMBL1394556 & 688267 & 4.25 & 5.1037 & TRN \\
\hline CHEMBL1537993 & 688267 & 4.4 & 5.1539 & TRN \\
\hline CHEMBL 1475888 & 688267 & 4.5 & 5.0474 & TST \\
\hline CHEMBL1349811 & 688267 & 4.0 & 5.059 & TRN \\
\hline CHEMBL1369687 & 688267 & 6.2 & 5.0419 & TRN \\
\hline CHEMBL1518553 & 688267 & 5.85 & 5.0651 & TRN \\
\hline CHEMBL 3208205 & 688267 & 4.0 & 5.0816 & TRN \\
\hline CHEMBL1581488 & 688267 & 4.65 & 5.0253 & TRN \\
\hline CHEMBL1333339 & 688267 & 4.35 & 5.092 & TRN \\
\hline CHEMBL1454645 & 688267 & 4.65 & 5.0449 & TRN \\
\hline CHEMBL1391463 & 688267 & 5.0 & 5.0551 & TRN \\
\hline CHEMBL1465781 & 688267 & 5.35 & 5.1536 & TRN \\
\hline CHEMBL1521349 & 688267 & 4.35 & 5.0595 & TRN \\
\hline CHEMBL1345109 & 688267 & 5.3 & 5.0708 & TRN \\
\hline CHEMBL1597711 & 688267 & 6.15 & 4.9693 & TST \\
\hline CHEMBL1530943 & 688267 & 6.2 & 4.9865 & TRN \\
\hline CHEMBL1358519 & 688267 & 4.8 & 5.0274 & TST \\
\hline CHEMBL1391523 & 688267 & 6.2 & 5.0307 & TRN \\
\hline CHEMBL1454698 & 688267 & 4.95 & 5.074 & TRN \\
\hline CHEMBL1339525 & 688267 & 5.35 & 5.0708 & TRN \\
\hline CHEMBL1391986 & 688267 & 6.2 & 5.1243 & TRN \\
\hline CHEMBL1329749 & 688267 & 5.8 & 5.0655 & TRN \\
\hline CHEMBL1339668 & 688267 & 6.2 & 5.0854 & TST \\
\hline CHEMBL1564770 & 688267 & 4.15 & 5.0939 & TRN \\
\hline CHEMBL3210905 & 688267 & 4.05 & 5.0145 & TRN \\
\hline CHEMBL1592668 & 688267 & 6.25 & 5.0648 & TST \\
\hline CHEMBL1484294 & 688267 & 4.35 & 5.1057 & TRN \\
\hline CHEMBL209204 & 688267 & 4.05 & 5.0619 & TRN \\
\hline CHEMBL1561540 & 688267 & 5.55 & 5.0 & TST \\
\hline CHEMBL1492130 & 688267 & 3.55 & 5.0483 & TRN \\
\hline CHEMBL1580445 & 688267 & 4.05 & 5.0631 & TST \\
\hline CHEMBL1500200 & 688267 & 5.6 & 5.098 & TST \\
\hline CHEMBL1578255 & 688267 & 4.55 & 5.0612 & TRN \\
\hline CHEMBL1494289 & 688267 & 3.95 & 5.0359 & TRN \\
\hline CHEMBL1483114 & 688267 & 4.0 & 5.0482 & TST \\
\hline CHEMBL1448642 & 688267 & 5.4 & 5.1129 & TRN \\
\hline CHEMBL1424563 & 688267 & 4.95 & 5.1328 & TRN \\
\hline CHEMBL1369786 & 688267 & 5.85 & 5.0353 & TRN \\
\hline CHEMBL1445149 & 688267 & 5.75 & 5.0746 & TRN \\
\hline CHEMBL1474134 & 688267 & 5.3 & 5.0908 & TST \\
\hline CHEMBL1428803 & 688267 & 4.3 & 5.1779 & TRN \\
\hline CHEMBL1364662 & 688267 & 6.2 & 5.0784 & TRN \\
\hline CHEMBL1406800 & 688267 & 4.05 & 5.0401 & TRN \\
\hline CHEMBL1377377 & 688267 & 5.45 & 5.021 & TRN \\
\hline CHEMBL1335808 & 688267 & 4.55 & 5.1572 & TRN \\
\hline CHEMBL1358046 & 688267 & 6.1 & 5.0894 & TRN \\
\hline
\end{tabular}




\begin{tabular}{|c|c|c|c|c|}
\hline \multicolumn{5}{|c|}{ Supplemental Table S2.txt } \\
\hline CHEMBL1506286 & 688267 & 6.2 & 5.1404 & TST \\
\hline CHEMBL1342440 & 688267 & 4.45 & 5.1095 & TST \\
\hline CHEMBL1394071 & 688267 & 4.4 & 5.1275 & TRN \\
\hline CHEMBL 209699 & 688267 & 4.25 & 5.0144 & TRN \\
\hline CHEMBL1365438 & 688267 & 6.5 & 5.1121 & TST \\
\hline CHEMBL1317689 & 688267 & 4.05 & 5.0216 & TST \\
\hline CHEMBL1375005 & 688267 & 5.65 & 5.0042 & TRN \\
\hline CHEMBL1338900 & 688267 & 4.05 & 5.0769 & TST \\
\hline CHEMBL1399789 & 688267 & 4.1 & 5.0414 & TRN \\
\hline CHEMBL1553847 & 688267 & 6.0 & 5.0715 & TRN \\
\hline CHEMBL1371865 & 688267 & 7.0501 & 5.0692 & TRN \\
\hline CHEMBL1544275 & 688267 & 5.6 & 5.0743 & TRN \\
\hline CHEMBL1389947 & 688267 & 6.2 & 5.058 & TRN \\
\hline CHEMBL1525725 & 688267 & 4.45 & 5.0628 & TRN \\
\hline CHEMBL1499723 & 688267 & 4.0 & 5.0772 & TRN \\
\hline CHEMBL1314724 & 688267 & 4.2 & 5.0349 & TRN \\
\hline CHEMBL1436194 & 688267 & 5.05 & 5.1686 & TRN \\
\hline CHEMBL1301464 & 688267 & 4.3 & 5.058 & TST \\
\hline CHEMBL1480384 & 688267 & 5.05 & 5.1433 & TRN \\
\hline CHEMBL1429076 & 688267 & 4.45 & 5.0585 & TRN \\
\hline CHEMBL1306807 & 688267 & 4.05 & 5.0426 & TRN \\
\hline CHEMBL1300749 & 688267 & 5.55 & 5.0523 & TST \\
\hline CHEMBL1378121 & 688267 & 6.2 & 5.0963 & TST \\
\hline CHEMBL1488469 & 688267 & 4.05 & 5.0503 & TRN \\
\hline CHEMBL1364420 & 688267 & 5.25 & 5.112 & TRN \\
\hline CHEMBL1479239 & 688267 & 5.0 & 5.007 & TRN \\
\hline CHEMBL1401075 & 688267 & 5.4 & 5.0748 & TRN \\
\hline CHEMBL1356861 & 688267 & 3.95 & 5.0703 & TRN \\
\hline CHEMBL1561514 & 688267 & 3.95 & 5.013 & TRN \\
\hline CHEMBL1517254 & 688267 & 5.75 & 5.1098 & TRN \\
\hline CHEMBL1568621 & 688267 & 6.2 & 5.0194 & TST \\
\hline CHEMBL1545627 & 688267 & 4.75 & 4.9835 & TRN \\
\hline CHEMBL1493608 & 688267 & 6.2 & 5.1225 & TST \\
\hline CHEMBL1437199 & 688267 & 5.5 & 5.0903 & TRN \\
\hline CHEMBL1477399 & 688267 & 4.3 & 5.0169 & TST \\
\hline CHEMBL1451630 & 688267 & 4.0 & 5.0428 & TRN \\
\hline CHEMBL1355594 & 688267 & 4.05 & 5.0765 & TRN \\
\hline CHEMBL3189188 & 688267 & 5.4 & 5.0957 & TST \\
\hline CHEMBL1358626 & 688267 & 5.25 & 5.0224 & TRN \\
\hline CHEMBL 3195421 & 688267 & 4.55 & 5.0496 & TST \\
\hline CHEMBL1347411 & 688267 & 4.1 & 5.0849 & TRN \\
\hline CHEMBL1587900 & 688267 & 3.95 & 5.0043 & TRN \\
\hline CHEMBL1394960 & 688267 & 4.0 & 5.0252 & TRN \\
\hline CHEMBL1589633 & 688267 & 4.45 & 5.0384 & TRN \\
\hline CHEMBL1503307 & 688267 & 4.25 & 5.0064 & TRN \\
\hline CHEMBL1458582 & 688267 & 5.35 & 5.035 & TRN \\
\hline CHEMBL1394821 & 688267 & 3.9 & 5.1336 & TRN \\
\hline CHEMBL1408940 & 688267 & 6.1 & 5.0575 & TRN \\
\hline
\end{tabular}




\begin{tabular}{|c|c|c|c|c|c|}
\hline \multirow[b]{2}{*}{ CHEMBL1560401 } & \multirow[b]{2}{*}{688267} & \\
\hline & & 6.5 & 5.0707 & TRN & \\
\hline CHEMBL1578235 & 688267 & 4.3 & 5.0032 & TRN & \\
\hline CHEMBL1374624 & 688267 & 6.2 & 5.0201 & TRN & \\
\hline CHEMBL1981150 & 688267 & 4.35 & 4.9911 & TST & \\
\hline CHEMBL1548208 & 688267 & 6.25 & 5.0814 & TRN & \\
\hline CHEMBL3191276 & 688267 & 4.25 & 4.9786 & TST & \\
\hline CHEMBL3189731 & 688267 & 6.25 & 5.0182 & TST & \\
\hline CHEMBL1306954 & 688267 & 5.25 & 5.0036 & TRN & \\
\hline CHEMBL1334948 & 688267 & 6.2 & 5.0455 & TRN & \\
\hline CHEMBL 270362 & 688267 & 4.0 & 5.045 & TST & \\
\hline CHEMBL1403916 & 688267 & 4.45 & 5.0043 & TRN & \\
\hline CHEMBL1438055 & 688267 & 5.8 & 5.013 & TST & \\
\hline CHEMBL1545524 & 688267 & 3.95 & 5.0083 & TRN & \\
\hline CHEMBL1365545 & 688267 & 3.9 & 5.103 & TRN & \\
\hline CHEMBL1383935 & 688267 & 4.15 & 5.1288 & TST & \\
\hline CHEMBL1342258 & 688267 & 6.25 & 5.1187 & TRN & \\
\hline CHEMBL1397697 & 688267 & 5.45 & 5.088 & TRN & \\
\hline CHEMBL1547217 & 688267 & 4.05 & 5.0321 & TRN & \\
\hline CHEMBL1592478 & 688267 & 6.15 & 5.1368 & TRN & \\
\hline CHEMBL1603415 & 688267 & 5.0 & 5.1003 & TST & \\
\hline CHEMBL1597506 & 688267 & 4.05 & 5.0009 & TRN & \\
\hline CHEMBL1590667 & 688267 & 5.95 & 5.0535 & TRN & \\
\hline CHEMBL1336307 & 688267 & 3.95 & 5.0738 & TST & \\
\hline CHEMBL1492194 & 688267 & 4.05 & 4.9653 & TRN & \\
\hline CHEMBL1494848 & 688267 & 6.25 & 5.1153 & TRN & \\
\hline CHEMBL1595976 & 688267 & 6.2 & 5.0567 & TRN & \\
\hline CHEMBL1587930 & 688267 & 5.05 & 5.065 & TRN & \\
\hline CHEMBL1609681 & 688267 & 6.2 & 5.1433 & TRN & \\
\hline CHEMBL1581854 & 688267 & 4.05 & 4.9857 & TST & \\
\hline CHEMBL1473212 & 688267 & 4.75 & 5.0867 & TRN & \\
\hline CHEMBL1523423 & 688267 & 4.35 & 5.1778 & TRN & \\
\hline CHEMBL1552055 & 688267 & 6.0 & 5.079 & TST & \\
\hline CHEMBL1381089 & 688267 & 4.4 & 5.0499 & TRN & \\
\hline CHEMBL165 & 688267 & 4.35 & 5.0445 & TST & \\
\hline CHEMBL1362373 & 688267 & 4.4 & 5.0255 & TST & \\
\hline CHEMBL1501104 & 688267 & 5.65 & 4.975 & TRN & \\
\hline CHEMBL1496029 & 688267 & 5.0 & 5.0188 & TRN & \\
\hline CHEMBL1346458 & 688267 & 4.0 & 5.0745 & TRN & \\
\hline CHEMBL1471201 & 688267 & 5.55 & 5.0294 & TRN & \\
\hline CHEMBL1377165 & 688267 & 5.8 & 5.0532 & TRN & \\
\hline CHEMBL1531783 & 688267 & 5.9 & 5.0413 & TRN & \\
\hline CHEMBL1535239 & 688267 & 4.45 & 5.1222 & TRN & \\
\hline CHEMBL1411483 & 688267 & 4.45 & $5.1160 e$ & 00000000005 & TRN \\
\hline CHEMBL1483709 & 688267 & 4.45 & 5.0637 & TST & \\
\hline CHEMBL1390446 & 688267 & 4.4 & $5.0310 e$ & 0000000001 & TST \\
\hline CHEMBL1611857 & 688267 & 6.25 & 5.0343 & TRN & \\
\hline CHEMBL1543890 & 688267 & 5.3 & 5.0116 & TRN & \\
\hline CHEMBL1523768 & 688267 & 5.3 & 5.0381 & TRN & \\
\hline & & & & 1788 & \\
\hline
\end{tabular}




\begin{tabular}{|c|c|c|c|c|}
\hline \multicolumn{5}{|c|}{ Supplemental Table S2.txt } \\
\hline CHEMBL1476034 & 688267 & 6.2 & 5.146 & TST \\
\hline CHEMBL1328921 & 688267 & 4.35 & 5.0679 & TRN \\
\hline CHEMBL1569866 & 688267 & 5.45 & 5.1425 & TRN \\
\hline CHEMBL1320297 & 688267 & 4.05 & 5.0352 & TRN \\
\hline CHEMBL1513901 & 688267 & 5.85 & 5.0608 & TST \\
\hline CHEMBL1470795 & 688267 & 4.25 & 5.041 & TST \\
\hline CHEMBL1508569 & 688267 & 4.15 & 5.0192 & TST \\
\hline CHEMBL1455332 & 688267 & 6.25 & 5.0327 & TRN \\
\hline CHEMBL1557507 & 688267 & 4.1 & 5.0798 & TRN \\
\hline CHEMBL1444966 & 688267 & 5.6 & 5.1139 & TRN \\
\hline CHEMBL1496326 & 688267 & 4.4 & 5.0407 & TST \\
\hline CHEMBL1519124 & 688267 & 4.35 & 5.0152 & TRN \\
\hline CHEMBL1531136 & 688267 & 5.3 & 5.0862 & TRN \\
\hline CHEMBL1414769 & 688267 & 5.55 & 5.0841 & TRN \\
\hline CHEMBL1489776 & 688267 & 6.5 & 5.0896 & TRN \\
\hline CHEMBL1355441 & 688267 & 5.85 & 5.0298 & TRN \\
\hline CHEMBL1527666 & 688267 & 4.8 & 5.0935 & TRN \\
\hline CHEMBL1466871 & 688267 & 4.4 & 5.1146 & TRN \\
\hline CHEMBL1422812 & 688267 & 6.25 & 5.0387 & TST \\
\hline CHEMBL1345214 & 688267 & 4.6 & 5.05 & TST \\
\hline CHEMBL1330991 & 688267 & 3.95 & 5.0576 & TRN \\
\hline CHEMBL1404002 & 688267 & 6.2 & 5.0651 & TRN \\
\hline CHEMBL1377107 & 688267 & 6.15 & 5.0384 & TST \\
\hline CHEMBL1408084 & 688267 & 4.4 & 5.0514 & TRN \\
\hline CHEMBL1357686 & 688267 & 6.2 & 5.1284 & TRN \\
\hline CHEMBL1565936 & 688267 & 5.85 & 5.1 & TST \\
\hline CHEMBL1539297 & 688267 & 5.1 & 5.0179 & TRN \\
\hline CHEMBL1305308 & 688267 & 5.9 & 5.0743 & TRN \\
\hline CHEMBL1554643 & 688267 & 5.75 & 5.0552 & TRN \\
\hline CHEMBL1394480 & 688267 & 6.5 & 5.1309 & TRN \\
\hline CHEMBL1503599 & 688267 & 4.45 & 5.0886 & TST \\
\hline CHEMBL1461865 & 688267 & 4.05 & 5.0429 & TST \\
\hline CHEMBL1492805 & 688267 & 4.85 & 5.1167 & TRN \\
\hline CHEMBL1359108 & 688267 & 4.1 & 5.0944 & TRN \\
\hline CHEMBL1502892 & 688267 & 4.05 & 5.1016 & TRN \\
\hline CHEMBL1478162 & 688267 & 4.85 & 5.0708 & TST \\
\hline CHEMBL1414996 & 688267 & 5.2 & 5.0687 & TST \\
\hline CHEMBL1356177 & 688267 & 4.0 & 5.0315 & TRN \\
\hline CHEMBL1409678 & 688267 & 4.7 & 5.1368 & TRN \\
\hline CHEMBL1402644 & 688267 & 6.15 & 5.1235 & TRN \\
\hline CHEMBL1487446 & 688267 & 4.05 & 5.0356 & TRN \\
\hline CHEMBL1354667 & 688267 & 4.6 & 5.0559 & TRN \\
\hline CHEMBL3195289 & 688267 & 5.3 & 4.9733 & TRN \\
\hline CHEMBL1506893 & 688267 & 4.15 & 4.9978 & TRN \\
\hline CHEMBL1553676 & 688267 & 4.0 & 5.1626 & TRN \\
\hline CHEMBL1445038 & 688267 & 5.05 & 5.1104 & TRN \\
\hline CHEMBL1419993 & 688267 & 5.85 & 5.0778 & TRN \\
\hline CHEMBL 267179 & 688267 & 4.1 & 5.0214 & TRN \\
\hline
\end{tabular}




\begin{tabular}{|c|c|c|c|c|c|}
\hline \multirow[b]{2}{*}{ CHEMBL1309961 } & \multicolumn{5}{|c|}{ Supplemental Table S2.txt } \\
\hline & 688267 & 5.45 & 5.1047 & TRN & \\
\hline CHEMBL1467973 & 688267 & 6.25 & 5.11600 & 00000000005 & TRN \\
\hline CHEMBL1533972 & 688267 & 5.4 & 5.1288 & TRN & \\
\hline CHEMBL1509037 & 688267 & 6.25 & 5.0749 & TST & \\
\hline CHEMBL1567598 & 688267 & 6.25 & 5.0394 & TST & \\
\hline CHEMBL1396941 & 688267 & 4.3 & 5.0711 & TRN & \\
\hline CHEMBL3212175 & 688267 & 4.1 & 5.0525 & TST & \\
\hline CHEMBL1591031 & 688267 & 4.0 & 5.0955 & TRN & \\
\hline CHEMBL1458420 & 688267 & 3.9 & 5.0498 & TST & \\
\hline CHEMBL1590415 & 688267 & 5.05 & 5.1328 & TRN & \\
\hline CHEMBL1299537 & 688267 & 4.5 & 5.026 & TST & \\
\hline CHEMBL1390424 & 688267 & 6.2 & 5.0586 & TST & \\
\hline CHEMBL1408013 & 688267 & 6.8499 & 5.0117 & TRN & \\
\hline CHEMBL1584068 & 688267 & 3.95 & 5.0492 & TRN & \\
\hline CHEMBL1563010 & 688267 & 4.0 & 5.0415 & TST & \\
\hline CHEMBL1591218 & 688267 & 4.65 & 5.103 & TRN & \\
\hline CHEMBL1315838 & 688267 & 5.35 & 5.0554 & TRN & \\
\hline CHEMBL1553692 & 688267 & 6.5 & 5.0821 & TRN & \\
\hline CHEMBL 23894 & 688267 & 5.05 & 5.0687 & TST & \\
\hline CHEMBL3192275 & 688267 & 6.45 & 5.0967 & TST & \\
\hline CHEMBL1439818 & 688267 & 4.6 & 5.088 & TRN & \\
\hline CHEMBL171289 & 688267 & 5.8 & 5.0552 & TRN & \\
\hline CHEMBL1439569 & 688267 & 4.05 & 5.0639 & TST & \\
\hline CHEMBL1372144 & 688267 & 6.5 & 5.1141 & TST & \\
\hline CHEMBL1443873 & 688267 & 5.05 & 4.9597 & TST & \\
\hline CHEMBL1492722 & 688267 & 4.0 & 5.0112 & TRN & \\
\hline CHEMBL1594820 & 688267 & 4.35 & 5.038 & TRN & \\
\hline CHEMBL1559590 & 688267 & 5.65 & 5.1046 & TRN & \\
\hline CHEMBL1534343 & 688267 & 4.55 & 5.0055 & TRN & \\
\hline CHEMBL1598815 & 688267 & 4.65 & 5.1252 & TRN & \\
\hline CHEMBL1387987 & 688267 & 5.95 & 5.0933 & TRN & \\
\hline CHEMBL1585423 & 688267 & 4.15 & 5.0505 & TRN & \\
\hline CHEMBL1516971 & 688267 & 6.15 & 5.0696 & TRN & \\
\hline CHEMBL1488557 & 688267 & 5.45 & 5.0314 & TRN & \\
\hline CHEMBL1370049 & 688267 & 5.8 & 5.0923 & TRN & \\
\hline CHEMBL1461247 & 688267 & 4.0 & 5.1657 & TRN & \\
\hline CHEMBL1590947 & 688267 & 4.1 & 5.0295 & TRN & \\
\hline CHEMBL1477180 & 688267 & 4.5 & 5.066 & TRN & \\
\hline CHEMBL1341860 & 688267 & 6.5 & 5.0553 & TRN & \\
\hline CHEMBL1972824 & 688267 & 5.2 & 4.9886 & TRN & \\
\hline CHEMBL1544637 & 688267 & 6.25 & 4.9682 & TRN & \\
\hline CHEMBL1555388 & 688267 & 6.2 & 4.9715 & TRN & \\
\hline CHEMBL1461658 & 688267 & 5.35 & 5.0653 & TST & \\
\hline CHEMBL1527980 & 688267 & 4.6 & 5.0793 & TRN & \\
\hline CHEMBL1499967 & 688267 & 6.15 & 5.0244 & TRN & \\
\hline CHEMBL3190624 & 688267 & 6.5 & 5.0525 & TRN & \\
\hline CHEMBL 1555616 & 688267 & 4.05 & 5.078 & TRN & \\
\hline CHEMBL1396852 & 688267 & 5.35 & 5.0884 & TRN & \\
\hline
\end{tabular}




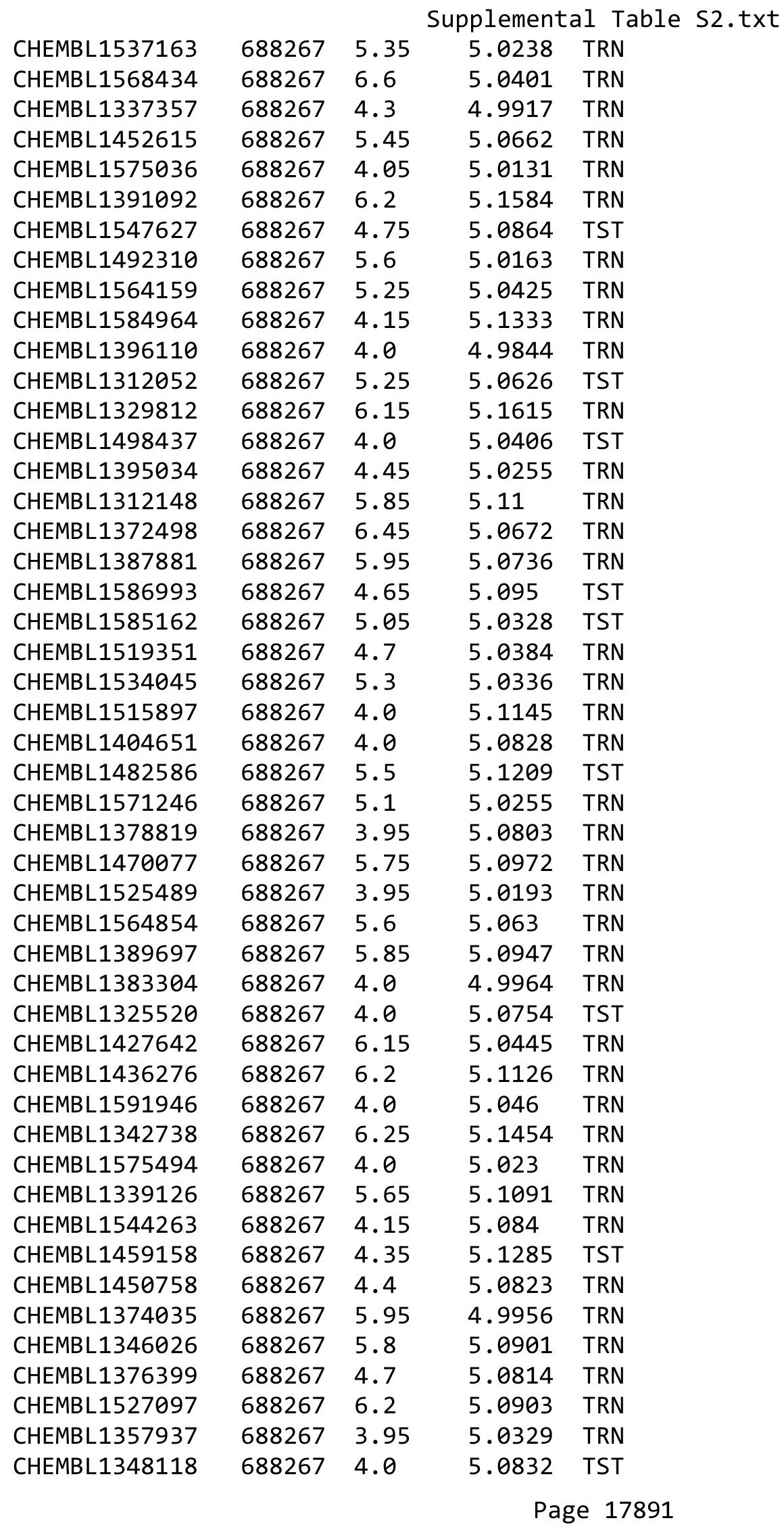




\begin{tabular}{|c|c|c|c|c|}
\hline & & & ipplement & al $\mathrm{T}$ \\
\hline CHEMBL1307978 & 688267 & 4.25 & 5.0448 & TST \\
\hline CHEMBL1475452 & 688267 & 6.25 & 5.0295 & TRN \\
\hline CHEMBL1537381 & 688267 & 4.35 & 5.0051 & TST \\
\hline CHEMBL1459205 & 688267 & 5.1 & 5.1218 & TRN \\
\hline CHEMBL1590139 & 688267 & 6.2 & 5.1341 & TRN \\
\hline CHEMBL3196049 & 688267 & 4.4 & 5.0156 & TST \\
\hline CHEMBL1363795 & 688267 & 6.15 & 5.0648 & TRN \\
\hline CHEMBL1365540 & 688267 & 4.0 & 5.0417 & TRN \\
\hline CHEMBL1444608 & 688267 & 4.8 & 5.0589 & TST \\
\hline CHEMBL1445055 & 688267 & 4.05 & 5.1016 & TST \\
\hline CHEMBL1346103 & 688267 & 5.6 & 5.0705 & TRN \\
\hline CHEMBL1393895 & 688267 & 5.5 & 5.0016 & TRN \\
\hline CHEMBL1481813 & 688267 & 5.0 & 5.0839 & TRN \\
\hline CHEMBL1358936 & 688267 & 5.3 & 5.0488 & TST \\
\hline CHEMBL1498168 & 688267 & 4.9 & 5.0621 & TRN \\
\hline CHEMBL1463632 & 688267 & 6.2 & 5.1125 & TRN \\
\hline CHEMBL1352999 & 688267 & 5.8 & 5.0856 & TRN \\
\hline CHEMBL46885 & 688267 & 4.45 & 5.1346 & TRN \\
\hline CHEMBL1395368 & 688267 & 6.2 & 5.1124 & TRN \\
\hline CHEMBL1472892 & 688267 & 4.15 & 5.0408 & TRN \\
\hline CHEMBL1311003 & 688267 & 4.5 & 5.0916 & TRN \\
\hline CHEMBL1376690 & 688267 & 4.5 & 5.0273 & TST \\
\hline CHEMBL1404122 & 688267 & 5.2 & 5.0347 & TRN \\
\hline CHEMBL1356707 & 688267 & 5.2 & 5.0361 & TRN \\
\hline CHEMBL1466555 & 688267 & 4.4 & 5.0493 & TRN \\
\hline CHEMBL1376344 & 688267 & 5.75 & 5.1379 & TRN \\
\hline CHEMBL1554713 & 688267 & 6.2 & 4.9593 & TRN \\
\hline CHEMBL1313793 & 688267 & 5.5 & 5.0992 & TRN \\
\hline CHEMBL1322983 & 688267 & 5.1 & 5.0655 & TRN \\
\hline CHEMBL1369278 & 688267 & 6.15 & 5.0069 & TST \\
\hline CHEMBL1574418 & 688267 & 6.15 & 5.0642 & TRN \\
\hline CHEMBL1433657 & 688267 & 4.95 & 5.0209 & TRN \\
\hline CHEMBL1595686 & 688267 & 5.55 & 5.003 & TRN \\
\hline CHEMBL1505521 & 688267 & 6.15 & 5.0369 & TST \\
\hline CHEMBL1387071 & 688267 & 4.5 & 5.0578 & TRN \\
\hline CHEMBL1401091 & 688267 & 5.2 & 5.0245 & TRN \\
\hline CHEMBL3211403 & 688267 & 6.0 & 5.0539 & TRN \\
\hline CHEMBL1416385 & 688267 & 6.2 & 5.0496 & TRN \\
\hline CHEMBL3198231 & 688267 & 6.1 & 5.039 & TRN \\
\hline CHEMBL1365772 & 688267 & 6.2 & 4.9959 & TST \\
\hline CHEMBL1379955 & 688267 & 4.05 & 5.1182 & TRN \\
\hline CHEMBL1457329 & 688267 & 6.2 & 5.0756 & TRN \\
\hline CHEMBL1596102 & 688267 & 5.45 & 5.0703 & TRN \\
\hline CHEMBL1587240 & 688267 & 4.65 & 5.1361 & TRN \\
\hline CHEMBL1489724 & 688267 & 6.2 & 5.0233 & TRN \\
\hline CHEMBL1597923 & 688267 & 4.9 & 5.0507 & TRN \\
\hline CHEMBL1523482 & 688267 & 6.2 & 5.0926 & TRN \\
\hline CHEMBL1390149 & 688267 & 4.7 & 4.9813 & TRN \\
\hline
\end{tabular}




\begin{tabular}{|c|c|c|c|c|}
\hline & & & pplement & al $\mathrm{Ta}$ \\
\hline CHEMBL1465782 & 688267 & 4.75 & 5.0716 & TST \\
\hline CHEMBL1426450 & 688267 & 6.2 & 5.0768 & TRN \\
\hline CHEMBL1611624 & 688267 & 4.05 & 5.0348 & TRN \\
\hline CHEMBL1508494 & 688267 & 6.0 & 5.0548 & TST \\
\hline CHEMBL1419233 & 688267 & 5.4 & 5.0567 & TRN \\
\hline CHEMBL1489752 & 688267 & 4.0 & 5.0633 & TRN \\
\hline CHEMBL1425585 & 688267 & 5.8 & 5.0295 & TRN \\
\hline CHEMBL1548942 & 688267 & 3.95 & 5.0334 & TRN \\
\hline CHEMBL1537916 & 688267 & 4.45 & 5.0289 & TRN \\
\hline CHEMBL1327876 & 688267 & 6.2 & 5.0884 & TRN \\
\hline CHEMBL1366601 & 688267 & 5.35 & 5.0427 & TST \\
\hline CHEMBL1315044 & 688267 & 3.95 & 5.022 & TST \\
\hline CHEMBL1450542 & 688267 & 4.25 & 5.0996 & TRN \\
\hline CHEMBL1533934 & 688267 & 5.3 & 5.1158 & TRN \\
\hline CHEMBL1560708 & 688267 & 5.05 & 5.0505 & TST \\
\hline CHEMBL1558134 & 688267 & 4.05 & 5.052 & TRN \\
\hline CHEMBL1589149 & 688267 & 4.1 & 5.0523 & TRN \\
\hline CHEMBL1489742 & 688267 & 4.05 & 5.0212 & TRN \\
\hline CHEMBL1363588 & 688267 & 6.15 & 5.0569 & TRN \\
\hline CHEMBL1339154 & 688267 & 4.0 & 5.0762 & TST \\
\hline CHEMBL3197660 & 688267 & 4.1 & 5.0839 & TST \\
\hline CHEMBL1606860 & 688267 & 5.7 & 5.0993 & TRN \\
\hline CHEMBL1306595 & 688267 & 4.15 & 5.035 & TST \\
\hline CHEMBL1357646 & 688267 & 5.45 & 5.0327 & TST \\
\hline CHEMBL3191949 & 688267 & 4.85 & 5.0165 & TST \\
\hline CHEMBL1415448 & 688267 & 5.05 & 5.0682 & TST \\
\hline CHEMBL1361289 & 688267 & 4.4 & 5.0271 & TRN \\
\hline CHEMBL1451549 & 688267 & 6.2 & 5.0537 & TRN \\
\hline CHEMBL1549414 & 688267 & 5.35 & 5.0072 & TRN \\
\hline CHEMBL1325744 & 688267 & 4.05 & 5.1109 & TRN \\
\hline CHEMBL1519933 & 688267 & 6.2 & 5.0829 & TRN \\
\hline CHEMBL1432855 & 688267 & 4.6 & 5.0315 & TRN \\
\hline CHEMBL1574434 & 688267 & 5.6 & 5.1807 & TRN \\
\hline CHEMBL1521848 & 688267 & 6.2 & 5.1696 & TRN \\
\hline CHEMBL1435187 & 688267 & 5.45 & 5.0089 & TST \\
\hline CHEMBL1501694 & 688267 & 4.5 & 5.0409 & TST \\
\hline CHEMBL1332779 & 688267 & 4.4 & 5.0577 & TST \\
\hline CHEMBL1439366 & 688267 & 4.4 & 5.0196 & TRN \\
\hline CHEMBL1465584 & 688267 & 3.95 & 5.0606 & TRN \\
\hline CHEMBL1355173 & 688267 & 6.2 & 5.0641 & TRN \\
\hline CHEMBL1569709 & 688267 & 4.4 & 5.0727 & TST \\
\hline CHEMBL1358909 & 688267 & 4.05 & 4.9975 & TRN \\
\hline CHEMBL1448291 & 688267 & 4.25 & 4.9996 & TRN \\
\hline CHEMBL3193612 & 688267 & 4.05 & 4.9814 & TRN \\
\hline CHEMBL1457939 & 688267 & 5.35 & 5.0859 & TST \\
\hline CHEMBL3191439 & 688267 & 6.2 & 5.0509 & TST \\
\hline CHEMBL1438311 & 688267 & 5.4 & 5.0522 & TRN \\
\hline CHEMBL1520893 & 688267 & 5.35 & 5.0847 & TRN \\
\hline
\end{tabular}




\begin{tabular}{|c|c|c|c|c|c|}
\hline \multicolumn{6}{|c|}{ Supplemental Table S2.txt } \\
\hline CHEMBL1404853 & 688267 & 5.25 & 5.0528 & TRN & \\
\hline CHEMBL1470859 & 688267 & 6.5 & 5.1219 & TST & \\
\hline CHEMBL1398107 & 688267 & 5.55 & 5.0085 & TRN & \\
\hline CHEMBL1396518 & 688267 & 4.5 & 5.0351 & TRN & \\
\hline CHEMBL 3208560 & 688267 & 5.6 & 4.9306 & TRN & \\
\hline CHEMBL1513883 & 688267 & 5.15 & 5.1 & TRN & \\
\hline CHEMBL1409414 & 688267 & 5.3 & 4.9667 & TRN & \\
\hline CHEMBL1524269 & 688267 & 4.1 & 5.01699 & 99999999995 & TRN \\
\hline CHEMBL1391142 & 688267 & 5.25 & 5.0509 & TRN & \\
\hline CHEMBL3191273 & 688267 & 4.45 & 5.0173 & TRN & \\
\hline CHEMBL1351580 & 688267 & 5.8 & 5.0227 & TRN & \\
\hline CHEMBL1454130 & 688267 & 4.0 & 5.0377 & TRN & \\
\hline CHEMBL1472014 & 688267 & 5.3 & 5.0278 & TRN & \\
\hline CHEMBL1462105 & 688267 & 5.05 & 5.0414 & TRN & \\
\hline CHEMBL1586826 & 688267 & 6.2 & 5.0225 & TRN & \\
\hline CHEMBL1356169 & 688267 & 4.0 & 5.01399 & 9999999999 & TRN \\
\hline CHEMBL1589175 & 688267 & 5.35 & 5.1305 & TST & \\
\hline CHEMBL1483626 & 688267 & 5.05 & 5.0774 & TRN & \\
\hline CHEMBL1387338 & 688267 & 4.35 & 5.0213 & TRN & \\
\hline CHEMBL1410617 & 688267 & 5.3 & 5.1009 & TRN & \\
\hline CHEMBL1474258 & 688267 & 3.95 & 5.0433 & TRN & \\
\hline CHEMBL1506851 & 688267 & 6.15 & 5.0327 & TRN & \\
\hline CHEMBL1459661 & 688267 & 3.95 & $5.0310 e$ & 0000000001 & TST \\
\hline CHEMBL1389971 & 688267 & 5.35 & 5.1588 & TRN & \\
\hline CHEMBL1338191 & 688267 & 4.55 & 5.0061 & TRN & \\
\hline CHEMBL1475090 & 688267 & 4.5 & 5.0985 & TRN & \\
\hline CHEMBL1322499 & 688267 & 5.35 & 5.0625 & TRN & \\
\hline CHEMBL1372685 & 688267 & 4.6 & 5.0335 & TST & \\
\hline CHEMBL1441763 & 688267 & 4.0 & 5.052 & TST & \\
\hline CHEMBL1388667 & 688267 & 5.45 & 5.0321 & TST & \\
\hline CHEMBL1412310 & 688267 & 6.2 & 5.0733 & TST & \\
\hline CHEMBL1316404 & 688267 & 6.2 & 5.0319 & TRN & \\
\hline CHEMBL1382939 & 688267 & 4.0 & 5.022 & TST & \\
\hline CHEMBL1419472 & 688267 & 5.0 & 5.0626 & TRN & \\
\hline CHEMBL1609796 & 688267 & 4.35 & 5.0268 & TRN & \\
\hline CHEMBL1564099 & 688267 & 4.75 & 5.0123 & TST & \\
\hline CHEMBL1551333 & 688267 & 4.75 & $5.1110 e$ & 0000000001 & TRN \\
\hline CHEMBL1599646 & 688267 & 5.55 & 5.0018 & TRN & \\
\hline CHEMBL1565654 & 688267 & 4.45 & 5.1068 & TST & \\
\hline CHEMBL1593095 & 688267 & 6.25 & 5.0025 & TRN & \\
\hline CHEMBL1326931 & 688267 & 5.45 & 5.0996 & TRN & \\
\hline CHEMBL1408479 & 688267 & 4.6 & 5.0357 & TRN & \\
\hline CHEMBL1593159 & 688267 & 3.95 & 5.0087 & TRN & \\
\hline CHEMBL1515731 & 688267 & 5.95 & 5.0863 & TRN & \\
\hline CHEMBL3194064 & 688267 & 6.2 & 5.1089 & TRN & \\
\hline CHEMBL1517145 & 688267 & 5.3 & 5.1447 & TRN & \\
\hline CHEMBL1307468 & 688267 & 6.2 & 5.0009 & TST & \\
\hline CHEMBL1402742 & 688267 & 4.65 & 5.045 & TRN & \\
\hline
\end{tabular}




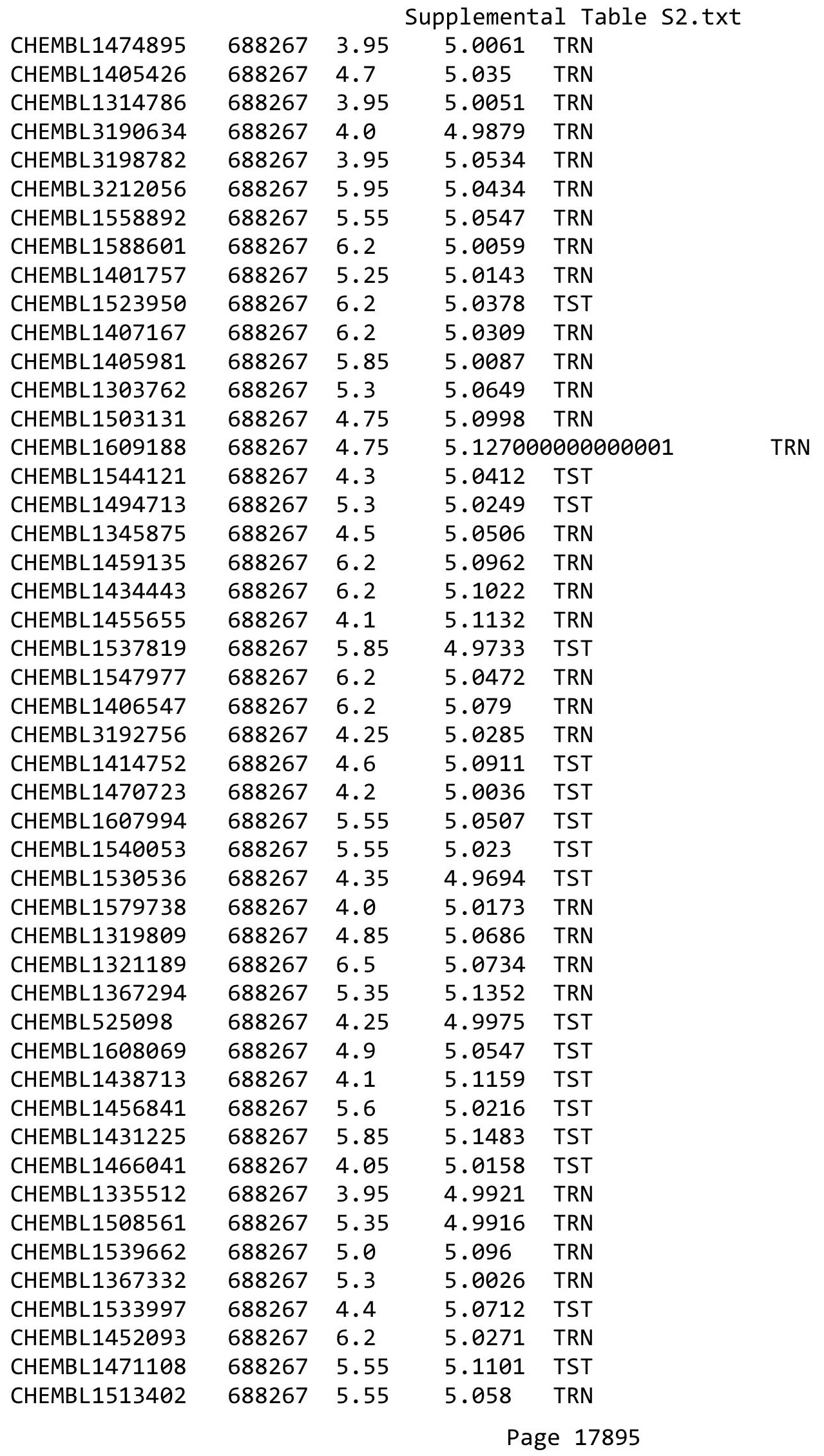




\begin{tabular}{|c|c|c|c|c|}
\hline & & & oplement & al Table S \\
\hline CHEMBL1556859 & 688267 & 4.0 & 5.0254 & TRN \\
\hline CHEMBL1314870 & 688267 & 5.0 & 5.0648 & TRN \\
\hline CHEMBL1336291 & 688267 & 5.8 & 5.13200 & 0000000001 \\
\hline CHEMBL1372067 & 688267 & 5.95 & 5.0963 & TRN \\
\hline CHEMBL1354525 & 688267 & 3.95 & 5.1106 & TRN \\
\hline CHEMBL1477974 & 688267 & 4.65 & 5.0773 & TRN \\
\hline CHEMBL1514538 & 688267 & 4.0 & 5.0556 & TRN \\
\hline CHEMBL1507160 & 688267 & 5.85 & 5.0452 & TRN \\
\hline CHEMBL1438272 & 688267 & 4.05 & 5.0783 & TRN \\
\hline CHEMBL1453822 & 688267 & 4.1 & 5.1239 & TRN \\
\hline CHEMBL589909 & 688267 & 6.2 & 5.0314 & TRN \\
\hline CHEMBL1524167 & 688267 & 5.25 & 5.0571 & TRN \\
\hline CHEMBL1458840 & 688267 & 4.4 & 5.1023 & TST \\
\hline CHEMBL1427403 & 688267 & 4.3 & 5.0184 & TST \\
\hline CHEMBL1570524 & 688267 & 4.1 & 5.0362 & TRN \\
\hline CHEMBL1337783 & 688267 & 5.85 & 5.0595 & TRN \\
\hline CHEMBL252901 & 688267 & 6.2 & 5.0059 & TRN \\
\hline CHEMBL1559287 & 688267 & 5.05 & 5.056 & TRN \\
\hline CHEMBL1491179 & 688267 & 5.3 & 5.0769 & TRN \\
\hline CHEMBL1401427 & 688267 & 5.0 & 5.0028 & TRN \\
\hline CHEMBL1557185 & 688267 & 4.3 & 5.0408 & TRN \\
\hline CHEMBL1593384 & 688267 & 4.25 & 5.0508 & TRN \\
\hline CHEMBL3198727 & 688267 & 6.25 & 5.0164 & TRN \\
\hline CHEMBL1465520 & 688267 & 4.0 & 5.001 & TRN \\
\hline CHEMBL1493063 & 688267 & 4.45 & 5.0042 & TRN \\
\hline CHEMBL1360048 & 688267 & 4.35 & 5.0587 & TRN \\
\hline CHEMBL1534055 & 688267 & 6.2 & 5.0992 & TRN \\
\hline CHEMBL3208346 & 688267 & 4.7 & 5.0608 & TRN \\
\hline CHEMBL1473329 & 688267 & 6.15 & 5.0858 & TRN \\
\hline CHEMBL1556669 & 688267 & 4.65 & 5.0582 & TST \\
\hline CHEMBL1309048 & 688267 & 6.2 & 5.1521 & TRN \\
\hline CHEMBL1372456 & 688267 & 4.5 & 5.0127 & TRN \\
\hline CHEMBL1558187 & 688267 & 4.0 & 5.0284 & TRN \\
\hline CHEMBL1406119 & 688267 & 4.15 & 4.9992 & TRN \\
\hline CHEMBL1555318 & 688267 & 4.05 & 5.0935 & TRN \\
\hline CHEMBL1593704 & 688267 & 5.7 & 5.0738 & TRN \\
\hline CHEMBL1507735 & 688267 & 6.2 & 5.1085 & TRN \\
\hline CHEMBL1493583 & 688267 & 4.35 & 4.9845 & TST \\
\hline CHEMBL3198160 & 688267 & 4.35 & 5.006 & TST \\
\hline CHEMBL1515182 & 688267 & 5.6 & 5.0215 & TRN \\
\hline CHEMBL1320321 & 688267 & 5.4 & 5.0415 & TRN \\
\hline CHEMBL1539686 & 688267 & 4.0 & 5.0018 & TRN \\
\hline CHEMBL1547471 & 688267 & 4.15 & 5.0166 & TRN \\
\hline CHEMBL1411868 & 688267 & 4.6 & 4.9891 & TRN \\
\hline CHEMBL1323766 & 688267 & 5.9 & 5.0837 & TRN \\
\hline CHEMBL1577338 & 688267 & 4.05 & 5.0261 & TRN \\
\hline CHEMBL1352657 & 688267 & 6.2 & 5.1191 & TRN \\
\hline CHEMBL1311963 & 688267 & 4.5 & 5.0429 & TRN \\
\hline
\end{tabular}

TRN 


\begin{tabular}{|c|c|c|c|c|}
\hline \multicolumn{5}{|c|}{ Supplemental Table S2.txt } \\
\hline CHEMBL 3211054 & 688267 & 4.0 & 5.0645 & TST \\
\hline CHEMBL1537526 & 688267 & 4.55 & 5.029 & TRN \\
\hline CHEMBL1435141 & 688267 & 5.55 & 5.1196 & TRN \\
\hline CHEMBL1417693 & 688267 & 4.0 & 5.1102 & TRN \\
\hline CHEMBL1271429 & 688267 & 5.85 & 5.0017 & TRN \\
\hline CHEMBL1407 & 688267 & 5.3 & 5.0947 & TRN \\
\hline CHEMBL3213099 & 688267 & 4.0 & 5.0543 & TST \\
\hline CHEMBL1499033 & 688267 & 5.3 & 4.9954 & TST \\
\hline CHEMBL1334625 & 688267 & 4.45 & 5.0611 & TRN \\
\hline CHEMBL1332073 & 688267 & 5.1 & 5.0268 & TST \\
\hline CHEMBL1368746 & 688267 & 6.2 & 5.0017 & TRN \\
\hline CHEMBL1528899 & 688267 & 5.4 & 5.0435 & TRN \\
\hline CHEMBL1528391 & 688267 & 5.1 & 5.0955 & TRN \\
\hline CHEMBL 3207581 & 688267 & 4.05 & 4.9964 & TRN \\
\hline CHEMBL1452302 & 688267 & 4.05 & 5.0046 & TRN \\
\hline CHEMBL1368467 & 688267 & 6.15 & 5.0558 & TRN \\
\hline CHEMBL1481677 & 688267 & 4.35 & 5.0557 & TRN \\
\hline CHEMBL3189276 & 688267 & 4.0 & 5.0837 & TST \\
\hline CHEMBL503763 & 688267 & 6.15 & 5.0168 & TST \\
\hline CHEMBL1564085 & 688267 & 4.5 & 5.035 & TRN \\
\hline CHEMBL1415515 & 688267 & 6.15 & 5.0242 & TRN \\
\hline CHEMBL1360883 & 688267 & 4.1 & 5.1387 & TRN \\
\hline CHEMBL1357132 & 688267 & 3.95 & 4.9914 & TRN \\
\hline CHEMBL1486238 & 688267 & 5.95 & 5.026 & TRN \\
\hline CHEMBL1355211 & 688267 & 6.45 & 5.0572 & TRN \\
\hline CHEMBL1492517 & 688267 & 4.35 & 5.0557 & TST \\
\hline CHEMBL1578328 & 688267 & 4.0 & 5.0827 & TST \\
\hline CHEMBL1441882 & 688267 & 6.2 & 5.0919 & TRN \\
\hline CHEMBL1539369 & 688267 & 4.0 & 5.0736 & TRN \\
\hline CHEMBL1393791 & 688267 & 4.0 & 5.1524 & TRN \\
\hline CHEMBL1571325 & 688267 & 4.55 & 5.0446 & TRN \\
\hline CHEMBL1398162 & 688267 & 6.2 & 5.0804 & TRN \\
\hline CHEMBL1469188 & 688267 & 5.8 & 5.0384 & TST \\
\hline CHEMBL1453045 & 688267 & 5.4 & 5.1122 & TST \\
\hline CHEMBL1551323 & 688267 & 5.1 & 5.0204 & TRN \\
\hline CHEMBL3196441 & 688267 & 4.05 & 5.0155 & TST \\
\hline CHEMBL1380955 & 688267 & 4.25 & 5.0837 & TST \\
\hline CHEMBL1602900 & 688267 & 4.5 & 5.0163 & TRN \\
\hline CHEMBL1598089 & 688267 & 6.2 & 5.0701 & TRN \\
\hline CHEMBL1367440 & 688267 & 5.55 & 5.0572 & TRN \\
\hline CHEMBL1311523 & 688267 & 6.0 & 5.0947 & TRN \\
\hline CHEMBL1397340 & 688267 & 5.9 & 5.0361 & TRN \\
\hline CHEMBL1365981 & 688267 & 4.25 & 5.0543 & TST \\
\hline CHEMBL1542158 & 688267 & 3.95 & 5.0817 & TST \\
\hline CHEMBL1544519 & 688267 & 5.55 & 5.0316 & TRN \\
\hline CHEMBL1401467 & 688267 & 4.65 & 5.0718 & TST \\
\hline CHEMBL1563702 & 688267 & 4.25 & 4.9788 & TRN \\
\hline CHEMBL1422055 & 688267 & 5.35 & 5.1012 & TRN \\
\hline
\end{tabular}




\begin{tabular}{|c|c|c|c|c|c|}
\hline \\
\hline CHEMBL1381362 & 688267 & 6.2 & 5.0567 & TST & \\
\hline CHEMBL1479346 & 688267 & 6.2 & 5.0336 & TST & \\
\hline CHEMBL1565772 & 688267 & 4.0 & 5.0944 & TRN & \\
\hline CHEMBL1321019 & 688267 & 4.6 & 5.0256 & TST & \\
\hline CHEMBL1328978 & 688267 & 5.0 & 5.0345 & TRN & \\
\hline CHEMBL1469110 & 688267 & 4.25 & 5.0236 & TRN & \\
\hline CHEMBL1307243 & 688267 & 5.6 & 5.0193 & TRN & \\
\hline CHEMBL1490686 & 688267 & 6.5 & 5.0535 & TRN & \\
\hline CHEMBL1336981 & 688267 & 4.4 & 5.0813 & TST & \\
\hline CHEMBL1374317 & 688267 & 4.05 & 5.0666 & TRN & \\
\hline CHEMBL1582217 & 688267 & 6.2 & 5.0332 & TRN & \\
\hline CHEMBL1583161 & 688267 & 6.25 & 5.0642 & TRN & \\
\hline CHEMBL561020 & 688267 & 4.55 & 5.0171 & TST & \\
\hline CHEMBL1341312 & 688267 & 4.0 & 5.0343 & TRN & \\
\hline CHEMBL1461095 & 688267 & 5.4 & 5.0695 & TRN & \\
\hline CHEMBL1391672 & 688267 & 6.5 & 5.047 & TRN & \\
\hline CHEMBL1317028 & 688267 & 5.55 & 5.093 & TRN & \\
\hline CHEMBL1557620 & 688267 & 4.1 & 5.02 & TRN & \\
\hline CHEMBL1520102 & 688267 & 4.0 & 5.063 & TST & \\
\hline CHEMBL1555390 & 688267 & 4.35 & 5.093 & TRN & \\
\hline CHEMBL1439492 & 688267 & 5.6 & 5.0132 & TRN & \\
\hline CHEMBL1329386 & 688267 & 4.05 & 5.0775 & TRN & \\
\hline CHEMBL1555549 & 688267 & 4.6 & 5.0436 & TRN & \\
\hline CHEMBL1608664 & 688267 & 5.05 & 5.0611 & TRN & \\
\hline CHEMBL1354846 & 688267 & 4.45 & 5.0588 & TRN & \\
\hline CHEMBL1486179 & 688267 & 6.25 & 5.0396 & TRN & \\
\hline CHEMBL1306612 & 688267 & 6.05 & 5.095 & TRN & \\
\hline CHEMBL1332596 & 688267 & 5.55 & 5.0581 & TRN & \\
\hline CHEMBL1353916 & 688267 & 6.25 & 5.0977 & TRN & \\
\hline CHEMBL1449018 & 688267 & 4.0 & 5.0282 & TST & \\
\hline CHEMBL1573583 & 688267 & 5.9 & 5.0329 & TST & \\
\hline CHEMBL1584213 & 688267 & 4.0 & 5.0083 & TRN & \\
\hline CHEMBL1577397 & 688267 & 5.1 & $5.0710 e$ & 2000000001 & TST \\
\hline CHEMBL1583606 & 688267 & 4.4 & 5.0138 & TRN & \\
\hline CHEMBL1489564 & 688267 & 6.15 & 5.0698 & TRN & \\
\hline CHEMBL1348476 & 688267 & 4.5 & 5.0943 & TST & \\
\hline CHEMBL1308886 & 688267 & 4.75 & 5.0755 & TRN & \\
\hline CHEMBL1537632 & 688267 & 5.1 & 5.0432 & TRN & \\
\hline CHEMBL1561682 & 688267 & 4.4 & 5.0233 & TRN & \\
\hline CHEMBL1329830 & 688267 & 4.05 & 5.0761 & TST & \\
\hline CHEMBL1359300 & 688267 & 4.4 & 5.0797 & TST & \\
\hline CHEMBL1994709 & 688267 & 4.05 & 4.9714 & TRN & \\
\hline CHEMBL1465145 & 688267 & 4.0 & 5.0031 & TST & \\
\hline CHEMBL1509206 & 688267 & 6.2 & 5.1181 & TST & \\
\hline CHEMBL1529603 & 688267 & 5.0 & 5.0789 & TST & \\
\hline CHEMBL1449683 & 688267 & 6.2 & 5.002 & TRN & \\
\hline CHEMBL1509513 & 688267 & 5.0 & 5.0954 & TST & \\
\hline CHEMBL1394935 & 688267 & 5.1 & 5.0154 & TRN & \\
\hline
\end{tabular}




\begin{tabular}{|c|c|c|c|c|}
\hline \multicolumn{5}{|c|}{ Supplemental Table } \\
\hline CHEMBL1513738 & 688267 & 5.45 & 5.0894 & TRN \\
\hline CHEMBL1447629 & 688267 & 6.5 & 5.0514 & TST \\
\hline CHEMBL1315012 & 688267 & 5.5 & 5.0628 & TRN \\
\hline CHEMBL1582046 & 688267 & 4.3 & 5.0665 & TRN \\
\hline CHEMBL1502870 & 688267 & 4.05 & 5.0828 & TRN \\
\hline CHEMBL1396833 & 688267 & 4.4 & 5.1168 & TRN \\
\hline CHEMBL1570121 & 688267 & 5.55 & 5.0294 & TRN \\
\hline CHEMBL1554843 & 688267 & 6.2 & 5.0576 & TST \\
\hline CHEMBL1350096 & 688267 & 4.95 & 5.1067 & TRN \\
\hline CHEMBL1508400 & 688267 & 4.55 & 5.0959 & TST \\
\hline CHEMBL1435433 & 688267 & 4.05 & 5.1022 & TRN \\
\hline CHEMBL1473355 & 688267 & 4.0 & 5.0383 & TRN \\
\hline CHEMBL1570461 & 688267 & 4.0 & 5.0018 & TST \\
\hline CHEMBL1470105 & 688267 & 4.4 & 5.0937 & TST \\
\hline CHEMBL1582440 & 688267 & 5.75 & 5.0596 & TST \\
\hline CHEMBL3208960 & 688267 & 6.2 & 5.0563 & TRN \\
\hline CHEMBL1436895 & 688267 & 5.85 & 5.0467 & TRN \\
\hline CHEMBL1299567 & 688267 & 5.0 & 5.1082 & TRN \\
\hline CHEMBL1586706 & 688267 & 4.05 & 5.0048 & TRN \\
\hline CHEMBL1395691 & 688267 & 5.35 & 5.0679 & TST \\
\hline CHEMBL1487482 & 688267 & 6.2 & 5.0944 & TRN \\
\hline CHEMBL1356198 & 688267 & 6.25 & 5.08 & TRN \\
\hline CHEMBL1593622 & 688267 & 5.6 & 5.0243 & TRN \\
\hline CHEMBL1329449 & 688267 & 6.15 & 5.1149 & TRN \\
\hline CHEMBL1340150 & 688267 & 4.1 & 4.992 & TST \\
\hline CHEMBL1566275 & 688267 & 4.05 & 5.0798 & TRN \\
\hline CHEMBL1370940 & 688267 & 6.2 & 5.1142 & TRN \\
\hline CHEMBL1495558 & 688267 & 4.5 & 5.0666 & TRN \\
\hline CHEMBL1391850 & 688267 & 5.45 & 5.1481 & TST \\
\hline CHEMBL1463721 & 688267 & 5.0 & 5.0688 & TST \\
\hline CHEMBL1328218 & 688267 & 5.55 & 5.0597 & TRN \\
\hline CHEMBL1533069 & 688267 & 4.4 & 5.0658 & TST \\
\hline CHEMBL1490301 & 688267 & 5.85 & 5.0635 & TRN \\
\hline CHEMBL1352257 & 688267 & 4.35 & 5.1316 & TRN \\
\hline CHEMBL1590756 & 688267 & 4.05 & 5.0127 & TRN \\
\hline CHEMBL1591648 & 688267 & 6.2 & 5.0669 & TRN \\
\hline CHEMBL1489471 & 688267 & 4.35 & 5.0417 & TST \\
\hline CHEMBL1613531 & 688267 & 4.35 & 5.0205 & TRN \\
\hline CHEMBL1416132 & 688267 & 5.5 & 5.0613 & TST \\
\hline CHEMBL1410987 & 688267 & 6.2 & 5.0295 & TRN \\
\hline CHEMBL1358373 & 688267 & 6.2 & 5.0446 & TRN \\
\hline CHEMBL1577496 & 688267 & 4.95 & 5.0574 & TRN \\
\hline CHEMBL1612667 & 688267 & 4.25 & 5.0076 & TRN \\
\hline CHEMBL1480660 & 688267 & 5.05 & 5.1157 & TST \\
\hline CHEMBL1468683 & 688267 & 4.3 & 5.0214 & TST \\
\hline CHEMBL1375768 & 688267 & 4.35 & 5.0359 & TRN \\
\hline CHEMBL1313249 & 688267 & 4.7 & 4.9891 & TRN \\
\hline CHEMBL1531078 & 688267 & 6.2 & 5.064 & TRN \\
\hline
\end{tabular}




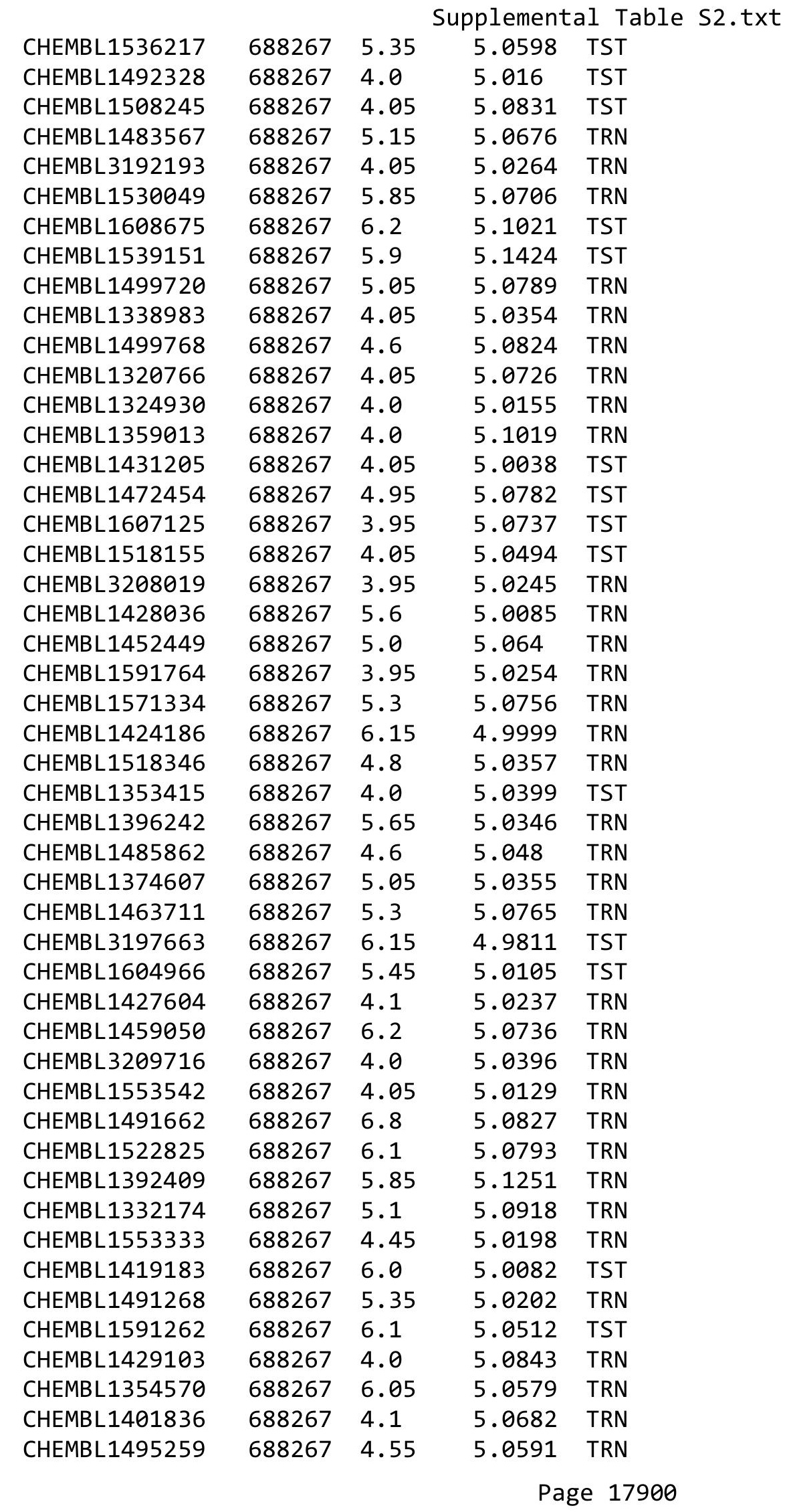




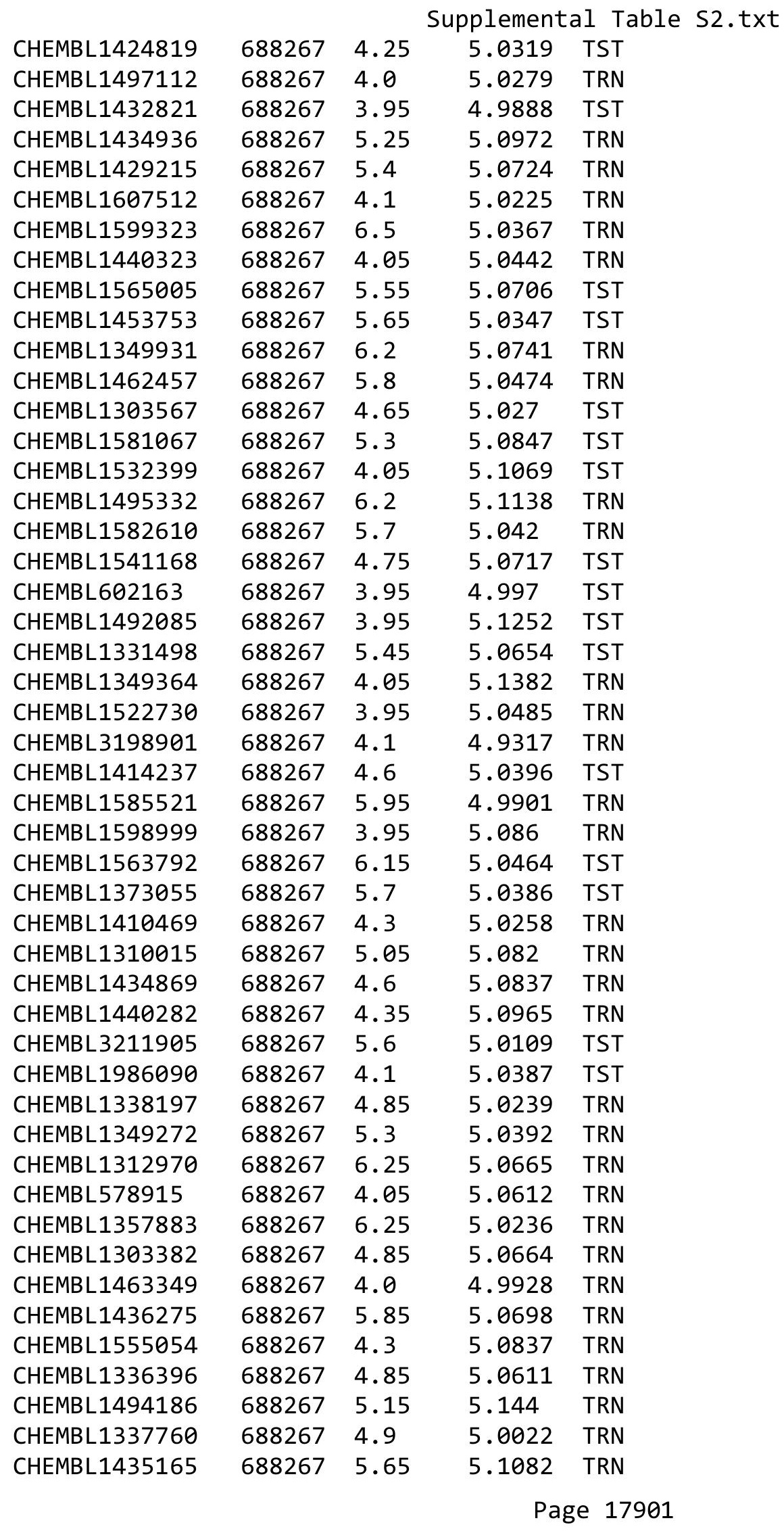




\begin{tabular}{|c|c|c|c|c|}
\hline & & & pplement & al $\mathrm{Ta}$ \\
\hline CHEMBL1525427 & 688267 & 4.7 & 5.1016 & TRN \\
\hline CHEMBL1463249 & 688267 & 4.4 & 5.0503 & TRN \\
\hline CHEMBL1369884 & 688267 & 5.4 & 5.1132 & TRN \\
\hline CHEMBL1575786 & 688267 & 5.6 & 5.0319 & TST \\
\hline CHEMBL1971727 & 688267 & 5.95 & 4.9996 & TST \\
\hline CHEMBL1592576 & 688267 & 5.45 & 5.0022 & TRN \\
\hline CHEMBL1514159 & 688267 & 6.05 & 5.0868 & TRN \\
\hline CHEMBL1338669 & 688267 & 4.4 & 5.0787 & TRN \\
\hline CHEMBL1407152 & 688267 & 3.95 & 5.0079 & TRN \\
\hline CHEMBL1353611 & 688267 & 6.5 & 5.0224 & TST \\
\hline CHEMBL1561448 & 688267 & 5.35 & 5.0307 & TRN \\
\hline CHEMBL1308602 & 688267 & 5.65 & 5.1271 & TRN \\
\hline CHEMBL3189183 & 688267 & 4.0 & 5.0111 & TRN \\
\hline CHEMBL1397912 & 688267 & 4.15 & 5.0209 & TRN \\
\hline CHEMBL1591319 & 688267 & 5.35 & 5.1118 & TRN \\
\hline CHEMBL1590435 & 688267 & 4.6 & 5.0799 & TRN \\
\hline CHEMBL1399185 & 688267 & 4.0 & 5.0922 & TRN \\
\hline CHEMBL1423030 & 688267 & 6.2 & 5.1101 & TRN \\
\hline CHEMBL1394486 & 688267 & 5.35 & 5.0402 & TRN \\
\hline CHEMBL1370297 & 688267 & 4.4 & 5.0044 & TRN \\
\hline CHEMBL1529292 & 688267 & 5.65 & 5.0683 & TRN \\
\hline CHEMBL1528994 & 688267 & 6.25 & 5.145 & TRN \\
\hline CHEMBL1531653 & 688267 & 4.75 & 5.1151 & TRN \\
\hline CHEMBL1445380 & 688267 & 3.95 & 5.0737 & TRN \\
\hline CHEMBL1533037 & 688267 & 4.85 & 5.0706 & TRN \\
\hline CHEMBL1556629 & 688267 & 4.1 & 5.0158 & TRN \\
\hline CHEMBL1449748 & 688267 & 5.3 & 5.0216 & TRN \\
\hline CHEMBL1384213 & 688267 & 3.95 & 4.9993 & TRN \\
\hline CHEMBL1433914 & 688267 & 6.2 & 5.0298 & TST \\
\hline CHEMBL1535859 & 688267 & 6.5 & 5.1027 & TRN \\
\hline CHEMBL1309661 & 688267 & 4.35 & 5.0379 & TRN \\
\hline CHEMBL1430539 & 688267 & 4.1 & 5.0403 & TRN \\
\hline CHEMBL1432856 & 688267 & 4.35 & 5.1135 & TRN \\
\hline CHEMBL1338760 & 688267 & 4.2 & 5.1076 & TST \\
\hline CHEMBL1572647 & 688267 & 6.05 & 5.0682 & TRN \\
\hline CHEMBL1362518 & 688267 & 5.05 & 5.1045 & TST \\
\hline CHEMBL1299529 & 688267 & 4.45 & 5.0456 & TRN \\
\hline CHEMBL1468895 & 688267 & 4.35 & 5.0682 & TRN \\
\hline CHEMBL1357566 & 688267 & 5.55 & 5.0908 & TRN \\
\hline CHEMBL1472314 & 688267 & 6.2 & 5.0581 & TRN \\
\hline CHEMBL1420294 & 688267 & 4.85 & 5.0527 & TRN \\
\hline CHEMBL1455506 & 688267 & 4.95 & 5.0623 & TRN \\
\hline CHEMBL1550072 & 688267 & 4.1 & 5.0443 & TRN \\
\hline CHEMBL1486843 & 688267 & 4.15 & 5.0632 & TST \\
\hline CHEMBL1567933 & 688267 & 4.15 & 5.0073 & TRN \\
\hline CHEMBL1557884 & 688267 & 3.95 & 5.0192 & TRN \\
\hline CHEMBL1595443 & 688267 & 6.25 & 5.0164 & TRN \\
\hline CHEMBL1456055 & 688267 & 4.05 & 5.0596 & TRN \\
\hline
\end{tabular}




\begin{tabular}{|c|c|c|c|c|}
\hline & & & pplement & al $\mathrm{T}$ \\
\hline CHEMBL1446677 & 688267 & 4.1 & 5.0805 & TST \\
\hline CHEMBL1413835 & 688267 & 5.5 & 5.0828 & TRN \\
\hline CHEMBL1398247 & 688267 & 6.25 & 5.0874 & TRN \\
\hline CHEMBL1345551 & 688267 & 4.25 & 5.0177 & TRN \\
\hline CHEMBL3144973 & 688267 & 4.55 & 4.9917 & TRN \\
\hline CHEMBL 3198071 & 688267 & 4.55 & 5.0178 & TRN \\
\hline CHEMBL1385814 & 688267 & 4.4 & 5.0307 & TRN \\
\hline CHEMBL1346063 & 688267 & 4.95 & 5.0257 & TRN \\
\hline CHEMBL1484387 & 688267 & 5.4 & 5.0262 & TRN \\
\hline CHEMBL1417729 & 688267 & 6.5 & 5.0717 & TRN \\
\hline CHEMBL1352811 & 688267 & 5.55 & 5.0576 & TRN \\
\hline CHEMBL1592118 & 688267 & 4.35 & 5.0312 & TRN \\
\hline CHEMBL1514328 & 688267 & 5.35 & 5.0597 & TRN \\
\hline CHEMBL1347354 & 688267 & 4.05 & 5.0731 & TST \\
\hline CHEMBL1538650 & 688267 & 6.05 & 5.0415 & TST \\
\hline CHEMBL1339544 & 688267 & 4.4 & 5.0356 & TRN \\
\hline CHEMBL1496244 & 688267 & 4.35 & 5.0518 & TRN \\
\hline CHEMBL1598930 & 688267 & 4.55 & 5.1806 & TRN \\
\hline CHEMBL1380386 & 688267 & 4.5 & 5.1392 & TRN \\
\hline CHEMBL1607351 & 688267 & 6.5501 & 5.0313 & TRN \\
\hline CHEMBL1491973 & 688267 & 5.9 & 5.061 & TST \\
\hline CHEMBL1325407 & 688267 & 5.55 & 5.0566 & TRN \\
\hline CHEMBL1479016 & 688267 & 5.25 & 5.0626 & TST \\
\hline CHEMBL1609157 & 688267 & 5.35 & 5.0669 & TRN \\
\hline CHEMBL591370 & 688267 & 4.1 & 5.0063 & TRN \\
\hline CHEMBL1610710 & 688267 & 4.05 & 5.0584 & TRN \\
\hline CHEMBL1354839 & 688267 & 4.3 & 5.1498 & TRN \\
\hline CHEMBL1421826 & 688267 & 6.2 & 5.0525 & TRN \\
\hline CHEMBL1561607 & 688267 & 4.35 & 5.0991 & TST \\
\hline CHEMBL1427588 & 688267 & 5.85 & 5.0861 & TRN \\
\hline CHEMBL1471873 & 688267 & 4.0 & 5.0486 & TRN \\
\hline CHEMBL1303700 & 688267 & 4.65 & 5.0316 & TST \\
\hline CHEMBL1315132 & 688267 & 4.05 & 5.0164 & TRN \\
\hline CHEMBL1402042 & 688267 & 4.6 & 5.0748 & TRN \\
\hline CHEMBL 3198450 & 688267 & 4.25 & 5.0688 & TRN \\
\hline CHEMBL1540356 & 688267 & 4.25 & 5.0872 & TRN \\
\hline CHEMBL1602496 & 688267 & 5.6 & 4.9943 & TRN \\
\hline CHEMBL1441245 & 688267 & 5.1 & 5.0478 & TRN \\
\hline CHEMBL1355310 & 688267 & 4.75 & 5.0682 & TRN \\
\hline CHEMBL1580568 & 688267 & 6.2 & 5.0279 & TST \\
\hline CHEMBL1469050 & 688267 & 5.8 & 4.975 & TRN \\
\hline CHEMBL1548130 & 688267 & 4.4 & 5.0661 & TRN \\
\hline CHEMBL1522934 & 688267 & 6.2 & 5.0222 & TRN \\
\hline CHEMBL1325873 & 688267 & 6.25 & 5.0259 & TRN \\
\hline CHEMBL1398773 & 688267 & 6.25 & 5.0213 & TRN \\
\hline CHEMBL1567616 & 688267 & 6.05 & 5.027 & TRN \\
\hline CHEMBL1358843 & 688267 & 5.3 & 5.1637 & TRN \\
\hline CHEMBL1613351 & 688267 & 4.25 & 5.0502 & TRN \\
\hline
\end{tabular}




\begin{tabular}{|c|c|c|c|c|c|}
\hline \multicolumn{6}{|c|}{ Supplemental Table S2.txt } \\
\hline CHEMBL1492522 & 688267 & 5.65 & 5.1056 & TRN & \\
\hline CHEMBL1531905 & 688267 & 6.15 & 4.995 & TRN & \\
\hline CHEMBL1322030 & 688267 & 4.95 & 5.0727 & TRN & \\
\hline CHEMBL1609955 & 688267 & 3.95 & 5.1325 & TRN & \\
\hline CHEMBL 1434630 & 688267 & 5.55 & 4.9973 & TRN & \\
\hline CHEMBL1553007 & 688267 & 4.4 & 5.1051 & TRN & \\
\hline CHEMBL1589513 & 688267 & 5.95 & 5.0268 & TRN & \\
\hline CHEMBL1521145 & 688267 & 5.55 & 5.0119 & TRN & \\
\hline CHEMBL1310572 & 688267 & 4.05 & 5.1086 & TRN & \\
\hline CHEMBL 1385538 & 688267 & 6.2 & 4.9999 & TRN & \\
\hline CHEMBL1403286 & 688267 & 4.25 & 5.0493 & TRN & \\
\hline CHEMBL1357321 & 688267 & 6.2 & 5.02800 & 00000000005 & TRN \\
\hline CHEMBL1552634 & 688267 & 6.2 & 5.0575 & TST & \\
\hline CHEMBL1593820 & 688267 & 4.65 & 5.0779 & TRN & \\
\hline CHEMBL1433736 & 688267 & 6.5501 & 5.0303 & TRN & \\
\hline CHEMBL1532160 & 688267 & 4.5 & 5.0009 & TST & \\
\hline CHEMBL1440196 & 688267 & 6.45 & 5.0577 & TST & \\
\hline CHEMBL1445746 & 688267 & 3.95 & 5.0074 & TRN & \\
\hline CHEMBL1362074 & 688267 & 4.0 & 5.0545 & TRN & \\
\hline CHEMBL1584914 & 688267 & 4.0 & 5.0638 & TRN & \\
\hline CHEMBL1495244 & 688267 & 5.05 & 5.0336 & TRN & \\
\hline CHEMBL1386163 & 688267 & 5.1 & 5.0512 & TST & \\
\hline CHEMBL1551816 & 688267 & 5.0 & 5.0704 & TRN & \\
\hline CHEMBL1494758 & 688267 & 6.05 & 5.0496 & TRN & \\
\hline CHEMBL1403379 & 688267 & 4.0 & 5.0393 & TRN & \\
\hline CHEMBL1442138 & 688267 & 4.6 & 5.118 & TRN & \\
\hline CHEMBL1494493 & 688267 & 5.0 & 5.1133 & TRN & \\
\hline CHEMBL1334954 & 688267 & 5.8 & 5.0838 & TRN & \\
\hline CHEMBL1357809 & 688267 & 5.9 & 5.1136 & TRN & \\
\hline CHEMBL1525278 & 688267 & 4.35 & 5.015 & TRN & \\
\hline CHEMBL1561805 & 688267 & 6.5 & 5.042 & TRN & \\
\hline CHEMBL1357015 & 688267 & 6.2 & 4.9827 & TRN & \\
\hline CHEMBL1529594 & 688267 & 4.0 & 5.0351 & TRN & \\
\hline CHEMBL1403569 & 688267 & 4.9 & 5.0525 & TST & \\
\hline CHEMBL1432043 & 688267 & 5.25 & 5.1065 & TRN & \\
\hline CHEMBL1401822 & 688267 & 4.6 & 5.0871 & TRN & \\
\hline CHEMBL1330438 & 688267 & 5.75 & 5.1193 & TRN & \\
\hline CHEMBL1557892 & 688267 & 6.2 & 5.0563 & TRN & \\
\hline CHEMBL1314440 & 688267 & 5.45 & 5.1323 & TRN & \\
\hline CHEMBL1560169 & 688267 & 6.2 & 5.1164 & TRN & \\
\hline CHEMBL1574794 & 688267 & 6.2 & 5.1184 & TRN & \\
\hline CHEMBL1602608 & 688267 & 6.15 & 5.0315 & TST & \\
\hline CHEMBL1468639 & 688267 & 4.25 & 5.0444 & TRN & \\
\hline CHEMBL3193400 & 688267 & 5.55 & 5.0533 & TRN & \\
\hline CHEMBL1597622 & 688267 & 4.3 & 5.0638 & TRN & \\
\hline CHEMBL3189883 & 688267 & 4.35 & 4.9758 & TRN & \\
\hline CHEMBL1304928 & 688267 & 5.0 & 5.0974 & TRN & \\
\hline CHEMBL1547002 & 688267 & 4.25 & 5.0722 & TRN & \\
\hline
\end{tabular}




\begin{tabular}{|c|c|c|c|c|}
\hline \multicolumn{5}{|c|}{ Supplemental Table S2.txt } \\
\hline CHEMBL1510592 & 688267 & 5.15 & 5.1205 & TRN \\
\hline CHEMBL1447695 & 688267 & 6.25 & 5.0491 & TRN \\
\hline CHEMBL1594714 & 688267 & 4.05 & 5.0158 & TRN \\
\hline CHEMBL1319032 & 688267 & 5.6 & 5.1721 & TRN \\
\hline CHEMBL1411271 & 688267 & 5.3 & 5.0314 & TST \\
\hline CHEMBL1601542 & 688267 & 6.2 & 5.1005 & TRN \\
\hline CHEMBL1340830 & 688267 & 5.5 & 5.0744 & TRN \\
\hline CHEMBL1349832 & 688267 & 4.25 & 5.1151 & TRN \\
\hline CHEMBL1390374 & 688267 & 4.6 & 4.9787 & TRN \\
\hline CHEMBL1379980 & 688267 & 5.85 & 5.0301 & TRN \\
\hline CHEMBL1384331 & 688267 & 4.2 & 5.0467 & TRN \\
\hline CHEMBL1395181 & 688267 & 6.25 & 4.9857 & TRN \\
\hline CHEMBL1381486 & 688267 & 3.95 & 5.0237 & TRN \\
\hline CHEMBL1519258 & 688267 & 4.4 & 5.1118 & TRN \\
\hline CHEMBL1981840 & 688267 & 4.9 & 4.9972 & TST \\
\hline CHEMBL1409604 & 688267 & 4.4 & 5.055 & TRN \\
\hline CHEMBL1347007 & 688267 & 4.1 & 5.1259 & TRN \\
\hline CHEMBL1361491 & 688267 & 6.25 & 4.9969 & TRN \\
\hline CHEMBL1441770 & 688267 & 4.4 & 5.0534 & TST \\
\hline CHEMBL1304434 & 688267 & 4.05 & 5.1359 & TST \\
\hline CHEMBL1535054 & 688267 & 4.95 & 5.0189 & TRN \\
\hline CHEMBL1552387 & 688267 & 4.55 & 5.0098 & TRN \\
\hline CHEMBL1357653 & 688267 & 3.95 & 5.0533 & TRN \\
\hline CHEMBL1460194 & 688267 & 5.0 & 5.0073 & TST \\
\hline CHEMBL1448063 & 688267 & 4.05 & 5.023 & TST \\
\hline CHEMBL1407183 & 688267 & 4.75 & 5.0227 & TRN \\
\hline CHEMBL1512638 & 688267 & 4.4 & 5.051 & TST \\
\hline CHEMBL1575806 & 688267 & 6.15 & 5.0982 & TST \\
\hline CHEMBL1466543 & 688267 & 5.3 & 5.0127 & TRN \\
\hline CHEMBL1539037 & 688267 & 4.55 & 5.0355 & TRN \\
\hline CHEMBL1356257 & 688267 & 6.2 & 5.1043 & TRN \\
\hline CHEMBL1585626 & 688267 & 4.1 & 4.9929 & TRN \\
\hline CHEMBL1334949 & 688267 & 4.25 & 5.0601 & TRN \\
\hline CHEMBL1574320 & 688267 & 5.95 & 5.0203 & TST \\
\hline CHEMBL1477025 & 688267 & 4.9 & 5.0416 & TST \\
\hline CHEMBL1508665 & 688267 & 6.15 & 5.005 & TRN \\
\hline CHEMBL1585633 & 688267 & 5.05 & 4.9959 & TST \\
\hline CHEMBL1371851 & 688267 & 5.45 & 5.0553 & TRN \\
\hline CHEMBL1528805 & 688267 & 5.45 & 5.0677 & TRN \\
\hline CHEMBL1504180 & 688267 & 6.2 & 5.0402 & TRN \\
\hline CHEMBL1337144 & 688267 & 4.0 & 4.9729 & TST \\
\hline CHEMBL1344834 & 688267 & 3.95 & 5.0908 & TRN \\
\hline CHEMBL1308679 & 688267 & 4.45 & 5.074 & TRN \\
\hline CHEMBL1518886 & 688267 & 5.0 & 5.1193 & TST \\
\hline CHEMBL1539271 & 688267 & 5.55 & 5.0705 & TST \\
\hline CHEMBL1363855 & 688267 & 4.05 & 5.0203 & TRN \\
\hline CHEMBL1554281 & 688267 & 4.0 & 5.0306 & TRN \\
\hline CHEMBL1513011 & 688267 & 4.35 & 5.0562 & TST \\
\hline
\end{tabular}




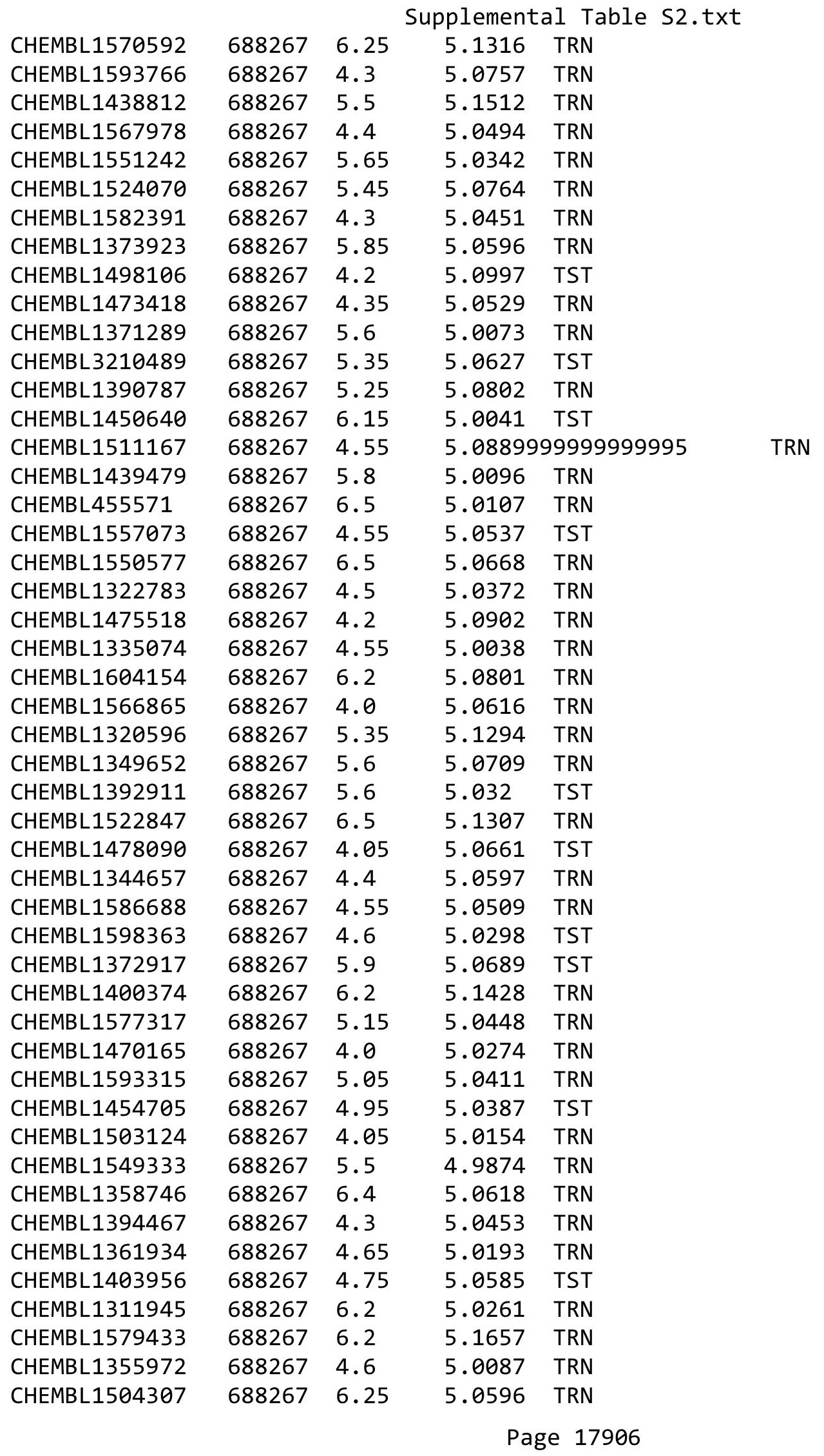




\begin{tabular}{|c|c|c|c|c|c|}
\hline \multicolumn{6}{|c|}{ Supplemental Table S2.txt } \\
\hline CHEMBL1466094 & 688267 & 4.95 & 5.0942 & TRN & \\
\hline CHEMBL1368099 & 688267 & 5.45 & 4.9871 & TRN & \\
\hline CHEMBL1574218 & 688267 & 4.3 & 5.1049 & TST & \\
\hline CHEMBL1457092 & 688267 & 6.2 & 5.0152 & TRN & \\
\hline CHEMBL1373451 & 688267 & 4.0 & 5.1156 & TRN & \\
\hline CHEMBL1513067 & 688267 & 5.6 & 5.0105 & TRN & \\
\hline CHEMBL1304826 & 688267 & 6.2 & 5.0725 & TRN & \\
\hline CHEMBL1596617 & 688267 & 6.25 & 5.09699 & 99999999995 & TRN \\
\hline CHEMBL1549082 & 688267 & 6.25 & 5.0202 & TRN & \\
\hline CHEMBL1556758 & 688267 & 4.0 & 5.0358 & TRN & \\
\hline CHEMBL1404237 & 688267 & 5.6 & 5.0287 & TRN & \\
\hline CHEMBL1593165 & 688267 & 4.05 & 5.0742 & TRN & \\
\hline CHEMBL1562402 & 688267 & 6.2 & 4.9857 & TRN & \\
\hline CHEMBL578329 & 688267 & 4.4 & 5.114 & TRN & \\
\hline CHEMBL1365903 & 688267 & 5.1 & 5.1294 & TRN & \\
\hline CHEMBL1393653 & 688267 & 6.2 & 5.0781 & TRN & \\
\hline CHEMBL1532911 & 688267 & 5.6 & 5.1396 & TRN & \\
\hline CHEMBL1600507 & 688267 & 4.45 & 5.027 & TRN & \\
\hline CHEMBL1451605 & 688267 & 4.0 & 5.0215 & TST & \\
\hline CHEMBL1570969 & 688267 & 4.85 & 5.0227 & TRN & \\
\hline CHEMBL1554999 & 688267 & 6.25 & 5.0616 & TRN & \\
\hline CHEMBL1311687 & 688267 & 4.05 & 5.033 & TRN & \\
\hline CHEMBL1605554 & 688267 & 4.15 & 5.0573 & TST & \\
\hline CHEMBL1534990 & 688267 & 4.35 & 5.0645 & TRN & \\
\hline CHEMBL1319743 & 688267 & 5.95 & 5.0347 & TRN & \\
\hline CHEMBL1547384 & 688267 & 4.0 & 5.0245 & TRN & \\
\hline CHEMBL1396830 & 688267 & 3.95 & 5.0737 & TRN & \\
\hline CHEMBL1399812 & 688267 & 4.05 & 5.0169 & TRN & \\
\hline CHEMBL1315240 & 688267 & 5.0 & 5.0593 & TRN & \\
\hline CHEMBL1376981 & 688267 & 4.75 & 5.0741 & TRN & \\
\hline CHEMBL1533523 & 688267 & 3.95 & 5.0037 & TRN & \\
\hline CHEMBL23731 & 688267 & 5.0 & 5.0388 & TST & \\
\hline CHEMBL582256 & 688267 & 4.0 & 5.0428 & TRN & \\
\hline CHEMBL1484262 & 688267 & 4.0 & 5.0264 & TRN & \\
\hline CHEMBL1565324 & 688267 & 4.8 & 5.0878 & TST & \\
\hline CHEMBL1310392 & 688267 & 3.95 & 5.0991 & TST & \\
\hline CHEMBL1486402 & 688267 & 6.6499 & 5.0659 & TRN & \\
\hline CHEMBL1603516 & 688267 & 5.0 & 5.1058 & TRN & \\
\hline CHEMBL1453754 & 688267 & 5.05 & 5.0298 & TRN & \\
\hline CHEMBL1476689 & 688267 & 5.35 & 5.0076 & TRN & \\
\hline CHEMBL1422867 & 688267 & 5.0 & 5.0871 & TRN & \\
\hline CHEMBL1382851 & 688267 & 4.35 & 5.0441 & TST & \\
\hline CHEMBL1588052 & 688267 & 4.35 & 5.0035 & TRN & \\
\hline CHEMBL1480599 & 688267 & 5.35 & 5.0195 & TST & \\
\hline CHEMBL3189363 & 688267 & 4.45 & 4.988 & TRN & \\
\hline CHEMBL1417110 & 688267 & 4.5 & 5.0326 & TRN & \\
\hline CHEMBL1476064 & 688267 & 4.4 & 5.0753 & TRN & \\
\hline CHEMBL1382045 & 688267 & 4.7 & 5.0946 & TRN & \\
\hline
\end{tabular}




\begin{tabular}{|c|c|c|c|c|c|}
\hline & & \multicolumn{4}{|c|}{ Supplemental Table S2.txt } \\
\hline CHEMBL1528366 & 688267 & 3.95 & 4.9997 & TRN & \\
\hline CHEMBL1349400 & 688267 & 5.4 & 5.0317 & TRN & \\
\hline CHEMBL1547332 & 688267 & 5.1 & 5.0676 & TST & \\
\hline CHEMBL 3195554 & 688267 & 4.4 & 5.0287 & TRN & \\
\hline CHEMBL1546225 & 688267 & 4.55 & 5.043 & TRN & \\
\hline CHEMBL425808 & 688267 & 6.2 & 5.0761 & TST & \\
\hline CHEMBL1542440 & 688267 & 5.05 & 5.1146 & TRN & \\
\hline CHEMBL1602223 & 688267 & 5.75 & \multicolumn{2}{|c|}{5.0089999999999995} & TRN \\
\hline CHEMBL1578849 & 688267 & 6.2 & 5.0365 & TRN & \\
\hline CHEMBL3211707 & 688267 & 4.0 & 5.0321 & TST & \\
\hline CHEMBL1358855 & 688267 & 3.95 & 5.0719 & TRN & \\
\hline CHEMBL1494572 & 688267 & 5.7 & 5.0394 & TRN & \\
\hline CHEMBL1433699 & 688267 & 4.5 & 4.9682 & TRN & \\
\hline CHEMBL1604528 & 688267 & 5.8 & 5.0823 & TRN & \\
\hline CHEMBL1561456 & 688267 & 4.95 & 5.0393 & TRN & \\
\hline CHEMBL1399221 & 688267 & 3.95 & 4.971 & TST & \\
\hline CHEMBL1308712 & 688267 & 4.0 & 5.1173 & TRN & \\
\hline CHEMBL1416405 & 688267 & 6.0 & 5.0277 & TRN & \\
\hline CHEMBL1503790 & 688267 & 5.95 & 5.1246 & TRN & \\
\hline CHEMBL1407022 & 688267 & 6.2 & 5.0179 & TRN & \\
\hline CHEMBL1325248 & 688267 & 4.05 & 5.0791 & TRN & \\
\hline CHEMBL1513167 & 688267 & 4.25 & 5.0371 & TRN & \\
\hline CHEMBL1376139 & 688267 & 4.4 & 5.0682 & TRN & \\
\hline CHEMBL1493947 & 688267 & 6.15 & 5.0653 & TRN & \\
\hline CHEMBL1412315 & 688267 & 5.6 & 5.0214 & TST & \\
\hline CHEMBL270337 & 688267 & 5.55 & 5.0789 & TRN & \\
\hline CHEMBL1426027 & 688267 & 6.2 & 5.005 & TST & \\
\hline CHEMBL1384634 & 688267 & 4.05 & 5.1106 & TRN & \\
\hline CHEMBL1547639 & 688267 & 4.3 & 5.0696 & TST & \\
\hline CHEMBL1390293 & 688267 & 4.6 & \multicolumn{2}{|c|}{5.031000000000001} & TST \\
\hline CHEMBL1445430 & 688267 & 6.2 & 5.0067 & TRN & \\
\hline CHEMBL3198695 & 688267 & 6.2 & 5.1107 & TRN & \\
\hline CHEMBL1431888 & 688267 & 5.0 & 5.0816 & TRN & \\
\hline CHEMBL1417053 & 688267 & 4.35 & \multicolumn{2}{|c|}{5.127999999999999} & TRN \\
\hline CHEMBL1577434 & 688267 & 6.45 & 5.0867 & TRN & \\
\hline CHEMBL1564319 & 688267 & 3.95 & 5.0876 & TRN & \\
\hline CHEMBL1404741 & 688267 & 6.2 & 5.0977 & TST & \\
\hline CHEMBL3196249 & 688267 & 4.85 & 5.1315 & TST & \\
\hline CHEMBL1457633 & 688267 & 4.0 & 5.0356 & TRN & \\
\hline CHEMBL1575170 & 688267 & 4.3 & 5.0 & TST & \\
\hline CHEMBL236059 & 688267 & 6.15 & 5.0293 & TRN & \\
\hline CHEMBL3193658 & 688267 & 4.0 & 4.9847 & TRN & \\
\hline CHEMBL1319190 & 688267 & 4.05 & 5.0202 & TST & \\
\hline CHEMBL1431548 & 688267 & 4.5 & 5.0547 & TRN & \\
\hline CHEMBL1487193 & 688267 & 5.9 & 5.1149 & TRN & \\
\hline CHEMBL1474777 & 688267 & 5.5 & 5.0253 & TRN & \\
\hline CHEMBL1372328 & 688267 & 4.25 & 5.0696 & TRN & \\
\hline CHEMBL1450615 & 688267 & 4.0 & 5.083 & TST & \\
\hline
\end{tabular}




\begin{tabular}{|c|c|c|c|c|}
\hline \multicolumn{5}{|c|}{ Supplemental Tabl } \\
\hline CHEMBL1495402 & 688267 & 6.2 & 5.0666 & TRN \\
\hline CHEMBL1310829 & 688267 & 4.05 & 5.1359 & TRN \\
\hline CHEMBL1478361 & 688267 & 4.8 & 5.0614 & TRN \\
\hline CHEMBL1325726 & 688267 & 6.15 & 5.113 & TST \\
\hline CHEMBL1544978 & 688267 & 4.45 & 5.0005 & TST \\
\hline CHEMBL1573131 & 688267 & 5.25 & 5.088 & TRN \\
\hline CHEMBL1461634 & 688267 & 6.1 & 5.0146 & TRN \\
\hline CHEMBL1511609 & 688267 & 4.3 & 5.0885 & TST \\
\hline CHEMBL1522137 & 688267 & 5.6 & 5.0668 & TRN \\
\hline CHEMBL1479487 & 688267 & 4.1 & 4.9729 & TRN \\
\hline CHEMBL1522240 & 688267 & 6.1 & 5.0885 & TRN \\
\hline CHEMBL1380338 & 688267 & 4.3 & 5.0204 & TRN \\
\hline CHEMBL1594520 & 688267 & 4.3 & 5.1565 & TRN \\
\hline CHEMBL1416549 & 688267 & 6.2 & 5.0444 & TST \\
\hline CHEMBL1518227 & 688267 & 6.25 & 5.0568 & TRN \\
\hline CHEMBL1478272 & 688267 & 4.0 & 5.0268 & TRN \\
\hline CHEMBL1328406 & 688267 & 6.25 & 5.0367 & TRN \\
\hline CHEMBL1458494 & 688267 & 5.4 & 5.1305 & TRN \\
\hline CHEMBL1314500 & 688267 & 5.6 & 5.0512 & TRN \\
\hline CHEMBL1314209 & 688267 & 4.35 & 5.0156 & TRN \\
\hline CHEMBL1557665 & 688267 & 4.95 & 4.9924 & TRN \\
\hline CHEMBL1387555 & 688267 & 5.75 & 5.0285 & TST \\
\hline CHEMBL1424969 & 688267 & 6.15 & 5.0975 & TRN \\
\hline CHEMBL1384888 & 688267 & 5.1 & 5.0246 & TST \\
\hline CHEMBL1313227 & 688267 & 4.4 & 5.1114 & TRN \\
\hline CHEMBL1551405 & 688267 & 5.05 & 4.9919 & TRN \\
\hline CHEMBL1518801 & 688267 & 5.05 & 5.0222 & TRN \\
\hline CHEMBL1572767 & 688267 & 4.05 & 5.0581 & TRN \\
\hline CHEMBL1551289 & 688267 & 6.1 & 5.0323 & TRN \\
\hline CHEMBL1564751 & 688267 & 4.05 & 5.1463 & TRN \\
\hline CHEMBL3193942 & 688267 & 4.6 & 4.9932 & TRN \\
\hline CHEMBL1360981 & 688267 & 4.05 & 5.0002 & TRN \\
\hline CHEMBL1422372 & 688267 & 5.85 & 5.1211 & TRN \\
\hline CHEMBL1408477 & 688267 & 5.15 & 5.1096 & TRN \\
\hline CHEMBL1385648 & 688267 & 4.5 & 5.0561 & TRN \\
\hline CHEMBL1432772 & 688267 & 4.05 & 5.0343 & TRN \\
\hline CHEMBL1580264 & 688267 & 4.45 & 5.1277 & TRN \\
\hline CHEMBL1428791 & 688267 & 5.2 & 5.1593 & TRN \\
\hline CHEMBL1611273 & 688267 & 7.2 & 5.026 & TRN \\
\hline CHEMBL1535722 & 688267 & 4.55 & 5.0481 & TRN \\
\hline CHEMBL1380054 & 688267 & 5.9 & 5.0 & TRN \\
\hline CHEMBL1425190 & 688267 & 5.4 & 5.1059 & TRN \\
\hline CHEMBL1313764 & 688267 & 6.2 & 4.9688 & TRN \\
\hline CHEMBL1488536 & 688267 & 4.3 & 5.0383 & TRN \\
\hline CHEMBL1315235 & 688267 & 4.55 & 5.103 & TRN \\
\hline CHEMBL118481 & 688267 & 4.8 & 4.9941 & TRN \\
\hline CHEMBL1443905 & 688267 & 3.95 & 5.0357 & TRN \\
\hline CHEMBL1564386 & 688267 & 4.3 & 4.9476 & TST \\
\hline
\end{tabular}




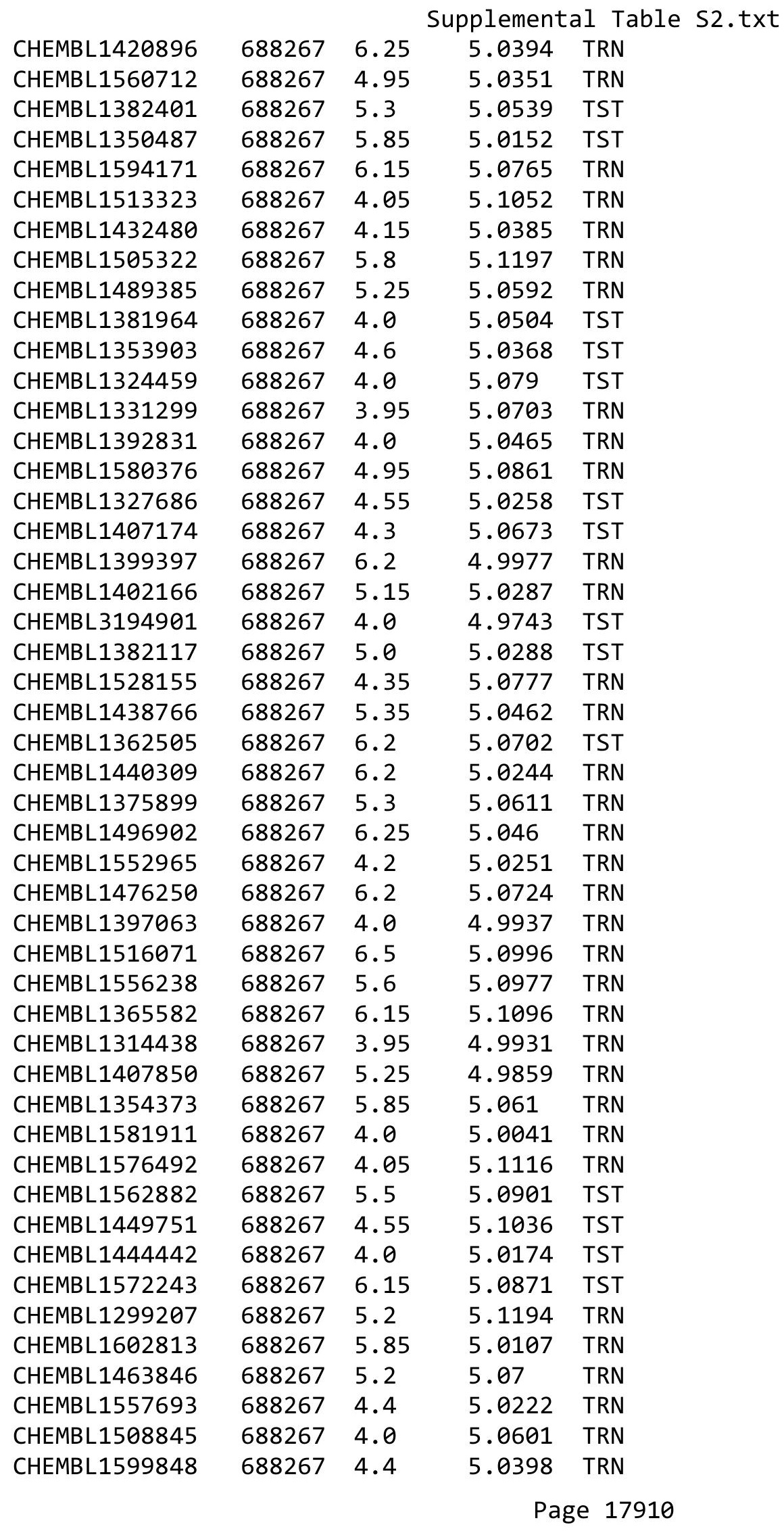




\begin{tabular}{|c|c|c|c|c|}
\hline \multicolumn{5}{|c|}{ Supplemental Table S2.txt } \\
\hline CHEMBL1379417 & 688267 & 6.15 & 5.0413 & TRN \\
\hline CHEMBL1438029 & 688267 & 5.45 & 5.0525 & TRN \\
\hline CHEMBL1339274 & 688267 & 4.95 & 5.0485 & TRN \\
\hline CHEMBL1502317 & 688267 & 5.3 & 5.0121 & TRN \\
\hline CHEMBL1314990 & 688267 & 4.2 & 5.0608 & TRN \\
\hline CHEMBL1484793 & 688267 & 4.35 & 5.027 & TST \\
\hline CHEMBL1368927 & 688267 & 6.15 & 5.065 & TST \\
\hline CHEMBL1309412 & 688267 & 4.0 & 5.0457 & TRN \\
\hline CHEMBL1398116 & 688267 & 4.65 & 5.0985 & TRN \\
\hline CHEMBL1391172 & 688267 & 5.55 & 4.9681 & TRN \\
\hline CHEMBL1573099 & 688267 & 4.0 & 5.1204 & TRN \\
\hline CHEMBL1308490 & 688267 & 3.95 & 5.1084 & TRN \\
\hline CHEMBL1390047 & 688267 & 5.35 & 5.0157 & TRN \\
\hline CHEMBL1412567 & 688267 & 5.05 & 5.0582 & TRN \\
\hline CHEMBL3212456 & 688267 & 6.45 & 5.0722 & TST \\
\hline CHEMBL1370303 & 688267 & 6.25 & 5.1393 & TRN \\
\hline CHEMBL1435417 & 688267 & 4.0 & 5.0569 & TRN \\
\hline CHEMBL1310864 & 688267 & 5.55 & 5.1319 & TRN \\
\hline CHEMBL1409804 & 688267 & 4.3 & 5.1578 & TRN \\
\hline CHEMBL1585659 & 688267 & 4.1 & 5.0785 & TRN \\
\hline CHEMBL1407210 & 688267 & 4.3 & 5.1184 & TRN \\
\hline CHEMBL2369218 & 688267 & 4.5 & 5.0142 & TST \\
\hline CHEMBL1494103 & 688267 & 4.7 & 5.058 & TRN \\
\hline CHEMBL1407481 & 688267 & 4.1 & 4.995 & TRN \\
\hline CHEMBL1413268 & 688267 & 5.0 & 5.0637 & TRN \\
\hline CHEMBL1540934 & 688267 & 4.3 & 5.0711 & TRN \\
\hline CHEMBL1315133 & 688267 & 5.6 & 5.1054 & TRN \\
\hline CHEMBL1558173 & 688267 & 5.8 & 5.0317 & TRN \\
\hline CHEMBL1524176 & 688267 & 4.05 & 5.1211 & TST \\
\hline CHEMBL1507493 & 688267 & 4.0 & 5.1201 & TRN \\
\hline CHEMBL1397931 & 688267 & 5.35 & 5.0395 & TRN \\
\hline CHEMBL3193393 & 688267 & 5.55 & 4.9961 & TRN \\
\hline CHEMBL1413648 & 688267 & 4.55 & 5.0272 & TRN \\
\hline CHEMBL1508980 & 688267 & 4.95 & 5.0836 & TRN \\
\hline CHEMBL1540074 & 688267 & 6.6 & 5.0577 & TST \\
\hline CHEMBL1411772 & 688267 & 5.25 & 5.101 & TRN \\
\hline CHEMBL1595913 & 688267 & 5.5 & 5.0655 & TST \\
\hline CHEMBL1342749 & 688267 & 6.2 & 5.0822 & TRN \\
\hline CHEMBL1388319 & 688267 & 6.2 & 5.0309 & TST \\
\hline CHEMBL1473091 & 688267 & 5.3 & 5.0317 & TRN \\
\hline CHEMBL3210534 & 688267 & 5.35 & 5.0235 & TRN \\
\hline CHEMBL1487312 & 688267 & 4.25 & 5.0785 & TRN \\
\hline CHEMBL1354579 & 688267 & 4.05 & 5.1574 & TRN \\
\hline CHEMBL1364893 & 688267 & 4.5 & 5.074 & TRN \\
\hline CHEMBL1443121 & 688267 & 6.2 & 5.0429 & TRN \\
\hline CHEMBL1484469 & 688267 & 4.4 & 5.016 & TRN \\
\hline CHEMBL1995681 & 688267 & 5.0 & 5.0101 & TST \\
\hline CHEMBL1492616 & 688267 & 4.85 & 5.0519 & TRN \\
\hline
\end{tabular}




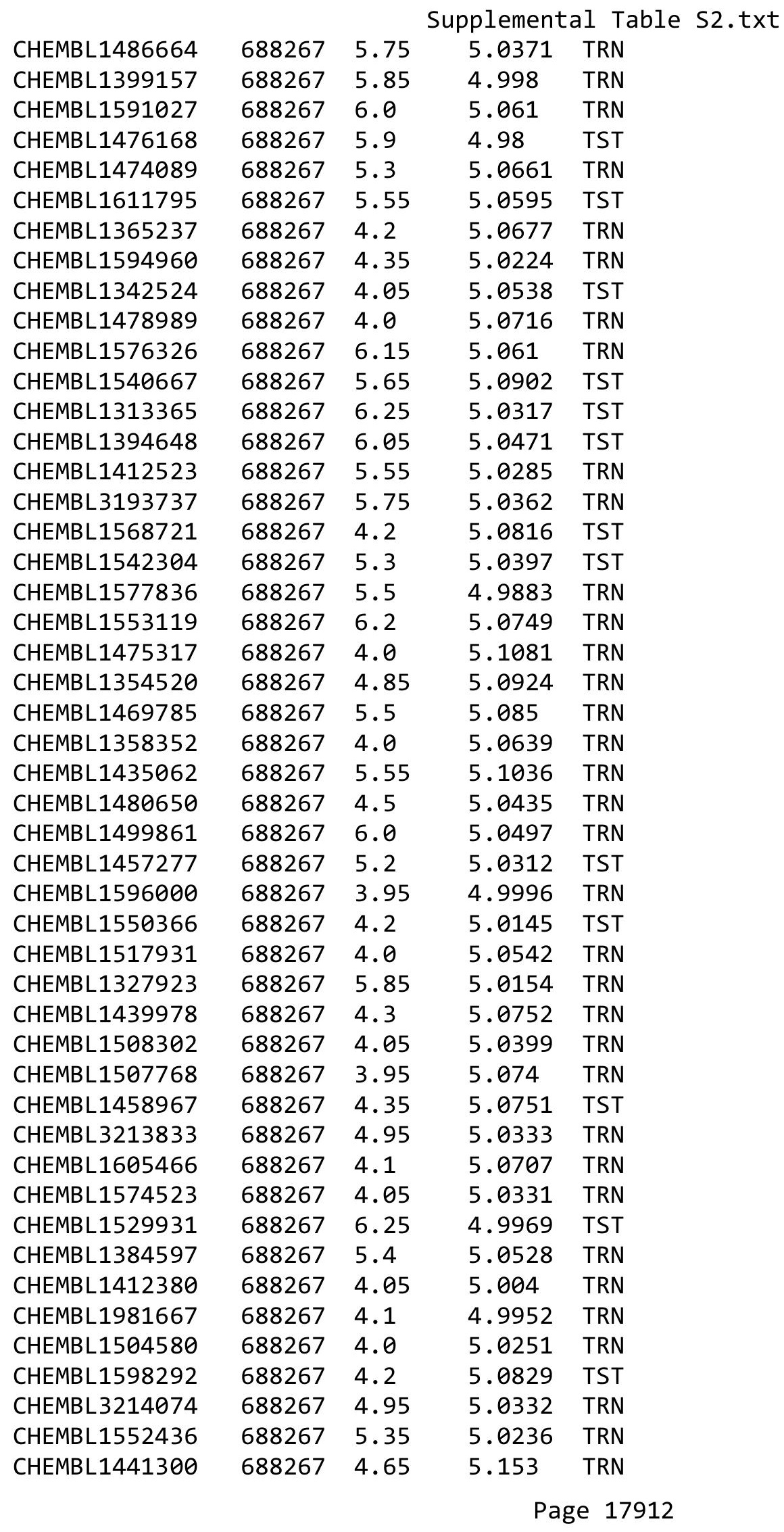




\begin{tabular}{|c|c|c|c|c|}
\hline \multicolumn{5}{|c|}{ Supplemental Table S2.txt } \\
\hline CHEMBL1498957 & 688267 & 5.0 & 5.0905 & TRN \\
\hline CHEMBL1521068 & 688267 & 6.1 & 5.0389 & TRN \\
\hline CHEMBL1559254 & 688267 & 4.6 & 5.0729 & TRN \\
\hline CHEMBL1433901 & 688267 & 4.0 & 5.078 & TRN \\
\hline CHEMBL1317203 & 688267 & 4.05 & 5.0263 & TRN \\
\hline CHEMBL1594793 & 688267 & 5.45 & 5.1011 & TST \\
\hline CHEMBL1325383 & 688267 & 5.0 & 5.0234 & TRN \\
\hline CHEMBL1314290 & 688267 & 4.4 & 5.056 & TST \\
\hline CHEMBL1356556 & 688267 & 4.05 & 5.018 & TRN \\
\hline CHEMBL1312499 & 688267 & 5.95 & 5.0785 & TRN \\
\hline CHEMBL1361953 & 688267 & 4.3 & 5.0604 & TRN \\
\hline CHEMBL1434972 & 688267 & 5.75 & 5.0438 & TST \\
\hline CHEMBL1445027 & 688267 & 6.05 & 5.0753 & TRN \\
\hline CHEMBL1408399 & 688267 & 4.4 & 5.0078 & TST \\
\hline CHEMBL1539934 & 688267 & 5.15 & 5.0039 & TRN \\
\hline CHEMBL1390416 & 688267 & 6.25 & 5.0561 & TST \\
\hline CHEMBL1370283 & 688267 & 6.25 & 5.0267 & TRN \\
\hline CHEMBL1439913 & 688267 & 6.2 & 5.1012 & TRN \\
\hline CHEMBL1337029 & 688267 & 5.75 & 5.1078 & TRN \\
\hline CHEMBL1571041 & 688267 & 4.25 & 5.021 & TST \\
\hline CHEMBL1331925 & 688267 & 5.8 & 5.0743 & TRN \\
\hline CHEMBL1414505 & 688267 & 6.45 & 5.0557 & TRN \\
\hline CHEMBL1445171 & 688267 & 6.2 & 5.1038 & TST \\
\hline CHEMBL3212689 & 688267 & 4.3 & 5.0267 & TRN \\
\hline CHEMBL1546590 & 688267 & 5.0 & 5.1283 & TRN \\
\hline CHEMBL1382657 & 688267 & 4.0 & 5.0966 & TST \\
\hline CHEMBL1509704 & 688267 & 5.55 & 5.0283 & TST \\
\hline CHEMBL3197739 & 688267 & 4.1 & 5.0505 & TST \\
\hline CHEMBL1371068 & 688267 & 4.6 & 5.098 & TRN \\
\hline CHEMBL1595023 & 688267 & 5.9 & 5.0891 & TRN \\
\hline CHEMBL1572674 & 688267 & 4.0 & 5.0673 & TST \\
\hline CHEMBL1334161 & 688267 & 6.3 & 5.1227 & TRN \\
\hline CHEMBL1321345 & 688267 & 5.8 & 5.0765 & TRN \\
\hline CHEMBL1369370 & 688267 & 4.7 & 5.0048 & TRN \\
\hline CHEMBL1415980 & 688267 & 5.55 & 5.1024 & TRN \\
\hline CHEMBL1524782 & 688267 & 4.9 & 5.0723 & TRN \\
\hline CHEMBL1353522 & 688267 & 4.95 & 5.0594 & TRN \\
\hline CHEMBL1338054 & 688267 & 5.05 & 5.0665 & TRN \\
\hline CHEMBL1373620 & 688267 & 4.05 & 5.0472 & TRN \\
\hline CHEMBL1498361 & 688267 & 6.25 & 5.0029 & TRN \\
\hline CHEMBL1367176 & 688267 & 4.0 & 5.0168 & TRN \\
\hline CHEMBL1332305 & 688267 & 6.2 & 5.1117 & TRN \\
\hline CHEMBL1451772 & 688267 & 5.9 & 5.0287 & TST \\
\hline CHEMBL1517633 & 688267 & 5.0 & 5.0371 & TRN \\
\hline CHEMBL1338700 & 688267 & 4.45 & 5.0509 & TRN \\
\hline CHEMBL1414352 & 688267 & 6.2 & 5.0941 & TRN \\
\hline CHEMBL3189396 & 688267 & 4.25 & 5.0208 & TRN \\
\hline CHEMBL1499352 & 688267 & 5.55 & 5.07 & TRN \\
\hline
\end{tabular}




\begin{tabular}{|c|c|c|c|c|c|}
\hline & & \multicolumn{4}{|c|}{ Supplemental Table s2.txt } \\
\hline CHEMBL208484 & 688267 & 6.15 & 4.9924 & TST & \\
\hline CHEMBL1424537 & 688267 & 4.65 & 5.0572 & TST & \\
\hline CHEMBL1357683 & 688267 & 5.7 & 4.9898 & TRN & \\
\hline CHEMBL1474031 & 688267 & 4.35 & 5.0085 & TRN & \\
\hline CHEMBL1510550 & 688267 & 4.25 & 5.0232 & TST & \\
\hline CHEMBL1529154 & 688267 & 4.05 & 4.9778 & TRN & \\
\hline CHEMBL1512287 & 688267 & 3.95 & 5.1074 & TRN & \\
\hline CHEMBL1600056 & 688267 & 4.05 & 5.0384 & TRN & \\
\hline CHEMBL1358075 & 688267 & 5.55 & 5.0939 & TRN & \\
\hline CHEMBL1586989 & 688267 & 6.0 & 5.0446 & TRN & \\
\hline CHEMBL1588637 & 688267 & 5.75 & 5.0581 & TST & \\
\hline CHEMBL1323108 & 688267 & 4.6 & 5.0722 & TRN & \\
\hline CHEMBL1338236 & 688267 & 5.3 & 5.0876 & TRN & \\
\hline CHEMBL1532543 & 688267 & 6.15 & 5.1432 & TRN & \\
\hline CHEMBL1389769 & 688267 & 5.95 & 5.0006 & TRN & \\
\hline CHEMBL1592048 & 688267 & 5.5 & 5.1574 & TRN & \\
\hline CHEMBL1516021 & 688267 & 4.9 & 5.0503 & TST & \\
\hline CHEMBL1597661 & 688267 & 4.35 & 5.0113 & TRN & \\
\hline CHEMBL1480829 & 688267 & 5.5 & 5.0534 & TRN & \\
\hline CHEMBL1593404 & 688267 & 5.6 & 5.0806 & TRN & \\
\hline CHEMBL1594062 & 688267 & 5.95 & 5.0596 & TRN & \\
\hline CHEMBL1521969 & 688267 & 5.7 & 5.0501 & TRN & \\
\hline CHEMBL1328450 & 688267 & 6.5 & 5.1119 & TRN & \\
\hline CHEMBL1453312 & 688267 & 5.05 & 5.0941 & TRN & \\
\hline CHEMBL1524448 & 688267 & 5.85 & 5.0216 & TRN & \\
\hline CHEMBL1355024 & 688267 & 5.15 & 5.1091 & TRN & \\
\hline CHEMBL1339878 & 688267 & 4.1 & 5.0485 & TRN & \\
\hline CHEMBL1359941 & 688267 & 4.0 & 5.0959 & TRN & \\
\hline CHEMBL1383591 & 688267 & 5.15 & 5.0597 & TRN & \\
\hline CHEMBL1531257 & 688267 & 6.2 & 4.9977 & TST & \\
\hline CHEMBL1473107 & 688267 & 4.4 & 5.0074 & TST & \\
\hline CHEMBL1456629 & 688267 & 6.25 & 5.0571 & TRN & \\
\hline CHEMBL1361540 & 688267 & 4.25 & 5.0935 & TRN & \\
\hline CHEMBL1516184 & 688267 & 6.05 & 5.1251 & TRN & \\
\hline CHEMBL1336938 & 688267 & 4.3 & 5.0332 & TST & \\
\hline CHEMBL1301062 & 688267 & 6.25 & 5.0392 & TRN & \\
\hline CHEMBL1564493 & 688267 & 6.15 & 5.0889 & TRN & \\
\hline CHEMBL1491860 & 688267 & 5.35 & 4.9929 & TRN & \\
\hline CHEMBL1499454 & 688267 & 5.6 & 5.0972 & TST & \\
\hline CHEMBL1532398 & 688267 & 5.85 & 5.1356 & TRN & \\
\hline CHEMBL1526273 & 688267 & 5.6 & 5.0629 & TRN & \\
\hline CHEMBL1321688 & 688267 & 4.35 & 5.0161 & TRN & \\
\hline CHEMBL1540193 & 688267 & 4.9 & 5.0164 & TRN & \\
\hline CHEMBL1450378 & 688267 & 4.15 & 5.0839 & TRN & \\
\hline CHEMBL1896181 & 688267 & 6.2 & 4.98600 & 0000000001 & TRN \\
\hline CHEMBL1339551 & 688267 & 3.9 & 5.0607 & TRN & \\
\hline CHEMBL1325164 & 688267 & 4.3 & 5.121 & TST & \\
\hline CHEMBL1457372 & 688267 & 5.75 & 5.0499 & TRN & \\
\hline
\end{tabular}




\begin{tabular}{|c|c|c|c|c|c|}
\hline \\
\hline CHEMBL1451386 & 688267 & 4.4 & 5.0749 & TST & \\
\hline CHEMBL1384870 & 688267 & 4.0 & 5.0601 & TST & \\
\hline CHEMBL1554697 & 688267 & 6.2 & 5.0653 & TRN & \\
\hline CHEMBL1538456 & 688267 & 6.15 & 5.1192 & TST & \\
\hline CHEMBL1460092 & 688267 & 5.55 & 4.9919 & TRN & \\
\hline CHEMBL1563261 & 688267 & 6.2 & 5.0582 & TRN & \\
\hline CHEMBL1414404 & 688267 & 5.25 & 5.0252 & TRN & \\
\hline CHEMBL1514127 & 688267 & 4.4 & 5.0148 & TRN & \\
\hline CHEMBL1358040 & 688267 & 4.25 & 5.0546 & TRN & \\
\hline CHEMBL1447987 & 688267 & 4.0 & 5.0831 & TST & \\
\hline CHEMBL1457554 & 688267 & 4.4 & 5.0833 & TRN & \\
\hline CHEMBL1470011 & 688267 & 5.3 & $5.1160 e$ & 00000000005 & TRN \\
\hline CHEMBL1391416 & 688267 & 5.3 & 5.0848 & TRN & \\
\hline CHEMBL1505412 & 688267 & 4.75 & 5.073 & TRN & \\
\hline CHEMBL1436683 & 688267 & 4.05 & 5.1094 & TRN & \\
\hline CHEMBL1357960 & 688267 & 6.15 & 5.1504 & TRN & \\
\hline CHEMBL1354236 & 688267 & 5.55 & 5.0616 & TRN & \\
\hline CHEMBL1340415 & 688267 & 4.5 & 5.0436 & TRN & \\
\hline CHEMBL1499475 & 688267 & 3.95 & 4.9684 & TRN & \\
\hline CHEMBL1437616 & 688267 & 4.0 & 5.0436 & TRN & \\
\hline CHEMBL1332341 & 688267 & 4.0 & 5.0185 & TRN & \\
\hline CHEMBL1424914 & 688267 & 5.3 & 5.077 & TRN & \\
\hline CHEMBL1325438 & 688267 & 4.3 & 5.1447 & TRN & \\
\hline CHEMBL1335171 & 688267 & 4.1 & 4.9698 & TRN & \\
\hline CHEMBL1500134 & 688267 & 4.3 & 5.0022 & TRN & \\
\hline CHEMBL1341642 & 688267 & 6.45 & 5.0748 & TST & \\
\hline CHEMBL1421973 & 688267 & 5.4 & 5.0181 & TST & \\
\hline CHEMBL1533299 & 688267 & 3.95 & 5.1084 & TRN & \\
\hline CHEMBL1371960 & 688267 & 5.5 & 5.0608 & TST & \\
\hline CHEMBL1430892 & 688267 & 6.1 & 5.0254 & TRN & \\
\hline CHEMBL1541720 & 688267 & 6.15 & 5.0268 & TST & \\
\hline CHEMBL1365239 & 688267 & 4.35 & 5.0476 & TRN & \\
\hline CHEMBL1407428 & 688267 & 4.0 & 5.0566 & TRN & \\
\hline CHEMBL1478116 & 688267 & 4.65 & 5.115 & TRN & \\
\hline CHEMBL3195621 & 688267 & 4.5 & 5.0595 & TRN & \\
\hline CHEMBL1414233 & 688267 & 4.0 & 5.1017 & TRN & \\
\hline CHEMBL1477161 & 688267 & 4.05 & 5.0444 & TRN & \\
\hline CHEMBL1516376 & 688267 & 6.2 & 5.0856 & TRN & \\
\hline CHEMBL1455646 & 688267 & 4.0 & 5.0974 & TRN & \\
\hline CHEMBL1491448 & 688267 & 5.1 & 5.0908 & TRN & \\
\hline CHEMBL1520417 & 688267 & 6.2 & 5.083 & TRN & \\
\hline CHEMBL1597072 & 688267 & 4.05 & 5.0326 & TRN & \\
\hline CHEMBL1477906 & 688267 & 5.8 & 5.0417 & TRN & \\
\hline CHEMBL1508135 & 688267 & 6.2 & 4.9719 & TRN & \\
\hline CHEMBL1582850 & 688267 & 4.5 & 5.0356 & TST & \\
\hline CHEMBL1567474 & 688267 & 6.2 & 5.0659 & TST & \\
\hline CHEMBL1461186 & 688267 & 5.8 & 5.0458 & TRN & \\
\hline CHEMBL1361505 & 688267 & 4.3 & 5.0294 & TRN & \\
\hline & & & & 791 & \\
\hline
\end{tabular}




\begin{tabular}{|c|c|c|c|c|c|}
\hline \multicolumn{6}{|c|}{ Supplemental Table S2.txt } \\
\hline CHEMBL1445409 & 688267 & 4.05 & 5.0688 & TRN & \\
\hline CHEMBL1474436 & 688267 & 4.95 & 5.1327 & TRN & \\
\hline CHEMBL1319793 & 688267 & 4.0 & 5.0975 & TRN & \\
\hline CHEMBL1354927 & 688267 & 4.4 & 5.0006 & TRN & \\
\hline CHEMBL1541293 & 688267 & 4.45 & 5.1412 & TRN & \\
\hline CHEMBL1358577 & 688267 & 5.55 & 5.0042 & TRN & \\
\hline CHEMBL1535594 & 688267 & 4.35 & 5.1462 & TRN & \\
\hline CHEMBL1400908 & 688267 & 4.1 & 5.0616 & TRN & \\
\hline CHEMBL1521598 & 688267 & 6.15 & 5.0861 & TRN & \\
\hline CHEMBL1581934 & 688267 & 4.0 & 5.0881 & TRN & \\
\hline CHEMBL1437558 & 688267 & 5.4 & 5.0282 & TRN & \\
\hline CHEMBL1476821 & 688267 & 5.15 & 5.1368 & TRN & \\
\hline CHEMBL1408446 & 688267 & 6.5501 & 5.0518 & TRN & \\
\hline CHEMBL1603979 & 688267 & 6.2 & 5.03600 & 00000000005 & TRN \\
\hline CHEMBL1597575 & 688267 & 6.2 & 5.0972 & TST & \\
\hline CHEMBL1583226 & 688267 & 5.3 & 5.0834 & TRN & \\
\hline CHEMBL3191701 & 688267 & 4.05 & 4.9844 & TRN & \\
\hline CHEMBL1358944 & 688267 & 4.0 & 5.1221 & TRN & \\
\hline CHEMBL1481785 & 688267 & 4.05 & 5.1269 & TRN & \\
\hline CHEMBL1459611 & 688267 & 4.15 & 4.9809 & TRN & \\
\hline CHEMBL1384999 & 688267 & 5.6 & 5.0696 & TST & \\
\hline CHEMBL1578270 & 688267 & 5.25 & 5.0453 & TST & \\
\hline CHEMBL1610161 & 688267 & 6.2 & 5.0531 & TRN & \\
\hline CHEMBL1324614 & 688267 & 4.55 & 5.0263 & TRN & \\
\hline CHEMBL1486074 & 688267 & 4.7 & 5.0436 & TRN & \\
\hline CHEMBL1555371 & 688267 & 4.7 & 5.0827 & TRN & \\
\hline CHEMBL1601372 & 688267 & 5.05 & 5.0252 & TRN & \\
\hline CHEMBL1495159 & 688267 & 6.0 & 5.0533 & TST & \\
\hline CHEMBL1469007 & 688267 & 4.1 & 5.0192 & TRN & \\
\hline CHEMBL1558756 & 688267 & 4.1 & 5.0799 & TST & \\
\hline CHEMBL1398343 & 688267 & 5.6 & 5.0318 & TRN & \\
\hline CHEMBL1446901 & 688267 & 6.2 & 5.0941 & TRN & \\
\hline CHEMBL1327818 & 688267 & 4.95 & 5.0594 & TRN & \\
\hline CHEMBL1452150 & 688267 & 4.35 & 5.0953 & TRN & \\
\hline CHEMBL1361739 & 688267 & 4.8 & 5.0479 & TST & \\
\hline CHEMBL1554161 & 688267 & 5.15 & 5.1749 & TRN & \\
\hline CHEMBL1330218 & 688267 & 5.85 & 5.1556 & TRN & \\
\hline CHEMBL1427718 & 688267 & 5.65 & 5.0058 & TRN & \\
\hline CHEMBL1364511 & 688267 & 4.05 & 5.0533 & TRN & \\
\hline CHEMBL1306792 & 688267 & 4.7 & 5.0454 & TRN & \\
\hline CHEMBL1322308 & 688267 & 4.65 & 5.0188 & TRN & \\
\hline CHEMBL1571838 & 688267 & 6.2 & 5.1097 & TRN & \\
\hline CHEMBL1525883 & 688267 & 5.0 & 5.0879 & TRN & \\
\hline CHEMBL1436669 & 688267 & 6.1 & 5.0682 & TRN & \\
\hline CHEMBL1554105 & 688267 & 5.8 & 5.1042 & TRN & \\
\hline CHEMBL1590665 & 688267 & 4.2 & 4.9937 & TRN & \\
\hline CHEMBL1359396 & 688267 & 6.45 & 5.0122 & TRN & \\
\hline CHEMBL1332333 & 688267 & 6.2 & 5.105 & TST & \\
\hline
\end{tabular}




\begin{tabular}{|c|c|c|c|c|}
\hline \multicolumn{5}{|c|}{ Supplemental Table S2.txt } \\
\hline CHEMBL3193162 & 688267 & 6.35 & 5.003 & TRN \\
\hline CHEMBL1430380 & 688267 & 4.8 & 5.0853 & TRN \\
\hline CHEMBL1523771 & 688267 & 4.15 & 4.9871 & TST \\
\hline CHEMBL1588394 & 688267 & 4.05 & 4.998 & TRN \\
\hline CHEMBL1477252 & 688267 & 4.45 & 5.0091 & TRN \\
\hline CHEMBL1423206 & 688267 & 4.95 & 5.1231 & TRN \\
\hline CHEMBL1596801 & 688267 & 6.15 & 5.0268 & TRN \\
\hline CHEMBL1406275 & 688267 & 6.1 & 5.0257 & TRN \\
\hline CHEMBL1316807 & 688267 & 4.0 & 5.0536 & TST \\
\hline CHEMBL1356835 & 688267 & 4.1 & 5.1102 & TRN \\
\hline CHEMBL1495645 & 688267 & 4.55 & 5.0349 & TRN \\
\hline CHEMBL1560486 & 688267 & 6.15 & 5.0948 & TST \\
\hline CHEMBL1413855 & 688267 & 4.85 & 5.0322 & TRN \\
\hline CHEMBL1385646 & 688267 & 5.4 & 5.0423 & TRN \\
\hline CHEMBL1576967 & 688267 & 4.45 & 5.064 & TRN \\
\hline CHEMBL1463770 & 688267 & 4.0 & 5.0638 & TRN \\
\hline CHEMBL1514649 & 688267 & 6.0 & 5.0564 & TRN \\
\hline CHEMBL1432412 & 688267 & 4.0 & 5.0268 & TRN \\
\hline CHEMBL1396593 & 688267 & 5.95 & 5.0929 & TRN \\
\hline CHEMBL1445031 & 688267 & 4.9 & 5.0085 & TRN \\
\hline CHEMBL1482100 & 688267 & 5.45 & 5.0223 & TRN \\
\hline CHEMBL1404865 & 688267 & 4.4 & 5.0194 & TRN \\
\hline CHEMBL1347607 & 688267 & 6.2 & 5.0826 & TRN \\
\hline CHEMBL1394321 & 688267 & 5.35 & 5.0871 & TRN \\
\hline CHEMBL1464424 & 688267 & 4.45 & 5.0305 & TRN \\
\hline CHEMBL 2374075 & 688267 & 5.15 & 5.0552 & TRN \\
\hline CHEMBL1541991 & 688267 & 4.55 & 5.0926 & TRN \\
\hline CHEMBL1445168 & 688267 & 6.5 & 4.9792 & TST \\
\hline CHEMBL1433166 & 688267 & 5.3 & 5.0865 & TST \\
\hline CHEMBL1323279 & 688267 & 3.95 & 4.9655 & TRN \\
\hline CHEMBL1462656 & 688267 & 5.45 & 4.9988 & TRN \\
\hline CHEMBL1587088 & 688267 & 5.3 & 4.9619 & TST \\
\hline CHEMBL1503630 & 688267 & 5.2 & 5.0689 & TRN \\
\hline CHEMBL1605963 & 688267 & 4.05 & 5.1214 & TRN \\
\hline CHEMBL1554073 & 688267 & 6.0 & 5.1081 & TRN \\
\hline CHEMBL1373614 & 688267 & 5.05 & 5.0541 & TRN \\
\hline CHEMBL1349674 & 688267 & 4.25 & 5.0142 & TST \\
\hline CHEMBL1473658 & 688267 & 5.6 & 4.9902 & TRN \\
\hline CHEMBL1319802 & 688267 & 5.7 & 5.0673 & TST \\
\hline CHEMBL1374584 & 688267 & 4.1 & 5.0188 & TRN \\
\hline CHEMBL1312108 & 688267 & 3.95 & 5.0187 & TST \\
\hline CHEMBL1574639 & 688267 & 4.0 & 5.0781 & TST \\
\hline CHEMBL1507577 & 688267 & 5.1 & 5.0503 & TRN \\
\hline CHEMBL1388729 & 688267 & 5.35 & 5.0645 & TST \\
\hline CHEMBL1476837 & 688267 & 4.0 & 5.0793 & TRN \\
\hline CHEMBL1609229 & 688267 & 4.05 & 5.1082 & TRN \\
\hline CHEMBL1553105 & 688267 & 4.0 & 5.0132 & TRN \\
\hline CHEMBL1595936 & 688267 & 4.95 & 4.997 & TRN \\
\hline
\end{tabular}




\begin{tabular}{|c|c|c|c|c|c|}
\hline \\
\hline CHEMBL1358678 & 688267 & 5.3 & 5.0234 & TRN & \\
\hline CHEMBL1361622 & 688267 & 4.0 & 5.0925 & TRN & \\
\hline CHEMBL1456267 & 688267 & 6.45 & 5.0403 & TRN & \\
\hline CHEMBL1305983 & 688267 & 5.4 & 5.0192 & TRN & \\
\hline CHEMBL1601977 & 688267 & 3.95 & 5.0671 & TRN & \\
\hline CHEMBL1408561 & 688267 & 5.25 & 5.0441 & TRN & \\
\hline CHEMBL1424170 & 688267 & 4.05 & $4.9830 e$ & 00000000005 & TRN \\
\hline CHEMBL1488880 & 688267 & 4.75 & 5.0427 & TST & \\
\hline CHEMBL3191965 & 688267 & 4.7 & 4.9873 & TRN & \\
\hline CHEMBL1396642 & 688267 & 4.0 & 5.104 & TRN & \\
\hline CHEMBL1561009 & 688267 & 4.05 & 5.0083 & TRN & \\
\hline CHEMBL1978051 & 688267 & 5.6 & 4.9598 & TST & \\
\hline CHEMBL1492187 & 688267 & 4.65 & 5.0733 & TRN & \\
\hline CHEMBL1367644 & 688267 & 4.0 & 5.0981 & TRN & \\
\hline CHEMBL1461084 & 688267 & 5.0 & 5.02800 & 00000000005 & TRN \\
\hline CHEMBL1357704 & 688267 & 4.3 & 5.0971 & TRN & \\
\hline CHEMBL1597900 & 688267 & 5.8 & 5.0888 & TRN & \\
\hline CHEMBL1556295 & 688267 & 4.4 & 5.0295 & TRN & \\
\hline CHEMBL1352096 & 688267 & 5.15 & 5.0987 & TRN & \\
\hline CHEMBL1407901 & 688267 & 5.35 & 5.0546 & TRN & \\
\hline CHEMBL1530850 & 688267 & 4.0 & 5.0497 & TST & \\
\hline CHEMBL1351366 & 688267 & 4.45 & 5.006 & TRN & \\
\hline CHEMBL1406215 & 688267 & 4.0 & 5.0836 & TRN & \\
\hline CHEMBL1400048 & 688267 & 6.15 & 5.1188 & TRN & \\
\hline CHEMBL1551798 & 688267 & 4.4 & 5.0287 & TRN & \\
\hline CHEMBL1363315 & 688267 & 5.55 & 5.0277 & TRN & \\
\hline CHEMBL1316832 & 688267 & 6.0 & 5.0559 & TRN & \\
\hline CHEMBL1474882 & 688267 & 4.0 & 5.1126 & TRN & \\
\hline CHEMBL1256139 & 688267 & 6.2 & 5.0689 & TST & \\
\hline CHEMBL1326053 & 688267 & 6.15 & 5.0928 & TRN & \\
\hline CHEMBL1608596 & 688267 & 6.2 & 5.027 & TRN & \\
\hline CHEMBL1517710 & 688267 & 6.05 & 5.0628 & TRN & \\
\hline CHEMBL1318142 & 688267 & 4.6 & 5.0408 & TRN & \\
\hline CHEMBL1512873 & 688267 & 6.45 & 5.0445 & TRN & \\
\hline CHEMBL3209107 & 688267 & 4.0 & 5.0146 & TST & \\
\hline CHEMBL1462465 & 688267 & 5.15 & 5.1205 & TST & \\
\hline CHEMBL260001 & 688267 & 3.95 & 5.0755 & TRN & \\
\hline CHEMBL1354482 & 688267 & 4.4 & 5.0425 & TRN & \\
\hline CHEMBL1442413 & 688267 & 4.5 & 5.0707 & TRN & \\
\hline CHEMBL1435879 & 688267 & 4.1 & 5.1886 & TRN & \\
\hline CHEMBL1374970 & 688267 & 6.2 & 5.0023 & TST & \\
\hline CHEMBL1362465 & 688267 & 4.45 & 5.0808 & TRN & \\
\hline CHEMBL1606781 & 688267 & 4.45 & 5.0271 & TRN & \\
\hline CHEMBL1553587 & 688267 & 4.55 & 5.034 & TRN & \\
\hline CHEMBL1516162 & 688267 & 6.4 & 5.1344 & TRN & \\
\hline CHEMBL1437188 & 688267 & 4.2 & 5.0407 & TST & \\
\hline CHEMBL1421885 & 688267 & 4.6 & 5.0254 & TRN & \\
\hline CHEMBL1593481 & 688267 & 6.2 & 4.9901 & TRN & \\
\hline
\end{tabular}




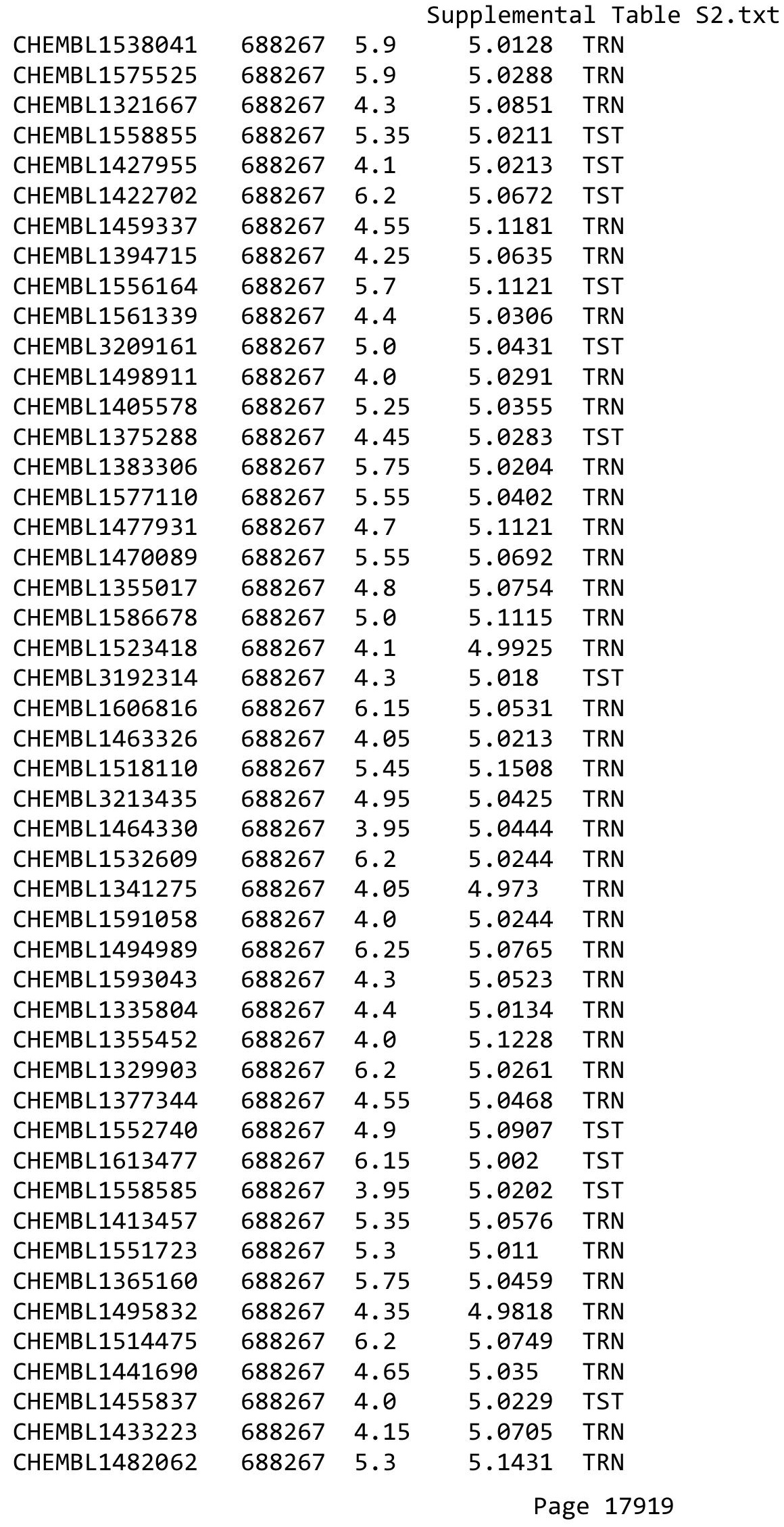




\begin{tabular}{|c|c|c|c|c|c|}
\hline \multicolumn{6}{|c|}{ Supplemental Table S2.txt } \\
\hline CHEMBL1464720 & 688267 & 5.35 & 5.0443 & TST & \\
\hline CHEMBL1469182 & 688267 & 6.15 & 5.095 & TRN & \\
\hline CHEMBL1555544 & 688267 & 6.15 & 5.0699 & TRN & \\
\hline CHEMBL1560754 & 688267 & 4.2 & 5.0808 & TRN & \\
\hline CHEMBL1546896 & 688267 & 4.35 & 5.1055 & TRN & \\
\hline CHEMBL1574601 & 688267 & 4.05 & 5.0612 & TRN & \\
\hline CHEMBL1513536 & 688267 & 4.35 & 5.1271 & TRN & \\
\hline CHEMBL1444469 & 688267 & 6.2 & 5.1008 & TRN & \\
\hline CHEMBL1405205 & 688267 & 5.35 & 5.0691 & TRN & \\
\hline CHEMBL1300781 & 688267 & 4.0 & 5.0644 & TRN & \\
\hline CHEMBL1342948 & 688267 & 3.95 & 5.0317 & TRN & \\
\hline CHEMBL1608051 & 688267 & 4.25 & 5.1232 & TRN & \\
\hline CHEMBL1488037 & 688267 & 4.25 & 5.0505 & TST & \\
\hline CHEMBL1473069 & 688267 & 6.25 & 5.0244 & TRN & \\
\hline CHEMBL1571755 & 688267 & 4.9 & 5.0023 & TRN & \\
\hline CHEMBL1381720 & 688267 & 4.55 & 5.0061 & TRN & \\
\hline CHEMBL1391040 & 688267 & 6.2 & 5.0135 & TRN & \\
\hline CHEMBL1443769 & 688267 & 4.0 & 5.1149 & TST & \\
\hline CHEMBL1450145 & 688267 & 4.0 & 5.0051 & TRN & \\
\hline CHEMBL1423023 & 688267 & 5.3 & 5.0152 & TRN & \\
\hline CHEMBL1484356 & 688267 & 5.95 & 5.1326 & TRN & \\
\hline CHEMBL1435291 & 688267 & 5.8 & 5.0209 & TRN & \\
\hline CHEMBL1397032 & 688267 & 4.3 & 5.02800 & 00000000005 & TRN \\
\hline CHEMBL1361232 & 688267 & 5.0 & 5.0226 & TST & \\
\hline CHEMBL1510820 & 688267 & 5.4 & 5.0548 & TRN & \\
\hline CHEMBL1474105 & 688267 & 5.25 & 5.0243 & TRN & \\
\hline CHEMBL1397429 & 688267 & 4.4 & 5.0395 & TRN & \\
\hline CHEMBL1351525 & 688267 & 4.1 & 5.0298 & TRN & \\
\hline CHEMBL1325836 & 688267 & 6.15 & 5.0833 & TRN & \\
\hline CHEMBL1472657 & 688267 & 4.55 & 5.0395 & TRN & \\
\hline CHEMBL1382980 & 688267 & 4.0 & 5.0818 & TRN & \\
\hline CHEMBL1372545 & 688267 & 5.3 & 5.1072 & TRN & \\
\hline CHEMBL1980584 & 688267 & 4.3 & 4.9979 & TST & \\
\hline CHEMBL1378345 & 688267 & 5.8 & 5.0136 & TRN & \\
\hline CHEMBL 24988 & 688267 & 5.0 & 5.0448 & TST & \\
\hline CHEMBL1362894 & 688267 & 4.05 & 5.0556 & TRN & \\
\hline CHEMBL1362680 & 688267 & 6.2 & 5.0139 & TRN & \\
\hline CHEMBL1515166 & 688267 & 6.5 & 5.115 & TRN & \\
\hline CHEMBL1547444 & 688267 & 5.5 & 5.0435 & TRN & \\
\hline CHEMBL1320879 & 688267 & 5.25 & 5.0797 & TRN & \\
\hline CHEMBL1375656 & 688267 & 4.05 & 5.0412 & TRN & \\
\hline CHEMBL1486191 & 688267 & 6.0 & 4.9951 & TST & \\
\hline CHEMBL3193077 & 688267 & 6.2 & 5.0608 & TRN & \\
\hline CHEMBL1488306 & 688267 & 4.4 & 5.0829 & TST & \\
\hline CHEMBL1418914 & 688267 & 4.5 & 5.0017 & TST & \\
\hline CHEMBL1423712 & 688267 & 5.45 & 5.0255 & TRN & \\
\hline CHEMBL1362199 & 688267 & 6.2 & 5.0624 & TST & \\
\hline CHEMBL1571897 & 688267 & 5.6 & 5.0582 & TRN & \\
\hline
\end{tabular}




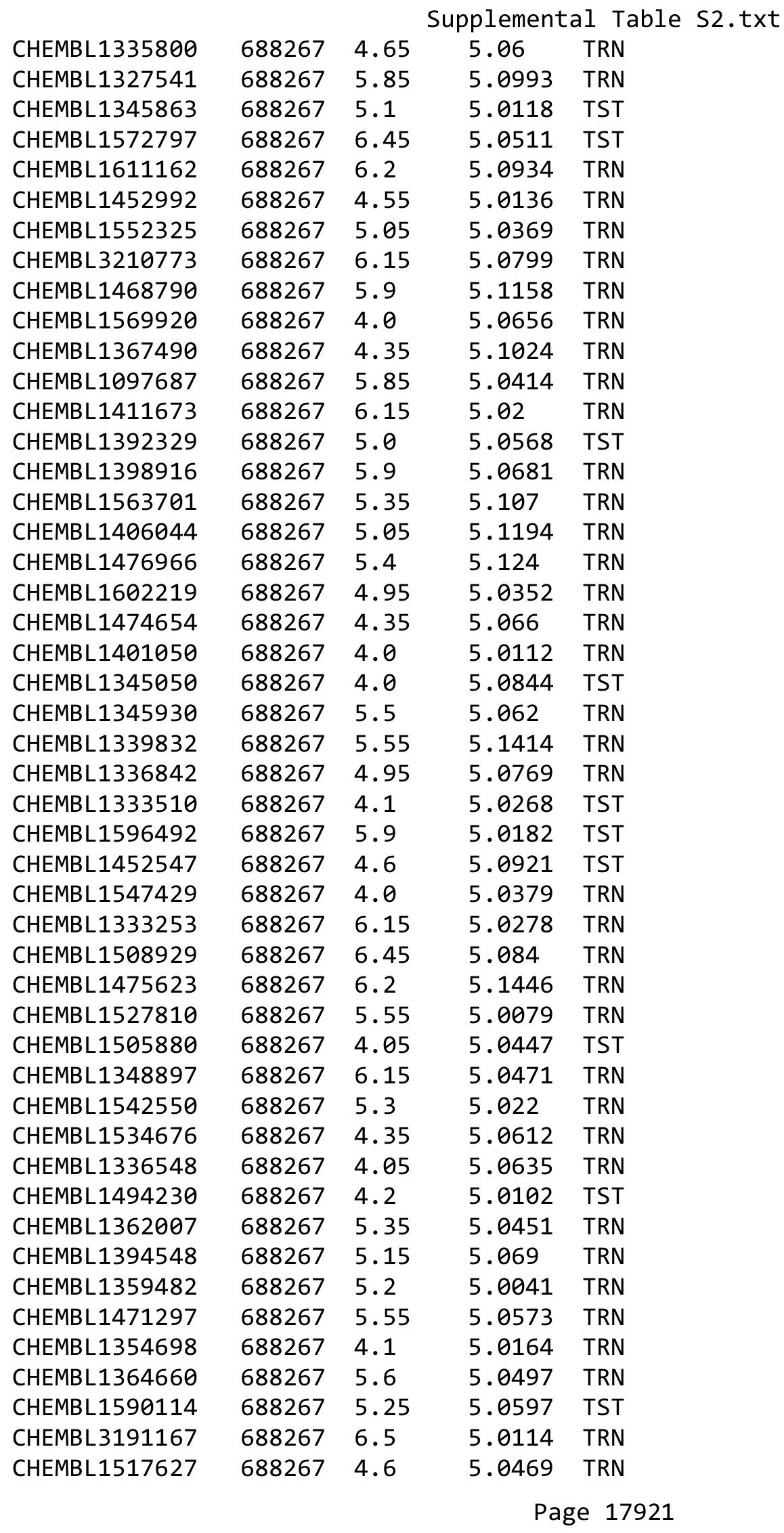




\begin{tabular}{|c|c|c|c|c|c|}
\hline \\
\hline CHEMBL1396775 & 688267 & 6.2 & 5.0565 & TRN & \\
\hline CHEMBL1476554 & 688267 & 5.75 & 5.0785 & TRN & \\
\hline CHEMBL1502839 & 688267 & 5.3 & 5.0396 & TST & \\
\hline CHEMBL1547302 & 688267 & 4.05 & 5.059 & TRN & \\
\hline CHEMBL1353544 & 688267 & 5.9 & 5.0721 & TST & \\
\hline CHEMBL3145366 & 688267 & 6.2 & 5.0338 & TRN & \\
\hline CHEMBL1324043 & 688267 & 4.3 & 5.0217 & TRN & \\
\hline CHEMBL1523022 & 688267 & 5.2 & 5.0897 & TRN & \\
\hline CHEMBL1345822 & 688267 & 5.7 & 5.0432 & TRN & \\
\hline CHEMBL1605205 & 688267 & 6.2 & 5.16299 & 9999999999 & TRN \\
\hline CHEMBL1381824 & 688267 & 5.3 & 5.0155 & TRN & \\
\hline CHEMBL1520291 & 688267 & 5.55 & 5.0307 & TRN & \\
\hline CHEMBL1476999 & 688267 & 5.55 & 5.0633 & TRN & \\
\hline CHEMBL1467006 & 688267 & 6.25 & 5.0312 & TST & \\
\hline CHEMBL1479340 & 688267 & 4.75 & 5.0178 & TST & \\
\hline CHEMBL1410719 & 688267 & 4.0 & 5.0435 & TRN & \\
\hline CHEMBL1381537 & 688267 & 5.5 & 5.0257 & TRN & \\
\hline CHEMBL1399412 & 688267 & 4.05 & 5.1107 & TRN & \\
\hline CHEMBL1365736 & 688267 & 4.4 & 5.1914 & TRN & \\
\hline CHEMBL1561027 & 688267 & 5.45 & 5.0248 & TRN & \\
\hline CHEMBL1580751 & 688267 & 4.0 & 5.0001 & TRN & \\
\hline CHEMBL3212112 & 688267 & 5.75 & 5.0034 & TST & \\
\hline CHEMBL1340390 & 688267 & 4.65 & 5.1353 & TRN & \\
\hline CHEMBL1605854 & 688267 & 3.95 & 4.9733 & TRN & \\
\hline CHEMBL1555696 & 688267 & 5.55 & 5.1213 & TRN & \\
\hline CHEMBL1971636 & 688267 & 4.0 & 5.0352 & TRN & \\
\hline CHEMBL1327899 & 688267 & 4.35 & 5.1163 & TRN & \\
\hline CHEMBL1588249 & 688267 & 4.35 & 5.1146 & TRN & \\
\hline CHEMBL1465242 & 688267 & 6.25 & 5.0021 & TRN & \\
\hline CHEMBL1330086 & 688267 & 6.2 & 5.0314 & TRN & \\
\hline CHEMBL1403527 & 688267 & 5.45 & 5.0418 & TST & \\
\hline CHEMBL1515460 & 688267 & 4.0 & 5.0635 & TRN & \\
\hline CHEMBL1593452 & 688267 & 6.25 & 5.117 & TST & \\
\hline CHEMBL1413013 & 688267 & 5.4 & 5.0535 & TRN & \\
\hline CHEMBL1535186 & 688267 & 5.4 & 5.0179 & TRN & \\
\hline CHEMBL1363637 & 688267 & 6.2 & 5.0911 & TRN & \\
\hline CHEMBL1545188 & 688267 & 5.35 & 5.1105 & TRN & \\
\hline CHEMBL1477011 & 688267 & 4.0 & 5.0282 & TRN & \\
\hline CHEMBL3209842 & 688267 & 3.95 & 5.0026 & TST & \\
\hline CHEMBL1588654 & 688267 & 4.4 & 5.1216 & TRN & \\
\hline CHEMBL1310399 & 688267 & 4.0 & 5.1204 & TRN & \\
\hline CHEMBL1335986 & 688267 & 4.45 & 5.1353 & TRN & \\
\hline CHEMBL1474814 & 688267 & 6.15 & 5.0432 & TST & \\
\hline CHEMBL1549149 & 688267 & 5.0 & 5.0506 & TRN & \\
\hline CHEMBL1517782 & 688267 & 4.0 & 5.0049 & TST & \\
\hline CHEMBL1556759 & 688267 & 3.95 & 5.0335 & TRN & \\
\hline CHEMBL2369190 & 688267 & 4.0 & 4.989 & TST & \\
\hline CHEMBL1484756 & 688267 & 6.2 & 5.0948 & TST & \\
\hline & & & & 17922 & \\
\hline
\end{tabular}




\begin{tabular}{|c|c|c|c|c|c|}
\hline & & \multicolumn{4}{|c|}{ Supplemental Table s2.txt } \\
\hline CHEMBL1350636 & 688267 & 4.4 & 5.1635 & TST & \\
\hline CHEMBL1308934 & 688267 & 6.0 & 5.011 & TRN & \\
\hline CHEMBL1542589 & 688267 & 5.45 & 5.0779 & TRN & \\
\hline CHEMBL1605851 & 688267 & 5.55 & 4.9963 & TRN & \\
\hline CHEMBL1492287 & 688267 & 6.0 & 5.0316 & TRN & \\
\hline CHEMBL1598595 & 688267 & 5.5 & 5.0292 & TRN & \\
\hline CHEMBL1317997 & 688267 & 4.3 & 5.0609 & TST & \\
\hline CHEMBL442951 & 688267 & 5.5 & 5.0876 & TRN & \\
\hline CHEMBL546885 & 688267 & 4.35 & 5.0264 & TRN & \\
\hline CHEMBL3209717 & 688267 & 6.0 & 5.0211 & TST & \\
\hline CHEMBL1613440 & 688267 & 4.25 & 5.0675 & TST & \\
\hline CHEMBL1507329 & 688267 & 6.2 & 5.0927 & TRN & \\
\hline CHEMBL1438273 & 688267 & 5.35 & 5.0793 & TRN & \\
\hline CHEMBL1317903 & 688267 & 6.2 & 5.0516 & TRN & \\
\hline CHEMBL1369229 & 688267 & 4.35 & 5.0414 & TRN & \\
\hline CHEMBL1562231 & 688267 & 4.0 & 5.1046 & TRN & \\
\hline CHEMBL1593488 & 688267 & 4.35 & 5.0559 & TRN & \\
\hline CHEMBL1472931 & 688267 & 5.95 & 5.0583 & TRN & \\
\hline CHEMBL1421698 & 688267 & 6.2 & 5.0635 & TRN & \\
\hline CHEMBL1400542 & 688267 & 5.0 & 5.0367 & TST & \\
\hline CHEMBL1511125 & 688267 & 5.15 & 5.0446 & TRN & \\
\hline CHEMBL1979047 & 688267 & 4.8 & 5.0683 & TRN & \\
\hline CHEMBL1515293 & 688267 & 3.95 & 5.102 & TRN & \\
\hline CHEMBL1329391 & 688267 & 6.15 & 5.06 & TRN & \\
\hline CHEMBL1537182 & 688267 & 4.25 & 5.0915 & TRN & \\
\hline CHEMBL1552248 & 688267 & 6.15 & 5.065 & TRN & \\
\hline CHEMBL1612606 & 688267 & 4.05 & 5.0365 & TRN & \\
\hline CHEMBL1350320 & 688267 & 6.2 & 5.0642 & TRN & \\
\hline CHEMBL1459140 & 688267 & 6.2 & 5.0199 & TST & \\
\hline CHEMBL1555939 & 688267 & 4.55 & 5.0088 & TRN & \\
\hline CHEMBL1427382 & 688267 & 4.8 & 5.1044 & TRN & \\
\hline CHEMBL1440868 & 688267 & 4.25 & 5.0417 & TST & \\
\hline CHEMBL1465801 & 688267 & 4.0 & 5.0487 & TRN & \\
\hline CHEMBL1390052 & 688267 & 5.95 & 5.0302 & TRN & \\
\hline CHEMBL1466949 & 688267 & 4.1 & 5.0151 & TRN & \\
\hline CHEMBL1367814 & 688267 & 5.1 & 5.0726 & TRN & \\
\hline CHEMBL1316768 & 688267 & 6.2 & 5.0669 & TST & \\
\hline CHEMBL1503915 & 688267 & 5.15 & 5.1356 & TRN & \\
\hline CHEMBL1554180 & 688267 & 6.15 & 5.1087 & TRN & \\
\hline CHEMBL1409797 & 688267 & 6.2 & 4.9983 & TRN & \\
\hline CHEMBL1590751 & 688267 & 5.0 & 5.0001 & TST & \\
\hline CHEMBL1337764 & 688267 & 5.85 & 5.0992 & TRN & \\
\hline CHEMBL1447496 & 688267 & 4.5 & 5.0661 & TRN & \\
\hline CHEMBL1590030 & 688267 & 4.85 & 5.1021 & TRN & \\
\hline CHEMBL3209014 & 688267 & 5.6 & 5.00899 & 99999999995 & TRN \\
\hline CHEMBL1453197 & 688267 & 4.35 & 5.0888 & TRN & \\
\hline CHEMBL1505727 & 688267 & 4.45 & 5.0422 & TST & \\
\hline CHEMBL1401634 & 688267 & 5.75 & 5.0129 & TRN & \\
\hline
\end{tabular}




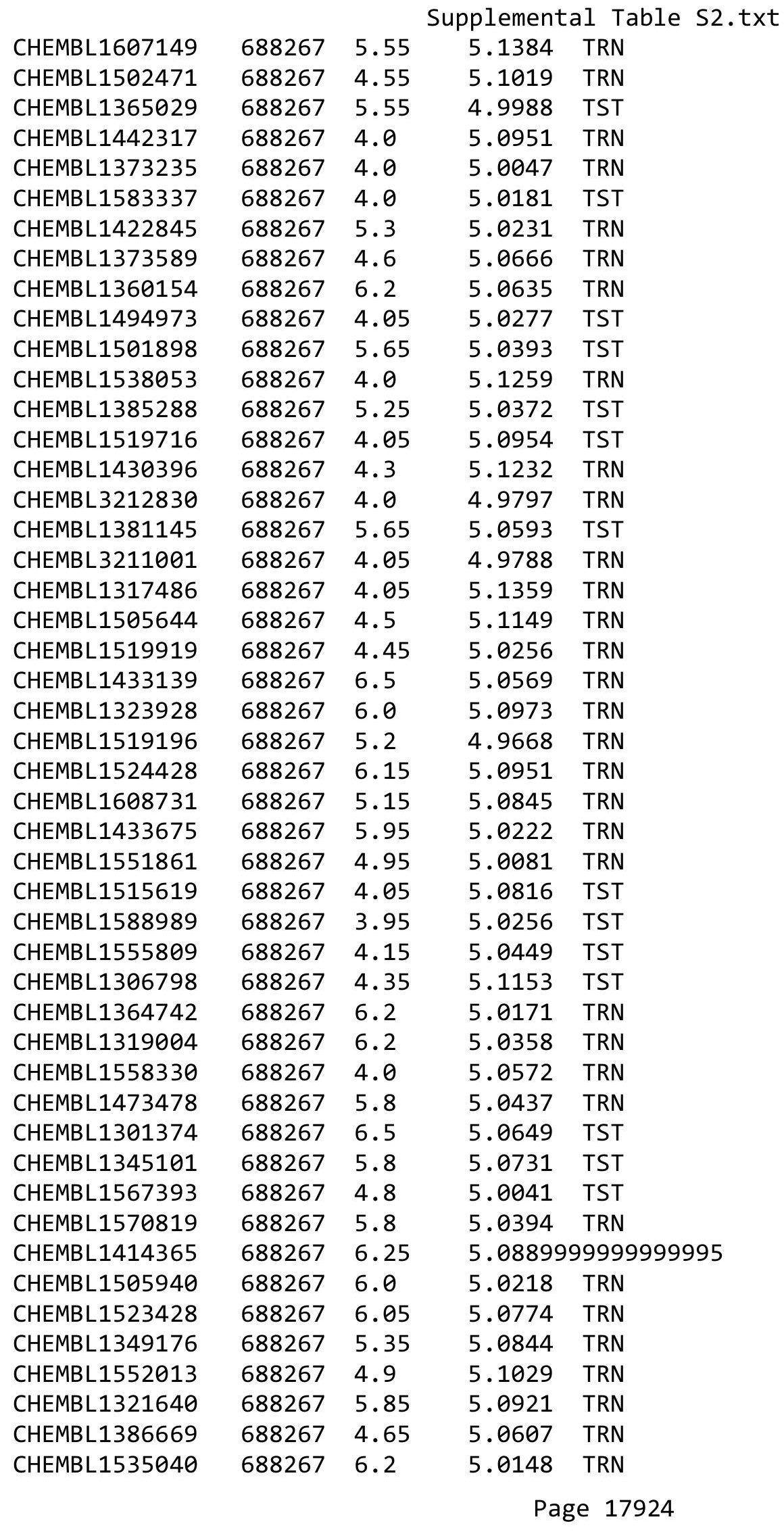




\begin{tabular}{|c|c|c|c|c|c|}
\hline \multirow{3}{*}{$\begin{array}{l}\text { CHEMBL } 3209219 \\
\text { CHEMBL1571302 }\end{array}$} & \multirow{3}{*}{$\begin{array}{l}688267 \\
688267\end{array}$} & \multicolumn{4}{|c|}{ Supplemental Table S2.txt } \\
\hline & & 4.6 & 5.0169 & 99999999995 & TRN \\
\hline & & 5.3 & 5.0625 & TRN & \\
\hline CHEMBL1454493 & 688267 & 6.5 & 5.0318 & TST & \\
\hline CHEMBL1487692 & 688267 & 5.45 & 5.0577 & TST & \\
\hline CHEMBL1462525 & 688267 & 5.5 & 5.0472 & TRN & \\
\hline CHEMBL1386552 & 688267 & 5.05 & 5.0975 & TRN & \\
\hline CHEMBL1421203 & 688267 & 4.35 & 5.0945 & TRN & \\
\hline CHEMBL3195706 & 688267 & 4.1 & 4.9909 & TRN & \\
\hline CHEMBL1455804 & 688267 & 4.65 & 5.0912 & TRN & \\
\hline CHEMBL1433466 & 688267 & 4.0 & 5.1536 & TRN & \\
\hline CHEMBL1459222 & 688267 & 5.25 & 5.1101 & TRN & \\
\hline CHEMBL1433208 & 688267 & 5.3 & 5.0199 & TRN & \\
\hline CHEMBL1326846 & 688267 & 5.3 & 5.1078 & TRN & \\
\hline CHEMBL1306233 & 688267 & 5.1 & 5.0524 & TRN & \\
\hline CHEMBL1375729 & 688267 & 4.4 & 5.1047 & TRN & \\
\hline CHEMBL1602301 & 688267 & 4.35 & 5.102 & TRN & \\
\hline CHEMBL1362837 & 688267 & 4.2 & 5.1104 & TRN & \\
\hline CHEMBL409695 & 688267 & 6.5 & 5.0417 & TRN & \\
\hline CHEMBL1316065 & 688267 & 4.15 & 5.0105 & TRN & \\
\hline CHEMBL1487712 & 688267 & 5.85 & 5.15 & TRN & \\
\hline CHEMBL1395093 & 688267 & 5.45 & 5.0301 & TRN & \\
\hline CHEMBL1373685 & 688267 & 4.15 & 5.0537 & TRN & \\
\hline CHEMBL1356308 & 688267 & 5.75 & 5.0752 & TRN & \\
\hline CHEMBL1503175 & 688267 & 3.95 & 4.9997 & TST & \\
\hline CHEMBL1516168 & 688267 & 6.25 & 5.1367 & TRN & \\
\hline CHEMBL1362194 & 688267 & 4.4 & 5.022 & TRN & \\
\hline CHEMBL1314893 & 688267 & 6.2 & 5.0702 & TRN & \\
\hline CHEMBL1494161 & 688267 & 4.1 & 5.0973 & TRN & \\
\hline CHEMBL1392096 & 688267 & 5.4 & 5.0257 & TRN & \\
\hline CHEMBL3214032 & 688267 & 4.95 & 5.019 & TRN & \\
\hline CHEMBL1375156 & 688267 & 4.25 & 5.047 & TST & \\
\hline CHEMBL1336500 & 688267 & 4.2 & 5.0884 & TST & \\
\hline CHEMBL1607397 & 688267 & 5.15 & 5.1231 & TRN & \\
\hline CHEMBL1601284 & 688267 & 5.75 & 5.0162 & TRN & \\
\hline CHEMBL1373087 & 688267 & 4.1 & 5.1161 & TST & \\
\hline CHEMBL3192610 & 688267 & 5.15 & 5.1131 & TRN & \\
\hline CHEMBL1550122 & 688267 & 5.35 & 5.0096 & TRN & \\
\hline CHEMBL1527521 & 688267 & 5.35 & 5.0562 & TRN & \\
\hline CHEMBL1410424 & 688267 & 4.1 & 4.9757 & TRN & \\
\hline CHEMBL1552389 & 688267 & 4.2 & 5.0794 & TST & \\
\hline CHEMBL1569013 & 688267 & 4.05 & 5.0593 & TRN & \\
\hline CHEMBL3199409 & 688267 & 6.15 & 4.9953 & TRN & \\
\hline CHEMBL1439233 & 688267 & 5.1 & 5.0315 & TRN & \\
\hline CHEMBL1358084 & 688267 & 4.05 & 5.0523 & TRN & \\
\hline CHEMBL1335560 & 688267 & 4.05 & 5.0143 & TST & \\
\hline CHEMBL1416436 & 688267 & 6.2 & 5.1111 & TST & \\
\hline CHEMBL1470948 & 688267 & 4.35 & 5.1159 & TRN & \\
\hline CHEMBL1377282 & 688267 & 6.2 & 5.0412 & TST & \\
\hline
\end{tabular}




\begin{tabular}{|c|c|c|c|c|c|}
\hline \multirow{3}{*}{$\begin{array}{l}\text { CHEMBL1394365 } \\
\text { CHEMBL1609095 }\end{array}$} & \multirow{3}{*}{$\begin{array}{l}688267 \\
688267\end{array}$} & \multicolumn{4}{|c|}{ Supplemental Table S2.txt } \\
\hline & & 5.05 & \multicolumn{2}{|c|}{5.053999999999999} & TST \\
\hline & & 5.35 & 5.0227 & TRN & \\
\hline CHEMBL1400443 & 688267 & 5.3 & 5.0445 & TRN & \\
\hline CHEMBL1532309 & 688267 & 5.5 & 5.0675 & TST & \\
\hline CHEMBL 1374030 & 688267 & 4.4 & 5.0574 & TRN & \\
\hline CHEMBL3213578 & 688267 & 4.8 & 5.0684 & TST & \\
\hline CHEMBL1395526 & 688267 & 6.0 & 5.0762 & TRN & \\
\hline CHEMBL1395977 & 688267 & 6.2 & 5.0809 & TST & \\
\hline CHEMBL1575110 & 688267 & 6.15 & 5.1359 & TST & \\
\hline CHEMBL1416457 & 688267 & 5.45 & 5.0507 & TST & \\
\hline CHEMBL1414299 & 688267 & 4.65 & 5.0335 & TST & \\
\hline CHEMBL1376933 & 688267 & 5.5 & 5.0255 & TST & \\
\hline CHEMBL1437799 & 688267 & 4.35 & 5.1051 & TST & \\
\hline CHEMBL1599527 & 688267 & 6.2 & 5.0454 & TST & \\
\hline CHEMBL1578671 & 688267 & 4.3 & 5.1431 & TRN & \\
\hline CHEMBL1389162 & 688267 & 6.15 & 5.0576 & TRN & \\
\hline CHEMBL1306900 & 688267 & 4.35 & 5.0645 & TRN & \\
\hline CHEMBL1410428 & 688267 & 5.3 & 5.0477 & TRN & \\
\hline CHEMBL1332723 & 688267 & 5.3 & 5.0827 & TRN & \\
\hline CHEMBL1563408 & 688267 & 5.5 & 5.1368 & TRN & \\
\hline CHEMBL1565929 & 688267 & 5.2 & 5.06 & TST & \\
\hline CHEMBL1386258 & 688267 & 4.0 & 5.0711 & TRN & \\
\hline CHEMBL1550760 & 688267 & 4.15 & 5.0088 & TST & \\
\hline CHEMBL1355860 & 688267 & 5.45 & 5.0633 & TRN & \\
\hline CHEMBL1494336 & 688267 & 4.6 & 5.0795 & TRN & \\
\hline CHEMBL1598988 & 688267 & 6.25 & 5.0962 & TRN & \\
\hline CHEMBL1606925 & 688267 & 4.3 & 5.0195 & TRN & \\
\hline CHEMBL1599086 & 688267 & 4.2 & 5.0838 & TST & \\
\hline CHEMBL1520017 & 688267 & 4.0 & 5.1017 & TRN & \\
\hline CHEMBL1506649 & 688267 & 6.2 & 5.0792 & TRN & \\
\hline CHEMBL1567167 & 688267 & 4.05 & 5.1607 & TST & \\
\hline CHEMBL1352817 & 688267 & 4.0 & 5.0001 & TRN & \\
\hline CHEMBL1339155 & 688267 & 6.2 & 5.0293 & TRN & \\
\hline CHEMBL1361957 & 688267 & 5.5 & 5.0828 & TRN & \\
\hline CHEMBL1381606 & 688267 & 5.3 & 5.0512 & TRN & \\
\hline CHEMBL1418154 & 688267 & 5.25 & 5.0198 & TST & \\
\hline CHEMBL 1358800 & 688267 & 6.25 & 5.1059 & TRN & \\
\hline CHEMBL260311 & 688267 & 5.6 & 5.0187 & TST & \\
\hline CHEMBL3189847 & 688267 & 3.95 & 4.9912 & TRN & \\
\hline CHEMBL1414661 & 688267 & 4.8 & 5.0292 & TRN & \\
\hline CHEMBL1388480 & 688267 & 4.35 & 5.0712 & TST & \\
\hline CHEMBL1589968 & 688267 & 4.35 & 5.0337 & TRN & \\
\hline CHEMBL1322571 & 688267 & 5.45 & 5.0077 & TRN & \\
\hline CHEMBL1533315 & 688267 & 5.4 & 5.0962 & TRN & \\
\hline CHEMBL1522209 & 688267 & 6.2 & 5.078 & TRN & \\
\hline CHEMBL1397027 & 688267 & 5.6 & 5.1061 & TRN & \\
\hline CHEMBL1497481 & 688267 & 4.0 & 5.0097 & TRN & \\
\hline CHEMBL1333067 & 688267 & 6.2 & 5.0132 & TRN & \\
\hline
\end{tabular}




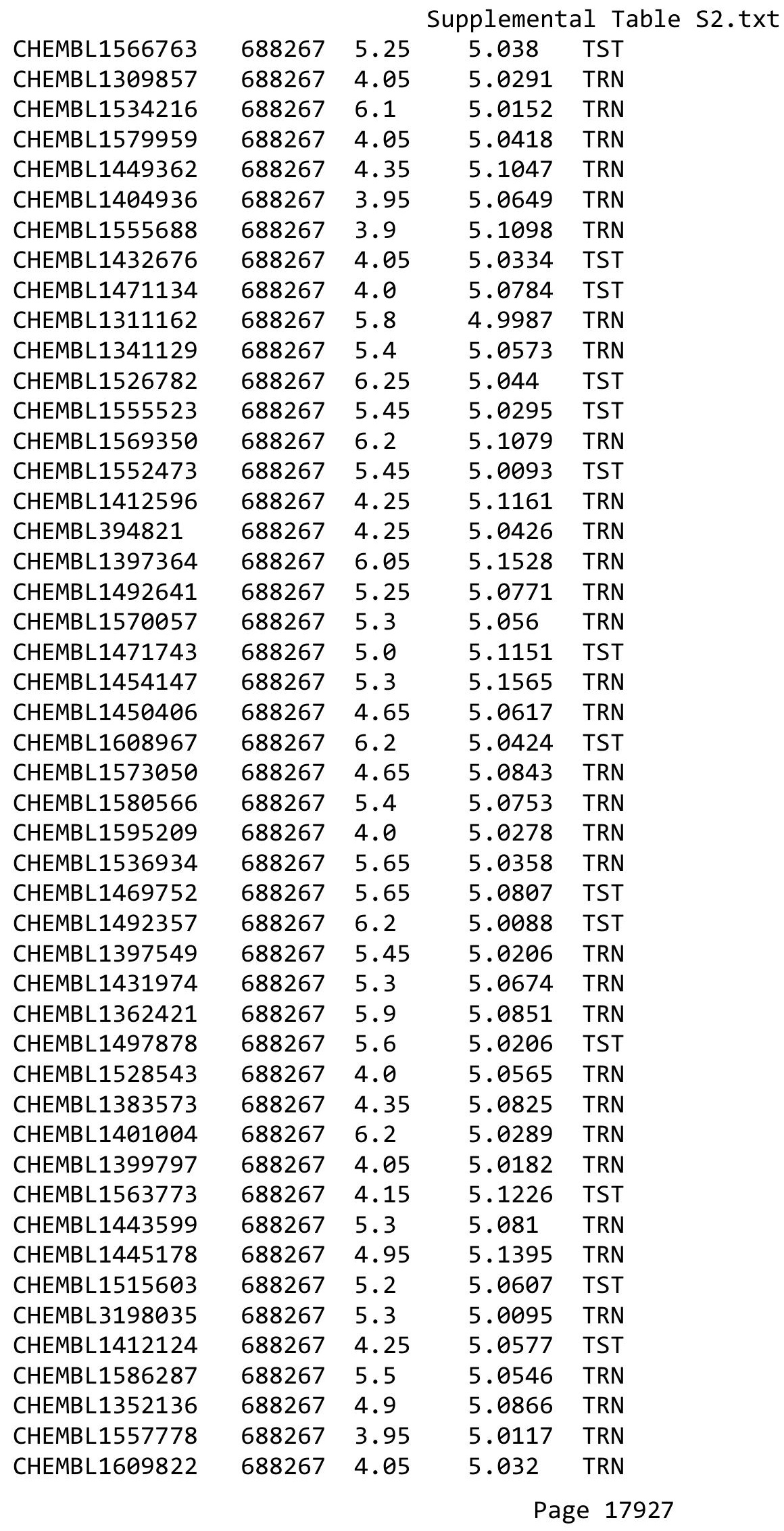




\begin{tabular}{|c|c|c|c|c|c|}
\hline \\
\hline CHEMBL1442631 & 688267 & 6.2 & 5.0515 & TRN & \\
\hline CHEMBL1445490 & 688267 & 5.3 & 5.0309 & TRN & \\
\hline CHEMBL1407874 & 688267 & 5.85 & 5.0637 & TRN & \\
\hline CHEMBL1474586 & 688267 & 6.05 & 5.0836 & TRN & \\
\hline CHEMBL1368101 & 688267 & 5.55 & 5.0084 & TRN & \\
\hline CHEMBL1422888 & 688267 & 4.55 & 5.0543 & TST & \\
\hline CHEMBL1371738 & 688267 & 4.3 & 5.0789 & TST & \\
\hline CHEMBL1457582 & 688267 & 6.25 & 5.056 & TRN & \\
\hline CHEMBL1610848 & 688267 & 5.8 & 5.08899 & 99999999995 & TRN \\
\hline CHEMBL1582382 & 688267 & 5.3 & 5.1053 & TRN & \\
\hline CHEMBL1384159 & 688267 & 4.05 & 5.09 & TRN & \\
\hline CHEMBL1339795 & 688267 & 6.5 & 5.02800 & 00000000005 & TRN \\
\hline CHEMBL1560612 & 688267 & 4.55 & 4.9905 & TRN & \\
\hline CHEMBL1404083 & 688267 & 4.15 & 5.0569 & TST & \\
\hline CHEMBL567529 & 688267 & 5.75 & 5.0187 & TRN & \\
\hline CHEMBL1603459 & 688267 & 4.35 & 4.9976 & TST & \\
\hline CHEMBL1389317 & 688267 & 5.95 & 5.1799 & TST & \\
\hline CHEMBL1413720 & 688267 & 3.95 & 5.0638 & TST & \\
\hline CHEMBL1602398 & 688267 & 5.4 & 5.0219 & TRN & \\
\hline CHEMBL1397290 & 688267 & 5.5 & 5.0177 & TRN & \\
\hline CHEMBL1560548 & 688267 & 3.9 & 5.0525 & TRN & \\
\hline CHEMBL1968458 & 688267 & 4.1 & 4.9883 & TRN & \\
\hline CHEMBL1608511 & 688267 & 4.8 & 5.0369 & TRN & \\
\hline CHEMBL1419481 & 688267 & 4.3 & 5.0494 & TST & \\
\hline CHEMBL1489676 & 688267 & 4.0 & 5.0461 & TRN & \\
\hline CHEMBL1517321 & 688267 & 6.15 & 5.0788 & TRN & \\
\hline CHEMBL1328117 & 688267 & 4.55 & 5.0927 & TRN & \\
\hline CHEMBL1394965 & 688267 & 6.15 & 5.1325 & TRN & \\
\hline CHEMBL1479858 & 688267 & 6.2 & 5.1233 & TRN & \\
\hline CHEMBL1612805 & 688267 & 4.2 & 5.0412 & TRN & \\
\hline CHEMBL1438394 & 688267 & 4.05 & 4.9656 & TRN & \\
\hline CHEMBL1608155 & 688267 & 4.0 & 5.0985 & TRN & \\
\hline CHEMBL1502225 & 688267 & 4.65 & 5.0717 & TST & \\
\hline CHEMBL1414289 & 688267 & 4.6 & 5.0151 & TRN & \\
\hline CHEMBL1387786 & 688267 & 4.35 & 4.9923 & TRN & \\
\hline CHEMBL1471119 & 688267 & 5.0 & 5.0884 & TST & \\
\hline CHEMBL1351230 & 688267 & 5.3 & 5.0126 & TRN & \\
\hline CHEMBL1321703 & 688267 & 4.05 & 4.9745 & TRN & \\
\hline CHEMBL1449520 & 688267 & 4.15 & 5.0094 & TRN & \\
\hline CHEMBL1526562 & 688267 & 5.1 & 5.0338 & TRN & \\
\hline CHEMBL1398210 & 688267 & 6.15 & 5.1066 & TRN & \\
\hline CHEMBL1419671 & 688267 & 4.0 & 5.0401 & TST & \\
\hline CHEMBL1531365 & 688267 & 5.45 & 5.1051 & TRN & \\
\hline CHEMBL1524883 & 688267 & 6.2 & 5.0717 & TRN & \\
\hline CHEMBL1565201 & 688267 & 4.0 & 5.0544 & TRN & \\
\hline CHEMBL1406272 & 688267 & 4.85 & 4.9953 & TRN & \\
\hline CHEMBL1357198 & 688267 & 4.95 & 5.0267 & TRN & \\
\hline CHEMBL1531034 & 688267 & 5.7 & 5.0896 & TRN & \\
\hline
\end{tabular}




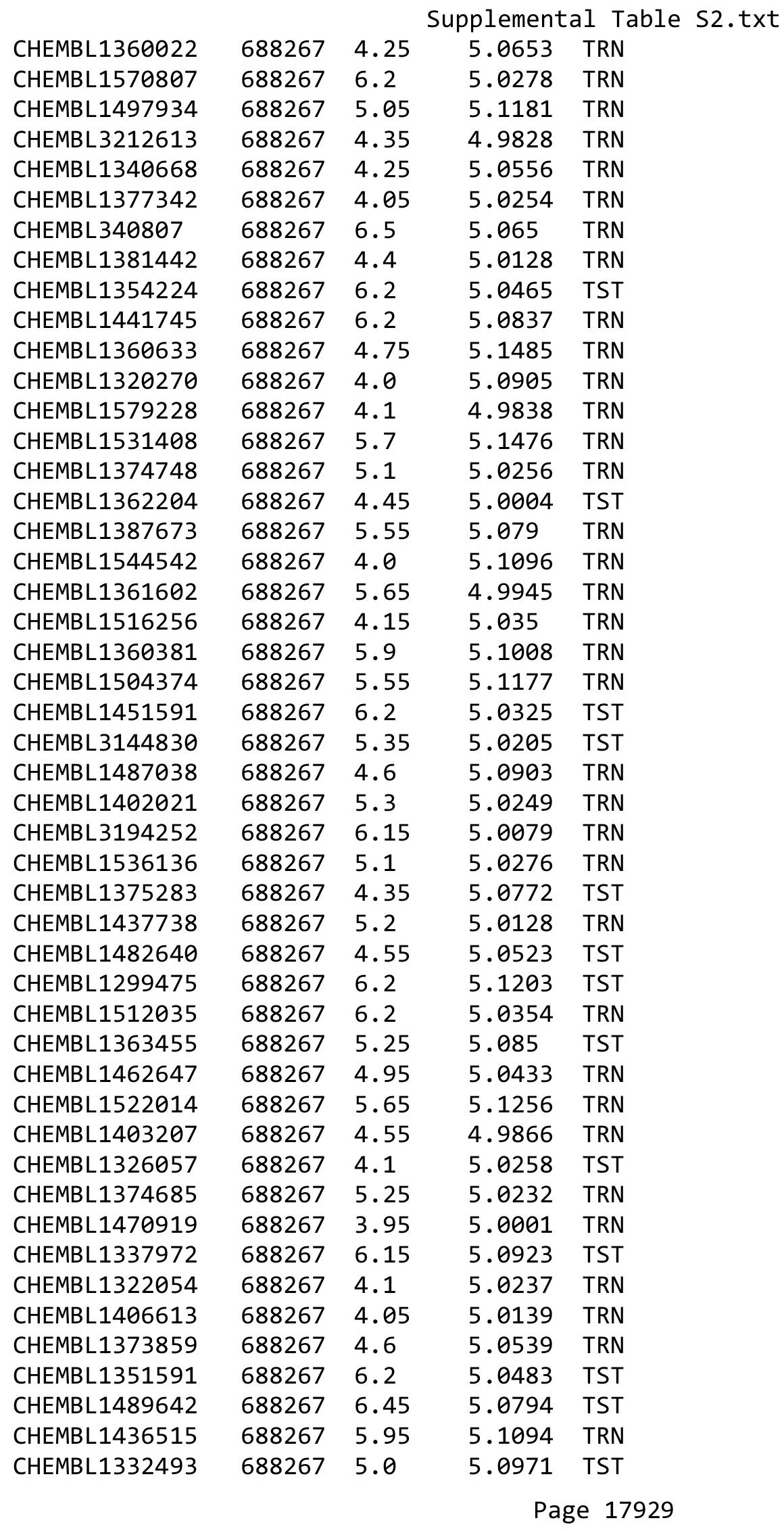




\begin{tabular}{|c|c|c|c|c|c|}
\hline \multicolumn{6}{|c|}{ Supplemental Table S2.txt } \\
\hline CHEMBL1569896 & 688267 & 4.05 & 5.1424 & TRN & \\
\hline CHEMBL3210496 & 688267 & 5.2 & 5.1167 & TRN & \\
\hline CHEMBL1361305 & 688267 & 4.15 & 5.0515 & TST & \\
\hline CHEMBL1971611 & 688267 & 6.2 & 4.9793 & TRN & \\
\hline CHEMBL1520872 & 688267 & 6.25 & 5.0429 & TRN & \\
\hline CHEMBL601184 & 688267 & 4.35 & 5.07600 & 00000000005 & TST \\
\hline CHEMBL1419888 & 688267 & 6.2 & 5.0556 & TST & \\
\hline CHEMBL1481827 & 688267 & 4.35 & 5.1152 & TRN & \\
\hline CHEMBL1394268 & 688267 & 4.7 & 5.0599 & TST & \\
\hline CHEMBL1453209 & 688267 & 4.05 & 5.0171 & TRN & \\
\hline CHEMBL1436070 & 688267 & 4.0 & 5.0443 & TRN & \\
\hline CHEMBL1562737 & 688267 & 5.25 & 5.0268 & TRN & \\
\hline CHEMBL1386029 & 688267 & 5.55 & 5.0788 & TRN & \\
\hline CHEMBL1532181 & 688267 & 5.1 & 5.0401 & TRN & \\
\hline CHEMBL1598452 & 688267 & 5.3 & 5.0553 & TST & \\
\hline CHEMBL1347594 & 688267 & 4.4 & 5.0201 & TRN & \\
\hline CHEMBL1338753 & 688267 & 6.2 & 5.02800 & 00000000005 & TRN \\
\hline CHEMBL1596268 & 688267 & 5.25 & 5.0633 & TRN & \\
\hline CHEMBL1466733 & 688267 & 4.0 & 5.0376 & TRN & \\
\hline CHEMBL1386639 & 688267 & 6.2 & 5.0205 & TRN & \\
\hline CHEMBL3207580 & 688267 & 4.95 & 5.0177 & TRN & \\
\hline CHEMBL1588869 & 688267 & 4.65 & 5.0587 & TRN & \\
\hline CHEMBL1517238 & 688267 & 6.15 & 5.021 & TRN & \\
\hline CHEMBL1460124 & 688267 & 4.3 & 4.9708 & TRN & \\
\hline CHEMBL1305271 & 688267 & 4.35 & 5.0164 & TST & \\
\hline CHEMBL1572247 & 688267 & 5.85 & 5.0783 & TRN & \\
\hline CHEMBL1588722 & 688267 & 5.3 & 5.0713 & TRN & \\
\hline CHEMBL1256191 & 688267 & 5.1 & 5.063 & TST & \\
\hline CHEMBL1490972 & 688267 & 5.5 & 5.0383 & TRN & \\
\hline CHEMBL1541441 & 688267 & 4.3 & 5.0275 & TST & \\
\hline CHEMBL1463300 & 688267 & 5.4 & 5.0568 & TRN & \\
\hline CHEMBL1563922 & 688267 & 3.95 & 5.0807 & TRN & \\
\hline CHEMBL1430957 & 688267 & 6.2 & 5.0426 & TST & \\
\hline CHEMBL1505651 & 688267 & 4.85 & 5.0771 & TRN & \\
\hline CHEMBL1344589 & 688267 & 5.15 & 5.1109 & TRN & \\
\hline CHEMBL1368724 & 688267 & 5.05 & 5.0684 & TRN & \\
\hline CHEMBL1510990 & 688267 & 4.7 & 4.9959 & TST & \\
\hline CHEMBL1535845 & 688267 & 4.05 & 5.0573 & TST & \\
\hline CHEMBL1584277 & 688267 & 5.8 & 5.075 & TRN & \\
\hline CHEMBL1586964 & 688267 & 4.05 & 5.0313 & TRN & \\
\hline CHEMBL1345790 & 688267 & 4.75 & 5.0425 & TST & \\
\hline CHEMBL1334345 & 688267 & 4.0 & 5.0802 & TRN & \\
\hline CHEMBL1317478 & 688267 & 4.15 & 5.0966 & TST & \\
\hline CHEMBL1388637 & 688267 & 6.15 & 5.0135 & TRN & \\
\hline CHEMBL1603511 & 688267 & 5.95 & 5.0782 & TRN & \\
\hline CHEMBL1412827 & 688267 & 4.0 & 5.0839 & TRN & \\
\hline CHEMBL1412050 & 688267 & 6.2 & 5.1015 & TRN & \\
\hline CHEMBL1600224 & 688267 & 5.35 & 5.0642 & TRN & \\
\hline
\end{tabular}




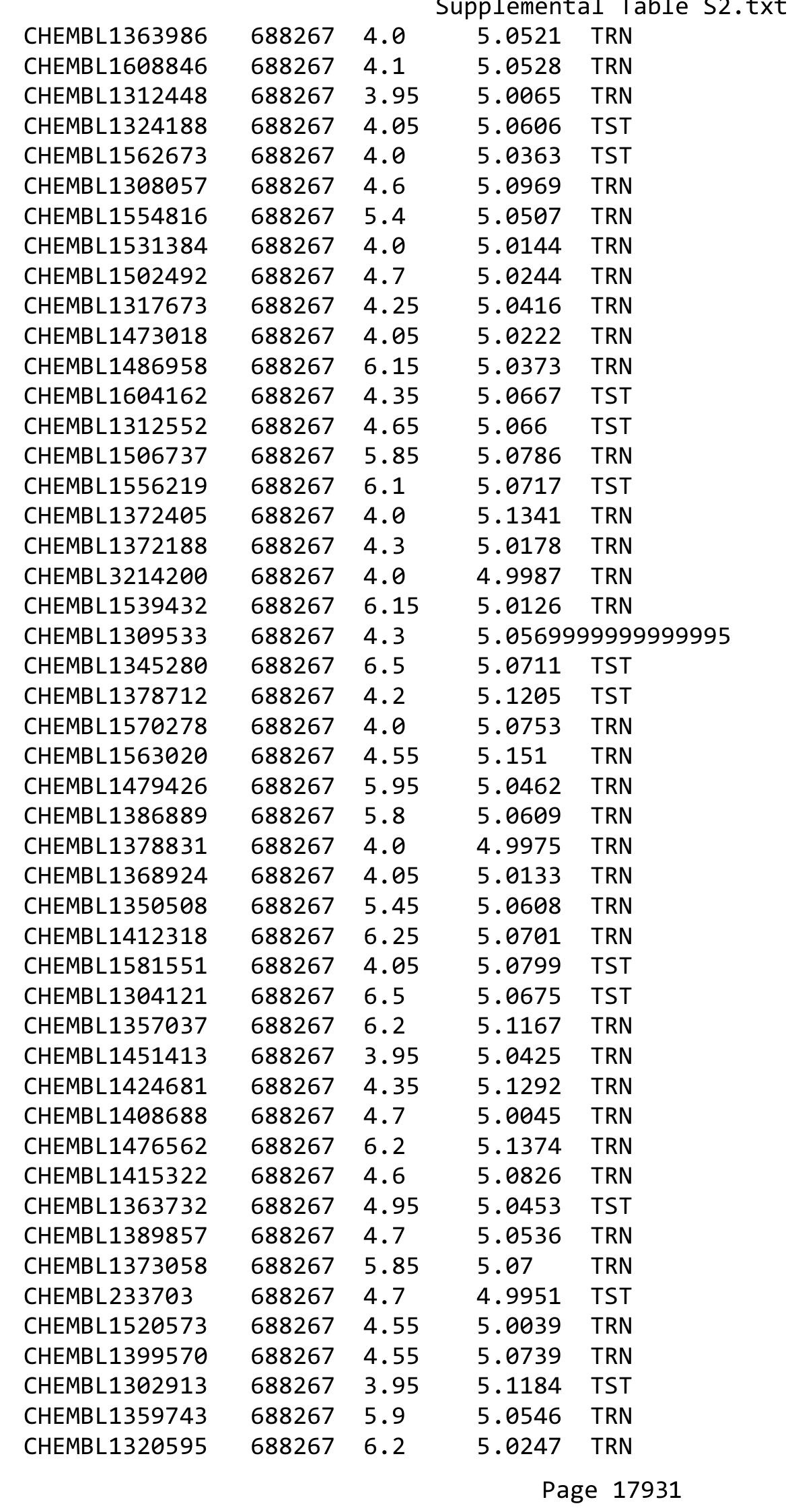




\begin{tabular}{|c|c|c|c|c|c|}
\hline \\
\hline CHEMBL1496249 & 688267 & 4.5 & 5.01 & TRN & \\
\hline CHEMBL1416368 & 688267 & 4.55 & 5.0752 & TRN & \\
\hline CHEMBL1424770 & 688267 & 4.25 & 5.0273 & TRN & \\
\hline CHEMBL1331552 & 688267 & 5.35 & 5.0626 & TST & \\
\hline CHEMBL1411297 & 688267 & 5.5 & 5.1473 & TRN & \\
\hline CHEMBL1359179 & 688267 & 5.1 & 5.0495 & TRN & \\
\hline CHEMBL1483119 & 688267 & 4.1 & 5.0347 & TRN & \\
\hline CHEMBL1426000 & 688267 & 4.5 & 4.9873 & TRN & \\
\hline CHEMBL1424813 & 688267 & 5.35 & 5.0575 & TST & \\
\hline CHEMBL1577414 & 688267 & 5.75 & 5.0443 & TRN & \\
\hline CHEMBL1587803 & 688267 & 5.25 & 5.0693 & TRN & \\
\hline CHEMBL1573791 & 688267 & 6.2 & 5.047 & TRN & \\
\hline CHEMBL1473427 & 688267 & 4.1 & 5.0936 & TRN & \\
\hline CHEMBL1567977 & 688267 & 6.2 & 5.1255 & TRN & \\
\hline CHEMBL3212192 & 688267 & 5.55 & 5.0059 & TST & \\
\hline CHEMBL1569251 & 688267 & 5.3 & 5.0217 & TST & \\
\hline CHEMBL1457700 & 688267 & 3.95 & 5.0432 & TST & \\
\hline CHEMBL1466372 & 688267 & 4.5 & 5.0722 & TRN & \\
\hline CHEMBL1454981 & 688267 & 4.6 & 5.0425 & TST & \\
\hline CHEMBL521035 & 688267 & 5.6 & 5.0959 & TST & \\
\hline CHEMBL3195760 & 688267 & 5.5 & 5.01399 & 9999999999 & TRN \\
\hline CHEMBL1500059 & 688267 & 4.25 & 5.0118 & TRN & \\
\hline CHEMBL1613047 & 688267 & 5.2 & 5.0859 & TST & \\
\hline CHEMBL1378367 & 688267 & 4.4 & 5.0564 & TRN & \\
\hline CHEMBL1502128 & 688267 & 4.4 & 5.0547 & TST & \\
\hline CHEMBL1446013 & 688267 & 4.4 & 5.1264 & TRN & \\
\hline CHEMBL1435999 & 688267 & 5.35 & 5.0084 & TRN & \\
\hline CHEMBL1466907 & 688267 & 4.35 & 5.0348 & TRN & \\
\hline CHEMBL1480128 & 688267 & 3.95 & 5.079 & TRN & \\
\hline CHEMBL1493909 & 688267 & 5.4 & 5.1195 & TRN & \\
\hline CHEMBL1535295 & 688267 & 4.3 & 5.0554 & TST & \\
\hline CHEMBL1469315 & 688267 & 5.3 & 5.0089 & TRN & \\
\hline CHEMBL1431126 & 688267 & 5.2 & 4.9956 & TRN & \\
\hline CHEMBL1388074 & 688267 & 4.4 & 5.0854 & TRN & \\
\hline CHEMBL1564715 & 688267 & 4.6 & 5.0066 & TRN & \\
\hline CHEMBL1460141 & 688267 & 4.2 & 5.041 & TST & \\
\hline CHEMBL1511794 & 688267 & 4.25 & 5.0768 & TRN & \\
\hline CHEMBL1590486 & 688267 & 6.2 & 5.1185 & TRN & \\
\hline CHEMBL1399375 & 688267 & 5.1 & 5.0445 & TRN & \\
\hline CHEMBL1578073 & 688267 & 5.6 & 5.0617 & TRN & \\
\hline CHEMBL3210663 & 688267 & 5.55 & 5.0456 & TRN & \\
\hline CHEMBL1492603 & 688267 & 5.1 & 5.0541 & TRN & \\
\hline CHEMBL1377370 & 688267 & 4.75 & 5.0397 & TRN & \\
\hline CHEMBL1466701 & 688267 & 4.0 & 5.1902 & TRN & \\
\hline CHEMBL1301811 & 688267 & 7.6498 & 4.9815 & TST & \\
\hline CHEMBL1534460 & 688267 & 4.5 & 5.0424 & TRN & \\
\hline CHEMBL1610767 & 688267 & 4.45 & 5.1269 & TRN & \\
\hline CHEMBL1588977 & 688267 & 5.4 & 5.1128 & TRN & \\
\hline
\end{tabular}




\begin{tabular}{|c|c|c|c|c|c|}
\hline \multicolumn{6}{|c|}{ Supplemental Table S2.txt } \\
\hline CHEMBL1521915 & 688267 & 4.15 & 5.05 & TRN & \\
\hline CHEMBL1344733 & 688267 & 4.6 & 5.0557 & TST & \\
\hline CHEMBL1398359 & 688267 & 6.2 & 5.11600 & 00000000005 & TRN \\
\hline CHEMBL1449229 & 688267 & 4.35 & 5.0684 & TRN & \\
\hline CHEMBL1347742 & 688267 & 4.35 & 5.02800 & 00000000005 & TST \\
\hline CHEMBL1312518 & 688267 & 5.9 & 5.1057 & TRN & \\
\hline CHEMBL1557621 & 688267 & 6.15 & 5.1151 & TRN & \\
\hline CHEMBL1517153 & 688267 & 4.6 & 5.0363 & TRN & \\
\hline CHEMBL1968278 & 688267 & 4.0 & 5.0092 & TST & \\
\hline CHEMBL1456808 & 688267 & 4.55 & 5.1482 & TRN & \\
\hline CHEMBL1325649 & 688267 & 5.35 & 5.0537 & TRN & \\
\hline CHEMBL1443950 & 688267 & 6.2 & 5.0493 & TRN & \\
\hline CHEMBL1344325 & 688267 & 4.0 & 5.1402 & TRN & \\
\hline CHEMBL1398034 & 688267 & 6.2 & 5.1006 & TRN & \\
\hline CHEMBL1450585 & 688267 & 4.05 & 5.0563 & TRN & \\
\hline CHEMBL1525945 & 688267 & 5.15 & 5.0201 & TST & \\
\hline CHEMBL1570144 & 688267 & 6.2 & 5.0753 & TST & \\
\hline CHEMBL3195826 & 688267 & 6.25 & 5.0304 & TRN & \\
\hline CHEMBL1529606 & 688267 & 6.15 & 5.0128 & TRN & \\
\hline CHEMBL1505900 & 688267 & 4.05 & 5.0968 & TRN & \\
\hline CHEMBL1593325 & 688267 & 4.0 & 5.0325 & TRN & \\
\hline CHEMBL1567254 & 688267 & 6.2 & 5.0034 & TST & \\
\hline CHEMBL1411727 & 688267 & 4.3 & 5.0071 & TRN & \\
\hline CHEMBL3192700 & 688267 & 4.05 & 5.0386 & TRN & \\
\hline CHEMBL1447227 & 688267 & 6.25 & 5.0419 & TRN & \\
\hline CHEMBL1577564 & 688267 & 7.2 & 5.066 & TST & \\
\hline CHEMBL1435982 & 688267 & 4.2 & 5.1103 & TRN & \\
\hline CHEMBL1482670 & 688267 & 4.1 & 4.9569 & TRN & \\
\hline CHEMBL1318010 & 688267 & 6.25 & 5.008 & TRN & \\
\hline CHEMBL1319838 & 688267 & 4.85 & 5.0563 & TST & \\
\hline CHEMBL1563209 & 688267 & 4.3 & 5.0557 & TRN & \\
\hline CHEMBL1418080 & 688267 & 4.05 & 5.0377 & TRN & \\
\hline CHEMBL1390513 & 688267 & 6.2 & 5.0248 & TRN & \\
\hline CHEMBL1401355 & 688267 & 4.65 & 5.0731 & TST & \\
\hline CHEMBL1429155 & 688267 & 4.05 & 5.0935 & TRN & \\
\hline CHEMBL1401942 & 688267 & 4.85 & 5.0416 & TRN & \\
\hline CHEMBL1328074 & 688267 & 4.7 & 5.0119 & TRN & \\
\hline CHEMBL1347565 & 688267 & 4.45 & 5.0861 & TST & \\
\hline CHEMBL1445523 & 688267 & 6.2 & 5.0421 & TRN & \\
\hline CHEMBL1508681 & 688267 & 6.2 & 5.0336 & TST & \\
\hline CHEMBL1610925 & 688267 & 4.55 & 5.0686 & TST & \\
\hline CHEMBL1441207 & 688267 & 4.2 & 5.0978 & TRN & \\
\hline CHEMBL1377147 & 688267 & 5.4 & 5.125 & TRN & \\
\hline CHEMBL1434872 & 688267 & 5.35 & 5.0391 & TRN & \\
\hline CHEMBL1411277 & 688267 & 6.2 & 5.1003 & TRN & \\
\hline CHEMBL1361804 & 688267 & 4.0 & 5.0843 & TRN & \\
\hline CHEMBL1441018 & 688267 & 6.45 & 5.0451 & TST & \\
\hline CHEMBL1415195 & 688267 & 4.0 & 4.9959 & TRN & \\
\hline
\end{tabular}




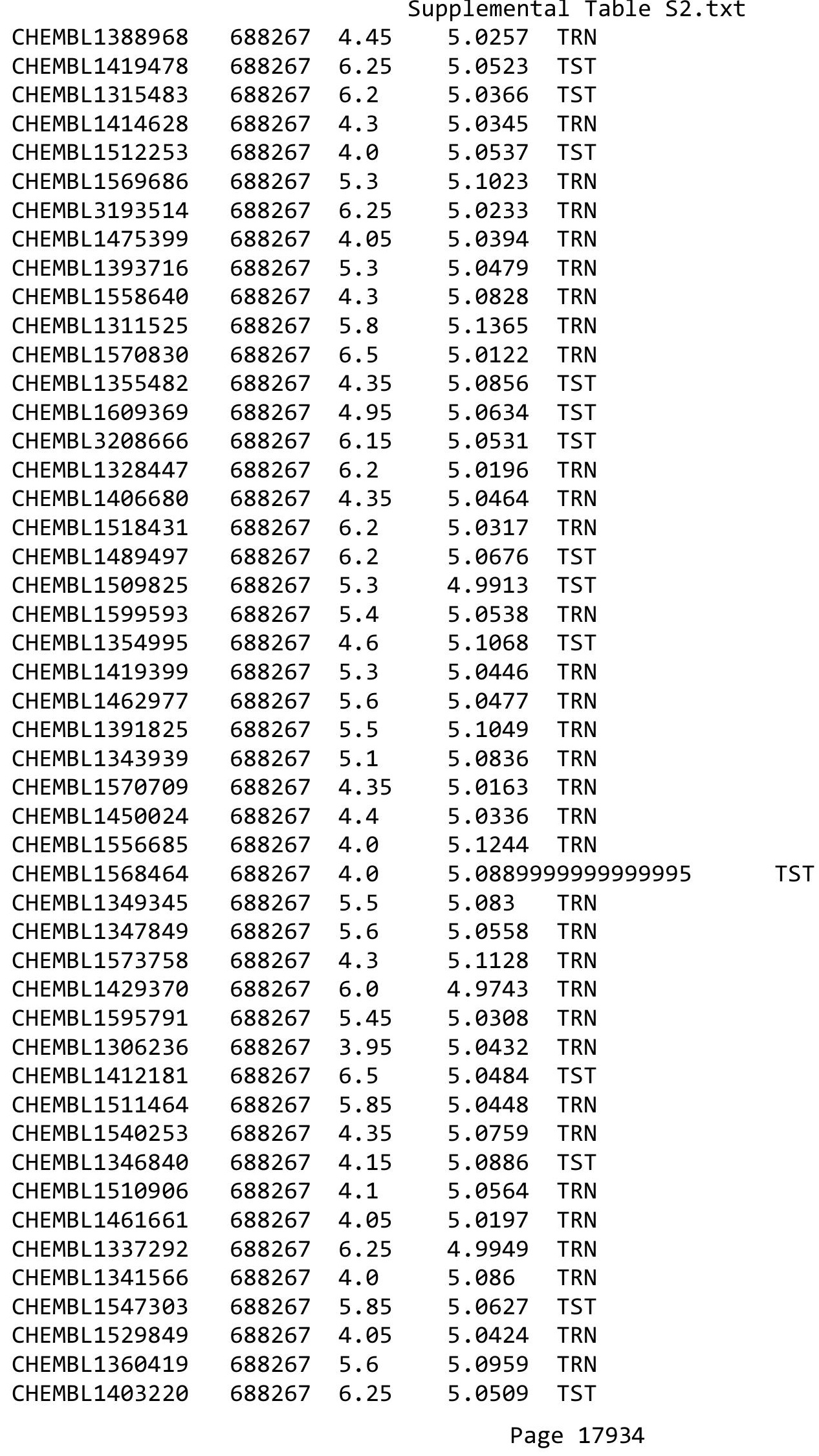




\begin{tabular}{|c|c|c|c|c|c|}
\hline \multicolumn{6}{|c|}{ Supplemental Table S2.txt } \\
\hline CHEMBL1587052 & 688267 & 5.45 & 5.0439 & TRN & \\
\hline CHEMBL1398272 & 688267 & 5.25 & 5.0693 & TRN & \\
\hline CHEMBL1550220 & 688267 & 5.75 & 5.0945 & TST & \\
\hline CHEMBL1573616 & 688267 & 4.5 & 5.0832 & TRN & \\
\hline CHEMBL1472223 & 688267 & 4.45 & 5.0719 & TRN & \\
\hline CHEMBL1573797 & 688267 & 4.4 & 5.0838 & TRN & \\
\hline CHEMBL1333009 & 688267 & 5.45 & 5.0333 & TRN & \\
\hline CHEMBL1439470 & 688267 & 6.2 & 5.1103 & TRN & \\
\hline CHEMBL1986444 & 688267 & 4.0 & 4.9745 & TRN & \\
\hline CHEMBL1379511 & 688267 & 6.2 & 4.9431 & TRN & \\
\hline CHEMBL1573139 & 688267 & 5.05 & 5.1116 & TST & \\
\hline CHEMBL1380509 & 688267 & 4.25 & 5.0388 & TRN & \\
\hline CHEMBL1467271 & 688267 & 5.15 & 5.0373 & TRN & \\
\hline CHEMBL1524355 & 688267 & 4.5 & 5.0574 & TRN & \\
\hline CHEMBL1391610 & 688267 & 4.1 & 5.0559 & TST & \\
\hline CHEMBL1334022 & 688267 & 5.35 & 5.0926 & TRN & \\
\hline CHEMBL1578672 & 688267 & 5.4 & 5.0571 & TRN & \\
\hline CHEMBL1521905 & 688267 & 6.2 & 5.0556 & TRN & \\
\hline CHEMBL1580319 & 688267 & 6.2 & 5.0175 & TRN & \\
\hline CHEMBL1590298 & 688267 & 5.85 & 5.0349 & TRN & \\
\hline CHEMBL1390116 & 688267 & 5.35 & 4.9987 & TRN & \\
\hline CHEMBL1537421 & 688267 & 4.1 & 5.0701 & TRN & \\
\hline CHEMBL1434597 & 688267 & 3.95 & 5.0828 & TRN & \\
\hline CHEMBL1431881 & 688267 & 5.25 & 5.0224 & TRN & \\
\hline CHEMBL1326566 & 688267 & 4.05 & 5.0667 & TRN & \\
\hline CHEMBL1327675 & 688267 & 4.4 & 5.0724 & TRN & \\
\hline CHEMBL1302582 & 688267 & 6.1 & 5.0781 & TRN & \\
\hline CHEMBL1495837 & 688267 & 4.25 & 5.1101 & TRN & \\
\hline CHEMBL1588686 & 688267 & 4.45 & 5.05399 & 9999999999 & TST \\
\hline CHEMBL1499927 & 688267 & 4.25 & 5.0963 & TRN & \\
\hline CHEMBL3207475 & 688267 & 5.0 & 5.1392 & TST & \\
\hline CHEMBL1425294 & 688267 & 4.4 & 5.0674 & TRN & \\
\hline CHEMBL1256396 & 688267 & 5.0 & 5.0402 & TST & \\
\hline CHEMBL1363941 & 688267 & 5.3 & 5.0134 & TRN & \\
\hline CHEMBL1450880 & 688267 & 6.15 & 5.0668 & TRN & \\
\hline CHEMBL1610392 & 688267 & 4.9 & 5.0223 & TRN & \\
\hline CHEMBL1461244 & 688267 & 4.4 & 5.03600 & 00000000005 & TST \\
\hline CHEMBL1521206 & 688267 & 5.35 & 5.026 & TRN & \\
\hline CHEMBL1433906 & 688267 & 3.95 & 5.0438 & TRN & \\
\hline CHEMBL1553876 & 688267 & 5.55 & 5.1295 & TRN & \\
\hline CHEMBL1411495 & 688267 & 5.0 & 5.0998 & TRN & \\
\hline CHEMBL1610316 & 688267 & 5.5 & 5.0001 & TST & \\
\hline CHEMBL1329427 & 688267 & 4.3 & 5.0909 & TRN & \\
\hline CHEMBL1521128 & 688267 & 4.35 & 5.0656 & TRN & \\
\hline CHEMBL1592897 & 688267 & 5.5 & 5.086 & TRN & \\
\hline CHEMBL1489623 & 688267 & 6.05 & 5.0073 & TRN & \\
\hline CHEMBL1386737 & 688267 & 6.25 & 5.0305 & TRN & \\
\hline CHEMBL1322670 & 688267 & 4.6 & 5.027 & TRN & \\
\hline
\end{tabular}




\begin{tabular}{|c|c|c|c|c|c|}
\hline \multicolumn{6}{|c|}{ oplemental Table S2 } \\
\hline CHEMBL1348860 & 688267 & 4.0 & 5.0909 & TST & \\
\hline CHEMBL1486703 & 688267 & 4.75 & 5.1255 & TRN & \\
\hline CHEMBL1358447 & 688267 & 5.9 & 5.1255 & TRN & \\
\hline CHEMBL3196146 & 688267 & 4.65 & 5.0545 & TST & \\
\hline CHEMBL177754 & 688267 & 4.0 & 5.0155 & TRN & \\
\hline CHEMBL1609753 & 688267 & 6.25 & 5.0384 & TRN & \\
\hline CHEMBL1310041 & 688267 & 4.25 & 4.9931 & TRN & \\
\hline CHEMBL1467928 & 688267 & 4.4 & 5.0675 & TST & \\
\hline CHEMBL1523919 & 688267 & 6.0 & 5.0499 & TRN & \\
\hline CHEMBL1429287 & 688267 & 5.75 & 5.041 & TRN & \\
\hline CHEMBL1489717 & 688267 & 4.0 & 5.0602 & TRN & \\
\hline CHEMBL3197884 & 688267 & 4.0 & 5.0197 & TST & \\
\hline CHEMBL1431793 & 688267 & 4.5 & 5.0449 & TRN & \\
\hline CHEMBL1528461 & 688267 & 4.2 & 5.0532 & TRN & \\
\hline CHEMBL 3189820 & 688267 & 6.2 & 5.0383 & TRN & \\
\hline CHEMBL1358175 & 688267 & 6.2 & 5.0112 & TRN & \\
\hline CHEMBL1316702 & 688267 & 4.0 & 5.0246 & TRN & \\
\hline CHEMBL1605611 & 688267 & 4.55 & 5.1293 & TRN & \\
\hline CHEMBL1379476 & 688267 & 4.0 & 5.067 & TRN & \\
\hline CHEMBL 3145025 & 688267 & 5.3 & 5.00899 & 99999999995 & TST \\
\hline CHEMBL1517797 & 688267 & 4.0 & 5.0245 & TRN & \\
\hline CHEMBL1551530 & 688267 & 6.2 & 5.0975 & TRN & \\
\hline CHEMBL1367061 & 688267 & 4.1 & 5.024 & TRN & \\
\hline CHEMBL1366542 & 688267 & 6.25 & 5.0386 & TRN & \\
\hline CHEMBL1369380 & 688267 & 4.0 & 5.0467 & TST & \\
\hline CHEMBL1576963 & 688267 & 4.6 & 5.0226 & TRN & \\
\hline CHEMBL1479893 & 688267 & 4.5 & 5.0589 & TST & \\
\hline CHEMBL1385319 & 688267 & 5.3 & 5.0701 & TRN & \\
\hline CHEMBL1467362 & 688267 & 4.3 & 5.0865 & TRN & \\
\hline CHEMBL1555026 & 688267 & 4.05 & 5.0812 & TRN & \\
\hline CHEMBL1603187 & 688267 & 4.6 & 5.0679 & TRN & \\
\hline CHEMBL1349861 & 688267 & 6.2 & 5.0672 & TRN & \\
\hline CHEMBL1370085 & 688267 & 4.35 & 5.0531 & TRN & \\
\hline CHEMBL1405549 & 688267 & 5.25 & 5.0588 & TST & \\
\hline CHEMBL602174 & 688267 & 4.45 & 5.0802 & TST & \\
\hline CHEMBL1324385 & 688267 & 4.2 & 5.0818 & TRN & \\
\hline CHEMBL1543318 & 688267 & 5.5 & 5.0243 & TRN & \\
\hline CHEMBL1530713 & 688267 & 4.85 & 5.0255 & TST & \\
\hline CHEMBL1310292 & 688267 & 4.45 & 5.112 & TRN & \\
\hline CHEMBL1585671 & 688267 & 4.3 & 5.0835 & TRN & \\
\hline CHEMBL1474645 & 688267 & 4.4 & 5.0035 & TRN & \\
\hline CHEMBL1438703 & 688267 & 5.55 & 5.0788 & TST & \\
\hline CHEMBL1584652 & 688267 & 6.2 & 5.0678 & TST & \\
\hline CHEMBL1433198 & 688267 & 3.95 & 5.0157 & TRN & \\
\hline CHEMBL1370379 & 688267 & 5.25 & 5.0225 & TST & \\
\hline CHEMBL1474027 & 688267 & 4.35 & 5.0467 & TRN & \\
\hline CHEMBL3197261 & 688267 & 4.25 & 5.0168 & TST & \\
\hline CHEMBL1343737 & 688267 & 5.4 & 5.0517 & TST & \\
\hline
\end{tabular}




\begin{tabular}{|c|c|c|c|c|c|}
\hline & & & & & \\
\hline CHEMBL1300934 & 688267 & 4.0 & 5.0297 & TST & \\
\hline CHEMBL1460086 & 688267 & 4.1 & 5.0423 & TRN & \\
\hline CHEMBL1518013 & 688267 & 5.95 & 5.0705 & TRN & \\
\hline CHEMBL1598464 & 688267 & 4.8 & 5.0054 & TRN & \\
\hline CHEMBL1536953 & 688267 & 6.2 & 5.0357 & TST & \\
\hline CHEMBL1412006 & 688267 & 4.0 & 5.0735 & TRN & \\
\hline CHEMBL3209630 & 688267 & 5.75 & $5.0280 e$ & 00000000005 & TRN \\
\hline CHEMBL1532276 & 688267 & 5.3 & 5.0327 & TST & \\
\hline CHEMBL1362273 & 688267 & 4.35 & 5.0515 & TRN & \\
\hline CHEMBL1431540 & 688267 & 4.15 & 5.0204 & TST & \\
\hline CHEMBL1544050 & 688267 & 5.65 & 5.0507 & TRN & \\
\hline CHEMBL1329723 & 688267 & 4.55 & 5.1243 & TRN & \\
\hline CHEMBL1367493 & 688267 & 4.0 & 5.0148 & TRN & \\
\hline CHEMBL1370676 & 688267 & 4.3 & 5.0292 & TRN & \\
\hline CHEMBL1516794 & 688267 & 6.45 & 5.042 & TRN & \\
\hline CHEMBL1517509 & 688267 & 5.5 & 5.0996 & TRN & \\
\hline CHEMBL1575694 & 688267 & 5.3 & 5.0897 & TRN & \\
\hline CHEMBL1563818 & 688267 & 4.85 & 5.0673 & TST & \\
\hline CHEMBL1310068 & 688267 & 5.25 & 5.1444 & TST & \\
\hline CHEMBL1593476 & 688267 & 4.65 & 5.0333 & TRN & \\
\hline CHEMBL1383822 & 688267 & 4.35 & 5.0353 & TRN & \\
\hline CHEMBL1544882 & 688267 & 5.5 & 5.0375 & TST & \\
\hline CHEMBL1381164 & 688267 & 5.4 & 5.1157 & TRN & \\
\hline CHEMBL1520733 & 688267 & 4.05 & 5.0143 & TRN & \\
\hline CHEMBL1427400 & 688267 & 5.4 & 5.0445 & TST & \\
\hline CHEMBL1590033 & 688267 & 5.05 & 5.0568 & TRN & \\
\hline CHEMBL1346061 & 688267 & 4.95 & 5.0792 & TRN & \\
\hline CHEMBL1980197 & 688267 & 6.25 & 4.978 & TRN & \\
\hline CHEMBL1448571 & 688267 & 5.25 & 5.0203 & TRN & \\
\hline CHEMBL1520923 & 688267 & 4.35 & 5.0315 & TRN & \\
\hline CHEMBL1394057 & 688267 & 6.2 & 5.0567 & TRN & \\
\hline CHEMBL1331472 & 688267 & 6.9 & 5.0817 & TST & \\
\hline CHEMBL3195019 & 688267 & 5.1 & 4.9492 & TRN & \\
\hline CHEMBL1526839 & 688267 & 6.25 & 5.0447 & TRN & \\
\hline CHEMBL1407172 & 688267 & 3.95 & 5.0998 & TRN & \\
\hline CHEMBL1493115 & 688267 & 5.1 & 5.0776 & TRN & \\
\hline CHEMBL1340976 & 688267 & 4.95 & 5.141 & TRN & \\
\hline CHEMBL3214496 & 688267 & 4.1 & 4.9817 & TRN & \\
\hline CHEMBL1437495 & 688267 & 5.85 & 5.0347 & TRN & \\
\hline CHEMBL1301502 & 688267 & 5.1 & 5.0706 & TRN & \\
\hline CHEMBL1597586 & 688267 & 4.0 & 5.0176 & TRN & \\
\hline CHEMBL1426846 & 688267 & 4.3 & 5.0904 & TST & \\
\hline CHEMBL1431697 & 688267 & 4.0 & 5.0657 & TRN & \\
\hline CHEMBL1358316 & 688267 & 5.15 & 5.0356 & TRN & \\
\hline CHEMBL1553338 & 688267 & 4.35 & 4.9712 & TST & \\
\hline CHEMBL1479659 & 688267 & 4.05 & 5.0452 & TRN & \\
\hline CHEMBL 1256740 & 688267 & 5.0 & 5.05699 & 99999999995 & TST \\
\hline CHEMBL1451593 & 688267 & 4.0 & 4.9835 & TRN & \\
\hline & & & & 17937 & \\
\hline
\end{tabular}




\begin{tabular}{|c|c|c|c|c|c|}
\hline \multicolumn{6}{|c|}{ Supplemental Table S2.txt } \\
\hline CHEMBL1464980 & 688267 & 4.75 & 5.0079 & TST & \\
\hline CHEMBL1512261 & 688267 & 3.95 & 5.0524 & TRN & \\
\hline CHEMBL1412414 & 688267 & 5.05 & 5.0274 & TRN & \\
\hline CHEMBL1403124 & 688267 & 5.05 & 5.0262 & TRN & \\
\hline CHEMBL1478261 & 688267 & 4.0 & 5.0662 & TRN & \\
\hline CHEMBL1426060 & 688267 & 5.85 & 5.0916 & TRN & \\
\hline CHEMBL1340562 & 688267 & 5.6 & 5.0729 & TST & \\
\hline CHEMBL1564340 & 688267 & 3.9 & 5.0115 & TRN & \\
\hline CHEMBL1446123 & 688267 & 5.4 & 5.1029 & TRN & \\
\hline CHEMBL1613341 & 688267 & 5.8 & 5.0051 & TRN & \\
\hline CHEMBL1426603 & 688267 & 6.1 & 5.0669 & TST & \\
\hline CHEMBL1407163 & 688267 & 4.3 & 5.0296 & TRN & \\
\hline CHEMBL1384265 & 688267 & 4.5 & 5.0325 & TRN & \\
\hline CHEMBL1541388 & 688267 & 5.0 & 5.0745 & TRN & \\
\hline CHEMBL1588738 & 688267 & 4.1 & 5.0402 & TST & \\
\hline CHEMBL1314617 & 688267 & 6.1 & 5.0433 & TRN & \\
\hline CHEMBL1571572 & 688267 & 4.35 & 5.0431 & TRN & \\
\hline CHEMBL1427082 & 688267 & 4.35 & 5.0014 & TRN & \\
\hline CHEMBL1400560 & 688267 & 6.05 & 5.0605 & TST & \\
\hline CHEMBL1460720 & 688267 & 5.25 & 5.0053 & TST & \\
\hline CHEMBL1416694 & 688267 & 5.55 & 5.0537 & TRN & \\
\hline CHEMBL1520979 & 688267 & 4.25 & 5.0789 & TRN & \\
\hline CHEMBL1437146 & 688267 & 4.95 & 5.0495 & TRN & \\
\hline CHEMBL1370145 & 688267 & 4.85 & 5.0252 & TRN & \\
\hline CHEMBL1543466 & 688267 & 5.45 & 5.0643 & TRN & \\
\hline CHEMBL1393742 & 688267 & 4.1 & 5.0586 & TRN & \\
\hline CHEMBL1318599 & 688267 & 5.0 & 5.0464 & TRN & \\
\hline CHEMBL1499635 & 688267 & 3.95 & 5.0481 & TRN & \\
\hline CHEMBL1611023 & 688267 & 5.9 & 5.0375 & TRN & \\
\hline CHEMBL1379885 & 688267 & 5.25 & 5.1355 & TRN & \\
\hline CHEMBL1410585 & 688267 & 4.0 & 5.0422 & TRN & \\
\hline CHEMBL1465214 & 688267 & 4.2 & 5.052 & TRN & \\
\hline CHEMBL1475984 & 688267 & 4.05 & 5.0233 & TST & \\
\hline CHEMBL1417099 & 688267 & 4.0 & 5.0126 & TST & \\
\hline CHEMBL1364209 & 688267 & 4.4 & $5.0760 e$ & 00000000005 & TST \\
\hline CHEMBL1560700 & 688267 & 5.7 & 4.9887 & TRN & \\
\hline CHEMBL1314839 & 688267 & 6.25 & 5.0522 & TRN & \\
\hline CHEMBL1350937 & 688267 & 5.8 & 5.0937 & TST & \\
\hline CHEMBL1386636 & 688267 & 4.5 & 4.9735 & TRN & \\
\hline CHEMBL1329206 & 688267 & 4.9 & 5.0582 & TRN & \\
\hline CHEMBL1605364 & 688267 & 4.4 & 5.0477 & TRN & \\
\hline CHEMBL1571211 & 688267 & 4.8 & 5.157 & TRN & \\
\hline CHEMBL1316416 & 688267 & 4.05 & 5.0567 & TRN & \\
\hline CHEMBL1430194 & 688267 & 4.3 & 5.0754 & TST & \\
\hline CHEMBL1306321 & 688267 & 4.85 & 5.0551 & TRN & \\
\hline CHEMBL1470072 & 688267 & 4.05 & 5.046 & TST & \\
\hline CHEMBL1474457 & 688267 & 5.2 & 5.0613 & TRN & \\
\hline CHEMBL1534521 & 688267 & 4.1 & 5.0331 & TRN & \\
\hline
\end{tabular}




\begin{tabular}{|c|c|c|c|c|c|}
\hline \multicolumn{6}{|c|}{ Supplemental Table s2.txt } \\
\hline CHEMBL1413368 & 688267 & 5.75 & 5.1089 & TST & \\
\hline CHEMBL1510989 & 688267 & 4.3 & 5.0633 & TST & \\
\hline CHEMBL3212850 & 688267 & 4.05 & 5.0331 & TRN & \\
\hline CHEMBL1421465 & 688267 & 6.2 & 5.0555 & TST & \\
\hline CHEMBL1385763 & 688267 & 3.95 & 5.0775 & TST & \\
\hline CHEMBL1454603 & 688267 & 5.9 & 5.0553 & TST & \\
\hline CHEMBL1571622 & 688267 & 6.2 & 5.0006 & TRN & \\
\hline CHEMBL1389107 & 688267 & 4.05 & 4.9936 & TRN & \\
\hline CHEMBL1583863 & 688267 & 5.0 & 5.101 & TRN & \\
\hline CHEMBL1319448 & 688267 & 4.1 & 5.1112 & TRN & \\
\hline CHEMBL1358246 & 688267 & 5.4 & 5.0703 & TRN & \\
\hline CHEMBL1372806 & 688267 & 4.45 & 5.0283 & TRN & \\
\hline CHEMBL1318143 & 688267 & 6.1 & 5.0483 & TRN & \\
\hline CHEMBL1304280 & 688267 & 5.35 & 5.0821 & TRN & \\
\hline CHEMBL1513303 & 688267 & 5.4 & 5.0652 & TRN & \\
\hline CHEMBL1319852 & 688267 & 5.3 & 5.1211 & TRN & \\
\hline CHEMBL1446648 & 688267 & 4.05 & 5.0606 & TRN & \\
\hline CHEMBL1472168 & 688267 & 5.3 & 5.0639 & TRN & \\
\hline CHEMBL1302644 & 688267 & 4.5 & 5.0381 & TST & \\
\hline CHEMBL1412133 & 688267 & 6.2 & 5.0052 & TRN & \\
\hline CHEMBL1593548 & 688267 & 5.5 & 5.1115 & TRN & \\
\hline CHEMBL3213559 & 688267 & 4.3 & 5.003 & TRN & \\
\hline CHEMBL1544868 & 688267 & 4.3 & 5.0624 & TRN & \\
\hline CHEMBL1364767 & 688267 & 5.0 & 5.0675 & TRN & \\
\hline CHEMBL1479478 & 688267 & 4.0 & 5.0506 & TST & \\
\hline CHEMBL1413138 & 688267 & 4.95 & 5.0117 & TRN & \\
\hline CHEMBL1605184 & 688267 & 4.35 & 5.0284 & TST & \\
\hline CHEMBL1487325 & 688267 & 5.35 & 5.04899 & 99999999995 & TST \\
\hline CHEMBL51085 & 688267 & 4.05 & 5.0136 & TST & \\
\hline CHEMBL1564762 & 688267 & 6.2 & 4.9918 & TRN & \\
\hline CHEMBL1603682 & 688267 & 5.3 & 5.0674 & TRN & \\
\hline CHEMBL1418311 & 688267 & 6.2 & 5.0526 & TST & \\
\hline CHEMBL 1455480 & 688267 & 6.25 & 5.0546 & TRN & \\
\hline CHEMBL1462120 & 688267 & 4.4 & 5.0207 & TRN & \\
\hline CHEMBL1587748 & 688267 & 4.2 & 5.0141 & TRN & \\
\hline CHEMBL1431314 & 688267 & 4.15 & 4.9915 & TRN & \\
\hline CHEMBL1364454 & 688267 & 4.05 & 4.9998 & TST & \\
\hline CHEMBL1564830 & 688267 & 6.25 & 5.1163 & TRN & \\
\hline CHEMBL1490415 & 688267 & 3.95 & 4.9931 & TST & \\
\hline CHEMBL1354770 & 688267 & 5.2 & 5.1114 & TRN & \\
\hline CHEMBL1551546 & 688267 & 4.4 & 5.0739 & TST & \\
\hline CHEMBL1372075 & 688267 & 6.2 & 5.0978 & TRN & \\
\hline CHEMBL1356743 & 688267 & 6.15 & 5.1583 & TRN & \\
\hline CHEMBL1599409 & 688267 & 5.2 & 5.1285 & TRN & \\
\hline CHEMBL1393317 & 688267 & 5.95 & 5.0592 & TRN & \\
\hline CHEMBL1431203 & 688267 & 5.1 & 5.1153 & TRN & \\
\hline CHEMBL1367642 & 688267 & 6.5 & 5.0279 & TRN & \\
\hline CHEMBL1334174 & 688267 & 4.2 & 5.0461 & TRN & \\
\hline
\end{tabular}




\begin{tabular}{|c|c|c|c|c|c|}
\hline \multicolumn{6}{|c|}{ Supplemental Table S2.txt } \\
\hline CHEMBL1318643 & 688267 & 4.6 & 5.0925 & TRN & \\
\hline CHEMBL1489467 & 688267 & 4.05 & 5.0345 & TRN & \\
\hline CHEMBL1402068 & 688267 & 4.55 & 5.0694 & TST & \\
\hline CHEMBL1462631 & 688267 & 6.1 & 5.0638 & TST & \\
\hline CHEMBL1378219 & 688267 & 5.45 & 5.0488 & TST & \\
\hline CHEMBL1432408 & 688267 & 6.2 & 5.0379 & TST & \\
\hline CHEMBL1523692 & 688267 & 6.2 & 5.042 & TRN & \\
\hline CHEMBL1412826 & 688267 & 6.2 & 5.0995 & TRN & \\
\hline CHEMBL1516386 & 688267 & 4.85 & 5.0012 & TRN & \\
\hline CHEMBL1477066 & 688267 & 6.25 & 5.0818 & TRN & \\
\hline CHEMBL1360626 & 688267 & 4.6 & 5.0645 & TRN & \\
\hline CHEMBL1575234 & 688267 & 4.6 & 5.1402 & TST & \\
\hline CHEMBL1602609 & 688267 & 4.2 & 5.0394 & TRN & \\
\hline CHEMBL1334318 & 688267 & 4.05 & 5.1058 & TRN & \\
\hline CHEMBL1571468 & 688267 & 6.05 & 5.0748 & TRN & \\
\hline CHEMBL1502967 & 688267 & 4.6 & 5.0296 & TRN & \\
\hline CHEMBL1421562 & 688267 & 5.9 & 5.1014 & TRN & \\
\hline CHEMBL1587300 & 688267 & 5.3 & 5.1375 & TRN & \\
\hline CHEMBL1341075 & 688267 & 4.45 & 5.0604 & TRN & \\
\hline CHEMBL1350811 & 688267 & 6.25 & 5.1311 & TRN & \\
\hline CHEMBL1304763 & 688267 & 6.2 & 5.0245 & TRN & \\
\hline CHEMBL1411081 & 688267 & 7.8013 & 5.0607 & TRN & \\
\hline CHEMBL1533153 & 688267 & 4.15 & 4.9947 & TRN & \\
\hline CHEMBL1357240 & 688267 & 4.75 & 5.0323 & TRN & \\
\hline CHEMBL1453949 & 688267 & 4.95 & 5.0464 & TST & \\
\hline CHEMBL1603006 & 688267 & 5.9 & 5.0056 & TRN & \\
\hline CHEMBL3195874 & 688267 & 6.05 & 5.0316 & TRN & \\
\hline CHEMBL1326168 & 688267 & 5.8 & 5.1311 & TRN & \\
\hline CHEMBL1422598 & 688267 & 6.2 & 5.0467 & TRN & \\
\hline CHEMBL1560265 & 688267 & 4.0 & 5.1222 & TRN & \\
\hline CHEMBL3194001 & 688267 & 4.6 & 5.0171 & TRN & \\
\hline CHEMBL1364542 & 688267 & 4.1 & 5.0661 & TRN & \\
\hline CHEMBL1349640 & 688267 & 4.0 & 5.0444 & TST & \\
\hline CHEMBL1515530 & 688267 & 5.4 & 5.0059 & TRN & \\
\hline CHEMBL1595454 & 688267 & 4.05 & 5.0559 & TST & \\
\hline CHEMBL1516302 & 688267 & 5.25 & 5.0857 & TRN & \\
\hline CHEMBL1596305 & 688267 & 6.2 & 5.0257 & TST & \\
\hline CHEMBL1355390 & 688267 & 3.95 & 5.0129 & TRN & \\
\hline CHEMBL1601445 & 688267 & 5.85 & 5.0281 & TRN & \\
\hline CHEMBL1370298 & 688267 & 7.8013 & 5.0607 & TRN & \\
\hline CHEMBL1306671 & 688267 & 5.5 & 5.1086 & TRN & \\
\hline CHEMBL1541668 & 688267 & 4.5 & 5.0562 & TRN & \\
\hline CHEMBL1403844 & 688267 & 4.4 & 5.08899 & 99999999995 & TRN \\
\hline CHEMBL1375811 & 688267 & 3.9 & 5.0347 & TRN & \\
\hline CHEMBL1507823 & 688267 & 3.95 & 5.0961 & TST & \\
\hline CHEMBL1411350 & 688267 & 5.3 & 5.07100 & 0000000001 & TST \\
\hline CHEMBL1493843 & 688267 & 4.35 & 5.0508 & TRN & \\
\hline CHEMBL1416099 & 688267 & 5.05 & 5.0428 & TRN & \\
\hline
\end{tabular}




\begin{tabular}{|c|c|c|c|c|c|}
\hline \multicolumn{6}{|c|}{ plemental } \\
\hline CHEMBL1579774 & 688267 & 6.5 & 5.0284 & TRN & \\
\hline CHEMBL1474487 & 688267 & 6.1 & 5.0406 & TRN & \\
\hline CHEMBL1516243 & 688267 & 5.35 & 5.1408 & TRN & \\
\hline CHEMBL1565529 & 688267 & 4.05 & 5.0678 & TRN & \\
\hline CHEMBL1311210 & 688267 & 3.95 & 5.003 & TST & \\
\hline CHEMBL1468549 & 688267 & 5.35 & 5.1596 & TST & \\
\hline CHEMBL1463225 & 688267 & 3.95 & 5.0132 & TRN & \\
\hline CHEMBL1362338 & 688267 & 4.65 & 5.1536 & TRN & \\
\hline CHEMBL3195673 & 688267 & 4.35 & 5.0302 & TRN & \\
\hline CHEMBL600765 & 688267 & 4.4 & 5.1156 & TST & \\
\hline CHEMBL1367909 & 688267 & 5.65 & 5.0347 & TRN & \\
\hline CHEMBL1550057 & 688267 & 6.2 & 5.1176 & TST & \\
\hline CHEMBL1482434 & 688267 & 3.95 & 5.0945 & TRN & \\
\hline CHEMBL1456559 & 688267 & 5.55 & 5.0262 & TRN & \\
\hline CHEMBL1355192 & 688267 & 3.95 & 5.0104 & TST & \\
\hline CHEMBL1318536 & 688267 & 4.4 & 5.1382 & TRN & \\
\hline CHEMBL1482693 & 688267 & 4.65 & 5.0327 & TST & \\
\hline CHEMBL1450975 & 688267 & 5.45 & 5.0879 & TRN & \\
\hline CHEMBL1534328 & 688267 & 4.5 & $5.1270 e$ & 0000000001 & TRN \\
\hline CHEMBL1299938 & 688267 & 5.0 & 5.0132 & TST & \\
\hline CHEMBL1444336 & 688267 & 5.55 & 5.0755 & TRN & \\
\hline CHEMBL1384454 & 688267 & 5.5 & 5.0429 & TST & \\
\hline CHEMBL1376959 & 688267 & 4.3 & 5.0974 & TRN & \\
\hline CHEMBL1493306 & 688267 & 5.9 & 5.1349 & TRN & \\
\hline CHEMBL1323755 & 688267 & 4.05 & 5.033 & TST & \\
\hline CHEMBL1473501 & 688267 & 4.65 & 5.0954 & TST & \\
\hline CHEMBL1481795 & 688267 & 6.2 & 5.003 & TST & \\
\hline CHEMBL1370563 & 688267 & 5.8 & 5.0294 & TST & \\
\hline CHEMBL1377167 & 688267 & 5.55 & 5.0484 & TRN & \\
\hline CHEMBL1503672 & 688267 & 4.8 & 5.0731 & TRN & \\
\hline CHEMBL1535668 & 688267 & 4.05 & 5.0622 & TRN & \\
\hline CHEMBL1471326 & 688267 & 4.3 & 5.0087 & TST & \\
\hline CHEMBL418068 & 688267 & 4.1 & $5.0280 e$ & 00000000005 & TST \\
\hline CHEMBL1396968 & 688267 & 3.95 & 5.0069 & TRN & \\
\hline CHEMBL1575791 & 688267 & 5.85 & 5.0651 & TRN & \\
\hline CHEMBL1314144 & 688267 & 4.1 & 4.9533 & TRN & \\
\hline CHEMBL1530950 & 688267 & 6.2 & 5.0101 & TRN & \\
\hline CHEMBL1517863 & 688267 & 6.05 & 5.0534 & TRN & \\
\hline CHEMBL1430211 & 688267 & 4.0 & 5.0871 & TST & \\
\hline CHEMBL1573550 & 688267 & 4.05 & 5.0195 & TST & \\
\hline CHEMBL1418295 & 688267 & 5.25 & 5.0459 & TRN & \\
\hline CHEMBL1556761 & 688267 & 4.0 & 5.0688 & TRN & \\
\hline CHEMBL1310935 & 688267 & 4.35 & 5.0763 & TRN & \\
\hline CHEMBL1493758 & 688267 & 4.35 & 5.1525 & TRN & \\
\hline CHEMBL1418719 & 688267 & 6.2 & 5.0267 & TRN & \\
\hline CHEMBL1433099 & 688267 & 4.0 & 5.0156 & TST & \\
\hline CHEMBL1438853 & 688267 & 4.0 & 5.0515 & TRN & \\
\hline CHEMBL1355060 & 688267 & 4.0 & 5.0886 & TRN & \\
\hline
\end{tabular}




\begin{tabular}{|c|c|c|c|c|}
\hline \multicolumn{5}{|c|}{ Supplemental Table S2.txt } \\
\hline CHEMBL1432719 & 688267 & 5.35 & 5.1211 & TRN \\
\hline CHEMBL1445100 & 688267 & 4.8 & 5.0196 & TRN \\
\hline CHEMBL1341170 & 688267 & 4.6 & 5.0812 & TRN \\
\hline CHEMBL1493911 & 688267 & 5.85 & 5.0601 & TRN \\
\hline CHEMBL1550166 & 688267 & 6.25 & 5.0754 & TRN \\
\hline CHEMBL1467678 & 688267 & 6.2 & 5.0249 & TST \\
\hline CHEMBL1314539 & 688267 & 6.2 & 5.0127 & TRN \\
\hline CHEMBL1365969 & 688267 & 5.85 & 5.0412 & TST \\
\hline CHEMBL1532726 & 688267 & 4.25 & 5.0357 & TRN \\
\hline CHEMBL1335046 & 688267 & 4.5 & 5.1282 & TRN \\
\hline CHEMBL1599637 & 688267 & 5.8 & 5.0359 & TRN \\
\hline CHEMBL1444752 & 688267 & 3.95 & 4.9895 & TRN \\
\hline CHEMBL1567832 & 688267 & 5.55 & 5.074 & TRN \\
\hline CHEMBL1360041 & 688267 & 6.15 & 5.0872 & TRN \\
\hline CHEMBL1421043 & 688267 & 4.95 & 5.0963 & TRN \\
\hline CHEMBL1398778 & 688267 & 6.2 & 5.0252 & TST \\
\hline CHEMBL1557782 & 688267 & 5.0 & 5.038 & TRN \\
\hline CHEMBL1579401 & 688267 & 5.0 & 5.1013 & TRN \\
\hline CHEMBL1469900 & 688267 & 4.0 & 5.1024 & TST \\
\hline CHEMBL1478210 & 688267 & 4.35 & 5.0954 & TRN \\
\hline CHEMBL1548226 & 688267 & 4.55 & 5.0985 & TRN \\
\hline CHEMBL1574878 & 688267 & 4.4 & 5.0566 & TRN \\
\hline CHEMBL1564933 & 688267 & 5.0 & 5.0338 & TRN \\
\hline CHEMBL1306361 & 688267 & 4.05 & 5.0803 & TRN \\
\hline CHEMBL1484411 & 688267 & 4.5 & 5.0505 & TRN \\
\hline CHEMBL1436573 & 688267 & 4.85 & 5.1004 & TRN \\
\hline CHEMBL1334264 & 688267 & 5.55 & 5.0391 & TRN \\
\hline CHEMBL1496780 & 688267 & 6.15 & 5.0463 & TRN \\
\hline CHEMBL1418760 & 688267 & 5.7 & 5.0493 & TST \\
\hline CHEMBL1443465 & 688267 & 5.35 & 5.0431 & TST \\
\hline CHEMBL1379177 & 688267 & 6.2 & 5.098 & TST \\
\hline CHEMBL1484388 & 688267 & 4.95 & 5.145 & TRN \\
\hline CHEMBL1410385 & 688267 & 6.1 & 4.9929 & TRN \\
\hline CHEMBL1605808 & 688267 & 6.15 & 5.0836 & TRN \\
\hline CHEMBL1521961 & 688267 & 4.75 & 5.0063 & TRN \\
\hline CHEMBL1345122 & 688267 & 4.2 & 5.1029 & TRN \\
\hline CHEMBL1392471 & 688267 & 4.0 & 4.9812 & TRN \\
\hline CHEMBL1550627 & 688267 & 6.6499 & 5.0164 & TRN \\
\hline CHEMBL1421896 & 688267 & 4.05 & 5.0551 & TST \\
\hline CHEMBL1459513 & 688267 & 5.55 & 5.0318 & TRN \\
\hline CHEMBL1444827 & 688267 & 5.35 & 5.0869 & TRN \\
\hline CHEMBL1558966 & 688267 & 4.05 & 5.0347 & TRN \\
\hline CHEMBL1580123 & 688267 & 6.05 & 5.0634 & TRN \\
\hline CHEMBL1996679 & 688267 & 4.75 & 5.0088 & TRN \\
\hline CHEMBL1574528 & 688267 & 5.45 & 5.1024 & TRN \\
\hline CHEMBL1354875 & 688267 & 4.0 & 5.0601 & TRN \\
\hline CHEMBL1377981 & 688267 & 4.75 & 5.0737 & TRN \\
\hline CHEMBL1378147 & 688267 & 6.2 & 5.0542 & TRN \\
\hline
\end{tabular}




\begin{tabular}{|c|c|c|c|c|c|}
\hline \multicolumn{6}{|c|}{ Supplemental Table S2.txt } \\
\hline CHEMBL1536008 & 688267 & 4.05 & 5.0153 & TRN & \\
\hline CHEMBL1599622 & 688267 & 4.7 & 5.0708 & TRN & \\
\hline CHEMBL3208552 & 688267 & 6.2 & 5.0295 & TRN & \\
\hline CHEMBL1374495 & 688267 & 5.25 & 5.0304 & TRN & \\
\hline CHEMBL1479107 & 688267 & 4.55 & 5.0517 & TST & \\
\hline CHEMBL1320953 & 688267 & 6.15 & 5.0884 & TST & \\
\hline CHEMBL1560831 & 688267 & 5.45 & 5.0426 & TST & \\
\hline CHEMBL1554205 & 688267 & 5.15 & 5.048 & TST & \\
\hline CHEMBL1320861 & 688267 & 5.6 & 5.0551 & TRN & \\
\hline CHEMBL1553236 & 688267 & 6.2 & 5.1068 & TRN & \\
\hline CHEMBL1319258 & 688267 & 4.35 & 5.027 & TRN & \\
\hline CHEMBL1402670 & 688267 & 5.0 & 5.0306 & TST & \\
\hline CHEMBL1364220 & 688267 & 5.0 & 5.104 & TRN & \\
\hline CHEMBL1376234 & 688267 & 4.2 & 5.0543 & TRN & \\
\hline CHEMBL1530819 & 688267 & 4.45 & 5.058 & TRN & \\
\hline CHEMBL1515336 & 688267 & 5.55 & 5.0129 & TRN & \\
\hline CHEMBL1205406 & 688267 & 5.9 & 5.088 & TST & \\
\hline CHEMBL1498615 & 688267 & 4.3 & 5.0264 & TRN & \\
\hline CHEMBL1528814 & 688267 & 4.95 & 5.06800 & 00000000005 & TRN \\
\hline CHEMBL1575541 & 688267 & 5.25 & 5.1024 & TRN & \\
\hline CHEMBL1382848 & 688267 & 4.05 & 5.0577 & TRN & \\
\hline CHEMBL1305280 & 688267 & 4.15 & 5.0804 & TST & \\
\hline CHEMBL1329202 & 688267 & 4.9 & 5.0542 & TRN & \\
\hline CHEMBL1351271 & 688267 & 4.4 & 5.0265 & TRN & \\
\hline CHEMBL1351116 & 688267 & 5.5 & 4.9901 & TRN & \\
\hline CHEMBL1572417 & 688267 & 4.35 & 5.0605 & TRN & \\
\hline CHEMBL1968983 & 688267 & 5.9 & 5.0376 & TRN & \\
\hline CHEMBL600342 & 688267 & 4.0 & 5.0582 & TRN & \\
\hline CHEMBL1565593 & 688267 & 4.05 & 5.075 & TRN & \\
\hline CHEMBL1300074 & 688267 & 6.45 & 5.018 & TRN & \\
\hline CHEMBL1487624 & 688267 & 4.55 & 5.0461 & TRN & \\
\hline CHEMBL1541625 & 688267 & 4.9 & 5.1083 & TRN & \\
\hline CHEMBL1524392 & 688267 & 5.3 & 4.9956 & TRN & \\
\hline CHEMBL1592407 & 688267 & 4.0 & 5.0725 & TRN & \\
\hline CHEMBL1327519 & 688267 & 5.2 & 5.0955 & TRN & \\
\hline CHEMBL1558038 & 688267 & 4.0 & 5.0124 & TST & \\
\hline CHEMBL1324501 & 688267 & 3.4 & 5.1091 & TST & \\
\hline CHEMBL3190437 & 688267 & 6.2 & 5.0207 & TST & \\
\hline CHEMBL1437993 & 688267 & 4.0 & 5.0917 & TRN & \\
\hline CHEMBL1359461 & 688267 & 5.9 & 5.0792 & TST & \\
\hline CHEMBL1515082 & 688267 & 4.05 & 5.1285 & TST & \\
\hline CHEMBL1318442 & 688267 & 5.85 & 5.0498 & TRN & \\
\hline CHEMBL1316173 & 688267 & 6.25 & 5.0289 & TRN & \\
\hline CHEMBL1439152 & 688267 & 4.0 & 5.0942 & TRN & \\
\hline CHEMBL1567956 & 688267 & 5.75 & 5.0366 & TRN & \\
\hline CHEMBL1452275 & 688267 & 3.2 & 5.0815 & TRN & \\
\hline CHEMBL1605677 & 688267 & 4.4 & 5.0529 & TRN & \\
\hline CHEMBL1315113 & 688267 & 6.2 & 5.0629 & TRN & \\
\hline
\end{tabular}




\begin{tabular}{|c|c|c|c|c|c|}
\hline & & & & & \\
\hline CHEMBL1450278 & 688267 & 4.1 & 5.0524 & TST & \\
\hline CHEMBL1578959 & 688267 & 4.5 & 5.0824 & TST & \\
\hline CHEMBL1565689 & 688267 & 3.95 & 5.1079 & TRN & \\
\hline CHEMBL1378880 & 688267 & 4.3 & 5.0248 & TRN & \\
\hline CHEMBL1520656 & 688267 & 4.0 & 5.0837 & TRN & \\
\hline CHEMBL1477453 & 688267 & 4.2 & 5.0312 & TRN & \\
\hline CHEMBL1531756 & 688267 & 5.15 & 5.0923 & TST & \\
\hline CHEMBL1454435 & 688267 & 5.5 & 5.0387 & TRN & \\
\hline CHEMBL1453938 & 688267 & 6.0 & 5.096 & TRN & \\
\hline CHEMBL1402494 & 688267 & 4.4 & 5.0318 & TRN & \\
\hline CHEMBL1504448 & 688267 & 5.4 & 5.1575 & TRN & \\
\hline CHEMBL1463339 & 688267 & 6.05 & 5.096 & TRN & \\
\hline CHEMBL1363824 & 688267 & 4.25 & 5.0831 & TRN & \\
\hline CHEMBL1599872 & 688267 & 4.6 & 5.1266 & TST & \\
\hline CHEMBL1485754 & 688267 & 5.35 & 5.0787 & TST & \\
\hline CHEMBL1487621 & 688267 & 3.95 & 5.0187 & TRN & \\
\hline CHEMBL1385090 & 688267 & 5.35 & 5.0997 & TRN & \\
\hline CHEMBL1457080 & 688267 & 4.8 & 5.078 & TRN & \\
\hline CHEMBL1323937 & 688267 & 4.25 & 5.0823 & TRN & \\
\hline CHEMBL1569113 & 688267 & 5.05 & 5.059 & TRN & \\
\hline CHEMBL3197555 & 688267 & 5.65 & 5.0137 & TST & \\
\hline CHEMBL1449798 & 688267 & 4.35 & 5.0919 & TRN & \\
\hline CHEMBL1348043 & 688267 & 4.6 & 5.1011 & TST & \\
\hline CHEMBL1368085 & 688267 & 6.15 & 5.0802 & TRN & \\
\hline CHEMBL1591097 & 688267 & 6.2 & 5.0524 & TRN & \\
\hline CHEMBL1535705 & 688267 & 5.4 & 5.1137 & TRN & \\
\hline CHEMBL1414132 & 688267 & 4.05 & 5.0239 & TST & \\
\hline CHEMBL1534764 & 688267 & 6.0 & 5.1296 & TST & \\
\hline CHEMBL1513668 & 688267 & 6.2 & 5.0853 & TRN & \\
\hline CHEMBL1468081 & 688267 & 4.05 & 5.0437 & TST & \\
\hline CHEMBL1508457 & 688267 & 5.3 & 5.0175 & TRN & \\
\hline CHEMBL1403299 & 688267 & 6.25 & 5.0708 & TRN & \\
\hline CHEMBL1342396 & 688267 & 4.55 & 4.9975 & TRN & \\
\hline CHEMBL1492555 & 688267 & 3.95 & 5.1264 & TRN & \\
\hline CHEMBL1595620 & 688267 & 6.2 & 5.0935 & TRN & \\
\hline CHEMBL1557574 & 688267 & 4.9 & 5.0696 & TST & \\
\hline CHEMBL 1482110 & 688267 & 4.05 & 5.0314 & TRN & \\
\hline CHEMBL1303279 & 688267 & 4.05 & 5.0421 & TRN & \\
\hline CHEMBL1344110 & 688267 & 4.9 & 5.0707 & TRN & \\
\hline CHEMBL1492848 & 688267 & 5.4 & 5.0577 & TRN & \\
\hline CHEMBL1304661 & 688267 & 6.2 & 5.0417 & TRN & \\
\hline CHEMBL1495366 & 688267 & 4.55 & 5.0984 & TRN & \\
\hline CHEMBL3214562 & 688267 & 4.0 & 5.0698 & TRN & \\
\hline CHEMBL1311716 & 688267 & 4.05 & 5.1291 & TRN & \\
\hline CHEMBL1613617 & 688267 & 6.15 & 5.1066 & TST & \\
\hline CHEMBL1310845 & 688267 & 4.35 & 5.033 & TRN & \\
\hline CHEMBL1408165 & 688267 & 5.65 & 5.12299 & 9999999999 & TRN \\
\hline CHEMBL1435027 & 688267 & 6.15 & 5.1079 & TRN & \\
\hline & & & & 17944 & \\
\hline
\end{tabular}




\begin{tabular}{|c|c|c|c|c|c|}
\hline \multicolumn{6}{|c|}{ Supplemental Table S2.txt } \\
\hline CHEMBL1200344 & 688267 & 4.0 & 5.0415 & TRN & \\
\hline CHEMBL1576964 & 688267 & 4.15 & 5.0087 & TRN & \\
\hline CHEMBL1601612 & 688267 & 4.1 & 4.9946 & TRN & \\
\hline CHEMBL1537702 & 688267 & 3.95 & 5.1113 & TRN & \\
\hline CHEMBL1564605 & 688267 & 3.95 & 5.0596 & TST & \\
\hline CHEMBL1560453 & 688267 & 4.0 & $5.1220 e$ & 0000000001 & TRN \\
\hline CHEMBL1328056 & 688267 & 5.3 & 5.0199 & TRN & \\
\hline CHEMBL1368239 & 688267 & 5.7 & 5.058 & TST & \\
\hline CHEMBL1335213 & 688267 & 5.2 & 5.0851 & TRN & \\
\hline CHEMBL1376489 & 688267 & 5.0 & 5.0289 & TRN & \\
\hline CHEMBL1339513 & 688267 & 6.8 & 5.1245 & TRN & \\
\hline CHEMBL1457517 & 688267 & 4.4 & 5.0475 & TRN & \\
\hline CHEMBL1492133 & 688267 & 4.0 & 5.1326 & TRN & \\
\hline CHEMBL1485062 & 688267 & 5.6 & 5.0206 & TST & \\
\hline CHEMBL1321941 & 688267 & 6.45 & 5.051 & TRN & \\
\hline CHEMBL1358776 & 688267 & 3.95 & 5.0134 & TST & \\
\hline CHEMBL1302306 & 688267 & 5.05 & 5.0675 & TRN & \\
\hline CHEMBL1316806 & 688267 & 5.55 & 5.0709 & TRN & \\
\hline CHEMBL1575813 & 688267 & 4.3 & 5.029 & TRN & \\
\hline CHEMBL1420232 & 688267 & 5.3 & 5.1106 & TRN & \\
\hline CHEMBL1495612 & 688267 & 5.05 & 5.1052 & TRN & \\
\hline CHEMBL1362284 & 688267 & 5.45 & 5.0346 & TRN & \\
\hline CHEMBL1457733 & 688267 & 5.9 & 5.0414 & TST & \\
\hline CHEMBL1481952 & 688267 & 4.1 & 4.9991 & TRN & \\
\hline CHEMBL1595943 & 688267 & 6.2 & 5.0756 & TRN & \\
\hline CHEMBL1435496 & 688267 & 6.15 & 5.0293 & TRN & \\
\hline CHEMBL1364920 & 688267 & 5.55 & 5.0154 & TRN & \\
\hline CHEMBL1354669 & 688267 & 4.0 & 5.03 & TRN & \\
\hline CHEMBL1342176 & 688267 & 6.2 & 5.0277 & TRN & \\
\hline CHEMBL1406307 & 688267 & 5.45 & 5.0021 & TST & \\
\hline CHEMBL1466039 & 688267 & 4.35 & 5.0156 & TRN & \\
\hline CHEMBL1607355 & 688267 & 5.75 & $5.0710 e$ & 0000000001 & TST \\
\hline CHEMBL435539 & 688267 & 5.0 & 5.0392 & TST & \\
\hline CHEMBL1578528 & 688267 & 5.8 & 5.0556 & TRN & \\
\hline CHEMBL1579531 & 688267 & 4.05 & 5.0864 & TRN & \\
\hline CHEMBL1594750 & 688267 & 5.5 & 5.0596 & TRN & \\
\hline CHEMBL1389655 & 688267 & 6.15 & 5.0632 & TRN & \\
\hline CHEMBL1611671 & 688267 & 4.0 & 5.0424 & TRN & \\
\hline CHEMBL1593730 & 688267 & 4.1 & $5.1270 e$ & 0000000001 & TRN \\
\hline CHEMBL1553866 & 688267 & 5.6 & 5.0235 & TRN & \\
\hline CHEMBL1333387 & 688267 & 6.0 & 5.0163 & TRN & \\
\hline CHEMBL1311846 & 688267 & 6.2 & 5.0827 & TRN & \\
\hline CHEMBL1609932 & 688267 & 4.0 & 5.0666 & TRN & \\
\hline CHEMBL1513815 & 688267 & 4.0 & 5.0498 & TRN & \\
\hline CHEMBL1517810 & 688267 & 5.9 & 5.1319 & TRN & \\
\hline CHEMBL1422269 & 688267 & 6.2 & 5.0444 & TRN & \\
\hline CHEMBL3212644 & 688267 & 4.3 & 5.0351 & TST & \\
\hline CHEMBL1316308 & 688267 & 5.85 & 5.021 & TRN & \\
\hline
\end{tabular}




\begin{tabular}{|c|c|c|c|c|}
\hline \multicolumn{5}{|c|}{ Supplemental Table S2.txt } \\
\hline CHEMBL1384637 & 688267 & 6.2 & 5.0138 & TRN \\
\hline CHEMBL1612543 & 688267 & 4.0 & 5.0449 & TRN \\
\hline CHEMBL1550771 & 688267 & 6.2 & 5.1167 & TRN \\
\hline CHEMBL1604229 & 688267 & 5.65 & 5.066 & TRN \\
\hline CHEMBL1441565 & 688267 & 4.0 & 5.0792 & TRN \\
\hline CHEMBL1496704 & 688267 & 4.25 & 5.1105 & TRN \\
\hline CHEMBL1407321 & 688267 & 6.25 & 5.0293 & TRN \\
\hline CHEMBL1609854 & 688267 & 4.25 & 5.0261 & TST \\
\hline CHEMBL1463627 & 688267 & 4.25 & 5.0137 & TRN \\
\hline CHEMBL1435920 & 688267 & 4.05 & 5.0179 & TRN \\
\hline CHEMBL1436574 & 688267 & 6.45 & 5.0058 & TRN \\
\hline CHEMBL1607421 & 688267 & 6.25 & 5.1296 & TRN \\
\hline CHEMBL1591290 & 688267 & 5.55 & 5.0511 & TRN \\
\hline CHEMBL1452838 & 688267 & 6.2 & 5.066 & TST \\
\hline CHEMBL1483968 & 688267 & 4.3 & 5.1162 & TST \\
\hline CHEMBL1405238 & 688267 & 6.2 & 5.0442 & TST \\
\hline CHEMBL1400588 & 688267 & 5.1 & 4.9986 & TRN \\
\hline CHEMBL1354474 & 688267 & 6.15 & 5.0174 & TRN \\
\hline CHEMBL1441654 & 688267 & 5.15 & 5.0502 & TRN \\
\hline CHEMBL1596360 & 688267 & 5.05 & 5.1043 & TRN \\
\hline CHEMBL1471549 & 688267 & 5.75 & 5.0426 & TRN \\
\hline CHEMBL1330365 & 688267 & 5.15 & 5.1026 & TRN \\
\hline CHEMBL1444911 & 688267 & 4.4 & 5.0383 & TRN \\
\hline CHEMBL1367083 & 688267 & 4.55 & 5.0732 & TRN \\
\hline CHEMBL1351257 & 688267 & 4.35 & 5.0951 & TRN \\
\hline CHEMBL1541154 & 688267 & 6.15 & 5.0153 & TRN \\
\hline CHEMBL1471393 & 688267 & 4.65 & 5.0781 & TRN \\
\hline CHEMBL1348228 & 688267 & 4.0 & 5.1726 & TRN \\
\hline CHEMBL1557628 & 688267 & 4.15 & 5.0211 & TRN \\
\hline CHEMBL1476376 & 688267 & 4.4 & 5.0601 & TRN \\
\hline CHEMBL1544307 & 688267 & 4.45 & 5.0228 & TST \\
\hline CHEMBL1388139 & 688267 & 6.15 & 5.1058 & TST \\
\hline CHEMBL1590526 & 688267 & 6.5501 & 5.0347 & TRN \\
\hline CHEMBL1476001 & 688267 & 5.4 & 5.1222 & TRN \\
\hline CHEMBL1375635 & 688267 & 5.65 & 5.0817 & TRN \\
\hline CHEMBL1508540 & 688267 & 4.6 & 5.0425 & TRN \\
\hline CHEMBL1418678 & 688267 & 6.45 & 5.0529 & TRN \\
\hline CHEMBL1422383 & 688267 & 5.9 & 5.0859 & TRN \\
\hline CHEMBL1478562 & 688267 & 5.0 & 5.024 & TST \\
\hline CHEMBL1588646 & 688267 & 5.4 & 5.0826 & TRN \\
\hline CHEMBL1345429 & 688267 & 5.55 & 5.1355 & TRN \\
\hline CHEMBL1500510 & 688267 & 5.9 & 4.9954 & TRN \\
\hline CHEMBL1415341 & 688267 & 4.8 & 5.026 & TRN \\
\hline CHEMBL1351160 & 688267 & 4.55 & 5.0464 & TRN \\
\hline CHEMBL1523435 & 688267 & 4.4 & 5.0728 & TRN \\
\hline CHEMBL1488923 & 688267 & 5.2 & 5.0028 & TST \\
\hline CHEMBL1540020 & 688267 & 5.75 & 4.9995 & TRN \\
\hline CHEMBL1360857 & 688267 & 4.05 & 5.0374 & TRN \\
\hline
\end{tabular}




\begin{tabular}{|c|c|c|c|c|c|}
\hline \multicolumn{6}{|c|}{ Supplemental Table S2.txt } \\
\hline CHEMBL1487363 & 688267 & 6.25 & 5.0718 & TST & \\
\hline CHEMBL1333874 & 688267 & 4.45 & 5.0375 & TRN & \\
\hline CHEMBL1353875 & 688267 & 6.0 & 5.0304 & TRN & \\
\hline CHEMBL1591563 & 688267 & 4.65 & 5.0414 & TRN & \\
\hline CHEMBL1329977 & 688267 & 5.55 & 5.0258 & TST & \\
\hline CHEMBL1452430 & 688267 & 6.2 & 5.1307 & TRN & \\
\hline CHEMBL1335561 & 688267 & 6.2 & 5.0078 & TRN & \\
\hline CHEMBL1553563 & 688267 & 4.65 & 5.0775 & TRN & \\
\hline CHEMBL1311294 & 688267 & 4.7 & 5.0857 & TRN & \\
\hline CHEMBL1446368 & 688267 & 6.45 & 5.0366 & TST & \\
\hline CHEMBL1504041 & 688267 & 4.75 & 5.0272 & TST & \\
\hline CHEMBL3198711 & 688267 & 4.0 & 5.0209 & TRN & \\
\hline CHEMBL1514686 & 688267 & 5.35 & 5.0496 & TRN & \\
\hline CHEMBL1468306 & 688267 & 4.0 & 5.0694 & TST & \\
\hline CHEMBL1543417 & 688267 & 5.2 & 5.0542 & TST & \\
\hline CHEMBL1307275 & 688267 & 4.25 & 5.0183 & TST & \\
\hline CHEMBL1346706 & 688267 & 6.1 & 5.03100 & 0000000001 & TRN \\
\hline CHEMBL1315015 & 688267 & 4.0 & 5.1169 & TRN & \\
\hline CHEMBL1402898 & 688267 & 5.3 & 5.0242 & TST & \\
\hline CHEMBL1507866 & 688267 & 4.0 & 5.0539 & TRN & \\
\hline CHEMBL1304843 & 688267 & 4.2 & 5.0792 & TRN & \\
\hline CHEMBL1374027 & 688267 & 6.45 & 5.0841 & TRN & \\
\hline CHEMBL1414129 & 688267 & 5.0 & 5.0835 & TRN & \\
\hline CHEMBL1460463 & 688267 & 4.05 & 4.9821 & TRN & \\
\hline CHEMBL1312312 & 688267 & 4.0 & 5.0833 & TST & \\
\hline CHEMBL1493219 & 688267 & 4.05 & 5.1356 & TRN & \\
\hline CHEMBL1590940 & 688267 & 4.2 & 5.0041 & TRN & \\
\hline CHEMBL1508678 & 688267 & 5.5 & 5.0663 & TRN & \\
\hline CHEMBL1540163 & 688267 & 4.9 & 5.1106 & TRN & \\
\hline CHEMBL1344397 & 688267 & 6.45 & 5.0703 & TRN & \\
\hline CHEMBL252387 & 688267 & 6.15 & 5.0367 & TRN & \\
\hline CHEMBL1338726 & 688267 & 4.4 & 5.092 & TST & \\
\hline CHEMBL1512062 & 688267 & 3.95 & 5.1074 & TRN & \\
\hline CHEMBL1466123 & 688267 & 6.45 & 5.0485 & TRN & \\
\hline CHEMBL1498393 & 688267 & 3.95 & 5.0173 & TRN & \\
\hline CHEMBL1519703 & 688267 & 4.4 & 5.0713 & TRN & \\
\hline CHEMBL1561656 & 688267 & 5.4 & 5.1446 & TRN & \\
\hline CHEMBL1368279 & 688267 & 4.55 & 5.0254 & TRN & \\
\hline CHEMBL1515518 & 688267 & 4.65 & 4.9964 & TRN & \\
\hline CHEMBL1482593 & 688267 & 4.0 & 5.0253 & TRN & \\
\hline CHEMBL1451534 & 688267 & 6.15 & 5.0408 & TST & \\
\hline CHEMBL1483680 & 688267 & 4.15 & 5.0521 & TRN & \\
\hline CHEMBL1421291 & 688267 & 6.2 & 5.0846 & TRN & \\
\hline CHEMBL1483863 & 688267 & 4.7 & 5.0416 & TRN & \\
\hline CHEMBL1491823 & 688267 & 6.2 & 5.0373 & TRN & \\
\hline CHEMBL1413129 & 688267 & 4.1 & 5.1088 & TRN & \\
\hline CHEMBL1398502 & 688267 & 6.2 & 5.0711 & TRN & \\
\hline CHEMBL1598809 & 688267 & 4.0 & 5.0174 & TST & \\
\hline
\end{tabular}




\begin{tabular}{|c|c|c|c|c|}
\hline & & & pplement & al $\mathrm{Ta}$ \\
\hline CHEMBL1472679 & 688267 & 3.9 & 5.0688 & TRN \\
\hline CHEMBL1612397 & 688267 & 5.5 & 5.0716 & TRN \\
\hline CHEMBL1391777 & 688267 & 4.1 & 5.0156 & TST \\
\hline CHEMBL1512849 & 688267 & 6.45 & 5.0949 & TRN \\
\hline CHEMBL1990383 & 688267 & 5.5 & 5.0062 & TST \\
\hline CHEMBL3192949 & 688267 & 4.0 & 5.0278 & TRN \\
\hline CHEMBL1456023 & 688267 & 4.1 & 5.0445 & TRN \\
\hline CHEMBL1360305 & 688267 & 5.35 & 4.9914 & TST \\
\hline CHEMBL1415317 & 688267 & 6.2 & 5.0534 & TRN \\
\hline CHEMBL1397342 & 688267 & 4.05 & 5.1343 & TRN \\
\hline CHEMBL1584493 & 688267 & 4.6 & 4.9982 & TRN \\
\hline CHEMBL1463635 & 688267 & 4.1 & 5.035 & TST \\
\hline CHEMBL1499456 & 688267 & 4.25 & 5.0576 & TRN \\
\hline CHEMBL1606072 & 688267 & 6.15 & 5.0827 & TRN \\
\hline CHEMBL1408246 & 688267 & 6.1 & 4.9974 & TRN \\
\hline CHEMBL1386757 & 688267 & 5.0 & 5.045 & TRN \\
\hline CHEMBL2002517 & 688267 & 5.05 & 5.0595 & TRN \\
\hline CHEMBL1412173 & 688267 & 4.55 & 5.0489 & TRN \\
\hline CHEMBL1445656 & 688267 & 6.25 & 5.0407 & TRN \\
\hline CHEMBL1589383 & 688267 & 4.0 & 5.0556 & TRN \\
\hline CHEMBL1542206 & 688267 & 6.0 & 5.0205 & TRN \\
\hline CHEMBL1501974 & 688267 & 5.35 & 5.0329 & TRN \\
\hline CHEMBL1606590 & 688267 & 5.5 & 5.105 & TST \\
\hline CHEMBL464770 & 688267 & 5.25 & 5.0892 & TST \\
\hline CHEMBL1435596 & 688267 & 6.2 & 5.0889 & TRN \\
\hline CHEMBL512090 & 688267 & 4.0 & 5.0626 & TST \\
\hline CHEMBL1553053 & 688267 & 5.95 & 5.0338 & TRN \\
\hline CHEMBL1311611 & 688267 & 5.7 & 5.0439 & TRN \\
\hline CHEMBL1424125 & 688267 & 4.4 & 5.0397 & TST \\
\hline CHEMBL1315988 & 688267 & 4.2 & 5.0116 & TRN \\
\hline CHEMBL1431603 & 688267 & 6.2 & 5.0485 & TRN \\
\hline CHEMBL1540697 & 688267 & 4.3 & 5.0187 & TRN \\
\hline CHEMBL1301491 & 688267 & 4.25 & 5.0367 & TRN \\
\hline CHEMBL1722765 & 688267 & 6.45 & 5.1218 & TRN \\
\hline CHEMBL1415380 & 688267 & 4.65 & 5.0345 & TRN \\
\hline CHEMBL1452461 & 688267 & 4.0 & 5.0984 & TST \\
\hline CHEMBL1358521 & 688267 & 5.7 & 5.1338 & TST \\
\hline CHEMBL1428367 & 688267 & 3.95 & 5.0115 & TRN \\
\hline CHEMBL1332221 & 688267 & 6.15 & 5.099 & TRN \\
\hline CHEMBL1552843 & 688267 & 5.9 & 5.0483 & TRN \\
\hline CHEMBL1525925 & 688267 & 4.5 & 5.0699 & TRN \\
\hline CHEMBL1524714 & 688267 & 4.4 & 5.0284 & TST \\
\hline CHEMBL1585925 & 688267 & 4.65 & 5.0323 & TRN \\
\hline CHEMBL1332673 & 688267 & 4.4 & 5.0305 & TST \\
\hline CHEMBL1415106 & 688267 & 4.3 & 5.0456 & TST \\
\hline CHEMBL1416046 & 688267 & 6.2 & 5.0684 & TRN \\
\hline CHEMBL1378517 & 688267 & 6.2 & 5.0449 & TRN \\
\hline CHEMBL1509305 & 688267 & 5.35 & 5.0906 & TST \\
\hline
\end{tabular}




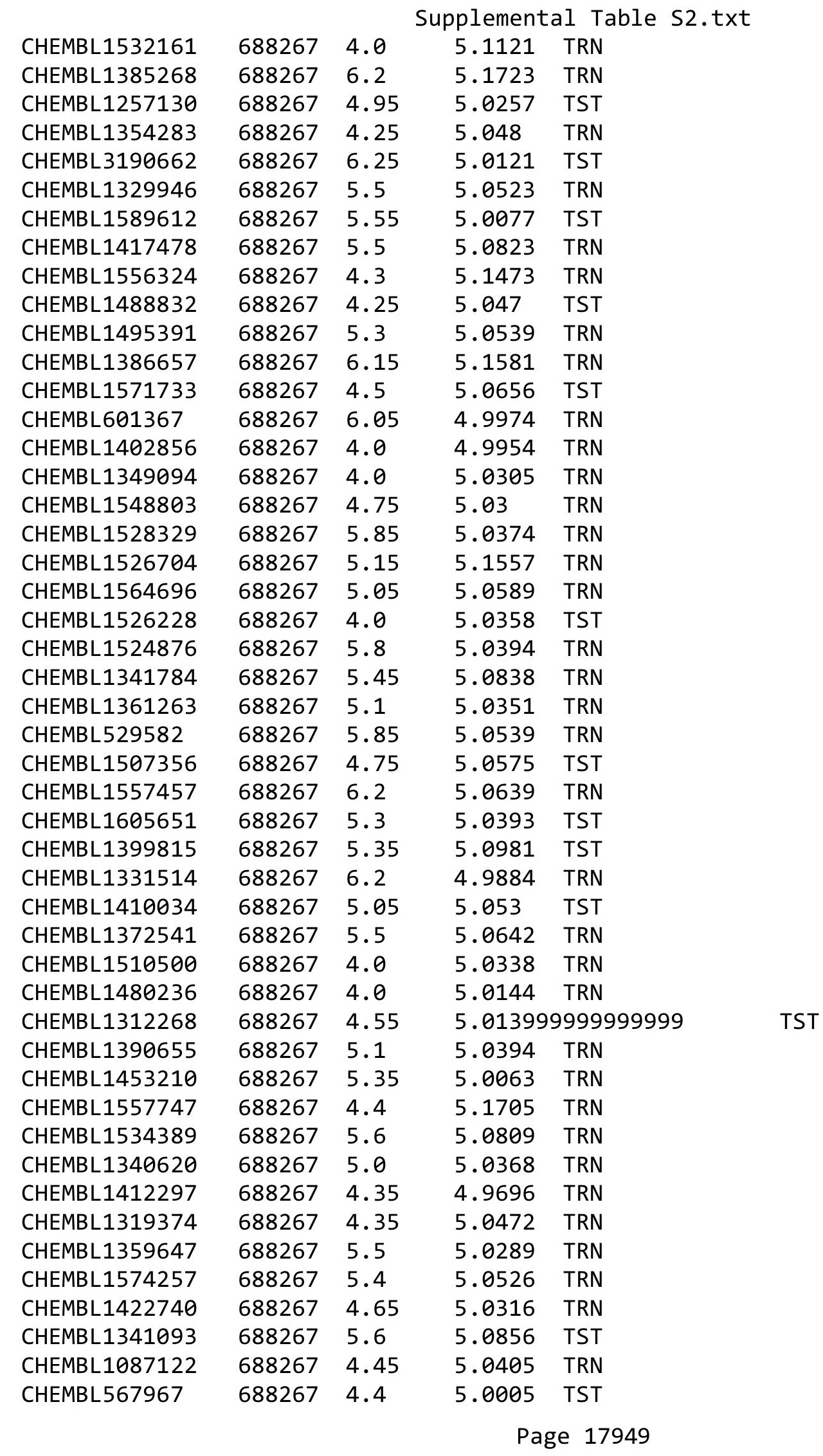




\begin{tabular}{|c|c|c|c|c|c|}
\hline \\
\hline CHEMBL1414960 & 688267 & 4.5 & 5.0426 & TST & \\
\hline CHEMBL1586677 & 688267 & 5.85 & 5.0866 & TST & \\
\hline CHEMBL1428792 & 688267 & 6.2 & 5.1112 & TRN & \\
\hline CHEMBL1575457 & 688267 & 4.45 & 5.1033 & TRN & \\
\hline CHEMBL1567746 & 688267 & 5.65 & 5.0716 & TST & \\
\hline CHEMBL1485973 & 688267 & 3.85 & 5.0838 & TRN & \\
\hline CHEMBL1596301 & 688267 & 4.4 & 5.0606 & TRN & \\
\hline CHEMBL1380388 & 688267 & 4.0 & 5.0557 & TST & \\
\hline CHEMBL1462841 & 688267 & 6.2 & 5.10800 & 00000000005 & TRN \\
\hline CHEMBL1337433 & 688267 & 4.4 & 5.0344 & TRN & \\
\hline CHEMBL1475544 & 688267 & 5.0 & 5.0358 & TRN & \\
\hline CHEMBL1516628 & 688267 & 4.4 & 5.0832 & TST & \\
\hline CHEMBL1357108 & 688267 & 5.55 & 5.0339 & TRN & \\
\hline CHEMBL1441122 & 688267 & 5.35 & 5.0812 & TST & \\
\hline CHEMBL1546371 & 688267 & 4.6 & 5.0749 & TRN & \\
\hline CHEMBL1314915 & 688267 & 4.85 & 5.0834 & TST & \\
\hline CHEMBL1510903 & 688267 & 4.25 & 5.1076 & TST & \\
\hline CHEMBL1465189 & 688267 & 6.2 & 4.997 & TRN & \\
\hline CHEMBL1369244 & 688267 & 4.7 & 5.065 & TST & \\
\hline CHEMBL1519355 & 688267 & 6.15 & 5.0884 & TST & \\
\hline CHEMBL1588470 & 688267 & 5.75 & 5.0275 & TRN & \\
\hline CHEMBL1406579 & 688267 & 5.85 & 5.0647 & TRN & \\
\hline CHEMBL1396930 & 688267 & 4.85 & 5.0927 & TRN & \\
\hline CHEMBL1319576 & 688267 & 5.8 & 5.0661 & TRN & \\
\hline CHEMBL1447268 & 688267 & 6.2 & 5.05699 & 99999999995 & TRN \\
\hline CHEMBL1511663 & 688267 & 5.55 & 5.13399 & 99999999995 & TRN \\
\hline CHEMBL1397445 & 688267 & 5.6 & 5.0186 & TRN & \\
\hline CHEMBL1576946 & 688267 & 5.45 & 5.0516 & TST & \\
\hline CHEMBL1604544 & 688267 & 4.05 & 5.1111 & TRN & \\
\hline CHEMBL1387038 & 688267 & 4.7 & 5.0583 & TST & \\
\hline CHEMBL1393249 & 688267 & 4.85 & 5.1094 & TRN & \\
\hline CHEMBL1362035 & 688267 & 6.2 & 4.9957 & TRN & \\
\hline CHEMBL1442681 & 688267 & 3.95 & 5.032 & TRN & \\
\hline CHEMBL1340084 & 688267 & 5.15 & 5.052 & TRN & \\
\hline CHEMBL1399220 & 688267 & 6.25 & 5.0963 & TRN & \\
\hline CHEMBL1472302 & 688267 & 6.2 & 5.0596 & TRN & \\
\hline CHEMBL3209868 & 688267 & 6.2 & 4.9573 & TRN & \\
\hline CHEMBL1521999 & 688267 & 4.1 & 5.0705 & TRN & \\
\hline CHEMBL1479259 & 688267 & 6.2 & 5.1119 & TRN & \\
\hline CHEMBL598997 & 688267 & 4.6 & 5.0397 & TST & \\
\hline CHEMBL1528199 & 688267 & 4.15 & 5.0245 & TST & \\
\hline CHEMBL1544988 & 688267 & 4.35 & 5.0657 & TST & \\
\hline CHEMBL3190986 & 688267 & 5.3 & 4.9862 & TST & \\
\hline CHEMBL3191535 & 688267 & 5.55 & 5.0013 & TRN & \\
\hline CHEMBL1557750 & 688267 & 4.0 & 5.1075 & TRN & \\
\hline CHEMBL1558110 & 688267 & 5.45 & 5.0619 & TRN & \\
\hline CHEMBL1599698 & 688267 & 4.0 & 5.0047 & TRN & \\
\hline CHEMBL1409523 & 688267 & 5.85 & 5.1011 & TRN & \\
\hline
\end{tabular}




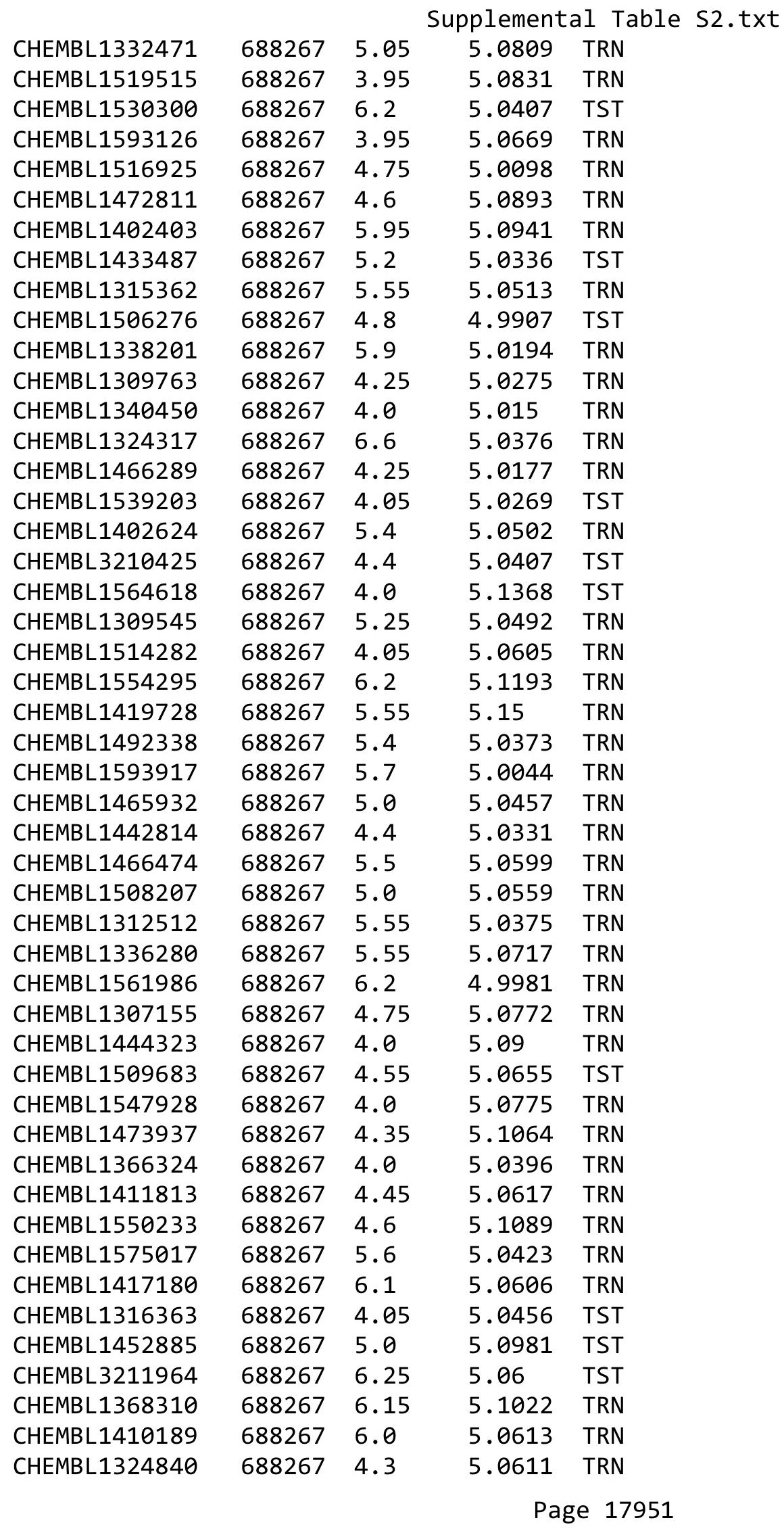




\begin{tabular}{|c|c|c|c|c|}
\hline \multicolumn{5}{|c|}{ Supplemental Table } \\
\hline CHEMBL1527004 & 688267 & 5.75 & 5.0948 & TRN \\
\hline CHEMBL1529169 & 688267 & 4.55 & 5.0938 & TRN \\
\hline CHEMBL1565036 & 688267 & 5.3 & 5.064 & TRN \\
\hline CHEMBL1514635 & 688267 & 3.95 & 4.9932 & TRN \\
\hline CHEMBL1315767 & 688267 & 4.05 & 5.1245 & TRN \\
\hline CHEMBL1435090 & 688267 & 4.4 & 5.0661 & TRN \\
\hline CHEMBL1589470 & 688267 & 4.85 & 5.0734 & TST \\
\hline CHEMBL1349669 & 688267 & 4.55 & 5.1661 & TRN \\
\hline CHEMBL1328847 & 688267 & 4.4 & 5.0605 & TST \\
\hline CHEMBL1560255 & 688267 & 5.85 & 5.0647 & TRN \\
\hline CHEMBL1557454 & 688267 & 5.4 & 5.1897 & TRN \\
\hline CHEMBL1369657 & 688267 & 5.95 & 5.0198 & TRN \\
\hline CHEMBL1393519 & 688267 & 4.6 & 5.0059 & TRN \\
\hline CHEMBL3196181 & 688267 & 4.0 & 5.1006 & TRN \\
\hline CHEMBL1497997 & 688267 & 4.0 & 5.0578 & TRN \\
\hline CHEMBL1393380 & 688267 & 5.6 & 5.0249 & TRN \\
\hline CHEMBL1319176 & 688267 & 4.05 & 5.0626 & TRN \\
\hline CHEMBL1405994 & 688267 & 4.1 & 5.1132 & TST \\
\hline CHEMBL579366 & 688267 & 4.45 & 5.0416 & TRN \\
\hline CHEMBL1554661 & 688267 & 4.05 & 5.0142 & TRN \\
\hline CHEMBL1330216 & 688267 & 4.6 & 5.0347 & TRN \\
\hline CHEMBL1590826 & 688267 & 5.75 & 5.0383 & TST \\
\hline CHEMBL1607039 & 688267 & 4.05 & 5.021 & TRN \\
\hline CHEMBL1538294 & 688267 & 4.05 & 5.1172 & TST \\
\hline CHEMBL1331654 & 688267 & 3.95 & 5.082 & TRN \\
\hline CHEMBL1517412 & 688267 & 5.8 & 4.9956 & TRN \\
\hline CHEMBL1613299 & 688267 & 4.05 & 5.0799 & TRN \\
\hline CHEMBL1396364 & 688267 & 4.45 & 5.0646 & TRN \\
\hline CHEMBL1568954 & 688267 & 6.2 & 5.0669 & TRN \\
\hline CHEMBL1399321 & 688267 & 6.15 & 5.0999 & TRN \\
\hline CHEMBL1474940 & 688267 & 5.6 & 4.9773 & TRN \\
\hline CHEMBL1439955 & 688267 & 6.2 & 5.141 & TRN \\
\hline CHEMBL1554110 & 688267 & 4.45 & 5.0495 & TRN \\
\hline CHEMBL1401804 & 688267 & 4.05 & 5.0483 & TRN \\
\hline CHEMBL1549222 & 688267 & 4.05 & 5.0039 & TST \\
\hline CHEMBL1492124 & 688267 & 5.75 & 5.1111 & TRN \\
\hline CHEMBL1413085 & 688267 & 4.4 & 5.0059 & TST \\
\hline CHEMBL1438774 & 688267 & 5.2 & 5.0577 & TRN \\
\hline CHEMBL1578428 & 688267 & 4.95 & 5.0664 & TRN \\
\hline CHEMBL1538938 & 688267 & 5.6 & 5.0749 & TST \\
\hline CHEMBL1369391 & 688267 & 4.55 & 5.0638 & TRN \\
\hline CHEMBL1583180 & 688267 & 5.25 & 5.066 & TRN \\
\hline CHEMBL1399408 & 688267 & 5.05 & 5.0028 & TRN \\
\hline CHEMBL1305166 & 688267 & 5.8 & 5.0893 & TST \\
\hline CHEMBL 1488445 & 688267 & 5.8 & 5.0714 & TRN \\
\hline CHEMBL1606080 & 688267 & 6.0 & 5.046 & TRN \\
\hline CHEMBL1489159 & 688267 & 6.5 & 5.0527 & TST \\
\hline CHEMBL1596890 & 688267 & 5.3 & 5.072 & TST \\
\hline
\end{tabular}




\begin{tabular}{|c|c|c|c|c|c|}
\hline \multirow[b]{2}{*}{ CHEMBL1422184 } & \multirow[b]{2}{*}{688267} & \\
\hline & & 4.85 & 5.0544 & TRN & \\
\hline CHEMBL1597782 & 688267 & 5.05 & 5.047 & TRN & \\
\hline CHEMBL1356679 & 688267 & 4.9 & 5.0668 & TRN & \\
\hline CHEMBL1364080 & 688267 & 6.2 & 5.0876 & TRN & \\
\hline CHEMBL1559079 & 688267 & 5.3 & 4.9894 & TRN & \\
\hline CHEMBL1492403 & 688267 & 4.45 & 5.0786 & TRN & \\
\hline CHEMBL1421750 & 688267 & 4.1 & 5.0679 & TRN & \\
\hline CHEMBL1538555 & 688267 & 5.3 & 5.085 & TRN & \\
\hline CHEMBL1352335 & 688267 & 4.05 & 5.1327 & TRN & \\
\hline CHEMBL3210643 & 688267 & 5.4 & 5.0845 & TST & \\
\hline CHEMBL1593359 & 688267 & 4.2 & \multicolumn{2}{|c|}{5.0280000000000005} & TST \\
\hline CHEMBL1529092 & 688267 & 4.3 & 5.0919 & TRN & \\
\hline CHEMBL1385592 & 688267 & 4.55 & \multicolumn{2}{|c|}{5.0969999999999995} & TRN \\
\hline CHEMBL1463580 & 688267 & 5.05 & 5.1004 & TRN & \\
\hline CHEMBL1321857 & 688267 & 5.9 & 5.1054 & TRN & \\
\hline CHEMBL1592522 & 688267 & 6.2 & 5.0955 & TRN & \\
\hline CHEMBL1427667 & 688267 & 6.05 & 5.0764 & TRN & \\
\hline CHEMBL1335749 & 688267 & 4.05 & 5.0327 & TRN & \\
\hline CHEMBL1316774 & 688267 & 5.85 & 5.0342 & TST & \\
\hline CHEMBL1552576 & 688267 & 5.3 & 5.0879 & TRN & \\
\hline CHEMBL1313356 & 688267 & 6.2 & 5.045 & TST & \\
\hline CHEMBL1574927 & 688267 & 4.4 & 5.1049 & TRN & \\
\hline CHEMBL1402144 & 688267 & 3.95 & 5.075 & TRN & \\
\hline CHEMBL1402079 & 688267 & 4.35 & 5.0534 & TST & \\
\hline CHEMBL1325601 & 688267 & 4.5 & 5.0371 & TRN & \\
\hline CHEMBL1473168 & 688267 & 4.6 & 5.1018 & TRN & \\
\hline CHEMBL1340825 & 688267 & 5.3 & 5.0762 & TST & \\
\hline CHEMBL1593279 & 688267 & 6.2 & 5.1131 & TRN & \\
\hline CHEMBL1517768 & 688267 & 5.3 & 5.0009 & TST & \\
\hline CHEMBL1517421 & 688267 & 6.15 & 5.0567 & TST & \\
\hline CHEMBL1345723 & 688267 & 5.95 & 5.024 & TRN & \\
\hline CHEMBL1609042 & 688267 & 5.9 & 5.0338 & TRN & \\
\hline CHEMBL1558156 & 688267 & 4.0 & 5.0455 & TRN & \\
\hline CHEMBL1336626 & 688267 & 4.2 & 5.0296 & TST & \\
\hline CHEMBL1543887 & 688267 & 4.05 & 5.078 & TRN & \\
\hline CHEMBL1342107 & 688267 & 4.25 & 5.0867 & TRN & \\
\hline CHEMBL1450779 & 688267 & 6.2 & 5.0884 & TST & \\
\hline CHEMBL1354457 & 688267 & 4.05 & 5.112 & TRN & \\
\hline CHEMBL1386227 & 688267 & 4.3 & 5.0263 & TRN & \\
\hline CHEMBL1480635 & 688267 & 4.85 & 5.0623 & TRN & \\
\hline CHEMBL1332487 & 688267 & 4.3 & 4.9998 & TRN & \\
\hline CHEMBL3207510 & 688267 & 4.3 & 5.1055 & TRN & \\
\hline CHEMBL1343458 & 688267 & 4.05 & 5.0068 & TRN & \\
\hline CHEMBL1424247 & 688267 & 6.2 & 5.1216 & TRN & \\
\hline CHEMBL1353547 & 688267 & 4.55 & 5.1299 & TST & \\
\hline CHEMBL1560333 & 688267 & 5.2 & 5.1642 & TRN & \\
\hline CHEMBL1552545 & 688267 & 4.05 & 5.1143 & TRN & \\
\hline \multirow[t]{2}{*}{ CHEMBL1350716 } & 688267 & 4.05 & \multicolumn{2}{|c|}{5.1160000000000005} & TRN \\
\hline & & & \multicolumn{2}{|c|}{ Page 17953} & \\
\hline
\end{tabular}




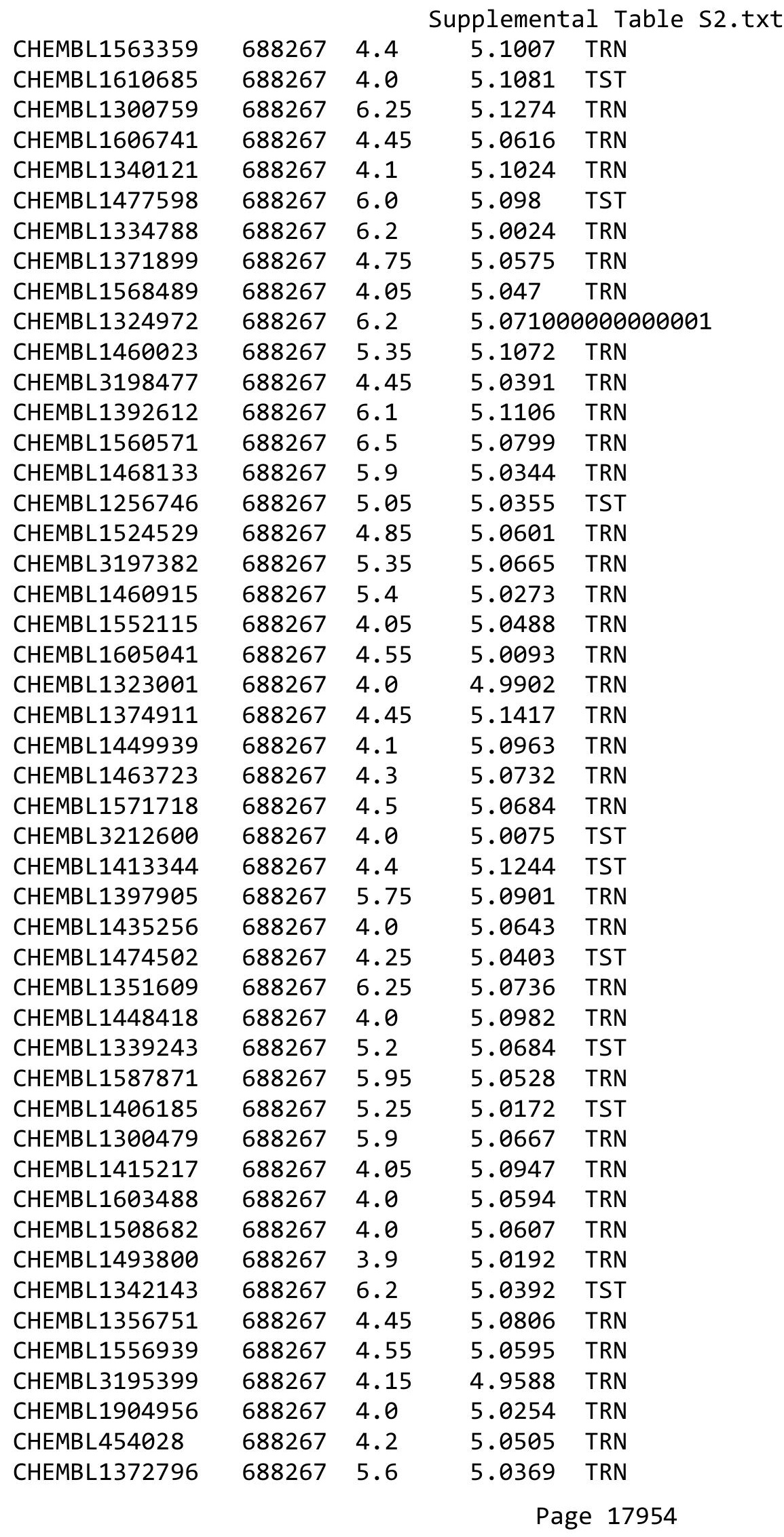




\begin{tabular}{|c|c|c|c|c|c|}
\hline \multicolumn{6}{|c|}{ Supplemental Table S2.txt } \\
\hline CHEMBL1607573 & 688267 & 4.35 & 5.0807 & TRN & \\
\hline CHEMBL1347957 & 688267 & 4.9 & 5.1697 & TRN & \\
\hline CHEMBL1333633 & 688267 & 5.55 & 5.0261 & TST & \\
\hline CHEMBL1585022 & 688267 & 5.55 & 5.1081 & TRN & \\
\hline CHEMBL1537348 & 688267 & 4.15 & 5.006 & TRN & \\
\hline CHEMBL1435052 & 688267 & 6.25 & 5.0645 & TRN & \\
\hline CHEMBL1570133 & 688267 & 5.45 & 5.1088 & TRN & \\
\hline CHEMBL1406366 & 688267 & 4.05 & 5.1406 & TRN & \\
\hline CHEMBL1257078 & 688267 & 4.95 & 5.0796 & TST & \\
\hline CHEMBL1318023 & 688267 & 4.5 & 5.1048 & TRN & \\
\hline CHEMBL1446962 & 688267 & 6.2 & 5.0116 & TRN & \\
\hline CHEMBL 3212229 & 688267 & 5.0 & 5.0976 & TRN & \\
\hline CHEMBL1408240 & 688267 & 5.45 & 5.0358 & TRN & \\
\hline CHEMBL1237212 & 688267 & 5.25 & 5.0969 & TST & \\
\hline CHEMBL1564518 & 688267 & 4.1 & 5.0611 & TRN & \\
\hline CHEMBL1478512 & 688267 & 6.15 & 5.084 & TST & \\
\hline CHEMBL3193353 & 688267 & 6.2 & 5.0401 & TRN & \\
\hline CHEMBL1336773 & 688267 & 5.3 & 5.1615 & TRN & \\
\hline CHEMBL1499198 & 688267 & 6.25 & 5.0567 & TRN & \\
\hline CHEMBL1360950 & 688267 & 4.0 & 5.05399 & 9999999999 & TRN \\
\hline CHEMBL1436610 & 688267 & 6.2 & 4.9957 & TRN & \\
\hline CHEMBL 373481 & 688267 & 4.55 & 5.0249 & TST & \\
\hline CHEMBL1479462 & 688267 & 4.0 & 5.0775 & TST & \\
\hline CHEMBL1497518 & 688267 & 6.15 & 5.038 & TRN & \\
\hline CHEMBL3210404 & 688267 & 5.85 & 5.0596 & TRN & \\
\hline CHEMBL1514421 & 688267 & 5.85 & 5.0893 & TRN & \\
\hline CHEMBL1357527 & 688267 & 4.5 & 5.1438 & TRN & \\
\hline CHEMBL1426823 & 688267 & 4.05 & 5.0091 & TRN & \\
\hline CHEMBL1427070 & 688267 & 4.05 & 5.052 & TRN & \\
\hline CHEMBL1469065 & 688267 & 5.3 & 5.0643 & TRN & \\
\hline CHEMBL1524603 & 688267 & 3.95 & 5.0119 & TRN & \\
\hline CHEMBL1479140 & 688267 & 6.2 & 5.0685 & TRN & \\
\hline CHEMBL1532274 & 688267 & 6.2 & 5.0842 & TRN & \\
\hline CHEMBL1553897 & 688267 & 4.55 & 5.1769 & TRN & \\
\hline CHEMBL1491479 & 688267 & 4.1 & 5.0039 & TRN & \\
\hline CHEMBL1593355 & 688267 & 5.35 & 5.0306 & TRN & \\
\hline CHEMBL1506618 & 688267 & 4.4 & 5.0312 & TST & \\
\hline CHEMBL1398450 & 688267 & 5.9 & 5.0834 & TRN & \\
\hline CHEMBL1410422 & 688267 & 6.2 & 5.0528 & TRN & \\
\hline CHEMBL1436430 & 688267 & 6.25 & 5.02800 & 00000000005 & TRN \\
\hline CHEMBL81324 & 688267 & 5.25 & 5.0586 & TST & \\
\hline CHEMBL1354992 & 688267 & 6.15 & 5.0741 & TRN & \\
\hline CHEMBL1520358 & 688267 & 5.3 & 5.0648 & TRN & \\
\hline CHEMBL1376255 & 688267 & 6.2 & 5.0604 & TST & \\
\hline CHEMBL1361336 & 688267 & 6.5 & 5.1064 & TST & \\
\hline CHEMBL1409642 & 688267 & 4.4 & 5.0275 & TST & \\
\hline CHEMBL1475826 & 688267 & 4.3 & 4.9924 & TST & \\
\hline CHEMBL1447572 & 688267 & 5.1 & 5.082 & TRN & \\
\hline
\end{tabular}




\begin{tabular}{|c|c|c|c|c|}
\hline \multicolumn{5}{|c|}{ Supplemental Table S2.txt } \\
\hline CHEMBL1349997 & 688267 & 5.0 & 5.0371 & TRN \\
\hline CHEMBL1573695 & 688267 & 3.95 & 5.1187 & TRN \\
\hline CHEMBL1455812 & 688267 & 3.95 & 5.0505 & TRN \\
\hline CHEMBL1408890 & 688267 & 4.05 & 5.0259 & TST \\
\hline CHEMBL1478733 & 688267 & 5.3 & 4.9914 & TRN \\
\hline CHEMBL1315853 & 688267 & 6.2 & 5.0433 & TRN \\
\hline CHEMBL1565701 & 688267 & 6.15 & 5.0344 & TRN \\
\hline CHEMBL1597957 & 688267 & 4.55 & 5.0524 & TRN \\
\hline CHEMBL1335565 & 688267 & 5.4 & 5.1254 & TRN \\
\hline CHEMBL1322781 & 688267 & 6.2 & 5.0117 & TRN \\
\hline CHEMBL1356360 & 688267 & 5.5 & 5.0733 & TRN \\
\hline CHEMBL1551681 & 688267 & 6.5501 & 5.0123 & TRN \\
\hline CHEMBL1302253 & 688267 & 5.25 & 5.0427 & TRN \\
\hline CHEMBL1440346 & 688267 & 4.05 & 5.0499 & TRN \\
\hline CHEMBL1559774 & 688267 & 5.5 & 5.1035 & TRN \\
\hline CHEMBL1471596 & 688267 & 4.9 & 5.0542 & TST \\
\hline CHEMBL1368590 & 688267 & 3.95 & 5.062 & TRN \\
\hline CHEMBL1375381 & 688267 & 5.4 & 5.1213 & TRN \\
\hline CHEMBL1508808 & 688267 & 4.1 & 5.0785 & TRN \\
\hline CHEMBL1603562 & 688267 & 4.1 & 5.0281 & TRN \\
\hline CHEMBL1493194 & 688267 & 4.7 & 5.0321 & TST \\
\hline CHEMBL1399758 & 688267 & 6.0 & 4.9852 & TST \\
\hline CHEMBL1401664 & 688267 & 6.2 & 5.0786 & TST \\
\hline CHEMBL1456051 & 688267 & 5.9 & 5.0615 & TRN \\
\hline CHEMBL1478868 & 688267 & 4.1 & 5.0789 & TST \\
\hline CHEMBL1390288 & 688267 & 4.4 & 5.1018 & TST \\
\hline CHEMBL1597613 & 688267 & 4.3 & 5.0926 & TST \\
\hline CHEMBL1467633 & 688267 & 3.95 & 5.0511 & TST \\
\hline CHEMBL1607164 & 688267 & 4.7 & 5.112 & TRN \\
\hline CHEMBL1612471 & 688267 & 4.55 & 5.0397 & TRN \\
\hline CHEMBL1396479 & 688267 & 4.75 & 5.0888 & TRN \\
\hline CHEMBL1465309 & 688267 & 4.0 & 5.0627 & TST \\
\hline CHEMBL1416324 & 688267 & 5.0 & 5.1326 & TRN \\
\hline CHEMBL1451729 & 688267 & 4.4 & 5.0683 & TRN \\
\hline CHEMBL1483311 & 688267 & 4.1 & 5.0362 & TST \\
\hline CHEMBL1305780 & 688267 & 4.5 & 5.0346 & TST \\
\hline CHEMBL1456947 & 688267 & 4.05 & 5.0396 & TRN \\
\hline CHEMBL1417676 & 688267 & 6.45 & 5.0114 & TRN \\
\hline CHEMBL1532239 & 688267 & 5.3 & 4.9939 & TRN \\
\hline CHEMBL1518517 & 688267 & 5.5 & 5.1226 & TRN \\
\hline CHEMBL1599904 & 688267 & 6.2 & 5.0287 & TST \\
\hline CHEMBL1599337 & 688267 & 4.45 & 5.0621 & TRN \\
\hline CHEMBL1405609 & 688267 & 4.6 & 5.0385 & TRN \\
\hline CHEMBL1475515 & 688267 & 3.95 & 5.0518 & TRN \\
\hline CHEMBL1544194 & 688267 & 6.15 & 5.0381 & TRN \\
\hline CHEMBL1397242 & 688267 & 6.2 & 5.0962 & TST \\
\hline CHEMBL1594226 & 688267 & 6.5501 & 5.0056 & TRN \\
\hline CHEMBL1561356 & 688267 & 4.05 & 5.1068 & TRN \\
\hline
\end{tabular}




\begin{tabular}{|c|c|c|c|c|c|}
\hline \\
\hline CHEMBL1357472 & 688267 & 4.1 & 5.0603 & TST & \\
\hline CHEMBL1473360 & 688267 & 4.2 & 5.0236 & TRN & \\
\hline CHEMBL1328133 & 688267 & 6.2 & 5.0997 & TRN & \\
\hline CHEMBL1442073 & 688267 & 3.95 & 5.1139 & TRN & \\
\hline CHEMBL1392635 & 688267 & 4.1 & 5.0011 & TRN & \\
\hline CHEMBL81782 & 688267 & 5.0 & 5.0121 & TRN & \\
\hline CHEMBL1348109 & 688267 & 4.35 & 5.0525 & TST & \\
\hline CHEMBL1410389 & 688267 & 5.75 & 5.047 & TST & \\
\hline CHEMBL1590960 & 688267 & 5.5 & 5.1148 & TRN & \\
\hline CHEMBL1609287 & 688267 & 6.2 & 5.022 & TRN & \\
\hline CHEMBL1541735 & 688267 & 6.2 & 5.0254 & TRN & \\
\hline CHEMBL1370976 & 688267 & 5.35 & 5.0539 & TRN & \\
\hline CHEMBL1315067 & 688267 & 4.0 & 5.0543 & TRN & \\
\hline CHEMBL1535301 & 688267 & 4.35 & 5.1075 & TRN & \\
\hline CHEMBL1437815 & 688267 & 6.0 & 5.0716 & TRN & \\
\hline CHEMBL1555960 & 688267 & 4.35 & 5.0193 & TRN & \\
\hline CHEMBL1343706 & 688267 & 5.35 & 5.0286 & TRN & \\
\hline CHEMBL1429407 & 688267 & 4.25 & 5.1006 & TRN & \\
\hline CHEMBL1522959 & 688267 & 4.0 & 5.0342 & TRN & \\
\hline CHEMBL1305050 & 688267 & 4.2 & 5.0055 & TRN & \\
\hline CHEMBL1304769 & 688267 & 4.3 & 5.0204 & TRN & \\
\hline CHEMBL1478560 & 688267 & 4.4 & 5.0414 & TST & \\
\hline CHEMBL1386914 & 688267 & 5.9 & 5.0256 & TRN & \\
\hline CHEMBL1473198 & 688267 & 5.9 & 5.1226 & TRN & \\
\hline CHEMBL 1305350 & 688267 & 5.8 & 5.0645 & TRN & \\
\hline CHEMBL1488224 & 688267 & 3.95 & 5.0632 & TRN & \\
\hline CHEMBL1308483 & 688267 & 4.05 & 5.0357 & TRN & \\
\hline CHEMBL 3198044 & 688267 & 4.5 & 5.0139 & 9999999999 & TRN \\
\hline CHEMBL1465047 & 688267 & 5.45 & 5.0966 & TST & \\
\hline CHEMBL1486412 & 688267 & 4.55 & 5.03 & TRN & \\
\hline CHEMBL1482519 & 688267 & 3.95 & 5.0569 & TRN & \\
\hline CHEMBL3196765 & 688267 & 6.2 & 5.0616 & TST & \\
\hline CHEMBL1609338 & 688267 & 5.25 & 5.1477 & TST & \\
\hline CHEMBL1517019 & 688267 & 5.5 & 5.0614 & TRN & \\
\hline CHEMBL 1558186 & 688267 & 5.2 & 5.0889 & 99999999995 & TRN \\
\hline CHEMBL1546836 & 688267 & 4.2 & 5.0315 & TRN & \\
\hline CHEMBL1542570 & 688267 & 5.1 & 5.0377 & TRN & \\
\hline CHEMBL1506244 & 688267 & 4.35 & 4.9823 & TST & \\
\hline CHEMBL1347102 & 688267 & 4.0 & 5.0779 & TST & \\
\hline CHEMBL1348021 & 688267 & 5.55 & 5.0145 & TRN & \\
\hline CHEMBL3209135 & 688267 & 4.35 & 5.0225 & TRN & \\
\hline CHEMBL1537440 & 688267 & 6.2 & 5.0029 & TST & \\
\hline CHEMBL1376957 & 688267 & 6.2 & 5.0957 & TST & \\
\hline CHEMBL1367351 & 688267 & 5.3 & 5.0498 & TRN & \\
\hline CHEMBL1597884 & 688267 & 5.6 & 5.0395 & TRN & \\
\hline CHEMBL1311637 & 688267 & 5.3 & 5.0693 & TRN & \\
\hline CHEMBL1437327 & 688267 & 5.55 & 5.0851 & TRN & \\
\hline CHEMBL1367270 & 688267 & 5.9 & 5.1108 & TRN & \\
\hline
\end{tabular}




\begin{tabular}{|c|c|c|c|c|c|}
\hline \multicolumn{6}{|c|}{ Supplemental Table S2.txt } \\
\hline CHEMBL1334715 & 688267 & 5.4 & 5.1012 & TRN & \\
\hline CHEMBL1392666 & 688267 & 5.3 & 5.0763 & TRN & \\
\hline CHEMBL1254832 & 688267 & 4.2 & 5.0826 & TRN & \\
\hline CHEMBL1385752 & 688267 & 4.65 & 5.0481 & TRN & \\
\hline CHEMBL1597502 & 688267 & 4.5 & 5.0636 & TST & \\
\hline CHEMBL1346203 & 688267 & 4.35 & 5.1593 & TST & \\
\hline CHEMBL1338946 & 688267 & 6.15 & 5.0338 & TRN & \\
\hline CHEMBL1457504 & 688267 & 6.6 & 5.0903 & TRN & \\
\hline CHEMBL1524565 & 688267 & 5.6 & 5.1026 & TRN & \\
\hline CHEMBL1362666 & 688267 & 4.95 & 5.1168 & TRN & \\
\hline CHEMBL1405992 & 688267 & 5.0 & 5.0711 & TST & \\
\hline CHEMBL1586023 & 688267 & 4.0 & 5.1004 & TST & \\
\hline CHEMBL1499168 & 688267 & 4.4 & 5.1472 & TRN & \\
\hline CHEMBL1574479 & 688267 & 6.2 & 5.0628 & TRN & \\
\hline CHEMBL1407589 & 688267 & 6.2 & 5.0257 & TRN & \\
\hline CHEMBL1357495 & 688267 & 6.15 & 5.0443 & TRN & \\
\hline CHEMBL1462309 & 688267 & 4.4 & 5.0025 & TST & \\
\hline CHEMBL1365435 & 688267 & 6.45 & 5.1062 & TRN & \\
\hline CHEMBL1565148 & 688267 & 6.15 & 5.0289 & TRN & \\
\hline CHEMBL1519277 & 688267 & 5.95 & 5.11 & TRN & \\
\hline CHEMBL1425985 & 688267 & 5.55 & 5.0396 & TRN & \\
\hline CHEMBL1361317 & 688267 & 4.0 & 5.0157 & TRN & \\
\hline CHEMBL1397248 & 688267 & 5.6 & 5.069 & TRN & \\
\hline CHEMBL1403301 & 688267 & 4.1 & 5.0953 & TRN & \\
\hline CHEMBL1478830 & 688267 & 4.05 & 5.0956 & TST & \\
\hline CHEMBL1324860 & 688267 & 6.2 & 5.0588 & TRN & \\
\hline CHEMBL1582075 & 688267 & 5.35 & 5.0455 & TRN & \\
\hline CHEMBL1505040 & 688267 & 4.05 & 5.0484 & TST & \\
\hline CHEMBL1457449 & 688267 & 5.7 & $5.0280 e$ & 00000000005 & TRN \\
\hline CHEMBL1321522 & 688267 & 6.15 & 5.1018 & TRN & \\
\hline CHEMBL3199874 & 688267 & 4.0 & 5.0158 & TRN & \\
\hline CHEMBL1540222 & 688267 & 4.4 & 5.0663 & TRN & \\
\hline CHEMBL1535044 & 688267 & 5.3 & 5.0247 & TRN & \\
\hline CHEMBL1365484 & 688267 & 6.2 & 5.0689 & TRN & \\
\hline CHEMBL1326457 & 688267 & 6.2 & 5.0373 & TRN & \\
\hline CHEMBL3196330 & 688267 & 4.3 & 5.0041 & TRN & \\
\hline CHEMBL1403635 & 688267 & 5.55 & 5.0714 & TRN & \\
\hline CHEMBL1573335 & 688267 & 5.6 & 5.1477 & TRN & \\
\hline CHEMBL1558047 & 688267 & 6.25 & 5.1008 & TST & \\
\hline CHEMBL1344064 & 688267 & 4.25 & 5.0101 & TST & \\
\hline CHEMBL1451820 & 688267 & 6.25 & 5.0045 & TST & \\
\hline CHEMBL1467643 & 688267 & 4.3 & 5.0747 & TRN & \\
\hline CHEMBL1538934 & 688267 & 6.15 & 5.0911 & TST & \\
\hline CHEMBL1537897 & 688267 & 5.1 & 5.0124 & TRN & \\
\hline CHEMBL1576363 & 688267 & 4.25 & 4.9907 & TRN & \\
\hline CHEMBL1395827 & 688267 & 5.25 & 5.0875 & TRN & \\
\hline CHEMBL1603495 & 688267 & 4.65 & 5.0504 & TRN & \\
\hline CHEMBL1478987 & 688267 & 5.6 & 5.0292 & TRN & \\
\hline
\end{tabular}




\begin{tabular}{|c|c|c|c|c|}
\hline \multicolumn{5}{|c|}{ Supplemental Table S2.txt } \\
\hline CHEMBL1316129 & 688267 & 5.3 & 5.0212 & TRN \\
\hline CHEMBL1395261 & 688267 & 4.85 & 5.0648 & TRN \\
\hline CHEMBL1514752 & 688267 & 5.75 & 5.1068 & TRN \\
\hline CHEMBL1602030 & 688267 & 5.3 & 5.0549 & TRN \\
\hline CHEMBL1439912 & 688267 & 5.35 & 5.1505 & TRN \\
\hline CHEMBL1576760 & 688267 & 4.3 & 5.0426 & TST \\
\hline CHEMBL1395319 & 688267 & 4.4 & 5.0602 & TRN \\
\hline CHEMBL1598353 & 688267 & 5.35 & 5.1664 & TRN \\
\hline CHEMBL1610310 & 688267 & 4.5 & 5.0914 & TRN \\
\hline CHEMBL1557800 & 688267 & 4.05 & 5.0992 & TRN \\
\hline CHEMBL1409913 & 688267 & 4.9 & 5.023 & TRN \\
\hline CHEMBL1488239 & 688267 & 4.0 & 5.0238 & TRN \\
\hline CHEMBL1400705 & 688267 & 4.05 & 5.0237 & TRN \\
\hline CHEMBL1434470 & 688267 & 5.5 & 5.0329 & TRN \\
\hline CHEMBL1490053 & 688267 & 5.8 & 5.093 & TRN \\
\hline CHEMBL1538462 & 688267 & 5.45 & 5.0159 & TST \\
\hline CHEMBL1455280 & 688267 & 6.5 & 5.1491 & TRN \\
\hline CHEMBL1520024 & 688267 & 4.55 & 5.1238 & TRN \\
\hline CHEMBL1450361 & 688267 & 4.05 & 5.0671 & TRN \\
\hline CHEMBL1336968 & 688267 & 5.65 & 5.1334 & TRN \\
\hline CHEMBL1444262 & 688267 & 3.95 & 5.0379 & TRN \\
\hline CHEMBL1362253 & 688267 & 4.0 & 5.1205 & TRN \\
\hline CHEMBL3209150 & 688267 & 5.1 & 5.0573 & TST \\
\hline CHEMBL 3211744 & 688267 & 5.4 & 5.0832 & TST \\
\hline CHEMBL1523533 & 688267 & 5.45 & 5.0937 & TST \\
\hline CHEMBL1489289 & 688267 & 5.5 & 5.0738 & TRN \\
\hline CHEMBL1326827 & 688267 & 5.45 & 5.087 & TRN \\
\hline CHEMBL1330006 & 688267 & 4.35 & 5.0043 & TRN \\
\hline CHEMBL1415891 & 688267 & 7.3497 & 5.0303 & TRN \\
\hline CHEMBL1365624 & 688267 & 6.1 & 5.0665 & TRN \\
\hline CHEMBL1513127 & 688267 & 5.3 & 4.9888 & TRN \\
\hline CHEMBL1372490 & 688267 & 5.75 & 5.0656 & TRN \\
\hline CHEMBL1455356 & 688267 & 4.0 & 5.07 & TRN \\
\hline CHEMBL1474455 & 688267 & 6.25 & 5.0591 & TRN \\
\hline CHEMBL1490614 & 688267 & 4.0 & 5.1483 & TRN \\
\hline CHEMBL1398289 & 688267 & 5.6 & 5.038 & TRN \\
\hline CHEMBL1413818 & 688267 & 4.75 & 5.0852 & TRN \\
\hline CHEMBL3214545 & 688267 & 5.85 & 4.9859 & TST \\
\hline CHEMBL1404928 & 688267 & 4.45 & 5.069 & TRN \\
\hline CHEMBL1332972 & 688267 & 4.0 & 5.088 & TRN \\
\hline CHEMBL3195728 & 688267 & 5.65 & 5.0191 & TRN \\
\hline CHEMBL 1451210 & 688267 & 4.4 & 5.0325 & TRN \\
\hline CHEMBL1520513 & 688267 & 5.8 & 5.1191 & TRN \\
\hline CHEMBL1596459 & 688267 & 4.0 & 5.0384 & TST \\
\hline CHEMBL1324266 & 688267 & 4.05 & 5.0049 & TST \\
\hline CHEMBL1405780 & 688267 & 4.0 & 5.0426 & TRN \\
\hline CHEMBL1546081 & 688267 & 5.75 & 5.0592 & TRN \\
\hline CHEMBL1530444 & 688267 & 4.4 & 5.0725 & TST \\
\hline
\end{tabular}




\begin{tabular}{|c|c|c|c|c|c|}
\hline \multicolumn{6}{|c|}{ Supplemental Table S2.txt } \\
\hline CHEMBL3214125 & 688267 & 4.0 & 5.0583 & TRN & \\
\hline CHEMBL1561360 & 688267 & 5.55 & 5.0024 & TRN & \\
\hline CHEMBL1357631 & 688267 & 4.05 & 5.0562 & TST & \\
\hline CHEMBL1417933 & 688267 & 4.3 & 5.0653 & TST & \\
\hline CHEMBL1327237 & 688267 & 4.05 & 5.0201 & TST & \\
\hline CHEMBL1565519 & 688267 & 4.0 & 5.0864 & TRN & \\
\hline CHEMBL1438242 & 688267 & 6.2 & 5.0328 & TRN & \\
\hline CHEMBL1364984 & 688267 & 5.75 & 5.0395 & TST & \\
\hline CHEMBL1319582 & 688267 & 4.35 & 5.0265 & TRN & \\
\hline CHEMBL1434225 & 688267 & 6.5 & 5.0211 & TRN & \\
\hline CHEMBL1399748 & 688267 & 4.35 & 5.0949 & TRN & \\
\hline CHEMBL1506996 & 688267 & 4.2 & 4.9916 & TRN & \\
\hline CHEMBL1598883 & 688267 & 4.55 & 5.0435 & TST & \\
\hline CHEMBL1476103 & 688267 & 4.2 & 5.0133 & TRN & \\
\hline CHEMBL1445921 & 688267 & 4.7 & 5.0522 & TST & \\
\hline CHEMBL1452569 & 688267 & 6.25 & 5.148 & TRN & \\
\hline CHEMBL1344182 & 688267 & 6.2 & 5.088 & TRN & \\
\hline CHEMBL1436118 & 688267 & 6.2 & 5.0941 & TRN & \\
\hline CHEMBL1319079 & 688267 & 6.25 & 4.9849 & TRN & \\
\hline CHEMBL1459718 & 688267 & 5.45 & 5.0506 & TRN & \\
\hline CHEMBL1303325 & 688267 & 4.55 & 5.0015 & TST & \\
\hline CHEMBL1363333 & 688267 & 6.2 & 5.0696 & TRN & \\
\hline CHEMBL1610807 & 688267 & 5.45 & 5.0313 & TRN & \\
\hline CHEMBL1399178 & 688267 & 5.3 & 5.0307 & TRN & \\
\hline CHEMBL1361439 & 688267 & 6.25 & 5.0617 & TRN & \\
\hline CHEMBL1566612 & 688267 & 4.25 & 5.0278 & TST & \\
\hline CHEMBL3195118 & 688267 & 6.6499 & 4.9778 & TRN & \\
\hline CHEMBL1565833 & 688267 & 5.75 & 5.11600 & 00000000005 & TRN \\
\hline CHEMBL1492286 & 688267 & 5.5 & 5.0164 & TRN & \\
\hline CHEMBL1479835 & 688267 & 6.2 & 5.09399 & 9999999999 & TRN \\
\hline CHEMBL1383399 & 688267 & 5.4 & 5.08899 & 99999999995 & TRN \\
\hline CHEMBL592819 & 688267 & 3.95 & 5.0412 & TRN & \\
\hline CHEMBL1502891 & 688267 & 3.95 & 5.0354 & TST & \\
\hline CHEMBL1368699 & 688267 & 5.65 & 5.0505 & TRN & \\
\hline CHEMBL3193835 & 688267 & 6.15 & 5.0275 & TST & \\
\hline CHEMBL1443543 & 688267 & 4.7 & 5.0519 & TRN & \\
\hline CHEMBL1370185 & 688267 & 6.2 & 5.0798 & TRN & \\
\hline CHEMBL1400634 & 688267 & 4.35 & 5.1255 & TRN & \\
\hline CHEMBL1412589 & 688267 & 4.7 & 5.0598 & TRN & \\
\hline CHEMBL3191152 & 688267 & 4.55 & 5.0044 & TST & \\
\hline CHEMBL1591888 & 688267 & 5.35 & 5.1227 & TRN & \\
\hline CHEMBL1593037 & 688267 & 6.6 & 4.9757 & TRN & \\
\hline CHEMBL1442761 & 688267 & 5.35 & 5.0244 & TRN & \\
\hline CHEMBL1563494 & 688267 & 4.25 & 5.1291 & TRN & \\
\hline CHEMBL1360033 & 688267 & 4.35 & 5.0106 & TRN & \\
\hline CHEMBL1581440 & 688267 & 5.9 & 5.0446 & TRN & \\
\hline CHEMBL1358019 & 688267 & 5.6 & 5.0853 & TRN & \\
\hline CHEMBL1346516 & 688267 & 6.25 & 4.949 & TRN & \\
\hline
\end{tabular}




\begin{tabular}{|c|c|c|c|c|}
\hline \multicolumn{5}{|c|}{ Supplemental Table S2.txt } \\
\hline CHEMBL3197999 & 688267 & 5.55 & 4.9894 & TST \\
\hline CHEMBL1355206 & 688267 & 4.35 & 5.0899 & TRN \\
\hline CHEMBL1527601 & 688267 & 4.0 & 5.0857 & TST \\
\hline CHEMBL1582913 & 688267 & 6.05 & 5.0803 & TRN \\
\hline CHEMBL1522346 & 688267 & 5.3 & 5.0317 & TRN \\
\hline CHEMBL1347384 & 688267 & 4.45 & 5.0242 & TRN \\
\hline CHEMBL1547281 & 688267 & 3.95 & 5.0622 & TST \\
\hline CHEMBL1451523 & 688267 & 6.2 & 5.0658 & TST \\
\hline CHEMBL1319708 & 688267 & 4.0 & 5.0391 & TRN \\
\hline CHEMBL1533349 & 688267 & 4.75 & 5.0956 & TST \\
\hline CHEMBL599305 & 688267 & 6.2 & 5.1006 & TST \\
\hline CHEMBL1458923 & 688267 & 6.05 & 5.0839 & TST \\
\hline CHEMBL1414062 & 688267 & 4.05 & 5.058 & TRN \\
\hline CHEMBL1541763 & 688267 & 4.6 & 5.0709 & TRN \\
\hline CHEMBL1301375 & 688267 & 4.05 & 5.1544 & TRN \\
\hline CHEMBL1495262 & 688267 & 5.55 & 5.0871 & TRN \\
\hline CHEMBL1489984 & 688267 & 5.7 & 5.1158 & TRN \\
\hline CHEMBL1333925 & 688267 & 6.15 & 5.0807 & TRN \\
\hline CHEMBL1341673 & 688267 & 4.05 & 4.9992 & TST \\
\hline CHEMBL1461335 & 688267 & 5.9 & 5.0986 & TRN \\
\hline CHEMBL1554048 & 688267 & 6.7501 & 5.1108 & TRN \\
\hline CHEMBL1572329 & 688267 & 4.35 & 5.0173 & TST \\
\hline CHEMBL1375557 & 688267 & 5.05 & 5.0779 & TRN \\
\hline CHEMBL1504486 & 688267 & 4.95 & 5.0292 & TRN \\
\hline CHEMBL1547183 & 688267 & 4.35 & 5.11 & TRN \\
\hline CHEMBL1463921 & 688267 & 4.0 & 5.0458 & TRN \\
\hline CHEMBL1343820 & 688267 & 4.35 & 5.0303 & TRN \\
\hline CHEMBL1468799 & 688267 & 4.1 & 5.1564 & TRN \\
\hline CHEMBL1563098 & 688267 & 5.05 & 5.1469 & TRN \\
\hline CHEMBL1353372 & 688267 & 4.5 & 5.1378 & TST \\
\hline CHEMBL3198574 & 688267 & 3.95 & 5.0425 & TRN \\
\hline CHEMBL1979040 & 688267 & 6.05 & 5.0814 & TRN \\
\hline CHEMBL52460 & 688267 & 4.05 & 5.0612 & TST \\
\hline CHEMBL1338770 & 688267 & 4.0 & 5.0608 & TST \\
\hline CHEMBL1432665 & 688267 & 6.1 & 5.0843 & TRN \\
\hline CHEMBL 3212234 & 688267 & 6.2 & 5.0404 & TST \\
\hline CHEMBL 1340371 & 688267 & 5.9 & 5.0764 & TRN \\
\hline CHEMBL3213729 & 688267 & 4.4 & 5.0709 & TRN \\
\hline CHEMBL1310171 & 688267 & 4.25 & 5.0477 & TRN \\
\hline CHEMBL1603946 & 688267 & 5.55 & 5.0174 & TRN \\
\hline CHEMBL1473789 & 688267 & 3.95 & 5.0314 & TRN \\
\hline CHEMBL1591558 & 688267 & 4.65 & 5.0116 & TRN \\
\hline CHEMBL1399626 & 688267 & 5.05 & 5.0486 & TRN \\
\hline CHEMBL1429843 & 688267 & 6.2 & 5.0833 & TRN \\
\hline CHEMBL1607934 & 688267 & 3.95 & 5.0872 & TRN \\
\hline CHEMBL1504478 & 688267 & 4.4 & 5.0219 & TST \\
\hline CHEMBL1456772 & 688267 & 4.05 & 5.0406 & TRN \\
\hline CHEMBL1371814 & 688267 & 4.1 & 5.0313 & TRN \\
\hline
\end{tabular}




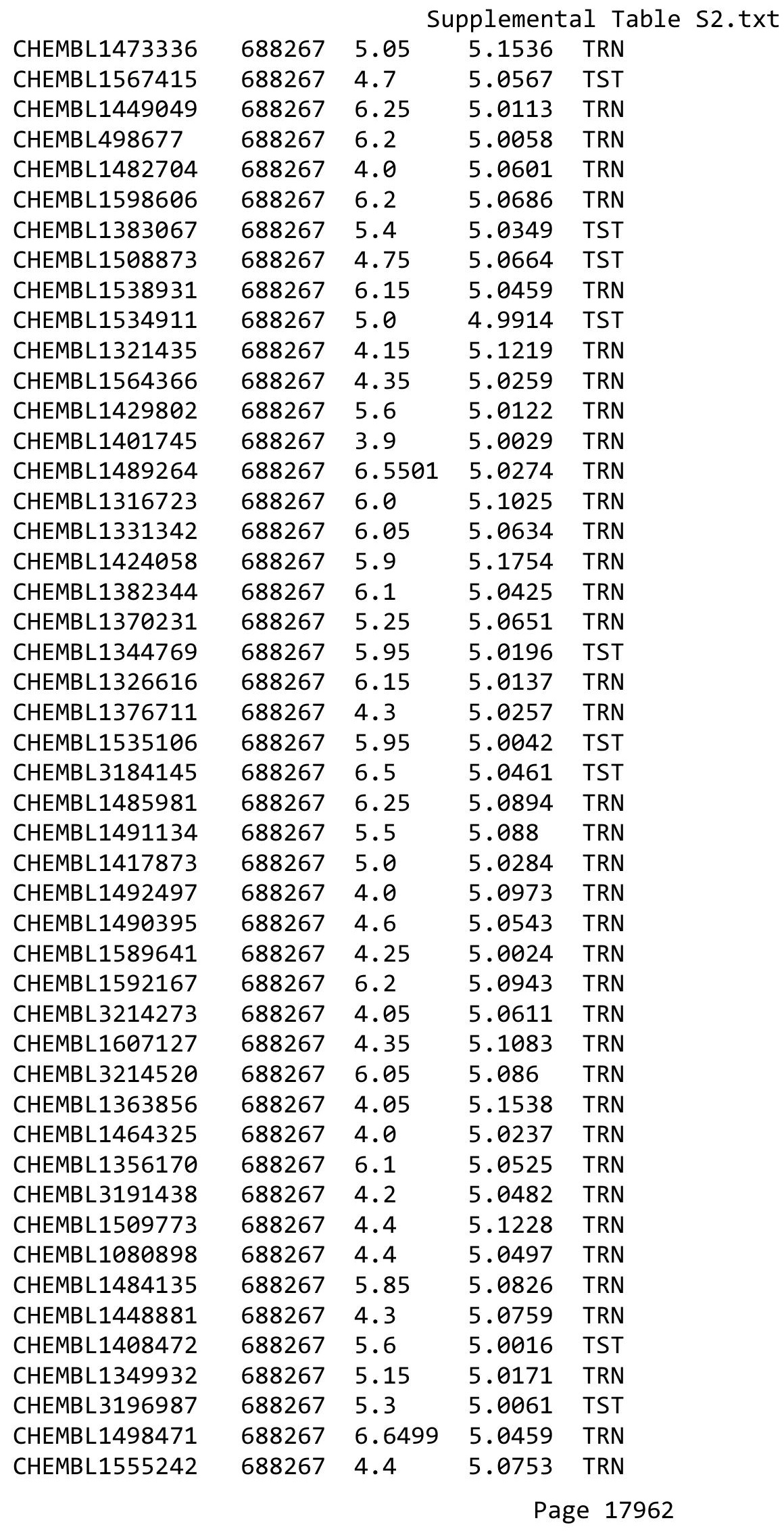




\begin{tabular}{|c|c|c|c|c|}
\hline & & & pplement & al $\mathrm{Ta}$ \\
\hline CHEMBL1501687 & 688267 & 4.65 & 5.0429 & TST \\
\hline CHEMBL1379390 & 688267 & 4.25 & 5.0636 & TRN \\
\hline CHEMBL1464711 & 688267 & 6.1 & 5.012 & TRN \\
\hline CHEMBL1381095 & 688267 & 4.4 & 5.0335 & TRN \\
\hline CHEMBL1334441 & 688267 & 5.3 & 5.0406 & TRN \\
\hline CHEMBL1450604 & 688267 & 6.15 & 5.1699 & TRN \\
\hline CHEMBL1436655 & 688267 & 5.35 & 5.0006 & TRN \\
\hline CHEMBL1396769 & 688267 & 5.5 & 5.0655 & TST \\
\hline CHEMBL1328630 & 688267 & 5.55 & 5.0886 & TRN \\
\hline CHEMBL1493116 & 688267 & 4.6 & 5.064 & TST \\
\hline CHEMBL1536606 & 688267 & 4.35 & 5.0286 & TST \\
\hline CHEMBL1418740 & 688267 & 5.45 & 5.003 & TRN \\
\hline CHEMBL1375092 & 688267 & 5.6 & 5.0611 & TST \\
\hline CHEMBL1463848 & 688267 & 4.2 & 5.04 & TST \\
\hline CHEMBL1405364 & 688267 & 4.6 & 5.065 & TST \\
\hline CHEMBL1386809 & 688267 & 4.3 & 5.0447 & TRN \\
\hline CHEMBL1421362 & 688267 & 4.4 & 5.1152 & TST \\
\hline CHEMBL1471800 & 688267 & 5.25 & 5.1398 & TRN \\
\hline CHEMBL1434153 & 688267 & 6.25 & 5.0543 & TRN \\
\hline CHEMBL1443855 & 688267 & 3.95 & 5.0845 & TRN \\
\hline CHEMBL1511553 & 688267 & 4.45 & 5.0402 & TRN \\
\hline CHEMBL1369349 & 688267 & 6.2 & 5.1064 & TRN \\
\hline CHEMBL1413204 & 688267 & 4.0 & 5.0283 & TRN \\
\hline CHEMBL1440469 & 688267 & 5.55 & 5.055 & TRN \\
\hline CHEMBL1571212 & 688267 & 5.6 & 5.0479 & TRN \\
\hline CHEMBL1372964 & 688267 & 6.2 & 5.0582 & TST \\
\hline CHEMBL1319609 & 688267 & 4.5 & 5.1423 & TRN \\
\hline CHEMBL1351306 & 688267 & 5.0 & 5.1388 & TRN \\
\hline CHEMBL1419849 & 688267 & 5.25 & 5.023 & TRN \\
\hline CHEMBL1383598 & 688267 & 5.3 & 5.0418 & TRN \\
\hline CHEMBL1404249 & 688267 & 6.6 & 5.0729 & TRN \\
\hline CHEMBL1370205 & 688267 & 6.15 & 5.0552 & TRN \\
\hline CHEMBL1424673 & 688267 & 6.0 & 5.0194 & TST \\
\hline CHEMBL1327389 & 688267 & 6.0 & 5.0565 & TRN \\
\hline CHEMBL1465567 & 688267 & 5.3 & 5.1156 & TST \\
\hline CHEMBL1301485 & 688267 & 4.6 & 5.0296 & TRN \\
\hline CHEMBL1356252 & 688267 & 5.5 & 5.0486 & TRN \\
\hline CHEMBL1414086 & 688267 & 4.05 & 5.0953 & TRN \\
\hline CHEMBL1531268 & 688267 & 6.2 & 5.0764 & TRN \\
\hline CHEMBL1450832 & 688267 & 5.95 & 5.1553 & TRN \\
\hline CHEMBL1356089 & 688267 & 3.95 & 5.0904 & TRN \\
\hline CHEMBL1516991 & 688267 & 5.1 & 5.0754 & TST \\
\hline CHEMBL3199782 & 688267 & 6.1 & 4.9931 & TRN \\
\hline CHEMBL1514724 & 688267 & 4.05 & 5.0859 & TRN \\
\hline CHEMBL1610991 & 688267 & 5.4 & 5.0329 & TST \\
\hline CHEMBL1480904 & 688267 & 6.2 & 5.0219 & TST \\
\hline CHEMBL1510459 & 688267 & 4.35 & 5.0001 & TRN \\
\hline CHEMBL1355377 & 688267 & 5.95 & 5.0233 & TRN \\
\hline
\end{tabular}




\begin{tabular}{|c|c|c|c|c|}
\hline \multicolumn{5}{|c|}{ Supplemental Table S2.txt } \\
\hline CHEMBL1558546 & 688267 & 3.95 & 5.0837 & TRN \\
\hline CHEMBL1318319 & 688267 & 5.05 & 5.0932 & TRN \\
\hline CHEMBL1591944 & 688267 & 3.95 & 5.1093 & TRN \\
\hline CHEMBL1505680 & 688267 & 4.4 & 5.1479 & TRN \\
\hline CHEMBL1516585 & 688267 & 5.3 & 5.1025 & TRN \\
\hline CHEMBL 3209788 & 688267 & 5.65 & 5.0548 & TRN \\
\hline CHEMBL1395606 & 688267 & 4.55 & 5.0681 & TRN \\
\hline CHEMBL1556905 & 688267 & 4.2 & 5.0453 & TRN \\
\hline CHEMBL1581722 & 688267 & 4.4 & 5.0708 & TST \\
\hline CHEMBL1423935 & 688267 & 4.05 & 4.9985 & TRN \\
\hline CHEMBL1479747 & 688267 & 4.95 & 5.0393 & TRN \\
\hline CHEMBL1552274 & 688267 & 4.05 & 5.085 & TRN \\
\hline CHEMBL1987928 & 688267 & 4.25 & 5.0302 & TRN \\
\hline CHEMBL1419896 & 688267 & 5.35 & 5.1322 & TRN \\
\hline CHEMBL1572162 & 688267 & 6.15 & 5.0176 & TRN \\
\hline CHEMBL1312920 & 688267 & 5.0 & 5.0781 & TRN \\
\hline CHEMBL1571052 & 688267 & 6.0 & 5.056 & TRN \\
\hline CHEMBL1465349 & 688267 & 5.1 & 5.0423 & TRN \\
\hline CHEMBL1339373 & 688267 & 6.2 & 5.0972 & TRN \\
\hline CHEMBL1344026 & 688267 & 4.95 & 5.0524 & TRN \\
\hline CHEMBL1574032 & 688267 & 4.65 & 5.0559 & TST \\
\hline CHEMBL1539822 & 688267 & 3.95 & 5.0465 & TRN \\
\hline CHEMBL1313193 & 688267 & 5.95 & 5.0759 & TRN \\
\hline CHEMBL1564974 & 688267 & 6.2 & 5.0618 & TST \\
\hline CHEMBL1560796 & 688267 & 4.0 & 4.9915 & TRN \\
\hline CHEMBL1335739 & 688267 & 3.95 & 5.1081 & TRN \\
\hline CHEMBL1354792 & 688267 & 5.55 & 5.0391 & TRN \\
\hline CHEMBL1385011 & 688267 & 6.2 & 5.0655 & TRN \\
\hline CHEMBL1379296 & 688267 & 5.0 & 4.9954 & TST \\
\hline CHEMBL1391570 & 688267 & 4.4 & 5.0841 & TRN \\
\hline CHEMBL1459444 & 688267 & 4.05 & 5.0821 & TST \\
\hline CHEMBL3207864 & 688267 & 4.05 & 4.9886 & TRN \\
\hline CHEMBL1543414 & 688267 & 4.65 & 5.0911 & TRN \\
\hline CHEMBL1427489 & 688267 & 5.45 & 5.1634 & TRN \\
\hline CHEMBL1313598 & 688267 & 4.55 & 5.0038 & TRN \\
\hline CHEMBL1429118 & 688267 & 6.15 & 5.109 & TRN \\
\hline CHEMBL1431640 & 688267 & 4.05 & 5.1084 & TST \\
\hline CHEMBL1596889 & 688267 & 6.45 & 5.0866 & TRN \\
\hline CHEMBL1372252 & 688267 & 5.0 & 5.0482 & TST \\
\hline CHEMBL1309580 & 688267 & 5.45 & 5.0244 & TRN \\
\hline CHEMBL1418980 & 688267 & 5.4 & 5.0581 & TST \\
\hline CHEMBL1422331 & 688267 & 4.0 & 5.0818 & TRN \\
\hline CHEMBL1464425 & 688267 & 5.55 & 5.0201 & TRN \\
\hline CHEMBL 2000748 & 688267 & 5.85 & 5.0513 & TRN \\
\hline CHEMBL1415461 & 688267 & 4.2 & 5.0386 & TRN \\
\hline CHEMBL1425658 & 688267 & 6.25 & 5.0383 & TRN \\
\hline CHEMBL1557151 & 688267 & 5.9 & 5.0734 & TRN \\
\hline CHEMBL1326742 & 688267 & 5.1 & 5.0471 & TRN \\
\hline
\end{tabular}




\begin{tabular}{|c|c|c|c|c|}
\hline \multicolumn{5}{|c|}{ Supplemental Table S2.txt } \\
\hline CHEMBL1439854 & 688267 & 4.4 & 5.0429 & TRN \\
\hline CHEMBL1463879 & 688267 & 6.15 & 5.0712 & TRN \\
\hline CHEMBL1559071 & 688267 & 6.25 & 5.1014 & TRN \\
\hline CHEMBL1324127 & 688267 & 5.1 & 5.0887 & TRN \\
\hline CHEMBL1396414 & 688267 & 6.2 & 5.0038 & TST \\
\hline CHEMBL1528940 & 688267 & 6.2 & 5.0634 & TRN \\
\hline CHEMBL1395571 & 688267 & 4.55 & 5.0402 & TRN \\
\hline CHEMBL 288174 & 688267 & 6.2 & 5.0573 & TST \\
\hline CHEMBL1437283 & 688267 & 6.5 & 5.1152 & TRN \\
\hline CHEMBL1360468 & 688267 & 6.3 & 5.0723 & TRN \\
\hline CHEMBL1317187 & 688267 & 4.05 & 5.1054 & TST \\
\hline CHEMBL1549756 & 688267 & 4.0 & 5.0574 & TRN \\
\hline CHEMBL1534421 & 688267 & 5.0 & 5.0197 & TRN \\
\hline CHEMBL1572964 & 688267 & 5.9 & 5.0613 & TRN \\
\hline CHEMBL1427909 & 688267 & 4.05 & 5.0639 & TST \\
\hline CHEMBL1415817 & 688267 & 5.55 & 5.0334 & TRN \\
\hline CHEMBL1506135 & 688267 & 4.65 & 5.0807 & TRN \\
\hline CHEMBL1561572 & 688267 & 5.9 & 5.0601 & TST \\
\hline CHEMBL1305851 & 688267 & 6.2 & 5.1044 & TRN \\
\hline CHEMBL1571059 & 688267 & 4.05 & 5.0547 & TRN \\
\hline CHEMBL1434854 & 688267 & 4.0 & 5.0058 & TRN \\
\hline CHEMBL1419309 & 688267 & 5.35 & 5.0824 & TRN \\
\hline CHEMBL1555881 & 688267 & 5.3 & 5.0575 & TST \\
\hline CHEMBL1299291 & 688267 & 4.0 & 5.0473 & TRN \\
\hline CHEMBL1494262 & 688267 & 4.35 & 5.1075 & TRN \\
\hline CHEMBL1526950 & 688267 & 4.0 & 5.0445 & TRN \\
\hline CHEMBL1313755 & 688267 & 6.45 & 5.0758 & TRN \\
\hline CHEMBL1351020 & 688267 & 5.05 & 4.994 & TRN \\
\hline CHEMBL1519208 & 688267 & 6.2 & 5.1353 & TRN \\
\hline CHEMBL1559811 & 688267 & 3.95 & 5.0589 & TRN \\
\hline CHEMBL1560502 & 688267 & 6.15 & 5.058 & TRN \\
\hline CHEMBL1340730 & 688267 & 5.55 & 5.1171 & TRN \\
\hline CHEMBL1400441 & 688267 & 3.95 & 5.0632 & TRN \\
\hline CHEMBL1381655 & 688267 & 5.25 & 4.9905 & TRN \\
\hline CHEMBL1349480 & 688267 & 4.5 & 5.0732 & TRN \\
\hline CHEMBL1452970 & 688267 & 5.35 & 5.0817 & TST \\
\hline CHEMBL1589108 & 688267 & 4.4 & 5.0366 & TRN \\
\hline CHEMBL1453831 & 688267 & 4.3 & 5.0311 & TRN \\
\hline CHEMBL1530975 & 688267 & 4.05 & 5.0656 & TRN \\
\hline CHEMBL1523065 & 688267 & 6.2 & 5.077 & TRN \\
\hline CHEMBL1515485 & 688267 & 5.8 & 5.081 & TRN \\
\hline CHEMBL1981928 & 688267 & 4.0 & 5.0613 & TST \\
\hline CHEMBL1561381 & 688267 & 4.05 & 5.0788 & TRN \\
\hline CHEMBL1354156 & 688267 & 5.3 & 5.1043 & TRN \\
\hline CHEMBL1522651 & 688267 & 5.9 & 5.0126 & TRN \\
\hline CHEMBL1388768 & 688267 & 4.55 & 5.0204 & TST \\
\hline CHEMBL1387251 & 688267 & 4.4 & 5.0318 & TRN \\
\hline CHEMBL1309409 & 688267 & 5.9 & 5.0751 & TRN \\
\hline
\end{tabular}




\begin{tabular}{|c|c|c|c|c|}
\hline & & & upplement & al $\mathrm{T}$ \\
\hline CHEMBL1531695 & 688267 & 4.35 & 5.0977 & TST \\
\hline CHEMBL1449176 & 688267 & 6.2 & 5.0569 & TRN \\
\hline CHEMBL1347062 & 688267 & 4.45 & 5.0553 & TST \\
\hline CHEMBL1322622 & 688267 & 5.15 & 5.0973 & TST \\
\hline CHEMBL1351520 & 688267 & 4.5 & 4.9978 & TRN \\
\hline CHEMBL1594434 & 688267 & 6.05 & 5.0442 & TRN \\
\hline CHEMBL1305384 & 688267 & 6.25 & 5.0639 & TST \\
\hline CHEMBL1404531 & 688267 & 3.9 & 5.1081 & TRN \\
\hline CHEMBL1582041 & 688267 & 5.85 & 5.129 & TRN \\
\hline CHEMBL1612596 & 688267 & 4.2 & 4.9831 & TRN \\
\hline CHEMBL1379463 & 688267 & 4.4 & 5.1602 & TST \\
\hline CHEMBL1595358 & 688267 & 3.95 & 5.0497 & TST \\
\hline CHEMBL1333990 & 688267 & 4.1 & 5.1022 & TST \\
\hline CHEMBL1361042 & 688267 & 5.55 & 5.0444 & TRN \\
\hline CHEMBL1395371 & 688267 & 3.95 & 4.9641 & TRN \\
\hline CHEMBL1329437 & 688267 & 5.3 & 5.0291 & TRN \\
\hline CHEMBL1362114 & 688267 & 4.05 & 5.1415 & TST \\
\hline CHEMBL1557447 & 688267 & 5.5 & 5.0302 & TST \\
\hline CHEMBL1301369 & 688267 & 4.3 & 5.0687 & TRN \\
\hline CHEMBL1491793 & 688267 & 4.65 & 5.0908 & TRN \\
\hline CHEMBL1373381 & 688267 & 4.6 & 5.0897 & TRN \\
\hline CHEMBL1369949 & 688267 & 4.4 & 5.0401 & TST \\
\hline CHEMBL1593290 & 688267 & 4.0 & 5.0297 & TRN \\
\hline CHEMBL1370131 & 688267 & 6.5 & 5.0675 & TRN \\
\hline CHEMBL1398559 & 688267 & 4.25 & 5.075 & TRN \\
\hline CHEMBL1588482 & 688267 & 6.15 & 5.0768 & TST \\
\hline CHEMBL1375149 & 688267 & 4.5 & 5.033 & TST \\
\hline CHEMBL1550834 & 688267 & 4.0 & 5.1208 & TRN \\
\hline CHEMBL1556638 & 688267 & 4.1 & 5.0228 & TST \\
\hline CHEMBL1447986 & 688267 & 6.2 & 5.1357 & TRN \\
\hline CHEMBL1404631 & 688267 & 5.35 & 5.0309 & TRN \\
\hline CHEMBL1417373 & 688267 & 5.45 & 5.0461 & TRN \\
\hline CHEMBL1449510 & 688267 & 5.35 & 5.072 & TRN \\
\hline CHEMBL1556624 & 688267 & 4.0 & 5.0303 & TST \\
\hline CHEMBL1589845 & 688267 & 4.4 & 5.1194 & TRN \\
\hline CHEMBL1988731 & 688267 & 4.05 & 5.0232 & TST \\
\hline CHEMBL1385106 & 688267 & 6.0 & 5.1443 & TRN \\
\hline CHEMBL1416174 & 688267 & 4.4 & 5.0079 & TRN \\
\hline CHEMBL1571079 & 688267 & 4.3 & 5.1045 & TST \\
\hline CHEMBL3191221 & 688267 & 4.45 & 5.0103 & TST \\
\hline CHEMBL1385412 & 688267 & 4.45 & 5.0907 & TRN \\
\hline CHEMBL1392896 & 688267 & 4.0 & 5.1283 & TST \\
\hline CHEMBL1374869 & 688267 & 6.15 & 5.0658 & TRN \\
\hline CHEMBL1346172 & 688267 & 4.05 & 5.0105 & TRN \\
\hline CHEMBL1437702 & 688267 & 6.2 & 5.0982 & TRN \\
\hline CHEMBL1450878 & 688267 & 5.1 & 5.0893 & TRN \\
\hline CHEMBL1526144 & 688267 & 3.95 & 5.037 & TST \\
\hline CHEMBL1571040 & 688267 & 4.45 & 5.0399 & TST \\
\hline
\end{tabular}




\begin{tabular}{|c|c|c|c|c|c|}
\hline & & \multicolumn{4}{|c|}{ Supplemental Table S2.txt } \\
\hline CHEMBL1485400 & 688267 & 5.65 & 5.0101 & TRN & \\
\hline CHEMBL3197319 & 688267 & 4.6 & 5.0457 & TST & \\
\hline CHEMBL1443526 & 688267 & 3.95 & 5.0402 & TRN & \\
\hline CHEMBL1487183 & 688267 & 5.15 & 5.0829 & TST & \\
\hline CHEMBL600491 & 688267 & 5.65 & 5.01699 & 99999999995 & TST \\
\hline CHEMBL1373899 & 688267 & 6.2 & 5.0027 & TST & \\
\hline CHEMBL 3198584 & 688267 & 5.35 & 5.0641 & TRN & \\
\hline CHEMBL1397262 & 688267 & 6.2 & 5.0823 & TRN & \\
\hline CHEMBL1605761 & 688267 & 5.95 & 5.0742 & TRN & \\
\hline CHEMBL3191753 & 688267 & 5.65 & 5.0555 & TST & \\
\hline CHEMBL1355413 & 688267 & 5.55 & 5.1074 & TST & \\
\hline CHEMBL1503894 & 688267 & 5.35 & 5.1251 & TRN & \\
\hline CHEMBL1330586 & 688267 & 5.0 & 5.1015 & TRN & \\
\hline CHEMBL1613580 & 688267 & 4.25 & 5.0108 & TRN & \\
\hline CHEMBL1444657 & 688267 & 4.35 & 5.0924 & TST & \\
\hline CHEMBL1595953 & 688267 & 4.7 & 5.0433 & TRN & \\
\hline CHEMBL1478637 & 688267 & 4.35 & 5.0406 & TRN & \\
\hline CHEMBL1334472 & 688267 & 5.25 & 5.0236 & TST & \\
\hline CHEMBL1513236 & 688267 & 5.85 & 5.0055 & TRN & \\
\hline CHEMBL1404041 & 688267 & 5.3 & 5.102 & TST & \\
\hline CHEMBL1406880 & 688267 & 5.5 & 5.0935 & TRN & \\
\hline CHEMBL1539362 & 688267 & 4.35 & 5.1064 & TRN & \\
\hline CHEMBL1488551 & 688267 & 5.65 & 4.9801 & TRN & \\
\hline CHEMBL1610122 & 688267 & 4.75 & 5.0595 & TRN & \\
\hline CHEMBL1397640 & 688267 & 6.0 & 5.0511 & TRN & \\
\hline CHEMBL1424479 & 688267 & 5.3 & 4.9907 & TRN & \\
\hline CHEMBL1493766 & 688267 & 3.55 & 5.0524 & TST & \\
\hline CHEMBL1397693 & 688267 & 4.95 & 5.0316 & TRN & \\
\hline CHEMBL1552081 & 688267 & 6.3 & 5.0596 & TRN & \\
\hline CHEMBL1607846 & 688267 & 4.4 & 5.0199 & TRN & \\
\hline CHEMBL1485949 & 688267 & 4.05 & 5.03 & TRN & \\
\hline CHEMBL1363681 & 688267 & 5.9 & 5.051 & TRN & \\
\hline CHEMBL1577443 & 688267 & 5.65 & 5.0045 & TRN & \\
\hline CHEMBL1358426 & 688267 & 4.4 & 5.1287 & TRN & \\
\hline CHEMBL1585438 & 688267 & 6.15 & 5.0207 & TRN & \\
\hline CHEMBL1520499 & 688267 & 5.4 & 5.0882 & TRN & \\
\hline CHEMBL 3214042 & 688267 & 6.45 & 5.053 & TST & \\
\hline CHEMBL1522505 & 688267 & 3.95 & 4.9777 & TRN & \\
\hline CHEMBL1435993 & 688267 & 4.0 & 5.067 & TRN & \\
\hline CHEMBL1466744 & 688267 & 4.4 & 5.0114 & TRN & \\
\hline CHEMBL1405094 & 688267 & 4.7 & 5.0357 & TST & \\
\hline CHEMBL607574 & 688267 & 6.2 & 5.0909 & TST & \\
\hline CHEMBL3191913 & 688267 & 5.55 & 5.035 & TRN & \\
\hline CHEMBL1333819 & 688267 & 4.4 & 5.0468 & TRN & \\
\hline CHEMBL1313297 & 688267 & 5.65 & 5.0536 & TRN & \\
\hline CHEMBL1355513 & 688267 & 6.2 & 5.1029 & TST & \\
\hline CHEMBL1368447 & 688267 & 4.0 & 5.0488 & TST & \\
\hline CHEMBL3210325 & 688267 & 4.3 & 5.0406 & TRN & \\
\hline
\end{tabular}




\begin{tabular}{|c|c|c|c|c|}
\hline & & & upplement & al $\mathrm{Ta}$ \\
\hline CHEMBL1566455 & 688267 & 4.35 & 5.1427 & TRN \\
\hline CHEMBL1323701 & 688267 & 5.25 & 5.0402 & TRN \\
\hline CHEMBL1530588 & 688267 & 6.2 & 5.1049 & TST \\
\hline CHEMBL1608629 & 688267 & 3.95 & 5.0708 & TRN \\
\hline CHEMBL1513532 & 688267 & 6.0 & 5.0644 & TST \\
\hline CHEMBL1500840 & 688267 & 4.85 & 5.0073 & TRN \\
\hline CHEMBL1415505 & 688267 & 5.25 & 4.9973 & TRN \\
\hline CHEMBL1302559 & 688267 & 4.55 & 5.0498 & TST \\
\hline CHEMBL1571144 & 688267 & 5.25 & 5.0171 & TST \\
\hline CHEMBL1362235 & 688267 & 5.95 & 5.0122 & TRN \\
\hline CHEMBL3195276 & 688267 & 4.15 & 5.0394 & TRN \\
\hline CHEMBL1542733 & 688267 & 5.0 & 5.0661 & TRN \\
\hline CHEMBL1442172 & 688267 & 6.0 & 5.0216 & TRN \\
\hline CHEMBL1462606 & 688267 & 5.1 & 5.0752 & TRN \\
\hline CHEMBL1334140 & 688267 & 5.95 & 5.125 & TRN \\
\hline CHEMBL1349867 & 688267 & 5.35 & 5.0834 & TRN \\
\hline CHEMBL1568587 & 688267 & 4.55 & 5.0003 & TST \\
\hline CHEMBL143703 & 688267 & 4.0 & 5.0104 & TRN \\
\hline CHEMBL1551929 & 688267 & 3.95 & 5.1243 & TRN \\
\hline CHEMBL1390147 & 688267 & 6.25 & 5.0425 & TRN \\
\hline CHEMBL1460158 & 688267 & 4.25 & 5.1538 & TRN \\
\hline CHEMBL1591947 & 688267 & 5.55 & 5.0532 & TRN \\
\hline CHEMBL1554104 & 688267 & 5.05 & 5.0227 & TRN \\
\hline CHEMBL1544449 & 688267 & 4.1 & 5.1107 & TST \\
\hline CHEMBL1479455 & 688267 & 5.3 & 5.0893 & TRN \\
\hline CHEMBL1459710 & 688267 & 6.2 & 5.0503 & TST \\
\hline CHEMBL1547804 & 688267 & 4.45 & 5.026 & TRN \\
\hline CHEMBL1607024 & 688267 & 4.35 & 4.9545 & TRN \\
\hline CHEMBL1445704 & 688267 & 4.0 & 5.0839 & TRN \\
\hline CHEMBL1555600 & 688267 & 5.5 & 5.0323 & TRN \\
\hline CHEMBL1374503 & 688267 & 6.0 & 5.0378 & TRN \\
\hline CHEMBL1459063 & 688267 & 5.55 & 5.0436 & TST \\
\hline CHEMBL1605258 & 688267 & 6.45 & 5.0219 & TRN \\
\hline CHEMBL1435772 & 688267 & 5.45 & 5.0223 & TRN \\
\hline CHEMBL1527021 & 688267 & 3.95 & 5.1167 & TRN \\
\hline CHEMBL1526377 & 688267 & 5.8 & 5.0226 & TST \\
\hline CHEMBL3192684 & 688267 & 5.75 & 4.9918 & TRN \\
\hline CHEMBL1303405 & 688267 & 4.0 & 4.9854 & TRN \\
\hline CHEMBL1345732 & 688267 & 5.2 & 5.0566 & TST \\
\hline CHEMBL1470090 & 688267 & 5.25 & 5.135 & TRN \\
\hline CHEMBL1310816 & 688267 & 5.45 & 5.0867 & TRN \\
\hline CHEMBL1475852 & 688267 & 5.3 & 5.0387 & TRN \\
\hline CHEMBL1540393 & 688267 & 4.7 & 4.9985 & TRN \\
\hline CHEMBL1575532 & 688267 & 4.2 & 4.9957 & TST \\
\hline CHEMBL1418027 & 688267 & 4.15 & 4.9948 & TRN \\
\hline CHEMBL1423293 & 688267 & 5.85 & 5.0276 & TST \\
\hline CHEMBL1523067 & 688267 & 5.0 & 5.0782 & TRN \\
\hline CHEMBL1387937 & 688267 & 5.4 & 5.032 & TRN \\
\hline
\end{tabular}




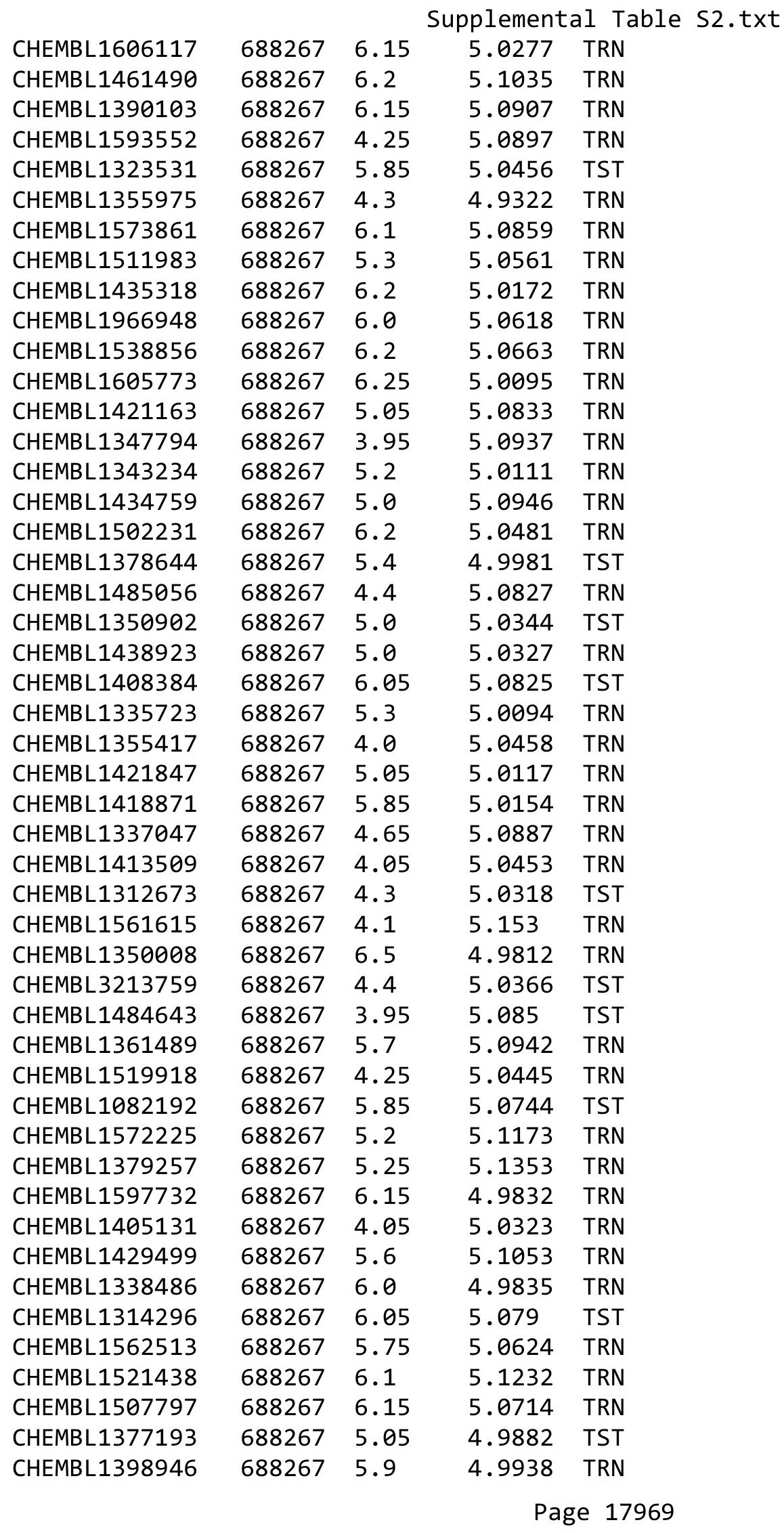




\begin{tabular}{|c|c|c|c|c|c|}
\hline \multicolumn{6}{|c|}{ Supplemental Table S2.txt } \\
\hline CHEMBL1392788 & 688267 & 4.05 & 5.0947 & TRN & \\
\hline CHEMBL1370465 & 688267 & 4.05 & 5.1076 & TRN & \\
\hline CHEMBL1314697 & 688267 & 5.25 & 5.0527 & TRN & \\
\hline CHEMBL1475839 & 688267 & 6.2 & 5.0446 & TRN & \\
\hline CHEMBL1301382 & 688267 & 4.65 & 5.0386 & TRN & \\
\hline CHEMBL1318154 & 688267 & 4.1 & 5.04 & TRN & \\
\hline CHEMBL1449846 & 688267 & 4.1 & 5.0262 & TRN & \\
\hline CHEMBL1321378 & 688267 & 5.2 & 5.0342 & TRN & \\
\hline CHEMBL1368428 & 688267 & 5.0 & 5.0402 & TST & \\
\hline CHEMBL1528210 & 688267 & 6.1 & \multicolumn{2}{|c|}{5.127999999999999} & TRN \\
\hline CHEMBL1445147 & 688267 & 5.6 & 5.0214 & TRN & \\
\hline CHEMBL1419230 & 688267 & 4.3 & 5.1026 & TRN & \\
\hline CHEMBL1481829 & 688267 & 6.6499 & 5.0523 & TRN & \\
\hline CHEMBL1309273 & 688267 & 3.95 & 5.0683 & TRN & \\
\hline CHEMBL1462684 & 688267 & 5.15 & 5.0237 & TRN & \\
\hline CHEMBL1535875 & 688267 & 4.3 & 5.0672 & TST & \\
\hline CHEMBL1527885 & 688267 & 4.05 & 4.9865 & TST & \\
\hline CHEMBL1317407 & 688267 & 4.05 & 5.0753 & TRN & \\
\hline CHEMBL1580313 & 688267 & 4.4 & 4.9915 & TRN & \\
\hline CHEMBL1543184 & 688267 & 4.3 & 5.051 & TRN & \\
\hline CHEMBL1313962 & 688267 & 4.8 & 5.0226 & TRN & \\
\hline CHEMBL1317063 & 688267 & 5.45 & 5.0326 & TRN & \\
\hline CHEMBL1324415 & 688267 & 4.4 & 5.0109 & TRN & \\
\hline CHEMBL1535205 & 688267 & 4.75 & 5.1043 & TRN & \\
\hline CHEMBL1320489 & 688267 & 5.45 & 5.0505 & TST & \\
\hline CHEMBL1490640 & 688267 & 5.35 & 5.0891 & TRN & \\
\hline CHEMBL1490711 & 688267 & 4.0 & 4.9715 & TRN & \\
\hline CHEMBL3194322 & 688267 & 5.3 & 5.0391 & TST & \\
\hline CHEMBL1434215 & 688267 & 5.0 & 5.0304 & TRN & \\
\hline CHEMBL3213279 & 688267 & 3.95 & 4.9976 & TRN & \\
\hline CHEMBL1449145 & 688267 & 4.35 & 5.029 & TRN & \\
\hline CHEMBL1563119 & 688267 & 5.55 & 5.0434 & TST & \\
\hline CHEMBL1370447 & 688267 & 4.8 & 5.0349 & TRN & \\
\hline CHEMBL3189850 & 688267 & 5.25 & 5.0128 & TST & \\
\hline CHEMBL1585770 & 688267 & 5.5 & 5.1212 & TRN & \\
\hline CHEMBL1489237 & 688267 & 3.95 & 5.0579 & TRN & \\
\hline CHEMBL1538333 & 688267 & 6.5501 & 5.1052 & TRN & \\
\hline CHEMBL1390001 & 688267 & 4.35 & 5.0862 & TRN & \\
\hline CHEMBL1559317 & 688267 & 4.85 & 5.059 & TRN & \\
\hline CHEMBL3207804 & 688267 & 4.4 & 5.0552 & TRN & \\
\hline CHEMBL1340291 & 688267 & 4.55 & 5.0133 & TRN & \\
\hline CHEMBL1564262 & 688267 & 5.9 & 5.0897 & TRN & \\
\hline CHEMBL1356061 & 688267 & 5.3 & 5.0205 & TST & \\
\hline CHEMBL1553040 & 688267 & 6.5 & 5.0832 & TRN & \\
\hline CHEMBL1523753 & 688267 & 4.0 & 5.0448 & TRN & \\
\hline CHEMBL1305485 & 688267 & 5.35 & 5.0642 & TRN & \\
\hline CHEMBL1578062 & 688267 & 4.4 & 5.0815 & TRN & \\
\hline \multirow[t]{2}{*}{ CHEMBL1556423 } & 688267 & 6.15 & \multicolumn{2}{|c|}{5.167000000000001} & TRN \\
\hline & & & & 17970 & \\
\hline
\end{tabular}




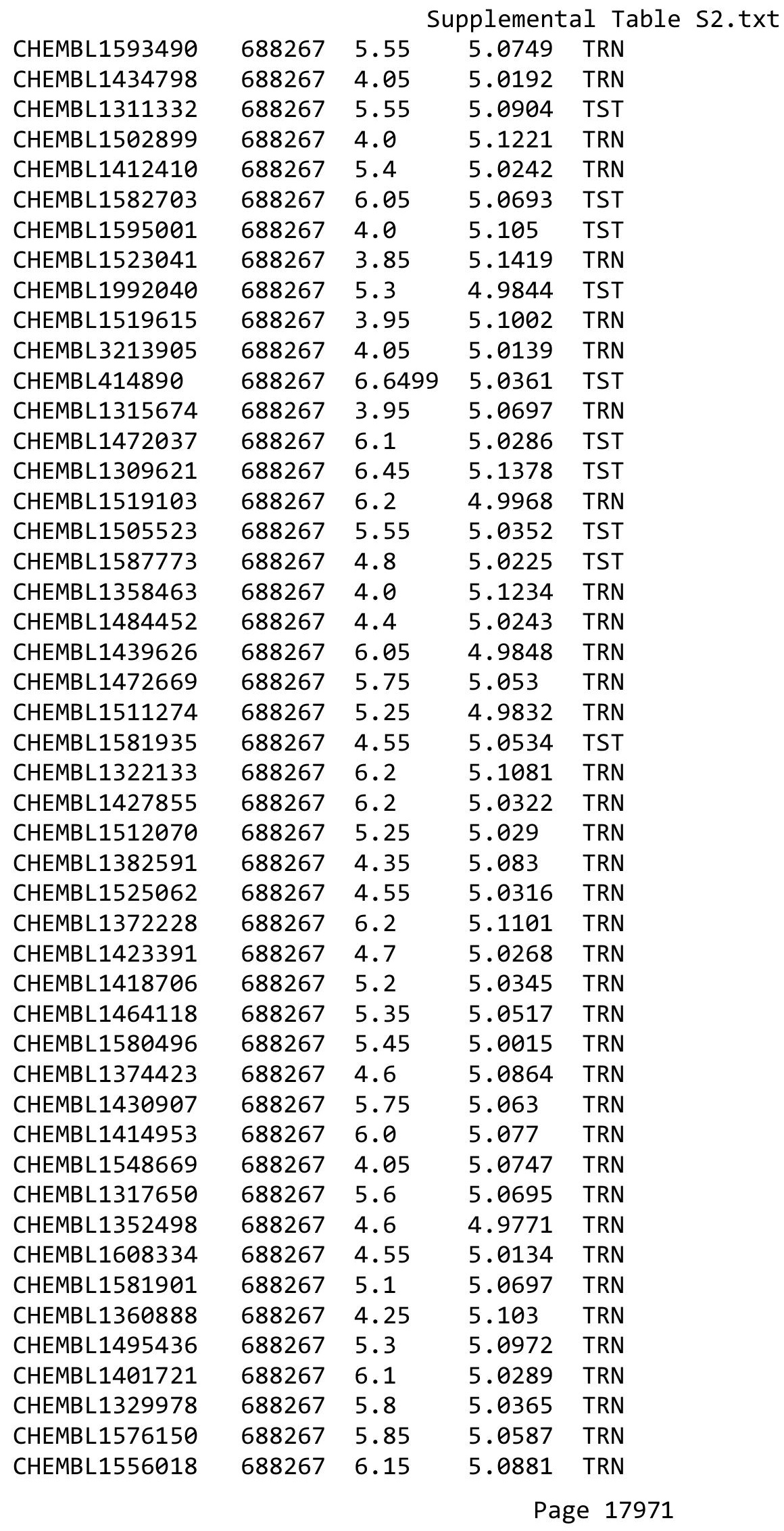




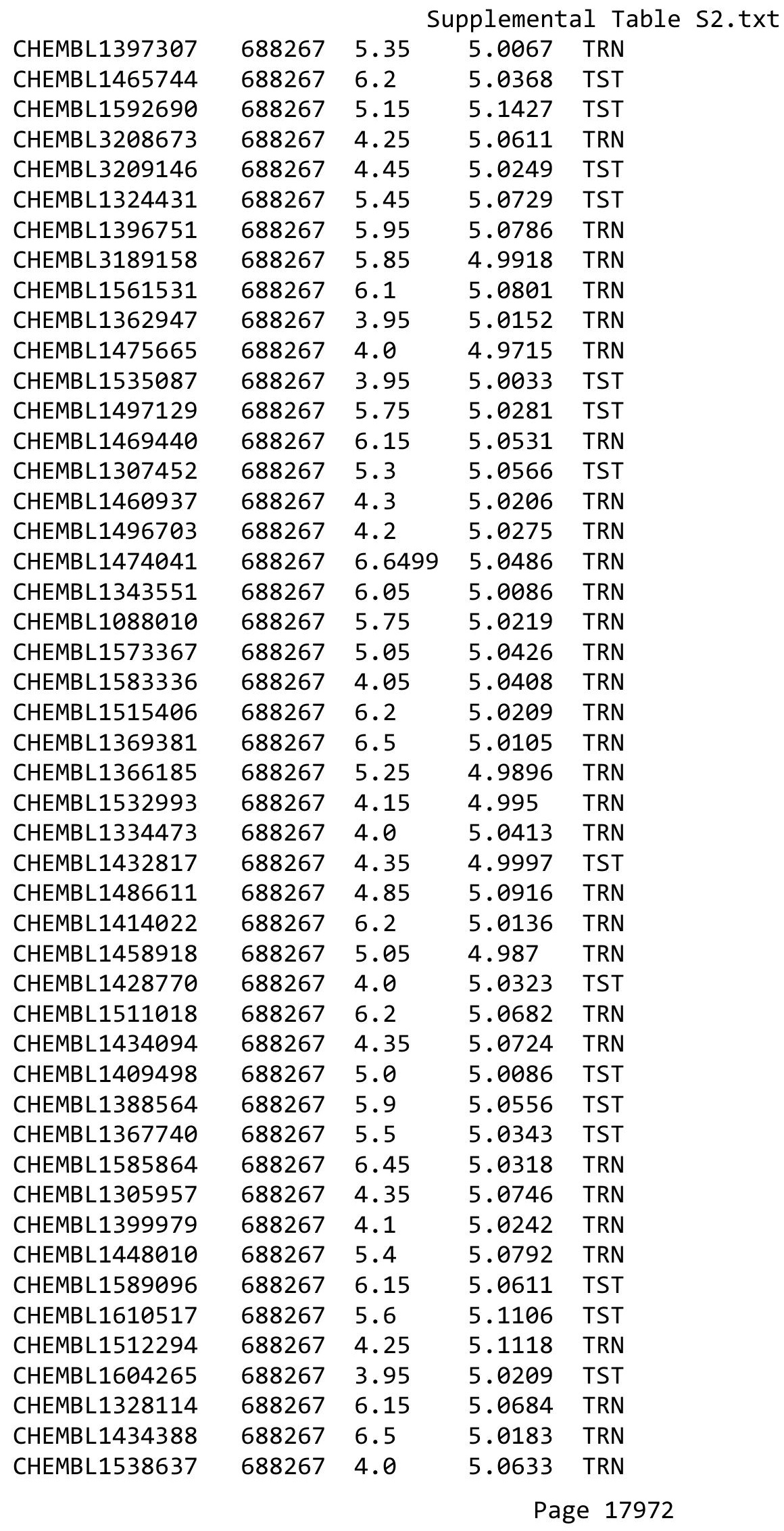




\begin{tabular}{|c|c|c|c|c|c|}
\hline & & \multicolumn{4}{|c|}{ Supplemental Table S2.txt } \\
\hline CHEMBL1447341 & 688267 & 3.95 & 5.0475 & TST & \\
\hline CHEMBL1398340 & 688267 & 5.0 & 5.0133 & TRN & \\
\hline CHEMBL1369656 & 688267 & 5.3 & 5.0712 & TRN & \\
\hline CHEMBL1557506 & 688267 & 4.15 & 5.1114 & TRN & \\
\hline CHEMBL1612739 & 688267 & 5.45 & 5.073 & TST & \\
\hline CHEMBL1299877 & 688267 & 5.2 & 5.0926 & TST & \\
\hline CHEMBL1327952 & 688267 & 4.55 & 5.0598 & TRN & \\
\hline CHEMBL1448964 & 688267 & 4.8 & 5.058 & TRN & \\
\hline CHEMBL1498752 & 688267 & 4.45 & 5.0788 & TRN & \\
\hline CHEMBL1367280 & 688267 & 5.05 & 5.0394 & TRN & \\
\hline CHEMBL1345031 & 688267 & 5.3 & 5.1478 & TRN & \\
\hline CHEMBL1544701 & 688267 & 5.55 & 5.0515 & TRN & \\
\hline CHEMBL1535520 & 688267 & 5.65 & 5.0695 & TRN & \\
\hline CHEMBL1586365 & 688267 & 4.9 & 5.0211 & TRN & \\
\hline CHEMBL1447312 & 688267 & 5.5 & 5.0479 & TRN & \\
\hline CHEMBL1524785 & 688267 & 4.95 & 5.0829 & TRN & \\
\hline CHEMBL3199227 & 688267 & 5.55 & 5.007 & TRN & \\
\hline CHEMBL1580704 & 688267 & 4.05 & 5.079 & TRN & \\
\hline CHEMBL1345738 & 688267 & 5.35 & 5.0457 & TRN & \\
\hline CHEMBL1451582 & 688267 & 5.3 & 5.0762 & TRN & \\
\hline CHEMBL1364979 & 688267 & 4.0 & 4.9887 & TST & \\
\hline CHEMBL1481844 & 688267 & 5.6 & 5.0415 & TRN & \\
\hline CHEMBL1362560 & 688267 & 6.5 & 5.0182 & TRN & \\
\hline CHEMBL 3196881 & 688267 & 4.0 & 5.0545 & TST & \\
\hline CHEMBL1424807 & 688267 & 4.35 & 5.0949 & TRN & \\
\hline CHEMBL1398038 & 688267 & 6.2 & 5.0019 & TRN & \\
\hline CHEMBL1473593 & 688267 & 5.55 & 5.0293 & TRN & \\
\hline CHEMBL1537600 & 688267 & 6.15 & 5.0254 & TST & \\
\hline CHEMBL1519383 & 688267 & 4.55 & 5.0855 & TRN & \\
\hline CHEMBL1557005 & 688267 & 5.85 & 5.0695 & TST & \\
\hline CHEMBL1496965 & 688267 & 5.4 & 5.0494 & TST & \\
\hline CHEMBL1337343 & 688267 & 5.35 & 5.01399 & & TRN \\
\hline CHEMBL1523189 & 688267 & 4.35 & 5.0569 & TST & \\
\hline CHEMBL1466106 & 688267 & 4.55 & 5.0289 & TST & \\
\hline CHEMBL1555919 & 688267 & 5.2 & 5.0989 & TRN & \\
\hline CHEMBL1454096 & 688267 & 4.2 & 5.002 & TRN & \\
\hline CHEMBL1300671 & 688267 & 6.15 & 5.1257 & TRN & \\
\hline CHEMBL1575634 & 688267 & 4.05 & 4.9963 & TRN & \\
\hline CHEMBL1522071 & 688267 & 5.95 & 5.0041 & TST & \\
\hline CHEMBL201325 & 688267 & 6.2 & 4.9676 & TRN & \\
\hline CHEMBL1604531 & 688267 & 5.55 & 5.0362 & TRN & \\
\hline CHEMBL1426675 & 688267 & 4.0 & 5.0813 & TRN & \\
\hline CHEMBL3211993 & 688267 & 3.95 & 5.0141 & TST & \\
\hline CHEMBL1566531 & 688267 & 4.35 & 5.0379 & TRN & \\
\hline CHEMBL1368318 & 688267 & 3.95 & 5.0768 & TST & \\
\hline CHEMBL1317697 & 688267 & 4.55 & 5.1336 & TRN & \\
\hline CHEMBL1529317 & 688267 & 4.85 & 5.0103 & TRN & \\
\hline CHEMBL1534458 & 688267 & 5.35 & 5.1175 & TRN & \\
\hline
\end{tabular}




\begin{tabular}{|c|c|c|c|c|c|}
\hline \\
\hline CHEMBL1389997 & 688267 & 4.3 & 5.0347 & TRN & \\
\hline CHEMBL1556582 & 688267 & 4.0 & 4.993 & TST & \\
\hline CHEMBL1317405 & 688267 & 3.95 & 5.0043 & TRN & \\
\hline CHEMBL1472970 & 688267 & 3.95 & 5.013 & TRN & \\
\hline CHEMBL1563891 & 688267 & 4.55 & 5.0259 & TRN & \\
\hline CHEMBL1338279 & 688267 & 4.0 & 5.0234 & TST & \\
\hline CHEMBL1465033 & 688267 & 5.35 & 5.1438 & TRN & \\
\hline CHEMBL1462616 & 688267 & 6.15 & 5.0849 & TST & \\
\hline CHEMBL3212576 & 688267 & 6.2 & 5.0067 & TRN & \\
\hline CHEMBL3196357 & 688267 & 4.65 & 5.0651 & TRN & \\
\hline CHEMBL1382176 & 688267 & 4.45 & 5.1021 & TRN & \\
\hline CHEMBL1358680 & 688267 & 5.8 & 5.1382 & TRN & \\
\hline CHEMBL258699 & 688267 & 4.45 & 5.0892 & TST & \\
\hline CHEMBL1601545 & 688267 & 6.2 & 5.0287 & TRN & \\
\hline CHEMBL1534604 & 688267 & 5.25 & 5.0533 & TRN & \\
\hline CHEMBL1311691 & 688267 & 4.0 & 5.0784 & TRN & \\
\hline CHEMBL1524065 & 688267 & 4.05 & 5.0135 & TRN & \\
\hline CHEMBL1316061 & 688267 & 6.05 & 5.0921 & TRN & \\
\hline CHEMBL1521513 & 688267 & 4.0 & 5.0383 & TRN & \\
\hline CHEMBL1550598 & 688267 & 6.2 & 5.1383 & TRN & \\
\hline CHEMBL3197725 & 688267 & 4.95 & 5.0406 & TST & \\
\hline CHEMBL1532789 & 688267 & 4.35 & 5.069 & TRN & \\
\hline CHEMBL1613168 & 688267 & 6.2 & 5.0371 & TRN & \\
\hline CHEMBL1369905 & 688267 & 4.8 & 5.0522 & TRN & \\
\hline CHEMBL1299647 & 688267 & 4.15 & 5.0806 & TST & \\
\hline CHEMBL1589165 & 688267 & 5.3 & 5.055 & TRN & \\
\hline CHEMBL1426682 & 688267 & 4.0 & 5.0982 & TRN & \\
\hline CHEMBL1531435 & 688267 & 5.85 & 5.0315 & TST & \\
\hline CHEMBL1566114 & 688267 & 5.6 & 5.0918 & TRN & \\
\hline CHEMBL1306389 & 688267 & 6.2 & 5.0586 & TST & \\
\hline CHEMBL1459877 & 688267 & 4.6 & 5.0944 & TRN & \\
\hline CHEMBL1563456 & 688267 & 4.45 & 5.0945 & TRN & \\
\hline CHEMBL1355005 & 688267 & 5.45 & 5.0319 & TRN & \\
\hline CHEMBL1518205 & 688267 & 4.3 & 5.0339 & TRN & \\
\hline CHEMBL1432761 & 688267 & 4.8 & 5.1193 & TRN & \\
\hline CHEMBL1557327 & 688267 & 4.35 & 5.1239 & TST & \\
\hline CHEMBL1566942 & 688267 & 4.35 & 5.131 & TRN & \\
\hline CHEMBL1438635 & 688267 & 4.3 & 5.0986 & TST & \\
\hline CHEMBL1448222 & 688267 & 5.45 & 5.0457 & TRN & \\
\hline CHEMBL1527291 & 688267 & 5.55 & 5.0574 & TST & \\
\hline CHEMBL1488298 & 688267 & 4.05 & 5.0062 & TRN & \\
\hline CHEMBL1329484 & 688267 & 4.0 & 5.0785 & TST & \\
\hline CHEMBL1561926 & 688267 & 6.15 & 5.0853 & TRN & \\
\hline CHEMBL1555943 & 688267 & 4.35 & 5.0613 & TRN & \\
\hline CHEMBL1431819 & 688267 & 4.2 & 5.0425 & TRN & \\
\hline CHEMBL1533559 & 688267 & 5.25 & 5.1626 & TRN & \\
\hline CHEMBL3193060 & 688267 & 4.0 & $4.9860 e$ & 0000000001 & TRN \\
\hline CHEMBL1588830 & 688267 & 4.0 & 5.0688 & TRN & \\
\hline & & & & 17974 & \\
\hline
\end{tabular}




\begin{tabular}{|c|c|c|c|c|c|}
\hline \\
\hline CHEMBL1431509 & 688267 & 4.9 & 5.0389 & TRN & \\
\hline CHEMBL1315098 & 688267 & 4.75 & 5.0475 & TRN & \\
\hline CHEMBL1314851 & 688267 & 6.45 & 5.0448 & TRN & \\
\hline CHEMBL1367152 & 688267 & 5.55 & 5.0546 & TRN & \\
\hline CHEMBL1313295 & 688267 & 6.15 & 5.0384 & TRN & \\
\hline CHEMBL1351713 & 688267 & 4.1 & 5.1186 & TRN & \\
\hline CHEMBL1361627 & 688267 & 3.95 & 5.159 & TRN & \\
\hline CHEMBL1379293 & 688267 & 5.55 & 5.0615 & TRN & \\
\hline CHEMBL1492686 & 688267 & 4.0 & 5.0158 & TRN & \\
\hline CHEMBL1396219 & 688267 & 4.05 & 5.0319 & TRN & \\
\hline CHEMBL1354277 & 688267 & 6.2 & 5.0902 & TST & \\
\hline CHEMBL1453497 & 688267 & 5.65 & 5.0262 & TRN & \\
\hline CHEMBL1976599 & 688267 & 6.25 & 4.9714 & TRN & \\
\hline CHEMBL1495455 & 688267 & 5.55 & 5.0074 & TRN & \\
\hline CHEMBL1576253 & 688267 & 4.25 & 5.0912 & TRN & \\
\hline CHEMBL1321276 & 688267 & 4.45 & 5.0482 & TST & \\
\hline CHEMBL1528041 & 688267 & 6.25 & 5.0374 & TRN & \\
\hline CHEMBL1363464 & 688267 & 6.5 & 5.0615 & TRN & \\
\hline CHEMBL1471325 & 688267 & 6.2 & 5.1412 & TRN & \\
\hline CHEMBL1461878 & 688267 & 4.4 & 5.0422 & TRN & \\
\hline CHEMBL1570602 & 688267 & 5.5 & 5.1332 & TRN & \\
\hline CHEMBL1465633 & 688267 & 4.35 & 5.0745 & TST & \\
\hline CHEMBL1390978 & 688267 & 6.2 & 5.0437 & TRN & \\
\hline CHEMBL1514672 & 688267 & 5.15 & 5.0641 & TRN & \\
\hline CHEMBL1416435 & 688267 & 4.05 & 5.0527 & TRN & \\
\hline CHEMBL1372862 & 688267 & 5.25 & 5.0467 & TRN & \\
\hline CHEMBL 1344654 & 688267 & 4.05 & 5.09699 & 99999999995 & TRN \\
\hline CHEMBL1419275 & 688267 & 4.55 & 4.9991 & TRN & \\
\hline CHEMBL1450731 & 688267 & 3.95 & 4.9726 & TRN & \\
\hline CHEMBL1526712 & 688267 & 4.05 & 5.1063 & TRN & \\
\hline CHEMBL1453014 & 688267 & 6.2 & 5.0532 & TST & \\
\hline CHEMBL1445267 & 688267 & 5.55 & 5.0048 & TRN & \\
\hline CHEMBL1384967 & 688267 & 4.05 & 5.0538 & TRN & \\
\hline CHEMBL1368693 & 688267 & 4.35 & 5.1096 & TRN & \\
\hline CHEMBL1366435 & 688267 & 4.25 & 5.1197 & TRN & \\
\hline CHEMBL 2373595 & 688267 & 4.0 & 5.0703 & TRN & \\
\hline CHEMBL1308117 & 688267 & 5.1 & 5.0485 & TRN & \\
\hline CHEMBL1473128 & 688267 & 6.05 & 5.1315 & TRN & \\
\hline CHEMBL1430215 & 688267 & 6.5 & 5.0893 & TRN & \\
\hline CHEMBL1455545 & 688267 & 4.65 & 5.0719 & TST & \\
\hline CHEMBL1373613 & 688267 & 4.25 & 5.1019 & TRN & \\
\hline CHEMBL1421062 & 688267 & 5.3 & 5.082 & TST & \\
\hline CHEMBL1470924 & 688267 & 4.4 & 5.082 & TST & \\
\hline CHEMBL1375342 & 688267 & 4.35 & 5.0732 & TST & \\
\hline CHEMBL3214463 & 688267 & 6.45 & 5.0618 & TST & \\
\hline CHEMBL1398531 & 688267 & 4.3 & 5.0173 & TRN & \\
\hline CHEMBL1442247 & 688267 & 4.0 & 5.0665 & TST & \\
\hline CHEMBL1554924 & 688267 & 3.9 & 5.1246 & TRN & \\
\hline
\end{tabular}




\begin{tabular}{|c|c|c|c|c|}
\hline \multicolumn{5}{|c|}{ Supplemental Table } \\
\hline CHEMBL1407821 & 688267 & 4.0 & 5.0695 & TST \\
\hline CHEMBL1582781 & 688267 & 4.3 & 5.021 & TRN \\
\hline CHEMBL1458191 & 688267 & 5.3 & 5.0136 & TRN \\
\hline CHEMBL1448666 & 688267 & 4.45 & 5.0506 & TST \\
\hline CHEMBL1377692 & 688267 & 4.4 & 5.0495 & TRN \\
\hline CHEMBL1590901 & 688267 & 4.15 & 5.0078 & TRN \\
\hline CHEMBL1575599 & 688267 & 5.65 & 5.0819 & TRN \\
\hline CHEMBL1594706 & 688267 & 4.6 & 5.1305 & TRN \\
\hline CHEMBL1504054 & 688267 & 4.35 & 5.0866 & TRN \\
\hline CHEMBL1440936 & 688267 & 4.6 & 5.1916 & TRN \\
\hline CHEMBL1612277 & 688267 & 4.1 & 5.0135 & TRN \\
\hline CHEMBL1475347 & 688267 & 4.05 & 5.0032 & TRN \\
\hline CHEMBL1558181 & 688267 & 4.05 & 5.0212 & TRN \\
\hline CHEMBL1200783 & 688267 & 6.3 & 5.0743 & TST \\
\hline CHEMBL1557711 & 688267 & 6.25 & 5.1062 & TRN \\
\hline CHEMBL1383121 & 688267 & 4.4 & 5.0258 & TRN \\
\hline CHEMBL1485247 & 688267 & 6.2 & 5.1275 & TRN \\
\hline CHEMBL1559147 & 688267 & 6.2 & 5.0379 & TST \\
\hline CHEMBL1385750 & 688267 & 5.05 & 5.0708 & TRN \\
\hline CHEMBL1349539 & 688267 & 5.25 & 5.0559 & TST \\
\hline CHEMBL1564217 & 688267 & 4.0 & 5.0133 & TST \\
\hline CHEMBL1502677 & 688267 & 5.25 & 5.1262 & TRN \\
\hline CHEMBL1314879 & 688267 & 6.5 & 5.0678 & TRN \\
\hline CHEMBL1418301 & 688267 & 4.6 & 5.0238 & TRN \\
\hline CHEMBL1565313 & 688267 & 5.8 & 5.0221 & TST \\
\hline CHEMBL1565700 & 688267 & 3.95 & 5.0462 & TRN \\
\hline CHEMBL1592912 & 688267 & 4.05 & 4.9617 & TRN \\
\hline CHEMBL134791 & 688267 & 5.85 & 5.0118 & TRN \\
\hline CHEMBL1403262 & 688267 & 4.4 & 5.0418 & TST \\
\hline CHEMBL1428074 & 688267 & 6.25 & 5.1266 & TRN \\
\hline CHEMBL1536157 & 688267 & 5.45 & 5.0603 & TRN \\
\hline CHEMBL3190196 & 688267 & 6.2 & 5.1183 & TRN \\
\hline CHEMBL1453025 & 688267 & 5.2 & 5.0961 & TRN \\
\hline CHEMBL1525458 & 688267 & 4.1 & 5.0619 & TRN \\
\hline CHEMBL1595508 & 688267 & 4.15 & 5.0257 & TRN \\
\hline CHEMBL1481789 & 688267 & 5.5 & 5.0827 & TRN \\
\hline CHEMBL1601579 & 688267 & 5.55 & 5.0429 & TRN \\
\hline CHEMBL1415901 & 688267 & 4.0 & 5.0405 & TST \\
\hline CHEMBL1490097 & 688267 & 5.4 & 5.0598 & TRN \\
\hline CHEMBL1485692 & 688267 & 4.1 & 5.0176 & TRN \\
\hline CHEMBL1445734 & 688267 & 5.35 & 5.0706 & TRN \\
\hline CHEMBL1531295 & 688267 & 5.95 & 5.1146 & TRN \\
\hline CHEMBL1528676 & 688267 & 5.6 & 5.0313 & TRN \\
\hline CHEMBL1571561 & 688267 & 5.45 & 5.0174 & TRN \\
\hline CHEMBL1518317 & 688267 & 6.2 & 5.0969 & TRN \\
\hline CHEMBL1585651 & 688267 & 5.95 & 5.0384 & TRN \\
\hline CHEMBL1483413 & 688267 & 5.0 & 5.1153 & TRN \\
\hline CHEMBL1473023 & 688267 & 4.35 & 5.0871 & TST \\
\hline
\end{tabular}




\begin{tabular}{|c|c|c|c|c|}
\hline \multicolumn{5}{|c|}{ Supplemental Table S2.txt } \\
\hline CHEMBL1417050 & 688267 & 4.0 & 5.0425 & TST \\
\hline CHEMBL1498012 & 688267 & 5.15 & 5.0782 & TRN \\
\hline CHEMBL1472425 & 688267 & 6.2 & 5.0406 & TRN \\
\hline CHEMBL1316027 & 688267 & 6.1 & 5.0697 & TRN \\
\hline CHEMBL1450082 & 688267 & 4.5 & 5.0025 & TRN \\
\hline CHEMBL1421838 & 688267 & 4.3 & 5.0858 & TRN \\
\hline CHEMBL1451974 & 688267 & 5.2 & 5.0812 & TRN \\
\hline CHEMBL1450920 & 688267 & 4.05 & 5.051 & TST \\
\hline CHEMBL1518770 & 688267 & 5.9 & 5.0611 & TRN \\
\hline CHEMBL1420160 & 688267 & 3.95 & 5.1465 & TRN \\
\hline CHEMBL1445362 & 688267 & 5.25 & 5.0794 & TRN \\
\hline CHEMBL1608687 & 688267 & 5.35 & 5.1003 & TRN \\
\hline CHEMBL1335124 & 688267 & 5.55 & 4.9751 & TRN \\
\hline CHEMBL1301884 & 688267 & 6.2 & 5.0344 & TRN \\
\hline CHEMBL1592753 & 688267 & 5.5 & 5.0263 & TRN \\
\hline CHEMBL1405020 & 688267 & 4.2 & 5.0951 & TRN \\
\hline CHEMBL1529701 & 688267 & 4.35 & 5.0097 & TRN \\
\hline CHEMBL1443521 & 688267 & 5.55 & 5.0909 & TST \\
\hline CHEMBL1500735 & 688267 & 5.15 & 5.0295 & TST \\
\hline CHEMBL1315297 & 688267 & 3.95 & 5.0483 & TRN \\
\hline CHEMBL1410394 & 688267 & 5.55 & 5.0798 & TRN \\
\hline CHEMBL1554877 & 688267 & 5.5 & 5.0681 & TRN \\
\hline CHEMBL1510821 & 688267 & 5.0 & 5.0945 & TRN \\
\hline CHEMBL1316991 & 688267 & 4.25 & 5.0026 & TRN \\
\hline CHEMBL1236104 & 688267 & 5.4 & 5.0469 & TST \\
\hline CHEMBL1489573 & 688267 & 4.3 & 5.0343 & TRN \\
\hline CHEMBL1562393 & 688267 & 6.05 & 5.0063 & TRN \\
\hline CHEMBL1375546 & 688267 & 4.25 & 5.0268 & TRN \\
\hline CHEMBL1384697 & 688267 & 4.05 & 5.0371 & TST \\
\hline CHEMBL1350764 & 688267 & 5.5 & 5.0817 & TRN \\
\hline CHEMBL1450662 & 688267 & 5.3 & 5.081 & TRN \\
\hline CHEMBL1402757 & 688267 & 4.95 & 5.1223 & TRN \\
\hline CHEMBL1428841 & 688267 & 4.5 & 5.0823 & TST \\
\hline CHEMBL1608864 & 688267 & 4.0 & 5.0194 & TRN \\
\hline CHEMBL1589564 & 688267 & 6.2 & 5.0898 & TST \\
\hline CHEMBL1467755 & 688267 & 4.05 & 4.9985 & TRN \\
\hline CHEMBL1352214 & 688267 & 4.75 & 5.0971 & TST \\
\hline CHEMBL1402317 & 688267 & 5.15 & 5.0965 & TRN \\
\hline CHEMBL3208811 & 688267 & 3.95 & 5.061 & TRN \\
\hline CHEMBL1460955 & 688267 & 4.3 & 5.0437 & TST \\
\hline CHEMBL1394580 & 688267 & 5.4 & 5.0748 & TST \\
\hline CHEMBL1385985 & 688267 & 4.05 & 5.1036 & TRN \\
\hline CHEMBL1503148 & 688267 & 3.95 & 5.1032 & TRN \\
\hline CHEMBL1454821 & 688267 & 6.15 & 5.0675 & TRN \\
\hline CHEMBL1419696 & 688267 & 5.6 & 5.0111 & TRN \\
\hline CHEMBL1598188 & 688267 & 6.7501 & 5.0243 & TRN \\
\hline CHEMBL1320912 & 688267 & 4.25 & 5.0384 & TRN \\
\hline CHEMBL1358627 & 688267 & 4.35 & 5.0331 & TRN \\
\hline
\end{tabular}




\begin{tabular}{|c|c|c|c|c|c|}
\hline \multicolumn{6}{|c|}{ Supplemental Table S2.txt } \\
\hline CHEMBL1536379 & 688267 & 4.25 & 5.0572 & TRN & \\
\hline CHEMBL1371291 & 688267 & 6.25 & 4.9634 & TRN & \\
\hline CHEMBL3213071 & 688267 & 4.35 & 5.0538 & TST & \\
\hline CHEMBL1573485 & 688267 & 4.1 & 5.0285 & TRN & \\
\hline CHEMBL1533965 & 688267 & 4.7 & 5.0384 & TST & \\
\hline CHEMBL1569511 & 688267 & 4.05 & 5.0624 & TRN & \\
\hline CHEMBL1593968 & 688267 & 6.25 & 5.0509 & TRN & \\
\hline CHEMBL1449202 & 688267 & 4.55 & 5.0563 & TRN & \\
\hline CHEMBL1534121 & 688267 & 5.0 & 5.0132 & TRN & \\
\hline CHEMBL1572800 & 688267 & 4.0 & 5.0843 & TST & \\
\hline CHEMBL1505447 & 688267 & 4.25 & 5.0582 & TRN & \\
\hline CHEMBL1486066 & 688267 & 5.35 & 4.9594 & TRN & \\
\hline CHEMBL1593041 & 688267 & 4.5 & 5.0244 & TRN & \\
\hline CHEMBL1419380 & 688267 & 6.2 & 5.0779 & TRN & \\
\hline CHEMBL1548935 & 688267 & 4.35 & 5.0995 & TST & \\
\hline CHEMBL1588723 & 688267 & 5.2 & 5.0978 & TST & \\
\hline CHEMBL1527433 & 688267 & 6.2 & 4.9968 & TST & \\
\hline CHEMBL1437943 & 688267 & 5.8 & 4.9973 & TRN & \\
\hline CHEMBL1537624 & 688267 & 5.3 & 5.006 & TRN & \\
\hline CHEMBL1408068 & 688267 & 5.65 & 5.0333 & TST & \\
\hline CHEMBL1515636 & 688267 & 4.0 & 5.1085 & TRN & \\
\hline CHEMBL1467791 & 688267 & 4.05 & 5.0292 & TRN & \\
\hline CHEMBL1431512 & 688267 & 4.6 & 5.0062 & TRN & \\
\hline CHEMBL1378553 & 688267 & 4.75 & 5.0232 & TRN & \\
\hline CHEMBL1570022 & 688267 & 4.35 & 5.099 & TRN & \\
\hline CHEMBL1408565 & 688267 & 5.9 & 5.0724 & TRN & \\
\hline CHEMBL1400237 & 688267 & 5.55 & 5.0886 & TRN & \\
\hline CHEMBL1435716 & 688267 & 4.1 & 5.0425 & TRN & \\
\hline CHEMBL1412796 & 688267 & 4.35 & 5.0575 & TRN & \\
\hline CHEMBL1320252 & 688267 & 4.2 & 5.01399 & 9999999999 & TRN \\
\hline CHEMBL1486920 & 688267 & 4.35 & 5.0138 & TST & \\
\hline CHEMBL1523980 & 688267 & 4.5 & 5.0408 & TST & \\
\hline CHEMBL1566123 & 688267 & 6.2 & 5.0845 & TRN & \\
\hline CHEMBL1320168 & 688267 & 5.1 & 5.0006 & TRN & \\
\hline CHEMBL1541976 & 688267 & 4.05 & 5.0776 & TRN & \\
\hline CHEMBL1480692 & 688267 & 6.2 & 5.0721 & TST & \\
\hline CHEMBL1525657 & 688267 & 4.05 & 5.1229 & TST & \\
\hline CHEMBL1544582 & 688267 & 6.2 & 5.088 & TRN & \\
\hline CHEMBL1353546 & 688267 & 3.95 & 5.0486 & TRN & \\
\hline CHEMBL1325510 & 688267 & 6.2 & 5.0745 & TST & \\
\hline CHEMBL1510049 & 688267 & 4.65 & 5.095 & TRN & \\
\hline CHEMBL1532707 & 688267 & 4.6 & $5.0680 e$ & 00000000005 & TRN \\
\hline CHEMBL1376403 & 688267 & 5.9 & 5.1038 & TRN & \\
\hline CHEMBL1318087 & 688267 & 5.3 & 4.998 & TRN & \\
\hline CHEMBL1549090 & 688267 & 5.3 & $5.1720 e$ & 0000000001 & TRN \\
\hline CHEMBL1498378 & 688267 & 5.4 & 4.9973 & TRN & \\
\hline CHEMBL1586966 & 688267 & 5.6 & 5.0694 & TRN & \\
\hline CHEMBL1579629 & 688267 & 6.2 & 5.01 & TST & \\
\hline
\end{tabular}




\begin{tabular}{|c|c|c|c|c|c|}
\hline \\
\hline CHEMBL1515333 & 688267 & 6.5 & 5.0834 & TRN & \\
\hline CHEMBL1482506 & 688267 & 5.85 & 5.0371 & TST & \\
\hline CHEMBL3212015 & 688267 & 6.45 & 5.0227 & TRN & \\
\hline CHEMBL1606495 & 688267 & 4.0 & 5.0688 & TRN & \\
\hline CHEMBL1533869 & 688267 & 4.0 & 5.1309 & TRN & \\
\hline CHEMBL1305019 & 688267 & 4.0 & 5.0669 & TST & \\
\hline CHEMBL1562486 & 688267 & 4.3 & 5.0604 & TRN & \\
\hline CHEMBL1362664 & 688267 & 6.2 & 5.0616 & TRN & \\
\hline CHEMBL1436341 & 688267 & 4.4 & 5.0785 & TRN & \\
\hline CHEMBL1535488 & 688267 & 4.05 & 5.0209 & TST & \\
\hline CHEMBL1469365 & 688267 & 4.0 & 4.9932 & TRN & \\
\hline CHEMBL1529662 & 688267 & 5.5 & 5.0452 & TST & \\
\hline CHEMBL1551928 & 688267 & 5.75 & 5.0941 & TRN & \\
\hline CHEMBL1378629 & 688267 & 5.05 & 5.1273 & TRN & \\
\hline CHEMBL1572158 & 688267 & 6.2 & 5.0456 & TRN & \\
\hline CHEMBL1477496 & 688267 & 5.95 & 5.0386 & TRN & \\
\hline CHEMBL1585994 & 688267 & 4.5 & 5.1209 & TRN & \\
\hline CHEMBL1375015 & 688267 & 4.05 & 5.1074 & TRN & \\
\hline CHEMBL1551827 & 688267 & 5.35 & 5.0375 & TST & \\
\hline CHEMBL1486060 & 688267 & 5.8 & 5.0366 & TRN & \\
\hline CHEMBL1568013 & 688267 & 3.9 & 5.1355 & TRN & \\
\hline CHEMBL3191737 & 688267 & 4.9 & 5.0373 & TST & \\
\hline CHEMBL1457199 & 688267 & 6.45 & 5.0127 & TST & \\
\hline CHEMBL1421590 & 688267 & 6.2 & 5.0545 & TRN & \\
\hline CHEMBL1476968 & 688267 & 4.1 & 4.987 & TST & \\
\hline CHEMBL1372824 & 688267 & 5.35 & 5.0341 & TRN & \\
\hline CHEMBL1561920 & 688267 & 4.7 & 5.0446 & TRN & \\
\hline CHEMBL1324341 & 688267 & 4.25 & 5.0486 & TRN & \\
\hline CHEMBL1595662 & 688267 & 4.8 & 5.0465 & TST & \\
\hline CHEMBL1395105 & 688267 & 6.25 & 5.0312 & TRN & \\
\hline CHEMBL1605716 & 688267 & 4.0 & 5.0751 & TRN & \\
\hline CHEMBL1443600 & 688267 & 5.55 & 5.0216 & TRN & \\
\hline CHEMBL1594795 & 688267 & 5.65 & $4.9830 e$ & 00000000005 & TRN \\
\hline CHEMBL1567986 & 688267 & 4.0 & 5.0804 & TST & \\
\hline CHEMBL1453205 & 688267 & 5.6 & 5.0838 & TRN & \\
\hline CHEMBL1357473 & 688267 & 6.45 & 5.0368 & TRN & \\
\hline CHEMBL1975756 & 688267 & 4.05 & 4.9712 & TST & \\
\hline CHEMBL1429500 & 688267 & 4.0 & 5.0208 & TRN & \\
\hline CHEMBL1380825 & 688267 & 5.35 & 5.0342 & TRN & \\
\hline CHEMBL1367193 & 688267 & 5.4 & 5.0224 & TRN & \\
\hline CHEMBL1347815 & 688267 & 4.05 & $5.0310 e$ & $\partial 000000001$ & TRN \\
\hline CHEMBL1428266 & 688267 & 5.85 & 5.0627 & TRN & \\
\hline CHEMBL1603707 & 688267 & 3.95 & 5.0777 & TRN & \\
\hline CHEMBL1556517 & 688267 & 6.45 & 5.0157 & TRN & \\
\hline CHEMBL3213787 & 688267 & 4.95 & 5.0188 & TRN & \\
\hline CHEMBL1492368 & 688267 & 5.35 & 5.0765 & TRN & \\
\hline CHEMBL1364402 & 688267 & 4.1 & 4.9924 & TRN & \\
\hline CHEMBL1371802 & 688267 & 4.65 & 5.0797 & TST & \\
\hline
\end{tabular}




\begin{tabular}{|c|c|c|c|c|c|}
\hline \multicolumn{6}{|c|}{ Supplemental Table S2.txt } \\
\hline CHEMBL1353126 & 688267 & 4.35 & 5.0536 & TRN & \\
\hline CHEMBL1499048 & 688267 & 5.35 & 5.0628 & TRN & \\
\hline CHEMBL3194824 & 688267 & 5.3 & 5.0116 & TRN & \\
\hline CHEMBL1573832 & 688267 & 4.5 & 5.075 & TRN & \\
\hline CHEMBL1439173 & 688267 & 6.2 & 5.0198 & TRN & \\
\hline CHEMBL1407969 & 688267 & 4.0 & 5.0474 & TRN & \\
\hline CHEMBL3190954 & 688267 & 4.1 & 5.0661 & TRN & \\
\hline CHEMBL1311671 & 688267 & 4.25 & 5.0546 & TST & \\
\hline CHEMBL1396013 & 688267 & 4.05 & 5.0458 & TST & \\
\hline CHEMBL1321619 & 688267 & 6.2 & 5.0892 & TRN & \\
\hline CHEMBL1543335 & 688267 & 5.5 & 5.1457 & TRN & \\
\hline CHEMBL3192742 & 688267 & 6.3 & 5.0399 & TST & \\
\hline CHEMBL1493875 & 688267 & 4.65 & 5.0407 & TRN & \\
\hline CHEMBL1325266 & 688267 & 4.0 & 5.0553 & TST & \\
\hline CHEMBL1318777 & 688267 & 5.65 & 5.04899 & 99999999995 & TST \\
\hline CHEMBL1530318 & 688267 & 4.3 & 5.0324 & TRN & \\
\hline CHEMBL1456331 & 688267 & 3.95 & 5.0388 & TST & \\
\hline CHEMBL1524127 & 688267 & 3.95 & 5.0602 & TRN & \\
\hline CHEMBL1485039 & 688267 & 5.25 & 5.0586 & TRN & \\
\hline CHEMBL1516279 & 688267 & 3.95 & 5.0397 & TRN & \\
\hline CHEMBL1305358 & 688267 & 4.25 & 5.0164 & TRN & \\
\hline CHEMBL1391811 & 688267 & 4.75 & 5.081 & TST & \\
\hline CHEMBL1419326 & 688267 & 5.6 & 5.0122 & TRN & \\
\hline CHEMBL1311855 & 688267 & 5.3 & 5.0454 & TRN & \\
\hline CHEMBL1455881 & 688267 & 6.25 & 5.0592 & TRN & \\
\hline CHEMBL1532829 & 688267 & 4.05 & 5.0463 & TST & \\
\hline CHEMBL1474283 & 688267 & 5.3 & 5.0717 & TRN & \\
\hline CHEMBL1337526 & 688267 & 4.65 & 5.0921 & TST & \\
\hline CHEMBL1319062 & 688267 & 6.2 & 5.022 & TRN & \\
\hline CHEMBL1346851 & 688267 & 4.4 & 5.0916 & TST & \\
\hline CHEMBL1308663 & 688267 & 5.3 & 5.0637 & TRN & \\
\hline CHEMBL1564483 & 688267 & 5.85 & 4.9965 & TRN & \\
\hline CHEMBL1398081 & 688267 & 6.15 & 5.1135 & TRN & \\
\hline CHEMBL1513066 & 688267 & 4.15 & 5.0367 & TRN & \\
\hline CHEMBL3198623 & 688267 & 4.15 & 5.0278 & TRN & \\
\hline CHEMBL1338474 & 688267 & 4.4 & 5.0496 & TRN & \\
\hline CHEMBL1350288 & 688267 & 4.05 & 5.0921 & TRN & \\
\hline CHEMBL1609989 & 688267 & 5.75 & 5.0432 & TRN & \\
\hline CHEMBL1436357 & 688267 & 4.1 & 5.1104 & TRN & \\
\hline CHEMBL1464023 & 688267 & 4.0 & 5.0455 & TRN & \\
\hline CHEMBL1584287 & 688267 & 5.0 & 5.0753 & TRN & \\
\hline CHEMBL1399356 & 688267 & 5.8 & 5.0813 & TRN & \\
\hline CHEMBL1982742 & 688267 & 6.1 & 5.0275 & TRN & \\
\hline CHEMBL1449710 & 688267 & 5.65 & 5.1294 & TRN & \\
\hline CHEMBL1607812 & 688267 & 5.8 & 5.0726 & TST & \\
\hline CHEMBL1514814 & 688267 & 3.95 & 5.0665 & TST & \\
\hline CHEMBL1462360 & 688267 & 4.0 & 5.0403 & TST & \\
\hline CHEMBL1490339 & 688267 & 6.15 & 5.038 & TRN & \\
\hline
\end{tabular}




\begin{tabular}{|c|c|c|c|c|}
\hline \multicolumn{5}{|c|}{ Supplemental Tabl } \\
\hline CHEMBL1577208 & 688267 & 5.75 & 5.0193 & TRN \\
\hline CHEMBL1453869 & 688267 & 5.5 & 5.0917 & TST \\
\hline CHEMBL1496379 & 688267 & 6.2 & 5.0323 & TRN \\
\hline CHEMBL1366706 & 688267 & 4.3 & 5.081 & TRN \\
\hline CHEMBL1349653 & 688267 & 4.5 & 5.0586 & TRN \\
\hline CHEMBL1509493 & 688267 & 4.05 & 5.018 & TST \\
\hline CHEMBL1359199 & 688267 & 4.0 & 5.0168 & TRN \\
\hline CHEMBL1404074 & 688267 & 5.8 & 5.1189 & TRN \\
\hline CHEMBL1493713 & 688267 & 5.3 & 5.0478 & TRN \\
\hline CHEMBL528647 & 688267 & 5.95 & 5.0167 & TST \\
\hline CHEMBL1483750 & 688267 & 3.9 & 5.1036 & TRN \\
\hline CHEMBL1588965 & 688267 & 6.1 & 5.0738 & TRN \\
\hline CHEMBL1463915 & 688267 & 5.4 & 5.0906 & TRN \\
\hline CHEMBL 3214578 & 688267 & 4.05 & 5.0343 & TRN \\
\hline CHEMBL1399986 & 688267 & 6.15 & 5.0207 & TRN \\
\hline CHEMBL1368369 & 688267 & 5.1 & 5.0337 & TRN \\
\hline CHEMBL1312469 & 688267 & 4.2 & 5.0281 & TRN \\
\hline CHEMBL1514014 & 688267 & 5.45 & 5.1198 & TRN \\
\hline CHEMBL1607745 & 688267 & 3.95 & 5.0335 & TRN \\
\hline CHEMBL1603908 & 688267 & 6.5 & 5.043 & TRN \\
\hline CHEMBL1399651 & 688267 & 4.2 & 5.0744 & TST \\
\hline CHEMBL1375972 & 688267 & 6.25 & 5.0813 & TRN \\
\hline CHEMBL1484767 & 688267 & 3.95 & 5.0929 & TRN \\
\hline CHEMBL1301273 & 688267 & 4.5 & 5.0398 & TST \\
\hline CHEMBL1306285 & 688267 & 4.5 & 5.0808 & TRN \\
\hline CHEMBL1483876 & 688267 & 5.25 & 5.0926 & TRN \\
\hline CHEMBL1352724 & 688267 & 6.2 & 5.1247 & TST \\
\hline CHEMBL1391855 & 688267 & 4.9 & 5.0354 & TST \\
\hline CHEMBL1303070 & 688267 & 4.0 & 4.9898 & TRN \\
\hline CHEMBL1554124 & 688267 & 5.05 & 5.0437 & TRN \\
\hline CHEMBL1569397 & 688267 & 6.5 & 5.0601 & TRN \\
\hline CHEMBL1398933 & 688267 & 4.0 & 5.0136 & TRN \\
\hline CHEMBL1222386 & 688267 & 5.3 & 5.0853 & TRN \\
\hline CHEMBL1415734 & 688267 & 6.2 & 5.0037 & TRN \\
\hline CHEMBL1560394 & 688267 & 3.95 & 5.0764 & TRN \\
\hline CHEMBL1479974 & 688267 & 6.2 & 4.9853 & TRN \\
\hline CHEMBL1339743 & 688267 & 6.25 & 5.013 & TRN \\
\hline CHEMBL416984 & 688267 & 4.0 & 5.12 & TRN \\
\hline CHEMBL1500369 & 688267 & 4.2 & 5.0443 & TRN \\
\hline CHEMBL1440918 & 688267 & 4.05 & 5.0592 & TRN \\
\hline CHEMBL1497502 & 688267 & 4.05 & 5.0883 & TRN \\
\hline CHEMBL1509640 & 688267 & 4.6 & 4.9972 & TRN \\
\hline CHEMBL1599461 & 688267 & 5.55 & 5.0401 & TRN \\
\hline CHEMBL1315817 & 688267 & 3.95 & 5.1295 & TRN \\
\hline CHEMBL1307686 & 688267 & 5.4 & 5.0737 & TST \\
\hline CHEMBL 3207621 & 688267 & 4.45 & 5.0906 & TRN \\
\hline CHEMBL2373613 & 688267 & 5.3 & 5.0472 & TRN \\
\hline CHEMBL1333279 & 688267 & 5.3 & 5.0153 & TRN \\
\hline
\end{tabular}




\begin{tabular}{|c|c|c|c|c|}
\hline \multicolumn{5}{|c|}{ Supplemental Table s2.txt } \\
\hline CHEMBL1358965 & 688267 & 4.45 & 5.1305 & TRN \\
\hline CHEMBL1594061 & 688267 & 4.05 & 5.037 & TST \\
\hline CHEMBL1459029 & 688267 & 4.6 & 5.0102 & TST \\
\hline CHEMBL1355328 & 688267 & 5.7 & 5.0391 & TRN \\
\hline CHEMBL1528985 & 688267 & 4.05 & 5.0272 & TST \\
\hline CHEMBL1473748 & 688267 & 6.15 & 5.0088 & TRN \\
\hline CHEMBL1368905 & 688267 & 5.55 & 5.0262 & TRN \\
\hline CHEMBL1456705 & 688267 & 5.35 & 5.0398 & TRN \\
\hline CHEMBL1567017 & 688267 & 3.95 & 5.0093 & TRN \\
\hline CHEMBL1410260 & 688267 & 4.65 & 5.0386 & TRN \\
\hline CHEMBL1305923 & 688267 & 5.0 & 5.1458 & TRN \\
\hline CHEMBL1570809 & 688267 & 6.2 & 5.0946 & TRN \\
\hline CHEMBL1444779 & 688267 & 6.2 & 5.0473 & TRN \\
\hline CHEMBL1325810 & 688267 & 4.05 & 5.0725 & TRN \\
\hline CHEMBL1552189 & 688267 & 4.4 & 5.0399 & TRN \\
\hline CHEMBL1611494 & 688267 & 5.6 & 5.0897 & TRN \\
\hline CHEMBL1331977 & 688267 & 4.7 & 5.0996 & TRN \\
\hline CHEMBL1429659 & 688267 & 4.0 & 5.0132 & TRN \\
\hline CHEMBL1397521 & 688267 & 5.35 & 5.0299 & TRN \\
\hline CHEMBL1399451 & 688267 & 5.35 & 5.1066 & TRN \\
\hline CHEMBL1488500 & 688267 & 6.2 & 5.0747 & TRN \\
\hline CHEMBL1322157 & 688267 & 5.3 & 5.0632 & TRN \\
\hline CHEMBL1389006 & 688267 & 5.0 & 5.0311 & TRN \\
\hline CHEMBL1576942 & 688267 & 5.05 & 5.0378 & TRN \\
\hline CHEMBL1448028 & 688267 & 5.0 & 5.0185 & TRN \\
\hline CHEMBL1388833 & 688267 & 3.95 & 5.0779 & TRN \\
\hline CHEMBL1398837 & 688267 & 3.95 & 5.0433 & TRN \\
\hline CHEMBL1420992 & 688267 & 4.1 & 5.0218 & TRN \\
\hline CHEMBL1392787 & 688267 & 5.6 & 5.0253 & TRN \\
\hline CHEMBL1590368 & 688267 & 3.95 & 5.015 & TRN \\
\hline CHEMBL1359127 & 688267 & 5.45 & 5.0157 & TRN \\
\hline CHEMBL1473634 & 688267 & 4.0 & 5.1615 & TRN \\
\hline CHEMBL1492675 & 688267 & 6.2 & 5.0603 & TRN \\
\hline CHEMBL1409394 & 688267 & 6.2 & 4.9776 & TST \\
\hline CHEMBL1513100 & 688267 & 5.0 & 5.0582 & TRN \\
\hline CHEMBL1393960 & 688267 & 6.45 & 5.1351 & TRN \\
\hline CHEMBL1401751 & 688267 & 5.95 & 5.1857 & TRN \\
\hline CHEMBL1436142 & 688267 & 4.0 & 5.0492 & TRN \\
\hline CHEMBL1560331 & 688267 & 4.05 & 5.1025 & TRN \\
\hline CHEMBL1370728 & 688267 & 4.1 & 5.0575 & TST \\
\hline CHEMBL1544298 & 688267 & 6.15 & 5.0678 & TRN \\
\hline CHEMBL1330476 & 688267 & 5.25 & 5.0431 & TRN \\
\hline CHEMBL1481467 & 688267 & 4.8 & 5.0524 & TRN \\
\hline CHEMBL1322361 & 688267 & 5.3 & 5.07106 & 0000000001 \\
\hline CHEMBL1595764 & 688267 & 5.25 & 5.1253 & TRN \\
\hline CHEMBL1439288 & 688267 & 6.2 & 5.0559 & TST \\
\hline CHEMBL1442199 & 688267 & 4.0 & 5.0843 & TRN \\
\hline CHEMBL1330082 & 688267 & 5.85 & 5.0615 & TRN \\
\hline
\end{tabular}




\begin{tabular}{|c|c|c|c|c|c|}
\hline \multirow{3}{*}{$\begin{array}{l}\text { CHEMBL1561362 } \\
\text { CHEMBL2001933 }\end{array}$} & \multirow{3}{*}{$\begin{array}{l}688267 \\
688267\end{array}$} & \multicolumn{4}{|c|}{ Supplemental Table S2.txt } \\
\hline & & 5.1 & \multicolumn{2}{|c|}{5.0569999999999995} & TRN \\
\hline & & 4.05 & 5.06 & TRN & \\
\hline CHEMBL1584663 & 688267 & 4.05 & 5.042 & TRN & \\
\hline CHEMBL1455648 & 688267 & 5.3 & 5.1341 & TRN & \\
\hline CHEMBL1404478 & 688267 & 5.8 & 5.096 & TRN & \\
\hline CHEMBL1567742 & 688267 & 6.15 & 5.1391 & TRN & \\
\hline CHEMBL1518991 & 688267 & 3.95 & 5.0792 & TRN & \\
\hline CHEMBL1573482 & 688267 & 4.05 & 5.004 & TST & \\
\hline CHEMBL1546054 & 688267 & 6.2 & 5.103 & TRN & \\
\hline CHEMBL1363703 & 688267 & 5.6 & 5.0605 & TST & \\
\hline CHEMBL1348432 & 688267 & 4.05 & 5.0204 & TRN & \\
\hline CHEMBL1538653 & 688267 & 4.1 & 5.1107 & TRN & \\
\hline CHEMBL1579964 & 688267 & 6.2 & 5.0859 & TST & \\
\hline CHEMBL1303445 & 688267 & 5.1 & 5.1083 & TRN & \\
\hline CHEMBL1491750 & 688267 & 5.45 & 5.0134 & TST & \\
\hline CHEMBL1437212 & 688267 & 6.2 & 5.0962 & TRN & \\
\hline CHEMBL1578192 & 688267 & 6.2 & 5.1303 & TRN & \\
\hline CHEMBL1351776 & 688267 & 5.5 & 5.0215 & TRN & \\
\hline CHEMBL1585990 & 688267 & 4.1 & 5.0344 & TRN & \\
\hline CHEMBL1538499 & 688267 & 6.15 & 5.1043 & TRN & \\
\hline CHEMBL1366282 & 688267 & 6.15 & 5.1064 & TRN & \\
\hline CHEMBL1592071 & 688267 & 4.1 & 5.1069 & TRN & \\
\hline CHEMBL1457243 & 688267 & 5.3 & 5.148 & TRN & \\
\hline CHEMBL1434417 & 688267 & 5.55 & 5.0562 & TRN & \\
\hline CHEMBL1447023 & 688267 & 6.2 & 5.0905 & TRN & \\
\hline CHEMBL1510683 & 688267 & 5.75 & 5.1096 & TRN & \\
\hline CHEMBL1332342 & 688267 & 4.65 & 5.0198 & TST & \\
\hline CHEMBL1357640 & 688267 & 6.2 & 5.1449 & TRN & \\
\hline CHEMBL1518181 & 688267 & 6.15 & 5.1649 & TRN & \\
\hline CHEMBL1300582 & 688267 & 6.2 & 5.0811 & TRN & \\
\hline CHEMBL1353453 & 688267 & 6.2 & 5.059 & TST & \\
\hline CHEMBL1319569 & 688267 & 6.2 & 5.0407 & TRN & \\
\hline CHEMBL1408789 & 688267 & 4.0 & 5.0284 & TRN & \\
\hline CHEMBL1337453 & 688267 & 4.2 & 5.0062 & TRN & \\
\hline CHEMBL1472806 & 688267 & 6.45 & 5.0999 & TRN & \\
\hline CHEMBL1556061 & 688267 & 4.0 & 5.0381 & TRN & \\
\hline CHEMBL1371701 & 688267 & 6.1 & 5.0849 & TRN & \\
\hline CHEMBL1596980 & 688267 & 5.2 & 5.0656 & TRN & \\
\hline CHEMBL1418783 & 688267 & 5.8 & 5.0237 & TRN & \\
\hline CHEMBL1456361 & 688267 & 6.2 & 5.0394 & TRN & \\
\hline CHEMBL1543494 & 688267 & 4.25 & 5.0144 & TRN & \\
\hline CHEMBL 3212545 & 688267 & 4.6 & 5.0949 & TST & \\
\hline CHEMBL1320973 & 688267 & 6.2 & 5.0672 & TRN & \\
\hline CHEMBL3207607 & 688267 & 4.65 & 5.0681 & TRN & \\
\hline CHEMBL1312744 & 688267 & 4.35 & 5.04 & TRN & \\
\hline CHEMBL1448870 & 688267 & 6.15 & 5.0681 & TRN & \\
\hline CHEMBL1304442 & 688267 & 5.1 & 5.0892 & TRN & \\
\hline CHEMBL201289 & 688267 & 4.4 & 5.0676 & TRN & \\
\hline
\end{tabular}




\begin{tabular}{|c|c|c|c|c|c|}
\hline \multicolumn{6}{|c|}{ Supplemental Table S2.txt } \\
\hline CHEMBL1600685 & 688267 & 4.45 & 5.0202 & TRN & \\
\hline CHEMBL1324545 & 688267 & 5.6 & 5.0028 & TRN & \\
\hline CHEMBL1299227 & 688267 & 5.45 & 5.0493 & TRN & \\
\hline CHEMBL1358264 & 688267 & 5.05 & 5.0865 & TRN & \\
\hline CHEMBL1365010 & 688267 & 3.95 & 5.0558 & TRN & \\
\hline CHEMBL1486424 & 688267 & 4.05 & 5.0894 & TRN & \\
\hline CHEMBL1387566 & 688267 & 4.05 & 5.0093 & TRN & \\
\hline CHEMBL1484991 & 688267 & 4.05 & 5.0932 & TRN & \\
\hline CHEMBL1468792 & 688267 & 6.2 & 5.0192 & TRN & \\
\hline CHEMBL1588421 & 688267 & 4.05 & 5.0624 & TRN & \\
\hline CHEMBL1485609 & 688267 & 4.0 & 4.9541 & TRN & \\
\hline CHEMBL1593002 & 688267 & 5.3 & 4.988 & TRN & \\
\hline CHEMBL1299702 & 688267 & 4.55 & 5.0032 & TRN & \\
\hline CHEMBL1389598 & 688267 & 4.45 & 5.0725 & TRN & \\
\hline CHEMBL1485385 & 688267 & 5.15 & 5.0468 & TST & \\
\hline CHEMBL1438924 & 688267 & 4.35 & 5.1562 & TRN & \\
\hline CHEMBL1519657 & 688267 & 5.3 & 5.0153 & TRN & \\
\hline CHEMBL1347902 & 688267 & 5.25 & 5.0541 & TST & \\
\hline CHEMBL1610535 & 688267 & 4.0 & 5.0412 & TRN & \\
\hline CHEMBL1583695 & 688267 & 5.9 & 5.0415 & TRN & \\
\hline CHEMBL1366223 & 688267 & 5.2 & 5.0273 & TST & \\
\hline CHEMBL1452962 & 688267 & 6.5 & 5.0036 & TST & \\
\hline CHEMBL3212058 & 688267 & 6.2 & 5.0782 & TST & \\
\hline CHEMBL1338609 & 688267 & 4.55 & 5.0635 & TRN & \\
\hline CHEMBL1519958 & 688267 & 4.5 & 5.0177 & TST & \\
\hline CHEMBL1589625 & 688267 & 5.55 & 5.0023 & TRN & \\
\hline CHEMBL1489167 & 688267 & 6.0 & 4.998 & TRN & \\
\hline CHEMBL1437779 & 688267 & 5.55 & 5.03100 & 0000000001 & TRN \\
\hline CHEMBL1578666 & 688267 & 5.1 & 5.0634 & TRN & \\
\hline CHEMBL1355103 & 688267 & 4.15 & 5.0839 & TST & \\
\hline CHEMBL1422530 & 688267 & 5.85 & 5.0677 & TRN & \\
\hline CHEMBL1417119 & 688267 & 4.0 & 5.0274 & TRN & \\
\hline CHEMBL1542878 & 688267 & 5.45 & 5.0508 & TST & \\
\hline CHEMBL1385235 & 688267 & 4.4 & 4.9946 & TRN & \\
\hline CHEMBL1575689 & 688267 & 4.6 & 5.0117 & TST & \\
\hline CHEMBL1713992 & 688267 & 4.35 & 5.1026 & TRN & \\
\hline CHEMBL1612826 & 688267 & 5.55 & 5.1145 & TRN & \\
\hline CHEMBL1593368 & 688267 & 4.05 & 5.0065 & TRN & \\
\hline CHEMBL1511426 & 688267 & 5.25 & 5.0258 & TRN & \\
\hline CHEMBL1345524 & 688267 & 5.25 & 5.0792 & TRN & \\
\hline CHEMBL1587700 & 688267 & 5.45 & 5.0517 & TRN & \\
\hline CHEMBL1987563 & 688267 & 5.6 & 5.0197 & TST & \\
\hline CHEMBL1519322 & 688267 & 5.25 & 5.033 & TRN & \\
\hline CHEMBL1481918 & 688267 & 5.65 & 5.0949 & TRN & \\
\hline CHEMBL1493915 & 688267 & 4.05 & 5.0406 & TRN & \\
\hline CHEMBL1332829 & 688267 & 5.85 & 5.0569 & TRN & \\
\hline CHEMBL1429537 & 688267 & 4.05 & 5.0473 & TST & \\
\hline CHEMBL1455284 & 688267 & 4.4 & 5.1029 & TRN & \\
\hline
\end{tabular}




\begin{tabular}{|c|c|c|c|c|}
\hline & & & pplement & al \\
\hline CHEMBL1476156 & 688267 & 4.0 & 5.0313 & TRN \\
\hline CHEMBL1544057 & 688267 & 6.15 & 5.0353 & TRN \\
\hline CHEMBL1375425 & 688267 & 6.2 & 5.0819 & TRN \\
\hline CHEMBL1513084 & 688267 & 4.25 & 5.0276 & TRN \\
\hline CHEMBL1304547 & 688267 & 4.6 & 5.1314 & TRN \\
\hline CHEMBL1561187 & 688267 & 4.05 & 5.06 & TST \\
\hline CHEMBL1306029 & 688267 & 4.75 & 5.0287 & TRN \\
\hline CHEMBL1480745 & 688267 & 4.05 & 5.053 & TRN \\
\hline CHEMBL1312338 & 688267 & 5.5 & 5.0341 & TRN \\
\hline CHEMBL1518754 & 688267 & 4.65 & 5.1289 & TRN \\
\hline CHEMBL1520078 & 688267 & 5.65 & 5.1 & TST \\
\hline CHEMBL1428175 & 688267 & 6.5 & 5.0319 & TST \\
\hline CHEMBL1456312 & 688267 & 4.15 & 5.074 & TST \\
\hline CHEMBL1486043 & 688267 & 4.1 & 5.0368 & TRN \\
\hline CHEMBL1301476 & 688267 & 4.2 & 5.1235 & TRN \\
\hline CHEMBL1389472 & 688267 & 3.95 & 5.0952 & TST \\
\hline CHEMBL1451029 & 688267 & 5.45 & 5.0577 & TRN \\
\hline CHEMBL1608645 & 688267 & 5.95 & 5.0986 & TRN \\
\hline CHEMBL1477606 & 688267 & 4.4 & 5.0601 & TRN \\
\hline CHEMBL1492840 & 688267 & 4.1 & 5.0004 & TST \\
\hline CHEMBL1489332 & 688267 & 4.0 & 5.0146 & TRN \\
\hline CHEMBL198630 & 688267 & 4.7 & 5.0541 & TRN \\
\hline CHEMBL1411501 & 688267 & 4.25 & 5.046 & TST \\
\hline CHEMBL1501745 & 688267 & 5.25 & 5.0443 & TRN \\
\hline CHEMBL1393305 & 688267 & 3.95 & 5.1007 & TRN \\
\hline CHEMBL1361101 & 688267 & 4.25 & 5.1079 & TRN \\
\hline CHEMBL1413988 & 688267 & 6.45 & 5.0747 & TRN \\
\hline CHEMBL1569411 & 688267 & 6.0 & 5.0588 & TRN \\
\hline CHEMBL1333567 & 688267 & 3.95 & 5.0502 & TRN \\
\hline CHEMBL1505716 & 688267 & 4.0 & 5.0964 & TRN \\
\hline CHEMBL 267373 & 688267 & 6.2 & 5.0104 & TRN \\
\hline CHEMBL1591106 & 688267 & 5.05 & 5.0613 & TRN \\
\hline CHEMBL1490299 & 688267 & 3.9 & 5.0498 & TST \\
\hline CHEMBL1535056 & 688267 & 6.15 & 5.0318 & TRN \\
\hline CHEMBL1466046 & 688267 & 5.2 & 5.1087 & TST \\
\hline CHEMBL1590809 & 688267 & 4.4 & 5.0151 & TRN \\
\hline CHEMBL 1454746 & 688267 & 6.45 & 5.1283 & TRN \\
\hline CHEMBL1567849 & 688267 & 4.7 & 5.0631 & TRN \\
\hline CHEMBL1553501 & 688267 & 4.3 & 5.1236 & TRN \\
\hline CHEMBL1466011 & 688267 & 4.4 & 5.0836 & TST \\
\hline CHEMBL1512879 & 688267 & 4.0 & 5.0235 & TRN \\
\hline CHEMBL1326128 & 688267 & 4.25 & 5.0704 & TRN \\
\hline CHEMBL1430066 & 688267 & 5.55 & 5.013 & TST \\
\hline CHEMBL1330660 & 688267 & 4.45 & 5.0674 & TRN \\
\hline CHEMBL1434301 & 688267 & 5.35 & 5.077 & TRN \\
\hline CHEMBL1410561 & 688267 & 5.6 & 5.0981 & TST \\
\hline CHEMBL1530255 & 688267 & 5.6 & 5.09 & TRN \\
\hline CHEMBL1491016 & 688267 & 6.15 & 5.0004 & TRN \\
\hline
\end{tabular}




\begin{tabular}{|c|c|c|c|c|c|}
\hline \multicolumn{6}{|c|}{ Supplemental Table S2.txt } \\
\hline CHEMBL1337644 & 688267 & 5.15 & 5.0299 & TST & \\
\hline CHEMBL1321133 & 688267 & 3.95 & 5.1037 & TRN & \\
\hline CHEMBL1323002 & 688267 & 5.8 & 5.0499 & TRN & \\
\hline CHEMBL1595106 & 688267 & 6.15 & 5.1005 & TRN & \\
\hline CHEMBL1327558 & 688267 & 5.15 & 5.0946 & TRN & \\
\hline CHEMBL1372135 & 688267 & 6.2 & 5.0318 & TRN & \\
\hline CHEMBL1468440 & 688267 & 5.3 & 5.0959 & TRN & \\
\hline CHEMBL1382270 & 688267 & 5.6 & 5.0544 & TRN & \\
\hline CHEMBL1440568 & 688267 & 4.2 & 5.0406 & TRN & \\
\hline CHEMBL1549887 & 688267 & 6.15 & 5.1110 & 2000000001 & TRN \\
\hline CHEMBL1598661 & 688267 & 5.35 & 5.0996 & TRN & \\
\hline CHEMBL1489599 & 688267 & 6.05 & 5.0504 & TST & \\
\hline CHEMBL1307338 & 688267 & 4.0 & 5.0747 & TST & \\
\hline CHEMBL1402198 & 688267 & 4.5 & 5.1152 & TRN & \\
\hline CHEMBL1512257 & 688267 & 5.45 & 5.0152 & TRN & \\
\hline CHEMBL1501963 & 688267 & 4.15 & 5.0768 & TRN & \\
\hline CHEMBL1412637 & 688267 & 4.15 & 4.9959 & TRN & \\
\hline CHEMBL1384308 & 688267 & 6.2 & 5.0585 & TST & \\
\hline CHEMBL1579666 & 688267 & 5.55 & 5.1066 & TRN & \\
\hline CHEMBL1313420 & 688267 & 6.0 & 5.0169 & TRN & \\
\hline CHEMBL1379188 & 688267 & 6.2 & 5.0213 & TST & \\
\hline CHEMBL1439273 & 688267 & 4.0 & 5.0509 & TRN & \\
\hline CHEMBL1411147 & 688267 & 5.35 & 5.1069 & TRN & \\
\hline CHEMBL1399297 & 688267 & 5.3 & 5.0046 & TRN & \\
\hline CHEMBL1379336 & 688267 & 5.15 & 5.1079 & TRN & \\
\hline CHEMBL1579223 & 688267 & 4.3 & 4.9681 & TRN & \\
\hline CHEMBL1364415 & 688267 & 5.75 & 5.0018 & TRN & \\
\hline CHEMBL1522577 & 688267 & 4.35 & 5.1105 & TRN & \\
\hline CHEMBL1480335 & 688267 & 5.8 & 5.0739 & TST & \\
\hline CHEMBL1326571 & 688267 & 6.5501 & 5.0482 & TRN & \\
\hline CHEMBL1510180 & 688267 & 6.2 & 5.0573 & TRN & \\
\hline CHEMBL1434548 & 688267 & 6.45 & 5.055 & TRN & \\
\hline CHEMBL1572637 & 688267 & 6.2 & 5.0473 & TRN & \\
\hline CHEMBL1540573 & 688267 & 4.55 & 5.075 & TRN & \\
\hline CHEMBL1611352 & 688267 & 5.55 & 5.1542 & TRN & \\
\hline CHEMBL1401155 & 688267 & 6.2 & 5.0541 & TRN & \\
\hline CHEMBL 1557560 & 688267 & 5.45 & 5.0503 & TST & \\
\hline CHEMBL1491996 & 688267 & 6.2 & 5.0 & TRN & \\
\hline CHEMBL125596 & 688267 & 6.15 & 5.042 & TRN & \\
\hline CHEMBL1442558 & 688267 & 6.15 & 5.1032 & TST & \\
\hline CHEMBL1400544 & 688267 & 4.35 & 5.0235 & TST & \\
\hline CHEMBL 1487426 & 688267 & 4.15 & 5.0335 & TRN & \\
\hline CHEMBL1390138 & 688267 & 5.6 & 5.0225 & TST & \\
\hline CHEMBL1327667 & 688267 & 3.95 & 5.059 & TRN & \\
\hline CHEMBL1416400 & 688267 & 6.15 & 5.0991 & TRN & \\
\hline CHEMBL1421533 & 688267 & 4.6 & 5.0478 & TST & \\
\hline CHEMBL1611390 & 688267 & 4.05 & 5.0079 & TRN & \\
\hline CHEMBL1352844 & 688267 & 3.95 & 4.9793 & TRN & \\
\hline
\end{tabular}




\begin{tabular}{|c|c|c|c|c|}
\hline & & & pplement & al $\mathrm{Ta}$ \\
\hline CHEMBL1419014 & 688267 & 6.6 & 5.0665 & TST \\
\hline CHEMBL1365886 & 688267 & 5.0 & 5.1448 & TRN \\
\hline CHEMBL1473516 & 688267 & 6.0 & 5.0191 & TRN \\
\hline CHEMBL1550403 & 688267 & 5.3 & 5.0551 & TRN \\
\hline CHEMBL1376719 & 688267 & 5.0 & 5.002 & TRN \\
\hline CHEMBL1595359 & 688267 & 6.2 & 5.1017 & TRN \\
\hline CHEMBL1563982 & 688267 & 6.2 & 5.1186 & TST \\
\hline CHEMBL1342384 & 688267 & 5.6 & 5.0747 & TRN \\
\hline CHEMBL1540753 & 688267 & 6.2 & 5.0825 & TRN \\
\hline CHEMBL1351442 & 688267 & 5.55 & 5.0329 & TST \\
\hline CHEMBL1595744 & 688267 & 4.05 & 5.0667 & TRN \\
\hline CHEMBL1494037 & 688267 & 4.0 & 5.0174 & TST \\
\hline CHEMBL1589515 & 688267 & 5.0 & 5.0786 & TST \\
\hline CHEMBL1366497 & 688267 & 3.95 & 5.0636 & TST \\
\hline CHEMBL1578673 & 688267 & 4.25 & 5.0816 & TRN \\
\hline CHEMBL1335658 & 688267 & 6.2 & 5.0705 & TST \\
\hline CHEMBL1316916 & 688267 & 5.05 & 5.0099 & TRN \\
\hline CHEMBL1476747 & 688267 & 3.95 & 5.1125 & TST \\
\hline CHEMBL1489566 & 688267 & 4.0 & 5.0127 & TRN \\
\hline CHEMBL1541915 & 688267 & 4.4 & 5.0062 & TRN \\
\hline CHEMBL1410766 & 688267 & 4.0 & 5.0422 & TRN \\
\hline CHEMBL1391085 & 688267 & 4.05 & 5.0879 & TRN \\
\hline CHEMBL1407331 & 688267 & 4.4 & 5.0569 & TRN \\
\hline CHEMBL1462474 & 688267 & 4.4 & 5.0648 & TST \\
\hline CHEMBL1476232 & 688267 & 6.2 & 5.063 & TST \\
\hline CHEMBL1332115 & 688267 & 4.25 & 5.08 & TST \\
\hline CHEMBL3197489 & 688267 & 4.1 & 5.0363 & TST \\
\hline CHEMBL1555169 & 688267 & 6.15 & 5.0929 & TRN \\
\hline CHEMBL1386367 & 688267 & 5.3 & 5.0323 & TRN \\
\hline CHEMBL 1608180 & 688267 & 4.0 & 4.9467 & TRN \\
\hline CHEMBL1599601 & 688267 & 6.25 & 5.0251 & TRN \\
\hline CHEMBL3190915 & 688267 & 5.05 & 5.0172 & TRN \\
\hline CHEMBL1405947 & 688267 & 5.5 & 5.032 & TST \\
\hline CHEMBL1553722 & 688267 & 4.5 & 5.1258 & TRN \\
\hline CHEMBL1586099 & 688267 & 4.95 & 5.1239 & TRN \\
\hline CHEMBL1387733 & 688267 & 5.55 & 5.0681 & TRN \\
\hline CHEMBL1601968 & 688267 & 5.15 & 5.0419 & TRN \\
\hline CHEMBL1461221 & 688267 & 6.2 & 5.0315 & TRN \\
\hline CHEMBL1572233 & 688267 & 6.2 & 5.0613 & TRN \\
\hline CHEMBL1419757 & 688267 & 4.0 & 5.0535 & TRN \\
\hline CHEMBL1577762 & 688267 & 4.25 & 5.053 & TRN \\
\hline CHEMBL1556821 & 688267 & 5.1 & 5.0572 & TRN \\
\hline CHEMBL1335698 & 688267 & 6.2 & 5.1165 & TRN \\
\hline CHEMBL3197981 & 688267 & 5.0 & 4.9844 & TRN \\
\hline CHEMBL1378405 & 688267 & 6.2 & 5.0425 & TST \\
\hline CHEMBL1363708 & 688267 & 5.25 & 5.0671 & TRN \\
\hline CHEMBL1414855 & 688267 & 5.95 & 5.0113 & TRN \\
\hline CHEMBL1390461 & 688267 & 5.8 & 5.0149 & TRN \\
\hline
\end{tabular}




\begin{tabular}{|c|c|c|c|c|}
\hline \multicolumn{5}{|c|}{ Supplemental Table S2.txt } \\
\hline CHEMBL1563652 & 688267 & 4.05 & 5.0712 & TRN \\
\hline CHEMBL1318908 & 688267 & 5.7 & 5.0444 & TRN \\
\hline CHEMBL1459879 & 688267 & 5.95 & 5.1069 & TRN \\
\hline CHEMBL1384004 & 688267 & 6.2 & 5.0257 & TST \\
\hline CHEMBL1512563 & 688267 & 4.05 & 5.0209 & TST \\
\hline CHEMBL1340578 & 688267 & 4.5 & 5.1049 & TRN \\
\hline CHEMBL1320761 & 688267 & 4.0 & 5.0463 & TRN \\
\hline CHEMBL1485489 & 688267 & 7.0501 & 5.0777 & TRN \\
\hline CHEMBL1414691 & 688267 & 6.2 & 4.9834 & TRN \\
\hline CHEMBL1338862 & 688267 & 5.05 & 5.0357 & TRN \\
\hline CHEMBL1300467 & 688267 & 5.6 & 5.0504 & TRN \\
\hline CHEMBL1332238 & 688267 & 6.2 & 5.0777 & TRN \\
\hline CHEMBL1403644 & 688267 & 6.2 & 5.0158 & TRN \\
\hline CHEMBL1556150 & 688267 & 5.55 & 5.0911 & TRN \\
\hline CHEMBL1310131 & 688267 & 4.4 & 5.0513 & TRN \\
\hline CHEMBL3211859 & 688267 & 5.9 & 5.0071 & TRN \\
\hline CHEMBL1447148 & 688267 & 5.6 & 5.1373 & TRN \\
\hline CHEMBL1331714 & 688267 & 4.3 & 5.0156 & TRN \\
\hline CHEMBL1396900 & 688267 & 4.75 & 5.0744 & TRN \\
\hline CHEMBL1595606 & 688267 & 5.45 & 5.0438 & TRN \\
\hline CHEMBL1467413 & 688267 & 5.55 & 5.0696 & TRN \\
\hline CHEMBL1501320 & 688267 & 4.0 & 5.1262 & TRN \\
\hline CHEMBL3191696 & 688267 & 6.5 & 4.9967 & TRN \\
\hline CHEMBL1506404 & 688267 & 5.0 & 5.0812 & TRN \\
\hline CHEMBL1534125 & 688267 & 4.0 & 5.0082 & TRN \\
\hline CHEMBL1576804 & 688267 & 4.75 & 5.0807 & TST \\
\hline CHEMBL1533035 & 688267 & 4.55 & 5.0456 & TRN \\
\hline CHEMBL1508890 & 688267 & 4.45 & 5.1066 & TRN \\
\hline CHEMBL1404153 & 688267 & 4.05 & 5.0955 & TRN \\
\hline CHEMBL1551360 & 688267 & 4.0 & 5.0366 & TRN \\
\hline CHEMBL1529882 & 688267 & 5.45 & 5.0654 & TRN \\
\hline CHEMBL1375384 & 688267 & 6.15 & 5.0828 & TRN \\
\hline CHEMBL1585090 & 688267 & 4.35 & 5.083 & TST \\
\hline CHEMBL1341306 & 688267 & 4.3 & 5.0701 & TRN \\
\hline CHEMBL1380569 & 688267 & 6.2 & 5.0507 & TRN \\
\hline CHEMBL1341918 & 688267 & 4.7 & 5.0889 & TRN \\
\hline CHEMBL 1610578 & 688267 & 5.95 & 5.1115 & TRN \\
\hline CHEMBL1364116 & 688267 & 5.8 & 5.0628 & TRN \\
\hline CHEMBL1588124 & 688267 & 4.95 & 5.0485 & TST \\
\hline CHEMBL1611835 & 688267 & 4.3 & 5.0053 & TST \\
\hline CHEMBL1485457 & 688267 & 5.1 & 5.0568 & TRN \\
\hline CHEMBL1356105 & 688267 & 4.0 & 5.0006 & TRN \\
\hline CHEMBL1426291 & 688267 & 4.45 & 5.0863 & TST \\
\hline CHEMBL1475087 & 688267 & 6.2 & 5.0714 & TRN \\
\hline CHEMBL1524635 & 688267 & 4.0 & 5.0311 & TRN \\
\hline CHEMBL1525243 & 688267 & 3.95 & 4.9908 & TRN \\
\hline CHEMBL1569919 & 688267 & 5.35 & 5.0069 & TST \\
\hline CHEMBL1488941 & 688267 & 4.65 & 5.0585 & TRN \\
\hline
\end{tabular}




\begin{tabular}{|c|c|c|c|c|c|}
\hline \multicolumn{6}{|c|}{ Supplemental Table S2.txt } \\
\hline CHEMBL1590133 & 688267 & 4.35 & 5.0194 & TRN & \\
\hline CHEMBL1470388 & 688267 & 4.15 & 5.1053 & TRN & \\
\hline CHEMBL1584917 & 688267 & 4.3 & 5.011 & TST & \\
\hline CHEMBL1414295 & 688267 & 5.25 & 5.015 & TRN & \\
\hline CHEMBL1419914 & 688267 & 5.6 & 5.016 & TRN & \\
\hline CHEMBL1602339 & 688267 & 5.0 & 5.1431 & TRN & \\
\hline CHEMBL1468964 & 688267 & 6.15 & 5.0483 & TST & \\
\hline CHEMBL1577088 & 688267 & 4.35 & 5.0479 & TRN & \\
\hline CHEMBL1482167 & 688267 & 4.0 & 5.069 & TRN & \\
\hline CHEMBL1569679 & 688267 & 6.25 & 5.0852 & TRN & \\
\hline CHEMBL1494623 & 688267 & 4.15 & 5.0534 & TRN & \\
\hline CHEMBL1548764 & 688267 & 6.0 & 5.1124 & TST & \\
\hline CHEMBL1316186 & 688267 & 4.0 & 5.1191 & TRN & \\
\hline CHEMBL1459562 & 688267 & 6.2 & 5.0343 & TST & \\
\hline CHEMBL1326695 & 688267 & 4.0 & 5.0604 & TRN & \\
\hline CHEMBL1468681 & 688267 & 4.1 & 5.0921 & TRN & \\
\hline CHEMBL1321912 & 688267 & 5.35 & 5.083 & TRN & \\
\hline CHEMBL1574475 & 688267 & 4.95 & 5.1317 & TRN & \\
\hline CHEMBL1525031 & 688267 & 5.75 & 5.0835 & TRN & \\
\hline CHEMBL1430538 & 688267 & 4.0 & 5.064 & TRN & \\
\hline CHEMBL1308579 & 688267 & 3.95 & 5.1003 & TST & \\
\hline CHEMBL1354473 & 688267 & 5.45 & 5.0115 & TRN & \\
\hline CHEMBL1563578 & 688267 & 4.0 & 5.0621 & TRN & \\
\hline CHEMBL1301462 & 688267 & 5.55 & 5.0357 & TRN & \\
\hline CHEMBL1402506 & 688267 & 4.4 & 5.1128 & TRN & \\
\hline CHEMBL1600928 & 688267 & 5.55 & 5.1091 & TST & \\
\hline CHEMBL1365817 & 688267 & 6.1 & 5.0395 & TRN & \\
\hline CHEMBL1400330 & 688267 & 3.95 & 5.0192 & TRN & \\
\hline CHEMBL1423686 & 688267 & 6.6 & 5.0221 & TRN & \\
\hline CHEMBL1371220 & 688267 & 6.0 & 5.0958 & TRN & \\
\hline CHEMBL1440473 & 688267 & 6.2 & 5.0463 & TST & \\
\hline CHEMBL1359046 & 688267 & 3.95 & 5.0108 & TRN & \\
\hline CHEMBL1565240 & 688267 & 5.05 & 5.0156 & TRN & \\
\hline CHEMBL1528145 & 688267 & 4.1 & 5.0619 & TRN & \\
\hline CHEMBL1333799 & 688267 & 3.95 & 5.1381 & TRN & \\
\hline CHEMBL1338072 & 688267 & 5.75 & 5.0206 & TRN & \\
\hline CHEMBL1423315 & 688267 & 6.15 & 5.0507 & TRN & \\
\hline CHEMBL1497402 & 688267 & 5.85 & 5.1718 & TST & \\
\hline CHEMBL1338146 & 688267 & 6.2 & 5.0997 & TRN & \\
\hline CHEMBL1566574 & 688267 & 4.4 & 5.0871 & TST & \\
\hline CHEMBL1537947 & 688267 & 6.45 & 5.0 & TRN & \\
\hline CHEMBL1557925 & 688267 & 5.8 & 5.05699 & 99999999995 & TRN \\
\hline CHEMBL1519461 & 688267 & 4.0 & 4.9916 & TRN & \\
\hline CHEMBL1512963 & 688267 & 5.95 & 5.059 & TST & \\
\hline CHEMBL1515023 & 688267 & 6.2 & 5.0271 & TST & \\
\hline CHEMBL1390731 & 688267 & 4.0 & 5.0201 & TST & \\
\hline CHEMBL1355705 & 688267 & 5.45 & 5.0309 & TRN & \\
\hline CHEMBL1433106 & 688267 & 4.6 & 5.0663 & TRN & \\
\hline
\end{tabular}




\begin{tabular}{|c|c|c|c|c|}
\hline \multicolumn{5}{|c|}{ Supplemental Table S2.txt } \\
\hline CHEMBL1552088 & 688267 & 4.4 & 5.0698 & TST \\
\hline CHEMBL1395918 & 688267 & 4.0 & 4.985 & TRN \\
\hline CHEMBL1579070 & 688267 & 4.05 & 5.0304 & TST \\
\hline CHEMBL1391957 & 688267 & 6.15 & 5.0203 & TRN \\
\hline CHEMBL1307319 & 688267 & 4.55 & 5.0235 & TST \\
\hline CHEMBL1305648 & 688267 & 4.1 & 5.0383 & TRN \\
\hline CHEMBL1365323 & 688267 & 4.35 & 4.9989 & TRN \\
\hline CHEMBL1510382 & 688267 & 3.95 & 5.1202 & TST \\
\hline CHEMBL1445069 & 688267 & 4.3 & 5.0611 & TRN \\
\hline CHEMBL1495002 & 688267 & 4.05 & 5.0511 & TST \\
\hline CHEMBL1532794 & 688267 & 4.1 & 5.0683 & TST \\
\hline CHEMBL1548051 & 688267 & 6.2 & 5.0732 & TRN \\
\hline CHEMBL1579020 & 688267 & 4.3 & 5.0574 & TST \\
\hline CHEMBL1349706 & 688267 & 6.25 & 5.0468 & TST \\
\hline CHEMBL1311838 & 688267 & 4.0 & 5.0578 & TST \\
\hline CHEMBL1313228 & 688267 & 6.2 & 5.0472 & TST \\
\hline CHEMBL243644 & 688267 & 4.4 & 5.0495 & TRN \\
\hline CHEMBL1598065 & 688267 & 6.2 & 5.0103 & TRN \\
\hline CHEMBL1321650 & 688267 & 4.0 & 5.0797 & TRN \\
\hline CHEMBL1436752 & 688267 & 6.0 & 4.9905 & TRN \\
\hline CHEMBL1541791 & 688267 & 4.5 & 5.0274 & TST \\
\hline CHEMBL1604022 & 688267 & 5.9 & 5.1005 & TRN \\
\hline CHEMBL1345945 & 688267 & 5.35 & 5.0551 & TST \\
\hline CHEMBL1311681 & 688267 & 5.65 & 5.0385 & TST \\
\hline CHEMBL1501213 & 688267 & 4.25 & 5.0791 & TST \\
\hline CHEMBL1468960 & 688267 & 4.65 & 5.0206 & TRN \\
\hline CHEMBL1396938 & 688267 & 4.4 & 4.9814 & TRN \\
\hline CHEMBL1530446 & 688267 & 4.35 & 5.0544 & TST \\
\hline CHEMBL1412806 & 688267 & 4.25 & 5.024 & TST \\
\hline CHEMBL1362120 & 688267 & 4.6 & 5.0134 & TST \\
\hline CHEMBL1515097 & 688267 & 4.0 & 5.0794 & TRN \\
\hline CHEMBL1478497 & 688267 & 6.2 & 5.0571 & TRN \\
\hline CHEMBL1340880 & 688267 & 5.25 & 5.1717 & TRN \\
\hline CHEMBL1363182 & 688267 & 4.6 & 5.1298 & TRN \\
\hline CHEMBL1446385 & 688267 & 5.4 & 5.008 & TRN \\
\hline CHEMBL3210680 & 688267 & 4.15 & 5.0314 & TRN \\
\hline CHEMBL1530070 & 688267 & 4.35 & 5.0939 & TST \\
\hline CHEMBL1424983 & 688267 & 4.3 & 5.0249 & TST \\
\hline CHEMBL1520751 & 688267 & 6.2 & 5.0325 & TRN \\
\hline CHEMBL1331851 & 688267 & 5.65 & 5.0138 & TRN \\
\hline CHEMBL1576268 & 688267 & 5.4 & 5.1103 & TRN \\
\hline CHEMBL3208023 & 688267 & 5.3 & 5.0166 & TST \\
\hline CHEMBL1559605 & 688267 & 4.4 & 4.9926 & TST \\
\hline CHEMBL1581232 & 688267 & 6.0 & 5.0755 & TRN \\
\hline CHEMBL1305832 & 688267 & 5.2 & 5.0241 & TST \\
\hline CHEMBL3189873 & 688267 & 4.05 & 5.0247 & TST \\
\hline CHEMBL1537824 & 688267 & 3.95 & 5.093 & TRN \\
\hline CHEMBL1357965 & 688267 & 6.2 & 4.9993 & TRN \\
\hline
\end{tabular}




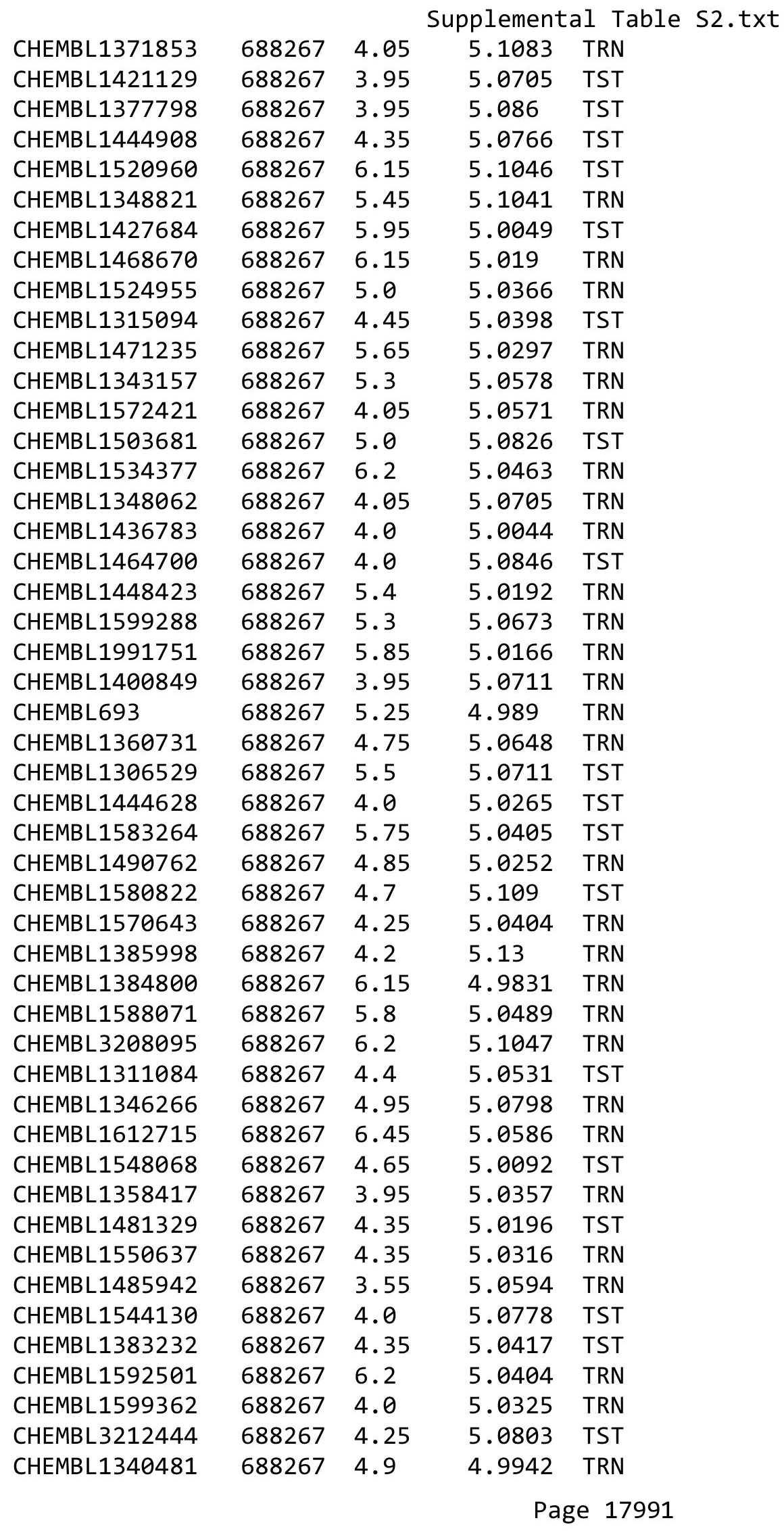




\begin{tabular}{|c|c|c|c|c|}
\hline & & & upplemen & al $\mathrm{T}$ \\
\hline CHEMBL1394564 & 688267 & 4.8 & 5.1021 & TRN \\
\hline CHEMBL1561051 & 688267 & 4.2 & 4.9701 & TRN \\
\hline CHEMBL1546794 & 688267 & 4.65 & 5.002 & TRN \\
\hline CHEMBL1497240 & 688267 & 5.0 & 5.0678 & TRN \\
\hline CHEMBL1387336 & 688267 & 4.15 & 5.0665 & TST \\
\hline CHEMBL1436431 & 688267 & 5.3 & 5.0635 & TRN \\
\hline CHEMBL1473387 & 688267 & 6.2 & 5.1219 & TRN \\
\hline CHEMBL1345331 & 688267 & 5.25 & 5.0636 & TRN \\
\hline CHEMBL1552521 & 688267 & 6.2 & 5.0108 & TRN \\
\hline CHEMBL1324532 & 688267 & 4.45 & 5.0723 & TRN \\
\hline CHEMBL1579364 & 688267 & 4.35 & 5.0077 & TRN \\
\hline CHEMBL520156 & 688267 & 5.2 & 5.0316 & TST \\
\hline CHEMBL1384982 & 688267 & 5.3 & 5.0322 & TRN \\
\hline CHEMBL1522352 & 688267 & 3.85 & 5.03 & TRN \\
\hline CHEMBL1419096 & 688267 & 5.55 & 5.0092 & TRN \\
\hline CHEMBL1594021 & 688267 & 6.1 & 5.0694 & TRN \\
\hline CHEMBL1518188 & 688267 & 5.25 & 5.113 & TRN \\
\hline CHEMBL1339709 & 688267 & 4.3 & 5.046 & TRN \\
\hline CHEMBL1315454 & 688267 & 5.65 & 5.1117 & TRN \\
\hline CHEMBL1571414 & 688267 & 3.95 & 5.001 & TRN \\
\hline CHEMBL1599796 & 688267 & 5.95 & 5.01 & TRN \\
\hline CHEMBL1377915 & 688267 & 5.55 & 5.1261 & TST \\
\hline CHEMBL1470441 & 688267 & 4.0 & 5.0585 & TRN \\
\hline CHEMBL1366283 & 688267 & 5.4 & 5.0717 & TRN \\
\hline CHEMBL1351456 & 688267 & 4.95 & 5.1415 & TST \\
\hline CHEMBL3211036 & 688267 & 4.05 & 5.0474 & TRN \\
\hline CHEMBL1493277 & 688267 & 4.55 & 4.9973 & TRN \\
\hline CHEMBL446216 & 688267 & 4.2 & 5.0086 & TRN \\
\hline CHEMBL1594789 & 688267 & 5.4 & 5.0708 & TRN \\
\hline CHEMBL1473577 & 688267 & 4.35 & 5.0799 & TRN \\
\hline CHEMBL1346656 & 688267 & 4.75 & 4.9675 & TRN \\
\hline CHEMBL1482565 & 688267 & 5.1 & 4.9981 & TST \\
\hline CHEMBL1517165 & 688267 & 6.15 & 5.0622 & TRN \\
\hline CHEMBL1465800 & 688267 & 4.2 & 5.0673 & TST \\
\hline CHEMBL1405013 & 688267 & 5.4 & 5.0498 & TRN \\
\hline CHEMBL1358144 & 688267 & 4.95 & 5.0478 & TRN \\
\hline CHEMBL1353638 & 688267 & 6.15 & 5.0596 & TRN \\
\hline CHEMBL1401675 & 688267 & 4.05 & 5.1123 & TRN \\
\hline CHEMBL1598845 & 688267 & 4.05 & 5.0526 & TRN \\
\hline CHEMBL1591802 & 688267 & 6.5 & 5.0624 & TRN \\
\hline CHEMBL1401557 & 688267 & 4.55 & 5.0913 & TRN \\
\hline CHEMBL1502509 & 688267 & 5.35 & 5.1071 & TRN \\
\hline CHEMBL1613227 & 688267 & 6.25 & 5.0371 & TRN \\
\hline CHEMBL1467255 & 688267 & 4.4 & 4.9978 & TRN \\
\hline CHEMBL3197968 & 688267 & 4.35 & 5.0093 & TRN \\
\hline CHEMBL1507994 & 688267 & 5.0 & 5.0541 & TRN \\
\hline CHEMBL1558127 & 688267 & 4.5 & 5.0729 & TST \\
\hline CHEMBL1489012 & 688267 & 4.95 & 5.0856 & TRN \\
\hline
\end{tabular}




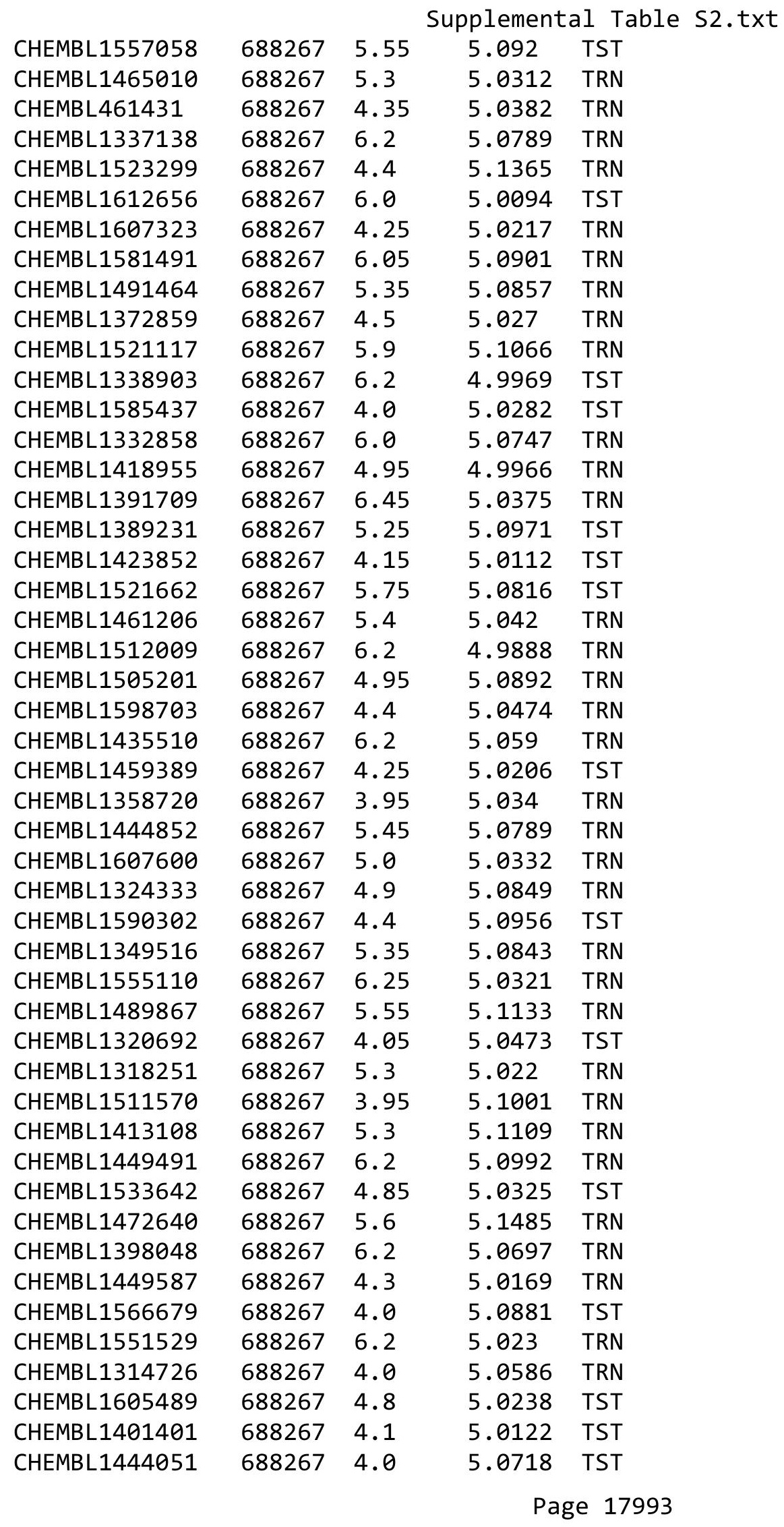




\begin{tabular}{|c|c|c|c|c|}
\hline \multicolumn{5}{|c|}{ Supplemental Tabl } \\
\hline CHEMBL1514515 & 688267 & 5.55 & 4.9729 & TRN \\
\hline CHEMBL1466262 & 688267 & 6.2 & 5.0899 & TST \\
\hline CHEMBL1496394 & 688267 & 6.2 & 5.084 & TRN \\
\hline CHEMBL1607400 & 688267 & 4.45 & 5.0837 & TRN \\
\hline CHEMBL1495627 & 688267 & 4.0 & 5.0491 & TRN \\
\hline CHEMBL1341280 & 688267 & 6.0 & 5.016 & TST \\
\hline CHEMBL1534982 & 688267 & 3.95 & 5.0832 & TRN \\
\hline CHEMBL1398412 & 688267 & 4.25 & 5.0376 & TRN \\
\hline CHEMBL1414814 & 688267 & 4.5 & 5.0371 & TRN \\
\hline CHEMBL1398274 & 688267 & 3.95 & 5.1135 & TST \\
\hline CHEMBL1447882 & 688267 & 4.1 & 5.019 & TST \\
\hline CHEMBL1431007 & 688267 & 6.2 & 5.0108 & TRN \\
\hline CHEMBL1494900 & 688267 & 5.35 & 5.0373 & TRN \\
\hline CHEMBL1395765 & 688267 & 5.55 & 5.0528 & TRN \\
\hline CHEMBL1533440 & 688267 & 6.2 & 5.0991 & TRN \\
\hline CHEMBL1334147 & 688267 & 6.45 & 5.0121 & TRN \\
\hline CHEMBL1395100 & 688267 & 5.05 & 4.9794 & TST \\
\hline CHEMBL1309817 & 688267 & 4.25 & 5.0523 & TRN \\
\hline CHEMBL1461720 & 688267 & 6.2 & 5.1135 & TRN \\
\hline CHEMBL1563758 & 688267 & 5.45 & 5.0237 & TRN \\
\hline CHEMBL1557109 & 688267 & 4.95 & 5.0787 & TRN \\
\hline CHEMBL1465904 & 688267 & 4.05 & 5.0035 & TRN \\
\hline CHEMBL1565020 & 688267 & 5.5 & 4.9845 & TRN \\
\hline CHEMBL1330664 & 688267 & 4.5 & 5.0617 & TRN \\
\hline CHEMBL1485892 & 688267 & 6.2 & 4.9473 & TRN \\
\hline CHEMBL1520680 & 688267 & 4.05 & 5.1178 & TRN \\
\hline CHEMBL3195294 & 688267 & 6.15 & 5.0401 & TST \\
\hline CHEMBL1590062 & 688267 & 4.05 & 5.035 & TRN \\
\hline CHEMBL1544907 & 688267 & 4.4 & 5.0031 & TRN \\
\hline CHEMBL1305674 & 688267 & 6.2 & 5.0196 & TST \\
\hline CHEMBL1358420 & 688267 & 5.0 & 5.0311 & TRN \\
\hline CHEMBL1513434 & 688267 & 4.0 & 5.0816 & TRN \\
\hline CHEMBL1458604 & 688267 & 5.35 & 5.1055 & TRN \\
\hline CHEMBL1540470 & 688267 & 6.25 & 5.1111 & TRN \\
\hline CHEMBL 2001950 & 688267 & 6.15 & 5.0774 & TST \\
\hline CHEMBL1330116 & 688267 & 5.85 & 5.0331 & TRN \\
\hline CHEMBL1481908 & 688267 & 6.05 & 5.0536 & TRN \\
\hline CHEMBL1472952 & 688267 & 6.2 & 5.0843 & TST \\
\hline CHEMBL1382862 & 688267 & 4.45 & 5.0674 & TST \\
\hline CHEMBL1605645 & 688267 & 4.1 & 5.117 & TRN \\
\hline CHEMBL1387488 & 688267 & 4.45 & 5.0924 & TST \\
\hline CHEMBL1380641 & 688267 & 5.45 & 5.06 & TST \\
\hline CHEMBL1357377 & 688267 & 6.15 & 5.0154 & TST \\
\hline CHEMBL1552513 & 688267 & 6.05 & 5.0608 & TST \\
\hline CHEMBL1444391 & 688267 & 5.2 & 5.0846 & TRN \\
\hline CHEMBL1354362 & 688267 & 4.2 & 5.1157 & TST \\
\hline CHEMBL1346389 & 688267 & 4.35 & 5.0446 & TRN \\
\hline CHEMBL1609587 & 688267 & 5.6 & 5.0673 & TRN \\
\hline
\end{tabular}




\begin{tabular}{|c|c|c|c|c|c|}
\hline \multicolumn{6}{|c|}{ Supplemental Table S2.txt } \\
\hline CHEMBL1374039 & 688267 & 6.15 & 5.0351 & TRN & \\
\hline CHEMBL1512545 & 688267 & 4.2 & 5.0465 & TRN & \\
\hline CHEMBL1337712 & 688267 & 4.4 & 5.0277 & TRN & \\
\hline CHEMBL1595676 & 688267 & 6.1 & $5.1270 e$ & 2000000001 & TRN \\
\hline CHEMBL1593899 & 688267 & 5.25 & 5.1528 & TST & \\
\hline CHEMBL1443514 & 688267 & 5.15 & 5.0701 & TRN & \\
\hline CHEMBL1552711 & 688267 & 3.95 & 5.0371 & TRN & \\
\hline CHEMBL1578042 & 688267 & 5.3 & 5.0325 & TST & \\
\hline CHEMBL3213306 & 688267 & 5.0 & 5.0444 & TRN & \\
\hline CHEMBL3194040 & 688267 & 5.85 & 5.0058 & TRN & \\
\hline CHEMBL1597966 & 688267 & 4.55 & 5.0348 & TRN & \\
\hline CHEMBL1387570 & 688267 & 6.2 & 5.0659 & TRN & \\
\hline CHEMBL1365190 & 688267 & 4.3 & 5.0479 & TRN & \\
\hline CHEMBL1346169 & 688267 & 5.6 & 5.0935 & TRN & \\
\hline CHEMBL1365683 & 688267 & 5.9 & 5.0575 & TST & \\
\hline CHEMBL1389941 & 688267 & 5.55 & 5.0304 & TST & \\
\hline CHEMBL1509386 & 688267 & 4.0 & 5.1607 & TRN & \\
\hline CHEMBL3189696 & 688267 & 4.1 & 4.9972 & TST & \\
\hline CHEMBL1336745 & 688267 & 4.15 & 5.0739 & TRN & \\
\hline CHEMBL1419522 & 688267 & 5.15 & 5.0663 & TRN & \\
\hline CHEMBL1571893 & 688267 & 4.65 & 4.9993 & TRN & \\
\hline CHEMBL1383029 & 688267 & 5.85 & 5.0331 & TRN & \\
\hline CHEMBL1508998 & 688267 & 6.2 & 5.0511 & TST & \\
\hline CHEMBL1552132 & 688267 & 5.5 & 5.0703 & TRN & \\
\hline CHEMBL3209127 & 688267 & 5.4 & 5.0251 & TST & \\
\hline CHEMBL1435903 & 688267 & 3.95 & 5.0862 & TRN & \\
\hline CHEMBL1572430 & 688267 & 5.05 & 5.0414 & TST & \\
\hline CHEMBL1500206 & 688267 & 4.1 & 5.0619 & TRN & \\
\hline CHEMBL1354649 & 688267 & 6.25 & 4.9699 & TRN & \\
\hline CHEMBL3210796 & 688267 & 6.15 & 5.0094 & TST & \\
\hline CHEMBL1321481 & 688267 & 4.9 & 5.0863 & TRN & \\
\hline CHEMBL1516954 & 688267 & 4.05 & 4.9985 & TRN & \\
\hline CHEMBL1581035 & 688267 & 4.3 & 5.0241 & TRN & \\
\hline CHEMBL1323605 & 688267 & 4.25 & 5.015 & TST & \\
\hline CHEMBL1592877 & 688267 & 4.0 & 5.0981 & TRN & \\
\hline CHEMBL1479494 & 688267 & 3.95 & 5.0971 & TRN & \\
\hline CHEMBL1359135 & 688267 & 4.45 & 5.0252 & TST & \\
\hline CHEMBL1532415 & 688267 & 4.1 & 5.0694 & TRN & \\
\hline CHEMBL1598913 & 688267 & 5.35 & 5.0961 & TST & \\
\hline CHEMBL1457707 & 688267 & 4.0 & 5.0827 & TRN & \\
\hline CHEMBL1323753 & 688267 & 4.3 & 5.0176 & TST & \\
\hline CHEMBL1569897 & 688267 & 6.5 & 5.1221 & TST & \\
\hline CHEMBL1511626 & 688267 & 3.95 & 5.0745 & TRN & \\
\hline CHEMBL1535600 & 688267 & 5.0 & 5.0768 & TST & \\
\hline CHEMBL1450060 & 688267 & 5.6 & 5.0015 & TRN & \\
\hline CHEMBL1330801 & 688267 & 6.1 & 5.04899 & 99999999995 & TRN \\
\hline CHEMBL1461349 & 688267 & 4.05 & 5.0422 & TST & \\
\hline CHEMBL1371433 & 688267 & 6.2 & 5.0573 & TRN & \\
\hline
\end{tabular}




\begin{tabular}{|c|c|c|c|c|c|}
\hline \multicolumn{6}{|c|}{ Supplemental Table S2 } \\
\hline CHEMBL1467984 & 688267 & 5.9 & 5.0477 & TRN & \\
\hline CHEMBL1497208 & 688267 & 5.6 & 5.048 & TRN & \\
\hline CHEMBL1582129 & 688267 & 5.65 & 5.0593 & TRN & \\
\hline CHEMBL1439432 & 688267 & 4.0 & 5.09699 & 99999999995 & TST \\
\hline CHEMBL1360577 & 688267 & 6.2 & 5.041 & TRN & \\
\hline CHEMBL1466857 & 688267 & 5.8 & 5.0677 & TRN & \\
\hline CHEMBL1452968 & 688267 & 5.5 & 5.109 & TRN & \\
\hline CHEMBL1472568 & 688267 & 4.95 & 5.1386 & TRN & \\
\hline CHEMBL1314960 & 688267 & 6.1 & 5.0408 & TRN & \\
\hline CHEMBL1299903 & 688267 & 4.3 & 5.0556 & TRN & \\
\hline CHEMBL1521252 & 688267 & 4.35 & 5.1387 & TRN & \\
\hline CHEMBL1471212 & 688267 & 4.25 & 5.073 & TRN & \\
\hline CHEMBL1378536 & 688267 & 6.5 & 5.0236 & TST & \\
\hline CHEMBL1416587 & 688267 & 5.8 & 5.1629 & TRN & \\
\hline CHEMBL1397377 & 688267 & 5.25 & 5.0704 & TRN & \\
\hline CHEMBL1354566 & 688267 & 7.1002 & 5.0828 & TRN & \\
\hline CHEMBL1374803 & 688267 & 5.5 & 5.0326 & TRN & \\
\hline CHEMBL1410931 & 688267 & 6.5 & 5.0174 & TRN & \\
\hline CHEMBL3211950 & 688267 & 4.4 & 5.0174 & TRN & \\
\hline CHEMBL1502334 & 688267 & 4.5 & 5.0257 & TRN & \\
\hline CHEMBL1562933 & 688267 & 5.45 & 5.0531 & TRN & \\
\hline CHEMBL1436696 & 688267 & 6.2 & 5.0513 & TRN & \\
\hline CHEMBL1515880 & 688267 & 4.05 & 5.0331 & TST & \\
\hline CHEMBL1502130 & 688267 & 4.05 & 5.0316 & TRN & \\
\hline CHEMBL1353010 & 688267 & 5.9 & 5.061 & TRN & \\
\hline CHEMBL 3193637 & 688267 & 4.05 & 5.0513 & TST & \\
\hline CHEMBL1465089 & 688267 & 4.1 & 5.0685 & TRN & \\
\hline CHEMBL1464121 & 688267 & 6.15 & 5.0727 & TRN & \\
\hline CHEMBL1368157 & 688267 & 4.05 & 5.1077 & TRN & \\
\hline CHEMBL1502515 & 688267 & 6.25 & 5.1208 & TRN & \\
\hline CHEMBL1472022 & 688267 & 4.0 & 5.0365 & TRN & \\
\hline CHEMBL1568540 & 688267 & 6.45 & 5.1072 & TRN & \\
\hline CHEMBL1437765 & 688267 & 5.45 & 4.9971 & TRN & \\
\hline CHEMBL1568269 & 688267 & 5.15 & 5.0267 & TST & \\
\hline CHEMBL1565530 & 688267 & 4.8 & 5.1034 & TST & \\
\hline CHEMBL1314679 & 688267 & 3.95 & 5.0942 & TRN & \\
\hline CHEMBL1428618 & 688267 & 5.6 & 5.0498 & TRN & \\
\hline CHEMBL1392748 & 688267 & 4.1 & 4.9981 & TRN & \\
\hline CHEMBL1541038 & 688267 & 4.55 & 5.0735 & TRN & \\
\hline CHEMBL1459377 & 688267 & 5.35 & 5.0845 & TRN & \\
\hline CHEMBL1492042 & 688267 & 4.25 & 5.0371 & TRN & \\
\hline CHEMBL1553372 & 688267 & 4.0 & 5.0596 & TRN & \\
\hline CHEMBL1463599 & 688267 & 4.3 & 5.0834 & TRN & \\
\hline CHEMBL1473173 & 688267 & 4.05 & 5.0068 & TRN & \\
\hline CHEMBL1540594 & 688267 & 6.2 & 5.0129 & TST & \\
\hline CHEMBL1317994 & 688267 & 4.0 & 5.0114 & TST & \\
\hline CHEMBL1564880 & 688267 & 4.15 & 5.1319 & TRN & \\
\hline CHEMBL1333704 & 688267 & 6.15 & 5.0139 & TRN & \\
\hline & & & & 17996 & \\
\hline
\end{tabular}




\begin{tabular}{|c|c|c|c|c|c|}
\hline \multicolumn{6}{|c|}{ pıemental } \\
\hline CHEMBL1344463 & 688267 & 4.35 & 5.0464 & TST & \\
\hline CHEMBL1546980 & 688267 & 4.1 & 5.0325 & TRN & \\
\hline CHEMBL1450580 & 688267 & 5.85 & 5.0911 & TRN & \\
\hline CHEMBL1569059 & 688267 & 5.0 & 5.1417 & TST & \\
\hline CHEMBL1355734 & 688267 & 5.3 & 5.0517 & TRN & \\
\hline CHEMBL1449598 & 688267 & 4.0 & 5.0106 & TST & \\
\hline CHEMBL1303295 & 688267 & 4.45 & 5.0553 & TRN & \\
\hline CHEMBL1355208 & 688267 & 5.8 & 4.9791 & TRN & \\
\hline CHEMBL1347320 & 688267 & 4.9 & 5.16299 & 9999999999 & TRN \\
\hline CHEMBL1370120 & 688267 & 5.8 & 5.0209 & TRN & \\
\hline CHEMBL448602 & 688267 & 5.55 & 5.066 & TRN & \\
\hline CHEMBL1556021 & 688267 & 5.4 & 5.0145 & TRN & \\
\hline CHEMBL1315167 & 688267 & 6.15 & 5.0658 & TRN & \\
\hline CHEMBL1483694 & 688267 & 5.45 & 5.0174 & TRN & \\
\hline CHEMBL1609475 & 688267 & 5.9 & 5.1209 & TRN & \\
\hline CHEMBL1582170 & 688267 & 4.0 & 5.1453 & TRN & \\
\hline CHEMBL1467726 & 688267 & 5.45 & 5.0903 & TRN & \\
\hline CHEMBL1558895 & 688267 & 4.4 & 5.0741 & TRN & \\
\hline CHEMBL1324792 & 688267 & 6.0 & 5.0079 & TRN & \\
\hline CHEMBL1329555 & 688267 & 4.65 & 5.0693 & TST & \\
\hline CHEMBL1465299 & 688267 & 5.25 & 5.1556 & TRN & \\
\hline CHEMBL1562271 & 688267 & 5.3 & 5.0252 & TRN & \\
\hline CHEMBL1361793 & 688267 & 5.4 & 5.0725 & TRN & \\
\hline CHEMBL1361089 & 688267 & 5.9 & 5.1085 & TRN & \\
\hline CHEMBL3209764 & 688267 & 5.1 & 5.0326 & TST & \\
\hline CHEMBL1343834 & 688267 & 5.0 & 5.0842 & TRN & \\
\hline CHEMBL1485564 & 688267 & 4.5 & 5.0611 & TST & \\
\hline CHEMBL1364729 & 688267 & 5.9 & 5.1029 & TST & \\
\hline CHEMBL1315889 & 688267 & 4.4 & 5.0779 & TRN & \\
\hline CHEMBL1426850 & 688267 & 4.45 & 5.0266 & TRN & \\
\hline CHEMBL1414469 & 688267 & 5.35 & 5.0672 & TRN & \\
\hline CHEMBL1325028 & 688267 & 4.3 & 4.9941 & TRN & \\
\hline CHEMBL1526132 & 688267 & 6.0 & 5.0127 & TRN & \\
\hline CHEMBL1606043 & 688267 & 5.85 & 5.0459 & TRN & \\
\hline CHEMBL1394512 & 688267 & 4.05 & 5.0305 & TRN & \\
\hline CHEMBL1399399 & 688267 & 4.15 & 5.042 & TRN & \\
\hline CHEMBL1566111 & 688267 & 5.95 & 5.0775 & TRN & \\
\hline CHEMBL1382246 & 688267 & 5.55 & 5.0746 & TST & \\
\hline CHEMBL3195629 & 688267 & 5.8 & 5.0142 & TRN & \\
\hline CHEMBL1399164 & 688267 & 5.25 & 5.0142 & TST & \\
\hline CHEMBL3212358 & 688267 & 5.3 & 5.00899 & 99999999995 & TRN \\
\hline CHEMBL1561587 & 688267 & 4.4 & 5.0335 & TST & \\
\hline CHEMBL1355789 & 688267 & 6.15 & 5.0041 & TRN & \\
\hline CHEMBL1365277 & 688267 & 4.8 & 5.1053 & TRN & \\
\hline CHEMBL1329696 & 688267 & 4.2 & 5.1537 & TRN & \\
\hline CHEMBL1477378 & 688267 & 4.5 & 5.0177 & TST & \\
\hline CHEMBL116541 & 688267 & 5.35 & 5.0247 & TRN & \\
\hline CHEMBL1343276 & 688267 & 4.9 & 5.0386 & TST & \\
\hline
\end{tabular}




\begin{tabular}{|c|c|c|c|c|c|}
\hline & & \multicolumn{4}{|c|}{ Supplemental Table S2.txt } \\
\hline CHEMBL1437265 & 688267 & 4.55 & 5.109 & TRN & \\
\hline CHEMBL1581555 & 688267 & 6.2 & 5.086 & TRN & \\
\hline CHEMBL3189207 & 688267 & 5.85 & 5.0588 & TST & \\
\hline CHEMBL1395237 & 688267 & 4.1 & 5.0224 & TRN & \\
\hline CHEMBL1599340 & 688267 & 5.35 & 5.0295 & TRN & \\
\hline CHEMBL1531913 & 688267 & 5.5 & 4.9822 & TRN & \\
\hline CHEMBL1372625 & 688267 & 3.95 & 5.0476 & TST & \\
\hline CHEMBL1304211 & 688267 & 4.05 & 5.0576 & TRN & \\
\hline CHEMBL1557647 & 688267 & 3.95 & 5.1226 & TRN & \\
\hline CHEMBL1448279 & 688267 & 4.0 & 5.0847 & TST & \\
\hline CHEMBL1457336 & 688267 & 4.05 & 5.0387 & TRN & \\
\hline CHEMBL1573902 & 688267 & 5.5 & 5.0099 & TST & \\
\hline CHEMBL1498025 & 688267 & 4.6 & 5.008 & TST & \\
\hline CHEMBL1392510 & 688267 & 5.35 & 5.0483 & TRN & \\
\hline CHEMBL1477638 & 688267 & 4.0 & 5.1308 & TRN & \\
\hline CHEMBL1437142 & 688267 & 4.35 & 5.083 & TRN & \\
\hline CHEMBL1496459 & 688267 & 4.1 & 5.0310 & 0000000001 & TRN \\
\hline CHEMBL1328322 & 688267 & 5.5 & 5.0388 & TRN & \\
\hline CHEMBL1607414 & 688267 & 6.2 & 5.0684 & TST & \\
\hline CHEMBL1550527 & 688267 & 4.25 & 5.0573 & TST & \\
\hline CHEMBL1385826 & 688267 & 6.2 & 5.0771 & TRN & \\
\hline CHEMBL1548238 & 688267 & 4.3 & 5.0456 & TRN & \\
\hline CHEMBL1459163 & 688267 & 4.25 & 5.0185 & TRN & \\
\hline CHEMBL1423119 & 688267 & 4.65 & 5.0162 & TRN & \\
\hline CHEMBL1398775 & 688267 & 4.55 & 5.0284 & TST & \\
\hline CHEMBL1600461 & 688267 & 4.5 & 5.0375 & TRN & \\
\hline CHEMBL1523473 & 688267 & 5.4 & 5.0486 & TRN & \\
\hline CHEMBL1489953 & 688267 & 5.55 & 5.1286 & TRN & \\
\hline CHEMBL1539952 & 688267 & 5.1 & 5.0804 & TRN & \\
\hline CHEMBL1310556 & 688267 & 5.25 & 5.032 & TRN & \\
\hline CHEMBL1478356 & 688267 & 4.05 & 5.0282 & TRN & \\
\hline CHEMBL1360417 & 688267 & 6.5 & 5.0745 & TRN & \\
\hline CHEMBL1450857 & 688267 & 6.2 & 5.0574 & TRN & \\
\hline CHEMBL1309437 & 688267 & 5.3 & 5.0139 & TST & \\
\hline CHEMBL1519010 & 688267 & 5.35 & 5.1133 & TRN & \\
\hline CHEMBL1584981 & 688267 & 5.95 & 5.1008 & TRN & \\
\hline CHEMBL1563433 & 688267 & 5.2 & 5.0286 & TRN & \\
\hline CHEMBL1325739 & 688267 & 5.25 & 4.9947 & TST & \\
\hline CHEMBL1384212 & 688267 & 4.25 & 5.0261 & TRN & \\
\hline CHEMBL1342150 & 688267 & 6.15 & 4.9928 & TRN & \\
\hline CHEMBL1592513 & 688267 & 4.95 & 5.0760 & 00000000005 & TRN \\
\hline CHEMBL1488511 & 688267 & 4.3 & 5.0265 & TRN & \\
\hline CHEMBL1270705 & 688267 & 6.2 & 5.007 & TRN & \\
\hline CHEMBL1480272 & 688267 & 4.25 & 5.0556 & TRN & \\
\hline CHEMBL1355494 & 688267 & 5.95 & 5.022 & TRN & \\
\hline CHEMBL1338355 & 688267 & 6.2 & 5.0997 & TST & \\
\hline CHEMBL1551432 & 688267 & 5.45 & 5.0414 & TST & \\
\hline CHEMBL1472110 & 688267 & 5.4 & 4.9697 & TRN & \\
\hline
\end{tabular}




\begin{tabular}{|c|c|c|c|c|c|}
\hline & & \multicolumn{4}{|c|}{ Supplemental Table s2.txt } \\
\hline CHEMBL1579479 & 688267 & 3.95 & 5.0535 & TRN & \\
\hline CHEMBL1567541 & 688267 & 4.4 & 5.0525 & TRN & \\
\hline CHEMBL1543475 & 688267 & 4.4 & 5.0684 & TRN & \\
\hline CHEMBL1302482 & 688267 & 5.45 & 5.0522 & TRN & \\
\hline CHEMBL1313739 & 688267 & 5.35 & 5.0889 & TRN & \\
\hline CHEMBL1541723 & 688267 & 5.25 & 5.0104 & TRN & \\
\hline CHEMBL1416354 & 688267 & 5.05 & 5.0371 & TRN & \\
\hline CHEMBL1551092 & 688267 & 5.95 & 5.0245 & TRN & \\
\hline CHEMBL1463907 & 688267 & 5.05 & 5.0438 & TST & \\
\hline CHEMBL1309833 & 688267 & 5.85 & 5.0687 & TRN & \\
\hline CHEMBL1546331 & 688267 & 5.35 & 5.1267 & TRN & \\
\hline CHEMBL1389484 & 688267 & 5.85 & 5.1132 & TRN & \\
\hline CHEMBL1400679 & 688267 & 4.55 & 5.0736 & TRN & \\
\hline CHEMBL1480741 & 688267 & 4.4 & 5.095 & TST & \\
\hline CHEMBL1487052 & 688267 & 4.55 & 5.0791 & TRN & \\
\hline CHEMBL1442546 & 688267 & 6.2 & 5.0761 & TST & \\
\hline CHEMBL3198447 & 688267 & 5.4 & 5.0413 & TRN & \\
\hline CHEMBL1437607 & 688267 & 4.15 & 5.044 & TRN & \\
\hline CHEMBL1524561 & 688267 & 5.3 & 5.0831 & TRN & \\
\hline CHEMBL1482796 & 688267 & 5.9 & 5.0358 & TRN & \\
\hline CHEMBL1439911 & 688267 & 4.0 & 4.9927 & TRN & \\
\hline CHEMBL1367693 & 688267 & 4.5 & 5.046 & TRN & \\
\hline CHEMBL1472643 & 688267 & 4.0 & 5.0297 & TRN & \\
\hline CHEMBL1545944 & 688267 & 6.2 & 5.1504 & TRN & \\
\hline CHEMBL1515399 & 688267 & 4.0 & 5.0926 & TRN & \\
\hline CHEMBL1576843 & 688267 & 5.2 & 4.9836 & TRN & \\
\hline CHEMBL1565747 & 688267 & 6.1 & 5.0509 & TST & \\
\hline CHEMBL1472349 & 688267 & 6.5 & 5.1107 & TRN & \\
\hline CHEMBL1569508 & 688267 & 6.2 & 5.0252 & TRN & \\
\hline CHEMBL1475645 & 688267 & 3.95 & 5.0931 & TRN & \\
\hline CHEMBL1299351 & 688267 & 3.95 & 5.0112 & TRN & \\
\hline CHEMBL1508016 & 688267 & 5.7 & 5.0383 & TST & \\
\hline CHEMBL1461751 & 688267 & 6.15 & 5.0637 & TRN & \\
\hline CHEMBL1545297 & 688267 & 5.45 & 5.0971 & TRN & \\
\hline CHEMBL1576383 & 688267 & 6.2 & 5.0662 & TRN & \\
\hline CHEMBL1354659 & 688267 & 3.95 & 5.035 & TST & \\
\hline CHEMBL1383621 & 688267 & 6.2 & 5.0763 & TST & \\
\hline CHEMBL1504758 & 688267 & 4.35 & 5.0492 & TRN & \\
\hline CHEMBL1596586 & 688267 & 5.1 & 4.9892 & TRN & \\
\hline CHEMBL1537223 & 688267 & 6.0 & 5.0233 & TRN & \\
\hline CHEMBL1585422 & 688267 & 4.5 & 5.1098 & TRN & \\
\hline CHEMBL1437241 & 688267 & 3.95 & 5.01399 & 9999999999 & TRN \\
\hline CHEMBL1391953 & 688267 & 3.95 & 5.0996 & TRN & \\
\hline CHEMBL1301833 & 688267 & 4.3 & 5.1038 & TRN & \\
\hline CHEMBL1560426 & 688267 & 4.35 & 5.0373 & TRN & \\
\hline CHEMBL1312827 & 688267 & 5.9 & 5.04899 & 99999999995 & TST \\
\hline CHEMBL3192061 & 688267 & 4.15 & 5.0179 & TRN & \\
\hline CHEMBL1308397 & 688267 & 4.25 & 5.0392 & TRN & \\
\hline
\end{tabular}




\begin{tabular}{|c|c|c|c|c|c|}
\hline \\
\hline CHEMBL 3211140 & 688267 & 5.6 & 5.0343 & TRN & \\
\hline CHEMBL1543743 & 688267 & 4.05 & 5.1302 & TRN & \\
\hline CHEMBL1326653 & 688267 & 4.4 & 4.9919 & TST & \\
\hline CHEMBL1373487 & 688267 & 5.3 & 4.9935 & TRN & \\
\hline CHEMBL1320442 & 688267 & 5.2 & 5.0772 & TRN & \\
\hline CHEMBL1509716 & 688267 & 5.55 & 4.9987 & TST & \\
\hline CHEMBL1376056 & 688267 & 5.65 & 5.0293 & TRN & \\
\hline CHEMBL1299978 & 688267 & 5.25 & 5.083 & TRN & \\
\hline CHEMBL1554330 & 688267 & 4.05 & 5.0094 & TRN & \\
\hline CHEMBL1501894 & 688267 & 4.05 & 5.0402 & TST & \\
\hline CHEMBL1393746 & 688267 & 6.2 & 5.0646 & TRN & \\
\hline CHEMBL1603746 & 688267 & 6.15 & 5.0286 & TRN & \\
\hline CHEMBL1338462 & 688267 & 4.1 & 5.0098 & TST & \\
\hline CHEMBL1341233 & 688267 & 4.45 & 5.0775 & TRN & \\
\hline CHEMBL1420451 & 688267 & 6.15 & 5.0659 & TST & \\
\hline CHEMBL1377768 & 688267 & 6.25 & 5.1487 & TRN & \\
\hline CHEMBL1408917 & 688267 & 5.15 & 5.0057 & TRN & \\
\hline CHEMBL1310742 & 688267 & 5.35 & 5.0175 & TRN & \\
\hline CHEMBL1601738 & 688267 & 4.45 & 5.0663 & TRN & \\
\hline CHEMBL1385250 & 688267 & 5.7 & 5.0619 & TRN & \\
\hline CHEMBL1361900 & 688267 & 3.95 & 5.0825 & TRN & \\
\hline CHEMBL1602469 & 688267 & 4.25 & 5.0622 & TRN & \\
\hline CHEMBL572180 & 688267 & 5.05 & 5.0633 & TRN & \\
\hline CHEMBL1367404 & 688267 & 4.0 & 5.048 & TRN & \\
\hline CHEMBL1530302 & 688267 & 5.75 & 5.034 & TST & \\
\hline CHEMBL1414082 & 688267 & 6.15 & 5.1478 & TRN & \\
\hline CHEMBL1582079 & 688267 & 6.15 & 5.0788 & TST & \\
\hline CHEMBL1568758 & 688267 & 5.9 & 5.0657 & TRN & \\
\hline CHEMBL1461626 & 688267 & 3.4 & 5.0414 & TST & \\
\hline CHEMBL1333496 & 688267 & 5.35 & 5.1058 & TRN & \\
\hline CHEMBL1525710 & 688267 & 4.2 & 5.0903 & TRN & \\
\hline CHEMBL1319929 & 688267 & 5.5 & 5.0654 & TST & \\
\hline CHEMBL1389537 & 688267 & 5.0 & 5.1066 & TST & \\
\hline CHEMBL1551705 & 688267 & 5.75 & 5.08 & TRN & \\
\hline CHEMBL1485563 & 688267 & 4.0 & 5.0152 & TST & \\
\hline CHEMBL1342425 & 688267 & 4.25 & 5.0703 & TST & \\
\hline CHEMBL 3212948 & 688267 & 4.7 & 5.0334 & TRN & \\
\hline CHEMBL1307774 & 688267 & 4.4 & 5.1568 & TRN & \\
\hline CHEMBL1543468 & 688267 & 5.4 & 5.1208 & TRN & \\
\hline CHEMBL1359712 & 688267 & 5.3 & 5.0539 & 9999999999 & TRN \\
\hline CHEMBL1439002 & 688267 & 5.55 & 5.1224 & TRN & \\
\hline CHEMBL1403196 & 688267 & 4.2 & 5.1110 & 0000000001 & TRN \\
\hline CHEMBL1319167 & 688267 & 6.2 & 5.0879 & TRN & \\
\hline CHEMBL1317526 & 688267 & 6.2 & 5.1418 & TRN & \\
\hline CHEMBL1570359 & 688267 & 4.85 & 5.0776 & TRN & \\
\hline CHEMBL 3189740 & 688267 & 4.2 & 4.9714 & TRN & \\
\hline CHEMBL1367921 & 688267 & 5.55 & 5.0433 & TRN & \\
\hline CHEMBL1520674 & 688267 & 4.25 & 5.0251 & TRN & \\
\hline
\end{tabular}




\begin{tabular}{|c|c|c|c|c|c|}
\hline \multicolumn{6}{|c|}{ Supplemental Table S2.txt } \\
\hline CHEMBL1601194 & 688267 & 5.55 & 5.1389 & TRN & \\
\hline CHEMBL1557622 & 688267 & 4.3 & 5.0184 & TRN & \\
\hline CHEMBL1352307 & 688267 & 4.0 & 5.0191 & TST & \\
\hline CHEMBL1533566 & 688267 & 6.05 & 5.0669 & TST & \\
\hline CHEMBL 3198520 & 688267 & 4.6 & 5.0739 & TRN & \\
\hline CHEMBL1367109 & 688267 & 5.9 & 5.0676 & TST & \\
\hline CHEMBL1418646 & 688267 & 6.2 & 5.0635 & TRN & \\
\hline CHEMBL1385116 & 688267 & 4.35 & 5.0399 & TRN & \\
\hline CHEMBL1447017 & 688267 & 5.35 & 5.0777 & TRN & \\
\hline CHEMBL1412281 & 688267 & 6.0 & 5.0591 & TST & \\
\hline CHEMBL 3208839 & 688267 & 4.65 & 4.9987 & TRN & \\
\hline CHEMBL1313453 & 688267 & 5.6 & 5.0996 & TRN & \\
\hline CHEMBL1607897 & 688267 & 4.55 & 5.0483 & TST & \\
\hline CHEMBL1508235 & 688267 & 4.2 & 5.0327 & TRN & \\
\hline CHEMBL1415206 & 688267 & 5.35 & 5.0297 & TRN & \\
\hline CHEMBL1575427 & 688267 & 4.55 & 5.0285 & TRN & \\
\hline CHEMBL1583953 & 688267 & 4.9 & 5.0915 & TRN & \\
\hline CHEMBL1513048 & 688267 & 6.15 & 5.1423 & TRN & \\
\hline CHEMBL1459069 & 688267 & 4.05 & 5.0602 & TRN & \\
\hline CHEMBL1410972 & 688267 & 3.95 & 5.0589 & TST & \\
\hline CHEMBL1449345 & 688267 & 5.6 & 5.1162 & TRN & \\
\hline CHEMBL 3213460 & 688267 & 4.25 & 5.046 & TST & \\
\hline CHEMBL1345151 & 688267 & 5.3 & 5.1302 & TST & \\
\hline CHEMBL1336059 & 688267 & 6.2 & 5.035 & TST & \\
\hline CHEMBL1488824 & 688267 & 6.2 & 5.0622 & TRN & \\
\hline CHEMBL1601539 & 688267 & 5.55 & 5.0611 & TRN & \\
\hline CHEMBL1513046 & 688267 & 4.0 & 5.0329 & TST & \\
\hline CHEMBL1548358 & 688267 & 4.2 & 5.118 & TST & \\
\hline CHEMBL1612465 & 688267 & 5.1 & 5.0433 & TRN & \\
\hline CHEMBL1405876 & 688267 & 6.15 & 5.0455 & TRN & \\
\hline CHEMBL1492471 & 688267 & 6.45 & 5.0476 & TRN & \\
\hline CHEMBL 3196803 & 688267 & 5.45 & 5.0104 & TRN & \\
\hline CHEMBL1513218 & 688267 & 4.0 & 5.0402 & TST & \\
\hline CHEMBL1498325 & 688267 & 5.15 & 5.1218 & TRN & \\
\hline CHEMBL1387126 & 688267 & 6.2 & 5.0936 & TRN & \\
\hline CHEMBL1495222 & 688267 & 6.1 & 5.0712 & TRN & \\
\hline CHEMBL1484633 & 688267 & 4.05 & 5.0555 & TRN & \\
\hline CHEMBL1315350 & 688267 & 6.2 & 5.1121 & TRN & \\
\hline CHEMBL 3196056 & 688267 & 4.95 & 4.9781 & TRN & \\
\hline CHEMBL1993165 & 688267 & 4.8 & 4.9986 & TRN & \\
\hline CHEMBL1331938 & 688267 & 4.4 & 5.12299 & 9999999999 & TRN \\
\hline CHEMBL1526182 & 688267 & 4.2 & 5.07600 & 00000000005 & TRN \\
\hline CHEMBL1408763 & 688267 & 5.2 & 5.0409 & TRN & \\
\hline CHEMBL1488116 & 688267 & 4.0 & 5.0216 & TRN & \\
\hline CHEMBL1416552 & 688267 & 5.35 & 5.1241 & TRN & \\
\hline CHEMBL1544639 & 688267 & 4.2 & 5.1348 & TST & \\
\hline CHEMBL1344669 & 688267 & 4.2 & 5.0245 & TST & \\
\hline CHEMBL1549814 & 688267 & 6.15 & 5.0632 & TRN & \\
\hline
\end{tabular}




\begin{tabular}{|c|c|c|c|c|}
\hline \multicolumn{5}{|c|}{ Supplemental Table S2.txt } \\
\hline CHEMBL1536693 & 688267 & 4.55 & 5.0932 & TRN \\
\hline CHEMBL1425396 & 688267 & 6.1 & 5.087 & TST \\
\hline CHEMBL1559709 & 688267 & 4.7 & 5.0352 & TST \\
\hline CHEMBL1482966 & 688267 & 4.05 & 5.0821 & TST \\
\hline CHEMBL1421196 & 688267 & 4.05 & 5.013 & TST \\
\hline CHEMBL1520119 & 688267 & 5.3 & 5.0617 & TRN \\
\hline CHEMBL1377954 & 688267 & 6.2 & 5.0344 & TRN \\
\hline CHEMBL1459182 & 688267 & 5.1 & 5.0604 & TRN \\
\hline CHEMBL1398409 & 688267 & 4.45 & 5.1122 & TRN \\
\hline CHEMBL1312313 & 688267 & 5.4 & 5.0284 & TST \\
\hline CHEMBL1505587 & 688267 & 6.2 & 5.0457 & TRN \\
\hline CHEMBL1497705 & 688267 & 5.55 & 5.0683 & TRN \\
\hline CHEMBL1573570 & 688267 & 6.2 & 5.0565 & TST \\
\hline CHEMBL1458110 & 688267 & 6.15 & 5.0397 & TST \\
\hline CHEMBL1979784 & 688267 & 4.35 & 5.0905 & TRN \\
\hline CHEMBL1433570 & 688267 & 5.1 & 4.947 & TRN \\
\hline CHEMBL1468714 & 688267 & 4.4 & 5.0481 & TRN \\
\hline CHEMBL1383308 & 688267 & 4.35 & 5.0579 & TRN \\
\hline CHEMBL1436101 & 688267 & 3.95 & 5.0296 & TRN \\
\hline CHEMBL1518849 & 688267 & 5.15 & 5.0521 & TRN \\
\hline CHEMBL1601775 & 688267 & 4.35 & 4.9745 & TRN \\
\hline CHEMBL1417501 & 688267 & 6.2 & 5.0343 & TRN \\
\hline CHEMBL1413703 & 688267 & 6.15 & 5.0642 & TST \\
\hline CHEMBL1328112 & 688267 & 4.55 & 5.0421 & TRN \\
\hline CHEMBL1395170 & 688267 & 3.95 & 5.1338 & TRN \\
\hline CHEMBL1499096 & 688267 & 6.1 & 5.0503 & TRN \\
\hline CHEMBL1310444 & 688267 & 5.3 & 5.0866 & TRN \\
\hline CHEMBL1403646 & 688267 & 5.8 & 5.0469 & TST \\
\hline CHEMBL1360223 & 688267 & 4.3 & 5.1206 & TST \\
\hline CHEMBL1444757 & 688267 & 4.55 & 5.0422 & TST \\
\hline CHEMBL1456377 & 688267 & 4.2 & 5.023 & TRN \\
\hline CHEMBL1472816 & 688267 & 4.3 & 5.0615 & TRN \\
\hline CHEMBL1514738 & 688267 & 6.2 & 5.0659 & TRN \\
\hline CHEMBL1529361 & 688267 & 3.95 & 5.0521 & TRN \\
\hline CHEMBL1608094 & 688267 & 4.65 & 5.0194 & TRN \\
\hline CHEMBL1591919 & 688267 & 5.3 & 5.0155 & TRN \\
\hline CHEMBL1594035 & 688267 & 4.45 & 5.121 & TRN \\
\hline CHEMBL1329799 & 688267 & 5.75 & 5.0474 & TRN \\
\hline CHEMBL1597440 & 688267 & 5.15 & 5.0298 & TRN \\
\hline CHEMBL1388607 & 688267 & 4.55 & 5.1225 & TST \\
\hline CHEMBL1517198 & 688267 & 5.35 & 5.0158 & TST \\
\hline CHEMBL1311337 & 688267 & 6.15 & 5.1601 & TRN \\
\hline CHEMBL1512505 & 688267 & 5.25 & 5.0032 & TRN \\
\hline CHEMBL1587659 & 688267 & 4.0 & 5.0782 & TRN \\
\hline CHEMBL1339686 & 688267 & 5.35 & 5.0655 & TRN \\
\hline CHEMBL1395480 & 688267 & 4.15 & 5.0612 & TRN \\
\hline CHEMBL 1326718 & 688267 & 4.05 & 5.0758 & TRN \\
\hline CHEMBL1425235 & 688267 & 5.9 & 5.0269 & TRN \\
\hline
\end{tabular}




\begin{tabular}{|c|c|c|c|c|c|}
\hline \multicolumn{6}{|c|}{ Supplemental Table S2.txt } \\
\hline CHEMBL1496507 & 688267 & 5.55 & 5.0522 & TST & \\
\hline CHEMBL1481053 & 688267 & 3.95 & 5.0289 & TRN & \\
\hline CHEMBL1256131 & 688267 & 5.6 & 5.0864 & TRN & \\
\hline CHEMBL1570604 & 688267 & 5.75 & 5.0526 & TST & \\
\hline CHEMBL1373678 & 688267 & 4.1 & 5.0147 & TST & \\
\hline CHEMBL1337342 & 688267 & 5.05 & 5.0641 & TRN & \\
\hline CHEMBL1453504 & 688267 & 4.05 & 5.0368 & TRN & \\
\hline CHEMBL1357908 & 688267 & 6.15 & 5.1443 & TRN & \\
\hline CHEMBL1318690 & 688267 & 6.2 & 5.0127 & TRN & \\
\hline CHEMBL1301351 & 688267 & 5.35 & 5.1157 & TRN & \\
\hline CHEMBL1563535 & 688267 & 5.0 & 5.1291 & TRN & \\
\hline CHEMBL1491887 & 688267 & 4.05 & 5.10800 & 00000000005 & TRN \\
\hline CHEMBL1420616 & 688267 & 4.1 & 5.0339 & TRN & \\
\hline CHEMBL1493182 & 688267 & 4.7 & 5.086 & TRN & \\
\hline CHEMBL1508376 & 688267 & 6.1 & 5.0538 & TRN & \\
\hline CHEMBL1519582 & 688267 & 6.2 & 5.0116 & TRN & \\
\hline CHEMBL1515087 & 688267 & 4.0 & 5.0603 & TRN & \\
\hline CHEMBL1326521 & 688267 & 4.6 & 5.0732 & TRN & \\
\hline CHEMBL1531322 & 688267 & 4.25 & 5.0403 & TST & \\
\hline CHEMBL1386892 & 688267 & 6.2 & 5.0288 & TRN & \\
\hline CHEMBL1447415 & 688267 & 5.85 & 5.0195 & TRN & \\
\hline CHEMBL1451567 & 688267 & 5.45 & 5.0569 & TRN & \\
\hline CHEMBL1397037 & 688267 & 4.85 & 5.0197 & TRN & \\
\hline CHEMBL1470359 & 688267 & 4.3 & 5.0315 & TST & \\
\hline CHEMBL1423874 & 688267 & 5.35 & 5.0233 & TRN & \\
\hline CHEMBL1529692 & 688267 & 5.85 & 5.1103 & TRN & \\
\hline CHEMBL1476635 & 688267 & 4.1 & 5.0718 & TST & \\
\hline CHEMBL1342550 & 688267 & 5.3 & 4.9989 & TRN & \\
\hline CHEMBL1305981 & 688267 & 4.2 & 5.0305 & TRN & \\
\hline CHEMBL1593155 & 688267 & 4.25 & 5.0361 & TST & \\
\hline CHEMBL1477102 & 688267 & 6.5501 & 5.0822 & TRN & \\
\hline CHEMBL3208389 & 688267 & 5.2 & 4.9646 & TRN & \\
\hline CHEMBL1365212 & 688267 & 6.25 & 4.9956 & TRN & \\
\hline CHEMBL1316135 & 688267 & 6.15 & 5.0291 & TRN & \\
\hline CHEMBL1518029 & 688267 & 4.05 & 5.0283 & TST & \\
\hline CHEMBL1598588 & 688267 & 5.3 & 5.1146 & TRN & \\
\hline CHEMBL1337024 & 688267 & 4.0 & 5.0131 & TRN & \\
\hline CHEMBL1500608 & 688267 & 5.8 & 5.0157 & TRN & \\
\hline CHEMBL1594770 & 688267 & 5.15 & 5.0876 & TRN & \\
\hline CHEMBL1441223 & 688267 & 5.3 & 5.0594 & TST & \\
\hline CHEMBL1526124 & 688267 & 4.3 & 5.0402 & TRN & \\
\hline CHEMBL1427816 & 688267 & 6.35 & 5.1391 & TRN & \\
\hline CHEMBL 2003888 & 688267 & 4.0 & 4.99100 & 00000000005 & TRN \\
\hline CHEMBL1362239 & 688267 & 4.3 & 5.0349 & TRN & \\
\hline CHEMBL1448368 & 688267 & 5.4 & 5.0824 & TST & \\
\hline CHEMBL1440957 & 688267 & 4.0 & 5.0513 & TRN & \\
\hline CHEMBL3212136 & 688267 & 5.55 & 4.9862 & TST & \\
\hline CHEMBL1590771 & 688267 & 6.2 & 5.1043 & TRN & \\
\hline
\end{tabular}




\begin{tabular}{|c|c|c|c|c|}
\hline \multicolumn{5}{|c|}{ mental Table s2.t } \\
\hline CHEMBL1513287 & 688267 & 5.1 & 5.0845 & TRN \\
\hline CHEMBL1367650 & 688267 & 6.2 & 5.0076 & TRN \\
\hline CHEMBL1364812 & 688267 & 4.7 & 5.0609 & TRN \\
\hline CHEMBL1427943 & 688267 & 5.4 & 5.0213 & TRN \\
\hline CHEMBL1453659 & 688267 & 4.5 & 5.0031 & TRN \\
\hline CHEMBL1419467 & 688267 & 4.05 & 5.0045 & TRN \\
\hline CHEMBL1312036 & 688267 & 4.05 & 5.0539 & TRN \\
\hline CHEMBL1328997 & 688267 & 4.6 & 5.1018 & TRN \\
\hline CHEMBL1449252 & 688267 & 5.95 & 5.1146 & TRN \\
\hline CHEMBL1430438 & 688267 & 5.6 & 5.0502 & TRN \\
\hline CHEMBL1453546 & 688267 & 3.9 & 5.0532 & TRN \\
\hline CHEMBL1314319 & 688267 & 4.05 & 4.9818 & TRN \\
\hline CHEMBL1430406 & 688267 & 6.2 & 5.1127 & TRN \\
\hline CHEMBL1315302 & 688267 & 6.0 & 5.0633 & TRN \\
\hline CHEMBL3214452 & 688267 & 5.0 & 5.0131 & TST \\
\hline CHEMBL1565353 & 688267 & 5.8 & 5.0899 & TRN \\
\hline CHEMBL1310737 & 688267 & 5.45 & 5.0393 & TRN \\
\hline CHEMBL1583984 & 688267 & 6.25 & 5.0814 & TRN \\
\hline CHEMBL1365171 & 688267 & 6.15 & 5.0932 & TRN \\
\hline CHEMBL1449680 & 688267 & 4.0 & 5.0631 & TRN \\
\hline CHEMBL1415685 & 688267 & 6.2 & 5.0387 & TST \\
\hline CHEMBL1350251 & 688267 & 4.55 & 5.062 & TST \\
\hline CHEMBL1402341 & 688267 & 6.2 & 5.1112 & TRN \\
\hline CHEMBL1373030 & 688267 & 3.95 & 5.0703 & TST \\
\hline CHEMBL1552282 & 688267 & 6.2 & 5.1223 & TRN \\
\hline CHEMBL1582309 & 688267 & 4.95 & 5.0446 & TRN \\
\hline CHEMBL1419037 & 688267 & 6.25 & 5.0721 & TRN \\
\hline CHEMBL1524495 & 688267 & 4.4 & 5.0124 & TST \\
\hline CHEMBL1416057 & 688267 & 5.6 & 5.0642 & TRN \\
\hline CHEMBL1394782 & 688267 & 5.3 & 5.0392 & TRN \\
\hline CHEMBL1500702 & 688267 & 6.25 & 5.0878 & TRN \\
\hline CHEMBL1552960 & 688267 & 5.3 & 5.0193 & TRN \\
\hline CHEMBL1377418 & 688267 & 6.2 & 5.0341 & TRN \\
\hline CHEMBL1506183 & 688267 & 6.2 & 5.1188 & TRN \\
\hline CHEMBL1559299 & 688267 & 4.95 & 5.0671 & TRN \\
\hline CHEMBL1484719 & 688267 & 4.0 & 4.9795 & TST \\
\hline CHEMBL1436657 & 688267 & 3.95 & 5.0454 & TRN \\
\hline CHEMBL1364903 & 688267 & 4.05 & 5.0369 & TST \\
\hline CHEMBL3194119 & 688267 & 4.05 & 5.0481 & TRN \\
\hline CHEMBL3210691 & 688267 & 4.4 & 5.0081 & TST \\
\hline CHEMBL1482262 & 688267 & 5.1 & 5.0583 & TRN \\
\hline CHEMBL1582123 & 688267 & 4.35 & 4.9988 & TST \\
\hline CHEMBL1373792 & 688267 & 4.55 & 5.0259 & TRN \\
\hline CHEMBL1613439 & 688267 & 3.95 & 5.0836 & TRN \\
\hline CHEMBL1376983 & 688267 & 5.4 & 5.12206 & 0000000001 \\
\hline CHEMBL1598070 & 688267 & 6.2 & 5.1405 & TRN \\
\hline CHEMBL1526199 & 688267 & 4.35 & 5.0225 & TRN \\
\hline CHEMBL1452076 & 688267 & 4.0 & 5.1194 & TRN \\
\hline
\end{tabular}




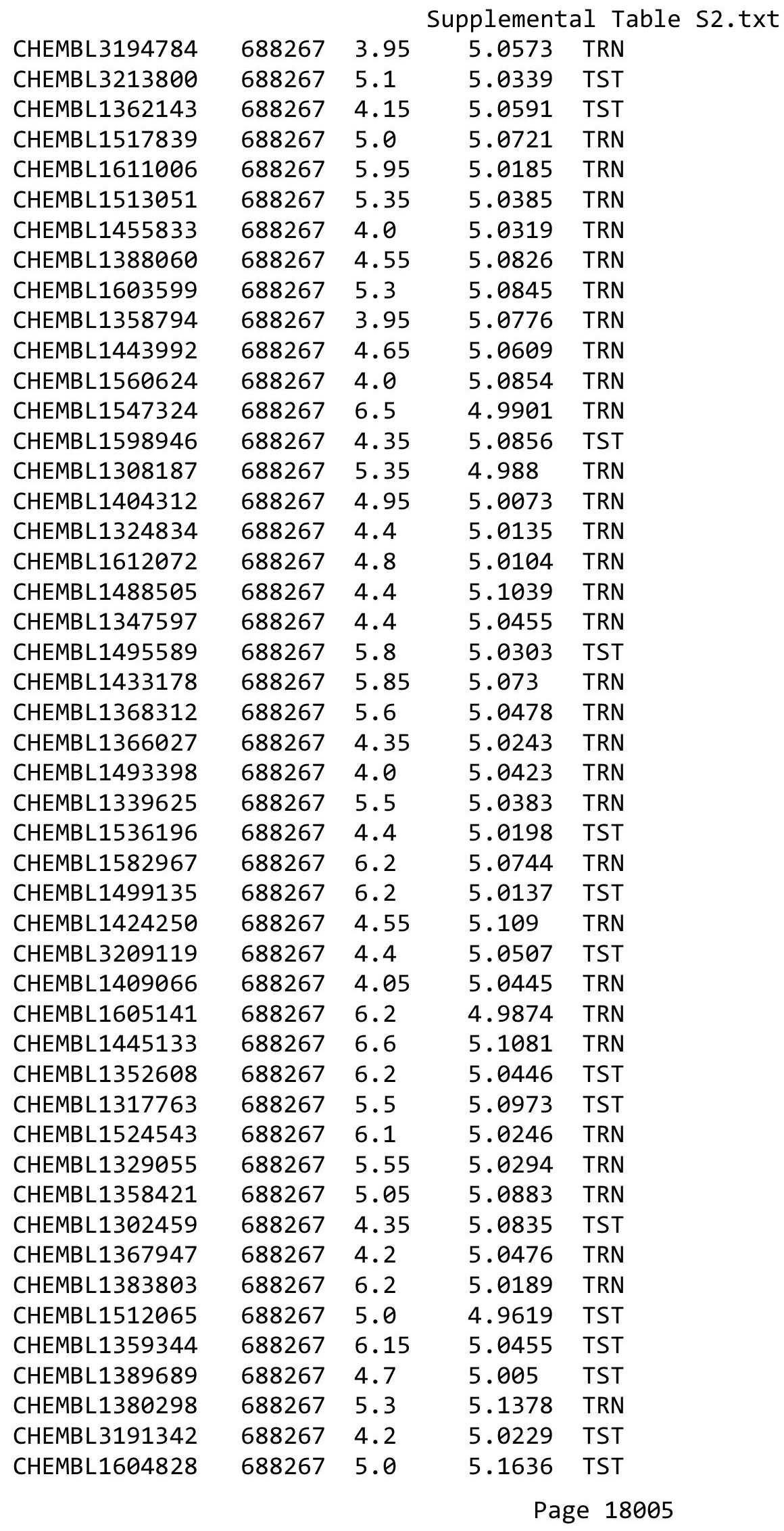




\begin{tabular}{|c|c|c|c|c|c|}
\hline \\
\hline CHEMBL1569157 & 688267 & 6.2 & 5.1134 & TST & \\
\hline CHEMBL1522798 & 688267 & 6.1 & 5.0261 & TRN & \\
\hline CHEMBL1339929 & 688267 & 5.55 & 5.0404 & TRN & \\
\hline CHEMBL1306775 & 688267 & 5.5 & 5.0543 & TRN & \\
\hline CHEMBL1577177 & 688267 & 4.35 & 5.0006 & TRN & \\
\hline CHEMBL1413840 & 688267 & 4.05 & 5.0122 & TRN & \\
\hline CHEMBL1607724 & 688267 & 5.55 & 5.1415 & TRN & \\
\hline CHEMBL1579973 & 688267 & 4.15 & 4.977 & TST & \\
\hline CHEMBL1463645 & 688267 & 4.2 & 5.0256 & TRN & \\
\hline CHEMBL1418111 & 688267 & 5.6 & 5.1413 & TRN & \\
\hline CHEMBL1469631 & 688267 & 4.95 & 5.0613 & TRN & \\
\hline CHEMBL1581309 & 688267 & 5.05 & 5.0506 & TST & \\
\hline CHEMBL1453054 & 688267 & 4.0 & 5.0627 & TST & \\
\hline CHEMBL1546869 & 688267 & 4.9 & 5.12200 & 0000000001 & TRN \\
\hline CHEMBL1519603 & 688267 & 5.55 & 4.9939 & TST & \\
\hline CHEMBL1412354 & 688267 & 6.5 & 5.0323 & TST & \\
\hline CHEMBL1491812 & 688267 & 5.3 & 5.0461 & TRN & \\
\hline CHEMBL1538490 & 688267 & 4.45 & 5.0911 & TRN & \\
\hline CHEMBL1323782 & 688267 & 4.45 & 5.0651 & TRN & \\
\hline CHEMBL1429584 & 688267 & 4.25 & 5.0241 & TRN & \\
\hline CHEMBL1439906 & 688267 & 4.65 & 5.0296 & TRN & \\
\hline CHEMBL1388208 & 688267 & 4.4 & 5.0019 & TST & \\
\hline CHEMBL1338106 & 688267 & 5.3 & 5.1193 & TRN & \\
\hline CHEMBL1315625 & 688267 & 5.55 & 4.9829 & TST & \\
\hline CHEMBL1360792 & 688267 & 4.05 & 5.0029 & TST & \\
\hline CHEMBL1317940 & 688267 & 4.0 & 5.0109 & TRN & \\
\hline CHEMBL1471348 & 688267 & 4.2 & 5.0509 & TRN & \\
\hline CHEMBL1437997 & 688267 & 4.4 & 4.9948 & TST & \\
\hline CHEMBL1355016 & 688267 & 4.05 & 5.0204 & TRN & \\
\hline CHEMBL1509938 & 688267 & 5.6 & 5.0939 & TRN & \\
\hline CHEMBL1515870 & 688267 & 6.05 & 5.0595 & TRN & \\
\hline CHEMBL1412251 & 688267 & 6.2 & 5.0637 & TRN & \\
\hline CHEMBL1354991 & 688267 & 6.0 & 5.0011 & TRN & \\
\hline CHEMBL1512855 & 688267 & 6.2 & 5.1208 & TRN & \\
\hline CHEMBL1367261 & 688267 & 4.55 & 5.0905 & TRN & \\
\hline CHEMBL1560691 & 688267 & 4.05 & 5.0151 & TRN & \\
\hline CHEMBL1601879 & 688267 & 5.65 & 5.12200 & 0000000001 & TST \\
\hline CHEMBL1466282 & 688267 & 6.15 & 5.1289 & TRN & \\
\hline CHEMBL1420608 & 688267 & 3.9 & 5.0645 & TST & \\
\hline CHEMBL1478896 & 688267 & 4.3 & 5.0279 & TST & \\
\hline CHEMBL1386840 & 688267 & 4.45 & 5.0879 & TRN & \\
\hline CHEMBL1579554 & 688267 & 5.5 & 5.0346 & TST & \\
\hline CHEMBL1457234 & 688267 & 4.25 & 5.0608 & TRN & \\
\hline CHEMBL1361532 & 688267 & 4.75 & 5.0399 & TRN & \\
\hline CHEMBL1355154 & 688267 & 5.0 & 5.0652 & TRN & \\
\hline CHEMBL1592113 & 688267 & 4.4 & 5.0105 & TST & \\
\hline CHEMBL1359207 & 688267 & 4.35 & 5.0823 & TST & \\
\hline CHEMBL1569258 & 688267 & 4.4 & 5.0848 & TRN & \\
\hline
\end{tabular}




\begin{tabular}{|c|c|c|c|c|c|}
\hline \multicolumn{6}{|c|}{ Supplemental Table S2.txt } \\
\hline CHEMBL1379922 & 688267 & 4.15 & 5.0571 & TRN & \\
\hline CHEMBL1474451 & 688267 & 4.55 & 5.1539 & TRN & \\
\hline CHEMBL1556800 & 688267 & 3.75 & 5.0541 & TRN & \\
\hline CHEMBL1535999 & 688267 & 4.85 & 4.9987 & TST & \\
\hline CHEMBL1437032 & 688267 & 5.9 & 5.0764 & TRN & \\
\hline CHEMBL1579693 & 688267 & 4.05 & 5.0221 & TRN & \\
\hline CHEMBL1512857 & 688267 & 6.2 & 5.0057 & TST & \\
\hline CHEMBL1518488 & 688267 & 6.2 & 5.1627 & TRN & \\
\hline CHEMBL1444552 & 688267 & 5.25 & 5.1347 & TRN & \\
\hline CHEMBL1487832 & 688267 & 4.4 & 5.0265 & TST & \\
\hline CHEMBL1605932 & 688267 & 4.35 & 5.1474 & TRN & \\
\hline CHEMBL1401135 & 688267 & 4.35 & 5.0026 & TRN & \\
\hline CHEMBL1328730 & 688267 & 4.75 & 5.0869 & TRN & \\
\hline CHEMBL1434250 & 688267 & 5.8 & 5.0299 & TRN & \\
\hline CHEMBL1481303 & 688267 & 4.0 & 5.0417 & TRN & \\
\hline CHEMBL1306908 & 688267 & 5.0 & 5.0473 & TST & \\
\hline CHEMBL1531543 & 688267 & 5.85 & 5.0515 & TST & \\
\hline CHEMBL1541470 & 688267 & 4.55 & 5.007 & TRN & \\
\hline CHEMBL1315934 & 688267 & 5.45 & 5.0288 & TST & \\
\hline CHEMBL1537432 & 688267 & 5.35 & 5.0957 & TRN & \\
\hline CHEMBL 2006615 & 688267 & 4.7 & 4.9974 & TST & \\
\hline CHEMBL1477576 & 688267 & 5.5 & 5.0308 & TRN & \\
\hline CHEMBL1551869 & 688267 & 4.35 & 5.1258 & TRN & \\
\hline CHEMBL1524820 & 688267 & 4.0 & 5.0355 & TRN & \\
\hline CHEMBL1306889 & 688267 & 4.7 & 5.0997 & TST & \\
\hline CHEMBL1493401 & 688267 & 4.6 & 5.0458 & TRN & \\
\hline CHEMBL1579266 & 688267 & 5.05 & 5.0578 & TRN & \\
\hline CHEMBL1603962 & 688267 & 6.2 & 5.02800 & 00000000005 & TRN \\
\hline CHEMBL1472071 & 688267 & 4.6 & 5.0419 & TST & \\
\hline CHEMBL1505398 & 688267 & 4.4 & 5.0429 & TST & \\
\hline CHEMBL1400350 & 688267 & 4.35 & 5.079 & TRN & \\
\hline CHEMBL3192816 & 688267 & 6.05 & 5.0171 & TST & \\
\hline CHEMBL1456415 & 688267 & 4.3 & 5.0487 & TRN & \\
\hline CHEMBL1401416 & 688267 & 4.05 & 5.0917 & TRN & \\
\hline CHEMBL1396588 & 688267 & 5.25 & 5.0207 & TST & \\
\hline CHEMBL2003063 & 688267 & 5.25 & 5.0196 & TST & \\
\hline CHEMBL1510264 & 688267 & 4.25 & 5.0358 & TST & \\
\hline CHEMBL1393625 & 688267 & 4.35 & 5.0812 & TST & \\
\hline CHEMBL1399501 & 688267 & 5.25 & 4.9819 & TRN & \\
\hline CHEMBL1554947 & 688267 & 6.2 & 5.0278 & TRN & \\
\hline CHEMBL1600443 & 688267 & 4.05 & 5.0884 & TRN & \\
\hline CHEMBL3392025 & 688267 & 4.0 & 5.0526 & TST & \\
\hline CHEMBL3214147 & 688267 & 4.25 & 5.007 & TST & \\
\hline CHEMBL1440930 & 688267 & 6.25 & 5.0293 & TRN & \\
\hline CHEMBL1432049 & 688267 & 6.25 & 5.067 & TST & \\
\hline CHEMBL1427458 & 688267 & 5.85 & 5.0475 & TRN & \\
\hline CHEMBL1374005 & 688267 & 3.95 & 5.1154 & TRN & \\
\hline CHEMBL1574440 & 688267 & 6.25 & 5.0987 & TRN & \\
\hline
\end{tabular}




\begin{tabular}{|c|c|c|c|c|c|}
\hline \multicolumn{6}{|c|}{ oplemental Table Sz } \\
\hline CHEMBL1374854 & 688267 & 4.2 & 5.0442 & TST & \\
\hline CHEMBL1486657 & 688267 & 4.0 & 5.1049 & TRN & \\
\hline CHEMBL1432083 & 688267 & 5.4 & 5.0222 & TRN & \\
\hline CHEMBL1331823 & 688267 & 5.5 & 5.0749 & TST & \\
\hline CHEMBL1583674 & 688267 & 5.5 & 5.0417 & TST & \\
\hline CHEMBL1540682 & 688267 & 4.3 & 5.0664 & TST & \\
\hline CHEMBL1345231 & 688267 & 4.35 & 5.1167 & TRN & \\
\hline CHEMBL1481119 & 688267 & 4.2 & 5.0335 & TRN & \\
\hline CHEMBL1311068 & 688267 & 4.05 & 5.0683 & TRN & \\
\hline CHEMBL1501263 & 688267 & 4.05 & 4.9928 & TRN & \\
\hline CHEMBL1309761 & 688267 & 5.05 & 5.0577 & TRN & \\
\hline CHEMBL1328257 & 688267 & 6.15 & 5.0851 & TRN & \\
\hline CHEMBL1536882 & 688267 & 4.3 & 5.1175 & TRN & \\
\hline CHEMBL1463291 & 688267 & 4.1 & 5.0846 & TRN & \\
\hline CHEMBL1327465 & 688267 & 4.65 & 5.0125 & TRN & \\
\hline CHEMBL1393141 & 688267 & 4.05 & 5.1013 & TST & \\
\hline CHEMBL1491568 & 688267 & 4.75 & 5.1151 & TRN & \\
\hline CHEMBL1382010 & 688267 & 4.0 & 5.0321 & TRN & \\
\hline CHEMBL1507840 & 688267 & 4.7 & 5.0383 & TST & \\
\hline CHEMBL1358324 & 688267 & 4.5 & 5.0612 & TST & \\
\hline CHEMBL1431536 & 688267 & 6.2 & 5.0306 & TRN & \\
\hline CHEMBL1383770 & 688267 & 4.4 & 5.0873 & TRN & \\
\hline CHEMBL1397411 & 688267 & 4.35 & $5.0680 e$ & 00000000005 & TST \\
\hline CHEMBL1352553 & 688267 & 5.1 & 5.1046 & TRN & \\
\hline CHEMBL1401278 & 688267 & 4.65 & 5.0492 & TRN & \\
\hline CHEMBL1455334 & 688267 & 5.9 & 5.0631 & TST & \\
\hline CHEMBL1456561 & 688267 & 6.5 & 5.0079 & TRN & \\
\hline CHEMBL1412845 & 688267 & 5.6 & 5.0263 & TST & \\
\hline CHEMBL1567396 & 688267 & 4.5 & 5.0725 & TRN & \\
\hline CHEMBL1475996 & 688267 & 5.2 & 5.0825 & TRN & \\
\hline CHEMBL1507341 & 688267 & 4.05 & 5.066 & TST & \\
\hline CHEMBL1407727 & 688267 & 5.05 & 5.1444 & TRN & \\
\hline CHEMBL1355953 & 688267 & 6.25 & 5.0031 & TRN & \\
\hline CHEMBL1377949 & 688267 & 4.3 & 5.1422 & TRN & \\
\hline CHEMBL1387264 & 688267 & 6.2 & 5.0223 & TRN & \\
\hline CHEMBL1316509 & 688267 & 4.95 & 5.0095 & TRN & \\
\hline CHEMBL1415046 & 688267 & 6.4 & 5.1586 & TRN & \\
\hline CHEMBL 3193460 & 688267 & 3.95 & 5.0717 & TRN & \\
\hline CHEMBL1569546 & 688267 & 4.1 & 4.9955 & TRN & \\
\hline CHEMBL1321170 & 688267 & 3.95 & 5.0554 & TRN & \\
\hline CHEMBL1453673 & 688267 & 4.05 & 5.0554 & TRN & \\
\hline CHEMBL1378425 & 688267 & 5.05 & 5.0193 & TRN & \\
\hline CHEMBL1420417 & 688267 & 4.6 & 5.0434 & TST & \\
\hline CHEMBL1533365 & 688267 & 6.2 & 5.0667 & TRN & \\
\hline CHEMBL1371094 & 688267 & 6.15 & 5.0832 & TRN & \\
\hline CHEMBL1544341 & 688267 & 5.5 & 5.0679 & TRN & \\
\hline CHEMBL1491679 & 688267 & 6.15 & 5.07 & TRN & \\
\hline CHEMBL489340 & 688267 & 5.4 & 4.9795 & TRN & \\
\hline
\end{tabular}




\begin{tabular}{|c|c|c|c|c|c|}
\hline \multirow[b]{2}{*}{ CHEMBL1549192 } & \multirow[b]{2}{*}{688267} & \\
\hline & & 5.1 & 5.0941 & TRN & \\
\hline CHEMBL1339599 & 688267 & 4.1 & 5.0196 & TRN & \\
\hline CHEMBL1540137 & 688267 & 6.15 & 5.074 & TRN & \\
\hline CHEMBL1464992 & 688267 & 4.0 & 5.0512 & TRN & \\
\hline CHEMBL1329464 & 688267 & 6.15 & 5.1453 & TST & \\
\hline CHEMBL1538675 & 688267 & 3.95 & 5.007 & TST & \\
\hline CHEMBL1587618 & 688267 & 5.4 & 5.0824 & TRN & \\
\hline CHEMBL1476646 & 688267 & 4.05 & 5.0281 & TRN & \\
\hline CHEMBL1355728 & 688267 & 4.5 & 5.0697 & TRN & \\
\hline CHEMBL1558899 & 688267 & 6.5 & 5.0342 & TRN & \\
\hline CHEMBL1589064 & 688267 & 5.3 & 5.1059 & TRN & \\
\hline CHEMBL1554166 & 688267 & 4.65 & 5.0277 & TRN & \\
\hline CHEMBL1477086 & 688267 & 4.55 & 5.1025 & TRN & \\
\hline CHEMBL1482934 & 688267 & 6.25 & 5.0752 & TRN & \\
\hline CHEMBL1562357 & 688267 & 5.45 & 5.02 & TST & \\
\hline CHEMBL1470420 & 688267 & 4.15 & 5.05699 & 99999999995 & TRN \\
\hline CHEMBL1449835 & 688267 & 6.2 & 5.0345 & TRN & \\
\hline CHEMBL1541315 & 688267 & 5.55 & 5.03600 & 20000000005 & TST \\
\hline CHEMBL1522086 & 688267 & 4.6 & 5.0598 & TRN & \\
\hline CHEMBL1499246 & 688267 & 4.3 & 5.0905 & TRN & \\
\hline CHEMBL1464196 & 688267 & 4.3 & 5.10800 & 00000000005 & TRN \\
\hline CHEMBL1457766 & 688267 & 6.5 & 5.0703 & TRN & \\
\hline CHEMBL1581238 & 688267 & 4.55 & 5.0572 & TST & \\
\hline CHEMBL1371296 & 688267 & 5.25 & 5.0233 & TRN & \\
\hline CHEMBL3196779 & 688267 & 4.75 & 5.0847 & TST & \\
\hline CHEMBL1361773 & 688267 & 5.3 & 5.1217 & TRN & \\
\hline CHEMBL1501301 & 688267 & 5.0 & 5.0135 & TST & \\
\hline CHEMBL1356282 & 688267 & 6.2 & 5.0463 & TRN & \\
\hline CHEMBL1300967 & 688267 & 6.15 & 5.0205 & TST & \\
\hline CHEMBL1557494 & 688267 & 6.2 & 5.041 & TRN & \\
\hline CHEMBL1536619 & 688267 & 5.3 & 5.0512 & TRN & \\
\hline CHEMBL1442151 & 688267 & 6.05 & 5.0549 & TRN & \\
\hline CHEMBL1402550 & 688267 & 5.25 & 5.0834 & TRN & \\
\hline CHEMBL1403386 & 688267 & 6.2 & 5.0315 & TST & \\
\hline CHEMBL1606554 & 688267 & 6.2 & 5.052 & TRN & \\
\hline CHEMBL1542619 & 688267 & 4.2 & 5.0591 & TRN & \\
\hline CHEMBL1467279 & 688267 & 5.3 & 5.0463 & TRN & \\
\hline CHEMBL1548375 & 688267 & 5.25 & 5.0445 & TRN & \\
\hline CHEMBL1429256 & 688267 & 6.15 & 5.0283 & TST & \\
\hline CHEMBL1339964 & 688267 & 4.25 & 5.1027 & TRN & \\
\hline CHEMBL1315217 & 688267 & 5.85 & 5.1351 & TRN & \\
\hline CHEMBL1539320 & 688267 & 4.25 & 4.9979 & TRN & \\
\hline CHEMBL1446206 & 688267 & 4.0 & 4.9929 & TRN & \\
\hline CHEMBL1367797 & 688267 & 4.65 & 5.0982 & TRN & \\
\hline CHEMBL1407249 & 688267 & 6.2 & 5.1056 & TRN & \\
\hline CHEMBL1612109 & 688267 & 5.5 & 5.0505 & TRN & \\
\hline CHEMBL1307216 & 688267 & 4.6 & 5.0244 & TST & \\
\hline CHEMBL1580288 & 688267 & 4.95 & 5.099 & TRN & \\
\hline & & & & 1800 & \\
\hline
\end{tabular}




\begin{tabular}{|c|c|c|c|c|c|}
\hline \multicolumn{6}{|c|}{ Supplemental Table S2.txt } \\
\hline CHEMBL1364123 & 688267 & 3.95 & 5.0959 & TRN & \\
\hline CHEMBL1536530 & 688267 & 4.8 & 5.0325 & TST & \\
\hline CHEMBL1342897 & 688267 & 4.05 & 5.0111 & TRN & \\
\hline CHEMBL1530927 & 688267 & 4.25 & 5.0597 & TRN & \\
\hline CHEMBL1339995 & 688267 & 4.0 & 5.0107 & TRN & \\
\hline CHEMBL1336330 & 688267 & 6.2 & 5.0504 & TRN & \\
\hline CHEMBL1553472 & 688267 & 6.2 & 5.0497 & TRN & \\
\hline CHEMBL1548053 & 688267 & 4.5 & 5.0868 & TRN & \\
\hline CHEMBL3189194 & 688267 & 4.6 & 5.0001 & TST & \\
\hline CHEMBL1424223 & 688267 & 6.2 & 5.0838 & TRN & \\
\hline CHEMBL1317683 & 688267 & 4.0 & 4.9887 & TRN & \\
\hline CHEMBL1430344 & 688267 & 4.5 & 5.0265 & TRN & \\
\hline CHEMBL1480699 & 688267 & 5.9 & 5.0824 & TRN & \\
\hline CHEMBL1330157 & 688267 & 4.9 & 5.04899 & 99999999995 & TRN \\
\hline CHEMBL1344241 & 688267 & 4.05 & 5.0645 & TRN & \\
\hline CHEMBL1565362 & 688267 & 5.8 & 5.0929 & TRN & \\
\hline CHEMBL1584424 & 688267 & 4.55 & 5.0713 & TRN & \\
\hline CHEMBL1326208 & 688267 & 4.0 & 5.0392 & TRN & \\
\hline CHEMBL1521428 & 688267 & 4.05 & 5.0121 & TRN & \\
\hline CHEMBL1411069 & 688267 & 4.05 & 5.0542 & TST & \\
\hline CHEMBL1449283 & 688267 & 5.8 & 5.0789 & TRN & \\
\hline CHEMBL1314482 & 688267 & 4.3 & 5.0816 & TRN & \\
\hline CHEMBL1573286 & 688267 & 6.0 & 5.0288 & TRN & \\
\hline CHEMBL1516269 & 688267 & 6.2 & 5.1437 & TRN & \\
\hline CHEMBL1420997 & 688267 & 4.25 & 5.0995 & TRN & \\
\hline CHEMBL1409136 & 688267 & 4.1 & 5.0246 & TRN & \\
\hline CHEMBL1366054 & 688267 & 5.4 & 4.9984 & TRN & \\
\hline CHEMBL1586584 & 688267 & 4.55 & 5.0843 & TRN & \\
\hline CHEMBL1570506 & 688267 & 4.35 & 5.117 & TRN & \\
\hline CHEMBL1393922 & 688267 & 5.45 & 5.0984 & TRN & \\
\hline CHEMBL1318608 & 688267 & 6.25 & 5.1368 & TRN & \\
\hline CHEMBL1416751 & 688267 & 4.3 & 5.013 & TST & \\
\hline CHEMBL1325790 & 688267 & 6.5 & 5.0302 & TST & \\
\hline CHEMBL1538110 & 688267 & 6.1 & 5.0819 & TRN & \\
\hline CHEMBL1351991 & 688267 & 5.65 & 4.9859 & TRN & \\
\hline CHEMBL1304918 & 688267 & 5.85 & 5.0359 & TRN & \\
\hline CHEMBL1476924 & 688267 & 5.9 & 5.1254 & TRN & \\
\hline CHEMBL1408074 & 688267 & 6.25 & 5.01399 & 9999999999 & TST \\
\hline CHEMBL1460434 & 688267 & 4.45 & 5.0262 & TRN & \\
\hline CHEMBL1567501 & 688267 & 6.2 & 5.1014 & TRN & \\
\hline CHEMBL1315886 & 688267 & 4.55 & 5.0243 & TRN & \\
\hline CHEMBL1601101 & 688267 & 4.0 & 4.9998 & TRN & \\
\hline CHEMBL1330791 & 688267 & 4.25 & 5.0486 & TST & \\
\hline CHEMBL1457788 & 688267 & 4.35 & 5.0506 & TST & \\
\hline CHEMBL1459028 & 688267 & 7.4498 & 5.1172 & TRN & \\
\hline CHEMBL1512310 & 688267 & 4.4 & 5.1073 & TRN & \\
\hline CHEMBL1305841 & 688267 & 5.0 & 5.0455 & TRN & \\
\hline CHEMBL1310653 & 688267 & 4.8 & 5.058 & TRN & \\
\hline
\end{tabular}




\begin{tabular}{|c|c|c|c|c|}
\hline \multicolumn{5}{|c|}{ Supplemental Table s2.txt } \\
\hline CHEMBL1498030 & 688267 & 5.3 & 5.0559 & TRN \\
\hline CHEMBL1542089 & 688267 & 6.15 & 5.0483 & TRN \\
\hline CHEMBL1600594 & 688267 & 5.55 & 5.0521 & TRN \\
\hline CHEMBL1373141 & 688267 & 5.8 & 5.1258 & TRN \\
\hline CHEMBL1303231 & 688267 & 4.0 & 5.0343 & TST \\
\hline CHEMBL1590708 & 688267 & 5.45 & 5.0528 & TRN \\
\hline CHEMBL1548833 & 688267 & 4.65 & 5.061 & TRN \\
\hline CHEMBL1534733 & 688267 & 4.25 & 5.0065 & TST \\
\hline CHEMBL1316251 & 688267 & 4.9 & 5.1788 & TRN \\
\hline CHEMBL1364659 & 688267 & 4.5 & 5.1322 & TRN \\
\hline CHEMBL1604330 & 688267 & 4.95 & 5.0926 & TRN \\
\hline CHEMBL1330293 & 688267 & 4.0 & 5.0585 & TRN \\
\hline CHEMBL1975504 & 688267 & 4.05 & 4.9996 & TST \\
\hline CHEMBL1456065 & 688267 & 4.45 & 5.1016 & TRN \\
\hline CHEMBL1357310 & 688267 & 5.4 & 5.0574 & TST \\
\hline CHEMBL1551630 & 688267 & 4.25 & 5.0773 & TRN \\
\hline CHEMBL1484733 & 688267 & 5.05 & 5.0766 & TRN \\
\hline CHEMBL1593798 & 688267 & 4.05 & 5.021 & TRN \\
\hline CHEMBL1339620 & 688267 & 4.0 & 5.0562 & TRN \\
\hline CHEMBL1384680 & 688267 & 4.0 & 5.0474 & TST \\
\hline CHEMBL1507347 & 688267 & 6.2 & 5.0845 & TRN \\
\hline CHEMBL1423671 & 688267 & 5.25 & 5.0937 & TRN \\
\hline CHEMBL1430273 & 688267 & 5.85 & 5.0558 & TRN \\
\hline CHEMBL1301349 & 688267 & 5.6 & 5.0797 & TST \\
\hline CHEMBL 1457676 & 688267 & 4.6 & 5.0902 & TRN \\
\hline CHEMBL1350607 & 688267 & 4.5 & 5.0327 & TRN \\
\hline CHEMBL1534176 & 688267 & 4.85 & 5.0799 & TRN \\
\hline CHEMBL1414520 & 688267 & 6.2 & 5.1394 & TRN \\
\hline CHEMBL1306449 & 688267 & 4.6 & 5.0332 & TRN \\
\hline CHEMBL1371425 & 688267 & 4.05 & 5.0559 & TRN \\
\hline CHEMBL1582452 & 688267 & 3.95 & 5.1053 & TRN \\
\hline CHEMBL1505266 & 688267 & 5.7 & 5.1227 & TRN \\
\hline CHEMBL1315120 & 688267 & 4.35 & 5.1757 & TST \\
\hline CHEMBL1476052 & 688267 & 5.35 & 5.0838 & TRN \\
\hline CHEMBL1461988 & 688267 & 5.85 & 5.0534 & TST \\
\hline CHEMBL1447242 & 688267 & 4.7 & 5.0568 & TRN \\
\hline CHEMBL1536330 & 688267 & 4.05 & 5.0482 & TRN \\
\hline CHEMBL1430237 & 688267 & 4.1 & 5.0487 & TST \\
\hline CHEMBL1580210 & 688267 & 4.35 & 5.0327 & TRN \\
\hline CHEMBL1573155 & 688267 & 4.3 & 5.0767 & TRN \\
\hline CHEMBL1381365 & 688267 & 5.3 & 5.0578 & TRN \\
\hline CHEMBL1431799 & 688267 & 6.15 & 5.056 & TST \\
\hline CHEMBL 1305884 & 688267 & 6.25 & 5.0506 & TRN \\
\hline CHEMBL1311075 & 688267 & 5.1 & 5.0133 & TRN \\
\hline CHEMBL1519310 & 688267 & 6.1 & 5.0281 & TRN \\
\hline CHEMBL1405918 & 688267 & 4.25 & 5.0725 & TRN \\
\hline CHEMBL1407075 & 688267 & 4.0 & 5.07600 & 00000000005 \\
\hline CHEMBL1505808 & 688267 & 5.6 & 5.0281 & TRN \\
\hline
\end{tabular}




\begin{tabular}{|c|c|c|c|c|c|}
\hline \multirow[b]{2}{*}{ CHEMBL1353929 } & \multirow[b]{2}{*}{688267} & \\
\hline & & 4.9 & 5.0436 & TST & \\
\hline CHEMBL1397166 & 688267 & 5.0 & 5.008 & TRN & \\
\hline CHEMBL1476612 & 688267 & 4.25 & 5.0521 & TST & \\
\hline CHEMBL1455687 & 688267 & 6.5 & 5.0444 & TRN & \\
\hline CHEMBL1415899 & 688267 & 5.3 & 5.0347 & TRN & \\
\hline CHEMBL1565541 & 688267 & 4.4 & 5.0991 & TRN & \\
\hline CHEMBL3189827 & 688267 & 4.0 & \multicolumn{2}{|c|}{5.0489999999999995} & TRN \\
\hline CHEMBL1449668 & 688267 & 5.05 & 5.0623 & TRN & \\
\hline CHEMBL1372041 & 688267 & 5.05 & 5.0099 & TRN & \\
\hline CHEMBL1413286 & 688267 & 4.05 & 5.0239 & TRN & \\
\hline CHEMBL1398268 & 688267 & 4.8 & 5.0787 & TRN & \\
\hline CHEMBL1586269 & 688267 & 4.1 & 5.0123 & TRN & \\
\hline CHEMBL1482951 & 688267 & 6.25 & 4.9962 & TRN & \\
\hline CHEMBL1334572 & 688267 & 3.95 & 5.0551 & TST & \\
\hline CHEMBL1450190 & 688267 & 6.45 & 5.0568 & TRN & \\
\hline CHEMBL1481845 & 688267 & 4.25 & 4.9922 & TRN & \\
\hline CHEMBL1481493 & 688267 & 4.25 & 4.9872 & TRN & \\
\hline CHEMBL1459706 & 688267 & 4.45 & 5.0622 & TRN & \\
\hline CHEMBL1423723 & 688267 & 4.25 & 5.0012 & TRN & \\
\hline CHEMBL1354314 & 688267 & 5.4 & 5.0443 & TRN & \\
\hline CHEMBL1346080 & 688267 & 4.45 & 5.0443 & TRN & \\
\hline CHEMBL1606149 & 688267 & 5.6 & 5.0317 & TRN & \\
\hline CHEMBL1477263 & 688267 & 5.6 & 5.0434 & TRN & \\
\hline CHEMBL1505162 & 688267 & 4.75 & 4.9978 & TRN & \\
\hline CHEMBL1577386 & 688267 & 5.4 & 5.0478 & TRN & \\
\hline CHEMBL1562755 & 688267 & 4.7 & \multicolumn{2}{|c|}{5.031000000000001} & TRN \\
\hline CHEMBL1346135 & 688267 & 5.95 & 5.0415 & TRN & \\
\hline CHEMBL1549591 & 688267 & 4.1 & 5.016 & TST & \\
\hline CHEMBL1348517 & 688267 & 5.2 & \multicolumn{2}{|c|}{5.0489999999999995} & TRN \\
\hline CHEMBL1551739 & 688267 & 5.4 & 4.981 & TRN & \\
\hline CHEMBL1412842 & 688267 & 6.0 & 5.0833 & TST & \\
\hline CHEMBL1416677 & 688267 & 4.0 & 5.1534 & TRN & \\
\hline CHEMBL1487826 & 688267 & 5.35 & 5.0293 & TRN & \\
\hline CHEMBL1426948 & 688267 & 4.6 & 5.124 & TST & \\
\hline CHEMBL1390651 & 688267 & 4.3 & 5.0471 & TRN & \\
\hline CHEMBL1599124 & 688267 & 5.0 & 5.0253 & TRN & \\
\hline CHEMBL1362209 & 688267 & 4.7 & 5.0512 & TST & \\
\hline CHEMBL1512589 & 688267 & 4.0 & 5.0785 & TRN & \\
\hline CHEMBL1498396 & 688267 & 4.0 & 5.1203 & TRN & \\
\hline CHEMBL1412409 & 688267 & 4.5 & 5.0142 & TST & \\
\hline CHEMBL1448030 & 688267 & 6.2 & 5.0756 & TRN & \\
\hline CHEMBL1393739 & 688267 & 6.15 & 4.9992 & TRN & \\
\hline CHEMBL1346033 & 688267 & 4.4 & 5.1173 & TRN & \\
\hline CHEMBL3211594 & 688267 & 4.6 & 5.0989 & TST & \\
\hline CHEMBL1507152 & 688267 & 4.05 & 5.091 & TRN & \\
\hline CHEMBL1383965 & 688267 & 5.45 & 5.0294 & TST & \\
\hline CHEMBL1430056 & 688267 & 6.2 & 5.0374 & TRN & \\
\hline \multirow[t]{2}{*}{ CHEMBL1308664 } & 688267 & 3.9 & 5.0414 & TRN & \\
\hline & & \multicolumn{4}{|c|}{ Page 18012} \\
\hline
\end{tabular}




\begin{tabular}{|c|c|c|c|c|}
\hline & & & pplement & \\
\hline CHEMBL1511674 & 688267 & 6.2 & 5.1015 & TRN \\
\hline CHEMBL1541195 & 688267 & 3.95 & 5.0298 & TST \\
\hline CHEMBL1310391 & 688267 & 5.25 & 5.0141 & TRN \\
\hline CHEMBL 279539 & 688267 & 6.2 & 4.9811 & TRN \\
\hline CHEMBL1326055 & 688267 & 4.6 & 4.9867 & TRN \\
\hline CHEMBL1482713 & 688267 & 3.95 & 5.0183 & TRN \\
\hline CHEMBL1310174 & 688267 & 5.85 & 5.1277 & TRN \\
\hline CHEMBL1316146 & 688267 & 3.95 & 5.095 & TRN \\
\hline CHEMBL1421600 & 688267 & 6.1 & 5.0919 & TRN \\
\hline CHEMBL1427838 & 688267 & 4.2 & 5.0708 & TRN \\
\hline CHEMBL1566849 & 688267 & 4.55 & 5.077 & TRN \\
\hline CHEMBL1539551 & 688267 & 4.0 & 5.0594 & TRN \\
\hline CHEMBL1411016 & 688267 & 5.05 & 5.0072 & TRN \\
\hline CHEMBL1527207 & 688267 & 4.5 & 5.0105 & TRN \\
\hline CHEMBL1315370 & 688267 & 5.35 & 5.1227 & TRN \\
\hline CHEMBL1442557 & 688267 & 3.95 & 5.0676 & TST \\
\hline CHEMBL1579310 & 688267 & 4.6 & 5.0623 & TRN \\
\hline CHEMBL1473572 & 688267 & 6.2 & 5.0338 & TRN \\
\hline CHEMBL1591991 & 688267 & 6.2 & 5.0347 & TRN \\
\hline CHEMBL1416602 & 688267 & 6.2 & 5.013 & TRN \\
\hline CHEMBL1605094 & 688267 & 4.6 & 5.0475 & TRN \\
\hline CHEMBL1449294 & 688267 & 4.1 & 5.0487 & TRN \\
\hline CHEMBL1396928 & 688267 & 3.95 & 5.0782 & TRN \\
\hline CHEMBL1319942 & 688267 & 4.0 & 5.1092 & TRN \\
\hline CHEMBL1460716 & 688267 & 4.3 & 5.0856 & TST \\
\hline CHEMBL1526596 & 688267 & 5.4 & 5.1025 & TRN \\
\hline CHEMBL1548993 & 688267 & 4.2 & 5.1306 & TRN \\
\hline CHEMBL1567465 & 688267 & 4.0 & 5.1296 & TRN \\
\hline CHEMBL1327845 & 688267 & 5.6 & 5.0398 & TRN \\
\hline CHEMBL1557765 & 688267 & 4.25 & 5.0967 & TRN \\
\hline CHEMBL1344859 & 688267 & 4.35 & 5.1009 & TRN \\
\hline CHEMBL1522516 & 688267 & 4.05 & 5.0157 & TST \\
\hline CHEMBL1537823 & 688267 & 4.25 & 5.0434 & TST \\
\hline CHEMBL1607635 & 688267 & 5.05 & 5.058 & TRN \\
\hline CHEMBL 3189268 & 688267 & 4.0 & 4.975 & TRN \\
\hline CHEMBL1372745 & 688267 & 4.05 & 5.07 & TRN \\
\hline CHEMBL1318583 & 688267 & 4.05 & 5.0877 & TRN \\
\hline CHEMBL1356478 & 688267 & 5.55 & 5.086 & TRN \\
\hline CHEMBL1579680 & 688267 & 4.6 & 5.0674 & TST \\
\hline CHEMBL 3199877 & 688267 & 6.1 & 5.0642 & TRN \\
\hline CHEMBL1423334 & 688267 & 6.25 & 5.0408 & TRN \\
\hline CHEMBL1575874 & 688267 & 5.05 & 5.1172 & TST \\
\hline CHEMBL1573595 & 688267 & 6.15 & 5.0234 & TST \\
\hline CHEMBL1468645 & 688267 & 6.15 & 5.1083 & TRN \\
\hline CHEMBL1546764 & 688267 & 4.65 & 5.0622 & TST \\
\hline CHEMBL1512779 & 688267 & 4.1 & 5.0837 & TRN \\
\hline CHEMBL1419114 & 688267 & 4.55 & 5.1479 & TRN \\
\hline CHEMBL1439199 & 688267 & 4.5 & 5.0135 & TRN \\
\hline
\end{tabular}




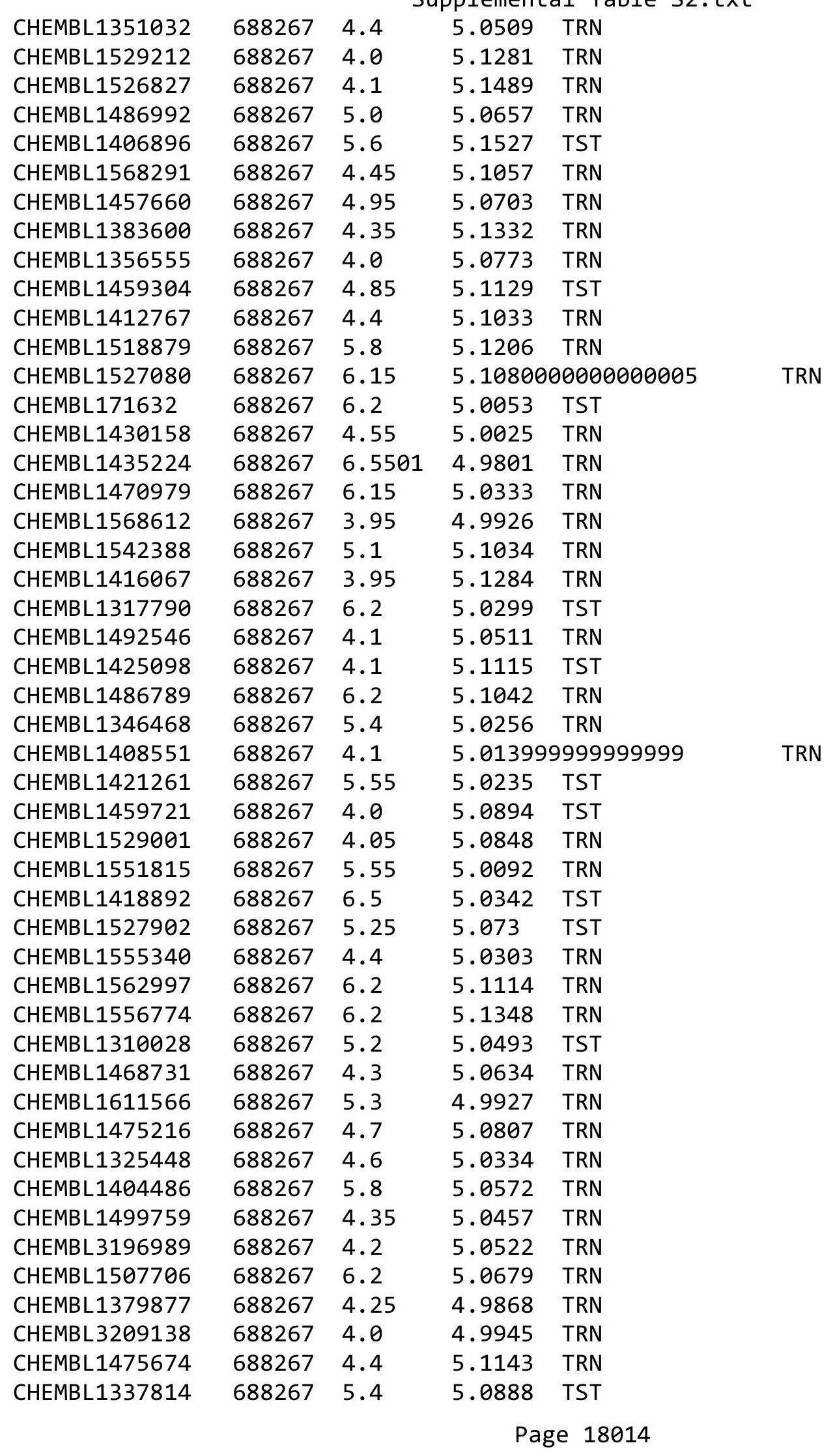




\begin{tabular}{|c|c|c|c|c|}
\hline & & & pplement & al $\mathrm{Ta}$ \\
\hline CHEMBL1576115 & 688267 & 5.6 & 5.053 & TRN \\
\hline CHEMBL1462371 & 688267 & 6.2 & 5.0872 & TST \\
\hline CHEMBL1389262 & 688267 & 4.95 & 5.0801 & TST \\
\hline CHEMBL1457567 & 688267 & 3.95 & 4.9783 & TRN \\
\hline CHEMBL1351428 & 688267 & 5.95 & 5.0346 & TRN \\
\hline CHEMBL1453616 & 688267 & 5.95 & 5.0899 & TRN \\
\hline CHEMBL1476456 & 688267 & 5.8 & 5.0663 & TRN \\
\hline CHEMBL1519724 & 688267 & 4.5 & 5.0404 & TRN \\
\hline CHEMBL1556840 & 688267 & 5.4 & 5.0015 & TST \\
\hline CHEMBL1414283 & 688267 & 5.3 & 5.1076 & TRN \\
\hline CHEMBL1426874 & 688267 & 4.05 & 5.0261 & TST \\
\hline CHEMBL1465850 & 688267 & 5.55 & 5.0136 & TRN \\
\hline CHEMBL1565001 & 688267 & 4.2 & 5.0736 & TRN \\
\hline CHEMBL1512646 & 688267 & 4.0 & 5.0226 & TRN \\
\hline CHEMBL1372553 & 688267 & 4.4 & 4.9932 & TST \\
\hline CHEMBL1335495 & 688267 & 5.85 & 5.1173 & TST \\
\hline CHEMBL1567345 & 688267 & 5.15 & 5.0968 & TST \\
\hline CHEMBL1454725 & 688267 & 5.85 & 5.0861 & TST \\
\hline CHEMBL1467835 & 688267 & 3.95 & 5.1343 & TRN \\
\hline CHEMBL1512356 & 688267 & 6.2 & 5.1074 & TRN \\
\hline CHEMBL1481701 & 688267 & 4.25 & 5.0156 & TRN \\
\hline CHEMBL1344188 & 688267 & 5.35 & 5.0248 & TST \\
\hline CHEMBL1434160 & 688267 & 5.8 & 5.0589 & TRN \\
\hline CHEMBL1569586 & 688267 & 4.4 & 5.0841 & TRN \\
\hline CHEMBL1476598 & 688267 & 4.0 & 5.0867 & TRN \\
\hline CHEMBL1355198 & 688267 & 5.6 & 5.0292 & TRN \\
\hline CHEMBL1359211 & 688267 & 5.0 & 5.0761 & TRN \\
\hline CHEMBL1580343 & 688267 & 5.3 & 5.0346 & TST \\
\hline CHEMBL1461924 & 688267 & 6.1 & 5.1053 & TRN \\
\hline CHEMBL1453825 & 688267 & 5.6 & 5.0131 & TRN \\
\hline CHEMBL1382548 & 688267 & 6.15 & 5.0979 & TRN \\
\hline CHEMBL1395502 & 688267 & 4.05 & 5.0375 & TRN \\
\hline CHEMBL1610104 & 688267 & 4.4 & 5.0631 & TRN \\
\hline CHEMBL1589156 & 688267 & 5.5 & 5.0884 & TST \\
\hline CHEMBL1306601 & 688267 & 6.2 & 5.0928 & TRN \\
\hline CHEMBL1439633 & 688267 & 3.95 & 5.0865 & TRN \\
\hline CHEMBL1305734 & 688267 & 4.3 & 5.0096 & TRN \\
\hline CHEMBL3192860 & 688267 & 6.2 & 5.0168 & TRN \\
\hline CHEMBL1562040 & 688267 & 6.5 & 5.0074 & TRN \\
\hline CHEMBL1588331 & 688267 & 5.95 & 5.0497 & TRN \\
\hline CHEMBL1441261 & 688267 & 4.3 & 5.0752 & TRN \\
\hline CHEMBL1376382 & 688267 & 4.0 & 5.0955 & TRN \\
\hline CHEMBL1571405 & 688267 & 4.0 & 5.0221 & TST \\
\hline CHEMBL1559931 & 688267 & 6.15 & 5.047 & TRN \\
\hline CHEMBL1363208 & 688267 & 5.25 & 5.0778 & TRN \\
\hline CHEMBL1545116 & 688267 & 4.55 & 5.0048 & TRN \\
\hline CHEMBL1427328 & 688267 & 6.2 & 5.0924 & TRN \\
\hline CHEMBL1537462 & 688267 & 4.0 & 5.0609 & TRN \\
\hline
\end{tabular}




\begin{tabular}{|c|c|c|c|c|}
\hline & & & pplement & al $\mathrm{Ta}$ \\
\hline CHEMBL1518006 & 688267 & 6.2 & 5.0242 & TRN \\
\hline CHEMBL1538390 & 688267 & 5.6 & 5.0808 & TRN \\
\hline CHEMBL1374375 & 688267 & 4.1 & 5.0447 & TRN \\
\hline CHEMBL1524941 & 688267 & 5.95 & 5.0732 & TST \\
\hline CHEMBL1581216 & 688267 & 4.35 & 5.0121 & TST \\
\hline CHEMBL491747 & 688267 & 4.2 & 5.0869 & TRN \\
\hline CHEMBL1460688 & 688267 & 6.25 & 5.1059 & TST \\
\hline CHEMBL1345071 & 688267 & 6.2 & 5.0132 & TRN \\
\hline CHEMBL1423482 & 688267 & 6.3 & 5.0022 & TRN \\
\hline CHEMBL1399308 & 688267 & 3.95 & 5.1404 & TRN \\
\hline CHEMBL1464595 & 688267 & 6.0 & 4.9992 & TRN \\
\hline CHEMBL1365227 & 688267 & 6.5 & 5.1049 & TRN \\
\hline CHEMBL1332256 & 688267 & 3.95 & 5.0772 & TRN \\
\hline CHEMBL1348754 & 688267 & 6.15 & 5.0593 & TST \\
\hline CHEMBL1574417 & 688267 & 4.5 & 5.0496 & TST \\
\hline CHEMBL1393735 & 688267 & 4.1 & 5.0951 & TST \\
\hline CHEMBL1576977 & 688267 & 6.15 & 5.001 & TRN \\
\hline CHEMBL1608979 & 688267 & 4.0 & 5.06 & TST \\
\hline CHEMBL1420812 & 688267 & 5.8 & 5.0182 & TRN \\
\hline CHEMBL1366122 & 688267 & 6.2 & 5.0348 & TRN \\
\hline CHEMBL1385733 & 688267 & 6.15 & 5.0265 & TRN \\
\hline CHEMBL1534543 & 688267 & 5.45 & 5.0365 & TRN \\
\hline CHEMBL1448621 & 688267 & 4.05 & 5.1015 & TRN \\
\hline CHEMBL1592381 & 688267 & 5.7 & 5.043 & TRN \\
\hline CHEMBL1321061 & 688267 & 4.9 & 5.0504 & TRN \\
\hline CHEMBL1339982 & 688267 & 6.2 & 5.0193 & TRN \\
\hline CHEMBL1306951 & 688267 & 5.8 & 5.102 & TRN \\
\hline CHEMBL1455623 & 688267 & 4.25 & 5.0319 & TRN \\
\hline CHEMBL1423627 & 688267 & 4.85 & 5.1473 & TRN \\
\hline CHEMBL1486056 & 688267 & 5.4 & 5.0854 & TRN \\
\hline CHEMBL1385843 & 688267 & 4.4 & 5.0381 & TRN \\
\hline CHEMBL1451618 & 688267 & 4.25 & 5.0781 & TRN \\
\hline CHEMBL1488003 & 688267 & 5.55 & 5.0292 & TRN \\
\hline CHEMBL1403419 & 688267 & 5.15 & 5.0603 & TRN \\
\hline CHEMBL1528657 & 688267 & 5.45 & 5.0213 & TRN \\
\hline CHEMBL1484589 & 688267 & 4.65 & 5.0842 & TRN \\
\hline CHEMBL1471993 & 688267 & 4.1 & 5.0409 & TRN \\
\hline CHEMBL1375157 & 688267 & 5.8 & 5.0144 & TRN \\
\hline CHEMBL1306933 & 688267 & 5.45 & 5.0366 & TRN \\
\hline CHEMBL1497082 & 688267 & 4.3 & 5.0457 & TRN \\
\hline CHEMBL1417743 & 688267 & 5.45 & 5.0476 & TRN \\
\hline CHEMBL1329347 & 688267 & 4.0 & 5.0177 & TRN \\
\hline CHEMBL1604870 & 688267 & 4.0 & 5.0381 & TRN \\
\hline CHEMBL1465603 & 688267 & 5.3 & 5.1058 & TRN \\
\hline CHEMBL1469319 & 688267 & 5.3 & 5.1668 & TST \\
\hline CHEMBL1363104 & 688267 & 6.15 & 4.9942 & TST \\
\hline CHEMBL1314694 & 688267 & 4.05 & 5.0143 & TRN \\
\hline CHEMBL1307878 & 688267 & 5.35 & 5.0535 & TRN \\
\hline
\end{tabular}




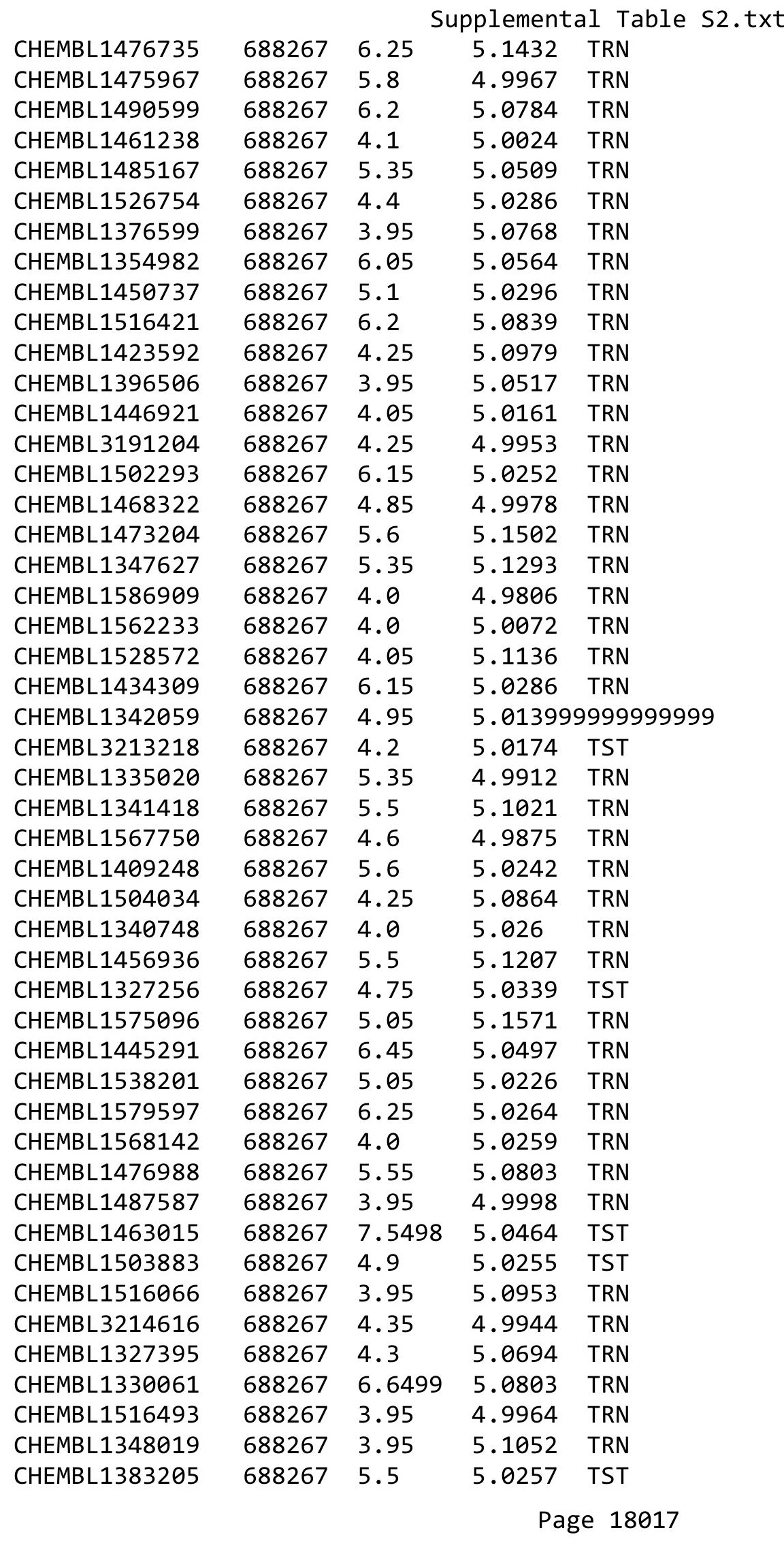




\begin{tabular}{|c|c|c|c|c|c|}
\hline \\
\hline CHEMBL1458022 & 688267 & 4.0 & 5.0171 & TST & \\
\hline CHEMBL1489354 & 688267 & 5.1 & 5.0755 & TRN & \\
\hline CHEMBL1521273 & 688267 & 6.15 & 5.026 & TRN & \\
\hline CHEMBL1478898 & 688267 & 4.05 & 5.1726 & TRN & \\
\hline CHEMBL1483632 & 688267 & 6.2 & 5.0363 & TRN & \\
\hline CHEMBL1380274 & 688267 & 5.35 & 5.0146 & TRN & \\
\hline CHEMBL1418262 & 688267 & 4.4 & 5.0902 & TRN & \\
\hline CHEMBL1551955 & 688267 & 6.2 & 5.1186 & TRN & \\
\hline CHEMBL3194581 & 688267 & 4.9 & 4.9816 & TST & \\
\hline CHEMBL1450989 & 688267 & 4.4 & 5.0303 & TRN & \\
\hline CHEMBL1490232 & 688267 & 4.1 & 5.0438 & TRN & \\
\hline CHEMBL1438657 & 688267 & 4.3 & 5.041 & TST & \\
\hline CHEMBL1442194 & 688267 & 4.35 & 5.0696 & TRN & \\
\hline CHEMBL1571214 & 688267 & 6.2 & 4.9741 & TST & \\
\hline CHEMBL1424461 & 688267 & 6.25 & 5.0198 & TRN & \\
\hline CHEMBL1526711 & 688267 & 4.15 & 5.1301 & TST & \\
\hline CHEMBL1613618 & 688267 & 3.95 & 5.0626 & TRN & \\
\hline CHEMBL3193665 & 688267 & 5.5 & 5.0323 & TRN & \\
\hline CHEMBL1411017 & 688267 & 4.35 & 5.06 & TRN & \\
\hline CHEMBL1334738 & 688267 & 6.2 & 5.0439 & TRN & \\
\hline CHEMBL567861 & 688267 & 6.1 & 5.0673 & TRN & \\
\hline CHEMBL1382994 & 688267 & 3.95 & 5.0701 & TRN & \\
\hline CHEMBL1603310 & 688267 & 5.4 & 5.0172 & TRN & \\
\hline CHEMBL1574005 & 688267 & 5.2 & 5.0365 & TRN & \\
\hline CHEMBL1456168 & 688267 & 4.5 & 5.0973 & TST & \\
\hline CHEMBL1498217 & 688267 & 5.5 & 5.0758 & TST & \\
\hline CHEMBL1550191 & 688267 & 6.45 & 5.0377 & TRN & \\
\hline CHEMBL1399262 & 688267 & 5.25 & 5.095 & TRN & \\
\hline CHEMBL1306627 & 688267 & 6.2 & 5.09399 & 9999999999 & TRN \\
\hline CHEMBL1500814 & 688267 & 4.0 & 5.0599 & TRN & \\
\hline CHEMBL1449544 & 688267 & 6.0 & 5.0718 & TRN & \\
\hline CHEMBL1498906 & 688267 & 4.35 & 5.0406 & TRN & \\
\hline CHEMBL1570850 & 688267 & 5.35 & 5.0214 & TRN & \\
\hline CHEMBL1432156 & 688267 & 5.95 & 5.0138 & TRN & \\
\hline CHEMBL1456507 & 688267 & 6.2 & 5.0591 & TRN & \\
\hline CHEMBL1406204 & 688267 & 5.8 & 5.0036 & TST & \\
\hline CHEMBL1302389 & 688267 & 5.3 & 5.034 & TRN & \\
\hline CHEMBL1497476 & 688267 & 5.9 & 5.05399 & 9999999999 & TRN \\
\hline CHEMBL1408405 & 688267 & 6.2 & 5.0827 & TST & \\
\hline CHEMBL1436166 & 688267 & 6.5 & 5.0373 & TRN & \\
\hline CHEMBL1314683 & 688267 & 6.2 & 5.1344 & TRN & \\
\hline CHEMBL1410347 & 688267 & 6.2 & 5.1005 & TST & \\
\hline CHEMBL1328946 & 688267 & 5.2 & 4.9799 & TRN & \\
\hline CHEMBL1307475 & 688267 & 6.15 & 5.1056 & TRN & \\
\hline CHEMBL1538361 & 688267 & 4.65 & 5.0952 & TST & \\
\hline CHEMBL1368325 & 688267 & 6.25 & 5.1128 & TST & \\
\hline CHEMBL1541290 & 688267 & 4.1 & 5.074 & TST & \\
\hline CHEMBL1310582 & 688267 & 4.35 & 5.0521 & TST & \\
\hline
\end{tabular}




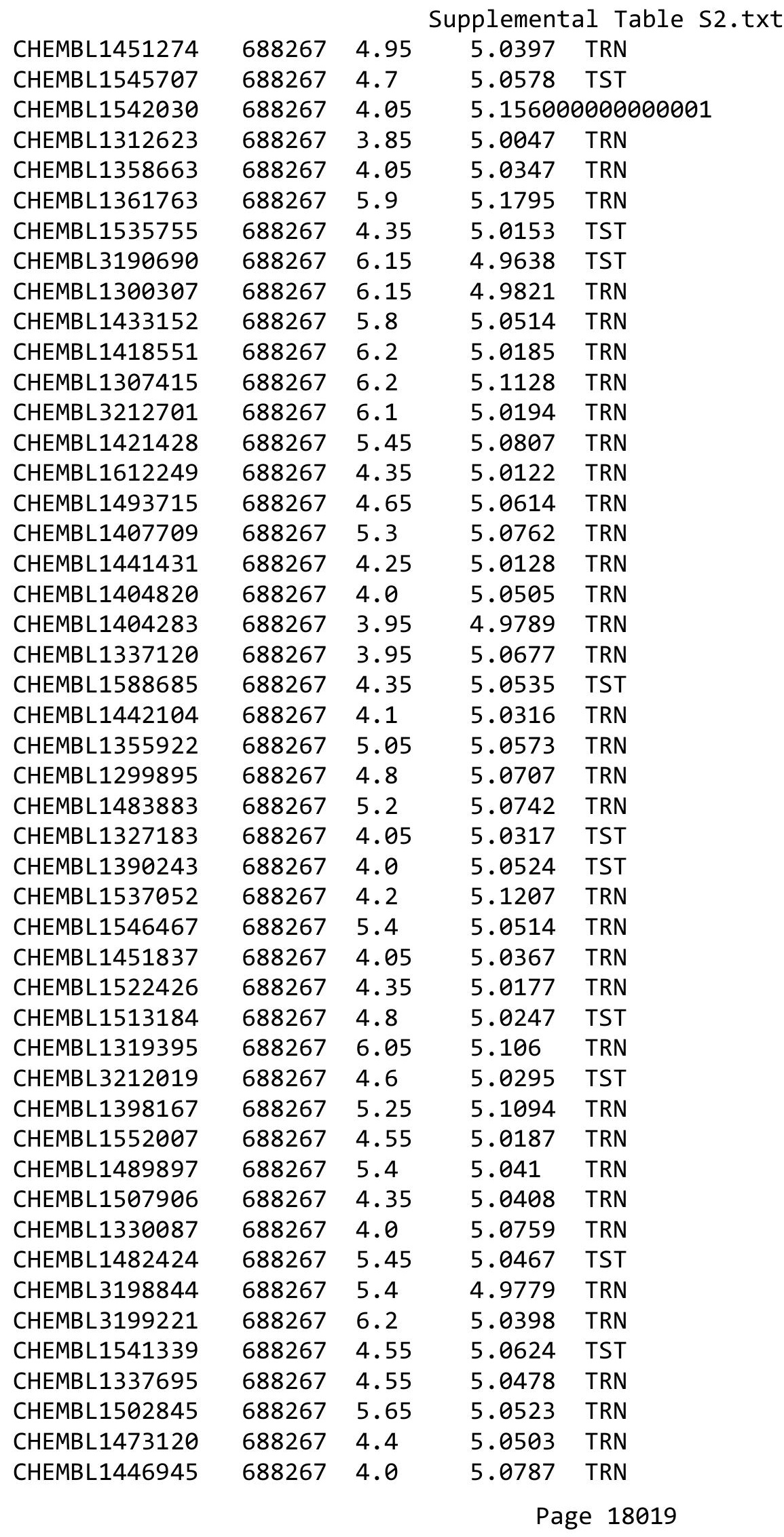

TRN 


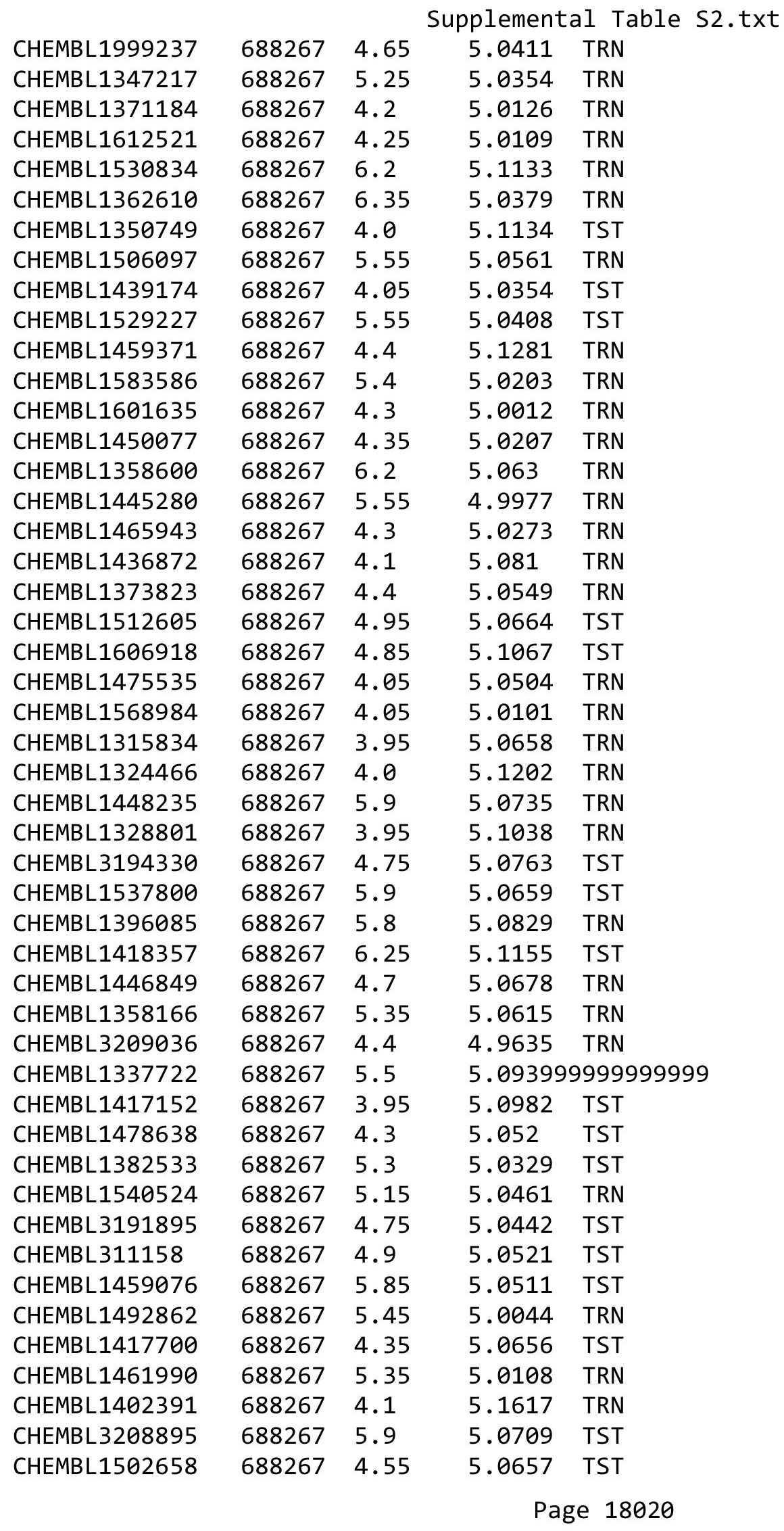




\begin{tabular}{|c|c|c|c|c|}
\hline & & & pplement & $\mathrm{Ta}$ \\
\hline CHEMBL1703256 & 688267 & 4.5 & 5.013 & TRN \\
\hline CHEMBL1436990 & 688267 & 4.9 & 5.1031 & TRN \\
\hline CHEMBL1302168 & 688267 & 6.2 & 5.0165 & TRN \\
\hline CHEMBL1363963 & 688267 & 6.15 & 5.0783 & TRN \\
\hline CHEMBL3191760 & 688267 & 4.35 & 5.0163 & TRN \\
\hline CHEMBL1537361 & 688267 & 5.35 & 5.0963 & TRN \\
\hline CHEMBL1409778 & 688267 & 5.65 & 5.0875 & TRN \\
\hline CHEMBL1486788 & 688267 & 4.05 & 5.0975 & TRN \\
\hline CHEMBL1358027 & 688267 & 4.0 & 5.0283 & TRN \\
\hline CHEMBL1568082 & 688267 & 5.05 & 5.0631 & TRN \\
\hline CHEMBL1361476 & 688267 & 4.2 & 5.0441 & TRN \\
\hline CHEMBL1399695 & 688267 & 5.65 & 5.0777 & TRN \\
\hline CHEMBL1489647 & 688267 & 4.0 & 5.105 & TRN \\
\hline CHEMBL1373157 & 688267 & 5.3 & 5.0474 & TRN \\
\hline CHEMBL1580067 & 688267 & 6.2 & 5.1019 & TRN \\
\hline CHEMBL1536171 & 688267 & 6.25 & 5.0309 & TRN \\
\hline CHEMBL1580060 & 688267 & 4.25 & 5.091 & TST \\
\hline CHEMBL1389684 & 688267 & 5.6 & 5.0386 & TST \\
\hline CHEMBL1363131 & 688267 & 4.2 & 5.0358 & TRN \\
\hline CHEMBL1420119 & 688267 & 5.3 & 5.019 & TST \\
\hline CHEMBL1472155 & 688267 & 5.8 & 5.0263 & TST \\
\hline CHEMBL1529113 & 688267 & 4.0 & 5.0573 & TRN \\
\hline CHEMBL1457941 & 688267 & 5.65 & 5.0221 & TRN \\
\hline CHEMBL1356249 & 688267 & 5.2 & 5.0294 & TRN \\
\hline CHEMBL1593215 & 688267 & 4.6 & 5.0892 & TRN \\
\hline CHEMBL1310900 & 688267 & 5.9 & 5.0827 & TRN \\
\hline CHEMBL1385678 & 688267 & 5.2 & 5.0577 & TST \\
\hline CHEMBL1383293 & 688267 & 6.2 & 5.0429 & TRN \\
\hline CHEMBL1365274 & 688267 & 5.3 & 5.0458 & TRN \\
\hline CHEMBL1412835 & 688267 & 3.95 & 5.0725 & TRN \\
\hline CHEMBL1456852 & 688267 & 5.4 & 5.0879 & TRN \\
\hline CHEMBL595331 & 688267 & 4.05 & 5.1071 & TRN \\
\hline CHEMBL1419515 & 688267 & 6.25 & 5.1332 & TRN \\
\hline CHEMBL1563275 & 688267 & 4.8 & 5.0678 & TRN \\
\hline CHEMBL1386502 & 688267 & 5.55 & 5.0985 & TRN \\
\hline CHEMBL1501650 & 688267 & 5.85 & 4.9922 & TST \\
\hline CHEMBL3191295 & 688267 & 5.95 & 4.9773 & TRN \\
\hline CHEMBL1536023 & 688267 & 6.1 & 5.0727 & TRN \\
\hline CHEMBL1490116 & 688267 & 4.4 & 4.9715 & TRN \\
\hline CHEMBL1439076 & 688267 & 5.5 & 5.0406 & TRN \\
\hline CHEMBL3194286 & 688267 & 6.05 & 4.9744 & TST \\
\hline CHEMBL1440296 & 688267 & 5.85 & 5.0344 & TRN \\
\hline CHEMBL1335115 & 688267 & 5.6 & 5.1023 & TRN \\
\hline CHEMBL1540598 & 688267 & 4.0 & 5.0579 & TRN \\
\hline CHEMBL1396804 & 688267 & 5.95 & 5.038 & TRN \\
\hline CHEMBL1482124 & 688267 & 5.05 & 5.0693 & TRN \\
\hline CHEMBL1551489 & 688267 & 5.0 & 5.148 & TRN \\
\hline CHEMBL1426351 & 688267 & 4.0 & 5.0913 & TST \\
\hline
\end{tabular}




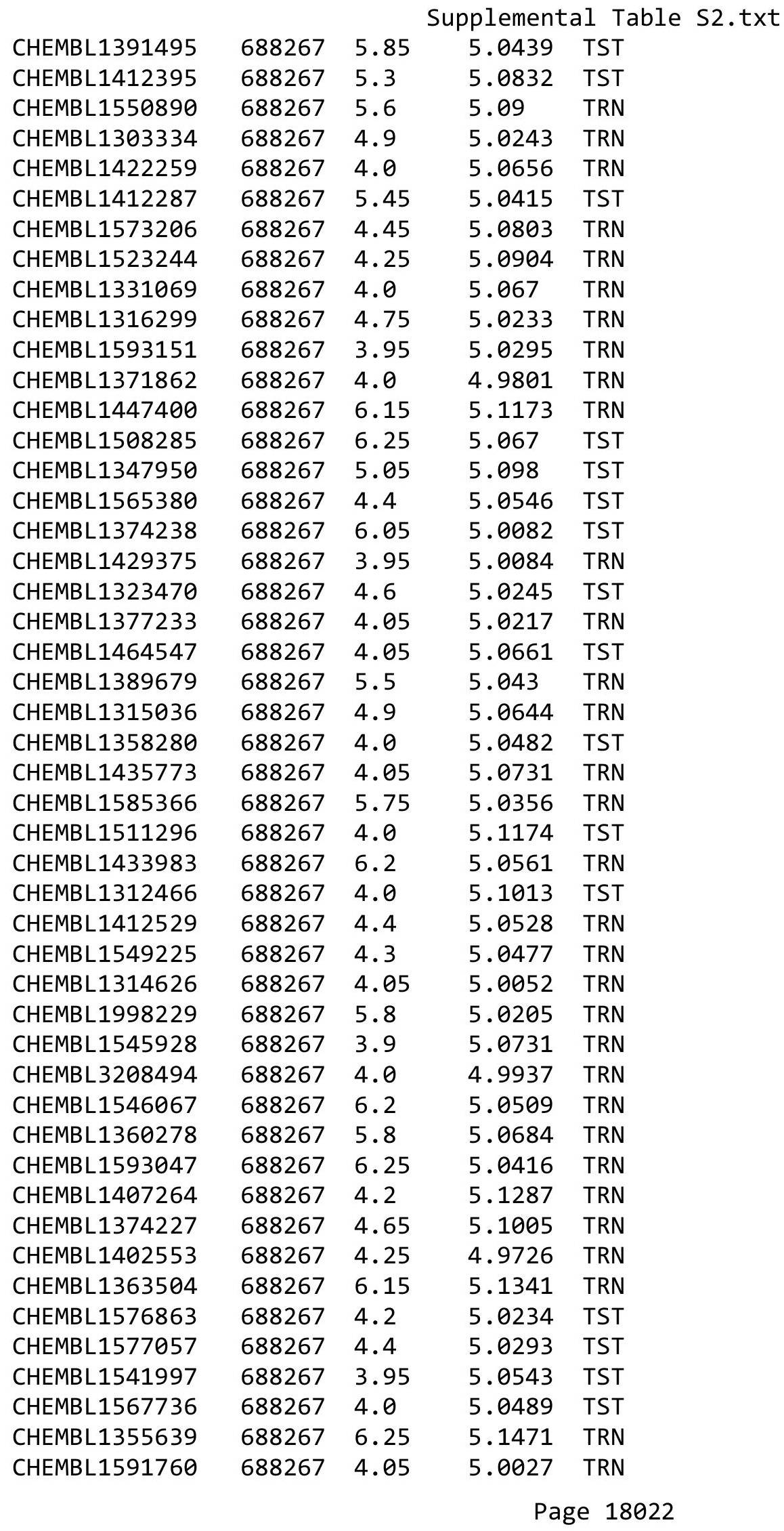




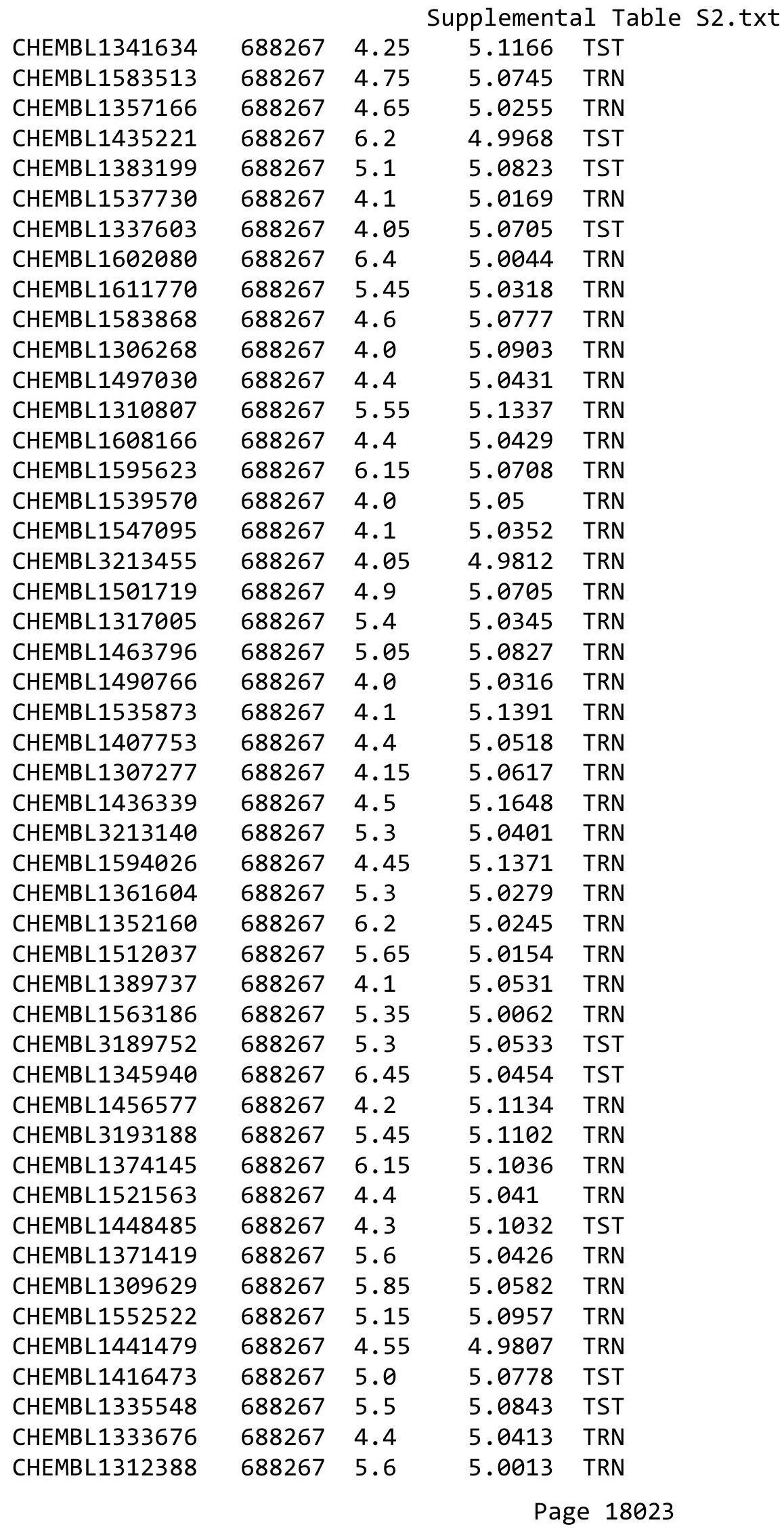




\begin{tabular}{|c|c|c|c|c|}
\hline \multicolumn{5}{|c|}{ Supplemental Table S2.txt } \\
\hline CHEMBL1512127 & 688267 & 5.25 & 5.0919 & TRN \\
\hline CHEMBL1577042 & 688267 & 5.35 & 5.1057 & TRN \\
\hline CHEMBL1433934 & 688267 & 4.25 & 5.0426 & TRN \\
\hline CHEMBL1572677 & 688267 & 5.5 & 5.0184 & TRN \\
\hline CHEMBL1565449 & 688267 & 6.2 & 5.0315 & TRN \\
\hline CHEMBL1476353 & 688267 & 5.65 & 5.1027 & TRN \\
\hline CHEMBL406120 & 688267 & 5.45 & 5.0502 & TST \\
\hline CHEMBL1420771 & 688267 & 5.85 & 5.0379 & TRN \\
\hline CHEMBL1370310 & 688267 & 4.35 & 5.0586 & TST \\
\hline CHEMBL1974063 & 688267 & 4.35 & 4.9795 & TST \\
\hline CHEMBL1465972 & 688267 & 5.0 & 5.0623 & TST \\
\hline CHEMBL1581424 & 688267 & 5.5 & 5.1003 & TRN \\
\hline CHEMBL1453579 & 688267 & 6.2 & 5.0951 & TRN \\
\hline CHEMBL1553988 & 688267 & 6.15 & 5.0545 & TRN \\
\hline CHEMBL1303273 & 688267 & 4.6 & 5.072 & TRN \\
\hline CHEMBL1378946 & 688267 & 4.05 & 5.0937 & TRN \\
\hline CHEMBL1439145 & 688267 & 5.55 & 5.0094 & TRN \\
\hline CHEMBL1466796 & 688267 & 4.35 & 5.0082 & TST \\
\hline CHEMBL1419883 & 688267 & 5.0 & 5.0982 & TST \\
\hline CHEMBL1504400 & 688267 & 5.15 & 5.0276 & TRN \\
\hline CHEMBL1544259 & 688267 & 4.4 & 5.0668 & TST \\
\hline CHEMBL1336275 & 688267 & 4.7 & 5.0772 & TRN \\
\hline CHEMBL1600504 & 688267 & 4.3 & 5.0012 & TST \\
\hline CHEMBL1345314 & 688267 & 5.5 & 5.0495 & TST \\
\hline CHEMBL1336476 & 688267 & 4.05 & 5.0265 & TRN \\
\hline CHEMBL1571617 & 688267 & 5.85 & 5.1312 & TRN \\
\hline CHEMBL1414414 & 688267 & 4.0 & 5.0159 & TRN \\
\hline CHEMBL595840 & 688267 & 5.1 & 5.008 & TST \\
\hline CHEMBL70141 & 688267 & 4.9 & 5.0059 & TST \\
\hline CHEMBL1432267 & 688267 & 4.5 & 5.067 & TST \\
\hline CHEMBL1601067 & 688267 & 4.0 & 5.1331 & TRN \\
\hline CHEMBL1435866 & 688267 & 5.85 & 5.1294 & TST \\
\hline CHEMBL1374846 & 688267 & 5.15 & 5.0376 & TRN \\
\hline CHEMBL1550580 & 688267 & 4.55 & 5.0305 & TRN \\
\hline CHEMBL1408137 & 688267 & 6.2 & 5.0811 & TRN \\
\hline CHEMBL1469093 & 688267 & 5.6 & 5.072 & TST \\
\hline CHEMBL1595728 & 688267 & 4.0 & 5.0497 & TRN \\
\hline CHEMBL1609412 & 688267 & 5.4 & 5.098 & TRN \\
\hline CHEMBL1576707 & 688267 & 4.55 & 5.0984 & TST \\
\hline CHEMBL1519203 & 688267 & 5.1 & 5.0726 & TRN \\
\hline CHEMBL1564139 & 688267 & 4.0 & 5.1398 & TST \\
\hline CHEMBL1447032 & 688267 & 5.5 & 5.0054 & TRN \\
\hline CHEMBL1407605 & 688267 & 4.05 & 4.985 & TRN \\
\hline CHEMBL1492156 & 688267 & 6.5 & 5.0772 & TRN \\
\hline CHEMBL1489412 & 688267 & 4.8 & 5.0656 & TST \\
\hline CHEMBL1306437 & 688267 & 5.3 & 5.0331 & TRN \\
\hline CHEMBL1555673 & 688267 & 6.15 & 5.0217 & TRN \\
\hline CHEMBL1325603 & 688267 & 6.15 & 5.1134 & TRN \\
\hline
\end{tabular}




\begin{tabular}{|c|c|c|c|c|c|}
\hline \\
\hline CHEMBL597047 & 688267 & 4.1 & 5.0131 & TST & \\
\hline CHEMBL1378614 & 688267 & 5.35 & 5.1543 & TST & \\
\hline CHEMBL1597148 & 688267 & 5.4 & 5.0312 & TRN & \\
\hline CHEMBL1605733 & 688267 & 5.3 & 4.975 & TST & \\
\hline CHEMBL1351568 & 688267 & 4.05 & 5.0868 & TRN & \\
\hline CHEMBL1550485 & 688267 & 4.0 & 5.0176 & TRN & \\
\hline CHEMBL1323597 & 688267 & 5.35 & 5.1044 & TRN & \\
\hline CHEMBL1488732 & 688267 & 4.3 & 5.1083 & TRN & \\
\hline CHEMBL1356434 & 688267 & 4.55 & 5.0739 & TST & \\
\hline CHEMBL1343354 & 688267 & 5.45 & 5.0369 & TRN & \\
\hline CHEMBL1396629 & 688267 & 4.55 & 5.0649 & TRN & \\
\hline CHEMBL1525671 & 688267 & 4.5 & 5.047 & TST & \\
\hline CHEMBL1494100 & 688267 & 4.5 & 5.0209 & TRN & \\
\hline CHEMBL2369189 & 688267 & 4.0 & 5.0011 & TST & \\
\hline CHEMBL1300776 & 688267 & 4.6 & 5.0714 & TRN & \\
\hline CHEMBL1560005 & 688267 & 4.9 & 5.0222 & TST & \\
\hline CHEMBL1420071 & 688267 & 6.6499 & 5.0898 & TRN & \\
\hline CHEMBL1486730 & 688267 & 5.55 & 5.0308 & TRN & \\
\hline CHEMBL1489965 & 688267 & 4.55 & 5.0334 & TST & \\
\hline CHEMBL1428674 & 688267 & 6.5 & 5.0767 & TRN & \\
\hline CHEMBL 2374051 & 688267 & 5.5 & 5.0325 & TRN & \\
\hline CHEMBL1487101 & 688267 & 4.55 & 5.0948 & TRN & \\
\hline CHEMBL1485999 & 688267 & 6.15 & 5.0031 & TST & \\
\hline CHEMBL415959 & 688267 & 6.05 & 5.0231 & TST & \\
\hline CHEMBL1526717 & 688267 & 4.8 & 5.0356 & TRN & \\
\hline CHEMBL1534430 & 688267 & 6.2 & 5.0906 & TRN & \\
\hline CHEMBL1348625 & 688267 & 4.3 & 5.0209 & TRN & \\
\hline CHEMBL1366036 & 688267 & 6.1 & 5.0179 & TRN & \\
\hline CHEMBL1303457 & 688267 & 4.0 & 5.03600 & 00000000005 & TRN \\
\hline CHEMBL1449381 & 688267 & 6.25 & 5.0491 & TST & \\
\hline CHEMBL1444404 & 688267 & 3.95 & 5.0269 & TST & \\
\hline CHEMBL602219 & 688267 & 6.25 & 5.0499 & TRN & \\
\hline CHEMBL1487254 & 688267 & 4.75 & 5.0816 & TST & \\
\hline CHEMBL1463936 & 688267 & 5.4 & 5.0822 & TRN & \\
\hline CHEMBL1371475 & 688267 & 4.0 & 5.1029 & TST & \\
\hline CHEMBL1590575 & 688267 & 6.1 & 5.0297 & TRN & \\
\hline CHEMBL1435019 & 688267 & 6.45 & 5.0303 & TRN & \\
\hline CHEMBL1445284 & 688267 & 4.35 & 5.0935 & TRN & \\
\hline CHEMBL1578176 & 688267 & 4.0 & 5.0897 & TRN & \\
\hline CHEMBL1398170 & 688267 & 6.15 & 5.0463 & TST & \\
\hline CHEMBL1309836 & 688267 & 5.75 & 5.01 & TST & \\
\hline CHEMBL3212864 & 688267 & 5.65 & 5.0658 & TRN & \\
\hline CHEMBL1351472 & 688267 & 5.6 & 5.0854 & TRN & \\
\hline CHEMBL1302937 & 688267 & 4.45 & 5.0608 & TRN & \\
\hline CHEMBL1349536 & 688267 & 6.15 & 5.0205 & TRN & \\
\hline CHEMBL1523643 & 688267 & 5.9 & 5.0451 & TRN & \\
\hline CHEMBL1477474 & 688267 & 6.15 & 5.0246 & TRN & \\
\hline CHEMBL1439838 & 688267 & 6.2 & 5.0599 & TRN & \\
\hline
\end{tabular}




\begin{tabular}{|c|c|c|c|c|}
\hline & & & pplement & $d \perp$ \\
\hline CHEMBL1311784 & 688267 & 4.5 & 5.1028 & TST \\
\hline CHEMBL 3214282 & 688267 & 6.2 & 5.1022 & TRN \\
\hline CHEMBL1503862 & 688267 & 4.3 & 5.1057 & TRN \\
\hline CHEMBL1343931 & 688267 & 4.0 & 5.1211 & TST \\
\hline CHEMBL1475114 & 688267 & 6.2 & 4.9678 & TRN \\
\hline CHEMBL1333217 & 688267 & 6.2 & 5.0972 & TRN \\
\hline CHEMBL1383190 & 688267 & 4.2 & 5.0447 & TST \\
\hline CHEMBL1511416 & 688267 & 5.6 & 5.0348 & TRN \\
\hline CHEMBL1480721 & 688267 & 5.6 & 5.0252 & TST \\
\hline CHEMBL1326376 & 688267 & 4.5 & 5.0995 & TRN \\
\hline CHEMBL1586839 & 688267 & 4.0 & 5.0568 & TRN \\
\hline CHEMBL1514400 & 688267 & 5.45 & 5.0558 & TRN \\
\hline CHEMBL1326582 & 688267 & 4.05 & 5.0509 & TST \\
\hline CHEMBL1424346 & 688267 & 5.35 & 5.0273 & TST \\
\hline CHEMBL1514556 & 688267 & 5.35 & 5.0234 & TRN \\
\hline CHEMBL1484495 & 688267 & 4.7 & 5.0939 & TST \\
\hline CHEMBL1576030 & 688267 & 5.4 & 5.0487 & TST \\
\hline CHEMBL1413851 & 688267 & 4.0 & 5.0876 & TST \\
\hline CHEMBL1449269 & 688267 & 5.35 & 5.0281 & TRN \\
\hline CHEMBL1346559 & 688267 & 5.5 & 5.015 & TRN \\
\hline CHEMBL1345485 & 688267 & 4.05 & 5.0376 & TST \\
\hline CHEMBL1431892 & 688267 & 4.25 & 5.052 & TST \\
\hline CHEMBL3208381 & 688267 & 5.2 & 5.0254 & TRN \\
\hline CHEMBL534353 & 688267 & 4.6 & 5.0216 & TRN \\
\hline CHEMBL1551696 & 688267 & 4.0 & 5.0379 & TRN \\
\hline CHEMBL1542714 & 688267 & 5.4 & 5.0528 & TRN \\
\hline CHEMBL1036 & 688267 & 7.4001 & 5.0971 & TST \\
\hline CHEMBL1431810 & 688267 & 4.7 & 4.9829 & TST \\
\hline CHEMBL1365310 & 688267 & 5.2 & 5.0146 & TRN \\
\hline CHEMBL1601412 & 688267 & 4.4 & 4.9818 & TRN \\
\hline CHEMBL1602425 & 688267 & 4.75 & 5.0387 & TRN \\
\hline CHEMBL1380015 & 688267 & 6.2 & 5.0563 & TRN \\
\hline CHEMBL1489241 & 688267 & 6.2 & 5.0654 & TRN \\
\hline CHEMBL1376332 & 688267 & 4.65 & 5.0322 & TRN \\
\hline CHEMBL1391121 & 688267 & 4.05 & 5.0638 & TRN \\
\hline CHEMBL1406761 & 688267 & 5.5 & 5.0179 & TRN \\
\hline CHEMBL1361021 & 688267 & 3.95 & 5.082 & TRN \\
\hline CHEMBL1575020 & 688267 & 6.15 & 5.0817 & TRN \\
\hline CHEMBL1455187 & 688267 & 3.95 & 4.9929 & TRN \\
\hline CHEMBL1372446 & 688267 & 4.0 & 5.0437 & TRN \\
\hline CHEMBL1486729 & 688267 & 4.0 & 5.0564 & TST \\
\hline CHEMBL1353976 & 688267 & 4.0 & 5.0347 & TRN \\
\hline CHEMBL1498933 & 688267 & 3.95 & 5.0595 & TST \\
\hline CHEMBL 244328 & 688267 & 5.0 & 5.0625 & TRN \\
\hline CHEMBL1571213 & 688267 & 6.15 & 5.0723 & TRN \\
\hline CHEMBL1588284 & 688267 & 4.75 & 5.0389 & TRN \\
\hline CHEMBL1494270 & 688267 & 5.1 & 5.1056 & TRN \\
\hline CHEMBL1377641 & 688267 & 4.4 & 5.0544 & TRN \\
\hline
\end{tabular}




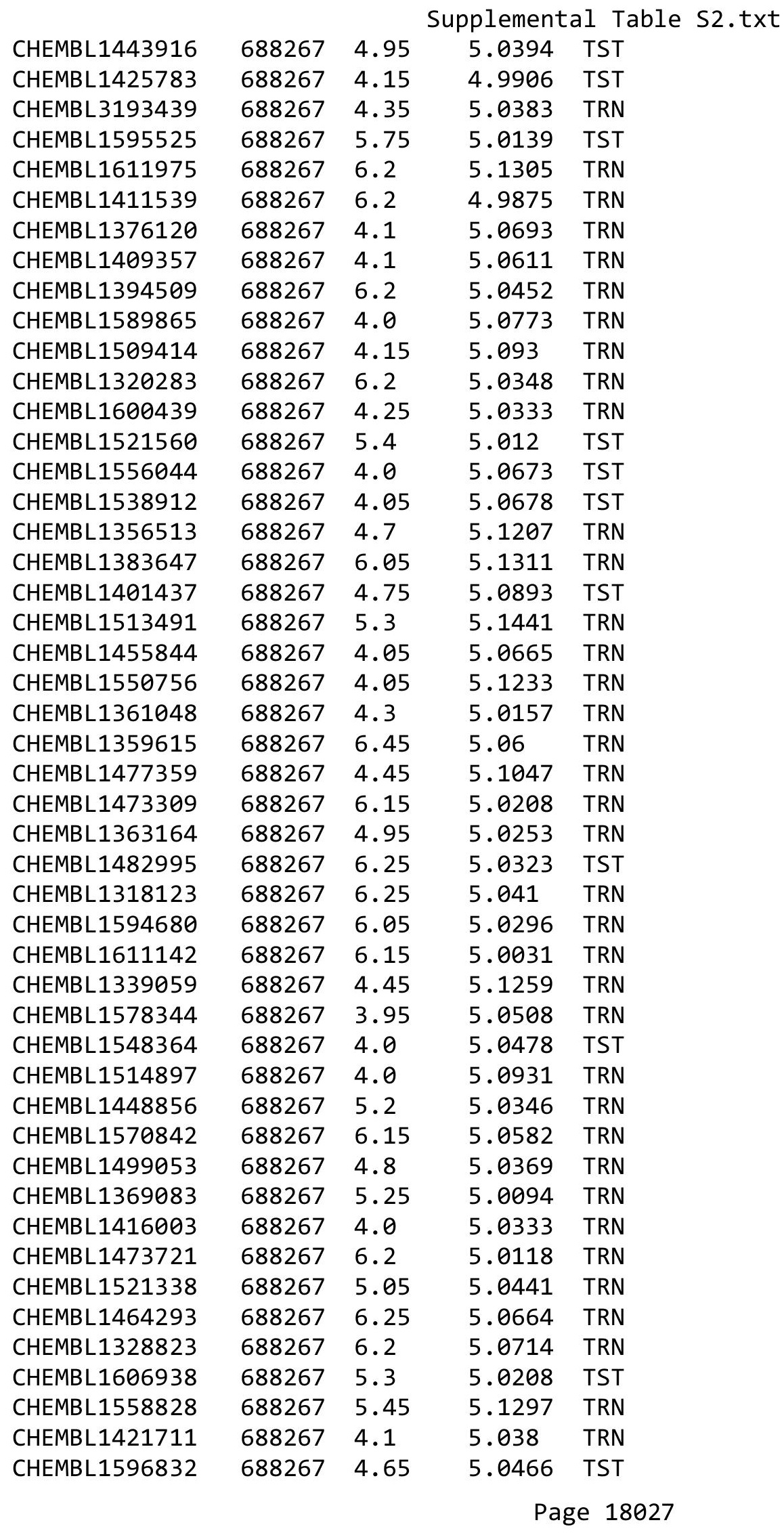




\begin{tabular}{|c|c|c|c|c|}
\hline & & & oplement & al $\mathrm{Ta}$ \\
\hline CHEMBL1500799 & 688267 & 6.2 & 5.0202 & TST \\
\hline CHEMBL1573943 & 688267 & 3.95 & 5.0186 & TRN \\
\hline CHEMBL1514350 & 688267 & 6.1 & 5.1162 & TRN \\
\hline CHEMBL1447640 & 688267 & 6.1 & 5.0901 & TRN \\
\hline CHEMBL1477244 & 688267 & 6.6499 & 5.0559 & TRN \\
\hline CHEMBL1523017 & 688267 & 4.4 & 5.0536 & TRN \\
\hline CHEMBL1325851 & 688267 & 5.4 & 5.0596 & TST \\
\hline CHEMBL1589871 & 688267 & 6.1 & 5.0487 & TRN \\
\hline CHEMBL1523204 & 688267 & 4.8 & 5.0502 & TST \\
\hline CHEMBL1376582 & 688267 & 4.05 & 5.0472 & TRN \\
\hline CHEMBL1391517 & 688267 & 4.4 & 5.021 & TRN \\
\hline CHEMBL1506877 & 688267 & 6.2 & 5.0264 & TRN \\
\hline CHEMBL1400178 & 688267 & 6.25 & 5.1534 & TRN \\
\hline CHEMBL1449138 & 688267 & 5.45 & 5.0502 & TRN \\
\hline CHEMBL1373598 & 688267 & 4.0 & 5.0804 & TST \\
\hline CHEMBL1377307 & 688267 & 4.9 & 5.06 & TRN \\
\hline CHEMBL1534594 & 688267 & 4.6 & 5.1299 & TRN \\
\hline CHEMBL1476477 & 688267 & 4.05 & 5.0211 & TRN \\
\hline CHEMBL1329240 & 688267 & 4.1 & 5.0376 & TRN \\
\hline CHEMBL1385553 & 688267 & 4.45 & 5.0141 & TST \\
\hline CHEMBL1466284 & 688267 & 5.85 & 5.0732 & TRN \\
\hline CHEMBL1337157 & 688267 & 4.35 & 5.1372 & TRN \\
\hline CHEMBL1458158 & 688267 & 5.0 & 5.0254 & TRN \\
\hline CHEMBL1594411 & 688267 & 5.45 & 5.0515 & TRN \\
\hline CHEMBL1468980 & 688267 & 4.3 & 5.0591 & TST \\
\hline CHEMBL1313218 & 688267 & 4.3 & 5.078 & TRN \\
\hline CHEMBL1589250 & 688267 & 4.0 & 5.0156 & TRN \\
\hline CHEMBL1527446 & 688267 & 4.4 & 5.0062 & TST \\
\hline CHEMBL1603765 & 688267 & 4.05 & 5.0133 & TST \\
\hline CHEMBL1329276 & 688267 & 5.4 & 5.0784 & TRN \\
\hline CHEMBL1362704 & 688267 & 4.45 & 5.0636 & TRN \\
\hline CHEMBL1397700 & 688267 & 6.25 & 5.0864 & TST \\
\hline CHEMBL1442027 & 688267 & 4.6 & 5.0125 & TRN \\
\hline CHEMBL1462875 & 688267 & 6.25 & 5.0696 & TRN \\
\hline CHEMBL3189557 & 688267 & 4.45 & 5.1022 & TST \\
\hline CHEMBL1472852 & 688267 & 4.1 & 4.9994 & TRN \\
\hline CHEMBL1450780 & 688267 & 5.7 & 5.0053 & TRN \\
\hline CHEMBL1402344 & 688267 & 6.15 & 5.0346 & TRN \\
\hline CHEMBL3208752 & 688267 & 5.0 & 5.0103 & TRN \\
\hline CHEMBL1371894 & 688267 & 5.8 & 5.0516 & TRN \\
\hline CHEMBL1455799 & 688267 & 4.05 & 5.0446 & TRN \\
\hline CHEMBL1449625 & 688267 & 4.0 & 5.1112 & TST \\
\hline CHEMBL1469563 & 688267 & 4.5 & 5.0245 & TRN \\
\hline CHEMBL1551759 & 688267 & 4.25 & 5.0202 & TST \\
\hline CHEMBL1317287 & 688267 & 4.2 & 5.0413 & TRN \\
\hline CHEMBL1403959 & 688267 & 5.1 & 5.0467 & TRN \\
\hline CHEMBL1520423 & 688267 & 5.2 & 5.0245 & TRN \\
\hline CHEMBL1456004 & 688267 & 6.5 & 5.0778 & TRN \\
\hline
\end{tabular}




\begin{tabular}{|c|c|c|c|c|c|}
\hline \multicolumn{6}{|c|}{$c 0$} \\
\hline CHEMBL1584243 & 688267 & 4.55 & 5.0007 & TRN & \\
\hline CHEMBL1598774 & 688267 & 5.55 & 4.9893 & TRN & \\
\hline CHEMBL1588553 & 688267 & 4.6 & 5.0245 & TRN & \\
\hline CHEMBL 78150 & 688267 & 5.15 & 5.0333 & TST & \\
\hline CHEMBL1546599 & 688267 & 6.5 & 5.0595 & TST & \\
\hline CHEMBL1530901 & 688267 & 6.2 & 5.0707 & TRN & \\
\hline CHEMBL1329680 & 688267 & 4.4 & 5.1538 & TRN & \\
\hline CHEMBL1311119 & 688267 & 5.45 & 5.1157 & TRN & \\
\hline CHEMBL1606111 & 688267 & 6.15 & 5.0697 & TRN & \\
\hline CHEMBL1612458 & 688267 & 5.6 & 5.0166 & TRN & \\
\hline CHEMBL1324141 & 688267 & 6.0 & 5.0698 & TRN & \\
\hline CHEMBL1553025 & 688267 & 4.4 & 5.0437 & TRN & \\
\hline CHEMBL1539575 & 688267 & 4.5 & 5.0544 & TRN & \\
\hline CHEMBL 3194970 & 688267 & 6.25 & 5.0008 & TST & \\
\hline CHEMBL1322539 & 688267 & 4.6 & 5.0432 & TRN & \\
\hline CHEMBL1316244 & 688267 & 4.65 & 5.1316 & TRN & \\
\hline CHEMBL1595172 & 688267 & 4.4 & 5.0261 & TST & \\
\hline CHEMBL1366753 & 688267 & 6.0 & 5.0214 & TRN & \\
\hline CHEMBL1513693 & 688267 & 6.45 & 5.0766 & TRN & \\
\hline CHEMBL1447457 & 688267 & 5.35 & 5.02800 & 00000000005 & TST \\
\hline CHEMBL1470855 & 688267 & 4.35 & 5.0667 & TRN & \\
\hline CHEMBL1540581 & 688267 & 6.25 & 5.0952 & TRN & \\
\hline CHEMBL1507042 & 688267 & 6.2 & 5.0698 & TRN & \\
\hline CHEMBL1361962 & 688267 & 4.55 & 5.0799 & TRN & \\
\hline CHEMBL1519677 & 688267 & 4.15 & 4.9707 & TRN & \\
\hline CHEMBL1562036 & 688267 & 5.6 & 5.0274 & TST & \\
\hline CHEMBL3208297 & 688267 & 6.15 & 5.0928 & TST & \\
\hline CHEMBL1328431 & 688267 & 5.25 & 5.0779 & TRN & \\
\hline CHEMBL1522854 & 688267 & 5.05 & 5.0327 & TRN & \\
\hline CHEMBL1377955 & 688267 & 4.2 & 5.0453 & TRN & \\
\hline CHEMBL1427414 & 688267 & 4.1 & 4.9894 & TRN & \\
\hline CHEMBL1425951 & 688267 & 4.05 & 5.12299 & 9999999999 & TRN \\
\hline CHEMBL1371137 & 688267 & 4.25 & 5.0046 & TRN & \\
\hline CHEMBL1558733 & 688267 & 4.35 & 4.9912 & TRN & \\
\hline CHEMBL474786 & 688267 & 4.1 & 4.9928 & TRN & \\
\hline CHEMBL273807 & 688267 & 5.05 & 5.03600 & 00000000005 & TST \\
\hline CHEMBL1530199 & 688267 & 4.05 & 5.1227 & TST & \\
\hline CHEMBL1389371 & 688267 & 4.4 & 5.0273 & TRN & \\
\hline CHEMBL1418735 & 688267 & 4.15 & 5.1093 & TRN & \\
\hline CHEMBL1554666 & 688267 & 5.35 & 5.0785 & TRN & \\
\hline CHEMBL1595523 & 688267 & 4.35 & 5.0857 & TRN & \\
\hline CHEMBL1378783 & 688267 & 5.4 & 5.0613 & TST & \\
\hline CHEMBL1445911 & 688267 & 4.45 & 5.0599 & TRN & \\
\hline CHEMBL587433 & 688267 & 6.15 & 5.02 & TRN & \\
\hline CHEMBL 3192482 & 688267 & 4.4 & 4.9782 & TST & \\
\hline CHEMBL1531406 & 688267 & 4.0 & 5.0244 & TRN & \\
\hline CHEMBL1536092 & 688267 & 5.85 & 5.0828 & TRN & \\
\hline CHEMBL1513022 & 688267 & 5.3 & 5.072 & TRN & \\
\hline
\end{tabular}




\begin{tabular}{|c|c|c|c|c|}
\hline \multicolumn{5}{|c|}{ Supplemental Table S2.txt } \\
\hline CHEMBL1334558 & 688267 & 4.9 & 5.0944 & TRN \\
\hline CHEMBL1542762 & 688267 & 3.95 & 5.0435 & TRN \\
\hline CHEMBL1610564 & 688267 & 5.55 & 5.0635 & TST \\
\hline CHEMBL1610255 & 688267 & 4.0 & 5.0136 & TRN \\
\hline CHEMBL1318920 & 688267 & 4.35 & 5.1081 & TRN \\
\hline CHEMBL1564211 & 688267 & 4.7 & 5.1023 & TRN \\
\hline CHEMBL1392205 & 688267 & 5.6 & 5.0355 & TST \\
\hline CHEMBL1358997 & 688267 & 5.4 & 5.104 & TST \\
\hline CHEMBL1458064 & 688267 & 4.15 & 5.084 & TST \\
\hline CHEMBL1524917 & 688267 & 6.2 & 5.0508 & TRN \\
\hline CHEMBL1373013 & 688267 & 5.1 & 5.0221 & TRN \\
\hline CHEMBL1376900 & 688267 & 4.05 & 5.0809 & TRN \\
\hline CHEMBL1400487 & 688267 & 4.95 & 4.9851 & TRN \\
\hline CHEMBL1580158 & 688267 & 5.3 & 5.0718 & TRN \\
\hline CHEMBL1538714 & 688267 & 5.05 & 5.081 & TRN \\
\hline CHEMBL1527758 & 688267 & 5.35 & 5.045 & TRN \\
\hline CHEMBL1380855 & 688267 & 5.9 & 5.1049 & TRN \\
\hline CHEMBL1454123 & 688267 & 4.25 & 5.0124 & TRN \\
\hline CHEMBL1453818 & 688267 & 6.2 & 5.0827 & TST \\
\hline CHEMBL1456788 & 688267 & 5.95 & 5.0665 & TRN \\
\hline CHEMBL1408687 & 688267 & 4.0 & 4.9955 & TRN \\
\hline CHEMBL1596436 & 688267 & 4.15 & 5.0373 & TRN \\
\hline CHEMBL1355015 & 688267 & 4.3 & 5.0967 & TRN \\
\hline CHEMBL1465151 & 688267 & 6.5501 & 5.0217 & TRN \\
\hline CHEMBL1595074 & 688267 & 5.25 & 5.0416 & TRN \\
\hline CHEMBL1409020 & 688267 & 4.05 & 5.0418 & TRN \\
\hline CHEMBL1543837 & 688267 & 5.3 & 5.0873 & TRN \\
\hline CHEMBL1423607 & 688267 & 6.2 & 4.9755 & TRN \\
\hline CHEMBL1548096 & 688267 & 6.15 & 5.0572 & TST \\
\hline CHEMBL1516884 & 688267 & 5.15 & 5.0745 & TRN \\
\hline CHEMBL1445839 & 688267 & 4.35 & 5.0334 & TRN \\
\hline CHEMBL1437114 & 688267 & 4.3 & 5.0369 & TRN \\
\hline CHEMBL1524858 & 688267 & 4.0 & 5.1307 & TRN \\
\hline CHEMBL411236 & 688267 & 6.5 & 5.0417 & TRN \\
\hline CHEMBL1388443 & 688267 & 5.5 & 5.085 & TST \\
\hline CHEMBL3197954 & 688267 & 4.4 & 5.0175 & TRN \\
\hline CHEMBL 1255966 & 688267 & 5.3 & 5.1003 & TST \\
\hline CHEMBL1511706 & 688267 & 5.1 & 5.0405 & TRN \\
\hline CHEMBL1353867 & 688267 & 5.1 & 5.0119 & TRN \\
\hline CHEMBL1591014 & 688267 & 5.45 & 5.0636 & TRN \\
\hline CHEMBL1323765 & 688267 & 5.45 & 5.0525 & TRN \\
\hline CHEMBL1540691 & 688267 & 4.15 & 5.0812 & TRN \\
\hline CHEMBL1534069 & 688267 & 4.25 & 5.0347 & TRN \\
\hline CHEMBL1331242 & 688267 & 6.2 & 4.9994 & TRN \\
\hline CHEMBL1410208 & 688267 & 3.95 & 5.0325 & TRN \\
\hline CHEMBL1392888 & 688267 & 4.5 & 4.9916 & TRN \\
\hline CHEMBL1557217 & 688267 & 4.55 & 5.085 & TRN \\
\hline CHEMBL1554369 & 688267 & 6.2 & 4.9831 & TRN \\
\hline
\end{tabular}




\begin{tabular}{|c|c|c|c|c|c|}
\hline \multicolumn{6}{|c|}{ Supplemental Table S2.txt } \\
\hline CHEMBL1531296 & 688267 & 4.0 & 5.1028 & TRN & \\
\hline CHEMBL1411840 & 688267 & 4.75 & 5.1311 & TRN & \\
\hline CHEMBL1520649 & 688267 & 5.35 & 5.0825 & TST & \\
\hline CHEMBL1483983 & 688267 & 4.45 & 5.1034 & TRN & \\
\hline CHEMBL1413889 & 688267 & 6.2 & 5.0619 & TST & \\
\hline CHEMBL1372481 & 688267 & 5.2 & 5.0541 & TRN & \\
\hline CHEMBL1385878 & 688267 & 6.25 & 5.0783 & TRN & \\
\hline CHEMBL1357884 & 688267 & 4.4 & 5.0127 & TRN & \\
\hline CHEMBL1301817 & 688267 & 4.0 & 5.0182 & TRN & \\
\hline CHEMBL1474123 & 688267 & 6.15 & 5.0001 & TRN & \\
\hline CHEMBL3189279 & 688267 & 5.65 & 5.0168 & TRN & \\
\hline CHEMBL1436920 & 688267 & 4.0 & 5.0638 & TRN & \\
\hline CHEMBL1596738 & 688267 & 5.2 & 5.0613 & TRN & \\
\hline CHEMBL1380486 & 688267 & 4.35 & 5.0485 & TST & \\
\hline CHEMBL1463983 & 688267 & 5.8 & 5.0182 & TST & \\
\hline CHEMBL1427059 & 688267 & 6.2 & $5.0310 e$ & 0000000001 & TRN \\
\hline CHEMBL1487096 & 688267 & 4.35 & 5.0553 & TRN & \\
\hline CHEMBL1299314 & 688267 & 4.35 & 5.0598 & TRN & \\
\hline CHEMBL1360127 & 688267 & 6.2 & 5.0378 & TRN & \\
\hline CHEMBL1353490 & 688267 & 4.65 & 5.0552 & TST & \\
\hline CHEMBL1419074 & 688267 & 6.2 & 5.0943 & TRN & \\
\hline CHEMBL1301307 & 688267 & 5.3 & 4.9697 & TRN & \\
\hline CHEMBL1454570 & 688267 & 4.25 & 5.0711 & TRN & \\
\hline CHEMBL1975032 & 688267 & 5.75 & 5.0364 & TST & \\
\hline CHEMBL1606189 & 688267 & 6.2 & 5.1253 & TRN & \\
\hline CHEMBL1361083 & 688267 & 5.45 & 5.0605 & TRN & \\
\hline CHEMBL1474798 & 688267 & 4.0 & 5.1058 & TST & \\
\hline CHEMBL1334279 & 688267 & 6.2 & 5.1587 & TRN & \\
\hline CHEMBL1413568 & 688267 & 4.2 & 5.0233 & TRN & \\
\hline CHEMBL1352935 & 688267 & 4.55 & 4.9884 & TRN & \\
\hline CHEMBL1520402 & 688267 & 6.2 & 5.0934 & TRN & \\
\hline CHEMBL1531210 & 688267 & 4.1 & 5.0533 & TRN & \\
\hline CHEMBL1558027 & 688267 & 5.1 & 5.1105 & TRN & \\
\hline CHEMBL1991565 & 688267 & 5.35 & 5.0403 & TST & \\
\hline CHEMBL3209257 & 688267 & 4.0 & $4.9910 e$ & 00000000005 & TRN \\
\hline CHEMBL1350712 & 688267 & 4.35 & 5.0452 & TRN & \\
\hline CHEMBL1315128 & 688267 & 6.45 & 5.0627 & TRN & \\
\hline CHEMBL1591584 & 688267 & 3.8 & 5.0291 & TRN & \\
\hline CHEMBL566706 & 688267 & 4.15 & 5.0533 & TRN & \\
\hline CHEMBL1463858 & 688267 & 4.05 & 5.0904 & TST & \\
\hline CHEMBL1339121 & 688267 & 5.35 & 4.9724 & TRN & \\
\hline CHEMBL1346817 & 688267 & 4.55 & 5.0705 & TRN & \\
\hline CHEMBL66675 & 688267 & 5.35 & 5.0848 & TRN & \\
\hline CHEMBL1550169 & 688267 & 5.3 & 5.1592 & TRN & \\
\hline CHEMBL1563506 & 688267 & 5.7 & 5.0407 & TST & \\
\hline CHEMBL1464837 & 688267 & 6.2 & 5.0377 & TST & \\
\hline CHEMBL1511133 & 688267 & 6.0 & 5.0444 & TRN & \\
\hline CHEMBL1391507 & 688267 & 5.85 & 5.0985 & TST & \\
\hline
\end{tabular}




\begin{tabular}{|c|c|c|c|c|c|}
\hline & & \multicolumn{4}{|c|}{ Supplemental Table S2.txt } \\
\hline CHEMBL3208255 & 688267 & 3.95 & 5.0927 & TRN & \\
\hline CHEMBL1378047 & 688267 & 5.25 & 5.0966 & TRN & \\
\hline CHEMBL1076696 & 688267 & 5.55 & 5.1271 & TRN & \\
\hline CHEMBL1612875 & 688267 & 5.45 & 5.0615 & TRN & \\
\hline CHEMBL1395958 & 688267 & 4.15 & 5.0039 & TRN & \\
\hline CHEMBL1602857 & 688267 & 4.0 & 5.1151 & TRN & \\
\hline CHEMBL1611608 & 688267 & 5.25 & 5.079 & TST & \\
\hline CHEMBL1312155 & 688267 & 6.25 & 5.083 & TST & \\
\hline CHEMBL1487065 & 688267 & 5.3 & 5.0057 & TST & \\
\hline CHEMBL1440996 & 688267 & 4.0 & 5.0228 & TRN & \\
\hline CHEMBL1559036 & 688267 & 6.25 & 5.01399 & 9999999999 & TRN \\
\hline CHEMBL1321048 & 688267 & 4.0 & 5.0585 & TRN & \\
\hline CHEMBL1569789 & 688267 & 5.8 & 5.0576 & TRN & \\
\hline CHEMBL1565975 & 688267 & 5.05 & 5.1538 & TRN & \\
\hline CHEMBL1321613 & 688267 & 4.7 & 5.0692 & TRN & \\
\hline CHEMBL3207946 & 688267 & 4.35 & 5.0172 & TST & \\
\hline CHEMBL1355037 & 688267 & 5.45 & 5.0331 & TRN & \\
\hline CHEMBL1602728 & 688267 & 5.55 & 5.0761 & TRN & \\
\hline CHEMBL1525768 & 688267 & 4.0 & 5.075 & TRN & \\
\hline CHEMBL1585341 & 688267 & 5.75 & 5.1806 & TRN & \\
\hline CHEMBL1417739 & 688267 & 3.95 & 5.0792 & TRN & \\
\hline CHEMBL1397827 & 688267 & 5.2 & 5.0617 & TRN & \\
\hline CHEMBL1536945 & 688267 & 4.75 & 4.9978 & TRN & \\
\hline CHEMBL116569 & 688267 & 4.25 & 4.996 & TRN & \\
\hline CHEMBL1476583 & 688267 & 4.0 & 5.0882 & TST & \\
\hline CHEMBL3197672 & 688267 & 4.3 & 4.9958 & TST & \\
\hline CHEMBL1347059 & 688267 & 5.75 & 5.0192 & TRN & \\
\hline CHEMBL1458280 & 688267 & 6.2 & 5.002 & TST & \\
\hline CHEMBL1334013 & 688267 & 6.2 & 5.1013 & TST & \\
\hline CHEMBL1597467 & 688267 & 4.0 & 5.0425 & TRN & \\
\hline CHEMBL1609176 & 688267 & 5.5 & 5.0749 & TRN & \\
\hline CHEMBL1385010 & 688267 & 5.4 & 4.99 & TRN & \\
\hline CHEMBL1416561 & 688267 & 5.3 & 5.0573 & TRN & \\
\hline CHEMBL1379111 & 688267 & 4.0 & 5.0352 & TRN & \\
\hline CHEMBL1389932 & 688267 & 6.2 & 5.0865 & TRN & \\
\hline CHEMBL1455853 & 688267 & 4.25 & 5.0066 & TRN & \\
\hline CHEMBL1568106 & 688267 & 5.45 & 5.0245 & TRN & \\
\hline CHEMBL1486391 & 688267 & 6.2 & 4.9841 & TRN & \\
\hline CHEMBL1463729 & 688267 & 4.05 & 5.1445 & TRN & \\
\hline CHEMBL1369593 & 688267 & 6.2 & 5.0421 & TRN & \\
\hline CHEMBL1369875 & 688267 & 4.05 & 5.0611 & TST & \\
\hline CHEMBL1336610 & 688267 & 5.1 & 5.0805 & TRN & \\
\hline CHEMBL1411985 & 688267 & 4.55 & 5.0423 & TRN & \\
\hline CHEMBL1316269 & 688267 & 4.5 & 5.0415 & TST & \\
\hline CHEMBL1503624 & 688267 & 5.25 & 5.0629 & TRN & \\
\hline CHEMBL1476696 & 688267 & 5.65 & 5.0761 & TST & \\
\hline CHEMBL1528144 & 688267 & 6.0 & 4.9946 & TRN & \\
\hline CHEMBL1400711 & 688267 & 3.95 & 5.0919 & TRN & \\
\hline
\end{tabular}




\begin{tabular}{|c|c|c|c|c|c|}
\hline \multicolumn{6}{|c|}{ Supplemental Table S2.txt } \\
\hline CHEMBL1393441 & 688267 & 4.6 & 5.0694 & TRN & \\
\hline CHEMBL1530407 & 688267 & 6.5 & 5.136 & TRN & \\
\hline CHEMBL1545461 & 688267 & 5.6 & 5.1556 & TRN & \\
\hline CHEMBL1317779 & 688267 & 6.2 & 5.1247 & TRN & \\
\hline CHEMBL1593409 & 688267 & 4.1 & 5.0337 & TRN & \\
\hline CHEMBL1380709 & 688267 & 5.85 & 5.0265 & TRN & \\
\hline CHEMBL1467361 & 688267 & 5.25 & 5.0175 & TST & \\
\hline CHEMBL1350514 & 688267 & 4.0 & 4.9918 & TST & \\
\hline CHEMBL1403601 & 688267 & 5.85 & 5.1246 & TRN & \\
\hline CHEMBL1413162 & 688267 & 5.3 & 5.1019 & TRN & \\
\hline CHEMBL1405199 & 688267 & 5.3 & 5.033 & TST & \\
\hline CHEMBL1414701 & 688267 & 4.65 & 5.0548 & TRN & \\
\hline CHEMBL1411588 & 688267 & 4.3 & 5.1297 & TRN & \\
\hline CHEMBL1569337 & 688267 & 4.25 & 5.0067 & TRN & \\
\hline CHEMBL 255881 & 688267 & 5.45 & 5.0128 & TRN & \\
\hline CHEMBL1533700 & 688267 & 6.2 & 5.0804 & TRN & \\
\hline CHEMBL1356594 & 688267 & 4.45 & 5.0884 & TRN & \\
\hline CHEMBL1554892 & 688267 & 3.95 & 5.1149 & TST & \\
\hline CHEMBL1574689 & 688267 & 4.0 & 5.0641 & TRN & \\
\hline CHEMBL1601806 & 688267 & 4.35 & 5.0053 & TRN & \\
\hline CHEMBL1544182 & 688267 & 4.75 & 5.035 & TRN & \\
\hline CHEMBL1593154 & 688267 & 6.2 & 5.0016 & TST & \\
\hline CHEMBL1520686 & 688267 & 3.95 & 5.1788 & TRN & \\
\hline CHEMBL1591153 & 688267 & 4.15 & 4.989 & TRN & \\
\hline CHEMBL1594684 & 688267 & 5.0 & 5.0185 & TST & \\
\hline CHEMBL1574505 & 688267 & 4.95 & 5.0723 & TST & \\
\hline CHEMBL1353257 & 688267 & 4.0 & 5.0067 & TRN & \\
\hline CHEMBL1329523 & 688267 & 4.2 & 5.0106 & TST & \\
\hline CHEMBL1300402 & 688267 & 4.3 & 5.0175 & TRN & \\
\hline CHEMBL1334510 & 688267 & 5.0 & 5.0287 & TRN & \\
\hline CHEMBL1404328 & 688267 & 5.85 & 5.0667 & TST & \\
\hline CHEMBL1362709 & 688267 & 4.45 & 5.0639 & TRN & \\
\hline CHEMBL1438590 & 688267 & 5.8 & 5.06800 & 00000000005 & TRN \\
\hline CHEMBL1597866 & 688267 & 6.15 & 5.0209 & TRN & \\
\hline CHEMBL1494777 & 688267 & 4.35 & 5.0041 & TRN & \\
\hline CHEMBL1535707 & 688267 & 4.95 & 5.0225 & TST & \\
\hline CHEMBL1554693 & 688267 & 5.45 & 5.0589 & TRN & \\
\hline CHEMBL1362398 & 688267 & 5.5 & 4.9916 & TRN & \\
\hline CHEMBL1446959 & 688267 & 4.4 & 5.1059 & TRN & \\
\hline CHEMBL1329982 & 688267 & 5.55 & 5.1275 & TRN & \\
\hline CHEMBL1301608 & 688267 & 4.6 & 4.9971 & TRN & \\
\hline CHEMBL1445378 & 688267 & 5.4 & 5.0564 & TRN & \\
\hline CHEMBL1300503 & 688267 & 4.05 & 5.0991 & TST & \\
\hline CHEMBL1514874 & 688267 & 4.55 & 5.1215 & TST & \\
\hline CHEMBL1322970 & 688267 & 5.7 & 5.0262 & TRN & \\
\hline CHEMBL 3191641 & 688267 & 6.15 & 5.0539 & TST & \\
\hline CHEMBL3190784 & 688267 & 5.15 & 5.0043 & TST & \\
\hline CHEMBL1572893 & 688267 & 4.15 & 5.0592 & TRN & \\
\hline
\end{tabular}




\begin{tabular}{|c|c|c|c|c|}
\hline \multicolumn{5}{|c|}{ Supplemental Table S2.txt } \\
\hline CHEMBL1351036 & 688267 & 6.2 & 5.0586 & TST \\
\hline CHEMBL1420713 & 688267 & 6.2 & 5.1192 & TRN \\
\hline CHEMBL1303949 & 688267 & 4.35 & 5.0832 & TST \\
\hline CHEMBL1610417 & 688267 & 4.0 & 5.0036 & TST \\
\hline CHEMBL1468162 & 688267 & 5.25 & 5.0945 & TRN \\
\hline CHEMBL1389709 & 688267 & 5.05 & 5.1512 & TST \\
\hline CHEMBL1529253 & 688267 & 4.0 & 5.0113 & TRN \\
\hline CHEMBL1381593 & 688267 & 3.95 & 5.1117 & TST \\
\hline CHEMBL1363400 & 688267 & 6.2 & 5.1176 & TRN \\
\hline CHEMBL1505693 & 688267 & 6.2 & 5.1118 & TRN \\
\hline CHEMBL1501289 & 688267 & 4.0 & 5.0392 & TRN \\
\hline CHEMBL1320348 & 688267 & 4.2 & 5.0346 & TRN \\
\hline CHEMBL 384903 & 688267 & 5.85 & 5.018 & TST \\
\hline CHEMBL1604724 & 688267 & 4.25 & 4.9822 & TST \\
\hline CHEMBL1587258 & 688267 & 4.1 & 5.0169 & TST \\
\hline CHEMBL1405387 & 688267 & 5.8 & 5.0148 & TRN \\
\hline CHEMBL1497105 & 688267 & 4.15 & 5.0645 & TST \\
\hline CHEMBL1566741 & 688267 & 4.95 & 5.0108 & TRN \\
\hline CHEMBL1301823 & 688267 & 5.95 & 5.0569 & TRN \\
\hline CHEMBL1316639 & 688267 & 5.9 & 5.0469 & TRN \\
\hline CHEMBL1504237 & 688267 & 5.9 & 4.9767 & TRN \\
\hline CHEMBL1580844 & 688267 & 5.85 & 5.0113 & TRN \\
\hline CHEMBL1543394 & 688267 & 4.95 & 5.0762 & TRN \\
\hline CHEMBL1553170 & 688267 & 5.65 & 5.0577 & TRN \\
\hline CHEMBL1565181 & 688267 & 4.05 & 5.0233 & TRN \\
\hline CHEMBL1541346 & 688267 & 6.6 & 5.0933 & TRN \\
\hline CHEMBL1404986 & 688267 & 5.1 & 5.0224 & TRN \\
\hline CHEMBL1361799 & 688267 & 5.3 & 5.0597 & TRN \\
\hline CHEMBL1356364 & 688267 & 4.35 & 5.051 & TRN \\
\hline CHEMBL1502359 & 688267 & 4.7 & 5.015 & TST \\
\hline CHEMBL1485019 & 688267 & 6.2 & 5.0261 & TRN \\
\hline CHEMBL1391838 & 688267 & 4.9 & 5.0642 & TRN \\
\hline CHEMBL1431557 & 688267 & 4.05 & 5.0251 & TST \\
\hline CHEMBL1555644 & 688267 & 5.05 & 5.0251 & TST \\
\hline CHEMBL1451600 & 688267 & 4.65 & 5.1107 & TST \\
\hline CHEMBL1603479 & 688267 & 6.2 & 4.9834 & TRN \\
\hline CHEMBL1407836 & 688267 & 4.0 & 5.1265 & TRN \\
\hline CHEMBL1428941 & 688267 & 4.4 & 4.9983 & TRN \\
\hline CHEMBL1319264 & 688267 & 4.3 & 4.9893 & TRN \\
\hline CHEMBL1605316 & 688267 & 4.4 & 5.0239 & TRN \\
\hline CHEMBL1552658 & 688267 & 5.45 & 5.0587 & TRN \\
\hline CHEMBL3197212 & 688267 & 4.35 & 5.0259 & TST \\
\hline CHEMBL1328740 & 688267 & 6.15 & 5.0757 & TST \\
\hline CHEMBL1436885 & 688267 & 6.15 & 5.0482 & TST \\
\hline CHEMBL1586833 & 688267 & 6.2 & 5.0579 & TRN \\
\hline CHEMBL1491248 & 688267 & 4.0 & 5.1271 & TST \\
\hline CHEMBL1321328 & 688267 & 4.0 & 5.0706 & TRN \\
\hline CHEMBL1607706 & 688267 & 6.15 & 5.0626 & TRN \\
\hline
\end{tabular}




\begin{tabular}{|c|c|c|c|c|c|}
\hline & & & & & \\
\hline CHEMBL1374460 & 688267 & 5.1 & 5.0621 & TRN & \\
\hline CHEMBL1384258 & 688267 & 6.0 & 5.1282 & TRN & \\
\hline CHEMBL1387950 & 688267 & 4.25 & 5.0948 & TST & \\
\hline CHEMBL1413311 & 688267 & 4.55 & 5.0989 & TRN & \\
\hline CHEMBL1565161 & 688267 & 5.15 & 5.1498 & TRN & \\
\hline CHEMBL1460815 & 688267 & 4.35 & 5.0161 & TRN & \\
\hline CHEMBL1319694 & 688267 & 6.2 & 5.1155 & TRN & \\
\hline CHEMBL1553672 & 688267 & 6.2 & 5.064 & TRN & \\
\hline CHEMBL1408369 & 688267 & 3.95 & 5.1551 & TRN & \\
\hline CHEMBL1438558 & 688267 & 6.2 & 4.9754 & TRN & \\
\hline CHEMBL1376072 & 688267 & 5.05 & 5.0726 & TRN & \\
\hline CHEMBL1200889 & 688267 & 5.2 & 5.0787 & TST & \\
\hline CHEMBL1368796 & 688267 & 4.5 & 5.0574 & TRN & \\
\hline CHEMBL1324541 & 688267 & 5.9 & 5.0773 & TRN & \\
\hline CHEMBL1331747 & 688267 & 4.0 & 5.0281 & TRN & \\
\hline CHEMBL1370167 & 688267 & 4.1 & 5.0611 & TST & \\
\hline CHEMBL1352394 & 688267 & 5.35 & 5.0475 & TRN & \\
\hline CHEMBL1497723 & 688267 & 6.2 & 5.1324 & TRN & \\
\hline CHEMBL1531720 & 688267 & 4.05 & 5.0739 & TRN & \\
\hline CHEMBL3211142 & 688267 & 5.3 & 5.0033 & TRN & \\
\hline CHEMBL1360096 & 688267 & 4.3 & 5.09699 & 99999999995 & TRN \\
\hline CHEMBL1319950 & 688267 & 5.3 & 5.0783 & TRN & \\
\hline CHEMBL1505831 & 688267 & 4.7 & 5.1299 & TST & \\
\hline CHEMBL1509655 & 688267 & 4.0 & 5.0793 & TRN & \\
\hline CHEMBL3191047 & 688267 & 4.6 & 5.0911 & TST & \\
\hline CHEMBL1580444 & 688267 & 4.0 & 5.0542 & TST & \\
\hline CHEMBL1361210 & 688267 & 5.25 & 5.0632 & TRN & \\
\hline CHEMBL1506691 & 688267 & 3.95 & 5.0517 & TRN & \\
\hline CHEMBL1474609 & 688267 & 4.0 & 5.1066 & TRN & \\
\hline CHEMBL1612353 & 688267 & 4.6 & 5.0222 & TRN & \\
\hline CHEMBL1385575 & 688267 & 4.05 & 5.0858 & TRN & \\
\hline CHEMBL471401 & 688267 & 6.15 & 5.0373 & TST & \\
\hline CHEMBL1396529 & 688267 & 6.2 & 5.0726 & TRN & \\
\hline CHEMBL1422467 & 688267 & 5.3 & 5.0671 & TRN & \\
\hline CHEMBL1552423 & 688267 & 6.2 & 5.1043 & TRN & \\
\hline CHEMBL1479015 & 688267 & 4.25 & 5.0758 & TRN & \\
\hline CHEMBL1588197 & 688267 & 3.95 & 5.0224 & TRN & \\
\hline CHEMBL1439068 & 688267 & 4.0 & 5.0701 & TST & \\
\hline CHEMBL1399940 & 688267 & 6.25 & $5.0760 e$ & 00000000005 & TRN \\
\hline CHEMBL1414802 & 688267 & 4.4 & 5.007 & TST & \\
\hline CHEMBL1349357 & 688267 & 6.2 & 5.0393 & TRN & \\
\hline CHEMBL1385089 & 688267 & 5.05 & 5.0673 & TST & \\
\hline CHEMBL1322728 & 688267 & 4.0 & 5.084 & TRN & \\
\hline CHEMBL1561039 & 688267 & 5.5 & 5.077 & TRN & \\
\hline CHEMBL1300951 & 688267 & 4.85 & 5.095 & TST & \\
\hline CHEMBL1449815 & 688267 & 4.0 & 5.0301 & TRN & \\
\hline CHEMBL1594818 & 688267 & 5.25 & 5.042 & TST & \\
\hline CHEMBL1302926 & 688267 & 6.05 & $5.0360 e$ & 20000000005 & TRN \\
\hline & & & & 18035 & \\
\hline
\end{tabular}




\begin{tabular}{|c|c|c|c|c|c|}
\hline \\
\hline CHEMBL1340251 & 688267 & 6.2 & 5.0547 & TRN & \\
\hline CHEMBL1337789 & 688267 & 4.65 & 5.0023 & TRN & \\
\hline CHEMBL1448746 & 688267 & 6.2 & 5.0429 & TRN & \\
\hline CHEMBL1456306 & 688267 & 4.3 & 5.0312 & TRN & \\
\hline CHEMBL1472869 & 688267 & 4.65 & 5.085 & TRN & \\
\hline CHEMBL1420739 & 688267 & 4.45 & 5.0455 & TST & \\
\hline CHEMBL1317835 & 688267 & 5.25 & 5.0754 & TST & \\
\hline CHEMBL1346910 & 688267 & 6.7501 & 5.0385 & TST & \\
\hline CHEMBL1332259 & 688267 & 5.85 & 5.0566 & TRN & \\
\hline CHEMBL1590707 & 688267 & 3.95 & 5.0422 & TRN & \\
\hline CHEMBL1495034 & 688267 & 5.05 & 5.1628 & TRN & \\
\hline CHEMBL1410445 & 688267 & 5.75 & 5.1002 & TRN & \\
\hline CHEMBL1487794 & 688267 & 4.3 & 5.058 & TRN & \\
\hline CHEMBL1595724 & 688267 & 4.45 & 5.0668 & TRN & \\
\hline CHEMBL1305486 & 688267 & 4.1 & 5.0575 & TRN & \\
\hline CHEMBL1489645 & 688267 & 5.05 & 5.00899 & 99999999995 & TRN \\
\hline CHEMBL1414329 & 688267 & 4.25 & 5.0297 & TST & \\
\hline CHEMBL1370958 & 688267 & 5.75 & 5.0108 & TST & \\
\hline CHEMBL1576317 & 688267 & 4.0 & 5.0738 & TRN & \\
\hline CHEMBL1573506 & 688267 & 5.0 & 5.0119 & TRN & \\
\hline CHEMBL1364971 & 688267 & 5.3 & 5.0979 & TRN & \\
\hline CHEMBL1565632 & 688267 & 4.45 & 5.0747 & TRN & \\
\hline CHEMBL1535326 & 688267 & 3.95 & 5.0655 & TST & \\
\hline CHEMBL1536724 & 688267 & 5.8 & 5.0314 & TST & \\
\hline CHEMBL1528580 & 688267 & 6.15 & 5.1122 & TRN & \\
\hline CHEMBL1328395 & 688267 & 5.95 & 5.025 & TRN & \\
\hline CHEMBL1316079 & 688267 & 4.0 & 5.007 & TRN & \\
\hline CHEMBL1371147 & 688267 & 6.2 & 5.0118 & TRN & \\
\hline CHEMBL1304208 & 688267 & 4.7 & 5.1517 & TST & \\
\hline CHEMBL1339233 & 688267 & 6.05 & 5.042 & TRN & \\
\hline CHEMBL1410017 & 688267 & 6.2 & 5.0768 & TRN & \\
\hline CHEMBL1304853 & 688267 & 4.05 & 5.0774 & TRN & \\
\hline CHEMBL1463348 & 688267 & 6.25 & 5.0907 & TST & \\
\hline CHEMBL1318782 & 688267 & 5.25 & 5.0447 & TRN & \\
\hline CHEMBL1520361 & 688267 & 5.6 & 5.0175 & TRN & \\
\hline CHEMBL1452645 & 688267 & 4.0 & 5.032 & TRN & \\
\hline CHEMBL1536676 & 688267 & 4.0 & 5.0951 & TRN & \\
\hline CHEMBL1611842 & 688267 & 5.25 & 5.0817 & TRN & \\
\hline CHEMBL1347754 & 688267 & 6.2 & 5.0752 & TRN & \\
\hline CHEMBL1382899 & 688267 & 4.55 & 5.0529 & TRN & \\
\hline CHEMBL1314452 & 688267 & 6.2 & 5.0445 & TRN & \\
\hline CHEMBL1394145 & 688267 & 5.95 & 5.0524 & TST & \\
\hline CHEMBL1406277 & 688267 & 4.0 & 5.0041 & TST & \\
\hline CHEMBL1517717 & 688267 & 6.2 & 5.0934 & TRN & \\
\hline CHEMBL1344580 & 688267 & 6.2 & 5.0951 & TRN & \\
\hline CHEMBL 1447276 & 688267 & 5.5 & 5.1322 & TST & \\
\hline CHEMBL1313881 & 688267 & 5.85 & 5.0257 & TST & \\
\hline CHEMBL1544369 & 688267 & 4.0 & 5.0335 & TRN & \\
\hline
\end{tabular}




\begin{tabular}{|c|c|c|c|c|}
\hline & & & pplement & al $\mathrm{Ta}$ \\
\hline CHEMBL1583469 & 688267 & 4.3 & 5.0427 & TST \\
\hline CHEMBL1404665 & 688267 & 5.55 & 5.0845 & TRN \\
\hline CHEMBL1560157 & 688267 & 6.5 & 5.0838 & TRN \\
\hline CHEMBL1402161 & 688267 & 4.4 & 5.0446 & TRN \\
\hline CHEMBL1405004 & 688267 & 5.65 & 5.059 & TST \\
\hline CHEMBL1360443 & 688267 & 5.45 & 5.1077 & TRN \\
\hline CHEMBL466518 & 688267 & 5.0 & 5.0553 & TRN \\
\hline CHEMBL1514347 & 688267 & 5.5 & 5.0393 & TRN \\
\hline CHEMBL1382136 & 688267 & 4.85 & 5.1045 & TRN \\
\hline CHEMBL1462615 & 688267 & 5.85 & 4.9718 & TST \\
\hline CHEMBL1570611 & 688267 & 4.25 & 5.0608 & TRN \\
\hline CHEMBL1467845 & 688267 & 5.8 & 5.0089 & TRN \\
\hline CHEMBL1981883 & 688267 & 4.1 & 5.0004 & TST \\
\hline CHEMBL1590012 & 688267 & 6.15 & 5.0256 & TRN \\
\hline CHEMBL1515758 & 688267 & 6.2 & 5.0987 & TRN \\
\hline CHEMBL1461765 & 688267 & 4.9 & 5.0893 & TRN \\
\hline CHEMBL1462825 & 688267 & 5.35 & 5.034 & TRN \\
\hline CHEMBL1326380 & 688267 & 5.9 & 5.069 & TRN \\
\hline CHEMBL1393863 & 688267 & 5.4 & 5.0052 & TRN \\
\hline CHEMBL1590555 & 688267 & 4.8 & 5.0038 & TRN \\
\hline CHEMBL1497883 & 688267 & 5.5 & 5.0568 & TST \\
\hline CHEMBL1505741 & 688267 & 5.45 & 5.0531 & TRN \\
\hline CHEMBL1419050 & 688267 & 5.75 & 5.13 & TRN \\
\hline CHEMBL1441598 & 688267 & 5.25 & 5.0886 & TRN \\
\hline CHEMBL1458166 & 688267 & 4.0 & 5.0577 & TRN \\
\hline CHEMBL1514047 & 688267 & 5.95 & 5.0926 & TRN \\
\hline CHEMBL1611879 & 688267 & 4.65 & 5.0634 & TRN \\
\hline CHEMBL1481646 & 688267 & 4.45 & 5.0419 & TRN \\
\hline CHEMBL1456216 & 688267 & 4.05 & 5.0581 & TST \\
\hline CHEMBL1510183 & 688267 & 4.0 & 5.041 & TRN \\
\hline CHEMBL1578687 & 688267 & 5.3 & 5.0565 & TRN \\
\hline CHEMBL1499328 & 688267 & 4.0 & 5.0347 & TRN \\
\hline CHEMBL1564304 & 688267 & 4.55 & 5.1212 & TRN \\
\hline CHEMBL1447532 & 688267 & 5.3 & 5.0214 & TRN \\
\hline CHEMBL1575873 & 688267 & 4.9 & 5.0319 & TRN \\
\hline CHEMBL1489149 & 688267 & 6.2 & 5.0603 & TST \\
\hline CHEMBL3213941 & 688267 & 4.35 & 5.0469 & TST \\
\hline CHEMBL1339595 & 688267 & 4.05 & 5.0153 & TRN \\
\hline CHEMBL1603246 & 688267 & 4.4 & 5.0174 & TST \\
\hline CHEMBL1495223 & 688267 & 4.95 & 5.0323 & TRN \\
\hline CHEMBL1538405 & 688267 & 4.3 & 5.0517 & TRN \\
\hline CHEMBL1447395 & 688267 & 4.4 & 5.0246 & TRN \\
\hline CHEMBL1428057 & 688267 & 6.5501 & 5.1025 & TRN \\
\hline CHEMBL3210132 & 688267 & 4.05 & 5.0197 & TST \\
\hline CHEMBL1342658 & 688267 & 5.3 & 5.0451 & TST \\
\hline CHEMBL1379993 & 688267 & 4.7 & 5.0985 & TRN \\
\hline CHEMBL1363705 & 688267 & 6.2 & 5.1347 & TST \\
\hline CHEMBL1387077 & 688267 & 4.3 & 5.1157 & TRN \\
\hline
\end{tabular}




\begin{tabular}{|c|c|c|c|c|c|}
\hline \multicolumn{6}{|c|}{ 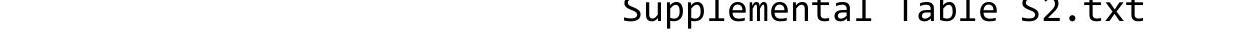 } \\
\hline CHEMBL1356238 & 688267 & 5.3 & 5.0332 & TST & \\
\hline CHEMBL1468196 & 688267 & 5.7 & 5.125 & TRN & \\
\hline CHEMBL1348430 & 688267 & 4.65 & 5.0468 & TRN & \\
\hline CHEMBL1309134 & 688267 & 5.55 & 5.019 & TST & \\
\hline CHEMBL198830 & 688267 & 3.95 & 5.0353 & TRN & \\
\hline CHEMBL1599310 & 688267 & 5.5 & 5.0959 & TRN & \\
\hline CHEMBL1465295 & 688267 & 4.0 & 5.1877 & TRN & \\
\hline CHEMBL1529249 & 688267 & 4.5 & 5.0895 & TRN & \\
\hline CHEMBL1462746 & 688267 & 5.05 & 4.9913 & TRN & \\
\hline CHEMBL1476523 & 688267 & 5.85 & 5.0614 & TRN & \\
\hline CHEMBL1355811 & 688267 & 4.0 & 5.0441 & TRN & \\
\hline CHEMBL1548332 & 688267 & 5.5 & 5.0179 & TST & \\
\hline CHEMBL1584110 & 688267 & 6.15 & 5.0476 & TRN & \\
\hline CHEMBL1468074 & 688267 & 4.9 & 5.0349 & TRN & \\
\hline CHEMBL1557135 & 688267 & 5.2 & 5.0072 & TRN & \\
\hline CHEMBL3193409 & 688267 & 5.45 & 4.9681 & TRN & \\
\hline CHEMBL1486484 & 688267 & 6.2 & 5.059 & TST & \\
\hline CHEMBL1434743 & 688267 & 4.45 & 5.0226 & TST & \\
\hline CHEMBL1329716 & 688267 & 4.4 & 5.1592 & TRN & \\
\hline CHEMBL1528336 & 688267 & 4.65 & 5.0874 & TRN & \\
\hline CHEMBL1522339 & 688267 & 5.8 & 5.0821 & TST & \\
\hline CHEMBL1395203 & 688267 & 5.55 & 5.0422 & TST & \\
\hline CHEMBL1364170 & 688267 & 4.65 & 5.0923 & TRN & \\
\hline CHEMBL1549862 & 688267 & 6.15 & 5.0721 & TRN & \\
\hline CHEMBL1396160 & 688267 & 4.05 & 5.0189 & TRN & \\
\hline CHEMBL1429699 & 688267 & 4.0 & 5.0619 & TRN & \\
\hline CHEMBL1299540 & 688267 & 4.4 & 5.0558 & TRN & \\
\hline CHEMBL1538303 & 688267 & 4.45 & 5.1304 & TRN & \\
\hline CHEMBL3211571 & 688267 & 5.2 & 5.04899 & 99999999995 & TST \\
\hline CHEMBL1532558 & 688267 & 4.45 & 5.0621 & TRN & \\
\hline CHEMBL1402626 & 688267 & 4.0 & 5.0778 & TRN & \\
\hline CHEMBL1386836 & 688267 & 4.05 & 5.1534 & TST & \\
\hline CHEMBL1396264 & 688267 & 5.9 & 5.0367 & TRN & \\
\hline CHEMBL1366231 & 688267 & 4.65 & 5.0306 & TRN & \\
\hline CHEMBL1607939 & 688267 & 5.05 & 5.0302 & TRN & \\
\hline CHEMBL1592103 & 688267 & 4.0 & 5.0626 & TRN & \\
\hline CHEMBL3212288 & 688267 & 5.85 & 5.0349 & TRN & \\
\hline CHEMBL1455566 & 688267 & 5.4 & 5.0533 & TST & \\
\hline CHEMBL1546718 & 688267 & 4.1 & 5.0697 & TST & \\
\hline CHEMBL1384055 & 688267 & 5.1 & 5.1268 & TRN & \\
\hline CHEMBL1507080 & 688267 & 6.15 & 5.0149 & TST & \\
\hline CHEMBL1444259 & 688267 & 5.65 & 5.0806 & TRN & \\
\hline CHEMBL1389756 & 688267 & 5.45 & 4.9927 & TRN & \\
\hline CHEMBL240524 & 688267 & 4.35 & 5.0816 & TST & \\
\hline CHEMBL1449609 & 688267 & 5.85 & 5.0307 & TRN & \\
\hline CHEMBL1512235 & 688267 & 5.85 & 5.1117 & TRN & \\
\hline CHEMBL1507869 & 688267 & 5.8 & 5.0738 & TRN & \\
\hline CHEMBL1403754 & 688267 & 4.65 & 5.0088 & TRN & \\
\hline
\end{tabular}




\begin{tabular}{|c|c|c|c|c|}
\hline & & & ipplement & $d \perp 1$ \\
\hline CHEMBL1559717 & 688267 & 5.8 & 5.0659 & TST \\
\hline CHEMBL1368757 & 688267 & 5.7 & 5.0927 & TST \\
\hline CHEMBL1505284 & 688267 & 4.05 & 5.0248 & TRN \\
\hline CHEMBL1606213 & 688267 & 4.0 & 5.0728 & TRN \\
\hline CHEMBL1538860 & 688267 & 5.05 & 5.0823 & TRN \\
\hline CHEMBL1324258 & 688267 & 5.5 & 5.1217 & TRN \\
\hline CHEMBL1520976 & 688267 & 6.0 & 5.077 & TST \\
\hline CHEMBL1347391 & 688267 & 4.25 & 5.008 & TST \\
\hline CHEMBL3212746 & 688267 & 4.0 & 5.0143 & TRN \\
\hline CHEMBL1421588 & 688267 & 5.0 & 5.0626 & TRN \\
\hline CHEMBL1466792 & 688267 & 6.2 & 5.0145 & TST \\
\hline CHEMBL 1344374 & 688267 & 4.05 & 5.0858 & TRN \\
\hline CHEMBL1472718 & 688267 & 3.95 & 5.1328 & TRN \\
\hline CHEMBL1538265 & 688267 & 4.2 & 5.0532 & TRN \\
\hline CHEMBL1520879 & 688267 & 4.4 & 5.081 & TRN \\
\hline CHEMBL1321289 & 688267 & 4.25 & 5.0491 & TRN \\
\hline CHEMBL1355472 & 688267 & 6.25 & 5.1115 & TRN \\
\hline CHEMBL1541239 & 688267 & 6.2 & 5.0219 & TRN \\
\hline CHEMBL1444211 & 688267 & 4.6 & 5.0972 & TST \\
\hline CHEMBL1605747 & 688267 & 4.1 & 5.0556 & TST \\
\hline CHEMBL1558447 & 688267 & 5.0 & 5.0511 & TRN \\
\hline CHEMBL1584417 & 688267 & 6.25 & 4.9784 & TRN \\
\hline CHEMBL1525174 & 688267 & 5.95 & 5.0799 & TRN \\
\hline CHEMBL1497365 & 688267 & 5.85 & 5.0444 & TRN \\
\hline CHEMBL1563232 & 688267 & 4.35 & 5.1285 & TRN \\
\hline CHEMBL1481546 & 688267 & 4.3 & 5.0775 & TRN \\
\hline CHEMBL1356449 & 688267 & 5.4 & 5.0315 & TRN \\
\hline CHEMBL 3210400 & 688267 & 4.35 & 4.9945 & TST \\
\hline CHEMBL1436448 & 688267 & 5.1 & 5.0942 & TRN \\
\hline CHEMBL1584150 & 688267 & 4.3 & 5.0164 & TST \\
\hline CHEMBL1373337 & 688267 & 4.5 & 5.1295 & TRN \\
\hline CHEMBL1521556 & 688267 & 3.9 & 5.0764 & TRN \\
\hline CHEMBL1541322 & 688267 & 4.45 & 5.0269 & TRN \\
\hline CHEMBL 3212584 & 688267 & 4.0 & 5.0263 & TRN \\
\hline CHEMBL3196239 & 688267 & 5.95 & 5.0406 & TST \\
\hline CHEMBL1486826 & 688267 & 5.35 & 5.0503 & TRN \\
\hline CHEMBL1599548 & 688267 & 6.15 & 5.1022 & TST \\
\hline CHEMBL1408193 & 688267 & 4.15 & 4.9944 & TRN \\
\hline CHEMBL1424954 & 688267 & 5.6 & 5.0604 & TRN \\
\hline CHEMBL3209855 & 688267 & 5.25 & 5.0336 & TRN \\
\hline CHEMBL1448840 & 688267 & 3.95 & 5.0158 & TRN \\
\hline CHEMBL1436954 & 688267 & 4.4 & 5.124 & TRN \\
\hline CHEMBL1590155 & 688267 & 6.2 & 5.0429 & TRN \\
\hline CHEMBL1432971 & 688267 & 6.15 & 5.1499 & TRN \\
\hline CHEMBL1329070 & 688267 & 6.25 & 5.0101 & TRN \\
\hline CHEMBL1313585 & 688267 & 4.8 & 5.0294 & TRN \\
\hline CHEMBL1590301 & 688267 & 4.6 & 5.0647 & TST \\
\hline CHEMBL1415836 & 688267 & 4.1 & 5.0056 & TRN \\
\hline
\end{tabular}




\begin{tabular}{|c|c|c|c|c|}
\hline & & & upplement & al $\mathrm{T}$ \\
\hline CHEMBL1607175 & 688267 & 4.4 & 4.9945 & TST \\
\hline CHEMBL3207773 & 688267 & 4.35 & 5.0332 & TRN \\
\hline CHEMBL1433621 & 688267 & 3.95 & 5.0444 & TRN \\
\hline CHEMBL1342232 & 688267 & 4.3 & 5.046 & TST \\
\hline CHEMBL3192046 & 688267 & 6.2 & 4.992 & TRN \\
\hline CHEMBL1313083 & 688267 & 5.95 & 5.079 & TST \\
\hline CHEMBL1403552 & 688267 & 5.4 & 5.0391 & TRN \\
\hline CHEMBL1474837 & 688267 & 5.05 & 5.0969 & TRN \\
\hline CHEMBL1585105 & 688267 & 5.35 & 5.0029 & TRN \\
\hline CHEMBL1361369 & 688267 & 4.4 & 5.0276 & TST \\
\hline CHEMBL1533773 & 688267 & 6.2 & 5.0358 & TRN \\
\hline CHEMBL1430845 & 688267 & 4.05 & 5.0166 & TRN \\
\hline CHEMBL1519772 & 688267 & 4.9 & 5.048 & TST \\
\hline CHEMBL1448080 & 688267 & 4.35 & 5.0659 & TRN \\
\hline CHEMBL3189905 & 688267 & 3.95 & 5.0551 & TST \\
\hline CHEMBL1511938 & 688267 & 6.45 & 5.0652 & TRN \\
\hline CHEMBL1331866 & 688267 & 4.9 & 5.0505 & TST \\
\hline CHEMBL1376561 & 688267 & 4.0 & 5.1628 & TRN \\
\hline CHEMBL3198532 & 688267 & 4.2 & 5.0673 & TST \\
\hline CHEMBL1568133 & 688267 & 6.5 & 5.0587 & TST \\
\hline CHEMBL1451148 & 688267 & 3.95 & 5.0912 & TRN \\
\hline CHEMBL3195052 & 688267 & 4.0 & 5.0459 & TRN \\
\hline CHEMBL1608111 & 688267 & 6.2 & 5.0245 & TRN \\
\hline CHEMBL1576624 & 688267 & 4.3 & 5.0308 & TST \\
\hline CHEMBL1363239 & 688267 & 5.6 & 5.0618 & TST \\
\hline CHEMBL1544350 & 688267 & 4.3 & 5.0909 & TRN \\
\hline CHEMBL1483211 & 688267 & 4.35 & 5.1023 & TST \\
\hline CHEMBL1612885 & 688267 & 6.2 & 5.0298 & TRN \\
\hline CHEMBL1510162 & 688267 & 4.55 & 5.1705 & TRN \\
\hline CHEMBL1482525 & 688267 & 4.85 & 5.0764 & TRN \\
\hline CHEMBL1364885 & 688267 & 4.0 & 5.1174 & TRN \\
\hline CHEMBL1351672 & 688267 & 4.0 & 5.0786 & TRN \\
\hline CHEMBL1376314 & 688267 & 4.6 & 5.0307 & TRN \\
\hline CHEMBL1457018 & 688267 & 5.05 & 5.0879 & TRN \\
\hline CHEMBL1364199 & 688267 & 5.45 & 5.0651 & TRN \\
\hline CHEMBL1484768 & 688267 & 4.05 & 5.0774 & TRN \\
\hline CHEMBL1355209 & 688267 & 6.1 & 5.046 & TRN \\
\hline CHEMBL1583825 & 688267 & 5.05 & 5.0134 & TRN \\
\hline CHEMBL1530305 & 688267 & 4.05 & 5.0725 & TRN \\
\hline CHEMBL1528979 & 688267 & 4.95 & 5.0171 & TRN \\
\hline CHEMBL1581609 & 688267 & 4.4 & 5.0843 & TST \\
\hline CHEMBL1530664 & 688267 & 6.2 & 5.0974 & TRN \\
\hline CHEMBL1341295 & 688267 & 5.35 & 5.0474 & TRN \\
\hline CHEMBL1341106 & 688267 & 5.75 & 4.9914 & TRN \\
\hline CHEMBL1362325 & 688267 & 5.95 & 5.0539 & TRN \\
\hline CHEMBL1410936 & 688267 & 5.9 & 5.0949 & TST \\
\hline CHEMBL1376964 & 688267 & 6.2 & 5.0644 & TST \\
\hline CHEMBL1452059 & 688267 & 6.2 & 5.1202 & TRN \\
\hline
\end{tabular}




\begin{tabular}{|c|c|c|c|c|c|}
\hline \\
\hline CHEMBL1398489 & 688267 & 5.1 & 5.1191 & TRN & \\
\hline CHEMBL1474738 & 688267 & 4.65 & 5.0778 & TRN & \\
\hline CHEMBL1435660 & 688267 & 4.0 & 5.0999 & TRN & \\
\hline CHEMBL1590867 & 688267 & 4.55 & 5.0645 & TRN & \\
\hline CHEMBL1393408 & 688267 & 4.0 & 5.0598 & TRN & \\
\hline CHEMBL3193174 & 688267 & 5.35 & 5.0186 & TST & \\
\hline CHEMBL1489331 & 688267 & 4.65 & 5.0398 & TRN & \\
\hline CHEMBL1491261 & 688267 & 4.7 & 5.0157 & TRN & \\
\hline CHEMBL1318032 & 688267 & 5.15 & 5.0743 & TRN & \\
\hline CHEMBL1437246 & 688267 & 4.35 & 5.0883 & TRN & \\
\hline CHEMBL1510854 & 688267 & 5.25 & 5.10800 & 20000000005 & TRN \\
\hline CHEMBL1519237 & 688267 & 6.2 & 5.056 & TST & \\
\hline CHEMBL3211369 & 688267 & 4.45 & 5.0073 & TRN & \\
\hline CHEMBL1555845 & 688267 & 5.75 & 5.004 & TRN & \\
\hline CHEMBL1344381 & 688267 & 4.55 & 5.0258 & TST & \\
\hline CHEMBL1397649 & 688267 & 6.2 & 5.117 & TRN & \\
\hline CHEMBL1591033 & 688267 & 4.0 & 5.0882 & TST & \\
\hline CHEMBL1372035 & 688267 & 4.4 & 5.0704 & TRN & \\
\hline CHEMBL1311267 & 688267 & 5.3 & 5.0628 & TRN & \\
\hline CHEMBL1420024 & 688267 & 5.5 & 5.1067 & TRN & \\
\hline CHEMBL1317934 & 688267 & 4.2 & 5.1054 & TRN & \\
\hline CHEMBL1501843 & 688267 & 6.2 & 5.0312 & TRN & \\
\hline CHEMBL1475379 & 688267 & 5.4 & 5.0469 & TST & \\
\hline CHEMBL1310300 & 688267 & 4.05 & 4.9696 & TRN & \\
\hline CHEMBL1486894 & 688267 & 4.0 & 5.0539 & TRN & \\
\hline CHEMBL1408824 & 688267 & 4.0 & 5.12 & TRN & \\
\hline CHEMBL1403392 & 688267 & 6.15 & 5.0792 & TRN & \\
\hline CHEMBL1501072 & 688267 & 3.95 & 5.1151 & TST & \\
\hline CHEMBL1459540 & 688267 & 6.2 & 5.1017 & TST & \\
\hline CHEMBL1521740 & 688267 & 6.2 & 5.0337 & TST & \\
\hline CHEMBL1350652 & 688267 & 5.9 & 5.0298 & TRN & \\
\hline CHEMBL1496040 & 688267 & 4.0 & 5.0554 & TRN & \\
\hline CHEMBL1478945 & 688267 & 4.0 & 5.0505 & TRN & \\
\hline CHEMBL1553625 & 688267 & 7.0501 & 5.1022 & TRN & \\
\hline CHEMBL1446845 & 688267 & 6.2 & 5.0462 & TRN & \\
\hline CHEMBL1320991 & 688267 & 6.2 & 5.0244 & TRN & \\
\hline CHEMBL1577848 & 688267 & 4.35 & 5.0774 & TRN & \\
\hline CHEMBL1459466 & 688267 & 5.35 & 5.0483 & TRN & \\
\hline CHEMBL1328134 & 688267 & 4.0 & 5.0971 & TRN & \\
\hline CHEMBL1344088 & 688267 & 6.15 & 5.0082 & TST & \\
\hline CHEMBL1491510 & 688267 & 4.4 & 5.1027 & TRN & \\
\hline CHEMBL1317030 & 688267 & 5.15 & 5.0891 & TRN & \\
\hline CHEMBL1370655 & 688267 & 5.7 & 5.0378 & TRN & \\
\hline CHEMBL3190582 & 688267 & 6.1 & 5.0228 & TRN & \\
\hline CHEMBL1403761 & 688267 & 6.5 & 5.106 & TRN & \\
\hline CHEMBL3194808 & 688267 & 5.75 & 5.0394 & TST & \\
\hline CHEMBL1352055 & 688267 & 4.4 & 5.092 & TST & \\
\hline CHEMBL1387108 & 688267 & 4.0 & 5.0347 & TRN & \\
\hline
\end{tabular}




\begin{tabular}{|c|c|c|c|c|}
\hline & & & pplement & al $\mathrm{Ta}$ \\
\hline CHEMBL1355167 & 688267 & 5.5 & 5.1177 & TRN \\
\hline CHEMBL1595468 & 688267 & 5.35 & 5.0549 & TST \\
\hline CHEMBL1373388 & 688267 & 4.25 & 5.0408 & TRN \\
\hline CHEMBL1593497 & 688267 & 5.8 & 5.0512 & TRN \\
\hline CHEMBL1452002 & 688267 & 4.25 & 5.1208 & TST \\
\hline CHEMBL1393260 & 688267 & 5.95 & 5.0607 & TST \\
\hline CHEMBL1495845 & 688267 & 4.0 & 5.0379 & TRN \\
\hline CHEMBL1544078 & 688267 & 4.25 & 5.0428 & TRN \\
\hline CHEMBL1594683 & 688267 & 6.2 & 5.0542 & TRN \\
\hline CHEMBL1457646 & 688267 & 5.0 & 5.1129 & TRN \\
\hline CHEMBL1299324 & 688267 & 4.85 & 5.1052 & TRN \\
\hline CHEMBL1485599 & 688267 & 6.2 & 5.0573 & TRN \\
\hline CHEMBL1350474 & 688267 & 6.15 & 5.0934 & TRN \\
\hline CHEMBL2369229 & 688267 & 4.0 & 5.0667 & TRN \\
\hline CHEMBL1567198 & 688267 & 5.3 & 5.0518 & TRN \\
\hline CHEMBL1364419 & 688267 & 4.3 & 5.0799 & TRN \\
\hline CHEMBL1397423 & 688267 & 6.15 & 5.037 & TRN \\
\hline CHEMBL1598423 & 688267 & 6.05 & 5.0496 & TST \\
\hline CHEMBL1607578 & 688267 & 4.35 & 5.0038 & TRN \\
\hline CHEMBL1559799 & 688267 & 4.4 & 5.0288 & TRN \\
\hline CHEMBL1602059 & 688267 & 4.35 & 5.0394 & TRN \\
\hline CHEMBL1529147 & 688267 & 5.25 & 5.1224 & TST \\
\hline CHEMBL1469575 & 688267 & 4.0 & 5.0892 & TRN \\
\hline CHEMBL 3196701 & 688267 & 4.4 & 5.0109 & TST \\
\hline CHEMBL1302227 & 688267 & 5.0 & 5.0623 & TRN \\
\hline CHEMBL1436313 & 688267 & 3.95 & 5.0578 & TRN \\
\hline CHEMBL1376626 & 688267 & 4.4 & 5.1152 & TRN \\
\hline CHEMBL 3212260 & 688267 & 4.25 & 4.9991 & TST \\
\hline CHEMBL1344354 & 688267 & 4.0 & 5.0287 & TST \\
\hline CHEMBL1324811 & 688267 & 5.25 & 5.1343 & TRN \\
\hline CHEMBL1585132 & 688267 & 4.45 & 5.0809 & TRN \\
\hline CHEMBL1503398 & 688267 & 4.4 & 5.1585 & TRN \\
\hline CHEMBL1337220 & 688267 & 4.25 & 5.0755 & TRN \\
\hline CHEMBL1431843 & 688267 & 4.0 & 4.9933 & TRN \\
\hline CHEMBL1562606 & 688267 & 5.35 & 5.0137 & TRN \\
\hline CHEMBL1329432 & 688267 & 6.2 & 5.0086 & TST \\
\hline CHEMBL1604987 & 688267 & 5.85 & 5.0769 & TRN \\
\hline CHEMBL1353697 & 688267 & 6.2 & 5.0689 & TRN \\
\hline CHEMBL1307211 & 688267 & 4.0 & 5.0298 & TST \\
\hline CHEMBL1415065 & 688267 & 4.05 & 5.0762 & TRN \\
\hline CHEMBL1390059 & 688267 & 5.1 & 5.0082 & TRN \\
\hline CHEMBL1413027 & 688267 & 4.2 & 5.0357 & TRN \\
\hline CHEMBL1588713 & 688267 & 5.55 & 5.0113 & TRN \\
\hline CHEMBL1563601 & 688267 & 5.95 & 5.124 & TST \\
\hline CHEMBL1596576 & 688267 & 3.95 & 5.1078 & TST \\
\hline CHEMBL261782 & 688267 & 4.3 & 5.0617 & TST \\
\hline CHEMBL117813 & 688267 & 5.85 & 5.0189 & TST \\
\hline CHEMBL1409202 & 688267 & 6.45 & 5.0661 & TRN \\
\hline
\end{tabular}




\begin{tabular}{|c|c|c|c|c|c|}
\hline & & \multicolumn{4}{|c|}{ Supplemental Table S2.txt } \\
\hline CHEMBL1305416 & 688267 & 5.1 & 5.0497 & TST & \\
\hline CHEMBL1552742 & 688267 & 4.0 & 4.9853 & TRN & \\
\hline CHEMBL1575056 & 688267 & 4.15 & 5.0548 & TRN & \\
\hline CHEMBL1342157 & 688267 & 4.25 & 4.9916 & TRN & \\
\hline CHEMBL1515304 & 688267 & 5.4 & 5.0421 & TRN & \\
\hline CHEMBL1365655 & 688267 & 6.2 & 5.1365 & TRN & \\
\hline CHEMBL1495545 & 688267 & 4.0 & 5.0284 & TST & \\
\hline CHEMBL1312146 & 688267 & 4.6 & 5.004 & TRN & \\
\hline CHEMBL1495299 & 688267 & 5.45 & 5.0901 & TST & \\
\hline CHEMBL1402394 & 688267 & 5.6 & 5.092 & TRN & \\
\hline CHEMBL1442243 & 688267 & 5.9 & 5.0673 & TRN & \\
\hline CHEMBL1554990 & 688267 & 4.5 & 5.0619 & TRN & \\
\hline CHEMBL1381592 & 688267 & 6.2 & 5.05 & TRN & \\
\hline CHEMBL1574230 & 688267 & 5.25 & 5.0319 & TRN & \\
\hline CHEMBL3209618 & 688267 & 5.0 & 5.056 & TST & \\
\hline CHEMBL1450950 & 688267 & 4.05 & 5.1275 & TRN & \\
\hline CHEMBL1483402 & 688267 & 4.0 & 4.9679 & TRN & \\
\hline CHEMBL1434622 & 688267 & 4.25 & 4.9941 & TST & \\
\hline CHEMBL1447539 & 688267 & 6.45 & 5.0394 & TRN & \\
\hline CHEMBL1304008 & 688267 & 6.5 & 4.9938 & TRN & \\
\hline CHEMBL1597396 & 688267 & 4.05 & 5.0426 & TRN & \\
\hline CHEMBL379099 & 688267 & 4.85 & 5.0111 & TRN & \\
\hline CHEMBL1343284 & 688267 & 4.1 & 5.0775 & TRN & \\
\hline CHEMBL1354589 & 688267 & 5.9 & 5.0737 & TRN & \\
\hline CHEMBL1359880 & 688267 & 6.2 & 5.0962 & TRN & \\
\hline CHEMBL1488034 & 688267 & 5.2 & 5.0255 & TRN & \\
\hline CHEMBL1489762 & 688267 & 4.05 & 5.1024 & TRN & \\
\hline CHEMBL1449859 & 688267 & 4.05 & 5.0542 & TRN & \\
\hline CHEMBL1255737 & 688267 & 4.35 & 5.0189 & TST & \\
\hline CHEMBL1454342 & 688267 & 4.55 & 5.1029 & TST & \\
\hline CHEMBL1418211 & 688267 & 4.65 & 4.9975 & TRN & \\
\hline CHEMBL1364637 & 688267 & 5.6 & 4.9906 & TST & \\
\hline CHEMBL1530919 & 688267 & 6.15 & 5.0205 & TRN & \\
\hline CHEMBL1570035 & 688267 & 5.5 & 5.01399 & 9999999999 & TRN \\
\hline CHEMBL1604372 & 688267 & 4.35 & $5.0760 e$ & 00000000005 & TRN \\
\hline CHEMBL1541833 & 688267 & 4.0 & 5.0038 & TST & \\
\hline CHEMBL1337534 & 688267 & 4.0 & 5.1317 & TRN & \\
\hline CHEMBL1376280 & 688267 & 4.4 & 5.0597 & TRN & \\
\hline CHEMBL1559017 & 688267 & 6.15 & 5.0352 & TRN & \\
\hline CHEMBL1556387 & 688267 & 6.15 & 4.9997 & TST & \\
\hline CHEMBL1304336 & 688267 & 4.05 & 5.0588 & TRN & \\
\hline CHEMBL1355714 & 688267 & 4.95 & 5.1066 & TRN & \\
\hline CHEMBL1450535 & 688267 & 4.2 & 5.1337 & TRN & \\
\hline CHEMBL1460475 & 688267 & 5.1 & 5.0541 & TST & \\
\hline CHEMBL1359116 & 688267 & 4.6 & 5.0707 & TST & \\
\hline CHEMBL1388238 & 688267 & 5.35 & 5.0829 & TRN & \\
\hline CHEMBL3212160 & 688267 & 5.85 & 5.0739 & TRN & \\
\hline CHEMBL1880070 & 688267 & 6.1 & 5.0332 & TST & \\
\hline
\end{tabular}




\begin{tabular}{|c|c|c|c|c|}
\hline \multicolumn{5}{|c|}{ Supplemental Table S2.txt } \\
\hline CHEMBL1448661 & 688267 & 5.95 & 5.1045 & TRN \\
\hline CHEMBL1563786 & 688267 & 5.65 & 5.0316 & TRN \\
\hline CHEMBL1429424 & 688267 & 4.15 & 5.0783 & TRN \\
\hline CHEMBL1521458 & 688267 & 5.35 & 5.0171 & TRN \\
\hline CHEMBL1321004 & 688267 & 3.95 & 5.0531 & TST \\
\hline CHEMBL1389278 & 688267 & 4.4 & 5.0435 & TRN \\
\hline CHEMBL1371604 & 688267 & 3.95 & 5.0668 & TRN \\
\hline CHEMBL1567201 & 688267 & 6.15 & 5.0474 & TRN \\
\hline CHEMBL1449499 & 688267 & 3.95 & 5.0479 & TRN \\
\hline CHEMBL1578728 & 688267 & 4.05 & 5.0649 & TST \\
\hline CHEMBL3190562 & 688267 & 5.35 & 4.9606 & TRN \\
\hline CHEMBL 3197283 & 688267 & 4.3 & 5.0761 & TRN \\
\hline CHEMBL1336026 & 688267 & 4.55 & 5.0237 & TRN \\
\hline CHEMBL1426677 & 688267 & 4.05 & 5.0594 & TRN \\
\hline CHEMBL1508177 & 688267 & 5.4 & 5.0082 & TRN \\
\hline CHEMBL1525613 & 688267 & 5.0 & 4.9916 & TRN \\
\hline CHEMBL1490736 & 688267 & 4.05 & 5.0469 & TRN \\
\hline CHEMBL1319144 & 688267 & 4.3 & 5.0693 & TRN \\
\hline CHEMBL1484304 & 688267 & 6.25 & 5.0919 & TRN \\
\hline CHEMBL1477675 & 688267 & 5.0 & 5.0965 & TRN \\
\hline CHEMBL1379306 & 688267 & 5.6 & 5.035 & TST \\
\hline CHEMBL1362049 & 688267 & 6.2 & 5.0976 & TRN \\
\hline CHEMBL1520849 & 688267 & 5.95 & 5.0138 & TRN \\
\hline CHEMBL1566121 & 688267 & 6.5 & 5.0604 & TRN \\
\hline CHEMBL1416062 & 688267 & 4.3 & 5.1004 & TST \\
\hline CHEMBL1546288 & 688267 & 4.5 & 5.0525 & TST \\
\hline CHEMBL1404022 & 688267 & 5.3 & 4.9959 & TRN \\
\hline CHEMBL1471789 & 688267 & 4.0 & 5.0222 & TRN \\
\hline CHEMBL3209915 & 688267 & 4.5 & 5.0634 & TRN \\
\hline CHEMBL1432556 & 688267 & 6.2 & 5.0378 & TST \\
\hline CHEMBL1578993 & 688267 & 5.6 & 5.0327 & TRN \\
\hline CHEMBL1327783 & 688267 & 4.05 & 5.0855 & TRN \\
\hline CHEMBL1500231 & 688267 & 4.8 & 5.0832 & TST \\
\hline CHEMBL1542857 & 688267 & 6.5 & 5.0753 & TRN \\
\hline CHEMBL1440169 & 688267 & 5.9 & 5.0413 & TRN \\
\hline CHEMBL1467572 & 688267 & 3.95 & 5.0796 & TRN \\
\hline CHEMBL1440979 & 688267 & 6.5 & 5.1614 & TRN \\
\hline CHEMBL1561683 & 688267 & 4.3 & 5.118 & TRN \\
\hline CHEMBL1453803 & 688267 & 5.25 & 5.0943 & TST \\
\hline CHEMBL1408746 & 688267 & 6.15 & 5.0124 & TRN \\
\hline CHEMBL 257475 & 688267 & 3.95 & 5.1075 & TRN \\
\hline CHEMBL1398417 & 688267 & 6.5 & 5.0694 & TRN \\
\hline CHEMBL1522541 & 688267 & 4.9 & 5.0591 & TRN \\
\hline CHEMBL1425954 & 688267 & 4.65 & 5.0218 & TRN \\
\hline CHEMBL1550530 & 688267 & 4.9 & 5.1349 & TST \\
\hline CHEMBL1399459 & 688267 & 3.95 & 5.0083 & TRN \\
\hline CHEMBL1317842 & 688267 & 6.1 & 5.0406 & TRN \\
\hline CHEMBL1503911 & 688267 & 4.5 & 5.1106 & TRN \\
\hline
\end{tabular}




\begin{tabular}{|c|c|c|c|c|c|}
\hline \\
\hline CHEMBL1453834 & 688267 & 6.5 & 4.9963 & TRN & \\
\hline CHEMBL1598311 & 688267 & 4.8 & 4.9855 & TRN & \\
\hline CHEMBL1584779 & 688267 & 4.55 & 5.0127 & TST & \\
\hline CHEMBL1525368 & 688267 & 4.05 & 5.0489 & TST & \\
\hline CHEMBL1337980 & 688267 & 5.95 & 5.04 & TRN & \\
\hline CHEMBL1557900 & 688267 & 5.65 & 5.0206 & TRN & \\
\hline CHEMBL1561162 & 688267 & 4.05 & 5.0479 & TST & \\
\hline CHEMBL1473266 & 688267 & 5.35 & 4.9973 & TRN & \\
\hline CHEMBL1424091 & 688267 & 5.45 & 5.1037 & TRN & \\
\hline CHEMBL1451840 & 688267 & 4.35 & 5.0901 & TRN & \\
\hline CHEMBL1587876 & 688267 & 5.0 & 5.0147 & TST & \\
\hline CHEMBL1380371 & 688267 & 4.0 & 5.1204 & TRN & \\
\hline CHEMBL1560366 & 688267 & 4.85 & 5.0253 & TST & \\
\hline CHEMBL1606046 & 688267 & 6.2 & 5.0023 & TRN & \\
\hline CHEMBL1586219 & 688267 & 4.9 & 5.0255 & TRN & \\
\hline CHEMBL1392586 & 688267 & 5.85 & 4.9851 & TST & \\
\hline CHEMBL1526702 & 688267 & 6.25 & 5.0222 & TRN & \\
\hline CHEMBL1325940 & 688267 & 6.5 & 5.0486 & TRN & \\
\hline CHEMBL1340567 & 688267 & 5.3 & 5.0942 & TRN & \\
\hline CHEMBL1461072 & 688267 & 4.5 & 5.0486 & TRN & \\
\hline CHEMBL1475644 & 688267 & 4.3 & 5.0741 & TRN & \\
\hline CHEMBL1420051 & 688267 & 6.2 & 5.1208 & TRN & \\
\hline CHEMBL1565843 & 688267 & 5.25 & 5.1008 & TRN & \\
\hline CHEMBL1357552 & 688267 & 5.0 & 5.0899 & TRN & \\
\hline CHEMBL1457741 & 688267 & 4.65 & 5.0927 & TST & \\
\hline CHEMBL1574502 & 688267 & 3.95 & 5.0459 & TST & \\
\hline CHEMBL1373453 & 688267 & 4.75 & 5.01699 & 99999999995 & TST \\
\hline CHEMBL1333694 & 688267 & 4.5 & 5.0646 & TRN & \\
\hline CHEMBL1508080 & 688267 & 4.5 & 5.0631 & TST & \\
\hline CHEMBL1526146 & 688267 & 4.6 & 5.0793 & TST & \\
\hline CHEMBL1371550 & 688267 & 6.1 & 5.0667 & TRN & \\
\hline CHEMBL1303844 & 688267 & 4.0 & 5.0363 & TRN & \\
\hline CHEMBL1403923 & 688267 & 4.0 & 5.0216 & TRN & \\
\hline CHEMBL1605933 & 688267 & 4.35 & 5.0798 & TST & \\
\hline CHEMBL1386468 & 688267 & 5.45 & 5.0411 & TRN & \\
\hline CHEMBL1578087 & 688267 & 4.5 & 5.0068 & TRN & \\
\hline CHEMBL1494155 & 688267 & 4.2 & 5.012 & TRN & \\
\hline CHEMBL1566307 & 688267 & 5.75 & 5.0646 & TST & \\
\hline CHEMBL1380373 & 688267 & 4.55 & 5.0277 & TRN & \\
\hline CHEMBL1543592 & 688267 & 6.25 & 5.058 & TST & \\
\hline CHEMBL1594214 & 688267 & 4.4 & 4.9991 & TRN & \\
\hline CHEMBL1349788 & 688267 & 6.2 & 5.0423 & TRN & \\
\hline CHEMBL1469759 & 688267 & 4.6 & 5.10800 & 00000000005 & TST \\
\hline CHEMBL1504887 & 688267 & 4.15 & 5.0317 & TRN & \\
\hline CHEMBL1460146 & 688267 & 4.4 & 5.0861 & TST & \\
\hline CHEMBL1476460 & 688267 & 4.35 & 5.0655 & TRN & \\
\hline CHEMBL1328555 & 688267 & 5.8 & 5.0552 & TST & \\
\hline CHEMBL3189165 & 688267 & 6.15 & 5.0094 & TST & \\
\hline
\end{tabular}




\begin{tabular}{|c|c|c|c|c|}
\hline & & & pplement & \\
\hline CHEMBL1464036 & 688267 & 5.6 & 5.0472 & TRN \\
\hline CHEMBL1517385 & 688267 & 5.95 & 5.0363 & TRN \\
\hline CHEMBL1416439 & 688267 & 4.1 & 5.0234 & TRN \\
\hline CHEMBL1439992 & 688267 & 5.35 & 5.0468 & TRN \\
\hline CHEMBL3191930 & 688267 & 4.35 & 5.0472 & TST \\
\hline CHEMBL1513229 & 688267 & 3.95 & 5.0608 & TRN \\
\hline CHEMBL1562694 & 688267 & 4.75 & 5.0318 & TST \\
\hline CHEMBL1557024 & 688267 & 5.35 & 5.1497 & TRN \\
\hline CHEMBL1371792 & 688267 & 4.6 & 5.0953 & TRN \\
\hline CHEMBL1566968 & 688267 & 6.15 & 5.0597 & TRN \\
\hline CHEMBL1986251 & 688267 & 4.05 & 5.0268 & TST \\
\hline CHEMBL1409318 & 688267 & 5.3 & 5.0112 & TRN \\
\hline CHEMBL1368027 & 688267 & 6.1 & 5.0327 & TRN \\
\hline CHEMBL1389453 & 688267 & 4.25 & 5.0918 & TRN \\
\hline CHEMBL1589524 & 688267 & 4.2 & 5.0886 & TRN \\
\hline CHEMBL1341434 & 688267 & 6.2 & 5.0491 & TRN \\
\hline CHEMBL1489753 & 688267 & 6.1 & 5.0641 & TRN \\
\hline CHEMBL1409737 & 688267 & 5.25 & 5.0476 & TRN \\
\hline CHEMBL1508354 & 688267 & 5.55 & 5.0329 & TST \\
\hline CHEMBL1465937 & 688267 & 5.4 & 5.0621 & TST \\
\hline CHEMBL1405184 & 688267 & 5.05 & 5.0049 & TST \\
\hline CHEMBL1434422 & 688267 & 4.4 & 5.0171 & TST \\
\hline CHEMBL1557496 & 688267 & 6.15 & 5.0466 & TRN \\
\hline CHEMBL1444197 & 688267 & 4.0 & 5.0395 & TRN \\
\hline CHEMBL1600244 & 688267 & 4.0 & 5.0564 & TRN \\
\hline CHEMBL1404723 & 688267 & 6.15 & 5.1189 & TRN \\
\hline CHEMBL1317158 & 688267 & 4.25 & 5.061 & TRN \\
\hline CHEMBL1554522 & 688267 & 4.05 & 5.0647 & TRN \\
\hline CHEMBL1353140 & 688267 & 5.25 & 5.0928 & TRN \\
\hline CHEMBL1418912 & 688267 & 4.0 & 4.9862 & TRN \\
\hline CHEMBL1552029 & 688267 & 6.2 & 5.0279 & TRN \\
\hline CHEMBL1496661 & 688267 & 5.9 & 5.0806 & TRN \\
\hline CHEMBL 3190088 & 688267 & 4.55 & 5.0417 & TRN \\
\hline CHEMBL1366863 & 688267 & 5.3 & 4.9993 & TRN \\
\hline CHEMBL1531795 & 688267 & 6.1 & 5.0765 & TRN \\
\hline CHEMBL1337221 & 688267 & 4.0 & 5.0791 & TST \\
\hline CHEMBL1603911 & 688267 & 4.2 & 5.0583 & TRN \\
\hline CHEMBL1591457 & 688267 & 6.25 & 5.1329 & TRN \\
\hline CHEMBL1352941 & 688267 & 5.35 & 5.0133 & TRN \\
\hline CHEMBL1395483 & 688267 & 4.4 & 5.0351 & TST \\
\hline CHEMBL1508515 & 688267 & 6.2 & 5.1262 & TRN \\
\hline CHEMBL1384205 & 688267 & 4.0 & 5.021 & TST \\
\hline CHEMBL1355619 & 688267 & 5.65 & 5.0082 & TRN \\
\hline CHEMBL1344214 & 688267 & 6.1 & 5.0777 & TRN \\
\hline CHEMBL1401599 & 688267 & 4.55 & 5.0286 & TRN \\
\hline CHEMBL1593450 & 688267 & 6.25 & 5.112 & TRN \\
\hline CHEMBL1445123 & 688267 & 5.05 & 5.0851 & TRN \\
\hline CHEMBL1420790 & 688267 & 4.4 & 5.0497 & TST \\
\hline
\end{tabular}




\begin{tabular}{|c|c|c|c|c|c|}
\hline & & & & & \\
\hline CHEMBL1549229 & 688267 & 4.0 & 5.0324 & TST & \\
\hline CHEMBL1353717 & 688267 & 5.05 & 5.1347 & TRN & \\
\hline CHEMBL1338734 & 688267 & 5.45 & 5.0492 & TRN & \\
\hline CHEMBL1537346 & 688267 & 5.15 & 5.1041 & TRN & \\
\hline CHEMBL1546180 & 688267 & 4.45 & 5.0435 & TRN & \\
\hline CHEMBL1330759 & 688267 & 4.45 & 5.0156 & TRN & \\
\hline CHEMBL1480110 & 688267 & 4.05 & 5.088 & TRN & \\
\hline CHEMBL1347982 & 688267 & 4.55 & 5.0385 & TRN & \\
\hline CHEMBL1592924 & 688267 & 5.55 & 5.10800 & 00000000005 & TRN \\
\hline CHEMBL1546222 & 688267 & 4.0 & 5.0238 & TST & \\
\hline CHEMBL1522911 & 688267 & 3.95 & 5.0091 & TRN & \\
\hline CHEMBL1496414 & 688267 & 5.5 & 5.0196 & TST & \\
\hline CHEMBL1481524 & 688267 & 6.15 & 5.0333 & TRN & \\
\hline CHEMBL 3208094 & 688267 & 6.25 & 5.0953 & TST & \\
\hline CHEMBL1414550 & 688267 & 3.95 & 5.1637 & TST & \\
\hline CHEMBL1537837 & 688267 & 5.15 & 5.0761 & TRN & \\
\hline CHEMBL1454128 & 688267 & 4.25 & 5.0135 & TST & \\
\hline CHEMBL1397234 & 688267 & 5.85 & 5.0037 & TRN & \\
\hline CHEMBL1613594 & 688267 & 4.6 & 5.0234 & TRN & \\
\hline CHEMBL1513713 & 688267 & 6.15 & 5.0452 & TRN & \\
\hline CHEMBL1551276 & 688267 & 5.5 & 5.0771 & TRN & \\
\hline CHEMBL1333788 & 688267 & 5.85 & 4.9993 & TRN & \\
\hline CHEMBL1359620 & 688267 & 4.7 & 5.0316 & TRN & \\
\hline CHEMBL1499181 & 688267 & 5.85 & 5.1232 & TRN & \\
\hline CHEMBL1478563 & 688267 & 5.2 & 5.0444 & TRN & \\
\hline CHEMBL1340675 & 688267 & 4.35 & 5.0831 & TST & \\
\hline CHEMBL1382285 & 688267 & 4.95 & 5.0328 & TRN & \\
\hline CHEMBL1553128 & 688267 & 6.1 & 5.0481 & TST & \\
\hline CHEMBL1588811 & 688267 & 5.3 & 5.0978 & TST & \\
\hline CHEMBL557686 & 688267 & 5.85 & 5.1009 & TRN & \\
\hline CHEMBL1397801 & 688267 & 4.15 & 5.0808 & TRN & \\
\hline CHEMBL1386894 & 688267 & 4.25 & 5.072 & TST & \\
\hline CHEMBL1607371 & 688267 & 5.85 & 5.0455 & TRN & \\
\hline CHEMBL1351402 & 688267 & 5.15 & 5.0764 & TRN & \\
\hline CHEMBL1538050 & 688267 & 5.55 & 5.1169 & TST & \\
\hline CHEMBL1988133 & 688267 & 5.05 & 4.9829 & TRN & \\
\hline CHEMBL1562199 & 688267 & 4.45 & 5.0188 & TST & \\
\hline CHEMBL1528550 & 688267 & 5.45 & 5.0008 & TRN & \\
\hline CHEMBL3210213 & 688267 & 4.0 & 5.0339 & TST & \\
\hline CHEMBL1301498 & 688267 & 5.6 & 5.0493 & TRN & \\
\hline CHEMBL1539547 & 688267 & 5.25 & 5.0905 & TRN & \\
\hline CHEMBL1429160 & 688267 & 4.0 & 5.047 & TRN & \\
\hline CHEMBL1451887 & 688267 & 6.5 & 5.0461 & TRN & \\
\hline CHEMBL1499007 & 688267 & 4.0 & 5.0499 & TRN & \\
\hline CHEMBL1327133 & 688267 & 5.05 & 5.0657 & TST & \\
\hline CHEMBL1309403 & 688267 & 4.7 & 5.0214 & TST & \\
\hline CHEMBL 1474575 & 688267 & 4.7 & 4.97199 & 99999999995 & TRN \\
\hline CHEMBL1434122 & 688267 & 3.95 & 5.0295 & TST & \\
\hline & & & & 18047 & \\
\hline
\end{tabular}




\begin{tabular}{|c|c|c|c|c|c|}
\hline \multicolumn{6}{|c|}{ Supplemental Table S2.txt } \\
\hline CHEMBL3191435 & 688267 & 5.6 & 5.0421 & TRN & \\
\hline CHEMBL1364157 & 688267 & 4.5 & 5.0305 & TRN & \\
\hline CHEMBL1445325 & 688267 & 6.3 & 5.0839 & TRN & \\
\hline CHEMBL1476868 & 688267 & 6.2 & 5.05 & TRN & \\
\hline CHEMBL1521359 & 688267 & 4.55 & 5.0951 & TRN & \\
\hline CHEMBL1351576 & 688267 & 4.0 & 5.0471 & TRN & \\
\hline CHEMBL1602135 & 688267 & 4.05 & 5.0417 & TRN & \\
\hline CHEMBL1432898 & 688267 & 4.2 & 5.0966 & TRN & \\
\hline CHEMBL1488113 & 688267 & 5.85 & 5.0408 & TRN & \\
\hline CHEMBL1470630 & 688267 & 6.2 & 5.109 & TST & \\
\hline CHEMBL1433792 & 688267 & 4.0 & 5.0891 & TRN & \\
\hline CHEMBL1329531 & 688267 & 4.05 & 5.0223 & TRN & \\
\hline CHEMBL1398280 & 688267 & 4.15 & 4.9954 & TRN & \\
\hline CHEMBL1557159 & 688267 & 4.55 & 5.07600 & 00000000005 & TRN \\
\hline CHEMBL1498764 & 688267 & 3.95 & 5.0807 & TRN & \\
\hline CHEMBL1594416 & 688267 & 4.0 & 5.0546 & TST & \\
\hline CHEMBL1334615 & 688267 & 5.55 & 5.087 & TRN & \\
\hline CHEMBL1412655 & 688267 & 5.5 & 5.0397 & TRN & \\
\hline CHEMBL1472734 & 688267 & 6.15 & 5.0453 & TST & \\
\hline CHEMBL1441624 & 688267 & 3.95 & 5.0253 & TRN & \\
\hline CHEMBL1577698 & 688267 & 4.7 & 5.0273 & TST & \\
\hline CHEMBL1330566 & 688267 & 4.15 & 5.1102 & TRN & \\
\hline CHEMBL1418014 & 688267 & 5.4 & 5.0596 & TRN & \\
\hline CHEMBL1463105 & 688267 & 4.35 & 5.0258 & TRN & \\
\hline CHEMBL1385247 & 688267 & 4.35 & 5.0443 & TST & \\
\hline CHEMBL1329624 & 688267 & 6.2 & 5.0346 & TRN & \\
\hline CHEMBL1515926 & 688267 & 4.45 & 5.1168 & TRN & \\
\hline CHEMBL1589583 & 688267 & 5.65 & 4.9751 & TST & \\
\hline CHEMBL1428566 & 688267 & 4.75 & 5.0309 & TRN & \\
\hline CHEMBL1577541 & 688267 & 4.3 & 5.0265 & TST & \\
\hline CHEMBL1612367 & 688267 & 5.25 & 5.1262 & TRN & \\
\hline CHEMBL1303237 & 688267 & 3.95 & 5.0153 & TRN & \\
\hline CHEMBL1366960 & 688267 & 4.25 & 5.0315 & TRN & \\
\hline CHEMBL1444977 & 688267 & 4.65 & 5.0008 & TST & \\
\hline CHEMBL1459702 & 688267 & 4.35 & 5.0586 & TST & \\
\hline CHEMBL1569683 & 688267 & 6.2 & 5.0672 & TST & \\
\hline CHEMBL1385713 & 688267 & 5.0 & 5.0742 & TRN & \\
\hline CHEMBL1524221 & 688267 & 5.9 & 5.0803 & TRN & \\
\hline CHEMBL1495355 & 688267 & 6.2 & 5.0385 & TRN & \\
\hline CHEMBL1554296 & 688267 & 4.7 & 5.0214 & TRN & \\
\hline CHEMBL1610488 & 688267 & 6.5 & 5.0915 & TRN & \\
\hline CHEMBL1308320 & 688267 & 5.5 & 5.1038 & TST & \\
\hline CHEMBL1302230 & 688267 & 4.75 & 5.0658 & TST & \\
\hline CHEMBL1406407 & 688267 & 5.9 & 5.0697 & TRN & \\
\hline CHEMBL1597676 & 688267 & 4.3 & 5.1117 & TST & \\
\hline CHEMBL1554215 & 688267 & 4.9 & 5.0273 & TRN & \\
\hline CHEMBL1402694 & 688267 & 4.15 & 5.0692 & TRN & \\
\hline CHEMBL1512824 & 688267 & 4.7 & 5.1247 & TRN & \\
\hline
\end{tabular}




\begin{tabular}{|c|c|c|c|c|}
\hline \multicolumn{5}{|c|}{ Supplemental Table S2.txt } \\
\hline CHEMBL1480466 & 688267 & 5.25 & 5.0654 & TRN \\
\hline CHEMBL1584470 & 688267 & 5.8 & 5.0682 & TRN \\
\hline CHEMBL1557433 & 688267 & 4.35 & 5.0037 & TRN \\
\hline CHEMBL1586541 & 688267 & 6.25 & 5.1232 & TRN \\
\hline CHEMBL1386133 & 688267 & 5.3 & 5.0571 & TRN \\
\hline CHEMBL1473805 & 688267 & 4.05 & 5.0736 & TRN \\
\hline CHEMBL1583284 & 688267 & 4.3 & 5.0204 & TRN \\
\hline CHEMBL3197166 & 688267 & 6.25 & 5.043 & TRN \\
\hline CHEMBL1351873 & 688267 & 6.15 & 5.0327 & TRN \\
\hline CHEMBL1483503 & 688267 & 4.35 & 5.0851 & TRN \\
\hline CHEMBL1401036 & 688267 & 4.05 & 5.0216 & TST \\
\hline CHEMBL1430734 & 688267 & 5.45 & 5.034 & TRN \\
\hline CHEMBL1391869 & 688267 & 4.0 & 5.0645 & TST \\
\hline CHEMBL1491253 & 688267 & 5.5 & 5.0218 & TRN \\
\hline CHEMBL1347513 & 688267 & 4.75 & 5.0166 & TST \\
\hline CHEMBL1395175 & 688267 & 4.95 & 5.0755 & TRN \\
\hline CHEMBL1453404 & 688267 & 6.15 & 5.0723 & TRN \\
\hline CHEMBL1379833 & 688267 & 6.2 & 5.0267 & TST \\
\hline CHEMBL1396222 & 688267 & 5.9 & 4.9891 & TRN \\
\hline CHEMBL1590346 & 688267 & 5.5 & 5.0737 & TRN \\
\hline CHEMBL1569858 & 688267 & 6.2 & 5.0274 & TST \\
\hline CHEMBL1319007 & 688267 & 5.15 & 5.0251 & TRN \\
\hline CHEMBL1379438 & 688267 & 5.0 & 5.0618 & TRN \\
\hline CHEMBL1355495 & 688267 & 4.05 & 5.041 & TRN \\
\hline CHEMBL1605790 & 688267 & 4.2 & 4.9685 & TRN \\
\hline CHEMBL1463611 & 688267 & 6.25 & 5.1201 & TRN \\
\hline CHEMBL1342410 & 688267 & 4.0 & 5.0352 & TRN \\
\hline CHEMBL1367683 & 688267 & 5.5 & 5.0567 & TST \\
\hline CHEMBL1495670 & 688267 & 4.3 & 5.013 & TST \\
\hline CHEMBL1480912 & 688267 & 4.8 & 5.0841 & TRN \\
\hline CHEMBL1453807 & 688267 & 4.4 & 5.0951 & TRN \\
\hline CHEMBL1413722 & 688267 & 6.05 & 5.1027 & TRN \\
\hline CHEMBL1360931 & 688267 & 5.15 & 5.0588 & TST \\
\hline CHEMBL1544874 & 688267 & 6.2 & 5.1208 & TRN \\
\hline CHEMBL1486419 & 688267 & 5.2 & 5.0523 & TRN \\
\hline CHEMBL1572879 & 688267 & 5.05 & 5.0414 & TRN \\
\hline CHEMBL1382640 & 688267 & 3.95 & 5.0488 & TRN \\
\hline CHEMBL1374952 & 688267 & 5.75 & 5.088 & TRN \\
\hline CHEMBL1563983 & 688267 & 6.5 & 5.0198 & TRN \\
\hline CHEMBL1568908 & 688267 & 3.75 & 5.0678 & TST \\
\hline CHEMBL1489381 & 688267 & 4.05 & 5.0634 & TST \\
\hline CHEMBL1496523 & 688267 & 6.2 & 5.064 & TRN \\
\hline CHEMBL1487761 & 688267 & 4.35 & 5.0059 & TRN \\
\hline CHEMBL1569130 & 688267 & 5.65 & 5.0195 & TRN \\
\hline CHEMBL1578230 & 688267 & 4.25 & 5.0249 & TST \\
\hline CHEMBL1377017 & 688267 & 5.55 & 5.0539 & TRN \\
\hline CHEMBL1453516 & 688267 & 6.2 & 5.0361 & TST \\
\hline CHEMBL1381646 & 688267 & 4.45 & 5.098 & TRN \\
\hline
\end{tabular}




\begin{tabular}{|c|c|c|c|c|c|}
\hline \multicolumn{6}{|c|}{ Supplemental Table S2.txt } \\
\hline CHEMBL1392202 & 688267 & 5.35 & 5.1016 & TRN & \\
\hline CHEMBL1300196 & 688267 & 6.2 & 5.0224 & TRN & \\
\hline CHEMBL1572542 & 688267 & 5.05 & 5.0857 & TST & \\
\hline CHEMBL1464230 & 688267 & 4.55 & 5.0838 & TRN & \\
\hline CHEMBL1464024 & 688267 & 4.45 & 5.1446 & TRN & \\
\hline CHEMBL1573835 & 688267 & 4.25 & 5.081 & TRN & \\
\hline CHEMBL1592654 & 688267 & 6.2 & 5.118 & TRN & \\
\hline CHEMBL1350625 & 688267 & 4.4 & 5.0772 & TRN & \\
\hline CHEMBL1554221 & 688267 & 4.5 & 5.0208 & TRN & \\
\hline CHEMBL1546688 & 688267 & 5.9 & 5.0791 & TST & \\
\hline CHEMBL1405771 & 688267 & 6.0 & 5.0624 & TST & \\
\hline CHEMBL1324330 & 688267 & 4.6 & 5.0932 & TST & \\
\hline CHEMBL1469133 & 688267 & 5.5 & 5.0152 & TST & \\
\hline CHEMBL1524449 & 688267 & 6.15 & 5.0787 & TRN & \\
\hline CHEMBL1564777 & 688267 & 5.2 & 5.0263 & TRN & \\
\hline CHEMBL1466353 & 688267 & 4.0 & 5.0224 & TST & \\
\hline CHEMBL1444417 & 688267 & 4.85 & 5.0173 & TRN & \\
\hline CHEMBL1562650 & 688267 & 6.2 & 5.0346 & TST & \\
\hline CHEMBL1579234 & 688267 & 4.25 & 5.0239 & TST & \\
\hline CHEMBL3191304 & 688267 & 6.6 & 5.0075 & TST & \\
\hline CHEMBL1389854 & 688267 & 4.55 & 5.1104 & TST & \\
\hline CHEMBL1613084 & 688267 & 3.95 & 5.0908 & TRN & \\
\hline CHEMBL3208691 & 688267 & 5.85 & 4.9565 & TST & \\
\hline CHEMBL1465213 & 688267 & 4.5 & 4.9957 & TRN & \\
\hline CHEMBL1519157 & 688267 & 5.6 & 5.1025 & TRN & \\
\hline CHEMBL1349132 & 688267 & 5.15 & 5.0618 & TRN & \\
\hline CHEMBL1438850 & 688267 & 4.35 & 5.11100 & 0000000001 & TRN \\
\hline CHEMBL1318592 & 688267 & 4.0 & 5.1046 & TRN & \\
\hline CHEMBL1316143 & 688267 & 6.2 & 4.9828 & TRN & \\
\hline CHEMBL1610338 & 688267 & 5.3 & 5.0766 & TRN & \\
\hline CHEMBL1317355 & 688267 & 3.95 & 5.0888 & TRN & \\
\hline CHEMBL1446772 & 688267 & 6.2 & 5.0367 & TRN & \\
\hline CHEMBL1470552 & 688267 & 4.0 & 5.0336 & TST & \\
\hline CHEMBL1459556 & 688267 & 6.2 & 5.063 & TRN & \\
\hline CHEMBL1416049 & 688267 & 6.2 & 5.0444 & TST & \\
\hline CHEMBL1535858 & 688267 & 4.55 & 4.9902 & TST & \\
\hline CHEMBL1565377 & 688267 & 4.3 & 5.0817 & TRN & \\
\hline CHEMBL1381542 & 688267 & 3.95 & 5.0697 & TRN & \\
\hline CHEMBL1481414 & 688267 & 5.25 & 5.0552 & TRN & \\
\hline CHEMBL1570895 & 688267 & 4.3 & 5.0547 & TST & \\
\hline CHEMBL1521144 & 688267 & 5.8 & 5.0014 & TRN & \\
\hline CHEMBL1381848 & 688267 & 4.55 & 5.0464 & TST & \\
\hline CHEMBL1452743 & 688267 & 4.15 & 5.0301 & TST & \\
\hline CHEMBL1584889 & 688267 & 5.15 & 5.0127 & TRN & \\
\hline CHEMBL1419523 & 688267 & 4.05 & 5.0417 & TRN & \\
\hline CHEMBL1483308 & 688267 & 4.55 & 5.0524 & TRN & \\
\hline CHEMBL1341621 & 688267 & 5.55 & 5.1811 & TRN & \\
\hline CHEMBL1413006 & 688267 & 6.2 & 5.0996 & TST & \\
\hline
\end{tabular}




\begin{tabular}{|c|c|c|c|c|}
\hline \multicolumn{5}{|c|}{ Supplemental Table S2.txt } \\
\hline CHEMBL1423295 & 688267 & 3.95 & 5.0597 & TRN \\
\hline CHEMBL1437402 & 688267 & 4.4 & 5.029 & TRN \\
\hline CHEMBL1449256 & 688267 & 5.75 & 5.0705 & TST \\
\hline CHEMBL1434726 & 688267 & 4.05 & 5.0542 & TRN \\
\hline CHEMBL1323040 & 688267 & 5.0 & 5.0023 & TRN \\
\hline CHEMBL1585965 & 688267 & 5.3 & 5.0587 & TRN \\
\hline CHEMBL1457359 & 688267 & 5.8 & 5.0002 & TRN \\
\hline CHEMBL1381680 & 688267 & 3.95 & 5.1083 & TRN \\
\hline CHEMBL1556261 & 688267 & 4.55 & 5.1321 & TRN \\
\hline CHEMBL1502025 & 688267 & 5.75 & 5.0756 & TRN \\
\hline CHEMBL1323845 & 688267 & 6.2 & 5.1011 & TRN \\
\hline CHEMBL1466545 & 688267 & 5.3 & 5.0673 & TRN \\
\hline CHEMBL1571304 & 688267 & 4.05 & 5.1399 & TST \\
\hline CHEMBL1363364 & 688267 & 5.2 & 5.0334 & TST \\
\hline CHEMBL1432308 & 688267 & 5.1 & 5.1061 & TRN \\
\hline CHEMBL1432110 & 688267 & 4.0 & 5.0194 & TRN \\
\hline CHEMBL1450075 & 688267 & 4.3 & 5.011 & TST \\
\hline CHEMBL1476468 & 688267 & 6.2 & 5.0178 & TRN \\
\hline CHEMBL1514508 & 688267 & 3.95 & 5.1446 & TRN \\
\hline CHEMBL1461070 & 688267 & 5.05 & 5.1041 & TRN \\
\hline CHEMBL1526256 & 688267 & 5.45 & 5.03 & TST \\
\hline CHEMBL1496126 & 688267 & 4.55 & 5.0137 & TRN \\
\hline CHEMBL1359358 & 688267 & 4.05 & 5.0275 & TRN \\
\hline CHEMBL342224 & 688267 & 4.05 & 5.0589 & TRN \\
\hline CHEMBL1307210 & 688267 & 5.55 & 5.1145 & TRN \\
\hline CHEMBL1464621 & 688267 & 5.45 & 5.0543 & TRN \\
\hline CHEMBL1379354 & 688267 & 6.2 & 5.0201 & TRN \\
\hline CHEMBL1399298 & 688267 & 4.0 & 5.0149 & TRN \\
\hline CHEMBL1580656 & 688267 & 5.2 & 5.0389 & TRN \\
\hline CHEMBL1363858 & 688267 & 4.0 & 5.0606 & TRN \\
\hline CHEMBL1575181 & 688267 & 5.35 & 5.095 & TST \\
\hline CHEMBL1387843 & 688267 & 4.95 & 5.0548 & TST \\
\hline CHEMBL3210973 & 688267 & 6.15 & 5.0668 & TRN \\
\hline CHEMBL1412725 & 688267 & 4.55 & 5.0577 & TRN \\
\hline CHEMBL1303662 & 688267 & 4.05 & 5.0984 & TRN \\
\hline CHEMBL1542284 & 688267 & 6.45 & 5.1066 & TST \\
\hline CHEMBL1080548 & 688267 & 3.95 & 5.0163 & TRN \\
\hline CHEMBL1598073 & 688267 & 6.0 & 5.0381 & TRN \\
\hline CHEMBL1402677 & 688267 & 5.8 & 5.0169 & TST \\
\hline CHEMBL1418991 & 688267 & 3.95 & 5.0672 & TST \\
\hline CHEMBL1529293 & 688267 & 5.55 & 5.0505 & TRN \\
\hline CHEMBL1415234 & 688267 & 4.0 & 5.1319 & TRN \\
\hline CHEMBL1386878 & 688267 & 5.1 & 5.0567 & TRN \\
\hline CHEMBL1504728 & 688267 & 5.65 & 5.0898 & TRN \\
\hline CHEMBL1340273 & 688267 & 5.35 & 5.0631 & TRN \\
\hline CHEMBL1416582 & 688267 & 4.4 & 5.02 & TRN \\
\hline CHEMBL1486909 & 688267 & 4.25 & 5.0342 & TRN \\
\hline CHEMBL1472586 & 688267 & 4.45 & 5.0444 & TRN \\
\hline
\end{tabular}




\begin{tabular}{|c|c|c|c|c|c|}
\hline \multicolumn{6}{|c|}{ Supplemental Table S2.txt } \\
\hline CHEMBL1391484 & 688267 & 6.15 & 4.9887 & TRN & \\
\hline CHEMBL1487918 & 688267 & 4.95 & 5.0891 & TRN & \\
\hline CHEMBL3210885 & 688267 & 5.95 & 5.056 & TRN & \\
\hline CHEMBL1549876 & 688267 & 3.9 & 5.1424 & TRN & \\
\hline CHEMBL1366057 & 688267 & 5.3 & 5.1158 & TRN & \\
\hline CHEMBL1317305 & 688267 & 5.55 & 5.077 & TRN & \\
\hline CHEMBL1441481 & 688267 & 4.0 & 5.0544 & TRN & \\
\hline CHEMBL1473291 & 688267 & 4.05 & 5.061 & TRN & \\
\hline CHEMBL1575258 & 688267 & 6.25 & 5.0446 & TRN & \\
\hline CHEMBL1471436 & 688267 & 5.95 & 5.0007 & TRN & \\
\hline CHEMBL1569371 & 688267 & 4.6 & 5.0481 & TRN & \\
\hline CHEMBL1611794 & 688267 & 4.05 & 5.0635 & TRN & \\
\hline CHEMBL1542356 & 688267 & 5.5 & 4.9632 & TRN & \\
\hline CHEMBL1341544 & 688267 & 5.3 & 5.042 & TRN & \\
\hline CHEMBL3213614 & 688267 & 4.05 & 5.0391 & TST & \\
\hline CHEMBL1565509 & 688267 & 4.2 & 5.0583 & TRN & \\
\hline CHEMBL1542873 & 688267 & 4.45 & 5.0452 & TRN & \\
\hline CHEMBL1465373 & 688267 & 4.3 & 5.0568 & TST & \\
\hline CHEMBL1441844 & 688267 & 5.85 & 4.9725 & TRN & \\
\hline CHEMBL1590609 & 688267 & 5.75 & 5.0726 & TRN & \\
\hline CHEMBL1477358 & 688267 & 4.0 & 5.038 & TRN & \\
\hline CHEMBL1613493 & 688267 & 4.0 & 4.9879 & TRN & \\
\hline CHEMBL1424315 & 688267 & 4.8 & 5.0066 & TRN & \\
\hline CHEMBL1439767 & 688267 & 5.15 & 5.09699 & 99999999995 & TST \\
\hline CHEMBL1436596 & 688267 & 4.55 & 5.0258 & TRN & \\
\hline CHEMBL1571155 & 688267 & 6.15 & 5.0605 & TRN & \\
\hline CHEMBL1358469 & 688267 & 5.0 & 5.0814 & TRN & \\
\hline CHEMBL567175 & 688267 & 5.55 & 5.0532 & TST & \\
\hline CHEMBL1548067 & 688267 & 4.05 & 5.045 & TST & \\
\hline CHEMBL1430992 & 688267 & 4.55 & 5.0358 & TRN & \\
\hline CHEMBL1420474 & 688267 & 4.35 & 5.0692 & TRN & \\
\hline CHEMBL1536505 & 688267 & 5.45 & 5.053 & TST & \\
\hline CHEMBL1553381 & 688267 & 4.15 & 4.9955 & TRN & \\
\hline CHEMBL1502996 & 688267 & 5.2 & 5.0427 & TST & \\
\hline CHEMBL1441357 & 688267 & 5.5 & 5.0435 & TRN & \\
\hline CHEMBL1474785 & 688267 & 4.95 & 5.1238 & TRN & \\
\hline CHEMBL1466263 & 688267 & 6.1 & 5.141 & TRN & \\
\hline CHEMBL1436646 & 688267 & 4.15 & 5.1091 & TRN & \\
\hline CHEMBL1466025 & 688267 & 6.25 & 5.0462 & TRN & \\
\hline CHEMBL1477720 & 688267 & 4.45 & 5.1054 & TST & \\
\hline CHEMBL1370182 & 688267 & 5.15 & 5.0485 & TRN & \\
\hline CHEMBL1603807 & 688267 & 4.25 & 5.0773 & TRN & \\
\hline CHEMBL3196939 & 688267 & 5.95 & 5.0193 & TST & \\
\hline CHEMBL1499137 & 688267 & 4.0 & 5.0593 & TRN & \\
\hline CHEMBL1438715 & 688267 & 5.8 & 5.0984 & TRN & \\
\hline CHEMBL1499095 & 688267 & 5.8 & 5.1463 & TST & \\
\hline CHEMBL1331687 & 688267 & 6.2 & 5.1297 & TRN & \\
\hline CHEMBL3192154 & 688267 & 4.05 & 5.0235 & TRN & \\
\hline
\end{tabular}




\begin{tabular}{|c|c|c|c|c|}
\hline \multicolumn{5}{|c|}{ Supplemental Table S2.txt } \\
\hline CHEMBL1399779 & 688267 & 5.25 & 5.0644 & TRN \\
\hline CHEMBL1550791 & 688267 & 4.05 & 4.9979 & TST \\
\hline CHEMBL1457871 & 688267 & 5.1 & 5.0594 & TRN \\
\hline CHEMBL1603118 & 688267 & 5.5 & 5.0985 & TRN \\
\hline CHEMBL1406487 & 688267 & 5.25 & 5.1234 & TST \\
\hline CHEMBL601353 & 688267 & 4.45 & 4.9919 & TST \\
\hline CHEMBL1609883 & 688267 & 4.3 & 5.1053 & TRN \\
\hline CHEMBL1493139 & 688267 & 4.0 & 5.1027 & TRN \\
\hline CHEMBL1545278 & 688267 & 4.4 & 5.0116 & TRN \\
\hline CHEMBL1561584 & 688267 & 4.45 & 5.1906 & TRN \\
\hline CHEMBL1425620 & 688267 & 5.05 & 5.0151 & TRN \\
\hline CHEMBL1553414 & 688267 & 4.0 & 5.0985 & TRN \\
\hline CHEMBL1305259 & 688267 & 5.3 & 5.0165 & TRN \\
\hline CHEMBL1375380 & 688267 & 6.25 & 5.0889 & TRN \\
\hline CHEMBL1480755 & 688267 & 4.55 & 5.1586 & TRN \\
\hline CHEMBL1514078 & 688267 & 3.95 & 5.0086 & TRN \\
\hline CHEMBL1477856 & 688267 & 4.0 & 5.042 & TRN \\
\hline CHEMBL3199790 & 688267 & 5.6 & 5.0218 & TRN \\
\hline CHEMBL1534919 & 688267 & 5.05 & 5.0071 & TRN \\
\hline CHEMBL1574244 & 688267 & 6.15 & 5.058 & TRN \\
\hline CHEMBL1469151 & 688267 & 4.05 & 5.0422 & TRN \\
\hline CHEMBL1523489 & 688267 & 4.5 & 5.0694 & TRN \\
\hline CHEMBL1453998 & 688267 & 4.3 & 5.0486 & TST \\
\hline CHEMBL1514378 & 688267 & 4.0 & 5.0681 & TRN \\
\hline CHEMBL1535393 & 688267 & 6.2 & 5.0144 & TRN \\
\hline CHEMBL1476087 & 688267 & 4.55 & 4.9874 & TRN \\
\hline CHEMBL1300469 & 688267 & 5.75 & 4.9986 & TRN \\
\hline CHEMBL1316303 & 688267 & 4.05 & 5.0588 & TRN \\
\hline CHEMBL1505399 & 688267 & 5.8 & 5.0126 & TRN \\
\hline CHEMBL1394868 & 688267 & 5.55 & 5.0562 & TRN \\
\hline CHEMBL1321167 & 688267 & 6.15 & 5.0349 & TRN \\
\hline CHEMBL1555526 & 688267 & 3.9 & 5.0148 & TRN \\
\hline CHEMBL1609667 & 688267 & 3.95 & 5.1263 & TRN \\
\hline CHEMBL1332086 & 688267 & 3.95 & 5.0681 & TRN \\
\hline CHEMBL 3212400 & 688267 & 5.3 & 5.0153 & TRN \\
\hline CHEMBL1528609 & 688267 & 4.4 & 5.0942 & TRN \\
\hline CHEMBL1596364 & 688267 & 5.45 & 5.1425 & TRN \\
\hline CHEMBL1537411 & 688267 & 6.2 & 5.0402 & TST \\
\hline CHEMBL1375924 & 688267 & 3.95 & 5.1403 & TRN \\
\hline CHEMBL1595073 & 688267 & 6.25 & 5.0705 & TST \\
\hline CHEMBL1498966 & 688267 & 4.8 & 5.019 & TST \\
\hline CHEMBL1371331 & 688267 & 5.85 & 5.0262 & TRN \\
\hline CHEMBL1594677 & 688267 & 6.2 & 5.1198 & TRN \\
\hline CHEMBL1345221 & 688267 & 5.55 & 5.0938 & TRN \\
\hline CHEMBL1355197 & 688267 & 4.4 & 5.0453 & TRN \\
\hline CHEMBL1332456 & 688267 & 5.35 & 4.9818 & TRN \\
\hline CHEMBL1403283 & 688267 & 6.25 & 5.092 & TRN \\
\hline CHEMBL1469610 & 688267 & 4.0 & 4.9882 & TRN \\
\hline
\end{tabular}




\begin{tabular}{|c|c|c|c|c|c|}
\hline \\
\hline CHEMBL1392544 & 688267 & 4.5 & 5.0644 & TRN & \\
\hline CHEMBL1479167 & 688267 & 6.05 & 5.0247 & TRN & \\
\hline CHEMBL1566489 & 688267 & 4.7 & 5.0874 & TRN & \\
\hline CHEMBL1407702 & 688267 & 4.2 & 5.058 & TRN & \\
\hline CHEMBL1458236 & 688267 & 5.3 & 5.07 & TRN & \\
\hline CHEMBL1512461 & 688267 & 5.8 & 5.1004 & TST & \\
\hline CHEMBL1534465 & 688267 & 4.4 & 5.0073 & TRN & \\
\hline CHEMBL1399001 & 688267 & 6.25 & 5.0855 & TRN & \\
\hline CHEMBL1450454 & 688267 & 5.0 & 5.05699 & 99999999995 & TRN \\
\hline CHEMBL1604526 & 688267 & 5.9 & 5.0784 & TRN & \\
\hline CHEMBL1512613 & 688267 & 6.05 & 5.0306 & TRN & \\
\hline CHEMBL1601410 & 688267 & 6.15 & 5.0454 & TRN & \\
\hline CHEMBL1490562 & 688267 & 4.65 & 5.0552 & TRN & \\
\hline CHEMBL1398990 & 688267 & 4.35 & 5.0479 & TRN & \\
\hline CHEMBL1541834 & 688267 & 5.3 & 5.0765 & TST & \\
\hline CHEMBL1573638 & 688267 & 6.2 & 5.0936 & TRN & \\
\hline CHEMBL1357483 & 688267 & 4.35 & 5.0259 & TRN & \\
\hline CHEMBL1555002 & 688267 & 6.2 & 5.0395 & TRN & \\
\hline CHEMBL1475249 & 688267 & 5.55 & 5.1304 & TRN & \\
\hline CHEMBL3190358 & 688267 & 4.8 & 5.0343 & TST & \\
\hline CHEMBL1338156 & 688267 & 4.5 & 5.0689 & TST & \\
\hline CHEMBL1446310 & 688267 & 4.4 & 5.0966 & TRN & \\
\hline CHEMBL1451426 & 688267 & 5.55 & 5.0311 & TRN & \\
\hline CHEMBL3195999 & 688267 & 6.15 & 5.0052 & TRN & \\
\hline CHEMBL1377496 & 688267 & 4.0 & 5.0086 & TRN & \\
\hline CHEMBL1532101 & 688267 & 5.05 & 5.0395 & TRN & \\
\hline CHEMBL1590090 & 688267 & 5.5 & 5.1614 & TRN & \\
\hline CHEMBL1453811 & 688267 & 4.95 & 5.0406 & TRN & \\
\hline CHEMBL1533606 & 688267 & 4.05 & 5.1198 & TRN & \\
\hline CHEMBL1517405 & 688267 & 4.05 & 5.0069 & TRN & \\
\hline CHEMBL1305879 & 688267 & 4.6 & 5.0808 & TRN & \\
\hline CHEMBL1543952 & 688267 & 6.15 & 5.027 & TRN & \\
\hline CHEMBL1432297 & 688267 & 4.45 & 5.0897 & TRN & \\
\hline CHEMBL1420899 & 688267 & 4.9 & 5.0556 & TRN & \\
\hline CHEMBL1458083 & 688267 & 4.35 & 5.0395 & TRN & \\
\hline CHEMBL1578576 & 688267 & 5.35 & 5.029 & TRN & \\
\hline CHEMBL1312740 & 688267 & 4.05 & 5.1237 & TRN & \\
\hline CHEMBL1427194 & 688267 & 6.5 & 5.0938 & TRN & \\
\hline CHEMBL1314235 & 688267 & 5.4 & 5.0349 & TRN & \\
\hline CHEMBL1476063 & 688267 & 4.0 & 5.0508 & TST & \\
\hline CHEMBL1432437 & 688267 & 4.4 & 5.0482 & TRN & \\
\hline CHEMBL1466868 & 688267 & 5.55 & 5.0141 & TST & \\
\hline CHEMBL1552935 & 688267 & 5.3 & 5.0151 & TRN & \\
\hline CHEMBL1408335 & 688267 & 5.1 & 5.1417 & TRN & \\
\hline CHEMBL1348142 & 688267 & 4.1 & 5.0061 & TRN & \\
\hline CHEMBL1396362 & 688267 & 4.15 & 5.0398 & TRN & \\
\hline CHEMBL1424506 & 688267 & 5.45 & 5.0274 & TRN & \\
\hline CHEMBL1451599 & 688267 & 5.8 & 5.0884 & TST & \\
\hline
\end{tabular}




\begin{tabular}{|c|c|c|c|c|}
\hline \multicolumn{5}{|c|}{ Supplemental Table S2.txt } \\
\hline CHEMBL1422024 & 688267 & 4.35 & 5.0739 & TRN \\
\hline CHEMBL1322741 & 688267 & 3.95 & 5.0464 & TRN \\
\hline CHEMBL1591575 & 688267 & 5.55 & 5.0526 & TRN \\
\hline CHEMBL1611880 & 688267 & 5.05 & 5.1296 & TRN \\
\hline CHEMBL1551450 & 688267 & 5.0 & 5.1301 & TRN \\
\hline CHEMBL1468493 & 688267 & 5.55 & 5.0117 & TRN \\
\hline CHEMBL1473068 & 688267 & 6.5501 & 5.0386 & TRN \\
\hline CHEMBL1607841 & 688267 & 4.05 & 5.0436 & TRN \\
\hline CHEMBL1534894 & 688267 & 6.2 & 5.0393 & TRN \\
\hline CHEMBL1441784 & 688267 & 7.0501 & 5.0758 & TRN \\
\hline CHEMBL1365366 & 688267 & 5.4 & 5.0726 & TRN \\
\hline CHEMBL1332826 & 688267 & 5.5 & 5.0654 & TRN \\
\hline CHEMBL1556675 & 688267 & 4.05 & 5.0541 & TRN \\
\hline CHEMBL1609506 & 688267 & 4.0 & 5.0363 & TRN \\
\hline CHEMBL1356162 & 688267 & 6.15 & 5.1106 & TRN \\
\hline CHEMBL1398395 & 688267 & 5.1 & 5.1152 & TRN \\
\hline CHEMBL1456244 & 688267 & 6.15 & 5.0738 & TST \\
\hline CHEMBL1601504 & 688267 & 4.3 & 5.0775 & TRN \\
\hline CHEMBL1547197 & 688267 & 6.1 & 5.1039 & TRN \\
\hline CHEMBL1363980 & 688267 & 4.45 & 5.0263 & TRN \\
\hline CHEMBL1590083 & 688267 & 6.2 & 5.0871 & TRN \\
\hline CHEMBL1363521 & 688267 & 4.6 & 5.0242 & TRN \\
\hline CHEMBL1535131 & 688267 & 4.1 & 5.0359 & TRN \\
\hline CHEMBL1313540 & 688267 & 4.55 & 5.0408 & TRN \\
\hline CHEMBL1418526 & 688267 & 6.2 & 5.0657 & TRN \\
\hline CHEMBL1307794 & 688267 & 4.35 & 5.0601 & TST \\
\hline CHEMBL1347482 & 688267 & 5.1 & 5.0495 & TRN \\
\hline CHEMBL1393997 & 688267 & 4.35 & 5.0965 & TRN \\
\hline CHEMBL1334951 & 688267 & 5.45 & 5.0074 & TRN \\
\hline CHEMBL1329009 & 688267 & 5.6 & 5.0186 & TRN \\
\hline CHEMBL1603967 & 688267 & 6.25 & 5.0039 & TRN \\
\hline CHEMBL1397271 & 688267 & 4.45 & 5.0381 & TRN \\
\hline CHEMBL1492597 & 688267 & 5.0 & 5.0127 & TRN \\
\hline CHEMBL1378504 & 688267 & 4.25 & 5.077 & TRN \\
\hline CHEMBL1321630 & 688267 & 4.6 & 5.0531 & TST \\
\hline CHEMBL1408641 & 688267 & 4.05 & 5.1093 & TRN \\
\hline CHEMBL1559451 & 688267 & 4.0 & 5.0831 & TRN \\
\hline CHEMBL1391275 & 688267 & 4.35 & 5.088 & TRN \\
\hline CHEMBL1429222 & 688267 & 5.0 & 5.0229 & TST \\
\hline CHEMBL153 & 688267 & 5.1 & 5.0395 & TST \\
\hline CHEMBL1482112 & 688267 & 6.2 & 5.1239 & TRN \\
\hline CHEMBL1476920 & 688267 & 4.0 & 4.9915 & TRN \\
\hline CHEMBL1601241 & 688267 & 4.4 & 5.0235 & TRN \\
\hline CHEMBL1611934 & 688267 & 5.3 & 5.131 & TRN \\
\hline CHEMBL1396370 & 688267 & 5.9 & 5.0473 & TRN \\
\hline CHEMBL1512635 & 688267 & 5.2 & 5.0946 & TRN \\
\hline CHEMBL1412036 & 688267 & 6.1 & 5.1349 & TRN \\
\hline CHEMBL1424372 & 688267 & 5.65 & 5.0449 & TRN \\
\hline
\end{tabular}




\begin{tabular}{|c|c|c|c|c|}
\hline & & & pplement & $d \pm$ \\
\hline CHEMBL 3199631 & 688267 & 5.5 & 5.0062 & TST \\
\hline CHEMBL1360694 & 688267 & 5.0 & 5.0741 & TRN \\
\hline CHEMBL1460445 & 688267 & 6.15 & 5.0125 & TRN \\
\hline CHEMBL1377847 & 688267 & 5.9 & 5.0887 & TRN \\
\hline CHEMBL1406341 & 688267 & 4.45 & 5.0233 & TRN \\
\hline CHEMBL1537825 & 688267 & 5.75 & 5.0379 & TST \\
\hline CHEMBL 3198818 & 688267 & 4.5 & 4.9952 & TRN \\
\hline CHEMBL 3211680 & 688267 & 4.05 & 5.0207 & TST \\
\hline CHEMBL1445449 & 688267 & 4.3 & 5.0364 & TRN \\
\hline CHEMBL3208939 & 688267 & 5.9 & 5.0822 & TST \\
\hline CHEMBL3213799 & 688267 & 5.25 & 5.0689 & TRN \\
\hline CHEMBL1360488 & 688267 & 6.15 & 5.0408 & TRN \\
\hline CHEMBL1428345 & 688267 & 6.15 & 5.0554 & TST \\
\hline CHEMBL1491523 & 688267 & 6.2 & 5.0329 & TRN \\
\hline CHEMBL1553452 & 688267 & 6.2 & 5.0579 & TRN \\
\hline CHEMBL1600760 & 688267 & 5.5 & 5.0765 & TST \\
\hline CHEMBL1554671 & 688267 & 6.15 & 5.1001 & TRN \\
\hline CHEMBL1407369 & 688267 & 5.45 & 5.1542 & TRN \\
\hline CHEMBL1561944 & 688267 & 5.35 & 5.0894 & TRN \\
\hline CHEMBL1366794 & 688267 & 6.25 & 4.9749 & TST \\
\hline CHEMBL1605579 & 688267 & 5.3 & 5.1036 & TRN \\
\hline CHEMBL1524571 & 688267 & 6.25 & 5.063 & TRN \\
\hline CHEMBL1351695 & 688267 & 3.95 & 5.0256 & TRN \\
\hline CHEMBL1589053 & 688267 & 3.95 & 5.0299 & TRN \\
\hline CHEMBL1413797 & 688267 & 4.35 & 5.007 & TRN \\
\hline CHEMBL1333699 & 688267 & 5.45 & 5.1081 & TST \\
\hline CHEMBL1394547 & 688267 & 4.0 & 5.0312 & TRN \\
\hline CHEMBL1384731 & 688267 & 4.45 & 5.1111 & TST \\
\hline CHEMBL 3210105 & 688267 & 5.95 & 5.0253 & TRN \\
\hline CHEMBL1380302 & 688267 & 6.2 & 5.0427 & TRN \\
\hline CHEMBL1431841 & 688267 & 4.3 & 5.0723 & TRN \\
\hline CHEMBL1509441 & 688267 & 5.9 & 5.0687 & TST \\
\hline CHEMBL1338635 & 688267 & 4.05 & 5.078 & TRN \\
\hline CHEMBL1549740 & 688267 & 6.2 & 5.0195 & TST \\
\hline CHEMBL1316287 & 688267 & 5.6 & 5.0471 & TRN \\
\hline CHEMBL1488198 & 688267 & 5.55 & 5.0713 & TRN \\
\hline CHEMBL 1457190 & 688267 & 5.3 & 5.0535 & TST \\
\hline CHEMBL3198266 & 688267 & 4.4 & 4.9957 & TRN \\
\hline CHEMBL1520860 & 688267 & 4.5 & 5.0158 & TRN \\
\hline CHEMBL1515149 & 688267 & 5.35 & 5.0172 & TRN \\
\hline CHEMBL1606734 & 688267 & 5.8 & 5.0615 & TRN \\
\hline CHEMBL1372678 & 688267 & 4.1 & 5.0455 & TRN \\
\hline CHEMBL1410248 & 688267 & 6.15 & 5.1288 & TRN \\
\hline CHEMBL1500897 & 688267 & 5.6 & 5.0207 & TRN \\
\hline CHEMBL1423002 & 688267 & 6.2 & 5.0215 & TST \\
\hline CHEMBL1438520 & 688267 & 4.1 & 4.9964 & TRN \\
\hline CHEMBL1414871 & 688267 & 4.0 & 4.9914 & TRN \\
\hline CHEMBL1571967 & 688267 & 4.3 & 5.1316 & TRN \\
\hline
\end{tabular}




\begin{tabular}{|c|c|c|c|c|}
\hline \multicolumn{5}{|c|}{ Supplemental Table S2.txt } \\
\hline CHEMBL1449855 & 688267 & 5.55 & 5.0536 & TRN \\
\hline CHEMBL1547178 & 688267 & 4.35 & 5.0386 & TRN \\
\hline CHEMBL1511191 & 688267 & 4.3 & 5.1399 & TRN \\
\hline CHEMBL1588757 & 688267 & 5.8 & 4.9949 & TRN \\
\hline CHEMBL1555961 & 688267 & 5.55 & 5.0252 & TRN \\
\hline CHEMBL3198499 & 688267 & 4.6 & 4.9772 & TRN \\
\hline CHEMBL1309492 & 688267 & 4.25 & 5.0832 & TRN \\
\hline CHEMBL1524513 & 688267 & 6.5 & 5.0373 & TRN \\
\hline CHEMBL1554142 & 688267 & 4.6 & 5.032 & TRN \\
\hline CHEMBL1437235 & 688267 & 5.3 & 5.091 & TRN \\
\hline CHEMBL1566219 & 688267 & 4.55 & 5.1075 & TRN \\
\hline CHEMBL1522603 & 688267 & 5.95 & 5.0579 & TRN \\
\hline CHEMBL1612821 & 688267 & 5.4 & 5.1056 & TRN \\
\hline CHEMBL1469031 & 688267 & 4.0 & 5.0028 & TRN \\
\hline CHEMBL1411134 & 688267 & 4.0 & 5.0697 & TST \\
\hline CHEMBL1310371 & 688267 & 5.8 & 5.042 & TRN \\
\hline CHEMBL1479916 & 688267 & 4.3 & 5.1128 & TRN \\
\hline CHEMBL1551603 & 688267 & 3.95 & 5.1784 & TRN \\
\hline CHEMBL1549532 & 688267 & 4.0 & 5.0302 & TRN \\
\hline CHEMBL1535910 & 688267 & 4.0 & 5.0624 & TST \\
\hline CHEMBL1512553 & 688267 & 6.3 & 5.0849 & TRN \\
\hline CHEMBL1337575 & 688267 & 4.15 & 5.0184 & TRN \\
\hline CHEMBL1530007 & 688267 & 4.65 & 5.0192 & TST \\
\hline CHEMBL1604371 & 688267 & 4.95 & 5.0267 & TRN \\
\hline CHEMBL1396982 & 688267 & 4.5 & 5.0825 & TRN \\
\hline CHEMBL1475955 & 688267 & 4.05 & 5.0632 & TRN \\
\hline CHEMBL1397402 & 688267 & 4.0 & 5.1012 & TRN \\
\hline CHEMBL1600067 & 688267 & 5.95 & 5.0321 & TRN \\
\hline CHEMBL1551948 & 688267 & 4.0 & 5.0153 & TRN \\
\hline CHEMBL1456165 & 688267 & 5.5 & 5.1027 & TRN \\
\hline CHEMBL1458653 & 688267 & 5.5 & 5.0235 & TST \\
\hline CHEMBL1357699 & 688267 & 4.7 & 5.0422 & TRN \\
\hline CHEMBL1393671 & 688267 & 5.0 & 5.0699 & TRN \\
\hline CHEMBL1557040 & 688267 & 4.35 & 5.0703 & TST \\
\hline CHEMBL1498556 & 688267 & 5.1 & 5.1252 & TRN \\
\hline CHEMBL572994 & 688267 & 6.2 & 5.0327 & TST \\
\hline CHEMBL 1434279 & 688267 & 5.25 & 5.0959 & TRN \\
\hline CHEMBL1468050 & 688267 & 4.0 & 5.0817 & TST \\
\hline CHEMBL1466395 & 688267 & 3.95 & 5.0322 & TST \\
\hline CHEMBL1335636 & 688267 & 4.8 & 5.0952 & TRN \\
\hline CHEMBL1332098 & 688267 & 5.35 & 5.0329 & TRN \\
\hline CHEMBL1583687 & 688267 & 5.5 & 5.0281 & TRN \\
\hline CHEMBL1419798 & 688267 & 4.05 & 5.0165 & TST \\
\hline CHEMBL 2000380 & 688267 & 4.45 & 4.9812 & TST \\
\hline CHEMBL1551867 & 688267 & 4.0 & 5.0973 & TRN \\
\hline CHEMBL1356757 & 688267 & 4.3 & 5.0271 & TRN \\
\hline CHEMBL 1464830 & 688267 & 4.65 & 5.0032 & TRN \\
\hline CHEMBL1565466 & 688267 & 3.95 & 5.0686 & TRN \\
\hline
\end{tabular}




\begin{tabular}{|c|c|c|c|c|c|}
\hline \multicolumn{6}{|c|}{ Supplemental Table S2.txt } \\
\hline CHEMBL1403282 & 688267 & 6.15 & 5.0292 & TRN & \\
\hline CHEMBL1394338 & 688267 & 5.35 & 5.1182 & TRN & \\
\hline CHEMBL1311633 & 688267 & 6.0 & 5.0091 & TRN & \\
\hline CHEMBL1557179 & 688267 & 4.3 & 4.9692 & TRN & \\
\hline CHEMBL1599435 & 688267 & 4.0 & 5.022 & TRN & \\
\hline CHEMBL1306598 & 688267 & 4.4 & 5.0259 & TRN & \\
\hline CHEMBL1317325 & 688267 & 5.25 & 4.9996 & TRN & \\
\hline CHEMBL1396995 & 688267 & 6.2 & 5.0909 & TRN & \\
\hline CHEMBL1509186 & 688267 & 4.35 & 5.1325 & TRN & \\
\hline CHEMBL1534099 & 688267 & 3.95 & 5.0633 & TRN & \\
\hline CHEMBL1484726 & 688267 & 5.7 & 5.0468 & TRN & \\
\hline CHEMBL1380782 & 688267 & 5.35 & 5.0157 & TRN & \\
\hline CHEMBL1406264 & 688267 & 4.5 & 5.0827 & TRN & \\
\hline CHEMBL1566152 & 688267 & 5.25 & 5.0874 & TRN & \\
\hline CHEMBL1370876 & 688267 & 5.45 & 5.0569 & TRN & \\
\hline CHEMBL1366356 & 688267 & 4.35 & 5.1079 & TRN & \\
\hline CHEMBL1570399 & 688267 & 5.9 & 5.0277 & TRN & \\
\hline CHEMBL1510824 & 688267 & 3.95 & 5.0494 & TST & \\
\hline CHEMBL1366487 & 688267 & 5.9 & 5.062 & TRN & \\
\hline CHEMBL1467666 & 688267 & 5.75 & 5.0639 & TST & \\
\hline CHEMBL1352253 & 688267 & 5.0 & 5.1114 & TRN & \\
\hline CHEMBL1510938 & 688267 & 4.4 & 5.0901 & TST & \\
\hline CHEMBL1380488 & 688267 & 6.2 & 5.0745 & TST & \\
\hline CHEMBL1340473 & 688267 & 3.95 & 5.072 & TST & \\
\hline CHEMBL1473148 & 688267 & 4.4 & 5.069 & TRN & \\
\hline CHEMBL1299572 & 688267 & 4.45 & 5.0446 & TST & \\
\hline CHEMBL1529218 & 688267 & 4.0 & 4.9888 & TRN & \\
\hline CHEMBL1405235 & 688267 & 5.1 & 4.98300 & 00000000005 & TRN \\
\hline CHEMBL1533715 & 688267 & 4.15 & 5.0767 & TRN & \\
\hline CHEMBL602424 & 688267 & 6.15 & 5.1028 & TRN & \\
\hline CHEMBL1489018 & 688267 & 5.65 & 5.0914 & TRN & \\
\hline CHEMBL1412160 & 688267 & 5.05 & 5.1857 & TRN & \\
\hline CHEMBL1594148 & 688267 & 5.25 & 5.0955 & TRN & \\
\hline CHEMBL1401213 & 688267 & 5.8 & 5.0621 & TRN & \\
\hline CHEMBL1441397 & 688267 & 5.45 & 5.0762 & TRN & \\
\hline CHEMBL1413977 & 688267 & 4.7 & 5.1622 & TRN & \\
\hline CHEMBL1377158 & 688267 & 3.95 & 5.0523 & TRN & \\
\hline CHEMBL1536725 & 688267 & 5.05 & 5.0195 & TRN & \\
\hline CHEMBL1365948 & 688267 & 5.5 & 5.0282 & TRN & \\
\hline CHEMBL1525570 & 688267 & 5.0 & 5.1329 & TRN & \\
\hline CHEMBL1437884 & 688267 & 6.2 & 5.029 & TRN & \\
\hline CHEMBL1494125 & 688267 & 5.3 & 5.0833 & TRN & \\
\hline CHEMBL1397509 & 688267 & 4.05 & 5.0125 & TRN & \\
\hline CHEMBL1513483 & 688267 & 4.25 & 5.0507 & TRN & \\
\hline CHEMBL1364470 & 688267 & 5.9 & 5.0241 & TST & \\
\hline CHEMBL1473693 & 688267 & 4.35 & 4.9833 & TRN & \\
\hline CHEMBL1577711 & 688267 & 4.35 & 5.0018 & TRN & \\
\hline CHEMBL1452061 & 688267 & 5.0 & 5.0514 & TST & \\
\hline
\end{tabular}




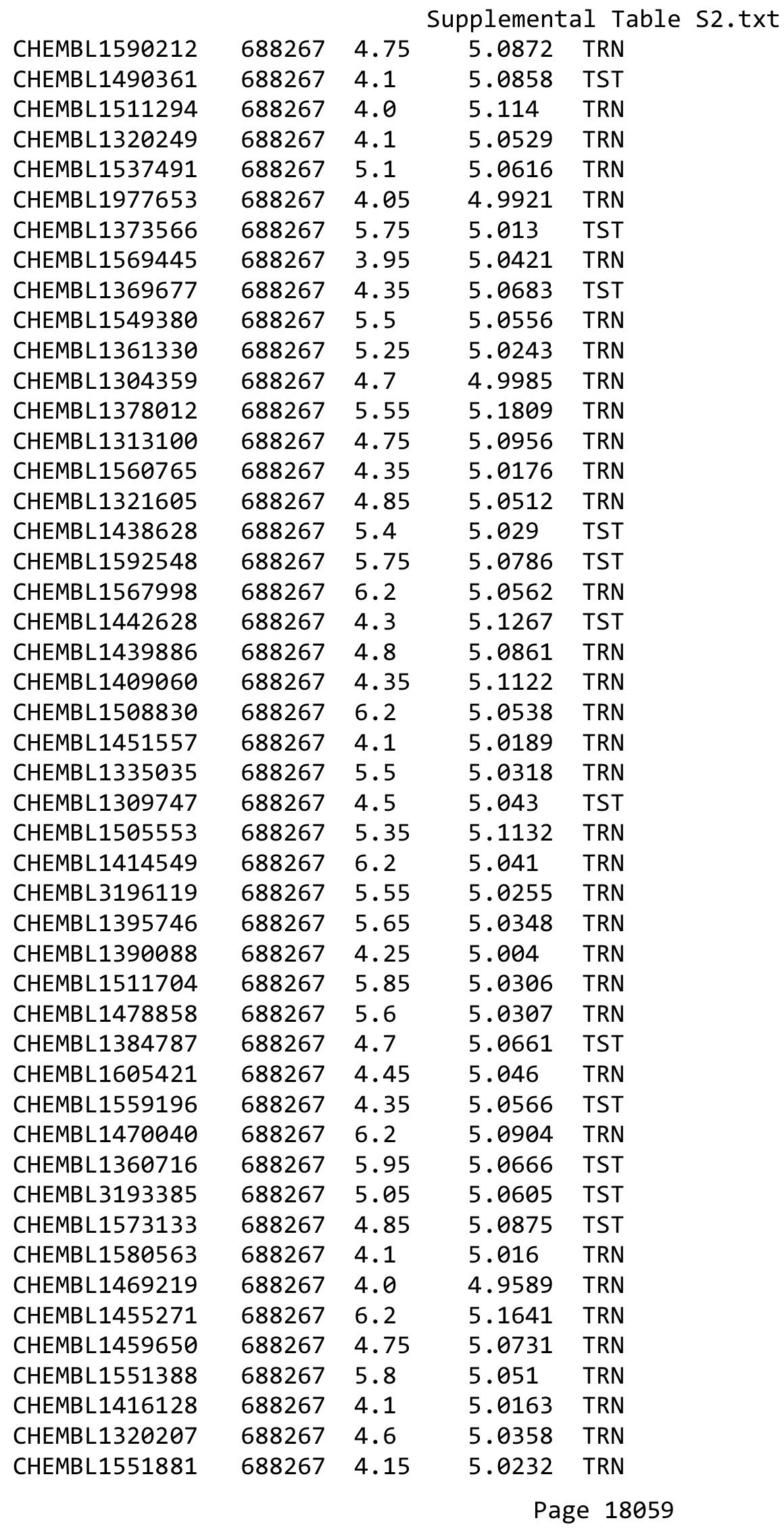




\begin{tabular}{|c|c|c|c|c|c|}
\hline \multicolumn{6}{|c|}{ 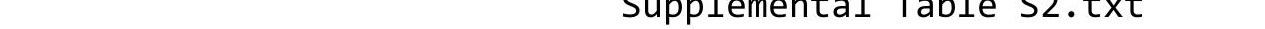 } \\
\hline CHEMBL1524683 & 688267 & 5.3 & 5.1507 & TST & \\
\hline CHEMBL3193153 & 688267 & 5.35 & 5.02800 & 00000000005 & TRN \\
\hline CHEMBL1347575 & 688267 & 4.25 & 5.0962 & TST & \\
\hline CHEMBL1326284 & 688267 & 4.5 & 4.9901 & TST & \\
\hline CHEMBL1439122 & 688267 & 4.4 & 4.9627 & TRN & \\
\hline CHEMBL3198056 & 688267 & 4.6 & 5.0485 & TST & \\
\hline CHEMBL1531870 & 688267 & 6.2 & 5.0214 & TRN & \\
\hline CHEMBL1606964 & 688267 & 5.05 & 5.0144 & TRN & \\
\hline CHEMBL1609701 & 688267 & 5.55 & 5.0534 & TRN & \\
\hline CHEMBL1392604 & 688267 & 6.2 & 5.0168 & TST & \\
\hline CHEMBL1402256 & 688267 & 4.0 & 5.0426 & TRN & \\
\hline CHEMBL1425072 & 688267 & 4.05 & 5.047 & TST & \\
\hline CHEMBL1377126 & 688267 & 4.1 & 5.0359 & TRN & \\
\hline CHEMBL1469165 & 688267 & 3.95 & 5.0972 & TRN & \\
\hline CHEMBL1563206 & 688267 & 4.0 & 5.0779 & TRN & \\
\hline CHEMBL1565850 & 688267 & 5.8 & 5.0522 & TRN & \\
\hline CHEMBL1385367 & 688267 & 4.2 & 5.0644 & TST & \\
\hline CHEMBL1515330 & 688267 & 5.8 & 5.0316 & TRN & \\
\hline CHEMBL1338684 & 688267 & 4.35 & 5.0496 & TRN & \\
\hline CHEMBL1538094 & 688267 & 5.6 & 4.9951 & TRN & \\
\hline CHEMBL1354718 & 688267 & 5.9 & 5.038 & TRN & \\
\hline CHEMBL1324791 & 688267 & 4.45 & 5.0956 & TST & \\
\hline CHEMBL1369350 & 688267 & 4.1 & 5.1161 & TRN & \\
\hline CHEMBL1591354 & 688267 & 6.2 & 5.0494 & TRN & \\
\hline CHEMBL1344406 & 688267 & 4.4 & 5.0701 & TRN & \\
\hline CHEMBL1329475 & 688267 & 6.25 & 5.0028 & TRN & \\
\hline CHEMBL1419603 & 688267 & 5.9 & 5.0707 & TRN & \\
\hline CHEMBL1469025 & 688267 & 5.85 & 5.0665 & TRN & \\
\hline CHEMBL1309005 & 688267 & 5.5 & 5.0116 & TST & \\
\hline CHEMBL1333412 & 688267 & 4.25 & 4.9928 & TRN & \\
\hline CHEMBL1528173 & 688267 & 6.2 & 5.0951 & TST & \\
\hline CHEMBL1383982 & 688267 & 4.8 & 5.0331 & TRN & \\
\hline CHEMBL1516078 & 688267 & 7.1002 & 5.0871 & TRN & \\
\hline CHEMBL1348541 & 688267 & 5.5 & 5.0681 & TRN & \\
\hline CHEMBL1308730 & 688267 & 4.0 & 5.085 & TST & \\
\hline CHEMBL1434438 & 688267 & 5.75 & 5.0895 & TRN & \\
\hline CHEMBL1605240 & 688267 & 6.25 & 5.0371 & TRN & \\
\hline CHEMBL1572399 & 688267 & 4.0 & 4.9829 & TRN & \\
\hline CHEMBL1528384 & 688267 & 4.95 & 5.0007 & TST & \\
\hline CHEMBL1404154 & 688267 & 5.4 & 5.0398 & TRN & \\
\hline CHEMBL1351122 & 688267 & 4.35 & 5.0426 & TRN & \\
\hline CHEMBL1364498 & 688267 & 5.7 & 5.0586 & TST & \\
\hline CHEMBL1532532 & 688267 & 6.2 & 5.0338 & TRN & \\
\hline CHEMBL1535234 & 688267 & 4.95 & 5.0572 & TRN & \\
\hline CHEMBL1336251 & 688267 & 4.6 & 5.0958 & TRN & \\
\hline CHEMBL1534868 & 688267 & 5.05 & 4.9874 & TRN & \\
\hline CHEMBL1603589 & 688267 & 3.9 & 5.0782 & TRN & \\
\hline CHEMBL1414213 & 688267 & 4.3 & 5.045 & TRN & \\
\hline
\end{tabular}




\begin{tabular}{|c|c|c|c|c|c|}
\hline \multicolumn{6}{|c|}{ Supplemental Table S2.txt } \\
\hline CHEMBL1398156 & 688267 & 3.95 & 5.0867 & TRN & \\
\hline CHEMBL1499354 & 688267 & 4.0 & 5.0356 & TST & \\
\hline CHEMBL1328231 & 688267 & 4.0 & 5.0247 & TST & \\
\hline CHEMBL1496317 & 688267 & 5.0 & 5.1023 & TRN & \\
\hline CHEMBL1591878 & 688267 & 4.55 & 5.0581 & TRN & \\
\hline CHEMBL1488746 & 688267 & 6.2 & 5.0584 & TRN & \\
\hline CHEMBL1591344 & 688267 & 5.55 & 5.042 & TRN & \\
\hline CHEMBL1487637 & 688267 & 4.35 & 5.07 & TRN & \\
\hline CHEMBL1401496 & 688267 & 6.5501 & 5.0838 & TRN & \\
\hline CHEMBL1410552 & 688267 & 5.6 & 5.0091 & TST & \\
\hline CHEMBL1462728 & 688267 & 6.15 & 5.0635 & TRN & \\
\hline CHEMBL1461388 & 688267 & 5.25 & 5.104 & TRN & \\
\hline CHEMBL1322603 & 688267 & 5.35 & 5.1649 & TRN & \\
\hline CHEMBL1300581 & 688267 & 5.25 & 5.0546 & TRN & \\
\hline CHEMBL1309719 & 688267 & 5.55 & 5.0651 & TRN & \\
\hline CHEMBL1444600 & 688267 & 4.55 & 5.13899 & 9999999999 & TRN \\
\hline CHEMBL1403485 & 688267 & 3.95 & 5.0684 & TRN & \\
\hline CHEMBL1332203 & 688267 & 6.25 & 5.0358 & TRN & \\
\hline CHEMBL1319219 & 688267 & 4.15 & 5.0982 & TRN & \\
\hline CHEMBL1354085 & 688267 & 5.5 & 5.0952 & TRN & \\
\hline CHEMBL1402192 & 688267 & 6.2 & 5.0677 & TRN & \\
\hline CHEMBL1453149 & 688267 & 4.05 & 5.1356 & TRN & \\
\hline CHEMBL1589501 & 688267 & 4.6 & 5.0038 & TRN & \\
\hline CHEMBL1527488 & 688267 & 3.95 & 5.0436 & TRN & \\
\hline CHEMBL1454250 & 688267 & 5.55 & 5.0833 & TRN & \\
\hline CHEMBL1472831 & 688267 & 5.4 & 5.0568 & TRN & \\
\hline CHEMBL1387433 & 688267 & 3.95 & 5.0555 & TRN & \\
\hline CHEMBL1350368 & 688267 & 4.6 & 4.9896 & TRN & \\
\hline CHEMBL1541579 & 688267 & 5.3 & 5.0242 & TRN & \\
\hline CHEMBL1434730 & 688267 & 4.85 & 4.9995 & TST & \\
\hline CHEMBL1489417 & 688267 & 4.05 & 5.004 & TRN & \\
\hline CHEMBL1327989 & 688267 & 5.0 & 5.0737 & TRN & \\
\hline CHEMBL1402170 & 688267 & 4.05 & 5.0102 & TST & \\
\hline CHEMBL1480528 & 688267 & 4.6 & 5.0218 & TRN & \\
\hline CHEMBL1483809 & 688267 & 6.2 & 5.0209 & TST & \\
\hline CHEMBL1499239 & 688267 & 4.3 & 5.0613 & TST & \\
\hline CHEMBL 1453320 & 688267 & 4.1 & 5.0169 & TRN & \\
\hline CHEMBL1482616 & 688267 & 5.45 & 5.0025 & TRN & \\
\hline CHEMBL1513852 & 688267 & 6.25 & 4.9827 & TRN & \\
\hline CHEMBL1465400 & 688267 & 5.8 & 5.047 & TRN & \\
\hline CHEMBL1405254 & 688267 & 4.55 & 5.0452 & TST & \\
\hline CHEMBL1308994 & 688267 & 6.2 & 5.0881 & TST & \\
\hline CHEMBL1478252 & 688267 & 5.35 & 5.0842 & TST & \\
\hline CHEMBL1376123 & 688267 & 3.95 & 5.0178 & TRN & \\
\hline CHEMBL1390417 & 688267 & 4.05 & 5.0251 & TST & \\
\hline CHEMBL1331843 & 688267 & 6.2 & 5.0521 & TRN & \\
\hline CHEMBL1593389 & 688267 & 5.15 & 5.1272 & TRN & \\
\hline CHEMBL1495529 & 688267 & 6.15 & 5.0376 & TRN & \\
\hline
\end{tabular}




\begin{tabular}{|c|c|c|c|c|c|}
\hline \multicolumn{6}{|c|}{ Supplemental Table S2.txt } \\
\hline CHEMBL1606205 & 688267 & 6.15 & 5.0818 & TRN & \\
\hline CHEMBL1306438 & 688267 & 5.55 & 5.0085 & TST & \\
\hline CHEMBL1440044 & 688267 & 3.95 & 5.0377 & TRN & \\
\hline CHEMBL1512233 & 688267 & 4.05 & 5.0652 & TRN & \\
\hline CHEMBL1408417 & 688267 & 4.0 & 5.05 & TRN & \\
\hline CHEMBL1485711 & 688267 & 5.7 & 5.0381 & TRN & \\
\hline CHEMBL1392784 & 688267 & 4.55 & 5.0581 & TST & \\
\hline CHEMBL1590699 & 688267 & 4.15 & 5.1241 & TRN & \\
\hline CHEMBL1340986 & 688267 & 4.05 & 5.0212 & TST & \\
\hline CHEMBL1609565 & 688267 & 6.15 & 5.0448 & TRN & \\
\hline CHEMBL 2005655 & 688267 & 3.95 & 5.0611 & TRN & \\
\hline CHEMBL1565357 & 688267 & 4.6 & 5.06 & TRN & \\
\hline CHEMBL3192528 & 688267 & 5.35 & 4.9786 & TRN & \\
\hline CHEMBL1590561 & 688267 & 4.0 & 5.0733 & TST & \\
\hline CHEMBL1441313 & 688267 & 6.2 & 5.0032 & TST & \\
\hline CHEMBL1433619 & 688267 & 5.5 & 5.0302 & TRN & \\
\hline CHEMBL1517845 & 688267 & 6.1 & 5.0972 & TRN & \\
\hline CHEMBL1372401 & 688267 & 4.45 & 5.0241 & TRN & \\
\hline CHEMBL1486458 & 688267 & 4.05 & 5.0444 & TST & \\
\hline CHEMBL1361389 & 688267 & 6.2 & 5.0832 & TST & \\
\hline CHEMBL1505000 & 688267 & 4.55 & 5.0453 & TST & \\
\hline CHEMBL1519764 & 688267 & 4.05 & 5.0621 & TST & \\
\hline CHEMBL1528738 & 688267 & 4.4 & 5.0667 & TRN & \\
\hline CHEMBL1547101 & 688267 & 4.6 & 5.073 & TST & \\
\hline CHEMBL1346344 & 688267 & 5.8 & 5.1293 & TRN & \\
\hline CHEMBL1476947 & 688267 & 6.2 & 5.0552 & TRN & \\
\hline CHEMBL1496770 & 688267 & 4.9 & 5.0267 & TST & \\
\hline CHEMBL1391583 & 688267 & 5.4 & 5.0202 & TRN & \\
\hline CHEMBL1518548 & 688267 & 4.95 & 5.0737 & TRN & \\
\hline CHEMBL1530968 & 688267 & 5.85 & 5.0876 & TRN & \\
\hline CHEMBL579749 & 688267 & 5.85 & 5.0698 & TRN & \\
\hline CHEMBL1383513 & 688267 & 5.5 & 5.0795 & TRN & \\
\hline CHEMBL1568161 & 688267 & 5.9 & 5.1106 & TRN & \\
\hline CHEMBL1418168 & 688267 & 4.65 & 5.0499 & TST & \\
\hline CHEMBL1561925 & 688267 & 4.35 & 5.0675 & TRN & \\
\hline CHEMBL1454009 & 688267 & 4.7 & 5.11600 & 00000000005 & TST \\
\hline CHEMBL1575767 & 688267 & 4.3 & 4.9903 & TRN & \\
\hline CHEMBL1546801 & 688267 & 6.2 & 5.0339 & TST & \\
\hline CHEMBL1594423 & 688267 & 3.95 & 5.1036 & TRN & \\
\hline CHEMBL1402055 & 688267 & 4.4 & 5.0508 & TST & \\
\hline CHEMBL1366290 & 688267 & 5.05 & 5.0624 & TRN & \\
\hline CHEMBL1306703 & 688267 & 4.05 & 5.126 & TST & \\
\hline CHEMBL1341824 & 688267 & 4.4 & 5.0284 & TRN & \\
\hline CHEMBL1349170 & 688267 & 4.3 & 5.0178 & TRN & \\
\hline CHEMBL1585545 & 688267 & 5.85 & 5.0494 & TRN & \\
\hline CHEMBL1610043 & 688267 & 5.75 & 5.0275 & TRN & \\
\hline CHEMBL1319966 & 688267 & 4.0 & 5.0102 & TRN & \\
\hline CHEMBL1360752 & 688267 & 6.25 & 5.0401 & TRN & \\
\hline
\end{tabular}




\begin{tabular}{|c|c|c|c|c|}
\hline \multicolumn{5}{|c|}{ Supplemental Table S2.txt } \\
\hline CHEMBL1589535 & 688267 & 5.25 & 5.0693 & TRN \\
\hline CHEMBL1585829 & 688267 & 5.5 & 5.0712 & TRN \\
\hline CHEMBL1304903 & 688267 & 5.85 & 4.9935 & TST \\
\hline CHEMBL1353007 & 688267 & 6.15 & 5.1454 & TRN \\
\hline CHEMBL1425015 & 688267 & 4.4 & 5.0843 & TRN \\
\hline CHEMBL1492654 & 688267 & 5.45 & 5.0782 & TRN \\
\hline CHEMBL1596601 & 688267 & 6.15 & 5.0298 & TRN \\
\hline CHEMBL 3213610 & 688267 & 4.35 & 5.0284 & TST \\
\hline CHEMBL1444365 & 688267 & 6.2 & 5.0998 & TRN \\
\hline CHEMBL1355582 & 688267 & 4.4 & 5.0146 & TRN \\
\hline CHEMBL1411898 & 688267 & 4.0 & 5.041 & TRN \\
\hline CHEMBL1562032 & 688267 & 6.2 & 5.0461 & TST \\
\hline CHEMBL1302680 & 688267 & 5.4 & 5.0822 & TST \\
\hline CHEMBL1517570 & 688267 & 5.5 & 5.0758 & TRN \\
\hline CHEMBL1478204 & 688267 & 5.9 & 5.1333 & TRN \\
\hline CHEMBL1308549 & 688267 & 4.0 & 5.0318 & TRN \\
\hline CHEMBL1396121 & 688267 & 4.0 & 5.1655 & TRN \\
\hline CHEMBL1579494 & 688267 & 4.0 & 5.0996 & TRN \\
\hline CHEMBL1365627 & 688267 & 4.0 & 5.1106 & TST \\
\hline CHEMBL1592900 & 688267 & 6.05 & 5.0789 & TRN \\
\hline CHEMBL1438308 & 688267 & 4.25 & 5.0845 & TRN \\
\hline CHEMBL1346874 & 688267 & 6.15 & 5.0258 & TRN \\
\hline CHEMBL1534163 & 688267 & 4.3 & 5.0378 & TRN \\
\hline CHEMBL1491436 & 688267 & 4.4 & 5.1149 & TRN \\
\hline CHEMBL1597219 & 688267 & 6.25 & 5.1507 & TRN \\
\hline CHEMBL1481592 & 688267 & 5.6 & 5.0856 & TRN \\
\hline CHEMBL3214374 & 688267 & 4.1 & 4.9889 & TST \\
\hline CHEMBL1449268 & 688267 & 3.95 & 4.9996 & TRN \\
\hline CHEMBL1523333 & 688267 & 4.6 & 5.0926 & TRN \\
\hline CHEMBL1498363 & 688267 & 3.95 & 5.0362 & TRN \\
\hline CHEMBL3209467 & 688267 & 4.3 & 5.0583 & TRN \\
\hline CHEMBL1398064 & 688267 & 4.25 & 5.0362 & TRN \\
\hline CHEMBL1382908 & 688267 & 5.75 & 5.124 & TRN \\
\hline CHEMBL1522075 & 688267 & 5.15 & 5.0278 & TST \\
\hline CHEMBL1368158 & 688267 & 5.85 & 5.0138 & TRN \\
\hline CHEMBL1391458 & 688267 & 4.0 & 5.1048 & TRN \\
\hline CHEMBL1561248 & 688267 & 4.3 & 5.0178 & TST \\
\hline CHEMBL1546013 & 688267 & 6.25 & 5.1065 & TRN \\
\hline CHEMBL1497701 & 688267 & 5.55 & 5.0689 & TST \\
\hline CHEMBL1371812 & 688267 & 6.2 & 5.0975 & TRN \\
\hline CHEMBL1386037 & 688267 & 5.3 & 5.1166 & TRN \\
\hline CHEMBL1437093 & 688267 & 4.4 & 5.0572 & TRN \\
\hline CHEMBL1486725 & 688267 & 5.15 & 5.0313 & TRN \\
\hline CHEMBL1303092 & 688267 & 6.2 & 5.0937 & TRN \\
\hline CHEMBL1478355 & 688267 & 6.05 & 5.1187 & TRN \\
\hline CHEMBL1549049 & 688267 & 4.4 & 5.0125 & TST \\
\hline CHEMBL1311151 & 688267 & 5.3 & 5.1039 & TRN \\
\hline CHEMBL1346753 & 688267 & 5.55 & 5.0551 & TST \\
\hline
\end{tabular}




\begin{tabular}{|c|c|c|c|c|c|}
\hline \multicolumn{6}{|c|}{ plemental } \\
\hline CHEMBL1514146 & 688267 & 4.3 & 5.1247 & TRN & \\
\hline CHEMBL1468107 & 688267 & 5.2 & 5.0463 & TST & \\
\hline CHEMBL1394440 & 688267 & 6.0 & 5.0342 & TRN & \\
\hline CHEMBL1430031 & 688267 & 4.75 & 5.051 & TRN & \\
\hline CHEMBL1489631 & 688267 & 4.0 & 5.0411 & TRN & \\
\hline CHEMBL1567919 & 688267 & 4.05 & 5.149 & TRN & \\
\hline CHEMBL1332318 & 688267 & 4.35 & 5.0507 & TRN & \\
\hline CHEMBL1415492 & 688267 & 4.0 & 5.0311 & TRN & \\
\hline CHEMBL3197701 & 688267 & 5.55 & 5.0856 & TRN & \\
\hline CHEMBL1561789 & 688267 & 6.2 & 5.0273 & TRN & \\
\hline CHEMBL1383278 & 688267 & 4.3 & 5.1227 & TST & \\
\hline CHEMBL1329778 & 688267 & 5.45 & 5.0816 & TRN & \\
\hline CHEMBL1456751 & 688267 & 5.6 & 5.0384 & TRN & \\
\hline CHEMBL1470499 & 688267 & 4.45 & 5.0283 & TRN & \\
\hline CHEMBL 3214537 & 688267 & 4.0 & 4.9732 & TRN & \\
\hline CHEMBL1566326 & 688267 & 6.15 & 5.0206 & TST & \\
\hline CHEMBL1418445 & 688267 & 6.2 & 5.0638 & TRN & \\
\hline CHEMBL1377236 & 688267 & 4.85 & 5.0342 & TRN & \\
\hline CHEMBL1481561 & 688267 & 4.3 & 5.0293 & TRN & \\
\hline CHEMBL1433779 & 688267 & 4.3 & 5.0664 & TRN & \\
\hline CHEMBL1548079 & 688267 & 4.15 & 5.0057 & TRN & \\
\hline CHEMBL1543416 & 688267 & 4.1 & 5.0649 & TST & \\
\hline CHEMBL1418951 & 688267 & 5.2 & 5.0581 & TST & \\
\hline CHEMBL1504883 & 688267 & 4.0 & 5.0652 & TST & \\
\hline CHEMBL1392221 & 688267 & 6.15 & 5.0144 & TRN & \\
\hline CHEMBL1973874 & 688267 & 4.9 & 4.9736 & TST & \\
\hline CHEMBL1368616 & 688267 & 4.45 & 5.0447 & TRN & \\
\hline CHEMBL1325934 & 688267 & 4.05 & 5.04899 & 99999999995 & TRN \\
\hline CHEMBL1605080 & 688267 & 4.4 & 4.9916 & TRN & \\
\hline CHEMBL1466753 & 688267 & 4.55 & 4.999 & TRN & \\
\hline CHEMBL1583771 & 688267 & 6.25 & 5.059 & TRN & \\
\hline CHEMBL1593326 & 688267 & 5.8 & 5.0282 & TRN & \\
\hline CHEMBL 254833 & 688267 & 5.65 & 5.0327 & TRN & \\
\hline CHEMBL1313414 & 688267 & 6.15 & 5.0487 & TST & \\
\hline CHEMBL1576934 & 688267 & 4.0 & 5.0549 & TST & \\
\hline CHEMBL1543204 & 688267 & 5.9 & 5.1157 & TRN & \\
\hline CHEMBL1379314 & 688267 & 5.3 & 5.0532 & TST & \\
\hline CHEMBL1444221 & 688267 & 4.0 & 4.989 & TST & \\
\hline CHEMBL1347420 & 688267 & 4.3 & 5.0077 & TRN & \\
\hline CHEMBL1595557 & 688267 & 4.05 & 5.01399 & 9999999999 & TRN \\
\hline CHEMBL1384928 & 688267 & 4.4 & 5.0897 & TST & \\
\hline CHEMBL1309569 & 688267 & 5.4 & 5.023 & TST & \\
\hline CHEMBL1504032 & 688267 & 6.2 & 5.0398 & TRN & \\
\hline CHEMBL3196209 & 688267 & 4.2 & 4.9769 & TRN & \\
\hline CHEMBL1609061 & 688267 & 6.15 & 5.0211 & TST & \\
\hline CHEMBL1375747 & 688267 & 5.45 & 5.0455 & TRN & \\
\hline CHEMBL1305129 & 688267 & 5.85 & 5.0721 & TRN & \\
\hline CHEMBL1583979 & 688267 & 6.2 & 5.0361 & TRN & \\
\hline
\end{tabular}




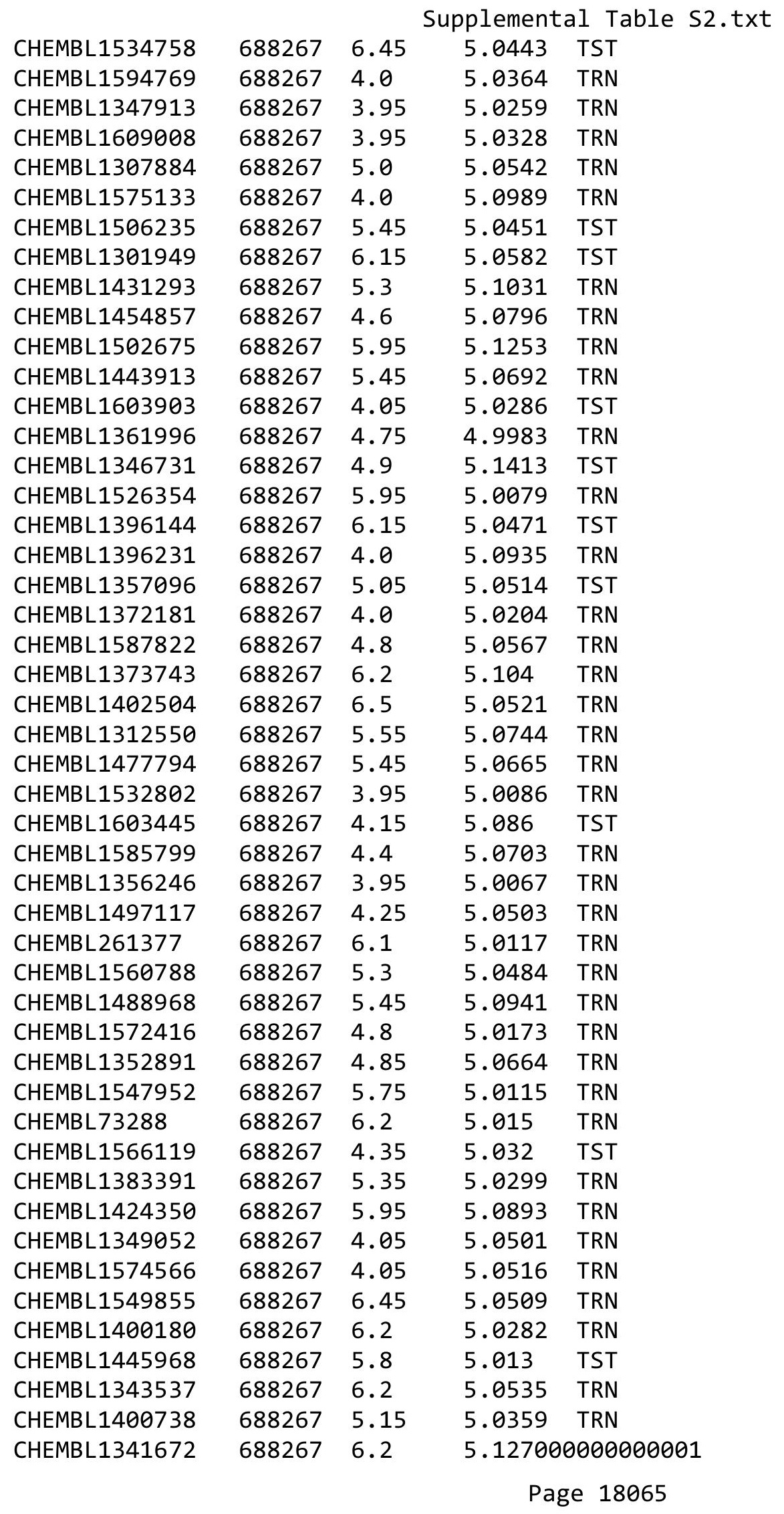




\begin{tabular}{|c|c|c|c|c|}
\hline \multicolumn{5}{|c|}{ Supplemental Table S2.txt } \\
\hline CHEMBL1611669 & 688267 & 4.6 & 5.0259 & TRN \\
\hline CHEMBL1496215 & 688267 & 5.85 & 5.0259 & TST \\
\hline CHEMBL1379259 & 688267 & 5.95 & 5.0375 & TRN \\
\hline CHEMBL1487803 & 688267 & 4.25 & 5.1038 & TST \\
\hline CHEMBL1368530 & 688267 & 6.15 & 5.0025 & TRN \\
\hline CHEMBL1471727 & 688267 & 4.05 & 4.9928 & TRN \\
\hline CHEMBL1466816 & 688267 & 5.5 & 5.0977 & TRN \\
\hline CHEMBL1529245 & 688267 & 5.85 & 5.0397 & TRN \\
\hline CHEMBL1465587 & 688267 & 5.85 & 5.0422 & TRN \\
\hline CHEMBL1513394 & 688267 & 6.2 & 5.0384 & TST \\
\hline CHEMBL1337105 & 688267 & 4.35 & 5.1383 & TRN \\
\hline CHEMBL1486781 & 688267 & 6.2 & 5.0709 & TRN \\
\hline CHEMBL1409473 & 688267 & 5.6 & 5.0406 & TRN \\
\hline CHEMBL1518948 & 688267 & 6.5501 & 5.0892 & TST \\
\hline CHEMBL1448651 & 688267 & 5.5 & 5.012 & TRN \\
\hline CHEMBL1539820 & 688267 & 5.55 & 5.039 & TRN \\
\hline CHEMBL1548925 & 688267 & 6.1 & 5.0049 & TRN \\
\hline CHEMBL1363096 & 688267 & 4.0 & 5.0362 & TRN \\
\hline CHEMBL1378639 & 688267 & 4.55 & 5.1087 & TST \\
\hline CHEMBL1570182 & 688267 & 4.05 & 5.0628 & TRN \\
\hline CHEMBL1419678 & 688267 & 6.2 & 5.098 & TRN \\
\hline CHEMBL1436477 & 688267 & 6.25 & 5.0756 & TRN \\
\hline CHEMBL1452812 & 688267 & 6.0 & 5.1657 & TRN \\
\hline CHEMBL1340942 & 688267 & 4.0 & 5.0903 & TRN \\
\hline CHEMBL1357389 & 688267 & 4.05 & 4.9962 & TRN \\
\hline CHEMBL1516288 & 688267 & 3.9 & 5.0097 & TRN \\
\hline CHEMBL1582629 & 688267 & 4.3 & 5.0588 & TST \\
\hline CHEMBL1326456 & 688267 & 4.75 & 5.0474 & TRN \\
\hline CHEMBL1331077 & 688267 & 5.5 & 5.112 & TRN \\
\hline CHEMBL1612744 & 688267 & 4.9 & 5.1176 & TST \\
\hline CHEMBL1399866 & 688267 & 6.25 & 4.9939 & TRN \\
\hline CHEMBL1538219 & 688267 & 4.95 & 5.1034 & TRN \\
\hline CHEMBL1597384 & 688267 & 5.85 & 5.0275 & TRN \\
\hline CHEMBL1590794 & 688267 & 6.25 & 5.0794 & TRN \\
\hline CHEMBL1479729 & 688267 & 6.15 & 5.0394 & TRN \\
\hline CHEMBL1573385 & 688267 & 5.15 & 5.0505 & TST \\
\hline CHEMBL1356865 & 688267 & 6.5 & 5.1057 & TRN \\
\hline CHEMBL1435668 & 688267 & 4.35 & 5.0182 & TRN \\
\hline CHEMBL1396812 & 688267 & 4.0 & 5.0627 & TRN \\
\hline CHEMBL1452596 & 688267 & 4.05 & 5.1229 & TRN \\
\hline CHEMBL1409734 & 688267 & 5.5 & 5.0576 & TST \\
\hline CHEMBL1611128 & 688267 & 5.3 & 5.103 & TRN \\
\hline CHEMBL1400514 & 688267 & 4.05 & 5.0544 & TST \\
\hline CHEMBL44876 & 688267 & 3.95 & 5.1104 & TRN \\
\hline CHEMBL1438583 & 688267 & 5.05 & 5.0427 & TRN \\
\hline CHEMBL1515143 & 688267 & 6.25 & 5.055 & TRN \\
\hline CHEMBL1356895 & 688267 & 5.35 & 5.0318 & TRN \\
\hline CHEMBL1520514 & 688267 & 5.7 & 5.0496 & TRN \\
\hline
\end{tabular}




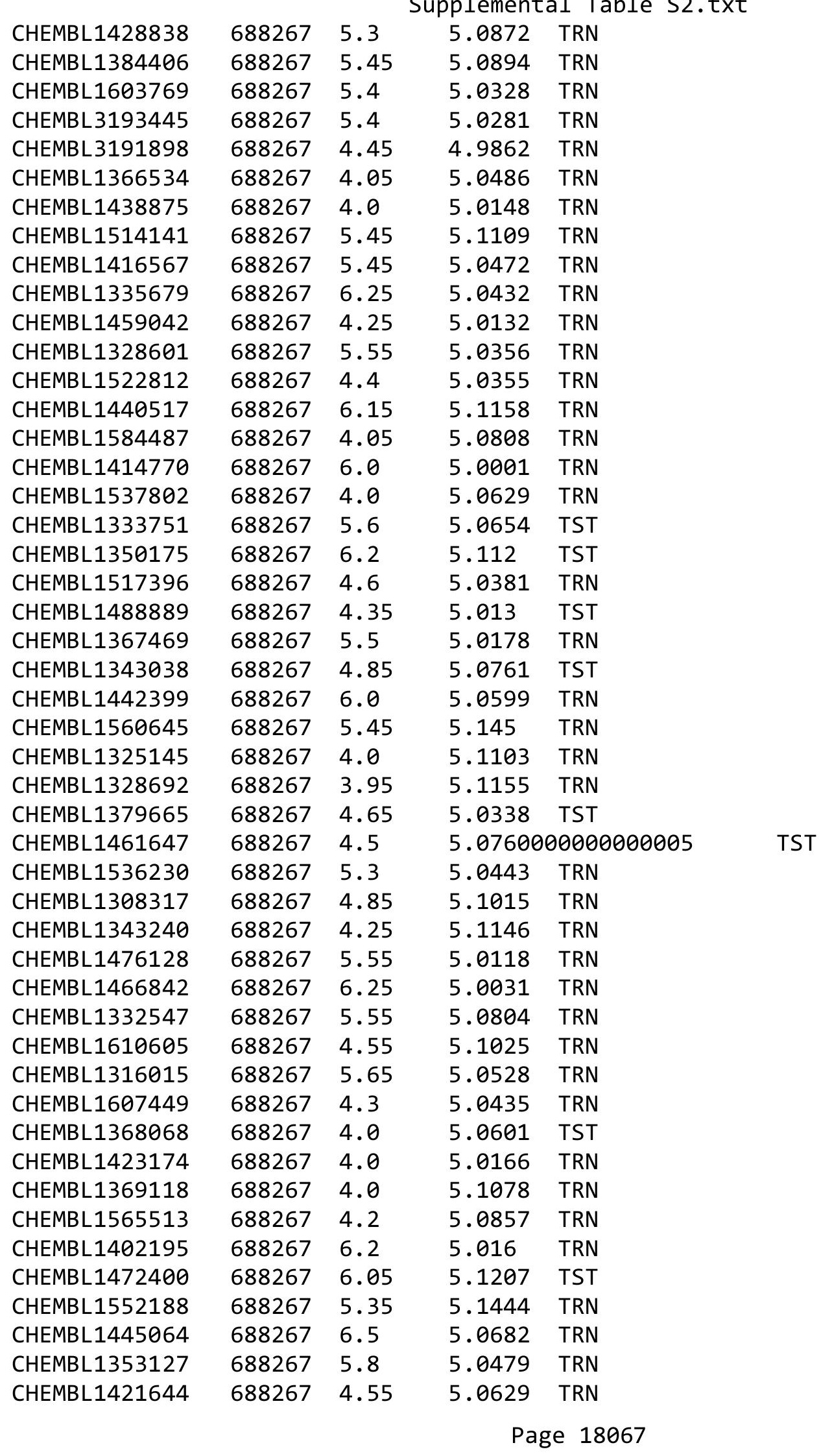




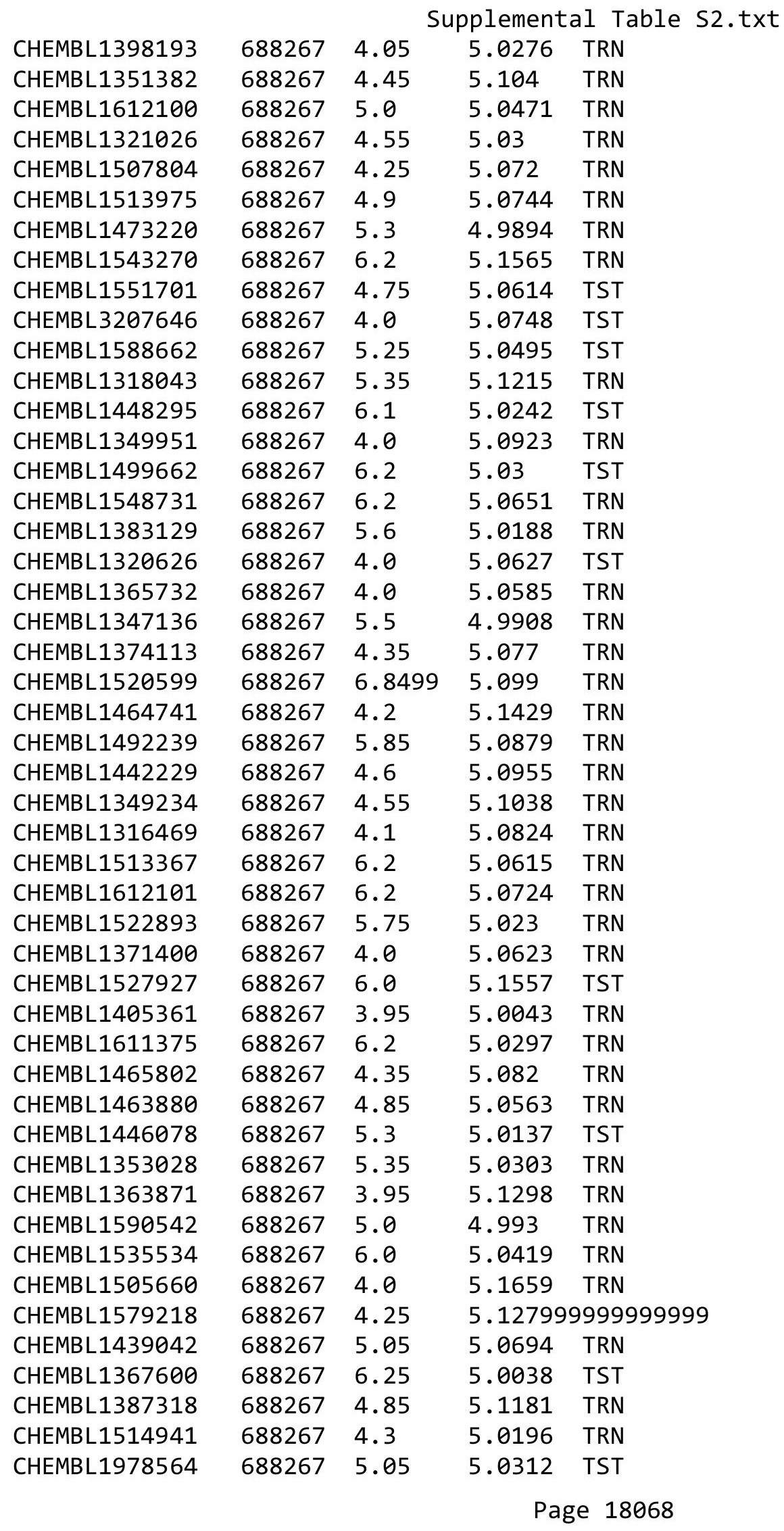

TRN 


\begin{tabular}{|c|c|c|c|c|c|}
\hline \multirow[b]{2}{*}{ CHEMBL1341762 } & \multirow[b]{2}{*}{688267} & \multicolumn{4}{|c|}{ Supplemental Table S2.txt } \\
\hline & & 4.35 & 5.0705 & TRN & \\
\hline CHEMBL1590786 & 688267 & 4.0 & 5.0904 & TRN & \\
\hline CHEMBL1589252 & 688267 & 5.05 & 5.0576 & TST & \\
\hline CHEMBL1309598 & 688267 & 5.35 & 4.9962 & TST & \\
\hline CHEMBL1405339 & 688267 & 3.95 & \multicolumn{2}{|c|}{5.071000000000001} & TST \\
\hline CHEMBL1439504 & 688267 & 5.55 & 5.1488 & TRN & \\
\hline CHEMBL1539730 & 688267 & 4.3 & 5.0692 & TRN & \\
\hline CHEMBL1473687 & 688267 & 6.15 & 5.0864 & TRN & \\
\hline CHEMBL1353835 & 688267 & 6.2 & 5.0861 & TRN & \\
\hline CHEMBL1572197 & 688267 & 4.35 & 5.1016 & TRN & \\
\hline CHEMBL3213156 & 688267 & 4.6 & 5.0011 & TRN & \\
\hline CHEMBL1356745 & 688267 & 4.05 & 5.0592 & TRN & \\
\hline CHEMBL1347524 & 688267 & 4.45 & 5.0896 & TRN & \\
\hline CHEMBL1197859 & 688267 & 4.05 & 5.0614 & TRN & \\
\hline CHEMBL1409425 & 688267 & 4.55 & 5.0387 & TRN & \\
\hline CHEMBL1431569 & 688267 & 5.55 & 5.0192 & TST & \\
\hline CHEMBL1370224 & 688267 & 5.55 & 5.113 & TRN & \\
\hline CHEMBL1407412 & 688267 & 5.9 & 5.011 & TRN & \\
\hline CHEMBL1510967 & 688267 & 4.55 & 5.0758 & TRN & \\
\hline CHEMBL3210160 & 688267 & 4.05 & 4.9998 & TRN & \\
\hline CHEMBL1588614 & 688267 & 6.1 & 5.1123 & TST & \\
\hline CHEMBL1495099 & 688267 & 5.4 & 5.037 & TRN & \\
\hline CHEMBL1404387 & 688267 & 4.05 & 5.1345 & TRN & \\
\hline CHEMBL1503055 & 688267 & 5.3 & 5.0329 & TST & \\
\hline CHEMBL1367677 & 688267 & 6.4 & 4.9867 & TRN & \\
\hline CHEMBL1593598 & 688267 & 6.5 & 5.0538 & TRN & \\
\hline CHEMBL1580904 & 688267 & 4.05 & 5.0542 & TST & \\
\hline CHEMBL1486386 & 688267 & 5.0 & 5.0199 & TST & \\
\hline CHEMBL1512994 & 688267 & 6.2 & 5.0671 & TRN & \\
\hline CHEMBL504381 & 688267 & 5.75 & 5.0367 & TST & \\
\hline CHEMBL1559984 & 688267 & 6.45 & 5.1378 & TST & \\
\hline CHEMBL1401633 & 688267 & 4.5 & 5.0007 & TRN & \\
\hline CHEMBL1362183 & 688267 & 5.4 & 5.0195 & TRN & \\
\hline CHEMBL1362985 & 688267 & 4.0 & 5.0634 & TRN & \\
\hline CHEMBL1479253 & 688267 & 5.0 & 5.06 & TRN & \\
\hline CHEMBL1486806 & 688267 & 4.15 & 5.0593 & TRN & \\
\hline CHEMBL1568072 & 688267 & 5.5 & 5.0115 & TST & \\
\hline CHEMBL1560407 & 688267 & 4.4 & 5.0259 & TRN & \\
\hline CHEMBL1316229 & 688267 & 4.05 & 5.0568 & TRN & \\
\hline CHEMBL1582884 & 688267 & 4.0 & 5.0552 & TRN & \\
\hline CHEMBL1503374 & 688267 & 5.3 & 5.0013 & TRN & \\
\hline CHEMBL1557862 & 688267 & 6.15 & 5.0173 & TRN & \\
\hline CHEMBL1318049 & 688267 & 4.05 & 5.0142 & TRN & \\
\hline CHEMBL485683 & 688267 & 4.65 & 5.0806 & TST & \\
\hline CHEMBL1421377 & 688267 & 4.45 & 5.0138 & TST & \\
\hline CHEMBL1366455 & 688267 & 4.7 & 5.0767 & TRN & \\
\hline CHEMBL1562270 & 688267 & 5.0 & 5.1092 & TRN & \\
\hline CHEMBL1324774 & 688267 & 6.2 & 5.03600 & 00000000005 & TRN \\
\hline & & & & 18069 & \\
\hline
\end{tabular}




\begin{tabular}{|c|c|c|c|c|c|}
\hline \multicolumn{6}{|c|}{ Supplemental Table S2.txt } \\
\hline CHEMBL3144944 & 688267 & 4.45 & 5.0136 & TST & \\
\hline CHEMBL1319939 & 688267 & 4.4 & 5.0386 & TST & \\
\hline CHEMBL1605452 & 688267 & 6.15 & 5.1591 & TRN & \\
\hline CHEMBL1540092 & 688267 & 6.2 & 5.0275 & TRN & \\
\hline CHEMBL1601154 & 688267 & 4.1 & 5.0692 & TRN & \\
\hline CHEMBL3191769 & 688267 & 6.25 & 5.0168 & TRN & \\
\hline CHEMBL1557887 & 688267 & 5.7 & 5.0298 & TRN & \\
\hline CHEMBL1518568 & 688267 & 5.0 & 5.055 & TST & \\
\hline CHEMBL1363053 & 688267 & 4.0 & 5.0618 & TRN & \\
\hline CHEMBL1494245 & 688267 & 5.4 & 5.0503 & TRN & \\
\hline CHEMBL1552122 & 688267 & 5.1 & 5.0561 & TST & \\
\hline CHEMBL1337200 & 688267 & 4.95 & 5.1185 & TST & \\
\hline CHEMBL1612819 & 688267 & 5.85 & 5.1153 & TST & \\
\hline CHEMBL 3213765 & 688267 & 5.2 & 5.0789 & TRN & \\
\hline CHEMBL1405700 & 688267 & 4.95 & 5.0652 & TRN & \\
\hline CHEMBL1533548 & 688267 & 4.55 & 5.0982 & TRN & \\
\hline CHEMBL1595136 & 688267 & 4.15 & 5.1297 & TRN & \\
\hline CHEMBL1992912 & 688267 & 5.9 & 4.9815 & TRN & \\
\hline CHEMBL1336306 & 688267 & 4.55 & 4.9797 & TRN & \\
\hline CHEMBL1574977 & 688267 & 5.05 & 5.0166 & TRN & \\
\hline CHEMBL1350627 & 688267 & 3.95 & 5.0652 & TRN & \\
\hline CHEMBL1353856 & 688267 & 5.3 & 5.0684 & TRN & \\
\hline CHEMBL1576814 & 688267 & 5.55 & 5.0137 & TRN & \\
\hline CHEMBL1504458 & 688267 & 6.15 & 5.0899 & TRN & \\
\hline CHEMBL1613187 & 688267 & 5.05 & 5.0604 & TST & \\
\hline CHEMBL1588110 & 688267 & 4.35 & 5.0768 & TRN & \\
\hline CHEMBL1574354 & 688267 & 5.05 & 5.0687 & TRN & \\
\hline CHEMBL1311658 & 688267 & 6.2 & 5.0978 & TRN & \\
\hline CHEMBL1426513 & 688267 & 4.7 & 5.1221 & TRN & \\
\hline CHEMBL1449908 & 688267 & 4.05 & 5.056 & TRN & \\
\hline CHEMBL1482854 & 688267 & 5.9 & 5.1151 & TRN & \\
\hline CHEMBL1410693 & 688267 & 4.75 & 5.08899 & 99999999995 & TST \\
\hline CHEMBL1433519 & 688267 & 6.2 & 5.0488 & TRN & \\
\hline CHEMBL1325031 & 688267 & 4.0 & 5.0624 & TST & \\
\hline CHEMBL1395895 & 688267 & 5.85 & 5.0311 & TRN & \\
\hline CHEMBL1311702 & 688267 & 5.3 & 5.0322 & TST & \\
\hline CHEMBL1468429 & 688267 & 6.2 & 5.0834 & TRN & \\
\hline CHEMBL1476853 & 688267 & 6.0 & 5.1077 & TST & \\
\hline CHEMBL1422332 & 688267 & 4.5 & 5.0268 & TRN & \\
\hline CHEMBL1333818 & 688267 & 6.15 & 5.12299 & 9999999999 & TRN \\
\hline CHEMBL1444505 & 688267 & 6.2 & 5.0384 & TRN & \\
\hline CHEMBL1451045 & 688267 & 3.95 & 5.0842 & TRN & \\
\hline CHEMBL1485994 & 688267 & 4.4 & 5.1876 & TRN & \\
\hline CHEMBL3208629 & 688267 & 5.8 & 5.0509 & TST & \\
\hline CHEMBL1394168 & 688267 & 4.55 & 5.0999 & TRN & \\
\hline CHEMBL1438122 & 688267 & 4.9 & 5.0099 & TRN & \\
\hline CHEMBL1597640 & 688267 & 4.55 & 5.1078 & TRN & \\
\hline CHEMBL1502330 & 688267 & 4.25 & 5.0299 & TRN & \\
\hline
\end{tabular}




\begin{tabular}{|c|c|c|c|c|c|}
\hline \multicolumn{6}{|c|}{ Supplemental Table S2.txt } \\
\hline CHEMBL1471101 & 688267 & 4.15 & 5.0656 & TRN & \\
\hline CHEMBL1574593 & 688267 & 5.0 & 5.0941 & TRN & \\
\hline CHEMBL1454799 & 688267 & 4.0 & 5.0062 & TRN & \\
\hline CHEMBL1459370 & 688267 & 4.1 & 5.0503 & TST & \\
\hline CHEMBL1322442 & 688267 & 4.25 & 5.0513 & TRN & \\
\hline CHEMBL1362368 & 688267 & 4.7 & 4.9904 & TST & \\
\hline CHEMBL1368475 & 688267 & 6.2 & 4.999 & TRN & \\
\hline CHEMBL1428397 & 688267 & 4.4 & 5.0209 & TRN & \\
\hline CHEMBL1402710 & 688267 & 5.45 & 5.1487 & TRN & \\
\hline CHEMBL1310370 & 688267 & 4.5 & 5.1473 & TRN & \\
\hline CHEMBL1358706 & 688267 & 4.0 & 5.1168 & TRN & \\
\hline CHEMBL1512820 & 688267 & 3.95 & 5.0636 & TST & \\
\hline CHEMBL1438893 & 688267 & 6.25 & 5.0697 & TRN & \\
\hline CHEMBL1471299 & 688267 & 6.2 & 5.0727 & TRN & \\
\hline CHEMBL1325900 & 688267 & 5.1 & 5.0859 & TRN & \\
\hline CHEMBL1366912 & 688267 & 5.75 & 5.0307 & TRN & \\
\hline CHEMBL1434182 & 688267 & 4.2 & 5.0189 & TRN & \\
\hline CHEMBL602718 & 688267 & 4.4 & 5.0459 & TRN & \\
\hline CHEMBL3191123 & 688267 & 5.6 & 5.0769 & TST & \\
\hline CHEMBL1524034 & 688267 & 4.0 & 5.037 & TRN & \\
\hline CHEMBL1605910 & 688267 & 6.15 & $5.0280 e$ & 00000000005 & TRN \\
\hline CHEMBL3196967 & 688267 & 4.3 & 5.0689 & TRN & \\
\hline CHEMBL1581101 & 688267 & 4.2 & 5.0652 & TRN & \\
\hline CHEMBL1444084 & 688267 & 4.05 & 5.0043 & TRN & \\
\hline CHEMBL1346962 & 688267 & 5.3 & 5.0153 & TRN & \\
\hline CHEMBL1500198 & 688267 & 5.35 & 5.0298 & TRN & \\
\hline CHEMBL3197795 & 688267 & 4.6 & 5.0555 & TRN & \\
\hline CHEMBL1595373 & 688267 & 4.35 & 5.011 & TRN & \\
\hline CHEMBL1386560 & 688267 & 6.2 & 5.0588 & TRN & \\
\hline CHEMBL1321165 & 688267 & 5.0 & 5.1257 & TRN & \\
\hline CHEMBL1509057 & 688267 & 4.45 & 5.0316 & TRN & \\
\hline CHEMBL1437132 & 688267 & 4.6 & 5.0458 & TRN & \\
\hline CHEMBL1519508 & 688267 & 6.2 & 5.0804 & TRN & \\
\hline CHEMBL1590253 & 688267 & 4.0 & 5.0132 & TRN & \\
\hline CHEMBL1393855 & 688267 & 4.9 & 4.9987 & TRN & \\
\hline CHEMBL1518368 & 688267 & 4.4 & 5.0526 & TRN & \\
\hline CHEMBL1465577 & 688267 & 4.1 & 5.1024 & TRN & \\
\hline CHEMBL1557452 & 688267 & 4.0 & 5.0622 & TRN & \\
\hline CHEMBL1367560 & 688267 & 6.25 & 5.1173 & TRN & \\
\hline CHEMBL1404238 & 688267 & 6.0 & 5.0033 & TRN & \\
\hline CHEMBL1380906 & 688267 & 5.7 & 5.1225 & TRN & \\
\hline CHEMBL1493858 & 688267 & 5.85 & 5.0873 & TRN & \\
\hline CHEMBL1355163 & 688267 & 4.0 & 5.0202 & TRN & \\
\hline CHEMBL1308494 & 688267 & 4.7 & 5.0738 & TRN & \\
\hline CHEMBL1554961 & 688267 & 6.2 & 5.0117 & TRN & \\
\hline CHEMBL1380279 & 688267 & 5.25 & 5.1036 & TRN & \\
\hline CHEMBL1351670 & 688267 & 5.3 & $5.0760 e$ & 00000000005 & TRN \\
\hline CHEMBL1436684 & 688267 & 4.0 & 5.0824 & TRN & \\
\hline
\end{tabular}




\begin{tabular}{|c|c|c|c|c|c|}
\hline \multicolumn{6}{|c|}{ Supplemental Table S2.txt } \\
\hline CHEMBL1474933 & 688267 & 5.5 & 5.1238 & TRN & \\
\hline CHEMBL1567838 & 688267 & 5.45 & 5.021 & TRN & \\
\hline CHEMBL1514349 & 688267 & 4.0 & 5.0887 & TRN & \\
\hline CHEMBL1518814 & 688267 & 4.75 & 5.1094 & TRN & \\
\hline CHEMBL3193423 & 688267 & 4.1 & 5.0377 & TRN & \\
\hline CHEMBL1487807 & 688267 & 4.15 & 4.9862 & TRN & \\
\hline CHEMBL3145130 & 688267 & 4.1 & 5.0092 & TST & \\
\hline CHEMBL1489312 & 688267 & 4.0 & 5.1099 & TST & \\
\hline CHEMBL1515713 & 688267 & 5.55 & 5.12299 & 9999999999 & TRN \\
\hline CHEMBL1311106 & 688267 & 4.0 & 5.0757 & TRN & \\
\hline CHEMBL1425924 & 688267 & 4.4 & 5.0514 & TST & \\
\hline CHEMBL1360082 & 688267 & 5.55 & 5.1103 & TST & \\
\hline CHEMBL1509429 & 688267 & 4.2 & 5.0499 & TRN & \\
\hline CHEMBL1445360 & 688267 & 4.2 & 5.0365 & TRN & \\
\hline CHEMBL1373867 & 688267 & 4.9 & 4.9998 & TRN & \\
\hline CHEMBL1597683 & 688267 & 6.05 & 5.0234 & TRN & \\
\hline CHEMBL1379083 & 688267 & 5.0 & 5.06800 & 00000000005 & TRN \\
\hline CHEMBL1368050 & 688267 & 5.25 & 5.0641 & TRN & \\
\hline CHEMBL1369175 & 688267 & 6.2 & 5.0181 & TRN & \\
\hline CHEMBL1360807 & 688267 & 5.3 & 5.0558 & TST & \\
\hline CHEMBL1398281 & 688267 & 6.05 & 5.0983 & TRN & \\
\hline CHEMBL1413445 & 688267 & 4.25 & 5.0713 & TRN & \\
\hline CHEMBL1609830 & 688267 & 4.25 & 5.0829 & TRN & \\
\hline CHEMBL1414140 & 688267 & 4.0 & 5.084 & TRN & \\
\hline CHEMBL1427825 & 688267 & 6.2 & 5.0488 & TRN & \\
\hline CHEMBL1459122 & 688267 & 4.05 & 5.0546 & TRN & \\
\hline CHEMBL1531860 & 688267 & 4.6 & 5.1338 & TRN & \\
\hline CHEMBL1571964 & 688267 & 5.45 & 5.1191 & TRN & \\
\hline CHEMBL3211149 & 688267 & 4.25 & 5.023 & TST & \\
\hline CHEMBL1326965 & 688267 & 5.35 & 5.02 & TST & \\
\hline CHEMBL1505455 & 688267 & 5.05 & 5.0481 & TRN & \\
\hline CHEMBL1387628 & 688267 & 5.55 & 5.0601 & TST & \\
\hline CHEMBL1535055 & 688267 & 5.6 & 5.0356 & TRN & \\
\hline CHEMBL1358099 & 688267 & 5.9 & 5.0601 & TRN & \\
\hline CHEMBL1387083 & 688267 & 6.45 & 5.0586 & TRN & \\
\hline CHEMBL1528866 & 688267 & 4.8 & 5.041 & TRN & \\
\hline CHEMBL1476906 & 688267 & 6.2 & 5.1262 & TST & \\
\hline CHEMBL1502467 & 688267 & 6.2 & 5.0201 & TST & \\
\hline CHEMBL1578136 & 688267 & 5.4 & 5.1152 & TRN & \\
\hline CHEMBL1513424 & 688267 & 5.25 & 5.0855 & TRN & \\
\hline CHEMBL1442715 & 688267 & 6.25 & 5.067 & TRN & \\
\hline CHEMBL1373427 & 688267 & 5.55 & 5.0233 & TRN & \\
\hline CHEMBL1319270 & 688267 & 6.2 & 5.0474 & TRN & \\
\hline CHEMBL1590791 & 688267 & 4.95 & 5.1087 & TRN & \\
\hline CHEMBL1587756 & 688267 & 4.6 & 5.0212 & TRN & \\
\hline CHEMBL1496411 & 688267 & 5.0 & 5.0072 & TST & \\
\hline CHEMBL1603662 & 688267 & 6.2 & 5.0069 & TRN & \\
\hline CHEMBL1424658 & 688267 & 4.7 & 5.0941 & TST & \\
\hline
\end{tabular}




\begin{tabular}{|c|c|c|c|c|c|}
\hline \multicolumn{6}{|c|}{ Supplemental Table S2.txt } \\
\hline CHEMBL1374295 & 688267 & 4.8 & 5.033 & TRN & \\
\hline CHEMBL1316185 & 688267 & 6.5501 & 5.0468 & TRN & \\
\hline CHEMBL1362290 & 688267 & 6.5 & 5.0478 & TRN & \\
\hline CHEMBL1503310 & 688267 & 4.0 & 5.05399 & 9999999999 & TRN \\
\hline CHEMBL1505970 & 688267 & 6.45 & 5.0612 & TRN & \\
\hline CHEMBL1336895 & 688267 & 5.2 & 5.037 & TRN & \\
\hline CHEMBL1604776 & 688267 & 4.5 & 5.0634 & TST & \\
\hline CHEMBL1451143 & 688267 & 5.65 & 5.0412 & TST & \\
\hline CHEMBL1537478 & 688267 & 6.25 & 5.0529 & TRN & \\
\hline CHEMBL1440540 & 688267 & 4.4 & 5.0666 & TRN & \\
\hline CHEMBL1397282 & 688267 & 5.8 & 5.0636 & TRN & \\
\hline CHEMBL1337710 & 688267 & 4.1 & 5.0042 & TRN & \\
\hline CHEMBL1396300 & 688267 & 5.25 & 5.0447 & TRN & \\
\hline CHEMBL1435169 & 688267 & 6.2 & 5.0709 & TRN & \\
\hline CHEMBL1337037 & 688267 & 4.5 & 5.1137 & TRN & \\
\hline CHEMBL1424839 & 688267 & 5.5 & 5.0799 & TRN & \\
\hline CHEMBL1446941 & 688267 & 5.8 & 5.1087 & TRN & \\
\hline CHEMBL1592573 & 688267 & 6.2 & 5.0519 & TRN & \\
\hline CHEMBL1383483 & 688267 & 5.95 & 5.0367 & TRN & \\
\hline CHEMBL1364387 & 688267 & 5.5 & 5.0522 & TST & \\
\hline CHEMBL408982 & 688267 & 4.5 & 5.05399 & 9999999999 & TRN \\
\hline CHEMBL1507198 & 688267 & 4.2 & 5.0676 & TST & \\
\hline CHEMBL1333827 & 688267 & 3.95 & 5.0294 & TRN & \\
\hline CHEMBL1593903 & 688267 & 6.1 & 5.0113 & TST & \\
\hline CHEMBL582473 & 688267 & 5.3 & 5.0621 & TRN & \\
\hline CHEMBL1514743 & 688267 & 5.35 & 5.0697 & TRN & \\
\hline CHEMBL1594257 & 688267 & 5.75 & 5.0535 & TST & \\
\hline CHEMBL1541571 & 688267 & 4.4 & 5.1153 & TRN & \\
\hline CHEMBL1515217 & 688267 & 6.15 & 5.1222 & TRN & \\
\hline CHEMBL1323363 & 688267 & 5.55 & 5.1071 & TRN & \\
\hline CHEMBL1511148 & 688267 & 5.3 & 5.1367 & TRN & \\
\hline CHEMBL1518677 & 688267 & 4.95 & 5.0124 & TRN & \\
\hline CHEMBL1430106 & 688267 & 5.55 & 5.0337 & TST & \\
\hline CHEMBL1588826 & 688267 & 4.65 & 5.0066 & TRN & \\
\hline CHEMBL1374887 & 688267 & 4.3 & 5.0391 & TRN & \\
\hline CHEMBL1316196 & 688267 & 5.3 & 5.0353 & TRN & \\
\hline CHEMBL1310759 & 688267 & 4.05 & 5.0655 & TST & \\
\hline CHEMBL1304577 & 688267 & 3.95 & 5.0511 & TST & \\
\hline CHEMBL1549061 & 688267 & 4.35 & 5.0272 & TRN & \\
\hline CHEMBL1474046 & 688267 & 6.5 & 5.0241 & TRN & \\
\hline CHEMBL1323103 & 688267 & 6.2 & 5.0801 & TRN & \\
\hline CHEMBL1599206 & 688267 & 6.2 & 5.0414 & TRN & \\
\hline CHEMBL1438476 & 688267 & 5.35 & 5.0064 & TRN & \\
\hline CHEMBL1581943 & 688267 & 6.15 & 5.0669 & TRN & \\
\hline CHEMBL1302552 & 688267 & 4.5 & 5.0395 & TRN & \\
\hline CHEMBL1527402 & 688267 & 5.65 & 5.0256 & TRN & \\
\hline CHEMBL1519718 & 688267 & 4.4 & 5.0779 & TST & \\
\hline CHEMBL1570831 & 688267 & 4.9 & 5.0219 & TST & \\
\hline
\end{tabular}




\begin{tabular}{|c|c|c|c|c|}
\hline \multicolumn{5}{|c|}{ Supplemental Table S2.txt } \\
\hline CHEMBL1602423 & 688267 & 6.0 & 5.0423 & TRN \\
\hline CHEMBL1346762 & 688267 & 4.2 & 5.0029 & TST \\
\hline CHEMBL1339755 & 688267 & 4.35 & 5.1058 & TST \\
\hline CHEMBL1430929 & 688267 & 6.15 & 5.0776 & TRN \\
\hline CHEMBL 1474438 & 688267 & 4.05 & 5.0755 & TRN \\
\hline CHEMBL1468450 & 688267 & 3.95 & 5.0644 & TRN \\
\hline CHEMBL1604694 & 688267 & 4.05 & 5.0304 & TST \\
\hline CHEMBL1564582 & 688267 & 4.3 & 5.0532 & TST \\
\hline CHEMBL1463487 & 688267 & 6.2 & 5.1285 & TRN \\
\hline CHEMBL1524849 & 688267 & 6.45 & 5.0903 & TRN \\
\hline CHEMBL1537307 & 688267 & 4.05 & 4.9847 & TRN \\
\hline CHEMBL1344597 & 688267 & 3.95 & 5.0351 & TRN \\
\hline CHEMBL1393466 & 688267 & 5.3 & 5.0645 & TRN \\
\hline CHEMBL1474626 & 688267 & 6.15 & 5.0545 & TST \\
\hline CHEMBL1607465 & 688267 & 4.4 & 5.063 & TRN \\
\hline CHEMBL1379514 & 688267 & 4.55 & 5.0086 & TRN \\
\hline CHEMBL1422866 & 688267 & 4.55 & 5.0031 & TRN \\
\hline CHEMBL1392300 & 688267 & 5.15 & 5.0949 & TST \\
\hline CHEMBL1314901 & 688267 & 5.55 & 5.0377 & TRN \\
\hline CHEMBL1334097 & 688267 & 6.2 & 5.1116 & TST \\
\hline CHEMBL1373312 & 688267 & 4.05 & 5.0531 & TRN \\
\hline CHEMBL1357942 & 688267 & 5.2 & 5.1078 & TRN \\
\hline CHEMBL1388708 & 688267 & 5.7 & 5.0371 & TST \\
\hline CHEMBL1391152 & 688267 & 4.6 & 5.1478 & TRN \\
\hline CHEMBL1473931 & 688267 & 5.55 & 5.1088 & TRN \\
\hline CHEMBL3191340 & 688267 & 6.15 & 5.0048 & TRN \\
\hline CHEMBL311822 & 688267 & 6.1 & 5.0666 & TRN \\
\hline CHEMBL3213762 & 688267 & 5.15 & 5.0507 & TST \\
\hline CHEMBL1346443 & 688267 & 6.25 & 5.0916 & TRN \\
\hline CHEMBL1397977 & 688267 & 4.25 & 5.0194 & TRN \\
\hline CHEMBL 2003599 & 688267 & 6.15 & 5.0665 & TST \\
\hline CHEMBL1517330 & 688267 & 3.95 & 5.0728 & TRN \\
\hline CHEMBL1439857 & 688267 & 4.65 & 5.0303 & TRN \\
\hline CHEMBL1591439 & 688267 & 4.05 & 5.109 & TRN \\
\hline CHEMBL1379518 & 688267 & 5.35 & 5.138 & TRN \\
\hline CHEMBL1341407 & 688267 & 4.0 & 5.0607 & TST \\
\hline CHEMBL 1471780 & 688267 & 6.5 & 5.0953 & TRN \\
\hline CHEMBL1313207 & 688267 & 4.6 & 5.1054 & TRN \\
\hline CHEMBL1319135 & 688267 & 4.45 & 5.0707 & TRN \\
\hline CHEMBL1327655 & 688267 & 5.4 & 5.0235 & TRN \\
\hline CHEMBL3197306 & 688267 & 5.5 & 4.9875 & TRN \\
\hline CHEMBL1324503 & 688267 & 4.3 & 5.018 & TRN \\
\hline CHEMBL1582621 & 688267 & 4.0 & 5.0858 & TRN \\
\hline CHEMBL3194413 & 688267 & 5.05 & 4.9654 & TRN \\
\hline CHEMBL1437173 & 688267 & 4.05 & 5.0613 & TRN \\
\hline CHEMBL1316426 & 688267 & 4.35 & 5.0831 & TRN \\
\hline CHEMBL1456291 & 688267 & 4.1 & 5.0941 & TRN \\
\hline CHEMBL1352181 & 688267 & 4.05 & 5.0237 & TRN \\
\hline
\end{tabular}




\begin{tabular}{|c|c|c|c|c|}
\hline \multicolumn{5}{|c|}{ Supplemental Table S2.txt } \\
\hline CHEMBL1331934 & 688267 & 6.0 & 5.1029 & TRN \\
\hline CHEMBL1556002 & 688267 & 6.2 & 5.0289 & TRN \\
\hline CHEMBL1346280 & 688267 & 6.15 & 5.0347 & TRN \\
\hline CHEMBL1420399 & 688267 & 6.2 & 5.061 & TRN \\
\hline CHEMBL1357992 & 688267 & 5.35 & 5.0519 & TRN \\
\hline CHEMBL1349157 & 688267 & 4.95 & 5.0673 & TRN \\
\hline CHEMBL1451194 & 688267 & 4.0 & 5.0481 & TRN \\
\hline CHEMBL1527631 & 688267 & 5.0 & 5.1002 & TRN \\
\hline CHEMBL1563498 & 688267 & 6.2 & 5.0629 & TRN \\
\hline CHEMBL3211296 & 688267 & 5.9 & 5.0182 & TST \\
\hline CHEMBL1579920 & 688267 & 5.45 & 5.0724 & TRN \\
\hline CHEMBL1565318 & 688267 & 5.25 & 4.9854 & TRN \\
\hline CHEMBL1475638 & 688267 & 5.5 & 5.0273 & TRN \\
\hline CHEMBL1519604 & 688267 & 5.65 & 5.011 & TRN \\
\hline CHEMBL576186 & 688267 & 4.05 & 4.9788 & TRN \\
\hline CHEMBL3208331 & 688267 & 6.5 & 5.0973 & TST \\
\hline CHEMBL1349692 & 688267 & 4.05 & 5.0789 & TST \\
\hline CHEMBL1477539 & 688267 & 4.35 & 5.081 & TRN \\
\hline CHEMBL1498939 & 688267 & 4.05 & 5.1027 & TST \\
\hline CHEMBL1378654 & 688267 & 6.15 & 4.9793 & TRN \\
\hline CHEMBL1466238 & 688267 & 5.6 & 5.0698 & TRN \\
\hline CHEMBL1435983 & 688267 & 6.1 & 5.1162 & TRN \\
\hline CHEMBL1471480 & 688267 & 4.5 & 5.0702 & TRN \\
\hline CHEMBL1544758 & 688267 & 5.65 & 5.0424 & TRN \\
\hline CHEMBL1367166 & 688267 & 4.4 & 5.1456 & TRN \\
\hline CHEMBL1324386 & 688267 & 4.35 & 5.0637 & TST \\
\hline CHEMBL1585850 & 688267 & 4.55 & 5.074 & TST \\
\hline CHEMBL1420629 & 688267 & 3.45 & 5.0501 & TRN \\
\hline CHEMBL1578431 & 688267 & 3.95 & 5.0369 & TST \\
\hline CHEMBL1510333 & 688267 & 5.9 & 5.0258 & TST \\
\hline CHEMBL1388673 & 688267 & 4.05 & 5.0301 & TRN \\
\hline CHEMBL1516371 & 688267 & 6.15 & 5.0313 & TST \\
\hline CHEMBL1415199 & 688267 & 5.4 & 5.0512 & TRN \\
\hline CHEMBL1428378 & 688267 & 4.05 & 5.0361 & TRN \\
\hline CHEMBL1568791 & 688267 & 5.3 & 5.0687 & TRN \\
\hline CHEMBL1402443 & 688267 & 3.95 & 5.0264 & TRN \\
\hline CHEMBL1480227 & 688267 & 6.1 & 5.0727 & TRN \\
\hline CHEMBL1477323 & 688267 & 4.0 & 5.0366 & TST \\
\hline CHEMBL1500884 & 688267 & 4.05 & 5.0023 & TST \\
\hline CHEMBL1607771 & 688267 & 6.0 & 5.0305 & TRN \\
\hline CHEMBL3211716 & 688267 & 5.35 & 5.0105 & TRN \\
\hline CHEMBL1331184 & 688267 & 4.6 & 4.9972 & TST \\
\hline CHEMBL3194167 & 688267 & 4.05 & 5.0191 & TRN \\
\hline CHEMBL1566769 & 688267 & 5.15 & 5.0597 & TRN \\
\hline CHEMBL1591145 & 688267 & 5.3 & 5.0044 & TRN \\
\hline CHEMBL1385802 & 688267 & 5.3 & 5.0596 & TRN \\
\hline CHEMBL1427629 & 688267 & 4.0 & 5.0077 & TRN \\
\hline CHEMBL1571508 & 688267 & 3.7 & 5.0139 & TRN \\
\hline
\end{tabular}




\begin{tabular}{|c|c|c|c|c|c|}
\hline \multicolumn{6}{|c|}{ Supplemental Table S2.txt } \\
\hline CHEMBL1373329 & 688267 & 5.6 & 5.0677 & TST & \\
\hline CHEMBL1328014 & 688267 & 4.2 & 5.1008 & TRN & \\
\hline CHEMBL1573194 & 688267 & 4.35 & 5.0148 & TST & \\
\hline CHEMBL1543514 & 688267 & 5.75 & 5.0998 & TRN & \\
\hline CHEMBL1549642 & 688267 & 6.15 & 5.0519 & TRN & \\
\hline CHEMBL1558271 & 688267 & 4.3 & 5.0377 & TST & \\
\hline CHEMBL1535389 & 688267 & 4.65 & 4.9943 & TRN & \\
\hline CHEMBL3199630 & 688267 & 5.0 & 5.0407 & TRN & \\
\hline CHEMBL1357115 & 688267 & 5.2 & 5.1474 & TRN & \\
\hline CHEMBL1507466 & 688267 & 5.95 & 5.1659 & TRN & \\
\hline CHEMBL1321419 & 688267 & 4.05 & 5.103 & TRN & \\
\hline CHEMBL1438456 & 688267 & 4.1 & 4.9854 & TRN & \\
\hline CHEMBL1577061 & 688267 & 5.4 & 5.058 & TST & \\
\hline CHEMBL1524835 & 688267 & 4.3 & 5.0071 & TRN & \\
\hline CHEMBL1357876 & 688267 & 3.95 & 5.0984 & TRN & \\
\hline CHEMBL1430336 & 688267 & 4.5 & 5.0242 & TRN & \\
\hline CHEMBL1392013 & 688267 & 4.35 & 5.0996 & TRN & \\
\hline CHEMBL1428908 & 688267 & 5.9 & 5.0167 & TRN & \\
\hline CHEMBL1473314 & 688267 & 5.55 & 5.0575 & TRN & \\
\hline CHEMBL1551411 & 688267 & 6.2 & 5.0252 & TRN & \\
\hline CHEMBL1544947 & 688267 & 4.95 & 5.0194 & TRN & \\
\hline CHEMBL1353648 & 688267 & 5.1 & 5.05 & TRN & \\
\hline CHEMBL1475177 & 688267 & 5.2 & 5.0739 & TRN & \\
\hline CHEMBL1560994 & 688267 & 4.0 & 5.1117 & TRN & \\
\hline CHEMBL1301721 & 688267 & 6.2 & 5.0565 & TRN & \\
\hline CHEMBL1513056 & 688267 & 6.25 & 5.0634 & TRN & \\
\hline CHEMBL1552776 & 688267 & 5.85 & 5.1377 & TRN & \\
\hline CHEMBL1580122 & 688267 & 4.65 & 5.0841 & TRN & \\
\hline CHEMBL1600963 & 688267 & 6.15 & 5.0023 & TRN & \\
\hline CHEMBL1495559 & 688267 & 4.25 & 4.9932 & TRN & \\
\hline CHEMBL473326 & 688267 & 6.2 & 5.0476 & TRN & \\
\hline CHEMBL602736 & 688267 & 6.5 & 5.0635 & TRN & \\
\hline CHEMBL1314762 & 688267 & 4.1 & 5.037 & TRN & \\
\hline CHEMBL1400125 & 688267 & 4.05 & 5.0361 & TRN & \\
\hline CHEMBL1584648 & 688267 & 6.45 & 5.1243 & TRN & \\
\hline CHEMBL1336698 & 688267 & 5.45 & 5.0828 & TRN & \\
\hline CHEMBL1344316 & 688267 & 5.45 & 5.0733 & TRN & \\
\hline CHEMBL250916 & 688267 & 4.0 & 5.1 & TRN & \\
\hline CHEMBL1314382 & 688267 & 3.95 & 5.0339 & TRN & \\
\hline CHEMBL1524288 & 688267 & 5.05 & 5.069 & TST & \\
\hline CHEMBL1407099 & 688267 & 4.95 & $5.0760 e$ & 00000000005 & TRN \\
\hline CHEMBL1435776 & 688267 & 3.95 & 5.0203 & TRN & \\
\hline CHEMBL1491082 & 688267 & 4.35 & 5.0623 & TRN & \\
\hline CHEMBL1352370 & 688267 & 4.7 & 5.0318 & TRN & \\
\hline CHEMBL1388600 & 688267 & 5.05 & 5.0299 & TST & \\
\hline CHEMBL1327794 & 688267 & 6.25 & 5.0303 & TST & \\
\hline CHEMBL1305778 & 688267 & 5.3 & 5.0817 & TST & \\
\hline CHEMBL1303362 & 688267 & 5.35 & 5.1014 & TRN & \\
\hline
\end{tabular}




\begin{tabular}{|c|c|c|c|c|}
\hline \multicolumn{5}{|c|}{ Supplemental Table S2.txt } \\
\hline CHEMBL1499389 & 688267 & 5.8 & 5.0997 & TRN \\
\hline CHEMBL1476186 & 688267 & 4.35 & 5.1289 & TRN \\
\hline CHEMBL1324206 & 688267 & 5.35 & 5.0538 & TST \\
\hline CHEMBL1473227 & 688267 & 6.5 & 5.0854 & TRN \\
\hline CHEMBL3211550 & 688267 & 4.95 & 5.1203 & TRN \\
\hline CHEMBL1461100 & 688267 & 4.5 & 5.0636 & TRN \\
\hline CHEMBL1443888 & 688267 & 6.15 & 5.1935 & TST \\
\hline CHEMBL1326393 & 688267 & 4.0 & 5.0408 & TRN \\
\hline CHEMBL1405874 & 688267 & 5.4 & 5.0848 & TST \\
\hline CHEMBL1590369 & 688267 & 6.2 & 5.1116 & TST \\
\hline CHEMBL1564612 & 688267 & 4.4 & 5.0281 & TRN \\
\hline CHEMBL1417382 & 688267 & 6.1 & 5.0085 & TRN \\
\hline CHEMBL1485736 & 688267 & 5.25 & 5.0164 & TRN \\
\hline CHEMBL1528612 & 688267 & 4.9 & 5.1486 & TRN \\
\hline CHEMBL1526912 & 688267 & 4.25 & 5.0105 & TRN \\
\hline CHEMBL1596210 & 688267 & 6.25 & 5.007 & TRN \\
\hline CHEMBL1438090 & 688267 & 4.1 & 5.1125 & TRN \\
\hline CHEMBL1584398 & 688267 & 5.3 & 5.1048 & TST \\
\hline CHEMBL1434126 & 688267 & 4.1 & 5.046 & TRN \\
\hline CHEMBL1347652 & 688267 & 5.0 & 5.0869 & TRN \\
\hline CHEMBL1367590 & 688267 & 6.15 & 5.0868 & TRN \\
\hline CHEMBL1394203 & 688267 & 6.45 & 5.0272 & TRN \\
\hline CHEMBL1354074 & 688267 & 4.0 & 5.0161 & TST \\
\hline CHEMBL1299274 & 688267 & 4.05 & 5.0895 & TRN \\
\hline CHEMBL3213303 & 688267 & 6.15 & 5.0325 & TST \\
\hline CHEMBL1332160 & 688267 & 4.15 & 5.0792 & TRN \\
\hline CHEMBL1542971 & 688267 & 5.35 & 5.0834 & TST \\
\hline CHEMBL1574636 & 688267 & 6.15 & 5.0894 & TRN \\
\hline CHEMBL1364912 & 688267 & 4.35 & 5.109 & TRN \\
\hline CHEMBL1366108 & 688267 & 4.0 & 5.0692 & TRN \\
\hline CHEMBL1415144 & 688267 & 6.2 & 5.0806 & TRN \\
\hline CHEMBL1540447 & 688267 & 4.4 & 5.0564 & TRN \\
\hline CHEMBL1593489 & 688267 & 5.95 & 5.0378 & TRN \\
\hline CHEMBL171620 & 688267 & 4.05 & 5.0432 & TST \\
\hline CHEMBL1427640 & 688267 & 4.95 & 5.0193 & TST \\
\hline CHEMBL1531746 & 688267 & 6.2 & 5.0313 & TRN \\
\hline CHEMBL 1440356 & 688267 & 4.35 & 5.0227 & TST \\
\hline CHEMBL1536864 & 688267 & 4.0 & 5.0434 & TRN \\
\hline CHEMBL1574617 & 688267 & 6.2 & 5.0957 & TRN \\
\hline CHEMBL1441151 & 688267 & 4.35 & 5.0188 & TRN \\
\hline CHEMBL1541021 & 688267 & 3.95 & 5.1046 & TRN \\
\hline CHEMBL1304621 & 688267 & 5.8 & 5.0837 & TST \\
\hline CHEMBL1499087 & 688267 & 4.4 & 5.0093 & TRN \\
\hline CHEMBL1582925 & 688267 & 4.95 & 5.0264 & TST \\
\hline CHEMBL1558951 & 688267 & 6.2 & 5.0372 & TRN \\
\hline CHEMBL1429024 & 688267 & 6.2 & 5.0539 & TST \\
\hline CHEMBL1339178 & 688267 & 6.05 & 5.0504 & TST \\
\hline CHEMBL1591318 & 688267 & 3.95 & 5.0341 & TRN \\
\hline
\end{tabular}




\begin{tabular}{|c|c|c|c|c|}
\hline \multicolumn{5}{|c|}{ Supplemental Table S2.txt } \\
\hline CHEMBL1387406 & 688267 & 5.0 & 5.0567 & TST \\
\hline CHEMBL1504571 & 688267 & 4.0 & 5.0335 & TST \\
\hline CHEMBL1352044 & 688267 & 4.55 & 5.0343 & TST \\
\hline CHEMBL1375264 & 688267 & 6.2 & 5.0194 & TRN \\
\hline CHEMBL1447773 & 688267 & 4.45 & 5.0471 & TRN \\
\hline CHEMBL1338807 & 688267 & 4.2 & 5.0142 & TRN \\
\hline CHEMBL1309257 & 688267 & 5.45 & 5.0596 & TRN \\
\hline CHEMBL1446330 & 688267 & 3.95 & 5.0206 & TRN \\
\hline CHEMBL1595863 & 688267 & 4.3 & 5.0704 & TRN \\
\hline CHEMBL1320113 & 688267 & 6.15 & 5.0373 & TRN \\
\hline CHEMBL1313525 & 688267 & 5.8 & 5.0185 & TRN \\
\hline CHEMBL1409940 & 688267 & 5.4 & 5.0203 & TRN \\
\hline CHEMBL1568958 & 688267 & 6.5501 & 5.0238 & TST \\
\hline CHEMBL1558580 & 688267 & 3.95 & 5.0523 & TRN \\
\hline CHEMBL1324574 & 688267 & 6.25 & 5.0735 & TRN \\
\hline CHEMBL1420548 & 688267 & 4.1 & 5.0266 & TRN \\
\hline CHEMBL1590165 & 688267 & 6.2 & 5.0943 & TST \\
\hline CHEMBL1353091 & 688267 & 5.95 & 5.0107 & TST \\
\hline CHEMBL1436373 & 688267 & 3.95 & 5.0487 & TRN \\
\hline CHEMBL1610561 & 688267 & 3.95 & 5.0211 & TRN \\
\hline CHEMBL1612164 & 688267 & 4.9 & 5.0299 & TRN \\
\hline CHEMBL1327995 & 688267 & 6.25 & 5.0652 & TRN \\
\hline CHEMBL1595946 & 688267 & 5.3 & 5.0608 & TRN \\
\hline CHEMBL1597469 & 688267 & 4.65 & 5.0391 & TRN \\
\hline CHEMBL1481229 & 688267 & 6.25 & 5.0707 & TRN \\
\hline CHEMBL1552137 & 688267 & 6.2 & 5.0561 & TRN \\
\hline CHEMBL1569644 & 688267 & 5.75 & 5.0896 & TRN \\
\hline CHEMBL1330856 & 688267 & 4.6 & 5.02 & TRN \\
\hline CHEMBL1317383 & 688267 & 4.8 & 5.0895 & TST \\
\hline CHEMBL1353150 & 688267 & 4.45 & 5.0031 & TST \\
\hline CHEMBL1583905 & 688267 & 4.0 & 5.0175 & TST \\
\hline CHEMBL1444038 & 688267 & 4.15 & 5.1377 & TRN \\
\hline CHEMBL1312128 & 688267 & 4.0 & 5.0543 & TRN \\
\hline CHEMBL1523631 & 688267 & 4.0 & 5.0797 & TST \\
\hline CHEMBL1503698 & 688267 & 4.25 & 5.0339 & TRN \\
\hline CHEMBL1513055 & 688267 & 4.25 & 5.0157 & TRN \\
\hline CHEMBL1388809 & 688267 & 4.4 & 5.0286 & TRN \\
\hline CHEMBL1556791 & 688267 & 6.15 & 5.0114 & TRN \\
\hline CHEMBL1501381 & 688267 & 5.0 & 5.0439 & TRN \\
\hline CHEMBL1502635 & 688267 & 4.0 & 5.0 & TST \\
\hline CHEMBL1359451 & 688267 & 4.05 & 5.0347 & TRN \\
\hline CHEMBL1449319 & 688267 & 6.0 & 5.107 & TST \\
\hline CHEMBL1355126 & 688267 & 4.15 & 5.0207 & TRN \\
\hline CHEMBL1488006 & 688267 & 4.8 & 5.0515 & TST \\
\hline CHEMBL1395223 & 688267 & 5.0 & 5.0723 & TRN \\
\hline CHEMBL1360845 & 688267 & 5.0 & 5.0606 & TST \\
\hline CHEMBL1450651 & 688267 & 4.45 & 5.1378 & TRN \\
\hline CHEMBL1380011 & 688267 & 4.25 & 5.046 & TST \\
\hline
\end{tabular}




\begin{tabular}{|c|c|c|c|c|c|}
\hline \\
\hline CHEMBL1462512 & 688267 & 4.0 & 5.0337 & TRN & \\
\hline CHEMBL186368 & 688267 & 4.5 & 5.0199 & TRN & \\
\hline CHEMBL1600690 & 688267 & 5.5 & 5.0397 & TRN & \\
\hline CHEMBL1991440 & 688267 & 4.0 & 4.978 & TRN & \\
\hline CHEMBL1602973 & 688267 & 6.15 & 5.0922 & TRN & \\
\hline CHEMBL1304702 & 688267 & 5.05 & 5.06800 & 00000000005 & TRN \\
\hline CHEMBL1588885 & 688267 & 5.0 & 5.0833 & TST & \\
\hline CHEMBL1476515 & 688267 & 4.1 & 5.0283 & TRN & \\
\hline CHEMBL1300913 & 688267 & 5.35 & 5.0521 & TRN & \\
\hline CHEMBL1605004 & 688267 & 4.35 & 5.1577 & TRN & \\
\hline CHEMBL1322807 & 688267 & 5.0 & 4.9839 & TRN & \\
\hline CHEMBL1610815 & 688267 & 6.2 & 5.0511 & TRN & \\
\hline CHEMBL3193745 & 688267 & 5.05 & 5.0122 & TST & \\
\hline CHEMBL1477319 & 688267 & 4.4 & 5.0664 & TRN & \\
\hline CHEMBL1390621 & 688267 & 4.6 & 5.0494 & TST & \\
\hline CHEMBL1575040 & 688267 & 5.5 & 5.0901 & TST & \\
\hline CHEMBL1334639 & 688267 & 5.35 & 5.0581 & TST & \\
\hline CHEMBL1501347 & 688267 & 4.05 & 5.0927 & TST & \\
\hline CHEMBL1413136 & 688267 & 6.25 & 5.1193 & TST & \\
\hline CHEMBL1426824 & 688267 & 4.4 & 5.0479 & TRN & \\
\hline CHEMBL1594872 & 688267 & 4.3 & 5.0953 & TRN & \\
\hline CHEMBL3194621 & 688267 & 4.05 & 5.0127 & TRN & \\
\hline CHEMBL1311620 & 688267 & 4.25 & 5.0911 & TRN & \\
\hline CHEMBL1446176 & 688267 & 4.9 & 5.0266 & TST & \\
\hline CHEMBL1583937 & 688267 & 5.85 & 5.1231 & TRN & \\
\hline CHEMBL1383775 & 688267 & 4.2 & 5.0618 & TRN & \\
\hline CHEMBL1567822 & 688267 & 6.5 & 5.0572 & TST & \\
\hline CHEMBL1519142 & 688267 & 4.65 & 5.0235 & TRN & \\
\hline CHEMBL1599120 & 688267 & 4.0 & 5.067 & TRN & \\
\hline CHEMBL1593716 & 688267 & 4.45 & 5.1033 & TRN & \\
\hline CHEMBL1361563 & 688267 & 4.6 & 5.0872 & TRN & \\
\hline CHEMBL1464276 & 688267 & 5.55 & 4.968 & TRN & \\
\hline CHEMBL1563002 & 688267 & 4.05 & 5.0514 & TST & \\
\hline CHEMBL1989225 & 688267 & 5.3 & 5.01699 & 99999999995 & TST \\
\hline CHEMBL1523327 & 688267 & 4.05 & 5.0314 & TRN & \\
\hline CHEMBL1307269 & 688267 & 6.25 & 5.0593 & TRN & \\
\hline CHEMBL3190396 & 688267 & 5.85 & 4.9665 & TRN & \\
\hline CHEMBL1391676 & 688267 & 4.7 & 5.0627 & TRN & \\
\hline CHEMBL1359518 & 688267 & 6.15 & 5.0386 & TRN & \\
\hline CHEMBL1360850 & 688267 & 6.2 & 5.0082 & TST & \\
\hline CHEMBL1446661 & 688267 & 6.2 & 4.9759 & TRN & \\
\hline CHEMBL1553522 & 688267 & 4.4 & 5.0694 & TRN & \\
\hline CHEMBL1299942 & 688267 & 6.15 & 5.013 & TRN & \\
\hline CHEMBL1407066 & 688267 & 4.0 & 5.0377 & TRN & \\
\hline CHEMBL1544336 & 688267 & 5.9 & 5.0086 & TRN & \\
\hline CHEMBL1400700 & 688267 & 4.25 & 5.0338 & TRN & \\
\hline CHEMBL1455336 & 688267 & 6.2 & 5.0302 & TRN & \\
\hline CHEMBL1414630 & 688267 & 4.3 & 5.0625 & TST & \\
\hline
\end{tabular}




\begin{tabular}{|c|c|c|c|c|c|}
\hline \multicolumn{6}{|c|}{ Supplemental Table S2.txt } \\
\hline CHEMBL1523413 & 688267 & 6.2 & 5.0526 & TRN & \\
\hline CHEMBL1563269 & 688267 & 4.35 & 5.1092 & TRN & \\
\hline CHEMBL1310219 & 688267 & 5.25 & 5.0614 & TRN & \\
\hline CHEMBL1349846 & 688267 & 4.5 & 5.0404 & TRN & \\
\hline CHEMBL1479921 & 688267 & 4.45 & 5.0628 & TRN & \\
\hline CHEMBL 3197847 & 688267 & 5.0 & 4.9745 & TRN & \\
\hline CHEMBL1348700 & 688267 & 6.25 & 5.0577 & TRN & \\
\hline CHEMBL3189575 & 688267 & 5.25 & 5.0837 & TST & \\
\hline CHEMBL1384109 & 688267 & 4.7 & 4.9989 & TRN & \\
\hline CHEMBL1578580 & 688267 & 6.15 & 4.9857 & TRN & \\
\hline CHEMBL1591539 & 688267 & 6.05 & 5.0725 & TRN & \\
\hline CHEMBL1488289 & 688267 & 4.7 & 5.0193 & TRN & \\
\hline CHEMBL1377587 & 688267 & 4.05 & 5.0596 & TRN & \\
\hline CHEMBL1546926 & 688267 & 4.35 & 5.0931 & TRN & \\
\hline CHEMBL1558949 & 688267 & 4.3 & 5.0955 & TRN & \\
\hline CHEMBL1352956 & 688267 & 5.3 & 4.9997 & TST & \\
\hline CHEMBL1570635 & 688267 & 4.4 & 5.0791 & TRN & \\
\hline CHEMBL1460651 & 688267 & 4.35 & 5.1023 & TST & \\
\hline CHEMBL1608467 & 688267 & 6.2 & 4.9845 & TRN & \\
\hline CHEMBL1600384 & 688267 & 6.2 & 5.0249 & TRN & \\
\hline CHEMBL1540692 & 688267 & 5.9 & 5.0199 & TRN & \\
\hline CHEMBL438298 & 688267 & 4.55 & 5.0442 & TRN & \\
\hline CHEMBL1436694 & 688267 & 4.55 & 5.0328 & TST & \\
\hline CHEMBL1394570 & 688267 & 5.8 & 5.0077 & TRN & \\
\hline CHEMBL1451028 & 688267 & 5.5 & 5.0183 & TST & \\
\hline CHEMBL1371340 & 688267 & 5.05 & 5.0821 & TRN & \\
\hline CHEMBL1453362 & 688267 & 4.45 & 5.0933 & TRN & \\
\hline CHEMBL1415375 & 688267 & 4.4 & 5.08899 & & TRN \\
\hline CHEMBL1559352 & 688267 & 5.55 & 5.0496 & TRN & \\
\hline CHEMBL1362989 & 688267 & 5.6 & 5.1005 & TST & \\
\hline CHEMBL1341435 & 688267 & 6.15 & 5.0948 & TRN & \\
\hline CHEMBL1478052 & 688267 & 4.4 & 5.0533 & TRN & \\
\hline CHEMBL1368537 & 688267 & 5.75 & 5.0989 & TRN & \\
\hline CHEMBL1351182 & 688267 & 6.15 & 5.0939 & TRN & \\
\hline CHEMBL1488580 & 688267 & 5.6 & 5.0599 & TRN & \\
\hline CHEMBL1360974 & 688267 & 5.65 & 5.0239 & TST & \\
\hline CHEMBL1565655 & 688267 & 4.0 & 5.1115 & TRN & \\
\hline CHEMBL1483025 & 688267 & 4.55 & 5.0302 & TRN & \\
\hline CHEMBL1303254 & 688267 & 5.2 & 5.0427 & TRN & \\
\hline CHEMBL1607589 & 688267 & 4.1 & 5.059 & TST & \\
\hline CHEMBL1487286 & 688267 & 6.15 & 5.0594 & TRN & \\
\hline CHEMBL1494454 & 688267 & 4.2 & 5.0841 & TRN & \\
\hline CHEMBL1317420 & 688267 & 6.15 & 5.0939 & TRN & \\
\hline CHEMBL1354804 & 688267 & 5.35 & 5.0967 & TRN & \\
\hline CHEMBL1560075 & 688267 & 5.85 & 5.0842 & TRN & \\
\hline CHEMBL1363743 & 688267 & 4.65 & 5.0643 & TST & \\
\hline CHEMBL1475671 & 688267 & 3.95 & 5.0712 & TRN & \\
\hline CHEMBL1312381 & 688267 & 4.95 & 5.145 & TRN & \\
\hline
\end{tabular}




\begin{tabular}{|c|c|c|c|c|}
\hline \multicolumn{5}{|c|}{ Supplemental Table S2.txt } \\
\hline CHEMBL1490318 & 688267 & 5.85 & 5.0192 & TRN \\
\hline CHEMBL1396534 & 688267 & 4.3 & 5.0505 & TRN \\
\hline CHEMBL1554279 & 688267 & 5.85 & 5.0707 & TST \\
\hline CHEMBL1316448 & 688267 & 5.2 & 5.0672 & TRN \\
\hline CHEMBL1409069 & 688267 & 4.0 & 5.1471 & TRN \\
\hline CHEMBL1372090 & 688267 & 5.25 & 5.1189 & TRN \\
\hline CHEMBL1468993 & 688267 & 4.3 & 5.0178 & TST \\
\hline CHEMBL95703 & 688267 & 5.15 & 4.974 & TST \\
\hline CHEMBL1319129 & 688267 & 5.25 & 5.0668 & TRN \\
\hline CHEMBL1470050 & 688267 & 6.15 & 5.1262 & TRN \\
\hline CHEMBL1389170 & 688267 & 5.15 & 5.0944 & TRN \\
\hline CHEMBL1560587 & 688267 & 6.2 & 5.0586 & TRN \\
\hline CHEMBL1608914 & 688267 & 4.0 & 5.044 & TRN \\
\hline CHEMBL1376404 & 688267 & 5.4 & 5.1926 & TRN \\
\hline CHEMBL3198094 & 688267 & 5.2 & 5.0371 & TRN \\
\hline CHEMBL1599695 & 688267 & 5.5 & 5.0387 & TRN \\
\hline CHEMBL1423175 & 688267 & 4.7 & 5.056 & TST \\
\hline CHEMBL1581022 & 688267 & 3.95 & 4.9838 & TRN \\
\hline CHEMBL1558887 & 688267 & 4.0 & 5.0299 & TRN \\
\hline CHEMBL1506923 & 688267 & 6.2 & 5.0214 & TRN \\
\hline CHEMBL1531707 & 688267 & 5.15 & 5.0758 & TRN \\
\hline CHEMBL1340042 & 688267 & 4.1 & 5.0355 & TRN \\
\hline CHEMBL3213373 & 688267 & 4.0 & 5.048 & TST \\
\hline CHEMBL1467860 & 688267 & 5.45 & 5.0532 & TRN \\
\hline CHEMBL1438277 & 688267 & 4.0 & 5.0409 & TRN \\
\hline CHEMBL1304665 & 688267 & 6.2 & 5.1354 & TRN \\
\hline CHEMBL1319832 & 688267 & 5.4 & 5.02 & TRN \\
\hline CHEMBL1489489 & 688267 & 6.2 & 5.0236 & TRN \\
\hline CHEMBL1347722 & 688267 & 5.5 & 5.0375 & TRN \\
\hline CHEMBL1303030 & 688267 & 5.45 & 4.9667 & TRN \\
\hline CHEMBL1317265 & 688267 & 4.2 & 5.112 & TRN \\
\hline CHEMBL1367457 & 688267 & 4.3 & 5.0602 & TST \\
\hline CHEMBL1407982 & 688267 & 4.05 & 4.9962 & TRN \\
\hline CHEMBL1340702 & 688267 & 4.0 & 5.1636 & TST \\
\hline CHEMBL1330704 & 688267 & 4.0 & 5.0011 & TST \\
\hline CHEMBL1438940 & 688267 & 4.3 & 5.0023 & TRN \\
\hline CHEMBL1558525 & 688267 & 4.05 & 5.0085 & TRN \\
\hline CHEMBL1331804 & 688267 & 4.0 & 5.0498 & TRN \\
\hline CHEMBL1430248 & 688267 & 4.0 & 5.0912 & TST \\
\hline CHEMBL1330235 & 688267 & 4.4 & 5.0369 & TRN \\
\hline CHEMBL1461950 & 688267 & 6.2 & 5.1233 & TRN \\
\hline CHEMBL1418409 & 688267 & 3.95 & 5.0338 & TST \\
\hline CHEMBL1450826 & 688267 & 4.05 & 5.0572 & TST \\
\hline CHEMBL1452738 & 688267 & 4.5 & 4.9923 & TRN \\
\hline CHEMBL1340641 & 688267 & 4.0 & 5.0402 & TST \\
\hline CHEMBL1436487 & 688267 & 4.0 & 5.0221 & TRN \\
\hline CHEMBL 1356750 & 688267 & 6.2 & 5.0112 & TST \\
\hline CHEMBL 3214207 & 688267 & 6.2 & 5.0567 & TST \\
\hline
\end{tabular}




\begin{tabular}{|c|c|c|c|c|}
\hline & & & upplement & al $\mathrm{T}$ \\
\hline CHEMBL 3214083 & 688267 & 4.0 & 5.0443 & TST \\
\hline CHEMBL1582681 & 688267 & 5.25 & 5.0927 & TST \\
\hline CHEMBL1425563 & 688267 & 4.05 & 5.0507 & TRN \\
\hline CHEMBL1318891 & 688267 & 5.5 & 5.075 & TRN \\
\hline CHEMBL1477128 & 688267 & 5.55 & 5.0829 & TST \\
\hline CHEMBL1552220 & 688267 & 4.1 & 5.0784 & TRN \\
\hline CHEMBL1594043 & 688267 & 4.25 & 5.0289 & TRN \\
\hline CHEMBL1468621 & 688267 & 5.7 & 5.0181 & TRN \\
\hline CHEMBL1570729 & 688267 & 4.35 & 5.0919 & TST \\
\hline CHEMBL1482955 & 688267 & 5.4 & 5.0014 & TRN \\
\hline CHEMBL1328771 & 688267 & 6.25 & 5.0896 & TRN \\
\hline CHEMBL1421647 & 688267 & 4.0 & 5.078 & TRN \\
\hline CHEMBL1475612 & 688267 & 6.2 & 4.9912 & TRN \\
\hline CHEMBL1473389 & 688267 & 4.05 & 5.0519 & TST \\
\hline CHEMBL1494536 & 688267 & 6.2 & 5.0194 & TRN \\
\hline CHEMBL1460504 & 688267 & 4.55 & 5.1131 & TRN \\
\hline CHEMBL1574054 & 688267 & 6.15 & 5.0754 & TST \\
\hline CHEMBL1532351 & 688267 & 4.4 & 4.9951 & TRN \\
\hline CHEMBL1517467 & 688267 & 6.5 & 5.1119 & TRN \\
\hline CHEMBL3190018 & 688267 & 5.15 & 4.9997 & TST \\
\hline CHEMBL1577790 & 688267 & 6.25 & 5.0877 & TRN \\
\hline CHEMBL1567704 & 688267 & 5.0 & 5.0567 & TRN \\
\hline CHEMBL1299201 & 688267 & 4.65 & 5.1063 & TRN \\
\hline CHEMBL1514602 & 688267 & 6.25 & 5.0161 & TRN \\
\hline CHEMBL1355239 & 688267 & 6.0 & 5.0554 & TST \\
\hline CHEMBL1308666 & 688267 & 5.05 & 5.1133 & TRN \\
\hline CHEMBL1452077 & 688267 & 5.45 & 5.0763 & TST \\
\hline CHEMBL1589133 & 688267 & 6.2 & 5.0187 & TST \\
\hline CHEMBL547313 & 688267 & 6.2 & 5.0875 & TRN \\
\hline CHEMBL1464358 & 688267 & 5.8 & 5.032 & TRN \\
\hline CHEMBL1495852 & 688267 & 4.05 & 5.0348 & TRN \\
\hline CHEMBL1453472 & 688267 & 6.25 & 5.0612 & TRN \\
\hline CHEMBL1424294 & 688267 & 5.5 & 5.088 & TRN \\
\hline CHEMBL1419396 & 688267 & 6.2 & 5.1177 & TRN \\
\hline CHEMBL1321233 & 688267 & 6.1 & 5.0942 & TRN \\
\hline CHEMBL 2016647 & 688267 & 6.15 & 4.9627 & TRN \\
\hline CHEMBL1481840 & 688267 & 6.25 & 5.0774 & TRN \\
\hline CHEMBL1547307 & 688267 & 4.65 & 5.0704 & TRN \\
\hline CHEMBL1988314 & 688267 & 4.9 & 5.0223 & TRN \\
\hline CHEMBL1464667 & 688267 & 5.15 & 4.9906 & TRN \\
\hline CHEMBL1552622 & 688267 & 4.45 & 5.0355 & TRN \\
\hline CHEMBL1320727 & 688267 & 5.55 & 5.0371 & TST \\
\hline CHEMBL1331278 & 688267 & 3.95 & 5.0465 & TRN \\
\hline CHEMBL1514434 & 688267 & 6.5 & 5.0229 & TRN \\
\hline CHEMBL1416434 & 688267 & 3.95 & 5.1016 & TRN \\
\hline CHEMBL1552441 & 688267 & 5.35 & 5.0338 & TRN \\
\hline CHEMBL1594783 & 688267 & 6.25 & 5.0221 & TRN \\
\hline CHEMBL1457537 & 688267 & 4.0 & 5.0561 & TST \\
\hline
\end{tabular}




\begin{tabular}{|c|c|c|c|c|c|}
\hline \multicolumn{6}{|c|}{ Supplemental Table S2.txt } \\
\hline CHEMBL1390426 & 688267 & 7.0 & 5.0986 & TRN & \\
\hline CHEMBL1965472 & 688267 & 4.45 & 5.0136 & TST & \\
\hline CHEMBL1426415 & 688267 & 5.35 & 5.0463 & TRN & \\
\hline CHEMBL1543564 & 688267 & 4.05 & 5.0372 & TRN & \\
\hline CHEMBL1552206 & 688267 & 4.55 & 5.0452 & TRN & \\
\hline CHEMBL1554797 & 688267 & 6.2 & 5.0333 & TRN & \\
\hline CHEMBL1568826 & 688267 & 3.95 & 5.0182 & TRN & \\
\hline CHEMBL590911 & 688267 & 6.2 & 5.0029 & TRN & \\
\hline CHEMBL 3194566 & 688267 & 4.25 & 5.0482 & TST & \\
\hline CHEMBL1515656 & 688267 & 4.15 & 5.066 & TST & \\
\hline CHEMBL1390810 & 688267 & 4.6 & 5.0101 & TRN & \\
\hline CHEMBL1591756 & 688267 & 5.6 & 5.037 & TRN & \\
\hline CHEMBL1346968 & 688267 & 5.9 & 5.0412 & TRN & \\
\hline CHEMBL1494789 & 688267 & 4.0 & 5.029 & TST & \\
\hline CHEMBL1384437 & 688267 & 6.2 & 5.0702 & TRN & \\
\hline CHEMBL1481041 & 688267 & 5.15 & 5.1089 & TRN & \\
\hline CHEMBL1387999 & 688267 & 5.7 & 5.1027 & TST & \\
\hline CHEMBL3209937 & 688267 & 6.2 & 5.1111 & TRN & \\
\hline CHEMBL1451213 & 688267 & 4.05 & 5.1146 & TRN & \\
\hline CHEMBL1561760 & 688267 & 4.55 & 5.1023 & TRN & \\
\hline CHEMBL1470049 & 688267 & 4.15 & 5.1345 & TRN & \\
\hline CHEMBL1430835 & 688267 & 5.5 & 5.0164 & TRN & \\
\hline CHEMBL1319293 & 688267 & 4.4 & 5.1101 & TRN & \\
\hline CHEMBL1500541 & 688267 & 4.6 & 5.065 & TRN & \\
\hline CHEMBL1552160 & 688267 & 5.4 & 5.0237 & TRN & \\
\hline CHEMBL164271 & 688267 & 4.05 & 5.0647 & TST & \\
\hline CHEMBL1302870 & 688267 & 5.8 & 5.0028 & TRN & \\
\hline CHEMBL1406469 & 688267 & 3.95 & 5.1043 & TST & \\
\hline CHEMBL3191247 & 688267 & 4.95 & 5.0464 & TRN & \\
\hline CHEMBL1340636 & 688267 & 5.6 & 5.0818 & TRN & \\
\hline CHEMBL1419852 & 688267 & 4.15 & 5.1027 & TRN & \\
\hline CHEMBL1403782 & 688267 & 5.95 & 5.1114 & TRN & \\
\hline CHEMBL1418984 & 688267 & 6.8499 & 5.0838 & TRN & \\
\hline CHEMBL1343301 & 688267 & 5.2 & 5.098 & TRN & \\
\hline CHEMBL1541389 & 688267 & 4.95 & 5.0721 & TRN & \\
\hline CHEMBL1300935 & 688267 & 4.9 & 5.1320 & 0000000001 & TRN \\
\hline CHEMBL1409062 & 688267 & 4.1 & 5.1266 & TRN & \\
\hline CHEMBL1470913 & 688267 & 5.8 & 5.1365 & TRN & \\
\hline CHEMBL1579845 & 688267 & 5.55 & 5.077 & TST & \\
\hline CHEMBL1532462 & 688267 & 5.95 & 5.0711 & TRN & \\
\hline CHEMBL1379204 & 688267 & 3.95 & 5.0431 & TRN & \\
\hline CHEMBL1351648 & 688267 & 5.4 & 5.082 & TRN & \\
\hline CHEMBL1396082 & 688267 & 5.65 & 5.0953 & TRN & \\
\hline CHEMBL3195048 & 688267 & 4.4 & 5.0347 & TRN & \\
\hline CHEMBL1513539 & 688267 & 4.0 & 5.0072 & TST & \\
\hline CHEMBL1436305 & 688267 & 5.35 & 5.0315 & TRN & \\
\hline CHEMBL1545667 & 688267 & 4.0 & 5.0495 & TRN & \\
\hline CHEMBL3195220 & 688267 & 4.25 & 5.0 & TRN & \\
\hline
\end{tabular}




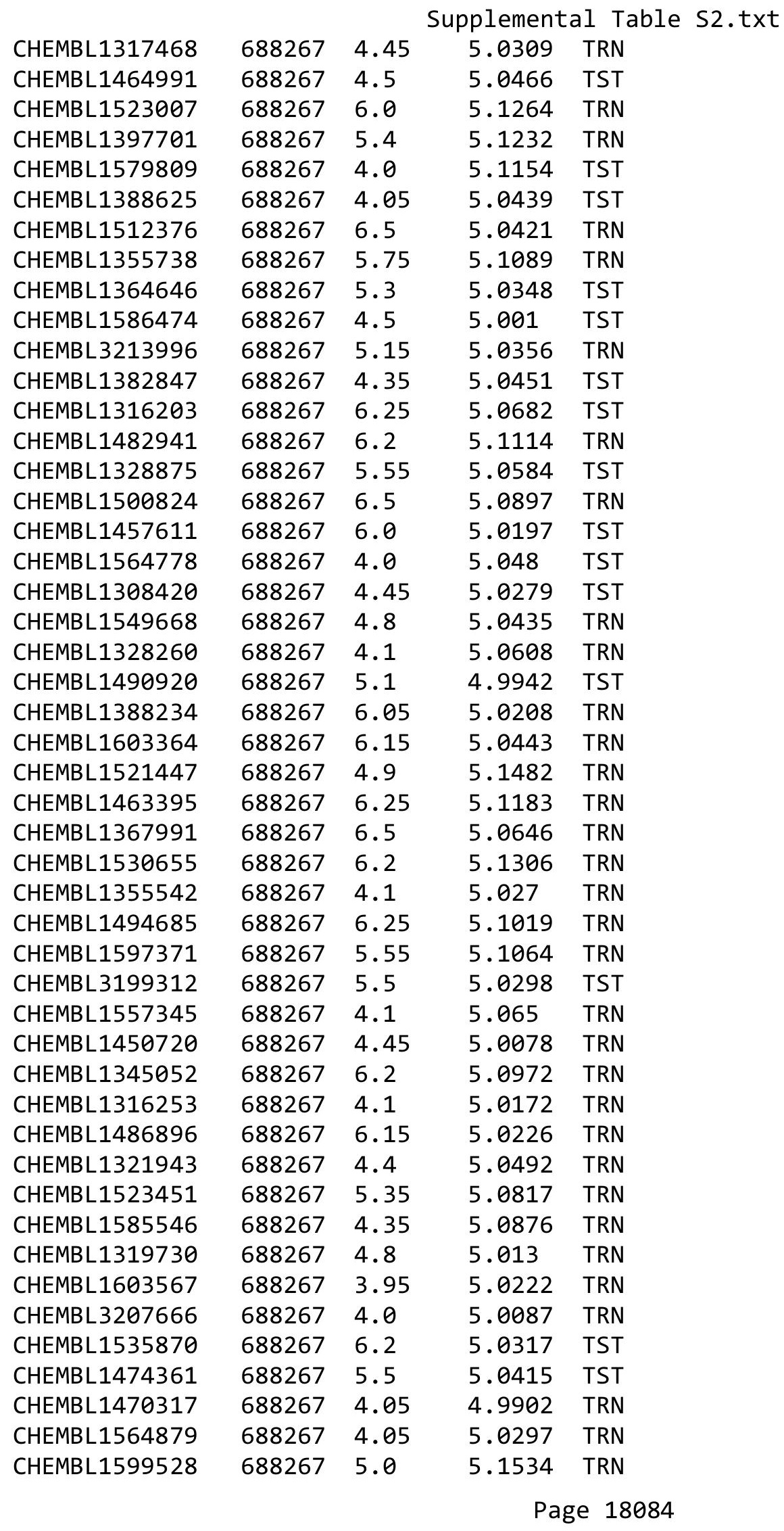




\begin{tabular}{|c|c|c|c|c|c|}
\hline & & & & & \\
\hline CHEMBL1398401 & 688267 & 5.1 & 5.0906 & TRN & \\
\hline CHEMBL1357637 & 688267 & 4.35 & 5.04 & TST & \\
\hline CHEMBL3212438 & 688267 & 4.7 & 5.0524 & TRN & \\
\hline CHEMBL1375794 & 688267 & 3.95 & 5.0719 & TRN & \\
\hline CHEMBL1592931 & 688267 & 5.75 & 5.0991 & TRN & \\
\hline CHEMBL1393396 & 688267 & 4.05 & 4.9994 & TRN & \\
\hline CHEMBL1448495 & 688267 & 6.05 & 5.0648 & TST & \\
\hline CHEMBL1606986 & 688267 & 3.95 & 5.0676 & TRN & \\
\hline CHEMBL1342033 & 688267 & 5.3 & 5.05699 & 99999999995 & TRN \\
\hline CHEMBL1594649 & 688267 & 4.6 & 4.9995 & TRN & \\
\hline CHEMBL1525409 & 688267 & 4.0 & 5.0501 & TST & \\
\hline CHEMBL1606317 & 688267 & 5.55 & 4.9853 & TRN & \\
\hline CHEMBL1304940 & 688267 & 5.25 & 5.0243 & TST & \\
\hline CHEMBL1417721 & 688267 & 5.45 & 5.0853 & TRN & \\
\hline CHEMBL600008 & 688267 & 4.5 & 5.0336 & TST & \\
\hline CHEMBL1362997 & 688267 & 4.45 & 5.0292 & TST & \\
\hline CHEMBL1336881 & 688267 & 4.4 & 5.0358 & TST & \\
\hline CHEMBL1605429 & 688267 & 5.95 & 5.1023 & TRN & \\
\hline CHEMBL1473948 & 688267 & 5.0 & 5.1516 & TRN & \\
\hline CHEMBL1577923 & 688267 & 6.2 & 5.0993 & TRN & \\
\hline CHEMBL1373963 & 688267 & 4.05 & 5.107 & TRN & \\
\hline CHEMBL1411569 & 688267 & 3.95 & 5.105 & TRN & \\
\hline CHEMBL1588213 & 688267 & 4.0 & 5.0286 & TRN & \\
\hline CHEMBL1450458 & 688267 & 5.4 & 5.023 & TST & \\
\hline CHEMBL1350331 & 688267 & 5.3 & 5.0796 & TRN & \\
\hline CHEMBL1366897 & 688267 & 5.45 & 5.074 & TRN & \\
\hline CHEMBL1458314 & 688267 & 4.05 & 5.0394 & TRN & \\
\hline CHEMBL1330262 & 688267 & 5.95 & 5.0397 & TRN & \\
\hline CHEMBL1305281 & 688267 & 5.1 & 5.0542 & TRN & \\
\hline CHEMBL1438336 & 688267 & 4.0 & 5.0346 & TRN & \\
\hline CHEMBL1420672 & 688267 & 5.65 & 5.0434 & TRN & \\
\hline CHEMBL1593146 & 688267 & 6.25 & 5.0009 & TRN & \\
\hline CHEMBL1515751 & 688267 & 4.5 & 5.0141 & TRN & \\
\hline CHEMBL1361091 & 688267 & 4.95 & 5.067 & TRN & \\
\hline CHEMBL1462476 & 688267 & 5.35 & 5.0202 & TRN & \\
\hline CHEMBL1388884 & 688267 & 5.85 & 5.0414 & TRN & \\
\hline CHEMBL1578832 & 688267 & 5.05 & 5.0767 & TRN & \\
\hline CHEMBL1372621 & 688267 & 5.4 & 5.0044 & TST & \\
\hline CHEMBL1323953 & 688267 & 6.2 & 5.13 & TRN & \\
\hline CHEMBL1606961 & 688267 & 6.15 & 5.1388 & TRN & \\
\hline CHEMBL1323117 & 688267 & 3.9 & 5.0864 & TRN & \\
\hline CHEMBL1593366 & 688267 & 5.1 & 4.9764 & TRN & \\
\hline CHEMBL1484171 & 688267 & 6.15 & 5.042 & TST & \\
\hline CHEMBL1611250 & 688267 & 6.5 & 5.0115 & TST & \\
\hline CHEMBL1470140 & 688267 & 4.65 & 5.0128 & TRN & \\
\hline CHEMBL1354023 & 688267 & 4.05 & 5.0218 & TRN & \\
\hline CHEMBL1493532 & 688267 & 4.0 & 4.9874 & TRN & \\
\hline CHEMBL1581940 & 688267 & 4.4 & $5.0760 e$ & 00000000005 & TRN \\
\hline & & & & 18085 & \\
\hline
\end{tabular}




\begin{tabular}{|c|c|c|c|c|}
\hline \multicolumn{5}{|c|}{ Supplemental Table S2.txt } \\
\hline CHEMBL1336590 & 688267 & 4.15 & 5.0627 & TRN \\
\hline CHEMBL1449765 & 688267 & 5.15 & 5.1047 & TRN \\
\hline CHEMBL1578210 & 688267 & 6.5 & 4.9973 & TRN \\
\hline CHEMBL1540917 & 688267 & 6.2 & 5.046 & TST \\
\hline CHEMBL1365098 & 688267 & 6.2 & 5.0251 & TRN \\
\hline CHEMBL3190585 & 688267 & 4.15 & 4.9854 & TRN \\
\hline CHEMBL1507170 & 688267 & 4.05 & 5.0525 & TRN \\
\hline CHEMBL1453890 & 688267 & 4.4 & 5.0348 & TRN \\
\hline CHEMBL1552800 & 688267 & 5.55 & 5.0815 & TRN \\
\hline CHEMBL1356116 & 688267 & 4.75 & 5.0376 & TRN \\
\hline CHEMBL1491383 & 688267 & 5.45 & 5.0813 & TRN \\
\hline CHEMBL1467128 & 688267 & 4.0 & 5.1066 & TST \\
\hline CHEMBL1456342 & 688267 & 6.25 & 5.0961 & TRN \\
\hline CHEMBL1454361 & 688267 & 4.0 & 5.0693 & TST \\
\hline CHEMBL1521482 & 688267 & 5.45 & 4.9857 & TRN \\
\hline CHEMBL1350987 & 688267 & 4.3 & 5.0662 & TRN \\
\hline CHEMBL1304144 & 688267 & 4.4 & 5.0642 & TST \\
\hline CHEMBL1315284 & 688267 & 6.2 & 5.0862 & TRN \\
\hline CHEMBL1537073 & 688267 & 5.55 & 5.0414 & TRN \\
\hline CHEMBL1606243 & 688267 & 6.25 & 4.9716 & TRN \\
\hline CHEMBL1379130 & 688267 & 4.55 & 5.0962 & TST \\
\hline CHEMBL1303085 & 688267 & 4.4 & 5.0579 & TRN \\
\hline CHEMBL1386102 & 688267 & 6.2 & 5.0271 & TRN \\
\hline CHEMBL1303812 & 688267 & 4.05 & 5.0814 & TRN \\
\hline CHEMBL1527890 & 688267 & 6.0 & 5.0378 & TRN \\
\hline CHEMBL1494721 & 688267 & 4.5 & 5.1467 & TRN \\
\hline CHEMBL1360092 & 688267 & 4.0 & 5.0995 & TRN \\
\hline CHEMBL1574310 & 688267 & 4.0 & 5.0377 & TRN \\
\hline CHEMBL1466063 & 688267 & 4.1 & 5.0567 & TRN \\
\hline CHEMBL1609149 & 688267 & 4.0 & 5.0068 & TRN \\
\hline CHEMBL3197349 & 688267 & 5.45 & 5.0341 & TST \\
\hline CHEMBL1426192 & 688267 & 4.45 & 5.0938 & TRN \\
\hline CHEMBL1456301 & 688267 & 4.35 & 5.0071 & TRN \\
\hline CHEMBL1372265 & 688267 & 4.05 & 5.0695 & TST \\
\hline CHEMBL1366801 & 688267 & 5.25 & 5.1157 & TST \\
\hline CHEMBL1456069 & 688267 & 4.0 & 5.0048 & TST \\
\hline CHEMBL 1457417 & 688267 & 6.15 & 5.1454 & TRN \\
\hline CHEMBL1335815 & 688267 & 4.0 & 5.0437 & TST \\
\hline CHEMBL1364916 & 688267 & 5.45 & 5.0852 & TRN \\
\hline CHEMBL1326862 & 688267 & 4.6 & 5.0258 & TRN \\
\hline CHEMBL1513714 & 688267 & 6.2 & 5.0396 & TRN \\
\hline CHEMBL1469896 & 688267 & 5.4 & 5.0187 & TRN \\
\hline CHEMBL1553666 & 688267 & 4.35 & 5.0386 & TRN \\
\hline CHEMBL1441970 & 688267 & 4.05 & 5.0934 & TST \\
\hline CHEMBL1519934 & 688267 & 4.4 & 5.0674 & TRN \\
\hline CHEMBL1385099 & 688267 & 4.1 & 5.0244 & TST \\
\hline CHEMBL1427561 & 688267 & 4.1 & 5.0564 & TRN \\
\hline CHEMBL1395812 & 688267 & 6.15 & 5.0435 & TST \\
\hline
\end{tabular}




\begin{tabular}{|c|c|c|c|c|c|}
\hline \\
\hline CHEMBL1461347 & 688267 & 6.3 & 5.1074 & TST & \\
\hline CHEMBL1554950 & 688267 & 6.15 & 5.1305 & TRN & \\
\hline CHEMBL1544842 & 688267 & 4.45 & 5.0506 & TRN & \\
\hline CHEMBL1501436 & 688267 & 6.0 & 5.0612 & TRN & \\
\hline CHEMBL1477540 & 688267 & 6.0 & 5.0696 & TRN & \\
\hline CHEMBL1529542 & 688267 & 6.15 & 5.0925 & TRN & \\
\hline CHEMBL1416419 & 688267 & 5.7 & 5.0525 & TRN & \\
\hline CHEMBL1374219 & 688267 & 4.4 & 5.0296 & TRN & \\
\hline CHEMBL1344783 & 688267 & 6.05 & 5.0235 & TRN & \\
\hline CHEMBL1474200 & 688267 & 3.95 & 5.0706 & TRN & \\
\hline CHEMBL1577402 & 688267 & 4.55 & 5.0731 & TST & \\
\hline CHEMBL1373265 & 688267 & 4.0 & 5.0442 & TRN & \\
\hline CHEMBL1409403 & 688267 & 4.35 & 5.1014 & TRN & \\
\hline CHEMBL1410545 & 688267 & 4.2 & 5.1474 & TRN & \\
\hline CHEMBL3194267 & 688267 & 4.05 & 5.0119 & TST & \\
\hline CHEMBL1333138 & 688267 & 4.0 & 5.0397 & TST & \\
\hline CHEMBL1395537 & 688267 & 6.2 & 5.0345 & TRN & \\
\hline CHEMBL1323104 & 688267 & 4.1 & 5.1385 & TRN & \\
\hline CHEMBL1395440 & 688267 & 6.2 & 5.0656 & TRN & \\
\hline CHEMBL1589127 & 688267 & 4.15 & 5.0291 & TRN & \\
\hline CHEMBL1419223 & 688267 & 4.55 & 4.955 & TRN & \\
\hline CHEMBL1430400 & 688267 & 4.0 & 5.1037 & TRN & \\
\hline CHEMBL1457934 & 688267 & 4.05 & 5.0737 & TRN & \\
\hline CHEMBL3212827 & 688267 & 4.0 & 5.0418 & TRN & \\
\hline CHEMBL1476780 & 688267 & 3.95 & 5.0985 & TRN & \\
\hline CHEMBL1342528 & 688267 & 4.0 & 5.1348 & TRN & \\
\hline CHEMBL3192446 & 688267 & 4.9 & 5.0758 & TRN & \\
\hline CHEMBL1316070 & 688267 & 6.5 & 5.0762 & TRN & \\
\hline CHEMBL1605365 & 688267 & 5.15 & 5.04899 & 99999999995 & TRN \\
\hline CHEMBL1427448 & 688267 & 4.05 & 5.0422 & TST & \\
\hline CHEMBL1438663 & 688267 & 5.95 & 5.0687 & TRN & \\
\hline CHEMBL1446084 & 688267 & 6.2 & 5.0109 & TRN & \\
\hline CHEMBL1421381 & 688267 & 4.05 & 4.98600 & 0000000001 & TRN \\
\hline CHEMBL1520906 & 688267 & 5.25 & 5.0739 & TRN & \\
\hline CHEMBL1344837 & 688267 & 4.05 & 5.0076 & TST & \\
\hline CHEMBL1472335 & 688267 & 4.05 & 4.9857 & TRN & \\
\hline CHEMBL1466442 & 688267 & 5.45 & 4.9733 & TRN & \\
\hline CHEMBL1394058 & 688267 & 5.6 & 5.0616 & TST & \\
\hline CHEMBL1325599 & 688267 & 6.2 & 5.0237 & TST & \\
\hline CHEMBL1557921 & 688267 & 6.2 & 5.0825 & TRN & \\
\hline CHEMBL1437426 & 688267 & 4.25 & 5.0437 & TRN & \\
\hline CHEMBL1593729 & 688267 & 5.85 & 5.0916 & TRN & \\
\hline CHEMBL1549849 & 688267 & 5.35 & 5.0438 & TRN & \\
\hline CHEMBL1432357 & 688267 & 4.35 & 5.0032 & TST & \\
\hline CHEMBL1596716 & 688267 & 4.35 & 5.0529 & TRN & \\
\hline CHEMBL1403924 & 688267 & 5.75 & 5.0778 & TST & \\
\hline CHEMBL1555020 & 688267 & 6.15 & 5.1021 & TRN & \\
\hline CHEMBL1334554 & 688267 & 5.25 & 5.1234 & TRN & \\
\hline
\end{tabular}




\begin{tabular}{|c|c|c|c|c|}
\hline \multicolumn{5}{|c|}{ Supplemental Table S2.txt } \\
\hline CHEMBL1359723 & 688267 & 4.35 & 5.0685 & TST \\
\hline CHEMBL1515678 & 688267 & 5.3 & 5.0282 & TRN \\
\hline CHEMBL1390958 & 688267 & 3.9 & 5.0114 & TRN \\
\hline CHEMBL1578772 & 688267 & 4.0 & 5.0492 & TRN \\
\hline CHEMBL1609879 & 688267 & 3.95 & 5.0291 & TRN \\
\hline CHEMBL1346854 & 688267 & 4.05 & 5.0362 & TRN \\
\hline CHEMBL1325424 & 688267 & 6.25 & 5.0637 & TRN \\
\hline CHEMBL1442326 & 688267 & 4.3 & 5.0279 & TST \\
\hline CHEMBL1364519 & 688267 & 4.15 & 5.0587 & TRN \\
\hline CHEMBL1495256 & 688267 & 6.1 & 5.0878 & TRN \\
\hline CHEMBL1442572 & 688267 & 4.0 & 5.0428 & TRN \\
\hline CHEMBL1357594 & 688267 & 5.8 & 5.0539 & TRN \\
\hline CHEMBL1601444 & 688267 & 4.8 & 5.0555 & TRN \\
\hline CHEMBL1586783 & 688267 & 4.35 & 5.0543 & TRN \\
\hline CHEMBL1536265 & 688267 & 5.5 & 5.0703 & TST \\
\hline CHEMBL1394709 & 688267 & 6.45 & 5.0982 & TRN \\
\hline CHEMBL1546756 & 688267 & 3.95 & 5.0477 & TST \\
\hline CHEMBL1504846 & 688267 & 4.0 & 5.0753 & TRN \\
\hline CHEMBL1325622 & 688267 & 4.1 & 5.0623 & TRN \\
\hline CHEMBL1606907 & 688267 & 4.3 & 4.9993 & TRN \\
\hline CHEMBL1474112 & 688267 & 4.05 & 5.0895 & TRN \\
\hline CHEMBL1307638 & 688267 & 4.0 & 5.1236 & TST \\
\hline CHEMBL1592156 & 688267 & 6.2 & 5.0949 & TRN \\
\hline CHEMBL3197076 & 688267 & 4.0 & 5.1052 & TST \\
\hline CHEMBL1601370 & 688267 & 6.2 & 5.0931 & TRN \\
\hline CHEMBL3190020 & 688267 & 6.15 & 4.9926 & TRN \\
\hline CHEMBL1359589 & 688267 & 4.4 & 4.9874 & TRN \\
\hline CHEMBL1491189 & 688267 & 5.8 & 5.0377 & TRN \\
\hline CHEMBL1591914 & 688267 & 5.1 & 5.1165 & TRN \\
\hline CHEMBL1352823 & 688267 & 4.15 & 5.1416 & TRN \\
\hline CHEMBL1588727 & 688267 & 6.5 & 5.0793 & TST \\
\hline CHEMBL1436545 & 688267 & 4.05 & 5.0657 & TRN \\
\hline CHEMBL1397366 & 688267 & 4.35 & 5.1033 & TRN \\
\hline CHEMBL1576656 & 688267 & 5.0 & 5.063 & TST \\
\hline CHEMBL1307107 & 688267 & 5.9 & 5.0717 & TST \\
\hline CHEMBL1600214 & 688267 & 6.15 & 5.0728 & TRN \\
\hline CHEMBL1554517 & 688267 & 4.05 & 5.0627 & TRN \\
\hline CHEMBL1366719 & 688267 & 4.05 & 5.0082 & TRN \\
\hline CHEMBL1481285 & 688267 & 6.25 & 5.1126 & TRN \\
\hline CHEMBL1541191 & 688267 & 6.45 & 5.0919 & TST \\
\hline CHEMBL1437600 & 688267 & 4.0 & 5.0175 & TRN \\
\hline CHEMBL1392428 & 688267 & 5.35 & 5.0501 & TRN \\
\hline CHEMBL1523705 & 688267 & 4.5 & 5.0905 & TRN \\
\hline CHEMBL1497769 & 688267 & 4.0 & 4.9779 & TRN \\
\hline CHEMBL1391749 & 688267 & 5.9 & 5.0469 & TST \\
\hline CHEMBL1309567 & 688267 & 5.15 & 5.0979 & TRN \\
\hline CHEMBL1556571 & 688267 & 6.25 & 5.0259 & TST \\
\hline CHEMBL1566351 & 688267 & 4.25 & 5.1263 & TRN \\
\hline
\end{tabular}




\begin{tabular}{|c|c|c|c|c|c|}
\hline \multicolumn{6}{|c|}{ Supplemental Table S2.txt } \\
\hline CHEMBL1413589 & 688267 & 6.15 & 5.0132 & TRN & \\
\hline CHEMBL1300001 & 688267 & 4.6 & 5.1784 & TRN & \\
\hline CHEMBL1512590 & 688267 & 5.45 & 5.0279 & TRN & \\
\hline CHEMBL1346796 & 688267 & 4.95 & 5.0005 & TST & \\
\hline CHEMBL1590495 & 688267 & 6.2 & 5.0741 & TRN & \\
\hline CHEMBL1395069 & 688267 & 5.45 & 5.0241 & TRN & \\
\hline CHEMBL1365402 & 688267 & 6.45 & 5.0288 & TST & \\
\hline CHEMBL1333692 & 688267 & 5.1 & 5.03100 & $\partial 000000001$ & TRN \\
\hline CHEMBL1558727 & 688267 & 4.5 & 5.0336 & TRN & \\
\hline CHEMBL1513789 & 688267 & 5.15 & 5.0234 & TRN & \\
\hline CHEMBL1589873 & 688267 & 4.0 & 5.0405 & TRN & \\
\hline CHEMBL1338070 & 688267 & 4.0 & 5.0666 & TRN & \\
\hline CHEMBL1382699 & 688267 & 6.2 & 5.1189 & TRN & \\
\hline CHEMBL1519404 & 688267 & 5.6 & 5.0186 & TST & \\
\hline CHEMBL1483038 & 688267 & 4.4 & 5.0347 & TRN & \\
\hline CHEMBL1473327 & 688267 & 6.2 & 5.0735 & TRN & \\
\hline CHEMBL1558030 & 688267 & 5.8 & 5.0429 & TRN & \\
\hline CHEMBL1466782 & 688267 & 4.0 & 5.0408 & TST & \\
\hline CHEMBL1561443 & 688267 & 4.25 & 5.021 & TRN & \\
\hline CHEMBL1412360 & 688267 & 4.0 & 5.0602 & TRN & \\
\hline CHEMBL1539476 & 688267 & 4.25 & 5.1322 & TRN & \\
\hline CHEMBL1466966 & 688267 & 4.4 & 5.0507 & TRN & \\
\hline CHEMBL1488293 & 688267 & 6.15 & 5.0204 & TRN & \\
\hline CHEMBL1322866 & 688267 & 4.4 & 5.0134 & TRN & \\
\hline CHEMBL1412524 & 688267 & 5.25 & 5.0845 & TST & \\
\hline CHEMBL1488341 & 688267 & 4.95 & 5.1215 & TRN & \\
\hline CHEMBL1381547 & 688267 & 5.4 & 5.0755 & TRN & \\
\hline CHEMBL1586100 & 688267 & 6.0 & 5.053 & TST & \\
\hline CHEMBL1430037 & 688267 & 4.0 & 5.0445 & TRN & \\
\hline CHEMBL1602944 & 688267 & 4.1 & 5.0524 & TRN & \\
\hline CHEMBL1431755 & 688267 & 6.2 & 5.0959 & TST & \\
\hline CHEMBL1555722 & 688267 & 5.9 & 5.1347 & TRN & \\
\hline CHEMBL1328192 & 688267 & 6.2 & 5.1492 & TRN & \\
\hline CHEMBL1304915 & 688267 & 6.2 & 5.022 & TRN & \\
\hline CHEMBL1312332 & 688267 & 5.9 & 5.0807 & TRN & \\
\hline CHEMBL1440038 & 688267 & 4.0 & 5.0206 & TST & \\
\hline CHEMBL1491163 & 688267 & 4.2 & 5.0505 & TRN & \\
\hline CHEMBL1607012 & 688267 & 5.45 & 5.1103 & TRN & \\
\hline CHEMBL3195091 & 688267 & 5.75 & 4.9906 & TST & \\
\hline CHEMBL1319361 & 688267 & 5.9 & 5.0978 & TST & \\
\hline CHEMBL1395233 & 688267 & 3.95 & 5.0443 & TRN & \\
\hline CHEMBL1449965 & 688267 & 5.9 & 5.1195 & TRN & \\
\hline CHEMBL1537921 & 688267 & 6.05 & 5.1001 & TST & \\
\hline CHEMBL1382853 & 688267 & 6.1 & 5.0655 & TST & \\
\hline CHEMBL1377394 & 688267 & 5.25 & 5.0796 & TRN & \\
\hline CHEMBL1397908 & 688267 & 4.0 & 5.0624 & TRN & \\
\hline CHEMBL1588333 & 688267 & 5.4 & 5.0302 & TRN & \\
\hline CHEMBL1327566 & 688267 & 6.2 & 5.0154 & TRN & \\
\hline
\end{tabular}




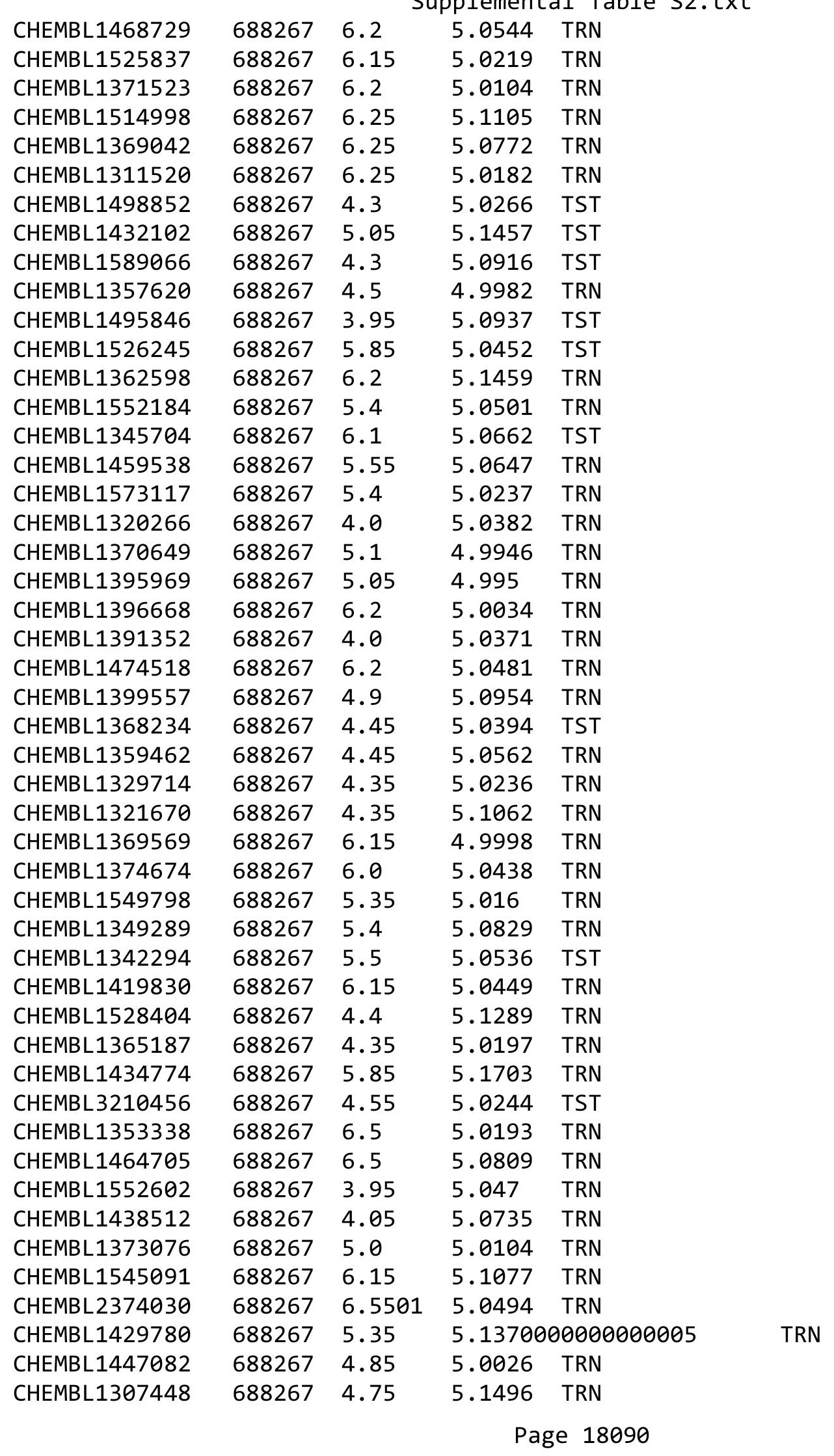




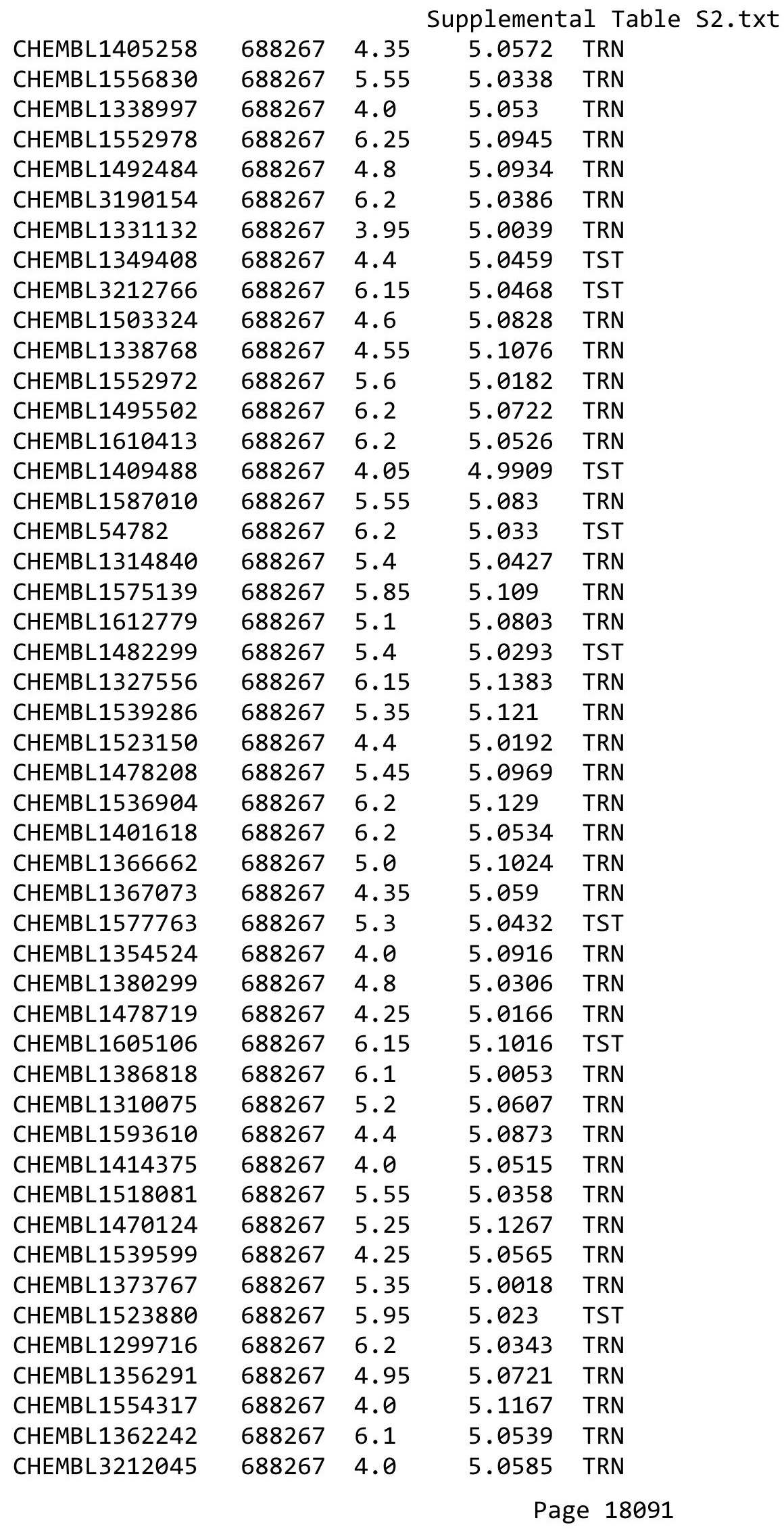




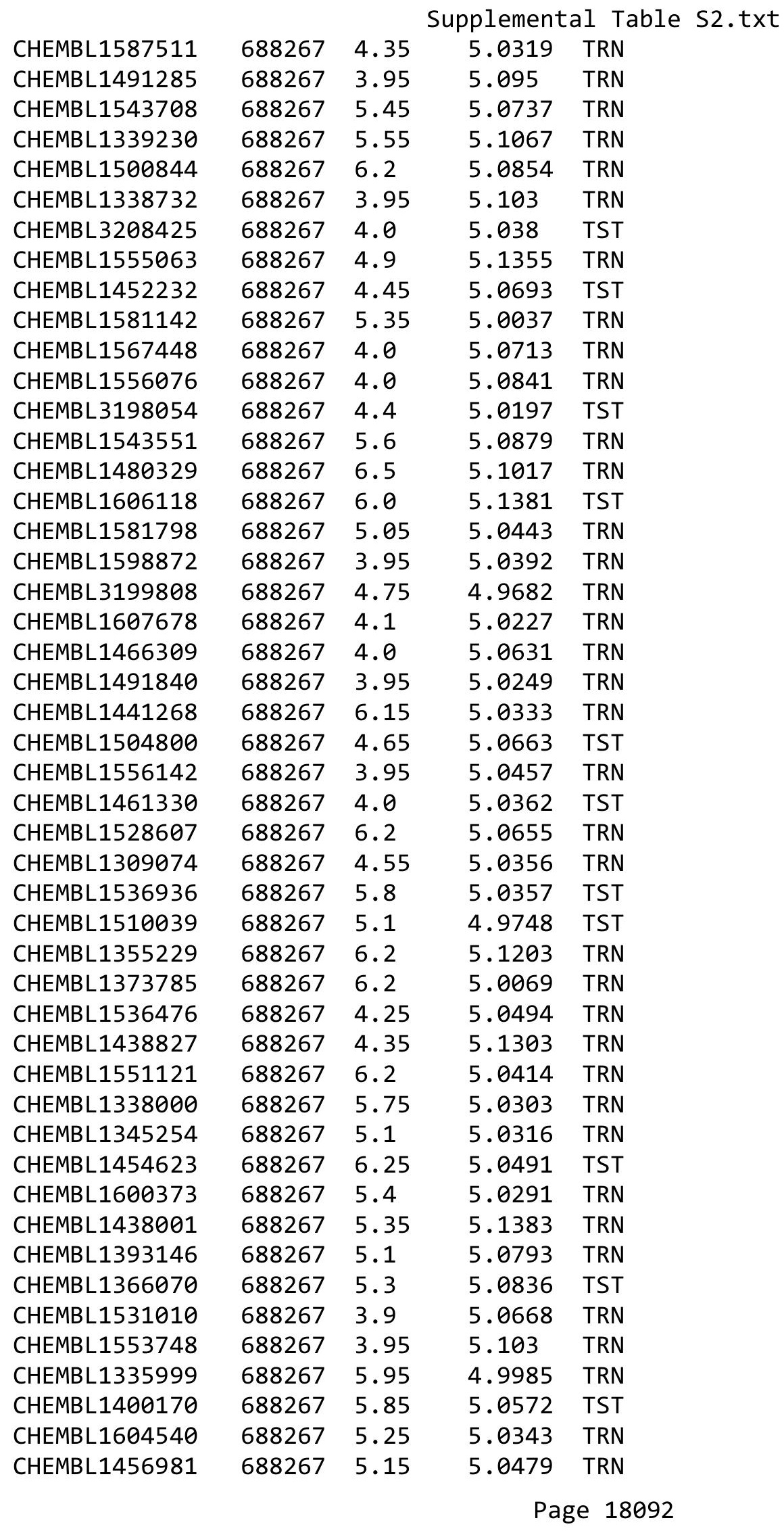




\begin{tabular}{|c|c|c|c|c|}
\hline & & & pplement & al $\mathrm{Ta}$ \\
\hline CHEMBL1577892 & 688267 & 6.0 & 5.0812 & TRN \\
\hline CHEMBL1478285 & 688267 & 5.5 & 4.9953 & TRN \\
\hline CHEMBL1578310 & 688267 & 4.35 & 4.9935 & TRN \\
\hline CHEMBL1483078 & 688267 & 4.05 & 5.1202 & TRN \\
\hline CHEMBL1332506 & 688267 & 6.25 & 5.0029 & TRN \\
\hline CHEMBL1536004 & 688267 & 6.2 & 5.0734 & TST \\
\hline CHEMBL1364975 & 688267 & 5.55 & 5.0328 & TRN \\
\hline CHEMBL3213042 & 688267 & 4.05 & 5.0636 & TRN \\
\hline CHEMBL1415007 & 688267 & 4.15 & 5.0155 & TRN \\
\hline CHEMBL1554740 & 688267 & 4.05 & 5.1348 & TRN \\
\hline CHEMBL1468353 & 688267 & 4.4 & 5.0421 & TRN \\
\hline CHEMBL1314643 & 688267 & 5.65 & 5.0686 & TRN \\
\hline CHEMBL1376721 & 688267 & 5.35 & 5.0778 & TRN \\
\hline CHEMBL1532973 & 688267 & 4.0 & 5.1435 & TST \\
\hline CHEMBL1480652 & 688267 & 4.45 & 5.0458 & TRN \\
\hline CHEMBL1564620 & 688267 & 4.4 & 5.0664 & TST \\
\hline CHEMBL1489136 & 688267 & 4.1 & 5.0672 & TRN \\
\hline CHEMBL1306196 & 688267 & 6.5 & 5.023 & TRN \\
\hline CHEMBL3191403 & 688267 & 5.2 & 5.0785 & TRN \\
\hline CHEMBL1586086 & 688267 & 4.8 & 5.0922 & TRN \\
\hline CHEMBL1377202 & 688267 & 6.2 & 5.1049 & TRN \\
\hline CHEMBL1430889 & 688267 & 5.4 & 5.04 & TRN \\
\hline CHEMBL1403174 & 688267 & 3.95 & 5.0606 & TRN \\
\hline CHEMBL109037 & 688267 & 4.3 & 5.0625 & TST \\
\hline CHEMBL1533333 & 688267 & 6.2 & 5.0409 & TRN \\
\hline CHEMBL1480797 & 688267 & 6.05 & 5.0994 & TRN \\
\hline CHEMBL1368854 & 688267 & 5.9 & 5.0244 & TRN \\
\hline CHEMBL1576224 & 688267 & 5.0 & 5.0753 & TRN \\
\hline CHEMBL3207559 & 688267 & 4.05 & 5.1052 & TRN \\
\hline CHEMBL1494768 & 688267 & 4.05 & 5.0948 & TRN \\
\hline CHEMBL1390196 & 688267 & 5.75 & 5.0242 & TRN \\
\hline CHEMBL1516157 & 688267 & 4.0 & 5.0065 & TRN \\
\hline CHEMBL1573932 & 688267 & 4.6 & 5.0625 & TRN \\
\hline CHEMBL3198973 & 688267 & 4.6 & 5.0605 & TST \\
\hline CHEMBL1555350 & 688267 & 5.45 & 5.0374 & TST \\
\hline CHEMBL1438861 & 688267 & 4.05 & 5.0453 & TRN \\
\hline CHEMBL1606428 & 688267 & 4.1 & 5.0739 & TRN \\
\hline CHEMBL1543234 & 688267 & 4.4 & 5.0192 & TST \\
\hline CHEMBL1384915 & 688267 & 4.25 & 5.0313 & TRN \\
\hline CHEMBL1565989 & 688267 & 4.0 & 4.9943 & TRN \\
\hline CHEMBL1403351 & 688267 & 6.1 & 5.0399 & TST \\
\hline CHEMBL1512672 & 688267 & 4.0 & 5.1018 & TRN \\
\hline CHEMBL1490176 & 688267 & 5.5 & 5.0688 & TRN \\
\hline CHEMBL1425603 & 688267 & 4.1 & 5.0699 & TST \\
\hline CHEMBL1430797 & 688267 & 4.25 & 5.0105 & TST \\
\hline CHEMBL1409359 & 688267 & 5.4 & 5.0261 & TRN \\
\hline CHEMBL1550639 & 688267 & 6.2 & 5.0896 & TRN \\
\hline CHEMBL1578606 & 688267 & 3.95 & 5.1039 & TRN \\
\hline
\end{tabular}




\begin{tabular}{|c|c|c|c|c|}
\hline \multicolumn{5}{|c|}{ Supplemental Table S2.txt } \\
\hline CHEMBL1382666 & 688267 & 4.65 & 5.0329 & TRN \\
\hline CHEMBL1588617 & 688267 & 5.5 & 5.0194 & TRN \\
\hline CHEMBL1546581 & 688267 & 4.85 & 5.0976 & TRN \\
\hline CHEMBL1375919 & 688267 & 4.05 & $5.1110 e$ & 0000000001 \\
\hline CHEMBL1451987 & 688267 & 5.3 & 5.0717 & TRN \\
\hline CHEMBL1545201 & 688267 & 4.25 & 5.0396 & TST \\
\hline CHEMBL1595387 & 688267 & 5.95 & 5.0798 & TRN \\
\hline CHEMBL1501778 & 688267 & 6.15 & 5.0354 & TRN \\
\hline CHEMBL1600278 & 688267 & 5.05 & 5.1133 & TST \\
\hline CHEMBL1574010 & 688267 & 4.15 & 5.0171 & TRN \\
\hline CHEMBL1553898 & 688267 & 4.3 & 5.0891 & TRN \\
\hline CHEMBL1576886 & 688267 & 6.2 & 5.0134 & TST \\
\hline CHEMBL1601702 & 688267 & 4.75 & 5.0737 & TRN \\
\hline CHEMBL1566158 & 688267 & 4.55 & 5.0868 & TRN \\
\hline CHEMBL1473716 & 688267 & 4.65 & 5.0321 & TRN \\
\hline CHEMBL1356031 & 688267 & 5.55 & 5.0269 & TRN \\
\hline CHEMBL1521045 & 688267 & 5.8 & 5.141 & TRN \\
\hline CHEMBL1607872 & 688267 & 4.75 & 5.0229 & TST \\
\hline CHEMBL1455319 & 688267 & 5.9 & 5.006 & TST \\
\hline CHEMBL1500609 & 688267 & 4.0 & 5.0004 & TST \\
\hline CHEMBL1370386 & 688267 & 6.15 & 5.101 & TRN \\
\hline CHEMBL1570768 & 688267 & 4.05 & 5.1027 & TRN \\
\hline CHEMBL1430459 & 688267 & 5.9 & 5.0498 & TST \\
\hline CHEMBL1402746 & 688267 & 5.55 & 5.1043 & TRN \\
\hline CHEMBL1455739 & 688267 & 4.95 & 5.0171 & TST \\
\hline CHEMBL1604290 & 688267 & 4.0 & 5.1397 & TRN \\
\hline CHEMBL1353997 & 688267 & 5.15 & 5.1003 & TRN \\
\hline CHEMBL1502881 & 688267 & 5.3 & 5.0716 & TRN \\
\hline CHEMBL1381026 & 688267 & 5.25 & 5.0225 & TRN \\
\hline CHEMBL1608401 & 688267 & 4.35 & 5.021 & TRN \\
\hline CHEMBL1559876 & 688267 & 3.95 & 5.0434 & TST \\
\hline CHEMBL1339260 & 688267 & 6.15 & 5.0701 & TRN \\
\hline CHEMBL1465878 & 688267 & 6.25 & 5.0303 & TRN \\
\hline CHEMBL1606235 & 688267 & 5.3 & 5.0932 & TRN \\
\hline CHEMBL1471158 & 688267 & 5.25 & 5.1701 & TRN \\
\hline CHEMBL1324885 & 688267 & 4.3 & 5.0321 & TST \\
\hline CHEMBL1322920 & 688267 & 3.95 & 5.0286 & TRN \\
\hline CHEMBL1612930 & 688267 & 4.3 & 5.0276 & TRN \\
\hline CHEMBL1417802 & 688267 & 5.25 & 5.1124 & TRN \\
\hline CHEMBL1514266 & 688267 & 5.75 & 5.1172 & TRN \\
\hline CHEMBL1524367 & 688267 & 6.7001 & 5.0301 & TST \\
\hline CHEMBL1451298 & 688267 & 3.95 & 5.0509 & TRN \\
\hline CHEMBL1419306 & 688267 & 5.0 & 5.042 & TST \\
\hline CHEMBL1491148 & 688267 & 4.1 & 5.0624 & TRN \\
\hline CHEMBL1558575 & 688267 & 4.65 & 5.0498 & TRN \\
\hline CHEMBL1567811 & 688267 & 4.55 & 5.0138 & TST \\
\hline CHEMBL1336661 & 688267 & 3.95 & 5.0786 & TST \\
\hline CHEMBL1357993 & 688267 & 4.6 & 5.0591 & TRN \\
\hline
\end{tabular}

TRN 


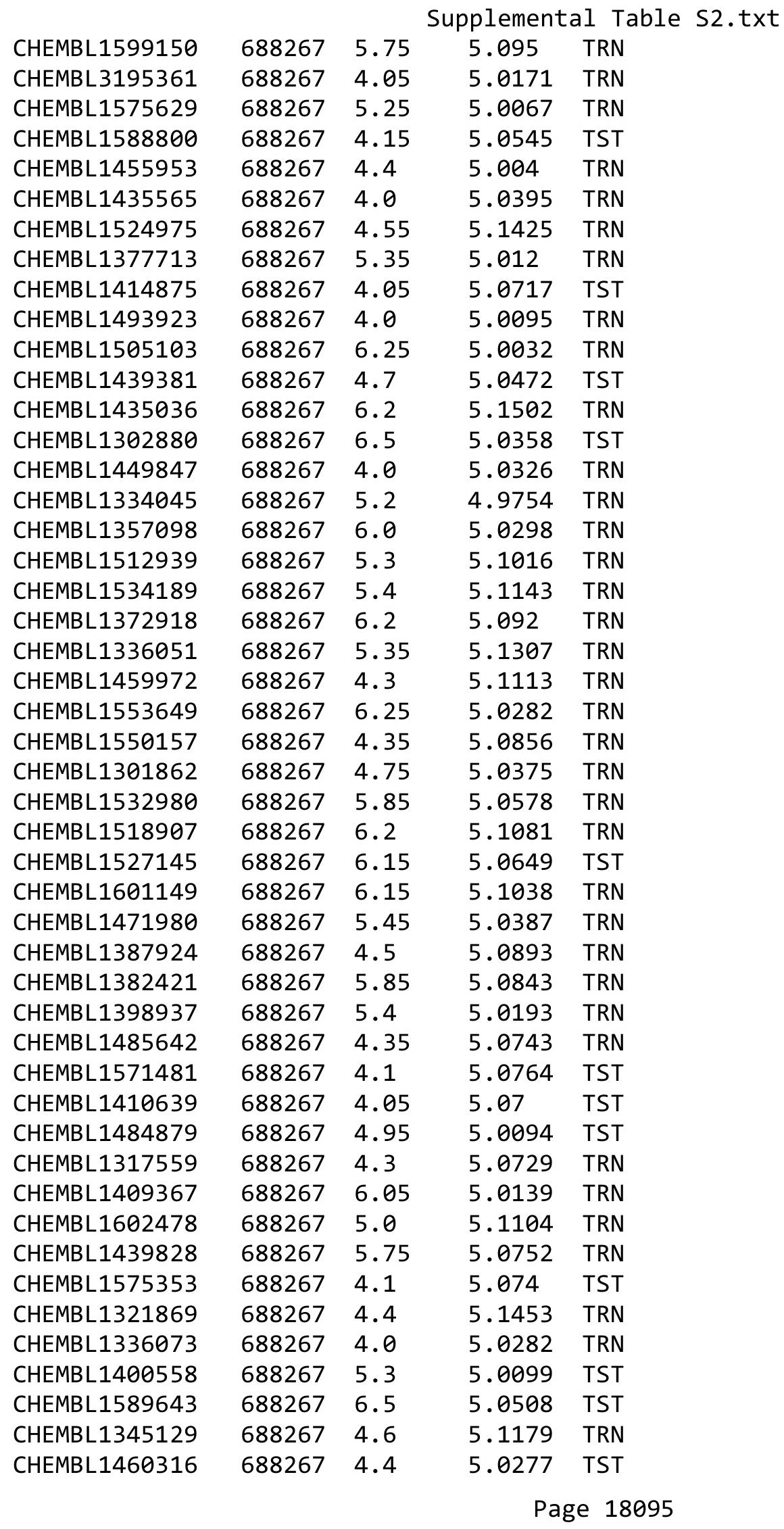




\begin{tabular}{|c|c|c|c|c|}
\hline \multicolumn{5}{|c|}{ Supplemental Table S2.txt } \\
\hline CHEMBL1473166 & 688267 & 4.9 & 5.0698 & TRN \\
\hline CHEMBL1472158 & 688267 & 3.95 & 5.0413 & TRN \\
\hline CHEMBL1322688 & 688267 & 5.25 & 5.0529 & TRN \\
\hline CHEMBL1605162 & 688267 & 4.35 & 5.0123 & TST \\
\hline CHEMBL1316089 & 688267 & 4.75 & 5.0774 & TST \\
\hline CHEMBL1494593 & 688267 & 5.1 & 5.0399 & TRN \\
\hline CHEMBL1446423 & 688267 & 6.25 & 5.1318 & TRN \\
\hline CHEMBL1385450 & 688267 & 6.5 & 5.1016 & TRN \\
\hline CHEMBL1440651 & 688267 & 5.95 & 5.1029 & TRN \\
\hline CHEMBL1487397 & 688267 & 6.25 & 5.0378 & TRN \\
\hline CHEMBL1400631 & 688267 & 6.2 & 5.0757 & TRN \\
\hline CHEMBL1420707 & 688267 & 5.1 & 5.0337 & TRN \\
\hline CHEMBL1526820 & 688267 & 4.3 & 5.0647 & TRN \\
\hline CHEMBL1502667 & 688267 & 4.4 & 4.9978 & TRN \\
\hline CHEMBL1452016 & 688267 & 6.25 & 5.0563 & TRN \\
\hline CHEMBL1573710 & 688267 & 4.45 & 5.0422 & TST \\
\hline CHEMBL1317282 & 688267 & 5.2 & 5.0087 & TRN \\
\hline CHEMBL1407498 & 688267 & 4.1 & 5.1249 & TRN \\
\hline CHEMBL1590463 & 688267 & 4.0 & 5.102 & TRN \\
\hline CHEMBL1355876 & 688267 & 4.05 & 5.1072 & TRN \\
\hline CHEMBL1407543 & 688267 & 4.1 & 5.0932 & TST \\
\hline CHEMBL1463002 & 688267 & 6.2 & 5.0768 & TRN \\
\hline CHEMBL1349029 & 688267 & 4.25 & 5.0406 & TRN \\
\hline CHEMBL1305186 & 688267 & 5.6 & 5.082 & TRN \\
\hline CHEMBL1351354 & 688267 & 6.2 & 5.0403 & TST \\
\hline CHEMBL1307153 & 688267 & 6.2 & 5.0753 & TRN \\
\hline CHEMBL1371965 & 688267 & 6.2 & 5.0476 & TRN \\
\hline CHEMBL1444578 & 688267 & 4.15 & 5.0458 & TRN \\
\hline CHEMBL1569543 & 688267 & 3.95 & 5.0061 & TST \\
\hline CHEMBL1331692 & 688267 & 6.25 & 5.0255 & TRN \\
\hline CHEMBL1510110 & 688267 & 5.3 & 5.0743 & TRN \\
\hline CHEMBL1314729 & 688267 & 4.7 & 5.0869 & TRN \\
\hline CHEMBL1357761 & 688267 & 6.2 & 5.0243 & TRN \\
\hline CHEMBL1394879 & 688267 & 5.25 & 5.0434 & TRN \\
\hline CHEMBL1414294 & 688267 & 6.2 & 5.003 & TST \\
\hline CHEMBL1332732 & 688267 & 4.6 & 5.0905 & TRN \\
\hline CHEMBL1573584 & 688267 & 4.0 & 5.1046 & TRN \\
\hline CHEMBL1534897 & 688267 & 5.35 & 5.1556 & TRN \\
\hline CHEMBL1319455 & 688267 & 6.0 & 5.1107 & TRN \\
\hline CHEMBL1325823 & 688267 & 5.85 & 4.984 & TST \\
\hline CHEMBL1549671 & 688267 & 4.0 & 5.1525 & TRN \\
\hline CHEMBL1502239 & 688267 & 5.85 & 5.0717 & TRN \\
\hline CHEMBL1382751 & 688267 & 4.9 & 5.0674 & TRN \\
\hline CHEMBL1449311 & 688267 & 4.0 & 5.0821 & TRN \\
\hline CHEMBL1422775 & 688267 & 4.1 & 5.1066 & TRN \\
\hline CHEMBL1348320 & 688267 & 4.05 & 5.0892 & TRN \\
\hline CHEMBL 1384822 & 688267 & 4.05 & 5.0134 & TRN \\
\hline CHEMBL1505318 & 688267 & 4.05 & 5.0825 & TRN \\
\hline
\end{tabular}




\begin{tabular}{|c|c|c|c|c|c|}
\hline \\
\hline CHEMBL1481293 & 688267 & 5.5 & 5.0671 & TRN & \\
\hline CHEMBL1553638 & 688267 & 6.95 & 5.0675 & TST & \\
\hline CHEMBL1444622 & 688267 & 4.6 & 5.0516 & TST & \\
\hline CHEMBL1503936 & 688267 & 5.15 & 5.0132 & TST & \\
\hline CHEMBL1317874 & 688267 & 4.0 & 5.0939 & TRN & \\
\hline CHEMBL1550455 & 688267 & 6.05 & 5.0109 & TST & \\
\hline CHEMBL1329813 & 688267 & 5.0 & 5.1018 & TST & \\
\hline CHEMBL1553205 & 688267 & 4.85 & 5.0256 & TST & \\
\hline CHEMBL1473606 & 688267 & 5.55 & 5.0384 & TRN & \\
\hline CHEMBL1426895 & 688267 & 6.15 & 5.0933 & TRN & \\
\hline CHEMBL1605171 & 688267 & 5.9 & 5.0531 & TST & \\
\hline CHEMBL1315850 & 688267 & 4.75 & 5.0369 & TRN & \\
\hline CHEMBL1314488 & 688267 & 5.3 & 5.0566 & TRN & \\
\hline CHEMBL1604257 & 688267 & 4.35 & 5.0112 & TRN & \\
\hline CHEMBL1582141 & 688267 & 5.0 & 5.0423 & TRN & \\
\hline CHEMBL1301783 & 688267 & 5.25 & 5.13200 & $\partial 000000001$ & TST \\
\hline CHEMBL1381731 & 688267 & 6.5 & 5.0462 & TST & \\
\hline CHEMBL1328840 & 688267 & 4.4 & 5.0111 & TRN & \\
\hline CHEMBL3194550 & 688267 & 5.1 & 5.0249 & TST & \\
\hline CHEMBL1564647 & 688267 & 4.0 & 5.095 & TRN & \\
\hline CHEMBL1306909 & 688267 & 5.45 & 5.0134 & TRN & \\
\hline CHEMBL1430121 & 688267 & 5.05 & 5.011 & TST & \\
\hline CHEMBL1396671 & 688267 & 6.2 & 5.1208 & TRN & \\
\hline CHEMBL1534997 & 688267 & 5.75 & 5.0803 & TST & \\
\hline CHEMBL1345411 & 688267 & 6.2 & 4.9981 & TRN & \\
\hline CHEMBL1431429 & 688267 & 4.05 & 5.0123 & TRN & \\
\hline CHEMBL10895 & 688267 & 6.0 & 5.04 & TST & \\
\hline CHEMBL3197367 & 688267 & 4.05 & 5.0364 & TST & \\
\hline CHEMBL1596921 & 688267 & 5.0 & 5.0822 & TRN & \\
\hline CHEMBL3214271 & 688267 & 4.05 & 5.0605 & TST & \\
\hline CHEMBL1361650 & 688267 & 4.55 & 5.1047 & TRN & \\
\hline CHEMBL1359039 & 688267 & 4.55 & 5.0658 & TRN & \\
\hline CHEMBL1500623 & 688267 & 5.45 & 5.0713 & TRN & \\
\hline CHEMBL1530416 & 688267 & 6.15 & 5.0469 & TRN & \\
\hline CHEMBL1540194 & 688267 & 5.55 & 5.08899 & 99999999995 & TRN \\
\hline CHEMBL1461896 & 688267 & 5.1 & 5.0218 & TRN & \\
\hline CHEMBL1448630 & 688267 & 4.1 & 5.08 & TRN & \\
\hline CHEMBL1310615 & 688267 & 5.05 & 5.0847 & TST & \\
\hline CHEMBL1386293 & 688267 & 3.95 & 5.0357 & TRN & \\
\hline CHEMBL1300373 & 688267 & 6.0 & 5.1103 & TRN & \\
\hline CHEMBL1501270 & 688267 & 4.0 & 5.042 & TRN & \\
\hline CHEMBL1334368 & 688267 & 4.15 & 5.033 & TRN & \\
\hline CHEMBL1331609 & 688267 & 5.6 & 5.141 & TRN & \\
\hline CHEMBL1404073 & 688267 & 4.45 & 5.0234 & TRN & \\
\hline CHEMBL1531780 & 688267 & 6.25 & 5.0051 & TRN & \\
\hline CHEMBL3210504 & 688267 & 6.2 & 5.0248 & TRN & \\
\hline CHEMBL1373856 & 688267 & 3.95 & 5.1005 & TRN & \\
\hline CHEMBL1315047 & 688267 & 4.0 & 5.0877 & TRN & \\
\hline
\end{tabular}




\begin{tabular}{|c|c|c|c|c|}
\hline \multicolumn{5}{|c|}{ Supplemental Table S2.txt } \\
\hline CHEMBL1327722 & 688267 & 4.4 & 5.0909 & TRN \\
\hline CHEMBL1483001 & 688267 & 4.75 & 5.0662 & TST \\
\hline CHEMBL1361327 & 688267 & 4.0 & 5.0693 & TST \\
\hline CHEMBL1508936 & 688267 & 4.2 & 5.0551 & TRN \\
\hline CHEMBL1518420 & 688267 & 6.5 & 5.0919 & TRN \\
\hline CHEMBL1302363 & 688267 & 4.45 & 5.0476 & TRN \\
\hline CHEMBL1454190 & 688267 & 4.45 & 5.0945 & TST \\
\hline CHEMBL1446088 & 688267 & 5.4 & 5.0785 & TRN \\
\hline CHEMBL1574961 & 688267 & 4.25 & 5.0527 & TST \\
\hline CHEMBL3213208 & 688267 & 4.95 & 5.0601 & TRN \\
\hline CHEMBL1603059 & 688267 & 3.95 & 5.0215 & TST \\
\hline CHEMBL1313702 & 688267 & 3.95 & 5.0438 & TRN \\
\hline CHEMBL 295234 & 688267 & 5.2 & 5.0405 & TRN \\
\hline CHEMBL1303458 & 688267 & 5.0 & 5.0247 & TRN \\
\hline CHEMBL1392522 & 688267 & 5.1 & 5.141 & TRN \\
\hline CHEMBL1361483 & 688267 & 5.6 & 4.9909 & TRN \\
\hline CHEMBL1514616 & 688267 & 6.2 & 5.0982 & TRN \\
\hline CHEMBL1606440 & 688267 & 4.4 & 5.1058 & TRN \\
\hline CHEMBL1388029 & 688267 & 4.0 & 5.0597 & TRN \\
\hline CHEMBL1546992 & 688267 & 5.5 & 5.0497 & TRN \\
\hline CHEMBL1366213 & 688267 & 4.0 & 5.0218 & TRN \\
\hline CHEMBL1411368 & 688267 & 6.2 & 5.1218 & TRN \\
\hline CHEMBL1448361 & 688267 & 6.1 & 5.0191 & TRN \\
\hline CHEMBL1349047 & 688267 & 5.45 & 5.0394 & TST \\
\hline CHEMBL1593711 & 688267 & 4.0 & 5.0112 & TST \\
\hline CHEMBL1517248 & 688267 & 4.35 & 5.0763 & TST \\
\hline CHEMBL1514794 & 688267 & 6.2 & 5.0059 & TRN \\
\hline CHEMBL1440462 & 688267 & 3.9 & 5.0162 & TRN \\
\hline CHEMBL1317438 & 688267 & 3.95 & 5.1155 & TRN \\
\hline CHEMBL1586778 & 688267 & 4.2 & 5.0571 & TST \\
\hline CHEMBL1591407 & 688267 & 4.0 & 5.1143 & TRN \\
\hline CHEMBL1503044 & 688267 & 4.5 & 5.1367 & TRN \\
\hline CHEMBL1554629 & 688267 & 5.3 & 5.0667 & TRN \\
\hline CHEMBL1461077 & 688267 & 4.3 & 5.0603 & TST \\
\hline CHEMBL1395167 & 688267 & 4.4 & 5.1228 & TRN \\
\hline CHEMBL1303229 & 688267 & 4.65 & 5.0606 & TST \\
\hline CHEMBL1422802 & 688267 & 6.2 & 5.0716 & TST \\
\hline CHEMBL1344521 & 688267 & 6.15 & 5.035 & TRN \\
\hline CHEMBL1357915 & 688267 & 6.15 & 5.0841 & TST \\
\hline CHEMBL1591633 & 688267 & 4.35 & 5.0553 & TRN \\
\hline CHEMBL1371606 & 688267 & 4.0 & 5.1313 & TRN \\
\hline CHEMBL3199337 & 688267 & 5.95 & 5.0152 & TRN \\
\hline CHEMBL1383313 & 688267 & 4.0 & 5.1707 & TST \\
\hline CHEMBL1306098 & 688267 & 4.4 & 5.0329 & TRN \\
\hline CHEMBL1606162 & 688267 & 5.6 & 5.0804 & TRN \\
\hline CHEMBL1376812 & 688267 & 3.95 & 5.0188 & TRN \\
\hline CHEMBL1335279 & 688267 & 4.7 & 5.027 & TRN \\
\hline CHEMBL1502519 & 688267 & 5.8 & 5.0306 & TRN \\
\hline
\end{tabular}




\begin{tabular}{|c|c|c|c|c|}
\hline \multicolumn{5}{|c|}{ Supplemental Table S2.txt } \\
\hline CHEMBL1442682 & 688267 & 5.45 & 5.0221 & TRN \\
\hline CHEMBL1328206 & 688267 & 4.1 & 5.0225 & TRN \\
\hline CHEMBL1516181 & 688267 & 6.25 & 4.9785 & TRN \\
\hline CHEMBL1535680 & 688267 & 5.25 & 5.0329 & TRN \\
\hline CHEMBL1497359 & 688267 & 6.2 & 5.0517 & TST \\
\hline CHEMBL1390073 & 688267 & 5.8 & 5.0771 & TRN \\
\hline CHEMBL1523799 & 688267 & 5.0 & 5.0655 & TST \\
\hline CHEMBL1270410 & 688267 & 6.5 & 5.0002 & TRN \\
\hline CHEMBL355318 & 688267 & 4.65 & 5.0323 & TRN \\
\hline CHEMBL1326579 & 688267 & 6.25 & 5.1355 & TRN \\
\hline CHEMBL3198803 & 688267 & 4.35 & 5.0453 & TST \\
\hline CHEMBL1373754 & 688267 & 4.05 & 5.0207 & TRN \\
\hline CHEMBL1513814 & 688267 & 6.25 & 5.0836 & TRN \\
\hline CHEMBL1598835 & 688267 & 4.3 & 5.0265 & TRN \\
\hline CHEMBL1383279 & 688267 & 6.25 & 5.0322 & TST \\
\hline CHEMBL1481323 & 688267 & 4.1 & 5.0956 & TRN \\
\hline CHEMBL1325126 & 688267 & 6.0 & 5.064 & TRN \\
\hline CHEMBL1437267 & 688267 & 6.15 & 5.0372 & TRN \\
\hline CHEMBL1423417 & 688267 & 4.3 & 5.0253 & TRN \\
\hline CHEMBL168276 & 688267 & 5.5 & 5.0225 & TST \\
\hline CHEMBL1305883 & 688267 & 4.0 & 5.0185 & TRN \\
\hline CHEMBL1440470 & 688267 & 4.0 & 5.0703 & TRN \\
\hline CHEMBL1522717 & 688267 & 5.65 & 5.0588 & TRN \\
\hline CHEMBL1601074 & 688267 & 4.0 & 5.0806 & TRN \\
\hline CHEMBL462227 & 688267 & 5.55 & 5.1047 & TRN \\
\hline CHEMBL1431649 & 688267 & 4.0 & 5.0665 & TST \\
\hline CHEMBL3190160 & 688267 & 5.7 & 5.0016 & TRN \\
\hline CHEMBL1434751 & 688267 & 4.95 & 5.1222 & TRN \\
\hline CHEMBL1388630 & 688267 & 5.9 & 5.1406 & TRN \\
\hline CHEMBL1557067 & 688267 & 4.75 & 5.0135 & TRN \\
\hline CHEMBL3197554 & 688267 & 6.2 & 4.9942 & TRN \\
\hline CHEMBL1397686 & 688267 & 4.05 & 5.0767 & TRN \\
\hline CHEMBL1443219 & 688267 & 6.25 & 5.1078 & TRN \\
\hline CHEMBL3196761 & 688267 & 5.05 & 5.0385 & TST \\
\hline CHEMBL1457566 & 688267 & 5.35 & 5.0358 & TRN \\
\hline CHEMBL1424654 & 688267 & 4.05 & 5.0844 & TST \\
\hline CHEMBL1308589 & 688267 & 4.35 & 5.0799 & TST \\
\hline CHEMBL1405652 & 688267 & 4.05 & 5.0556 & TRN \\
\hline CHEMBL1564530 & 688267 & 4.0 & 5.0933 & TST \\
\hline CHEMBL1563180 & 688267 & 6.2 & 5.0246 & TST \\
\hline CHEMBL1301257 & 688267 & 6.5 & 5.0938 & TRN \\
\hline CHEMBL1496982 & 688267 & 4.05 & 5.1334 & TRN \\
\hline CHEMBL1323336 & 688267 & 4.05 & 5.0169 & TST \\
\hline CHEMBL1304419 & 688267 & 5.9 & 5.0485 & TRN \\
\hline CHEMBL1562009 & 688267 & 5.85 & 5.1212 & TRN \\
\hline CHEMBL1515941 & 688267 & 5.3 & 5.1286 & TRN \\
\hline CHEMBL1370749 & 688267 & 4.1 & 5.1626 & TRN \\
\hline CHEMBL1359907 & 688267 & 5.95 & 5.0722 & TRN \\
\hline
\end{tabular}




\begin{tabular}{|c|c|c|c|c|c|}
\hline \multicolumn{6}{|c|}{ Supplemental Table S2.txt } \\
\hline CHEMBL1401438 & 688267 & 5.35 & 5.0536 & TRN & \\
\hline CHEMBL 3190642 & 688267 & 4.45 & 5.0364 & TST & \\
\hline CHEMBL1580489 & 688267 & 5.05 & 5.0231 & TRN & \\
\hline CHEMBL1557658 & 688267 & 5.8 & 5.1188 & TRN & \\
\hline CHEMBL1303339 & 688267 & 5.95 & 5.0394 & TRN & \\
\hline CHEMBL1299776 & 688267 & 4.7 & 5.0698 & TRN & \\
\hline CHEMBL1564246 & 688267 & 4.35 & 5.0193 & TRN & \\
\hline CHEMBL1475692 & 688267 & 4.45 & 5.1186 & TST & \\
\hline CHEMBL1339496 & 688267 & 4.35 & 5.0608 & TRN & \\
\hline CHEMBL1461838 & 688267 & 6.25 & 5.0855 & TRN & \\
\hline CHEMBL1493516 & 688267 & 4.4 & 4.9974 & TST & \\
\hline CHEMBL1421891 & 688267 & 4.05 & 5.0372 & TST & \\
\hline CHEMBL1369840 & 688267 & 4.5 & 5.029 & TRN & \\
\hline CHEMBL1376754 & 688267 & 4.05 & 5.0843 & TST & \\
\hline CHEMBL201221 & 688267 & 4.2 & 4.9836 & TST & \\
\hline CHEMBL355496 & 688267 & 4.4 & 4.9924 & TST & \\
\hline CHEMBL1564749 & 688267 & 4.35 & 5.0529 & TRN & \\
\hline CHEMBL1477332 & 688267 & 4.0 & 4.9746 & TST & \\
\hline CHEMBL1565926 & 688267 & 5.4 & 5.0514 & TST & \\
\hline CHEMBL1437720 & 688267 & 5.85 & 5.0322 & TRN & \\
\hline CHEMBL1371388 & 688267 & 4.4 & 5.033 & TRN & \\
\hline CHEMBL1609488 & 688267 & 5.75 & 5.0533 & TRN & \\
\hline CHEMBL1255664 & 688267 & 5.2 & 5.0351 & TST & \\
\hline CHEMBL1451644 & 688267 & 4.5 & 5.0626 & TRN & \\
\hline CHEMBL1989847 & 688267 & 5.25 & 5.0457 & TST & \\
\hline CHEMBL1553971 & 688267 & 4.1 & 5.0286 & TRN & \\
\hline CHEMBL1331895 & 688267 & 6.1 & 5.0209 & TST & \\
\hline CHEMBL1538930 & 688267 & 6.2 & 5.0246 & TRN & \\
\hline CHEMBL1458059 & 688267 & 3.95 & 5.0117 & TRN & \\
\hline CHEMBL1511249 & 688267 & 4.0 & 5.0123 & TST & \\
\hline CHEMBL1577908 & 688267 & 6.15 & 5.0369 & TST & \\
\hline CHEMBL1334984 & 688267 & 4.4 & 5.0718 & TST & \\
\hline CHEMBL3191314 & 688267 & 4.0 & 5.0252 & TST & \\
\hline CHEMBL1495488 & 688267 & 5.25 & 5.11 & TRN & \\
\hline CHEMBL1403570 & 688267 & 6.1 & 5.03600 & 00000000005 & TRN \\
\hline CHEMBL1497952 & 688267 & 4.3 & 5.0976 & TRN & \\
\hline CHEMBL1438374 & 688267 & 5.25 & 5.0362 & TST & \\
\hline CHEMBL1602452 & 688267 & 4.0 & 5.0419 & TST & \\
\hline CHEMBL1525324 & 688267 & 4.2 & 5.0749 & TST & \\
\hline CHEMBL1549250 & 688267 & 4.7 & 5.0206 & TST & \\
\hline CHEMBL1374720 & 688267 & 4.15 & 4.993 & TST & \\
\hline CHEMBL1455447 & 688267 & 4.35 & 5.1305 & TRN & \\
\hline CHEMBL1436989 & 688267 & 6.0 & 5.0249 & TST & \\
\hline CHEMBL1576082 & 688267 & 5.8 & 5.1035 & TRN & \\
\hline CHEMBL1339522 & 688267 & 4.8 & 5.0115 & TRN & \\
\hline CHEMBL1511388 & 688267 & 6.2 & 5.0577 & TRN & \\
\hline CHEMBL1512705 & 688267 & 5.55 & 5.083 & TRN & \\
\hline CHEMBL1440905 & 688267 & 3.95 & 5.1137 & TRN & \\
\hline
\end{tabular}




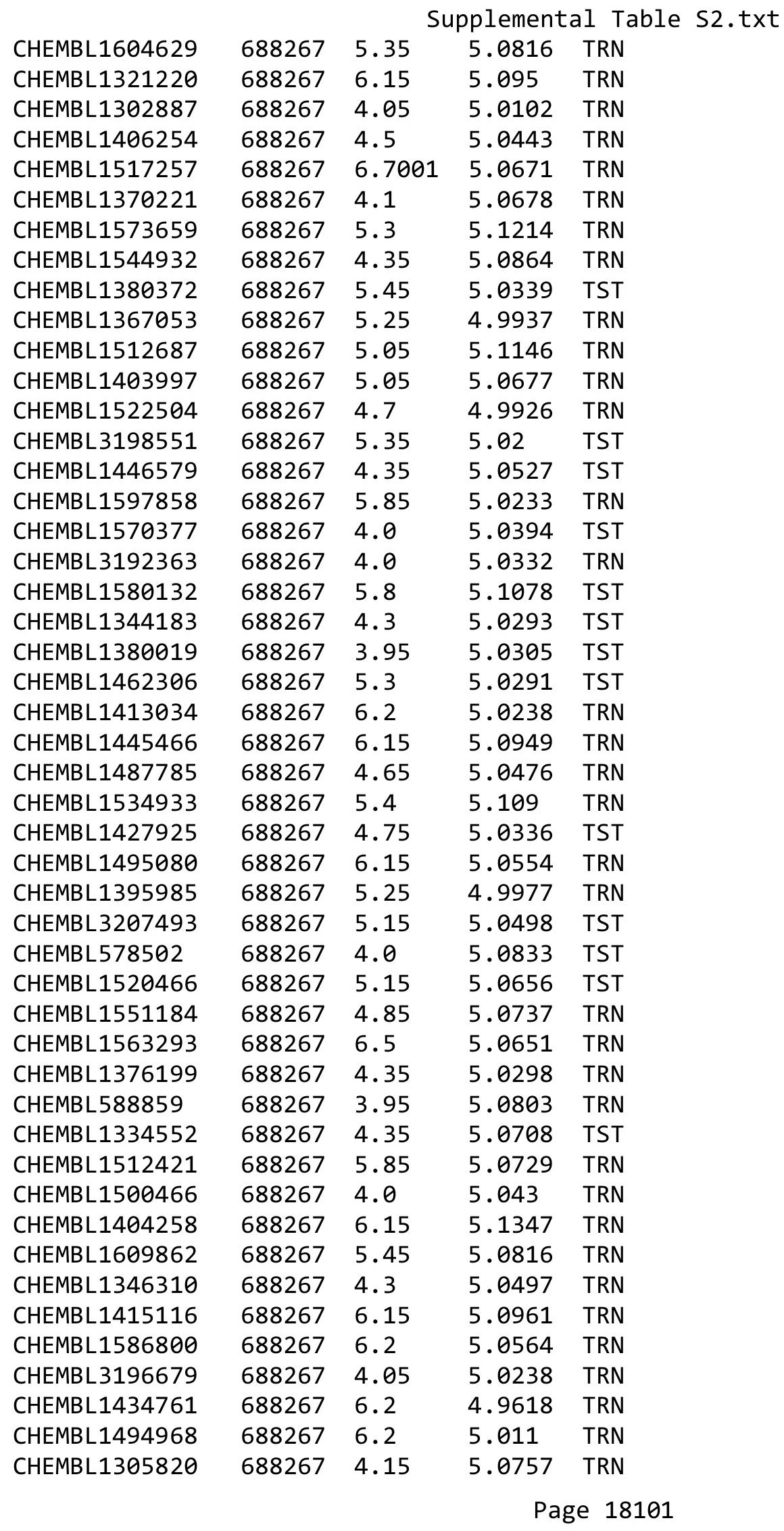




\begin{tabular}{|c|c|c|c|c|c|}
\hline & & & & & \\
\hline CHEMBL1478035 & 688267 & 6.0 & 5.0207 & TRN & \\
\hline CHEMBL1608199 & 688267 & 5.35 & 5.1121 & TRN & \\
\hline CHEMBL1500228 & 688267 & 4.35 & 5.0308 & TRN & \\
\hline CHEMBL1419709 & 688267 & 6.25 & 5.0982 & TRN & \\
\hline CHEMBL1423851 & 688267 & 6.25 & 5.0116 & TRN & \\
\hline CHEMBL1501997 & 688267 & 4.4 & 5.0592 & TRN & \\
\hline CHEMBL1392452 & 688267 & 4.05 & 5.047 & TRN & \\
\hline CHEMBL1386698 & 688267 & 5.4 & 5.07600 & 00000000005 & TRN \\
\hline CHEMBL1311997 & 688267 & 5.25 & 5.13899 & 9999999999 & TST \\
\hline CHEMBL1341786 & 688267 & 4.0 & 5.0969 & TRN & \\
\hline CHEMBL1305776 & 688267 & 4.85 & 5.0612 & TST & \\
\hline CHEMBL1488666 & 688267 & 4.95 & 5.1211 & TRN & \\
\hline CHEMBL1474382 & 688267 & 4.45 & 5.0937 & TRN & \\
\hline CHEMBL1321817 & 688267 & 4.5 & 5.0477 & TST & \\
\hline CHEMBL1546290 & 688267 & 5.65 & 5.0577 & TST & \\
\hline CHEMBL1601686 & 688267 & 4.0 & 5.0372 & TST & \\
\hline CHEMBL1581955 & 688267 & 5.55 & 5.1633 & TRN & \\
\hline CHEMBL1560056 & 688267 & 6.15 & 5.0507 & TST & \\
\hline CHEMBL1595659 & 688267 & 5.05 & 5.0042 & TRN & \\
\hline CHEMBL1310512 & 688267 & 4.0 & 5.0786 & TRN & \\
\hline CHEMBL1316307 & 688267 & 5.3 & 5.1116 & TRN & \\
\hline CHEMBL1430481 & 688267 & 3.95 & 5.0401 & TRN & \\
\hline CHEMBL1611677 & 688267 & 5.75 & 5.1236 & TRN & \\
\hline CHEMBL1413047 & 688267 & 5.3 & 5.0256 & TRN & \\
\hline CHEMBL1310453 & 688267 & 4.7 & 5.0376 & TRN & \\
\hline CHEMBL1440720 & 688267 & 4.35 & 5.1166 & TRN & \\
\hline CHEMBL1329184 & 688267 & 5.3 & 5.0932 & TRN & \\
\hline CHEMBL1562528 & 688267 & 5.6 & 5.0114 & TRN & \\
\hline CHEMBL1457314 & 688267 & 4.2 & 5.113 & TRN & \\
\hline CHEMBL566495 & 688267 & 5.95 & 5.0096 & TRN & \\
\hline CHEMBL1562722 & 688267 & 6.4 & 5.03600 & 00000000005 & TRN \\
\hline CHEMBL405386 & 688267 & 4.4 & 5.0346 & TRN & \\
\hline CHEMBL1307264 & 688267 & 4.3 & 5.0325 & TRN & \\
\hline CHEMBL1588747 & 688267 & 5.3 & 5.0938 & TST & \\
\hline CHEMBL1413588 & 688267 & 4.0 & 5.0151 & TRN & \\
\hline CHEMBL1552254 & 688267 & 5.1 & 5.1183 & TRN & \\
\hline CHEMBL1466577 & 688267 & 4.4 & 5.0163 & TRN & \\
\hline CHEMBL1496646 & 688267 & 4.0 & 5.1313 & TRN & \\
\hline CHEMBL 3209174 & 688267 & 5.25 & 5.0426 & TRN & \\
\hline CHEMBL1496870 & 688267 & 4.45 & 5.0725 & TRN & \\
\hline CHEMBL1342385 & 688267 & 5.65 & 5.0129 & TRN & \\
\hline CHEMBL1484525 & 688267 & 4.5 & 5.0056 & TRN & \\
\hline CHEMBL1514813 & 688267 & 5.35 & 5.148 & TRN & \\
\hline CHEMBL1514764 & 688267 & 4.4 & 5.1232 & TRN & \\
\hline CHEMBL1334627 & 688267 & 4.45 & 5.0437 & TRN & \\
\hline CHEMBL1494405 & 688267 & 4.75 & 5.0591 & TRN & \\
\hline CHEMBL1613670 & 688267 & 5.75 & 5.0301 & TRN & \\
\hline CHEMBL1302235 & 688267 & 6.45 & 5.0561 & TST & \\
\hline
\end{tabular}




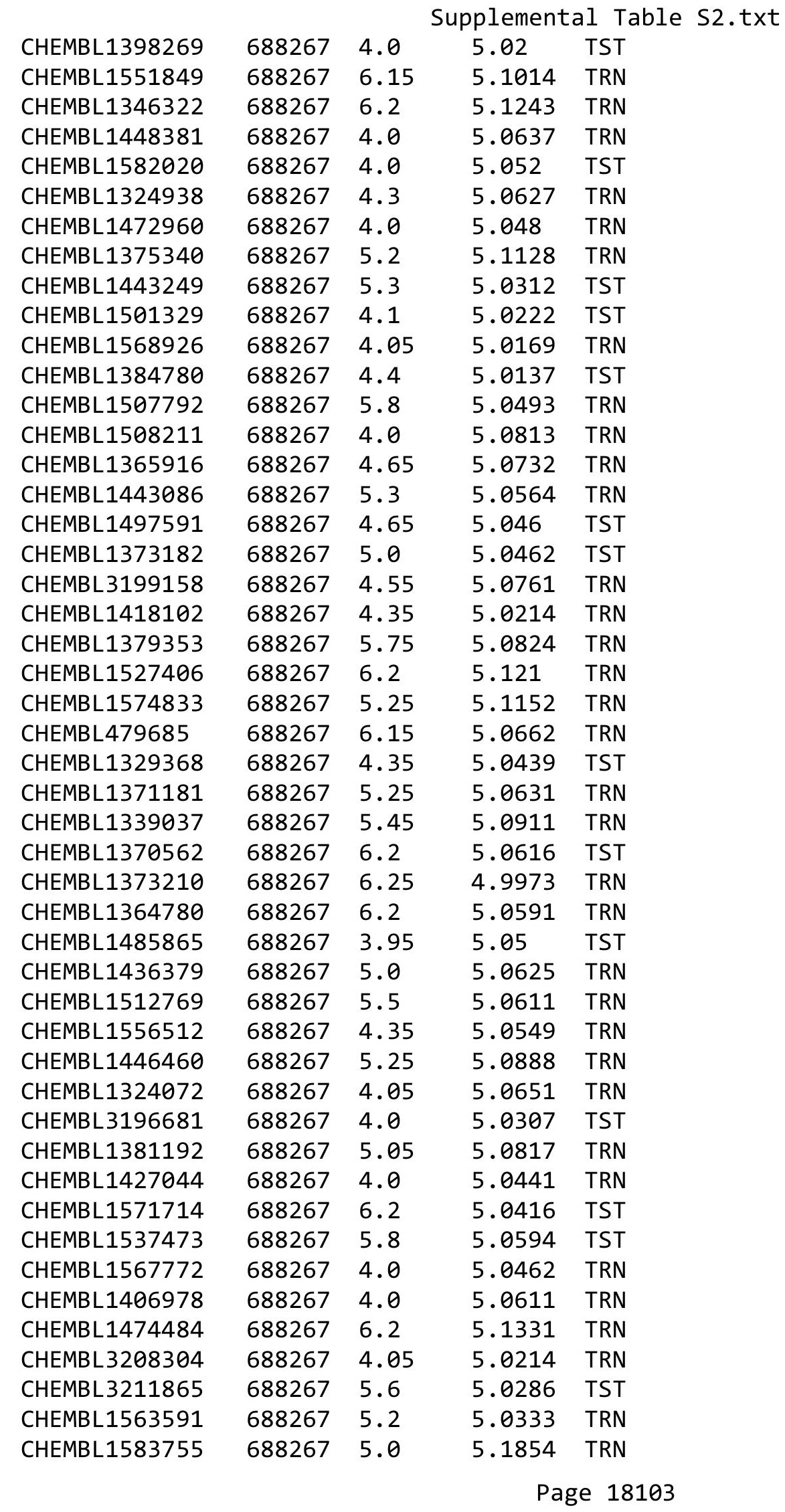




\begin{tabular}{|c|c|c|c|c|}
\hline \multicolumn{5}{|c|}{ Supplemental Table s2.txt } \\
\hline CHEMBL1383364 & 688267 & 5.2 & 5.0059 & TRN \\
\hline CHEMBL1511003 & 688267 & 4.6 & 5.1077 & TST \\
\hline CHEMBL1367702 & 688267 & 5.45 & 5.0934 & TRN \\
\hline CHEMBL1458014 & 688267 & 6.15 & 5.0395 & TRN \\
\hline CHEMBL1546795 & 688267 & 6.2 & 5.1 & TRN \\
\hline CHEMBL1306258 & 688267 & 5.65 & 4.9912 & TRN \\
\hline CHEMBL3212150 & 688267 & 6.25 & $5.0360 e$ & 00000000005 \\
\hline CHEMBL1515213 & 688267 & 4.35 & 5.0326 & TRN \\
\hline CHEMBL1380244 & 688267 & 4.95 & 5.0537 & TST \\
\hline CHEMBL1520739 & 688267 & 6.2 & 5.1121 & TRN \\
\hline CHEMBL536932 & 688267 & 4.05 & 5.0458 & TRN \\
\hline CHEMBL1537828 & 688267 & 4.4 & 5.0754 & TRN \\
\hline CHEMBL1312197 & 688267 & 5.25 & 5.0499 & TRN \\
\hline CHEMBL1538365 & 688267 & 3.95 & 5.1028 & TRN \\
\hline CHEMBL1323078 & 688267 & 3.95 & 5.0355 & TRN \\
\hline CHEMBL1588109 & 688267 & 4.25 & 5.0729 & TRN \\
\hline CHEMBL1310739 & 688267 & 6.2 & 5.1027 & TRN \\
\hline CHEMBL1468771 & 688267 & 4.45 & 5.0423 & TRN \\
\hline CHEMBL1584757 & 688267 & 5.3 & 5.0679 & TST \\
\hline CHEMBL1612802 & 688267 & 4.35 & 5.073 & TST \\
\hline CHEMBL1303047 & 688267 & 4.25 & 5.0333 & TST \\
\hline CHEMBL1473019 & 688267 & 5.4 & 5.0964 & TST \\
\hline CHEMBL1423015 & 688267 & 5.05 & 5.0465 & TST \\
\hline CHEMBL1355600 & 688267 & 3.95 & 5.0302 & TRN \\
\hline CHEMBL1514497 & 688267 & 5.7 & 5.0649 & TRN \\
\hline CHEMBL1373869 & 688267 & 5.3 & 5.0814 & TRN \\
\hline CHEMBL1340288 & 688267 & 4.35 & 5.0619 & TRN \\
\hline CHEMBL1486263 & 688267 & 4.4 & 5.0392 & TRN \\
\hline CHEMBL1385279 & 688267 & 6.15 & 5.067 & TRN \\
\hline CHEMBL1598968 & 688267 & 5.1 & 5.0432 & TST \\
\hline CHEMBL1423248 & 688267 & 5.35 & 5.0316 & TRN \\
\hline CHEMBL66966 & 688267 & 6.0 & 5.0215 & TST \\
\hline CHEMBL1578839 & 688267 & 5.25 & 5.0982 & TRN \\
\hline CHEMBL1482561 & 688267 & 4.6 & 5.038 & TRN \\
\hline CHEMBL1384984 & 688267 & 4.3 & 5.0199 & TRN \\
\hline CHEMBL1338511 & 688267 & 6.15 & 5.0817 & TRN \\
\hline CHEMBL1428759 & 688267 & 4.45 & 5.1294 & TST \\
\hline CHEMBL1587045 & 688267 & 4.4 & 5.0682 & TRN \\
\hline CHEMBL1395039 & 688267 & 6.45 & 5.073 & TRN \\
\hline CHEMBL1319524 & 688267 & 5.0 & 5.0548 & TRN \\
\hline CHEMBL1580839 & 688267 & 4.05 & 5.0317 & TRN \\
\hline CHEMBL1532900 & 688267 & 5.05 & 5.0546 & TRN \\
\hline CHEMBL1475694 & 688267 & 4.05 & 5.0757 & TRN \\
\hline CHEMBL1582439 & 688267 & 6.2 & 5.0185 & TRN \\
\hline CHEMBL1355403 & 688267 & 5.95 & 5.0001 & TRN \\
\hline CHEMBL1341370 & 688267 & 4.35 & 5.0515 & TRN \\
\hline CHEMBL1544792 & 688267 & 4.0 & 5.0739 & TRN \\
\hline CHEMBL1486220 & 688267 & 5.3 & 5.0711 & TRN \\
\hline
\end{tabular}




\begin{tabular}{|c|c|c|c|c|c|}
\hline \multicolumn{6}{|c|}{ plemental labıe S2. } \\
\hline CHEMBL1418850 & 688267 & 6.2 & 5.1146 & TRN & \\
\hline CHEMBL1334994 & 688267 & 6.15 & 5.0519 & TRN & \\
\hline CHEMBL1602845 & 688267 & 6.15 & 5.1151 & TRN & \\
\hline CHEMBL1434623 & 688267 & 5.4 & 5.0411 & TRN & \\
\hline CHEMBL1606841 & 688267 & 5.55 & 5.0339 & TST & \\
\hline CHEMBL1565896 & 688267 & 6.2 & 5.0695 & TRN & \\
\hline CHEMBL1495179 & 688267 & 4.45 & 5.0561 & TST & \\
\hline CHEMBL1481965 & 688267 & 4.35 & 5.0879 & TRN & \\
\hline CHEMBL1473525 & 688267 & 6.25 & 5.0237 & TRN & \\
\hline CHEMBL108861 & 688267 & 5.0 & 5.0474 & TRN & \\
\hline CHEMBL1499455 & 688267 & 5.5 & 5.0484 & TRN & \\
\hline CHEMBL1431913 & 688267 & 4.35 & 5.0442 & TST & \\
\hline CHEMBL1362783 & 688267 & 6.25 & 5.0389 & TST & \\
\hline CHEMBL1610344 & 688267 & 5.0 & 5.0899 & TRN & \\
\hline CHEMBL1343609 & 688267 & 4.35 & 5.0314 & TST & \\
\hline CHEMBL1367654 & 688267 & 6.2 & 5.0413 & TRN & \\
\hline CHEMBL51773 & 688267 & 4.1 & 5.039 & TRN & \\
\hline CHEMBL1579719 & 688267 & 4.1 & 5.063 & TRN & \\
\hline CHEMBL1602285 & 688267 & 4.1 & 5.0736 & TRN & \\
\hline CHEMBL2000640 & 688267 & 6.2 & 5.0532 & TST & \\
\hline CHEMBL1449715 & 688267 & 4.2 & 5.0738 & TST & \\
\hline CHEMBL1462806 & 688267 & 5.6 & 5.0217 & TST & \\
\hline CHEMBL1573373 & 688267 & 4.15 & 5.0381 & TST & \\
\hline CHEMBL1347076 & 688267 & 5.55 & 5.04899 & 99999999995 & TRN \\
\hline CHEMBL1573065 & 688267 & 5.4 & 5.0492 & TRN & \\
\hline CHEMBL1360943 & 688267 & 5.3 & 5.0728 & TRN & \\
\hline CHEMBL1341674 & 688267 & 4.35 & $5.0310 e$ & 0000000001 & TST \\
\hline CHEMBL1485721 & 688267 & 4.4 & 5.0489 & TRN & \\
\hline CHEMBL1410783 & 688267 & 4.45 & 5.0535 & TST & \\
\hline CHEMBL3189712 & 688267 & 4.95 & 4.9885 & TST & \\
\hline CHEMBL196605 & 688267 & 5.65 & 5.0167 & TRN & \\
\hline CHEMBL1395474 & 688267 & 6.1 & 5.0611 & TRN & \\
\hline CHEMBL1379338 & 688267 & 4.35 & 4.9987 & TRN & \\
\hline CHEMBL1324935 & 688267 & 6.15 & 5.0601 & TRN & \\
\hline CHEMBL1466695 & 688267 & 5.35 & 5.0665 & TRN & \\
\hline CHEMBL3191655 & 688267 & 4.05 & 5.0465 & TRN & \\
\hline CHEMBL1473880 & 688267 & 4.1 & 5.0361 & TRN & \\
\hline CHEMBL1471283 & 688267 & 4.25 & 5.0756 & TRN & \\
\hline CHEMBL1576359 & 688267 & 5.1 & 5.0233 & TRN & \\
\hline CHEMBL1464076 & 688267 & 5.1 & 5.0045 & TST & \\
\hline CHEMBL1474694 & 688267 & 4.6 & 5.1003 & TRN & \\
\hline CHEMBL1511760 & 688267 & 6.2 & 5.0523 & TRN & \\
\hline CHEMBL1368765 & 688267 & 5.35 & 5.0362 & TST & \\
\hline CHEMBL1359367 & 688267 & 4.05 & 5.0708 & TRN & \\
\hline CHEMBL1346857 & 688267 & 4.3 & 5.0366 & TST & \\
\hline CHEMBL1461329 & 688267 & 6.2 & 5.0815 & TRN & \\
\hline CHEMBL1419356 & 688267 & 6.15 & 5.0562 & TRN & \\
\hline CHEMBL1448278 & 688267 & 4.25 & 5.077 & TRN & \\
\hline
\end{tabular}




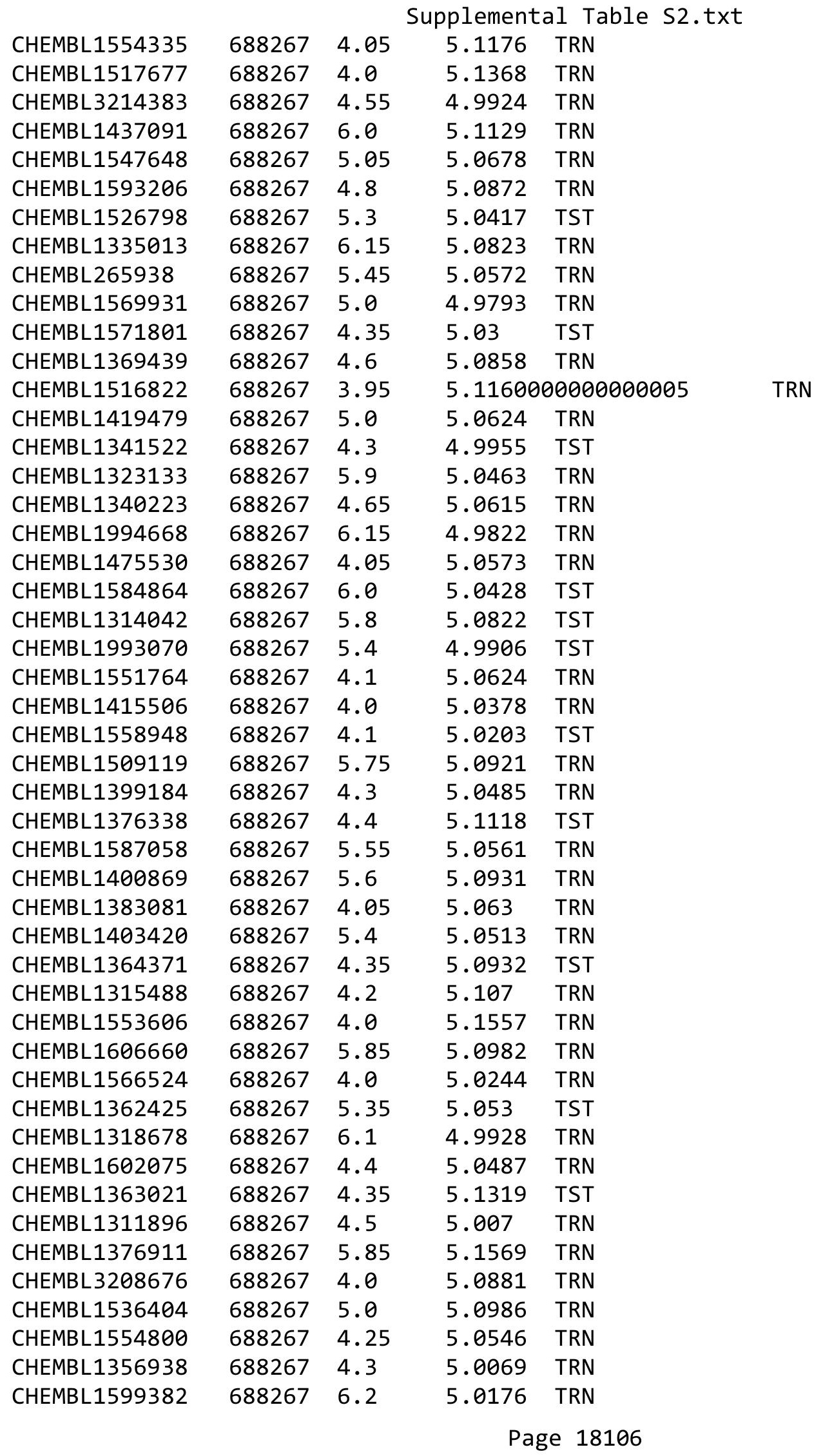




\begin{tabular}{|c|c|c|c|c|}
\hline & & & pplement & al $\mathrm{Ta}$ \\
\hline CHEMBL1445994 & 688267 & 5.3 & 5.0628 & TRN \\
\hline CHEMBL1308181 & 688267 & 5.9 & 5.1247 & TST \\
\hline CHEMBL169662 & 688267 & 5.8 & 5.0444 & TRN \\
\hline CHEMBL1322326 & 688267 & 4.05 & 5.0615 & TRN \\
\hline CHEMBL1465665 & 688267 & 3.95 & 5.0692 & TST \\
\hline CHEMBL1492951 & 688267 & 4.0 & 5.0474 & TRN \\
\hline CHEMBL1482533 & 688267 & 5.75 & 5.0442 & TRN \\
\hline CHEMBL1355443 & 688267 & 5.6 & 5.1007 & TST \\
\hline CHEMBL1602999 & 688267 & 5.4 & 5.0544 & TST \\
\hline CHEMBL1542224 & 688267 & 6.5 & 5.0897 & TRN \\
\hline CHEMBL1520467 & 688267 & 4.0 & 5.1089 & TRN \\
\hline CHEMBL1397491 & 688267 & 4.0 & 5.0334 & TRN \\
\hline CHEMBL1484662 & 688267 & 5.35 & 5.0744 & TRN \\
\hline CHEMBL1552902 & 688267 & 5.5 & 5.0055 & TRN \\
\hline CHEMBL1341069 & 688267 & 5.5 & 5.008 & TRN \\
\hline CHEMBL1562153 & 688267 & 6.05 & 5.0805 & TRN \\
\hline CHEMBL1421186 & 688267 & 4.25 & 5.093 & TST \\
\hline CHEMBL1494426 & 688267 & 5.3 & 5.0291 & TRN \\
\hline CHEMBL1488017 & 688267 & 6.25 & 5.0652 & TRN \\
\hline CHEMBL1518676 & 688267 & 4.0 & 5.081 & TRN \\
\hline CHEMBL3194307 & 688267 & 5.45 & 5.0444 & TRN \\
\hline CHEMBL1355971 & 688267 & 4.35 & 5.0766 & TRN \\
\hline CHEMBL1354587 & 688267 & 4.55 & 5.066 & TST \\
\hline CHEMBL1311211 & 688267 & 3.95 & 5.0514 & TRN \\
\hline CHEMBL1335230 & 688267 & 4.35 & 5.0033 & TRN \\
\hline CHEMBL1329142 & 688267 & 4.05 & 5.0489 & TST \\
\hline CHEMBL 3190151 & 688267 & 4.0 & 5.0513 & TST \\
\hline CHEMBL1435289 & 688267 & 5.5 & 5.0919 & TRN \\
\hline CHEMBL1446502 & 688267 & 4.4 & 5.0222 & TRN \\
\hline CHEMBL1587577 & 688267 & 6.15 & 5.0961 & TRN \\
\hline CHEMBL1556449 & 688267 & 5.8 & 5.0673 & TRN \\
\hline CHEMBL1537810 & 688267 & 4.25 & 5.0271 & TST \\
\hline CHEMBL1450211 & 688267 & 4.35 & 5.061 & TST \\
\hline CHEMBL1512001 & 688267 & 6.45 & 4.967 & TRN \\
\hline CHEMBL1324185 & 688267 & 5.0 & 5.0758 & TRN \\
\hline CHEMBL330756 & 688267 & 4.0 & 5.0728 & TST \\
\hline CHEMBL1374684 & 688267 & 4.45 & 5.0513 & TRN \\
\hline CHEMBL3209417 & 688267 & 5.3 & 5.0161 & TST \\
\hline CHEMBL1579794 & 688267 & 5.4 & 5.0983 & TST \\
\hline CHEMBL1428010 & 688267 & 4.3 & 5.0358 & TST \\
\hline CHEMBL1499427 & 688267 & 4.3 & 5.0234 & TRN \\
\hline CHEMBL1609391 & 688267 & 5.5 & 5.1273 & TRN \\
\hline CHEMBL1559467 & 688267 & 6.2 & 5.0083 & TRN \\
\hline CHEMBL1305346 & 688267 & 4.35 & 5.0111 & TRN \\
\hline CHEMBL1456754 & 688267 & 4.05 & 5.0395 & TRN \\
\hline CHEMBL1566947 & 688267 & 6.2 & 5.0265 & TRN \\
\hline CHEMBL1582453 & 688267 & 5.35 & 5.0692 & TST \\
\hline CHEMBL1340004 & 688267 & 6.2 & 5.0767 & TRN \\
\hline
\end{tabular}




\begin{tabular}{|c|c|c|c|c|c|}
\hline \multicolumn{6}{|c|}{ Supplemental Table S2.txt } \\
\hline CHEMBL1538078 & 688267 & 5.55 & 4.9917 & TRN & \\
\hline CHEMBL1332535 & 688267 & 5.85 & 5.039 & TRN & \\
\hline CHEMBL1353749 & 688267 & 6.0 & 5.0284 & TRN & \\
\hline CHEMBL1320421 & 688267 & 4.75 & 5.0658 & TRN & \\
\hline CHEMBL1863606 & 688267 & 4.85 & 5.0092 & TRN & \\
\hline CHEMBL1419539 & 688267 & 4.35 & 5.0345 & TRN & \\
\hline CHEMBL1357996 & 688267 & 6.25 & 5.0407 & TRN & \\
\hline CHEMBL1312277 & 688267 & 5.15 & 5.1361 & TRN & \\
\hline CHEMBL1535374 & 688267 & 4.0 & 5.1099 & TRN & \\
\hline CHEMBL1547921 & 688267 & 4.4 & 5.0305 & TRN & \\
\hline CHEMBL1316040 & 688267 & 5.6 & 5.0688 & TRN & \\
\hline CHEMBL1505973 & 688267 & 5.5 & 5.0002 & TRN & \\
\hline CHEMBL1316521 & 688267 & 5.2 & 5.0486 & TRN & \\
\hline CHEMBL1591266 & 688267 & 5.65 & 5.1455 & TRN & \\
\hline CHEMBL1415146 & 688267 & 6.2 & 5.1321 & TRN & \\
\hline CHEMBL1350820 & 688267 & 6.25 & 5.0607 & TST & \\
\hline CHEMBL1411817 & 688267 & 4.5 & 5.0468 & TRN & \\
\hline CHEMBL1309344 & 688267 & 5.8 & 5.1012 & TRN & \\
\hline CHEMBL1452184 & 688267 & 4.1 & 5.0263 & TST & \\
\hline CHEMBL1329470 & 688267 & 3.95 & 5.0283 & TRN & \\
\hline CHEMBL1326876 & 688267 & 4.15 & 5.0767 & TRN & \\
\hline CHEMBL1412588 & 688267 & 6.15 & 5.0402 & TST & \\
\hline CHEMBL1459743 & 688267 & 5.8 & 5.1497 & TRN & \\
\hline CHEMBL1548969 & 688267 & 6.2 & 5.0404 & TRN & \\
\hline CHEMBL3211327 & 688267 & 4.3 & 5.0841 & TRN & \\
\hline CHEMBL576362 & 688267 & 5.5 & 5.069 & TRN & \\
\hline CHEMBL1576695 & 688267 & 5.8 & 5.1541 & TRN & \\
\hline CHEMBL1513859 & 688267 & 4.0 & 5.0408 & TST & \\
\hline CHEMBL1499940 & 688267 & 3.95 & 5.0591 & TST & \\
\hline CHEMBL1516699 & 688267 & 5.55 & 5.0839 & TST & \\
\hline CHEMBL1459195 & 688267 & 3.95 & 5.01399 & 9999999999 & TRN \\
\hline CHEMBL1549350 & 688267 & 5.65 & 5.0453 & TRN & \\
\hline CHEMBL1385369 & 688267 & 4.6 & 5.1126 & TRN & \\
\hline CHEMBL1559919 & 688267 & 6.5 & 5.0375 & TRN & \\
\hline CHEMBL1392651 & 688267 & 4.4 & 5.0282 & TST & \\
\hline CHEMBL1530082 & 688267 & 5.25 & 5.1754 & TRN & \\
\hline CHEMBL1474563 & 688267 & 6.1 & 5.0703 & TRN & \\
\hline CHEMBL1373116 & 688267 & 4.4 & 5.0061 & TST & \\
\hline CHEMBL1605980 & 688267 & 4.1 & 5.0773 & TRN & \\
\hline CHEMBL1599338 & 688267 & 4.4 & 5.0745 & TRN & \\
\hline CHEMBL1593407 & 688267 & 5.35 & 5.0788 & TRN & \\
\hline CHEMBL1300946 & 688267 & 4.0 & 5.0451 & TRN & \\
\hline CHEMBL1556694 & 688267 & 6.2 & 4.9842 & TRN & \\
\hline CHEMBL1518464 & 688267 & 4.35 & 5.0626 & TRN & \\
\hline CHEMBL1331058 & 688267 & 4.15 & 5.1389 & TRN & \\
\hline CHEMBL1302659 & 688267 & 5.75 & 5.0565 & TRN & \\
\hline CHEMBL1608744 & 688267 & 6.0 & 4.9729 & TRN & \\
\hline CHEMBL1314321 & 688267 & 4.4 & 5.1801 & TRN & \\
\hline
\end{tabular}




\begin{tabular}{|c|c|c|c|c|c|}
\hline \\
\hline CHEMBL1505128 & 688267 & 5.3 & 5.0385 & TST & \\
\hline CHEMBL3193241 & 688267 & 4.8 & 5.0301 & TRN & \\
\hline CHEMBL1367119 & 688267 & 5.7 & 5.1188 & TRN & \\
\hline CHEMBL1402196 & 688267 & 6.15 & 5.0838 & TRN & \\
\hline CHEMBL1509750 & 688267 & 6.2 & 5.1438 & TRN & \\
\hline CHEMBL1544009 & 688267 & 4.1 & 4.9923 & TRN & \\
\hline CHEMBL1452074 & 688267 & 4.4 & 5.0224 & TST & \\
\hline CHEMBL1438961 & 688267 & 5.15 & 5.1155 & TRN & \\
\hline CHEMBL1401206 & 688267 & 4.85 & 5.1326 & TRN & \\
\hline CHEMBL1370268 & 688267 & 6.5 & 5.0809 & TRN & \\
\hline CHEMBL1338180 & 688267 & 6.2 & 5.0839 & TRN & \\
\hline CHEMBL1533708 & 688267 & 4.1 & 5.0748 & TRN & \\
\hline CHEMBL1394051 & 688267 & 4.4 & 4.9994 & TRN & \\
\hline CHEMBL1547099 & 688267 & 6.2 & 5.0816 & TST & \\
\hline CHEMBL1303173 & 688267 & 4.1 & 5.0776 & TRN & \\
\hline CHEMBL1383004 & 688267 & 6.2 & 5.0427 & TST & \\
\hline CHEMBL1385088 & 688267 & 5.9 & 5.13399 & 99999999995 & TST \\
\hline CHEMBL1446605 & 688267 & 6.2 & 5.0362 & TRN & \\
\hline CHEMBL1305878 & 688267 & 4.4 & 5.1199 & TRN & \\
\hline CHEMBL3207555 & 688267 & 4.55 & 5.065 & TST & \\
\hline CHEMBL1426806 & 688267 & 5.95 & 5.0484 & TST & \\
\hline CHEMBL1467754 & 688267 & 5.35 & 5.0336 & TST & \\
\hline CHEMBL1437062 & 688267 & 5.15 & 5.0139 & TRN & \\
\hline CHEMBL3209201 & 688267 & 5.8 & 5.0953 & TST & \\
\hline CHEMBL451574 & 688267 & 4.6 & 5.0888 & TST & \\
\hline CHEMBL1335502 & 688267 & 5.75 & 5.0491 & TRN & \\
\hline CHEMBL1409955 & 688267 & 4.0 & 5.0203 & TRN & \\
\hline CHEMBL1612905 & 688267 & 6.2 & 5.0886 & TST & \\
\hline CHEMBL1339655 & 688267 & 4.8 & 5.1141 & TST & \\
\hline CHEMBL1321398 & 688267 & 5.2 & 5.0175 & TST & \\
\hline CHEMBL1500693 & 688267 & 5.25 & 5.0824 & TRN & \\
\hline CHEMBL1396251 & 688267 & 4.35 & 5.0326 & TRN & \\
\hline CHEMBL1437635 & 688267 & 5.3 & 5.1089 & TRN & \\
\hline CHEMBL1609643 & 688267 & 4.85 & 5.0629 & TST & \\
\hline CHEMBL1353267 & 688267 & 5.5 & 5.0995 & TRN & \\
\hline CHEMBL1489765 & 688267 & 5.35 & 5.0171 & TRN & \\
\hline CHEMBL1563926 & 688267 & 4.3 & 4.9872 & TRN & \\
\hline CHEMBL1481871 & 688267 & 4.5 & 5.0991 & TRN & \\
\hline CHEMBL1545988 & 688267 & 5.3 & 5.0459 & TRN & \\
\hline CHEMBL1333141 & 688267 & 5.9 & 5.0595 & TRN & \\
\hline CHEMBL1556499 & 688267 & 6.25 & 5.0915 & TRN & \\
\hline CHEMBL1507881 & 688267 & 4.6 & 5.045 & TST & \\
\hline CHEMBL1507436 & 688267 & 4.0 & 5.0115 & TRN & \\
\hline CHEMBL1487015 & 688267 & 5.3 & 5.0267 & TRN & \\
\hline CHEMBL1383905 & 688267 & 4.5 & 5.0754 & TRN & \\
\hline CHEMBL1550281 & 688267 & 6.2 & 5.0907 & TRN & \\
\hline CHEMBL1477146 & 688267 & 5.35 & 5.0355 & TRN & \\
\hline CHEMBL1497858 & 688267 & 6.05 & 5.0055 & TST & \\
\hline
\end{tabular}




\begin{tabular}{|c|c|c|c|c|c|}
\hline \\
\hline CHEMBL3207671 & 688267 & 5.4 & 5.0765 & TRN & \\
\hline CHEMBL1390901 & 688267 & 5.1 & 5.1184 & TRN & \\
\hline CHEMBL1356892 & 688267 & 4.5 & 5.0944 & TRN & \\
\hline CHEMBL1526895 & 688267 & 4.75 & 5.1113 & TRN & \\
\hline CHEMBL1423591 & 688267 & 4.55 & 5.0916 & TRN & \\
\hline CHEMBL1598914 & 688267 & 5.5 & 5.0462 & TRN & \\
\hline CHEMBL1406398 & 688267 & 6.2 & 5.1047 & TRN & \\
\hline CHEMBL1579131 & 688267 & 6.05 & 5.0047 & TRN & \\
\hline CHEMBL1598560 & 688267 & 4.0 & 5.0265 & TRN & \\
\hline CHEMBL1076559 & 688267 & 4.4 & 4.9733 & TST & \\
\hline CHEMBL1304687 & 688267 & 5.6 & 5.0516 & TRN & \\
\hline CHEMBL1411165 & 688267 & 4.35 & 5.0532 & TST & \\
\hline CHEMBL1450889 & 688267 & 5.55 & 5.0938 & TST & \\
\hline CHEMBL1444603 & 688267 & 5.1 & 5.0406 & TRN & \\
\hline CHEMBL1398350 & 688267 & 6.25 & 5.0028 & TRN & \\
\hline CHEMBL1452306 & 688267 & 6.15 & 5.0487 & TRN & \\
\hline CHEMBL1329233 & 688267 & 4.35 & 5.0587 & TRN & \\
\hline CHEMBL1484123 & 688267 & 4.55 & 5.0986 & TRN & \\
\hline CHEMBL1401413 & 688267 & 5.3 & 5.1063 & TRN & \\
\hline CHEMBL1499543 & 688267 & 5.0 & 5.0572 & TRN & \\
\hline CHEMBL1402565 & 688267 & 5.65 & 5.0151 & TRN & \\
\hline CHEMBL1575185 & 688267 & 6.5 & 5.0236 & TRN & \\
\hline CHEMBL1305726 & 688267 & 5.85 & 5.0128 & TRN & \\
\hline CHEMBL1490157 & 688267 & 5.45 & 5.0847 & TRN & \\
\hline CHEMBL1506009 & 688267 & 6.1 & 5.11600 & 20000000005 & TRN \\
\hline CHEMBL1411746 & 688267 & 6.15 & 5.0837 & TST & \\
\hline CHEMBL1504113 & 688267 & 4.25 & 5.1161 & TRN & \\
\hline CHEMBL1571436 & 688267 & 5.3 & 5.0574 & TRN & \\
\hline CHEMBL1526163 & 688267 & 6.5 & 5.0593 & TRN & \\
\hline CHEMBL1351104 & 688267 & 5.85 & 4.9814 & TRN & \\
\hline CHEMBL14284 & 688267 & 3.95 & 5.0007 & TRN & \\
\hline CHEMBL1339730 & 688267 & 4.45 & 5.0867 & TRN & \\
\hline CHEMBL1536886 & 688267 & 4.0 & 5.1182 & TRN & \\
\hline CHEMBL1591242 & 688267 & 5.9 & 5.0336 & TRN & \\
\hline CHEMBL1325629 & 688267 & 4.25 & 5.1161 & TRN & \\
\hline CHEMBL1347409 & 688267 & 6.2 & 5.012 & TRN & \\
\hline CHEMBL1528322 & 688267 & 4.55 & 5.04 & TRN & \\
\hline CHEMBL1520451 & 688267 & 4.25 & 5.0273 & TRN & \\
\hline CHEMBL1306813 & 688267 & 5.3 & 5.0086 & TRN & \\
\hline CHEMBL1357121 & 688267 & 6.2 & 5.0487 & TRN & \\
\hline CHEMBL1414830 & 688267 & 3.95 & 5.0453 & TST & \\
\hline CHEMBL1341221 & 688267 & 4.35 & 5.0463 & TRN & \\
\hline CHEMBL3195645 & 688267 & 4.0 & 5.0522 & TST & \\
\hline CHEMBL1538197 & 688267 & 4.05 & 5.0264 & TRN & \\
\hline CHEMBL1387185 & 688267 & 6.25 & 5.0239 & TRN & \\
\hline CHEMBL1348201 & 688267 & 4.35 & 4.9909 & TRN & \\
\hline CHEMBL1489968 & 688267 & 4.45 & 5.0657 & TRN & \\
\hline CHEMBL1316254 & 688267 & 3.75 & 5.0233 & TRN & \\
\hline & & & & 811 & \\
\hline
\end{tabular}




\begin{tabular}{|c|c|c|c|c|c|}
\hline \multicolumn{6}{|c|}{ Supplemental Table S2.txt } \\
\hline CHEMBL1543580 & 688267 & 4.45 & 5.1167 & TRN & \\
\hline CHEMBL1336959 & 688267 & 4.25 & 4.9914 & TRN & \\
\hline CHEMBL1562881 & 688267 & 4.9 & 4.9956 & TRN & \\
\hline CHEMBL1484148 & 688267 & 5.7 & 5.0702 & TRN & \\
\hline CHEMBL1523764 & 688267 & 5.65 & 5.0682 & TRN & \\
\hline CHEMBL1384095 & 688267 & 4.3 & 5.0381 & TRN & \\
\hline CHEMBL1498140 & 688267 & 4.35 & 5.0214 & TST & \\
\hline CHEMBL1595573 & 688267 & 5.4 & 5.0907 & TST & \\
\hline CHEMBL1343779 & 688267 & 4.45 & 5.0543 & TRN & \\
\hline CHEMBL1462370 & 688267 & 4.4 & 5.1211 & TST & \\
\hline CHEMBL1308285 & 688267 & 5.25 & 5.0602 & TRN & \\
\hline CHEMBL1400373 & 688267 & 4.3 & 5.1406 & TRN & \\
\hline CHEMBL1592359 & 688267 & 6.1 & 5.0599 & TRN & \\
\hline CHEMBL1527015 & 688267 & 4.05 & 5.1132 & TRN & \\
\hline CHEMBL1521427 & 688267 & 4.25 & 5.05399 & 9999999999 & TST \\
\hline CHEMBL1335209 & 688267 & 6.5 & 5.0459 & TST & \\
\hline CHEMBL1517737 & 688267 & 4.4 & 5.013 & TST & \\
\hline CHEMBL1532146 & 688267 & 4.4 & 5.1374 & TST & \\
\hline CHEMBL3211799 & 688267 & 5.3 & 5.0666 & TRN & \\
\hline CHEMBL1396859 & 688267 & 4.3 & 5.0318 & TRN & \\
\hline CHEMBL1427867 & 688267 & 5.65 & 5.0097 & TRN & \\
\hline CHEMBL1356402 & 688267 & 6.2 & 5.0146 & TRN & \\
\hline CHEMBL1357666 & 688267 & 4.05 & 5.0214 & TRN & \\
\hline CHEMBL1309127 & 688267 & 5.4 & 4.9901 & TRN & \\
\hline CHEMBL1505595 & 688267 & 6.2 & 5.1432 & TRN & \\
\hline CHEMBL1483831 & 688267 & 6.15 & 5.0184 & TRN & \\
\hline CHEMBL1329772 & 688267 & 4.7 & 5.0266 & TST & \\
\hline CHEMBL1387306 & 688267 & 5.45 & 5.1075 & TST & \\
\hline CHEMBL1480160 & 688267 & 5.45 & 5.1585 & TRN & \\
\hline CHEMBL1601728 & 688267 & 3.95 & 5.0429 & TST & \\
\hline CHEMBL1439833 & 688267 & 5.55 & 5.0614 & TRN & \\
\hline CHEMBL1334956 & 688267 & 4.3 & 5.1049 & TST & \\
\hline CHEMBL1362033 & 688267 & 6.1 & 4.9913 & TST & \\
\hline CHEMBL1590513 & 688267 & 5.25 & 4.9972 & TST & \\
\hline CHEMBL1582929 & 688267 & 3.8 & 5.0273 & TRN & \\
\hline CHEMBL1507889 & 688267 & 5.75 & 5.0285 & TST & \\
\hline CHEMBL1408531 & 688267 & 5.85 & 5.0719 & TRN & \\
\hline CHEMBL1583661 & 688267 & 5.3 & 5.1245 & TRN & \\
\hline CHEMBL1451094 & 688267 & 6.1 & 5.0837 & TRN & \\
\hline CHEMBL1343585 & 688267 & 6.2 & 5.1346 & TRN & \\
\hline CHEMBL1338472 & 688267 & 4.2 & 5.0833 & TST & \\
\hline CHEMBL1382157 & 688267 & 5.8 & 5.0812 & TST & \\
\hline CHEMBL3213720 & 688267 & 4.0 & 5.0754 & TST & \\
\hline CHEMBL1485914 & 688267 & 3.95 & 5.044 & TRN & \\
\hline CHEMBL1381412 & 688267 & 5.85 & 5.0805 & TRN & \\
\hline CHEMBL1504007 & 688267 & 5.3 & 5.0404 & TRN & \\
\hline CHEMBL1560494 & 688267 & 4.2 & 5.075 & TST & \\
\hline CHEMBL1504705 & 688267 & 6.15 & 5.1081 & TRN & \\
\hline
\end{tabular}




\begin{tabular}{|c|c|c|c|c|c|}
\hline \\
\hline CHEMBL1429511 & 688267 & 6.2 & 5.0825 & TRN & \\
\hline CHEMBL3194845 & 688267 & 4.65 & 5.0496 & TST & \\
\hline CHEMBL1334057 & 688267 & 5.45 & 5.08 & TRN & \\
\hline CHEMBL1606677 & 688267 & 4.0 & 5.0075 & TRN & \\
\hline CHEMBL1374603 & 688267 & 6.5 & 5.1085 & TST & \\
\hline CHEMBL1500389 & 688267 & 3.9 & 5.0454 & TST & \\
\hline CHEMBL1475134 & 688267 & 6.2 & 5.0694 & TRN & \\
\hline CHEMBL1304712 & 688267 & 4.4 & 5.0369 & TRN & \\
\hline CHEMBL1408266 & 688267 & 4.7 & 5.0582 & TRN & \\
\hline CHEMBL1430352 & 688267 & 4.55 & 5.06800 & 00000000005 & TRN \\
\hline CHEMBL1481960 & 688267 & 6.2 & 5.1124 & TRN & \\
\hline CHEMBL1317880 & 688267 & 5.8 & 5.0233 & TST & \\
\hline CHEMBL1431595 & 688267 & 4.35 & 5.0597 & TST & \\
\hline CHEMBL1591723 & 688267 & 5.3 & 5.0747 & TRN & \\
\hline CHEMBL1356448 & 688267 & 4.05 & 5.053 & TRN & \\
\hline CHEMBL567323 & 688267 & 5.05 & 5.0705 & TRN & \\
\hline CHEMBL1440148 & 688267 & 5.05 & 5.0357 & TST & \\
\hline CHEMBL1358014 & 688267 & 4.95 & 5.0366 & TST & \\
\hline CHEMBL1611977 & 688267 & 5.3 & 5.0776 & TRN & \\
\hline CHEMBL1397856 & 688267 & 4.55 & 5.1076 & TRN & \\
\hline CHEMBL1318620 & 688267 & 4.7 & 5.0531 & TRN & \\
\hline CHEMBL1512972 & 688267 & 6.2 & 5.0763 & TRN & \\
\hline CHEMBL1403655 & 688267 & 6.25 & 5.0717 & TRN & \\
\hline CHEMBL1502022 & 688267 & 5.25 & 5.0512 & TRN & \\
\hline CHEMBL1552684 & 688267 & 5.35 & 5.1278 & TRN & \\
\hline CHEMBL1528774 & 688267 & 4.4 & 5.0524 & TST & \\
\hline CHEMBL1359974 & 688267 & 5.85 & 5.1099 & TRN & \\
\hline CHEMBL1358642 & 688267 & 3.95 & 5.0531 & TRN & \\
\hline CHEMBL1540255 & 688267 & 4.65 & 5.144 & TRN & \\
\hline CHEMBL1563071 & 688267 & 5.35 & 5.0952 & TRN & \\
\hline CHEMBL1466486 & 688267 & 6.8499 & 5.1423 & TST & \\
\hline CHEMBL1301693 & 688267 & 4.9 & 5.03600 & 30000000005 & TST \\
\hline CHEMBL1413633 & 688267 & 5.9 & 5.0145 & TRN & \\
\hline CHEMBL1576836 & 688267 & 4.65 & 4.9986 & TST & \\
\hline CHEMBL1443082 & 688267 & 4.3 & 5.0204 & TRN & \\
\hline CHEMBL1606126 & 688267 & 4.5 & 5.0309 & TRN & \\
\hline CHEMBL1348930 & 688267 & 4.05 & 5.053 & TRN & \\
\hline CHEMBL1556441 & 688267 & 6.2 & 5.0229 & TRN & \\
\hline CHEMBL1399791 & 688267 & 4.35 & 5.091 & TRN & \\
\hline CHEMBL1510377 & 688267 & 6.25 & 5.087 & TRN & \\
\hline CHEMBL1455382 & 688267 & 3.95 & 5.0505 & TRN & \\
\hline CHEMBL1432726 & 688267 & 4.35 & 5.1264 & TST & \\
\hline CHEMBL1308983 & 688267 & 5.4 & 5.0914 & TRN & \\
\hline CHEMBL1307770 & 688267 & 6.1 & 5.0283 & TRN & \\
\hline CHEMBL1371067 & 688267 & 4.2 & 5.0611 & TRN & \\
\hline CHEMBL1515370 & 688267 & 5.4 & 5.1034 & TRN & \\
\hline CHEMBL1309726 & 688267 & 5.25 & 5.0664 & TRN & \\
\hline CHEMBL1410065 & 688267 & 6.25 & 5.0116 & TRN & \\
\hline
\end{tabular}




\begin{tabular}{|c|c|c|c|c|c|}
\hline \multicolumn{6}{|c|}{ שנte } \\
\hline CHEMBL1546106 & 688267 & 5.6 & 5.0531 & TST & \\
\hline CHEMBL1580880 & 688267 & 5.5 & 5.0567 & TRN & \\
\hline CHEMBL1432254 & 688267 & 6.2 & 5.0254 & TST & \\
\hline CHEMBL1491898 & 688267 & 5.75 & 5.0476 & TRN & \\
\hline CHEMBL1564053 & 688267 & 4.8 & 5.026 & TRN & \\
\hline CHEMBL1421722 & 688267 & 4.0 & 5.0182 & TRN & \\
\hline CHEMBL1433838 & 688267 & 4.4 & 5.0405 & TST & \\
\hline CHEMBL1496002 & 688267 & 4.9 & 5.0047 & TRN & \\
\hline CHEMBL1308808 & 688267 & 4.6 & 5.1183 & TST & \\
\hline CHEMBL1354544 & 688267 & 4.55 & 5.0396 & TST & \\
\hline CHEMBL1335614 & 688267 & 6.2 & 5.1 & TRN & \\
\hline CHEMBL1356250 & 688267 & 5.6 & 5.0402 & TRN & \\
\hline CHEMBL1324161 & 688267 & 6.15 & 5.0512 & TRN & \\
\hline CHEMBL1409242 & 688267 & 6.2 & 5.0848 & TRN & \\
\hline CHEMBL1465686 & 688267 & 4.35 & 5.0457 & TRN & \\
\hline CHEMBL1515096 & 688267 & 6.15 & 5.0173 & TRN & \\
\hline CHEMBL3199828 & 688267 & 4.55 & 5.0139 & TRN & \\
\hline CHEMBL1410794 & 688267 & 4.05 & 5.0717 & TRN & \\
\hline CHEMBL1522845 & 688267 & 5.75 & $5.1160 e$ & 00000000005 & TRN \\
\hline CHEMBL1472070 & 688267 & 6.2 & 5.0697 & TRN & \\
\hline CHEMBL1585661 & 688267 & 4.15 & 4.9813 & TRN & \\
\hline CHEMBL1485819 & 688267 & 4.05 & 4.9651 & TST & \\
\hline CHEMBL1441636 & 688267 & 4.15 & 5.0378 & TRN & \\
\hline CHEMBL569958 & 688267 & 4.05 & 5.0333 & TRN & \\
\hline CHEMBL1530565 & 688267 & 5.85 & 5.0404 & TRN & \\
\hline CHEMBL1465327 & 688267 & 4.0 & 5.0934 & TST & \\
\hline CHEMBL1492852 & 688267 & 5.35 & 5.0371 & TRN & \\
\hline CHEMBL1578650 & 688267 & 4.8 & 5.0599 & TRN & \\
\hline CHEMBL1447754 & 688267 & 4.9 & 5.0359 & TRN & \\
\hline CHEMBL1466507 & 688267 & 6.2 & 5.0994 & TRN & \\
\hline CHEMBL1408033 & 688267 & 6.15 & 5.0781 & TRN & \\
\hline CHEMBL1447833 & 688267 & 4.0 & 4.9703 & TRN & \\
\hline CHEMBL1571288 & 688267 & 6.2 & 5.0591 & TRN & \\
\hline CHEMBL1605959 & 688267 & 4.05 & 5.0374 & TST & \\
\hline CHEMBL1344758 & 688267 & 6.2 & 5.0578 & TRN & \\
\hline CHEMBL1315892 & 688267 & 6.2 & 5.0284 & TRN & \\
\hline CHEMBL1434274 & 688267 & 6.2 & 5.0251 & TRN & \\
\hline CHEMBL1414739 & 688267 & 6.2 & 5.0442 & TRN & \\
\hline CHEMBL1417994 & 688267 & 5.05 & 5.1034 & TRN & \\
\hline CHEMBL1371875 & 688267 & 4.65 & 5.0619 & TRN & \\
\hline CHEMBL1330494 & 688267 & 4.65 & 5.1 & TST & \\
\hline CHEMBL1533571 & 688267 & 5.9 & 5.0376 & TRN & \\
\hline CHEMBL1446778 & 688267 & 5.2 & 5.0068 & TST & \\
\hline CHEMBL1518797 & 688267 & 4.4 & 5.0342 & TRN & \\
\hline CHEMBL1482502 & 688267 & 5.15 & 5.1235 & TST & \\
\hline CHEMBL1551078 & 688267 & 5.0 & 5.1288 & TRN & \\
\hline CHEMBL1410466 & 688267 & 4.2 & 5.0116 & TST & \\
\hline CHEMBL1407493 & 688267 & 6.45 & 5.0949 & TRN & \\
\hline & & & & 18113 & \\
\hline
\end{tabular}




\begin{tabular}{|c|c|c|c|c|c|}
\hline \multicolumn{6}{|c|}{ Supplemental Table s2.txt } \\
\hline CHEMBL1461316 & 688267 & 4.6 & 5.1228 & TRN & \\
\hline CHEMBL1482559 & 688267 & 6.45 & 5.0677 & TRN & \\
\hline CHEMBL1433826 & 688267 & 4.45 & 5.0873 & TRN & \\
\hline CHEMBL1328650 & 688267 & 6.2 & 5.0032 & TRN & \\
\hline CHEMBL1610882 & 688267 & 5.35 & 4.9926 & TST & \\
\hline CHEMBL1368212 & 688267 & 4.1 & 5.0241 & TST & \\
\hline CHEMBL1610459 & 688267 & 5.85 & 5.0753 & TST & \\
\hline CHEMBL1465159 & 688267 & 5.95 & 5.0981 & TRN & \\
\hline CHEMBL1611253 & 688267 & 4.85 & 5.0714 & TRN & \\
\hline CHEMBL1522272 & 688267 & 6.0 & 5.0043 & TRN & \\
\hline CHEMBL1314782 & 688267 & 6.2 & 5.0874 & TRN & \\
\hline CHEMBL1566145 & 688267 & 4.7 & 5.0205 & TRN & \\
\hline CHEMBL1400465 & 688267 & 6.15 & 5.0541 & TRN & \\
\hline CHEMBL1415603 & 688267 & 5.95 & 4.9868 & TRN & \\
\hline CHEMBL1388969 & 688267 & 6.15 & 4.9672 & TRN & \\
\hline CHEMBL1359395 & 688267 & 4.25 & 5.0517 & TRN & \\
\hline CHEMBL1525386 & 688267 & 6.25 & 4.9822 & TST & \\
\hline CHEMBL1306208 & 688267 & 5.8 & 5.0739 & TRN & \\
\hline CHEMBL1475418 & 688267 & 5.35 & 5.0404 & TRN & \\
\hline CHEMBL1606780 & 688267 & 6.2 & 5.0447 & TRN & \\
\hline CHEMBL1355906 & 688267 & 6.05 & 5.0828 & TRN & \\
\hline CHEMBL1527496 & 688267 & 5.85 & 5.0324 & TST & \\
\hline CHEMBL1603756 & 688267 & 5.95 & 5.0414 & TRN & \\
\hline CHEMBL1422846 & 688267 & 4.0 & 5.0515 & TST & \\
\hline CHEMBL1384755 & 688267 & 4.45 & 5.0385 & TRN & \\
\hline CHEMBL1300837 & 688267 & 3.9 & 5.0346 & TST & \\
\hline CHEMBL1441633 & 688267 & 4.05 & 5.0956 & TRN & \\
\hline CHEMBL1333211 & 688267 & 4.9 & 5.0984 & TST & \\
\hline CHEMBL1501802 & 688267 & 6.15 & 5.1577 & TRN & \\
\hline CHEMBL1546082 & 688267 & 6.15 & $5.1220 e$ & 0000000001 & TRN \\
\hline CHEMBL1372321 & 688267 & 4.0 & 5.0352 & TRN & \\
\hline CHEMBL1344980 & 688267 & 5.45 & 5.0608 & TRN & \\
\hline CHEMBL1433080 & 688267 & 5.85 & 5.0143 & TRN & \\
\hline CHEMBL1596457 & 688267 & 4.3 & 5.018 & TRN & \\
\hline CHEMBL1426207 & 688267 & 4.8 & 5.0615 & TRN & \\
\hline CHEMBL1397868 & 688267 & 6.2 & 5.0329 & TRN & \\
\hline CHEMBL1481022 & 688267 & 4.05 & 5.1241 & TRN & \\
\hline CHEMBL1518332 & 688267 & 5.3 & 5.0209 & TRN & \\
\hline CHEMBL1302636 & 688267 & 4.15 & 5.0882 & TRN & \\
\hline CHEMBL1445316 & 688267 & 5.35 & 5.0763 & TRN & \\
\hline CHEMBL1602284 & 688267 & 3.95 & 5.0483 & TRN & \\
\hline CHEMBL1446332 & 688267 & 6.2 & 5.0025 & TRN & \\
\hline CHEMBL1482504 & 688267 & 5.85 & 5.0629 & TRN & \\
\hline CHEMBL1540538 & 688267 & 4.3 & 5.0601 & TST & \\
\hline CHEMBL1345270 & 688267 & 5.55 & 5.0641 & TRN & \\
\hline CHEMBL1463913 & 688267 & 6.5 & 5.0682 & TRN & \\
\hline CHEMBL1413008 & 688267 & 4.4 & 5.103 & TST & \\
\hline CHEMBL1485830 & 688267 & 5.75 & 5.0955 & TRN & \\
\hline
\end{tabular}




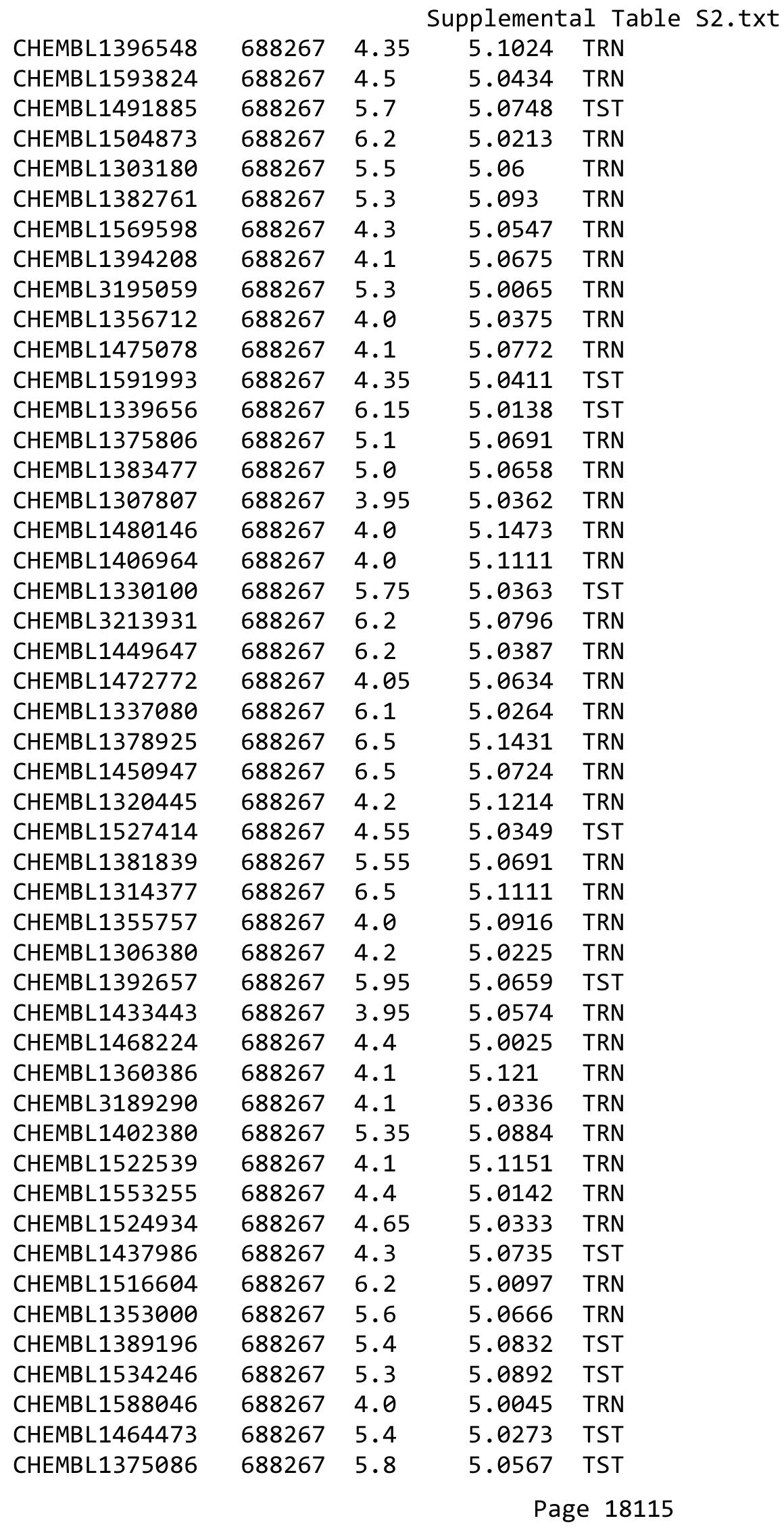




\begin{tabular}{|c|c|c|c|c|c|}
\hline \multicolumn{6}{|c|}{ Supplemental Table S2.txt } \\
\hline CHEMBL1556633 & 688267 & 4.6 & 5.0137 & TRN & \\
\hline CHEMBL1580474 & 688267 & 4.35 & 5.0452 & TRN & \\
\hline CHEMBL1500760 & 688267 & 4.3 & 5.1071 & TRN & \\
\hline CHEMBL1490895 & 688267 & 4.5 & 5.1261 & TRN & \\
\hline CHEMBL1327663 & 688267 & 4.75 & 5.1295 & TRN & \\
\hline CHEMBL1402098 & 688267 & 5.9 & 5.0119 & TRN & \\
\hline CHEMBL 2003539 & 688267 & 4.85 & 5.0484 & TRN & \\
\hline CHEMBL1502393 & 688267 & 5.7 & 5.072 & TRN & \\
\hline CHEMBL1402176 & 688267 & 3.95 & 5.0544 & TRN & \\
\hline CHEMBL1531378 & 688267 & 6.25 & 5.107 & TST & \\
\hline CHEMBL1528142 & 688267 & 4.5 & 5.02 & TRN & \\
\hline CHEMBL1546844 & 688267 & 4.4 & 5.1075 & TRN & \\
\hline CHEMBL1467313 & 688267 & 4.65 & 5.0774 & TRN & \\
\hline CHEMBL1612037 & 688267 & 4.0 & 5.0231 & TRN & \\
\hline CHEMBL1514564 & 688267 & 4.0 & 5.0022 & TRN & \\
\hline CHEMBL1567140 & 688267 & 6.2 & 5.0351 & TRN & \\
\hline CHEMBL1490252 & 688267 & 5.25 & 5.0321 & TRN & \\
\hline CHEMBL1415610 & 688267 & 5.4 & 5.1022 & TRN & \\
\hline CHEMBL1459161 & 688267 & 4.05 & 5.0541 & TRN & \\
\hline CHEMBL1391425 & 688267 & 5.3 & 5.1253 & TST & \\
\hline CHEMBL1501910 & 688267 & 6.2 & 5.0643 & TRN & \\
\hline CHEMBL1455970 & 688267 & 5.2 & 5.0746 & TRN & \\
\hline CHEMBL1363729 & 688267 & 3.95 & 5.1127 & TRN & \\
\hline CHEMBL1468532 & 688267 & 3.9 & 5.0525 & TST & \\
\hline CHEMBL1345672 & 688267 & 5.3 & 5.0023 & TRN & \\
\hline CHEMBL1359792 & 688267 & 5.5 & 5.0633 & TRN & \\
\hline CHEMBL1355056 & 688267 & 5.85 & 5.0896 & TRN & \\
\hline CHEMBL1559949 & 688267 & 5.4 & 5.1532 & TRN & \\
\hline CHEMBL3209789 & 688267 & 4.05 & 5.0326 & TRN & \\
\hline CHEMBL1535720 & 688267 & 4.3 & 5.0481 & TST & \\
\hline CHEMBL1604795 & 688267 & 4.8 & 5.0578 & TST & \\
\hline CHEMBL1389079 & 688267 & 4.4 & 5.0338 & TRN & \\
\hline CHEMBL1336426 & 688267 & 6.2 & 5.1052 & TRN & \\
\hline CHEMBL1488971 & 688267 & 5.25 & 5.1053 & TRN & \\
\hline CHEMBL1509864 & 688267 & 5.3 & 5.0634 & TST & \\
\hline CHEMBL1365764 & 688267 & 6.2 & 5.1336 & TRN & \\
\hline CHEMBL1547664 & 688267 & 4.1 & 5.0814 & TST & \\
\hline CHEMBL1592224 & 688267 & 5.2 & 4.9830 & 00000000005 & TRN \\
\hline CHEMBL1501998 & 688267 & 5.3 & 5.105 & TRN & \\
\hline CHEMBL1549199 & 688267 & 5.9 & 5.0527 & TRN & \\
\hline CHEMBL1528439 & 688267 & 5.6 & 5.1227 & TRN & \\
\hline CHEMBL1428765 & 688267 & 5.2 & 5.0843 & TRN & \\
\hline CHEMBL1586290 & 688267 & 4.0 & 5.0667 & TST & \\
\hline CHEMBL1510418 & 688267 & 4.05 & 5.0491 & TRN & \\
\hline CHEMBL1463847 & 688267 & 4.25 & 5.0333 & TRN & \\
\hline CHEMBL1326037 & 688267 & 4.7 & 5.0333 & TRN & \\
\hline CHEMBL1546447 & 688267 & 4.2 & 5.0282 & TRN & \\
\hline CHEMBL1611813 & 688267 & 5.5 & 5.1037 & TRN & \\
\hline
\end{tabular}




\begin{tabular}{|c|c|c|c|c|c|}
\hline & & \multicolumn{4}{|c|}{ Supplemental Table S2.txt } \\
\hline CHEMBL1378268 & 688267 & 4.0 & 5.0863 & TRN & \\
\hline CHEMBL1360564 & 688267 & 6.15 & 5.0585 & TRN & \\
\hline CHEMBL1476203 & 688267 & 5.0 & 5.0871 & TRN & \\
\hline CHEMBL1520419 & 688267 & 4.3 & 5.0068 & TRN & \\
\hline CHEMBL1474766 & 688267 & 6.25 & 5.1066 & TRN & \\
\hline CHEMBL1409123 & 688267 & 5.9 & 5.152 & TRN & \\
\hline CHEMBL1483973 & 688267 & 5.6 & 5.0719 & TRN & \\
\hline CHEMBL1603748 & 688267 & 4.6 & 5.0711 & TRN & \\
\hline CHEMBL1356407 & 688267 & 6.25 & 5.0312 & TRN & \\
\hline CHEMBL1476439 & 688267 & 5.45 & 5.0667 & TRN & \\
\hline CHEMBL1341226 & 688267 & 4.65 & 5.0642 & TRN & \\
\hline CHEMBL1436566 & 688267 & 4.25 & 5.0976 & TRN & \\
\hline CHEMBL1604818 & 688267 & 4.0 & 5.0696 & TRN & \\
\hline CHEMBL1331424 & 688267 & 5.75 & 5.0943 & TRN & \\
\hline CHEMBL1572192 & 688267 & 4.75 & 5.1109 & TRN & \\
\hline CHEMBL1329185 & 688267 & 4.8 & 5.0253 & TRN & \\
\hline CHEMBL1504727 & 688267 & 3.95 & 5.09399 & 9999999999 & TRN \\
\hline CHEMBL1348122 & 688267 & 4.05 & 5.0192 & TRN & \\
\hline CHEMBL1602100 & 688267 & 5.3 & 5.1248 & TRN & \\
\hline CHEMBL1523776 & 688267 & 4.35 & 5.0593 & TRN & \\
\hline CHEMBL1443618 & 688267 & 6.0 & 5.1087 & TST & \\
\hline CHEMBL1338190 & 688267 & 4.1 & 5.0506 & TST & \\
\hline CHEMBL1480056 & 688267 & 4.25 & 5.0012 & TST & \\
\hline CHEMBL1394697 & 688267 & 6.1 & 5.0677 & TRN & \\
\hline CHEMBL1526694 & 688267 & 5.1 & 5.1003 & TST & \\
\hline CHEMBL1590612 & 688267 & 6.5 & 5.0624 & TRN & \\
\hline CHEMBL1531732 & 688267 & 4.45 & 5.1442 & TRN & \\
\hline CHEMBL3210382 & 688267 & 6.2 & 5.0188 & TRN & \\
\hline CHEMBL1600422 & 688267 & 6.2 & 5.0763 & TRN & \\
\hline CHEMBL1355381 & 688267 & 4.0 & 5.0189 & TRN & \\
\hline CHEMBL1426010 & 688267 & 4.1 & 5.0258 & TST & \\
\hline CHEMBL1455994 & 688267 & 4.0 & 5.1153 & TRN & \\
\hline CHEMBL1536916 & 688267 & 4.5 & 5.0494 & TST & \\
\hline CHEMBL1592525 & 688267 & 4.6 & 5.0388 & TRN & \\
\hline CHEMBL3194955 & 688267 & 5.1 & 5.1126 & TRN & \\
\hline CHEMBL1433462 & 688267 & 5.5 & 5.0202 & TRN & \\
\hline CHEMBL1587681 & 688267 & 5.0 & 5.0245 & TRN & \\
\hline CHEMBL1326546 & 688267 & 4.3 & 5.0504 & TRN & \\
\hline CHEMBL1563551 & 688267 & 4.0 & 5.0659 & TRN & \\
\hline CHEMBL1471039 & 688267 & 5.25 & 4.9833 & TST & \\
\hline CHEMBL1539794 & 688267 & 5.0 & 5.0611 & TST & \\
\hline CHEMBL1299679 & 688267 & 5.35 & 5.0664 & TST & \\
\hline CHEMBL3193156 & 688267 & 4.05 & 5.0274 & TST & \\
\hline CHEMBL1526603 & 688267 & 5.3 & 5.1059 & TRN & \\
\hline CHEMBL1473504 & 688267 & 4.4 & 5.0142 & TST & \\
\hline CHEMBL1320821 & 688267 & 4.0 & 5.1042 & TST & \\
\hline CHEMBL1427486 & 688267 & 5.0 & 5.027 & TRN & \\
\hline CHEMBL1451899 & 688267 & 3.95 & 5.0369 & TRN & \\
\hline
\end{tabular}




\begin{tabular}{|c|c|c|c|c|c|}
\hline \\
\hline CHEMBL1383207 & 688267 & 4.3 & 5.0461 & TST & \\
\hline CHEMBL1516255 & 688267 & 6.05 & 5.0583 & TRN & \\
\hline CHEMBL1556543 & 688267 & 5.15 & 5.0325 & TRN & \\
\hline CHEMBL1593608 & 688267 & 6.5 & 5.063 & TRN & \\
\hline CHEMBL1469321 & 688267 & 6.0 & 5.0375 & TRN & \\
\hline CHEMBL1603077 & 688267 & 4.05 & 5.0511 & TRN & \\
\hline CHEMBL1440330 & 688267 & 4.3 & 5.0635 & TRN & \\
\hline CHEMBL1366099 & 688267 & 5.1 & 5.0839 & TRN & \\
\hline CHEMBL1479320 & 688267 & 4.0 & 4.9686 & TRN & \\
\hline CHEMBL3191393 & 688267 & 6.15 & 5.0181 & TRN & \\
\hline CHEMBL1456050 & 688267 & 5.4 & 5.0243 & TRN & \\
\hline CHEMBL1569950 & 688267 & 6.5 & 5.0819 & TRN & \\
\hline CHEMBL1515623 & 688267 & 4.0 & 5.046 & TRN & \\
\hline CHEMBL3192012 & 688267 & 4.55 & 4.9834 & TRN & \\
\hline CHEMBL1335172 & 688267 & 4.15 & 5.0699 & TRN & \\
\hline CHEMBL1502980 & 688267 & 4.1 & 5.0379 & TST & \\
\hline CHEMBL1343831 & 688267 & 4.65 & 5.0967 & TRN & \\
\hline CHEMBL1308702 & 688267 & 4.1 & 5.0236 & TRN & \\
\hline CHEMBL3209512 & 688267 & 4.75 & 5.048 & TST & \\
\hline CHEMBL1529428 & 688267 & 4.05 & 5.0462 & TRN & \\
\hline CHEMBL1545852 & 688267 & 5.05 & 5.0834 & TST & \\
\hline CHEMBL1392574 & 688267 & 4.25 & 5.1118 & TST & \\
\hline CHEMBL1356288 & 688267 & 4.5 & 5.0602 & TRN & \\
\hline CHEMBL1482817 & 688267 & 5.0 & 5.0731 & TRN & \\
\hline CHEMBL1313203 & 688267 & 4.65 & 5.0362 & TRN & \\
\hline CHEMBL1377256 & 688267 & 4.05 & 5.03106 & 2000000001 & TRN \\
\hline CHEMBL3195505 & 688267 & 3.95 & 5.0048 & TST & \\
\hline CHEMBL1466428 & 688267 & 5.25 & 5.0779 & TRN & \\
\hline CHEMBL1398458 & 688267 & 5.65 & 5.0968 & TRN & \\
\hline CHEMBL1586231 & 688267 & 4.6 & 5.0463 & TRN & \\
\hline CHEMBL1554752 & 688267 & 4.05 & 5.0009 & TRN & \\
\hline CHEMBL1536844 & 688267 & 4.55 & 5.059 & TST & \\
\hline CHEMBL1380834 & 688267 & 4.65 & 5.0082 & TST & \\
\hline CHEMBL1519507 & 688267 & 6.2 & 5.0207 & TRN & \\
\hline CHEMBL1591112 & 688267 & 5.3 & 5.0972 & TRN & \\
\hline CHEMBL1312782 & 688267 & 6.2 & 5.0671 & TRN & \\
\hline CHEMBL1443185 & 688267 & 4.3 & 5.0441 & TRN & \\
\hline CHEMBL1419366 & 688267 & 4.2 & 5.0646 & TST & \\
\hline CHEMBL1373989 & 688267 & 4.05 & 4.9778 & TRN & \\
\hline CHEMBL1472466 & 688267 & 5.15 & 5.0909 & TST & \\
\hline CHEMBL1499351 & 688267 & 5.6 & 5.1056 & TRN & \\
\hline CHEMBL1504651 & 688267 & 5.75 & 5.0125 & TST & \\
\hline CHEMBL1459489 & 688267 & 5.3 & 5.1469 & TRN & \\
\hline CHEMBL1487069 & 688267 & 5.95 & 5.0221 & TST & \\
\hline CHEMBL1606119 & 688267 & 5.85 & 5.0178 & TST & \\
\hline CHEMBL1572982 & 688267 & 6.2 & 5.1203 & TST & \\
\hline CHEMBL1543479 & 688267 & 5.3 & 5.1476 & TRN & \\
\hline CHEMBL1597157 & 688267 & 6.5501 & 5.1032 & TRN & \\
\hline
\end{tabular}




\begin{tabular}{|c|c|c|c|c|c|}
\hline \multicolumn{6}{|c|}{ Supplemental Table S2.txt } \\
\hline CHEMBL1488059 & 688267 & 6.25 & 5.0404 & TRN & \\
\hline CHEMBL1602497 & 688267 & 3.95 & 5.0337 & TRN & \\
\hline CHEMBL1575078 & 688267 & 4.35 & 5.0875 & TRN & \\
\hline CHEMBL 3211273 & 688267 & 4.2 & 5.029 & TRN & \\
\hline CHEMBL1430894 & 688267 & 4.55 & 5.0792 & TST & \\
\hline CHEMBL1380832 & 688267 & 4.0 & 5.107 & TRN & \\
\hline CHEMBL1404187 & 688267 & 5.0 & 5.0777 & TRN & \\
\hline CHEMBL1480076 & 688267 & 5.15 & 5.0493 & TRN & \\
\hline CHEMBL1611163 & 688267 & 5.1 & 5.019 & TRN & \\
\hline CHEMBL3191909 & 688267 & 5.9 & 5.024 & TRN & \\
\hline CHEMBL1515937 & 688267 & 4.4 & 5.0645 & TRN & \\
\hline CHEMBL1410567 & 688267 & 5.55 & 4.9607 & TRN & \\
\hline CHEMBL1487789 & 688267 & 5.05 & 5.1237 & TRN & \\
\hline CHEMBL1337249 & 688267 & 6.2 & 5.153 & TRN & \\
\hline CHEMBL1325547 & 688267 & 4.05 & 5.0151 & TRN & \\
\hline CHEMBL1518960 & 688267 & 6.2 & 5.0703 & TST & \\
\hline CHEMBL1526414 & 688267 & 4.35 & 4.9675 & TST & \\
\hline CHEMBL1471165 & 688267 & 5.5 & 5.0588 & TRN & \\
\hline CHEMBL1563833 & 688267 & 5.5 & 5.0296 & TRN & \\
\hline CHEMBL1431706 & 688267 & 3.95 & 5.1266 & TRN & \\
\hline CHEMBL1442303 & 688267 & 4.35 & 5.0683 & TST & \\
\hline CHEMBL1352520 & 688267 & 5.35 & 5.0409 & TRN & \\
\hline CHEMBL1395657 & 688267 & 5.3 & 5.1326 & TRN & \\
\hline CHEMBL1372954 & 688267 & 6.2 & 5.0332 & TRN & \\
\hline CHEMBL1575275 & 688267 & 4.95 & 5.0134 & TRN & \\
\hline CHEMBL1503827 & 688267 & 4.3 & 4.9993 & TST & \\
\hline CHEMBL1363641 & 688267 & 6.2 & 5.05699 & 99999999995 & TRN \\
\hline CHEMBL1494841 & 688267 & 4.25 & 5.1232 & TRN & \\
\hline CHEMBL1480292 & 688267 & 5.75 & 5.0855 & TRN & \\
\hline CHEMBL1597987 & 688267 & 5.95 & 5.0451 & TRN & \\
\hline CHEMBL1364936 & 688267 & 4.5 & 5.0604 & TRN & \\
\hline CHEMBL1591999 & 688267 & 4.35 & 5.0537 & TRN & \\
\hline CHEMBL1346876 & 688267 & 4.4 & 4.9743 & TST & \\
\hline CHEMBL1593447 & 688267 & 4.0 & 5.1115 & TRN & \\
\hline CHEMBL1534659 & 688267 & 6.2 & 4.9867 & TRN & \\
\hline CHEMBL1463304 & 688267 & 6.2 & 5.0601 & TST & \\
\hline CHEMBL 3191334 & 688267 & 4.0 & 5.0239 & TST & \\
\hline CHEMBL1527590 & 688267 & 6.1 & 5.0016 & TST & \\
\hline CHEMBL1382335 & 688267 & 5.05 & 5.0752 & TRN & \\
\hline CHEMBL1508317 & 688267 & 5.0 & 5.0948 & TRN & \\
\hline CHEMBL1412372 & 688267 & 4.05 & 5.0587 & TST & \\
\hline CHEMBL1550520 & 688267 & 3.85 & 5.0254 & TRN & \\
\hline CHEMBL1487726 & 688267 & 6.2 & 5.0069 & TRN & \\
\hline CHEMBL1539150 & 688267 & 6.2 & 5.041 & TST & \\
\hline CHEMBL1433771 & 688267 & 6.5 & 5.0438 & TRN & \\
\hline CHEMBL1512576 & 688267 & 6.2 & 5.098 & TRN & \\
\hline CHEMBL1400388 & 688267 & 5.65 & 5.0663 & TRN & \\
\hline CHEMBL3198781 & 688267 & 5.5 & 5.0147 & TST & \\
\hline
\end{tabular}




\begin{tabular}{|c|c|c|c|c|}
\hline \multicolumn{5}{|c|}{ Supplemental Table S2.txt } \\
\hline CHEMBL1469889 & 688267 & 3.95 & 5.0334 & TST \\
\hline CHEMBL1354546 & 688267 & 4.05 & 5.1042 & TRN \\
\hline CHEMBL1328288 & 688267 & 4.35 & 5.0872 & TRN \\
\hline CHEMBL1393005 & 688267 & 5.6 & 5.0524 & TRN \\
\hline CHEMBL1417422 & 688267 & 6.2 & 5.0353 & TST \\
\hline CHEMBL1424318 & 688267 & 4.1 & 5.0694 & TRN \\
\hline CHEMBL1526034 & 688267 & 4.0 & 5.0329 & TRN \\
\hline CHEMBL1457396 & 688267 & 4.55 & 5.0489 & TRN \\
\hline CHEMBL1457394 & 688267 & 4.7 & 5.1073 & TRN \\
\hline CHEMBL1458814 & 688267 & 6.2 & 5.0966 & TRN \\
\hline CHEMBL1345143 & 688267 & 4.05 & 5.0367 & TST \\
\hline CHEMBL1326005 & 688267 & 4.1 & 5.0626 & TRN \\
\hline CHEMBL1398521 & 688267 & 6.2 & 5.0595 & TRN \\
\hline CHEMBL1521320 & 688267 & 6.2 & 5.0836 & TRN \\
\hline CHEMBL1440158 & 688267 & 5.55 & 5.0387 & TRN \\
\hline CHEMBL1495573 & 688267 & 3.9 & 5.0503 & TRN \\
\hline CHEMBL1399905 & 688267 & 5.3 & 5.0477 & TST \\
\hline CHEMBL1484075 & 688267 & 5.3 & 5.0305 & TRN \\
\hline CHEMBL1548762 & 688267 & 4.4 & 5.0601 & TRN \\
\hline CHEMBL1552391 & 688267 & 5.5 & 5.0405 & TRN \\
\hline CHEMBL1450294 & 688267 & 5.05 & 5.0322 & TRN \\
\hline CHEMBL1510637 & 688267 & 5.2 & 5.0755 & TRN \\
\hline CHEMBL1461303 & 688267 & 4.45 & 5.0457 & TRN \\
\hline CHEMBL1457548 & 688267 & 5.65 & 5.1092 & TST \\
\hline CHEMBL1473646 & 688267 & 4.0 & 5.0447 & TRN \\
\hline CHEMBL1602660 & 688267 & 6.2 & 5.052 & TST \\
\hline CHEMBL1574573 & 688267 & 4.0 & 5.0428 & TRN \\
\hline CHEMBL3192876 & 688267 & 5.9 & 5.0285 & TST \\
\hline CHEMBL1347248 & 688267 & 4.05 & 5.114 & TRN \\
\hline CHEMBL1473671 & 688267 & 5.95 & 5.0317 & TST \\
\hline CHEMBL1569954 & 688267 & 6.2 & 5.0548 & TRN \\
\hline CHEMBL1551146 & 688267 & 6.2 & 5.1152 & TRN \\
\hline CHEMBL1545039 & 688267 & 5.15 & 5.042 & TST \\
\hline CHEMBL1445486 & 688267 & 4.5 & 5.0749 & TRN \\
\hline CHEMBL1562239 & 688267 & 4.05 & 5.0048 & TST \\
\hline CHEMBL1602036 & 688267 & 4.05 & 5.0392 & TRN \\
\hline CHEMBL3189959 & 688267 & 4.6 & 5.0575 & TST \\
\hline CHEMBL1477491 & 688267 & 4.05 & 5.0845 & TRN \\
\hline CHEMBL1575507 & 688267 & 4.5 & 5.0658 & TRN \\
\hline CHEMBL1416183 & 688267 & 5.35 & 5.0924 & TRN \\
\hline CHEMBL1435729 & 688267 & 6.5 & 5.0957 & TRN \\
\hline CHEMBL3392078 & 688267 & 5.5 & 5.0672 & TST \\
\hline CHEMBL3198020 & 688267 & 6.05 & 5.0429 & TRN \\
\hline CHEMBL3193316 & 688267 & 5.4 & 5.0835 & TST \\
\hline CHEMBL1392198 & 688267 & 5.0 & 5.0466 & TRN \\
\hline CHEMBL1524098 & 688267 & 6.25 & 5.0998 & TRN \\
\hline CHEMBL 1474320 & 688267 & 5.65 & 5.0423 & TRN \\
\hline CHEMBL1540265 & 688267 & 5.55 & 5.0271 & TRN \\
\hline
\end{tabular}




\begin{tabular}{|c|c|c|c|c|}
\hline \multicolumn{5}{|c|}{ Supplemental Table S2.txt } \\
\hline CHEMBL1429372 & 688267 & 5.9 & 5.0698 & TRN \\
\hline CHEMBL1547711 & 688267 & 4.3 & 5.0172 & TRN \\
\hline CHEMBL1341080 & 688267 & 5.1 & 5.04899 & 99999999995 \\
\hline CHEMBL1473075 & 688267 & 6.25 & 5.0696 & TRN \\
\hline CHEMBL1432144 & 688267 & 4.0 & 5.0118 & TRN \\
\hline CHEMBL1354737 & 688267 & 5.35 & 5.0741 & TRN \\
\hline CHEMBL1576269 & 688267 & 6.2 & 5.0816 & TST \\
\hline CHEMBL1364676 & 688267 & 4.0 & 5.1044 & TRN \\
\hline CHEMBL1599277 & 688267 & 4.4 & 5.0622 & TST \\
\hline CHEMBL1524747 & 688267 & 5.55 & 5.0303 & TRN \\
\hline CHEMBL1362115 & 688267 & 4.15 & 5.0506 & TRN \\
\hline CHEMBL1468161 & 688267 & 6.05 & 5.0769 & TRN \\
\hline CHEMBL1403714 & 688267 & 7.0501 & 5.0279 & TST \\
\hline CHEMBL1477722 & 688267 & 5.6 & 5.0727 & TST \\
\hline CHEMBL1433434 & 688267 & 6.2 & 5.0189 & TRN \\
\hline CHEMBL1418383 & 688267 & 5.7 & 5.0698 & TRN \\
\hline CHEMBL1255583 & 688267 & 4.55 & 5.0829 & TST \\
\hline CHEMBL1547455 & 688267 & 5.65 & 5.0706 & TRN \\
\hline CHEMBL1520476 & 688267 & 4.0 & 5.0079 & TRN \\
\hline CHEMBL1433884 & 688267 & 6.5 & 5.0586 & TRN \\
\hline CHEMBL1367712 & 688267 & 3.95 & 5.0402 & TRN \\
\hline CHEMBL1545476 & 688267 & 6.2 & 5.1349 & TRN \\
\hline CHEMBL1411828 & 688267 & 5.75 & 5.0299 & TRN \\
\hline CHEMBL3197313 & 688267 & 4.35 & 4.9842 & TRN \\
\hline CHEMBL1509084 & 688267 & 6.2 & 5.0349 & TRN \\
\hline CHEMBL1488158 & 688267 & 6.2 & 5.0707 & TRN \\
\hline CHEMBL1423532 & 688267 & 6.15 & 5.0337 & TRN \\
\hline CHEMBL1474845 & 688267 & 4.0 & 5.0201 & TST \\
\hline CHEMBL1302865 & 688267 & 5.3 & 5.047 & TRN \\
\hline CHEMBL1500519 & 688267 & 4.0 & 5.0359 & TST \\
\hline CHEMBL1330505 & 688267 & 4.35 & 5.0659 & TRN \\
\hline CHEMBL1549477 & 688267 & 5.05 & 5.0316 & TRN \\
\hline CHEMBL1477229 & 688267 & 4.0 & 5.0138 & TST \\
\hline CHEMBL1351541 & 688267 & 3.95 & 5.1089 & TRN \\
\hline CHEMBL1578743 & 688267 & 6.15 & 5.0293 & TST \\
\hline CHEMBL1447998 & 688267 & 5.35 & 5.1034 & TRN \\
\hline CHEMBL1375886 & 688267 & 4.0 & 4.9557 & TRN \\
\hline CHEMBL1319449 & 688267 & 4.35 & 5.0599 & TRN \\
\hline CHEMBL1564220 & 688267 & 5.3 & 5.0451 & TRN \\
\hline CHEMBL1579302 & 688267 & 4.65 & 5.0166 & TRN \\
\hline CHEMBL1331529 & 688267 & 4.4 & 5.0411 & TRN \\
\hline CHEMBL1536719 & 688267 & 5.3 & 5.1013 & TRN \\
\hline CHEMBL1362397 & 688267 & 5.15 & 5.0024 & TRN \\
\hline CHEMBL1516649 & 688267 & 5.8 & 5.0149 & TRN \\
\hline CHEMBL1474966 & 688267 & 6.2 & 5.0474 & TRN \\
\hline CHEMBL1388860 & 688267 & 4.1 & 5.0067 & TRN \\
\hline CHEMBL1360701 & 688267 & 5.8 & 4.9944 & TRN \\
\hline CHEMBL1380788 & 688267 & 4.2 & 5.0133 & TRN \\
\hline
\end{tabular}




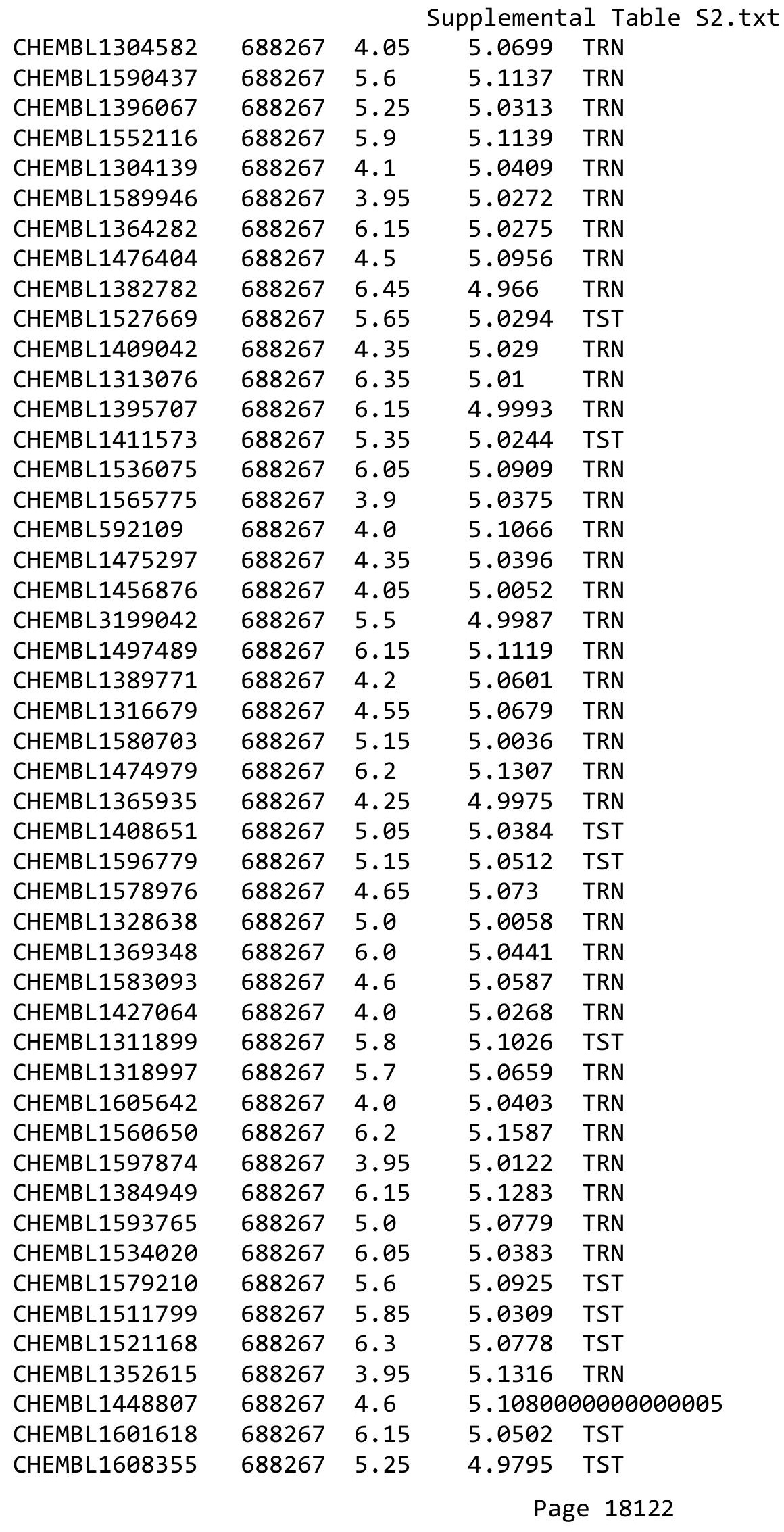

TRN 


\begin{tabular}{|c|c|c|c|c|}
\hline \multicolumn{5}{|c|}{ Supplemental Table S2.txt } \\
\hline CHEMBL1484169 & 688267 & 3.95 & 5.0867 & TST \\
\hline CHEMBL1549833 & 688267 & 5.5 & 4.9953 & TRN \\
\hline CHEMBL1374888 & 688267 & 5.25 & 5.1163 & TRN \\
\hline CHEMBL1525721 & 688267 & 4.7 & 5.1189 & TRN \\
\hline CHEMBL1393669 & 688267 & 5.2 & 5.0577 & TRN \\
\hline CHEMBL1510324 & 688267 & 4.35 & 5.0648 & TST \\
\hline CHEMBL1330954 & 688267 & 3.95 & 5.0245 & TRN \\
\hline CHEMBL1374813 & 688267 & 5.55 & 5.0404 & TRN \\
\hline CHEMBL1455840 & 688267 & 4.35 & 5.0147 & TRN \\
\hline CHEMBL1516589 & 688267 & 5.4 & 5.1514 & TRN \\
\hline CHEMBL1604134 & 688267 & 4.5 & 5.1215 & TRN \\
\hline CHEMBL1481026 & 688267 & 5.65 & 5.1106 & TST \\
\hline CHEMBL1562990 & 688267 & 4.05 & 5.0102 & TRN \\
\hline CHEMBL1473540 & 688267 & 5.5 & 5.0187 & TRN \\
\hline CHEMBL1356986 & 688267 & 5.0 & 5.1352 & TST \\
\hline CHEMBL1370720 & 688267 & 6.2 & 5.0491 & TRN \\
\hline CHEMBL1310952 & 688267 & 6.2 & 5.0393 & TST \\
\hline CHEMBL1383248 & 688267 & 4.6 & 5.1418 & TRN \\
\hline CHEMBL1300885 & 688267 & 4.5 & 5.0521 & TRN \\
\hline CHEMBL1589796 & 688267 & 4.0 & 4.9839 & TRN \\
\hline CHEMBL1400289 & 688267 & 4.4 & 5.0049 & TST \\
\hline CHEMBL1415394 & 688267 & 4.25 & 5.1018 & TRN \\
\hline CHEMBL1407990 & 688267 & 4.35 & 5.0694 & TRN \\
\hline CHEMBL1417592 & 688267 & 5.85 & 5.0252 & TRN \\
\hline CHEMBL1507478 & 688267 & 5.35 & 5.0567 & TRN \\
\hline CHEMBL1544534 & 688267 & 5.9 & 5.0773 & TST \\
\hline CHEMBL1399340 & 688267 & 4.0 & 5.0455 & TRN \\
\hline CHEMBL1580452 & 688267 & 4.5 & 5.0911 & TRN \\
\hline CHEMBL1413925 & 688267 & 6.2 & 5.0533 & TST \\
\hline CHEMBL1369864 & 688267 & 5.75 & 5.0617 & TRN \\
\hline CHEMBL1316691 & 688267 & 4.75 & 4.9828 & TST \\
\hline CHEMBL1555335 & 688267 & 4.0 & 5.0158 & TRN \\
\hline CHEMBL 29861 & 688267 & 4.05 & 5.0176 & TST \\
\hline CHEMBL1463341 & 688267 & 6.2 & 5.1059 & TST \\
\hline CHEMBL1494769 & 688267 & 4.05 & 5.0506 & TRN \\
\hline CHEMBL1440909 & 688267 & 5.65 & 5.0737 & TRN \\
\hline CHEMBL1534551 & 688267 & 5.5 & 5.1177 & TRN \\
\hline CHEMBL1591280 & 688267 & 6.2 & 5.0389 & TRN \\
\hline CHEMBL1519860 & 688267 & 6.25 & 5.0387 & TST \\
\hline CHEMBL1527671 & 688267 & 4.0 & 5.0602 & TST \\
\hline CHEMBL1457074 & 688267 & 6.15 & 5.048 & TRN \\
\hline CHEMBL1557448 & 688267 & 6.2 & 5.0476 & TRN \\
\hline CHEMBL1511366 & 688267 & 6.15 & 5.1292 & TRN \\
\hline CHEMBL3191684 & 688267 & 6.15 & 5.0286 & TST \\
\hline CHEMBL1412888 & 688267 & 5.9 & 5.0793 & TRN \\
\hline CHEMBL1570406 & 688267 & 5.1 & 5.0496 & TRN \\
\hline CHEMBL1544664 & 688267 & 4.95 & 4.9822 & TST \\
\hline CHEMBL1494022 & 688267 & 6.15 & 5.1147 & TRN \\
\hline
\end{tabular}




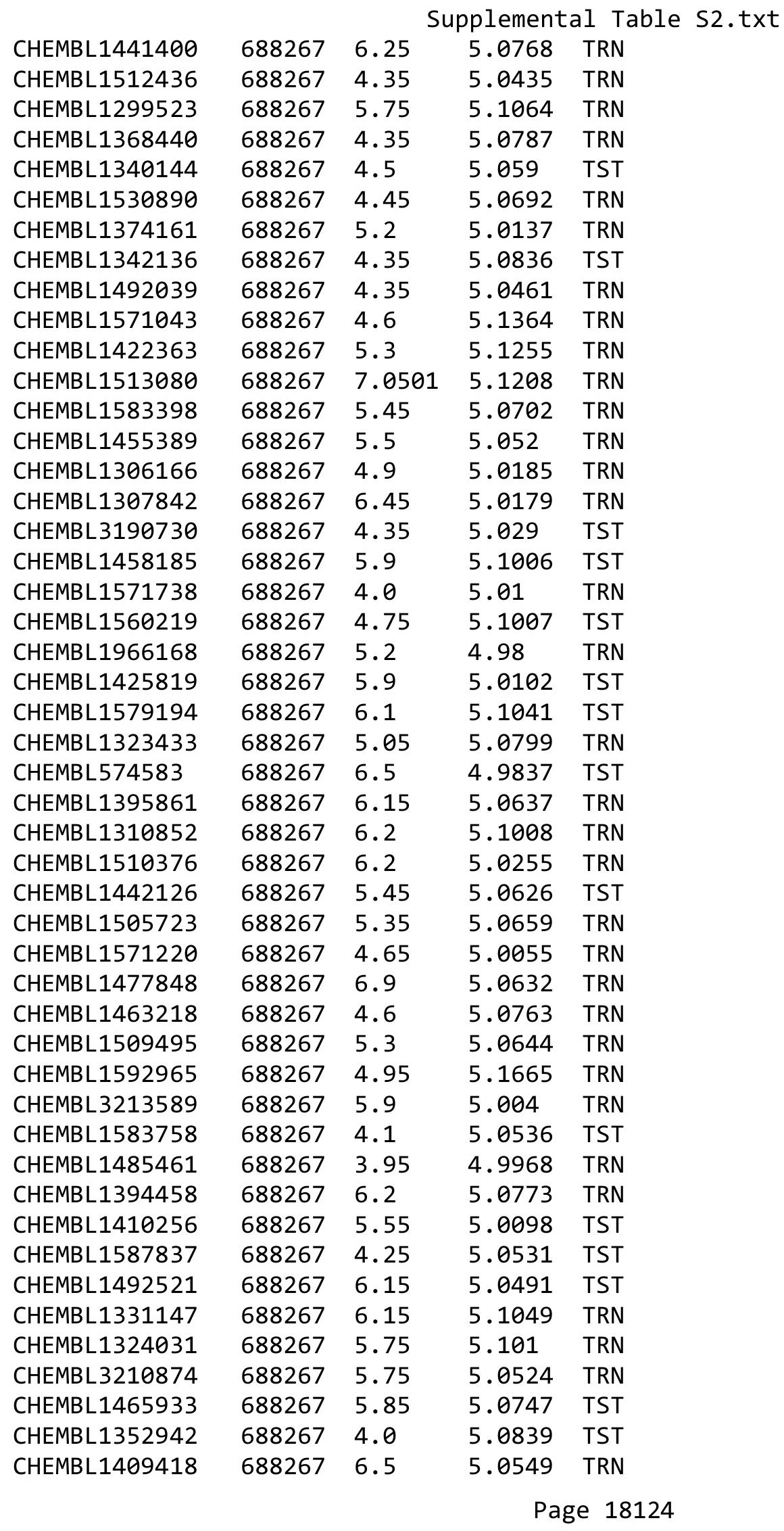




\begin{tabular}{|c|c|c|c|c|}
\hline & & & pplement & al $\mathrm{Ta}$ \\
\hline CHEMBL1613494 & 688267 & 4.3 & 5.0496 & TRN \\
\hline CHEMBL1318978 & 688267 & 6.2 & 5.0394 & TRN \\
\hline CHEMBL1378867 & 688267 & 6.05 & 5.0622 & TRN \\
\hline CHEMBL1364158 & 688267 & 5.85 & 5.0312 & TRN \\
\hline CHEMBL1501508 & 688267 & 5.45 & 5.0273 & TST \\
\hline CHEMBL 250711 & 688267 & 5.5 & 5.0415 & TST \\
\hline CHEMBL1334786 & 688267 & 4.35 & 5.0864 & TRN \\
\hline CHEMBL1564690 & 688267 & 4.0 & 5.0279 & TRN \\
\hline CHEMBL1471733 & 688267 & 5.25 & 5.0263 & TRN \\
\hline CHEMBL406819 & 688267 & 5.55 & 5.08 & TST \\
\hline CHEMBL3193701 & 688267 & 6.15 & 5.0213 & TRN \\
\hline CHEMBL1473236 & 688267 & 6.45 & 5.078 & TRN \\
\hline CHEMBL1480251 & 688267 & 5.9 & 5.0807 & TRN \\
\hline CHEMBL292051 & 688267 & 4.0 & 5.0302 & TRN \\
\hline CHEMBL1573776 & 688267 & 5.25 & 5.0705 & TST \\
\hline CHEMBL1457530 & 688267 & 4.1 & 5.0682 & TRN \\
\hline CHEMBL1578490 & 688267 & 5.6 & 5.0571 & TRN \\
\hline CHEMBL1565462 & 688267 & 4.0 & 5.0802 & TRN \\
\hline CHEMBL1387312 & 688267 & 3.95 & 5.0503 & TST \\
\hline CHEMBL1562995 & 688267 & 4.25 & 5.0407 & TST \\
\hline CHEMBL1580916 & 688267 & 5.4 & 5.0437 & TRN \\
\hline CHEMBL1318265 & 688267 & 4.95 & 5.0842 & TRN \\
\hline CHEMBL1522830 & 688267 & 4.3 & 5.1127 & TRN \\
\hline CHEMBL1609702 & 688267 & 4.4 & 5.0422 & TRN \\
\hline CHEMBL1397531 & 688267 & 4.0 & 5.0567 & TST \\
\hline CHEMBL1511537 & 688267 & 6.2 & 5.1144 & TRN \\
\hline CHEMBL1455734 & 688267 & 6.2 & 5.0152 & TRN \\
\hline CHEMBL1529107 & 688267 & 4.75 & 5.0361 & TRN \\
\hline CHEMBL1441568 & 688267 & 4.05 & 5.0803 & TRN \\
\hline CHEMBL1503921 & 688267 & 5.85 & 5.0934 & TRN \\
\hline CHEMBL1402254 & 688267 & 3.95 & 5.0292 & TRN \\
\hline CHEMBL1478296 & 688267 & 5.05 & 5.037 & TST \\
\hline CHEMBL1361386 & 688267 & 6.2 & 5.0584 & TRN \\
\hline CHEMBL1532897 & 688267 & 4.35 & 5.0448 & TST \\
\hline CHEMBL1611731 & 688267 & 6.15 & 5.0058 & TRN \\
\hline CHEMBL1605110 & 688267 & 6.2 & 5.0339 & TRN \\
\hline CHEMBL1476470 & 688267 & 4.05 & 4.9942 & TRN \\
\hline CHEMBL1310225 & 688267 & 4.6 & 5.0791 & TRN \\
\hline CHEMBL1592952 & 688267 & 5.1 & 5.053 & TRN \\
\hline CHEMBL1338310 & 688267 & 6.2 & 5.0528 & TRN \\
\hline CHEMBL1440294 & 688267 & 5.4 & 5.1401 & TRN \\
\hline CHEMBL1600581 & 688267 & 4.0 & 5.0386 & TRN \\
\hline CHEMBL1506500 & 688267 & 5.4 & 5.0782 & TRN \\
\hline CHEMBL1304398 & 688267 & 3.8 & 5.0562 & TRN \\
\hline CHEMBL1391117 & 688267 & 5.4 & 5.1612 & TRN \\
\hline CHEMBL1317073 & 688267 & 4.35 & 4.9889 & TRN \\
\hline CHEMBL1565372 & 688267 & 4.25 & 5.0359 & TST \\
\hline CHEMBL1574004 & 688267 & 5.9 & 5.0929 & TRN \\
\hline
\end{tabular}




\begin{tabular}{|c|c|c|c|c|}
\hline \multicolumn{5}{|c|}{ Supplemental Table S2.txt } \\
\hline CHEMBL1383531 & 688267 & 4.3 & 5.0119 & TRN \\
\hline CHEMBL1539374 & 688267 & 6.15 & 5.0342 & TRN \\
\hline CHEMBL1452602 & 688267 & 4.25 & 5.0204 & TRN \\
\hline CHEMBL1362468 & 688267 & 4.5 & 4.9985 & TRN \\
\hline CHEMBL1320687 & 688267 & 5.8 & 5.1372 & TST \\
\hline CHEMBL1478070 & 688267 & 4.05 & 5.052 & TRN \\
\hline CHEMBL1462730 & 688267 & 5.1 & 5.0387 & TRN \\
\hline CHEMBL1359418 & 688267 & 5.15 & 5.0746 & TRN \\
\hline CHEMBL1345668 & 688267 & 4.5 & 5.033 & TST \\
\hline CHEMBL1509570 & 688267 & 5.4 & 5.1446 & TRN \\
\hline CHEMBL1608304 & 688267 & 4.25 & 5.0334 & TRN \\
\hline CHEMBL1325657 & 688267 & 4.0 & 5.0712 & TRN \\
\hline CHEMBL1573864 & 688267 & 5.45 & 5.0166 & TRN \\
\hline CHEMBL1561298 & 688267 & 4.4 & 5.0866 & TRN \\
\hline CHEMBL1357394 & 688267 & 4.75 & 5.0727 & TRN \\
\hline CHEMBL1447111 & 688267 & 4.35 & 5.0717 & TST \\
\hline CHEMBL1359112 & 688267 & 6.2 & 5.0208 & TRN \\
\hline CHEMBL600747 & 688267 & 4.15 & 4.9952 & TRN \\
\hline CHEMBL1559221 & 688267 & 4.0 & 5.0715 & TST \\
\hline CHEMBL1574099 & 688267 & 5.35 & 5.0841 & TRN \\
\hline CHEMBL1551612 & 688267 & 5.0 & 5.0964 & TST \\
\hline CHEMBL1518467 & 688267 & 5.5 & 5.041 & TRN \\
\hline CHEMBL1334394 & 688267 & 5.9 & 5.1622 & TRN \\
\hline CHEMBL1331440 & 688267 & 6.2 & 5.1047 & TRN \\
\hline CHEMBL1451783 & 688267 & 6.0 & 5.0625 & TRN \\
\hline CHEMBL1419273 & 688267 & 5.4 & 5.0336 & TST \\
\hline CHEMBL3196274 & 688267 & 4.05 & 5.0514 & TRN \\
\hline CHEMBL1495963 & 688267 & 4.35 & 5.0895 & TRN \\
\hline CHEMBL1552606 & 688267 & 6.8 & 5.1037 & TRN \\
\hline CHEMBL1356125 & 688267 & 5.75 & 5.0653 & TRN \\
\hline CHEMBL1306539 & 688267 & 6.15 & 5.01 & TST \\
\hline CHEMBL1548117 & 688267 & 4.85 & 5.0886 & TST \\
\hline CHEMBL1367739 & 688267 & 5.3 & 5.0552 & TRN \\
\hline CHEMBL1397603 & 688267 & 4.15 & 5.0859 & TRN \\
\hline CHEMBL1371161 & 688267 & 5.0 & 5.1065 & TRN \\
\hline CHEMBL1563471 & 688267 & 5.25 & 5.0495 & TRN \\
\hline CHEMBL1492164 & 688267 & 4.0 & 5.0412 & TRN \\
\hline CHEMBL1448799 & 688267 & 4.35 & 5.1047 & TST \\
\hline CHEMBL1376412 & 688267 & 5.4 & 5.0315 & TRN \\
\hline CHEMBL1525228 & 688267 & 4.6 & 4.9993 & TRN \\
\hline CHEMBL1519263 & 688267 & 6.0 & 4.9966 & TRN \\
\hline CHEMBL1603185 & 688267 & 5.3 & 5.0652 & TRN \\
\hline CHEMBL1521493 & 688267 & 6.1 & 5.0877 & TRN \\
\hline CHEMBL1596936 & 688267 & 4.85 & 5.0439 & TRN \\
\hline CHEMBL1326271 & 688267 & 6.05 & 5.1171 & TRN \\
\hline CHEMBL378695 & 688267 & 6.5 & 5.013 & TRN \\
\hline CHEMBL73285 & 688267 & 4.55 & 5.0827 & TST \\
\hline CHEMBL1352433 & 688267 & 5.3 & 5.067 & TRN \\
\hline
\end{tabular}




\begin{tabular}{|c|c|c|c|c|c|}
\hline \multicolumn{6}{|c|}{ Supplemental Table S2.txt } \\
\hline CHEMBL3210391 & 688267 & 4.45 & 5.1091 & TRN & \\
\hline CHEMBL1325250 & 688267 & 4.55 & 5.0636 & TST & \\
\hline CHEMBL1592033 & 688267 & 4.35 & 5.1431 & TRN & \\
\hline CHEMBL1315064 & 688267 & 4.3 & 5.1379 & TRN & \\
\hline CHEMBL1457335 & 688267 & 4.35 & 5.0047 & TST & \\
\hline CHEMBL1565869 & 688267 & 6.2 & 5.1206 & TRN & \\
\hline CHEMBL1522690 & 688267 & 5.6 & 5.0863 & TRN & \\
\hline CHEMBL1334591 & 688267 & 4.1 & 5.0019 & TST & \\
\hline CHEMBL3189812 & 688267 & 5.85 & 5.015 & TST & \\
\hline CHEMBL3189289 & 688267 & 6.2 & 4.9903 & TRN & \\
\hline CHEMBL1327428 & 688267 & 4.6 & 5.0625 & TRN & \\
\hline CHEMBL1399018 & 688267 & 6.2 & 5.0973 & TST & \\
\hline CHEMBL1479829 & 688267 & 6.1 & 4.97199 & 99999999995 & TRN \\
\hline CHEMBL1371467 & 688267 & 5.3 & 5.0508 & TRN & \\
\hline CHEMBL1350931 & 688267 & 4.35 & 4.9691 & TRN & \\
\hline CHEMBL1597296 & 688267 & 6.2 & 5.0602 & TST & \\
\hline CHEMBL1343839 & 688267 & 4.4 & 5.1197 & TRN & \\
\hline CHEMBL1565101 & 688267 & 6.2 & 5.0212 & TRN & \\
\hline CHEMBL1583026 & 688267 & 5.0 & 4.9948 & TST & \\
\hline CHEMBL1566989 & 688267 & 5.75 & 5.046 & TRN & \\
\hline CHEMBL1372071 & 688267 & 5.6 & 5.032 & TST & \\
\hline CHEMBL1449142 & 688267 & 4.9 & 5.1064 & TRN & \\
\hline CHEMBL1566445 & 688267 & 6.5 & 5.0459 & TRN & \\
\hline CHEMBL1311650 & 688267 & 5.45 & 5.1111 & TRN & \\
\hline CHEMBL1499552 & 688267 & 5.55 & 5.0397 & TST & \\
\hline CHEMBL1445513 & 688267 & 4.4 & 5.0615 & TRN & \\
\hline CHEMBL1558352 & 688267 & 5.3 & 5.0545 & TRN & \\
\hline CHEMBL1580354 & 688267 & 5.65 & 5.0197 & TRN & \\
\hline CHEMBL1556547 & 688267 & 5.6 & 5.0404 & TRN & \\
\hline CHEMBL1396535 & 688267 & 4.4 & 5.0271 & TRN & \\
\hline CHEMBL1406967 & 688267 & 6.2 & 5.0928 & TRN & \\
\hline CHEMBL1418908 & 688267 & 4.65 & 4.9969 & TST & \\
\hline CHEMBL1429048 & 688267 & 5.45 & 5.0424 & TRN & \\
\hline CHEMBL1594147 & 688267 & 4.0 & 5.0529 & TRN & \\
\hline CHEMBL1363543 & 688267 & 4.05 & 5.0538 & TST & \\
\hline CHEMBL1490230 & 688267 & 5.95 & 5.12799 & 9999999999 & TRN \\
\hline CHEMBL1520094 & 688267 & 6.2 & 5.01399 & 9999999999 & TRN \\
\hline CHEMBL1580737 & 688267 & 4.45 & 5.0193 & TST & \\
\hline CHEMBL1527159 & 688267 & 5.95 & 5.0637 & TST & \\
\hline CHEMBL1506860 & 688267 & 4.0 & 5.1065 & TST & \\
\hline CHEMBL1545939 & 688267 & 5.25 & 5.0519 & TRN & \\
\hline CHEMBL1337348 & 688267 & 4.35 & 5.0483 & TRN & \\
\hline CHEMBL1428673 & 688267 & 6.15 & 5.0131 & TRN & \\
\hline CHEMBL1424911 & 688267 & 4.0 & 5.0465 & TRN & \\
\hline CHEMBL1356595 & 688267 & 5.0 & 5.0625 & TRN & \\
\hline CHEMBL1374792 & 688267 & 5.5 & 5.0543 & TRN & \\
\hline CHEMBL1413397 & 688267 & 4.35 & 5.1266 & TRN & \\
\hline CHEMBL1554953 & 688267 & 4.4 & 5.0401 & TRN & \\
\hline
\end{tabular}




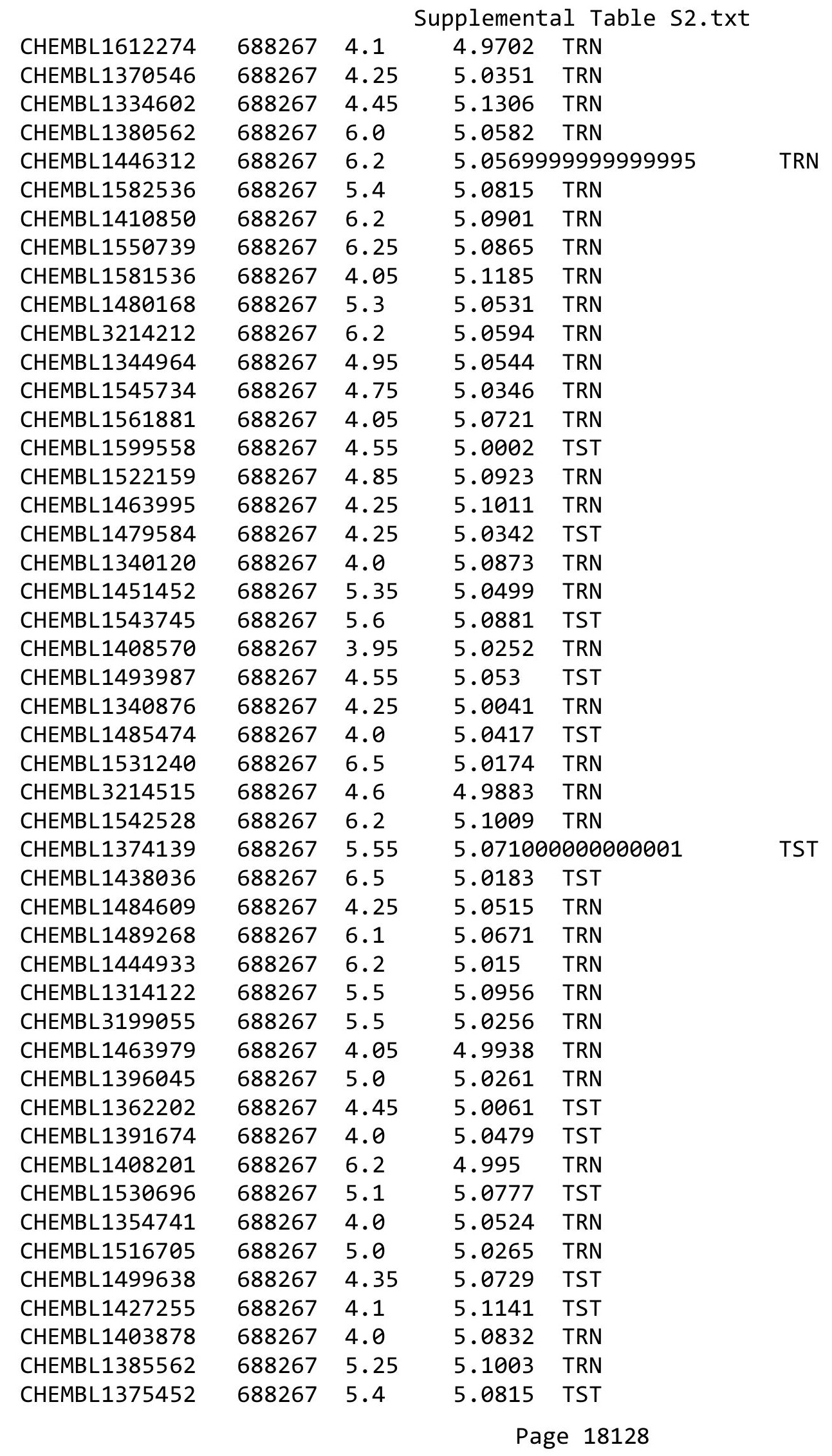




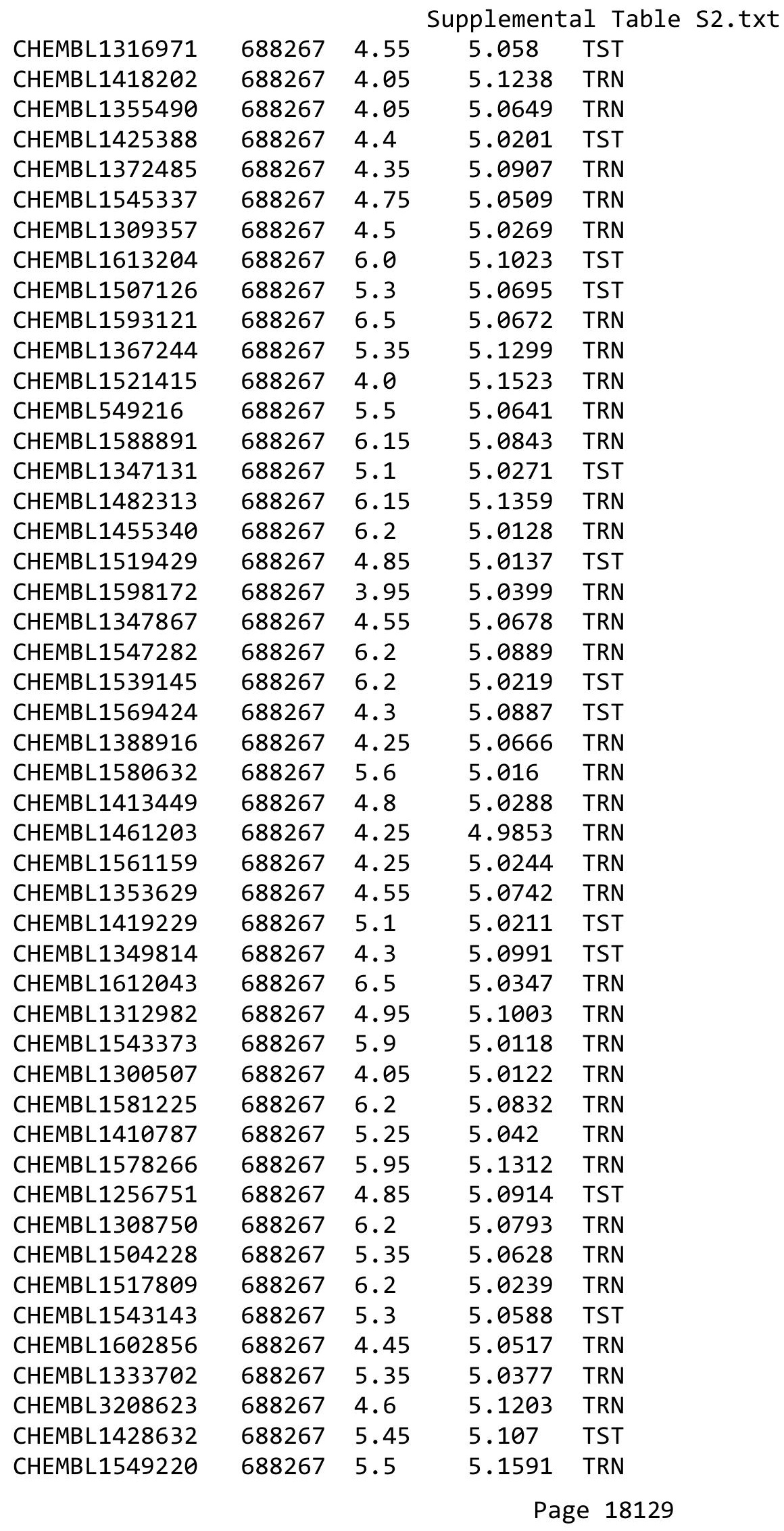




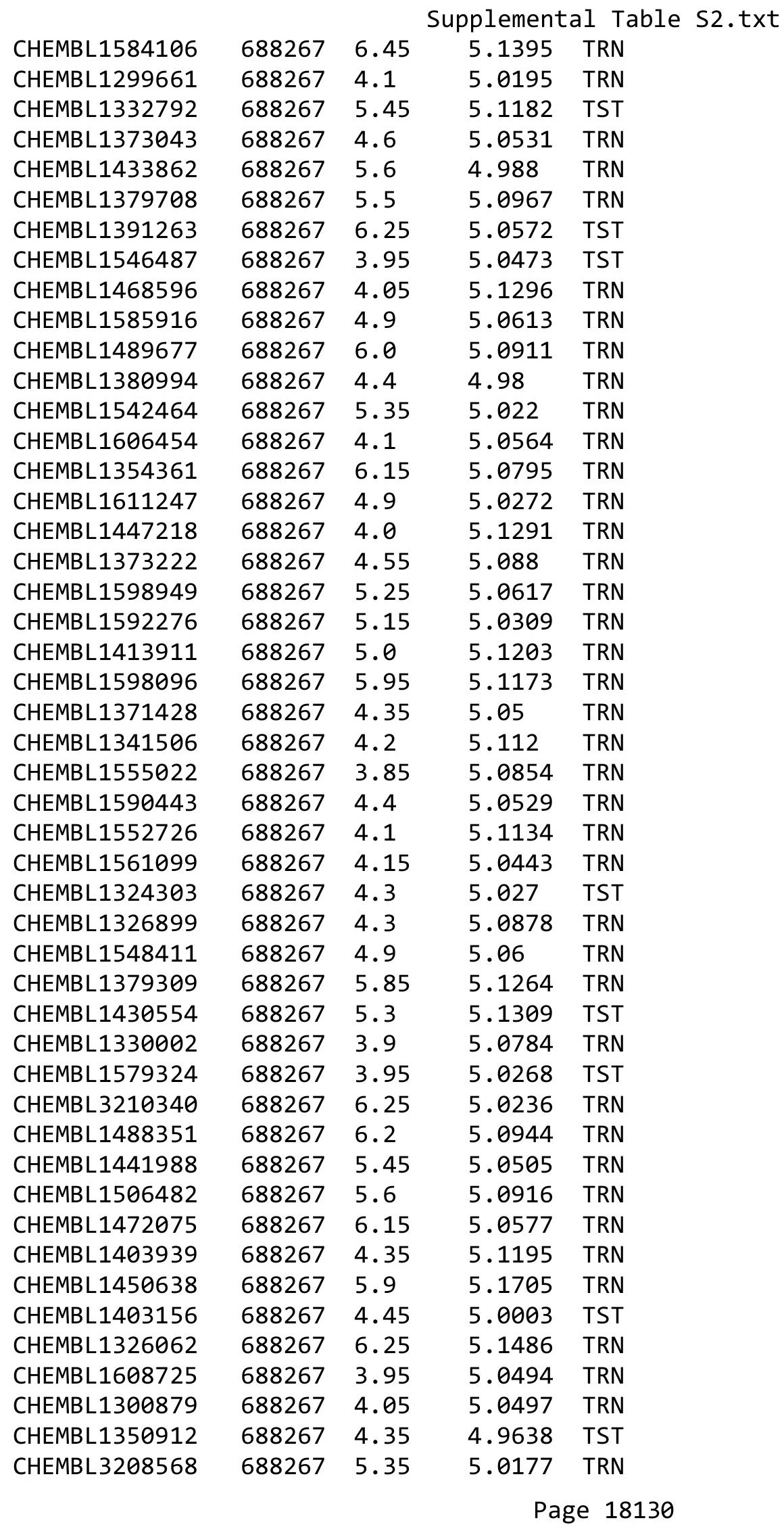




\begin{tabular}{|c|c|c|c|c|}
\hline \multicolumn{5}{|c|}{ Supplemental Table s2.txt } \\
\hline CHEMBL1371253 & 688267 & 6.1 & 5.0975 & TRN \\
\hline CHEMBL1388787 & 688267 & 4.45 & 5.0408 & TRN \\
\hline CHEMBL1456252 & 688267 & 5.35 & 5.0388 & TRN \\
\hline CHEMBL1459930 & 688267 & 4.1 & 4.9761 & TRN \\
\hline CHEMBL1326977 & 688267 & 3.95 & 5.0984 & TRN \\
\hline CHEMBL1505056 & 688267 & 5.55 & 5.0474 & TRN \\
\hline CHEMBL1597002 & 688267 & 5.0 & 5.0232 & TRN \\
\hline CHEMBL1364608 & 688267 & 3.95 & 5.0893 & TRN \\
\hline CHEMBL1373514 & 688267 & 5.4 & 5.0538 & TST \\
\hline CHEMBL1605395 & 688267 & 4.0 & 5.0148 & TRN \\
\hline CHEMBL1495957 & 688267 & 3.95 & 5.0383 & TRN \\
\hline CHEMBL1305333 & 688267 & 4.0 & 5.1076 & TRN \\
\hline CHEMBL1373368 & 688267 & 3.95 & 5.0264 & TRN \\
\hline CHEMBL 3212812 & 688267 & 4.55 & 5.0135 & TRN \\
\hline CHEMBL1577692 & 688267 & 5.3 & 5.0695 & TST \\
\hline CHEMBL1386718 & 688267 & 6.2 & 5.0745 & TST \\
\hline CHEMBL1458274 & 688267 & 4.0 & 5.0451 & TST \\
\hline CHEMBL1320130 & 688267 & 5.85 & 5.1263 & TRN \\
\hline CHEMBL1612332 & 688267 & 4.35 & 5.1221 & TRN \\
\hline CHEMBL3193029 & 688267 & 6.15 & 4.999 & TST \\
\hline CHEMBL1511203 & 688267 & 4.4 & 5.0561 & TRN \\
\hline CHEMBL1337147 & 688267 & 5.8 & 4.9835 & TRN \\
\hline CHEMBL1604873 & 688267 & 5.95 & 5.0724 & TST \\
\hline CHEMBL1506083 & 688267 & 5.75 & 5.0321 & TRN \\
\hline CHEMBL1583583 & 688267 & 5.7 & 5.0859 & TST \\
\hline CHEMBL1554475 & 688267 & 5.25 & 5.0081 & TRN \\
\hline CHEMBL1900030 & 688267 & 4.4 & 5.1313 & TRN \\
\hline CHEMBL1590237 & 688267 & 6.15 & 5.0717 & TRN \\
\hline CHEMBL1417330 & 688267 & 4.6 & 5.0538 & TRN \\
\hline CHEMBL1496274 & 688267 & 3.95 & 5.0419 & TST \\
\hline CHEMBL1377748 & 688267 & 5.65 & 5.0437 & TRN \\
\hline CHEMBL1364899 & 688267 & 6.0 & 5.0684 & TRN \\
\hline CHEMBL1451243 & 688267 & 5.35 & 5.0966 & TRN \\
\hline CHEMBL1331186 & 688267 & 5.05 & 5.0336 & TRN \\
\hline CHEMBL1369721 & 688267 & 6.2 & 5.0214 & TST \\
\hline CHEMBL1598741 & 688267 & 5.9 & 5.1411 & TRN \\
\hline CHEMBL1473213 & 688267 & 5.3 & 5.14 & TST \\
\hline CHEMBL1450172 & 688267 & 4.1 & 5.1417 & TRN \\
\hline CHEMBL1570568 & 688267 & 5.5 & 5.0711 & TRN \\
\hline CHEMBL1406591 & 688267 & 5.85 & 5.0947 & TRN \\
\hline CHEMBL1515114 & 688267 & 6.05 & 5.1329 & TRN \\
\hline CHEMBL1313104 & 688267 & 4.4 & 5.0008 & TRN \\
\hline CHEMBL1519900 & 688267 & 4.1 & 5.1192 & TRN \\
\hline CHEMBL1339148 & 688267 & 5.85 & 5.0799 & TRN \\
\hline CHEMBL1392745 & 688267 & 6.25 & 5.0715 & TST \\
\hline CHEMBL1340515 & 688267 & 5.95 & 5.0113 & TST \\
\hline CHEMBL1403342 & 688267 & 4.2 & 5.0873 & TST \\
\hline CHEMBL1592536 & 688267 & 5.55 & 5.0246 & TRN \\
\hline
\end{tabular}




\begin{tabular}{|c|c|c|c|c|}
\hline & & & & al Table S2 \\
\hline CHEMBL1451219 & 688267 & 4.0 & 5.0864 & TRN \\
\hline CHEMBL1330410 & 688267 & 6.2 & 5.0039 & TRN \\
\hline CHEMBL1323406 & 688267 & 4.4 & 5.0523 & TST \\
\hline CHEMBL531672 & 688267 & 4.35 & 5.0774 & TRN \\
\hline CHEMBL1387771 & 688267 & 4.0 & 5.0362 & TRN \\
\hline CHEMBL1317410 & 688267 & 6.0 & 5.0833 & TRN \\
\hline CHEMBL1322429 & 688267 & 4.4 & 5.0671 & TST \\
\hline CHEMBL1533745 & 688267 & 5.8 & 5.0652 & TST \\
\hline CHEMBL1605728 & 688267 & 5.75 & 5.0848 & TRN \\
\hline CHEMBL1421306 & 688267 & 4.0 & 5.0211 & TRN \\
\hline CHEMBL1347875 & 688267 & 6.2 & 5.0943 & TRN \\
\hline CHEMBL1313172 & 688267 & 6.1 & 5.0526 & TST \\
\hline CHEMBL1514277 & 688267 & 6.5 & 4.9923 & TRN \\
\hline CHEMBL1427528 & 688267 & 4.2 & 5.1461 & TST \\
\hline CHEMBL1516114 & 688267 & 5.15 & 5.0474 & TRN \\
\hline CHEMBL1596216 & 688267 & 4.5 & 5.0784 & TST \\
\hline CHEMBL1469717 & 688267 & 5.8 & 5.0293 & TRN \\
\hline CHEMBL1459914 & 688267 & 4.1 & 4.998 & TRN \\
\hline CHEMBL1611236 & 688267 & 5.25 & 5.0224 & TRN \\
\hline CHEMBL1555370 & 688267 & 4.0 & 4.9934 & TRN \\
\hline CHEMBL1418033 & 688267 & 4.7 & 4.9995 & TRN \\
\hline CHEMBL1543418 & 688267 & 4.55 & 5.0034 & TRN \\
\hline CHEMBL1497079 & 688267 & 4.5 & 5.0752 & TRN \\
\hline CHEMBL1519517 & 688267 & 5.55 & 5.0068 & TRN \\
\hline CHEMBL 1306115 & 688267 & 5.6 & 5.0652 & TST \\
\hline CHEMBL1402071 & 688267 & 6.45 & 5.0864 & TRN \\
\hline CHEMBL 1465440 & 688267 & 4.3 & 5.04899 & 99999999995 \\
\hline CHEMBL1308875 & 688267 & 6.15 & 5.0496 & TRN \\
\hline CHEMBL1336741 & 688267 & 4.0 & 5.0608 & TRN \\
\hline CHEMBL1490154 & 688267 & 4.5 & 5.0345 & TRN \\
\hline CHEMBL1360323 & 688267 & 5.5 & 5.0578 & TRN \\
\hline CHEMBL1558264 & 688267 & 4.55 & 5.0967 & TRN \\
\hline CHEMBL1334432 & 688267 & 6.2 & 5.1107 & TST \\
\hline CHEMBL1336058 & 688267 & 6.25 & 5.0344 & TRN \\
\hline CHEMBL1408258 & 688267 & 6.5 & 5.0796 & TST \\
\hline CHEMBL1437505 & 688267 & 6.1 & 5.0326 & TRN \\
\hline CHEMBL1395926 & 688267 & 3.95 & 5.1202 & TRN \\
\hline CHEMBL1605572 & 688267 & 5.05 & 5.0182 & TST \\
\hline CHEMBL1367553 & 688267 & 4.0 & 5.0792 & TST \\
\hline CHEMBL1483349 & 688267 & 6.2 & 5.1176 & TST \\
\hline CHEMBL1476659 & 688267 & 6.2 & 5.0786 & TRN \\
\hline CHEMBL1395498 & 688267 & 4.85 & 5.084 & TRN \\
\hline CHEMBL1547936 & 688267 & 4.0 & 5.0114 & TRN \\
\hline CHEMBL1310569 & 688267 & 5.2 & 5.0524 & TRN \\
\hline CHEMBL 1514412 & 688267 & 6.0 & 5.0361 & TRN \\
\hline CHEMBL1364809 & 688267 & 5.5 & 5.0136 & TST \\
\hline CHEMBL1567123 & 688267 & 6.15 & 5.0751 & TRN \\
\hline CHEMBL1435812 & 688267 & 5.4 & 5.0666 & TRN \\
\hline
\end{tabular}




\begin{tabular}{|c|c|c|c|c|c|}
\hline \multicolumn{6}{|c|}{ Supplemental Table S2.txt } \\
\hline CHEMBL1545810 & 688267 & 5.55 & 5.037 & TRN & \\
\hline CHEMBL1386385 & 688267 & 5.15 & 5.0345 & TRN & \\
\hline CHEMBL1466779 & 688267 & 5.55 & 5.1073 & TST & \\
\hline CHEMBL1309131 & 688267 & 5.0 & 5.026 & TST & \\
\hline CHEMBL1414048 & 688267 & 4.35 & 5.0755 & TRN & \\
\hline CHEMBL1423766 & 688267 & 3.95 & 5.1201 & TRN & \\
\hline CHEMBL1407504 & 688267 & 3.95 & 5.0983 & TST & \\
\hline CHEMBL1513224 & 688267 & 5.5 & 5.1082 & TRN & \\
\hline CHEMBL1604931 & 688267 & 6.25 & 5.0713 & TRN & \\
\hline CHEMBL3192836 & 688267 & 4.3 & 5.0397 & TRN & \\
\hline CHEMBL1528868 & 688267 & 4.6 & 5.1435 & TRN & \\
\hline CHEMBL1305907 & 688267 & 5.8 & 5.0245 & TRN & \\
\hline CHEMBL1581921 & 688267 & 6.2 & 5.0618 & TRN & \\
\hline CHEMBL1305146 & 688267 & 5.75 & 4.9668 & TST & \\
\hline CHEMBL1567233 & 688267 & 5.9 & 5.09399 & 9999999999 & TRN \\
\hline CHEMBL1416577 & 688267 & 6.2 & 5.0839 & TRN & \\
\hline CHEMBL1305527 & 688267 & 4.2 & 4.9893 & TST & \\
\hline CHEMBL1548120 & 688267 & 4.05 & 5.0966 & TRN & \\
\hline CHEMBL1999756 & 688267 & 6.5 & 4.9836 & TRN & \\
\hline CHEMBL1515812 & 688267 & 5.35 & 5.0749 & TRN & \\
\hline CHEMBL1574395 & 688267 & 4.6 & 4.9975 & TRN & \\
\hline CHEMBL1411213 & 688267 & 4.8 & 5.045 & TRN & \\
\hline CHEMBL1506264 & 688267 & 4.2 & 4.9946 & TRN & \\
\hline CHEMBL1347107 & 688267 & 4.05 & 5.0134 & TST & \\
\hline CHEMBL3196986 & 688267 & 4.5 & 5.0141 & TRN & \\
\hline CHEMBL1447264 & 688267 & 5.35 & 5.0609 & TRN & \\
\hline CHEMBL1449152 & 688267 & 4.4 & 5.0469 & TST & \\
\hline CHEMBL1521720 & 688267 & 5.3 & 5.1702 & TRN & \\
\hline CHEMBL1522646 & 688267 & 5.4 & 5.0689 & TST & \\
\hline CHEMBL1538061 & 688267 & 4.1 & 5.0321 & TST & \\
\hline CHEMBL338115 & 688267 & 5.45 & 5.0631 & TRN & \\
\hline CHEMBL1530065 & 688267 & 5.25 & 5.0951 & TST & \\
\hline CHEMBL3208316 & 688267 & 4.35 & 5.0192 & TRN & \\
\hline CHEMBL1552479 & 688267 & 5.3 & 5.0165 & TRN & \\
\hline CHEMBL183640 & 688267 & 4.0 & 4.9905 & TRN & \\
\hline CHEMBL1565639 & 688267 & 4.5 & 5.0161 & TST & \\
\hline CHEMBL1534526 & 688267 & 4.75 & 5.0204 & TST & \\
\hline CHEMBL1379266 & 688267 & 4.75 & 5.1705 & TRN & \\
\hline CHEMBL579219 & 688267 & 6.15 & 5.0316 & TST & \\
\hline CHEMBL1410247 & 688267 & 5.4 & 5.0383 & TRN & \\
\hline CHEMBL1561997 & 688267 & 5.15 & 5.0701 & TRN & \\
\hline CHEMBL1489778 & 688267 & 4.25 & 5.0125 & TST & \\
\hline CHEMBL1509250 & 688267 & 4.1 & 5.0359 & TRN & \\
\hline CHEMBL1521996 & 688267 & 6.25 & 5.0708 & TRN & \\
\hline CHEMBL1388421 & 688267 & 4.45 & 5.0374 & TRN & \\
\hline CHEMBL1331991 & 688267 & 4.1 & 5.1118 & TRN & \\
\hline CHEMBL3199027 & 688267 & 4.55 & 4.9978 & TRN & \\
\hline CHEMBL1517057 & 688267 & 4.35 & 5.0173 & TRN & \\
\hline
\end{tabular}




\begin{tabular}{|c|c|c|c|c|c|}
\hline \\
\hline CHEMBL1300959 & 688267 & 4.3 & 5.0142 & TST & \\
\hline CHEMBL1356584 & 688267 & 6.0 & 5.0715 & TRN & \\
\hline CHEMBL1384627 & 688267 & 4.0 & 5.0904 & TRN & \\
\hline CHEMBL1512293 & 688267 & 5.35 & 5.0066 & TRN & \\
\hline CHEMBL1398117 & 688267 & 5.6 & 5.0704 & TRN & \\
\hline CHEMBL1304353 & 688267 & 4.1 & 5.0255 & TRN & \\
\hline CHEMBL1600515 & 688267 & 5.5 & 5.1095 & TRN & \\
\hline CHEMBL1569346 & 688267 & 5.05 & 5.0395 & TRN & \\
\hline CHEMBL1308988 & 688267 & 6.2 & 5.1638 & TRN & \\
\hline CHEMBL1464469 & 688267 & 5.0 & 5.0159 & TRN & \\
\hline CHEMBL1406925 & 688267 & 5.55 & 5.0312 & TRN & \\
\hline CHEMBL1594695 & 688267 & 6.25 & 5.0116 & TST & \\
\hline CHEMBL1304520 & 688267 & 4.05 & 5.0717 & TST & \\
\hline CHEMBL1475167 & 688267 & 6.5 & 5.0834 & TRN & \\
\hline CHEMBL1533713 & 688267 & 4.45 & 5.0545 & TRN & \\
\hline CHEMBL1532259 & 688267 & 4.35 & 5.1113 & TRN & \\
\hline CHEMBL1608437 & 688267 & 6.05 & 5.1664 & TRN & \\
\hline CHEMBL1352477 & 688267 & 4.35 & 5.106 & TRN & \\
\hline CHEMBL1423537 & 688267 & 4.45 & 5.0253 & TRN & \\
\hline CHEMBL1314934 & 688267 & 6.2 & 5.0432 & TRN & \\
\hline CHEMBL1605336 & 688267 & 4.0 & 5.1793 & TRN & \\
\hline CHEMBL1323286 & 688267 & 3.95 & 5.1219 & TRN & \\
\hline CHEMBL1598765 & 688267 & 4.25 & 5.0524 & TST & \\
\hline CHEMBL1462103 & 688267 & 5.45 & 5.0713 & TRN & \\
\hline CHEMBL1379871 & 688267 & 6.2 & 5.0388 & TRN & \\
\hline CHEMBL1333591 & 688267 & 4.95 & 5.0371 & TRN & \\
\hline CHEMBL1316425 & 688267 & 5.95 & 5.1058 & TRN & \\
\hline CHEMBL1384145 & 688267 & 4.0 & 5.0959 & TST & \\
\hline CHEMBL1344991 & 688267 & 5.95 & 5.0535 & TST & \\
\hline CHEMBL1405053 & 688267 & 4.35 & 5.0797 & TRN & \\
\hline CHEMBL1357515 & 688267 & 4.0 & 5.0515 & TRN & \\
\hline CHEMBL1427722 & 688267 & 5.95 & 5.0099 & TRN & \\
\hline CHEMBL1450866 & 688267 & 4.6 & 5.0965 & TRN & \\
\hline CHEMBL1603513 & 688267 & 5.05 & 5.0658 & TRN & \\
\hline CHEMBL1382838 & 688267 & 4.35 & 5.0886 & TRN & \\
\hline CHEMBL1523036 & 688267 & 5.85 & 4.9915 & TRN & \\
\hline CHEMBL1466410 & 688267 & 4.3 & 5.1184 & TRN & \\
\hline CHEMBL1405460 & 688267 & 5.3 & 5.1014 & TST & \\
\hline CHEMBL1416813 & 688267 & 5.75 & 5.0704 & TRN & \\
\hline CHEMBL1591434 & 688267 & 6.5 & $5.0760 e$ & 00000000005 & TRN \\
\hline CHEMBL1519938 & 688267 & 6.2 & 5.1022 & TST & \\
\hline CHEMBL1370514 & 688267 & 6.2 & 5.1455 & TST & \\
\hline CHEMBL1337606 & 688267 & 4.6 & 5.0536 & TRN & \\
\hline CHEMBL1601029 & 688267 & 5.6 & 5.0814 & TRN & \\
\hline CHEMBL1455307 & 688267 & 5.65 & 5.0375 & TRN & \\
\hline CHEMBL1481287 & 688267 & 5.65 & 5.0234 & TST & \\
\hline CHEMBL1527308 & 688267 & 4.5 & 5.1217 & TRN & \\
\hline CHEMBL1328519 & 688267 & 5.85 & 5.082 & TRN & \\
\hline
\end{tabular}




\begin{tabular}{|c|c|c|c|c|c|}
\hline \\
\hline CHEMBL1415523 & 688267 & 4.0 & 5.0997 & TRN & \\
\hline CHEMBL1555875 & 688267 & 5.2 & 5.1015 & TRN & \\
\hline CHEMBL3208033 & 688267 & 6.2 & 5.0402 & TRN & \\
\hline CHEMBL1309044 & 688267 & 6.2 & 5.0419 & TRN & \\
\hline CHEMBL1407095 & 688267 & 6.2 & 5.0177 & TRN & \\
\hline CHEMBL3192060 & 688267 & 3.95 & 5.0057 & TST & \\
\hline CHEMBL1437441 & 688267 & 4.35 & 5.0621 & TST & \\
\hline CHEMBL1600740 & 688267 & 4.25 & 5.0389 & TRN & \\
\hline CHEMBL1548251 & 688267 & 4.05 & 5.0394 & TST & \\
\hline CHEMBL1256697 & 688267 & 5.15 & 5.044 & TST & \\
\hline CHEMBL1569062 & 688267 & 5.3 & 5.0851 & TRN & \\
\hline CHEMBL1436502 & 688267 & 4.2 & 5.0339 & TRN & \\
\hline CHEMBL1373301 & 688267 & 4.05 & 5.083 & TRN & \\
\hline CHEMBL1537619 & 688267 & 5.35 & 5.0583 & TST & \\
\hline CHEMBL1521775 & 688267 & 5.3 & 5.0657 & TRN & \\
\hline CHEMBL1513505 & 688267 & 4.0 & 5.0438 & TRN & \\
\hline CHEMBL1555178 & 688267 & 6.5 & 5.0326 & TST & \\
\hline CHEMBL1429284 & 688267 & 4.45 & 5.0657 & TRN & \\
\hline CHEMBL1449553 & 688267 & 6.15 & 5.0689 & TRN & \\
\hline CHEMBL1561293 & 688267 & 4.05 & 4.9986 & TRN & \\
\hline CHEMBL1401935 & 688267 & 6.45 & 5.1166 & TST & \\
\hline CHEMBL1337180 & 688267 & 5.3 & 5.0677 & TST & \\
\hline CHEMBL1563239 & 688267 & 5.15 & 5.0466 & TRN & \\
\hline CHEMBL1463241 & 688267 & 4.0 & 5.1062 & TRN & \\
\hline CHEMBL1368873 & 688267 & 5.6 & 5.0173 & TRN & \\
\hline CHEMBL1486334 & 688267 & 4.05 & 5.0249 & TRN & \\
\hline CHEMBL3196841 & 688267 & 5.05 & 5.0155 & TRN & \\
\hline CHEMBL1548423 & 688267 & 4.55 & 5.0635 & TRN & \\
\hline CHEMBL1354946 & 688267 & 4.5 & 5.06800 & 00000000005 & TRN \\
\hline CHEMBL3189288 & 688267 & 5.3 & 4.9964 & TRN & \\
\hline CHEMBL1403269 & 688267 & 6.25 & 5.1358 & TRN & \\
\hline CHEMBL1475696 & 688267 & 5.95 & 5.0798 & TST & \\
\hline CHEMBL1506546 & 688267 & 5.6 & 5.0605 & TRN & \\
\hline CHEMBL1530399 & 688267 & 6.05 & 5.0171 & TRN & \\
\hline CHEMBL1382813 & 688267 & 4.0 & 5.0859 & TRN & \\
\hline CHEMBL1606767 & 688267 & 5.65 & 5.0311 & TRN & \\
\hline CHEMBL1476089 & 688267 & 4.4 & 5.0598 & TST & \\
\hline CHEMBL1593936 & 688267 & 4.75 & 5.0742 & TRN & \\
\hline CHEMBL1364589 & 688267 & 4.05 & 5.0387 & TST & \\
\hline CHEMBL1375501 & 688267 & 4.25 & 5.053 & TRN & \\
\hline CHEMBL1328417 & 688267 & 5.1 & 5.1481 & TRN & \\
\hline CHEMBL1393363 & 688267 & 4.05 & 4.9997 & TRN & \\
\hline CHEMBL1529105 & 688267 & 5.3 & 5.1817 & TRN & \\
\hline CHEMBL1437383 & 688267 & 6.15 & 5.0739 & TRN & \\
\hline CHEMBL1451150 & 688267 & 4.35 & 5.0714 & TRN & \\
\hline CHEMBL1560319 & 688267 & 4.45 & 5.0863 & TRN & \\
\hline CHEMBL1360871 & 688267 & 6.5 & 5.0397 & TRN & \\
\hline CHEMBL1494903 & 688267 & 4.4 & 5.0944 & TRN & \\
\hline & & & & 18135 & \\
\hline
\end{tabular}




\begin{tabular}{|c|c|c|c|c|c|}
\hline \multirow[b]{2}{*}{ CHEMBL1545836 } & & \multicolumn{4}{|c|}{ Supplemental Table S2.txt } \\
\hline & 688267 & 3.95 & 4.97 & TST & \\
\hline CHEMBL1484441 & 688267 & 3.95 & \multicolumn{2}{|c|}{4.986000000000001} & TRN \\
\hline CHEMBL1471193 & 688267 & 4.25 & 5.0269 & TRN & \\
\hline CHEMBL1311430 & 688267 & 6.2 & 5.0311 & TRN & \\
\hline CHEMBL227447 & 688267 & 4.0 & 5.0971 & TRN & \\
\hline CHEMBL1561447 & 688267 & 6.15 & 5.2016 & TST & \\
\hline CHEMBL1349390 & 688267 & 6.0 & 5.011 & TRN & \\
\hline CHEMBL1390414 & 688267 & 4.0 & 5.0623 & TRN & \\
\hline CHEMBL1492315 & 688267 & 5.3 & 5.0181 & TRN & \\
\hline CHEMBL1473972 & 688267 & 5.45 & 5.0533 & TRN & \\
\hline CHEMBL1445054 & 688267 & 5.75 & 5.1053 & TRN & \\
\hline CHEMBL1528673 & 688267 & 5.5 & 5.0466 & TRN & \\
\hline CHEMBL1331580 & 688267 & 4.0 & 5.1047 & TST & \\
\hline CHEMBL1366929 & 688267 & 5.75 & 5.0362 & TRN & \\
\hline CHEMBL1451634 & 688267 & 5.8 & 4.9797 & TST & \\
\hline CHEMBL1446687 & 688267 & 4.05 & 5.0277 & TST & \\
\hline CHEMBL1325842 & 688267 & 5.6 & 5.0748 & TRN & \\
\hline CHEMBL1577344 & 688267 & 5.2 & 4.9957 & TRN & \\
\hline CHEMBL3210172 & 688267 & 4.35 & 5.0528 & TRN & \\
\hline CHEMBL1318206 & 688267 & 4.15 & 5.015 & TST & \\
\hline CHEMBL1398222 & 688267 & 4.0 & 4.9819 & TRN & \\
\hline CHEMBL1360484 & 688267 & 4.0 & 5.1 & TRN & \\
\hline CHEMBL1336515 & 688267 & 4.0 & 5.0673 & TRN & \\
\hline CHEMBL1525830 & 688267 & 4.05 & 5.0222 & TRN & \\
\hline CHEMBL1533187 & 688267 & 6.15 & 5.0828 & TRN & \\
\hline CHEMBL1316282 & 688267 & 4.05 & 5.0147 & TRN & \\
\hline CHEMBL1302792 & 688267 & 5.8 & 5.0235 & TRN & \\
\hline CHEMBL1535745 & 688267 & 4.0 & 5.09699 & 99999999995 & TST \\
\hline CHEMBL1413923 & 688267 & 4.75 & 5.0407 & TST & \\
\hline CHEMBL1461752 & 688267 & 5.45 & 5.0484 & TRN & \\
\hline CHEMBL1514026 & 688267 & 6.25 & 5.0987 & TRN & \\
\hline CHEMBL1526978 & 688267 & 4.75 & 5.0188 & TRN & \\
\hline CHEMBL1490410 & 688267 & 4.0 & 5.0958 & TRN & \\
\hline CHEMBL1306818 & 688267 & 5.65 & 5.0218 & TRN & \\
\hline CHEMBL1415348 & 688267 & 5.75 & 5.1047 & TRN & \\
\hline CHEMBL1578171 & 688267 & 4.45 & 5.0067 & TRN & \\
\hline CHEMBL1364818 & 688267 & 6.2 & 5.0676 & TST & \\
\hline CHEMBL1504284 & 688267 & 5.8 & 5.0636 & TRN & \\
\hline CHEMBL1373778 & 688267 & 6.0 & 5.1334 & TRN & \\
\hline CHEMBL1365710 & 688267 & 4.1 & 5.1241 & TRN & \\
\hline CHEMBL1609809 & 688267 & 5.5 & 5.084 & TST & \\
\hline CHEMBL1304272 & 688267 & 5.35 & 5.0603 & TRN & \\
\hline CHEMBL1507641 & 688267 & 6.25 & $5.1110 e$ & 3000000001 & TRN \\
\hline CHEMBL1351133 & 688267 & 4.7 & 5.0664 & TRN & \\
\hline CHEMBL1329537 & 688267 & 5.6 & 5.04899 & 99999999995 & TST \\
\hline CHEMBL1339598 & 688267 & 5.15 & 5.0772 & TRN & \\
\hline CHEMBL1396636 & 688267 & 5.65 & 5.0274 & TRN & \\
\hline CHEMBL1588263 & 688267 & 6.2 & 5.0619 & TRN & \\
\hline
\end{tabular}




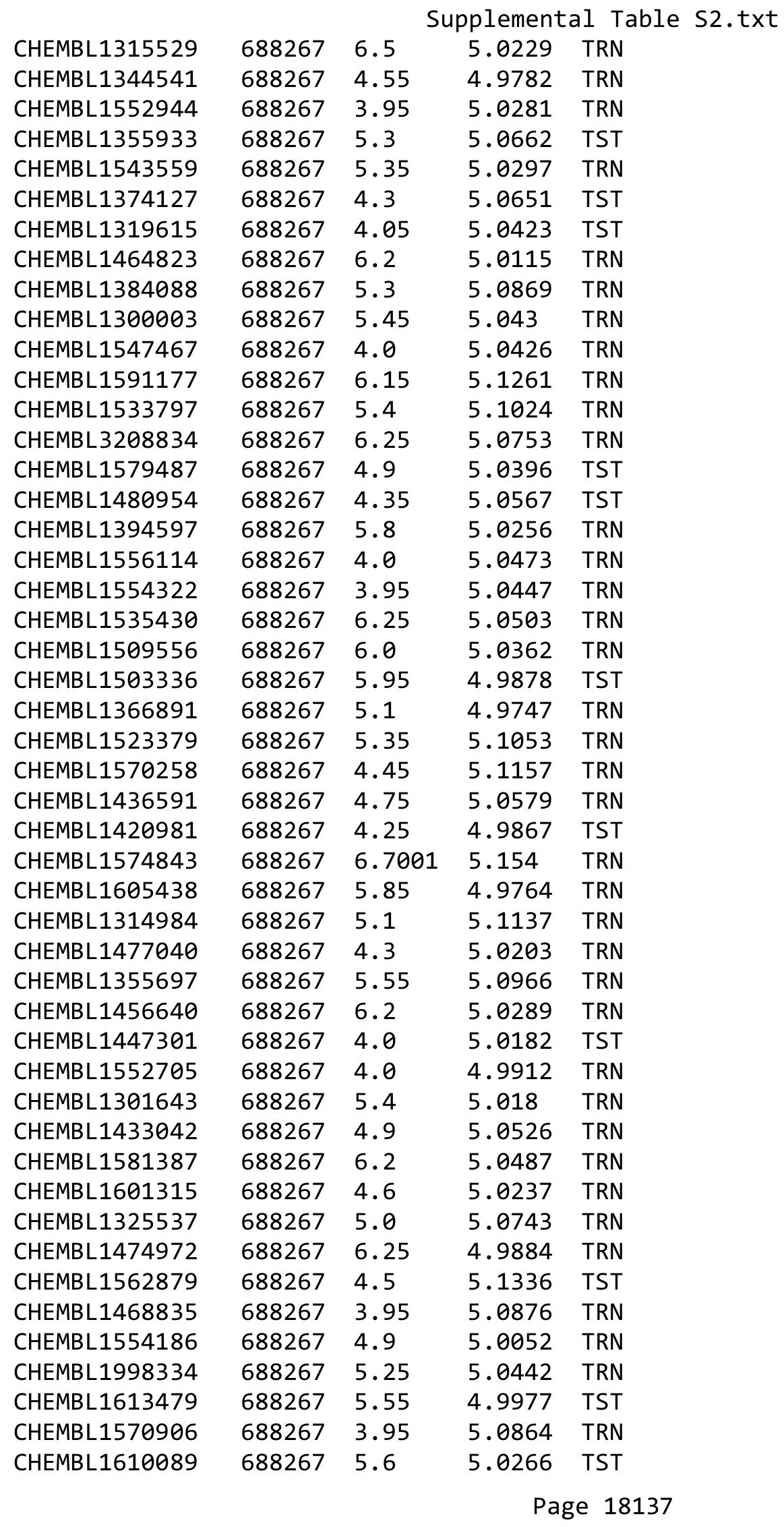




\begin{tabular}{|c|c|c|c|c|}
\hline \multicolumn{5}{|c|}{ Supplemental Table S2.txt } \\
\hline CHEMBL1321931 & 688267 & 4.1 & 5.0733 & TRN \\
\hline CHEMBL1398991 & 688267 & 5.35 & 5.1008 & TRN \\
\hline CHEMBL1463273 & 688267 & 4.55 & 5.0899 & TRN \\
\hline CHEMBL1407523 & 688267 & 4.0 & 5.0421 & TRN \\
\hline CHEMBL1528125 & 688267 & 4.85 & 5.0513 & TRN \\
\hline CHEMBL1524984 & 688267 & 5.6 & 5.0876 & TST \\
\hline CHEMBL1564422 & 688267 & 6.15 & 5.1577 & TRN \\
\hline CHEMBL1609119 & 688267 & 5.8 & 5.1062 & TRN \\
\hline CHEMBL1484585 & 688267 & 5.55 & 5.1112 & TST \\
\hline CHEMBL1521733 & 688267 & 6.6 & 5.0571 & TST \\
\hline CHEMBL1502929 & 688267 & 4.1 & 5.0354 & TST \\
\hline CHEMBL1518004 & 688267 & 4.9 & 5.0446 & TRN \\
\hline CHEMBL1406402 & 688267 & 4.1 & 5.0468 & TRN \\
\hline CHEMBL1314562 & 688267 & 4.0 & 4.982 & TRN \\
\hline CHEMBL1602860 & 688267 & 6.35 & 5.0269 & TST \\
\hline CHEMBL224633 & 688267 & 4.35 & 5.0665 & TST \\
\hline CHEMBL1553198 & 688267 & 3.95 & 5.0722 & TRN \\
\hline CHEMBL1529268 & 688267 & 4.25 & 5.0472 & TRN \\
\hline CHEMBL1313357 & 688267 & 4.95 & 5.0534 & TRN \\
\hline CHEMBL1365702 & 688267 & 5.45 & 5.0086 & TRN \\
\hline CHEMBL1472889 & 688267 & 4.6 & 5.0694 & TRN \\
\hline CHEMBL1509476 & 688267 & 5.4 & 5.1067 & TRN \\
\hline CHEMBL1576158 & 688267 & 5.0 & 5.0265 & TRN \\
\hline CHEMBL1505617 & 688267 & 4.4 & 5.092 & TRN \\
\hline CHEMBL1368598 & 688267 & 4.05 & 5.0653 & TST \\
\hline CHEMBL1367171 & 688267 & 6.2 & 5.0754 & TRN \\
\hline CHEMBL1584041 & 688267 & 4.55 & 5.0409 & TRN \\
\hline CHEMBL1305074 & 688267 & 5.5 & 5.0024 & TRN \\
\hline CHEMBL1325443 & 688267 & 6.2 & 5.0249 & TRN \\
\hline CHEMBL1512774 & 688267 & 5.85 & 5.1133 & TRN \\
\hline CHEMBL1326176 & 688267 & 4.05 & 5.1314 & TRN \\
\hline CHEMBL1375307 & 688267 & 4.65 & 5.0364 & TRN \\
\hline CHEMBL1469103 & 688267 & 6.1 & 4.9666 & TST \\
\hline CHEMBL1560437 & 688267 & 4.0 & 5.0476 & TRN \\
\hline CHEMBL1371450 & 688267 & 3.95 & 5.0965 & TRN \\
\hline CHEMBL1377072 & 688267 & 5.9 & 5.0875 & TST \\
\hline CHEMBL 1404272 & 688267 & 5.35 & 5.001 & TRN \\
\hline CHEMBL1482201 & 688267 & 5.6 & 5.0359 & TST \\
\hline CHEMBL1356991 & 688267 & 4.4 & 5.0947 & TRN \\
\hline CHEMBL1357799 & 688267 & 4.5 & 5.0708 & TRN \\
\hline CHEMBL1558870 & 688267 & 4.4 & 5.0661 & TRN \\
\hline CHEMBL1591025 & 688267 & 5.05 & 5.1682 & TRN \\
\hline CHEMBL1523042 & 688267 & 5.6 & 5.1302 & TST \\
\hline CHEMBL1396421 & 688267 & 3.95 & 5.1077 & TRN \\
\hline CHEMBL1594435 & 688267 & 4.0 & 5.0842 & TRN \\
\hline CHEMBL1561897 & 688267 & 4.55 & 5.0204 & TRN \\
\hline CHEMBL1557818 & 688267 & 4.4 & 5.1528 & TRN \\
\hline CHEMBL1337390 & 688267 & 5.5 & 5.0632 & TRN \\
\hline
\end{tabular}




\begin{tabular}{|c|c|c|c|c|c|}
\hline \\
\hline CHEMBL1512409 & 688267 & 4.5 & 5.1303 & TRN & \\
\hline CHEMBL1535940 & 688267 & 5.75 & 5.0155 & TRN & \\
\hline CHEMBL1585239 & 688267 & 4.0 & 5.0363 & TRN & \\
\hline CHEMBL1308440 & 688267 & 6.15 & 5.1363 & TST & \\
\hline CHEMBL1507705 & 688267 & 5.95 & 5.0833 & TRN & \\
\hline CHEMBL1425489 & 688267 & 4.15 & 5.027 & TST & \\
\hline CHEMBL1467723 & 688267 & 5.05 & 5.0878 & TRN & \\
\hline CHEMBL1368430 & 688267 & 5.55 & 5.0016 & TST & \\
\hline CHEMBL1356496 & 688267 & 4.35 & 5.0212 & TRN & \\
\hline CHEMBL1342873 & 688267 & 5.8 & 5.0197 & TST & \\
\hline CHEMBL1377901 & 688267 & 4.35 & 5.05699 & 99999999995 & TRN \\
\hline CHEMBL1386167 & 688267 & 6.5501 & 5.0301 & TRN & \\
\hline CHEMBL1545617 & 688267 & 4.8 & 5.0152 & TRN & \\
\hline CHEMBL1512416 & 688267 & 4.3 & 5.0645 & TST & \\
\hline CHEMBL1514875 & 688267 & 4.0 & 5.1314 & TRN & \\
\hline CHEMBL1537072 & 688267 & 4.05 & 5.0828 & TRN & \\
\hline CHEMBL1603726 & 688267 & 4.25 & 4.9908 & TRN & \\
\hline CHEMBL1330787 & 688267 & 4.05 & 4.9968 & TST & \\
\hline CHEMBL1491422 & 688267 & 5.5 & 5.1171 & TRN & \\
\hline CHEMBL1472771 & 688267 & 6.25 & 5.0415 & TRN & \\
\hline CHEMBL1393314 & 688267 & 4.0 & 5.1166 & TRN & \\
\hline CHEMBL1455981 & 688267 & 4.5 & 5.0721 & TRN & \\
\hline CHEMBL1316826 & 688267 & 4.4 & 5.1251 & TST & \\
\hline CHEMBL1403942 & 688267 & 3.95 & 5.0109 & TRN & \\
\hline CHEMBL3212376 & 688267 & 4.15 & 5.0814 & TRN & \\
\hline CHEMBL1557870 & 688267 & 4.95 & 5.0086 & TRN & \\
\hline CHEMBL1471917 & 688267 & 6.2 & 5.0582 & TRN & \\
\hline CHEMBL1405806 & 688267 & 4.35 & 5.0492 & TRN & \\
\hline CHEMBL1435489 & 688267 & 5.7 & 5.113 & TRN & \\
\hline CHEMBL1459468 & 688267 & 6.2 & 4.9836 & TRN & \\
\hline CHEMBL 2003595 & 688267 & 5.8 & 4.9924 & TRN & \\
\hline CHEMBL1463256 & 688267 & 5.65 & 5.0427 & TRN & \\
\hline CHEMBL1572796 & 688267 & 6.15 & 5.1691 & TRN & \\
\hline CHEMBL1432192 & 688267 & 4.65 & 5.0224 & TST & \\
\hline CHEMBL3210931 & 688267 & 5.2 & 4.9796 & TRN & \\
\hline CHEMBL1318323 & 688267 & 5.55 & 4.9732 & TRN & \\
\hline CHEMBL1514247 & 688267 & 5.6 & 5.0366 & TRN & \\
\hline CHEMBL1599137 & 688267 & 5.55 & 5.082 & TST & \\
\hline CHEMBL1559537 & 688267 & 4.0 & 4.9928 & TRN & \\
\hline CHEMBL1366379 & 688267 & 4.6 & 5.0622 & TST & \\
\hline CHEMBL3145172 & 688267 & 4.7 & 4.9734 & TRN & \\
\hline CHEMBL1406199 & 688267 & 5.45 & 5.0417 & TRN & \\
\hline CHEMBL1545310 & 688267 & 4.4 & 5.0967 & TRN & \\
\hline CHEMBL1397733 & 688267 & 5.2 & 5.0229 & TRN & \\
\hline CHEMBL1397600 & 688267 & 4.1 & 4.9749 & TRN & \\
\hline CHEMBL563503 & 688267 & 4.0 & 5.0258 & TRN & \\
\hline CHEMBL1320536 & 688267 & 4.45 & 5.0 & TST & \\
\hline CHEMBL1316047 & 688267 & 4.0 & 5.1387 & TST & \\
\hline
\end{tabular}




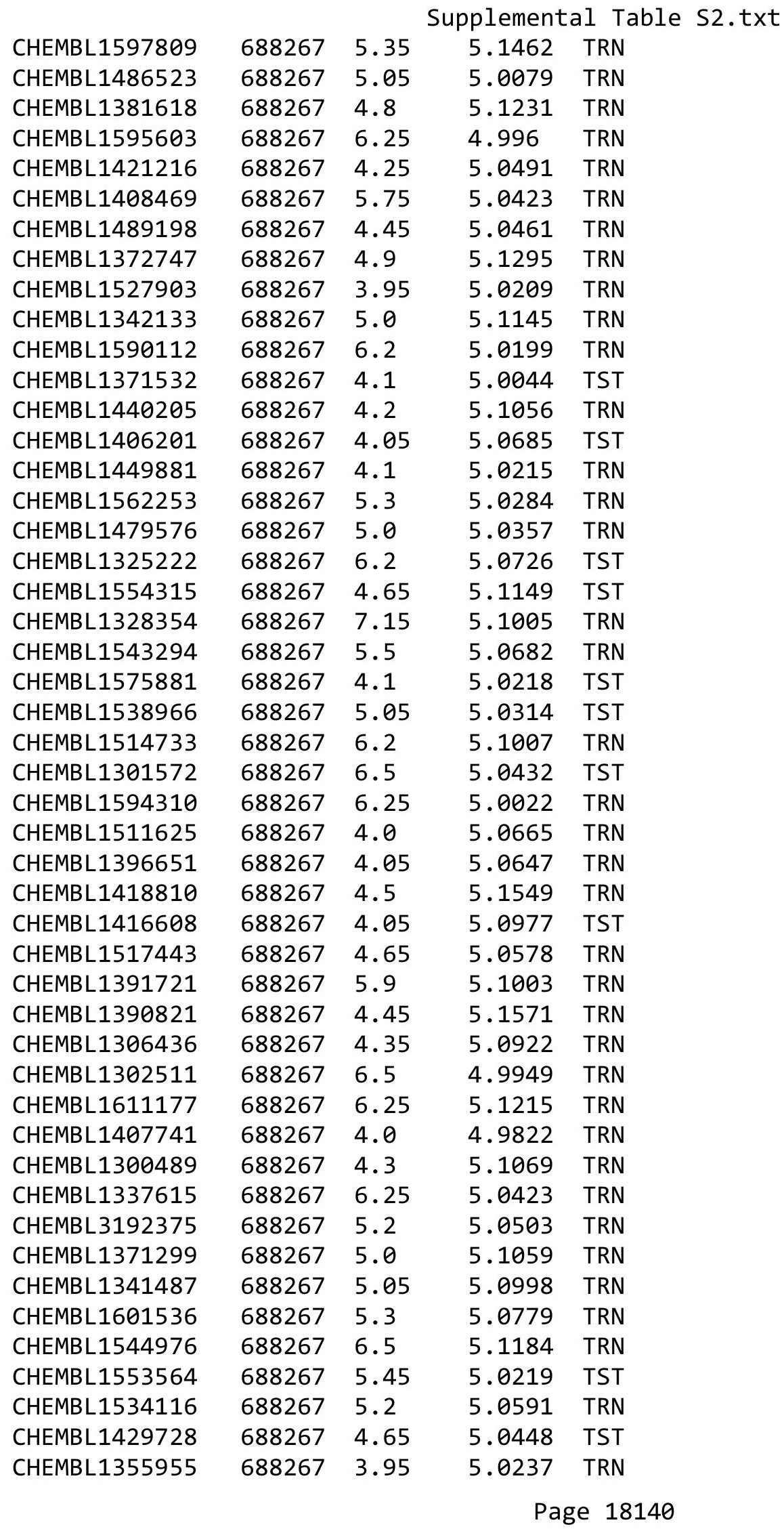




\begin{tabular}{|c|c|c|c|c|c|}
\hline \multicolumn{6}{|c|}{ opıemental } \\
\hline CHEMBL1454023 & 688267 & 6.2 & 5.1019 & TRN & \\
\hline CHEMBL1363199 & 688267 & 5.6 & 5.0916 & TRN & \\
\hline CHEMBL1600715 & 688267 & 6.15 & 5.0867 & TST & \\
\hline CHEMBL1356689 & 688267 & 5.05 & 5.0403 & TRN & \\
\hline CHEMBL1326390 & 688267 & 6.2 & 5.0446 & TRN & \\
\hline CHEMBL1573739 & 688267 & 6.15 & 5.0245 & TST & \\
\hline CHEMBL1384927 & 688267 & 4.05 & 5.0342 & TRN & \\
\hline CHEMBL1573001 & 688267 & 6.5501 & 5.1608 & TRN & \\
\hline CHEMBL1375466 & 688267 & 5.05 & 5.0055 & TRN & \\
\hline CHEMBL1446412 & 688267 & 4.05 & 4.9953 & TST & \\
\hline CHEMBL1439302 & 688267 & 5.35 & 5.077 & TST & \\
\hline CHEMBL1556678 & 688267 & 4.55 & 5.1137 & TST & \\
\hline CHEMBL1312531 & 688267 & 6.6499 & 5.0316 & TRN & \\
\hline CHEMBL1408365 & 688267 & 5.5 & 5.0083 & TRN & \\
\hline CHEMBL1593982 & 688267 & 6.25 & 5.1363 & TRN & \\
\hline CHEMBL1561861 & 688267 & 4.3 & 5.1048 & TST & \\
\hline CHEMBL1456543 & 688267 & 6.45 & 5.0281 & TST & \\
\hline CHEMBL1393387 & 688267 & 4.0 & 5.1521 & TRN & \\
\hline CHEMBL1524478 & 688267 & 4.05 & 5.058 & TST & \\
\hline CHEMBL585840 & 688267 & 4.15 & 5.0622 & TST & \\
\hline CHEMBL1415704 & 688267 & 6.2 & 5.0367 & TRN & \\
\hline CHEMBL1562019 & 688267 & 4.35 & 5.0116 & TRN & \\
\hline CHEMBL1362232 & 688267 & 4.5 & 5.1063 & TRN & \\
\hline CHEMBL1310787 & 688267 & 4.05 & 5.0539 & TRN & \\
\hline CHEMBL1420078 & 688267 & 4.25 & 5.0489 & TST & \\
\hline CHEMBL1412294 & 688267 & 6.15 & 4.9951 & TRN & \\
\hline CHEMBL1569849 & 688267 & 4.25 & 5.0176 & TRN & \\
\hline CHEMBL1490089 & 688267 & 4.0 & 5.0883 & TRN & \\
\hline CHEMBL1360232 & 688267 & 4.0 & 5.0797 & TRN & \\
\hline CHEMBL1574913 & 688267 & 4.0 & 5.0754 & TRN & \\
\hline CHEMBL1514849 & 688267 & 5.55 & 5.1262 & TRN & \\
\hline CHEMBL1415200 & 688267 & 5.1 & 4.9983 & TRN & \\
\hline CHEMBL1347016 & 688267 & 4.4 & 5.0736 & TST & \\
\hline CHEMBL1565978 & 688267 & 6.2 & 5.0482 & TRN & \\
\hline CHEMBL1313863 & 688267 & 6.2 & 5.0499 & TRN & \\
\hline CHEMBL1606518 & 688267 & 5.7 & 5.0412 & TST & \\
\hline CHEMBL1460913 & 688267 & 6.5 & 5.10800 & 00000000005 & TRN \\
\hline CHEMBL1408277 & 688267 & 5.5 & 5.0722 & TST & \\
\hline CHEMBL1571390 & 688267 & 4.0 & 5.0657 & TST & \\
\hline CHEMBL1241132 & 688267 & 5.25 & 5.0057 & TRN & \\
\hline CHEMBL1422277 & 688267 & 4.05 & 5.1003 & TRN & \\
\hline CHEMBL1607318 & 688267 & 6.2 & 5.025 & TRN & \\
\hline CHEMBL1320257 & 688267 & 4.4 & 5.0206 & TST & \\
\hline CHEMBL1384995 & 688267 & 5.8 & 5.0613 & TRN & \\
\hline CHEMBL 3211737 & 688267 & 6.2 & 4.9691 & TRN & \\
\hline CHEMBL1540664 & 688267 & 5.05 & 5.0644 & TRN & \\
\hline CHEMBL3208775 & 688267 & 5.55 & 5.0218 & TRN & \\
\hline CHEMBL1318890 & 688267 & 6.25 & 5.0825 & TRN & \\
\hline
\end{tabular}




\begin{tabular}{|c|c|c|c|c|c|}
\hline & & & & & \\
\hline CHEMBL1789996 & 688267 & 4.5 & 5.0202 & TST & \\
\hline CHEMBL1371293 & 688267 & 4.05 & 5.0366 & TST & \\
\hline CHEMBL1574683 & 688267 & 4.4 & 5.0287 & TRN & \\
\hline CHEMBL1303192 & 688267 & 4.4 & 5.0931 & TRN & \\
\hline CHEMBL1303147 & 688267 & 4.6 & 4.9619 & TRN & \\
\hline CHEMBL1540636 & 688267 & 4.3 & 5.0947 & TRN & \\
\hline CHEMBL1594972 & 688267 & 6.2 & 5.04899 & 99999999995 & TRN \\
\hline CHEMBL285819 & 688267 & 4.15 & 5.0628 & TRN & \\
\hline CHEMBL1542978 & 688267 & 6.5 & 5.035 & TRN & \\
\hline CHEMBL1558324 & 688267 & 5.2 & 5.0589 & TST & \\
\hline CHEMBL1414100 & 688267 & 5.55 & 5.0259 & TST & \\
\hline CHEMBL1521185 & 688267 & 4.0 & 5.0004 & TRN & \\
\hline CHEMBL1435795 & 688267 & 4.8 & 5.1008 & TRN & \\
\hline CHEMBL1351596 & 688267 & 6.15 & 5.0344 & TST & \\
\hline CHEMBL1374155 & 688267 & 5.05 & 5.0452 & TRN & \\
\hline CHEMBL1329699 & 688267 & 4.0 & 5.0723 & TST & \\
\hline CHEMBL1428471 & 688267 & 6.5 & 5.1003 & TRN & \\
\hline CHEMBL1382936 & 688267 & 4.1 & 4.9821 & TRN & \\
\hline CHEMBL1392766 & 688267 & 5.45 & 5.1154 & TRN & \\
\hline CHEMBL1608973 & 688267 & 6.2 & 5.0358 & TRN & \\
\hline CHEMBL1425383 & 688267 & 4.05 & 5.0996 & TRN & \\
\hline CHEMBL1428865 & 688267 & 6.5501 & 5.0462 & TST & \\
\hline CHEMBL1575568 & 688267 & 4.0 & 4.9781 & TRN & \\
\hline CHEMBL1561072 & 688267 & 4.4 & 5.1046 & TRN & \\
\hline CHEMBL1438052 & 688267 & 5.55 & 5.0106 & TRN & \\
\hline CHEMBL1459096 & 688267 & 5.5 & 5.0119 & TRN & \\
\hline CHEMBL1494247 & 688267 & 3.95 & 5.1065 & TST & \\
\hline CHEMBL1594018 & 688267 & 5.35 & 5.0468 & TRN & \\
\hline CHEMBL1338525 & 688267 & 4.25 & 5.0744 & TST & \\
\hline CHEMBL1606459 & 688267 & 6.15 & 5.1809 & TRN & \\
\hline CHEMBL1510596 & 688267 & 6.2 & 5.0315 & TRN & \\
\hline CHEMBL1429488 & 688267 & 4.0 & 4.9619 & TRN & \\
\hline CHEMBL1397964 & 688267 & 4.35 & 5.0182 & TRN & \\
\hline CHEMBL1369477 & 688267 & 6.9 & 4.9897 & TRN & \\
\hline CHEMBL1534958 & 688267 & 5.25 & 5.1393 & TRN & \\
\hline CHEMBL1303484 & 688267 & 4.9 & 5.0724 & TRN & \\
\hline CHEMBL1310812 & 688267 & 4.35 & 5.0302 & TST & \\
\hline CHEMBL1402922 & 688267 & 4.4 & 5.1384 & TRN & \\
\hline CHEMBL1470010 & 688267 & 5.55 & 5.0893 & TRN & \\
\hline CHEMBL1586181 & 688267 & 5.8 & 4.9886 & TRN & \\
\hline CHEMBL1456201 & 688267 & 4.0 & 5.0493 & TST & \\
\hline CHEMBL1595039 & 688267 & 5.5 & 5.0803 & TRN & \\
\hline CHEMBL1345927 & 688267 & 4.3 & 5.0435 & TRN & \\
\hline CHEMBL1473378 & 688267 & 4.55 & 5.0963 & TRN & \\
\hline CHEMBL1309323 & 688267 & 5.05 & 5.0739 & TRN & \\
\hline CHEMBL1396164 & 688267 & 5.55 & 5.0594 & TRN & \\
\hline CHEMBL1413376 & 688267 & 4.05 & 5.099 & TRN & \\
\hline CHEMBL1476085 & 688267 & 5.5 & 5.0802 & TST & \\
\hline
\end{tabular}




\begin{tabular}{|c|c|c|c|c|}
\hline \multicolumn{5}{|c|}{ Supplemental Table S2.txt } \\
\hline CHEMBL1435428 & 688267 & 6.15 & 5.0944 & TRN \\
\hline CHEMBL1455413 & 688267 & 4.85 & 5.1025 & TST \\
\hline CHEMBL1323797 & 688267 & 5.45 & 5.0684 & TRN \\
\hline CHEMBL1389996 & 688267 & 4.5 & 5.0727 & TRN \\
\hline CHEMBL1454309 & 688267 & 4.9 & 5.0586 & TRN \\
\hline CHEMBL1354677 & 688267 & 5.3 & 5.0979 & TRN \\
\hline CHEMBL1536181 & 688267 & 5.85 & 5.1001 & TRN \\
\hline CHEMBL1411902 & 688267 & 5.55 & 5.0561 & TST \\
\hline CHEMBL1370731 & 688267 & 4.0 & 5.1009 & TRN \\
\hline CHEMBL1412905 & 688267 & 4.0 & 5.0207 & TRN \\
\hline CHEMBL1561701 & 688267 & 6.2 & 5.0245 & TRN \\
\hline CHEMBL1474010 & 688267 & 6.2 & 5.0157 & TST \\
\hline CHEMBL1329013 & 688267 & 5.5 & 5.0344 & TRN \\
\hline CHEMBL1379586 & 688267 & 4.4 & 5.0963 & TST \\
\hline CHEMBL1359926 & 688267 & 6.6499 & 5.0966 & TRN \\
\hline CHEMBL1314403 & 688267 & 5.05 & 5.0222 & TRN \\
\hline CHEMBL1364654 & 688267 & 4.95 & 5.0967 & TST \\
\hline CHEMBL3194987 & 688267 & 4.0 & 5.047 & TRN \\
\hline CHEMBL1364138 & 688267 & 3.95 & 5.1032 & TRN \\
\hline CHEMBL1594031 & 688267 & 5.5 & 5.0364 & TRN \\
\hline CHEMBL1557132 & 688267 & 4.3 & 5.0228 & TRN \\
\hline CHEMBL1368584 & 688267 & 4.4 & 5.1155 & TRN \\
\hline CHEMBL491550 & 688267 & 4.0 & 5.0635 & TRN \\
\hline CHEMBL1307410 & 688267 & 6.2 & 5.0305 & TST \\
\hline CHEMBL1594516 & 688267 & 4.2 & 5.1663 & TRN \\
\hline CHEMBL1328821 & 688267 & 5.05 & 5.0616 & TRN \\
\hline CHEMBL1445910 & 688267 & 4.15 & 5.0613 & TRN \\
\hline CHEMBL1478751 & 688267 & 4.4 & 5.0361 & TRN \\
\hline CHEMBL1584042 & 688267 & 4.45 & 5.0649 & TRN \\
\hline CHEMBL1445196 & 688267 & 4.65 & 5.1351 & TRN \\
\hline CHEMBL1305225 & 688267 & 5.05 & 4.9769 & TRN \\
\hline CHEMBL1437162 & 688267 & 6.2 & 5.008 & TST \\
\hline CHEMBL1585784 & 688267 & 4.35 & 5.1234 & TST \\
\hline CHEMBL1430409 & 688267 & 6.2 & 5.1032 & TRN \\
\hline CHEMBL1350294 & 688267 & 4.95 & 5.1661 & TRN \\
\hline CHEMBL1345300 & 688267 & 6.2 & 5.0206 & TRN \\
\hline CHEMBL1436788 & 688267 & 5.1 & 5.1089 & TRN \\
\hline CHEMBL1392492 & 688267 & 6.15 & 5.11 & TST \\
\hline CHEMBL1482686 & 688267 & 4.0 & 5.0348 & TST \\
\hline CHEMBL1312022 & 688267 & 6.25 & 5.0012 & TRN \\
\hline CHEMBL1593832 & 688267 & 6.2 & 5.1386 & TRN \\
\hline CHEMBL1316791 & 688267 & 6.5 & 5.0394 & TRN \\
\hline CHEMBL1496082 & 688267 & 6.2 & 5.0694 & TRN \\
\hline CHEMBL1397612 & 688267 & 5.55 & 5.0368 & TRN \\
\hline CHEMBL1308424 & 688267 & 6.2 & 5.0438 & TRN \\
\hline CHEMBL1326828 & 688267 & 5.4 & 5.0733 & TRN \\
\hline CHEMBL1473495 & 688267 & 4.35 & 5.0573 & TRN \\
\hline CHEMBL1480506 & 688267 & 4.25 & 5.1168 & TRN \\
\hline
\end{tabular}




\begin{tabular}{|c|c|c|c|c|c|}
\hline \multicolumn{6}{|c|}{ Supplemental Table S2.txt } \\
\hline CHEMBL1478473 & 688267 & 4.0 & 5.019 & TRN & \\
\hline CHEMBL1529121 & 688267 & 5.4 & 5.0154 & TRN & \\
\hline CHEMBL1410975 & 688267 & 4.05 & 5.098 & TRN & \\
\hline CHEMBL1451419 & 688267 & 4.65 & 5.0401 & TRN & \\
\hline CHEMBL1361517 & 688267 & 4.05 & 5.0983 & TRN & \\
\hline CHEMBL1572231 & 688267 & 4.05 & 5.0683 & TRN & \\
\hline CHEMBL483137 & 688267 & 6.5 & 4.9825 & TRN & \\
\hline CHEMBL1430233 & 688267 & 5.25 & 5.0661 & TRN & \\
\hline CHEMBL1313925 & 688267 & 4.75 & 5.0428 & TST & \\
\hline CHEMBL1569944 & 688267 & 6.2 & 5.0217 & TRN & \\
\hline CHEMBL1413625 & 688267 & 4.4 & 5.0438 & TRN & \\
\hline CHEMBL1517559 & 688267 & 4.15 & 5.022 & TST & \\
\hline CHEMBL1601270 & 688267 & 6.0 & 5.0787 & TST & \\
\hline CHEMBL1546049 & 688267 & 5.0 & 5.0953 & TRN & \\
\hline CHEMBL1302513 & 688267 & 5.0 & 5.1252 & TST & \\
\hline CHEMBL1593336 & 688267 & 5.45 & 5.0954 & TRN & \\
\hline CHEMBL1566138 & 688267 & 5.4 & 5.0301 & TRN & \\
\hline CHEMBL1445393 & 688267 & 5.85 & 5.0865 & TRN & \\
\hline CHEMBL1398553 & 688267 & 4.1 & 5.0159 & TRN & \\
\hline CHEMBL1339493 & 688267 & 5.35 & 5.0156 & TST & \\
\hline CHEMBL1357988 & 688267 & 3.8 & 5.1245 & TST & \\
\hline CHEMBL1399177 & 688267 & 4.95 & 5.0859 & TRN & \\
\hline CHEMBL1322519 & 688267 & 4.65 & 5.0812 & TST & \\
\hline CHEMBL1560482 & 688267 & 4.0 & 5.0333 & TRN & \\
\hline CHEMBL1367580 & 688267 & 4.25 & 5.0481 & TST & \\
\hline CHEMBL1591628 & 688267 & 6.15 & 5.0056 & TRN & \\
\hline CHEMBL1458324 & 688267 & 3.95 & 5.0443 & TST & \\
\hline CHEMBL1464004 & 688267 & 5.0 & 5.1114 & TRN & \\
\hline CHEMBL1331178 & 688267 & 5.25 & 5.0818 & TRN & \\
\hline CHEMBL1488592 & 688267 & 4.05 & 5.0539 & TRN & \\
\hline CHEMBL1607598 & 688267 & 3.95 & 5.0166 & TRN & \\
\hline CHEMBL1492353 & 688267 & 5.9 & 5.1567 & TRN & \\
\hline CHEMBL1516940 & 688267 & 5.9 & 5.0941 & TRN & \\
\hline CHEMBL1325531 & 688267 & 6.0 & 5.0921 & TRN & \\
\hline CHEMBL1577964 & 688267 & 5.05 & 5.0608 & TRN & \\
\hline CHEMBL1314702 & 688267 & 5.85 & 5.0291 & TRN & \\
\hline CHEMBL1307154 & 688267 & 6.2 & 4.98600 & 0000000001 & TRN \\
\hline CHEMBL1572111 & 688267 & 5.4 & 5.0175 & TST & \\
\hline CHEMBL1532585 & 688267 & 5.55 & 5.1191 & TRN & \\
\hline CHEMBL1579376 & 688267 & 4.6 & 5.0797 & TRN & \\
\hline CHEMBL1569239 & 688267 & 4.7 & 5.0161 & TRN & \\
\hline CHEMBL581939 & 688267 & 5.45 & 5.0853 & TST & \\
\hline CHEMBL1548112 & 688267 & 6.15 & 5.1261 & TRN & \\
\hline CHEMBL1401460 & 688267 & 4.0 & 4.9953 & TRN & \\
\hline CHEMBL1327452 & 688267 & 6.2 & 5.1227 & TRN & \\
\hline CHEMBL1606160 & 688267 & 6.15 & 5.0901 & TRN & \\
\hline CHEMBL1401747 & 688267 & 4.4 & 5.0245 & TRN & \\
\hline CHEMBL1449065 & 688267 & 4.4 & 5.1028 & TRN & \\
\hline
\end{tabular}




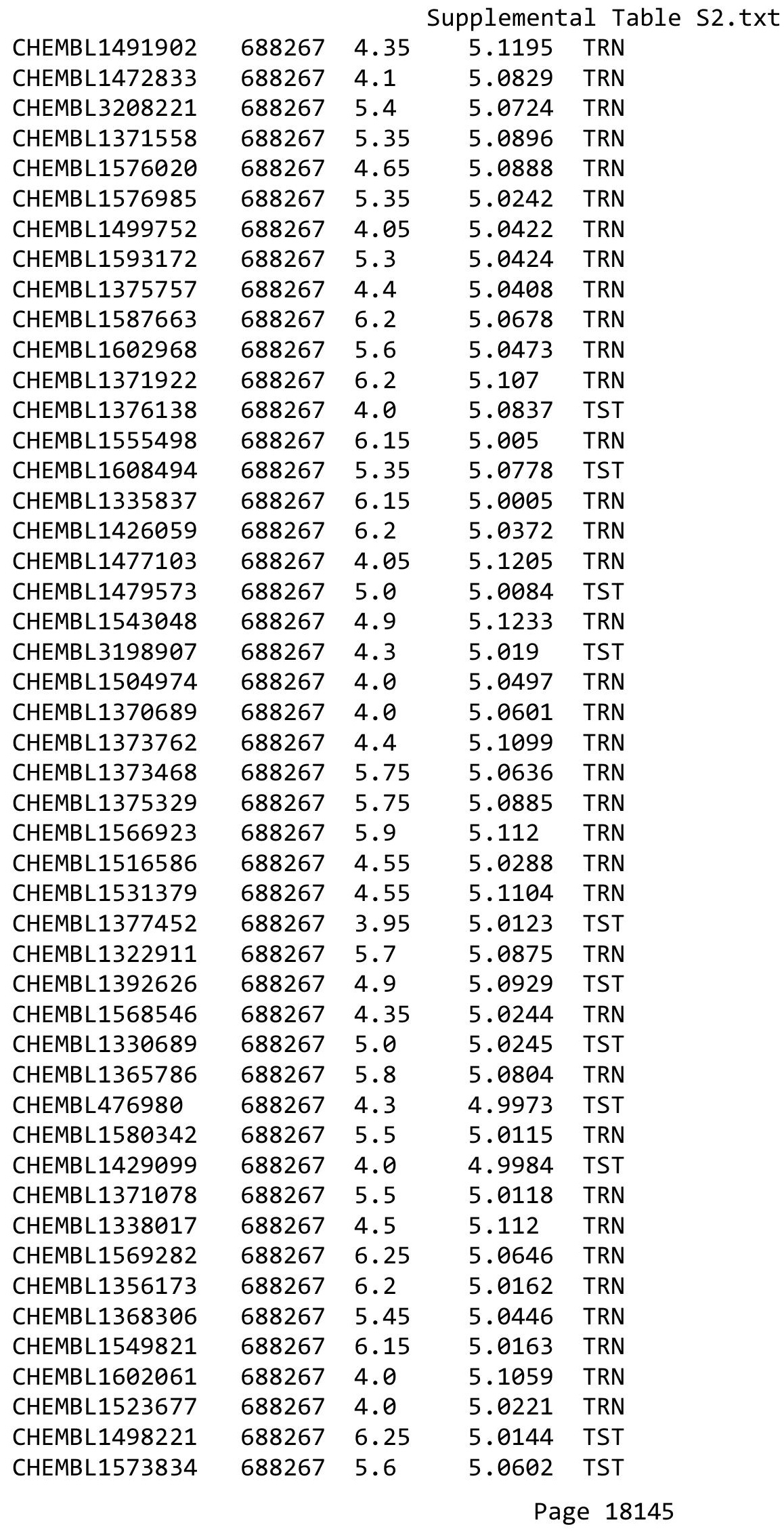




\begin{tabular}{|c|c|c|c|c|}
\hline \multicolumn{5}{|c|}{ Supplemental Table S2.txt } \\
\hline CHEMBL1361442 & 688267 & 4.05 & 5.0835 & TRN \\
\hline CHEMBL1335906 & 688267 & 5.55 & 5.0629 & TRN \\
\hline CHEMBL1569623 & 688267 & 6.2 & 5.0118 & TRN \\
\hline CHEMBL1401138 & 688267 & 6.15 & 5.0234 & TRN \\
\hline CHEMBL1329285 & 688267 & 4.85 & 5.0158 & TRN \\
\hline CHEMBL1583998 & 688267 & 4.25 & 4.988 & TRN \\
\hline CHEMBL1489919 & 688267 & 4.05 & 5.1191 & TRN \\
\hline CHEMBL1347718 & 688267 & 5.95 & 5.0138 & TRN \\
\hline CHEMBL1562704 & 688267 & 6.2 & 5.0894 & TRN \\
\hline CHEMBL1538768 & 688267 & 6.15 & 5.0071 & TRN \\
\hline CHEMBL1503959 & 688267 & 4.8 & 5.118 & TRN \\
\hline CHEMBL1547516 & 688267 & 4.95 & 5.0263 & TRN \\
\hline CHEMBL1494918 & 688267 & 5.85 & 5.0103 & TRN \\
\hline CHEMBL1363227 & 688267 & 4.95 & 5.0321 & TRN \\
\hline CHEMBL1477885 & 688267 & 3.95 & 5.0579 & TST \\
\hline CHEMBL1979539 & 688267 & 6.2 & 5.026 & TRN \\
\hline CHEMBL1418456 & 688267 & 4.45 & 5.0653 & TRN \\
\hline CHEMBL1540064 & 688267 & 4.85 & 5.0735 & TRN \\
\hline CHEMBL1434389 & 688267 & 6.2 & 5.0188 & TRN \\
\hline CHEMBL1552875 & 688267 & 3.95 & 5.0986 & TRN \\
\hline CHEMBL1403199 & 688267 & 5.8 & 5.0195 & TRN \\
\hline CHEMBL1465687 & 688267 & 5.2 & 5.0597 & TRN \\
\hline CHEMBL3198595 & 688267 & 5.2 & 4.9935 & TRN \\
\hline CHEMBL1458252 & 688267 & 4.05 & 5.0798 & TRN \\
\hline CHEMBL1518228 & 688267 & 4.05 & 5.0371 & TST \\
\hline CHEMBL1575714 & 688267 & 4.35 & 5.1447 & TRN \\
\hline CHEMBL1424143 & 688267 & 4.5 & 5.1037 & TRN \\
\hline CHEMBL1562808 & 688267 & 6.15 & 5.1022 & TRN \\
\hline CHEMBL1437717 & 688267 & 6.25 & 5.0429 & TST \\
\hline CHEMBL1542945 & 688267 & 5.85 & 5.0218 & TST \\
\hline CHEMBL1320649 & 688267 & 4.05 & 5.1105 & TRN \\
\hline CHEMBL1452167 & 688267 & 6.2 & 5.0059 & TRN \\
\hline CHEMBL1354628 & 688267 & 5.7 & 5.0837 & TST \\
\hline CHEMBL1600890 & 688267 & 6.2 & 5.0395 & TRN \\
\hline CHEMBL1459907 & 688267 & 4.0 & 5.0416 & TRN \\
\hline CHEMBL1458090 & 688267 & 4.25 & 5.0167 & TRN \\
\hline CHEMBL1460251 & 688267 & 4.3 & 5.1205 & TRN \\
\hline CHEMBL1436723 & 688267 & 6.2 & 5.0702 & TRN \\
\hline CHEMBL1590945 & 688267 & 5.65 & 5.0001 & TRN \\
\hline CHEMBL1605597 & 688267 & 4.0 & 4.9989 & TRN \\
\hline CHEMBL1437266 & 688267 & 5.85 & 5.1622 & TRN \\
\hline CHEMBL1453677 & 688267 & 5.3 & 5.0639 & TST \\
\hline CHEMBL1354965 & 688267 & 4.3 & 5.039 & TRN \\
\hline CHEMBL1403140 & 688267 & 4.55 & 5.0808 & TST \\
\hline CHEMBL1411514 & 688267 & 4.05 & 5.0687 & TST \\
\hline CHEMBL1470600 & 688267 & 6.2 & 5.0498 & TRN \\
\hline CHEMBL1384715 & 688267 & 4.45 & 5.0266 & TRN \\
\hline CHEMBL1327169 & 688267 & 4.6 & 5.0025 & TRN \\
\hline
\end{tabular}




\begin{tabular}{|c|c|c|c|c|c|}
\hline & & \multicolumn{4}{|c|}{ Supplemental Table S2.txt } \\
\hline CHEMBL1467042 & 688267 & 4.0 & 4.9754 & TST & \\
\hline CHEMBL1384535 & 688267 & 5.45 & 5.1462 & TRN & \\
\hline CHEMBL263893 & 688267 & 3.95 & 5.0401 & TRN & \\
\hline CHEMBL1599244 & 688267 & 4.25 & 5.0981 & TRN & \\
\hline CHEMBL1317586 & 688267 & 6.2 & 5.0132 & TRN & \\
\hline CHEMBL1500514 & 688267 & 4.6 & 5.0707 & TST & \\
\hline CHEMBL1551272 & 688267 & 6.0 & 5.1442 & TRN & \\
\hline CHEMBL1419565 & 688267 & 6.1 & 5.0556 & TRN & \\
\hline CHEMBL1087004 & 688267 & 4.25 & 5.0314 & TRN & \\
\hline CHEMBL1405251 & 688267 & 5.75 & 5.0257 & TST & \\
\hline CHEMBL1526302 & 688267 & 4.4 & 4.9799 & TRN & \\
\hline CHEMBL1425793 & 688267 & 5.35 & 5.0216 & TRN & \\
\hline CHEMBL1603390 & 688267 & 6.2 & 4.9678 & TRN & \\
\hline CHEMBL 3190745 & 688267 & 5.75 & 5.0009 & TST & \\
\hline CHEMBL1512753 & 688267 & 5.5 & 5.0161 & TRN & \\
\hline CHEMBL1427797 & 688267 & 5.9 & 5.0554 & TRN & \\
\hline CHEMBL1444043 & 688267 & 6.2 & 5.083 & TRN & \\
\hline CHEMBL1300011 & 688267 & 6.15 & 5.0871 & TRN & \\
\hline CHEMBL1323177 & 688267 & 4.35 & 5.065 & TST & \\
\hline CHEMBL1586496 & 688267 & 5.25 & 5.1505 & TRN & \\
\hline CHEMBL1355244 & 688267 & 5.55 & 5.0492 & TRN & \\
\hline CHEMBL1426161 & 688267 & 6.15 & 5.0537 & TRN & \\
\hline CHEMBL3211873 & 688267 & 5.6 & 5.0725 & TRN & \\
\hline CHEMBL1585114 & 688267 & 6.2 & 5.0629 & TRN & \\
\hline CHEMBL1521813 & 688267 & 4.85 & 4.9969 & TRN & \\
\hline CHEMBL1385953 & 688267 & 6.2 & 5.0977 & TRN & \\
\hline CHEMBL1403810 & 688267 & 6.1 & 5.1437 & TST & \\
\hline CHEMBL1597033 & 688267 & 3.9 & 5.0591 & TRN & \\
\hline CHEMBL1543291 & 688267 & 5.1 & 5.0403 & TST & \\
\hline CHEMBL1551178 & 688267 & 5.5 & 5.0421 & TRN & \\
\hline CHEMBL1520638 & 688267 & 6.25 & 5.0509 & TST & \\
\hline CHEMBL1514039 & 688267 & 4.45 & 5.0521 & TRN & \\
\hline CHEMBL1500501 & 688267 & 5.6 & 5.0367 & TST & \\
\hline CHEMBL1594701 & 688267 & 4.6 & 5.032 & TST & \\
\hline CHEMBL1398689 & 688267 & 5.25 & 5.00899 & 99999999995 & TRN \\
\hline CHEMBL1482709 & 688267 & 4.75 & 5.0033 & TRN & \\
\hline CHEMBL1512311 & 688267 & 5.6 & 5.0702 & TRN & \\
\hline CHEMBL1398796 & 688267 & 6.25 & 5.0483 & TRN & \\
\hline CHEMBL1427122 & 688267 & 4.05 & 5.0722 & TST & \\
\hline CHEMBL1338449 & 688267 & 5.55 & 5.1041 & TRN & \\
\hline CHEMBL1496795 & 688267 & 4.5 & 5.0455 & TRN & \\
\hline CHEMBL1435078 & 688267 & 5.55 & 5.0713 & TST & \\
\hline CHEMBL3210316 & 688267 & 4.4 & 5.0906 & TRN & \\
\hline CHEMBL1381566 & 688267 & 5.3 & 5.1011 & TRN & \\
\hline CHEMBL1365783 & 688267 & 4.6 & 5.044 & TRN & \\
\hline CHEMBL1342589 & 688267 & 5.4 & 5.1141 & TRN & \\
\hline CHEMBL1396547 & 688267 & 4.35 & 4.9807 & TRN & \\
\hline CHEMBL1362831 & 688267 & 4.8 & 5.0736 & TRN & \\
\hline
\end{tabular}




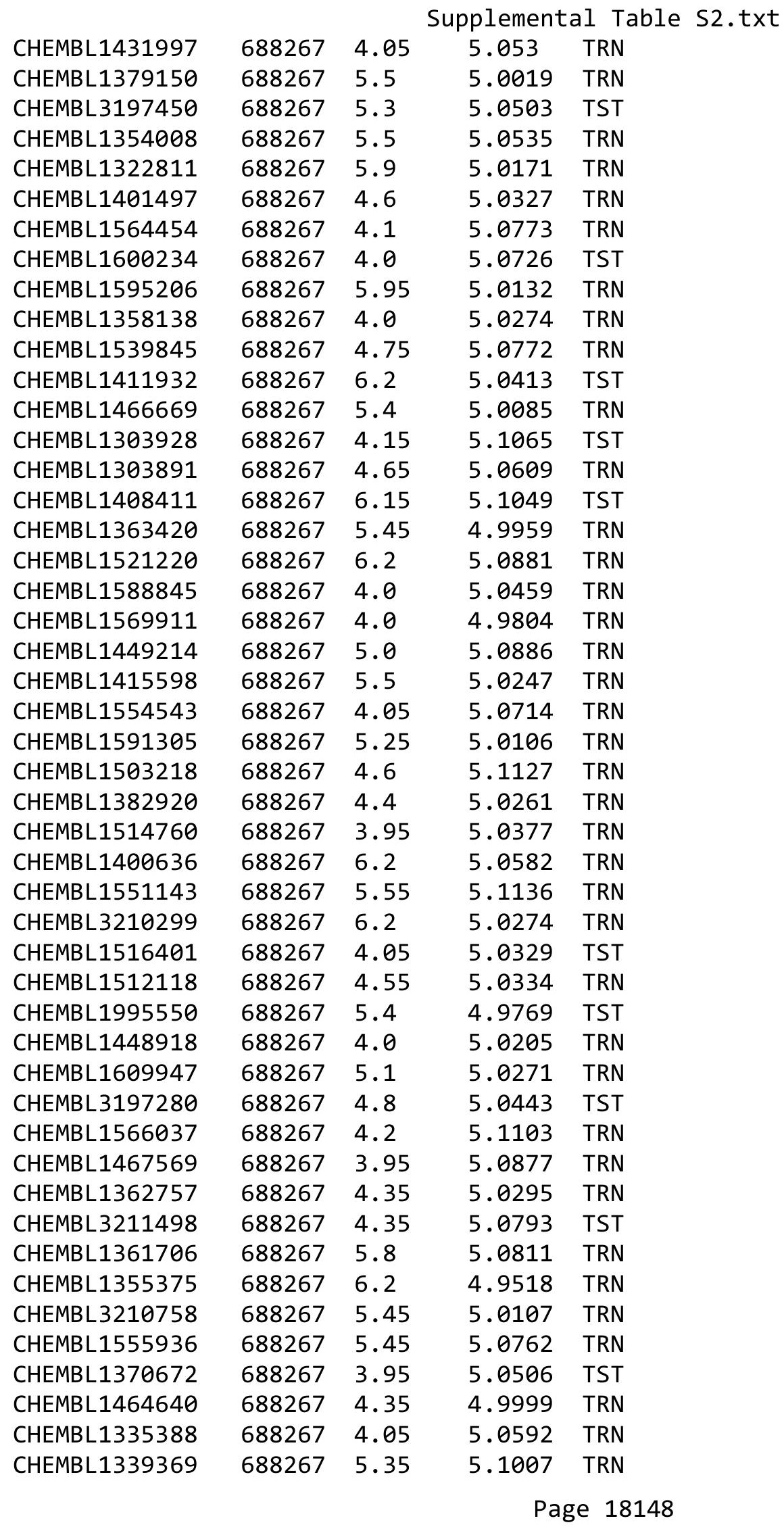




\begin{tabular}{|c|c|c|c|c|c|}
\hline \multicolumn{6}{|c|}{ Supplemental Table S2.txt } \\
\hline CHEMBL1447281 & 688267 & 4.4 & 4.9916 & TRN & \\
\hline CHEMBL1488296 & 688267 & 4.35 & 5.0273 & TRN & \\
\hline CHEMBL1512147 & 688267 & 5.55 & 5.0978 & TRN & \\
\hline CHEMBL1604834 & 688267 & 4.4 & 5.0635 & TRN & \\
\hline CHEMBL1610633 & 688267 & 3.9 & 4.9966 & TRN & \\
\hline CHEMBL1501356 & 688267 & 4.15 & 5.0219 & TRN & \\
\hline CHEMBL1322019 & 688267 & 4.0 & 5.1355 & TRN & \\
\hline CHEMBL1320216 & 688267 & 4.7 & 5.035 & TRN & \\
\hline CHEMBL1370081 & 688267 & 4.25 & 5.1271 & TRN & \\
\hline CHEMBL1437796 & 688267 & 4.45 & 5.1132 & TRN & \\
\hline CHEMBL1312601 & 688267 & 4.5 & 5.0422 & TST & \\
\hline CHEMBL1422855 & 688267 & 6.5 & 5.0516 & TRN & \\
\hline CHEMBL1402977 & 688267 & 5.6 & 5.0568 & TRN & \\
\hline CHEMBL1526281 & 688267 & 4.35 & 5.0551 & TRN & \\
\hline CHEMBL1494004 & 688267 & 6.15 & 5.0704 & TRN & \\
\hline CHEMBL474933 & 688267 & 5.45 & 5.0432 & TST & \\
\hline CHEMBL1406025 & 688267 & 5.05 & 5.0978 & TRN & \\
\hline CHEMBL1363125 & 688267 & 6.2 & 5.0114 & TST & \\
\hline CHEMBL1437104 & 688267 & 4.65 & 5.0638 & TST & \\
\hline CHEMBL1326438 & 688267 & 4.35 & 5.015 & TRN & \\
\hline CHEMBL1514015 & 688267 & 5.5 & 5.0245 & TRN & \\
\hline CHEMBL1315470 & 688267 & 6.25 & 5.1283 & TRN & \\
\hline CHEMBL1465826 & 688267 & 5.4 & $5.0280 e$ & 00000000005 & TRN \\
\hline CHEMBL1299987 & 688267 & 4.35 & 5.055 & TRN & \\
\hline CHEMBL1378380 & 688267 & 3.9 & 5.0655 & TRN & \\
\hline CHEMBL1463392 & 688267 & 5.85 & 5.1629 & TRN & \\
\hline CHEMBL1609436 & 688267 & 5.05 & 5.0293 & TRN & \\
\hline CHEMBL1366552 & 688267 & 4.05 & 5.1059 & TRN & \\
\hline CHEMBL3209102 & 688267 & 4.65 & 5.0262 & TST & \\
\hline CHEMBL1594521 & 688267 & 5.0 & 5.0141 & TRN & \\
\hline CHEMBL1486952 & 688267 & 6.2 & 5.0315 & TRN & \\
\hline CHEMBL1472033 & 688267 & 4.35 & 5.1515 & TRN & \\
\hline CHEMBL1468724 & 688267 & 4.6 & 5.0848 & TRN & \\
\hline CHEMBL1611894 & 688267 & 4.0 & 5.0768 & TRN & \\
\hline CHEMBL1613635 & 688267 & 6.15 & 5.052 & TRN & \\
\hline CHEMBL1515462 & 688267 & 4.25 & 5.0256 & TRN & \\
\hline CHEMBL1399759 & 688267 & 5.15 & 5.13 & TRN & \\
\hline CHEMBL 3208021 & 688267 & 4.65 & 5.0257 & TRN & \\
\hline CHEMBL1434177 & 688267 & 6.5 & 5.0871 & TRN & \\
\hline CHEMBL1570132 & 688267 & 5.55 & 5.0138 & TRN & \\
\hline CHEMBL1389491 & 688267 & 5.05 & 5.0316 & TST & \\
\hline CHEMBL3199548 & 688267 & 4.05 & 4.9821 & TST & \\
\hline CHEMBL1404641 & 688267 & 5.15 & 5.0815 & TRN & \\
\hline CHEMBL1448117 & 688267 & 4.05 & 5.0091 & TRN & \\
\hline CHEMBL1475002 & 688267 & 5.6 & 5.0167 & TRN & \\
\hline CHEMBL1592282 & 688267 & 4.35 & 5.0345 & TST & \\
\hline CHEMBL1549599 & 688267 & 6.2 & 5.0306 & TST & \\
\hline CHEMBL1357178 & 688267 & 4.05 & 5.0475 & TST & \\
\hline
\end{tabular}




\begin{tabular}{|c|c|c|c|c|}
\hline \multicolumn{5}{|c|}{ Supplemental Table S2.txt } \\
\hline CHEMBL1595547 & 688267 & 4.6 & 5.113 & TRN \\
\hline CHEMBL1568047 & 688267 & 4.45 & 5.0788 & TRN \\
\hline CHEMBL1389686 & 688267 & 4.35 & 5.0453 & TRN \\
\hline CHEMBL1489503 & 688267 & 5.85 & 5.0318 & TRN \\
\hline CHEMBL1544510 & 688267 & 5.65 & 5.0763 & TRN \\
\hline CHEMBL1590290 & 688267 & 4.05 & 5.0691 & TRN \\
\hline CHEMBL1545849 & 688267 & 6.2 & 4.9891 & TRN \\
\hline CHEMBL447111 & 688267 & 5.35 & 5.0659 & TST \\
\hline CHEMBL1470418 & 688267 & 5.35 & 5.1729 & TRN \\
\hline CHEMBL1315713 & 688267 & 6.2 & 5.0094 & TRN \\
\hline CHEMBL1506533 & 688267 & 5.35 & 5.0184 & TRN \\
\hline CHEMBL1499981 & 688267 & 5.9 & 5.1144 & TRN \\
\hline CHEMBL1517454 & 688267 & 6.5 & 5.0897 & TRN \\
\hline CHEMBL1365865 & 688267 & 6.2 & 5.0433 & TRN \\
\hline CHEMBL1456983 & 688267 & 6.05 & 5.0398 & TRN \\
\hline CHEMBL1583146 & 688267 & 6.2 & 5.0751 & TRN \\
\hline CHEMBL1404926 & 688267 & 5.3 & 5.075 & TRN \\
\hline CHEMBL1604759 & 688267 & 5.6 & 5.0547 & TST \\
\hline CHEMBL1351548 & 688267 & 5.9 & 5.0667 & TST \\
\hline CHEMBL1529412 & 688267 & 5.45 & 5.0076 & TRN \\
\hline CHEMBL1312258 & 688267 & 4.8 & 5.0578 & TRN \\
\hline CHEMBL1436192 & 688267 & 4.05 & 5.0581 & TRN \\
\hline CHEMBL1348460 & 688267 & 4.55 & 5.043 & TST \\
\hline CHEMBL1401218 & 688267 & 6.25 & 5.1254 & TRN \\
\hline CHEMBL1990036 & 688267 & 4.4 & 5.005 & TRN \\
\hline CHEMBL1379788 & 688267 & 4.0 & 5.0656 & TST \\
\hline CHEMBL1341643 & 688267 & 4.25 & 5.077 & TRN \\
\hline CHEMBL1499083 & 688267 & 4.4 & 5.0743 & TST \\
\hline CHEMBL1426765 & 688267 & 6.2 & 5.0962 & TRN \\
\hline CHEMBL1334813 & 688267 & 5.6 & 5.0371 & TST \\
\hline CHEMBL1330777 & 688267 & 4.3 & 5.0818 & TRN \\
\hline CHEMBL1519752 & 688267 & 4.0 & 5.0375 & TRN \\
\hline CHEMBL1612459 & 688267 & 4.4 & 5.1164 & TRN \\
\hline CHEMBL1562312 & 688267 & 6.25 & 4.9691 & TRN \\
\hline CHEMBL1317169 & 688267 & 4.4 & 5.098 & TRN \\
\hline CHEMBL3209736 & 688267 & 4.4 & 4.9965 & TRN \\
\hline CHEMBL1598187 & 688267 & 5.25 & 5.0201 & TST \\
\hline CHEMBL1577503 & 688267 & 4.3 & 5.0427 & TRN \\
\hline CHEMBL1555542 & 688267 & 4.0 & 5.0835 & TRN \\
\hline CHEMBL1488030 & 688267 & 4.0 & 5.1115 & TRN \\
\hline CHEMBL1543918 & 688267 & 4.4 & 5.0837 & TRN \\
\hline CHEMBL1569494 & 688267 & 6.2 & 5.0046 & TRN \\
\hline CHEMBL3197838 & 688267 & 4.45 & 5.0397 & TST \\
\hline CHEMBL1361954 & 688267 & 5.6 & 5.1216 & TST \\
\hline CHEMBL1580436 & 688267 & 4.2 & 5.1165 & TRN \\
\hline CHEMBL1349727 & 688267 & 5.2 & 5.0066 & TST \\
\hline CHEMBL1324035 & 688267 & 3.95 & 5.1161 & TRN \\
\hline CHEMBL1567071 & 688267 & 3.95 & 5.0543 & TRN \\
\hline
\end{tabular}




\begin{tabular}{|c|c|c|c|c|c|}
\hline \\
\hline CHEMBL1394601 & 688267 & 5.9 & 5.0977 & TRN & \\
\hline CHEMBL1483764 & 688267 & 4.5 & 5.0562 & TRN & \\
\hline CHEMBL1394808 & 688267 & 4.0 & 5.0905 & TRN & \\
\hline CHEMBL1351425 & 688267 & 4.2 & 5.0355 & TRN & \\
\hline CHEMBL1481639 & 688267 & 5.55 & 5.0192 & TRN & \\
\hline CHEMBL1468418 & 688267 & 4.3 & 5.0832 & TST & \\
\hline CHEMBL1409208 & 688267 & 4.6 & 5.0662 & TRN & \\
\hline CHEMBL1436285 & 688267 & 5.1 & 5.0417 & TRN & \\
\hline CHEMBL1483063 & 688267 & 5.4 & 5.0608 & TRN & \\
\hline CHEMBL1382530 & 688267 & 4.0 & 5.0723 & TST & \\
\hline CHEMBL3194025 & 688267 & 4.4 & 5.1292 & TRN & \\
\hline CHEMBL1406135 & 688267 & 4.6 & 5.0744 & TRN & \\
\hline CHEMBL1348182 & 688267 & 4.1 & 4.9833 & TRN & \\
\hline CHEMBL1515770 & 688267 & 5.55 & 5.0228 & TRN & \\
\hline CHEMBL1316238 & 688267 & 5.9 & 5.0614 & TRN & \\
\hline CHEMBL1337173 & 688267 & 4.05 & 5.0661 & TRN & \\
\hline CHEMBL1497167 & 688267 & 4.05 & 5.0995 & TST & \\
\hline CHEMBL1453525 & 688267 & 5.25 & 5.0792 & TRN & \\
\hline CHEMBL530963 & 688267 & 5.85 & 5.1079 & TST & \\
\hline CHEMBL1448580 & 688267 & 3.95 & 5.0572 & TST & \\
\hline CHEMBL1573002 & 688267 & 6.25 & 4.9874 & TST & \\
\hline CHEMBL1392007 & 688267 & 3.95 & 5.1574 & TRN & \\
\hline CHEMBL1531838 & 688267 & 5.25 & 5.1242 & TRN & \\
\hline CHEMBL1579873 & 688267 & 4.15 & 5.0457 & TST & \\
\hline CHEMBL1357041 & 688267 & 6.2 & 5.1003 & TRN & \\
\hline CHEMBL3194652 & 688267 & 5.85 & 4.9818 & TRN & \\
\hline CHEMBL1343626 & 688267 & 4.6 & 5.0237 & TRN & \\
\hline CHEMBL1354538 & 688267 & 4.4 & 5.1169 & TRN & \\
\hline CHEMBL1571713 & 688267 & 4.05 & 5.091 & TRN & \\
\hline CHEMBL1523555 & 688267 & 4.95 & 5.0437 & TRN & \\
\hline CHEMBL1419758 & 688267 & 4.8 & 5.0479 & TRN & \\
\hline CHEMBL1475271 & 688267 & 4.1 & 5.0136 & TRN & \\
\hline CHEMBL1609833 & 688267 & 6.0 & 5.0396 & TRN & \\
\hline CHEMBL1487260 & 688267 & 6.2 & 5.0208 & TRN & \\
\hline CHEMBL1508083 & 688267 & 4.35 & 5.0546 & TST & \\
\hline CHEMBL1547971 & 688267 & 4.0 & 5.077 & TRN & \\
\hline CHEMBL1301370 & 688267 & 4.65 & 5.1417 & TRN & \\
\hline CHEMBL1351634 & 688267 & 4.15 & 5.0732 & TRN & \\
\hline CHEMBL1323741 & 688267 & 4.6 & 5.0982 & TRN & \\
\hline CHEMBL 1608010 & 688267 & 4.0 & 5.00899 & 99999999995 & TRN \\
\hline CHEMBL1468333 & 688267 & 5.25 & 5.0769 & TST & \\
\hline CHEMBL1459898 & 688267 & 4.0 & 4.9513 & TRN & \\
\hline CHEMBL1526520 & 688267 & 6.2 & 5.0197 & TRN & \\
\hline CHEMBL1480348 & 688267 & 5.25 & 5.1021 & TRN & \\
\hline CHEMBL1554862 & 688267 & 5.0 & 5.136 & TRN & \\
\hline CHEMBL1377407 & 688267 & 5.75 & 5.1131 & TST & \\
\hline CHEMBL1993643 & 688267 & 5.55 & 5.0431 & TRN & \\
\hline CHEMBL1992651 & 688267 & 5.4 & 5.0006 & TRN & \\
\hline
\end{tabular}




\begin{tabular}{|c|c|c|c|c|}
\hline & & & oplement & al Table S \\
\hline CHEMBL1471839 & 688267 & 5.5 & 5.0236 & TST \\
\hline CHEMBL1525452 & 688267 & 6.2 & 5.1125 & TRN \\
\hline CHEMBL1482677 & 688267 & 5.3 & 5.12799 & 9999999999 \\
\hline CHEMBL1530540 & 688267 & 5.3 & 5.0673 & TRN \\
\hline CHEMBL1447029 & 688267 & 5.05 & 5.0318 & TRN \\
\hline CHEMBL1595815 & 688267 & 5.95 & 5.0065 & TRN \\
\hline CHEMBL1592165 & 688267 & 4.35 & 5.0312 & TST \\
\hline CHEMBL1550048 & 688267 & 4.1 & 5.0113 & TRN \\
\hline CHEMBL1332521 & 688267 & 6.0 & 5.0233 & TRN \\
\hline CHEMBL1480863 & 688267 & 6.2 & 5.0455 & TST \\
\hline CHEMBL1457644 & 688267 & 5.2 & 5.0636 & TRN \\
\hline CHEMBL1446373 & 688267 & 5.25 & 5.0887 & TRN \\
\hline CHEMBL1576888 & 688267 & 4.35 & 5.0789 & TRN \\
\hline CHEMBL1412833 & 688267 & 5.4 & 5.0308 & TRN \\
\hline CHEMBL3198832 & 688267 & 4.3 & 5.0284 & TRN \\
\hline CHEMBL1373696 & 688267 & 4.4 & 5.0162 & TRN \\
\hline CHEMBL1082160 & 688267 & 4.55 & 5.0512 & TRN \\
\hline CHEMBL1549041 & 688267 & 4.0 & 5.0695 & TST \\
\hline CHEMBL1446444 & 688267 & 5.9 & 5.0729 & TRN \\
\hline CHEMBL1354662 & 688267 & 4.35 & 5.1072 & TRN \\
\hline CHEMBL1352064 & 688267 & 4.65 & 5.0026 & TST \\
\hline CHEMBL1542667 & 688267 & 5.6 & 5.0513 & TST \\
\hline CHEMBL1419317 & 688267 & 5.85 & 5.0552 & TRN \\
\hline CHEMBL1432258 & 688267 & 4.3 & 5.0862 & TRN \\
\hline CHEMBL1458581 & 688267 & 4.15 & 5.0572 & TST \\
\hline CHEMBL1354876 & 688267 & 6.2 & 5.005 & TST \\
\hline CHEMBL1483766 & 688267 & 4.55 & 4.987 & TRN \\
\hline CHEMBL1434757 & 688267 & 6.2 & 5.0741 & TRN \\
\hline CHEMBL1340254 & 688267 & 5.45 & 5.0008 & TRN \\
\hline CHEMBL1585327 & 688267 & 5.3 & 5.0118 & TRN \\
\hline CHEMBL1330095 & 688267 & 4.4 & 5.0299 & TRN \\
\hline CHEMBL1349339 & 688267 & 4.95 & 5.0577 & TST \\
\hline CHEMBL1497305 & 688267 & 4.6 & 5.1313 & TRN \\
\hline CHEMBL539507 & 688267 & 5.3 & 5.088 & TRN \\
\hline CHEMBL1394200 & 688267 & 4.0 & 5.0856 & TRN \\
\hline CHEMBL1522495 & 688267 & 4.0 & 5.0352 & TRN \\
\hline CHEMBL1597927 & 688267 & 4.2 & 5.0508 & TRN \\
\hline CHEMBL1335734 & 688267 & 5.3 & 5.0106 & TRN \\
\hline CHEMBL1469619 & 688267 & 6.15 & 5.0823 & TRN \\
\hline CHEMBL1416415 & 688267 & 4.95 & 5.1 & TRN \\
\hline CHEMBL1377792 & 688267 & 4.4 & 5.0493 & TRN \\
\hline CHEMBL1309613 & 688267 & 6.2 & 5.0621 & TRN \\
\hline CHEMBL1570808 & 688267 & 4.35 & 5.0737 & TRN \\
\hline CHEMBL1590344 & 688267 & 4.95 & 5.0223 & TRN \\
\hline CHEMBL1555508 & 688267 & 5.35 & 5.1129 & TST \\
\hline CHEMBL1517200 & 688267 & 5.35 & 5.0878 & TRN \\
\hline CHEMBL1449287 & 688267 & 4.65 & 5.0213 & TRN \\
\hline CHEMBL1408392 & 688267 & 5.1 & 5.0063 & TST \\
\hline
\end{tabular}




\begin{tabular}{|c|c|c|c|c|c|}
\hline \multirow[b]{2}{*}{ CHEMBL1329377 } & \multicolumn{5}{|c|}{ Supplemental Table S2.txt } \\
\hline & 688267 & 6.5501 & 5.113 & TRN & \\
\hline CHEMBL1320477 & 688267 & 6.2 & 5.165 & TRN & \\
\hline CHEMBL1311071 & 688267 & 5.35 & 5.0809 & TRN & \\
\hline CHEMBL1365635 & 688267 & 4.0 & 5.0058 & TRN & \\
\hline CHEMBL1499247 & 688267 & 5.9 & 5.0223 & TST & \\
\hline CHEMBL1369966 & 688267 & 4.0 & 5.064 & TRN & \\
\hline CHEMBL1551370 & 688267 & 5.9 & 5.0318 & TRN & \\
\hline CHEMBL1421688 & 688267 & 5.55 & 5.0542 & TRN & \\
\hline CHEMBL1082518 & 688267 & 6.5 & 5.1081 & TRN & \\
\hline CHEMBL1341797 & 688267 & 6.1 & 5.0429 & TRN & \\
\hline CHEMBL1346530 & 688267 & 5.05 & 5.09399 & 9999999999 & TRN \\
\hline CHEMBL1537176 & 688267 & 5.5 & 5.0503 & TRN & \\
\hline CHEMBL1381454 & 688267 & 4.0 & 5.0391 & TST & \\
\hline CHEMBL1607738 & 688267 & 5.85 & 5.0622 & TST & \\
\hline CHEMBL1318036 & 688267 & 5.15 & 5.023 & TRN & \\
\hline CHEMBL1405501 & 688267 & 4.05 & 4.9955 & TRN & \\
\hline CHEMBL1584751 & 688267 & 5.9 & 5.0589 & TRN & \\
\hline CHEMBL1369474 & 688267 & 4.1 & 5.045 & TRN & \\
\hline CHEMBL3190598 & 688267 & 5.1 & 5.0773 & TST & \\
\hline CHEMBL1462768 & 688267 & 6.2 & 5.0708 & TRN & \\
\hline CHEMBL1602992 & 688267 & 4.05 & 4.9852 & TRN & \\
\hline CHEMBL1586611 & 688267 & 4.6 & 4.9432 & TRN & \\
\hline CHEMBL1434637 & 688267 & 5.55 & 5.0029 & TRN & \\
\hline CHEMBL1496580 & 688267 & 5.2 & 5.0669 & TRN & \\
\hline CHEMBL1457120 & 688267 & 4.65 & 5.0372 & TRN & \\
\hline CHEMBL1506711 & 688267 & 4.15 & 5.0374 & TRN & \\
\hline CHEMBL1985855 & 688267 & 4.65 & 5.0166 & TST & \\
\hline CHEMBL1526040 & 688267 & 5.9 & 5.0103 & TRN & \\
\hline CHEMBL1444081 & 688267 & 5.05 & 5.1118 & TRN & \\
\hline CHEMBL1549452 & 688267 & 4.35 & 5.0762 & TRN & \\
\hline CHEMBL1561517 & 688267 & 4.0 & 5.1203 & TRN & \\
\hline CHEMBL1572034 & 688267 & 6.2 & 5.0983 & TRN & \\
\hline CHEMBL1329725 & 688267 & 4.3 & 5.0748 & TRN & \\
\hline CHEMBL1510692 & 688267 & 6.2 & 5.1314 & TRN & \\
\hline CHEMBL1481466 & 688267 & 6.2 & 5.0473 & TRN & \\
\hline CHEMBL1413319 & 688267 & 4.05 & 5.0601 & TRN & \\
\hline CHEMBL1538334 & 688267 & 5.4 & 5.0658 & TRN & \\
\hline CHEMBL1442231 & 688267 & 6.15 & 5.0716 & TRN & \\
\hline CHEMBL1482754 & 688267 & 4.35 & 5.0815 & TRN & \\
\hline CHEMBL1446047 & 688267 & 5.05 & 5.0479 & TRN & \\
\hline CHEMBL1471195 & 688267 & 5.35 & 5.13899 & 9999999999 & TRN \\
\hline CHEMBL1557591 & 688267 & 5.35 & 5.0505 & TRN & \\
\hline CHEMBL1396983 & 688267 & 4.85 & 5.0705 & TRN & \\
\hline CHEMBL1535338 & 688267 & 4.05 & 5.0137 & TRN & \\
\hline CHEMBL1333739 & 688267 & 6.5501 & 5.0353 & TST & \\
\hline CHEMBL 1467537 & 688267 & 4.2 & 5.0606 & TRN & \\
\hline CHEMBL1573989 & 688267 & 5.65 & 5.0898 & TST & \\
\hline CHEMBL1365704 & 688267 & 4.0 & 5.0282 & TRN & \\
\hline
\end{tabular}




\begin{tabular}{|c|c|c|c|c|c|}
\hline \multicolumn{6}{|c|}{ Supplemental Table S2.txt } \\
\hline CHEMBL1587345 & 688267 & 4.35 & 5.0583 & TRN & \\
\hline CHEMBL 3212614 & 688267 & 5.0 & 5.0454 & TST & \\
\hline CHEMBL1595490 & 688267 & 5.35 & 5.0641 & TST & \\
\hline CHEMBL1467767 & 688267 & 4.3 & 5.0506 & TST & \\
\hline CHEMBL1593086 & 688267 & 4.25 & 5.0937 & TST & \\
\hline CHEMBL1498162 & 688267 & 5.6 & 5.0797 & TRN & \\
\hline CHEMBL1301465 & 688267 & 4.85 & 5.0344 & TRN & \\
\hline CHEMBL1560282 & 688267 & 4.2 & 5.1181 & TST & \\
\hline CHEMBL1316947 & 688267 & 3.95 & 5.0726 & TST & \\
\hline CHEMBL1344081 & 688267 & 4.1 & 5.0074 & TRN & \\
\hline CHEMBL1306603 & 688267 & 4.2 & 5.0714 & TRN & \\
\hline CHEMBL1529634 & 688267 & 6.25 & 5.0555 & TRN & \\
\hline CHEMBL1429666 & 688267 & 5.85 & 5.1018 & TRN & \\
\hline CHEMBL1446639 & 688267 & 5.45 & 5.0387 & TST & \\
\hline CHEMBL1343894 & 688267 & 4.4 & 5.0799 & TRN & \\
\hline CHEMBL1598088 & 688267 & 4.8 & 5.0632 & TRN & \\
\hline CHEMBL1521258 & 688267 & 4.1 & 4.9998 & TRN & \\
\hline CHEMBL1359459 & 688267 & 5.2 & 5.0779 & TRN & \\
\hline CHEMBL1506358 & 688267 & 4.2 & 5.0036 & TRN & \\
\hline CHEMBL1465338 & 688267 & 4.3 & 4.9798 & TRN & \\
\hline CHEMBL1327570 & 688267 & 6.5 & 5.1257 & TST & \\
\hline CHEMBL1480310 & 688267 & 5.2 & 5.044 & TRN & \\
\hline CHEMBL1385675 & 688267 & 6.15 & 5.0578 & TRN & \\
\hline CHEMBL1447632 & 688267 & 5.3 & 5.0299 & TRN & \\
\hline CHEMBL1337456 & 688267 & 4.5 & 5.1749 & TRN & \\
\hline CHEMBL1503268 & 688267 & 4.0 & 5.0877 & TRN & \\
\hline CHEMBL1519246 & 688267 & 3.95 & 5.005 & TRN & \\
\hline CHEMBL1364941 & 688267 & 6.2 & 5.1432 & TRN & \\
\hline CHEMBL1427703 & 688267 & 6.2 & 5.0358 & TRN & \\
\hline CHEMBL1391801 & 688267 & 4.75 & 5.0603 & TRN & \\
\hline CHEMBL1493717 & 688267 & 4.1 & 5.0872 & TRN & \\
\hline CHEMBL1380081 & 688267 & 5.8 & 5.0447 & TRN & \\
\hline CHEMBL1576699 & 688267 & 4.35 & 5.0431 & TST & \\
\hline CHEMBL1355069 & 688267 & 4.3 & 5.0369 & TRN & \\
\hline CHEMBL1415576 & 688267 & 3.9 & 5.0254 & TRN & \\
\hline CHEMBL1513597 & 688267 & 4.5 & 5.0760 & 00000000005 & TRN \\
\hline CHEMBL1308207 & 688267 & 4.0 & 5.0479 & TST & \\
\hline CHEMBL1493538 & 688267 & 5.9 & 5.0082 & TST & \\
\hline CHEMBL1354950 & 688267 & 6.2 & 5.0176 & TRN & \\
\hline CHEMBL1381749 & 688267 & 5.0 & 5.1443 & TRN & \\
\hline CHEMBL1501328 & 688267 & 6.2 & 5.0794 & TRN & \\
\hline CHEMBL1438345 & 688267 & 6.2 & 5.115 & TRN & \\
\hline CHEMBL1460585 & 688267 & 4.0 & 5.0329 & TST & \\
\hline CHEMBL1597338 & 688267 & 3.95 & 5.1067 & TRN & \\
\hline CHEMBL1518189 & 688267 & 4.0 & 4.9959 & TRN & \\
\hline CHEMBL1611900 & 688267 & 4.6 & 5.0465 & TRN & \\
\hline CHEMBL1397537 & 688267 & 5.4 & 5.1484 & TRN & \\
\hline CHEMBL1410053 & 688267 & 4.35 & 5.0651 & TRN & \\
\hline
\end{tabular}




\begin{tabular}{|c|c|c|c|c|}
\hline \multicolumn{5}{|c|}{ Supplemental Table S2.t) } \\
\hline CHEMBL1494577 & 688267 & 6.5 & 5.0316 & TRN \\
\hline CHEMBL1173522 & 688267 & 6.2 & 5.0558 & TST \\
\hline CHEMBL1433802 & 688267 & 6.2 & 5.0481 & TRN \\
\hline CHEMBL1375395 & 688267 & 4.1 & 5.0099 & TRN \\
\hline CHEMBL1486024 & 688267 & 4.4 & 5.0706 & TRN \\
\hline CHEMBL1415711 & 688267 & 4.6 & 5.0773 & TRN \\
\hline CHEMBL1515262 & 688267 & 6.6 & 5.0391 & TRN \\
\hline CHEMBL 3212582 & 688267 & 4.35 & 5.0613 & TST \\
\hline CHEMBL1313950 & 688267 & 6.0 & 5.1304 & TRN \\
\hline CHEMBL1337636 & 688267 & 5.2 & 5.1388 & TST \\
\hline CHEMBL1454202 & 688267 & 5.05 & 5.046 & TRN \\
\hline CHEMBL1315117 & 688267 & 5.55 & 5.0609 & TRN \\
\hline CHEMBL1597128 & 688267 & 5.0 & 5.1252 & TST \\
\hline CHEMBL3210979 & 688267 & 4.05 & 5.0808 & TST \\
\hline CHEMBL1527229 & 688267 & 5.15 & 5.0334 & TRN \\
\hline CHEMBL1335522 & 688267 & 4.25 & 5.027 & TST \\
\hline CHEMBL1524163 & 688267 & 4.95 & 4.9928 & TRN \\
\hline CHEMBL1557845 & 688267 & 4.0 & 5.0806 & TRN \\
\hline CHEMBL1300101 & 688267 & 4.35 & 5.0431 & TST \\
\hline CHEMBL3214607 & 688267 & 5.6 & 5.0246 & TST \\
\hline CHEMBL1374616 & 688267 & 5.55 & 5.0346 & TRN \\
\hline CHEMBL1370909 & 688267 & 4.05 & 4.9874 & TRN \\
\hline CHEMBL1303566 & 688267 & 4.0 & 5.0999 & TRN \\
\hline CHEMBL1306858 & 688267 & 5.55 & 5.0652 & TRN \\
\hline CHEMBL 3207450 & 688267 & 5.3 & 5.0768 & TRN \\
\hline CHEMBL1544844 & 688267 & 4.65 & 5.0593 & TRN \\
\hline CHEMBL1563024 & 688267 & 6.2 & 5.11100 & 0000000001 \\
\hline CHEMBL 2374070 & 688267 & 5.05 & 5.0568 & TRN \\
\hline CHEMBL1374981 & 688267 & 6.2 & 5.0723 & TRN \\
\hline CHEMBL1444944 & 688267 & 5.35 & 5.0642 & TRN \\
\hline CHEMBL1412419 & 688267 & 4.0 & 5.0241 & TRN \\
\hline CHEMBL3192319 & 688267 & 5.2 & 5.0236 & TRN \\
\hline CHEMBL1471721 & 688267 & 6.2 & 5.0494 & TST \\
\hline CHEMBL1345679 & 688267 & 4.0 & 5.0594 & TRN \\
\hline CHEMBL1564197 & 688267 & 5.7 & 5.0267 & TRN \\
\hline CHEMBL1439601 & 688267 & 5.95 & 5.0327 & TRN \\
\hline CHEMBL1607741 & 688267 & 4.0 & 5.0685 & TRN \\
\hline CHEMBL1318747 & 688267 & 5.5 & 5.0182 & TRN \\
\hline CHEMBL1460730 & 688267 & 4.0 & 5.1144 & TRN \\
\hline CHEMBL1324504 & 688267 & 6.1 & 5.0407 & TRN \\
\hline CHEMBL1343560 & 688267 & 6.0 & 5.0187 & TRN \\
\hline CHEMBL1362936 & 688267 & 4.1 & 5.0313 & TRN \\
\hline CHEMBL1460126 & 688267 & 4.3 & 5.0099 & TRN \\
\hline CHEMBL1371196 & 688267 & 4.4 & 5.1127 & TRN \\
\hline CHEMBL1354977 & 688267 & 5.25 & 5.0901 & TRN \\
\hline CHEMBL1356028 & 688267 & 6.25 & 5.1371 & TRN \\
\hline CHEMBL1313638 & 688267 & 5.8 & 5.047 & TST \\
\hline CHEMBL1598591 & 688267 & 4.55 & 5.0678 & TST \\
\hline
\end{tabular}




\begin{tabular}{|c|c|c|c|c|}
\hline \multicolumn{5}{|c|}{ Supplemental Table S2.txt } \\
\hline CHEMBL1475435 & 688267 & 4.45 & 5.0999 & TRN \\
\hline CHEMBL1485611 & 688267 & 3.95 & 5.0288 & TRN \\
\hline CHEMBL1574333 & 688267 & 4.0 & 5.0406 & TRN \\
\hline CHEMBL1337140 & 688267 & 5.7 & 4.9835 & TST \\
\hline CHEMBL1598505 & 688267 & 5.5 & 5.0148 & TRN \\
\hline CHEMBL1974450 & 688267 & 5.55 & 4.984 & TST \\
\hline CHEMBL1550054 & 688267 & 5.85 & 5.1204 & TRN \\
\hline CHEMBL1594400 & 688267 & 5.45 & 5.0755 & TRN \\
\hline CHEMBL1482413 & 688267 & 5.8 & 5.0427 & TST \\
\hline CHEMBL1344060 & 688267 & 6.15 & 5.129 & TST \\
\hline CHEMBL3208596 & 688267 & 5.55 & 5.0204 & TRN \\
\hline CHEMBL1591334 & 688267 & 4.05 & 5.0549 & TRN \\
\hline CHEMBL1564609 & 688267 & 6.2 & 5.0458 & TST \\
\hline CHEMBL1487768 & 688267 & 5.0 & 5.0142 & TRN \\
\hline CHEMBL1529540 & 688267 & 4.95 & 5.0381 & TRN \\
\hline CHEMBL1458853 & 688267 & 5.45 & 5.1244 & TRN \\
\hline CHEMBL1368145 & 688267 & 4.1 & 5.0974 & TRN \\
\hline CHEMBL1356158 & 688267 & 5.3 & 5.0255 & TRN \\
\hline CHEMBL1435196 & 688267 & 4.35 & 5.0229 & TRN \\
\hline CHEMBL1305614 & 688267 & 4.35 & 5.0405 & TST \\
\hline CHEMBL1554814 & 688267 & 4.0 & 5.0472 & TRN \\
\hline CHEMBL1417296 & 688267 & 4.05 & 5.0425 & TRN \\
\hline CHEMBL1324487 & 688267 & 3.95 & 5.0095 & TRN \\
\hline CHEMBL1435389 & 688267 & 4.0 & 5.0117 & TRN \\
\hline CHEMBL1477550 & 688267 & 4.4 & 4.9696 & TRN \\
\hline CHEMBL1585754 & 688267 & 6.2 & 5.0097 & TRN \\
\hline CHEMBL1489915 & 688267 & 4.65 & 4.9727 & TST \\
\hline CHEMBL1355534 & 688267 & 6.2 & 5.0951 & TST \\
\hline CHEMBL1422646 & 688267 & 4.4 & 5.0668 & TST \\
\hline CHEMBL1549597 & 688267 & 6.25 & 5.0052 & TRN \\
\hline CHEMBL3207919 & 688267 & 5.5 & 5.0344 & TRN \\
\hline CHEMBL 1460810 & 688267 & 5.1 & 5.0907 & TRN \\
\hline CHEMBL1560704 & 688267 & 5.4 & 5.0661 & TRN \\
\hline CHEMBL1609548 & 688267 & 4.1 & 5.0878 & TST \\
\hline CHEMBL1372269 & 688267 & 5.9 & 5.1081 & TRN \\
\hline CHEMBL1318558 & 688267 & 5.95 & 5.0172 & TRN \\
\hline CHEMBL 1456144 & 688267 & 4.35 & 4.9974 & TRN \\
\hline CHEMBL1572734 & 688267 & 4.0 & 4.9787 & TRN \\
\hline CHEMBL1583706 & 688267 & 6.15 & 5.0272 & TST \\
\hline CHEMBL1514057 & 688267 & 4.3 & 5.0795 & TRN \\
\hline CHEMBL1572002 & 688267 & 4.05 & 5.0985 & TRN \\
\hline CHEMBL452818 & 688267 & 4.0 & 5.0662 & TRN \\
\hline CHEMBL1337795 & 688267 & 6.2 & 5.0147 & TST \\
\hline CHEMBL1437373 & 688267 & 4.25 & 4.9738 & TRN \\
\hline CHEMBL1396290 & 688267 & 6.2 & 5.0143 & TRN \\
\hline CHEMBL1448357 & 688267 & 4.0 & 5.0642 & TRN \\
\hline CHEMBL1352983 & 688267 & 5.8 & 5.0075 & TST \\
\hline CHEMBL1610281 & 688267 & 5.35 & 5.0554 & TRN \\
\hline
\end{tabular}




\begin{tabular}{|c|c|c|c|c|}
\hline \multicolumn{5}{|c|}{ Supplemental Table S2.txt } \\
\hline CHEMBL1303611 & 688267 & 6.2 & 4.9994 & TRN \\
\hline CHEMBL1410713 & 688267 & 5.05 & 5.1115 & TRN \\
\hline CHEMBL1573409 & 688267 & 4.95 & 5.0588 & TST \\
\hline CHEMBL1407972 & 688267 & 6.0 & 4.9873 & TRN \\
\hline CHEMBL1547923 & 688267 & 6.25 & 5.0104 & TST \\
\hline CHEMBL1411446 & 688267 & 4.45 & 5.0319 & TRN \\
\hline CHEMBL1360555 & 688267 & 4.75 & 5.0583 & TRN \\
\hline CHEMBL1367147 & 688267 & 5.9 & 5.0072 & TST \\
\hline CHEMBL1492065 & 688267 & 4.0 & 5.1157 & TRN \\
\hline CHEMBL1561666 & 688267 & 4.1 & 5.0188 & TST \\
\hline CHEMBL1460977 & 688267 & 4.1 & 5.1112 & TRN \\
\hline CHEMBL1373505 & 688267 & 5.9 & 5.0809 & TRN \\
\hline CHEMBL1394317 & 688267 & 4.65 & 5.1131 & TRN \\
\hline CHEMBL1371872 & 688267 & 6.15 & 5.0865 & TRN \\
\hline CHEMBL1327136 & 688267 & 4.15 & 5.0411 & TRN \\
\hline CHEMBL1316565 & 688267 & 5.55 & 5.0458 & TRN \\
\hline CHEMBL1357749 & 688267 & 4.75 & 5.0837 & TRN \\
\hline CHEMBL1613616 & 688267 & 4.05 & 4.9996 & TST \\
\hline CHEMBL1537660 & 688267 & 4.35 & 5.0509 & TRN \\
\hline CHEMBL1327668 & 688267 & 5.9 & 5.0595 & TRN \\
\hline CHEMBL1581482 & 688267 & 4.0 & 5.1013 & TST \\
\hline CHEMBL1461608 & 688267 & 5.3 & 5.081 & TST \\
\hline CHEMBL1494465 & 688267 & 4.0 & 5.0935 & TST \\
\hline CHEMBL1527908 & 688267 & 5.35 & 5.0905 & TRN \\
\hline CHEMBL1359096 & 688267 & 6.2 & 5.0643 & TRN \\
\hline CHEMBL876 & 688267 & 4.5 & 5.0263 & TST \\
\hline CHEMBL1449505 & 688267 & 4.05 & 5.102 & TST \\
\hline CHEMBL1570085 & 688267 & 3.95 & 4.9732 & TRN \\
\hline CHEMBL1378762 & 688267 & 5.9 & 5.0868 & TRN \\
\hline CHEMBL1501303 & 688267 & 5.15 & 5.0479 & TRN \\
\hline CHEMBL1519195 & 688267 & 4.0 & 5.0627 & TRN \\
\hline CHEMBL1303626 & 688267 & 4.85 & 5.0278 & TST \\
\hline CHEMBL1368329 & 688267 & 4.5 & 5.0409 & TRN \\
\hline CHEMBL1460322 & 688267 & 5.4 & 5.0617 & TRN \\
\hline CHEMBL1592082 & 688267 & 5.4 & 5.0644 & TRN \\
\hline CHEMBL1406822 & 688267 & 4.5 & 5.0701 & TRN \\
\hline CHEMBL1542490 & 688267 & 4.0 & 5.0565 & TRN \\
\hline CHEMBL1606138 & 688267 & 5.95 & 5.1064 & TRN \\
\hline CHEMBL1446728 & 688267 & 6.2 & 5.0863 & TRN \\
\hline CHEMBL1426760 & 688267 & 4.35 & 5.0502 & TST \\
\hline CHEMBL1542099 & 688267 & 4.1 & 5.0539 & TRN \\
\hline CHEMBL1564126 & 688267 & 5.35 & 5.0154 & TRN \\
\hline CHEMBL1372306 & 688267 & 5.5 & 5.0102 & TRN \\
\hline CHEMBL1549795 & 688267 & 4.95 & 5.1069 & TRN \\
\hline CHEMBL1486583 & 688267 & 3.95 & 5.138 & TRN \\
\hline CHEMBL1518395 & 688267 & 6.2 & 5.069 & TRN \\
\hline CHEMBL1411796 & 688267 & 5.4 & 5.1345 & TRN \\
\hline CHEMBL3207900 & 688267 & 5.7 & 5.0059 & TRN \\
\hline
\end{tabular}




\begin{tabular}{|c|c|c|c|c|}
\hline \multicolumn{5}{|c|}{ Supplemental Table S2.txt } \\
\hline CHEMBL1404063 & 688267 & 4.0 & 5.1002 & TRN \\
\hline CHEMBL1376889 & 688267 & 4.0 & 5.0444 & TRN \\
\hline CHEMBL1399924 & 688267 & 4.55 & 5.0498 & TRN \\
\hline CHEMBL1553368 & 688267 & 5.95 & 5.0254 & TST \\
\hline CHEMBL1555421 & 688267 & 5.75 & 4.9887 & TST \\
\hline CHEMBL1584328 & 688267 & 4.15 & 5.0803 & TST \\
\hline CHEMBL1314678 & 688267 & 4.25 & 5.0109 & TRN \\
\hline CHEMBL1588035 & 688267 & 4.0 & 5.0156 & TRN \\
\hline CHEMBL1551937 & 688267 & 4.0 & 5.0321 & TRN \\
\hline CHEMBL1317565 & 688267 & 6.45 & 5.09 & TRN \\
\hline CHEMBL1466638 & 688267 & 5.05 & 5.0342 & TRN \\
\hline CHEMBL1514692 & 688267 & 3.95 & 5.0429 & TRN \\
\hline CHEMBL1598905 & 688267 & 4.7 & 5.0105 & TRN \\
\hline CHEMBL1572120 & 688267 & 4.0 & 5.0349 & TST \\
\hline CHEMBL1577150 & 688267 & 4.25 & 5.104 & TRN \\
\hline CHEMBL1481818 & 688267 & 6.2 & 5.0703 & TRN \\
\hline CHEMBL1480280 & 688267 & 4.05 & 5.0269 & TRN \\
\hline CHEMBL1419555 & 688267 & 5.55 & 4.9821 & TRN \\
\hline CHEMBL1594361 & 688267 & 4.05 & 5.0202 & TRN \\
\hline CHEMBL1370974 & 688267 & 4.85 & 5.0066 & TRN \\
\hline CHEMBL1375219 & 688267 & 4.0 & 4.9961 & TST \\
\hline CHEMBL1584343 & 688267 & 4.05 & 5.1554 & TST \\
\hline CHEMBL1389722 & 688267 & 5.3 & 5.0384 & TST \\
\hline CHEMBL1457096 & 688267 & 3.95 & 5.0359 & TRN \\
\hline CHEMBL1525447 & 688267 & 6.2 & 5.0124 & TRN \\
\hline CHEMBL1372965 & 688267 & 6.2 & 5.0275 & TRN \\
\hline CHEMBL1574746 & 688267 & 5.25 & 5.0881 & TST \\
\hline CHEMBL1473505 & 688267 & 5.35 & 5.0243 & TRN \\
\hline CHEMBL1407688 & 688267 & 4.7 & 5.0376 & TRN \\
\hline CHEMBL1358825 & 688267 & 6.2 & 5.1054 & TRN \\
\hline CHEMBL1459018 & 688267 & 4.1 & 5.1085 & TRN \\
\hline CHEMBL1451202 & 688267 & 5.35 & 5.0473 & TST \\
\hline CHEMBL1530729 & 688267 & 5.45 & 5.0725 & TRN \\
\hline CHEMBL1598379 & 688267 & 5.8 & 5.0136 & TRN \\
\hline CHEMBL1365315 & 688267 & 3.95 & 5.096 & TST \\
\hline CHEMBL1509584 & 688267 & 5.5 & 5.1094 & TST \\
\hline CHEMBL1516208 & 688267 & 4.5 & 5.038 & TRN \\
\hline CHEMBL1314248 & 688267 & 5.5 & 5.0671 & TRN \\
\hline CHEMBL1446593 & 688267 & 5.4 & 5.0092 & TST \\
\hline CHEMBL1374693 & 688267 & 6.15 & 5.0647 & TST \\
\hline CHEMBL1437094 & 688267 & 6.0 & 5.1199 & TRN \\
\hline CHEMBL1346835 & 688267 & 5.75 & 5.0996 & TRN \\
\hline CHEMBL1576728 & 688267 & 4.0 & 5.0661 & TST \\
\hline CHEMBL1366109 & 688267 & 4.7 & 5.0403 & TRN \\
\hline CHEMBL1458242 & 688267 & 6.2 & 5.1583 & TRN \\
\hline CHEMBL1534013 & 688267 & 4.35 & 5.113 & TRN \\
\hline CHEMBL1512125 & 688267 & 4.05 & 5.0724 & TRN \\
\hline CHEMBL1415733 & 688267 & 4.0 & 4.9924 & TRN \\
\hline
\end{tabular}




\begin{tabular}{|c|c|c|c|c|c|}
\hline & & \multicolumn{4}{|c|}{ Supplemental Table S2.txt } \\
\hline CHEMBL1465712 & 688267 & 6.15 & 5.1314 & TRN & \\
\hline CHEMBL1561328 & 688267 & 5.2 & 5.0043 & TST & \\
\hline CHEMBL1514179 & 688267 & 4.35 & 5.0128 & TRN & \\
\hline CHEMBL1605807 & 688267 & 4.25 & 5.0629 & TRN & \\
\hline CHEMBL1368860 & 688267 & 5.7 & 5.0641 & TRN & \\
\hline CHEMBL1340994 & 688267 & 3.95 & 5.0918 & TRN & \\
\hline CHEMBL1573718 & 688267 & 4.15 & 5.0875 & TST & \\
\hline CHEMBL1337510 & 688267 & 4.4 & 5.0771 & TRN & \\
\hline CHEMBL1562634 & 688267 & 4.2 & 5.0559 & TRN & \\
\hline CHEMBL1318181 & 688267 & 6.15 & 5.0457 & TRN & \\
\hline CHEMBL1540548 & 688267 & 4.4 & 5.0849 & TRN & \\
\hline CHEMBL1539899 & 688267 & 6.45 & 5.0781 & TRN & \\
\hline CHEMBL1554156 & 688267 & 4.0 & 5.0359 & TRN & \\
\hline CHEMBL1359677 & 688267 & 5.35 & 4.9994 & TST & \\
\hline CHEMBL 3212007 & 688267 & 4.8 & 5.0623 & TST & \\
\hline CHEMBL1413469 & 688267 & 4.65 & 5.1341 & TRN & \\
\hline CHEMBL1480702 & 688267 & 5.45 & 5.0887 & TRN & \\
\hline CHEMBL1399768 & 688267 & 4.2 & 4.9899 & TRN & \\
\hline CHEMBL1321930 & 688267 & 4.75 & 5.0277 & TRN & \\
\hline CHEMBL1577601 & 688267 & 4.35 & 5.016 & TRN & \\
\hline CHEMBL1388043 & 688267 & 6.2 & 5.1348 & TST & \\
\hline CHEMBL1446951 & 688267 & 4.1 & 5.0485 & TRN & \\
\hline CHEMBL1522482 & 688267 & 4.05 & 5.0085 & TRN & \\
\hline CHEMBL1500348 & 688267 & 4.95 & 5.0231 & TRN & \\
\hline CHEMBL1317509 & 688267 & 4.35 & 5.059 & TRN & \\
\hline CHEMBL1597764 & 688267 & 4.05 & 5.0559 & TRN & \\
\hline CHEMBL1461980 & 688267 & 4.35 & 5.0193 & TST & \\
\hline CHEMBL1304371 & 688267 & 6.0 & 5.0791 & TRN & \\
\hline CHEMBL582491 & 688267 & 4.45 & 4.9925 & TST & \\
\hline CHEMBL 1544935 & 688267 & 5.9 & 5.0773 & TRN & \\
\hline CHEMBL1307956 & 688267 & 4.35 & 5.0699 & TRN & \\
\hline CHEMBL1394276 & 688267 & 4.0 & 5.0054 & TST & \\
\hline CHEMBL1497860 & 688267 & 4.4 & 5.0358 & TRN & \\
\hline CHEMBL1447948 & 688267 & 4.55 & 5.1035 & TRN & \\
\hline CHEMBL1385741 & 688267 & 5.25 & 5.098 & TST & \\
\hline CHEMBL1314929 & 688267 & 5.5 & 5.0 & TRN & \\
\hline CHEMBL1524471 & 688267 & 4.3 & 5.1048 & TRN & \\
\hline CHEMBL1378533 & 688267 & 4.6 & 5.0321 & TRN & \\
\hline CHEMBL1591352 & 688267 & 4.05 & 5.0066 & TRN & \\
\hline CHEMBL1510029 & 688267 & 4.9 & 5.0724 & TST & \\
\hline CHEMBL1525588 & 688267 & 6.2 & 5.0928 & TRN & \\
\hline CHEMBL1399024 & 688267 & 5.25 & 5.0505 & TRN & \\
\hline CHEMBL1454643 & 688267 & 3.95 & 5.1056 & TRN & \\
\hline CHEMBL1608718 & 688267 & 6.0 & 5.0281 & TRN & \\
\hline CHEMBL1539846 & 688267 & 6.2 & 5.0624 & TST & \\
\hline CHEMBL1345773 & 688267 & 4.05 & 5.1032 & TST & \\
\hline CHEMBL 1543712 & 688267 & 4.0 & 5.0252 & TRN & \\
\hline CHEMBL1562935 & 688267 & 5.9 & 5.13299 & 9999999999 & TRN \\
\hline & & & & 18159 & \\
\hline
\end{tabular}




\begin{tabular}{|c|c|c|c|c|c|}
\hline \\
\hline CHEMBL1527110 & 688267 & 6.1 & 5.0826 & TRN & \\
\hline CHEMBL1307787 & 688267 & 4.4 & 5.1189 & TRN & \\
\hline CHEMBL1342333 & 688267 & 3.9 & 5.0777 & TST & \\
\hline CHEMBL1380225 & 688267 & 4.55 & 5.0552 & TRN & \\
\hline CHEMBL3213160 & 688267 & 4.25 & 5.0896 & TST & \\
\hline CHEMBL1369623 & 688267 & 4.05 & 4.9959 & TST & \\
\hline CHEMBL1378005 & 688267 & 6.15 & 5.1241 & TRN & \\
\hline CHEMBL1467599 & 688267 & 5.2 & 5.0768 & TRN & \\
\hline CHEMBL1597810 & 688267 & 4.05 & 5.0416 & TST & \\
\hline CHEMBL1444541 & 688267 & 6.2 & 5.0271 & TRN & \\
\hline CHEMBL1399393 & 688267 & 3.95 & 5.1032 & TRN & \\
\hline CHEMBL1334055 & 688267 & 6.15 & 5.0787 & TST & \\
\hline CHEMBL1382368 & 688267 & 4.0 & 5.0911 & TST & \\
\hline CHEMBL1423982 & 688267 & 4.0 & 5.0022 & TRN & \\
\hline CHEMBL1476726 & 688267 & 5.35 & 5.1414 & TRN & \\
\hline CHEMBL1432028 & 688267 & 4.7 & 5.0758 & TST & \\
\hline CHEMBL1532197 & 688267 & 4.05 & 5.0421 & TRN & \\
\hline CHEMBL1409571 & 688267 & 5.45 & 5.0058 & TRN & \\
\hline CHEMBL1307037 & 688267 & 6.2 & 5.0668 & TRN & \\
\hline CHEMBL1570316 & 688267 & 6.15 & 5.07100 & 0000000001 & TRN \\
\hline CHEMBL1369511 & 688267 & 4.6 & 5.0244 & TRN & \\
\hline CHEMBL1444042 & 688267 & 4.15 & 5.07600 & 00000000005 & TST \\
\hline CHEMBL1359150 & 688267 & 4.25 & 5.1115 & TRN & \\
\hline CHEMBL1348591 & 688267 & 5.85 & 5.0029 & TRN & \\
\hline CHEMBL1553861 & 688267 & 6.15 & 5.0837 & TRN & \\
\hline CHEMBL1436440 & 688267 & 4.05 & 4.9788 & TRN & \\
\hline CHEMBL1405573 & 688267 & 6.5 & 5.0591 & TRN & \\
\hline CHEMBL1371866 & 688267 & 4.55 & 5.0061 & TRN & \\
\hline CHEMBL46535 & 688267 & 5.9 & 5.1148 & TRN & \\
\hline CHEMBL1492783 & 688267 & 4.9 & 5.0024 & TRN & \\
\hline CHEMBL1514608 & 688267 & 4.45 & 5.1306 & TRN & \\
\hline CHEMBL585628 & 688267 & 4.0 & 5.0152 & TST & \\
\hline CHEMBL1592403 & 688267 & 6.2 & 5.0224 & TRN & \\
\hline CHEMBL1367618 & 688267 & 4.45 & 5.067 & TRN & \\
\hline CHEMBL1589396 & 688267 & 4.55 & 5.0635 & TRN & \\
\hline CHEMBL1451251 & 688267 & 6.15 & 4.9941 & TST & \\
\hline CHEMBL1320582 & 688267 & 6.2 & 5.0619 & TST & \\
\hline CHEMBL1569283 & 688267 & 5.95 & 5.0334 & TRN & \\
\hline CHEMBL1381672 & 688267 & 6.2 & 5.0589 & TRN & \\
\hline CHEMBL1336178 & 688267 & 4.35 & 5.1688 & TRN & \\
\hline CHEMBL1436409 & 688267 & 4.9 & 5.0225 & TRN & \\
\hline CHEMBL1529918 & 688267 & 4.0 & 5.0373 & TRN & \\
\hline CHEMBL1397030 & 688267 & 6.2 & 5.0277 & TRN & \\
\hline CHEMBL1424480 & 688267 & 4.1 & 5.1036 & TRN & \\
\hline CHEMBL1330621 & 688267 & 5.55 & 5.0694 & TST & \\
\hline CHEMBL1416411 & 688267 & 4.45 & 5.0023 & TRN & \\
\hline CHEMBL1426088 & 688267 & 4.05 & 5.0353 & TRN & \\
\hline CHEMBL1325216 & 688267 & 5.0 & 5.0496 & TRN & \\
\hline
\end{tabular}




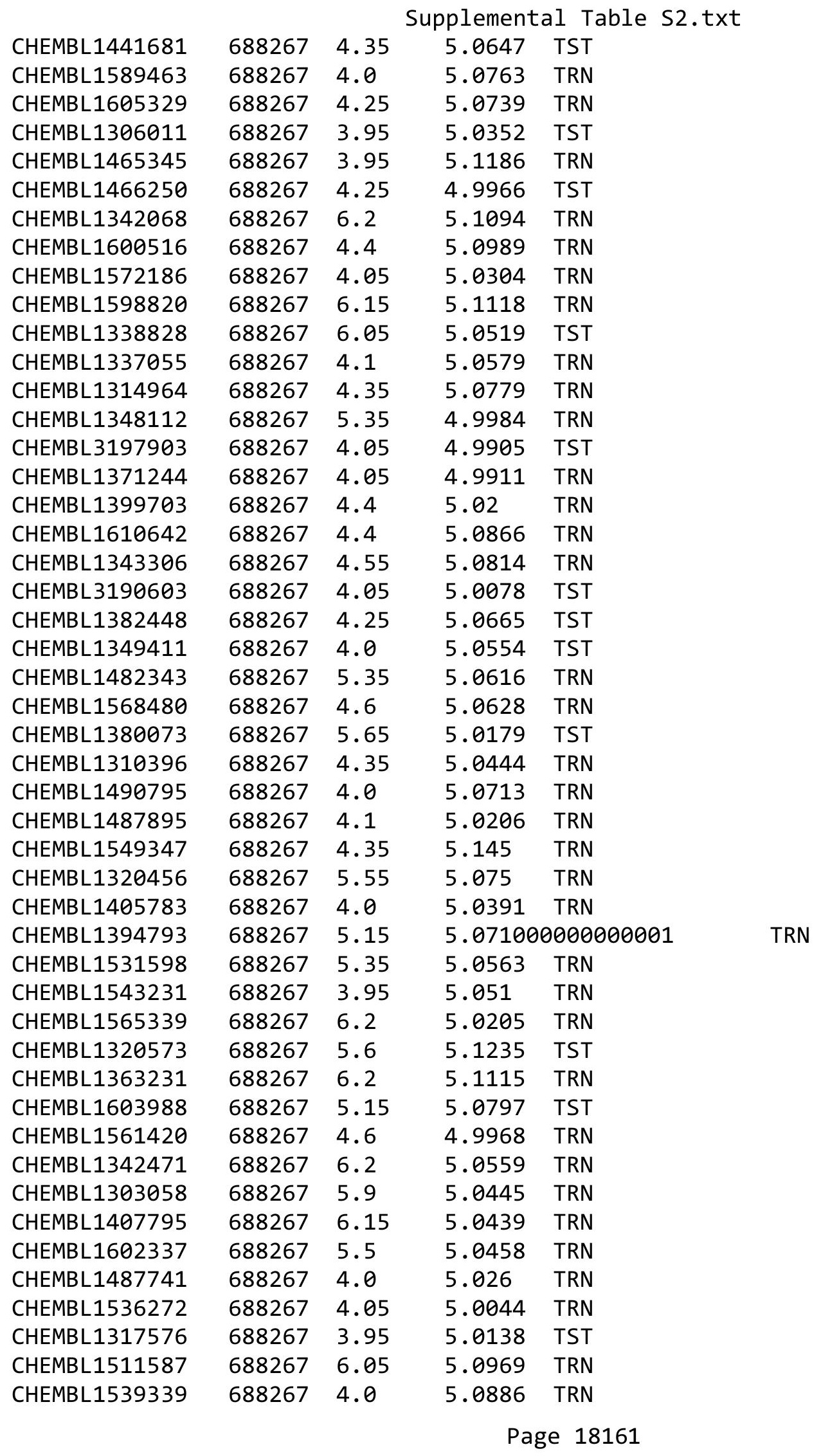




\begin{tabular}{|c|c|c|c|c|}
\hline & & & pplement & al $\mathrm{Ta}$ \\
\hline CHEMBL1495869 & 688267 & 5.6 & 5.0535 & TST \\
\hline CHEMBL1309831 & 688267 & 5.25 & 5.0637 & TRN \\
\hline CHEMBL1576137 & 688267 & 6.2 & 5.0262 & TRN \\
\hline CHEMBL1402301 & 688267 & 6.15 & 5.0721 & TRN \\
\hline CHEMBL1441458 & 688267 & 5.1 & 5.002 & TRN \\
\hline CHEMBL1579608 & 688267 & 3.95 & 5.0685 & TRN \\
\hline CHEMBL1597754 & 688267 & 5.25 & 4.9864 & TRN \\
\hline CHEMBL1601478 & 688267 & 4.05 & 5.0789 & TRN \\
\hline CHEMBL1593674 & 688267 & 5.25 & 5.0482 & TRN \\
\hline CHEMBL1431289 & 688267 & 6.0 & 5.1102 & TST \\
\hline CHEMBL1514701 & 688267 & 4.0 & 5.044 & TRN \\
\hline CHEMBL1585806 & 688267 & 4.3 & 5.0477 & TRN \\
\hline CHEMBL3197078 & 688267 & 4.05 & 4.9969 & TRN \\
\hline CHEMBL1344448 & 688267 & 5.8 & 5.0816 & TRN \\
\hline CHEMBL1504085 & 688267 & 4.15 & 5.1261 & TST \\
\hline CHEMBL1415986 & 688267 & 5.7 & 5.0422 & TRN \\
\hline CHEMBL1452765 & 688267 & 4.05 & 5.064 & TST \\
\hline CHEMBL1331996 & 688267 & 5.4 & 5.0794 & TRN \\
\hline CHEMBL1467459 & 688267 & 5.8 & 5.118 & TST \\
\hline CHEMBL1998291 & 688267 & 4.3 & 4.9808 & TST \\
\hline CHEMBL1510893 & 688267 & 4.35 & 5.0484 & TRN \\
\hline CHEMBL1383619 & 688267 & 5.45 & 5.0257 & TRN \\
\hline CHEMBL1470917 & 688267 & 5.2 & 5.0287 & TRN \\
\hline CHEMBL1352315 & 688267 & 4.35 & 5.0445 & TRN \\
\hline CHEMBL1352312 & 688267 & 4.4 & 5.081 & TRN \\
\hline CHEMBL1536900 & 688267 & 3.95 & 5.063 & TST \\
\hline CHEMBL1610120 & 688267 & 6.2 & 5.1048 & TRN \\
\hline CHEMBL1579638 & 688267 & 5.3 & 5.052 & TRN \\
\hline CHEMBL1517946 & 688267 & 5.6 & 5.0926 & TRN \\
\hline CHEMBL1498041 & 688267 & 4.9 & 5.0275 & TST \\
\hline CHEMBL1988289 & 688267 & 4.35 & 4.9845 & TRN \\
\hline CHEMBL1489621 & 688267 & 4.35 & 5.0852 & TRN \\
\hline CHEMBL1421583 & 688267 & 6.25 & 4.9693 & TRN \\
\hline CHEMBL1375696 & 688267 & 6.25 & 5.0473 & TRN \\
\hline CHEMBL324389 & 688267 & 3.95 & 4.9904 & TRN \\
\hline CHEMBL1451570 & 688267 & 4.4 & 5.0389 & TRN \\
\hline CHEMBL1473542 & 688267 & 4.0 & 5.1551 & TRN \\
\hline CHEMBL1328021 & 688267 & 4.25 & 5.0932 & TRN \\
\hline CHEMBL1573858 & 688267 & 4.15 & 5.0593 & TST \\
\hline CHEMBL1360702 & 688267 & 5.05 & 5.0449 & TRN \\
\hline CHEMBL1357095 & 688267 & 4.4 & 5.0887 & TRN \\
\hline CHEMBL1334748 & 688267 & 4.95 & 5.1226 & TST \\
\hline CHEMBL1555123 & 688267 & 4.3 & 5.0597 & TRN \\
\hline CHEMBL1521328 & 688267 & 5.15 & 5.1705 & TRN \\
\hline CHEMBL1592068 & 688267 & 4.1 & 5.0995 & TRN \\
\hline CHEMBL1356753 & 688267 & 4.0 & 5.1034 & TRN \\
\hline CHEMBL1461052 & 688267 & 5.25 & 5.0574 & TRN \\
\hline CHEMBL1386115 & 688267 & 5.35 & 5.055 & TST \\
\hline
\end{tabular}




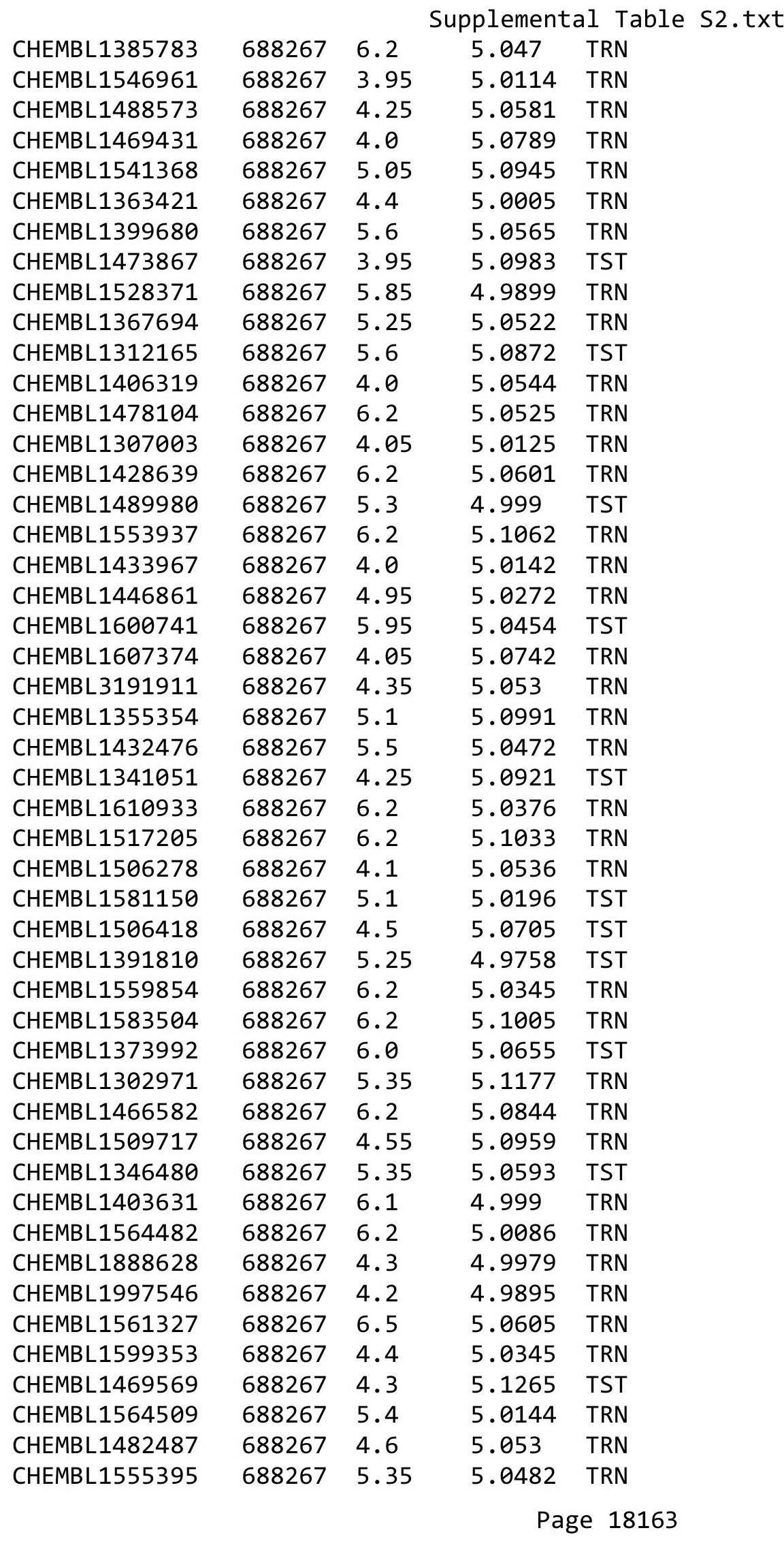




\begin{tabular}{|c|c|c|c|c|}
\hline & & & pplement & al $\mathrm{Ta}$ \\
\hline CHEMBL1583587 & 688267 & 5.3 & 5.0847 & TRN \\
\hline CHEMBL3197525 & 688267 & 4.0 & 5.0665 & TRN \\
\hline CHEMBL1574574 & 688267 & 6.2 & 5.0892 & TRN \\
\hline CHEMBL1379147 & 688267 & 4.05 & 5.056 & TRN \\
\hline CHEMBL1336536 & 688267 & 5.6 & 5.0702 & TRN \\
\hline CHEMBL1440092 & 688267 & 4.35 & 5.0777 & TRN \\
\hline CHEMBL1364124 & 688267 & 6.05 & 5.0581 & TRN \\
\hline CHEMBL1520186 & 688267 & 5.95 & 5.1143 & TRN \\
\hline CHEMBL1521837 & 688267 & 4.0 & 5.0979 & TRN \\
\hline CHEMBL1592480 & 688267 & 5.45 & 5.1 & TRN \\
\hline CHEMBL1318398 & 688267 & 6.2 & 5.0309 & TRN \\
\hline CHEMBL1384149 & 688267 & 6.2 & 5.0409 & TRN \\
\hline CHEMBL1566511 & 688267 & 6.2 & 5.0421 & TRN \\
\hline CHEMBL1473010 & 688267 & 6.25 & 5.0131 & TRN \\
\hline CHEMBL1397756 & 688267 & 4.4 & 5.0207 & TRN \\
\hline CHEMBL1469122 & 688267 & 4.5 & 5.0394 & TRN \\
\hline CHEMBL1456966 & 688267 & 4.55 & 5.05 & TRN \\
\hline CHEMBL1376797 & 688267 & 4.1 & 5.0648 & TRN \\
\hline CHEMBL1502645 & 688267 & 4.25 & 5.0754 & TRN \\
\hline CHEMBL1362950 & 688267 & 4.55 & 5.012 & TST \\
\hline CHEMBL1322926 & 688267 & 5.35 & 5.0726 & TRN \\
\hline CHEMBL1479508 & 688267 & 5.65 & 5.1304 & TST \\
\hline CHEMBL1454298 & 688267 & 4.1 & 5.0256 & TST \\
\hline CHEMBL1391192 & 688267 & 6.05 & 5.0195 & TRN \\
\hline CHEMBL1447701 & 688267 & 4.4 & 5.0559 & TRN \\
\hline CHEMBL1479228 & 688267 & 5.5 & 5.0979 & TRN \\
\hline CHEMBL1433331 & 688267 & 4.0 & 5.103 & TST \\
\hline CHEMBL1437956 & 688267 & 5.2 & 5.0369 & TRN \\
\hline CHEMBL1444190 & 688267 & 4.6 & 5.106 & TST \\
\hline CHEMBL1485275 & 688267 & 5.05 & 5.0586 & TRN \\
\hline CHEMBL1457191 & 688267 & 4.0 & 5.0498 & TRN \\
\hline CHEMBL1355597 & 688267 & 6.2 & 5.0611 & TRN \\
\hline CHEMBL1517435 & 688267 & 4.0 & 5.0074 & TRN \\
\hline CHEMBL1591476 & 688267 & 4.6 & 5.0429 & TRN \\
\hline CHEMBL1303115 & 688267 & 6.2 & 4.9638 & TST \\
\hline CHEMBL1454975 & 688267 & 5.65 & 4.9888 & TST \\
\hline CHEMBL1450929 & 688267 & 4.0 & 5.0395 & TST \\
\hline CHEMBL1480775 & 688267 & 4.0 & 5.0289 & TRN \\
\hline CHEMBL1353072 & 688267 & 3.95 & 5.056 & TST \\
\hline CHEMBL1553397 & 688267 & 6.25 & 4.9772 & TRN \\
\hline CHEMBL1599568 & 688267 & 4.2 & 5.1212 & TRN \\
\hline CHEMBL1451217 & 688267 & 4.55 & 5.1024 & TRN \\
\hline CHEMBL1444464 & 688267 & 4.05 & 5.1075 & TRN \\
\hline CHEMBL1589834 & 688267 & 6.25 & 5.0618 & TRN \\
\hline CHEMBL1337838 & 688267 & 6.2 & 5.0534 & TST \\
\hline CHEMBL1490864 & 688267 & 6.5 & 5.0728 & TRN \\
\hline CHEMBL1353204 & 688267 & 6.45 & 5.0516 & TRN \\
\hline CHEMBL1363544 & 688267 & 5.45 & 5.0275 & TRN \\
\hline
\end{tabular}




\begin{tabular}{|c|c|c|c|c|c|}
\hline \multicolumn{6}{|c|}{ Supplemental Table S2.txt } \\
\hline CHEMBL1471665 & 688267 & 4.25 & 5.0291 & TRN & \\
\hline CHEMBL1469032 & 688267 & 6.2 & 4.9813 & TRN & \\
\hline CHEMBL6703 & 688267 & 4.95 & 5.0345 & TRN & \\
\hline CHEMBL1303917 & 688267 & 6.0 & 5.0797 & TST & \\
\hline CHEMBL1380354 & 688267 & 4.65 & 5.0547 & TRN & \\
\hline CHEMBL1529252 & 688267 & 5.25 & 5.0015 & TST & \\
\hline CHEMBL1335132 & 688267 & 6.2 & 5.0525 & TST & \\
\hline CHEMBL1379412 & 688267 & 4.0 & 5.086 & TRN & \\
\hline CHEMBL 3213028 & 688267 & 4.9 & 5.0458 & TRN & \\
\hline CHEMBL3190909 & 688267 & 4.95 & 5.01 & TRN & \\
\hline CHEMBL1330798 & 688267 & 4.75 & 5.0845 & TRN & \\
\hline CHEMBL1437163 & 688267 & 5.35 & 5.061 & TRN & \\
\hline CHEMBL 3208936 & 688267 & 4.0 & 5.056 & TST & \\
\hline CHEMBL1450961 & 688267 & 4.15 & 5.0502 & TST & \\
\hline CHEMBL1477605 & 688267 & 4.05 & 5.0267 & TRN & \\
\hline CHEMBL1378316 & 688267 & 4.0 & 4.9898 & TRN & \\
\hline CHEMBL1356568 & 688267 & 5.6 & 5.0267 & TRN & \\
\hline CHEMBL3190271 & 688267 & 6.2 & 5.04 & TST & \\
\hline CHEMBL1509510 & 688267 & 4.6 & 5.0716 & TST & \\
\hline CHEMBL1485550 & 688267 & 4.25 & 5.1229 & TRN & \\
\hline CHEMBL1401837 & 688267 & 5.25 & 5.0411 & TRN & \\
\hline CHEMBL1402599 & 688267 & 4.9 & 5.0117 & TRN & \\
\hline CHEMBL1335609 & 688267 & 4.6 & 5.1056 & TST & \\
\hline CHEMBL1550715 & 688267 & 5.55 & 5.0812 & TST & \\
\hline CHEMBL1394565 & 688267 & 4.6 & 5.0714 & TRN & \\
\hline CHEMBL 3197288 & 688267 & 6.15 & 5.0098 & TST & \\
\hline CHEMBL1601915 & 688267 & 3.95 & 4.9985 & TRN & \\
\hline CHEMBL1575936 & 688267 & 6.0 & 5.0881 & TRN & \\
\hline CHEMBL1323140 & 688267 & 4.1 & 5.0297 & TRN & \\
\hline CHEMBL1557659 & 688267 & 5.15 & 5.0407 & TRN & \\
\hline CHEMBL3195907 & 688267 & 4.0 & 5.0032 & TRN & \\
\hline CHEMBL1450034 & 688267 & 5.35 & 5.019 & TRN & \\
\hline CHEMBL1524902 & 688267 & 4.35 & 5.1172 & TRN & \\
\hline CHEMBL1555131 & 688267 & 5.45 & 4.9981 & TRN & \\
\hline CHEMBL1372189 & 688267 & 4.05 & 5.0518 & TST & \\
\hline CHEMBL1351807 & 688267 & 6.25 & 5.1154 & TRN & \\
\hline CHEMBL1458015 & 688267 & 4.35 & 5.0161 & TRN & \\
\hline CHEMBL1450494 & 688267 & 4.05 & 5.0558 & TRN & \\
\hline CHEMBL1536219 & 688267 & 6.25 & 5.11600 & 00000000005 & TRN \\
\hline CHEMBL1389585 & 688267 & 4.85 & 5.098 & TRN & \\
\hline CHEMBL1338337 & 688267 & 4.1 & 5.0917 & TRN & \\
\hline CHEMBL1317707 & 688267 & 5.35 & 5.0095 & TRN & \\
\hline CHEMBL1584152 & 688267 & 4.0 & 4.9927 & TRN & \\
\hline CHEMBL1604607 & 688267 & 5.85 & 5.1047 & TRN & \\
\hline CHEMBL1480322 & 688267 & 4.0 & 5.0586 & TRN & \\
\hline CHEMBL1446856 & 688267 & 6.15 & 5.0451 & TRN & \\
\hline CHEMBL1567021 & 688267 & 6.1 & 5.0701 & TRN & \\
\hline CHEMBL1454276 & 688267 & 6.95 & 5.0718 & TRN & \\
\hline
\end{tabular}




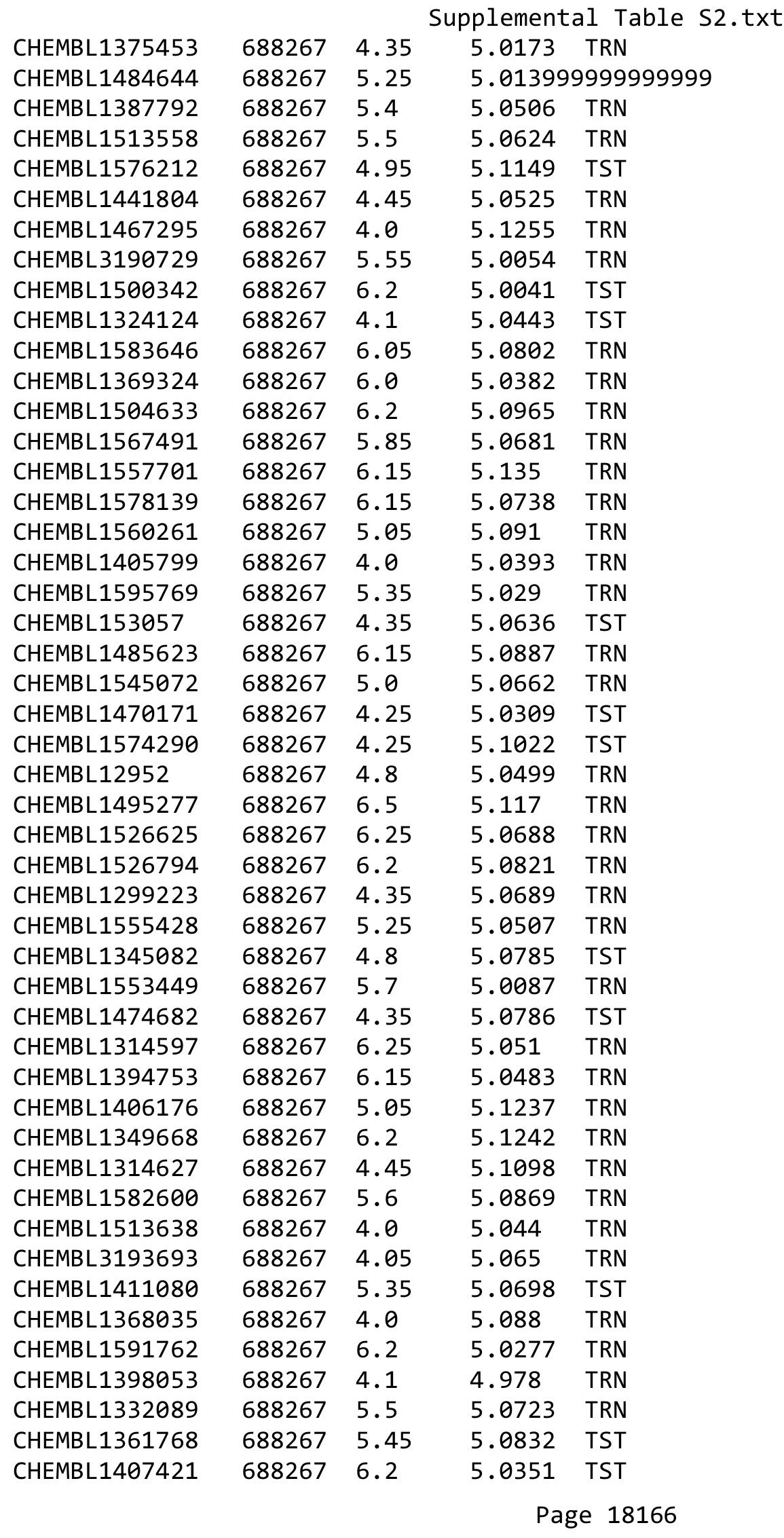

TRN 


\begin{tabular}{|c|c|c|c|c|}
\hline \multicolumn{5}{|c|}{ Supplemental Table S2.txt } \\
\hline CHEMBL1510690 & 688267 & 4.1 & 5.0926 & TRN \\
\hline CHEMBL1309091 & 688267 & 6.15 & 4.982 & TRN \\
\hline CHEMBL1336421 & 688267 & 5.55 & 5.0775 & TST \\
\hline CHEMBL1365989 & 688267 & 4.4 & 5.0563 & TST \\
\hline CHEMBL1413759 & 688267 & 6.15 & 5.1263 & TRN \\
\hline CHEMBL1592699 & 688267 & 5.45 & 5.0209 & TRN \\
\hline CHEMBL1343388 & 688267 & 5.2 & 5.0383 & TRN \\
\hline CHEMBL1604517 & 688267 & 4.25 & 5.1199 & TRN \\
\hline CHEMBL1553480 & 688267 & 3.9 & 5.086 & TST \\
\hline CHEMBL1307268 & 688267 & 4.35 & 5.0437 & TST \\
\hline CHEMBL1418633 & 688267 & 4.8 & 4.9861 & TRN \\
\hline CHEMBL1593738 & 688267 & 4.5 & 5.0542 & TRN \\
\hline CHEMBL1348876 & 688267 & 6.15 & 5.0076 & TRN \\
\hline CHEMBL1513266 & 688267 & 4.0 & 5.0606 & TRN \\
\hline CHEMBL1438901 & 688267 & 5.75 & 5.1054 & TRN \\
\hline CHEMBL1477298 & 688267 & 6.2 & 5.0415 & TRN \\
\hline CHEMBL1493936 & 688267 & 4.05 & 4.9959 & TRN \\
\hline CHEMBL1556967 & 688267 & 4.05 & 5.0185 & TRN \\
\hline CHEMBL1452700 & 688267 & 4.35 & 5.0452 & TRN \\
\hline CHEMBL1434475 & 688267 & 4.0 & 5.035 & TRN \\
\hline CHEMBL1567076 & 688267 & 4.4 & 5.0454 & TST \\
\hline CHEMBL1534041 & 688267 & 4.55 & 5.0624 & TRN \\
\hline CHEMBL1475022 & 688267 & 4.05 & 5.0638 & TRN \\
\hline CHEMBL1374307 & 688267 & 4.05 & 5.0537 & TRN \\
\hline CHEMBL1302729 & 688267 & 6.15 & 5.0961 & TRN \\
\hline CHEMBL1565162 & 688267 & 4.6 & 5.0413 & TRN \\
\hline CHEMBL1410446 & 688267 & 3.95 & 5.0983 & TRN \\
\hline CHEMBL1397426 & 688267 & 7.2 & 5.1016 & TRN \\
\hline CHEMBL1454246 & 688267 & 5.4 & 5.0642 & TRN \\
\hline CHEMBL1573447 & 688267 & 4.15 & 5.0358 & TRN \\
\hline CHEMBL1317428 & 688267 & 5.5 & 5.0234 & TRN \\
\hline CHEMBL1458078 & 688267 & 4.0 & 5.0371 & TRN \\
\hline CHEMBL1364401 & 688267 & 4.35 & 5.1292 & TST \\
\hline CHEMBL3192288 & 688267 & 6.25 & 5.0139 & TRN \\
\hline CHEMBL1308475 & 688267 & 6.25 & 5.0704 & TRN \\
\hline CHEMBL1349555 & 688267 & 6.2 & 5.0851 & TST \\
\hline CHEMBL1368348 & 688267 & 4.4 & 5.1618 & TRN \\
\hline CHEMBL1334381 & 688267 & 5.1 & 5.0587 & TRN \\
\hline CHEMBL1520118 & 688267 & 5.05 & 5.0204 & TRN \\
\hline CHEMBL1392564 & 688267 & 6.25 & 5.0578 & TRN \\
\hline CHEMBL1454285 & 688267 & 5.25 & 5.0179 & TRN \\
\hline CHEMBL1348450 & 688267 & 4.3 & 5.1359 & TRN \\
\hline CHEMBL1473871 & 688267 & 4.05 & 5.0435 & TRN \\
\hline CHEMBL1373599 & 688267 & 5.25 & 5.0754 & TST \\
\hline CHEMBL1426160 & 688267 & 6.2 & 4.9916 & TST \\
\hline CHEMBL1505937 & 688267 & 4.0 & 5.0053 & TST \\
\hline CHEMBL1350468 & 688267 & 3.95 & 5.0787 & TST \\
\hline CHEMBL1402294 & 688267 & 4.8 & 5.0498 & TRN \\
\hline
\end{tabular}




\begin{tabular}{|c|c|c|c|c|c|}
\hline \multirow[b]{2}{*}{ CHEMBL1508768 } & \multirow[b]{2}{*}{688267} & \multicolumn{4}{|c|}{ Supplemental Table S2.txt } \\
\hline & & 5.75 & 5.0532 & TRN & \\
\hline CHEMBL1316206 & 688267 & 5.25 & 5.0272 & TRN & \\
\hline CHEMBL1540811 & 688267 & 5.55 & \multicolumn{2}{|c|}{5.0089999999999995} & TST \\
\hline CHEMBL1435271 & 688267 & 4.95 & 5.1024 & TST & \\
\hline CHEMBL1432033 & 688267 & 4.25 & 5.0099 & TST & \\
\hline CHEMBL1434341 & 688267 & 6.0 & 5.019 & TRN & \\
\hline CHEMBL1352839 & 688267 & 6.2 & 5.0331 & TRN & \\
\hline CHEMBL1551079 & 688267 & 4.1 & 5.0215 & TRN & \\
\hline CHEMBL1578248 & 688267 & 6.2 & 5.0481 & TRN & \\
\hline CHEMBL1572996 & 688267 & 5.1 & 5.0656 & TRN & \\
\hline CHEMBL1547204 & 688267 & 4.05 & 5.0128 & TST & \\
\hline CHEMBL1490221 & 688267 & 6.25 & 5.1197 & TRN & \\
\hline CHEMBL1430347 & 688267 & 5.1 & 4.9975 & TST & \\
\hline CHEMBL1327273 & 688267 & 6.2 & 5.06 & TRN & \\
\hline CHEMBL1302602 & 688267 & 5.9 & 5.0572 & TRN & \\
\hline CHEMBL3214504 & 688267 & 3.95 & 5.0974 & TRN & \\
\hline CHEMBL1450246 & 688267 & 5.2 & 5.1065 & TRN & \\
\hline CHEMBL1299932 & 688267 & 5.5 & 5.0012 & TRN & \\
\hline CHEMBL1324464 & 688267 & 4.4 & 5.0711 & TRN & \\
\hline CHEMBL1477887 & 688267 & 5.3 & 5.0734 & TRN & \\
\hline CHEMBL3197315 & 688267 & 5.75 & 4.9886 & TRN & \\
\hline CHEMBL1493499 & 688267 & 4.05 & 5.011 & TST & \\
\hline CHEMBL1449107 & 688267 & 5.85 & 5.0523 & TRN & \\
\hline CHEMBL1993056 & 688267 & 6.15 & 4.9943 & TST & \\
\hline CHEMBL 1605020 & 688267 & 5.35 & 5.0357 & TRN & \\
\hline CHEMBL1306065 & 688267 & 5.5 & 5.029 & TRN & \\
\hline CHEMBL1313894 & 688267 & 5.15 & 5.037 & TRN & \\
\hline CHEMBL1378152 & 688267 & 5.3 & 5.0697 & TRN & \\
\hline CHEMBL1446566 & 688267 & 6.0 & 5.1084 & TRN & \\
\hline CHEMBL1412451 & 688267 & 6.0 & \multicolumn{2}{|c|}{5.0889999999999995} & TRN \\
\hline CHEMBL1583640 & 688267 & 6.2 & 4.9992 & TRN & \\
\hline CHEMBL1570003 & 688267 & 4.4 & 5.0663 & TRN & \\
\hline CHEMBL1598534 & 688267 & 4.1 & 5.0332 & TST & \\
\hline CHEMBL1365464 & 688267 & 4.4 & 5.0276 & TRN & \\
\hline CHEMBL1529200 & 688267 & 6.15 & 5.0375 & TST & \\
\hline CHEMBL1435134 & 688267 & 5.05 & 5.0382 & TRN & \\
\hline CHEMBL1522177 & 688267 & 6.25 & 5.0387 & TRN & \\
\hline CHEMBL1610868 & 688267 & 5.5 & 4.9973 & TST & \\
\hline CHEMBL1311223 & 688267 & 4.35 & 5.1176 & TRN & \\
\hline CHEMBL1366247 & 688267 & 4.0 & 5.1019 & TRN & \\
\hline CHEMBL1355027 & 688267 & 4.2 & 5.0563 & TRN & \\
\hline CHEMBL1396608 & 688267 & 5.5 & 5.0605 & TRN & \\
\hline CHEMBL1591466 & 688267 & 5.3 & 5.0287 & TRN & \\
\hline CHEMBL1501158 & 688267 & 5.25 & 5.0869 & TRN & \\
\hline CHEMBL1435365 & 688267 & 3.85 & 5.0187 & TST & \\
\hline CHEMBL1434746 & 688267 & 6.15 & 5.0473 & TRN & \\
\hline CHEMBL1562851 & 688267 & 4.3 & 4.9891 & TRN & \\
\hline \multirow[t]{2}{*}{ CHEMBL1475614 } & 688267 & 4.35 & 5.0884 & TRN & \\
\hline & & \multicolumn{4}{|c|}{ Page 18168} \\
\hline
\end{tabular}




\begin{tabular}{|c|c|c|c|c|c|}
\hline & & & & & \\
\hline CHEMBL1357777 & 688267 & 4.4 & 5.0685 & TRN & \\
\hline CHEMBL1356131 & 688267 & 5.2 & 5.0179 & TRN & \\
\hline CHEMBL1458230 & 688267 & 3.95 & 5.0392 & TST & \\
\hline CHEMBL1305592 & 688267 & 4.6 & 5.0252 & TRN & \\
\hline CHEMBL1535206 & 688267 & 4.15 & 4.9827 & TRN & \\
\hline CHEMBL1389617 & 688267 & 4.8 & 5.0417 & TRN & \\
\hline CHEMBL1356048 & 688267 & 4.55 & 5.1118 & TRN & \\
\hline CHEMBL1588729 & 688267 & 4.45 & 5.0339 & TST & \\
\hline CHEMBL 3213529 & 688267 & 4.05 & 5.0474 & TRN & \\
\hline CHEMBL1576453 & 688267 & 6.15 & 5.0772 & TST & \\
\hline CHEMBL1585042 & 688267 & 5.05 & 5.0836 & TRN & \\
\hline CHEMBL1364606 & 688267 & 6.2 & 5.0628 & TST & \\
\hline CHEMBL1405998 & 688267 & 5.3 & 5.0637 & TRN & \\
\hline CHEMBL1322492 & 688267 & 3.95 & 5.0771 & TRN & \\
\hline CHEMBL1386394 & 688267 & 3.95 & 5.0931 & TRN & \\
\hline CHEMBL1403990 & 688267 & 5.55 & 5.0431 & TRN & \\
\hline CHEMBL1324613 & 688267 & 4.0 & 5.0528 & TRN & \\
\hline CHEMBL1376405 & 688267 & 4.0 & 5.0599 & TRN & \\
\hline CHEMBL1347117 & 688267 & 4.3 & 5.0449 & TST & \\
\hline CHEMBL1516832 & 688267 & 5.45 & 5.1284 & TRN & \\
\hline CHEMBL1476403 & 688267 & 6.2 & 5.0013 & TRN & \\
\hline CHEMBL1390488 & 688267 & 5.85 & 4.9928 & TRN & \\
\hline CHEMBL1421617 & 688267 & 6.2 & 5.0179 & TST & \\
\hline CHEMBL1497068 & 688267 & 6.2 & 5.0568 & TST & \\
\hline CHEMBL1543328 & 688267 & 5.9 & 5.0674 & TRN & \\
\hline CHEMBL1520473 & 688267 & 4.0 & 5.0648 & TRN & \\
\hline CHEMBL1547005 & 688267 & 6.2 & 5.0296 & TST & \\
\hline CHEMBL1467608 & 688267 & 6.2 & 5.0525 & TRN & \\
\hline CHEMBL1400809 & 688267 & 5.5 & 5.0662 & TRN & \\
\hline CHEMBL1598001 & 688267 & 4.2 & 5.1283 & TRN & \\
\hline CHEMBL1980889 & 688267 & 5.3 & 4.9801 & TST & \\
\hline CHEMBL1465906 & 688267 & 4.35 & 5.0223 & TRN & \\
\hline CHEMBL1397903 & 688267 & 4.65 & 5.0618 & TRN & \\
\hline CHEMBL1324702 & 688267 & 5.4 & 5.0727 & TRN & \\
\hline CHEMBL1388302 & 688267 & 4.05 & 5.0556 & TRN & \\
\hline CHEMBL3214561 & 688267 & 4.05 & 4.9712 & TRN & \\
\hline CHEMBL1466394 & 688267 & 5.05 & 5.0833 & TRN & \\
\hline CHEMBL1441460 & 688267 & 6.25 & 5.027 & TRN & \\
\hline CHEMBL1529233 & 688267 & 6.25 & 4.9929 & TST & \\
\hline CHEMBL1534462 & 688267 & 5.25 & 5.0789 & TRN & \\
\hline CHEMBL1547473 & 688267 & 4.25 & 5.0449 & TRN & \\
\hline CHEMBL1566232 & 688267 & 5.5 & 5.0417 & TST & \\
\hline CHEMBL3195066 & 688267 & 4.05 & 4.9853 & TRN & \\
\hline CHEMBL1310197 & 688267 & 4.65 & 5.095 & TST & \\
\hline CHEMBL1388405 & 688267 & 4.3 & 5.0825 & TST & \\
\hline CHEMBL1565920 & 688267 & 4.65 & 5.0904 & TRN & \\
\hline CHEMBL1391497 & 688267 & 5.55 & 5.0223 & TST & \\
\hline CHEMBL1335351 & 688267 & 4.6 & 5.08899 & 99999999995 & TRN \\
\hline & & & & 18169 & \\
\hline
\end{tabular}




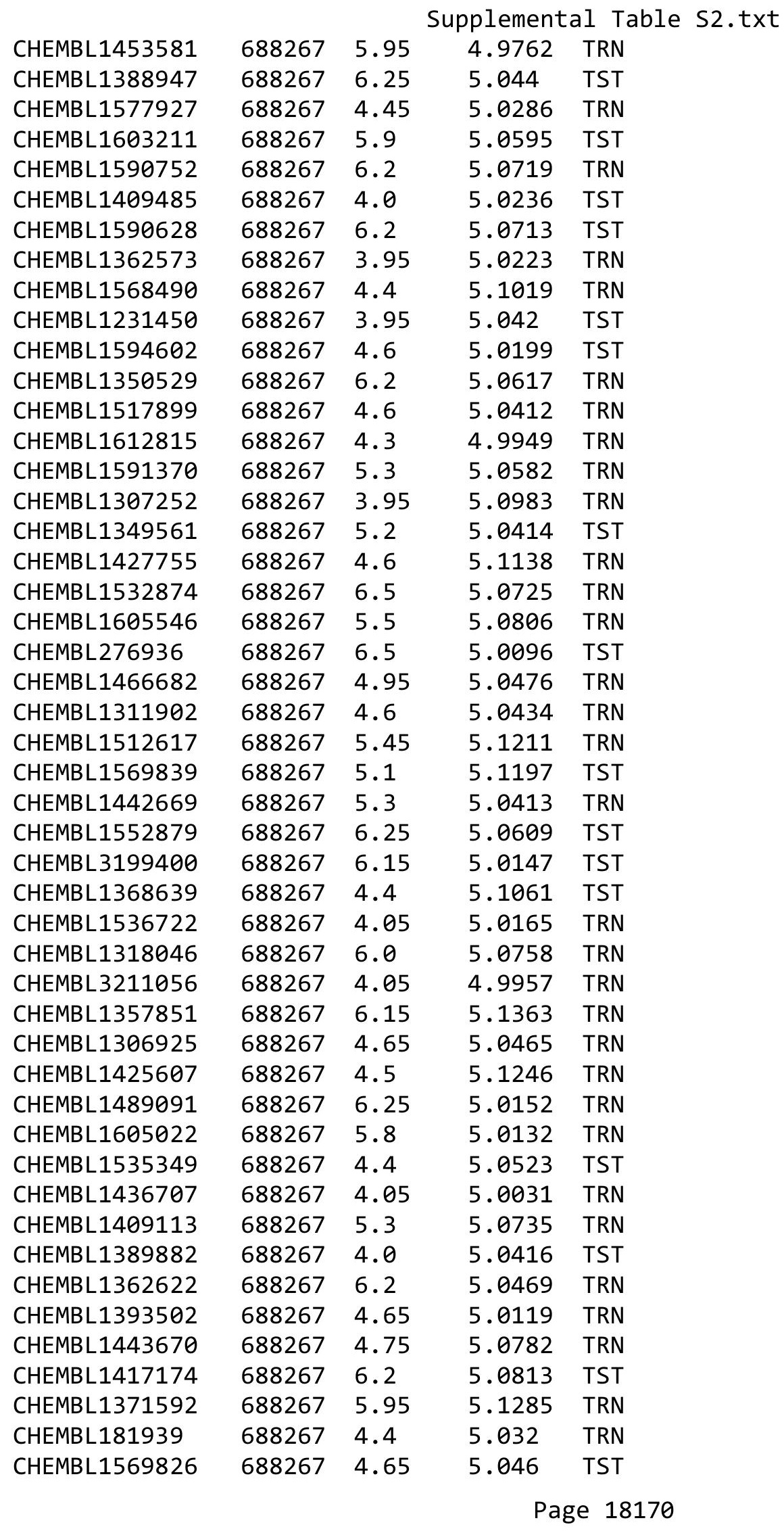




\begin{tabular}{|c|c|c|c|c|}
\hline \multicolumn{5}{|c|}{ Supplemental Table S2.txt } \\
\hline CHEMBL1558026 & 688267 & 4.3 & 5.0607 & TRN \\
\hline CHEMBL1571089 & 688267 & 5.8 & 5.0901 & TST \\
\hline CHEMBL1474495 & 688267 & 4.35 & 5.0524 & TRN \\
\hline CHEMBL1427720 & 688267 & 4.0 & 5.086 & TRN \\
\hline CHEMBL1588388 & 688267 & 5.3 & 5.003 & TRN \\
\hline CHEMBL1569176 & 688267 & 6.25 & 5.0809 & TST \\
\hline CHEMBL1489594 & 688267 & 4.1 & 5.0284 & TRN \\
\hline CHEMBL1479952 & 688267 & 4.35 & 5.0373 & TRN \\
\hline CHEMBL1303861 & 688267 & 4.05 & 5.0227 & TRN \\
\hline CHEMBL1473820 & 688267 & 4.65 & 5.0737 & TRN \\
\hline CHEMBL1385359 & 688267 & 4.0 & 5.1683 & TRN \\
\hline CHEMBL1333683 & 688267 & 4.55 & 5.1365 & TRN \\
\hline CHEMBL1569457 & 688267 & 6.15 & 5.0275 & TRN \\
\hline CHEMBL1376174 & 688267 & 4.05 & 5.0397 & TST \\
\hline CHEMBL1476336 & 688267 & 6.15 & 5.0463 & TRN \\
\hline CHEMBL1567608 & 688267 & 4.4 & 5.0353 & TRN \\
\hline CHEMBL1607357 & 688267 & 5.45 & 5.0122 & TRN \\
\hline CHEMBL1458997 & 688267 & 5.45 & 5.0411 & TRN \\
\hline CHEMBL1399133 & 688267 & 5.4 & 5.0404 & TRN \\
\hline CHEMBL1594990 & 688267 & 4.0 & 4.9834 & TRN \\
\hline CHEMBL1391424 & 688267 & 4.25 & 5.0438 & TST \\
\hline CHEMBL1531020 & 688267 & 6.2 & 5.0659 & TST \\
\hline CHEMBL1606139 & 688267 & 3.95 & 4.9934 & TRN \\
\hline CHEMBL1445352 & 688267 & 5.7 & 5.1041 & TRN \\
\hline CHEMBL1448560 & 688267 & 6.2 & 5.0926 & TST \\
\hline CHEMBL3189410 & 688267 & 5.55 & 5.1096 & TST \\
\hline CHEMBL1368540 & 688267 & 6.0 & 5.0727 & TRN \\
\hline CHEMBL1447063 & 688267 & 5.7 & 5.0764 & TRN \\
\hline CHEMBL1468318 & 688267 & 4.6 & 4.9787 & TST \\
\hline CHEMBL1462405 & 688267 & 5.05 & 5.0776 & TRN \\
\hline CHEMBL1321154 & 688267 & 5.9 & 5.0144 & TST \\
\hline CHEMBL1398309 & 688267 & 5.75 & 5.0213 & TRN \\
\hline CHEMBL1496110 & 688267 & 5.7 & 5.0891 & TRN \\
\hline CHEMBL1469403 & 688267 & 5.6 & 5.0392 & TRN \\
\hline CHEMBL1432825 & 688267 & 5.15 & 5.0868 & TRN \\
\hline CHEMBL1575998 & 688267 & 6.0 & 5.0422 & TRN \\
\hline CHEMBL1547461 & 688267 & 4.0 & 5.0784 & TST \\
\hline CHEMBL1453808 & 688267 & 3.95 & 5.0362 & TRN \\
\hline CHEMBL1429421 & 688267 & 4.0 & 5.0131 & TST \\
\hline CHEMBL1494870 & 688267 & 4.85 & 5.0414 & TST \\
\hline CHEMBL1591867 & 688267 & 4.3 & 5.0015 & TRN \\
\hline CHEMBL1437167 & 688267 & 4.05 & 5.042 & TST \\
\hline CHEMBL1399434 & 688267 & 5.3 & 5.0715 & TRN \\
\hline CHEMBL1460912 & 688267 & 4.1 & 5.0793 & TRN \\
\hline CHEMBL1327779 & 688267 & 5.85 & 5.0806 & TRN \\
\hline CHEMBL1436993 & 688267 & 4.1 & 5.0661 & TRN \\
\hline CHEMBL1365854 & 688267 & 5.5 & 5.0363 & TRN \\
\hline CHEMBL1453415 & 688267 & 4.15 & 5.0289 & TRN \\
\hline
\end{tabular}




\begin{tabular}{|c|c|c|c|c|c|}
\hline \multicolumn{6}{|c|}{ Supplemental Table S2.txt } \\
\hline CHEMBL1401595 & 688267 & 5.85 & 5.0378 & TRN & \\
\hline CHEMBL1426858 & 688267 & 5.6 & 5.095 & TST & \\
\hline CHEMBL1592484 & 688267 & 6.0 & 5.1068 & TST & \\
\hline CHEMBL1426236 & 688267 & 6.15 & 4.9734 & TST & \\
\hline CHEMBL1515347 & 688267 & 6.1 & 5.0609 & TRN & \\
\hline CHEMBL290077 & 688267 & 3.95 & 5.0621 & TRN & \\
\hline CHEMBL1328050 & 688267 & 4.4 & 5.0422 & TRN & \\
\hline CHEMBL1407573 & 688267 & 4.0 & 5.0846 & TST & \\
\hline CHEMBL1471323 & 688267 & 6.2 & 5.055 & TRN & \\
\hline CHEMBL3197560 & 688267 & 6.25 & 4.9871 & TST & \\
\hline CHEMBL1513955 & 688267 & 3.9 & 5.0167 & TRN & \\
\hline CHEMBL1526679 & 688267 & 6.2 & 5.0372 & TRN & \\
\hline CHEMBL 3195473 & 688267 & 5.9 & 4.9848 & TRN & \\
\hline CHEMBL1533400 & 688267 & 5.9 & 5.1534 & TRN & \\
\hline CHEMBL1333487 & 688267 & 4.8 & 5.0417 & TST & \\
\hline CHEMBL1607550 & 688267 & 6.2 & 5.056 & TST & \\
\hline CHEMBL1327901 & 688267 & 6.15 & 5.1073 & TRN & \\
\hline CHEMBL1333842 & 688267 & 4.0 & 5.0224 & TRN & \\
\hline CHEMBL1580003 & 688267 & 5.55 & 5.0449 & TRN & \\
\hline CHEMBL1469644 & 688267 & 4.45 & 5.1265 & TRN & \\
\hline CHEMBL1590834 & 688267 & 6.15 & 5.0181 & TRN & \\
\hline CHEMBL1313299 & 688267 & 5.25 & 4.9976 & TST & \\
\hline CHEMBL1595502 & 688267 & 4.0 & 5.025 & TRN & \\
\hline CHEMBL1585951 & 688267 & 5.3 & 5.06 & TRN & \\
\hline CHEMBL3190639 & 688267 & 6.2 & 5.0534 & TST & \\
\hline CHEMBL1434123 & 688267 & 6.1 & 5.1345 & TRN & \\
\hline CHEMBL1390627 & 688267 & 5.6 & 5.03 & TRN & \\
\hline CHEMBL1421585 & 688267 & 5.35 & 5.0996 & TRN & \\
\hline CHEMBL3209623 & 688267 & 4.8 & 4.9911 & TRN & \\
\hline CHEMBL1479864 & 688267 & 5.3 & 5.0339 & TRN & \\
\hline CHEMBL1506407 & 688267 & 6.0 & 5.02 & TRN & \\
\hline CHEMBL1582078 & 688267 & 5.55 & 4.9946 & TRN & \\
\hline CHEMBL1435639 & 688267 & 5.35 & 5.0537 & TRN & \\
\hline CHEMBL1386427 & 688267 & 5.55 & 5.0414 & TRN & \\
\hline CHEMBL1443551 & 688267 & 5.3 & 5.1615 & TRN & \\
\hline CHEMBL1390385 & 688267 & 4.05 & 5.0481 & TRN & \\
\hline CHEMBL1319380 & 688267 & 4.4 & 5.1306 & TRN & \\
\hline CHEMBL1592292 & 688267 & 4.05 & 5.048 & TRN & \\
\hline CHEMBL1500421 & 688267 & 5.6 & 5.0121 & TRN & \\
\hline CHEMBL1520303 & 688267 & 6.15 & 5.0979 & TRN & \\
\hline CHEMBL1494840 & 688267 & 6.2 & 5.0911 & TST & \\
\hline CHEMBL1364645 & 688267 & 6.2 & 5.12299 & 9999999999 & TRN \\
\hline CHEMBL1384823 & 688267 & 4.3 & 5.0293 & TRN & \\
\hline CHEMBL 3208445 & 688267 & 4.0 & 5.044 & TST & \\
\hline CHEMBL1518335 & 688267 & 4.0 & 5.0762 & TRN & \\
\hline CHEMBL1592049 & 688267 & 4.1 & 4.9945 & TRN & \\
\hline CHEMBL1383529 & 688267 & 4.0 & 5.0242 & TRN & \\
\hline CHEMBL1374100 & 688267 & 5.6 & 5.0935 & TST & \\
\hline
\end{tabular}




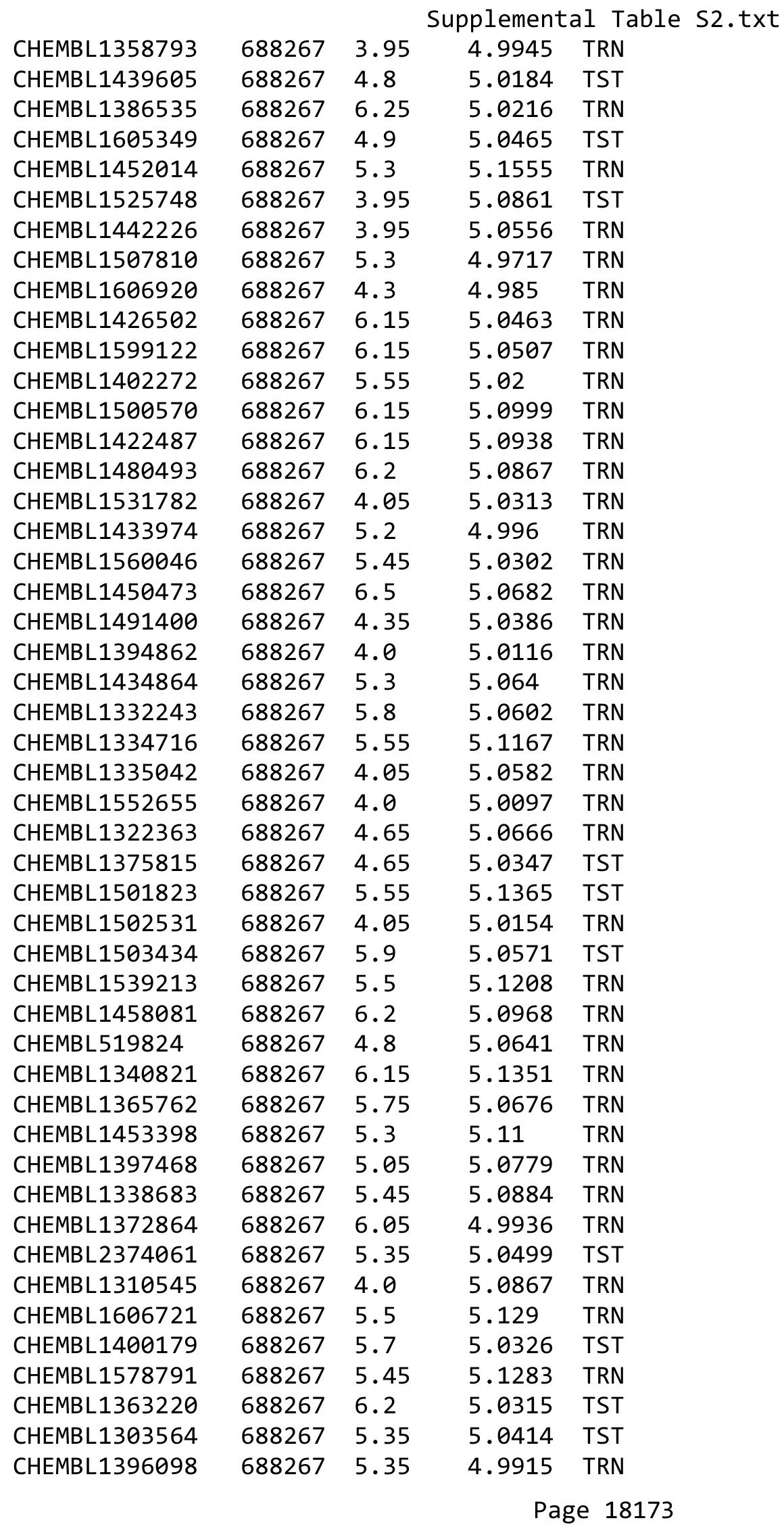




\begin{tabular}{|c|c|c|c|c|c|}
\hline \\
\hline CHEMBL1303389 & 688267 & 5.9 & 5.0075 & TRN & \\
\hline CHEMBL1449217 & 688267 & 5.85 & 5.0538 & TRN & \\
\hline CHEMBL1426718 & 688267 & 4.45 & 5.0562 & TRN & \\
\hline CHEMBL1546090 & 688267 & 5.7 & 5.1102 & TRN & \\
\hline CHEMBL1374781 & 688267 & 4.6 & 5.0922 & TRN & \\
\hline CHEMBL1436810 & 688267 & 4.0 & 5.0105 & TST & \\
\hline CHEMBL1455169 & 688267 & 6.0 & 5.0936 & TRN & \\
\hline CHEMBL153036 & 688267 & 6.0 & 5.0218 & TST & \\
\hline CHEMBL1438640 & 688267 & 5.3 & 5.024 & TRN & \\
\hline CHEMBL1534701 & 688267 & 4.5 & 5.0275 & TST & \\
\hline CHEMBL1558097 & 688267 & 4.2 & 5.0217 & TRN & \\
\hline CHEMBL1314243 & 688267 & 4.05 & 5.0358 & TRN & \\
\hline CHEMBL1355992 & 688267 & 4.85 & 5.1467 & TRN & \\
\hline CHEMBL1335398 & 688267 & 5.4 & 5.0678 & TST & \\
\hline CHEMBL1332412 & 688267 & 4.0 & 5.0858 & TST & \\
\hline CHEMBL1446573 & 688267 & 4.3 & 5.032 & TST & \\
\hline CHEMBL1613271 & 688267 & 4.25 & 5.0489 & TRN & \\
\hline CHEMBL1528279 & 688267 & 6.2 & 5.0286 & TRN & \\
\hline CHEMBL1355761 & 688267 & 5.45 & 5.0296 & TRN & \\
\hline CHEMBL1429440 & 688267 & 5.0 & 4.9927 & TST & \\
\hline CHEMBL1555571 & 688267 & 5.55 & 5.1102 & TRN & \\
\hline CHEMBL1304872 & 688267 & 5.3 & 5.0185 & TRN & \\
\hline CHEMBL1456385 & 688267 & 5.9 & 5.0895 & TRN & \\
\hline CHEMBL1545983 & 688267 & 5.0 & 5.1067 & TRN & \\
\hline CHEMBL1420154 & 688267 & 5.0 & 5.0675 & TST & \\
\hline CHEMBL1453620 & 688267 & 5.2 & 5.0429 & TRN & \\
\hline CHEMBL1395588 & 688267 & 5.55 & 5.06800 & 00000000005 & TRN \\
\hline CHEMBL1345683 & 688267 & 4.0 & 5.0339 & TST & \\
\hline CHEMBL1400089 & 688267 & 5.3 & 5.0559 & TRN & \\
\hline CHEMBL1524069 & 688267 & 6.0 & 5.0836 & TST & \\
\hline CHEMBL1447133 & 688267 & 5.85 & 5.0343 & TST & \\
\hline CHEMBL1339277 & 688267 & 4.65 & 5.0506 & TST & \\
\hline CHEMBL1476611 & 688267 & 4.3 & 5.0237 & TRN & \\
\hline CHEMBL1367248 & 688267 & 5.8 & 4.9797 & TRN & \\
\hline CHEMBL1429752 & 688267 & 4.0 & 5.0645 & TRN & \\
\hline CHEMBL1396568 & 688267 & 4.4 & 5.1022 & TRN & \\
\hline CHEMBL1409094 & 688267 & 4.95 & 5.0742 & TST & \\
\hline CHEMBL1484963 & 688267 & 6.2 & 5.0127 & TRN & \\
\hline CHEMBL1320914 & 688267 & 4.8 & 5.1508 & TRN & \\
\hline CHEMBL1551058 & 688267 & 6.2 & 5.0376 & TRN & \\
\hline CHEMBL1543002 & 688267 & 4.4 & 5.0204 & TRN & \\
\hline CHEMBL1441589 & 688267 & 5.2 & 5.0111 & TRN & \\
\hline CHEMBL1525880 & 688267 & 5.05 & 5.0284 & TST & \\
\hline CHEMBL1475956 & 688267 & 6.0 & 5.0861 & TRN & \\
\hline CHEMBL1456847 & 688267 & 4.65 & 5.0232 & TRN & \\
\hline CHEMBL350675 & 688267 & 5.25 & 5.0452 & TST & \\
\hline CHEMBL1427076 & 688267 & 4.1 & 5.1191 & TRN & \\
\hline CHEMBL1398405 & 688267 & 4.0 & 5.0326 & TRN & \\
\hline
\end{tabular}




\begin{tabular}{|c|c|c|c|c|c|}
\hline \multirow[b]{2}{*}{ CHEMBL1401919 } & \multicolumn{5}{|c|}{ Supplemental Table S2.txt } \\
\hline & 688267 & 5.75 & 5.0304 & TST & \\
\hline CHEMBL1396803 & 688267 & 4.05 & 5.02800 & 00000000005 & TRN \\
\hline CHEMBL1392029 & 688267 & 4.3 & 5.1046 & TRN & \\
\hline CHEMBL1573093 & 688267 & 4.25 & 5.0996 & TST & \\
\hline CHEMBL1394491 & 688267 & 5.75 & 5.1312 & TRN & \\
\hline CHEMBL1334075 & 688267 & 4.1 & 5.0009 & TST & \\
\hline CHEMBL1528302 & 688267 & 4.65 & 5.0971 & TRN & \\
\hline CHEMBL1525549 & 688267 & 5.45 & 5.1117 & TST & \\
\hline CHEMBL1328534 & 688267 & 4.95 & 5.0868 & TRN & \\
\hline CHEMBL1453679 & 688267 & 6.0 & 5.0312 & TST & \\
\hline CHEMBL1464841 & 688267 & 4.5 & 5.0386 & TST & \\
\hline CHEMBL1348292 & 688267 & 5.8 & 5.0149 & TRN & \\
\hline CHEMBL3192042 & 688267 & 5.9 & 5.0286 & TST & \\
\hline CHEMBL1530270 & 688267 & 6.8499 & 5.1006 & TST & \\
\hline CHEMBL1391383 & 688267 & 4.65 & 5.0754 & TRN & \\
\hline CHEMBL1525719 & 688267 & 5.6 & 5.0165 & TRN & \\
\hline CHEMBL3211876 & 688267 & 5.8 & 5.0415 & TST & \\
\hline CHEMBL1447841 & 688267 & 4.35 & 5.0719 & TST & \\
\hline CHEMBL1556779 & 688267 & 4.3 & 5.0079 & TRN & \\
\hline CHEMBL1401814 & 688267 & 5.5 & 5.0971 & TST & \\
\hline CHEMBL1463284 & 688267 & 4.45 & 5.0648 & TRN & \\
\hline CHEMBL1591440 & 688267 & 5.45 & 5.0396 & TRN & \\
\hline CHEMBL1456573 & 688267 & 4.45 & 5.0331 & TRN & \\
\hline CHEMBL1394772 & 688267 & 4.0 & 5.0754 & TRN & \\
\hline CHEMBL1503236 & 688267 & 6.2 & 5.0707 & TRN & \\
\hline CHEMBL1087005 & 688267 & 4.35 & 5.0207 & TRN & \\
\hline CHEMBL1532549 & 688267 & 6.5 & 5.0046 & TST & \\
\hline CHEMBL1420074 & 688267 & 6.2 & 5.1139 & TST & \\
\hline CHEMBL1506510 & 688267 & 6.2 & 5.0362 & TRN & \\
\hline CHEMBL1610968 & 688267 & 4.6 & 5.0394 & TRN & \\
\hline CHEMBL1420490 & 688267 & 4.55 & 5.0335 & TRN & \\
\hline CHEMBL1608781 & 688267 & 4.25 & 5.0936 & TRN & \\
\hline CHEMBL1528037 & 688267 & 5.3 & 4.9982 & TRN & \\
\hline CHEMBL1562759 & 688267 & 5.25 & 5.0146 & TRN & \\
\hline CHEMBL1580059 & 688267 & 4.0 & 5.0572 & TRN & \\
\hline CHEMBL1485065 & 688267 & 3.95 & 5.0592 & TRN & \\
\hline CHEMBL1474391 & 688267 & 6.45 & 5.09 & TRN & \\
\hline CHEMBL1448897 & 688267 & 4.25 & 5.0883 & TRN & \\
\hline CHEMBL1522795 & 688267 & 6.25 & 5.0948 & TRN & \\
\hline CHEMBL1417206 & 688267 & 5.3 & 5.0763 & TST & \\
\hline CHEMBL1503104 & 688267 & 4.6 & 5.0333 & TRN & \\
\hline CHEMBL1381895 & 688267 & 5.35 & 5.0748 & TRN & \\
\hline CHEMBL1329362 & 688267 & 4.0 & 5.1047 & TRN & \\
\hline CHEMBL1433130 & 688267 & 4.9 & 5.0434 & TST & \\
\hline CHEMBL 3212282 & 688267 & 6.15 & 5.0326 & TST & \\
\hline CHEMBL1433848 & 688267 & 5.35 & 5.0539 & TRN & \\
\hline CHEMBL1321365 & 688267 & 5.25 & 5.0131 & TRN & \\
\hline CHEMBL1467628 & 688267 & 4.5 & 5.154 & TRN & \\
\hline
\end{tabular}




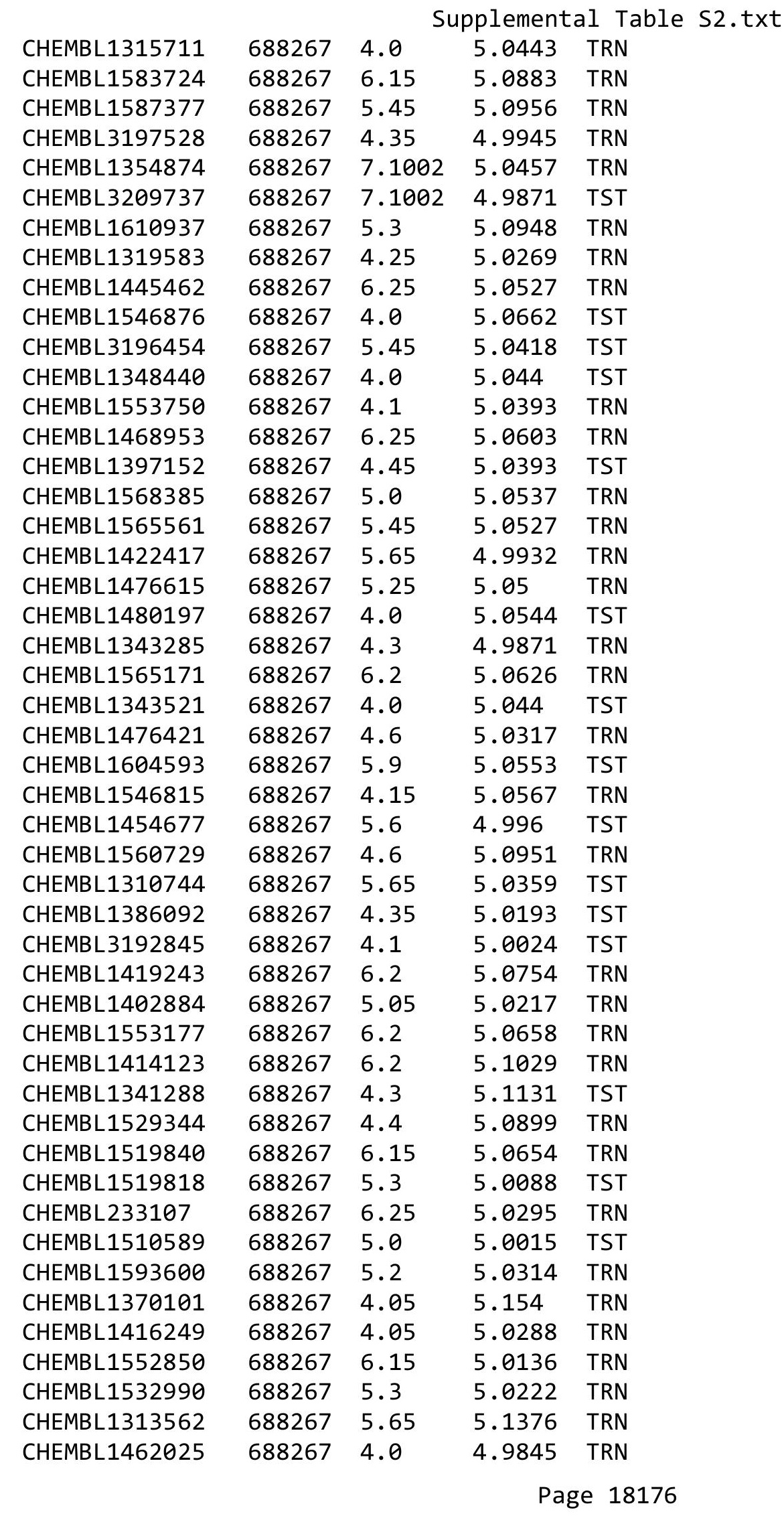




\begin{tabular}{|c|c|c|c|c|}
\hline \multicolumn{5}{|c|}{ Supplemental Table S2.txt } \\
\hline CHEMBL1420795 & 688267 & 5.8 & 5.0014 & TRN \\
\hline CHEMBL1539966 & 688267 & 4.35 & 5.1096 & TRN \\
\hline CHEMBL1603161 & 688267 & 5.35 & 5.0525 & TRN \\
\hline CHEMBL1367713 & 688267 & 4.6 & 5.0836 & TRN \\
\hline CHEMBL1569882 & 688267 & 4.05 & 5.048 & TRN \\
\hline CHEMBL1474439 & 688267 & 5.45 & 5.0088 & TRN \\
\hline CHEMBL1463906 & 688267 & 5.0 & 5.0524 & TST \\
\hline CHEMBL1439081 & 688267 & 4.1 & 5.0573 & TST \\
\hline CHEMBL1336150 & 688267 & 6.25 & 5.0318 & TRN \\
\hline CHEMBL1372756 & 688267 & 4.05 & 5.0412 & TST \\
\hline CHEMBL1353301 & 688267 & 4.3 & 5.0163 & TRN \\
\hline CHEMBL1483088 & 688267 & 5.35 & 5.027 & TRN \\
\hline CHEMBL1392142 & 688267 & 4.6 & 4.9979 & TRN \\
\hline CHEMBL3211835 & 688267 & 4.05 & 4.9917 & TRN \\
\hline CHEMBL581194 & 688267 & 4.0 & 5.0433 & TRN \\
\hline CHEMBL1424523 & 688267 & 5.5 & 5.0179 & TRN \\
\hline CHEMBL1548220 & 688267 & 5.75 & 5.1155 & TRN \\
\hline CHEMBL1519135 & 688267 & 4.0 & 5.0792 & TRN \\
\hline CHEMBL1594954 & 688267 & 6.2 & 5.0334 & TRN \\
\hline CHEMBL1603604 & 688267 & 4.05 & 5.0288 & TST \\
\hline CHEMBL1407314 & 688267 & 6.2 & 5.0467 & TRN \\
\hline CHEMBL1390411 & 688267 & 5.5 & 5.0576 & TST \\
\hline CHEMBL1593298 & 688267 & 5.95 & 5.0826 & TRN \\
\hline CHEMBL1539912 & 688267 & 4.65 & 5.0402 & TRN \\
\hline CHEMBL1488900 & 688267 & 5.1 & 5.1222 & TRN \\
\hline CHEMBL1305534 & 688267 & 5.2 & 5.0828 & TRN \\
\hline CHEMBL1446281 & 688267 & 5.75 & 5.1081 & TST \\
\hline CHEMBL1433709 & 688267 & 4.0 & 5.1006 & TRN \\
\hline CHEMBL1561340 & 688267 & 4.0 & 5.0096 & TRN \\
\hline CHEMBL1419136 & 688267 & 6.05 & 5.0358 & TST \\
\hline CHEMBL1492837 & 688267 & 4.05 & 5.0616 & TRN \\
\hline CHEMBL1502462 & 688267 & 5.1 & 5.0002 & TST \\
\hline CHEMBL1554005 & 688267 & 4.35 & 5.0406 & TST \\
\hline CHEMBL1508191 & 688267 & 6.15 & 5.0916 & TST \\
\hline CHEMBL1482634 & 688267 & 4.7 & 5.0524 & TST \\
\hline CHEMBL1538732 & 688267 & 4.05 & 5.0672 & TRN \\
\hline CHEMBL 1558088 & 688267 & 4.25 & 5.0755 & TST \\
\hline CHEMBL1585421 & 688267 & 5.3 & 5.1303 & TRN \\
\hline CHEMBL1309075 & 688267 & 4.4 & 5.0448 & TRN \\
\hline CHEMBL1414559 & 688267 & 6.05 & 5.0521 & TRN \\
\hline CHEMBL1613664 & 688267 & 4.35 & 5.0721 & TRN \\
\hline CHEMBL1543710 & 688267 & 5.65 & 5.0494 & TRN \\
\hline CHEMBL1590748 & 688267 & 5.9 & 5.0698 & TRN \\
\hline CHEMBL3392240 & 688267 & 5.85 & 5.0063 & TST \\
\hline CHEMBL1346683 & 688267 & 5.6 & 5.0164 & TST \\
\hline CHEMBL1519179 & 688267 & 4.1 & 5.0846 & TRN \\
\hline CHEMBL3195067 & 688267 & 4.45 & 5.0172 & TRN \\
\hline CHEMBL1321424 & 688267 & 6.2 & 5.0641 & TST \\
\hline
\end{tabular}




\begin{tabular}{|c|c|c|c|c|}
\hline \multicolumn{5}{|c|}{ Supplemental Table S2.txt } \\
\hline CHEMBL1384284 & 688267 & 4.9 & 5.1201 & TRN \\
\hline CHEMBL1302841 & 688267 & 3.95 & 5.1272 & TRN \\
\hline CHEMBL1462087 & 688267 & 4.2 & 5.0904 & TRN \\
\hline CHEMBL1487391 & 688267 & 4.0 & 5.0297 & TRN \\
\hline CHEMBL1527878 & 688267 & 5.35 & 5.0857 & TRN \\
\hline CHEMBL1484397 & 688267 & 4.6 & 5.0385 & TRN \\
\hline CHEMBL1435797 & 688267 & 5.6 & 5.0167 & TRN \\
\hline CHEMBL3197603 & 688267 & 4.9 & 5.0614 & TST \\
\hline CHEMBL1572061 & 688267 & 6.0 & 5.0456 & TRN \\
\hline CHEMBL1565980 & 688267 & 5.9 & 5.0365 & TRN \\
\hline CHEMBL1385175 & 688267 & 4.4 & 5.0307 & TRN \\
\hline CHEMBL1499677 & 688267 & 3.95 & 5.0158 & TRN \\
\hline CHEMBL1374165 & 688267 & 4.0 & 5.034 & TRN \\
\hline CHEMBL1548684 & 688267 & 4.0 & 5.0221 & TRN \\
\hline CHEMBL1528608 & 688267 & 4.35 & 5.053 & TST \\
\hline CHEMBL1565571 & 688267 & 3.95 & 5.1713 & TRN \\
\hline CHEMBL1406705 & 688267 & 4.4 & 5.1161 & TRN \\
\hline CHEMBL1402425 & 688267 & 3.95 & 5.0347 & TRN \\
\hline CHEMBL1596995 & 688267 & 4.45 & 5.0305 & TST \\
\hline CHEMBL1449950 & 688267 & 4.45 & 4.9783 & TST \\
\hline CHEMBL1419197 & 688267 & 4.9 & 5.1014 & TST \\
\hline CHEMBL1398551 & 688267 & 5.35 & 5.0967 & TRN \\
\hline CHEMBL1391966 & 688267 & 5.55 & 5.1295 & TRN \\
\hline CHEMBL1420820 & 688267 & 6.2 & 5.0992 & TRN \\
\hline CHEMBL1474841 & 688267 & 6.45 & 5.1 & TRN \\
\hline CHEMBL1602776 & 688267 & 4.05 & 5.1255 & TRN \\
\hline CHEMBL1323251 & 688267 & 5.4 & 5.1354 & TST \\
\hline CHEMBL3190896 & 688267 & 4.55 & 5.0525 & TRN \\
\hline CHEMBL1448653 & 688267 & 4.5 & 5.0113 & TRN \\
\hline CHEMBL3208645 & 688267 & 6.2 & 5.0473 & TRN \\
\hline CHEMBL1583491 & 688267 & 4.55 & 5.0193 & TRN \\
\hline CHEMBL1430570 & 688267 & 4.1 & 5.0578 & TRN \\
\hline CHEMBL1479500 & 688267 & 6.2 & 5.0852 & TRN \\
\hline CHEMBL1491230 & 688267 & 4.25 & 5.0625 & TST \\
\hline CHEMBL1413512 & 688267 & 6.2 & 5.0488 & TRN \\
\hline CHEMBL1465183 & 688267 & 5.15 & 5.1186 & TRN \\
\hline CHEMBL1495035 & 688267 & 6.2 & 5.1024 & TST \\
\hline CHEMBL1481883 & 688267 & 6.45 & 5.0942 & TRN \\
\hline CHEMBL585059 & 688267 & 4.0 & 5.0457 & TRN \\
\hline CHEMBL3144869 & 688267 & 5.9 & 5.0027 & TRN \\
\hline CHEMBL3189831 & 688267 & 4.0 & 5.0622 & TST \\
\hline CHEMBL1483690 & 688267 & 4.05 & 5.1291 & TRN \\
\hline CHEMBL1484661 & 688267 & 6.2 & 5.01 & TRN \\
\hline CHEMBL1551366 & 688267 & 4.05 & 5.0779 & TST \\
\hline CHEMBL1461032 & 688267 & 4.0 & 5.024 & TST \\
\hline CHEMBL1542675 & 688267 & 5.65 & 5.105 & TST \\
\hline CHEMBL1595224 & 688267 & 4.0 & 5.0603 & TST \\
\hline CHEMBL1428013 & 688267 & 3.9 & 5.0616 & TRN \\
\hline
\end{tabular}




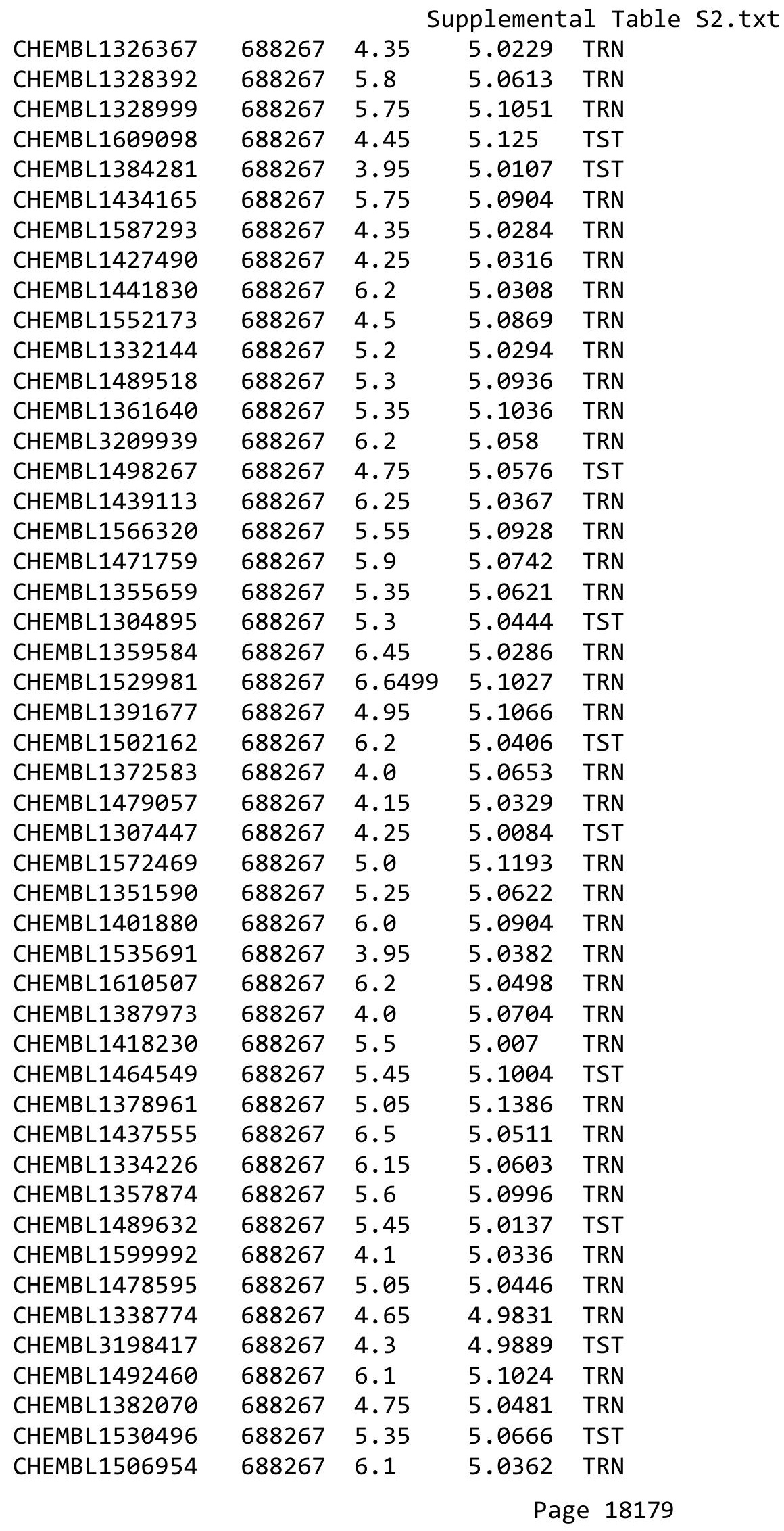




\begin{tabular}{|c|c|c|c|c|c|}
\hline \multicolumn{6}{|c|}{ Supplemental Table s2.txt } \\
\hline CHEMBL1314090 & 688267 & 6.5501 & 5.0412 & TST & \\
\hline CHEMBL1405048 & 688267 & 4.8 & 5.0972 & TRN & \\
\hline CHEMBL1577104 & 688267 & 4.3 & 5.0199 & TRN & \\
\hline CHEMBL1325606 & 688267 & 6.2 & 5.1004 & TST & \\
\hline CHEMBL1320258 & 688267 & 5.0 & 5.1641 & TRN & \\
\hline CHEMBL1378941 & 688267 & 6.2 & 5.0658 & TRN & \\
\hline CHEMBL1302821 & 688267 & 5.2 & 5.102 & TRN & \\
\hline CHEMBL1453870 & 688267 & 4.85 & 5.0126 & TRN & \\
\hline CHEMBL1503327 & 688267 & 6.15 & 5.0653 & TRN & \\
\hline CHEMBL1606859 & 688267 & 4.9 & 5.0675 & TRN & \\
\hline CHEMBL1609410 & 688267 & 4.05 & 5.0641 & TST & \\
\hline CHEMBL1506335 & 688267 & 5.05 & 5.1082 & TST & \\
\hline CHEMBL1564323 & 688267 & 5.05 & 5.0968 & TRN & \\
\hline CHEMBL 3193076 & 688267 & 6.45 & 5.0034 & TRN & \\
\hline CHEMBL1409106 & 688267 & 4.05 & 5.1116 & TST & \\
\hline CHEMBL1571950 & 688267 & 5.3 & 5.1316 & TRN & \\
\hline CHEMBL3197643 & 688267 & 4.45 & 5.0448 & TST & \\
\hline CHEMBL1363954 & 688267 & 5.4 & 5.1019 & TRN & \\
\hline CHEMBL1490494 & 688267 & 6.2 & 5.1208 & TST & \\
\hline CHEMBL1563490 & 688267 & 6.15 & 5.0412 & TST & \\
\hline CHEMBL3207670 & 688267 & 6.5 & 5.0749 & TST & \\
\hline CHEMBL1357012 & 688267 & 6.45 & 5.0238 & TRN & \\
\hline CHEMBL1445215 & 688267 & 5.15 & 5.0846 & TRN & \\
\hline CHEMBL1540056 & 688267 & 4.05 & 5.055 & TRN & \\
\hline CHEMBL1418778 & 688267 & 4.05 & 5.0133 & TRN & \\
\hline CHEMBL1337008 & 688267 & 4.0 & 5.1122 & TRN & \\
\hline CHEMBL1501702 & 688267 & 4.3 & 5.0588 & TRN & \\
\hline CHEMBL1372607 & 688267 & 4.0 & 5.05399 & э999999999 & TRN \\
\hline CHEMBL1396621 & 688267 & 5.1 & 5.1384 & TRN & \\
\hline CHEMBL1490634 & 688267 & 5.5 & 5.102 & TRN & \\
\hline CHEMBL1516814 & 688267 & 6.2 & 5.0491 & TRN & \\
\hline CHEMBL 3190684 & 688267 & 4.05 & 5.0929 & TRN & \\
\hline CHEMBL1337114 & 688267 & 5.55 & 5.0935 & TRN & \\
\hline CHEMBL1984772 & 688267 & 4.0 & 4.9937 & TRN & \\
\hline CHEMBL1498078 & 688267 & 5.6 & 5.0119 & TST & \\
\hline CHEMBL1441165 & 688267 & 5.3 & 5.1068 & TRN & \\
\hline CHEMBL1374948 & 688267 & 5.25 & 5.0018 & TRN & \\
\hline CHEMBL1481742 & 688267 & 4.35 & 5.0317 & TST & \\
\hline CHEMBL1460949 & 688267 & 4.2 & 5.0491 & TRN & \\
\hline CHEMBL1338221 & 688267 & 4.5 & 5.0239 & TRN & \\
\hline CHEMBL1402206 & 688267 & 5.6 & 5.0522 & TRN & \\
\hline CHEMBL1443260 & 688267 & 6.2 & 5.0543 & TST & \\
\hline CHEMBL1517207 & 688267 & 4.15 & 5.0001 & TRN & \\
\hline CHEMBL1478062 & 688267 & 5.45 & 5.1011 & TRN & \\
\hline CHEMBL1303718 & 688267 & 4.65 & 5.0711 & TRN & \\
\hline CHEMBL388978 & 688267 & 4.35 & 5.0616 & TST & \\
\hline CHEMBL1444731 & 688267 & 5.25 & 5.1374 & TRN & \\
\hline CHEMBL1577017 & 688267 & 5.45 & 5.0323 & TST & \\
\hline
\end{tabular}




\begin{tabular}{|c|c|c|c|c|c|}
\hline \multicolumn{6}{|c|}{ Supplemental Table S2.txt } \\
\hline CHEMBL1304298 & 688267 & 4.45 & 5.0258 & TRN & \\
\hline CHEMBL1555964 & 688267 & 6.1 & 5.0873 & TRN & \\
\hline CHEMBL1307664 & 688267 & 5.75 & 5.0207 & TRN & \\
\hline CHEMBL1482639 & 688267 & 5.45 & 4.9861 & TRN & \\
\hline CHEMBL1403992 & 688267 & 4.05 & 5.1337 & TRN & \\
\hline CHEMBL1509270 & 688267 & 4.55 & 5.0737 & TRN & \\
\hline CHEMBL1496578 & 688267 & 4.35 & 5.088 & TRN & \\
\hline CHEMBL1398346 & 688267 & 4.65 & 4.9781 & TRN & \\
\hline CHEMBL1336049 & 688267 & 3.95 & 5.0617 & TRN & \\
\hline CHEMBL1535354 & 688267 & 5.15 & 5.0437 & TST & \\
\hline CHEMBL1559444 & 688267 & 5.4 & 5.0542 & TRN & \\
\hline CHEMBL1483258 & 688267 & 5.6 & 5.0847 & TRN & \\
\hline CHEMBL1552763 & 688267 & 6.2 & 5.0501 & TRN & \\
\hline CHEMBL1454613 & 688267 & 6.6499 & 5.0704 & TRN & \\
\hline CHEMBL591522 & 688267 & 4.4 & 4.9957 & TRN & \\
\hline CHEMBL1424904 & 688267 & 5.5 & 5.0816 & TST & \\
\hline CHEMBL1340228 & 688267 & 5.2 & 5.0222 & TRN & \\
\hline CHEMBL1476180 & 688267 & 4.7 & 5.0028 & TRN & \\
\hline CHEMBL1554376 & 688267 & 4.5 & 5.1037 & TRN & \\
\hline CHEMBL1553681 & 688267 & 4.35 & 5.0458 & TRN & \\
\hline CHEMBL1578543 & 688267 & 6.15 & 5.1061 & TRN & \\
\hline CHEMBL602633 & 688267 & 4.35 & 5.0623 & TST & \\
\hline CHEMBL1437923 & 688267 & 5.8 & 5.0523 & TRN & \\
\hline CHEMBL1479760 & 688267 & 6.2 & 5.0714 & TRN & \\
\hline CHEMBL3194251 & 688267 & 4.65 & 5.0159 & TRN & \\
\hline CHEMBL1363555 & 688267 & 6.2 & 5.0631 & TRN & \\
\hline CHEMBL1319654 & 688267 & 5.3 & 5.0919 & TRN & \\
\hline CHEMBL1440120 & 688267 & 5.85 & 5.006 & TRN & \\
\hline CHEMBL1305713 & 688267 & 6.25 & 5.0286 & TRN & \\
\hline CHEMBL1444511 & 688267 & 3.95 & 5.1453 & TRN & \\
\hline CHEMBL1546567 & 688267 & 6.2 & 5.0445 & TRN & \\
\hline CHEMBL1439450 & 688267 & 6.0 & 5.0458 & TST & \\
\hline CHEMBL1436889 & 688267 & 4.2 & 5.0888 & TRN & \\
\hline CHEMBL1408079 & 688267 & 6.5 & 5.0558 & TRN & \\
\hline CHEMBL1355872 & 688267 & 4.2 & 5.11600 & 00000000005 & TRN \\
\hline CHEMBL1609341 & 688267 & 6.15 & 5.0792 & TST & \\
\hline CHEMBL1411304 & 688267 & 4.05 & 5.055 & TST & \\
\hline CHEMBL1573084 & 688267 & 5.85 & 5.0483 & TST & \\
\hline CHEMBL1465695 & 688267 & 5.35 & 5.0952 & TRN & \\
\hline CHEMBL1447086 & 688267 & 4.15 & 5.0437 & TRN & \\
\hline CHEMBL3192411 & 688267 & 5.8 & 4.9934 & TRN & \\
\hline CHEMBL1396891 & 688267 & 5.35 & 5.0868 & TST & \\
\hline CHEMBL1490524 & 688267 & 4.0 & 5.1019 & TRN & \\
\hline CHEMBL1475817 & 688267 & 6.35 & 5.0059 & TRN & \\
\hline CHEMBL1352260 & 688267 & 4.45 & 5.0989 & TRN & \\
\hline CHEMBL1397025 & 688267 & 4.55 & 4.9856 & TRN & \\
\hline CHEMBL1343328 & 688267 & 6.25 & 5.1052 & TRN & \\
\hline CHEMBL1484018 & 688267 & 6.2 & 5.0265 & TST & \\
\hline
\end{tabular}




\begin{tabular}{|c|c|c|c|c|}
\hline & & & pplement & al $\mathrm{Ta}$ \\
\hline CHEMBL1563126 & 688267 & 6.2 & 5.1145 & TST \\
\hline CHEMBL 1456710 & 688267 & 4.3 & 5.0426 & TRN \\
\hline CHEMBL1503192 & 688267 & 4.25 & 5.0761 & TST \\
\hline CHEMBL1357532 & 688267 & 4.0 & 5.0278 & TST \\
\hline CHEMBL1608856 & 688267 & 5.55 & 5.0586 & TRN \\
\hline CHEMBL1536463 & 688267 & 6.15 & 5.1246 & TRN \\
\hline CHEMBL1571132 & 688267 & 4.0 & 5.0266 & TRN \\
\hline CHEMBL1585023 & 688267 & 5.9 & 5.0178 & TRN \\
\hline CHEMBL1370125 & 688267 & 4.55 & 5.0803 & TST \\
\hline CHEMBL1577768 & 688267 & 5.9 & 5.0232 & TRN \\
\hline CHEMBL 1483800 & 688267 & 3.95 & 5.0368 & TRN \\
\hline CHEMBL1435801 & 688267 & 3.95 & 5.0818 & TRN \\
\hline CHEMBL1472383 & 688267 & 5.6 & 5.1195 & TRN \\
\hline CHEMBL1488217 & 688267 & 5.05 & 5.0168 & TRN \\
\hline CHEMBL1467245 & 688267 & 5.3 & 5.0456 & TRN \\
\hline CHEMBL1494988 & 688267 & 4.45 & 5.1573 & TRN \\
\hline CHEMBL1514780 & 688267 & 4.05 & 5.0874 & TRN \\
\hline CHEMBL1535083 & 688267 & 5.45 & 5.0511 & TRN \\
\hline CHEMBL1343436 & 688267 & 6.25 & 5.105 & TRN \\
\hline CHEMBL1329668 & 688267 & 4.05 & 5.0956 & TST \\
\hline CHEMBL1603990 & 688267 & 5.85 & 5.1748 & TRN \\
\hline CHEMBL1608385 & 688267 & 6.2 & 5.0383 & TRN \\
\hline CHEMBL1371989 & 688267 & 4.05 & 4.9937 & TRN \\
\hline CHEMBL1334434 & 688267 & 5.7 & 5.1227 & TRN \\
\hline CHEMBL1592511 & 688267 & 4.05 & 5.0741 & TRN \\
\hline CHEMBL1512644 & 688267 & 6.2 & 5.1177 & TRN \\
\hline CHEMBL1429565 & 688267 & 4.6 & 5.0498 & TRN \\
\hline CHEMBL1438399 & 688267 & 4.45 & 5.0275 & TRN \\
\hline CHEMBL1566265 & 688267 & 4.75 & 5.0089 & TST \\
\hline CHEMBL1392170 & 688267 & 5.0 & 5.0565 & TRN \\
\hline CHEMBL1472251 & 688267 & 4.65 & 5.0609 & TST \\
\hline CHEMBL1305992 & 688267 & 4.0 & 5.0168 & TRN \\
\hline CHEMBL3212866 & 688267 & 6.15 & 5.0364 & TST \\
\hline CHEMBL604122 & 688267 & 4.65 & 5.0419 & TRN \\
\hline CHEMBL1323324 & 688267 & 4.05 & 5.0852 & TRN \\
\hline CHEMBL1385097 & 688267 & 5.55 & 5.0393 & TRN \\
\hline CHEMBL1396181 & 688267 & 4.05 & 5.0263 & TST \\
\hline CHEMBL1526272 & 688267 & 5.65 & 4.9829 & TRN \\
\hline CHEMBL3212533 & 688267 & 4.3 & 4.9832 & TRN \\
\hline CHEMBL1549033 & 688267 & 5.55 & 5.044 & TRN \\
\hline CHEMBL1443355 & 688267 & 5.6 & 5.0303 & TRN \\
\hline CHEMBL1314743 & 688267 & 4.1 & 4.961 & TRN \\
\hline CHEMBL1338097 & 688267 & 3.95 & 5.1182 & TST \\
\hline CHEMBL1978651 & 688267 & 5.3 & 5.0065 & TRN \\
\hline CHEMBL1303065 & 688267 & 6.2 & 4.9866 & TST \\
\hline CHEMBL1436904 & 688267 & 5.8 & 5.0417 & TRN \\
\hline CHEMBL1536160 & 688267 & 5.25 & 5.019 & TRN \\
\hline CHEMBL1423916 & 688267 & 4.25 & 5.0867 & TRN \\
\hline
\end{tabular}




\begin{tabular}{|c|c|c|c|c|}
\hline \multicolumn{5}{|c|}{ Supplemental Table S2.txt } \\
\hline CHEMBL1595025 & 688267 & 4.0 & 5.0539 & TRN \\
\hline CHEMBL1591966 & 688267 & 4.55 & 5.1116 & TRN \\
\hline CHEMBL1513903 & 688267 & 6.5 & 5.0676 & TRN \\
\hline CHEMBL1443823 & 688267 & 5.5 & 5.1215 & TRN \\
\hline CHEMBL1299747 & 688267 & 5.0 & 5.0894 & TRN \\
\hline CHEMBL1356552 & 688267 & 4.0 & 4.9927 & TRN \\
\hline CHEMBL1383953 & 688267 & 5.4 & 5.157 & TRN \\
\hline CHEMBL1459107 & 688267 & 4.25 & 4.9983 & TRN \\
\hline CHEMBL1512005 & 688267 & 4.75 & 5.0953 & TRN \\
\hline CHEMBL1302198 & 688267 & 4.25 & 5.0528 & TRN \\
\hline CHEMBL1452111 & 688267 & 4.95 & 5.0322 & TRN \\
\hline CHEMBL1321684 & 688267 & 4.8 & 5.099 & TRN \\
\hline CHEMBL1417768 & 688267 & 5.95 & 5.0788 & TRN \\
\hline CHEMBL1454233 & 688267 & 5.3 & 5.0938 & TST \\
\hline CHEMBL1317596 & 688267 & 5.25 & 5.0883 & TRN \\
\hline CHEMBL1350477 & 688267 & 4.4 & 5.0928 & TRN \\
\hline CHEMBL1449116 & 688267 & 6.5 & 5.0241 & TRN \\
\hline CHEMBL1415719 & 688267 & 5.95 & 5.0959 & TRN \\
\hline CHEMBL1591296 & 688267 & 5.35 & 5.0541 & TRN \\
\hline CHEMBL1610137 & 688267 & 4.05 & 5.0422 & TST \\
\hline CHEMBL1355104 & 688267 & 5.55 & 5.0497 & TST \\
\hline CHEMBL1378803 & 688267 & 4.0 & 4.9827 & TST \\
\hline CHEMBL1324709 & 688267 & 3.95 & 5.0609 & TRN \\
\hline CHEMBL1408123 & 688267 & 4.05 & 5.0257 & TST \\
\hline CHEMBL1514705 & 688267 & 3.95 & 5.0053 & TST \\
\hline CHEMBL511995 & 688267 & 3.95 & 5.0804 & TRN \\
\hline CHEMBL1567226 & 688267 & 4.25 & 5.0093 & TST \\
\hline CHEMBL1449338 & 688267 & 4.35 & 5.0216 & TRN \\
\hline CHEMBL1337168 & 688267 & 4.3 & 5.1109 & TST \\
\hline CHEMBL1409278 & 688267 & 4.25 & 5.0103 & TRN \\
\hline CHEMBL1348240 & 688267 & 3.95 & 5.1377 & TRN \\
\hline CHEMBL1513574 & 688267 & 6.2 & 5.0818 & TRN \\
\hline CHEMBL1403224 & 688267 & 6.5501 & 5.0036 & TRN \\
\hline CHEMBL1407872 & 688267 & 4.35 & 5.0426 & TST \\
\hline CHEMBL1552067 & 688267 & 6.15 & 5.0469 & TRN \\
\hline CHEMBL1403852 & 688267 & 5.65 & 5.0425 & TRN \\
\hline CHEMBL1323580 & 688267 & 5.35 & 5.0898 & TRN \\
\hline CHEMBL1455055 & 688267 & 4.35 & 5.0866 & TST \\
\hline CHEMBL1449388 & 688267 & 4.05 & 5.0831 & TRN \\
\hline CHEMBL1323980 & 688267 & 4.6 & 5.042 & TST \\
\hline CHEMBL1391491 & 688267 & 5.3 & 5.0846 & TST \\
\hline CHEMBL1438438 & 688267 & 4.45 & 5.1692 & TRN \\
\hline CHEMBL1394913 & 688267 & 6.2 & 5.0838 & TRN \\
\hline CHEMBL1522202 & 688267 & 4.4 & 5.1061 & TRN \\
\hline CHEMBL1505097 & 688267 & 4.0 & 5.08 & TRN \\
\hline CHEMBL1363875 & 688267 & 5.55 & 5.1358 & TRN \\
\hline CHEMBL1399358 & 688267 & 5.45 & 5.0139 & 9999999999 \\
\hline CHEMBL1591444 & 688267 & 3.95 & 5.0328 & TRN \\
\hline
\end{tabular}




\begin{tabular}{|c|c|c|c|c|c|}
\hline \multicolumn{6}{|c|}{ Supplemental Table S2.txt } \\
\hline CHEMBL1368573 & 688267 & 6.25 & 5.121 & TRN & \\
\hline CHEMBL1348993 & 688267 & 5.6 & 5.0281 & TRN & \\
\hline CHEMBL1566898 & 688267 & 6.2 & 5.1092 & TRN & \\
\hline CHEMBL1494957 & 688267 & 4.0 & 5.038 & TRN & \\
\hline CHEMBL1538241 & 688267 & 4.3 & 5.0641 & TST & \\
\hline CHEMBL1347473 & 688267 & 5.8 & 5.0582 & TST & \\
\hline CHEMBL3191763 & 688267 & 5.35 & 5.0141 & TST & \\
\hline CHEMBL1393323 & 688267 & 6.2 & 5.0476 & TRN & \\
\hline CHEMBL1315545 & 688267 & 4.0 & 5.0491 & TRN & \\
\hline CHEMBL1370588 & 688267 & 4.0 & 5.0982 & TRN & \\
\hline CHEMBL1454777 & 688267 & 5.95 & 5.0439 & TST & \\
\hline CHEMBL1510512 & 688267 & 5.5 & 5.0628 & TST & \\
\hline CHEMBL1532424 & 688267 & 4.3 & 5.0918 & TST & \\
\hline CHEMBL1508236 & 688267 & 6.15 & 5.0444 & TRN & \\
\hline CHEMBL1539744 & 688267 & 7.1002 & 5.0591 & TST & \\
\hline CHEMBL1358692 & 688267 & 6.15 & 5.0418 & TRN & \\
\hline CHEMBL1533450 & 688267 & 4.55 & 5.0266 & TRN & \\
\hline CHEMBL1547248 & 688267 & 4.15 & 5.064 & TRN & \\
\hline CHEMBL1302532 & 688267 & 4.3 & 5.1056 & TRN & \\
\hline CHEMBL1552140 & 688267 & 3.95 & 5.0387 & TST & \\
\hline CHEMBL1390008 & 688267 & 5.65 & 5.0171 & TRN & \\
\hline CHEMBL1462407 & 688267 & 4.3 & 5.0525 & TST & \\
\hline CHEMBL1384782 & 688267 & 6.05 & 5.0698 & TST & \\
\hline CHEMBL1418151 & 688267 & 4.2 & 5.098 & TRN & \\
\hline CHEMBL1516450 & 688267 & 4.0 & 5.0707 & TRN & \\
\hline CHEMBL1470740 & 688267 & 5.05 & 5.1194 & TRN & \\
\hline CHEMBL1600369 & 688267 & 6.15 & 5.0356 & TRN & \\
\hline CHEMBL1476394 & 688267 & 5.9 & 5.0199 & TRN & \\
\hline CHEMBL1352924 & 688267 & 6.2 & 5.059 & TRN & \\
\hline CHEMBL1392308 & 688267 & 6.15 & 5.1189 & TRN & \\
\hline CHEMBL1412223 & 688267 & 4.3 & 5.006 & TRN & \\
\hline CHEMBL1323772 & 688267 & 5.85 & 5.0369 & TRN & \\
\hline CHEMBL1523849 & 688267 & 4.95 & 5.0545 & TST & \\
\hline CHEMBL1558572 & 688267 & 5.35 & 5.004 & TRN & \\
\hline CHEMBL1465437 & 688267 & 5.3 & 5.0519 & TRN & \\
\hline CHEMBL1585445 & 688267 & 4.0 & 5.0253 & TRN & \\
\hline CHEMBL1316496 & 688267 & 5.3 & 5.0511 & TST & \\
\hline CHEMBL1302249 & 688267 & 4.0 & 4.9703 & TRN & \\
\hline CHEMBL1397199 & 688267 & 6.15 & 5.1176 & TRN & \\
\hline CHEMBL1475968 & 688267 & 4.75 & 5.01699 & 99999999995 & TRN \\
\hline CHEMBL1550275 & 688267 & 5.3 & 5.0455 & TST & \\
\hline CHEMBL1423688 & 688267 & 4.35 & 5.025 & TRN & \\
\hline CHEMBL1495294 & 688267 & 5.4 & 5.1209 & TST & \\
\hline CHEMBL1369329 & 688267 & 5.45 & 5.0468 & TRN & \\
\hline CHEMBL 3209751 & 688267 & 4.6 & 5.0129 & TRN & \\
\hline CHEMBL1549433 & 688267 & 4.6 & 5.0619 & TRN & \\
\hline CHEMBL1319735 & 688267 & 4.0 & 5.0624 & TRN & \\
\hline CHEMBL1565759 & 688267 & 3.95 & 5.1347 & TRN & \\
\hline
\end{tabular}




\begin{tabular}{|c|c|c|c|c|}
\hline & & & pplement & \\
\hline CHEMBL1391494 & 688267 & 6.5 & 5.0947 & TRN \\
\hline CHEMBL1548797 & 688267 & 5.55 & 5.0413 & TRN \\
\hline CHEMBL1593735 & 688267 & 6.15 & 5.0405 & TRN \\
\hline CHEMBL1545515 & 688267 & 4.0 & 5.046 & TRN \\
\hline CHEMBL1492292 & 688267 & 4.05 & 5.1579 & TRN \\
\hline CHEMBL1445574 & 688267 & 4.05 & 5.0267 & TRN \\
\hline CHEMBL1319668 & 688267 & 5.3 & 5.0832 & TST \\
\hline CHEMBL1582363 & 688267 & 5.6 & 5.0901 & TRN \\
\hline CHEMBL1589401 & 688267 & 4.3 & 5.0737 & TST \\
\hline CHEMBL1300537 & 688267 & 4.6 & 5.0359 & TRN \\
\hline CHEMBL3197681 & 688267 & 5.4 & 4.9865 & TRN \\
\hline CHEMBL1388085 & 688267 & 6.25 & 5.0363 & TRN \\
\hline CHEMBL1565488 & 688267 & 4.65 & 5.1265 & TRN \\
\hline CHEMBL1406672 & 688267 & 3.95 & 5.0187 & TRN \\
\hline CHEMBL1568265 & 688267 & 6.5 & 5.0516 & TRN \\
\hline CHEMBL1448827 & 688267 & 6.15 & 5.0157 & TRN \\
\hline CHEMBL1995720 & 688267 & 4.5 & 5.1129 & TRN \\
\hline CHEMBL3210716 & 688267 & 4.85 & 5.0117 & TST \\
\hline CHEMBL1611990 & 688267 & 5.55 & 5.0568 & TST \\
\hline CHEMBL1515343 & 688267 & 6.25 & 5.0419 & TRN \\
\hline CHEMBL1610548 & 688267 & 4.45 & 5.0095 & TRN \\
\hline CHEMBL1346724 & 688267 & 4.95 & 5.0391 & TRN \\
\hline CHEMBL1363443 & 688267 & 4.3 & 5.0299 & TRN \\
\hline CHEMBL1478243 & 688267 & 6.2 & 5.0921 & TRN \\
\hline CHEMBL1567867 & 688267 & 5.95 & 5.0503 & TST \\
\hline CHEMBL1310111 & 688267 & 6.2 & 5.0306 & TST \\
\hline CHEMBL1554361 & 688267 & 4.0 & 5.065 & TST \\
\hline CHEMBL1518776 & 688267 & 5.55 & 5.1148 & TRN \\
\hline CHEMBL1541795 & 688267 & 4.1 & 5.0665 & TRN \\
\hline CHEMBL1552190 & 688267 & 5.05 & 5.0411 & TRN \\
\hline CHEMBL1316462 & 688267 & 6.2 & 5.03 & TRN \\
\hline CHEMBL1345425 & 688267 & 4.4 & 5.0251 & TRN \\
\hline CHEMBL1518450 & 688267 & 5.1 & 5.0237 & TRN \\
\hline CHEMBL1405175 & 688267 & 6.2 & 5.0451 & TRN \\
\hline CHEMBL1392530 & 688267 & 4.55 & 5.0813 & TRN \\
\hline CHEMBL1480435 & 688267 & 4.35 & 4.9828 & TRN \\
\hline CHEMBL1541647 & 688267 & 5.3 & 5.0899 & TRN \\
\hline CHEMBL1336116 & 688267 & 4.15 & 5.0943 & TRN \\
\hline CHEMBL1526387 & 688267 & 6.2 & 5.044 & TRN \\
\hline CHEMBL1594686 & 688267 & 5.45 & 5.0426 & TRN \\
\hline CHEMBL1477272 & 688267 & 4.05 & 5.0854 & TST \\
\hline CHEMBL1505052 & 688267 & 4.9 & 5.0025 & TRN \\
\hline CHEMBL1605644 & 688267 & 4.35 & 5.0376 & TRN \\
\hline CHEMBL1563397 & 688267 & 6.5 & 5.0761 & TRN \\
\hline CHEMBL1389277 & 688267 & 6.0 & 5.0804 & TST \\
\hline CHEMBL1340000 & 688267 & 3.95 & 5.0131 & TRN \\
\hline CHEMBL1338378 & 688267 & 4.0 & 5.0214 & TRN \\
\hline CHEMBL1548601 & 688267 & 4.4 & 5.021 & TRN \\
\hline
\end{tabular}




\begin{tabular}{|c|c|c|c|c|c|}
\hline \multicolumn{6}{|c|}{ Supplemental Table S2.txt } \\
\hline CHEMBL3211275 & 688267 & 4.95 & 5.0455 & TRN & \\
\hline CHEMBL1301365 & 688267 & 6.2 & 5.0375 & TRN & \\
\hline CHEMBL1319974 & 688267 & 6.2 & 5.0536 & TRN & \\
\hline CHEMBL1408959 & 688267 & 4.4 & 5.0647 & TRN & \\
\hline CHEMBL1383705 & 688267 & 6.25 & 5.12799 & 9999999999 & TRN \\
\hline CHEMBL1498804 & 688267 & 7.2503 & 5.1466 & TRN & \\
\hline CHEMBL1497189 & 688267 & 4.25 & 5.0595 & TST & \\
\hline CHEMBL1358628 & 688267 & 5.25 & 5.1281 & TST & \\
\hline CHEMBL1426031 & 688267 & 4.45 & 5.0156 & TRN & \\
\hline CHEMBL1361122 & 688267 & 4.0 & 4.9961 & TRN & \\
\hline CHEMBL1386690 & 688267 & 5.85 & 5.0356 & TRN & \\
\hline CHEMBL 3210428 & 688267 & 5.45 & 4.9823 & TST & \\
\hline CHEMBL1543808 & 688267 & 6.15 & 5.0503 & TRN & \\
\hline CHEMBL1307779 & 688267 & 4.05 & 5.0037 & TRN & \\
\hline CHEMBL1541010 & 688267 & 4.3 & 5.0157 & TST & \\
\hline CHEMBL1336941 & 688267 & 4.1 & 5.0619 & TRN & \\
\hline CHEMBL1424864 & 688267 & 4.45 & 5.0887 & TST & \\
\hline CHEMBL1429986 & 688267 & 5.55 & 5.0952 & TST & \\
\hline CHEMBL1606551 & 688267 & 5.85 & 5.0443 & TST & \\
\hline CHEMBL1305472 & 688267 & 6.2 & 5.0265 & TST & \\
\hline CHEMBL1475801 & 688267 & 3.95 & 5.0785 & TRN & \\
\hline CHEMBL1315584 & 688267 & 5.05 & 5.1285 & TRN & \\
\hline CHEMBL1363461 & 688267 & 5.35 & 5.0446 & TRN & \\
\hline CHEMBL1521689 & 688267 & 5.5 & 5.1084 & TRN & \\
\hline CHEMBL1420129 & 688267 & 3.95 & 5.0225 & TST & \\
\hline CHEMBL1360542 & 688267 & 4.9 & 5.07600 & 00000000005 & TRN \\
\hline CHEMBL1510154 & 688267 & 6.2 & 5.0391 & TRN & \\
\hline CHEMBL1337072 & 688267 & 6.5501 & 5.1343 & TRN & \\
\hline CHEMBL1574165 & 688267 & 4.2 & 5.0213 & TRN & \\
\hline CHEMBL1444596 & 688267 & 5.4 & 5.0794 & TRN & \\
\hline CHEMBL1446637 & 688267 & 4.65 & 5.0898 & TST & \\
\hline CHEMBL1498814 & 688267 & 6.15 & 5.1328 & TRN & \\
\hline CHEMBL1512787 & 688267 & 4.05 & 5.0204 & TST & \\
\hline CHEMBL1560028 & 688267 & 4.35 & 5.0465 & TST & \\
\hline CHEMBL1517142 & 688267 & 5.0 & 5.0794 & TRN & \\
\hline CHEMBL1606030 & 688267 & 4.6 & 5.0148 & TRN & \\
\hline CHEMBL1336531 & 688267 & 4.4 & 5.0158 & TST & \\
\hline CHEMBL1398651 & 688267 & 5.55 & 5.0596 & TRN & \\
\hline CHEMBL1473340 & 688267 & 4.0 & 5.0096 & TRN & \\
\hline CHEMBL1404214 & 688267 & 4.55 & 4.9989 & TST & \\
\hline CHEMBL1490087 & 688267 & 6.2 & 5.0116 & TRN & \\
\hline CHEMBL1549955 & 688267 & 5.5 & 5.1128 & TRN & \\
\hline CHEMBL213580 & 688267 & 4.0 & 5.0411 & TST & \\
\hline CHEMBL1424925 & 688267 & 4.2 & 5.044 & TRN & \\
\hline CHEMBL1474344 & 688267 & 3.95 & 5.03600 & 00000000005 & TRN \\
\hline CHEMBL1362915 & 688267 & 3.95 & 5.0808 & TRN & \\
\hline CHEMBL1563167 & 688267 & 5.1 & 5.1436 & TRN & \\
\hline CHEMBL1497304 & 688267 & 4.4 & 5.0167 & TRN & \\
\hline
\end{tabular}




\begin{tabular}{|c|c|c|c|c|c|}
\hline \\
\hline CHEMBL1417251 & 688267 & 6.1 & 5.0772 & TST & \\
\hline CHEMBL1314316 & 688267 & 6.2 & 5.1518 & TRN & \\
\hline CHEMBL1598203 & 688267 & 4.05 & 5.0394 & TRN & \\
\hline CHEMBL1537697 & 688267 & 6.2 & 5.113 & TRN & \\
\hline CHEMBL1556526 & 688267 & 6.2 & 5.159 & TRN & \\
\hline CHEMBL1375669 & 688267 & 5.05 & 4.9947 & TST & \\
\hline CHEMBL1600781 & 688267 & 5.05 & 5.0029 & TRN & \\
\hline CHEMBL3211500 & 688267 & 6.2 & 5.0323 & TRN & \\
\hline CHEMBL1319728 & 688267 & 4.65 & 4.9913 & TRN & \\
\hline CHEMBL1337609 & 688267 & 5.75 & 5.0743 & TRN & \\
\hline CHEMBL1504009 & 688267 & 4.35 & 5.0424 & TRN & \\
\hline CHEMBL1501446 & 688267 & 4.3 & 5.1381 & TRN & \\
\hline CHEMBL1461530 & 688267 & 4.95 & 5.0013 & TRN & \\
\hline CHEMBL1350045 & 688267 & 6.15 & 5.0239 & TRN & \\
\hline CHEMBL1475031 & 688267 & 3.95 & 5.0943 & TRN & \\
\hline CHEMBL1328895 & 688267 & 4.55 & 5.1242 & TRN & \\
\hline CHEMBL1576307 & 688267 & 5.45 & 5.0204 & TST & \\
\hline CHEMBL1430101 & 688267 & 5.85 & 5.0368 & TRN & \\
\hline CHEMBL1313587 & 688267 & 3.95 & 5.0232 & TRN & \\
\hline CHEMBL1378000 & 688267 & 4.0 & 5.0516 & TRN & \\
\hline CHEMBL1437306 & 688267 & 4.0 & 4.9908 & TRN & \\
\hline CHEMBL1303482 & 688267 & 5.4 & 5.0494 & TRN & \\
\hline CHEMBL1591557 & 688267 & 5.85 & 5.0238 & TRN & \\
\hline CHEMBL1507201 & 688267 & 4.6 & 5.0736 & TST & \\
\hline CHEMBL1387521 & 688267 & 4.0 & 5.09399 & 9999999999 & TRN \\
\hline CHEMBL1324366 & 688267 & 5.3 & 5.0509 & TRN & \\
\hline CHEMBL1423692 & 688267 & 4.5 & 5.1116 & TRN & \\
\hline CHEMBL1389391 & 688267 & 4.35 & 5.0201 & TRN & \\
\hline CHEMBL1410679 & 688267 & 4.4 & 5.0413 & TST & \\
\hline CHEMBL1347906 & 688267 & 6.1 & 5.1215 & TST & \\
\hline CHEMBL1349728 & 688267 & 4.45 & 5.0061 & TRN & \\
\hline CHEMBL608847 & 688267 & 4.4 & 5.1065 & TST & \\
\hline CHEMBL1506948 & 688267 & 4.35 & 5.1266 & TST & \\
\hline CHEMBL1453098 & 688267 & 4.35 & 5.0098 & TRN & \\
\hline CHEMBL1436625 & 688267 & 5.05 & 5.1356 & TRN & \\
\hline CHEMBL1531614 & 688267 & 4.0 & 5.0047 & TRN & \\
\hline CHEMBL1365448 & 688267 & 6.15 & 5.0866 & TRN & \\
\hline CHEMBL1501502 & 688267 & 5.0 & 5.0732 & TST & \\
\hline CHEMBL1393280 & 688267 & 5.5 & 5.0302 & TRN & \\
\hline CHEMBL 1445326 & 688267 & 5.1 & 5.0294 & TRN & \\
\hline CHEMBL1507231 & 688267 & 4.25 & 4.9981 & TRN & \\
\hline CHEMBL1458606 & 688267 & 6.25 & 5.1088 & TST & \\
\hline CHEMBL1509579 & 688267 & 5.55 & 5.0144 & TST & \\
\hline CHEMBL1214033 & 688267 & 5.35 & 5.0313 & TST & \\
\hline CHEMBL1464563 & 688267 & 5.55 & 5.0402 & TRN & \\
\hline CHEMBL1583664 & 688267 & 4.5 & 5.0137 & TRN & \\
\hline CHEMBL1369573 & 688267 & 4.05 & 5.0383 & TRN & \\
\hline CHEMBL1326517 & 688267 & 6.15 & 5.0543 & TST & \\
\hline
\end{tabular}




\begin{tabular}{|c|c|c|c|c|c|}
\hline \\
\hline CHEMBL1380983 & 688267 & 5.3 & 5.0352 & TRN & \\
\hline CHEMBL1355346 & 688267 & 5.1 & 5.0083 & TRN & \\
\hline CHEMBL1333603 & 688267 & 6.25 & 4.9977 & TST & \\
\hline CHEMBL1601725 & 688267 & 4.1 & 5.0782 & TRN & \\
\hline CHEMBL1548496 & 688267 & 5.0 & 5.0176 & TRN & \\
\hline CHEMBL1374480 & 688267 & 5.55 & 5.0573 & TST & \\
\hline CHEMBL1494774 & 688267 & 4.45 & 5.1244 & TST & \\
\hline CHEMBL1435499 & 688267 & 4.4 & 5.0491 & TRN & \\
\hline CHEMBL3209899 & 688267 & 4.1 & 5.0952 & TST & \\
\hline CHEMBL1581509 & 688267 & 5.55 & 5.1615 & TST & \\
\hline CHEMBL1515286 & 688267 & 5.95 & 4.9977 & TRN & \\
\hline CHEMBL1362356 & 688267 & 5.2 & 5.0408 & TRN & \\
\hline CHEMBL1386047 & 688267 & 4.65 & 5.0807 & TRN & \\
\hline CHEMBL1513775 & 688267 & 3.95 & 5.0541 & TRN & \\
\hline CHEMBL1351530 & 688267 & 4.0 & 5.11 & TRN & \\
\hline CHEMBL1460623 & 688267 & 5.8 & 5.0893 & TST & \\
\hline CHEMBL1462201 & 688267 & 5.8 & 5.0928 & TST & \\
\hline CHEMBL1515122 & 688267 & 4.8 & 5.0634 & TRN & \\
\hline CHEMBL1602375 & 688267 & 4.55 & 5.0198 & TRN & \\
\hline CHEMBL1565354 & 688267 & 5.9 & 5.0719 & TRN & \\
\hline CHEMBL1574497 & 688267 & 4.25 & 5.084 & TRN & \\
\hline CHEMBL1553207 & 688267 & 6.2 & 5.1454 & TRN & \\
\hline CHEMBL1581426 & 688267 & 5.9 & 5.0553 & TRN & \\
\hline CHEMBL250872 & 688267 & 4.05 & 5.0789 & TRN & \\
\hline CHEMBL1544712 & 688267 & 4.05 & 5.0857 & TRN & \\
\hline CHEMBL1570287 & 688267 & 5.45 & 4.9888 & TRN & \\
\hline CHEMBL3190208 & 688267 & 4.0 & 5.0459 & TST & \\
\hline CHEMBL1444416 & 688267 & 4.85 & 5.0416 & TRN & \\
\hline CHEMBL1521489 & 688267 & 6.05 & 5.0865 & TRN & \\
\hline CHEMBL1540812 & 688267 & 4.6 & 5.0792 & TRN & \\
\hline CHEMBL1304187 & 688267 & 5.75 & 4.999 & TST & \\
\hline CHEMBL1992745 & 688267 & 6.05 & 4.9672 & TRN & \\
\hline CHEMBL1502408 & 688267 & 4.35 & 5.0896 & TRN & \\
\hline CHEMBL1453122 & 688267 & 5.65 & 5.053 & TRN & \\
\hline CHEMBL1316795 & 688267 & 4.7 & 5.0264 & TRN & \\
\hline CHEMBL1394859 & 688267 & 4.0 & 5.01699 & 99999999995 & TRN \\
\hline CHEMBL1436677 & 688267 & 4.05 & 5.0378 & TRN & \\
\hline CHEMBL1337196 & 688267 & 3.95 & 5.0641 & TRN & \\
\hline CHEMBL1428640 & 688267 & 4.4 & 5.0848 & TST & \\
\hline CHEMBL1394460 & 688267 & 6.2 & 5.0922 & TRN & \\
\hline CHEMBL1557866 & 688267 & 6.2 & 5.0878 & TRN & \\
\hline CHEMBL1368132 & 688267 & 6.2 & 4.9988 & TRN & \\
\hline CHEMBL1543005 & 688267 & 4.25 & 5.0382 & TST & \\
\hline CHEMBL1413135 & 688267 & 4.05 & 5.0413 & TRN & \\
\hline CHEMBL1520447 & 688267 & 4.45 & 5.0744 & TRN & \\
\hline CHEMBL1519405 & 688267 & 6.05 & 5.1353 & TRN & \\
\hline CHEMBL1460301 & 688267 & 4.4 & 5.0448 & TST & \\
\hline CHEMBL3208287 & 688267 & 5.35 & 5.0639 & TST & \\
\hline
\end{tabular}




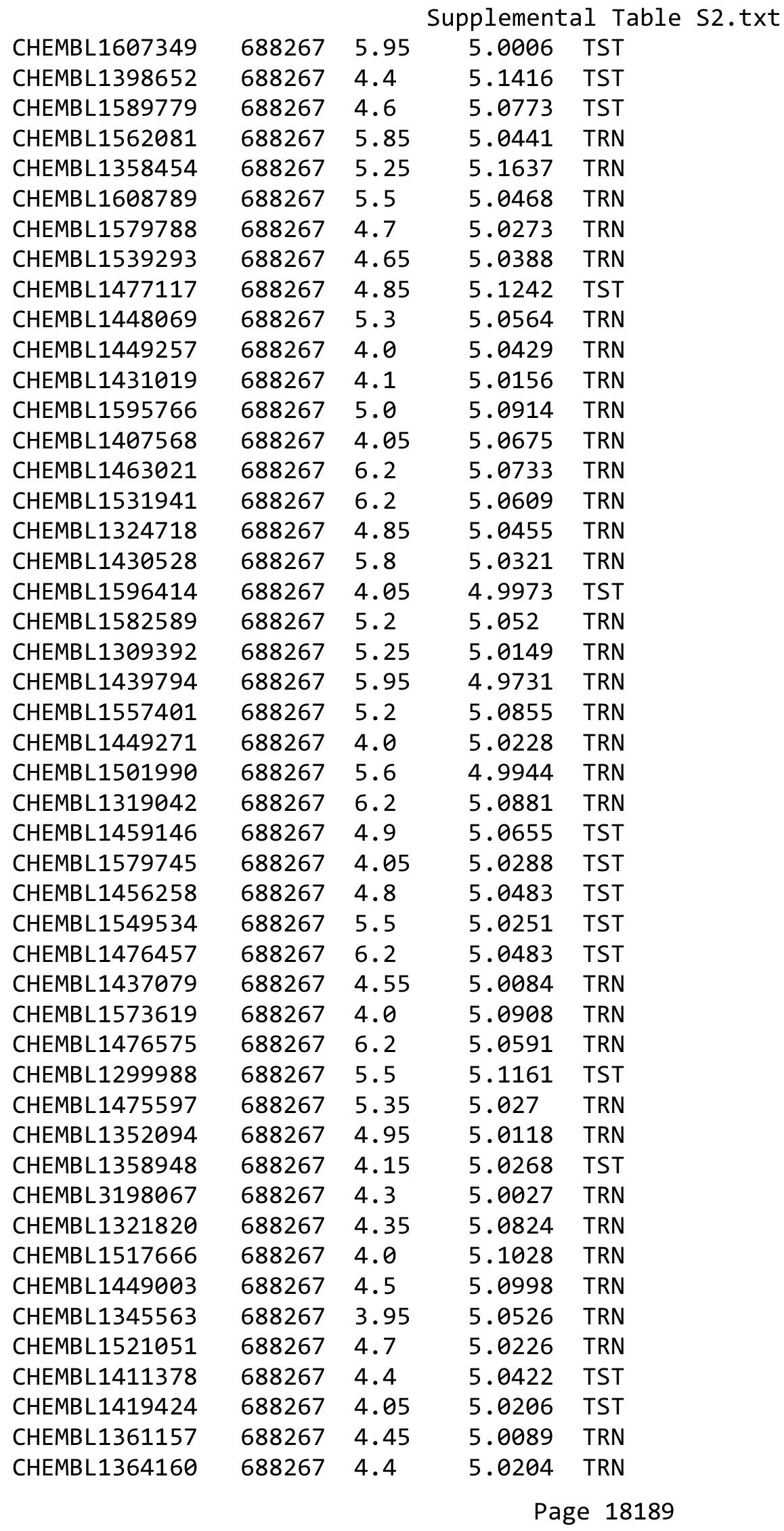




\begin{tabular}{|c|c|c|c|c|}
\hline & & & pplement & al $\mathrm{Ta}$ \\
\hline CHEMBL1374915 & 688267 & 5.3 & 4.987 & TRN \\
\hline CHEMBL1399292 & 688267 & 5.7 & 5.1312 & TRN \\
\hline CHEMBL1318986 & 688267 & 3.95 & 5.0604 & TRN \\
\hline CHEMBL1360689 & 688267 & 4.75 & 5.1238 & TRN \\
\hline CHEMBL1351130 & 688267 & 3.95 & 5.1275 & TRN \\
\hline CHEMBL1591829 & 688267 & 3.95 & 5.0711 & TST \\
\hline CHEMBL1318009 & 688267 & 6.2 & 5.1143 & TRN \\
\hline CHEMBL1367629 & 688267 & 4.2 & 5.0414 & TST \\
\hline CHEMBL1554346 & 688267 & 5.2 & 5.0213 & TRN \\
\hline CHEMBL1477791 & 688267 & 4.45 & 5.0695 & TST \\
\hline CHEMBL1557535 & 688267 & 6.5 & 4.9977 & TST \\
\hline CHEMBL1588782 & 688267 & 4.35 & 5.0739 & TRN \\
\hline CHEMBL1470397 & 688267 & 5.55 & 5.1206 & TRN \\
\hline CHEMBL1494429 & 688267 & 5.15 & 5.0896 & TRN \\
\hline CHEMBL1566944 & 688267 & 4.35 & 5.0563 & TST \\
\hline CHEMBL1306390 & 688267 & 6.2 & 5.0747 & TRN \\
\hline CHEMBL1440997 & 688267 & 5.55 & 5.0573 & TRN \\
\hline CHEMBL1611954 & 688267 & 4.0 & 5.0526 & TRN \\
\hline CHEMBL1535568 & 688267 & 4.45 & 5.0465 & TST \\
\hline CHEMBL1557879 & 688267 & 6.15 & 5.1419 & TRN \\
\hline CHEMBL1595198 & 688267 & 5.55 & 5.0474 & TRN \\
\hline CHEMBL1351102 & 688267 & 4.05 & 5.0206 & TRN \\
\hline CHEMBL1300926 & 688267 & 5.5 & 5.0392 & TRN \\
\hline CHEMBL1353146 & 688267 & 6.05 & 5.0966 & TST \\
\hline CHEMBL1597696 & 688267 & 4.0 & 5.0045 & TRN \\
\hline CHEMBL1307804 & 688267 & 4.0 & 5.0059 & TST \\
\hline CHEMBL1313004 & 688267 & 4.8 & 5.0237 & TRN \\
\hline CHEMBL1301078 & 688267 & 4.1 & 5.0538 & TRN \\
\hline CHEMBL1515179 & 688267 & 3.95 & 5.0344 & TRN \\
\hline CHEMBL1432653 & 688267 & 5.35 & 5.0908 & TRN \\
\hline CHEMBL1507188 & 688267 & 5.55 & 5.059 & TST \\
\hline CHEMBL1309232 & 688267 & 5.5 & 5.0342 & TRN \\
\hline CHEMBL1316182 & 688267 & 5.15 & 5.0115 & TRN \\
\hline CHEMBL1471181 & 688267 & 4.1 & 5.0803 & TRN \\
\hline CHEMBL1316859 & 688267 & 6.2 & 5.1028 & TRN \\
\hline CHEMBL1365476 & 688267 & 4.35 & 4.989 & TRN \\
\hline CHEMBL1408955 & 688267 & 4.15 & 5.0323 & TRN \\
\hline CHEMBL1445392 & 688267 & 4.7 & 5.0259 & TRN \\
\hline CHEMBL1593528 & 688267 & 4.1 & 4.981 & TRN \\
\hline CHEMBL1330190 & 688267 & 6.5 & 5.0942 & TST \\
\hline CHEMBL1545713 & 688267 & 4.0 & 5.1157 & TST \\
\hline CHEMBL1512044 & 688267 & 4.0 & 5.1121 & TRN \\
\hline CHEMBL1412469 & 688267 & 5.0 & 5.0185 & TRN \\
\hline CHEMBL1302696 & 688267 & 4.0 & 4.9829 & TRN \\
\hline CHEMBL1446096 & 688267 & 4.0 & 5.1825 & TRN \\
\hline CHEMBL1365549 & 688267 & 4.2 & 5.1153 & TRN \\
\hline CHEMBL1578506 & 688267 & 6.25 & 5.0205 & TST \\
\hline CHEMBL1596138 & 688267 & 3.95 & 5.0605 & TRN \\
\hline
\end{tabular}




\begin{tabular}{|c|c|c|c|c|}
\hline & & & pplement & al $\mathrm{T}$ \\
\hline CHEMBL1996804 & 688267 & 4.2 & 5.0477 & TRN \\
\hline CHEMBL1606657 & 688267 & 5.45 & 5.0709 & TRN \\
\hline CHEMBL1351316 & 688267 & 4.05 & 5.0996 & TST \\
\hline CHEMBL1422180 & 688267 & 4.25 & 4.9968 & TST \\
\hline CHEMBL1547226 & 688267 & 6.15 & 5.0604 & TRN \\
\hline CHEMBL1331127 & 688267 & 4.05 & 5.1182 & TRN \\
\hline CHEMBL1384956 & 688267 & 4.4 & 5.0024 & TRN \\
\hline CHEMBL1489629 & 688267 & 4.1 & 5.0556 & TST \\
\hline CHEMBL3208141 & 688267 & 5.5 & 5.0354 & TRN \\
\hline CHEMBL1426077 & 688267 & 5.25 & 5.069 & TRN \\
\hline CHEMBL1385184 & 688267 & 5.25 & 5.0181 & TST \\
\hline CHEMBL1305656 & 688267 & 5.05 & 5.0778 & TRN \\
\hline CHEMBL1538068 & 688267 & 4.05 & 5.0698 & TRN \\
\hline CHEMBL1554449 & 688267 & 6.7001 & 5.0464 & TRN \\
\hline CHEMBL1393362 & 688267 & 4.25 & 5.0754 & TRN \\
\hline CHEMBL1458469 & 688267 & 4.3 & 5.0721 & TST \\
\hline CHEMBL1321347 & 688267 & 6.5 & 5.0378 & TST \\
\hline CHEMBL1449857 & 688267 & 4.65 & 5.0454 & TRN \\
\hline CHEMBL1351942 & 688267 & 6.2 & 5.0963 & TRN \\
\hline CHEMBL1515339 & 688267 & 6.2 & 5.1584 & TRN \\
\hline CHEMBL1559224 & 688267 & 5.65 & 5.0547 & TRN \\
\hline CHEMBL1489691 & 688267 & 5.95 & 5.1191 & TRN \\
\hline CHEMBL1556578 & 688267 & 4.05 & 5.0952 & TRN \\
\hline CHEMBL1539426 & 688267 & 5.55 & 5.1383 & TRN \\
\hline CHEMBL1327509 & 688267 & 4.1 & 5.046 & TRN \\
\hline CHEMBL1501084 & 688267 & 4.5 & 5.0751 & TRN \\
\hline CHEMBL1459015 & 688267 & 4.65 & 5.0036 & TRN \\
\hline CHEMBL1598223 & 688267 & 6.1 & 5.0405 & TST \\
\hline CHEMBL1315862 & 688267 & 3.95 & 5.0819 & TRN \\
\hline CHEMBL1356564 & 688267 & 5.9 & 5.1 & TRN \\
\hline CHEMBL1468507 & 688267 & 4.6 & 5.0631 & TST \\
\hline CHEMBL1969647 & 688267 & 6.15 & 4.9424 & TST \\
\hline CHEMBL1374003 & 688267 & 6.15 & 5.0354 & TST \\
\hline CHEMBL1572784 & 688267 & 6.2 & 5.0704 & TRN \\
\hline CHEMBL1333586 & 688267 & 4.4 & 5.0903 & TRN \\
\hline CHEMBL1468952 & 688267 & 5.8 & 5.0946 & TRN \\
\hline CHEMBL3207776 & 688267 & 5.75 & 5.0061 & TST \\
\hline CHEMBL1471434 & 688267 & 4.5 & 5.0588 & TST \\
\hline CHEMBL1491401 & 688267 & 4.35 & 5.1264 & TRN \\
\hline CHEMBL1302878 & 688267 & 4.05 & 5.1064 & TRN \\
\hline CHEMBL1505700 & 688267 & 6.15 & 5.0297 & TRN \\
\hline CHEMBL1541709 & 688267 & 6.2 & 5.1141 & TRN \\
\hline CHEMBL3192987 & 688267 & 4.35 & 5.0965 & TRN \\
\hline CHEMBL1426170 & 688267 & 6.25 & 5.0354 & TRN \\
\hline CHEMBL1512399 & 688267 & 5.45 & 5.0771 & TRN \\
\hline CHEMBL1304390 & 688267 & 5.45 & 5.0208 & TRN \\
\hline CHEMBL1341146 & 688267 & 6.5 & 5.0398 & TRN \\
\hline CHEMBL585462 & 688267 & 6.2 & 5.0551 & TRN \\
\hline
\end{tabular}




\begin{tabular}{|c|c|c|c|c|}
\hline & & & pplement & $d \perp$ \\
\hline CHEMBL1513425 & 688267 & 6.2 & 4.9947 & TRN \\
\hline CHEMBL1596174 & 688267 & 4.3 & 5.0332 & TST \\
\hline CHEMBL1530623 & 688267 & 5.4 & 5.1177 & TRN \\
\hline CHEMBL3196386 & 688267 & 4.8 & 5.0115 & TST \\
\hline CHEMBL1374959 & 688267 & 6.1 & 5.1412 & TRN \\
\hline CHEMBL1347530 & 688267 & 5.2 & 5.0805 & TST \\
\hline CHEMBL1316484 & 688267 & 4.05 & 5.1322 & TST \\
\hline CHEMBL1539048 & 688267 & 4.3 & 5.1123 & TST \\
\hline CHEMBL1471173 & 688267 & 5.5 & 5.1206 & TRN \\
\hline CHEMBL1347103 & 688267 & 4.05 & 4.9936 & TST \\
\hline CHEMBL1470763 & 688267 & 6.0 & 5.0223 & TRN \\
\hline CHEMBL1321425 & 688267 & 4.0 & 5.0688 & TRN \\
\hline CHEMBL1383424 & 688267 & 4.4 & 5.0681 & TST \\
\hline CHEMBL1376386 & 688267 & 5.85 & 5.0496 & TST \\
\hline CHEMBL1552584 & 688267 & 6.5 & 4.9976 & TRN \\
\hline CHEMBL1592424 & 688267 & 4.35 & 5.0659 & TRN \\
\hline CHEMBL1486616 & 688267 & 5.85 & 5.0795 & TST \\
\hline CHEMBL1589334 & 688267 & 5.95 & 4.998 & TRN \\
\hline CHEMBL1362734 & 688267 & 4.5 & 5.0012 & TST \\
\hline CHEMBL1091787 & 688267 & 4.9 & 5.0324 & TRN \\
\hline CHEMBL1582756 & 688267 & 6.15 & 5.0727 & TRN \\
\hline CHEMBL3856090 & 688267 & 4.45 & 4.9878 & TRN \\
\hline CHEMBL1467296 & 688267 & 4.75 & 5.0308 & TRN \\
\hline CHEMBL1329941 & 688267 & 6.2 & 5.0327 & TRN \\
\hline CHEMBL1316911 & 688267 & 5.55 & 5.0154 & TRN \\
\hline CHEMBL1496107 & 688267 & 6.2 & 5.0749 & TST \\
\hline CHEMBL1526769 & 688267 & 4.9 & 5.0402 & TRN \\
\hline CHEMBL1432115 & 688267 & 4.95 & 5.006 & TRN \\
\hline CHEMBL1533799 & 688267 & 5.9 & 5.0427 & TST \\
\hline CHEMBL1328408 & 688267 & 6.15 & 4.959 & TRN \\
\hline CHEMBL1523997 & 688267 & 4.35 & 5.0053 & TST \\
\hline CHEMBL1598197 & 688267 & 5.85 & 5.0477 & TRN \\
\hline CHEMBL1351368 & 688267 & 6.2 & 5.0185 & TRN \\
\hline CHEMBL1541730 & 688267 & 6.2 & 5.066 & TST \\
\hline CHEMBL1486327 & 688267 & 5.25 & 5.0695 & TST \\
\hline CHEMBL1477755 & 688267 & 4.35 & 5.0458 & TRN \\
\hline CHEMBL1315202 & 688267 & 6.15 & 5.1061 & TRN \\
\hline CHEMBL1419913 & 688267 & 4.05 & 5.0324 & TRN \\
\hline CHEMBL1340615 & 688267 & 4.75 & 5.0743 & TST \\
\hline CHEMBL1434523 & 688267 & 5.5 & 5.0918 & TRN \\
\hline CHEMBL1449894 & 688267 & 4.4 & 5.0292 & TST \\
\hline CHEMBL1472475 & 688267 & 4.0 & 5.129 & TRN \\
\hline CHEMBL1610084 & 688267 & 5.2 & 5.0953 & TRN \\
\hline CHEMBL1473310 & 688267 & 4.55 & 5.1233 & TRN \\
\hline CHEMBL1449212 & 688267 & 5.85 & 5.032 & TRN \\
\hline CHEMBL1533619 & 688267 & 6.7001 & 5.1451 & TST \\
\hline CHEMBL1602483 & 688267 & 6.25 & 5.0761 & TRN \\
\hline CHEMBL1329856 & 688267 & 4.55 & 5.0623 & TST \\
\hline
\end{tabular}




\begin{tabular}{|c|c|c|c|c|}
\hline \multicolumn{5}{|c|}{ Supplemental Table S2.txt } \\
\hline CHEMBL1507162 & 688267 & 4.05 & 5.0591 & TRN \\
\hline CHEMBL1589054 & 688267 & 4.3 & 5.1083 & TRN \\
\hline CHEMBL1477986 & 688267 & 4.45 & 5.0564 & TST \\
\hline CHEMBL1402652 & 688267 & 6.25 & 5.0157 & TRN \\
\hline CHEMBL1394627 & 688267 & 6.3 & 5.0768 & TRN \\
\hline CHEMBL3194615 & 688267 & 4.0 & 5.0015 & TST \\
\hline CHEMBL1382245 & 688267 & 5.8 & 5.1457 & TRN \\
\hline CHEMBL1379945 & 688267 & 4.5 & 4.9939 & TRN \\
\hline CHEMBL1507595 & 688267 & 4.05 & 4.9927 & TRN \\
\hline CHEMBL1552263 & 688267 & 6.15 & 5.1151 & TST \\
\hline CHEMBL1314812 & 688267 & 4.15 & 5.1067 & TST \\
\hline CHEMBL1440271 & 688267 & 5.8 & 5.1599 & TST \\
\hline CHEMBL494081 & 688267 & 5.5 & 5.1044 & TRN \\
\hline CHEMBL1329686 & 688267 & 5.9 & 5.0305 & TRN \\
\hline CHEMBL1399201 & 688267 & 4.4 & 4.9687 & TRN \\
\hline CHEMBL1500373 & 688267 & 6.2 & 5.0765 & TRN \\
\hline CHEMBL1381850 & 688267 & 4.05 & 4.9759 & TRN \\
\hline CHEMBL1447097 & 688267 & 6.2 & 5.0819 & TRN \\
\hline CHEMBL1526986 & 688267 & 4.05 & 5.0228 & TRN \\
\hline CHEMBL1426733 & 688267 & 6.15 & 5.0124 & TRN \\
\hline CHEMBL1377186 & 688267 & 5.25 & 5.0173 & TST \\
\hline CHEMBL1361853 & 688267 & 4.0 & 5.0302 & TRN \\
\hline CHEMBL1437900 & 688267 & 5.0 & 5.1261 & TRN \\
\hline CHEMBL1441548 & 688267 & 4.05 & 4.9889 & TRN \\
\hline CHEMBL1395114 & 688267 & 4.0 & 5.0664 & TRN \\
\hline CHEMBL1592301 & 688267 & 4.1 & 5.0687 & TRN \\
\hline CHEMBL1420134 & 688267 & 4.0 & 5.0456 & TRN \\
\hline CHEMBL1551490 & 688267 & 3.95 & 5.0783 & TRN \\
\hline CHEMBL1437361 & 688267 & 6.25 & 5.0054 & TRN \\
\hline CHEMBL1494809 & 688267 & 4.6 & 5.058 & TRN \\
\hline CHEMBL1308306 & 688267 & 5.85 & 5.0791 & TST \\
\hline CHEMBL1495297 & 688267 & 5.55 & 5.0874 & TRN \\
\hline CHEMBL1416295 & 688267 & 5.8 & 5.0838 & TRN \\
\hline CHEMBL1493085 & 688267 & 6.45 & 5.0535 & TST \\
\hline CHEMBL1455595 & 688267 & 5.4 & 5.0173 & TST \\
\hline CHEMBL1342967 & 688267 & 4.55 & 5.0456 & TRN \\
\hline CHEMBL1525732 & 688267 & 5.55 & 5.0713 & TRN \\
\hline CHEMBL1485324 & 688267 & 4.8 & 5.1798 & TRN \\
\hline CHEMBL1544136 & 688267 & 6.25 & 5.0799 & TRN \\
\hline CHEMBL1491888 & 688267 & 5.45 & 5.0754 & TST \\
\hline CHEMBL1392226 & 688267 & 4.3 & 5.0963 & TRN \\
\hline CHEMBL1580811 & 688267 & 5.25 & 5.0747 & TRN \\
\hline CHEMBL1357330 & 688267 & 4.0 & 5.0374 & TST \\
\hline CHEMBL1390198 & 688267 & 4.9 & 4.9887 & TRN \\
\hline CHEMBL1474954 & 688267 & 4.0 & 5.1041 & TST \\
\hline CHEMBL3190626 & 688267 & 3.95 & 5.0393 & TST \\
\hline CHEMBL1482302 & 688267 & 4.0 & 5.1452 & TRN \\
\hline CHEMBL1213608 & 688267 & 6.1 & 4.9906 & TRN \\
\hline
\end{tabular}




\begin{tabular}{|c|c|c|c|c|}
\hline & & & pplement & al $\mathrm{Ta}$ \\
\hline CHEMBL1342478 & 688267 & 6.25 & 5.0655 & TRN \\
\hline CHEMBL1505070 & 688267 & 5.8 & 4.9954 & TRN \\
\hline CHEMBL 3213343 & 688267 & 4.55 & 5.0275 & TRN \\
\hline CHEMBL1465792 & 688267 & 4.3 & 4.9893 & TRN \\
\hline CHEMBL1443952 & 688267 & 6.25 & 5.0714 & TRN \\
\hline CHEMBL1300953 & 688267 & 5.8 & 5.0502 & TST \\
\hline CHEMBL1598672 & 688267 & 5.6 & 5.1158 & TRN \\
\hline CHEMBL1317929 & 688267 & 4.05 & 5.0462 & TRN \\
\hline CHEMBL1391373 & 688267 & 5.7 & 5.029 & TST \\
\hline CHEMBL1529936 & 688267 & 5.05 & 4.9997 & TRN \\
\hline CHEMBL1316271 & 688267 & 4.0 & 5.1139 & TRN \\
\hline CHEMBL1413581 & 688267 & 6.2 & 5.0598 & TRN \\
\hline CHEMBL1529346 & 688267 & 4.4 & 5.0142 & TRN \\
\hline CHEMBL1423631 & 688267 & 5.6 & 5.0863 & TRN \\
\hline CHEMBL1516082 & 688267 & 6.0 & 5.0173 & TRN \\
\hline CHEMBL1444582 & 688267 & 5.15 & 5.0403 & TRN \\
\hline CHEMBL1438627 & 688267 & 4.0 & 5.0722 & TST \\
\hline CHEMBL1414819 & 688267 & 4.4 & 5.003 & TRN \\
\hline CHEMBL1519013 & 688267 & 3.9 & 5.0755 & TRN \\
\hline CHEMBL1474640 & 688267 & 4.55 & 5.0154 & TST \\
\hline CHEMBL1309820 & 688267 & 4.0 & 5.027 & TST \\
\hline CHEMBL1341703 & 688267 & 4.35 & 5.0456 & TRN \\
\hline CHEMBL1320293 & 688267 & 5.35 & 5.0179 & TRN \\
\hline CHEMBL1473076 & 688267 & 4.65 & 5.1242 & TRN \\
\hline CHEMBL1452414 & 688267 & 5.5 & 5.0845 & TST \\
\hline CHEMBL175451 & 688267 & 5.55 & 5.0386 & TST \\
\hline CHEMBL 3198614 & 688267 & 6.15 & 5.0496 & TST \\
\hline CHEMBL1439219 & 688267 & 6.2 & 4.9883 & TRN \\
\hline CHEMBL1478310 & 688267 & 5.8 & 5.0299 & TST \\
\hline CHEMBL1459103 & 688267 & 4.5 & 5.0621 & TRN \\
\hline CHEMBL1410792 & 688267 & 4.4 & 5.0637 & TRN \\
\hline CHEMBL1458046 & 688267 & 6.15 & 5.0862 & TST \\
\hline CHEMBL1407860 & 688267 & 4.65 & 5.1592 & TRN \\
\hline CHEMBL1440682 & 688267 & 4.15 & 5.0705 & TRN \\
\hline CHEMBL1589521 & 688267 & 4.0 & 5.0106 & TST \\
\hline CHEMBL1406904 & 688267 & 4.95 & 5.0597 & TST \\
\hline CHEMBL1332369 & 688267 & 5.85 & 5.0881 & TRN \\
\hline CHEMBL1556131 & 688267 & 6.15 & 5.0209 & TRN \\
\hline CHEMBL1611270 & 688267 & 6.5 & 4.9882 & TRN \\
\hline CHEMBL1410259 & 688267 & 5.5 & 5.0506 & TRN \\
\hline CHEMBL1564213 & 688267 & 3.95 & 5.0976 & TRN \\
\hline CHEMBL1339753 & 688267 & 4.35 & 5.0498 & TRN \\
\hline CHEMBL1343722 & 688267 & 5.45 & 5.1012 & TST \\
\hline CHEMBL1323602 & 688267 & 4.05 & 5.0419 & TRN \\
\hline CHEMBL1591300 & 688267 & 5.35 & 5.0269 & TRN \\
\hline CHEMBL1495116 & 688267 & 4.75 & 5.0115 & TST \\
\hline CHEMBL1590326 & 688267 & 4.0 & 5.1471 & TRN \\
\hline CHEMBL1544063 & 688267 & 4.1 & 5.0578 & TST \\
\hline
\end{tabular}




\begin{tabular}{|c|c|c|c|c|c|}
\hline \\
\hline CHEMBL1558488 & 688267 & 6.2 & 5.143 & TRN & \\
\hline CHEMBL1418679 & 688267 & 3.95 & 4.9999 & TRN & \\
\hline CHEMBL1547783 & 688267 & 4.5 & 5.1135 & TRN & \\
\hline CHEMBL1376643 & 688267 & 4.45 & 5.0629 & TRN & \\
\hline CHEMBL1608509 & 688267 & 6.2 & 5.0142 & TRN & \\
\hline CHEMBL1611040 & 688267 & 4.35 & 5.1175 & TRN & \\
\hline CHEMBL1612154 & 688267 & 6.2 & 5.0359 & TRN & \\
\hline CHEMBL1469815 & 688267 & 4.75 & 5.0762 & TRN & \\
\hline CHEMBL1432737 & 688267 & 6.2 & 5.0703 & TRN & \\
\hline CHEMBL1494662 & 688267 & 5.3 & 5.1053 & TRN & \\
\hline CHEMBL1495298 & 688267 & 3.95 & 5.0784 & TRN & \\
\hline CHEMBL1447866 & 688267 & 6.05 & 5.0265 & TRN & \\
\hline CHEMBL1556152 & 688267 & 5.35 & 5.0913 & TST & \\
\hline CHEMBL1434326 & 688267 & 4.4 & 5.11 & TRN & \\
\hline CHEMBL558842 & 688267 & 4.05 & 5.01399 & 9999999999 & TST \\
\hline CHEMBL1317830 & 688267 & 6.4 & 5.025 & TRN & \\
\hline CHEMBL1521090 & 688267 & 6.45 & 5.023 & TST & \\
\hline CHEMBL1553927 & 688267 & 4.0 & 5.1378 & TRN & \\
\hline CHEMBL1577769 & 688267 & 4.05 & 5.0252 & TST & \\
\hline CHEMBL1583467 & 688267 & 6.2 & 5.0073 & TRN & \\
\hline CHEMBL1360636 & 688267 & 3.95 & 5.0354 & TRN & \\
\hline CHEMBL1503683 & 688267 & 4.0 & 5.0178 & TST & \\
\hline CHEMBL1367245 & 688267 & 4.25 & 5.0377 & TRN & \\
\hline CHEMBL1507528 & 688267 & 4.45 & 5.0712 & TRN & \\
\hline CHEMBL1425360 & 688267 & 4.2 & 5.098 & TST & \\
\hline CHEMBL1551207 & 688267 & 5.4 & 5.0487 & TRN & \\
\hline CHEMBL1395887 & 688267 & 6.2 & 5.0799 & TRN & \\
\hline CHEMBL1563065 & 688267 & 4.35 & 5.0489 & TRN & \\
\hline CHEMBL1540550 & 688267 & 4.25 & 5.0096 & TRN & \\
\hline CHEMBL1477489 & 688267 & 6.2 & 5.0733 & TRN & \\
\hline CHEMBL3198131 & 688267 & 4.0 & 4.9713 & TRN & \\
\hline CHEMBL1535822 & 688267 & 5.4 & 5.1276 & TRN & \\
\hline CHEMBL1972760 & 688267 & 5.3 & 4.9888 & TST & \\
\hline CHEMBL1452046 & 688267 & 5.65 & 5.1702 & TRN & \\
\hline CHEMBL1306097 & 688267 & 5.85 & 5.0956 & TRN & \\
\hline CHEMBL1463702 & 688267 & 4.35 & 5.0837 & TRN & \\
\hline CHEMBL1571473 & 688267 & 6.2 & 5.0779 & TRN & \\
\hline CHEMBL1355483 & 688267 & 4.35 & 5.0842 & TRN & \\
\hline CHEMBL1534826 & 688267 & 6.45 & 5.0174 & TRN & \\
\hline CHEMBL1495041 & 688267 & 5.35 & 5.1324 & TRN & \\
\hline CHEMBL1414394 & 688267 & 5.65 & 5.0561 & TRN & \\
\hline CHEMBL1549023 & 688267 & 5.55 & 5.0733 & TRN & \\
\hline CHEMBL1603565 & 688267 & 5.5 & 5.0954 & TRN & \\
\hline CHEMBL1563224 & 688267 & 4.6 & 5.0002 & TRN & \\
\hline CHEMBL1377669 & 688267 & 4.0 & 4.9729 & TRN & \\
\hline CHEMBL261011 & 688267 & 4.55 & 5.0307 & TRN & \\
\hline CHEMBL1377146 & 688267 & 6.25 & 5.0317 & TST & \\
\hline CHEMBL1560606 & 688267 & 4.95 & 5.0674 & TRN & \\
\hline
\end{tabular}




\begin{tabular}{|c|c|c|c|c|c|}
\hline \multicolumn{6}{|c|}{ Supplemental Table S2.txt } \\
\hline CHEMBL1477965 & 688267 & 6.4 & 5.0238 & TRN & \\
\hline CHEMBL1574179 & 688267 & 5.2 & 5.0707 & TST & \\
\hline CHEMBL1469000 & 688267 & 5.15 & 5.0935 & TRN & \\
\hline CHEMBL1367265 & 688267 & 6.2 & 5.1041 & TRN & \\
\hline CHEMBL1362881 & 688267 & 4.6 & 5.0133 & TST & \\
\hline CHEMBL1350584 & 688267 & 4.7 & 5.0062 & TST & \\
\hline CHEMBL1434529 & 688267 & 4.0 & 5.1528 & TRN & \\
\hline CHEMBL1610824 & 688267 & 6.0 & 5.1078 & TRN & \\
\hline CHEMBL1575167 & 688267 & 4.4 & 5.0579 & TST & \\
\hline CHEMBL1353319 & 688267 & 4.2 & 5.0531 & TST & \\
\hline CHEMBL1385448 & 688267 & 5.3 & 5.026 & TRN & \\
\hline CHEMBL1438794 & 688267 & 5.6 & 5.0727 & TRN & \\
\hline CHEMBL1608019 & 688267 & 5.1 & 5.1102 & TRN & \\
\hline CHEMBL1555333 & 688267 & 5.35 & 5.0716 & TRN & \\
\hline CHEMBL1415737 & 688267 & 6.2 & 5.1219 & TRN & \\
\hline CHEMBL3193489 & 688267 & 4.15 & 5.0276 & TRN & \\
\hline CHEMBL1531141 & 688267 & 5.0 & 5.0365 & TRN & \\
\hline CHEMBL1300808 & 688267 & 4.6 & 5.0885 & TRN & \\
\hline CHEMBL1503043 & 688267 & 4.3 & 5.0402 & TRN & \\
\hline CHEMBL1609457 & 688267 & 4.0 & 5.0089 & TRN & \\
\hline CHEMBL1468352 & 688267 & 5.25 & 5.023 & TST & \\
\hline CHEMBL1398504 & 688267 & 4.3 & 5.0598 & TRN & \\
\hline CHEMBL1594636 & 688267 & 4.25 & 5.0901 & TST & \\
\hline CHEMBL1475905 & 688267 & 5.95 & 5.13700 & 00000000005 & TRN \\
\hline CHEMBL1573736 & 688267 & 6.0 & 5.0633 & TST & \\
\hline CHEMBL1390491 & 688267 & 6.15 & 5.0442 & TST & \\
\hline CHEMBL1572602 & 688267 & 3.9 & 5.1165 & TRN & \\
\hline CHEMBL1410785 & 688267 & 4.4 & 5.0448 & TRN & \\
\hline CHEMBL1369404 & 688267 & 4.05 & 5.0631 & TST & \\
\hline CHEMBL1429383 & 688267 & 6.25 & 5.1032 & TRN & \\
\hline CHEMBL1310018 & 688267 & 5.25 & 5.0935 & TRN & \\
\hline CHEMBL1430567 & 688267 & 5.3 & 5.0111 & TRN & \\
\hline CHEMBL1377583 & 688267 & 5.35 & 5.0909 & TRN & \\
\hline CHEMBL1515500 & 688267 & 4.0 & 5.0407 & TRN & \\
\hline CHEMBL1303572 & 688267 & 5.05 & 5.1241 & TRN & \\
\hline CHEMBL1326502 & 688267 & 5.85 & 5.0584 & TRN & \\
\hline CHEMBL1477328 & 688267 & 5.8 & 5.0399 & TRN & \\
\hline CHEMBL1419586 & 688267 & 6.2 & 5.0185 & TRN & \\
\hline CHEMBL1367163 & 688267 & 5.95 & 5.0828 & TRN & \\
\hline CHEMBL1336652 & 688267 & 4.0 & 5.0319 & TRN & \\
\hline CHEMBL1597031 & 688267 & 5.8 & 5.1267 & TST & \\
\hline CHEMBL1324063 & 688267 & 4.0 & 5.1067 & TRN & \\
\hline CHEMBL1475857 & 688267 & 5.85 & 5.0878 & TRN & \\
\hline CHEMBL1391242 & 688267 & 4.55 & 5.0571 & TRN & \\
\hline CHEMBL1513032 & 688267 & 4.2 & 5.0687 & TRN & \\
\hline CHEMBL1546362 & 688267 & 4.55 & 5.0725 & TRN & \\
\hline CHEMBL1370079 & 688267 & 5.85 & 5.0644 & TRN & \\
\hline CHEMBL1327543 & 688267 & 5.65 & 5.0397 & TRN & \\
\hline
\end{tabular}




\begin{tabular}{|c|c|c|c|c|}
\hline & & & pplement & al $\mathrm{Ta}$ \\
\hline CHEMBL1560898 & 688267 & 6.2 & 5.0725 & TRN \\
\hline CHEMBL1483471 & 688267 & 4.25 & 5.0262 & TST \\
\hline CHEMBL427692 & 688267 & 6.25 & 5.0651 & TRN \\
\hline CHEMBL1344742 & 688267 & 6.2 & 5.0836 & TST \\
\hline CHEMBL1591072 & 688267 & 4.0 & 5.0913 & TRN \\
\hline CHEMBL1371214 & 688267 & 4.2 & 5.0856 & TRN \\
\hline CHEMBL1580531 & 688267 & 4.1 & 5.0517 & TRN \\
\hline CHEMBL1555532 & 688267 & 4.05 & 5.0194 & TST \\
\hline CHEMBL3214385 & 688267 & 4.3 & 4.9965 & TRN \\
\hline CHEMBL1386271 & 688267 & 4.3 & 5.0848 & TRN \\
\hline CHEMBL1580870 & 688267 & 6.2 & 5.0161 & TRN \\
\hline CHEMBL1557719 & 688267 & 4.35 & 5.1323 & TRN \\
\hline CHEMBL1521777 & 688267 & 4.9 & 5.0731 & TRN \\
\hline CHEMBL1485040 & 688267 & 6.2 & 5.0236 & TRN \\
\hline CHEMBL1477136 & 688267 & 4.3 & 5.0219 & TRN \\
\hline CHEMBL1559006 & 688267 & 5.9 & 5.0965 & TRN \\
\hline CHEMBL1479774 & 688267 & 5.0 & 5.012 & TRN \\
\hline CHEMBL1473288 & 688267 & 6.2 & 5.0655 & TRN \\
\hline CHEMBL1560832 & 688267 & 5.55 & 5.1002 & TRN \\
\hline CHEMBL1574915 & 688267 & 5.15 & 5.0116 & TRN \\
\hline CHEMBL1358877 & 688267 & 5.9 & 5.1037 & TRN \\
\hline CHEMBL1362781 & 688267 & 3.95 & 5.0825 & TRN \\
\hline CHEMBL1427549 & 688267 & 5.1 & 5.0802 & TRN \\
\hline CHEMBL1390884 & 688267 & 4.4 & 5.0045 & TRN \\
\hline CHEMBL1490564 & 688267 & 5.6 & 5.048 & TST \\
\hline CHEMBL1429567 & 688267 & 5.55 & 5.0406 & TST \\
\hline CHEMBL1340034 & 688267 & 6.2 & 5.0783 & TST \\
\hline CHEMBL1479250 & 688267 & 3.95 & 5.0317 & TRN \\
\hline CHEMBL1421487 & 688267 & 5.0 & 5.0889 & TRN \\
\hline CHEMBL3196430 & 688267 & 4.35 & 5.05 & TRN \\
\hline CHEMBL1411941 & 688267 & 4.1 & 5.0587 & TRN \\
\hline CHEMBL 3199754 & 688267 & 5.5 & 5.0207 & TRN \\
\hline CHEMBL1314149 & 688267 & 4.25 & 5.0056 & TST \\
\hline CHEMBL1498282 & 688267 & 4.5 & 5.0226 & TRN \\
\hline CHEMBL1471479 & 688267 & 5.3 & 4.999 & TRN \\
\hline CHEMBL1436560 & 688267 & 4.95 & 5.0625 & TRN \\
\hline CHEMBL1593667 & 688267 & 6.2 & 5.0007 & TRN \\
\hline CHEMBL1500620 & 688267 & 5.0 & 5.0945 & TST \\
\hline CHEMBL1384507 & 688267 & 5.95 & 5.0417 & TRN \\
\hline CHEMBL1406872 & 688267 & 3.95 & 5.1277 & TRN \\
\hline CHEMBL1410194 & 688267 & 6.25 & 5.1169 & TRN \\
\hline CHEMBL1575522 & 688267 & 6.15 & 5.1122 & TRN \\
\hline CHEMBL1417198 & 688267 & 4.1 & 5.1056 & TRN \\
\hline CHEMBL1370146 & 688267 & 5.5 & 5.0519 & TRN \\
\hline CHEMBL1553450 & 688267 & 4.65 & 5.1066 & TRN \\
\hline CHEMBL1495269 & 688267 & 6.2 & 5.1041 & TRN \\
\hline CHEMBL1395439 & 688267 & 4.0 & 4.9917 & TRN \\
\hline CHEMBL1534155 & 688267 & 6.2 & 5.0288 & TST \\
\hline
\end{tabular}




\begin{tabular}{|c|c|c|c|c|c|}
\hline \multicolumn{6}{|c|}{ Supplemental Table S2.txt } \\
\hline CHEMBL1476637 & 688267 & 6.2 & 5.0688 & TRN & \\
\hline CHEMBL1498116 & 688267 & 6.15 & 5.117 & TRN & \\
\hline CHEMBL1341375 & 688267 & 4.15 & 5.0494 & TRN & \\
\hline CHEMBL1357353 & 688267 & 6.15 & 5.0513 & TRN & \\
\hline CHEMBL1509884 & 688267 & 6.2 & 5.037 & TRN & \\
\hline CHEMBL1376228 & 688267 & 4.4 & 5.0859 & TRN & \\
\hline CHEMBL1423109 & 688267 & 5.05 & 5.0967 & TRN & \\
\hline CHEMBL1425297 & 688267 & 4.25 & 5.024 & TRN & \\
\hline CHEMBL1481536 & 688267 & 4.5 & 5.077 & TRN & \\
\hline CHEMBL1554681 & 688267 & 5.05 & 5.1556 & TRN & \\
\hline CHEMBL1341362 & 688267 & 4.4 & 5.0223 & TRN & \\
\hline CHEMBL1438907 & 688267 & 4.05 & 5.0257 & TST & \\
\hline CHEMBL1497162 & 688267 & 4.3 & 5.0207 & TRN & \\
\hline CHEMBL1564899 & 688267 & 5.4 & 5.0465 & TRN & \\
\hline CHEMBL1353183 & 688267 & 6.45 & 5.0736 & TRN & \\
\hline CHEMBL3207584 & 688267 & 4.35 & 4.9928 & TRN & \\
\hline CHEMBL1320701 & 688267 & 5.05 & 5.0642 & TST & \\
\hline CHEMBL1323383 & 688267 & 5.3 & 5.0466 & TRN & \\
\hline CHEMBL1982808 & 688267 & 6.2 & 4.9829 & TST & \\
\hline CHEMBL1344908 & 688267 & 5.3 & 5.0956 & TRN & \\
\hline CHEMBL1386387 & 688267 & 4.5 & 5.0775 & TRN & \\
\hline CHEMBL1458976 & 688267 & 5.5 & 5.1146 & TRN & \\
\hline CHEMBL1612285 & 688267 & 4.35 & 5.015 & TRN & \\
\hline CHEMBL1380329 & 688267 & 3.95 & 5.1087 & TRN & \\
\hline CHEMBL1490912 & 688267 & 4.0 & 5.0816 & TRN & \\
\hline CHEMBL1372093 & 688267 & 4.75 & 5.021 & TRN & \\
\hline CHEMBL1528872 & 688267 & 6.5 & 5.0246 & TRN & \\
\hline CHEMBL1503994 & 688267 & 5.5 & 5.06800 & 00000000005 & TST \\
\hline CHEMBL1321926 & 688267 & 5.15 & 5.0882 & TRN & \\
\hline CHEMBL 3197824 & 688267 & 6.2 & 5.0162 & TST & \\
\hline CHEMBL1480455 & 688267 & 5.95 & 5.081 & TRN & \\
\hline CHEMBL1551319 & 688267 & 5.9 & 5.0301 & TRN & \\
\hline CHEMBL1543391 & 688267 & 4.4 & 5.0989 & TST & \\
\hline CHEMBL1439419 & 688267 & 5.0 & 5.0659 & TST & \\
\hline CHEMBL1425371 & 688267 & 4.0 & 5.1247 & TRN & \\
\hline CHEMBL1340375 & 688267 & 4.55 & 5.0883 & TRN & \\
\hline CHEMBL1408999 & 688267 & 4.25 & 5.0855 & TRN & \\
\hline CHEMBL1306500 & 688267 & 5.5 & 5.1577 & TRN & \\
\hline CHEMBL1436216 & 688267 & 4.35 & 5.0872 & TRN & \\
\hline CHEMBL1357854 & 688267 & 4.15 & 5.0679 & TRN & \\
\hline CHEMBL3213783 & 688267 & 5.35 & 5.0441 & TST & \\
\hline CHEMBL1531852 & 688267 & 5.3 & 5.0046 & TRN & \\
\hline CHEMBL1535082 & 688267 & 6.15 & 5.0349 & TRN & \\
\hline CHEMBL1565158 & 688267 & 5.1 & 5.1046 & TRN & \\
\hline CHEMBL1389174 & 688267 & 6.2 & 5.0514 & TRN & \\
\hline CHEMBL1388966 & 688267 & 4.4 & 5.0511 & TRN & \\
\hline CHEMBL1497126 & 688267 & 4.65 & 5.1262 & TRN & \\
\hline CHEMBL1537508 & 688267 & 5.3 & 5.0754 & TRN & \\
\hline
\end{tabular}




\begin{tabular}{|c|c|c|c|c|}
\hline & & & pplement & al $\mathrm{Ta}$ \\
\hline CHEMBL1574800 & 688267 & 4.7 & 5.1095 & TRN \\
\hline CHEMBL1434917 & 688267 & 6.6499 & 5.1656 & TRN \\
\hline CHEMBL1568224 & 688267 & 4.65 & 5.1129 & TRN \\
\hline CHEMBL 1460850 & 688267 & 4.25 & 5.0129 & TST \\
\hline CHEMBL1321046 & 688267 & 5.95 & 5.0811 & TRN \\
\hline CHEMBL1330537 & 688267 & 4.0 & 5.02 & TST \\
\hline CHEMBL1528388 & 688267 & 6.25 & 5.0757 & TRN \\
\hline CHEMBL1491953 & 688267 & 5.65 & 5.0767 & TRN \\
\hline CHEMBL1469231 & 688267 & 6.2 & 5.0302 & TRN \\
\hline CHEMBL1523986 & 688267 & 5.6 & 5.0786 & TRN \\
\hline CHEMBL1550903 & 688267 & 5.5 & 5.0997 & TRN \\
\hline CHEMBL1410337 & 688267 & 4.15 & 5.0491 & TRN \\
\hline CHEMBL1482907 & 688267 & 4.3 & 5.0772 & TRN \\
\hline CHEMBL1589323 & 688267 & 4.0 & 5.0413 & TRN \\
\hline CHEMBL1319308 & 688267 & 6.15 & 5.0855 & TRN \\
\hline CHEMBL1476408 & 688267 & 3.95 & 4.9951 & TRN \\
\hline CHEMBL3189555 & 688267 & 4.0 & 5.0442 & TST \\
\hline CHEMBL1423147 & 688267 & 4.9 & 5.0139 & TST \\
\hline CHEMBL1368910 & 688267 & 6.15 & 4.9861 & TRN \\
\hline CHEMBL1360346 & 688267 & 3.95 & 4.9703 & TRN \\
\hline CHEMBL1441659 & 688267 & 3.95 & 5.0344 & TRN \\
\hline CHEMBL1461165 & 688267 & 4.2 & 5.1394 & TST \\
\hline CHEMBL1369423 & 688267 & 4.4 & 5.0791 & TST \\
\hline CHEMBL1330023 & 688267 & 4.7 & 5.037 & TRN \\
\hline CHEMBL1540528 & 688267 & 4.05 & 5.0912 & TST \\
\hline CHEMBL1367450 & 688267 & 5.0 & 5.0626 & TST \\
\hline CHEMBL1413299 & 688267 & 4.0 & 5.0526 & TST \\
\hline CHEMBL1500087 & 688267 & 4.4 & 5.1731 & TRN \\
\hline CHEMBL 1305640 & 688267 & 4.6 & 5.1093 & TRN \\
\hline CHEMBL1352713 & 688267 & 6.45 & 5.0751 & TST \\
\hline CHEMBL1387776 & 688267 & 6.2 & 5.125 & TRN \\
\hline CHEMBL1394221 & 688267 & 4.0 & 5.0231 & TRN \\
\hline CHEMBL1321526 & 688267 & 5.45 & 5.1119 & TRN \\
\hline CHEMBL1496690 & 688267 & 4.0 & 5.1118 & TRN \\
\hline CHEMBL1531655 & 688267 & 6.15 & 5.1265 & TRN \\
\hline CHEMBL1539751 & 688267 & 5.2 & 5.0737 & TRN \\
\hline CHEMBL1472402 & 688267 & 6.25 & 5.0293 & TRN \\
\hline CHEMBL1603481 & 688267 & 5.55 & 4.9678 & TRN \\
\hline CHEMBL1514438 & 688267 & 4.35 & 5.0205 & TRN \\
\hline CHEMBL1308277 & 688267 & 6.2 & 5.1298 & TRN \\
\hline CHEMBL1551003 & 688267 & 4.55 & 5.0318 & TRN \\
\hline CHEMBL1080915 & 688267 & 3.95 & 5.0603 & TRN \\
\hline CHEMBL1450401 & 688267 & 6.15 & 5.0362 & TST \\
\hline CHEMBL1479147 & 688267 & 4.4 & 5.1034 & TRN \\
\hline CHEMBL1575652 & 688267 & 4.25 & 4.9994 & TST \\
\hline CHEMBL1389373 & 688267 & 6.2 & 5.069 & TRN \\
\hline CHEMBL1585340 & 688267 & 6.2 & 5.0816 & TST \\
\hline CHEMBL1370144 & 688267 & 4.15 & 5.1075 & TRN \\
\hline
\end{tabular}




\begin{tabular}{|c|c|c|c|c|}
\hline \multicolumn{5}{|c|}{ Supplemental Table S2.txt } \\
\hline CHEMBL1577349 & 688267 & 4.0 & 5.1275 & TRN \\
\hline CHEMBL1330256 & 688267 & 4.45 & 5.0174 & TRN \\
\hline CHEMBL1494410 & 688267 & 4.65 & 5.0421 & TRN \\
\hline CHEMBL1502856 & 688267 & 5.25 & 5.0133 & TRN \\
\hline CHEMBL1599114 & 688267 & 5.15 & 5.1179 & TST \\
\hline CHEMBL1424354 & 688267 & 4.95 & 5.0867 & TRN \\
\hline CHEMBL1507944 & 688267 & 5.25 & 5.1543 & TRN \\
\hline CHEMBL1551317 & 688267 & 5.5 & 5.015 & TRN \\
\hline CHEMBL1553066 & 688267 & 4.25 & 5.0793 & TRN \\
\hline CHEMBL1992551 & 688267 & 4.2 & 5.004 & TST \\
\hline CHEMBL1486120 & 688267 & 4.05 & 5.0567 & TRN \\
\hline CHEMBL1436503 & 688267 & 6.0 & 5.1106 & TRN \\
\hline CHEMBL1392433 & 688267 & 4.0 & 5.1283 & TRN \\
\hline CHEMBL1534765 & 688267 & 4.0 & 5.0523 & TRN \\
\hline CHEMBL1593709 & 688267 & 6.5 & 5.0643 & TST \\
\hline CHEMBL1522938 & 688267 & 4.0 & 5.0451 & TST \\
\hline CHEMBL1410894 & 688267 & 6.7501 & 5.0685 & TRN \\
\hline CHEMBL1439521 & 688267 & 5.5 & 5.1288 & TRN \\
\hline CHEMBL1431537 & 688267 & 4.05 & 5.0613 & TRN \\
\hline CHEMBL1484465 & 688267 & 4.4 & 5.0611 & TST \\
\hline CHEMBL1453636 & 688267 & 4.45 & 5.0105 & TRN \\
\hline CHEMBL1543383 & 688267 & 3.95 & 5.0585 & TRN \\
\hline CHEMBL582715 & 688267 & 4.5 & 5.0485 & TRN \\
\hline CHEMBL1574762 & 688267 & 5.1 & 5.044 & TRN \\
\hline CHEMBL1596297 & 688267 & 5.7 & 5.1275 & TRN \\
\hline CHEMBL1572272 & 688267 & 4.2 & 5.1113 & TST \\
\hline CHEMBL1549046 & 688267 & 5.55 & 5.0987 & TST \\
\hline CHEMBL1524533 & 688267 & 5.3 & 5.0565 & TRN \\
\hline CHEMBL1446802 & 688267 & 3.95 & 5.0534 & TST \\
\hline CHEMBL3190643 & 688267 & 5.7 & 5.0816 & TST \\
\hline CHEMBL1574234 & 688267 & 3.95 & 5.0076 & TRN \\
\hline CHEMBL1356686 & 688267 & 5.85 & 5.0658 & TRN \\
\hline CHEMBL1450618 & 688267 & 5.3 & 5.0988 & TRN \\
\hline CHEMBL1365746 & 688267 & 5.5 & 5.0477 & TST \\
\hline CHEMBL1494656 & 688267 & 4.1 & 5.01 & TST \\
\hline CHEMBL1342630 & 688267 & 4.45 & 5.0171 & TRN \\
\hline CHEMBL1361436 & 688267 & 4.3 & 5.0294 & TRN \\
\hline CHEMBL1436809 & 688267 & 5.95 & 5.0529 & TST \\
\hline CHEMBL1523913 & 688267 & 5.65 & 5.0195 & TRN \\
\hline CHEMBL1479493 & 688267 & 6.25 & 5.0369 & TRN \\
\hline CHEMBL1613424 & 688267 & 4.35 & 5.0616 & TRN \\
\hline CHEMBL1353361 & 688267 & 5.5 & 5.0996 & TRN \\
\hline CHEMBL1402865 & 688267 & 4.1 & 5.1074 & TRN \\
\hline CHEMBL1528668 & 688267 & 3.95 & 5.0743 & TST \\
\hline CHEMBL1429823 & 688267 & 5.5 & 5.0078 & TST \\
\hline CHEMBL1562599 & 688267 & 6.25 & 5.0137 & TRN \\
\hline CHEMBL1606261 & 688267 & 4.35 & 5.0525 & TRN \\
\hline CHEMBL1353524 & 688267 & 4.55 & 5.1218 & TST \\
\hline
\end{tabular}




\begin{tabular}{|c|c|c|c|c|c|}
\hline \multicolumn{6}{|c|}{ Supplemental Table S2.txt } \\
\hline CHEMBL1351561 & 688267 & 5.15 & 5.0191 & TRN & \\
\hline CHEMBL1458524 & 688267 & 5.1 & 5.0507 & TRN & \\
\hline CHEMBL1447280 & 688267 & 4.95 & 5.1576 & TRN & \\
\hline CHEMBL1543747 & 688267 & 5.5 & 5.0494 & TRN & \\
\hline CHEMBL1436015 & 688267 & 4.7 & 5.03100 & 0000000001 & TRN \\
\hline CHEMBL1337766 & 688267 & 4.4 & 5.072 & TRN & \\
\hline CHEMBL1397592 & 688267 & 4.25 & 5.0684 & TRN & \\
\hline CHEMBL1356514 & 688267 & 5.25 & 5.1022 & TRN & \\
\hline CHEMBL1554802 & 688267 & 5.3 & 5.0522 & TRN & \\
\hline CHEMBL1323053 & 688267 & 5.9 & 5.0674 & TST & \\
\hline CHEMBL1556242 & 688267 & 4.85 & 5.0319 & TST & \\
\hline CHEMBL1383847 & 688267 & 4.0 & 5.0255 & TRN & \\
\hline CHEMBL1603430 & 688267 & 4.65 & 5.0634 & TST & \\
\hline CHEMBL1385307 & 688267 & 5.5 & 5.0866 & TST & \\
\hline CHEMBL1363161 & 688267 & 4.0 & 5.0223 & TRN & \\
\hline CHEMBL1320534 & 688267 & 5.05 & 5.0844 & TRN & \\
\hline CHEMBL1505016 & 688267 & 4.05 & 5.0177 & TST & \\
\hline CHEMBL1510748 & 688267 & 5.35 & 5.1194 & TST & \\
\hline CHEMBL1529822 & 688267 & 5.0 & 5.0898 & TRN & \\
\hline CHEMBL1593666 & 688267 & 4.0 & 5.01399 & 9999999999 & TRN \\
\hline CHEMBL1347523 & 688267 & 4.0 & 5.095 & TRN & \\
\hline CHEMBL1516273 & 688267 & 4.25 & 5.0814 & TRN & \\
\hline CHEMBL1339741 & 688267 & 6.2 & 5.00899 & 99999999995 & TRN \\
\hline CHEMBL3208183 & 688267 & 5.4 & 5.0954 & TRN & \\
\hline CHEMBL1598487 & 688267 & 4.8 & 5.0795 & TRN & \\
\hline CHEMBL1582748 & 688267 & 5.55 & 5.0627 & TST & \\
\hline CHEMBL1354108 & 688267 & 5.3 & 5.0354 & TRN & \\
\hline CHEMBL1483551 & 688267 & 4.5 & 5.0794 & TRN & \\
\hline CHEMBL1426916 & 688267 & 5.9 & 5.1524 & TRN & \\
\hline CHEMBL1355562 & 688267 & 4.0 & 5.0578 & TRN & \\
\hline CHEMBL1419357 & 688267 & 4.05 & 5.01399 & 9999999999 & TRN \\
\hline CHEMBL388594 & 688267 & 5.0 & 5.0478 & TST & \\
\hline CHEMBL 3145378 & 688267 & 4.0 & 5.0026 & TRN & \\
\hline CHEMBL1564549 & 688267 & 6.2 & 5.0872 & TST & \\
\hline CHEMBL1437154 & 688267 & 6.0 & 5.0594 & TRN & \\
\hline CHEMBL1435050 & 688267 & 5.2 & 5.0339 & TST & \\
\hline CHEMBL1433600 & 688267 & 5.5 & 5.0216 & TRN & \\
\hline CHEMBL3197825 & 688267 & 5.85 & 5.0193 & TST & \\
\hline CHEMBL1516380 & 688267 & 4.4 & 5.0418 & TRN & \\
\hline CHEMBL1425032 & 688267 & 3.15 & 5.0608 & TRN & \\
\hline CHEMBL1575247 & 688267 & 4.55 & 5.0636 & TST & \\
\hline CHEMBL1990539 & 688267 & 4.4 & 5.0114 & TRN & \\
\hline CHEMBL1500046 & 688267 & 6.15 & 5.0793 & TRN & \\
\hline CHEMBL1499165 & 688267 & 6.1 & 5.0763 & TRN & \\
\hline CHEMBL1554748 & 688267 & 4.45 & 5.1279 & TRN & \\
\hline CHEMBL1410132 & 688267 & 4.45 & 5.1104 & TRN & \\
\hline CHEMBL1594898 & 688267 & 4.45 & 5.0607 & TRN & \\
\hline CHEMBL1327611 & 688267 & 4.25 & 5.0554 & TRN & \\
\hline
\end{tabular}




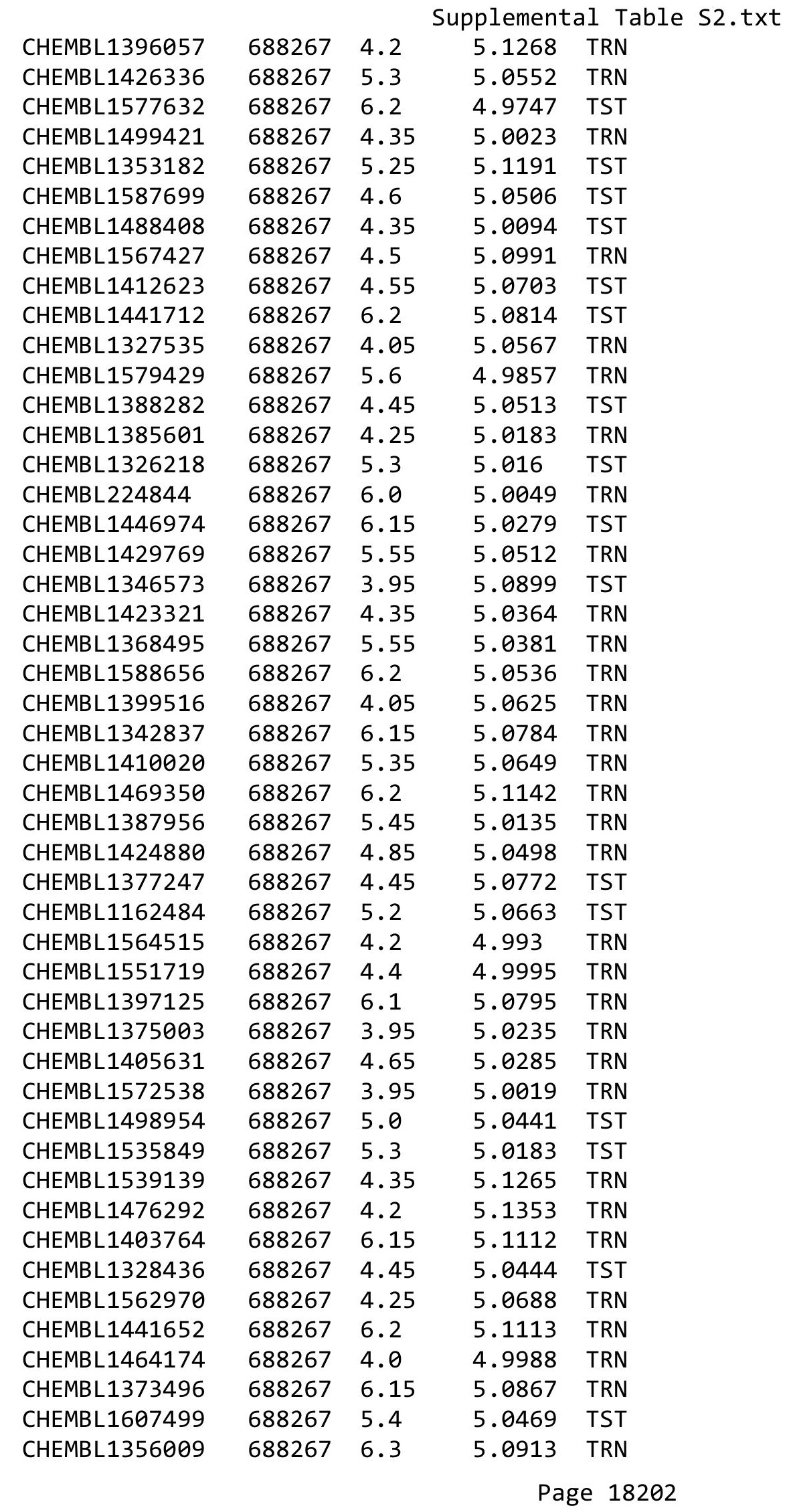




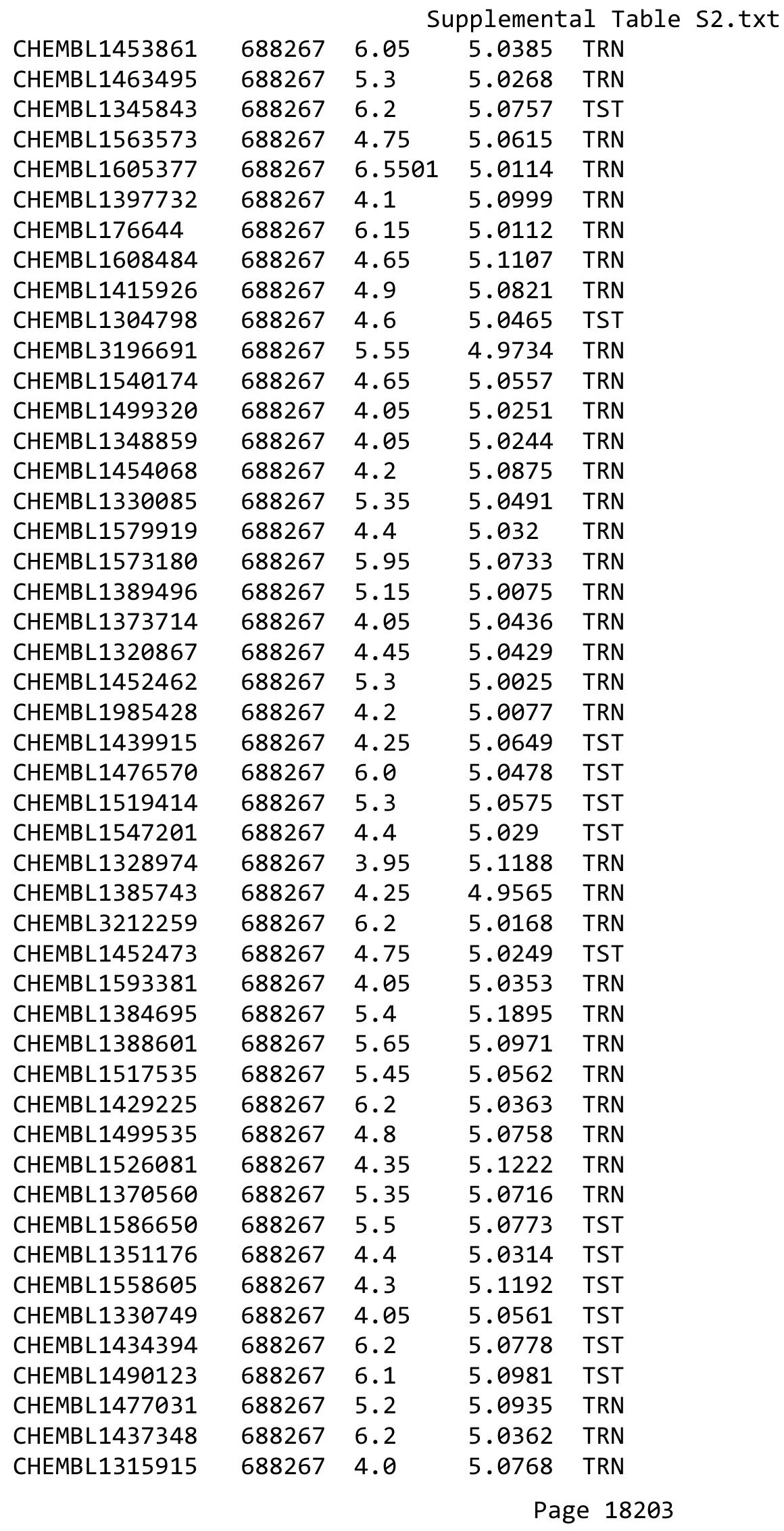




\begin{tabular}{|c|c|c|c|c|}
\hline \multicolumn{5}{|c|}{ Supplemental Table S2.txt } \\
\hline CHEMBL1575243 & 688267 & 4.0 & 4.9991 & TRN \\
\hline CHEMBL1428390 & 688267 & 4.35 & 5.1225 & TRN \\
\hline CHEMBL1497229 & 688267 & 6.25 & 5.002 & TST \\
\hline CHEMBL1355568 & 688267 & 5.35 & 5.0485 & TRN \\
\hline CHEMBL 3209785 & 688267 & 4.85 & 5.0077 & TRN \\
\hline CHEMBL1502883 & 688267 & 4.5 & 5.0085 & TRN \\
\hline CHEMBL1603030 & 688267 & 5.1 & 5.0972 & TRN \\
\hline CHEMBL1460318 & 688267 & 4.4 & 5.0751 & TST \\
\hline CHEMBL1508428 & 688267 & 4.7 & 5.0504 & TRN \\
\hline CHEMBL1423223 & 688267 & 4.45 & 5.0516 & TRN \\
\hline CHEMBL1527281 & 688267 & 3.95 & 5.0843 & TRN \\
\hline CHEMBL3211462 & 688267 & 5.35 & 5.0312 & TST \\
\hline CHEMBL1466006 & 688267 & 5.1 & 5.0397 & TRN \\
\hline CHEMBL1306276 & 688267 & 4.0 & 5.1196 & TST \\
\hline CHEMBL1343325 & 688267 & 5.8 & 5.0655 & TST \\
\hline CHEMBL1456750 & 688267 & 5.7 & 5.0489 & TRN \\
\hline CHEMBL1380758 & 688267 & 5.6 & 5.0583 & TRN \\
\hline CHEMBL1320243 & 688267 & 6.5 & 5.0374 & TRN \\
\hline CHEMBL1431070 & 688267 & 4.6 & 4.9831 & TRN \\
\hline CHEMBL1979671 & 688267 & 4.5 & 5.0022 & TRN \\
\hline CHEMBL1445939 & 688267 & 4.4 & 5.0399 & TRN \\
\hline CHEMBL1367971 & 688267 & 6.25 & 4.9975 & TST \\
\hline CHEMBL1488670 & 688267 & 4.2 & 5.0296 & TRN \\
\hline CHEMBL1607860 & 688267 & 4.25 & 5.0243 & TST \\
\hline CHEMBL1417720 & 688267 & 5.05 & 5.0755 & TST \\
\hline CHEMBL1570716 & 688267 & 4.8 & 5.0272 & TRN \\
\hline CHEMBL1506198 & 688267 & 4.3 & 5.1051 & TRN \\
\hline CHEMBL1429814 & 688267 & 5.45 & 5.112 & TRN \\
\hline CHEMBL1505213 & 688267 & 4.05 & 5.0408 & TRN \\
\hline CHEMBL1575236 & 688267 & 4.1 & 5.0503 & TRN \\
\hline CHEMBL1360735 & 688267 & 6.2 & 5.0436 & TST \\
\hline CHEMBL1560175 & 688267 & 4.4 & 5.1114 & TRN \\
\hline CHEMBL1576673 & 688267 & 5.0 & 5.0533 & TST \\
\hline CHEMBL1458700 & 688267 & 4.5 & 4.9805 & TRN \\
\hline CHEMBL1394030 & 688267 & 6.5 & 5.0549 & TRN \\
\hline CHEMBL1555044 & 688267 & 6.0 & 5.0227 & TRN \\
\hline CHEMBL 1388529 & 688267 & 5.45 & 5.0329 & TRN \\
\hline CHEMBL1437614 & 688267 & 4.9 & 5.0834 & TST \\
\hline CHEMBL1425131 & 688267 & 4.0 & 4.9542 & TRN \\
\hline CHEMBL1392181 & 688267 & 4.65 & 5.0245 & TST \\
\hline CHEMBL1344231 & 688267 & 5.05 & 5.0801 & TST \\
\hline CHEMBL1368725 & 688267 & 4.7 & 5.0442 & TST \\
\hline CHEMBL1611258 & 688267 & 5.85 & 5.0024 & TRN \\
\hline CHEMBL1522189 & 688267 & 5.8 & 5.0903 & TST \\
\hline CHEMBL1445552 & 688267 & 5.8 & 5.066 & TRN \\
\hline CHEMBL1567893 & 688267 & 6.0 & 5.0278 & TRN \\
\hline CHEMBL 2000067 & 688267 & 5.5 & 4.9841 & TST \\
\hline CHEMBL1403699 & 688267 & 5.65 & 5.1467 & TRN \\
\hline
\end{tabular}




\begin{tabular}{|c|c|c|c|c|c|}
\hline \multicolumn{6}{|c|}{ Supplemental Table S2.txt } \\
\hline CHEMBL1506514 & 688267 & 5.1 & 5.0319 & TST & \\
\hline CHEMBL1459248 & 688267 & 5.25 & 5.0342 & TRN & \\
\hline CHEMBL3209458 & 688267 & 6.05 & 5.0502 & TST & \\
\hline CHEMBL3190376 & 688267 & 4.6 & 5.0045 & TST & \\
\hline CHEMBL1445653 & 688267 & 4.65 & 5.0752 & TRN & \\
\hline CHEMBL1528844 & 688267 & 6.2 & 5.0143 & TST & \\
\hline CHEMBL1454945 & 688267 & 5.25 & 5.0712 & TRN & \\
\hline CHEMBL1503199 & 688267 & 5.3 & 5.053 & TRN & \\
\hline CHEMBL1289297 & 688267 & 4.95 & 5.0186 & TRN & \\
\hline CHEMBL1494882 & 688267 & 6.2 & 5.0571 & TRN & \\
\hline CHEMBL1599665 & 688267 & 5.75 & 5.0692 & TRN & \\
\hline CHEMBL1330657 & 688267 & 5.05 & $5.1270 e$ & 0000000001 & TST \\
\hline CHEMBL1610403 & 688267 & 6.25 & 5.0227 & TRN & \\
\hline CHEMBL1588354 & 688267 & 6.5 & 5.0577 & TST & \\
\hline CHEMBL1512059 & 688267 & 5.95 & 5.0039 & TRN & \\
\hline CHEMBL447714 & 688267 & 4.25 & 5.0623 & TRN & \\
\hline CHEMBL1528047 & 688267 & 4.3 & $5.1220 e$ & 0000000001 & TRN \\
\hline CHEMBL1436518 & 688267 & 6.2 & 5.0947 & TRN & \\
\hline CHEMBL1588767 & 688267 & 5.9 & 5.0395 & TRN & \\
\hline CHEMBL1326027 & 688267 & 4.15 & 5.0873 & TRN & \\
\hline CHEMBL1319901 & 688267 & 4.3 & 5.1381 & TRN & \\
\hline CHEMBL1341447 & 688267 & 4.05 & 5.0524 & TRN & \\
\hline CHEMBL1601990 & 688267 & 6.2 & 5.0355 & TRN & \\
\hline CHEMBL1417150 & 688267 & 4.05 & 5.0036 & TRN & \\
\hline CHEMBL1301768 & 688267 & 4.05 & 5.0552 & TST & \\
\hline CHEMBL1531005 & 688267 & 4.0 & 4.9662 & TRN & \\
\hline CHEMBL3199122 & 688267 & 5.85 & 5.0011 & TRN & \\
\hline CHEMBL1327581 & 688267 & 6.2 & 5.1042 & TRN & \\
\hline CHEMBL1437360 & 688267 & 4.0 & 5.0447 & TRN & \\
\hline CHEMBL1470382 & 688267 & 4.55 & 4.9585 & TRN & \\
\hline CHEMBL1487714 & 688267 & 4.55 & 5.0747 & TRN & \\
\hline CHEMBL1592765 & 688267 & 3.95 & 5.0399 & TRN & \\
\hline CHEMBL1410107 & 688267 & 5.25 & 5.1161 & TRN & \\
\hline CHEMBL1505144 & 688267 & 4.95 & 5.0411 & TRN & \\
\hline CHEMBL1536605 & 688267 & 6.25 & 5.0516 & TRN & \\
\hline CHEMBL1528296 & 688267 & 6.5 & 5.0714 & TRN & \\
\hline CHEMBL1447620 & 688267 & 3.9 & 5.0809 & TRN & \\
\hline CHEMBL1466512 & 688267 & 4.4 & 5.0174 & TRN & \\
\hline CHEMBL1581687 & 688267 & 6.15 & 5.0715 & TRN & \\
\hline CHEMBL1406497 & 688267 & 5.35 & 5.0653 & TRN & \\
\hline CHEMBL1372735 & 688267 & 4.9 & 5.0904 & TRN & \\
\hline CHEMBL1401215 & 688267 & 7.0501 & 5.0223 & TRN & \\
\hline CHEMBL1468697 & 688267 & 4.05 & 5.0564 & TST & \\
\hline CHEMBL1316459 & 688267 & 3.95 & 5.1135 & TRN & \\
\hline CHEMBL1526394 & 688267 & 5.05 & 5.0991 & TRN & \\
\hline CHEMBL1589479 & 688267 & 5.3 & 5.0596 & TST & \\
\hline CHEMBL1436302 & 688267 & 4.6 & 5.105 & TRN & \\
\hline CHEMBL1338727 & 688267 & 4.0 & 5.0207 & TRN & \\
\hline
\end{tabular}




\begin{tabular}{|c|c|c|c|c|c|}
\hline \multicolumn{6}{|c|}{ Supplemental Table S2.txt } \\
\hline CHEMBL1437503 & 688267 & 5.55 & 5.0991 & TRN & \\
\hline CHEMBL1465742 & 688267 & 5.15 & 5.1491 & TRN & \\
\hline CHEMBL1489327 & 688267 & 6.2 & 5.0699 & TRN & \\
\hline CHEMBL1505092 & 688267 & 6.45 & 5.0633 & TRN & \\
\hline CHEMBL1318952 & 688267 & 5.3 & 5.0316 & TRN & \\
\hline CHEMBL1413747 & 688267 & 3.95 & 5.0358 & TRN & \\
\hline CHEMBL1414403 & 688267 & 5.15 & 5.0473 & TST & \\
\hline CHEMBL3208599 & 688267 & 4.0 & 5.0894 & TST & \\
\hline CHEMBL1484406 & 688267 & 4.0 & 5.0757 & TRN & \\
\hline CHEMBL1558409 & 688267 & 6.5 & 5.0964 & TRN & \\
\hline CHEMBL1411943 & 688267 & 4.05 & 5.1026 & TRN & \\
\hline CHEMBL1301800 & 688267 & 6.0 & 5.03600 & 00000000005 & TRN \\
\hline CHEMBL1404148 & 688267 & 5.3 & 5.0469 & TRN & \\
\hline CHEMBL1516218 & 688267 & 5.3 & 5.0646 & TST & \\
\hline CHEMBL1348153 & 688267 & 4.45 & 5.1088 & TRN & \\
\hline CHEMBL1486429 & 688267 & 4.95 & 5.0394 & TRN & \\
\hline CHEMBL1593101 & 688267 & 4.3 & 5.0437 & TST & \\
\hline CHEMBL1419333 & 688267 & 6.45 & 5.0638 & TRN & \\
\hline CHEMBL1336436 & 688267 & 6.2 & 4.9699 & TRN & \\
\hline CHEMBL1511583 & 688267 & 5.95 & 5.0584 & TST & \\
\hline CHEMBL1590477 & 688267 & 4.3 & 5.1628 & TRN & \\
\hline CHEMBL1543707 & 688267 & 4.4 & 5.1173 & TRN & \\
\hline CHEMBL1512224 & 688267 & 6.25 & 5.1333 & TRN & \\
\hline CHEMBL1495481 & 688267 & 6.05 & 5.0066 & TST & \\
\hline CHEMBL1440198 & 688267 & 5.5 & 5.171 & TRN & \\
\hline CHEMBL1469939 & 688267 & 4.95 & 5.0512 & TST & \\
\hline CHEMBL1437224 & 688267 & 4.0 & 5.0833 & TST & \\
\hline CHEMBL1528370 & 688267 & 5.75 & 5.069 & TST & \\
\hline CHEMBL1588451 & 688267 & 5.45 & 5.0969 & TRN & \\
\hline CHEMBL1375418 & 688267 & 4.2 & 4.9816 & TRN & \\
\hline CHEMBL3212810 & 688267 & 4.05 & 5.0185 & TST & \\
\hline CHEMBL1333887 & 688267 & 5.8 & 5.0481 & TRN & \\
\hline CHEMBL1357223 & 688267 & 5.7 & 5.0302 & TRN & \\
\hline CHEMBL1403091 & 688267 & 4.1 & 5.0384 & TRN & \\
\hline CHEMBL1349627 & 688267 & 5.5 & 5.0523 & TRN & \\
\hline CHEMBL1388985 & 688267 & 4.7 & 5.046 & TRN & \\
\hline CHEMBL1439617 & 688267 & 5.3 & 5.1187 & TRN & \\
\hline CHEMBL1480736 & 688267 & 3.95 & 5.0791 & TRN & \\
\hline CHEMBL1364869 & 688267 & 4.55 & 5.0711 & TST & \\
\hline CHEMBL 3190424 & 688267 & 4.75 & 5.0025 & TRN & \\
\hline CHEMBL1407929 & 688267 & 5.55 & 5.0615 & TRN & \\
\hline CHEMBL3198573 & 688267 & 5.3 & 4.9884 & TST & \\
\hline CHEMBL1473745 & 688267 & 4.0 & 4.9832 & TRN & \\
\hline CHEMBL1552350 & 688267 & 4.0 & 5.0512 & TRN & \\
\hline CHEMBL1454849 & 688267 & 6.2 & 5.0547 & TST & \\
\hline CHEMBL1355429 & 688267 & 4.1 & 5.0327 & TRN & \\
\hline CHEMBL1480264 & 688267 & 6.25 & 5.0134 & TRN & \\
\hline CHEMBL1592250 & 688267 & 4.55 & 5.1082 & TRN & \\
\hline
\end{tabular}




\begin{tabular}{|c|c|c|c|c|c|}
\hline \multicolumn{6}{|c|}{ pplemental labıe S2 } \\
\hline CHEMBL1313377 & 688267 & 4.7 & 5.0053 & TST & \\
\hline CHEMBL1372996 & 688267 & 4.65 & 5.0244 & TRN & \\
\hline CHEMBL1586015 & 688267 & 5.6 & 5.12200 & 0000000001 & TRN \\
\hline CHEMBL1477129 & 688267 & 5.0 & 5.0641 & TRN & \\
\hline CHEMBL3199110 & 688267 & 6.2 & 5.0139 & TRN & \\
\hline CHEMBL1482476 & 688267 & 3.95 & 5.0395 & TST & \\
\hline CHEMBL1611101 & 688267 & 6.5 & 5.0771 & TST & \\
\hline CHEMBL1536584 & 688267 & 5.05 & 5.0355 & TRN & \\
\hline CHEMBL1478173 & 688267 & 5.5 & 5.0776 & TRN & \\
\hline CHEMBL1399825 & 688267 & 5.05 & 5.0285 & TRN & \\
\hline CHEMBL1302085 & 688267 & 4.1 & 5.1233 & TRN & \\
\hline CHEMBL1561590 & 688267 & 4.0 & 5.0365 & TST & \\
\hline CHEMBL1456330 & 688267 & 5.05 & 5.0273 & TST & \\
\hline CHEMBL1344265 & 688267 & 4.55 & 4.9847 & TST & \\
\hline CHEMBL1335616 & 688267 & 4.45 & 5.0069 & TRN & \\
\hline CHEMBL3189270 & 688267 & 4.25 & 5.0085 & TRN & \\
\hline CHEMBL1569658 & 688267 & 5.8 & 5.079 & TRN & \\
\hline CHEMBL1589283 & 688267 & 6.45 & 5.0651 & TRN & \\
\hline CHEMBL1312239 & 688267 & 4.75 & 5.0359 & TST & \\
\hline CHEMBL1388544 & 688267 & 5.1 & 5.0489 & TRN & \\
\hline CHEMBL1479341 & 688267 & 4.0 & 5.0398 & TST & \\
\hline CHEMBL1466502 & 688267 & 5.9 & 5.0612 & TST & \\
\hline CHEMBL1420076 & 688267 & 5.3 & 5.0563 & TRN & \\
\hline CHEMBL1392066 & 688267 & 4.05 & 5.0191 & TRN & \\
\hline CHEMBL1527094 & 688267 & 5.85 & 5.0266 & TRN & \\
\hline CHEMBL1549782 & 688267 & 4.1 & 5.1106 & TST & \\
\hline CHEMBL1410038 & 688267 & 4.9 & 5.0395 & TRN & \\
\hline CHEMBL1468805 & 688267 & 5.4 & 5.0041 & TST & \\
\hline CHEMBL1467063 & 688267 & 5.65 & 5.1097 & TRN & \\
\hline CHEMBL3198880 & 688267 & 4.0 & 5.0119 & TRN & \\
\hline CHEMBL1573511 & 688267 & 5.25 & 5.099 & TRN & \\
\hline CHEMBL1317357 & 688267 & 5.6 & 5.0346 & TRN & \\
\hline CHEMBL1325433 & 688267 & 5.9 & 5.1132 & TRN & \\
\hline CHEMBL1540100 & 688267 & 5.15 & 5.062 & TRN & \\
\hline CHEMBL1346059 & 688267 & 5.05 & 5.0775 & TRN & \\
\hline CHEMBL1416425 & 688267 & 4.05 & 5.0224 & TRN & \\
\hline CHEMBL1463686 & 688267 & 4.0 & 5.0008 & TRN & \\
\hline CHEMBL3212183 & 688267 & 5.95 & 5.0137 & TRN & \\
\hline CHEMBL1436436 & 688267 & 4.6 & 5.0389 & TRN & \\
\hline CHEMBL1600295 & 688267 & 4.05 & 5.0172 & TST & \\
\hline CHEMBL1416240 & 688267 & 4.05 & 5.135 & TRN & \\
\hline CHEMBL1472628 & 688267 & 6.2 & 5.0053 & TRN & \\
\hline CHEMBL1442959 & 688267 & 5.3 & 5.0275 & TRN & \\
\hline CHEMBL1441444 & 688267 & 5.0 & 5.0129 & TRN & \\
\hline CHEMBL1434619 & 688267 & 5.75 & 5.0608 & TRN & \\
\hline CHEMBL1398328 & 688267 & 5.2 & 5.0849 & TRN & \\
\hline CHEMBL1563625 & 688267 & 4.4 & 5.1063 & TST & \\
\hline CHEMBL1313493 & 688267 & 4.6 & 5.0349 & TST & \\
\hline
\end{tabular}




\begin{tabular}{|c|c|c|c|c|c|}
\hline & & \multicolumn{4}{|c|}{ Supplemental Table S2.txt } \\
\hline CHEMBL1406461 & 688267 & 6.15 & 4.999 & TRN & \\
\hline CHEMBL1475116 & 688267 & 4.6 & 5.1155 & TRN & \\
\hline CHEMBL3211943 & 688267 & 4.95 & 5.0169 & TRN & \\
\hline CHEMBL1303009 & 688267 & 4.55 & 5.0896 & TRN & \\
\hline CHEMBL1313696 & 688267 & 6.2 & 5.0574 & TRN & \\
\hline CHEMBL1439574 & 688267 & 5.25 & 5.0855 & TRN & \\
\hline CHEMBL1377766 & 688267 & 4.5 & 5.1108 & TRN & \\
\hline CHEMBL1581566 & 688267 & 4.8 & 5.0344 & TRN & \\
\hline CHEMBL1409215 & 688267 & 5.9 & 5.007 & TRN & \\
\hline CHEMBL1424330 & 688267 & 4.2 & 5.0779 & TST & \\
\hline CHEMBL1301757 & 688267 & 6.2 & 5.0807 & TRN & \\
\hline CHEMBL1476100 & 688267 & 4.0 & 5.0358 & TST & \\
\hline CHEMBL1575169 & 688267 & 5.45 & 5.0625 & TRN & \\
\hline CHEMBL1585698 & 688267 & 4.8 & 5.0137 & TRN & \\
\hline CHEMBL1464739 & 688267 & 5.3 & 5.0042 & TRN & \\
\hline CHEMBL1383470 & 688267 & 4.25 & 5.0317 & TST & \\
\hline CHEMBL1518518 & 688267 & 5.55 & 5.1028 & TRN & \\
\hline CHEMBL1440631 & 688267 & 4.5 & 5.0733 & TRN & \\
\hline CHEMBL 3212468 & 688267 & 6.2 & 5.0952 & TRN & \\
\hline CHEMBL1459544 & 688267 & 5.3 & 5.0883 & TST & \\
\hline CHEMBL1400071 & 688267 & 6.2 & 5.0864 & TST & \\
\hline CHEMBL1483559 & 688267 & 6.25 & 4.9834 & TRN & \\
\hline CHEMBL475441 & 688267 & 4.0 & 5.0033 & TRN & \\
\hline CHEMBL1467698 & 688267 & 4.3 & 5.0444 & TRN & \\
\hline CHEMBL1612859 & 688267 & 6.15 & 5.0295 & TRN & \\
\hline CHEMBL1313255 & 688267 & 5.85 & 5.0449 & TRN & \\
\hline CHEMBL1527184 & 688267 & 4.05 & 5.1328 & TRN & \\
\hline CHEMBL1450387 & 688267 & 4.0 & 5.0275 & TST & \\
\hline CHEMBL1301885 & 688267 & 4.55 & 5.0725 & TRN & \\
\hline CHEMBL3199633 & 688267 & 4.25 & 4.9571 & TRN & \\
\hline CHEMBL1464534 & 688267 & 4.35 & 5.0526 & TRN & \\
\hline CHEMBL1612214 & 688267 & 5.2 & 5.0443 & TRN & \\
\hline CHEMBL1542484 & 688267 & 4.4 & 5.0445 & TRN & \\
\hline CHEMBL1345735 & 688267 & 5.45 & 5.13299 & 7999999999 & TST \\
\hline CHEMBL1381803 & 688267 & 4.7 & 5.0457 & TRN & \\
\hline CHEMBL1590504 & 688267 & 4.15 & 5.0593 & TRN & \\
\hline CHEMBL1599921 & 688267 & 5.05 & 5.0162 & TRN & \\
\hline CHEMBL1442083 & 688267 & 5.7 & 5.0562 & TRN & \\
\hline CHEMBL1518213 & 688267 & 4.55 & 5.0536 & TST & \\
\hline CHEMBL1412939 & 688267 & 4.9 & 5.046 & TRN & \\
\hline CHEMBL1399183 & 688267 & 5.0 & 5.0894 & TRN & \\
\hline CHEMBL1443054 & 688267 & 5.0 & 5.0744 & TST & \\
\hline CHEMBL1415775 & 688267 & 5.85 & 5.0632 & TRN & \\
\hline CHEMBL1457971 & 688267 & 4.3 & 5.0756 & TRN & \\
\hline CHEMBL1602998 & 688267 & 5.3 & 5.0347 & TRN & \\
\hline CHEMBL1333245 & 688267 & 5.35 & 5.0877 & TRN & \\
\hline CHEMBL1529300 & 688267 & 4.05 & 4.9949 & TRN & \\
\hline CHEMBL1313908 & 688267 & 5.25 & 5.0783 & TRN & \\
\hline
\end{tabular}




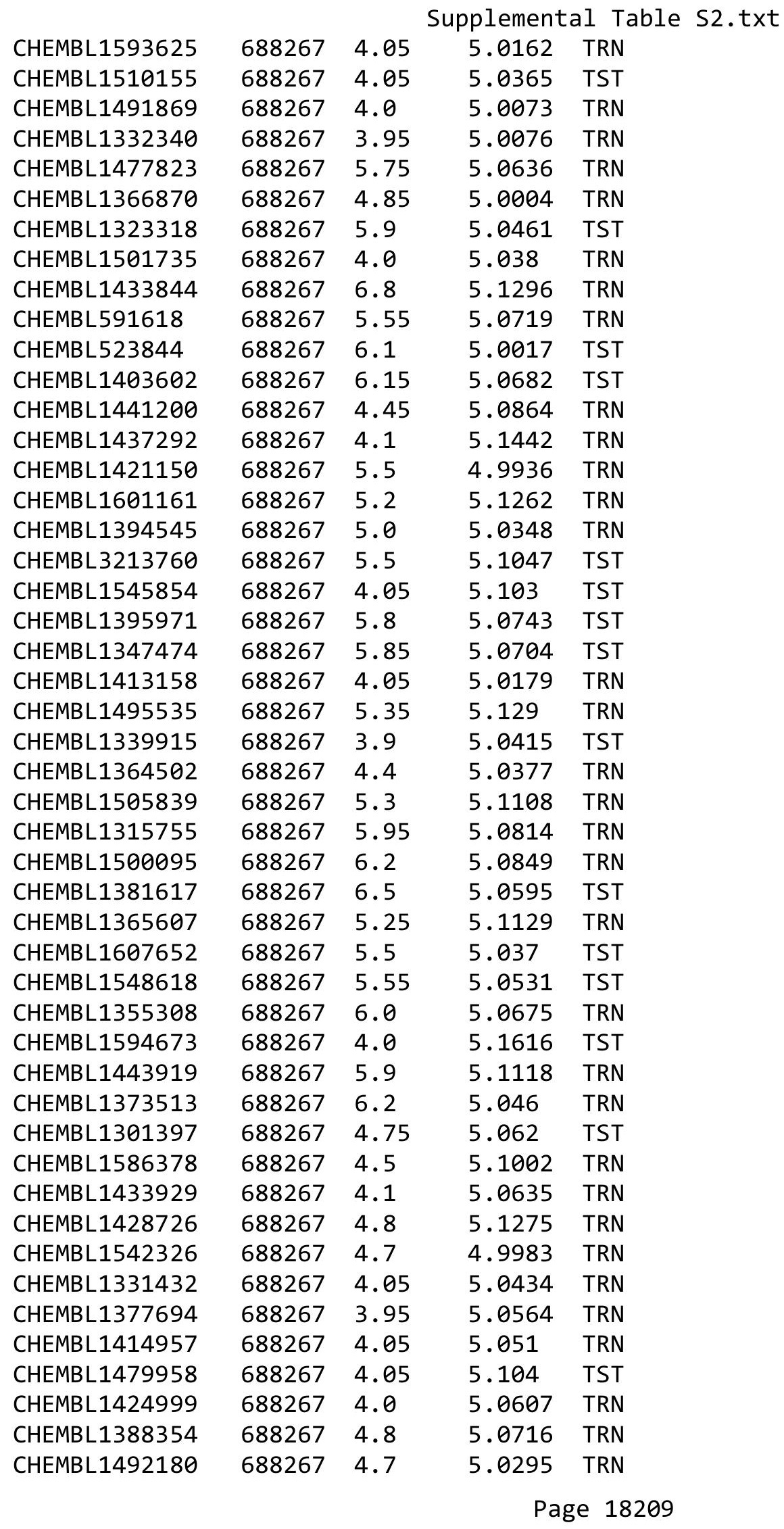




\begin{tabular}{|c|c|c|c|c|}
\hline & & & pplement & al $\mathrm{Ta}$ \\
\hline CHEMBL1414347 & 688267 & 4.6 & 5.0794 & TRN \\
\hline CHEMBL1426623 & 688267 & 3.95 & 5.0003 & TRN \\
\hline CHEMBL1611094 & 688267 & 4.05 & 5.0463 & TST \\
\hline CHEMBL1573403 & 688267 & 6.15 & 5.0013 & TRN \\
\hline CHEMBL1516930 & 688267 & 4.25 & 5.0799 & TST \\
\hline CHEMBL1483857 & 688267 & 5.5 & 5.0315 & TRN \\
\hline CHEMBL1464529 & 688267 & 4.05 & 5.1146 & TST \\
\hline CHEMBL1373878 & 688267 & 5.85 & 5.0635 & TRN \\
\hline CHEMBL1607629 & 688267 & 4.05 & 5.0114 & TRN \\
\hline CHEMBL1554551 & 688267 & 4.0 & 5.0645 & TST \\
\hline CHEMBL1386578 & 688267 & 4.4 & 5.0378 & TST \\
\hline CHEMBL1435704 & 688267 & 5.0 & 5.059 & TRN \\
\hline CHEMBL1479387 & 688267 & 4.3 & 5.0111 & TST \\
\hline CHEMBL3213198 & 688267 & 4.3 & 5.0475 & TST \\
\hline CHEMBL1510867 & 688267 & 6.25 & 5.0253 & TRN \\
\hline CHEMBL1561773 & 688267 & 4.75 & 5.154 & TST \\
\hline CHEMBL1517603 & 688267 & 5.45 & 5.0186 & TRN \\
\hline CHEMBL1354222 & 688267 & 4.5 & 5.0387 & TRN \\
\hline CHEMBL1479460 & 688267 & 4.2 & 5.1316 & TRN \\
\hline CHEMBL1557516 & 688267 & 4.0 & 5.0787 & TRN \\
\hline CHEMBL1565570 & 688267 & 5.55 & 5.0256 & TST \\
\hline CHEMBL1370491 & 688267 & 5.2 & 5.0364 & TRN \\
\hline CHEMBL1480769 & 688267 & 3.95 & 5.0728 & TRN \\
\hline CHEMBL1500713 & 688267 & 4.0 & 4.9973 & TRN \\
\hline CHEMBL3199313 & 688267 & 4.45 & 5.1205 & TRN \\
\hline CHEMBL1448189 & 688267 & 5.55 & 5.0825 & TRN \\
\hline CHEMBL1570444 & 688267 & 4.8 & 5.0241 & TRN \\
\hline CHEMBL1502994 & 688267 & 5.3 & 5.0816 & TRN \\
\hline CHEMBL1430223 & 688267 & 5.8 & 5.1524 & TRN \\
\hline CHEMBL1551140 & 688267 & 3.95 & 5.0246 & TRN \\
\hline CHEMBL1357196 & 688267 & 5.35 & 5.0532 & TRN \\
\hline CHEMBL1611005 & 688267 & 5.9 & 4.9964 & TRN \\
\hline CHEMBL1602610 & 688267 & 6.15 & 5.0206 & TRN \\
\hline CHEMBL1509942 & 688267 & 4.55 & 5.0914 & TST \\
\hline CHEMBL1449144 & 688267 & 5.35 & 5.0097 & TST \\
\hline CHEMBL3199319 & 688267 & 5.0 & 5.0184 & TRN \\
\hline CHEMBL1531265 & 688267 & 5.35 & 4.9898 & TRN \\
\hline CHEMBL1608017 & 688267 & 4.0 & 5.0206 & TST \\
\hline CHEMBL1340950 & 688267 & 4.0 & 5.0162 & TRN \\
\hline CHEMBL1332355 & 688267 & 3.95 & 5.0197 & TST \\
\hline CHEMBL1521634 & 688267 & 4.95 & 5.0258 & TRN \\
\hline CHEMBL1345068 & 688267 & 4.35 & 5.1004 & TRN \\
\hline CHEMBL1520671 & 688267 & 5.05 & 4.9831 & TST \\
\hline CHEMBL1492912 & 688267 & 6.2 & 5.0311 & TST \\
\hline CHEMBL1598195 & 688267 & 5.0 & 5.1008 & TRN \\
\hline CHEMBL1356692 & 688267 & 4.0 & 5.0319 & TRN \\
\hline CHEMBL1603191 & 688267 & 4.0 & 5.0457 & TRN \\
\hline CHEMBL1603475 & 688267 & 4.4 & 5.0375 & TST \\
\hline
\end{tabular}




\begin{tabular}{|c|c|c|c|c|c|}
\hline \multirow[b]{2}{*}{ CHEMBL3208032 } & \multirow[b]{2}{*}{688267} & \multicolumn{4}{|c|}{ Supplemental Table S2.txt } \\
\hline & & 4.35 & 5.0082 & TRN & \\
\hline CHEMBL1460171 & 688267 & 5.4 & 5.05699 & 99999999995 & TST \\
\hline CHEMBL1586587 & 688267 & 5.25 & 5.0643 & TST & \\
\hline CHEMBL1350805 & 688267 & 3.95 & 5.0828 & TRN & \\
\hline CHEMBL1435746 & 688267 & 6.2 & 5.1194 & TRN & \\
\hline CHEMBL1456482 & 688267 & 4.0 & 5.0404 & TRN & \\
\hline CHEMBL1465350 & 688267 & 5.05 & 5.1205 & TST & \\
\hline CHEMBL1491346 & 688267 & 4.0 & 5.0614 & TRN & \\
\hline CHEMBL1568529 & 688267 & 5.8 & 5.0237 & TRN & \\
\hline CHEMBL1348052 & 688267 & 4.45 & 5.0926 & TRN & \\
\hline CHEMBL1469777 & 688267 & 4.15 & 5.0806 & TRN & \\
\hline CHEMBL1324144 & 688267 & 5.1 & 5.1253 & TRN & \\
\hline CHEMBL1515836 & 688267 & 4.3 & 5.1155 & TRN & \\
\hline CHEMBL1480666 & 688267 & 6.2 & 5.0831 & TRN & \\
\hline CHEMBL1432674 & 688267 & 4.35 & 5.0839 & TRN & \\
\hline CHEMBL1607061 & 688267 & 4.9 & 5.0633 & TRN & \\
\hline CHEMBL1486845 & 688267 & 4.4 & 5.0321 & TST & \\
\hline CHEMBL1587327 & 688267 & 5.55 & 5.0557 & TRN & \\
\hline CHEMBL1310817 & 688267 & 5.35 & 5.1289 & TRN & \\
\hline CHEMBL1539000 & 688267 & 4.25 & 5.0035 & TRN & \\
\hline CHEMBL1533430 & 688267 & 4.05 & 5.0474 & TRN & \\
\hline CHEMBL1535401 & 688267 & 6.15 & 5.0462 & TRN & \\
\hline CHEMBL1348570 & 688267 & 5.05 & 5.0732 & TST & \\
\hline CHEMBL1454084 & 688267 & 3.95 & 5.0242 & TRN & \\
\hline CHEMBL1525230 & 688267 & 5.05 & 5.1082 & TRN & \\
\hline CHEMBL1434903 & 688267 & 5.45 & 4.9971 & TRN & \\
\hline CHEMBL1505035 & 688267 & 4.5 & 5.0642 & TRN & \\
\hline CHEMBL1493218 & 688267 & 4.2 & 5.1038 & TRN & \\
\hline CHEMBL1301261 & 688267 & 5.6 & 5.0874 & TRN & \\
\hline CHEMBL1508040 & 688267 & 5.85 & 5.1018 & TRN & \\
\hline CHEMBL1344261 & 688267 & 4.5 & 5.1257 & TRN & \\
\hline CHEMBL1400892 & 688267 & 4.25 & 5.0141 & TRN & \\
\hline CHEMBL1596892 & 688267 & 4.4 & 5.0605 & TRN & \\
\hline CHEMBL1461208 & 688267 & 4.4 & 5.1207 & TRN & \\
\hline CHEMBL1326993 & 688267 & 4.05 & 5.0569 & TST & \\
\hline CHEMBL2374080 & 688267 & 5.5 & 5.0412 & TRN & \\
\hline CHEMBL1310835 & 688267 & 4.05 & 5.0321 & TST & \\
\hline CHEMBL3191860 & 688267 & 4.25 & 5.0962 & TRN & \\
\hline CHEMBL1347745 & 688267 & 4.0 & 5.1028 & TRN & \\
\hline CHEMBL1314027 & 688267 & 3.95 & 5.0649 & TRN & \\
\hline CHEMBL1415945 & 688267 & 4.35 & 5.0002 & TRN & \\
\hline CHEMBL1539174 & 688267 & 5.45 & 5.0432 & TST & \\
\hline CHEMBL1473616 & 688267 & 6.2 & 5.104 & TRN & \\
\hline CHEMBL1369962 & 688267 & 5.1 & 5.0675 & TST & \\
\hline CHEMBL1515994 & 688267 & 5.9 & 5.0953 & TRN & \\
\hline CHEMBL3211541 & 688267 & 5.4 & 5.0626 & TST & \\
\hline CHEMBL1324524 & 688267 & 5.55 & 5.0494 & TRN & \\
\hline CHEMBL1397034 & 688267 & 4.75 & 5.0162 & TRN & \\
\hline
\end{tabular}




\begin{tabular}{|c|c|c|c|c|}
\hline \multicolumn{5}{|c|}{ Supplemental Table S2.txt } \\
\hline CHEMBL1374126 & 688267 & 4.85 & 4.9909 & TRN \\
\hline CHEMBL1582530 & 688267 & 4.35 & 5.0185 & TRN \\
\hline CHEMBL1517917 & 688267 & 6.0 & 5.051 & TRN \\
\hline CHEMBL1598666 & 688267 & 5.6 & 5.022 & TST \\
\hline CHEMBL3210302 & 688267 & 6.2 & 5.0896 & TRN \\
\hline CHEMBL1394334 & 688267 & 5.05 & 5.0333 & TRN \\
\hline CHEMBL1478672 & 688267 & 4.05 & 5.144 & TST \\
\hline CHEMBL1446479 & 688267 & 4.1 & 5.1098 & TST \\
\hline CHEMBL1584645 & 688267 & 5.0 & 5.1297 & TRN \\
\hline CHEMBL1495093 & 688267 & 4.0 & 5.0305 & TRN \\
\hline CHEMBL1477198 & 688267 & 6.2 & 5.1066 & TRN \\
\hline CHEMBL1536617 & 688267 & 4.6 & 5.0342 & TRN \\
\hline CHEMBL1507414 & 688267 & 5.25 & 5.0537 & TRN \\
\hline CHEMBL475754 & 688267 & 4.25 & 4.9953 & TRN \\
\hline CHEMBL1388492 & 688267 & 5.4 & 5.0673 & TRN \\
\hline CHEMBL1551994 & 688267 & 4.4 & 5.0397 & TRN \\
\hline CHEMBL1519854 & 688267 & 5.6 & 5.0349 & TRN \\
\hline CHEMBL1478079 & 688267 & 4.05 & 5.0686 & TRN \\
\hline CHEMBL1315137 & 688267 & 6.2 & 4.9994 & TRN \\
\hline CHEMBL1547433 & 688267 & 3.95 & 5.0883 & TRN \\
\hline CHEMBL1369914 & 688267 & 6.25 & 5.0696 & TRN \\
\hline CHEMBL1529571 & 688267 & 4.0 & 5.0722 & TST \\
\hline CHEMBL1319806 & 688267 & 5.75 & 5.0692 & TRN \\
\hline CHEMBL1403337 & 688267 & 5.4 & 5.0355 & TST \\
\hline CHEMBL1593038 & 688267 & 4.55 & 5.0709 & TRN \\
\hline CHEMBL1586581 & 688267 & 6.5 & 5.0688 & TST \\
\hline CHEMBL1412202 & 688267 & 4.45 & 5.1142 & TRN \\
\hline CHEMBL1363937 & 688267 & 5.05 & 5.0456 & TRN \\
\hline CHEMBL1464608 & 688267 & 4.8 & 5.0186 & TRN \\
\hline CHEMBL1567871 & 688267 & 5.8 & 5.0107 & TRN \\
\hline CHEMBL 3199641 & 688267 & 4.0 & 5.0 & TST \\
\hline CHEMBL1355305 & 688267 & 4.35 & 5.0452 & TRN \\
\hline CHEMBL1596789 & 688267 & 4.55 & 5.0661 & TRN \\
\hline CHEMBL1316336 & 688267 & 5.3 & 5.1034 & TRN \\
\hline CHEMBL1600197 & 688267 & 4.0 & 5.0078 & TST \\
\hline CHEMBL1397297 & 688267 & 5.4 & 5.0662 & TRN \\
\hline CHEMBL1494143 & 688267 & 4.05 & 5.1041 & TRN \\
\hline CHEMBL1323225 & 688267 & 5.15 & 5.0395 & TRN \\
\hline CHEMBL1411353 & 688267 & 5.25 & 5.0838 & TST \\
\hline CHEMBL1417835 & 688267 & 4.6 & 5.0374 & TRN \\
\hline CHEMBL1578152 & 688267 & 5.95 & 5.0393 & TRN \\
\hline CHEMBL1571777 & 688267 & 3.95 & 5.0365 & TRN \\
\hline CHEMBL1520229 & 688267 & 6.45 & 5.025 & TRN \\
\hline CHEMBL1355591 & 688267 & 6.15 & 5.0924 & TRN \\
\hline CHEMBL1481676 & 688267 & 4.45 & 5.0911 & TRN \\
\hline CHEMBL1524287 & 688267 & 4.05 & 5.0504 & TST \\
\hline CHEMBL1507981 & 688267 & 5.9 & 5.0298 & TRN \\
\hline CHEMBL 3196419 & 688267 & 4.3 & 5.0044 & TRN \\
\hline
\end{tabular}




\begin{tabular}{|c|c|c|c|c|c|}
\hline \multicolumn{6}{|c|}{ Supplemental Table S2.txt } \\
\hline CHEMBL1585387 & 688267 & 3.85 & 5.0968 & TRN & \\
\hline CHEMBL1594183 & 688267 & 4.45 & 5.0803 & TRN & \\
\hline CHEMBL1551033 & 688267 & 4.35 & 5.01699 & 99999999995 & TRN \\
\hline CHEMBL1381842 & 688267 & 5.55 & 5.0444 & TST & \\
\hline CHEMBL1544732 & 688267 & 5.05 & 5.0826 & TST & \\
\hline CHEMBL1507621 & 688267 & 4.65 & 5.0321 & TRN & \\
\hline CHEMBL1597620 & 688267 & 4.4 & 5.0254 & TRN & \\
\hline CHEMBL3194823 & 688267 & 6.0 & 5.0322 & TST & \\
\hline CHEMBL1475866 & 688267 & 4.35 & 5.0379 & TRN & \\
\hline CHEMBL1540319 & 688267 & 5.6 & 5.0176 & TST & \\
\hline CHEMBL1592106 & 688267 & 4.05 & 5.0815 & TRN & \\
\hline CHEMBL1582649 & 688267 & 4.25 & 5.0409 & TST & \\
\hline CHEMBL1326486 & 688267 & 6.3 & 5.1122 & TRN & \\
\hline CHEMBL1536138 & 688267 & 5.4 & 5.0217 & TRN & \\
\hline CHEMBL1592759 & 688267 & 6.2 & 5.0651 & TRN & \\
\hline CHEMBL1300710 & 688267 & 5.5 & 5.1033 & TST & \\
\hline CHEMBL1441809 & 688267 & 6.5 & 5.1099 & TST & \\
\hline CHEMBL1362088 & 688267 & 5.2 & 5.0679 & TST & \\
\hline CHEMBL1541656 & 688267 & 4.35 & 5.0404 & TRN & \\
\hline CHEMBL1374119 & 688267 & 6.2 & 5.1327 & TRN & \\
\hline CHEMBL1521165 & 688267 & 6.2 & 5.0349 & TRN & \\
\hline CHEMBL1301981 & 688267 & 4.1 & 5.0947 & TST & \\
\hline CHEMBL1465241 & 688267 & 4.3 & 5.0558 & TRN & \\
\hline CHEMBL 2004291 & 688267 & 5.7 & 5.0333 & TST & \\
\hline CHEMBL1594804 & 688267 & 5.2 & 5.0219 & TST & \\
\hline CHEMBL1447240 & 688267 & 5.4 & 5.0015 & TRN & \\
\hline CHEMBL1328197 & 688267 & 4.35 & 5.0522 & TRN & \\
\hline CHEMBL1514595 & 688267 & 5.65 & 5.0297 & TRN & \\
\hline CHEMBL1584448 & 688267 & 3.95 & 5.0414 & TRN & \\
\hline CHEMBL1347376 & 688267 & 6.25 & 5.0733 & TRN & \\
\hline CHEMBL1365603 & 688267 & 5.55 & 5.1006 & TRN & \\
\hline CHEMBL1358484 & 688267 & 4.0 & 5.0256 & TRN & \\
\hline CHEMBL1547784 & 688267 & 5.35 & 5.0738 & TRN & \\
\hline CHEMBL1382266 & 688267 & 6.15 & 5.055 & TRN & \\
\hline CHEMBL1326869 & 688267 & 5.95 & 5.0396 & TRN & \\
\hline CHEMBL1255662 & 688267 & 4.0 & 5.0434 & TST & \\
\hline CHEMBL1447117 & 688267 & 6.25 & 5.0113 & TRN & \\
\hline CHEMBL1569759 & 688267 & 4.35 & 5.056 & TRN & \\
\hline CHEMBL1531587 & 688267 & 5.3 & 5.0868 & TRN & \\
\hline CHEMBL1455244 & 688267 & 5.55 & 5.0649 & TRN & \\
\hline CHEMBL1607034 & 688267 & 4.0 & 5.037 & TRN & \\
\hline CHEMBL1547422 & 688267 & 4.4 & 5.0845 & TST & \\
\hline CHEMBL1417495 & 688267 & 4.05 & 5.0649 & TST & \\
\hline CHEMBL1379759 & 688267 & 5.25 & 5.1298 & TRN & \\
\hline CHEMBL1387135 & 688267 & 4.95 & 5.095 & TRN & \\
\hline CHEMBL1417132 & 688267 & 3.95 & 5.0188 & TRN & \\
\hline CHEMBL1317008 & 688267 & 5.75 & 5.0253 & TRN & \\
\hline CHEMBL1384610 & 688267 & 6.2 & 5.0699 & TRN & \\
\hline
\end{tabular}




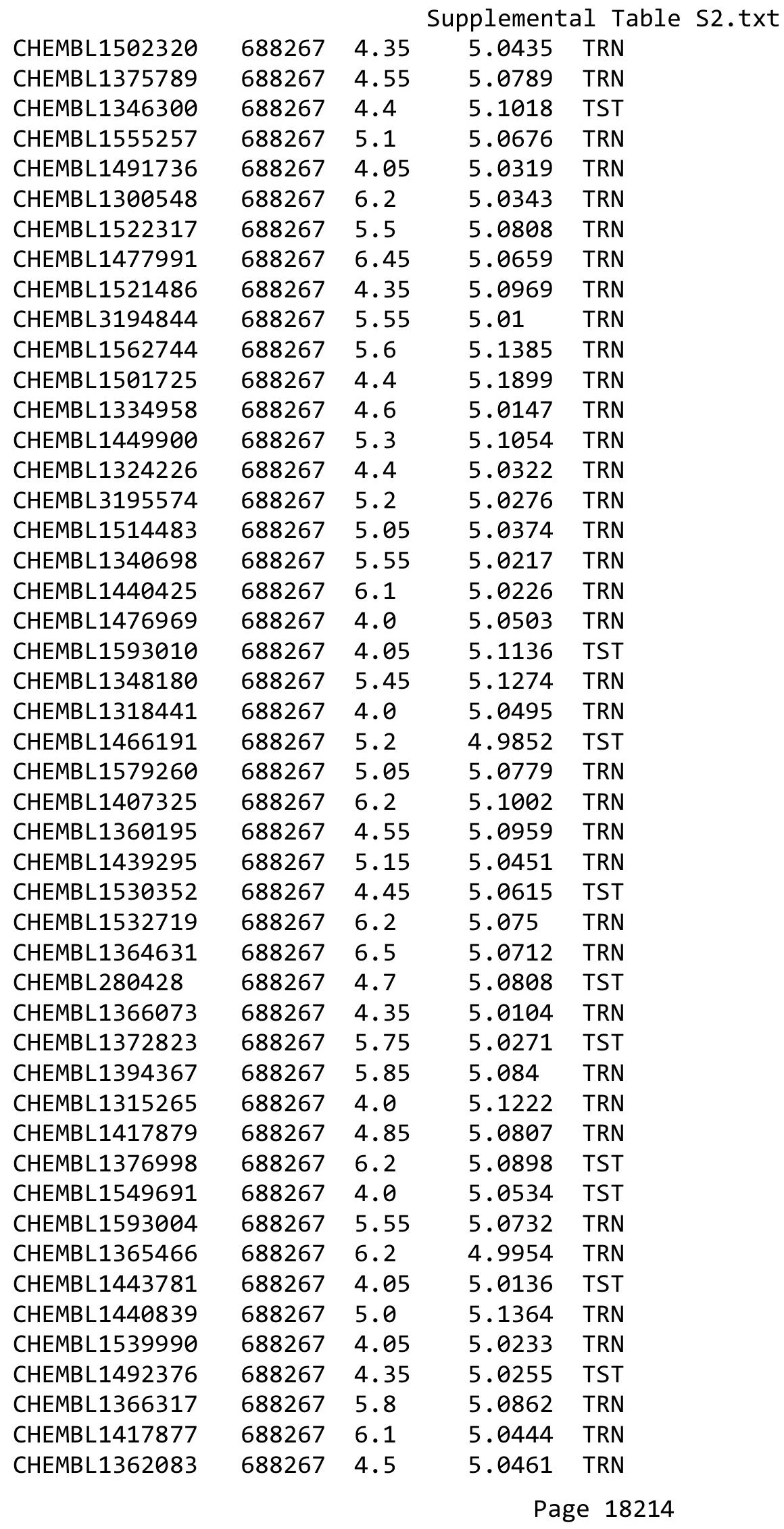




\begin{tabular}{|c|c|c|c|c|}
\hline \multicolumn{5}{|c|}{ Supplemental Table S2.txt } \\
\hline CHEMBL1605273 & 688267 & 6.2 & 5.0702 & TST \\
\hline CHEMBL1331274 & 688267 & 6.25 & 5.0234 & TRN \\
\hline CHEMBL1309240 & 688267 & 4.05 & 5.0709 & TST \\
\hline CHEMBL1324603 & 688267 & 5.1 & 5.0313 & TRN \\
\hline CHEMBL1319818 & 688267 & 6.15 & 5.0239 & TRN \\
\hline CHEMBL1337751 & 688267 & 6.15 & 4.9534 & TRN \\
\hline CHEMBL1497013 & 688267 & 4.5 & 5.0612 & TRN \\
\hline CHEMBL1513285 & 688267 & 5.55 & 5.0875 & TST \\
\hline CHEMBL1458992 & 688267 & 3.95 & 5.0215 & TRN \\
\hline CHEMBL1573013 & 688267 & 6.6499 & 5.034 & TRN \\
\hline CHEMBL1373217 & 688267 & 4.35 & 5.0705 & TRN \\
\hline CHEMBL1402573 & 688267 & 6.2 & 5.1248 & TST \\
\hline CHEMBL1457975 & 688267 & 4.75 & 4.9962 & TRN \\
\hline CHEMBL1497824 & 688267 & 4.65 & 5.0334 & TRN \\
\hline CHEMBL1445687 & 688267 & 4.2 & 5.0578 & TST \\
\hline CHEMBL1589912 & 688267 & 5.45 & 5.0215 & TRN \\
\hline CHEMBL1358844 & 688267 & 5.35 & 5.0984 & TRN \\
\hline CHEMBL1355400 & 688267 & 4.05 & 5.0586 & TRN \\
\hline CHEMBL1566129 & 688267 & 3.95 & 5.0013 & TRN \\
\hline CHEMBL1529358 & 688267 & 4.0 & 5.0551 & TRN \\
\hline CHEMBL1453502 & 688267 & 5.6 & 4.9819 & TRN \\
\hline CHEMBL1348084 & 688267 & 4.1 & 5.0688 & TRN \\
\hline CHEMBL1355196 & 688267 & 5.3 & 5.0928 & TST \\
\hline CHEMBL1517709 & 688267 & 4.3 & 5.056 & TST \\
\hline CHEMBL1366119 & 688267 & 6.2 & 5.0934 & TST \\
\hline CHEMBL1317502 & 688267 & 6.25 & 5.0375 & TST \\
\hline CHEMBL1592265 & 688267 & 6.15 & 5.1187 & TRN \\
\hline CHEMBL1326491 & 688267 & 4.25 & 5.0628 & TRN \\
\hline CHEMBL1469872 & 688267 & 5.7 & 5.0272 & TRN \\
\hline CHEMBL1461028 & 688267 & 4.7 & 5.0814 & TRN \\
\hline CHEMBL1484898 & 688267 & 6.2 & 5.1441 & TST \\
\hline CHEMBL1582177 & 688267 & 6.1 & 5.0812 & TRN \\
\hline CHEMBL1484170 & 688267 & 4.0 & 5.1106 & TRN \\
\hline CHEMBL3198829 & 688267 & 5.5 & 5.0164 & TRN \\
\hline CHEMBL1421877 & 688267 & 5.75 & 4.9426 & TRN \\
\hline CHEMBL1334237 & 688267 & 4.7 & 5.0873 & TRN \\
\hline CHEMBL1598969 & 688267 & 5.5 & 5.0476 & TRN \\
\hline CHEMBL1565347 & 688267 & 5.3 & 5.0002 & TST \\
\hline CHEMBL1408891 & 688267 & 4.95 & 4.9665 & TST \\
\hline CHEMBL1568828 & 688267 & 4.9 & 4.9905 & TRN \\
\hline CHEMBL1441768 & 688267 & 5.6 & 5.0701 & TRN \\
\hline CHEMBL1323997 & 688267 & 5.3 & 5.1201 & TRN \\
\hline CHEMBL1585065 & 688267 & 5.8 & 5.0526 & TRN \\
\hline CHEMBL1433103 & 688267 & 4.0 & 5.0663 & TST \\
\hline CHEMBL3190250 & 688267 & 6.2 & 5.0199 & TST \\
\hline CHEMBL1400069 & 688267 & 4.15 & 5.0988 & TRN \\
\hline CHEMBL1404157 & 688267 & 5.8 & 5.0553 & TRN \\
\hline CHEMBL1451060 & 688267 & 5.35 & 4.9868 & TST \\
\hline
\end{tabular}




\begin{tabular}{|c|c|c|c|c|}
\hline & & & pplement & al $\mathrm{Ta}$ \\
\hline CHEMBL1575682 & 688267 & 6.2 & 5.0774 & TRN \\
\hline CHEMBL1479220 & 688267 & 4.0 & 4.9722 & TRN \\
\hline CHEMBL1482469 & 688267 & 4.4 & 5.1242 & TST \\
\hline CHEMBL1530342 & 688267 & 4.35 & 5.1061 & TRN \\
\hline CHEMBL 3195808 & 688267 & 4.3 & 4.9998 & TRN \\
\hline CHEMBL1339622 & 688267 & 4.0 & 5.0085 & TST \\
\hline CHEMBL1320398 & 688267 & 5.45 & 5.0969 & TRN \\
\hline CHEMBL1528843 & 688267 & 5.45 & 5.0178 & TST \\
\hline CHEMBL3209824 & 688267 & 5.3 & 5.0342 & TRN \\
\hline CHEMBL1579318 & 688267 & 4.05 & 5.0161 & TRN \\
\hline CHEMBL1326446 & 688267 & 4.25 & 5.0341 & TRN \\
\hline CHEMBL1356228 & 688267 & 3.95 & 5.0237 & TRN \\
\hline CHEMBL1400625 & 688267 & 5.5 & 5.0433 & TRN \\
\hline CHEMBL3209120 & 688267 & 5.35 & 5.0352 & TST \\
\hline CHEMBL1518267 & 688267 & 5.85 & 5.0496 & TRN \\
\hline CHEMBL1357227 & 688267 & 4.2 & 5.0343 & TRN \\
\hline CHEMBL1338958 & 688267 & 4.95 & 5.0622 & TRN \\
\hline CHEMBL1368996 & 688267 & 4.45 & 5.099 & TRN \\
\hline CHEMBL1491178 & 688267 & 4.8 & 5.1382 & TST \\
\hline CHEMBL1611747 & 688267 & 4.9 & 5.1173 & TRN \\
\hline CHEMBL1498891 & 688267 & 4.0 & 5.1366 & TST \\
\hline CHEMBL1409535 & 688267 & 3.95 & 5.0013 & TRN \\
\hline CHEMBL1412512 & 688267 & 4.05 & 5.0738 & TST \\
\hline CHEMBL1601510 & 688267 & 4.3 & 5.0541 & TRN \\
\hline CHEMBL1403028 & 688267 & 5.5 & 5.0472 & TRN \\
\hline CHEMBL1552348 & 688267 & 4.05 & 5.0116 & TRN \\
\hline CHEMBL1444618 & 688267 & 4.6 & 5.0658 & TRN \\
\hline CHEMBL1535147 & 688267 & 4.0 & 5.0708 & TRN \\
\hline CHEMBL1396589 & 688267 & 6.5 & 5.0766 & TRN \\
\hline CHEMBL1491003 & 688267 & 4.5 & 4.9833 & TRN \\
\hline CHEMBL1321538 & 688267 & 4.2 & 5.0355 & TST \\
\hline CHEMBL1552402 & 688267 & 4.6 & 5.1019 & TRN \\
\hline CHEMBL1450255 & 688267 & 6.2 & 5.0346 & TST \\
\hline CHEMBL1494159 & 688267 & 5.5 & 5.0223 & TRN \\
\hline CHEMBL1489923 & 688267 & 4.05 & 5.0876 & TRN \\
\hline CHEMBL1596845 & 688267 & 5.9 & 5.0398 & TRN \\
\hline CHEMBL1469249 & 688267 & 6.2 & 5.0358 & TRN \\
\hline CHEMBL1391719 & 688267 & 4.4 & 5.0962 & TRN \\
\hline CHEMBL1332785 & 688267 & 4.05 & 5.1327 & TRN \\
\hline CHEMBL1357814 & 688267 & 5.7 & 5.0376 & TRN \\
\hline CHEMBL1395218 & 688267 & 4.15 & 5.0221 & TRN \\
\hline CHEMBL1499360 & 688267 & 4.05 & 5.0239 & TRN \\
\hline CHEMBL1391648 & 688267 & 5.85 & 5.1314 & TRN \\
\hline CHEMBL1541514 & 688267 & 4.2 & 5.1216 & TRN \\
\hline CHEMBL1317933 & 688267 & 6.15 & 5.1171 & TRN \\
\hline CHEMBL1582693 & 688267 & 4.95 & 5.1059 & TST \\
\hline CHEMBL1473013 & 688267 & 5.05 & 5.1123 & TRN \\
\hline CHEMBL1599849 & 688267 & 4.0 & 5.0168 & TRN \\
\hline
\end{tabular}




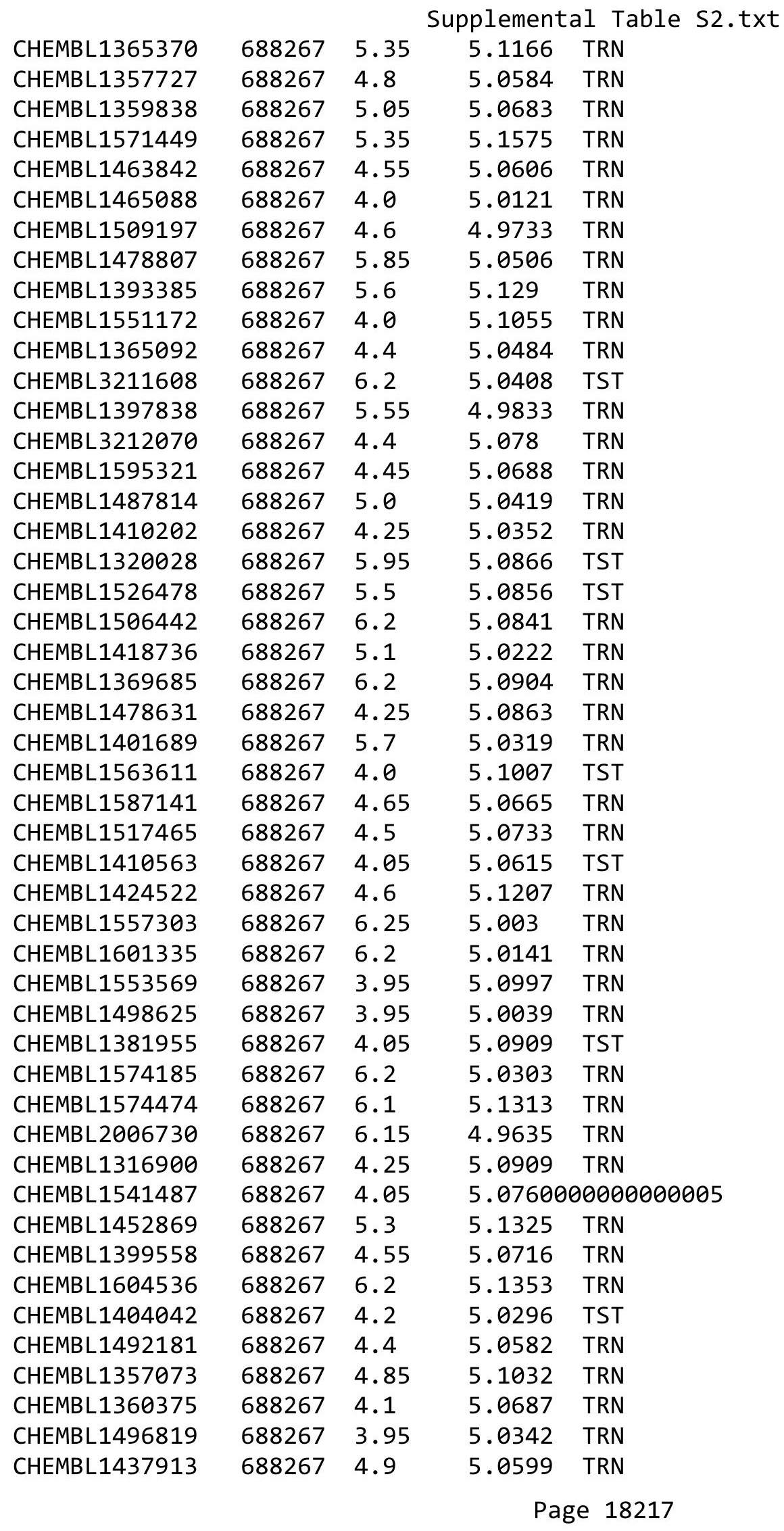




\begin{tabular}{|c|c|c|c|c|c|}
\hline \multicolumn{6}{|c|}{ pplementaI } \\
\hline CHEMBL1553507 & 688267 & 4.4 & 5.0672 & TRN & \\
\hline CHEMBL1440632 & 688267 & 6.2 & 5.1135 & TRN & \\
\hline CHEMBL1359963 & 688267 & 4.45 & 5.0557 & TST & \\
\hline CHEMBL 3212326 & 688267 & 6.2 & 5.0942 & TST & \\
\hline CHEMBL1489036 & 688267 & 5.35 & 5.0532 & TRN & \\
\hline CHEMBL1323000 & 688267 & 4.0 & 5.0723 & TST & \\
\hline CHEMBL1582006 & 688267 & 6.15 & 5.0841 & TRN & \\
\hline CHEMBL1401854 & 688267 & 5.85 & 5.1194 & TRN & \\
\hline CHEMBL1318011 & 688267 & 4.0 & 5.1279 & TRN & \\
\hline CHEMBL1489733 & 688267 & 4.0 & 5.0862 & TRN & \\
\hline CHEMBL1533426 & 688267 & 6.45 & 5.0848 & TRN & \\
\hline CHEMBL 1474108 & 688267 & 6.2 & 5.0419 & TRN & \\
\hline CHEMBL1374727 & 688267 & 4.25 & 5.0509 & TRN & \\
\hline CHEMBL1390579 & 688267 & 6.15 & 5.1082 & TRN & \\
\hline CHEMBL1591333 & 688267 & 4.0 & 5.1207 & TST & \\
\hline CHEMBL1594467 & 688267 & 5.85 & 5.0569 & TRN & \\
\hline CHEMBL1313987 & 688267 & 4.25 & 5.0189 & TRN & \\
\hline CHEMBL1437223 & 688267 & 4.4 & 5.044 & TRN & \\
\hline CHEMBL1409677 & 688267 & 6.2 & 4.9964 & TRN & \\
\hline CHEMBL1594989 & 688267 & 6.45 & 5.1068 & TRN & \\
\hline CHEMBL1439396 & 688267 & 7.2503 & 5.01699 & 99999999995 & TRN \\
\hline CHEMBL1571083 & 688267 & 5.35 & 5.0872 & TRN & \\
\hline CHEMBL1568378 & 688267 & 5.4 & 5.062 & TRN & \\
\hline CHEMBL1367961 & 688267 & 4.75 & 5.0257 & TST & \\
\hline CHEMBL94085 & 688267 & 6.2 & 4.9801 & TRN & \\
\hline CHEMBL1456637 & 688267 & 5.9 & 5.0811 & TRN & \\
\hline CHEMBL1597855 & 688267 & 4.25 & 5.0274 & TST & \\
\hline CHEMBL1396103 & 688267 & 4.0 & 4.9966 & TRN & \\
\hline CHEMBL1226 & 688267 & 4.6 & 5.0953 & TST & \\
\hline CHEMBL1567169 & 688267 & 6.25 & 5.0623 & TRN & \\
\hline CHEMBL1460764 & 688267 & 4.55 & 5.0519 & TST & \\
\hline CHEMBL1537864 & 688267 & 4.2 & 5.07 & TRN & \\
\hline CHEMBL1574226 & 688267 & 6.5501 & 5.0521 & TRN & \\
\hline CHEMBL1513427 & 688267 & 5.1 & 5.151 & TRN & \\
\hline CHEMBL1320499 & 688267 & 4.05 & 5.0529 & TRN & \\
\hline CHEMBL1523727 & 688267 & 5.55 & 5.0215 & TRN & \\
\hline CHEMBL1309595 & 688267 & 5.1 & 5.0169 & TST & \\
\hline CHEMBL1323698 & 688267 & 6.5 & 4.9988 & TRN & \\
\hline CHEMBL1385101 & 688267 & 3.95 & 5.1098 & TST & \\
\hline CHEMBL1403813 & 688267 & 6.15 & 5.0952 & TST & \\
\hline CHEMBL1326363 & 688267 & 5.5 & 5.0551 & TST & \\
\hline CHEMBL 3197234 & 688267 & 4.05 & 5.0208 & TRN & \\
\hline CHEMBL1529024 & 688267 & 5.9 & 5.1271 & TRN & \\
\hline CHEMBL1552415 & 688267 & 4.7 & 5.0646 & TRN & \\
\hline CHEMBL1529198 & 688267 & 4.2 & 5.0862 & TRN & \\
\hline CHEMBL1467167 & 688267 & 4.95 & 5.0587 & TRN & \\
\hline CHEMBL1597199 & 688267 & 4.05 & 5.0708 & TRN & \\
\hline CHEMBL1456031 & 688267 & 6.5 & 5.1096 & TRN & \\
\hline
\end{tabular}




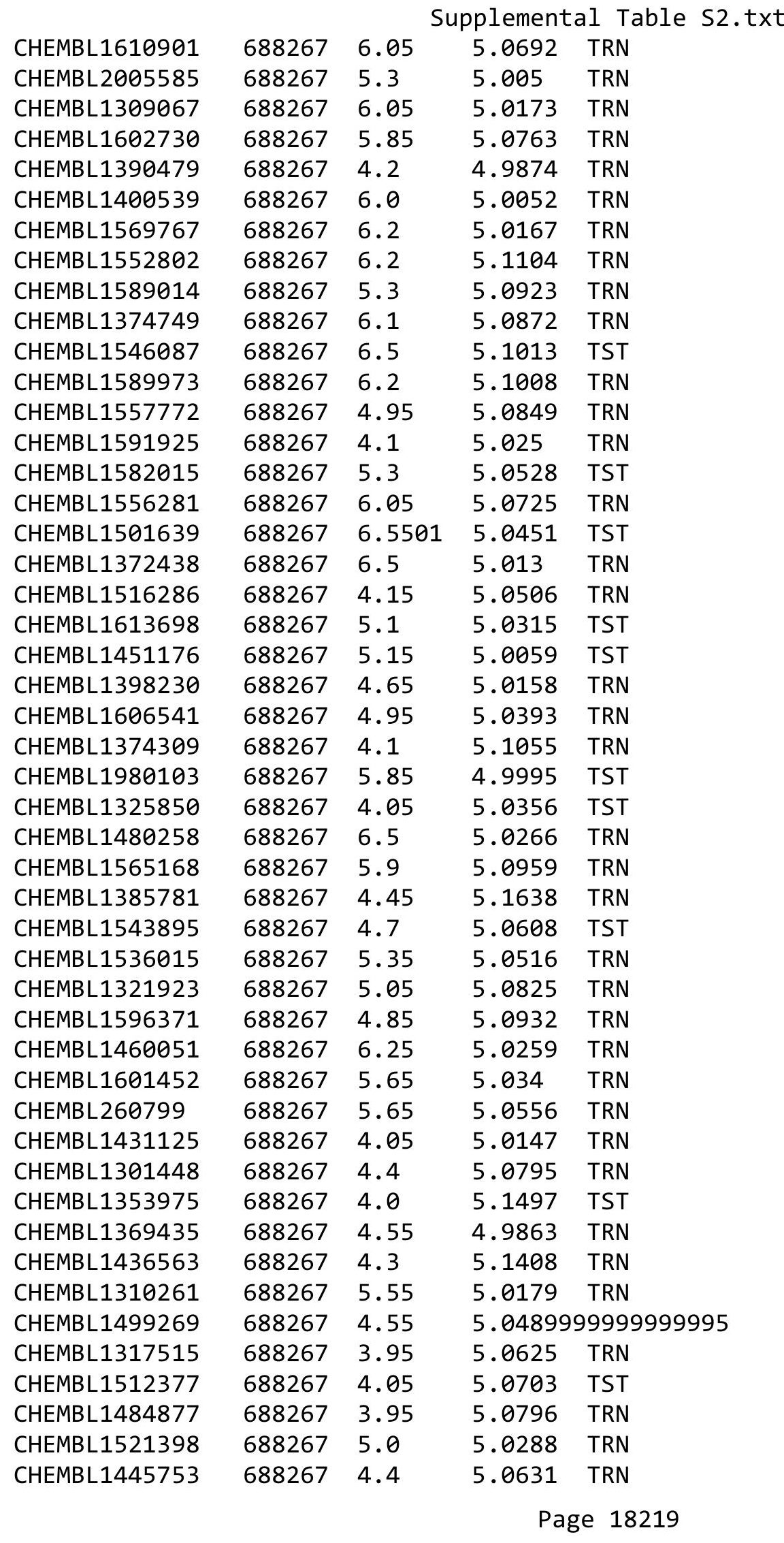




\begin{tabular}{|c|c|c|c|c|}
\hline \multicolumn{5}{|c|}{ Supplemental Table S2.txt } \\
\hline CHEMBL1304580 & 688267 & 4.05 & 5.0109 & TST \\
\hline CHEMBL1423358 & 688267 & 5.6 & 5.102 & TRN \\
\hline CHEMBL1516314 & 688267 & 4.1 & 5.0773 & TRN \\
\hline CHEMBL1441020 & 688267 & 4.9 & 5.1664 & TRN \\
\hline CHEMBL1612489 & 688267 & 5.25 & 5.0033 & TRN \\
\hline CHEMBL1318325 & 688267 & 5.25 & 5.0606 & TRN \\
\hline CHEMBL1492777 & 688267 & 4.05 & 5.0238 & TST \\
\hline CHEMBL1359975 & 688267 & 3.95 & 5.0396 & TRN \\
\hline CHEMBL1354784 & 688267 & 4.35 & 5.0951 & TRN \\
\hline CHEMBL1472113 & 688267 & 4.1 & 5.0224 & TRN \\
\hline CHEMBL1481040 & 688267 & 5.35 & 5.0418 & TRN \\
\hline CHEMBL1579682 & 688267 & 5.55 & 5.06 & TRN \\
\hline CHEMBL1368485 & 688267 & 5.9 & 5.0067 & TST \\
\hline CHEMBL1498951 & 688267 & 4.05 & 5.0723 & TRN \\
\hline CHEMBL1328076 & 688267 & 4.05 & 5.0317 & TRN \\
\hline CHEMBL1434102 & 688267 & 5.8 & 5.0666 & TRN \\
\hline CHEMBL1398633 & 688267 & 4.1 & 5.019 & TRN \\
\hline CHEMBL1461448 & 688267 & 4.3 & 5.0219 & TRN \\
\hline CHEMBL1518261 & 688267 & 4.35 & 5.0483 & TRN \\
\hline CHEMBL1435091 & 688267 & 5.85 & 5.0272 & TRN \\
\hline CHEMBL1501003 & 688267 & 5.9 & 5.0811 & TRN \\
\hline CHEMBL1419052 & 688267 & 4.4 & 5.0254 & TST \\
\hline CHEMBL1366445 & 688267 & 4.35 & 5.0364 & TRN \\
\hline CHEMBL1513744 & 688267 & 5.2 & 5.0388 & TRN \\
\hline CHEMBL1564980 & 688267 & 4.55 & 5.0577 & TRN \\
\hline CHEMBL1498213 & 688267 & 5.3 & 5.082 & TRN \\
\hline CHEMBL1413490 & 688267 & 6.15 & 5.0934 & TRN \\
\hline CHEMBL1546286 & 688267 & 5.45 & 5.0501 & TRN \\
\hline CHEMBL1585712 & 688267 & 4.85 & 5.0372 & TST \\
\hline CHEMBL1374124 & 688267 & 5.75 & 5.0516 & TRN \\
\hline CHEMBL1365644 & 688267 & 5.25 & 5.0465 & TRN \\
\hline CHEMBL1303315 & 688267 & 5.3 & 5.0533 & TRN \\
\hline CHEMBL1401376 & 688267 & 4.05 & 5.1048 & TST \\
\hline CHEMBL1398444 & 688267 & 5.2 & 5.0507 & TRN \\
\hline CHEMBL1546377 & 688267 & 4.4 & 5.148 & TRN \\
\hline CHEMBL1611543 & 688267 & 5.8 & 4.9975 & TRN \\
\hline CHEMBL1357311 & 688267 & 3.95 & 5.0084 & TRN \\
\hline CHEMBL1385207 & 688267 & 4.0 & 5.0182 & TRN \\
\hline CHEMBL1325479 & 688267 & 5.3 & 5.1103 & TRN \\
\hline CHEMBL1313135 & 688267 & 5.95 & 5.0168 & TRN \\
\hline CHEMBL1332306 & 688267 & 3.95 & 4.9913 & TRN \\
\hline CHEMBL1328940 & 688267 & 6.15 & 5.0662 & TRN \\
\hline CHEMBL1456645 & 688267 & 5.35 & 5.0147 & TRN \\
\hline CHEMBL1336048 & 688267 & 4.25 & 5.0628 & TRN \\
\hline CHEMBL1486910 & 688267 & 5.35 & 5.0142 & TRN \\
\hline CHEMBL1509920 & 688267 & 5.35 & 5.0919 & TRN \\
\hline CHEMBL1525266 & 688267 & 4.6 & 5.0772 & TRN \\
\hline CHEMBL1563211 & 688267 & 5.25 & 5.1243 & TRN \\
\hline
\end{tabular}




\begin{tabular}{|c|c|c|c|c|c|}
\hline \multirow[b]{2}{*}{ CHEMBL1446981 } & \multirow[b]{2}{*}{688267} & \multicolumn{4}{|c|}{ oplemental Table S2. } \\
\hline & & 5.45 & 5.0365 & TST & \multirow[b]{2}{*}{ TRN } \\
\hline CHEMBL1300547 & 688267 & 3.95 & \multicolumn{2}{|c|}{5.1080000000000005} & \\
\hline CHEMBL1581083 & 688267 & 4.0 & 5.0704 & TST & \\
\hline CHEMBL1492142 & 688267 & 4.0 & 5.069 & TRN & \\
\hline CHEMBL1389714 & 688267 & 4.5 & 5.1001 & TST & \\
\hline CHEMBL1357526 & 688267 & 4.05 & 5.021 & TRN & \\
\hline CHEMBL1364836 & 688267 & 4.4 & 5.0407 & TRN & \\
\hline CHEMBL1529977 & 688267 & 6.15 & 5.0223 & TRN & \\
\hline CHEMBL1396011 & 688267 & 4.55 & 5.0231 & TRN & \\
\hline CHEMBL1404728 & 688267 & 4.35 & 5.0685 & TRN & \\
\hline CHEMBL1512888 & 688267 & 4.0 & 5.0736 & TRN & \\
\hline CHEMBL1538498 & 688267 & 6.25 & 5.1339 & TRN & \\
\hline CHEMBL1396811 & 688267 & 4.05 & 5.1276 & TRN & \\
\hline CHEMBL1423795 & 688267 & 5.15 & 5.0609 & TST & \\
\hline CHEMBL1435962 & 688267 & 4.05 & 5.0259 & TRN & \\
\hline CHEMBL1326070 & 688267 & 5.7 & 5.0475 & TRN & \\
\hline CHEMBL1354468 & 688267 & 6.2 & 5.1154 & TRN & \\
\hline CHEMBL1450714 & 688267 & 3.95 & 5.0628 & TRN & \\
\hline CHEMBL1409029 & 688267 & 5.45 & 5.0846 & TRN & \\
\hline CHEMBL1411584 & 688267 & 4.95 & 5.1074 & TST & \\
\hline CHEMBL1324633 & 688267 & 4.35 & 5.1214 & TRN & \\
\hline CHEMBL1328244 & 688267 & 4.4 & \multicolumn{2}{|c|}{5.1160000000000005} & TRN \\
\hline CHEMBL1316928 & 688267 & 5.3 & 5.1136 & TRN & \\
\hline CHEMBL1316963 & 688267 & 6.25 & 5.0878 & TRN & \\
\hline CHEMBL1559058 & 688267 & 4.35 & 5.1004 & TST & \\
\hline CHEMBL3207608 & 688267 & 4.7 & 4.9701 & TST & \\
\hline CHEMBL1613140 & 688267 & 6.45 & 5.058 & TRN & \\
\hline CHEMBL3210096 & 688267 & 5.8 & 5.0414 & TRN & \\
\hline CHEMBL1502039 & 688267 & 5.05 & 5.0643 & TRN & \\
\hline CHEMBL1515657 & 688267 & 6.15 & 5.0211 & TRN & \\
\hline CHEMBL1538782 & 688267 & 3.95 & 5.0193 & TRN & \\
\hline CHEMBL1343391 & 688267 & 5.75 & 5.1286 & TRN & \\
\hline CHEMBL1445955 & 688267 & 7.7496 & 5.1151 & TRN & \\
\hline CHEMBL1578793 & 688267 & 5.3 & 5.1026 & TRN & \\
\hline CHEMBL1520349 & 688267 & 5.55 & 5.0855 & TRN & \\
\hline CHEMBL1302158 & 688267 & 5.55 & 5.1048 & TRN & \\
\hline CHEMBL1441910 & 688267 & 3.95 & 5.0813 & TRN & \\
\hline CHEMBL1539298 & 688267 & 4.65 & \multicolumn{2}{|c|}{5.0169999999999995} & TST \\
\hline CHEMBL1408001 & 688267 & 5.95 & 4.9917 & TRN & \\
\hline CHEMBL1504392 & 688267 & 5.1 & 5.0271 & TRN & \\
\hline CHEMBL1603534 & 688267 & 5.35 & 5.0667 & TST & \\
\hline CHEMBL1562937 & 688267 & 5.35 & 5.1432 & TRN & \\
\hline CHEMBL1475519 & 688267 & 3.95 & 5.1697 & TRN & \\
\hline CHEMBL1354550 & 688267 & 4.75 & 5.0686 & TRN & \\
\hline CHEMBL1548334 & 688267 & 5.1 & 5.1188 & TRN & \\
\hline CHEMBL1351323 & 688267 & 5.0 & 5.0553 & TRN & \\
\hline CHEMBL1371577 & 688267 & 4.4 & 5.0702 & TRN & \\
\hline \multirow[t]{2}{*}{ CHEMBL1426019 } & 688267 & 4.2 & 5.0579 & TRN & \\
\hline & & \multicolumn{4}{|c|}{ Page 18221} \\
\hline
\end{tabular}




\begin{tabular}{|c|c|c|c|c|c|}
\hline \multicolumn{6}{|c|}{ Supplemental Table S2.txt } \\
\hline CHEMBL1575273 & 688267 & 6.2 & 4.9885 & TST & \\
\hline CHEMBL1478348 & 688267 & 6.2 & 5.1007 & TRN & \\
\hline CHEMBL1463824 & 688267 & 4.05 & 5.0116 & TRN & \\
\hline CHEMBL1442090 & 688267 & 4.4 & 5.0599 & TST & \\
\hline CHEMBL1337061 & 688267 & 4.7 & 5.1312 & TRN & \\
\hline CHEMBL1550239 & 688267 & 5.45 & 5.0279 & TST & \\
\hline CHEMBL1389323 & 688267 & 4.75 & 5.1041 & TRN & \\
\hline CHEMBL3199099 & 688267 & 4.5 & 5.0061 & TRN & \\
\hline CHEMBL3195628 & 688267 & 4.1 & 5.0076 & TRN & \\
\hline CHEMBL1597280 & 688267 & 4.35 & 5.0605 & TST & \\
\hline CHEMBL1601540 & 688267 & 4.3 & 5.0416 & TRN & \\
\hline CHEMBL1533397 & 688267 & 3.95 & 5.0202 & TRN & \\
\hline CHEMBL 3190045 & 688267 & 5.85 & 5.0039 & TRN & \\
\hline CHEMBL1606105 & 688267 & 5.05 & 5.0142 & TST & \\
\hline CHEMBL1529898 & 688267 & 5.5 & 5.0791 & TRN & \\
\hline CHEMBL1355869 & 688267 & 4.35 & 5.0396 & TST & \\
\hline CHEMBL1565596 & 688267 & 5.35 & 5.1251 & TRN & \\
\hline CHEMBL3197479 & 688267 & 4.65 & 5.0016 & TST & \\
\hline CHEMBL1397042 & 688267 & 5.85 & 5.0574 & TRN & \\
\hline CHEMBL1486117 & 688267 & 4.6 & 5.0642 & TST & \\
\hline CHEMBL1378779 & 688267 & 4.05 & 5.0716 & TST & \\
\hline CHEMBL1400221 & 688267 & 4.05 & 5.0347 & TRN & \\
\hline CHEMBL1431020 & 688267 & 5.3 & 5.0591 & TRN & \\
\hline CHEMBL1354598 & 688267 & 4.35 & 5.0069 & TRN & \\
\hline CHEMBL1461992 & 688267 & 4.45 & 5.0078 & TRN & \\
\hline CHEMBL1592581 & 688267 & 6.2 & 5.0098 & TRN & \\
\hline CHEMBL1412056 & 688267 & 6.5 & 5.073 & TRN & \\
\hline CHEMBL1496198 & 688267 & 3.95 & 5.1662 & TRN & \\
\hline CHEMBL1388004 & 688267 & 4.3 & 5.0444 & TRN & \\
\hline CHEMBL1498528 & 688267 & 4.75 & 5.0412 & TST & \\
\hline CHEMBL1391664 & 688267 & 4.2 & 5.0622 & TRN & \\
\hline CHEMBL1567806 & 688267 & 4.35 & 5.1386 & TRN & \\
\hline CHEMBL1532625 & 688267 & 4.3 & 5.1028 & TST & \\
\hline CHEMBL1362025 & 688267 & 5.9 & 5.0449 & TRN & \\
\hline CHEMBL1437044 & 688267 & 4.55 & 5.0274 & TRN & \\
\hline CHEMBL1607516 & 688267 & 4.35 & 4.9672 & TRN & \\
\hline CHEMBL1331929 & 688267 & 4.35 & 5.0623 & TRN & \\
\hline CHEMBL1481198 & 688267 & 6.2 & 5.0227 & TST & \\
\hline CHEMBL1536940 & 688267 & 3.95 & 5.0527 & TRN & \\
\hline CHEMBL1323490 & 688267 & 4.3 & 4.9819 & TRN & \\
\hline CHEMBL1324430 & 688267 & 4.55 & 5.0287 & TRN & \\
\hline CHEMBL1530178 & 688267 & 4.35 & 5.0435 & TST & \\
\hline CHEMBL1517804 & 688267 & 4.4 & 5.0209 & TRN & \\
\hline CHEMBL1452719 & 688267 & 5.35 & $5.1160 e$ & 00000000005 & TRN \\
\hline CHEMBL1484054 & 688267 & 4.3 & 5.0429 & TRN & \\
\hline CHEMBL1329843 & 688267 & 5.45 & 5.1281 & TRN & \\
\hline CHEMBL1586555 & 688267 & 5.1 & 5.0489 & TRN & \\
\hline CHEMBL1511387 & 688267 & 6.2 & 5.0466 & TRN & \\
\hline
\end{tabular}




\begin{tabular}{|c|c|c|c|c|c|}
\hline \multicolumn{6}{|c|}{ Supplemental Table S2.txt } \\
\hline CHEMBL1323219 & 688267 & 6.2 & 5.0662 & TRN & \\
\hline CHEMBL1382996 & 688267 & 4.25 & 5.0872 & TST & \\
\hline CHEMBL1319693 & 688267 & 5.35 & 5.0209 & TRN & \\
\hline CHEMBL1338660 & 688267 & 6.2 & 5.0702 & TRN & \\
\hline CHEMBL1477764 & 688267 & 5.35 & 5.1077 & TRN & \\
\hline CHEMBL1539980 & 688267 & 4.05 & 5.005 & TST & \\
\hline CHEMBL1498031 & 688267 & 5.85 & 5.0859 & TST & \\
\hline CHEMBL1470790 & 688267 & 5.0 & 5.0459 & TRN & \\
\hline CHEMBL3209217 & 688267 & 5.4 & 5.0492 & TRN & \\
\hline CHEMBL1416355 & 688267 & 5.95 & 5.03 & TRN & \\
\hline CHEMBL1302185 & 688267 & 6.45 & 5.0861 & TRN & \\
\hline CHEMBL1352251 & 688267 & 4.45 & 5.0326 & TRN & \\
\hline CHEMBL1475171 & 688267 & 5.5 & 5.0637 & TRN & \\
\hline CHEMBL1451916 & 688267 & 6.1 & 5.0339 & TST & \\
\hline CHEMBL1382642 & 688267 & 5.8 & 5.0325 & TRN & \\
\hline CHEMBL1567571 & 688267 & 4.9 & 5.0172 & TST & \\
\hline CHEMBL1590293 & 688267 & 4.0 & 5.0336 & TRN & \\
\hline CHEMBL1606607 & 688267 & 4.75 & 5.0047 & TRN & \\
\hline CHEMBL1537856 & 688267 & 4.5 & 5.0411 & TRN & \\
\hline CHEMBL1562530 & 688267 & 4.6 & 5.0634 & TRN & \\
\hline CHEMBL1515353 & 688267 & 5.3 & 5.0882 & TRN & \\
\hline CHEMBL1487170 & 688267 & 4.25 & 5.1293 & TST & \\
\hline CHEMBL1360798 & 688267 & 4.5 & 5.091 & TRN & \\
\hline CHEMBL1437121 & 688267 & 5.55 & 5.0641 & TST & \\
\hline CHEMBL1587917 & 688267 & 4.55 & 5.1111 & TST & \\
\hline CHEMBL1326254 & 688267 & 6.2 & 5.0209 & TST & \\
\hline CHEMBL1407761 & 688267 & 6.2 & 5.1228 & TRN & \\
\hline CHEMBL1437780 & 688267 & 4.35 & 5.1208 & TRN & \\
\hline CHEMBL1495998 & 688267 & 5.15 & 4.9891 & TRN & \\
\hline CHEMBL1591624 & 688267 & 4.8 & 5.1279 & TRN & \\
\hline CHEMBL1377067 & 688267 & 4.75 & 5.0163 & TRN & \\
\hline CHEMBL1326864 & 688267 & 5.7 & 5.0196 & TRN & \\
\hline CHEMBL1402500 & 688267 & 4.75 & 5.0985 & TST & \\
\hline CHEMBL1412020 & 688267 & 5.9 & 5.0398 & TRN & \\
\hline CHEMBL1516831 & 688267 & 5.55 & 5.0612 & TRN & \\
\hline CHEMBL1475722 & 688267 & 4.2 & 5.0249 & TRN & \\
\hline CHEMBL1348694 & 688267 & 4.05 & 5.0791 & TRN & \\
\hline CHEMBL1371683 & 688267 & 5.75 & 5.058 & TST & \\
\hline CHEMBL1436119 & 688267 & 4.1 & 4.9847 & TRN & \\
\hline CHEMBL1501376 & 688267 & 4.65 & 5.0046 & TRN & \\
\hline CHEMBL1529801 & 688267 & 4.0 & $5.0710 e$ & 0000000001 & TRN \\
\hline CHEMBL1566093 & 688267 & 4.0 & 5.0552 & TRN & \\
\hline CHEMBL1598077 & 688267 & 5.3 & 5.0603 & TRN & \\
\hline CHEMBL1598908 & 688267 & 4.8 & 5.0679 & TRN & \\
\hline CHEMBL1367803 & 688267 & 4.05 & 5.1123 & TRN & \\
\hline CHEMBL1387694 & 688267 & 5.35 & 5.0637 & TRN & \\
\hline CHEMBL1495387 & 688267 & 4.05 & 5.0453 & TRN & \\
\hline CHEMBL1324984 & 688267 & 4.0 & 5.0118 & TRN & \\
\hline
\end{tabular}




\begin{tabular}{|c|c|c|c|c|}
\hline & & & pplement & al $\mathrm{Ta}$ \\
\hline CHEMBL1453047 & 688267 & 6.2 & 5.078 & TRN \\
\hline CHEMBL3212563 & 688267 & 4.25 & 5.0175 & TST \\
\hline CHEMBL1445900 & 688267 & 5.55 & 5.0625 & TRN \\
\hline CHEMBL1556892 & 688267 & 4.05 & 5.0603 & TRN \\
\hline CHEMBL1399022 & 688267 & 4.25 & 5.148 & TRN \\
\hline CHEMBL1539942 & 688267 & 5.85 & 5.1161 & TRN \\
\hline CHEMBL1525225 & 688267 & 4.0 & 5.0112 & TRN \\
\hline CHEMBL1598696 & 688267 & 5.5 & 5.0626 & TST \\
\hline CHEMBL1365248 & 688267 & 5.4 & 5.0466 & TST \\
\hline CHEMBL1579025 & 688267 & 6.05 & 5.052 & TRN \\
\hline CHEMBL1447146 & 688267 & 6.2 & 5.0262 & TRN \\
\hline CHEMBL1348740 & 688267 & 4.35 & 5.0644 & TRN \\
\hline CHEMBL1357045 & 688267 & 5.95 & 5.0998 & TRN \\
\hline CHEMBL1411812 & 688267 & 4.4 & 5.1579 & TRN \\
\hline CHEMBL1520974 & 688267 & 5.55 & 5.1345 & TRN \\
\hline CHEMBL1569168 & 688267 & 5.3 & 5.0211 & TRN \\
\hline CHEMBL1304773 & 688267 & 3.95 & 5.0505 & TST \\
\hline CHEMBL1326545 & 688267 & 6.25 & 5.0056 & TRN \\
\hline CHEMBL1308122 & 688267 & 5.3 & 5.0035 & TRN \\
\hline CHEMBL1422345 & 688267 & 5.1 & 5.0364 & TRN \\
\hline CHEMBL531043 & 688267 & 6.2 & 5.0035 & TRN \\
\hline CHEMBL1514493 & 688267 & 5.35 & 5.0067 & TST \\
\hline CHEMBL1445941 & 688267 & 6.2 & 5.0269 & TST \\
\hline CHEMBL1371612 & 688267 & 5.6 & 5.029 & TRN \\
\hline CHEMBL3212339 & 688267 & 4.6 & 4.9599 & TST \\
\hline CHEMBL1514526 & 688267 & 4.0 & 5.056 & TRN \\
\hline CHEMBL1453060 & 688267 & 6.2 & 5.0157 & TRN \\
\hline CHEMBL1523845 & 688267 & 4.3 & 5.0131 & TRN \\
\hline CHEMBL1358149 & 688267 & 6.2 & 5.0868 & TRN \\
\hline CHEMBL1382697 & 688267 & 3.85 & 5.0491 & TRN \\
\hline CHEMBL1507114 & 688267 & 6.2 & 5.0213 & TST \\
\hline CHEMBL1465900 & 688267 & 4.5 & 5.0598 & TRN \\
\hline CHEMBL1424484 & 688267 & 5.05 & 5.0931 & TRN \\
\hline CHEMBL1401908 & 688267 & 4.25 & 5.1573 & TRN \\
\hline CHEMBL1386627 & 688267 & 4.65 & 5.0468 & TRN \\
\hline CHEMBL1528921 & 688267 & 4.55 & 5.107 & TRN \\
\hline CHEMBL1536490 & 688267 & 5.7 & 4.9837 & TST \\
\hline CHEMBL1437138 & 688267 & 4.6 & 5.0477 & TRN \\
\hline CHEMBL1461478 & 688267 & 5.65 & 5.0412 & TRN \\
\hline CHEMBL1353433 & 688267 & 4.25 & 5.0715 & TRN \\
\hline CHEMBL1460933 & 688267 & 4.7 & 5.1049 & TRN \\
\hline CHEMBL1556769 & 688267 & 4.05 & 4.9812 & TST \\
\hline CHEMBL1478427 & 688267 & 6.25 & 5.0763 & TRN \\
\hline CHEMBL1450302 & 688267 & 6.1 & 5.1377 & TRN \\
\hline CHEMBL1432458 & 688267 & 6.2 & 5.0619 & TRN \\
\hline CHEMBL1384527 & 688267 & 6.05 & 5.0088 & TRN \\
\hline CHEMBL1507155 & 688267 & 3.95 & 5.0944 & TRN \\
\hline CHEMBL1528374 & 688267 & 6.2 & 5.1099 & TST \\
\hline
\end{tabular}




\begin{tabular}{|c|c|c|c|c|c|}
\hline \multicolumn{6}{|c|}{ oplemental İ } \\
\hline CHEMBL1401058 & 688267 & 4.8 & 5.1028 & TRN & \\
\hline CHEMBL1559615 & 688267 & 5.85 & 5.0403 & TST & \\
\hline CHEMBL1443636 & 688267 & 6.2 & 5.0256 & TRN & \\
\hline CHEMBL1439019 & 688267 & 6.15 & 5.0965 & TST & \\
\hline CHEMBL1563322 & 688267 & 4.6 & 5.0519 & TST & \\
\hline CHEMBL1439403 & 688267 & 5.9 & 5.0289 & TRN & \\
\hline CHEMBL1372999 & 688267 & 4.2 & 4.9989 & TST & \\
\hline CHEMBL1417641 & 688267 & 4.25 & 5.0695 & TRN & \\
\hline CHEMBL1374633 & 688267 & 5.75 & 5.0809 & TRN & \\
\hline CHEMBL1430824 & 688267 & 4.75 & 5.1008 & TRN & \\
\hline CHEMBL1583030 & 688267 & 5.25 & 5.0786 & TRN & \\
\hline CHEMBL346814 & 688267 & 6.15 & 5.0491 & TST & \\
\hline CHEMBL1549413 & 688267 & 4.4 & 5.0889 & TRN & \\
\hline CHEMBL1601844 & 688267 & 5.4 & 5.0839 & TRN & \\
\hline CHEMBL1417256 & 688267 & 3.9 & 5.0493 & TRN & \\
\hline CHEMBL1299959 & 688267 & 6.2 & 5.0964 & TST & \\
\hline CHEMBL1526407 & 688267 & 4.25 & 5.0505 & TRN & \\
\hline CHEMBL1545870 & 688267 & 4.2 & 5.0099 & TST & \\
\hline CHEMBL1579320 & 688267 & 5.6 & 5.0539 & TRN & \\
\hline CHEMBL1453324 & 688267 & 4.3 & 4.9749 & TRN & \\
\hline CHEMBL1457467 & 688267 & 6.2 & 5.0159 & TRN & \\
\hline CHEMBL1432262 & 688267 & 6.2 & 5.0684 & TRN & \\
\hline CHEMBL1388414 & 688267 & 4.3 & 5.0474 & TRN & \\
\hline CHEMBL1598316 & 688267 & 5.2 & 5.0536 & TRN & \\
\hline CHEMBL1353303 & 688267 & 6.05 & 5.0184 & TRN & \\
\hline CHEMBL1572069 & 688267 & 4.5 & 5.0601 & TRN & \\
\hline CHEMBL1481946 & 688267 & 6.2 & 5.0255 & TRN & \\
\hline CHEMBL1503133 & 688267 & 4.9 & 5.2028 & TRN & \\
\hline CHEMBL1387700 & 688267 & 4.55 & 5.0429 & TRN & \\
\hline CHEMBL1463916 & 688267 & 4.0 & 5.0814 & TRN & \\
\hline CHEMBL1347917 & 688267 & 6.2 & 5.0181 & TRN & \\
\hline CHEMBL210145 & 688267 & 6.5 & 5.0884 & TRN & \\
\hline CHEMBL1326896 & 688267 & 4.05 & 5.03100 & 0000000001 & TRN \\
\hline CHEMBL1395990 & 688267 & 5.05 & 5.0624 & TST & \\
\hline CHEMBL1440990 & 688267 & 6.15 & 5.0994 & TRN & \\
\hline CHEMBL1596149 & 688267 & 4.3 & 5.1084 & TST & \\
\hline CHEMBL1491790 & 688267 & 6.25 & 5.0388 & TRN & \\
\hline CHEMBL1525491 & 688267 & 4.0 & 5.1327 & TRN & \\
\hline CHEMBL1453302 & 688267 & 5.6 & 5.0381 & TRN & \\
\hline CHEMBL1360311 & 688267 & 6.2 & 5.0151 & TRN & \\
\hline CHEMBL1376779 & 688267 & 5.8 & 5.092 & TST & \\
\hline CHEMBL1469289 & 688267 & 6.2 & 5.0733 & TRN & \\
\hline CHEMBL1552547 & 688267 & 5.2 & 5.0101 & TRN & \\
\hline CHEMBL1525275 & 688267 & 4.05 & 5.0639 & TRN & \\
\hline CHEMBL1485706 & 688267 & 4.25 & 4.9922 & TST & \\
\hline CHEMBL1364388 & 688267 & 6.45 & 5.1 & TST & \\
\hline CHEMBL1563848 & 688267 & 4.25 & 5.0424 & TRN & \\
\hline CHEMBL1338516 & 688267 & 4.1 & 5.0565 & TRN & \\
\hline
\end{tabular}




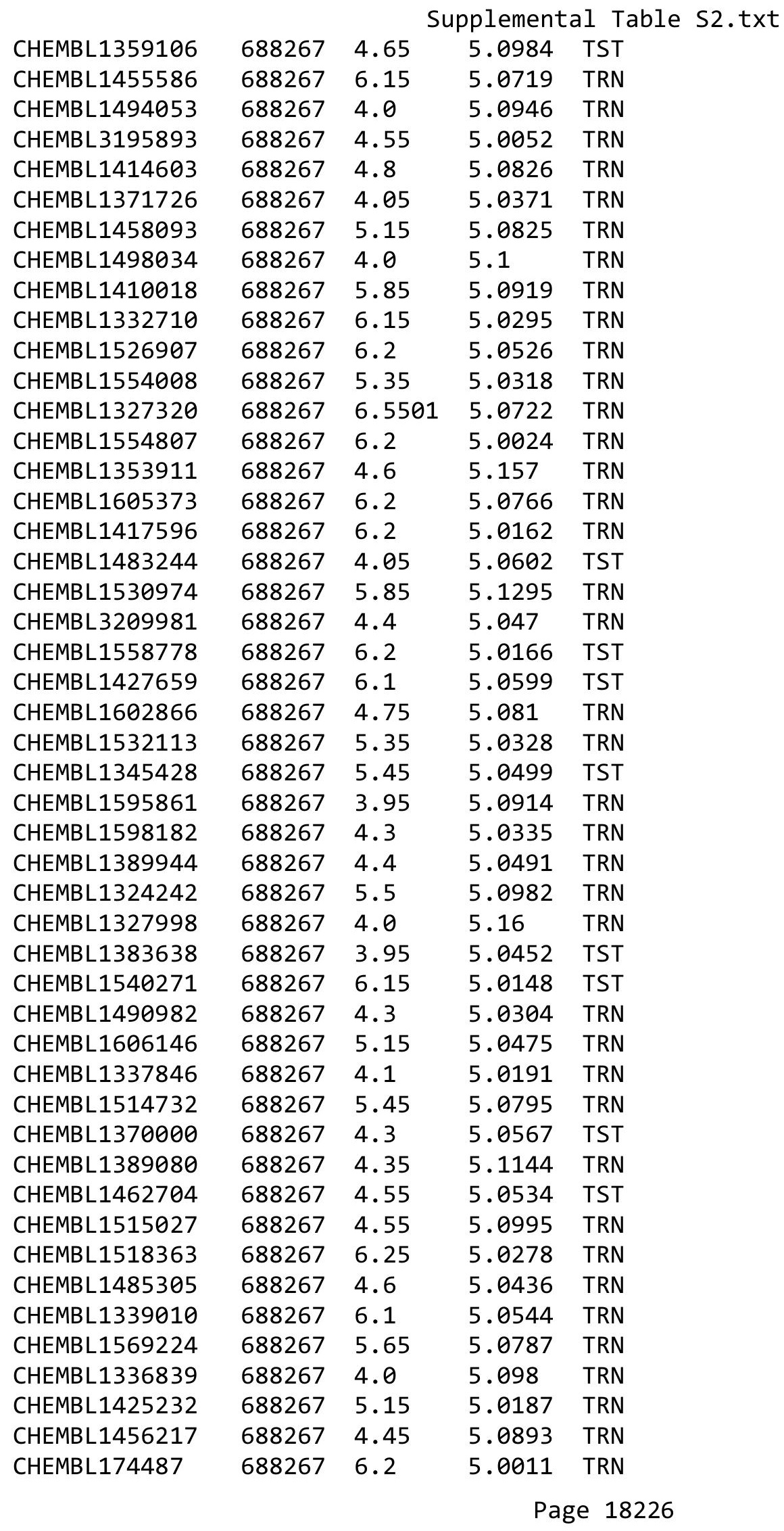




\begin{tabular}{|c|c|c|c|c|c|}
\hline \\
\hline CHEMBL1548805 & 688267 & 5.9 & 5.1143 & TST & \\
\hline CHEMBL1606013 & 688267 & 4.05 & 5.0743 & TRN & \\
\hline CHEMBL1311284 & 688267 & 4.1 & 5.0121 & TRN & \\
\hline CHEMBL1364016 & 688267 & 4.0 & 5.05 & TST & \\
\hline CHEMBL1497083 & 688267 & 4.9 & 5.1133 & TRN & \\
\hline CHEMBL1305651 & 688267 & 5.25 & 5.0567 & TST & \\
\hline CHEMBL1469922 & 688267 & 5.9 & 5.0311 & TRN & \\
\hline CHEMBL1408942 & 688267 & 6.25 & 5.0182 & TST & \\
\hline CHEMBL1558257 & 688267 & 6.15 & 5.0214 & TRN & \\
\hline CHEMBL1326442 & 688267 & 6.2 & 5.0143 & TST & \\
\hline CHEMBL3198150 & 688267 & 5.05 & 4.9971 & TST & \\
\hline CHEMBL1612077 & 688267 & 4.1 & 5.1395 & TST & \\
\hline CHEMBL1322733 & 688267 & 4.7 & 5.1461 & TRN & \\
\hline CHEMBL1465860 & 688267 & 4.35 & 5.0249 & TRN & \\
\hline CHEMBL1502805 & 688267 & 4.75 & 5.0328 & TRN & \\
\hline CHEMBL1435781 & 688267 & 4.05 & 5.16299 & 7999999999 & TRN \\
\hline CHEMBL1440498 & 688267 & 6.25 & 5.1306 & TRN & \\
\hline CHEMBL1322796 & 688267 & 4.35 & 5.0469 & TST & \\
\hline CHEMBL1446014 & 688267 & 4.35 & 5.0243 & TRN & \\
\hline CHEMBL1419967 & 688267 & 5.65 & 5.101 & TST & \\
\hline CHEMBL1457468 & 688267 & 4.0 & 5.0666 & TRN & \\
\hline CHEMBL1446620 & 688267 & 6.2 & 5.0955 & TST & \\
\hline CHEMBL1316986 & 688267 & 6.2 & 5.0057 & TRN & \\
\hline CHEMBL3193297 & 688267 & 5.15 & 5.0477 & TRN & \\
\hline CHEMBL1512218 & 688267 & 4.15 & 4.9845 & TRN & \\
\hline CHEMBL1495252 & 688267 & 4.95 & 5.0564 & TRN & \\
\hline CHEMBL1401297 & 688267 & 4.05 & 5.1107 & TRN & \\
\hline CHEMBL1408963 & 688267 & 4.05 & 5.0656 & TRN & \\
\hline CHEMBL1532548 & 688267 & 4.65 & 5.0446 & TRN & \\
\hline CHEMBL1515587 & 688267 & 5.35 & 5.0295 & TRN & \\
\hline CHEMBL1516508 & 688267 & 4.3 & 5.0782 & TRN & \\
\hline CHEMBL1523226 & 688267 & 4.1 & 4.9987 & TRN & \\
\hline CHEMBL1396101 & 688267 & 4.5 & 5.1532 & TRN & \\
\hline CHEMBL1352113 & 688267 & 4.25 & 5.1039 & TST & \\
\hline CHEMBL1555136 & 688267 & 5.6 & 5.025 & TRN & \\
\hline CHEMBL1361881 & 688267 & 4.0 & 5.1375 & TST & \\
\hline CHEMBL1538325 & 688267 & 5.55 & 5.0746 & TRN & \\
\hline CHEMBL1495405 & 688267 & 4.05 & 5.0648 & TST & \\
\hline CHEMBL1541015 & 688267 & 6.1 & 5.004 & TST & \\
\hline CHEMBL1301212 & 688267 & 4.6 & 5.03 & TRN & \\
\hline CHEMBL1397974 & 688267 & 5.35 & 5.0949 & TRN & \\
\hline CHEMBL1562577 & 688267 & 4.4 & 5.1329 & TST & \\
\hline CHEMBL1450428 & 688267 & 5.95 & 5.0982 & TRN & \\
\hline CHEMBL1583512 & 688267 & 4.35 & 5.015 & TRN & \\
\hline CHEMBL3210816 & 688267 & 5.05 & 4.9962 & TRN & \\
\hline CHEMBL 2003240 & 688267 & 4.05 & 5.0052 & TRN & \\
\hline CHEMBL1532894 & 688267 & 5.4 & 5.1191 & TRN & \\
\hline CHEMBL1501651 & 688267 & 4.25 & 5.0702 & TRN & \\
\hline
\end{tabular}




\begin{tabular}{|c|c|c|c|c|c|}
\hline \\
\hline CHEMBL1591093 & 688267 & 4.2 & 5.0952 & TRN & \\
\hline CHEMBL1592995 & 688267 & 4.05 & 5.0178 & TRN & \\
\hline CHEMBL1425111 & 688267 & 4.4 & 5.0575 & TST & \\
\hline CHEMBL1523328 & 688267 & 6.25 & 5.0194 & TRN & \\
\hline CHEMBL3209181 & 688267 & 3.95 & 5.0393 & TST & \\
\hline CHEMBL1508718 & 688267 & 5.2 & 5.0765 & TRN & \\
\hline CHEMBL1408544 & 688267 & 6.2 & 5.0661 & TRN & \\
\hline CHEMBL3213201 & 688267 & 5.55 & 5.0819 & TRN & \\
\hline CHEMBL1400973 & 688267 & 4.5 & 5.0823 & TRN & \\
\hline CHEMBL1586853 & 688267 & 4.4 & 5.0163 & TRN & \\
\hline CHEMBL1340772 & 688267 & 4.4 & 5.0397 & TRN & \\
\hline CHEMBL1367309 & 688267 & 5.55 & 5.0135 & TRN & \\
\hline CHEMBL1436474 & 688267 & 5.3 & 5.0742 & TRN & \\
\hline CHEMBL1531112 & 688267 & 6.2 & 5.0472 & TRN & \\
\hline CHEMBL1443694 & 688267 & 5.85 & 5.1506 & TST & \\
\hline CHEMBL1335930 & 688267 & 6.2 & 4.9927 & TRN & \\
\hline CHEMBL1472743 & 688267 & 5.05 & 5.0889 & TRN & \\
\hline CHEMBL1306334 & 688267 & 5.3 & 5.0806 & TRN & \\
\hline CHEMBL1502548 & 688267 & 4.4 & 5.0826 & TRN & \\
\hline CHEMBL1524877 & 688267 & 4.3 & 5.0019 & TRN & \\
\hline CHEMBL1557852 & 688267 & 5.8 & 5.0583 & TRN & \\
\hline CHEMBL1566957 & 688267 & 6.25 & 5.0413 & TRN & \\
\hline CHEMBL1326026 & 688267 & 5.25 & 4.9983 & TST & \\
\hline CHEMBL1459294 & 688267 & 4.05 & 5.073 & TRN & \\
\hline CHEMBL1547612 & 688267 & 4.35 & 5.0324 & TRN & \\
\hline CHEMBL1492321 & 688267 & 4.05 & 5.0367 & TST & \\
\hline CHEMBL1438660 & 688267 & 4.0 & 5.0505 & TRN & \\
\hline CHEMBL1553330 & 688267 & 6.2 & 5.0214 & TRN & \\
\hline CHEMBL1553979 & 688267 & 5.5 & 5.0812 & TRN & \\
\hline CHEMBL1554114 & 688267 & 5.4 & 5.0677 & TRN & \\
\hline CHEMBL1552881 & 688267 & 3.95 & 5.0746 & TRN & \\
\hline CHEMBL1451635 & 688267 & 5.5 & 5.1106 & TRN & \\
\hline CHEMBL1315518 & 688267 & 5.95 & 5.05399 & 9999999999 & TRN \\
\hline CHEMBL1487440 & 688267 & 4.05 & 5.0905 & TRN & \\
\hline CHEMBL1307760 & 688267 & 5.0 & 5.0272 & TST & \\
\hline CHEMBL1380504 & 688267 & 6.0 & 5.0091 & TST & \\
\hline CHEMBL1445463 & 688267 & 6.2 & 5.0997 & TRN & \\
\hline CHEMBL1459726 & 688267 & 4.35 & 4.9824 & TRN & \\
\hline CHEMBL1407528 & 688267 & 5.25 & 5.0209 & TRN & \\
\hline CHEMBL1512578 & 688267 & 6.15 & 5.1221 & TRN & \\
\hline CHEMBL1414216 & 688267 & 4.55 & 5.0895 & TST & \\
\hline CHEMBL1350630 & 688267 & 3.95 & 5.0349 & TRN & \\
\hline CHEMBL1560892 & 688267 & 4.4 & 5.0796 & TRN & \\
\hline CHEMBL1334654 & 688267 & 4.4 & 5.1237 & TRN & \\
\hline CHEMBL1360796 & 688267 & 5.3 & 5.0247 & TRN & \\
\hline CHEMBL1485179 & 688267 & 4.05 & 5.13899 & 9999999999 & TRN \\
\hline CHEMBL1323489 & 688267 & 4.25 & 5.0922 & TST & \\
\hline CHEMBL1474412 & 688267 & 6.2 & 5.0338 & TST & \\
\hline
\end{tabular}




\begin{tabular}{|c|c|c|c|c|}
\hline & & & ipplement & al Table S2 \\
\hline CHEMBL1438998 & 688267 & 5.5 & 5.0159 & TRN \\
\hline CHEMBL1491767 & 688267 & 4.4 & 5.0557 & TST \\
\hline CHEMBL1529614 & 688267 & 6.2 & 5.0448 & TRN \\
\hline CHEMBL1541904 & 688267 & 6.25 & 5.0672 & TST \\
\hline CHEMBL1435159 & 688267 & 5.6 & 5.0554 & TRN \\
\hline CHEMBL1511662 & 688267 & 6.2 & 5.1725 & TRN \\
\hline CHEMBL1378205 & 688267 & 5.3 & 5.0939 & TRN \\
\hline CHEMBL1494722 & 688267 & 5.3 & 5.0785 & TRN \\
\hline CHEMBL1563880 & 688267 & 6.2 & 5.1 & TRN \\
\hline CHEMBL1410636 & 688267 & 4.1 & 5.0503 & TRN \\
\hline CHEMBL1352600 & 688267 & 5.4 & 5.0091 & TRN \\
\hline CHEMBL1521688 & 688267 & 4.25 & 5.0584 & TRN \\
\hline CHEMBL1442272 & 688267 & 6.25 & 5.0132 & TRN \\
\hline CHEMBL1351261 & 688267 & 5.45 & 5.1175 & TRN \\
\hline CHEMBL1316906 & 688267 & 6.15 & 5.082 & TRN \\
\hline CHEMBL1393767 & 688267 & 4.85 & 5.0557 & TST \\
\hline CHEMBL1530837 & 688267 & 5.6 & 5.0303 & TRN \\
\hline CHEMBL1325140 & 688267 & 4.35 & 5.007 & TRN \\
\hline CHEMBL1527146 & 688267 & 5.1 & 5.0959 & TST \\
\hline CHEMBL1584883 & 688267 & 4.4 & 5.0356 & TST \\
\hline CHEMBL1534409 & 688267 & 4.05 & 5.0495 & TRN \\
\hline CHEMBL3199468 & 688267 & 4.05 & 4.9821 & TRN \\
\hline CHEMBL1528912 & 688267 & 4.75 & 5.0556 & TRN \\
\hline CHEMBL1319153 & 688267 & 4.5 & 5.0486 & TRN \\
\hline CHEMBL1449158 & 688267 & 6.25 & 5.0074 & TRN \\
\hline CHEMBL1331718 & 688267 & 5.55 & 5.0145 & TST \\
\hline CHEMBL1349609 & 688267 & 6.15 & 4.9784 & TST \\
\hline CHEMBL1447414 & 688267 & 5.6 & 5.029 & TST \\
\hline CHEMBL1428439 & 688267 & 4.4 & 5.0127 & TRN \\
\hline CHEMBL1581611 & 688267 & 4.85 & 5.0266 & TST \\
\hline CHEMBL1401726 & 688267 & 6.15 & 5.1501 & TRN \\
\hline CHEMBL1352155 & 688267 & 4.45 & 5.0075 & TRN \\
\hline CHEMBL1544777 & 688267 & 5.8 & 5.0598 & TRN \\
\hline CHEMBL1381629 & 688267 & 5.25 & 5.0139 & TRN \\
\hline CHEMBL1312630 & 688267 & 4.0 & 4.9694 & TST \\
\hline CHEMBL1396029 & 688267 & 5.6 & 5.0477 & TRN \\
\hline CHEMBL1464834 & 688267 & 6.15 & 5.0983 & TRN \\
\hline CHEMBL1544831 & 688267 & 5.6 & 5.0135 & TRN \\
\hline CHEMBL609036 & 688267 & 4.4 & 5.0439 & TST \\
\hline CHEMBL1438554 & 688267 & 5.35 & 4.9872 & TRN \\
\hline CHEMBL1416167 & 688267 & 6.2 & 5.05699 & 99999999995 \\
\hline CHEMBL1457398 & 688267 & 4.3 & 5.0388 & TST \\
\hline CHEMBL1356558 & 688267 & 6.2 & 4.9921 & TRN \\
\hline CHEMBL1485061 & 688267 & 4.8 & 5.1006 & TRN \\
\hline CHEMBL1459313 & 688267 & 4.4 & 5.0156 & TST \\
\hline CHEMBL1553588 & 688267 & 5.9 & 5.0866 & TST \\
\hline CHEMBL1321843 & 688267 & 4.25 & 5.0996 & TRN \\
\hline CHEMBL1557978 & 688267 & 5.7 & 5.01 & TRN \\
\hline
\end{tabular}




\begin{tabular}{|c|c|c|c|c|c|}
\hline \multicolumn{6}{|c|}{ Supplemental Table s2.txt } \\
\hline CHEMBL1309703 & 688267 & 4.0 & 5.135 & TRN & \\
\hline CHEMBL1559048 & 688267 & 3.95 & 5.0815 & TRN & \\
\hline CHEMBL1527298 & 688267 & 4.0 & 5.0607 & TST & \\
\hline CHEMBL1419214 & 688267 & 5.35 & 5.0137 & TRN & \\
\hline CHEMBL526468 & 688267 & 4.0 & 5.0439 & TRN & \\
\hline CHEMBL1497111 & 688267 & 6.2 & 5.0092 & TRN & \\
\hline CHEMBL1448094 & 688267 & 5.3 & 4.9962 & TRN & \\
\hline CHEMBL1554338 & 688267 & 4.05 & 5.0232 & TRN & \\
\hline CHEMBL1613214 & 688267 & 4.0 & 5.0521 & TRN & \\
\hline CHEMBL1550994 & 688267 & 5.8 & 5.0006 & TRN & \\
\hline CHEMBL 258317 & 688267 & 6.5 & 5.0945 & TRN & \\
\hline CHEMBL1606231 & 688267 & 4.2 & 5.0907 & TRN & \\
\hline CHEMBL1474090 & 688267 & 6.15 & 5.0597 & TST & \\
\hline CHEMBL1317127 & 688267 & 4.9 & 5.0008 & TRN & \\
\hline CHEMBL1307993 & 688267 & 5.8 & 5.0573 & TRN & \\
\hline CHEMBL1327786 & 688267 & 5.55 & 5.1059 & TRN & \\
\hline CHEMBL1426783 & 688267 & 6.25 & 5.1186 & TRN & \\
\hline CHEMBL1395359 & 688267 & 4.65 & 5.1062 & TRN & \\
\hline CHEMBL1313891 & 688267 & 4.8 & 5.0084 & TST & \\
\hline CHEMBL1336977 & 688267 & 4.0 & 5.0326 & TST & \\
\hline CHEMBL1964878 & 688267 & 5.25 & 5.0278 & TST & \\
\hline CHEMBL1598986 & 688267 & 5.3 & 5.0722 & TRN & \\
\hline CHEMBL1356563 & 688267 & 3.95 & 5.1071 & TRN & \\
\hline CHEMBL 3214558 & 688267 & 4.45 & 5.0366 & TST & \\
\hline CHEMBL1333379 & 688267 & 5.05 & 5.05 & TRN & \\
\hline CHEMBL1372077 & 688267 & 5.75 & 5.0641 & TRN & \\
\hline CHEMBL3211774 & 688267 & 4.65 & 5.0005 & TRN & \\
\hline CHEMBL1482868 & 688267 & 4.0 & 5.1223 & TRN & \\
\hline CHEMBL1503203 & 688267 & 6.1 & 4.9964 & TRN & \\
\hline CHEMBL1354005 & 688267 & 5.45 & 5.0704 & TRN & \\
\hline CHEMBL1382187 & 688267 & 6.15 & 5.1301 & TRN & \\
\hline CHEMBL1612986 & 688267 & 5.9 & 5.0201 & TRN & \\
\hline CHEMBL1509332 & 688267 & 3.9 & 5.0797 & TST & \\
\hline CHEMBL1299894 & 688267 & 4.35 & 5.1292 & TRN & \\
\hline CHEMBL1594525 & 688267 & 6.2 & 5.05699 & 99999999995 & TRN \\
\hline CHEMBL1528736 & 688267 & 5.1 & 5.0682 & TRN & \\
\hline CHEMBL1321886 & 688267 & 4.0 & 5.1276 & TRN & \\
\hline CHEMBL1565730 & 688267 & 6.5 & 5.1553 & TRN & \\
\hline CHEMBL1401798 & 688267 & 5.55 & 5.0398 & TST & \\
\hline CHEMBL1256109 & 688267 & 4.1 & 5.0112 & TRN & \\
\hline CHEMBL1409103 & 688267 & 5.45 & 5.0319 & TRN & \\
\hline CHEMBL1551600 & 688267 & 6.2 & 5.0543 & TST & \\
\hline CHEMBL1322283 & 688267 & 4.8 & 5.0716 & TST & \\
\hline CHEMBL1492657 & 688267 & 5.05 & 5.0259 & TST & \\
\hline CHEMBL1606789 & 688267 & 5.3 & 5.0022 & TRN & \\
\hline CHEMBL1365527 & 688267 & 4.55 & 5.12200 & 0000000001 & TRN \\
\hline CHEMBL1513772 & 688267 & 6.2 & 5.0403 & TRN & \\
\hline CHEMBL1307226 & 688267 & 5.35 & 5.0328 & TRN & \\
\hline
\end{tabular}


TRN 


\begin{tabular}{|c|c|c|c|c|c|}
\hline \multirow[b]{2}{*}{ CHEMBL1594666 } & \multirow[b]{2}{*}{688267} & \multicolumn{4}{|c|}{ Supplemental Table S2.t } \\
\hline & & 6.25 & 5.0749 & TST & \\
\hline CHEMBL1515047 & 688267 & 4.6 & 5.0101 & TRN & \\
\hline CHEMBL1300259 & 688267 & 6.2 & 5.038 & TST & \\
\hline CHEMBL1973669 & 688267 & 5.5 & 5.0121 & TRN & \\
\hline CHEMBL1454048 & 688267 & 5.65 & \multicolumn{2}{|c|}{5.0760000000000005} & TRN \\
\hline CHEMBL1327802 & 688267 & 4.35 & 5.0277 & TRN & \\
\hline CHEMBL1383037 & 688267 & 5.05 & 5.0738 & TRN & \\
\hline CHEMBL1338459 & 688267 & 4.0 & 5.0579 & TST & \\
\hline CHEMBL1310142 & 688267 & 4.3 & 5.0606 & TRN & \\
\hline CHEMBL1494491 & 688267 & 6.45 & 5.1059 & TRN & \\
\hline CHEMBL1366476 & 688267 & 6.25 & 5.0465 & TRN & \\
\hline CHEMBL1413028 & 688267 & 4.75 & 5.0572 & TRN & \\
\hline CHEMBL1573059 & 688267 & 4.95 & 5.0339 & TRN & \\
\hline CHEMBL1306238 & 688267 & 3.95 & 5.024 & TRN & \\
\hline CHEMBL1421736 & 688267 & 4.4 & 5.0061 & TRN & \\
\hline CHEMBL1522235 & 688267 & 4.55 & 4.9915 & TRN & \\
\hline CHEMBL1334046 & 688267 & 3.95 & 5.0314 & TRN & \\
\hline CHEMBL1549060 & 688267 & 5.65 & 5.0192 & TRN & \\
\hline CHEMBL1389400 & 688267 & 4.35 & 5.0625 & TST & \\
\hline CHEMBL1570920 & 688267 & 4.3 & 5.023 & TST & \\
\hline CHEMBL1404707 & 688267 & 3.95 & 5.0063 & TRN & \\
\hline CHEMBL1356526 & 688267 & 6.15 & \multicolumn{2}{|c|}{5.0680000000000005} & TST \\
\hline CHEMBL1307640 & 688267 & 5.4 & 5.1115 & TRN & \\
\hline CHEMBL1363133 & 688267 & 5.3 & 5.0363 & TRN & \\
\hline CHEMBL1491478 & 688267 & 5.55 & 5.0323 & TRN & \\
\hline CHEMBL1340694 & 688267 & 5.3 & 5.0873 & TRN & \\
\hline CHEMBL1583549 & 688267 & 6.5 & 5.1036 & TRN & \\
\hline CHEMBL1308248 & 688267 & 6.15 & 5.0322 & TRN & \\
\hline CHEMBL1420930 & 688267 & 4.4 & 5.0541 & TRN & \\
\hline CHEMBL1611848 & 688267 & 5.6 & 5.0709 & TRN & \\
\hline CHEMBL3192735 & 688267 & 4.75 & 4.977 & TRN & \\
\hline CHEMBL 3145182 & 688267 & 5.1 & 5.0562 & TST & \\
\hline CHEMBL 1476490 & 688267 & 4.0 & 5.025 & TRN & \\
\hline CHEMBL1417003 & 688267 & 6.2 & 5.0191 & TRN & \\
\hline CHEMBL1341656 & 688267 & 4.65 & 5.1123 & TRN & \\
\hline CHEMBL1493494 & 688267 & 6.2 & 5.1264 & TRN & \\
\hline CHEMBL1387131 & 688267 & 3.95 & 5.1285 & TRN & \\
\hline CHEMBL1334141 & 688267 & 5.55 & 5.1591 & TRN & \\
\hline CHEMBL1417295 & 688267 & 5.45 & 5.1144 & TST & \\
\hline CHEMBL1501603 & 688267 & 4.15 & 5.0757 & TST & \\
\hline CHEMBL1323307 & 688267 & 5.45 & 5.0211 & TRN & \\
\hline CHEMBL1427683 & 688267 & 5.05 & 5.074 & TRN & \\
\hline CHEMBL1553560 & 688267 & 4.0 & 5.0683 & TRN & \\
\hline CHEMBL1503416 & 688267 & 4.05 & 5.0501 & TRN & \\
\hline CHEMBL1500794 & 688267 & 5.3 & 5.0397 & TST & \\
\hline CHEMBL1519831 & 688267 & 4.25 & 5.1258 & TRN & \\
\hline CHEMBL1401725 & 688267 & 6.2 & 5.0634 & TRN & \\
\hline \multirow[t]{2}{*}{ CHEMBL1417137 } & 688267 & 4.45 & 5.0862 & TRN & \\
\hline & & \multicolumn{4}{|c|}{ Page 18232} \\
\hline
\end{tabular}




\begin{tabular}{|c|c|c|c|c|}
\hline & & & pplemen & al $\mathrm{T}$ \\
\hline CHEMBL1580544 & 688267 & 5.8 & 5.1011 & TRN \\
\hline CHEMBL1604121 & 688267 & 6.5 & 5.1091 & TRN \\
\hline CHEMBL1608291 & 688267 & 5.7 & 5.0713 & TST \\
\hline CHEMBL1480498 & 688267 & 5.4 & 5.0421 & TRN \\
\hline CHEMBL1484393 & 688267 & 4.25 & 5.0141 & TRN \\
\hline CHEMBL1533558 & 688267 & 3.95 & 5.0206 & TRN \\
\hline CHEMBL1493365 & 688267 & 4.4 & 5.0091 & TRN \\
\hline CHEMBL1361124 & 688267 & 4.05 & 5.0332 & TRN \\
\hline CHEMBL1474355 & 688267 & 4.35 & 5.1093 & TRN \\
\hline CHEMBL1568138 & 688267 & 4.3 & 4.9772 & TRN \\
\hline CHEMBL1569706 & 688267 & 6.2 & 5.0209 & TST \\
\hline CHEMBL1608630 & 688267 & 4.0 & 5.0257 & TRN \\
\hline CHEMBL1541688 & 688267 & 5.55 & 5.0791 & TRN \\
\hline CHEMBL1423906 & 688267 & 5.85 & 5.0536 & TRN \\
\hline CHEMBL1304347 & 688267 & 4.25 & 5.1139 & TST \\
\hline CHEMBL1558113 & 688267 & 5.4 & 5.1035 & TRN \\
\hline CHEMBL1520941 & 688267 & 5.5 & 5.019 & TRN \\
\hline CHEMBL1421546 & 688267 & 5.75 & 5.0531 & TRN \\
\hline CHEMBL1569751 & 688267 & 5.8 & 5.0234 & TST \\
\hline CHEMBL1520920 & 688267 & 5.5 & 5.0413 & TRN \\
\hline CHEMBL1515646 & 688267 & 5.2 & 5.0625 & TST \\
\hline CHEMBL1438485 & 688267 & 4.4 & 5.0544 & TRN \\
\hline CHEMBL1316705 & 688267 & 4.0 & 5.0187 & TST \\
\hline CHEMBL1453670 & 688267 & 4.65 & 5.0732 & TST \\
\hline CHEMBL1415744 & 688267 & 5.75 & 5.033 & TST \\
\hline CHEMBL1536658 & 688267 & 4.55 & 5.0065 & TST \\
\hline CHEMBL1439424 & 688267 & 5.4 & 5.052 & TRN \\
\hline CHEMBL1546193 & 688267 & 4.0 & 5.1223 & TST \\
\hline CHEMBL1484961 & 688267 & 5.35 & 5.0185 & TRN \\
\hline CHEMBL1327422 & 688267 & 4.2 & 5.0 & TRN \\
\hline CHEMBL1608887 & 688267 & 6.15 & 5.0845 & TST \\
\hline CHEMBL1376108 & 688267 & 6.0 & 5.0745 & TST \\
\hline CHEMBL1565948 & 688267 & 5.05 & 5.1117 & TRN \\
\hline CHEMBL1463577 & 688267 & 5.6 & 5.0494 & TRN \\
\hline CHEMBL1344410 & 688267 & 4.4 & 5.0632 & TRN \\
\hline CHEMBL1405297 & 688267 & 4.35 & 5.0298 & TRN \\
\hline CHEMBL1510642 & 688267 & 5.95 & 5.0349 & TRN \\
\hline CHEMBL1511331 & 688267 & 4.05 & 5.0319 & TRN \\
\hline CHEMBL1327958 & 688267 & 4.5 & 5.0995 & TRN \\
\hline CHEMBL 3208423 & 688267 & 5.85 & 5.0138 & TRN \\
\hline CHEMBL1463660 & 688267 & 6.1 & 5.0515 & TRN \\
\hline CHEMBL1407626 & 688267 & 6.0 & 5.0726 & TRN \\
\hline CHEMBL1334458 & 688267 & 4.25 & 5.1066 & TRN \\
\hline CHEMBL1492005 & 688267 & 3.95 & 5.0205 & TRN \\
\hline CHEMBL1485552 & 688267 & 5.7 & 5.1451 & TRN \\
\hline CHEMBL1558746 & 688267 & 6.25 & 5.0552 & TRN \\
\hline CHEMBL1508443 & 688267 & 3.95 & 5.1139 & TRN \\
\hline CHEMBL1603675 & 688267 & 4.05 & 5.1091 & TRN \\
\hline
\end{tabular}




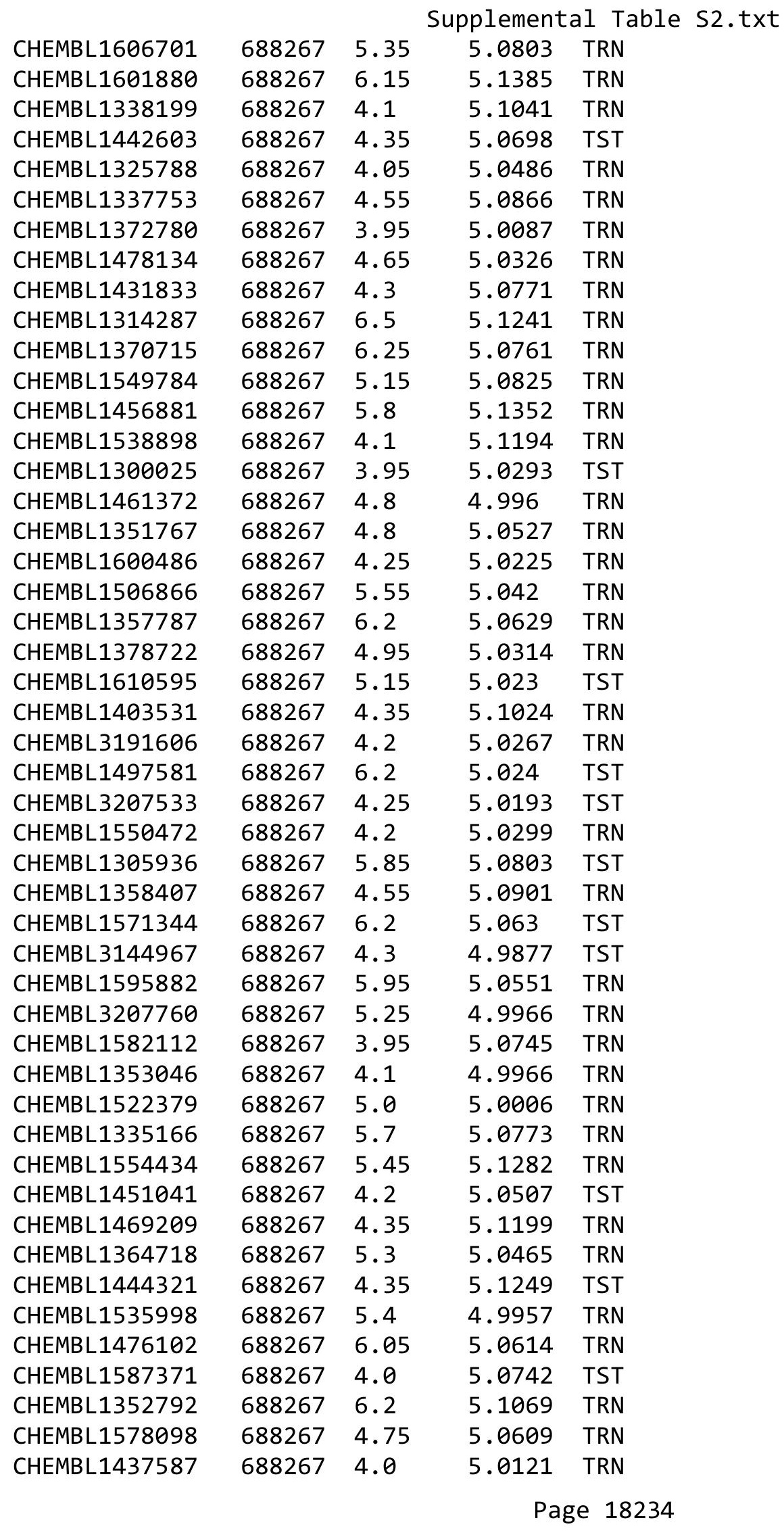




\begin{tabular}{|c|c|c|c|c|c|}
\hline \multicolumn{6}{|c|}{ Supplemental Table s2.txt } \\
\hline CHEMBL275066 & 688267 & 5.3 & 5.0328 & TST & \\
\hline CHEMBL1387224 & 688267 & 4.45 & 5.0937 & TRN & \\
\hline CHEMBL1390224 & 688267 & 5.3 & 5.0321 & TST & \\
\hline CHEMBL1601151 & 688267 & 6.2 & 5.0955 & TST & \\
\hline CHEMBL1309964 & 688267 & 4.05 & 5.0128 & TRN & \\
\hline CHEMBL1601147 & 688267 & 5.45 & 5.0535 & TRN & \\
\hline CHEMBL1582186 & 688267 & 5.25 & 5.0534 & TRN & \\
\hline CHEMBL1577222 & 688267 & 6.0 & 5.1133 & TST & \\
\hline CHEMBL1612495 & 688267 & 5.25 & 5.0862 & TRN & \\
\hline CHEMBL1989090 & 688267 & 4.0 & 4.9967 & TRN & \\
\hline CHEMBL1414692 & 688267 & 4.6 & 5.1263 & TRN & \\
\hline CHEMBL1569296 & 688267 & 3.95 & 5.0228 & TST & \\
\hline CHEMBL1321442 & 688267 & 4.0 & 5.0701 & TRN & \\
\hline CHEMBL1576508 & 688267 & 4.75 & 5.0931 & TST & \\
\hline CHEMBL1315935 & 688267 & 6.2 & 5.0041 & TRN & \\
\hline CHEMBL1324945 & 688267 & 5.95 & 5.0409 & TRN & \\
\hline CHEMBL1340365 & 688267 & 4.65 & 5.0684 & TRN & \\
\hline CHEMBL1393495 & 688267 & 5.25 & 5.02 & TRN & \\
\hline CHEMBL1515055 & 688267 & 4.0 & 5.0332 & TRN & \\
\hline CHEMBL1582165 & 688267 & 4.4 & 5.1189 & TRN & \\
\hline CHEMBL1315425 & 688267 & 5.35 & 5.0633 & TRN & \\
\hline CHEMBL1522744 & 688267 & 5.55 & 5.0921 & TRN & \\
\hline CHEMBL1393291 & 688267 & 4.35 & 5.0183 & TRN & \\
\hline CHEMBL1552262 & 688267 & 4.05 & 5.1157 & TRN & \\
\hline CHEMBL1564503 & 688267 & 4.2 & 5.0803 & TRN & \\
\hline CHEMBL1612113 & 688267 & 4.45 & 5.0548 & TRN & \\
\hline CHEMBL1354264 & 688267 & 5.45 & 5.1011 & TRN & \\
\hline CHEMBL1601519 & 688267 & 4.35 & 5.05699 & 99999999995 & TST \\
\hline CHEMBL1344721 & 688267 & 6.2 & 5.1121 & TRN & \\
\hline CHEMBL1322110 & 688267 & 4.0 & 5.0023 & TST & \\
\hline CHEMBL1378191 & 688267 & 5.5 & 5.0806 & TST & \\
\hline CHEMBL1360098 & 688267 & 6.2 & 5.0145 & TRN & \\
\hline CHEMBL1484563 & 688267 & 4.25 & 5.0994 & TRN & \\
\hline CHEMBL1307236 & 688267 & 4.35 & 5.0869 & TST & \\
\hline CHEMBL1340837 & 688267 & 6.25 & 5.0402 & TRN & \\
\hline CHEMBL1385436 & 688267 & 4.25 & 5.0248 & TRN & \\
\hline CHEMBL1534514 & 688267 & 4.05 & 5.0347 & TST & \\
\hline CHEMBL1305026 & 688267 & 5.0 & 5.0537 & TRN & \\
\hline CHEMBL1419404 & 688267 & 5.9 & 5.0442 & TRN & \\
\hline CHEMBL1353798 & 688267 & 4.0 & 5.0852 & TST & \\
\hline CHEMBL1380960 & 688267 & 6.25 & 5.078 & TRN & \\
\hline CHEMBL1387729 & 688267 & 6.2 & 5.1288 & TRN & \\
\hline CHEMBL3197409 & 688267 & 4.55 & 5.0293 & TST & \\
\hline CHEMBL1588852 & 688267 & 4.15 & 5.0083 & TRN & \\
\hline CHEMBL1512673 & 688267 & 4.0 & 5.0346 & TRN & \\
\hline CHEMBL1419854 & 688267 & 4.4 & 5.0846 & TRN & \\
\hline CHEMBL1602302 & 688267 & 5.35 & 5.0759 & TRN & \\
\hline CHEMBL1498260 & 688267 & 4.65 & 5.1057 & TST & \\
\hline
\end{tabular}




\begin{tabular}{|c|c|c|c|c|}
\hline \multicolumn{5}{|c|}{ Supplemental Table S2.txt } \\
\hline CHEMBL1515545 & 688267 & 4.1 & 5.0256 & TRN \\
\hline CHEMBL1303086 & 688267 & 4.95 & 5.0505 & TRN \\
\hline CHEMBL1536648 & 688267 & 4.45 & 5.0712 & TRN \\
\hline CHEMBL1316614 & 688267 & 4.6 & 4.9923 & TRN \\
\hline CHEMBL 1385876 & 688267 & 5.8 & 5.0102 & TRN \\
\hline CHEMBL1410325 & 688267 & 4.0 & 5.066 & TST \\
\hline CHEMBL1378360 & 688267 & 4.6 & 5.1369 & TRN \\
\hline CHEMBL1373522 & 688267 & 5.35 & 5.0324 & TRN \\
\hline CHEMBL1317403 & 688267 & 5.3 & 5.0522 & TST \\
\hline CHEMBL1605560 & 688267 & 6.5 & 5.0572 & TRN \\
\hline CHEMBL1475220 & 688267 & 5.95 & 5.0686 & TRN \\
\hline CHEMBL1537764 & 688267 & 4.5 & 5.0494 & TST \\
\hline CHEMBL1512405 & 688267 & 5.4 & 5.0087 & TRN \\
\hline CHEMBL1553702 & 688267 & 4.95 & 5.0631 & TST \\
\hline CHEMBL1421480 & 688267 & 5.55 & 5.0072 & TST \\
\hline CHEMBL1469950 & 688267 & 6.2 & 5.0158 & TRN \\
\hline CHEMBL1450712 & 688267 & 4.05 & 5.086 & TST \\
\hline CHEMBL1403508 & 688267 & 4.15 & 5.0792 & TRN \\
\hline CHEMBL1330941 & 688267 & 3.95 & 5.0374 & TRN \\
\hline CHEMBL1514908 & 688267 & 5.9 & 5.0547 & TRN \\
\hline CHEMBL1484833 & 688267 & 5.35 & 4.9889 & TST \\
\hline CHEMBL1563940 & 688267 & 4.0 & 5.0546 & TRN \\
\hline CHEMBL1368663 & 688267 & 4.05 & 5.0251 & TRN \\
\hline CHEMBL1545471 & 688267 & 4.35 & 5.0286 & TRN \\
\hline CHEMBL1504932 & 688267 & 5.3 & 5.0742 & TST \\
\hline CHEMBL1342861 & 688267 & 4.3 & 5.0621 & TRN \\
\hline CHEMBL1459334 & 688267 & 4.3 & 5.0157 & TRN \\
\hline CHEMBL1389753 & 688267 & 4.0 & 5.1016 & TRN \\
\hline CHEMBL1436157 & 688267 & 5.45 & 4.9901 & TRN \\
\hline CHEMBL1512799 & 688267 & 4.1 & 5.0998 & TRN \\
\hline CHEMBL1415299 & 688267 & 5.45 & 5.0629 & TRN \\
\hline CHEMBL1475295 & 688267 & 4.35 & 5.0214 & TRN \\
\hline CHEMBL1373591 & 688267 & 4.35 & 4.9903 & TST \\
\hline CHEMBL1448160 & 688267 & 4.0 & 4.977 & TRN \\
\hline CHEMBL1316531 & 688267 & 6.2 & 5.1041 & TRN \\
\hline CHEMBL1400921 & 688267 & 4.75 & 5.0778 & TRN \\
\hline CHEMBL3193590 & 688267 & 6.15 & 5.0499 & TST \\
\hline CHEMBL1576690 & 688267 & 4.75 & 5.016 & TRN \\
\hline CHEMBL1591699 & 688267 & 4.05 & 5.0279 & TRN \\
\hline CHEMBL1423751 & 688267 & 6.15 & 5.0016 & TRN \\
\hline CHEMBL1427173 & 688267 & 4.0 & 5.1325 & TST \\
\hline CHEMBL1604854 & 688267 & 4.15 & 5.0621 & TST \\
\hline CHEMBL1433428 & 688267 & 5.6 & 5.0617 & TST \\
\hline CHEMBL3212107 & 688267 & 4.0 & 5.0242 & TRN \\
\hline CHEMBL1474182 & 688267 & 5.85 & 5.0826 & TRN \\
\hline CHEMBL1422097 & 688267 & 4.05 & 5.018 & TST \\
\hline CHEMBL3195689 & 688267 & 5.05 & 5.0213 & TRN \\
\hline CHEMBL1525050 & 688267 & 5.0 & 5.0472 & TST \\
\hline
\end{tabular}




\begin{tabular}{|c|c|c|c|c|c|}
\hline \multirow{3}{*}{$\begin{array}{l}\text { CHEMBL1308851 } \\
\text { CHEMBL1507471 }\end{array}$} & \multirow{3}{*}{$\begin{array}{l}688267 \\
688267\end{array}$} & \multicolumn{4}{|c|}{ Supplemental Table S2.txt } \\
\hline & & 5.9 & 5.0310 & 0000000001 & TRN \\
\hline & & 4.6 & 5.0311 & TST & \\
\hline CHEMBL1519574 & 688267 & 5.35 & 5.0159 & TRN & \\
\hline CHEMBL1406464 & 688267 & 4.05 & 5.0528 & TRN & \\
\hline CHEMBL1481031 & 688267 & 5.05 & 5.0124 & TRN & \\
\hline CHEMBL1327851 & 688267 & 4.05 & 5.0364 & TRN & \\
\hline CHEMBL1422694 & 688267 & 6.05 & 5.0956 & TRN & \\
\hline CHEMBL1588462 & 688267 & 4.65 & 5.02 & TRN & \\
\hline CHEMBL3193038 & 688267 & 4.05 & 5.0077 & TRN & \\
\hline CHEMBL1531942 & 688267 & 6.2 & 5.0523 & TST & \\
\hline CHEMBL1330113 & 688267 & 5.45 & 5.0275 & TST & \\
\hline CHEMBL3211205 & 688267 & 4.65 & 5.0211 & TRN & \\
\hline CHEMBL1545841 & 688267 & 6.0 & 5.0371 & TRN & \\
\hline CHEMBL1490017 & 688267 & 5.65 & 5.0482 & TRN & \\
\hline CHEMBL1580258 & 688267 & 5.8 & 5.0491 & TST & \\
\hline CHEMBL1300694 & 688267 & 6.2 & 4.9877 & TRN & \\
\hline CHEMBL1483101 & 688267 & 3.95 & 5.0846 & TRN & \\
\hline CHEMBL1473970 & 688267 & 4.4 & 5.0994 & TRN & \\
\hline CHEMBL1385933 & 688267 & 4.35 & 4.976 & TRN & \\
\hline CHEMBL1610218 & 688267 & 5.3 & 5.0261 & TST & \\
\hline CHEMBL1592748 & 688267 & 4.9 & 5.1636 & TRN & \\
\hline CHEMBL1399895 & 688267 & 5.55 & 5.0402 & TRN & \\
\hline CHEMBL1403827 & 688267 & 5.0 & 5.0186 & TRN & \\
\hline CHEMBL1354493 & 688267 & 4.05 & 5.0669 & TRN & \\
\hline CHEMBL1466812 & 688267 & 4.45 & 5.1016 & TRN & \\
\hline CHEMBL1427685 & 688267 & 6.05 & 5.0481 & TST & \\
\hline CHEMBL1355376 & 688267 & 4.3 & 4.9744 & TRN & \\
\hline CHEMBL1528728 & 688267 & 4.25 & 5.0815 & TRN & \\
\hline CHEMBL1471135 & 688267 & 5.55 & 5.0664 & TRN & \\
\hline CHEMBL1574950 & 688267 & 5.6 & 5.0479 & TST & \\
\hline CHEMBL1442803 & 688267 & 6.2 & 5.0697 & TRN & \\
\hline CHEMBL1472857 & 688267 & 4.05 & 5.1044 & TST & \\
\hline CHEMBL1567196 & 688267 & 5.9 & 5.0038 & TRN & \\
\hline CHEMBL230143 & 688267 & 5.85 & 5.1163 & TRN & \\
\hline CHEMBL1520364 & 688267 & 4.0 & 5.1733 & TRN & \\
\hline CHEMBL3210616 & 688267 & 4.65 & 5.0163 & TST & \\
\hline CHEMBL1491453 & 688267 & 5.7 & 5.059 & TRN & \\
\hline CHEMBL1310178 & 688267 & 4.35 & 5.0712 & TRN & \\
\hline CHEMBL1393880 & 688267 & 6.15 & 5.027 & TRN & \\
\hline CHEMBL1397444 & 688267 & 6.0 & 5.0283 & TRN & \\
\hline CHEMBL405343 & 688267 & 6.15 & 5.0134 & TRN & \\
\hline CHEMBL1563847 & 688267 & 4.35 & 5.0491 & TRN & \\
\hline CHEMBL1579872 & 688267 & 6.45 & 5.0706 & TRN & \\
\hline CHEMBL1519271 & 688267 & 5.45 & 5.0317 & TRN & \\
\hline CHEMBL1608021 & 688267 & 6.3 & 5.0664 & TST & \\
\hline CHEMBL1332906 & 688267 & 5.75 & 4.9971 & TST & \\
\hline CHEMBL1478516 & 688267 & 4.4 & 5.0881 & TRN & \\
\hline CHEMBL1575519 & 688267 & 5.15 & 5.0586 & TRN & \\
\hline
\end{tabular}




\begin{tabular}{|c|c|c|c|c|c|}
\hline \multicolumn{6}{|c|}{ plemental lable s2. } \\
\hline CHEMBL1449577 & 688267 & 6.15 & 5.0127 & TRN & \\
\hline CHEMBL1376448 & 688267 & 6.2 & 5.1119 & TST & \\
\hline CHEMBL1489936 & 688267 & 4.4 & 5.0079 & TRN & \\
\hline CHEMBL1302678 & 688267 & 6.15 & 5.1173 & TRN & \\
\hline CHEMBL1357590 & 688267 & 3.95 & 5.1404 & TRN & \\
\hline CHEMBL1532868 & 688267 & 5.85 & 5.0856 & TRN & \\
\hline CHEMBL1403305 & 688267 & 4.35 & 5.0006 & TRN & \\
\hline CHEMBL1494094 & 688267 & 5.35 & 5.0913 & TST & \\
\hline CHEMBL1552817 & 688267 & 6.5 & 5.1199 & TRN & \\
\hline CHEMBL1516816 & 688267 & 6.2 & 5.0737 & TRN & \\
\hline CHEMBL1605172 & 688267 & 4.5 & 5.0704 & TRN & \\
\hline CHEMBL1333729 & 688267 & 6.15 & 5.0178 & TST & \\
\hline CHEMBL1609680 & 688267 & 4.35 & 5.0487 & TRN & \\
\hline CHEMBL1360946 & 688267 & 6.15 & 5.0097 & TRN & \\
\hline CHEMBL1564713 & 688267 & 6.15 & 4.9868 & TST & \\
\hline CHEMBL1356709 & 688267 & 5.4 & 5.0604 & TRN & \\
\hline CHEMBL1581997 & 688267 & 4.0 & 5.0109 & TST & \\
\hline CHEMBL1507520 & 688267 & 4.55 & 5.0856 & TST & \\
\hline CHEMBL1324421 & 688267 & 6.2 & 5.0518 & TRN & \\
\hline CHEMBL1483538 & 688267 & 4.0 & 5.0411 & TST & \\
\hline CHEMBL1351480 & 688267 & 6.25 & 5.0406 & TRN & \\
\hline CHEMBL1517648 & 688267 & 4.55 & 5.12799 & 9999999999 & TRN \\
\hline CHEMBL1525930 & 688267 & 4.0 & 5.0101 & TRN & \\
\hline CHEMBL1527253 & 688267 & 5.35 & 5.1093 & TRN & \\
\hline CHEMBL1416010 & 688267 & 5.0 & 5.0647 & TRN & \\
\hline CHEMBL1407061 & 688267 & 5.85 & 5.0405 & TRN & \\
\hline CHEMBL1337244 & 688267 & 4.05 & 5.1094 & TRN & \\
\hline CHEMBL1605864 & 688267 & 5.45 & 4.9803 & TRN & \\
\hline CHEMBL1324251 & 688267 & 4.45 & 5.0149 & TST & \\
\hline CHEMBL1533250 & 688267 & 5.4 & 5.1254 & TRN & \\
\hline CHEMBL1541676 & 688267 & 5.6 & 5.0525 & TRN & \\
\hline CHEMBL1572727 & 688267 & 4.2 & 5.025 & TRN & \\
\hline CHEMBL1721609 & 688267 & 5.95 & $5.0360 e$ & 00000000005 & TRN \\
\hline CHEMBL1441657 & 688267 & 4.35 & 4.9957 & TRN & \\
\hline CHEMBL1597557 & 688267 & 4.35 & 5.0652 & TRN & \\
\hline CHEMBL1510802 & 688267 & 5.45 & 5.0277 & TRN & \\
\hline CHEMBL1577511 & 688267 & 5.55 & 5.0591 & TRN & \\
\hline CHEMBL1480680 & 688267 & 5.35 & 5.0894 & TRN & \\
\hline CHEMBL1600947 & 688267 & 4.4 & 5.0373 & TRN & \\
\hline CHEMBL1309619 & 688267 & 4.4 & $5.1110 e$ & $\partial 000000001$ & TST \\
\hline CHEMBL1512243 & 688267 & 4.0 & 5.0484 & TRN & \\
\hline CHEMBL1553299 & 688267 & 5.4 & 5.0659 & TRN & \\
\hline CHEMBL1438348 & 688267 & 5.3 & 5.0571 & TST & \\
\hline CHEMBL1540648 & 688267 & 5.45 & 5.0361 & TRN & \\
\hline CHEMBL1535559 & 688267 & 4.1 & 5.05699 & 99999999995 & TRN \\
\hline CHEMBL1438363 & 688267 & 4.05 & 5.0418 & TRN & \\
\hline CHEMBL1597668 & 688267 & 4.0 & 5.004 & TST & \\
\hline CHEMBL1528048 & 688267 & 4.05 & 5.1155 & TRN & \\
\hline
\end{tabular}




\begin{tabular}{|c|c|c|c|c|c|}
\hline \multirow{3}{*}{$\begin{array}{l}\text { CHEMBL1546098 } \\
\text { CHEMBL1989690 }\end{array}$} & \multirow{3}{*}{$\begin{array}{l}688267 \\
688267\end{array}$} & \multicolumn{4}{|c|}{ Supplemental Table S2.txt } \\
\hline & & 4.6 & 5.0939 & 9999999999 & TST \\
\hline & & 5.25 & 5.1317 & TRN & \\
\hline CHEMBL1330497 & 688267 & 5.65 & 5.077 & TRN & \\
\hline CHEMBL1611972 & 688267 & 5.05 & 5.0432 & TRN & \\
\hline CHEMBL1496170 & 688267 & 4.0 & 5.0719 & TST & \\
\hline CHEMBL1518981 & 688267 & 6.2 & 5.0817 & TRN & \\
\hline CHEMBL1365011 & 688267 & 6.15 & 5.0694 & TST & \\
\hline CHEMBL1478685 & 688267 & 6.2 & 5.0064 & TRN & \\
\hline CHEMBL1472441 & 688267 & 5.05 & 5.1189 & TRN & \\
\hline CHEMBL1320593 & 688267 & 3.95 & 5.1024 & TRN & \\
\hline CHEMBL1543194 & 688267 & 5.05 & 5.0181 & TRN & \\
\hline CHEMBL1564862 & 688267 & 4.65 & 5.0585 & TST & \\
\hline CHEMBL1372505 & 688267 & 4.45 & 5.0389 & TRN & \\
\hline CHEMBL1484580 & 688267 & 5.6 & 5.0553 & TRN & \\
\hline CHEMBL1376935 & 688267 & 6.2 & 5.0418 & TRN & \\
\hline CHEMBL181930 & 688267 & 6.3 & 5.0066 & TRN & \\
\hline CHEMBL3192018 & 688267 & 4.05 & 4.965 & TRN & \\
\hline CHEMBL1474923 & 688267 & 4.85 & 5.0605 & TST & \\
\hline CHEMBL1419705 & 688267 & 5.15 & 5.0403 & TRN & \\
\hline CHEMBL1570162 & 688267 & 6.5 & 5.0591 & TRN & \\
\hline CHEMBL1356525 & 688267 & 5.3 & 5.0845 & TRN & \\
\hline CHEMBL1315720 & 688267 & 4.35 & 5.0438 & TRN & \\
\hline CHEMBL1301955 & 688267 & 5.9 & 5.0344 & TRN & \\
\hline CHEMBL1594892 & 688267 & 5.6 & 5.0717 & TRN & \\
\hline CHEMBL1500857 & 688267 & 6.2 & 5.0744 & TRN & \\
\hline CHEMBL1317936 & 688267 & 6.5 & 5.0374 & TRN & \\
\hline CHEMBL1513386 & 688267 & 5.5 & 5.0953 & TRN & \\
\hline CHEMBL1400696 & 688267 & 5.95 & 5.0593 & TRN & \\
\hline CHEMBL1415178 & 688267 & 4.7 & 5.0674 & TRN & \\
\hline CHEMBL1525367 & 688267 & 5.9 & 5.0305 & TRN & \\
\hline CHEMBL1536187 & 688267 & 5.25 & 5.0832 & TRN & \\
\hline CHEMBL1478169 & 688267 & 6.15 & 5.0722 & TRN & \\
\hline CHEMBL1410270 & 688267 & 4.05 & 4.9946 & TRN & \\
\hline CHEMBL1403448 & 688267 & 5.15 & 4.9999 & TST & \\
\hline CHEMBL1567134 & 688267 & 4.15 & 5.0286 & TST & \\
\hline CHEMBL1495137 & 688267 & 4.55 & 5.0443 & TRN & \\
\hline CHEMBL1507990 & 688267 & 6.15 & 5.039 & TRN & \\
\hline CHEMBL1335047 & 688267 & 6.25 & 4.9903 & TST & \\
\hline CHEMBL1389859 & 688267 & 4.5 & 5.0726 & TRN & \\
\hline CHEMBL1612022 & 688267 & 6.25 & 5.1008 & TRN & \\
\hline CHEMBL1305414 & 688267 & 6.2 & 5.1107 & TRN & \\
\hline CHEMBL1324670 & 688267 & 4.15 & 5.0965 & TRN & \\
\hline CHEMBL1305108 & 688267 & 6.15 & 5.0142 & TRN & \\
\hline CHEMBL1382030 & 688267 & 6.2 & 5.0914 & TRN & \\
\hline CHEMBL1335162 & 688267 & 5.4 & 5.0649 & TRN & \\
\hline CHEMBL1370165 & 688267 & 6.0 & 5.0169 & TRN & \\
\hline CHEMBL1319151 & 688267 & 6.2 & 5.0362 & TRN & \\
\hline CHEMBL1429554 & 688267 & 4.4 & 5.0735 & TST & \\
\hline
\end{tabular}




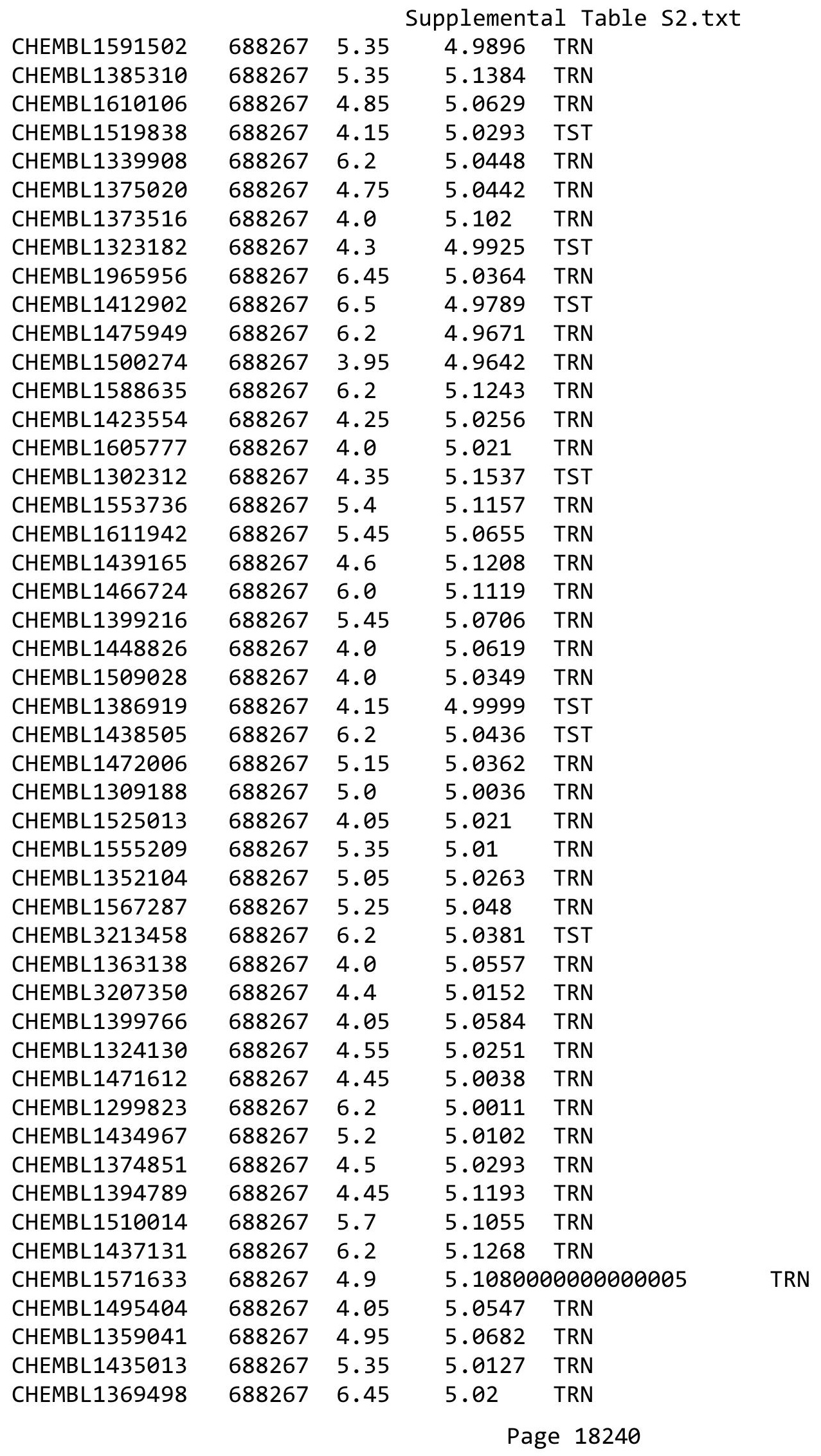




\begin{tabular}{|c|c|c|c|c|}
\hline & & & premer & \\
\hline CHEMBL1549800 & 688267 & 4.8 & 5.0609 & TST \\
\hline CHEMBL1519027 & 688267 & 4.05 & 5.0723 & TRN \\
\hline CHEMBL1575552 & 688267 & 4.35 & 5.1182 & TRN \\
\hline CHEMBL1460643 & 688267 & 6.2 & 5.0535 & TST \\
\hline CHEMBL1576008 & 688267 & 4.2 & 5.0444 & TST \\
\hline CHEMBL1512976 & 688267 & 5.95 & 5.0301 & TRN \\
\hline CHEMBL1502316 & 688267 & 4.0 & 5.0379 & TST \\
\hline CHEMBL1600348 & 688267 & 4.4 & 5.0442 & TST \\
\hline CHEMBL3196477 & 688267 & 4.8 & 5.0073 & TST \\
\hline CHEMBL1418067 & 688267 & 6.5501 & 5.0876 & TRN \\
\hline CHEMBL1368606 & 688267 & 6.2 & 5.0109 & TST \\
\hline CHEMBL1594381 & 688267 & 6.15 & 5.0519 & TRN \\
\hline CHEMBL1462857 & 688267 & 5.35 & 5.044 & TST \\
\hline CHEMBL1464947 & 688267 & 5.4 & 5.1539 & TRN \\
\hline CHEMBL1347201 & 688267 & 4.4 & 5.0535 & TST \\
\hline CHEMBL1432299 & 688267 & 5.1 & 5.0231 & TRN \\
\hline CHEMBL1611861 & 688267 & 6.2 & 5.1325 & TRN \\
\hline CHEMBL1501829 & 688267 & 4.45 & 5.0635 & TST \\
\hline CHEMBL1546335 & 688267 & 4.55 & 5.0632 & TRN \\
\hline CHEMBL1322789 & 688267 & 4.05 & 5.0751 & TRN \\
\hline CHEMBL1548813 & 688267 & 4.3 & 4.9966 & TRN \\
\hline CHEMBL1488970 & 688267 & 6.2 & 5.0648 & TRN \\
\hline CHEMBL1481081 & 688267 & 4.3 & 5.0192 & TST \\
\hline CHEMBL 3195584 & 688267 & 4.4 & 4.9623 & TRN \\
\hline CHEMBL1392621 & 688267 & 3.95 & 5.0621 & TST \\
\hline CHEMBL1613293 & 688267 & 4.4 & 5.1018 & TRN \\
\hline CHEMBL1403093 & 688267 & 5.05 & 5.0472 & TST \\
\hline CHEMBL1601485 & 688267 & 4.1 & 5.0938 & TRN \\
\hline CHEMBL1485549 & 688267 & 5.05 & 4.9893 & TRN \\
\hline CHEMBL1461407 & 688267 & 5.55 & 5.0985 & TRN \\
\hline CHEMBL1361894 & 688267 & 4.8 & 5.0184 & TRN \\
\hline CHEMBL1571104 & 688267 & 4.05 & 5.0206 & TRN \\
\hline CHEMBL1512522 & 688267 & 5.55 & 5.1263 & TRN \\
\hline CHEMBL1489307 & 688267 & 5.65 & 5.019 & TRN \\
\hline CHEMBL1310189 & 688267 & 4.65 & 5.07 & TRN \\
\hline CHEMBL1387556 & 688267 & 6.2 & 5.0168 & TRN \\
\hline CHEMBL1526329 & 688267 & 5.55 & 5.0475 & TRN \\
\hline CHEMBL1334474 & 688267 & 5.3 & 5.0492 & TRN \\
\hline CHEMBL1604193 & 688267 & 4.05 & 4.9945 & TRN \\
\hline CHEMBL1461363 & 688267 & 4.0 & 5.1273 & TRN \\
\hline CHEMBL1483535 & 688267 & 4.0 & 5.0288 & TST \\
\hline CHEMBL1591292 & 688267 & 4.35 & 5.003 & TRN \\
\hline CHEMBL1414962 & 688267 & 6.2 & 5.1002 & TRN \\
\hline CHEMBL1578780 & 688267 & 6.25 & 5.0385 & TRN \\
\hline CHEMBL1512930 & 688267 & 4.05 & 5.0837 & TRN \\
\hline CHEMBL1382606 & 688267 & 4.55 & 5.0541 & TRN \\
\hline CHEMBL1398103 & 688267 & 6.2 & 5.051 & TRN \\
\hline CHEMBL1566459 & 688267 & 5.75 & 5.0733 & TRN \\
\hline
\end{tabular}




\begin{tabular}{|c|c|c|c|c|c|}
\hline \\
\hline CHEMBL1578373 & 688267 & 5.5 & 5.1019 & TRN & \\
\hline CHEMBL1613087 & 688267 & 4.3 & 5.0338 & TRN & \\
\hline CHEMBL1409008 & 688267 & 3.95 & 5.0498 & TST & \\
\hline CHEMBL1573778 & 688267 & 4.35 & 5.0739 & TRN & \\
\hline CHEMBL1411628 & 688267 & 5.05 & 5.0223 & TRN & \\
\hline CHEMBL1347281 & 688267 & 4.35 & 5.1066 & TRN & \\
\hline CHEMBL1328824 & 688267 & 4.9 & 5.0327 & TST & \\
\hline CHEMBL126731 & 688267 & 3.8 & 5.0859 & TRN & \\
\hline CHEMBL1307043 & 688267 & 5.3 & 5.1065 & TRN & \\
\hline CHEMBL1364661 & 688267 & 5.0 & 5.085 & TRN & \\
\hline CHEMBL1301377 & 688267 & 5.05 & 5.067 & TRN & \\
\hline CHEMBL1496974 & 688267 & 5.5 & 5.0933 & TRN & \\
\hline CHEMBL1357257 & 688267 & 4.45 & 5.0968 & TRN & \\
\hline CHEMBL1447729 & 688267 & 5.45 & 5.0818 & TRN & \\
\hline CHEMBL1459591 & 688267 & 5.85 & 5.0236 & TRN & \\
\hline CHEMBL1397773 & 688267 & 5.65 & 5.1193 & TRN & \\
\hline CHEMBL1359288 & 688267 & 6.2 & 5.0756 & TST & \\
\hline CHEMBL1354638 & 688267 & 5.6 & 4.9988 & TRN & \\
\hline CHEMBL1423104 & 688267 & 5.5 & 5.0954 & TRN & \\
\hline CHEMBL1397167 & 688267 & 4.2 & 5.1162 & TRN & \\
\hline CHEMBL1458783 & 688267 & 3.95 & 5.0202 & TRN & \\
\hline CHEMBL229012 & 688267 & 4.9 & 5.0321 & TRN & \\
\hline CHEMBL1556661 & 688267 & 4.55 & 5.0115 & TST & \\
\hline CHEMBL1588299 & 688267 & 6.0 & 5.0066 & TST & \\
\hline CHEMBL1321593 & 688267 & 3.95 & 5.0229 & TST & \\
\hline CHEMBL1527140 & 688267 & 5.75 & 5.09699 & 99999999995 & TRN \\
\hline CHEMBL1568960 & 688267 & 3.95 & 5.0353 & TRN & \\
\hline CHEMBL1994913 & 688267 & 5.8 & 5.0318 & TST & \\
\hline CHEMBL1557247 & 688267 & 3.9 & 5.03 & TRN & \\
\hline CHEMBL1534613 & 688267 & 5.3 & 5.0869 & TRN & \\
\hline CHEMBL1480270 & 688267 & 4.3 & 5.06 & TRN & \\
\hline CHEMBL1452867 & 688267 & 4.0 & 5.0576 & TRN & \\
\hline CHEMBL1604369 & 688267 & 5.45 & 4.9889 & TRN & \\
\hline CHEMBL1482093 & 688267 & 5.8 & 5.0266 & TST & \\
\hline CHEMBL1360342 & 688267 & 4.05 & 5.0151 & TRN & \\
\hline CHEMBL 76447 & 688267 & 5.85 & 5.0262 & TST & \\
\hline CHEMBL1499468 & 688267 & 5.6 & 5.0649 & TRN & \\
\hline CHEMBL1351468 & 688267 & 4.25 & 5.0654 & TRN & \\
\hline CHEMBL1355894 & 688267 & 3.95 & 5.0271 & TRN & \\
\hline CHEMBL1526027 & 688267 & 4.05 & 5.0001 & TRN & \\
\hline CHEMBL1512338 & 688267 & 4.0 & 5.0149 & TRN & \\
\hline CHEMBL1406578 & 688267 & 4.65 & 5.035 & TRN & \\
\hline CHEMBL1415139 & 688267 & 5.05 & 5.0752 & TST & \\
\hline CHEMBL1597666 & 688267 & 4.7 & 5.0323 & TRN & \\
\hline CHEMBL1367011 & 688267 & 5.9 & 5.0274 & TRN & \\
\hline CHEMBL246957 & 688267 & 4.5 & 5.0722 & TST & \\
\hline CHEMBL1529835 & 688267 & 6.1 & 5.0144 & TRN & \\
\hline CHEMBL1480764 & 688267 & 6.2 & 5.0171 & TST & \\
\hline & & & & 18242 & \\
\hline
\end{tabular}




\begin{tabular}{|c|c|c|c|c|}
\hline \multicolumn{5}{|c|}{ Supplemental Table S2.txt } \\
\hline CHEMBL1552696 & 688267 & 5.5 & 4.9828 & TRN \\
\hline CHEMBL1553371 & 688267 & 4.0 & 5.0591 & TST \\
\hline CHEMBL1420567 & 688267 & 4.6 & 5.033 & TST \\
\hline CHEMBL1463969 & 688267 & 5.65 & 5.0597 & TRN \\
\hline CHEMBL1405017 & 688267 & 5.95 & 5.0377 & TST \\
\hline CHEMBL1322169 & 688267 & 4.55 & 5.0258 & TRN \\
\hline CHEMBL1486410 & 688267 & 6.2 & 5.1246 & TRN \\
\hline CHEMBL1488451 & 688267 & 4.05 & 5.0066 & TRN \\
\hline CHEMBL1338357 & 688267 & 4.0 & 5.1159 & TRN \\
\hline CHEMBL1323270 & 688267 & 5.1 & 5.1396 & TRN \\
\hline CHEMBL1428110 & 688267 & 5.2 & 5.0151 & TRN \\
\hline CHEMBL1371314 & 688267 & 6.5 & 5.0524 & TRN \\
\hline CHEMBL1573793 & 688267 & 5.7 & 5.0417 & TRN \\
\hline CHEMBL1417030 & 688267 & 4.0 & 5.0949 & TRN \\
\hline CHEMBL1402563 & 688267 & 5.25 & 5.0785 & TRN \\
\hline CHEMBL1424334 & 688267 & 4.55 & 5.0556 & TRN \\
\hline CHEMBL1485373 & 688267 & 6.2 & 5.0575 & TRN \\
\hline CHEMBL1352216 & 688267 & 5.3 & 5.0707 & TRN \\
\hline CHEMBL1598408 & 688267 & 3.95 & 5.1684 & TRN \\
\hline CHEMBL1421686 & 688267 & 6.2 & 5.0225 & TST \\
\hline CHEMBL1553828 & 688267 & 6.1 & 5.0735 & TRN \\
\hline CHEMBL1612019 & 688267 & 4.25 & 5.0987 & TST \\
\hline CHEMBL1309372 & 688267 & 5.65 & 5.0279 & TRN \\
\hline CHEMBL1422014 & 688267 & 5.55 & 4.9914 & TRN \\
\hline CHEMBL1346741 & 688267 & 4.1 & 5.0969 & TRN \\
\hline CHEMBL1330873 & 688267 & 5.95 & 5.0222 & TST \\
\hline CHEMBL1474139 & 688267 & 7.1002 & 5.0497 & TST \\
\hline CHEMBL1362267 & 688267 & 6.2 & 5.0593 & TRN \\
\hline CHEMBL1418937 & 688267 & 5.3 & 5.1285 & TST \\
\hline CHEMBL 3211473 & 688267 & 5.85 & 5.027 & TRN \\
\hline CHEMBL1441504 & 688267 & 5.3 & 5.0952 & TRN \\
\hline CHEMBL584881 & 688267 & 4.9 & 5.0733 & TRN \\
\hline CHEMBL1409108 & 688267 & 4.95 & 4.9941 & TRN \\
\hline CHEMBL1450010 & 688267 & 5.55 & 4.9911 & TRN \\
\hline CHEMBL1534422 & 688267 & 5.35 & 5.032 & TST \\
\hline CHEMBL1425432 & 688267 & 5.4 & 5.0793 & TST \\
\hline CHEMBL1374921 & 688267 & 5.25 & 5.1333 & TST \\
\hline CHEMBL1346919 & 688267 & 4.65 & 5.0735 & TRN \\
\hline CHEMBL1460455 & 688267 & 4.25 & 5.0712 & TRN \\
\hline CHEMBL1440236 & 688267 & 5.4 & 5.0479 & TRN \\
\hline CHEMBL1355919 & 688267 & 6.2 & 4.9959 & TST \\
\hline CHEMBL1388823 & 688267 & 6.5 & 5.0989 & TRN \\
\hline CHEMBL1537342 & 688267 & 3.95 & 5.1113 & TRN \\
\hline CHEMBL1448216 & 688267 & 4.05 & 5.0824 & TST \\
\hline CHEMBL1323941 & 688267 & 6.2 & 5.0793 & TRN \\
\hline CHEMBL1316598 & 688267 & 4.0 & 5.0213 & TRN \\
\hline CHEMBL1594919 & 688267 & 5.05 & 5.0497 & TRN \\
\hline CHEMBL1379287 & 688267 & 4.1 & 5.0884 & TRN \\
\hline
\end{tabular}




\begin{tabular}{|c|c|c|c|c|}
\hline \multicolumn{5}{|c|}{ Supplemental Table S2.txt } \\
\hline CHEMBL1529505 & 688267 & 4.0 & 5.0636 & TST \\
\hline CHEMBL1387169 & 688267 & 5.45 & 5.117 & TRN \\
\hline CHEMBL1357103 & 688267 & 4.55 & 5.0637 & TRN \\
\hline CHEMBL1520324 & 688267 & 4.95 & 5.0727 & TRN \\
\hline CHEMBL1338115 & 688267 & 4.3 & 5.0469 & TRN \\
\hline CHEMBL1434214 & 688267 & 4.85 & 5.0969 & TST \\
\hline CHEMBL1577871 & 688267 & 5.15 & 5.1071 & TRN \\
\hline CHEMBL1429981 & 688267 & 5.35 & 5.1461 & TST \\
\hline CHEMBL1588736 & 688267 & 4.75 & 5.1344 & TRN \\
\hline CHEMBL1487848 & 688267 & 5.5 & 5.1474 & TRN \\
\hline CHEMBL1519183 & 688267 & 4.05 & 5.0292 & TRN \\
\hline CHEMBL1440081 & 688267 & 4.0 & 5.0195 & TRN \\
\hline CHEMBL1451215 & 688267 & 5.85 & 5.0004 & TRN \\
\hline CHEMBL1553269 & 688267 & 4.25 & 5.0235 & TST \\
\hline CHEMBL1391000 & 688267 & 4.4 & 5.0175 & TRN \\
\hline CHEMBL1358939 & 688267 & 4.9 & 5.0506 & TRN \\
\hline CHEMBL1460992 & 688267 & 5.05 & 5.0612 & TRN \\
\hline CHEMBL1466359 & 688267 & 4.4 & 5.0245 & TRN \\
\hline CHEMBL1330705 & 688267 & 5.5 & 5.0177 & TST \\
\hline CHEMBL1486941 & 688267 & 5.35 & 5.0824 & TRN \\
\hline CHEMBL1550753 & 688267 & 6.2 & 5.0311 & TRN \\
\hline CHEMBL1317875 & 688267 & 6.15 & 5.0293 & TRN \\
\hline CHEMBL1436955 & 688267 & 5.45 & 5.02 & TRN \\
\hline CHEMBL1436982 & 688267 & 5.45 & 5.0693 & TRN \\
\hline CHEMBL1576102 & 688267 & 5.35 & 5.0316 & TRN \\
\hline CHEMBL1385454 & 688267 & 5.55 & 5.0317 & TST \\
\hline CHEMBL1590194 & 688267 & 6.2 & 5.0851 & TRN \\
\hline CHEMBL1362581 & 688267 & 3.95 & 5.0447 & TRN \\
\hline CHEMBL1367876 & 688267 & 5.5 & 5.1201 & TRN \\
\hline CHEMBL1512595 & 688267 & 6.0 & 5.0237 & TRN \\
\hline CHEMBL1532100 & 688267 & 5.1 & 5.041 & TST \\
\hline CHEMBL1303616 & 688267 & 6.2 & 4.9814 & TRN \\
\hline CHEMBL1495350 & 688267 & 4.05 & 5.0489 & TST \\
\hline CHEMBL1302134 & 688267 & 6.2 & 5.0823 & TRN \\
\hline CHEMBL1440575 & 688267 & 4.0 & 4.9592 & TRN \\
\hline CHEMBL1479028 & 688267 & 4.95 & 5.0162 & TRN \\
\hline CHEMBL1438366 & 688267 & 4.0 & 5.0501 & TRN \\
\hline CHEMBL1482568 & 688267 & 4.05 & 5.0494 & TRN \\
\hline CHEMBL1532744 & 688267 & 4.25 & 5.0862 & TRN \\
\hline CHEMBL1395791 & 688267 & 6.2 & 5.0238 & TRN \\
\hline CHEMBL1434815 & 688267 & 3.9 & 5.0851 & TRN \\
\hline CHEMBL1524490 & 688267 & 4.35 & 5.1197 & TRN \\
\hline CHEMBL1475880 & 688267 & 5.25 & 5.0363 & TRN \\
\hline CHEMBL1551545 & 688267 & 5.75 & 5.0523 & TST \\
\hline CHEMBL1516636 & 688267 & 6.15 & 5.066 & TRN \\
\hline CHEMBL1537089 & 688267 & 5.3 & 5.0227 & TST \\
\hline CHEMBL1602680 & 688267 & 5.9 & 5.1148 & TRN \\
\hline CHEMBL1560574 & 688267 & 4.6 & 4.9978 & TRN \\
\hline
\end{tabular}




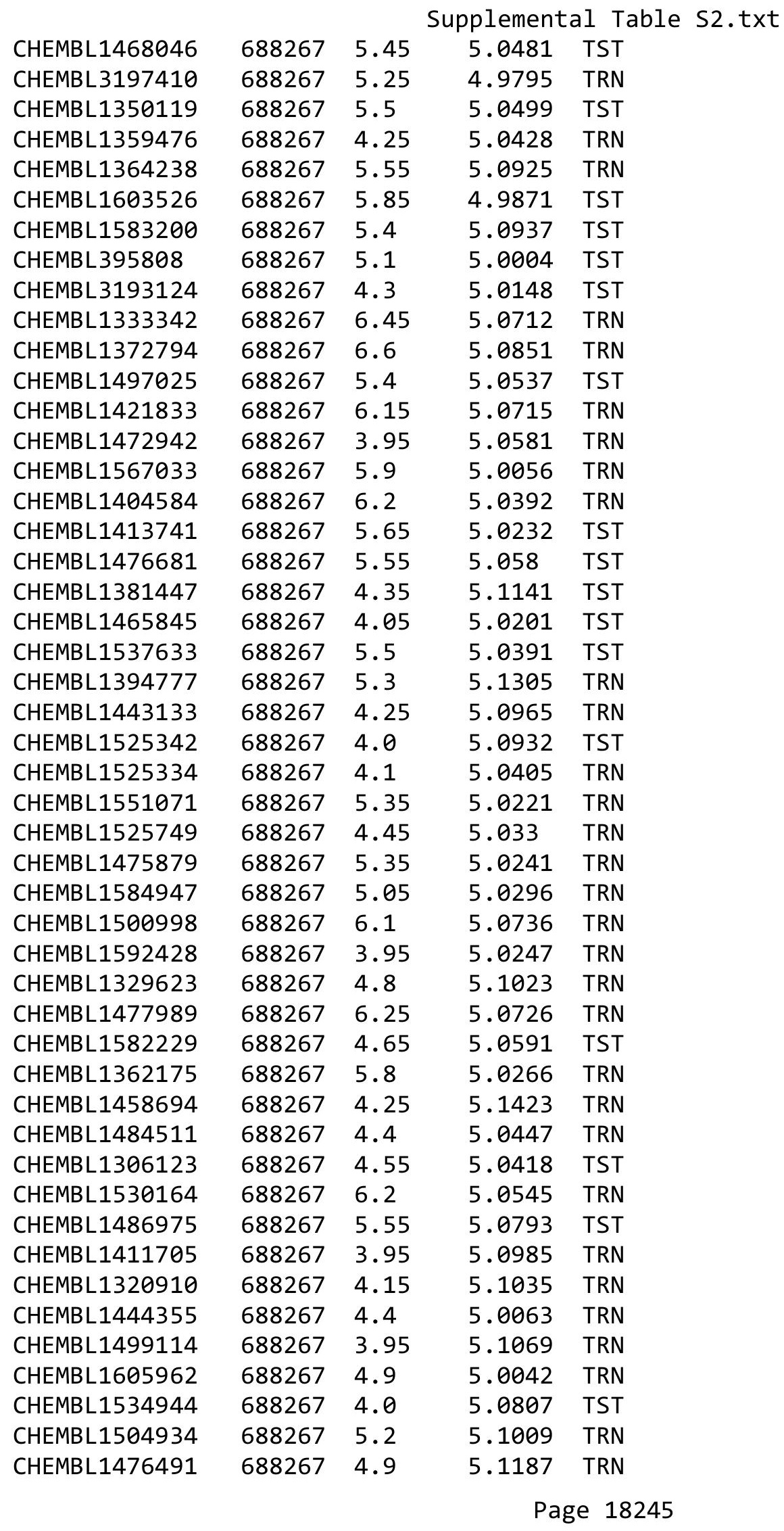




\begin{tabular}{|c|c|c|c|c|c|}
\hline \multicolumn{6}{|c|}{ splemental } \\
\hline CHEMBL1442786 & 688267 & 5.1 & 5.0776 & TST & \\
\hline CHEMBL1588574 & 688267 & 5.3 & 5.0893 & TST & \\
\hline CHEMBL1314670 & 688267 & 5.55 & 5.0089 & TRN & \\
\hline CHEMBL1440830 & 688267 & 5.6 & 5.0681 & TST & \\
\hline CHEMBL1364706 & 688267 & 4.1 & 5.0243 & TRN & \\
\hline CHEMBL504598 & 688267 & 6.25 & 4.9951 & TST & \\
\hline CHEMBL3191298 & 688267 & 4.75 & 5.0171 & TST & \\
\hline CHEMBL3210906 & 688267 & 5.45 & 5.0423 & TST & \\
\hline CHEMBL1312917 & 688267 & 6.15 & 5.0905 & TRN & \\
\hline CHEMBL1474608 & 688267 & 6.25 & 5.0519 & TRN & \\
\hline CHEMBL1577569 & 688267 & 5.4 & 5.1224 & TRN & \\
\hline CHEMBL1413076 & 688267 & 4.1 & 5.1107 & TST & \\
\hline CHEMBL1393841 & 688267 & 6.15 & 5.051 & TRN & \\
\hline CHEMBL1340955 & 688267 & 4.25 & 5.1423 & TRN & \\
\hline CHEMBL1395639 & 688267 & 6.0 & 5.0396 & TST & \\
\hline CHEMBL1983083 & 688267 & 4.4 & 4.9736 & TRN & \\
\hline CHEMBL3198351 & 688267 & 4.05 & 5.0353 & TST & \\
\hline CHEMBL1330379 & 688267 & 5.05 & 5.0915 & TRN & \\
\hline CHEMBL1449899 & 688267 & 5.8 & 5.041 & TRN & \\
\hline CHEMBL1398089 & 688267 & 4.4 & 5.0806 & TRN & \\
\hline CHEMBL1514294 & 688267 & 6.5501 & 5.0535 & TRN & \\
\hline CHEMBL1325801 & 688267 & 5.55 & 5.0806 & TRN & \\
\hline CHEMBL1563108 & 688267 & 5.45 & 5.0728 & TRN & \\
\hline CHEMBL1589805 & 688267 & 4.2 & 5.0906 & TST & \\
\hline CHEMBL1472289 & 688267 & 5.0 & 5.021 & TRN & \\
\hline CHEMBL1429766 & 688267 & 5.25 & 5.1319 & TRN & \\
\hline CHEMBL1355282 & 688267 & 6.2 & 5.0889 & TRN & \\
\hline CHEMBL1303026 & 688267 & 4.55 & 5.0401 & TST & \\
\hline CHEMBL1515661 & 688267 & 4.55 & 5.0984 & TRN & \\
\hline CHEMBL1344641 & 688267 & 5.8 & 5.0571 & TST & \\
\hline CHEMBL1430359 & 688267 & 6.15 & 5.0967 & TRN & \\
\hline CHEMBL1604948 & 688267 & 4.25 & 5.0163 & TRN & \\
\hline CHEMBL1980530 & 688267 & 4.35 & 4.999 & TST & \\
\hline CHEMBL1401123 & 688267 & 5.05 & 5.0559 & TRN & \\
\hline CHEMBL1421227 & 688267 & 4.35 & 5.0773 & TRN & \\
\hline CHEMBL1500090 & 688267 & 5.65 & 5.0809 & TRN & \\
\hline CHEMBL1486797 & 688267 & 5.45 & 5.088 & TRN & \\
\hline CHEMBL1502381 & 688267 & 4.35 & 5.0454 & TST & \\
\hline CHEMBL1974818 & 688267 & 5.55 & 5.06800 & 00000000005 & TST \\
\hline CHEMBL1329604 & 688267 & 4.85 & 4.9872 & TST & \\
\hline CHEMBL1469317 & 688267 & 5.4 & 5.027 & TST & \\
\hline CHEMBL1402385 & 688267 & 4.4 & 5.1016 & TRN & \\
\hline CHEMBL1581931 & 688267 & 5.15 & 5.0997 & TST & \\
\hline CHEMBL1553081 & 688267 & 3.95 & 5.1166 & TRN & \\
\hline CHEMBL1494947 & 688267 & 5.35 & 5.0661 & TST & \\
\hline CHEMBL1313640 & 688267 & 4.0 & 5.0756 & TST & \\
\hline CHEMBL1406156 & 688267 & 6.2 & 5.039 & TRN & \\
\hline CHEMBL1465771 & 688267 & 4.0 & 5.0511 & TRN & \\
\hline
\end{tabular}




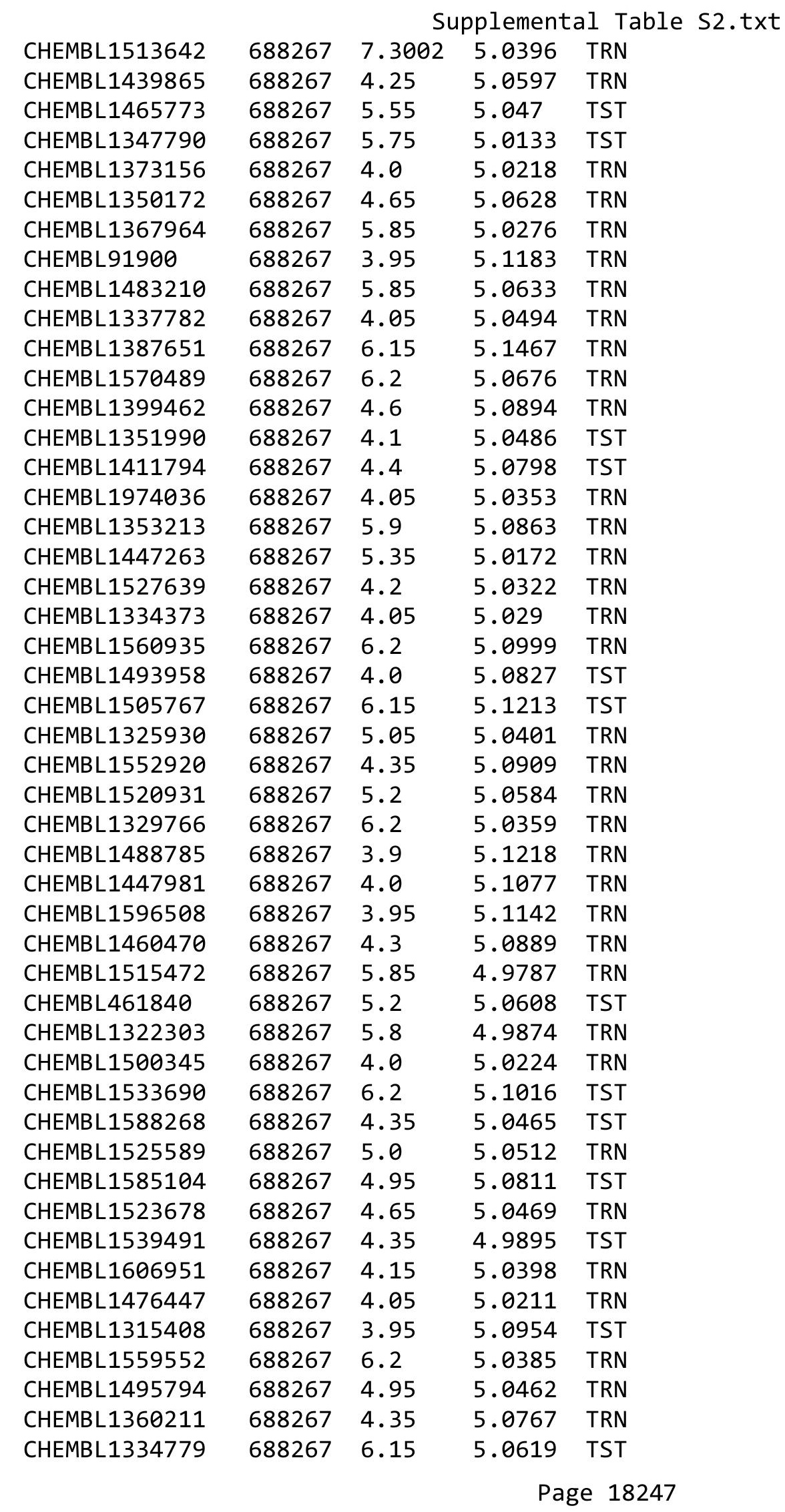




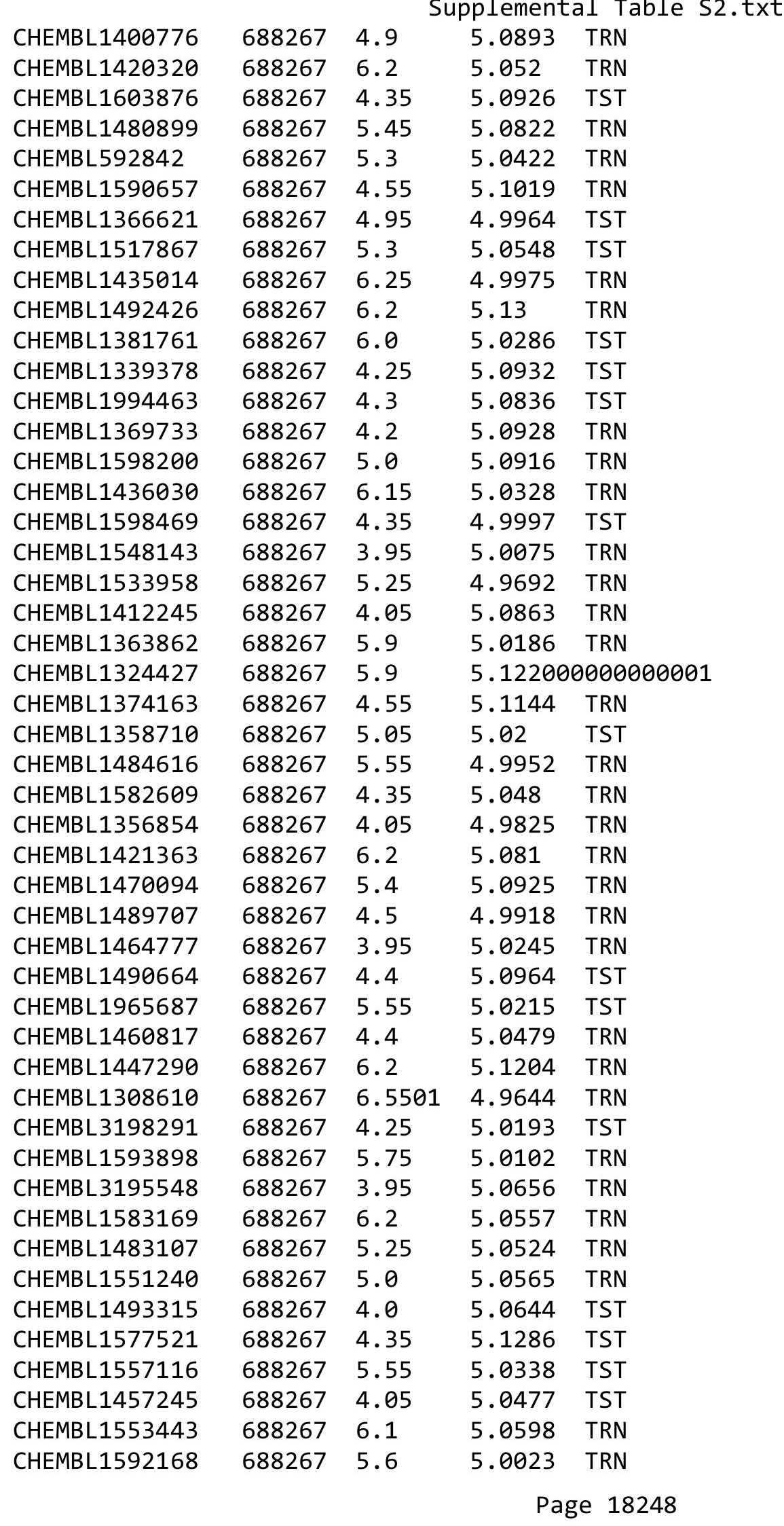




\begin{tabular}{|c|c|c|c|c|c|}
\hline \multicolumn{6}{|c|}{ Supplemental Table S2.txt } \\
\hline CHEMBL1507202 & 688267 & 4.55 & 5.0409 & TRN & \\
\hline CHEMBL1492961 & 688267 & 4.05 & 4.993 & TRN & \\
\hline CHEMBL1563817 & 688267 & 4.9 & 5.0936 & TST & \\
\hline CHEMBL1977247 & 688267 & 4.0 & 5.0235 & TRN & \\
\hline CHEMBL1376453 & 688267 & 4.4 & 5.0202 & TRN & \\
\hline CHEMBL1452897 & 688267 & 4.25 & 5.01699 & 99999999995 & TRN \\
\hline CHEMBL1414979 & 688267 & 6.2 & 5.1325 & TRN & \\
\hline CHEMBL1493286 & 688267 & 5.2 & 5.1174 & TST & \\
\hline CHEMBL1471712 & 688267 & 6.0 & 5.0022 & TST & \\
\hline CHEMBL1371813 & 688267 & 5.55 & 5.1525 & TRN & \\
\hline CHEMBL3209583 & 688267 & 5.8 & 5.0695 & TRN & \\
\hline CHEMBL1501353 & 688267 & 6.15 & 5.0686 & TRN & \\
\hline CHEMBL1512561 & 688267 & 4.7 & 5.0711 & TRN & \\
\hline CHEMBL1399296 & 688267 & 3.95 & 5.0303 & TRN & \\
\hline CHEMBL1380535 & 688267 & 4.3 & 4.9952 & TRN & \\
\hline CHEMBL1391246 & 688267 & 4.45 & 5.0495 & TRN & \\
\hline CHEMBL1515631 & 688267 & 5.1 & 5.1262 & TRN & \\
\hline CHEMBL1499192 & 688267 & 6.2 & 5.1448 & TRN & \\
\hline CHEMBL1481902 & 688267 & 5.25 & 5.0187 & TST & \\
\hline CHEMBL1349730 & 688267 & 6.2 & 5.0379 & TST & \\
\hline CHEMBL1458223 & 688267 & 4.3 & 5.1625 & TRN & \\
\hline CHEMBL1373299 & 688267 & 4.0 & 5.0887 & TRN & \\
\hline CHEMBL1367278 & 688267 & 4.4 & 5.0596 & TRN & \\
\hline CHEMBL1611765 & 688267 & 4.25 & 4.9597 & TRN & \\
\hline CHEMBL1380594 & 688267 & 6.15 & 5.0133 & TRN & \\
\hline CHEMBL1512497 & 688267 & 4.8 & 5.056 & TRN & \\
\hline CHEMBL1510937 & 688267 & 4.05 & 4.9727 & TRN & \\
\hline CHEMBL1432086 & 688267 & 4.55 & 5.0344 & TST & \\
\hline CHEMBL1333474 & 688267 & 6.25 & 5.0488 & TRN & \\
\hline CHEMBL1537836 & 688267 & 4.05 & 5.1021 & TST & \\
\hline CHEMBL1460149 & 688267 & 5.1 & 5.0436 & TRN & \\
\hline CHEMBL1385961 & 688267 & 6.3 & 5.0444 & TST & \\
\hline CHEMBL1452487 & 688267 & 5.35 & 5.0267 & TRN & \\
\hline CHEMBL1526057 & 688267 & 4.5 & 5.0518 & TRN & \\
\hline CHEMBL1515548 & 688267 & 5.95 & 5.0315 & TRN & \\
\hline CHEMBL 2007163 & 688267 & 4.45 & 4.9826 & TRN & \\
\hline CHEMBL1507909 & 688267 & 5.35 & 5.0457 & TST & \\
\hline CHEMBL1552102 & 688267 & 4.3 & 5.0638 & TRN & \\
\hline CHEMBL1439879 & 688267 & 4.0 & 5.055 & TST & \\
\hline CHEMBL1411307 & 688267 & 6.15 & 5.0438 & TST & \\
\hline CHEMBL1317470 & 688267 & 4.25 & 5.0543 & TRN & \\
\hline CHEMBL1338136 & 688267 & 5.55 & 5.0587 & TRN & \\
\hline CHEMBL1338988 & 688267 & 5.6 & 5.0668 & TRN & \\
\hline CHEMBL1397289 & 688267 & 6.25 & 5.0979 & TRN & \\
\hline CHEMBL1557360 & 688267 & 6.2 & 5.027 & TRN & \\
\hline CHEMBL1594071 & 688267 & 5.6 & 5.0042 & TRN & \\
\hline CHEMBL1416231 & 688267 & 4.45 & 4.9817 & TRN & \\
\hline CHEMBL1335792 & 688267 & 5.05 & 4.9808 & TRN & \\
\hline
\end{tabular}




\begin{tabular}{|c|c|c|c|c|c|}
\hline \\
\hline CHEMBL1393567 & 688267 & 4.6 & 5.0817 & TST & \\
\hline CHEMBL1542215 & 688267 & 6.2 & 4.9906 & TRN & \\
\hline CHEMBL1332916 & 688267 & 4.1 & 5.0071 & TST & \\
\hline CHEMBL1584046 & 688267 & 4.6 & 5.0996 & TRN & \\
\hline CHEMBL1456975 & 688267 & 5.35 & 5.0223 & TST & \\
\hline CHEMBL1339000 & 688267 & 5.05 & 5.039 & TRN & \\
\hline CHEMBL1559331 & 688267 & 4.35 & 5.0155 & TRN & \\
\hline CHEMBL1458989 & 688267 & 5.0 & 5.1396 & TRN & \\
\hline CHEMBL1443573 & 688267 & 5.5 & 5.0862 & TST & \\
\hline CHEMBL1392673 & 688267 & 5.85 & 4.9969 & TST & \\
\hline CHEMBL1304194 & 688267 & 6.25 & 5.0638 & TST & \\
\hline CHEMBL1415148 & 688267 & 5.5 & 5.0263 & TRN & \\
\hline CHEMBL1539153 & 688267 & 4.25 & 5.0795 & TRN & \\
\hline CHEMBL1520351 & 688267 & 6.15 & 5.0381 & TRN & \\
\hline CHEMBL1484245 & 688267 & 4.7 & 5.0183 & TST & \\
\hline CHEMBL1570256 & 688267 & 6.2 & 5.1129 & TRN & \\
\hline CHEMBL1415482 & 688267 & 5.05 & 5.0266 & TRN & \\
\hline CHEMBL1369219 & 688267 & 4.05 & 5.0032 & TST & \\
\hline CHEMBL1488129 & 688267 & 4.95 & 5.0698 & TRN & \\
\hline CHEMBL1553835 & 688267 & 6.5 & 5.1239 & TRN & \\
\hline CHEMBL1446132 & 688267 & 5.55 & 5.0552 & TRN & \\
\hline CHEMBL1549138 & 688267 & 4.6 & 5.043 & TST & \\
\hline CHEMBL1591160 & 688267 & 4.0 & 5.0439 & TRN & \\
\hline CHEMBL1514131 & 688267 & 5.55 & 5.1148 & TRN & \\
\hline CHEMBL1555824 & 688267 & 5.3 & 5.1286 & TRN & \\
\hline CHEMBL1360043 & 688267 & 5.9 & 5.0212 & TST & \\
\hline CHEMBL1422261 & 688267 & 5.6 & 5.0864 & TRN & \\
\hline CHEMBL1460951 & 688267 & 4.35 & 5.1249 & TST & \\
\hline CHEMBL1564146 & 688267 & 5.5 & 5.0605 & TRN & \\
\hline CHEMBL1443043 & 688267 & 3.95 & 5.0575 & TRN & \\
\hline CHEMBL1307508 & 688267 & 4.4 & 5.08899 & 99999999995 & TRN \\
\hline CHEMBL1453408 & 688267 & 4.45 & 5.0673 & TRN & \\
\hline CHEMBL1478289 & 688267 & 5.75 & 5.0425 & TRN & \\
\hline CHEMBL1300240 & 688267 & 5.5 & 5.0649 & TRN & \\
\hline CHEMBL1567944 & 688267 & 5.25 & 5.0908 & TRN & \\
\hline CHEMBL1410317 & 688267 & 5.05 & 5.1637 & TRN & \\
\hline CHEMBL1520658 & 688267 & 6.2 & 5.0038 & TRN & \\
\hline CHEMBL1478558 & 688267 & 5.25 & 5.0223 & TST & \\
\hline CHEMBL1581506 & 688267 & 3.95 & 5.0952 & TRN & \\
\hline CHEMBL1557840 & 688267 & 5.05 & 5.0965 & TST & \\
\hline CHEMBL1562034 & 688267 & 4.5 & 5.0709 & TRN & \\
\hline CHEMBL1589508 & 688267 & 4.05 & 5.1099 & TRN & \\
\hline CHEMBL1550990 & 688267 & 5.35 & 5.0485 & TST & \\
\hline CHEMBL1355475 & 688267 & 5.3 & 5.0715 & TRN & \\
\hline CHEMBL1323575 & 688267 & 4.05 & 5.0206 & TRN & \\
\hline CHEMBL1388101 & 688267 & 5.1 & 5.0296 & TRN & \\
\hline CHEMBL1329344 & 688267 & 4.05 & 4.9953 & TRN & \\
\hline CHEMBL1581887 & 688267 & 5.85 & 5.0438 & TRN & \\
\hline & & & & $\theta$ & \\
\hline
\end{tabular}




\begin{tabular}{|c|c|c|c|c|c|}
\hline \\
\hline CHEMBL1515151 & 688267 & 4.75 & 5.0892 & TRN & \\
\hline CHEMBL3199024 & 688267 & 4.35 & 5.0052 & TST & \\
\hline CHEMBL1478064 & 688267 & 6.3 & 5.0523 & TRN & \\
\hline CHEMBL1378063 & 688267 & 5.8 & 5.0744 & TRN & \\
\hline CHEMBL1434063 & 688267 & 5.3 & 5.0787 & TRN & \\
\hline CHEMBL1482382 & 688267 & 4.4 & 5.0918 & TRN & \\
\hline CHEMBL1338088 & 688267 & 4.2 & 5.0559 & TRN & \\
\hline CHEMBL1458551 & 688267 & 5.4 & 5.0309 & TST & \\
\hline CHEMBL1390311 & 688267 & 5.55 & 5.0526 & TST & \\
\hline CHEMBL1533460 & 688267 & 5.85 & 5.0345 & TRN & \\
\hline CHEMBL1431882 & 688267 & 3.95 & 5.0648 & TST & \\
\hline CHEMBL1593503 & 688267 & 3.95 & 5.0786 & TRN & \\
\hline CHEMBL1300804 & 688267 & 5.7 & 5.11600 & 00000000005 & TRN \\
\hline CHEMBL1373444 & 688267 & 4.55 & 5.0331 & TRN & \\
\hline CHEMBL1588505 & 688267 & 5.45 & 5.07100 & 0000000001 & TRN \\
\hline CHEMBL1573090 & 688267 & 5.3 & 5.0635 & TRN & \\
\hline CHEMBL1371071 & 688267 & 4.0 & 5.0392 & TRN & \\
\hline CHEMBL1515201 & 688267 & 6.3 & 5.0129 & TRN & \\
\hline CHEMBL3195532 & 688267 & 5.7 & 5.0452 & TRN & \\
\hline CHEMBL1590300 & 688267 & 6.15 & 5.061 & TRN & \\
\hline CHEMBL1527106 & 688267 & 4.75 & 5.0081 & TRN & \\
\hline CHEMBL1303976 & 688267 & 6.2 & 5.0269 & TST & \\
\hline CHEMBL1400359 & 688267 & 4.15 & 5.0154 & TST & \\
\hline CHEMBL1443730 & 688267 & 4.35 & 5.1287 & TRN & \\
\hline CHEMBL1483460 & 688267 & 5.3 & 5.0423 & TST & \\
\hline CHEMBL1562352 & 688267 & 6.2 & 5.0523 & TRN & \\
\hline CHEMBL1478037 & 688267 & 4.05 & 5.1024 & TRN & \\
\hline CHEMBL1391487 & 688267 & 4.35 & 5.0978 & TRN & \\
\hline CHEMBL1421288 & 688267 & 5.05 & 5.0613 & TST & \\
\hline CHEMBL1467725 & 688267 & 4.05 & 5.0348 & TST & \\
\hline CHEMBL1369332 & 688267 & 7.15 & 5.0533 & TRN & \\
\hline CHEMBL1375078 & 688267 & 5.5 & 5.1104 & TRN & \\
\hline CHEMBL1525829 & 688267 & 6.2 & 5.0663 & TRN & \\
\hline CHEMBL1408311 & 688267 & 4.0 & 5.0999 & TRN & \\
\hline CHEMBL1475296 & 688267 & 5.35 & 5.0464 & TRN & \\
\hline CHEMBL1413229 & 688267 & 4.7 & 5.0167 & TRN & \\
\hline CHEMBL1522522 & 688267 & 5.95 & 5.0777 & TRN & \\
\hline CHEMBL1516798 & 688267 & 4.0 & 5.0947 & TRN & \\
\hline CHEMBL1587627 & 688267 & 3.95 & 5.0259 & TRN & \\
\hline CHEMBL1516629 & 688267 & 4.0 & 4.9876 & TRN & \\
\hline CHEMBL3190246 & 688267 & 4.8 & 5.045 & TRN & \\
\hline CHEMBL1347919 & 688267 & 4.0 & 5.0554 & TRN & \\
\hline CHEMBL1390886 & 688267 & 7.0501 & 5.0178 & TST & \\
\hline CHEMBL1516582 & 688267 & 6.15 & 5.0395 & TRN & \\
\hline CHEMBL1327799 & 688267 & 5.65 & 5.0267 & TRN & \\
\hline CHEMBL1360591 & 688267 & 4.2 & 4.9706 & TRN & \\
\hline CHEMBL1315449 & 688267 & 6.2 & 5.0866 & TRN & \\
\hline CHEMBL1505299 & 688267 & 5.4 & 5.1063 & TRN & \\
\hline
\end{tabular}




\begin{tabular}{|c|c|c|c|c|}
\hline \multicolumn{5}{|c|}{ Supplemental Table s2.txt } \\
\hline CHEMBL1372646 & 688267 & 4.2 & 5.0494 & TST \\
\hline CHEMBL1571117 & 688267 & 5.45 & 5.1263 & TRN \\
\hline CHEMBL1419117 & 688267 & 4.05 & 5.0111 & TRN \\
\hline CHEMBL1452603 & 688267 & 4.05 & 5.0712 & TRN \\
\hline CHEMBL3212143 & 688267 & 5.55 & 4.9692 & TRN \\
\hline CHEMBL1451075 & 688267 & 5.3 & 5.0293 & TRN \\
\hline CHEMBL375781 & 688267 & 4.0 & 5.039 & TST \\
\hline CHEMBL1512087 & 688267 & 6.2 & 5.0692 & TRN \\
\hline CHEMBL1191237 & 688267 & 4.35 & 5.0432 & TRN \\
\hline CHEMBL1376942 & 688267 & 5.2 & 5.0219 & TRN \\
\hline CHEMBL1422821 & 688267 & 4.35 & 5.0208 & TST \\
\hline CHEMBL1492121 & 688267 & 4.25 & 5.0158 & TRN \\
\hline CHEMBL1394383 & 688267 & 6.15 & 5.0451 & TRN \\
\hline CHEMBL1562695 & 688267 & 5.55 & 5.0543 & TRN \\
\hline CHEMBL1394368 & 688267 & 6.45 & 5.0296 & TRN \\
\hline CHEMBL1332199 & 688267 & 4.0 & 5.0586 & TRN \\
\hline CHEMBL1496389 & 688267 & 5.3 & 5.0262 & TRN \\
\hline CHEMBL1436330 & 688267 & 6.25 & 5.0701 & TRN \\
\hline CHEMBL1483256 & 688267 & 6.5501 & 5.0815 & TRN \\
\hline CHEMBL1532607 & 688267 & 4.05 & 4.9716 & TRN \\
\hline CHEMBL1519518 & 688267 & 6.25 & 5.1167 & TRN \\
\hline CHEMBL1543879 & 688267 & 6.1 & 5.1033 & TRN \\
\hline CHEMBL1423827 & 688267 & 5.5 & 5.1447 & TRN \\
\hline CHEMBL1368992 & 688267 & 4.05 & 5.0551 & TRN \\
\hline CHEMBL1391852 & 688267 & 4.35 & 5.0556 & TRN \\
\hline CHEMBL1537841 & 688267 & 4.75 & 4.9926 & TST \\
\hline CHEMBL 2374081 & 688267 & 5.15 & 5.016 & TRN \\
\hline CHEMBL1320427 & 688267 & 5.9 & 5.051 & TRN \\
\hline CHEMBL1608728 & 688267 & 4.05 & 5.0483 & TRN \\
\hline CHEMBL1426086 & 688267 & 4.0 & 5.0591 & TRN \\
\hline CHEMBL1506234 & 688267 & 5.3 & 5.0723 & TRN \\
\hline CHEMBL1542425 & 688267 & 4.55 & 5.0421 & TRN \\
\hline CHEMBL1553663 & 688267 & 6.2 & 5.0182 & TRN \\
\hline CHEMBL1434760 & 688267 & 4.85 & 5.0225 & TRN \\
\hline CHEMBL1401457 & 688267 & 4.15 & 5.0639 & TRN \\
\hline CHEMBL1587181 & 688267 & 6.2 & 5.1085 & TST \\
\hline CHEMBL1355014 & 688267 & 6.2 & 5.0152 & TRN \\
\hline CHEMBL1587716 & 688267 & 4.35 & 5.1001 & TRN \\
\hline CHEMBL1388438 & 688267 & 5.75 & 4.9603 & TRN \\
\hline CHEMBL1576021 & 688267 & 3.95 & 5.0866 & TRN \\
\hline CHEMBL1556841 & 688267 & 5.45 & 5.044 & TRN \\
\hline CHEMBL1482973 & 688267 & 4.05 & 5.1117 & TRN \\
\hline CHEMBL1312249 & 688267 & 5.15 & 5.0919 & TRN \\
\hline CHEMBL1353831 & 688267 & 5.15 & 5.1206 & TRN \\
\hline CHEMBL1592096 & 688267 & 5.2 & 5.0455 & TST \\
\hline CHEMBL1305627 & 688267 & 4.95 & 5.091 & TRN \\
\hline CHEMBL1974112 & 688267 & 5.85 & 5.0712 & TRN \\
\hline CHEMBL1444651 & 688267 & 4.35 & 5.091 & TRN \\
\hline
\end{tabular}




\begin{tabular}{|c|c|c|c|c|c|}
\hline & & \multicolumn{4}{|c|}{ Supplemental Table S2.txt } \\
\hline CHEMBL1530437 & 688267 & 6.2 & 4.9885 & TRN & \\
\hline CHEMBL1391159 & 688267 & 6.2 & 5.0111 & TRN & \\
\hline CHEMBL1527416 & 688267 & 5.35 & 5.0291 & TRN & \\
\hline CHEMBL1534266 & 688267 & 5.45 & 4.9753 & TRN & \\
\hline CHEMBL1439810 & 688267 & 4.3 & 5.0299 & TRN & \\
\hline CHEMBL1512809 & 688267 & 4.05 & 5.0242 & TRN & \\
\hline CHEMBL1549557 & 688267 & 6.2 & 5.07100 & 0000000001 & TRN \\
\hline CHEMBL1509972 & 688267 & 5.2 & 5.0467 & TST & \\
\hline CHEMBL1608522 & 688267 & 6.3 & 5.0541 & TRN & \\
\hline CHEMBL1459528 & 688267 & 5.85 & 5.09 & TST & \\
\hline CHEMBL1320479 & 688267 & 6.1 & 5.0821 & TRN & \\
\hline CHEMBL1368614 & 688267 & 4.7 & 5.0409 & TST & \\
\hline CHEMBL1463177 & 688267 & 6.45 & 5.0379 & TRN & \\
\hline CHEMBL1345449 & 688267 & 3.95 & 5.0894 & TRN & \\
\hline CHEMBL1340147 & 688267 & 5.35 & 5.1194 & TST & \\
\hline CHEMBL1469786 & 688267 & 5.6 & 5.0814 & TRN & \\
\hline CHEMBL3207374 & 688267 & 4.1 & 5.0398 & TST & \\
\hline CHEMBL1607667 & 688267 & 5.45 & 5.0569 & TRN & \\
\hline CHEMBL3195432 & 688267 & 5.65 & 5.0334 & TRN & \\
\hline CHEMBL1353893 & 688267 & 6.2 & 5.0242 & TST & \\
\hline CHEMBL1448576 & 688267 & 5.85 & 5.0641 & TST & \\
\hline CHEMBL3191219 & 688267 & 6.2 & 5.04899 & 99999999995 & TRN \\
\hline CHEMBL1600372 & 688267 & 5.9 & 5.0604 & TST & \\
\hline CHEMBL1435585 & 688267 & 4.1 & 5.0598 & TRN & \\
\hline CHEMBL1469740 & 688267 & 6.15 & 5.0455 & TRN & \\
\hline CHEMBL1425865 & 688267 & 5.1 & 5.0743 & TRN & \\
\hline CHEMBL1309825 & 688267 & 5.25 & 5.0148 & TRN & \\
\hline CHEMBL1397707 & 688267 & 4.6 & 5.0306 & TRN & \\
\hline CHEMBL1524014 & 688267 & 5.75 & 5.1189 & TRN & \\
\hline CHEMBL1440656 & 688267 & 4.3 & 5.0132 & TST & \\
\hline CHEMBL1466708 & 688267 & 4.1 & 5.0387 & TRN & \\
\hline CHEMBL1318941 & 688267 & 6.2 & 5.0925 & TRN & \\
\hline CHEMBL1586400 & 688267 & 3.95 & 5.0584 & TST & \\
\hline CHEMBL1443108 & 688267 & 4.1 & 5.0182 & TRN & \\
\hline CHEMBL1564072 & 688267 & 4.05 & 5.0897 & TST & \\
\hline CHEMBL1421137 & 688267 & 5.0 & 4.995 & TST & \\
\hline CHEMBL1344576 & 688267 & 5.45 & 5.0048 & TRN & \\
\hline CHEMBL1485057 & 688267 & 4.5 & 5.1184 & TST & \\
\hline CHEMBL1592831 & 688267 & 6.2 & 4.9937 & TRN & \\
\hline CHEMBL1548277 & 688267 & 5.45 & 5.1235 & TST & \\
\hline CHEMBL1417864 & 688267 & 6.2 & 5.039 & TST & \\
\hline CHEMBL 3208488 & 688267 & 4.8 & 5.0928 & TRN & \\
\hline CHEMBL1551268 & 688267 & 6.2 & 5.0095 & TRN & \\
\hline CHEMBL1433711 & 688267 & 5.4 & 5.0957 & TRN & \\
\hline CHEMBL1502691 & 688267 & 4.3 & 4.9942 & TRN & \\
\hline CHEMBL1577005 & 688267 & 3.95 & 4.9932 & TRN & \\
\hline CHEMBL3211927 & 688267 & 4.0 & 4.9848 & TST & \\
\hline CHEMBL1305723 & 688267 & 4.05 & 5.0453 & TRN & \\
\hline
\end{tabular}




\begin{tabular}{|c|c|c|c|c|c|}
\hline & & \multicolumn{4}{|c|}{ Supplemental Table s2.txt } \\
\hline CHEMBL1563373 & 688267 & 4.35 & 4.9703 & TRN & \\
\hline CHEMBL1459288 & 688267 & 3.95 & 5.0306 & TST & \\
\hline CHEMBL1547666 & 688267 & 6.2 & 5.0209 & TRN & \\
\hline CHEMBL1396266 & 688267 & 5.55 & 5.0866 & TRN & \\
\hline CHEMBL1520716 & 688267 & 4.35 & 5.0442 & TRN & \\
\hline CHEMBL1336697 & 688267 & 5.55 & 5.0031 & TRN & \\
\hline CHEMBL1532774 & 688267 & 5.1 & 5.1279 & TRN & \\
\hline CHEMBL1316777 & 688267 & 5.3 & 5.0818 & TRN & \\
\hline CHEMBL1384196 & 688267 & 4.0 & 5.034 & TST & \\
\hline CHEMBL1474866 & 688267 & 4.6 & 5.0044 & TRN & \\
\hline CHEMBL1446588 & 688267 & 3.95 & 5.1014 & TRN & \\
\hline CHEMBL1373686 & 688267 & 4.2 & 5.0676 & TST & \\
\hline CHEMBL1479273 & 688267 & 4.4 & 5.0593 & TRN & \\
\hline CHEMBL 3194743 & 688267 & 5.25 & 5.0928 & TRN & \\
\hline CHEMBL1361204 & 688267 & 6.2 & 5.0282 & TST & \\
\hline CHEMBL1554118 & 688267 & 6.2 & 5.0851 & TRN & \\
\hline CHEMBL1506839 & 688267 & 4.0 & 5.0813 & TRN & \\
\hline CHEMBL1344257 & 688267 & 5.9 & 5.0463 & TRN & \\
\hline CHEMBL1352028 & 688267 & 4.0 & 5.1263 & TRN & \\
\hline CHEMBL1444896 & 688267 & 3.95 & 5.0317 & TRN & \\
\hline CHEMBL1321790 & 688267 & 5.3 & 4.9874 & TRN & \\
\hline CHEMBL1593097 & 688267 & 4.0 & 5.0138 & TRN & \\
\hline CHEMBL1511400 & 688267 & 5.25 & 5.0544 & TRN & \\
\hline CHEMBL1547465 & 688267 & 5.75 & 5.0791 & TRN & \\
\hline CHEMBL1412605 & 688267 & 5.3 & 5.07 & TRN & \\
\hline CHEMBL1396618 & 688267 & 5.0 & 5.0637 & TRN & \\
\hline CHEMBL1558238 & 688267 & 5.85 & 5.072 & TST & \\
\hline CHEMBL1341268 & 688267 & 5.85 & 5.0101 & TRN & \\
\hline CHEMBL1336110 & 688267 & 5.3 & 5.0389 & TRN & \\
\hline CHEMBL1596454 & 688267 & 5.1 & 5.0657 & TRN & \\
\hline CHEMBL1559746 & 688267 & 5.1 & 5.1002 & TRN & \\
\hline CHEMBL1388629 & 688267 & 4.35 & 5.1083 & TST & \\
\hline CHEMBL1379218 & 688267 & 4.35 & 5.0389 & TRN & \\
\hline CHEMBL1417154 & 688267 & 5.95 & 5.0363 & TST & \\
\hline CHEMBL1303226 & 688267 & 4.7 & 5.0196 & TRN & \\
\hline CHEMBL1537546 & 688267 & 5.4 & 5.1154 & TRN & \\
\hline CHEMBL1474883 & 688267 & 5.3 & 5.0411 & TRN & \\
\hline CHEMBL1519911 & 688267 & 4.75 & 5.0704 & TRN & \\
\hline CHEMBL1522454 & 688267 & 4.55 & 5.0303 & TRN & \\
\hline CHEMBL1407547 & 688267 & 6.25 & 5.0157 & TST & \\
\hline CHEMBL1526706 & 688267 & 4.0 & 5.1344 & TRN & \\
\hline CHEMBL1474377 & 688267 & 4.55 & 5.0352 & TRN & \\
\hline CHEMBL1469918 & 688267 & 5.7 & 5.0354 & TRN & \\
\hline CHEMBL1312905 & 688267 & 6.15 & 5.0375 & TRN & \\
\hline CHEMBL1402037 & 688267 & 6.2 & 5.053 & TST & \\
\hline CHEMBL1495964 & 688267 & 5.75 & 5.17299 & 9999999999 & TRN \\
\hline CHEMBL1596292 & 688267 & 6.2 & 4.9845 & TRN & \\
\hline CHEMBL1336430 & 688267 & 6.15 & 5.0387 & TST & \\
\hline
\end{tabular}




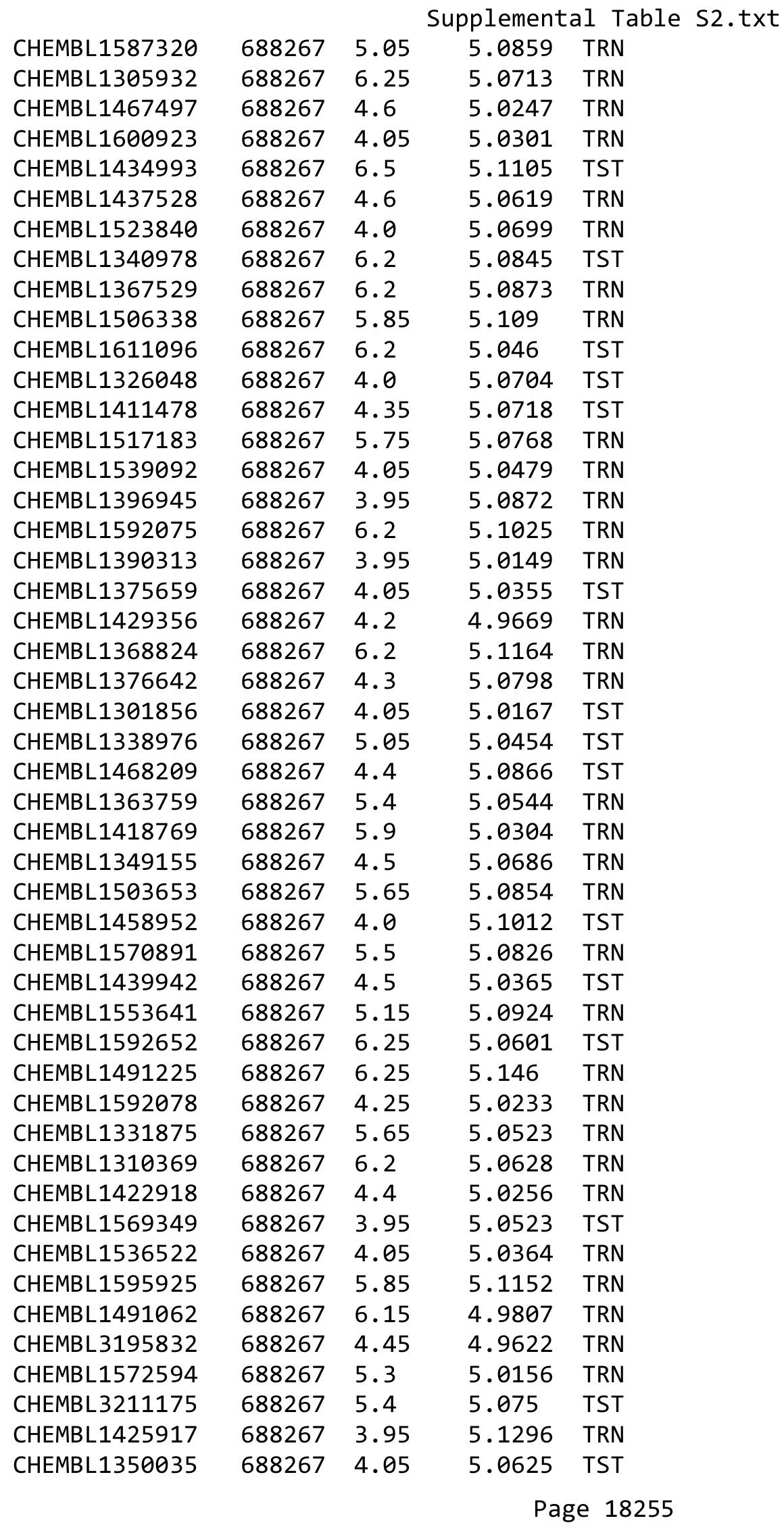




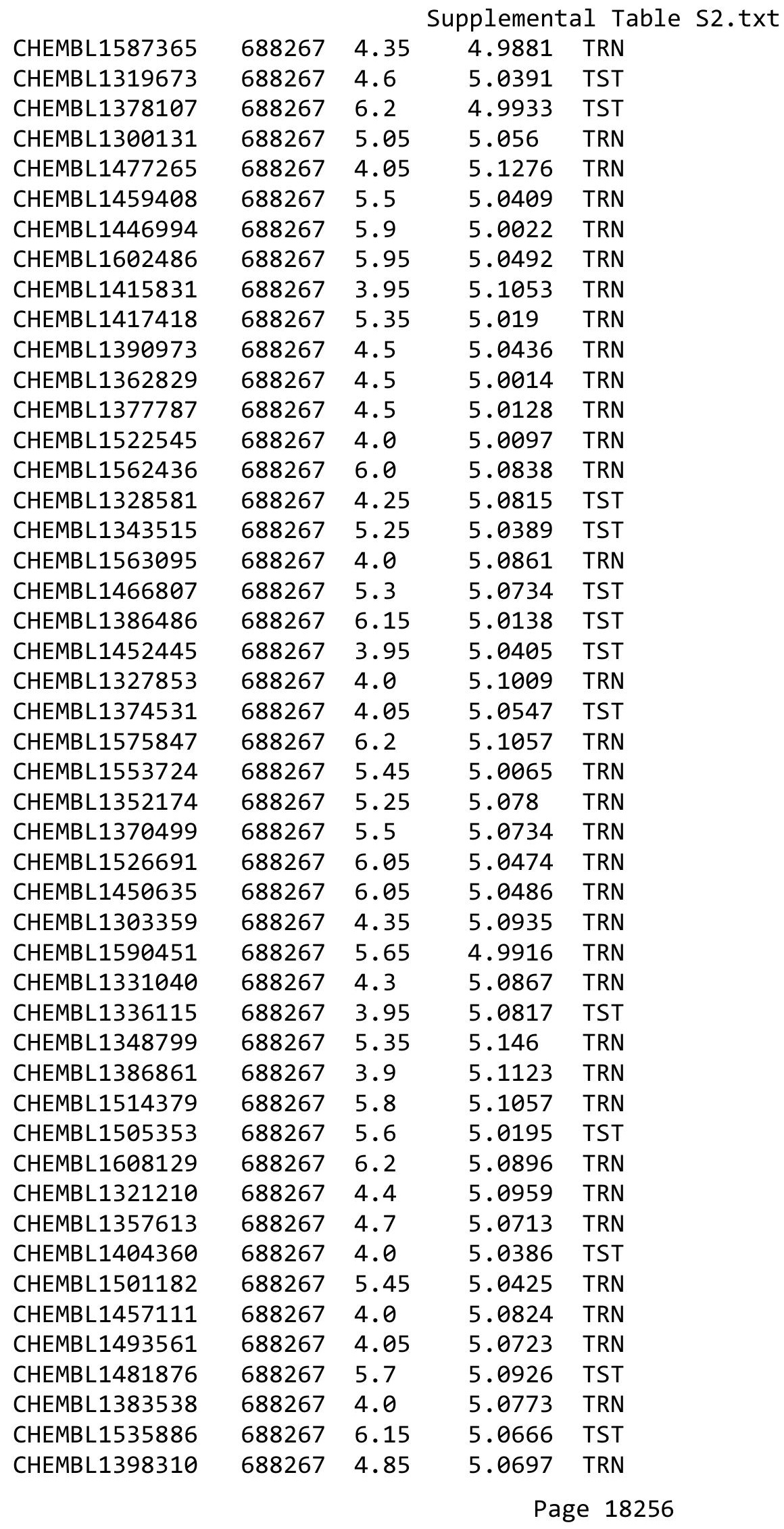




\begin{tabular}{|c|c|c|c|c|c|}
\hline \multicolumn{6}{|c|}{ Supplemental Table S2.txt } \\
\hline CHEMBL1396056 & 688267 & 5.5 & 5.0133 & TRN & \\
\hline CHEMBL1385712 & 688267 & 4.8 & 5.1009 & TST & \\
\hline CHEMBL1312110 & 688267 & 4.7 & 5.0539 & TRN & \\
\hline CHEMBL1305519 & 688267 & 6.45 & 5.0386 & TRN & \\
\hline CHEMBL1531846 & 688267 & 4.1 & 5.021 & TST & \\
\hline CHEMBL1544647 & 688267 & 5.4 & 5.0822 & TRN & \\
\hline CHEMBL1476283 & 688267 & 6.2 & 5.1201 & TRN & \\
\hline CHEMBL1488716 & 688267 & 4.7 & 5.035 & TST & \\
\hline CHEMBL1439377 & 688267 & 4.35 & 5.033 & TRN & \\
\hline CHEMBL1380965 & 688267 & 4.0 & 5.1227 & TRN & \\
\hline CHEMBL1475111 & 688267 & 6.2 & 5.1274 & TRN & \\
\hline CHEMBL1583181 & 688267 & 4.15 & 5.0872 & TST & \\
\hline CHEMBL1379947 & 688267 & 3.95 & 5.1001 & TRN & \\
\hline CHEMBL1578918 & 688267 & 4.35 & 5.0585 & TST & \\
\hline CHEMBL1491567 & 688267 & 4.05 & 5.0878 & TST & \\
\hline CHEMBL1372201 & 688267 & 4.4 & 5.072 & TRN & \\
\hline CHEMBL1387049 & 688267 & 3.25 & 5.0868 & TRN & \\
\hline CHEMBL1417685 & 688267 & 6.6499 & 5.0442 & TRN & \\
\hline CHEMBL1367525 & 688267 & 4.1 & 5.0037 & TRN & \\
\hline CHEMBL1547071 & 688267 & 4.95 & 5.0397 & TRN & \\
\hline CHEMBL1553267 & 688267 & 5.3 & 5.1104 & TST & \\
\hline CHEMBL1409478 & 688267 & 4.65 & 5.0439 & TRN & \\
\hline CHEMBL1607953 & 688267 & 5.25 & 4.9638 & TRN & \\
\hline CHEMBL1307814 & 688267 & 6.1 & 5.0573 & TRN & \\
\hline CHEMBL1422414 & 688267 & 5.35 & 5.0506 & TRN & \\
\hline CHEMBL1364708 & 688267 & 4.7 & 5.0104 & TRN & \\
\hline CHEMBL1555262 & 688267 & 5.6 & 5.062 & TST & \\
\hline CHEMBL1450197 & 688267 & 6.15 & 5.1312 & TST & \\
\hline CHEMBL1554759 & 688267 & 6.0 & 5.1118 & TRN & \\
\hline CHEMBL1342380 & 688267 & 3.95 & 5.1204 & TRN & \\
\hline CHEMBL1331726 & 688267 & 4.3 & 5.0287 & TST & \\
\hline CHEMBL1549787 & 688267 & 4.65 & 5.0123 & TRN & \\
\hline CHEMBL1353437 & 688267 & 5.6 & 5.0982 & TRN & \\
\hline CHEMBL1384827 & 688267 & 4.4 & 5.0572 & TRN & \\
\hline CHEMBL1516473 & 688267 & 5.85 & 5.0882 & TRN & \\
\hline CHEMBL1565983 & 688267 & 6.2 & 5.1614 & TRN & \\
\hline CHEMBL1562598 & 688267 & 4.0 & 5.0857 & TRN & \\
\hline CHEMBL1514809 & 688267 & 3.95 & 5.0356 & TRN & \\
\hline CHEMBL1325715 & 688267 & 5.3 & 5.0444 & TRN & \\
\hline CHEMBL1548052 & 688267 & 5.45 & 5.0991 & TST & \\
\hline CHEMBL1541207 & 688267 & 4.2 & 5.0124 & TRN & \\
\hline CHEMBL3189209 & 688267 & 4.0 & 5.0079 & TRN & \\
\hline CHEMBL1323806 & 688267 & 6.15 & 5.1061 & TRN & \\
\hline CHEMBL1363036 & 688267 & 5.0 & 5.03600 & 00000000005 & TRN \\
\hline CHEMBL1602603 & 688267 & 4.75 & 5.061 & TST & \\
\hline CHEMBL1387110 & 688267 & 4.0 & 4.9692 & TST & \\
\hline CHEMBL1336512 & 688267 & 5.15 & 5.0354 & TRN & \\
\hline CHEMBL1425929 & 688267 & 4.7 & 5.0775 & TRN & \\
\hline
\end{tabular}




\begin{tabular}{|c|c|c|c|c|c|}
\hline \multicolumn{6}{|c|}{ Supplemental Table S2.txt } \\
\hline CHEMBL1523324 & 688267 & 4.0 & 5.0469 & TST & \\
\hline CHEMBL1443870 & 688267 & 5.55 & 5.0547 & TRN & \\
\hline CHEMBL1591520 & 688267 & 4.35 & 5.1383 & TRN & \\
\hline CHEMBL1478313 & 688267 & 4.25 & 5.1103 & TRN & \\
\hline CHEMBL1337749 & 688267 & 5.85 & 5.0256 & TRN & \\
\hline CHEMBL1344631 & 688267 & 6.35 & 5.0159 & TST & \\
\hline CHEMBL3213826 & 688267 & 6.0 & 4.987 & TRN & \\
\hline CHEMBL1381356 & 688267 & 6.2 & 5.0776 & TRN & \\
\hline CHEMBL1394052 & 688267 & 4.45 & 5.0209 & TRN & \\
\hline CHEMBL1333492 & 688267 & 4.35 & 5.0476 & TST & \\
\hline CHEMBL1556351 & 688267 & 5.65 & 5.0388 & TST & \\
\hline CHEMBL1473302 & 688267 & 4.05 & 5.0671 & TRN & \\
\hline CHEMBL1528937 & 688267 & 5.7 & 5.0582 & TRN & \\
\hline CHEMBL1407229 & 688267 & 6.15 & 5.1091 & TRN & \\
\hline CHEMBL1327520 & 688267 & 4.1 & 5.0718 & TST & \\
\hline CHEMBL1322784 & 688267 & 5.4 & 5.0578 & TST & \\
\hline CHEMBL1301342 & 688267 & 4.4 & 5.016 & TRN & \\
\hline CHEMBL1364397 & 688267 & 6.2 & 5.0604 & TST & \\
\hline CHEMBL1510458 & 688267 & 5.0 & 5.0508 & TST & \\
\hline CHEMBL1481075 & 688267 & 4.4 & 5.0418 & TRN & \\
\hline CHEMBL1471823 & 688267 & 6.1 & 5.0306 & TRN & \\
\hline CHEMBL1460202 & 688267 & 5.5 & 5.1256 & TRN & \\
\hline CHEMBL1396634 & 688267 & 5.55 & 5.0446 & TST & \\
\hline CHEMBL1331092 & 688267 & 5.05 & 5.0482 & TRN & \\
\hline CHEMBL1404565 & 688267 & 4.0 & 5.0169 & TRN & \\
\hline CHEMBL1442960 & 688267 & 3.95 & 5.0694 & TRN & \\
\hline CHEMBL1531308 & 688267 & 4.0 & 4.9871 & TRN & \\
\hline CHEMBL1584116 & 688267 & 5.6 & 5.0764 & TST & \\
\hline CHEMBL1526100 & 688267 & 4.55 & 5.0043 & TRN & \\
\hline CHEMBL1324828 & 688267 & 6.2 & 5.1024 & TRN & \\
\hline CHEMBL1453037 & 688267 & 5.3 & 5.0905 & TST & \\
\hline CHEMBL1470214 & 688267 & 4.15 & 5.0278 & TST & \\
\hline CHEMBL1313790 & 688267 & 4.4 & 5.0893 & TST & \\
\hline CHEMBL3199241 & 688267 & 4.5 & 5.1223 & TRN & \\
\hline CHEMBL1609150 & 688267 & 4.35 & 5.0411 & TST & \\
\hline CHEMBL1405596 & 688267 & 5.35 & 5.0049 & TST & \\
\hline CHEMBL1477820 & 688267 & 5.1 & 5.0601 & TRN & \\
\hline CHEMBL1553423 & 688267 & 5.6 & 5.0398 & TRN & \\
\hline CHEMBL1561968 & 688267 & 4.85 & 5.06800 & 00000000005 & TRN \\
\hline CHEMBL1601675 & 688267 & 4.95 & 5.0849 & TRN & \\
\hline CHEMBL1340971 & 688267 & 4.0 & 5.0752 & TRN & \\
\hline CHEMBL3194739 & 688267 & 4.4 & 4.9668 & TRN & \\
\hline CHEMBL1320981 & 688267 & 5.1 & 5.0667 & TRN & \\
\hline CHEMBL1422483 & 688267 & 4.05 & 5.0232 & TRN & \\
\hline CHEMBL1479980 & 688267 & 6.2 & 5.0253 & TRN & \\
\hline CHEMBL1491956 & 688267 & 4.75 & 5.0758 & TST & \\
\hline CHEMBL1339101 & 688267 & 5.35 & 5.0329 & TRN & \\
\hline CHEMBL1603632 & 688267 & 6.2 & 5.052 & TRN & \\
\hline
\end{tabular}




\begin{tabular}{|c|c|c|c|c|}
\hline \multicolumn{5}{|c|}{ Supplemental Table S2.txt } \\
\hline CHEMBL1367021 & 688267 & 5.65 & 5.1031 & TRN \\
\hline CHEMBL1548625 & 688267 & 6.2 & 5.1154 & TRN \\
\hline CHEMBL1348624 & 688267 & 5.3 & 5.0418 & TRN \\
\hline CHEMBL1535616 & 688267 & 6.0 & 5.1455 & TRN \\
\hline CHEMBL1338600 & 688267 & 5.55 & 5.0622 & TRN \\
\hline CHEMBL1568586 & 688267 & 5.6 & 5.0324 & TST \\
\hline CHEMBL1457180 & 688267 & 4.45 & 5.0344 & TST \\
\hline CHEMBL1513404 & 688267 & 4.6 & 5.0529 & TRN \\
\hline CHEMBL1494379 & 688267 & 4.25 & 5.0062 & TST \\
\hline CHEMBL1444509 & 688267 & 5.9 & 5.0399 & TRN \\
\hline CHEMBL1377153 & 688267 & 4.6 & 5.0608 & TRN \\
\hline CHEMBL1378270 & 688267 & 4.75 & 5.0531 & TRN \\
\hline CHEMBL1410381 & 688267 & 4.85 & 5.081 & TST \\
\hline CHEMBL1584821 & 688267 & 3.95 & 5.0476 & TRN \\
\hline CHEMBL1610854 & 688267 & 4.0 & 5.0076 & TRN \\
\hline CHEMBL1378772 & 688267 & 5.3 & 5.0214 & TRN \\
\hline CHEMBL1559025 & 688267 & 5.85 & 5.0415 & TRN \\
\hline CHEMBL1453824 & 688267 & 5.55 & 5.0395 & TRN \\
\hline CHEMBL1555007 & 688267 & 4.75 & 5.072 & TST \\
\hline CHEMBL1472825 & 688267 & 3.95 & 5.087 & TRN \\
\hline CHEMBL1322457 & 688267 & 6.0 & 5.0363 & TRN \\
\hline CHEMBL1598248 & 688267 & 4.95 & 5.0169 & TRN \\
\hline CHEMBL1526357 & 688267 & 4.35 & 5.0783 & TST \\
\hline CHEMBL1519221 & 688267 & 6.2 & 5.0507 & TRN \\
\hline CHEMBL1441868 & 688267 & 5.6 & 5.0768 & TRN \\
\hline CHEMBL1331217 & 688267 & 4.35 & 5.0732 & TRN \\
\hline CHEMBL1558587 & 688267 & 4.4 & 5.0642 & TST \\
\hline CHEMBL1528514 & 688267 & 6.2 & 5.0158 & TRN \\
\hline CHEMBL1505174 & 688267 & 5.6 & 5.0047 & TST \\
\hline CHEMBL1393186 & 688267 & 4.5 & 5.05 & TRN \\
\hline CHEMBL1458566 & 688267 & 6.2 & 5.0484 & TST \\
\hline CHEMBL1389884 & 688267 & 5.35 & 5.1397 & TRN \\
\hline CHEMBL1480701 & 688267 & 6.95 & 5.0563 & TRN \\
\hline CHEMBL1428065 & 688267 & 5.5 & 5.0573 & TST \\
\hline CHEMBL1490446 & 688267 & 4.05 & 5.1053 & TRN \\
\hline CHEMBL1429252 & 688267 & 3.95 & 5.039 & TRN \\
\hline CHEMBL1432238 & 688267 & 5.35 & 5.0698 & TRN \\
\hline CHEMBL1315040 & 688267 & 6.1 & 5.0761 & TRN \\
\hline CHEMBL1476181 & 688267 & 5.85 & 5.1002 & TRN \\
\hline CHEMBL1496730 & 688267 & 5.05 & 5.1449 & TRN \\
\hline CHEMBL1473775 & 688267 & 5.9 & 5.0513 & TRN \\
\hline CHEMBL1392942 & 688267 & 4.1 & 5.1215 & TRN \\
\hline CHEMBL1527194 & 688267 & 4.7 & 5.0579 & TST \\
\hline CHEMBL1430898 & 688267 & 4.45 & 5.0314 & TRN \\
\hline CHEMBL42210 & 688267 & 5.7 & 5.0301 & TRN \\
\hline CHEMBL1492757 & 688267 & 4.2 & 5.073 & TRN \\
\hline CHEMBL1525819 & 688267 & 5.05 & 5.0959 & TRN \\
\hline CHEMBL1470331 & 688267 & 4.0 & 5.1199 & TRN \\
\hline
\end{tabular}




\begin{tabular}{|c|c|c|c|c|c|}
\hline \multicolumn{6}{|c|}{ plemental } \\
\hline CHEMBL1533980 & 688267 & 4.1 & 5.0416 & TRN & \\
\hline CHEMBL1410032 & 688267 & 6.15 & 5.1043 & TST & \\
\hline CHEMBL1532948 & 688267 & 6.2 & 5.0938 & TRN & \\
\hline CHEMBL3212615 & 688267 & 5.55 & 5.0318 & TRN & \\
\hline CHEMBL1435058 & 688267 & 6.2 & 5.0397 & TRN & \\
\hline CHEMBL1388813 & 688267 & 5.4 & 5.0707 & TRN & \\
\hline CHEMBL1431698 & 688267 & 5.25 & 5.0562 & TST & \\
\hline CHEMBL1397920 & 688267 & 4.05 & 5.0536 & TRN & \\
\hline CHEMBL1316406 & 688267 & 6.25 & 5.1481 & TRN & \\
\hline CHEMBL1392282 & 688267 & 6.15 & 5.0249 & TST & \\
\hline CHEMBL1355605 & 688267 & 4.6 & 5.0059 & TRN & \\
\hline CHEMBL1469084 & 688267 & 5.95 & 5.0163 & TST & \\
\hline CHEMBL1339125 & 688267 & 4.55 & 5.1043 & TRN & \\
\hline CHEMBL1499764 & 688267 & 5.3 & 5.0657 & TRN & \\
\hline CHEMBL1405367 & 688267 & 4.05 & 5.0618 & TRN & \\
\hline CHEMBL1460402 & 688267 & 4.7 & 5.06 & TST & \\
\hline CHEMBL1450792 & 688267 & 4.1 & 5.0628 & TRN & \\
\hline CHEMBL1572463 & 688267 & 6.15 & 5.0297 & TRN & \\
\hline CHEMBL1417716 & 688267 & 4.05 & 5.0902 & TST & \\
\hline CHEMBL1498461 & 688267 & 4.6 & 5.0175 & TRN & \\
\hline CHEMBL 3210502 & 688267 & 4.3 & 5.0974 & TST & \\
\hline CHEMBL1526118 & 688267 & 4.7 & 5.0359 & TRN & \\
\hline CHEMBL1578197 & 688267 & 3.95 & 5.0698 & TRN & \\
\hline CHEMBL1406521 & 688267 & 4.05 & 5.0336 & TRN & \\
\hline CHEMBL1338150 & 688267 & 6.2 & 5.0673 & TRN & \\
\hline CHEMBL1335667 & 688267 & 6.15 & $5.0360 e$ & 00000000005 & TRN \\
\hline CHEMBL1574987 & 688267 & 4.85 & 5.043 & TRN & \\
\hline CHEMBL1453307 & 688267 & 5.45 & 5.0538 & TRN & \\
\hline CHEMBL1472395 & 688267 & 3.95 & 5.0031 & TRN & \\
\hline CHEMBL1561101 & 688267 & 5.4 & 5.0237 & TRN & \\
\hline CHEMBL1481314 & 688267 & 6.2 & 5.1493 & TRN & \\
\hline CHEMBL 3214344 & 688267 & 4.3 & 5.0929 & TRN & \\
\hline CHEMBL1335588 & 688267 & 5.25 & 5.0306 & TRN & \\
\hline CHEMBL1380599 & 688267 & 5.3 & 5.0093 & TRN & \\
\hline CHEMBL1354759 & 688267 & 3.95 & 4.99 & TRN & \\
\hline CHEMBL1521936 & 688267 & 3.9 & 5.0254 & TRN & \\
\hline CHEMBL1343105 & 688267 & 5.1 & 5.0941 & TRN & \\
\hline CHEMBL1347265 & 688267 & 4.55 & 5.0846 & TRN & \\
\hline CHEMBL1591176 & 688267 & 4.3 & 5.0981 & TRN & \\
\hline CHEMBL1478654 & 688267 & 6.15 & 5.0384 & TRN & \\
\hline CHEMBL118009 & 688267 & 4.3 & 4.9915 & TRN & \\
\hline CHEMBL1587619 & 688267 & 5.5 & $5.0710 e$ & 0000000001 & TRN \\
\hline CHEMBL1602726 & 688267 & 3.95 & 4.9869 & TRN & \\
\hline CHEMBL1460185 & 688267 & 4.0 & 5.1063 & TRN & \\
\hline CHEMBL1413105 & 688267 & 6.15 & 5.1133 & TRN & \\
\hline CHEMBL1472709 & 688267 & 5.9 & 5.0632 & TRN & \\
\hline CHEMBL1537144 & 688267 & 5.25 & 5.05 & TRN & \\
\hline CHEMBL1324980 & 688267 & 5.45 & 5.093 & TRN & \\
\hline
\end{tabular}




\begin{tabular}{|c|c|c|c|c|c|}
\hline \multirow{3}{*}{$\begin{array}{l}\text { CHEMBL1370291 } \\
\text { CHEMBL } 1501849\end{array}$} & \multirow{3}{*}{$\begin{array}{l}688267 \\
688267\end{array}$} & \multicolumn{4}{|c|}{ Supplemental Table S2.txt } \\
\hline & & 6.15 & 5.0680 & 00000000005 & TST \\
\hline & & 5.45 & 5.1199 & TST & \\
\hline CHEMBL1461937 & 688267 & 4.75 & 5.0273 & TRN & \\
\hline CHEMBL1351936 & 688267 & 4.35 & 5.0505 & TRN & \\
\hline CHEMBL1348632 & 688267 & 6.2 & 4.9887 & TRN & \\
\hline CHEMBL1415497 & 688267 & 3.95 & 5.0198 & TRN & \\
\hline CHEMBL1327333 & 688267 & 5.85 & 5.0284 & TRN & \\
\hline CHEMBL1505717 & 688267 & 4.15 & 5.0227 & TRN & \\
\hline CHEMBL1438258 & 688267 & 4.4 & 5.1063 & TST & \\
\hline CHEMBL1363023 & 688267 & 6.5501 & 5.1087 & TRN & \\
\hline CHEMBL1582806 & 688267 & 4.6 & 5.0266 & TST & \\
\hline CHEMBL1598583 & 688267 & 4.85 & 5.0151 & TRN & \\
\hline CHEMBL3190738 & 688267 & 5.15 & 5.0022 & TRN & \\
\hline CHEMBL1448891 & 688267 & 5.1 & 5.0609 & TRN & \\
\hline CHEMBL1422916 & 688267 & 6.2 & 5.0409 & TST & \\
\hline CHEMBL1505985 & 688267 & 5.55 & 5.0478 & TST & \\
\hline CHEMBL1465791 & 688267 & 6.2 & 5.1272 & TRN & \\
\hline CHEMBL1405496 & 688267 & 6.2 & 5.0034 & TRN & \\
\hline CHEMBL1565878 & 688267 & 4.9 & 5.0877 & TRN & \\
\hline CHEMBL1321029 & 688267 & 6.2 & 5.0499 & TRN & \\
\hline CHEMBL1564630 & 688267 & 5.45 & 5.0784 & TST & \\
\hline CHEMBL1471923 & 688267 & 5.3 & 5.0233 & TRN & \\
\hline CHEMBL1476834 & 688267 & 6.15 & 5.0882 & TRN & \\
\hline CHEMBL1524341 & 688267 & 6.15 & 5.0615 & TRN & \\
\hline CHEMBL1453947 & 688267 & 3.95 & 5.008 & TST & \\
\hline CHEMBL1501515 & 688267 & 4.4 & 5.0166 & TRN & \\
\hline CHEMBL1384034 & 688267 & 5.3 & 5.0713 & TST & \\
\hline CHEMBL1346745 & 688267 & 4.6 & 5.0662 & TST & \\
\hline CHEMBL1488744 & 688267 & 5.05 & 5.0387 & TRN & \\
\hline CHEMBL1475706 & 688267 & 6.15 & 5.1035 & TRN & \\
\hline CHEMBL1355302 & 688267 & 4.1 & 5.0587 & TRN & \\
\hline CHEMBL1603618 & 688267 & 4.7 & 5.0371 & TST & \\
\hline CHEMBL1480220 & 688267 & 4.65 & 5.0167 & TRN & \\
\hline CHEMBL1523210 & 688267 & 4.4 & 5.0883 & TST & \\
\hline CHEMBL1341327 & 688267 & 5.85 & 5.1176 & TST & \\
\hline CHEMBL1320317 & 688267 & 4.35 & 5.0088 & TRN & \\
\hline CHEMBL1548588 & 688267 & 5.3 & 5.1063 & TRN & \\
\hline CHEMBL1320906 & 688267 & 5.65 & 5.0768 & TRN & \\
\hline CHEMBL1323568 & 688267 & 6.25 & 5.0986 & TRN & \\
\hline CHEMBL1303824 & 688267 & 5.25 & 5.0634 & TRN & \\
\hline CHEMBL1337945 & 688267 & 4.0 & 5.0777 & TRN & \\
\hline CHEMBL1315694 & 688267 & 6.2 & 5.1401 & TRN & \\
\hline CHEMBL1562117 & 688267 & 4.1 & 5.0207 & TRN & \\
\hline CHEMBL1586916 & 688267 & 5.95 & 5.0272 & TST & \\
\hline CHEMBL1314447 & 688267 & 4.4 & 5.1182 & TRN & \\
\hline CHEMBL1336950 & 688267 & 5.35 & 5.0691 & TST & \\
\hline CHEMBL1606531 & 688267 & 6.2 & 4.9954 & TRN & \\
\hline CHEMBL1594140 & 688267 & 5.4 & 5.0262 & TST & \\
\hline
\end{tabular}




\begin{tabular}{|c|c|c|c|c|c|}
\hline \multicolumn{6}{|c|}{ Supplemental Table S2.txt } \\
\hline CHEMBL1303123 & 688267 & 6.2 & 5.052 & TRN & \\
\hline CHEMBL1396913 & 688267 & 5.15 & 5.0716 & TRN & \\
\hline CHEMBL1394848 & 688267 & 4.5 & 5.1191 & TST & \\
\hline CHEMBL1604283 & 688267 & 6.15 & 5.0571 & TST & \\
\hline CHEMBL1391615 & 688267 & 4.35 & 5.114 & TST & \\
\hline CHEMBL1603368 & 688267 & 4.4 & 4.999 & TRN & \\
\hline CHEMBL1482421 & 688267 & 4.1 & 5.0186 & TRN & \\
\hline CHEMBL1462919 & 688267 & 5.3 & 5.0348 & TRN & \\
\hline CHEMBL1354699 & 688267 & 4.05 & 5.0579 & TRN & \\
\hline CHEMBL1328263 & 688267 & 6.15 & 5.0546 & TST & \\
\hline CHEMBL1442750 & 688267 & 4.05 & 5.0562 & TST & \\
\hline CHEMBL1450940 & 688267 & 5.3 & 5.0585 & TRN & \\
\hline CHEMBL1497879 & 688267 & 4.4 & 5.0157 & TRN & \\
\hline CHEMBL1554656 & 688267 & 6.05 & 5.1465 & TST & \\
\hline CHEMBL1513193 & 688267 & 4.05 & 5.0528 & TRN & \\
\hline CHEMBL1529675 & 688267 & 5.0 & 5.0819 & TRN & \\
\hline CHEMBL1317474 & 688267 & 4.9 & 5.1101 & TRN & \\
\hline CHEMBL1330001 & 688267 & 4.05 & 5.074 & TRN & \\
\hline CHEMBL1313870 & 688267 & 4.7 & 5.0105 & TST & \\
\hline CHEMBL1424785 & 688267 & 5.3 & 5.0935 & TRN & \\
\hline CHEMBL1357375 & 688267 & 4.6 & 5.0885 & TRN & \\
\hline CHEMBL1457476 & 688267 & 4.6 & 4.9825 & TRN & \\
\hline CHEMBL73441 & 688267 & 6.2 & 5.0518 & TRN & \\
\hline CHEMBL1610229 & 688267 & 4.6 & 5.10800 & 00000000005 & TRN \\
\hline CHEMBL1536534 & 688267 & 4.05 & 5.063 & TST & \\
\hline CHEMBL1386083 & 688267 & 4.4 & 5.0064 & TRN & \\
\hline CHEMBL1304855 & 688267 & 6.2 & 5.0202 & TRN & \\
\hline CHEMBL1373355 & 688267 & 4.6 & 5.0514 & TST & \\
\hline CHEMBL1468615 & 688267 & 4.6 & 5.0185 & TRN & \\
\hline CHEMBL1380441 & 688267 & 5.3 & 5.0804 & TST & \\
\hline CHEMBL1551864 & 688267 & 6.45 & 5.1077 & TST & \\
\hline CHEMBL1433542 & 688267 & 3.95 & 5.075 & TST & \\
\hline CHEMBL1323931 & 688267 & 6.25 & 5.012 & TRN & \\
\hline CHEMBL1484818 & 688267 & 5.85 & 5.029 & TRN & \\
\hline CHEMBL1485236 & 688267 & 5.85 & 5.0946 & TRN & \\
\hline CHEMBL1613355 & 688267 & 5.8 & 5.101 & TST & \\
\hline CHEMBL1325444 & 688267 & 4.0 & 5.0788 & TRN & \\
\hline CHEMBL1331430 & 688267 & 4.4 & 4.9949 & TRN & \\
\hline CHEMBL1412556 & 688267 & 4.4 & 5.1055 & TRN & \\
\hline CHEMBL597657 & 688267 & 5.3 & 5.04 & TRN & \\
\hline CHEMBL1379892 & 688267 & 6.15 & 4.9815 & TST & \\
\hline CHEMBL1510577 & 688267 & 5.15 & 5.0485 & TRN & \\
\hline CHEMBL1463223 & 688267 & 5.35 & 5.008 & TRN & \\
\hline CHEMBL1550371 & 688267 & 6.2 & 5.0852 & TRN & \\
\hline CHEMBL1436349 & 688267 & 4.0 & 5.0374 & TRN & \\
\hline CHEMBL1348741 & 688267 & 4.0 & 5.0953 & TRN & \\
\hline CHEMBL3209405 & 688267 & 6.2 & 5.038 & TST & \\
\hline CHEMBL1474229 & 688267 & 5.0 & 5.0486 & TRN & \\
\hline
\end{tabular}




\begin{tabular}{|c|c|c|c|c|c|}
\hline \multicolumn{6}{|c|}{ Supplemental Table S2.txt } \\
\hline CHEMBL1590381 & 688267 & 4.25 & 5.1046 & TRN & \\
\hline CHEMBL1509671 & 688267 & 5.7 & 5.0341 & TST & \\
\hline CHEMBL1587933 & 688267 & 4.25 & 5.0225 & TST & \\
\hline CHEMBL1463152 & 688267 & 6.25 & 5.0545 & TRN & \\
\hline CHEMBL1425953 & 688267 & 5.45 & 5.0953 & TRN & \\
\hline CHEMBL1234276 & 688267 & 4.0 & 5.1331 & TST & \\
\hline CHEMBL1460368 & 688267 & 4.0 & 5.1102 & TRN & \\
\hline CHEMBL1324913 & 688267 & 4.35 & 5.0595 & TRN & \\
\hline CHEMBL1423367 & 688267 & 5.85 & 4.9972 & TRN & \\
\hline CHEMBL1376866 & 688267 & 3.95 & 5.0136 & TRN & \\
\hline CHEMBL1342081 & 688267 & 4.95 & 5.0001 & TRN & \\
\hline CHEMBL3208024 & 688267 & 5.45 & 5.01699 & 99999999995 & TRN \\
\hline CHEMBL3208710 & 688267 & 5.25 & 5.0929 & TST & \\
\hline CHEMBL1474149 & 688267 & 4.55 & 5.0981 & TRN & \\
\hline CHEMBL1586653 & 688267 & 5.25 & 5.1461 & TST & \\
\hline CHEMBL1525667 & 688267 & 5.0 & 5.0749 & TRN & \\
\hline CHEMBL1376727 & 688267 & 4.55 & 4.9749 & TRN & \\
\hline CHEMBL1331266 & 688267 & 4.75 & 5.0516 & TRN & \\
\hline CHEMBL1520566 & 688267 & 4.7 & 5.0747 & TST & \\
\hline CHEMBL599712 & 688267 & 5.3 & 5.0703 & TRN & \\
\hline CHEMBL1425802 & 688267 & 6.2 & 5.0141 & TST & \\
\hline CHEMBL1457070 & 688267 & 6.2 & 5.0775 & TRN & \\
\hline CHEMBL1399883 & 688267 & 4.65 & 4.9996 & TRN & \\
\hline CHEMBL1326830 & 688267 & 6.25 & 5.0618 & TRN & \\
\hline CHEMBL1379282 & 688267 & 5.9 & 5.1082 & TRN & \\
\hline CHEMBL1529503 & 688267 & 6.2 & 5.1144 & TST & \\
\hline CHEMBL1549425 & 688267 & 4.35 & 5.0174 & TRN & \\
\hline CHEMBL1310055 & 688267 & 5.0 & 5.0293 & TRN & \\
\hline CHEMBL1571433 & 688267 & 4.05 & 5.0262 & TST & \\
\hline CHEMBL1468948 & 688267 & 4.85 & 5.0435 & TRN & \\
\hline CHEMBL1457705 & 688267 & 5.3 & 5.1251 & TRN & \\
\hline CHEMBL1481722 & 688267 & 4.25 & 5.0568 & TST & \\
\hline CHEMBL1521504 & 688267 & 6.25 & 5.0387 & TRN & \\
\hline CHEMBL1348664 & 688267 & 4.05 & 5.0371 & TRN & \\
\hline CHEMBL1593379 & 688267 & 4.0 & 5.0748 & TRN & \\
\hline CHEMBL1443518 & 688267 & 4.05 & 4.9999 & TST & \\
\hline CHEMBL1451320 & 688267 & 5.6 & 5.1145 & TRN & \\
\hline CHEMBL1538412 & 688267 & 6.1 & 5.0089 & TRN & \\
\hline CHEMBL1498141 & 688267 & 6.5 & 5.0914 & TRN & \\
\hline CHEMBL1577856 & 688267 & 5.25 & 5.0413 & TST & \\
\hline CHEMBL1531153 & 688267 & 4.05 & 5.0658 & TRN & \\
\hline CHEMBL1456271 & 688267 & 6.15 & 4.9935 & TRN & \\
\hline CHEMBL1560506 & 688267 & 4.9 & 5.0374 & TST & \\
\hline CHEMBL1497664 & 688267 & 5.8 & 5.0575 & TRN & \\
\hline CHEMBL1353817 & 688267 & 6.25 & 5.092 & TRN & \\
\hline CHEMBL1360234 & 688267 & 5.0 & 5.0446 & TST & \\
\hline CHEMBL1542058 & 688267 & 5.6 & 5.0248 & TST & \\
\hline CHEMBL1532373 & 688267 & 4.4 & 4.9862 & TRN & \\
\hline
\end{tabular}




\begin{tabular}{|c|c|c|c|c|c|}
\hline \\
\hline CHEMBL1386682 & 688267 & 4.4 & 5.0878 & TRN & \\
\hline CHEMBL1591184 & 688267 & 5.55 & 5.1043 & TRN & \\
\hline CHEMBL1342156 & 688267 & 4.6 & 4.988 & TST & \\
\hline CHEMBL1463703 & 688267 & 5.3 & 5.1267 & TRN & \\
\hline CHEMBL1600296 & 688267 & 4.1 & 4.9987 & TRN & \\
\hline CHEMBL1308582 & 688267 & 5.4 & 5.0702 & TRN & \\
\hline CHEMBL1612641 & 688267 & 5.55 & 5.1635 & TRN & \\
\hline CHEMBL1578512 & 688267 & 4.05 & 5.15799 & 99999999995 & TRN \\
\hline CHEMBL1330569 & 688267 & 4.75 & 4.9966 & TRN & \\
\hline CHEMBL1376879 & 688267 & 4.35 & 5.0117 & TRN & \\
\hline CHEMBL1303634 & 688267 & 5.2 & 5.0423 & TST & \\
\hline CHEMBL1517608 & 688267 & 5.45 & 4.9943 & TST & \\
\hline CHEMBL1504404 & 688267 & 6.2 & 4.995 & TRN & \\
\hline CHEMBL1318460 & 688267 & 5.8 & 5.0871 & TRN & \\
\hline CHEMBL1606400 & 688267 & 4.0 & 4.9933 & TRN & \\
\hline CHEMBL1518046 & 688267 & 4.4 & 5.0832 & TRN & \\
\hline CHEMBL1600493 & 688267 & 6.2 & 5.0445 & TST & \\
\hline CHEMBL1536581 & 688267 & 6.5 & 5.0906 & TST & \\
\hline CHEMBL1423568 & 688267 & 4.05 & 5.0815 & TRN & \\
\hline CHEMBL1305590 & 688267 & 5.9 & 5.0279 & TRN & \\
\hline CHEMBL1507039 & 688267 & 5.55 & 5.058 & TRN & \\
\hline CHEMBL1485050 & 688267 & 6.1 & 5.0533 & TRN & \\
\hline CHEMBL1473750 & 688267 & 4.35 & 5.02 & TRN & \\
\hline CHEMBL1439585 & 688267 & 5.45 & 5.0817 & TRN & \\
\hline CHEMBL1556502 & 688267 & 5.85 & 5.0241 & TRN & \\
\hline CHEMBL1507465 & 688267 & 4.15 & 5.0874 & TRN & \\
\hline CHEMBL1313691 & 688267 & 3.95 & 5.0405 & TRN & \\
\hline CHEMBL1342112 & 688267 & 5.3 & 5.0399 & TRN & \\
\hline CHEMBL1459036 & 688267 & 5.55 & 5.0373 & TST & \\
\hline CHEMBL1494011 & 688267 & 6.5 & 4.9962 & TST & \\
\hline CHEMBL1444472 & 688267 & 5.3 & 5.0079 & TRN & \\
\hline CHEMBL3214109 & 688267 & 4.05 & 5.056 & TRN & \\
\hline CHEMBL1971420 & 688267 & 4.75 & 5.0244 & TRN & \\
\hline CHEMBL1480278 & 688267 & 6.2 & 5.0597 & TRN & \\
\hline CHEMBL1423683 & 688267 & 4.25 & 5.1355 & TRN & \\
\hline CHEMBL1583205 & 688267 & 4.3 & 4.9571 & TRN & \\
\hline CHEMBL1516843 & 688267 & 5.2 & 5.0813 & TRN & \\
\hline CHEMBL1347876 & 688267 & 5.9 & 5.0219 & TST & \\
\hline CHEMBL1477242 & 688267 & 5.5 & 5.01699 & 99999999995 & TST \\
\hline CHEMBL1318281 & 688267 & 4.05 & 5.0324 & TRN & \\
\hline CHEMBL1534322 & 688267 & 4.4 & 5.092 & TRN & \\
\hline CHEMBL1472435 & 688267 & 4.4 & 5.09699 & 99999999995 & TRN \\
\hline CHEMBL1350019 & 688267 & 4.9 & 5.0056 & TRN & \\
\hline CHEMBL1435212 & 688267 & 5.55 & 5.0398 & TRN & \\
\hline CHEMBL1538573 & 688267 & 4.8 & 5.0838 & TRN & \\
\hline CHEMBL1475820 & 688267 & 4.05 & 5.056 & TRN & \\
\hline CHEMBL1348924 & 688267 & 5.5 & 5.1244 & TST & \\
\hline CHEMBL1596734 & 688267 & 4.6 & 5.0058 & TRN & \\
\hline
\end{tabular}




\begin{tabular}{|c|c|c|c|c|c|}
\hline & & \multicolumn{4}{|c|}{ Supplemental Table S2.txt } \\
\hline CHEMBL1376667 & 688267 & 4.0 & 5.0428 & TRN & \\
\hline CHEMBL1406630 & 688267 & 5.15 & 5.084 & TRN & \\
\hline CHEMBL1591019 & 688267 & 4.9 & 5.0476 & TRN & \\
\hline CHEMBL1315014 & 688267 & 5.65 & 5.0794 & TRN & \\
\hline CHEMBL1337192 & 688267 & 4.8 & 5.0619 & TRN & \\
\hline CHEMBL1441019 & 688267 & 6.45 & 5.0028 & TRN & \\
\hline CHEMBL1415098 & 688267 & 5.4 & 5.07 & TRN & \\
\hline CHEMBL1983839 & 688267 & 4.3 & $5.0310 e$ & 0000000001 & TRN \\
\hline CHEMBL1505593 & 688267 & 4.65 & 5.0215 & TRN & \\
\hline CHEMBL1516373 & 688267 & 6.2 & 5.0766 & TRN & \\
\hline CHEMBL1340138 & 688267 & 6.05 & 5.1445 & TRN & \\
\hline CHEMBL1601948 & 688267 & 4.25 & 5.0464 & TST & \\
\hline CHEMBL1519200 & 688267 & 5.0 & 5.0031 & TRN & \\
\hline CHEMBL1609021 & 688267 & 6.2 & 5.0348 & TRN & \\
\hline CHEMBL1564497 & 688267 & 4.5 & 5.0796 & TRN & \\
\hline CHEMBL1484774 & 688267 & 4.3 & 5.0808 & TRN & \\
\hline CHEMBL1334567 & 688267 & 5.95 & 5.0559 & TRN & \\
\hline CHEMBL1552246 & 688267 & 5.75 & 5.0751 & TRN & \\
\hline CHEMBL1445051 & 688267 & 4.5 & 5.0683 & TST & \\
\hline CHEMBL1308051 & 688267 & 5.5 & 5.0359 & TRN & \\
\hline CHEMBL1480787 & 688267 & 4.3 & 5.0736 & TRN & \\
\hline CHEMBL1366739 & 688267 & 5.85 & 5.0747 & TRN & \\
\hline CHEMBL1343999 & 688267 & 4.35 & 5.1063 & TRN & \\
\hline CHEMBL1308708 & 688267 & 5.4 & 5.0081 & TRN & \\
\hline CHEMBL1380430 & 688267 & 6.2 & 5.1368 & TRN & \\
\hline CHEMBL1508891 & 688267 & 4.3 & 5.0239 & TRN & \\
\hline CHEMBL1461504 & 688267 & 4.45 & 5.1083 & TRN & \\
\hline CHEMBL1533650 & 688267 & 5.65 & 5.1235 & TRN & \\
\hline CHEMBL1360959 & 688267 & 4.45 & 5.0117 & TRN & \\
\hline CHEMBL1591497 & 688267 & 5.85 & 5.034 & TRN & \\
\hline CHEMBL1305687 & 688267 & 4.95 & 5.1029 & TRN & \\
\hline CHEMBL1369956 & 688267 & 5.5 & 5.104 & TRN & \\
\hline CHEMBL1498155 & 688267 & 6.2 & 5.0352 & TST & \\
\hline CHEMBL1471367 & 688267 & 5.5 & 5.0154 & TRN & \\
\hline CHEMBL1440746 & 688267 & 6.2 & 5.0198 & TST & \\
\hline CHEMBL1598370 & 688267 & 5.65 & 5.0449 & TRN & \\
\hline CHEMBL1489013 & 688267 & 4.6 & 5.0537 & TRN & \\
\hline CHEMBL1605473 & 688267 & 4.45 & 5.048 & TRN & \\
\hline CHEMBL144345 & 688267 & 5.6 & 5.0324 & TST & \\
\hline CHEMBL1596413 & 688267 & 6.5 & 5.0466 & TRN & \\
\hline CHEMBL1389937 & 688267 & 5.0 & 4.9983 & TRN & \\
\hline CHEMBL1515428 & 688267 & 4.95 & 5.0764 & TRN & \\
\hline CHEMBL1406787 & 688267 & 5.65 & 5.0082 & TRN & \\
\hline CHEMBL1346116 & 688267 & 3.95 & 5.0491 & TRN & \\
\hline CHEMBL1573486 & 688267 & 6.0 & 5.0608 & TRN & \\
\hline CHEMBL1451522 & 688267 & 4.55 & 5.0086 & TRN & \\
\hline CHEMBL1318515 & 688267 & 5.35 & 5.0642 & TRN & \\
\hline CHEMBL1487850 & 688267 & 4.1 & 5.0527 & TRN & \\
\hline
\end{tabular}




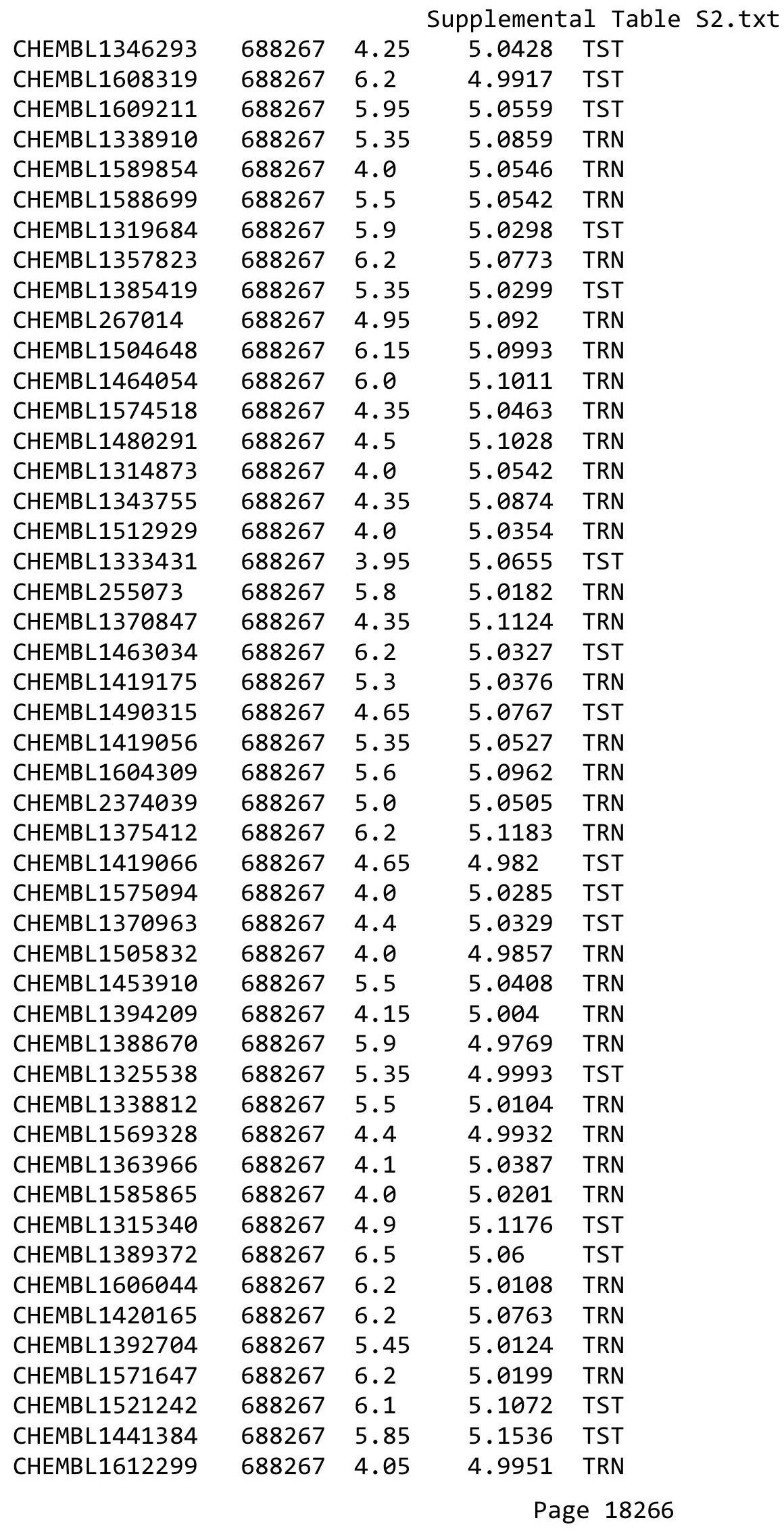




\begin{tabular}{|c|c|c|c|c|c|}
\hline & & \multicolumn{4}{|c|}{ Supplemental Table S2.txt } \\
\hline CHEMBL1334541 & 688267 & 3.95 & 5.0488 & TST & \\
\hline CHEMBL1315259 & 688267 & 5.4 & 5.081 & TRN & \\
\hline CHEMBL1603691 & 688267 & 4.0 & 5.06800 & 00000000005 & TRN \\
\hline CHEMBL1496522 & 688267 & 5.3 & 5.0212 & TRN & \\
\hline CHEMBL1307619 & 688267 & 4.75 & 5.0569 & TST & \\
\hline CHEMBL1417836 & 688267 & 4.6 & 5.0768 & TRN & \\
\hline CHEMBL1329099 & 688267 & 4.35 & 5.0478 & TRN & \\
\hline CHEMBL1540481 & 688267 & 4.55 & 5.0627 & TRN & \\
\hline CHEMBL1495344 & 688267 & 4.1 & 5.0691 & TRN & \\
\hline CHEMBL1359092 & 688267 & 4.45 & 4.9992 & TRN & \\
\hline CHEMBL1446449 & 688267 & 4.0 & 4.9893 & TRN & \\
\hline CHEMBL1612263 & 688267 & 5.05 & 5.0341 & TRN & \\
\hline CHEMBL1577457 & 688267 & 4.2 & 5.0452 & TRN & \\
\hline CHEMBL1342094 & 688267 & 4.05 & 5.0771 & TST & \\
\hline CHEMBL1466167 & 688267 & 5.75 & 4.9867 & TRN & \\
\hline CHEMBL1382576 & 688267 & 4.05 & 5.027 & TRN & \\
\hline CHEMBL1569717 & 688267 & 4.1 & 5.078 & TRN & \\
\hline CHEMBL3189303 & 688267 & 3.85 & 5.0391 & TRN & \\
\hline CHEMBL1349902 & 688267 & 4.95 & 5.1014 & TRN & \\
\hline CHEMBL1375116 & 688267 & 6.2 & 5.0185 & TST & \\
\hline CHEMBL1358951 & 688267 & 5.45 & 4.9991 & TRN & \\
\hline CHEMBL1389237 & 688267 & 5.3 & 5.1247 & TRN & \\
\hline CHEMBL1366971 & 688267 & 4.05 & 5.0193 & TRN & \\
\hline CHEMBL1555273 & 688267 & 5.55 & 5.0524 & TRN & \\
\hline CHEMBL1570298 & 688267 & 5.05 & 5.0928 & TRN & \\
\hline CHEMBL1355070 & 688267 & 4.4 & 5.1398 & TRN & \\
\hline CHEMBL1416043 & 688267 & 4.3 & 5.0463 & TRN & \\
\hline CHEMBL1524402 & 688267 & 4.3 & 5.048 & TST & \\
\hline CHEMBL1608273 & 688267 & 5.65 & 5.1398 & TRN & \\
\hline CHEMBL1305095 & 688267 & 5.5 & 5.112 & TRN & \\
\hline CHEMBL1493509 & 688267 & 4.0 & 5.0369 & TRN & \\
\hline CHEMBL1504358 & 688267 & 5.3 & 5.0092 & TRN & \\
\hline CHEMBL1435835 & 688267 & 3.95 & 5.0567 & TST & \\
\hline CHEMBL1341444 & 688267 & 4.35 & 5.0127 & TST & \\
\hline CHEMBL1376805 & 688267 & 4.0 & 5.0431 & TRN & \\
\hline CHEMBL1363968 & 688267 & 5.3 & 5.0387 & TRN & \\
\hline CHEMBL1390815 & 688267 & 4.4 & 5.09399 & 9999999999 & TRN \\
\hline CHEMBL1337478 & 688267 & 5.5 & 5.03 & TRN & \\
\hline CHEMBL1515821 & 688267 & 5.4 & 5.0355 & TRN & \\
\hline CHEMBL1351045 & 688267 & 6.05 & 5.0438 & TRN & \\
\hline CHEMBL1499330 & 688267 & 5.6 & 5.0346 & TST & \\
\hline CHEMBL1593563 & 688267 & 4.2 & 5.0212 & TST & \\
\hline CHEMBL1548302 & 688267 & 4.35 & 5.0673 & TST & \\
\hline CHEMBL3199552 & 688267 & 4.0 & 5.0277 & TRN & \\
\hline CHEMBL1300797 & 688267 & 4.55 & 5.0469 & TRN & \\
\hline CHEMBL1552712 & 688267 & 5.85 & 5.1094 & TRN & \\
\hline CHEMBL1345043 & 688267 & 6.15 & 5.0524 & TRN & \\
\hline CHEMBL1610349 & 688267 & 5.85 & 5.0028 & TST & \\
\hline
\end{tabular}




\begin{tabular}{|c|c|c|c|c|c|}
\hline \\
\hline CHEMBL1517686 & 688267 & 4.0 & 5.0041 & TRN & \\
\hline CHEMBL1517711 & 688267 & 5.2 & 5.0327 & TST & \\
\hline CHEMBL1324170 & 688267 & 4.45 & 5.0416 & TST & \\
\hline CHEMBL1443074 & 688267 & 5.4 & 4.9885 & TST & \\
\hline CHEMBL1571610 & 688267 & 3.95 & 4.985 & TRN & \\
\hline CHEMBL1553006 & 688267 & 5.8 & 5.0663 & TRN & \\
\hline CHEMBL1317658 & 688267 & 4.0 & 5.0455 & TRN & \\
\hline CHEMBL528492 & 688267 & 6.1 & 5.0686 & TST & \\
\hline CHEMBL1524050 & 688267 & 4.5 & 4.9809 & TST & \\
\hline CHEMBL1579151 & 688267 & 4.8 & 5.1139 & TRN & \\
\hline CHEMBL1340612 & 688267 & 5.3 & 5.0317 & TRN & \\
\hline CHEMBL1392515 & 688267 & 5.6 & 5.0378 & TST & \\
\hline CHEMBL1319622 & 688267 & 3.95 & 5.0709 & TRN & \\
\hline CHEMBL1362906 & 688267 & 3.95 & 5.056 & TRN & \\
\hline CHEMBL1505113 & 688267 & 6.2 & 4.9957 & TRN & \\
\hline CHEMBL1588165 & 688267 & 4.0 & 5.0527 & TRN & \\
\hline CHEMBL1587094 & 688267 & 4.0 & 5.0181 & TRN & \\
\hline CHEMBL1315686 & 688267 & 4.05 & 5.0558 & TRN & \\
\hline CHEMBL1572488 & 688267 & 4.15 & 5.0806 & TRN & \\
\hline CHEMBL1300179 & 688267 & 4.4 & 4.9871 & TRN & \\
\hline CHEMBL1482823 & 688267 & 4.95 & 5.112 & TST & \\
\hline CHEMBL1420854 & 688267 & 4.0 & 5.0084 & TRN & \\
\hline CHEMBL1535429 & 688267 & 3.95 & 5.1162 & TRN & \\
\hline CHEMBL1601119 & 688267 & 4.4 & 4.9969 & TRN & \\
\hline CHEMBL3210911 & 688267 & 6.2 & 5.0077 & TST & \\
\hline CHEMBL1327207 & 688267 & 4.35 & 5.024 & TRN & \\
\hline CHEMBL1316692 & 688267 & 5.15 & 5.1079 & TST & \\
\hline CHEMBL1514241 & 688267 & 4.4 & 5.118 & TRN & \\
\hline CHEMBL1320458 & 688267 & 4.9 & 5.02800 & 00000000005 & TST \\
\hline CHEMBL1394932 & 688267 & 6.2 & 5.0767 & TRN & \\
\hline CHEMBL1509629 & 688267 & 5.05 & 5.0462 & TRN & \\
\hline CHEMBL1439300 & 688267 & 5.85 & 5.0696 & TRN & \\
\hline CHEMBL1396122 & 688267 & 6.2 & 5.0663 & TRN & \\
\hline CHEMBL1525824 & 688267 & 5.3 & 5.0099 & TRN & \\
\hline CHEMBL1445855 & 688267 & 4.45 & 4.9957 & TRN & \\
\hline CHEMBL1592417 & 688267 & 3.95 & 5.0051 & TST & \\
\hline CHEMBL1604086 & 688267 & 4.0 & 5.0897 & TRN & \\
\hline CHEMBL280323 & 688267 & 6.25 & 5.016 & TST & \\
\hline CHEMBL1522367 & 688267 & 5.4 & 5.0674 & TST & \\
\hline CHEMBL1336054 & 688267 & 4.8 & 4.99100 & 00000000005 & TRN \\
\hline CHEMBL1453854 & 688267 & 5.15 & 5.0257 & TST & \\
\hline CHEMBL1514062 & 688267 & 5.65 & 5.1474 & TRN & \\
\hline CHEMBL1474742 & 688267 & 6.25 & 5.0619 & TST & \\
\hline CHEMBL1385417 & 688267 & 4.4 & 5.0184 & TST & \\
\hline CHEMBL1458471 & 688267 & 6.0 & 5.0253 & TRN & \\
\hline CHEMBL1345253 & 688267 & 6.2 & 5.0496 & TST & \\
\hline CHEMBL1406929 & 688267 & 5.45 & 5.0716 & TST & \\
\hline CHEMBL3191595 & 688267 & 4.3 & 4.9937 & TRN & \\
\hline
\end{tabular}




\begin{tabular}{|c|c|c|c|c|}
\hline & & & pplement & al $\mathrm{Ta}$ \\
\hline CHEMBL1449130 & 688267 & 6.2 & 5.0569 & TRN \\
\hline CHEMBL1533675 & 688267 & 6.2 & 5.0572 & TRN \\
\hline CHEMBL1209127 & 688267 & 5.45 & 5.0464 & TRN \\
\hline CHEMBL1410167 & 688267 & 4.05 & 5.0425 & TRN \\
\hline CHEMBL1579247 & 688267 & 5.25 & 5.0488 & TRN \\
\hline CHEMBL1469709 & 688267 & 5.45 & 5.1177 & TST \\
\hline CHEMBL1589431 & 688267 & 4.7 & 4.9914 & TRN \\
\hline CHEMBL1375383 & 688267 & 4.7 & 5.0476 & TRN \\
\hline CHEMBL1594380 & 688267 & 4.15 & 5.0398 & TRN \\
\hline CHEMBL1556795 & 688267 & 4.0 & 5.0905 & TST \\
\hline CHEMBL3392044 & 688267 & 5.95 & 5.0581 & TST \\
\hline CHEMBL1572465 & 688267 & 6.25 & 5.0586 & TRN \\
\hline CHEMBL1509263 & 688267 & 5.0 & 5.0399 & TRN \\
\hline CHEMBL1434506 & 688267 & 4.0 & 5.0512 & TST \\
\hline CHEMBL1454057 & 688267 & 6.25 & 5.0897 & TRN \\
\hline CHEMBL1520269 & 688267 & 4.8 & 5.0888 & TRN \\
\hline CHEMBL1383961 & 688267 & 4.0 & 5.032 & TST \\
\hline CHEMBL1463933 & 688267 & 5.8 & 4.9841 & TRN \\
\hline CHEMBL1442971 & 688267 & 5.85 & 5.0989 & TRN \\
\hline CHEMBL1598354 & 688267 & 3.95 & 5.0026 & TST \\
\hline CHEMBL1427559 & 688267 & 4.05 & 4.9882 & TRN \\
\hline CHEMBL1611712 & 688267 & 4.9 & 5.0488 & TRN \\
\hline CHEMBL1351736 & 688267 & 4.95 & 5.0227 & TRN \\
\hline CHEMBL1377961 & 688267 & 5.85 & 5.0073 & TRN \\
\hline CHEMBL1452068 & 688267 & 5.4 & 5.0897 & TRN \\
\hline CHEMBL1605297 & 688267 & 6.2 & 5.0495 & TRN \\
\hline CHEMBL2003239 & 688267 & 4.05 & 4.9919 & TST \\
\hline CHEMBL1453522 & 688267 & 6.6499 & 5.0728 & TRN \\
\hline CHEMBL1577249 & 688267 & 5.55 & 5.0131 & TST \\
\hline CHEMBL1362684 & 688267 & 4.1 & 5.0208 & TST \\
\hline CHEMBL1492463 & 688267 & 4.65 & 5.1225 & TRN \\
\hline CHEMBL1388898 & 688267 & 6.5 & 5.0518 & TRN \\
\hline CHEMBL1417247 & 688267 & 6.25 & 5.0829 & TRN \\
\hline CHEMBL1526048 & 688267 & 5.15 & 5.0864 & TRN \\
\hline CHEMBL1590093 & 688267 & 4.35 & 5.0327 & TST \\
\hline CHEMBL1324986 & 688267 & 6.2 & 5.1474 & TRN \\
\hline CHEMBL1417728 & 688267 & 4.05 & 5.0392 & TRN \\
\hline CHEMBL1357175 & 688267 & 5.55 & 5.0796 & TRN \\
\hline CHEMBL1312058 & 688267 & 4.3 & 5.0933 & TST \\
\hline CHEMBL1353353 & 688267 & 5.1 & 5.0745 & TRN \\
\hline CHEMBL1316662 & 688267 & 5.35 & 4.9727 & TRN \\
\hline CHEMBL1598346 & 688267 & 5.4 & 5.0435 & TRN \\
\hline CHEMBL1339292 & 688267 & 4.4 & 5.0531 & TRN \\
\hline CHEMBL1332738 & 688267 & 6.2 & 4.9923 & TRN \\
\hline CHEMBL1581671 & 688267 & 4.0 & 5.0429 & TRN \\
\hline CHEMBL1405864 & 688267 & 4.3 & 5.0686 & TRN \\
\hline CHEMBL1368976 & 688267 & 5.2 & 5.0899 & TRN \\
\hline CHEMBL1451090 & 688267 & 5.9 & 5.1457 & TRN \\
\hline
\end{tabular}




\begin{tabular}{|c|c|c|c|c|c|}
\hline \multicolumn{6}{|c|}{ plemental lable Sz. } \\
\hline CHEMBL1391407 & 688267 & 4.6 & 5.1063 & TRN & \\
\hline CHEMBL1415437 & 688267 & 4.0 & 5.0663 & TST & \\
\hline CHEMBL1570769 & 688267 & 4.95 & 5.047 & TST & \\
\hline CHEMBL1547289 & 688267 & 5.2 & 5.0694 & TRN & \\
\hline CHEMBL1432061 & 688267 & 5.2 & 5.1692 & TRN & \\
\hline CHEMBL1590783 & 688267 & 4.6 & 5.1006 & TRN & \\
\hline CHEMBL1433534 & 688267 & 6.25 & 5.112 & TRN & \\
\hline CHEMBL1580505 & 688267 & 6.2 & 5.1118 & TRN & \\
\hline CHEMBL1528602 & 688267 & 6.2 & 5.0993 & TRN & \\
\hline CHEMBL3210051 & 688267 & 4.05 & 5.023 & TST & \\
\hline CHEMBL1485344 & 688267 & 4.05 & 5.0548 & TRN & \\
\hline CHEMBL1484155 & 688267 & 6.2 & 5.0522 & TRN & \\
\hline CHEMBL1381064 & 688267 & 6.2 & 5.0417 & TRN & \\
\hline CHEMBL1389911 & 688267 & 5.85 & 5.1018 & TRN & \\
\hline CHEMBL1496993 & 688267 & 4.3 & 5.0263 & TRN & \\
\hline CHEMBL1380655 & 688267 & 5.9 & 5.0193 & TRN & \\
\hline CHEMBL1493467 & 688267 & 4.55 & 5.0509 & TRN & \\
\hline CHEMBL1482468 & 688267 & 5.65 & 5.03100 & 0000000001 & TRN \\
\hline CHEMBL1419720 & 688267 & 5.15 & 5.0683 & TRN & \\
\hline CHEMBL1551976 & 688267 & 5.4 & 5.098 & TRN & \\
\hline CHEMBL1546419 & 688267 & 5.55 & 5.0355 & TST & \\
\hline CHEMBL1484300 & 688267 & 4.0 & 5.1393 & TRN & \\
\hline CHEMBL1300061 & 688267 & 6.2 & 5.0582 & TST & \\
\hline CHEMBL1337503 & 688267 & 4.0 & 5.1076 & TRN & \\
\hline CHEMBL1343996 & 688267 & 5.55 & 5.0667 & TST & \\
\hline CHEMBL1348857 & 688267 & 4.15 & 5.1743 & TRN & \\
\hline CHEMBL1514529 & 688267 & 5.35 & 5.0478 & TRN & \\
\hline CHEMBL1384918 & 688267 & 4.05 & 5.1071 & TRN & \\
\hline CHEMBL1506555 & 688267 & 5.4 & 5.0533 & TRN & \\
\hline CHEMBL1439535 & 688267 & 3.95 & 5.0165 & TST & \\
\hline CHEMBL1538565 & 688267 & 5.75 & 5.0566 & TRN & \\
\hline CHEMBL1485722 & 688267 & 5.4 & 5.0952 & TRN & \\
\hline CHEMBL1530278 & 688267 & 4.55 & 5.1121 & TRN & \\
\hline CHEMBL1556874 & 688267 & 4.0 & 5.0801 & TST & \\
\hline CHEMBL1313901 & 688267 & 4.05 & 5.034 & TST & \\
\hline CHEMBL1305349 & 688267 & 4.95 & 5.08899 & 99999999995 & TRN \\
\hline CHEMBL1344194 & 688267 & 5.8 & 5.0453 & TRN & \\
\hline CHEMBL1435034 & 688267 & 4.9 & 5.1168 & TRN & \\
\hline CHEMBL1506337 & 688267 & 4.05 & 5.1452 & TST & \\
\hline CHEMBL1576335 & 688267 & 4.05 & 5.034 & TRN & \\
\hline CHEMBL1334947 & 688267 & 6.2 & 5.0136 & TST & \\
\hline CHEMBL1608769 & 688267 & 5.45 & 5.1426 & TRN & \\
\hline CHEMBL1462417 & 688267 & 5.85 & 4.98600 & 0000000001 & TRN \\
\hline CHEMBL1510430 & 688267 & 4.5 & 5.0427 & TRN & \\
\hline CHEMBL237442 & 688267 & 5.75 & 5.1033 & TRN & \\
\hline CHEMBL1491805 & 688267 & 5.8 & 4.9892 & TST & \\
\hline CHEMBL1313174 & 688267 & 4.55 & 5.0065 & TST & \\
\hline CHEMBL1324832 & 688267 & 4.9 & 5.023 & TRN & \\
\hline
\end{tabular}




\begin{tabular}{|c|c|c|c|c|c|}
\hline \multicolumn{6}{|c|}{ oplemental Table } \\
\hline CHEMBL1467202 & 688267 & 6.2 & 5.0222 & TST & \\
\hline CHEMBL1344836 & 688267 & 6.25 & 5.0189 & TRN & \\
\hline CHEMBL1499283 & 688267 & 6.25 & 5.0156 & TRN & \\
\hline CHEMBL1473994 & 688267 & 4.0 & 5.0866 & TST & \\
\hline CHEMBL3211687 & 688267 & 5.05 & 5.0361 & TRN & \\
\hline CHEMBL1359760 & 688267 & 4.0 & 5.0748 & TRN & \\
\hline CHEMBL1358448 & 688267 & 5.9 & 5.1267 & TRN & \\
\hline CHEMBL1387629 & 688267 & 6.1 & 5.0944 & TRN & \\
\hline CHEMBL 3198325 & 688267 & 3.95 & 4.9986 & TRN & \\
\hline CHEMBL1451151 & 688267 & 5.3 & 5.0403 & TRN & \\
\hline CHEMBL1572372 & 688267 & 5.55 & 5.0254 & TST & \\
\hline CHEMBL1393771 & 688267 & 5.3 & 5.0258 & TRN & \\
\hline CHEMBL1994683 & 688267 & 5.5 & 4.9932 & TST & \\
\hline CHEMBL1363112 & 688267 & 4.25 & 4.9869 & TRN & \\
\hline CHEMBL1593307 & 688267 & 4.25 & 5.0709 & TRN & \\
\hline CHEMBL1555237 & 688267 & 4.4 & 5.0777 & TRN & \\
\hline CHEMBL1473949 & 688267 & 6.2 & 5.0709 & TRN & \\
\hline CHEMBL1579230 & 688267 & 5.3 & 5.059 & TST & \\
\hline CHEMBL1409231 & 688267 & 3.95 & 5.095 & TRN & \\
\hline CHEMBL1569500 & 688267 & 4.7 & 5.0441 & TRN & \\
\hline CHEMBL1592057 & 688267 & 6.15 & 5.0164 & TST & \\
\hline CHEMBL1583788 & 688267 & 5.95 & 5.0413 & TRN & \\
\hline CHEMBL1424804 & 688267 & 4.2 & 5.0385 & TST & \\
\hline CHEMBL1317751 & 688267 & 4.7 & 5.0463 & TRN & \\
\hline CHEMBL1610943 & 688267 & 5.8 & 5.0574 & TRN & \\
\hline CHEMBL1471632 & 688267 & 4.0 & 5.0714 & TST & \\
\hline CHEMBL1529225 & 688267 & 5.25 & 5.0931 & TRN & \\
\hline CHEMBL1421972 & 688267 & 5.5 & $5.0710 e$ & 0000000001 & TST \\
\hline CHEMBL1327574 & 688267 & 4.5 & 5.0489 & TRN & \\
\hline CHEMBL1472238 & 688267 & 4.4 & 5.0534 & TRN & \\
\hline CHEMBL1563530 & 688267 & 5.75 & 5.0473 & TRN & \\
\hline CHEMBL1512402 & 688267 & 5.4 & 5.0859 & TRN & \\
\hline CHEMBL1586348 & 688267 & 4.4 & 5.0387 & TRN & \\
\hline CHEMBL1514747 & 688267 & 5.7 & 5.0476 & TRN & \\
\hline CHEMBL1517661 & 688267 & 6.2 & 5.0171 & TRN & \\
\hline CHEMBL1346719 & 688267 & 4.8 & 5.0573 & TST & \\
\hline CHEMBL1447201 & 688267 & 4.05 & 5.004 & TST & \\
\hline CHEMBL1333718 & 688267 & 6.2 & 5.0529 & TRN & \\
\hline CHEMBL1422098 & 688267 & 4.3 & 5.1002 & TRN & \\
\hline CHEMBL1518794 & 688267 & 4.95 & 5.1095 & TRN & \\
\hline CHEMBL1375780 & 688267 & 6.15 & 5.0791 & TST & \\
\hline CHEMBL1574554 & 688267 & 4.05 & 5.1066 & TRN & \\
\hline CHEMBL1354987 & 688267 & 5.05 & 5.0938 & TRN & \\
\hline CHEMBL1562387 & 688267 & 4.6 & 5.0556 & TRN & \\
\hline CHEMBL1517075 & 688267 & 4.6 & 5.0876 & TST & \\
\hline CHEMBL1560060 & 688267 & 5.8 & 5.0746 & TRN & \\
\hline CHEMBL1501173 & 688267 & 4.0 & 5.1119 & TRN & \\
\hline CHEMBL1428424 & 688267 & 6.15 & 5.103 & TRN & \\
\hline
\end{tabular}




\begin{tabular}{|c|c|c|c|c|c|}
\hline \multicolumn{6}{|c|}{ Supplemental Table S2.txt } \\
\hline CHEMBL3213811 & 688267 & 4.1 & 5.0115 & TRN & \\
\hline CHEMBL1422088 & 688267 & 4.0 & 5.0455 & TRN & \\
\hline CHEMBL1436296 & 688267 & 5.3 & 5.1225 & TRN & \\
\hline CHEMBL504911 & 688267 & 5.0 & 5.0136 & TRN & \\
\hline CHEMBL1510198 & 688267 & 5.95 & 5.066 & TRN & \\
\hline CHEMBL1574092 & 688267 & 4.1 & 5.0439 & TRN & \\
\hline CHEMBL1436481 & 688267 & 3.95 & 5.0258 & TRN & \\
\hline CHEMBL1326338 & 688267 & 6.2 & 5.0528 & TST & \\
\hline CHEMBL1512524 & 688267 & 5.5 & 5.0906 & TRN & \\
\hline CHEMBL1356762 & 688267 & 4.05 & 5.1053 & TRN & \\
\hline CHEMBL1598456 & 688267 & 5.2 & 5.0078 & TRN & \\
\hline CHEMBL1369240 & 688267 & 4.0 & 5.0262 & TRN & \\
\hline CHEMBL1406850 & 688267 & 4.25 & 5.0506 & TRN & \\
\hline CHEMBL1326312 & 688267 & 4.0 & 5.0524 & TST & \\
\hline CHEMBL3196925 & 688267 & 4.85 & 4.9957 & TST & \\
\hline CHEMBL1525365 & 688267 & 4.15 & 5.1038 & TST & \\
\hline CHEMBL1321122 & 688267 & 5.4 & 5.0645 & TST & \\
\hline CHEMBL1394305 & 688267 & 4.25 & 5.052 & TRN & \\
\hline CHEMBL1554519 & 688267 & 6.2 & 5.079 & TRN & \\
\hline CHEMBL1495707 & 688267 & 4.05 & 5.0657 & TRN & \\
\hline CHEMBL3196756 & 688267 & 4.7 & 5.0492 & TST & \\
\hline CHEMBL1307725 & 688267 & 5.4 & 5.0889 & TRN & \\
\hline CHEMBL1313777 & 688267 & 6.0 & 5.0452 & TRN & \\
\hline CHEMBL1456320 & 688267 & 5.1 & 5.0044 & TRN & \\
\hline CHEMBL1377976 & 688267 & 4.05 & 5.0555 & TRN & \\
\hline CHEMBL1426140 & 688267 & 5.35 & 5.0912 & TRN & \\
\hline CHEMBL1592896 & 688267 & 4.3 & 5.0956 & TRN & \\
\hline CHEMBL1394356 & 688267 & 4.3 & 5.0387 & TRN & \\
\hline CHEMBL1716992 & 688267 & 6.15 & 5.0512 & TST & \\
\hline CHEMBL1535252 & 688267 & 4.1 & 4.993 & TRN & \\
\hline CHEMBL1362343 & 688267 & 4.55 & 4.9924 & TRN & \\
\hline CHEMBL1456701 & 688267 & 4.55 & 5.0258 & TST & \\
\hline CHEMBL 1357652 & 688267 & 4.0 & 5.0627 & TRN & \\
\hline CHEMBL1326361 & 688267 & 4.4 & 4.9856 & TRN & \\
\hline CHEMBL1476921 & 688267 & 5.55 & 5.0933 & TRN & \\
\hline CHEMBL1394463 & 688267 & 4.0 & 5.0467 & TRN & \\
\hline CHEMBL1396940 & 688267 & 5.25 & 5.0934 & TST & \\
\hline CHEMBL1443889 & 688267 & 4.4 & 4.9849 & TRN & \\
\hline CHEMBL1556668 & 688267 & 6.2 & 5.0356 & TRN & \\
\hline CHEMBL1352800 & 688267 & 6.2 & 5.0280 & 00000000005 & TRN \\
\hline CHEMBL1566224 & 688267 & 4.4 & 5.0873 & TST & \\
\hline CHEMBL1509965 & 688267 & 5.4 & 5.012 & TRN & \\
\hline CHEMBL1592374 & 688267 & 6.2 & 5.0163 & TRN & \\
\hline CHEMBL1604463 & 688267 & 6.2 & 5.0416 & TRN & \\
\hline CHEMBL1444439 & 688267 & 6.2 & 5.1329 & 9999999999 & TRN \\
\hline CHEMBL1611931 & 688267 & 4.6 & 5.0202 & TST & \\
\hline CHEMBL1343456 & 688267 & 3.95 & 5.0416 & TST & \\
\hline CHEMBL1441927 & 688267 & 5.45 & 5.0509 & TRN & \\
\hline
\end{tabular}




\begin{tabular}{|c|c|c|c|c|}
\hline \multicolumn{5}{|c|}{ Supplemental Table S2.txt } \\
\hline CHEMBL1544590 & 688267 & 5.0 & 5.0618 & TRN \\
\hline CHEMBL1471411 & 688267 & 4.65 & 5.0694 & TRN \\
\hline CHEMBL1333784 & 688267 & 6.0 & 5.148 & TRN \\
\hline CHEMBL1597164 & 688267 & 5.2 & 4.9798 & TRN \\
\hline CHEMBL1463785 & 688267 & 5.05 & 5.0515 & TRN \\
\hline CHEMBL1583615 & 688267 & 4.4 & 5.0833 & TRN \\
\hline CHEMBL1574850 & 688267 & 4.35 & 5.0424 & TRN \\
\hline CHEMBL1467988 & 688267 & 5.8 & 5.0706 & TRN \\
\hline CHEMBL1410905 & 688267 & 4.2 & 5.0325 & TRN \\
\hline CHEMBL1486528 & 688267 & 4.05 & 5.0541 & TST \\
\hline CHEMBL1408816 & 688267 & 4.4 & 5.0406 & TST \\
\hline CHEMBL1460300 & 688267 & 4.05 & 5.0809 & TRN \\
\hline CHEMBL140053 & 688267 & 4.35 & 5.0966 & TRN \\
\hline CHEMBL1455788 & 688267 & 4.35 & 5.0328 & TST \\
\hline CHEMBL1550861 & 688267 & 4.4 & 5.0308 & TRN \\
\hline CHEMBL1380245 & 688267 & 5.8 & 5.0733 & TST \\
\hline CHEMBL1385374 & 688267 & 6.2 & 5.0178 & TRN \\
\hline CHEMBL1393490 & 688267 & 4.25 & 5.0338 & TRN \\
\hline CHEMBL1541173 & 688267 & 4.4 & 4.9807 & TRN \\
\hline CHEMBL1376151 & 688267 & 6.2 & 5.0473 & TST \\
\hline CHEMBL1611767 & 688267 & 4.35 & 5.0513 & TRN \\
\hline CHEMBL1478616 & 688267 & 4.8 & 5.0361 & TRN \\
\hline CHEMBL1582585 & 688267 & 4.2 & 5.0019 & TRN \\
\hline CHEMBL1517789 & 688267 & 4.0 & 5.0501 & TRN \\
\hline CHEMBL1378616 & 688267 & 4.0 & 5.0401 & TRN \\
\hline CHEMBL1411401 & 688267 & 5.55 & 5.0647 & TRN \\
\hline CHEMBL3193551 & 688267 & 6.45 & 5.0191 & TRN \\
\hline CHEMBL1357719 & 688267 & 6.2 & 5.1259 & TRN \\
\hline CHEMBL1550150 & 688267 & 6.2 & 5.0771 & TRN \\
\hline CHEMBL1573618 & 688267 & 4.25 & 5.0305 & TRN \\
\hline CHEMBL1593100 & 688267 & 6.2 & 4.9813 & TRN \\
\hline CHEMBL1460404 & 688267 & 4.4 & 5.0481 & TST \\
\hline CHEMBL1397745 & 688267 & 4.25 & 5.0791 & TRN \\
\hline CHEMBL3214096 & 688267 & 4.05 & 5.0471 & TRN \\
\hline CHEMBL3212764 & 688267 & 6.15 & 5.0771 & TRN \\
\hline CHEMBL1493161 & 688267 & 6.2 & 5.0133 & TST \\
\hline CHEMBL1300346 & 688267 & 5.4 & 5.0583 & TRN \\
\hline CHEMBL1446327 & 688267 & 6.45 & 5.0522 & TRN \\
\hline CHEMBL1572673 & 688267 & 5.3 & 5.0541 & TRN \\
\hline CHEMBL1516018 & 688267 & 6.45 & 5.021 & TRN \\
\hline CHEMBL1427603 & 688267 & 5.8 & 5.1053 & TRN \\
\hline CHEMBL1610211 & 688267 & 6.2 & 5.062 & TRN \\
\hline CHEMBL1492719 & 688267 & 4.3 & 5.0675 & TRN \\
\hline CHEMBL1323809 & 688267 & 4.5 & 5.0495 & TRN \\
\hline CHEMBL1575406 & 688267 & 6.2 & 5.0595 & TRN \\
\hline CHEMBL1541337 & 688267 & 6.2 & 5.0446 & TST \\
\hline CHEMBL1512417 & 688267 & 4.9 & 5.0633 & TRN \\
\hline CHEMBL1445876 & 688267 & 5.5 & 5.0854 & TRN \\
\hline
\end{tabular}




\begin{tabular}{|c|c|c|c|c|}
\hline & & & pplement & al $\mathrm{Ta}$ \\
\hline CHEMBL1314675 & 688267 & 6.2 & 5.0445 & TRN \\
\hline CHEMBL603945 & 688267 & 5.4 & 5.0224 & TST \\
\hline CHEMBL1533595 & 688267 & 4.0 & 5.1237 & TRN \\
\hline CHEMBL1360915 & 688267 & 6.15 & 5.0798 & TRN \\
\hline CHEMBL1383254 & 688267 & 4.05 & 5.0323 & TRN \\
\hline CHEMBL1385056 & 688267 & 4.5 & 5.0784 & TRN \\
\hline CHEMBL1381287 & 688267 & 4.05 & 5.1505 & TRN \\
\hline CHEMBL2007247 & 688267 & 5.55 & 5.0061 & TST \\
\hline CHEMBL1476478 & 688267 & 4.0 & 5.0169 & TST \\
\hline CHEMBL1446126 & 688267 & 6.2 & 5.0841 & TST \\
\hline CHEMBL1441595 & 688267 & 6.0 & 5.0526 & TRN \\
\hline CHEMBL1375062 & 688267 & 5.35 & 5.1202 & TST \\
\hline CHEMBL1461249 & 688267 & 6.25 & 5.1004 & TRN \\
\hline CHEMBL1406595 & 688267 & 4.45 & 5.0473 & TST \\
\hline CHEMBL1518904 & 688267 & 4.1 & 5.114 & TRN \\
\hline CHEMBL1518023 & 688267 & 4.75 & 5.0349 & TST \\
\hline CHEMBL1495379 & 688267 & 3.95 & 5.0229 & TST \\
\hline CHEMBL1355063 & 688267 & 5.85 & 5.0589 & TRN \\
\hline CHEMBL1366378 & 688267 & 4.0 & 5.0276 & TST \\
\hline CHEMBL1310781 & 688267 & 6.2 & 5.0054 & TRN \\
\hline CHEMBL1531705 & 688267 & 4.35 & 4.9845 & TRN \\
\hline CHEMBL1353983 & 688267 & 5.6 & 5.0578 & TRN \\
\hline CHEMBL1506165 & 688267 & 4.1 & 5.0397 & TRN \\
\hline CHEMBL1550216 & 688267 & 4.55 & 5.0105 & TRN \\
\hline CHEMBL1572478 & 688267 & 4.35 & 5.0733 & TST \\
\hline CHEMBL1427756 & 688267 & 4.8 & 5.0705 & TRN \\
\hline CHEMBL1529179 & 688267 & 6.2 & 5.0233 & TST \\
\hline CHEMBL3190620 & 688267 & 5.55 & 5.0863 & TST \\
\hline CHEMBL1455899 & 688267 & 4.0 & 5.0258 & TRN \\
\hline CHEMBL1352407 & 688267 & 5.55 & 5.052 & TRN \\
\hline CHEMBL1531800 & 688267 & 6.2 & 5.0905 & TRN \\
\hline CHEMBL1537380 & 688267 & 6.2 & 5.0294 & TST \\
\hline CHEMBL1386927 & 688267 & 4.95 & 5.0218 & TRN \\
\hline CHEMBL1354802 & 688267 & 4.0 & 5.0307 & TRN \\
\hline CHEMBL1566642 & 688267 & 5.2 & 5.154 & TST \\
\hline CHEMBL1320737 & 688267 & 3.95 & 5.0919 & TRN \\
\hline CHEMBL1307471 & 688267 & 5.8 & 5.1209 & TRN \\
\hline CHEMBL1349262 & 688267 & 6.15 & 5.0756 & TRN \\
\hline CHEMBL1493864 & 688267 & 4.4 & 5.1229 & TRN \\
\hline CHEMBL1442536 & 688267 & 4.0 & 5.0581 & TST \\
\hline CHEMBL1566572 & 688267 & 4.05 & 5.1041 & TRN \\
\hline CHEMBL1438148 & 688267 & 4.0 & 5.0233 & TST \\
\hline CHEMBL1447732 & 688267 & 5.95 & 4.9918 & TRN \\
\hline CHEMBL1598721 & 688267 & 5.0 & 5.0835 & TRN \\
\hline CHEMBL1505272 & 688267 & 4.95 & 5.0169 & TRN \\
\hline CHEMBL1542975 & 688267 & 5.7 & 5.0286 & TRN \\
\hline CHEMBL1597320 & 688267 & 4.05 & 5.0717 & TRN \\
\hline CHEMBL1308574 & 688267 & 4.6 & 5.1332 & TRN \\
\hline
\end{tabular}




\begin{tabular}{|c|c|c|c|c|c|}
\hline \\
\hline CHEMBL1517065 & 688267 & 4.4 & 5.0253 & TST & \\
\hline CHEMBL1524848 & 688267 & 4.0 & 5.0901 & TRN & \\
\hline CHEMBL1524181 & 688267 & 5.05 & 5.0863 & TST & \\
\hline CHEMBL1355036 & 688267 & 6.25 & 5.083 & TRN & \\
\hline CHEMBL1403288 & 688267 & 5.5 & 4.984 & TRN & \\
\hline CHEMBL1327862 & 688267 & 5.95 & 5.0822 & TRN & \\
\hline CHEMBL1386180 & 688267 & 4.95 & 5.1153 & TRN & \\
\hline CHEMBL1498580 & 688267 & 4.0 & 5.0414 & TRN & \\
\hline CHEMBL1322865 & 688267 & 5.5 & 5.0537 & TRN & \\
\hline CHEMBL1466377 & 688267 & 4.9 & 5.101 & TRN & \\
\hline CHEMBL1450844 & 688267 & 6.45 & 5.1085 & TRN & \\
\hline CHEMBL1480950 & 688267 & 5.7 & 5.0318 & TST & \\
\hline CHEMBL1358362 & 688267 & 4.35 & 5.0792 & TRN & \\
\hline CHEMBL1300922 & 688267 & 4.45 & 5.0712 & TRN & \\
\hline CHEMBL1434139 & 688267 & 5.75 & 5.03600 & 20000000005 & TRN \\
\hline CHEMBL3210728 & 688267 & 6.15 & 5.0409 & TRN & \\
\hline CHEMBL1473655 & 688267 & 4.6 & 5.0674 & TRN & \\
\hline CHEMBL1414561 & 688267 & 4.95 & 5.01 & TRN & \\
\hline CHEMBL1446953 & 688267 & 5.0 & 5.024 & TRN & \\
\hline CHEMBL1462327 & 688267 & 4.0 & 5.0557 & TRN & \\
\hline CHEMBL1408087 & 688267 & 4.5 & 5.1104 & TRN & \\
\hline CHEMBL1318427 & 688267 & 5.75 & 5.04 & TRN & \\
\hline CHEMBL1328757 & 688267 & 4.0 & 5.0853 & TRN & \\
\hline CHEMBL1495326 & 688267 & 4.55 & 5.0387 & TRN & \\
\hline CHEMBL1521449 & 688267 & 5.2 & 5.03 & TRN & \\
\hline CHEMBL1457471 & 688267 & 5.1 & 5.0465 & TRN & \\
\hline CHEMBL1407507 & 688267 & 5.4 & 5.1172 & TRN & \\
\hline CHEMBL1568172 & 688267 & 6.2 & 5.0508 & TRN & \\
\hline CHEMBL1410861 & 688267 & 4.05 & 5.1315 & TRN & \\
\hline CHEMBL3194200 & 688267 & 4.4 & 4.9911 & TRN & \\
\hline CHEMBL1434408 & 688267 & 4.2 & 4.9857 & TRN & \\
\hline CHEMBL1308274 & 688267 & 4.25 & 5.061 & TST & \\
\hline CHEMBL1378770 & 688267 & 4.05 & 5.1594 & TST & \\
\hline CHEMBL 2005653 & 688267 & 6.5 & 5.0427 & TST & \\
\hline CHEMBL1348093 & 688267 & 4.0 & 5.0189 & TST & \\
\hline CHEMBL1990184 & 688267 & 4.9 & 4.996 & TRN & \\
\hline CHEMBL1554581 & 688267 & 4.35 & 5.0759 & TRN & \\
\hline CHEMBL1520871 & 688267 & 6.15 & 5.0229 & TRN & \\
\hline CHEMBL1571148 & 688267 & 5.5 & 5.1096 & TRN & \\
\hline CHEMBL1430808 & 688267 & 5.55 & 5.0802 & TRN & \\
\hline CHEMBL1301012 & 688267 & 5.75 & 5.0888 & TST & \\
\hline CHEMBL1344270 & 688267 & 5.55 & 5.0454 & TRN & \\
\hline CHEMBL1366074 & 688267 & 4.5 & 5.0929 & TRN & \\
\hline CHEMBL1363699 & 688267 & 4.35 & 5.1327 & TRN & \\
\hline CHEMBL1201091 & 688267 & 4.35 & 5.1339 & TST & \\
\hline CHEMBL1313408 & 688267 & 4.0 & 5.0681 & TST & \\
\hline CHEMBL1590939 & 688267 & 4.8 & 5.1072 & TRN & \\
\hline CHEMBL1392721 & 688267 & 5.95 & 4.9771 & TRN & \\
\hline
\end{tabular}




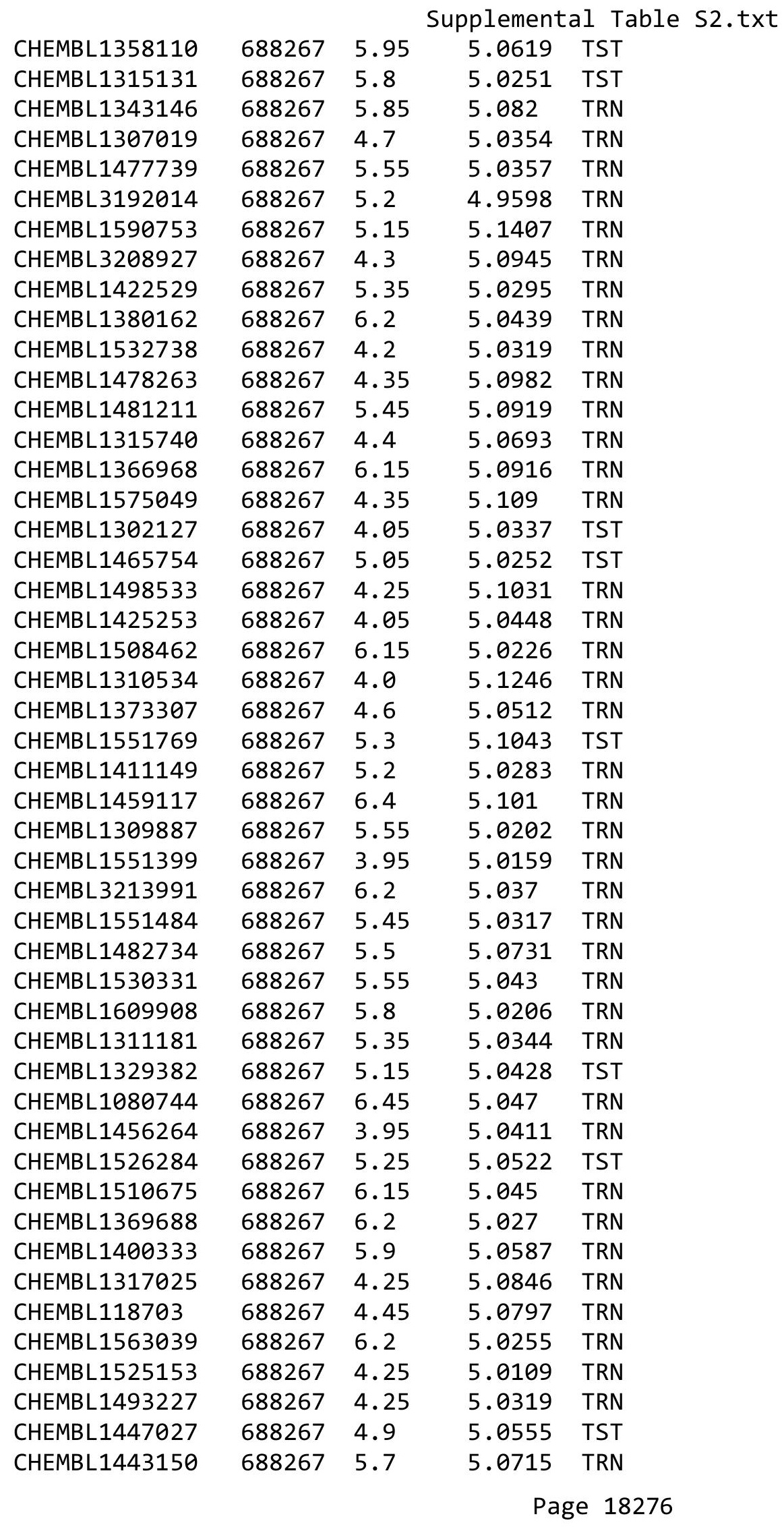




\begin{tabular}{|c|c|c|c|c|}
\hline & & & & al Table \\
\hline CHEMBL1568878 & 688267 & 4.8 & 5.1152 & TRN \\
\hline CHEMBL1553541 & 688267 & 5.3 & 5.11 & TRN \\
\hline CHEMBL1376565 & 688267 & 5.85 & 5.0367 & TRN \\
\hline CHEMBL1517504 & 688267 & 5.1 & 4.9832 & TRN \\
\hline CHEMBL1412757 & 688267 & 5.7 & 4.9992 & TST \\
\hline CHEMBL1581327 & 688267 & 4.0 & 5.0382 & TST \\
\hline CHEMBL1401591 & 688267 & 4.55 & 5.0758 & TST \\
\hline CHEMBL1562965 & 688267 & 4.55 & 5.0638 & TST \\
\hline CHEMBL1544892 & 688267 & 5.25 & 5.1209 & TRN \\
\hline CHEMBL1409459 & 688267 & 6.05 & 5.1137 & TRN \\
\hline CHEMBL1462673 & 688267 & 5.35 & 5.1306 & TRN \\
\hline CHEMBL1445783 & 688267 & 4.05 & 5.0539 & TRN \\
\hline CHEMBL1564584 & 688267 & 5.55 & 5.0326 & TST \\
\hline CHEMBL1311134 & 688267 & 6.15 & 5.1408 & TRN \\
\hline CHEMBL1566986 & 688267 & 4.45 & 5.0598 & TRN \\
\hline CHEMBL3214450 & 688267 & 6.2 & 5.1012 & TRN \\
\hline CHEMBL1426015 & 688267 & 6.0 & 5.0918 & TST \\
\hline CHEMBL1379092 & 688267 & 5.6 & 5.124 & TRN \\
\hline CHEMBL1473887 & 688267 & 5.9 & 5.05399 & 9999999999 \\
\hline CHEMBL1321631 & 688267 & 4.2 & 5.055 & TRN \\
\hline CHEMBL 3197227 & 688267 & 5.3 & 5.0463 & TST \\
\hline CHEMBL1411924 & 688267 & 6.2 & 5.0816 & TST \\
\hline CHEMBL1438560 & 688267 & 4.2 & 5.0581 & TRN \\
\hline CHEMBL1506123 & 688267 & 4.35 & 5.015 & TRN \\
\hline CHEMBL1520831 & 688267 & 5.4 & 5.0353 & TRN \\
\hline CHEMBL1499084 & 688267 & 4.35 & 5.0222 & TRN \\
\hline CHEMBL1476948 & 688267 & 5.4 & 5.0755 & TRN \\
\hline CHEMBL3192195 & 688267 & 5.35 & 5.0197 & TRN \\
\hline CHEMBL1436709 & 688267 & 4.4 & 5.0131 & TRN \\
\hline CHEMBL1434043 & 688267 & 4.0 & 5.0915 & TRN \\
\hline CHEMBL1516855 & 688267 & 4.0 & 5.0306 & TRN \\
\hline CHEMBL1321852 & 688267 & 5.35 & 5.0936 & TRN \\
\hline CHEMBL1534203 & 688267 & 4.5 & 5.0343 & TST \\
\hline CHEMBL1343531 & 688267 & 4.05 & 5.0427 & TST \\
\hline CHEMBL1559585 & 688267 & 4.25 & 5.0566 & TST \\
\hline CHEMBL1493244 & 688267 & 4.45 & 4.9912 & TRN \\
\hline CHEMBL1344308 & 688267 & 3.95 & 5.0726 & TRN \\
\hline CHEMBL1506885 & 688267 & 4.05 & 5.0641 & TRN \\
\hline CHEMBL1375722 & 688267 & 5.85 & 5.0414 & TRN \\
\hline CHEMBL1589514 & 688267 & 4.3 & 5.0258 & TRN \\
\hline CHEMBL1564280 & 688267 & 5.4 & 4.9924 & TRN \\
\hline CHEMBL1387617 & 688267 & 5.0 & 5.1282 & TST \\
\hline CHEMBL1366807 & 688267 & 4.6 & 5.0384 & TRN \\
\hline CHEMBL592572 & 688267 & 6.4 & 5.0591 & TRN \\
\hline CHEMBL1533801 & 688267 & 6.25 & 5.1033 & TST \\
\hline CHEMBL1326593 & 688267 & 4.3 & 5.0276 & TRN \\
\hline CHEMBL1402516 & 688267 & 6.15 & 5.0782 & TRN \\
\hline CHEMBL1481360 & 688267 & 5.3 & 5.0252 & TST \\
\hline
\end{tabular}




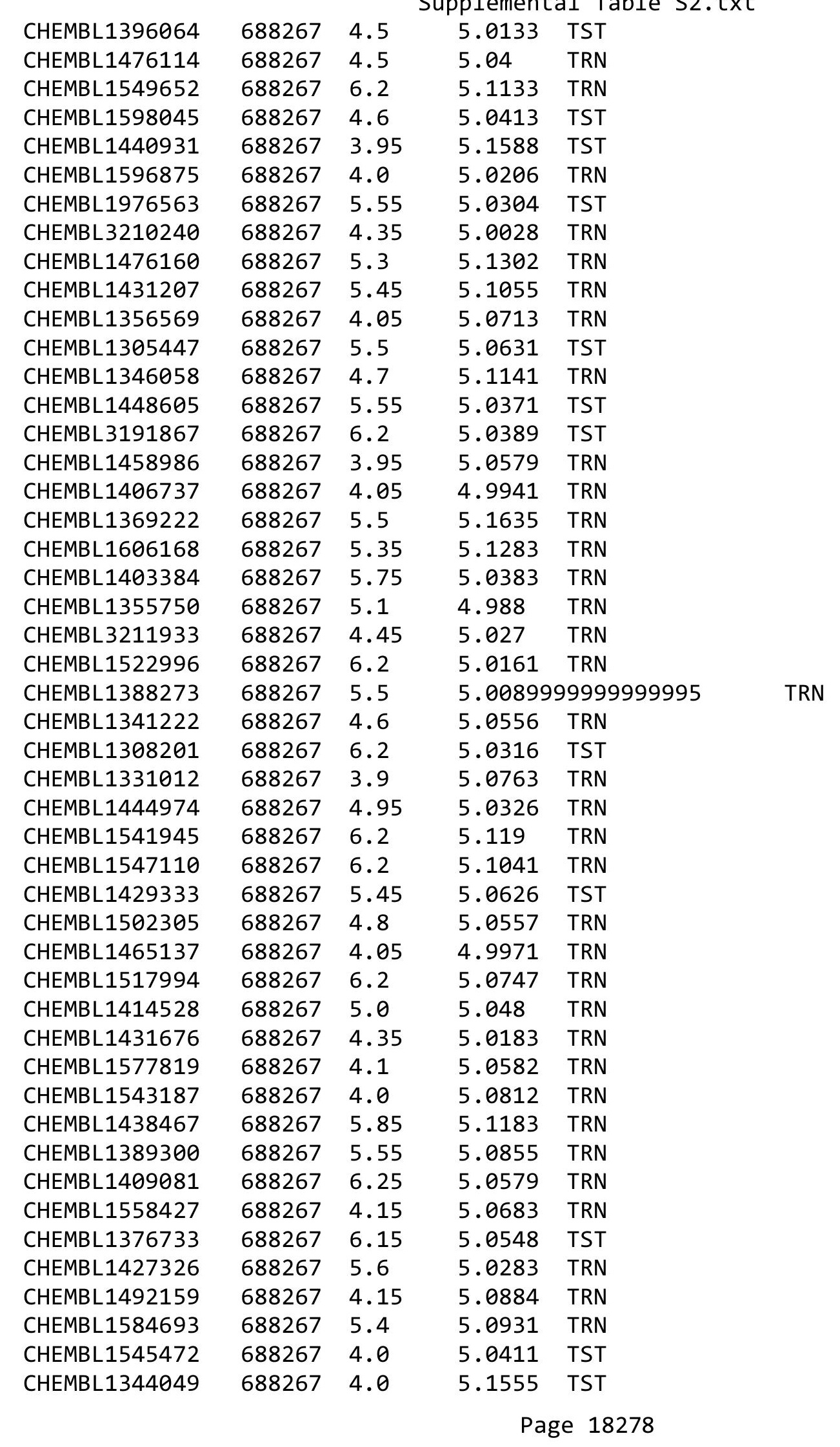




\begin{tabular}{|c|c|c|c|c|c|}
\hline \\
\hline CHEMBL1317566 & 688267 & 4.6 & 5.1269 & TRN & \\
\hline CHEMBL1543190 & 688267 & 5.7 & 5.1148 & TST & \\
\hline CHEMBL1576412 & 688267 & 4.3 & 5.0442 & TST & \\
\hline CHEMBL1507639 & 688267 & 6.2 & 5.0218 & TRN & \\
\hline CHEMBL1591967 & 688267 & 4.05 & 5.0489 & TRN & \\
\hline CHEMBL1371953 & 688267 & 4.4 & 5.0139 & TRN & \\
\hline CHEMBL1548987 & 688267 & 5.55 & 5.0395 & TST & \\
\hline CHEMBL1324897 & 688267 & 5.9 & 5.0835 & TRN & \\
\hline CHEMBL1316501 & 688267 & 4.5 & 5.1193 & TRN & \\
\hline CHEMBL1603370 & 688267 & 6.2 & 5.1319 & TST & \\
\hline CHEMBL601176 & 688267 & 4.6 & 5.1218 & TRN & \\
\hline CHEMBL1402996 & 688267 & 6.2 & 5.0579 & TRN & \\
\hline CHEMBL1589743 & 688267 & 4.2 & 4.995 & TRN & \\
\hline CHEMBL1501170 & 688267 & 5.2 & 5.0977 & TRN & \\
\hline CHEMBL1429058 & 688267 & 3.95 & 5.0275 & TRN & \\
\hline CHEMBL1553027 & 688267 & 4.4 & 5.0191 & TRN & \\
\hline CHEMBL1533066 & 688267 & 6.2 & 5.0913 & TST & \\
\hline CHEMBL1401125 & 688267 & 4.95 & 4.9771 & TRN & \\
\hline CHEMBL1345498 & 688267 & 5.3 & 5.0443 & TRN & \\
\hline CHEMBL1450611 & 688267 & 6.2 & 5.1055 & TRN & \\
\hline CHEMBL1529696 & 688267 & 6.15 & 5.0071 & TRN & \\
\hline CHEMBL1590204 & 688267 & 3.95 & 5.0065 & TRN & \\
\hline CHEMBL1328008 & 688267 & 5.45 & 5.0555 & TRN & \\
\hline CHEMBL1525224 & 688267 & 3.95 & 5.1118 & TST & \\
\hline CHEMBL1495081 & 688267 & 5.6 & 5.0399 & TRN & \\
\hline CHEMBL1335885 & 688267 & 4.4 & 5.085 & TRN & \\
\hline CHEMBL601123 & 688267 & 4.35 & 5.0235 & TST & \\
\hline CHEMBL1385620 & 688267 & 5.4 & 5.015 & TRN & \\
\hline CHEMBL1405122 & 688267 & 5.2 & 5.0603 & TST & \\
\hline CHEMBL1381316 & 688267 & 5.5 & 5.0421 & TST & \\
\hline CHEMBL1354491 & 688267 & 6.2 & 5.1147 & TRN & \\
\hline CHEMBL1480039 & 688267 & 4.0 & 4.9843 & TRN & \\
\hline CHEMBL1547652 & 688267 & 3.95 & 5.01699 & 99999999995 & TST \\
\hline CHEMBL1337762 & 688267 & 4.4 & 5.0441 & TRN & \\
\hline CHEMBL1536761 & 688267 & 6.2 & 5.051 & TRN & \\
\hline CHEMBL1552598 & 688267 & 4.05 & 5.0223 & TRN & \\
\hline CHEMBL1582859 & 688267 & 5.35 & 5.0806 & TRN & \\
\hline CHEMBL1457491 & 688267 & 4.0 & 5.0605 & TRN & \\
\hline CHEMBL1513953 & 688267 & 5.5 & 5.092 & TST & \\
\hline CHEMBL1497115 & 688267 & 4.3 & 5.0345 & TRN & \\
\hline CHEMBL1528160 & 688267 & 5.4 & 4.9595 & TRN & \\
\hline CHEMBL1379843 & 688267 & 5.35 & 5.0125 & TST & \\
\hline CHEMBL1330860 & 688267 & 5.45 & 5.0696 & TRN & \\
\hline CHEMBL1458627 & 688267 & 5.1 & 5.1622 & TST & \\
\hline CHEMBL3212119 & 688267 & 5.5 & 5.0644 & TRN & \\
\hline CHEMBL1515078 & 688267 & 5.85 & 5.0719 & TRN & \\
\hline CHEMBL1573933 & 688267 & 6.15 & 5.12299 & 9999999999 & TRN \\
\hline CHEMBL3199593 & 688267 & 5.4 & 5.0229 & TST & \\
\hline
\end{tabular}




\begin{tabular}{|c|c|c|c|c|}
\hline \multicolumn{5}{|c|}{ Supplemental Table S2.txt } \\
\hline CHEMBL1522676 & 688267 & 4.7 & 5.0168 & TST \\
\hline CHEMBL1561346 & 688267 & 4.85 & 5.042 & TRN \\
\hline CHEMBL1371611 & 688267 & 4.0 & 5.0463 & TRN \\
\hline CHEMBL1407135 & 688267 & 4.0 & 5.0278 & TRN \\
\hline CHEMBL1563447 & 688267 & 6.2 & 5.1076 & TRN \\
\hline CHEMBL1572815 & 688267 & 4.0 & 5.0708 & TRN \\
\hline CHEMBL1492651 & 688267 & 5.35 & 5.0926 & TRN \\
\hline CHEMBL1537157 & 688267 & 4.25 & 5.0056 & TRN \\
\hline CHEMBL1405028 & 688267 & 4.6 & 5.1883 & TRN \\
\hline CHEMBL1446274 & 688267 & 4.05 & 5.0797 & TRN \\
\hline CHEMBL1329126 & 688267 & 5.6 & 5.1435 & TRN \\
\hline CHEMBL1331222 & 688267 & 6.45 & 5.0677 & TRN \\
\hline CHEMBL1333929 & 688267 & 6.0 & 5.0345 & TRN \\
\hline CHEMBL1592930 & 688267 & 4.1 & 5.1288 & TRN \\
\hline CHEMBL1323819 & 688267 & 4.6 & 5.0892 & TST \\
\hline CHEMBL1450104 & 688267 & 4.35 & 5.0579 & TRN \\
\hline CHEMBL1592848 & 688267 & 4.25 & 5.0247 & TRN \\
\hline CHEMBL1427102 & 688267 & 4.45 & 5.1472 & TRN \\
\hline CHEMBL1391641 & 688267 & 4.25 & 5.0415 & TRN \\
\hline CHEMBL1342412 & 688267 & 4.0 & 5.0313 & TRN \\
\hline CHEMBL1442045 & 688267 & 5.25 & 5.1191 & TRN \\
\hline CHEMBL1531373 & 688267 & 5.55 & 5.0418 & TST \\
\hline CHEMBL1523234 & 688267 & 4.6 & 5.0485 & TRN \\
\hline CHEMBL1453159 & 688267 & 4.4 & 5.1237 & TRN \\
\hline CHEMBL1381475 & 688267 & 5.5 & 5.0081 & TST \\
\hline CHEMBL1332315 & 688267 & 5.2 & 5.086 & TRN \\
\hline CHEMBL1539957 & 688267 & 5.8 & 5.1428 & TRN \\
\hline CHEMBL1370732 & 688267 & 5.55 & 5.0734 & TRN \\
\hline CHEMBL1463037 & 688267 & 4.1 & 5.1051 & TRN \\
\hline CHEMBL 3192362 & 688267 & 5.45 & 5.0327 & TRN \\
\hline CHEMBL1424284 & 688267 & 6.2 & 5.0761 & TRN \\
\hline CHEMBL1346255 & 688267 & 4.0 & 5.0459 & TRN \\
\hline CHEMBL1419871 & 688267 & 4.5 & 5.0998 & TRN \\
\hline CHEMBL1476608 & 688267 & 5.2 & 5.1585 & TRN \\
\hline CHEMBL1331992 & 688267 & 4.4 & 5.0204 & TRN \\
\hline CHEMBL1439716 & 688267 & 4.55 & 5.0542 & TRN \\
\hline CHEMBL1412053 & 688267 & 5.35 & 5.0694 & TRN \\
\hline CHEMBL1380020 & 688267 & 4.0 & 5.0479 & TRN \\
\hline CHEMBL1404779 & 688267 & 5.5 & 5.0427 & TRN \\
\hline CHEMBL1530363 & 688267 & 4.25 & 5.0834 & TST \\
\hline CHEMBL1440588 & 688267 & 4.25 & 5.0609 & TRN \\
\hline CHEMBL1315548 & 688267 & 4.05 & 5.1046 & TST \\
\hline CHEMBL1504103 & 688267 & 5.15 & 5.0789 & TRN \\
\hline CHEMBL1585715 & 688267 & 6.2 & 5.075 & TRN \\
\hline CHEMBL1427468 & 688267 & 4.55 & 5.0761 & TST \\
\hline CHEMBL1380355 & 688267 & 4.15 & 5.0558 & TRN \\
\hline CHEMBL1560168 & 688267 & 4.05 & 5.0978 & TRN \\
\hline CHEMBL1551579 & 688267 & 6.2 & 5.0884 & TRN \\
\hline
\end{tabular}





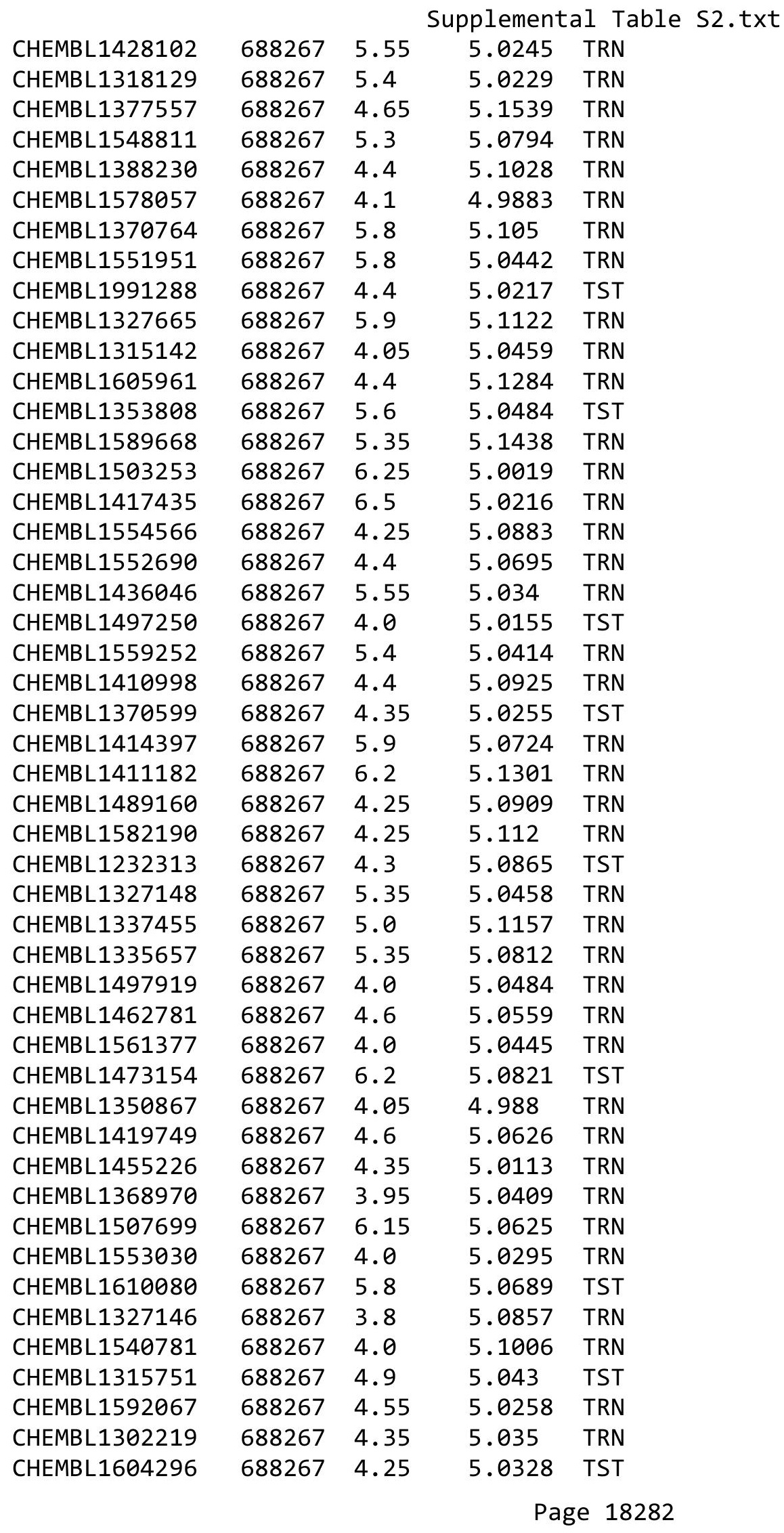




\begin{tabular}{|c|c|c|c|c|}
\hline \multicolumn{5}{|c|}{ Supplemental Table S2.txt } \\
\hline CHEMBL1339245 & 688267 & 5.1 & 5.0123 & TRN \\
\hline CHEMBL1470985 & 688267 & 4.4 & 5.1155 & TST \\
\hline CHEMBL1564385 & 688267 & 4.55 & 5.0298 & TST \\
\hline CHEMBL 3208585 & 688267 & 4.05 & 4.9801 & TST \\
\hline CHEMBL 1305170 & 688267 & 6.15 & 5.0985 & TRN \\
\hline CHEMBL1470634 & 688267 & 5.85 & 5.0654 & TRN \\
\hline CHEMBL1472801 & 688267 & 4.35 & 5.1125 & TRN \\
\hline CHEMBL1332047 & 688267 & 4.3 & 5.14 & TRN \\
\hline CHEMBL1572907 & 688267 & 6.0 & 5.0808 & TRN \\
\hline CHEMBL1492741 & 688267 & 6.15 & 5.0456 & TRN \\
\hline CHEMBL600847 & 688267 & 4.25 & 5.0266 & TST \\
\hline CHEMBL1422387 & 688267 & 5.85 & 5.0673 & TST \\
\hline CHEMBL1603771 & 688267 & 5.0 & 5.0364 & TRN \\
\hline CHEMBL1389779 & 688267 & 5.3 & 5.0175 & TST \\
\hline CHEMBL1565063 & 688267 & 4.05 & 5.1151 & TRN \\
\hline CHEMBL1333972 & 688267 & 4.0 & 5.0438 & TRN \\
\hline CHEMBL1523889 & 688267 & 4.8 & 5.0953 & TRN \\
\hline CHEMBL1581471 & 688267 & 4.85 & 5.0413 & TRN \\
\hline CHEMBL1331096 & 688267 & 5.35 & 5.0867 & TRN \\
\hline CHEMBL1558312 & 688267 & 6.2 & 5.0393 & TRN \\
\hline CHEMBL1315660 & 688267 & 4.45 & 5.1918 & TRN \\
\hline CHEMBL1539230 & 688267 & 5.3 & 5.0602 & TRN \\
\hline CHEMBL1329141 & 688267 & 4.3 & 5.0361 & TRN \\
\hline CHEMBL1609349 & 688267 & 4.9 & 5.0243 & TRN \\
\hline CHEMBL1587056 & 688267 & 5.95 & 5.0171 & TRN \\
\hline CHEMBL1989917 & 688267 & 5.1 & 5.0177 & TRN \\
\hline CHEMBL1408126 & 688267 & 4.0 & 5.0599 & TST \\
\hline CHEMBL1504735 & 688267 & 5.7 & 5.0436 & TST \\
\hline CHEMBL1364573 & 688267 & 4.8 & 5.0728 & TRN \\
\hline CHEMBL1335050 & 688267 & 5.15 & 5.0384 & TRN \\
\hline CHEMBL3197493 & 688267 & 5.2 & 5.0279 & TRN \\
\hline CHEMBL 3210402 & 688267 & 5.45 & 5.0328 & TRN \\
\hline CHEMBL1433478 & 688267 & 6.15 & 5.0876 & TRN \\
\hline CHEMBL1604300 & 688267 & 4.3 & 5.0259 & TRN \\
\hline CHEMBL1329251 & 688267 & 4.1 & 5.1001 & TRN \\
\hline CHEMBL1352448 & 688267 & 3.95 & 5.0075 & TST \\
\hline CHEMBL451748 & 688267 & 4.75 & 4.9731 & TST \\
\hline CHEMBL1394612 & 688267 & 4.0 & 5.0699 & TRN \\
\hline CHEMBL1591250 & 688267 & 4.45 & 5.0162 & TRN \\
\hline CHEMBL1596632 & 688267 & 3.95 & 5.0326 & TRN \\
\hline CHEMBL1437160 & 688267 & 5.5 & 5.0083 & TRN \\
\hline CHEMBL1367531 & 688267 & 4.9 & 5.0542 & TRN \\
\hline CHEMBL1574325 & 688267 & 6.2 & 5.1376 & TRN \\
\hline CHEMBL3194145 & 688267 & 5.05 & 5.0301 & TRN \\
\hline CHEMBL1340171 & 688267 & 4.4 & 5.0666 & TRN \\
\hline CHEMBL1549870 & 688267 & 4.75 & 5.0473 & TST \\
\hline CHEMBL1498113 & 688267 & 4.85 & 5.0112 & TST \\
\hline CHEMBL1558013 & 688267 & 4.3 & 5.0338 & TRN \\
\hline
\end{tabular}




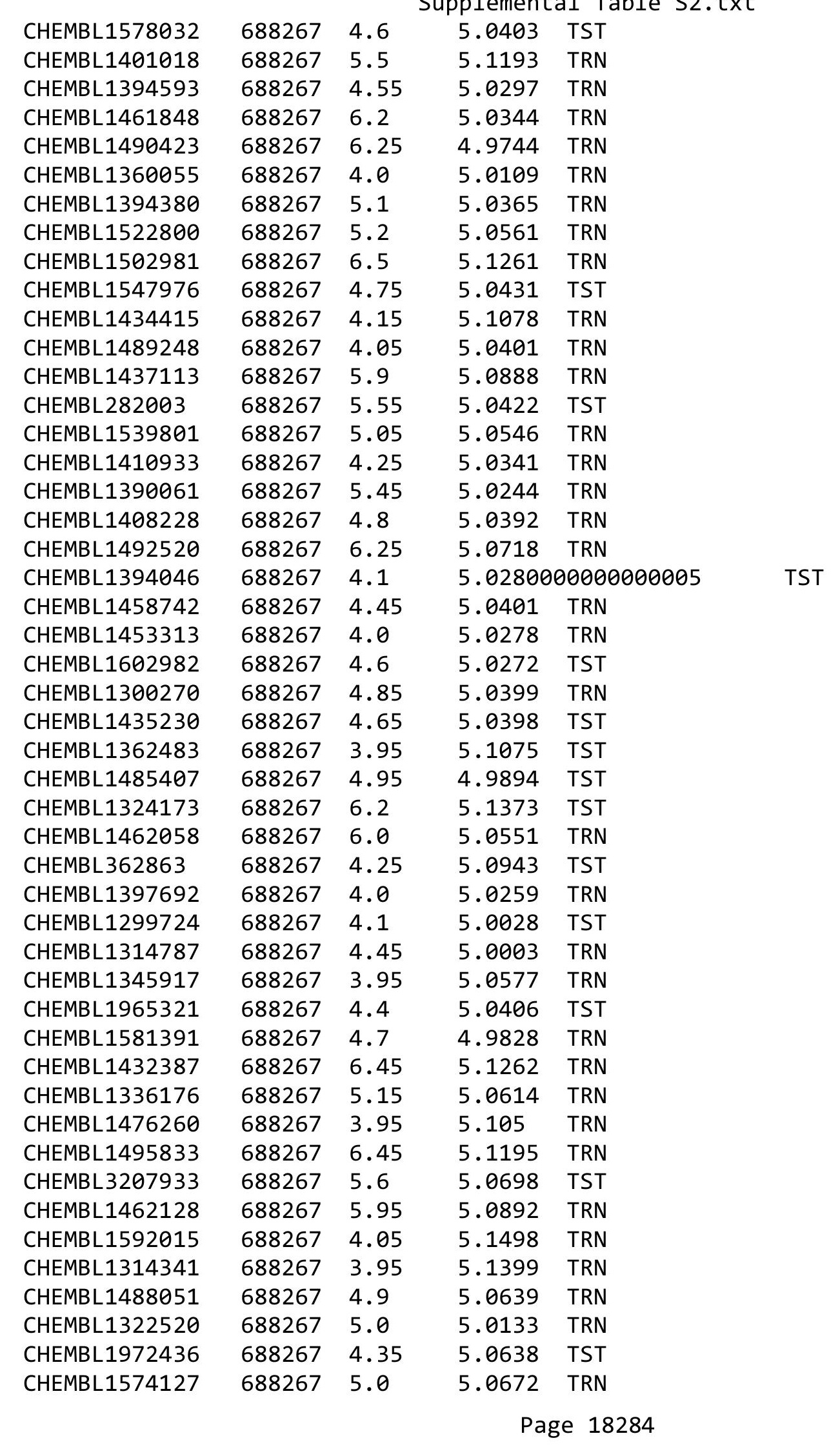




\begin{tabular}{|c|c|c|c|c|c|}
\hline \\
\hline CHEMBL1557957 & 688267 & 6.2 & 4.992 & TRN & \\
\hline CHEMBL1459046 & 688267 & 5.55 & 5.0323 & TRN & \\
\hline CHEMBL1538113 & 688267 & 5.6 & 5.0074 & TRN & \\
\hline CHEMBL1468105 & 688267 & 6.1 & 5.0683 & TRN & \\
\hline CHEMBL1591994 & 688267 & 5.25 & 5.067 & TRN & \\
\hline CHEMBL1429305 & 688267 & 5.5 & 5.0908 & TRN & \\
\hline CHEMBL1307165 & 688267 & 6.15 & 5.0876 & TRN & \\
\hline CHEMBL1518598 & 688267 & 6.2 & 5.0107 & TRN & \\
\hline CHEMBL1412624 & 688267 & 4.15 & 5.0433 & TRN & \\
\hline CHEMBL1484006 & 688267 & 5.1 & 5.0471 & TRN & \\
\hline CHEMBL1358231 & 688267 & 5.85 & 5.0958 & TRN & \\
\hline CHEMBL1383763 & 688267 & 4.0 & 5.0631 & TST & \\
\hline CHEMBL1318589 & 688267 & 5.4 & 5.0873 & TRN & \\
\hline CHEMBL1577728 & 688267 & 6.5 & 5.1191 & TRN & \\
\hline CHEMBL1395180 & 688267 & 5.25 & 5.0616 & TRN & \\
\hline CHEMBL1331473 & 688267 & 4.3 & 5.0069 & TRN & \\
\hline CHEMBL1326715 & 688267 & 6.15 & 5.0926 & TRN & \\
\hline CHEMBL1372462 & 688267 & 4.5 & 5.0953 & TRN & \\
\hline CHEMBL1416019 & 688267 & 5.3 & 5.0589 & TRN & \\
\hline CHEMBL1515704 & 688267 & 4.25 & 5.0295 & TRN & \\
\hline CHEMBL1406795 & 688267 & 4.35 & 5.0895 & TRN & \\
\hline CHEMBL1410218 & 688267 & 6.5 & 5.0597 & TRN & \\
\hline CHEMBL1355644 & 688267 & 4.35 & 5.0416 & TRN & \\
\hline CHEMBL1409495 & 688267 & 6.45 & 5.1145 & TRN & \\
\hline CHEMBL1465785 & 688267 & 4.05 & 5.0152 & TRN & \\
\hline CHEMBL3196799 & 688267 & 4.1 & 5.0543 & TST & \\
\hline CHEMBL1384500 & 688267 & 4.05 & 5.0482 & TST & \\
\hline CHEMBL1563668 & 688267 & 5.9 & 5.0639 & TST & \\
\hline CHEMBL1426538 & 688267 & 6.2 & 5.1063 & TST & \\
\hline CHEMBL1337137 & 688267 & 4.5 & 5.0166 & TRN & \\
\hline CHEMBL1605129 & 688267 & 3.95 & 5.1042 & TRN & \\
\hline CHEMBL1300679 & 688267 & 3.95 & 5.0421 & TRN & \\
\hline CHEMBL1561176 & 688267 & 4.0 & 5.0848 & TRN & \\
\hline CHEMBL1401905 & 688267 & 6.2 & 5.092 & TRN & \\
\hline CHEMBL1348248 & 688267 & 6.2 & 5.0823 & TRN & \\
\hline CHEMBL1446147 & 688267 & 4.05 & 5.0354 & TRN & \\
\hline CHEMBL1426081 & 688267 & 6.25 & 5.0744 & TRN & \\
\hline CHEMBL1391105 & 688267 & 6.2 & $5.0680 e$ & 20000000005 & TRN \\
\hline CHEMBL1328948 & 688267 & 4.55 & 5.1102 & TRN & \\
\hline CHEMBL1562106 & 688267 & 6.2 & 5.138 & TRN & \\
\hline CHEMBL1587076 & 688267 & 6.25 & 5.1784 & TRN & \\
\hline CHEMBL1492281 & 688267 & 5.8 & 5.0198 & TRN & \\
\hline CHEMBL1558182 & 688267 & 5.35 & 5.1021 & TRN & \\
\hline CHEMBL1412832 & 688267 & 5.65 & 5.0075 & TRN & \\
\hline CHEMBL1314548 & 688267 & 5.2 & 5.1031 & TRN & \\
\hline CHEMBL1574112 & 688267 & 6.15 & 5.0376 & TRN & \\
\hline CHEMBL3212938 & 688267 & 6.2 & 4.9915 & TRN & \\
\hline CHEMBL1459919 & 688267 & 5.3 & 5.0263 & TRN & \\
\hline
\end{tabular}




\begin{tabular}{|c|c|c|c|c|}
\hline \multicolumn{5}{|c|}{ Supplemental Table S2.txt } \\
\hline CHEMBL1411635 & 688267 & 6.45 & 5.0331 & TRN \\
\hline CHEMBL1572444 & 688267 & 4.05 & 5.0686 & TRN \\
\hline CHEMBL1359521 & 688267 & 5.3 & 4.9944 & TST \\
\hline CHEMBL 3145204 & 688267 & 5.2 & 5.0039 & TRN \\
\hline CHEMBL1381704 & 688267 & 5.35 & 5.0356 & TRN \\
\hline CHEMBL1476314 & 688267 & 4.0 & 5.0002 & TRN \\
\hline CHEMBL1519016 & 688267 & 5.45 & 4.9953 & TRN \\
\hline CHEMBL1351787 & 688267 & 4.3 & 5.0261 & TRN \\
\hline CHEMBL1603749 & 688267 & 6.5 & 5.0417 & TRN \\
\hline CHEMBL 1474240 & 688267 & 4.1 & 5.0146 & TRN \\
\hline CHEMBL1558345 & 688267 & 6.2 & 5.0122 & TRN \\
\hline CHEMBL1331738 & 688267 & 4.0 & 5.0093 & TST \\
\hline CHEMBL1478744 & 688267 & 4.05 & 5.0325 & TRN \\
\hline CHEMBL1310038 & 688267 & 6.25 & 5.0776 & TRN \\
\hline CHEMBL3190819 & 688267 & 5.0 & 5.0446 & TST \\
\hline CHEMBL3195792 & 688267 & 4.45 & 5.0298 & TRN \\
\hline CHEMBL1333499 & 688267 & 6.5 & 5.0685 & TRN \\
\hline CHEMBL1398127 & 688267 & 3.9 & 5.07 & TRN \\
\hline CHEMBL1354252 & 688267 & 4.1 & 4.9888 & TRN \\
\hline CHEMBL1569312 & 688267 & 4.5 & 5.0507 & TRN \\
\hline CHEMBL1336923 & 688267 & 5.75 & 5.0283 & TRN \\
\hline CHEMBL1493489 & 688267 & 6.2 & 5.0662 & TRN \\
\hline CHEMBL1543401 & 688267 & 4.05 & 5.0563 & TRN \\
\hline CHEMBL1451146 & 688267 & 4.75 & 5.0635 & TRN \\
\hline CHEMBL1559553 & 688267 & 4.7 & 5.0029 & TRN \\
\hline CHEMBL1395833 & 688267 & 3.95 & 5.0914 & TRN \\
\hline CHEMBL1587895 & 688267 & 4.4 & 5.0845 & TRN \\
\hline CHEMBL3189348 & 688267 & 4.45 & 5.0549 & TRN \\
\hline CHEMBL1581512 & 688267 & 6.35 & 5.0733 & TRN \\
\hline CHEMBL1508379 & 688267 & 4.0 & 5.0381 & TRN \\
\hline CHEMBL1586122 & 688267 & 6.15 & 5.1426 & TST \\
\hline CHEMBL1539629 & 688267 & 5.55 & 5.0652 & TRN \\
\hline CHEMBL1322867 & 688267 & 4.2 & 5.029 & TST \\
\hline CHEMBL1604988 & 688267 & 5.6 & 5.0236 & TRN \\
\hline CHEMBL1584107 & 688267 & 4.0 & 5.0979 & TRN \\
\hline CHEMBL1303175 & 688267 & 6.5 & 5.1243 & TST \\
\hline CHEMBL 1468759 & 688267 & 5.0 & 5.0724 & TRN \\
\hline CHEMBL1476588 & 688267 & 5.05 & 5.0456 & TRN \\
\hline CHEMBL3196572 & 688267 & 6.2 & 5.0139 & TST \\
\hline CHEMBL1343811 & 688267 & 4.45 & 5.0533 & TRN \\
\hline CHEMBL1488215 & 688267 & 5.4 & 5.0315 & TST \\
\hline CHEMBL1369206 & 688267 & 4.15 & 5.0619 & TRN \\
\hline CHEMBL1460338 & 688267 & 5.55 & 5.0128 & TRN \\
\hline CHEMBL1337043 & 688267 & 3.95 & 5.1051 & TST \\
\hline CHEMBL1394966 & 688267 & 4.2 & 5.0739 & TST \\
\hline CHEMBL1344249 & 688267 & 5.85 & 4.999 & TRN \\
\hline CHEMBL1608537 & 688267 & 4.05 & 5.0765 & TRN \\
\hline CHEMBL1322534 & 688267 & 5.3 & 5.0245 & TST \\
\hline
\end{tabular}




\begin{tabular}{|c|c|c|c|c|c|}
\hline \multicolumn{6}{|c|}{ Supplemental Table S2.txt } \\
\hline CHEMBL1592473 & 688267 & 5.1 & 5.0323 & TRN & \\
\hline CHEMBL1383702 & 688267 & 4.35 & 5.0823 & TRN & \\
\hline CHEMBL1416986 & 688267 & 5.55 & 4.9927 & TRN & \\
\hline CHEMBL1412458 & 688267 & 4.0 & 5.027 & TRN & \\
\hline CHEMBL1356399 & 688267 & 5.45 & 5.0133 & TRN & \\
\hline CHEMBL1492470 & 688267 & 4.5 & 5.0429 & TRN & \\
\hline CHEMBL289046 & 688267 & 4.35 & 5.0553 & TST & \\
\hline CHEMBL1523336 & 688267 & 5.65 & 5.0424 & TRN & \\
\hline CHEMBL1345284 & 688267 & 4.25 & 5.0218 & TST & \\
\hline CHEMBL1611404 & 688267 & 5.0 & 5.1137 & TRN & \\
\hline CHEMBL1561172 & 688267 & 5.05 & 5.0147 & TRN & \\
\hline CHEMBL1381829 & 688267 & 4.75 & 5.0592 & TST & \\
\hline CHEMBL1507925 & 688267 & 3.95 & 5.0528 & TRN & \\
\hline CHEMBL1370620 & 688267 & 5.3 & 5.0667 & TST & \\
\hline CHEMBL1369608 & 688267 & 4.6 & 5.1458 & TRN & \\
\hline CHEMBL1579795 & 688267 & 5.6 & 5.0339 & TST & \\
\hline CHEMBL1420413 & 688267 & 5.95 & 5.1553 & TRN & \\
\hline CHEMBL1530237 & 688267 & 5.6 & 5.0595 & TRN & \\
\hline CHEMBL1510170 & 688267 & 6.25 & 5.0578 & TRN & \\
\hline CHEMBL1508370 & 688267 & 4.85 & 5.0354 & TRN & \\
\hline CHEMBL1449140 & 688267 & 5.65 & 5.0303 & TRN & \\
\hline CHEMBL1494032 & 688267 & 5.95 & 5.0904 & TRN & \\
\hline CHEMBL1436781 & 688267 & 4.95 & 5.0708 & TRN & \\
\hline CHEMBL1346320 & 688267 & 4.4 & 5.0646 & TRN & \\
\hline CHEMBL1446996 & 688267 & 6.2 & 5.0818 & TRN & \\
\hline CHEMBL1609206 & 688267 & 4.05 & 5.0307 & TRN & \\
\hline CHEMBL1312949 & 688267 & 5.8 & 5.0262 & TRN & \\
\hline CHEMBL1594505 & 688267 & 4.1 & 5.0498 & TRN & \\
\hline CHEMBL1444425 & 688267 & 6.1 & 5.0884 & TRN & \\
\hline CHEMBL1490565 & 688267 & 6.25 & 5.1366 & TRN & \\
\hline CHEMBL1469790 & 688267 & 6.0 & 4.994 & TST & \\
\hline CHEMBL1414146 & 688267 & 5.25 & 5.0315 & TRN & \\
\hline CHEMBL1332052 & 688267 & 3.95 & 5.1065 & TRN & \\
\hline CHEMBL1428585 & 688267 & 6.1 & 5.0159 & TRN & \\
\hline CHEMBL1331796 & 688267 & 5.65 & 5.0517 & TRN & \\
\hline CHEMBL1453186 & 688267 & 5.9 & 5.0088 & TRN & \\
\hline CHEMBL1172021 & 688267 & 5.5 & $5.0710 e$ & 0000000001 & TRN \\
\hline CHEMBL1313339 & 688267 & 4.55 & 4.9952 & TRN & \\
\hline CHEMBL1456818 & 688267 & 4.3 & 5.0604 & TST & \\
\hline CHEMBL1340755 & 688267 & 6.1 & 5.1022 & TST & \\
\hline CHEMBL1550378 & 688267 & 5.35 & 5.1528 & TRN & \\
\hline CHEMBL1556820 & 688267 & 5.45 & 5.0477 & TRN & \\
\hline CHEMBL1486740 & 688267 & 4.35 & 5.0248 & TST & \\
\hline CHEMBL1516834 & 688267 & 4.7 & 5.0088 & TST & \\
\hline CHEMBL1480469 & 688267 & 4.05 & 5.0223 & TRN & \\
\hline CHEMBL1535337 & 688267 & 5.9 & 5.1023 & TST & \\
\hline CHEMBL1480555 & 688267 & 6.15 & 5.1023 & TRN & \\
\hline CHEMBL1604316 & 688267 & 4.05 & 5.085 & TRN & \\
\hline
\end{tabular}




\begin{tabular}{|c|c|c|c|c|c|}
\hline & & \multicolumn{4}{|c|}{ Supplemental Table s2.txt } \\
\hline CHEMBL1405856 & 688267 & 3.95 & 5.0268 & TRN & \\
\hline CHEMBL1575193 & 688267 & 4.05 & 5.0436 & TST & \\
\hline CHEMBL2007021 & 688267 & 4.6 & 5.0297 & TRN & \\
\hline CHEMBL1517706 & 688267 & 4.2 & 5.0091 & TST & \\
\hline CHEMBL1324301 & 688267 & 4.05 & 5.0798 & TRN & \\
\hline CHEMBL1379489 & 688267 & 5.3 & 5.0335 & TST & \\
\hline CHEMBL1359854 & 688267 & 6.25 & 5.0577 & TRN & \\
\hline CHEMBL1489920 & 688267 & 4.05 & 5.0558 & TST & \\
\hline CHEMBL1598185 & 688267 & 4.0 & 4.9914 & TRN & \\
\hline CHEMBL1339220 & 688267 & 5.45 & 5.129 & TST & \\
\hline CHEMBL1590983 & 688267 & 4.05 & 5.0949 & TRN & \\
\hline CHEMBL1335267 & 688267 & 4.3 & 5.061 & TST & \\
\hline CHEMBL1406598 & 688267 & 4.95 & 5.1063 & TST & \\
\hline CHEMBL1456572 & 688267 & 5.35 & 5.0903 & TRN & \\
\hline CHEMBL1499197 & 688267 & 4.3 & 5.1028 & TST & \\
\hline CHEMBL1544052 & 688267 & 5.0 & 5.0483 & TRN & \\
\hline CHEMBL1404606 & 688267 & 4.15 & 5.121 & TRN & \\
\hline CHEMBL1595655 & 688267 & 4.0 & 5.0458 & TST & \\
\hline CHEMBL1499420 & 688267 & 4.95 & 5.0296 & TST & \\
\hline CHEMBL1409260 & 688267 & 5.65 & 5.101 & TRN & \\
\hline CHEMBL1406143 & 688267 & 6.25 & 5.0233 & TRN & \\
\hline CHEMBL1539205 & 688267 & 5.85 & 5.1138 & TRN & \\
\hline CHEMBL1588576 & 688267 & 3.95 & 5.1675 & TRN & \\
\hline CHEMBL1593012 & 688267 & 5.2 & 5.0737 & TRN & \\
\hline CHEMBL1581069 & 688267 & 5.65 & 5.0694 & TRN & \\
\hline CHEMBL3191808 & 688267 & 5.55 & 5.074 & TRN & \\
\hline CHEMBL1543843 & 688267 & 6.2 & 5.0689 & TRN & \\
\hline CHEMBL1345496 & 688267 & 5.2 & 5.1094 & TRN & \\
\hline CHEMBL1358876 & 688267 & 5.45 & 5.01 & TRN & \\
\hline CHEMBL3198657 & 688267 & 4.55 & 5.0502 & TST & \\
\hline CHEMBL1373895 & 688267 & 4.0 & 5.096 & TRN & \\
\hline CHEMBL1495604 & 688267 & 4.15 & 5.0157 & TRN & \\
\hline CHEMBL1431916 & 688267 & 6.2 & 5.0545 & TRN & \\
\hline CHEMBL1421429 & 688267 & 4.0 & 5.0781 & TRN & \\
\hline CHEMBL1547839 & 688267 & 4.05 & 5.152 & TRN & \\
\hline CHEMBL1346284 & 688267 & 5.45 & 5.1102 & TRN & \\
\hline CHEMBL1331536 & 688267 & 4.6 & 5.1377 & TST & \\
\hline CHEMBL1459479 & 688267 & 6.2 & 5.0654 & TRN & \\
\hline CHEMBL1378193 & 688267 & 4.0 & 5.0248 & TRN & \\
\hline CHEMBL1567075 & 688267 & 6.2 & 4.9695 & TRN & \\
\hline CHEMBL1583182 & 688267 & 4.05 & 5.0772 & TRN & \\
\hline CHEMBL1492488 & 688267 & 5.25 & 5.0856 & TRN & \\
\hline CHEMBL1544726 & 688267 & 4.1 & 5.087 & TRN & \\
\hline CHEMBL1357907 & 688267 & 3.9 & 5.0403 & TRN & \\
\hline CHEMBL1375103 & 688267 & 5.55 & 5.0701 & TRN & \\
\hline CHEMBL1362106 & 688267 & 5.15 & 5.0228 & TRN & \\
\hline CHEMBL1434328 & 688267 & 6.5 & 4.994 & TRN & \\
\hline CHEMBL3192802 & 688267 & 4.3 & 5.03100 & 0000000001 & TRN \\
\hline & & & & 18288 & \\
\hline
\end{tabular}




\begin{tabular}{|c|c|c|c|c|}
\hline \multicolumn{5}{|c|}{ Supplemental Table S2.txt } \\
\hline CHEMBL1555747 & 688267 & 4.0 & 5.145 & TRN \\
\hline CHEMBL1435904 & 688267 & 4.35 & 4.9783 & TRN \\
\hline CHEMBL1587878 & 688267 & 5.45 & 5.0539 & TRN \\
\hline CHEMBL1336153 & 688267 & 5.3 & 5.0673 & TRN \\
\hline CHEMBL1543285 & 688267 & 5.5 & 5.065 & TRN \\
\hline CHEMBL1590934 & 688267 & 5.85 & 5.0727 & TST \\
\hline CHEMBL1427652 & 688267 & 6.5 & 5.1523 & TRN \\
\hline CHEMBL1579398 & 688267 & 4.5 & 5.0688 & TST \\
\hline CHEMBL1612322 & 688267 & 3.95 & 5.0583 & TST \\
\hline CHEMBL1321948 & 688267 & 5.3 & 5.0335 & TRN \\
\hline CHEMBL1605333 & 688267 & 6.2 & 5.0905 & TST \\
\hline CHEMBL1450885 & 688267 & 4.7 & 5.056 & TRN \\
\hline CHEMBL1413110 & 688267 & 4.0 & 5.1221 & TRN \\
\hline CHEMBL1440837 & 688267 & 4.05 & 5.0694 & TRN \\
\hline CHEMBL1611109 & 688267 & 4.0 & 5.0573 & TRN \\
\hline CHEMBL1352569 & 688267 & 4.25 & 5.0832 & TRN \\
\hline CHEMBL1304991 & 688267 & 5.3 & 5.0298 & TRN \\
\hline CHEMBL 3194850 & 688267 & 4.3 & 5.1189 & TRN \\
\hline CHEMBL1530130 & 688267 & 4.55 & 5.0428 & TST \\
\hline CHEMBL3197436 & 688267 & 4.35 & 5.0795 & TST \\
\hline CHEMBL1585170 & 688267 & 5.4 & 5.0771 & TRN \\
\hline CHEMBL1305275 & 688267 & 5.3 & 5.0879 & TST \\
\hline CHEMBL1553379 & 688267 & 4.05 & 5.0778 & TRN \\
\hline CHEMBL1468562 & 688267 & 4.25 & 5.0332 & TRN \\
\hline CHEMBL1417434 & 688267 & 6.2 & 5.0269 & TRN \\
\hline CHEMBL1532335 & 688267 & 4.9 & 5.0308 & TRN \\
\hline CHEMBL3214406 & 688267 & 5.8 & 5.0554 & TST \\
\hline CHEMBL1575757 & 688267 & 5.35 & 5.0159 & TRN \\
\hline CHEMBL1346198 & 688267 & 4.0 & 5.0831 & TRN \\
\hline CHEMBL1556981 & 688267 & 5.55 & 5.0931 & TRN \\
\hline CHEMBL1458414 & 688267 & 4.6 & 5.1154 & TRN \\
\hline CHEMBL1332870 & 688267 & 5.05 & 4.9981 & TRN \\
\hline CHEMBL1561838 & 688267 & 6.2 & 5.0506 & TRN \\
\hline CHEMBL1367458 & 688267 & 4.75 & 5.1068 & TRN \\
\hline CHEMBL1384170 & 688267 & 3.95 & 5.0482 & TRN \\
\hline CHEMBL1364830 & 688267 & 6.2 & 5.0533 & TRN \\
\hline CHEMBL1526673 & 688267 & 4.4 & 5.0574 & TST \\
\hline CHEMBL1451527 & 688267 & 5.15 & 5.0115 & TRN \\
\hline CHEMBL1529687 & 688267 & 4.05 & 5.0681 & TRN \\
\hline CHEMBL1345968 & 688267 & 4.4 & 5.0255 & TRN \\
\hline CHEMBL1394406 & 688267 & 4.55 & 5.0904 & TRN \\
\hline CHEMBL1575659 & 688267 & 5.55 & 5.1067 & TRN \\
\hline CHEMBL1480226 & 688267 & 5.35 & 5.03 & TRN \\
\hline CHEMBL1303579 & 688267 & 4.5 & 5.0952 & TRN \\
\hline CHEMBL1480357 & 688267 & 3.9 & 5.0404 & TRN \\
\hline CHEMBL1505899 & 688267 & 4.0 & 5.0476 & TRN \\
\hline CHEMBL1452153 & 688267 & 5.35 & 5.0395 & TRN \\
\hline CHEMBL1493811 & 688267 & 4.1 & 5.0509 & TRN \\
\hline
\end{tabular}




\begin{tabular}{|c|c|c|c|c|c|}
\hline \multicolumn{6}{|c|}{ Supplemental Table S2.txt } \\
\hline CHEMBL1326219 & 688267 & 4.15 & 5.0267 & TRN & \\
\hline CHEMBL1316270 & 688267 & 6.2 & 5.0433 & TRN & \\
\hline CHEMBL1334898 & 688267 & 5.0 & 5.1164 & TRN & \\
\hline CHEMBL1403999 & 688267 & 5.85 & 5.0546 & TRN & \\
\hline CHEMBL1368694 & 688267 & 4.15 & 5.0282 & TRN & \\
\hline CHEMBL1537748 & 688267 & 5.55 & 5.0715 & TRN & \\
\hline CHEMBL1592003 & 688267 & 4.0 & 5.0857 & TRN & \\
\hline CHEMBL1579709 & 688267 & 4.0 & 5.0361 & TRN & \\
\hline CHEMBL1533147 & 688267 & 5.25 & 5.0541 & TRN & \\
\hline CHEMBL1514890 & 688267 & 5.35 & 5.0971 & TRN & \\
\hline CHEMBL1530346 & 688267 & 6.25 & 5.0268 & TRN & \\
\hline CHEMBL1319430 & 688267 & 5.8 & 5.0027 & TRN & \\
\hline CHEMBL1378418 & 688267 & 4.0 & 5.0622 & TRN & \\
\hline CHEMBL1459250 & 688267 & 4.35 & 5.0451 & TRN & \\
\hline CHEMBL1509045 & 688267 & 5.65 & 5.0726 & TST & \\
\hline CHEMBL1527814 & 688267 & 5.85 & 5.0067 & TRN & \\
\hline CHEMBL1306133 & 688267 & 4.35 & 5.0445 & TRN & \\
\hline CHEMBL1515066 & 688267 & 6.5 & 5.0258 & TRN & \\
\hline CHEMBL1562113 & 688267 & 5.05 & 5.12799 & 9999999999 & TRN \\
\hline CHEMBL1314825 & 688267 & 4.25 & 5.0543 & TRN & \\
\hline CHEMBL1532225 & 688267 & 6.2 & 5.0801 & TRN & \\
\hline CHEMBL1480747 & 688267 & 4.95 & 5.0579 & TRN & \\
\hline CHEMBL1512941 & 688267 & 5.6 & 5.0391 & TST & \\
\hline CHEMBL1395954 & 688267 & 5.15 & 5.0799 & TRN & \\
\hline CHEMBL1553627 & 688267 & 6.45 & 5.0229 & TRN & \\
\hline CHEMBL1481553 & 688267 & 6.5 & 5.0651 & TRN & \\
\hline CHEMBL1489216 & 688267 & 6.45 & 5.07600 & 00000000005 & TRN \\
\hline CHEMBL1490141 & 688267 & 4.6 & 5.1217 & TRN & \\
\hline CHEMBL1446300 & 688267 & 6.15 & 5.0983 & TRN & \\
\hline CHEMBL1517739 & 688267 & 6.2 & 4.9933 & TRN & \\
\hline CHEMBL1350858 & 688267 & 6.2 & 5.0653 & TST & \\
\hline CHEMBL1497927 & 688267 & 6.15 & 5.1316 & TRN & \\
\hline CHEMBL1429077 & 688267 & 5.1 & 5.0656 & TRN & \\
\hline CHEMBL1545134 & 688267 & 5.35 & 5.0819 & TRN & \\
\hline CHEMBL1450282 & 688267 & 5.35 & 4.9962 & TRN & \\
\hline CHEMBL1462693 & 688267 & 6.25 & 5.0293 & TST & \\
\hline CHEMBL1464905 & 688267 & 5.55 & 5.0275 & TRN & \\
\hline CHEMBL1582223 & 688267 & 5.5 & 5.0293 & TRN & \\
\hline CHEMBL1325343 & 688267 & 5.2 & 5.0925 & TRN & \\
\hline CHEMBL1408194 & 688267 & 6.2 & 5.0128 & TST & \\
\hline CHEMBL1381140 & 688267 & 5.95 & 4.9953 & TRN & \\
\hline CHEMBL1527565 & 688267 & 4.2 & 5.0376 & TST & \\
\hline CHEMBL1514633 & 688267 & 5.1 & 5.0369 & TRN & \\
\hline CHEMBL3196468 & 688267 & 6.0 & 5.0486 & TST & \\
\hline CHEMBL1544093 & 688267 & 4.4 & 5.0923 & TST & \\
\hline CHEMBL1511320 & 688267 & 6.2 & 5.1396 & TRN & \\
\hline CHEMBL1492640 & 688267 & 4.0 & 5.1638 & TRN & \\
\hline CHEMBL1459502 & 688267 & 5.55 & 4.9845 & TRN & \\
\hline
\end{tabular}




\begin{tabular}{|c|c|c|c|c|}
\hline & & & pplement & al \\
\hline CHEMBL1413139 & 688267 & 4.0 & 5.0203 & TRN \\
\hline CHEMBL1982569 & 688267 & 5.6 & 5.0622 & TRN \\
\hline CHEMBL1513639 & 688267 & 4.35 & 5.1319 & TRN \\
\hline CHEMBL1461076 & 688267 & 6.2 & 5.0822 & TRN \\
\hline CHEMBL1496052 & 688267 & 4.35 & 5.0235 & TRN \\
\hline CHEMBL1372377 & 688267 & 4.4 & 4.9876 & TRN \\
\hline CHEMBL1553562 & 688267 & 4.05 & 5.1212 & TRN \\
\hline CHEMBL1448469 & 688267 & 5.25 & 5.0842 & TRN \\
\hline CHEMBL1583567 & 688267 & 5.3 & 5.0431 & TRN \\
\hline CHEMBL1428756 & 688267 & 6.35 & 5.1111 & TRN \\
\hline CHEMBL1379398 & 688267 & 4.95 & 4.9962 & TRN \\
\hline CHEMBL1518099 & 688267 & 4.0 & 5.0301 & TRN \\
\hline CHEMBL1500380 & 688267 & 5.0 & 5.0656 & TRN \\
\hline CHEMBL1485371 & 688267 & 4.3 & 5.1296 & TRN \\
\hline CHEMBL1520425 & 688267 & 5.0 & 5.0309 & TRN \\
\hline CHEMBL1445805 & 688267 & 4.45 & 5.0249 & TRN \\
\hline CHEMBL1434193 & 688267 & 5.85 & 5.0498 & TRN \\
\hline CHEMBL1598776 & 688267 & 4.25 & 4.9554 & TRN \\
\hline CHEMBL1299912 & 688267 & 6.15 & 5.0531 & TRN \\
\hline CHEMBL1571902 & 688267 & 3.95 & 5.0696 & TRN \\
\hline CHEMBL1393057 & 688267 & 7.15 & 5.0208 & TRN \\
\hline CHEMBL1477836 & 688267 & 4.0 & 5.0759 & TST \\
\hline CHEMBL1529184 & 688267 & 4.4 & 5.1044 & TRN \\
\hline CHEMBL1493302 & 688267 & 5.65 & 4.9851 & TRN \\
\hline CHEMBL1609538 & 688267 & 5.6 & 5.0134 & TST \\
\hline CHEMBL1451867 & 688267 & 4.3 & 5.1565 & TRN \\
\hline CHEMBL1531897 & 688267 & 4.05 & 5.0372 & TST \\
\hline CHEMBL1437897 & 688267 & 5.25 & 5.0621 & TRN \\
\hline CHEMBL1473409 & 688267 & 6.2 & 5.0362 & TRN \\
\hline CHEMBL1540063 & 688267 & 5.75 & 5.0923 & TRN \\
\hline CHEMBL1429732 & 688267 & 6.0 & 5.0524 & TRN \\
\hline CHEMBL1548270 & 688267 & 4.0 & 5.0822 & TRN \\
\hline CHEMBL1558730 & 688267 & 4.95 & 5.0278 & TRN \\
\hline CHEMBL1494463 & 688267 & 4.0 & 5.148 & TRN \\
\hline CHEMBL1414867 & 688267 & 4.0 & 5.0029 & TRN \\
\hline CHEMBL1363365 & 688267 & 4.35 & 5.1026 & TRN \\
\hline CHEMBL1299237 & 688267 & 5.3 & 5.0312 & TRN \\
\hline CHEMBL1418519 & 688267 & 6.2 & 5.025 & TRN \\
\hline CHEMBL1424719 & 688267 & 5.35 & 5.1015 & TRN \\
\hline CHEMBL1395554 & 688267 & 4.05 & 5.0325 & TRN \\
\hline CHEMBL1388291 & 688267 & 4.4 & 5.063 & TRN \\
\hline CHEMBL1598944 & 688267 & 4.85 & 5.0262 & TST \\
\hline CHEMBL1326151 & 688267 & 5.65 & 5.0681 & TRN \\
\hline CHEMBL1395230 & 688267 & 4.5 & 5.0611 & TRN \\
\hline CHEMBL1587605 & 688267 & 6.2 & 5.0275 & TRN \\
\hline CHEMBL1173140 & 688267 & 4.95 & 5.0386 & TRN \\
\hline CHEMBL1537854 & 688267 & 4.3 & 5.0387 & TST \\
\hline CHEMBL1365715 & 688267 & 6.25 & 5.0368 & TRN \\
\hline
\end{tabular}




\begin{tabular}{|c|c|c|c|c|c|}
\hline \multirow[b]{2}{*}{ CHEMBL1321372 } & \multirow[b]{2}{*}{688267} & \\
\hline & & 6.15 & 5.002 & TRN & \\
\hline CHEMBL1560178 & 688267 & 6.5 & 5.0884 & TRN & \\
\hline CHEMBL1520616 & 688267 & 4.0 & 5.0879 & TRN & \\
\hline CHEMBL1476833 & 688267 & 4.0 & 5.0075 & TRN & \\
\hline CHEMBL1489346 & 688267 & 5.55 & 5.0045 & TST & \\
\hline CHEMBL1454771 & 688267 & 5.35 & 5.1003 & TST & \\
\hline CHEMBL1385405 & 688267 & 6.2 & 5.0875 & TRN & \\
\hline CHEMBL1473797 & 688267 & 6.2 & \multicolumn{2}{|c|}{5.0969999999999995} & TRN \\
\hline CHEMBL1318290 & 688267 & 4.4 & 4.985 & TRN & \\
\hline CHEMBL1352141 & 688267 & 6.2 & 5.0999 & TST & \\
\hline CHEMBL1437290 & 688267 & 6.2 & 4.9996 & TRN & \\
\hline CHEMBL1403715 & 688267 & 4.4 & 5.0849 & TST & \\
\hline CHEMBL1507800 & 688267 & 5.8 & 5.063 & TRN & \\
\hline CHEMBL1331611 & 688267 & 5.85 & 5.1104 & TRN & \\
\hline CHEMBL1479210 & 688267 & 4.4 & 4.9969 & TRN & \\
\hline CHEMBL1593994 & 688267 & 4.4 & 5.0078 & TRN & \\
\hline CHEMBL1526848 & 688267 & 6.2 & 5.1039 & TRN & \\
\hline CHEMBL1355996 & 688267 & 4.4 & 5.1267 & TST & \\
\hline CHEMBL1318204 & 688267 & 5.5 & 5.0107 & TRN & \\
\hline CHEMBL3199262 & 688267 & 5.35 & 5.0326 & TST & \\
\hline CHEMBL1464835 & 688267 & 4.35 & 5.0408 & TRN & \\
\hline CHEMBL1447593 & 688267 & 5.25 & 5.0184 & TST & \\
\hline CHEMBL1562826 & 688267 & 5.0 & 5.0617 & TRN & \\
\hline CHEMBL1300380 & 688267 & 5.6 & 5.106 & TRN & \\
\hline CHEMBL1418193 & 688267 & 6.25 & 5.0141 & TRN & \\
\hline CHEMBL1457486 & 688267 & 5.0 & 5.0702 & TRN & \\
\hline CHEMBL1485090 & 688267 & 4.35 & 5.0531 & TRN & \\
\hline CHEMBL1417086 & 688267 & 4.55 & 5.0729 & TRN & \\
\hline CHEMBL1569796 & 688267 & 6.2 & 5.1076 & TRN & \\
\hline CHEMBL1448556 & 688267 & 5.3 & 5.0931 & TST & \\
\hline CHEMBL1561181 & 688267 & 6.2 & 5.05699 & 99999999995 & TRN \\
\hline CHEMBL1485796 & 688267 & 5.35 & 5.0121 & TST & \\
\hline CHEMBL1362187 & 688267 & 4.7 & 4.9809 & TRN & \\
\hline CHEMBL1415642 & 688267 & 6.2 & 5.0178 & TST & \\
\hline CHEMBL1518374 & 688267 & 4.4 & 5.02 & TRN & \\
\hline CHEMBL1473395 & 688267 & 6.15 & 5.0125 & TRN & \\
\hline CHEMBL1501907 & 688267 & 5.6 & 5.1102 & TRN & \\
\hline CHEMBL1531939 & 688267 & 4.05 & 5.1402 & TRN & \\
\hline CHEMBL1563583 & 688267 & 4.4 & 4.9945 & TRN & \\
\hline CHEMBL1573182 & 688267 & 4.45 & 5.0474 & TST & \\
\hline CHEMBL1523224 & 688267 & 4.55 & 5.0081 & TST & \\
\hline CHEMBL1576698 & 688267 & 3.95 & 5.1111 & TST & \\
\hline CHEMBL1315641 & 688267 & 4.2 & 5.0335 & TRN & \\
\hline CHEMBL1462722 & 688267 & 5.5 & 5.052 & TRN & \\
\hline CHEMBL3195411 & 688267 & 4.1 & 5.0068 & TRN & \\
\hline CHEMBL1368030 & 688267 & 4.35 & 5.0801 & TRN & \\
\hline CHEMBL1554474 & 688267 & 5.45 & 5.0192 & TRN & \\
\hline \multirow[t]{2}{*}{ CHEMBL1445601 } & 688267 & 6.15 & 5.0495 & TRN & \\
\hline & & \multicolumn{4}{|c|}{ Page 18292} \\
\hline
\end{tabular}




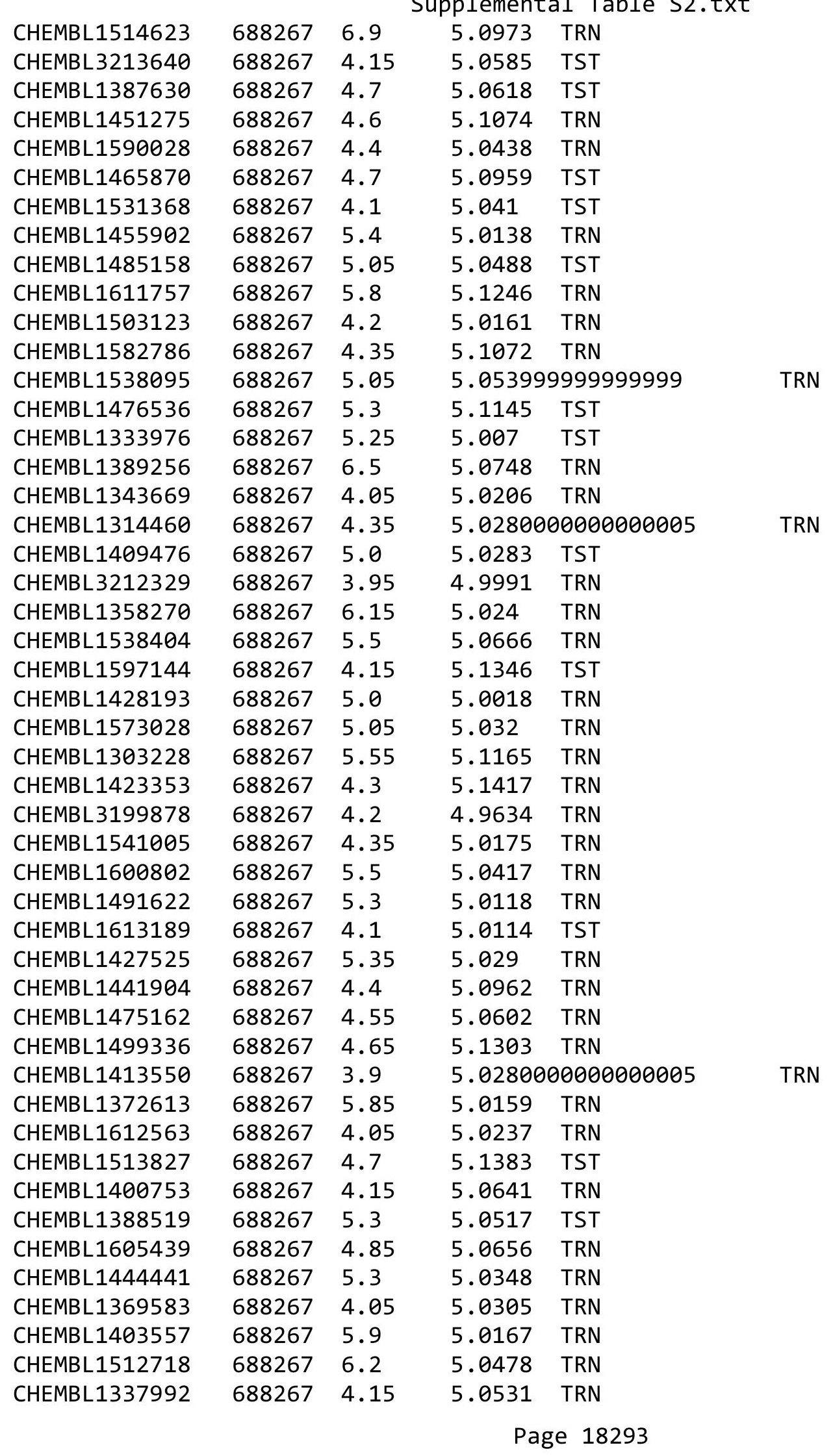




\begin{tabular}{|c|c|c|c|c|}
\hline \multicolumn{5}{|c|}{ Supplemental Table S2.txt } \\
\hline CHEMBL1329040 & 688267 & 5.55 & 5.0582 & TRN \\
\hline CHEMBL1567293 & 688267 & 4.0 & 5.0274 & TST \\
\hline CHEMBL1461133 & 688267 & 4.35 & 5.0381 & TRN \\
\hline CHEMBL1476383 & 688267 & 4.95 & 5.0558 & TST \\
\hline CHEMBL1489513 & 688267 & 4.35 & 5.0909 & TRN \\
\hline CHEMBL1530323 & 688267 & 4.0 & 5.083 & TRN \\
\hline CHEMBL1426101 & 688267 & 5.25 & 5.0428 & TST \\
\hline CHEMBL1409127 & 688267 & 4.05 & 5.0453 & TRN \\
\hline CHEMBL1405403 & 688267 & 6.2 & 5.0647 & TRN \\
\hline CHEMBL1470677 & 688267 & 4.0 & 5.0569 & TST \\
\hline CHEMBL1395393 & 688267 & 6.2 & 5.0515 & TST \\
\hline CHEMBL1426102 & 688267 & 6.2 & 5.0566 & TRN \\
\hline CHEMBL1312230 & 688267 & 5.6 & 5.0201 & TST \\
\hline CHEMBL1351604 & 688267 & 3.9 & 5.1153 & TRN \\
\hline CHEMBL1535535 & 688267 & 5.25 & 5.1256 & TRN \\
\hline CHEMBL1449485 & 688267 & 4.75 & 4.9948 & TRN \\
\hline CHEMBL 3209942 & 688267 & 4.6 & 5.0068 & TRN \\
\hline CHEMBL1487475 & 688267 & 4.0 & 5.0811 & TRN \\
\hline CHEMBL1557533 & 688267 & 5.05 & 5.0307 & TRN \\
\hline CHEMBL566061 & 688267 & 4.5 & 5.0215 & TRN \\
\hline CHEMBL1356243 & 688267 & 5.85 & 5.022 & TRN \\
\hline CHEMBL1552518 & 688267 & 4.55 & 5.1284 & TRN \\
\hline CHEMBL1359959 & 688267 & 5.55 & 5.0496 & TRN \\
\hline CHEMBL 3189179 & 688267 & 4.65 & 5.0342 & TRN \\
\hline CHEMBL1483289 & 688267 & 5.45 & 5.0049 & TST \\
\hline CHEMBL1573215 & 688267 & 6.25 & 5.0485 & TRN \\
\hline CHEMBL1548056 & 688267 & 4.05 & 5.0606 & TST \\
\hline CHEMBL1413767 & 688267 & 6.15 & 5.0258 & TRN \\
\hline CHEMBL1308281 & 688267 & 5.5 & 5.1559 & TRN \\
\hline CHEMBL1444255 & 688267 & 4.0 & 5.0266 & TRN \\
\hline CHEMBL1425295 & 688267 & 6.2 & 5.0544 & TST \\
\hline CHEMBL1475567 & 688267 & 5.5 & 5.0995 & TRN \\
\hline CHEMBL1337986 & 688267 & 5.0 & 5.0205 & TRN \\
\hline CHEMBL1571100 & 688267 & 6.2 & 5.0459 & TRN \\
\hline CHEMBL1352886 & 688267 & 4.95 & 5.0339 & TRN \\
\hline CHEMBL1437561 & 688267 & 4.7 & 5.1046 & TRN \\
\hline CHEMBL1342225 & 688267 & 5.6 & 5.1341 & TRN \\
\hline CHEMBL1448715 & 688267 & 5.05 & 5.129 & TRN \\
\hline CHEMBL1329428 & 688267 & 4.0 & 5.0816 & TRN \\
\hline CHEMBL1422481 & 688267 & 4.0 & 5.0251 & TST \\
\hline CHEMBL1326865 & 688267 & 6.2 & 5.1367 & TRN \\
\hline CHEMBL1470215 & 688267 & 4.1 & 5.0857 & TRN \\
\hline CHEMBL1570311 & 688267 & 3.95 & 5.0079 & TRN \\
\hline CHEMBL1588087 & 688267 & 5.95 & 5.0595 & TST \\
\hline CHEMBL1477044 & 688267 & 5.55 & 5.0187 & TRN \\
\hline CHEMBL1490838 & 688267 & 3.95 & 5.1268 & TRN \\
\hline CHEMBL1579808 & 688267 & 6.15 & 5.0179 & TST \\
\hline CHEMBL1452025 & 688267 & 5.5 & 5.0117 & TRN \\
\hline
\end{tabular}




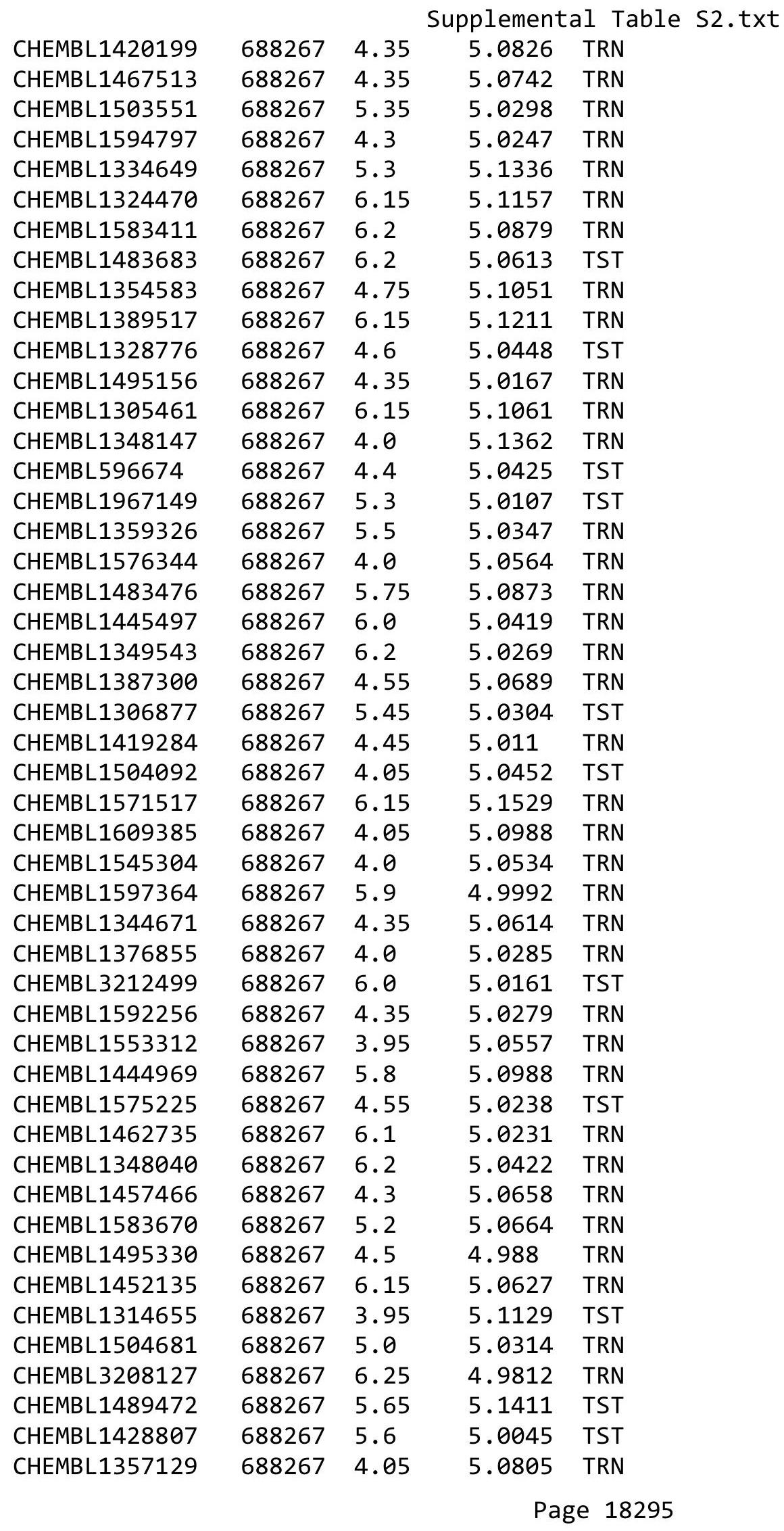




\begin{tabular}{|c|c|c|c|c|c|}
\hline \multicolumn{6}{|c|}{ Supplemental Table S2.txt } \\
\hline CHEMBL1335533 & 688267 & 4.0 & 5.0792 & TST & \\
\hline CHEMBL1489682 & 688267 & 4.0 & 5.0814 & TRN & \\
\hline CHEMBL1611116 & 688267 & 6.15 & 5.0003 & TRN & \\
\hline CHEMBL1395768 & 688267 & 6.2 & 5.0814 & TRN & \\
\hline CHEMBL1534231 & 688267 & 5.3 & 5.0228 & TRN & \\
\hline CHEMBL1524149 & 688267 & 4.05 & 5.0551 & TRN & \\
\hline CHEMBL3197779 & 688267 & 4.5 & 5.0024 & TRN & \\
\hline CHEMBL1514478 & 688267 & 5.85 & 5.0212 & TRN & \\
\hline CHEMBL1485826 & 688267 & 4.5 & 5.0741 & TRN & \\
\hline CHEMBL1554182 & 688267 & 6.4 & 5.0384 & TRN & \\
\hline CHEMBL229887 & 688267 & 6.45 & 4.9877 & TRN & \\
\hline CHEMBL1306431 & 688267 & 5.3 & 5.1146 & TRN & \\
\hline CHEMBL1584828 & 688267 & 4.45 & 5.0669 & TRN & \\
\hline CHEMBL1518299 & 688267 & 4.7 & 5.0682 & TRN & \\
\hline CHEMBL1388406 & 688267 & 6.05 & 5.0092 & TRN & \\
\hline CHEMBL 3194352 & 688267 & 4.3 & 5.04899 & 99999999995 & TST \\
\hline CHEMBL1404405 & 688267 & 4.35 & 5.0195 & TST & \\
\hline CHEMBL1556183 & 688267 & 4.35 & 5.0463 & TRN & \\
\hline CHEMBL1401827 & 688267 & 4.05 & 4.9644 & TST & \\
\hline CHEMBL1430356 & 688267 & 4.5 & 5.0537 & TRN & \\
\hline CHEMBL1518690 & 688267 & 3.95 & 5.0642 & TRN & \\
\hline CHEMBL1336194 & 688267 & 4.0 & 5.1316 & TRN & \\
\hline CHEMBL1378079 & 688267 & 4.4 & 5.1409 & TRN & \\
\hline CHEMBL1507877 & 688267 & 5.65 & 5.0898 & TST & \\
\hline CHEMBL1609706 & 688267 & 4.3 & 5.0744 & TST & \\
\hline CHEMBL1588256 & 688267 & 4.1 & 5.0377 & TRN & \\
\hline CHEMBL1455266 & 688267 & 4.45 & 5.0151 & TRN & \\
\hline CHEMBL1436814 & 688267 & 6.15 & 5.0759 & TRN & \\
\hline CHEMBL1434374 & 688267 & 4.0 & 5.0728 & TRN & \\
\hline CHEMBL1316875 & 688267 & 4.0 & 5.0194 & TRN & \\
\hline CHEMBL1516541 & 688267 & 6.15 & 5.0873 & TRN & \\
\hline CHEMBL1561724 & 688267 & 4.4 & 5.1354 & TRN & \\
\hline CHEMBL1476976 & 688267 & 4.4 & 5.1052 & TRN & \\
\hline CHEMBL1310764 & 688267 & 6.2 & 5.037 & TRN & \\
\hline CHEMBL1612461 & 688267 & 6.2 & 5.154 & TRN & \\
\hline CHEMBL3212198 & 688267 & 4.0 & 5.0357 & TST & \\
\hline CHEMBL 1608715 & 688267 & 4.75 & 5.077 & TRN & \\
\hline CHEMBL1607713 & 688267 & 5.1 & 4.9959 & TRN & \\
\hline CHEMBL1527714 & 688267 & 4.3 & 5.0523 & TRN & \\
\hline CHEMBL1569060 & 688267 & 4.35 & 5.113 & TST & \\
\hline CHEMBL1535320 & 688267 & 4.0 & 5.0367 & TRN & \\
\hline CHEMBL3195472 & 688267 & 6.2 & 5.0357 & TRN & \\
\hline CHEMBL1508336 & 688267 & 4.4 & 5.1095 & TRN & \\
\hline CHEMBL1479911 & 688267 & 5.95 & 5.0335 & TST & \\
\hline CHEMBL1537666 & 688267 & 4.35 & 5.0537 & TRN & \\
\hline CHEMBL1554355 & 688267 & 5.25 & 5.1186 & TRN & \\
\hline CHEMBL1358993 & 688267 & 6.25 & 5.0935 & TRN & \\
\hline CHEMBL1447134 & 688267 & 5.8 & 5.0779 & TRN & \\
\hline
\end{tabular}




\begin{tabular}{|c|c|c|c|c|c|}
\hline \multirow[b]{2}{*}{ CHEMBL1452328 } & \multirow[b]{2}{*}{688267} & \\
\hline & & 5.1 & 5.0278 & TRN & \\
\hline CHEMBL1552550 & 688267 & 4.4 & 5.14 & TRN & \\
\hline CHEMBL1396847 & 688267 & 4.25 & 5.0163 & TRN & \\
\hline CHEMBL1525014 & 688267 & 4.5 & 5.0876 & TRN & \\
\hline CHEMBL1481504 & 688267 & 6.15 & 5.0396 & TRN & \\
\hline CHEMBL1303258 & 688267 & 6.05 & 5.1265 & TRN & \\
\hline CHEMBL1327637 & 688267 & 5.55 & 5.1535 & TRN & \\
\hline CHEMBL1403020 & 688267 & 5.4 & 4.9903 & TRN & \\
\hline CHEMBL1594210 & 688267 & 4.85 & 5.0418 & TRN & \\
\hline CHEMBL1450419 & 688267 & 4.4 & 5.0156 & TRN & \\
\hline CHEMBL1438931 & 688267 & 5.0 & 4.9762 & TRN & \\
\hline CHEMBL1419532 & 688267 & 5.5 & 5.0898 & TRN & \\
\hline CHEMBL1341349 & 688267 & 4.2 & 5.0764 & TRN & \\
\hline CHEMBL1608364 & 688267 & 4.35 & 5.0411 & TRN & \\
\hline CHEMBL1415524 & 688267 & 4.6 & 5.0261 & TST & \\
\hline CHEMBL225313 & 688267 & 6.25 & 5.026 & TST & \\
\hline CHEMBL1514603 & 688267 & 6.2 & 5.0967 & TRN & \\
\hline CHEMBL1320868 & 688267 & 4.0 & 5.0003 & TRN & \\
\hline CHEMBL1343628 & 688267 & 4.0 & 5.0144 & TRN & \\
\hline CHEMBL1544689 & 688267 & 5.0 & 5.1047 & TRN & \\
\hline CHEMBL1568906 & 688267 & 4.5 & 5.0311 & TRN & \\
\hline CHEMBL1572607 & 688267 & 5.0 & 5.061 & TRN & \\
\hline CHEMBL1339961 & 688267 & 4.6 & 5.0599 & TST & \\
\hline CHEMBL1333965 & 688267 & 5.25 & 5.0882 & TST & \\
\hline CHEMBL1397547 & 688267 & 4.05 & 5.0492 & TRN & \\
\hline CHEMBL1556405 & 688267 & 4.95 & 5.1406 & TST & \\
\hline CHEMBL1328268 & 688267 & 6.1 & $5.0280 e$ & 20000000005 & TRN \\
\hline CHEMBL1470234 & 688267 & 4.7 & 5.01699 & 99999999995 & TRN \\
\hline CHEMBL1448413 & 688267 & 6.15 & 4.9717 & TRN & \\
\hline CHEMBL1315482 & 688267 & 5.2 & 5.0829 & TRN & \\
\hline CHEMBL1518414 & 688267 & 4.45 & 5.1441 & TRN & \\
\hline CHEMBL3210667 & 688267 & 5.35 & 5.0228 & TST & \\
\hline CHEMBL1595501 & 688267 & 6.2 & 5.0886 & TRN & \\
\hline CHEMBL1503858 & 688267 & 6.15 & 5.0631 & TRN & \\
\hline CHEMBL1532821 & 688267 & 4.35 & 5.0453 & TRN & \\
\hline CHEMBL1517274 & 688267 & 6.15 & 5.0424 & TRN & \\
\hline CHEMBL1552954 & 688267 & 4.05 & 5.069 & TRN & \\
\hline CHEMBL1499238 & 688267 & 5.0 & 5.035 & TRN & \\
\hline CHEMBL3210820 & 688267 & 5.1 & 5.0381 & TST & \\
\hline CHEMBL1591922 & 688267 & 4.3 & 5.1067 & TRN & \\
\hline CHEMBL1336339 & 688267 & 4.1 & 5.0326 & TRN & \\
\hline CHEMBL1545248 & 688267 & 5.75 & 5.0637 & TRN & \\
\hline CHEMBL1428405 & 688267 & 4.9 & 5.033 & TRN & \\
\hline CHEMBL1358312 & 688267 & 6.15 & 5.0276 & TRN & \\
\hline CHEMBL1498544 & 688267 & 6.45 & 5.1057 & TRN & \\
\hline CHEMBL1334896 & 688267 & 4.4 & 5.1145 & TRN & \\
\hline CHEMBL1487447 & 688267 & 5.35 & 5.0332 & TRN & \\
\hline CHEMBL1558766 & 688267 & 6.2 & 5.0468 & TRN & \\
\hline & & & & 18297 & \\
\hline
\end{tabular}




\begin{tabular}{|c|c|c|c|c|}
\hline \multicolumn{5}{|c|}{ Supplemental Table S2.txt } \\
\hline CHEMBL1474655 & 688267 & 4.45 & 5.0101 & TRN \\
\hline CHEMBL1551689 & 688267 & 5.2 & 5.0471 & TRN \\
\hline CHEMBL1509955 & 688267 & 5.55 & 5.1246 & TRN \\
\hline CHEMBL1470256 & 688267 & 5.9 & 5.0035 & TST \\
\hline CHEMBL1563634 & 688267 & 4.55 & 5.0292 & TRN \\
\hline CHEMBL1608851 & 688267 & 5.6 & 5.0692 & TRN \\
\hline CHEMBL1559178 & 688267 & 6.05 & 5.0505 & TRN \\
\hline CHEMBL1395766 & 688267 & 4.0 & 5.0349 & TRN \\
\hline CHEMBL597874 & 688267 & 4.6 & 5.0546 & TST \\
\hline CHEMBL1353824 & 688267 & 5.75 & 5.0322 & TST \\
\hline CHEMBL1558781 & 688267 & 6.15 & 5.0383 & TRN \\
\hline CHEMBL1453781 & 688267 & 4.3 & 5.0234 & TRN \\
\hline CHEMBL1558224 & 688267 & 4.0 & 5.131 & TRN \\
\hline CHEMBL1387404 & 688267 & 4.25 & 5.0198 & TST \\
\hline CHEMBL1545096 & 688267 & 6.15 & 5.1526 & TRN \\
\hline CHEMBL1353481 & 688267 & 4.45 & 5.0052 & TST \\
\hline CHEMBL1414260 & 688267 & 5.3 & 5.0632 & TRN \\
\hline CHEMBL1354910 & 688267 & 5.3 & 5.0241 & TRN \\
\hline CHEMBL1474405 & 688267 & 5.85 & 5.0467 & TRN \\
\hline CHEMBL1565537 & 688267 & 5.7 & 5.0345 & TST \\
\hline CHEMBL1502865 & 688267 & 5.35 & 5.0237 & TRN \\
\hline CHEMBL1410440 & 688267 & 5.85 & 5.0985 & TRN \\
\hline CHEMBL1433399 & 688267 & 6.6499 & 5.0194 & TRN \\
\hline CHEMBL 366435 & 688267 & 4.55 & 5.0039 & TRN \\
\hline CHEMBL1482906 & 688267 & 5.2 & 5.0147 & TST \\
\hline CHEMBL1349466 & 688267 & 4.0 & 5.1294 & TRN \\
\hline CHEMBL1429744 & 688267 & 4.1 & 5.025 & TRN \\
\hline CHEMBL 2236983 & 688267 & 4.0 & 4.9992 & TRN \\
\hline CHEMBL1528269 & 688267 & 4.05 & 5.1749 & TRN \\
\hline CHEMBL 1431206 & 688267 & 4.75 & 5.0513 & TRN \\
\hline CHEMBL1477409 & 688267 & 5.4 & 5.0199 & TRN \\
\hline CHEMBL1565579 & 688267 & 5.55 & 5.1541 & TRN \\
\hline CHEMBL1602822 & 688267 & 6.2 & 5.1491 & TRN \\
\hline CHEMBL1564861 & 688267 & 3.95 & 5.0739 & TRN \\
\hline CHEMBL1464564 & 688267 & 6.15 & 5.077 & TST \\
\hline CHEMBL1598827 & 688267 & 6.0 & 5.0917 & TRN \\
\hline CHEMBL1560618 & 688267 & 4.6 & 5.0637 & TRN \\
\hline CHEMBL1304631 & 688267 & 4.3 & 5.01399 & 9999999999 \\
\hline CHEMBL1310748 & 688267 & 6.2 & 5.1247 & TST \\
\hline CHEMBL1488773 & 688267 & 4.4 & 5.0897 & TRN \\
\hline CHEMBL1596888 & 688267 & 4.55 & 5.1117 & TRN \\
\hline CHEMBL1526844 & 688267 & 4.5 & 5.0591 & TRN \\
\hline CHEMBL1564986 & 688267 & 4.35 & 5.0256 & TRN \\
\hline CHEMBL1611183 & 688267 & 3.85 & 5.0359 & TST \\
\hline CHEMBL1432323 & 688267 & 5.2 & 5.0817 & TRN \\
\hline CHEMBL1431446 & 688267 & 5.55 & 5.0544 & TRN \\
\hline CHEMBL1496878 & 688267 & 5.85 & 5.0245 & TST \\
\hline CHEMBL1326763 & 688267 & 4.0 & 5.072 & TRN \\
\hline
\end{tabular}




\begin{tabular}{|c|c|c|c|c|c|}
\hline \\
\hline CHEMBL1452424 & 688267 & 5.5 & 4.9997 & TRN & \\
\hline CHEMBL1545507 & 688267 & 6.15 & 5.0269 & TST & \\
\hline CHEMBL1483179 & 688267 & 4.1 & 5.1156 & TST & \\
\hline CHEMBL1363804 & 688267 & 4.0 & 5.0649 & TRN & \\
\hline CHEMBL1306779 & 688267 & 5.5 & 5.0738 & TRN & \\
\hline CHEMBL1417981 & 688267 & 6.5 & 5.0565 & TRN & \\
\hline CHEMBL1501001 & 688267 & 4.75 & 5.015 & TST & \\
\hline CHEMBL3213836 & 688267 & 4.55 & 5.0576 & TST & \\
\hline CHEMBL1467065 & 688267 & 5.2 & 5.0704 & TRN & \\
\hline CHEMBL1323624 & 688267 & 5.85 & 5.0055 & TRN & \\
\hline CHEMBL454060 & 688267 & 4.35 & 5.0583 & TST & \\
\hline CHEMBL1572745 & 688267 & 4.3 & 5.0243 & TRN & \\
\hline CHEMBL3193263 & 688267 & 4.7 & 5.0641 & TST & \\
\hline CHEMBL507237 & 688267 & 6.5 & 5.0562 & TST & \\
\hline CHEMBL1514864 & 688267 & 4.85 & 5.0197 & TRN & \\
\hline CHEMBL1577036 & 688267 & 5.7 & 5.0206 & TST & \\
\hline CHEMBL1443344 & 688267 & 4.55 & 5.06800 & 00000000005 & TRN \\
\hline CHEMBL1491490 & 688267 & 6.25 & 5.0963 & TRN & \\
\hline CHEMBL1610252 & 688267 & 4.95 & 5.0795 & TRN & \\
\hline CHEMBL1369340 & 688267 & 4.4 & 5.0235 & TRN & \\
\hline CHEMBL1604705 & 688267 & 6.2 & 5.105 & TRN & \\
\hline CHEMBL1416112 & 688267 & 6.45 & 4.9965 & TRN & \\
\hline CHEMBL1411672 & 688267 & 5.75 & 5.0075 & TST & \\
\hline CHEMBL1338011 & 688267 & 5.85 & 5.0371 & TRN & \\
\hline CHEMBL1355117 & 688267 & 5.45 & 5.0235 & TRN & \\
\hline CHEMBL1537091 & 688267 & 4.0 & 5.0006 & TST & \\
\hline CHEMBL1361353 & 688267 & 6.2 & 5.0611 & TST & \\
\hline CHEMBL1360932 & 688267 & 4.1 & 5.0769 & TRN & \\
\hline CHEMBL1388759 & 688267 & 6.45 & 5.1548 & TRN & \\
\hline CHEMBL1375704 & 688267 & 6.15 & 5.0746 & TRN & \\
\hline CHEMBL3210650 & 688267 & 4.85 & 5.0175 & TRN & \\
\hline CHEMBL1474306 & 688267 & 4.0 & 5.066 & TRN & \\
\hline CHEMBL1483446 & 688267 & 4.55 & 5.0453 & TRN & \\
\hline CHEMBL1580200 & 688267 & 6.2 & 5.1355 & TRN & \\
\hline CHEMBL1372516 & 688267 & 6.15 & 5.1203 & TRN & \\
\hline CHEMBL3199412 & 688267 & 4.05 & 5.0019 & TRN & \\
\hline CHEMBL1561104 & 688267 & 6.25 & 5.1066 & TST & \\
\hline CHEMBL1548970 & 688267 & 6.45 & 4.9996 & TRN & \\
\hline CHEMBL1588117 & 688267 & 4.05 & 5.0585 & TRN & \\
\hline CHEMBL1609923 & 688267 & 5.5 & 5.112 & TST & \\
\hline CHEMBL1612441 & 688267 & 6.2 & 5.0848 & TRN & \\
\hline CHEMBL1611194 & 688267 & 4.2 & 5.0443 & TRN & \\
\hline CHEMBL1549391 & 688267 & 6.2 & 5.0689 & TST & \\
\hline CHEMBL1515531 & 688267 & 5.3 & 5.0599 & TRN & \\
\hline CHEMBL1477253 & 688267 & 4.05 & 5.0934 & TRN & \\
\hline CHEMBL1455411 & 688267 & 5.55 & 5.0182 & TRN & \\
\hline CHEMBL1466686 & 688267 & 6.2 & 5.0856 & TRN & \\
\hline CHEMBL1539467 & 688267 & 6.45 & 5.0696 & TST & \\
\hline
\end{tabular}




\begin{tabular}{|c|c|c|c|c|c|}
\hline & & \multicolumn{4}{|c|}{ Supplemental Table S2.txt } \\
\hline CHEMBL1342282 & 688267 & 4.7 & 5.05399 & 9999999999 & TRN \\
\hline CHEMBL1366689 & 688267 & 4.05 & 5.1028 & TRN & \\
\hline CHEMBL1356534 & 688267 & 3.95 & 5.0287 & TRN & \\
\hline CHEMBL1504962 & 688267 & 4.05 & 5.1198 & TRN & \\
\hline CHEMBL1397345 & 688267 & 4.35 & 5.0805 & TRN & \\
\hline CHEMBL1311299 & 688267 & 5.65 & 5.039 & TRN & \\
\hline CHEMBL1609147 & 688267 & 4.05 & 5.1189 & TST & \\
\hline CHEMBL1604315 & 688267 & 5.45 & 5.0402 & TRN & \\
\hline CHEMBL1451939 & 688267 & 4.0 & 5.0254 & TRN & \\
\hline CHEMBL1337228 & 688267 & 5.65 & 5.0345 & TRN & \\
\hline CHEMBL1608951 & 688267 & 5.55 & 5.058 & TST & \\
\hline CHEMBL1463903 & 688267 & 6.15 & 5.0044 & TRN & \\
\hline CHEMBL578257 & 688267 & 4.05 & 5.0062 & TST & \\
\hline CHEMBL3192499 & 688267 & 5.8 & 5.0002 & TRN & \\
\hline CHEMBL1421379 & 688267 & 5.9 & 5.085 & TST & \\
\hline CHEMBL1600313 & 688267 & 4.35 & 5.0121 & TRN & \\
\hline CHEMBL1560773 & 688267 & 4.35 & 5.0799 & TST & \\
\hline CHEMBL1587318 & 688267 & 4.75 & 5.0291 & TRN & \\
\hline CHEMBL1512169 & 688267 & 4.4 & 5.069 & TRN & \\
\hline CHEMBL1394555 & 688267 & 4.25 & 5.037 & TRN & \\
\hline CHEMBL1456935 & 688267 & 5.3 & 5.1281 & TRN & \\
\hline CHEMBL1603263 & 688267 & 5.3 & 5.0242 & TRN & \\
\hline CHEMBL1314336 & 688267 & 6.2 & 5.0215 & TRN & \\
\hline CHEMBL1388883 & 688267 & 5.35 & 5.0884 & TRN & \\
\hline CHEMBL1569631 & 688267 & 4.1 & 5.0571 & TST & \\
\hline CHEMBL1234599 & 688267 & 6.2 & 5.1445 & TRN & \\
\hline CHEMBL1430485 & 688267 & 4.0 & 5.0947 & TRN & \\
\hline CHEMBL1444615 & 688267 & 3.95 & 5.0265 & TRN & \\
\hline CHEMBL1538829 & 688267 & 4.6 & 5.0154 & TRN & \\
\hline CHEMBL1478292 & 688267 & 4.0 & 5.07100 & 0000000001 & TRN \\
\hline CHEMBL1570681 & 688267 & 5.5 & 5.099 & TRN & \\
\hline CHEMBL1592713 & 688267 & 5.75 & 5.1051 & TRN & \\
\hline CHEMBL1592993 & 688267 & 5.35 & 5.0707 & TRN & \\
\hline CHEMBL1305752 & 688267 & 4.45 & 5.0105 & TST & \\
\hline CHEMBL1311414 & 688267 & 4.4 & 5.077 & TRN & \\
\hline CHEMBL1323105 & 688267 & 5.35 & 5.0806 & TRN & \\
\hline CHEMBL1506703 & 688267 & 4.35 & 5.0768 & TRN & \\
\hline CHEMBL1378436 & 688267 & 5.95 & 5.1042 & TRN & \\
\hline CHEMBL1373518 & 688267 & 4.0 & 5.1215 & TRN & \\
\hline CHEMBL1323827 & 688267 & 5.35 & 5.069 & TRN & \\
\hline CHEMBL1580331 & 688267 & 5.15 & 5.0688 & TST & \\
\hline CHEMBL1531264 & 688267 & 4.5 & 5.0777 & TRN & \\
\hline CHEMBL1430936 & 688267 & 6.2 & 5.0171 & TRN & \\
\hline CHEMBL1599919 & 688267 & 6.15 & 5.0772 & TRN & \\
\hline CHEMBL1510814 & 688267 & 5.25 & 5.0547 & TRN & \\
\hline CHEMBL1370363 & 688267 & 4.05 & 5.1246 & TRN & \\
\hline CHEMBL1449182 & 688267 & 5.3 & 5.0896 & TRN & \\
\hline CHEMBL1337020 & 688267 & 4.0 & 5.1103 & TRN & \\
\hline
\end{tabular}




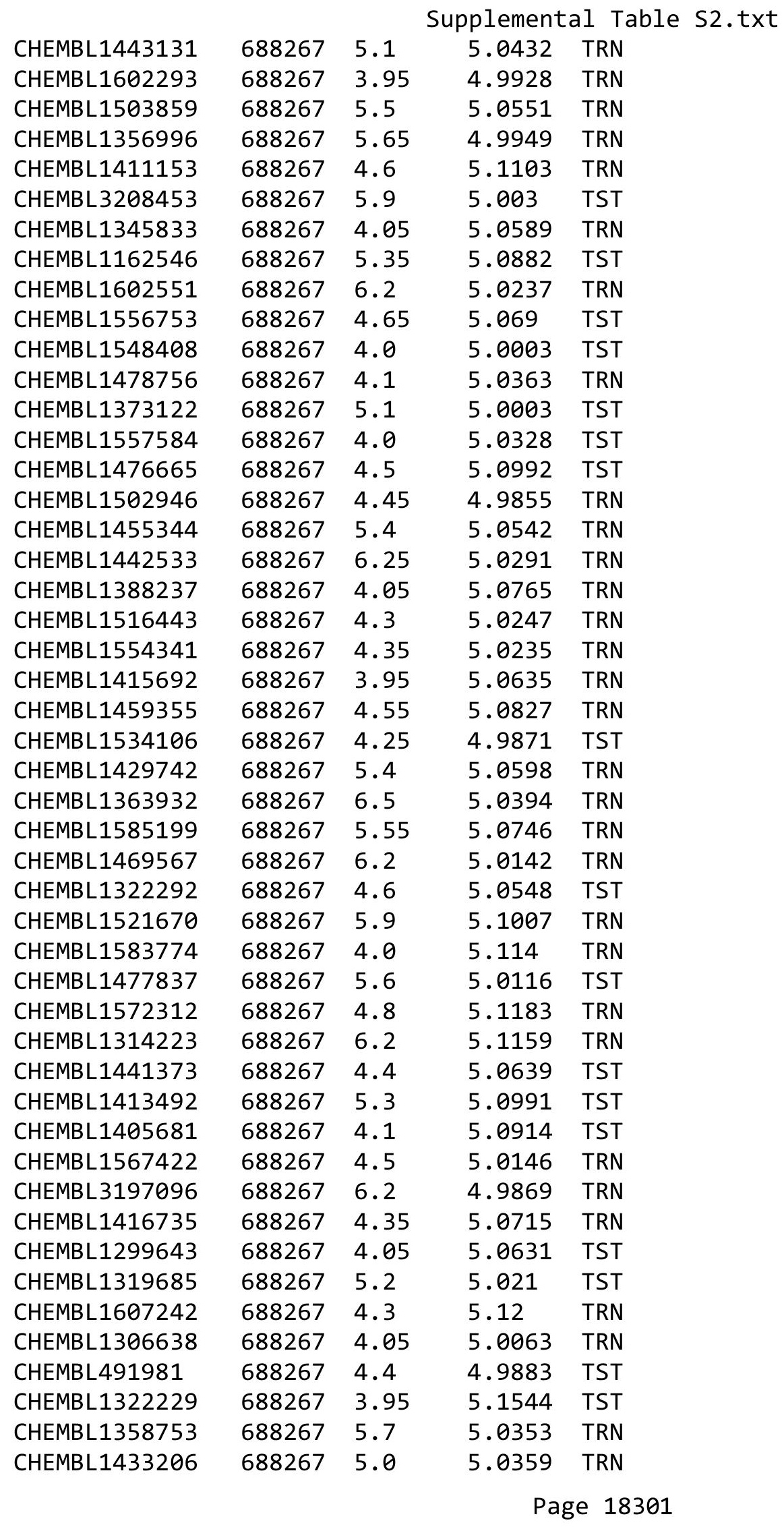




\begin{tabular}{|c|c|c|c|c|}
\hline & & & ipplement & al Table S \\
\hline CHEMBL1990586 & 688267 & 5.0 & 5.0423 & TRN \\
\hline CHEMBL1484886 & 688267 & 6.5 & 5.1009 & TRN \\
\hline CHEMBL1454258 & 688267 & 5.0 & 5.0322 & TRN \\
\hline CHEMBL1498897 & 688267 & 6.25 & 5.091 & TRN \\
\hline CHEMBL3212027 & 688267 & 5.95 & 5.0605 & TRN \\
\hline CHEMBL1498921 & 688267 & 6.2 & 5.1305 & TST \\
\hline CHEMBL1425765 & 688267 & 4.6 & 5.0401 & TRN \\
\hline CHEMBL1968992 & 688267 & 6.2 & 4.9899 & TRN \\
\hline CHEMBL1334080 & 688267 & 6.0 & 5.0638 & TRN \\
\hline CHEMBL1329622 & 688267 & 4.6 & 5.0659 & TST \\
\hline CHEMBL1533634 & 688267 & 4.5 & 5.0416 & TRN \\
\hline CHEMBL1544147 & 688267 & 4.1 & 5.0411 & TST \\
\hline CHEMBL1372768 & 688267 & 4.9 & 5.03100 & 0000000001 \\
\hline CHEMBL1328063 & 688267 & 4.0 & 5.0074 & TRN \\
\hline CHEMBL1592908 & 688267 & 5.9 & 5.0714 & TRN \\
\hline CHEMBL1587528 & 688267 & 6.1 & 5.0815 & TRN \\
\hline CHEMBL3211005 & 688267 & 5.05 & 5.0122 & TST \\
\hline CHEMBL1446891 & 688267 & 4.0 & 5.0793 & TRN \\
\hline CHEMBL3214547 & 688267 & 4.0 & 5.0374 & TST \\
\hline CHEMBL1395188 & 688267 & 4.4 & 5.0621 & TST \\
\hline CHEMBL1542423 & 688267 & 5.75 & 4.995 & TRN \\
\hline CHEMBL1552583 & 688267 & 5.75 & 5.1028 & TRN \\
\hline CHEMBL1095804 & 688267 & 5.45 & 5.0366 & TST \\
\hline CHEMBL1526616 & 688267 & 4.0 & 5.0649 & TRN \\
\hline CHEMBL1455550 & 688267 & 4.4 & 5.0835 & TRN \\
\hline CHEMBL1439045 & 688267 & 3.95 & 5.0515 & TRN \\
\hline CHEMBL1476454 & 688267 & 4.3 & 5.0629 & TRN \\
\hline CHEMBL1550860 & 688267 & 5.05 & 5.0255 & TRN \\
\hline CHEMBL1316219 & 688267 & 4.4 & 5.0321 & TST \\
\hline CHEMBL1479020 & 688267 & 4.05 & 5.0627 & TST \\
\hline CHEMBL1499398 & 688267 & 5.4 & 5.0175 & TRN \\
\hline CHEMBL1487413 & 688267 & 6.2 & 5.117 & TST \\
\hline CHEMBL1415907 & 688267 & 4.4 & 5.0241 & TST \\
\hline CHEMBL1523653 & 688267 & 5.95 & 5.0814 & TRN \\
\hline CHEMBL1553307 & 688267 & 4.25 & 5.053 & TST \\
\hline CHEMBL1509104 & 688267 & 6.15 & 5.0658 & TRN \\
\hline CHEMBL1352161 & 688267 & 6.2 & 5.0281 & TST \\
\hline CHEMBL1505446 & 688267 & 6.2 & 5.1128 & TRN \\
\hline CHEMBL1500691 & 688267 & 4.4 & 5.0515 & TST \\
\hline CHEMBL1372170 & 688267 & 4.4 & 5.045 & TRN \\
\hline CHEMBL1454722 & 688267 & 4.3 & 5.0733 & TST \\
\hline CHEMBL1383210 & 688267 & 6.2 & 5.0596 & TRN \\
\hline CHEMBL1323850 & 688267 & 3.95 & 5.1298 & TRN \\
\hline CHEMBL1462051 & 688267 & 5.3 & 5.011 & TST \\
\hline CHEMBL1594261 & 688267 & 4.05 & 5.0285 & TST \\
\hline CHEMBL3197946 & 688267 & 6.1 & 5.0169 & TST \\
\hline CHEMBL1529349 & 688267 & 5.3 & 5.1082 & TRN \\
\hline CHEMBL1312631 & 688267 & 6.25 & 5.0856 & TRN \\
\hline
\end{tabular}




\begin{tabular}{|c|c|c|c|c|c|}
\hline \\
\hline CHEMBL1581961 & 688267 & 5.0 & 4.9929 & TRN & \\
\hline CHEMBL1392642 & 688267 & 5.75 & 5.1266 & TRN & \\
\hline CHEMBL1459840 & 688267 & 6.5501 & 5.0714 & TRN & \\
\hline CHEMBL1303706 & 688267 & 5.55 & 5.0348 & TRN & \\
\hline CHEMBL3195436 & 688267 & 4.0 & 5.0202 & TRN & \\
\hline CHEMBL1444044 & 688267 & 4.35 & 5.1164 & TST & \\
\hline CHEMBL1570688 & 688267 & 4.4 & 4.9922 & TRN & \\
\hline CHEMBL1593905 & 688267 & 4.0 & 5.0058 & TRN & \\
\hline CHEMBL1601705 & 688267 & 5.8 & 5.0909 & TRN & \\
\hline CHEMBL1393745 & 688267 & 5.35 & 5.0912 & TRN & \\
\hline CHEMBL1606408 & 688267 & 4.05 & 5.0075 & TST & \\
\hline CHEMBL1531176 & 688267 & 5.0 & 5.0072 & TRN & \\
\hline CHEMBL1535451 & 688267 & 5.3 & 5.0176 & TRN & \\
\hline CHEMBL1390238 & 688267 & 5.0 & 5.0875 & TRN & \\
\hline CHEMBL1475632 & 688267 & 6.2 & 5.1135 & TRN & \\
\hline CHEMBL 1605430 & 688267 & 5.4 & 5.021 & TST & \\
\hline CHEMBL247129 & 688267 & 5.5 & 4.9844 & TRN & \\
\hline CHEMBL1518921 & 688267 & 5.8 & 5.041 & TST & \\
\hline CHEMBL1551880 & 688267 & 6.45 & 5.0801 & TRN & \\
\hline CHEMBL1537122 & 688267 & 4.05 & 5.0415 & TRN & \\
\hline CHEMBL1562051 & 688267 & 6.2 & 5.0073 & TRN & \\
\hline CHEMBL1498737 & 688267 & 6.2 & 5.0263 & TST & \\
\hline CHEMBL1511434 & 688267 & 4.35 & 5.0717 & TRN & \\
\hline CHEMBL1458152 & 688267 & 4.7 & 5.0243 & TRN & \\
\hline CHEMBL1410996 & 688267 & 5.25 & 5.05699 & 99999999995 & TRN \\
\hline CHEMBL1480629 & 688267 & 5.6 & 5.064 & TRN & \\
\hline CHEMBL1458171 & 688267 & 4.75 & 5.0173 & TST & \\
\hline CHEMBL1495036 & 688267 & 4.0 & 5.0186 & TRN & \\
\hline CHEMBL1494141 & 688267 & 5.65 & 5.0168 & TRN & \\
\hline CHEMBL1613255 & 688267 & 6.0 & 5.0752 & TST & \\
\hline CHEMBL1464985 & 688267 & 4.0 & 5.0234 & TRN & \\
\hline CHEMBL1404456 & 688267 & 5.2 & 5.0103 & TST & \\
\hline CHEMBL1587023 & 688267 & 5.25 & 5.0517 & TST & \\
\hline CHEMBL1507558 & 688267 & 4.4 & 5.0557 & TRN & \\
\hline CHEMBL1506256 & 688267 & 4.1 & 5.0618 & TST & \\
\hline CHEMBL1471550 & 688267 & 4.2 & 5.1109 & TRN & \\
\hline CHEMBL1505565 & 688267 & 6.0 & 5.0088 & TST & \\
\hline CHEMBL1392236 & 688267 & 5.3 & 5.0385 & TRN & \\
\hline CHEMBL1548044 & 688267 & 5.1 & 5.0006 & TRN & \\
\hline CHEMBL1408281 & 688267 & 4.25 & 4.9526 & TRN & \\
\hline CHEMBL1463647 & 688267 & 4.8 & 5.0679 & TST & \\
\hline CHEMBL1330313 & 688267 & 4.4 & 5.0945 & TRN & \\
\hline CHEMBL1433333 & 688267 & 5.3 & 5.053 & TST & \\
\hline CHEMBL1471548 & 688267 & 5.8 & 5.0718 & TRN & \\
\hline CHEMBL1508326 & 688267 & 4.0 & 5.0465 & TRN & \\
\hline CHEMBL1346611 & 688267 & 5.0 & 5.0937 & TRN & \\
\hline CHEMBL1601889 & 688267 & 4.4 & 5.0472 & TST & \\
\hline CHEMBL1339236 & 688267 & 5.9 & 5.1794 & TST & \\
\hline & & & & 18303 & \\
\hline
\end{tabular}




\begin{tabular}{|c|c|c|c|c|}
\hline \multicolumn{5}{|c|}{ Supplemental Table S2.txt } \\
\hline CHEMBL1591786 & 688267 & 4.5 & 5.0877 & TRN \\
\hline CHEMBL1504589 & 688267 & 4.5 & 5.1656 & TRN \\
\hline CHEMBL1325324 & 688267 & 5.45 & 5.0584 & TST \\
\hline CHEMBL1456075 & 688267 & 5.35 & 4.9804 & TRN \\
\hline CHEMBL3195104 & 688267 & 4.6 & 4.9873 & TRN \\
\hline CHEMBL1593952 & 688267 & 3.95 & 5.0433 & TRN \\
\hline CHEMBL3190291 & 688267 & 6.5 & 4.9977 & TRN \\
\hline CHEMBL1591572 & 688267 & 4.95 & 5.1588 & TRN \\
\hline CHEMBL1570915 & 688267 & 5.5 & 4.976 & TST \\
\hline CHEMBL3189733 & 688267 & 4.45 & 5.0145 & TRN \\
\hline CHEMBL 3212210 & 688267 & 5.35 & 5.0215 & TST \\
\hline CHEMBL1307580 & 688267 & 6.2 & 5.0481 & TRN \\
\hline CHEMBL1373665 & 688267 & 4.15 & 4.995 & TST \\
\hline CHEMBL1410421 & 688267 & 5.5 & 5.0234 & TRN \\
\hline CHEMBL1382964 & 688267 & 6.2 & 5.0179 & TST \\
\hline CHEMBL3209543 & 688267 & 5.0 & 5.0359 & TRN \\
\hline CHEMBL1459093 & 688267 & 4.0 & 5.0205 & TRN \\
\hline CHEMBL1384314 & 688267 & 5.2 & 5.13 & TRN \\
\hline CHEMBL1433927 & 688267 & 5.45 & 5.0393 & TRN \\
\hline CHEMBL1373985 & 688267 & 5.4 & 5.0217 & TST \\
\hline CHEMBL1541169 & 688267 & 3.95 & 5.0038 & TRN \\
\hline CHEMBL1462368 & 688267 & 4.5 & 5.0763 & TRN \\
\hline CHEMBL1601691 & 688267 & 6.5 & 5.0982 & TRN \\
\hline CHEMBL1329609 & 688267 & 5.4 & 5.1056 & TRN \\
\hline CHEMBL1387272 & 688267 & 4.35 & 5.0836 & TRN \\
\hline CHEMBL1338518 & 688267 & 5.15 & 5.0461 & TRN \\
\hline CHEMBL1564467 & 688267 & 4.95 & 5.0249 & TRN \\
\hline CHEMBL1325011 & 688267 & 5.0 & 5.0684 & TRN \\
\hline CHEMBL3195755 & 688267 & 5.85 & 5.0044 & TRN \\
\hline CHEMBL1500961 & 688267 & 6.15 & 5.0403 & TRN \\
\hline CHEMBL1392551 & 688267 & 4.0 & 5.0209 & TST \\
\hline CHEMBL1315890 & 688267 & 6.5 & 5.0341 & TRN \\
\hline CHEMBL1454753 & 688267 & 6.5 & 4.9711 & TRN \\
\hline CHEMBL3145381 & 688267 & 4.4 & 5.1209 & TRN \\
\hline CHEMBL1603031 & 688267 & 5.1 & 5.1402 & TRN \\
\hline CHEMBL1308453 & 688267 & 4.5 & 5.0701 & TST \\
\hline CHEMBL1425531 & 688267 & 5.45 & 5.0617 & TRN \\
\hline CHEMBL1384609 & 688267 & 4.55 & 5.0549 & TST \\
\hline CHEMBL3199302 & 688267 & 6.2 & 5.0037 & TST \\
\hline CHEMBL1484881 & 688267 & 6.2 & 5.061 & TRN \\
\hline CHEMBL1440520 & 688267 & 6.15 & 5.0251 & TRN \\
\hline CHEMBL1472769 & 688267 & 4.1 & 5.0012 & TRN \\
\hline CHEMBL1468992 & 688267 & 6.2 & 5.0222 & TST \\
\hline CHEMBL1411948 & 688267 & 5.05 & 5.11 & TRN \\
\hline CHEMBL1491687 & 688267 & 4.7 & 5.0333 & TST \\
\hline CHEMBL1580746 & 688267 & 5.3 & 5.1176 & TRN \\
\hline CHEMBL1599268 & 688267 & 5.4 & 5.0544 & TST \\
\hline CHEMBL1485683 & 688267 & 4.0 & 5.0259 & TRN \\
\hline
\end{tabular}




\begin{tabular}{|c|c|c|c|c|}
\hline & & & pplement & al Table S \\
\hline CHEMBL1359738 & 688267 & 6.05 & 5.1142 & TRN \\
\hline CHEMBL1365593 & 688267 & 6.2 & 5.0625 & TRN \\
\hline CHEMBL 3197987 & 688267 & 4.35 & $5.0310 e$ & 0000000001 \\
\hline CHEMBL1372969 & 688267 & 5.55 & 5.1169 & TRN \\
\hline CHEMBL1589454 & 688267 & 4.4 & 4.9995 & TRN \\
\hline CHEMBL1525208 & 688267 & 4.3 & 5.0542 & TRN \\
\hline CHEMBL1382000 & 688267 & 5.1 & 5.0648 & TRN \\
\hline CHEMBL1377860 & 688267 & 4.0 & 5.0667 & TRN \\
\hline CHEMBL1589985 & 688267 & 5.15 & 5.0587 & TRN \\
\hline CHEMBL1335917 & 688267 & 6.45 & 5.118 & TRN \\
\hline CHEMBL1357357 & 688267 & 4.05 & 5.0449 & TRN \\
\hline CHEMBL1454419 & 688267 & 6.2 & 5.0719 & TST \\
\hline CHEMBL1565771 & 688267 & 4.85 & 5.0639 & TRN \\
\hline CHEMBL1488231 & 688267 & 6.0 & 5.0189 & TRN \\
\hline CHEMBL1323926 & 688267 & 5.5 & 5.0584 & TRN \\
\hline CHEMBL1400964 & 688267 & 4.75 & 5.0534 & TRN \\
\hline CHEMBL1481273 & 688267 & 3.95 & 5.0132 & TST \\
\hline CHEMBL1323299 & 688267 & 5.6 & 5.0782 & TRN \\
\hline CHEMBL1357023 & 688267 & 5.55 & 5.1317 & TRN \\
\hline CHEMBL1470170 & 688267 & 4.25 & 5.1173 & TRN \\
\hline CHEMBL1611337 & 688267 & 4.8 & 5.0742 & TST \\
\hline CHEMBL1610112 & 688267 & 6.15 & 5.1151 & TST \\
\hline CHEMBL1317993 & 688267 & 5.45 & 5.0318 & TRN \\
\hline CHEMBL1300524 & 688267 & 5.3 & 5.0202 & TRN \\
\hline CHEMBL1310704 & 688267 & 5.8 & 5.087 & TRN \\
\hline CHEMBL1300486 & 688267 & 4.6 & 5.0153 & TRN \\
\hline CHEMBL1468608 & 688267 & 5.25 & 5.1242 & TRN \\
\hline CHEMBL1393561 & 688267 & 4.4 & 5.1204 & TST \\
\hline CHEMBL1447957 & 688267 & 5.3 & 5.048 & TRN \\
\hline CHEMBL1440813 & 688267 & 6.2 & 5.0309 & TRN \\
\hline CHEMBL1345784 & 688267 & 4.45 & 5.0622 & TRN \\
\hline CHEMBL1582677 & 688267 & 4.05 & 5.0811 & TST \\
\hline CHEMBL1408993 & 688267 & 6.2 & 5.0791 & TRN \\
\hline CHEMBL1368769 & 688267 & 6.1 & 5.0675 & TRN \\
\hline CHEMBL1381207 & 688267 & 5.0 & 5.1133 & TST \\
\hline CHEMBL1607500 & 688267 & 6.5 & 5.1327 & TRN \\
\hline CHEMBL1493794 & 688267 & 5.5 & 5.0878 & TRN \\
\hline CHEMBL1481291 & 688267 & 6.2 & 5.0539 & TRN \\
\hline CHEMBL1578924 & 688267 & 4.05 & 5.0058 & TRN \\
\hline CHEMBL1613666 & 688267 & 4.6 & 5.067 & TRN \\
\hline CHEMBL1305520 & 688267 & 4.45 & 5.0013 & TRN \\
\hline CHEMBL 3210392 & 688267 & 4.0 & 5.0773 & TRN \\
\hline CHEMBL1347024 & 688267 & 5.9 & 5.0178 & TRN \\
\hline CHEMBL1411164 & 688267 & 6.2 & 5.0375 & TRN \\
\hline CHEMBL1405557 & 688267 & 4.4 & 5.1255 & TST \\
\hline CHEMBL1569879 & 688267 & 6.5 & 4.9836 & TST \\
\hline CHEMBL1445498 & 688267 & 5.15 & 5.083 & TRN \\
\hline CHEMBL1339885 & 688267 & 4.55 & 5.0406 & TST \\
\hline
\end{tabular}




\begin{tabular}{|c|c|c|c|c|c|}
\hline \multicolumn{6}{|c|}{ Supplemental Table S2.txt } \\
\hline CHEMBL1464541 & 688267 & 5.55 & 5.0296 & TST & \\
\hline CHEMBL3195168 & 688267 & 4.3 & 5.0408 & TST & \\
\hline CHEMBL1484413 & 688267 & 5.45 & 5.1118 & TST & \\
\hline CHEMBL1256663 & 688267 & 5.55 & 5.0982 & TST & \\
\hline CHEMBL1425857 & 688267 & 4.4 & 5.0666 & TRN & \\
\hline CHEMBL1304753 & 688267 & 6.5 & 5.0701 & TRN & \\
\hline CHEMBL1610481 & 688267 & 4.15 & 5.0342 & TRN & \\
\hline CHEMBL1609562 & 688267 & 4.3 & 5.0923 & TRN & \\
\hline CHEMBL1513216 & 688267 & 5.8 & 5.1158 & TRN & \\
\hline CHEMBL1334801 & 688267 & 4.4 & 5.0497 & TRN & \\
\hline CHEMBL1169930 & 688267 & 5.4 & 5.0746 & TRN & \\
\hline CHEMBL3196968 & 688267 & 5.6 & 4.9987 & TRN & \\
\hline CHEMBL1484033 & 688267 & 6.2 & 5.1162 & TRN & \\
\hline CHEMBL1396770 & 688267 & 5.6 & 5.0274 & TRN & \\
\hline CHEMBL1373078 & 688267 & 6.15 & 5.1194 & TRN & \\
\hline CHEMBL1300771 & 688267 & 4.35 & 5.074 & TRN & \\
\hline CHEMBL92419 & 688267 & 6.5 & 5.1215 & TRN & \\
\hline CHEMBL3189325 & 688267 & 4.2 & 4.9874 & TST & \\
\hline CHEMBL1358437 & 688267 & 4.05 & 5.1099 & TRN & \\
\hline CHEMBL1483475 & 688267 & 5.3 & 5.0886 & TRN & \\
\hline CHEMBL1441068 & 688267 & 4.3 & 5.0702 & TRN & \\
\hline CHEMBL1434383 & 688267 & 4.5 & 5.027 & TRN & \\
\hline CHEMBL1439224 & 688267 & 5.95 & 5.1307 & TRN & \\
\hline CHEMBL1510612 & 688267 & 6.2 & 5.0964 & TRN & \\
\hline CHEMBL1605460 & 688267 & 4.4 & 5.0709 & TST & \\
\hline CHEMBL1517029 & 688267 & 4.45 & 5.0418 & TST & \\
\hline CHEMBL1393731 & 688267 & 6.7001 & 5.0389 & TRN & \\
\hline CHEMBL1343438 & 688267 & 5.3 & 5.086 & TRN & \\
\hline CHEMBL1601338 & 688267 & 5.5 & 5.1035 & TRN & \\
\hline CHEMBL258767 & 688267 & 5.05 & 5.0016 & TRN & \\
\hline CHEMBL3191138 & 688267 & 4.05 & 5.05 & TRN & \\
\hline CHEMBL1518138 & 688267 & 6.2 & 5.0294 & TRN & \\
\hline CHEMBL1532870 & 688267 & 6.15 & 5.0275 & TRN & \\
\hline CHEMBL1551878 & 688267 & 4.7 & 5.03100 & 0000000001 & TRN \\
\hline CHEMBL1456263 & 688267 & 5.4 & 5.1434 & TST & \\
\hline CHEMBL1593052 & 688267 & 6.2 & 5.0329 & TRN & \\
\hline CHEMBL1366368 & 688267 & 4.8 & 5.0514 & TST & \\
\hline CHEMBL1377268 & 688267 & 5.75 & 5.1125 & TRN & \\
\hline CHEMBL1531722 & 688267 & 3.95 & 5.0244 & TRN & \\
\hline CHEMBL1480566 & 688267 & 5.35 & 5.0724 & TRN & \\
\hline CHEMBL1478710 & 688267 & 6.2 & 4.9728 & TRN & \\
\hline CHEMBL1597431 & 688267 & 4.7 & 5.0602 & TRN & \\
\hline CHEMBL1080919 & 688267 & 6.1 & 5.1383 & TRN & \\
\hline CHEMBL1378887 & 688267 & 6.25 & 5.1032 & TRN & \\
\hline CHEMBL1323532 & 688267 & 4.3 & 5.09399 & 9999999999 & TRN \\
\hline CHEMBL1408931 & 688267 & 4.05 & 5.0507 & TRN & \\
\hline CHEMBL1592355 & 688267 & 4.45 & 5.1172 & TRN & \\
\hline CHEMBL1466098 & 688267 & 6.5 & 5.0162 & TRN & \\
\hline
\end{tabular}




\begin{tabular}{|c|c|c|c|c|}
\hline & & & upplement & al $\mathrm{T}$ \\
\hline CHEMBL1340045 & 688267 & 5.0 & 4.9915 & TST \\
\hline CHEMBL1316411 & 688267 & 4.35 & 5.1097 & TRN \\
\hline CHEMBL1547228 & 688267 & 4.1 & 5.0401 & TST \\
\hline CHEMBL1613029 & 688267 & 4.35 & 5.0168 & TST \\
\hline CHEMBL3189958 & 688267 & 3.95 & 5.0656 & TST \\
\hline CHEMBL1497296 & 688267 & 6.2 & 5.02 & TST \\
\hline CHEMBL1318269 & 688267 & 5.4 & 5.0906 & TRN \\
\hline CHEMBL1454337 & 688267 & 4.2 & 5.0754 & TST \\
\hline CHEMBL1312184 & 688267 & 5.0 & 5.0794 & TRN \\
\hline CHEMBL1442733 & 688267 & 5.85 & 4.9973 & TRN \\
\hline CHEMBL1518028 & 688267 & 4.95 & 5.0096 & TRN \\
\hline CHEMBL1470266 & 688267 & 5.25 & 5.1099 & TRN \\
\hline CHEMBL1413784 & 688267 & 4.2 & 4.9825 & TRN \\
\hline CHEMBL1474746 & 688267 & 5.25 & 5.038 & TRN \\
\hline CHEMBL1413270 & 688267 & 6.2 & 5.1065 & TRN \\
\hline CHEMBL1489362 & 688267 & 5.7 & 5.1043 & TRN \\
\hline CHEMBL1361011 & 688267 & 5.3 & 5.0646 & TST \\
\hline CHEMBL1361184 & 688267 & 5.2 & 5.0553 & TRN \\
\hline CHEMBL262871 & 688267 & 6.25 & 5.0372 & TRN \\
\hline CHEMBL1596281 & 688267 & 5.25 & 5.0267 & TRN \\
\hline CHEMBL1487747 & 688267 & 4.0 & 5.0813 & TRN \\
\hline CHEMBL1507102 & 688267 & 4.55 & 5.0894 & TRN \\
\hline CHEMBL1488256 & 688267 & 5.85 & 5.0582 & TRN \\
\hline CHEMBL1605317 & 688267 & 6.25 & 5.0598 & TST \\
\hline CHEMBL1476912 & 688267 & 4.95 & 5.0553 & TRN \\
\hline CHEMBL1380324 & 688267 & 4.35 & 5.0265 & TRN \\
\hline CHEMBL1421386 & 688267 & 5.85 & 5.0178 & TST \\
\hline CHEMBL1591282 & 688267 & 6.25 & 5.0178 & TST \\
\hline CHEMBL1502243 & 688267 & 4.3 & 5.047 & TST \\
\hline CHEMBL1584717 & 688267 & 6.2 & 5.0318 & TRN \\
\hline CHEMBL1477214 & 688267 & 4.5 & 5.0508 & TRN \\
\hline CHEMBL1610064 & 688267 & 5.75 & 5.0174 & TRN \\
\hline CHEMBL1403657 & 688267 & 6.15 & 4.9753 & TRN \\
\hline CHEMBL1402840 & 688267 & 4.4 & 4.9812 & TST \\
\hline CHEMBL1584781 & 688267 & 6.15 & 5.0854 & TRN \\
\hline CHEMBL1498873 & 688267 & 6.15 & 5.0085 & TRN \\
\hline CHEMBL1353184 & 688267 & 3.95 & 4.982 & TRN \\
\hline CHEMBL1422928 & 688267 & 4.45 & 5.0092 & TRN \\
\hline CHEMBL1601382 & 688267 & 4.05 & 5.0251 & TRN \\
\hline CHEMBL1567576 & 688267 & 4.3 & 5.0233 & TRN \\
\hline CHEMBL1304924 & 688267 & 4.35 & 5.0908 & TST \\
\hline CHEMBL1445533 & 688267 & 4.4 & 5.0558 & TST \\
\hline CHEMBL1454560 & 688267 & 4.0 & 5.0463 & TRN \\
\hline CHEMBL1504891 & 688267 & 6.15 & 5.1264 & TRN \\
\hline CHEMBL1325559 & 688267 & 3.95 & 5.0558 & TRN \\
\hline CHEMBL1360188 & 688267 & 5.35 & 5.0569 & TRN \\
\hline CHEMBL1578059 & 688267 & 5.5 & 4.9996 & TRN \\
\hline CHEMBL1428025 & 688267 & 4.3 & 5.0498 & TST \\
\hline
\end{tabular}




\begin{tabular}{|c|c|c|c|c|c|}
\hline \multicolumn{6}{|c|}{ Supplemental Table S2.txt } \\
\hline CHEMBL3212937 & 688267 & 6.15 & 5.0236 & TRN & \\
\hline CHEMBL1327079 & 688267 & 5.4 & 5.0234 & TST & \\
\hline CHEMBL1399546 & 688267 & 5.3 & 5.0532 & TRN & \\
\hline CHEMBL1562392 & 688267 & 5.95 & 5.0402 & TRN & \\
\hline CHEMBL1315260 & 688267 & 6.2 & 5.0716 & TRN & \\
\hline CHEMBL1328110 & 688267 & 4.6 & 5.0945 & TRN & \\
\hline CHEMBL1443890 & 688267 & 6.15 & 5.02 & TST & \\
\hline CHEMBL1377744 & 688267 & 6.25 & 5.0488 & TST & \\
\hline CHEMBL1515964 & 688267 & 6.25 & 5.0719 & TRN & \\
\hline CHEMBL1347428 & 688267 & 6.2 & 5.0898 & TRN & \\
\hline CHEMBL 3211385 & 688267 & 5.85 & 5.0767 & TST & \\
\hline CHEMBL1380602 & 688267 & 4.6 & 5.0976 & TRN & \\
\hline CHEMBL1315164 & 688267 & 5.3 & 5.0528 & TRN & \\
\hline CHEMBL1394478 & 688267 & 5.9 & 5.039 & TRN & \\
\hline CHEMBL1475825 & 688267 & 4.4 & 5.0942 & TRN & \\
\hline CHEMBL1570964 & 688267 & 6.15 & 5.001 & TRN & \\
\hline CHEMBL1499983 & 688267 & 4.35 & 5.085 & TRN & \\
\hline CHEMBL1541633 & 688267 & 4.75 & 5.053 & TRN & \\
\hline CHEMBL1567826 & 688267 & 6.25 & 5.0334 & TRN & \\
\hline CHEMBL1416284 & 688267 & 4.05 & 5.0471 & TRN & \\
\hline CHEMBL1525468 & 688267 & 6.5 & 5.0049 & TRN & \\
\hline CHEMBL1366557 & 688267 & 6.2 & 5.0728 & TRN & \\
\hline CHEMBL1570219 & 688267 & 5.1 & 5.0818 & TRN & \\
\hline CHEMBL1351445 & 688267 & 4.0 & 5.0759 & TRN & \\
\hline CHEMBL 3195028 & 688267 & 5.9 & 5.115 & TST & \\
\hline CHEMBL1593257 & 688267 & 6.2 & 5.081 & TRN & \\
\hline CHEMBL1363747 & 688267 & 4.3 & 5.1295 & TRN & \\
\hline CHEMBL1596375 & 688267 & 4.0 & 5.0728 & TRN & \\
\hline CHEMBL1314461 & 688267 & 6.2 & 5.0663 & TST & \\
\hline CHEMBL1548359 & 688267 & 4.05 & 5.03600 & 00000000005 & TRN \\
\hline CHEMBL1598330 & 688267 & 6.25 & 4.988 & TRN & \\
\hline CHEMBL1409503 & 688267 & 5.0 & 5.079 & TST & \\
\hline CHEMBL1598718 & 688267 & 4.05 & 5.0261 & TRN & \\
\hline CHEMBL1401515 & 688267 & 3.95 & 5.0995 & TRN & \\
\hline CHEMBL1381916 & 688267 & 4.55 & 5.1567 & TRN & \\
\hline CHEMBL1395600 & 688267 & 4.1 & 5.0721 & TST & \\
\hline CHEMBL1570622 & 688267 & 6.5 & 5.05399 & 9999999999 & TRN \\
\hline CHEMBL1528536 & 688267 & 5.85 & 5.0548 & TRN & \\
\hline CHEMBL1405140 & 688267 & 5.65 & 5.0923 & TRN & \\
\hline CHEMBL1409759 & 688267 & 4.25 & 5.0563 & TRN & \\
\hline CHEMBL1378050 & 688267 & 5.5 & 5.0758 & TRN & \\
\hline CHEMBL1461621 & 688267 & 5.6 & 5.0425 & TST & \\
\hline CHEMBL1591217 & 688267 & 5.15 & 5.1573 & TRN & \\
\hline CHEMBL1433159 & 688267 & 4.95 & 5.0819 & TRN & \\
\hline CHEMBL1562262 & 688267 & 5.35 & 5.0709 & TRN & \\
\hline CHEMBL1448171 & 688267 & 5.35 & 5.0194 & TST & \\
\hline CHEMBL1462365 & 688267 & 4.05 & 5.024 & TRN & \\
\hline CHEMBL1453912 & 688267 & 3.95 & 5.0688 & TRN & \\
\hline
\end{tabular}




\begin{tabular}{|c|c|c|c|c|c|}
\hline \multicolumn{6}{|c|}{ Supplemental Table S2.txt } \\
\hline CHEMBL1583622 & 688267 & 6.25 & 5.1512 & TRN & \\
\hline CHEMBL1469464 & 688267 & 5.55 & 5.0288 & TRN & \\
\hline CHEMBL1411663 & 688267 & 4.3 & 5.0603 & TRN & \\
\hline CHEMBL1455153 & 688267 & 4.0 & 5.1414 & TRN & \\
\hline CHEMBL1486743 & 688267 & 4.6 & 5.069 & TST & \\
\hline CHEMBL1393172 & 688267 & 6.6 & 4.9867 & TRN & \\
\hline CHEMBL1434974 & 688267 & 4.35 & 5.104 & TRN & \\
\hline CHEMBL1596100 & 688267 & 5.15 & 5.0072 & TRN & \\
\hline CHEMBL1579913 & 688267 & 6.15 & 5.11600 & 00000000005 & TRN \\
\hline CHEMBL1556058 & 688267 & 4.35 & 5.0628 & TRN & \\
\hline CHEMBL1425271 & 688267 & 4.9 & 5.0341 & TST & \\
\hline CHEMBL1330974 & 688267 & 6.2 & 5.086 & TRN & \\
\hline CHEMBL1328293 & 688267 & 5.65 & 5.037 & TST & \\
\hline CHEMBL1466720 & 688267 & 4.35 & 5.1209 & TST & \\
\hline CHEMBL1489034 & 688267 & 5.6 & 5.0523 & TRN & \\
\hline CHEMBL1361162 & 688267 & 5.3 & 5.0002 & TST & \\
\hline CHEMBL1530875 & 688267 & 4.05 & 5.0401 & TRN & \\
\hline CHEMBL1320597 & 688267 & 4.05 & 5.0813 & TRN & \\
\hline CHEMBL1315213 & 688267 & 7.15 & 5.0462 & TRN & \\
\hline CHEMBL3208464 & 688267 & 4.9 & 5.0532 & TRN & \\
\hline CHEMBL1458226 & 688267 & 4.05 & 5.023 & TRN & \\
\hline CHEMBL1360070 & 688267 & 6.2 & 5.0817 & TRN & \\
\hline CHEMBL1496800 & 688267 & 5.3 & 5.0545 & TRN & \\
\hline CHEMBL1586785 & 688267 & 4.55 & 5.1065 & TST & \\
\hline CHEMBL1330094 & 688267 & 4.7 & 5.0607 & TRN & \\
\hline CHEMBL1366543 & 688267 & 5.4 & 5.0944 & TRN & \\
\hline CHEMBL1414133 & 688267 & 4.45 & 5.0805 & TRN & \\
\hline CHEMBL1301126 & 688267 & 6.15 & 5.0526 & TST & \\
\hline CHEMBL1483573 & 688267 & 5.35 & 5.0211 & TST & \\
\hline CHEMBL1347228 & 688267 & 4.35 & 5.1102 & TRN & \\
\hline CHEMBL1507297 & 688267 & 5.0 & 5.0493 & TRN & \\
\hline CHEMBL1360104 & 688267 & 5.4 & 5.0199 & TST & \\
\hline CHEMBL1596431 & 688267 & 4.0 & 4.9747 & TST & \\
\hline CHEMBL1392655 & 688267 & 4.0 & 5.0032 & TRN & \\
\hline CHEMBL1364345 & 688267 & 4.65 & 5.0676 & TRN & \\
\hline CHEMBL1359833 & 688267 & 5.9 & 5.0478 & TRN & \\
\hline CHEMBL1468150 & 688267 & 4.0 & 4.9914 & TRN & \\
\hline CHEMBL1450102 & 688267 & 5.75 & 5.0967 & TRN & \\
\hline CHEMBL1459290 & 688267 & 6.15 & 5.0345 & TRN & \\
\hline CHEMBL1322151 & 688267 & 5.55 & 5.0044 & TRN & \\
\hline CHEMBL1396869 & 688267 & 5.55 & 5.0454 & TST & \\
\hline CHEMBL1431184 & 688267 & 5.9 & 5.024 & TRN & \\
\hline CHEMBL1444112 & 688267 & 3.95 & 5.0145 & TST & \\
\hline CHEMBL1491521 & 688267 & 5.5 & 5.0908 & TRN & \\
\hline CHEMBL1337600 & 688267 & 6.05 & 5.0614 & TRN & \\
\hline CHEMBL1373508 & 688267 & 4.0 & 5.0924 & TRN & \\
\hline CHEMBL1306403 & 688267 & 5.55 & 5.1294 & TRN & \\
\hline CHEMBL1588503 & 688267 & 5.4 & 5.0949 & TRN & \\
\hline
\end{tabular}




\begin{tabular}{|c|c|c|c|c|}
\hline & & & pplement & al $\mathrm{Ta}$ \\
\hline CHEMBL1560360 & 688267 & 6.15 & 4.9987 & TST \\
\hline CHEMBL1566094 & 688267 & 6.25 & 5.11 & TRN \\
\hline CHEMBL1579238 & 688267 & 5.9 & 5.0983 & TST \\
\hline CHEMBL1382333 & 688267 & 6.2 & 5.0693 & TST \\
\hline CHEMBL1365517 & 688267 & 4.0 & 5.0757 & TRN \\
\hline CHEMBL1521857 & 688267 & 4.05 & 5.0436 & TRN \\
\hline CHEMBL1459009 & 688267 & 5.35 & 5.0534 & TRN \\
\hline CHEMBL1588051 & 688267 & 4.05 & 5.1378 & TRN \\
\hline CHEMBL1376196 & 688267 & 5.9 & 5.1424 & TRN \\
\hline CHEMBL1336764 & 688267 & 4.0 & 5.1101 & TRN \\
\hline CHEMBL1302776 & 688267 & 5.55 & 5.079 & TST \\
\hline CHEMBL1488993 & 688267 & 5.55 & 5.0479 & TRN \\
\hline CHEMBL1428945 & 688267 & 4.25 & 5.1085 & TST \\
\hline CHEMBL 1407430 & 688267 & 5.0 & 5.0851 & TRN \\
\hline CHEMBL1429952 & 688267 & 6.0 & 5.1274 & TRN \\
\hline CHEMBL1325305 & 688267 & 4.55 & 5.0476 & TRN \\
\hline CHEMBL1522540 & 688267 & 5.3 & 5.1263 & TRN \\
\hline CHEMBL1511984 & 688267 & 5.5 & 5.0541 & TRN \\
\hline CHEMBL1400194 & 688267 & 4.0 & 5.0864 & TST \\
\hline CHEMBL1448568 & 688267 & 4.05 & 5.0934 & TST \\
\hline CHEMBL1563246 & 688267 & 5.3 & 5.0912 & TST \\
\hline CHEMBL1435103 & 688267 & 4.35 & 5.1258 & TRN \\
\hline CHEMBL1553934 & 688267 & 5.35 & 4.9995 & TRN \\
\hline CHEMBL1516568 & 688267 & 5.8 & 5.0885 & TRN \\
\hline CHEMBL1585515 & 688267 & 4.2 & 5.0241 & TRN \\
\hline CHEMBL1490210 & 688267 & 5.7 & 5.0528 & TRN \\
\hline CHEMBL1494366 & 688267 & 4.05 & 5.0967 & TRN \\
\hline CHEMBL1395802 & 688267 & 4.6 & 5.0712 & TRN \\
\hline CHEMBL1401596 & 688267 & 5.35 & 5.0529 & TST \\
\hline CHEMBL1481430 & 688267 & 4.8 & 5.0934 & TRN \\
\hline CHEMBL1316943 & 688267 & 5.0 & 5.1599 & TRN \\
\hline CHEMBL1469630 & 688267 & 6.25 & 5.0268 & TST \\
\hline CHEMBL1499433 & 688267 & 3.95 & 5.0258 & TRN \\
\hline CHEMBL1524010 & 688267 & 4.15 & 5.0927 & TRN \\
\hline CHEMBL1587160 & 688267 & 4.35 & 5.1037 & TRN \\
\hline CHEMBL1525377 & 688267 & 4.05 & 5.0379 & TRN \\
\hline CHEMBL1485702 & 688267 & 5.35 & 5.063 & TST \\
\hline CHEMBL1330029 & 688267 & 6.2 & 5.0393 & TST \\
\hline CHEMBL1452238 & 688267 & 4.2 & 5.1221 & TST \\
\hline CHEMBL1411138 & 688267 & 5.35 & 5.0368 & TRN \\
\hline CHEMBL1536870 & 688267 & 4.25 & 5.0789 & TST \\
\hline CHEMBL1415741 & 688267 & 5.95 & 5.0305 & TST \\
\hline CHEMBL1357971 & 688267 & 6.25 & 5.0747 & TRN \\
\hline CHEMBL1565709 & 688267 & 6.15 & 5.0534 & TRN \\
\hline CHEMBL1598612 & 688267 & 5.35 & 5.0115 & TRN \\
\hline CHEMBL1498218 & 688267 & 6.25 & 5.0548 & TST \\
\hline CHEMBL1443872 & 688267 & 4.95 & 5.1579 & TST \\
\hline CHEMBL1578250 & 688267 & 5.5 & 5.0433 & TRN \\
\hline
\end{tabular}




\begin{tabular}{|c|c|c|c|c|c|}
\hline \multirow[b]{2}{*}{ CHEMBL1590509 } & \multirow[b]{2}{*}{688267} & \multicolumn{4}{|c|}{ Supplemental Table s2.txt } \\
\hline & & 4.25 & 5.0457 & TRN & \\
\hline CHEMBL1328059 & 688267 & 6.25 & 5.0119 & TST & \\
\hline CHEMBL1582194 & 688267 & 5.55 & 5.099 & TRN & \\
\hline CHEMBL1439229 & 688267 & 4.45 & 5.0835 & TRN & \\
\hline CHEMBL 2007227 & 688267 & 4.6 & 5.0394 & TRN & \\
\hline CHEMBL576349 & 688267 & 5.3 & 5.0308 & TST & \\
\hline CHEMBL1460417 & 688267 & 5.85 & 5.0021 & TRN & \\
\hline CHEMBL1411155 & 688267 & 6.2 & 5.0507 & TRN & \\
\hline CHEMBL1338158 & 688267 & 4.7 & \multicolumn{2}{|c|}{5.122000000000001} & TST \\
\hline CHEMBL1520302 & 688267 & 5.3 & 5.098 & TRN & \\
\hline CHEMBL1234945 & 688267 & 5.8 & 5.0338 & TST & \\
\hline CHEMBL1493815 & 688267 & 4.0 & 5.0724 & TRN & \\
\hline CHEMBL1538418 & 688267 & 6.25 & 5.0988 & TRN & \\
\hline CHEMBL1536876 & 688267 & 4.0 & 5.0653 & TRN & \\
\hline CHEMBL1508274 & 688267 & 4.05 & 5.0384 & TRN & \\
\hline CHEMBL1433177 & 688267 & 4.55 & 5.1576 & TRN & \\
\hline CHEMBL1595939 & 688267 & 4.25 & 5.0378 & TRN & \\
\hline CHEMBL1368231 & 688267 & 5.3 & 5.1118 & TRN & \\
\hline CHEMBL1458596 & 688267 & 4.0 & 5.1745 & TRN & \\
\hline CHEMBL1210920 & 688267 & 6.2 & 5.0393 & TRN & \\
\hline CHEMBL1560879 & 688267 & 5.7 & \multicolumn{2}{|c|}{5.0360000000000005} & TRN \\
\hline CHEMBL1449270 & 688267 & 4.6 & 5.0704 & TRN & \\
\hline CHEMBL1469034 & 688267 & 6.25 & 5.0549 & TST & \\
\hline CHEMBL1340043 & 688267 & 6.25 & 5.1546 & TRN & \\
\hline CHEMBL1606624 & 688267 & 4.95 & 5.0554 & TRN & \\
\hline CHEMBL1352653 & 688267 & 5.75 & 5.0824 & TRN & \\
\hline CHEMBL1349755 & 688267 & 4.0 & 5.0557 & TRN & \\
\hline CHEMBL1535961 & 688267 & 4.4 & 5.0788 & TRN & \\
\hline CHEMBL1448343 & 688267 & 4.25 & \multicolumn{2}{|c|}{5.0169999999999995} & TST \\
\hline CHEMBL1491064 & 688267 & 6.2 & 5.0212 & TST & \\
\hline CHEMBL1413807 & 688267 & 6.5 & \multicolumn{2}{|c|}{5.0760000000000005} & TRN \\
\hline CHEMBL1447057 & 688267 & 4.35 & 5.1253 & TRN & \\
\hline CHEMBL1586264 & 688267 & 5.25 & 5.1344 & TRN & \\
\hline CHEMBL1533501 & 688267 & 4.25 & 5.0367 & TST & \\
\hline CHEMBL1996163 & 688267 & 4.05 & 4.9955 & TST & \\
\hline CHEMBL3209141 & 688267 & 6.0 & 5.0392 & TST & \\
\hline CHEMBL1418571 & 688267 & 5.6 & 5.0243 & TRN & \\
\hline CHEMBL1480182 & 688267 & 4.0 & 5.1319 & TRN & \\
\hline CHEMBL1442244 & 688267 & 5.3 & 5.0347 & TRN & \\
\hline CHEMBL1510804 & 688267 & 4.5 & 4.9939 & TRN & \\
\hline CHEMBL1429523 & 688267 & 5.55 & 5.1021 & TRN & \\
\hline CHEMBL1457773 & 688267 & 4.35 & 5.1083 & TRN & \\
\hline CHEMBL3191904 & 688267 & 4.05 & 5.0578 & TST & \\
\hline CHEMBL1337840 & 688267 & 4.35 & 5.0529 & TRN & \\
\hline CHEMBL1387260 & 688267 & 4.05 & 5.0481 & TRN & \\
\hline CHEMBL1553451 & 688267 & 6.35 & 5.0376 & TRN & \\
\hline CHEMBL1544320 & 688267 & 4.35 & 5.0009 & TRN & \\
\hline CHEMBL1439429 & 688267 & 4.0 & 5.0491 & TRN & \\
\hline & & & & 18311 & \\
\hline
\end{tabular}




\begin{tabular}{|c|c|c|c|c|c|}
\hline \multicolumn{6}{|c|}{ Supplemental Table S2.txt } \\
\hline CHEMBL66654 & 688267 & 5.15 & 5.0139 & TST & \\
\hline CHEMBL1524267 & 688267 & 4.3 & 5.0669 & TRN & \\
\hline CHEMBL1546310 & 688267 & 5.5 & \multicolumn{2}{|c|}{5.0969999999999995} & TRN \\
\hline CHEMBL1354405 & 688267 & 6.2 & 5.0832 & TRN & \\
\hline CHEMBL1606998 & 688267 & 5.55 & 5.0865 & TRN & \\
\hline CHEMBL1594454 & 688267 & 5.0 & 5.0915 & TRN & \\
\hline CHEMBL1522573 & 688267 & 4.3 & 5.0775 & TRN & \\
\hline CHEMBL1348747 & 688267 & 3.95 & 4.9988 & TRN & \\
\hline CHEMBL1471706 & 688267 & 5.0 & 5.115 & TST & \\
\hline CHEMBL1581923 & 688267 & 5.8 & 4.9873 & TRN & \\
\hline CHEMBL1582124 & 688267 & 5.85 & 5.0365 & TST & \\
\hline CHEMBL1395786 & 688267 & 3.95 & 5.1087 & TST & \\
\hline CHEMBL1429918 & 688267 & 4.25 & 5.1138 & TRN & \\
\hline CHEMBL1362196 & 688267 & 5.3 & 5.0309 & TRN & \\
\hline CHEMBL1524595 & 688267 & 5.45 & 5.0696 & TRN & \\
\hline CHEMBL1304721 & 688267 & 6.45 & 4.9824 & TRN & \\
\hline CHEMBL1560988 & 688267 & 4.75 & 5.0299 & TRN & \\
\hline CHEMBL1305909 & 688267 & 6.5 & 5.0627 & TST & \\
\hline CHEMBL1413683 & 688267 & 6.2 & 5.0608 & TRN & \\
\hline CHEMBL1533199 & 688267 & 4.55 & 5.0286 & TRN & \\
\hline CHEMBL1440212 & 688267 & 4.05 & 5.0575 & TRN & \\
\hline CHEMBL1317523 & 688267 & 4.55 & 5.1056 & TRN & \\
\hline CHEMBL1357636 & 688267 & 4.0 & 5.0232 & TRN & \\
\hline CHEMBL1534491 & 688267 & 4.8 & 5.0379 & TRN & \\
\hline CHEMBL1584281 & 688267 & 4.0 & 5.0284 & TRN & \\
\hline CHEMBL1558435 & 688267 & 6.5 & 5.0904 & TRN & \\
\hline CHEMBL1352156 & 688267 & 6.5 & 5.0179 & TRN & \\
\hline CHEMBL1422283 & 688267 & 4.6 & 5.0369 & TRN & \\
\hline CHEMBL1525524 & 688267 & 3.9 & 5.0211 & TRN & \\
\hline CHEMBL1436562 & 688267 & 4.05 & 5.0729 & TRN & \\
\hline CHEMBL1319765 & 688267 & 4.6 & 5.0535 & TRN & \\
\hline CHEMBL1383321 & 688267 & 5.0 & 5.0128 & TST & \\
\hline CHEMBL1536188 & 688267 & 4.65 & 5.0656 & TRN & \\
\hline CHEMBL1573386 & 688267 & 5.35 & 5.1077 & TRN & \\
\hline CHEMBL1415415 & 688267 & 6.2 & 5.0922 & TRN & \\
\hline CHEMBL1350828 & 688267 & 4.0 & 5.0126 & TRN & \\
\hline CHEMBL1347874 & 688267 & 6.25 & 5.0968 & TRN & \\
\hline CHEMBL1419964 & 688267 & 6.0 & 5.1158 & TRN & \\
\hline CHEMBL1426818 & 688267 & 4.1 & 5.0531 & TRN & \\
\hline CHEMBL1466219 & 688267 & 4.35 & 5.1441 & TRN & \\
\hline CHEMBL1387717 & 688267 & 6.2 & 5.0772 & TRN & \\
\hline CHEMBL1523386 & 688267 & 4.45 & 5.0537 & TRN & \\
\hline CHEMBL1332211 & 688267 & 5.5 & 5.0817 & TRN & \\
\hline CHEMBL1334979 & 688267 & 4.7 & 5.0887 & TST & \\
\hline CHEMBL1580609 & 688267 & 4.95 & 5.0695 & TST & \\
\hline CHEMBL1973504 & 688267 & 5.85 & 4.9953 & TRN & \\
\hline CHEMBL1544931 & 688267 & 5.45 & 5.13899 & 9999999999 & TRN \\
\hline CHEMBL1356965 & 688267 & 5.45 & 5.0565 & TRN & \\
\hline & & & & 18312 & \\
\hline
\end{tabular}




\begin{tabular}{|c|c|c|c|c|}
\hline & & & pplement & al $\mathrm{Ta}$ \\
\hline CHEMBL1352276 & 688267 & 6.2 & 5.0551 & TRN \\
\hline CHEMBL1391794 & 688267 & 4.55 & 5.1243 & TRN \\
\hline CHEMBL1543195 & 688267 & 4.5 & 4.9754 & TST \\
\hline CHEMBL1543554 & 688267 & 5.95 & 5.0964 & TRN \\
\hline CHEMBL1588514 & 688267 & 6.2 & 5.1175 & TRN \\
\hline CHEMBL1413501 & 688267 & 6.2 & 5.114 & TRN \\
\hline CHEMBL1314038 & 688267 & 4.55 & 4.9893 & TRN \\
\hline CHEMBL1525204 & 688267 & 5.35 & 5.0288 & TRN \\
\hline CHEMBL1393239 & 688267 & 4.25 & 5.0786 & TST \\
\hline CHEMBL1325375 & 688267 & 5.3 & 5.0189 & TRN \\
\hline CHEMBL1562957 & 688267 & 5.35 & 5.0866 & TRN \\
\hline CHEMBL1414324 & 688267 & 6.25 & 5.096 & TRN \\
\hline CHEMBL1469472 & 688267 & 6.15 & 5.1009 & TRN \\
\hline CHEMBL1594815 & 688267 & 5.65 & 5.0407 & TRN \\
\hline CHEMBL1334720 & 688267 & 4.0 & 5.1452 & TRN \\
\hline CHEMBL1495828 & 688267 & 4.4 & 5.037 & TST \\
\hline CHEMBL1403118 & 688267 & 4.5 & 5.0604 & TRN \\
\hline CHEMBL1339873 & 688267 & 6.45 & 5.0381 & TRN \\
\hline CHEMBL1590969 & 688267 & 6.2 & 4.9914 & TRN \\
\hline CHEMBL1375367 & 688267 & 3.95 & 5.0226 & TRN \\
\hline CHEMBL1487930 & 688267 & 6.2 & 5.0525 & TRN \\
\hline CHEMBL1527813 & 688267 & 5.1 & 5.0589 & TST \\
\hline CHEMBL1453662 & 688267 & 6.5 & 5.0824 & TRN \\
\hline CHEMBL1387411 & 688267 & 5.65 & 5.0513 & TRN \\
\hline CHEMBL1354969 & 688267 & 4.4 & 5.0524 & TRN \\
\hline CHEMBL1494277 & 688267 & 6.2 & 5.0521 & TRN \\
\hline CHEMBL1327035 & 688267 & 4.05 & 5.0969 & TRN \\
\hline CHEMBL1495267 & 688267 & 6.05 & 5.0379 & TST \\
\hline CHEMBL1303705 & 688267 & 4.0 & 5.0418 & TST \\
\hline CHEMBL1409992 & 688267 & 4.25 & 5.0434 & TRN \\
\hline CHEMBL1493951 & 688267 & 4.4 & 5.0551 & TRN \\
\hline CHEMBL1339299 & 688267 & 4.25 & 5.1904 & TRN \\
\hline CHEMBL1396631 & 688267 & 4.25 & 5.0626 & TRN \\
\hline CHEMBL1343924 & 688267 & 4.95 & 5.0587 & TRN \\
\hline CHEMBL1329594 & 688267 & 4.25 & 5.0565 & TRN \\
\hline CHEMBL1427054 & 688267 & 6.2 & 5.0423 & TRN \\
\hline CHEMBL1402064 & 688267 & 4.05 & 5.0138 & TRN \\
\hline CHEMBL1355336 & 688267 & 6.45 & 5.1362 & TRN \\
\hline CHEMBL1310236 & 688267 & 5.5 & 5.0155 & TRN \\
\hline CHEMBL1504713 & 688267 & 4.9 & 5.044 & TST \\
\hline CHEMBL1355091 & 688267 & 5.65 & 5.0729 & TRN \\
\hline CHEMBL1603067 & 688267 & 4.7 & 5.023 & TST \\
\hline CHEMBL1489326 & 688267 & 6.15 & 5.1064 & TRN \\
\hline CHEMBL1456175 & 688267 & 4.9 & 5.0274 & TRN \\
\hline CHEMBL1490492 & 688267 & 4.05 & 5.1243 & TRN \\
\hline CHEMBL1580747 & 688267 & 6.2 & 5.0409 & TST \\
\hline CHEMBL1408562 & 688267 & 5.5 & 5.0922 & TRN \\
\hline CHEMBL1515861 & 688267 & 6.2 & 5.0687 & TRN \\
\hline
\end{tabular}




\begin{tabular}{|c|c|c|c|c|}
\hline \multicolumn{5}{|c|}{ Supplemental Table S2.txt } \\
\hline CHEMBL1425101 & 688267 & 4.4 & 5.101 & TRN \\
\hline CHEMBL1516360 & 688267 & 5.45 & 5.0864 & TST \\
\hline CHEMBL1479533 & 688267 & 6.25 & 5.0624 & TRN \\
\hline CHEMBL1326261 & 688267 & 4.4 & 5.0248 & TRN \\
\hline CHEMBL1449074 & 688267 & 4.4 & 5.0481 & TRN \\
\hline CHEMBL1332111 & 688267 & 4.4 & 5.0039 & TRN \\
\hline CHEMBL1393027 & 688267 & 4.0 & 5.0771 & TRN \\
\hline CHEMBL1537535 & 688267 & 6.15 & 5.0852 & TRN \\
\hline CHEMBL1458792 & 688267 & 5.5 & 5.0526 & TST \\
\hline CHEMBL1576839 & 688267 & 5.05 & 5.0573 & TRN \\
\hline CHEMBL1350454 & 688267 & 4.95 & 5.1081 & TRN \\
\hline CHEMBL1348424 & 688267 & 5.55 & 5.0583 & TST \\
\hline CHEMBL1481663 & 688267 & 4.35 & 5.0524 & TST \\
\hline CHEMBL1593174 & 688267 & 5.55 & 5.0815 & TRN \\
\hline CHEMBL1318431 & 688267 & 4.45 & 5.0065 & TRN \\
\hline CHEMBL1416462 & 688267 & 4.6 & 5.0667 & TRN \\
\hline CHEMBL1381814 & 688267 & 6.15 & 5.0472 & TST \\
\hline CHEMBL1323826 & 688267 & 4.0 & 5.0887 & TRN \\
\hline CHEMBL1481864 & 688267 & 5.3 & 5.0084 & TST \\
\hline CHEMBL1433804 & 688267 & 5.25 & 5.0497 & TRN \\
\hline CHEMBL1454779 & 688267 & 4.35 & 4.993 & TRN \\
\hline CHEMBL1488483 & 688267 & 4.95 & 5.0362 & TRN \\
\hline CHEMBL1313716 & 688267 & 5.3 & 5.0813 & TRN \\
\hline CHEMBL1357001 & 688267 & 4.05 & 5.004 & TRN \\
\hline CHEMBL1597955 & 688267 & 5.85 & 5.066 & TRN \\
\hline CHEMBL1543178 & 688267 & 4.35 & 5.1149 & TRN \\
\hline CHEMBL1611910 & 688267 & 4.5 & 5.0067 & TRN \\
\hline CHEMBL1987082 & 688267 & 5.35 & 4.9773 & TST \\
\hline CHEMBL48830 & 688267 & 5.3 & 5.0464 & TRN \\
\hline CHEMBL1535079 & 688267 & 6.1 & 5.0466 & TRN \\
\hline CHEMBL1404798 & 688267 & 4.4 & 5.0872 & TRN \\
\hline CHEMBL1564339 & 688267 & 4.0 & 5.0163 & TST \\
\hline CHEMBL3213943 & 688267 & 6.25 & 5.0304 & TST \\
\hline CHEMBL1529220 & 688267 & 5.15 & 5.083 & TRN \\
\hline CHEMBL1412615 & 688267 & 5.4 & 5.0891 & TRN \\
\hline CHEMBL1538945 & 688267 & 4.25 & 5.1114 & TST \\
\hline CHEMBL1482875 & 688267 & 4.35 & 5.0317 & TST \\
\hline CHEMBL1357092 & 688267 & 6.0 & 5.0786 & TST \\
\hline CHEMBL1333090 & 688267 & 4.05 & 5.0927 & TRN \\
\hline CHEMBL1412081 & 688267 & 3.95 & 5.1168 & TRN \\
\hline CHEMBL1559311 & 688267 & 3.95 & 5.0416 & TST \\
\hline CHEMBL63976 & 688267 & 4.0 & 5.0095 & TST \\
\hline CHEMBL1346953 & 688267 & 5.55 & 5.0736 & TRN \\
\hline CHEMBL1313949 & 688267 & 6.5 & 5.0285 & TST \\
\hline CHEMBL1361234 & 688267 & 6.2 & 5.082 & TRN \\
\hline CHEMBL1526152 & 688267 & 4.9 & 5.0692 & TRN \\
\hline CHEMBL1536531 & 688267 & 4.1 & 5.0062 & TRN \\
\hline CHEMBL1565257 & 688267 & 6.15 & 5.0932 & TRN \\
\hline
\end{tabular}




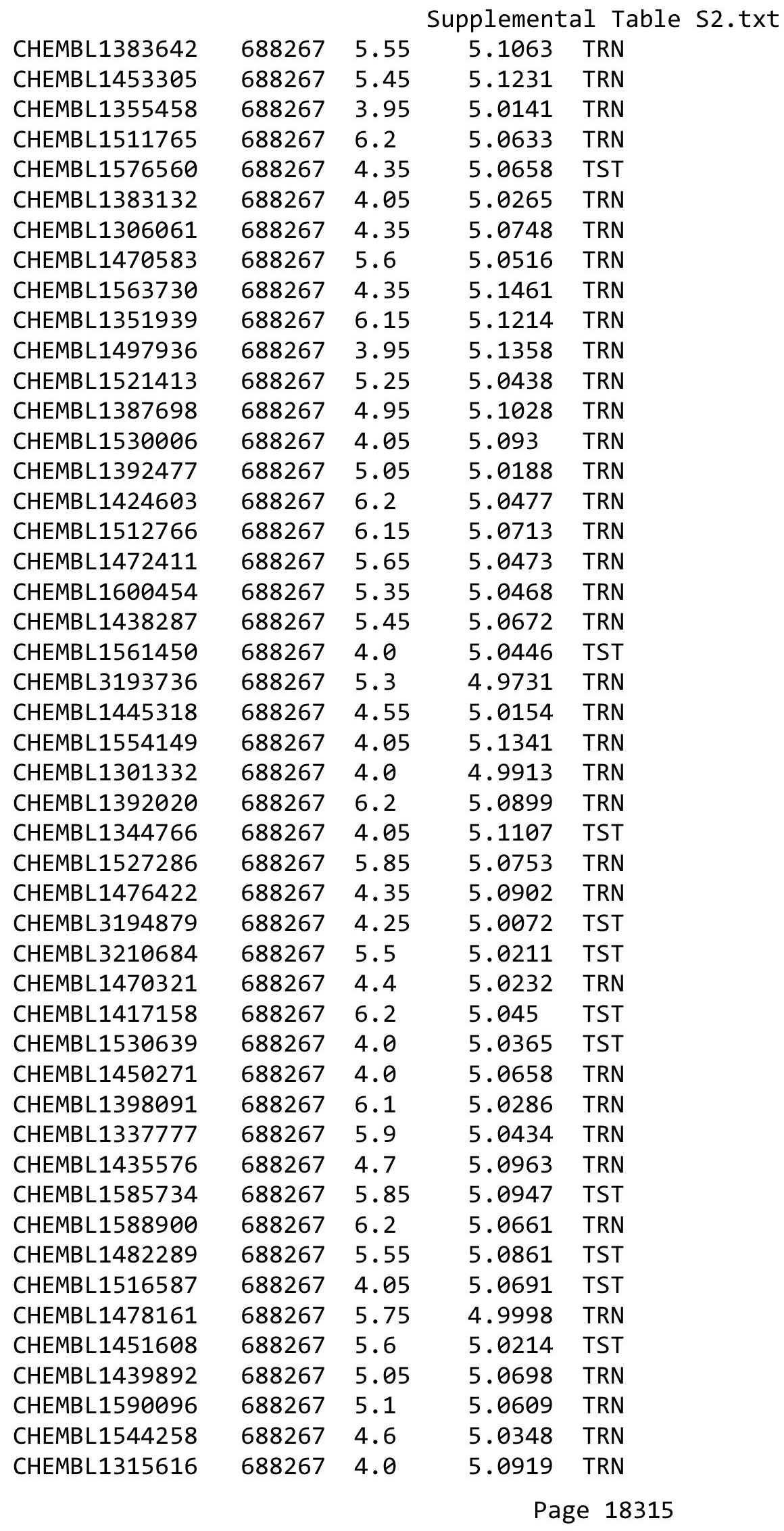




\begin{tabular}{|c|c|c|c|c|c|}
\hline \multicolumn{6}{|c|}{ Supplemental Table S2.txt } \\
\hline CHEMBL3191796 & 688267 & 5.55 & 5.0645 & TST & \\
\hline CHEMBL1518284 & 688267 & 4.0 & 5.0342 & TST & \\
\hline CHEMBL1543646 & 688267 & 5.35 & 5.0349 & TST & \\
\hline CHEMBL1606939 & 688267 & 5.3 & 5.0768 & TST & \\
\hline CHEMBL1435266 & 688267 & 6.25 & 5.0987 & TRN & \\
\hline CHEMBL1474761 & 688267 & 4.7 & 5.1242 & TRN & \\
\hline CHEMBL1504377 & 688267 & 5.8 & 5.0656 & TRN & \\
\hline CHEMBL1530767 & 688267 & 6.15 & 5.0478 & TRN & \\
\hline CHEMBL1397111 & 688267 & 3.9 & 5.0577 & TRN & \\
\hline CHEMBL1551042 & 688267 & 4.15 & 5.0362 & TRN & \\
\hline CHEMBL1490250 & 688267 & 4.35 & 5.056 & TRN & \\
\hline CHEMBL1608792 & 688267 & 4.05 & 5.09699 & 99999999995 & TRN \\
\hline CHEMBL1342854 & 688267 & 4.4 & 5.0356 & TRN & \\
\hline CHEMBL1394083 & 688267 & 5.0 & 4.9947 & TRN & \\
\hline CHEMBL1540547 & 688267 & 4.75 & 5.0511 & TRN & \\
\hline CHEMBL1340326 & 688267 & 4.45 & 5.0893 & TRN & \\
\hline CHEMBL1574307 & 688267 & 4.05 & 5.0271 & TRN & \\
\hline CHEMBL1465165 & 688267 & 3.95 & 5.0553 & TST & \\
\hline CHEMBL1485787 & 688267 & 4.7 & 5.0396 & TRN & \\
\hline CHEMBL1543948 & 688267 & 5.45 & 5.10800 & 00000000005 & TRN \\
\hline CHEMBL3210221 & 688267 & 4.4 & 5.0169 & TST & \\
\hline CHEMBL1510465 & 688267 & 5.6 & 5.0283 & TST & \\
\hline CHEMBL1438751 & 688267 & 5.1 & 5.0535 & TST & \\
\hline CHEMBL1383637 & 688267 & 5.9 & 5.0594 & TST & \\
\hline CHEMBL1462394 & 688267 & 5.4 & 5.0924 & TRN & \\
\hline CHEMBL1549143 & 688267 & 5.1 & 5.0501 & TRN & \\
\hline CHEMBL1592973 & 688267 & 5.9 & 5.0237 & TRN & \\
\hline CHEMBL3211057 & 688267 & 4.35 & 5.0343 & TST & \\
\hline CHEMBL1427615 & 688267 & 4.45 & 5.088 & TST & \\
\hline CHEMBL1355144 & 688267 & 3.95 & 5.0894 & TRN & \\
\hline CHEMBL1361174 & 688267 & 4.0 & 4.9983 & TRN & \\
\hline CHEMBL1475294 & 688267 & 4.05 & 5.0486 & TRN & \\
\hline CHEMBL1469374 & 688267 & 6.2 & 5.0357 & TRN & \\
\hline CHEMBL1502049 & 688267 & 5.9 & 4.9869 & TRN & \\
\hline CHEMBL1421765 & 688267 & 4.35 & 5.0705 & TRN & \\
\hline CHEMBL1608749 & 688267 & 6.2 & 4.9879 & TRN & \\
\hline CHEMBL1445951 & 688267 & 5.05 & 5.0621 & TRN & \\
\hline CHEMBL1461021 & 688267 & 6.2 & 5.0264 & TST & \\
\hline CHEMBL3193236 & 688267 & 5.5 & 4.9751 & TRN & \\
\hline CHEMBL1366484 & 688267 & 5.15 & 5.0418 & TST & \\
\hline CHEMBL1369662 & 688267 & 5.3 & 5.1092 & TRN & \\
\hline CHEMBL1486366 & 688267 & 5.95 & 5.039 & TRN & \\
\hline CHEMBL1603810 & 688267 & 4.95 & 5.0395 & TRN & \\
\hline CHEMBL1568952 & 688267 & 5.9 & 5.026 & TST & \\
\hline CHEMBL1510617 & 688267 & 4.85 & 5.0824 & TRN & \\
\hline CHEMBL1510066 & 688267 & 5.9 & 5.0322 & TRN & \\
\hline CHEMBL1608458 & 688267 & 6.15 & 5.0819 & TRN & \\
\hline CHEMBL1552828 & 688267 & 4.0 & 5.0715 & TRN & \\
\hline
\end{tabular}




\begin{tabular}{|c|c|c|c|c|c|}
\hline \multicolumn{6}{|c|}{ oplemental İ } \\
\hline CHEMBL1488883 & 688267 & 4.0 & 5.1076 & TST & \\
\hline CHEMBL1542404 & 688267 & 5.55 & 5.0527 & TRN & \\
\hline CHEMBL1538755 & 688267 & 5.35 & 5.1095 & TRN & \\
\hline CHEMBL1405519 & 688267 & 4.55 & 5.0325 & TRN & \\
\hline CHEMBL1406657 & 688267 & 3.95 & 5.1189 & TRN & \\
\hline CHEMBL1524032 & 688267 & 5.35 & 5.0511 & TRN & \\
\hline CHEMBL3209739 & 688267 & 5.25 & 5.141 & TST & \\
\hline CHEMBL1477882 & 688267 & 5.65 & 5.0557 & TRN & \\
\hline CHEMBL1518496 & 688267 & 5.65 & 5.0965 & TRN & \\
\hline CHEMBL1484693 & 688267 & 4.6 & 5.0652 & TST & \\
\hline CHEMBL1378895 & 688267 & 4.05 & 5.0503 & TST & \\
\hline CHEMBL1397253 & 688267 & 6.15 & 5.0819 & TRN & \\
\hline CHEMBL1591120 & 688267 & 6.2 & 5.0303 & TRN & \\
\hline CHEMBL1531670 & 688267 & 5.4 & 4.9691 & TRN & \\
\hline CHEMBL1305871 & 688267 & 6.25 & 5.0889 & TRN & \\
\hline CHEMBL1612984 & 688267 & 6.05 & 5.0291 & TRN & \\
\hline CHEMBL1344470 & 688267 & 4.05 & 4.9935 & TST & \\
\hline CHEMBL1384267 & 688267 & 5.05 & 5.06800 & 00000000005 & TST \\
\hline CHEMBL1394279 & 688267 & 6.15 & 5.033 & TRN & \\
\hline CHEMBL1485148 & 688267 & 4.05 & 5.0196 & TRN & \\
\hline CHEMBL1565625 & 688267 & 4.9 & 5.0201 & TRN & \\
\hline CHEMBL1476198 & 688267 & 5.95 & 5.1201 & TRN & \\
\hline CHEMBL1583431 & 688267 & 4.3 & 5.0532 & TRN & \\
\hline CHEMBL1334029 & 688267 & 6.15 & 5.046 & TRN & \\
\hline CHEMBL1513477 & 688267 & 5.25 & 5.0732 & TRN & \\
\hline CHEMBL1455982 & 688267 & 6.25 & 5.0759 & TRN & \\
\hline CHEMBL1542286 & 688267 & 6.2 & 5.0335 & TRN & \\
\hline CHEMBL274189 & 688267 & 5.25 & 5.0822 & TST & \\
\hline CHEMBL1586363 & 688267 & 6.2 & 5.0821 & TST & \\
\hline CHEMBL1530220 & 688267 & 4.05 & 4.9836 & TST & \\
\hline CHEMBL1303895 & 688267 & 6.15 & 5.0861 & TRN & \\
\hline CHEMBL1418300 & 688267 & 5.8 & 5.0717 & TRN & \\
\hline CHEMBL3193322 & 688267 & 5.8 & 5.0113 & TRN & \\
\hline CHEMBL1513817 & 688267 & 5.5 & 5.0487 & TRN & \\
\hline CHEMBL1983929 & 688267 & 5.95 & 5.0383 & TRN & \\
\hline CHEMBL3197127 & 688267 & 4.05 & 4.9697 & TRN & \\
\hline CHEMBL1344828 & 688267 & 5.8 & 5.1086 & TRN & \\
\hline CHEMBL1603602 & 688267 & 4.0 & 4.9992 & TRN & \\
\hline CHEMBL1459183 & 688267 & 4.95 & 5.0396 & TST & \\
\hline CHEMBL1365047 & 688267 & 4.0 & 5.0648 & TRN & \\
\hline CHEMBL1499366 & 688267 & 5.15 & 5.0653 & TRN & \\
\hline CHEMBL1499194 & 688267 & 5.6 & 5.1047 & TRN & \\
\hline CHEMBL1300559 & 688267 & 4.55 & 5.1419 & TRN & \\
\hline CHEMBL1598395 & 688267 & 4.0 & 5.0279 & TST & \\
\hline CHEMBL1530816 & 688267 & 5.25 & 5.0871 & TST & \\
\hline CHEMBL1449298 & 688267 & 5.5 & 5.1328 & TRN & \\
\hline CHEMBL1439371 & 688267 & 4.05 & 4.987 & TRN & \\
\hline CHEMBL1379772 & 688267 & 4.05 & 5.0722 & TRN & \\
\hline
\end{tabular}




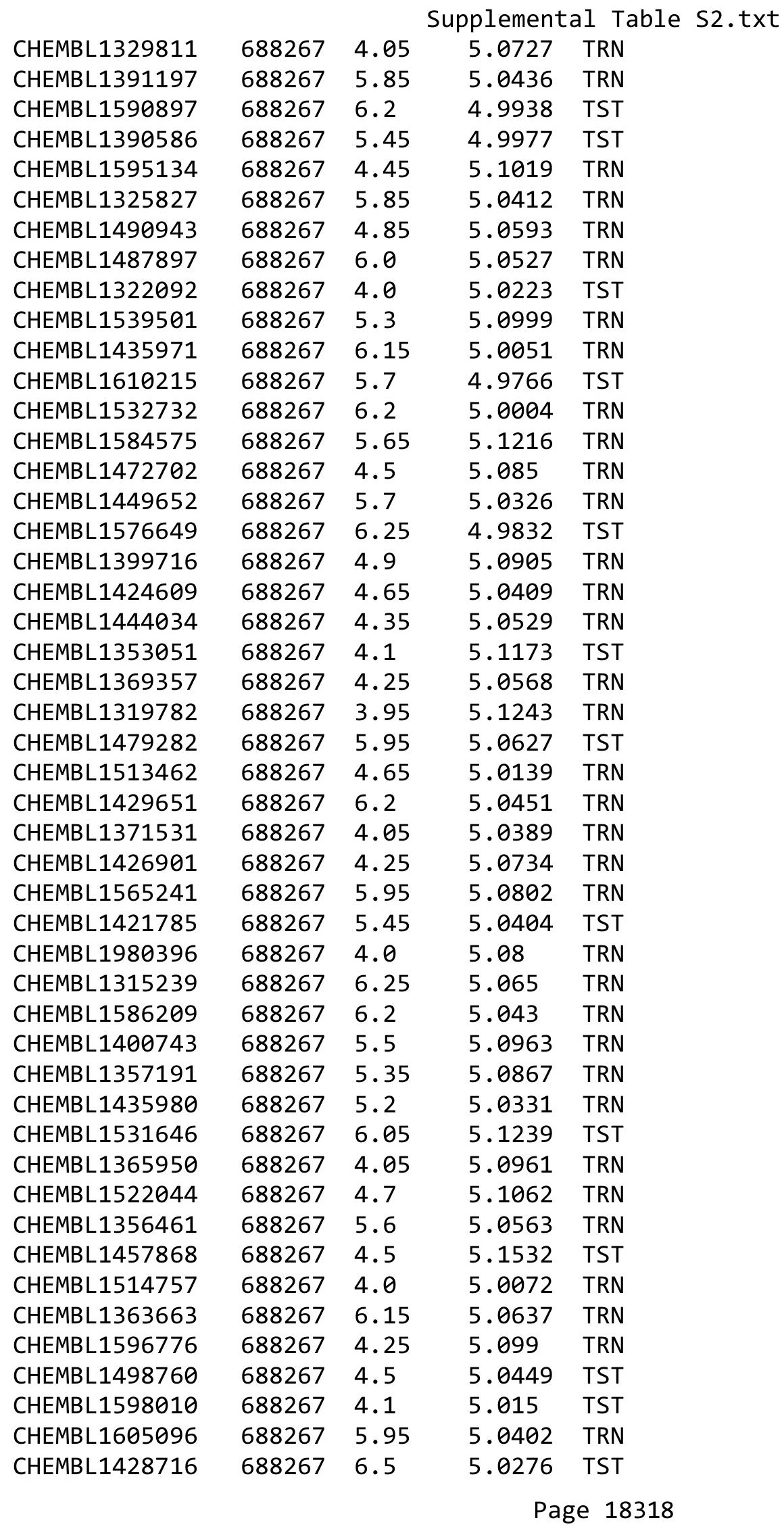




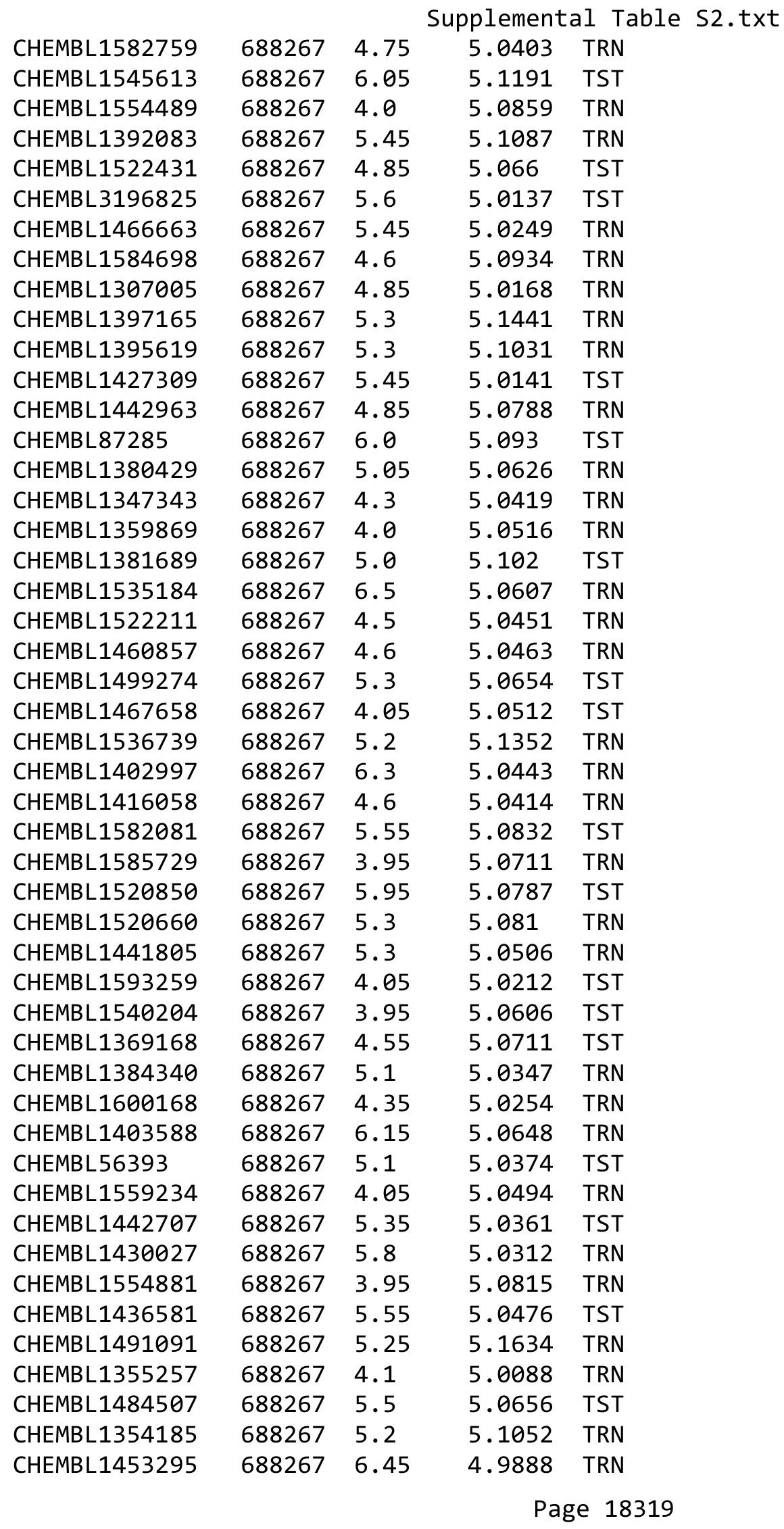




\begin{tabular}{|c|c|c|c|c|}
\hline \multicolumn{5}{|c|}{ Supplemental Table S2.txt } \\
\hline CHEMBL1416015 & 688267 & 6.5 & 5.0585 & TRN \\
\hline CHEMBL1367388 & 688267 & 4.3 & 5.0882 & TRN \\
\hline CHEMBL1365489 & 688267 & 4.15 & 5.0731 & TST \\
\hline CHEMBL1552142 & 688267 & 4.05 & 5.0385 & TRN \\
\hline CHEMBL1316882 & 688267 & 4.4 & 5.0113 & TRN \\
\hline CHEMBL1512178 & 688267 & 6.2 & 5.1134 & TRN \\
\hline CHEMBL1492428 & 688267 & 4.05 & 4.9987 & TRN \\
\hline CHEMBL1482779 & 688267 & 4.8 & 5.1209 & TRN \\
\hline CHEMBL190346 & 688267 & 4.5 & 5.0288 & TRN \\
\hline CHEMBL1405576 & 688267 & 5.3 & 5.0805 & TST \\
\hline CHEMBL1584816 & 688267 & 5.85 & 5.0928 & TRN \\
\hline CHEMBL1513788 & 688267 & 5.55 & 5.0859 & TRN \\
\hline CHEMBL1571960 & 688267 & 5.45 & 5.103 & TRN \\
\hline CHEMBL1583916 & 688267 & 5.55 & 5.0314 & TRN \\
\hline CHEMBL1566912 & 688267 & 5.55 & 5.1251 & TRN \\
\hline CHEMBL1477916 & 688267 & 4.1 & 5.0993 & TRN \\
\hline CHEMBL1501402 & 688267 & 4.6 & 5.0413 & TRN \\
\hline CHEMBL1498769 & 688267 & 4.3 & 5.0943 & TRN \\
\hline CHEMBL1499315 & 688267 & 5.85 & 5.1353 & TRN \\
\hline CHEMBL1313651 & 688267 & 4.0 & 5.0874 & TRN \\
\hline CHEMBL1309956 & 688267 & 6.5 & 5.0876 & TST \\
\hline CHEMBL1370854 & 688267 & 6.2 & 5.1038 & TRN \\
\hline CHEMBL1320078 & 688267 & 4.35 & 5.0767 & TST \\
\hline CHEMBL1570682 & 688267 & 6.15 & 5.0195 & TRN \\
\hline CHEMBL1439128 & 688267 & 5.1 & 5.1746 & TST \\
\hline CHEMBL1315033 & 688267 & 4.0 & 5.0476 & TST \\
\hline CHEMBL1475842 & 688267 & 5.65 & 5.0069 & TST \\
\hline CHEMBL 3192824 & 688267 & 4.05 & 5.0414 & TST \\
\hline CHEMBL1386852 & 688267 & 6.2 & 5.0537 & TRN \\
\hline CHEMBL1605628 & 688267 & 4.05 & 5.032 & TRN \\
\hline CHEMBL1579349 & 688267 & 6.25 & 5.0413 & TRN \\
\hline CHEMBL1496263 & 688267 & 6.2 & 5.0352 & TRN \\
\hline CHEMBL1338598 & 688267 & 4.4 & 5.0518 & TRN \\
\hline CHEMBL1516949 & 688267 & 5.5 & 5.022 & TRN \\
\hline CHEMBL1595964 & 688267 & 6.5 & 5.0782 & TST \\
\hline CHEMBL1486717 & 688267 & 6.45 & 5.0339 & TRN \\
\hline CHEMBL1525984 & 688267 & 4.6 & 5.0441 & TRN \\
\hline CHEMBL1405907 & 688267 & 6.2 & 5.0298 & TRN \\
\hline CHEMBL1564269 & 688267 & 4.4 & 5.1117 & TST \\
\hline CHEMBL1308138 & 688267 & 4.95 & 5.0443 & TST \\
\hline CHEMBL1492375 & 688267 & 5.25 & 5.0997 & TRN \\
\hline CHEMBL1427607 & 688267 & 4.8 & 5.0304 & TST \\
\hline CHEMBL1387444 & 688267 & 5.5 & 5.0196 & TRN \\
\hline CHEMBL1463179 & 688267 & 6.15 & 5.0501 & TST \\
\hline CHEMBL1402704 & 688267 & 4.05 & 5.029 & TRN \\
\hline CHEMBL1546716 & 688267 & 4.55 & 5.0627 & TST \\
\hline CHEMBL1302014 & 688267 & 6.2 & 5.1306 & TRN \\
\hline CHEMBL1421478 & 688267 & 5.2 & 5.0112 & TRN \\
\hline
\end{tabular}




\begin{tabular}{|c|c|c|c|c|c|}
\hline \multicolumn{6}{|c|}{ Supplemental Table S2.txt } \\
\hline CHEMBL 30707 & 688267 & 4.0 & 5.0208 & TRN & \\
\hline CHEMBL1402890 & 688267 & 4.0 & 5.0119 & TRN & \\
\hline CHEMBL1602044 & 688267 & 4.4 & 5.138 & TRN & \\
\hline CHEMBL1381012 & 688267 & 3.95 & 5.0517 & TRN & \\
\hline CHEMBL1317162 & 688267 & 5.4 & 5.0349 & TRN & \\
\hline CHEMBL1300601 & 688267 & 4.6 & 5.09699 & 99999999995 & TRN \\
\hline CHEMBL1366896 & 688267 & 5.15 & 5.0689 & TST & \\
\hline CHEMBL1531648 & 688267 & 5.15 & 5.04 & TST & \\
\hline CHEMBL1534744 & 688267 & 6.0 & 5.1051 & TRN & \\
\hline CHEMBL1351309 & 688267 & 5.65 & 5.0801 & TST & \\
\hline CHEMBL1591196 & 688267 & 4.4 & 5.0734 & TST & \\
\hline CHEMBL1342129 & 688267 & 4.0 & 5.0196 & TRN & \\
\hline CHEMBL1438956 & 688267 & 5.65 & 5.0902 & TST & \\
\hline CHEMBL1412829 & 688267 & 5.3 & 5.1236 & TRN & \\
\hline CHEMBL1445114 & 688267 & 6.45 & 5.1144 & TRN & \\
\hline CHEMBL1594120 & 688267 & 4.0 & 5.0702 & TRN & \\
\hline CHEMBL1602746 & 688267 & 6.15 & 5.0873 & TRN & \\
\hline CHEMBL1332898 & 688267 & 5.85 & 5.0419 & TRN & \\
\hline CHEMBL1390123 & 688267 & 5.6 & 5.0208 & TST & \\
\hline CHEMBL1485386 & 688267 & 6.5 & 5.0802 & TST & \\
\hline CHEMBL1371234 & 688267 & 4.75 & 4.9938 & TRN & \\
\hline CHEMBL1475883 & 688267 & 4.05 & 5.0982 & TRN & \\
\hline CHEMBL3207918 & 688267 & 5.35 & 5.0558 & TRN & \\
\hline CHEMBL1476721 & 688267 & 3.95 & 5.0658 & TRN & \\
\hline CHEMBL1460500 & 688267 & 4.3 & 5.0409 & TST & \\
\hline CHEMBL1318133 & 688267 & 5.0 & 5.1365 & TRN & \\
\hline CHEMBL1490016 & 688267 & 4.2 & 5.0224 & TST & \\
\hline CHEMBL1605305 & 688267 & 5.5 & 5.0887 & TRN & \\
\hline CHEMBL1397822 & 688267 & 4.85 & 5.1039 & TRN & \\
\hline CHEMBL3214624 & 688267 & 4.5 & 5.0451 & TRN & \\
\hline CHEMBL1554274 & 688267 & 4.25 & 5.0536 & TRN & \\
\hline CHEMBL1503631 & 688267 & 5.55 & 5.0349 & TRN & \\
\hline CHEMBL3144974 & 688267 & 4.5 & 5.0282 & TRN & \\
\hline CHEMBL1581470 & 688267 & 4.9 & 5.1011 & TST & \\
\hline CHEMBL1525011 & 688267 & 4.3 & 5.0316 & TST & \\
\hline CHEMBL1341417 & 688267 & 5.3 & 5.01 & TRN & \\
\hline CHEMBL1526179 & 688267 & 5.1 & 5.0819 & TRN & \\
\hline CHEMBL1311724 & 688267 & 5.5 & 4.9804 & TRN & \\
\hline CHEMBL1457615 & 688267 & 5.25 & 5.1014 & TRN & \\
\hline CHEMBL1360164 & 688267 & 4.1 & 5.0621 & TST & \\
\hline CHEMBL1580848 & 688267 & 4.05 & 4.9764 & TRN & \\
\hline CHEMBL3194873 & 688267 & 6.15 & 5.1222 & TRN & \\
\hline CHEMBL1471032 & 688267 & 3.95 & 5.1008 & TST & \\
\hline CHEMBL1333429 & 688267 & 4.4 & 4.9967 & TRN & \\
\hline CHEMBL1357728 & 688267 & 5.85 & 5.0939 & TRN & \\
\hline CHEMBL1435140 & 688267 & 4.05 & 5.0539 & TRN & \\
\hline CHEMBL1554776 & 688267 & 4.2 & 5.1115 & TRN & \\
\hline CHEMBL1323491 & 688267 & 4.0 & 5.0173 & TST & \\
\hline
\end{tabular}




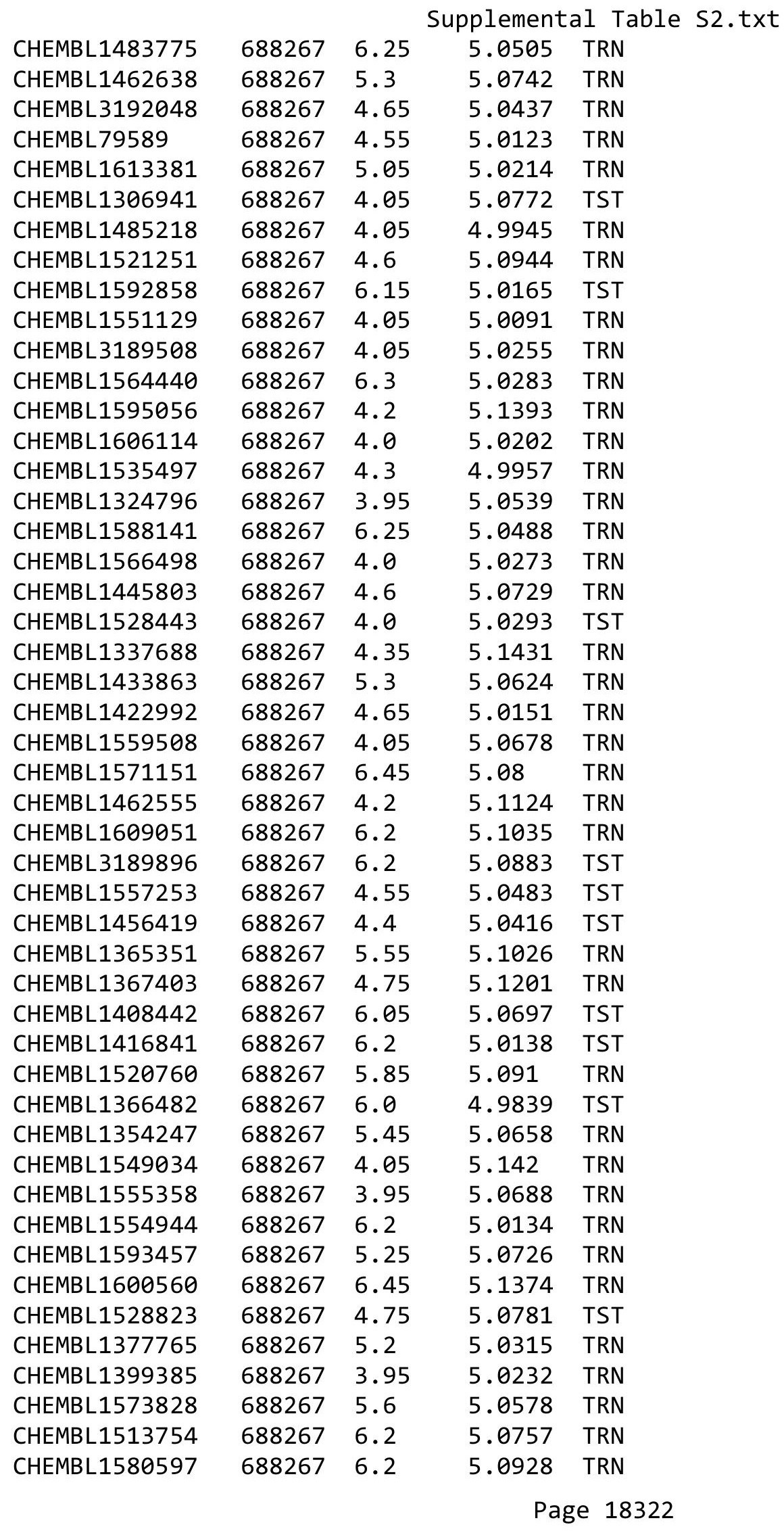




\begin{tabular}{|c|c|c|c|c|}
\hline & & & upplement & al $\mathrm{T}$ \\
\hline CHEMBL1421169 & 688267 & 6.2 & 4.9758 & TST \\
\hline CHEMBL1456206 & 688267 & 5.8 & 5.0338 & TRN \\
\hline CHEMBL1520214 & 688267 & 4.6 & 4.9967 & TST \\
\hline CHEMBL1315432 & 688267 & 5.2 & 5.1095 & TRN \\
\hline CHEMBL1467518 & 688267 & 5.0 & 5.0488 & TST \\
\hline CHEMBL1496442 & 688267 & 6.0 & 5.1148 & TRN \\
\hline CHEMBL1595028 & 688267 & 6.2 & 5.0587 & TST \\
\hline CHEMBL1403416 & 688267 & 6.2 & 5.0203 & TRN \\
\hline CHEMBL1425932 & 688267 & 4.05 & 5.0137 & TRN \\
\hline CHEMBL1368941 & 688267 & 6.15 & 5.0891 & TST \\
\hline CHEMBL1440858 & 688267 & 6.2 & 5.0737 & TRN \\
\hline CHEMBL1577354 & 688267 & 4.35 & 5.0341 & TST \\
\hline CHEMBL2374038 & 688267 & 5.3 & 5.0423 & TRN \\
\hline CHEMBL1570618 & 688267 & 5.75 & 5.0358 & TST \\
\hline CHEMBL1476233 & 688267 & 4.05 & 5.1768 & TRN \\
\hline CHEMBL1394310 & 688267 & 5.85 & 5.0472 & TRN \\
\hline CHEMBL327679 & 688267 & 5.25 & 5.0118 & TST \\
\hline CHEMBL1332833 & 688267 & 5.05 & 5.0805 & TRN \\
\hline CHEMBL1340980 & 688267 & 4.0 & 5.11 & TRN \\
\hline CHEMBL1576669 & 688267 & 4.35 & 5.0999 & TST \\
\hline CHEMBL1549845 & 688267 & 5.15 & 5.0468 & TST \\
\hline CHEMBL1346861 & 688267 & 4.0 & 5.0855 & TRN \\
\hline CHEMBL1530535 & 688267 & 3.95 & 5.0907 & TRN \\
\hline CHEMBL1566596 & 688267 & 3.95 & 5.1262 & TRN \\
\hline CHEMBL1558863 & 688267 & 6.45 & 4.9979 & TRN \\
\hline CHEMBL1446156 & 688267 & 5.05 & 5.0809 & TST \\
\hline CHEMBL1536977 & 688267 & 4.5 & 5.0457 & TST \\
\hline CHEMBL1303565 & 688267 & 5.9 & 5.0622 & TRN \\
\hline CHEMBL1509267 & 688267 & 5.0 & 4.9763 & TST \\
\hline CHEMBL1318415 & 688267 & 4.5 & 5.0684 & TRN \\
\hline CHEMBL1434413 & 688267 & 4.75 & 5.052 & TRN \\
\hline CHEMBL1362930 & 688267 & 4.95 & 5.1395 & TRN \\
\hline CHEMBL1557783 & 688267 & 5.15 & 5.0297 & TRN \\
\hline CHEMBL1315826 & 688267 & 5.45 & 5.1067 & TRN \\
\hline CHEMBL1351621 & 688267 & 4.9 & 5.0418 & TRN \\
\hline CHEMBL1435989 & 688267 & 4.05 & 5.0403 & TRN \\
\hline CHEMBL1360123 & 688267 & 5.4 & 5.078 & TRN \\
\hline CHEMBL1362412 & 688267 & 5.8 & 5.0107 & TRN \\
\hline CHEMBL1461129 & 688267 & 5.3 & 5.0826 & TRN \\
\hline CHEMBL 3192681 & 688267 & 5.2 & 5.0283 & TRN \\
\hline CHEMBL1363650 & 688267 & 5.6 & 5.1279 & TRN \\
\hline CHEMBL1434293 & 688267 & 4.0 & 5.12 & TRN \\
\hline CHEMBL1426400 & 688267 & 4.25 & 5.0668 & TRN \\
\hline CHEMBL571295 & 688267 & 4.85 & 5.1357 & TST \\
\hline CHEMBL1371715 & 688267 & 4.0 & 5.0891 & TRN \\
\hline CHEMBL1607118 & 688267 & 4.55 & 5.0225 & TRN \\
\hline CHEMBL1456394 & 688267 & 6.25 & 4.9908 & TRN \\
\hline CHEMBL1269633 & 688267 & 4.3 & 5.0203 & TRN \\
\hline
\end{tabular}




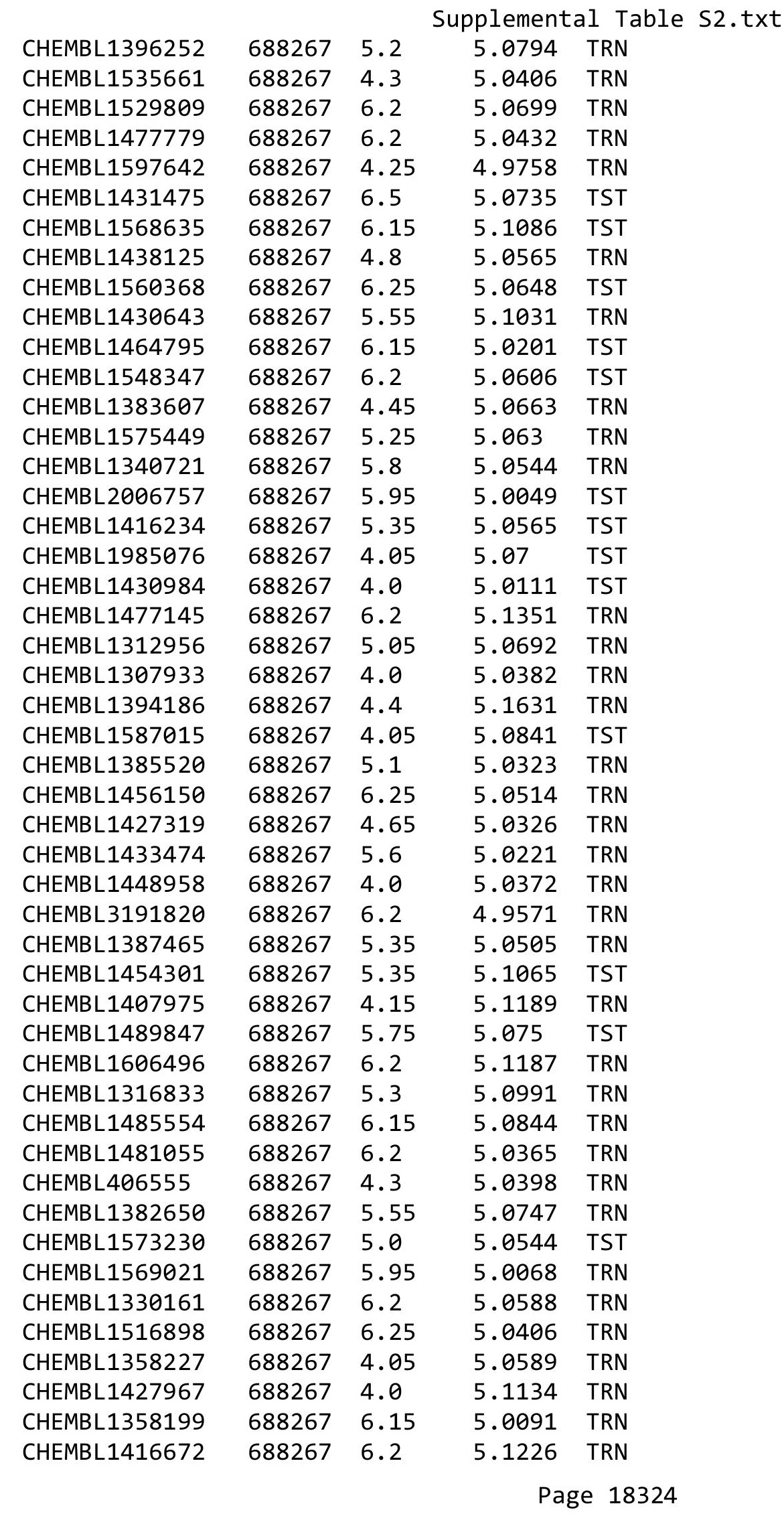




\begin{tabular}{|c|c|c|c|c|c|}
\hline & & \multicolumn{4}{|c|}{ Supplemental Table S2.txt } \\
\hline CHEMBL1552672 & 688267 & 5.35 & 5.1206 & TRN & \\
\hline CHEMBL1454866 & 688267 & 5.65 & 5.0731 & TRN & \\
\hline CHEMBL1513377 & 688267 & 5.1 & 5.1584 & TRN & \\
\hline CHEMBL1535974 & 688267 & 3.95 & 5.0137 & TRN & \\
\hline CHEMBL3207576 & 688267 & 4.9 & 5.0312 & TRN & \\
\hline CHEMBL1318429 & 688267 & 4.5 & 5.0423 & TRN & \\
\hline CHEMBL1587254 & 688267 & 4.2 & 5.0737 & TST & \\
\hline CHEMBL1392682 & 688267 & 6.25 & 5.0795 & TST & \\
\hline CHEMBL1398959 & 688267 & 6.2 & 5.0664 & TRN & \\
\hline CHEMBL1340188 & 688267 & 4.3 & 5.0942 & TRN & \\
\hline CHEMBL1422820 & 688267 & 6.2 & 5.0959 & TRN & \\
\hline CHEMBL1524435 & 688267 & 3.8 & 5.0953 & TRN & \\
\hline CHEMBL1337514 & 688267 & 4.55 & 5.0255 & TRN & \\
\hline CHEMBL1592524 & 688267 & 5.55 & 5.1582 & TRN & \\
\hline CHEMBL1475700 & 688267 & 5.35 & 5.0395 & TRN & \\
\hline CHEMBL1548540 & 688267 & 5.35 & 5.0245 & TRN & \\
\hline CHEMBL1611737 & 688267 & 4.1 & 5.0365 & TRN & \\
\hline CHEMBL1460090 & 688267 & 4.8 & 5.0385 & TRN & \\
\hline CHEMBL1582654 & 688267 & 5.0 & 4.9597 & TRN & \\
\hline CHEMBL1424489 & 688267 & 4.0 & 5.0116 & TST & \\
\hline CHEMBL1531389 & 688267 & 4.05 & 5.0238 & TRN & \\
\hline CHEMBL1369345 & 688267 & 6.2 & 5.1144 & TRN & \\
\hline CHEMBL1377057 & 688267 & 5.4 & 4.995 & TRN & \\
\hline CHEMBL1553107 & 688267 & 5.7 & 5.1092 & TRN & \\
\hline CHEMBL1471031 & 688267 & 6.2 & 5.0476 & TRN & \\
\hline CHEMBL1472247 & 688267 & 4.0 & 5.0437 & TST & \\
\hline CHEMBL1591436 & 688267 & 5.85 & 5.0293 & TRN & \\
\hline CHEMBL1399112 & 688267 & 6.2 & 5.0672 & TRN & \\
\hline CHEMBL1513886 & 688267 & 4.1 & 5.0256 & TRN & \\
\hline CHEMBL1605113 & 688267 & 3.95 & 5.1122 & TST & \\
\hline CHEMBL1326985 & 688267 & 3.95 & 5.1082 & TST & \\
\hline CHEMBL1576937 & 688267 & 6.15 & 5.0592 & TRN & \\
\hline CHEMBL1316010 & 688267 & 5.7 & 5.0554 & TRN & \\
\hline CHEMBL1359700 & 688267 & 4.35 & 5.062 & TST & \\
\hline CHEMBL1343230 & 688267 & 5.8 & 5.0981 & TRN & \\
\hline CHEMBL1590685 & 688267 & 4.55 & 5.0763 & TRN & \\
\hline CHEMBL1382589 & 688267 & 4.75 & 5.0733 & TRN & \\
\hline CHEMBL1468248 & 688267 & 6.1 & 5.1113 & TRN & \\
\hline CHEMBL1380450 & 688267 & 4.05 & 5.07 & TRN & \\
\hline CHEMBL1563543 & 688267 & 4.0 & 5.0132 & TRN & \\
\hline CHEMBL1301232 & 688267 & 5.5 & 4.9789 & TRN & \\
\hline CHEMBL1450157 & 688267 & 4.85 & $5.0310 e$ & 0000000001 & TRN \\
\hline CHEMBL1507278 & 688267 & 4.0 & 5.0422 & TRN & \\
\hline CHEMBL1486086 & 688267 & 4.0 & 5.1435 & TRN & \\
\hline CHEMBL1607155 & 688267 & 5.45 & 5.0359 & TST & \\
\hline CHEMBL1538052 & 688267 & 4.3 & 5.0454 & TRN & \\
\hline CHEMBL1374486 & 688267 & 3.9 & 5.0349 & TRN & \\
\hline CHEMBL1558459 & 688267 & 4.35 & 5.0498 & TST & \\
\hline
\end{tabular}




\begin{tabular}{|c|c|c|c|c|c|}
\hline \\
\hline CHEMBL1310842 & 688267 & 4.5 & 5.1188 & TRN & \\
\hline CHEMBL1354808 & 688267 & 4.75 & 5.0462 & TRN & \\
\hline CHEMBL1542706 & 688267 & 5.3 & 5.1721 & TRN & \\
\hline CHEMBL 3214103 & 688267 & 5.3 & 5.1007 & TST & \\
\hline CHEMBL1425837 & 688267 & 4.25 & 5.0356 & TRN & \\
\hline CHEMBL1376514 & 688267 & 4.4 & 5.029 & TST & \\
\hline CHEMBL1512004 & 688267 & 5.0 & 5.0269 & TRN & \\
\hline CHEMBL1386686 & 688267 & 5.35 & 5.0733 & TST & \\
\hline CHEMBL1595301 & 688267 & 4.5 & 5.0722 & TRN & \\
\hline CHEMBL1541545 & 688267 & 4.65 & 5.0614 & TRN & \\
\hline CHEMBL1979843 & 688267 & 4.75 & 5.0154 & TRN & \\
\hline CHEMBL 3195125 & 688267 & 4.05 & 5.0273 & TRN & \\
\hline CHEMBL1357194 & 688267 & 6.2 & 5.1295 & TST & \\
\hline CHEMBL1359063 & 688267 & 4.9 & 5.0669 & TST & \\
\hline CHEMBL1444760 & 688267 & 6.05 & 5.064 & TRN & \\
\hline CHEMBL1323165 & 688267 & 4.45 & 5.0182 & TRN & \\
\hline CHEMBL1324628 & 688267 & 6.2 & 5.0302 & TRN & \\
\hline CHEMBL1577838 & 688267 & 5.3 & 5.0398 & TRN & \\
\hline CHEMBL1472260 & 688267 & 6.05 & 5.0328 & TST & \\
\hline CHEMBL1401030 & 688267 & 5.6 & 5.0344 & TRN & \\
\hline CHEMBL1559445 & 688267 & 4.25 & 5.0304 & TST & \\
\hline CHEMBL1492689 & 688267 & 4.35 & 5.0807 & TRN & \\
\hline CHEMBL1546514 & 688267 & 4.65 & 5.0364 & TRN & \\
\hline CHEMBL1413536 & 688267 & 4.05 & 5.0642 & TST & \\
\hline CHEMBL1361895 & 688267 & 5.45 & 5.1134 & TRN & \\
\hline CHEMBL1425245 & 688267 & 5.65 & 5.1094 & TRN & \\
\hline CHEMBL1534860 & 688267 & 4.1 & 5.012 & TRN & \\
\hline CHEMBL1542917 & 688267 & 4.0 & 5.0857 & TRN & \\
\hline CHEMBL1325264 & 688267 & 5.85 & 5.0334 & TST & \\
\hline CHEMBL1467051 & 688267 & 5.25 & 5.13899 & 9999999999 & TRN \\
\hline CHEMBL1485628 & 688267 & 3.95 & 5.0428 & TRN & \\
\hline CHEMBL1504363 & 688267 & 4.0 & 5.0919 & TRN & \\
\hline CHEMBL1365263 & 688267 & 6.5501 & 5.1212 & TST & \\
\hline CHEMBL1569720 & 688267 & 5.05 & 5.0155 & TST & \\
\hline CHEMBL1327549 & 688267 & 4.0 & 5.0505 & TST & \\
\hline CHEMBL1410002 & 688267 & 4.65 & 5.0695 & TRN & \\
\hline CHEMBL1474290 & 688267 & 4.35 & 4.9679 & TRN & \\
\hline CHEMBL1526724 & 688267 & 5.1 & 5.0186 & TRN & \\
\hline CHEMBL1576210 & 688267 & 6.0 & 5.0379 & TST & \\
\hline CHEMBL1396272 & 688267 & 5.0 & 5.1389 & TRN & \\
\hline CHEMBL1442892 & 688267 & 5.4 & 5.0917 & TRN & \\
\hline CHEMBL1489274 & 688267 & 4.05 & 5.0546 & TRN & \\
\hline CHEMBL596838 & 688267 & 4.35 & 5.0323 & TRN & \\
\hline CHEMBL1592772 & 688267 & 6.2 & 5.0819 & TRN & \\
\hline CHEMBL1544313 & 688267 & 6.25 & 5.0862 & TRN & \\
\hline CHEMBL452241 & 688267 & 4.45 & 5.0704 & TRN & \\
\hline CHEMBL1325707 & 688267 & 4.35 & 5.0587 & TRN & \\
\hline CHEMBL1351202 & 688267 & 6.2 & 5.1185 & TRN & \\
\hline
\end{tabular}




\begin{tabular}{|c|c|c|c|c|}
\hline & & & pplement & al $\mathrm{Ta}$ \\
\hline CHEMBL1555278 & 688267 & 6.5 & 5.0796 & TRN \\
\hline CHEMBL1475221 & 688267 & 6.0 & 5.0765 & TRN \\
\hline CHEMBL1519176 & 688267 & 4.15 & 4.9742 & TRN \\
\hline CHEMBL1588986 & 688267 & 4.6 & 5.0699 & TRN \\
\hline CHEMBL1592869 & 688267 & 6.2 & 5.077 & TRN \\
\hline CHEMBL1461728 & 688267 & 4.05 & 5.0101 & TRN \\
\hline CHEMBL1587131 & 688267 & 4.7 & 5.0468 & TRN \\
\hline CHEMBL1430077 & 688267 & 6.15 & 5.0372 & TST \\
\hline CHEMBL1504615 & 688267 & 4.4 & 5.032 & TRN \\
\hline CHEMBL1557085 & 688267 & 4.95 & 5.082 & TRN \\
\hline CHEMBL1498094 & 688267 & 6.25 & 5.0635 & TRN \\
\hline CHEMBL1533110 & 688267 & 5.05 & 5.052 & TRN \\
\hline CHEMBL1514870 & 688267 & 4.0 & 5.0103 & TRN \\
\hline CHEMBL1464965 & 688267 & 6.2 & 5.1043 & TRN \\
\hline CHEMBL1315628 & 688267 & 4.9 & 5.081 & TRN \\
\hline CHEMBL1573440 & 688267 & 4.05 & 5.0424 & TST \\
\hline CHEMBL1447818 & 688267 & 5.05 & 5.0654 & TRN \\
\hline CHEMBL1540387 & 688267 & 5.95 & 5.0078 & TRN \\
\hline CHEMBL1308727 & 688267 & 5.6 & 5.1339 & TRN \\
\hline CHEMBL1311932 & 688267 & 4.9 & 5.0587 & TRN \\
\hline CHEMBL1368387 & 688267 & 4.95 & 5.0543 & TRN \\
\hline CHEMBL1473563 & 688267 & 5.4 & 5.0409 & TRN \\
\hline CHEMBL1590880 & 688267 & 5.95 & 5.027 & TRN \\
\hline CHEMBL1411374 & 688267 & 5.55 & 5.0266 & TST \\
\hline CHEMBL1490143 & 688267 & 4.3 & 5.0371 & TST \\
\hline CHEMBL1449427 & 688267 & 4.45 & 5.0387 & TST \\
\hline CHEMBL1333753 & 688267 & 4.75 & 5.1085 & TRN \\
\hline CHEMBL1358140 & 688267 & 5.2 & 4.9895 & TRN \\
\hline CHEMBL1346542 & 688267 & 4.0 & 5.1137 & TRN \\
\hline CHEMBL1479336 & 688267 & 5.65 & 5.1388 & TRN \\
\hline CHEMBL1349498 & 688267 & 5.65 & 5.0822 & TST \\
\hline CHEMBL1549081 & 688267 & 5.05 & 5.0247 & TRN \\
\hline CHEMBL1564887 & 688267 & 4.95 & 4.9592 & TRN \\
\hline CHEMBL1339587 & 688267 & 5.9 & 5.1737 & TST \\
\hline CHEMBL1598109 & 688267 & 4.0 & 5.023 & TRN \\
\hline CHEMBL1406274 & 688267 & 6.0 & 5.0207 & TST \\
\hline CHEMBL1472996 & 688267 & 4.0 & 5.0065 & TRN \\
\hline CHEMBL1513192 & 688267 & 5.4 & 5.0861 & TRN \\
\hline CHEMBL1557509 & 688267 & 5.25 & 5.039 & TRN \\
\hline CHEMBL1516605 & 688267 & 4.6 & 5.0566 & TRN \\
\hline CHEMBL1408255 & 688267 & 4.4 & 5.0938 & TRN \\
\hline CHEMBL1589022 & 688267 & 4.0 & 5.0995 & TST \\
\hline CHEMBL1426211 & 688267 & 5.8 & 5.0538 & TRN \\
\hline CHEMBL3212035 & 688267 & 4.4 & 5.0575 & TST \\
\hline CHEMBL1552239 & 688267 & 5.65 & 5.0117 & TRN \\
\hline CHEMBL1570390 & 688267 & 4.55 & 5.0487 & TRN \\
\hline CHEMBL1379038 & 688267 & 5.3 & 5.1051 & TRN \\
\hline CHEMBL1575158 & 688267 & 4.0 & 5.1158 & TRN \\
\hline
\end{tabular}




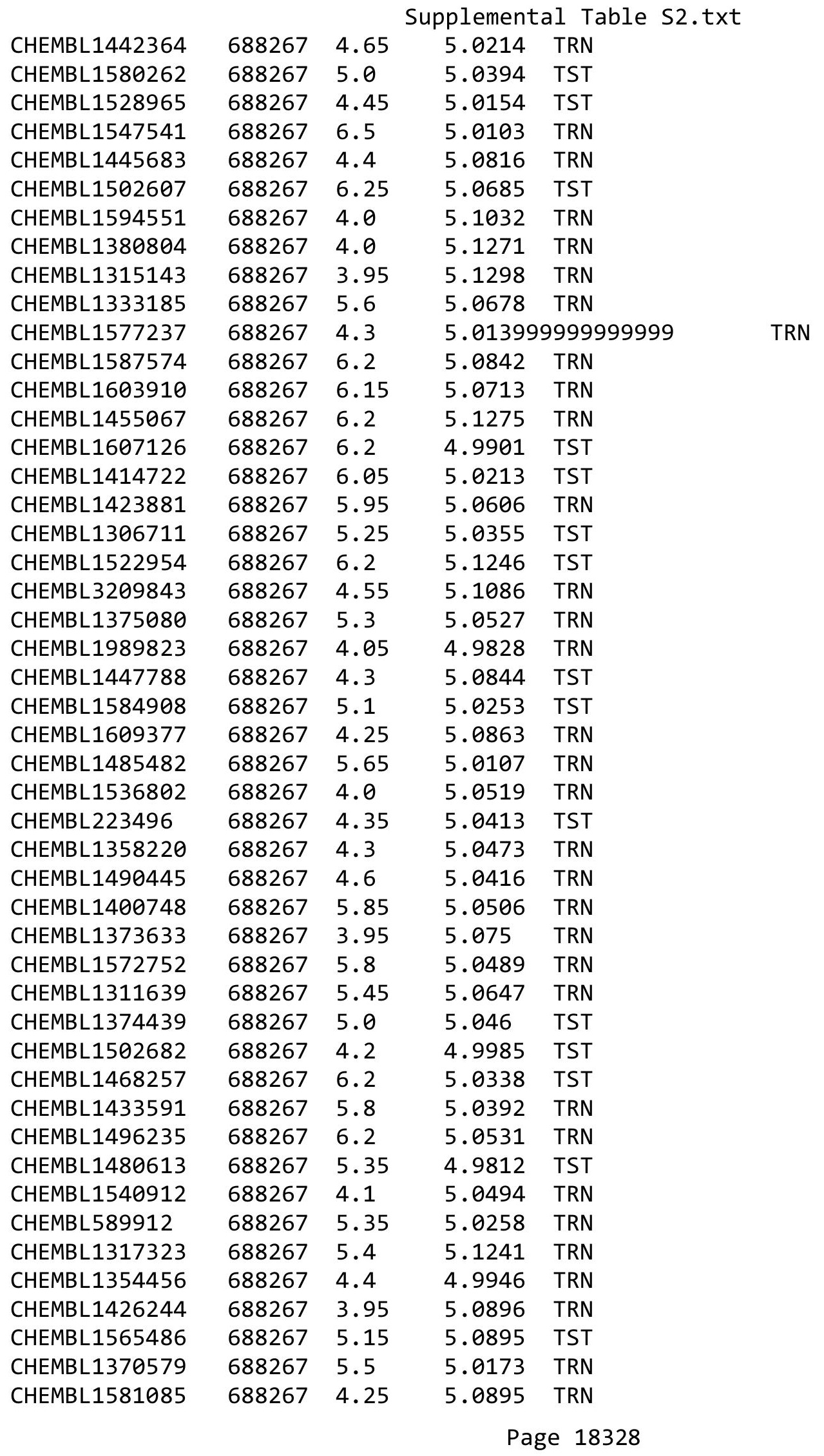




\begin{tabular}{|c|c|c|c|c|}
\hline & & & pplement & al $\mathrm{Ta}$ \\
\hline CHEMBL1536967 & 688267 & 5.9 & 5.0531 & TRN \\
\hline CHEMBL1392838 & 688267 & 6.25 & 4.9886 & TST \\
\hline CHEMBL1548316 & 688267 & 4.8 & 5.1226 & TRN \\
\hline CHEMBL1320863 & 688267 & 6.2 & 5.0579 & TRN \\
\hline CHEMBL1600314 & 688267 & 4.0 & 4.9923 & TRN \\
\hline CHEMBL1552797 & 688267 & 5.3 & 5.0233 & TRN \\
\hline CHEMBL1359168 & 688267 & 4.85 & 5.0264 & TRN \\
\hline CHEMBL1445923 & 688267 & 4.4 & 5.0495 & TRN \\
\hline CHEMBL3213879 & 688267 & 3.95 & 5.0237 & TRN \\
\hline CHEMBL1441234 & 688267 & 3.95 & 5.0731 & TST \\
\hline CHEMBL1479862 & 688267 & 5.5 & 5.0276 & TRN \\
\hline CHEMBL1454453 & 688267 & 5.4 & 5.0087 & TST \\
\hline CHEMBL1496018 & 688267 & 5.6 & 5.0967 & TRN \\
\hline CHEMBL1558000 & 688267 & 4.8 & 5.1014 & TRN \\
\hline CHEMBL1545151 & 688267 & 4.05 & 5.1316 & TST \\
\hline CHEMBL1359883 & 688267 & 4.0 & 5.0647 & TRN \\
\hline CHEMBL1523060 & 688267 & 4.0 & 5.0356 & TRN \\
\hline CHEMBL1586835 & 688267 & 4.55 & 5.0095 & TRN \\
\hline CHEMBL2000175 & 688267 & 5.85 & 5.0378 & TST \\
\hline CHEMBL1366045 & 688267 & 6.2 & 5.0066 & TRN \\
\hline CHEMBL1497746 & 688267 & 4.05 & 5.0181 & TRN \\
\hline CHEMBL1432196 & 688267 & 5.9 & 5.0515 & TST \\
\hline CHEMBL1490294 & 688267 & 6.15 & 5.0605 & TRN \\
\hline CHEMBL1545139 & 688267 & 4.5 & 5.0614 & TRN \\
\hline CHEMBL1476555 & 688267 & 5.3 & 5.1088 & TRN \\
\hline CHEMBL1483235 & 688267 & 3.95 & 5.0534 & TST \\
\hline CHEMBL1374350 & 688267 & 6.1 & 5.0572 & TRN \\
\hline CHEMBL1555228 & 688267 & 4.4 & 5.0318 & TRN \\
\hline CHEMBL1587069 & 688267 & 4.35 & 4.9975 & TRN \\
\hline CHEMBL1587839 & 688267 & 5.5 & 5.0666 & TRN \\
\hline CHEMBL1332185 & 688267 & 4.75 & 5.0509 & TRN \\
\hline CHEMBL1542212 & 688267 & 4.1 & 5.1342 & TST \\
\hline CHEMBL1335095 & 688267 & 4.4 & 5.0544 & TST \\
\hline CHEMBL1493319 & 688267 & 6.2 & 5.1726 & TRN \\
\hline CHEMBL1433691 & 688267 & 4.35 & 5.1053 & TRN \\
\hline CHEMBL1389186 & 688267 & 4.15 & 5.0192 & TRN \\
\hline CHEMBL1436362 & 688267 & 5.6 & 5.1358 & TRN \\
\hline CHEMBL1612977 & 688267 & 4.5 & 5.0505 & TRN \\
\hline CHEMBL1406779 & 688267 & 4.85 & 5.0445 & TRN \\
\hline CHEMBL1424784 & 688267 & 5.55 & 5.0661 & TRN \\
\hline CHEMBL1433712 & 688267 & 6.45 & 5.1214 & TST \\
\hline CHEMBL1470720 & 688267 & 6.2 & 5.1077 & TST \\
\hline CHEMBL1421270 & 688267 & 5.25 & 4.9836 & TST \\
\hline CHEMBL1425853 & 688267 & 5.7 & 5.0162 & TRN \\
\hline CHEMBL1318753 & 688267 & 4.0 & 5.1264 & TRN \\
\hline CHEMBL1592060 & 688267 & 5.3 & 5.112 & TRN \\
\hline CHEMBL1436616 & 688267 & 5.4 & 4.9975 & TRN \\
\hline CHEMBL1531518 & 688267 & 6.2 & 5.0811 & TRN \\
\hline
\end{tabular}




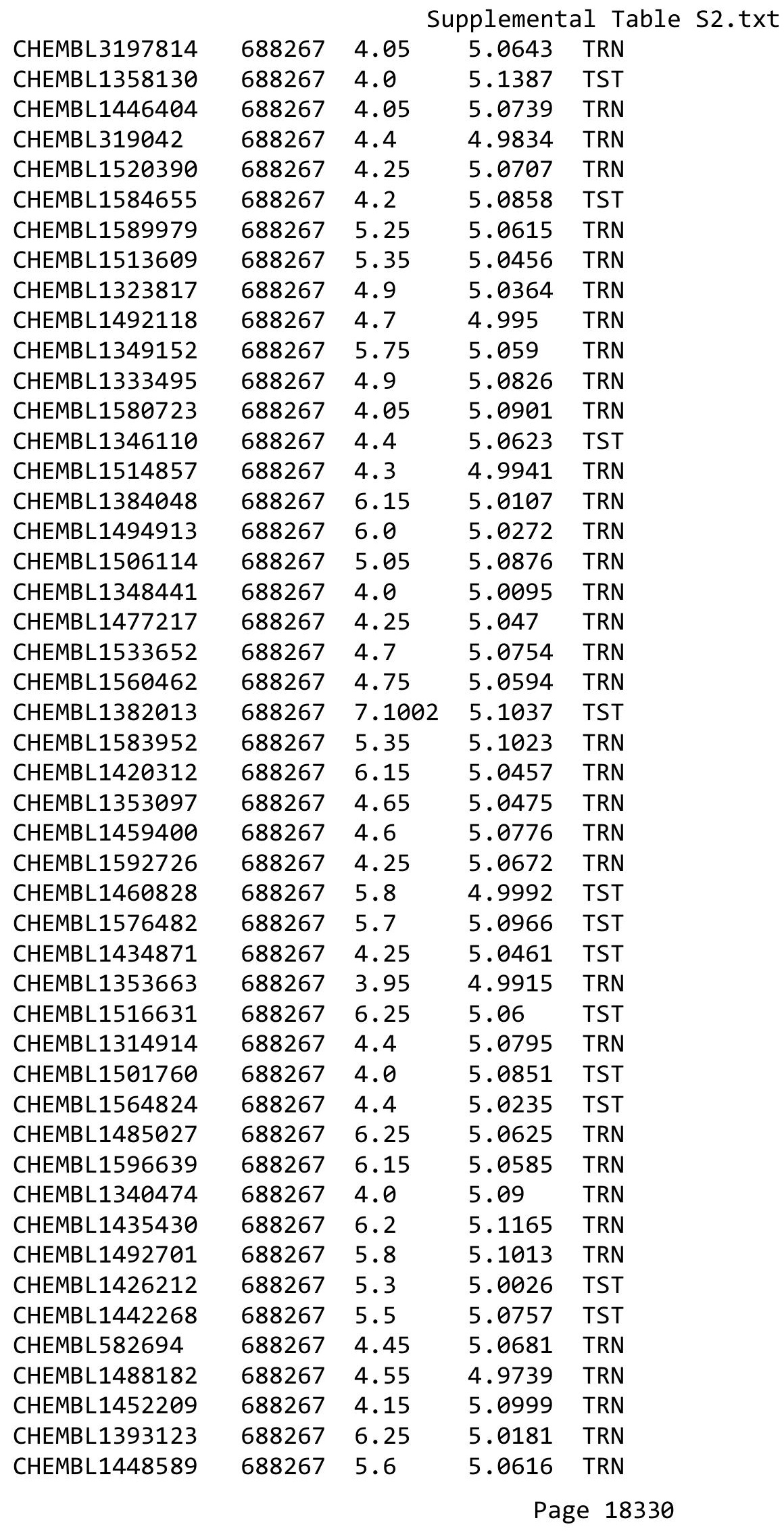




\begin{tabular}{|c|c|c|c|c|c|}
\hline \multicolumn{6}{|c|}{ Supplemental Table S2.txt } \\
\hline CHEMBL1393048 & 688267 & 4.05 & 5.0154 & TRN & \\
\hline CHEMBL1422166 & 688267 & 5.45 & 5.1141 & TRN & \\
\hline CHEMBL1373133 & 688267 & 4.35 & 5.0059 & TRN & \\
\hline CHEMBL1547305 & 688267 & 4.3 & 5.0799 & TST & \\
\hline CHEMBL1328410 & 688267 & 5.6 & 5.0348 & TRN & \\
\hline CHEMBL1567171 & 688267 & 6.15 & 5.0586 & TST & \\
\hline CHEMBL1452892 & 688267 & 4.0 & 5.0669 & TRN & \\
\hline CHEMBL1433595 & 688267 & 6.15 & 5.1488 & TRN & \\
\hline CHEMBL1565637 & 688267 & 5.75 & 5.051 & TRN & \\
\hline CHEMBL1531560 & 688267 & 4.0 & 5.005 & TST & \\
\hline CHEMBL1529527 & 688267 & 5.7 & 5.0933 & TRN & \\
\hline CHEMBL1305530 & 688267 & 5.8 & 5.0664 & TRN & \\
\hline CHEMBL1591545 & 688267 & 3.95 & 5.0761 & TRN & \\
\hline CHEMBL1355457 & 688267 & 4.4 & 5.0794 & TRN & \\
\hline CHEMBL1500695 & 688267 & 4.0 & 5.0566 & TST & \\
\hline CHEMBL1331314 & 688267 & 5.45 & 5.0686 & TRN & \\
\hline CHEMBL1411224 & 688267 & 4.95 & 5.0268 & TRN & \\
\hline CHEMBL 2262870 & 688267 & 4.4 & 5.0024 & TRN & \\
\hline CHEMBL1396890 & 688267 & 4.35 & 5.0974 & TRN & \\
\hline CHEMBL1402065 & 688267 & 4.2 & 5.0283 & TRN & \\
\hline CHEMBL1468342 & 688267 & 5.05 & 5.0909 & TRN & \\
\hline CHEMBL1534369 & 688267 & 4.3 & 5.099 & TRN & \\
\hline CHEMBL1592144 & 688267 & 4.0 & 5.0374 & TRN & \\
\hline CHEMBL1552756 & 688267 & 6.2 & 5.03600 & 00000000005 & TRN \\
\hline CHEMBL1597524 & 688267 & 4.0 & 5.0485 & TST & \\
\hline CHEMBL1514132 & 688267 & 4.6 & 5.0304 & TRN & \\
\hline CHEMBL1567604 & 688267 & 4.0 & 5.0819 & TRN & \\
\hline CHEMBL1486835 & 688267 & 6.2 & 5.1406 & TST & \\
\hline CHEMBL1361427 & 688267 & 4.35 & 5.0491 & TRN & \\
\hline CHEMBL1602500 & 688267 & 5.65 & 5.0976 & TRN & \\
\hline CHEMBL1442811 & 688267 & 6.25 & 5.0738 & TRN & \\
\hline CHEMBL1598707 & 688267 & 4.35 & 4.9779 & TRN & \\
\hline CHEMBL3198109 & 688267 & 4.05 & 5.0013 & TRN & \\
\hline CHEMBL3209187 & 688267 & 4.4 & 5.0677 & TRN & \\
\hline CHEMBL1445916 & 688267 & 4.0 & 5.0323 & TRN & \\
\hline CHEMBL1396047 & 688267 & 4.0 & 5.013 & TRN & \\
\hline CHEMBL1550340 & 688267 & 4.1 & 5.0201 & TRN & \\
\hline CHEMBL1318148 & 688267 & 6.25 & 5.1053 & TRN & \\
\hline CHEMBL1595190 & 688267 & 5.05 & 5.0357 & TRN & \\
\hline CHEMBL1606692 & 688267 & 4.05 & 5.0427 & TRN & \\
\hline CHEMBL1579321 & 688267 & 4.05 & 4.9968 & TRN & \\
\hline CHEMBL1445044 & 688267 & 6.2 & 5.0119 & TRN & \\
\hline CHEMBL1583468 & 688267 & 5.85 & 5.092 & TRN & \\
\hline CHEMBL1322841 & 688267 & 5.65 & 5.0718 & TST & \\
\hline CHEMBL1579581 & 688267 & 4.0 & 5.153 & TRN & \\
\hline CHEMBL1356747 & 688267 & 3.95 & 5.1169 & TRN & \\
\hline CHEMBL3192942 & 688267 & 5.3 & 5.0741 & TRN & \\
\hline CHEMBL1428840 & 688267 & 4.25 & 5.0492 & TRN & \\
\hline
\end{tabular}




\begin{tabular}{|c|c|c|c|c|}
\hline \multicolumn{5}{|c|}{ Supplemental Table S2.txt } \\
\hline CHEMBL1551420 & 688267 & 4.05 & 4.9965 & TRN \\
\hline CHEMBL1302341 & 688267 & 4.55 & 5.0556 & TRN \\
\hline CHEMBL1438220 & 688267 & 4.0 & 5.101 & TRN \\
\hline CHEMBL1582233 & 688267 & 5.75 & 5.0555 & TRN \\
\hline CHEMBL1435332 & 688267 & 6.15 & 5.0254 & TRN \\
\hline CHEMBL1311158 & 688267 & 4.9 & 5.095 & TRN \\
\hline CHEMBL1410530 & 688267 & 3.95 & 5.079 & TRN \\
\hline CHEMBL1559797 & 688267 & 5.0 & 5.0749 & TRN \\
\hline CHEMBL1417876 & 688267 & 4.95 & 5.0008 & TRN \\
\hline CHEMBL1408552 & 688267 & 6.25 & 5.0608 & TRN \\
\hline CHEMBL1580197 & 688267 & 5.55 & 5.0612 & TST \\
\hline CHEMBL1509536 & 688267 & 4.0 & 5.0751 & TRN \\
\hline CHEMBL1318563 & 688267 & 6.45 & 5.0405 & TRN \\
\hline CHEMBL1364698 & 688267 & 6.15 & 5.1019 & TRN \\
\hline CHEMBL1425137 & 688267 & 4.35 & 5.0007 & TST \\
\hline CHEMBL1354616 & 688267 & 5.0 & 5.0903 & TRN \\
\hline CHEMBL1556101 & 688267 & 5.35 & 5.0997 & TRN \\
\hline CHEMBL1586882 & 688267 & 4.15 & 5.1286 & TST \\
\hline CHEMBL1329132 & 688267 & 4.0 & 5.1032 & TRN \\
\hline CHEMBL1552074 & 688267 & 6.2 & 5.135 & TRN \\
\hline CHEMBL1495343 & 688267 & 4.0 & 5.1055 & TRN \\
\hline CHEMBL1572663 & 688267 & 5.15 & 5.0246 & TRN \\
\hline CHEMBL1591154 & 688267 & 5.2 & 4.9912 & TRN \\
\hline CHEMBL1385334 & 688267 & 6.25 & 5.1118 & TRN \\
\hline CHEMBL1399322 & 688267 & 5.25 & 5.0423 & TRN \\
\hline CHEMBL1489377 & 688267 & 5.45 & 5.1208 & TRN \\
\hline CHEMBL1366363 & 688267 & 5.8 & 5.0596 & TRN \\
\hline CHEMBL 2001226 & 688267 & 4.05 & 5.0355 & TST \\
\hline CHEMBL1510357 & 688267 & 4.95 & 5.1304 & TST \\
\hline CHEMBL1607761 & 688267 & 4.4 & 5.0293 & TST \\
\hline CHEMBL1865649 & 688267 & 4.1 & 5.0491 & TST \\
\hline CHEMBL1372248 & 688267 & 4.2 & 5.0162 & TRN \\
\hline CHEMBL1462190 & 688267 & 4.25 & 5.0435 & TRN \\
\hline CHEMBL1388248 & 688267 & 5.65 & 5.1074 & TRN \\
\hline CHEMBL1443279 & 688267 & 5.3 & 5.0106 & TRN \\
\hline CHEMBL567531 & 688267 & 4.65 & 4.9811 & TRN \\
\hline CHEMBL1420670 & 688267 & 5.6 & 5.0611 & TRN \\
\hline CHEMBL1554848 & 688267 & 4.05 & 5.0794 & TRN \\
\hline CHEMBL1377536 & 688267 & 4.05 & 5.0477 & TRN \\
\hline CHEMBL512845 & 688267 & 3.95 & 5.0962 & TRN \\
\hline CHEMBL1520582 & 688267 & 4.3 & 5.0249 & TRN \\
\hline CHEMBL1510911 & 688267 & 6.15 & 5.0375 & TST \\
\hline CHEMBL3197921 & 688267 & 4.4 & 4.9882 & TRN \\
\hline CHEMBL569146 & 688267 & 6.2 & 5.0787 & TST \\
\hline CHEMBL1428082 & 688267 & 4.05 & 5.0241 & TRN \\
\hline CHEMBL1324808 & 688267 & 4.3 & 5.1004 & TRN \\
\hline CHEMBL1373194 & 688267 & 3.9 & 5.0116 & TST \\
\hline CHEMBL1564926 & 688267 & 4.15 & 5.0698 & TRN \\
\hline
\end{tabular}




\begin{tabular}{|c|c|c|c|c|}
\hline \multicolumn{5}{|c|}{ Supplemental Table S2.txt } \\
\hline CHEMBL3190916 & 688267 & 5.35 & 5.0501 & TST \\
\hline CHEMBL1397428 & 688267 & 4.05 & 5.1086 & TRN \\
\hline CHEMBL1558944 & 688267 & 4.3 & 5.0245 & TRN \\
\hline CHEMBL 3212426 & 688267 & 6.2 & 5.0411 & TRN \\
\hline CHEMBL 1575750 & 688267 & 5.5 & 5.0863 & TRN \\
\hline CHEMBL1375515 & 688267 & 6.3 & 4.99 & TRN \\
\hline CHEMBL1525186 & 688267 & 6.15 & 5.0132 & TRN \\
\hline CHEMBL1522097 & 688267 & 4.3 & 5.0512 & TRN \\
\hline CHEMBL3193789 & 688267 & 4.05 & 5.0761 & TRN \\
\hline CHEMBL1453167 & 688267 & 6.15 & 5.0887 & TRN \\
\hline CHEMBL1563587 & 688267 & 5.25 & 5.1181 & TRN \\
\hline CHEMBL1410885 & 688267 & 6.15 & 5.1312 & TRN \\
\hline CHEMBL1352261 & 688267 & 5.65 & 5.0577 & TST \\
\hline CHEMBL1590506 & 688267 & 4.1 & 5.0265 & TRN \\
\hline CHEMBL1379952 & 688267 & 5.35 & 5.0464 & TRN \\
\hline CHEMBL1301251 & 688267 & 5.85 & 5.0506 & TRN \\
\hline CHEMBL1412606 & 688267 & 3.95 & 5.0413 & TRN \\
\hline CHEMBL1442910 & 688267 & 4.05 & 5.0557 & TST \\
\hline CHEMBL1487488 & 688267 & 6.15 & 5.02 & TST \\
\hline CHEMBL1534880 & 688267 & 3.95 & 4.9852 & TRN \\
\hline CHEMBL1486204 & 688267 & 4.3 & 5.0338 & TRN \\
\hline CHEMBL1327740 & 688267 & 5.6 & 5.0339 & TRN \\
\hline CHEMBL1388375 & 688267 & 4.55 & 5.0217 & TRN \\
\hline CHEMBL1428847 & 688267 & 4.25 & 5.1275 & TST \\
\hline CHEMBL1477649 & 688267 & 5.5 & 5.0364 & TST \\
\hline CHEMBL1467548 & 688267 & 5.65 & 5.1024 & TRN \\
\hline CHEMBL1606026 & 688267 & 4.25 & 5.0523 & TRN \\
\hline CHEMBL1349702 & 688267 & 5.3 & 5.0853 & TRN \\
\hline CHEMBL1355038 & 688267 & 4.25 & 5.0151 & TST \\
\hline CHEMBL1373399 & 688267 & 5.9 & 5.1054 & TRN \\
\hline CHEMBL1519792 & 688267 & 5.4 & 5.0149 & TRN \\
\hline CHEMBL1510394 & 688267 & 4.3 & 5.0647 & TRN \\
\hline CHEMBL1521271 & 688267 & 6.15 & 5.1454 & TRN \\
\hline CHEMBL1318762 & 688267 & 4.0 & 4.9894 & TRN \\
\hline CHEMBL3195227 & 688267 & 5.45 & 5.0172 & TST \\
\hline CHEMBL1326129 & 688267 & 6.15 & 5.0618 & TRN \\
\hline CHEMBL1431234 & 688267 & 4.5 & 4.9843 & TRN \\
\hline CHEMBL1567713 & 688267 & 4.0 & 4.9433 & TST \\
\hline CHEMBL1541079 & 688267 & 4.5 & 5.0425 & TST \\
\hline CHEMBL1463372 & 688267 & 5.4 & 5.0147 & TRN \\
\hline CHEMBL1567878 & 688267 & 6.15 & 5.0237 & TRN \\
\hline CHEMBL1446495 & 688267 & 4.0 & 5.0521 & TRN \\
\hline CHEMBL1505153 & 688267 & 6.2 & 5.0216 & TST \\
\hline CHEMBL1430375 & 688267 & 5.5 & 5.0868 & TRN \\
\hline CHEMBL1303076 & 688267 & 4.3 & 4.9869 & TRN \\
\hline CHEMBL1522971 & 688267 & 4.1 & 5.1202 & TRN \\
\hline CHEMBL1335143 & 688267 & 6.2 & 5.0515 & TRN \\
\hline CHEMBL1470779 & 688267 & 4.0 & 5.0487 & TRN \\
\hline
\end{tabular}




\begin{tabular}{|c|c|c|c|c|c|}
\hline \multicolumn{6}{|c|}{ Supplemental Table S2.txt } \\
\hline CHEMBL1383485 & 688267 & 4.0 & 5.0984 & TRN & \\
\hline CHEMBL1398679 & 688267 & 4.1 & 5.1106 & TRN & \\
\hline CHEMBL 3212227 & 688267 & 4.55 & 5.0171 & TRN & \\
\hline CHEMBL1555459 & 688267 & 6.2 & 5.039 & TST & \\
\hline CHEMBL1494543 & 688267 & 3.95 & 5.0726 & TRN & \\
\hline CHEMBL1489060 & 688267 & 4.7 & 5.0703 & TST & \\
\hline CHEMBL3197105 & 688267 & 6.2 & 5.0053 & TST & \\
\hline CHEMBL1463821 & 688267 & 5.3 & 5.1219 & TST & \\
\hline CHEMBL1600392 & 688267 & 4.75 & 4.9709 & TRN & \\
\hline CHEMBL1393630 & 688267 & 5.15 & 5.0353 & TRN & \\
\hline CHEMBL1568502 & 688267 & 3.95 & 5.1158 & TRN & \\
\hline CHEMBL1336771 & 688267 & 4.05 & 5.0303 & TRN & \\
\hline CHEMBL1412931 & 688267 & 5.55 & 5.0857 & TST & \\
\hline CHEMBL1378391 & 688267 & 6.2 & 4.9852 & TRN & \\
\hline CHEMBL1592646 & 688267 & 6.25 & 5.0645 & TRN & \\
\hline CHEMBL3194492 & 688267 & 4.25 & 5.0623 & TST & \\
\hline CHEMBL1493017 & 688267 & 6.2 & 5.0711 & TRN & \\
\hline CHEMBL1337680 & 688267 & 4.05 & 5.0451 & TRN & \\
\hline CHEMBL3191442 & 688267 & 5.55 & 4.9682 & TRN & \\
\hline CHEMBL1319882 & 688267 & 6.05 & 5.0538 & TRN & \\
\hline CHEMBL1339735 & 688267 & 4.35 & 5.0958 & TRN & \\
\hline CHEMBL1355908 & 688267 & 6.0 & 5.0457 & TRN & \\
\hline CHEMBL3193352 & 688267 & 5.5 & 5.0685 & TST & \\
\hline CHEMBL1475723 & 688267 & 6.05 & 5.0559 & TRN & \\
\hline CHEMBL1436145 & 688267 & 6.2 & 5.0598 & TRN & \\
\hline CHEMBL1438263 & 688267 & 4.65 & 5.065 & TRN & \\
\hline CHEMBL1556117 & 688267 & 6.2 & 5.0711 & TRN & \\
\hline CHEMBL1434775 & 688267 & 6.25 & 5.067 & TRN & \\
\hline CHEMBL1406075 & 688267 & 4.7 & 5.0377 & TRN & \\
\hline CHEMBL1313874 & 688267 & 6.2 & 5.09399 & 9999999999 & TRN \\
\hline CHEMBL1378228 & 688267 & 4.05 & 5.1092 & TRN & \\
\hline CHEMBL1432692 & 688267 & 6.2 & 5.0128 & TST & \\
\hline CHEMBL1344620 & 688267 & 5.4 & 5.0341 & TST & \\
\hline CHEMBL1441875 & 688267 & 5.65 & 5.0539 & TRN & \\
\hline CHEMBL1436594 & 688267 & 6.5501 & 5.0592 & TST & \\
\hline CHEMBL1388961 & 688267 & 6.2 & 5.1504 & TRN & \\
\hline CHEMBL1319355 & 688267 & 3.9 & 5.1082 & TRN & \\
\hline CHEMBL1519550 & 688267 & 5.4 & 5.058 & TRN & \\
\hline CHEMBL1465294 & 688267 & 5.45 & 5.1054 & TRN & \\
\hline CHEMBL1583493 & 688267 & 5.35 & 5.0285 & TRN & \\
\hline CHEMBL1444225 & 688267 & 5.95 & 5.1261 & TRN & \\
\hline CHEMBL1477664 & 688267 & 4.45 & 5.0095 & TRN & \\
\hline CHEMBL1456777 & 688267 & 4.7 & 5.0667 & TRN & \\
\hline CHEMBL1566277 & 688267 & 5.6 & 5.04899 & 99999999995 & TRN \\
\hline CHEMBL1429070 & 688267 & 4.3 & 5.0396 & TST & \\
\hline CHEMBL1352304 & 688267 & 6.25 & 4.9798 & TRN & \\
\hline CHEMBL1425197 & 688267 & 4.55 & 5.1209 & TRN & \\
\hline CHEMBL1608816 & 688267 & 4.55 & 5.0322 & TRN & \\
\hline
\end{tabular}




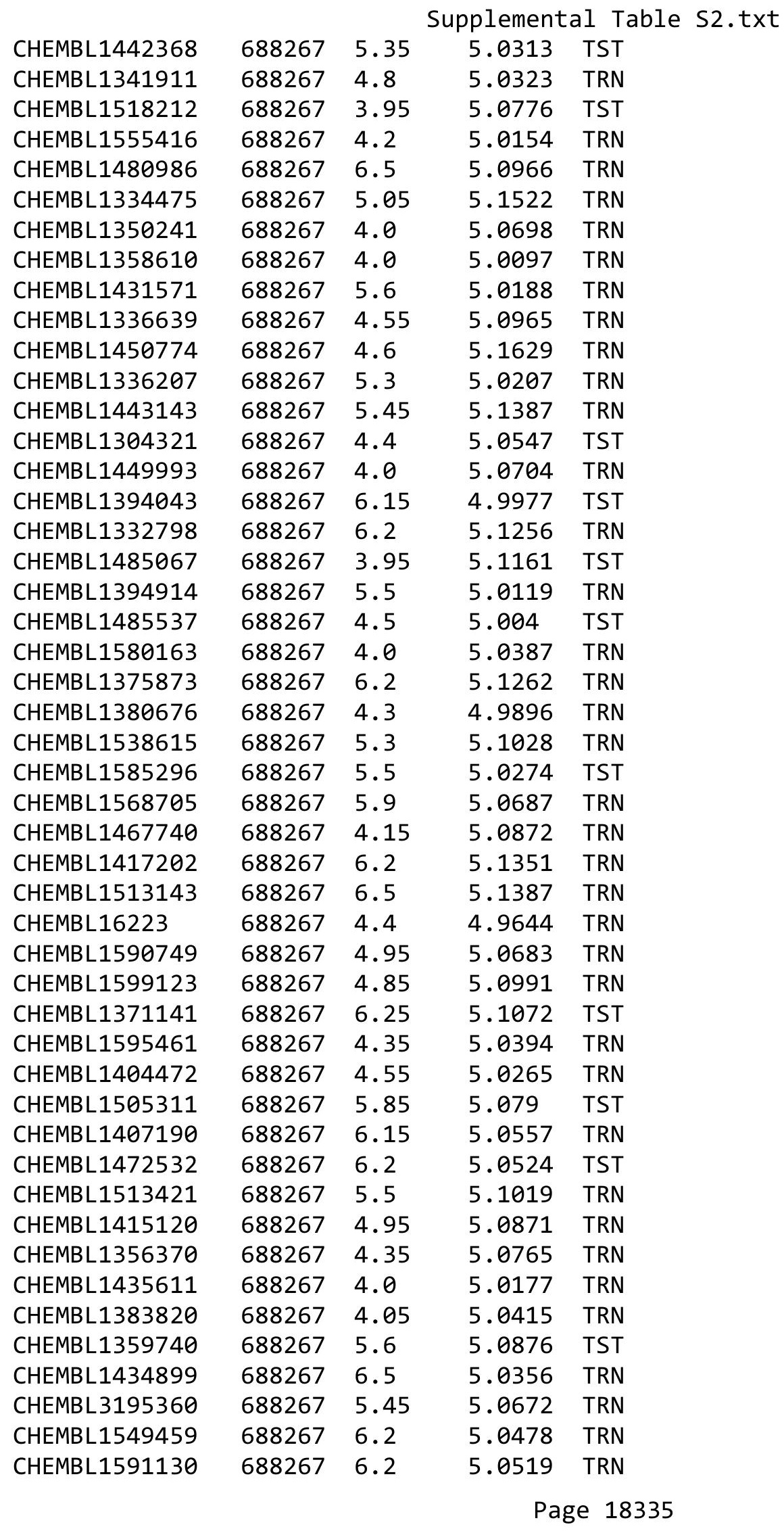




\begin{tabular}{|c|c|c|c|c|}
\hline & & & pplement & al $\mathrm{Ta}$ \\
\hline CHEMBL1552913 & 688267 & 6.5 & 5.0366 & TST \\
\hline CHEMBL3196678 & 688267 & 4.7 & 4.9761 & TST \\
\hline CHEMBL1425238 & 688267 & 6.0 & 5.0499 & TRN \\
\hline CHEMBL1478216 & 688267 & 4.0 & 4.9805 & TST \\
\hline CHEMBL1357471 & 688267 & 5.5 & 4.9968 & TRN \\
\hline CHEMBL1350333 & 688267 & 3.95 & 5.0475 & TRN \\
\hline CHEMBL1455011 & 688267 & 5.15 & 5.021 & TRN \\
\hline CHEMBL1449126 & 688267 & 6.2 & 5.0432 & TRN \\
\hline CHEMBL1403025 & 688267 & 6.05 & 5.0811 & TRN \\
\hline CHEMBL424459 & 688267 & 4.4 & 5.0799 & TRN \\
\hline CHEMBL1488866 & 688267 & 6.2 & 5.005 & TRN \\
\hline CHEMBL1304416 & 688267 & 3.95 & 5.0969 & TRN \\
\hline CHEMBL1427972 & 688267 & 6.15 & 5.0354 & TRN \\
\hline CHEMBL1394207 & 688267 & 4.0 & 5.0504 & TRN \\
\hline CHEMBL1315511 & 688267 & 4.7 & 5.0274 & TRN \\
\hline CHEMBL1560970 & 688267 & 6.2 & 5.09 & TRN \\
\hline CHEMBL1428006 & 688267 & 5.75 & 5.0345 & TST \\
\hline CHEMBL1406018 & 688267 & 6.2 & 5.0459 & TST \\
\hline CHEMBL1524971 & 688267 & 6.15 & 5.0602 & TRN \\
\hline CHEMBL1451585 & 688267 & 5.9 & 5.0634 & TST \\
\hline CHEMBL1565004 & 688267 & 4.0 & 5.0524 & TRN \\
\hline CHEMBL1542519 & 688267 & 4.2 & 5.0263 & TRN \\
\hline CHEMBL1358103 & 688267 & 4.05 & 5.065 & TRN \\
\hline CHEMBL1459770 & 688267 & 3.95 & 5.0561 & TRN \\
\hline CHEMBL1320419 & 688267 & 6.2 & 5.0152 & TST \\
\hline CHEMBL1451806 & 688267 & 4.3 & 5.0506 & TRN \\
\hline CHEMBL1472236 & 688267 & 6.2 & 5.0223 & TRN \\
\hline CHEMBL1511539 & 688267 & 6.15 & 5.0841 & TRN \\
\hline CHEMBL1489666 & 688267 & 5.45 & 5.0211 & TRN \\
\hline CHEMBL1415846 & 688267 & 4.2 & 5.082 & TST \\
\hline CHEMBL1256095 & 688267 & 4.0 & 5.0369 & TRN \\
\hline CHEMBL1393752 & 688267 & 6.15 & 5.1357 & TRN \\
\hline CHEMBL1501302 & 688267 & 4.05 & 5.0804 & TRN \\
\hline CHEMBL1349214 & 688267 & 4.05 & 5.0106 & TRN \\
\hline CHEMBL1462421 & 688267 & 4.5 & 5.0147 & TRN \\
\hline CHEMBL1579827 & 688267 & 5.55 & 5.0335 & TRN \\
\hline CHEMBL1511513 & 688267 & 5.85 & 5.0757 & TST \\
\hline CHEMBL1467224 & 688267 & 5.55 & 5.0175 & TRN \\
\hline CHEMBL1553603 & 688267 & 5.3 & 5.0466 & TST \\
\hline CHEMBL1471698 & 688267 & 4.5 & 5.0439 & TST \\
\hline CHEMBL1378237 & 688267 & 3.95 & 5.0855 & TRN \\
\hline CHEMBL1593467 & 688267 & 4.4 & 5.0881 & TRN \\
\hline CHEMBL1479886 & 688267 & 5.85 & 5.0273 & TRN \\
\hline CHEMBL1602171 & 688267 & 4.25 & 5.0436 & TST \\
\hline CHEMBL1362712 & 688267 & 4.55 & 5.0414 & TRN \\
\hline CHEMBL1317050 & 688267 & 4.25 & 5.0132 & TRN \\
\hline CHEMBL1346098 & 688267 & 4.35 & 5.1159 & TRN \\
\hline CHEMBL1320237 & 688267 & 4.25 & 5.0113 & TST \\
\hline
\end{tabular}




\begin{tabular}{|c|c|c|c|c|}
\hline \multicolumn{5}{|c|}{ Supplemental Table S2.txt } \\
\hline CHEMBL1445261 & 688267 & 6.2 & 5.1008 & TRN \\
\hline CHEMBL1592059 & 688267 & 5.3 & 5.0776 & TRN \\
\hline CHEMBL1470100 & 688267 & 6.2 & 5.1129 & TST \\
\hline CHEMBL1315152 & 688267 & 4.05 & 5.0115 & TRN \\
\hline CHEMBL1309527 & 688267 & 4.25 & 5.0524 & TRN \\
\hline CHEMBL1323742 & 688267 & 6.2 & 5.0111 & TST \\
\hline CHEMBL1513521 & 688267 & 4.0 & 5.1722 & TRN \\
\hline CHEMBL1569917 & 688267 & 4.05 & 5.0623 & TRN \\
\hline CHEMBL1476789 & 688267 & 4.35 & 5.0282 & TRN \\
\hline CHEMBL1503521 & 688267 & 4.9 & 5.0697 & TRN \\
\hline CHEMBL1359494 & 688267 & 6.25 & 5.0494 & TRN \\
\hline CHEMBL1330939 & 688267 & 5.65 & 4.9811 & TRN \\
\hline CHEMBL1460443 & 688267 & 6.25 & 5.0554 & TST \\
\hline CHEMBL1507064 & 688267 & 6.2 & 5.0408 & TRN \\
\hline CHEMBL1562648 & 688267 & 5.45 & 5.0347 & TST \\
\hline CHEMBL1553502 & 688267 & 4.25 & 5.0108 & TST \\
\hline CHEMBL1582817 & 688267 & 5.05 & 5.0191 & TRN \\
\hline CHEMBL3194727 & 688267 & 4.0 & 5.0401 & TST \\
\hline CHEMBL1383934 & 688267 & 4.75 & 5.0671 & TRN \\
\hline CHEMBL1967837 & 688267 & 6.2 & 4.9989 & TRN \\
\hline CHEMBL1581801 & 688267 & 4.85 & 5.1002 & TRN \\
\hline CHEMBL1444005 & 688267 & 6.2 & 5.0277 & TRN \\
\hline CHEMBL1522380 & 688267 & 3.95 & 5.0151 & TRN \\
\hline CHEMBL1520085 & 688267 & 4.7 & 5.0544 & TRN \\
\hline CHEMBL1544488 & 688267 & 6.25 & 5.061 & TRN \\
\hline CHEMBL1529086 & 688267 & 5.75 & 5.0075 & TRN \\
\hline CHEMBL1092473 & 688267 & 4.25 & 5.0376 & TST \\
\hline CHEMBL1397314 & 688267 & 4.05 & 5.0725 & TRN \\
\hline CHEMBL1610619 & 688267 & 5.5 & 5.0429 & TRN \\
\hline CHEMBL1463733 & 688267 & 4.25 & 5.0504 & TRN \\
\hline CHEMBL1513362 & 688267 & 5.8 & 5.0422 & TRN \\
\hline CHEMBL1481549 & 688267 & 4.05 & 5.1145 & TST \\
\hline CHEMBL3195757 & 688267 & 5.7 & 5.0176 & TRN \\
\hline CHEMBL1555270 & 688267 & 4.6 & 5.0239 & TRN \\
\hline CHEMBL1440664 & 688267 & 5.05 & 5.0548 & TST \\
\hline CHEMBL1525422 & 688267 & 6.5 & 5.0498 & TRN \\
\hline CHEMBL441473 & 688267 & 4.0 & 5.0389 & TRN \\
\hline CHEMBL1388874 & 688267 & 5.65 & 5.0073 & TST \\
\hline CHEMBL3212037 & 688267 & 5.2 & 5.0469 & TST \\
\hline CHEMBL1382372 & 688267 & 6.5 & 5.0546 & TST \\
\hline CHEMBL1542093 & 688267 & 6.15 & 5.0218 & TRN \\
\hline CHEMBL1598796 & 688267 & 4.95 & 5.039 & TRN \\
\hline CHEMBL1303496 & 688267 & 5.5 & 5.1017 & TRN \\
\hline CHEMBL1561611 & 688267 & 3.95 & 5.1648 & TRN \\
\hline CHEMBL3197566 & 688267 & 5.85 & 5.032 & TST \\
\hline CHEMBL1331234 & 688267 & 4.0 & 5.0546 & TST \\
\hline CHEMBL1593372 & 688267 & 4.5 & 5.0223 & TST \\
\hline CHEMBL1312255 & 688267 & 5.75 & 5.0178 & TRN \\
\hline
\end{tabular}




\begin{tabular}{|c|c|c|c|c|c|}
\hline \multicolumn{6}{|c|}{ Supplemental Table S2.txt } \\
\hline CHEMBL3212028 & 688267 & 6.25 & 5.0076 & TRN & \\
\hline CHEMBL1383715 & 688267 & 5.6 & 5.0426 & TRN & \\
\hline CHEMBL1421160 & 688267 & 3.95 & 5.0783 & TRN & \\
\hline CHEMBL1370368 & 688267 & 4.3 & 5.0684 & TST & \\
\hline CHEMBL1516900 & 688267 & 3.95 & 5.0748 & TST & \\
\hline CHEMBL1563620 & 688267 & 4.4 & 5.1246 & TRN & \\
\hline CHEMBL1423200 & 688267 & 5.35 & 5.0316 & TRN & \\
\hline CHEMBL1503853 & 688267 & 6.5 & 5.0449 & TRN & \\
\hline CHEMBL1358275 & 688267 & 3.95 & 4.98600 & 2000000001 & TRN \\
\hline CHEMBL1509244 & 688267 & 5.55 & 5.1409 & TRN & \\
\hline CHEMBL1516613 & 688267 & 6.2 & 5.0752 & TST & \\
\hline CHEMBL1367186 & 688267 & 4.8 & 5.0962 & TST & \\
\hline CHEMBL1340913 & 688267 & 4.0 & 5.0393 & TRN & \\
\hline CHEMBL1378203 & 688267 & 4.0 & 4.9912 & TRN & \\
\hline CHEMBL1495547 & 688267 & 3.8 & 5.045 & TRN & \\
\hline CHEMBL1519030 & 688267 & 5.4 & 5.0832 & TST & \\
\hline CHEMBL1392529 & 688267 & 6.15 & 5.0559 & TRN & \\
\hline CHEMBL1376761 & 688267 & 4.05 & 5.0643 & TRN & \\
\hline CHEMBL1480006 & 688267 & 6.15 & 5.052 & TRN & \\
\hline CHEMBL1544433 & 688267 & 4.6 & 5.0057 & TRN & \\
\hline CHEMBL1377411 & 688267 & 5.3 & 5.077 & TST & \\
\hline CHEMBL1401743 & 688267 & 5.25 & 5.0097 & TST & \\
\hline CHEMBL1511146 & 688267 & 4.55 & 5.0381 & TST & \\
\hline CHEMBL1609373 & 688267 & 4.5 & 5.0499 & TST & \\
\hline CHEMBL1601431 & 688267 & 6.2 & 5.0153 & TRN & \\
\hline CHEMBL1329515 & 688267 & 4.1 & 5.0916 & TST & \\
\hline CHEMBL1397073 & 688267 & 6.5 & 5.1016 & TST & \\
\hline CHEMBL1381028 & 688267 & 5.35 & 5.1322 & TRN & \\
\hline CHEMBL1429437 & 688267 & 4.1 & 5.0555 & TST & \\
\hline CHEMBL 3190897 & 688267 & 5.95 & 5.0635 & TST & \\
\hline CHEMBL1529099 & 688267 & 4.05 & 5.0991 & TST & \\
\hline CHEMBL1475013 & 688267 & 5.55 & 5.0946 & TRN & \\
\hline CHEMBL577223 & 688267 & 4.05 & 5.0769 & TST & \\
\hline CHEMBL1501992 & 688267 & 5.7 & 5.0928 & TRN & \\
\hline CHEMBL1434498 & 688267 & 4.7 & 5.0152 & TRN & \\
\hline CHEMBL1363246 & 688267 & 6.15 & 5.0844 & TST & \\
\hline CHEMBL1503386 & 688267 & 4.2 & 5.0131 & TST & \\
\hline CHEMBL1612053 & 688267 & 6.2 & 5.0587 & TRN & \\
\hline CHEMBL1369454 & 688267 & 5.75 & 5.023 & TRN & \\
\hline CHEMBL1397062 & 688267 & 4.4 & 5.0214 & TST & \\
\hline CHEMBL1444794 & 688267 & 4.6 & 5.0503 & TRN & \\
\hline CHEMBL1465732 & 688267 & 5.45 & 5.0645 & TRN & \\
\hline CHEMBL1213050 & 688267 & 6.25 & 5.0558 & TST & \\
\hline CHEMBL3212581 & 688267 & 5.75 & 5.1119 & TST & \\
\hline CHEMBL1433772 & 688267 & 4.0 & 5.0477 & TRN & \\
\hline CHEMBL1347797 & 688267 & 6.05 & 5.0323 & TRN & \\
\hline CHEMBL1385393 & 688267 & 5.05 & 5.1328 & TRN & \\
\hline CHEMBL1397421 & 688267 & 6.2 & 5.1092 & TRN & \\
\hline
\end{tabular}




\begin{tabular}{|c|c|c|c|c|}
\hline \multicolumn{5}{|c|}{ Supplemental Table s2.txt } \\
\hline CHEMBL1402474 & 688267 & 4.7 & 5.1157 & TRN \\
\hline CHEMBL1393318 & 688267 & 4.0 & 5.084 & TRN \\
\hline CHEMBL1522939 & 688267 & 6.5 & 5.1508 & TRN \\
\hline CHEMBL1080505 & 688267 & 4.7 & 5.1087 & TRN \\
\hline CHEMBL1591079 & 688267 & 5.55 & 5.0226 & TRN \\
\hline CHEMBL111951 & 688267 & 5.5 & 4.987 & TRN \\
\hline CHEMBL1491067 & 688267 & 5.0 & 5.113 & TRN \\
\hline CHEMBL1527007 & 688267 & 6.15 & 5.0337 & TST \\
\hline CHEMBL1330130 & 688267 & 4.0 & 5.0001 & TRN \\
\hline CHEMBL1322051 & 688267 & 5.75 & 5.0621 & TST \\
\hline CHEMBL1511175 & 688267 & 5.55 & 5.0103 & TRN \\
\hline CHEMBL1581218 & 688267 & 4.35 & 5.044 & TRN \\
\hline CHEMBL1391652 & 688267 & 6.15 & 5.1118 & TRN \\
\hline CHEMBL1453976 & 688267 & 5.75 & 5.0713 & TRN \\
\hline CHEMBL1540894 & 688267 & 4.6 & 5.0207 & TST \\
\hline CHEMBL1522413 & 688267 & 4.05 & 5.0192 & TRN \\
\hline CHEMBL1397901 & 688267 & 3.95 & 5.0565 & TST \\
\hline CHEMBL 3213902 & 688267 & 4.65 & 5.0879 & TST \\
\hline CHEMBL3213381 & 688267 & 6.6499 & 5.0546 & TST \\
\hline CHEMBL1318453 & 688267 & 5.5 & 5.0434 & TST \\
\hline CHEMBL1357903 & 688267 & 5.3 & 5.0418 & TRN \\
\hline CHEMBL1364382 & 688267 & 4.0 & 5.0012 & TRN \\
\hline CHEMBL1412982 & 688267 & 6.2 & 5.1059 & TST \\
\hline CHEMBL1468782 & 688267 & 4.6 & 5.0467 & TRN \\
\hline CHEMBL1270809 & 688267 & 6.45 & 5.0074 & TRN \\
\hline CHEMBL1362935 & 688267 & 5.7 & 5.0695 & TST \\
\hline CHEMBL1494753 & 688267 & 5.65 & 5.17 & TRN \\
\hline CHEMBL1368539 & 688267 & 5.6 & 5.045 & TRN \\
\hline CHEMBL1312002 & 688267 & 4.4 & 5.1251 & TRN \\
\hline CHEMBL1476046 & 688267 & 5.1 & 5.0663 & TRN \\
\hline CHEMBL1354953 & 688267 & 3.95 & 5.0406 & TRN \\
\hline CHEMBL1299573 & 688267 & 4.0 & 5.0697 & TRN \\
\hline CHEMBL1504503 & 688267 & 6.25 & 5.0447 & TRN \\
\hline CHEMBL1524100 & 688267 & 6.15 & 5.0393 & TRN \\
\hline CHEMBL1502267 & 688267 & 4.35 & 5.0828 & TST \\
\hline CHEMBL1435769 & 688267 & 6.1 & 5.119 & TRN \\
\hline CHEMBL1581605 & 688267 & 4.0 & 5.0321 & TRN \\
\hline CHEMBL1406299 & 688267 & 5.15 & 5.112 & TRN \\
\hline CHEMBL1453118 & 688267 & 5.35 & 4.9828 & TST \\
\hline CHEMBL1558114 & 688267 & 4.05 & 5.1224 & TST \\
\hline CHEMBL1443362 & 688267 & 4.5 & 5.0335 & TRN \\
\hline CHEMBL1317568 & 688267 & 6.2 & 5.075 & TRN \\
\hline CHEMBL1435602 & 688267 & 6.2 & 5.1161 & TST \\
\hline CHEMBL1327330 & 688267 & 5.35 & 5.0365 & TST \\
\hline CHEMBL1592620 & 688267 & 4.35 & 5.0464 & TRN \\
\hline CHEMBL1412442 & 688267 & 6.15 & 5.0422 & TRN \\
\hline CHEMBL1319472 & 688267 & 4.5 & 5.0781 & TRN \\
\hline CHEMBL1430016 & 688267 & 4.35 & 4.9918 & TRN \\
\hline
\end{tabular}




\begin{tabular}{|c|c|c|c|c|}
\hline \multicolumn{5}{|c|}{ Supplemental Table S2.txt } \\
\hline CHEMBL1377316 & 688267 & 4.0 & 5.0288 & TST \\
\hline CHEMBL1419285 & 688267 & 5.05 & 5.0218 & TRN \\
\hline CHEMBL1497093 & 688267 & 4.3 & 5.0754 & TRN \\
\hline CHEMBL1313071 & 688267 & 4.6 & 5.0368 & TST \\
\hline CHEMBL1462093 & 688267 & 4.1 & 5.0159 & TRN \\
\hline CHEMBL1539179 & 688267 & 4.95 & 5.0548 & TST \\
\hline CHEMBL1562445 & 688267 & 6.0 & 5.0316 & TRN \\
\hline CHEMBL1481944 & 688267 & 5.3 & 5.0057 & TST \\
\hline CHEMBL1415132 & 688267 & 5.5 & 5.0844 & TRN \\
\hline CHEMBL1319790 & 688267 & 5.3 & 5.1395 & TRN \\
\hline CHEMBL1380380 & 688267 & 6.2 & 5.0644 & TRN \\
\hline CHEMBL 3209320 & 688267 & 4.05 & 5.0468 & TRN \\
\hline CHEMBL1426380 & 688267 & 5.15 & 5.0451 & TRN \\
\hline CHEMBL1574790 & 688267 & 4.95 & 5.1689 & TRN \\
\hline CHEMBL1544650 & 688267 & 4.3 & 5.0446 & TRN \\
\hline CHEMBL1554649 & 688267 & 4.4 & 5.0586 & TRN \\
\hline CHEMBL1456221 & 688267 & 5.7 & 5.0639 & TRN \\
\hline CHEMBL1520929 & 688267 & 4.4 & 5.1001 & TRN \\
\hline CHEMBL1488528 & 688267 & 5.3 & 5.0071 & TRN \\
\hline CHEMBL1551795 & 688267 & 5.25 & 5.0723 & TRN \\
\hline CHEMBL1331672 & 688267 & 5.2 & 5.1042 & TRN \\
\hline CHEMBL1462119 & 688267 & 4.3 & 5.0458 & TRN \\
\hline CHEMBL1491850 & 688267 & 4.35 & 5.0907 & TST \\
\hline CHEMBL1444742 & 688267 & 4.0 & 4.9976 & TRN \\
\hline CHEMBL1443083 & 688267 & 5.3 & 5.0225 & TST \\
\hline CHEMBL1325695 & 688267 & 4.25 & 5.0385 & TRN \\
\hline CHEMBL1412115 & 688267 & 5.35 & 5.0992 & TST \\
\hline CHEMBL1525393 & 688267 & 6.15 & 5.1435 & TRN \\
\hline CHEMBL1593534 & 688267 & 6.15 & 5.0489 & TRN \\
\hline CHEMBL3197707 & 688267 & 4.0 & 5.011 & TST \\
\hline CHEMBL1534497 & 688267 & 6.2 & 5.0648 & TRN \\
\hline CHEMBL1477115 & 688267 & 4.45 & 5.1076 & TRN \\
\hline CHEMBL1452217 & 688267 & 6.2 & 5.0179 & TRN \\
\hline CHEMBL1404787 & 688267 & 4.3 & 5.0078 & TST \\
\hline CHEMBL1509961 & 688267 & 4.7 & 5.0868 & TST \\
\hline CHEMBL1420252 & 688267 & 4.3 & 5.0094 & TST \\
\hline CHEMBL1558859 & 688267 & 4.0 & 5.0446 & TRN \\
\hline CHEMBL1583341 & 688267 & 6.0 & 5.0711 & TRN \\
\hline CHEMBL1463005 & 688267 & 6.15 & 5.1106 & TRN \\
\hline CHEMBL1589844 & 688267 & 4.25 & 5.0267 & TRN \\
\hline CHEMBL1505929 & 688267 & 4.15 & 5.053 & TRN \\
\hline CHEMBL1594422 & 688267 & 4.6 & 5.0814 & TST \\
\hline CHEMBL1584184 & 688267 & 4.0 & 5.0631 & TRN \\
\hline CHEMBL1335194 & 688267 & 4.1 & 5.0567 & TST \\
\hline CHEMBL1339093 & 688267 & 4.1 & 5.0303 & TRN \\
\hline CHEMBL1464419 & 688267 & 4.6 & 5.0403 & TRN \\
\hline CHEMBL1481754 & 688267 & 3.95 & 5.0682 & TST \\
\hline CHEMBL3211097 & 688267 & 5.55 & 5.0459 & TST \\
\hline
\end{tabular}




\begin{tabular}{|c|c|c|c|c|c|}
\hline \multicolumn{6}{|c|}{ Supplemental Table S2.txt } \\
\hline CHEMBL1612944 & 688267 & 6.25 & 5.0761 & TST & \\
\hline CHEMBL1393298 & 688267 & 4.0 & 5.1188 & TRN & \\
\hline CHEMBL1449246 & 688267 & 6.15 & 5.1383 & TRN & \\
\hline CHEMBL1360451 & 688267 & 5.05 & 5.0942 & TRN & \\
\hline CHEMBL1599975 & 688267 & 5.3 & 5.0447 & TRN & \\
\hline CHEMBL1384396 & 688267 & 6.2 & 5.0077 & TRN & \\
\hline CHEMBL1379779 & 688267 & 4.0 & 5.0252 & TRN & \\
\hline CHEMBL1356746 & 688267 & 5.55 & 5.0318 & TRN & \\
\hline CHEMBL1490269 & 688267 & 4.5 & 5.0725 & TST & \\
\hline CHEMBL1551061 & 688267 & 4.85 & 5.0318 & TRN & \\
\hline CHEMBL1465314 & 688267 & 4.05 & 5.012 & TRN & \\
\hline CHEMBL1529744 & 688267 & 6.2 & 5.1065 & TRN & \\
\hline CHEMBL1586871 & 688267 & 5.6 & 5.0261 & TST & \\
\hline CHEMBL1434040 & 688267 & 4.9 & 5.1007 & TRN & \\
\hline CHEMBL1574369 & 688267 & 6.2 & 5.0335 & TRN & \\
\hline CHEMBL1559990 & 688267 & 5.5 & 5.0659 & TST & \\
\hline CHEMBL1321757 & 688267 & 5.4 & 5.1356 & TRN & \\
\hline CHEMBL1316672 & 688267 & 3.9 & 5.0233 & TRN & \\
\hline CHEMBL1325139 & 688267 & 6.2 & 5.0601 & TRN & \\
\hline CHEMBL1466568 & 688267 & 3.95 & 5.1106 & TST & \\
\hline CHEMBL1337142 & 688267 & 6.2 & 5.0153 & TRN & \\
\hline CHEMBL175916 & 688267 & 4.0 & 5.02 & TRN & \\
\hline CHEMBL1412640 & 688267 & 4.3 & 5.0342 & TRN & \\
\hline CHEMBL1405155 & 688267 & 5.9 & 5.0015 & TRN & \\
\hline CHEMBL1448166 & 688267 & 4.85 & 5.0696 & TRN & \\
\hline CHEMBL 296413 & 688267 & 5.6 & 5.1404 & TRN & \\
\hline CHEMBL1554726 & 688267 & 4.6 & 5.1218 & TRN & \\
\hline CHEMBL1485907 & 688267 & 4.3 & 4.9768 & TRN & \\
\hline CHEMBL1494500 & 688267 & 6.0 & 5.0824 & TST & \\
\hline CHEMBL1477186 & 688267 & 4.95 & 4.9948 & TST & \\
\hline CHEMBL1563237 & 688267 & 6.2 & 5.0515 & TRN & \\
\hline CHEMBL1579085 & 688267 & 5.6 & 5.0571 & TRN & \\
\hline CHEMBL1378749 & 688267 & 4.35 & 5.0252 & TST & \\
\hline CHEMBL1546323 & 688267 & 4.35 & 5.0755 & TST & \\
\hline CHEMBL1328845 & 688267 & 5.3 & 5.0867 & TST & \\
\hline CHEMBL1403533 & 688267 & 6.2 & 5.0131 & TRN & \\
\hline CHEMBL1351438 & 688267 & 5.55 & 5.0695 & TRN & \\
\hline CHEMBL1525026 & 688267 & 4.4 & 4.9943 & TRN & \\
\hline CHEMBL1354975 & 688267 & 5.35 & 5.1649 & TRN & \\
\hline CHEMBL1304209 & 688267 & 6.2 & 5.0553 & TST & \\
\hline CHEMBL1309003 & 688267 & 4.25 & 5.0642 & TRN & \\
\hline CHEMBL1337674 & 688267 & 4.4 & 5.0244 & TRN & \\
\hline CHEMBL1507213 & 688267 & 4.55 & 5.09699 & 99999999995 & TRN \\
\hline CHEMBL1360609 & 688267 & 4.05 & 5.0189 & TRN & \\
\hline CHEMBL1390880 & 688267 & 6.15 & 5.0487 & TRN & \\
\hline CHEMBL1355288 & 688267 & 3.85 & 5.058 & TRN & \\
\hline CHEMBL3190906 & 688267 & 5.85 & 5.0229 & TRN & \\
\hline CHEMBL1581719 & 688267 & 3.95 & 5.0348 & TRN & \\
\hline
\end{tabular}




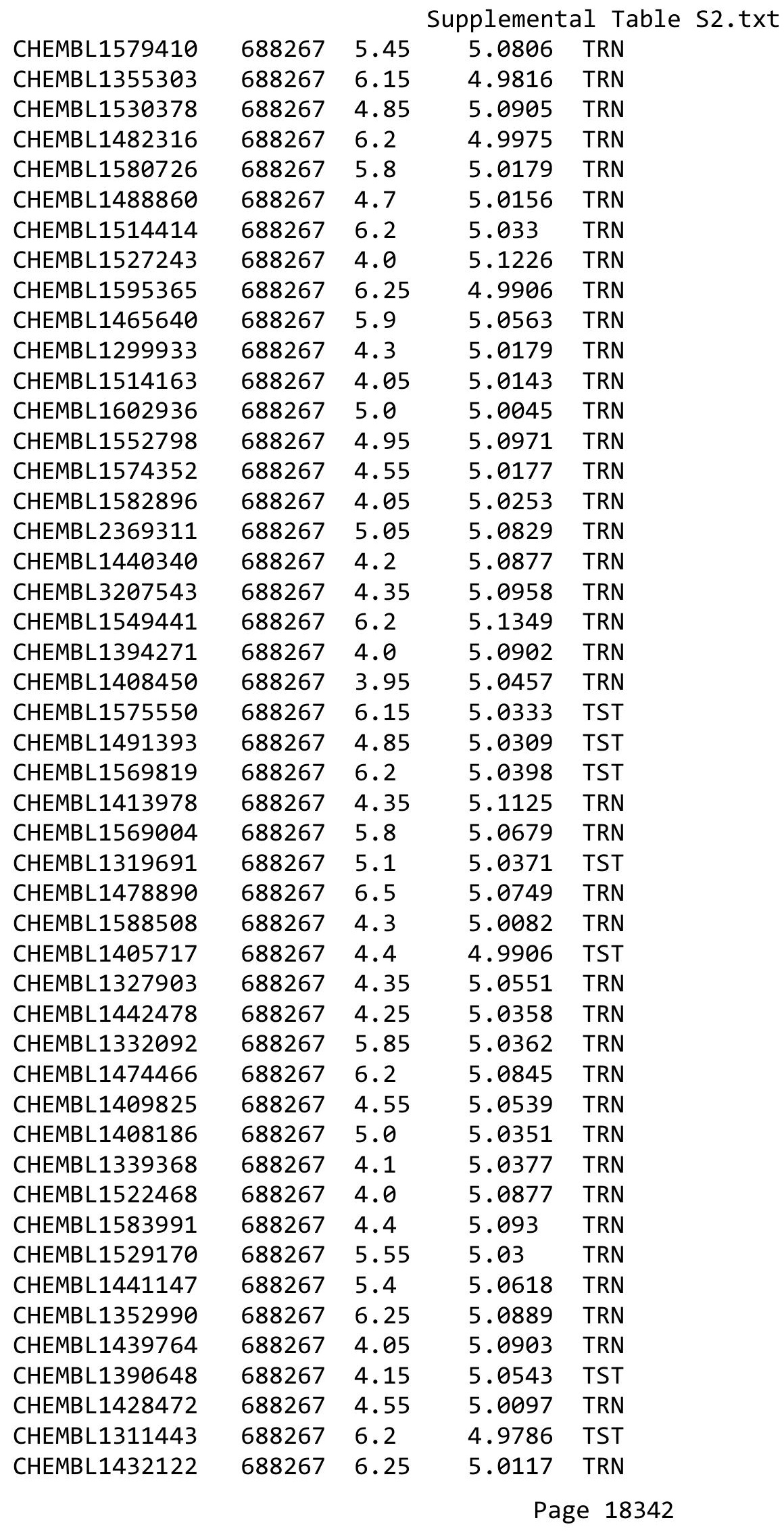




\begin{tabular}{|c|c|c|c|c|c|}
\hline \multicolumn{6}{|c|}{ Supplemental Table S2.txt } \\
\hline CHEMBL1351907 & 688267 & 4.05 & 5.0515 & TST & \\
\hline CHEMBL1531879 & 688267 & 5.45 & 4.9998 & TST & \\
\hline CHEMBL1544222 & 688267 & 5.0 & 5.0835 & TRN & \\
\hline CHEMBL1479356 & 688267 & 5.8 & 5.0361 & TRN & \\
\hline CHEMBL1429623 & 688267 & 5.75 & 5.0505 & TRN & \\
\hline CHEMBL1490126 & 688267 & 6.2 & 5.1425 & TRN & \\
\hline CHEMBL1536242 & 688267 & 6.5 & 4.9969 & TRN & \\
\hline CHEMBL1522968 & 688267 & 6.25 & 5.0387 & TRN & \\
\hline CHEMBL1311280 & 688267 & 4.0 & 5.0175 & TRN & \\
\hline CHEMBL1340153 & 688267 & 4.6 & 4.9857 & TST & \\
\hline CHEMBL1327339 & 688267 & 6.1 & 5.0684 & TRN & \\
\hline CHEMBL1547089 & 688267 & 4.1 & 5.0379 & TRN & \\
\hline CHEMBL1308004 & 688267 & 4.45 & 5.1201 & TRN & \\
\hline CHEMBL3207335 & 688267 & 5.25 & 5.0691 & TRN & \\
\hline CHEMBL1410667 & 688267 & 4.25 & 5.1271 & TRN & \\
\hline CHEMBL1512907 & 688267 & 5.2 & 5.0518 & TRN & \\
\hline CHEMBL1553956 & 688267 & 4.0 & 5.0291 & TRN & \\
\hline CHEMBL1571502 & 688267 & 5.5 & 5.03100 & 0000000001 & TRN \\
\hline CHEMBL1613383 & 688267 & 4.6 & 5.0444 & TST & \\
\hline CHEMBL1517013 & 688267 & 5.65 & 5.0901 & TRN & \\
\hline CHEMBL1580571 & 688267 & 4.45 & 5.1081 & TRN & \\
\hline CHEMBL3194340 & 688267 & 4.35 & 4.9956 & TST & \\
\hline CHEMBL1395101 & 688267 & 5.45 & 5.0232 & TRN & \\
\hline CHEMBL1396971 & 688267 & 4.35 & 5.1229 & TRN & \\
\hline CHEMBL1361078 & 688267 & 5.1 & 5.0713 & TRN & \\
\hline CHEMBL1610230 & 688267 & 4.15 & 5.0137 & TRN & \\
\hline CHEMBL1469308 & 688267 & 5.4 & 5.0507 & TRN & \\
\hline CHEMBL1578896 & 688267 & 5.45 & 5.0923 & TRN & \\
\hline CHEMBL1509492 & 688267 & 5.6 & 5.0639 & TRN & \\
\hline CHEMBL1351052 & 688267 & 4.05 & 4.9967 & TST & \\
\hline CHEMBL1311617 & 688267 & 4.0 & 5.0527 & TRN & \\
\hline CHEMBL1350910 & 688267 & 4.25 & 5.1216 & TRN & \\
\hline CHEMBL1498901 & 688267 & 4.05 & 5.0529 & TST & \\
\hline CHEMBL1527745 & 688267 & 4.2 & 5.0857 & TRN & \\
\hline CHEMBL1587488 & 688267 & 4.05 & 5.0399 & TRN & \\
\hline CHEMBL1307510 & 688267 & 4.3 & 5.0596 & TRN & \\
\hline CHEMBL1412051 & 688267 & 4.0 & 5.0628 & TST & \\
\hline CHEMBL1301238 & 688267 & 6.05 & 5.0291 & TRN & \\
\hline CHEMBL1536732 & 688267 & 5.0 & 5.0982 & TST & \\
\hline CHEMBL1572666 & 688267 & 4.3 & 5.0515 & TST & \\
\hline CHEMBL1355995 & 688267 & 4.55 & 5.1083 & TRN & \\
\hline CHEMBL1444453 & 688267 & 5.5 & 5.1096 & TRN & \\
\hline CHEMBL1322117 & 688267 & 4.65 & 5.1307 & TRN & \\
\hline CHEMBL1529040 & 688267 & 3.95 & 5.1014 & TRN & \\
\hline CHEMBL1559981 & 688267 & 4.05 & 5.0213 & TRN & \\
\hline CHEMBL1472554 & 688267 & 4.05 & 5.1385 & TRN & \\
\hline CHEMBL1590655 & 688267 & 4.3 & 5.0813 & TST & \\
\hline CHEMBL1483688 & 688267 & 4.0 & 5.0845 & TST & \\
\hline
\end{tabular}




\begin{tabular}{|c|c|c|c|c|}
\hline & & & pplement & al $\mathrm{Ta}$ \\
\hline CHEMBL1375165 & 688267 & 6.2 & 5.0273 & TRN \\
\hline CHEMBL1342783 & 688267 & 6.25 & 5.0468 & TRN \\
\hline CHEMBL1325912 & 688267 & 4.8 & 5.1059 & TRN \\
\hline CHEMBL1358873 & 688267 & 4.25 & 4.9977 & TRN \\
\hline CHEMBL1561094 & 688267 & 4.05 & 5.0473 & TST \\
\hline CHEMBL1364883 & 688267 & 4.05 & 5.1352 & TRN \\
\hline CHEMBL1598856 & 688267 & 4.45 & 5.0597 & TST \\
\hline CHEMBL1600015 & 688267 & 5.2 & 5.1446 & TRN \\
\hline CHEMBL1509189 & 688267 & 4.05 & 5.0127 & TST \\
\hline CHEMBL1341573 & 688267 & 5.85 & 5.0814 & TRN \\
\hline CHEMBL1471908 & 688267 & 4.0 & 5.0287 & TRN \\
\hline CHEMBL1553228 & 688267 & 6.15 & 5.1107 & TRN \\
\hline CHEMBL1968064 & 688267 & 6.6 & 5.0085 & TRN \\
\hline CHEMBL3213661 & 688267 & 4.9 & 5.0225 & TRN \\
\hline CHEMBL1436981 & 688267 & 3.95 & 4.952 & TRN \\
\hline CHEMBL1562217 & 688267 & 6.15 & 5.0608 & TST \\
\hline CHEMBL1353094 & 688267 & 3.9 & 5.0454 & TST \\
\hline CHEMBL1510649 & 688267 & 4.3 & 5.0567 & TST \\
\hline CHEMBL1509982 & 688267 & 5.35 & 5.1269 & TRN \\
\hline CHEMBL1340038 & 688267 & 5.45 & 5.0245 & TRN \\
\hline CHEMBL1561246 & 688267 & 5.3 & 5.0875 & TRN \\
\hline CHEMBL510515 & 688267 & 5.1 & 5.0307 & TRN \\
\hline CHEMBL1354245 & 688267 & 5.25 & 5.0574 & TRN \\
\hline CHEMBL1599331 & 688267 & 6.2 & 5.0811 & TRN \\
\hline CHEMBL1434667 & 688267 & 6.15 & 5.1505 & TRN \\
\hline CHEMBL1405462 & 688267 & 4.5 & 5.0828 & TRN \\
\hline CHEMBL1301830 & 688267 & 5.1 & 5.0572 & TRN \\
\hline CHEMBL1476475 & 688267 & 6.15 & 5.1045 & TST \\
\hline CHEMBL1375545 & 688267 & 5.45 & 5.1036 & TST \\
\hline CHEMBL1480902 & 688267 & 5.35 & 5.0746 & TST \\
\hline CHEMBL1355886 & 688267 & 6.2 & 5.0623 & TRN \\
\hline CHEMBL 3192249 & 688267 & 5.0 & 5.0614 & TRN \\
\hline CHEMBL1312910 & 688267 & 4.55 & 5.0184 & TST \\
\hline CHEMBL1603188 & 688267 & 4.4 & 5.1041 & TRN \\
\hline CHEMBL1517519 & 688267 & 6.25 & 5.0378 & TST \\
\hline CHEMBL1611581 & 688267 & 5.05 & 5.1668 & TRN \\
\hline CHEMBL1397961 & 688267 & 5.3 & 5.0193 & TST \\
\hline CHEMBL1365534 & 688267 & 4.1 & 5.05 & TRN \\
\hline CHEMBL1444510 & 688267 & 4.0 & 5.0261 & TRN \\
\hline CHEMBL1514767 & 688267 & 4.0 & 5.0797 & TRN \\
\hline CHEMBL1402302 & 688267 & 5.6 & 5.0358 & TRN \\
\hline CHEMBL1461317 & 688267 & 4.85 & 5.0255 & TRN \\
\hline CHEMBL1391031 & 688267 & 6.2 & 5.0477 & TRN \\
\hline CHEMBL1605098 & 688267 & 4.35 & 5.0499 & TRN \\
\hline CHEMBL1486233 & 688267 & 4.05 & 5.0815 & TRN \\
\hline CHEMBL1541184 & 688267 & 4.05 & 5.0794 & TRN \\
\hline CHEMBL1601037 & 688267 & 5.35 & 5.1375 & TRN \\
\hline CHEMBL1555449 & 688267 & 5.5 & 5.0128 & TRN \\
\hline
\end{tabular}




\begin{tabular}{|c|c|c|c|c|}
\hline \multicolumn{5}{|c|}{ Supplemental Table S2.txt } \\
\hline CHEMBL1596596 & 688267 & 3.95 & 5.1215 & TRN \\
\hline CHEMBL1532110 & 688267 & 5.8 & 5.0829 & TRN \\
\hline CHEMBL1378936 & 688267 & 6.2 & 5.1558 & TRN \\
\hline CHEMBL1332966 & 688267 & 5.15 & 5.0453 & TST \\
\hline CHEMBL1334309 & 688267 & 4.95 & 5.0094 & TRN \\
\hline CHEMBL1496600 & 688267 & 4.05 & 5.077 & TST \\
\hline CHEMBL1490193 & 688267 & 4.35 & 5.0915 & TRN \\
\hline CHEMBL1422179 & 688267 & 3.95 & 5.0254 & TST \\
\hline CHEMBL1341044 & 688267 & 5.6 & 5.0081 & TRN \\
\hline CHEMBL1590359 & 688267 & 4.05 & 5.0182 & TRN \\
\hline CHEMBL1321258 & 688267 & 5.5 & 5.0269 & TST \\
\hline CHEMBL1479822 & 688267 & 5.1 & 5.0654 & TRN \\
\hline CHEMBL1343361 & 688267 & 5.4 & 4.987 & TRN \\
\hline CHEMBL1299918 & 688267 & 6.7001 & 5.0648 & TRN \\
\hline CHEMBL1461754 & 688267 & 4.3 & 5.04 & TRN \\
\hline CHEMBL1320779 & 688267 & 6.2 & 5.0702 & TST \\
\hline CHEMBL1509319 & 688267 & 4.4 & 5.0374 & TRN \\
\hline CHEMBL1392234 & 688267 & 4.35 & 5.0627 & TST \\
\hline CHEMBL1328222 & 688267 & 6.6499 & 5.0793 & TRN \\
\hline CHEMBL1467543 & 688267 & 4.6 & 5.0289 & TRN \\
\hline CHEMBL1537951 & 688267 & 6.2 & 5.0544 & TST \\
\hline CHEMBL1364243 & 688267 & 3.9 & 5.0452 & TRN \\
\hline CHEMBL1520478 & 688267 & 5.75 & 5.1003 & TRN \\
\hline CHEMBL1548793 & 688267 & 6.2 & 5.0676 & TRN \\
\hline CHEMBL1508647 & 688267 & 6.1 & 5.0052 & TRN \\
\hline CHEMBL3210545 & 688267 & 5.2 & 5.1121 & TST \\
\hline CHEMBL1608384 & 688267 & 6.2 & 5.0629 & TRN \\
\hline CHEMBL1404303 & 688267 & 6.1 & 5.0061 & TST \\
\hline CHEMBL1398545 & 688267 & 5.45 & 5.0411 & TRN \\
\hline CHEMBL1241371 & 688267 & 4.05 & 5.0198 & TST \\
\hline CHEMBL1493725 & 688267 & 6.15 & 5.0367 & TRN \\
\hline CHEMBL1396866 & 688267 & 4.2 & 5.0959 & TRN \\
\hline CHEMBL1426830 & 688267 & 5.45 & 5.0802 & TRN \\
\hline CHEMBL1583242 & 688267 & 4.2 & 5.0171 & TST \\
\hline CHEMBL1502154 & 688267 & 5.65 & 5.046 & TRN \\
\hline CHEMBL1339213 & 688267 & 5.0 & 5.0289 & TRN \\
\hline CHEMBL1482650 & 688267 & 4.4 & 5.0834 & TRN \\
\hline CHEMBL1597721 & 688267 & 4.45 & 5.0884 & TRN \\
\hline CHEMBL1474141 & 688267 & 4.05 & 5.0993 & TRN \\
\hline CHEMBL1335250 & 688267 & 5.0 & 5.0346 & TRN \\
\hline CHEMBL1392828 & 688267 & 4.35 & 5.0489 & TRN \\
\hline CHEMBL1427524 & 688267 & 5.8 & 5.0998 & TRN \\
\hline CHEMBL1590016 & 688267 & 4.05 & 5.1006 & TRN \\
\hline CHEMBL1424623 & 688267 & 6.2 & 5.0042 & TRN \\
\hline CHEMBL1596048 & 688267 & 6.2 & 5.0596 & TRN \\
\hline CHEMBL1423305 & 688267 & 4.1 & 5.0363 & TRN \\
\hline CHEMBL1546974 & 688267 & 4.6 & 5.0137 & TRN \\
\hline CHEMBL1335107 & 688267 & 4.0 & 5.1137 & TRN \\
\hline
\end{tabular}




\begin{tabular}{|c|c|c|c|c|c|}
\hline \multicolumn{6}{|c|}{ Supplemental Table S2.txt } \\
\hline CHEMBL1442188 & 688267 & 5.6 & 5.073 & TRN & \\
\hline CHEMBL1547856 & 688267 & 5.45 & 5.0556 & TRN & \\
\hline CHEMBL1381123 & 688267 & 5.45 & 5.0731 & TRN & \\
\hline CHEMBL1565608 & 688267 & 4.25 & 5.0597 & TRN & \\
\hline CHEMBL1573590 & 688267 & 4.5 & 5.04899 & 99999999995 & TST \\
\hline CHEMBL1459430 & 688267 & 5.25 & 5.0193 & TRN & \\
\hline CHEMBL1484838 & 688267 & 6.2 & 5.0163 & TST & \\
\hline CHEMBL1446424 & 688267 & 5.55 & 5.0956 & TST & \\
\hline CHEMBL1557579 & 688267 & 5.75 & 5.0651 & TRN & \\
\hline CHEMBL1335204 & 688267 & 6.2 & 5.0477 & TST & \\
\hline CHEMBL1551588 & 688267 & 6.2 & 5.0589 & TRN & \\
\hline CHEMBL1367551 & 688267 & 4.0 & 5.1098 & TRN & \\
\hline CHEMBL1583836 & 688267 & 6.2 & 5.0899 & TST & \\
\hline CHEMBL1454567 & 688267 & 4.0 & 5.1646 & TRN & \\
\hline CHEMBL1418945 & 688267 & 5.85 & 5.038 & TRN & \\
\hline CHEMBL1578287 & 688267 & 5.4 & 5.0234 & TST & \\
\hline CHEMBL1514317 & 688267 & 5.1 & 5.1015 & TRN & \\
\hline CHEMBL1507501 & 688267 & 6.2 & 5.0457 & TRN & \\
\hline CHEMBL1454506 & 688267 & 5.35 & 5.0701 & TST & \\
\hline CHEMBL1488379 & 688267 & 6.2 & 5.0368 & TRN & \\
\hline CHEMBL1570712 & 688267 & 6.2 & 5.0638 & TRN & \\
\hline CHEMBL1433842 & 688267 & 3.95 & 5.0469 & TRN & \\
\hline CHEMBL1407730 & 688267 & 5.85 & 5.1096 & TRN & \\
\hline CHEMBL1490171 & 688267 & 5.05 & 5.0339 & TST & \\
\hline CHEMBL1499915 & 688267 & 4.0 & 5.1262 & TST & \\
\hline CHEMBL1598561 & 688267 & 5.55 & 5.0386 & TST & \\
\hline CHEMBL1505296 & 688267 & 3.9 & 4.9938 & TRN & \\
\hline CHEMBL1333548 & 688267 & 6.2 & 5.0432 & TRN & \\
\hline CHEMBL1364187 & 688267 & 4.6 & 5.1365 & TRN & \\
\hline CHEMBL1556773 & 688267 & 4.05 & 5.0282 & TRN & \\
\hline CHEMBL1526412 & 688267 & 4.05 & 5.10800 & 00000000005 & TRN \\
\hline CHEMBL1321666 & 688267 & 4.4 & 5.1301 & TRN & \\
\hline CHEMBL1590022 & 688267 & 6.2 & 5.0543 & TRN & \\
\hline CHEMBL3207687 & 688267 & 4.6 & 5.0125 & TRN & \\
\hline CHEMBL1448716 & 688267 & 4.25 & 5.0508 & TRN & \\
\hline CHEMBL1532827 & 688267 & 6.15 & 4.9944 & TST & \\
\hline CHEMBL1429668 & 688267 & 5.25 & 5.04899 & 99999999995 & TRN \\
\hline CHEMBL1577452 & 688267 & 4.4 & 4.9837 & TRN & \\
\hline CHEMBL1594025 & 688267 & 6.15 & 5.0698 & TRN & \\
\hline CHEMBL1315467 & 688267 & 6.45 & 5.026 & TRN & \\
\hline CHEMBL1320870 & 688267 & 5.0 & 5.0353 & TRN & \\
\hline CHEMBL1406907 & 688267 & 4.0 & 5.0233 & TST & \\
\hline CHEMBL1378056 & 688267 & 5.6 & 5.0228 & TRN & \\
\hline CHEMBL1581094 & 688267 & 4.05 & 5.1014 & TRN & \\
\hline CHEMBL1463992 & 688267 & 4.4 & 5.073 & TST & \\
\hline CHEMBL1328404 & 688267 & 4.35 & 5.1558 & TRN & \\
\hline CHEMBL1429873 & 688267 & 6.15 & 5.0071 & TST & \\
\hline CHEMBL1565249 & 688267 & 4.6 & 5.0251 & TRN & \\
\hline
\end{tabular}




\begin{tabular}{|c|c|c|c|c|}
\hline & & & pplement & al $\mathrm{Ta}$ \\
\hline CHEMBL1504930 & 688267 & 5.9 & 5.0765 & TST \\
\hline CHEMBL1564564 & 688267 & 5.6 & 5.0137 & TRN \\
\hline CHEMBL1329603 & 688267 & 6.2 & 5.0942 & TST \\
\hline CHEMBL1545225 & 688267 & 4.25 & 5.0232 & TRN \\
\hline CHEMBL1353860 & 688267 & 4.25 & 5.0809 & TRN \\
\hline CHEMBL39 & 688267 & 5.55 & 5.0455 & TRN \\
\hline CHEMBL1395534 & 688267 & 3.95 & 5.095 & TRN \\
\hline CHEMBL1554280 & 688267 & 5.65 & 5.0626 & TST \\
\hline CHEMBL1591716 & 688267 & 5.6 & 5.1171 & TRN \\
\hline CHEMBL1592487 & 688267 & 4.1 & 5.0537 & TRN \\
\hline CHEMBL1587087 & 688267 & 4.55 & 5.0408 & TRN \\
\hline CHEMBL222759 & 688267 & 4.05 & 4.9874 & TST \\
\hline CHEMBL1581316 & 688267 & 5.5 & 5.033 & TST \\
\hline CHEMBL1335640 & 688267 & 4.0 & 5.0327 & TST \\
\hline CHEMBL1306651 & 688267 & 5.55 & 5.0588 & TRN \\
\hline CHEMBL1299605 & 688267 & 4.0 & 5.0867 & TRN \\
\hline CHEMBL1398542 & 688267 & 5.05 & 5.0317 & TRN \\
\hline CHEMBL1599546 & 688267 & 3.95 & 5.0826 & TRN \\
\hline CHEMBL1522870 & 688267 & 4.4 & 5.1095 & TST \\
\hline CHEMBL1511393 & 688267 & 4.3 & 5.0261 & TST \\
\hline CHEMBL1587816 & 688267 & 5.85 & 5.0793 & TRN \\
\hline CHEMBL1389851 & 688267 & 6.2 & 5.1201 & TRN \\
\hline CHEMBL1376220 & 688267 & 4.2 & 5.0425 & TRN \\
\hline CHEMBL1595794 & 688267 & 5.3 & 5.0661 & TRN \\
\hline CHEMBL1473045 & 688267 & 4.35 & 5.0639 & TRN \\
\hline CHEMBL1310217 & 688267 & 4.1 & 4.9819 & TRN \\
\hline CHEMBL1360112 & 688267 & 6.2 & 5.0465 & TRN \\
\hline CHEMBL1561399 & 688267 & 6.25 & 4.979 & TRN \\
\hline CHEMBL1575298 & 688267 & 4.35 & 5.0795 & TRN \\
\hline CHEMBL1318386 & 688267 & 5.4 & 5.0238 & TRN \\
\hline CHEMBL1380493 & 688267 & 6.15 & 5.0179 & TRN \\
\hline CHEMBL1476957 & 688267 & 4.3 & 5.1349 & TRN \\
\hline CHEMBL1525182 & 688267 & 6.2 & 5.1394 & TRN \\
\hline CHEMBL1463768 & 688267 & 6.15 & 5.024 & TST \\
\hline CHEMBL1518074 & 688267 & 5.25 & 5.0958 & TRN \\
\hline CHEMBL3190408 & 688267 & 6.2 & 5.0703 & TRN \\
\hline CHEMBL 3193680 & 688267 & 5.2 & 4.9881 & TRN \\
\hline CHEMBL1568991 & 688267 & 4.8 & 5.0635 & TRN \\
\hline CHEMBL1086872 & 688267 & 5.75 & 5.0988 & TRN \\
\hline CHEMBL1346416 & 688267 & 4.0 & 5.0407 & TRN \\
\hline CHEMBL1512788 & 688267 & 4.0 & 5.0071 & TST \\
\hline CHEMBL1336413 & 688267 & 5.6 & 5.0837 & TRN \\
\hline CHEMBL1488489 & 688267 & 4.55 & 5.0626 & TST \\
\hline CHEMBL1394915 & 688267 & 4.4 & 5.0108 & TRN \\
\hline CHEMBL3192749 & 688267 & 4.2 & 5.0067 & TST \\
\hline CHEMBL1598693 & 688267 & 4.6 & 5.1786 & TRN \\
\hline CHEMBL1452723 & 688267 & 4.4 & 4.9997 & TST \\
\hline CHEMBL1571527 & 688267 & 6.05 & 5.0689 & TRN \\
\hline
\end{tabular}




\begin{tabular}{|c|c|c|c|c|}
\hline \multicolumn{5}{|c|}{ Supplemental Table S2.txt } \\
\hline CHEMBL1383453 & 688267 & 4.3 & 4.9899 & TRN \\
\hline CHEMBL1396009 & 688267 & 4.0 & 5.0439 & TRN \\
\hline CHEMBL1340571 & 688267 & 6.2 & 5.1291 & TRN \\
\hline CHEMBL1340613 & 688267 & 5.25 & 5.0307 & TRN \\
\hline CHEMBL 1430726 & 688267 & 6.5 & 5.1253 & TRN \\
\hline CHEMBL1362263 & 688267 & 4.15 & 5.0676 & TRN \\
\hline CHEMBL1425267 & 688267 & 4.6 & 5.0504 & TRN \\
\hline CHEMBL1476166 & 688267 & 5.55 & 5.0481 & TRN \\
\hline CHEMBL1412807 & 688267 & 6.05 & 5.1094 & TRN \\
\hline CHEMBL1430128 & 688267 & 5.45 & 4.9855 & TST \\
\hline CHEMBL1529636 & 688267 & 4.05 & 5.0974 & TST \\
\hline CHEMBL1304725 & 688267 & 4.6 & 5.0464 & TRN \\
\hline CHEMBL3214095 & 688267 & 4.1 & 4.9931 & TRN \\
\hline CHEMBL1394465 & 688267 & 5.85 & 5.025 & TRN \\
\hline CHEMBL1361596 & 688267 & 3.95 & 5.0923 & TST \\
\hline CHEMBL1325429 & 688267 & 5.9 & 5.0866 & TST \\
\hline CHEMBL1593136 & 688267 & 6.5501 & 5.0687 & TRN \\
\hline CHEMBL1584081 & 688267 & 5.0 & 5.0419 & TRN \\
\hline CHEMBL1423741 & 688267 & 4.35 & 5.0506 & TRN \\
\hline CHEMBL1417871 & 688267 & 4.3 & 5.073 & TRN \\
\hline CHEMBL1434620 & 688267 & 5.9 & 5.0488 & TRN \\
\hline CHEMBL1502783 & 688267 & 4.3 & 5.0409 & TRN \\
\hline CHEMBL1577295 & 688267 & 5.9 & 5.1169 & TRN \\
\hline CHEMBL1533356 & 688267 & 4.4 & 5.0706 & TRN \\
\hline CHEMBL1389761 & 688267 & 4.0 & 5.0305 & TRN \\
\hline CHEMBL510279 & 688267 & 4.35 & 5.0226 & TST \\
\hline CHEMBL1519031 & 688267 & 6.25 & 5.1138 & TRN \\
\hline CHEMBL1583902 & 688267 & 5.15 & 5.0609 & TRN \\
\hline CHEMBL1448832 & 688267 & 5.55 & 5.0889 & TST \\
\hline CHEMBL1503734 & 688267 & 4.05 & 5.0365 & TRN \\
\hline CHEMBL1553229 & 688267 & 5.6 & 5.064 & TRN \\
\hline CHEMBL1302179 & 688267 & 4.5 & 5.0384 & TRN \\
\hline CHEMBL473315 & 688267 & 5.85 & 4.9868 & TRN \\
\hline CHEMBL1315566 & 688267 & 6.0 & 5.0669 & TRN \\
\hline CHEMBL1356208 & 688267 & 4.0 & 5.0748 & TRN \\
\hline CHEMBL1545549 & 688267 & 4.0 & 5.05 & TRN \\
\hline CHEMBL1381006 & 688267 & 6.25 & 5.0843 & TRN \\
\hline CHEMBL1492493 & 688267 & 5.5 & 4.9955 & TRN \\
\hline CHEMBL1508641 & 688267 & 4.75 & 5.0792 & TRN \\
\hline CHEMBL1341392 & 688267 & 4.65 & 5.0268 & TRN \\
\hline CHEMBL1308633 & 688267 & 6.15 & 5.0781 & TRN \\
\hline CHEMBL1434444 & 688267 & 4.05 & 5.0275 & TRN \\
\hline CHEMBL1315481 & 688267 & 5.05 & 5.1139 & TRN \\
\hline CHEMBL1384206 & 688267 & 5.15 & 5.1379 & TST \\
\hline CHEMBL1564939 & 688267 & 5.5 & 5.0719 & TRN \\
\hline CHEMBL1448637 & 688267 & 4.0 & 5.0368 & TRN \\
\hline CHEMBL1432388 & 688267 & 4.6 & 5.0555 & TST \\
\hline CHEMBL1575136 & 688267 & 5.35 & 5.0708 & TST \\
\hline
\end{tabular}




\begin{tabular}{|c|c|c|c|c|}
\hline & & & pplement & $\mathrm{d} \perp$ \\
\hline CHEMBL1379616 & 688267 & 6.2 & 5.0278 & TST \\
\hline CHEMBL1406861 & 688267 & 6.2 & 5.012 & TRN \\
\hline CHEMBL1590519 & 688267 & 3.95 & 5.0512 & TST \\
\hline CHEMBL1412256 & 688267 & 6.25 & 5.0807 & TRN \\
\hline CHEMBL1469648 & 688267 & 4.25 & 5.0505 & TRN \\
\hline CHEMBL181568 & 688267 & 5.0 & 5.0795 & TST \\
\hline CHEMBL1487220 & 688267 & 5.55 & 5.1061 & TRN \\
\hline CHEMBL1479145 & 688267 & 4.0 & 5.0309 & TRN \\
\hline CHEMBL1612400 & 688267 & 5.35 & 5.0669 & TRN \\
\hline CHEMBL1421292 & 688267 & 3.95 & 5.0555 & TRN \\
\hline CHEMBL1402345 & 688267 & 6.15 & 5.02 & TST \\
\hline CHEMBL1372148 & 688267 & 3.95 & 5.059 & TRN \\
\hline CHEMBL1602521 & 688267 & 5.45 & 5.1301 & TRN \\
\hline CHEMBL1598333 & 688267 & 4.15 & 5.0931 & TRN \\
\hline CHEMBL1344068 & 688267 & 6.25 & 5.1129 & TRN \\
\hline CHEMBL1422907 & 688267 & 4.85 & 5.1299 & TRN \\
\hline CHEMBL1444581 & 688267 & 4.0 & 5.0584 & TRN \\
\hline CHEMBL1417990 & 688267 & 6.15 & 5.0518 & TST \\
\hline CHEMBL1546449 & 688267 & 6.2 & 5.0508 & TRN \\
\hline CHEMBL1308581 & 688267 & 4.35 & 5.1171 & TRN \\
\hline CHEMBL1457362 & 688267 & 6.25 & 5.0224 & TRN \\
\hline CHEMBL1310825 & 688267 & 6.5 & 5.0303 & TST \\
\hline CHEMBL1318652 & 688267 & 6.25 & 5.0768 & TRN \\
\hline CHEMBL1325767 & 688267 & 6.15 & 5.0728 & TRN \\
\hline CHEMBL1446755 & 688267 & 5.85 & 5.1085 & TRN \\
\hline CHEMBL1299855 & 688267 & 4.0 & 5.0455 & TST \\
\hline CHEMBL1312161 & 688267 & 4.65 & 5.0745 & TRN \\
\hline CHEMBL1435824 & 688267 & 3.9 & 5.0338 & TRN \\
\hline CHEMBL1537158 & 688267 & 6.2 & 5.0973 & TRN \\
\hline CHEMBL1481206 & 688267 & 5.7 & 5.0618 & TRN \\
\hline CHEMBL1365408 & 688267 & 5.2 & 5.0645 & TRN \\
\hline CHEMBL1386305 & 688267 & 6.2 & 5.0956 & TST \\
\hline CHEMBL1499256 & 688267 & 6.35 & 5.0587 & TST \\
\hline CHEMBL1594546 & 688267 & 4.05 & 5.0982 & TRN \\
\hline CHEMBL1347978 & 688267 & 4.0 & 5.0547 & TRN \\
\hline CHEMBL1594438 & 688267 & 3.95 & 5.1634 & TRN \\
\hline CHEMBL1331327 & 688267 & 5.75 & 5.043 & TRN \\
\hline CHEMBL1457225 & 688267 & 5.55 & 5.0142 & TRN \\
\hline CHEMBL1343300 & 688267 & 5.2 & 5.0287 & TRN \\
\hline CHEMBL1394073 & 688267 & 5.0 & 5.0506 & TRN \\
\hline CHEMBL1418054 & 688267 & 4.35 & 5.0327 & TRN \\
\hline CHEMBL1308384 & 688267 & 6.2 & 5.082 & TST \\
\hline CHEMBL1595081 & 688267 & 5.25 & 5.0577 & TRN \\
\hline CHEMBL1317878 & 688267 & 4.05 & 5.0473 & TRN \\
\hline CHEMBL1447074 & 688267 & 5.85 & 5.0281 & TST \\
\hline CHEMBL1471620 & 688267 & 5.8 & 5.1366 & TRN \\
\hline CHEMBL1456277 & 688267 & 4.0 & 5.0417 & TRN \\
\hline CHEMBL1451399 & 688267 & 6.2 & 5.0597 & TRN \\
\hline
\end{tabular}




\begin{tabular}{|c|c|c|c|c|}
\hline \multirow[b]{2}{*}{ CHEMBL1543167 } & \multicolumn{4}{|c|}{ Supplemental Ta } \\
\hline & 688267 & 4.8 & 5.0909 & TRN \\
\hline CHEMBL1467472 & 688267 & 4.65 & 5.0464 & TST \\
\hline CHEMBL1475205 & 688267 & 4.0 & 5.0636 & TRN \\
\hline CHEMBL1559880 & 688267 & 7.2 & 5.0831 & TRN \\
\hline CHEMBL1537187 & 688267 & 4.0 & 5.1427 & TRN \\
\hline CHEMBL1309633 & 688267 & 5.3 & 5.1032 & TST \\
\hline CHEMBL1406842 & 688267 & 5.35 & 5.0257 & TRN \\
\hline CHEMBL1324237 & 688267 & 6.2 & 5.0773 & TRN \\
\hline CHEMBL1360863 & 688267 & 4.0 & 4.9867 & TRN \\
\hline CHEMBL3208763 & 688267 & 4.1 & 5.0125 & TST \\
\hline CHEMBL1568231 & 688267 & 4.5 & 5.1141 & TRN \\
\hline CHEMBL1547972 & 688267 & 4.0 & 5.0041 & TRN \\
\hline CHEMBL1507388 & 688267 & 5.45 & 5.0176 & TRN \\
\hline CHEMBL1535097 & 688267 & 6.2 & 5.0834 & TST \\
\hline CHEMBL1332176 & 688267 & 3.95 & 5.0296 & TRN \\
\hline CHEMBL1387075 & 688267 & 4.55 & 4.9904 & TST \\
\hline CHEMBL1378396 & 688267 & 5.8 & 5.0644 & TRN \\
\hline CHEMBL1351855 & 688267 & 4.05 & 5.0135 & TRN \\
\hline CHEMBL1329834 & 688267 & 6.15 & 5.1035 & TRN \\
\hline CHEMBL1308027 & 688267 & 5.35 & 5.0257 & TRN \\
\hline CHEMBL1551057 & 688267 & 5.95 & 5.034 & TRN \\
\hline CHEMBL1522486 & 688267 & 5.45 & 5.0435 & TST \\
\hline CHEMBL1418401 & 688267 & 6.2 & 5.0342 & TST \\
\hline CHEMBL1570387 & 688267 & 6.1 & 5.0646 & TRN \\
\hline CHEMBL2373562 & 688267 & 6.6 & 5.0429 & TRN \\
\hline CHEMBL1593442 & 688267 & 6.5 & 5.1163 & TRN \\
\hline CHEMBL1455790 & 688267 & 4.1 & 5.061 & TRN \\
\hline CHEMBL1472361 & 688267 & 4.35 & 5.0341 & TRN \\
\hline CHEMBL1504504 & 688267 & 5.0 & 5.048 & TRN \\
\hline CHEMBL1604212 & 688267 & 4.45 & 5.0618 & TST \\
\hline CHEMBL1497521 & 688267 & 6.0 & 5.1423 & TST \\
\hline CHEMBL1390102 & 688267 & 3.95 & 5.0377 & TST \\
\hline CHEMBL1257039 & 688267 & 5.55 & 5.0681 & TST \\
\hline CHEMBL1478678 & 688267 & 5.75 & 5.1392 & TRN \\
\hline CHEMBL1397546 & 688267 & 5.25 & 5.0679 & TRN \\
\hline CHEMBL1475759 & 688267 & 5.75 & 5.0337 & TRN \\
\hline CHEMBL1602113 & 688267 & 5.5 & 5.0501 & TRN \\
\hline CHEMBL1467761 & 688267 & 4.0 & 5.0774 & TRN \\
\hline CHEMBL1459139 & 688267 & 5.8 & 5.0309 & TRN \\
\hline CHEMBL1607991 & 688267 & 6.2 & 5.0354 & TRN \\
\hline CHEMBL1434566 & 688267 & 6.2 & 5.0454 & TRN \\
\hline CHEMBL1386160 & 688267 & 5.5 & 5.0217 & TST \\
\hline CHEMBL1556482 & 688267 & 3.95 & 5.084 & TRN \\
\hline CHEMBL1309370 & 688267 & 5.35 & 5.0617 & TRN \\
\hline CHEMBL1439675 & 688267 & 4.2 & 5.0215 & TRN \\
\hline CHEMBL1604750 & 688267 & 6.2 & 5.0527 & TRN \\
\hline CHEMBL3213829 & 688267 & 4.3 & 5.078 & TRN \\
\hline CHEMBL1586387 & 688267 & 6.25 & 5.0679 & TRN \\
\hline
\end{tabular}




\begin{tabular}{|c|c|c|c|c|}
\hline & & & pplement & al $\mathrm{Ta}$ \\
\hline CHEMBL1496670 & 688267 & 6.0 & 5.0862 & TRN \\
\hline CHEMBL1607870 & 688267 & 6.2 & 5.0138 & TRN \\
\hline CHEMBL1300414 & 688267 & 6.2 & 5.0946 & TST \\
\hline CHEMBL1316837 & 688267 & 4.25 & 5.0292 & TRN \\
\hline CHEMBL1354535 & 688267 & 5.45 & 5.1138 & TRN \\
\hline CHEMBL1498056 & 688267 & 5.85 & 5.0498 & TRN \\
\hline CHEMBL1488441 & 688267 & 4.45 & 5.0717 & TRN \\
\hline CHEMBL1552825 & 688267 & 4.4 & 5.1496 & TRN \\
\hline CHEMBL1474530 & 688267 & 6.15 & 5.1047 & TRN \\
\hline CHEMBL1554605 & 688267 & 5.55 & 5.1175 & TST \\
\hline CHEMBL1547958 & 688267 & 6.45 & 5.0477 & TST \\
\hline CHEMBL1305160 & 688267 & 5.85 & 5.1451 & TRN \\
\hline CHEMBL1488973 & 688267 & 4.0 & 5.0411 & TST \\
\hline CHEMBL1335407 & 688267 & 5.15 & 5.1168 & TRN \\
\hline CHEMBL1394928 & 688267 & 4.05 & 5.0267 & TST \\
\hline CHEMBL1386932 & 688267 & 4.05 & 5.0724 & TRN \\
\hline CHEMBL1554660 & 688267 & 5.6 & 5.0219 & TST \\
\hline CHEMBL1363850 & 688267 & 4.3 & 5.0073 & TST \\
\hline CHEMBL1339301 & 688267 & 4.55 & 5.029 & TRN \\
\hline CHEMBL1545758 & 688267 & 5.05 & 5.0622 & TRN \\
\hline CHEMBL1491020 & 688267 & 4.55 & 5.1077 & TRN \\
\hline CHEMBL1499851 & 688267 & 6.15 & 5.0176 & TST \\
\hline CHEMBL1535352 & 688267 & 4.6 & 5.1066 & TRN \\
\hline CHEMBL1492976 & 688267 & 5.45 & 5.1028 & TST \\
\hline CHEMBL1330246 & 688267 & 6.2 & 5.0505 & TST \\
\hline CHEMBL1592834 & 688267 & 5.35 & 5.0686 & TRN \\
\hline CHEMBL1440168 & 688267 & 3.95 & 5.0398 & TST \\
\hline CHEMBL111896 & 688267 & 5.65 & 5.0709 & TRN \\
\hline CHEMBL1385490 & 688267 & 6.2 & 5.1107 & TST \\
\hline CHEMBL1397872 & 688267 & 4.0 & 5.0593 & TRN \\
\hline CHEMBL1316441 & 688267 & 4.05 & 5.0927 & TRN \\
\hline CHEMBL3190600 & 688267 & 2.95 & 5.0004 & TST \\
\hline CHEMBL1583710 & 688267 & 6.15 & 5.0932 & TRN \\
\hline CHEMBL1394164 & 688267 & 4.05 & 5.0888 & TRN \\
\hline CHEMBL1463269 & 688267 & 4.5 & 5.077 & TRN \\
\hline CHEMBL1429852 & 688267 & 6.2 & 5.0326 & TST \\
\hline CHEMBL3192145 & 688267 & 4.0 & 5.0462 & TRN \\
\hline CHEMBL1483371 & 688267 & 5.8 & 5.1287 & TRN \\
\hline CHEMBL1483736 & 688267 & 6.45 & 5.1134 & TRN \\
\hline CHEMBL3189277 & 688267 & 4.55 & 5.0966 & TRN \\
\hline CHEMBL1596559 & 688267 & 5.35 & 5.0591 & TRN \\
\hline CHEMBL1401588 & 688267 & 6.2 & 5.0293 & TRN \\
\hline CHEMBL1320226 & 688267 & 4.0 & 5.0332 & TRN \\
\hline CHEMBL1501983 & 688267 & 5.9 & 5.0728 & TRN \\
\hline CHEMBL1375872 & 688267 & 4.25 & 5.047 & TST \\
\hline CHEMBL1376351 & 688267 & 4.0 & 5.0776 & TRN \\
\hline CHEMBL 2134991 & 688267 & 5.8 & 5.0424 & TST \\
\hline CHEMBL1440098 & 688267 & 6.15 & 5.1272 & TRN \\
\hline
\end{tabular}




\begin{tabular}{|c|c|c|c|c|}
\hline & & & pplemen & al $\mathrm{T}$ \\
\hline CHEMBL1342130 & 688267 & 5.2 & 5.0324 & TRN \\
\hline CHEMBL1503061 & 688267 & 4.0 & 5.0629 & TST \\
\hline CHEMBL1567112 & 688267 & 5.55 & 5.0416 & TRN \\
\hline CHEMBL1433828 & 688267 & 5.0 & 5.0184 & TRN \\
\hline CHEMBL1555194 & 688267 & 4.6 & 5.0843 & TRN \\
\hline CHEMBL1590666 & 688267 & 5.55 & 5.0056 & TRN \\
\hline CHEMBL1449634 & 688267 & 4.05 & 5.0943 & TRN \\
\hline CHEMBL1347675 & 688267 & 4.1 & 5.1137 & TRN \\
\hline CHEMBL1380807 & 688267 & 4.6 & 5.0466 & TRN \\
\hline CHEMBL1411089 & 688267 & 4.3 & 5.0316 & TRN \\
\hline CHEMBL1399581 & 688267 & 5.35 & 5.0572 & TRN \\
\hline CHEMBL1425888 & 688267 & 5.05 & 5.0355 & TRN \\
\hline CHEMBL1343724 & 688267 & 4.15 & 5.0739 & TRN \\
\hline CHEMBL1605449 & 688267 & 5.5 & 5.0189 & TRN \\
\hline CHEMBL1540456 & 688267 & 5.8 & 5.0496 & TST \\
\hline CHEMBL564664 & 688267 & 5.65 & 5.0177 & TRN \\
\hline CHEMBL1540206 & 688267 & 4.55 & 5.0771 & TRN \\
\hline CHEMBL1489874 & 688267 & 5.8 & 5.0194 & TRN \\
\hline CHEMBL1437440 & 688267 & 4.25 & 4.9955 & TRN \\
\hline CHEMBL1543362 & 688267 & 4.3 & 5.045 & TRN \\
\hline CHEMBL1439489 & 688267 & 4.05 & 5.0392 & TRN \\
\hline CHEMBL1585695 & 688267 & 5.35 & 5.0265 & TRN \\
\hline CHEMBL1519177 & 688267 & 4.05 & 5.0351 & TRN \\
\hline CHEMBL1529708 & 688267 & 6.15 & 5.0714 & TRN \\
\hline CHEMBL1382890 & 688267 & 6.05 & 5.1058 & TRN \\
\hline CHEMBL1546924 & 688267 & 4.95 & 5.0504 & TRN \\
\hline CHEMBL1491476 & 688267 & 4.45 & 5.0877 & TRN \\
\hline CHEMBL 3191271 & 688267 & 5.4 & 5.0586 & TST \\
\hline CHEMBL1539546 & 688267 & 5.6 & 5.0265 & TRN \\
\hline CHEMBL1300297 & 688267 & 3.95 & 5.0098 & TRN \\
\hline CHEMBL1481526 & 688267 & 6.2 & 5.0332 & TRN \\
\hline CHEMBL1533923 & 688267 & 6.25 & 5.0556 & TST \\
\hline CHEMBL1541229 & 688267 & 5.85 & 5.0316 & TRN \\
\hline CHEMBL1299307 & 688267 & 5.5 & 5.0288 & TRN \\
\hline CHEMBL1301582 & 688267 & 5.05 & 5.0541 & TST \\
\hline CHEMBL1413687 & 688267 & 4.0 & 5.0671 & TRN \\
\hline CHEMBL1356797 & 688267 & 3.95 & 5.112 & TRN \\
\hline CHEMBL1354832 & 688267 & 6.1 & 5.0408 & TRN \\
\hline CHEMBL1544476 & 688267 & 5.1 & 5.067 & TRN \\
\hline CHEMBL1365805 & 688267 & 6.2 & 5.0718 & TRN \\
\hline CHEMBL1299657 & 688267 & 5.1 & 5.1014 & TRN \\
\hline CHEMBL1302611 & 688267 & 5.0 & 5.0431 & TRN \\
\hline CHEMBL1370637 & 688267 & 6.5 & 5.0576 & TRN \\
\hline CHEMBL1394134 & 688267 & 5.45 & 5.0576 & TRN \\
\hline CHEMBL1334505 & 688267 & 3.95 & 5.1204 & TST \\
\hline CHEMBL1333994 & 688267 & 4.65 & 5.0512 & TRN \\
\hline CHEMBL1398007 & 688267 & 5.3 & 4.9753 & TRN \\
\hline CHEMBL1326702 & 688267 & 6.15 & 5.1147 & TRN \\
\hline
\end{tabular}




\begin{tabular}{|c|c|c|c|c|}
\hline & & & pplement & al $\mathrm{T}$ \\
\hline CHEMBL1495114 & 688267 & 5.9 & 5.0575 & TRN \\
\hline CHEMBL1351439 & 688267 & 6.1 & 5.0496 & TST \\
\hline CHEMBL1611088 & 688267 & 6.5 & 5.0691 & TRN \\
\hline CHEMBL1414464 & 688267 & 5.7 & 5.037 & TRN \\
\hline CHEMBL1562391 & 688267 & 4.8 & 5.0349 & TST \\
\hline CHEMBL1347175 & 688267 & 5.4 & 5.0338 & TRN \\
\hline CHEMBL1548385 & 688267 & 5.55 & 5.0597 & TST \\
\hline CHEMBL1324608 & 688267 & 4.0 & 5.0233 & TRN \\
\hline CHEMBL1561755 & 688267 & 6.2 & 5.0165 & TRN \\
\hline CHEMBL1441854 & 688267 & 5.8 & 5.0627 & TST \\
\hline CHEMBL1472133 & 688267 & 5.3 & 5.0901 & TRN \\
\hline CHEMBL1418532 & 688267 & 4.05 & 5.0207 & TRN \\
\hline CHEMBL1303439 & 688267 & 5.8 & 5.0799 & TST \\
\hline CHEMBL1419455 & 688267 & 5.55 & 5.0547 & TRN \\
\hline CHEMBL1462267 & 688267 & 4.1 & 5.0097 & TST \\
\hline CHEMBL1568190 & 688267 & 6.0 & 5.1071 & TRN \\
\hline CHEMBL1455255 & 688267 & 4.6 & 5.0523 & TRN \\
\hline CHEMBL1538993 & 688267 & 6.15 & 5.0776 & TRN \\
\hline CHEMBL1429782 & 688267 & 4.4 & 5.0444 & TRN \\
\hline CHEMBL1568681 & 688267 & 7.1002 & 5.0232 & TST \\
\hline CHEMBL1433298 & 688267 & 5.0 & 5.0458 & TRN \\
\hline CHEMBL3209069 & 688267 & 4.0 & 5.0155 & TST \\
\hline CHEMBL1325993 & 688267 & 5.0 & 5.0726 & TRN \\
\hline CHEMBL1507437 & 688267 & 4.3 & 5.0885 & TRN \\
\hline CHEMBL1472266 & 688267 & 4.35 & 5.1012 & TRN \\
\hline CHEMBL 309848 & 688267 & 6.15 & 5.0518 & TRN \\
\hline CHEMBL1594234 & 688267 & 5.55 & 5.0139 & TRN \\
\hline CHEMBL1508884 & 688267 & 4.35 & 5.037 & TRN \\
\hline CHEMBL1517992 & 688267 & 4.45 & 5.0374 & TRN \\
\hline CHEMBL1530140 & 688267 & 5.55 & 5.0632 & TRN \\
\hline CHEMBL1441465 & 688267 & 5.25 & 5.0238 & TRN \\
\hline CHEMBL1448607 & 688267 & 4.85 & 5.1041 & TRN \\
\hline CHEMBL1300425 & 688267 & 4.1 & 5.0882 & TRN \\
\hline CHEMBL1462608 & 688267 & 5.15 & 5.0289 & TRN \\
\hline CHEMBL1607222 & 688267 & 5.2 & 5.0402 & TST \\
\hline CHEMBL1557723 & 688267 & 5.45 & 5.0364 & TRN \\
\hline CHEMBL1460381 & 688267 & 4.55 & 5.0295 & TRN \\
\hline CHEMBL1553254 & 688267 & 5.5 & 5.0436 & TRN \\
\hline CHEMBL369513 & 688267 & 6.5 & 5.0138 & TRN \\
\hline CHEMBL1586597 & 688267 & 4.05 & 5.0343 & TRN \\
\hline CHEMBL1404006 & 688267 & 5.4 & 5.1406 & TRN \\
\hline CHEMBL1483294 & 688267 & 6.5 & 5.0661 & TRN \\
\hline CHEMBL1505815 & 688267 & 4.0 & 5.0806 & TST \\
\hline CHEMBL1569575 & 688267 & 3.95 & 5.0348 & TST \\
\hline CHEMBL1607956 & 688267 & 6.2 & 5.0928 & TST \\
\hline CHEMBL1331479 & 688267 & 6.2 & 5.0477 & TRN \\
\hline CHEMBL1485225 & 688267 & 4.05 & 5.0736 & TRN \\
\hline CHEMBL1444788 & 688267 & 4.15 & 5.0767 & TRN \\
\hline
\end{tabular}




\begin{tabular}{|c|c|c|c|c|}
\hline \multicolumn{5}{|c|}{ Supplemental Table S2.txt } \\
\hline CHEMBL1547236 & 688267 & 4.05 & 5.0285 & TST \\
\hline CHEMBL1344512 & 688267 & 3.95 & 5.1376 & TRN \\
\hline CHEMBL1592764 & 688267 & 4.05 & 5.0984 & TRN \\
\hline CHEMBL1386647 & 688267 & 4.45 & 5.0761 & TST \\
\hline CHEMBL1430812 & 688267 & 4.2 & 4.9906 & TRN \\
\hline CHEMBL1609113 & 688267 & 3.95 & 5.0559 & TST \\
\hline CHEMBL1367389 & 688267 & 5.3 & 5.1137 & TST \\
\hline CHEMBL1537112 & 688267 & 4.1 & 5.0325 & TRN \\
\hline CHEMBL1600152 & 688267 & 5.5 & 5.0983 & TST \\
\hline CHEMBL1402958 & 688267 & 6.35 & 5.025 & TRN \\
\hline CHEMBL1604659 & 688267 & 4.8 & 5.0181 & TST \\
\hline CHEMBL1540796 & 688267 & 6.2 & 5.1088 & TRN \\
\hline CHEMBL1451263 & 688267 & 4.95 & 5.0231 & TRN \\
\hline CHEMBL1588950 & 688267 & 5.5 & 5.0295 & TRN \\
\hline CHEMBL1583956 & 688267 & 5.4 & 5.0124 & TRN \\
\hline CHEMBL1300178 & 688267 & 4.35 & 5.0945 & TRN \\
\hline CHEMBL1402282 & 688267 & 4.6 & 5.0295 & TST \\
\hline CHEMBL1529725 & 688267 & 6.2 & 5.0162 & TRN \\
\hline CHEMBL1384494 & 688267 & 5.05 & 5.0112 & TRN \\
\hline CHEMBL1419682 & 688267 & 4.3 & 5.0473 & TST \\
\hline CHEMBL1358354 & 688267 & 4.15 & 5.0761 & TRN \\
\hline CHEMBL1468413 & 688267 & 6.15 & 5.1183 & TRN \\
\hline CHEMBL1613425 & 688267 & 4.05 & 5.0512 & TRN \\
\hline CHEMBL1355871 & 688267 & 5.3 & 5.0847 & TRN \\
\hline CHEMBL1582699 & 688267 & 4.05 & 5.0638 & TRN \\
\hline CHEMBL3197312 & 688267 & 6.2 & 5.0591 & TST \\
\hline CHEMBL1567489 & 688267 & 4.3 & 5.0487 & TST \\
\hline CHEMBL1436675 & 688267 & 3.95 & 5.0053 & TRN \\
\hline CHEMBL1429150 & 688267 & 4.25 & 5.0143 & TRN \\
\hline CHEMBL1588478 & 688267 & 4.65 & 4.9947 & TST \\
\hline CHEMBL1469529 & 688267 & 4.0 & 5.006 & TST \\
\hline CHEMBL 1480020 & 688267 & 5.3 & 5.0209 & TST \\
\hline CHEMBL1612319 & 688267 & 5.55 & 5.169 & TRN \\
\hline CHEMBL1405742 & 688267 & 4.7 & 5.0727 & TRN \\
\hline CHEMBL1365703 & 688267 & 5.55 & 5.0528 & TRN \\
\hline CHEMBL1513025 & 688267 & 6.25 & 5.0185 & TRN \\
\hline CHEMBL1412113 & 688267 & 4.1 & 5.0218 & TRN \\
\hline CHEMBL1593320 & 688267 & 5.95 & 5.0674 & TRN \\
\hline CHEMBL1590454 & 688267 & 5.25 & 5.0695 & TRN \\
\hline CHEMBL1497474 & 688267 & 4.25 & 5.1069 & TRN \\
\hline CHEMBL1551355 & 688267 & 4.1 & 5.0398 & TRN \\
\hline CHEMBL1405615 & 688267 & 3.95 & 5.0293 & TRN \\
\hline CHEMBL1533748 & 688267 & 4.4 & 4.9968 & TRN \\
\hline CHEMBL 1425770 & 688267 & 5.85 & 5.1116 & TRN \\
\hline CHEMBL3194385 & 688267 & 4.4 & 5.0139 & TRN \\
\hline CHEMBL1594621 & 688267 & 5.3 & 5.0361 & TRN \\
\hline CHEMBL1613472 & 688267 & 4.4 & 5.0445 & TRN \\
\hline CHEMBL1560570 & 688267 & 6.5501 & 5.0492 & TST \\
\hline
\end{tabular}




\begin{tabular}{|c|c|c|c|c|c|}
\hline \multicolumn{6}{|c|}{ Supplemental Table S2.txt } \\
\hline CHEMBL1417089 & 688267 & 5.05 & 5.0697 & TRN & \\
\hline CHEMBL1370321 & 688267 & 5.5 & 5.0246 & TRN & \\
\hline CHEMBL1438531 & 688267 & 5.2 & 5.0632 & TRN & \\
\hline CHEMBL 3194664 & 688267 & 4.0 & 4.9944 & TST & \\
\hline CHEMBL1395268 & 688267 & 5.4 & 5.1259 & TRN & \\
\hline CHEMBL1523157 & 688267 & 5.05 & 5.0455 & TRN & \\
\hline CHEMBL1541665 & 688267 & 5.65 & 5.0498 & TRN & \\
\hline CHEMBL1383658 & 688267 & 6.2 & 5.0485 & TRN & \\
\hline CHEMBL1466104 & 688267 & 4.45 & 5.0317 & TRN & \\
\hline CHEMBL589232 & 688267 & 4.0 & 5.0714 & TRN & \\
\hline CHEMBL1480651 & 688267 & 5.35 & 5.0144 & TST & \\
\hline CHEMBL1611542 & 688267 & 4.0 & 5.0468 & TRN & \\
\hline CHEMBL1597461 & 688267 & 5.6 & 5.07100 & 3000000001 & TRN \\
\hline CHEMBL1341895 & 688267 & 6.5 & 5.0646 & TRN & \\
\hline CHEMBL428611 & 688267 & 6.6 & 5.0141 & TRN & \\
\hline CHEMBL3193817 & 688267 & 5.7 & 5.0157 & TRN & \\
\hline CHEMBL1397575 & 688267 & 3.95 & 5.1573 & TRN & \\
\hline CHEMBL1436900 & 688267 & 5.25 & 5.1241 & TRN & \\
\hline CHEMBL1543929 & 688267 & 5.3 & 5.0873 & TRN & \\
\hline CHEMBL1399589 & 688267 & 5.65 & 5.1431 & TRN & \\
\hline CHEMBL1475182 & 688267 & 3.95 & 5.0077 & TRN & \\
\hline CHEMBL1345642 & 688267 & 6.5 & 5.0366 & TRN & \\
\hline CHEMBL3209066 & 688267 & 5.4 & 4.9779 & TRN & \\
\hline CHEMBL1424511 & 688267 & 5.2 & 5.0379 & TRN & \\
\hline CHEMBL1356223 & 688267 & 3.95 & 5.1111 & TRN & \\
\hline CHEMBL1385563 & 688267 & 6.05 & 5.0514 & TST & \\
\hline CHEMBL1537743 & 688267 & 5.3 & 5.1294 & TST & \\
\hline CHEMBL1489345 & 688267 & 4.75 & 5.0949 & TRN & \\
\hline CHEMBL1513468 & 688267 & 4.2 & 5.0057 & TRN & \\
\hline CHEMBL 3208762 & 688267 & 4.0 & 5.0685 & TRN & \\
\hline CHEMBL1349092 & 688267 & 5.55 & 5.013 & TRN & \\
\hline CHEMBL1325753 & 688267 & 3.95 & 5.0846 & TST & \\
\hline CHEMBL1329010 & 688267 & 4.35 & 5.0727 & TRN & \\
\hline CHEMBL1461442 & 688267 & 6.2 & 5.1568 & TRN & \\
\hline CHEMBL1425553 & 688267 & 4.4 & 5.0093 & TST & \\
\hline CHEMBL1375285 & 688267 & 4.0 & 5.0332 & TRN & \\
\hline CHEMBL3192604 & 688267 & 6.5 & 5.0008 & TRN & \\
\hline CHEMBL1479423 & 688267 & 4.0 & 5.0364 & TRN & \\
\hline CHEMBL1972652 & 688267 & 4.35 & 5.0342 & TRN & \\
\hline CHEMBL1424847 & 688267 & 4.0 & 5.0952 & TRN & \\
\hline CHEMBL1375331 & 688267 & 5.05 & 5.0456 & TRN & \\
\hline CHEMBL1439795 & 688267 & 4.35 & 5.1128 & TRN & \\
\hline CHEMBL 1487022 & 688267 & 6.2 & 5.059 & TRN & \\
\hline CHEMBL1567692 & 688267 & 4.45 & 5.0279 & TRN & \\
\hline CHEMBL1470617 & 688267 & 5.55 & 5.0333 & TST & \\
\hline CHEMBL1524461 & 688267 & 5.3 & 4.9672 & TRN & \\
\hline CHEMBL1457549 & 688267 & 4.35 & 5.02 & TRN & \\
\hline CHEMBL1344204 & 688267 & 4.45 & 5.1281 & TRN & \\
\hline
\end{tabular}




\begin{tabular}{|c|c|c|c|c|}
\hline \multicolumn{5}{|c|}{ Supplemental Table S2.txt } \\
\hline CHEMBL1317424 & 688267 & 6.2 & 5.1226 & TRN \\
\hline CHEMBL1372529 & 688267 & 6.15 & 5.1047 & TRN \\
\hline CHEMBL1392123 & 688267 & 4.0 & 5.0193 & TST \\
\hline CHEMBL1571562 & 688267 & 4.5 & 5.0447 & TRN \\
\hline CHEMBL1446217 & 688267 & 4.25 & 5.0059 & TRN \\
\hline CHEMBL1610355 & 688267 & 6.2 & 5.0558 & TST \\
\hline CHEMBL1530163 & 688267 & 4.25 & 5.0063 & TRN \\
\hline CHEMBL1360091 & 688267 & 5.85 & 5.0894 & TST \\
\hline CHEMBL1337267 & 688267 & 4.95 & 5.0877 & TRN \\
\hline CHEMBL1549372 & 688267 & 5.85 & 5.0594 & TRN \\
\hline CHEMBL1506990 & 688267 & 5.5 & 5.04 & TST \\
\hline CHEMBL1422468 & 688267 & 5.5 & 5.0909 & TRN \\
\hline CHEMBL1315732 & 688267 & 6.45 & 5.0755 & TRN \\
\hline CHEMBL1342261 & 688267 & 4.3 & 5.1396 & TST \\
\hline CHEMBL1524036 & 688267 & 5.25 & 5.0318 & TRN \\
\hline CHEMBL1373053 & 688267 & 5.2 & 5.114 & TRN \\
\hline CHEMBL1358047 & 688267 & 4.35 & 5.0099 & TRN \\
\hline CHEMBL1534682 & 688267 & 4.05 & 5.0611 & TRN \\
\hline CHEMBL1534567 & 688267 & 5.4 & 5.0991 & TST \\
\hline CHEMBL1391675 & 688267 & 5.05 & 5.0202 & TRN \\
\hline CHEMBL1438297 & 688267 & 5.4 & 5.046 & TRN \\
\hline CHEMBL1319075 & 688267 & 5.25 & 5.019 & TRN \\
\hline CHEMBL1491666 & 688267 & 6.15 & 5.1139 & TRN \\
\hline CHEMBL1551852 & 688267 & 5.15 & 5.1336 & TRN \\
\hline CHEMBL1491183 & 688267 & 6.2 & 5.1277 & TRN \\
\hline CHEMBL1409654 & 688267 & 4.0 & 5.0503 & TRN \\
\hline CHEMBL1499492 & 688267 & 5.3 & 5.0645 & TST \\
\hline CHEMBL1330966 & 688267 & 5.8 & 5.1144 & TRN \\
\hline CHEMBL1401393 & 688267 & 4.0 & 5.0701 & TRN \\
\hline CHEMBL1472330 & 688267 & 4.0 & 5.0684 & TRN \\
\hline CHEMBL1499316 & 688267 & 4.25 & 5.0631 & TST \\
\hline CHEMBL1472354 & 688267 & 4.1 & 5.0847 & TRN \\
\hline CHEMBL1454416 & 688267 & 4.4 & 5.018 & TST \\
\hline CHEMBL1481109 & 688267 & 4.1 & 4.9946 & TRN \\
\hline CHEMBL1530566 & 688267 & 6.2 & 5.0358 & TRN \\
\hline CHEMBL1598004 & 688267 & 4.05 & 5.1131 & TST \\
\hline CHEMBL1462215 & 688267 & 4.05 & 5.0123 & TST \\
\hline CHEMBL1318981 & 688267 & 5.3 & 5.043 & TRN \\
\hline CHEMBL1430504 & 688267 & 5.55 & 5.0327 & TST \\
\hline CHEMBL1461898 & 688267 & 6.0 & 5.044 & TRN \\
\hline CHEMBL1490398 & 688267 & 6.2 & 5.0561 & TRN \\
\hline CHEMBL1529297 & 688267 & 5.5 & 5.0477 & TRN \\
\hline CHEMBL1345451 & 688267 & 5.0 & 5.0621 & TRN \\
\hline CHEMBL1328657 & 688267 & 4.65 & 5.0777 & TRN \\
\hline CHEMBL1347066 & 688267 & 6.2 & 5.0376 & TRN \\
\hline CHEMBL1457012 & 688267 & 5.75 & 5.1624 & TRN \\
\hline CHEMBL1466964 & 688267 & 4.0 & 5.0771 & TST \\
\hline CHEMBL1531948 & 688267 & 6.15 & 5.093 & TRN \\
\hline
\end{tabular}




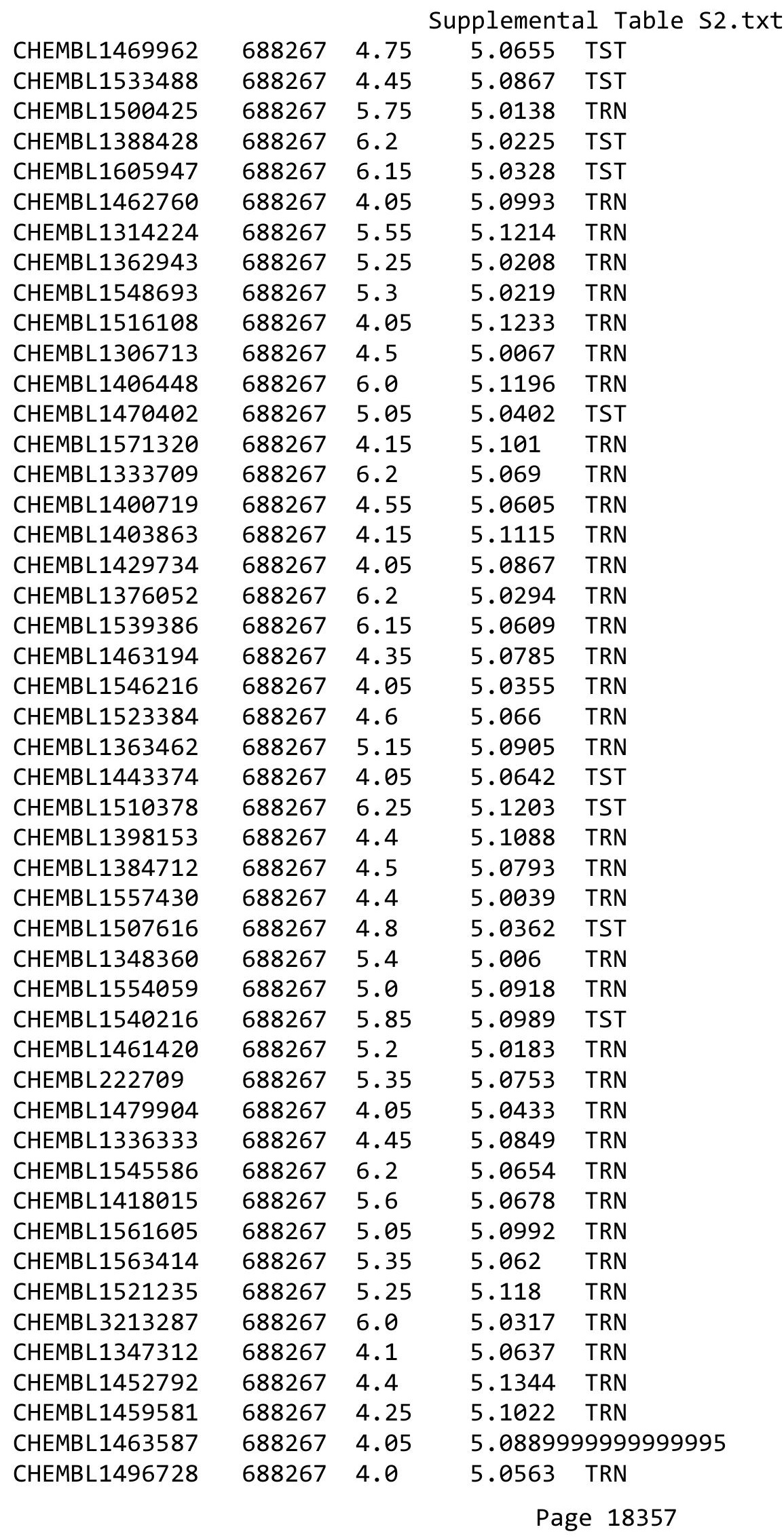




\begin{tabular}{|c|c|c|c|c|}
\hline & & & pplement & al $\mathrm{Ta}$ \\
\hline CHEMBL1367686 & 688267 & 5.2 & 5.0202 & TRN \\
\hline CHEMBL1559752 & 688267 & 4.35 & 5.0843 & TRN \\
\hline CHEMBL1426306 & 688267 & 5.5 & 5.0439 & TST \\
\hline CHEMBL 3213245 & 688267 & 4.7 & 4.9944 & TRN \\
\hline CHEMBL1473328 & 688267 & 4.0 & 5.0159 & TRN \\
\hline CHEMBL1603826 & 688267 & 5.0 & 5.0445 & TST \\
\hline CHEMBL1358094 & 688267 & 6.25 & 5.0653 & TST \\
\hline CHEMBL1548018 & 688267 & 5.4 & 5.0669 & TRN \\
\hline CHEMBL1515163 & 688267 & 4.35 & 5.0389 & TRN \\
\hline CHEMBL1488977 & 688267 & 5.3 & 5.1039 & TRN \\
\hline CHEMBL1326285 & 688267 & 6.05 & 5.1013 & TRN \\
\hline CHEMBL1435166 & 688267 & 5.6 & 5.0398 & TRN \\
\hline CHEMBL1385959 & 688267 & 5.05 & 5.0669 & TRN \\
\hline CHEMBL1317115 & 688267 & 4.75 & 5.0298 & TRN \\
\hline CHEMBL1376047 & 688267 & 4.15 & 5.0649 & TST \\
\hline CHEMBL1367145 & 688267 & 4.65 & 5.048 & TRN \\
\hline CHEMBL3214465 & 688267 & 3.95 & 5.1041 & TRN \\
\hline CHEMBL1483389 & 688267 & 6.45 & 5.0587 & TRN \\
\hline CHEMBL1587200 & 688267 & 5.9 & 5.0188 & TRN \\
\hline CHEMBL1356183 & 688267 & 4.0 & 5.0841 & TRN \\
\hline CHEMBL1467133 & 688267 & 4.7 & 4.9784 & TRN \\
\hline CHEMBL1453666 & 688267 & 4.6 & 5.1034 & TRN \\
\hline CHEMBL1584980 & 688267 & 5.4 & 5.0728 & TRN \\
\hline CHEMBL1474417 & 688267 & 4.0 & 4.9878 & TRN \\
\hline CHEMBL1317048 & 688267 & 5.15 & 5.0673 & TRN \\
\hline CHEMBL1486607 & 688267 & 4.35 & 5.0388 & TST \\
\hline CHEMBL1405396 & 688267 & 6.2 & 5.0979 & TRN \\
\hline CHEMBL1568950 & 688267 & 4.0 & 5.0145 & TRN \\
\hline CHEMBL1565732 & 688267 & 5.0 & 5.0881 & TST \\
\hline CHEMBL1440675 & 688267 & 6.2 & 5.0414 & TST \\
\hline CHEMBL1379846 & 688267 & 6.15 & 5.0702 & TST \\
\hline CHEMBL1313722 & 688267 & 5.9 & 5.126 & TRN \\
\hline CHEMBL 3194088 & 688267 & 5.3 & 5.1104 & TRN \\
\hline CHEMBL1440245 & 688267 & 5.9 & 5.1224 & TRN \\
\hline CHEMBL1590099 & 688267 & 4.1 & 5.092 & TRN \\
\hline CHEMBL1314476 & 688267 & 4.4 & 5.0981 & TRN \\
\hline CHEMBL1526013 & 688267 & 6.25 & 5.0606 & TRN \\
\hline CHEMBL1609276 & 688267 & 3.95 & 5.0286 & TRN \\
\hline CHEMBL1347362 & 688267 & 6.05 & 5.1023 & TST \\
\hline CHEMBL1438676 & 688267 & 5.65 & 5.034 & TRN \\
\hline CHEMBL1332112 & 688267 & 5.4 & 5.0532 & TRN \\
\hline CHEMBL1463324 & 688267 & 4.05 & 5.0852 & TST \\
\hline CHEMBL1340870 & 688267 & 5.4 & 5.0337 & TRN \\
\hline CHEMBL1328943 & 688267 & 3.95 & 5.0329 & TRN \\
\hline CHEMBL1583820 & 688267 & 5.35 & 4.9893 & TRN \\
\hline CHEMBL1471554 & 688267 & 4.3 & 5.0292 & TRN \\
\hline CHEMBL1542222 & 688267 & 6.2 & 5.0643 & TRN \\
\hline CHEMBL1551765 & 688267 & 4.0 & 5.0346 & TST \\
\hline
\end{tabular}




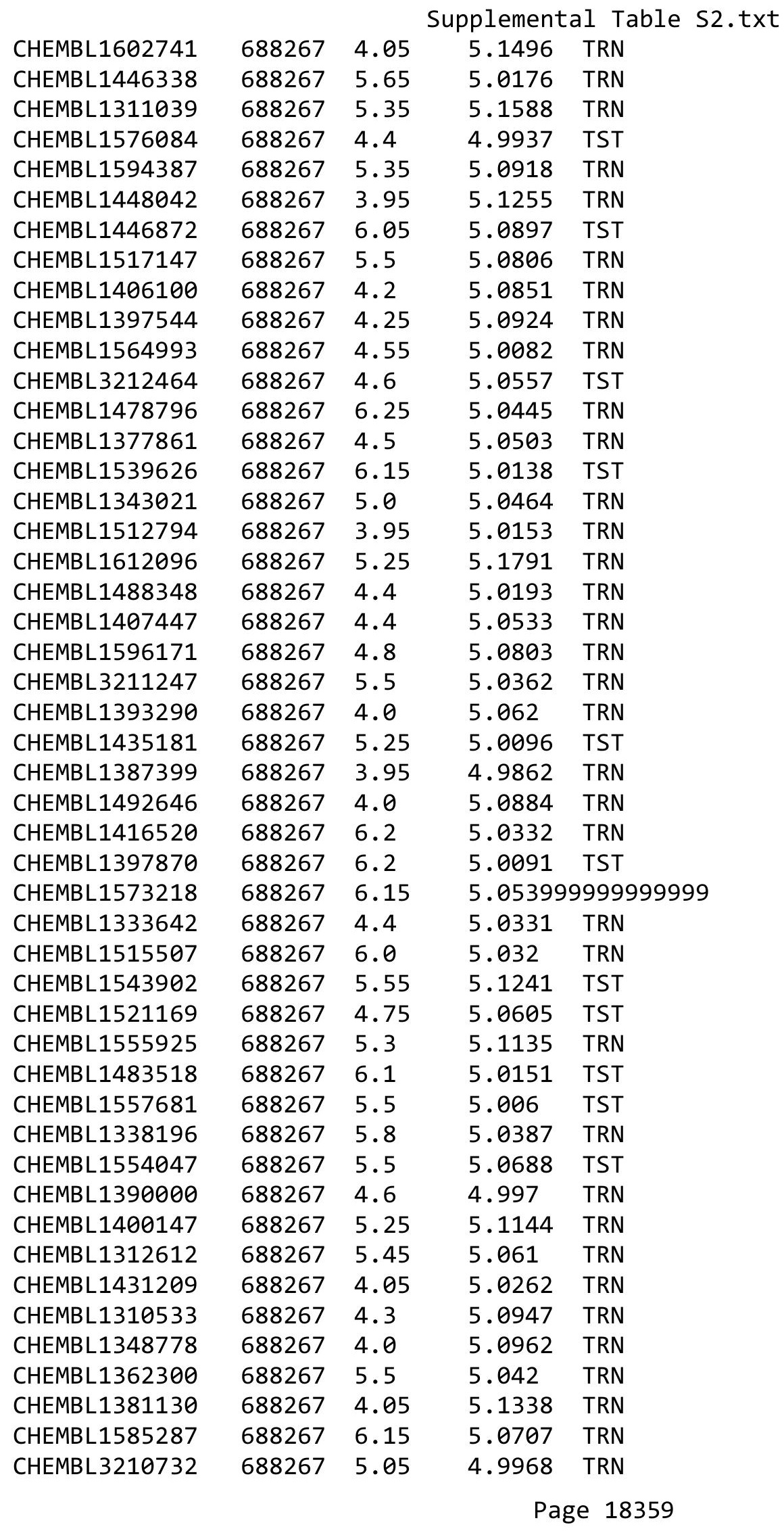




\begin{tabular}{|c|c|c|c|c|c|}
\hline & & & & & \\
\hline CHEMBL1402823 & 688267 & 5.3 & 5.0565 & TRN & \\
\hline CHEMBL1600995 & 688267 & 6.2 & 5.1215 & TST & \\
\hline CHEMBL1539789 & 688267 & 5.55 & 4.9853 & TST & \\
\hline CHEMBL1438856 & 688267 & 4.4 & 5.0336 & TRN & \\
\hline CHEMBL1601992 & 688267 & 7.699 & 5.0024 & TRN & \\
\hline CHEMBL1481574 & 688267 & 4.0 & 5.0239 & TST & \\
\hline CHEMBL1300184 & 688267 & 5.55 & 5.0178 & TST & \\
\hline CHEMBL1468519 & 688267 & 4.75 & 5.118 & TRN & \\
\hline CHEMBL1466913 & 688267 & 4.0 & 5.0212 & TST & \\
\hline CHEMBL3213378 & 688267 & 4.4 & 5.0103 & TST & \\
\hline CHEMBL1390984 & 688267 & 5.45 & 5.0299 & TRN & \\
\hline CHEMBL1353416 & 688267 & 4.0 & 5.13899 & 9999999999 & TRN \\
\hline CHEMBL1590407 & 688267 & 5.3 & 5.0644 & TST & \\
\hline CHEMBL1394828 & 688267 & 4.45 & 5.1367 & TRN & \\
\hline CHEMBL1491978 & 688267 & 5.0 & 5.04 & TRN & \\
\hline CHEMBL1414169 & 688267 & 3.95 & 5.0842 & TRN & \\
\hline CHEMBL1389187 & 688267 & 6.2 & 5.0654 & TRN & \\
\hline CHEMBL1546202 & 688267 & 4.05 & 5.043 & TST & \\
\hline CHEMBL1444226 & 688267 & 5.75 & 5.07600 & 00000000005 & TRN \\
\hline CHEMBL1604615 & 688267 & 4.1 & 5.0494 & TRN & \\
\hline CHEMBL1397652 & 688267 & 4.3 & 5.0607 & TST & \\
\hline CHEMBL1567890 & 688267 & 4.6 & 5.0806 & TST & \\
\hline CHEMBL1544945 & 688267 & 3.95 & 5.0098 & TRN & \\
\hline CHEMBL3190962 & 688267 & 5.35 & 5.0228 & TRN & \\
\hline CHEMBL1312587 & 688267 & 5.65 & 5.1662 & TRN & \\
\hline CHEMBL1378600 & 688267 & 4.05 & 5.0166 & TRN & \\
\hline CHEMBL1566471 & 688267 & 5.9 & 5.046 & TRN & \\
\hline CHEMBL1507089 & 688267 & 4.0 & 5.0283 & TST & \\
\hline CHEMBL1408707 & 688267 & 4.0 & 5.0372 & TRN & \\
\hline CHEMBL1529305 & 688267 & 4.5 & 5.0569 & TRN & \\
\hline CHEMBL1319812 & 688267 & 5.15 & 5.0627 & TRN & \\
\hline CHEMBL1423413 & 688267 & 5.5 & 5.0699 & TRN & \\
\hline CHEMBL1526189 & 688267 & 6.1 & 5.0299 & TST & \\
\hline CHEMBL1342758 & 688267 & 5.3 & 4.9884 & TRN & \\
\hline CHEMBL1508507 & 688267 & 5.2 & 5.0269 & TRN & \\
\hline CHEMBL1476284 & 688267 & 3.95 & 5.0469 & TRN & \\
\hline CHEMBL1415970 & 688267 & 6.2 & 5.055 & TRN & \\
\hline CHEMBL3187748 & 688267 & 5.1 & 5.1164 & TST & \\
\hline CHEMBL1596703 & 688267 & 5.1 & 5.0956 & TRN & \\
\hline CHEMBL1387707 & 688267 & 4.8 & 5.0071 & TST & \\
\hline CHEMBL1585452 & 688267 & 5.9 & 5.0275 & TRN & \\
\hline CHEMBL1551713 & 688267 & 6.2 & 5.1121 & TRN & \\
\hline CHEMBL1445769 & 688267 & 4.95 & 5.1189 & TRN & \\
\hline CHEMBL1600237 & 688267 & 3.95 & 5.0944 & TST & \\
\hline CHEMBL1568651 & 688267 & 4.75 & 5.1258 & TST & \\
\hline CHEMBL1376284 & 688267 & 5.15 & 5.0535 & TRN & \\
\hline CHEMBL1405376 & 688267 & 4.0 & 5.0595 & TST & \\
\hline CHEMBL1544496 & 688267 & 5.4 & 5.0297 & TRN & \\
\hline & & & & 18360 & \\
\hline
\end{tabular}




\begin{tabular}{|c|c|c|c|c|}
\hline & & & pplement & al $\mathrm{Ta}$ \\
\hline CHEMBL1473078 & 688267 & 4.6 & 5.039 & TRN \\
\hline CHEMBL1329355 & 688267 & 4.0 & 5.0961 & TRN \\
\hline CHEMBL1512641 & 688267 & 4.35 & 5.0057 & TRN \\
\hline CHEMBL1472396 & 688267 & 3.95 & 5.0125 & TRN \\
\hline CHEMBL1424008 & 688267 & 5.35 & 5.0957 & TRN \\
\hline CHEMBL586135 & 688267 & 4.35 & 5.0002 & TRN \\
\hline CHEMBL1597883 & 688267 & 5.95 & 5.0972 & TST \\
\hline CHEMBL1522064 & 688267 & 3.95 & 5.0023 & TRN \\
\hline CHEMBL1568769 & 688267 & 6.2 & 5.0497 & TRN \\
\hline CHEMBL1558769 & 688267 & 5.5 & 5.0448 & TRN \\
\hline CHEMBL1570613 & 688267 & 5.75 & 5.0031 & TRN \\
\hline CHEMBL1540938 & 688267 & 5.25 & 5.0662 & TST \\
\hline CHEMBL1607703 & 688267 & 4.05 & 5.0121 & TRN \\
\hline CHEMBL1352953 & 688267 & 5.9 & 5.1224 & TRN \\
\hline CHEMBL1316312 & 688267 & 5.1 & 5.0665 & TRN \\
\hline CHEMBL1384862 & 688267 & 4.75 & 5.0521 & TRN \\
\hline CHEMBL1523410 & 688267 & 5.6 & 5.1112 & TRN \\
\hline CHEMBL1359811 & 688267 & 6.15 & 5.0494 & TRN \\
\hline CHEMBL1431105 & 688267 & 4.95 & 5.1013 & TST \\
\hline CHEMBL1608071 & 688267 & 6.2 & 4.9723 & TRN \\
\hline CHEMBL1401304 & 688267 & 5.55 & 5.0489 & TRN \\
\hline CHEMBL1407973 & 688267 & 6.0 & 5.0366 & TRN \\
\hline CHEMBL1549937 & 688267 & 6.2 & 5.0271 & TRN \\
\hline CHEMBL1408003 & 688267 & 4.35 & 5.0715 & TRN \\
\hline CHEMBL1510746 & 688267 & 6.15 & 5.0367 & TRN \\
\hline CHEMBL1474965 & 688267 & 3.95 & 5.1361 & TRN \\
\hline CHEMBL1609232 & 688267 & 4.1 & 5.026 & TRN \\
\hline CHEMBL1352504 & 688267 & 4.1 & 5.0786 & TRN \\
\hline CHEMBL1321397 & 688267 & 6.2 & 5.0286 & TST \\
\hline CHEMBL1371224 & 688267 & 5.45 & 5.0233 & TST \\
\hline CHEMBL1508259 & 688267 & 3.95 & 5.0875 & TRN \\
\hline CHEMBL1543892 & 688267 & 4.0 & 5.0018 & TRN \\
\hline CHEMBL1471336 & 688267 & 6.1 & 5.044 & TRN \\
\hline CHEMBL1593485 & 688267 & 5.3 & 5.0495 & TRN \\
\hline CHEMBL1573080 & 688267 & 4.3 & 5.1233 & TRN \\
\hline CHEMBL1604527 & 688267 & 4.3 & 5.0289 & TRN \\
\hline CHEMBL1431128 & 688267 & 4.05 & 5.0554 & TRN \\
\hline CHEMBL1445249 & 688267 & 5.35 & 5.0109 & TRN \\
\hline CHEMBL1523896 & 688267 & 6.25 & 5.0352 & TRN \\
\hline CHEMBL1318807 & 688267 & 4.15 & 5.041 & TRN \\
\hline CHEMBL1492227 & 688267 & 4.5 & 5.0637 & TRN \\
\hline CHEMBL1543722 & 688267 & 6.6 & 5.0353 & TRN \\
\hline CHEMBL1538830 & 688267 & 4.3 & 5.0485 & TRN \\
\hline CHEMBL1356191 & 688267 & 6.2 & 5.0984 & TRN \\
\hline CHEMBL 3194641 & 688267 & 6.15 & 5.0134 & TST \\
\hline CHEMBL1606393 & 688267 & 5.35 & 5.0823 & TRN \\
\hline CHEMBL1355170 & 688267 & 5.95 & 5.126 & TRN \\
\hline CHEMBL1482494 & 688267 & 6.2 & 5.0227 & TRN \\
\hline
\end{tabular}




\begin{tabular}{|c|c|c|c|c|}
\hline \multicolumn{5}{|c|}{ Supplemental Table S2.tx } \\
\hline CHEMBL1306342 & 688267 & 5.0 & 5.1095 & TST \\
\hline CHEMBL1377554 & 688267 & 5.3 & 5.0904 & TRN \\
\hline CHEMBL1549313 & 688267 & 6.2 & 5.125 & TRN \\
\hline CHEMBL1336853 & 688267 & 4.0 & 4.9823 & TST \\
\hline CHEMBL1475531 & 688267 & 4.25 & 5.0254 & TRN \\
\hline CHEMBL1464998 & 688267 & 4.0 & 5.0425 & TRN \\
\hline CHEMBL1454571 & 688267 & 6.05 & 5.0344 & TRN \\
\hline CHEMBL1353577 & 688267 & 5.5 & 5.11100 & 0000000001 \\
\hline CHEMBL1318614 & 688267 & 5.6 & 5.0591 & TST \\
\hline CHEMBL1478328 & 688267 & 5.75 & 5.0627 & TST \\
\hline CHEMBL1598726 & 688267 & 4.25 & 5.0551 & TRN \\
\hline CHEMBL 1346770 & 688267 & 5.25 & 5.0862 & TRN \\
\hline CHEMBL1409149 & 688267 & 4.05 & 5.04 & TRN \\
\hline CHEMBL486760 & 688267 & 5.2 & 5.0431 & TST \\
\hline CHEMBL1572524 & 688267 & 4.0 & 5.0411 & TRN \\
\hline CHEMBL1508172 & 688267 & 5.45 & 5.0585 & TST \\
\hline CHEMBL1404013 & 688267 & 5.3 & 5.0378 & TST \\
\hline CHEMBL1544422 & 688267 & 4.05 & 5.0782 & TST \\
\hline CHEMBL1361034 & 688267 & 4.4 & 5.0317 & TST \\
\hline CHEMBL1482251 & 688267 & 4.1 & 5.1445 & TST \\
\hline CHEMBL1540113 & 688267 & 3.95 & 5.0586 & TRN \\
\hline CHEMBL1533008 & 688267 & 5.35 & 5.0765 & TRN \\
\hline CHEMBL1567539 & 688267 & 4.05 & 5.0829 & TRN \\
\hline CHEMBL1418821 & 688267 & 6.5 & 5.0418 & TST \\
\hline CHEMBL1551627 & 688267 & 6.2 & 5.118 & TST \\
\hline CHEMBL3192191 & 688267 & 4.25 & 5.0002 & TRN \\
\hline CHEMBL1397966 & 688267 & 4.2 & 5.074 & TRN \\
\hline CHEMBL1594958 & 688267 & 4.6 & 5.0309 & TST \\
\hline CHEMBL472437 & 688267 & 5.95 & 5.0949 & TST \\
\hline CHEMBL1365995 & 688267 & 5.8 & 5.0225 & TRN \\
\hline CHEMBL1557397 & 688267 & 4.0 & 5.0493 & TRN \\
\hline CHEMBL1333037 & 688267 & 4.35 & 5.0561 & TRN \\
\hline CHEMBL1519213 & 688267 & 4.3 & 5.0812 & TRN \\
\hline CHEMBL1561418 & 688267 & 5.7 & 5.0648 & TST \\
\hline CHEMBL3198533 & 688267 & 3.95 & 5.0233 & TST \\
\hline CHEMBL1344839 & 688267 & 5.3 & 5.0827 & TRN \\
\hline CHEMBL1512325 & 688267 & 5.25 & 5.0065 & TRN \\
\hline CHEMBL1483541 & 688267 & 4.0 & 5.1459 & TRN \\
\hline CHEMBL1447161 & 688267 & 4.3 & 5.1162 & TRN \\
\hline CHEMBL1370163 & 688267 & 6.15 & 5.0538 & TRN \\
\hline CHEMBL1426632 & 688267 & 5.85 & 5.1436 & TRN \\
\hline CHEMBL1421624 & 688267 & 5.7 & 5.1132 & TRN \\
\hline CHEMBL1357514 & 688267 & 5.9 & 5.0418 & TRN \\
\hline CHEMBL 2006594 & 688267 & 6.5 & 5.0065 & TST \\
\hline CHEMBL1509841 & 688267 & 6.5 & 5.085 & TST \\
\hline CHEMBL1382313 & 688267 & 6.3 & 5.0653 & TST \\
\hline CHEMBL1541646 & 688267 & 5.5 & 5.0624 & TRN \\
\hline CHEMBL1416642 & 688267 & 5.4 & 5.0725 & TRN \\
\hline
\end{tabular}




\begin{tabular}{|c|c|c|c|c|}
\hline \multicolumn{5}{|c|}{ Supplemental Table S2.txt } \\
\hline CHEMBL1477213 & 688267 & 3.95 & 4.982 & TRN \\
\hline CHEMBL1544054 & 688267 & 5.35 & 5.0961 & TRN \\
\hline CHEMBL1482334 & 688267 & 3.95 & 5.0629 & TRN \\
\hline CHEMBL1585185 & 688267 & 3.95 & 5.0691 & TRN \\
\hline CHEMBL1600189 & 688267 & 5.9 & 5.0857 & TRN \\
\hline CHEMBL1442287 & 688267 & 5.45 & 5.1124 & TRN \\
\hline CHEMBL1335389 & 688267 & 5.0 & 5.0724 & TRN \\
\hline CHEMBL1362822 & 688267 & 4.4 & 5.0664 & TRN \\
\hline CHEMBL1375087 & 688267 & 6.25 & 5.0368 & TRN \\
\hline CHEMBL1378091 & 688267 & 4.0 & 5.0347 & TRN \\
\hline CHEMBL1391402 & 688267 & 6.2 & 5.0825 & TRN \\
\hline CHEMBL1452651 & 688267 & 4.15 & 5.082 & TRN \\
\hline CHEMBL1403913 & 688267 & 4.5 & 5.0325 & TST \\
\hline CHEMBL1420480 & 688267 & 4.35 & 5.1141 & TRN \\
\hline CHEMBL1504726 & 688267 & 5.55 & 5.1136 & TST \\
\hline CHEMBL1590172 & 688267 & 5.8 & 5.0718 & TRN \\
\hline CHEMBL1348025 & 688267 & 6.2 & 5.0363 & TRN \\
\hline CHEMBL1323091 & 688267 & 4.6 & 5.0678 & TRN \\
\hline CHEMBL1408590 & 688267 & 4.05 & 5.029 & TRN \\
\hline CHEMBL1315728 & 688267 & 3.95 & 5.0223 & TST \\
\hline CHEMBL1341848 & 688267 & 5.35 & 5.0944 & TRN \\
\hline CHEMBL1381879 & 688267 & 5.75 & 4.9737 & TRN \\
\hline CHEMBL 3208387 & 688267 & 5.05 & 5.052 & TRN \\
\hline CHEMBL1417259 & 688267 & 4.7 & 5.124 & TRN \\
\hline CHEMBL1499903 & 688267 & 6.2 & 5.0613 & TST \\
\hline CHEMBL1354233 & 688267 & 4.05 & 5.0658 & TRN \\
\hline CHEMBL1407991 & 688267 & 5.1 & 5.0289 & TRN \\
\hline CHEMBL1314660 & 688267 & 6.45 & 5.1159 & TST \\
\hline CHEMBL1316264 & 688267 & 5.25 & 5.0279 & TRN \\
\hline CHEMBL1362937 & 688267 & 3.95 & 5.0032 & TRN \\
\hline CHEMBL1424514 & 688267 & 4.35 & 5.0849 & TRN \\
\hline CHEMBL1447794 & 688267 & 5.45 & 5.0821 & TRN \\
\hline CHEMBL3197985 & 688267 & 5.3 & 4.9978 & TST \\
\hline CHEMBL1592821 & 688267 & 5.5 & 5.0191 & TRN \\
\hline CHEMBL1586550 & 688267 & 4.0 & 5.0336 & TRN \\
\hline CHEMBL1364290 & 688267 & 5.6 & 5.0211 & TST \\
\hline CHEMBL 1473400 & 688267 & 4.0 & 5.0175 & TRN \\
\hline CHEMBL1421867 & 688267 & 5.6 & 5.1072 & TRN \\
\hline CHEMBL1462022 & 688267 & 6.2 & 5.1157 & TRN \\
\hline CHEMBL1316017 & 688267 & 4.15 & 5.0184 & TRN \\
\hline CHEMBL1557955 & 688267 & 6.25 & 5.0294 & TRN \\
\hline CHEMBL1441795 & 688267 & 4.25 & 4.9955 & TRN \\
\hline CHEMBL1345684 & 688267 & 5.6 & 5.1322 & TRN \\
\hline CHEMBL1394853 & 688267 & 6.15 & 5.1086 & TST \\
\hline CHEMBL1360182 & 688267 & 6.25 & 5.0624 & TRN \\
\hline CHEMBL1505862 & 688267 & 4.25 & 5.0196 & TST \\
\hline CHEMBL 1586630 & 688267 & 4.0 & 4.9861 & TRN \\
\hline CHEMBL1451782 & 688267 & 4.65 & 5.0957 & TRN \\
\hline
\end{tabular}




\begin{tabular}{|c|c|c|c|c|c|}
\hline \multicolumn{6}{|c|}{ Supplemental Table S2.txt } \\
\hline CHEMBL1507589 & 688267 & 4.55 & 5.0602 & TRN & \\
\hline CHEMBL1302365 & 688267 & 5.4 & 5.0536 & TRN & \\
\hline CHEMBL1427466 & 688267 & 6.15 & 4.9988 & TRN & \\
\hline CHEMBL1476445 & 688267 & 4.0 & 5.0587 & TRN & \\
\hline CHEMBL1515187 & 688267 & 5.3 & 5.1548 & TRN & \\
\hline CHEMBL1391014 & 688267 & 6.0 & 5.0024 & TRN & \\
\hline CHEMBL1536280 & 688267 & 5.85 & 5.1027 & TRN & \\
\hline CHEMBL1488720 & 688267 & 5.1 & 5.0551 & TRN & \\
\hline CHEMBL1570391 & 688267 & 4.45 & 5.0799 & TRN & \\
\hline CHEMBL1590343 & 688267 & 4.05 & 5.1121 & TRN & \\
\hline CHEMBL1570897 & 688267 & 5.65 & 5.0753 & TRN & \\
\hline CHEMBL1437620 & 688267 & 4.05 & 5.0841 & TRN & \\
\hline CHEMBL1485199 & 688267 & 4.1 & 5.09 & TRN & \\
\hline CHEMBL1341571 & 688267 & 6.2 & 5.0597 & TRN & \\
\hline CHEMBL1391500 & 688267 & 6.2 & 5.1177 & TST & \\
\hline CHEMBL1397884 & 688267 & 7.5498 & 5.13 & TRN & \\
\hline CHEMBL1376233 & 688267 & 5.4 & 5.093 & TRN & \\
\hline CHEMBL1570845 & 688267 & 3.95 & 5.0551 & TST & \\
\hline CHEMBL1343569 & 688267 & 6.2 & 5.0622 & TRN & \\
\hline CHEMBL1390686 & 688267 & 6.15 & 5.0792 & TRN & \\
\hline CHEMBL1423987 & 688267 & 4.0 & 5.0794 & TST & \\
\hline CHEMBL1465428 & 688267 & 4.25 & 5.0191 & TRN & \\
\hline CHEMBL1587034 & 688267 & 6.2 & 5.0665 & TST & \\
\hline CHEMBL1588444 & 688267 & 5.95 & 5.02800 & 20000000005 & TRN \\
\hline CHEMBL1313375 & 688267 & 5.9 & 5.0772 & TST & \\
\hline CHEMBL1319911 & 688267 & 6.25 & 5.0762 & TST & \\
\hline CHEMBL1437468 & 688267 & 6.3 & 5.0588 & TRN & \\
\hline CHEMBL1563393 & 688267 & 5.6 & 5.0541 & TST & \\
\hline CHEMBL1570061 & 688267 & 4.25 & 5.1018 & TRN & \\
\hline CHEMBL1341523 & 688267 & 4.0 & 5.0348 & TRN & \\
\hline CHEMBL1358248 & 688267 & 5.95 & 5.0953 & TRN & \\
\hline CHEMBL1317179 & 688267 & 4.65 & 5.0649 & TRN & \\
\hline CHEMBL1541126 & 688267 & 6.2 & 5.0111 & TRN & \\
\hline CHEMBL1611268 & 688267 & 4.85 & 4.9826 & TST & \\
\hline CHEMBL3209128 & 688267 & 4.4 & 5.0577 & TST & \\
\hline CHEMBL1475953 & 688267 & 5.5 & 5.1065 & TRN & \\
\hline CHEMBL1378677 & 688267 & 5.8 & 5.051 & TRN & \\
\hline CHEMBL1423679 & 688267 & 4.35 & 4.9891 & TRN & \\
\hline CHEMBL1321700 & 688267 & 6.1 & 5.0438 & TRN & \\
\hline CHEMBL1322272 & 688267 & 5.1 & 5.0437 & TRN & \\
\hline CHEMBL1423883 & 688267 & 5.95 & 5.0427 & TRN & \\
\hline CHEMBL1417623 & 688267 & 5.4 & 5.0715 & TST & \\
\hline CHEMBL1440592 & 688267 & 5.35 & 5.067 & TST & \\
\hline CHEMBL1555465 & 688267 & 3.95 & 5.0352 & TRN & \\
\hline CHEMBL1321126 & 688267 & 4.05 & 5.0635 & TST & \\
\hline CHEMBL1337473 & 688267 & 3.95 & 5.0119 & TRN & \\
\hline CHEMBL1463519 & 688267 & 5.8 & 5.0794 & TST & \\
\hline CHEMBL1333197 & 688267 & 5.35 & 5.0466 & TST & \\
\hline
\end{tabular}




\begin{tabular}{|c|c|c|c|c|}
\hline \multicolumn{5}{|c|}{ Supplemental Table S2.txt } \\
\hline CHEMBL1522956 & 688267 & 4.15 & 5.0236 & TRN \\
\hline CHEMBL1475397 & 688267 & 4.4 & 5.0702 & TRN \\
\hline CHEMBL1469127 & 688267 & 4.75 & 5.0934 & TST \\
\hline CHEMBL1549013 & 688267 & 5.45 & 5.0613 & TRN \\
\hline CHEMBL 1437125 & 688267 & 6.45 & 5.0049 & TRN \\
\hline CHEMBL1453264 & 688267 & 5.2 & 5.0598 & TRN \\
\hline CHEMBL3194101 & 688267 & 4.05 & 5.0481 & TRN \\
\hline CHEMBL1469849 & 688267 & 6.2 & 5.1046 & TRN \\
\hline CHEMBL1369799 & 688267 & 4.0 & 5.0168 & TRN \\
\hline CHEMBL1569197 & 688267 & 5.15 & 5.0395 & TST \\
\hline CHEMBL1317971 & 688267 & 5.55 & 5.0868 & TRN \\
\hline CHEMBL1608102 & 688267 & 5.75 & 5.2034 & TRN \\
\hline CHEMBL1545210 & 688267 & 3.95 & 5.0127 & TST \\
\hline CHEMBL1557891 & 688267 & 4.5 & 5.1114 & TRN \\
\hline CHEMBL1356506 & 688267 & 4.05 & 4.9756 & TRN \\
\hline CHEMBL1426358 & 688267 & 4.05 & 5.096 & TST \\
\hline CHEMBL1352578 & 688267 & 4.9 & 5.1087 & TRN \\
\hline CHEMBL1436205 & 688267 & 4.7 & 5.1078 & TST \\
\hline CHEMBL1432402 & 688267 & 4.95 & 5.0481 & TST \\
\hline CHEMBL1381698 & 688267 & 5.0 & 5.1473 & TRN \\
\hline CHEMBL1367313 & 688267 & 6.15 & 5.0204 & TRN \\
\hline CHEMBL1308024 & 688267 & 4.0 & 5.0391 & TRN \\
\hline CHEMBL1513671 & 688267 & 5.5 & 5.0027 & TRN \\
\hline CHEMBL1440865 & 688267 & 5.05 & 5.0037 & TRN \\
\hline CHEMBL1435930 & 688267 & 5.85 & 5.0088 & TRN \\
\hline CHEMBL1394142 & 688267 & 6.15 & 5.0452 & TRN \\
\hline CHEMBL1331488 & 688267 & 5.85 & 5.0364 & TRN \\
\hline CHEMBL1300502 & 688267 & 5.0 & 5.0313 & TRN \\
\hline CHEMBL1504445 & 688267 & 6.2 & 5.063 & TRN \\
\hline CHEMBL1434602 & 688267 & 6.5 & 5.0846 & TRN \\
\hline CHEMBL1368150 & 688267 & 3.95 & 5.0898 & TRN \\
\hline CHEMBL1405760 & 688267 & 4.6 & 4.9856 & TRN \\
\hline CHEMBL1494403 & 688267 & 4.5 & 5.0494 & TRN \\
\hline CHEMBL1550029 & 688267 & 5.8 & 5.1235 & TRN \\
\hline CHEMBL1530680 & 688267 & 3.95 & 5.0668 & TRN \\
\hline CHEMBL1389130 & 688267 & 4.05 & 5.059 & TRN \\
\hline CHEMBL1443666 & 688267 & 5.65 & 5.0479 & TRN \\
\hline CHEMBL1327645 & 688267 & 4.3 & 5.0603 & TRN \\
\hline CHEMBL1360308 & 688267 & 4.0 & 5.0512 & TST \\
\hline CHEMBL1546839 & 688267 & 4.35 & 5.0705 & TRN \\
\hline CHEMBL1355844 & 688267 & 5.95 & 5.1409 & TRN \\
\hline CHEMBL1487691 & 688267 & 4.0 & 5.0401 & TST \\
\hline CHEMBL3195084 & 688267 & 5.3 & 5.0355 & TRN \\
\hline CHEMBL1596525 & 688267 & 5.85 & 5.0375 & TRN \\
\hline CHEMBL1356931 & 688267 & 4.0 & 5.0653 & TRN \\
\hline CHEMBL1339977 & 688267 & 3.95 & 5.0756 & TRN \\
\hline CHEMBL1570619 & 688267 & 4.35 & 5.0799 & TRN \\
\hline CHEMBL1395041 & 688267 & 5.75 & 5.062 & TRN \\
\hline
\end{tabular}




\begin{tabular}{|c|c|c|c|c|c|}
\hline \multicolumn{6}{|c|}{ pplemental } \\
\hline CHEMBL1577379 & 688267 & 6.2 & 5.0841 & TRN & \\
\hline CHEMBL1365386 & 688267 & 4.3 & 5.0445 & TRN & \\
\hline CHEMBL1598390 & 688267 & 4.25 & 5.0662 & TRN & \\
\hline CHEMBL1392773 & 688267 & 6.2 & 5.053 & TRN & \\
\hline CHEMBL1371462 & 688267 & 4.95 & 5.1037 & TRN & \\
\hline CHEMBL1604178 & 688267 & 4.3 & 5.0786 & TST & \\
\hline CHEMBL1394807 & 688267 & 6.7501 & 5.0967 & TRN & \\
\hline CHEMBL1403348 & 688267 & 5.6 & 5.0515 & TRN & \\
\hline CHEMBL1347584 & 688267 & 4.55 & 5.0298 & TRN & \\
\hline CHEMBL1380218 & 688267 & 4.0 & 5.0278 & TST & \\
\hline CHEMBL1437404 & 688267 & 4.65 & 5.0962 & TRN & \\
\hline CHEMBL1533222 & 688267 & 5.9 & 5.0801 & TST & \\
\hline CHEMBL1595903 & 688267 & 6.2 & 5.1675 & TRN & \\
\hline CHEMBL1461702 & 688267 & 4.35 & 5.0283 & TST & \\
\hline CHEMBL1569569 & 688267 & 4.6 & 5.0322 & TRN & \\
\hline CHEMBL3209615 & 688267 & 6.2 & 5.0091 & TST & \\
\hline CHEMBL1598748 & 688267 & 4.7 & 5.0008 & TRN & \\
\hline CHEMBL1459618 & 688267 & 4.0 & 5.0873 & TRN & \\
\hline CHEMBL1509593 & 688267 & 3.9 & 5.0512 & TRN & \\
\hline CHEMBL1433575 & 688267 & 6.15 & 5.0314 & TRN & \\
\hline CHEMBL602409 & 688267 & 5.05 & 5.0472 & TST & \\
\hline CHEMBL1580382 & 688267 & 6.2 & 5.0126 & TRN & \\
\hline CHEMBL1372721 & 688267 & 4.9 & 5.0958 & TRN & \\
\hline CHEMBL1610147 & 688267 & 5.7 & 5.0702 & TRN & \\
\hline CHEMBL1455230 & 688267 & 4.25 & 5.0087 & TST & \\
\hline CHEMBL1612817 & 688267 & 6.2 & 5.0506 & TRN & \\
\hline CHEMBL1321451 & 688267 & 5.55 & 5.0452 & TRN & \\
\hline CHEMBL1436754 & 688267 & 4.0 & 5.1095 & TRN & \\
\hline CHEMBL1375619 & 688267 & 5.3 & 5.0803 & TRN & \\
\hline CHEMBL1473244 & 688267 & 5.0 & 5.0327 & TRN & \\
\hline CHEMBL1383655 & 688267 & 4.65 & 5.1114 & TRN & \\
\hline CHEMBL1314827 & 688267 & 3.95 & 5.0383 & TRN & \\
\hline CHEMBL1405863 & 688267 & 4.75 & 5.0205 & TST & \\
\hline CHEMBL1512363 & 688267 & 4.65 & 5.0298 & TRN & \\
\hline CHEMBL1317414 & 688267 & 4.0 & 5.0458 & TRN & \\
\hline CHEMBL1358967 & 688267 & 4.2 & 5.0847 & TRN & \\
\hline CHEMBL1512438 & 688267 & 5.15 & 5.0035 & TRN & \\
\hline CHEMBL1374311 & 688267 & 5.3 & 5.0903 & TRN & \\
\hline CHEMBL1564351 & 688267 & 6.2 & 5.0975 & TRN & \\
\hline CHEMBL1357062 & 688267 & 5.85 & 5.07100 & 0000000001 & TRN \\
\hline CHEMBL1344324 & 688267 & 4.5 & 5.1544 & TRN & \\
\hline CHEMBL1580368 & 688267 & 6.15 & 5.1054 & TRN & \\
\hline CHEMBL1441518 & 688267 & 4.25 & 5.0872 & TST & \\
\hline CHEMBL1435914 & 688267 & 3.95 & 5.0978 & TRN & \\
\hline CHEMBL1313137 & 688267 & 4.35 & 5.0383 & TRN & \\
\hline CHEMBL1552628 & 688267 & 5.5 & 5.019 & TRN & \\
\hline CHEMBL1573526 & 688267 & 3.95 & 5.0375 & TRN & \\
\hline CHEMBL1403323 & 688267 & 6.2 & 5.1081 & TRN & \\
\hline
\end{tabular}




\begin{tabular}{|c|c|c|c|c|c|}
\hline \multicolumn{6}{|c|}{ pplemental } \\
\hline CHEMBL1495983 & 688267 & 6.2 & 5.1017 & TRN & \\
\hline CHEMBL1307481 & 688267 & 5.8 & 5.1126 & TRN & \\
\hline CHEMBL1477840 & 688267 & 5.85 & 5.0267 & TRN & \\
\hline CHEMBL1378626 & 688267 & 4.05 & 5.1338 & TRN & \\
\hline CHEMBL1458216 & 688267 & 4.3 & 5.0291 & TRN & \\
\hline CHEMBL1605084 & 688267 & 4.0 & 5.0367 & TRN & \\
\hline CHEMBL1466651 & 688267 & 6.2 & 5.0271 & TRN & \\
\hline CHEMBL1315422 & 688267 & 5.45 & 5.0704 & TRN & \\
\hline CHEMBL1314244 & 688267 & 6.15 & 5.0482 & TRN & \\
\hline CHEMBL1315907 & 688267 & 5.4 & 5.1269 & TRN & \\
\hline CHEMBL1316472 & 688267 & 6.25 & 5.034 & TRN & \\
\hline CHEMBL1591350 & 688267 & 6.1 & 5.0341 & TRN & \\
\hline CHEMBL1573876 & 688267 & 5.25 & 5.088 & TST & \\
\hline CHEMBL1487887 & 688267 & 6.6 & 5.0009 & TRN & \\
\hline CHEMBL1364180 & 688267 & 4.25 & 5.1081 & TRN & \\
\hline CHEMBL1512716 & 688267 & 6.5 & 5.0342 & TRN & \\
\hline CHEMBL1601254 & 688267 & 4.6 & 5.0706 & TRN & \\
\hline CHEMBL1357415 & 688267 & 4.85 & 5.0553 & TRN & \\
\hline CHEMBL1334316 & 688267 & 4.0 & 5.1104 & TRN & \\
\hline CHEMBL1387982 & 688267 & 6.25 & 5.0626 & TRN & \\
\hline CHEMBL1424542 & 688267 & 5.85 & 5.0514 & TST & \\
\hline CHEMBL1477461 & 688267 & 5.2 & 5.086 & TRN & \\
\hline CHEMBL1343492 & 688267 & 6.15 & 5.0234 & TRN & \\
\hline CHEMBL1444939 & 688267 & 5.35 & 5.043 & TST & \\
\hline CHEMBL1549770 & 688267 & 4.15 & 5.0667 & TST & \\
\hline CHEMBL1334077 & 688267 & 4.25 & 5.1104 & TRN & \\
\hline CHEMBL1429087 & 688267 & 6.2 & 5.1156 & TRN & \\
\hline CHEMBL1588920 & 688267 & 6.25 & 5.0875 & TRN & \\
\hline CHEMBL1396948 & 688267 & 4.9 & 5.0229 & TRN & \\
\hline CHEMBL1404480 & 688267 & 5.1 & 5.0446 & TST & \\
\hline CHEMBL1527074 & 688267 & 4.1 & 5.0231 & TRN & \\
\hline CHEMBL1567671 & 688267 & 4.4 & 5.0558 & TST & \\
\hline CHEMBL1596681 & 688267 & 5.75 & 5.0934 & TST & \\
\hline CHEMBL1551377 & 688267 & 6.15 & 5.0659 & TST & \\
\hline CHEMBL1512408 & 688267 & 6.2 & 5.1564 & TRN & \\
\hline CHEMBL1565000 & 688267 & 6.2 & 5.1602 & TST & \\
\hline CHEMBL1445619 & 688267 & 4.0 & 4.9978 & TRN & \\
\hline CHEMBL3197634 & 688267 & 4.45 & 5.0268 & TST & \\
\hline CHEMBL3212977 & 688267 & 5.0 & 5.0411 & TRN & \\
\hline CHEMBL1545737 & 688267 & 4.35 & 4.9932 & TRN & \\
\hline CHEMBL1538311 & 688267 & 4.5 & 5.0811 & TRN & \\
\hline CHEMBL1608957 & 688267 & 6.15 & 5.09399 & 9999999999 & TRN \\
\hline CHEMBL1463816 & 688267 & 5.55 & 5.0269 & TRN & \\
\hline CHEMBL1524423 & 688267 & 6.25 & 5.0988 & TRN & \\
\hline CHEMBL1508068 & 688267 & 5.15 & 5.0695 & TRN & \\
\hline CHEMBL1434418 & 688267 & 4.2 & 5.0799 & TRN & \\
\hline CHEMBL1320834 & 688267 & 4.5 & 5.0126 & TST & \\
\hline CHEMBL1427157 & 688267 & 3.95 & 5.1274 & TST & \\
\hline
\end{tabular}




\begin{tabular}{|c|c|c|c|c|}
\hline \multicolumn{5}{|c|}{ Supplemental Table S2.txt } \\
\hline CHEMBL1523587 & 688267 & 4.25 & 5.0396 & TRN \\
\hline CHEMBL1566084 & 688267 & 5.0 & 5.0844 & TRN \\
\hline CHEMBL1576657 & 688267 & 6.15 & 4.9806 & TRN \\
\hline CHEMBL1440316 & 688267 & 5.05 & 5.1038 & TRN \\
\hline CHEMBL1402768 & 688267 & 5.3 & 5.1238 & TRN \\
\hline CHEMBL1608190 & 688267 & 4.95 & 5.0961 & TRN \\
\hline CHEMBL1512597 & 688267 & 5.85 & 5.0826 & TRN \\
\hline CHEMBL1313097 & 688267 & 5.55 & 5.0431 & TRN \\
\hline CHEMBL1594939 & 688267 & 4.8 & 5.0939 & TST \\
\hline CHEMBL 1307110 & 688267 & 6.0 & 5.1149 & TRN \\
\hline CHEMBL1477766 & 688267 & 6.25 & 5.0557 & TST \\
\hline CHEMBL1608677 & 688267 & 4.1 & 5.0678 & TRN \\
\hline CHEMBL1408349 & 688267 & 6.25 & 5.0613 & TRN \\
\hline CHEMBL 3214608 & 688267 & 5.3 & 5.0417 & TRN \\
\hline CHEMBL1354123 & 688267 & 4.4 & 5.0081 & TRN \\
\hline CHEMBL1574679 & 688267 & 4.4 & 5.085 & TRN \\
\hline CHEMBL1449329 & 688267 & 4.05 & 4.9953 & TRN \\
\hline CHEMBL1536626 & 688267 & 4.25 & 5.0323 & TST \\
\hline CHEMBL1399239 & 688267 & 5.15 & 5.0725 & TRN \\
\hline CHEMBL1357131 & 688267 & 4.05 & 5.0308 & TRN \\
\hline CHEMBL1553548 & 688267 & 4.65 & 5.0711 & TRN \\
\hline CHEMBL1580426 & 688267 & 5.55 & 5.0614 & TST \\
\hline CHEMBL1459704 & 688267 & 6.1 & 4.9724 & TRN \\
\hline CHEMBL1486224 & 688267 & 3.95 & 5.0298 & TRN \\
\hline CHEMBL1492449 & 688267 & 4.05 & 5.0377 & TRN \\
\hline CHEMBL1524270 & 688267 & 4.0 & 5.0333 & TST \\
\hline CHEMBL1423661 & 688267 & 4.55 & 5.0735 & TRN \\
\hline CHEMBL1433447 & 688267 & 6.25 & 5.0775 & TRN \\
\hline CHEMBL1525343 & 688267 & 4.2 & 5.0939 & TRN \\
\hline CHEMBL1335754 & 688267 & 4.7 & 5.016 & TRN \\
\hline CHEMBL1569509 & 688267 & 4.4 & 5.0301 & TRN \\
\hline CHEMBL1453920 & 688267 & 6.1 & 5.0543 & TRN \\
\hline CHEMBL1441714 & 688267 & 4.45 & 5.0453 & TRN \\
\hline CHEMBL3193175 & 688267 & 4.4 & 5.0618 & TRN \\
\hline CHEMBL1512145 & 688267 & 5.85 & 5.0408 & TRN \\
\hline CHEMBL1574641 & 688267 & 4.6 & 5.0517 & TRN \\
\hline CHEMBL1497437 & 688267 & 5.05 & 5.0458 & TRN \\
\hline CHEMBL1380460 & 688267 & 3.95 & 5.0602 & TRN \\
\hline CHEMBL1389381 & 688267 & 6.2 & 5.0213 & TRN \\
\hline CHEMBL1375008 & 688267 & 4.1 & 5.0316 & TST \\
\hline CHEMBL1529020 & 688267 & 6.2 & 5.0689 & TST \\
\hline CHEMBL1315938 & 688267 & 4.4 & 5.0422 & TRN \\
\hline CHEMBL1411137 & 688267 & 4.1 & 5.0049 & TST \\
\hline CHEMBL1612770 & 688267 & 5.95 & 5.0293 & TRN \\
\hline CHEMBL1555397 & 688267 & 4.0 & 5.0558 & TRN \\
\hline CHEMBL1306093 & 688267 & 4.4 & 5.0703 & TST \\
\hline CHEMBL1324365 & 688267 & 4.0 & 5.1466 & TRN \\
\hline CHEMBL1449940 & 688267 & 6.15 & 5.0484 & TRN \\
\hline
\end{tabular}




\begin{tabular}{|c|c|c|c|c|}
\hline \multicolumn{5}{|c|}{ Supplemental Table S2.txt } \\
\hline CHEMBL1442556 & 688267 & 6.15 & 5.0688 & TRN \\
\hline CHEMBL1608185 & 688267 & 5.35 & 5.0664 & TRN \\
\hline CHEMBL1319342 & 688267 & 3.85 & 5.0506 & TRN \\
\hline CHEMBL1339113 & 688267 & 4.45 & 5.0219 & TST \\
\hline CHEMBL1328557 & 688267 & 5.05 & 5.0472 & TRN \\
\hline CHEMBL1538949 & 688267 & 6.1 & 5.0453 & TST \\
\hline CHEMBL1607975 & 688267 & 5.25 & 5.0973 & TRN \\
\hline CHEMBL1461404 & 688267 & 5.9 & 5.0335 & TRN \\
\hline CHEMBL1404222 & 688267 & 4.35 & 5.0474 & TRN \\
\hline CHEMBL1585559 & 688267 & 5.55 & 5.0347 & TRN \\
\hline CHEMBL1353335 & 688267 & 4.2 & 5.0701 & TRN \\
\hline CHEMBL1577637 & 688267 & 5.45 & 5.0315 & TST \\
\hline CHEMBL1354858 & 688267 & 6.5 & 5.0564 & TRN \\
\hline CHEMBL1356100 & 688267 & 5.25 & 5.1471 & TRN \\
\hline CHEMBL1326396 & 688267 & 6.15 & 5.0743 & TRN \\
\hline CHEMBL 2002156 & 688267 & 5.75 & 5.0018 & TRN \\
\hline CHEMBL1450021 & 688267 & 5.6 & 5.0255 & TRN \\
\hline CHEMBL3199249 & 688267 & 5.45 & 5.0225 & TST \\
\hline CHEMBL1443380 & 688267 & 5.85 & 5.1025 & TRN \\
\hline CHEMBL1469237 & 688267 & 5.3 & 5.0351 & TRN \\
\hline CHEMBL1424117 & 688267 & 4.4 & 5.0172 & TRN \\
\hline CHEMBL1448389 & 688267 & 5.75 & 5.0683 & TRN \\
\hline CHEMBL1515191 & 688267 & 4.0 & 5.074 & TRN \\
\hline CHEMBL1565029 & 688267 & 7.2503 & 5.0582 & TRN \\
\hline CHEMBL1429636 & 688267 & 4.0 & 5.0148 & TRN \\
\hline CHEMBL1606182 & 688267 & 5.2 & 5.0799 & TST \\
\hline CHEMBL3210998 & 688267 & 5.85 & 4.9939 & TRN \\
\hline CHEMBL1425839 & 688267 & 4.6 & 4.981 & TRN \\
\hline CHEMBL1545257 & 688267 & 5.75 & 5.0387 & TRN \\
\hline CHEMBL1395400 & 688267 & 4.45 & 5.0286 & TRN \\
\hline CHEMBL1372496 & 688267 & 5.6 & 5.038 & TRN \\
\hline CHEMBL1372381 & 688267 & 5.0 & 5.1027 & TRN \\
\hline CHEMBL1371949 & 688267 & 4.65 & 5.0351 & TRN \\
\hline CHEMBL3211971 & 688267 & 3.95 & 5.0395 & TRN \\
\hline CHEMBL1431311 & 688267 & 4.35 & 5.0974 & TRN \\
\hline CHEMBL1524363 & 688267 & 3.95 & 5.0693 & TST \\
\hline CHEMBL1505692 & 688267 & 4.4 & 5.1385 & TRN \\
\hline CHEMBL1567932 & 688267 & 3.9 & 5.029 & TRN \\
\hline CHEMBL1500604 & 688267 & 4.05 & 5.0553 & TST \\
\hline CHEMBL1583577 & 688267 & 4.65 & 5.0028 & TST \\
\hline CHEMBL1441894 & 688267 & 6.5501 & 5.1247 & TRN \\
\hline CHEMBL1353382 & 688267 & 6.45 & 5.0781 & TST \\
\hline CHEMBL1558565 & 688267 & 3.95 & 5.0161 & TRN \\
\hline CHEMBL1590904 & 688267 & 4.1 & 5.1062 & TRN \\
\hline CHEMBL1593575 & 688267 & 5.4 & 5.0752 & TRN \\
\hline CHEMBL1353460 & 688267 & 5.1 & 5.1116 & TRN \\
\hline CHEMBL1517762 & 688267 & 4.3 & 5.0772 & TST \\
\hline CHEMBL1359416 & 688267 & 4.25 & 5.0227 & TRN \\
\hline
\end{tabular}




\begin{tabular}{|c|c|c|c|c|c|}
\hline \multicolumn{6}{|c|}{ Supplemental Table S2.txt } \\
\hline CHEMBL1323454 & 688267 & 4.45 & 5.0571 & TRN & \\
\hline CHEMBL1560310 & 688267 & 6.25 & 5.0442 & TST & \\
\hline CHEMBL1305940 & 688267 & 4.45 & 5.0752 & TRN & \\
\hline CHEMBL1395354 & 688267 & 3.95 & 5.1355 & TRN & \\
\hline CHEMBL1598566 & 688267 & 6.5 & 5.0275 & TRN & \\
\hline CHEMBL1367587 & 688267 & 5.35 & 5.0063 & TST & \\
\hline CHEMBL1499223 & 688267 & 6.2 & 5.1604 & TRN & \\
\hline CHEMBL1582040 & 688267 & 4.1 & 5.058 & TRN & \\
\hline CHEMBL1332676 & 688267 & 6.2 & 5.1255 & TRN & \\
\hline CHEMBL1378018 & 688267 & 4.35 & 5.0932 & TRN & \\
\hline CHEMBL1498728 & 688267 & 4.95 & 5.0309 & TRN & \\
\hline CHEMBL1445677 & 688267 & 4.7 & 5.1112 & TST & \\
\hline CHEMBL1468199 & 688267 & 6.25 & 5.0799 & TRN & \\
\hline CHEMBL1513716 & 688267 & 4.55 & 5.0506 & TRN & \\
\hline CHEMBL1310868 & 688267 & 4.65 & 5.0719 & TRN & \\
\hline CHEMBL3198449 & 688267 & 6.2 & 5.0414 & TST & \\
\hline CHEMBL81082 & 688267 & 6.5 & 5.0892 & TST & \\
\hline CHEMBL1409790 & 688267 & 5.3 & 5.1224 & TRN & \\
\hline CHEMBL1379302 & 688267 & 4.6 & 5.1065 & TRN & \\
\hline CHEMBL1362707 & 688267 & 5.4 & 5.1389 & TRN & \\
\hline CHEMBL1480460 & 688267 & 4.05 & 5.0516 & TRN & \\
\hline CHEMBL1515240 & 688267 & 4.4 & 5.0661 & TRN & \\
\hline CHEMBL1454245 & 688267 & 6.25 & 5.0005 & TST & \\
\hline CHEMBL1478286 & 688267 & 4.0 & 5.0465 & TRN & \\
\hline CHEMBL1309530 & 688267 & 4.2 & 5.0822 & TRN & \\
\hline CHEMBL1536134 & 688267 & 4.0 & 5.074 & TRN & \\
\hline CHEMBL1375602 & 688267 & 4.05 & 5.0588 & TRN & \\
\hline CHEMBL581251 & 688267 & 4.15 & 5.0211 & TST & \\
\hline CHEMBL1312693 & 688267 & 4.1 & 5.0664 & TRN & \\
\hline CHEMBL1527663 & 688267 & 4.15 & 5.0126 & TRN & \\
\hline CHEMBL1598640 & 688267 & 4.0 & 5.0314 & TRN & \\
\hline CHEMBL1325734 & 688267 & 4.0 & 5.0317 & TRN & \\
\hline CHEMBL1602573 & 688267 & 5.6 & 5.0882 & TRN & \\
\hline CHEMBL1455558 & 688267 & 5.0 & 5.0218 & TST & \\
\hline CHEMBL1512604 & 688267 & 4.2 & 5.1202 & TRN & \\
\hline CHEMBL1558068 & 688267 & 6.2 & 5.0215 & TRN & \\
\hline CHEMBL1491614 & 688267 & 4.6 & 5.1414 & TRN & \\
\hline CHEMBL1530542 & 688267 & 5.8 & 5.0448 & TST & \\
\hline CHEMBL1540872 & 688267 & 3.95 & 5.1622 & TRN & \\
\hline CHEMBL1414439 & 688267 & 4.0 & 5.0214 & TRN & \\
\hline CHEMBL3189531 & 688267 & 4.15 & 5.1018 & TST & \\
\hline CHEMBL1321301 & 688267 & 4.2 & 5.0809 & TRN & \\
\hline CHEMBL1484610 & 688267 & 4.45 & 5.05699 & 99999999995 & TRN \\
\hline CHEMBL1551485 & 688267 & 6.25 & 5.1253 & TRN & \\
\hline CHEMBL1336132 & 688267 & 6.15 & 5.13299 & 9999999999 & TRN \\
\hline CHEMBL1383456 & 688267 & 6.15 & 5.0959 & TRN & \\
\hline CHEMBL1420313 & 688267 & 5.55 & 5.0229 & TRN & \\
\hline CHEMBL1493003 & 688267 & 4.8 & 5.0598 & TRN & \\
\hline
\end{tabular}




\begin{tabular}{|c|c|c|c|c|c|}
\hline \multicolumn{6}{|c|}{ splemental } \\
\hline CHEMBL1362588 & 688267 & 6.2 & 5.0332 & TRN & \\
\hline CHEMBL1536247 & 688267 & 5.25 & 5.1121 & TRN & \\
\hline CHEMBL467382 & 688267 & 4.2 & 5.0254 & TST & \\
\hline CHEMBL1559368 & 688267 & 6.25 & 5.0683 & TST & \\
\hline CHEMBL1459101 & 688267 & 5.4 & 5.039 & TST & \\
\hline CHEMBL1568389 & 688267 & 4.0 & 5.0383 & TRN & \\
\hline CHEMBL1589205 & 688267 & 6.05 & 5.0974 & TRN & \\
\hline CHEMBL1384761 & 688267 & 5.15 & 5.101 & TRN & \\
\hline CHEMBL1588786 & 688267 & 4.3 & 5.0405 & TST & \\
\hline CHEMBL244090 & 688267 & 4.45 & 5.0546 & TST & \\
\hline CHEMBL1606542 & 688267 & 4.05 & 5.0384 & TRN & \\
\hline CHEMBL1431388 & 688267 & 4.5 & 5.056 & TRN & \\
\hline CHEMBL1424588 & 688267 & 6.25 & 5.0125 & TRN & \\
\hline CHEMBL1432084 & 688267 & 4.4 & 5.0788 & TRN & \\
\hline CHEMBL1489460 & 688267 & 5.55 & 5.1149 & TRN & \\
\hline CHEMBL1486847 & 688267 & 4.55 & 5.0464 & TRN & \\
\hline CHEMBL1490990 & 688267 & 5.5 & 5.0426 & TRN & \\
\hline CHEMBL1579947 & 688267 & 4.0 & 5.0728 & TRN & \\
\hline CHEMBL1554561 & 688267 & 4.25 & 5.0782 & TRN & \\
\hline CHEMBL1548414 & 688267 & 4.35 & 5.069 & TST & \\
\hline CHEMBL1409018 & 688267 & 4.05 & 5.0906 & TST & \\
\hline CHEMBL1530132 & 688267 & 4.9 & 5.0503 & TST & \\
\hline CHEMBL1589347 & 688267 & 4.3 & 5.1061 & TST & \\
\hline CHEMBL1376303 & 688267 & 5.0 & 5.0639 & TRN & \\
\hline CHEMBL1480766 & 688267 & 5.3 & 5.02800 & 20000000005 & TRN \\
\hline CHEMBL1591423 & 688267 & 3.95 & 5.0904 & TRN & \\
\hline CHEMBL1495107 & 688267 & 4.05 & 5.0846 & TRN & \\
\hline CHEMBL1454459 & 688267 & 5.6 & 5.0351 & TRN & \\
\hline CHEMBL1581981 & 688267 & 5.3 & 5.0079 & TRN & \\
\hline CHEMBL1377984 & 688267 & 4.4 & 5.0466 & TRN & \\
\hline CHEMBL1535665 & 688267 & 3.95 & 5.1386 & TRN & \\
\hline CHEMBL1512489 & 688267 & 6.0 & 5.0194 & TRN & \\
\hline CHEMBL1419090 & 688267 & 5.85 & 5.066 & TRN & \\
\hline CHEMBL1376555 & 688267 & 5.6 & 5.022 & TST & \\
\hline CHEMBL1487710 & 688267 & 5.4 & 5.0301 & TRN & \\
\hline CHEMBL1474843 & 688267 & 6.2 & 4.9838 & TRN & \\
\hline CHEMBL1435693 & 688267 & 4.4 & 4.9951 & TRN & \\
\hline CHEMBL1462883 & 688267 & 5.55 & 5.0389 & TRN & \\
\hline CHEMBL1584756 & 688267 & 6.15 & 5.0409 & TRN & \\
\hline CHEMBL1310651 & 688267 & 6.25 & 4.9965 & TST & \\
\hline CHEMBL1570955 & 688267 & 4.0 & 4.9918 & TRN & \\
\hline CHEMBL1586080 & 688267 & 4.15 & 5.03100 & 0000000001 & TRN \\
\hline CHEMBL1554940 & 688267 & 4.45 & 5.0533 & TRN & \\
\hline CHEMBL1318361 & 688267 & 6.7001 & 5.0171 & TRN & \\
\hline CHEMBL1584370 & 688267 & 4.6 & 5.1082 & TRN & \\
\hline CHEMBL66 & 688267 & 4.25 & 5.0419 & TST & \\
\hline CHEMBL3195942 & 688267 & 4.0 & 5.073 & TST & \\
\hline CHEMBL516029 & 688267 & 4.55 & 5.1023 & TRN & \\
\hline
\end{tabular}




\begin{tabular}{|c|c|c|c|c|}
\hline & & & pplement & al $\mathrm{Ta}$ \\
\hline CHEMBL1490309 & 688267 & 4.3 & 5.0997 & TRN \\
\hline CHEMBL1397705 & 688267 & 5.35 & 5.0026 & TRN \\
\hline CHEMBL1317900 & 688267 & 6.2 & 5.0495 & TRN \\
\hline CHEMBL1393352 & 688267 & 4.0 & 5.0108 & TRN \\
\hline CHEMBL1394744 & 688267 & 5.45 & 5.0242 & TRN \\
\hline CHEMBL1572574 & 688267 & 3.95 & 4.9706 & TST \\
\hline CHEMBL1314853 & 688267 & 5.5 & 5.1068 & TRN \\
\hline CHEMBL1488921 & 688267 & 6.25 & 5.0417 & TRN \\
\hline CHEMBL1367514 & 688267 & 6.15 & 5.0683 & TRN \\
\hline CHEMBL1573591 & 688267 & 3.95 & 5.0595 & TRN \\
\hline CHEMBL1571700 & 688267 & 5.8 & 5.005 & TST \\
\hline CHEMBL1354902 & 688267 & 6.2 & 4.9985 & TRN \\
\hline CHEMBL1524878 & 688267 & 5.45 & 5.0208 & TST \\
\hline CHEMBL1482665 & 688267 & 5.3 & 5.0472 & TST \\
\hline CHEMBL1559284 & 688267 & 5.3 & 5.029 & TST \\
\hline CHEMBL1538785 & 688267 & 4.35 & 5.0115 & TRN \\
\hline CHEMBL1485967 & 688267 & 4.95 & 5.1418 & TRN \\
\hline CHEMBL1336537 & 688267 & 6.5 & 5.1034 & TRN \\
\hline CHEMBL1403910 & 688267 & 5.25 & 5.0802 & TRN \\
\hline CHEMBL1540544 & 688267 & 4.35 & 5.073 & TST \\
\hline CHEMBL1435455 & 688267 & 5.05 & 5.0328 & TRN \\
\hline CHEMBL1374929 & 688267 & 4.3 & 4.9843 & TRN \\
\hline CHEMBL1349984 & 688267 & 5.85 & 5.0138 & TRN \\
\hline CHEMBL1560239 & 688267 & 6.45 & 5.0546 & TRN \\
\hline CHEMBL1308254 & 688267 & 6.2 & 5.0729 & TRN \\
\hline CHEMBL1590622 & 688267 & 4.0 & 5.0561 & TRN \\
\hline CHEMBL1505803 & 688267 & 4.0 & 5.1092 & TRN \\
\hline CHEMBL1330110 & 688267 & 6.2 & 4.9611 & TRN \\
\hline CHEMBL1397433 & 688267 & 4.0 & 5.0402 & TRN \\
\hline CHEMBL1427252 & 688267 & 4.8 & 5.0953 & TRN \\
\hline CHEMBL1452145 & 688267 & 4.35 & 5.0286 & TRN \\
\hline CHEMBL1462130 & 688267 & 5.55 & 5.0387 & TRN \\
\hline CHEMBL1604047 & 688267 & 4.55 & 5.0667 & TRN \\
\hline CHEMBL1580167 & 688267 & 6.1 & 5.1346 & TST \\
\hline CHEMBL1349168 & 688267 & 5.05 & 5.1628 & TRN \\
\hline CHEMBL1598811 & 688267 & 5.4 & 5.0365 & TRN \\
\hline CHEMBL3192431 & 688267 & 4.05 & 5.018 & TRN \\
\hline CHEMBL1330559 & 688267 & 4.05 & 4.9834 & TRN \\
\hline CHEMBL1585859 & 688267 & 6.2 & 5.0405 & TRN \\
\hline CHEMBL1327737 & 688267 & 6.5 & 4.9876 & TRN \\
\hline CHEMBL3213596 & 688267 & 4.0 & 5.019 & TRN \\
\hline CHEMBL261692 & 688267 & 4.0 & 5.0204 & TST \\
\hline CHEMBL1531526 & 688267 & 5.85 & 5.0295 & TST \\
\hline CHEMBL1320338 & 688267 & 4.35 & 5.0439 & TRN \\
\hline CHEMBL1341210 & 688267 & 6.2 & 5.0577 & TRN \\
\hline CHEMBL1391707 & 688267 & 6.2 & 5.0421 & TRN \\
\hline CHEMBL1437599 & 688267 & 5.0 & 5.0054 & TRN \\
\hline CHEMBL1398342 & 688267 & 3.95 & 5.0695 & TRN \\
\hline
\end{tabular}




\begin{tabular}{|c|c|c|c|c|c|}
\hline \multicolumn{6}{|c|}{ Supplemental Table S2.txt } \\
\hline CHEMBL1314998 & 688267 & 5.6 & 5.0518 & TRN & \\
\hline CHEMBL1436868 & 688267 & 4.45 & 5.0242 & TRN & \\
\hline CHEMBL1558561 & 688267 & 4.3 & 5.027 & TST & \\
\hline CHEMBL1527765 & 688267 & 6.2 & 5.0063 & TRN & \\
\hline CHEMBL1497024 & 688267 & 5.55 & 5.0227 & TRN & \\
\hline CHEMBL1572965 & 688267 & 3.95 & 5.0573 & TRN & \\
\hline CHEMBL1605101 & 688267 & 4.9 & 5.0479 & TRN & \\
\hline CHEMBL1550262 & 688267 & 5.3 & 5.0699 & TRN & \\
\hline CHEMBL1403489 & 688267 & 6.15 & 5.0245 & TRN & \\
\hline CHEMBL1595840 & 688267 & 6.2 & 5.0399 & TRN & \\
\hline CHEMBL1353683 & 688267 & 4.35 & 4.9966 & TRN & \\
\hline CHEMBL1571402 & 688267 & 5.35 & 5.0495 & TRN & \\
\hline CHEMBL1334828 & 688267 & 4.9 & 5.0466 & TST & \\
\hline CHEMBL1392364 & 688267 & 6.2 & 5.07100 & 2000000001 & TRN \\
\hline CHEMBL1590108 & 688267 & 6.5 & 5.0957 & TRN & \\
\hline CHEMBL1537847 & 688267 & 5.6 & 5.0227 & TRN & \\
\hline CHEMBL1342067 & 688267 & 4.75 & 5.0686 & TST & \\
\hline CHEMBL1600281 & 688267 & 5.8 & 5.0609 & TRN & \\
\hline CHEMBL1591261 & 688267 & 3.95 & 5.0123 & TRN & \\
\hline CHEMBL3189208 & 688267 & 4.35 & 4.9863 & TST & \\
\hline CHEMBL1454418 & 688267 & 5.75 & 5.0329 & TRN & \\
\hline CHEMBL1610556 & 688267 & 6.15 & 5.1375 & TRN & \\
\hline CHEMBL1357446 & 688267 & 4.2 & 5.0139 & TRN & \\
\hline CHEMBL1508725 & 688267 & 6.2 & 4.9907 & TRN & \\
\hline CHEMBL1605467 & 688267 & 4.5 & 5.0662 & TRN & \\
\hline CHEMBL1313630 & 688267 & 5.55 & 5.0386 & TRN & \\
\hline CHEMBL1525823 & 688267 & 4.4 & 5.087 & TRN & \\
\hline CHEMBL3193412 & 688267 & 3.95 & 5.0095 & TRN & \\
\hline CHEMBL1440369 & 688267 & 5.9 & 5.1045 & TRN & \\
\hline CHEMBL1457639 & 688267 & 4.05 & 5.096 & TST & \\
\hline CHEMBL1582956 & 688267 & 5.55 & 5.0055 & TRN & \\
\hline CHEMBL1565888 & 688267 & 4.25 & 5.0249 & TRN & \\
\hline CHEMBL1498491 & 688267 & 4.8 & 5.0804 & TRN & \\
\hline CHEMBL1595289 & 688267 & 5.3 & 5.0246 & TRN & \\
\hline CHEMBL 3214017 & 688267 & 5.25 & 5.0679 & TRN & \\
\hline CHEMBL3198430 & 688267 & 6.2 & 5.0217 & TST & \\
\hline CHEMBL1342807 & 688267 & 5.5 & 5.0155 & TRN & \\
\hline CHEMBL3196809 & 688267 & 6.5 & 4.9947 & TST & \\
\hline CHEMBL1314467 & 688267 & 5.8 & 5.0205 & TRN & \\
\hline CHEMBL1393531 & 688267 & 4.55 & 5.0863 & TRN & \\
\hline CHEMBL1311376 & 688267 & 4.95 & 5.0905 & TST & \\
\hline CHEMBL1536875 & 688267 & 4.55 & 5.0178 & TST & \\
\hline CHEMBL1401728 & 688267 & 4.15 & 5.0683 & TRN & \\
\hline CHEMBL1585088 & 688267 & 4.45 & 5.0176 & TRN & \\
\hline CHEMBL1434314 & 688267 & 4.0 & 5.0774 & TRN & \\
\hline CHEMBL1590776 & 688267 & 6.2 & 5.0381 & TRN & \\
\hline CHEMBL1454381 & 688267 & 6.0 & 5.0932 & TRN & \\
\hline CHEMBL3189761 & 688267 & 5.4 & 5.0129 & TST & \\
\hline
\end{tabular}




\begin{tabular}{|c|c|c|c|c|}
\hline \multicolumn{5}{|c|}{ Supplemental Table S2.txt } \\
\hline CHEMBL1500368 & 688267 & 4.0 & 5.0337 & TRN \\
\hline CHEMBL1586577 & 688267 & 3.95 & 5.0418 & TST \\
\hline CHEMBL1598386 & 688267 & 4.05 & 5.1087 & TST \\
\hline CHEMBL1445192 & 688267 & 5.0 & 5.0249 & TRN \\
\hline CHEMBL1571209 & 688267 & 5.4 & 5.0669 & TRN \\
\hline CHEMBL1340030 & 688267 & 4.05 & 5.1172 & TRN \\
\hline CHEMBL1545212 & 688267 & 4.25 & 5.0586 & TRN \\
\hline CHEMBL3208189 & 688267 & 5.3 & 5.0035 & TST \\
\hline CHEMBL1573889 & 688267 & 4.3 & 5.0733 & TST \\
\hline CHEMBL1322611 & 688267 & 4.05 & 5.0477 & TST \\
\hline CHEMBL1406717 & 688267 & 4.4 & 5.0217 & TRN \\
\hline CHEMBL1604643 & 688267 & 5.55 & 5.1013 & TRN \\
\hline CHEMBL3192370 & 688267 & 4.0 & 5.0714 & TST \\
\hline CHEMBL1325674 & 688267 & 5.35 & 5.0315 & TRN \\
\hline CHEMBL1367671 & 688267 & 4.55 & 5.0809 & TRN \\
\hline CHEMBL1424398 & 688267 & 5.05 & 5.0395 & TRN \\
\hline CHEMBL1518268 & 688267 & 4.4 & 5.05 & TRN \\
\hline CHEMBL3213281 & 688267 & 3.95 & 5.0443 & TRN \\
\hline CHEMBL1419098 & 688267 & 4.0 & 5.0612 & TRN \\
\hline CHEMBL1602115 & 688267 & 6.6499 & 5.1372 & TRN \\
\hline CHEMBL1503465 & 688267 & 4.0 & 5.0577 & TRN \\
\hline CHEMBL1523195 & 688267 & 6.2 & 5.1434 & TST \\
\hline CHEMBL1444339 & 688267 & 5.2 & 5.0353 & TRN \\
\hline CHEMBL1613586 & 688267 & 6.2 & 5.0721 & TRN \\
\hline CHEMBL1435386 & 688267 & 5.55 & 5.1543 & TRN \\
\hline CHEMBL1972129 & 688267 & 3.95 & 4.9813 & TRN \\
\hline CHEMBL1608712 & 688267 & 5.55 & 5.0611 & TRN \\
\hline CHEMBL1538926 & 688267 & 5.8 & 5.0661 & TRN \\
\hline CHEMBL3192376 & 688267 & 4.6 & 5.0187 & TRN \\
\hline CHEMBL1589128 & 688267 & 4.45 & 5.0436 & TST \\
\hline CHEMBL1377627 & 688267 & 4.7 & 5.1326 & TST \\
\hline CHEMBL1509626 & 688267 & 6.2 & 5.083 & TRN \\
\hline CHEMBL1508104 & 688267 & 4.5 & 5.0136 & TRN \\
\hline CHEMBL1442526 & 688267 & 4.05 & 5.0543 & TRN \\
\hline CHEMBL1465306 & 688267 & 5.0 & 4.9986 & TRN \\
\hline CHEMBL1425417 & 688267 & 5.8 & 5.0325 & TRN \\
\hline CHEMBL1451929 & 688267 & 4.05 & 5.1106 & TRN \\
\hline CHEMBL1505580 & 688267 & 4.65 & 5.0346 & TST \\
\hline CHEMBL1332135 & 688267 & 6.15 & 5.0593 & TRN \\
\hline CHEMBL1085162 & 688267 & 6.2 & 5.0277 & TRN \\
\hline CHEMBL1466472 & 688267 & 5.15 & 5.1035 & TRN \\
\hline CHEMBL1487258 & 688267 & 4.9 & 4.9803 & TRN \\
\hline CHEMBL1303833 & 688267 & 4.0 & 5.0722 & TRN \\
\hline CHEMBL1304907 & 688267 & 4.0 & 5.0598 & TST \\
\hline CHEMBL1303479 & 688267 & 4.0 & 5.1012 & TST \\
\hline CHEMBL1596636 & 688267 & 4.2 & 4.9944 & TRN \\
\hline CHEMBL1382517 & 688267 & 5.55 & 5.0354 & TST \\
\hline CHEMBL3199470 & 688267 & 4.95 & 4.9845 & TRN \\
\hline
\end{tabular}




\begin{tabular}{|c|c|c|c|c|c|}
\hline & & \multicolumn{4}{|c|}{ Supplemental Table S2.txt } \\
\hline CHEMBL1337613 & 688267 & 4.05 & 4.999 & TRN & \\
\hline CHEMBL1355337 & 688267 & 5.1 & 5.0985 & TRN & \\
\hline CHEMBL1349302 & 688267 & 4.1 & 5.1422 & TRN & \\
\hline CHEMBL3196523 & 688267 & 5.05 & 4.9912 & TRN & \\
\hline CHEMBL1523786 & 688267 & 4.75 & 5.0655 & TRN & \\
\hline CHEMBL592316 & 688267 & 4.4 & 5.1005 & TST & \\
\hline CHEMBL1312851 & 688267 & 4.0 & 5.0792 & TRN & \\
\hline CHEMBL1462296 & 688267 & 6.15 & 5.0538 & TST & \\
\hline CHEMBL1510477 & 688267 & 4.4 & 5.0882 & TST & \\
\hline CHEMBL1402939 & 688267 & 6.2 & 5.0336 & TRN & \\
\hline CHEMBL1524087 & 688267 & 4.0 & 5.0498 & TST & \\
\hline CHEMBL3193504 & 688267 & 5.3 & 5.0124 & TST & \\
\hline CHEMBL1308185 & 688267 & 4.15 & 5.0071 & TRN & \\
\hline CHEMBL1307185 & 688267 & 5.65 & 5.0295 & TST & \\
\hline CHEMBL1574042 & 688267 & 5.6 & 5.0999 & TRN & \\
\hline CHEMBL1495903 & 688267 & 5.3 & 5.0317 & TRN & \\
\hline CHEMBL1455316 & 688267 & 6.2 & 4.9917 & TRN & \\
\hline CHEMBL1322928 & 688267 & 3.95 & 5.0455 & TST & \\
\hline CHEMBL1304546 & 688267 & 6.15 & 5.0392 & TRN & \\
\hline CHEMBL1591490 & 688267 & 6.2 & 4.98300 & 20000000005 & TRN \\
\hline CHEMBL1544110 & 688267 & 5.55 & 5.0156 & TRN & \\
\hline CHEMBL1508990 & 688267 & 5.8 & 5.0228 & TRN & \\
\hline CHEMBL1539694 & 688267 & 5.6 & 5.066 & TRN & \\
\hline CHEMBL1609711 & 688267 & 6.15 & 5.1744 & TRN & \\
\hline CHEMBL1567164 & 688267 & 4.4 & 5.0419 & TRN & \\
\hline CHEMBL1379068 & 688267 & 6.25 & 5.1226 & TST & \\
\hline CHEMBL1500665 & 688267 & 4.3 & 5.0685 & TRN & \\
\hline CHEMBL1573153 & 688267 & 6.05 & 5.053 & TST & \\
\hline CHEMBL1443220 & 688267 & 6.2 & 4.9874 & TRN & \\
\hline CHEMBL1396683 & 688267 & 4.25 & 5.0506 & TRN & \\
\hline CHEMBL1573556 & 688267 & 4.85 & 5.0494 & TRN & \\
\hline CHEMBL1363168 & 688267 & 4.35 & 5.1066 & TST & \\
\hline CHEMBL1307458 & 688267 & 4.75 & 5.0137 & TRN & \\
\hline CHEMBL1478322 & 688267 & 6.5 & 5.0644 & TRN & \\
\hline CHEMBL1585245 & 688267 & 6.2 & 4.9816 & TRN & \\
\hline CHEMBL1527905 & 688267 & 4.35 & 5.1034 & TRN & \\
\hline CHEMBL1502028 & 688267 & 4.3 & 4.9997 & TRN & \\
\hline CHEMBL1432481 & 688267 & 4.6 & 5.1157 & TRN & \\
\hline CHEMBL1541702 & 688267 & 4.1 & 5.0496 & TST & \\
\hline CHEMBL1448253 & 688267 & 4.0 & 5.1513 & TRN & \\
\hline CHEMBL1443800 & 688267 & 4.25 & 5.051 & TST & \\
\hline CHEMBL1592695 & 688267 & 5.0 & 5.0757 & TRN & \\
\hline CHEMBL482642 & 688267 & 5.95 & 5.0261 & TST & \\
\hline CHEMBL1305230 & 688267 & 4.6 & 5.0744 & TST & \\
\hline CHEMBL1383512 & 688267 & 5.3 & 5.0606 & TRN & \\
\hline CHEMBL1453899 & 688267 & 5.1 & 5.0062 & TRN & \\
\hline CHEMBL1517052 & 688267 & 4.45 & 5.0947 & TRN & \\
\hline CHEMBL1354983 & 688267 & 4.05 & 5.0482 & TRN & \\
\hline
\end{tabular}




\begin{tabular}{|c|c|c|c|c|}
\hline & & & upplement & al $\mathrm{T}$ \\
\hline CHEMBL1410586 & 688267 & 5.9 & 5.0441 & TRN \\
\hline CHEMBL1356912 & 688267 & 6.2 & 5.1202 & TRN \\
\hline CHEMBL1533455 & 688267 & 5.4 & 5.0321 & TRN \\
\hline CHEMBL1374324 & 688267 & 6.15 & 5.0801 & TRN \\
\hline CHEMBL1491090 & 688267 & 4.0 & 5.056 & TST \\
\hline CHEMBL1300625 & 688267 & 4.0 & 5.0435 & TST \\
\hline CHEMBL1599607 & 688267 & 6.5 & 5.0525 & TST \\
\hline CHEMBL1602344 & 688267 & 6.25 & 5.0938 & TST \\
\hline CHEMBL1355856 & 688267 & 3.95 & 5.0778 & TRN \\
\hline CHEMBL1451874 & 688267 & 4.3 & 5.0391 & TST \\
\hline CHEMBL1528096 & 688267 & 4.05 & 5.0902 & TRN \\
\hline CHEMBL1585209 & 688267 & 4.55 & 5.0037 & TST \\
\hline CHEMBL1405555 & 688267 & 3.95 & 5.0199 & TRN \\
\hline CHEMBL1339228 & 688267 & 4.35 & 5.0299 & TRN \\
\hline CHEMBL1440894 & 688267 & 4.5 & 5.1168 & TRN \\
\hline CHEMBL1482360 & 688267 & 4.05 & 5.0881 & TRN \\
\hline CHEMBL1561385 & 688267 & 4.35 & 5.0372 & TRN \\
\hline CHEMBL1376717 & 688267 & 4.1 & 5.0073 & TRN \\
\hline CHEMBL1533448 & 688267 & 5.6 & 5.1799 & TRN \\
\hline CHEMBL1390081 & 688267 & 5.6 & 5.0643 & TRN \\
\hline CHEMBL1389586 & 688267 & 5.15 & 5.1389 & TRN \\
\hline CHEMBL1542138 & 688267 & 5.85 & 5.0863 & TST \\
\hline CHEMBL1397947 & 688267 & 4.05 & 4.9915 & TRN \\
\hline CHEMBL1583048 & 688267 & 5.65 & 5.0352 & TRN \\
\hline CHEMBL1354499 & 688267 & 4.15 & 5.005 & TRN \\
\hline CHEMBL1519243 & 688267 & 6.15 & 5.0406 & TST \\
\hline CHEMBL449081 & 688267 & 4.4 & 5.0578 & TST \\
\hline CHEMBL1501492 & 688267 & 3.95 & 5.0664 & TRN \\
\hline CHEMBL1366881 & 688267 & 5.3 & 5.0248 & TRN \\
\hline CHEMBL1496375 & 688267 & 4.0 & 4.9963 & TRN \\
\hline CHEMBL1457054 & 688267 & 5.05 & 5.0433 & TRN \\
\hline CHEMBL1575912 & 688267 & 4.05 & 5.0118 & TST \\
\hline CHEMBL1472711 & 688267 & 4.0 & 5.0212 & TRN \\
\hline CHEMBL1323027 & 688267 & 6.25 & 5.0468 & TRN \\
\hline CHEMBL1398884 & 688267 & 5.3 & 5.0083 & TRN \\
\hline CHEMBL1476953 & 688267 & 6.25 & 5.0007 & TRN \\
\hline CHEMBL1594283 & 688267 & 5.1 & 5.0647 & TRN \\
\hline CHEMBL1537981 & 688267 & 4.65 & 5.0134 & TRN \\
\hline CHEMBL1319105 & 688267 & 4.0 & 5.1336 & TRN \\
\hline CHEMBL1325409 & 688267 & 6.5 & 5.0768 & TST \\
\hline CHEMBL1593691 & 688267 & 4.1 & 5.0445 & TST \\
\hline CHEMBL1589243 & 688267 & 4.5 & 5.0219 & TRN \\
\hline CHEMBL84472 & 688267 & 4.0 & 5.0448 & TST \\
\hline CHEMBL1433083 & 688267 & 5.6 & 5.0578 & TST \\
\hline CHEMBL1375173 & 688267 & 5.1 & 5.0859 & TRN \\
\hline CHEMBL1429405 & 688267 & 4.45 & 5.0992 & TRN \\
\hline CHEMBL1556696 & 688267 & 5.2 & 4.9893 & TRN \\
\hline CHEMBL1575274 & 688267 & 4.05 & 5.0336 & TRN \\
\hline
\end{tabular}




\begin{tabular}{|c|c|c|c|c|c|}
\hline \multicolumn{6}{|c|}{ Supplemental Table S2.txt } \\
\hline CHEMBL1302858 & 688267 & 5.4 & 5.0987 & TRN & \\
\hline CHEMBL1560398 & 688267 & 5.95 & 5.04 & TRN & \\
\hline CHEMBL3211047 & 688267 & 5.05 & 5.0189 & TST & \\
\hline CHEMBL1370265 & 688267 & 4.05 & 4.9854 & TST & \\
\hline CHEMBL1496760 & 688267 & 4.05 & 5.0192 & TRN & \\
\hline CHEMBL1574736 & 688267 & 4.9 & 5.0176 & TRN & \\
\hline CHEMBL1537214 & 688267 & 4.15 & 5.034 & TRN & \\
\hline CHEMBL1416541 & 688267 & 5.35 & 5.013 & TRN & \\
\hline CHEMBL1612416 & 688267 & 6.15 & 5.0151 & TRN & \\
\hline CHEMBL1590740 & 688267 & 6.2 & 5.0448 & TRN & \\
\hline CHEMBL1313141 & 688267 & 5.9 & 5.0303 & TST & \\
\hline CHEMBL1486008 & 688267 & 4.15 & 5.0425 & TRN & \\
\hline CHEMBL1539381 & 688267 & 4.5 & 5.0332 & TRN & \\
\hline CHEMBL1429904 & 688267 & 4.05 & 5.0523 & TST & \\
\hline CHEMBL1477137 & 688267 & 5.6 & 5.077 & TRN & \\
\hline CHEMBL1459085 & 688267 & 6.25 & 5.0827 & TRN & \\
\hline CHEMBL1524090 & 688267 & 6.25 & 5.005 & TRN & \\
\hline CHEMBL1387828 & 688267 & 5.0 & 5.0315 & TRN & \\
\hline CHEMBL1511480 & 688267 & 4.4 & 5.0305 & TRN & \\
\hline CHEMBL3194518 & 688267 & 5.1 & 5.0334 & TST & \\
\hline CHEMBL1440792 & 688267 & 6.2 & 5.032 & TRN & \\
\hline CHEMBL1337389 & 688267 & 5.65 & 5.1096 & TRN & \\
\hline CHEMBL1362291 & 688267 & 6.5 & 5.0393 & TST & \\
\hline CHEMBL1331697 & 688267 & 4.0 & 5.0769 & TRN & \\
\hline CHEMBL1467703 & 688267 & 4.3 & 5.0381 & TST & \\
\hline CHEMBL1417406 & 688267 & 6.5 & 5.0229 & TRN & \\
\hline CHEMBL1495492 & 688267 & 4.1 & 5.0561 & TRN & \\
\hline CHEMBL1388903 & 688267 & 3.95 & 5.0468 & TRN & \\
\hline CHEMBL1399376 & 688267 & 6.25 & 5.059 & TRN & \\
\hline CHEMBL3208307 & 688267 & 4.7 & 5.0223 & TST & \\
\hline CHEMBL1603407 & 688267 & 5.0 & 5.0772 & TST & \\
\hline CHEMBL1334842 & 688267 & 5.55 & 5.09399 & 9999999999 & TST \\
\hline CHEMBL1518201 & 688267 & 4.0 & 5.0349 & TRN & \\
\hline CHEMBL1451160 & 688267 & 4.05 & 5.1337 & TRN & \\
\hline CHEMBL1493796 & 688267 & 4.0 & 5.0916 & TRN & \\
\hline CHEMBL1516700 & 688267 & 3.95 & 5.088 & TRN & \\
\hline CHEMBL1333517 & 688267 & 5.5 & 4.9755 & TRN & \\
\hline CHEMBL1439843 & 688267 & 5.9 & 5.0087 & TRN & \\
\hline CHEMBL1403518 & 688267 & 5.5 & 5.0301 & TRN & \\
\hline CHEMBL1581219 & 688267 & 5.1 & 5.0652 & TRN & \\
\hline CHEMBL1335004 & 688267 & 4.35 & 5.0319 & TRN & \\
\hline CHEMBL1338194 & 688267 & 6.2 & 5.0907 & TST & \\
\hline CHEMBL1321286 & 688267 & 5.35 & 5.1246 & TRN & \\
\hline CHEMBL1300210 & 688267 & 4.7 & 5.0426 & TST & \\
\hline CHEMBL1339533 & 688267 & 5.0 & 5.0344 & TST & \\
\hline CHEMBL1551710 & 688267 & 4.5 & 4.9814 & TRN & \\
\hline CHEMBL3198847 & 688267 & 4.75 & 4.9901 & TRN & \\
\hline CHEMBL1445864 & 688267 & 5.3 & 5.0989 & TST & \\
\hline
\end{tabular}




\begin{tabular}{|c|c|c|c|c|c|}
\hline & & \multicolumn{4}{|c|}{ Supplemental Table s2.txt } \\
\hline CHEMBL1516671 & 688267 & 4.05 & 5.12 & TRN & \\
\hline CHEMBL1588285 & 688267 & 5.5 & 5.0344 & TST & \\
\hline CHEMBL1354346 & 688267 & 6.25 & 5.0259 & TRN & \\
\hline CHEMBL1302805 & 688267 & 5.5 & 5.0122 & TRN & \\
\hline CHEMBL1441870 & 688267 & 5.9 & 5.101 & TRN & \\
\hline CHEMBL1606242 & 688267 & 6.2 & 5.0119 & TRN & \\
\hline CHEMBL1445272 & 688267 & 4.45 & 5.0814 & TRN & \\
\hline CHEMBL1382614 & 688267 & 4.05 & 5.0274 & TST & \\
\hline CHEMBL1447178 & 688267 & 5.4 & 5.0321 & TST & \\
\hline CHEMBL1534265 & 688267 & 4.1 & 5.0803 & TST & \\
\hline CHEMBL1329477 & 688267 & 4.65 & 5.0227 & TRN & \\
\hline CHEMBL1413705 & 688267 & 6.2 & 5.0403 & TRN & \\
\hline CHEMBL1326155 & 688267 & 5.9 & 5.1052 & TRN & \\
\hline CHEMBL1446082 & 688267 & 5.15 & 5.0972 & TRN & \\
\hline CHEMBL1384084 & 688267 & 6.2 & 5.12200 & 0000000001 & TST \\
\hline CHEMBL1087339 & 688267 & 5.5 & 5.0481 & TRN & \\
\hline CHEMBL1441980 & 688267 & 4.75 & 5.0323 & TRN & \\
\hline CHEMBL 30454 & 688267 & 4.8 & 5.0235 & TRN & \\
\hline CHEMBL1451682 & 688267 & 4.05 & 5.1064 & TRN & \\
\hline CHEMBL1372262 & 688267 & 5.05 & 5.0123 & TRN & \\
\hline CHEMBL1509192 & 688267 & 4.15 & 5.1079 & TRN & \\
\hline CHEMBL1422490 & 688267 & 4.35 & 5.0678 & TRN & \\
\hline CHEMBL1439669 & 688267 & 3.95 & 5.033 & TRN & \\
\hline CHEMBL3212653 & 688267 & 6.2 & 5.0379 & TRN & \\
\hline CHEMBL1330326 & 688267 & 4.15 & 5.0065 & TST & \\
\hline CHEMBL1308640 & 688267 & 6.15 & 5.0304 & TST & \\
\hline CHEMBL1365041 & 688267 & 5.0 & 5.0155 & TST & \\
\hline CHEMBL1514114 & 688267 & 3.95 & 5.0676 & TRN & \\
\hline CHEMBL1511383 & 688267 & 4.25 & 5.0381 & TRN & \\
\hline CHEMBL1443245 & 688267 & 4.0 & 5.0898 & TRN & \\
\hline CHEMBL1408504 & 688267 & 5.4 & 5.0538 & TRN & \\
\hline CHEMBL1447592 & 688267 & 6.0 & 5.1135 & TRN & \\
\hline CHEMBL1477347 & 688267 & 4.15 & 5.0669 & TRN & \\
\hline CHEMBL1393789 & 688267 & 3.95 & 5.0121 & TRN & \\
\hline CHEMBL3196559 & 688267 & 5.75 & 5.0268 & TST & \\
\hline CHEMBL1595775 & 688267 & 4.0 & 5.0697 & TST & \\
\hline CHEMBL1601558 & 688267 & 6.2 & 5.1736 & TRN & \\
\hline CHEMBL3195852 & 688267 & 6.15 & 5.0428 & TST & \\
\hline CHEMBL1458031 & 688267 & 5.5 & 5.0436 & TRN & \\
\hline CHEMBL1308076 & 688267 & 4.0 & 5.0109 & TRN & \\
\hline CHEMBL1583051 & 688267 & 4.6 & 5.0468 & TRN & \\
\hline CHEMBL1444186 & 688267 & 4.55 & 5.0762 & TRN & \\
\hline CHEMBL1380072 & 688267 & 4.35 & 5.0327 & TRN & \\
\hline CHEMBL1309159 & 688267 & 4.05 & 5.0604 & TRN & \\
\hline CHEMBL1538435 & 688267 & 5.3 & 5.0824 & TRN & \\
\hline CHEMBL1319338 & 688267 & 5.35 & 5.1462 & TRN & \\
\hline CHEMBL1583042 & 688267 & 3.95 & 5.0525 & TRN & \\
\hline CHEMBL1445925 & 688267 & 4.35 & 5.11 & TRN & \\
\hline
\end{tabular}




\begin{tabular}{|c|c|c|c|c|c|}
\hline \multicolumn{6}{|c|}{ Supplemental Table S2.txt } \\
\hline CHEMBL1465903 & 688267 & 4.75 & 5.0226 & TST & \\
\hline CHEMBL1586658 & 688267 & 4.4 & 5.0609 & TRN & \\
\hline CHEMBL1369434 & 688267 & 4.1 & 5.1246 & TRN & \\
\hline CHEMBL1362794 & 688267 & 4.5 & 5.0681 & TRN & \\
\hline CHEMBL1482772 & 688267 & 4.05 & 5.0651 & TRN & \\
\hline CHEMBL1354881 & 688267 & 4.05 & 5.0662 & TRN & \\
\hline CHEMBL1368013 & 688267 & 4.2 & 5.0187 & TRN & \\
\hline CHEMBL1309026 & 688267 & 4.55 & 4.9972 & TST & \\
\hline CHEMBL1478597 & 688267 & 4.4 & 5.0607 & TST & \\
\hline CHEMBL1472616 & 688267 & 4.1 & 5.1083 & TRN & \\
\hline CHEMBL1299584 & 688267 & 6.0 & 5.0606 & TST & \\
\hline CHEMBL1529148 & 688267 & 6.5 & 5.0258 & TRN & \\
\hline CHEMBL1329890 & 688267 & 4.0 & 5.0364 & TST & \\
\hline CHEMBL1555710 & 688267 & 5.9 & 5.0354 & TST & \\
\hline CHEMBL3193856 & 688267 & 4.4 & 4.98300 & 00000000005 & TRN \\
\hline CHEMBL1309651 & 688267 & 4.85 & 5.0809 & TRN & \\
\hline CHEMBL1612153 & 688267 & 5.45 & 5.1337 & TRN & \\
\hline CHEMBL1556016 & 688267 & 4.65 & 5.1245 & TRN & \\
\hline CHEMBL1575952 & 688267 & 5.45 & 5.0673 & TRN & \\
\hline CHEMBL1613671 & 688267 & 6.15 & 5.098 & TRN & \\
\hline CHEMBL1569317 & 688267 & 4.35 & 5.1049 & TRN & \\
\hline CHEMBL3207382 & 688267 & 6.15 & 5.0698 & TRN & \\
\hline CHEMBL1331768 & 688267 & 4.4 & 5.04 & TST & \\
\hline CHEMBL1535525 & 688267 & 4.05 & 5.091 & TRN & \\
\hline CHEMBL1528449 & 688267 & 6.1 & 5.0941 & TRN & \\
\hline CHEMBL1610165 & 688267 & 4.55 & 5.0376 & TST & \\
\hline CHEMBL1423896 & 688267 & 5.4 & 5.0147 & TRN & \\
\hline CHEMBL1414021 & 688267 & 5.0 & 5.0718 & TRN & \\
\hline CHEMBL1377289 & 688267 & 5.9 & 4.9656 & TRN & \\
\hline CHEMBL1453013 & 688267 & 6.15 & 5.083 & TST & \\
\hline CHEMBL1500584 & 688267 & 6.2 & 5.0473 & TST & \\
\hline CHEMBL1531142 & 688267 & 4.6 & 5.0973 & TST & \\
\hline CHEMBL1557582 & 688267 & 4.35 & 5.0687 & TRN & \\
\hline CHEMBL1453274 & 688267 & 4.35 & 5.0765 & TRN & \\
\hline CHEMBL1338767 & 688267 & 5.55 & 5.06800 & 00000000005 & TRN \\
\hline CHEMBL1447185 & 688267 & 4.2 & 5.0359 & TST & \\
\hline CHEMBL1441834 & 688267 & 4.05 & 5.0625 & TST & \\
\hline CHEMBL1316393 & 688267 & 6.2 & 5.0541 & TST & \\
\hline CHEMBL1408279 & 688267 & 5.95 & 5.0884 & TRN & \\
\hline CHEMBL1317205 & 688267 & 6.2 & 5.1372 & TRN & \\
\hline CHEMBL1383587 & 688267 & 6.2 & 5.1207 & TST & \\
\hline CHEMBL1452989 & 688267 & 3.95 & 5.025 & TST & \\
\hline CHEMBL1351857 & 688267 & 5.05 & 5.0426 & TRN & \\
\hline CHEMBL1342238 & 688267 & 5.85 & 5.038 & TRN & \\
\hline CHEMBL1609001 & 688267 & 5.1 & 5.0463 & TRN & \\
\hline CHEMBL1551413 & 688267 & 3.95 & 5.0722 & TRN & \\
\hline CHEMBL1523382 & 688267 & 6.25 & 5.1398 & TRN & \\
\hline CHEMBL1385200 & 688267 & 4.75 & 5.0496 & TST & \\
\hline
\end{tabular}




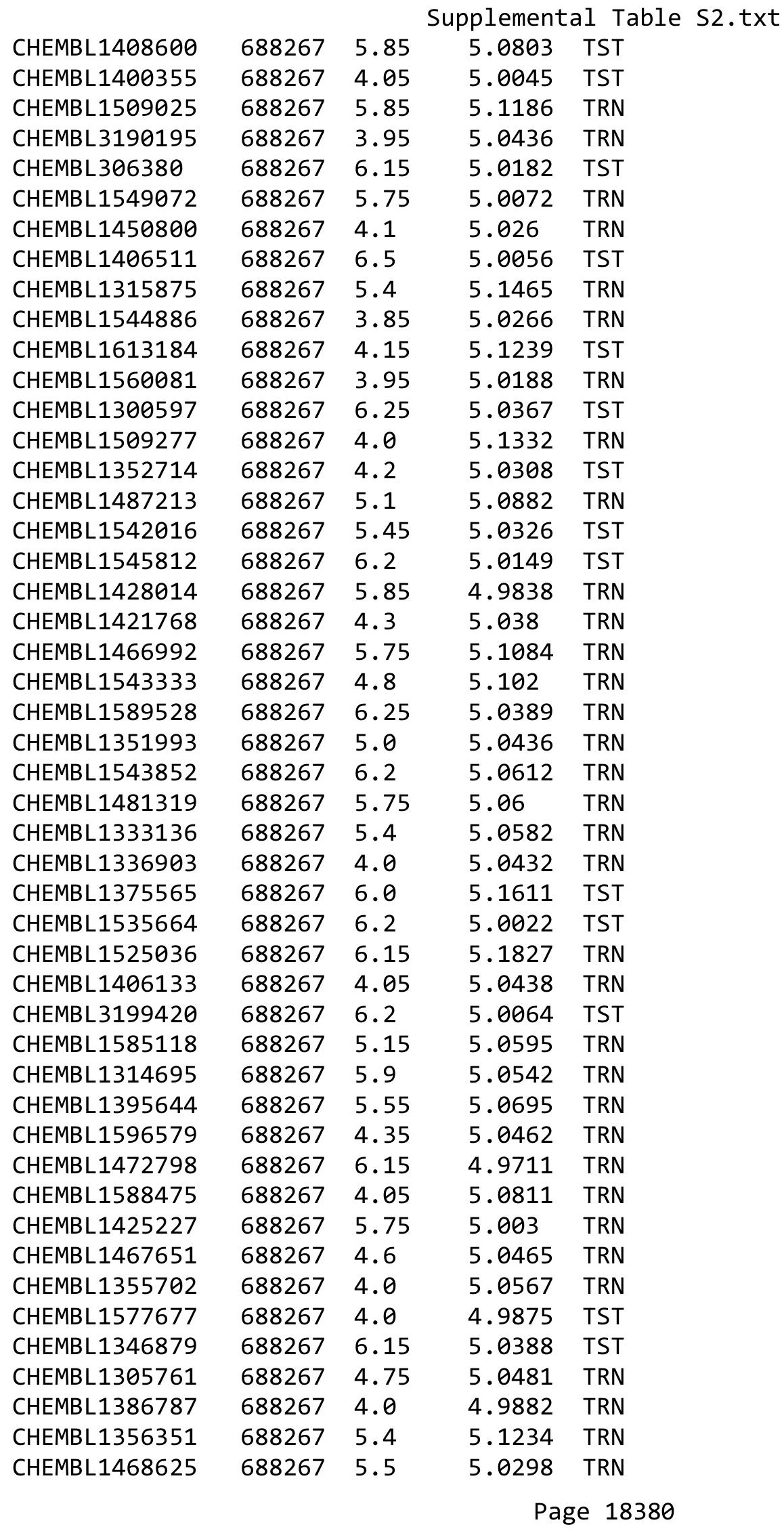




\begin{tabular}{|c|c|c|c|c|}
\hline \multicolumn{5}{|c|}{ Supplemental Table S2.txt } \\
\hline CHEMBL1573631 & 688267 & 6.2 & 5.0756 & TRN \\
\hline CHEMBL1369869 & 688267 & 5.6 & 5.117 & TRN \\
\hline CHEMBL1590210 & 688267 & 4.35 & 5.0104 & TRN \\
\hline CHEMBL1548349 & 688267 & 6.2 & 5.0877 & TRN \\
\hline CHEMBL1325725 & 688267 & 6.15 & 4.9735 & TRN \\
\hline CHEMBL1378837 & 688267 & 5.3 & 5.0368 & TST \\
\hline CHEMBL1562510 & 688267 & 5.15 & 5.0102 & TRN \\
\hline CHEMBL1537584 & 688267 & 5.95 & 5.12 & TRN \\
\hline CHEMBL1553013 & 688267 & 4.05 & 4.997 & TRN \\
\hline CHEMBL1456279 & 688267 & 4.35 & 5.0804 & TRN \\
\hline CHEMBL1603046 & 688267 & 6.0 & 5.0525 & TRN \\
\hline CHEMBL1363005 & 688267 & 4.9 & 4.9945 & TRN \\
\hline CHEMBL1396270 & 688267 & 4.0 & 5.0991 & TRN \\
\hline CHEMBL1569070 & 688267 & 5.9 & 5.0598 & TRN \\
\hline CHEMBL1407549 & 688267 & 3.95 & 5.0385 & TST \\
\hline CHEMBL1563864 & 688267 & 5.0 & 5.1277 & TST \\
\hline CHEMBL1351998 & 688267 & 4.3 & 5.1155 & TST \\
\hline CHEMBL1473080 & 688267 & 6.2 & 5.0778 & TST \\
\hline CHEMBL298036 & 688267 & 6.45 & 5.0731 & TRN \\
\hline CHEMBL1458297 & 688267 & 4.65 & 5.0716 & TRN \\
\hline CHEMBL1484048 & 688267 & 4.0 & 5.1258 & TST \\
\hline CHEMBL1565011 & 688267 & 6.2 & 5.1913 & TRN \\
\hline CHEMBL1345329 & 688267 & 4.65 & 5.0036 & TRN \\
\hline CHEMBL1975547 & 688267 & 5.3 & 5.0156 & TST \\
\hline CHEMBL1433578 & 688267 & 4.0 & 5.0482 & TST \\
\hline CHEMBL1593654 & 688267 & 6.5 & 5.0748 & TRN \\
\hline CHEMBL1355586 & 688267 & 6.25 & 5.0143 & TRN \\
\hline CHEMBL1584000 & 688267 & 6.05 & 5.0567 & TST \\
\hline CHEMBL1483406 & 688267 & 5.6 & 5.0716 & TRN \\
\hline CHEMBL1314238 & 688267 & 6.2 & 5.0073 & TRN \\
\hline CHEMBL1965444 & 688267 & 5.45 & 4.9724 & TRN \\
\hline CHEMBL1453665 & 688267 & 5.85 & 5.0484 & TRN \\
\hline CHEMBL1391448 & 688267 & 4.55 & 5.0766 & TRN \\
\hline CHEMBL1512618 & 688267 & 4.35 & 5.0312 & TRN \\
\hline CHEMBL1606833 & 688267 & 4.9 & 5.0179 & TST \\
\hline CHEMBL1563992 & 688267 & 4.95 & 5.0575 & TRN \\
\hline CHEMBL1398809 & 688267 & 4.1 & 5.0507 & TRN \\
\hline CHEMBL1332749 & 688267 & 5.85 & 5.0306 & TRN \\
\hline CHEMBL1424323 & 688267 & 4.1 & 5.0377 & TRN \\
\hline CHEMBL1444684 & 688267 & 5.45 & 5.0971 & TRN \\
\hline CHEMBL1520949 & 688267 & 5.9 & 5.0492 & TST \\
\hline CHEMBL1374362 & 688267 & 4.0 & 5.0966 & TST \\
\hline CHEMBL1320339 & 688267 & 4.55 & 5.0141 & TRN \\
\hline CHEMBL1507765 & 688267 & 4.7 & 5.0184 & TRN \\
\hline CHEMBL1522570 & 688267 & 4.05 & 5.0714 & TRN \\
\hline CHEMBL1529419 & 688267 & 3.95 & 5.0843 & TRN \\
\hline CHEMBL1447537 & 688267 & 5.15 & 5.1076 & TST \\
\hline CHEMBL1461038 & 688267 & 5.55 & 5.0195 & TST \\
\hline
\end{tabular}




\begin{tabular}{|c|c|c|c|c|c|}
\hline \multirow[b]{2}{*}{ CHEMBL1420066 } & \multirow[b]{2}{*}{688267} & \\
\hline & & 4.4 & 5.0888 & TRN & \\
\hline CHEMBL1525584 & 688267 & 5.2 & 5.0709 & TRN & \\
\hline CHEMBL1318354 & 688267 & 6.25 & 5.0965 & TRN & \\
\hline CHEMBL1581189 & 688267 & 5.9 & 5.1337 & TRN & \\
\hline CHEMBL1451180 & 688267 & 5.55 & 5.126 & TRN & \\
\hline CHEMBL1420624 & 688267 & 4.15 & 5.0753 & TRN & \\
\hline CHEMBL1383150 & 688267 & 4.05 & 5.1384 & TRN & \\
\hline CHEMBL1551901 & 688267 & 6.1 & \multicolumn{2}{|c|}{5.0889999999999995} & TRN \\
\hline CHEMBL1402343 & 688267 & 6.25 & 5.0544 & TRN & \\
\hline CHEMBL1347827 & 688267 & 4.6 & 5.1104 & TRN & \\
\hline CHEMBL1317954 & 688267 & 6.25 & 5.0415 & TRN & \\
\hline CHEMBL1470258 & 688267 & 4.05 & 5.0595 & TRN & \\
\hline CHEMBL1469463 & 688267 & 4.4 & 5.0179 & TRN & \\
\hline CHEMBL1546991 & 688267 & 5.6 & 5.0881 & TST & \\
\hline CHEMBL1496950 & 688267 & 4.05 & 5.0144 & TST & \\
\hline CHEMBL3209015 & 688267 & 4.45 & 5.053 & TRN & \\
\hline CHEMBL1568880 & 688267 & 5.4 & 5.1288 & TRN & \\
\hline CHEMBL1322459 & 688267 & 4.5 & 5.0808 & TRN & \\
\hline CHEMBL1601938 & 688267 & 4.0 & 5.0617 & TST & \\
\hline CHEMBL1529183 & 688267 & 5.85 & 5.0803 & TST & \\
\hline CHEMBL1422816 & 688267 & 4.25 & 4.9959 & TRN & \\
\hline CHEMBL1576407 & 688267 & 5.6 & \multicolumn{2}{|c|}{5.0489999999999995} & TRN \\
\hline CHEMBL3211806 & 688267 & 5.55 & 5.0784 & TRN & \\
\hline CHEMBL1501979 & 688267 & 4.8 & 5.0815 & TRN & \\
\hline CHEMBL1607445 & 688267 & 6.05 & 5.025 & TRN & \\
\hline CHEMBL1390342 & 688267 & 4.85 & 5.0873 & TRN & \\
\hline CHEMBL1365524 & 688267 & 6.45 & 5.0594 & TRN & \\
\hline CHEMBL1443184 & 688267 & 5.3 & 5.0739 & TRN & \\
\hline CHEMBL1492559 & 688267 & 4.4 & 5.0842 & TRN & \\
\hline CHEMBL1491845 & 688267 & 6.15 & 5.0754 & TST & \\
\hline CHEMBL1563806 & 688267 & 5.3 & 5.1881 & TRN & \\
\hline CHEMBL1517910 & 688267 & 4.0 & 5.0107 & TRN & \\
\hline CHEMBL1474388 & 688267 & 3.95 & 5.1038 & TRN & \\
\hline CHEMBL1467053 & 688267 & 5.6 & 5.0944 & TRN & \\
\hline CHEMBL3195550 & 688267 & 5.9 & 5.0417 & TST & \\
\hline CHEMBL1374195 & 688267 & 4.8 & 5.1032 & TRN & \\
\hline CHEMBL1547396 & 688267 & 4.3 & 5.1153 & TRN & \\
\hline CHEMBL1607235 & 688267 & 5.05 & 5.0471 & TST & \\
\hline CHEMBL1346097 & 688267 & 6.25 & 5.1174 & TRN & \\
\hline CHEMBL1395156 & 688267 & 5.1 & 5.0786 & TRN & \\
\hline CHEMBL1316232 & 688267 & 5.6 & 5.0644 & TRN & \\
\hline CHEMBL1308436 & 688267 & 4.0 & 5.0416 & TRN & \\
\hline CHEMBL1500081 & 688267 & 5.1 & 5.0199 & TST & \\
\hline CHEMBL1492703 & 688267 & 4.35 & 5.0744 & TST & \\
\hline CHEMBL1517725 & 688267 & 4.0 & 5.0569 & TRN & \\
\hline CHEMBL1586511 & 688267 & 4.95 & 5.0063 & TRN & \\
\hline CHEMBL1424307 & 688267 & 4.95 & 5.0596 & TRN & \\
\hline \multirow[t]{2}{*}{ CHEMBL1593954 } & 688267 & 5.9 & 5.0536 & TRN & \\
\hline & & \multicolumn{4}{|c|}{ Page 18382} \\
\hline
\end{tabular}




\begin{tabular}{|c|c|c|c|c|}
\hline & & & pplement & al $\mathrm{Ta}$ \\
\hline CHEMBL1360420 & 688267 & 4.35 & 5.0742 & TRN \\
\hline CHEMBL1388452 & 688267 & 6.25 & 5.0756 & TST \\
\hline CHEMBL1514995 & 688267 & 3.95 & 5.0863 & TRN \\
\hline CHEMBL1499779 & 688267 & 4.25 & 5.0653 & TRN \\
\hline CHEMBL1596423 & 688267 & 5.35 & 5.0634 & TRN \\
\hline CHEMBL1592890 & 688267 & 5.95 & 5.0635 & TRN \\
\hline CHEMBL1360276 & 688267 & 5.45 & 5.0583 & TRN \\
\hline CHEMBL1420579 & 688267 & 4.35 & 5.0447 & TST \\
\hline CHEMBL1323044 & 688267 & 4.35 & 5.1355 & TRN \\
\hline CHEMBL1414465 & 688267 & 5.9 & 4.9756 & TST \\
\hline CHEMBL1483623 & 688267 & 6.2 & 5.0618 & TRN \\
\hline CHEMBL1413753 & 688267 & 4.0 & 5.1021 & TRN \\
\hline CHEMBL1276244 & 688267 & 3.95 & 5.0525 & TST \\
\hline CHEMBL1442695 & 688267 & 5.5 & 5.0425 & TRN \\
\hline CHEMBL1386847 & 688267 & 5.65 & 5.1667 & TRN \\
\hline CHEMBL1409439 & 688267 & 4.25 & 5.0545 & TRN \\
\hline CHEMBL1612098 & 688267 & 5.5 & 5.1084 & TRN \\
\hline CHEMBL1609467 & 688267 & 3.9 & 5.1354 & TST \\
\hline CHEMBL1513688 & 688267 & 6.45 & 5.0296 & TRN \\
\hline CHEMBL1606815 & 688267 & 5.4 & 5.0663 & TST \\
\hline CHEMBL1343503 & 688267 & 4.6 & 4.9988 & TRN \\
\hline CHEMBL1420497 & 688267 & 6.15 & 5.052 & TST \\
\hline CHEMBL1560946 & 688267 & 3.95 & 5.0875 & TRN \\
\hline CHEMBL1558179 & 688267 & 4.75 & 5.0684 & TRN \\
\hline CHEMBL1488009 & 688267 & 6.5 & 5.0535 & TST \\
\hline CHEMBL1520438 & 688267 & 4.05 & 5.0368 & TST \\
\hline CHEMBL1433014 & 688267 & 4.0 & 5.052 & TST \\
\hline CHEMBL1510798 & 688267 & 4.2 & 5.0631 & TRN \\
\hline CHEMBL1591650 & 688267 & 5.5 & 5.0067 & TRN \\
\hline CHEMBL1543296 & 688267 & 4.55 & 5.1186 & TST \\
\hline CHEMBL1337486 & 688267 & 4.25 & 5.0326 & TRN \\
\hline CHEMBL1541447 & 688267 & 5.05 & 5.055 & TRN \\
\hline CHEMBL1585843 & 688267 & 5.95 & 5.0603 & TRN \\
\hline CHEMBL1597212 & 688267 & 5.65 & 5.0845 & TRN \\
\hline CHEMBL1414243 & 688267 & 4.05 & 5.0962 & TRN \\
\hline CHEMBL1597583 & 688267 & 6.2 & 5.0951 & TST \\
\hline CHEMBL3199187 & 688267 & 4.35 & 4.9851 & TRN \\
\hline CHEMBL1352762 & 688267 & 5.55 & 5.0309 & TRN \\
\hline CHEMBL1562597 & 688267 & 5.5 & 5.0242 & TRN \\
\hline CHEMBL1590774 & 688267 & 5.1 & 5.0226 & TRN \\
\hline CHEMBL3190100 & 688267 & 4.0 & 5.0249 & TST \\
\hline CHEMBL1341029 & 688267 & 4.4 & 5.0976 & TRN \\
\hline CHEMBL1505896 & 688267 & 4.35 & 5.0517 & TRN \\
\hline CHEMBL1453647 & 688267 & 5.55 & 5.0472 & TST \\
\hline CHEMBL1564123 & 688267 & 4.4 & 5.0523 & TRN \\
\hline CHEMBL1382935 & 688267 & 5.0 & 5.0826 & TRN \\
\hline CHEMBL1590313 & 688267 & 5.5 & 5.0181 & TRN \\
\hline CHEMBL1608773 & 688267 & 4.05 & 5.0297 & TRN \\
\hline
\end{tabular}




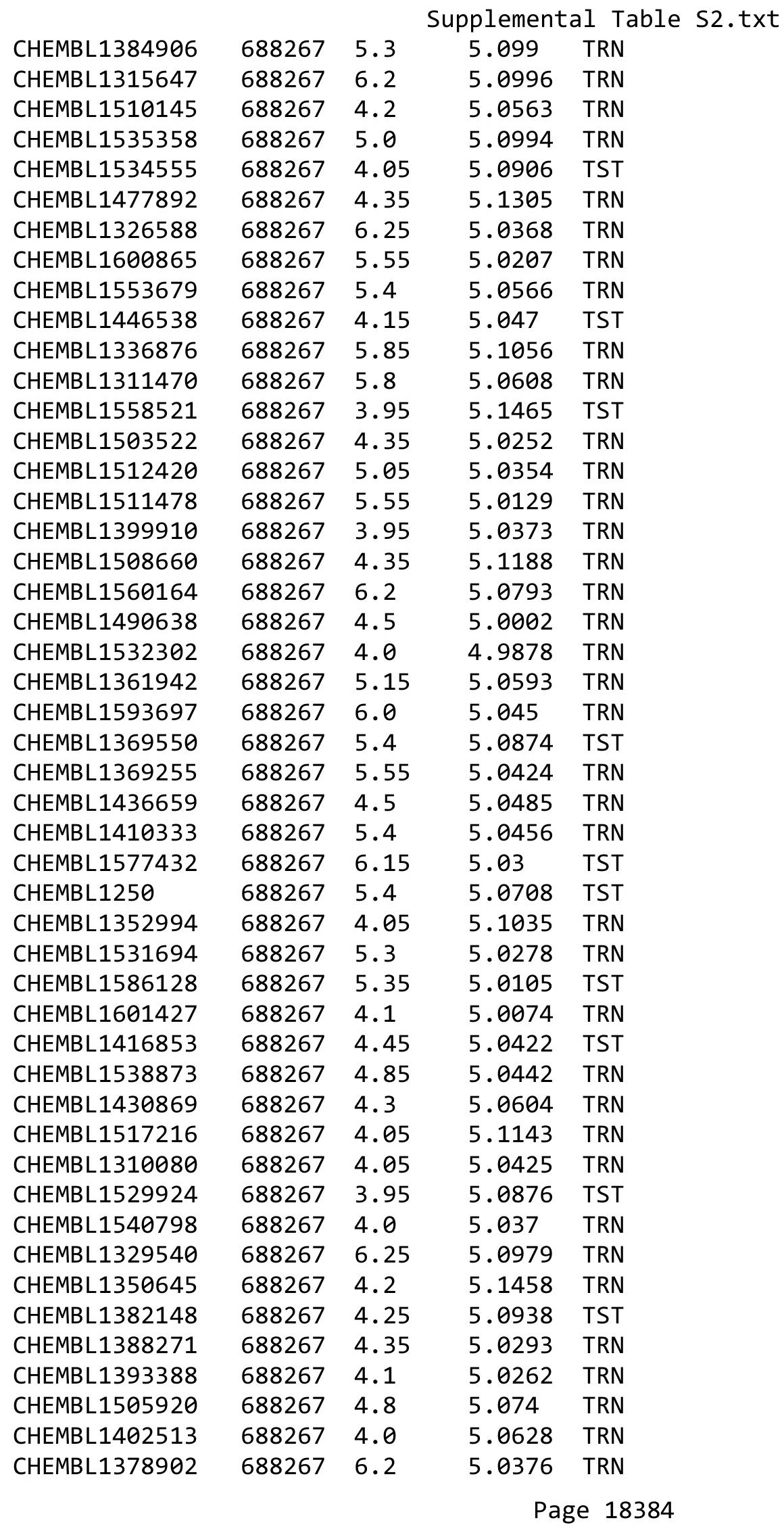




\begin{tabular}{|c|c|c|c|c|c|}
\hline & & \multicolumn{4}{|c|}{ Supplemental Table S2.txt } \\
\hline CHEMBL3194764 & 688267 & 5.25 & 5.0242 & TRN & \\
\hline CHEMBL1471381 & 688267 & 4.25 & 5.053 & TST & \\
\hline CHEMBL1613292 & 688267 & 6.2 & 5.12200 & 0000000001 & TRN \\
\hline CHEMBL1405932 & 688267 & 4.3 & 5.0337 & TST & \\
\hline CHEMBL1320392 & 688267 & 6.2 & 5.0367 & TRN & \\
\hline CHEMBL1563274 & 688267 & 4.35 & 5.0429 & TRN & \\
\hline CHEMBL1530364 & 688267 & 3.95 & 5.118 & TRN & \\
\hline CHEMBL1459397 & 688267 & 5.8 & 5.0648 & TRN & \\
\hline CHEMBL1397280 & 688267 & 5.3 & 5.0172 & TRN & \\
\hline CHEMBL1337347 & 688267 & 6.2 & 5.0157 & TRN & \\
\hline CHEMBL1448296 & 688267 & 5.45 & 4.9856 & TRN & \\
\hline CHEMBL1348179 & 688267 & 5.75 & 4.9867 & TST & \\
\hline CHEMBL1428613 & 688267 & 4.9 & 5.0416 & TRN & \\
\hline CHEMBL1547890 & 688267 & 5.05 & 5.0266 & TRN & \\
\hline CHEMBL1307999 & 688267 & 4.5 & 5.0592 & TRN & \\
\hline CHEMBL3197976 & 688267 & 5.4 & 5.044 & TST & \\
\hline CHEMBL1569319 & 688267 & 5.25 & 5.1255 & TRN & \\
\hline CHEMBL1586530 & 688267 & 6.2 & 5.0185 & TRN & \\
\hline CHEMBL1596642 & 688267 & 4.95 & 5.1123 & TRN & \\
\hline CHEMBL1366939 & 688267 & 5.15 & 5.051 & TRN & \\
\hline CHEMBL1473386 & 688267 & 5.2 & 5.1104 & TRN & \\
\hline CHEMBL1463424 & 688267 & 4.4 & 5.0605 & TRN & \\
\hline CHEMBL1544238 & 688267 & 6.2 & 5.1218 & TRN & \\
\hline CHEMBL1492953 & 688267 & 5.05 & 5.0839 & TST & \\
\hline CHEMBL1389204 & 688267 & 6.15 & 4.9288 & TRN & \\
\hline CHEMBL1555892 & 688267 & 4.6 & 5.0724 & TRN & \\
\hline CHEMBL1316419 & 688267 & 4.75 & 5.0969 & TRN & \\
\hline CHEMBL1305987 & 688267 & 5.9 & 4.9893 & TST & \\
\hline CHEMBL1472464 & 688267 & 4.3 & 5.0692 & TST & \\
\hline CHEMBL3197902 & 688267 & 4.05 & 5.0377 & TRN & \\
\hline CHEMBL1561202 & 688267 & 6.2 & 5.1052 & TST & \\
\hline CHEMBL1562179 & 688267 & 5.0 & 5.1167 & TRN & \\
\hline CHEMBL1321780 & 688267 & 6.2 & 5.1 & TRN & \\
\hline CHEMBL1433768 & 688267 & 4.15 & 5.0366 & TRN & \\
\hline CHEMBL3194017 & 688267 & 3.95 & 5.0149 & TST & \\
\hline CHEMBL227726 & 688267 & 5.5 & 5.0042 & TST & \\
\hline CHEMBL1435613 & 688267 & 6.2 & 5.05399 & 9999999999 & TST \\
\hline CHEMBL1367849 & 688267 & 6.2 & 5.0334 & TRN & \\
\hline CHEMBL1547732 & 688267 & 4.35 & 5.0393 & TRN & \\
\hline CHEMBL1392881 & 688267 & 4.55 & 5.1046 & TRN & \\
\hline CHEMBL1512267 & 688267 & 4.4 & 5.067 & TRN & \\
\hline CHEMBL1537264 & 688267 & 4.35 & 5.0583 & TRN & \\
\hline CHEMBL1551386 & 688267 & 5.55 & 5.0727 & TRN & \\
\hline CHEMBL1378619 & 688267 & 6.05 & 5.0796 & TRN & \\
\hline CHEMBL1300426 & 688267 & 4.65 & 5.0727 & TRN & \\
\hline CHEMBL1511954 & 688267 & 5.5 & 5.1072 & TRN & \\
\hline CHEMBL1571920 & 688267 & 4.3 & 5.0169 & TRN & \\
\hline CHEMBL1553903 & 688267 & 4.05 & 5.0392 & TST & \\
\hline
\end{tabular}




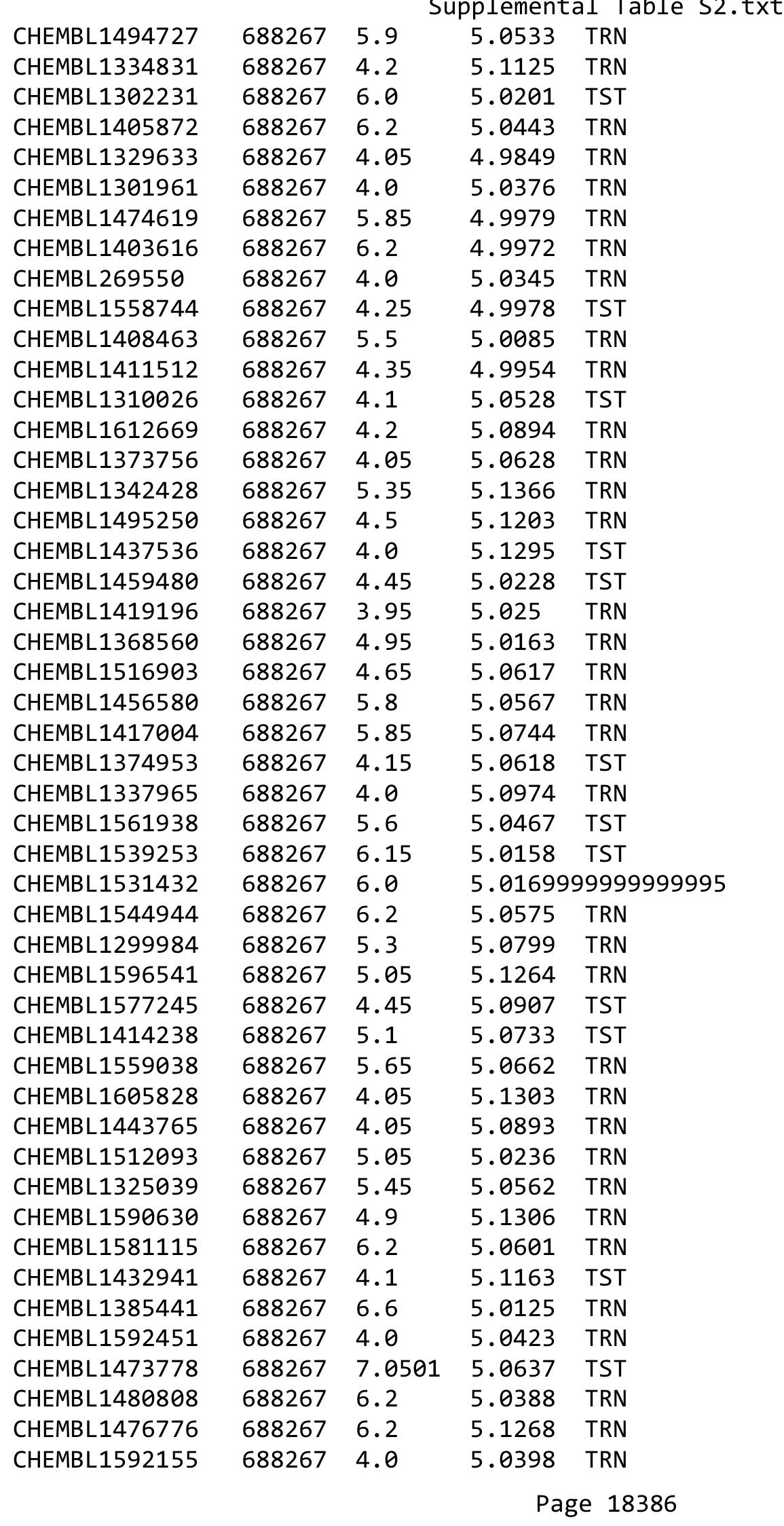




\begin{tabular}{|c|c|c|c|c|c|}
\hline \multicolumn{6}{|c|}{ Supplemental Table S2.txt } \\
\hline CHEMBL1483664 & 688267 & 6.45 & 5.0933 & TST & \\
\hline CHEMBL1392617 & 688267 & 4.55 & 5.0747 & TRN & \\
\hline CHEMBL1309082 & 688267 & 6.2 & 5.0449 & TRN & \\
\hline CHEMBL1483641 & 688267 & 5.6 & 5.1742 & TRN & \\
\hline CHEMBL1425170 & 688267 & 6.2 & 5.0728 & TRN & \\
\hline CHEMBL1517853 & 688267 & 6.2 & 5.0517 & TRN & \\
\hline CHEMBL1542627 & 688267 & 4.35 & 5.0186 & TRN & \\
\hline CHEMBL1368623 & 688267 & 5.35 & 5.0486 & TST & \\
\hline CHEMBL1496299 & 688267 & 6.2 & 5.0341 & TST & \\
\hline CHEMBL1558940 & 688267 & 3.95 & 5.1023 & TRN & \\
\hline CHEMBL1332072 & 688267 & 6.2 & 5.092 & TRN & \\
\hline CHEMBL3191250 & 688267 & 4.45 & 5.0394 & TST & \\
\hline CHEMBL1419731 & 688267 & 6.15 & 5.1238 & TST & \\
\hline CHEMBL1334387 & 688267 & 4.0 & 5.0776 & TRN & \\
\hline CHEMBL1594176 & 688267 & 4.6 & 4.9992 & TST & \\
\hline CHEMBL1342186 & 688267 & 5.55 & 5.0459 & TRN & \\
\hline CHEMBL1606265 & 688267 & 5.6 & 5.1107 & TRN & \\
\hline CHEMBL1590050 & 688267 & 6.2 & 5.0542 & TST & \\
\hline CHEMBL1602594 & 688267 & 4.05 & 5.1125 & TRN & \\
\hline CHEMBL1554378 & 688267 & 3.95 & 5.0337 & TRN & \\
\hline CHEMBL1394677 & 688267 & 4.05 & 5.0374 & TRN & \\
\hline CHEMBL1447850 & 688267 & 4.0 & 5.0491 & TST & \\
\hline CHEMBL1344015 & 688267 & 3.95 & 5.0429 & TRN & \\
\hline CHEMBL1393207 & 688267 & 4.65 & 5.05699 & 99999999995 & TRN \\
\hline CHEMBL1591972 & 688267 & 3.95 & 5.0614 & TRN & \\
\hline CHEMBL3212321 & 688267 & 6.0 & 4.9788 & TRN & \\
\hline CHEMBL1482470 & 688267 & 6.2 & 5.0235 & TRN & \\
\hline CHEMBL1503110 & 688267 & 4.55 & 4.9983 & TRN & \\
\hline CHEMBL1536262 & 688267 & 3.95 & 5.0355 & TRN & \\
\hline CHEMBL1358734 & 688267 & 5.55 & 4.9884 & TRN & \\
\hline CHEMBL1464663 & 688267 & 4.0 & 5.0297 & TRN & \\
\hline CHEMBL1605201 & 688267 & 4.1 & 5.0736 & TST & \\
\hline CHEMBL1402269 & 688267 & 5.85 & 5.1062 & TRN & \\
\hline CHEMBL1608411 & 688267 & 4.65 & 5.0211 & TRN & \\
\hline CHEMBL1493647 & 688267 & 6.15 & 5.0887 & TRN & \\
\hline CHEMBL1604234 & 688267 & 4.35 & 5.12700 & 0000000001 & TRN \\
\hline CHEMBL1583196 & 688267 & 4.0 & 5.1204 & TST & \\
\hline CHEMBL1473411 & 688267 & 3.95 & 5.0051 & TRN & \\
\hline CHEMBL1436812 & 688267 & 6.2 & 5.0927 & TRN & \\
\hline CHEMBL1529236 & 688267 & 4.3 & 5.0085 & TST & \\
\hline CHEMBL1456162 & 688267 & 3.95 & 5.0152 & TRN & \\
\hline CHEMBL1609750 & 688267 & 5.3 & 5.1132 & TRN & \\
\hline CHEMBL1479118 & 688267 & 4.2 & 5.0629 & TRN & \\
\hline CHEMBL1354783 & 688267 & 5.75 & 5.0807 & TRN & \\
\hline CHEMBL1405968 & 688267 & 5.8 & 5.0096 & TRN & \\
\hline CHEMBL1347956 & 688267 & 5.35 & 5.0393 & TST & \\
\hline CHEMBL1379170 & 688267 & 5.45 & 4.9916 & TRN & \\
\hline CHEMBL1412957 & 688267 & 5.5 & 5.0281 & TRN & \\
\hline
\end{tabular}




\begin{tabular}{|c|c|c|c|c|c|}
\hline & & \multicolumn{4}{|c|}{ Supplemental Table s2.txt } \\
\hline CHEMBL3199472 & 688267 & 6.25 & 5.0367 & TST & \\
\hline CHEMBL1541342 & 688267 & 5.35 & 5.0738 & TRN & \\
\hline CHEMBL1600185 & 688267 & 6.2 & 5.0448 & TRN & \\
\hline CHEMBL1376886 & 688267 & 5.55 & 5.1191 & TRN & \\
\hline CHEMBL1398003 & 688267 & 5.05 & 5.0329 & TRN & \\
\hline CHEMBL1443937 & 688267 & 4.7 & 5.0936 & TRN & \\
\hline CHEMBL1552358 & 688267 & 5.9 & 5.0061 & TRN & \\
\hline CHEMBL1383517 & 688267 & 4.45 & 5.0543 & TRN & \\
\hline CHEMBL1418988 & 688267 & 4.35 & 5.0528 & TRN & \\
\hline CHEMBL1606396 & 688267 & 4.0 & 5.0647 & TST & \\
\hline CHEMBL1390115 & 688267 & 6.45 & 5.1114 & TST & \\
\hline CHEMBL1512322 & 688267 & 4.55 & 5.1082 & TRN & \\
\hline CHEMBL1503935 & 688267 & 4.0 & 5.0768 & TST & \\
\hline CHEMBL1473070 & 688267 & 4.25 & 5.0983 & TRN & \\
\hline CHEMBL1472997 & 688267 & 5.0 & 5.0562 & TRN & \\
\hline CHEMBL1374580 & 688267 & 4.05 & 5.0213 & TRN & \\
\hline CHEMBL1408390 & 688267 & 4.65 & 5.0423 & TRN & \\
\hline CHEMBL3213736 & 688267 & 5.55 & 5.0365 & TST & \\
\hline CHEMBL1554125 & 688267 & 6.2 & 5.048 & TRN & \\
\hline CHEMBL1322062 & 688267 & 4.3 & 5.0699 & TRN & \\
\hline CHEMBL1547255 & 688267 & 4.75 & 5.0462 & TRN & \\
\hline CHEMBL1553042 & 688267 & 4.0 & 5.0119 & TRN & \\
\hline CHEMBL1372387 & 688267 & 4.55 & 5.0296 & TST & \\
\hline CHEMBL1436187 & 688267 & 5.1 & 5.0269 & TST & \\
\hline CHEMBL1523082 & 688267 & 4.5 & 5.0249 & TRN & \\
\hline CHEMBL1356056 & 688267 & 4.6 & 5.0245 & TRN & \\
\hline CHEMBL1459378 & 688267 & 4.6 & 5.0494 & TRN & \\
\hline CHEMBL1566730 & 688267 & 4.1 & 5.0738 & TST & \\
\hline CHEMBL1314876 & 688267 & 6.25 & 5.0373 & TRN & \\
\hline CHEMBL1578981 & 688267 & 5.45 & 5.07600 & 00000000005 & TST \\
\hline CHEMBL1460243 & 688267 & 5.55 & 5.1053 & TRN & \\
\hline CHEMBL1431030 & 688267 & 6.1 & 5.1079 & TRN & \\
\hline CHEMBL1456902 & 688267 & 4.8 & 5.0157 & TRN & \\
\hline CHEMBL1585480 & 688267 & 5.8 & 5.0229 & TST & \\
\hline CHEMBL1328655 & 688267 & 4.25 & 5.0513 & TST & \\
\hline CHEMBL1357901 & 688267 & 5.2 & 5.0439 & TRN & \\
\hline CHEMBL1568574 & 688267 & 4.35 & 5.078 & TST & \\
\hline CHEMBL1590355 & 688267 & 4.25 & 5.1311 & TST & \\
\hline CHEMBL1476949 & 688267 & 5.3 & 5.0322 & TRN & \\
\hline CHEMBL1310403 & 688267 & 4.0 & 5.0421 & TST & \\
\hline CHEMBL1470807 & 688267 & 4.45 & 5.0663 & TRN & \\
\hline CHEMBL1442535 & 688267 & 6.5 & 5.0181 & TST & \\
\hline CHEMBL1482348 & 688267 & 5.7 & 5.0489 & TRN & \\
\hline CHEMBL1383782 & 688267 & 4.25 & 5.0647 & TRN & \\
\hline CHEMBL1509218 & 688267 & 5.9 & 5.0556 & TRN & \\
\hline CHEMBL1486598 & 688267 & 5.85 & 5.0318 & TRN & \\
\hline CHEMBL1583961 & 688267 & 6.15 & 5.0321 & TRN & \\
\hline CHEMBL1343767 & 688267 & 5.95 & 5.0586 & TRN & \\
\hline
\end{tabular}




\begin{tabular}{|c|c|c|c|c|c|}
\hline \\
\hline CHEMBL1516381 & 688267 & 4.3 & 5.0149 & TST & \\
\hline CHEMBL1584888 & 688267 & 5.2 & 5.0861 & TRN & \\
\hline CHEMBL1597270 & 688267 & 6.45 & 5.1177 & TST & \\
\hline CHEMBL1576433 & 688267 & 4.0 & 5.0598 & TST & \\
\hline CHEMBL1338491 & 688267 & 5.5 & 5.0966 & TRN & \\
\hline CHEMBL1339302 & 688267 & 6.2 & 5.0526 & TST & \\
\hline CHEMBL1521236 & 688267 & 6.2 & 5.0134 & TRN & \\
\hline CHEMBL1541257 & 688267 & 6.2 & 5.0802 & TST & \\
\hline CHEMBL1567543 & 688267 & 5.8 & 5.0298 & TRN & \\
\hline CHEMBL1319168 & 688267 & 6.0 & 5.0626 & TST & \\
\hline CHEMBL2374069 & 688267 & 6.45 & 5.0449 & TRN & \\
\hline CHEMBL1441125 & 688267 & 5.05 & 5.066 & TRN & \\
\hline CHEMBL1584958 & 688267 & 4.0 & 4.994 & TRN & \\
\hline CHEMBL1562157 & 688267 & 4.4 & 5.0097 & TST & \\
\hline CHEMBL1378241 & 688267 & 4.1 & 5.0615 & TRN & \\
\hline CHEMBL1306400 & 688267 & 5.95 & 5.0405 & TRN & \\
\hline CHEMBL1437195 & 688267 & 6.2 & 5.0544 & TRN & \\
\hline CHEMBL1583500 & 688267 & 5.0 & 5.1002 & TST & \\
\hline CHEMBL1601598 & 688267 & 4.0 & 5.0387 & TRN & \\
\hline CHEMBL1610477 & 688267 & 5.1 & 5.13299 & 9999999999 & TRN \\
\hline CHEMBL1603290 & 688267 & 6.2 & 5.1003 & TRN & \\
\hline CHEMBL 261120 & 688267 & 4.8 & 5.0797 & TST & \\
\hline CHEMBL1391162 & 688267 & 5.5 & 4.9897 & TRN & \\
\hline CHEMBL1502100 & 688267 & 4.05 & 5.0694 & TRN & \\
\hline CHEMBL1299356 & 688267 & 4.4 & 5.0455 & TST & \\
\hline CHEMBL1388469 & 688267 & 5.45 & 5.0712 & TRN & \\
\hline CHEMBL1569207 & 688267 & 6.15 & 5.1219 & TST & \\
\hline CHEMBL1495195 & 688267 & 6.15 & 4.9775 & TRN & \\
\hline CHEMBL1478746 & 688267 & 5.4 & 5.0726 & TST & \\
\hline CHEMBL1495543 & 688267 & 5.5 & 5.0267 & TRN & \\
\hline CHEMBL1398061 & 688267 & 4.0 & 5.0077 & TST & \\
\hline CHEMBL1417566 & 688267 & 6.05 & 5.1084 & TRN & \\
\hline CHEMBL1556934 & 688267 & 6.2 & 5.1445 & TRN & \\
\hline CHEMBL1345466 & 688267 & 6.2 & 5.0472 & TST & \\
\hline CHEMBL1403429 & 688267 & 5.85 & 5.0317 & TST & \\
\hline CHEMBL1338637 & 688267 & 5.35 & 5.0694 & TRN & \\
\hline CHEMBL1558675 & 688267 & 4.0 & 5.0686 & TRN & \\
\hline CHEMBL1567093 & 688267 & 5.5 & 5.0147 & TRN & \\
\hline CHEMBL1521795 & 688267 & 5.85 & 4.9868 & TRN & \\
\hline CHEMBL1317693 & 688267 & 6.25 & 5.0739 & TRN & \\
\hline CHEMBL1476372 & 688267 & 4.35 & 5.0955 & TRN & \\
\hline CHEMBL1506971 & 688267 & 4.4 & 5.0416 & TST & \\
\hline CHEMBL1518144 & 688267 & 6.2 & 5.0861 & TRN & \\
\hline CHEMBL1500798 & 688267 & 3.95 & 5.0388 & TRN & \\
\hline CHEMBL1374108 & 688267 & 4.25 & 5.0509 & TRN & \\
\hline CHEMBL1481237 & 688267 & 5.75 & 5.0607 & TRN & \\
\hline CHEMBL1472914 & 688267 & 6.15 & 5.0484 & TRN & \\
\hline CHEMBL1330847 & 688267 & 6.2 & 5.0995 & TRN & \\
\hline
\end{tabular}




\begin{tabular}{|c|c|c|c|c|c|}
\hline \multicolumn{6}{|c|}{ Supplemental Table S2.txt } \\
\hline CHEMBL1535111 & 688267 & 4.4 & 5.0465 & TST & \\
\hline CHEMBL1364751 & 688267 & 4.0 & 5.0551 & TRN & \\
\hline CHEMBL1340073 & 688267 & 5.05 & 5.0114 & TRN & \\
\hline CHEMBL1571954 & 688267 & 4.9 & 5.0375 & TRN & \\
\hline CHEMBL1529146 & 688267 & 5.1 & 4.9971 & TST & \\
\hline CHEMBL1588115 & 688267 & 5.75 & 5.0626 & TRN & \\
\hline CHEMBL1329590 & 688267 & 4.8 & 5.0594 & TRN & \\
\hline CHEMBL1396969 & 688267 & 4.05 & 5.0037 & TRN & \\
\hline CHEMBL1455148 & 688267 & 6.15 & 5.0515 & TST & \\
\hline CHEMBL1559971 & 688267 & 5.8 & 5.0847 & TRN & \\
\hline CHEMBL1976236 & 688267 & 4.1 & 5.0059 & TST & \\
\hline CHEMBL 3211807 & 688267 & 5.2 & 5.1002 & TST & \\
\hline CHEMBL1332479 & 688267 & 6.15 & 5.1434 & TRN & \\
\hline CHEMBL1321254 & 688267 & 6.2 & 5.0561 & TRN & \\
\hline CHEMBL1487704 & 688267 & 6.2 & 5.0491 & TST & \\
\hline CHEMBL1596415 & 688267 & 6.0 & 5.0215 & TRN & \\
\hline CHEMBL1461952 & 688267 & 5.75 & 5.0233 & TRN & \\
\hline CHEMBL3194613 & 688267 & 5.4 & 4.9972 & TRN & \\
\hline CHEMBL1452578 & 688267 & 4.4 & 5.0439 & TST & \\
\hline CHEMBL3211532 & 688267 & 4.05 & 5.0886 & TST & \\
\hline CHEMBL1416193 & 688267 & 6.2 & 5.0616 & TRN & \\
\hline CHEMBL1542211 & 688267 & 4.1 & 5.0434 & TRN & \\
\hline CHEMBL1493735 & 688267 & 6.1 & 5.1371 & TRN & \\
\hline CHEMBL1087003 & 688267 & 4.1 & 5.0199 & TRN & \\
\hline CHEMBL1386200 & 688267 & 4.95 & 5.0276 & TST & \\
\hline CHEMBL1333978 & 688267 & 5.2 & 5.0294 & TRN & \\
\hline CHEMBL1353200 & 688267 & 6.25 & 5.0147 & TST & \\
\hline CHEMBL1088762 & 688267 & 6.5 & 5.1213 & TRN & \\
\hline CHEMBL1599343 & 688267 & 4.7 & 5.0281 & TRN & \\
\hline CHEMBL1391741 & 688267 & 7.3002 & 5.0482 & TRN & \\
\hline CHEMBL1452793 & 688267 & 5.4 & 5.0333 & TRN & \\
\hline CHEMBL1382046 & 688267 & 4.55 & 5.1003 & TRN & \\
\hline CHEMBL1515600 & 688267 & 4.0 & 5.0139 & TRN & \\
\hline CHEMBL1551829 & 688267 & 4.25 & 5.0831 & TRN & \\
\hline CHEMBL1495951 & 688267 & 3.95 & 5.0106 & TRN & \\
\hline CHEMBL1577263 & 688267 & 5.7 & 4.974 & TRN & \\
\hline CHEMBL1439351 & 688267 & 5.05 & 5.0537 & TRN & \\
\hline CHEMBL1531940 & 688267 & 4.05 & 5.0956 & TRN & \\
\hline CHEMBL1354708 & 688267 & 6.6 & 5.0363 & TRN & \\
\hline CHEMBL1347387 & 688267 & 4.25 & 5.0786 & TRN & \\
\hline CHEMBL1584486 & 688267 & 4.1 & 5.0545 & TRN & \\
\hline CHEMBL1608219 & 688267 & 4.7 & 5.0801 & TRN & \\
\hline CHEMBL1415425 & 688267 & 4.5 & 5.0023 & TRN & \\
\hline CHEMBL1449240 & 688267 & 6.15 & $5.0760 e$ & 00000000005 & TRN \\
\hline CHEMBL1422679 & 688267 & 5.85 & 5.1544 & TRN & \\
\hline CHEMBL1361588 & 688267 & 4.1 & 5.0151 & TST & \\
\hline CHEMBL1528771 & 688267 & 5.55 & 5.1123 & TRN & \\
\hline CHEMBL1526384 & 688267 & 6.5 & 5.0114 & TRN & \\
\hline
\end{tabular}




\begin{tabular}{|c|c|c|c|c|c|}
\hline \multicolumn{6}{|c|}{ Supplemental Table S2.txt } \\
\hline CHEMBL1377820 & 688267 & 4.35 & 5.0472 & TRN & \\
\hline CHEMBL1511910 & 688267 & 4.0 & 5.0728 & TRN & \\
\hline CHEMBL1387598 & 688267 & 4.0 & 5.0321 & TRN & \\
\hline CHEMBL1413652 & 688267 & 4.45 & 5.101 & TRN & \\
\hline CHEMBL1434525 & 688267 & 6.15 & 5.1276 & TRN & \\
\hline CHEMBL1388948 & 688267 & 4.05 & 5.0404 & TRN & \\
\hline CHEMBL3191906 & 688267 & 5.35 & 4.9854 & TRN & \\
\hline CHEMBL255156 & 688267 & 6.15 & 5.0338 & TST & \\
\hline CHEMBL 3212874 & 688267 & 6.25 & 5.1158 & TST & \\
\hline CHEMBL1486094 & 688267 & 5.15 & 5.0266 & TRN & \\
\hline CHEMBL1591383 & 688267 & 5.75 & 5.1506 & TRN & \\
\hline CHEMBL1423897 & 688267 & 4.7 & 5.1118 & TRN & \\
\hline CHEMBL1513645 & 688267 & 6.2 & 4.9946 & TST & \\
\hline CHEMBL1352451 & 688267 & 5.0 & 5.0318 & TST & \\
\hline CHEMBL1389112 & 688267 & 6.25 & 5.1077 & TRN & \\
\hline CHEMBL1436751 & 688267 & 4.15 & 5.0877 & TRN & \\
\hline CHEMBL1475064 & 688267 & 4.65 & 5.1174 & TRN & \\
\hline CHEMBL1439798 & 688267 & 6.25 & 5.0396 & TRN & \\
\hline CHEMBL1545271 & 688267 & 5.8 & 5.1172 & TRN & \\
\hline CHEMBL1365121 & 688267 & 5.6 & 5.129 & TRN & \\
\hline CHEMBL1536238 & 688267 & 4.75 & 5.0312 & TRN & \\
\hline CHEMBL1462667 & 688267 & 4.1 & 5.0776 & TST & \\
\hline CHEMBL1552500 & 688267 & 6.0 & 5.1184 & TRN & \\
\hline CHEMBL1351693 & 688267 & 5.35 & 5.0735 & TST & \\
\hline CHEMBL1575647 & 688267 & 6.5 & 5.0219 & TST & \\
\hline CHEMBL1393762 & 688267 & 5.85 & 5.0593 & TST & \\
\hline CHEMBL1456727 & 688267 & 6.2 & 5.0365 & TRN & \\
\hline CHEMBL1498403 & 688267 & 5.0 & 5.1784 & TRN & \\
\hline CHEMBL1390468 & 688267 & 4.0 & 5.0255 & TRN & \\
\hline CHEMBL1533719 & 688267 & 4.7 & 5.0272 & TRN & \\
\hline CHEMBL1501742 & 688267 & 5.85 & 5.0167 & TRN & \\
\hline CHEMBL1302946 & 688267 & 4.5 & 5.0215 & TRN & \\
\hline CHEMBL1347332 & 688267 & 4.4 & 4.9878 & TST & \\
\hline CHEMBL1592570 & 688267 & 5.85 & 5.1599 & TRN & \\
\hline CHEMBL1425541 & 688267 & 5.55 & 5.08899 & 99999999995 & TRN \\
\hline CHEMBL1427693 & 688267 & 4.7 & 5.0579 & TST & \\
\hline CHEMBL1427746 & 688267 & 3.95 & 5.0745 & TST & \\
\hline CHEMBL1520294 & 688267 & 4.0 & 4.9805 & TRN & \\
\hline CHEMBL1489147 & 688267 & 6.25 & 4.9887 & TST & \\
\hline CHEMBL1612762 & 688267 & 4.35 & 5.0197 & TRN & \\
\hline CHEMBL1520773 & 688267 & 6.05 & 5.0203 & TST & \\
\hline CHEMBL1448408 & 688267 & 3.95 & 5.0205 & TRN & \\
\hline CHEMBL1312582 & 688267 & 5.8 & 5.0302 & TST & \\
\hline CHEMBL1434313 & 688267 & 4.6 & 5.0893 & TRN & \\
\hline CHEMBL1475268 & 688267 & 5.6 & 5.0478 & TRN & \\
\hline CHEMBL1372577 & 688267 & 5.0 & 5.0641 & TRN & \\
\hline CHEMBL1377156 & 688267 & 5.7 & 5.0226 & TRN & \\
\hline CHEMBL1361240 & 688267 & 3.95 & 5.0995 & TST & \\
\hline
\end{tabular}




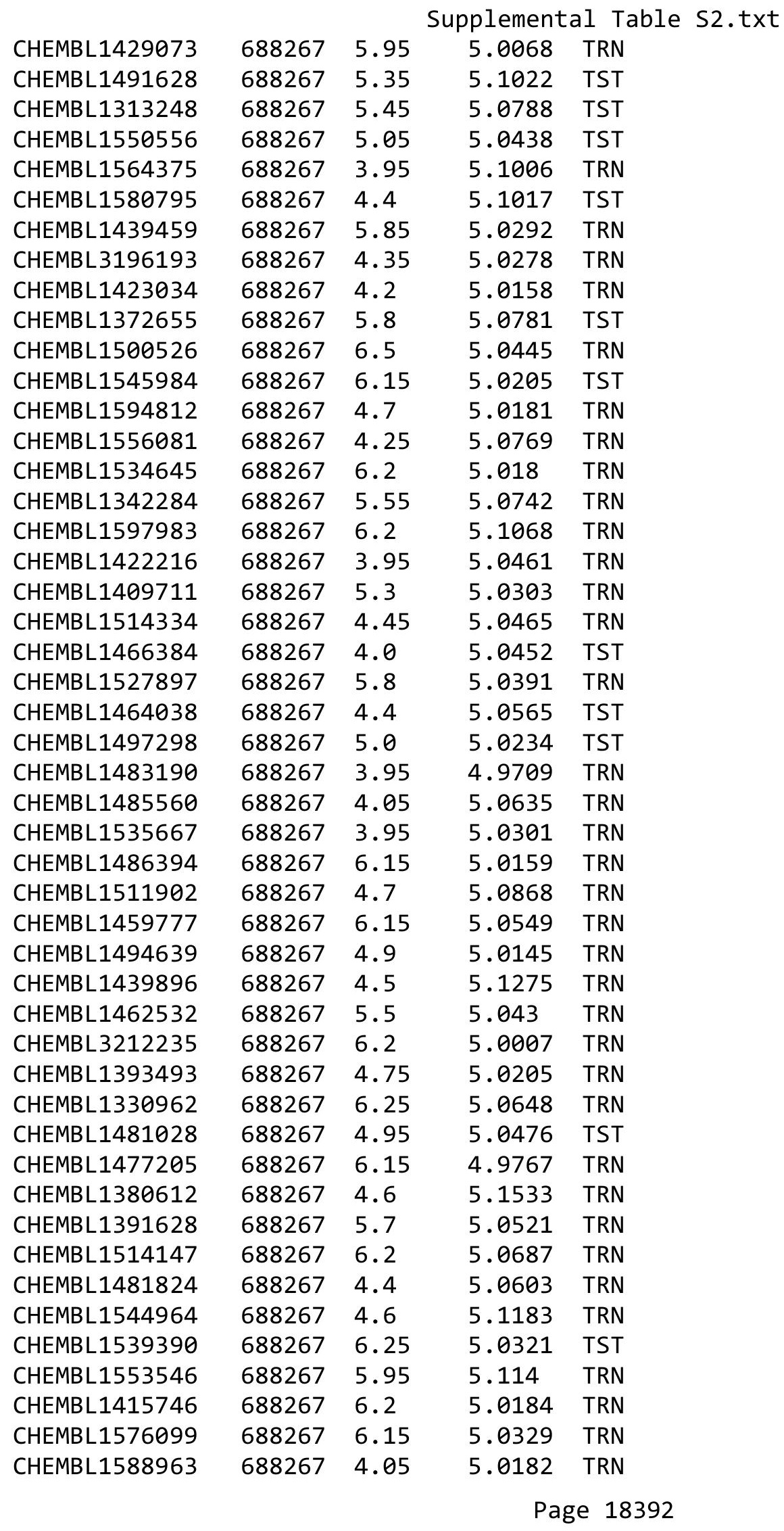




\begin{tabular}{|c|c|c|c|c|c|}
\hline \multicolumn{6}{|c|}{ Supplemental Table S2.txt } \\
\hline CHEMBL1472030 & 688267 & 4.95 & 5.0156 & TST & \\
\hline CHEMBL1355695 & 688267 & 4.0 & 5.0585 & TRN & \\
\hline CHEMBL1595155 & 688267 & 5.7 & 5.0686 & TRN & \\
\hline CHEMBL1511085 & 688267 & 3.95 & 5.1024 & TRN & \\
\hline CHEMBL1399534 & 688267 & 6.2 & 5.0558 & TRN & \\
\hline CHEMBL1482925 & 688267 & 6.2 & 5.03600 & 00000000005 & TRN \\
\hline CHEMBL1330331 & 688267 & 4.85 & 5.0335 & TRN & \\
\hline CHEMBL1562397 & 688267 & 4.35 & 4.9879 & TRN & \\
\hline CHEMBL1387944 & 688267 & 6.2 & 5.0481 & TRN & \\
\hline CHEMBL1482277 & 688267 & 5.9 & 5.0385 & TST & \\
\hline CHEMBL1601619 & 688267 & 4.55 & 5.0078 & TST & \\
\hline CHEMBL1449936 & 688267 & 6.5501 & 5.0437 & TST & \\
\hline CHEMBL1447524 & 688267 & 5.6 & 5.0185 & TRN & \\
\hline CHEMBL1570511 & 688267 & 6.05 & 5.0313 & TRN & \\
\hline CHEMBL1466057 & 688267 & 4.35 & 5.0237 & TRN & \\
\hline CHEMBL1564294 & 688267 & 4.15 & 5.0494 & TST & \\
\hline CHEMBL1447226 & 688267 & 6.2 & 5.0638 & TRN & \\
\hline CHEMBL1496678 & 688267 & 4.0 & 5.1115 & TRN & \\
\hline CHEMBL1583943 & 688267 & 6.2 & 5.0226 & TRN & \\
\hline CHEMBL1476541 & 688267 & 4.45 & 5.1426 & TRN & \\
\hline CHEMBL3191786 & 688267 & 5.15 & 5.0038 & TST & \\
\hline CHEMBL1547708 & 688267 & 4.25 & 5.0743 & TST & \\
\hline CHEMBL67932 & 688267 & 5.5 & 5.0645 & TRN & \\
\hline CHEMBL1585091 & 688267 & 4.0 & 5.0232 & TST & \\
\hline CHEMBL1607017 & 688267 & 4.5 & 5.0858 & TRN & \\
\hline CHEMBL1524542 & 688267 & 3.95 & 5.0839 & TST & \\
\hline CHEMBL1606059 & 688267 & 5.85 & 5.064 & TRN & \\
\hline CHEMBL1366832 & 688267 & 4.25 & 5.0375 & TST & \\
\hline CHEMBL1414552 & 688267 & 4.55 & 5.0727 & TST & \\
\hline CHEMBL1414015 & 688267 & 4.55 & 5.0611 & TST & \\
\hline CHEMBL1571058 & 688267 & 3.95 & 4.987 & TRN & \\
\hline CHEMBL1444562 & 688267 & 4.35 & 5.1315 & TRN & \\
\hline CHEMBL1401707 & 688267 & 4.35 & 5.01399 & 9999999999 & TRN \\
\hline CHEMBL1409273 & 688267 & 4.4 & 5.0393 & TRN & \\
\hline CHEMBL1533556 & 688267 & 4.0 & 5.1132 & TRN & \\
\hline CHEMBL1454874 & 688267 & 6.15 & 5.0738 & TRN & \\
\hline CHEMBL1446465 & 688267 & 6.15 & 5.0697 & TRN & \\
\hline CHEMBL1375797 & 688267 & 4.4 & 5.053 & TRN & \\
\hline CHEMBL1587995 & 688267 & 5.1 & 5.0697 & TRN & \\
\hline CHEMBL1574483 & 688267 & 4.25 & 5.1372 & TRN & \\
\hline CHEMBL3213078 & 688267 & 4.25 & 5.0333 & TRN & \\
\hline CHEMBL1307543 & 688267 & 5.45 & 5.0611 & TRN & \\
\hline CHEMBL1967474 & 688267 & 4.45 & 5.0847 & TST & \\
\hline CHEMBL1334807 & 688267 & 4.2 & 5.073 & TRN & \\
\hline CHEMBL1404350 & 688267 & 4.0 & 5.0195 & TRN & \\
\hline CHEMBL1311309 & 688267 & 6.2 & 5.0645 & TRN & \\
\hline CHEMBL1580622 & 688267 & 4.0 & 5.0333 & TST & \\
\hline CHEMBL1478042 & 688267 & 4.05 & 5.0277 & TST & \\
\hline
\end{tabular}




\begin{tabular}{|c|c|c|c|c|c|}
\hline \multicolumn{6}{|c|}{ Supplemental Table S2.txt } \\
\hline CHEMBL1378608 & 688267 & 5.55 & 5.0942 & TRN & \\
\hline CHEMBL1544302 & 688267 & 4.3 & 5.0848 & TRN & \\
\hline CHEMBL1454230 & 688267 & 4.9 & 5.0203 & TST & \\
\hline CHEMBL 20730 & 688267 & 4.05 & 5.0977 & TST & \\
\hline CHEMBL1468343 & 688267 & 4.05 & 5.0327 & TRN & \\
\hline CHEMBL1371607 & 688267 & 4.15 & 5.0607 & TRN & \\
\hline CHEMBL1596795 & 688267 & 5.95 & 5.033 & TRN & \\
\hline CHEMBL1608148 & 688267 & 6.25 & 5.018 & TRN & \\
\hline CHEMBL1434678 & 688267 & 4.0 & 4.9793 & TRN & \\
\hline CHEMBL1368334 & 688267 & 5.45 & 5.0382 & TRN & \\
\hline CHEMBL1356237 & 688267 & 4.05 & 5.0048 & TRN & \\
\hline CHEMBL1400659 & 688267 & 5.6 & 5.0587 & TST & \\
\hline CHEMBL1475299 & 688267 & 4.0 & 5.0601 & TRN & \\
\hline CHEMBL1447373 & 688267 & 4.1 & 5.0247 & TST & \\
\hline CHEMBL1359365 & 688267 & 5.1 & 5.0589 & TST & \\
\hline CHEMBL1447641 & 688267 & 4.4 & 5.0288 & TRN & \\
\hline CHEMBL1578562 & 688267 & 6.25 & 5.0368 & TRN & \\
\hline CHEMBL1336832 & 688267 & 5.6 & 5.048 & TST & \\
\hline CHEMBL1427398 & 688267 & 5.55 & 5.0634 & TRN & \\
\hline CHEMBL1537972 & 688267 & 4.9 & 5.0878 & TRN & \\
\hline CHEMBL1542780 & 688267 & 4.05 & 5.0322 & TRN & \\
\hline CHEMBL1494633 & 688267 & 6.15 & 5.0568 & TST & \\
\hline CHEMBL1352154 & 688267 & 4.4 & 5.0177 & TRN & \\
\hline CHEMBL1473835 & 688267 & 6.15 & 5.0874 & TRN & \\
\hline CHEMBL1437511 & 688267 & 4.45 & 5.0363 & TRN & \\
\hline CHEMBL1467798 & 688267 & 6.25 & 5.0138 & TST & \\
\hline CHEMBL1539971 & 688267 & 4.0 & 5.0517 & TRN & \\
\hline CHEMBL1469399 & 688267 & 4.2 & 5.13200 & 0000000001 & TRN \\
\hline CHEMBL1351861 & 688267 & 4.9 & 5.0578 & TRN & \\
\hline CHEMBL1538636 & 688267 & 4.7 & 4.9963 & TST & \\
\hline CHEMBL1333319 & 688267 & 4.05 & 5.0458 & TST & \\
\hline CHEMBL1349517 & 688267 & 5.85 & 5.0552 & TRN & \\
\hline CHEMBL1411425 & 688267 & 4.4 & 5.0525 & TRN & \\
\hline CHEMBL1318606 & 688267 & 5.25 & 5.1208 & TRN & \\
\hline CHEMBL1375028 & 688267 & 4.6 & 5.0154 & TRN & \\
\hline CHEMBL1343981 & 688267 & 4.55 & 5.098 & TRN & \\
\hline CHEMBL1358000 & 688267 & 5.65 & 5.061 & TRN & \\
\hline CHEMBL1397261 & 688267 & 5.9 & 5.066 & TRN & \\
\hline CHEMBL1304562 & 688267 & 3.95 & 5.0991 & TST & \\
\hline CHEMBL1306602 & 688267 & 6.2 & 5.0411 & TRN & \\
\hline CHEMBL1544392 & 688267 & 5.45 & 4.9922 & TST & \\
\hline CHEMBL1380127 & 688267 & 5.3 & 5.1336 & TRN & \\
\hline CHEMBL1566854 & 688267 & 3.95 & 5.0759 & TST & \\
\hline CHEMBL1312568 & 688267 & 4.4 & 5.0396 & TRN & \\
\hline CHEMBL1512067 & 688267 & 6.2 & 5.0717 & TRN & \\
\hline CHEMBL1305301 & 688267 & 4.75 & 5.063 & TRN & \\
\hline CHEMBL1437969 & 688267 & 4.0 & 5.0379 & TST & \\
\hline CHEMBL1388448 & 688267 & 4.3 & 5.0097 & TST & \\
\hline
\end{tabular}




\begin{tabular}{|c|c|c|c|c|c|}
\hline \multicolumn{6}{|c|}{ Supplemental Table S2.txt } \\
\hline CHEMBL1592488 & 688267 & 5.05 & 5.0196 & TRN & \\
\hline CHEMBL1551858 & 688267 & 4.7 & 5.0862 & TRN & \\
\hline CHEMBL1570424 & 688267 & 6.2 & 5.0707 & TRN & \\
\hline CHEMBL1498736 & 688267 & 5.35 & 5.004 & TST & \\
\hline CHEMBL1613606 & 688267 & 4.6 & 5.0883 & TST & \\
\hline CHEMBL1590134 & 688267 & 4.0 & 5.0876 & TRN & \\
\hline CHEMBL1444460 & 688267 & 4.7 & 5.1025 & TST & \\
\hline CHEMBL1348585 & 688267 & 5.9 & 4.9927 & TRN & \\
\hline CHEMBL1317850 & 688267 & 3.95 & 5.056 & TRN & \\
\hline CHEMBL1529186 & 688267 & 5.05 & 5.0742 & TRN & \\
\hline CHEMBL1350971 & 688267 & 5.9 & 5.083 & TST & \\
\hline CHEMBL1343423 & 688267 & 5.2 & 5.0445 & TRN & \\
\hline CHEMBL1375677 & 688267 & 5.0 & 5.0794 & TRN & \\
\hline CHEMBL1542599 & 688267 & 4.0 & 5.0725 & TST & \\
\hline CHEMBL1520917 & 688267 & 5.5 & 5.0269 & TST & \\
\hline CHEMBL1588277 & 688267 & 4.4 & 5.0726 & TRN & \\
\hline CHEMBL1305253 & 688267 & 4.85 & 5.0011 & TRN & \\
\hline CHEMBL1485178 & 688267 & 4.3 & 5.09399 & 9999999999 & TRN \\
\hline CHEMBL1479022 & 688267 & 6.05 & 5.04899 & 99999999995 & TRN \\
\hline CHEMBL1316554 & 688267 & 6.2 & 5.0532 & TRN & \\
\hline CHEMBL1406416 & 688267 & 4.5 & 5.101 & TRN & \\
\hline CHEMBL1502566 & 688267 & 4.65 & 5.0339 & TRN & \\
\hline CHEMBL3207976 & 688267 & 5.55 & 5.0934 & TST & \\
\hline CHEMBL580183 & 688267 & 4.8 & 5.0628 & TST & \\
\hline CHEMBL1405886 & 688267 & 4.3 & 5.0696 & TRN & \\
\hline CHEMBL1429493 & 688267 & 4.7 & 5.0214 & TRN & \\
\hline CHEMBL1472730 & 688267 & 5.4 & 5.0371 & TRN & \\
\hline CHEMBL1377849 & 688267 & 6.2 & 4.965 & TST & \\
\hline CHEMBL1505705 & 688267 & 5.6 & 5.0278 & TRN & \\
\hline CHEMBL3192894 & 688267 & 6.15 & 5.0207 & TST & \\
\hline CHEMBL1316643 & 688267 & 6.2 & 5.1314 & TST & \\
\hline CHEMBL1464944 & 688267 & 5.4 & 5.1045 & TRN & \\
\hline CHEMBL1359588 & 688267 & 4.0 & 5.0237 & TRN & \\
\hline CHEMBL1493857 & 688267 & 5.65 & 5.0552 & TRN & \\
\hline CHEMBL1589982 & 688267 & 5.4 & 5.0125 & TRN & \\
\hline CHEMBL1606661 & 688267 & 4.0 & 5.0073 & TRN & \\
\hline CHEMBL1470608 & 688267 & 6.15 & 5.0318 & TRN & \\
\hline CHEMBL1423801 & 688267 & 5.65 & 5.0598 & TRN & \\
\hline CHEMBL1458160 & 688267 & 4.6 & 5.0135 & TRN & \\
\hline CHEMBL1554735 & 688267 & 4.6 & 5.0225 & TRN & \\
\hline CHEMBL1594370 & 688267 & 3.95 & 5.0402 & TRN & \\
\hline CHEMBL1490472 & 688267 & 4.0 & 5.0125 & TRN & \\
\hline CHEMBL1454455 & 688267 & 6.2 & 5.0437 & TRN & \\
\hline CHEMBL1353973 & 688267 & 4.4 & 5.0769 & TST & \\
\hline CHEMBL1964573 & 688267 & 4.0 & 4.961 & TRN & \\
\hline CHEMBL1338482 & 688267 & 5.9 & 5.0413 & TRN & \\
\hline CHEMBL1367167 & 688267 & 6.25 & 5.0483 & TRN & \\
\hline CHEMBL1305753 & 688267 & 6.2 & 5.0819 & TST & \\
\hline
\end{tabular}




\begin{tabular}{|c|c|c|c|c|}
\hline & & & pplement & al $\mathrm{Ta}$ \\
\hline CHEMBL1401988 & 688267 & 6.2 & 4.9929 & TRN \\
\hline CHEMBL1586790 & 688267 & 4.35 & 5.0105 & TRN \\
\hline CHEMBL1311439 & 688267 & 5.15 & 5.0946 & TRN \\
\hline CHEMBL1377468 & 688267 & 4.5 & 5.0163 & TRN \\
\hline CHEMBL1550324 & 688267 & 4.55 & 5.0461 & TST \\
\hline CHEMBL1485801 & 688267 & 4.15 & 5.0115 & TRN \\
\hline CHEMBL1382487 & 688267 & 5.55 & 5.0687 & TST \\
\hline CHEMBL1601385 & 688267 & 4.6 & 5.1143 & TST \\
\hline CHEMBL1350634 & 688267 & 5.0 & 5.0761 & TRN \\
\hline CHEMBL1332659 & 688267 & 5.35 & 5.0417 & TRN \\
\hline CHEMBL1550529 & 688267 & 4.0 & 5.1531 & TRN \\
\hline CHEMBL1365822 & 688267 & 3.9 & 5.1118 & TRN \\
\hline CHEMBL1491642 & 688267 & 4.25 & 5.0773 & TRN \\
\hline CHEMBL1596680 & 688267 & 4.15 & 5.0856 & TRN \\
\hline CHEMBL1371704 & 688267 & 6.0 & 5.0628 & TST \\
\hline CHEMBL1594670 & 688267 & 3.95 & 4.981 & TRN \\
\hline CHEMBL1555057 & 688267 & 6.2 & 5.0418 & TRN \\
\hline CHEMBL1509927 & 688267 & 5.55 & 5.0636 & TRN \\
\hline CHEMBL474589 & 688267 & 4.1 & 5.0004 & TST \\
\hline CHEMBL1440046 & 688267 & 5.9 & 5.0898 & TST \\
\hline CHEMBL1473466 & 688267 & 4.35 & 5.0194 & TRN \\
\hline CHEMBL1426061 & 688267 & 4.45 & 5.0712 & TST \\
\hline CHEMBL1436306 & 688267 & 4.7 & 5.0706 & TRN \\
\hline CHEMBL1546874 & 688267 & 5.0 & 5.0722 & TRN \\
\hline CHEMBL1428980 & 688267 & 4.1 & 5.0602 & TST \\
\hline CHEMBL1334606 & 688267 & 4.05 & 5.1107 & TRN \\
\hline CHEMBL 3196315 & 688267 & 4.4 & 5.0686 & TRN \\
\hline CHEMBL1555180 & 688267 & 5.3 & 5.0252 & TST \\
\hline CHEMBL1372884 & 688267 & 5.05 & 5.1363 & TST \\
\hline CHEMBL1357936 & 688267 & 5.3 & 5.0509 & TRN \\
\hline CHEMBL1436926 & 688267 & 5.45 & 5.0311 & TRN \\
\hline CHEMBL1396865 & 688267 & 6.0 & 5.0401 & TRN \\
\hline CHEMBL1462652 & 688267 & 4.1 & 5.1071 & TRN \\
\hline CHEMBL1388700 & 688267 & 5.75 & 4.9806 & TRN \\
\hline CHEMBL1425612 & 688267 & 4.0 & 5.1004 & TST \\
\hline CHEMBL1461457 & 688267 & 4.5 & 5.0211 & TST \\
\hline CHEMBL1602393 & 688267 & 4.05 & 5.0692 & TRN \\
\hline CHEMBL1387321 & 688267 & 5.65 & 5.0922 & TST \\
\hline CHEMBL1511739 & 688267 & 4.85 & 4.9553 & TRN \\
\hline CHEMBL1541013 & 688267 & 6.2 & 5.063 & TRN \\
\hline CHEMBL1423735 & 688267 & 5.75 & 5.0771 & TRN \\
\hline CHEMBL1409188 & 688267 & 5.35 & 5.0373 & TST \\
\hline CHEMBL1479017 & 688267 & 6.1 & 5.0321 & TRN \\
\hline CHEMBL1555042 & 688267 & 4.35 & 5.0576 & TST \\
\hline CHEMBL1519534 & 688267 & 4.3 & 5.118 & TRN \\
\hline CHEMBL1563327 & 688267 & 5.55 & 5.0422 & TST \\
\hline CHEMBL1356436 & 688267 & 5.3 & 5.0176 & TRN \\
\hline CHEMBL1594558 & 688267 & 4.35 & 4.9835 & TRN \\
\hline
\end{tabular}




\begin{tabular}{|c|c|c|c|c|c|}
\hline \multicolumn{6}{|c|}{ Supplemental Table S2.txt } \\
\hline CHEMBL293749 & 688267 & 5.55 & 5.008 & TRN & \\
\hline CHEMBL1555893 & 688267 & 4.3 & 5.0891 & TRN & \\
\hline CHEMBL1486053 & 688267 & 6.2 & 5.0316 & TST & \\
\hline CHEMBL1366098 & 688267 & 4.35 & 4.9943 & TST & \\
\hline CHEMBL3392461 & 688267 & 6.2 & 5.1196 & TST & \\
\hline CHEMBL1399331 & 688267 & 4.4 & 5.0484 & TST & \\
\hline CHEMBL1480945 & 688267 & 5.6 & 4.995 & TST & \\
\hline CHEMBL1572742 & 688267 & 6.25 & 5.07 & TRN & \\
\hline CHEMBL3212844 & 688267 & 4.4 & 5.0369 & TRN & \\
\hline CHEMBL1582651 & 688267 & 5.5 & 5.0452 & TST & \\
\hline CHEMBL1383351 & 688267 & 4.35 & 5.143 & TRN & \\
\hline CHEMBL1305756 & 688267 & 5.4 & 5.0219 & TRN & \\
\hline CHEMBL1319086 & 688267 & 6.05 & 5.0964 & TST & \\
\hline CHEMBL1324320 & 688267 & 4.75 & 5.0446 & TST & \\
\hline CHEMBL1592942 & 688267 & 4.0 & 5.0033 & TRN & \\
\hline CHEMBL1610046 & 688267 & 4.05 & 5.08899 & 99999999995 & TRN \\
\hline CHEMBL1428307 & 688267 & 4.3 & 5.0159 & TRN & \\
\hline CHEMBL1446010 & 688267 & 4.4 & 5.0904 & TRN & \\
\hline CHEMBL1420612 & 688267 & 5.5 & 5.0774 & TST & \\
\hline CHEMBL1464743 & 688267 & 6.2 & 5.0622 & TST & \\
\hline CHEMBL1551620 & 688267 & 4.2 & 5.0096 & TRN & \\
\hline CHEMBL1457183 & 688267 & 6.2 & 5.0218 & TRN & \\
\hline CHEMBL1476796 & 688267 & 5.8 & 5.0285 & TRN & \\
\hline CHEMBL1555328 & 688267 & 6.15 & 5.1024 & TRN & \\
\hline CHEMBL1326901 & 688267 & 5.85 & 5.0222 & TST & \\
\hline CHEMBL1389348 & 688267 & 4.0 & 5.1127 & TRN & \\
\hline CHEMBL1389526 & 688267 & 5.0 & 5.1244 & TRN & \\
\hline CHEMBL1429128 & 688267 & 4.35 & 5.0453 & TST & \\
\hline CHEMBL1351968 & 688267 & 5.3 & 5.1048 & TRN & \\
\hline CHEMBL1494084 & 688267 & 6.15 & 5.1075 & TST & \\
\hline CHEMBL1316053 & 688267 & 4.6 & 5.0207 & TRN & \\
\hline CHEMBL1314551 & 688267 & 4.05 & 5.0638 & TRN & \\
\hline CHEMBL1455261 & 688267 & 5.05 & 5.0696 & TRN & \\
\hline CHEMBL1421759 & 688267 & 4.9 & 5.0501 & TST & \\
\hline CHEMBL1389376 & 688267 & 4.8 & 5.0359 & TRN & \\
\hline CHEMBL1484278 & 688267 & 5.35 & 5.0093 & TRN & \\
\hline CHEMBL1395298 & 688267 & 5.3 & 5.0894 & TRN & \\
\hline CHEMBL1340845 & 688267 & 5.85 & 5.0573 & TST & \\
\hline CHEMBL1537528 & 688267 & 3.95 & 5.0382 & TRN & \\
\hline CHEMBL1534074 & 688267 & 4.45 & 5.0744 & TST & \\
\hline CHEMBL1306866 & 688267 & 4.05 & 5.1327 & TRN & \\
\hline CHEMBL582070 & 688267 & 5.45 & 5.0495 & TRN & \\
\hline CHEMBL1564033 & 688267 & 4.4 & 5.0207 & TRN & \\
\hline CHEMBL1532155 & 688267 & 4.7 & 5.0163 & TRN & \\
\hline CHEMBL1434850 & 688267 & 3.95 & 5.0626 & TRN & \\
\hline CHEMBL1594724 & 688267 & 6.05 & 5.0493 & TRN & \\
\hline CHEMBL3191114 & 688267 & 5.9 & 5.0241 & TRN & \\
\hline CHEMBL1426711 & 688267 & 5.65 & 5.0572 & TST & \\
\hline
\end{tabular}




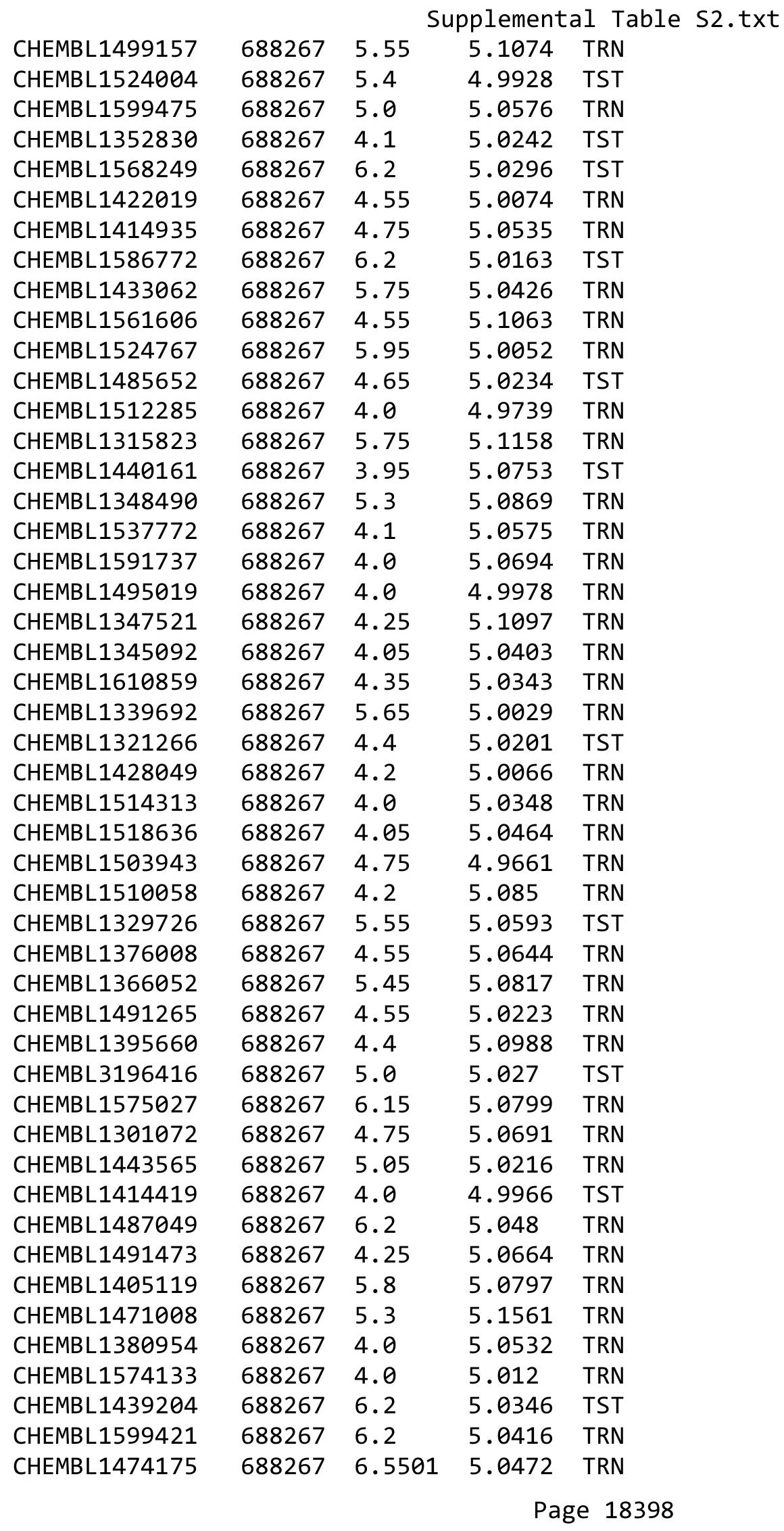




\begin{tabular}{|c|c|c|c|c|}
\hline \multicolumn{5}{|c|}{ Supplemental Table S2.txt } \\
\hline CHEMBL1599110 & 688267 & 4.0 & 5.0825 & TRN \\
\hline CHEMBL1459570 & 688267 & 5.05 & 5.0799 & TST \\
\hline CHEMBL1438732 & 688267 & 5.3 & 5.001 & TRN \\
\hline CHEMBL1570833 & 688267 & 5.85 & 5.0349 & TRN \\
\hline CHEMBL1552757 & 688267 & 4.55 & 5.0949 & TRN \\
\hline CHEMBL1554313 & 688267 & 6.15 & 5.1275 & TST \\
\hline CHEMBL1376818 & 688267 & 5.55 & 5.1208 & TRN \\
\hline CHEMBL3197898 & 688267 & 5.4 & 5.0276 & TST \\
\hline CHEMBL1437792 & 688267 & 4.45 & 5.1253 & TRN \\
\hline CHEMBL1380090 & 688267 & 4.65 & 5.0795 & TRN \\
\hline CHEMBL1319016 & 688267 & 3.95 & 5.0517 & TRN \\
\hline CHEMBL1317772 & 688267 & 4.05 & 5.0549 & TRN \\
\hline CHEMBL1485951 & 688267 & 3.95 & 5.0586 & TRN \\
\hline CHEMBL1364683 & 688267 & 4.05 & 5.0551 & TST \\
\hline CHEMBL1341821 & 688267 & 5.55 & 5.1125 & TRN \\
\hline CHEMBL1316722 & 688267 & 5.25 & 5.0699 & TRN \\
\hline CHEMBL1409967 & 688267 & 4.0 & 5.0785 & TRN \\
\hline CHEMBL1486387 & 688267 & 4.35 & 5.0092 & TST \\
\hline CHEMBL1460839 & 688267 & 5.05 & 5.0733 & TRN \\
\hline CHEMBL1463786 & 688267 & 6.0 & 4.9819 & TRN \\
\hline CHEMBL1500683 & 688267 & 5.2 & 5.0814 & TST \\
\hline CHEMBL1457613 & 688267 & 6.5 & 5.0413 & TRN \\
\hline CHEMBL1423744 & 688267 & 4.05 & 5.0432 & TRN \\
\hline CHEMBL1424724 & 688267 & 4.85 & 5.1228 & TRN \\
\hline CHEMBL 2143754 & 688267 & 4.25 & 5.0581 & TST \\
\hline CHEMBL1445496 & 688267 & 4.15 & 5.0426 & TST \\
\hline CHEMBL1592050 & 688267 & 4.55 & 5.0406 & TRN \\
\hline CHEMBL1514970 & 688267 & 4.4 & 5.0622 & TRN \\
\hline CHEMBL1395559 & 688267 & 3.95 & 5.1479 & TRN \\
\hline CHEMBL1478863 & 688267 & 4.05 & 5.033 & TRN \\
\hline CHEMBL3191117 & 688267 & 4.1 & 4.9622 & TRN \\
\hline CHEMBL1369607 & 688267 & 5.95 & 5.0591 & TRN \\
\hline CHEMBL1482380 & 688267 & 4.5 & 5.0967 & TRN \\
\hline CHEMBL1330645 & 688267 & 4.25 & 5.0709 & TRN \\
\hline CHEMBL1320054 & 688267 & 5.45 & 5.0614 & TST \\
\hline CHEMBL1473362 & 688267 & 4.9 & 5.043 & TRN \\
\hline CHEMBL1315046 & 688267 & 4.2 & 5.1037 & TRN \\
\hline CHEMBL1424095 & 688267 & 6.2 & 5.0249 & TRN \\
\hline CHEMBL1476240 & 688267 & 4.0 & 5.1791 & TRN \\
\hline CHEMBL 3198434 & 688267 & 4.35 & 5.0034 & TRN \\
\hline CHEMBL1441890 & 688267 & 4.05 & 5.0116 & TRN \\
\hline CHEMBL1367899 & 688267 & 4.5 & 5.0619 & TRN \\
\hline CHEMBL1413574 & 688267 & 4.55 & 5.0439 & TST \\
\hline CHEMBL1549572 & 688267 & 4.55 & 5.0504 & TRN \\
\hline CHEMBL1398154 & 688267 & 5.95 & 5.0228 & TRN \\
\hline CHEMBL1316792 & 688267 & 4.35 & 5.0728 & TRN \\
\hline CHEMBL1573223 & 688267 & 4.3 & 5.0505 & TRN \\
\hline CHEMBL1475242 & 688267 & 4.3 & 5.0596 & TRN \\
\hline
\end{tabular}




\begin{tabular}{|c|c|c|c|c|c|}
\hline \multicolumn{6}{|c|}{ Supplemental Table S2.txt } \\
\hline CHEMBL1372772 & 688267 & 4.3 & 5.1063 & TRN & \\
\hline CHEMBL1447339 & 688267 & 4.35 & 5.101 & TRN & \\
\hline CHEMBL1431549 & 688267 & 5.45 & 4.9838 & TRN & \\
\hline CHEMBL1368995 & 688267 & 5.2 & 5.0193 & TRN & \\
\hline CHEMBL1577134 & 688267 & 4.0 & 5.0275 & TST & \\
\hline CHEMBL1612340 & 688267 & 5.05 & 5.0401 & TST & \\
\hline CHEMBL1395336 & 688267 & 4.55 & 5.0428 & TRN & \\
\hline CHEMBL1571018 & 688267 & 5.05 & 4.9746 & TRN & \\
\hline CHEMBL1406103 & 688267 & 4.4 & 5.0509 & TRN & \\
\hline CHEMBL1612288 & 688267 & 4.55 & 5.0212 & TRN & \\
\hline CHEMBL1370138 & 688267 & 5.15 & 5.1114 & TST & \\
\hline CHEMBL1409370 & 688267 & 4.0 & 5.0236 & TRN & \\
\hline CHEMBL1392652 & 688267 & 5.35 & 5.0798 & TRN & \\
\hline CHEMBL1566147 & 688267 & 6.25 & 5.0194 & TRN & \\
\hline CHEMBL1506650 & 688267 & 3.95 & 5.0253 & TST & \\
\hline CHEMBL1522311 & 688267 & 4.2 & 5.0122 & TRN & \\
\hline CHEMBL1433263 & 688267 & 4.65 & 5.0447 & TRN & \\
\hline CHEMBL1341480 & 688267 & 4.5 & 5.086 & TST & \\
\hline CHEMBL1317337 & 688267 & 5.05 & 5.0522 & TRN & \\
\hline CHEMBL1414582 & 688267 & 5.35 & 5.0122 & TRN & \\
\hline CHEMBL1590713 & 688267 & 4.6 & 5.0602 & TRN & \\
\hline CHEMBL1343309 & 688267 & 4.4 & 4.9726 & TST & \\
\hline CHEMBL1317155 & 688267 & 3.95 & 5.0864 & TRN & \\
\hline CHEMBL1564893 & 688267 & 4.0 & 5.1201 & TRN & \\
\hline CHEMBL1408719 & 688267 & 4.05 & 5.0827 & TRN & \\
\hline CHEMBL1512273 & 688267 & 4.4 & 5.0851 & TRN & \\
\hline CHEMBL1471628 & 688267 & 5.25 & 4.99100 & 00000000005 & TRN \\
\hline CHEMBL1534032 & 688267 & 4.05 & 4.996 & TRN & \\
\hline CHEMBL1501896 & 688267 & 4.55 & 5.0672 & TRN & \\
\hline CHEMBL1552632 & 688267 & 4.95 & 5.0677 & TRN & \\
\hline CHEMBL1530085 & 688267 & 4.6 & 5.0115 & TRN & \\
\hline CHEMBL3209323 & 688267 & 5.5 & 5.0451 & TST & \\
\hline CHEMBL1300361 & 688267 & 5.3 & 5.1495 & TRN & \\
\hline CHEMBL1422764 & 688267 & 5.1 & 5.1282 & TRN & \\
\hline CHEMBL1363847 & 688267 & 5.8 & 5.007 & TRN & \\
\hline CHEMBL1514223 & 688267 & 4.0 & 5.0456 & TRN & \\
\hline CHEMBL1376156 & 688267 & 4.65 & 5.0449 & TRN & \\
\hline CHEMBL1359823 & 688267 & 6.05 & 5.0154 & TRN & \\
\hline CHEMBL1599292 & 688267 & 5.5 & 5.0883 & TRN & \\
\hline CHEMBL1328986 & 688267 & 4.0 & 5.0512 & TST & \\
\hline CHEMBL1339813 & 688267 & 6.2 & 5.1031 & TRN & \\
\hline CHEMBL1355264 & 688267 & 4.6 & 5.0258 & TRN & \\
\hline CHEMBL1399390 & 688267 & 6.2 & 5.0307 & TRN & \\
\hline CHEMBL1397622 & 688267 & 4.1 & 5.1034 & TRN & \\
\hline CHEMBL1399544 & 688267 & 5.6 & 5.0758 & TST & \\
\hline CHEMBL1300313 & 688267 & 5.4 & 5.0564 & TRN & \\
\hline CHEMBL1559561 & 688267 & 6.25 & 5.07100 & 0000000001 & TST \\
\hline CHEMBL1510204 & 688267 & 4.6 & 5.1029 & TRN & \\
\hline
\end{tabular}




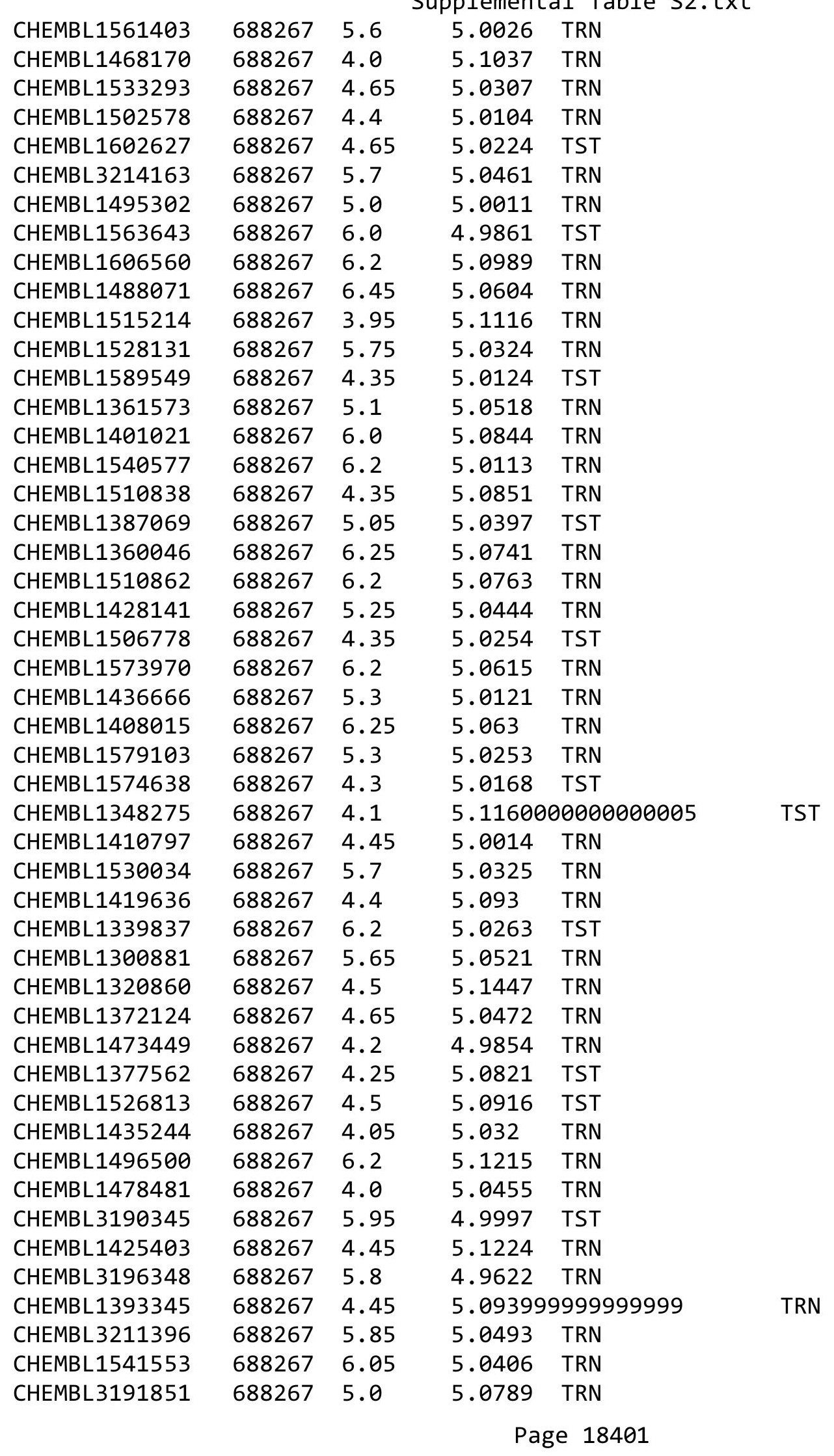




\begin{tabular}{|c|c|c|c|c|c|}
\hline & & & & & \\
\hline CHEMBL1538257 & 688267 & 4.3 & 4.999 & TRN & \\
\hline CHEMBL1553781 & 688267 & 5.7 & 5.1105 & TRN & \\
\hline CHEMBL1437097 & 688267 & 6.2 & 5.0952 & TRN & \\
\hline CHEMBL1556562 & 688267 & 4.4 & 5.0829 & TST & \\
\hline CHEMBL1612314 & 688267 & 6.0 & 5.03 & TRN & \\
\hline CHEMBL1561911 & 688267 & 4.0 & 5.0436 & TRN & \\
\hline CHEMBL1599841 & 688267 & 3.95 & 5.1413 & TRN & \\
\hline CHEMBL1457991 & 688267 & 4.65 & 5.0085 & TRN & \\
\hline CHEMBL1323168 & 688267 & 4.7 & 5.08899 & 99999999995 & TRN \\
\hline CHEMBL1591101 & 688267 & 5.15 & 5.0558 & TRN & \\
\hline CHEMBL1553290 & 688267 & 5.95 & 5.0468 & TST & \\
\hline CHEMBL1391061 & 688267 & 6.2 & 5.0237 & TST & \\
\hline CHEMBL1425899 & 688267 & 4.35 & 5.022 & TRN & \\
\hline CHEMBL1556053 & 688267 & 5.15 & 5.0895 & TST & \\
\hline CHEMBL1451563 & 688267 & 4.0 & 5.0052 & TST & \\
\hline CHEMBL1441191 & 688267 & 4.95 & 5.0957 & TRN & \\
\hline CHEMBL1415001 & 688267 & 4.75 & 5.08 & TRN & \\
\hline CHEMBL1368948 & 688267 & 4.85 & 5.0317 & TST & \\
\hline CHEMBL1419858 & 688267 & 5.2 & 5.0196 & TST & \\
\hline CHEMBL1552322 & 688267 & 4.9 & 5.1492 & TRN & \\
\hline CHEMBL1555440 & 688267 & 5.6 & 5.048 & TRN & \\
\hline CHEMBL1545169 & 688267 & 4.35 & 5.077 & TST & \\
\hline CHEMBL3212354 & 688267 & 5.95 & 5.1031 & TRN & \\
\hline CHEMBL1418560 & 688267 & 5.1 & 5.0943 & TRN & \\
\hline CHEMBL1438276 & 688267 & 4.5 & 5.0441 & TST & \\
\hline CHEMBL1591735 & 688267 & 4.1 & 5.096 & TRN & \\
\hline CHEMBL1566082 & 688267 & 5.5 & 5.0403 & TRN & \\
\hline CHEMBL1438462 & 688267 & 5.5 & 5.0427 & TST & \\
\hline CHEMBL1553216 & 688267 & 5.25 & 5.0437 & TRN & \\
\hline CHEMBL1567117 & 688267 & 4.8 & 5.0308 & TST & \\
\hline CHEMBL1464955 & 688267 & 6.05 & 5.0682 & TRN & \\
\hline CHEMBL1603189 & 688267 & 5.25 & 5.05699 & 99999999995 & TRN \\
\hline CHEMBL1982381 & 688267 & 5.1 & 5.0175 & TRN & \\
\hline CHEMBL1475569 & 688267 & 6.2 & 5.0063 & TRN & \\
\hline CHEMBL1533846 & 688267 & 6.5 & 5.0241 & TRN & \\
\hline CHEMBL1581467 & 688267 & 4.85 & 5.1225 & TRN & \\
\hline CHEMBL1495774 & 688267 & 4.0 & 5.008 & TRN & \\
\hline CHEMBL1542277 & 688267 & 6.2 & 5.0283 & TRN & \\
\hline CHEMBL1091457 & 688267 & 4.65 & 5.1348 & TRN & \\
\hline CHEMBL1590347 & 688267 & 2.9 & 5.0646 & TRN & \\
\hline CHEMBL1581900 & 688267 & 4.5 & 5.1306 & TRN & \\
\hline CHEMBL3195240 & 688267 & 5.0 & 5.0034 & TST & \\
\hline CHEMBL1591088 & 688267 & 4.25 & 5.0598 & TRN & \\
\hline CHEMBL1459894 & 688267 & 5.85 & 5.0586 & TST & \\
\hline CHEMBL1380628 & 688267 & 5.15 & 5.0591 & TRN & \\
\hline CHEMBL1523174 & 688267 & 4.8 & 5.0934 & TRN & \\
\hline CHEMBL1599996 & 688267 & 5.55 & 5.1157 & TST & \\
\hline CHEMBL149163 & 688267 & 4.0 & 5.0735 & TRN & \\
\hline & & & & 18402 & \\
\hline
\end{tabular}




\begin{tabular}{|c|c|c|c|c|c|}
\hline \multicolumn{6}{|c|}{ Supplemental Table S2.txt } \\
\hline CHEMBL1516772 & 688267 & 4.45 & 5.0045 & TST & \\
\hline CHEMBL1371673 & 688267 & 4.35 & 5.0205 & TST & \\
\hline CHEMBL1438740 & 688267 & 4.15 & 5.0716 & TRN & \\
\hline CHEMBL1588570 & 688267 & 5.55 & 5.059 & TRN & \\
\hline CHEMBL1366115 & 688267 & 4.65 & 4.9948 & TST & \\
\hline CHEMBL1472757 & 688267 & 4.0 & 5.0723 & TRN & \\
\hline CHEMBL1402012 & 688267 & 4.1 & 4.9961 & TRN & \\
\hline CHEMBL1516420 & 688267 & 4.0 & 5.0525 & TRN & \\
\hline CHEMBL1398477 & 688267 & 6.2 & 5.0889 & TRN & \\
\hline CHEMBL1479104 & 688267 & 3.95 & 5.1141 & TRN & \\
\hline CHEMBL1600759 & 688267 & 5.2 & 5.0028 & TST & \\
\hline CHEMBL1608466 & 688267 & 5.45 & 5.0403 & TRN & \\
\hline CHEMBL1535025 & 688267 & 6.5 & 5.1001 & TRN & \\
\hline CHEMBL1346521 & 688267 & 6.15 & 5.01 & TRN & \\
\hline CHEMBL1362651 & 688267 & 4.55 & 5.05699 & 99999999995 & TST \\
\hline CHEMBL1609826 & 688267 & 5.1 & 5.0968 & TRN & \\
\hline CHEMBL1402150 & 688267 & 5.75 & 5.1317 & TRN & \\
\hline CHEMBL1375037 & 688267 & 4.6 & 5.0197 & TRN & \\
\hline CHEMBL1373639 & 688267 & 3.95 & 5.0702 & TRN & \\
\hline CHEMBL1454749 & 688267 & 3.95 & 5.0255 & TRN & \\
\hline CHEMBL1418331 & 688267 & 4.05 & 5.0206 & TST & \\
\hline CHEMBL1408716 & 688267 & 6.15 & 5.1003 & TRN & \\
\hline CHEMBL1400937 & 688267 & 5.35 & 5.0322 & TRN & \\
\hline CHEMBL1405451 & 688267 & 6.0 & 5.0409 & TRN & \\
\hline CHEMBL1376741 & 688267 & 4.05 & 5.0866 & TRN & \\
\hline CHEMBL1303982 & 688267 & 5.85 & 5.1105 & TRN & \\
\hline CHEMBL1364539 & 688267 & 3.95 & 5.0991 & TRN & \\
\hline CHEMBL1491293 & 688267 & 5.9 & 5.0423 & TRN & \\
\hline CHEMBL1507408 & 688267 & 6.0 & 5.0677 & TRN & \\
\hline CHEMBL1430723 & 688267 & 4.8 & 5.001 & TRN & \\
\hline CHEMBL1394523 & 688267 & 5.55 & 5.0977 & TRN & \\
\hline CHEMBL1592087 & 688267 & 4.65 & 5.0977 & TST & \\
\hline CHEMBL1383692 & 688267 & 6.2 & 5.0623 & TRN & \\
\hline CHEMBL1400354 & 688267 & 4.6 & 5.0653 & TRN & \\
\hline CHEMBL1480933 & 688267 & 4.0 & 5.0597 & TRN & \\
\hline CHEMBL1506473 & 688267 & 6.2 & 5.0471 & TRN & \\
\hline CHEMBL1513577 & 688267 & 6.25 & 5.105 & TRN & \\
\hline CHEMBL1457322 & 688267 & 6.25 & 5.063 & TST & \\
\hline CHEMBL1334964 & 688267 & 3.95 & 5.0168 & TRN & \\
\hline CHEMBL1578177 & 688267 & 5.45 & 5.1109 & TRN & \\
\hline CHEMBL1513599 & 688267 & 6.2 & 4.9938 & TRN & \\
\hline CHEMBL1587701 & 688267 & 4.25 & 5.0185 & TRN & \\
\hline CHEMBL1453742 & 688267 & 5.85 & 5.029 & TST & \\
\hline CHEMBL3208266 & 688267 & 5.1 & 5.0148 & TST & \\
\hline CHEMBL1439889 & 688267 & 5.5 & 5.0598 & TST & \\
\hline CHEMBL1498563 & 688267 & 4.1 & 5.1484 & TRN & \\
\hline CHEMBL1377947 & 688267 & 4.0 & 5.0813 & TRN & \\
\hline CHEMBL1363744 & 688267 & 5.3 & 5.0113 & TRN & \\
\hline
\end{tabular}




\begin{tabular}{|c|c|c|c|c|c|}
\hline \\
\hline CHEMBL1388095 & 688267 & 6.2 & 5.0903 & TRN & \\
\hline CHEMBL1513194 & 688267 & 5.6 & 5.05 & TRN & \\
\hline CHEMBL1609466 & 688267 & 5.2 & 5.01399 & 9999999999 & TRN \\
\hline CHEMBL1571592 & 688267 & 5.8 & 5.0934 & TST & \\
\hline CHEMBL1321548 & 688267 & 4.45 & 5.1476 & TRN & \\
\hline CHEMBL1335665 & 688267 & 5.4 & 5.0351 & TST & \\
\hline CHEMBL1532164 & 688267 & 5.5 & 5.0214 & TRN & \\
\hline CHEMBL1377824 & 688267 & 5.15 & 5.0877 & TST & \\
\hline CHEMBL1396638 & 688267 & 6.0 & 5.1277 & TST & \\
\hline CHEMBL1397943 & 688267 & 6.25 & 5.0967 & TRN & \\
\hline CHEMBL1567187 & 688267 & 4.5 & 5.0796 & TRN & \\
\hline CHEMBL1314894 & 688267 & 4.1 & 5.1099 & TRN & \\
\hline CHEMBL1398698 & 688267 & 6.2 & 5.0968 & TST & \\
\hline CHEMBL1378187 & 688267 & 5.35 & 5.0524 & TRN & \\
\hline CHEMBL1551968 & 688267 & 4.0 & 5.1027 & TRN & \\
\hline CHEMBL1450283 & 688267 & 5.1 & 5.0341 & TRN & \\
\hline CHEMBL1353639 & 688267 & 4.35 & 5.0474 & TRN & \\
\hline CHEMBL3209622 & 688267 & 4.0 & 5.0653 & TRN & \\
\hline CHEMBL1414374 & 688267 & 5.5 & 5.1854 & TRN & \\
\hline CHEMBL1334299 & 688267 & 4.6 & 5.1026 & TRN & \\
\hline CHEMBL1551714 & 688267 & 3.95 & 5.0648 & TRN & \\
\hline CHEMBL1457651 & 688267 & 4.6 & 5.0193 & TRN & \\
\hline CHEMBL1499392 & 688267 & 6.2 & 5.0665 & TRN & \\
\hline CHEMBL1373050 & 688267 & 3.95 & 5.0433 & TRN & \\
\hline CHEMBL1407913 & 688267 & 4.3 & 5.117 & TRN & \\
\hline CHEMBL1611644 & 688267 & 5.05 & 5.039 & TST & \\
\hline CHEMBL1319481 & 688267 & 6.1 & 5.0801 & TRN & \\
\hline CHEMBL1603233 & 688267 & 5.7 & 5.0864 & TRN & \\
\hline CHEMBL1483520 & 688267 & 4.35 & 5.0253 & TST & \\
\hline CHEMBL3207903 & 688267 & 6.2 & 5.0127 & TRN & \\
\hline CHEMBL1602039 & 688267 & 4.0 & 5.0276 & TST & \\
\hline CHEMBL1528294 & 688267 & 4.45 & 5.0481 & TRN & \\
\hline CHEMBL1539976 & 688267 & 5.8 & 5.0612 & TST & \\
\hline CHEMBL1394355 & 688267 & 5.95 & 5.1096 & TRN & \\
\hline CHEMBL1479550 & 688267 & 4.3 & 5.0663 & TRN & \\
\hline CHEMBL1486658 & 688267 & 6.25 & 5.0355 & TRN & \\
\hline CHEMBL1555861 & 688267 & 6.2 & 4.9946 & TRN & \\
\hline CHEMBL1538118 & 688267 & 6.25 & 5.0429 & TRN & \\
\hline CHEMBL1547321 & 688267 & 4.1 & 5.0095 & TST & \\
\hline CHEMBL1507778 & 688267 & 5.0 & 5.1211 & TST & \\
\hline CHEMBL1580757 & 688267 & 4.4 & 4.9746 & TRN & \\
\hline CHEMBL1348478 & 688267 & 5.85 & 5.0617 & TRN & \\
\hline CHEMBL1405613 & 688267 & 3.95 & 5.1041 & TRN & \\
\hline CHEMBL1575197 & 688267 & 4.35 & 5.0016 & TST & \\
\hline CHEMBL3193450 & 688267 & 6.5 & 4.9975 & TST & \\
\hline CHEMBL1384577 & 688267 & 5.8 & 5.0689 & TRN & \\
\hline CHEMBL602922 & 688267 & 6.2 & 5.0424 & TRN & \\
\hline CHEMBL1369475 & 688267 & 6.15 & 5.0562 & TST & \\
\hline
\end{tabular}




\begin{tabular}{|c|c|c|c|c|c|}
\hline \multicolumn{6}{|c|}{ Supplemental Table S2.txt } \\
\hline CHEMBL3197998 & 688267 & 5.75 & 5.0487 & TRN & \\
\hline CHEMBL1354857 & 688267 & 6.45 & 5.0676 & TRN & \\
\hline CHEMBL1613235 & 688267 & 5.35 & 5.1155 & TRN & \\
\hline CHEMBL1386940 & 688267 & 4.55 & 5.0581 & TRN & \\
\hline CHEMBL1449759 & 688267 & 4.05 & 5.0027 & TRN & \\
\hline CHEMBL1315688 & 688267 & 3.95 & 5.0779 & TST & \\
\hline CHEMBL1597872 & 688267 & 4.35 & 5.0363 & TST & \\
\hline CHEMBL3194626 & 688267 & 4.05 & 4.9781 & TRN & \\
\hline CHEMBL1530457 & 688267 & 5.6 & 5.0575 & TRN & \\
\hline CHEMBL1382249 & 688267 & 4.15 & 5.0496 & TRN & \\
\hline CHEMBL1519778 & 688267 & 4.8 & 5.0365 & TST & \\
\hline CHEMBL1349808 & 688267 & 4.0 & 5.065 & TRN & \\
\hline CHEMBL1347864 & 688267 & 5.55 & 5.038 & TRN & \\
\hline CHEMBL1489051 & 688267 & 4.15 & 5.0917 & TRN & \\
\hline CHEMBL1346639 & 688267 & 6.2 & 5.0286 & TRN & \\
\hline CHEMBL1492223 & 688267 & 4.0 & 5.0205 & TRN & \\
\hline CHEMBL1539669 & 688267 & 6.15 & 5.0878 & TST & \\
\hline CHEMBL1315198 & 688267 & 5.3 & 4.9779 & TRN & \\
\hline CHEMBL1451883 & 688267 & 4.2 & 4.9842 & TRN & \\
\hline CHEMBL1593157 & 688267 & 5.15 & 5.1152 & TRN & \\
\hline CHEMBL1491330 & 688267 & 5.05 & 5.0723 & TRN & \\
\hline CHEMBL1594983 & 688267 & 4.95 & 5.0411 & TRN & \\
\hline CHEMBL1579354 & 688267 & 4.3 & 5.0261 & TST & \\
\hline CHEMBL1407413 & 688267 & 5.95 & 5.0894 & TST & \\
\hline CHEMBL1480274 & 688267 & 4.6 & 5.0487 & TRN & \\
\hline CHEMBL1451327 & 688267 & 4.6 & 5.1034 & TST & \\
\hline CHEMBL1548256 & 688267 & 6.2 & 5.0709 & TRN & \\
\hline CHEMBL1370073 & 688267 & 4.05 & 5.0977 & TRN & \\
\hline CHEMBL1376293 & 688267 & 5.3 & 5.0817 & TRN & \\
\hline CHEMBL1324916 & 688267 & 5.05 & 5.0275 & TST & \\
\hline CHEMBL1482158 & 688267 & 4.2 & 5.0342 & TST & \\
\hline CHEMBL1424579 & 688267 & 5.3 & 5.12200 & 0000000001 & TRN \\
\hline CHEMBL1435419 & 688267 & 4.0 & 5.104 & TRN & \\
\hline CHEMBL1442334 & 688267 & 4.75 & 5.0091 & TRN & \\
\hline CHEMBL1600412 & 688267 & 3.95 & 5.1556 & TRN & \\
\hline CHEMBL1423625 & 688267 & 3.95 & 5.0516 & TST & \\
\hline CHEMBL1532284 & 688267 & 5.3 & 5.0179 & TRN & \\
\hline CHEMBL1390205 & 688267 & 5.95 & 5.0654 & TRN & \\
\hline CHEMBL1302129 & 688267 & 4.15 & 5.0318 & TRN & \\
\hline CHEMBL1561453 & 688267 & 4.05 & 4.9691 & TRN & \\
\hline CHEMBL1403832 & 688267 & 5.0 & 5.0356 & TST & \\
\hline CHEMBL1584985 & 688267 & 4.05 & 5.0488 & TRN & \\
\hline CHEMBL1534326 & 688267 & 4.35 & 5.0143 & TRN & \\
\hline CHEMBL1472692 & 688267 & 5.4 & 5.1082 & TRN & \\
\hline CHEMBL1348634 & 688267 & 5.55 & 5.1041 & TRN & \\
\hline CHEMBL1536200 & 688267 & 4.3 & 5.1077 & TST & \\
\hline CHEMBL1304417 & 688267 & 4.55 & 5.0716 & TST & \\
\hline CHEMBL1502778 & 688267 & 6.0 & 5.0517 & TRN & \\
\hline
\end{tabular}




\begin{tabular}{|c|c|c|c|c|c|}
\hline \multicolumn{6}{|c|}{ oplemental Table s } \\
\hline CHEMBL1511082 & 688267 & 4.3 & 5.0203 & TRN & \\
\hline CHEMBL1597444 & 688267 & 4.05 & 5.0892 & TRN & \\
\hline CHEMBL1501190 & 688267 & 4.3 & 5.0606 & TST & \\
\hline CHEMBL1360432 & 688267 & 6.2 & 5.0473 & TRN & \\
\hline CHEMBL1408948 & 688267 & 4.0 & 5.0441 & TRN & \\
\hline CHEMBL1316449 & 688267 & 5.35 & 5.1073 & TRN & \\
\hline CHEMBL1544616 & 688267 & 5.75 & 5.0757 & TRN & \\
\hline CHEMBL584520 & 688267 & 4.4 & 5.0137 & TST & \\
\hline CHEMBL1460373 & 688267 & 4.4 & 5.0409 & TRN & \\
\hline CHEMBL1327714 & 688267 & 4.5 & 5.0434 & TST & \\
\hline CHEMBL1580344 & 688267 & 5.5 & 5.0623 & TST & \\
\hline CHEMBL1437304 & 688267 & 5.55 & 4.9849 & TRN & \\
\hline CHEMBL1486306 & 688267 & 5.95 & 5.1124 & TRN & \\
\hline CHEMBL3210653 & 688267 & 4.55 & 5.0028 & TST & \\
\hline CHEMBL1558137 & 688267 & 5.25 & 5.0593 & TRN & \\
\hline CHEMBL1977487 & 688267 & 5.55 & 5.0933 & TRN & \\
\hline CHEMBL1314020 & 688267 & 4.65 & 5.0625 & TRN & \\
\hline CHEMBL1341577 & 688267 & 4.8 & 5.09399 & 9999999999 & TRN \\
\hline CHEMBL1483886 & 688267 & 4.35 & 5.0173 & TST & \\
\hline CHEMBL1551509 & 688267 & 6.0 & 5.0933 & TRN & \\
\hline CHEMBL1571686 & 688267 & 5.9 & 5.0508 & TRN & \\
\hline CHEMBL1490384 & 688267 & 4.1 & 5.0382 & TRN & \\
\hline CHEMBL1585309 & 688267 & 6.15 & 5.0108 & TRN & \\
\hline CHEMBL1359905 & 688267 & 5.3 & 5.0164 & TRN & \\
\hline CHEMBL1374775 & 688267 & 4.4 & 5.0315 & TRN & \\
\hline CHEMBL1330779 & 688267 & 5.35 & 5.1429 & TRN & \\
\hline CHEMBL1611397 & 688267 & 4.3 & 5.04 & TRN & \\
\hline CHEMBL1340716 & 688267 & 6.1 & 4.9788 & TRN & \\
\hline CHEMBL1302199 & 688267 & 5.0 & 5.0657 & TRN & \\
\hline CHEMBL1601497 & 688267 & 4.45 & 5.0581 & TST & \\
\hline CHEMBL3212626 & 688267 & 6.15 & 5.0752 & TST & \\
\hline CHEMBL1570160 & 688267 & 5.7 & 5.043 & TRN & \\
\hline CHEMBL1511613 & 688267 & 5.4 & 5.0793 & TRN & \\
\hline CHEMBL1564583 & 688267 & 4.0 & 5.1045 & TST & \\
\hline CHEMBL1494683 & 688267 & 6.45 & 5.0435 & TRN & \\
\hline CHEMBL1304863 & 688267 & 4.4 & 5.1108 & TRN & \\
\hline CHEMBL1474920 & 688267 & 4.2 & 5.055 & TRN & \\
\hline CHEMBL1521377 & 688267 & 4.0 & 5.0592 & TRN & \\
\hline CHEMBL1503311 & 688267 & 6.5 & 5.0512 & TRN & \\
\hline CHEMBL1319737 & 688267 & 4.15 & 5.0385 & TRN & \\
\hline CHEMBL1310135 & 688267 & 4.0 & 5.1067 & TRN & \\
\hline CHEMBL1519287 & 688267 & 5.6 & 5.0808 & TRN & \\
\hline CHEMBL1494138 & 688267 & 6.15 & 5.0198 & TRN & \\
\hline CHEMBL1478763 & 688267 & 6.2 & 5.1066 & TST & \\
\hline CHEMBL579766 & 688267 & 4.45 & 5.0927 & TRN & \\
\hline CHEMBL1599739 & 688267 & 5.75 & 5.1344 & TRN & \\
\hline CHEMBL1432011 & 688267 & 6.5 & 5.0394 & TST & \\
\hline CHEMBL1529789 & 688267 & 4.15 & 5.1245 & TRN & \\
\hline
\end{tabular}




\begin{tabular}{|c|c|c|c|c|c|}
\hline \multicolumn{6}{|c|}{ Supplemental Table S2.txt } \\
\hline CHEMBL1609997 & 688267 & 5.4 & 5.0528 & TST & \\
\hline CHEMBL1487157 & 688267 & 4.05 & 5.022 & TST & \\
\hline CHEMBL1455061 & 688267 & 5.75 & 4.9868 & TRN & \\
\hline CHEMBL1256885 & 688267 & 5.95 & 5.0734 & TST & \\
\hline CHEMBL 3190804 & 688267 & 6.45 & 5.0011 & TST & \\
\hline CHEMBL1544537 & 688267 & 6.15 & 5.0207 & TST & \\
\hline CHEMBL1587893 & 688267 & 4.05 & 5.0192 & TRN & \\
\hline CHEMBL1484653 & 688267 & 4.95 & 5.0716 & TRN & \\
\hline CHEMBL1440728 & 688267 & 5.3 & 5.0986 & TRN & \\
\hline CHEMBL1495929 & 688267 & 3.95 & 4.9851 & TRN & \\
\hline CHEMBL451477 & 688267 & 6.15 & 5.0387 & TST & \\
\hline CHEMBL1314350 & 688267 & 6.2 & 5.0233 & TRN & \\
\hline CHEMBL 2003602 & 688267 & 6.2 & 4.9718 & TST & \\
\hline CHEMBL1480192 & 688267 & 5.9 & 5.0255 & TRN & \\
\hline CHEMBL1527711 & 688267 & 6.15 & 5.043 & TRN & \\
\hline CHEMBL1553369 & 688267 & 5.45 & 5.0751 & TRN & \\
\hline CHEMBL1330199 & 688267 & 4.95 & 5.0432 & TRN & \\
\hline CHEMBL1309630 & 688267 & 5.65 & 5.0947 & TST & \\
\hline CHEMBL1441523 & 688267 & 6.1 & 5.0469 & TRN & \\
\hline CHEMBL1350984 & 688267 & 5.6 & 5.0961 & TRN & \\
\hline CHEMBL1487798 & 688267 & 4.1 & 5.1179 & TRN & \\
\hline CHEMBL1438104 & 688267 & 4.45 & 5.0347 & TRN & \\
\hline CHEMBL1316627 & 688267 & 6.15 & 5.0638 & TST & \\
\hline CHEMBL1504899 & 688267 & 5.25 & 4.96899 & 9999999999 & TRN \\
\hline CHEMBL1366431 & 688267 & 4.3 & 5.0388 & TRN & \\
\hline CHEMBL1396204 & 688267 & 4.05 & 5.0373 & TST & \\
\hline CHEMBL1354458 & 688267 & 6.0 & 5.0744 & TRN & \\
\hline CHEMBL1489335 & 688267 & 5.55 & 5.0243 & TST & \\
\hline CHEMBL1394215 & 688267 & 6.0 & 5.0439 & TRN & \\
\hline CHEMBL1515258 & 688267 & 6.15 & 5.0659 & TRN & \\
\hline CHEMBL1458671 & 688267 & 5.95 & 5.0613 & TRN & \\
\hline CHEMBL1430915 & 688267 & 4.6 & 5.0476 & TRN & \\
\hline CHEMBL3210997 & 688267 & 5.3 & 5.0011 & TRN & \\
\hline CHEMBL1567687 & 688267 & 6.2 & 5.0225 & TRN & \\
\hline CHEMBL329673 & 688267 & 5.55 & 5.0188 & TST & \\
\hline CHEMBL1365602 & 688267 & 5.95 & 5.1333 & TRN & \\
\hline CHEMBL1546537 & 688267 & 6.25 & 5.0339 & TST & \\
\hline CHEMBL1541724 & 688267 & 4.0 & 5.0466 & TST & \\
\hline CHEMBL1570014 & 688267 & 5.75 & 5.0727 & TST & \\
\hline CHEMBL1349906 & 688267 & 5.6 & 5.0132 & TRN & \\
\hline CHEMBL1344893 & 688267 & 6.2 & 5.0664 & TRN & \\
\hline CHEMBL1419310 & 688267 & 5.65 & 5.0902 & TRN & \\
\hline CHEMBL1593388 & 688267 & 6.2 & 5.022 & TST & \\
\hline CHEMBL1595306 & 688267 & 4.95 & 5.0277 & TRN & \\
\hline CHEMBL1407442 & 688267 & 4.3 & 5.0521 & TST & \\
\hline CHEMBL1404780 & 688267 & 4.85 & 5.0705 & TRN & \\
\hline CHEMBL1337682 & 688267 & 5.85 & 5.1524 & TRN & \\
\hline CHEMBL1415092 & 688267 & 4.05 & 5.0581 & TRN & \\
\hline
\end{tabular}




\begin{tabular}{|c|c|c|c|c|}
\hline \multirow[b]{2}{*}{ CHEMBL1471651 } & \multicolumn{4}{|c|}{ Supplemental Table S2.txt } \\
\hline & 688267 & 6.2 & 5.0983 & TST \\
\hline CHEMBL1458974 & 688267 & 6.25 & 5.1027 & TRN \\
\hline CHEMBL3194603 & 688267 & 4.55 & 5.0194 & TRN \\
\hline CHEMBL1391951 & 688267 & 4.05 & 5.0672 & TRN \\
\hline CHEMBL1551946 & 688267 & 4.05 & 5.0526 & TRN \\
\hline CHEMBL387618 & 688267 & 5.9 & 5.0252 & TRN \\
\hline CHEMBL1439129 & 688267 & 4.95 & 5.1277 & TRN \\
\hline CHEMBL1382209 & 688267 & 5.9 & 4.9864 & TRN \\
\hline CHEMBL1306878 & 688267 & 5.15 & 5.077 & TRN \\
\hline CHEMBL1609407 & 688267 & 6.25 & 4.9799 & TRN \\
\hline CHEMBL1571198 & 688267 & 4.1 & 5.1412 & TRN \\
\hline CHEMBL1325281 & 688267 & 4.35 & 5.0476 & TRN \\
\hline CHEMBL1451535 & 688267 & 5.45 & 5.0176 & TRN \\
\hline CHEMBL1544269 & 688267 & 4.05 & 5.0646 & TST \\
\hline CHEMBL1592184 & 688267 & 3.95 & 5.0632 & TRN \\
\hline CHEMBL1532796 & 688267 & 6.2 & 5.0417 & TRN \\
\hline CHEMBL1510868 & 688267 & 5.85 & 5.0339 & TST \\
\hline CHEMBL1564668 & 688267 & 5.2 & 5.0293 & TRN \\
\hline CHEMBL1554063 & 688267 & 3.95 & 5.0669 & TRN \\
\hline CHEMBL1611971 & 688267 & 5.55 & 5.0588 & TRN \\
\hline CHEMBL1358771 & 688267 & 6.05 & 5.0628 & TRN \\
\hline CHEMBL1524136 & 688267 & 4.55 & 5.1106 & TST \\
\hline CHEMBL 3193144 & 688267 & 4.35 & 5.0602 & TST \\
\hline CHEMBL1457366 & 688267 & 6.15 & 5.0287 & TST \\
\hline CHEMBL1517954 & 688267 & 6.2 & 5.0589 & TRN \\
\hline CHEMBL1326162 & 688267 & 6.0 & 5.0656 & TRN \\
\hline CHEMBL1304522 & 688267 & 4.05 & 5.1495 & TST \\
\hline CHEMBL1562415 & 688267 & 4.1 & 5.0009 & TRN \\
\hline CHEMBL1610725 & 688267 & 5.6 & 5.0765 & TST \\
\hline CHEMBL1343749 & 688267 & 5.6 & 5.0672 & TRN \\
\hline CHEMBL1409360 & 688267 & 4.8 & 5.0629 & TRN \\
\hline CHEMBL1526979 & 688267 & 4.25 & 5.0706 & TRN \\
\hline CHEMBL1313013 & 688267 & 4.4 & 5.011 & TRN \\
\hline CHEMBL1601699 & 688267 & 4.05 & 5.0839 & TST \\
\hline CHEMBL1459670 & 688267 & 5.65 & 5.1116 & TRN \\
\hline CHEMBL1499035 & 688267 & 4.0 & 5.0144 & TRN \\
\hline CHEMBL1559572 & 688267 & 4.5 & 5.1209 & TRN \\
\hline CHEMBL1519361 & 688267 & 4.0 & 5.0688 & TRN \\
\hline CHEMBL1426971 & 688267 & 8.2007 & 5.0492 & TRN \\
\hline CHEMBL1331010 & 688267 & 4.95 & 5.0188 & TST \\
\hline CHEMBL3192916 & 688267 & 4.4 & 5.0782 & TST \\
\hline CHEMBL1572437 & 688267 & 3.95 & 5.0732 & TRN \\
\hline CHEMBL1584237 & 688267 & 4.35 & 5.0679 & TRN \\
\hline CHEMBL1548846 & 688267 & 4.0 & 5.0311 & TRN \\
\hline CHEMBL1472480 & 688267 & 6.15 & 5.0803 & TRN \\
\hline CHEMBL3195994 & 688267 & 4.0 & 4.9829 & TRN \\
\hline CHEMBL1553675 & 688267 & 5.05 & 5.0793 & TRN \\
\hline CHEMBL1518179 & 688267 & 5.35 & 5.1005 & TRN \\
\hline
\end{tabular}




\begin{tabular}{|c|c|c|c|c|c|}
\hline \multirow{3}{*}{$\begin{array}{l}\text { CHEMBL1328223 } \\
\text { CHEMBL1375504 }\end{array}$} & \multirow{3}{*}{$\begin{array}{l}688267 \\
688267\end{array}$} & \multicolumn{4}{|c|}{ Supplemental Table S2.txt } \\
\hline & & 4.6 & 5.0939 & 9999999999 & TRN \\
\hline & & 4.35 & 5.1016 & TRN & \\
\hline CHEMBL1309235 & 688267 & 6.2 & 5.0365 & TST & \\
\hline CHEMBL1494856 & 688267 & 3.95 & 5.0953 & TRN & \\
\hline CHEMBL1591775 & 688267 & 4.45 & 5.0247 & TRN & \\
\hline CHEMBL1491235 & 688267 & 6.2 & 5.0987 & TRN & \\
\hline CHEMBL1398704 & 688267 & 4.05 & 5.1518 & TST & \\
\hline CHEMBL1312570 & 688267 & 4.35 & 5.0146 & TRN & \\
\hline CHEMBL1443172 & 688267 & 4.05 & 4.9887 & TRN & \\
\hline CHEMBL1318305 & 688267 & 4.65 & 4.9971 & TRN & \\
\hline CHEMBL1572833 & 688267 & 4.2 & 5.0397 & TRN & \\
\hline CHEMBL1352650 & 688267 & 5.3 & 5.0813 & TRN & \\
\hline CHEMBL1328285 & 688267 & 4.35 & 5.0084 & TRN & \\
\hline CHEMBL1433200 & 688267 & 4.0 & 5.0045 & TRN & \\
\hline CHEMBL1514457 & 688267 & 6.2 & 5.0909 & TRN & \\
\hline CHEMBL1362565 & 688267 & 5.0 & 5.112 & TRN & \\
\hline CHEMBL1407353 & 688267 & 5.35 & 5.0667 & TST & \\
\hline CHEMBL1504104 & 688267 & 4.55 & 5.0535 & TRN & \\
\hline CHEMBL1599946 & 688267 & 3.95 & 5.0042 & TST & \\
\hline CHEMBL1598519 & 688267 & 6.5 & 5.0551 & TRN & \\
\hline CHEMBL1331185 & 688267 & 5.85 & 5.119 & TRN & \\
\hline CHEMBL1316717 & 688267 & 4.95 & 5.0985 & TRN & \\
\hline CHEMBL1507883 & 688267 & 5.3 & 5.0658 & TST & \\
\hline CHEMBL1558666 & 688267 & 5.6 & 5.0556 & TRN & \\
\hline CHEMBL1433936 & 688267 & 6.2 & 5.0803 & TRN & \\
\hline CHEMBL1478843 & 688267 & 4.5 & 5.0822 & TRN & \\
\hline CHEMBL1491384 & 688267 & 5.35 & 5.0164 & TRN & \\
\hline CHEMBL1484977 & 688267 & 4.35 & 5.0637 & TRN & \\
\hline CHEMBL1327285 & 688267 & 6.2 & 5.0382 & TRN & \\
\hline CHEMBL1355133 & 688267 & 5.65 & 5.0243 & TRN & \\
\hline CHEMBL1428504 & 688267 & 5.4 & 5.0934 & TST & \\
\hline CHEMBL1474718 & 688267 & 4.0 & 5.0458 & TRN & \\
\hline CHEMBL1316510 & 688267 & 6.05 & 5.0321 & TRN & \\
\hline CHEMBL1581898 & 688267 & 5.3 & 5.0965 & TRN & \\
\hline CHEMBL1389031 & 688267 & 5.5 & 5.021 & TRN & \\
\hline CHEMBL1522275 & 688267 & 5.85 & 5.0701 & TST & \\
\hline CHEMBL1469057 & 688267 & 6.15 & 5.0087 & TRN & \\
\hline CHEMBL1334252 & 688267 & 5.35 & 5.0622 & TST & \\
\hline CHEMBL3189394 & 688267 & 5.7 & 5.0031 & TRN & \\
\hline CHEMBL1371766 & 688267 & 4.45 & 4.9785 & TRN & \\
\hline CHEMBL1378810 & 688267 & 5.0 & 5.0582 & TRN & \\
\hline CHEMBL1434968 & 688267 & 5.05 & 5.0802 & TRN & \\
\hline CHEMBL1975484 & 688267 & 5.15 & 4.9996 & TRN & \\
\hline CHEMBL 1333250 & 688267 & 5.65 & 5.0716 & TRN & \\
\hline CHEMBL1422142 & 688267 & 4.4 & 5.0409 & TST & \\
\hline CHEMBL3189667 & 688267 & 5.55 & 5.0191 & TST & \\
\hline CHEMBL 1603420 & 688267 & 4.65 & 5.033 & TRN & \\
\hline CHEMBL1335339 & 688267 & 4.4 & 5.0784 & TRN & \\
\hline
\end{tabular}




\begin{tabular}{|c|c|c|c|c|c|}
\hline \multicolumn{6}{|c|}{ pıemental } \\
\hline CHEMBL1489072 & 688267 & 4.3 & 5.0122 & TRN & \\
\hline CHEMBL1494538 & 688267 & 6.2 & 5.1559 & TRN & \\
\hline CHEMBL1433071 & 688267 & 6.2 & 5.0841 & TRN & \\
\hline CHEMBL1317547 & 688267 & 4.05 & 5.1309 & TRN & \\
\hline CHEMBL1448471 & 688267 & 4.5 & 5.106 & TRN & \\
\hline CHEMBL1410941 & 688267 & 5.6 & 5.01699 & 99999999995 & TRN \\
\hline CHEMBL1428664 & 688267 & 5.85 & 5.0182 & TST & \\
\hline CHEMBL1361381 & 688267 & 4.4 & 5.0159 & TRN & \\
\hline CHEMBL1321448 & 688267 & 6.15 & 5.0328 & TRN & \\
\hline CHEMBL1468192 & 688267 & 5.5 & 4.9862 & TST & \\
\hline CHEMBL1321875 & 688267 & 4.05 & 5.098 & TRN & \\
\hline CHEMBL1395653 & 688267 & 4.3 & 5.091 & TRN & \\
\hline CHEMBL1408699 & 688267 & 5.8 & 5.1005 & TST & \\
\hline CHEMBL1402353 & 688267 & 5.45 & 5.0579 & TRN & \\
\hline CHEMBL1479509 & 688267 & 4.7 & 5.0157 & TRN & \\
\hline CHEMBL1427686 & 688267 & 4.05 & 5.0351 & TST & \\
\hline CHEMBL1476628 & 688267 & 4.25 & 4.993 & TRN & \\
\hline CHEMBL1470593 & 688267 & 4.45 & 5.0564 & TRN & \\
\hline CHEMBL1590037 & 688267 & 5.75 & 5.1369 & TRN & \\
\hline CHEMBL3190800 & 688267 & 5.9 & 5.0179 & TRN & \\
\hline CHEMBL1447382 & 688267 & 4.65 & 5.0426 & TRN & \\
\hline CHEMBL1520581 & 688267 & 6.2 & 5.0489 & TRN & \\
\hline CHEMBL1542679 & 688267 & 4.0 & 5.1241 & TRN & \\
\hline CHEMBL1376452 & 688267 & 4.0 & 5.0931 & TRN & \\
\hline CHEMBL1578533 & 688267 & 4.0 & 5.0778 & TRN & \\
\hline CHEMBL1413814 & 688267 & 6.05 & 5.12299 & 9999999999 & TRN \\
\hline CHEMBL1413072 & 688267 & 5.2 & 5.0506 & TRN & \\
\hline CHEMBL1434001 & 688267 & 5.65 & 5.0201 & TRN & \\
\hline CHEMBL1434594 & 688267 & 5.2 & 5.0143 & TRN & \\
\hline CHEMBL1302161 & 688267 & 5.0 & 5.0245 & TRN & \\
\hline CHEMBL1308115 & 688267 & 4.05 & 5.0291 & TST & \\
\hline CHEMBL1430919 & 688267 & 4.05 & 4.975 & TST & \\
\hline CHEMBL1451262 & 688267 & 4.35 & 5.0776 & TST & \\
\hline CHEMBL1428315 & 688267 & 5.3 & 4.9968 & TRN & \\
\hline CHEMBL1333023 & 688267 & 4.9 & 5.0955 & TRN & \\
\hline CHEMBL1422930 & 688267 & 5.75 & 5.0911 & TST & \\
\hline CHEMBL1560446 & 688267 & 5.45 & 5.03100 & 0000000001 & TRN \\
\hline CHEMBL1349833 & 688267 & 5.7 & 5.0458 & TST & \\
\hline CHEMBL1315600 & 688267 & 6.15 & 5.0227 & TRN & \\
\hline CHEMBL1351093 & 688267 & 6.2 & 5.1028 & TRN & \\
\hline CHEMBL1335174 & 688267 & 4.35 & 5.0285 & TRN & \\
\hline CHEMBL1546099 & 688267 & 6.15 & 5.0681 & TRN & \\
\hline CHEMBL1596200 & 688267 & 5.3 & 5.1 & TRN & \\
\hline CHEMBL1302500 & 688267 & 5.8 & 5.0369 & TRN & \\
\hline CHEMBL1351874 & 688267 & 6.5 & 5.08899 & 99999999995 & TST \\
\hline CHEMBL1374364 & 688267 & 5.2 & 5.1056 & TST & \\
\hline CHEMBL1585794 & 688267 & 4.0 & 5.0514 & TRN & \\
\hline CHEMBL1344540 & 688267 & 5.4 & 5.0306 & TRN & \\
\hline
\end{tabular}




\begin{tabular}{|c|c|c|c|c|c|}
\hline \multicolumn{6}{|c|}{ Supplemental Table S2.txt } \\
\hline CHEMBL1428866 & 688267 & 5.55 & 5.0158 & TST & \\
\hline CHEMBL1564447 & 688267 & 4.4 & 5.0088 & TRN & \\
\hline CHEMBL1514368 & 688267 & 3.95 & 5.0403 & TRN & \\
\hline CHEMBL1383601 & 688267 & 4.95 & 4.9816 & TRN & \\
\hline CHEMBL1589311 & 688267 & 4.0 & 5.0402 & TRN & \\
\hline CHEMBL1369899 & 688267 & 4.4 & 5.0835 & TRN & \\
\hline CHEMBL1470718 & 688267 & 4.4 & 5.0532 & TRN & \\
\hline CHEMBL1420349 & 688267 & 4.0 & 5.1131 & TRN & \\
\hline CHEMBL1437609 & 688267 & 5.3 & 5.0916 & TRN & \\
\hline CHEMBL1305263 & 688267 & 4.25 & 5.0784 & TST & \\
\hline CHEMBL1489055 & 688267 & 5.05 & 5.0551 & TRN & \\
\hline CHEMBL1385756 & 688267 & 5.55 & 5.0898 & TST & \\
\hline CHEMBL1531784 & 688267 & 6.15 & 5.0784 & TRN & \\
\hline CHEMBL1362474 & 688267 & 4.45 & 5.0723 & TRN & \\
\hline CHEMBL1369606 & 688267 & 5.1 & 5.0394 & TRN & \\
\hline CHEMBL1362181 & 688267 & 5.8 & 5.0018 & TRN & \\
\hline CHEMBL1557947 & 688267 & 3.95 & 4.9863 & TST & \\
\hline CHEMBL1473393 & 688267 & 5.45 & 5.0649 & TRN & \\
\hline CHEMBL1473326 & 688267 & 4.0 & 5.0271 & TRN & \\
\hline CHEMBL1540958 & 688267 & 4.3 & 5.0973 & TST & \\
\hline CHEMBL1531259 & 688267 & 4.05 & 5.0558 & TRN & \\
\hline CHEMBL1300161 & 688267 & 5.45 & 5.0762 & TST & \\
\hline CHEMBL1407129 & 688267 & 4.65 & 5.0721 & TRN & \\
\hline CHEMBL1571539 & 688267 & 4.4 & 5.0004 & TRN & \\
\hline CHEMBL1552376 & 688267 & 4.05 & 5.1005 & TRN & \\
\hline CHEMBL1516573 & 688267 & 4.4 & 5.0486 & TRN & \\
\hline CHEMBL1476004 & 688267 & 5.0 & 5.1162 & TRN & \\
\hline CHEMBL1410007 & 688267 & 5.25 & 5.0405 & TRN & \\
\hline CHEMBL1388536 & 688267 & 6.25 & 5.005 & TRN & \\
\hline CHEMBL46918 & 688267 & 6.0 & 5.1148 & TRN & \\
\hline CHEMBL 3190723 & 688267 & 6.45 & 5.0059 & TRN & \\
\hline CHEMBL1383017 & 688267 & 5.0 & 5.0446 & TRN & \\
\hline CHEMBL1577389 & 688267 & 5.5 & 5.0126 & TRN & \\
\hline CHEMBL 3210477 & 688267 & 5.1 & 5.1007 & TST & \\
\hline CHEMBL1541462 & 688267 & 4.0 & 5.0982 & TRN & \\
\hline CHEMBL1500461 & 688267 & 4.0 & 5.1445 & TRN & \\
\hline CHEMBL1554682 & 688267 & 4.4 & 5.06800 & 00000000005 & TRN \\
\hline CHEMBL1315267 & 688267 & 5.45 & 5.0576 & TRN & \\
\hline CHEMBL1491764 & 688267 & 4.7 & 5.0208 & TRN & \\
\hline CHEMBL1459038 & 688267 & 6.15 & 5.0763 & TST & \\
\hline CHEMBL1601321 & 688267 & 5.5 & 5.0917 & TRN & \\
\hline CHEMBL1586374 & 688267 & 5.95 & 5.0583 & TRN & \\
\hline CHEMBL1330562 & 688267 & 4.5 & 5.0457 & TRN & \\
\hline CHEMBL1492565 & 688267 & 6.0 & 5.0024 & TST & \\
\hline CHEMBL3196163 & 688267 & 4.0 & 5.0 & TST & \\
\hline CHEMBL1375840 & 688267 & 4.65 & 5.0324 & TRN & \\
\hline CHEMBL1434253 & 688267 & 5.05 & 5.0077 & TRN & \\
\hline CHEMBL1077994 & 688267 & 4.0 & 5.0515 & TRN & \\
\hline
\end{tabular}




\begin{tabular}{|c|c|c|c|c|}
\hline \multicolumn{5}{|c|}{ Supplemental Table S2.txt } \\
\hline CHEMBL1571101 & 688267 & 5.1 & 5.0169 & TRN \\
\hline CHEMBL1577881 & 688267 & 5.9 & 5.0505 & TRN \\
\hline CHEMBL1316997 & 688267 & 4.05 & 5.1407 & TRN \\
\hline CHEMBL1490829 & 688267 & 5.35 & 5.0412 & TRN \\
\hline CHEMBL1371175 & 688267 & 5.45 & 5.0351 & TRN \\
\hline CHEMBL1424962 & 688267 & 4.35 & 5.0171 & TRN \\
\hline CHEMBL1490327 & 688267 & 4.0 & 5.0077 & TRN \\
\hline CHEMBL1473562 & 688267 & 5.45 & 5.1133 & TST \\
\hline CHEMBL1455828 & 688267 & 5.35 & 5.0941 & TRN \\
\hline CHEMBL1338490 & 688267 & 4.5 & 5.0333 & TRN \\
\hline CHEMBL1513357 & 688267 & 5.45 & 4.9914 & TRN \\
\hline CHEMBL1330178 & 688267 & 5.65 & 5.1068 & TRN \\
\hline CHEMBL1610825 & 688267 & 5.05 & 5.0867 & TRN \\
\hline CHEMBL1585732 & 688267 & 6.15 & 5.0178 & TRN \\
\hline CHEMBL1402774 & 688267 & 6.2 & 5.0854 & TRN \\
\hline CHEMBL1302212 & 688267 & 6.15 & 5.0125 & TRN \\
\hline CHEMBL1478851 & 688267 & 3.95 & 5.0437 & TST \\
\hline CHEMBL1360349 & 688267 & 5.25 & 5.1307 & TRN \\
\hline CHEMBL1362819 & 688267 & 4.0 & 5.0864 & TRN \\
\hline CHEMBL1369073 & 688267 & 4.55 & 5.0272 & TRN \\
\hline CHEMBL1482725 & 688267 & 4.55 & 5.006 & TRN \\
\hline CHEMBL1319045 & 688267 & 4.2 & 5.1235 & TRN \\
\hline CHEMBL1508005 & 688267 & 6.2 & 5.0643 & TRN \\
\hline CHEMBL1418885 & 688267 & 4.1 & 4.9937 & TRN \\
\hline CHEMBL1450925 & 688267 & 4.75 & 5.0728 & TRN \\
\hline CHEMBL1343016 & 688267 & 4.35 & 5.1186 & TRN \\
\hline CHEMBL1523548 & 688267 & 4.05 & 5.0131 & TRN \\
\hline CHEMBL1596567 & 688267 & 4.2 & 5.05 & TST \\
\hline CHEMBL1477306 & 688267 & 3.95 & 5.0027 & TST \\
\hline CHEMBL1320337 & 688267 & 4.1 & 5.0064 & TRN \\
\hline CHEMBL1395197 & 688267 & 3.85 & 5.0352 & TRN \\
\hline CHEMBL1405078 & 688267 & 4.85 & 5.0398 & TST \\
\hline CHEMBL1421222 & 688267 & 5.55 & 5.0542 & TST \\
\hline CHEMBL1329539 & 688267 & 6.15 & 5.1042 & TRN \\
\hline CHEMBL1443859 & 688267 & 4.55 & 5.0338 & TST \\
\hline CHEMBL1381150 & 688267 & 4.35 & 5.0906 & TRN \\
\hline CHEMBL1431308 & 688267 & 5.2 & 5.0927 & TRN \\
\hline CHEMBL1317644 & 688267 & 4.6 & 5.0632 & TRN \\
\hline CHEMBL1453688 & 688267 & 4.0 & 5.0416 & TST \\
\hline CHEMBL1371618 & 688267 & 5.8 & 5.0246 & TST \\
\hline CHEMBL1542807 & 688267 & 4.7 & 5.0776 & TST \\
\hline CHEMBL1417024 & 688267 & 5.6 & 5.0721 & TRN \\
\hline CHEMBL1303280 & 688267 & 3.95 & 4.9853 & TRN \\
\hline CHEMBL1501941 & 688267 & 4.6 & 4.9661 & TRN \\
\hline CHEMBL1320357 & 688267 & 5.3 & 5.0623 & TRN \\
\hline CHEMBL1538238 & 688267 & 6.15 & 5.0983 & TRN \\
\hline CHEMBL1552301 & 688267 & 3.95 & 5.0955 & TRN \\
\hline CHEMBL1308532 & 688267 & 4.0 & 5.0544 & TRN \\
\hline
\end{tabular}




\begin{tabular}{|c|c|c|c|c|c|}
\hline \multicolumn{6}{|c|}{ Supplemental Table S2.txt } \\
\hline CHEMBL1318680 & 688267 & 5.55 & 5.0221 & TRN & \\
\hline CHEMBL1548769 & 688267 & 5.0 & 4.9984 & TST & \\
\hline CHEMBL1336975 & 688267 & 3.95 & 5.0472 & TRN & \\
\hline CHEMBL1406903 & 688267 & 6.2 & 5.1049 & TRN & \\
\hline CHEMBL1579639 & 688267 & 5.55 & 5.0741 & TRN & \\
\hline CHEMBL1515212 & 688267 & 5.1 & 5.0936 & TRN & \\
\hline CHEMBL1587496 & 688267 & 5.9 & 5.0334 & TRN & \\
\hline CHEMBL1390541 & 688267 & 5.25 & 5.1169 & TRN & \\
\hline CHEMBL1990959 & 688267 & 6.2 & 4.9542 & TRN & \\
\hline CHEMBL1611571 & 688267 & 5.35 & 5.0926 & TST & \\
\hline CHEMBL1566582 & 688267 & 3.35 & 5.0693 & TST & \\
\hline CHEMBL1470701 & 688267 & 4.4 & 5.0317 & TRN & \\
\hline CHEMBL1428086 & 688267 & 5.3 & 5.0938 & TRN & \\
\hline CHEMBL1588276 & 688267 & 5.3 & 5.1136 & TST & \\
\hline CHEMBL1579903 & 688267 & 4.05 & 5.0401 & TRN & \\
\hline CHEMBL1366059 & 688267 & 6.2 & 5.05699 & 99999999995 & TST \\
\hline CHEMBL1550114 & 688267 & 4.4 & 5.07 & TRN & \\
\hline CHEMBL1316720 & 688267 & 5.3 & 5.1085 & TRN & \\
\hline CHEMBL1594613 & 688267 & 5.85 & 5.0903 & TRN & \\
\hline CHEMBL3190710 & 688267 & 5.85 & 5.0576 & TRN & \\
\hline CHEMBL1609136 & 688267 & 6.2 & 5.114 & TRN & \\
\hline CHEMBL1455888 & 688267 & 4.5 & 5.0356 & TST & \\
\hline CHEMBL1530889 & 688267 & 6.2 & 5.0164 & TRN & \\
\hline CHEMBL1440126 & 688267 & 4.0 & 5.029 & TRN & \\
\hline CHEMBL1433398 & 688267 & 4.85 & 5.0458 & TST & \\
\hline CHEMBL1553176 & 688267 & 5.25 & 5.0671 & TRN & \\
\hline CHEMBL1543764 & 688267 & 6.0 & 5.1114 & TRN & \\
\hline CHEMBL1433695 & 688267 & 4.25 & 5.1041 & TRN & \\
\hline CHEMBL1544475 & 688267 & 6.5 & 5.0436 & TRN & \\
\hline CHEMBL1533379 & 688267 & 4.0 & 5.0434 & TRN & \\
\hline CHEMBL1413553 & 688267 & 5.1 & 5.0533 & TRN & \\
\hline CHEMBL1482886 & 688267 & 5.85 & 5.1135 & TRN & \\
\hline CHEMBL1485934 & 688267 & 4.05 & 5.098 & TRN & \\
\hline CHEMBL1593521 & 688267 & 5.5 & 5.0791 & TRN & \\
\hline CHEMBL1580447 & 688267 & 5.65 & 5.0995 & TRN & \\
\hline CHEMBL1572304 & 688267 & 3.95 & 5.0416 & TRN & \\
\hline CHEMBL1452355 & 688267 & 4.0 & 5.0082 & TST & \\
\hline CHEMBL1470031 & 688267 & 5.1 & 5.0941 & TRN & \\
\hline CHEMBL1432151 & 688267 & 5.5 & 5.0773 & TST & \\
\hline CHEMBL1523220 & 688267 & 4.85 & 5.0288 & TRN & \\
\hline CHEMBL1576134 & 688267 & 6.15 & 5.0125 & TRN & \\
\hline CHEMBL1556366 & 688267 & 4.6 & 5.0405 & TRN & \\
\hline CHEMBL1579860 & 688267 & 6.15 & 5.0851 & TST & \\
\hline CHEMBL1609409 & 688267 & 5.45 & 5.0569 & TRN & \\
\hline CHEMBL1351781 & 688267 & 4.0 & 5.0595 & TRN & \\
\hline CHEMBL1364710 & 688267 & 5.2 & 5.0898 & TRN & \\
\hline CHEMBL1510733 & 688267 & 4.0 & 5.0144 & TRN & \\
\hline CHEMBL1507243 & 688267 & 6.05 & 5.0398 & TRN & \\
\hline
\end{tabular}




\begin{tabular}{|c|c|c|c|c|}
\hline \multirow[b]{2}{*}{ CHEMBL1509952 } & & & ipplement & al $\mathrm{T}$ \\
\hline & 688267 & 6.1 & 5.013 & TRN \\
\hline CHEMBL485012 & 688267 & 5.0 & 5.0112 & TRN \\
\hline CHEMBL1324435 & 688267 & 4.25 & 5.0773 & TRN \\
\hline CHEMBL1412889 & 688267 & 4.45 & 5.0971 & TRN \\
\hline CHEMBL1609742 & 688267 & 4.4 & 5.0855 & TRN \\
\hline CHEMBL1525713 & 688267 & 4.1 & 5.0515 & TST \\
\hline CHEMBL1613063 & 688267 & 4.15 & 5.0319 & TRN \\
\hline CHEMBL1976839 & 688267 & 5.55 & 5.0365 & TRN \\
\hline CHEMBL1613030 & 688267 & 5.2 & 5.0649 & TRN \\
\hline CHEMBL1543434 & 688267 & 5.55 & 4.9983 & TRN \\
\hline CHEMBL1588892 & 688267 & 6.25 & 5.0261 & TRN \\
\hline CHEMBL1613553 & 688267 & 6.2 & 5.0498 & TST \\
\hline CHEMBL1611777 & 688267 & 5.75 & 5.0329 & TRN \\
\hline CHEMBL1554370 & 688267 & 3.95 & 5.1161 & TRN \\
\hline CHEMBL1334908 & 688267 & 3.95 & 5.0169 & TRN \\
\hline CHEMBL1556300 & 688267 & 4.55 & 5.0784 & TRN \\
\hline CHEMBL1574375 & 688267 & 5.85 & 5.0462 & TRN \\
\hline CHEMBL1363340 & 688267 & 6.45 & 4.9919 & TRN \\
\hline CHEMBL1552964 & 688267 & 6.45 & 5.0339 & TRN \\
\hline CHEMBL1437604 & 688267 & 5.8 & 5.1553 & TST \\
\hline CHEMBL1489656 & 688267 & 4.0 & 5.0621 & TRN \\
\hline CHEMBL1577411 & 688267 & 5.55 & 5.0295 & TRN \\
\hline CHEMBL1561064 & 688267 & 5.35 & 5.0307 & TRN \\
\hline CHEMBL1372845 & 688267 & 5.35 & 5.0981 & TRN \\
\hline CHEMBL1976225 & 688267 & 3.95 & 5.0112 & TST \\
\hline CHEMBL1311942 & 688267 & 6.2 & 5.0936 & TRN \\
\hline CHEMBL1489120 & 688267 & 4.4 & 5.0895 & TRN \\
\hline CHEMBL1387939 & 688267 & 5.45 & 5.1163 & TRN \\
\hline CHEMBL1552537 & 688267 & 6.2 & 5.0842 & TST \\
\hline CHEMBL1534017 & 688267 & 3.95 & 5.0158 & TRN \\
\hline CHEMBL1429463 & 688267 & 4.25 & 5.1194 & TST \\
\hline CHEMBL1507604 & 688267 & 5.5 & 5.042 & TST \\
\hline CHEMBL1554316 & 688267 & 5.55 & 5.0688 & TRN \\
\hline CHEMBL1486385 & 688267 & 5.4 & 5.0392 & TRN \\
\hline CHEMBL 2373575 & 688267 & 6.45 & 5.0616 & TRN \\
\hline CHEMBL1412443 & 688267 & 4.05 & 5.0184 & TRN \\
\hline CHEMBL1470616 & 688267 & 4.0 & 5.1125 & TRN \\
\hline CHEMBL1406660 & 688267 & 3.95 & 5.0096 & TRN \\
\hline CHEMBL3208111 & 688267 & 5.2 & 5.0595 & TRN \\
\hline CHEMBL1437279 & 688267 & 4.0 & 5.0097 & TRN \\
\hline CHEMBL1411319 & 688267 & 4.95 & 5.0374 & TRN \\
\hline CHEMBL1482620 & 688267 & 5.55 & 5.0363 & TRN \\
\hline CHEMBL3189708 & 688267 & 3.95 & 5.0482 & TRN \\
\hline CHEMBL1446493 & 688267 & 4.45 & 5.1087 & TRN \\
\hline CHEMBL1473181 & 688267 & 4.8 & 5.0864 & TST \\
\hline CHEMBL1489766 & 688267 & 6.2 & 5.0092 & TRN \\
\hline CHEMBL1351871 & 688267 & 4.75 & 5.0972 & TST \\
\hline CHEMBL1454999 & 688267 & 6.25 & 4.974 & TST \\
\hline
\end{tabular}




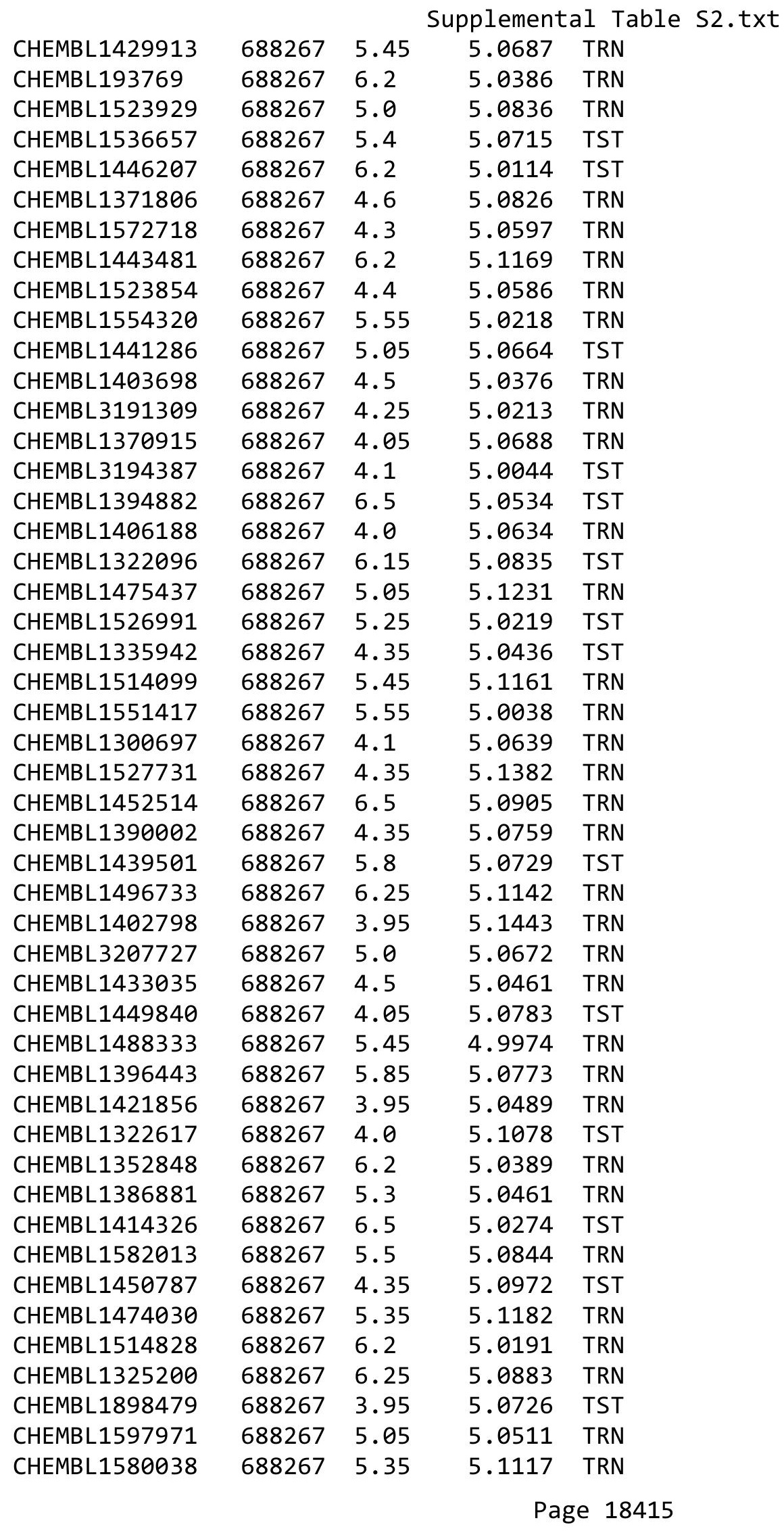




\begin{tabular}{|c|c|c|c|c|}
\hline \multicolumn{5}{|c|}{ Supplemental Table S2.txt } \\
\hline CHEMBL1569359 & 688267 & 6.15 & 5.0551 & TRN \\
\hline CHEMBL1327738 & 688267 & 5.05 & 5.0991 & TRN \\
\hline CHEMBL1539118 & 688267 & 6.2 & 5.0383 & TRN \\
\hline CHEMBL1396563 & 688267 & 4.25 & 5.0333 & TRN \\
\hline CHEMBL1544998 & 688267 & 4.4 & 5.0083 & TRN \\
\hline CHEMBL1601843 & 688267 & 5.55 & 5.0386 & TRN \\
\hline CHEMBL1594835 & 688267 & 5.6 & 4.9941 & TST \\
\hline CHEMBL1604992 & 688267 & 5.0 & 5.0512 & TST \\
\hline CHEMBL1413626 & 688267 & 5.15 & 5.0352 & TRN \\
\hline CHEMBL1324981 & 688267 & 3.95 & 5.0413 & TRN \\
\hline CHEMBL1599039 & 688267 & 4.7 & 5.115 & TRN \\
\hline CHEMBL1519431 & 688267 & 5.1 & 5.0376 & TRN \\
\hline CHEMBL1399031 & 688267 & 6.3 & 5.0676 & TST \\
\hline CHEMBL1593357 & 688267 & 6.45 & 5.0616 & TRN \\
\hline CHEMBL1314380 & 688267 & 4.3 & 5.0191 & TRN \\
\hline CHEMBL1333087 & 688267 & 4.0 & 4.9981 & TRN \\
\hline CHEMBL1562389 & 688267 & 4.1 & 5.0487 & TRN \\
\hline CHEMBL1473969 & 688267 & 4.0 & 4.9929 & TRN \\
\hline CHEMBL1378402 & 688267 & 4.6 & 5.0032 & TRN \\
\hline CHEMBL1357434 & 688267 & 4.0 & 5.0992 & TRN \\
\hline CHEMBL3198347 & 688267 & 4.8 & 5.0421 & TST \\
\hline CHEMBL1366240 & 688267 & 5.35 & 5.0533 & TRN \\
\hline CHEMBL1471205 & 688267 & 4.15 & 5.0718 & TRN \\
\hline CHEMBL1541594 & 688267 & 4.4 & 5.0306 & TRN \\
\hline CHEMBL1424865 & 688267 & 4.8 & 5.129 & TRN \\
\hline CHEMBL1395713 & 688267 & 4.3 & 5.0494 & TRN \\
\hline CHEMBL1300418 & 688267 & 6.2 & 5.0156 & TST \\
\hline CHEMBL1372066 & 688267 & 4.95 & 5.0293 & TRN \\
\hline CHEMBL1512423 & 688267 & 6.15 & 5.0616 & TRN \\
\hline CHEMBL1304555 & 688267 & 4.05 & 5.0536 & TST \\
\hline CHEMBL1303609 & 688267 & 5.45 & 5.0679 & TRN \\
\hline CHEMBL1442586 & 688267 & 5.05 & 4.9996 & TST \\
\hline CHEMBL1434689 & 688267 & 6.2 & 5.0315 & TRN \\
\hline CHEMBL3193158 & 688267 & 4.0 & 5.0811 & TST \\
\hline CHEMBL1538012 & 688267 & 4.8 & 5.0424 & TRN \\
\hline CHEMBL3211216 & 688267 & 6.2 & 5.0781 & TRN \\
\hline CHEMBL578276 & 688267 & 4.05 & 5.0563 & TRN \\
\hline CHEMBL1402908 & 688267 & 4.35 & 4.9722 & TRN \\
\hline CHEMBL3189171 & 688267 & 5.9 & 5.0373 & TRN \\
\hline CHEMBL1539602 & 688267 & 4.4 & 5.0518 & TRN \\
\hline CHEMBL1326925 & 688267 & 4.05 & 5.117 & TRN \\
\hline CHEMBL1360823 & 688267 & 4.5 & 5.0683 & TRN \\
\hline CHEMBL1429166 & 688267 & 6.2 & 5.0319 & TRN \\
\hline CHEMBL1431377 & 688267 & 5.2 & 5.0097 & TST \\
\hline CHEMBL520992 & 688267 & 5.05 & 5.0746 & TST \\
\hline CHEMBL 264702 & 688267 & 6.0 & 5.0351 & TRN \\
\hline CHEMBL1401823 & 688267 & 5.3 & 5.0751 & TST \\
\hline CHEMBL1495635 & 688267 & 4.05 & 5.1081 & TRN \\
\hline
\end{tabular}




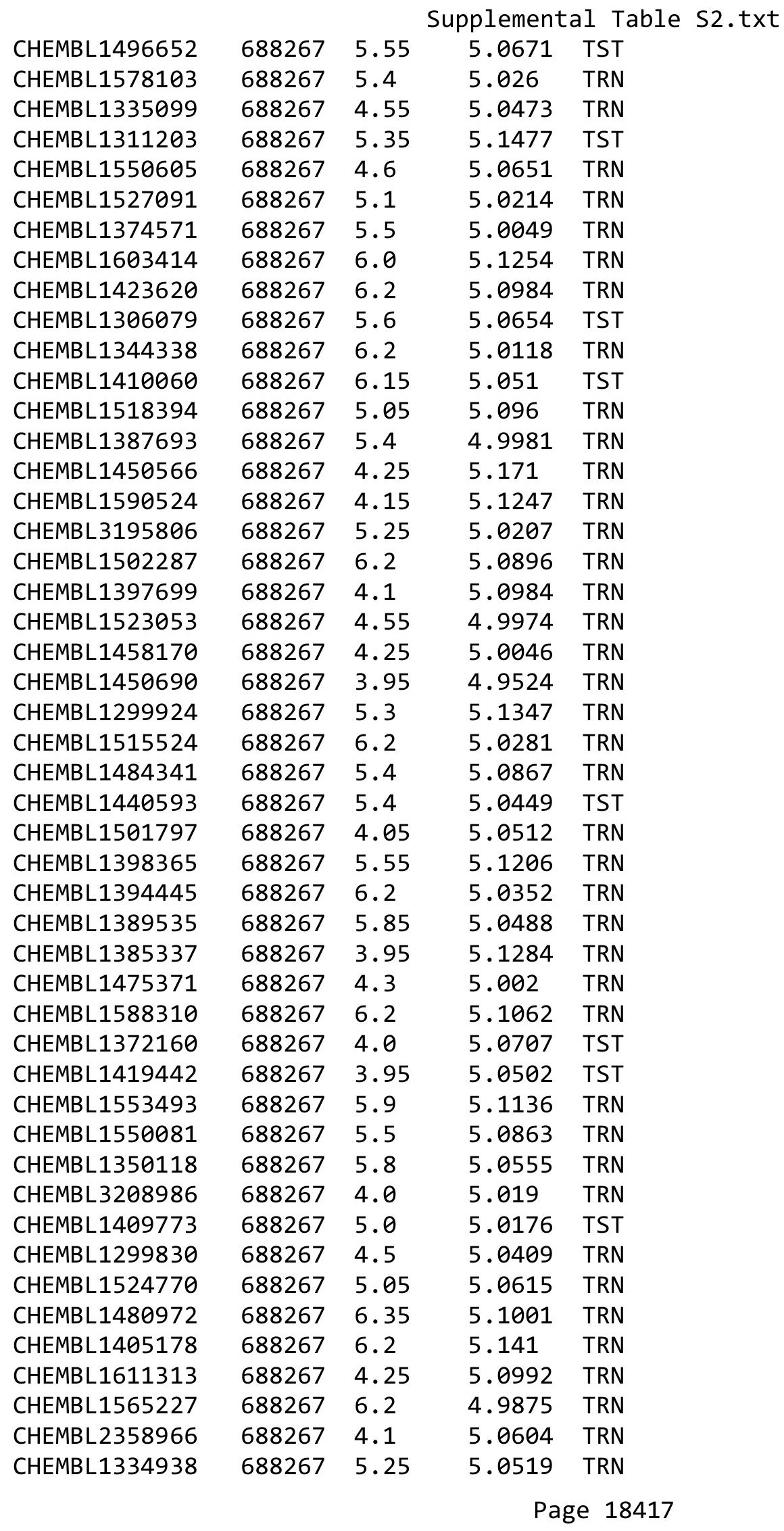




\begin{tabular}{|c|c|c|c|c|c|}
\hline \multicolumn{6}{|c|}{ plemental } \\
\hline CHEMBL1560781 & 688267 & 6.2 & 5.0446 & TST & \\
\hline CHEMBL1531286 & 688267 & 4.0 & 5.0292 & TRN & \\
\hline CHEMBL1611547 & 688267 & 4.0 & 5.1119 & TRN & \\
\hline CHEMBL1324693 & 688267 & 6.1 & 5.0268 & TRN & \\
\hline CHEMBL1418625 & 688267 & 5.25 & 5.0083 & TST & \\
\hline CHEMBL1397796 & 688267 & 5.0 & 5.0718 & TRN & \\
\hline CHEMBL1594256 & 688267 & 4.3 & 5.0988 & TRN & \\
\hline CHEMBL1388092 & 688267 & 6.2 & 5.1225 & TRN & \\
\hline CHEMBL1517136 & 688267 & 6.2 & 5.062 & TRN & \\
\hline CHEMBL1457297 & 688267 & 4.55 & 5.0655 & TST & \\
\hline CHEMBL1346381 & 688267 & 4.05 & 5.0054 & TRN & \\
\hline CHEMBL1326905 & 688267 & 4.35 & 5.1225 & TRN & \\
\hline CHEMBL1557153 & 688267 & 4.0 & 5.1538 & TRN & \\
\hline CHEMBL1612758 & 688267 & 5.85 & 5.113 & TRN & \\
\hline CHEMBL1352339 & 688267 & 4.6 & 5.0462 & TST & \\
\hline CHEMBL1485111 & 688267 & 4.9 & 5.085 & TRN & \\
\hline CHEMBL1602142 & 688267 & 4.95 & 5.0356 & TST & \\
\hline CHEMBL1526054 & 688267 & 5.85 & 5.0491 & TRN & \\
\hline CHEMBL1536167 & 688267 & 4.0 & 5.0014 & TRN & \\
\hline CHEMBL1968376 & 688267 & 5.3 & 5.048 & TST & \\
\hline CHEMBL1394569 & 688267 & 3.9 & 5.0212 & TRN & \\
\hline CHEMBL1411530 & 688267 & 5.1 & 5.0926 & TRN & \\
\hline CHEMBL1538503 & 688267 & 4.1 & 5.0007 & TST & \\
\hline CHEMBL1491661 & 688267 & 4.05 & 5.0229 & TRN & \\
\hline CHEMBL1399139 & 688267 & 4.25 & 5.0921 & TRN & \\
\hline CHEMBL1563629 & 688267 & 5.2 & 5.0127 & TRN & \\
\hline CHEMBL1590673 & 688267 & 4.25 & 5.032 & TST & \\
\hline CHEMBL1374232 & 688267 & 4.1 & 5.0254 & TRN & \\
\hline CHEMBL1598831 & 688267 & 5.15 & 5.084 & TST & \\
\hline CHEMBL1453860 & 688267 & 5.3 & 5.0219 & TRN & \\
\hline CHEMBL1363310 & 688267 & 5.3 & 5.0937 & TST & \\
\hline CHEMBL1354938 & 688267 & 6.2 & 4.9906 & TRN & \\
\hline CHEMBL1314541 & 688267 & 4.05 & 5.0619 & TRN & \\
\hline CHEMBL1312729 & 688267 & 5.05 & 5.0189 & TRN & \\
\hline CHEMBL1411276 & 688267 & 4.5 & 5.112 & TRN & \\
\hline CHEMBL1602838 & 688267 & 5.2 & 5.1266 & TRN & \\
\hline CHEMBL1428570 & 688267 & 4.75 & 5.1156 & TRN & \\
\hline CHEMBL1565953 & 688267 & 6.15 & $5.0310 e$ & 0000000001 & TRN \\
\hline CHEMBL1454076 & 688267 & 6.15 & 5.0496 & TRN & \\
\hline CHEMBL1583899 & 688267 & 6.15 & 5.0618 & TRN & \\
\hline CHEMBL1493169 & 688267 & 4.3 & 5.0826 & TRN & \\
\hline CHEMBL1367669 & 688267 & 5.8 & 5.1285 & TST & \\
\hline CHEMBL1444480 & 688267 & 5.3 & 5.0431 & TST & \\
\hline CHEMBL1325380 & 688267 & 6.25 & 5.0811 & TRN & \\
\hline CHEMBL1422749 & 688267 & 4.0 & 5.005 & TST & \\
\hline CHEMBL1451172 & 688267 & 6.2 & 5.1526 & TRN & \\
\hline CHEMBL1593299 & 688267 & 5.6 & 5.0115 & TRN & \\
\hline CHEMBL1396496 & 688267 & 3.95 & 5.0835 & TRN & \\
\hline
\end{tabular}




\begin{tabular}{|c|c|c|c|c|}
\hline & & & upplement & $\mathrm{d} \perp$ \\
\hline CHEMBL1410086 & 688267 & 6.3 & 5.0516 & TST \\
\hline CHEMBL1439251 & 688267 & 5.85 & 5.0338 & TST \\
\hline CHEMBL1609443 & 688267 & 4.2 & 5.0515 & TST \\
\hline CHEMBL1557163 & 688267 & 6.15 & 5.0274 & TRN \\
\hline CHEMBL3197805 & 688267 & 4.55 & 5.032 & TST \\
\hline CHEMBL1444676 & 688267 & 3.95 & 5.1429 & TRN \\
\hline CHEMBL1552058 & 688267 & 4.35 & 4.9775 & TRN \\
\hline CHEMBL1475219 & 688267 & 4.05 & 5.0934 & TRN \\
\hline CHEMBL1391033 & 688267 & 5.25 & 5.0656 & TRN \\
\hline CHEMBL1428820 & 688267 & 4.35 & 5.0558 & TRN \\
\hline CHEMBL1352986 & 688267 & 6.2 & 5.0292 & TRN \\
\hline CHEMBL1539964 & 688267 & 6.15 & 5.104 & TRN \\
\hline CHEMBL1554388 & 688267 & 4.0 & 5.1183 & TRN \\
\hline CHEMBL1596905 & 688267 & 4.4 & 5.1499 & TRN \\
\hline CHEMBL1490369 & 688267 & 3.95 & 5.0063 & TRN \\
\hline CHEMBL1423234 & 688267 & 6.15 & 5.0884 & TRN \\
\hline CHEMBL1322048 & 688267 & 5.4 & 5.0838 & TRN \\
\hline CHEMBL1562818 & 688267 & 4.55 & 5.1017 & TRN \\
\hline CHEMBL1546737 & 688267 & 4.0 & 5.0463 & TRN \\
\hline CHEMBL1300158 & 688267 & 5.9 & 4.9835 & TRN \\
\hline CHEMBL1484546 & 688267 & 3.9 & 5.0354 & TRN \\
\hline CHEMBL380109 & 688267 & 5.2 & 5.0738 & TRN \\
\hline CHEMBL1443440 & 688267 & 5.55 & 5.0335 & TST \\
\hline CHEMBL1588772 & 688267 & 6.05 & 5.1069 & TST \\
\hline CHEMBL1594655 & 688267 & 5.65 & 5.019 & TRN \\
\hline CHEMBL1432626 & 688267 & 5.45 & 5.0064 & TRN \\
\hline CHEMBL1432232 & 688267 & 4.35 & 5.0281 & TRN \\
\hline CHEMBL1368861 & 688267 & 4.0 & 5.1097 & TST \\
\hline CHEMBL1456991 & 688267 & 4.05 & 5.0894 & TST \\
\hline CHEMBL1314054 & 688267 & 4.0 & 5.0142 & TST \\
\hline CHEMBL1383806 & 688267 & 5.75 & 5.0498 & TST \\
\hline CHEMBL1324321 & 688267 & 3.95 & 5.1451 & TRN \\
\hline CHEMBL1447743 & 688267 & 5.35 & 5.0587 & TST \\
\hline CHEMBL1533459 & 688267 & 4.0 & 5.1175 & TRN \\
\hline CHEMBL1513097 & 688267 & 4.3 & 5.0463 & TRN \\
\hline CHEMBL1420959 & 688267 & 4.05 & 5.0919 & TST \\
\hline CHEMBL1377888 & 688267 & 5.95 & 5.0313 & TRN \\
\hline CHEMBL1579394 & 688267 & 4.65 & 5.0177 & TRN \\
\hline CHEMBL1532481 & 688267 & 6.15 & 5.0757 & TST \\
\hline CHEMBL1316478 & 688267 & 3.95 & 5.0315 & TST \\
\hline CHEMBL1388899 & 688267 & 4.0 & 5.0843 & TST \\
\hline CHEMBL1435304 & 688267 & 4.4 & 5.0453 & TRN \\
\hline CHEMBL1556100 & 688267 & 6.2 & 5.0374 & TRN \\
\hline CHEMBL1324456 & 688267 & 5.85 & 5.1009 & TRN \\
\hline CHEMBL1490503 & 688267 & 6.15 & 5.1362 & TST \\
\hline CHEMBL1304911 & 688267 & 4.4 & 5.0205 & TST \\
\hline CHEMBL1405689 & 688267 & 4.25 & 5.0967 & TRN \\
\hline CHEMBL1508535 & 688267 & 5.35 & 5.0163 & TST \\
\hline
\end{tabular}




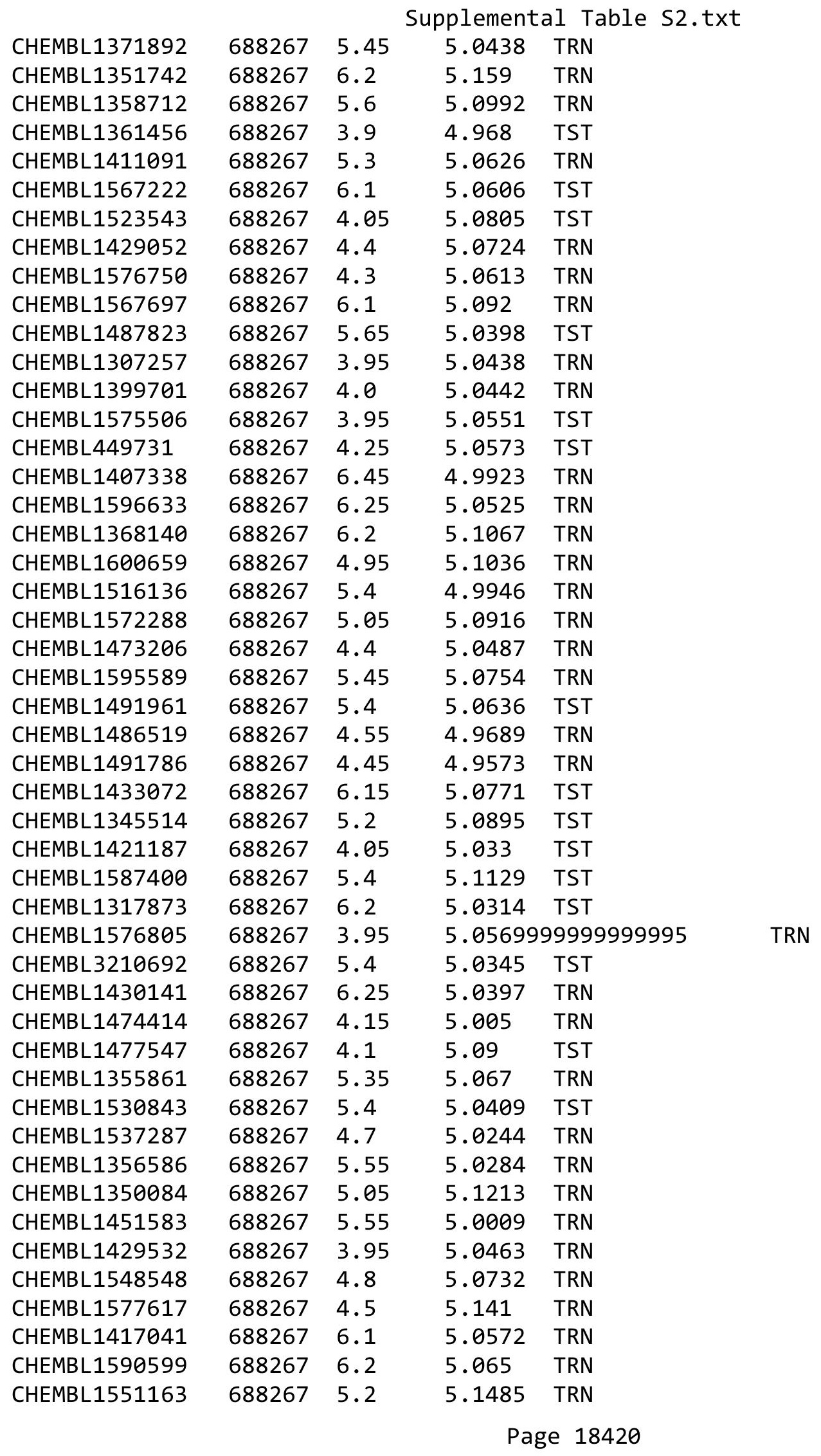




\begin{tabular}{|c|c|c|c|c|c|}
\hline \\
\hline CHEMBL1586638 & 688267 & 5.3 & 5.0997 & TRN & \\
\hline CHEMBL1529187 & 688267 & 4.85 & 5.1336 & TRN & \\
\hline CHEMBL1338470 & 688267 & 5.95 & 5.0652 & TRN & \\
\hline CHEMBL1607194 & 688267 & 5.3 & 5.0349 & TRN & \\
\hline CHEMBL1599662 & 688267 & 7.9508 & 5.0154 & TST & \\
\hline CHEMBL1422029 & 688267 & 4.4 & 5.0702 & TRN & \\
\hline CHEMBL1537592 & 688267 & 4.05 & 5.0098 & TRN & \\
\hline CHEMBL1507780 & 688267 & 4.4 & 5.0419 & TST & \\
\hline CHEMBL1394481 & 688267 & 5.35 & 5.0192 & TRN & \\
\hline CHEMBL1475488 & 688267 & 6.15 & 5.0817 & TRN & \\
\hline CHEMBL1534916 & 688267 & 4.35 & 5.1023 & TRN & \\
\hline CHEMBL1612262 & 688267 & 4.95 & 4.9908 & TRN & \\
\hline CHEMBL1500805 & 688267 & 4.3 & 5.0657 & TST & \\
\hline CHEMBL1424730 & 688267 & 4.05 & 5.0494 & TRN & \\
\hline CHEMBL1543629 & 688267 & 4.65 & 5.0795 & TRN & \\
\hline CHEMBL1497786 & 688267 & 4.0 & 5.0335 & TRN & \\
\hline CHEMBL1354428 & 688267 & 4.4 & 5.0164 & TRN & \\
\hline CHEMBL1469243 & 688267 & 5.85 & 5.0251 & TRN & \\
\hline CHEMBL1459747 & 688267 & 4.8 & 5.0337 & TRN & \\
\hline CHEMBL1431935 & 688267 & 4.6 & 5.0038 & TST & \\
\hline CHEMBL1590249 & 688267 & 5.05 & 5.0931 & TRN & \\
\hline CHEMBL1470307 & 688267 & 5.45 & 5.1028 & TRN & \\
\hline CHEMBL1426876 & 688267 & 6.1 & 5.1084 & TRN & \\
\hline CHEMBL1523021 & 688267 & 6.2 & 5.0666 & TRN & \\
\hline CHEMBL1396991 & 688267 & 5.25 & 5.1051 & TRN & \\
\hline CHEMBL1587398 & 688267 & 5.4 & 5.0243 & TRN & \\
\hline CHEMBL1301073 & 688267 & 5.3 & 5.0326 & TRN & \\
\hline CHEMBL1432933 & 688267 & 4.45 & 5.0743 & TRN & \\
\hline CHEMBL1416538 & 688267 & 4.4 & 5.1076 & TRN & \\
\hline CHEMBL1401402 & 688267 & 4.25 & 5.1052 & TRN & \\
\hline CHEMBL1356109 & 688267 & 4.0 & 5.0282 & TRN & \\
\hline CHEMBL1555275 & 688267 & 6.2 & 5.06800 & 20000000005 & TRN \\
\hline CHEMBL1410098 & 688267 & 5.05 & 5.0593 & TRN & \\
\hline CHEMBL1585630 & 688267 & 6.2 & 5.0684 & TRN & \\
\hline CHEMBL1562403 & 688267 & 5.65 & 5.0975 & TRN & \\
\hline CHEMBL1560391 & 688267 & 6.2 & 5.0699 & TRN & \\
\hline CHEMBL1372774 & 688267 & 5.45 & 5.0306 & TRN & \\
\hline CHEMBL1424469 & 688267 & 4.4 & 5.0183 & TST & \\
\hline CHEMBL1313544 & 688267 & 6.2 & 4.9953 & TST & \\
\hline CHEMBL1608133 & 688267 & 4.05 & 5.0712 & TRN & \\
\hline CHEMBL1356035 & 688267 & 5.4 & 5.0126 & TRN & \\
\hline CHEMBL1324839 & 688267 & 6.25 & 5.08 & TRN & \\
\hline CHEMBL1448639 & 688267 & 6.2 & 5.0492 & TST & \\
\hline CHEMBL1461704 & 688267 & 5.0 & 5.1222 & TRN & \\
\hline CHEMBL1373578 & 688267 & 5.45 & 5.0747 & TRN & \\
\hline CHEMBL1551278 & 688267 & 4.0 & 5.1002 & TRN & \\
\hline CHEMBL1307958 & 688267 & 4.35 & 5.0766 & TRN & \\
\hline CHEMBL442964 & 688267 & 6.2 & 5.0016 & TST & \\
\hline
\end{tabular}




\begin{tabular}{|c|c|c|c|c|c|}
\hline \multicolumn{6}{|c|}{ Supplemental Table S2.txt } \\
\hline CHEMBL1539691 & 688267 & 4.05 & 5.0765 & TST & \\
\hline CHEMBL1473541 & 688267 & 6.05 & 5.0951 & TRN & \\
\hline CHEMBL1363090 & 688267 & 5.15 & 5.0361 & TRN & \\
\hline CHEMBL1324941 & 688267 & 5.35 & 5.0676 & TRN & \\
\hline CHEMBL127023 & 688267 & 5.35 & 5.093 & TRN & \\
\hline CHEMBL1459622 & 688267 & 5.1 & 5.1044 & TRN & \\
\hline CHEMBL1548532 & 688267 & 5.85 & 5.0247 & TST & \\
\hline CHEMBL1476882 & 688267 & 6.1 & 5.0696 & TRN & \\
\hline CHEMBL3198293 & 688267 & 6.2 & 5.1042 & TST & \\
\hline CHEMBL1473142 & 688267 & 5.3 & 5.0217 & TRN & \\
\hline CHEMBL1610796 & 688267 & 4.6 & 5.0765 & TRN & \\
\hline CHEMBL1357075 & 688267 & 5.15 & 5.0148 & TRN & \\
\hline CHEMBL1437156 & 688267 & 4.0 & 5.12799 & 9999999999 & TST \\
\hline CHEMBL1532495 & 688267 & 5.8 & 5.0606 & TRN & \\
\hline CHEMBL68997 & 688267 & 5.8 & 5.0321 & TRN & \\
\hline CHEMBL 3212610 & 688267 & 4.4 & 5.0294 & TRN & \\
\hline CHEMBL1551492 & 688267 & 4.75 & 5.0703 & TST & \\
\hline CHEMBL1538741 & 688267 & 4.65 & 5.0062 & TRN & \\
\hline CHEMBL1321893 & 688267 & 4.7 & 5.1158 & TRN & \\
\hline CHEMBL1554379 & 688267 & 5.35 & 5.0596 & TRN & \\
\hline CHEMBL1321584 & 688267 & 5.65 & 5.0772 & TST & \\
\hline CHEMBL1573470 & 688267 & 4.1 & 5.1236 & TRN & \\
\hline CHEMBL 2373631 & 688267 & 6.05 & 5.0365 & TRN & \\
\hline CHEMBL1538877 & 688267 & 6.2 & 5.1308 & TST & \\
\hline CHEMBL1599263 & 688267 & 4.35 & 5.0921 & TRN & \\
\hline CHEMBL1310274 & 688267 & 6.25 & 5.0229 & TST & \\
\hline CHEMBL1433247 & 688267 & 6.0 & 5.012 & TRN & \\
\hline CHEMBL1342760 & 688267 & 4.05 & 5.0165 & TRN & \\
\hline CHEMBL1584447 & 688267 & 5.6 & 5.0816 & TST & \\
\hline CHEMBL1972750 & 688267 & 4.65 & 5.0411 & TST & \\
\hline CHEMBL1485797 & 688267 & 6.45 & 5.0635 & TRN & \\
\hline CHEMBL1336232 & 688267 & 5.45 & 5.0143 & TRN & \\
\hline CHEMBL1475889 & 688267 & 5.05 & 5.0916 & TRN & \\
\hline CHEMBL1511380 & 688267 & 4.25 & 5.1156 & TST & \\
\hline CHEMBL1430891 & 688267 & 6.5 & 5.0316 & TST & \\
\hline CHEMBL1541762 & 688267 & 3.95 & 5.0948 & TRN & \\
\hline CHEMBL1526552 & 688267 & 6.15 & 5.0598 & TRN & \\
\hline CHEMBL1593618 & 688267 & 5.95 & 5.0342 & TRN & \\
\hline CHEMBL1547982 & 688267 & 5.6 & 5.025 & TST & \\
\hline CHEMBL1574405 & 688267 & 5.2 & 5.0704 & TRN & \\
\hline CHEMBL1532995 & 688267 & 5.55 & 5.0197 & TRN & \\
\hline CHEMBL1560258 & 688267 & 4.1 & 5.0085 & TRN & \\
\hline CHEMBL1359812 & 688267 & 6.2 & 5.0276 & TRN & \\
\hline CHEMBL1452773 & 688267 & 5.55 & 5.0574 & TRN & \\
\hline CHEMBL1376194 & 688267 & 4.45 & 5.0071 & TST & \\
\hline CHEMBL1345365 & 688267 & 6.2 & 5.0201 & TST & \\
\hline CHEMBL1316732 & 688267 & 5.2 & 5.0913 & TRN & \\
\hline CHEMBL3210117 & 688267 & 6.6 & 4.9955 & TRN & \\
\hline
\end{tabular}




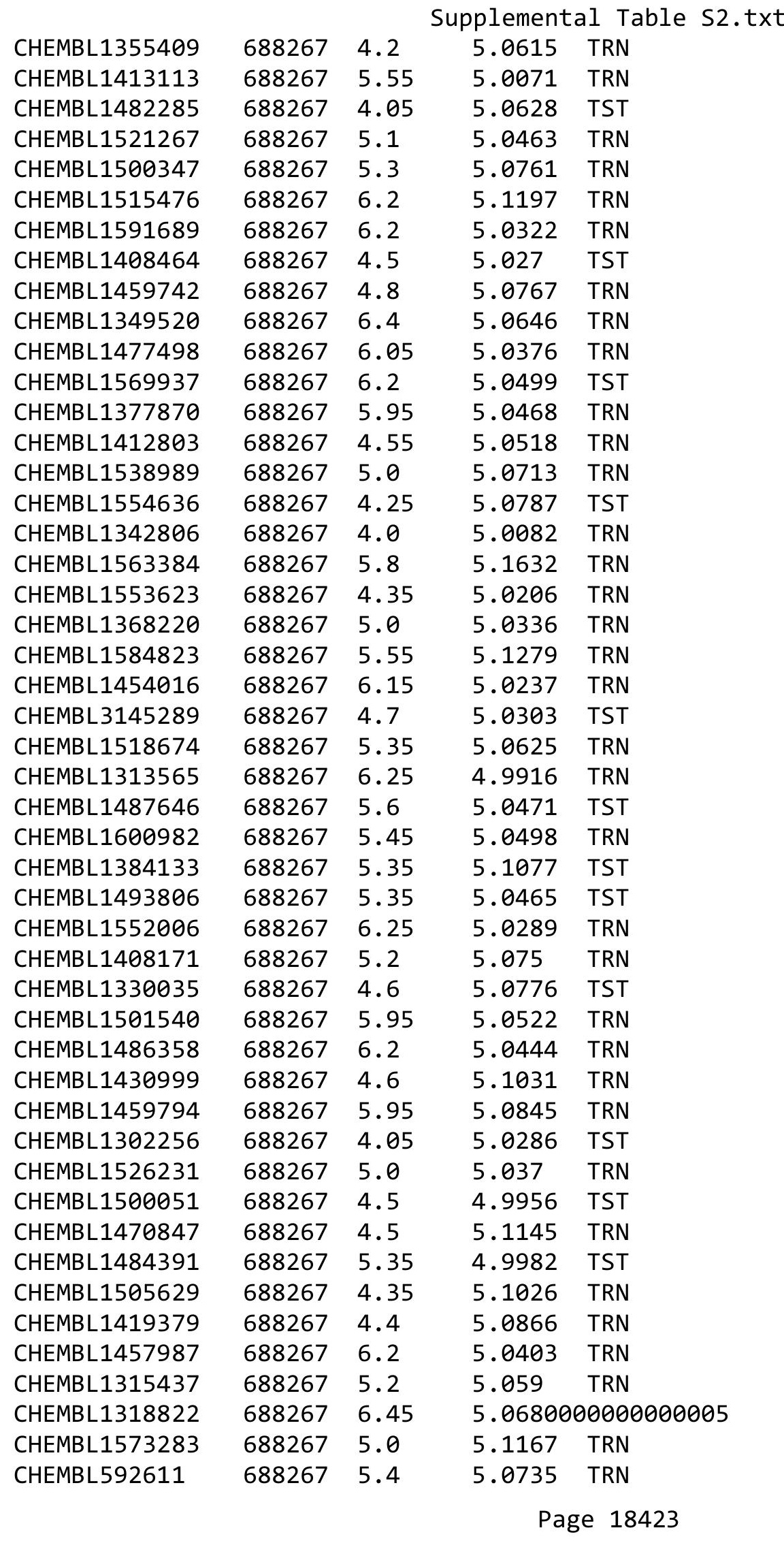




\begin{tabular}{|c|c|c|c|c|}
\hline \multicolumn{5}{|c|}{ Supplemental Table S2.txt } \\
\hline CHEMBL1478565 & 688267 & 4.15 & 5.0126 & TST \\
\hline CHEMBL1526853 & 688267 & 6.0 & 4.9936 & TRN \\
\hline CHEMBL1415500 & 688267 & 6.5 & 4.9764 & TRN \\
\hline CHEMBL3194029 & 688267 & 3.95 & 4.9985 & TRN \\
\hline CHEMBL1458929 & 688267 & 5.0 & 4.9996 & TRN \\
\hline CHEMBL1440707 & 688267 & 5.2 & 5.045 & TRN \\
\hline CHEMBL1609640 & 688267 & 4.35 & 5.0215 & TRN \\
\hline CHEMBL1409648 & 688267 & 5.35 & 5.0622 & TRN \\
\hline CHEMBL1505119 & 688267 & 4.05 & 5.0692 & TST \\
\hline CHEMBL3193950 & 688267 & 5.05 & 4.9534 & TRN \\
\hline CHEMBL1345298 & 688267 & 4.5 & 5.1224 & TST \\
\hline CHEMBL1530101 & 688267 & 4.4 & 5.0338 & TST \\
\hline CHEMBL1393237 & 688267 & 4.25 & 5.0584 & TRN \\
\hline CHEMBL1519412 & 688267 & 6.2 & 5.0202 & TRN \\
\hline CHEMBL1364578 & 688267 & 4.4 & 5.0778 & TRN \\
\hline CHEMBL3392366 & 688267 & 6.5 & 5.088 & TRN \\
\hline CHEMBL1441597 & 688267 & 5.8 & 5.0203 & TRN \\
\hline CHEMBL169143 & 688267 & 4.05 & 5.0364 & TRN \\
\hline CHEMBL1428555 & 688267 & 5.05 & 5.075 & TST \\
\hline CHEMBL1300701 & 688267 & 3.95 & 5.0737 & TST \\
\hline CHEMBL1360831 & 688267 & 4.05 & 5.1188 & TRN \\
\hline CHEMBL1562501 & 688267 & 4.65 & 5.0071 & TRN \\
\hline CHEMBL1458351 & 688267 & 6.15 & 5.0413 & TRN \\
\hline CHEMBL1336946 & 688267 & 5.6 & 5.0984 & TRN \\
\hline CHEMBL1322075 & 688267 & 4.25 & 5.0268 & TRN \\
\hline CHEMBL1322327 & 688267 & 5.85 & 5.0338 & TRN \\
\hline CHEMBL1610775 & 688267 & 4.5 & 5.0033 & TRN \\
\hline CHEMBL1487432 & 688267 & 4.35 & 5.1572 & TRN \\
\hline CHEMBL1439757 & 688267 & 4.15 & 5.0663 & TRN \\
\hline CHEMBL1484015 & 688267 & 5.25 & 5.003 & TRN \\
\hline CHEMBL1554640 & 688267 & 6.2 & 5.0219 & TRN \\
\hline CHEMBL1577004 & 688267 & 4.0 & 5.0844 & TST \\
\hline CHEMBL1524116 & 688267 & 4.7 & 5.0454 & TRN \\
\hline CHEMBL1367896 & 688267 & 4.95 & 5.0177 & TRN \\
\hline CHEMBL1567243 & 688267 & 6.2 & 5.086 & TRN \\
\hline CHEMBL1563586 & 688267 & 4.3 & 5.1019 & TST \\
\hline CHEMBL1325614 & 688267 & 4.05 & 5.0364 & TRN \\
\hline CHEMBL1485532 & 688267 & 4.75 & 5.052 & TRN \\
\hline CHEMBL1299376 & 688267 & 5.8 & 5.0807 & TST \\
\hline CHEMBL1410645 & 688267 & 4.25 & 5.0902 & TST \\
\hline CHEMBL1611996 & 688267 & 5.5 & 5.0318 & TRN \\
\hline CHEMBL1584330 & 688267 & 5.55 & 5.0925 & TRN \\
\hline CHEMBL1408659 & 688267 & 4.0 & 5.0088 & TRN \\
\hline CHEMBL1609856 & 688267 & 5.85 & 5.0628 & TRN \\
\hline CHEMBL1596916 & 688267 & 4.95 & 5.0976 & TRN \\
\hline CHEMBL1306616 & 688267 & 6.4 & 5.0471 & TRN \\
\hline CHEMBL1523462 & 688267 & 5.45 & 5.0503 & TRN \\
\hline CHEMBL1479579 & 688267 & 5.9 & 5.0203 & TRN \\
\hline
\end{tabular}




\begin{tabular}{|c|c|c|c|c|c|}
\hline \\
\hline CHEMBL1970493 & 688267 & 5.3 & 5.0237 & TST & \\
\hline CHEMBL1435686 & 688267 & 5.9 & 5.0582 & TRN & \\
\hline CHEMBL1542470 & 688267 & 6.2 & 5.0857 & TRN & \\
\hline CHEMBL1993944 & 688267 & 4.75 & 5.0624 & TST & \\
\hline CHEMBL1613603 & 688267 & 4.0 & 5.1246 & TRN & \\
\hline CHEMBL3197932 & 688267 & 4.25 & 4.9921 & TRN & \\
\hline CHEMBL1438846 & 688267 & 4.35 & 5.0695 & TST & \\
\hline CHEMBL1451980 & 688267 & 6.15 & 5.1199 & TRN & \\
\hline CHEMBL1498782 & 688267 & 4.4 & 5.0587 & TRN & \\
\hline CHEMBL1320615 & 688267 & 4.45 & 4.9806 & TRN & \\
\hline CHEMBL1398550 & 688267 & 6.2 & 5.0094 & TRN & \\
\hline CHEMBL1570829 & 688267 & 5.15 & 5.01399 & 9999999999 & TRN \\
\hline CHEMBL1540208 & 688267 & 4.55 & 5.0398 & TST & \\
\hline CHEMBL1539222 & 688267 & 6.25 & 5.09 & TST & \\
\hline CHEMBL1604762 & 688267 & 6.05 & 5.0753 & TRN & \\
\hline CHEMBL1457087 & 688267 & 3.95 & 5.0028 & TRN & \\
\hline CHEMBL1463718 & 688267 & 5.35 & 5.0315 & TRN & \\
\hline CHEMBL1603712 & 688267 & 5.55 & 5.0034 & TRN & \\
\hline CHEMBL3213717 & 688267 & 4.35 & 5.0365 & TRN & \\
\hline CHEMBL1498682 & 688267 & 5.8 & 5.1183 & TRN & \\
\hline CHEMBL1568676 & 688267 & 4.15 & 5.0261 & TRN & \\
\hline CHEMBL1470231 & 688267 & 4.95 & 5.0111 & TRN & \\
\hline CHEMBL578878 & 688267 & 4.4 & 5.0372 & TRN & \\
\hline CHEMBL1528471 & 688267 & 5.45 & 5.0809 & TRN & \\
\hline CHEMBL1325760 & 688267 & 4.0 & 5.0353 & TRN & \\
\hline CHEMBL1563729 & 688267 & 4.35 & 5.0554 & TRN & \\
\hline CHEMBL1591880 & 688267 & 4.0 & 4.9967 & TRN & \\
\hline CHEMBL1606779 & 688267 & 5.25 & 5.0445 & TRN & \\
\hline CHEMBL1491303 & 688267 & 4.35 & 5.0923 & TST & \\
\hline CHEMBL1546566 & 688267 & 6.25 & 5.0161 & TRN & \\
\hline CHEMBL1604137 & 688267 & 6.5 & 5.1072 & TRN & \\
\hline CHEMBL1423727 & 688267 & 4.3 & 4.9714 & TRN & \\
\hline CHEMBL1514725 & 688267 & 5.25 & 5.1146 & TRN & \\
\hline CHEMBL1464620 & 688267 & 4.25 & 5.0387 & TRN & \\
\hline CHEMBL1363508 & 688267 & 4.0 & 5.0786 & TRN & \\
\hline CHEMBL1370041 & 688267 & 4.05 & 5.0672 & TRN & \\
\hline CHEMBL1542920 & 688267 & 4.5 & 5.0713 & TST & \\
\hline CHEMBL1501912 & 688267 & 5.5 & 5.13399 & 99999999995 & TRN \\
\hline CHEMBL1448924 & 688267 & 6.0 & 5.0519 & TST & \\
\hline CHEMBL1394705 & 688267 & 5.5 & 5.0967 & TRN & \\
\hline CHEMBL1541721 & 688267 & 4.3 & 5.0678 & TRN & \\
\hline CHEMBL1463394 & 688267 & 5.25 & 5.0792 & TRN & \\
\hline CHEMBL1455472 & 688267 & 6.2 & 5.0455 & TRN & \\
\hline CHEMBL1394072 & 688267 & 5.1 & 5.0824 & TST & \\
\hline CHEMBL1475373 & 688267 & 5.2 & 5.1009 & TRN & \\
\hline CHEMBL1602002 & 688267 & 6.45 & 5.004 & TST & \\
\hline CHEMBL1371863 & 688267 & 5.95 & 5.0727 & TST & \\
\hline CHEMBL1561994 & 688267 & 4.85 & 5.056 & TRN & \\
\hline
\end{tabular}




\begin{tabular}{|c|c|c|c|c|c|}
\hline \multicolumn{6}{|c|}{ Supplemental Table S2.txt } \\
\hline CHEMBL1456483 & 688267 & 5.6 & 5.0133 & TRN & \\
\hline CHEMBL1506762 & 688267 & 5.45 & 5.0704 & TRN & \\
\hline CHEMBL1446100 & 688267 & 4.75 & 5.0355 & TST & \\
\hline CHEMBL1339831 & 688267 & 6.1 & 5.1291 & TST & \\
\hline CHEMBL1495689 & 688267 & 4.1 & 5.0503 & TRN & \\
\hline CHEMBL1605394 & 688267 & 4.9 & 5.101 & TRN & \\
\hline CHEMBL1538024 & 688267 & 4.05 & 5.052 & TRN & \\
\hline CHEMBL1382327 & 688267 & 4.95 & 5.0262 & TRN & \\
\hline CHEMBL1390718 & 688267 & 4.05 & 5.0007 & TRN & \\
\hline CHEMBL1513492 & 688267 & 5.5 & 5.0014 & TRN & \\
\hline CHEMBL1574824 & 688267 & 4.2 & 5.0883 & TRN & \\
\hline CHEMBL1583950 & 688267 & 4.0 & 5.066 & TRN & \\
\hline CHEMBL 3190241 & 688267 & 4.55 & 5.0019 & TRN & \\
\hline CHEMBL1398085 & 688267 & 5.9 & 5.046 & TRN & \\
\hline CHEMBL 3212113 & 688267 & 4.75 & 5.0139 & TRN & \\
\hline CHEMBL1591721 & 688267 & 3.95 & 4.996 & TRN & \\
\hline CHEMBL1600518 & 688267 & 4.0 & 5.0131 & TRN & \\
\hline CHEMBL1356298 & 688267 & 4.05 & 5.0101 & TST & \\
\hline CHEMBL1451119 & 688267 & 4.25 & 5.022 & TST & \\
\hline CHEMBL1577015 & 688267 & 5.45 & 5.0589 & TRN & \\
\hline CHEMBL1414793 & 688267 & 6.25 & 5.0451 & TST & \\
\hline CHEMBL1339360 & 688267 & 5.05 & 5.0925 & TRN & \\
\hline CHEMBL1527582 & 688267 & 4.25 & 5.01699 & 99999999995 & TRN \\
\hline CHEMBL1303447 & 688267 & 6.2 & 5.0741 & TRN & \\
\hline CHEMBL1484486 & 688267 & 4.05 & 5.0309 & TRN & \\
\hline CHEMBL1613435 & 688267 & 4.25 & 5.0074 & TRN & \\
\hline CHEMBL1419739 & 688267 & 4.55 & 5.0971 & TRN & \\
\hline CHEMBL1386529 & 688267 & 4.0 & 5.0678 & TST & \\
\hline CHEMBL1307539 & 688267 & 5.35 & 5.0709 & TRN & \\
\hline CHEMBL1590296 & 688267 & 6.25 & 5.0084 & TRN & \\
\hline CHEMBL1533180 & 688267 & 4.25 & 5.1034 & TRN & \\
\hline CHEMBL1598514 & 688267 & 4.8 & 5.0661 & TST & \\
\hline CHEMBL1601287 & 688267 & 5.35 & 5.0374 & TST & \\
\hline CHEMBL1304032 & 688267 & 4.05 & 5.0753 & TST & \\
\hline CHEMBL1496655 & 688267 & 4.05 & 5.0746 & TRN & \\
\hline CHEMBL1476315 & 688267 & 4.3 & 5.0412 & TRN & \\
\hline CHEMBL1358162 & 688267 & 6.2 & 5.0999 & TST & \\
\hline CHEMBL1333247 & 688267 & 6.2 & 5.0668 & TRN & \\
\hline CHEMBL1547468 & 688267 & 4.8 & 4.9941 & TST & \\
\hline CHEMBL1379108 & 688267 & 6.25 & 5.077 & TST & \\
\hline CHEMBL1462095 & 688267 & 4.4 & 5.0209 & TRN & \\
\hline CHEMBL1582888 & 688267 & 5.0 & 5.0696 & TST & \\
\hline CHEMBL1324076 & 688267 & 4.4 & 5.0875 & TRN & \\
\hline CHEMBL1567281 & 688267 & 5.35 & 5.0888 & TRN & \\
\hline CHEMBL1534477 & 688267 & 4.25 & 4.9799 & TRN & \\
\hline CHEMBL1608512 & 688267 & 6.2 & 5.1423 & TRN & \\
\hline CHEMBL3195983 & 688267 & 4.15 & 5.0057 & TRN & \\
\hline CHEMBL1596328 & 688267 & 4.2 & 5.1087 & TRN & \\
\hline
\end{tabular}




\begin{tabular}{|c|c|c|c|c|c|}
\hline \multicolumn{6}{|c|}{ Supplemental Table s2.txt } \\
\hline CHEMBL1569592 & 688267 & 6.25 & 5.0729 & TRN & \\
\hline CHEMBL1351041 & 688267 & 4.7 & 5.0058 & TRN & \\
\hline CHEMBL594783 & 688267 & 5.75 & 5.0294 & TRN & \\
\hline CHEMBL1456095 & 688267 & 4.6 & 5.02800 & 00000000005 & TST \\
\hline CHEMBL1307548 & 688267 & 4.35 & 4.9903 & TRN & \\
\hline CHEMBL1401956 & 688267 & 6.6 & 5.0819 & TST & \\
\hline CHEMBL1581570 & 688267 & 4.35 & 5.0216 & TRN & \\
\hline CHEMBL1417085 & 688267 & 5.75 & 5.0595 & TRN & \\
\hline CHEMBL1437048 & 688267 & 6.2 & 5.0565 & TRN & \\
\hline CHEMBL1397836 & 688267 & 4.3 & 5.1115 & TRN & \\
\hline CHEMBL1311951 & 688267 & 4.2 & 5.0696 & TST & \\
\hline CHEMBL1443084 & 688267 & 3.95 & 5.0329 & TST & \\
\hline CHEMBL1398629 & 688267 & 3.95 & 5.0224 & TRN & \\
\hline CHEMBL1312352 & 688267 & 4.0 & 5.0603 & TST & \\
\hline CHEMBL1402676 & 688267 & 6.2 & 5.0221 & TST & \\
\hline CHEMBL1358464 & 688267 & 6.2 & 5.0365 & TRN & \\
\hline CHEMBL1576515 & 688267 & 6.5501 & 5.0398 & TRN & \\
\hline CHEMBL1547211 & 688267 & 4.55 & 5.0372 & TST & \\
\hline CHEMBL1599502 & 688267 & 4.9 & 4.9936 & TRN & \\
\hline CHEMBL1328858 & 688267 & 4.5 & 5.1019 & TRN & \\
\hline CHEMBL1391868 & 688267 & 5.8 & 5.0234 & TRN & \\
\hline CHEMBL1454460 & 688267 & 4.0 & 5.0171 & TST & \\
\hline CHEMBL1442973 & 688267 & 5.3 & 5.0904 & TST & \\
\hline CHEMBL1520509 & 688267 & 4.75 & 4.9876 & TRN & \\
\hline CHEMBL1365522 & 688267 & 5.25 & 5.0271 & TRN & \\
\hline CHEMBL1543954 & 688267 & 5.35 & 5.0588 & TRN & \\
\hline CHEMBL1440741 & 688267 & 4.6 & 5.0599 & TRN & \\
\hline CHEMBL1440260 & 688267 & 4.7 & 5.1085 & TRN & \\
\hline CHEMBL1527573 & 688267 & 5.25 & 5.0775 & TRN & \\
\hline CHEMBL1559727 & 688267 & 6.2 & 5.0453 & TRN & \\
\hline CHEMBL1613465 & 688267 & 5.75 & 5.0726 & TRN & \\
\hline CHEMBL1584467 & 688267 & 6.25 & 5.0381 & TRN & \\
\hline CHEMBL1362632 & 688267 & 3.95 & 5.1299 & TRN & \\
\hline CHEMBL1601457 & 688267 & 4.1 & 5.0647 & TRN & \\
\hline CHEMBL1540853 & 688267 & 4.4 & 5.0895 & TRN & \\
\hline CHEMBL1541196 & 688267 & 6.2 & 5.0474 & TRN & \\
\hline CHEMBL1558109 & 688267 & 4.65 & 5.0609 & TST & \\
\hline CHEMBL1606325 & 688267 & 5.9 & 5.0302 & TRN & \\
\hline CHEMBL1456131 & 688267 & 4.9 & 5.0674 & TRN & \\
\hline CHEMBL3191974 & 688267 & 4.0 & 5.0044 & TST & \\
\hline CHEMBL1442685 & 688267 & 6.2 & 5.0358 & TST & \\
\hline CHEMBL83294 & 688267 & 4.25 & 5.0198 & TRN & \\
\hline CHEMBL3190627 & 688267 & 5.3 & 5.0522 & TRN & \\
\hline CHEMBL1434414 & 688267 & 5.05 & 5.1036 & TRN & \\
\hline CHEMBL1336463 & 688267 & 4.75 & 5.07600 & 00000000005 & TRN \\
\hline CHEMBL1522251 & 688267 & 5.45 & 5.062 & TST & \\
\hline CHEMBL1495410 & 688267 & 5.9 & 5.1007 & TST & \\
\hline CHEMBL1445213 & 688267 & 6.25 & 5.1207 & TRN & \\
\hline
\end{tabular}




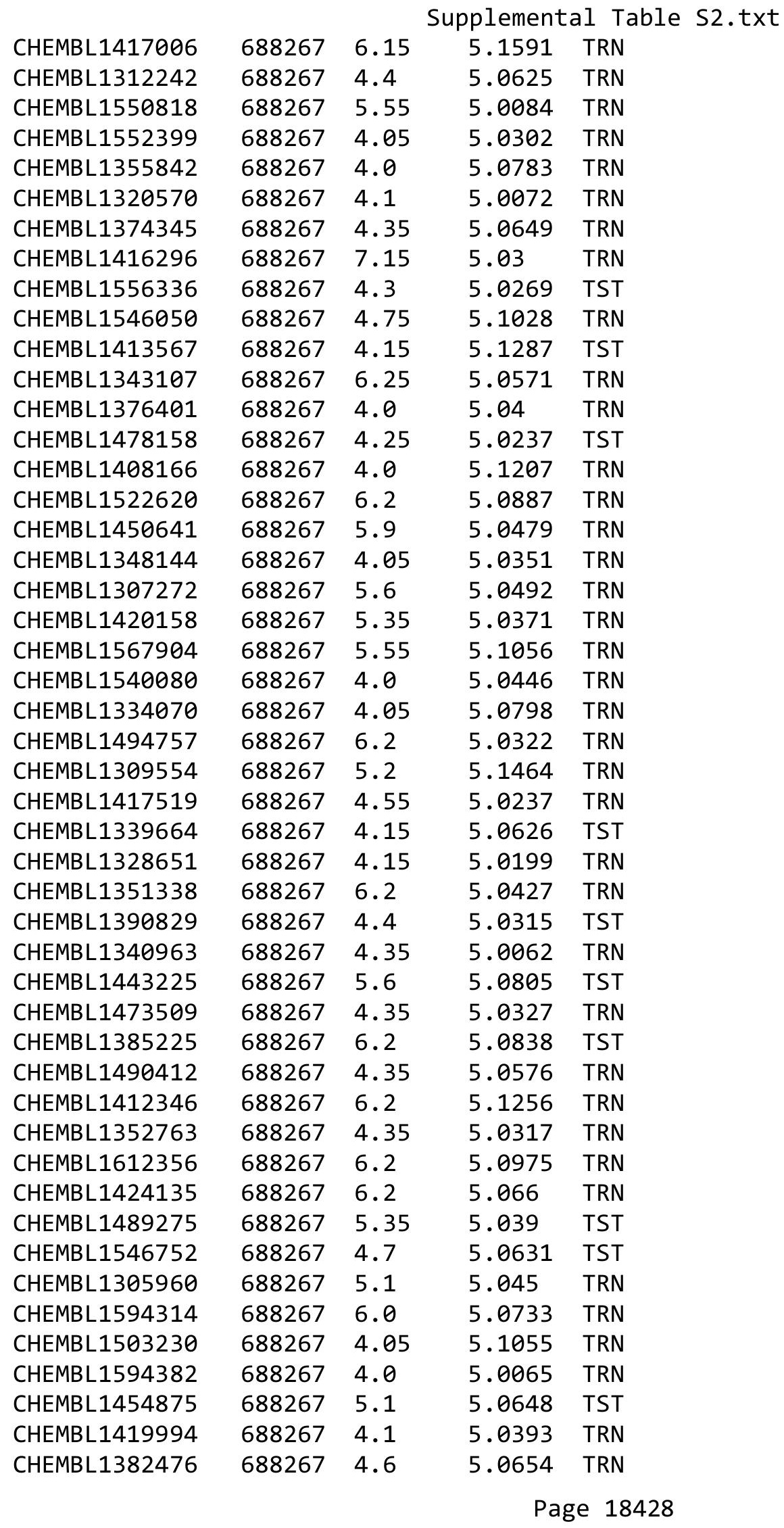




\begin{tabular}{|c|c|c|c|c|}
\hline \multicolumn{5}{|c|}{ Supplemental Table s2.txt } \\
\hline CHEMBL1320793 & 688267 & 6.2 & 5.0586 & TRN \\
\hline CHEMBL1594643 & 688267 & 5.65 & 5.0894 & TST \\
\hline CHEMBL1497007 & 688267 & 5.5 & 5.0917 & TRN \\
\hline CHEMBL1465383 & 688267 & 5.55 & 5.0051 & TST \\
\hline CHEMBL1360415 & 688267 & 4.05 & 5.0138 & TRN \\
\hline CHEMBL1556882 & 688267 & 4.05 & 5.0442 & TRN \\
\hline CHEMBL1512840 & 688267 & 5.6 & 5.0742 & TRN \\
\hline CHEMBL1609448 & 688267 & 4.0 & 5.0256 & TRN \\
\hline CHEMBL1436599 & 688267 & 4.1 & 5.037 & TRN \\
\hline CHEMBL1597674 & 688267 & 5.85 & 5.0689 & TST \\
\hline CHEMBL1326986 & 688267 & 6.0 & 5.1276 & TRN \\
\hline CHEMBL1455017 & 688267 & 4.05 & 5.0177 & TRN \\
\hline CHEMBL1316460 & 688267 & 5.3 & 5.0148 & TRN \\
\hline CHEMBL1415820 & 688267 & 4.05 & 5.0193 & TRN \\
\hline CHEMBL1433018 & 688267 & 5.3 & 5.0732 & TRN \\
\hline CHEMBL1362303 & 688267 & 3.95 & 5.1661 & TRN \\
\hline CHEMBL1506637 & 688267 & 5.35 & 5.0201 & TRN \\
\hline CHEMBL1514101 & 688267 & 6.15 & 5.0698 & TRN \\
\hline CHEMBL1345550 & 688267 & 4.0 & 5.1112 & TRN \\
\hline CHEMBL1581913 & 688267 & 4.35 & 5.0292 & TRN \\
\hline CHEMBL1459678 & 688267 & 6.0 & 5.0514 & TRN \\
\hline CHEMBL1549099 & 688267 & 4.05 & 4.9979 & TST \\
\hline CHEMBL1453095 & 688267 & 6.2 & 5.0378 & TST \\
\hline CHEMBL1369412 & 688267 & 4.8 & 5.0194 & TST \\
\hline CHEMBL1595941 & 688267 & 4.35 & 4.9915 & TRN \\
\hline CHEMBL1593811 & 688267 & 4.4 & 5.1493 & TRN \\
\hline CHEMBL1471047 & 688267 & 4.05 & 5.023 & TRN \\
\hline CHEMBL1377714 & 688267 & 4.3 & 5.0758 & TRN \\
\hline CHEMBL578515 & 688267 & 5.55 & 4.995 & TRN \\
\hline CHEMBL1413332 & 688267 & 5.4 & 5.0437 & TST \\
\hline CHEMBL1299565 & 688267 & 3.95 & 5.0013 & TST \\
\hline CHEMBL1380705 & 688267 & 3.9 & 5.1195 & TST \\
\hline CHEMBL1488784 & 688267 & 5.0 & 5.0538 & TST \\
\hline CHEMBL1313244 & 688267 & 4.35 & 5.1362 & TST \\
\hline CHEMBL1593016 & 688267 & 4.75 & 5.0001 & TRN \\
\hline CHEMBL1465504 & 688267 & 4.6 & 5.0719 & TRN \\
\hline CHEMBL3214037 & 688267 & 4.0 & 5.038 & TRN \\
\hline CHEMBL1411903 & 688267 & 6.5 & 5.0451 & TRN \\
\hline CHEMBL1305086 & 688267 & 5.9 & 5.0052 & TRN \\
\hline CHEMBL1599260 & 688267 & 6.6499 & 4.979 & TRN \\
\hline CHEMBL1378116 & 688267 & 6.2 & 4.979 & TRN \\
\hline CHEMBL1391341 & 688267 & 5.75 & 5.0383 & TRN \\
\hline CHEMBL11475 & 688267 & 4.25 & 5.0417 & TST \\
\hline CHEMBL1410578 & 688267 & 4.0 & 5.0805 & TRN \\
\hline CHEMBL1425408 & 688267 & 4.0 & 5.0091 & TRN \\
\hline CHEMBL1331219 & 688267 & 5.45 & 5.0551 & TRN \\
\hline CHEMBL1541157 & 688267 & 5.3 & 5.0089 & TRN \\
\hline CHEMBL1549768 & 688267 & 5.75 & 5.0402 & TRN \\
\hline
\end{tabular}




\begin{tabular}{|c|c|c|c|c|c|}
\hline \multicolumn{6}{|c|}{ Supplemental Table S2.txt } \\
\hline CHEMBL1337458 & 688267 & 6.15 & 5.0654 & TRN & \\
\hline CHEMBL1475719 & 688267 & 6.15 & 5.0626 & TRN & \\
\hline CHEMBL1425862 & 688267 & 5.15 & 5.0893 & TRN & \\
\hline CHEMBL1441370 & 688267 & 4.1 & 5.0962 & TRN & \\
\hline CHEMBL1538690 & 688267 & 6.2 & 5.0687 & TRN & \\
\hline CHEMBL1409080 & 688267 & 5.25 & 5.07 & TST & \\
\hline CHEMBL1491597 & 688267 & 5.1 & 5.0552 & TRN & \\
\hline CHEMBL1519963 & 688267 & 5.3 & 5.0268 & TRN & \\
\hline CHEMBL1576439 & 688267 & 5.75 & 5.0887 & TRN & \\
\hline CHEMBL1360384 & 688267 & 6.5 & 5.0811 & TRN & \\
\hline CHEMBL1440769 & 688267 & 4.6 & 5.0567 & TST & \\
\hline CHEMBL1518140 & 688267 & 4.05 & 5.0359 & TRN & \\
\hline CHEMBL1451808 & 688267 & 5.1 & 5.0345 & TRN & \\
\hline CHEMBL1467060 & 688267 & 6.2 & 5.0442 & TRN & \\
\hline CHEMBL1440782 & 688267 & 5.85 & 5.086 & TRN & \\
\hline CHEMBL1595204 & 688267 & 4.1 & 5.1329 & TRN & \\
\hline CHEMBL1318683 & 688267 & 6.2 & 5.099 & TRN & \\
\hline CHEMBL1373440 & 688267 & 6.2 & 5.0605 & TST & \\
\hline CHEMBL3194835 & 688267 & 4.05 & 5.0055 & TST & \\
\hline CHEMBL1540146 & 688267 & 6.15 & 5.1418 & TST & \\
\hline CHEMBL1503801 & 688267 & 4.4 & 5.1211 & TRN & \\
\hline CHEMBL1518002 & 688267 & 5.5 & 5.0625 & TRN & \\
\hline CHEMBL1575471 & 688267 & 4.0 & 5.0436 & TRN & \\
\hline CHEMBL1546357 & 688267 & 4.4 & 5.0773 & TRN & \\
\hline CHEMBL1411534 & 688267 & 6.2 & 5.0801 & TRN & \\
\hline CHEMBL1468791 & 688267 & 5.25 & 5.0529 & TST & \\
\hline CHEMBL1306161 & 688267 & 3.95 & 5.0622 & TRN & \\
\hline CHEMBL1374768 & 688267 & 5.5 & 5.0512 & TRN & \\
\hline CHEMBL1460863 & 688267 & 4.0 & 5.0257 & TST & \\
\hline CHEMBL1476113 & 688267 & 6.5 & 5.0491 & TST & \\
\hline CHEMBL1541933 & 688267 & 4.05 & 5.0085 & TST & \\
\hline CHEMBL1355684 & 688267 & 5.8 & 4.9939 & TST & \\
\hline CHEMBL1579935 & 688267 & 4.55 & 5.08899 & 99999999995 & TRN \\
\hline CHEMBL1371963 & 688267 & 6.45 & 5.0994 & TRN & \\
\hline CHEMBL1515702 & 688267 & 5.35 & 4.989 & TRN & \\
\hline CHEMBL1608383 & 688267 & 3.95 & 5.0169 & TST & \\
\hline CHEMBL1476497 & 688267 & 5.85 & 5.1173 & TRN & \\
\hline CHEMBL1480407 & 688267 & 4.2 & 5.02800 & 00000000005 & TRN \\
\hline CHEMBL1526688 & 688267 & 6.2 & 5.0401 & TST & \\
\hline CHEMBL1520368 & 688267 & 4.25 & 5.0357 & TRN & \\
\hline CHEMBL1571485 & 688267 & 6.2 & 5.0251 & TRN & \\
\hline CHEMBL1524445 & 688267 & 4.0 & 4.9836 & TRN & \\
\hline CHEMBL1306741 & 688267 & 4.05 & 5.0978 & TRN & \\
\hline CHEMBL1512185 & 688267 & 4.0 & 5.078 & TRN & \\
\hline CHEMBL1558956 & 688267 & 4.8 & 5.0366 & TRN & \\
\hline CHEMBL1514058 & 688267 & 5.5 & 5.1075 & TST & \\
\hline CHEMBL1478491 & 688267 & 4.0 & 4.9929 & TST & \\
\hline CHEMBL1354896 & 688267 & 5.9 & 5.0864 & TRN & \\
\hline
\end{tabular}




\begin{tabular}{|c|c|c|c|c|c|}
\hline & & \multicolumn{4}{|c|}{ Supplemental Table S2.txt } \\
\hline CHEMBL1371447 & 688267 & 4.1 & 5.0618 & TRN & \\
\hline CHEMBL1329445 & 688267 & 4.4 & 5.037 & TRN & \\
\hline CHEMBL1349482 & 688267 & 4.0 & 4.9977 & TST & \\
\hline CHEMBL1571255 & 688267 & 5.55 & 5.1802 & TRN & \\
\hline CHEMBL1400184 & 688267 & 6.15 & 5.0361 & TRN & \\
\hline CHEMBL1570563 & 688267 & 5.6 & 5.0664 & TRN & \\
\hline CHEMBL1981638 & 688267 & 6.2 & 4.9764 & TRN & \\
\hline CHEMBL1424798 & 688267 & 5.85 & 5.0368 & TRN & \\
\hline CHEMBL1511319 & 688267 & 4.0 & 5.0688 & TRN & \\
\hline CHEMBL1380684 & 688267 & 6.0 & 5.0663 & TST & \\
\hline CHEMBL1523939 & 688267 & 6.2 & 5.0832 & TRN & \\
\hline CHEMBL1355735 & 688267 & 4.35 & 5.0244 & TST & \\
\hline CHEMBL1534331 & 688267 & 4.05 & 5.0722 & TRN & \\
\hline CHEMBL1484598 & 688267 & 5.35 & 5.1438 & TRN & \\
\hline CHEMBL1508362 & 688267 & 4.95 & 5.0355 & TRN & \\
\hline CHEMBL1432054 & 688267 & 5.0 & 5.0731 & TST & \\
\hline CHEMBL3192730 & 688267 & 3.9 & 4.9953 & TRN & \\
\hline CHEMBL1317259 & 688267 & 5.25 & 5.0706 & TRN & \\
\hline CHEMBL1539982 & 688267 & 5.95 & 5.0739 & TRN & \\
\hline CHEMBL1418693 & 688267 & 6.2 & 5.033 & TRN & \\
\hline CHEMBL1548060 & 688267 & 4.1 & 5.0307 & TST & \\
\hline CHEMBL1579002 & 688267 & 4.0 & 5.1388 & TRN & \\
\hline CHEMBL1575987 & 688267 & 4.4 & 5.0633 & TRN & \\
\hline CHEMBL1508651 & 688267 & 4.6 & 5.0367 & TRN & \\
\hline CHEMBL1567290 & 688267 & 4.05 & 5.0265 & TRN & \\
\hline CHEMBL3198162 & 688267 & 4.05 & 5.0243 & TST & \\
\hline CHEMBL1375755 & 688267 & 4.35 & 5.0803 & TRN & \\
\hline CHEMBL1372594 & 688267 & 4.7 & 5.0408 & TRN & \\
\hline CHEMBL1528966 & 688267 & 4.35 & 5.1151 & TRN & \\
\hline CHEMBL1356458 & 688267 & 4.0 & 5.1366 & TRN & \\
\hline CHEMBL1440426 & 688267 & 5.75 & 5.0471 & TRN & \\
\hline CHEMBL1532342 & 688267 & 4.95 & 5.0545 & TRN & \\
\hline CHEMBL1368089 & 688267 & 5.35 & 5.0828 & TRN & \\
\hline CHEMBL1315379 & 688267 & 4.4 & 5.1458 & TRN & \\
\hline CHEMBL1566613 & 688267 & 6.2 & 5.0155 & TST & \\
\hline CHEMBL1348242 & 688267 & 4.55 & 5.0014 & TRN & \\
\hline CHEMBL1585781 & 688267 & 4.15 & 5.0785 & TRN & \\
\hline CHEMBL1554898 & 688267 & 5.1 & 5.0466 & TRN & \\
\hline CHEMBL1500112 & 688267 & 5.4 & 5.1057 & TRN & \\
\hline CHEMBL1556422 & 688267 & 4.5 & 5.1169 & TRN & \\
\hline CHEMBL1306831 & 688267 & 5.05 & 5.007 & TRN & \\
\hline CHEMBL3196151 & 688267 & 5.75 & 5.0612 & TRN & \\
\hline CHEMBL1606617 & 688267 & 5.6 & 5.038 & TRN & \\
\hline CHEMBL1436483 & 688267 & 5.2 & 5.0411 & TRN & \\
\hline CHEMBL1491494 & 688267 & 5.8 & 5.08899 & 99999999995 & TRN \\
\hline CHEMBL45152 & 688267 & 4.2 & 5.0018 & TRN & \\
\hline CHEMBL1475067 & 688267 & 5.95 & 5.1556 & TST & \\
\hline CHEMBL1477735 & 688267 & 4.0 & 4.982 & TRN & \\
\hline
\end{tabular}




\begin{tabular}{|c|c|c|c|c|}
\hline & & & pplement & al $\mathrm{Ta}$ \\
\hline CHEMBL1552483 & 688267 & 6.5 & 5.0371 & TRN \\
\hline CHEMBL1355744 & 688267 & 5.35 & 5.0482 & TRN \\
\hline CHEMBL1421136 & 688267 & 5.6 & 5.0726 & TST \\
\hline CHEMBL1469948 & 688267 & 4.7 & 5.1239 & TST \\
\hline CHEMBL1508770 & 688267 & 5.25 & 5.0165 & TRN \\
\hline CHEMBL1330376 & 688267 & 5.45 & 5.0076 & TRN \\
\hline CHEMBL1511803 & 688267 & 4.4 & 5.0745 & TRN \\
\hline CHEMBL1500703 & 688267 & 5.45 & 5.072 & TRN \\
\hline CHEMBL1603948 & 688267 & 4.75 & 5.0439 & TRN \\
\hline CHEMBL1494206 & 688267 & 4.5 & 5.0703 & TRN \\
\hline CHEMBL1473363 & 688267 & 4.25 & 5.0558 & TRN \\
\hline CHEMBL1524879 & 688267 & 6.2 & 5.1027 & TRN \\
\hline CHEMBL1561903 & 688267 & 4.0 & 5.0611 & TRN \\
\hline CHEMBL3210983 & 688267 & 4.95 & 5.0299 & TRN \\
\hline CHEMBL1391932 & 688267 & 4.85 & 5.1394 & TRN \\
\hline CHEMBL1522115 & 688267 & 4.45 & 5.0017 & TST \\
\hline CHEMBL1362953 & 688267 & 5.25 & 5.1164 & TRN \\
\hline CHEMBL1581892 & 688267 & 4.35 & 5.1021 & TST \\
\hline CHEMBL1445264 & 688267 & 5.1 & 5.0938 & TRN \\
\hline CHEMBL1558963 & 688267 & 6.2 & 4.9874 & TRN \\
\hline CHEMBL1325713 & 688267 & 6.1 & 5.0543 & TRN \\
\hline CHEMBL1388736 & 688267 & 5.75 & 5.0487 & TRN \\
\hline CHEMBL1498527 & 688267 & 5.75 & 5.0175 & TRN \\
\hline CHEMBL1311027 & 688267 & 4.4 & 5.0528 & TST \\
\hline CHEMBL1596031 & 688267 & 5.05 & 5.008 & TRN \\
\hline CHEMBL1405970 & 688267 & 4.4 & 5.1158 & TRN \\
\hline CHEMBL1442549 & 688267 & 6.15 & 5.066 & TRN \\
\hline CHEMBL1362854 & 688267 & 6.2 & 5.0134 & TST \\
\hline CHEMBL1393016 & 688267 & 4.8 & 5.0446 & TST \\
\hline CHEMBL1347316 & 688267 & 5.8 & 5.0546 & TST \\
\hline CHEMBL1305916 & 688267 & 4.05 & 5.0648 & TST \\
\hline CHEMBL1494492 & 688267 & 5.45 & 5.0383 & TRN \\
\hline CHEMBL1348344 & 688267 & 4.5 & 4.9966 & TRN \\
\hline CHEMBL1327804 & 688267 & 4.6 & 5.0208 & TRN \\
\hline CHEMBL90181 & 688267 & 4.95 & 5.0449 & TST \\
\hline CHEMBL1478584 & 688267 & 5.85 & 5.0984 & TST \\
\hline CHEMBL1395878 & 688267 & 6.5 & 5.0201 & TRN \\
\hline CHEMBL1457148 & 688267 & 4.3 & 5.0502 & TST \\
\hline CHEMBL1377586 & 688267 & 5.85 & 5.055 & TRN \\
\hline CHEMBL1603318 & 688267 & 5.25 & 5.0632 & TRN \\
\hline CHEMBL1393010 & 688267 & 5.2 & 5.1231 & TRN \\
\hline CHEMBL1455638 & 688267 & 4.0 & 5.0943 & TRN \\
\hline CHEMBL1377610 & 688267 & 4.35 & 5.0158 & TST \\
\hline CHEMBL1472178 & 688267 & 4.6 & 5.1363 & TRN \\
\hline CHEMBL1487750 & 688267 & 4.05 & 5.0127 & TRN \\
\hline CHEMBL1561135 & 688267 & 5.9 & 5.067 & TRN \\
\hline CHEMBL1328491 & 688267 & 5.6 & 5.0297 & TRN \\
\hline CHEMBL1306549 & 688267 & 4.5 & 5.0626 & TRN \\
\hline
\end{tabular}




\begin{tabular}{|c|c|c|c|c|}
\hline \multicolumn{5}{|c|}{ Supplemental Table S2.txt } \\
\hline CHEMBL1500310 & 688267 & 5.85 & 5.0351 & TST \\
\hline CHEMBL1422347 & 688267 & 5.85 & 5.1058 & TRN \\
\hline CHEMBL1567180 & 688267 & 4.25 & 5.0174 & TRN \\
\hline CHEMBL1515617 & 688267 & 4.05 & 5.0425 & TRN \\
\hline CHEMBL1554658 & 688267 & 4.55 & 5.023 & TRN \\
\hline CHEMBL1549470 & 688267 & 6.45 & 5.1133 & TRN \\
\hline CHEMBL1512924 & 688267 & 5.85 & 5.0806 & TRN \\
\hline CHEMBL1466531 & 688267 & 5.65 & 5.1389 & TRN \\
\hline CHEMBL1543040 & 688267 & 4.15 & 5.0745 & TRN \\
\hline CHEMBL3213018 & 688267 & 6.2 & 5.0533 & TST \\
\hline CHEMBL581049 & 688267 & 6.15 & 5.0343 & TRN \\
\hline CHEMBL1352742 & 688267 & 5.75 & 5.0762 & TRN \\
\hline CHEMBL1600328 & 688267 & 4.7 & 5.0261 & TRN \\
\hline CHEMBL1359642 & 688267 & 5.55 & 5.0469 & TRN \\
\hline CHEMBL1451123 & 688267 & 5.5 & 5.1574 & TST \\
\hline CHEMBL1529939 & 688267 & 6.0 & 5.0293 & TRN \\
\hline CHEMBL1463650 & 688267 & 3.95 & 5.0694 & TRN \\
\hline CHEMBL1366007 & 688267 & 5.5 & 5.0375 & TRN \\
\hline CHEMBL1416386 & 688267 & 4.0 & 5.1497 & TRN \\
\hline CHEMBL1333881 & 688267 & 4.35 & 5.0458 & TST \\
\hline CHEMBL1549913 & 688267 & 4.4 & 5.0639 & TRN \\
\hline CHEMBL1537168 & 688267 & 4.4 & 5.0406 & TRN \\
\hline CHEMBL1388701 & 688267 & 4.35 & 5.0213 & TRN \\
\hline CHEMBL1333889 & 688267 & 4.25 & 5.037 & TRN \\
\hline CHEMBL1487775 & 688267 & 4.1 & 5.1103 & TRN \\
\hline CHEMBL1395719 & 688267 & 6.2 & 5.1158 & TRN \\
\hline CHEMBL1390146 & 688267 & 5.3 & 5.0151 & TRN \\
\hline CHEMBL1548712 & 688267 & 5.4 & 4.998 & TST \\
\hline CHEMBL1406385 & 688267 & 4.05 & 5.1134 & TST \\
\hline CHEMBL1395799 & 688267 & 4.9 & 5.0328 & TRN \\
\hline CHEMBL3212879 & 688267 & 4.0 & 5.0254 & TST \\
\hline CHEMBL1603085 & 688267 & 5.0 & 4.987 & TST \\
\hline CHEMBL1300971 & 688267 & 4.05 & 5.0178 & TST \\
\hline CHEMBL1540823 & 688267 & 4.45 & 5.0817 & TRN \\
\hline CHEMBL1556622 & 688267 & 5.55 & 5.0842 & TRN \\
\hline CHEMBL1538602 & 688267 & 5.3 & 5.048 & TRN \\
\hline CHEMBL1534213 & 688267 & 5.55 & 5.0471 & TRN \\
\hline CHEMBL1481955 & 688267 & 5.3 & 5.0914 & TRN \\
\hline CHEMBL1425737 & 688267 & 5.1 & 5.0651 & TRN \\
\hline CHEMBL1512519 & 688267 & 5.6 & 5.0515 & TRN \\
\hline CHEMBL1530181 & 688267 & 4.5 & 5.1031 & TRN \\
\hline CHEMBL1312401 & 688267 & 6.6 & 5.0122 & TST \\
\hline CHEMBL1330634 & 688267 & 4.0 & 5.0424 & TST \\
\hline CHEMBL1395682 & 688267 & 6.25 & 5.0208 & TRN \\
\hline CHEMBL1494118 & 688267 & 4.4 & 5.0125 & TST \\
\hline CHEMBL1308337 & 688267 & 4.75 & 5.0532 & TRN \\
\hline CHEMBL1543949 & 688267 & 5.0 & 5.0479 & TST \\
\hline CHEMBL1599724 & 688267 & 6.2 & 5.121 & TRN \\
\hline
\end{tabular}




\begin{tabular}{|c|c|c|c|c|}
\hline & & & pplement & al $\mathrm{Ta}$ \\
\hline CHEMBL1438442 & 688267 & 5.3 & 5.0535 & TST \\
\hline CHEMBL1411799 & 688267 & 4.85 & 5.0917 & TRN \\
\hline CHEMBL1385281 & 688267 & 4.6 & 5.06 & TST \\
\hline CHEMBL1436170 & 688267 & 5.3 & 5.0195 & TRN \\
\hline CHEMBL1397222 & 688267 & 4.0 & 5.0976 & TRN \\
\hline CHEMBL1440343 & 688267 & 5.05 & 5.0971 & TRN \\
\hline CHEMBL1503075 & 688267 & 6.2 & 5.0748 & TRN \\
\hline CHEMBL1501981 & 688267 & 5.65 & 5.0801 & TRN \\
\hline CHEMBL1411152 & 688267 & 5.75 & 5.0189 & TRN \\
\hline CHEMBL1357478 & 688267 & 6.25 & 5.0703 & TRN \\
\hline CHEMBL1518507 & 688267 & 5.45 & 5.0687 & TRN \\
\hline CHEMBL3196911 & 688267 & 5.65 & 5.0035 & TRN \\
\hline CHEMBL1355625 & 688267 & 5.25 & 5.0166 & TRN \\
\hline CHEMBL1356784 & 688267 & 4.1 & 5.0313 & TRN \\
\hline CHEMBL1506906 & 688267 & 3.95 & 5.051 & TRN \\
\hline CHEMBL1417162 & 688267 & 4.35 & 5.1585 & TRN \\
\hline CHEMBL1518478 & 688267 & 5.1 & 5.1231 & TST \\
\hline CHEMBL1469854 & 688267 & 6.2 & 5.0549 & TST \\
\hline CHEMBL1422349 & 688267 & 4.3 & 5.0191 & TRN \\
\hline CHEMBL1386230 & 688267 & 4.05 & 5.0258 & TRN \\
\hline CHEMBL1550506 & 688267 & 5.05 & 5.0719 & TST \\
\hline CHEMBL1396560 & 688267 & 4.6 & 5.0407 & TRN \\
\hline CHEMBL1305244 & 688267 & 5.05 & 5.0494 & TRN \\
\hline CHEMBL1464143 & 688267 & 4.0 & 5.1082 & TRN \\
\hline CHEMBL1589872 & 688267 & 5.4 & 5.0737 & TST \\
\hline CHEMBL1317818 & 688267 & 4.35 & 5.0969 & TRN \\
\hline CHEMBL1527799 & 688267 & 5.4 & 5.0086 & TRN \\
\hline CHEMBL1535893 & 688267 & 5.95 & 5.0274 & TRN \\
\hline CHEMBL1607740 & 688267 & 6.15 & 5.0639 & TRN \\
\hline CHEMBL1477436 & 688267 & 5.55 & 5.0399 & TRN \\
\hline CHEMBL1520350 & 688267 & 4.95 & 5.0699 & TRN \\
\hline CHEMBL1418145 & 688267 & 5.5 & 5.0056 & TST \\
\hline CHEMBL1429575 & 688267 & 5.5 & 5.0518 & TST \\
\hline CHEMBL1608966 & 688267 & 6.15 & 5.051 & TRN \\
\hline CHEMBL1347187 & 688267 & 4.55 & 5.0345 & TRN \\
\hline CHEMBL1605703 & 688267 & 5.3 & 5.1042 & TRN \\
\hline CHEMBL1396355 & 688267 & 5.0 & 5.1269 & TRN \\
\hline CHEMBL1310659 & 688267 & 4.5 & 5.0276 & TRN \\
\hline CHEMBL1505812 & 688267 & 5.25 & 5.0573 & TST \\
\hline CHEMBL1332999 & 688267 & 4.1 & 5.0326 & TRN \\
\hline CHEMBL1560143 & 688267 & 6.5 & 5.0508 & TRN \\
\hline CHEMBL1450504 & 688267 & 4.55 & 5.0266 & TST \\
\hline CHEMBL1521881 & 688267 & 4.55 & 5.1246 & TRN \\
\hline CHEMBL1456141 & 688267 & 5.3 & 5.0502 & TRN \\
\hline CHEMBL1392006 & 688267 & 4.5 & 5.0529 & TRN \\
\hline CHEMBL1589489 & 688267 & 6.0 & 5.0955 & TRN \\
\hline CHEMBL1513170 & 688267 & 4.4 & 5.0489 & TRN \\
\hline CHEMBL1603198 & 688267 & 4.0 & 5.0553 & TRN \\
\hline
\end{tabular}




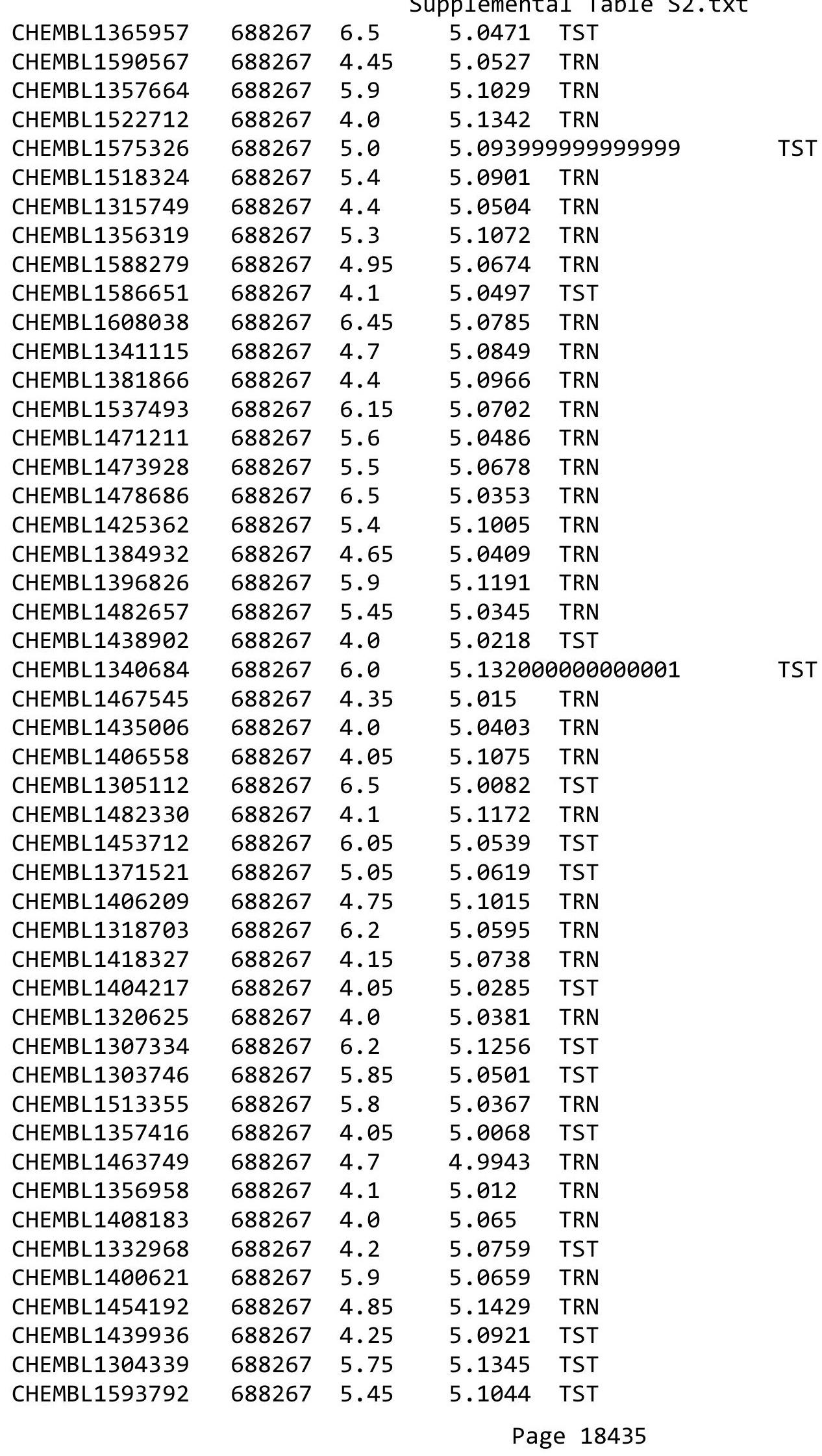




\begin{tabular}{|c|c|c|c|c|c|}
\hline \multicolumn{6}{|c|}{ Supplemental Table S2.txt } \\
\hline CHEMBL1342859 & 688267 & 6.15 & 5.0047 & TST & \\
\hline CHEMBL1410557 & 688267 & 4.3 & 5.0702 & TRN & \\
\hline CHEMBL1434288 & 688267 & 4.5 & 5.0273 & TRN & \\
\hline CHEMBL1582690 & 688267 & 5.3 & 5.0853 & TRN & \\
\hline CHEMBL1449682 & 688267 & 5.55 & 5.0174 & TRN & \\
\hline CHEMBL1351359 & 688267 & 5.0 & 5.0792 & TRN & \\
\hline CHEMBL1558549 & 688267 & 6.0 & 5.0051 & TRN & \\
\hline CHEMBL1591696 & 688267 & 6.25 & 5.0275 & TRN & \\
\hline CHEMBL1343765 & 688267 & 6.15 & 5.0678 & TST & \\
\hline CHEMBL1355046 & 688267 & 5.45 & 5.0382 & TRN & \\
\hline CHEMBL1339691 & 688267 & 4.25 & 5.0298 & TST & \\
\hline CHEMBL1536484 & 688267 & 4.45 & 5.0091 & TST & \\
\hline CHEMBL1513768 & 688267 & 6.2 & 5.0646 & TRN & \\
\hline CHEMBL1304719 & 688267 & 4.9 & 5.0287 & TRN & \\
\hline CHEMBL1388476 & 688267 & 6.2 & 5.1054 & TRN & \\
\hline CHEMBL1497541 & 688267 & 5.7 & 5.0505 & TRN & \\
\hline CHEMBL1416564 & 688267 & 6.2 & 5.0532 & TRN & \\
\hline CHEMBL1425546 & 688267 & 5.7 & 5.0728 & TRN & \\
\hline CHEMBL1306046 & 688267 & 5.55 & 5.0707 & TRN & \\
\hline CHEMBL1436568 & 688267 & 5.6 & 5.0854 & TST & \\
\hline CHEMBL1326958 & 688267 & 5.35 & 5.0655 & TRN & \\
\hline CHEMBL603024 & 688267 & 4.35 & 5.0374 & TST & \\
\hline CHEMBL1470904 & 688267 & 6.2 & 4.9898 & TRN & \\
\hline CHEMBL1332602 & 688267 & 6.0 & 4.9949 & TRN & \\
\hline CHEMBL1450679 & 688267 & 4.05 & 5.0152 & TST & \\
\hline CHEMBL1548070 & 688267 & 6.2 & 5.0968 & TRN & \\
\hline CHEMBL1404362 & 688267 & 5.35 & 5.0538 & TRN & \\
\hline CHEMBL1523241 & 688267 & 4.95 & 5.0673 & TST & \\
\hline CHEMBL1389652 & 688267 & 4.05 & 5.0704 & TRN & \\
\hline CHEMBL1340298 & 688267 & 4.25 & 4.9649 & TRN & \\
\hline CHEMBL1418108 & 688267 & 4.05 & 5.0794 & TST & \\
\hline CHEMBL1584412 & 688267 & 4.35 & 5.0539 & TRN & \\
\hline CHEMBL1591642 & 688267 & 4.05 & 5.0539 & TRN & \\
\hline CHEMBL1599230 & 688267 & 4.0 & 5.0307 & TRN & \\
\hline CHEMBL1348417 & 688267 & 6.5 & 5.0717 & TST & \\
\hline CHEMBL1597466 & 688267 & 4.25 & 5.1665 & TRN & \\
\hline CHEMBL1332110 & 688267 & 5.45 & 5.0634 & TRN & \\
\hline CHEMBL1498130 & 688267 & 5.9 & 5.012 & TRN & \\
\hline CHEMBL1304373 & 688267 & 5.65 & 5.13899 & 9999999999 & TRN \\
\hline CHEMBL1578200 & 688267 & 4.55 & 5.026 & TRN & \\
\hline CHEMBL1410610 & 688267 & 5.55 & 5.1054 & TRN & \\
\hline CHEMBL1412267 & 688267 & 4.4 & 5.0586 & TST & \\
\hline CHEMBL1553615 & 688267 & 6.15 & 5.1453 & TRN & \\
\hline CHEMBL1513297 & 688267 & 3.95 & 5.1093 & TRN & \\
\hline CHEMBL1364778 & 688267 & 4.0 & 5.0873 & TRN & \\
\hline CHEMBL1574753 & 688267 & 5.3 & 5.0546 & TRN & \\
\hline CHEMBL1318205 & 688267 & 4.0 & 5.0488 & TRN & \\
\hline CHEMBL1417197 & 688267 & 5.15 & $5.0280 e$ & 00000000005 & TRN \\
\hline & & & & 18436 & \\
\hline
\end{tabular}




\begin{tabular}{|c|c|c|c|c|c|}
\hline \multicolumn{6}{|c|}{ Supplemental Table S2 } \\
\hline CHEMBL1459698 & 688267 & 4.6 & 5.0356 & TRN & \\
\hline CHEMBL1984703 & 688267 & 5.85 & 4.9848 & TRN & \\
\hline CHEMBL1381466 & 688267 & 4.25 & 4.9979 & TRN & \\
\hline CHEMBL1376499 & 688267 & 4.05 & $5.0280 e$ & 00000000005 & TST \\
\hline CHEMBL3210817 & 688267 & 5.55 & 5.0051 & TRN & \\
\hline CHEMBL1346551 & 688267 & 4.0 & 5.0376 & TRN & \\
\hline CHEMBL1456388 & 688267 & 4.35 & 5.0565 & TRN & \\
\hline CHEMBL1455565 & 688267 & 6.15 & 5.1019 & TRN & \\
\hline CHEMBL1599755 & 688267 & 5.45 & 5.0324 & TST & \\
\hline CHEMBL2005198 & 688267 & 6.25 & 4.9953 & TRN & \\
\hline CHEMBL1433834 & 688267 & 3.95 & 5.1055 & TRN & \\
\hline CHEMBL3213625 & 688267 & 6.15 & 5.088 & TRN & \\
\hline CHEMBL1321555 & 688267 & 4.35 & 5.0929 & TST & \\
\hline CHEMBL1524326 & 688267 & 5.15 & 5.0077 & TRN & \\
\hline CHEMBL1402999 & 688267 & 6.5 & 5.0847 & TST & \\
\hline CHEMBL1492973 & 688267 & 4.3 & 5.0165 & TST & \\
\hline CHEMBL1515900 & 688267 & 4.3 & 5.0536 & TRN & \\
\hline CHEMBL1378118 & 688267 & 6.1 & 5.0374 & TST & \\
\hline CHEMBL1610670 & 688267 & 4.45 & 5.0796 & TRN & \\
\hline CHEMBL1540612 & 688267 & 4.15 & 5.0532 & TRN & \\
\hline CHEMBL1364384 & 688267 & 6.45 & 5.0878 & TRN & \\
\hline CHEMBL1585068 & 688267 & 6.2 & 5.0712 & TRN & \\
\hline CHEMBL1338867 & 688267 & 4.4 & 5.0343 & TRN & \\
\hline CHEMBL1499487 & 688267 & 6.2 & 5.1594 & TRN & \\
\hline CHEMBL1377783 & 688267 & 4.6 & 5.0855 & TRN & \\
\hline CHEMBL1334480 & 688267 & 5.7 & 5.1228 & TRN & \\
\hline CHEMBL1535800 & 688267 & 4.25 & 5.0111 & TRN & \\
\hline CHEMBL1480297 & 688267 & 4.3 & 5.0462 & TRN & \\
\hline CHEMBL1554013 & 688267 & 3.95 & 5.1067 & TST & \\
\hline CHEMBL1550213 & 688267 & 6.25 & 5.102 & TST & \\
\hline CHEMBL1524960 & 688267 & 5.8 & 5.0513 & TRN & \\
\hline CHEMBL1542510 & 688267 & 4.25 & 5.0886 & TRN & \\
\hline CHEMBL1580700 & 688267 & 5.25 & 5.0885 & TRN & \\
\hline CHEMBL1500776 & 688267 & 5.0 & 5.1184 & TRN & \\
\hline CHEMBL1545298 & 688267 & 4.35 & 5.0232 & TRN & \\
\hline CHEMBL1499120 & 688267 & 4.25 & 5.0598 & TST & \\
\hline CHEMBL1526012 & 688267 & 6.5 & 5.0541 & TRN & \\
\hline CHEMBL1382826 & 688267 & 5.35 & 5.0698 & TRN & \\
\hline CHEMBL1351793 & 688267 & 6.2 & 5.0193 & TRN & \\
\hline CHEMBL1430345 & 688267 & 5.1 & 5.1168 & TST & \\
\hline CHEMBL1577965 & 688267 & 4.0 & 5.0407 & TRN & \\
\hline CHEMBL1502705 & 688267 & 5.95 & 5.0461 & TST & \\
\hline CHEMBL1553779 & 688267 & 6.2 & 5.0391 & TST & \\
\hline CHEMBL1372396 & 688267 & 4.0 & 5.0265 & TRN & \\
\hline CHEMBL1395590 & 688267 & 4.1 & 5.0589 & TRN & \\
\hline CHEMBL1531967 & 688267 & 5.15 & 5.1074 & TRN & \\
\hline CHEMBL1434577 & 688267 & 5.05 & 5.0846 & TRN & \\
\hline CHEMBL1498320 & 688267 & 6.45 & 5.0385 & TRN & \\
\hline & & & & 18437 & \\
\hline
\end{tabular}




\begin{tabular}{|c|c|c|c|c|}
\hline \multicolumn{5}{|c|}{ Supplemental Table S2.txt } \\
\hline CHEMBL1357970 & 688267 & 3.95 & 5.1161 & TRN \\
\hline CHEMBL1512039 & 688267 & 5.05 & 5.0882 & TRN \\
\hline CHEMBL1500060 & 688267 & 6.2 & 5.0231 & TRN \\
\hline CHEMBL1479176 & 688267 & 6.25 & 5.0189 & TRN \\
\hline CHEMBL1577714 & 688267 & 4.0 & 5.0539 & TRN \\
\hline CHEMBL1513626 & 688267 & 6.2 & 5.0226 & TRN \\
\hline CHEMBL1429273 & 688267 & 4.35 & 5.0738 & TST \\
\hline CHEMBL1532547 & 688267 & 4.15 & 5.0972 & TST \\
\hline CHEMBL1357143 & 688267 & 4.0 & 5.0616 & TRN \\
\hline CHEMBL1550486 & 688267 & 4.95 & 4.9914 & TRN \\
\hline CHEMBL1338071 & 688267 & 4.0 & 5.0891 & TRN \\
\hline CHEMBL1584728 & 688267 & 4.05 & 5.003 & TRN \\
\hline CHEMBL1572852 & 688267 & 4.15 & 5.0221 & TRN \\
\hline CHEMBL1593116 & 688267 & 5.45 & 5.1089 & TRN \\
\hline CHEMBL1511219 & 688267 & 4.95 & 4.9881 & TRN \\
\hline CHEMBL1552458 & 688267 & 5.25 & 4.9765 & TST \\
\hline CHEMBL1300777 & 688267 & 6.15 & 5.0372 & TST \\
\hline CHEMBL1476787 & 688267 & 4.1 & 4.9925 & TRN \\
\hline CHEMBL1355986 & 688267 & 4.0 & 5.0467 & TST \\
\hline CHEMBL1395144 & 688267 & 4.05 & 5.0414 & TRN \\
\hline CHEMBL1568149 & 688267 & 6.05 & 5.0902 & TRN \\
\hline CHEMBL1356908 & 688267 & 4.0 & 5.1125 & TRN \\
\hline CHEMBL1580851 & 688267 & 5.3 & 5.0817 & TRN \\
\hline CHEMBL1507428 & 688267 & 4.0 & 5.0185 & TST \\
\hline CHEMBL1541529 & 688267 & 5.2 & 5.0893 & TRN \\
\hline CHEMBL1460922 & 688267 & 3.95 & 5.0226 & TST \\
\hline CHEMBL1565272 & 688267 & 5.5 & 5.013 & TRN \\
\hline CHEMBL1533964 & 688267 & 4.3 & 5.0208 & TST \\
\hline CHEMBL1562249 & 688267 & 5.3 & 5.0472 & TRN \\
\hline CHEMBL573127 & 688267 & 4.55 & 5.0378 & TRN \\
\hline CHEMBL1535889 & 688267 & 4.35 & 5.0832 & TRN \\
\hline CHEMBL1341925 & 688267 & 5.6 & 5.1148 & TRN \\
\hline CHEMBL1476781 & 688267 & 6.15 & 5.0423 & TRN \\
\hline CHEMBL1559353 & 688267 & 4.25 & 4.9986 & TRN \\
\hline CHEMBL1419996 & 688267 & 4.0 & 5.019 & TST \\
\hline CHEMBL1384271 & 688267 & 4.35 & 5.1122 & TRN \\
\hline CHEMBL1594601 & 688267 & 4.2 & 5.1417 & TRN \\
\hline CHEMBL1419347 & 688267 & 4.05 & 5.0272 & TRN \\
\hline CHEMBL1461159 & 688267 & 4.65 & 5.0466 & TRN \\
\hline CHEMBL1337364 & 688267 & 4.05 & 5.0022 & TST \\
\hline CHEMBL1594779 & 688267 & 5.3 & 5.0225 & TST \\
\hline CHEMBL1554429 & 688267 & 5.45 & 5.1198 & TST \\
\hline CHEMBL1436211 & 688267 & 5.35 & 5.0288 & TRN \\
\hline CHEMBL1304044 & 688267 & 4.0 & 5.0352 & TRN \\
\hline CHEMBL1550946 & 688267 & 4.65 & 5.065 & TST \\
\hline CHEMBL1408887 & 688267 & 4.05 & 5.0889 & TRN \\
\hline CHEMBL1380523 & 688267 & 6.2 & 5.0171 & TRN \\
\hline CHEMBL1315354 & 688267 & 4.5 & 5.0186 & TRN \\
\hline
\end{tabular}




\begin{tabular}{|c|c|c|c|c|}
\hline & & & pplement & al $\mathrm{Ta}$ \\
\hline CHEMBL1414492 & 688267 & 4.3 & 5.0204 & TRN \\
\hline CHEMBL1546624 & 688267 & 4.55 & 4.9995 & TRN \\
\hline CHEMBL1437907 & 688267 & 5.05 & 5.0772 & TRN \\
\hline CHEMBL1370729 & 688267 & 6.2 & 5.0084 & TRN \\
\hline CHEMBL1456862 & 688267 & 5.55 & 5.0654 & TRN \\
\hline CHEMBL1538601 & 688267 & 5.0 & 5.0381 & TST \\
\hline CHEMBL1500825 & 688267 & 6.2 & 5.081 & TST \\
\hline CHEMBL1591683 & 688267 & 5.55 & 5.1045 & TRN \\
\hline CHEMBL1582501 & 688267 & 6.2 & 5.0492 & TST \\
\hline CHEMBL1307331 & 688267 & 4.25 & 5.0946 & TRN \\
\hline CHEMBL1878966 & 688267 & 5.6 & 5.0397 & TST \\
\hline CHEMBL1521781 & 688267 & 5.95 & 5.0687 & TRN \\
\hline CHEMBL1332228 & 688267 & 4.25 & 5.1255 & TST \\
\hline CHEMBL1321559 & 688267 & 5.9 & 5.0607 & TST \\
\hline CHEMBL1568175 & 688267 & 4.05 & 5.0821 & TRN \\
\hline CHEMBL1472724 & 688267 & 6.25 & 5.0402 & TRN \\
\hline CHEMBL3197588 & 688267 & 5.65 & 5.0286 & TRN \\
\hline CHEMBL1333969 & 688267 & 4.4 & 5.0609 & TRN \\
\hline CHEMBL1381992 & 688267 & 6.05 & 5.0442 & TST \\
\hline CHEMBL1367999 & 688267 & 5.35 & 5.0577 & TRN \\
\hline CHEMBL1409382 & 688267 & 4.05 & 5.1375 & TRN \\
\hline CHEMBL1454587 & 688267 & 4.85 & 5.0913 & TST \\
\hline CHEMBL1588192 & 688267 & 6.25 & 5.0325 & TRN \\
\hline CHEMBL1514406 & 688267 & 6.15 & 4.9868 & TRN \\
\hline CHEMBL1534062 & 688267 & 4.05 & 5.1043 & TST \\
\hline CHEMBL1462255 & 688267 & 5.35 & 5.0387 & TST \\
\hline CHEMBL1358041 & 688267 & 4.55 & 5.0451 & TRN \\
\hline CHEMBL1576629 & 688267 & 6.2 & 5.0454 & TST \\
\hline CHEMBL1478758 & 688267 & 5.8 & 5.0712 & TST \\
\hline CHEMBL1593077 & 688267 & 6.05 & 5.1255 & TRN \\
\hline CHEMBL1582744 & 688267 & 4.6 & 5.0787 & TRN \\
\hline CHEMBL1519977 & 688267 & 4.05 & 5.0242 & TRN \\
\hline CHEMBL1346274 & 688267 & 4.85 & 5.0174 & TST \\
\hline CHEMBL1434387 & 688267 & 4.0 & 4.9829 & TRN \\
\hline CHEMBL1594049 & 688267 & 5.0 & 5.0406 & TRN \\
\hline CHEMBL1402243 & 688267 & 5.3 & 5.0949 & TRN \\
\hline CHEMBL1590972 & 688267 & 5.45 & 5.1054 & TRN \\
\hline CHEMBL1584449 & 688267 & 6.2 & 5.0368 & TRN \\
\hline CHEMBL1426611 & 688267 & 5.6 & 5.0043 & TRN \\
\hline CHEMBL1513245 & 688267 & 5.9 & 5.0033 & TST \\
\hline CHEMBL1516635 & 688267 & 5.3 & 4.9979 & TRN \\
\hline CHEMBL97643 & 688267 & 4.95 & 5.0276 & TST \\
\hline CHEMBL1304806 & 688267 & 4.35 & 5.0495 & TRN \\
\hline CHEMBL1419782 & 688267 & 4.4 & 5.0919 & TRN \\
\hline CHEMBL1444063 & 688267 & 5.3 & 5.1536 & TRN \\
\hline CHEMBL1403824 & 688267 & 6.15 & 5.0055 & TRN \\
\hline CHEMBL1401464 & 688267 & 3.95 & 5.0723 & TRN \\
\hline CHEMBL1572255 & 688267 & 5.3 & 5.0204 & TRN \\
\hline
\end{tabular}




\begin{tabular}{|c|c|c|c|c|}
\hline & & & pplement & al $\mathrm{Ta}$ \\
\hline CHEMBL1514922 & 688267 & 6.25 & 5.0874 & TST \\
\hline CHEMBL1441376 & 688267 & 5.55 & 5.0139 & TRN \\
\hline CHEMBL1324985 & 688267 & 5.85 & 5.0701 & TRN \\
\hline CHEMBL3208866 & 688267 & 5.15 & 5.1206 & TRN \\
\hline CHEMBL1590188 & 688267 & 4.05 & 5.0491 & TRN \\
\hline CHEMBL1549886 & 688267 & 5.25 & 5.0714 & TRN \\
\hline CHEMBL1429628 & 688267 & 5.2 & 5.0628 & TRN \\
\hline CHEMBL1479479 & 688267 & 5.05 & 5.1379 & TRN \\
\hline CHEMBL1475454 & 688267 & 5.05 & 5.0655 & TRN \\
\hline CHEMBL1310499 & 688267 & 4.3 & 5.0068 & TRN \\
\hline CHEMBL1378898 & 688267 & 5.5 & 5.0692 & TRN \\
\hline CHEMBL1361484 & 688267 & 4.6 & 5.0021 & TRN \\
\hline CHEMBL1450556 & 688267 & 4.4 & 5.0051 & TRN \\
\hline CHEMBL1524972 & 688267 & 4.45 & 4.9597 & TRN \\
\hline CHEMBL1605539 & 688267 & 6.2 & 5.0797 & TRN \\
\hline CHEMBL1400604 & 688267 & 5.35 & 5.1286 & TRN \\
\hline CHEMBL1532824 & 688267 & 5.4 & 5.0752 & TRN \\
\hline CHEMBL1885024 & 688267 & 5.6 & 4.9958 & TRN \\
\hline CHEMBL1423090 & 688267 & 4.05 & 5.0509 & TRN \\
\hline CHEMBL1436171 & 688267 & 5.4 & 5.1412 & TRN \\
\hline CHEMBL1311540 & 688267 & 4.0 & 5.1071 & TST \\
\hline CHEMBL1562072 & 688267 & 5.9 & 5.1208 & TRN \\
\hline CHEMBL1376006 & 688267 & 6.2 & 5.0043 & TRN \\
\hline CHEMBL1361070 & 688267 & 5.65 & 5.0161 & TRN \\
\hline CHEMBL1335113 & 688267 & 6.25 & 5.1431 & TRN \\
\hline CHEMBL1510308 & 688267 & 5.3 & 5.0149 & TST \\
\hline CHEMBL1499375 & 688267 & 3.95 & 5.14 & TRN \\
\hline CHEMBL1326814 & 688267 & 4.25 & 5.0105 & TST \\
\hline CHEMBL1357545 & 688267 & 4.05 & 5.0777 & TRN \\
\hline CHEMBL1325534 & 688267 & 3.95 & 5.0073 & TST \\
\hline CHEMBL1357711 & 688267 & 6.05 & 5.0029 & TRN \\
\hline CHEMBL1343415 & 688267 & 4.25 & 5.0449 & TRN \\
\hline CHEMBL1548167 & 688267 & 4.45 & 5.0256 & TRN \\
\hline CHEMBL1394668 & 688267 & 4.6 & 5.0859 & TRN \\
\hline CHEMBL1397767 & 688267 & 6.15 & 5.0569 & TRN \\
\hline CHEMBL1345520 & 688267 & 4.35 & 5.0699 & TST \\
\hline CHEMBL1403123 & 688267 & 4.15 & 5.0117 & TRN \\
\hline CHEMBL1339789 & 688267 & 6.6 & 5.0225 & TRN \\
\hline CHEMBL1493601 & 688267 & 4.05 & 5.1611 & TRN \\
\hline CHEMBL1564666 & 688267 & 4.4 & 5.04 & TST \\
\hline CHEMBL1327795 & 688267 & 4.0 & 5.0461 & TRN \\
\hline CHEMBL1441089 & 688267 & 4.35 & 5.0318 & TRN \\
\hline CHEMBL1320050 & 688267 & 5.45 & 5.0327 & TRN \\
\hline CHEMBL1407274 & 688267 & 5.05 & 5.0285 & TRN \\
\hline CHEMBL459302 & 688267 & 4.35 & 5.0472 & TRN \\
\hline CHEMBL1607580 & 688267 & 6.15 & 5.1171 & TRN \\
\hline CHEMBL1348783 & 688267 & 4.35 & 5.0623 & TRN \\
\hline CHEMBL1375076 & 688267 & 5.3 & 5.0562 & TRN \\
\hline
\end{tabular}




\begin{tabular}{|c|c|c|c|c|}
\hline & & & pplement & al $\mathrm{Ta}$ \\
\hline CHEMBL1379191 & 688267 & 6.2 & 5.0512 & TRN \\
\hline CHEMBL1515307 & 688267 & 6.2 & 5.0447 & TRN \\
\hline CHEMBL1499473 & 688267 & 5.25 & 5.0452 & TRN \\
\hline CHEMBL1593295 & 688267 & 4.5 & 5.02 & TRN \\
\hline CHEMBL1541295 & 688267 & 6.2 & 5.0725 & TST \\
\hline CHEMBL1401154 & 688267 & 4.25 & 5.1272 & TRN \\
\hline CHEMBL1418469 & 688267 & 4.55 & 5.0358 & TRN \\
\hline CHEMBL1554128 & 688267 & 4.1 & 4.9961 & TRN \\
\hline CHEMBL1479861 & 688267 & 6.05 & 5.0268 & TRN \\
\hline CHEMBL1515037 & 688267 & 4.25 & 5.0263 & TRN \\
\hline CHEMBL1472300 & 688267 & 5.3 & 5.1285 & TRN \\
\hline CHEMBL1334697 & 688267 & 6.25 & 5.1122 & TRN \\
\hline CHEMBL1460426 & 688267 & 5.3 & 5.1859 & TRN \\
\hline CHEMBL1517353 & 688267 & 5.95 & 5.0657 & TRN \\
\hline CHEMBL1609793 & 688267 & 4.25 & 5.0021 & TST \\
\hline CHEMBL1606718 & 688267 & 6.15 & 5.1064 & TRN \\
\hline CHEMBL1306859 & 688267 & 6.25 & 5.0774 & TRN \\
\hline CHEMBL1506446 & 688267 & 4.0 & 5.0488 & TRN \\
\hline CHEMBL1561139 & 688267 & 5.6 & 5.0276 & TST \\
\hline CHEMBL1455145 & 688267 & 4.25 & 5.0527 & TRN \\
\hline CHEMBL1605925 & 688267 & 4.25 & 5.0601 & TRN \\
\hline CHEMBL1561660 & 688267 & 4.95 & 5.0419 & TRN \\
\hline CHEMBL1301581 & 688267 & 4.4 & 5.0934 & TRN \\
\hline CHEMBL1600710 & 688267 & 4.2 & 5.0698 & TRN \\
\hline CHEMBL1521898 & 688267 & 4.4 & 5.0433 & TRN \\
\hline CHEMBL1605731 & 688267 & 6.2 & 5.1055 & TST \\
\hline CHEMBL1454222 & 688267 & 6.45 & 4.9969 & TRN \\
\hline CHEMBL1312689 & 688267 & 4.35 & 5.0435 & TRN \\
\hline CHEMBL1612425 & 688267 & 6.2 & 5.0147 & TST \\
\hline CHEMBL1311046 & 688267 & 4.35 & 5.0453 & TRN \\
\hline CHEMBL1367894 & 688267 & 5.7 & 5.0309 & TRN \\
\hline CHEMBL1527675 & 688267 & 4.85 & 5.0646 & TST \\
\hline CHEMBL1560130 & 688267 & 6.1 & 5.0701 & TRN \\
\hline CHEMBL1571581 & 688267 & 3.95 & 5.0187 & TRN \\
\hline CHEMBL1608949 & 688267 & 3.95 & 5.0487 & TRN \\
\hline CHEMBL1391132 & 688267 & 6.2 & 5.0179 & TRN \\
\hline CHEMBL1542160 & 688267 & 6.2 & 5.0969 & TRN \\
\hline CHEMBL1384031 & 688267 & 4.25 & 5.0999 & TRN \\
\hline CHEMBL1374882 & 688267 & 4.7 & 5.0879 & TRN \\
\hline CHEMBL1531731 & 688267 & 6.5 & 5.0504 & TRN \\
\hline CHEMBL1584764 & 688267 & 4.55 & 5.0493 & TRN \\
\hline CHEMBL1577879 & 688267 & 5.55 & 5.0143 & TST \\
\hline CHEMBL1356253 & 688267 & 3.9 & 5.0552 & TRN \\
\hline CHEMBL1364991 & 688267 & 4.1 & 5.0857 & TST \\
\hline CHEMBL1609134 & 688267 & 5.3 & 5.0477 & TST \\
\hline CHEMBL1403647 & 688267 & 4.4 & 5.0865 & TST \\
\hline CHEMBL1522425 & 688267 & 4.35 & 5.0682 & TRN \\
\hline CHEMBL1317729 & 688267 & 3.95 & 5.0713 & TRN \\
\hline
\end{tabular}




\begin{tabular}{|c|c|c|c|c|c|}
\hline \multicolumn{6}{|c|}{ Supplemental Table S2.txt } \\
\hline CHEMBL1400271 & 688267 & 5.2 & 5.0874 & TRN & \\
\hline CHEMBL1350982 & 688267 & 6.05 & 5.1122 & TRN & \\
\hline CHEMBL1477041 & 688267 & 3.95 & 5.0307 & TRN & \\
\hline CHEMBL1490578 & 688267 & 5.0 & 5.0688 & TRN & \\
\hline CHEMBL3208781 & 688267 & 5.35 & 5.0808 & TRN & \\
\hline CHEMBL1451390 & 688267 & 4.1 & 5.0182 & TRN & \\
\hline CHEMBL1581375 & 688267 & 6.2 & 5.1789 & TRN & \\
\hline CHEMBL1613690 & 688267 & 6.15 & 5.0795 & TRN & \\
\hline CHEMBL1469603 & 688267 & 5.2 & 5.0536 & TRN & \\
\hline CHEMBL1362372 & 688267 & 5.3 & 5.0076 & TST & \\
\hline CHEMBL1574895 & 688267 & 3.9 & 5.0874 & TST & \\
\hline CHEMBL1419666 & 688267 & 6.2 & 5.043 & TRN & \\
\hline CHEMBL1400296 & 688267 & 6.2 & 5.0933 & TST & \\
\hline CHEMBL1526974 & 688267 & 6.2 & 5.07 & TST & \\
\hline CHEMBL1547792 & 688267 & 6.15 & 5.0035 & TRN & \\
\hline CHEMBL1570276 & 688267 & 5.25 & 5.0179 & TST & \\
\hline CHEMBL1457576 & 688267 & 4.3 & 5.0399 & TRN & \\
\hline CHEMBL1611249 & 688267 & 4.05 & 5.0172 & TRN & \\
\hline CHEMBL1503008 & 688267 & 5.5 & 5.1004 & TRN & \\
\hline CHEMBL1405466 & 688267 & 5.3 & 5.1292 & TRN & \\
\hline CHEMBL1609260 & 688267 & 4.05 & 5.0192 & TRN & \\
\hline CHEMBL1450956 & 688267 & 6.2 & 5.0083 & TRN & \\
\hline CHEMBL1611988 & 688267 & 6.2 & 5.1184 & TRN & \\
\hline CHEMBL1424945 & 688267 & 4.6 & 5.02 & TST & \\
\hline CHEMBL1425625 & 688267 & 5.2 & 5.0704 & TRN & \\
\hline CHEMBL1529890 & 688267 & 6.25 & 5.0455 & TST & \\
\hline CHEMBL1584197 & 688267 & 6.2 & 5.0924 & TRN & \\
\hline CHEMBL1403004 & 688267 & 5.4 & 5.0526 & TRN & \\
\hline CHEMBL3213295 & 688267 & 4.05 & 5.0768 & TRN & \\
\hline CHEMBL1494021 & 688267 & 6.2 & 5.1336 & TST & \\
\hline CHEMBL1609251 & 688267 & 5.0 & 5.0068 & TRN & \\
\hline CHEMBL1442325 & 688267 & 4.0 & 5.107 & TST & \\
\hline CHEMBL1610584 & 688267 & 4.35 & 4.9711 & TRN & \\
\hline CHEMBL3194182 & 688267 & 6.5 & 5.0666 & TRN & \\
\hline CHEMBL1453751 & 688267 & 5.25 & 5.0653 & TST & \\
\hline CHEMBL1575690 & 688267 & 3.95 & 5.0634 & TRN & \\
\hline CHEMBL1556043 & 688267 & 4.75 & $5.0680 e$ & 00000000005 & TRN \\
\hline CHEMBL1543449 & 688267 & 4.95 & 5.09 & TST & \\
\hline CHEMBL1501361 & 688267 & 6.1 & 5.0346 & TRN & \\
\hline CHEMBL1413194 & 688267 & 3.95 & 5.1347 & TST & \\
\hline CHEMBL1440415 & 688267 & 4.2 & 5.007 & TRN & \\
\hline CHEMBL1455263 & 688267 & 4.4 & 5.0268 & TST & \\
\hline CHEMBL1522254 & 688267 & 4.05 & 5.037 & TRN & \\
\hline CHEMBL1318523 & 688267 & 5.5 & 5.0402 & TRN & \\
\hline CHEMBL1354993 & 688267 & 4.5 & 5.0907 & TRN & \\
\hline CHEMBL1553447 & 688267 & 4.0 & 5.0141 & TRN & \\
\hline CHEMBL1481594 & 688267 & 4.05 & 5.0385 & TRN & \\
\hline CHEMBL1368967 & 688267 & 4.05 & 5.0413 & TRN & \\
\hline
\end{tabular}




\begin{tabular}{|c|c|c|c|c|c|}
\hline \multicolumn{6}{|c|}{ Supplemental Table S2.txt } \\
\hline CHEMBL1327977 & 688267 & 4.15 & 5.0889 & TST & \\
\hline CHEMBL1443772 & 688267 & 5.5 & 5.0522 & TST & \\
\hline CHEMBL1476761 & 688267 & 5.5 & 5.0484 & TRN & \\
\hline CHEMBL 238798 & 688267 & 5.95 & 5.0844 & TST & \\
\hline CHEMBL1582949 & 688267 & 5.4 & 5.1108 & TRN & \\
\hline CHEMBL1495011 & 688267 & 5.6 & 5.1242 & TRN & \\
\hline CHEMBL1318433 & 688267 & 4.0 & 5.0547 & TST & \\
\hline CHEMBL1376596 & 688267 & 5.7 & 5.1047 & TRN & \\
\hline CHEMBL1310365 & 688267 & 4.15 & 5.1052 & TST & \\
\hline CHEMBL1544848 & 688267 & 4.5 & 5.1236 & TRN & \\
\hline CHEMBL1418638 & 688267 & 4.5 & 5.0043 & TRN & \\
\hline CHEMBL1503130 & 688267 & 5.4 & 5.0684 & TST & \\
\hline CHEMBL1372449 & 688267 & 5.9 & 5.015 & TST & \\
\hline CHEMBL1613427 & 688267 & 4.35 & 5.0746 & TRN & \\
\hline CHEMBL1509901 & 688267 & 4.35 & 5.0597 & TRN & \\
\hline CHEMBL1578892 & 688267 & 4.25 & 5.1251 & TRN & \\
\hline CHEMBL1591293 & 688267 & 4.15 & 5.1078 & TRN & \\
\hline CHEMBL1336847 & 688267 & 4.0 & 4.9901 & TST & \\
\hline CHEMBL1584082 & 688267 & 6.2 & 5.0645 & TST & \\
\hline CHEMBL3189489 & 688267 & 4.05 & 5.0012 & TRN & \\
\hline CHEMBL1472893 & 688267 & 5.55 & 5.0519 & TRN & \\
\hline CHEMBL3213562 & 688267 & 5.6 & 5.0565 & TST & \\
\hline CHEMBL1592742 & 688267 & 6.25 & 5.0208 & TRN & \\
\hline CHEMBL1353923 & 688267 & 5.8 & 5.0631 & TRN & \\
\hline CHEMBL1395535 & 688267 & 4.0 & 5.0513 & TRN & \\
\hline CHEMBL1588077 & 688267 & 4.0 & 5.0186 & TST & \\
\hline CHEMBL1574772 & 688267 & 4.7 & 5.0389 & TRN & \\
\hline CHEMBL1486481 & 688267 & 6.15 & 5.0606 & TRN & \\
\hline CHEMBL1586072 & 688267 & 4.95 & 5.0523 & TST & \\
\hline CHEMBL1514600 & 688267 & 4.2 & 5.0357 & TRN & \\
\hline CHEMBL1519181 & 688267 & 5.9 & 5.0171 & TST & \\
\hline CHEMBL1337800 & 688267 & 4.55 & 5.0317 & TST & \\
\hline CHEMBL1354877 & 688267 & 4.1 & 4.9975 & TRN & \\
\hline CHEMBL1471568 & 688267 & 6.2 & 5.0479 & TRN & \\
\hline CHEMBL1433230 & 688267 & 4.0 & $5.1160 €$ & 00000000005 & TST \\
\hline CHEMBL1336084 & 688267 & 6.05 & 5.1202 & TRN & \\
\hline CHEMBL1332166 & 688267 & 4.3 & 5.0728 & TST & \\
\hline CHEMBL1483368 & 688267 & 4.4 & 5.055 & TST & \\
\hline CHEMBL1352748 & 688267 & 4.35 & 5.1152 & TRN & \\
\hline CHEMBL1472618 & 688267 & 6.0 & 5.0507 & TRN & \\
\hline CHEMBL1531912 & 688267 & 5.3 & $5.1110 €$ & 0000000001 & TRN \\
\hline CHEMBL1335041 & 688267 & 4.5 & 5.0155 & TRN & \\
\hline CHEMBL1327309 & 688267 & 4.9 & 5.0817 & TRN & \\
\hline CHEMBL1595226 & 688267 & 4.05 & 5.0378 & TRN & \\
\hline CHEMBL1494756 & 688267 & 5.55 & 4.9976 & TRN & \\
\hline CHEMBL1316849 & 688267 & 4.0 & 5.1145 & TRN & \\
\hline CHEMBL1601366 & 688267 & 4.0 & 5.0513 & TRN & \\
\hline CHEMBL1473883 & 688267 & 5.05 & 5.0403 & TRN & \\
\hline
\end{tabular}




\begin{tabular}{|c|c|c|c|c|c|}
\hline & & \multicolumn{4}{|c|}{ Supplemental Table S2.txt } \\
\hline CHEMBL1394685 & 688267 & 5.95 & 5.0707 & TRN & \\
\hline CHEMBL1441244 & 688267 & 5.05 & 5.0537 & TRN & \\
\hline CHEMBL1495266 & 688267 & 5.85 & 5.0797 & TRN & \\
\hline CHEMBL1414435 & 688267 & 4.0 & 5.1112 & TRN & \\
\hline CHEMBL1503447 & 688267 & 4.25 & 5.13200 & 0000000001 & TRN \\
\hline CHEMBL1368389 & 688267 & 5.15 & 5.0979 & TRN & \\
\hline CHEMBL3213721 & 688267 & 5.0 & 5.0395 & TRN & \\
\hline CHEMBL1462786 & 688267 & 4.3 & 5.1518 & TRN & \\
\hline CHEMBL1376182 & 688267 & 5.5 & 5.117 & TRN & \\
\hline CHEMBL1563150 & 688267 & 6.5 & 5.0451 & TST & \\
\hline CHEMBL1420472 & 688267 & 3.95 & 5.1054 & TRN & \\
\hline CHEMBL1536630 & 688267 & 4.65 & 4.9882 & TRN & \\
\hline CHEMBL3211269 & 688267 & 6.0 & 5.045 & TRN & \\
\hline CHEMBL1429282 & 688267 & 5.4 & 5.0659 & TST & \\
\hline CHEMBL1427751 & 688267 & 4.0 & 5.0714 & TRN & \\
\hline CHEMBL1572842 & 688267 & 4.6 & 5.1125 & TST & \\
\hline CHEMBL1383562 & 688267 & 5.3 & 5.0294 & TRN & \\
\hline CHEMBL1571977 & 688267 & 4.05 & 5.023 & TST & \\
\hline CHEMBL1356181 & 688267 & 4.0 & 5.0039 & TRN & \\
\hline CHEMBL1597104 & 688267 & 4.4 & 5.0664 & TRN & \\
\hline CHEMBL1507852 & 688267 & 5.85 & 5.0421 & TRN & \\
\hline CHEMBL1388094 & 688267 & 5.0 & 5.034 & TRN & \\
\hline CHEMBL1463630 & 688267 & 5.4 & 5.0649 & TST & \\
\hline CHEMBL1584391 & 688267 & 4.4 & 4.9947 & TRN & \\
\hline CHEMBL1434000 & 688267 & 5.65 & 5.1015 & TST & \\
\hline CHEMBL1390383 & 688267 & 5.3 & 5.0315 & TST & \\
\hline CHEMBL1438189 & 688267 & 5.85 & 5.1313 & TRN & \\
\hline CHEMBL3209159 & 688267 & 4.7 & 4.9434 & TRN & \\
\hline CHEMBL3198928 & 688267 & 6.15 & 5.0919 & TRN & \\
\hline CHEMBL1488318 & 688267 & 4.0 & 5.0888 & TST & \\
\hline CHEMBL1561323 & 688267 & 6.2 & 5.0579 & TRN & \\
\hline CHEMBL1590987 & 688267 & 4.65 & 5.0458 & TRN & \\
\hline CHEMBL1600503 & 688267 & 4.0 & 5.1395 & TRN & \\
\hline CHEMBL1582779 & 688267 & 5.8 & 5.1108 & TRN & \\
\hline CHEMBL1523683 & 688267 & 3.95 & 5.0687 & TRN & \\
\hline CHEMBL1599971 & 688267 & 6.1 & 5.0532 & TST & \\
\hline CHEMBL1596103 & 688267 & 6.05 & 5.0713 & TRN & \\
\hline CHEMBL1316457 & 688267 & 4.0 & 5.0782 & TRN & \\
\hline CHEMBL1398406 & 688267 & 5.3 & 5.0225 & TRN & \\
\hline CHEMBL1373036 & 688267 & 4.0 & 5.1029 & TRN & \\
\hline CHEMBL1411655 & 688267 & 5.55 & 4.9994 & TST & \\
\hline CHEMBL1509849 & 688267 & 4.3 & 5.0033 & TRN & \\
\hline CHEMBL1553395 & 688267 & 5.7 & 5.0595 & TST & \\
\hline CHEMBL1396711 & 688267 & 4.05 & 5.0512 & TRN & \\
\hline CHEMBL1580963 & 688267 & 4.0 & 4.9992 & TRN & \\
\hline CHEMBL1380102 & 688267 & 5.45 & 5.0305 & TRN & \\
\hline CHEMBL1513474 & 688267 & 4.7 & 5.0443 & TRN & \\
\hline CHEMBL1525564 & 688267 & 4.6 & 5.0395 & TRN & \\
\hline
\end{tabular}




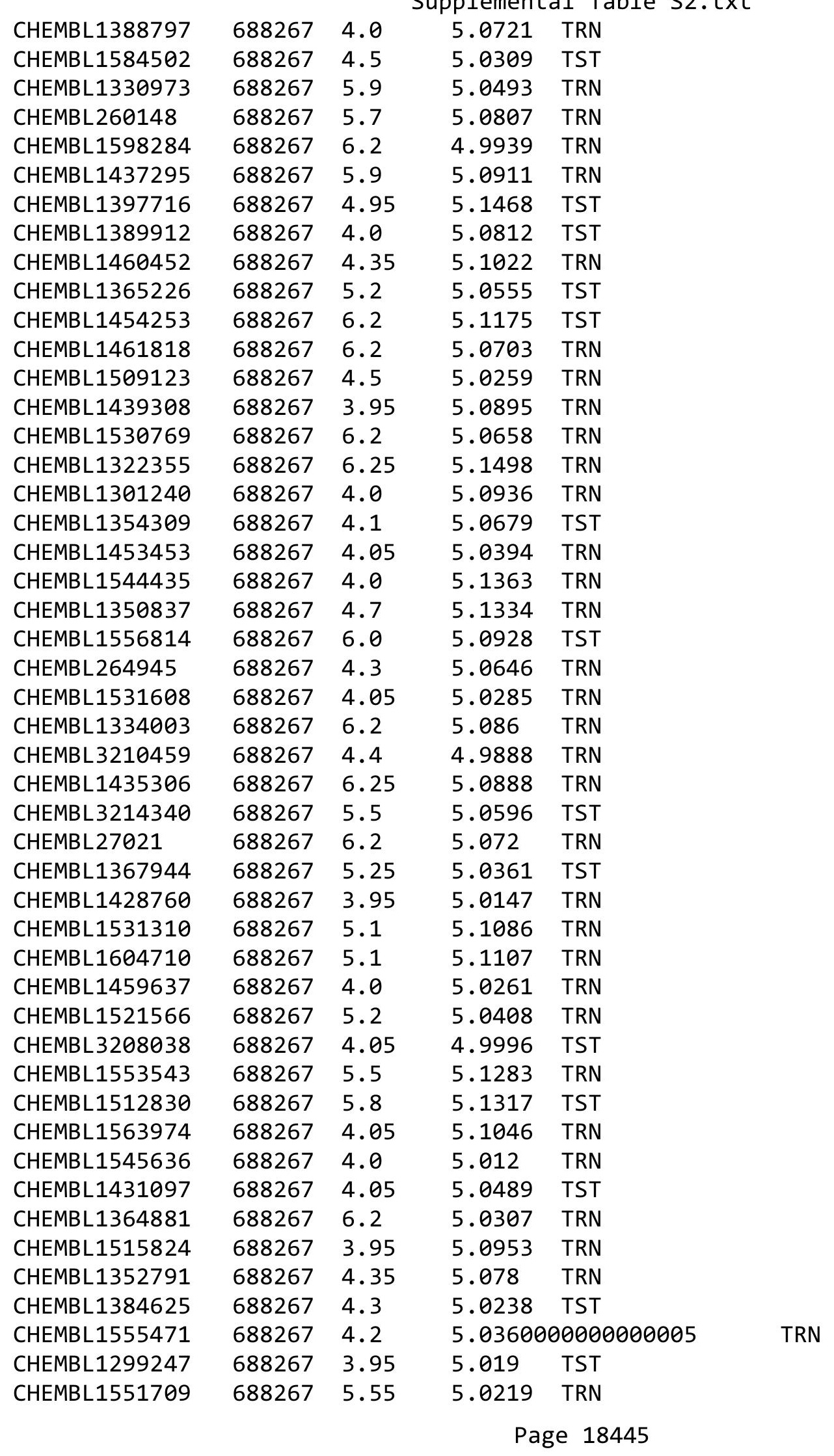




\begin{tabular}{|c|c|c|c|c|c|}
\hline \multicolumn{6}{|c|}{ Supplemental Table S2.txt } \\
\hline CHEMBL1547909 & 688267 & 4.35 & 5.1203 & TRN & \\
\hline CHEMBL1578795 & 688267 & 4.0 & 5.029 & TST & \\
\hline CHEMBL3214231 & 688267 & 4.45 & 5.1093 & TRN & \\
\hline CHEMBL1377088 & 688267 & 6.2 & 5.1173 & TRN & \\
\hline CHEMBL1567510 & 688267 & 5.3 & 5.0528 & TRN & \\
\hline CHEMBL1504751 & 688267 & 4.6 & 5.0696 & TST & \\
\hline CHEMBL1377638 & 688267 & 6.2 & 5.1234 & TRN & \\
\hline CHEMBL1462878 & 688267 & 5.35 & 5.05 & TST & \\
\hline CHEMBL1599350 & 688267 & 5.25 & 5.0845 & TRN & \\
\hline CHEMBL1375279 & 688267 & 5.55 & 5.0712 & TRN & \\
\hline CHEMBL1554755 & 688267 & 5.55 & 5.13 & TRN & \\
\hline CHEMBL 3210560 & 688267 & 4.75 & 5.0316 & TRN & \\
\hline CHEMBL1451265 & 688267 & 4.5 & 5.1034 & TST & \\
\hline CHEMBL1514974 & 688267 & 6.2 & 5.0033 & TRN & \\
\hline CHEMBL1417628 & 688267 & 5.0 & 5.0551 & TST & \\
\hline CHEMBL1526760 & 688267 & 4.6 & 5.0482 & TRN & \\
\hline CHEMBL1370768 & 688267 & 3.95 & 5.064 & TRN & \\
\hline CHEMBL1426500 & 688267 & 6.6499 & 5.096 & TST & \\
\hline CHEMBL1332912 & 688267 & 5.55 & 5.0743 & TRN & \\
\hline CHEMBL1484425 & 688267 & 4.25 & 5.0169 & TST & \\
\hline CHEMBL1589835 & 688267 & 4.6 & 5.1744 & TRN & \\
\hline CHEMBL1439532 & 688267 & 5.4 & 5.0885 & TST & \\
\hline CHEMBL1453043 & 688267 & 4.4 & 5.0817 & TST & \\
\hline CHEMBL1498661 & 688267 & 4.0 & 5.0489 & TST & \\
\hline CHEMBL1506209 & 688267 & 4.15 & 5.1069 & TRN & \\
\hline CHEMBL1556048 & 688267 & 5.2 & 5.0226 & TST & \\
\hline CHEMBL1417245 & 688267 & 4.5 & 5.04899 & 99999999995 & TRN \\
\hline CHEMBL1547079 & 688267 & 4.3 & 5.0036 & TST & \\
\hline CHEMBL1584379 & 688267 & 4.25 & 4.9892 & TST & \\
\hline CHEMBL1474224 & 688267 & 4.3 & 5.04899 & 99999999995 & TST \\
\hline CHEMBL1578788 & 688267 & 5.6 & 5.0301 & TST & \\
\hline CHEMBL1520560 & 688267 & 5.45 & 5.0831 & TRN & \\
\hline CHEMBL1352208 & 688267 & 4.0 & 5.0579 & TST & \\
\hline CHEMBL1360201 & 688267 & 4.75 & 5.0022 & TRN & \\
\hline CHEMBL1495007 & 688267 & 6.2 & 5.0376 & TRN & \\
\hline CHEMBL1329925 & 688267 & 4.05 & 5.0169 & TST & \\
\hline CHEMBL1352921 & 688267 & 4.35 & 5.0786 & TST & \\
\hline CHEMBL1529563 & 688267 & 4.15 & 5.0787 & TRN & \\
\hline CHEMBL1532856 & 688267 & 4.7 & 5.0057 & TST & \\
\hline CHEMBL1360928 & 688267 & 4.35 & 4.9799 & TRN & \\
\hline CHEMBL1515950 & 688267 & 4.0 & 5.1081 & TST & \\
\hline CHEMBL1490448 & 688267 & 4.0 & 5.0651 & TRN & \\
\hline CHEMBL1523499 & 688267 & 4.35 & 5.0398 & TRN & \\
\hline CHEMBL1428177 & 688267 & 5.9 & 5.1075 & TRN & \\
\hline CHEMBL1562630 & 688267 & 4.1 & 5.10800 & 00000000005 & TRN \\
\hline CHEMBL1544251 & 688267 & 3.95 & 5.0584 & TRN & \\
\hline CHEMBL1396947 & 688267 & 6.2 & 5.0557 & TRN & \\
\hline CHEMBL1396313 & 688267 & 3.9 & 5.0673 & TRN & \\
\hline
\end{tabular}




\begin{tabular}{|c|c|c|c|c|c|}
\hline \multicolumn{6}{|c|}{ Supplemental Table S2.txt } \\
\hline CHEMBL1345621 & 688267 & 4.05 & 5.0276 & TRN & \\
\hline CHEMBL1559392 & 688267 & 5.75 & 5.1129 & TRN & \\
\hline CHEMBL1325289 & 688267 & 5.25 & 5.1124 & TRN & \\
\hline CHEMBL1462364 & 688267 & 6.2 & 5.0047 & TST & \\
\hline CHEMBL1609901 & 688267 & 4.3 & 5.0304 & TRN & \\
\hline CHEMBL1367522 & 688267 & 4.0 & 5.0186 & TRN & \\
\hline CHEMBL1552129 & 688267 & 4.9 & 5.1096 & TRN & \\
\hline CHEMBL1407385 & 688267 & 6.15 & 5.0208 & TRN & \\
\hline CHEMBL1385395 & 688267 & 4.4 & 5.1074 & TRN & \\
\hline CHEMBL1302575 & 688267 & 5.55 & 5.084 & TRN & \\
\hline CHEMBL1596197 & 688267 & 6.2 & 5.0472 & TRN & \\
\hline CHEMBL1331822 & 688267 & 4.65 & 5.008 & TST & \\
\hline CHEMBL1491402 & 688267 & 4.15 & 5.0461 & TST & \\
\hline CHEMBL1326213 & 688267 & 4.65 & 5.1157 & TRN & \\
\hline CHEMBL1364488 & 688267 & 4.05 & 5.0454 & TST & \\
\hline CHEMBL1472760 & 688267 & 4.8 & 5.0729 & TRN & \\
\hline CHEMBL1356604 & 688267 & 4.05 & 5.1399 & TRN & \\
\hline CHEMBL1530690 & 688267 & 4.0 & 5.0397 & TRN & \\
\hline CHEMBL1303031 & 688267 & 5.05 & 5.0591 & TST & \\
\hline CHEMBL1575129 & 688267 & 5.5 & 5.067 & TRN & \\
\hline CHEMBL1397932 & 688267 & 4.85 & 5.1245 & TRN & \\
\hline CHEMBL1480785 & 688267 & 5.05 & 5.1224 & TRN & \\
\hline CHEMBL1405882 & 688267 & 4.0 & 5.1027 & TRN & \\
\hline CHEMBL1509150 & 688267 & 5.1 & 5.0549 & TRN & \\
\hline CHEMBL1499361 & 688267 & 4.25 & 4.9707 & TRN & \\
\hline CHEMBL1458808 & 688267 & 6.2 & 5.0712 & TRN & \\
\hline CHEMBL1345476 & 688267 & 4.4 & 5.0596 & TRN & \\
\hline CHEMBL1528983 & 688267 & 5.3 & 5.0203 & TRN & \\
\hline CHEMBL1486352 & 688267 & 5.4 & 4.9963 & TST & \\
\hline CHEMBL1492968 & 688267 & 6.0 & 5.0649 & TRN & \\
\hline CHEMBL1606720 & 688267 & 6.25 & 5.0205 & TRN & \\
\hline CHEMBL 239673 & 688267 & 5.8 & 5.0901 & TRN & \\
\hline CHEMBL1568592 & 688267 & 4.35 & 5.03100 & 0000000001 & TRN \\
\hline CHEMBL1453576 & 688267 & 6.2 & 5.0197 & TRN & \\
\hline CHEMBL1474657 & 688267 & 4.0 & 5.1913 & TRN & \\
\hline CHEMBL1533682 & 688267 & 4.5 & 5.1089 & TRN & \\
\hline CHEMBL1394161 & 688267 & 3.9 & 4.9802 & TST & \\
\hline CHEMBL1412979 & 688267 & 4.35 & 5.0652 & TRN & \\
\hline CHEMBL1575342 & 688267 & 4.25 & 5.0695 & TRN & \\
\hline CHEMBL1562961 & 688267 & 5.4 & 5.1124 & TST & \\
\hline CHEMBL1461470 & 688267 & 4.7 & 5.0004 & TRN & \\
\hline CHEMBL1302310 & 688267 & 5.25 & 5.0535 & TRN & \\
\hline CHEMBL1349571 & 688267 & 5.25 & 5.0832 & TRN & \\
\hline CHEMBL1487064 & 688267 & 5.85 & 5.0929 & TRN & \\
\hline CHEMBL1367050 & 688267 & 6.45 & 5.0938 & TST & \\
\hline CHEMBL1415967 & 688267 & 4.4 & 5.1402 & TRN & \\
\hline CHEMBL1470804 & 688267 & 6.2 & 5.1259 & TRN & \\
\hline CHEMBL1318656 & 688267 & 5.3 & 5.0478 & TRN & \\
\hline
\end{tabular}




\begin{tabular}{|c|c|c|c|c|c|}
\hline \multicolumn{6}{|c|}{ Supplemental Table S2.txt } \\
\hline CHEMBL1436825 & 688267 & 4.05 & 5.0975 & TRN & \\
\hline CHEMBL1564052 & 688267 & 6.15 & 5.0612 & TST & \\
\hline CHEMBL1369964 & 688267 & 3.95 & 5.0754 & TRN & \\
\hline CHEMBL1341618 & 688267 & 5.05 & 5.0962 & TRN & \\
\hline CHEMBL1405706 & 688267 & 5.8 & 5.0556 & TST & \\
\hline CHEMBL1327843 & 688267 & 4.25 & 5.0948 & TRN & \\
\hline CHEMBL1400128 & 688267 & 6.25 & 5.0121 & TRN & \\
\hline CHEMBL1578734 & 688267 & 6.2 & 5.0591 & TST & \\
\hline CHEMBL1347750 & 688267 & 5.3 & 5.0523 & TST & \\
\hline CHEMBL1348716 & 688267 & 5.75 & 5.153 & TST & \\
\hline CHEMBL1314576 & 688267 & 5.3 & 5.0692 & TRN & \\
\hline CHEMBL1469977 & 688267 & 5.4 & 5.0207 & TRN & \\
\hline CHEMBL1371702 & 688267 & 5.7 & 4.9888 & TRN & \\
\hline CHEMBL1515312 & 688267 & 4.4 & 5.0744 & TRN & \\
\hline CHEMBL1500103 & 688267 & 3.95 & 5.0445 & TRN & \\
\hline CHEMBL1488525 & 688267 & 6.25 & 5.1181 & TRN & \\
\hline CHEMBL1515639 & 688267 & 5.2 & 5.0226 & TRN & \\
\hline CHEMBL1374056 & 688267 & 6.5 & 5.0204 & TRN & \\
\hline CHEMBL1402019 & 688267 & 4.05 & 5.0939 & TRN & \\
\hline CHEMBL1332463 & 688267 & 3.95 & 5.0339 & TRN & \\
\hline CHEMBL1352005 & 688267 & 4.3 & 5.0496 & TST & \\
\hline CHEMBL1558718 & 688267 & 5.5 & 5.0725 & TST & \\
\hline CHEMBL1563703 & 688267 & 4.25 & 5.03600 & 00000000005 & TRN \\
\hline CHEMBL1304513 & 688267 & 4.4 & 5.0237 & TST & \\
\hline CHEMBL1517154 & 688267 & 5.35 & 5.0445 & TRN & \\
\hline CHEMBL1532071 & 688267 & 6.25 & 5.0928 & TRN & \\
\hline CHEMBL1371252 & 688267 & 6.25 & 5.0163 & TST & \\
\hline CHEMBL1299511 & 688267 & 4.55 & 5.0155 & TRN & \\
\hline CHEMBL1590594 & 688267 & 5.8 & 5.0392 & TRN & \\
\hline CHEMBL1319563 & 688267 & 5.05 & 5.0501 & TRN & \\
\hline CHEMBL1416290 & 688267 & 3.95 & 5.0958 & TRN & \\
\hline CHEMBL1476093 & 688267 & 5.85 & 5.0969 & TRN & \\
\hline CHEMBL1323933 & 688267 & 5.65 & 5.0854 & TRN & \\
\hline CHEMBL1477512 & 688267 & 4.35 & 5.1098 & TRN & \\
\hline CHEMBL1328337 & 688267 & 5.0 & 5.0625 & TRN & \\
\hline CHEMBL1551609 & 688267 & 4.0 & 5.029 & TRN & \\
\hline CHEMBL1456442 & 688267 & 6.2 & 5.1191 & TRN & \\
\hline CHEMBL1410059 & 688267 & 6.2 & 5.0975 & TRN & \\
\hline CHEMBL1372750 & 688267 & 3.95 & 5.0615 & TRN & \\
\hline CHEMBL1611340 & 688267 & 6.15 & 5.0785 & TRN & \\
\hline CHEMBL1350608 & 688267 & 4.0 & 5.0517 & TRN & \\
\hline CHEMBL3191028 & 688267 & 5.1 & 5.0077 & TRN & \\
\hline CHEMBL1345035 & 688267 & 4.2 & 5.0616 & TRN & \\
\hline CHEMBL1560728 & 688267 & 4.65 & 5.1278 & TRN & \\
\hline CHEMBL1528485 & 688267 & 4.4 & 5.0827 & TRN & \\
\hline CHEMBL1434030 & 688267 & 4.05 & 5.05 & TRN & \\
\hline CHEMBL1475365 & 688267 & 4.55 & 5.1659 & TRN & \\
\hline CHEMBL1361380 & 688267 & 6.2 & 5.0908 & TST & \\
\hline
\end{tabular}




\begin{tabular}{|c|c|c|c|c|c|}
\hline \multicolumn{6}{|c|}{ Supplemental Table S2.txt } \\
\hline CHEMBL1346539 & 688267 & 5.4 & 5.0269 & TRN & \\
\hline CHEMBL1593831 & 688267 & 5.4 & 5.0643 & TRN & \\
\hline CHEMBL1473626 & 688267 & 5.75 & 5.1074 & TRN & \\
\hline CHEMBL1307720 & 688267 & 5.15 & 5.0348 & TRN & \\
\hline CHEMBL1562101 & 688267 & 4.25 & 5.061 & TRN & \\
\hline CHEMBL1599093 & 688267 & 4.7 & 5.0536 & TRN & \\
\hline CHEMBL1481792 & 688267 & 5.05 & 5.0365 & TST & \\
\hline CHEMBL1469139 & 688267 & 5.25 & 5.1046 & TRN & \\
\hline CHEMBL1392178 & 688267 & 6.2 & 5.0938 & TRN & \\
\hline CHEMBL1558583 & 688267 & 3.95 & 5.0682 & TRN & \\
\hline CHEMBL1610674 & 688267 & 4.75 & 5.0474 & TRN & \\
\hline CHEMBL1370373 & 688267 & 4.3 & 5.0041 & TRN & \\
\hline CHEMBL1604902 & 688267 & 6.15 & 5.0978 & TRN & \\
\hline CHEMBL1517109 & 688267 & 6.2 & 5.0622 & TST & \\
\hline CHEMBL1401999 & 688267 & 5.45 & 5.0832 & TST & \\
\hline CHEMBL1378054 & 688267 & 5.1 & 5.0315 & TRN & \\
\hline CHEMBL1427084 & 688267 & 6.15 & 4.9916 & TRN & \\
\hline CHEMBL1529109 & 688267 & 4.6 & 5.0765 & TRN & \\
\hline CHEMBL1357232 & 688267 & 5.45 & 5.0546 & TRN & \\
\hline CHEMBL1395363 & 688267 & 6.2 & 5.0129 & TRN & \\
\hline CHEMBL1477344 & 688267 & 5.85 & 5.0789 & TRN & \\
\hline CHEMBL1505702 & 688267 & 4.55 & 5.06800 & 00000000005 & TRN \\
\hline CHEMBL1349433 & 688267 & 4.0 & 5.0538 & TST & \\
\hline CHEMBL1331711 & 688267 & 6.5 & 5.0764 & TRN & \\
\hline CHEMBL1363530 & 688267 & 6.2 & 4.9865 & TST & \\
\hline CHEMBL1440492 & 688267 & 5.05 & 5.0599 & TRN & \\
\hline CHEMBL1359889 & 688267 & 4.55 & 5.0347 & TRN & \\
\hline CHEMBL1558089 & 688267 & 4.9 & 5.1256 & TRN & \\
\hline CHEMBL1587575 & 688267 & 5.5 & 4.9966 & TRN & \\
\hline CHEMBL1306578 & 688267 & 5.3 & 5.037 & TRN & \\
\hline CHEMBL1565697 & 688267 & 6.1 & 5.0111 & TST & \\
\hline CHEMBL1351072 & 688267 & 4.0 & 5.0077 & TRN & \\
\hline CHEMBL1571854 & 688267 & 5.9 & 5.0487 & TRN & \\
\hline CHEMBL1407068 & 688267 & 4.25 & 5.0373 & TRN & \\
\hline CHEMBL1409835 & 688267 & 3.95 & 5.0127 & TST & \\
\hline CHEMBL1321583 & 688267 & 6.2 & 5.0377 & TRN & \\
\hline CHEMBL 3199446 & 688267 & 6.15 & 5.0155 & TRN & \\
\hline CHEMBL1454092 & 688267 & 6.2 & 5.13299 & 9999999999 & TRN \\
\hline CHEMBL1324522 & 688267 & 5.3 & 5.0396 & TRN & \\
\hline CHEMBL1523865 & 688267 & 4.05 & 4.9762 & TRN & \\
\hline CHEMBL1484374 & 688267 & 5.85 & 5.0529 & TRN & \\
\hline CHEMBL1435826 & 688267 & 5.15 & 5.11 & TRN & \\
\hline CHEMBL1434676 & 688267 & 4.0 & 5.0563 & TRN & \\
\hline CHEMBL1498072 & 688267 & 4.65 & 5.0255 & TRN & \\
\hline CHEMBL1544460 & 688267 & 6.2 & 5.0021 & TRN & \\
\hline CHEMBL1405509 & 688267 & 6.25 & 5.0566 & TST & \\
\hline CHEMBL1548209 & 688267 & 5.35 & 5.0881 & TRN & \\
\hline CHEMBL1589083 & 688267 & 5.3 & 5.0294 & TRN & \\
\hline
\end{tabular}




\begin{tabular}{|c|c|c|c|c|c|}
\hline \multicolumn{6}{|c|}{ Supplemental Table S2.txt } \\
\hline CHEMBL1299966 & 688267 & 5.8 & 4.9985 & TRN & \\
\hline CHEMBL1498696 & 688267 & 6.45 & 5.0256 & TRN & \\
\hline CHEMBL1328281 & 688267 & 4.4 & 5.0029 & TRN & \\
\hline CHEMBL1515794 & 688267 & 4.3 & 5.0191 & TRN & \\
\hline CHEMBL1355548 & 688267 & 6.2 & 5.0593 & TST & \\
\hline CHEMBL1420578 & 688267 & 4.0 & 5.0813 & TRN & \\
\hline CHEMBL1489464 & 688267 & 5.5 & 5.0842 & TRN & \\
\hline CHEMBL1377539 & 688267 & 6.2 & 5.1266 & TRN & \\
\hline CHEMBL1471026 & 688267 & 4.35 & 5.006 & TRN & \\
\hline CHEMBL1605370 & 688267 & 5.05 & 5.0962 & TRN & \\
\hline CHEMBL1495766 & 688267 & 3.85 & 5.1214 & TRN & \\
\hline CHEMBL1490418 & 688267 & 5.4 & 5.0324 & TST & \\
\hline CHEMBL1337919 & 688267 & 5.8 & 4.9973 & TST & \\
\hline CHEMBL1474133 & 688267 & 5.3 & 5.0936 & TST & \\
\hline CHEMBL1401848 & 688267 & 4.9 & 5.024 & TST & \\
\hline CHEMBL1408295 & 688267 & 5.6 & 5.0153 & TST & \\
\hline CHEMBL1432605 & 688267 & 4.0 & 5.067 & TRN & \\
\hline CHEMBL1584995 & 688267 & 4.65 & 5.0845 & TRN & \\
\hline CHEMBL1448659 & 688267 & 4.55 & 5.0402 & TRN & \\
\hline CHEMBL1540620 & 688267 & 4.35 & 5.0426 & TRN & \\
\hline CHEMBL1421449 & 688267 & 4.5 & 5.0725 & TRN & \\
\hline CHEMBL1377081 & 688267 & 6.15 & 5.0358 & TRN & \\
\hline CHEMBL1581348 & 688267 & 4.95 & 5.0183 & TRN & \\
\hline CHEMBL1573676 & 688267 & 4.7 & 5.1308 & TRN & \\
\hline CHEMBL1588357 & 688267 & 4.65 & 5.0624 & TRN & \\
\hline CHEMBL1584674 & 688267 & 4.05 & 5.0426 & TRN & \\
\hline CHEMBL 3214012 & 688267 & 4.35 & 5.0116 & TST & \\
\hline CHEMBL1379024 & 688267 & 4.35 & 5.1523 & TRN & \\
\hline CHEMBL1526450 & 688267 & 6.2 & 5.0813 & TST & \\
\hline CHEMBL1564076 & 688267 & 4.05 & 5.06800 & 00000000005 & TRN \\
\hline CHEMBL1517303 & 688267 & 4.15 & 5.0013 & TRN & \\
\hline CHEMBL1507590 & 688267 & 5.8 & 5.0437 & TRN & \\
\hline CHEMBL1509092 & 688267 & 3.95 & 5.0573 & TRN & \\
\hline CHEMBL1484277 & 688267 & 5.15 & 5.0212 & TST & \\
\hline CHEMBL1458024 & 688267 & 6.0 & 5.0124 & TST & \\
\hline CHEMBL1397180 & 688267 & 4.1 & 5.1006 & TRN & \\
\hline CHEMBL1380875 & 688267 & 4.2 & 5.0591 & TRN & \\
\hline CHEMBL1973127 & 688267 & 5.35 & 4.9982 & TRN & \\
\hline CHEMBL1572906 & 688267 & 4.4 & 5.0993 & TRN & \\
\hline CHEMBL1353154 & 688267 & 5.4 & 5.0423 & TRN & \\
\hline CHEMBL1357542 & 688267 & 5.8 & 4.9858 & TRN & \\
\hline CHEMBL3196458 & 688267 & 4.3 & 5.1106 & TRN & \\
\hline CHEMBL1330431 & 688267 & 4.5 & 5.1153 & TRN & \\
\hline CHEMBL1462030 & 688267 & 3.95 & 5.0375 & TST & \\
\hline CHEMBL1609781 & 688267 & 4.05 & 5.0222 & TST & \\
\hline CHEMBL 3208088 & 688267 & 5.25 & 5.0304 & TRN & \\
\hline CHEMBL1303169 & 688267 & 6.15 & 5.0749 & TST & \\
\hline CHEMBL1350080 & 688267 & 5.0 & 5.0321 & TRN & \\
\hline
\end{tabular}




\begin{tabular}{|c|c|c|c|c|c|}
\hline \multicolumn{6}{|c|}{ Supplemental Table S2.txt } \\
\hline CHEMBL1399738 & 688267 & 4.0 & 5.0673 & TRN & \\
\hline CHEMBL1409770 & 688267 & 5.8 & 5.0483 & TRN & \\
\hline CHEMBL1417325 & 688267 & 4.0 & 5.0652 & TST & \\
\hline CHEMBL1369250 & 688267 & 6.15 & 5.0571 & TRN & \\
\hline CHEMBL1485162 & 688267 & 4.3 & 5.0222 & TRN & \\
\hline CHEMBL1371504 & 688267 & 4.9 & 5.0234 & TRN & \\
\hline CHEMBL1303104 & 688267 & 5.55 & 5.0149 & TST & \\
\hline CHEMBL1596594 & 688267 & 4.05 & 5.0345 & TST & \\
\hline CHEMBL1346707 & 688267 & 4.2 & 5.0906 & TST & \\
\hline CHEMBL1360029 & 688267 & 4.55 & 5.05699 & 99999999995 & TRN \\
\hline CHEMBL1331606 & 688267 & 5.25 & 5.0205 & TRN & \\
\hline CHEMBL1594625 & 688267 & 4.3 & 5.0353 & TRN & \\
\hline CHEMBL1454165 & 688267 & 4.05 & 5.1433 & TRN & \\
\hline CHEMBL1581889 & 688267 & 6.2 & 5.0724 & TRN & \\
\hline CHEMBL1534051 & 688267 & 4.35 & 5.0538 & TRN & \\
\hline CHEMBL1395651 & 688267 & 6.5 & 4.9976 & TRN & \\
\hline CHEMBL1575287 & 688267 & 4.2 & 4.9793 & TRN & \\
\hline CHEMBL1595179 & 688267 & 4.3 & 5.0064 & TRN & \\
\hline CHEMBL1455068 & 688267 & 4.3 & 5.1558 & TRN & \\
\hline CHEMBL1404326 & 688267 & 5.3 & 5.0474 & TRN & \\
\hline CHEMBL1436551 & 688267 & 5.1 & 5.1002 & TST & \\
\hline CHEMBL1458405 & 688267 & 3.95 & 5.0405 & TRN & \\
\hline CHEMBL1546173 & 688267 & 4.0 & 5.0589 & TRN & \\
\hline CHEMBL1611537 & 688267 & 5.8 & 5.1305 & TRN & \\
\hline CHEMBL1448900 & 688267 & 6.1 & 5.0505 & TRN & \\
\hline CHEMBL1531048 & 688267 & 4.5 & 5.0481 & TRN & \\
\hline CHEMBL1590586 & 688267 & 5.15 & 5.015 & TST & \\
\hline CHEMBL1427211 & 688267 & 5.0 & 5.0559 & TRN & \\
\hline CHEMBL1354775 & 688267 & 4.05 & 5.0946 & TRN & \\
\hline CHEMBL1560301 & 688267 & 6.2 & 4.9946 & TRN & \\
\hline CHEMBL1300556 & 688267 & 5.7 & 5.0554 & TST & \\
\hline CHEMBL1386863 & 688267 & 5.65 & 5.1238 & TRN & \\
\hline CHEMBL1394795 & 688267 & 4.2 & 5.0564 & TST & \\
\hline CHEMBL1308874 & 688267 & 6.0 & 5.0426 & TRN & \\
\hline CHEMBL1423849 & 688267 & 6.2 & 5.0643 & TRN & \\
\hline CHEMBL1607059 & 688267 & 4.65 & 5.0528 & TST & \\
\hline CHEMBL1510518 & 688267 & 6.2 & 5.0264 & TRN & \\
\hline CHEMBL1319473 & 688267 & 5.15 & 4.9941 & TST & \\
\hline CHEMBL1420105 & 688267 & 5.35 & 5.0737 & TRN & \\
\hline CHEMBL3196631 & 688267 & 4.85 & 5.0114 & TRN & \\
\hline CHEMBL1455658 & 688267 & 4.1 & 5.11 & TRN & \\
\hline CHEMBL1482002 & 688267 & 6.15 & 5.0561 & TST & \\
\hline CHEMBL1458254 & 688267 & 4.55 & 5.0534 & TRN & \\
\hline CHEMBL1433367 & 688267 & 5.3 & 5.0987 & TST & \\
\hline CHEMBL1401043 & 688267 & 5.55 & 5.0539 & TST & \\
\hline CHEMBL1345479 & 688267 & 5.8 & 5.0875 & TST & \\
\hline CHEMBL1301917 & 688267 & 4.05 & 5.0745 & TST & \\
\hline CHEMBL3196810 & 688267 & 3.95 & 4.9915 & TRN & \\
\hline
\end{tabular}




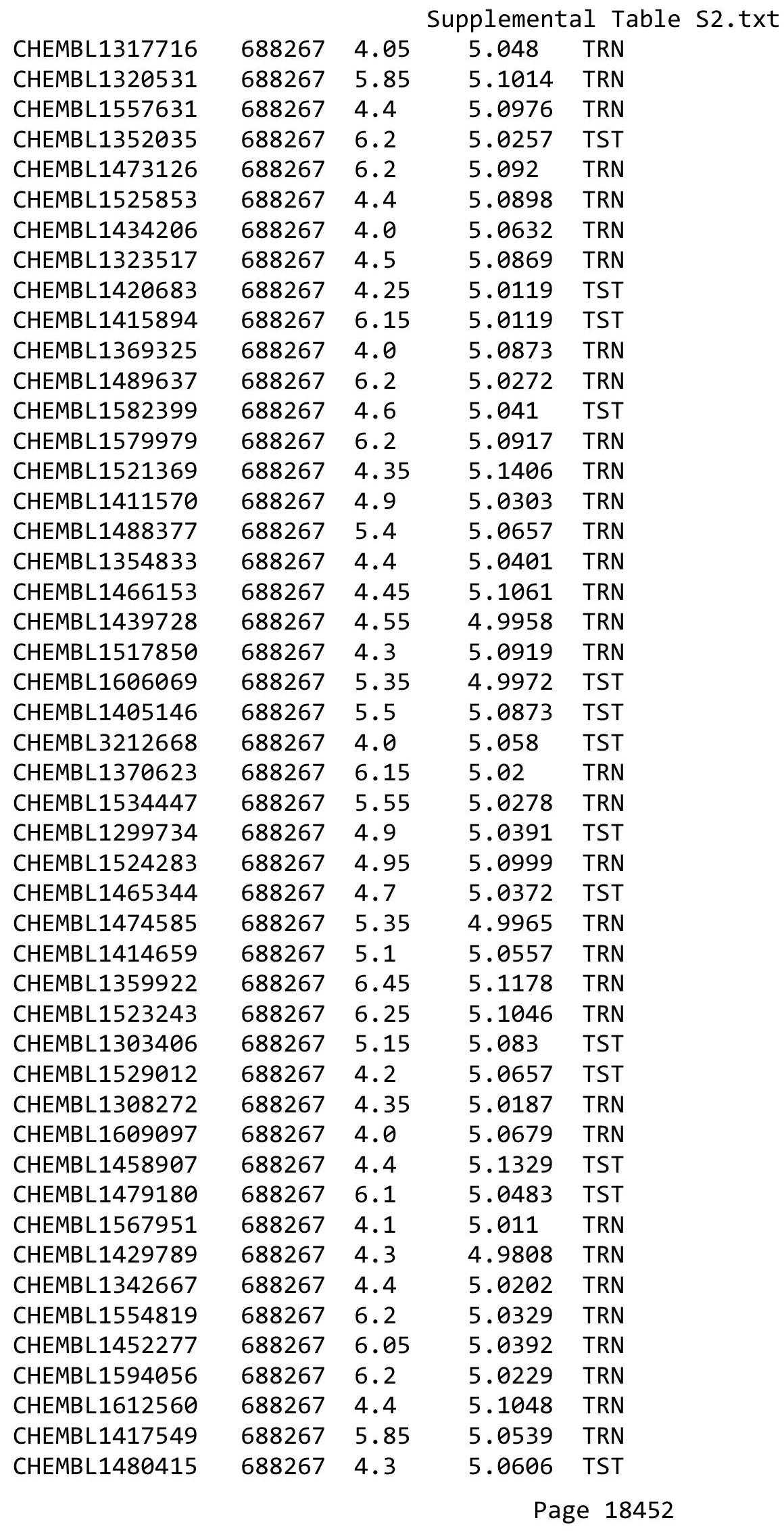




\begin{tabular}{|c|c|c|c|c|c|}
\hline \multicolumn{6}{|c|}{ Supplemental Table S2.txt } \\
\hline CHEMBL1311861 & 688267 & 6.15 & 5.101 & TRN & \\
\hline CHEMBL3210374 & 688267 & 6.15 & 5.0478 & TRN & \\
\hline CHEMBL1451580 & 688267 & 4.6 & 5.0001 & TRN & \\
\hline CHEMBL1405114 & 688267 & 5.0 & 5.0189 & TRN & \\
\hline CHEMBL1327071 & 688267 & 4.0 & 5.0182 & TRN & \\
\hline CHEMBL1457602 & 688267 & 3.95 & 5.1254 & TRN & \\
\hline CHEMBL1598614 & 688267 & 4.35 & 4.9932 & TRN & \\
\hline CHEMBL1588797 & 688267 & 5.55 & 5.0512 & TRN & \\
\hline CHEMBL1397684 & 688267 & 6.2 & 5.0357 & TRN & \\
\hline CHEMBL 2373664 & 688267 & 4.65 & 5.0472 & TST & \\
\hline CHEMBL1456964 & 688267 & 5.3 & 5.0702 & TRN & \\
\hline CHEMBL1329036 & 688267 & 6.9 & 5.0706 & TRN & \\
\hline CHEMBL1592669 & 688267 & 6.2 & 5.0432 & TRN & \\
\hline CHEMBL1444060 & 688267 & 5.55 & 5.0813 & TST & \\
\hline CHEMBL1586893 & 688267 & 4.95 & 5.0433 & TRN & \\
\hline CHEMBL1599588 & 688267 & 6.2 & 5.0078 & TRN & \\
\hline CHEMBL1410555 & 688267 & 4.35 & 5.0194 & TST & \\
\hline CHEMBL1394399 & 688267 & 5.25 & 5.079 & TRN & \\
\hline CHEMBL3196521 & 688267 & 4.75 & 4.9886 & TRN & \\
\hline CHEMBL1572026 & 688267 & 5.5 & 5.0612 & TRN & \\
\hline CHEMBL1300327 & 688267 & 4.35 & 5.1121 & TST & \\
\hline CHEMBL1533334 & 688267 & 6.15 & 5.0988 & TRN & \\
\hline CHEMBL1319446 & 688267 & 4.55 & 5.0923 & TRN & \\
\hline CHEMBL1502017 & 688267 & 5.2 & 4.9853 & TRN & \\
\hline CHEMBL1494608 & 688267 & 4.35 & 5.0787 & TRN & \\
\hline CHEMBL1371099 & 688267 & 6.1 & 5.0307 & TRN & \\
\hline CHEMBL1400216 & 688267 & 5.8 & 5.0508 & TST & \\
\hline CHEMBL1453493 & 688267 & 4.55 & 5.0032 & TRN & \\
\hline CHEMBL1504213 & 688267 & 5.95 & 5.0103 & TRN & \\
\hline CHEMBL1335873 & 688267 & 6.15 & 5.0206 & TRN & \\
\hline CHEMBL1527041 & 688267 & 4.45 & 5.05 & TRN & \\
\hline CHEMBL1416432 & 688267 & 4.0 & 5.07100 & 0000000001 & TST \\
\hline CHEMBL1507529 & 688267 & 6.25 & 5.0457 & TRN & \\
\hline CHEMBL1490677 & 688267 & 3.95 & 5.0258 & TST & \\
\hline CHEMBL1541000 & 688267 & 5.45 & 5.0589 & TRN & \\
\hline CHEMBL1383870 & 688267 & 4.4 & 5.0145 & TRN & \\
\hline CHEMBL1384415 & 688267 & 5.3 & 5.0854 & TRN & \\
\hline CHEMBL1415382 & 688267 & 6.2 & 5.1363 & TRN & \\
\hline CHEMBL1447194 & 688267 & 6.15 & 5.0257 & TST & \\
\hline CHEMBL1585166 & 688267 & 4.4 & 5.0288 & TRN & \\
\hline CHEMBL1551931 & 688267 & 6.2 & 5.0489 & TST & \\
\hline CHEMBL1560304 & 688267 & 6.2 & 5.1086 & TRN & \\
\hline CHEMBL1470494 & 688267 & 3.95 & 4.9754 & TRN & \\
\hline CHEMBL1423995 & 688267 & 4.25 & 5.0493 & TRN & \\
\hline CHEMBL3209355 & 688267 & 4.4 & 5.0427 & TST & \\
\hline CHEMBL1556120 & 688267 & 3.95 & 5.0032 & TRN & \\
\hline CHEMBL1597827 & 688267 & 5.95 & 5.0099 & TST & \\
\hline CHEMBL1485784 & 688267 & 4.2 & 4.9961 & TRN & \\
\hline
\end{tabular}




\begin{tabular}{|c|c|c|c|c|}
\hline \multicolumn{5}{|c|}{ Supplemental Table S2.txt } \\
\hline CHEMBL1491212 & 688267 & 5.7 & 5.1404 & TRN \\
\hline CHEMBL1590235 & 688267 & 5.2 & 5.0365 & TRN \\
\hline CHEMBL1592350 & 688267 & 4.3 & 5.0603 & TRN \\
\hline CHEMBL63715 & 688267 & 5.55 & 5.0394 & TRN \\
\hline CHEMBL1598642 & 688267 & 4.4 & 5.08 & TRN \\
\hline CHEMBL1317505 & 688267 & 4.0 & 5.0496 & TRN \\
\hline CHEMBL1437059 & 688267 & 5.9 & 5.0083 & TRN \\
\hline CHEMBL1514985 & 688267 & 4.7 & 5.0383 & TST \\
\hline CHEMBL1445976 & 688267 & 6.2 & 5.0356 & TRN \\
\hline CHEMBL1356566 & 688267 & 5.3 & 5.1363 & TRN \\
\hline CHEMBL1319797 & 688267 & 4.75 & 5.0688 & TRN \\
\hline CHEMBL1438533 & 688267 & 6.15 & 5.073 & TRN \\
\hline CHEMBL1352469 & 688267 & 6.15 & 5.0262 & TRN \\
\hline CHEMBL1362959 & 688267 & 4.35 & 5.0483 & TRN \\
\hline CHEMBL1422980 & 688267 & 5.3 & 5.0027 & TRN \\
\hline CHEMBL1371054 & 688267 & 4.9 & 5.1422 & TRN \\
\hline CHEMBL1494061 & 688267 & 4.35 & 5.1063 & TRN \\
\hline CHEMBL1526366 & 688267 & 4.0 & 4.9874 & TRN \\
\hline CHEMBL1552861 & 688267 & 5.95 & 5.1067 & TRN \\
\hline CHEMBL1462538 & 688267 & 6.45 & 4.998 & TRN \\
\hline CHEMBL1472979 & 688267 & 4.8 & 5.0436 & TRN \\
\hline CHEMBL1405215 & 688267 & 6.2 & 4.9869 & TRN \\
\hline CHEMBL1451037 & 688267 & 5.05 & 5.0184 & TRN \\
\hline CHEMBL1313327 & 688267 & 5.1 & 4.9644 & TRN \\
\hline CHEMBL1415015 & 688267 & 4.45 & 5.0288 & TRN \\
\hline CHEMBL1514260 & 688267 & 6.25 & 5.0256 & TRN \\
\hline CHEMBL1603987 & 688267 & 4.65 & 5.0711 & TRN \\
\hline CHEMBL3196848 & 688267 & 5.65 & 5.0758 & TST \\
\hline CHEMBL1303843 & 688267 & 5.8 & 5.1127 & TRN \\
\hline CHEMBL1405491 & 688267 & 6.15 & 5.0805 & TST \\
\hline CHEMBL1453805 & 688267 & 4.15 & 5.0208 & TRN \\
\hline CHEMBL1514154 & 688267 & 5.5 & 5.0302 & TRN \\
\hline CHEMBL1555134 & 688267 & 6.2 & 5.0459 & TRN \\
\hline CHEMBL1497485 & 688267 & 6.25 & 5.1445 & TRN \\
\hline CHEMBL1461042 & 688267 & 6.45 & 5.0634 & TRN \\
\hline CHEMBL1517062 & 688267 & 5.05 & 5.0702 & TRN \\
\hline CHEMBL1338957 & 688267 & 5.3 & 5.0705 & TRN \\
\hline CHEMBL1546685 & 688267 & 4.4 & 5.055 & TRN \\
\hline CHEMBL1457269 & 688267 & 6.1 & 5.0305 & TRN \\
\hline CHEMBL1339596 & 688267 & 4.55 & 5.0422 & TRN \\
\hline CHEMBL1329560 & 688267 & 4.65 & 5.0337 & TST \\
\hline CHEMBL1303398 & 688267 & 6.25 & 5.1188 & TRN \\
\hline CHEMBL1301429 & 688267 & 5.05 & 5.0008 & TRN \\
\hline CHEMBL3195475 & 688267 & 5.3 & 5.0061 & TRN \\
\hline CHEMBL1348612 & 688267 & 4.0 & 5.0273 & TST \\
\hline CHEMBL1414654 & 688267 & 4.8 & 5.1182 & TRN \\
\hline CHEMBL1543132 & 688267 & 4.35 & 5.0602 & TST \\
\hline CHEMBL1587053 & 688267 & 6.5 & 5.0852 & TRN \\
\hline
\end{tabular}




\begin{tabular}{|c|c|c|c|c|}
\hline & & & pplement & al $\mathrm{T}$ \\
\hline CHEMBL1559040 & 688267 & 5.1 & 5.0986 & TRN \\
\hline CHEMBL1324688 & 688267 & 5.0 & 5.098 & TRN \\
\hline CHEMBL1355956 & 688267 & 3.95 & 5.0082 & TRN \\
\hline CHEMBL1404760 & 688267 & 4.15 & 5.1068 & TRN \\
\hline CHEMBL1381450 & 688267 & 6.2 & 5.0258 & TRN \\
\hline CHEMBL1387800 & 688267 & 4.0 & 5.0783 & TST \\
\hline CHEMBL1473706 & 688267 & 5.45 & 5.0178 & TRN \\
\hline CHEMBL1388580 & 688267 & 4.3 & 5.0976 & TRN \\
\hline CHEMBL1436553 & 688267 & 4.0 & 5.0378 & TRN \\
\hline CHEMBL1318713 & 688267 & 6.2 & 5.0789 & TRN \\
\hline CHEMBL1574058 & 688267 & 5.25 & 5.0548 & TRN \\
\hline CHEMBL1311810 & 688267 & 4.7 & 5.0173 & TRN \\
\hline CHEMBL1591011 & 688267 & 6.2 & 5.104 & TRN \\
\hline CHEMBL1344639 & 688267 & 4.55 & 5.0325 & TRN \\
\hline CHEMBL1328864 & 688267 & 4.55 & 5.0151 & TRN \\
\hline CHEMBL442925 & 688267 & 4.35 & 4.9761 & TRN \\
\hline CHEMBL1514173 & 688267 & 7.6003 & 5.0718 & TST \\
\hline CHEMBL 3208741 & 688267 & 6.2 & 5.0632 & TRN \\
\hline CHEMBL1378262 & 688267 & 4.0 & 5.0889 & TRN \\
\hline CHEMBL1495167 & 688267 & 4.1 & 5.0644 & TRN \\
\hline CHEMBL 1577821 & 688267 & 3.9 & 5.1017 & TRN \\
\hline CHEMBL1330433 & 688267 & 6.2 & 5.045 & TRN \\
\hline CHEMBL1504242 & 688267 & 4.05 & 5.0964 & TST \\
\hline CHEMBL1417894 & 688267 & 5.9 & 5.0842 & TST \\
\hline CHEMBL1579754 & 688267 & 6.1 & 4.9839 & TST \\
\hline CHEMBL1536252 & 688267 & 5.4 & 5.05 & TST \\
\hline CHEMBL1512486 & 688267 & 5.95 & 5.0867 & TRN \\
\hline CHEMBL1582409 & 688267 & 5.85 & 5.0962 & TRN \\
\hline CHEMBL1588246 & 688267 & 6.2 & 5.0227 & TST \\
\hline CHEMBL1465070 & 688267 & 4.95 & 5.0368 & TST \\
\hline CHEMBL1366913 & 688267 & 4.0 & 5.0387 & TRN \\
\hline CHEMBL1597026 & 688267 & 5.9 & 4.9878 & TRN \\
\hline CHEMBL1450916 & 688267 & 4.95 & 5.0677 & TRN \\
\hline CHEMBL1425203 & 688267 & 4.6 & 5.1011 & TST \\
\hline CHEMBL1315176 & 688267 & 4.4 & 5.1203 & TRN \\
\hline CHEMBL1329256 & 688267 & 6.2 & 5.0098 & TST \\
\hline CHEMBL1487835 & 688267 & 3.95 & 5.0828 & TRN \\
\hline CHEMBL1505501 & 688267 & 4.65 & 5.0596 & TRN \\
\hline CHEMBL1509877 & 688267 & 6.15 & 5.0525 & TRN \\
\hline CHEMBL1356148 & 688267 & 4.0 & 5.0801 & TRN \\
\hline CHEMBL1452740 & 688267 & 4.0 & 5.0486 & TST \\
\hline CHEMBL1325034 & 688267 & 4.0 & 5.0456 & TRN \\
\hline CHEMBL 299853 & 688267 & 6.25 & 5.0091 & TST \\
\hline CHEMBL1473515 & 688267 & 4.35 & 5.0702 & TRN \\
\hline CHEMBL1401147 & 688267 & 3.95 & 5.0394 & TRN \\
\hline CHEMBL1601397 & 688267 & 3.95 & 4.9981 & TRN \\
\hline CHEMBL1606169 & 688267 & 4.45 & 5.0223 & TRN \\
\hline CHEMBL1557104 & 688267 & 5.3 & 5.045 & TRN \\
\hline
\end{tabular}




\begin{tabular}{|c|c|c|c|c|c|}
\hline \multicolumn{6}{|c|}{ Supplemental Table S2.txt } \\
\hline CHEMBL1476044 & 688267 & 4.0 & 5.0515 & TRN & \\
\hline CHEMBL1481019 & 688267 & 6.15 & 5.0061 & TRN & \\
\hline CHEMBL1419680 & 688267 & 6.2 & 4.9891 & TST & \\
\hline CHEMBL1531447 & 688267 & 5.95 & 5.0681 & TRN & \\
\hline CHEMBL1360374 & 688267 & 5.7 & 5.0706 & TRN & \\
\hline CHEMBL1473553 & 688267 & 4.0 & 5.05399 & 9999999999 & TRN \\
\hline CHEMBL1570112 & 688267 & 6.2 & 5.0429 & TRN & \\
\hline CHEMBL1501107 & 688267 & 5.6 & 5.0669 & TRN & \\
\hline CHEMBL1470863 & 688267 & 4.2 & 5.1453 & TST & \\
\hline CHEMBL1546854 & 688267 & 5.3 & 5.0107 & TST & \\
\hline CHEMBL1499436 & 688267 & 4.0 & 5.0015 & TST & \\
\hline CHEMBL1453536 & 688267 & 4.35 & 5.0451 & TST & \\
\hline CHEMBL1461086 & 688267 & 3.95 & 5.0619 & TRN & \\
\hline CHEMBL1350094 & 688267 & 4.5 & 5.0763 & TRN & \\
\hline CHEMBL1567735 & 688267 & 4.35 & 5.0432 & TRN & \\
\hline CHEMBL1574763 & 688267 & 5.25 & 5.0369 & TRN & \\
\hline CHEMBL1317935 & 688267 & 4.0 & 5.0241 & TRN & \\
\hline CHEMBL1492710 & 688267 & 4.05 & 5.0203 & TRN & \\
\hline CHEMBL1405293 & 688267 & 5.5 & 5.0232 & TRN & \\
\hline CHEMBL1472374 & 688267 & 5.5 & 5.03100 & 0000000001 & TRN \\
\hline CHEMBL1553041 & 688267 & 4.6 & 5.0916 & TRN & \\
\hline CHEMBL1431526 & 688267 & 5.35 & 5.0946 & TRN & \\
\hline CHEMBL1612307 & 688267 & 5.35 & 5.0785 & TRN & \\
\hline CHEMBL1320899 & 688267 & 6.5 & 5.0508 & TRN & \\
\hline CHEMBL1321813 & 688267 & 4.4 & 5.0913 & TRN & \\
\hline CHEMBL1607582 & 688267 & 4.35 & 5.0271 & TST & \\
\hline CHEMBL1524356 & 688267 & 6.15 & 5.0719 & TRN & \\
\hline CHEMBL1488957 & 688267 & 6.25 & 5.0805 & TRN & \\
\hline CHEMBL1409233 & 688267 & 6.25 & 5.1386 & TRN & \\
\hline CHEMBL1557297 & 688267 & 4.55 & 5.1094 & TRN & \\
\hline CHEMBL1463091 & 688267 & 4.05 & 5.0317 & TRN & \\
\hline CHEMBL1598106 & 688267 & 4.55 & 5.1384 & TRN & \\
\hline CHEMBL1519018 & 688267 & 6.15 & 5.0679 & TST & \\
\hline CHEMBL1543542 & 688267 & 5.0 & 5.0323 & TRN & \\
\hline CHEMBL1301712 & 688267 & 6.1 & 5.0479 & TRN & \\
\hline CHEMBL1392567 & 688267 & 4.4 & 5.0434 & TRN & \\
\hline CHEMBL1375315 & 688267 & 4.55 & 4.97 & TST & \\
\hline CHEMBL1454064 & 688267 & 4.85 & 5.0159 & TRN & \\
\hline CHEMBL3211155 & 688267 & 4.0 & 4.9934 & TST & \\
\hline CHEMBL172997 & 688267 & 6.15 & 4.9979 & TST & \\
\hline CHEMBL1407721 & 688267 & 5.7 & 5.0494 & TRN & \\
\hline CHEMBL1360148 & 688267 & 4.2 & 5.0732 & TRN & \\
\hline CHEMBL1577462 & 688267 & 6.0 & 5.0133 & TRN & \\
\hline CHEMBL1346981 & 688267 & 5.55 & 5.0166 & TST & \\
\hline CHEMBL1416696 & 688267 & 6.8499 & 5.0938 & TRN & \\
\hline CHEMBL1542794 & 688267 & 5.2 & 5.0931 & TRN & \\
\hline CHEMBL1475566 & 688267 & 4.55 & 5.0407 & TST & \\
\hline CHEMBL1503498 & 688267 & 4.8 & 5.1077 & TRN & \\
\hline
\end{tabular}




\begin{tabular}{|c|c|c|c|c|c|}
\hline \\
\hline CHEMBL1432741 & 688267 & 4.3 & 5.0137 & TRN & \\
\hline CHEMBL1499118 & 688267 & 4.3 & 5.0197 & TRN & \\
\hline CHEMBL1320993 & 688267 & 5.9 & 5.0524 & TST & \\
\hline CHEMBL1601959 & 688267 & 6.2 & 5.0697 & TST & \\
\hline CHEMBL1346663 & 688267 & 5.35 & 5.0754 & TST & \\
\hline CHEMBL1549988 & 688267 & 5.9 & 5.0192 & TRN & \\
\hline CHEMBL1315532 & 688267 & 6.6499 & 5.0629 & TST & \\
\hline CHEMBL1340100 & 688267 & 6.5501 & 5.0316 & TRN & \\
\hline CHEMBL1523963 & 688267 & 4.5 & 5.0681 & TRN & \\
\hline CHEMBL1463767 & 688267 & 6.5 & 5.0852 & TRN & \\
\hline CHEMBL1464312 & 688267 & 5.9 & 5.0366 & TST & \\
\hline CHEMBL1371126 & 688267 & 5.5 & 4.9998 & TST & \\
\hline CHEMBL2000656 & 688267 & 4.35 & 5.0197 & TST & \\
\hline CHEMBL1568289 & 688267 & 4.5 & 5.0494 & TRN & \\
\hline CHEMBL1464235 & 688267 & 4.1 & 5.02800 & 00000000005 & TRN \\
\hline CHEMBL1569797 & 688267 & 3.95 & 5.0533 & TRN & \\
\hline CHEMBL1413794 & 688267 & 4.0 & 5.0836 & TRN & \\
\hline CHEMBL1308677 & 688267 & 4.35 & 5.0298 & TST & \\
\hline CHEMBL1357072 & 688267 & 5.6 & 4.9959 & TRN & \\
\hline CHEMBL1398286 & 688267 & 4.35 & 5.0603 & TRN & \\
\hline CHEMBL1452282 & 688267 & 4.45 & 5.0042 & TST & \\
\hline CHEMBL1339787 & 688267 & 5.4 & 5.0848 & TRN & \\
\hline CHEMBL1532493 & 688267 & 5.3 & 5.0892 & TRN & \\
\hline CHEMBL1441722 & 688267 & 4.0 & 5.1247 & TRN & \\
\hline CHEMBL1446937 & 688267 & 4.55 & 5.0942 & TRN & \\
\hline CHEMBL1397208 & 688267 & 5.55 & 5.1101 & TRN & \\
\hline CHEMBL3210750 & 688267 & 4.1 & 5.0189 & TRN & \\
\hline CHEMBL1378596 & 688267 & 5.4 & 4.9819 & TRN & \\
\hline CHEMBL1316011 & 688267 & 4.05 & 5.0661 & TRN & \\
\hline CHEMBL1440226 & 688267 & 4.1 & 5.1225 & TRN & \\
\hline CHEMBL1514637 & 688267 & 4.3 & 5.01 & TRN & \\
\hline CHEMBL1320102 & 688267 & 6.45 & 5.0385 & TRN & \\
\hline CHEMBL1381022 & 688267 & 4.0 & 5.003 & TST & \\
\hline CHEMBL1479215 & 688267 & 5.7 & 5.0323 & TRN & \\
\hline CHEMBL1602253 & 688267 & 3.95 & 5.0492 & TRN & \\
\hline CHEMBL1993287 & 688267 & 4.0 & 5.0028 & TRN & \\
\hline CHEMBL1467636 & 688267 & 6.2 & 5.0116 & TRN & \\
\hline CHEMBL1326050 & 688267 & 6.2 & 5.0567 & TRN & \\
\hline CHEMBL1456601 & 688267 & 4.2 & 5.1145 & TRN & \\
\hline CHEMBL1595646 & 688267 & 5.05 & 5.06800 & 00000000005 & TST \\
\hline CHEMBL1492514 & 688267 & 5.85 & 5.1336 & TRN & \\
\hline CHEMBL1596747 & 688267 & 4.0 & 5.0449 & TRN & \\
\hline CHEMBL1571878 & 688267 & 6.2 & 5.0701 & TRN & \\
\hline CHEMBL1446831 & 688267 & 4.35 & 5.1067 & TRN & \\
\hline CHEMBL1542282 & 688267 & 5.6 & 5.0704 & TST & \\
\hline CHEMBL1497391 & 688267 & 4.6 & 4.9866 & TST & \\
\hline CHEMBL1548400 & 688267 & 5.55 & 5.0667 & TRN & \\
\hline CHEMBL1399182 & 688267 & 6.15 & 5.0821 & TRN & \\
\hline
\end{tabular}




\begin{tabular}{|c|c|c|c|c|}
\hline & & & pplement & \\
\hline CHEMBL1449530 & 688267 & 4.0 & 5.0915 & TRN \\
\hline CHEMBL1464606 & 688267 & 5.95 & 5.0473 & TRN \\
\hline CHEMBL1462817 & 688267 & 4.4 & 5.0382 & TRN \\
\hline CHEMBL1515470 & 688267 & 6.2 & 5.039 & TRN \\
\hline CHEMBL1570674 & 688267 & 5.0 & 5.0208 & TRN \\
\hline CHEMBL1575558 & 688267 & 4.0 & 5.083 & TRN \\
\hline CHEMBL1473836 & 688267 & 4.35 & 5.0978 & TRN \\
\hline CHEMBL1326234 & 688267 & 4.65 & 5.1123 & TRN \\
\hline CHEMBL1503637 & 688267 & 5.9 & 5.0945 & TRN \\
\hline CHEMBL3195509 & 688267 & 5.65 & 5.0509 & TRN \\
\hline CHEMBL1308608 & 688267 & 5.05 & 5.055 & TRN \\
\hline CHEMBL1466594 & 688267 & 5.4 & 5.0919 & TRN \\
\hline CHEMBL1545160 & 688267 & 4.4 & 5.065 & TST \\
\hline CHEMBL1463676 & 688267 & 5.35 & 5.0274 & TRN \\
\hline CHEMBL1317031 & 688267 & 4.0 & 5.0975 & TRN \\
\hline CHEMBL1301213 & 688267 & 5.85 & 5.0492 & TRN \\
\hline CHEMBL1356982 & 688267 & 4.0 & 5.056 & TRN \\
\hline CHEMBL1339279 & 688267 & 4.15 & 5.0308 & TST \\
\hline CHEMBL1356413 & 688267 & 4.6 & 5.0109 & TRN \\
\hline CHEMBL1420979 & 688267 & 4.0 & 5.0282 & TRN \\
\hline CHEMBL1446547 & 688267 & 4.35 & 5.0161 & TRN \\
\hline CHEMBL1461744 & 688267 & 5.35 & 5.0669 & TRN \\
\hline CHEMBL1502451 & 688267 & 4.35 & 5.0384 & TST \\
\hline CHEMBL1421710 & 688267 & 5.9 & 5.0498 & TST \\
\hline CHEMBL1345789 & 688267 & 6.1 & 5.0509 & TST \\
\hline CHEMBL1561562 & 688267 & 4.2 & 5.0452 & TRN \\
\hline CHEMBL1395444 & 688267 & 4.05 & 5.0527 & TRN \\
\hline CHEMBL1315786 & 688267 & 6.25 & 5.026 & TRN \\
\hline CHEMBL1338972 & 688267 & 4.2 & 5.0605 & TRN \\
\hline CHEMBL1364434 & 688267 & 6.25 & 5.1201 & TRN \\
\hline CHEMBL1554546 & 688267 & 5.5 & 5.0524 & TRN \\
\hline CHEMBL1446377 & 688267 & 5.95 & 5.0791 & TST \\
\hline CHEMBL1399727 & 688267 & 6.2 & 5.1043 & TRN \\
\hline CHEMBL1488254 & 688267 & 6.05 & 5.0695 & TRN \\
\hline CHEMBL1589284 & 688267 & 5.35 & 5.0259 & TRN \\
\hline CHEMBL1601611 & 688267 & 5.75 & 5.0431 & TST \\
\hline CHEMBL1571871 & 688267 & 4.4 & 5.0854 & TRN \\
\hline CHEMBL1425278 & 688267 & 4.05 & 5.0379 & TRN \\
\hline CHEMBL3199104 & 688267 & 4.0 & 4.9758 & TRN \\
\hline CHEMBL1453079 & 688267 & 4.0 & 5.0402 & TRN \\
\hline CHEMBL3207462 & 688267 & 4.2 & 5.0097 & TRN \\
\hline CHEMBL1320684 & 688267 & 5.0 & 5.1282 & TRN \\
\hline CHEMBL1388873 & 688267 & 5.3 & 4.9998 & TRN \\
\hline CHEMBL1410233 & 688267 & 5.3 & 5.0906 & TRN \\
\hline CHEMBL1583972 & 688267 & 6.2 & 5.0796 & TRN \\
\hline CHEMBL1446488 & 688267 & 4.2 & 5.0931 & TRN \\
\hline CHEMBL 1435783 & 688267 & 6.5 & 5.1044 & TRN \\
\hline CHEMBL1590216 & 688267 & 5.75 & 5.044 & TRN \\
\hline
\end{tabular}




\begin{tabular}{|c|c|c|c|c|}
\hline \multicolumn{5}{|c|}{ Supplemental Table S2.txt } \\
\hline CHEMBL1488148 & 688267 & 4.0 & 5.0314 & TST \\
\hline CHEMBL1320157 & 688267 & 4.05 & 4.9924 & TRN \\
\hline CHEMBL1431274 & 688267 & 5.85 & 5.1066 & TRN \\
\hline CHEMBL1468865 & 688267 & 4.25 & 5.1103 & TRN \\
\hline CHEMBL1607032 & 688267 & 6.2 & 5.0149 & TRN \\
\hline CHEMBL2369239 & 688267 & 4.2 & 5.0624 & TST \\
\hline CHEMBL3209903 & 688267 & 3.95 & 5.0355 & TRN \\
\hline CHEMBL1540511 & 688267 & 6.2 & 5.0871 & TRN \\
\hline CHEMBL1512961 & 688267 & 4.4 & 5.0102 & TRN \\
\hline CHEMBL1560766 & 688267 & 3.95 & 5.1387 & TRN \\
\hline CHEMBL1593445 & 688267 & 3.95 & 5.0239 & TRN \\
\hline CHEMBL1578472 & 688267 & 4.0 & 4.9648 & TRN \\
\hline CHEMBL3189307 & 688267 & 4.1 & 5.04 & TST \\
\hline CHEMBL1407700 & 688267 & 4.55 & 5.0755 & TRN \\
\hline CHEMBL1337638 & 688267 & 5.05 & 5.0179 & TRN \\
\hline CHEMBL1564101 & 688267 & 6.5 & 5.18 & TRN \\
\hline CHEMBL1367209 & 688267 & 6.15 & 5.1049 & TST \\
\hline CHEMBL1404802 & 688267 & 5.65 & 5.0726 & TST \\
\hline CHEMBL1571784 & 688267 & 4.05 & 5.027 & TRN \\
\hline CHEMBL1411658 & 688267 & 5.05 & 5.0578 & TRN \\
\hline CHEMBL1442315 & 688267 & 4.15 & 5.0362 & TST \\
\hline CHEMBL240836 & 688267 & 4.05 & 5.0543 & TST \\
\hline CHEMBL1594379 & 688267 & 4.3 & 5.0975 & TRN \\
\hline CHEMBL599890 & 688267 & 6.15 & 4.993 & TRN \\
\hline CHEMBL1567691 & 688267 & 5.75 & 5.0249 & TRN \\
\hline CHEMBL1461140 & 688267 & 4.65 & 5.0235 & TRN \\
\hline CHEMBL1339565 & 688267 & 6.8499 & 5.0441 & TRN \\
\hline CHEMBL1433682 & 688267 & 5.35 & 5.1546 & TRN \\
\hline CHEMBL1315059 & 688267 & 5.55 & 5.0434 & TRN \\
\hline CHEMBL1475909 & 688267 & 4.05 & 5.0538 & TRN \\
\hline CHEMBL3192076 & 688267 & 4.0 & 4.9837 & TRN \\
\hline CHEMBL1452668 & 688267 & 5.05 & 5.0301 & TRN \\
\hline CHEMBL1588483 & 688267 & 5.1 & 5.0306 & TRN \\
\hline CHEMBL1324000 & 688267 & 5.55 & 5.0299 & TRN \\
\hline CHEMBL1372686 & 688267 & 5.25 & 5.0122 & TRN \\
\hline CHEMBL1391271 & 688267 & 5.35 & 5.0086 & TRN \\
\hline CHEMBL3193743 & 688267 & 5.3 & 5.064 & TRN \\
\hline CHEMBL1503103 & 688267 & 5.0 & 5.0419 & TRN \\
\hline CHEMBL1459379 & 688267 & 6.2 & 5.0982 & TRN \\
\hline CHEMBL1598797 & 688267 & 6.2 & 5.063 & TRN \\
\hline CHEMBL1358461 & 688267 & 5.95 & 5.0261 & TRN \\
\hline CHEMBL1528834 & 688267 & 4.6 & 5.1299 & TRN \\
\hline CHEMBL1553213 & 688267 & 5.55 & 5.0612 & TRN \\
\hline CHEMBL1587923 & 688267 & 4.45 & 5.0566 & TRN \\
\hline CHEMBL1454081 & 688267 & 4.0 & 5.0477 & TRN \\
\hline CHEMBL1375278 & 688267 & 4.65 & 5.1049 & TRN \\
\hline CHEMBL1529672 & 688267 & 4.25 & 5.0043 & TRN \\
\hline CHEMBL1443190 & 688267 & 4.25 & 5.0839 & TRN \\
\hline
\end{tabular}




\begin{tabular}{|c|c|c|c|c|c|}
\hline \multicolumn{6}{|c|}{ Supplemental Table S2.txt } \\
\hline CHEMBL1480447 & 688267 & 5.65 & 5.0486 & TRN & \\
\hline CHEMBL1586500 & 688267 & 4.0 & 5.0776 & TRN & \\
\hline CHEMBL1403705 & 688267 & 3.95 & 5.0525 & TRN & \\
\hline CHEMBL1373560 & 688267 & 5.45 & 5.0117 & TRN & \\
\hline CHEMBL1524804 & 688267 & 4.5 & 5.0279 & TRN & \\
\hline CHEMBL1524882 & 688267 & 5.55 & 5.1361 & TRN & \\
\hline CHEMBL1335713 & 688267 & 5.3 & 5.0998 & TRN & \\
\hline CHEMBL1563203 & 688267 & 4.2 & 5.0811 & TRN & \\
\hline CHEMBL1434162 & 688267 & 4.45 & 5.01699 & 99999999995 & TRN \\
\hline CHEMBL1582071 & 688267 & 5.05 & 4.9813 & TRN & \\
\hline CHEMBL1443632 & 688267 & 5.45 & 5.0039 & TST & \\
\hline CHEMBL1415984 & 688267 & 4.4 & 5.1263 & TRN & \\
\hline CHEMBL1374294 & 688267 & 4.6 & 5.0318 & TRN & \\
\hline CHEMBL1472581 & 688267 & 4.05 & 5.0026 & TRN & \\
\hline CHEMBL1572489 & 688267 & 6.2 & 5.1009 & TRN & \\
\hline CHEMBL1340398 & 688267 & 5.95 & 5.0228 & TRN & \\
\hline CHEMBL1532127 & 688267 & 4.4 & 5.1404 & TRN & \\
\hline CHEMBL1569191 & 688267 & 4.0 & 5.0829 & TRN & \\
\hline CHEMBL1417884 & 688267 & 4.4 & 5.048 & TRN & \\
\hline CHEMBL1343802 & 688267 & 4.35 & 5.0675 & TRN & \\
\hline CHEMBL1479991 & 688267 & 6.25 & 5.1606 & TRN & \\
\hline CHEMBL1585963 & 688267 & 6.2 & 5.0284 & TST & \\
\hline CHEMBL1315571 & 688267 & 5.25 & 5.1061 & TRN & \\
\hline CHEMBL1326859 & 688267 & 5.05 & 5.1037 & TRN & \\
\hline CHEMBL1458934 & 688267 & 5.55 & 5.0428 & TRN & \\
\hline CHEMBL1355794 & 688267 & 5.5 & 5.0164 & TST & \\
\hline CHEMBL1480115 & 688267 & 4.2 & 5.04899 & 99999999995 & TRN \\
\hline CHEMBL1375657 & 688267 & 5.6 & 5.1637 & TRN & \\
\hline CHEMBL1571349 & 688267 & 6.2 & 5.0813 & TRN & \\
\hline CHEMBL1434879 & 688267 & 5.0 & 5.0828 & TRN & \\
\hline CHEMBL1401284 & 688267 & 4.7 & 4.9793 & TST & \\
\hline CHEMBL1299915 & 688267 & 4.0 & 5.1226 & TRN & \\
\hline CHEMBL1400371 & 688267 & 6.15 & 5.0424 & TRN & \\
\hline CHEMBL1487888 & 688267 & 5.55 & 5.1106 & TRN & \\
\hline CHEMBL1328159 & 688267 & 5.05 & 5.0744 & TRN & \\
\hline CHEMBL1489702 & 688267 & 6.45 & 5.0344 & TST & \\
\hline CHEMBL1571006 & 688267 & 4.9 & 5.0737 & TST & \\
\hline CHEMBL1360047 & 688267 & 5.35 & 5.1042 & TRN & \\
\hline CHEMBL1502527 & 688267 & 5.65 & 5.0383 & TST & \\
\hline CHEMBL1445483 & 688267 & 4.0 & 5.0914 & TRN & \\
\hline CHEMBL1549951 & 688267 & 6.25 & 5.1152 & TST & \\
\hline CHEMBL1487949 & 688267 & 6.5 & 5.061 & TRN & \\
\hline CHEMBL1302005 & 688267 & 3.9 & 5.0295 & TRN & \\
\hline CHEMBL1347329 & 688267 & 4.1 & 5.0769 & TRN & \\
\hline CHEMBL1375745 & 688267 & 4.25 & 5.042 & TRN & \\
\hline CHEMBL1402154 & 688267 & 3.95 & 5.0792 & TRN & \\
\hline CHEMBL1446630 & 688267 & 5.4 & 5.0367 & TRN & \\
\hline CHEMBL 3214542 & 688267 & 4.05 & 5.0609 & TRN & \\
\hline
\end{tabular}




\begin{tabular}{|c|c|c|c|c|}
\hline \multicolumn{5}{|c|}{ Supplemental Table S2.txt } \\
\hline CHEMBL1597644 & 688267 & 4.3 & 5.0569 & TRN \\
\hline CHEMBL1508810 & 688267 & 4.0 & 5.0233 & TST \\
\hline CHEMBL1503039 & 688267 & 4.45 & 5.0232 & TRN \\
\hline CHEMBL1312119 & 688267 & 4.25 & 5.056 & TST \\
\hline CHEMBL1415675 & 688267 & 5.45 & 5.0573 & TRN \\
\hline CHEMBL1466679 & 688267 & 6.2 & 5.0849 & TRN \\
\hline CHEMBL1303736 & 688267 & 5.45 & 5.0247 & TST \\
\hline CHEMBL1380638 & 688267 & 5.4 & 5.062 & TRN \\
\hline CHEMBL1537160 & 688267 & 4.7 & 5.0191 & TRN \\
\hline CHEMBL1446929 & 688267 & 4.05 & 5.0765 & TST \\
\hline CHEMBL1371691 & 688267 & 5.6 & 5.0478 & TRN \\
\hline CHEMBL1587938 & 688267 & 5.0 & 5.1043 & TST \\
\hline CHEMBL1454104 & 688267 & 4.1 & 5.0518 & TRN \\
\hline CHEMBL1514682 & 688267 & 4.4 & 5.0541 & TST \\
\hline CHEMBL1448720 & 688267 & 5.35 & 5.1488 & TRN \\
\hline CHEMBL3192731 & 688267 & 5.55 & 5.1062 & TST \\
\hline CHEMBL1353295 & 688267 & 6.05 & 5.0549 & TRN \\
\hline CHEMBL1329547 & 688267 & 4.1 & 5.0834 & TRN \\
\hline CHEMBL1567860 & 688267 & 4.0 & 4.9893 & TRN \\
\hline CHEMBL1409174 & 688267 & 3.95 & 5.055 & TRN \\
\hline CHEMBL1393122 & 688267 & 4.05 & 4.9995 & TRN \\
\hline CHEMBL1606987 & 688267 & 4.45 & 5.0378 & TRN \\
\hline CHEMBL1383630 & 688267 & 5.3 & 5.1368 & TRN \\
\hline CHEMBL1405965 & 688267 & 4.55 & 5.051 & TRN \\
\hline CHEMBL1362337 & 688267 & 4.3 & 5.0091 & TRN \\
\hline CHEMBL1445448 & 688267 & 5.85 & 5.0829 & TRN \\
\hline CHEMBL1484688 & 688267 & 4.65 & 5.0404 & TRN \\
\hline CHEMBL1544102 & 688267 & 4.1 & 5.0593 & TRN \\
\hline CHEMBL1607075 & 688267 & 4.05 & 5.0345 & TRN \\
\hline CHEMBL1320589 & 688267 & 6.2 & 5.0314 & TRN \\
\hline CHEMBL1337333 & 688267 & 6.2 & 5.0365 & TRN \\
\hline CHEMBL3191590 & 688267 & 5.15 & 4.9778 & TST \\
\hline CHEMBL1475703 & 688267 & 5.35 & 5.0869 & TRN \\
\hline CHEMBL1320314 & 688267 & 4.4 & 5.0465 & TRN \\
\hline CHEMBL1611154 & 688267 & 6.6499 & 5.044 & TRN \\
\hline CHEMBL1480234 & 688267 & 4.25 & 4.9994 & TST \\
\hline CHEMBL1358606 & 688267 & 4.0 & 5.0616 & TST \\
\hline CHEMBL1564616 & 688267 & 6.05 & 5.1477 & TRN \\
\hline CHEMBL1393573 & 688267 & 4.45 & 5.0349 & TST \\
\hline CHEMBL1394505 & 688267 & 4.3 & 5.0077 & TST \\
\hline CHEMBL1446429 & 688267 & 4.05 & 5.0359 & TRN \\
\hline CHEMBL1486957 & 688267 & 4.0 & 5.0643 & TST \\
\hline CHEMBL1607605 & 688267 & 3.95 & 4.9902 & TRN \\
\hline CHEMBL1304196 & 688267 & 5.8 & 4.9628 & TRN \\
\hline CHEMBL1516970 & 688267 & 5.0 & 5.088 & TRN \\
\hline CHEMBL1367314 & 688267 & 4.3 & 5.061 & TST \\
\hline CHEMBL1523269 & 688267 & 4.05 & 5.0885 & TST \\
\hline CHEMBL1324948 & 688267 & 4.15 & 5.0374 & TST \\
\hline
\end{tabular}




\begin{tabular}{|c|c|c|c|c|c|}
\hline \multicolumn{6}{|c|}{ Supplemental Table S2.txt } \\
\hline CHEMBL 3195553 & 688267 & 3.95 & 5.0468 & TST & \\
\hline CHEMBL1378547 & 688267 & 5.2 & 5.0998 & TRN & \\
\hline CHEMBL1325092 & 688267 & 4.05 & 5.1609 & TRN & \\
\hline CHEMBL1399251 & 688267 & 6.2 & 4.9928 & TST & \\
\hline CHEMBL1598622 & 688267 & 5.25 & 5.0583 & TST & \\
\hline CHEMBL1572547 & 688267 & 4.9 & 5.022 & TST & \\
\hline CHEMBL1362835 & 688267 & 6.2 & 5.0089 & TRN & \\
\hline CHEMBL1522963 & 688267 & 5.85 & 5.0765 & TRN & \\
\hline CHEMBL1590996 & 688267 & 5.15 & 5.1179 & TRN & \\
\hline CHEMBL1487184 & 688267 & 4.1 & 5.019 & TRN & \\
\hline CHEMBL1324621 & 688267 & 4.1 & 5.0938 & TRN & \\
\hline CHEMBL1588391 & 688267 & 3.95 & 5.0609 & TST & \\
\hline CHEMBL1422682 & 688267 & 5.5 & 5.0945 & TRN & \\
\hline CHEMBL1591310 & 688267 & 6.25 & 5.0863 & TRN & \\
\hline CHEMBL1558260 & 688267 & 4.35 & 5.038 & TRN & \\
\hline CHEMBL1560199 & 688267 & 4.3 & 5.1006 & TRN & \\
\hline CHEMBL1483020 & 688267 & 6.15 & 5.0914 & TRN & \\
\hline CHEMBL1518474 & 688267 & 6.2 & 5.0318 & TRN & \\
\hline CHEMBL1437531 & 688267 & 6.4 & 5.0581 & TRN & \\
\hline CHEMBL1435963 & 688267 & 6.7501 & 5.0454 & TRN & \\
\hline CHEMBL1481084 & 688267 & 5.5 & 5.0604 & TST & \\
\hline CHEMBL1561223 & 688267 & 5.75 & 5.0877 & TRN & \\
\hline CHEMBL1467022 & 688267 & 5.8 & 5.1476 & TRN & \\
\hline CHEMBL1419318 & 688267 & 4.4 & 5.0888 & TST & \\
\hline CHEMBL1580417 & 688267 & 5.25 & 5.0115 & TRN & \\
\hline CHEMBL1427788 & 688267 & 5.6 & 5.1636 & TRN & \\
\hline CHEMBL1611314 & 688267 & 5.75 & 5.0564 & TST & \\
\hline CHEMBL1478555 & 688267 & 6.25 & 4.9812 & TRN & \\
\hline CHEMBL1458204 & 688267 & 4.75 & 5.1008 & TRN & \\
\hline CHEMBL1375050 & 688267 & 4.0 & 4.9928 & TRN & \\
\hline CHEMBL1318671 & 688267 & 5.45 & 5.0611 & TRN & \\
\hline CHEMBL1571281 & 688267 & 6.2 & 5.09699 & 99999999995 & TRN \\
\hline CHEMBL1466424 & 688267 & 4.05 & 5.0213 & TST & \\
\hline CHEMBL1398733 & 688267 & 4.4 & 5.03600 & 00000000005 & TRN \\
\hline CHEMBL1427814 & 688267 & 3.65 & 5.0717 & TRN & \\
\hline CHEMBL1408451 & 688267 & 4.05 & 5.0211 & TST & \\
\hline CHEMBL1432127 & 688267 & 6.2 & 5.0965 & TST & \\
\hline CHEMBL1173475 & 688267 & 5.85 & 5.0192 & TST & \\
\hline CHEMBL1396022 & 688267 & 4.0 & 5.0302 & TRN & \\
\hline CHEMBL1329342 & 688267 & 6.2 & 5.1028 & TRN & \\
\hline CHEMBL1474616 & 688267 & 4.65 & 5.1065 & TST & \\
\hline CHEMBL1580082 & 688267 & 4.2 & 5.0792 & TST & \\
\hline CHEMBL1584518 & 688267 & 5.05 & 5.0234 & TRN & \\
\hline CHEMBL1460820 & 688267 & 4.35 & 5.0503 & TRN & \\
\hline CHEMBL1464533 & 688267 & 6.0 & 5.0731 & TRN & \\
\hline CHEMBL1383283 & 688267 & 4.15 & 4.995 & TST & \\
\hline CHEMBL1399235 & 688267 & 5.35 & 5.0842 & TRN & \\
\hline CHEMBL1560186 & 688267 & 4.9 & 5.0852 & TRN & \\
\hline
\end{tabular}




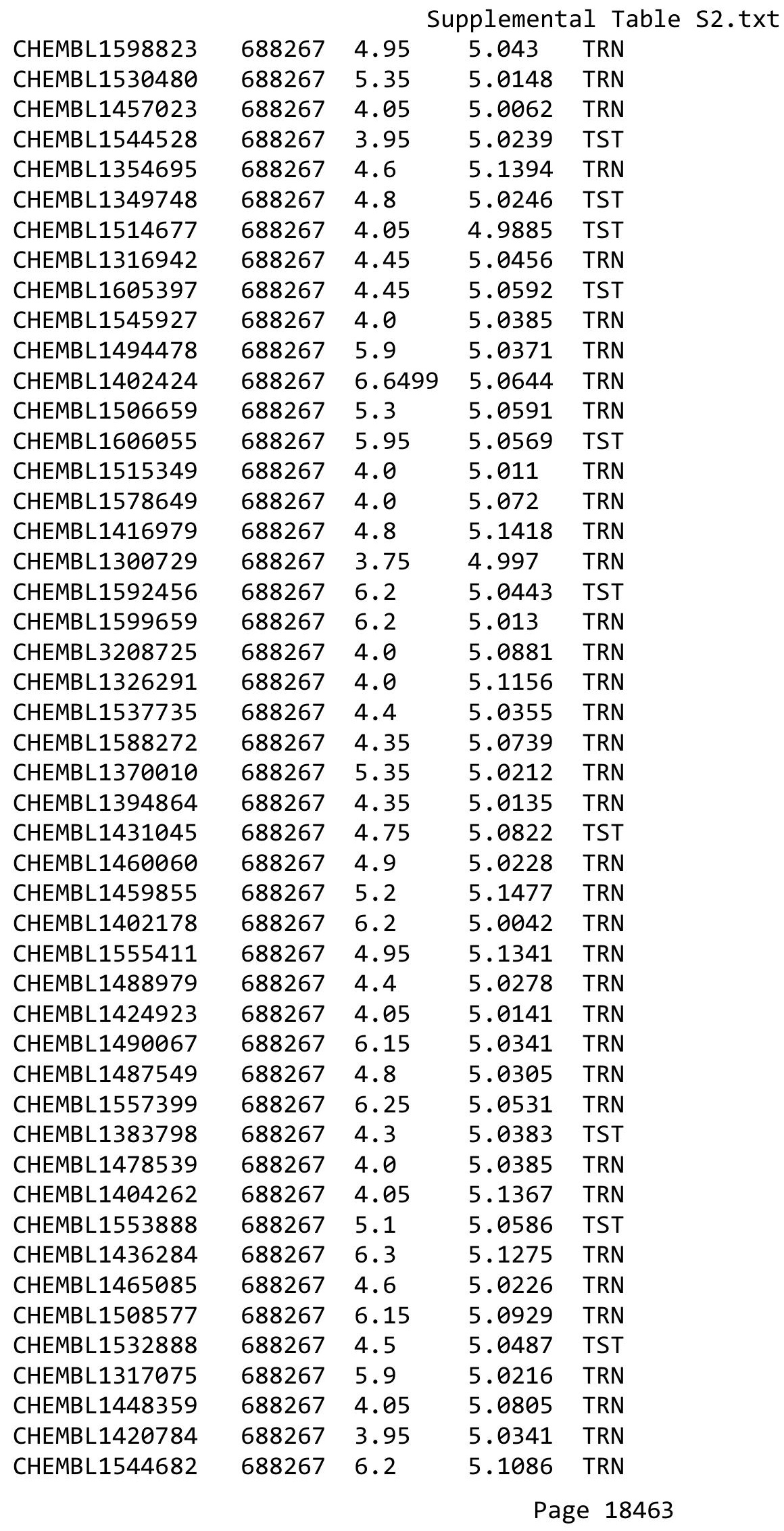




\begin{tabular}{|c|c|c|c|c|c|}
\hline \multirow{3}{*}{$\begin{array}{l}\text { CHEMBL1388553 } \\
\text { CHEMBL1381993 }\end{array}$} & \multirow{3}{*}{$\begin{array}{l}688267 \\
688267\end{array}$} & \multicolumn{4}{|c|}{ Supplemental Table s2.txt } \\
\hline & & 6.15 & \multicolumn{2}{|c|}{5.1370000000000005} & TRN \\
\hline & & 5.15 & 5.0759 & TRN & \\
\hline CHEMBL1475404 & 688267 & 3.95 & 5.0459 & TRN & \\
\hline CHEMBL1430364 & 688267 & 4.25 & 5.0166 & TST & \\
\hline CHEMBL85826 & 688267 & 4.15 & 5.029 & TST & \\
\hline CHEMBL1427646 & 688267 & 5.3 & 5.0797 & TST & \\
\hline CHEMBL1478684 & 688267 & 3.95 & 5.0719 & TRN & \\
\hline CHEMBL1510440 & 688267 & 5.0 & 5.0784 & TRN & \\
\hline CHEMBL1553912 & 688267 & 6.25 & 5.0143 & TRN & \\
\hline CHEMBL1462671 & 688267 & 6.2 & 5.065 & TRN & \\
\hline CHEMBL1493323 & 688267 & 4.05 & 5.0156 & TRN & \\
\hline CHEMBL1572172 & 688267 & 4.2 & 5.003 & TST & \\
\hline CHEMBL1430519 & 688267 & 4.0 & 5.0663 & TST & \\
\hline CHEMBL1370383 & 688267 & 4.1 & 5.0276 & TRN & \\
\hline CHEMBL1395330 & 688267 & 4.2 & 5.0222 & TRN & \\
\hline CHEMBL1491122 & 688267 & 6.2 & 5.0104 & TRN & \\
\hline CHEMBL1488597 & 688267 & 4.35 & 5.033 & TST & \\
\hline CHEMBL1569870 & 688267 & 4.25 & 5.0266 & TRN & \\
\hline CHEMBL1547046 & 688267 & 4.0 & 5.0764 & TRN & \\
\hline CHEMBL1415390 & 688267 & 5.65 & 5.0316 & TRN & \\
\hline CHEMBL1316633 & 688267 & 5.35 & 5.0895 & TRN & \\
\hline CHEMBL1603560 & 688267 & 6.25 & 4.9786 & TRN & \\
\hline CHEMBL1561316 & 688267 & 3.95 & 5.0354 & TRN & \\
\hline CHEMBL1311584 & 688267 & 6.2 & 5.0756 & TST & \\
\hline CHEMBL1455283 & 688267 & 4.0 & 5.0782 & TST & \\
\hline CHEMBL1606299 & 688267 & 6.15 & 5.0432 & TRN & \\
\hline CHEMBL1491712 & 688267 & 4.1 & 5.1219 & TRN & \\
\hline CHEMBL1459979 & 688267 & 4.55 & 5.0546 & TST & \\
\hline CHEMBL1560830 & 688267 & 6.25 & 5.0802 & TRN & \\
\hline CHEMBL1315864 & 688267 & 6.15 & 5.0728 & TRN & \\
\hline CHEMBL1461439 & 688267 & 6.2 & 5.0683 & TRN & \\
\hline CHEMBL1300014 & 688267 & 6.5 & 5.0911 & TRN & \\
\hline CHEMBL1368954 & 688267 & 4.7 & 5.0895 & TST & \\
\hline CHEMBL1486187 & 688267 & 4.35 & 5.0505 & TST & \\
\hline CHEMBL1560478 & 688267 & 4.1 & 5.0424 & TRN & \\
\hline CHEMBL1401290 & 688267 & 6.5 & 5.0479 & TST & \\
\hline CHEMBL1446293 & 688267 & 4.55 & 4.9783 & TRN & \\
\hline CHEMBL1449387 & 688267 & 6.1 & 5.0635 & TST & \\
\hline CHEMBL1562078 & 688267 & 5.7 & 5.0497 & TRN & \\
\hline CHEMBL1452778 & 688267 & 3.9 & 5.0614 & TRN & \\
\hline CHEMBL1315139 & 688267 & 4.25 & 5.0451 & TRN & \\
\hline CHEMBL1364796 & 688267 & 5.5 & 5.1152 & TRN & \\
\hline CHEMBL1525649 & 688267 & 5.6 & 5.1047 & TRN & \\
\hline CHEMBL1355759 & 688267 & 6.25 & 5.0398 & TRN & \\
\hline CHEMBL1303052 & 688267 & 4.35 & 5.0629 & TRN & \\
\hline CHEMBL1576432 & 688267 & 4.4 & $5.0280 e$ & 00000000005 & TRN \\
\hline CHEMBL1574749 & 688267 & 4.45 & 5.1145 & TRN & \\
\hline CHEMBL1316475 & 688267 & 6.5 & 5.0902 & TST & \\
\hline
\end{tabular}




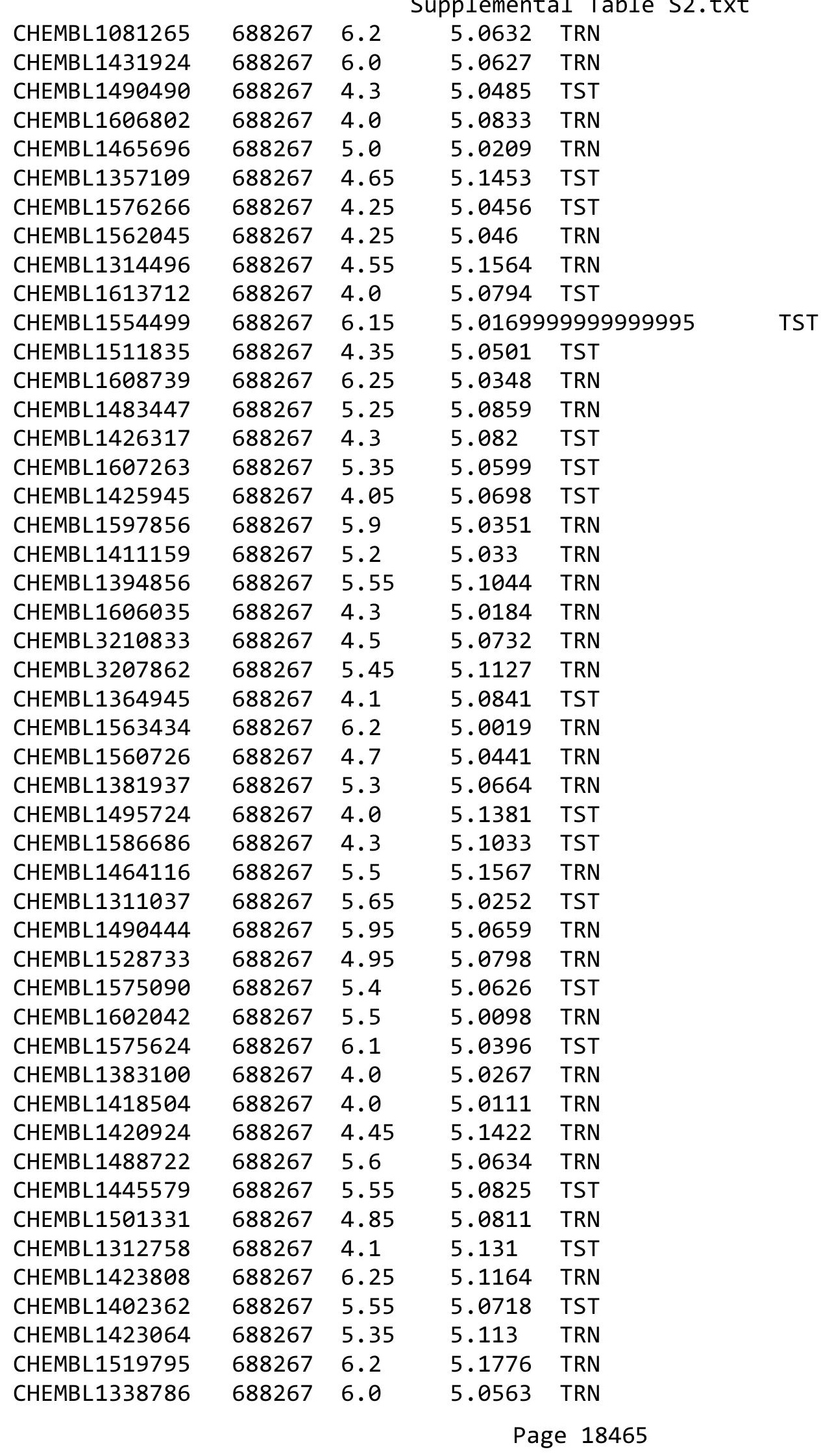




\begin{tabular}{|c|c|c|c|c|c|}
\hline \\
\hline CHEMBL1610283 & 688267 & 4.7 & 5.1373 & TST & \\
\hline CHEMBL1397674 & 688267 & 3.95 & 5.0583 & TRN & \\
\hline CHEMBL1594447 & 688267 & 3.95 & 4.982 & TRN & \\
\hline CHEMBL3189971 & 688267 & 6.15 & 5.0348 & TST & \\
\hline CHEMBL1493386 & 688267 & 5.65 & 5.13200 & 0000000001 & TRN \\
\hline CHEMBL1395341 & 688267 & 4.35 & 5.1003 & TRN & \\
\hline CHEMBL1445953 & 688267 & 6.2 & 5.0486 & TRN & \\
\hline CHEMBL1586216 & 688267 & 4.1 & 5.0417 & TST & \\
\hline CHEMBL1544584 & 688267 & 5.3 & 5.0062 & TST & \\
\hline CHEMBL1391054 & 688267 & 4.6 & 5.0348 & TRN & \\
\hline CHEMBL1549169 & 688267 & 4.35 & 5.0448 & TRN & \\
\hline CHEMBL1392079 & 688267 & 5.5 & 4.9977 & TRN & \\
\hline CHEMBL1375555 & 688267 & 3.95 & 5.0378 & TRN & \\
\hline CHEMBL1458515 & 688267 & 4.9 & 5.0358 & TRN & \\
\hline CHEMBL1359386 & 688267 & 4.0 & 5.10800 & 00000000005 & TRN \\
\hline CHEMBL1393145 & 688267 & 5.15 & 5.086 & TST & \\
\hline CHEMBL1566837 & 688267 & 4.05 & 5.0967 & TRN & \\
\hline CHEMBL1366467 & 688267 & 5.1 & 5.0782 & TRN & \\
\hline CHEMBL1509729 & 688267 & 4.7 & 5.1204 & TRN & \\
\hline CHEMBL1607670 & 688267 & 5.75 & 5.0281 & TST & \\
\hline CHEMBL1513416 & 688267 & 5.4 & 5.0882 & TRN & \\
\hline CHEMBL1388298 & 688267 & 6.2 & 5.0679 & TST & \\
\hline CHEMBL1464754 & 688267 & 4.3 & 5.1444 & TRN & \\
\hline CHEMBL1567023 & 688267 & 4.4 & 5.0825 & TRN & \\
\hline CHEMBL1457522 & 688267 & 5.25 & 5.0241 & TRN & \\
\hline CHEMBL1386309 & 688267 & 4.05 & 5.0612 & TRN & \\
\hline CHEMBL1447396 & 688267 & 4.5 & 5.0206 & TRN & \\
\hline CHEMBL3196964 & 688267 & 6.25 & 5.0264 & TRN & \\
\hline CHEMBL1501019 & 688267 & 5.6 & 5.0225 & TRN & \\
\hline CHEMBL1377217 & 688267 & 4.2 & 5.0388 & TRN & \\
\hline CHEMBL1434661 & 688267 & 6.2 & 4.9866 & TRN & \\
\hline CHEMBL1312209 & 688267 & 5.35 & 5.1179 & TRN & \\
\hline CHEMBL1555858 & 688267 & 6.2 & 5.0107 & TST & \\
\hline CHEMBL1355830 & 688267 & 6.25 & 5.1558 & TRN & \\
\hline CHEMBL1492072 & 688267 & 4.05 & 5.0523 & TST & \\
\hline CHEMBL1576746 & 688267 & 4.1 & 5.0333 & TST & \\
\hline CHEMBL1430366 & 688267 & 5.5 & 5.1421 & TST & \\
\hline CHEMBL1444930 & 688267 & 5.0 & 5.0342 & TRN & \\
\hline CHEMBL1522921 & 688267 & 4.55 & 5.1051 & TRN & \\
\hline CHEMBL1569880 & 688267 & 3.95 & 5.0391 & TRN & \\
\hline CHEMBL1338607 & 688267 & 6.45 & 5.0267 & TST & \\
\hline CHEMBL1550306 & 688267 & 4.35 & 5.1333 & TRN & \\
\hline CHEMBL3195020 & 688267 & 6.05 & 5.0612 & TST & \\
\hline CHEMBL1507343 & 688267 & 4.35 & 5.0025 & TRN & \\
\hline CHEMBL1425407 & 688267 & 5.1 & 4.9809 & TST & \\
\hline CHEMBL1405194 & 688267 & 6.0 & 5.0149 & TST & \\
\hline CHEMBL1500222 & 688267 & 6.25 & 5.05399 & 9999999999 & TRN \\
\hline CHEMBL1301222 & 688267 & 5.5 & 5.1173 & TRN & \\
\hline & & & & 8466 & \\
\hline
\end{tabular}




\begin{tabular}{|c|c|c|c|c|c|}
\hline \\
\hline CHEMBL1540980 & 688267 & 6.0 & 5.1128 & TRN & \\
\hline CHEMBL1590203 & 688267 & 5.1 & 5.1458 & TRN & \\
\hline CHEMBL1397418 & 688267 & 5.15 & 5.0663 & TRN & \\
\hline CHEMBL1504405 & 688267 & 4.4 & 5.0696 & TST & \\
\hline CHEMBL3195232 & 688267 & 5.6 & 5.0686 & TRN & \\
\hline CHEMBL1559633 & 688267 & 5.65 & 5.1062 & TRN & \\
\hline CHEMBL1351731 & 688267 & 4.3 & 5.0955 & TRN & \\
\hline CHEMBL576846 & 688267 & 3.95 & 4.9682 & TRN & \\
\hline CHEMBL1426553 & 688267 & 5.0 & 4.9765 & TRN & \\
\hline CHEMBL1428336 & 688267 & 3.95 & 5.0188 & TRN & \\
\hline CHEMBL1353404 & 688267 & 4.35 & 5.0529 & TRN & \\
\hline CHEMBL1552432 & 688267 & 4.05 & 5.0031 & TST & \\
\hline CHEMBL1596851 & 688267 & 5.65 & 5.1166 & TST & \\
\hline CHEMBL1530917 & 688267 & 5.05 & 5.1079 & TST & \\
\hline CHEMBL1558582 & 688267 & 4.8 & 5.0678 & TST & \\
\hline CHEMBL1336495 & 688267 & 4.65 & 5.0729 & TRN & \\
\hline CHEMBL1518822 & 688267 & 4.4 & 5.0296 & TST & \\
\hline CHEMBL1381591 & 688267 & 4.6 & 5.0769 & TRN & \\
\hline CHEMBL1551965 & 688267 & 3.95 & 5.1135 & TRN & \\
\hline CHEMBL3214517 & 688267 & 4.95 & 5.0634 & TST & \\
\hline CHEMBL1549656 & 688267 & 6.5 & 5.0317 & TST & \\
\hline CHEMBL1462050 & 688267 & 5.85 & 5.1778 & TRN & \\
\hline CHEMBL1431367 & 688267 & 5.9 & 5.0512 & TRN & \\
\hline CHEMBL1510658 & 688267 & 4.35 & 5.0234 & TST & \\
\hline CHEMBL1457207 & 688267 & 5.4 & 5.04 & TRN & \\
\hline CHEMBL1383574 & 688267 & 6.2 & 5.069 & TRN & \\
\hline CHEMBL1415761 & 688267 & 4.25 & 5.0464 & TRN & \\
\hline CHEMBL1423718 & 688267 & 4.3 & 5.0949 & TRN & \\
\hline CHEMBL1489143 & 688267 & 5.25 & 5.1714 & TRN & \\
\hline CHEMBL1554715 & 688267 & 6.2 & 5.0359 & TST & \\
\hline CHEMBL1441428 & 688267 & 6.25 & 5.0791 & TRN & \\
\hline CHEMBL1383852 & 688267 & 4.0 & 5.0373 & TRN & \\
\hline CHEMBL1435179 & 688267 & 4.4 & 5.0415 & TST & \\
\hline CHEMBL1519356 & 688267 & 6.2 & 5.0292 & TRN & \\
\hline CHEMBL3209966 & 688267 & 4.05 & 5.0409 & TRN & \\
\hline CHEMBL1376948 & 688267 & 4.35 & 5.043 & TRN & \\
\hline CHEMBL1304939 & 688267 & 6.45 & 5.1231 & TRN & \\
\hline CHEMBL1489761 & 688267 & 5.55 & 5.04899 & 99999999995 & TRN \\
\hline CHEMBL1596901 & 688267 & 5.45 & 5.1339 & TRN & \\
\hline CHEMBL1612511 & 688267 & 4.4 & 5.0945 & TRN & \\
\hline CHEMBL1543467 & 688267 & 6.2 & 5.0408 & TST & \\
\hline CHEMBL1339574 & 688267 & 5.55 & 5.0631 & TRN & \\
\hline CHEMBL1485768 & 688267 & 4.45 & 5.0116 & TRN & \\
\hline CHEMBL1396235 & 688267 & 4.05 & 5.0531 & TRN & \\
\hline CHEMBL1496400 & 688267 & 6.2 & 5.0521 & TRN & \\
\hline CHEMBL1351585 & 688267 & 4.55 & 5.1565 & TRN & \\
\hline CHEMBL1483023 & 688267 & 4.75 & 5.1131 & TRN & \\
\hline CHEMBL1446036 & 688267 & 5.25 & 5.1123 & TST & \\
\hline
\end{tabular}




\begin{tabular}{|c|c|c|c|c|}
\hline & & & pplement & al $\mathrm{Ta}$ \\
\hline CHEMBL1309292 & 688267 & 5.5 & 5.0571 & TRN \\
\hline CHEMBL1481673 & 688267 & 4.1 & 5.0253 & TRN \\
\hline CHEMBL1335915 & 688267 & 4.45 & 5.0268 & TRN \\
\hline CHEMBL1388455 & 688267 & 5.75 & 5.0583 & TRN \\
\hline CHEMBL1585899 & 688267 & 4.4 & 5.0492 & TRN \\
\hline CHEMBL1333684 & 688267 & 4.3 & 5.0083 & TRN \\
\hline CHEMBL1533048 & 688267 & 5.1 & 5.0568 & TRN \\
\hline CHEMBL1389877 & 688267 & 4.25 & 5.042 & TST \\
\hline CHEMBL1332657 & 688267 & 5.55 & 5.1003 & TRN \\
\hline CHEMBL1487385 & 688267 & 5.55 & 5.1367 & TRN \\
\hline CHEMBL3195018 & 688267 & 4.05 & 5.0046 & TRN \\
\hline CHEMBL1416082 & 688267 & 4.0 & 5.0408 & TRN \\
\hline CHEMBL1601613 & 688267 & 5.75 & 5.066 & TRN \\
\hline CHEMBL1425281 & 688267 & 5.4 & 5.1297 & TRN \\
\hline CHEMBL1314739 & 688267 & 4.85 & 5.1063 & TRN \\
\hline CHEMBL1476695 & 688267 & 5.8 & 5.018 & TRN \\
\hline CHEMBL 1605690 & 688267 & 6.2 & 5.0783 & TRN \\
\hline CHEMBL1490543 & 688267 & 4.5 & 5.0942 & TRN \\
\hline CHEMBL1585155 & 688267 & 5.8 & 5.0432 & TRN \\
\hline CHEMBL1361805 & 688267 & 4.25 & 4.9716 & TRN \\
\hline CHEMBL1340570 & 688267 & 4.65 & 5.035 & TRN \\
\hline CHEMBL1541837 & 688267 & 4.05 & 5.0303 & TRN \\
\hline CHEMBL 1486274 & 688267 & 4.35 & 5.0686 & TRN \\
\hline CHEMBL1350240 & 688267 & 5.25 & 5.0156 & TST \\
\hline CHEMBL1479923 & 688267 & 4.3 & 5.1009 & TRN \\
\hline CHEMBL1302825 & 688267 & 4.0 & 5.0314 & TRN \\
\hline CHEMBL1339722 & 688267 & 4.55 & 5.0618 & TST \\
\hline CHEMBL1561297 & 688267 & 6.2 & 5.0708 & TRN \\
\hline CHEMBL1399931 & 688267 & 4.85 & 5.0999 & TRN \\
\hline CHEMBL1589936 & 688267 & 6.2 & 5.0557 & TRN \\
\hline CHEMBL1350774 & 688267 & 5.75 & 5.0576 & TRN \\
\hline CHEMBL1437818 & 688267 & 5.25 & 4.999 & TRN \\
\hline CHEMBL1376308 & 688267 & 4.05 & 4.9914 & TST \\
\hline CHEMBL1519804 & 688267 & 4.95 & 5.0837 & TRN \\
\hline CHEMBL1992255 & 688267 & 5.85 & 5.0368 & TRN \\
\hline CHEMBL1593802 & 688267 & 6.25 & 5.0546 & TRN \\
\hline CHEMBL1343398 & 688267 & 4.0 & 5.0748 & TRN \\
\hline CHEMBL1506054 & 688267 & 5.55 & 5.0704 & TRN \\
\hline CHEMBL1427227 & 688267 & 5.55 & 5.115 & TRN \\
\hline CHEMBL1479563 & 688267 & 6.15 & 5.1271 & TST \\
\hline CHEMBL1593892 & 688267 & 4.2 & 5.0497 & TRN \\
\hline CHEMBL1340075 & 688267 & 6.0 & 5.121 & TRN \\
\hline CHEMBL1327696 & 688267 & 4.0 & 5.0855 & TRN \\
\hline CHEMBL1491881 & 688267 & 4.55 & 5.0387 & TST \\
\hline CHEMBL1382524 & 688267 & 6.25 & 5.1166 & TRN \\
\hline CHEMBL1404388 & 688267 & 6.15 & 5.1584 & TRN \\
\hline CHEMBL1574255 & 688267 & 6.2 & 4.9942 & TRN \\
\hline CHEMBL1591889 & 688267 & 5.15 & 5.0193 & TRN \\
\hline
\end{tabular}




\begin{tabular}{|c|c|c|c|c|c|}
\hline \multicolumn{6}{|c|}{ Supplemental Table S2.txt } \\
\hline CHEMBL1494919 & 688267 & 4.05 & 5.0752 & TRN & \\
\hline CHEMBL1394703 & 688267 & 3.95 & 5.0108 & TRN & \\
\hline CHEMBL1482577 & 688267 & 7.1002 & 5.0836 & TST & \\
\hline CHEMBL1320035 & 688267 & 6.2 & 5.0123 & TRN & \\
\hline CHEMBL1438585 & 688267 & 4.6 & 5.0277 & TST & \\
\hline CHEMBL1508485 & 688267 & 5.45 & 5.0249 & TST & \\
\hline CHEMBL1489685 & 688267 & 6.0 & 5.0143 & TST & \\
\hline CHEMBL1487963 & 688267 & 4.0 & 4.9947 & TRN & \\
\hline CHEMBL1592009 & 688267 & 4.4 & 5.029 & TRN & \\
\hline CHEMBL1394416 & 688267 & 4.3 & 5.0466 & TST & \\
\hline CHEMBL1335188 & 688267 & 4.75 & 5.0292 & TST & \\
\hline CHEMBL1574657 & 688267 & 6.45 & 5.0094 & TRN & \\
\hline CHEMBL1308177 & 688267 & 4.05 & 5.0592 & TRN & \\
\hline CHEMBL1574091 & 688267 & 5.85 & 5.0714 & TRN & \\
\hline CHEMBL1352350 & 688267 & 4.3 & 5.0893 & TST & \\
\hline CHEMBL1591884 & 688267 & 4.9 & 5.0678 & TRN & \\
\hline CHEMBL1329785 & 688267 & 5.2 & 4.9964 & TRN & \\
\hline CHEMBL1437330 & 688267 & 5.5 & 5.022 & TRN & \\
\hline CHEMBL1546588 & 688267 & 4.6 & 5.0274 & TRN & \\
\hline CHEMBL1592241 & 688267 & 3.95 & 5.115 & TRN & \\
\hline CHEMBL1414014 & 688267 & 4.0 & 5.0331 & TRN & \\
\hline CHEMBL3190150 & 688267 & 5.1 & 5.0491 & TST & \\
\hline CHEMBL3210211 & 688267 & 4.35 & 5.0312 & TRN & \\
\hline CHEMBL1531805 & 688267 & 3.95 & 5.0766 & TRN & \\
\hline CHEMBL1595705 & 688267 & 5.6 & 4.9535 & TRN & \\
\hline CHEMBL1408898 & 688267 & 4.05 & 4.99100 & 00000000005 & TRN \\
\hline CHEMBL1373761 & 688267 & 4.35 & 5.04899 & 99999999995 & TRN \\
\hline CHEMBL1349138 & 688267 & 5.6 & 5.0413 & TRN & \\
\hline CHEMBL1537162 & 688267 & 6.15 & 5.061 & TRN & \\
\hline CHEMBL1606240 & 688267 & 4.3 & 5.063 & TRN & \\
\hline CHEMBL1499005 & 688267 & 5.0 & 5.0199 & TST & \\
\hline CHEMBL1556796 & 688267 & 4.05 & 5.0878 & TST & \\
\hline CHEMBL1390877 & 688267 & 5.75 & 5.0564 & TRN & \\
\hline CHEMBL1420198 & 688267 & 4.0 & 5.0936 & TRN & \\
\hline CHEMBL1448777 & 688267 & 6.0 & 5.082 & TRN & \\
\hline CHEMBL1549171 & 688267 & 6.2 & 5.1243 & TRN & \\
\hline CHEMBL1548150 & 688267 & 4.55 & 5.0512 & TST & \\
\hline CHEMBL1597870 & 688267 & 5.05 & 5.0361 & TRN & \\
\hline CHEMBL1490266 & 688267 & 5.55 & 5.0236 & TST & \\
\hline CHEMBL1577179 & 688267 & 4.1 & 5.0148 & TRN & \\
\hline CHEMBL1316812 & 688267 & 5.35 & 5.072 & TRN & \\
\hline CHEMBL1424891 & 688267 & 6.15 & 5.0284 & TST & \\
\hline CHEMBL1509599 & 688267 & 4.3 & 5.0692 & TRN & \\
\hline CHEMBL1400490 & 688267 & 4.4 & 5.0356 & TRN & \\
\hline CHEMBL1320248 & 688267 & 5.25 & 5.0661 & TRN & \\
\hline CHEMBL1338721 & 688267 & 5.35 & 5.038 & TRN & \\
\hline CHEMBL1509670 & 688267 & 6.2 & 5.0592 & TST & \\
\hline CHEMBL1466029 & 688267 & 5.25 & 5.0437 & TRN & \\
\hline
\end{tabular}




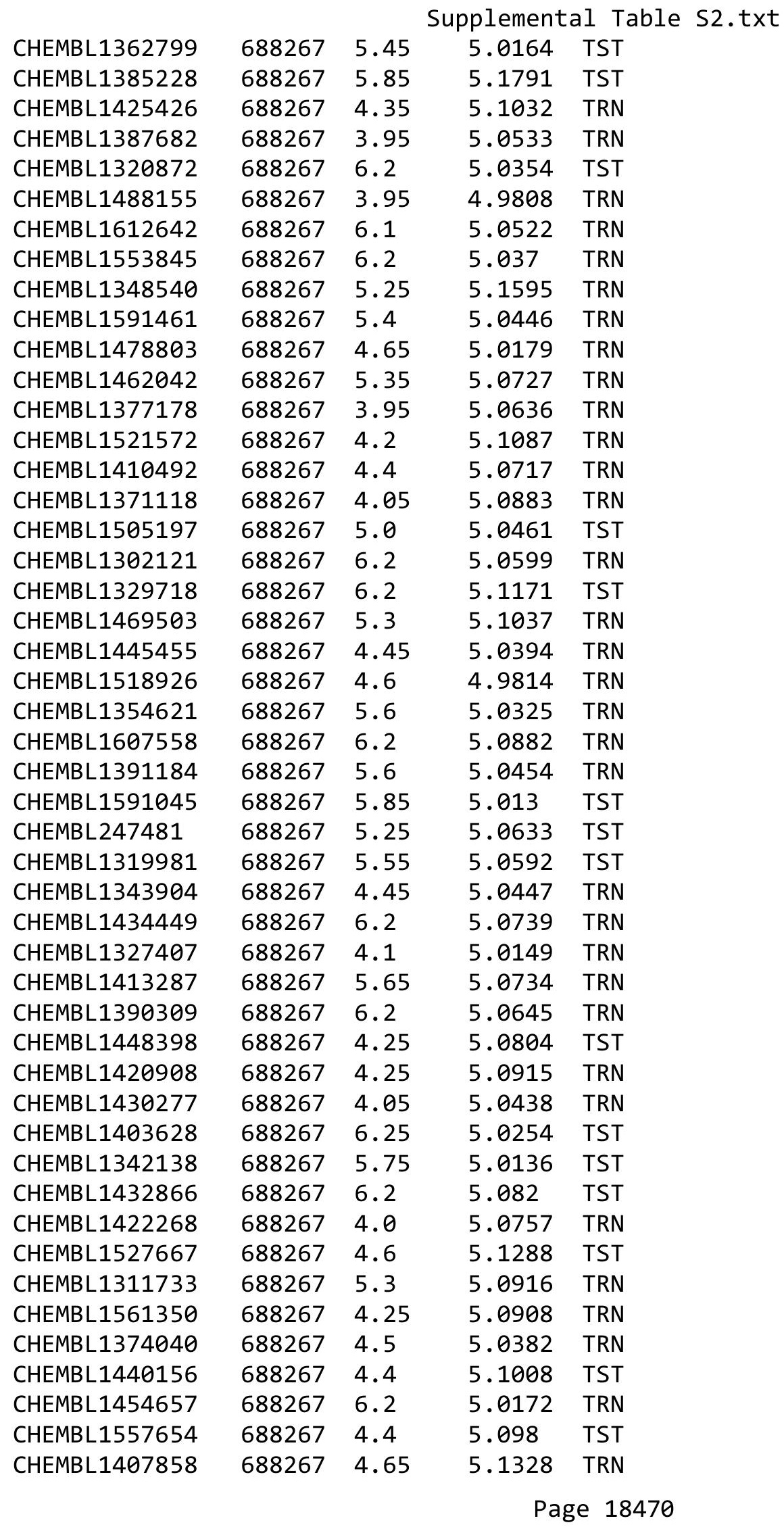




\begin{tabular}{|c|c|c|c|c|}
\hline \multicolumn{5}{|c|}{ Supplemental Table S2.txt } \\
\hline CHEMBL1560971 & 688267 & 6.2 & 5.0066 & TRN \\
\hline CHEMBL1610570 & 688267 & 6.2 & 5.0009 & TRN \\
\hline CHEMBL1578554 & 688267 & 4.1 & 5.1044 & TRN \\
\hline CHEMBL1435151 & 688267 & 4.35 & 5.0055 & TRN \\
\hline CHEMBL1514620 & 688267 & 6.2 & 5.1006 & TRN \\
\hline CHEMBL1518955 & 688267 & 4.0 & 5.0883 & TRN \\
\hline CHEMBL1567242 & 688267 & 4.25 & 5.0162 & TST \\
\hline CHEMBL 3192520 & 688267 & 6.9 & 5.0626 & TRN \\
\hline CHEMBL1536053 & 688267 & 6.15 & 5.0231 & TRN \\
\hline CHEMBL1441522 & 688267 & 4.4 & 5.06 & TRN \\
\hline CHEMBL1405223 & 688267 & 6.2 & 5.058 & TRN \\
\hline CHEMBL1402731 & 688267 & 5.05 & 5.1128 & TRN \\
\hline CHEMBL1482398 & 688267 & 6.15 & 5.0119 & TRN \\
\hline CHEMBL1314518 & 688267 & 3.95 & 5.0066 & TST \\
\hline CHEMBL1532298 & 688267 & 4.3 & 5.0657 & TST \\
\hline CHEMBL1432572 & 688267 & 6.2 & 5.0235 & TST \\
\hline CHEMBL1389634 & 688267 & 4.6 & 5.0598 & TRN \\
\hline CHEMBL1450951 & 688267 & 4.05 & 5.0405 & TST \\
\hline CHEMBL1354755 & 688267 & 4.0 & 5.0657 & TRN \\
\hline CHEMBL1573011 & 688267 & 5.15 & 5.0965 & TRN \\
\hline CHEMBL1418316 & 688267 & 4.05 & 5.0848 & TST \\
\hline CHEMBL1362072 & 688267 & 5.85 & 5.0713 & TRN \\
\hline CHEMBL1358460 & 688267 & 3.75 & 5.0613 & TST \\
\hline CHEMBL1566456 & 688267 & 4.95 & 5.006 & TRN \\
\hline CHEMBL3190413 & 688267 & 6.2 & 5.0271 & TRN \\
\hline CHEMBL1566562 & 688267 & 5.95 & 5.0757 & TST \\
\hline CHEMBL1423304 & 688267 & 6.0 & 5.0135 & TRN \\
\hline CHEMBL227897 & 688267 & 3.95 & 5.0113 & TRN \\
\hline CHEMBL1608317 & 688267 & 5.5 & 5.1098 & TRN \\
\hline CHEMBL1429110 & 688267 & 5.4 & 5.0511 & TRN \\
\hline CHEMBL1385057 & 688267 & 6.25 & 5.0589 & TST \\
\hline CHEMBL1474803 & 688267 & 4.0 & 5.0518 & TRN \\
\hline CHEMBL1421874 & 688267 & 5.35 & 5.0705 & TRN \\
\hline CHEMBL1611488 & 688267 & 4.3 & 5.0559 & TRN \\
\hline CHEMBL1461687 & 688267 & 4.4 & 5.0177 & TRN \\
\hline CHEMBL1493785 & 688267 & 6.2 & 5.0018 & TRN \\
\hline CHEMBL1553110 & 688267 & 5.3 & 5.012 & TRN \\
\hline CHEMBL1421397 & 688267 & 4.05 & 5.0549 & TRN \\
\hline CHEMBL1606156 & 688267 & 4.6 & 5.0209 & TST \\
\hline CHEMBL1271013 & 688267 & 5.85 & 5.0077 & TRN \\
\hline CHEMBL3213917 & 688267 & 5.35 & 5.0564 & TRN \\
\hline CHEMBL1357238 & 688267 & 6.05 & 5.1116 & TRN \\
\hline CHEMBL1443929 & 688267 & 6.2 & 5.0602 & TRN \\
\hline CHEMBL3191652 & 688267 & 4.0 & 5.0298 & TRN \\
\hline CHEMBL1590015 & 688267 & 3.95 & 5.0668 & TRN \\
\hline CHEMBL1379606 & 688267 & 5.95 & 5.0165 & TRN \\
\hline CHEMBL1599820 & 688267 & 6.2 & 5.0327 & TRN \\
\hline CHEMBL1521849 & 688267 & 6.15 & 5.0385 & TRN \\
\hline
\end{tabular}




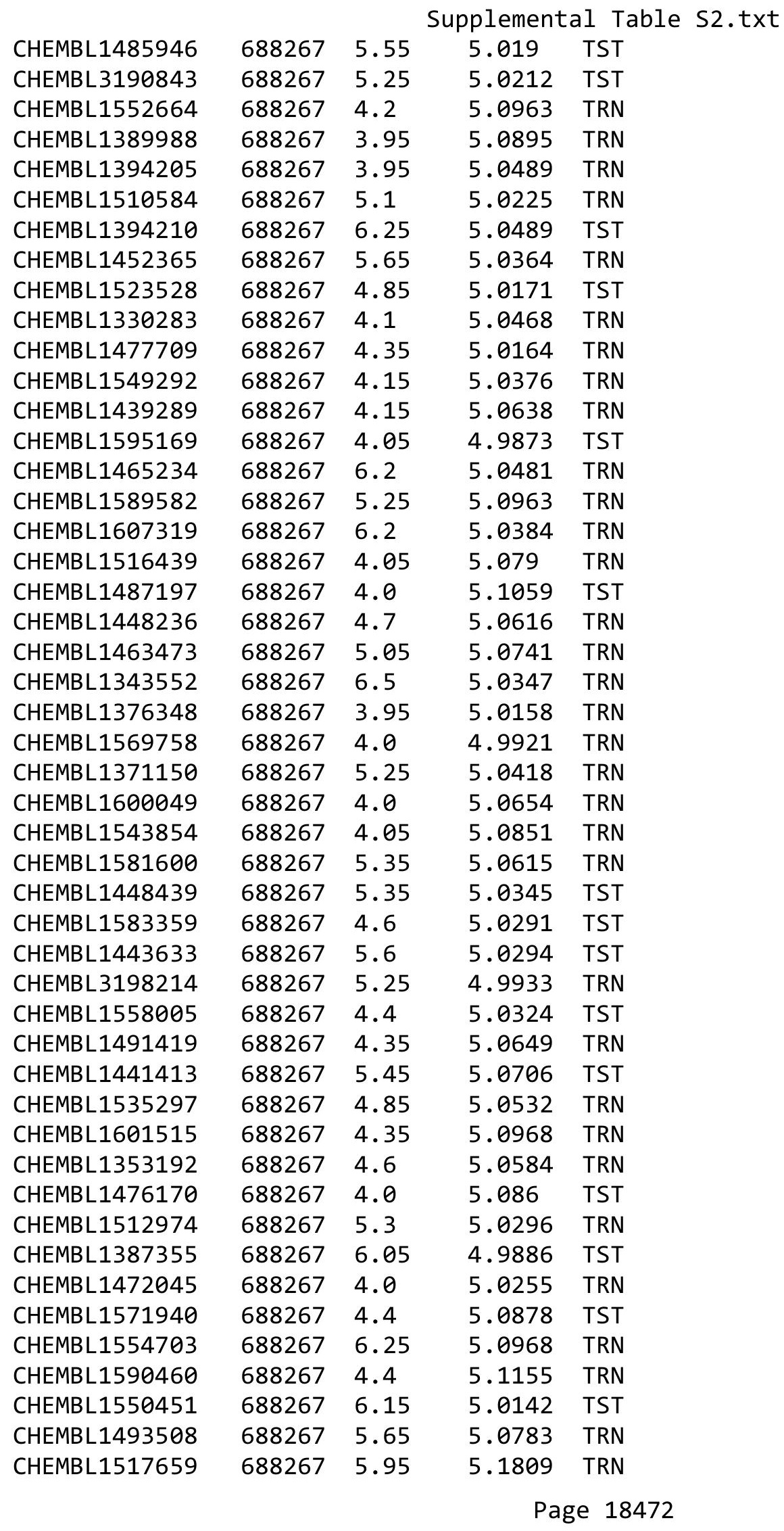




\begin{tabular}{|c|c|c|c|c|}
\hline \multicolumn{5}{|c|}{ Supplemental Table S2.txt } \\
\hline CHEMBL1382949 & 688267 & 4.75 & 5.0639 & TST \\
\hline CHEMBL1302175 & 688267 & 5.05 & 5.0327 & TST \\
\hline CHEMBL1413682 & 688267 & 4.3 & 5.07 & TRN \\
\hline CHEMBL1536416 & 688267 & 4.2 & 5.1358 & TRN \\
\hline CHEMBL1449721 & 688267 & 4.05 & 5.0711 & TST \\
\hline CHEMBL1582846 & 688267 & 6.15 & 5.0919 & TRN \\
\hline CHEMBL1504385 & 688267 & 5.8 & 5.0385 & TRN \\
\hline CHEMBL1509207 & 688267 & 4.45 & 5.0652 & TST \\
\hline CHEMBL1373733 & 688267 & 6.25 & 5.0105 & TRN \\
\hline CHEMBL 1403700 & 688267 & 4.25 & 5.039 & TST \\
\hline CHEMBL1442788 & 688267 & 4.75 & 5.0385 & TST \\
\hline CHEMBL1349260 & 688267 & 4.35 & 5.0758 & TST \\
\hline CHEMBL1569923 & 688267 & 4.35 & 5.0426 & TST \\
\hline CHEMBL1392281 & 688267 & 5.4 & 5.024 & TST \\
\hline CHEMBL1301924 & 688267 & 5.8 & 5.0307 & TST \\
\hline CHEMBL1572322 & 688267 & 4.8 & 5.0491 & TRN \\
\hline CHEMBL1344795 & 688267 & 4.55 & 5.0273 & TRN \\
\hline CHEMBL1518489 & 688267 & 4.25 & 5.021 & TRN \\
\hline CHEMBL1484790 & 688267 & 4.05 & 5.0616 & TRN \\
\hline CHEMBL1408326 & 688267 & 6.15 & 5.0233 & TRN \\
\hline CHEMBL1606181 & 688267 & 4.05 & 5.0062 & TRN \\
\hline CHEMBL1490442 & 688267 & 4.05 & 5.0745 & TRN \\
\hline CHEMBL1519244 & 688267 & 5.0 & 5.046 & TRN \\
\hline CHEMBL1310897 & 688267 & 5.45 & 5.1278 & TRN \\
\hline CHEMBL1584682 & 688267 & 4.85 & 5.1084 & TRN \\
\hline CHEMBL1510417 & 688267 & 4.35 & 5.0445 & TST \\
\hline CHEMBL1558782 & 688267 & 5.15 & 5.0014 & TRN \\
\hline CHEMBL1509214 & 688267 & 6.15 & 5.1026 & TRN \\
\hline CHEMBL1432523 & 688267 & 4.5 & 5.0116 & TRN \\
\hline CHEMBL1438193 & 688267 & 5.7 & 5.0277 & TRN \\
\hline CHEMBL1506419 & 688267 & 5.1 & 4.9801 & TRN \\
\hline CHEMBL1399506 & 688267 & 5.25 & 5.0787 & TST \\
\hline CHEMBL1540617 & 688267 & 5.6 & 5.1153 & TST \\
\hline CHEMBL1370750 & 688267 & 5.55 & 4.996 & TRN \\
\hline CHEMBL1606179 & 688267 & 4.35 & 5.04 & TST \\
\hline CHEMBL1534094 & 688267 & 4.1 & 5.1793 & TRN \\
\hline CHEMBL1335361 & 688267 & 4.1 & 5.1145 & TST \\
\hline CHEMBL1394791 & 688267 & 6.5501 & 5.0705 & TRN \\
\hline CHEMBL1444068 & 688267 & 5.45 & 5.0367 & TRN \\
\hline CHEMBL1413495 & 688267 & 5.9 & 5.0521 & TST \\
\hline CHEMBL1331483 & 688267 & 4.2 & 5.0521 & TRN \\
\hline CHEMBL1458446 & 688267 & 6.6 & 4.9885 & TRN \\
\hline CHEMBL1390533 & 688267 & 5.3 & 5.0611 & TRN \\
\hline CHEMBL1569977 & 688267 & 4.45 & 5.0451 & TRN \\
\hline CHEMBL1337400 & 688267 & 5.55 & 5.0636 & TRN \\
\hline CHEMBL1431580 & 688267 & 6.2 & 5.0659 & TRN \\
\hline CHEMBL1485970 & 688267 & 5.65 & 5.0397 & TST \\
\hline CHEMBL1466450 & 688267 & 4.0 & 5.0511 & TRN \\
\hline
\end{tabular}




\begin{tabular}{|c|c|c|c|c|}
\hline \multicolumn{5}{|c|}{ Supplemental Table S2.tx } \\
\hline CHEMBL1598854 & 688267 & 4.4 & 5.0972 & TRN \\
\hline CHEMBL1583150 & 688267 & 6.15 & 5.0665 & TRN \\
\hline CHEMBL1494371 & 688267 & 5.35 & 5.0488 & TRN \\
\hline CHEMBL1312774 & 688267 & 3.45 & 5.0909 & TRN \\
\hline CHEMBL1398325 & 688267 & 4.0 & 5.0118 & TRN \\
\hline CHEMBL1591736 & 688267 & 5.95 & 5.0404 & TRN \\
\hline CHEMBL1527487 & 688267 & 3.95 & 5.0486 & TRN \\
\hline CHEMBL1432546 & 688267 & 4.0 & 5.0916 & TST \\
\hline CHEMBL1517961 & 688267 & 3.95 & 5.0404 & TST \\
\hline CHEMBL1442785 & 688267 & 3.95 & 5.1411 & TRN \\
\hline CHEMBL1563897 & 688267 & 4.45 & 5.04899 & 99999999995 \\
\hline CHEMBL1591393 & 688267 & 4.5 & 5.1458 & TRN \\
\hline CHEMBL1515715 & 688267 & 6.2 & 5.0872 & TRN \\
\hline CHEMBL1588027 & 688267 & 4.1 & 5.0883 & TST \\
\hline CHEMBL1368676 & 688267 & 6.15 & 5.0134 & TST \\
\hline CHEMBL1594101 & 688267 & 5.4 & 5.0476 & TRN \\
\hline CHEMBL1328679 & 688267 & 5.4 & 5.0405 & TRN \\
\hline CHEMBL1424867 & 688267 & 4.05 & 5.0446 & TRN \\
\hline CHEMBL1532537 & 688267 & 4.2 & 5.1329 & TRN \\
\hline CHEMBL1602140 & 688267 & 5.95 & 5.0666 & TRN \\
\hline CHEMBL1330418 & 688267 & 6.25 & 5.0641 & TRN \\
\hline CHEMBL1388241 & 688267 & 4.45 & 5.0932 & TRN \\
\hline CHEMBL1427766 & 688267 & 4.1 & 5.0158 & TRN \\
\hline CHEMBL 1475892 & 688267 & 4.9 & 5.0079 & TRN \\
\hline CHEMBL1592747 & 688267 & 5.35 & 5.0597 & TRN \\
\hline CHEMBL1359807 & 688267 & 5.5 & 5.0219 & TRN \\
\hline CHEMBL1397991 & 688267 & 4.25 & 5.0621 & TRN \\
\hline CHEMBL1524522 & 688267 & 5.5 & 5.05 & TRN \\
\hline CHEMBL1548212 & 688267 & 6.05 & 5.0812 & TST \\
\hline CHEMBL1448912 & 688267 & 6.15 & 5.0768 & TRN \\
\hline CHEMBL1558502 & 688267 & 4.05 & 5.0352 & TRN \\
\hline CHEMBL1411322 & 688267 & 5.25 & 5.0555 & TRN \\
\hline CHEMBL1326250 & 688267 & 5.6 & 5.1158 & TRN \\
\hline CHEMBL1303411 & 688267 & 4.3 & 5.0359 & TRN \\
\hline CHEMBL1558694 & 688267 & 5.6 & 5.0919 & TRN \\
\hline CHEMBL1321778 & 688267 & 4.65 & 5.0088 & TRN \\
\hline CHEMBL1519247 & 688267 & 5.45 & 5.1064 & TRN \\
\hline CHEMBL1363012 & 688267 & 4.55 & 5.03 & TST \\
\hline CHEMBL1371368 & 688267 & 4.25 & 5.0916 & TRN \\
\hline CHEMBL1342056 & 688267 & 5.3 & 5.0258 & TRN \\
\hline CHEMBL1516674 & 688267 & 5.9 & 5.0247 & TST \\
\hline CHEMBL1516332 & 688267 & 4.0 & 5.0101 & TRN \\
\hline CHEMBL1592070 & 688267 & 6.2 & 5.1192 & TRN \\
\hline CHEMBL585443 & 688267 & 5.05 & 5.0844 & TRN \\
\hline CHEMBL 3209000 & 688267 & 4.25 & 4.9651 & TST \\
\hline CHEMBL1310220 & 688267 & 5.9 & 5.0277 & TRN \\
\hline CHEMBL 3212021 & 688267 & 7.6498 & 5.0823 & TRN \\
\hline CHEMBL1489900 & 688267 & 5.95 & 5.0025 & TRN \\
\hline
\end{tabular}




\begin{tabular}{|c|c|c|c|c|c|}
\hline \\
\hline CHEMBL1507861 & 688267 & 4.1 & 5.0173 & TRN & \\
\hline CHEMBL1601293 & 688267 & 5.6 & 5.0151 & TRN & \\
\hline CHEMBL1485790 & 688267 & 4.4 & 5.006 & TRN & \\
\hline CHEMBL1602380 & 688267 & 4.9 & 5.0994 & TRN & \\
\hline CHEMBL1397373 & 688267 & 6.5 & 4.9941 & TRN & \\
\hline CHEMBL1337743 & 688267 & 4.55 & 5.0313 & TST & \\
\hline CHEMBL1479485 & 688267 & 5.05 & 5.0605 & TRN & \\
\hline CHEMBL1353876 & 688267 & 5.35 & 5.0512 & TRN & \\
\hline CHEMBL1440163 & 688267 & 4.05 & 5.0694 & TRN & \\
\hline CHEMBL1380144 & 688267 & 6.5 & 5.0411 & TRN & \\
\hline CHEMBL1320132 & 688267 & 4.0 & 5.053 & TRN & \\
\hline CHEMBL1461711 & 688267 & 5.05 & 5.055 & TST & \\
\hline CHEMBL1475050 & 688267 & 3.95 & 5.0701 & TRN & \\
\hline CHEMBL1486949 & 688267 & 4.5 & 5.0199 & TST & \\
\hline CHEMBL1372337 & 688267 & 5.4 & 5.1219 & TRN & \\
\hline CHEMBL1386676 & 688267 & 5.55 & 5.0415 & TRN & \\
\hline CHEMBL1455977 & 688267 & 4.0 & 5.07600 & 00000000005 & TRN \\
\hline CHEMBL1366169 & 688267 & 6.0 & 5.0495 & TRN & \\
\hline CHEMBL1364531 & 688267 & 5.75 & 5.0561 & TRN & \\
\hline CHEMBL1400718 & 688267 & 4.6 & 5.05399 & 9999999999 & TRN \\
\hline CHEMBL1606076 & 688267 & 4.35 & 5.0123 & TST & \\
\hline CHEMBL1571913 & 688267 & 5.55 & 5.0498 & TRN & \\
\hline CHEMBL1402242 & 688267 & 6.5 & 5.0537 & TST & \\
\hline CHEMBL1439319 & 688267 & 5.5 & 5.043 & TRN & \\
\hline CHEMBL1324582 & 688267 & 4.45 & 5.0781 & TRN & \\
\hline CHEMBL1319231 & 688267 & 6.15 & 5.1379 & TRN & \\
\hline CHEMBL1337125 & 688267 & 6.2 & 5.1299 & TRN & \\
\hline CHEMBL1440688 & 688267 & 5.8 & 5.0462 & TRN & \\
\hline CHEMBL1552826 & 688267 & 5.1 & 5.025 & TRN & \\
\hline CHEMBL1335895 & 688267 & 4.35 & 5.1836 & TRN & \\
\hline CHEMBL1487758 & 688267 & 4.35 & 5.0427 & TRN & \\
\hline CHEMBL1594632 & 688267 & 4.0 & 5.0728 & TST & \\
\hline CHEMBL1566697 & 688267 & 6.2 & 5.0938 & TRN & \\
\hline CHEMBL1578882 & 688267 & 5.75 & 5.042 & TST & \\
\hline CHEMBL1546438 & 688267 & 5.0 & 5.0234 & TST & \\
\hline CHEMBL1376610 & 688267 & 6.2 & 5.1311 & TRN & \\
\hline CHEMBL1583343 & 688267 & 4.4 & 5.0369 & TRN & \\
\hline CHEMBL1473846 & 688267 & 6.2 & 5.0966 & TST & \\
\hline CHEMBL1313743 & 688267 & 5.45 & 5.1292 & TRN & \\
\hline CHEMBL1312656 & 688267 & 5.3 & 4.9516 & TRN & \\
\hline CHEMBL1602165 & 688267 & 3.95 & 4.99 & TRN & \\
\hline CHEMBL1469928 & 688267 & 4.1 & 5.0458 & TST & \\
\hline CHEMBL1994910 & 688267 & 5.4 & 5.0009 & TST & \\
\hline CHEMBL1325393 & 688267 & 4.05 & 5.0499 & TRN & \\
\hline CHEMBL1356097 & 688267 & 4.05 & 5.039 & TRN & \\
\hline CHEMBL1395939 & 688267 & 6.5 & 5.0967 & TRN & \\
\hline CHEMBL1438991 & 688267 & 5.65 & 5.0192 & TST & \\
\hline CHEMBL1326758 & 688267 & 5.3 & 5.0709 & TRN & \\
\hline
\end{tabular}




\begin{tabular}{|c|c|c|c|c|c|}
\hline \multicolumn{6}{|c|}{ Supplemental Table S2.txt } \\
\hline CHEMBL1551221 & 688267 & 6.2 & 5.1069 & TRN & \\
\hline CHEMBL1500597 & 688267 & 5.3 & 5.0641 & TRN & \\
\hline CHEMBL1471236 & 688267 & 5.35 & 5.01699 & 99999999995 & TST \\
\hline CHEMBL1517750 & 688267 & 5.05 & 5.0064 & TST & \\
\hline CHEMBL1377807 & 688267 & 4.1 & 5.0896 & TST & \\
\hline CHEMBL1492117 & 688267 & 4.05 & 5.0698 & TRN & \\
\hline CHEMBL1413497 & 688267 & 4.3 & 5.0417 & TST & \\
\hline CHEMBL1354300 & 688267 & 3.95 & 5.0852 & TRN & \\
\hline CHEMBL1589073 & 688267 & 5.85 & 5.0547 & TRN & \\
\hline CHEMBL1601008 & 688267 & 5.6 & 5.0563 & TRN & \\
\hline CHEMBL1536586 & 688267 & 5.45 & 5.0496 & TST & \\
\hline CHEMBL1523049 & 688267 & 5.8 & 5.0536 & TRN & \\
\hline CHEMBL1399528 & 688267 & 5.85 & 5.0324 & TRN & \\
\hline CHEMBL1378113 & 688267 & 6.1 & 5.1481 & TRN & \\
\hline CHEMBL3193359 & 688267 & 6.25 & 5.0112 & TRN & \\
\hline CHEMBL1457125 & 688267 & 6.45 & 5.0609 & TRN & \\
\hline CHEMBL1327194 & 688267 & 5.95 & 5.0749 & TST & \\
\hline CHEMBL1453401 & 688267 & 4.0 & 5.1388 & TRN & \\
\hline CHEMBL1485972 & 688267 & 5.05 & 5.1029 & TRN & \\
\hline CHEMBL257359 & 688267 & 4.3 & 5.0161 & TRN & \\
\hline CHEMBL1461486 & 688267 & 4.4 & 5.0046 & TST & \\
\hline CHEMBL1310463 & 688267 & 6.2 & 5.0389 & TRN & \\
\hline CHEMBL1321863 & 688267 & 5.85 & 5.1251 & TRN & \\
\hline CHEMBL1416517 & 688267 & 5.25 & 5.0847 & TRN & \\
\hline CHEMBL1354093 & 688267 & 4.6 & 4.9849 & TRN & \\
\hline CHEMBL1502272 & 688267 & 6.2 & 5.0549 & TST & \\
\hline CHEMBL1392854 & 688267 & 6.05 & 5.0959 & TRN & \\
\hline CHEMBL1418710 & 688267 & 4.05 & 5.0022 & TST & \\
\hline CHEMBL1398741 & 688267 & 5.25 & 5.034 & TRN & \\
\hline CHEMBL 1495853 & 688267 & 5.35 & 5.1686 & TRN & \\
\hline CHEMBL1368303 & 688267 & 4.05 & 5.013 & TRN & \\
\hline CHEMBL1364795 & 688267 & 4.6 & 5.0478 & TRN & \\
\hline CHEMBL1482967 & 688267 & 4.0 & 5.0505 & TRN & \\
\hline CHEMBL1518206 & 688267 & 5.85 & 5.0661 & TST & \\
\hline CHEMBL1322328 & 688267 & 4.5 & 5.0676 & TRN & \\
\hline CHEMBL3207318 & 688267 & 5.15 & 4.9957 & TRN & \\
\hline CHEMBL1457856 & 688267 & 5.6 & 5.0543 & TST & \\
\hline CHEMBL1405948 & 688267 & 4.95 & 5.043 & TRN & \\
\hline CHEMBL1325690 & 688267 & 4.4 & 5.0259 & TST & \\
\hline CHEMBL1326606 & 688267 & 4.1 & 5.0013 & TST & \\
\hline CHEMBL1470958 & 688267 & 4.35 & 4.9915 & TRN & \\
\hline CHEMBL1364001 & 688267 & 6.2 & 4.9883 & TRN & \\
\hline CHEMBL1517733 & 688267 & 5.15 & 5.0758 & TRN & \\
\hline CHEMBL1435437 & 688267 & 5.85 & 5.0002 & TRN & \\
\hline CHEMBL1548014 & 688267 & 5.5 & 5.0042 & TST & \\
\hline CHEMBL1574085 & 688267 & 6.2 & 5.0708 & TRN & \\
\hline CHEMBL1533648 & 688267 & 4.05 & 5.0761 & TST & \\
\hline CHEMBL1568985 & 688267 & 6.25 & 5.1006 & TST & \\
\hline
\end{tabular}




\begin{tabular}{|c|c|c|c|c|c|}
\hline \multicolumn{6}{|c|}{ pplemental lable s } \\
\hline CHEMBL1367180 & 688267 & 6.2 & 5.0193 & TRN & \\
\hline CHEMBL1396552 & 688267 & 6.2 & 5.0643 & TST & \\
\hline CHEMBL1435701 & 688267 & 4.3 & 5.095 & TRN & \\
\hline CHEMBL1397950 & 688267 & 5.35 & 5.0563 & TRN & \\
\hline CHEMBL1552163 & 688267 & 6.1 & 5.0511 & TST & \\
\hline CHEMBL1469841 & 688267 & 5.5 & 5.0736 & TRN & \\
\hline CHEMBL1512242 & 688267 & 5.2 & 5.1281 & TRN & \\
\hline CHEMBL1540564 & 688267 & 5.9 & 5.0279 & TRN & \\
\hline CHEMBL1584910 & 688267 & 6.25 & 5.035 & TST & \\
\hline CHEMBL1477225 & 688267 & 6.2 & 5.0412 & TRN & \\
\hline CHEMBL1412457 & 688267 & 4.55 & 5.0547 & TRN & \\
\hline CHEMBL1589867 & 688267 & 4.85 & 4.9995 & TRN & \\
\hline CHEMBL1378133 & 688267 & 5.55 & 5.0999 & TRN & \\
\hline CHEMBL1435071 & 688267 & 5.8 & 5.0911 & TRN & \\
\hline CHEMBL1583212 & 688267 & 4.3 & 5.0678 & TST & \\
\hline CHEMBL1542293 & 688267 & 4.0 & 5.1138 & TRN & \\
\hline CHEMBL1453296 & 688267 & 4.4 & 5.085 & TRN & \\
\hline CHEMBL1502562 & 688267 & 5.45 & 5.0405 & TST & \\
\hline CHEMBL1424206 & 688267 & 4.05 & 5.0426 & TST & \\
\hline CHEMBL1436602 & 688267 & 5.35 & 5.0353 & TRN & \\
\hline CHEMBL1356809 & 688267 & 4.85 & 5.0247 & TST & \\
\hline CHEMBL1484107 & 688267 & 5.1 & 4.9956 & TRN & \\
\hline CHEMBL1424432 & 688267 & 4.6 & 5.1019 & TRN & \\
\hline CHEMBL1557769 & 688267 & 4.8 & 5.0674 & TRN & \\
\hline CHEMBL1595887 & 688267 & 5.0 & 5.1307 & TRN & \\
\hline CHEMBL1410771 & 688267 & 6.15 & 5.0969 & TRN & \\
\hline CHEMBL1518535 & 688267 & 4.05 & 5.0518 & TRN & \\
\hline CHEMBL1526198 & 688267 & 4.65 & 5.0822 & TST & \\
\hline CHEMBL1415030 & 688267 & 5.35 & 4.9944 & TRN & \\
\hline CHEMBL1324824 & 688267 & 6.2 & 5.0523 & TRN & \\
\hline CHEMBL445184 & 688267 & 3.95 & 4.98606 & 2000000001 & TRN \\
\hline CHEMBL1445319 & 688267 & 5.9 & 5.0507 & TST & \\
\hline CHEMBL1321947 & 688267 & 4.3 & 5.0514 & TST & \\
\hline CHEMBL1520251 & 688267 & 6.6 & 5.0904 & TST & \\
\hline CHEMBL 1454660 & 688267 & 4.35 & 5.0474 & TRN & \\
\hline CHEMBL547506 & 688267 & 5.35 & 5.1003 & TRN & \\
\hline CHEMBL1364202 & 688267 & 4.0 & 5.0125 & TRN & \\
\hline CHEMBL1515328 & 688267 & 6.25 & 5.1856 & TRN & \\
\hline CHEMBL1482230 & 688267 & 6.25 & 5.0092 & TRN & \\
\hline CHEMBL1349525 & 688267 & 6.5501 & 5.1249 & TST & \\
\hline CHEMBL1477416 & 688267 & 6.0 & 5.1498 & TRN & \\
\hline CHEMBL1559754 & 688267 & 5.35 & 5.0104 & TRN & \\
\hline CHEMBL1450286 & 688267 & 6.25 & 5.053 & TRN & \\
\hline CHEMBL1596111 & 688267 & 6.15 & 5.0707 & TRN & \\
\hline CHEMBL1373955 & 688267 & 5.55 & 5.1414 & TRN & \\
\hline CHEMBL1310645 & 688267 & 4.85 & 5.0649 & TRN & \\
\hline CHEMBL1384462 & 688267 & 5.8 & 5.0149 & TRN & \\
\hline CHEMBL1314878 & 688267 & 5.75 & 5.0759 & TRN & \\
\hline
\end{tabular}




\begin{tabular}{|c|c|c|c|c|}
\hline \multicolumn{5}{|c|}{ Supplemental Table S2.txt } \\
\hline CHEMBL1439661 & 688267 & 4.6 & 5.0386 & TRN \\
\hline CHEMBL1318854 & 688267 & 5.3 & 5.032 & TRN \\
\hline CHEMBL1555555 & 688267 & 6.15 & 5.1014 & TRN \\
\hline CHEMBL1516212 & 688267 & 3.95 & 5.0346 & TRN \\
\hline CHEMBL1584308 & 688267 & 4.25 & 5.0461 & TRN \\
\hline CHEMBL1533093 & 688267 & 4.0 & 5.0718 & TRN \\
\hline CHEMBL1969910 & 688267 & 4.05 & 5.058 & TRN \\
\hline CHEMBL1606266 & 688267 & 4.95 & 5.0824 & TRN \\
\hline CHEMBL1449189 & 688267 & 5.45 & 5.1104 & TRN \\
\hline CHEMBL1450270 & 688267 & 4.4 & 5.0751 & TRN \\
\hline CHEMBL1346923 & 688267 & 6.45 & 5.0446 & TRN \\
\hline CHEMBL1366984 & 688267 & 6.35 & 5.0543 & TRN \\
\hline CHEMBL1601466 & 688267 & 5.45 & 5.0078 & TRN \\
\hline CHEMBL1326103 & 688267 & 5.5 & 5.1421 & TRN \\
\hline CHEMBL451532 & 688267 & 5.45 & 5.0764 & TST \\
\hline CHEMBL1346131 & 688267 & 5.0 & 5.0762 & TST \\
\hline CHEMBL1402728 & 688267 & 6.2 & 5.0906 & TRN \\
\hline CHEMBL1596670 & 688267 & 5.35 & 5.1271 & TRN \\
\hline CHEMBL1300654 & 688267 & 5.9 & 5.1124 & TST \\
\hline CHEMBL1373593 & 688267 & 3.95 & 5.0117 & TRN \\
\hline CHEMBL1570734 & 688267 & 4.05 & 5.0261 & TST \\
\hline CHEMBL1459485 & 688267 & 6.25 & 5.0707 & TRN \\
\hline CHEMBL1577743 & 688267 & 6.2 & 5.0107 & TRN \\
\hline CHEMBL1579104 & 688267 & 5.15 & 5.0456 & TST \\
\hline CHEMBL1369342 & 688267 & 5.65 & 5.0359 & TST \\
\hline CHEMBL1331190 & 688267 & 5.7 & 5.0324 & TRN \\
\hline CHEMBL1315561 & 688267 & 4.35 & 5.0424 & TRN \\
\hline CHEMBL1603107 & 688267 & 4.3 & 5.0217 & TRN \\
\hline CHEMBL1545532 & 688267 & 6.2 & 5.0609 & TRN \\
\hline CHEMBL1333967 & 688267 & 4.05 & 5.0174 & TST \\
\hline CHEMBL1604504 & 688267 & 6.2 & 5.0359 & TRN \\
\hline CHEMBL1574079 & 688267 & 6.25 & 5.0779 & TRN \\
\hline CHEMBL1337973 & 688267 & 6.2 & 5.048 & TRN \\
\hline CHEMBL1411551 & 688267 & 4.05 & 5.0127 & TST \\
\hline CHEMBL1487656 & 688267 & 4.05 & 5.047 & TRN \\
\hline CHEMBL1368564 & 688267 & 4.65 & 5.0418 & TST \\
\hline CHEMBL1330956 & 688267 & 4.05 & 5.0571 & TST \\
\hline CHEMBL1517419 & 688267 & 4.05 & 5.0528 & TRN \\
\hline CHEMBL1316626 & 688267 & 5.45 & 5.0555 & TRN \\
\hline CHEMBL1335660 & 688267 & 5.3 & 5.0404 & TST \\
\hline CHEMBL1552255 & 688267 & 5.75 & 5.0074 & TRN \\
\hline CHEMBL1313101 & 688267 & 5.5 & 4.9979 & TRN \\
\hline CHEMBL1429242 & 688267 & 5.8 & 5.0889 & TRN \\
\hline CHEMBL1352878 & 688267 & 5.6 & 5.088 & TRN \\
\hline CHEMBL1580219 & 688267 & 4.5 & 4.9902 & TRN \\
\hline CHEMBL1378419 & 688267 & 5.35 & 5.0076 & TST \\
\hline CHEMBL 1577586 & 688267 & 6.25 & 5.0983 & TRN \\
\hline CHEMBL1486914 & 688267 & 6.05 & 5.0723 & TST \\
\hline
\end{tabular}




\begin{tabular}{|c|c|c|c|c|c|}
\hline \multicolumn{6}{|c|}{ Supplemental Table s2.txt } \\
\hline CHEMBL1503244 & 688267 & 6.15 & 5.0366 & TRN & \\
\hline CHEMBL1426965 & 688267 & 6.15 & 5.0985 & TRN & \\
\hline CHEMBL1592565 & 688267 & 6.2 & 5.0836 & TST & \\
\hline CHEMBL1340023 & 688267 & 6.45 & 5.0444 & TRN & \\
\hline CHEMBL1489674 & 688267 & 5.1 & 5.141 & TRN & \\
\hline CHEMBL1315797 & 688267 & 5.35 & 5.0504 & TRN & \\
\hline CHEMBL1575584 & 688267 & 4.4 & 5.0255 & TST & \\
\hline CHEMBL1510968 & 688267 & 4.05 & 4.9875 & TRN & \\
\hline CHEMBL1384849 & 688267 & 6.15 & 5.1622 & TRN & \\
\hline CHEMBL1540323 & 688267 & 4.35 & 5.0126 & TRN & \\
\hline CHEMBL1403019 & 688267 & 4.4 & 5.0444 & TRN & \\
\hline CHEMBL1333539 & 688267 & 4.35 & 5.1188 & TRN & \\
\hline CHEMBL1354823 & 688267 & 4.0 & 5.051 & TRN & \\
\hline CHEMBL1973532 & 688267 & 5.3 & 4.9679 & TRN & \\
\hline CHEMBL1544060 & 688267 & 4.3 & 5.0622 & TRN & \\
\hline CHEMBL1419980 & 688267 & 6.5 & 5.0477 & TST & \\
\hline CHEMBL1339948 & 688267 & 6.2 & 5.1111 & TRN & \\
\hline CHEMBL1331188 & 688267 & 4.3 & 5.1093 & TRN & \\
\hline CHEMBL1475962 & 688267 & 4.4 & 5.0763 & TST & \\
\hline CHEMBL1439208 & 688267 & 5.5 & 5.0308 & TRN & \\
\hline CHEMBL1337551 & 688267 & 5.2 & 5.0734 & TRN & \\
\hline CHEMBL1359802 & 688267 & 3.95 & 5.1222 & TRN & \\
\hline CHEMBL1401046 & 688267 & 4.25 & 5.0681 & TRN & \\
\hline CHEMBL1413285 & 688267 & 6.15 & 5.0421 & TRN & \\
\hline CHEMBL1349744 & 688267 & 5.35 & 5.0313 & TRN & \\
\hline CHEMBL1328316 & 688267 & 5.25 & 5.1097 & TST & \\
\hline CHEMBL1443277 & 688267 & 4.75 & 5.0772 & TRN & \\
\hline CHEMBL1380649 & 688267 & 5.05 & 5.12 & TRN & \\
\hline CHEMBL1409960 & 688267 & 4.9 & 5.0591 & TRN & \\
\hline CHEMBL1435760 & 688267 & 4.05 & 5.058 & TRN & \\
\hline CHEMBL469362 & 688267 & 3.95 & 5.0022 & TRN & \\
\hline CHEMBL1420747 & 688267 & 6.1 & 5.0211 & TRN & \\
\hline CHEMBL1372911 & 688267 & 3.95 & 4.9928 & TRN & \\
\hline CHEMBL1324695 & 688267 & 6.25 & 5.0538 & TRN & \\
\hline CHEMBL1546804 & 688267 & 4.9 & 5.0348 & TRN & \\
\hline CHEMBL1403837 & 688267 & 6.15 & 4.9987 & TRN & \\
\hline CHEMBL1471052 & 688267 & 5.05 & 5.063 & TST & \\
\hline CHEMBL1465491 & 688267 & 6.45 & 5.0509 & TRN & \\
\hline CHEMBL1434407 & 688267 & 5.45 & 5.1113 & TST & \\
\hline CHEMBL1562416 & 688267 & 4.0 & 5.1357 & TRN & \\
\hline CHEMBL1380905 & 688267 & 4.1 & 5.0442 & TST & \\
\hline CHEMBL1367602 & 688267 & 4.9 & 5.0388 & TRN & \\
\hline CHEMBL1576120 & 688267 & 4.0 & 5.06800 & 00000000005 & TST \\
\hline CHEMBL1394157 & 688267 & 3.95 & 5.088 & TRN & \\
\hline CHEMBL1356644 & 688267 & 4.45 & 5.0454 & TRN & \\
\hline CHEMBL1455249 & 688267 & 6.2 & 5.0786 & TRN & \\
\hline CHEMBL1342621 & 688267 & 4.35 & 5.0137 & TRN & \\
\hline CHEMBL1407785 & 688267 & 4.0 & 5.0087 & TRN & \\
\hline
\end{tabular}




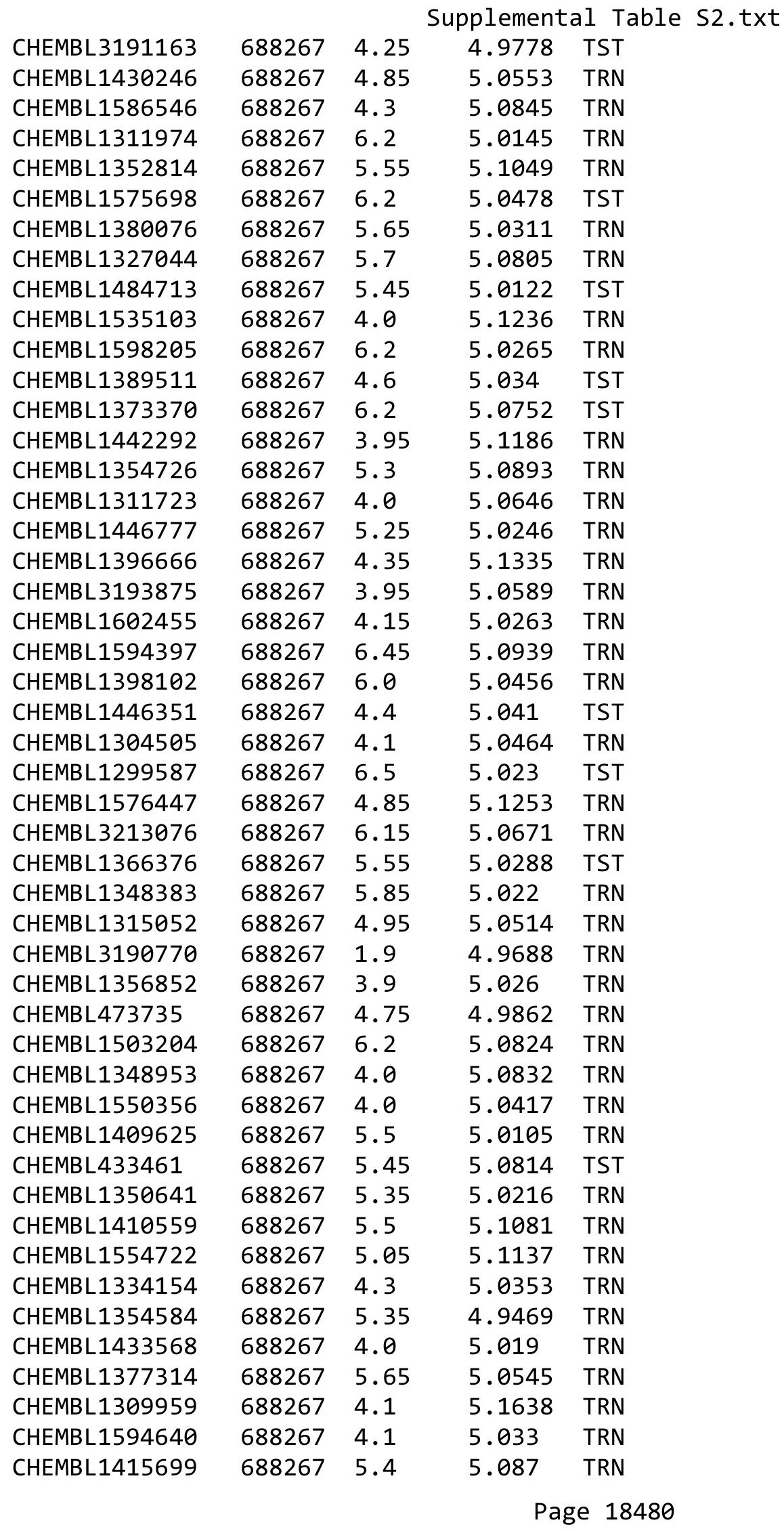




\begin{tabular}{|c|c|c|c|c|}
\hline \multicolumn{5}{|c|}{ Supplemental Table } \\
\hline CHEMBL1553817 & 688267 & 5.25 & 5.1306 & TRN \\
\hline CHEMBL1461194 & 688267 & 4.4 & 5.0723 & TRN \\
\hline CHEMBL1312842 & 688267 & 4.65 & 5.0286 & TST \\
\hline CHEMBL1493021 & 688267 & 4.4 & 5.0698 & TRN \\
\hline CHEMBL1557068 & 688267 & 6.15 & 5.1089 & TRN \\
\hline CHEMBL1392388 & 688267 & 5.1 & 5.1294 & TRN \\
\hline CHEMBL1552526 & 688267 & 3.95 & 4.9988 & TST \\
\hline CHEMBL1547156 & 688267 & 3.95 & 5.038 & TST \\
\hline CHEMBL1368117 & 688267 & 6.5 & 5.0795 & TRN \\
\hline CHEMBL1595239 & 688267 & 5.3 & 5.0676 & TRN \\
\hline CHEMBL1315829 & 688267 & 5.35 & 5.0648 & TRN \\
\hline CHEMBL1375927 & 688267 & 5.5 & 5.0738 & TRN \\
\hline CHEMBL1389072 & 688267 & 3.95 & 5.0881 & TST \\
\hline CHEMBL1328573 & 688267 & 4.45 & 5.1006 & TRN \\
\hline CHEMBL1410588 & 688267 & 4.4 & 5.0564 & TST \\
\hline CHEMBL1333859 & 688267 & 4.65 & 4.9674 & TRN \\
\hline CHEMBL1508224 & 688267 & 5.35 & 5.0308 & TST \\
\hline CHEMBL1406147 & 688267 & 4.9 & 5.0422 & TRN \\
\hline CHEMBL1433311 & 688267 & 5.3 & 5.0869 & TRN \\
\hline CHEMBL1344950 & 688267 & 4.4 & 5.0801 & TRN \\
\hline CHEMBL1515281 & 688267 & 6.2 & 4.9901 & TRN \\
\hline CHEMBL1534694 & 688267 & 4.65 & 5.0025 & TRN \\
\hline CHEMBL1457977 & 688267 & 4.05 & 5.0893 & TST \\
\hline CHEMBL1366364 & 688267 & 4.85 & 5.0833 & TRN \\
\hline CHEMBL1521503 & 688267 & 5.55 & 5.1193 & TST \\
\hline CHEMBL1610665 & 688267 & 6.2 & 4.9914 & TST \\
\hline CHEMBL1552566 & 688267 & 5.6 & 5.0834 & TRN \\
\hline CHEMBL1578635 & 688267 & 3.95 & 4.9966 & TST \\
\hline CHEMBL1358637 & 688267 & 4.0 & 5.0594 & TRN \\
\hline CHEMBL1334486 & 688267 & 4.0 & 5.0474 & TRN \\
\hline CHEMBL1486079 & 688267 & 4.4 & 5.0333 & TRN \\
\hline CHEMBL1470013 & 688267 & 6.25 & 5.1242 & TRN \\
\hline CHEMBL3191104 & 688267 & 6.2 & 5.0223 & TRN \\
\hline CHEMBL1368638 & 688267 & 5.55 & 5.0666 & TST \\
\hline CHEMBL1505577 & 688267 & 5.3 & 5.0676 & TST \\
\hline CHEMBL1556065 & 688267 & 6.2 & 5.0376 & TRN \\
\hline CHEMBL1450035 & 688267 & 6.2 & 5.0401 & TRN \\
\hline CHEMBL1432647 & 688267 & 6.2 & 5.0808 & TRN \\
\hline CHEMBL1594964 & 688267 & 5.85 & 5.0428 & TST \\
\hline CHEMBL1355866 & 688267 & 5.5 & 5.0717 & TRN \\
\hline CHEMBL1491924 & 688267 & 5.4 & 5.0452 & TRN \\
\hline CHEMBL1595902 & 688267 & 4.55 & 5.1278 & TRN \\
\hline CHEMBL1558362 & 688267 & 4.5 & 5.0354 & TRN \\
\hline CHEMBL1514712 & 688267 & 4.35 & 5.0652 & TRN \\
\hline CHEMBL1488334 & 688267 & 4.4 & 5.1231 & TST \\
\hline CHEMBL3190908 & 688267 & 5.85 & 5.0697 & TST \\
\hline CHEMBL1344606 & 688267 & 4.85 & 5.0389 & TRN \\
\hline CHEMBL1487986 & 688267 & 5.6 & 5.0165 & TST \\
\hline
\end{tabular}




\begin{tabular}{|c|c|c|c|c|}
\hline & & & pplement & al $\mathrm{Ta}$ \\
\hline CHEMBL1499875 & 688267 & 5.1 & 5.0557 & TRN \\
\hline CHEMBL1602902 & 688267 & 5.5 & 5.0176 & TRN \\
\hline CHEMBL1389409 & 688267 & 4.15 & 5.0446 & TRN \\
\hline CHEMBL1559054 & 688267 & 4.4 & 5.0254 & TRN \\
\hline CHEMBL1502581 & 688267 & 4.0 & 5.1132 & TRN \\
\hline CHEMBL1515563 & 688267 & 5.45 & 5.1128 & TRN \\
\hline CHEMBL1436887 & 688267 & 5.4 & 5.0993 & TRN \\
\hline CHEMBL1473114 & 688267 & 4.1 & 5.0725 & TRN \\
\hline CHEMBL1363982 & 688267 & 4.05 & 5.0046 & TST \\
\hline CHEMBL1433797 & 688267 & 6.5 & 5.027 & TST \\
\hline CHEMBL1426580 & 688267 & 5.6 & 5.1389 & TRN \\
\hline CHEMBL1315895 & 688267 & 4.05 & 5.0441 & TRN \\
\hline CHEMBL1439963 & 688267 & 5.4 & 5.1487 & TRN \\
\hline CHEMBL1477699 & 688267 & 4.0 & 5.0014 & TRN \\
\hline CHEMBL1473895 & 688267 & 6.2 & 5.1147 & TST \\
\hline CHEMBL1337713 & 688267 & 6.5 & 5.0542 & TST \\
\hline CHEMBL1417796 & 688267 & 4.3 & 5.0603 & TRN \\
\hline CHEMBL1568098 & 688267 & 5.9 & 5.0797 & TRN \\
\hline CHEMBL1316422 & 688267 & 5.35 & 5.0544 & TRN \\
\hline CHEMBL1594259 & 688267 & 6.2 & 5.0875 & TRN \\
\hline CHEMBL1414575 & 688267 & 4.05 & 5.0534 & TST \\
\hline CHEMBL1402634 & 688267 & 4.6 & 5.0947 & TRN \\
\hline CHEMBL1418134 & 688267 & 4.4 & 5.0095 & TST \\
\hline CHEMBL1405894 & 688267 & 4.0 & 5.0778 & TST \\
\hline CHEMBL1372826 & 688267 & 4.4 & 5.0585 & TRN \\
\hline CHEMBL1604850 & 688267 & 4.6 & 5.0862 & TST \\
\hline CHEMBL1561406 & 688267 & 4.45 & 5.072 & TRN \\
\hline CHEMBL1528703 & 688267 & 6.2 & 5.0493 & TRN \\
\hline CHEMBL1588565 & 688267 & 5.55 & 5.1527 & TRN \\
\hline CHEMBL1407964 & 688267 & 4.05 & 5.0267 & TRN \\
\hline CHEMBL1404127 & 688267 & 4.05 & 5.0522 & TRN \\
\hline CHEMBL1394340 & 688267 & 3.95 & 5.0576 & TST \\
\hline CHEMBL1480884 & 688267 & 5.15 & 5.0379 & TRN \\
\hline CHEMBL1520679 & 688267 & 4.15 & 5.1357 & TRN \\
\hline CHEMBL1394583 & 688267 & 4.45 & 5.1173 & TRN \\
\hline CHEMBL3193520 & 688267 & 5.65 & 4.9843 & TST \\
\hline CHEMBL1335699 & 688267 & 5.55 & 5.0394 & TRN \\
\hline CHEMBL1610012 & 688267 & 3.95 & 5.064 & TRN \\
\hline CHEMBL1316803 & 688267 & 5.3 & 5.0749 & TRN \\
\hline CHEMBL1441423 & 688267 & 5.5 & 5.044 & TRN \\
\hline CHEMBL1490784 & 688267 & 5.0 & 5.1013 & TRN \\
\hline CHEMBL1390617 & 688267 & 6.15 & 5.0301 & TRN \\
\hline CHEMBL1590490 & 688267 & 5.3 & 5.0249 & TRN \\
\hline CHEMBL1317826 & 688267 & 4.35 & 5.0706 & TRN \\
\hline CHEMBL1470896 & 688267 & 6.0 & 5.0568 & TRN \\
\hline CHEMBL1604806 & 688267 & 4.6 & 5.1069 & TST \\
\hline CHEMBL1512316 & 688267 & 4.4 & 5.0427 & TRN \\
\hline CHEMBL1355595 & 688267 & 6.2 & 5.1043 & TRN \\
\hline
\end{tabular}




\begin{tabular}{|c|c|c|c|c|}
\hline & & & pplement & $\mathrm{a} \perp \mathrm{Ta}$ \\
\hline CHEMBL1330826 & 688267 & 4.4 & 5.0582 & TST \\
\hline CHEMBL1513176 & 688267 & 3.95 & 5.0088 & TRN \\
\hline CHEMBL1458560 & 688267 & 4.05 & 5.0394 & TRN \\
\hline CHEMBL1538079 & 688267 & 6.15 & 5.0087 & TST \\
\hline CHEMBL3191578 & 688267 & 5.4 & 5.0675 & TRN \\
\hline CHEMBL1494101 & 688267 & 5.35 & 5.0451 & TST \\
\hline CHEMBL 3212347 & 688267 & 5.6 & 5.0294 & TST \\
\hline CHEMBL1597520 & 688267 & 4.3 & 5.0383 & TRN \\
\hline CHEMBL1391899 & 688267 & 4.35 & 5.0494 & TST \\
\hline CHEMBL1586760 & 688267 & 4.8 & 5.0033 & TRN \\
\hline CHEMBL1439177 & 688267 & 5.85 & 5.0965 & TRN \\
\hline CHEMBL1497935 & 688267 & 3.95 & 5.0413 & TST \\
\hline CHEMBL1465681 & 688267 & 4.0 & 4.9862 & TST \\
\hline CHEMBL1346775 & 688267 & 4.55 & 5.0648 & TRN \\
\hline CHEMBL1475005 & 688267 & 4.25 & 5.0756 & TRN \\
\hline CHEMBL1402325 & 688267 & 6.1 & 5.0097 & TRN \\
\hline CHEMBL1536935 & 688267 & 5.8 & 5.0293 & TRN \\
\hline CHEMBL1549461 & 688267 & 5.85 & 5.0641 & TST \\
\hline CHEMBL1335774 & 688267 & 4.55 & 5.1147 & TRN \\
\hline CHEMBL1366686 & 688267 & 3.95 & 5.0972 & TST \\
\hline CHEMBL1506626 & 688267 & 4.45 & 5.0557 & TST \\
\hline CHEMBL 3189741 & 688267 & 5.45 & 5.0784 & TRN \\
\hline CHEMBL 1028 & 688267 & 5.55 & 5.0597 & TRN \\
\hline CHEMBL1434218 & 688267 & 6.15 & 5.0145 & TST \\
\hline CHEMBL1521888 & 688267 & 5.55 & 5.0165 & TRN \\
\hline CHEMBL1531262 & 688267 & 5.35 & 5.0834 & TRN \\
\hline CHEMBL1313840 & 688267 & 5.1 & 5.0501 & TRN \\
\hline CHEMBL1393736 & 688267 & 4.0 & 5.0694 & TST \\
\hline CHEMBL1420574 & 688267 & 4.25 & 5.0705 & TRN \\
\hline CHEMBL1376627 & 688267 & 4.05 & 5.1292 & TRN \\
\hline CHEMBL1416897 & 688267 & 4.4 & 5.0878 & TRN \\
\hline CHEMBL1451652 & 688267 & 4.75 & 5.0513 & TRN \\
\hline CHEMBL1336184 & 688267 & 5.85 & 5.0984 & TRN \\
\hline CHEMBL1463658 & 688267 & 3.95 & 4.9694 & TRN \\
\hline CHEMBL1608373 & 688267 & 4.35 & 5.0531 & TRN \\
\hline CHEMBL1510819 & 688267 & 4.1 & 5.0519 & TRN \\
\hline CHEMBL1601201 & 688267 & 4.4 & 5.0919 & TRN \\
\hline CHEMBL1366564 & 688267 & 5.95 & 5.0446 & TRN \\
\hline CHEMBL1318198 & 688267 & 4.9 & 5.1307 & TRN \\
\hline CHEMBL1432471 & 688267 & 4.55 & 5.0906 & TRN \\
\hline CHEMBL1588777 & 688267 & 4.05 & 5.0244 & TRN \\
\hline CHEMBL1395313 & 688267 & 4.4 & 5.0745 & TRN \\
\hline CHEMBL1335201 & 688267 & 5.1 & 5.0475 & TRN \\
\hline CHEMBL1375068 & 688267 & 4.0 & 4.9838 & TRN \\
\hline CHEMBL1540369 & 688267 & 4.0 & 5.0561 & TRN \\
\hline CHEMBL1299268 & 688267 & 4.55 & 4.9906 & TRN \\
\hline CHEMBL1593583 & 688267 & 4.9 & 5.0902 & TRN \\
\hline CHEMBL1613006 & 688267 & 6.0 & 5.0591 & TRN \\
\hline
\end{tabular}




\begin{tabular}{|c|c|c|c|c|c|}
\hline \\
\hline CHEMBL1340979 & 688267 & 4.4 & 5.0751 & TRN & \\
\hline CHEMBL1571968 & 688267 & 4.35 & 5.0874 & TST & \\
\hline CHEMBL1563584 & 688267 & 6.15 & 5.0594 & TRN & \\
\hline CHEMBL1470430 & 688267 & 4.9 & 4.965 & TRN & \\
\hline CHEMBL1395560 & 688267 & 5.0 & 5.0788 & TRN & \\
\hline CHEMBL1594496 & 688267 & 4.7 & 5.0236 & TST & \\
\hline CHEMBL1472747 & 688267 & 5.25 & 5.0039 & TRN & \\
\hline CHEMBL1602477 & 688267 & 4.4 & 5.0967 & TST & \\
\hline CHEMBL1557732 & 688267 & 4.85 & 4.9836 & TRN & \\
\hline CHEMBL1456142 & 688267 & 4.7 & 5.0992 & TST & \\
\hline CHEMBL1332844 & 688267 & 5.8 & 5.0656 & TST & \\
\hline CHEMBL1571483 & 688267 & 4.35 & 4.9753 & TRN & \\
\hline CHEMBL1425708 & 688267 & 5.75 & 5.1306 & TST & \\
\hline CHEMBL3208106 & 688267 & 5.15 & 4.9965 & TRN & \\
\hline CHEMBL1545906 & 688267 & 5.85 & 5.0716 & TST & \\
\hline CHEMBL1545640 & 688267 & 4.1 & 5.0043 & TST & \\
\hline CHEMBL1322913 & 688267 & 5.65 & 5.1437 & TRN & \\
\hline CHEMBL1546155 & 688267 & 4.2 & 5.0754 & TRN & \\
\hline CHEMBL1305548 & 688267 & 4.8 & 5.0634 & TRN & \\
\hline CHEMBL416657 & 688267 & 5.4 & 5.0463 & TST & \\
\hline CHEMBL1505220 & 688267 & 4.25 & 5.1361 & TST & \\
\hline CHEMBL1602595 & 688267 & 4.05 & 5.026 & TST & \\
\hline CHEMBL1409921 & 688267 & 6.5 & 5.0616 & TST & \\
\hline CHEMBL1528597 & 688267 & 4.35 & 5.0947 & TRN & \\
\hline CHEMBL1416658 & 688267 & 5.2 & 5.0008 & TST & \\
\hline CHEMBL1507879 & 688267 & 6.25 & 5.1315 & TRN & \\
\hline CHEMBL1562784 & 688267 & 5.35 & 5.0343 & TRN & \\
\hline CHEMBL1411405 & 688267 & 6.2 & 5.0922 & TRN & \\
\hline CHEMBL1339131 & 688267 & 6.25 & 5.0875 & TRN & \\
\hline CHEMBL3189377 & 688267 & 4.05 & 5.0514 & TST & \\
\hline CHEMBL1409090 & 688267 & 6.2 & 5.046 & TRN & \\
\hline CHEMBL1499267 & 688267 & 5.1 & 5.0534 & TRN & \\
\hline CHEMBL1466056 & 688267 & 5.1 & 5.0332 & TRN & \\
\hline CHEMBL1370497 & 688267 & 4.4 & 4.9966 & TRN & \\
\hline CHEMBL1522355 & 688267 & 4.05 & 5.09699 & 99999999995 & TRN \\
\hline CHEMBL1416716 & 688267 & 4.05 & 5.0162 & TRN & \\
\hline CHEMBL1438331 & 688267 & 4.05 & 5.088 & TST & \\
\hline CHEMBL1308560 & 688267 & 3.95 & 5.0366 & TRN & \\
\hline CHEMBL1454072 & 688267 & 5.15 & 5.0521 & TRN & \\
\hline CHEMBL1486863 & 688267 & 5.75 & 5.0689 & TST & \\
\hline CHEMBL1448662 & 688267 & 4.35 & 5.102 & TRN & \\
\hline CHEMBL1603670 & 688267 & 6.25 & 5.1206 & TRN & \\
\hline CHEMBL1584605 & 688267 & 5.8 & 5.0151 & TRN & \\
\hline CHEMBL1345813 & 688267 & 4.5 & 5.0737 & TRN & \\
\hline CHEMBL1299423 & 688267 & 5.85 & 5.0913 & TRN & \\
\hline CHEMBL1410298 & 688267 & 6.2 & 5.01699 & 99999999995 & TRN \\
\hline CHEMBL1575782 & 688267 & 5.5 & 5.1289 & TRN & \\
\hline CHEMBL1603503 & 688267 & 5.05 & 5.0155 & TST & \\
\hline
\end{tabular}




\begin{tabular}{|c|c|c|c|c|}
\hline \multicolumn{5}{|c|}{ Supplemental Table S2.txt } \\
\hline CHEMBL1444797 & 688267 & 4.05 & 5.0172 & TRN \\
\hline CHEMBL1383716 & 688267 & 4.25 & 5.0509 & TST \\
\hline CHEMBL1560953 & 688267 & 5.5 & 5.0813 & TRN \\
\hline CHEMBL1603320 & 688267 & 6.2 & 5.0988 & TRN \\
\hline CHEMBL1388126 & 688267 & 4.1 & 5.0019 & TRN \\
\hline CHEMBL1382953 & 688267 & 4.35 & 5.0213 & TRN \\
\hline CHEMBL1598866 & 688267 & 5.75 & 5.0407 & TRN \\
\hline CHEMBL1405018 & 688267 & 5.45 & 5.0174 & TST \\
\hline CHEMBL1347477 & 688267 & 4.1 & 4.9764 & TRN \\
\hline CHEMBL1511761 & 688267 & 4.3 & 4.9984 & TRN \\
\hline CHEMBL1498689 & 688267 & 4.0 & 5.1488 & TRN \\
\hline CHEMBL1381894 & 688267 & 4.0 & 5.083 & TRN \\
\hline CHEMBL1489372 & 688267 & 5.0 & 5.0091 & TST \\
\hline CHEMBL1388805 & 688267 & 5.9 & 5.0668 & TRN \\
\hline CHEMBL1549139 & 688267 & 5.55 & 5.0596 & TRN \\
\hline CHEMBL1592039 & 688267 & 5.3 & 5.0077 & TRN \\
\hline CHEMBL1410869 & 688267 & 6.0 & 4.992 & TST \\
\hline CHEMBL1398623 & 688267 & 3.95 & 5.0806 & TST \\
\hline CHEMBL1541561 & 688267 & 5.45 & 5.0776 & TRN \\
\hline CHEMBL1575734 & 688267 & 4.95 & 5.0584 & TRN \\
\hline CHEMBL1588002 & 688267 & 4.0 & 5.0625 & TST \\
\hline CHEMBL1521147 & 688267 & 6.2 & 5.0751 & TRN \\
\hline CHEMBL1563945 & 688267 & 3.9 & 5.1159 & TST \\
\hline CHEMBL1416731 & 688267 & 4.1 & 5.0628 & TRN \\
\hline CHEMBL1558489 & 688267 & 6.1 & 5.0716 & TST \\
\hline CHEMBL1610419 & 688267 & 4.25 & 5.0261 & TST \\
\hline CHEMBL1397335 & 688267 & 5.8 & 5.0211 & TRN \\
\hline CHEMBL1316250 & 688267 & 3.95 & 5.0418 & TRN \\
\hline CHEMBL1332543 & 688267 & 4.1 & 4.9999 & TRN \\
\hline CHEMBL1322873 & 688267 & 5.5 & 5.0569 & TST \\
\hline CHEMBL1433456 & 688267 & 6.6 & 5.0725 & TRN \\
\hline CHEMBL1569141 & 688267 & 4.1 & 5.0546 & TRN \\
\hline CHEMBL1507156 & 688267 & 5.3 & 5.0305 & TRN \\
\hline CHEMBL1342154 & 688267 & 5.55 & 5.0704 & TRN \\
\hline CHEMBL1472815 & 688267 & 4.5 & 5.0693 & TRN \\
\hline CHEMBL1583073 & 688267 & 4.85 & 5.0581 & TST \\
\hline CHEMBL1471302 & 688267 & 5.55 & 5.0709 & TRN \\
\hline CHEMBL1479233 & 688267 & 4.55 & 5.0403 & TST \\
\hline CHEMBL1417355 & 688267 & 5.0 & 5.0576 & TRN \\
\hline CHEMBL1612308 & 688267 & 5.45 & 5.0679 & TRN \\
\hline CHEMBL1311962 & 688267 & 5.75 & 5.0806 & TRN \\
\hline CHEMBL1395613 & 688267 & 5.1 & 5.0416 & TRN \\
\hline CHEMBL1466862 & 688267 & 4.3 & 5.0293 & TRN \\
\hline CHEMBL1530408 & 688267 & 5.3 & 5.0658 & TRN \\
\hline CHEMBL1533696 & 688267 & 4.35 & 5.1473 & TRN \\
\hline CHEMBL1593672 & 688267 & 6.2 & 5.0489 & TRN \\
\hline CHEMBL2373601 & 688267 & 6.25 & 5.0558 & TST \\
\hline CHEMBL1305307 & 688267 & 5.8 & 5.0038 & TST \\
\hline
\end{tabular}




\begin{tabular}{|c|c|c|c|c|}
\hline \multicolumn{5}{|c|}{ Supplemental Table S2.txt } \\
\hline CHEMBL1445763 & 688267 & 5.45 & 5.0107 & TRN \\
\hline CHEMBL1380116 & 688267 & 6.2 & 5.0524 & TRN \\
\hline CHEMBL1427916 & 688267 & 4.6 & 5.1225 & TRN \\
\hline CHEMBL1299780 & 688267 & 4.0 & 5.0258 & TRN \\
\hline CHEMBL1608696 & 688267 & 6.25 & 5.0844 & TRN \\
\hline CHEMBL1448817 & 688267 & 5.6 & 5.0545 & TRN \\
\hline CHEMBL1602722 & 688267 & 3.9 & 5.0619 & TRN \\
\hline CHEMBL1561840 & 688267 & 5.3 & 5.0763 & TST \\
\hline CHEMBL1378860 & 688267 & 6.2 & 5.0407 & TRN \\
\hline CHEMBL1419746 & 688267 & 5.45 & 5.0703 & TRN \\
\hline CHEMBL1432727 & 688267 & 6.1 & 5.0338 & TST \\
\hline CHEMBL1601063 & 688267 & 6.2 & 4.9988 & TRN \\
\hline CHEMBL1482279 & 688267 & 5.7 & 5.1216 & TRN \\
\hline CHEMBL1346718 & 688267 & 4.4 & 5.0234 & TST \\
\hline CHEMBL1375378 & 688267 & 4.8 & 5.0503 & TST \\
\hline CHEMBL1518082 & 688267 & 3.95 & 5.0572 & TRN \\
\hline CHEMBL1435949 & 688267 & 5.5 & 5.0084 & TRN \\
\hline CHEMBL1517356 & 688267 & 6.25 & 5.0885 & TRN \\
\hline CHEMBL1411577 & 688267 & 4.55 & 5.0508 & TRN \\
\hline CHEMBL1578978 & 688267 & 4.05 & 5.0637 & TST \\
\hline CHEMBL1605197 & 688267 & 6.25 & 5.0412 & TRN \\
\hline CHEMBL1513441 & 688267 & 6.2 & 5.003 & TRN \\
\hline CHEMBL1505205 & 688267 & 6.15 & 5.0158 & TST \\
\hline CHEMBL1404635 & 688267 & 6.2 & 5.0362 & TRN \\
\hline CHEMBL1406671 & 688267 & 5.45 & 5.0905 & TST \\
\hline CHEMBL1399806 & 688267 & 4.15 & 4.9945 & TRN \\
\hline CHEMBL1353157 & 688267 & 6.2 & 4.9947 & TST \\
\hline CHEMBL1494394 & 688267 & 4.1 & 5.0652 & TRN \\
\hline CHEMBL1357578 & 688267 & 4.05 & 5.0614 & TRN \\
\hline CHEMBL1354820 & 688267 & 5.7 & 5.0334 & TRN \\
\hline CHEMBL1563411 & 688267 & 4.05 & 5.1457 & TST \\
\hline CHEMBL1362020 & 688267 & 4.05 & 5.0368 & TST \\
\hline CHEMBL1522597 & 688267 & 6.05 & 5.0332 & TRN \\
\hline CHEMBL1412293 & 688267 & 3.95 & 5.0427 & TRN \\
\hline CHEMBL3209151 & 688267 & 4.7 & 5.0816 & TRN \\
\hline CHEMBL1391151 & 688267 & 4.2 & 5.0861 & TRN \\
\hline CHEMBL3192038 & 688267 & 4.6 & 5.0223 & TRN \\
\hline CHEMBL1599318 & 688267 & 5.8 & 4.9868 & TRN \\
\hline CHEMBL1471854 & 688267 & 6.2 & 5.1094 & TST \\
\hline CHEMBL1591790 & 688267 & 4.0 & 5.0518 & TRN \\
\hline CHEMBL1407682 & 688267 & 3.95 & 5.1305 & TRN \\
\hline CHEMBL1575686 & 688267 & 6.05 & 5.0781 & TRN \\
\hline CHEMBL1992276 & 688267 & 4.0 & 5.0164 & TST \\
\hline CHEMBL1437108 & 688267 & 4.7 & 5.015 & TRN \\
\hline CHEMBL1412092 & 688267 & 4.75 & 5.0661 & TRN \\
\hline CHEMBL1446108 & 688267 & 3.95 & 5.0537 & TRN \\
\hline CHEMBL1461946 & 688267 & 6.1 & 5.072 & TRN \\
\hline CHEMBL1406240 & 688267 & 5.6 & 5.1008 & TRN \\
\hline
\end{tabular}




\begin{tabular}{|c|c|c|c|c|}
\hline \multicolumn{5}{|c|}{ Supplemental Table S2.txt } \\
\hline CHEMBL1495425 & 688267 & 5.15 & 5.1091 & TRN \\
\hline CHEMBL1606702 & 688267 & 5.8 & 5.0481 & TRN \\
\hline CHEMBL1590743 & 688267 & 4.3 & 5.1066 & TST \\
\hline CHEMBL1513473 & 688267 & 4.1 & 5.0565 & TRN \\
\hline CHEMBL1173673 & 688267 & 4.2 & 5.0144 & TRN \\
\hline CHEMBL1560362 & 688267 & 5.65 & 5.029 & TRN \\
\hline CHEMBL1543216 & 688267 & 5.25 & 5.0017 & TRN \\
\hline CHEMBL1324705 & 688267 & 6.15 & 5.0748 & TRN \\
\hline CHEMBL1561257 & 688267 & 4.3 & 5.0635 & TRN \\
\hline CHEMBL1301812 & 688267 & 4.5 & 5.0238 & TRN \\
\hline CHEMBL1391428 & 688267 & 4.3 & 5.0345 & TST \\
\hline CHEMBL1353325 & 688267 & 4.55 & 5.0258 & TRN \\
\hline CHEMBL3191471 & 688267 & 6.25 & 4.9507 & TRN \\
\hline CHEMBL1448003 & 688267 & 4.2 & 5.1119 & TRN \\
\hline CHEMBL1402923 & 688267 & 4.4 & 5.052 & TST \\
\hline CHEMBL1508000 & 688267 & 6.2 & 5.0316 & TST \\
\hline CHEMBL2005991 & 688267 & 4.2 & 4.9944 & TST \\
\hline CHEMBL1365143 & 688267 & 3.95 & 4.9909 & TRN \\
\hline CHEMBL1583127 & 688267 & 5.05 & 4.9815 & TRN \\
\hline CHEMBL1596447 & 688267 & 6.05 & 5.1204 & TRN \\
\hline CHEMBL1604320 & 688267 & 3.95 & 5.1261 & TRN \\
\hline CHEMBL1449141 & 688267 & 4.55 & 4.981 & TRN \\
\hline CHEMBL1356051 & 688267 & 6.2 & 5.0033 & TST \\
\hline CHEMBL1513527 & 688267 & 4.75 & 5.0185 & TRN \\
\hline CHEMBL1518550 & 688267 & 5.75 & 5.0224 & TST \\
\hline CHEMBL1368829 & 688267 & 4.4 & 5.0805 & TRN \\
\hline CHEMBL1527600 & 688267 & 4.6 & 5.06 & TRN \\
\hline CHEMBL1434364 & 688267 & 5.4 & 5.0038 & TST \\
\hline CHEMBL1445956 & 688267 & 4.95 & 5.0567 & TRN \\
\hline CHEMBL1606750 & 688267 & 4.15 & 5.0719 & TRN \\
\hline CHEMBL1535878 & 688267 & 5.05 & 5.0209 & TRN \\
\hline CHEMBL1439270 & 688267 & 6.2 & 5.1296 & TRN \\
\hline CHEMBL1549628 & 688267 & 4.85 & 5.006 & TRN \\
\hline CHEMBL1439363 & 688267 & 5.3 & 5.0129 & TST \\
\hline CHEMBL1389101 & 688267 & 5.65 & 5.125 & TRN \\
\hline CHEMBL1525907 & 688267 & 4.95 & 5.0373 & TST \\
\hline CHEMBL1486096 & 688267 & 3.95 & 5.0261 & TRN \\
\hline CHEMBL1396359 & 688267 & 5.95 & 5.0471 & TRN \\
\hline CHEMBL1435452 & 688267 & 5.35 & 5.0889 & TRN \\
\hline CHEMBL1451934 & 688267 & 5.25 & 5.06 & TRN \\
\hline CHEMBL1320831 & 688267 & 3.95 & 5.0181 & TRN \\
\hline CHEMBL1611891 & 688267 & 5.45 & 5.0386 & TRN \\
\hline CHEMBL279335 & 688267 & 5.05 & 4.984 & TRN \\
\hline CHEMBL1331705 & 688267 & 4.4 & 5.0129 & TST \\
\hline CHEMBL1384233 & 688267 & 5.5 & 5.0422 & TST \\
\hline CHEMBL1487863 & 688267 & 6.05 & 5.1163 & TST \\
\hline CHEMBL1522171 & 688267 & 4.15 & 5.0668 & TST \\
\hline CHEMBL1413985 & 688267 & 4.35 & 5.019 & TST \\
\hline
\end{tabular}




\begin{tabular}{|c|c|c|c|c|c|}
\hline \multicolumn{6}{|c|}{ Supplemental Table S2.txt } \\
\hline CHEMBL1518900 & 688267 & 5.55 & 5.0328 & TST & \\
\hline CHEMBL1438234 & 688267 & 5.55 & 5.0981 & TRN & \\
\hline CHEMBL1603405 & 688267 & 6.2 & 5.0412 & TRN & \\
\hline CHEMBL1388573 & 688267 & 4.0 & 5.0591 & TST & \\
\hline CHEMBL1364544 & 688267 & 4.85 & 5.0394 & TRN & \\
\hline CHEMBL1536671 & 688267 & 6.2 & 5.056 & TRN & \\
\hline CHEMBL1477292 & 688267 & 6.0 & 5.1001 & TRN & \\
\hline CHEMBL3213782 & 688267 & 5.0 & 5.0323 & TST & \\
\hline CHEMBL1485812 & 688267 & 4.4 & 5.0476 & TST & \\
\hline CHEMBL1518551 & 688267 & 4.45 & 5.0764 & TRN & \\
\hline CHEMBL1479144 & 688267 & 4.95 & 4.9877 & TST & \\
\hline CHEMBL1541121 & 688267 & 5.05 & 5.0977 & TRN & \\
\hline CHEMBL1460812 & 688267 & 4.3 & 5.0208 & TST & \\
\hline CHEMBL1571989 & 688267 & 4.35 & 5.1412 & TRN & \\
\hline CHEMBL1382488 & 688267 & 4.3 & 4.9888 & TRN & \\
\hline CHEMBL3211585 & 688267 & 5.0 & 4.9926 & TRN & \\
\hline CHEMBL1521603 & 688267 & 6.15 & 5.1253 & TRN & \\
\hline CHEMBL1428535 & 688267 & 5.1 & 5.102 & TRN & \\
\hline CHEMBL1477895 & 688267 & 4.35 & 5.0698 & TRN & \\
\hline CHEMBL1595277 & 688267 & 4.75 & 5.0247 & TST & \\
\hline CHEMBL1427435 & 688267 & 5.9 & 5.0362 & TRN & \\
\hline CHEMBL1408005 & 688267 & 5.95 & 5.0959 & TRN & \\
\hline CHEMBL1438854 & 688267 & 3.95 & 5.0599 & TRN & \\
\hline CHEMBL1301615 & 688267 & 5.9 & 5.0911 & TRN & \\
\hline CHEMBL1313670 & 688267 & 5.45 & 5.01699 & 99999999995 & TRN \\
\hline CHEMBL1456886 & 688267 & 3.95 & 5.0558 & TRN & \\
\hline CHEMBL1449769 & 688267 & 6.2 & 5.0491 & TRN & \\
\hline CHEMBL1493130 & 688267 & 5.45 & 5.106 & TST & \\
\hline CHEMBL1326489 & 688267 & 4.05 & 5.006 & TST & \\
\hline CHEMBL3212521 & 688267 & 6.5501 & 5.078 & TST & \\
\hline CHEMBL1345762 & 688267 & 6.2 & 5.0325 & TRN & \\
\hline CHEMBL1340956 & 688267 & 4.6 & 5.056 & TRN & \\
\hline CHEMBL1449418 & 688267 & 5.05 & 5.0057 & TRN & \\
\hline CHEMBL1477202 & 688267 & 5.0 & 5.1119 & TRN & \\
\hline CHEMBL1369090 & 688267 & 4.5 & 5.0258 & TRN & \\
\hline CHEMBL1362572 & 688267 & 5.3 & 5.0293 & TST & \\
\hline CHEMBL3207953 & 688267 & 5.9 & 4.9835 & TST & \\
\hline CHEMBL1594485 & 688267 & 5.55 & 5.08899 & 99999999995 & TRN \\
\hline CHEMBL1567408 & 688267 & 4.25 & 5.0046 & TRN & \\
\hline CHEMBL1338515 & 688267 & 6.2 & 5.0874 & TRN & \\
\hline CHEMBL1326617 & 688267 & 5.05 & 5.0475 & TST & \\
\hline CHEMBL1458536 & 688267 & 4.4 & 5.0364 & TRN & \\
\hline CHEMBL1318190 & 688267 & 3.95 & 5.0744 & TRN & \\
\hline CHEMBL1452650 & 688267 & 5.5 & 5.1254 & TRN & \\
\hline CHEMBL1604462 & 688267 & 6.2 & 5.0827 & TST & \\
\hline CHEMBL1373243 & 688267 & 4.5 & 5.0798 & TRN & \\
\hline CHEMBL1380729 & 688267 & 5.1 & 5.0536 & TRN & \\
\hline CHEMBL1476012 & 688267 & 5.2 & 5.0862 & TRN & \\
\hline
\end{tabular}




\begin{tabular}{|c|c|c|c|c|c|}
\hline \multicolumn{6}{|c|}{ Supplemental Table S2.txt } \\
\hline CHEMBL1467654 & 688267 & 4.95 & 5.0981 & TRN & \\
\hline CHEMBL1449877 & 688267 & 6.15 & 5.0384 & TRN & \\
\hline CHEMBL1528864 & 688267 & 4.15 & 5.0031 & TRN & \\
\hline CHEMBL1520081 & 688267 & 5.6 & 5.0546 & TRN & \\
\hline CHEMBL1536524 & 688267 & 6.2 & 5.0114 & TRN & \\
\hline CHEMBL1460674 & 688267 & 5.55 & 5.0652 & TRN & \\
\hline CHEMBL1535587 & 688267 & 4.65 & 5.0258 & TRN & \\
\hline CHEMBL1520596 & 688267 & 6.2 & 5.0715 & TRN & \\
\hline CHEMBL1344911 & 688267 & 4.7 & 5.0395 & TRN & \\
\hline CHEMBL1325051 & 688267 & 6.15 & 5.0395 & TRN & \\
\hline CHEMBL1549981 & 688267 & 5.8 & 5.0367 & TRN & \\
\hline CHEMBL1435461 & 688267 & 6.1 & 5.0537 & TRN & \\
\hline CHEMBL1305407 & 688267 & 5.25 & 5.0265 & TRN & \\
\hline CHEMBL1593678 & 688267 & 6.25 & 4.9595 & TRN & \\
\hline CHEMBL1573636 & 688267 & 4.35 & 5.0097 & TRN & \\
\hline CHEMBL1605209 & 688267 & 4.0 & 5.0012 & TRN & \\
\hline CHEMBL3199918 & 688267 & 4.05 & 5.0303 & TRN & \\
\hline CHEMBL1446094 & 688267 & 4.05 & 5.0218 & TRN & \\
\hline CHEMBL1368869 & 688267 & 6.0 & 5.0695 & TRN & \\
\hline CHEMBL1613693 & 688267 & 4.0 & 4.9998 & TST & \\
\hline CHEMBL1516123 & 688267 & 4.15 & 5.0144 & TRN & \\
\hline CHEMBL1438825 & 688267 & 4.05 & 5.0913 & TRN & \\
\hline CHEMBL1612937 & 688267 & 4.9 & 5.0284 & TRN & \\
\hline CHEMBL1361722 & 688267 & 5.6 & 5.008 & TRN & \\
\hline CHEMBL1611282 & 688267 & 4.75 & 5.03100 & 0000000001 & TST \\
\hline CHEMBL1595820 & 688267 & 4.2 & 5.035 & TRN & \\
\hline CHEMBL1450331 & 688267 & 6.0 & 5.0147 & TRN & \\
\hline CHEMBL1582315 & 688267 & 4.4 & 5.0591 & TRN & \\
\hline CHEMBL1425990 & 688267 & 4.0 & 4.9716 & TST & \\
\hline CHEMBL1308598 & 688267 & 5.65 & 5.0282 & TST & \\
\hline CHEMBL1540838 & 688267 & 4.0 & 5.06800 & 00000000005 & TRN \\
\hline CHEMBL1397864 & 688267 & 4.4 & 5.0517 & TRN & \\
\hline CHEMBL1521198 & 688267 & 4.35 & 5.022 & TRN & \\
\hline CHEMBL3214162 & 688267 & 4.4 & 5.0128 & TRN & \\
\hline CHEMBL1514284 & 688267 & 6.15 & 5.1194 & TRN & \\
\hline CHEMBL1596307 & 688267 & 3.95 & 5.1459 & TRN & \\
\hline CHEMBL1325523 & 688267 & 4.25 & 5.0328 & TST & \\
\hline CHEMBL1576838 & 688267 & 4.1 & 5.0356 & TRN & \\
\hline CHEMBL1447728 & 688267 & 6.2 & 5.0635 & TRN & \\
\hline CHEMBL1470954 & 688267 & 5.2 & 5.0302 & TRN & \\
\hline CHEMBL1529136 & 688267 & 4.35 & 5.0725 & TST & \\
\hline CHEMBL1373806 & 688267 & 4.9 & 5.063 & TST & \\
\hline CHEMBL1583056 & 688267 & 6.25 & 5.0238 & TST & \\
\hline CHEMBL1548557 & 688267 & 4.4 & 5.1033 & TRN & \\
\hline CHEMBL1434658 & 688267 & 4.1 & 5.0656 & TRN & \\
\hline CHEMBL1480338 & 688267 & 5.3 & 5.0736 & TRN & \\
\hline CHEMBL1380455 & 688267 & 4.65 & 5.0451 & TRN & \\
\hline CHEMBL1499766 & 688267 & 4.3 & 5.1323 & TRN & \\
\hline
\end{tabular}




\begin{tabular}{|c|c|c|c|c|}
\hline & & & pplement & al $\mathrm{Ta}$ \\
\hline CHEMBL1496666 & 688267 & 4.3 & 5.0956 & TRN \\
\hline CHEMBL1581374 & 688267 & 4.05 & 5.016 & TRN \\
\hline CHEMBL1348713 & 688267 & 3.95 & 5.1151 & TRN \\
\hline CHEMBL1509223 & 688267 & 4.4 & 5.0984 & TRN \\
\hline CHEMBL1494853 & 688267 & 6.5 & 5.13 & TRN \\
\hline CHEMBL1435758 & 688267 & 4.0 & 5.0935 & TRN \\
\hline CHEMBL1418790 & 688267 & 4.8 & 5.0272 & TRN \\
\hline CHEMBL1579174 & 688267 & 5.15 & 5.0551 & TRN \\
\hline CHEMBL1314632 & 688267 & 4.2 & 5.0047 & TRN \\
\hline CHEMBL1480773 & 688267 & 5.8 & 5.08 & TRN \\
\hline CHEMBL1381464 & 688267 & 6.0 & 5.0649 & TRN \\
\hline CHEMBL1365210 & 688267 & 4.45 & 5.0653 & TRN \\
\hline CHEMBL1397540 & 688267 & 4.95 & 5.0649 & TST \\
\hline CHEMBL1465277 & 688267 & 3.95 & 5.0312 & TRN \\
\hline CHEMBL1482366 & 688267 & 6.25 & 5.0173 & TRN \\
\hline CHEMBL1567816 & 688267 & 4.95 & 5.012 & TRN \\
\hline CHEMBL1408167 & 688267 & 3.95 & 5.0408 & TST \\
\hline CHEMBL1443382 & 688267 & 5.85 & 5.0843 & TRN \\
\hline CHEMBL1583787 & 688267 & 5.35 & 5.0295 & TRN \\
\hline CHEMBL1367517 & 688267 & 4.05 & 5.0258 & TRN \\
\hline CHEMBL1403236 & 688267 & 4.45 & 5.0124 & TST \\
\hline CHEMBL1467684 & 688267 & 5.4 & 5.0203 & TRN \\
\hline CHEMBL1435603 & 688267 & 4.55 & 5.0488 & TRN \\
\hline CHEMBL1489710 & 688267 & 4.5 & 5.0442 & TST \\
\hline CHEMBL1521927 & 688267 & 3.95 & 5.0249 & TRN \\
\hline CHEMBL1303555 & 688267 & 5.05 & 5.045 & TRN \\
\hline CHEMBL1565300 & 688267 & 6.2 & 5.0804 & TRN \\
\hline CHEMBL1585265 & 688267 & 4.0 & 5.1555 & TRN \\
\hline CHEMBL1458954 & 688267 & 5.55 & 5.0697 & TRN \\
\hline CHEMBL1344949 & 688267 & 4.45 & 5.096 & TRN \\
\hline CHEMBL1588633 & 688267 & 5.25 & 5.0239 & TRN \\
\hline CHEMBL1516693 & 688267 & 4.7 & 5.0527 & TST \\
\hline CHEMBL1474631 & 688267 & 3.95 & 5.0813 & TRN \\
\hline CHEMBL1331559 & 688267 & 5.25 & 5.0868 & TRN \\
\hline CHEMBL1471667 & 688267 & 5.3 & 5.0738 & TRN \\
\hline CHEMBL1574590 & 688267 & 6.15 & 5.0459 & TRN \\
\hline CHEMBL3199019 & 688267 & 3.9 & 5.0113 & TRN \\
\hline CHEMBL1386858 & 688267 & 6.6 & 5.0819 & TST \\
\hline CHEMBL1255976 & 688267 & 3.95 & 5.0303 & TRN \\
\hline CHEMBL1596830 & 688267 & 4.8 & 5.099 & TST \\
\hline CHEMBL1472689 & 688267 & 4.35 & 5.0992 & TRN \\
\hline CHEMBL1601406 & 688267 & 5.85 & 5.0408 & TRN \\
\hline CHEMBL1562623 & 688267 & 5.55 & 5.0149 & TST \\
\hline CHEMBL1563850 & 688267 & 5.05 & 5.038 & TST \\
\hline CHEMBL1428047 & 688267 & 5.15 & 5.0387 & TRN \\
\hline CHEMBL1451909 & 688267 & 4.65 & 5.1166 & TST \\
\hline CHEMBL3192410 & 688267 & 4.35 & 5.0268 & TRN \\
\hline CHEMBL1476282 & 688267 & 5.35 & 5.0915 & TRN \\
\hline
\end{tabular}




\begin{tabular}{|c|c|c|c|c|c|}
\hline \\
\hline CHEMBL1340076 & 688267 & 6.2 & 5.0367 & TST & \\
\hline CHEMBL1344380 & 688267 & 5.3 & 5.0508 & TST & \\
\hline CHEMBL1583376 & 688267 & 4.6 & 5.0626 & TRN & \\
\hline CHEMBL1320381 & 688267 & 4.5 & 5.0902 & TRN & \\
\hline CHEMBL1376851 & 688267 & 4.7 & 5.0683 & TST & \\
\hline CHEMBL1468733 & 688267 & 5.35 & 4.9908 & TST & \\
\hline CHEMBL1606195 & 688267 & 6.2 & 5.1088 & TST & \\
\hline CHEMBL1464232 & 688267 & 5.25 & 5.1066 & TRN & \\
\hline CHEMBL1590500 & 688267 & 3.95 & 5.0527 & TRN & \\
\hline CHEMBL1430830 & 688267 & 4.3 & 5.1414 & TRN & \\
\hline CHEMBL1492889 & 688267 & 5.3 & 5.0451 & TRN & \\
\hline CHEMBL1468356 & 688267 & 6.5 & 5.0265 & TRN & \\
\hline CHEMBL1491111 & 688267 & 5.5 & 5.1313 & TRN & \\
\hline CHEMBL1381143 & 688267 & 6.2 & 5.0089 & TRN & \\
\hline CHEMBL1368130 & 688267 & 4.0 & 4.9991 & TRN & \\
\hline CHEMBL1410387 & 688267 & 6.2 & 5.0761 & TRN & \\
\hline CHEMBL1379900 & 688267 & 5.3 & 5.0429 & TRN & \\
\hline CHEMBL1525806 & 688267 & 4.55 & 5.0945 & TRN & \\
\hline CHEMBL1551482 & 688267 & 4.55 & 5.1306 & TRN & \\
\hline CHEMBL1471880 & 688267 & 5.45 & 5.0677 & TRN & \\
\hline CHEMBL1308232 & 688267 & 4.0 & 5.0234 & TRN & \\
\hline CHEMBL1415289 & 688267 & 4.4 & 5.0226 & TRN & \\
\hline CHEMBL1517915 & 688267 & 5.95 & 4.9897 & TRN & \\
\hline CHEMBL1556380 & 688267 & 5.0 & 5.0718 & TST & \\
\hline CHEMBL1457325 & 688267 & 4.05 & 5.0389 & TRN & \\
\hline CHEMBL1514207 & 688267 & 3.95 & 5.0464 & TRN & \\
\hline CHEMBL1337116 & 688267 & 4.05 & 5.0177 & TRN & \\
\hline CHEMBL1437603 & 688267 & 4.55 & 5.0585 & TRN & \\
\hline CHEMBL1574973 & 688267 & 6.2 & 5.0717 & TRN & \\
\hline CHEMBL1561351 & 688267 & 4.0 & 5.0774 & TRN & \\
\hline CHEMBL1494374 & 688267 & 6.05 & 5.048 & TRN & \\
\hline CHEMBL1526056 & 688267 & 5.0 & 5.0344 & TRN & \\
\hline CHEMBL1577623 & 688267 & 4.0 & 5.026 & TST & \\
\hline CHEMBL1350160 & 688267 & 5.0 & 5.0741 & TST & \\
\hline CHEMBL1331152 & 688267 & 5.0 & 5.0146 & TST & \\
\hline CHEMBL1455900 & 688267 & 4.0 & $5.0360 e$ & 20000000005 & TRN \\
\hline CHEMBL1394880 & 688267 & 5.95 & 5.0648 & TRN & \\
\hline CHEMBL1347435 & 688267 & 5.55 & 5.0167 & TST & \\
\hline CHEMBL1551755 & 688267 & 5.85 & 5.0632 & TRN & \\
\hline CHEMBL1309065 & 688267 & 4.3 & 5.0361 & TST & \\
\hline CHEMBL1334005 & 688267 & 4.9 & 5.042 & TRN & \\
\hline CHEMBL1505212 & 688267 & 5.85 & 5.0562 & TRN & \\
\hline CHEMBL1512430 & 688267 & 4.5 & 5.0628 & TRN & \\
\hline CHEMBL1498018 & 688267 & 5.95 & 5.1178 & TST & \\
\hline CHEMBL1462342 & 688267 & 4.7 & 5.1039 & TRN & \\
\hline CHEMBL1486698 & 688267 & 4.4 & 5.1007 & TRN & \\
\hline CHEMBL1480521 & 688267 & 6.25 & 5.0662 & TRN & \\
\hline CHEMBL 3212240 & 688267 & 5.35 & 4.9798 & TRN & \\
\hline
\end{tabular}




\begin{tabular}{|c|c|c|c|c|}
\hline & & & pplement & al $\mathrm{Ta}$ \\
\hline CHEMBL1594225 & 688267 & 4.85 & 5.0266 & TST \\
\hline CHEMBL1604319 & 688267 & 5.55 & 5.1132 & TRN \\
\hline CHEMBL1391312 & 688267 & 3.95 & 5.0854 & TRN \\
\hline CHEMBL1519452 & 688267 & 4.0 & 5.0232 & TRN \\
\hline CHEMBL1576762 & 688267 & 4.55 & 5.0835 & TST \\
\hline CHEMBL1397052 & 688267 & 5.95 & 5.1019 & TRN \\
\hline CHEMBL1575284 & 688267 & 4.35 & 5.0176 & TRN \\
\hline CHEMBL1550941 & 688267 & 4.0 & 5.0024 & TRN \\
\hline CHEMBL1385899 & 688267 & 5.0 & 5.056 & TST \\
\hline CHEMBL1433458 & 688267 & 4.0 & 5.0454 & TRN \\
\hline CHEMBL1428356 & 688267 & 4.0 & 5.1209 & TRN \\
\hline CHEMBL1424956 & 688267 & 5.3 & 5.0947 & TRN \\
\hline CHEMBL1358715 & 688267 & 4.7 & 5.1164 & TST \\
\hline CHEMBL1332374 & 688267 & 5.4 & 5.1168 & TRN \\
\hline CHEMBL1460826 & 688267 & 5.5 & 5.0052 & TRN \\
\hline CHEMBL592838 & 688267 & 6.25 & 5.1104 & TRN \\
\hline CHEMBL1579180 & 688267 & 5.35 & 5.0804 & TRN \\
\hline CHEMBL1357068 & 688267 & 4.05 & 5.0142 & TRN \\
\hline CHEMBL1470710 & 688267 & 4.3 & 5.1227 & TRN \\
\hline CHEMBL1378664 & 688267 & 4.35 & 5.1122 & TRN \\
\hline CHEMBL3211924 & 688267 & 6.15 & 5.0455 & TST \\
\hline CHEMBL1317243 & 688267 & 6.15 & 5.0654 & TRN \\
\hline CHEMBL1580517 & 688267 & 4.0 & 5.0619 & TRN \\
\hline CHEMBL1548819 & 688267 & 4.1 & 5.1131 & TRN \\
\hline CHEMBL1422317 & 688267 & 5.1 & 5.0628 & TRN \\
\hline CHEMBL1433671 & 688267 & 4.2 & 5.0844 & TRN \\
\hline CHEMBL1596419 & 688267 & 3.95 & 5.0954 & TST \\
\hline CHEMBL1573006 & 688267 & 4.6 & 5.0759 & TRN \\
\hline CHEMBL1494380 & 688267 & 4.35 & 5.1359 & TRN \\
\hline CHEMBL1609171 & 688267 & 6.2 & 4.9687 & TRN \\
\hline CHEMBL1548845 & 688267 & 4.05 & 5.0475 & TRN \\
\hline CHEMBL1304327 & 688267 & 5.25 & 5.0901 & TST \\
\hline CHEMBL1562974 & 688267 & 4.6 & 5.0187 & TRN \\
\hline CHEMBL1595052 & 688267 & 4.0 & 5.0509 & TST \\
\hline CHEMBL1514491 & 688267 & 6.2 & 5.083 & TRN \\
\hline CHEMBL1342636 & 688267 & 4.65 & 5.0324 & TST \\
\hline CHEMBL1310673 & 688267 & 4.3 & 5.0172 & TRN \\
\hline CHEMBL1553309 & 688267 & 6.15 & 5.0366 & TRN \\
\hline CHEMBL1483931 & 688267 & 6.15 & 5.0958 & TRN \\
\hline CHEMBL1491937 & 688267 & 5.25 & 5.065 & TRN \\
\hline CHEMBL1589458 & 688267 & 4.35 & 5.0778 & TST \\
\hline CHEMBL1404336 & 688267 & 4.0 & 5.029 & TRN \\
\hline CHEMBL1372697 & 688267 & 4.05 & 5.0616 & TRN \\
\hline CHEMBL590914 & 688267 & 6.2 & 5.0897 & TRN \\
\hline CHEMBL1560171 & 688267 & 5.75 & 5.0642 & TRN \\
\hline CHEMBL1422035 & 688267 & 5.25 & 5.0803 & TRN \\
\hline CHEMBL1612617 & 688267 & 5.85 & 5.1124 & TRN \\
\hline CHEMBL1406765 & 688267 & 6.45 & 5.0754 & TRN \\
\hline
\end{tabular}




\begin{tabular}{|c|c|c|c|c|c|}
\hline \multicolumn{6}{|c|}{ Supplemental Table s2.txt } \\
\hline CHEMBL1457723 & 688267 & 6.2 & 5.0463 & TST & \\
\hline CHEMBL1358486 & 688267 & 6.2 & 5.0122 & TRN & \\
\hline CHEMBL478 & 688267 & 5.75 & 5.0861 & TRN & \\
\hline CHEMBL1476150 & 688267 & 6.2 & 5.0705 & TRN & \\
\hline CHEMBL1442443 & 688267 & 4.0 & 5.0769 & TRN & \\
\hline CHEMBL1449799 & 688267 & 4.7 & 5.0109 & TST & \\
\hline CHEMBL1603494 & 688267 & 5.25 & 5.0925 & TRN & \\
\hline CHEMBL1447705 & 688267 & 5.25 & 5.0523 & TST & \\
\hline CHEMBL1414274 & 688267 & 5.2 & 5.1046 & TST & \\
\hline CHEMBL1299991 & 688267 & 5.75 & 4.9883 & TST & \\
\hline CHEMBL1417572 & 688267 & 5.0 & 5.1468 & TRN & \\
\hline CHEMBL1603992 & 688267 & 4.15 & 5.0521 & TRN & \\
\hline CHEMBL1496328 & 688267 & 4.5 & 5.1121 & TST & \\
\hline CHEMBL1342736 & 688267 & 4.3 & 5.0273 & TST & \\
\hline CHEMBL596271 & 688267 & 4.55 & 5.0708 & TRN & \\
\hline CHEMBL1611144 & 688267 & 6.2 & 5.12299 & 9999999999 & TRN \\
\hline CHEMBL1364574 & 688267 & 6.25 & 5.0437 & TST & \\
\hline CHEMBL1560167 & 688267 & 5.75 & 5.1056 & TRN & \\
\hline CHEMBL1367295 & 688267 & 4.05 & 5.0045 & TST & \\
\hline CHEMBL1569284 & 688267 & 4.35 & 5.0046 & TST & \\
\hline CHEMBL1353004 & 688267 & 5.7 & 5.0104 & TRN & \\
\hline CHEMBL1361239 & 688267 & 5.05 & 5.0919 & TRN & \\
\hline CHEMBL1461743 & 688267 & 6.2 & 5.0866 & TRN & \\
\hline CHEMBL1552638 & 688267 & 5.35 & 5.0429 & TRN & \\
\hline CHEMBL1491259 & 688267 & 5.0 & 5.0718 & TRN & \\
\hline CHEMBL1535647 & 688267 & 5.55 & 5.0575 & TRN & \\
\hline CHEMBL1446833 & 688267 & 5.1 & 5.153 & TRN & \\
\hline CHEMBL1521256 & 688267 & 5.3 & 5.013 & TRN & \\
\hline CHEMBL1328355 & 688267 & 4.05 & 5.0131 & TRN & \\
\hline CHEMBL1590881 & 688267 & 4.0 & 4.9978 & TRN & \\
\hline CHEMBL1540913 & 688267 & 4.35 & 5.0937 & TST & \\
\hline CHEMBL1561621 & 688267 & 4.95 & 5.0426 & TRN & \\
\hline CHEMBL1436482 & 688267 & 4.0 & 5.0044 & TRN & \\
\hline CHEMBL1564667 & 688267 & 4.6 & 5.051 & TST & \\
\hline CHEMBL1560827 & 688267 & 6.2 & 5.1017 & TRN & \\
\hline CHEMBL1359978 & 688267 & 5.3 & 5.0228 & TRN & \\
\hline CHEMBL1343005 & 688267 & 4.1 & 5.0842 & TRN & \\
\hline CHEMBL1562801 & 688267 & 6.2 & 5.0319 & TST & \\
\hline CHEMBL1431627 & 688267 & 3.95 & 5.0648 & TRN & \\
\hline CHEMBL1584737 & 688267 & 5.6 & 5.1059 & TRN & \\
\hline CHEMBL1555914 & 688267 & 4.3 & 5.0946 & TST & \\
\hline CHEMBL1554617 & 688267 & 4.55 & 5.0403 & TST & \\
\hline CHEMBL1585187 & 688267 & 5.35 & 5.0136 & TRN & \\
\hline CHEMBL1604986 & 688267 & 5.55 & 5.0423 & TRN & \\
\hline CHEMBL1449094 & 688267 & 4.0 & 5.0249 & TST & \\
\hline CHEMBL1520583 & 688267 & 6.25 & 5.0772 & TST & \\
\hline CHEMBL1564312 & 688267 & 3.7 & 5.0577 & TRN & \\
\hline CHEMBL1606642 & 688267 & 6.2 & 5.0864 & TRN & \\
\hline
\end{tabular}




\begin{tabular}{|c|c|c|c|c|c|}
\hline \multicolumn{6}{|c|}{ Supplemental Table S2.txt } \\
\hline CHEMBL1328195 & 688267 & 4.0 & 5.0617 & TST & \\
\hline CHEMBL3212004 & 688267 & 4.35 & 5.0333 & TST & \\
\hline CHEMBL1354630 & 688267 & 4.35 & 5.0059 & TST & \\
\hline CHEMBL1491096 & 688267 & 5.8 & 5.1323 & TRN & \\
\hline CHEMBL1559251 & 688267 & 5.45 & 5.0134 & TRN & \\
\hline CHEMBL1602716 & 688267 & 6.25 & 4.9735 & TRN & \\
\hline CHEMBL1612321 & 688267 & 5.45 & 5.0776 & TST & \\
\hline CHEMBL1311760 & 688267 & 4.6 & 5.0588 & TRN & \\
\hline CHEMBL1354374 & 688267 & 4.6 & 5.011 & TST & \\
\hline CHEMBL1464871 & 688267 & 5.7 & 5.0662 & TRN & \\
\hline CHEMBL1409057 & 688267 & 4.35 & 5.0502 & TRN & \\
\hline CHEMBL 1446500 & 688267 & 5.85 & 5.0826 & TRN & \\
\hline CHEMBL1386453 & 688267 & 4.0 & 5.0592 & TRN & \\
\hline CHEMBL1434716 & 688267 & 3.95 & 5.0687 & TST & \\
\hline CHEMBL1324936 & 688267 & 4.4 & 5.1328 & TRN & \\
\hline CHEMBL1592321 & 688267 & 4.1 & 5.0675 & TRN & \\
\hline CHEMBL1599385 & 688267 & 4.05 & 5.0889 & TRN & \\
\hline CHEMBL1320107 & 688267 & 3.95 & 5.1289 & TRN & \\
\hline CHEMBL1528554 & 688267 & 5.35 & 5.0843 & TRN & \\
\hline CHEMBL1438004 & 688267 & 5.55 & 5.0692 & TRN & \\
\hline CHEMBL1394381 & 688267 & 4.2 & 4.9817 & TRN & \\
\hline CHEMBL1514361 & 688267 & 5.0 & 5.07100 & 0000000001 & TST \\
\hline CHEMBL1556062 & 688267 & 5.05 & 5.038 & TST & \\
\hline CHEMBL1301079 & 688267 & 5.35 & 5.1343 & TRN & \\
\hline CHEMBL3211579 & 688267 & 5.55 & 5.0668 & TRN & \\
\hline CHEMBL1510846 & 688267 & 6.25 & 5.1452 & TST & \\
\hline CHEMBL1316544 & 688267 & 6.25 & 5.0436 & TRN & \\
\hline CHEMBL1433297 & 688267 & 4.4 & 5.0202 & TRN & \\
\hline CHEMBL1317117 & 688267 & 5.6 & 5.0217 & TST & \\
\hline CHEMBL1334370 & 688267 & 5.3 & 5.0341 & TRN & \\
\hline CHEMBL1536106 & 688267 & 5.35 & 5.09399 & 9999999999 & TST \\
\hline CHEMBL1538841 & 688267 & 5.8 & 4.9673 & TRN & \\
\hline CHEMBL1466265 & 688267 & 6.7501 & 5.0742 & TST & \\
\hline CHEMBL1598755 & 688267 & 4.0 & 5.0601 & TRN & \\
\hline CHEMBL1517878 & 688267 & 4.0 & 5.0833 & TRN & \\
\hline CHEMBL1537510 & 688267 & 4.1 & 5.0011 & TST & \\
\hline CHEMBL1535362 & 688267 & 4.4 & 5.0978 & TRN & \\
\hline CHEMBL1410981 & 688267 & 5.45 & 5.0883 & TRN & \\
\hline CHEMBL1533081 & 688267 & 4.25 & 5.0226 & TST & \\
\hline CHEMBL1305634 & 688267 & 5.85 & 5.1179 & TRN & \\
\hline CHEMBL1502861 & 688267 & 5.45 & 5.052 & TRN & \\
\hline CHEMBL1478448 & 688267 & 4.0 & 5.1245 & TST & \\
\hline CHEMBL1556653 & 688267 & 4.4 & 5.0855 & TRN & \\
\hline CHEMBL1369269 & 688267 & 6.2 & 5.0868 & TST & \\
\hline CHEMBL1479187 & 688267 & 5.05 & 5.0525 & TRN & \\
\hline CHEMBL1486166 & 688267 & 4.1 & 5.0275 & TST & \\
\hline CHEMBL1500500 & 688267 & 4.85 & 5.063 & TRN & \\
\hline CHEMBL1352392 & 688267 & 5.3 & 5.0883 & TRN & \\
\hline
\end{tabular}




\begin{tabular}{|c|c|c|c|c|c|}
\hline \multicolumn{6}{|c|}{ Supplemental Table S2.txt } \\
\hline CHEMBL1493375 & 688267 & 4.35 & 5.1031 & TST & \\
\hline CHEMBL1353355 & 688267 & 5.35 & 5.0502 & TRN & \\
\hline CHEMBL1486430 & 688267 & 4.3 & 5.0369 & TST & \\
\hline CHEMBL1421857 & 688267 & 6.15 & 5.1021 & TST & \\
\hline CHEMBL1405503 & 688267 & 5.75 & 5.0369 & TRN & \\
\hline CHEMBL1569951 & 688267 & 4.5 & 5.0393 & TRN & \\
\hline CHEMBL1547073 & 688267 & 6.2 & 5.0767 & TRN & \\
\hline CHEMBL1569580 & 688267 & 4.1 & 5.0347 & TRN & \\
\hline CHEMBL1517657 & 688267 & 4.0 & 5.07100 & 2000000001 & TRN \\
\hline CHEMBL1528742 & 688267 & 5.55 & 4.9984 & TRN & \\
\hline CHEMBL1456093 & 688267 & 5.8 & 5.0797 & TST & \\
\hline CHEMBL3194964 & 688267 & 6.15 & 5.0706 & TST & \\
\hline CHEMBL1349204 & 688267 & 4.9 & 4.9953 & TRN & \\
\hline CHEMBL1386790 & 688267 & 4.15 & 5.0391 & TST & \\
\hline CHEMBL1380157 & 688267 & 5.3 & 5.0807 & TRN & \\
\hline CHEMBL1430740 & 688267 & 4.0 & 5.0097 & TST & \\
\hline CHEMBL1491525 & 688267 & 4.1 & 5.1222 & TRN & \\
\hline CHEMBL1543594 & 688267 & 4.55 & 5.0728 & TST & \\
\hline CHEMBL1447191 & 688267 & 4.05 & 5.0468 & TST & \\
\hline CHEMBL1365433 & 688267 & 6.2 & 5.0018 & TST & \\
\hline CHEMBL1543148 & 688267 & 4.45 & 5.0331 & TRN & \\
\hline CHEMBL1570907 & 688267 & 5.4 & 5.0621 & TST & \\
\hline CHEMBL1483847 & 688267 & 4.05 & 4.9837 & TRN & \\
\hline CHEMBL1361198 & 688267 & 5.05 & 5.0524 & TST & \\
\hline CHEMBL1356214 & 688267 & 4.65 & 5.0878 & TRN & \\
\hline CHEMBL1299614 & 688267 & 6.2 & 5.0681 & TRN & \\
\hline CHEMBL1469626 & 688267 & 4.05 & 5.0018 & TRN & \\
\hline CHEMBL1307339 & 688267 & 6.05 & 5.0638 & TRN & \\
\hline CHEMBL1539858 & 688267 & 6.15 & 5.0999 & TRN & \\
\hline CHEMBL1507383 & 688267 & 6.2 & 5.0258 & TRN & \\
\hline CHEMBL1494716 & 688267 & 4.0 & 5.0401 & TRN & \\
\hline CHEMBL1428333 & 688267 & 3.95 & 5.0766 & TRN & \\
\hline CHEMBL1330523 & 688267 & 4.9 & 5.0517 & TRN & \\
\hline CHEMBL1501445 & 688267 & 4.55 & 5.0522 & TRN & \\
\hline CHEMBL1459549 & 688267 & 4.6 & 5.0646 & TRN & \\
\hline CHEMBL1340302 & 688267 & 5.3 & 5.0673 & TRN & \\
\hline CHEMBL1304550 & 688267 & 4.65 & 5.1137 & TRN & \\
\hline CHEMBL1368173 & 688267 & 5.85 & 5.0464 & TRN & \\
\hline CHEMBL1522498 & 688267 & 5.85 & 5.0352 & TRN & \\
\hline CHEMBL1336584 & 688267 & 5.55 & 5.1085 & TRN & \\
\hline CHEMBL1512305 & 688267 & 5.3 & 5.0845 & TST & \\
\hline CHEMBL1515737 & 688267 & 5.45 & 5.0359 & TRN & \\
\hline CHEMBL1486397 & 688267 & 5.0 & 5.0266 & TRN & \\
\hline CHEMBL1525124 & 688267 & 4.4 & 5.1225 & TRN & \\
\hline CHEMBL 3207758 & 688267 & 4.4 & 5.0505 & TST & \\
\hline CHEMBL1307061 & 688267 & 4.9 & 5.0048 & TST & \\
\hline CHEMBL1597759 & 688267 & 4.35 & 5.0257 & TRN & \\
\hline CHEMBL1582832 & 688267 & 5.25 & 5.1391 & TRN & \\
\hline
\end{tabular}




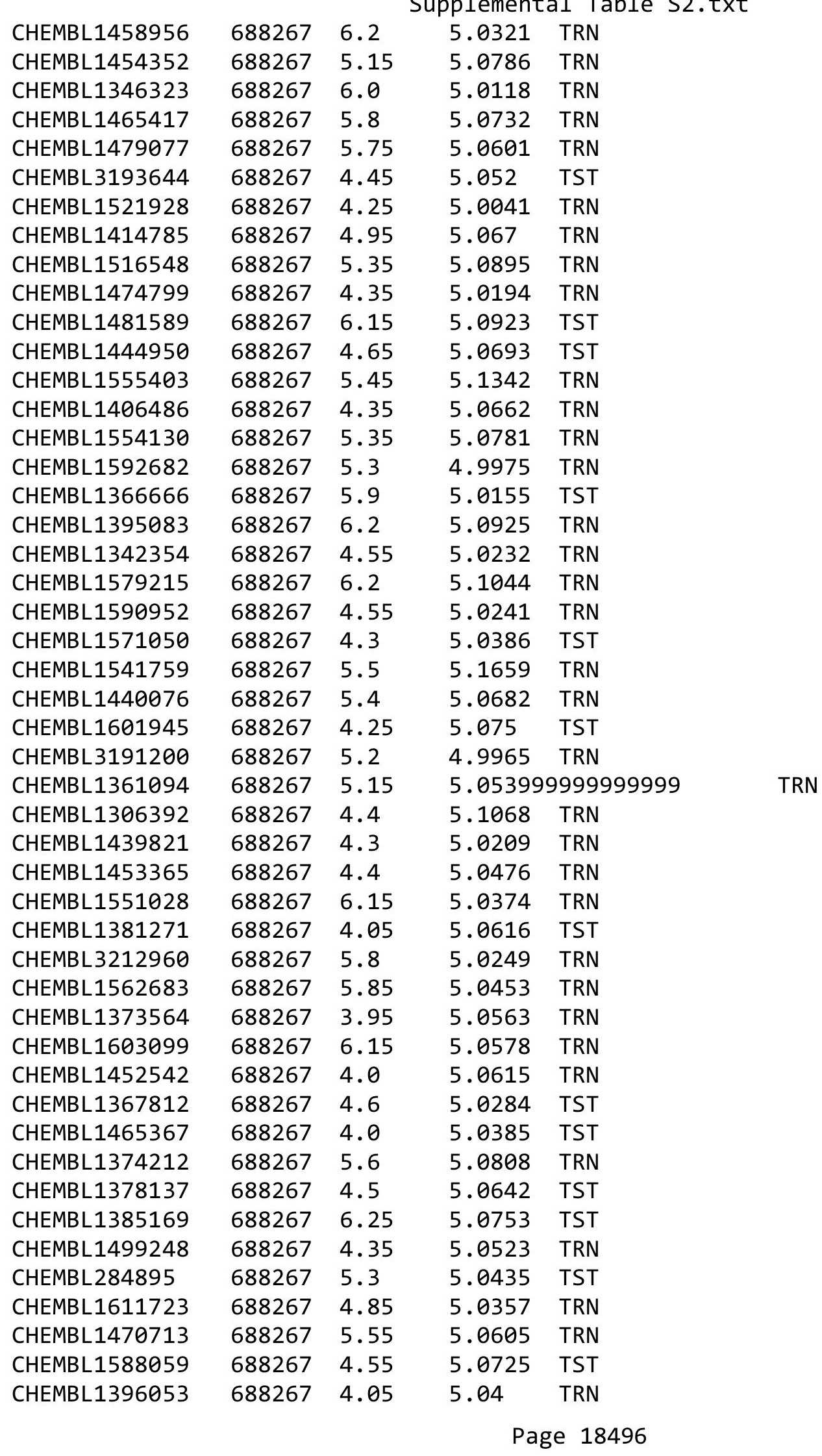




\begin{tabular}{|c|c|c|c|c|c|}
\hline \multicolumn{6}{|c|}{ Supplemental Table S2.txt } \\
\hline CHEMBL1365915 & 688267 & 5.6 & 5.0442 & TRN & \\
\hline CHEMBL1301256 & 688267 & 4.55 & 5.0884 & TST & \\
\hline CHEMBL1317190 & 688267 & 5.15 & 5.0874 & TRN & \\
\hline CHEMBL1520957 & 688267 & 5.1 & 5.0566 & TRN & \\
\hline CHEMBL1403136 & 688267 & 6.2 & 5.0053 & TST & \\
\hline CHEMBL3194354 & 688267 & 5.55 & 5.041 & TST & \\
\hline CHEMBL1409646 & 688267 & 5.65 & 5.0448 & TRN & \\
\hline CHEMBL469977 & 688267 & 5.1 & 5.0178 & TRN & \\
\hline CHEMBL 3212148 & 688267 & 5.55 & 5.0283 & TST & \\
\hline CHEMBL1449341 & 688267 & 3.95 & 5.1964 & TST & \\
\hline CHEMBL1523373 & 688267 & 5.8 & 5.0224 & TST & \\
\hline CHEMBL1430335 & 688267 & 6.2 & 5.0168 & TRN & \\
\hline CHEMBL1543053 & 688267 & 5.35 & 5.0651 & TRN & \\
\hline CHEMBL1418058 & 688267 & 4.65 & 5.0444 & TRN & \\
\hline CHEMBL1422703 & 688267 & 5.65 & 5.0399 & TRN & \\
\hline CHEMBL3210671 & 688267 & 4.2 & 5.0631 & TST & \\
\hline CHEMBL1423171 & 688267 & 4.55 & 5.0667 & TRN & \\
\hline CHEMBL1475305 & 688267 & 6.05 & 5.1498 & TST & \\
\hline CHEMBL1502659 & 688267 & 4.95 & 5.1079 & TRN & \\
\hline CHEMBL1526502 & 688267 & 4.4 & 5.0285 & TRN & \\
\hline CHEMBL1501564 & 688267 & 4.25 & 5.066 & TRN & \\
\hline CHEMBL1591172 & 688267 & 5.35 & 5.1287 & TST & \\
\hline CHEMBL1516944 & 688267 & 4.3 & 5.0568 & TRN & \\
\hline CHEMBL1354182 & 688267 & 4.75 & 5.07 & TST & \\
\hline CHEMBL1310364 & 688267 & 6.5 & 5.0321 & TRN & \\
\hline CHEMBL1372218 & 688267 & 4.0 & 5.0564 & TRN & \\
\hline CHEMBL1358240 & 688267 & 6.2 & 5.0685 & TRN & \\
\hline CHEMBL1369141 & 688267 & 5.55 & 5.02800 & 00000000005 & TRN \\
\hline CHEMBL1406070 & 688267 & 6.2 & 5.1272 & TRN & \\
\hline CHEMBL1543097 & 688267 & 6.15 & 5.0001 & TRN & \\
\hline CHEMBL1473676 & 688267 & 5.3 & 5.0046 & TRN & \\
\hline CHEMBL1479301 & 688267 & 6.1 & 4.9995 & TRN & \\
\hline CHEMBL1313839 & 688267 & 4.65 & 5.1105 & TRN & \\
\hline CHEMBL1480676 & 688267 & 6.2 & 5.0416 & TST & \\
\hline CHEMBL1309556 & 688267 & 5.9 & 5.0921 & TRN & \\
\hline CHEMBL1474836 & 688267 & 6.25 & 5.0162 & TST & \\
\hline CHEMBL1612785 & 688267 & 3.75 & 5.0359 & TRN & \\
\hline CHEMBL1477085 & 688267 & 4.0 & 5.0932 & TRN & \\
\hline CHEMBL1393639 & 688267 & 4.55 & 5.0645 & TRN & \\
\hline CHEMBL1445363 & 688267 & 5.55 & 5.1074 & TRN & \\
\hline CHEMBL1398362 & 688267 & 4.25 & 5.0524 & TRN & \\
\hline CHEMBL1576700 & 688267 & 4.65 & 5.0385 & TRN & \\
\hline CHEMBL3190573 & 688267 & 4.55 & 5.1042 & TRN & \\
\hline CHEMBL1346508 & 688267 & 5.55 & 5.0982 & TRN & \\
\hline CHEMBL1324862 & 688267 & 4.55 & 5.0393 & TST & \\
\hline CHEMBL1339001 & 688267 & 5.9 & 5.0515 & TRN & \\
\hline CHEMBL1548237 & 688267 & 6.2 & 5.0162 & TRN & \\
\hline CHEMBL1329088 & 688267 & 4.1 & 4.9834 & TRN & \\
\hline
\end{tabular}




\begin{tabular}{|c|c|c|c|c|c|}
\hline \\
\hline CHEMBL1314801 & 688267 & 4.0 & 5.0307 & TRN & \\
\hline CHEMBL1559685 & 688267 & 5.3 & 5.0263 & TRN & \\
\hline CHEMBL1442855 & 688267 & 4.6 & 5.1271 & TRN & \\
\hline CHEMBL1560784 & 688267 & 4.1 & 5.1141 & TST & \\
\hline CHEMBL1433670 & 688267 & 5.55 & 5.0679 & TRN & \\
\hline CHEMBL1489963 & 688267 & 3.95 & 5.0295 & TRN & \\
\hline CHEMBL1520677 & 688267 & 6.05 & 5.0941 & TST & \\
\hline CHEMBL1558205 & 688267 & 5.05 & 5.0869 & TST & \\
\hline CHEMBL1398479 & 688267 & 4.0 & 5.0463 & TRN & \\
\hline CHEMBL1537167 & 688267 & 6.2 & 5.0306 & TRN & \\
\hline CHEMBL1401738 & 688267 & 6.2 & 5.0414 & TRN & \\
\hline CHEMBL1587002 & 688267 & 5.1 & 5.0438 & TST & \\
\hline CHEMBL1511982 & 688267 & 5.9 & 5.0581 & TRN & \\
\hline CHEMBL1496225 & 688267 & 4.8 & 5.1218 & TST & \\
\hline CHEMBL1369683 & 688267 & 6.2 & 5.0645 & TRN & \\
\hline CHEMBL1448462 & 688267 & 5.85 & 5.0943 & TRN & \\
\hline CHEMBL1551975 & 688267 & 5.05 & 5.0512 & TRN & \\
\hline CHEMBL3199029 & 688267 & 6.5 & 5.0021 & TRN & \\
\hline CHEMBL1606930 & 688267 & 6.2 & 5.046 & TST & \\
\hline CHEMBL1492489 & 688267 & 5.5 & 5.0809 & TST & \\
\hline CHEMBL1561310 & 688267 & 4.35 & 5.046 & TST & \\
\hline CHEMBL1472486 & 688267 & 6.05 & 5.1392 & TRN & \\
\hline CHEMBL1477555 & 688267 & 6.15 & 5.1074 & TRN & \\
\hline CHEMBL1339999 & 688267 & 4.25 & 5.0174 & TST & \\
\hline CHEMBL1445190 & 688267 & 4.7 & 5.0509 & TST & \\
\hline CHEMBL1312208 & 688267 & 4.25 & $5.0310 e$ & $\partial 000000001$ & TST \\
\hline CHEMBL1409691 & 688267 & 4.7 & 5.1165 & TRN & \\
\hline CHEMBL1324116 & 688267 & 5.3 & 5.0393 & TRN & \\
\hline CHEMBL1541544 & 688267 & 5.3 & 5.0269 & TRN & \\
\hline CHEMBL1423028 & 688267 & 4.4 & 5.0302 & TST & \\
\hline CHEMBL1311812 & 688267 & 6.5 & 5.0749 & TST & \\
\hline CHEMBL1419334 & 688267 & 4.6 & 4.9993 & TST & \\
\hline CHEMBL1504638 & 688267 & 5.45 & 5.0229 & TST & \\
\hline CHEMBL1350844 & 688267 & 5.05 & 5.0075 & TRN & \\
\hline CHEMBL3212856 & 688267 & 6.2 & 5.0107 & TRN & \\
\hline CHEMBL1324197 & 688267 & 5.8 & 5.0254 & TRN & \\
\hline CHEMBL1371365 & 688267 & 5.3 & 5.0109 & TRN & \\
\hline CHEMBL1403768 & 688267 & 4.0 & 5.0427 & TRN & \\
\hline CHEMBL1486328 & 688267 & 4.95 & 5.0655 & TRN & \\
\hline CHEMBL1568457 & 688267 & 6.2 & 5.0268 & TRN & \\
\hline CHEMBL1578038 & 688267 & 5.25 & 5.157 & TST & \\
\hline CHEMBL1600614 & 688267 & 6.2 & 5.0297 & TRN & \\
\hline CHEMBL1420205 & 688267 & 5.35 & 5.0659 & TST & \\
\hline CHEMBL1572754 & 688267 & 4.4 & 5.0335 & TRN & \\
\hline CHEMBL1605114 & 688267 & 4.3 & 5.12799 & 9999999999 & TRN \\
\hline CHEMBL1520730 & 688267 & 5.2 & 5.0899 & TRN & \\
\hline CHEMBL1327488 & 688267 & 4.05 & 5.0731 & TST & \\
\hline CHEMBL1447783 & 688267 & 4.0 & 5.0143 & TRN & \\
\hline
\end{tabular}




\begin{tabular}{|c|c|c|c|c|c|}
\hline \multicolumn{6}{|c|}{ Supplemental Table S2.txt } \\
\hline CHEMBL1444301 & 688267 & 5.85 & 5.0667 & TRN & \\
\hline CHEMBL1445740 & 688267 & 4.05 & 5.0547 & TST & \\
\hline CHEMBL1538286 & 688267 & 4.3 & 5.0231 & TST & \\
\hline CHEMBL1477432 & 688267 & 6.2 & 5.0589 & TST & \\
\hline CHEMBL1600374 & 688267 & 5.3 & 5.056 & TRN & \\
\hline CHEMBL1541160 & 688267 & 5.9 & 5.08 & TRN & \\
\hline CHEMBL1340850 & 688267 & 4.4 & 5.0866 & TRN & \\
\hline CHEMBL1592121 & 688267 & 4.45 & 5.0983 & TRN & \\
\hline CHEMBL1590879 & 688267 & 6.2 & 5.0637 & TRN & \\
\hline CHEMBL1481272 & 688267 & 4.8 & 5.0571 & TRN & \\
\hline CHEMBL1394339 & 688267 & 4.0 & 5.0235 & TRN & \\
\hline CHEMBL57481 & 688267 & 4.6 & 5.0581 & TST & \\
\hline CHEMBL1576677 & 688267 & 4.15 & 5.0039 & TRN & \\
\hline CHEMBL1436647 & 688267 & 4.5 & 4.9997 & TRN & \\
\hline CHEMBL1408085 & 688267 & 4.1 & 5.0963 & TST & \\
\hline CHEMBL1352841 & 688267 & 4.3 & 5.0597 & TST & \\
\hline CHEMBL3189934 & 688267 & 5.45 & 5.03 & TST & \\
\hline CHEMBL1347365 & 688267 & 6.2 & 5.0349 & TRN & \\
\hline CHEMBL1352172 & 688267 & 3.95 & 5.0208 & TST & \\
\hline CHEMBL1388824 & 688267 & 4.6 & 4.9928 & TST & \\
\hline CHEMBL1416900 & 688267 & 6.2 & 5.0647 & TST & \\
\hline CHEMBL1477752 & 688267 & 4.0 & 5.0098 & TRN & \\
\hline CHEMBL1339295 & 688267 & 5.6 & 5.1409 & TST & \\
\hline CHEMBL1402687 & 688267 & 4.15 & 5.183 & TRN & \\
\hline CHEMBL1329719 & 688267 & 6.45 & 5.06 & TST & \\
\hline CHEMBL1389353 & 688267 & 5.25 & 5.085 & TRN & \\
\hline CHEMBL1474929 & 688267 & 4.0 & 4.995 & TRN & \\
\hline CHEMBL1404692 & 688267 & 4.0 & 5.0818 & TRN & \\
\hline CHEMBL1545361 & 688267 & 4.9 & 5.01699 & 99999999995 & TRN \\
\hline CHEMBL1474206 & 688267 & 4.9 & 5.08 & TRN & \\
\hline CHEMBL1328934 & 688267 & 5.25 & 5.0527 & TRN & \\
\hline CHEMBL1610388 & 688267 & 4.05 & 5.0088 & TRN & \\
\hline CHEMBL3190638 & 688267 & 5.9 & 5.0511 & TST & \\
\hline CHEMBL1401326 & 688267 & 3.95 & 5.043 & TRN & \\
\hline CHEMBL1474853 & 688267 & 4.0 & 5.0268 & TRN & \\
\hline CHEMBL1553729 & 688267 & 4.25 & 5.0148 & TRN & \\
\hline CHEMBL1326109 & 688267 & 4.0 & 5.064 & TST & \\
\hline CHEMBL1537046 & 688267 & 6.6 & 5.0544 & TRN & \\
\hline CHEMBL1433107 & 688267 & 4.55 & 5.0261 & TRN & \\
\hline CHEMBL1417426 & 688267 & 3.95 & 5.0926 & TRN & \\
\hline CHEMBL3191096 & 688267 & 5.25 & 5.0729 & TRN & \\
\hline CHEMBL1505829 & 688267 & 5.25 & 5.0993 & TST & \\
\hline CHEMBL1313866 & 688267 & 5.25 & 4.9929 & TRN & \\
\hline CHEMBL 1367416 & 688267 & 5.4 & 5.1325 & TRN & \\
\hline CHEMBL1328598 & 688267 & 6.0 & 5.018 & TRN & \\
\hline CHEMBL1314802 & 688267 & 4.4 & 5.1047 & TRN & \\
\hline CHEMBL1448367 & 688267 & 4.0 & 5.046 & TST & \\
\hline CHEMBL1486824 & 688267 & 5.3 & 5.06 & TRN & \\
\hline
\end{tabular}




\begin{tabular}{|c|c|c|c|c|c|}
\hline \multicolumn{6}{|c|}{ Supplemental Table S2.txt } \\
\hline CHEMBL1550327 & 688267 & 5.15 & 5.0789 & TST & \\
\hline CHEMBL3214334 & 688267 & 4.0 & 5.0102 & TRN & \\
\hline CHEMBL1569522 & 688267 & 5.5 & 5.0195 & TRN & \\
\hline CHEMBL1546615 & 688267 & 4.3 & 5.0259 & TRN & \\
\hline CHEMBL1361600 & 688267 & 4.85 & 5.0429 & TRN & \\
\hline CHEMBL1508193 & 688267 & 5.45 & 5.0245 & TST & \\
\hline CHEMBL1577023 & 688267 & 6.2 & 5.0084 & TRN & \\
\hline CHEMBL1344474 & 688267 & 6.2 & 5.1243 & TRN & \\
\hline CHEMBL1306544 & 688267 & 6.0 & 5.0541 & TRN & \\
\hline CHEMBL1491053 & 688267 & 5.6 & 5.0697 & TRN & \\
\hline CHEMBL1314997 & 688267 & 4.5 & 5.0769 & TRN & \\
\hline CHEMBL1576054 & 688267 & 5.2 & 5.05699 & 99999999995 & TST \\
\hline CHEMBL1515995 & 688267 & 4.0 & 5.0511 & TRN & \\
\hline CHEMBL1587920 & 688267 & 4.3 & 5.0364 & TRN & \\
\hline CHEMBL1596195 & 688267 & 5.4 & 5.0182 & TRN & \\
\hline CHEMBL1591987 & 688267 & 5.65 & 5.048 & TRN & \\
\hline CHEMBL1469067 & 688267 & 5.2 & 5.0225 & TRN & \\
\hline CHEMBL1488782 & 688267 & 3.95 & 5.0222 & TRN & \\
\hline CHEMBL1464526 & 688267 & 5.05 & 4.9937 & TST & \\
\hline CHEMBL1512811 & 688267 & 5.55 & 5.0489 & TRN & \\
\hline CHEMBL1377044 & 688267 & 4.05 & 5.0273 & TST & \\
\hline CHEMBL1393877 & 688267 & 5.35 & 5.03 & TST & \\
\hline CHEMBL1551052 & 688267 & 4.0 & 5.055 & TRN & \\
\hline CHEMBL1328814 & 688267 & 4.0 & 5.0576 & TRN & \\
\hline CHEMBL1456286 & 688267 & 4.75 & 5.022 & TST & \\
\hline CHEMBL1555282 & 688267 & 5.6 & 5.0556 & TRN & \\
\hline CHEMBL1442381 & 688267 & 4.0 & 5.074 & TRN & \\
\hline CHEMBL1493366 & 688267 & 6.15 & 5.1329 & TRN & \\
\hline CHEMBL1521180 & 688267 & 5.0 & 5.05399 & 9999999999 & TRN \\
\hline CHEMBL1454707 & 688267 & 4.25 & 5.0611 & TST & \\
\hline CHEMBL 1450174 & 688267 & 6.45 & 5.0664 & TRN & \\
\hline CHEMBL1593444 & 688267 & 4.4 & 5.0723 & TST & \\
\hline CHEMBL3212902 & 688267 & 6.15 & 5.0553 & TRN & \\
\hline CHEMBL1594083 & 688267 & 6.25 & 5.1231 & TRN & \\
\hline CHEMBL1474778 & 688267 & 3.95 & 5.1106 & TRN & \\
\hline CHEMBL1514034 & 688267 & 5.5 & 5.0281 & TRN & \\
\hline CHEMBL1475121 & 688267 & 5.3 & 5.0044 & TRN & \\
\hline CHEMBL1390388 & 688267 & 5.45 & 5.0219 & TST & \\
\hline CHEMBL1604152 & 688267 & 3.95 & 5.0576 & TST & \\
\hline CHEMBL1445988 & 688267 & 4.1 & 5.07 & TRN & \\
\hline CHEMBL1517455 & 688267 & 5.4 & 4.9994 & TRN & \\
\hline CHEMBL1316252 & 688267 & 4.25 & 5.1202 & TRN & \\
\hline CHEMBL1413417 & 688267 & 6.15 & 5.0817 & TRN & \\
\hline CHEMBL1584649 & 688267 & 4.65 & 5.0895 & TRN & \\
\hline CHEMBL1416780 & 688267 & 6.2 & 5.0399 & TRN & \\
\hline CHEMBL1599026 & 688267 & 6.25 & 5.0387 & TST & \\
\hline CHEMBL1493634 & 688267 & 4.8 & 5.0506 & TST & \\
\hline CHEMBL1593046 & 688267 & 6.1 & 5.0853 & TRN & \\
\hline
\end{tabular}




\begin{tabular}{|c|c|c|c|c|}
\hline \multicolumn{5}{|c|}{ Supplemental Table S2.txt } \\
\hline CHEMBL3199671 & 688267 & 4.1 & 5.0028 & TRN \\
\hline CHEMBL1311884 & 688267 & 5.3 & 5.0457 & TRN \\
\hline CHEMBL1493206 & 688267 & 3.95 & 5.0939 & TRN \\
\hline CHEMBL1470973 & 688267 & 4.1 & 5.0152 & TRN \\
\hline CHEMBL1580451 & 688267 & 5.95 & 5.0188 & TST \\
\hline CHEMBL1510874 & 688267 & 6.2 & 5.0517 & TST \\
\hline CHEMBL1401381 & 688267 & 4.4 & 5.055 & TRN \\
\hline CHEMBL1326738 & 688267 & 5.9 & 5.0415 & TRN \\
\hline CHEMBL1376607 & 688267 & 5.3 & 5.0732 & TRN \\
\hline CHEMBL1324676 & 688267 & 4.05 & 5.0213 & TRN \\
\hline CHEMBL1436897 & 688267 & 6.5 & 5.0566 & TRN \\
\hline CHEMBL1433738 & 688267 & 5.5 & 5.0127 & TRN \\
\hline CHEMBL1532840 & 688267 & 6.2 & 5.0736 & TRN \\
\hline CHEMBL1361046 & 688267 & 4.05 & 5.0673 & TRN \\
\hline CHEMBL1322454 & 688267 & 3.95 & 5.0239 & TRN \\
\hline CHEMBL1485594 & 688267 & 6.1 & 5.0808 & TRN \\
\hline CHEMBL3195614 & 688267 & 6.25 & 5.0522 & TRN \\
\hline CHEMBL1422712 & 688267 & 4.05 & 5.0559 & TRN \\
\hline CHEMBL1563228 & 688267 & 6.15 & 5.038 & TST \\
\hline CHEMBL1308819 & 688267 & 4.25 & 5.1185 & TRN \\
\hline CHEMBL1328446 & 688267 & 5.85 & 5.0395 & TRN \\
\hline CHEMBL1451547 & 688267 & 4.0 & 5.0404 & TRN \\
\hline CHEMBL1314104 & 688267 & 4.05 & 5.0113 & TRN \\
\hline CHEMBL1385298 & 688267 & 4.65 & 5.0813 & TST \\
\hline CHEMBL1500652 & 688267 & 5.55 & 5.0443 & TRN \\
\hline CHEMBL3198173 & 688267 & 4.05 & 5.0438 & TST \\
\hline CHEMBL3209211 & 688267 & 6.0 & 5.0177 & TRN \\
\hline CHEMBL1462016 & 688267 & 5.4 & 5.0533 & TRN \\
\hline CHEMBL1608280 & 688267 & 4.15 & 5.0143 & TRN \\
\hline CHEMBL1546587 & 688267 & 5.3 & 5.0796 & TRN \\
\hline CHEMBL1446788 & 688267 & 5.4 & 5.039 & TST \\
\hline CHEMBL1576043 & 688267 & 6.2 & 5.0764 & TRN \\
\hline CHEMBL1506678 & 688267 & 5.3 & 5.0774 & TRN \\
\hline CHEMBL1544672 & 688267 & 4.25 & 5.0171 & TST \\
\hline CHEMBL1455616 & 688267 & 4.1 & 5.0389 & TST \\
\hline CHEMBL1531788 & 688267 & 4.55 & 5.0451 & TRN \\
\hline CHEMBL1546275 & 688267 & 5.6 & 5.0288 & TST \\
\hline CHEMBL1552429 & 688267 & 6.2 & 5.0942 & TRN \\
\hline CHEMBL1446698 & 688267 & 4.6 & 5.1529 & TRN \\
\hline CHEMBL1430458 & 688267 & 6.05 & 5.0761 & TRN \\
\hline CHEMBL1381833 & 688267 & 5.75 & 5.0541 & TST \\
\hline CHEMBL1340609 & 688267 & 4.85 & 5.05 & TRN \\
\hline CHEMBL1612772 & 688267 & 5.6 & 5.0235 & TRN \\
\hline CHEMBL1512610 & 688267 & 4.0 & 5.1365 & TRN \\
\hline CHEMBL1607214 & 688267 & 5.15 & 5.0996 & TRN \\
\hline CHEMBL1359276 & 688267 & 6.0 & 5.0237 & TRN \\
\hline CHEMBL1323275 & 688267 & 4.0 & 5.0697 & TRN \\
\hline CHEMBL1610850 & 688267 & 6.15 & 5.095 & TRN \\
\hline
\end{tabular}




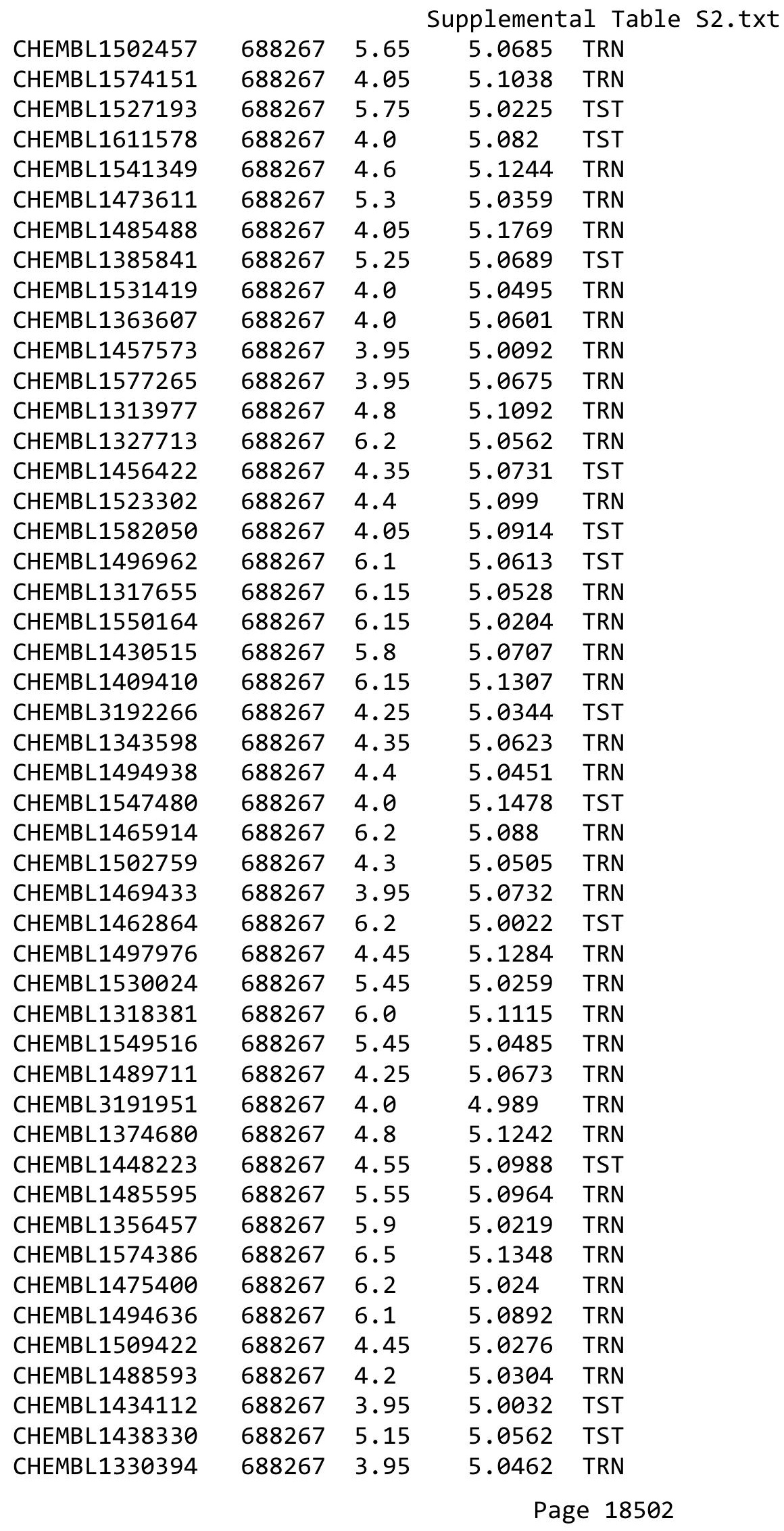




\begin{tabular}{|c|c|c|c|c|c|}
\hline \multicolumn{6}{|c|}{ oplemental Table s } \\
\hline CHEMBL1485690 & 688267 & 4.25 & 5.0172 & TRN & \\
\hline CHEMBL3189895 & 688267 & 4.0 & 5.0321 & TST & \\
\hline CHEMBL1573573 & 688267 & 5.8 & 5.0038 & TST & \\
\hline CHEMBL1474902 & 688267 & 4.4 & 5.0808 & TRN & \\
\hline CHEMBL1386959 & 688267 & 4.3 & 5.0288 & TRN & \\
\hline CHEMBL1445126 & 688267 & 5.55 & 5.0516 & TRN & \\
\hline CHEMBL1564850 & 688267 & 5.35 & 5.1255 & TRN & \\
\hline CHEMBL1422295 & 688267 & 6.0 & 4.9823 & TRN & \\
\hline CHEMBL1377305 & 688267 & 6.5501 & 5.0187 & TRN & \\
\hline CHEMBL 3197470 & 688267 & 4.35 & 5.0398 & TRN & \\
\hline CHEMBL1302956 & 688267 & 4.35 & 5.1295 & TRN & \\
\hline CHEMBL1519669 & 688267 & 6.2 & 5.0747 & TRN & \\
\hline CHEMBL1345755 & 688267 & 4.35 & 5.0204 & TRN & \\
\hline CHEMBL1377451 & 688267 & 5.6 & 5.0474 & TRN & \\
\hline CHEMBL1608449 & 688267 & 5.55 & 5.0006 & TRN & \\
\hline CHEMBL1320158 & 688267 & 4.7 & 5.0444 & TST & \\
\hline CHEMBL1592134 & 688267 & 4.0 & 5.1069 & TST & \\
\hline CHEMBL1404940 & 688267 & 4.8 & 5.0706 & TRN & \\
\hline CHEMBL1586430 & 688267 & 4.05 & 5.0842 & TRN & \\
\hline CHEMBL1515911 & 688267 & 4.05 & 5.1142 & TRN & \\
\hline CHEMBL1333609 & 688267 & 4.05 & 4.9935 & TST & \\
\hline CHEMBL1420542 & 688267 & 4.0 & 5.0513 & TST & \\
\hline CHEMBL1380170 & 688267 & 5.35 & 5.023 & TST & \\
\hline CHEMBL1521608 & 688267 & 5.15 & 5.06 & TRN & \\
\hline CHEMBL1372149 & 688267 & 4.0 & 5.034 & TRN & \\
\hline CHEMBL 1476617 & 688267 & 4.15 & 5.03100 & 0000000001 & TRN \\
\hline CHEMBL1375459 & 688267 & 5.85 & 5.0242 & TRN & \\
\hline CHEMBL1529106 & 688267 & 5.85 & 5.0264 & TST & \\
\hline CHEMBL1529880 & 688267 & 5.45 & 5.0353 & TRN & \\
\hline CHEMBL 3193491 & 688267 & 4.6 & 5.0302 & TST & \\
\hline CHEMBL1573060 & 688267 & 5.6 & 5.0491 & TRN & \\
\hline CHEMBL1514753 & 688267 & 5.9 & 5.0072 & TST & \\
\hline CHEMBL 1436718 & 688267 & 3.95 & 4.9828 & TRN & \\
\hline CHEMBL1611596 & 688267 & 3.95 & 5.0902 & TST & \\
\hline CHEMBL1468803 & 688267 & 4.65 & 5.035 & TST & \\
\hline CHEMBL1610842 & 688267 & 5.0 & 5.0615 & TST & \\
\hline CHEMBL1347401 & 688267 & 5.35 & 5.088 & TRN & \\
\hline CHEMBL1552591 & 688267 & 5.5 & 4.9964 & TRN & \\
\hline CHEMBL1302456 & 688267 & 4.55 & 5.0834 & TRN & \\
\hline CHEMBL1409931 & 688267 & 6.15 & 5.08 & TRN & \\
\hline CHEMBL1459278 & 688267 & 4.75 & 5.1056 & TRN & \\
\hline CHEMBL1320063 & 688267 & 6.1 & 5.0465 & TRN & \\
\hline CHEMBL1425389 & 688267 & 6.25 & 5.0498 & TRN & \\
\hline CHEMBL1369508 & 688267 & 5.65 & 5.0769 & TRN & \\
\hline CHEMBL1575899 & 688267 & 5.85 & 5.0266 & TRN & \\
\hline CHEMBL1556824 & 688267 & 5.3 & 5.0267 & TST & \\
\hline CHEMBL1384737 & 688267 & 4.5 & 5.0578 & TST & \\
\hline CHEMBL1501228 & 688267 & 5.6 & 5.0687 & TRN & \\
\hline
\end{tabular}




\begin{tabular}{|c|c|c|c|c|c|}
\hline \multicolumn{6}{|c|}{ Supplemental Table S2.txt } \\
\hline CHEMBL1601295 & 688267 & 6.45 & 5.1008 & TRN & \\
\hline CHEMBL1578043 & 688267 & 4.0 & 5.0489 & TRN & \\
\hline CHEMBL1506208 & 688267 & 4.95 & 5.0388 & TRN & \\
\hline CHEMBL1437239 & 688267 & 4.0 & 5.008 & TST & \\
\hline CHEMBL3210989 & 688267 & 4.55 & 5.0364 & TST & \\
\hline CHEMBL1396729 & 688267 & 5.3 & 5.02800 & 00000000005 & TRN \\
\hline CHEMBL1541667 & 688267 & 3.95 & 5.0471 & TST & \\
\hline CHEMBL3213511 & 688267 & 5.55 & 5.0634 & TRN & \\
\hline CHEMBL1379407 & 688267 & 5.5 & 5.1073 & TRN & \\
\hline CHEMBL1483082 & 688267 & 5.15 & 5.0251 & TRN & \\
\hline CHEMBL1436176 & 688267 & 5.35 & 5.0397 & TRN & \\
\hline CHEMBL1351365 & 688267 & 5.35 & 4.9796 & TRN & \\
\hline CHEMBL1504938 & 688267 & 6.2 & 5.0966 & TRN & \\
\hline CHEMBL3145282 & 688267 & 5.3 & 5.0339 & TST & \\
\hline CHEMBL 1474449 & 688267 & 5.95 & 5.0339 & TRN & \\
\hline CHEMBL1612823 & 688267 & 4.05 & 5.0919 & TRN & \\
\hline CHEMBL1403200 & 688267 & 6.4 & 5.0212 & TRN & \\
\hline CHEMBL1431470 & 688267 & 5.85 & 5.0611 & TRN & \\
\hline CHEMBL1432691 & 688267 & 4.8 & 5.1104 & TRN & \\
\hline CHEMBL1348013 & 688267 & 4.75 & 5.023 & TST & \\
\hline CHEMBL1589244 & 688267 & 3.95 & 4.9949 & TRN & \\
\hline CHEMBL1340617 & 688267 & 4.65 & 5.1165 & TRN & \\
\hline CHEMBL1328935 & 688267 & 5.3 & 5.0523 & TRN & \\
\hline CHEMBL1467350 & 688267 & 6.1 & 5.0431 & TRN & \\
\hline CHEMBL1571563 & 688267 & 4.15 & 5.0679 & TST & \\
\hline CHEMBL1593529 & 688267 & 5.75 & 5.1007 & TRN & \\
\hline CHEMBL1592990 & 688267 & 4.7 & 4.9929 & TRN & \\
\hline CHEMBL1567349 & 688267 & 3.95 & 5.0965 & TRN & \\
\hline CHEMBL1388124 & 688267 & 4.0 & 5.0408 & TST & \\
\hline CHEMBL1381954 & 688267 & 5.3 & 5.0155 & TRN & \\
\hline CHEMBL3189769 & 688267 & 5.55 & 5.0925 & TRN & \\
\hline CHEMBL1500337 & 688267 & 6.2 & 5.1001 & TRN & \\
\hline CHEMBL1436959 & 688267 & 5.85 & 5.0314 & TRN & \\
\hline CHEMBL1489755 & 688267 & 6.0 & 4.9915 & TRN & \\
\hline CHEMBL1404694 & 688267 & 5.3 & 5.0961 & TRN & \\
\hline CHEMBL1580035 & 688267 & 4.05 & 5.0946 & TST & \\
\hline CHEMBL1596719 & 688267 & 4.0 & 5.0002 & TST & \\
\hline CHEMBL1586749 & 688267 & 4.0 & 5.0005 & TST & \\
\hline CHEMBL1375908 & 688267 & 4.05 & 5.1301 & TRN & \\
\hline CHEMBL1309141 & 688267 & 4.05 & 5.0492 & TRN & \\
\hline CHEMBL1474728 & 688267 & 4.55 & 5.1188 & TRN & \\
\hline CHEMBL 1443550 & 688267 & 5.6 & 5.1053 & TRN & \\
\hline CHEMBL1346254 & 688267 & 5.8 & 5.0529 & TRN & \\
\hline CHEMBL1318587 & 688267 & 5.3 & 5.1206 & TST & \\
\hline CHEMBL1392971 & 688267 & 6.15 & 5.0754 & TST & \\
\hline CHEMBL1356442 & 688267 & 4.1 & 5.144 & TRN & \\
\hline CHEMBL 1316520 & 688267 & 4.25 & 5.1096 & TRN & \\
\hline CHEMBL1566910 & 688267 & 4.65 & 5.0707 & TRN & \\
\hline
\end{tabular}




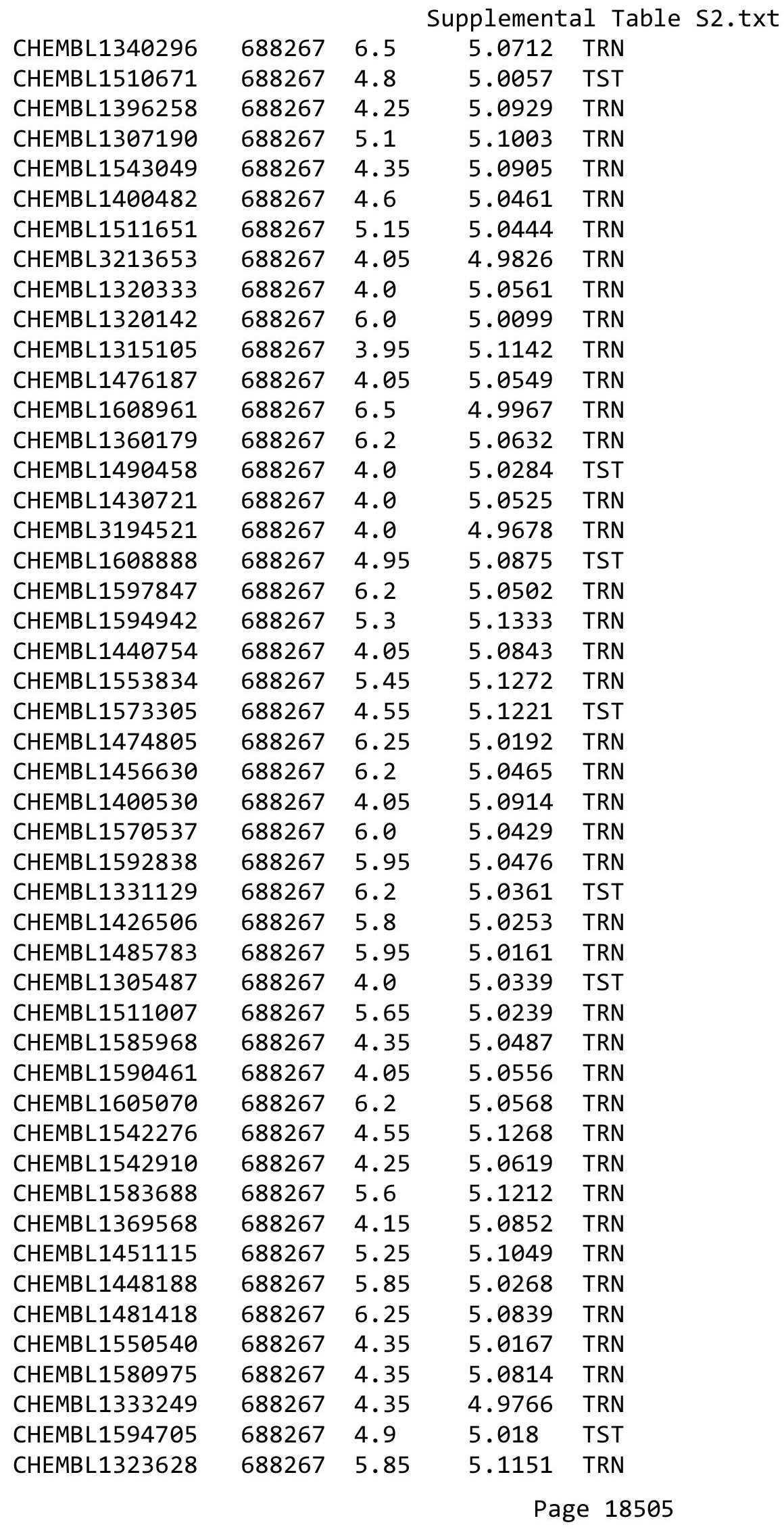




\begin{tabular}{|c|c|c|c|c|c|}
\hline \multicolumn{6}{|c|}{ Supplemental Table s2.txt } \\
\hline CHEMBL 1474800 & 688267 & 5.6 & 5.0178 & TRN & \\
\hline CHEMBL1409611 & 688267 & 4.05 & 5.0247 & TST & \\
\hline CHEMBL1598061 & 688267 & 4.65 & 5.0588 & TRN & \\
\hline CHEMBL1450902 & 688267 & 4.35 & 5.1119 & TRN & \\
\hline CHEMBL1542495 & 688267 & 4.25 & 5.0459 & TRN & \\
\hline CHEMBL1589686 & 688267 & 4.4 & 4.9741 & TRN & \\
\hline CHEMBL1455524 & 688267 & 4.9 & 5.0659 & TST & \\
\hline CHEMBL1525522 & 688267 & 6.8499 & 5.1275 & TRN & \\
\hline CHEMBL1409920 & 688267 & 6.2 & 5.0901 & TRN & \\
\hline CHEMBL3199261 & 688267 & 5.8 & $5.0710 e$ & 0000000001 & TST \\
\hline CHEMBL1514194 & 688267 & 3.95 & 5.0428 & TRN & \\
\hline CHEMBL1598697 & 688267 & 5.55 & 5.0316 & TRN & \\
\hline CHEMBL1529549 & 688267 & 5.3 & 5.0672 & TRN & \\
\hline CHEMBL1395222 & 688267 & 5.5 & 5.0709 & TRN & \\
\hline CHEMBL1563034 & 688267 & 5.25 & 5.0574 & TRN & \\
\hline CHEMBL1484929 & 688267 & 3.95 & 5.0563 & TRN & \\
\hline CHEMBL1999166 & 688267 & 4.3 & 5.0156 & TST & \\
\hline CHEMBL1461594 & 688267 & 5.15 & 5.1262 & TST & \\
\hline CHEMBL1604422 & 688267 & 4.25 & 5.0694 & TRN & \\
\hline CHEMBL1505797 & 688267 & 3.95 & 5.013 & TRN & \\
\hline CHEMBL1455608 & 688267 & 6.1 & 5.0368 & TRN & \\
\hline CHEMBL1578236 & 688267 & 5.9 & 5.0521 & TST & \\
\hline CHEMBL1343892 & 688267 & 4.35 & 5.072 & TRN & \\
\hline CHEMBL1578645 & 688267 & 4.35 & 5.0857 & TRN & \\
\hline CHEMBL1587935 & 688267 & 3.95 & 5.0757 & TRN & \\
\hline CHEMBL1417513 & 688267 & 4.0 & 5.0988 & TRN & \\
\hline CHEMBL1395232 & 688267 & 5.5 & 5.1073 & TRN & \\
\hline CHEMBL1346588 & 688267 & 4.45 & 5.0837 & TRN & \\
\hline CHEMBL1364552 & 688267 & 4.15 & 4.9787 & TRN & \\
\hline CHEMBL 1488639 & 688267 & 6.2 & 5.0889 & TRN & \\
\hline CHEMBL1573310 & 688267 & 3.95 & 5.003 & TRN & \\
\hline CHEMBL 1485270 & 688267 & 4.0 & 5.0514 & TRN & \\
\hline CHEMBL1325294 & 688267 & 6.2 & 5.0896 & TRN & \\
\hline CHEMBL1325446 & 688267 & 4.15 & 5.0564 & TST & \\
\hline CHEMBL1515425 & 688267 & 5.1 & 5.0363 & TRN & \\
\hline CHEMBL3191767 & 688267 & 6.2 & 5.0108 & TST & \\
\hline CHEMBL1356925 & 688267 & 3.95 & 5.0723 & TST & \\
\hline CHEMBL1477724 & 688267 & 4.5 & 5.0521 & TRN & \\
\hline CHEMBL1599570 & 688267 & 4.15 & 4.9753 & TRN & \\
\hline CHEMBL1589398 & 688267 & 6.2 & 5.0609 & TST & \\
\hline CHEMBL1613557 & 688267 & 4.15 & 5.0495 & TRN & \\
\hline CHEMBL1613373 & 688267 & 4.1 & 5.0966 & TRN & \\
\hline CHEMBL1485011 & 688267 & 5.8 & 5.0561 & TST & \\
\hline CHEMBL1568839 & 688267 & 4.75 & 5.0389 & TRN & \\
\hline CHEMBL1567397 & 688267 & 6.2 & 5.0919 & TST & \\
\hline CHEMBL1447763 & 688267 & 5.4 & 5.1259 & TRN & \\
\hline CHEMBL1607180 & 688267 & 4.4 & 5.0426 & TST & \\
\hline CHEMBL1564256 & 688267 & 6.2 & 5.1857 & TRN & \\
\hline
\end{tabular}




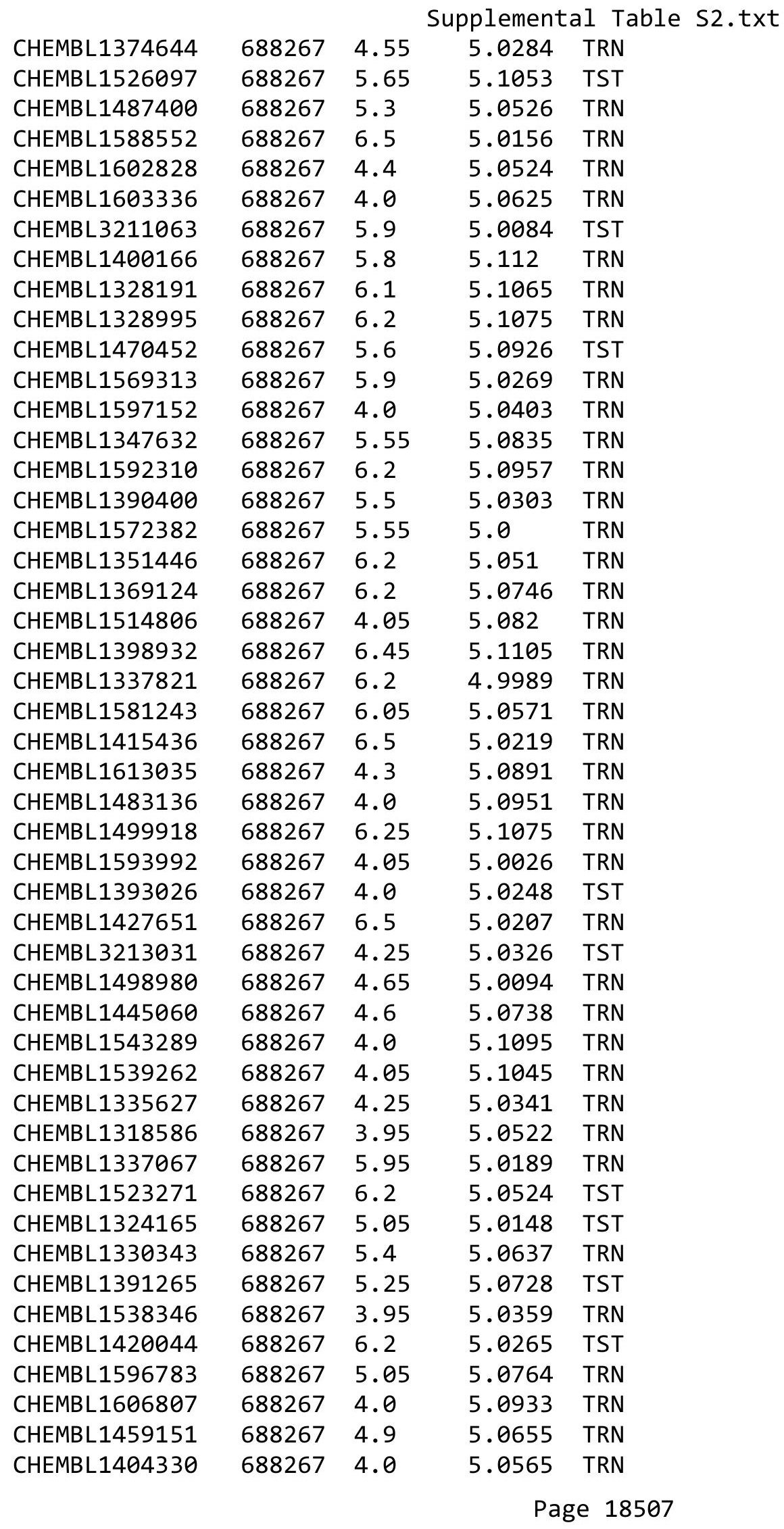




\begin{tabular}{|c|c|c|c|c|}
\hline & & & pplement & al $\mathrm{Ta}$ \\
\hline CHEMBL1349691 & 688267 & 6.0 & 5.0845 & TST \\
\hline CHEMBL1305537 & 688267 & 4.3 & 5.0376 & TRN \\
\hline CHEMBL1322464 & 688267 & 5.5 & 4.9991 & TST \\
\hline CHEMBL1572324 & 688267 & 5.5 & 4.9939 & TRN \\
\hline CHEMBL1556929 & 688267 & 5.6 & 5.0516 & TRN \\
\hline CHEMBL1474392 & 688267 & 3.95 & 5.0769 & TST \\
\hline CHEMBL1320732 & 688267 & 4.45 & 5.0719 & TRN \\
\hline CHEMBL1358066 & 688267 & 6.2 & 5.0325 & TRN \\
\hline CHEMBL1577100 & 688267 & 5.8 & 5.0676 & TRN \\
\hline CHEMBL1522141 & 688267 & 5.6 & 5.0441 & TST \\
\hline CHEMBL1560800 & 688267 & 4.05 & 5.0415 & TRN \\
\hline CHEMBL1561247 & 688267 & 6.2 & 5.0651 & TRN \\
\hline CHEMBL1488950 & 688267 & 6.15 & 5.0314 & TRN \\
\hline CHEMBL1339494 & 688267 & 4.65 & 5.0608 & TST \\
\hline CHEMBL1301960 & 688267 & 6.15 & 5.0859 & TRN \\
\hline CHEMBL1403751 & 688267 & 5.8 & 5.0223 & TRN \\
\hline CHEMBL1305428 & 688267 & 4.4 & 5.0301 & TRN \\
\hline CHEMBL1431519 & 688267 & 4.65 & 5.0165 & TRN \\
\hline CHEMBL1449123 & 688267 & 4.55 & 5.0358 & TRN \\
\hline CHEMBL1434011 & 688267 & 6.2 & 5.0856 & TRN \\
\hline CHEMBL1499400 & 688267 & 4.0 & 5.0423 & TST \\
\hline CHEMBL494783 & 688267 & 6.2 & 5.061 & TRN \\
\hline CHEMBL1344944 & 688267 & 4.45 & 5.0041 & TRN \\
\hline CHEMBL1305119 & 688267 & 4.15 & 5.0509 & TST \\
\hline CHEMBL1421182 & 688267 & 3.95 & 4.9891 & TRN \\
\hline CHEMBL1549605 & 688267 & 5.35 & 5.0865 & TST \\
\hline CHEMBL1376184 & 688267 & 4.05 & 4.9916 & TST \\
\hline CHEMBL1390967 & 688267 & 5.55 & 5.1338 & TST \\
\hline CHEMBL1502774 & 688267 & 4.4 & 5.0244 & TRN \\
\hline CHEMBL1450587 & 688267 & 5.1 & 5.0747 & TRN \\
\hline CHEMBL1381198 & 688267 & 4.05 & 5.0632 & TST \\
\hline CHEMBL1325565 & 688267 & 4.05 & 5.0393 & TRN \\
\hline CHEMBL1414594 & 688267 & 5.35 & 5.0816 & TRN \\
\hline CHEMBL1574858 & 688267 & 4.4 & 5.0802 & TRN \\
\hline CHEMBL1341760 & 688267 & 4.4 & 5.0427 & TST \\
\hline CHEMBL1407598 & 688267 & 4.0 & 5.0529 & TRN \\
\hline CHEMBL1520620 & 688267 & 4.9 & 5.0906 & TRN \\
\hline CHEMBL1558654 & 688267 & 6.2 & 5.0348 & TRN \\
\hline CHEMBL1485544 & 688267 & 5.55 & 5.0725 & TRN \\
\hline CHEMBL1410711 & 688267 & 4.2 & 5.0377 & TRN \\
\hline CHEMBL1449851 & 688267 & 6.5 & 5.0785 & TRN \\
\hline CHEMBL1403838 & 688267 & 4.1 & 5.1088 & TRN \\
\hline CHEMBL1357718 & 688267 & 4.0 & 5.0508 & TRN \\
\hline CHEMBL1415544 & 688267 & 6.2 & 5.0934 & TRN \\
\hline CHEMBL1414562 & 688267 & 5.6 & 5.0801 & TST \\
\hline CHEMBL1536803 & 688267 & 5.1 & 5.0426 & TRN \\
\hline CHEMBL1399466 & 688267 & 4.1 & 5.0194 & TRN \\
\hline CHEMBL1440544 & 688267 & 6.2 & 5.0712 & TRN \\
\hline
\end{tabular}




\begin{tabular}{|c|c|c|c|c|c|}
\hline \multicolumn{6}{|c|}{ Supplemental Table S2.txt } \\
\hline CHEMBL1590080 & 688267 & 5.35 & 5.0639 & TRN & \\
\hline CHEMBL1405679 & 688267 & 5.55 & 5.0249 & TST & \\
\hline CHEMBL1590472 & 688267 & 5.9 & 5.1086 & TRN & \\
\hline CHEMBL1452460 & 688267 & 4.05 & 5.0256 & TRN & \\
\hline CHEMBL1518016 & 688267 & 5.75 & 5.0436 & TRN & \\
\hline CHEMBL1373262 & 688267 & 4.05 & 5.0076 & TRN & \\
\hline CHEMBL1381703 & 688267 & 4.05 & 5.0147 & TST & \\
\hline CHEMBL1373666 & 688267 & 5.8 & 5.091 & TST & \\
\hline CHEMBL1543678 & 688267 & 6.5 & 5.0456 & TST & \\
\hline CHEMBL1553964 & 688267 & 3.9 & 5.0505 & TST & \\
\hline CHEMBL1499690 & 688267 & 5.55 & 5.0668 & TRN & \\
\hline CHEMBL1440919 & 688267 & 5.45 & 5.0544 & TST & \\
\hline CHEMBL1349843 & 688267 & 5.4 & 5.0927 & TRN & \\
\hline CHEMBL1440062 & 688267 & 5.4 & 5.0431 & TST & \\
\hline CHEMBL1499916 & 688267 & 4.05 & 4.9895 & TRN & \\
\hline CHEMBL1325783 & 688267 & 4.5 & 5.0688 & TST & \\
\hline CHEMBL1366777 & 688267 & 5.2 & 5.0097 & TST & \\
\hline CHEMBL1540114 & 688267 & 5.35 & 5.0185 & TRN & \\
\hline CHEMBL1613633 & 688267 & 5.65 & 5.0578 & TRN & \\
\hline CHEMBL3194424 & 688267 & 4.9 & 5.053 & TRN & \\
\hline CHEMBL1533833 & 688267 & 4.65 & 5.0402 & TRN & \\
\hline CHEMBL1377222 & 688267 & 4.35 & 5.1015 & TRN & \\
\hline CHEMBL1380465 & 688267 & 5.0 & 5.1125 & TRN & \\
\hline CHEMBL1607083 & 688267 & 5.05 & 5.0999 & TRN & \\
\hline CHEMBL1518135 & 688267 & 5.55 & 5.0407 & TRN & \\
\hline CHEMBL1308438 & 688267 & 4.35 & 5.0779 & TST & \\
\hline CHEMBL1467305 & 688267 & 4.35 & 5.0861 & TST & \\
\hline CHEMBL1557652 & 688267 & 5.35 & 5.0988 & TRN & \\
\hline CHEMBL1326264 & 688267 & 5.45 & 4.9995 & TRN & \\
\hline CHEMBL1565395 & 688267 & 4.55 & 5.0512 & TST & \\
\hline CHEMBL1382227 & 688267 & 4.25 & 5.0334 & TRN & \\
\hline CHEMBL1533585 & 688267 & 4.05 & 5.0605 & TRN & \\
\hline CHEMBL1538645 & 688267 & 6.2 & 5.0782 & TRN & \\
\hline CHEMBL1421193 & 688267 & 5.8 & 5.0983 & TRN & \\
\hline CHEMBL1325789 & 688267 & 4.7 & 5.0811 & TRN & \\
\hline CHEMBL1556230 & 688267 & 5.35 & 5.06800 & 00000000005 & TST \\
\hline CHEMBL1435108 & 688267 & 4.0 & 5.0254 & TRN & \\
\hline CHEMBL1472694 & 688267 & 4.4 & 5.0706 & TST & \\
\hline CHEMBL1520048 & 688267 & 4.3 & 5.0403 & TRN & \\
\hline CHEMBL1410908 & 688267 & 4.3 & 5.0063 & TRN & \\
\hline CHEMBL1519861 & 688267 & 5.0 & 5.0041 & TRN & \\
\hline CHEMBL1477662 & 688267 & 5.9 & 5.0722 & TRN & \\
\hline CHEMBL1361821 & 688267 & 5.6 & 5.0167 & TST & \\
\hline CHEMBL1523778 & 688267 & 4.05 & 5.0009 & TRN & \\
\hline CHEMBL1447479 & 688267 & 4.35 & 5.0222 & TRN & \\
\hline CHEMBL1391534 & 688267 & 6.2 & 5.0893 & TRN & \\
\hline CHEMBL1351948 & 688267 & 5.65 & 5.0717 & TRN & \\
\hline CHEMBL1554085 & 688267 & 4.0 & 5.0581 & TRN & \\
\hline
\end{tabular}




\begin{tabular}{|c|c|c|c|c|c|}
\hline & & \\
\hline CHEMBL1319741 & 688267 & 5.3 & 5.0836 & TST & \\
\hline CHEMBL1582990 & 688267 & 4.05 & 5.1032 & TRN & \\
\hline CHEMBL1373988 & 688267 & 6.2 & 5.0331 & TRN & \\
\hline CHEMBL1591071 & 688267 & 4.05 & 5.0475 & TRN & \\
\hline CHEMBL1501139 & 688267 & 6.2 & 5.0741 & TST & \\
\hline CHEMBL1354791 & 688267 & 4.3 & 5.1093 & TRN & \\
\hline CHEMBL1583149 & 688267 & 6.25 & 4.992 & TRN & \\
\hline CHEMBL1972405 & 688267 & 4.55 & 5.00899 & 99999999995 & TST \\
\hline CHEMBL1340874 & 688267 & 4.45 & 5.0325 & TST & \\
\hline CHEMBL1546675 & 688267 & 5.25 & 5.056 & TST & \\
\hline CHEMBL1501920 & 688267 & 5.9 & 5.1029 & TRN & \\
\hline CHEMBL1342701 & 688267 & 4.05 & 5.0083 & TRN & \\
\hline CHEMBL3214293 & 688267 & 5.7 & 5.0504 & TST & \\
\hline CHEMBL1305930 & 688267 & 4.7 & 5.0264 & TST & \\
\hline CHEMBL1448044 & 688267 & 5.35 & 5.0051 & TRN & \\
\hline CHEMBL1556847 & 688267 & 5.5 & 5.0313 & TRN & \\
\hline CHEMBL1396545 & 688267 & 4.05 & 5.0372 & TRN & \\
\hline CHEMBL1381250 & 688267 & 4.0 & 5.0602 & TRN & \\
\hline CHEMBL1504482 & 688267 & 5.95 & 5.0803 & TRN & \\
\hline CHEMBL1386964 & 688267 & 4.25 & 4.9889 & TRN & \\
\hline CHEMBL1321998 & 688267 & 4.35 & 5.1215 & TRN & \\
\hline CHEMBL1552835 & 688267 & 5.55 & 5.0337 & TRN & \\
\hline CHEMBL1390210 & 688267 & 5.1 & 5.0351 & TRN & \\
\hline CHEMBL1575486 & 688267 & 5.85 & 5.0243 & TRN & \\
\hline CHEMBL1438569 & 688267 & 5.6 & 5.091 & TRN & \\
\hline CHEMBL1387892 & 688267 & 4.05 & 5.0058 & TRN & \\
\hline CHEMBL1369084 & 688267 & 5.75 & 5.0806 & TRN & \\
\hline CHEMBL1496136 & 688267 & 4.3 & 5.0446 & TRN & \\
\hline CHEMBL1423375 & 688267 & 5.4 & 5.0377 & TRN & \\
\hline CHEMBL1398747 & 688267 & 4.05 & 5.0423 & TRN & \\
\hline CHEMBL1355673 & 688267 & 6.2 & 5.0445 & TRN & \\
\hline CHEMBL1492071 & 688267 & 4.0 & 5.0502 & TRN & \\
\hline CHEMBL1554273 & 688267 & 5.4 & 5.008 & TRN & \\
\hline CHEMBL1326360 & 688267 & 4.7 & 5.0512 & TRN & \\
\hline CHEMBL1308746 & 688267 & 5.95 & 5.1079 & TRN & \\
\hline CHEMBL1577960 & 688267 & 6.2 & 5.051 & TST & \\
\hline CHEMBL1425084 & 688267 & 4.5 & 5.0955 & TRN & \\
\hline CHEMBL1562108 & 688267 & 4.25 & 5.0594 & TRN & \\
\hline CHEMBL1404111 & 688267 & 4.85 & 5.0178 & TRN & \\
\hline CHEMBL1523365 & 688267 & 4.05 & 5.06 & TRN & \\
\hline CHEMBL1578308 & 688267 & 6.0 & 5.0234 & TRN & \\
\hline CHEMBL1545023 & 688267 & 5.8 & 5.1306 & TRN & \\
\hline CHEMBL1405179 & 688267 & 4.2 & 5.1002 & TRN & \\
\hline CHEMBL1480560 & 688267 & 6.15 & 5.0781 & TST & \\
\hline CHEMBL1610002 & 688267 & 5.85 & 5.00899 & 99999999995 & TST \\
\hline CHEMBL1612637 & 688267 & 6.2 & 5.1 & TRN & \\
\hline CHEMBL1567004 & 688267 & 6.15 & 5.0885 & TRN & \\
\hline CHEMBL1317260 & 688267 & 6.2 & $5.1160 e$ & 00000000005 & TRN \\
\hline & & & & 18510 & \\
\hline
\end{tabular}




\begin{tabular}{|c|c|c|c|c|}
\hline \multicolumn{5}{|c|}{ Supplemental Table S2.txt } \\
\hline CHEMBL1578488 & 688267 & 4.5 & 4.9851 & TST \\
\hline CHEMBL1306026 & 688267 & 4.05 & 5.077 & TST \\
\hline CHEMBL1329745 & 688267 & 4.55 & 5.1221 & TRN \\
\hline CHEMBL1424534 & 688267 & 5.9 & 5.0708 & TST \\
\hline CHEMBL1428330 & 688267 & 4.9 & 5.1481 & TRN \\
\hline CHEMBL1589879 & 688267 & 3.95 & 5.0772 & TRN \\
\hline CHEMBL1527999 & 688267 & 4.0 & 5.0298 & TRN \\
\hline CHEMBL1557361 & 688267 & 4.0 & 4.9999 & TRN \\
\hline CHEMBL1306498 & 688267 & 4.0 & 5.0563 & TRN \\
\hline CHEMBL1397228 & 688267 & 4.5 & 5.022 & TRN \\
\hline CHEMBL1358943 & 688267 & 4.0 & 5.058 & TST \\
\hline CHEMBL1589928 & 688267 & 4.55 & 5.0345 & TRN \\
\hline CHEMBL1320926 & 688267 & 4.0 & 4.9931 & TRN \\
\hline CHEMBL1348208 & 688267 & 5.25 & 5.0643 & TRN \\
\hline CHEMBL1478312 & 688267 & 4.55 & 4.9877 & TRN \\
\hline CHEMBL1518486 & 688267 & 6.25 & 5.0909 & TRN \\
\hline CHEMBL1560536 & 688267 & 3.95 & 5.0199 & TRN \\
\hline CHEMBL 3196957 & 688267 & 4.65 & 5.0098 & TST \\
\hline CHEMBL1478335 & 688267 & 6.2 & 5.0667 & TRN \\
\hline CHEMBL1450841 & 688267 & 4.35 & 5.0169 & TST \\
\hline CHEMBL1311753 & 688267 & 6.2 & 5.0517 & TRN \\
\hline CHEMBL1345026 & 688267 & 6.15 & 5.0328 & TST \\
\hline CHEMBL1554469 & 688267 & 4.5 & 5.1072 & TRN \\
\hline CHEMBL 3199198 & 688267 & 4.05 & 4.999 & TRN \\
\hline CHEMBL1535510 & 688267 & 5.5 & 5.0766 & TST \\
\hline CHEMBL1433256 & 688267 & 4.4 & 5.0673 & TRN \\
\hline CHEMBL1299266 & 688267 & 4.5 & 5.0516 & TRN \\
\hline CHEMBL1589662 & 688267 & 6.5501 & 5.0796 & TST \\
\hline CHEMBL1300457 & 688267 & 5.55 & 5.1031 & TRN \\
\hline CHEMBL1394723 & 688267 & 5.35 & 5.0355 & TRN \\
\hline CHEMBL1437684 & 688267 & 4.4 & 5.0263 & TRN \\
\hline CHEMBL1363575 & 688267 & 4.35 & 5.0519 & TRN \\
\hline CHEMBL1312863 & 688267 & 4.0 & 5.0551 & TRN \\
\hline CHEMBL1461464 & 688267 & 5.6 & 5.0035 & TRN \\
\hline CHEMBL1547423 & 688267 & 4.25 & 5.0985 & TRN \\
\hline CHEMBL1469523 & 688267 & 4.0 & 5.0622 & TRN \\
\hline CHEMBL1611662 & 688267 & 5.95 & 5.0076 & TST \\
\hline CHEMBL3190093 & 688267 & 6.25 & 5.0053 & TRN \\
\hline CHEMBL1535551 & 688267 & 5.65 & 5.0528 & TST \\
\hline CHEMBL1477765 & 688267 & 5.9 & 5.0669 & TRN \\
\hline CHEMBL1424872 & 688267 & 5.4 & 5.059 & TRN \\
\hline CHEMBL1306852 & 688267 & 5.95 & 5.1236 & TST \\
\hline CHEMBL1304266 & 688267 & 4.65 & 5.0305 & TST \\
\hline CHEMBL1557262 & 688267 & 6.15 & 5.0778 & TRN \\
\hline CHEMBL1539961 & 688267 & 4.5 & 5.0409 & TRN \\
\hline CHEMBL1542609 & 688267 & 6.2 & 5.1599 & TRN \\
\hline CHEMBL1423067 & 688267 & 6.15 & 5.0826 & TRN \\
\hline CHEMBL1412022 & 688267 & 6.5 & 5.0701 & TRN \\
\hline
\end{tabular}




\begin{tabular}{|c|c|c|c|c|c|}
\hline \multicolumn{6}{|c|}{ Supplemental Table S2.txt } \\
\hline CHEMBL1496551 & 688267 & 6.45 & 5.0695 & TRN & \\
\hline CHEMBL1469886 & 688267 & 5.2 & 5.0723 & TST & \\
\hline CHEMBL1315643 & 688267 & 4.45 & 5.0732 & TRN & \\
\hline CHEMBL1562814 & 688267 & 4.05 & 5.1133 & TRN & \\
\hline CHEMBL1586965 & 688267 & 4.95 & 5.1191 & TRN & \\
\hline CHEMBL1437250 & 688267 & 5.4 & 5.079 & TRN & \\
\hline CHEMBL1371658 & 688267 & 6.5 & 5.0583 & TST & \\
\hline CHEMBL1455823 & 688267 & 6.2 & 5.1129 & TRN & \\
\hline CHEMBL1378854 & 688267 & 4.1 & 5.0019 & TRN & \\
\hline CHEMBL3210908 & 688267 & 4.05 & 4.9641 & TRN & \\
\hline CHEMBL1488383 & 688267 & 6.5 & 5.0598 & TST & \\
\hline CHEMBL1385818 & 688267 & 4.55 & 5.0607 & TRN & \\
\hline CHEMBL1550505 & 688267 & 6.2 & 5.1473 & TRN & \\
\hline CHEMBL1331610 & 688267 & 4.75 & 5.16 & TRN & \\
\hline CHEMBL3214625 & 688267 & 6.2 & 5.0285 & TRN & \\
\hline CHEMBL1542358 & 688267 & 5.55 & 5.0335 & TST & \\
\hline CHEMBL1477369 & 688267 & 5.8 & 5.0267 & TRN & \\
\hline CHEMBL1487732 & 688267 & 6.1 & 5.1071 & TRN & \\
\hline CHEMBL1415310 & 688267 & 6.25 & 4.9936 & TRN & \\
\hline CHEMBL1323129 & 688267 & 5.45 & 5.0552 & TRN & \\
\hline CHEMBL1568719 & 688267 & 5.1 & 5.0908 & TRN & \\
\hline CHEMBL1435959 & 688267 & 5.25 & 5.0869 & TST & \\
\hline CHEMBL1489243 & 688267 & 5.55 & 5.029 & TRN & \\
\hline CHEMBL1475678 & 688267 & 4.05 & 5.0277 & TST & \\
\hline CHEMBL1494455 & 688267 & 6.2 & 5.0386 & TST & \\
\hline CHEMBL1611230 & 688267 & 4.95 & 5.0666 & TST & \\
\hline CHEMBL1453967 & 688267 & 6.2 & 5.0884 & TRN & \\
\hline CHEMBL1602320 & 688267 & 6.25 & 5.0277 & TST & \\
\hline CHEMBL1405419 & 688267 & 4.05 & 5.0303 & TRN & \\
\hline CHEMBL1336359 & 688267 & 4.2 & 5.0785 & TRN & \\
\hline CHEMBL1559822 & 688267 & 4.0 & 5.1369 & TRN & \\
\hline CHEMBL128427 & 688267 & 5.5 & 4.998 & TRN & \\
\hline CHEMBL1527322 & 688267 & 6.2 & 5.0349 & TRN & \\
\hline CHEMBL1473947 & 688267 & 4.05 & 5.0637 & TRN & \\
\hline CHEMBL1487942 & 688267 & 4.25 & 5.0321 & TRN & \\
\hline CHEMBL1337807 & 688267 & 3.95 & 5.0701 & TRN & \\
\hline CHEMBL1514165 & 688267 & 5.55 & 5.05399 & 9999999999 & TRN \\
\hline CHEMBL1521257 & 688267 & 4.0 & 5.0792 & TRN & \\
\hline CHEMBL1565374 & 688267 & 5.35 & 5.0435 & TRN & \\
\hline CHEMBL1566207 & 688267 & 4.6 & 5.0836 & TRN & \\
\hline CHEMBL1533076 & 688267 & 4.35 & 5.0405 & TRN & \\
\hline CHEMBL1565825 & 688267 & 5.2 & 5.1074 & TRN & \\
\hline CHEMBL1387200 & 688267 & 5.3 & 5.0304 & TRN & \\
\hline CHEMBL1348619 & 688267 & 5.5 & 5.0913 & TRN & \\
\hline CHEMBL1410253 & 688267 & 5.6 & 5.0667 & TRN & \\
\hline CHEMBL1467332 & 688267 & 3.95 & 4.9872 & TRN & \\
\hline CHEMBL1514848 & 688267 & 4.0 & 5.0595 & TRN & \\
\hline CHEMBL1424456 & 688267 & 6.2 & 5.1055 & TST & \\
\hline
\end{tabular}




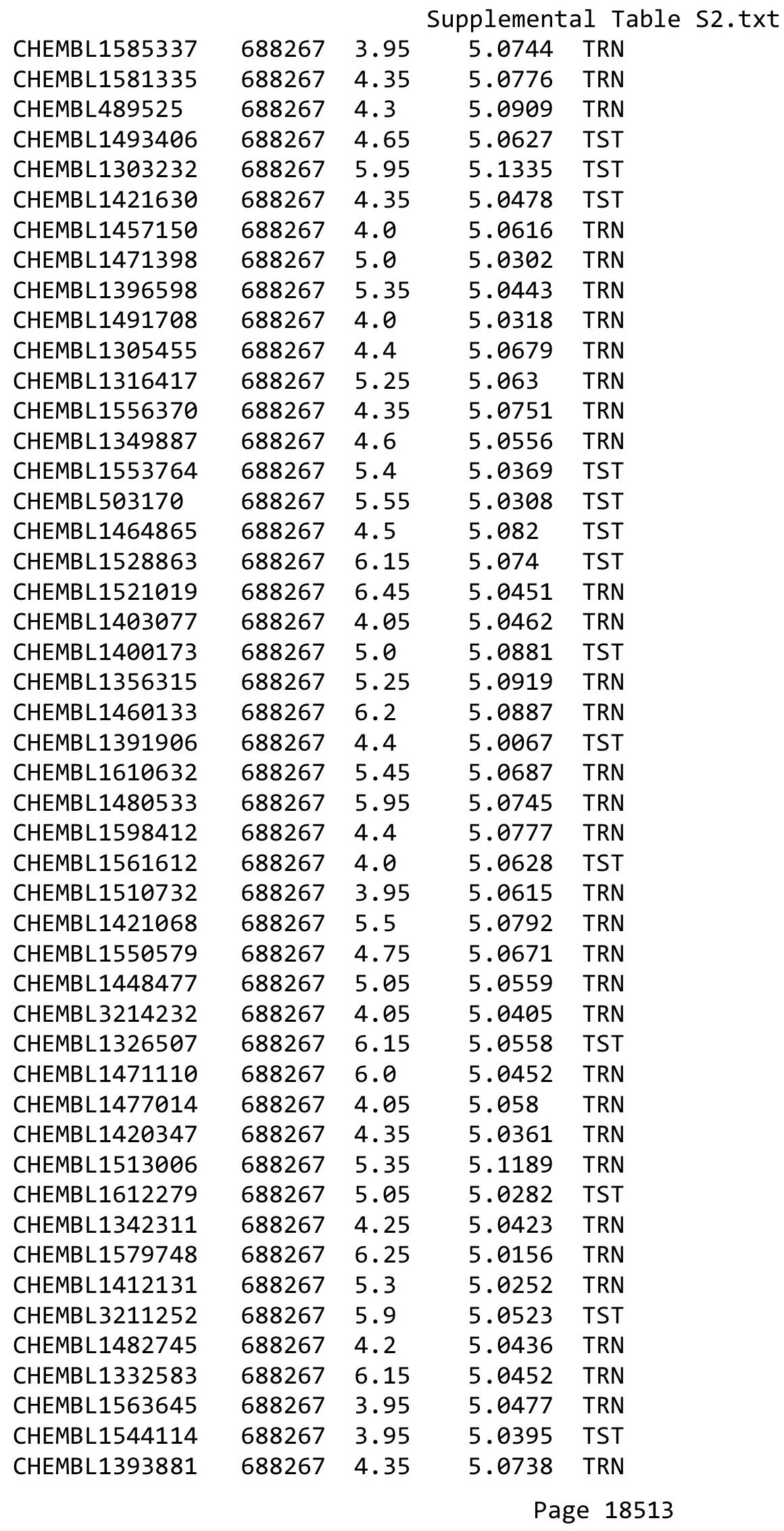




\begin{tabular}{|c|c|c|c|c|c|}
\hline \multicolumn{6}{|c|}{ pplemental Table Sz } \\
\hline CHEMBL3197530 & 688267 & 4.4 & 5.0416 & TRN & \\
\hline CHEMBL1611801 & 688267 & 4.4 & 5.0214 & TST & \\
\hline CHEMBL1323917 & 688267 & 4.0 & 4.9958 & TST & \\
\hline CHEMBL1364908 & 688267 & 4.0 & 5.0543 & TRN & \\
\hline CHEMBL451208 & 688267 & 4.25 & 5.0681 & TRN & \\
\hline CHEMBL1256178 & 688267 & 5.2 & 5.0879 & TST & \\
\hline CHEMBL1493732 & 688267 & 5.25 & 5.0613 & TRN & \\
\hline CHEMBL1399389 & 688267 & 6.25 & 5.0479 & TST & \\
\hline CHEMBL1341657 & 688267 & 4.05 & 5.1013 & TRN & \\
\hline CHEMBL1356612 & 688267 & 4.05 & 5.0284 & TRN & \\
\hline CHEMBL1348764 & 688267 & 5.85 & 5.1119 & TST & \\
\hline CHEMBL1339453 & 688267 & 5.8 & 5.0985 & TRN & \\
\hline CHEMBL1566408 & 688267 & 4.45 & 5.0301 & TST & \\
\hline CHEMBL1477568 & 688267 & 4.35 & 5.0644 & TRN & \\
\hline CHEMBL1352961 & 688267 & 4.05 & 5.0664 & TST & \\
\hline CHEMBL1577886 & 688267 & 4.05 & 5.0305 & TST & \\
\hline CHEMBL1582506 & 688267 & 4.75 & 5.1405 & TRN & \\
\hline CHEMBL1602604 & 688267 & 4.35 & 5.1207 & TST & \\
\hline CHEMBL1412766 & 688267 & 4.25 & 5.0062 & TRN & \\
\hline CHEMBL1319119 & 688267 & 4.15 & 5.0496 & TRN & \\
\hline CHEMBL1393130 & 688267 & 4.6 & 5.0696 & TRN & \\
\hline CHEMBL1335167 & 688267 & 5.65 & 5.1324 & TRN & \\
\hline CHEMBL1331033 & 688267 & 6.2 & 5.06806 & 00000000005 & TRN \\
\hline CHEMBL1494542 & 688267 & 4.55 & 5.0097 & TRN & \\
\hline CHEMBL1870697 & 688267 & 5.6 & 4.9794 & TRN & \\
\hline CHEMBL1395905 & 688267 & 6.15 & 5.0998 & TRN & \\
\hline CHEMBL1476934 & 688267 & 4.0 & 5.0433 & TST & \\
\hline CHEMBL3198561 & 688267 & 4.15 & 5.0144 & TRN & \\
\hline CHEMBL1347619 & 688267 & 6.15 & 5.1261 & TRN & \\
\hline CHEMBL1313773 & 688267 & 4.4 & 5.0139 & TRN & \\
\hline CHEMBL1474614 & 688267 & 4.0 & 5.0276 & TRN & \\
\hline CHEMBL1440134 & 688267 & 4.85 & 5.0931 & TRN & \\
\hline CHEMBL559612 & 688267 & 5.1 & 5.0763 & TST & \\
\hline CHEMBL1525973 & 688267 & 4.25 & 5.0781 & TRN & \\
\hline CHEMBL1335458 & 688267 & 5.45 & 5.058 & TST & \\
\hline CHEMBL1980448 & 688267 & 6.25 & 5.0327 & TRN & \\
\hline CHEMBL1414640 & 688267 & 4.1 & 5.0761 & TST & \\
\hline CHEMBL1312090 & 688267 & 5.55 & 5.0963 & TST & \\
\hline CHEMBL1432288 & 688267 & 6.5 & 5.1163 & TST & \\
\hline CHEMBL1403625 & 688267 & 5.25 & 5.0298 & TRN & \\
\hline CHEMBL1382159 & 688267 & 5.85 & 5.0504 & TST & \\
\hline CHEMBL1492431 & 688267 & 6.2 & 5.0582 & TRN & \\
\hline CHEMBL1558709 & 688267 & 4.55 & 5.0192 & TRN & \\
\hline CHEMBL1434558 & 688267 & 6.5 & 4.9956 & TRN & \\
\hline CHEMBL3212724 & 688267 & 5.9 & 5.0594 & TRN & \\
\hline CHEMBL1327764 & 688267 & 6.2 & 5.1155 & TRN & \\
\hline CHEMBL1610331 & 688267 & 6.2 & 5.1249 & TRN & \\
\hline CHEMBL1483068 & 688267 & 5.05 & 5.0119 & TRN & \\
\hline
\end{tabular}




\begin{tabular}{|c|c|c|c|c|c|}
\hline \multicolumn{6}{|c|}{ Supplemental Table S2.txt } \\
\hline CHEMBL1611636 & 688267 & 4.1 & 5.0354 & TRN & \\
\hline CHEMBL1339348 & 688267 & 4.05 & 5.0349 & TRN & \\
\hline CHEMBL1439632 & 688267 & 4.1 & 4.9876 & TRN & \\
\hline CHEMBL1498102 & 688267 & 4.4 & 5.0374 & TST & \\
\hline CHEMBL1437669 & 688267 & 6.2 & 5.0482 & TRN & \\
\hline CHEMBL1409003 & 688267 & 6.15 & 5.0415 & TRN & \\
\hline CHEMBL1559526 & 688267 & 5.3 & 5.077 & TRN & \\
\hline CHEMBL1474519 & 688267 & 4.0 & 5.0323 & TRN & \\
\hline CHEMBL1539479 & 688267 & 5.65 & 5.0496 & TST & \\
\hline CHEMBL1453135 & 688267 & 4.0 & 5.0907 & TRN & \\
\hline CHEMBL1492061 & 688267 & 4.2 & 5.056 & TRN & \\
\hline CHEMBL1389639 & 688267 & 6.2 & 5.0799 & TRN & \\
\hline CHEMBL1544491 & 688267 & 5.3 & 5.0339 & TRN & \\
\hline CHEMBL1378642 & 688267 & 4.35 & 5.0841 & TRN & \\
\hline CHEMBL1373897 & 688267 & 4.35 & 5.0812 & TRN & \\
\hline CHEMBL1316746 & 688267 & 4.0 & 4.9937 & TRN & \\
\hline CHEMBL1545564 & 688267 & 5.2 & 5.0788 & TRN & \\
\hline CHEMBL1412609 & 688267 & 6.2 & 5.047 & TST & \\
\hline CHEMBL1443068 & 688267 & 3.95 & 5.0871 & TRN & \\
\hline CHEMBL1320082 & 688267 & 6.2 & 5.0372 & TRN & \\
\hline CHEMBL1602708 & 688267 & 6.05 & 4.9984 & TRN & \\
\hline CHEMBL1349335 & 688267 & 4.6 & 5.0155 & TRN & \\
\hline CHEMBL1315646 & 688267 & 5.8 & 5.05699 & 99999999995 & TRN \\
\hline CHEMBL1493933 & 688267 & 5.35 & 5.1153 & TRN & \\
\hline CHEMBL1461115 & 688267 & 4.95 & 5.0418 & TRN & \\
\hline CHEMBL1472306 & 688267 & 4.0 & 4.9862 & TRN & \\
\hline CHEMBL 3212424 & 688267 & 5.45 & 5.0498 & TST & \\
\hline CHEMBL1504003 & 688267 & 4.35 & 5.0666 & TRN & \\
\hline CHEMBL1402245 & 688267 & 4.3 & 5.01 & TRN & \\
\hline CHEMBL1595999 & 688267 & 6.25 & 5.1161 & TRN & \\
\hline CHEMBL1502275 & 688267 & 6.2 & 5.0411 & TRN & \\
\hline CHEMBL1303853 & 688267 & 4.1 & 5.0628 & TRN & \\
\hline CHEMBL1558207 & 688267 & 5.35 & 5.0957 & TRN & \\
\hline CHEMBL1311144 & 688267 & 4.25 & 5.0151 & TST & \\
\hline CHEMBL1561629 & 688267 & 6.45 & 5.0315 & TRN & \\
\hline CHEMBL1548844 & 688267 & 5.3 & 5.0507 & TRN & \\
\hline CHEMBL1444602 & 688267 & 5.5 & 5.0376 & TRN & \\
\hline CHEMBL1507150 & 688267 & 4.6 & 5.0389 & TRN & \\
\hline CHEMBL1483673 & 688267 & 6.15 & 4.9814 & TST & \\
\hline CHEMBL1443954 & 688267 & 5.05 & 5.0066 & TRN & \\
\hline CHEMBL1449615 & 688267 & 4.0 & 5.0364 & TST & \\
\hline CHEMBL1400428 & 688267 & 4.35 & 5.0486 & TRN & \\
\hline CHEMBL1591232 & 688267 & 6.25 & 5.0301 & TRN & \\
\hline CHEMBL1515080 & 688267 & 5.3 & 5.0702 & TST & \\
\hline CHEMBL1562211 & 688267 & 4.35 & 5.1077 & TRN & \\
\hline CHEMBL1542907 & 688267 & 6.2 & 5.0659 & TRN & \\
\hline CHEMBL1592853 & 688267 & 4.05 & 5.0361 & TRN & \\
\hline CHEMBL1490483 & 688267 & 6.2 & 4.9992 & TRN & \\
\hline
\end{tabular}




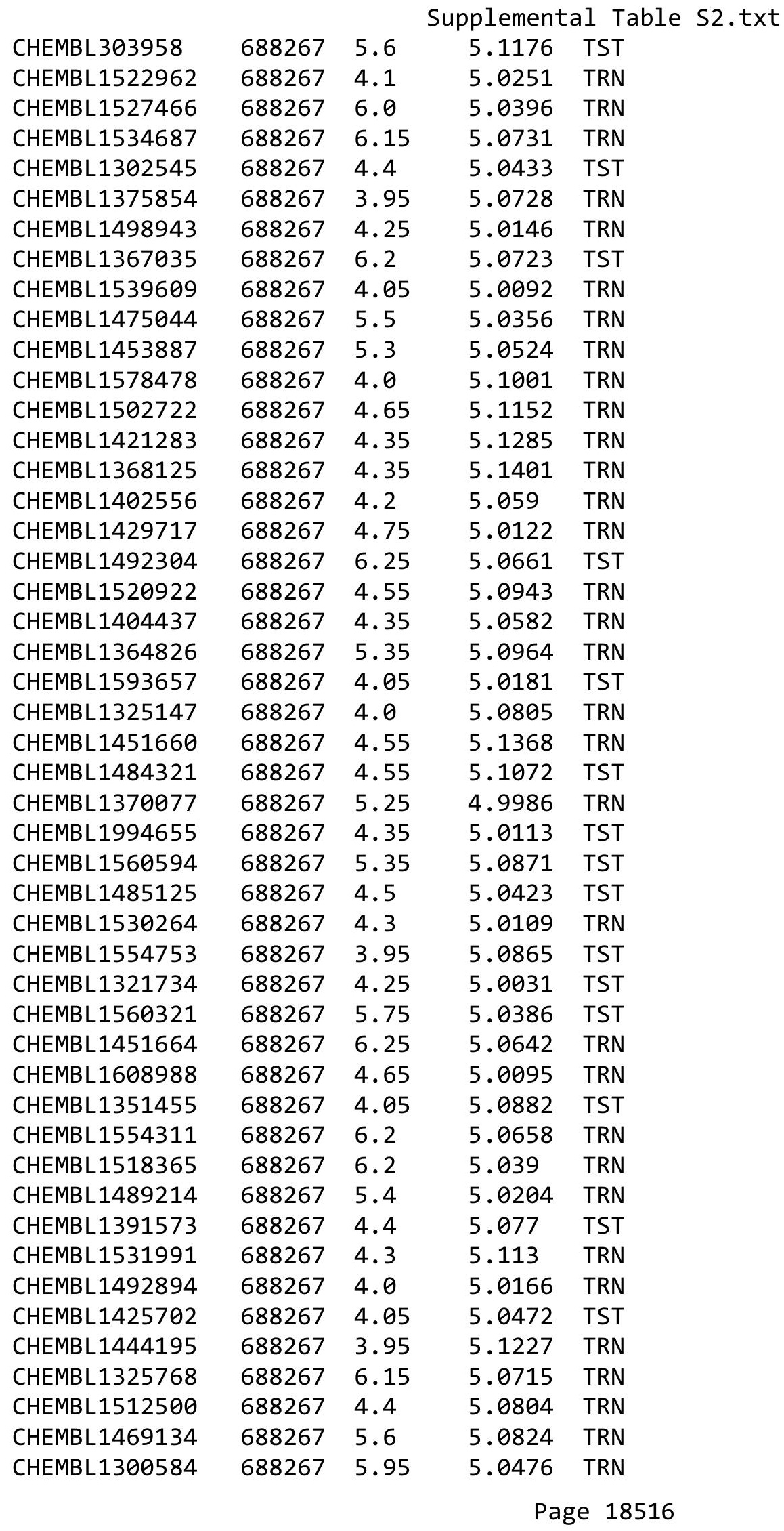




\begin{tabular}{|c|c|c|c|c|}
\hline \multicolumn{5}{|c|}{ Supplemental Table S2.txt } \\
\hline CHEMBL1352500 & 688267 & 4.0 & 5.0733 & TRN \\
\hline CHEMBL1583683 & 688267 & 5.25 & 5.0571 & TRN \\
\hline CHEMBL1520422 & 688267 & 6.9 & 5.0611 & TST \\
\hline CHEMBL1444172 & 688267 & 5.65 & 5.0141 & TRN \\
\hline CHEMBL1558136 & 688267 & 3.95 & 5.0325 & TST \\
\hline CHEMBL1491995 & 688267 & 5.3 & 5.0108 & TRN \\
\hline CHEMBL1416076 & 688267 & 6.25 & 5.0003 & TRN \\
\hline CHEMBL1565188 & 688267 & 4.0 & 5.0783 & TRN \\
\hline CHEMBL1450369 & 688267 & 4.3 & 5.0812 & TST \\
\hline CHEMBL1601047 & 688267 & 4.05 & 5.0251 & TRN \\
\hline CHEMBL1306291 & 688267 & 5.65 & 5.0413 & TRN \\
\hline CHEMBL1581507 & 688267 & 5.6 & 5.0886 & TRN \\
\hline CHEMBL1328697 & 688267 & 5.15 & 5.0489 & TRN \\
\hline CHEMBL1323111 & 688267 & 5.9 & 5.0493 & TRN \\
\hline CHEMBL1481619 & 688267 & 5.7 & 5.0047 & TRN \\
\hline CHEMBL1529117 & 688267 & 6.15 & 5.032 & TST \\
\hline CHEMBL1458214 & 688267 & 5.3 & 5.0906 & TRN \\
\hline CHEMBL1558504 & 688267 & 6.2 & 5.0123 & TRN \\
\hline CHEMBL1594139 & 688267 & 6.15 & 5.0839 & TRN \\
\hline CHEMBL1362729 & 688267 & 4.35 & 5.0626 & TST \\
\hline CHEMBL1313181 & 688267 & 4.95 & 5.0454 & TRN \\
\hline CHEMBL3189872 & 688267 & 6.1 & 4.9842 & TST \\
\hline CHEMBL1364432 & 688267 & 5.1 & 5.0103 & TRN \\
\hline CHEMBL1537455 & 688267 & 6.45 & 5.0228 & TRN \\
\hline CHEMBL1365312 & 688267 & 5.55 & 5.1312 & TRN \\
\hline CHEMBL1503725 & 688267 & 5.6 & 5.1162 & TRN \\
\hline CHEMBL1496617 & 688267 & 6.2 & 5.0671 & TRN \\
\hline CHEMBL3208128 & 688267 & 5.5 & 5.0496 & TST \\
\hline CHEMBL1485467 & 688267 & 4.7 & 5.1332 & TRN \\
\hline CHEMBL3199768 & 688267 & 4.3 & 4.9769 & TRN \\
\hline CHEMBL1351740 & 688267 & 6.25 & 5.0676 & TRN \\
\hline CHEMBL3207696 & 688267 & 5.35 & 5.0514 & TRN \\
\hline CHEMBL1612909 & 688267 & 6.2 & 5.0776 & TST \\
\hline CHEMBL1492378 & 688267 & 4.55 & 5.067 & TRN \\
\hline CHEMBL1589095 & 688267 & 4.4 & 5.0072 & TRN \\
\hline CHEMBL1326105 & 688267 & 4.05 & 5.0387 & TRN \\
\hline CHEMBL 1405226 & 688267 & 4.1 & 5.0711 & TRN \\
\hline CHEMBL1441829 & 688267 & 5.9 & 5.0206 & TRN \\
\hline CHEMBL1419095 & 688267 & 4.0 & 5.1121 & TRN \\
\hline CHEMBL1488787 & 688267 & 4.2 & 5.0129 & TRN \\
\hline CHEMBL1396685 & 688267 & 5.6 & 5.1189 & TST \\
\hline CHEMBL1423515 & 688267 & 6.2 & 5.0908 & TRN \\
\hline CHEMBL1601257 & 688267 & 5.3 & 5.0497 & TST \\
\hline CHEMBL1362811 & 688267 & 5.2 & 5.1034 & TRN \\
\hline CHEMBL3198821 & 688267 & 4.95 & 5.0307 & TST \\
\hline CHEMBL1492482 & 688267 & 5.5 & 5.0935 & TRN \\
\hline CHEMBL1556788 & 688267 & 6.2 & 5.0083 & TRN \\
\hline CHEMBL1556195 & 688267 & 4.7 & 5.0354 & TRN \\
\hline
\end{tabular}




\begin{tabular}{|c|c|c|c|c|c|}
\hline \multicolumn{6}{|c|}{ Supplemental Table S2.txt } \\
\hline CHEMBL1531762 & 688267 & 6.2 & 5.1128 & TRN & \\
\hline CHEMBL1487592 & 688267 & 5.35 & 5.1211 & TRN & \\
\hline CHEMBL1530855 & 688267 & 5.55 & 5.0637 & TST & \\
\hline CHEMBL1415253 & 688267 & 4.0 & 5.0583 & TRN & \\
\hline CHEMBL1326981 & 688267 & 4.05 & 5.1 & TRN & \\
\hline CHEMBL1323349 & 688267 & 4.35 & 5.052 & TST & \\
\hline CHEMBL1299794 & 688267 & 5.2 & 5.0942 & TRN & \\
\hline CHEMBL1371113 & 688267 & 6.05 & 5.0606 & TST & \\
\hline CHEMBL1568477 & 688267 & 5.75 & 5.0975 & TRN & \\
\hline CHEMBL1457629 & 688267 & 3.9 & 5.0851 & TRN & \\
\hline CHEMBL1586087 & 688267 & 3.95 & 5.1632 & TRN & \\
\hline CHEMBL1599798 & 688267 & 6.2 & 5.1013 & TRN & \\
\hline CHEMBL1300873 & 688267 & 6.2 & 5.0033 & TRN & \\
\hline CHEMBL1489949 & 688267 & 6.45 & 5.0211 & TST & \\
\hline CHEMBL468341 & 688267 & 4.8 & 5.0301 & TRN & \\
\hline CHEMBL3191013 & 688267 & 4.4 & 5.0639 & TST & \\
\hline CHEMBL1404477 & 688267 & 5.4 & 5.0582 & TRN & \\
\hline CHEMBL1316034 & 688267 & 6.15 & 5.0255 & TRN & \\
\hline CHEMBL1413269 & 688267 & 5.8 & 5.0428 & TRN & \\
\hline CHEMBL1570493 & 688267 & 5.0 & 5.1053 & TRN & \\
\hline CHEMBL1360206 & 688267 & 5.7 & 5.0204 & TRN & \\
\hline CHEMBL1429630 & 688267 & 5.35 & 5.045 & TRN & \\
\hline CHEMBL1323922 & 688267 & 4.1 & 5.0397 & TST & \\
\hline CHEMBL1377414 & 688267 & 5.25 & 5.0043 & TRN & \\
\hline CHEMBL1524338 & 688267 & 5.05 & 5.07 & TRN & \\
\hline CHEMBL1500489 & 688267 & 4.45 & 5.1799 & TRN & \\
\hline CHEMBL1538736 & 688267 & 5.6 & 5.0362 & TRN & \\
\hline CHEMBL1322742 & 688267 & 4.1 & 5.0793 & TRN & \\
\hline CHEMBL1423663 & 688267 & 4.1 & 5.0851 & TRN & \\
\hline CHEMBL1349632 & 688267 & 4.3 & 5.0211 & TRN & \\
\hline CHEMBL1454120 & 688267 & 5.5 & 5.1162 & TRN & \\
\hline CHEMBL1517635 & 688267 & 6.6 & 5.0757 & TRN & \\
\hline CHEMBL1395008 & 688267 & 5.55 & 5.029 & TRN & \\
\hline CHEMBL1368936 & 688267 & 6.5 & 5.0249 & TST & \\
\hline CHEMBL1344341 & 688267 & 6.25 & 5.052 & TST & \\
\hline CHEMBL1569999 & 688267 & 4.4 & 5.0498 & TST & \\
\hline CHEMBL1382779 & 688267 & 6.2 & 5.0404 & TRN & \\
\hline CHEMBL1530614 & 688267 & 5.45 & 5.1022 & TST & \\
\hline CHEMBL1425132 & 688267 & 4.8 & 5.0552 & TST & \\
\hline CHEMBL1612633 & 688267 & 4.25 & 5.0493 & TST & \\
\hline CHEMBL1302625 & 688267 & 5.4 & 5.0558 & TST & \\
\hline CHEMBL1318667 & 688267 & 5.3 & $5.0310 e$ & 0000000001 & TRN \\
\hline CHEMBL1490471 & 688267 & 4.4 & 5.0306 & TRN & \\
\hline CHEMBL1348254 & 688267 & 5.75 & 5.0072 & TRN & \\
\hline CHEMBL1594017 & 688267 & 6.0 & 5.0919 & TRN & \\
\hline CHEMBL1471334 & 688267 & 4.45 & 5.0414 & TRN & \\
\hline CHEMBL1307347 & 688267 & 5.35 & 5.1118 & TRN & \\
\hline CHEMBL1576584 & 688267 & 6.2 & 5.141 & TRN & \\
\hline
\end{tabular}




\begin{tabular}{|c|c|c|c|c|c|}
\hline \multicolumn{6}{|c|}{ Supplemental Table S2.txt } \\
\hline CHEMBL3192985 & 688267 & 4.4 & 5.0587 & TRN & \\
\hline CHEMBL1505685 & 688267 & 4.0 & 5.033 & TRN & \\
\hline CHEMBL1341981 & 688267 & 4.85 & 5.0514 & TRN & \\
\hline CHEMBL1494269 & 688267 & 6.05 & 5.0163 & TRN & \\
\hline CHEMBL1366813 & 688267 & 4.95 & 5.0878 & TST & \\
\hline CHEMBL1536352 & 688267 & 4.7 & 5.0629 & TRN & \\
\hline CHEMBL1473180 & 688267 & 6.0 & 5.0476 & TST & \\
\hline CHEMBL1459293 & 688267 & 4.0 & 5.03 & TRN & \\
\hline CHEMBL1366576 & 688267 & 4.65 & 5.0935 & TST & \\
\hline CHEMBL1309446 & 688267 & 6.2 & 5.0822 & TRN & \\
\hline CHEMBL1336998 & 688267 & 6.1 & 5.1481 & TRN & \\
\hline CHEMBL1359359 & 688267 & 4.5 & 5.0259 & TST & \\
\hline CHEMBL1368600 & 688267 & 6.15 & 5.0392 & TRN & \\
\hline CHEMBL1387065 & 688267 & 5.35 & 5.08899 & 99999999995 & TRN \\
\hline CHEMBL1596780 & 688267 & 5.4 & 5.0159 & TRN & \\
\hline CHEMBL1380742 & 688267 & 5.95 & 5.0941 & TRN & \\
\hline CHEMBL1612180 & 688267 & 5.55 & 5.0923 & TRN & \\
\hline CHEMBL1535496 & 688267 & 4.05 & 5.0229 & TRN & \\
\hline CHEMBL1538925 & 688267 & 6.15 & 5.1088 & TRN & \\
\hline CHEMBL1361247 & 688267 & 4.15 & 5.0429 & TRN & \\
\hline CHEMBL1525122 & 688267 & 4.0 & 5.0909 & TRN & \\
\hline CHEMBL1396929 & 688267 & 4.05 & 5.0786 & TRN & \\
\hline CHEMBL1358051 & 688267 & 6.15 & 5.0933 & TRN & \\
\hline CHEMBL1437326 & 688267 & 4.25 & 5.084 & TRN & \\
\hline CHEMBL1480503 & 688267 & 4.6 & 5.0525 & TRN & \\
\hline CHEMBL1461866 & 688267 & 5.95 & 5.1264 & TRN & \\
\hline CHEMBL1602027 & 688267 & 4.35 & 5.0396 & TRN & \\
\hline CHEMBL1517564 & 688267 & 5.6 & 5.0783 & TRN & \\
\hline CHEMBL1593862 & 688267 & 6.2 & 4.9792 & TRN & \\
\hline CHEMBL1372295 & 688267 & 4.1 & 4.9825 & TRN & \\
\hline CHEMBL1387070 & 688267 & 6.5 & 5.0337 & TRN & \\
\hline CHEMBL1403500 & 688267 & 6.05 & 5.093 & TRN & \\
\hline CHEMBL3210448 & 688267 & 5.0 & 5.0544 & TRN & \\
\hline CHEMBL1415309 & 688267 & 6.2 & 5.0425 & TRN & \\
\hline CHEMBL1533115 & 688267 & 5.95 & 5.0365 & TRN & \\
\hline CHEMBL1382211 & 688267 & 6.45 & 5.1221 & TRN & \\
\hline CHEMBL1540527 & 688267 & 4.75 & 5.0636 & TRN & \\
\hline CHEMBL1395870 & 688267 & 4.6 & 5.0939 & TST & \\
\hline CHEMBL1363236 & 688267 & 5.4 & 5.084 & TRN & \\
\hline CHEMBL565812 & 688267 & 4.35 & 5.0491 & TRN & \\
\hline CHEMBL1464703 & 688267 & 5.2 & 5.0567 & TST & \\
\hline CHEMBL1460603 & 688267 & 5.35 & 5.0782 & TRN & \\
\hline CHEMBL1590971 & 688267 & 3.95 & 5.0255 & TRN & \\
\hline CHEMBL1420740 & 688267 & 6.0 & 5.0186 & TRN & \\
\hline CHEMBL1410751 & 688267 & 5.1 & 5.0061 & TRN & \\
\hline CHEMBL1600482 & 688267 & 5.05 & 5.0234 & TRN & \\
\hline CHEMBL1548010 & 688267 & 5.5 & 5.0783 & TRN & \\
\hline CHEMBL1456024 & 688267 & 4.8 & 5.013 & TRN & \\
\hline
\end{tabular}




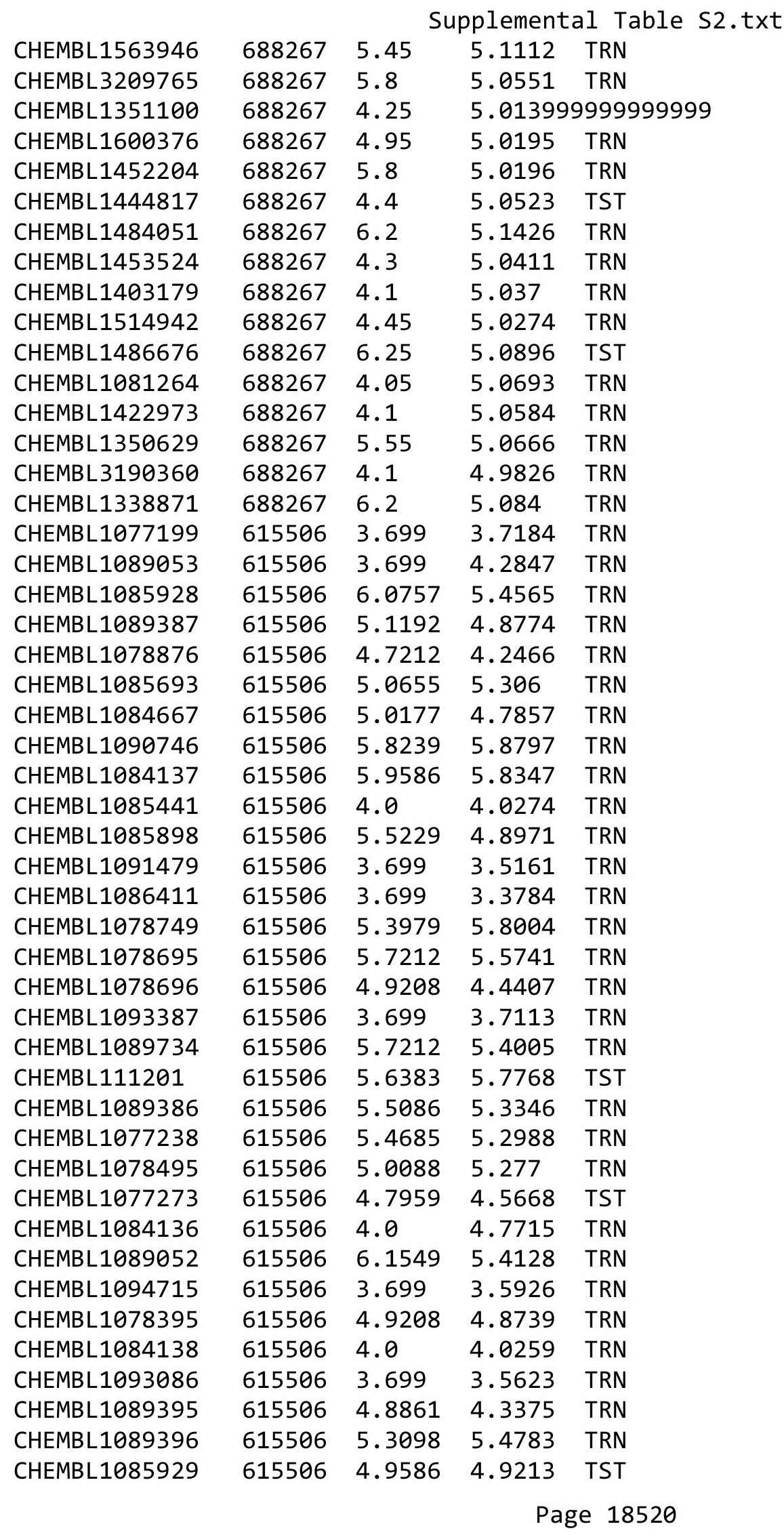

TRN 


\begin{tabular}{|c|c|c|c|c|c|c|}
\hline \multicolumn{7}{|c|}{ Supplemental Table S2.txt } \\
\hline CHEMBL1091478 & 615506 & 3.699 & 3.779 & TST & & \\
\hline CHEMBL1084144 & 615506 & 5.5229 & 5.0516 & TRN & & \\
\hline CHEMBL1090425 & 615506 & 5.0809 & 5.3404 & TRN & & \\
\hline CHEMBL1089725 & 615506 & 6.2218 & 6.4944 & TRN & & \\
\hline CHEMBL1086149 & 615506 & 4.0 & 5.1312 & TRN & & \\
\hline CHEMBL1088076 & 615506 & 3.699 & 3.733 & TRN & & \\
\hline CHEMBL1083216 & 615506 & 3.699 & 4.2844 & TRN & & \\
\hline CHEMBL1091816 & 615506 & 3.699 & 4.3288 & TRN & & \\
\hline CHEMBL1078465 & 615506 & 5.6198 & 5.3147 & TRN & & \\
\hline CHEMBL1089735 & 615506 & 3.699 & 4.4684 & TRN & & \\
\hline CHEMBL1085444 & 615506 & 5.8539 & 4.66100 & 000000000 & TST & \\
\hline CHEMBL1078575 & 615506 & 5.7696 & 5.1759 & TRN & & \\
\hline CHEMBL1085694 & 615506 & 3.699 & 4.8165 & TRN & & \\
\hline CHEMBL1085442 & 615506 & 4.0 & 4.1781 & TRN & & \\
\hline CHEMBL1083832 & 615506 & 5.2218 & 4.5716 & TST & & \\
\hline CHEMBL1078576 & 615506 & 5.3872 & 4.8948 & TRN & & \\
\hline CHEMBL1078394 & 615506 & 4.0 & 4.7658 & TST & & \\
\hline CHEMBL1090424 & 615506 & 4.0 & 4.873 & TST & & \\
\hline CHEMBL1090416 & 615506 & 3.699 & 3.6095 & TST & & \\
\hline CHEMBL1095042 & 615506 & 3.699 & 3.2858 & TST & & \\
\hline CHEMBL1084145 & 615506 & 5.4437 & 3.9698 & TST & & \\
\hline CHEMBL1092502 & 615506 & 4.7212 & 4.6942 & TST & & \\
\hline CHEMBL1078496 & 615506 & 4.0 & 5.4666 & TST & & \\
\hline CHEMBL1083831 & 615506 & 5.301 & 5.504 & TST & & \\
\hline CHEMBL1085897 & 615506 & 3.699 & 4.0291 & TST & & \\
\hline CHEMBL3704952 & 1528353 & 5.3188 & 5.2791 & TRN & & \\
\hline CHEMBL 3669040 & 1528353 & 5.6778 & 5.7322 & TRN & & \\
\hline CHEMBL3704959 & 1528353 & 6.0851 & 6.0838 & TRN & & \\
\hline CHEMBL3704938 & 1528353 & 6.1675 & 6.1952 & TRN & & \\
\hline CHEMBL3669029 & 1528353 & 6.3605 & 6.2177 & TRN & & \\
\hline CHEMBL3669032 & 1528353 & 7.0 & 6.3076 & TST & & \\
\hline CHEMBL3669038 & 1528353 & 6.4306 & 6.2307 & TRN & & \\
\hline CHEMBL 3704934 & 1528353 & 6.1979 & 6.2233 & TRN & & \\
\hline CHEMBL3669044 & 1528353 & 5.4089 & 5.3691 & TRN & & \\
\hline CHEMBL3704943 & 1528353 & 6.0 & 5.9454 & TRN & & \\
\hline CHEMBL3704958 & 1528353 & 6.7235 & 6.6729 & TRN & & \\
\hline CHEMBL3967710 & 1528353 & 5.2441 & 5.642 & TST & & \\
\hline CHEMBL 3929103 & 1528353 & 6.0 & 6.6805 & TST & & \\
\hline CHEMBL3704953 & 1528353 & 6.1549 & 6.1703 & TRN & & \\
\hline CHEMBL3669035 & 1528353 & 6.76200 & 00000000 & 005 & 6.7170000000000005 & TRN \\
\hline CHEMBL3704929 & 1528353 & 7.6021 & 7.7045 & TST & & \\
\hline CHEMBL3704956 & 1528353 & 6.0841 & 6.0702 & TRN & & \\
\hline CHEMBL3704955 & 1528353 & 5.8239 & 5.8266 & TRN & & \\
\hline CHEMBL3597970 & 1528353 & 6.2503 & 5.687 & TST & & \\
\hline CHEMBL 3704930 & 1528353 & 6.6421 & 7.4678 & TST & & \\
\hline CHEMBL 3669048 & 1528353 & 4.0 & 4.7704 & TST & & \\
\hline CHEMBL3669050 & 1528353 & 5.6383 & 5.4473 & TST & & \\
\hline CHEMBL3704941 & 1528353 & 6.8239 & 6.7859 & TRN & & \\
\hline
\end{tabular}


Supplemental Table S2.txt

\begin{tabular}{|c|c|c|c|c|c|}
\hline CHEMBL 3918636 & 1528353 & 5.6021 & 6.1197 & TST & \\
\hline CHEMBL3669028 & 1528353 & 5.396 & 5.5922 & TST & \\
\hline CHEMBL3669031 & 1528353 & 5.3098 & 5.4372 & TST & \\
\hline CHEMBL3704931 & 1528353 & 6.2314 & \multicolumn{2}{|c|}{7.077000000000001} & TST \\
\hline CHEMBL3704925 & 1528353 & 6.6635 & 6.7222 & TRN & \\
\hline CHEMBL3704939 & 1528353 & 6.0 & 5.9111 & TRN & \\
\hline CHEMBL3704950 & 1528353 & 6.1831 & 6.1143 & TRN & \\
\hline CHEMBL 3704945 & 1528353 & 6.4895 & 6.4546 & TRN & \\
\hline CHEMBL3704946 & 1528353 & 5.6914 & 5.7551 & TRN & \\
\hline CHEMBL3669046 & 1528353 & 4.0 & 4.0332 & TRN & \\
\hline CHEMBL 3704924 & 1528353 & 6.5376 & 6.4139 & TRN & \\
\hline CHEMBL3983903 & 1528353 & 4.0 & 5.8246 & TST & \\
\hline CHEMBL 3704940 & 1528353 & 6.6234 & 6.7283 & TRN & \\
\hline CHEMBL 3669034 & 1528353 & 5.1549 & 5.6224 & TST & \\
\hline CHEMBL3704965 & 1528353 & 6.3107 & 6.3065 & TRN & \\
\hline CHEMBL3669051 & 1528353 & 4.0 & 5.334 & TST & \\
\hline CHEMBL3704932 & 1528353 & 5.6874 & 7.1239 & TST & \\
\hline CHEMBL 3704957 & 1528353 & 6.0 & \multicolumn{2}{|c|}{6.082000000000001} & TRN \\
\hline CHEMBL 3669042 & 1528353 & 5.5686 & 5.4588 & TRN & \\
\hline CHEMBL 3669025 & 1528353 & 5.7238 & 5.6532 & TRN & \\
\hline CHEMBL 3669043 & 1528353 & 4.0 & 4.4818 & TRN & \\
\hline CHEMBL3669027 & 1528353 & 5.8861 & 6.0075 & TRN & \\
\hline CHEMBL 3669023 & 1528353 & 5.8239 & 5.6711 & TRN & \\
\hline CHEMBL 3669045 & 1528353 & 5.2147 & 4.9762 & TRN & \\
\hline CHEMBL3704944 & 1528353 & 6.6819 & 6.852 & TRN & \\
\hline CHEMBL 3669047 & 1528353 & 5.8539 & 5.8415 & TRN & \\
\hline CHEMBL3704942 & 1528353 & 6.2255 & 6.2656 & TRN & \\
\hline CHEMBL3704935 & 1528353 & 6.0 & 6.1896 & TRN & \\
\hline CHEMBL 3669037 & 1528353 & 5.4815 & 5.5255 & TRN & \\
\hline CHEMBL3704927 & 1528353 & 7.3979 & 7.4011 & TRN & \\
\hline CHEMBL3669036 & 1528353 & 4.0 & 5.2251 & TST & \\
\hline CHEMBL3669033 & 1528353 & 5.1938 & 5.0571 & TRN & \\
\hline CHEMBL 3597969 & 1528353 & 6.6556 & 6.706 & TRN & \\
\hline CHEMBL3704926 & 1528353 & 6.585 & 6.6462 & TRN & \\
\hline CHEMBL3704933 & 1528353 & 6.8416 & 6.8609 & TRN & \\
\hline CHEMBL3704966 & 1528353 & 5.8861 & 5.812 & TRN & \\
\hline CHEMBL3704928 & 1528353 & 6.9355 & 7.0055 & TRN & \\
\hline CHEMBL3669026 & 1528353 & 5.0223 & 4.9979 & TRN & \\
\hline CHEMBL3669039 & 1528353 & 6.3134 & 6.3812 & TRN & \\
\hline CHEMBL3669041 & 1528353 & 5.3768 & 5.4005 & TRN & \\
\hline CHEMBL3669049 & 1528353 & 5.284 & 5.5256 & TST & \\
\hline CHEMBL3704960 & 1528353 & 6.5467 & 6.6132 & TRN & \\
\hline CHEMBL3704954 & 1528353 & 6.1319 & 5.9893 & TRN & \\
\hline CHEMBL3704947 & 1528353 & 7.041 & 6.9981 & TRN & \\
\hline CHEMBL 3669030 & 1528353 & 5.8861 & 6.0647 & TRN & \\
\hline CHEMBL3704951 & 1528353 & 6.0 & 6.02 & TRN & \\
\hline CHEMBL 3704964 & 1528353 & 6.5513 & 6.5212 & TRN & \\
\hline CHEMBL3640038 & 1528353 & 6.2941 & 6.1991 & TRN & \\
\hline
\end{tabular}

Page 18522 
Supplemental Table S2.txt

\begin{tabular}{|c|c|c|c|c|}
\hline CHEMBL1802602 & 755794 & 8.3979 & 8.0702 & TRN \\
\hline CHEMBL1802832 & 755794 & 8.3979 & 8.3955 & TRN \\
\hline CHEMBL1802915 & 755794 & 7.8539 & 8.0685 & TRN \\
\hline CHEMBL1802917 & 755794 & 8.585 & 8.4751 & TRN \\
\hline CHEMBL1803005 & 755794 & 5.6383 & \multicolumn{2}{|c|}{5.736000000000001} \\
\hline CHEMBL1802913 & 755794 & 8.5229 & 8.427 & TRN \\
\hline CHEMBL1803006 & 755794 & 4.0 & 5.5884 & TST \\
\hline CHEMBL1802904 & 755794 & 9.699 & 9.6543 & TRN \\
\hline CHEMBL1802829 & 755794 & 8.3979 & 8.4893 & TRN \\
\hline CHEMBL1802588 & 755794 & 7.0506 & 7.2035 & TRN \\
\hline CHEMBL1802822 & 755794 & 7.5686 & 7.5089 & TRN \\
\hline CHEMBL1803009 & 755794 & 5.9586 & 5.8557 & TST \\
\hline CHEMBL1802824 & 755794 & 6.4089 & 6.3854 & TRN \\
\hline CHEMBL1802604 & 755794 & 7.7212 & 7.5506 & TRN \\
\hline CHEMBL1802836 & 755794 & 8.5229 & 8.4766 & TRN \\
\hline CHEMBL1802594 & 755794 & 7.3372 & 7.4196 & TRN \\
\hline CHEMBL1802830 & 755794 & 8.699 & 8.942 & TRN \\
\hline CHEMBL1802914 & 755794 & 8.699 & 8.5411 & TRN \\
\hline CHEMBL1802597 & 755794 & 6.7447 & 6.7566 & TRN \\
\hline CHEMBL1803010 & 755794 & 6.1079 & 5.857 & TRN \\
\hline CHEMBL1802834 & 755794 & 8.5229 & 8.3636 & TRN \\
\hline CHEMBL1802827 & 755794 & 5.585 & 5.6849 & TRN \\
\hline CHEMBL1802826 & 755794 & 7.5086 & 6.9579 & TRN \\
\hline CHEMBL1802585 & 755794 & 7.0315 & 6.8863 & TRN \\
\hline CHEMBL1802903 & 755794 & 8.699 & 8.6328 & TRN \\
\hline CHEMBL1803008 & 755794 & 6.1135 & 5.3303 & TST \\
\hline CHEMBL1615181 & 755794 & 7.5528 & 7.5785 & TST \\
\hline CHEMBL1802906 & 755794 & 8.5229 & 8.7217 & TRN \\
\hline CHEMBL1802908 & 755794 & 8.3979 & 8.5238 & TRN \\
\hline CHEMBL1803015 & 755794 & 5.5229 & 6.2078 & TST \\
\hline CHEMBL1802589 & 755794 & 7.4949 & 7.4969 & TRN \\
\hline CHEMBL1803011 & 755794 & 6.4202 & 6.6038 & TRN \\
\hline CHEMBL1802905 & 755794 & 6.8861 & 6.7946 & TRN \\
\hline CHEMBL1802593 & 755794 & 7.3468 & 7.4301 & TRN \\
\hline CHEMBL1802831 & 755794 & 8.699 & 8.8846 & TRN \\
\hline CHEMBL1802591 & 755794 & 7.7959 & 7.751 & TRN \\
\hline CHEMBL1803004 & 755794 & 7.5086 & 6.7224 & TRN \\
\hline CHEMBL1802586 & 755794 & 7.3372 & 7.2283 & TRN \\
\hline CHEMBL1802592 & 755794 & 6.5528 & 6.4971 & TRN \\
\hline CHEMBL1802595 & 755794 & 7.5229 & 7.6916 & TRN \\
\hline CHEMBL1800105 & 755794 & 4.0 & 4.437 & TRN \\
\hline CHEMBL1802606 & 755794 & 7.9586 & 8.133 & TRN \\
\hline CHEMBL1802825 & 755794 & 7.0 & 6.9578 & TRN \\
\hline CHEMBL1802598 & 755794 & 7.1938 & 7.1487 & TRN \\
\hline CHEMBL1802823 & 755794 & 6.8861 & 6.9452 & TRN \\
\hline CHEMBL1802605 & 755794 & 8.301 & 8.6205 & TRN \\
\hline CHEMBL1802601 & 755794 & 6.7696 & 6.9897 & TRN \\
\hline CHEMBL1802590 & 755794 & 7.6198 & 7.4966 & TRN \\
\hline
\end{tabular}




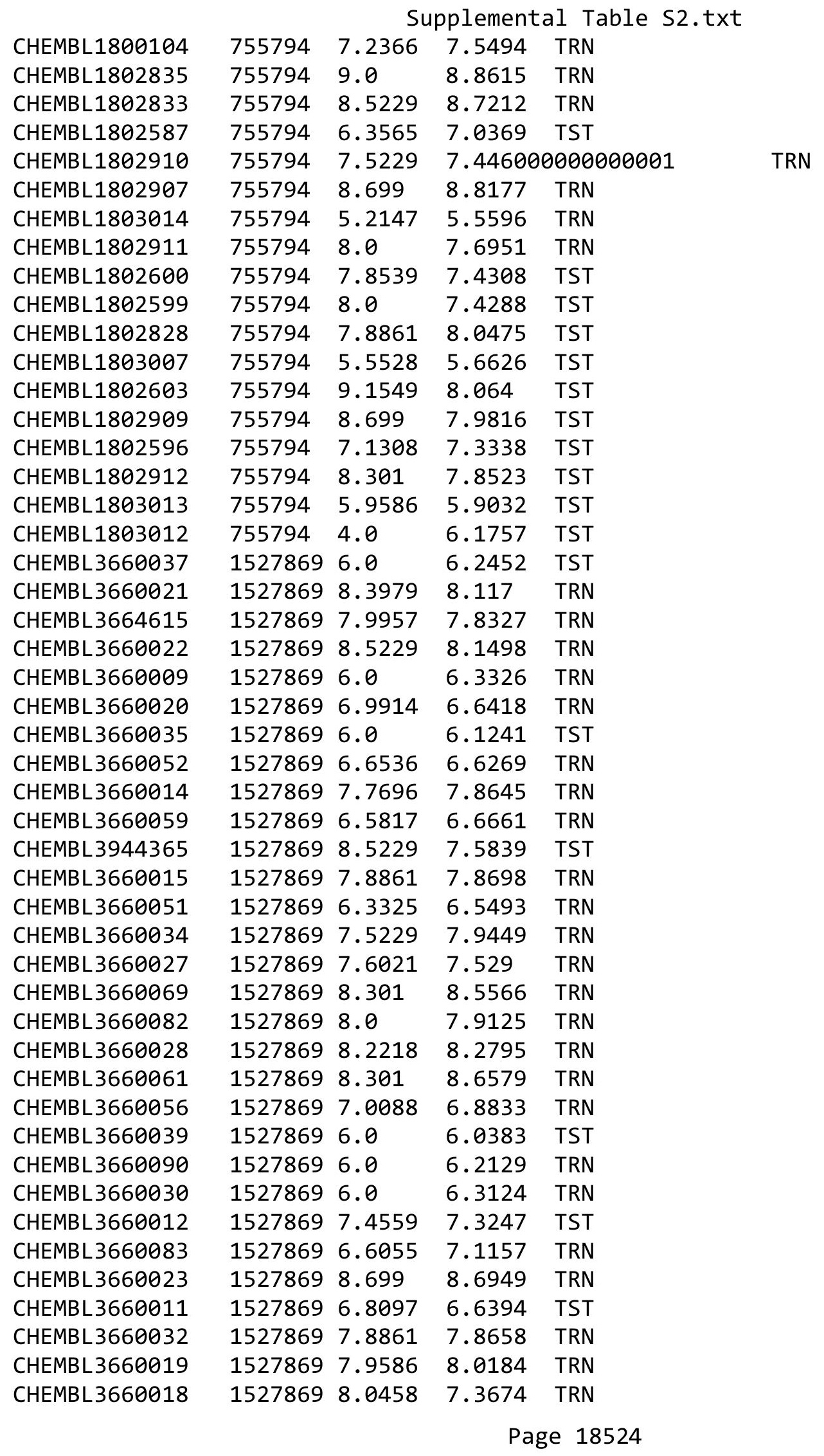


Supplemental Table S2.txt

\begin{tabular}{|c|c|c|c|c|c|}
\hline CHEMBL 3660067 & 1527869 & 6.9508 & 6.6784 & TRN & \\
\hline CHEMBL 3660086 & 1527869 & 6.0 & 5.8595 & TRN & \\
\hline CHEMBL 3660064 & 1527869 & 8.0 & 8.1912 & TRN & \\
\hline CHEMBL 3660025 & 1527869 & 8.301 & 8.1643 & TRN & \\
\hline CHEMBL 3660024 & 1527869 & 8.699 & 8.9398 & TRN & \\
\hline CHEMBL 3660063 & 1527869 & 8.5229 & 8.4872 & TRN & \\
\hline CHEMBL 3660058 & 1527869 & 6.1379 & 6.1963 & TRN & \\
\hline CHEMBL 3660029 & 1527869 & 8.3979 & 8.5019 & TRN & \\
\hline CHEMBL 3664616 & 1527869 & 8.0555 & 7.8613 & TRN & \\
\hline CHEMBL 3660008 & 1527869 & 7.6021 & 7.6676 & TRN & \\
\hline CHEMBL 3660007 & 1527869 & 6.3487 & 6.285 & TRN & \\
\hline CHEMBL 3660048 & 1527869 & 6.0 & 6.1145 & TRN & \\
\hline CHEMBL 3660006 & 1527869 & 8.3565 & 7.7078 & TRN & \\
\hline CHEMBL 3660042 & 1527869 & 7.3372 & 7.8592 & TST & \\
\hline CHEMBL 3660084 & 1527869 & 7.6198 & 7.3167 & TST & \\
\hline CHEMBL 3660016 & 1527869 & 6.0 & 6.7167 & TST & \\
\hline CHEMBL3660049 & 1527869 & 8.0 & 7.2994 & TST & \\
\hline CHEMBL 3660033 & 1527869 & 8.3979 & 8.1561 & TST & \\
\hline CHEMBL 3660013 & 1527869 & 7.0315 & 6.8494 & TST & \\
\hline CHEMBL 3660053 & 1527869 & 7.6198 & 7.4771 & TST & \\
\hline CHEMBL514499 & 954500 & 7.3734 & 7.2567 & TRN & \\
\hline CHEMBL 209148 & 954500 & 4.9972 & 4.8427 & TRN & \\
\hline CHEMBL379975 & 954500 & 6.8697 & 6.5326 & TRN & \\
\hline CHEMBL135561 & 954500 & 5.6451 & 4.70100 & 00000000005 & TRN \\
\hline CHEMBL 222102 & 954500 & 4.5988 & 4.6489 & TRN & \\
\hline CHEMBL 213100 & 954500 & 4.8379 & 5.5836 & TRN & \\
\hline CHEMBL 379300 & 954500 & 6.591 & 6.4241 & TRN & \\
\hline CHEMBL188678 & 954500 & 5.4668 & 5.4712 & TRN & \\
\hline CHEMBL 258844 & 954500 & 4.1804 & 4.1578 & TRN & \\
\hline CHEMBL 2363137 & 954500 & 5.1662 & 4.8291 & TRN & \\
\hline CHEMBL1190711 & 954500 & 6.2352 & 6.1751 & TRN & \\
\hline CHEMBL558642 & 954500 & 5.0556 & 4.9886 & TRN & \\
\hline CHEMBL1230020 & 954500 & 4.89 & 4.643 & TRN & \\
\hline CHEMBL472940 & 954500 & 5.5363 & 5.5368 & TRN & \\
\hline CHEMBL483847 & 954500 & 3.843 & 4.2766 & TRN & \\
\hline CHEMBL300389 & 954500 & 7.3111 & 6.9215 & TRN & \\
\hline CHEMBL1357247 & 954500 & 3.9341 & 3.4286 & TRN & \\
\hline CHEMBL1516890 & 954500 & 3.8635 & 4.1353 & TRN & \\
\hline CHEMBL 210618 & 954500 & 4.6512 & 4.1802 & TRN & \\
\hline CHEMBL1970879 & 954500 & 5.5425 & 5.2507 & TRN & \\
\hline CHEMBL1643959 & 954500 & 3.6353 & 3.7086 & TRN & \\
\hline CHEMBL515416 & 954500 & 3.8961 & 4.5121 & TRN & \\
\hline CHEMBL1788116 & 954500 & 3.6299 & 4.0767 & TRN & \\
\hline CHEMBL192566 & 954500 & 6.2779 & 8.1496 & TST & \\
\hline CHEMBL92309 & 954500 & 3.3725 & 3.6643 & TST & \\
\hline CHEMBL221137 & 954500 & 5.2763 & 5.1726 & TST & \\
\hline CHEMBL 220241 & 954500 & 6.3098 & 5.9157 & TRN & \\
\hline CHEMBL102714 & 954500 & 4.8058 & 4.4882 & TRN & \\
\hline
\end{tabular}


Supplemental Table S2.txt

\begin{tabular}{|c|c|c|c|c|}
\hline 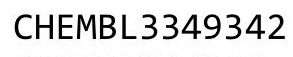 & & 063 & 3244 & \\
\hline HEMBL 240954 & 54500 & 3.8238 & 4.8129 & \\
\hline AEMBL189584 & 54500 & 598 & 1829 & \\
\hline AEMBL512 & 54500 & 387 & 112 & \\
\hline HEMBL1404918 & 54500 & 369 & 2902 & \\
\hline AEMBL 2005886 & 54500 & 835 & 2319 & \\
\hline AEMBL1909414 & 54500 & 4.3208 & .6273 & \\
\hline AEMBL509032 & 500 & 778 & 6534 & \\
\hline IEMBL585951 & 54500 & 6.4642 & 335 & \\
\hline HEMBL65 & 54500 & 105 & 528 & \\
\hline AEMBL573107 & 54500 & 823 & .7001 & \\
\hline HEMBL483849 & 54500 & 3.3134 & 3.3515 & \\
\hline AEMBL1256459 & 00 & 7.0939 & 64 & \\
\hline HEMBL393929 & 00 & & 62 & \\
\hline HEMBL 3392440 & 00 & & 65 & \\
\hline AEMBL412142 & 954500 & 987 & 847 & \\
\hline AEMBL191334 & 00 & 936 & 16 & \\
\hline HEMBL202721 & $\partial 0$ & 5 . & 29 & \\
\hline AEMBL259181 & 00 & & & \\
\hline HEMBL3199475 & 00 & 44 & 775 & \\
\hline AEMBL373751 & 00 & 918 & 78 & \\
\hline AEMBL1590308 & 00 & & 3. & \\
\hline AEMBL1673039 & 00 & & 84 & \\
\hline HEMBL1242367 & & & & \\
\hline HEMBL 180127 & 00 & 3. & 66 & \\
\hline AEMBL449158 & 00 & 085 & 48 & \\
\hline AEMBL577784 & 00 & 07 & 404 & \\
\hline AEMBL3186408 & & & 93 & \\
\hline AEMBL9470 & 95 & & 19 & \\
\hline HEMBL 392695 & 00 & 27 & 88 & \\
\hline HEMBL2144069 & 00 & & 01 & \\
\hline AEMBL3676061 & 1528479 & & 968 & \\
\hline 3L3675927 & 79 & & & \\
\hline 575909 & 9 & $\Gamma$ & & \\
\hline L 3671140 & 15 & 5 & 78 & . \\
\hline AEMBL3676072 & 1528479 & 5 . & 4221 & \\
\hline AEMBL3675942 & 28479 & & 347 & \\
\hline 3676101 & & 3. & 34 & RI \\
\hline 3675923 & 9 & 6 . & 88 & NTw \\
\hline HEMBL3675914 & 1528479 & 5.0 & 1712 & RN \\
\hline AEMBL3675934 & 1528479 & 5 . & 208 & $R$ \\
\hline HEMBL 3676079 & 1528 & 5 . & 82 & 5 \\
\hline CHEMBL3676099 & & 6.21 & & \\
\hline CHEMBL3671144 & 1528479 & 5.0 & & nIN \\
\hline HEMBL3675952 & 1528479 & 5.0 & .4564 & ST \\
\hline HEMBL 3675954 & 1528479 & 6.1561 & .9924 & TR \\
\hline HEMBL 3675961 & 152 & 5.0 & & \\
\hline 4 & סרתמת & - & .8705 & \\
\hline
\end{tabular}

Page 18526 


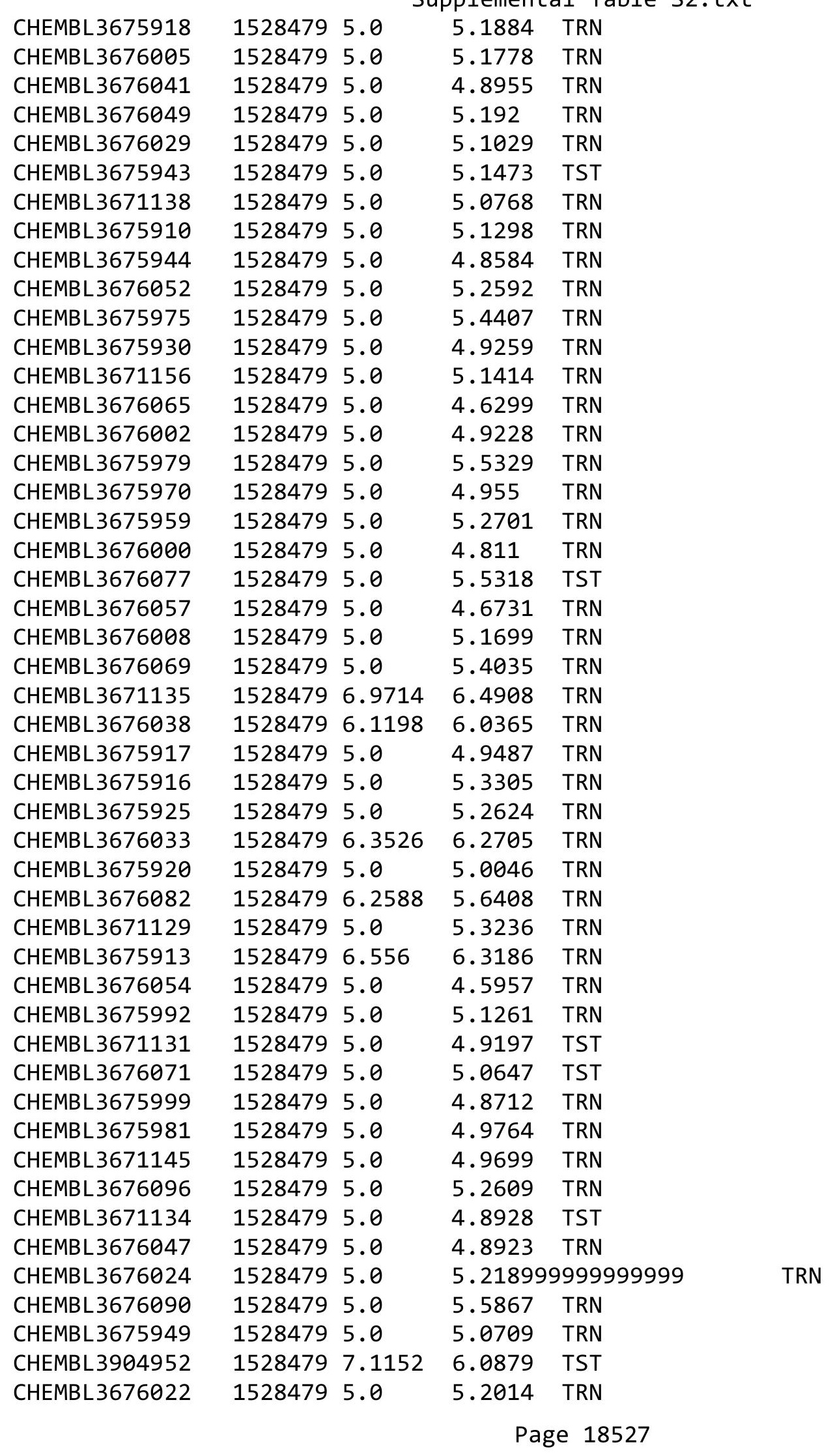


Supplemental Table S2.txt

\begin{tabular}{|c|c|c|c|c|c|}
\hline CHEMBL 3676089 & 1528479 & 6.3509 & 5.6167 & TRN & \\
\hline CHEMBL3671132 & 1528479 & 5.0 & 4.7966 & TRN & \\
\hline CHEMBL3675935 & 1528479 & 5.0 & 5.101 & TST & \\
\hline CHEMBL3675948 & 1528479 & 5.0 & 4.5801 & TRN & \\
\hline CHEMBL3676032 & 1528479 & 5.0 & 5.38899 & 9999999999 & TST \\
\hline CHEMBL3675967 & 1528479 & 5.0 & 4.6784 & TRN & \\
\hline CHEMBL3675982 & 1528479 & 5.0 & 4.9704 & TRN & \\
\hline CHEMBL3675953 & 1528479 & 5.0 & 4.8087 & TST & \\
\hline CHEMBL3675937 & 1528479 & 6.1555 & 5.2623 & TST & \\
\hline CHEMBL3675912 & 1528479 & 7.3737 & 6.7576 & TRN & \\
\hline CHEMBL3676056 & 1528479 & 5.0 & 4.446006 & 0000000001 & TRN \\
\hline CHEMBL3955007 & 1528479 & 5.0 & 5.3115 & TST & \\
\hline CHEMBL3676074 & 1528479 & 5.0 & 5.9184 & TST & \\
\hline CHEMBL3675922 & 1528479 & 6.4112 & 6.1224 & TRN & \\
\hline CHEMBL3675950 & 1528479 & 5.0 & 4.8194 & TRN & \\
\hline CHEMBL3676015 & 1528479 & 5.0 & 5.0405 & TRN & \\
\hline CHEMBL3675973 & 1528479 & 5.0 & 5.3021 & TRN & \\
\hline CHEMBL3676046 & 1528479 & 5.0 & 4.9815 & TRN & \\
\hline CHEMBL3675968 & 1528479 & 5.0 & 5.2329 & TRN & \\
\hline CHEMBL3676095 & 1528479 & 5.0 & 5.0148 & TRN & \\
\hline CHEMBL3675951 & 1528479 & 5.0 & 4.7381 & TST & \\
\hline CHEMBL3676055 & 1528479 & 5.0 & 4.6566 & TRN & \\
\hline CHEMBL3676010 & 1528479 & 5.0 & 4.9347 & TRN & \\
\hline CHEMBL3671142 & 1528479 & 6.3279 & 5.9024 & TRN & \\
\hline CHEMBL3675924 & 1528479 & 5.0 & 5.0154 & TRN & \\
\hline CHEMBL3676006 & 1528479 & 5.0 & 4.9916 & TRN & \\
\hline CHEMBL3675966 & 1528479 & 5.0 & 5.2615 & TRN & \\
\hline CHEMBL3675932 & 1528479 & 5.0 & 5.1188 & TRN & \\
\hline CHEMBL3676023 & 1528479 & 5.0 & 4.9074 & TRN & \\
\hline CHEMBL 3676013 & 1528479 & 5.0 & \multicolumn{2}{|c|}{5.462000000000001} & TRN \\
\hline CHEMBL3639748 & 1528479 & 5.0 & 5.5693 & TST & \\
\hline CHEMBL3676051 & 1528479 & 5.0 & 4.9384 & TRN & \\
\hline CHEMBL3675963 & 1528479 & 5.0 & 4.9186 & TRN & \\
\hline CHEMBL3675915 & 1528479 & 5.0 & 5.6568 & TRN & \\
\hline CHEMBL3676040 & 1528479 & 5.0 & 4.5631 & TRN & \\
\hline CHEMBL3676068 & 1528479 & 5.0 & 4.8093 & TRN & \\
\hline CHEMBL3675929 & 1528479 & 5.0 & 5.4257 & TRN & \\
\hline CHEMBL3675955 & 1528479 & 6.061 & 5.5021 & TRN & \\
\hline CHEMBL3676016 & 1528479 & 5.0 & 5.0891 & TST & \\
\hline CHEMBL3671137 & 1528479 & 5.0 & 5.0025 & TRN & \\
\hline CHEMBL 3676050 & 1528479 & 5.0 & 5.1934 & TRN & \\
\hline CHEMBL3676059 & 1528479 & 5.0 & 4.4888 & TRN & \\
\hline CHEMBL3676076 & 1528479 & 5.0 & 5.9435 & TST & \\
\hline CHEMBL3676067 & 1528479 & 5.0 & 5.3737 & TRN & \\
\hline CHEMBL3671139 & 1528479 & 5.0 & 5.2396 & TRN & \\
\hline CHEMBL3671130 & 1528479 & 5.0 & 5.3631 & TST & \\
\hline CHEMBL3676064 & 1528479 & 5.0 & 4.8743 & TRN & \\
\hline CHEMBL3676019 & 1528479 & 5.0 & 5.2038 & TRN & \\
\hline
\end{tabular}




\begin{tabular}{|c|c|c|c|c|c|}
\hline & & & & & \\
\hline CHEMBL 3676048 & 1528479 & 5.0 & 4.9358 & TRN & \\
\hline CHEMBL3676084 & 1528479 & 5.0 & 5.1493 & TST & \\
\hline CHEMBL3675976 & 1528479 & 5.0 & 5.2662 & TRN & \\
\hline CHEMBL3675941 & 1528479 & 5.0 & 5.0678 & TRN & \\
\hline CHEMBL3675940 & 1528479 & 6.2403 & 6.0362 & TRN & \\
\hline CHEMBL 3676025 & 1528479 & 6.2807 & 5.9926 & TRN & \\
\hline CHEMBL3675962 & 1528479 & 5.0 & 5.3879 & TST & \\
\hline CHEMBL3671148 & 1528479 & 6.5901 & 5.8227 & TRN & \\
\hline CHEMBL3676078 & 1528479 & 5.0 & 5.3368 & TST & \\
\hline CHEMBL3676039 & 1528479 & 5.0 & 5.0857 & TRN & \\
\hline CHEMBL3675958 & 1528479 & 5.0 & 5.1444 & TRN & \\
\hline CHEMBL 3676034 & 1528479 & 5.0 & 5.0743 & TRN & \\
\hline CHEMBL3675919 & 1528479 & 5.0 & 5.5139 & TRN & \\
\hline CHEMBL3671150 & 1528479 & 5.0 & 4.6877 & TST & \\
\hline CHEMBL3676093 & 1528479 & 5.0 & 5.2435 & TRN & \\
\hline CHEMBL3676086 & 1528479 & 5.0 & 5.1544 & TST & \\
\hline CHEMBL3676012 & 1528479 & 5.0 & 5.3103 & TST & \\
\hline CHEMBL3676085 & 1528479 & 5.0 & 5.3529 & TST & \\
\hline CHEMBL3676075 & 1528479 & 5.0 & 5.3691 & TST & \\
\hline CHEMBL3676018 & 1528479 & 5.0 & 5.3425 & TRN & \\
\hline CHEMBL3676045 & 1528479 & 5.0 & 5.1582 & TRN & \\
\hline CHEMBL3675926 & 1528479 & 6.3675 & 6.1845 & TRN & \\
\hline CHEMBL3676080 & 1528479 & 5.0 & 5.2663 & TST & \\
\hline CHEMBL3671151 & 1528479 & 5.0 & 4.9169 & TST & \\
\hline CHEMBL3676031 & 1528479 & 5.0 & 5.1381 & TRN & \\
\hline CHEMBL 3676073 & 1528479 & 5.0 & 4.8858 & TST & \\
\hline CHEMBL3676053 & 1528479 & 5.0 & 5.2242 & TRN & \\
\hline CHEMBL3676094 & 1528479 & 5.0 & 4.8745 & TRN & \\
\hline CHEMBL3675986 & 1528479 & 5.0 & 4.9247 & TRN & \\
\hline CHEMBL3675964 & 1528479 & 5.0 & 5.1184 & TST & \\
\hline CHEMBL3676070 & 1528479 & 5.0 & 5.4441 & TST & \\
\hline CHEMBL3671133 & 1528479 & 5.0 & 4.7179 & TST & \\
\hline CHEMBL3675985 & 1528479 & 5.0 & 4.8644 & TRN & \\
\hline CHEMBL3675908 & 1528479 & 5.0 & 5.2662 & TRN & \\
\hline CHEMBL3675993 & 1528479 & 5.0 & 4.961 & TRN & \\
\hline CHEMBL3676042 & 1528479 & 5.0 & 5.2708 & TRN & \\
\hline CHEMBL3676091 & 1528479 & 5.0 & 4.91100 & 20000000005 & TRN \\
\hline CHEMBL3671152 & 1528479 & 5.0 & 5.0147 & TST & \\
\hline CHEMBL3676001 & 1528479 & 5.0 & 4.8679 & TRN & \\
\hline CHEMBL3675991 & 1528479 & 5.0 & 4.8956 & TRN & \\
\hline CHEMBL3676030 & 1528479 & 5.0 & 5.3047 & TRN & \\
\hline CHEMBL3671149 & 1528479 & 5.0 & 4.7843 & TST & \\
\hline CHEMBL3675956 & 1528479 & 6.1765 & 5.6721 & TRN & \\
\hline CHEMBL3675965 & 1528479 & 6.3261 & 5.7162 & TST & \\
\hline CHEMBL3675988 & 1528479 & 5.0 & 4.6533 & TRN & \\
\hline CHEMBL 3675957 & 1528479 & 5.0 & 5.5345 & TRN & \\
\hline CHEMBL3675947 & 1528479 & 5.0 & 5.3087 & TRN & \\
\hline CHEMBL3675945 & 1528479 & 5.0 & 5.7114 & TRN & \\
\hline & & & & 185 & \\
\hline
\end{tabular}


Supplemental Table S2.txt

\begin{tabular}{|c|c|c|c|c|c|}
\hline CHEMBL3675911 & 1528479 & 7.6308 & \multicolumn{2}{|c|}{6.287999999999999} & TRN \\
\hline CHEMBL3675936 & 1528479 & 5.0 & 5.0258 & TRN & \\
\hline CHEMBL3671143 & 1528479 & 6.8069 & 5.28 & TST & \\
\hline CHEMBL3937419 & 1528479 & 6.3019 & 6.0038 & TST & \\
\hline CHEMBL3675960 & 1528479 & 5.0 & 5.3049 & TST & \\
\hline CHEMBL3675972 & 1528479 & 5.0 & 5.1199 & TRN & \\
\hline CHEMBL3676026 & 1528479 & 5.0 & 5.2886 & TRN & \\
\hline CHEMBL3902802 & 1528479 & 5.0 & 5.4001 & TST & \\
\hline CHEMBL3675931 & 1528479 & 5.0 & 5.3721 & TRN & \\
\hline CHEMBL 3676081 & 1528479 & 6.1739 & 5.9383 & TRN & \\
\hline CHEMBL3676060 & 1528479 & 5.0 & 4.9071 & TRN & \\
\hline CHEMBL3675969 & 1528479 & 5.0 & 4.8632 & TRN & \\
\hline CHEMBL3676092 & 1528479 & 6.1768 & 5.7237 & TRN & \\
\hline CHEMBL3671136 & 1528479 & 5.0 & 5.1697 & TRN & \\
\hline CHEMBL3971680 & 1528479 & 5.0 & 5.566 & TST & \\
\hline CHEMBL3676087 & 1528479 & 5.0 & 4.7921 & TST & \\
\hline CHEMBL3675971 & 1528479 & 5.0 & 4.8431 & TRN & \\
\hline CHEMBL 3676088 & 1528479 & 5.0 & 5.3408 & TRN & \\
\hline CHEMBL3676011 & 1528479 & 5.0 & 4.9167 & TRN & \\
\hline CHEMBL3676037 & 1528479 & 5.0 & 4.9443 & TRN & \\
\hline CHEMBL3671153 & 1528479 & 5.0 & 5.3548 & TRN & \\
\hline CHEMBL3671155 & 1528479 & 5.0 & 4.8627 & TRN & \\
\hline CHEMBL3675933 & 1528479 & 5.0 & 5.2932 & TRN & \\
\hline CHEMBL 3671141 & 1528479 & 5.0 & 5.8585 & TRN & \\
\hline CHEMBL3676058 & 1528479 & 5.0 & 5.2733 & TST & \\
\hline CHEMBL3675946 & 1528479 & 5.0 & 5.0954 & TST & \\
\hline CHEMBL3676063 & 1528479 & 5.0 & 5.4606 & TST & \\
\hline CHEMBL3979775 & 1642220 & 7.0142 & 7.2375 & TRN & \\
\hline CHEMBL3926717 & 1642220 & 5.4795 & 6.2964 & TST & \\
\hline CHEMBL 3898147 & 1642220 & 6.4488 & 7.3288 & TST & \\
\hline CHEMBL3967197 & 1642220 & 8.11 & 7.6019 & TRN & \\
\hline CHEMBL3978016 & 1642220 & 5.8687 & 5.7286 & TRN & \\
\hline CHEMBL3956094 & 1642220 & 7.3476 & 7.17700 & 00000000005 & TST \\
\hline CHEMBL3918315 & 1642220 & 7.1612 & 7.6072 & TST & \\
\hline CHEMBL3915893 & 1642220 & 7.8604 & 7.7714 & TRN & \\
\hline CHEMBL3931049 & 1642220 & 6.4363 & 6.4903 & TRN & \\
\hline CHEMBL3915082 & 1642220 & 6.4383 & 6.3407 & TRN & \\
\hline CHEMBL3927262 & 1642220 & 5.506 & 6.7019 & TST & \\
\hline CHEMBL3959263 & 1642220 & 5.7003 & 5.6719 & TRN & \\
\hline CHEMBL3894334 & 1642220 & 5.3747 & 5.5692 & TRN & \\
\hline CHEMBL3923862 & 1642220 & 6.8462 & 6.8497 & TRN & \\
\hline CHEMBL3912999 & 1642220 & 6.9363 & 7.1131 & TRN & \\
\hline CHEMBL3904722 & 1642220 & 8.0839 & 8.1201 & TRN & \\
\hline CHEMBL 3984724 & 1642220 & 5.8262 & 6.0122 & TRN & \\
\hline CHEMBL3916859 & 1642220 & 7.0898 & 7.001 & TRN & \\
\hline CHEMBL3977296 & 1642220 & 6.0509 & 6.2665 & TRN & \\
\hline CHEMBL 3924074 & 1642220 & 6.0961 & 5.9827 & TRN & \\
\hline CHEMBL3951262 & 1642220 & 9.1612 & 9.121 & TRN & \\
\hline
\end{tabular}


Supplemental Table S2.txt

\begin{tabular}{|c|c|c|c|c|}
\hline ILI & 2220 & 652 & & \\
\hline & 642220 & 5.7731 & 5.8926 & \\
\hline & 20 & 291 & & \\
\hline AEMBL & 220 & 9622 & & \\
\hline AEMBL3902064 & 542220 & 049 & & \\
\hline HEMBL3936219 & 642220 & 7.1607 & 0123 & \\
\hline & 20 & 312 & & \\
\hline IFMRI = & & & & \\
\hline HEMBL 391 & 220 & 055 & 8635 & \\
\hline HEMBL 394 & 220 & 474 & 5143 & \\
\hline AEMBL392 & 220 & 5.8864 & 8497 & \\
\hline IEMBL3C & 20 & 79 & 596 & \\
\hline AEMBL3 & & & & \\
\hline HEMBL39 & 20 & 725 & .5027 & \\
\hline HEMBL397 & 20 & & & \\
\hline AEMBL39 & 20 & 931 & 15 & \\
\hline AEMBL3S & 20 & & & \\
\hline HEMBL3\& & & & & \\
\hline HEMBL39 & & 378 & 8784 & \\
\hline AEMBL38 & & & & \\
\hline AEMBL & 20 & & 32 & \\
\hline HEMBL: & 0 & & & \\
\hline HEMBL; & & & & \\
\hline HFMRI & & & & \\
\hline AEMBL38 & & & & \\
\hline HEMBL3S & 20 & & 672 & RN \\
\hline HEMBL3 & 20 & & 392 & RN \\
\hline HFMBI 3 & 20 & 49 & 56 & \\
\hline HEMBL3S & & & 686 & $\Gamma \mathrm{RN}$ \\
\hline HEMBL 392 & & & & I RN \\
\hline HEMBL3S & 20 & & 621 & RIV \\
\hline HEMBL & 20 & & & וד \\
\hline HEMBL3 & & & 091 & \\
\hline HEMBL 389 & 20 & & 68 & Th \\
\hline HEMBL 395 & 20 & 7. & 578 & TST \\
\hline HEMBL3 & 20 & 71 & 986 & RN \\
\hline 4 & 20 & 28 & & RIV \\
\hline HEMBL3 & & & 378 & ГST \\
\hline HEMBL393 & 20 & 441 & 335 & TST \\
\hline IEMBL39 & 20 & & & TRN \\
\hline HEMBL3S & 20 & 91 & 914 & \\
\hline CHEMBL 39 & & & & RN \\
\hline HEMBL39 & 20 & & 2118 & RN \\
\hline HEMBL 398 & 20 & 6.9809 & 9866 & TRN \\
\hline $\mathrm{MRI}=$ & & & & TST \\
\hline HEMBL3 & & 18 & & \\
\hline CHEMBL 391 & 220 & & .4923 & \\
\hline CHEMBL3953881 & 1642220 & 6.1473 & 6.0645 & RN \\
\hline
\end{tabular}

Page 18531 
Supplemental Table S2.txt

\begin{tabular}{|c|c|c|c|c|c|}
\hline CHEMBL3961621 & 1642220 & 6.2734 & 6.4527 & TST & \\
\hline CHEMBL 3924881 & 1642220 & 6.8105 & 6.6843 & TRN & \\
\hline CHEMBL3932113 & 1642220 & 7.4559 & 7.6915 & TST & \\
\hline CHEMBL3965266 & 1642220 & 6.6459 & 6.7743 & TRN & \\
\hline CHEMBL 3929422 & 1642220 & 5.8139 & \multicolumn{2}{|c|}{5.952999999999999} & TRN \\
\hline CHEMBL3937213 & 1642220 & 6.8877 & 6.6426 & TRN & \\
\hline CHEMBL 3907101 & 1642220 & 7.8665 & 8.0063 & TRN & \\
\hline CHEMBL3907865 & 1642220 & 7.7755 & 7.7751 & TRN & \\
\hline CHEMBL3932859 & 1642220 & 6.1731 & 6.0915 & TRN & \\
\hline CHEMBL 3932724 & 1642220 & 7.9473 & 7.8841 & TRN & \\
\hline CHEMBL3952233 & 1642220 & 5.9706 & 6.1354 & TRN & \\
\hline CHEMBL3918096 & 1642220 & 6.8055 & 6.6428 & TST & \\
\hline CHEMBL1439938 & 822044 & 6.5686 & 6.1466 & TRN & \\
\hline CHEMBL423698 & 822044 & 5.5258 & 5.4987 & TRN & \\
\hline CHEMBL1987720 & 822044 & 5.4225 & 5.7689 & TST & \\
\hline CHEMBL 2036330 & 822044 & 5.1379 & 5.1658 & TRN & \\
\hline CHEMBL584437 & 822044 & 4.95 & 5.0598 & TST & \\
\hline CHEMBL1770713 & 822044 & 4.6366 & 4.7847 & TST & \\
\hline CHEMBL 2036347 & 822044 & 4.6381 & 4.4995 & TRN & \\
\hline CHEMBL 2036342 & 822044 & 5.7375 & 5.8038 & TRN & \\
\hline CHEMBL509621 & 822044 & 4.5882 & 4.2909 & TRN & \\
\hline CHEMBL116438 & 822044 & 4.7129 & 4.9456 & TRN & \\
\hline CHEMBL477054 & 822044 & 5.3344 & 5.6722 & TRN & \\
\hline CHEMBL598461 & 822044 & 5.2269 & 5.2809 & TST & \\
\hline CHEMBL17212 & 822044 & 5.8928 & 5.2859 & TST & \\
\hline CHEMBL452101 & 822044 & 4.6392 & \multicolumn{2}{|c|}{4.156000000000001} & TRN \\
\hline CHEMBL485636 & 822044 & 5.0315 & 4.8893 & TRN & \\
\hline CHEMBL 2036341 & 822044 & 5.6556 & 5.8393 & TRN & \\
\hline CHEMBL477256 & 822044 & 4.9255 & 5.0236 & TRN & \\
\hline CHEMBL 2036334 & 822044 & 5.0846 & 5.274 & TRN & \\
\hline CHEMBL244023 & 822044 & 4.7846 & 5.0225 & TRN & \\
\hline CHEMBL 2036338 & 822044 & 5.5317 & 4.9145 & TST & \\
\hline CHEMBL128729 & 822044 & 5.3768 & 5.2718 & TRN & \\
\hline CHEMBL1461633 & 822044 & 4.7279 & 4.8293 & TST & \\
\hline CHEMBL496340 & 822044 & 4.6024 & 4.6279 & TRN & \\
\hline CHEMBL2036335 & 822044 & 5.0726 & 5.3738 & TRN & \\
\hline CHEMBL475523 & 822044 & 4.8681 & 4.7201 & TRN & \\
\hline CHEMBL512585 & 822044 & 5.4401 & 5.5892 & TRN & \\
\hline CHEMBL496321 & 822044 & 4.7781 & 5.1018 & TST & \\
\hline CHEMBL 2036345 & 822044 & 6.1549 & 6.0731 & TRN & \\
\hline CHEMBL1224790 & 822044 & 5.1568 & 5.0506 & TRN & \\
\hline CHEMBL 2036348 & 822044 & 5.1811 & 5.2117 & TRN & \\
\hline CHEMBL2036343 & 822044 & 6.284 & 5.8946 & TST & \\
\hline CHEMBL482410 & 822044 & 4.9083 & 4.8462 & TRN & \\
\hline CHEMBL 2036331 & 822044 & 5.2132 & 5.3427 & TRN & \\
\hline CHEMBL482409 & 822044 & 4.8778 & 4.7371 & TRN & \\
\hline CHEMBL 2035948 & 822044 & 3.5229 & 4.3854 & TRN & \\
\hline CHEMBL1314028 & 822044 & 5.0851 & 5.1692 & TST & \\
\hline
\end{tabular}




\begin{tabular}{|c|c|c|c|c|c|c|}
\hline \multirow[b]{2}{*}{ CHEMBL358894 } & \multicolumn{6}{|c|}{ 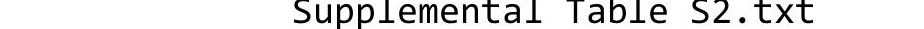 } \\
\hline & 822044 & 5.5421 & 5.5675 & TRN & & \\
\hline CHEMBL1224755 & 822044 & 5.6737 & 5.4887 & TRN & & \\
\hline CHEMBL1224757 & 822044 & 5.6655 & 5.3808 & TRN & & \\
\hline CHEMBL2036340 & 822044 & 5.7258 & 5.5465 & TST & & \\
\hline CHEMBL 2036344 & 822044 & 6.0177 & 6.0887 & TRN & & \\
\hline CHEMBL129073 & 822044 & 5.0462 & 4.8481 & TST & & \\
\hline CHEMBL 2036339 & 822044 & 5.2534 & 5.101 & TRN & & \\
\hline CHEMBL474918 & 822044 & 4.9465 & 4.9855 & TRN & & \\
\hline CHEMBL 2036333 & 822044 & 5.5622 & 5.7544 & TST & & \\
\hline CHEMBL498373 & 822044 & 5.0009 & 5.1324 & TRN & & \\
\hline CHEMBL493001 & 822044 & 5.4672 & 5.6636 & TST & & \\
\hline CHEMBL476220 & 822044 & 4.8184 & 5.1463 & TST & & \\
\hline CHEMBL 2036337 & 822044 & 6.5528 & \multicolumn{3}{|c|}{6.207999999999999} & TRN \\
\hline CHEMBL476846 & 822044 & 4.7215 & 4.6663 & TRN & & \\
\hline CHEMBL129134 & 822044 & 5.0141 & 4.8545 & TST & & \\
\hline CHEMBL 2036349 & 822044 & \multicolumn{3}{|c|}{5.3839999999999995} & 5.3201 & TRN \\
\hline CHEMBL 2036329 & 822044 & 5.2262 & 5.2991 & TRN & & \\
\hline CHEMBL387599 & 822044 & 5.2097 & 5.3617 & TRN & & \\
\hline CHEMBL 2036332 & 822044 & 6.041 & 6.0387 & TRN & & \\
\hline CHEMBL 2036328 & 822044 & 5.71 & \multicolumn{3}{|c|}{5.412000000000001} & TRN \\
\hline CHEMBL1964663 & 822044 & \multicolumn{3}{|c|}{ 5.382999999999999 } & 5.5257 & TRN \\
\hline CHEMBL1322375 & 822044 & 4.8085 & 4.7621 & TRN & & \\
\hline CHEMBL 2036346 & 822044 & 4.8371 & 4.8045 & TRN & & \\
\hline CHEMBL472887 & 822044 & 5.284 & 5.2952 & TRN & & \\
\hline CHEMBL2036336 & 822044 & 5.9469 & 6.0486 & TRN & & \\
\hline CHEMBL1492668 & 736838 & 3.1002 & 3.0564 & TRN & & \\
\hline CHEMBL1491640 & 736838 & 3.1002 & 3.125 & TST & & \\
\hline CHEMBL 2000167 & 736838 & 5.1786 & 5.6216 & TRN & & \\
\hline CHEMBL3190951 & 736838 & 5.1161 & 4.8608 & TRN & & \\
\hline CHEMBL1360572 & 736838 & 3.1002 & 3.1022 & TRN & & \\
\hline CHEMBL1371394 & 736838 & 3.1002 & 3.0772 & TRN & & \\
\hline CHEMBL1981200 & 736838 & 4.8042 & 4.7423 & TRN & & \\
\hline CHEMBL1418466 & 736838 & 3.1002 & 3.0889 & TRN & & \\
\hline CHEMBL1534728 & 736838 & 3.1002 & 3.0505 & TRN & & \\
\hline CHEMBL3212510 & 736838 & 3.1002 & 2.9422 & TRN & & \\
\hline CHEMBL1343390 & 736838 & 3.1002 & 3.13100 & 0000000000 & 02 & TRN \\
\hline CHEMBL1417070 & 736838 & 4.7073 & 4.4337 & TST & & \\
\hline CHEMBL1428328 & 736838 & 3.1002 & 2.95 & TRN & & \\
\hline CHEMBL599924 & 736838 & 4.8854 & 4.7357 & TRN & & \\
\hline CHEMBL1443268 & 736838 & \multicolumn{3}{|c|}{5.582999999999999} & 5.0469 & TRN \\
\hline CHEMBL1340439 & 736838 & 3.1002 & 2.9918 & TRN & & \\
\hline CHEMBL1535167 & 736838 & 3.1002 & 3.1424 & TRN & & \\
\hline CHEMBL1438889 & 736838 & \multicolumn{3}{|c|}{5.4270000000000005} & 5.5415 & TRN \\
\hline CHEMBL1412887 & 736838 & 3.1002 & 3.1391 & TRN & & \\
\hline CHEMBL1574353 & 736838 & 3.1002 & 3.1278 & TRN & & \\
\hline CHEMBL1492463 & 736838 & 3.1002 & 3.0794 & TRN & & \\
\hline CHEMBL1325945 & 736838 & 5.7486 & 6.1376 & TRN & & \\
\hline \multirow[t]{2}{*}{ CHEMBL1307336 } & 736838 & 3.1002 & 3.0241 & TRN & & \\
\hline & & \multicolumn{5}{|c|}{ Page 18533} \\
\hline
\end{tabular}


Supplemental Table S2.txt

\begin{tabular}{|c|c|c|c|c|c|}
\hline CHEMBL1429070 & 736838 & 4.1173 & 3.1047 & TST & \\
\hline CHEMBL1976414 & 736838 & 4.1888 & 4.2629 & TRN & \\
\hline CHEMBL1343286 & 736838 & 3.1002 & 3.1297 & TRN & \\
\hline CHEMBL1455026 & 736838 & 3.1002 & 3.2784 & TRN & \\
\hline CHEMBL1549636 & 736838 & 3.1002 & 3.2867 & TRN & \\
\hline CHEMBL1424694 & 736838 & 5.6121 & 5.4455 & TRN & \\
\hline CHEMBL1385167 & 736838 & 3.1002 & 3.293 & TRN & \\
\hline CHEMBL1993612 & 736838 & 3.1002 & 3.3055 & TRN & \\
\hline CHEMBL3145282 & 736838 & 3.1002 & 3.2044 & TST & \\
\hline CHEMBL1458847 & 736838 & 3.1002 & 2.9811 & TRN & \\
\hline CHEMBL1606761 & 736838 & 3.1002 & 3.1576 & TRN & \\
\hline CHEMBL1556336 & 736838 & 3.1002 & 3.1289 & TRN & \\
\hline CHEMBL1344691 & 736838 & 3.1002 & 3.2631 & TRN & \\
\hline CHEMBL3208035 & 736838 & 3.1002 & 3.0426 & TRN & \\
\hline CHEMBL1701224 & 736838 & 6.9066 & 6.8856 & TRN & \\
\hline CHEMBL1426096 & 736838 & 5.2398 & 5.5136 & TRN & \\
\hline CHEMBL1493152 & 736838 & 3.1002 & 3.1039 & TRN & \\
\hline CHEMBL1600686 & 736838 & 3.1002 & 3.11800 & 00000000003 & TRN \\
\hline CHEMBL1499300 & 736838 & 3.1002 & 3.0686 & TRN & \\
\hline CHEMBL1445032 & 736838 & 3.1002 & 2.9958 & TRN & \\
\hline CHEMBL1439815 & 736838 & 5.3396 & 5.0139 & TRN & \\
\hline CHEMBL3211928 & 736838 & 3.1002 & 3.0376 & TST & \\
\hline CHEMBL1565650 & 736838 & 3.1002 & 3.1694 & TST & \\
\hline CHEMBL1445488 & 736838 & 6.9066 & 6.5795 & TRN & \\
\hline CHEMBL1327743 & 736838 & 3.1002 & 3.0008 & TRN & \\
\hline CHEMBL1385669 & 736838 & 3.1002 & 3.0762 & TRN & \\
\hline CHEMBL1486682 & 736838 & 3.1002 & 3.1135 & TRN & \\
\hline CHEMBL1567100 & 736838 & 3.1002 & 3.1168 & TRN & \\
\hline CHEMBL1309430 & 736838 & 4.1616 & 4.0417 & TST & \\
\hline CHEMBL1373137 & 736838 & 3.1002 & \multicolumn{2}{|c|}{3.1430000000000002} & TST \\
\hline CHEMBL1341830 & 736838 & 3.1002 & 3.2384 & TST & \\
\hline CHEMBL1383176 & 736838 & 3.1002 & 3.193 & TRN & \\
\hline CHEMBL1527520 & 736838 & 5.1647 & 4.7593 & TST & \\
\hline CHEMBL601757 & 736838 & 6.9066 & 6.8098 & TRN & \\
\hline CHEMBL1580263 & 736838 & 5.2137 & 5.0372 & TRN & \\
\hline CHEMBL1444606 & 736838 & 3.1002 & 3.1351 & TRN & \\
\hline CHEMBL1444644 & 736838 & 3.1002 & 3.2779 & TRN & \\
\hline CHEMBL1371816 & 736838 & 5.1635 & 5.4194 & TRN & \\
\hline CHEMBL1529554 & 736838 & 4.6658 & 4.8385 & TRN & \\
\hline CHEMBL1330067 & 736838 & 3.1002 & 2.9071 & TRN & \\
\hline CHEMBL3192388 & 736838 & 3.1002 & 3.2268 & TRN & \\
\hline CHEMBL3193406 & 736838 & 3.1002 & 3.1695 & TRN & \\
\hline CHEMBL1467425 & 736838 & 3.1002 & 3.0153 & TRN & \\
\hline CHEMBL3209512 & 736838 & 3.1002 & 3.0928 & TRN & \\
\hline CHEMBL1393012 & 736838 & 3.1002 & 3.0594 & TRN & \\
\hline CHEMBL1521466 & 736838 & 3.1002 & 3.157 & TRN & \\
\hline CHEMBL1576652 & 736838 & 3.1002 & 3.2908 & TRN & \\
\hline CHEMBL1585090 & 736838 & 3.1002 & 3.1286 & TRN & \\
\hline
\end{tabular}


Supplemental Table S2.txt

\begin{tabular}{|c|c|c|c|c|c|}
\hline CHEMBL1202929 & 736838 & 3.1002 & 3.1532 & TRN & \\
\hline CHEMBL1335318 & 736838 & 3.1002 & 3.1004 & TRN & \\
\hline CHEMBL1568025 & 736838 & 3.1002 & 3.0198 & TRN & \\
\hline CHEMBL1439711 & 736838 & 3.1002 & 3.3437 & TST & \\
\hline CHEMBL1443048 & 736838 & 3.1002 & 3.0208 & TRN & \\
\hline CHEMBL1337760 & 736838 & 3.1002 & 2.9464 & TST & \\
\hline CHEMBL1442148 & 736838 & 3.1002 & 3.2467 & TST & \\
\hline CHEMBL1479359 & 736838 & 3.1002 & 3.0013 & TRN & \\
\hline CHEMBL1404195 & 736838 & 3.1002 & 3.0823 & TRN & \\
\hline CHEMBL1326115 & 736838 & 3.1002 & 3.2205 & TRN & \\
\hline CHEMBL1413468 & 736838 & 3.1002 & 3.3054 & TRN & \\
\hline CHEMBL1543833 & 736838 & 3.1002 & 3.0022 & TRN & \\
\hline CHEMBL1416842 & 736838 & 3.1002 & 3.1606 & TRN & \\
\hline CHEMBL1452770 & 736838 & 3.1002 & 3.2073 & TRN & \\
\hline CHEMBL3196559 & 736838 & 3.1002 & 3.0008 & TST & \\
\hline CHEMBL 2001743 & 736838 & 6.9066 & 6.3656 & TRN & \\
\hline CHEMBL1557469 & 736838 & 3.1002 & 3.1219 & TRN & \\
\hline CHEMBL1584670 & 736838 & 3.1002 & 3.1211 & TRN & \\
\hline CHEMBL1359401 & 736838 & 3.1002 & 3.1125 & TRN & \\
\hline CHEMBL1548647 & 736838 & 3.1002 & 3.17 & TRN & \\
\hline CHEMBL1441174 & 736838 & 3.1002 & 3.2105 & TRN & \\
\hline CHEMBL1505659 & 736838 & 3.1002 & 3.0437 & TRN & \\
\hline CHEMBL1536896 & 736838 & 5.1391 & 5.8903 & TRN & \\
\hline CHEMBL1586851 & 736838 & 4.1234 & 3.2075 & TRN & \\
\hline CHEMBL1431216 & 736838 & 3.1002 & 3.1293 & TRN & \\
\hline CHEMBL3198585 & 736838 & 3.1002 & 3.358 & TRN & \\
\hline CHEMBL1580949 & 736838 & 3.1002 & 3.1463 & TRN & \\
\hline CHEMBL1343895 & 736838 & 3.1002 & 3.0946 & TRN & \\
\hline CHEMBL1508571 & 736838 & 3.1002 & 3.2798 & TRN & \\
\hline CHEMBL1306172 & 736838 & 3.1002 & 3.1685 & TRN & \\
\hline CHEMBL1535241 & 736838 & 3.1002 & 3.0926 & TRN & \\
\hline CHEMBL1471865 & 736838 & 5.0664 & 5.0032 & TRN & \\
\hline CHEMBL1414751 & 736838 & 3.1002 & 3.157 & TST & \\
\hline CHEMBL570345 & 736838 & 5.6211 & 5.6767 & TRN & \\
\hline CHEMBL1448367 & 736838 & 3.1002 & 3.0555 & TRN & \\
\hline CHEMBL1581837 & 736838 & 3.1002 & 3.245 & TRN & \\
\hline CHEMBL1574873 & 736838 & 3.1002 & 3.0576 & TRN & \\
\hline CHEMBL1465095 & 736838 & 3.1002 & \multicolumn{2}{|c|}{3.2430000000000003} & TRN \\
\hline CHEMBL1301248 & 736838 & 3.1002 & 3.0673 & TRN & \\
\hline CHEMBL1547129 & 736838 & 3.1002 & 2.9928 & TRN & \\
\hline CHEMBL1503817 & 736838 & 3.1002 & 3.0418 & TRN & \\
\hline CHEMBL1338178 & 736838 & 3.1002 & 3.1 & TRN & \\
\hline CHEMBL1458343 & 736838 & 3.1002 & 3.1392 & TRN & \\
\hline CHEMBL1499702 & 736838 & 3.1002 & 3.0168 & TRN & \\
\hline CHEMBL1307807 & 736838 & 3.1002 & 3.1697 & TRN & \\
\hline CHEMBL1578734 & 736838 & 3.1002 & 3.0699 & TRN & \\
\hline CHEMBL1464805 & 736838 & 4.797 & 4.3661 & TRN & \\
\hline CHEMBL1492305 & 736838 & 5.3225 & 5.36299 & 99999999995 & TRN \\
\hline
\end{tabular}

Page 18535 
Supplemental Table S2.txt

\begin{tabular}{|c|c|c|c|c|}
\hline CHEMBL1448279 & 736838 & 3.1002 & 3.0749 & TRN \\
\hline CHEMBL1576746 & 736838 & 4.4951 & 4.4047 & TST \\
\hline CHEMBL1321843 & 736838 & 3.1002 & 3.0434 & TST \\
\hline CHEMBL1304417 & 736838 & 3.1002 & 3.1026 & TST \\
\hline CHEMBL1340558 & 736838 & 3.1002 & 2.9694 & TST \\
\hline CHEMBL1490435 & 736838 & 3.1002 & 3.097 & TST \\
\hline CHEMBL1320181 & 736838 & 5.4226 & 6.3698 & TST \\
\hline CHEMBL1488035 & 736838 & 4.8796 & 4.8136 & TST \\
\hline CHEMBL3209125 & 736838 & 3.1002 & 3.1604 & TST \\
\hline CHEMBL1444510 & 736838 & 3.1002 & 3.1592 & TST \\
\hline CHEMBL578512 & 736838 & 5.8697 & 6.3372 & TST \\
\hline CHEMBL1546449 & 736838 & 3.1002 & 3.1984 & TST \\
\hline CHEMBL1323857 & 736838 & 3.1002 & 2.9222 & TST \\
\hline CHEMBL1583199 & 736838 & 3.1002 & 3.512 & TST \\
\hline CHEMBL1524972 & 736838 & 3.1002 & 3.2261 & TST \\
\hline CHEMBL1302136 & 736838 & 3.1002 & 3.0591 & TST \\
\hline CHEMBL3208812 & 736838 & 3.1002 & 3.2377 & TST \\
\hline CHEMBL1442305 & 736838 & 3.1002 & 3.182 & TST \\
\hline CHEMBL1484610 & 736838 & 3.1002 & 3.0337 & TST \\
\hline CHEMBL1533230 & 736838 & 5.2242 & 4.7318 & TST \\
\hline CHEMBL1609158 & 736838 & 3.1002 & 3.1103 & TST \\
\hline CHEMBL188798 & 306315 & 8.3979 & 8.3689 & TRN \\
\hline CHEMBL433968 & 306315 & 8.2518 & 8.1549 & TRN \\
\hline CHEMBL184556 & 306315 & 9.3979 & 9.6171 & TRN \\
\hline CHEMBL 366300 & 306315 & 7.8539 & 7.7224 & TRN \\
\hline CHEMBL185805 & 306315 & 8.0969 & 8.1587 & TRN \\
\hline CHEMBL188835 & 306315 & 6.3979 & 6.3181 & TRN \\
\hline CHEMBL184343 & 306315 & 8.0605 & 8.0281 & TRN \\
\hline CHEMBL185807 & 306315 & 7.3979 & 7.5091 & TRN \\
\hline CHEMBL186654 & 306315 & 8.2218 & 8.2229 & TRN \\
\hline CHEMBL188834 & 306315 & 8.8539 & 8.7679 & TRN \\
\hline CHEMBL 364610 & 306315 & 8.0969 & 8.1484 & TRN \\
\hline CHEMBL188833 & 306315 & 8.3979 & 8.4082 & TRN \\
\hline CHEMBL426067 & 306315 & 7.5229 & 7.5976 & TRN \\
\hline CHEMBL186219 & 306315 & 8.301 & 8.2066 & TRN \\
\hline CHEMBL359566 & 306315 & 9.0 & 9.1894 & TST \\
\hline CHEMBL184171 & 306315 & 8.4949 & 8.2013 & TST \\
\hline CHEMBL186138 & 306315 & 8.4815 & 8.6319 & TST \\
\hline CHEMBL184162 & 306315 & 7.2218 & 7.2454 & TRN \\
\hline CHEMBL189722 & 306315 & 8.1938 & 8.0529 & TST \\
\hline CHEMBL188481 & 306315 & 8.301 & 8.2985 & TRN \\
\hline CHEMBL 278471 & 306315 & 9.1549 & 9.1987 & TRN \\
\hline CHEMBL363055 & 306315 & 9.699 & 9.7732 & TRN \\
\hline CHEMBL189709 & 306315 & 9.0 & 9.0802 & TRN \\
\hline CHEMBL187909 & 306315 & 6.9281 & 7.0721 & TRN \\
\hline CHEMBL189869 & 306315 & 7.3979 & 7.32700 & 0000000001 \\
\hline CHEMBL360407 & 306315 & 7.3979 & 7.4786 & TRN \\
\hline CHEMBL186468 & 306315 & 8.699 & 8.7075 & TRN \\
\hline
\end{tabular}




\begin{tabular}{|c|c|c|c|c|}
\hline \multicolumn{5}{|c|}{ Supplemental } \\
\hline CHEMBL189759 & 306315 & 8.7959 & 8.9354 & \\
\hline CHEMBL185730 & 06315 & 9.3979 & 9.3733 & \\
\hline HEMBL189553 & 6315 & & & \\
\hline HEMBL 364592 & 06315 & 9.699 & 5214 & \\
\hline HEMBL188799 & 06315 & 9.1549 & 1082 & \\
\hline HEMBL427523 & 06315 & 9.0 & 8.9989 & \\
\hline HEMBL & 26315 & 8.5229 & .5428 & \\
\hline HEMBL: & 15 & & 43 & \\
\hline HEMBL189033 & 06315 & 8.699 & 8.6974 & \\
\hline HEMBL3 & 06315 & 6.3979 & 6.4058 & \\
\hline HEMBL1 & 06315 & 8.699 & 8.506 & \\
\hline AEMBL & 15 & 086 & .8033 & \\
\hline HEMBL & 15 & & 32 & \\
\hline HEMBL] & 15 & 8.3565 & 8.4045 & \\
\hline HEMBL & 15 & & 7.9188 & \\
\hline 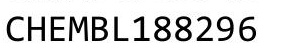 & 15 & 9 . & 9.1636 & \\
\hline HEMBL & 5 & & 18 & \\
\hline HEMBL & 5 & 7 & 917 & \\
\hline HFMRI & 15 & & 8.4087 & \\
\hline HEMBL & 15 & & 84 & \\
\hline HEMBL & $\Gamma$ & & 8.4 & \\
\hline HEMBL & 5 & & 29 & \\
\hline CHEMBL & 5 & 8.7212 & 8 & \\
\hline 547 & 598 & & 88 & \\
\hline HEMBL: & 98 & 4. & 67 & \\
\hline HEMBL: & 161 & 4.2218 & 4.2178 & \\
\hline HEMBL & 8 & 4. & 4.3 & \\
\hline HEMPI & 8 & 4. & 387 & \\
\hline 908 & 98 & 3.0506 & 2.9003 & \\
\hline HEMBL: & 8 & & 78 & \\
\hline HEMBL & 161 & 4.0177 & 4.6 & \\
\hline CHEMBL & 16 & 3.0 & 3. & \\
\hline 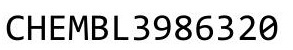 & 8 & 4.9586 & $1 c$ & \\
\hline HEMBL & 161 & 3.0 & 2.9764 & \\
\hline CHEMBL3 & 1617 & 4.2076 & 4.2043 & \\
\hline CHEMBL & 98 & & 3.5162 & \\
\hline CHEMBL & 8 & 3. & 2.9 & \\
\hline CHEMBL & 161 & 3.0 & 3.0501 & \\
\hline CHEMBL & 1617698 & 4.0605 & 4.09 & \\
\hline CHEMBL3 & 1617698 & 3.0 & 2.9907 & \\
\hline CHEMBL & 161 & 3. & 2.9851 & \\
\hline CHEMBL: & 161 & 4.0132 & 4.1076 & \\
\hline CHEMBL & 1617 & 4.7212 & 4.7205 & \\
\hline CHEMBL3 & 1617698 & 3.0 & 2.992 & \\
\hline CHEMBL 39 & 1617698 & 3.0 & 3.0131 & \\
\hline CHEMBL & 1617 & & 4.1173 & \\
\hline CHEMBL3 & 1617698 & 4.8861 & 4.8857 & \\
\hline CHEMBL 3967047 & 1617698 & 4.1249 & 4.1294 & \\
\hline
\end{tabular}

Page 18537 


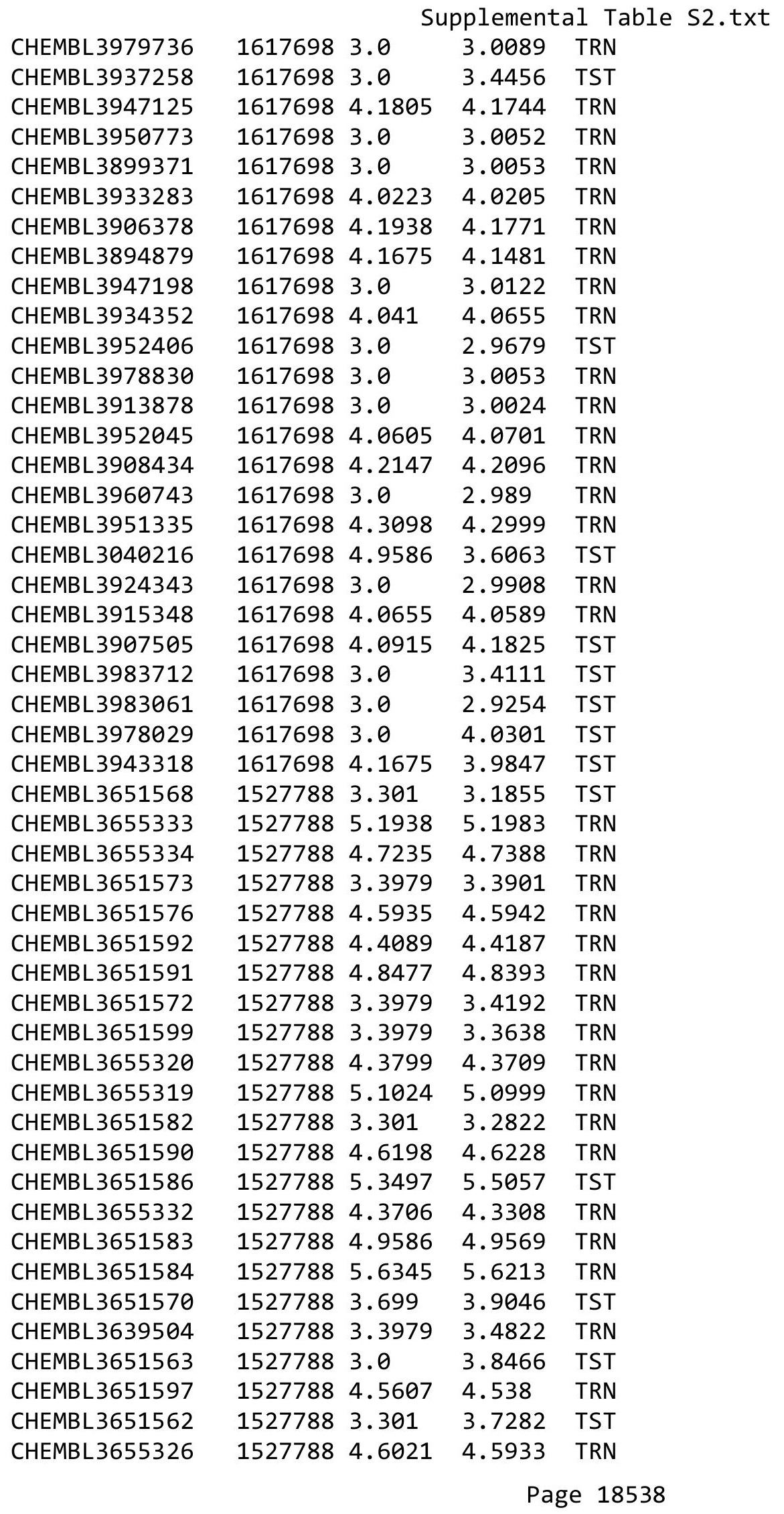


Supplemental Table S2.txt

\begin{tabular}{|c|c|c|c|c|}
\hline CHEMBL3651585 & 1527788 & 4.9586 & 4.9853 & TRN \\
\hline CHEMBL 3651571 & 1527788 & 3.3979 & 3.8028 & TST \\
\hline CHEMBL3651598 & 1527788 & 4.5031 & 4.5345 & TRN \\
\hline CHEMBL 3651595 & 1527788 & 3.3979 & 3.4061 & TRN \\
\hline CHEMBL 3651578 & 1527788 & 4.1308 & 3.87100 & 00000000004 \\
\hline CHEMBL 3655331 & 1527788 & 4.5575 & 4.5665 & TRN \\
\hline CHEMBL 3651600 & 1527788 & 3.3979 & 3.5038 & TRN \\
\hline CHEMBL3651561 & 1527788 & 3.301 & 3.8779 & TST \\
\hline CHEMBL3651564 & 1527788 & 3.301 & 3.4269 & TST \\
\hline CHEMBL3651565 & 1527788 & 3.301 & 3.411 & TST \\
\hline CHEMBL 3655328 & 1527788 & 4.4214 & 4.3738 & TRN \\
\hline CHEMBL 3651587 & 1527788 & 4.6556 & 4.6566 & TRN \\
\hline CHEMBL3655335 & 1527788 & 3.3979 & 3.4175 & TRN \\
\hline CHEMBL3651579 & 1527788 & 3.0 & 3.7997 & TST \\
\hline CHEMBL 3655324 & 1527788 & 4.4962 & 4.5083 & TRN \\
\hline CHEMBL 3655330 & 1527788 & 3.3979 & 3.41 & TRN \\
\hline CHEMBL3655322 & 1527788 & 4.4157 & 4.3852 & TRN \\
\hline CHEMBL3655329 & 1527788 & 4.5867 & 4.5917 & TRN \\
\hline CHEMBL3651566 & 1527788 & 3.301 & 3.4761 & TST \\
\hline CHEMBL 3651596 & 1527788 & 4.5258 & 4.529 & TRN \\
\hline CHEMBL 3655323 & 1527788 & 5.0915 & 5.1119 & TRN \\
\hline CHEMBL 3651567 & 1527788 & 3.301 & 3.3187 & TRN \\
\hline CHEMBL 3651581 & 1527788 & 3.301 & 3.2828 & TRN \\
\hline CHEMBL3651569 & 1527788 & 3.0 & 3.7146 & TST \\
\hline CHEMBL 3651594 & 1527788 & 4.5031 & 4.445 & TRN \\
\hline CHEMBL3108900 & 1527788 & 4.8297 & 4.8503 & TRN \\
\hline CHEMBL3651588 & 1527788 & 3.3979 & 3.2969 & TRN \\
\hline CHEMBL 3655321 & 1527788 & 5.0655 & 5.0696 & TRN \\
\hline CHEMBL 3651577 & 1527788 & 3.3979 & 3.7336 & TST \\
\hline CHEMBL3655325 & 1527788 & 3.3979 & 3.3833 & TRN \\
\hline CHEMBL 3651593 & 1527788 & 4.6696 & 4.6979 & TRN \\
\hline CHEMBL 3651589 & 1527788 & 4.6326 & 4.6077 & TRN \\
\hline CHEMBL 3655327 & 1527788 & 3.3979 & 3.3961 & TRN \\
\hline CHEMBL53994 & 28340 & 7.1135 & 6.2718 & TRN \\
\hline CHEMBL54549 & 28340 & 6.5686 & 7.0801 & TRN \\
\hline CHEMBL52517 & 28340 & 6.9208 & 6.8339 & TRN \\
\hline CHEMBL52857 & 28340 & 7.3188 & 6.8289 & TRN \\
\hline CHEMBL53922 & 28340 & 6.7696 & 6.403 & TRN \\
\hline CHEMBL52470 & 28340 & 5.6021 & 6.6146 & TST \\
\hline CHEMBL53836 & 28340 & 6.4202 & 5.6837 & TRN \\
\hline CHEMBL52596 & 28340 & 5.9208 & 6.1722 & TRN \\
\hline CHEMBL 264451 & 28340 & 6.1871 & 6.4017 & TRN \\
\hline CHEMBL53989 & 28340 & 7.3468 & 6.9841 & TRN \\
\hline CHEMBL52185 & 28340 & 6.6021 & 6.4501 & TST \\
\hline CHEMBL300081 & 28340 & 6.8239 & 6.3908 & TRN \\
\hline CHEMBL545433 & 28340 & 5.3768 & 5.6176 & TRN \\
\hline CHEMBL53597 & 28340 & 7.1024 & 6.4017 & TRN \\
\hline CHEMBL296163 & 28340 & 6.9586 & 7.1803 & TRN \\
\hline
\end{tabular}




\begin{tabular}{|c|c|c|c|c|c|}
\hline & & & & & \\
\hline CHEMBL299352 & 28340 & 6.3665 & 6.2223 & TRN & \\
\hline CHEMBL52233 & 28340 & 7.2924 & 6.8007 & TRN & \\
\hline CHEMBL446403 & 28340 & 6.3098 & 7.1846 & TRN & \\
\hline CHEMBL296055 & 28340 & 7.7696 & 6.3481 & TST & \\
\hline CHEMBL52189 & 28340 & 6.9586 & 6.9121 & TRN & \\
\hline CHEMBL299964 & 28340 & 5.9208 & 6.387006 & 00000000005 & TRN \\
\hline CHEMBL36784 & 28340 & 5.5528 & 5.4945 & TRN & \\
\hline CHEMBL54639 & 28340 & 5.7696 & 6.2718 & TRN & \\
\hline CHEMBL300915 & 28340 & 7.0809 & 7.1697 & TRN & \\
\hline CHEMBL544499 & 28340 & 6.0177 & 6.0216 & TST & \\
\hline CHEMBL53227 & 28340 & 6.9586 & 7.1697 & TRN & \\
\hline CHEMBL52973 & 28340 & 6.8239 & 6.4009 & TRN & \\
\hline CHEMBL53071 & 28340 & 6.3098 & 6.5665 & TRN & \\
\hline CHEMBL52617 & 28340 & 7.284 & 6.9866 & TRN & \\
\hline CHEMBL54180 & 28340 & 6.4318 & 6.4205 & TRN & \\
\hline CHEMBL54216 & 28340 & 5.585 & 5.8982 & TRN & \\
\hline CHEMBL51666 & 28340 & 7.0458 & 6.6795 & TST & \\
\hline CHEMBL53660 & 28340 & 6.1192 & 6.4684 & TRN & \\
\hline CHEMBL55001 & 28340 & 7.301 & 7.2749 & TRN & \\
\hline CHEMBL301119 & 28340 & 7.0969 & 7.1931 & TRN & \\
\hline CHEMBL55059 & 28340 & 5.1192 & 5.9677 & TRN & \\
\hline CHEMBL54129 & 28340 & 7.0915 & 6.2718 & TRN & \\
\hline CHEMBL53468 & 28340 & 5.7212 & 5.9773 & TRN & \\
\hline CHEMBL294451 & 28340 & 5.4437 & 5.8674 & TRN & \\
\hline CHEMBL300440 & 28340 & 5.6021 & 6.0804 & TST & \\
\hline CHEMBL53378 & 28340 & 6.4202 & 5.8706 & TRN & \\
\hline CHEMBL53421 & 28340 & 6.2757 & 5.9324 & TRN & \\
\hline CHEMBL22373 & 28340 & 7.1367 & 7.3385 & TST & \\
\hline CHEMBL300462 & 28340 & 7.3468 & 7.13299 & 9999999999 & TRN \\
\hline CHEMBL298883 & 28340 & 6.0 & 6.1059 & TRN & \\
\hline CHEMBL298533 & 28340 & 6.3565 & 6.1817 & TRN & \\
\hline CHEMBL300617 & 28340 & 6.6383 & 7.1697 & TRN & \\
\hline CHEMBL298941 & 28340 & 6.0 & 6.5147 & TRN & \\
\hline CHEMBL54040 & 28340 & 6.3872 & 6.7199 & TRN & \\
\hline CHEMBL52365 & 28340 & 7.3468 & 7.1697 & TRN & \\
\hline CHEMBL52353 & 28340 & 5.4949 & 5.7088 & TRN & \\
\hline CHEMBL298682 & 28340 & 6.5229 & 6.5297 & TRN & \\
\hline CHEMBL54809 & 28340 & 7.0969 & 6.516 & TRN & \\
\hline CHEMBL299188 & 28340 & 6.7959 & 6.5354 & TRN & \\
\hline CHEMBL444579 & 28340 & 6.0 & 6.6694 & TRN & \\
\hline CHEMBL300273 & 28340 & 6.3979 & 5.9784 & TST & \\
\hline CHEMBL293941 & 28340 & 6.2147 & 6.5481 & TST & \\
\hline CHEMBL54724 & 28340 & 7.3098 & 7.1697 & TRN & \\
\hline CHEMBL416665 & 28340 & 6.699 & 6.1059 & TRN & \\
\hline CHEMBL299211 & 28340 & 5.6383 & 6.0542 & TRN & \\
\hline CHEMBL301165 & 28340 & 6.3665 & 6.4296 & TST & \\
\hline CHEMBL432118 & 28340 & 7.2924 & 6.4684 & TRN & \\
\hline CHEMBL50351 & 28340 & 6.4815 & 6.4343 & TRN & \\
\hline & & & & 18540 & \\
\hline
\end{tabular}




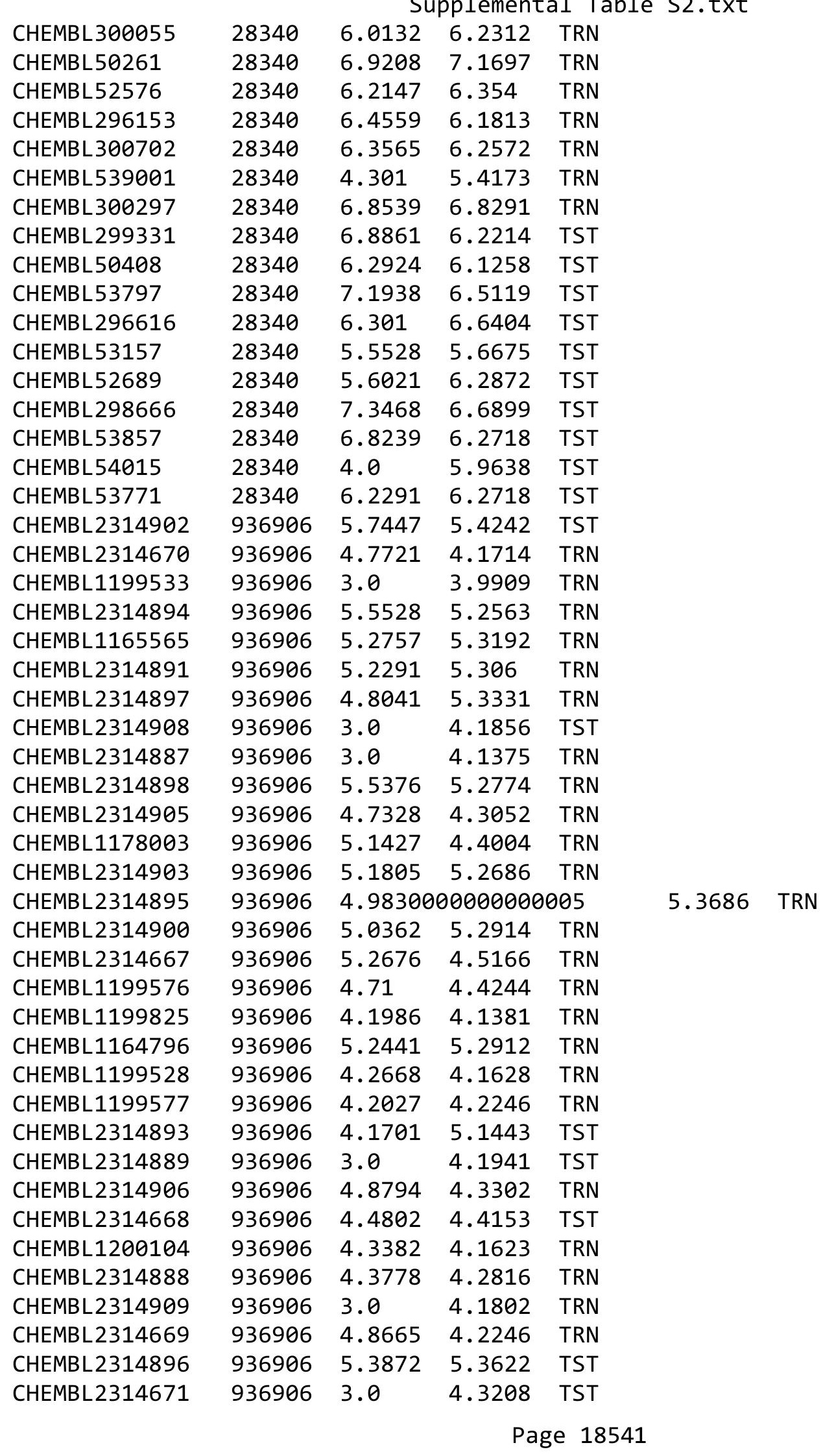




\begin{tabular}{|c|c|c|c|c|c|c|}
\hline & & \multicolumn{5}{|c|}{ Supplemental Table S2.txt } \\
\hline CHEMBL2314899 & 936906 & 5.7447 & 5.3041 & TST & & \\
\hline CHEMBL 2314672 & 936906 & 4.7959 & 4.1914 & TRN & & \\
\hline CHEMBL1164886 & 936906 & 5.4089 & 5.1895 & TST & & \\
\hline CHEMBL 2314892 & 936906 & 4.9547 & 5.2413 & TST & & \\
\hline CHEMBL1199532 & 936906 & 4.8416 & 4.3207 & TRN & & \\
\hline CHEMBL1164885 & 936906 & 5.2757 & 5.3345 & TST & & \\
\hline CHEMBL 2314907 & 936906 & 4.3382 & 4.1364 & TRN & & \\
\hline CHEMBL1199961 & 936906 & 4.762 & 4.3999 & TRN & & \\
\hline CHEMBL 2314883 & 936906 & 4.5317 & 4.3411 & TRN & & \\
\hline CHEMBL 2314890 & 936906 & 3.0 & 4.0343 & TRN & & \\
\hline CHEMBL 2314885 & 936906 & 4.71 & 4.1234 & TRN & & \\
\hline CHEMBL 2314901 & 936906 & 5.4202 & 5.3341 & TST & & \\
\hline CHEMBL1199529 & 936906 & 4.3439 & 4.1652 & TRN & & \\
\hline CHEMBL 2314886 & 936906 & 4.1618 & 4.2135 & TRN & & \\
\hline CHEMBL1199826 & 936906 & 4.4123 & 4.2671 & TRN & & \\
\hline CHEMBL 2314666 & 936906 & 4.6655 & 4.4449 & TRN & & \\
\hline CHEMBL1199575 & 936906 & 4.9208 & 4.4602 & TRN & & \\
\hline CHEMBL 2314884 & 936906 & 3.0 & 4.3507 & TRN & & \\
\hline CHEMBL 2314904 & 936906 & 3.0 & 4.2707 & TRN & & \\
\hline CHEMBL1165622 & 936906 & 5.0915 & 5.2462 & TST & & \\
\hline CHEMBL3975757 & 1641545 & 8.4437 & 8.6909 & TST & & \\
\hline CHEMBL3961369 & 1641545 & 5.5935 & 6.2743 & TST & & \\
\hline CHEMBL 3922813 & 1641545 & 5.9318 & 6.1875 & TRN & & \\
\hline CHEMBL 3891129 & 1641545 & 8.7447 & 8.5948 & TRN & & \\
\hline CHEMBL 3934348 & 1641545 & 7.6073 & 7.852 & TRN & & \\
\hline CHEMBL3914893 & 1641545 & 8.3768 & 8.451 & TRN & & \\
\hline CHEMBL 3937631 & 1641545 & 8.28399 & 99999999 & 99 & 8.2894 & TRN \\
\hline CHEMBL 3899717 & 1641545 & 7.7878 & 7.4633 & TST & & \\
\hline CHEMBL 3904424 & 1641545 & 7.9136 & 7.9201 & TRN & & \\
\hline CHEMBL3968444 & 1641545 & 8.4318 & 8.1988 & TRN & & \\
\hline CHEMBL 3932060 & 1641545 & 6.9172 & 7.0972 & TRN & & \\
\hline CHEMBL3909724 & 1641545 & 6.6271 & 6.1484 & TST & & \\
\hline CHEMBL3890504 & 1641545 & 9.1871 & 9.5411 & TRN & & \\
\hline CHEMBL 3912882 & 1641545 & 8.0915 & 7.9802 & TRN & & \\
\hline CHEMBL3985704 & 1641545 & 7.4921 & 7.4873 & TRN & & \\
\hline CHEMBL3897399 & 1641545 & 7.9626 & 8.3118 & TRN & & \\
\hline CHEMBL3966509 & 1641545 & 7.3575 & 7.4873 & TST & & \\
\hline CHEMBL3904028 & 1641545 & 7.9666 & 7.9355 & TRN & & \\
\hline CHEMBL 3955197 & 1641545 & 8.0862 & 8.2158 & TRN & & \\
\hline CHEMBL3919510 & 1641545 & 8.0 & 7.8105 & TRN & & \\
\hline CHEMBL 3950445 & 1641545 & 8.0555 & 7.7999 & TRN & & \\
\hline CHEMBL3928904 & 1641545 & 8.8239 & 8.7577 & TRN & & \\
\hline CHEMBL3927275 & 1641545 & 8.7212 & 8.8589 & TRN & & \\
\hline CHEMBL 3933951 & 1641545 & 7.6253 & 7.3116 & TRN & & \\
\hline CHEMBL3969291 & 1641545 & 9.301 & 9.1575 & TRN & & \\
\hline CHEMBL 3893773 & 1641545 & 6.6364 & 6.8592 & TRN & & \\
\hline CHEMBL3935168 & 1641545 & 7.7144 & 7.6759 & TRN & & \\
\hline CHEMBL3974497 & 1641545 & 8.9208 & 8.7375 & TRN & & \\
\hline
\end{tabular}


Supplemental Table S2.txt

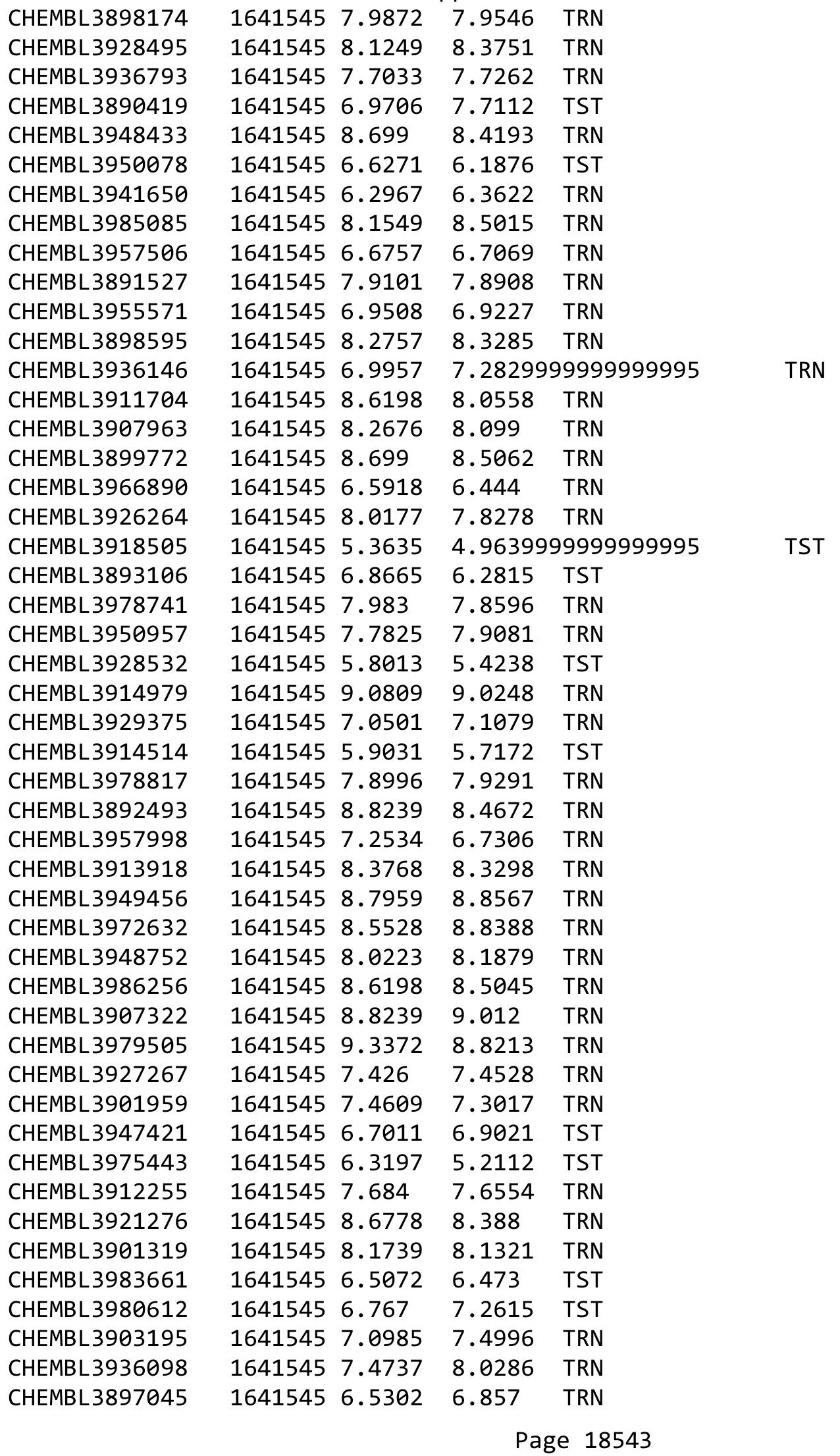


Supplemental Table S2.txt

\begin{tabular}{|c|c|c|c|c|c|}
\hline CHEMBL3918287 & 1641545 & 7.9508 & 7.9034 & TRN & \\
\hline CHEMBL3916955 & 1641545 & 6.8861 & 6.949 & TST & \\
\hline CHEMBL3982460 & 1641545 & 8.2291 & 8.14 & TRN & \\
\hline CHEMBL 3979883 & 1641545 & 8.1739 & 8.1978 & TST & \\
\hline CHEMBL 3911074 & 1641545 & 8.2366 & 8.1153 & TRN & \\
\hline CHEMBL 3939648 & 1641545 & 8.8861 & 8.7004 & TRN & \\
\hline CHEMBL3920492 & 1641545 & 7.2125 & 7.5328 & TST & \\
\hline CHEMBL3936731 & 1641545 & 6.9066 & 6.99299 & 9999999999 & TRN \\
\hline CHEMBL3923025 & 1641545 & 7.4486 & 7.7156 & TRN & \\
\hline CHEMBL 3918319 & 1641545 & 7.585 & 7.96399 & 99999999995 & TRN \\
\hline CHEMBL 3971671 & 1641545 & 6.5901 & 6.9707 & TRN & \\
\hline CHEMBL3891841 & 1641545 & 7.1331 & 7.553 & TRN & \\
\hline CHEMBL 3908833 & 1641545 & 8.3468 & 8.308 & TRN & \\
\hline CHEMBL3970319 & 1641545 & 7.71899 & 99999999 & 7.8191 & TRN \\
\hline CHEMBL 3985382 & 1641545 & 7.7959 & 6.8823 & TST & \\
\hline CHEMBL 3958758 & 1641545 & 7.7721 & 6.8853 & TST & \\
\hline CHEMBL3982509 & 1641545 & 7.9101 & 7.22 & TRN & \\
\hline CHEMBL 3907177 & 1641545 & 7.3904 & 7.5384 & TRN & \\
\hline CHEMBL3984959 & 1641545 & 7.0269 & 7.082006 & 0000000001 & TRN \\
\hline CHEMBL 3933936 & 1641545 & 7.9957 & 8.3595 & TRN & \\
\hline CHEMBL 3923948 & 1641545 & 7.9066 & 8.0089 & TRN & \\
\hline CHEMBL3912330 & 1641545 & 8.4815 & 8.7995 & TRN & \\
\hline CHEMBL 3970220 & 1641545 & 8.699 & 8.7602 & TRN & \\
\hline CHEMBL3926083 & 1641545 & 7.6459 & 7.7657 & TRN & \\
\hline CHEMBL 3916296 & 1641545 & 7.1481 & 7.6903 & TRN & \\
\hline CHEMBL 3944456 & 1641545 & 6.6882 & 6.2624 & TST & \\
\hline CHEMBL 3904365 & 1641545 & 8.4685 & 8.5204 & TRN & \\
\hline CHEMBL 3908562 & 1641545 & 6.2041 & 6.3443 & TRN & \\
\hline CHEMBL3926000 & 1641545 & 8.1739 & 8.1777 & TRN & \\
\hline CHEMBL 3906254 & 1641545 & 9.2441 & 8.7037 & TRN & \\
\hline CHEMBL3939676 & 1641545 & 7.7496 & 8.0421 & TRN & \\
\hline CHEMBL 3957775 & 1641545 & 7.4425 & 7.2113 & TRN & \\
\hline CHEMBL 3940693 & 1641545 & 7.5129 & 7.5399 & TRN & \\
\hline CHEMBL3973801 & 1641545 & 8.1249 & 8.0896 & TST & \\
\hline CHEMBL 3964534 & 1641545 & 6.0 & 6.425 & TRN & \\
\hline CHEMBL3924817 & 1641545 & 6.5086 & 6.8928 & TRN & \\
\hline CHEMBL 3980983 & 1641545 & 7.3872 & 6.9592 & TRN & \\
\hline CHEMBL 3977309 & 1641545 & 6.3747 & 6.4314 & TRN & \\
\hline CHEMBL3917193 & 1641545 & 8.5086 & 8.1371 & TST & \\
\hline CHEMBL 3891840 & 1641545 & 7.1409 & 7.1477 & TRN & \\
\hline CHEMBL3953714 & 1641545 & 7.2449 & 7.6206 & TRN & \\
\hline CHEMBL 3933555 & 1641545 & 8.7212 & 8.644 & TRN & \\
\hline CHEMBL 3951857 & 1641545 & 7.6421 & 7.66299 & 9999999999 & TRN \\
\hline CHEMBL 3979084 & 1641545 & 8.1871 & 7.9125 & TRN & \\
\hline CHEMBL3951923 & 1641545 & 7.2218 & 6.6392 & TRN & \\
\hline CHEMBL 3894835 & 1641545 & 7.4855 & 7.5377 & TRN & \\
\hline CHEMBL 3924634 & 1641545 & 8.3188 & 7.2066 & TST & \\
\hline CHEMBL 3895651 & 1641545 & 6.3107 & 6.9024 & TST & \\
\hline
\end{tabular}


Supplemental Table S2.txt

\begin{tabular}{|c|c|c|c|c|}
\hline CHEMBL3931332 & 1641545 & 7.0362 & 7.1235 & TRN \\
\hline CHEMBL3893686 & 1641545 & 7.2684 & 7.4483 & TRN \\
\hline CHEMBL3953827 & 1641545 & 9.1079 & 8.8331 & TRN \\
\hline CHEMBL3954903 & 1641545 & 8.2676 & 7.2231 & TRN \\
\hline CHEMBL3957020 & 1641545 & 8.4949 & 8.2539 & TRN \\
\hline CHEMBL3964603 & 1641545 & 7.3696 & \multicolumn{2}{|c|}{7.172000000000001} \\
\hline CHEMBL3947766 & 1641545 & 7.4935 & 7.5043 & TRN \\
\hline CHEMBL3953353 & 1641545 & 8.5376 & 8.7608 & TRN \\
\hline CHEMBL3926639 & 1641545 & 9.0605 & 8.6315 & TRN \\
\hline CHEMBL3906879 & 1641545 & 6.8827 & 6.6418 & TRN \\
\hline CHEMBL3941303 & 1641545 & 8.4089 & 8.4113 & TRN \\
\hline CHEMBL3941493 & 1641545 & 6.0137 & 6.3747 & TRN \\
\hline CHEMBL3979067 & 1641545 & 7.8097 & 7.7469 & TRN \\
\hline CHEMBL 3917088 & 1641545 & 7.767 & 7.6416 & TRN \\
\hline CHEMBL3914365 & 1641545 & 6.7496 & 6.6833 & TRN \\
\hline CHEMBL3889659 & 1641545 & 8.301 & 8.1265 & TRN \\
\hline CHEMBL3976575 & 1641545 & 8.1367 & 8.0152 & TRN \\
\hline CHEMBL3912703 & 1641545 & 6.1146 & 6.0455 & TRN \\
\hline CHEMBL3890730 & 1641545 & 7.6498 & 7.8401 & TRN \\
\hline CHEMBL3958824 & 1641545 & 7.6478 & 7.9931 & TRN \\
\hline CHEMBL3953097 & 1641545 & 7.5935 & 7.7121 & TST \\
\hline CHEMBL3983842 & 1641545 & 7.8827 & 7.7171 & TRN \\
\hline CHEMBL3970135 & 1641545 & 8.0223 & 8.1952 & TRN \\
\hline CHEMBL3903136 & 1641545 & 8.3979 & 8.4449 & TRN \\
\hline CHEMBL3904317 & 1641545 & 8.1938 & 8.1385 & TRN \\
\hline CHEMBL3950858 & 1641545 & 9.0044 & 8.8469 & TRN \\
\hline CHEMBL3916580 & 1641545 & 7.5702 & 7.421 & TRN \\
\hline CHEMBL3901761 & 1641545 & 8.6778 & 8.6091 & TRN \\
\hline CHEMBL3954042 & 1641545 & 8.0915 & 8.395 & TRN \\
\hline CHEMBL 3948404 & 1641545 & 5.9469 & 6.7168 & TRN \\
\hline CHEMBL3982329 & 1641545 & 8.9208 & 8.8213 & TRN \\
\hline CHEMBL3936236 & 1641545 & 6.8182 & 7.2447 & TST \\
\hline CHEMBL3978601 & 1641545 & 8.2757 & 8.2944 & TRN \\
\hline CHEMBL3930704 & 1641545 & 5.8894 & 5.4877 & TRN \\
\hline CHEMBL3898658 & 1641545 & 7.9914 & 8.1979 & TST \\
\hline CHEMBL3922345 & 1641545 & 8.9208 & 7.9351 & TST \\
\hline CHEMBL3928793 & 1641545 & 8.2366 & 8.334 & TRN \\
\hline CHEMBL 3894401 & 1641545 & 6.9666 & 7.4555 & TRN \\
\hline CHEMBL3899118 & 1641545 & 7.8665 & 7.7338 & TRN \\
\hline CHEMBL3963357 & 1641545 & 7.7496 & 7.6734 & TRN \\
\hline CHEMBL3939053 & 1641545 & 7.5003 & 8.009 & TRN \\
\hline CHEMBL3960784 & 1641545 & 8.301 & 8.4855 & TRN \\
\hline CHEMBL3925425 & 1641545 & 8.9208 & 8.6995 & TRN \\
\hline CHEMBL3943834 & 1641545 & 8.7959 & 8.748 & TRN \\
\hline CHEMBL3891226 & 1641545 & 8.2924 & 8.0352 & TRN \\
\hline CHEMBL3906270 & 1641545 & 7.1325 & 7.8036 & TRN \\
\hline CHEMBL3982262 & 1641545 & 8.4437 & 8.4173 & TRN \\
\hline CHEMBL3958767 & 1641545 & 7.9914 & 8.0523 & TRN \\
\hline
\end{tabular}


Supplemental Table S2.txt

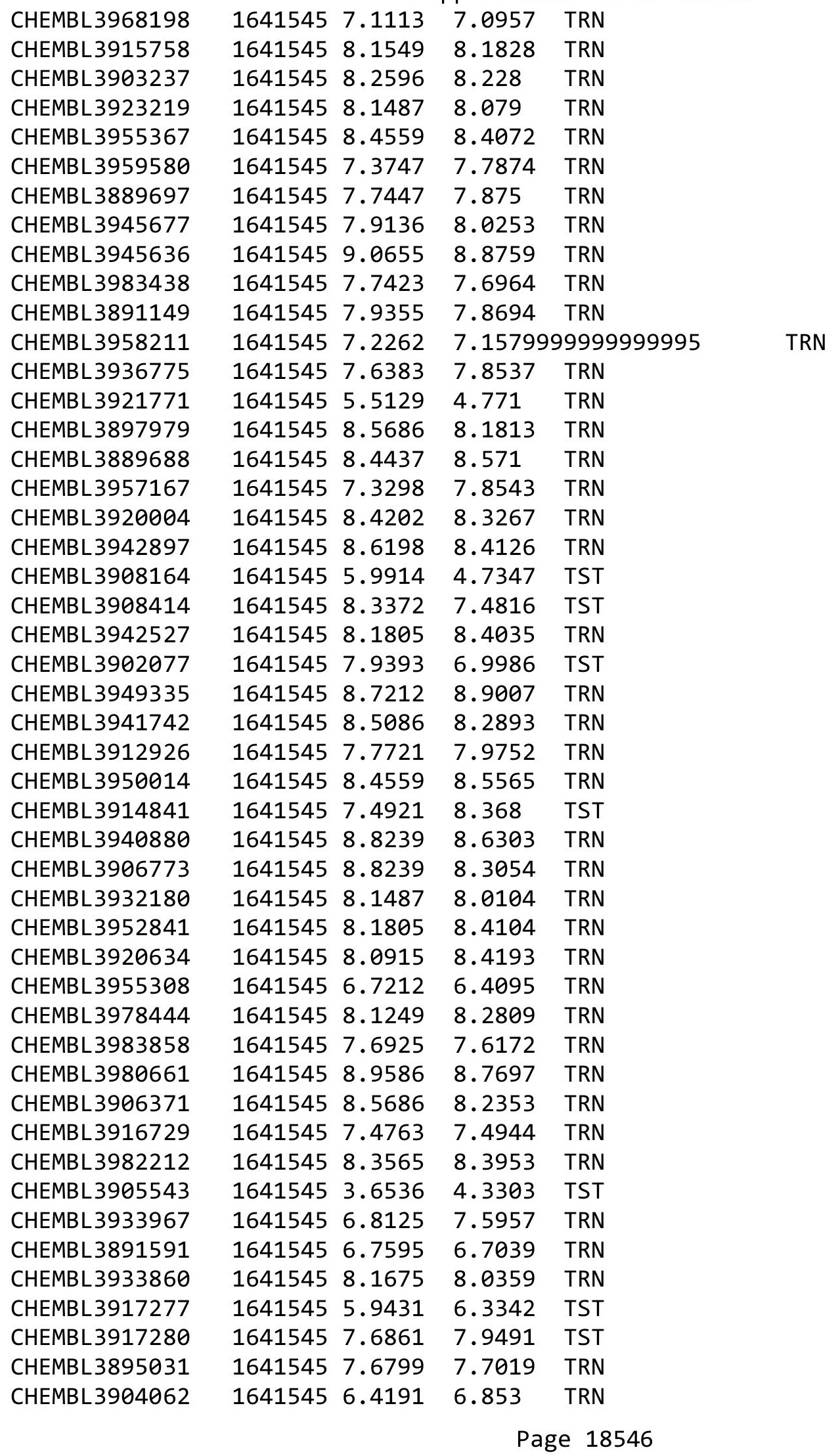


Supplemental Table S2.txt

\begin{tabular}{|c|c|c|c|c|}
\hline the & 541545 & .4685 & & \\
\hline & & 8.7696 & 5015 & \\
\hline & & & & \\
\hline HEMBL 391 & & 6576 & & S \\
\hline HEMBL395 & +5 & 506 & & \\
\hline HEMBL3910860 & 641545 & 6.3134 & .5375 & \\
\hline 60 & & 576 & & \\
\hline IFMBI 38 & & & & \\
\hline HEMBL3896993 & & 8.2757 & & \\
\hline HEMBL 390 & 45 & 768 & 3027 & \\
\hline HEMBL3891958 & 45 & 7.7471 & 21 & \\
\hline IEMBL397 & 15 & 147 & & \\
\hline JEMBL 38 & & & & \\
\hline HEMBL397 & & 8.3188 & 8.1023 & \\
\hline AEMBL 389 & 45 & 372 & & \\
\hline AEMBL389 & 6 & 9. & .6973 & \\
\hline AEMBL39 & a & 7. & 86 & \\
\hline HEMBL39 & & & & \\
\hline HEMBL38 & & 94 & 7.7126 & \\
\hline AEMBL39 & & & & \\
\hline HEIMBLSS & 62 & 8 & 36 & - \\
\hline AEMBL & & & & ST \\
\hline AEMBL3S & & & 71 & \\
\hline 102 & & & & \\
\hline AEMBL39e & & & & I NIV \\
\hline HEMBL3S & 6 & & & SI \\
\hline AEMBL3 & & & & RN \\
\hline HFMBI 36 & & & 58 & \\
\hline HEMBL38 & & & & TIV \\
\hline HEMBL 394 & & & & I RIV \\
\hline HEMBL39 & & & & RN \\
\hline HEMBL3 & & & & ST \\
\hline AEMBL39 & & & 34 & $\mathrm{RN}$ \\
\hline HEMBL392 & & & & IRN \\
\hline HEMBL3915649 & 6 & & 6.9493 & TST \\
\hline HEMBL39 & & & & RN \\
\hline HFMRI 3 & & & & $\Gamma \mathrm{RN}$ \\
\hline HEMBL3 & & & & RN \\
\hline HEMBL3979492 & & & 6. & TRN \\
\hline IEMBL394 & & & 74 & $\Gamma \mathrm{RN}$ \\
\hline HEMBL39 & 6 & & 81 & 80 \\
\hline CHEMBL393 & & & & RIN \\
\hline HEMBL391 & & & 8.4325 & RN \\
\hline HEMBL3908231 & 45 & 8.0132 & 02 & TRN \\
\hline MBL3 & & & & \\
\hline HEMBL 394 & & & 7.3853 & \\
\hline CHEMBL3926269 & & 8.3188 & 7.9615 & \\
\hline CHEMBL3960489 & 1641545 & 7.8297 & 7.834 & ГRN \\
\hline
\end{tabular}

Page 18547 
Supplemental Table S2.txt

\begin{tabular}{|c|c|c|c|c|}
\hline CHEMBL 3960737 & 1641545 & 7.1002 & 7.9531 & TST \\
\hline CHEMBL3930051 & 1641545 & 7.0878 & 6.8184 & TST \\
\hline CHEMBL3918136 & 1641545 & 6.7721 & 6.825 & TST \\
\hline CHEMBL 3897898 & 1641545 & 6.3536 & 6.1794 & TRN \\
\hline CHEMBL3967185 & 1641545 & 7.8182 & 8.3262 & TRN \\
\hline CHEMBL3935404 & 1641545 & 7.7212 & 7.7745 & TRN \\
\hline CHEMBL3944006 & 1641545 & 6.9957 & 6.2101 & TST \\
\hline CHEMBL 3920048 & 1641545 & 8.3098 & 8.0311 & TRN \\
\hline CHEMBL3897186 & 1641545 & 7.6289 & 7.5567 & TRN \\
\hline CHEMBL3962043 & 1641545 & 8.2924 & 8.144 & TST \\
\hline CHEMBL3927753 & 1641545 & 7.7212 & 7.3291 & TST \\
\hline CHEMBL3949150 & 1641545 & 6.5622 & 6.727 & TRN \\
\hline CHEMBL3931770 & 1641545 & 6.8182 & 6.5878 & TRN \\
\hline CHEMBL3943316 & 1641545 & 8.3665 & 8.6736 & TRN \\
\hline CHEMBL3943998 & 1641545 & 9.1675 & 8.1974 & TRN \\
\hline CHEMBL3914223 & 1641545 & 8.4815 & 8.6279 & TRN \\
\hline CHEMBL3927729 & 1641545 & 8.9208 & 8.6051 & TRN \\
\hline CHEMBL3911104 & 1641545 & 8.7959 & 8.5722 & TRN \\
\hline CHEMBL3930727 & 1641545 & 7.5272 & 7.6667 & TRN \\
\hline CHEMBL3905932 & 1641545 & 8.0655 & 8.2366 & TRN \\
\hline CHEMBL3931499 & 1641545 & 7.6615 & 7.7232 & TRN \\
\hline CHEMBL3913327 & 1641545 & 7.1118 & 7.5854 & TST \\
\hline CHEMBL3919590 & 1641545 & 8.4685 & 8.4379 & TRN \\
\hline CHEMBL3909584 & 1641545 & 8.0605 & 7.7273 & TRN \\
\hline CHEMBL3931527 & 1641545 & 7.5901 & 7.2701 & TRN \\
\hline CHEMBL3965455 & 1641545 & 7.0757 & 7.4942 & TRN \\
\hline CHEMBL3910575 & 1641545 & 8.9586 & 9.2581 & TRN \\
\hline CHEMBL3894885 & 1641545 & 6.5171 & 7.88899 & 9999999999 \\
\hline CHEMBL 3945583 & 1641545 & 8.7447 & 8.5589 & TRN \\
\hline CHEMBL3964225 & 1641545 & 8.7696 & 8.5115 & TRN \\
\hline CHEMBL3901199 & 1641545 & 8.6198 & 8.3689 & TST \\
\hline CHEMBL3974181 & 1641545 & 8.3372 & 8.2579 & TRN \\
\hline CHEMBL3928825 & 1641545 & 7.1986 & 7.3066 & TRN \\
\hline CHEMBL3921115 & 1641545 & 9.2924 & 7.8584 & TST \\
\hline CHEMBL3924540 & 1641545 & 7.8447 & 7.9296 & TRN \\
\hline CHEMBL3975377 & 1641545 & 6.8153 & 6.718 & TRN \\
\hline CHEMBL3921544 & 1641545 & 6.5086 & 6.8664 & TRN \\
\hline CHEMBL3950512 & 1641545 & 8.7447 & 8.8213 & TRN \\
\hline CHEMBL3946189 & 1641545 & 7.8447 & 8.0051 & TRN \\
\hline CHEMBL3964678 & 1641545 & 8.4437 & 8.4295 & TRN \\
\hline CHEMBL3927745 & 1641545 & 8.2218 & 8.296 & TRN \\
\hline CHEMBL3924952 & 1641545 & 7.5969 & 7.9484 & TST \\
\hline CHEMBL3907558 & 1641545 & 8.9586 & 8.7357 & TST \\
\hline CHEMBL3895660 & 1641545 & 6.0 & 6.7887 & TST \\
\hline CHEMBL3917701 & 1641545 & 8.0862 & 8.1456 & TST \\
\hline CHEMBL3955072 & 1641545 & 8.5229 & 8.2693 & TST \\
\hline CHEMBL3973984 & 1641545 & 8.7696 & 8.4043 & TST \\
\hline CHEMBL3937908 & 1641545 & 6.5654 & 6.671 & TST \\
\hline
\end{tabular}


Supplemental Table S2.txt

\begin{tabular}{|c|c|c|c|c|c|}
\hline CHEMBL3980048 & 1641545 & 7.4179 & 8.118 & TST & \\
\hline CHEMBL3931182 & 1641545 & 8.3768 & 8.2952 & TST & \\
\hline CHEMBL3982526 & 1641545 & 8.4559 & 8.2797 & TST & \\
\hline CHEMBL3898684 & 1641545 & 9.6021 & 9.256 & TST & \\
\hline CHEMBL3904546 & 1641545 & 6.2041 & 5.8176 & TST & \\
\hline CHEMBL3987016 & 1641545 & 8.8539 & 8.5987 & TST & \\
\hline CHEMBL3909486 & 1641545 & 8.6778 & 8.2632 & TST & \\
\hline CHEMBL3960347 & 1641545 & 5.5229 & 6.3406 & TST & \\
\hline CHEMBL3963683 & 1641545 & 8.4815 & 8.4234 & TST & \\
\hline CHEMBL3953746 & 1641545 & 7.9872 & 8.5077 & TST & \\
\hline CHEMBL3917370 & 1641545 & 7.5143 & 7.7445 & TST & \\
\hline CHEMBL3965721 & 1641545 & 8.0132 & 7.9202 & TST & \\
\hline CHEMBL3951504 & 1641545 & 8.2518 & 8.2812 & TST & \\
\hline CHEMBL3918915 & 1641545 & 7.6162 & 8.1902 & TST & \\
\hline CHEMBL3907303 & 1641545 & 7.2708 & 7.8199 & TST & \\
\hline CHEMBL3941894 & 1641545 & 7.8962 & 8.2513 & TST & \\
\hline CHEMBL3940538 & 1641545 & 8.7212 & 9.1677 & TST & \\
\hline CHEMBL3977412 & 1641545 & 8.4685 & 8.4407 & TST & \\
\hline CHEMBL3978548 & 1641545 & 9.1024 & 8.5958 & TST & \\
\hline CHEMBL3969220 & 1641545 & 8.2218 & 8.0623 & TST & \\
\hline CHEMBL3906205 & 1641545 & 8.2147 & 8.2223 & TST & \\
\hline CHEMBL3982940 & 1641545 & 6.7375 & 6.7725 & TST & \\
\hline CHEMBL3976953 & 1641545 & 8.3768 & 8.2153 & TST & \\
\hline CHEMBL3889757 & 1641545 & 9.1249 & 8.6076 & TST & \\
\hline CHEMBL3941801 & 1641545 & 7.1618 & 6.7739 & TST & \\
\hline CHEMBL3896902 & 1641545 & 7.0585 & 7.3888 & TST & \\
\hline CHEMBL3907725 & 1641545 & 7.6615 & 7.8747 & TST & \\
\hline CHEMBL 73080 & 75589 & 5.4535 & 5.0029 & TRN & \\
\hline CHEMBL 72607 & 75589 & 5.5376 & 5.8827 & TRN & \\
\hline CHEMBL 73794 & 75589 & 5.8297 & 5.8864 & TRN & \\
\hline CHEMBL306527 & 75589 & 4.0 & 4.1382 & TRN & \\
\hline CHEMBL 76390 & 75589 & 4.0 & 3.9993 & TRN & \\
\hline CHEMBL441258 & 75589 & 5.4949 & 5.4268 & TRN & \\
\hline CHEMBL 306047 & 75589 & 5.71899 & 999999999 & 5.5783 & TRN \\
\hline CHEMBL 72069 & 75589 & 6.1487 & 5.9367 & TRN & \\
\hline CHEMBL308479 & 75589 & 5.1255 & 5.6653 & TRN & \\
\hline CHEMBL 73413 & 75589 & 5.6289 & 5.4894 & TRN & \\
\hline CHEMBL 72754 & 75589 & 5.9469 & 5.6063 & TRN & \\
\hline CHEMBL308994 & 75589 & 4.0 & 3.8526 & TRN & \\
\hline CHEMBL 75952 & 75589 & 5.4202 & \multicolumn{2}{|c|}{5.5760000000000005} & TRN \\
\hline CHEMBL 75984 & 75589 & 5.475 & 5.081 & TRN & \\
\hline CHEMBL306367 & 75589 & 4.0 & 4.2793 & TRN & \\
\hline CHEMBL 307630 & 75589 & 5.6073 & \multicolumn{2}{|c|}{5.5729999999999995} & TRN \\
\hline CHEMBL73485 & 75589 & 5.8861 & 6.0661 & TRN & \\
\hline CHEMBL 76337 & 75589 & 5.9586 & 5.7033 & TST & \\
\hline CHEMBL311851 & 75589 & 5.9788 & \multicolumn{2}{|c|}{6.156000000000001} & TRA \\
\hline CHEMBL 72808 & 75589 & 4.0 & 4.7247 & TST & \\
\hline CHEMBL 306045 & 75589 & 4.8601 & 4.8822 & TRN & \\
\hline
\end{tabular}

Page 18549 


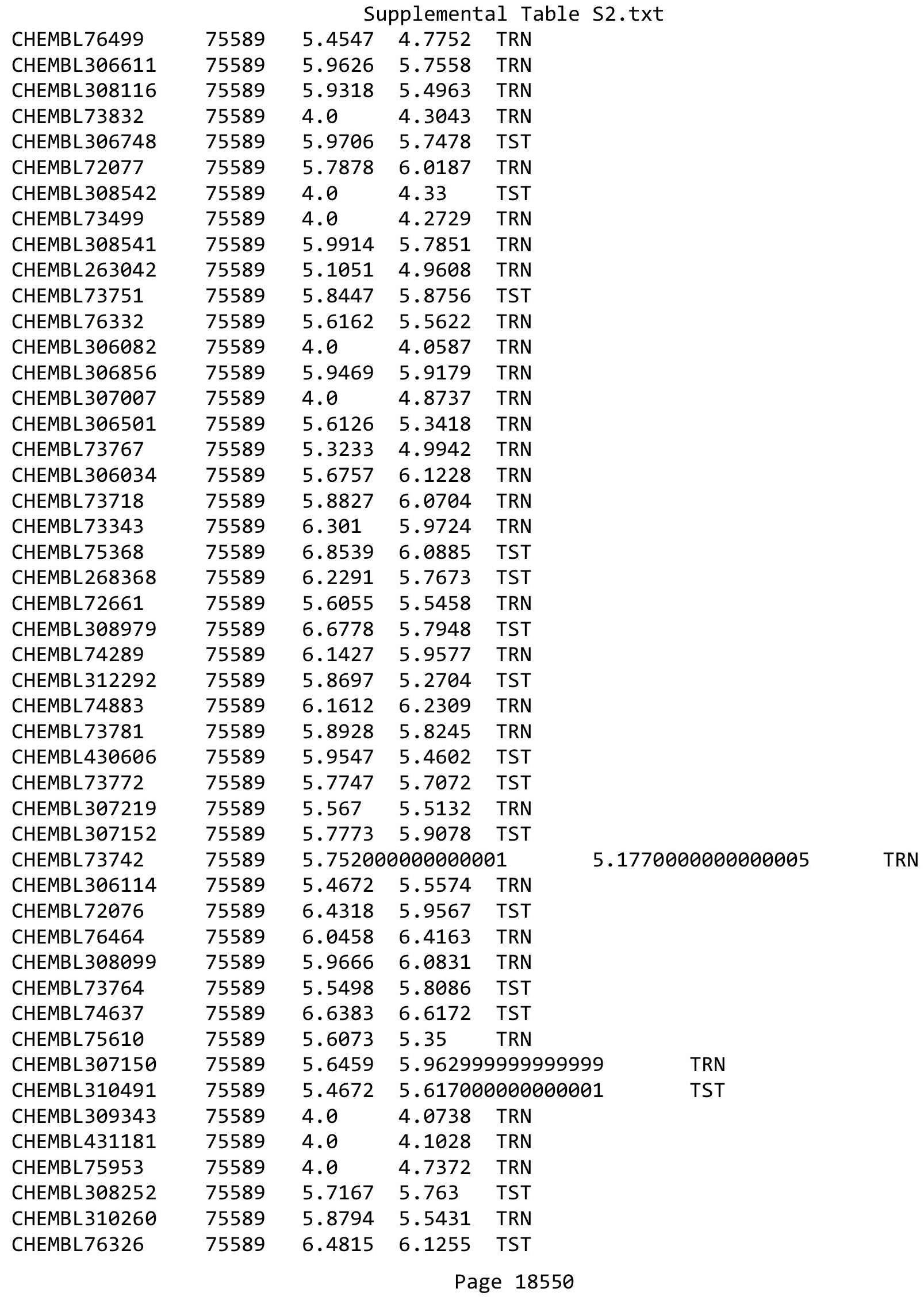




\begin{tabular}{|c|c|c|c|c|c|}
\hline & & & & & \\
\hline CHEMBL514647 & 540544 & 6.4685 & 5.944 & TST & \\
\hline CHEMBL479921 & 540544 & 6.6778 & 6.6069 & TRN & \\
\hline CHEMBL149174 & 540544 & 9.9208 & 10.3565 & TRN & \\
\hline CHEMBL150124 & 540544 & 9.8239 & 9.9786 & TRN & \\
\hline CHEMBL301715 & 540544 & 4.1871 & 5.8562 & TRN & \\
\hline CHEMBL139395 & 540544 & 6.1871 & 6.0651 & TRN & \\
\hline CHEMBL475299 & 540544 & 4.0 & 5.5121 & TST & \\
\hline CHEMBL471468 & 540544 & 6.3468 & 5.9827 & TST & \\
\hline CHEMBL149116 & 540544 & 9.8239 & 9.6945 & TRN & \\
\hline CHEMBL147814 & 540544 & 9.8239 & 9.8343 & TRN & \\
\hline CHEMBL150057 & 540544 & 9.8239 & 9.6647 & TRN & \\
\hline CHEMBL342983 & 540544 & 9.1427 & 9.9063 & TRN & \\
\hline CHEMBL138876 & 540544 & 5.8539 & 6.0442 & TRN & \\
\hline CHEMBL146182 & 540544 & 9.8239 & 10.1618 & TRN & \\
\hline CHEMBL508592 & 540544 & 4.9586 & 6.4581 & TST & \\
\hline CHEMBL149197 & 540544 & 9.8239 & 10.0175 & TRN & \\
\hline CHEMBL356695 & 540544 & 9.8239 & 10.0759 & TRN & \\
\hline CHEMBL148304 & 540544 & 9.8239 & 9.7644 & TRN & \\
\hline CHEMBL146699 & 540544 & 9.8239 & 10.002 & TRN & \\
\hline CHEMBL475088 & 540544 & 5.5229 & 6.3619 & TST & \\
\hline CHEMBL157102 & 540544 & 4.9208 & 4.4203 & TRN & \\
\hline CHEMBL186389 & 540544 & 3.699 & 5.6705 & TST & \\
\hline CHEMBL356437 & 540544 & 9.8239 & 9.8059 & TRN & \\
\hline CHEMBL136258 & 540544 & 6.7447 & 6.3929 & TRN & \\
\hline CHEMBL138413 & 540544 & 6.1871 & 6.2328 & TRN & \\
\hline CHEMBL148716 & 540544 & 9.8239 & 9.6595 & TRN & \\
\hline CHEMBL189399 & 540544 & 4.3979 & 5.6935 & TST & \\
\hline CHEMBL342014 & 540544 & 6.585 & 6.1267 & TRN & \\
\hline CHEMBL347817 & 540544 & 3.9101 & 4.5101 & TRN & \\
\hline CHEMBL513232 & 540544 & 5.4949 & 5.8476 & TST & \\
\hline CHEMBL151794 & 540544 & 4.8539 & 5.2197 & TRN & \\
\hline CHEMBL149664 & 540544 & 9.8239 & 10.0101 & TRN & \\
\hline CHEMBL146197 & 540544 & 9.8239 & 9.9324 & TRN & \\
\hline CHEMBL421982 & 540544 & 3.3768 & 4.4147 & TRN & \\
\hline CHEMBL336034 & 540544 & 6.7212 & 6.3474 & TRN & \\
\hline CHEMBL356135 & 540544 & 8.9208 & 9.6719 & TRN & \\
\hline CHEMBL344256 & 540544 & 5.8539 & 6.201006 & 00000000005 & TRN \\
\hline CHEMBL473480 & 540544 & 4.1675 & 5.8649 & TST & \\
\hline CHEMBL60469 & 540544 & 5.8239 & 5.608 & TRN & \\
\hline CHEMBL342043 & 540544 & 6.7212 & 6.2338 & TST & \\
\hline CHEMBL456220 & 540544 & 10.5229 & 8.3865 & TRN & \\
\hline CHEMBL504793 & 540544 & 9.7212 & 8.8397 & TRN & \\
\hline CHEMBL421758 & 540544 & 6.0506 & 6.1336 & TST & \\
\hline CHEMBL473686 & 540544 & 7.6021 & 6.1376 & TRN & \\
\hline CHEMBL188254 & 540544 & 4.3979 & 5.6852 & TST & \\
\hline CHEMBL474303 & 540544 & 7.3979 & 7.1804 & TST & \\
\hline CHEMBL358153 & 540544 & 9.9508 & 9.9207 & TRN & \\
\hline CHEMBL117969 & 540544 & 6.0 & 6.6523 & TRN & \\
\hline
\end{tabular}




\begin{tabular}{|c|c|c|c|c|c|}
\hline & & \multicolumn{4}{|c|}{ Supplemental Table S2.txt } \\
\hline CHEMBL152335 & 540544 & 5.4815 & 4.9536 & TRN & \\
\hline CHEMBL346387 & 540544 & 9.8861 & 9.27 & TRN & \\
\hline CHEMBL543437 & 2126 & 6.0 & 5.7953 & TRN & \\
\hline CHEMBL543674 & 2126 & 6.5072 & 6.3098 & TRN & \\
\hline CHEMBL544146 & 2126 & 5.0 & 5.5277 & TRN & \\
\hline CHEMBL543438 & 2126 & 5.4742 & 6.5617 & TST & \\
\hline CHEMBL138992 & 2126 & 6.4023 & 6.4378 & TRN & \\
\hline CHEMBL136495 & 2126 & 6.5654 & 6.7009 & TRN & \\
\hline CHEMBL136621 & 2126 & 6.9957 & 7.3612 & TRN & \\
\hline CHEMBL439609 & 2126 & 5.9363 & 6.2114 & TST & \\
\hline CHEMBL139110 & 2126 & 7.2757 & 6.2297 & TRN & \\
\hline CHEMBL136068 & 2126 & 5.0 & 6.2973 & TRN & \\
\hline CHEMBL344240 & 2126 & 5.0 & 6.2026 & TRN & \\
\hline CHEMBL543412 & 2126 & 7.8239 & 7.1609 & TRN & \\
\hline CHEMBL555975 & 2126 & 5.0 & 6.1955 & TRN & \\
\hline CHEMBL541603 & 2126 & 5.0602 & 5.6865 & TRN & \\
\hline CHEMBL544614 & 2126 & 6.3054 & 6.5386 & TRN & \\
\hline CHEMBL136064 & 2126 & 8.4437 & 8.6745 & TRN & \\
\hline CHEMBL539042 & 2126 & 6.7282 & 5.6034 & TRN & \\
\hline CHEMBL545081 & 2126 & 8.0 & 7.006 & TRN & \\
\hline CHEMBL136794 & 2126 & 8.4815 & 8.4629 & TRN & \\
\hline CHEMBL555993 & 2126 & 6.0 & 5.6471 & TRN & \\
\hline CHEMBL136590 & 2126 & 5.945 & 5.5285 & TRN & \\
\hline CHEMBL542246 & 2126 & 6.8633 & 6.3312 & TRN & \\
\hline CHEMBL136509 & 2126 & 7.7696 & 7.9188 & TST & \\
\hline CHEMBL540578 & 2126 & 6.5654 & 6.25299 & 9999999999 & TRN \\
\hline CHEMBL539553 & 2126 & 6.0273 & 5.8556 & TST & \\
\hline CHEMBL545549 & 2126 & 6.9431 & 6.4233 & TRN & \\
\hline CHEMBL440345 & 2126 & 6.9281 & 7.0994 & TRN & \\
\hline CHEMBL442965 & 2126 & 6.5376 & 6.7137 & TRN & \\
\hline CHEMBL137502 & 2126 & 6.0 & 6.4584 & TST & \\
\hline CHEMBL46463 & 2126 & 5.5501 & 5.41799 & 9999999999 & TRN \\
\hline CHEMBL540585 & 2126 & 8.0 & 7.6515 & TRN & \\
\hline CHEMBL136594 & 2126 & 6.0 & 6.1663 & TRN & \\
\hline CHEMBL136429 & 2126 & 6.5421 & 5.6371 & TRN & \\
\hline CHEMBL555544 & 2126 & 4.0 & 5.3334 & TRN & \\
\hline CHEMBL337124 & 2126 & 5.7683 & 6.0702 & TRN & \\
\hline CHEMBL424281 & 2126 & $6.7620 e$ & 00000000 & 6.5833 & TRN \\
\hline CHEMBL137776 & 2126 & 4.0 & 5.3626 & TRN & \\
\hline CHEMBL136381 & 2126 & 7.5086 & 6.7327 & TRN & \\
\hline CHEMBL139963 & 2126 & 8.0757 & 8.5975 & TRN & \\
\hline CHEMBL335327 & 2126 & 8.0458 & 7.1022 & TRN & \\
\hline CHEMBL545781 & 2126 & 4.0 & 5.8776 & TRN & \\
\hline CHEMBL136622 & 2126 & 7.1871 & 7.3034 & TST & \\
\hline CHEMBL137768 & 2126 & 6.4559 & 6.4961 & TRN & \\
\hline CHEMBL422627 & 2126 & 6.0 & 6.1389 & TRN & \\
\hline CHEMBL543440 & 2126 & 6.7305 & 6.5344 & TRN & \\
\hline CHEMBL136701 & 2126 & 7.3872 & 7.2078 & TST & \\
\hline
\end{tabular}




\begin{tabular}{|c|c|c|c|c|c|}
\hline \multicolumn{6}{|c|}{ Supplemental Table S } \\
\hline CHEMBL137250 & 2126 & 6.0 & 6.2337 & TRN & \\
\hline CHEMBL334466 & 2126 & 6.5003 & 7.04299 & 9999999999 & TRN \\
\hline CHEMBL344422 & 2126 & 4.0 & 5.3829 & TRN & \\
\hline CHEMBL544375 & 2126 & 5.7951 & 6.0 & TST & \\
\hline CHEMBL139370 & 2126 & 6.3507 & 6.0976 & TST & \\
\hline CHEMBL545546 & 2126 & 6.4437 & 7.0662 & TST & \\
\hline CHEMBL137563 & 2126 & 5.0 & 6.1363 & TRN & \\
\hline CHEMBL544616 & 2126 & 7.9208 & 7.6811 & TRN & \\
\hline CHEMBL136615 & 2126 & 7.8239 & 7.54 & TST & \\
\hline CHEMBL337810 & 2126 & 6.585 & 6.6108 & TRN & \\
\hline CHEMBL134578 & 2126 & 6.5045 & 6.0191 & TRN & \\
\hline CHEMBL538532 & 2126 & 7.3872 & 6.7695 & TRN & \\
\hline CHEMBL544147 & 2126 & 6.301 & 6.7682 & TRN & \\
\hline CHEMBL136877 & 2126 & 6.0 & 5.6059 & TRN & \\
\hline CHEMBL423355 & 2126 & 6.9508 & 6.7037 & TRN & \\
\hline CHEMBL543439 & 2126 & 7.0605 & 6.7451 & TRN & \\
\hline CHEMBL543206 & 2126 & 6.2526 & 5.567 & TRN & \\
\hline CHEMBL554678 & 2126 & 6.6498 & 6.46299 & 9999999999 & TRN \\
\hline CHEMBL558819 & 2126 & 6.5045 & 6.5963 & TRN & \\
\hline CHEMBL136395 & 2126 & 6.6676 & 5.7321 & TRN & \\
\hline CHEMBL136835 & 2126 & 7.4202 & 7.1956 & TRN & \\
\hline CHEMBL136789 & 2126 & 6.6819 & 6.5579 & TRN & \\
\hline CHEMBL543910 & 2126 & 5.7251 & 6.2505 & TRN & \\
\hline CHEMBL539567 & 2126 & 6.5513 & 7.1814 & TRN & \\
\hline CHEMBL136768 & 2126 & 7.585 & 7.3505 & TRN & \\
\hline CHEMBL337711 & 2126 & 6.2336 & 5.7513 & TRN & \\
\hline CHEMBL542740 & 2126 & 6.6003 & 7.2086 & TRN & \\
\hline CHEMBL137658 & 2126 & 7.3279 & 5.965 & TRN & \\
\hline CHEMBL543917 & 2126 & 6.556 & 5.8203 & TRN & \\
\hline CHEMBL136963 & 2126 & 7.6198 & 7.1619 & TRN & \\
\hline CHEMBL555865 & 2126 & 7.585 & 7.8698 & TRN & \\
\hline CHEMBL134527 & 2126 & 8.0969 & 8.1019 & TRN & \\
\hline CHEMBL540322 & 2126 & 7.4949 & 7.3297 & TRN & \\
\hline CHEMBL545552 & 2126 & 7.6021 & 7.4054 & TRN & \\
\hline CHEMBL60859 & 2126 & 6.3872 & 7.4202 & TST & \\
\hline CHEMBL539358 & 2126 & 7.5528 & 7.1953 & TRN & \\
\hline CHEMBL542737 & 2126 & 6.8962 & 6.7315 & TRN & \\
\hline CHEMBL138281 & 2126 & 8.2218 & 7.6195 & TRN & \\
\hline CHEMBL545784 & 2126 & 5.0 & 6.8527 & TRN & \\
\hline CHEMBL137159 & 2126 & 7.2596 & 5.6541 & TRN & \\
\hline CHEMBL136388 & 2126 & 6.3585 & 5.6005 & TRN & \\
\hline CHEMBL422634 & 2126 & 5.0 & 6.4747 & TRN & \\
\hline CHEMBL555443 & 2126 & 6.4908 & 6.7306 & TRN & \\
\hline CHEMBL539302 & 2126 & 7.3979 & 5.9461 & TST & \\
\hline CHEMBL 342267 & 2126 & 7.699 & 7.1287 & TST & \\
\hline CHEMBL342948 & 2126 & 6.9355 & 5.4544 & TST & \\
\hline CHEMBL137085 & 2126 & 7.6198 & 7.3087 & TST & \\
\hline CHEMBL337337 & 2126 & 8.0 & 8.2496 & TST & \\
\hline
\end{tabular}




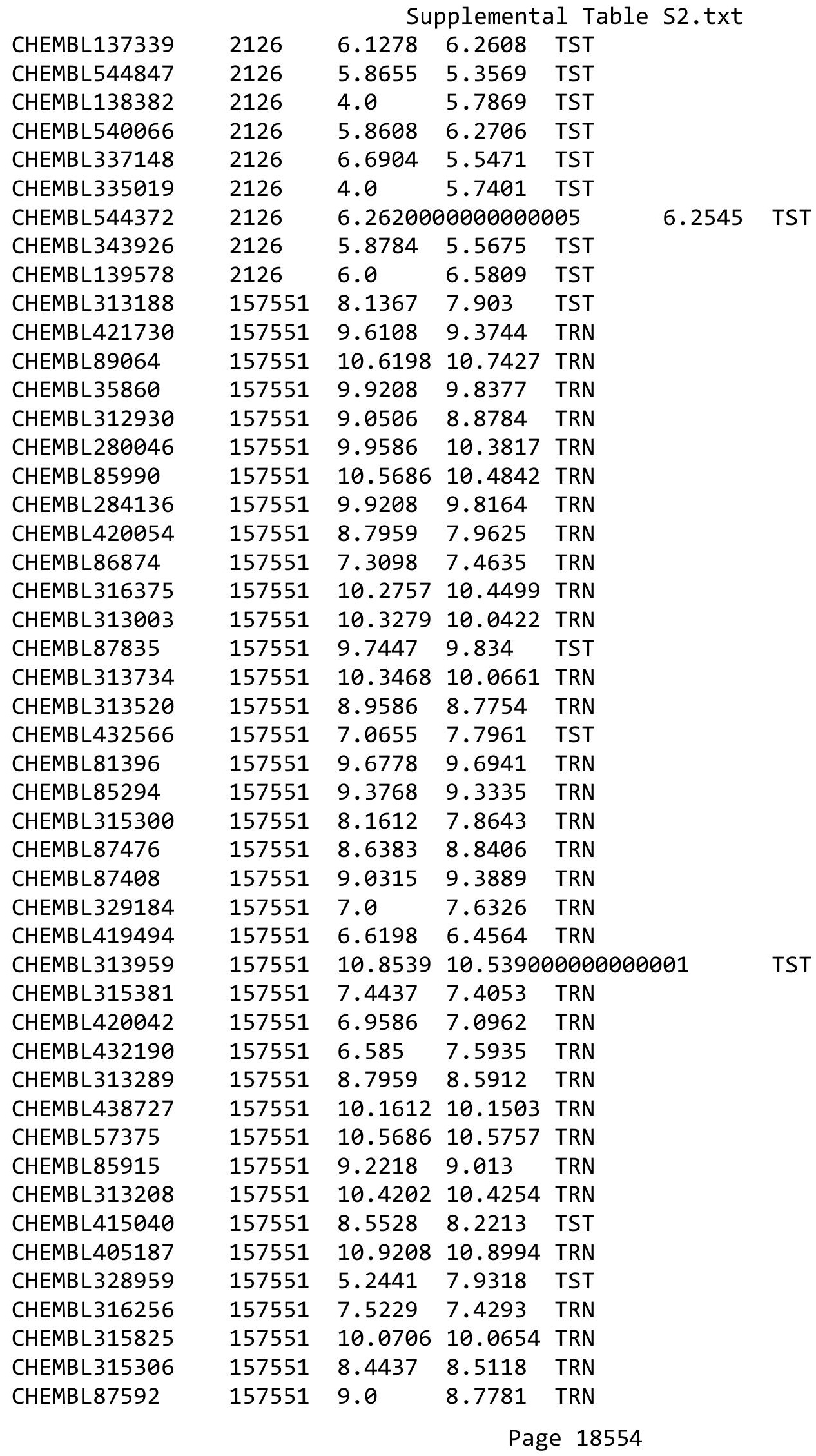




\begin{tabular}{|c|c|c|c|c|c|c|}
\hline & & \multicolumn{5}{|c|}{ Supplemental Table S2.txt } \\
\hline CHEMBL314709 & 157551 & \multicolumn{4}{|c|}{$8.283999999999999 \quad 8.5327$} & TRN \\
\hline CHEMBL284314 & 157551 & \multicolumn{3}{|c|}{8.283999999999999} & 8.3343 & TRN \\
\hline CHEMBL316147 & 157551 & 10.7447 & 10.7895 & TRN & & \\
\hline CHEMBL87919 & 157551 & 7.5686 & 7.6675 & TRN & & \\
\hline CHEMBL315174 & 157551 & 8.8539 & 8.6461 & TRN & & \\
\hline CHEMBL316408 & 157551 & 9.0655 & 9.2211 & TRN & & \\
\hline CHEMBL313732 & 157551 & 8.8539 & 8.9398 & TRN & & \\
\hline CHEMBL314052 & 157551 & 8.3372 & 7.5935 & TRN & & \\
\hline CHEMBL412810 & 157551 & 9.4815 & 9.5207 & TRN & & \\
\hline CHEMBL84734 & 157551 & 8.1549 & 8.2227 & TRN & & \\
\hline CHEMBL313516 & 157551 & 8.6198 & 8.8837 & TRN & & \\
\hline CHEMBL311499 & 157551 & 10.4089 & 10.5096 & TRN & & \\
\hline CHEMBL313357 & 157551 & 10.1249 & 10.1358 & TRN & & \\
\hline CHEMBL89132 & 157551 & 10.1938 & 10.1739 & TRN & & \\
\hline CHEMBL32733 & 157551 & 8.0969 & 8.2668 & TRN & & \\
\hline CHEMBL315177 & 157551 & 7.0458 & 7.4701 & TRN & & \\
\hline CHEMBL313599 & 157551 & 7.2218 & 7.0369 & TRN & & \\
\hline CHEMBL87503 & 157551 & 8.7447 & 8.012 & TST & & \\
\hline CHEMBL87690 & 157551 & 5.9586 & 6.0163 & TRN & & \\
\hline CHEMBL86398 & 157551 & 10.6021 & 10.4429 & TRN & & \\
\hline CHEMBL312890 & 157551 & 5.7282 & 6.5592 & TST & & \\
\hline CHEMBL405189 & 157551 & 9.3872 & 9.6598 & TRN & & \\
\hline CHEMBL313008 & 157551 & 7.6576 & 8.0596 & TST & & \\
\hline CHEMBL314944 & 157551 & 7.6576 & 7.6002 & TRN & & \\
\hline CHEMBL408834 & 157551 & 10.7959 & 10.6443 & TRN & & \\
\hline CHEMBL89794 & 157551 & 6.8041 & 7.2516 & TRN & & \\
\hline CHEMBL 85585 & 157551 & 9.585 & 9.5511 & TRN & & \\
\hline CHEMBL314008 & 157551 & 9.4449 & 9.3185 & TRN & & \\
\hline CHEMBL275024 & 157551 & 9.6778 & 9.4598 & TRN & & \\
\hline CHEMBL81383 & 157551 & 10.3665 & 10.5445 & TRN & & \\
\hline CHEMBL314901 & 157551 & 5.1135 & 4.9851 & TRN & & \\
\hline CHEMBL424427 & 157551 & 5.3979 & 7.6542 & TST & & \\
\hline CHEMBL262378 & 157551 & \multicolumn{3}{|c|}{10.699000000000002} & 10.8207 & TRN \\
\hline CHEMBL422772 & 157551 & 8.2441 & 8.0266 & TRN & & \\
\hline CHEMBL86913 & 157551 & 9.3726 & 9.36399 & 9999999999 & & TRN \\
\hline CHEMBL316407 & 157551 & 10.0177 & 9.6638 & TRN & & \\
\hline CHEMBL82606 & 157551 & 10.1805 & 10.2378 & TRN & & \\
\hline CHEMBL316445 & 157551 & 9.1302 & 9.3624 & TRN & & \\
\hline CHEMBL290576 & 157551 & 8.5229 & 8.5784 & TRN & & \\
\hline CHEMBL315569 & 157551 & 10.7959 & 10.9268 & TRN & & \\
\hline CHEMBL431306 & 157551 & 8.6778 & 8.3894 & TRN & & \\
\hline CHEMBL262642 & 157551 & 10.7447 & 11.2564 & TST & & \\
\hline CHEMBL431017 & 157551 & 9.8182 & 10.1681 & TST & & \\
\hline CHEMBL 87491 & 157551 & 9.3665 & 9.9562 & TST & & \\
\hline CHEMBL313944 & 157551 & 8.6002 & 9.957 & TST & & \\
\hline CHEMBL87142 & 157551 & 7.4685 & 7.5286 & TST & & \\
\hline CHEMBL87991 & 157551 & \multicolumn{3}{|c|}{8.283999999999999} & 8.6578 & TRN \\
\hline CHEMBL284491 & 157551 & 7.9208 & 7.8302 & TRN & & \\
\hline
\end{tabular}




\begin{tabular}{|c|c|c|c|c|c|}
\hline \multicolumn{6}{|c|}{ Supplemental Table S2.txt } \\
\hline CHEMBL291677 & 157551 & 10.8539 & 10.2639 & TST & \\
\hline CHEMBL315639 & 157551 & 8.0132 & 8.2081 & TRN & \\
\hline CHEMBL33647 & 157551 & 9.5086 & 8.9828 & TRN & \\
\hline CHEMBL86441 & 157551 & 9.2373 & 9.4257 & TST & \\
\hline CHEMBL314984 & 157551 & 8.1549 & 7.8833 & TRN & \\
\hline CHEMBL 313348 & 157551 & 10.9208 & 10.1158 & TST & \\
\hline CHEMBL87999 & 157551 & 9.3872 & 8.8139 & TST & \\
\hline CHEMBL313288 & 157551 & 10.6383 & 10.3551 & TST & \\
\hline CHEMBL315439 & 157551 & 6.8386 & 8.2866 & TST & \\
\hline CHEMBL287355 & 157551 & 8.8861 & 8.6759 & TRN & \\
\hline CHEMBL314058 & 157551 & 9.9393 & 10.0791 & TST & \\
\hline CHEMBL285417 & 157551 & 9.8539 & 10.0289 & TRN & \\
\hline CHEMBL418939 & 157551 & 8.5229 & 8.7153 & TRN & \\
\hline CHEMBL86454 & 157551 & 10.2007 & 10.3666 & TST & \\
\hline CHEMBL85653 & 157551 & 10.9586 & 10.4524 & TST & \\
\hline CHEMBL316433 & 157551 & 7.2924 & 7.2255 & TRN & \\
\hline CHEMBL287274 & 157551 & 8.3665 & 8.4653 & TRN & \\
\hline CHEMBL87329 & 157551 & 9.5528 & 9.2497 & TRN & \\
\hline CHEMBL32828 & 157551 & 7.4318 & 8.2937 & TRN & \\
\hline CHEMBL11266 & 157551 & 10.6198 & 10.4924 & TST & \\
\hline CHEMBL88016 & 157551 & 9.1549 & 9.6804 & TST & \\
\hline CHEMBL85771 & 157551 & 8.8539 & 8.52799 & 9999999999 & TRN \\
\hline CHEMBL86959 & 157551 & 8.8239 & 8.9245 & TRN & \\
\hline CHEMBL315929 & 157551 & 10.69900 & 300000006 & 10.0449 & TST \\
\hline CHEMBL433404 & 157551 & 9.5376 & 10.2861 & TST & \\
\hline CHEMBL 284472 & 157551 & 8.8539 & 8.4975 & TRN & \\
\hline CHEMBL 86368 & 157551 & 8.7212 & 9.4108 & TST & \\
\hline CHEMBL21145 & 157551 & 9.4685 & 9.4028 & TRN & \\
\hline CHEMBL423500 & 157551 & 6.0969 & 6.1639 & TRN & \\
\hline CHEMBL431027 & 157551 & 10.4559 & 10.5732 & TST & \\
\hline CHEMBL 3287348 & 1365574 & 8.585 & 7.8378 & TRN & \\
\hline CHEMBL3287063 & 1365574 & 7.3979 & 7.5927 & TRN & \\
\hline CHEMBL3287347 & 1365574 & 7.3979 & 7.845 & TRN & \\
\hline CHEMBL491870 & 1365574 & 9.5528 & 9.5343 & TRN & \\
\hline CHEMBL3287070 & 1365574 & 6.6904 & 6.5214 & TRN & \\
\hline CHEMBL3287354 & 1365574 & 7.6576 & 7.8413 & TRN & \\
\hline CHEMBL3287327 & 1365574 & 9.3468 & 10.0475 & TRN & \\
\hline CHEMBL3287066 & 1365574 & 7.8239 & 6.6865 & TST & \\
\hline CHEMBL412536 & 1365574 & 9.3768 & 8.252 & TST & \\
\hline CHEMBL3287342 & 1365574 & 8.1772 & 8.1267 & TRN & \\
\hline CHEMBL3287071 & 1365574 & 4.0 & 4.63 & TRN & \\
\hline CHEMBL3287345 & 1365574 & 6.9208 & 7.21899 & 9999999999 & TRN \\
\hline CHEMBL3287349 & 1365574 & 6.0177 & 6.4811 & TRN & \\
\hline CHEMBL264190 & 1365574 & 9.0315 & 8.4183 & TRN & \\
\hline CHEMBL3287329 & 1365574 & 9.7212 & 9.7736 & TRN & \\
\hline CHEMBL 3287351 & 1365574 & 6.7959 & 7.1534 & TRN & \\
\hline CHEMBL3287069 & 1365574 & 8.7212 & 8.9273 & TRN & \\
\hline CHEMBL3287338 & 1365574 & 8.4437 & 8.3864 & TRN & \\
\hline
\end{tabular}


Supplemental Table S2.txt

\begin{tabular}{|c|c|c|c|c|}
\hline CHEMBL3287337 & 1365574 & 7.6198 & 7.4482 & TRN \\
\hline CHEMBL3287324 & 1365574 & 9.585 & 9.5146 & TRN \\
\hline CHEMBL3287343 & 1365574 & 7.2441 & 6.7209 & TRN \\
\hline CHEMBL3287352 & 1365574 & 7.8239 & 7.5987 & TRN \\
\hline CHEMBL432201 & 1365574 & 7.4949 & 8.4003 & TST \\
\hline CHEMBL3287331 & 1365574 & 6.9431 & 7.1463 & TRN \\
\hline CHEMBL3287335 & 1365574 & 6.5528 & 6.9177 & TRN \\
\hline CHEMBL3287344 & 1365574 & 8.0177 & \multicolumn{2}{|c|}{8.136000000000001} \\
\hline CHEMBL3287074 & 1365574 & 7.5528 & 7.4315 & TRN \\
\hline CHEMBL3287328 & 1365574 & 9.6778 & 9.3545 & TRN \\
\hline CHEMBL3287339 & 1365574 & 7.0506 & 6.4984 & TRN \\
\hline CHEMBL3287072 & 1365574 & 8.2757 & 8.2247 & TRN \\
\hline CHEMBL3287356 & 1365574 & 7.6778 & 7.7773 & TRN \\
\hline CHEMBL437050 & 1365574 & 7.1367 & 8.3833 & TST \\
\hline CHEMBL3287062 & 1365574 & 7.1249 & 8.0427 & TST \\
\hline CHEMBL3287323 & 1365574 & 9.9208 & 9.9516 & TST \\
\hline CHEMBL3287353 & 1365574 & 6.9586 & 6.5014 & TRN \\
\hline CHEMBL3287073 & 1365574 & 6.71 & 6.7788 & TST \\
\hline CHEMBL3287330 & 1365574 & 8.2924 & 8.1741 & TRN \\
\hline CHEMBL275303 & 1365574 & 6.5272 & 6.5136 & TST \\
\hline CHEMBL 3287340 & 1365574 & 6.6925 & 7.0615 & TRN \\
\hline CHEMBL322610 & 1365574 & 8.9031 & 9.4717 & TST \\
\hline CHEMBL3287350 & 1365574 & 7.8239 & 8.0212 & TRN \\
\hline CHEMBL3287355 & 1365574 & 6.6021 & 6.9278 & TRN \\
\hline CHEMBL3287341 & 1365574 & 5.6459 & 6.2372 & TRN \\
\hline CHEMBL405174 & 1365574 & 8.6635 & 9.0386 & TST \\
\hline CHEMBL3287334 & 1365574 & 8.3706 & 7.5456 & TRN \\
\hline CHEMBL3287060 & 1365574 & 8.2076 & 8.339 & TST \\
\hline CHEMBL3287325 & 1365574 & 9.5376 & \multicolumn{2}{|c|}{9.777000000000001} \\
\hline CHEMBL3287336 & 1365574 & 8.1296 & 7.9206 & TRN \\
\hline CHEMBL3287068 & 1365574 & 7.1192 & 7.6975 & TST \\
\hline CHEMBL3287067 & 1365574 & 7.3188 & 7.8602 & TST \\
\hline CHEMBL3287333 & 1365574 & 7.699 & 7.8391 & TRN \\
\hline CHEMBL3287346 & 1365574 & 6.1938 & 5.489 & TRN \\
\hline CHEMBL3287357 & 1365574 & 6.9586 & 6.9674 & TRN \\
\hline CHEMBL3287326 & 1365574 & 9.3979 & 9.4633 & TRN \\
\hline CHEMBL3287322 & 1365574 & 9.6198 & 9.6111 & TRN \\
\hline CHEMBL1911553 & 775394 & 6.2874 & 5.0865 & TRN \\
\hline CHEMBL1911440 & 775394 & 6.3179 & 5.9764 & TST \\
\hline CHEMBL1911554 & 775394 & 5.0 & 5.3218 & TRN \\
\hline CHEMBL1911437 & 775394 & 5.9747 & 5.8868 & TRN \\
\hline CHEMBL1911563 & 775394 & 5.0 & 5.3686 & TRN \\
\hline CHEMBL1911562 & 775394 & 5.0 & 5.4721 & TST \\
\hline CHEMBL1911426 & 775394 & 5.0 & 5.7528 & TRN \\
\hline CHEMBL1911580 & 775394 & 5.8477 & 6.0554 & TRN \\
\hline CHEMBL1911572 & 775394 & 4.301 & 6.023 & TRN \\
\hline CHEMBL1911558 & 775394 & 5.0 & 5.7311 & TST \\
\hline CHEMBL1911566 & 775394 & 5.0 & 4.7363 & TRN \\
\hline
\end{tabular}


Supplemental Table S2.txt

\begin{tabular}{|c|c|c|c|c|c|}
\hline CHEMBL1911434 & 775394 & 6.6968 & 6.0953 & TRN & \\
\hline CHEMBL1911576 & 775394 & 7.0458 & 6.3414 & TRN & \\
\hline CHEMBL1911439 & 775394 & 6.3391 & 6.0342 & TRN & \\
\hline CHEMBL1911431 & 775394 & 5.8182 & 5.8793 & TRN & \\
\hline CHEMBL1911442 & 775394 & 5.0 & 5.787999 & 9999999999 & TRN \\
\hline CHEMBL1911569 & 775394 & 5.0 & 4.9843 & TRN & \\
\hline CHEMBL1911432 & 775394 & 5.0 & 5.6716 & TRN & \\
\hline CHEMBL1911429 & 775394 & 6.6596 & 5.7391 & TRN & \\
\hline CHEMBL1911416 & 775394 & 6.4214 & 5.6092 & TST & \\
\hline CHEMBL1911428 & 775394 & 5.0 & 5.7832 & TRN & \\
\hline CHEMBL1911443 & 775394 & 5.0 & 5.3547 & TRN & \\
\hline CHEMBL1911557 & 775394 & 5.0 & 5.5362 & TST & \\
\hline CHEMBL1911573 & 775394 & 6.3958 & 6.1217 & TRN & \\
\hline CHEMBL1911559 & 775394 & 5.0 & 5.9372 & TST & \\
\hline CHEMBL1911552 & 775394 & 5.0 & 5.2691 & TRN & \\
\hline CHEMBL1911427 & 775394 & 5.0 & 5.6787 & TRN & \\
\hline CHEMBL1911419 & 775394 & 5.0 & 5.7834 & TST & \\
\hline CHEMBL1911574 & 775394 & 6.4413 & 6.0629 & TRN & \\
\hline CHEMBL1911581 & 775394 & 6.4145 & 6.2719 & TRN & \\
\hline CHEMBL1911417 & 775394 & 4.301 & 5.284 & TST & \\
\hline CHEMBL1911424 & 775394 & 6.4413 & 5.8137 & TRN & \\
\hline CHEMBL1911418 & 775394 & 6.2958 & 5.6863 & TST & \\
\hline CHEMBL1911444 & 775394 & 6.2457 & 5.6706 & TRN & \\
\hline CHEMBL1911438 & 775394 & 5.0 & 5.9342 & TRN & \\
\hline CHEMBL1911441 & 775394 & 5.0 & 5.7637 & TRN & \\
\hline CHEMBL1911571 & 775394 & 5.0 & 4.8536 & TRN & \\
\hline CHEMBL1911565 & 775394 & 5.0 & 5.3475 & TRN & \\
\hline CHEMBL1911561 & 775394 & 5.0 & 5.29 & TST & \\
\hline CHEMBL1911420 & 775394 & 6.3546 & 5.7877 & TRN & \\
\hline CHEMBL1911568 & 775394 & 5.0 & 4.7077 & TRN & \\
\hline CHEMBL1911560 & 775394 & 4.301 & 5.4516 & TST & \\
\hline CHEMBL1911430 & 775394 & 5.0 & 5.7583 & TRN & \\
\hline CHEMBL1911579 & 775394 & 7.1367 & 6.1749 & TRN & \\
\hline CHEMBL1911575 & 775394 & 6.7932 & 6.1733 & TRN & \\
\hline CHEMBL1911583 & 775394 & 5.0 & 5.5037 & TRN & \\
\hline CHEMBL1911550 & 775394 & 5.0 & 4.8845 & TRN & \\
\hline CHEMBL1911577 & 775394 & 6.2366 & 6.2283 & TRN & \\
\hline CHEMBL1911421 & 775394 & \multicolumn{3}{|c|}{6.327000000000001} & TRN \\
\hline CHEMBL1911556 & 775394 & 5.0 & 5.285 & TST & \\
\hline CHEMBL1911555 & 775394 & 5.0 & 5.2732 & TST & \\
\hline CHEMBL1911433 & 775394 & 5.0 & 5.9277 & TRN & \\
\hline CHEMBL1911551 & 775394 & 5.0 & 5.6399 & TRN & \\
\hline CHEMBL1911423 & 775394 & 6.3215 & 5.9105 & TRN & \\
\hline CHEMBL1911436 & 775394 & 6.3665 & 5.867999 & э999999999 & TST \\
\hline CHEMBL1911435 & 775394 & 6.2518 & 5.9505 & TRN & \\
\hline CHEMBL1911425 & 775394 & 5.8761 & 5.7242 & TRN & \\
\hline CHEMBL1911570 & 775394 & 6.0092 & 5.1336 & TRN & \\
\hline CHEMBL1911422 & 775394 & 6.0026 & 5.8077 & TRN & \\
\hline
\end{tabular}

Page 18558 
Supplemental Table S2.txt

\begin{tabular}{|c|c|c|c|c|c|}
\hline CHEMBL1911578 & 775394 & 6.8069 & 6.1904 & TRN & \\
\hline CHEMBL1911582 & 775394 & 6.5622 & 6.17899 & 9999999999 & TST \\
\hline CHEMBL1911564 & 775394 & 5.4486 & 5.5367 & TST & \\
\hline CHEMBL1911567 & 775394 & 5.0 & 4.9479 & TRN & \\
\hline CHEMBL 2426469 & 983409 & 6.9586 & 6.9947 & TRN & \\
\hline CHEMBL 2426485 & 983409 & 6.5686 & 5.6055 & TRN & \\
\hline CHEMBL 2426363 & 983409 & 7.0177 & 7.055 & TRN & \\
\hline CHEMBL 2426493 & 983409 & 6.0809 & 5.9618 & TRN & \\
\hline CHEMBL 2426490 & 983409 & 6.9208 & 6.9799 & TRN & \\
\hline CHEMBL 2426374 & 983409 & 6.6198 & 6.9716 & TST & \\
\hline CHEMBL 2426473 & 983409 & 5.7696 & 5.0308 & TST & \\
\hline CHEMBL 2426372 & 983409 & 3.5229 & 4.1198 & TRN & \\
\hline CHEMBL 2426366 & 983409 & 7.3188 & 7.2825 & TRN & \\
\hline CHEMBL1235119 & 983409 & 5.5086 & 5.5451 & TRN & \\
\hline CHEMBL 2426474 & 983409 & 4.0 & 5.6055 & TRN & \\
\hline CHEMBL 2426376 & 983409 & 6.7696 & 6.6418 & TST & \\
\hline CHEMBL 2426361 & 983409 & 6.1612 & 6.2984 & TRN & \\
\hline CHEMBL 2426484 & 983409 & 6.6383 & 5.6055 & TRN & \\
\hline CHEMBL 2426482 & 983409 & 6.7696 & 6.772 & TRN & \\
\hline CHEMBL 2426467 & 983409 & 5.5086 & 5.6028 & TRN & \\
\hline CHEMBL 2426464 & 983409 & 5.4437 & 5.6705 & TRN & \\
\hline CHEMBL 2426471 & 983409 & 6.3979 & 6.2828 & TRN & \\
\hline CHEMBL 2426462 & 983409 & 6.6021 & 6.6864 & TRN & \\
\hline CHEMBL 2426368 & 983409 & 7.1805 & 7.2271 & TRN & \\
\hline CHEMBL 2426466 & 983409 & 6.2518 & 6.0209 & TRN & \\
\hline CHEMBL 2426479 & 983409 & 5.9586 & 6.0631 & TRN & \\
\hline CHEMBL 2426359 & 983409 & 6.6778 & 6.6468 & TRN & \\
\hline CHEMBL 2426476 & 983409 & 6.9208 & 7.0112 & TRN & \\
\hline CHEMBL 2426370 & 983409 & 5.9208 & 4.1563 & TST & \\
\hline CHEMBL 2426358 & 983409 & 6.6778 & 7.0259 & TST & \\
\hline CHEMBL 2426477 & 983409 & 6.7959 & 6.8198 & TRN & \\
\hline CHEMBL 2426369 & 983409 & 5.3872 & 5.2813 & TRN & \\
\hline CHEMBL 2426360 & 983409 & 7.1427 & 7.0143 & TRN & \\
\hline CHEMBL 2426367 & 983409 & 7.2366 & 7.1775 & TRN & \\
\hline CHEMBL 2426373 & 983409 & 6.4318 & \multicolumn{2}{|c|}{6.5889999999999995} & TST \\
\hline CHEMBL 2426465 & 983409 & 5.7447 & 5.7246 & TRN & \\
\hline CHEMBL 2426461 & 983409 & 6.4815 & 6.5404 & TRN & \\
\hline CHEMBL 2426492 & 983409 & 5.4202 & 5.3583 & TRN & \\
\hline CHEMBL 2426364 & 983409 & 7.1938 & 7.2886 & TRN & \\
\hline CHEMBL 2426365 & 983409 & 7.4089 & 7.4849 & TRN & \\
\hline CHEMBL 2426483 & 983409 & 6.8539 & 6.7556 & TRN & \\
\hline CHEMBL 2426371 & 983409 & 5.4949 & 5.3068 & TRN & \\
\hline CHEMBL 2426472 & 983409 & 6.1938 & 5.6728 & TRN & \\
\hline CHEMBL 2426480 & 983409 & 6.9208 & 7.0686 & TRN & \\
\hline CHEMBL 2426486 & 983409 & 5.8239 & 5.8922 & TRN & \\
\hline CHEMBL 2426362 & 983409 & 6.2757 & 6.2884 & TRN & \\
\hline CHEMBL 2426375 & 983409 & 6.7696 & 6.0507 & TST & \\
\hline CHEMBL 2426478 & 983409 & 6.6383 & 6.6914 & TRN & \\
\hline
\end{tabular}


Supplemental Table S2.txt

\begin{tabular}{|c|c|c|c|c|c|}
\hline CHEMBL 2426496 & 983409 & 7.0177 & 6.9947 & TRN & \\
\hline CHEMBL 2426481 & 983409 & 7.0044 & 6.9921 & TRN & \\
\hline CHEMBL2426497 & 983409 & 6.4437 & 6.1818 & TRN & \\
\hline CHEMBL 2426498 & 983409 & 7.1487 & 6.9553 & TRN & \\
\hline CHEMBL 2424677 & 983409 & 6.8861 & 6.5453 & TST & \\
\hline CHEMBL 2426470 & 983409 & 6.3979 & 6.7578 & TRN & \\
\hline CHEMBL 2426489 & 983409 & 6.8539 & 6.9237 & TRN & \\
\hline CHEMBL 2426468 & 983409 & 5.3372 & 5.3735 & TST & \\
\hline CHEMBL 2426491 & 983409 & 6.1308 & 6.2497 & TRN & \\
\hline CHEMBL 2426475 & 983409 & 4.0 & 3.9598 & TRN & \\
\hline CHEMBL 2426463 & 983409 & 6.1675 & 6.3448 & TST & \\
\hline CHEMBL 2426495 & 983409 & 6.7959 & 7.1527 & TST & \\
\hline CHEMBL 2426494 & 983409 & 6.5229 & 6.1388 & TST & \\
\hline CHEMBL 2426487 & 983409 & 5.6198 & 5.202999 & 7999999999 & TST \\
\hline CHEMBL 2426488 & 983409 & 6.5086 & 5.9502 & TST & \\
\hline CHEMBL 2424678 & 983409 & 6.9586 & 7.2121 & TST & \\
\hline CHEMBL558642 & 954763 & 3.2518 & 3.1973 & TRN & \\
\hline CHEMBL379975 & 954763 & 5.6603 & 5.2738 & TRN & \\
\hline CHEMBL213100 & 954763 & 6.5057 & 6.1455 & TRN & \\
\hline CHEMBL259181 & 954763 & 3.247 & 3.5645 & TRN & \\
\hline CHEMBL392695 & 954763 & 3.7145 & 3.8134 & TRN & \\
\hline CHEMBL 379300 & 954763 & 4.8395 & 5.3967 & TRN & \\
\hline CHEMBL 2144069 & 954763 & 7.5909 & 7.8342 & TRN & \\
\hline CHEMBL585951 & 954763 & 6.2839 & 6.751 & TRN & \\
\hline CHEMBL1909414 & 954763 & 6.0146 & 5.5229 & TRN & \\
\hline CHEMBL449158 & 954763 & 7.4928 & 8.0667 & TST & \\
\hline CHEMBL 373751 & 954763 & 3.4755 & 3.6675 & TRN & \\
\hline CHEMBL1230020 & 954763 & 6.4093 & 6.5183 & TRN & \\
\hline CHEMBL1673039 & 954763 & 4.6819 & 4.2655 & TRN & \\
\hline CHEMBL1404918 & 954763 & 2.8702 & 3.1569 & TRN & \\
\hline CHEMBL515416 & 954763 & 3.4383 & 3.6961 & TRN & \\
\hline CHEMBL 2134202 & 954763 & 3.9976 & 3.9542 & TRN & \\
\hline CHEMBL483849 & 954763 & 2.1443 & 1.9601 & TST & \\
\hline CHEMBL472940 & 954763 & 2.5027 & 2.2031 & TRN & \\
\hline CHEMBL9470 & 954763 & 6.1818 & 5.8015 & TST & \\
\hline CHEMBL3199475 & 954763 & 3.6984 & 3.7955 & TRN & \\
\hline CHEMBL1516890 & 954763 & 4.1013 & 4.2695 & TRN & \\
\hline CHEMBL1970879 & 954763 & 4.4736 & 3.8603 & TRN & \\
\hline CHEMBL210618 & 954763 & 3.3632 & 3.4861 & TRN & \\
\hline CHEMBL 2137530 & 954763 & 3.7674 & 4.5354 & TRN & \\
\hline CHEMBL 222102 & 954763 & 4.4155 & 4.0948 & TRN & \\
\hline CHEMBL 221137 & 954763 & 5.2765 & 4.4318 & TST & \\
\hline CHEMBL102714 & 954763 & 4.2646 & 4.5512 & TRN & \\
\hline CHEMBL509032 & 954763 & 4.5458 & 4.2063 & TRN & \\
\hline CHEMBL 255342 & 954763 & 4.0186 & 3.8472 & TRN & \\
\hline CHEMBL92309 & 954763 & \multicolumn{3}{|c|}{3.9530000000000003} & ובנו \\
\hline CHEMBL 217354 & 954763 & 6.1546 & 6.231 & TRN & \\
\hline CHEMBL192566 & 954763 & 7.5255 & 7.9296 & TST & \\
\hline
\end{tabular}


Supplemental Table S2.txt

\begin{tabular}{|c|c|c|c|c|}
\hline CHEMBL240954 & 954763 & 3.9622 & 3.5543 & TST \\
\hline CHEMBL483847 & 954763 & 4.3074 & 4.7043 & TRN \\
\hline CHEMBL1242367 & 954763 & 3.6941 & 3.6221 & TRN \\
\hline CHEMBL300389 & 954763 & 5.3792 & 5.4918 & TRN \\
\hline CHEMBL202721 & 954763 & 5.5786 & 5.0303 & TRN \\
\hline CHEMBL1357247 & 954763 & 3.448 & \multicolumn{2}{|c|}{3.3989999999999996} \\
\hline CHEMBL1186585 & 954763 & 4.279 & 4.0867 & TRN \\
\hline CHEMBL512504 & 954763 & 4.8042 & 4.504 & TRN \\
\hline CHEMBL1643959 & 954763 & 3.2318 & 3.5153 & TRN \\
\hline CHEMBL191334 & 954763 & 5.1401 & 5.2957 & TRN \\
\hline CHEMBL573107 & 954763 & 5.4358 & 5.2627 & TRN \\
\hline CHEMBL3392440 & 954763 & 3.8088 & 4.4217 & TRN \\
\hline CHEMBL 393929 & 954763 & 3.7464 & 3.7694 & TRN \\
\hline CHEMBL2363137 & 954763 & 6.0838 & 5.8676 & TRN \\
\hline CHEMBL65 & 954763 & 7.9329 & 8.0446 & TRN \\
\hline CHEMBL412142 & 954763 & 5.5582 & 5.4133 & TRN \\
\hline CHEMBL258844 & 954763 & 4.5038 & 4.1514 & TRN \\
\hline CHEMBL577784 & 954763 & 4.7342 & 5.0853 & TRN \\
\hline CHEMBL1590308 & 954763 & 4.5711 & 3.4466 & TST \\
\hline CHEMBL220241 & 954763 & 5.4892 & 5.4262 & TRN \\
\hline CHEMBL209148 & 954763 & 3.2738 & 3.4577 & TRN \\
\hline CHEMBL135561 & 954763 & 5.5299 & 4.8962 & TRN \\
\hline CHEMBL1256459 & 954763 & 6.6846 & 6.2548 & TRN \\
\hline CHEMBL 3186408 & 954763 & 4.0694 & 3.509 & TST \\
\hline CHEMBL1190711 & 954763 & 3.0519 & 3.4438 & TRN \\
\hline CHEMBL 3349342 & 954763 & 5.7618 & 7.2334 & TST \\
\hline CHEMBL514499 & 954763 & 5.2032 & 5.9399 & TST \\
\hline CHEMBL 2005886 & 954763 & 3.5616 & 4.49 & TST \\
\hline CHEMBL189584 & 954763 & 3.7745 & 5.1197 & TST \\
\hline CHEMBL188678 & 954763 & 4.1658 & 4.8306 & TST \\
\hline CHEMBL180127 & 954763 & 4.2602 & 3.8058 & TST \\
\hline CHEMBL1788116 & 954763 & 4.6489 & \multicolumn{2}{|c|}{4.1739999999999995} \\
\hline CHEMBL 399530 & 954763 & 4.6808 & 4.2285 & TST \\
\hline CHEMBL 3217249 & 977513 & 4.1568 & 4.5761 & TRN \\
\hline CHEMBL 3216825 & 977513 & 6.7375 & 7.4534 & TRN \\
\hline CHEMBL3217253 & 977513 & 4.0888 & 4.5647 & TRN \\
\hline CHEMBL 3216826 & 977513 & 3.9626 & 3.9623 & TRN \\
\hline CHEMBL 3707184 & 977513 & 8.5229 & 7.7708 & TRN \\
\hline CHEMBL 2418032 & 977513 & 8.301 & 8.1598 & TRN \\
\hline CHEMBL3216823 & 977513 & 4.8665 & 4.875 & TRN \\
\hline CHEMBL 3217240 & 977513 & 4.5834 & 4.2259 & TRN \\
\hline CHEMBL 2418042 & 977513 & 5.5751 & 6.7701 & TST \\
\hline CHEMBL3215696 & 977513 & 2.6234 & 4.0182 & TST \\
\hline CHEMBL 2418018 & 977513 & 7.6198 & 7.635 & TRN \\
\hline CHEMBL 2418044 & 977513 & 5.3556 & 5.2221 & TRN \\
\hline CHEMBL 3215691 & 977513 & 4.2976 & 3.6194 & TRN \\
\hline CHEMBL 3217038 & 977513 & 4.4123 & 4.2981 & TRN \\
\hline CHEMBL3216144 & 977513 & 4.4597 & 4.4692 & TRN \\
\hline
\end{tabular}

Page 18561 


\begin{tabular}{|c|c|c|c|c|c|}
\hline \multirow[b]{2}{*}{ CHEMBL2418047 } & \multicolumn{5}{|c|}{ Supplemental Table S2.txt } \\
\hline & 977513 & 5.4034 & 5.3983 & TRN & \\
\hline CHEMBL 2418029 & 977513 & 8.301 & 8.0525 & TRN & \\
\hline CHEMBL91187 & 977513 & 6.3179 & 5.968 & TRN & \\
\hline CHEMBL3217032 & 977513 & 3.8894 & 3.4781 & TRN & \\
\hline CHEMBL3215927 & 977513 & 6.9586 & 6.6805 & TRN & \\
\hline CHEMBL2418046 & 977513 & 5.8894 & 5.875 & TRN & \\
\hline CHEMBL 2418048 & 977513 & 5.5229 & 5.7292 & TST & \\
\hline CHEMBL2418052 & 977513 & 5.8697 & 5.3386 & TST & \\
\hline CHEMBL 2418045 & 977513 & 5.567 & 5.8886 & TST & \\
\hline CHEMBL2418041 & 977513 & 5.7212 & 6.45200 & 0000000001 & TRN \\
\hline CHEMBL3216142 & 977513 & 7.4685 & 7.5656 & TST & \\
\hline CHEMBL3215697 & 977513 & 4.1018 & 4.1953 & TRN & \\
\hline CHEMBL2418055 & 977513 & 7.6576 & 8.038 & TRN & \\
\hline CHEMBL3215690 & 977513 & 4.5884 & 4.3942 & TRN & \\
\hline CHEMBL3216586 & 977513 & 3.7932 & 3.8285 & TRN & \\
\hline CHEMBL 2418020 & 977513 & 6.9136 & 7.6339 & TRN & \\
\hline CHEMBL 2418038 & 977513 & 8.3979 & 8.077 & TRN & \\
\hline CHEMBL3217243 & 977513 & 4.8327 & 4.9753 & TRN & \\
\hline CHEMBL 2417998 & 977513 & 8.5229 & 8.0694 & TRN & \\
\hline CHEMBL2418049 & 977513 & 5.6737 & 5.608 & TST & \\
\hline CHEMBL 2418051 & 977513 & 7.041 & 6.5122 & TST & \\
\hline CHEMBL3217035 & 977513 & 5.1618 & 4.9197 & TRN & \\
\hline CHEMBL 2418019 & 977513 & 7.7696 & 7.5943 & TRN & \\
\hline CHEMBL 2418043 & 977513 & 5.4306 & 5.9773 & TST & \\
\hline CHEMBL3217033 & 977513 & 4.5784 & 4.8747 & TRN & \\
\hline CHEMBL 2418015 & 977513 & 7.7696 & 7.9086 & TRN & \\
\hline CHEMBL 2418040 & 977513 & 5.7352 & 5.9968 & TST & \\
\hline CHEMBL3217252 & 977513 & 8.301 & 7.8152 & TRN & \\
\hline CHEMBL 3217034 & 977513 & 4.2211 & 4.53100 & 0000000001 & TRN \\
\hline CHEMBL3216596 & 977513 & 3.8041 & 4.0044 & TRN & \\
\hline CHEMBL3216143 & 977513 & 4.308 & 4.7164 & TRN & \\
\hline CHEMBL2418035 & 977513 & 8.0 & 8.0628 & TRN & \\
\hline CHEMBL3217030 & 977513 & 4.7258 & 3.585 & TRN & \\
\hline CHEMBL3216588 & 977513 & 4.2993 & 4.9372 & TRN & \\
\hline CHEMBL90971 & 977513 & 5.0306 & 6.6164 & TST & \\
\hline CHEMBL 2418034 & 977513 & 7.7212 & 7.659 & TRN & \\
\hline CHEMBL 2418010 & 977513 & 7.5528 & 7.1623 & TST & \\
\hline CHEMBL 2418050 & 977513 & 5.1379 & 6.1043 & TST & \\
\hline CHEMBL3216355 & 977513 & 4.056 & 4.2776 & TRN & \\
\hline CHEMBL3216587 & 977513 & 2.6498 & 3.4291 & TRN & \\
\hline CHEMBL3217039 & 977513 & 4.1244 & 4.64 & TRN & \\
\hline CHEMBL 24057 & 977513 & 8.5229 & 7.4885 & TST & \\
\hline CHEMBL2418011 & 977513 & 7.0132 & 7.4458 & TST & \\
\hline CHEMBL3217251 & 977513 & 4.58 & 4.2572 & TRN & \\
\hline CHEMBL2418012 & 977513 & 7.7959 & 7.9695 & TRN & \\
\hline CHEMBL 2418024 & 977513 & 7.6198 & 7.6732 & TST & \\
\hline CHEMBL 3217029 & 977513 & 4.6198 & 4.0997 & TRN & \\
\hline CHEMBL2418026 & 977513 & 8.1549 & 8.065 & TRN & \\
\hline
\end{tabular}




\begin{tabular}{|c|c|c|c|c|}
\hline \multicolumn{5}{|c|}{ Supplemental Table } \\
\hline CHEMBL 2041667 & 824281 & 6.1938 & 6.0178 & TRN \\
\hline CHEMBL 2041424 & 824281 & 5.3002 & 4.9679 & TRN \\
\hline CHEMBL2041645 & 824281 & 3.6021 & 3.3756 & TRN \\
\hline CHEMBL 2041661 & 824281 & 5.1135 & 3.9141 & TRN \\
\hline CHEMBL 2041430 & 824281 & 3.6021 & 4.6971 & TRN \\
\hline CHEMBL2041452 & 824281 & 5.6108 & 5.3748 & TRN \\
\hline CHEMBL 2041474 & 824281 & 3.6021 & 3.5203 & TRN \\
\hline CHEMBL2041664 & 824281 & 6.6778 & 6.3708 & TRN \\
\hline CHEMBL 2041628 & 824281 & 3.6021 & 3.7379 & TRN \\
\hline CHEMBL 2041446 & 824281 & 5.9318 & 5.8732 & TRN \\
\hline CHEMBL2041421 & 824281 & 3.6021 & 4.1648 & TRN \\
\hline CHEMBL 2041437 & 824281 & 5.9393 & 5.2089 & TRN \\
\hline CHEMBL 2041456 & 824281 & 6.0367 & 5.4725 & TRN \\
\hline CHEMBL 2041651 & 824281 & 3.6021 & 3.2103 & TST \\
\hline CHEMBL 2041648 & 824281 & 3.6021 & 3.3286 & TST \\
\hline CHEMBL 2041426 & 824281 & 5.3809 & 5.3891 & TRN \\
\hline CHEMBL 2041641 & 824281 & 5.3134 & 3.7425 & TRN \\
\hline CHEMBL1421500 & 824281 & 3.6021 & 3.3446 & TRN \\
\hline CHEMBL 2041463 & 824281 & 5.7721 & 5.0518 & TRN \\
\hline CHEMBL 2041631 & 824281 & 3.6021 & 5.5043 & TRN \\
\hline CHEMBL2041629 & 824281 & 3.6021 & 4.4286 & TRN \\
\hline CHEMBL 2041435 & 824281 & 5.8761 & 5.7325 & TRN \\
\hline CHEMBL 2041417 & 824281 & 3.6021 & 3.9898 & TST \\
\hline CHEMBL 2041642 & 824281 & 3.6021 & 3.5582 & TRN \\
\hline CHEMBL 2041640 & 824281 & 5.8697 & 4.8814 & TRN \\
\hline CHEMBL2041445 & 824281 & 5.4306 & 4.7166 & TST \\
\hline CHEMBL 2041643 & 824281 & 3.6021 & 3.3738 & TRN \\
\hline CHEMBL 2041447 & 824281 & 5.7773 & 6.0609 & TRN \\
\hline CHEMBL 2041470 & 824281 & 5.8097 & 5.4929 & TRN \\
\hline CHEMBL 2041419 & 824281 & 3.6021 & 4.8688 & TST \\
\hline CHEMBL2041650 & 824281 & 3.6021 & 3.5094 & TST \\
\hline CHEMBL 2041637 & 824281 & 3.6021 & 4.2256 & TRN \\
\hline CHEMBL 2041638 & 824281 & 3.6021 & 3.4539 & TRN \\
\hline CHEMBL 2041665 & 824281 & 6.699 & 6.0803 & TRN \\
\hline CHEMBL 2041438 & 824281 & 3.6021 & 4.8923 & TRN \\
\hline CHEMBL2041469 & 824281 & 6.6198 & 6.2399 & TRN \\
\hline CHEMBL 2041635 & 824281 & 3.6021 & 3.298 & TRN \\
\hline CHEMBL 2041662 & 824281 & 6.5686 & 6.1414 & TRN \\
\hline CHEMBL 2041455 & 824281 & 5.5867 & 5.7656 & TRN \\
\hline CHEMBL 2041658 & 824281 & 5.7696 & 5.5058 & TRN \\
\hline CHEMBL2041436 & 824281 & 5.3134 & 5.4784 & TRN \\
\hline CHEMBL 2041466 & 824281 & 3.6021 & 3.7503 & TRN \\
\hline CHEMBL 2041442 & 824281 & 5.644 & 5.0458 & TRN \\
\hline CHEMBL 2041639 & 824281 & 3.6021 & 3.3665 & TRN \\
\hline CHEMBL 2041443 & 824281 & 3.6021 & 3.3331 & TRN \\
\hline CHEMBL2041475 & 824281 & 3.6021 & 3.3884 & TRN \\
\hline CHEMBL 2041454 & 824281 & 6.0555 & 5.6754 & TRN \\
\hline CHEMBL 2041451 & 824281 & 6.0269 & 5.6927 & TRN \\
\hline
\end{tabular}


Supplemental Table S2.txt

\begin{tabular}{|c|c|c|c|c|}
\hline 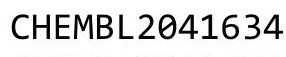 & & & 3.4759 & \\
\hline HEMBL 2041434 & 24281 & 2007 & 763 & \\
\hline HEMBL2041653 & 24281 & 6021 & 4857 & \\
\hline IEM & & & 7398 & \\
\hline IEMBL 2041440 & & 21 & 8526 & \\
\hline HEMBL2041441 & 24281 & 596 & 0876 & \\
\hline HEMBL 2041471 & 24281 & .6021 & .4843 & \\
\hline HEMBL3215664 & 281 & 021 & .705 & \\
\hline IEMBL20 & & 21 & .9566 & \\
\hline IEMBL20 & & 36 & 3734 & \\
\hline HEMBL2041655 & 81 & 5021 & 3526 & \\
\hline HEMBL 2041448 & 24281 & 18 & .0301 & \\
\hline HEMBL 204 & 81 & 21 & .7677 & \\
\hline HEMBL 204 & & 21 & .6832 & \\
\hline HEMBL 204 & & & .7352 & \\
\hline HEMBL 204 & & $\partial 1$ & 2954 & \\
\hline HEMBL 2041461 & 31 & 21 & 4.2589 & \\
\hline HEMBL 204 & & 51 & 5095 & \\
\hline HEMBL 20 & & & & \\
\hline HEMBL 20 & & & 878 & RN \\
\hline HEMBL 204 & & 21 & 935 & \\
\hline HEMBL 204 & 31 & 1 & 156 & RN \\
\hline HEMBL 20 & & & 588 & \\
\hline HEMBL 20 & & & & \\
\hline HEM & & & 96 & RN \\
\hline IEMBL 20 & & & & RN \\
\hline HEMBL 204 & & 1 & 45 & SI \\
\hline HEMBL $20 \angle$ & & & 85 & $\mathrm{RI}$ \\
\hline HEM & & & & RN \\
\hline HEM & & & 61 & RN \\
\hline HEMBL 20 & & & & RN \\
\hline HEMBL 2041422 & & & 1.9653 & RN \\
\hline HEMBL 20 & & & 233 & RN \\
\hline 0 & & & & RN \\
\hline HEMBL 20 & & & 3.2177 & RN \\
\hline HEMBL 204 & & & 5.4462 & ST \\
\hline HEMBL 2041652 & & & .4448 & ST \\
\hline JEMBL204 & & & 778 & RN \\
\hline 8 & & & & ST \\
\hline HEMBL 204 & & & & ST \\
\hline HEMBL $20 \angle$ & & & .6055 & ST \\
\hline HEMBL 20 & & & 3.3589 & ST \\
\hline HEMBL 204 & & & .0321 & \\
\hline HEMBL 204 & & & 3.4629 & ST \\
\hline HEMBL 20 & & & .6072 & ST \\
\hline HEMBL 20 & & 1 & .5594 & ST \\
\hline$L 20$ & & & & \\
\hline & $02-$ & 502 & & \\
\hline
\end{tabular}

Page 18564 


\begin{tabular}{|c|c|c|c|c|c|}
\hline \multirow[b]{2}{*}{ CHEMBL 2041432} & \multicolumn{5}{|c|}{ Supplemental Table S2.txt } \\
\hline & 824281 & 3.6021 & 3.759 & TST & \\
\hline CHEMBL 2041636 & 824281 & 3.6021 & 3.3152 & TST & \\
\hline CHEMBL 2041425 & 824281 & 6.5528 & 5.9482 & TST & \\
\hline CHEMBL 2041654 & 824281 & 3.6021 & 4.4897 & TST & \\
\hline CHEMBL359819 & 305785 & 4.0 & 4.157 & TRN & \\
\hline CHEMBL177241 & 305785 & 4.9465 & 5.1632 & TRN & \\
\hline CHEMBL175892 & 305785 & 5.0329 & 5.0378 & TRN & \\
\hline CHEMBL178976 & 305785 & 4.0 & 3.7761 & TST & \\
\hline CHEMBL180529 & 305785 & 4.9801 & 3.1929 & TST & \\
\hline CHEMBL3085293 & 305785 & 4.0 & 3.9331 & TRN & \\
\hline CHEMBL179925 & 305785 & 4.0 & 4.0844 & TRN & \\
\hline CHEMBL175978 & 305785 & 4.0 & 4.2651 & TST & \\
\hline CHEMBL179242 & 305785 & 6.5528 & 6.4165 & TRN & \\
\hline CHEMBL179001 & 305785 & 4.0 & 3.9188 & TRN & \\
\hline CHEMBL433802 & 305785 & 5.2434 & 5.1986 & TRN & \\
\hline CHEMBL 361608 & 305785 & 5.066 & 4.9797 & TRN & \\
\hline CHEMBL426944 & 305785 & 4.0 & 4.1146 & TRN & \\
\hline CHEMBL179043 & 305785 & 5.699 & 5.7652 & TRN & \\
\hline CHEMBL368236 & 305785 & 4.0 & 3.8955 & TRN & \\
\hline CHEMBL177938 & 305785 & 5.7167 & 5.6911 & TRN & \\
\hline CHEMBL 179002 & 305785 & 5.1752 & 5.3469 & TRN & \\
\hline CHEMBL177279 & 305785 & 5.4895 & 5.5416 & TRN & \\
\hline CHEMBL175883 & 305785 & 6.4089 & 6.1691 & TRN & \\
\hline CHEMBL176436 & 305785 & 5.4881 & 5.5105 & TRN & \\
\hline CHEMBL367537 & 305785 & 5.9031 & 5.9817 & TRN & \\
\hline CHEMBL361588 & 305785 & 5.2716 & 5.2293 & TRN & \\
\hline CHEMBL440378 & 305785 & 4.0 & 3.8968 & TRN & \\
\hline CHEMBL367262 & 305785 & 5.317 & 5.4026 & TRN & \\
\hline CHEMBL176193 & 305785 & 5.1733 & 5.2788 & TRN & \\
\hline CHEMBL179641 & 305785 & 5.1765 & 5.3557 & TRN & \\
\hline CHEMBL435542 & 305785 & 5.4962 & 4.4556 & TST & \\
\hline CHEMBL177998 & 305785 & 4.0 & 3.1214 & TST & \\
\hline CHEMBL176280 & 305785 & 5.4535 & 5.5922 & TRN & \\
\hline CHEMBL179922 & 305785 & 4.0 & 3.9341 & TRN & \\
\hline CHEMBL179695 & 305785 & 4.0 & 4.0651 & TRN & \\
\hline CHEMBL179640 & 305785 & 5.2882 & 5.2552 & TRN & \\
\hline CHEMBL179168 & 305785 & 5.7721 & 5.8569 & TRN & \\
\hline CHEMBL 367141 & 305785 & 5.6968 & 5.8556 & TRN & \\
\hline CHEMBL361530 & 305785 & 5.5513 & 4.7239 & TST & \\
\hline CHEMBL177059 & 305785 & 4.0 & 3.93600 & 00000000004 & TRN \\
\hline CHEMBL177997 & 305785 & 5.0726 & 4.0344 & TST & \\
\hline CHEMBL175510 & 305785 & 5.75700 & 30000000 & 5.6777 & TRN \\
\hline CHEMBL175661 & 305785 & 4.0 & 4.2727 & TRN & \\
\hline CHEMBL435507 & 305785 & 6.7212 & 6.7116 & TRN & \\
\hline CHEMBL179914 & 305785 & 5.2097 & 5.2646 & TRN & \\
\hline CHEMBL179292 & 305785 & 4.0 & 3.9154 & TST & \\
\hline CHEMBL369146 & 305785 & 5.6498 & 5.729 & TRN & \\
\hline CHEMBL283196 & 305785 & 5.3028 & 5.2424 & TRN & \\
\hline
\end{tabular}




\begin{tabular}{|c|c|c|c|c|c|}
\hline \multirow[b]{2}{*}{ CHEMBL436080 } & \multicolumn{5}{|c|}{ Supplemental Table S2.txt } \\
\hline & 305785 & 5.2434 & 5.0396 & TRN & \\
\hline CHEMBL425868 & 305785 & 4.0 & 4.1345 & TRN & \\
\hline CHEMBL97024 & 305785 & 5.9208 & 6.0017 & TRN & \\
\hline CHEMBL179094 & 305785 & 4.0 & 4.1007 & TST & \\
\hline CHEMBL176052 & 305785 & 4.0 & 4.1245 & TST & \\
\hline CHEMBL180213 & 305785 & 4.0 & 3.9668 & TST & \\
\hline CHEMBL369487 & 305785 & 4.0 & 4.0989 & TRN & \\
\hline CHEMBL367315 & 305785 & 5.8996 & 6.0367 & TRN & \\
\hline CHEMBL360038 & 305785 & 5.8601 & 5.8484 & TRN & \\
\hline CHEMBL176233 & 305785 & 6.585 & 6.5637 & TRN & \\
\hline CHEMBL176325 & 305785 & 4.961 & 4.9681 & TRN & \\
\hline CHEMBL178970 & 305785 & 4.0 & 3.8746 & TST & \\
\hline CHEMBL179822 & 305785 & 4.0 & 4.1432 & TST & \\
\hline CHEMBL179591 & 305785 & 5.4855 & 5.6007 & TRN & \\
\hline CHEMBL175944 & 305785 & 5.7932 & 5.6963 & TRN & \\
\hline CHEMBL369452 & 305785 & 5.0942 & 4.914 & TRN & \\
\hline CHEMBL275638 & 305785 & 4.0 & 5.1885 & TST & \\
\hline CHEMBL426040 & 305785 & 4.0 & 3.302 & TST & \\
\hline CHEMBL104468 & 305785 & 6.6383 & 6.3342 & TRN & \\
\hline CHEMBL179635 & 305785 & 5.7825 & 5.9065 & TRN & \\
\hline CHEMBL179412 & 305785 & \multicolumn{2}{|c|}{5.382999999999999} & 5.4836 & TRN \\
\hline CHEMBL176114 & 305785 & 5.055 & 4.7338 & TRN & \\
\hline CHEMBL175459 & 305785 & 6.0223 & 5.8436 & TRN & \\
\hline CHEMBL179968 & 305785 & 4.0 & 4.9423 & TST & \\
\hline CHEMBL177991 & 305785 & 4.0 & 3.8659 & TRN & \\
\hline CHEMBL176064 & 305785 & 5.3307 & 5.3227 & TRN & \\
\hline CHEMBL178977 & 305785 & 4.0 & 3.89300 & 00000000002 & TST \\
\hline CHEMBL179463 & 305785 & 4.0 & 4.8206 & TST & \\
\hline CHEMBL177497 & 305785 & 4.0 & 3.9778 & TRN & \\
\hline CHEMBL179276 & 305785 & 5.1135 & 4.8588 & TRN & \\
\hline CHEMBL178969 & 305785 & 5.7212 & 5.5615 & TRN & \\
\hline CHEMBL175450 & 305785 & 4.0 & 4.0674 & TRN & \\
\hline CHEMBL180023 & 305785 & 5.1878 & 4.6597 & TST & \\
\hline CHEMBL367468 & 305785 & 5.4191 & 5.3796 & TRN & \\
\hline CHEMBL175663 & 305785 & 4.0 & 4.004 & TRN & \\
\hline CHEMBL179108 & 305785 & 6.4437 & 6.56 & TRN & \\
\hline CHEMBL415763 & 305785 & 4.0 & 3.2086 & TST & \\
\hline CHEMBL177118 & 305785 & 4.0 & 3.7206 & TST & \\
\hline CHEMBL220125 & 494689 & 7.3188 & 7.7377 & TRN & \\
\hline CHEMBL486979 & 494689 & 6.1549 & 2.7456 & TST & \\
\hline CHEMBL486981 & 494689 & 2.5229 & 2.2018 & TST & \\
\hline CHEMBL223694 & 494689 & 6.3979 & 5.91299 & 9999999999 & TRN \\
\hline CHEMBL512203 & 494689 & 3.0 & 3.0974 & TRN & \\
\hline CHEMBL182199 & 494689 & 9.28399 & 99999999 & 9.279 & TRN \\
\hline CHEMBL499014 & 494689 & 5.5229 & 5.726 & TRN & \\
\hline CHEMBL458941 & 494689 & 7.2147 & 9.3925 & TRN & \\
\hline CHEMBL456447 & 494689 & 7.5086 & 6.91700 & 0000000001 & TRN \\
\hline CHEMBL515538 & 494689 & 7.7447 & 6.5477 & TRN & \\
\hline
\end{tabular}




\begin{tabular}{|c|c|c|c|c|c|}
\hline & & \multicolumn{4}{|c|}{ Supplemental Table S2.txt } \\
\hline CHEMBL387376 & 494689 & 7.301 & 7.5565 & TRN & \\
\hline CHEMBL373961 & 494689 & 5.2218 & 5.4324 & TRN & \\
\hline CHEMBL457739 & 494689 & 3.0 & 3.3981 & TRN & \\
\hline CHEMBL226938 & 494689 & 9.0 & 8.955 & TRN & \\
\hline CHEMBL219932 & 494689 & 7.8239 & 8.1141 & TRN & \\
\hline CHEMBL506385 & 494689 & 4.8794 & 5.6973 & TRN & \\
\hline CHEMBL485926 & 494689 & 6.2147 & 7.3147 & TRN & \\
\hline CHEMBL179760 & 494689 & 9.4089 & 9.279 & TRN & \\
\hline CHEMBL222463 & 494689 & 7.301 & 7.7453 & TRN & \\
\hline CHEMBL457506 & 494689 & 7.7696 & 6.9149 & TRN & \\
\hline CHEMBL388599 & 494689 & 9.0458 & 7.9368 & TRN & \\
\hline CHEMBL347894 & 494689 & 6.0862 & 1.7457 & TST & \\
\hline CHEMBL91416 & 494689 & 7.0 & 4.2623 & TST & \\
\hline CHEMBL220005 & 494689 & 7.3979 & 7.5113 & TRN & \\
\hline CHEMBL499698 & 494689 & 5.0 & 4.7713 & TST & \\
\hline CHEMBL459161 & 494689 & 6.9586 & 5.9434 & TRN & \\
\hline CHEMBL464186 & 494689 & 9.5229 & 9.1588 & TRN & \\
\hline CHEMBL92681 & 494689 & 4.5391 & 3.8517 & TST & \\
\hline CHEMBL 385097 & 494689 & 8.0 & 7.6015 & TRN & \\
\hline CHEMBL457924 & 494689 & 8.6383 & 8.2526 & TRN & \\
\hline CHEMBL511434 & 494689 & 4.0 & 4.6702 & TRN & \\
\hline CHEMBL 227046 & 494689 & 9.1249 & 9.2697 & TRN & \\
\hline CHEMBL375573 & 494689 & 6.8861 & 6.6816 & TRN & \\
\hline CHEMBL459004 & 494689 & 7.9586 & 7.0502 & TRN & \\
\hline CHEMBL367966 & 494689 & 9.5528 & 9.279 & TRN & \\
\hline CHEMBL177577 & 494689 & 5.3279 & 7.385 & TRN & \\
\hline CHEMBL220844 & 494689 & 6.1249 & 6.2513 & TRN & \\
\hline CHEMBL229484 & 494689 & 7.6021 & 7.4559 & TRN & \\
\hline CHEMBL229592 & 494689 & 5.2218 & 6.5211 & TRN & \\
\hline CHEMBL175854 & 494689 & 9.699 & 9.279 & TRN & \\
\hline CHEMBL222614 & 494689 & 7.2076 & 6.6096 & TRN & \\
\hline CHEMBL515533 & 494689 & 7.2518 & 7.7225 & TRN & \\
\hline CHEMBL219674 & 494689 & 7.5528 & 7.48799 & 99999999995 & TRN \\
\hline CHEMBL503462 & 494689 & 3.0 & 4.2014 & TRN & \\
\hline CHEMBL219955 & 494689 & 7.0458 & 7.2241 & TRN & \\
\hline CHEMBL458812 & 494689 & 3.0 & 4.0077 & TRN & \\
\hline CHEMBL276233 & 494689 & 6.5229 & 5.9847 & TRN & \\
\hline CHEMBL457517 & 494689 & 3.0 & 4.1551 & TRN & \\
\hline CHEMBL467368 & 494689 & 8.9586 & 6.71899 & 9999999999 & TST \\
\hline CHEMBL459162 & 494689 & 6.8861 & 5.5197 & TRN & \\
\hline CHEMBL90258 & 494689 & 6.8861 & 4.1039 & TST & \\
\hline CHEMBL220518 & 494689 & 7.3979 & 7.8303 & TRN & \\
\hline CHEMBL257638 & 494689 & 8.1612 & 9.1144 & TRN & \\
\hline CHEMBL374895 & 494689 & 8.699 & 8.3677 & TRN & \\
\hline CHEMBL222613 & 494689 & 7.2218 & 6.87799 & 9999999999 & TRN \\
\hline CHEMBL457712 & 494689 & 3.0 & 5.7634 & TST & \\
\hline CHEMBL222415 & 494689 & 6.7696 & 6.6614 & TRN & \\
\hline CHEMBL90308 & 494689 & 6.8539 & 4.1039 & TST & \\
\hline
\end{tabular}




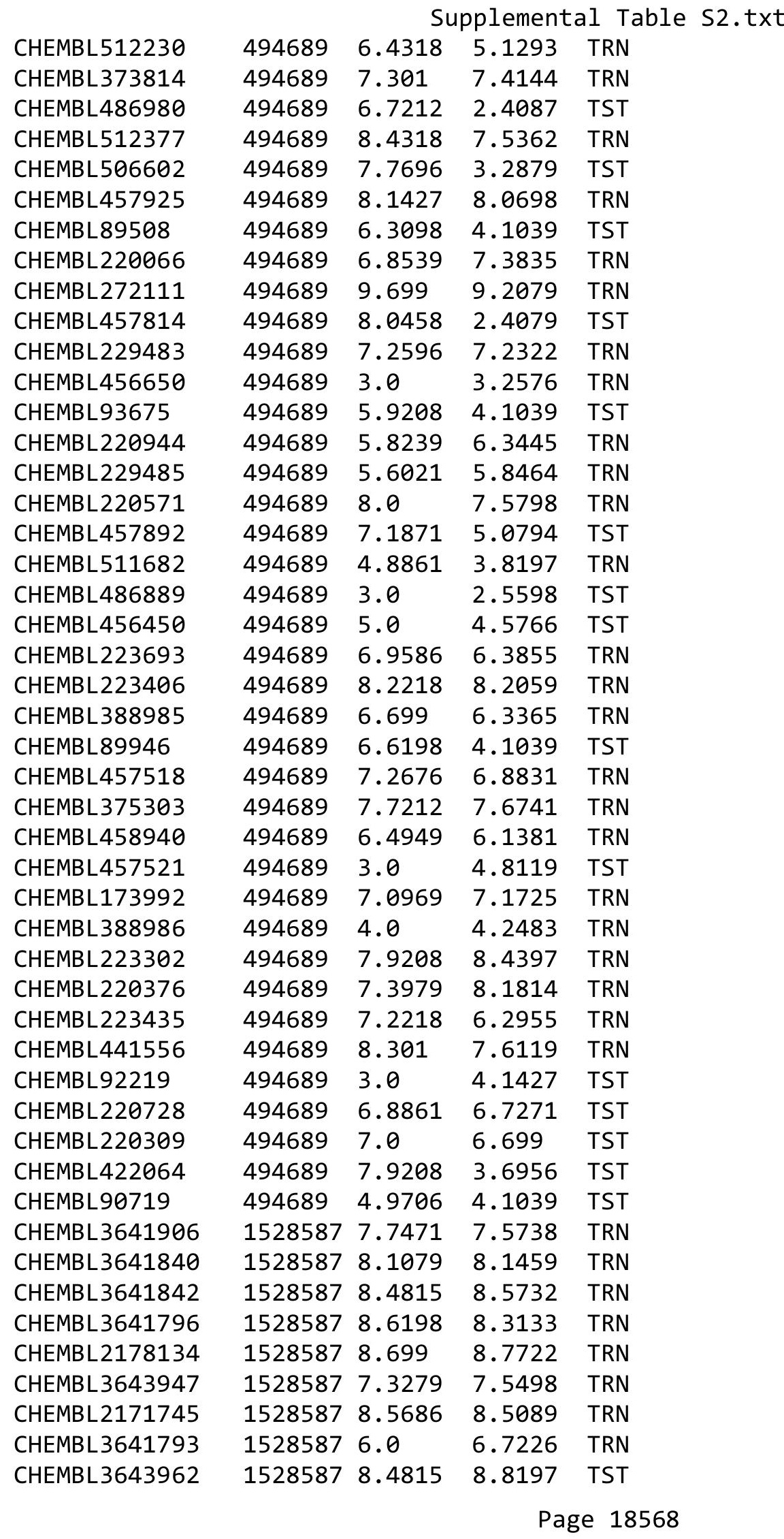


Supplemental Table S2.txt

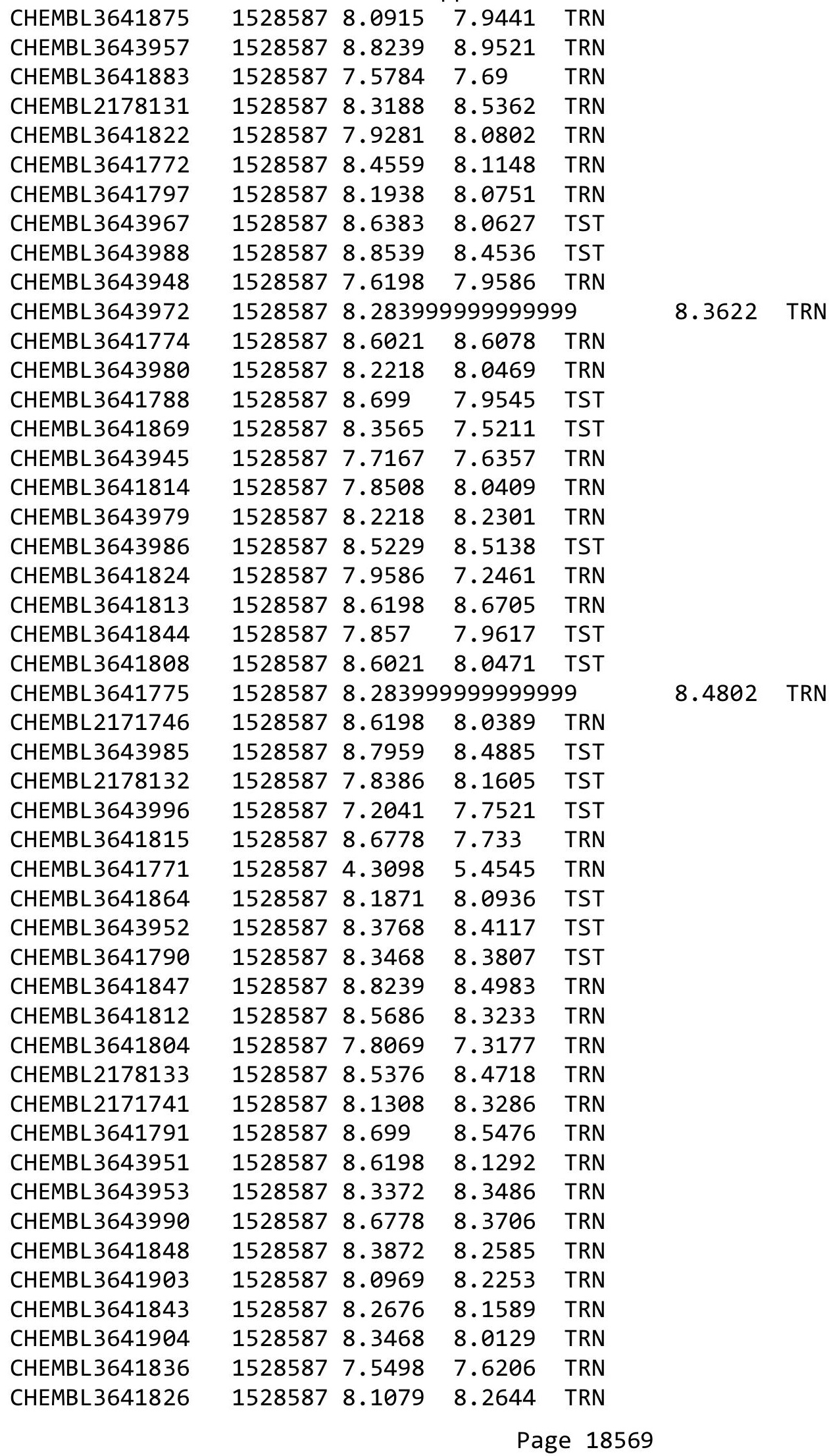


Supplemental Table S2.txt

\begin{tabular}{|c|c|c|c|c|c|}
\hline CHEMBL 3641769 & 1528587 & 8.2147 & 8.6157 & TST & \\
\hline CHEMBL3641894 & 1528587 & 6.0 & 6.6543 & TRN & \\
\hline CHEMBL 3641834 & 1528587 & 8.3468 & 8.1644 & TRN & \\
\hline CHEMBL 3641829 & 1528587 & 8.0506 & 8.0804 & TRN & \\
\hline CHEMBL 3641827 & 1528587 & 8.4559 & \multicolumn{2}{|c|}{8.347000000000001} & TRN \\
\hline CHEMBL 3641850 & 1528587 & 8.3872 & 8.4713 & TRN & \\
\hline CHEMBL 3641841 & 1528587 & 8.2441 & 8.1589 & TRN & \\
\hline CHEMBL 3643968 & 1528587 & 9.2218 & 8.5551 & TST & \\
\hline CHEMBL 3643944 & 1528587 & 8.301 & 8.5533 & TRN & \\
\hline CHEMBL 3641830 & 1528587 & 8.5528 & 8.5962 & TRN & \\
\hline CHEMBL 3639428 & 1528587 & 8.7959 & 8.8442 & TRN & \\
\hline CHEMBL3641863 & 1528587 & 7.6216 & 7.2662 & TRN & \\
\hline CHEMBL 3641802 & 1528587 & 8.2924 & 8.2984 & TRN & \\
\hline CHEMBL 3641876 & 1528587 & 7.5784 & 8.0749 & TRN & \\
\hline CHEMBL 3641789 & 1528587 & 7.8861 & 7.5394 & TRN & \\
\hline CHEMBL 3641818 & 1528587 & 8.0177 & 7.5773 & TRN & \\
\hline CHEMBL3641800 & 1528587 & 8.4202 & 8.4191 & TRN & \\
\hline CHEMBL 3641880 & 1528587 & 8.3768 & 8.40317 & TRN & \\
\hline CHEMBL3643946 & 1528587 & 7.3279 & \multicolumn{2}{|c|}{7.582999999999999} & $\mathrm{TR}$ \\
\hline CHEMBL 3641877 & 1528587 & 8.1675 & 7.8424 & TST & \\
\hline CHEMBL 3641768 & 1528587 & 7.3507 & 7.9128 & TST & \\
\hline CHEMBL3641785 & 1528587 & 8.5528 & 8.4571 & TRN & \\
\hline CHEMBL3641857 & 1528587 & 8.1612 & 7.8203 & TRN & \\
\hline CHEMBL3641896 & 1528587 & 8.0088 & 8.0982 & TST & \\
\hline CHEMBL3641856 & 1528587 & 7.1662 & 7.5997 & TRN & \\
\hline CHEMBL 3643991 & 1528587 & 6.8601 & 7.3036 & TRN & \\
\hline CHEMBL3641819 & 1528587 & 8.2218 & 7.7271 & TRN & \\
\hline CHEMBL3641870 & 1528587 & 8.0177 & 7.9317 & TST & \\
\hline CHEMBL 3641831 & 1528587 & 8.0655 & 8.0003 & TRN & \\
\hline CHEMBL3641833 & 1528587 & \multicolumn{3}{|c|}{8.283999999999999} & TRN \\
\hline CHEMBL3643950 & 1528587 & 7.4815 & 8.0509 & TRN & \\
\hline CHEMBL3641872 & 1528587 & 7.9172 & 6.791 & TST & \\
\hline CHEMBL3643977 & 1528587 & 8.5686 & 8.5203 & TRN & \\
\hline CHEMBL 2178126 & 1528587 & 8.699 & 8.5008 & TRN & \\
\hline CHEMBL 3641846 & 1528587 & 7.4776 & 7.7151 & TRN & \\
\hline CHEMBL 3641873 & 1528587 & 8.3372 & 7.8731 & TST & \\
\hline CHEMBL 3641786 & 1528587 & 8.3665 & 8.2005 & TRN & \\
\hline CHEMBL3641879 & 1528587 & 8.0269 & 7.6388 & TRN & \\
\hline CHEMBL3641839 & 1528587 & 8.1612 & 8.1273 & TRN & \\
\hline CHEMBL 3643974 & 1528587 & 7.699 & 7.2097 & TRN & \\
\hline CHEMBL 3641823 & 1528587 & 8.0315 & 7.905 & TRN & \\
\hline CHEMBL 3639407 & 1528587 & 8.2518 & 8.1809 & TST & \\
\hline CHEMBL3639406 & 1528587 & 8.6021 & 8.5081 & TST & \\
\hline CHEMBL 3641810 & 1528587 & 8.6021 & 8.5236 & TRN & \\
\hline CHEMBL 3641853 & 1528587 & 8.3279 & \multicolumn{2}{|c|}{8.527000000000001} & 1 \\
\hline CHEMBL 3641887 & 1528587 & 8.28399 & 999999999 & 8.5304 & TRN \\
\hline CHEMBL 3641828 & 1528587 & 8.0315 & 7.9217 & TRN & \\
\hline CHEMBL 3641867 & 1528587 & 8.1805 & 7.984 & TST & \\
\hline
\end{tabular}


Supplemental Table S2.txt

\begin{tabular}{|c|c|c|c|c|c|}
\hline CHEMBL 3641888 & 1528587 & 8.4318 & 8.5112 & TRN & \\
\hline CHEMBL3641837 & 1528587 & 8.1675 & 8.4706 & TRN & \\
\hline CHEMBL 3641778 & 1528587 & 8.5528 & 8.1588 & TRN & \\
\hline CHEMBL 3641886 & 1528587 & 8.0458 & 8.3914 & TRN & \\
\hline CHEMBL3643982 & 1528587 & 8.2924 & 8.4245 & TST & \\
\hline CHEMBL 3641858 & 1528587 & 7.8697 & 7.5836 & TRN & \\
\hline CHEMBL3641809 & 1528587 & 8.5528 & 8.5218 & TRN & \\
\hline CHEMBL 3641852 & 1528587 & 8.7447 & 8.5797 & TRN & \\
\hline CHEMBL 3641907 & 1528587 & 8.699 & 8.8571 & TRN & \\
\hline CHEMBL3643959 & 1528587 & 8.7696 & 8.6913 & TRN & \\
\hline CHEMBL 2178127 & 1528587 & 8.4685 & 8.7642 & TRN & \\
\hline CHEMBL 3641781 & 1528587 & 8.4437 & 8.1861 & TRN & \\
\hline CHEMBL 3643978 & 1528587 & 8.0269 & 8.40299 & 7999999999 & TRN \\
\hline CHEMBL 3643954 & 1528587 & 8.0969 & 8.4112 & TRN & \\
\hline CHEMBL3643969 & 1528587 & 8.9586 & 8.8291 & TST & \\
\hline CHEMBL 3641900 & 1528587 & 8.301 & 8.6475 & TRN & \\
\hline CHEMBL3641860 & 1528587 & 8.2007 & 8.2614 & TRN & \\
\hline CHEMBL 3641855 & 1528587 & 7.0482 & 6.2977 & TRN & \\
\hline CHEMBL 3643970 & 1528587 & 7.8928 & 7.7617 & TRN & \\
\hline CHEMBL3641859 & 1528587 & 7.8447 & 7.7415 & TRN & \\
\hline CHEMBL3641770 & 1528587 & 8.6198 & 8.2695 & TST & \\
\hline CHEMBL 3641784 & 1528587 & 8.3768 & 8.0055 & TST & \\
\hline CHEMBL 3643983 & 1528587 & 8.6383 & 8.524 & TST & \\
\hline CHEMBL 3643956 & 1528587 & 8.6021 & 8.4585 & TRN & \\
\hline CHEMBL 3641821 & 1528587 & 8.2441 & 8.2613 & TRN & \\
\hline CHEMBL3641892 & 1528587 & 8.2147 & 8.5372 & TRN & \\
\hline CHEMBL 3641868 & 1528587 & 8.1675 & 8.1874 & TST & \\
\hline CHEMBL 3643984 & 1528587 & 8.2291 & 8.3364 & TST & \\
\hline CHEMBL 3641882 & 1528587 & 8.6021 & 8.6203 & TRN & \\
\hline CHEMBL 3641787 & 1528587 & 8.2924 & 8.2225 & TST & \\
\hline CHEMBL 3643971 & 1528587 & 8.1871 & 8.2904 & TRN & \\
\hline CHEMBL 3641801 & 1528587 & 8.6198 & 8.717 & TRN & \\
\hline CHEMBL 3641779 & 1528587 & 8.4202 & 8.529 & TRN & \\
\hline CHEMBL 3641803 & 1528587 & 8.0969 & 8.1543 & TRN & \\
\hline CHEMBL 3641871 & 1528587 & 8.4815 & 8.2206 & TRN & \\
\hline CHEMBL3643975 & 1528587 & 8.1249 & 8.3732 & TRN & \\
\hline CHEMBL 3643949 & 1528587 & 7.699 & 7.6974 & TRN & \\
\hline CHEMBL 3641792 & 1528587 & 8.6383 & 8.2266 & TST & \\
\hline CHEMBL 2178124 & 1528587 & 8.699 & 8.74 & TRN & \\
\hline CHEMBL 3641898 & 1528587 & 8.5528 & 8.5188 & TST & \\
\hline CHEMBL3641799 & 1528587 & 8.6383 & 8.613 & TRN & \\
\hline CHEMBL3641806 & 1528587 & 8.8239 & 8.7597 & TRN & \\
\hline CHEMBL3641816 & 1528587 & 8.7447 & 8.5905 & TRN & \\
\hline CHEMBL 3641777 & 1528587 & 8.4685 & 8.2932 & TRN & \\
\hline CHEMBL 3641878 & 1528587 & 7.7352 & 7.8114 & TRN & \\
\hline CHEMBL3643981 & 1528587 & 8.0458 & 8.4412 & TRN & \\
\hline CHEMBL 3641884 & 1528587 & 8.4685 & 8.5897 & TRN & \\
\hline CHEMBL 3643961 & 1528587 & 8.3872 & 8.7362 & TRN & \\
\hline
\end{tabular}

Page 18571 
Supplemental Table S2.txt

\begin{tabular}{|c|c|c|}
\hline AEMBL3641835 & & \\
\hline HEMBL3641776 & 1528587 & \\
\hline IEMBL 3641845 & 28587 & \\
\hline EMBL 3641849 & 28587 & \\
\hline AEMBL3641901 & 528587 & \\
\hline HEMBL 3641874 & 1528587 & \\
\hline AEMBL3641773 & 528587 & \\
\hline EMBL 3641891 & 528587 & \\
\hline HEMBL 3641838 & 1528587 & \\
\hline HEMBL3641820 & 1528587 & \\
\hline HEMBL3643989 & 1528587 & \\
\hline AEMBL3643992 & 1528587 & \\
\hline IEMBL 3643964 & 1528587 & \\
\hline HEMBL3641811 & 1528587 & \\
\hline HEMBL3641897 & 1528587 & \\
\hline HEMBL 3641832 & 1528587 & \\
\hline HEMBL3641862 & 1528587 & \\
\hline AEMBL3641851 & 1528587 & \\
\hline HEMBL 3643966 & 1528587 & \\
\hline AEMBL3641865 & 1528587 & \\
\hline AEMBL3641881 & 587 & \\
\hline HEMBL 3641825 & 1528587 & \\
\hline HEMBL 3643994 & 587 & \\
\hline AEMBL 2178142 & 587 & \\
\hline AEMBL3641885 & 1528587 & \\
\hline AEMBL3641854 & 587 & \\
\hline HEMBL3643960 & 1528587 & \\
\hline AEMBL3641895 & 587 & \\
\hline HEMBL 3643965 & 587 & \\
\hline AEMBL3643963 & 1528587 & \\
\hline AEMBL3641899 & 587 & \\
\hline HEMBL 3641782 & 587 & \\
\hline AEMBL 3641805 & 152 & \\
\hline AEMBL 3643958 & 87 & \\
\hline HEMBL 3641817 & 1528587 & \\
\hline AEMBL3641780 & 1528587 & \\
\hline CHEMBL3643987 & 87 & \\
\hline CHEMBL3643955 & 87 & \\
\hline CHEMBL3643995 & 528587 & \\
\hline CHEMBL3641889 & 1528587 & \\
\hline CHEMBL 3641890 & 528587 & \\
\hline CHEMBL3641807 & 152 & \\
\hline CHEMBL3641905 & 1528587 & \\
\hline CHEMBL3641902 & 1528587 & \\
\hline CHEMBL3643976 & 1528587 & \\
\hline CHEMBL 3641861 & 1528587 & \\
\hline CHEMBL 3641 & & \\
\hline CHEN & & \\
\hline
\end{tabular}

$\begin{array}{ll}8.1447 & \text { TRN } \\ 8.6684 & \text { TRN } \\ 8.3008 & \text { TRN } \\ 7.609 & \text { TST } \\ 8.4222 & \text { TRN } \\ 7.9782 & \text { TST } \\ 8.1488 & \text { TRN } \\ 8.0759 & \text { TRN } \\ 8.3853 & \text { TRN } \\ 7.4364 & \text { TRN } \\ 8.5074 & \text { TST } \\ 8.4756 & \text { TRN } \\ 8.3355 & \text { TRN } \\ 7.9497 & \text { TST } \\ 8.3844 & \text { TST } \\ 7.8199 & \text { TST } \\ 7.6283 & \text { TRN } \\ 8.7164 & \text { TRN } \\ 8.5402 & \text { TRN } \\ 7.9051 & \text { TST } \\ 8.4197 & \text { TRN } \\ 7.8833 & \text { TST } \\ 7.4108 & \text { TRN } \\ 7.7935 & \text { TRN } \\ 8.4459 & \text { TRN } \\ 8.0298 & \text { TST } \\ 8.5962 & \text { TRN } \\ 8.8694 & \text { TRN } \\ 8.776 & \text { TRN } \\ 8.7573 & \text { TRN } \\ 7.7926 & \text { TRN } \\ 8.4944 & \text { TST } \\ 8.5157 & \text { TRN } \\ 8.276 & \text { TST } \\ 7.9987 & \text { TRN } \\ 8.4583 & \text { TRN } \\ 8.6249 & \text { TST } \\ 7.632000000000001 \\ 7.8108 & \text { TRN } \\ 7.727 & \text { TST } \\ 8.254 & \text { TRN } \\ 7.6096 & \text { TRN } \\ 7.7423 & \text { TRN } \\ 8.1833 & \text { TST } \\ 7.9399 & \text { TRN } \\ 8.3215 & \text { TRN } \\ 8.7271 & \text { TRN } \\ 8.6041 & \text { TRN } \\ & \end{array}$

Page 18572 
Supplemental Table S2.txt

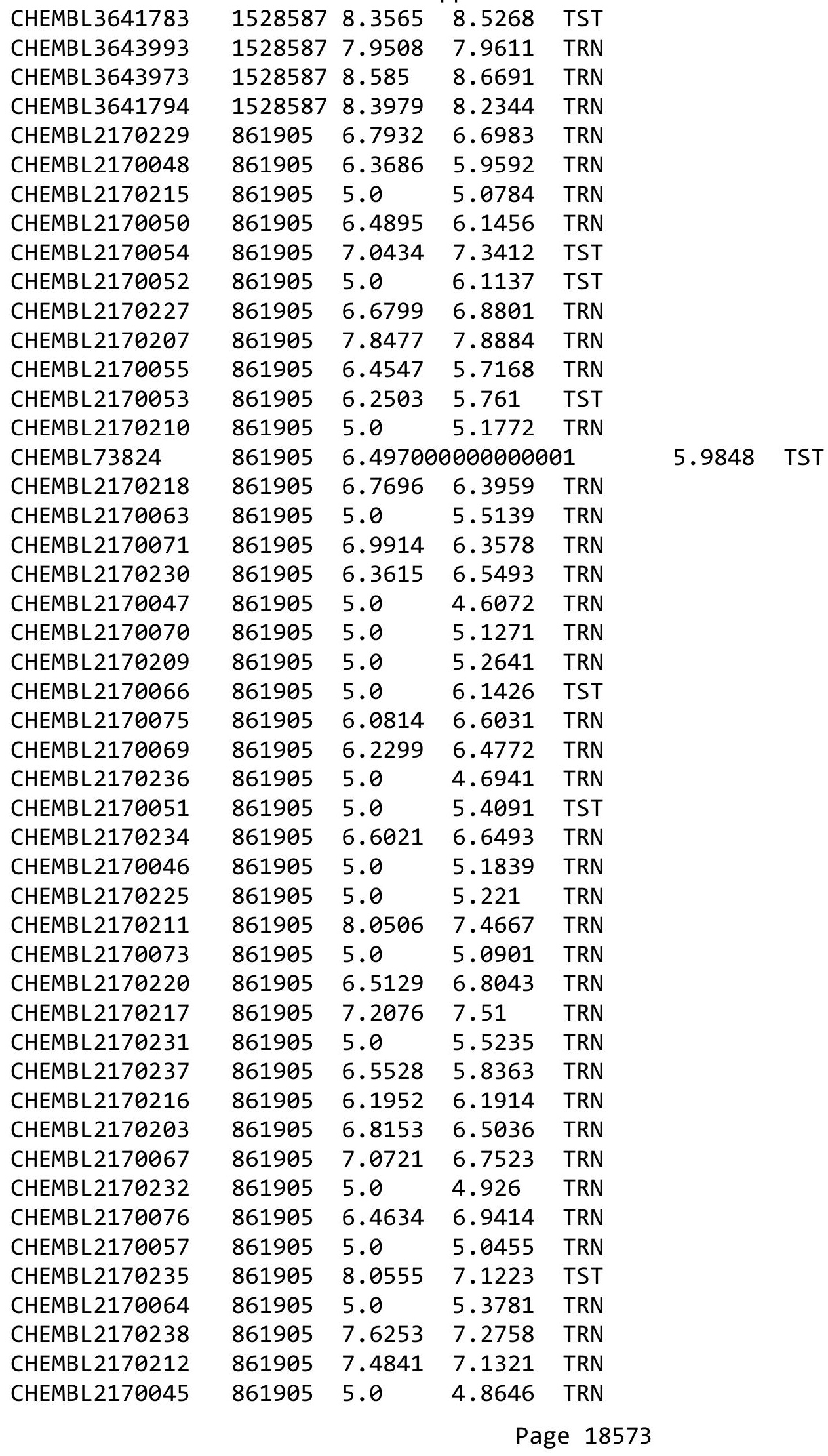




\begin{tabular}{|c|c|c|c|c|c|c|}
\hline & & \multicolumn{5}{|c|}{ Supplemental Table S2.txt } \\
\hline CHEMBL 2170222 & 861905 & 7.8996 & 7.459 & TRN & & \\
\hline CHEMBL 2170233 & 861905 & 6.2495 & 6.2094 & TRN & & \\
\hline CHEMBL 2170213 & 861905 & 5.0 & 5.6024 & TRN & & \\
\hline CHEMBL 2170061 & 861905 & 5.0 & 5.0241 & TRN & & \\
\hline CHEMBL 2170060 & 861905 & 6.4473 & 6.3561 & TRN & & \\
\hline CHEMBL 2170062 & 861905 & 5.0 & 5.0553 & TRN & & \\
\hline CHEMBL 2170226 & 861905 & 6.3161 & 6.7144 & TRN & & \\
\hline CHEMBL 2170206 & 861905 & 7.1785 & 7.3245 & TRN & & \\
\hline CHEMBL2169891 & 861905 & 6.4045 & 6.7228 & TRN & & \\
\hline CHEMBL 2170224 & 861905 & 7.5735 & 7.9527 & TRN & & \\
\hline CHEMBL2170059 & 861905 & 5.0 & 4.9651 & TRN & & \\
\hline CHEMBL2170074 & 861905 & 5.0 & 5.0072 & TRN & & \\
\hline CHEMBL 2170223 & 861905 & 7.3233 & 7.6346 & TRN & & \\
\hline CHEMBL 2170208 & 861905 & 5.0 & 4.9475 & TRN & & \\
\hline CHEMBL 2170228 & 861905 & 7.1972 & 6.8801 & TRN & & \\
\hline CHEMBL 2170214 & 861905 & 5.0 & 4.9535 & TRN & & \\
\hline CHEMBL 2170056 & 861905 & 5.0 & 4.4221 & TST & & \\
\hline CHEMBL 2170068 & 861905 & 6.4034 & 6.5734 & TST & & \\
\hline CHEMBL 2170049 & 861905 & 6.6459 & 5.9363 & TST & & \\
\hline CHEMBL 2170058 & 861905 & 5.0 & 4.6612 & TST & & \\
\hline CHEMBL 2170072 & 861905 & 7.34200 & 00000000 & 005 & 6.8728 & TST \\
\hline CHEMBL 2170239 & 861905 & 7.1891 & 7.4667 & TST & & \\
\hline CHEMBL 2170221 & 861905 & 6.6108 & 6.1158 & TST & & \\
\hline CHEMBL 2170205 & 861905 & 7.3344 & 7.21200 & 0000000001 & & TST \\
\hline CHEMBL 2170204 & 861905 & 6.983 & 7.3127 & TST & & \\
\hline CHEMBL 2170219 & 861905 & 7.4295 & 8.2574 & TST & & \\
\hline CHEMBL2170065 & 861905 & 5.0 & 4.8797 & TST & & \\
\hline CHEMBL3926717 & 1642219 & 5.49799 & 99999999 & & 5.9206 & TST \\
\hline CHEMBL3910515 & 1642219 & 6.0255 & 6.11100 & 0000000001 & & TRN \\
\hline CHEMBL3984492 & 1642219 & 6.7678 & 6.8137 & TRN & & \\
\hline CHEMBL 3927261 & 1642219 & 5.2676 & 5.3396 & TRN & & \\
\hline CHEMBL3916859 & 1642219 & 6.9292 & 6.9758 & TRN & & \\
\hline CHEMBL 3938355 & 1642219 & 7.2519 & 7.2719 & TST & & \\
\hline CHEMBL3927055 & 1642219 & 6.9508 & 6.987 & TRN & & \\
\hline CHEMBL 3964844 & 1642219 & 5.1138 & 5.1241 & TRN & & \\
\hline CHEMBL3931442 & 1642219 & 6.8088 & 6.7391 & TRN & & \\
\hline CHEMBL3904873 & 1642219 & 6.256 & 6.2726 & TRN & & \\
\hline CHEMBL 3898147 & 1642219 & 6.7956 & 7.2549 & TST & & \\
\hline CHEMBL3952233 & 1642219 & 5.9889 & 6.0276 & TRN & & \\
\hline CHEMBL 3924074 & 1642219 & 5.9048 & 5.9137 & TRN & & \\
\hline CHEMBL 3959263 & 1642219 & 6.05200 & 00000000 & 005 & 6.0818 & I R I \\
\hline CHEMBL 3912880 & 1642219 & 5.6245 & 5.5454 & TRN & & \\
\hline CHEMBL3922996 & 1642219 & 5.9176 & 5.9675 & TRN & & \\
\hline CHEMBL3932724 & 1642219 & 7.0605 & 7.1654 & TRN & & \\
\hline CHEMBL3912999 & 1642219 & 6.0543 & 5.8196 & TRN & & \\
\hline CHEMBL 3977296 & 1642219 & 6.4454 & 6.4878 & TRN & & \\
\hline CHEMBL3914207 & 1642219 & 6.5768 & 7.3149 & TST & & \\
\hline CHEMBL3911835 & 1642219 & 6.5941 & 6.5678 & TRN & & \\
\hline
\end{tabular}


Supplemental Table S2.txt

\begin{tabular}{|c|c|c|c|c|c|}
\hline CHEMBL 3949575 & 1642219 & 6.3749 & 6.3134 & TRN & \\
\hline CHEMBL 3923862 & 1642219 & 6.034 & 6.0127 & TRN & \\
\hline CHEMBL 3899232 & 1642219 & 6.6015 & 6.6744 & TRN & \\
\hline CHEMBL 3969645 & 1642219 & 5.2707 & 5.2816 & TRN & \\
\hline CHEMBL3890282 & 1642219 & 5.7022 & 6.2418 & TST & \\
\hline CHEMBL3971418 & 1642219 & 8.5528 & 8.4625 & TRN & \\
\hline CHEMBL3960329 & 1642219 & 7.287000 & 0000000 & 7.0481 & TST \\
\hline CHEMBL 3925667 & 1642219 & 6.6442 & 6.4945 & TST & \\
\hline CHEMBL 3918474 & 1642219 & 5.1222 & 5.1279 & TRN & \\
\hline CHEMBL3937213 & 1642219 & 5.9435 & 5.9779 & TRN & \\
\hline CHEMBL3971426 & 1642219 & 6.5885 & 6.5909 & TRN & \\
\hline CHEMBL3894501 & 1642219 & 5.8351 & 6.6299 & TST & \\
\hline CHEMBL 3984724 & 1642219 & 5.0058 & 4.9073 & TRN & \\
\hline CHEMBL 3942086 & 1642219 & 6.1656 & 6.1219 & TRN & \\
\hline CHEMBL3971668 & 1642219 & 6.2531 & 6.2278 & TRN & \\
\hline CHEMBL3979775 & 1642219 & 6.585 & 6.5637 & TRN & \\
\hline CHEMBL3924881 & 1642219 & 7.2297 & 7.3105 & TRN & \\
\hline CHEMBL3952594 & 1642219 & 7.4132 & 7.279 & TST & \\
\hline CHEMBL 3921171 & 1642219 & 7.3468 & 6.8273 & TST & \\
\hline CHEMBL3932113 & 1642219 & 7.0605 & 7.5838 & TST & \\
\hline CHEMBL 3907101 & 1642219 & 7.4955 & 7.542006 & 0000000001 & TRN \\
\hline CHEMBL 3947138 & 1642219 & 6.9646 & 6.693 & TRN & \\
\hline CHEMBL3932859 & 1642219 & 6.8604 & 6.862 & TRN & \\
\hline CHEMBL 3927262 & 1642219 & 5.0441 & 5.2892 & TST & \\
\hline CHEMBL3976431 & 1642219 & 6.7838 & 6.6894 & TRN & \\
\hline CHEMBL 3950717 & 1642219 & 6.3959 & 6.4658 & TRN & \\
\hline CHEMBL3967197 & 1642219 & 6.9755 & 7.0997 & TRN & \\
\hline CHEMBL3969146 & 1642219 & 5.311 & 6.1253 & TST & \\
\hline CHEMBL 3914892 & 1642219 & 5.4661 & 5.5474 & TRN & \\
\hline CHEMBL3895779 & 1642219 & 6.3279 & 6.8015 & TST & \\
\hline CHEMBL3931932 & 1642219 & 5.9531 & 6.1721 & TST & \\
\hline CHEMBL3929422 & 1642219 & 5.0656 & 5.0167 & TRN & \\
\hline CHEMBL3965266 & 1642219 & 6.3908 & 6.3579 & TRN & \\
\hline CHEMBL 3947380 & 1642219 & 5.9805 & 5.9824 & TRN & \\
\hline CHEMBL3954987 & 1642219 & 6.3558 & 6.3421 & TRN & \\
\hline CHEMBL 3894334 & 1642219 & 5.0034 & 4.9635 & TRN & \\
\hline CHEMBL3951262 & 1642219 & 8.6778 & 8.6342 & TRN & \\
\hline CHEMBL3936219 & 1642219 & 6.1791 & 6.1445 & TRN & \\
\hline CHEMBL3931049 & 1642219 & 6.8072 & 6.814 & TRN & \\
\hline CHEMBL3890281 & 1642219 & 6.2507 & 6.3162 & TRN & \\
\hline CHEMBL 3982750 & 1642219 & 6.1089 & 6.2022 & TRN & \\
\hline CHEMBL3953881 & 1642219 & 5.8167 & 5.8157 & TRN & \\
\hline CHEMBL3918096 & 1642219 & 5.8742 & 6.1097 & TRN & \\
\hline CHEMBL 3893604 & 1642219 & 6.0849 & 6.1115 & TRN & \\
\hline CHEMBL3902064 & 1642219 & 7.0747 & 6.9798 & TST & \\
\hline CHEMBL 3956094 & 1642219 & 7.4612 & 6.7923 & TST & \\
\hline CHEMBL 3961621 & 1642219 & 6.6885 & 6.733 & TST & \\
\hline CHEMBL3915082 & 1642219 & 5.9314 & 5.8853 & TRN & \\
\hline
\end{tabular}


Supplemental Table S2.txt

\begin{tabular}{|c|c|c|c|c|}
\hline CHEMBL3921501 & 1642219 & 5.3977 & 5.3861 & TRN \\
\hline CHEMBL3915893 & 1642219 & 7.5403 & 7.5752 & TRN \\
\hline CHEMBL3921866 & 1642219 & 6.0638 & 6.0392 & TRN \\
\hline CHEMBL3978016 & 1642219 & 6.7459 & 6.789 & TRN \\
\hline CHEMBL 3899548 & 1642219 & 5.5864 & 5.5934 & TRN \\
\hline CHEMBL3918315 & 1642219 & 6.5686 & 7.2453 & TST \\
\hline CHEMBL3929364 & 1642219 & 6.0158 & 5.9689 & TRN \\
\hline CHEMBL3907865 & 1642219 & 7.2949 & 7.1967 & TRN \\
\hline CHEMBL3930021 & 1642219 & 6.9991 & 7.1358 & TST \\
\hline CHEMBL3903123 & 1642219 & 5.3063 & 5.3331 & TRN \\
\hline CHEMBL3904722 & 1642219 & 8.0915 & 8.0119 & TRN \\
\hline CHEMBL3962047 & 1642219 & 5.8661 & 6.6033 & TST \\
\hline CHEMBL 2158964 & 856700 & 6.6021 & 6.6309 & TRN \\
\hline CHEMBL 2159038 & 856700 & 6.6198 & 6.3824 & TRN \\
\hline CHEMBL 2158967 & 856700 & 6.585 & 6.572 & TRN \\
\hline CHEMBL 2158962 & 856700 & 6.6198 & 6.4625 & TST \\
\hline CHEMBL 2159044 & 856700 & 6.6198 & 6.8283 & TRN \\
\hline CHEMBL 2158980 & 856700 & 6.4089 & 6.4777 & TRN \\
\hline CHEMBL 2159029 & 856700 & 4.0 & 3.9307 & TRN \\
\hline CHEMBL 2159043 & 856700 & 5.06 & 4.9677 & TRN \\
\hline CHEMBL 2158981 & 856700 & 6.8239 & 6.7224 & TRN \\
\hline CHEMBL 2159018 & 856700 & 5.0 & 5.7727 & TST \\
\hline CHEMBL 2158975 & 856700 & 5.7423 & 5.3187 & TST \\
\hline CHEMBL595227 & 856700 & 6.3565 & 6.4453 & TRN \\
\hline CHEMBL 2159031 & 856700 & 5.5817 & 5.6259 & TRN \\
\hline CHEMBL 2158977 & 856700 & 6.4949 & 6.4816 & TRN \\
\hline CHEMBL 2159020 & 856700 & 6.3468 & 6.3958 & TRN \\
\hline CHEMBL 2159037 & 856700 & 6.5686 & 6.4579 & TRN \\
\hline CHEMBL 2159039 & 856700 & 6.0915 & 6.2042 & TRN \\
\hline CHEMBL 2159027 & 856700 & 5.8996 & 6.0482 & TRN \\
\hline CHEMBL 2158974 & 856700 & 5.5622 & 5.4679 & TST \\
\hline CHEMBL 2159021 & 856700 & 6.2676 & 6.2797 & TRN \\
\hline CHEMBL 2159019 & 856700 & 5.0 & 5.8 & TST \\
\hline CHEMBL 2159017 & 856700 & 6.6021 & 6.7095 & TRN \\
\hline CHEMBL 2159024 & 856700 & 6.4202 & 6.4733 & TRN \\
\hline CHEMBL 2159030 & 856700 & 4.0 & 4.0685 & TRN \\
\hline CHEMBL 2158972 & 856700 & 5.8386 & 6.4073 & TST \\
\hline CHEMBL 2159025 & 856700 & 6.4089 & 6.2486 & TRN \\
\hline CHEMBL 2159028 & 856700 & 5.9245 & 6.0543 & TRN \\
\hline CHEMBL 2158973 & 856700 & 6.3565 & 5.75299 & 9999999999 \\
\hline CHEMBL 2159022 & 856700 & 6.585 & 6.6878 & TRN \\
\hline CHEMBL 2159026 & 856700 & 5.9318 & 6.0908 & TRN \\
\hline CHEMBL 2159036 & 856700 & 6.4949 & 6.4046 & TRN \\
\hline CHEMBL 2159035 & 856700 & 6.3872 & 6.3621 & TRN \\
\hline CHEMBL 2159033 & 856700 & 6.4949 & 6.3926 & TRN \\
\hline CHEMBL 2158966 & 856700 & 6.6576 & 6.5585 & TRN \\
\hline CHEMBL 2158963 & 856700 & 4.0 & 5.5397 & TST \\
\hline CHEMBL 2159016 & 856700 & 6.585 & 6.6238 & TRN \\
\hline
\end{tabular}




\begin{tabular}{|c|c|c|c|c|c|c|}
\hline & & \multicolumn{5}{|c|}{ Supplemental Table S2.txt } \\
\hline CHEMBL2158976 & 856700 & 6.6021 & 6.5686 & TRN & & \\
\hline CHEMBL2159032 & 856700 & 6.8239 & 6.6668 & TRN & & \\
\hline CHEMBL2158979 & 856700 & 6.699 & 6.6633 & TRN & & \\
\hline CHEMBL2158968 & 856700 & 6.3768 & 6.402 & TST & & \\
\hline CHEMBL2159041 & 856700 & 6.3372 & 6.3019 & TRN & & \\
\hline CHEMBL 2159040 & 856700 & 6.3565 & 6.2959 & TRN & & \\
\hline CHEMBL2158978 & 856700 & 6.3188 & 6.1461 & TRN & & \\
\hline CHEMBL2159034 & 856700 & 5.8697 & 6.2313 & TRN & & \\
\hline CHEMBL 2158965 & 856700 & 6.699 & 6.682 & TRN & & \\
\hline CHEMBL2158969 & 856700 & 5.2907 & 6.2971 & TST & & \\
\hline CHEMBL 2159023 & 856700 & 6.699 & 6.5428 & TRN & & \\
\hline CHEMBL 2158970 & 856700 & 6.6021 & 6.3214 & TST & & \\
\hline CHEMBL2158971 & 856700 & \multicolumn{3}{|c|}{5.7620000000000005} & .1327 & TST \\
\hline CHEMBL 2159042 & 856700 & 6.2596 & 6.2616 & TST & & \\
\hline CHEMBL3670602 & 1527648 & 7.8539 & 6.8483 & TST & & \\
\hline CHEMBL 3670529 & 1527648 & 7.3665 & 6.7173 & TST & & \\
\hline CHEMBL3670559 & 1527648 & 6.4672 & 6.1411 & TRN & & \\
\hline CHEMBL 3670543 & 1527648 & 6.5575 & 6.1062 & TRN & & \\
\hline CHEMBL3670556 & 1527648 & 6.0731 & 5.9957 & TRN & & \\
\hline CHEMBL3670609 & 1527648 & 6.4306 & 6.2067 & TRN & & \\
\hline CHEMBL 3670512 & 1527648 & 5.0 & 4.8951 & TRN & & \\
\hline CHEMBL3665639 & 1527648 & 6.0926 & 5.772 & TST & & \\
\hline CHEMBL 3670527 & 1527648 & 7.6383 & 7.6439 & TRN & & \\
\hline CHEMBL3670596 & 1527648 & 5.3872 & 5.5758 & TRN & & \\
\hline CHEMBL 3665650 & 1527648 & 5.0 & 5.9391 & TRN & & \\
\hline CHEMBL 3665622 & 1527648 & 6.6861 & 6.4465 & TRN & & \\
\hline CHEMBL3665651 & 1527648 & 6.2041 & 6.591 & TRN & & \\
\hline CHEMBL3670629 & 1527648 & 5.9172 & 6.15799 & 99999999995 & & TRN \\
\hline CHEMBL3670625 & 1527648 & 5.9817 & 6.0517 & TRN & & \\
\hline CHEMBL3670515 & 1527648 & 5.0 & 4.9219 & TRN & & \\
\hline CHEMBL 3665620 & 1527648 & 6.5952 & 6.5464 & TST & & \\
\hline CHEMBL3670531 & 1527648 & 6.8928 & 6.2502 & TST & & \\
\hline CHEMBL3670557 & 1527648 & 5.0 & 5.4654 & TRN & & \\
\hline CHEMBL3670570 & 1527648 & 5.0 & 4.8659 & TRN & & \\
\hline CHEMBL 3665617 & 1527648 & 6.1811 & 6.6405 & TST & & \\
\hline CHEMBL3670611 & 1527648 & 7.1079 & 7.2037 & TRN & & \\
\hline CHEMBL3670626 & 1527648 & 6.9318 & 6.5851 & TRN & & \\
\hline CHEMBL3665632 & 1527648 & 5.4478 & 5.5634 & TRN & & \\
\hline CHEMBL3670587 & 1527648 & 5.0 & 4.9342 & TST & & \\
\hline CHEMBL3670594 & 1527648 & 5.0 & 5.2394 & TRN & & \\
\hline CHEMBL 3670520 & 1527648 & 5.0 & 5.0305 & TRN & & \\
\hline CHEMBL3670616 & 1527648 & 7.3565 & 6.8473 & TST & & \\
\hline CHEMBL3670614 & 1527648 & 6.3251 & 6.4686 & TRN & & \\
\hline CHEMBL3670509 & 1527648 & 5.3835 & 5.5312 & TRN & & \\
\hline CHEMBL3670581 & 1527648 & 5.0 & 4.99 & TRN & & \\
\hline CHEMBL3670585 & 1527648 & 5.1549 & 5.6302 & TST & & \\
\hline CHEMBL 3670553 & 1527648 & 5.4816 & 5.8302 & TRN & & \\
\hline CHEMBL3670525 & 1527648 & 6.75200 & t00000006 & & .1704 & TRN \\
\hline
\end{tabular}


Supplemental Table S2.txt

\begin{tabular}{|c|c|c|c|c|c|}
\hline CHEMBL 3670579 & 1527648 & 5.9034 & 6.0549 & TRN & \\
\hline CHEMBL 3670548 & 1527648 & 5.1871 & 5.729 & TRN & \\
\hline CHEMBL 3665643 & 1527648 & 5.301 & 5.6922 & TRN & \\
\hline CHEMBL 3670567 & 1527648 & 5.0 & 5.1235 & TRN & \\
\hline CHEMBL3670633 & 1527648 & 6.3188 & 6.5023 & TRN & \\
\hline CHEMBL3670566 & 1527648 & 5.4949 & 5.4295 & TRN & \\
\hline CHEMBL 3670588 & 1527648 & 5.0 & 5.102 & TRN & \\
\hline CHEMBL 3665626 & 1527648 & 6.3645 & 6.0141 & TST & \\
\hline CHEMBL 3670521 & 1527648 & 5.301 & 4.9518 & TRN & \\
\hline CHEMBL3670541 & 1527648 & 5.0 & 4.7396 & TRN & \\
\hline CHEMBL3665615 & 1527648 & 7.6576 & 7.2212 & TRN & \\
\hline CHEMBL3665641 & 1527648 & 5.0153 & 5.4547 & TRN & \\
\hline CHEMBL3670536 & 1527648 & 5.0 & 5.5362 & TRN & \\
\hline CHEMBL 3670523 & 1527648 & 5.0458 & 5.2755 & TRN & \\
\hline CHEMBL 3670624 & 1527648 & 7.3279 & 7.4592 & TRN & \\
\hline CHEMBL3670613 & 1527648 & 6.4214 & 6.6743 & TRN & \\
\hline CHEMBL3670601 & 1527648 & 7.7959 & 7.1193 & TST & \\
\hline CHEMBL3670597 & 1527648 & 5.0 & 4.9662 & TRN & \\
\hline CHEMBL 3670518 & 1527648 & 5.0 & 4.5161 & TRN & \\
\hline CHEMBL3670612 & 1527648 & 7.0177 & 6.7559 & TRN & \\
\hline CHEMBL 3670565 & 1527648 & 5.4089 & 5.70799 & 9999999999 & TRN \\
\hline CHEMBL 3670568 & 1527648 & 5.2219 & 5.5938 & TRN & \\
\hline CHEMBL3670507 & 1527648 & 5.2994 & 5.0007 & TRN & \\
\hline CHEMBL 3670605 & 1527648 & 7.2147 & 7.0246 & TRN & \\
\hline CHEMBL3670546 & 1527648 & 5.0 & 5.3484 & TST & \\
\hline CHEMBL 3665627 & 1527648 & 6.983 & 6.1579 & TST & \\
\hline CHEMBL 3670592 & 1527648 & 6.2218 & 6.0713 & TRN & \\
\hline CHEMBL3665636 & 1527648 & 5.0 & 5.1595 & TRN & \\
\hline CHEMBL 3670620 & 1527648 & 6.4815 & 6.545 & TRN & \\
\hline CHEMBL3665624 & 1527648 & 6.9431 & 6.7491 & TRN & \\
\hline CHEMBL 3670532 & 1527648 & 7.0223 & 6.511 & TST & \\
\hline CHEMBL 3670634 & 1527648 & 6.1568 & 6.0761 & TRN & \\
\hline CHEMBL3670530 & 1527648 & 7.041 & 6.3065 & TST & \\
\hline CHEMBL 3665647 & 1527648 & 5.0 & 5.3437 & TRN & \\
\hline CHEMBL3670576 & 1527648 & 5.1367 & 5.3322 & TRN & \\
\hline CHEMBL 3670550 & 1527648 & 5.0458 & 5.4041 & TRN & \\
\hline CHEMBL3670547 & 1527648 & 5.7828 & 5.7512 & TRN & \\
\hline CHEMBL 3670582 & 1527648 & 5.0 & 5.5276 & TST & \\
\hline CHEMBL 3670534 & 1527648 & 5.4817 & 5.8176 & TRN & \\
\hline CHEMBL3665640 & 1527648 & 5.9722 & 6.1428 & TST & \\
\hline CHEMBL 3670584 & 1527648 & 5.6198 & 5.604 & TST & \\
\hline CHEMBL3670562 & 1527648 & 5.9208 & 5.7055 & TRN & \\
\hline CHEMBL3670608 & 1527648 & 8.0969 & 8.1386 & TRN & \\
\hline CHEMBL 3670578 & 1527648 & 6.4067 & 6.1485 & TRN & \\
\hline CHEMBL3670583 & 1527648 & 5.0 & 5.0658 & TRN & \\
\hline CHEMBL 3670586 & 1527648 & 5.0 & 5.4651 & TST & \\
\hline CHEMBL 3670552 & 1527648 & 5.0 & 5.0177 & TRN & \\
\hline CHEMBL 3670560 & 1527648 & 5.7324 & 5.6868 & TRN & \\
\hline
\end{tabular}


Supplemental Table S2.txt

\begin{tabular}{|c|c|c|c|c|c|}
\hline CHEMBL 3670575 & 1527648 & 6.6596 & 6.2852 & TRN & \\
\hline CHEMBL 3670540 & 1527648 & 5.7959 & 5.5546 & TRN & \\
\hline CHEMBL3670630 & 1527648 & 6.3556 & 6.0703 & TRN & \\
\hline CHEMBL3670607 & 1527648 & 8.0969 & 7.7314 & TRN & \\
\hline CHEMBL3670538 & 1527648 & 6.5768 & 6.2969 & TRN & \\
\hline CHEMBL3931064 & 1527648 & 5.0 & 4.5404 & TRN & \\
\hline CHEMBL3665635 & 1527648 & 5.0 & 4.9592 & TRN & \\
\hline CHEMBL3670516 & 1527648 & 5.0 & 4.8733 & TRN & \\
\hline CHEMBL3670537 & 1527648 & 5.9944 & 5.9366 & TRN & \\
\hline CHEMBL3670514 & 1527648 & 5.4515 & 5.0204 & TRN & \\
\hline CHEMBL3665616 & 1527648 & 6.8447 & 7.2178 & TST & \\
\hline CHEMBL3670544 & 1527648 & 6.8697 & 6.3359 & TRN & \\
\hline CHEMBL3665633 & 1527648 & 5.0153 & 4.9975 & TRN & \\
\hline CHEMBL3670589 & 1527648 & 5.0 & 4.7425 & TRN & \\
\hline CHEMBL3665625 & 1527648 & 6.0 & 6.3163 & TRN & \\
\hline CHEMBL3670563 & 1527648 & 5.8153 & 5.8746 & TRN & \\
\hline CHEMBL3670535 & 1527648 & 5.2622 & 5.4355 & TRN & \\
\hline CHEMBL 3665649 & 1527648 & 5.4318 & 5.1745 & TRN & \\
\hline CHEMBL3670623 & 1527648 & 6.8729 & 6.2566 & TRN & \\
\hline CHEMBL3670551 & 1527648 & 5.0 & 4.8347 & TRN & \\
\hline CHEMBL3670561 & 1527648 & 6.16299 & 999999999 & 99 & 6.082000000000001 \\
\hline CHEMBL3670619 & 1527648 & 6.3809 & 6.4555 & TRN & \\
\hline CHEMBL 3665637 & 1527648 & 5.301 & 5.0782 & TRN & \\
\hline CHEMBL3670610 & 1527648 & 7.7447 & 7.5737 & TRN & \\
\hline CHEMBL3665623 & 1527648 & 6.5884 & 6.7749 & TRN & \\
\hline CHEMBL3670564 & 1527648 & 6.0655 & 6.0084 & TRN & \\
\hline CHEMBL 3670555 & 1527648 & 6.1007 & 6.0768 & TRN & \\
\hline CHEMBL 3670595 & 1527648 & 5.8861 & 5.8279 & TRN & \\
\hline CHEMBL 3665618 & 1527648 & 6.6253 & 6.5055 & TST & \\
\hline CHEMBL3670593 & 1527648 & 5.0 & 4.7982 & TRN & \\
\hline CHEMBL3665646 & 1527648 & 5.0862 & 4.8982 & TRN & \\
\hline CHEMBL 3670591 & 1527648 & 6.8069 & 6.8407 & TRN & \\
\hline CHEMBL 3670590 & 1527648 & 5.0 & 5.3155 & TRN & \\
\hline CHEMBL3670627 & 1527648 & 7.1135 & 7.0271 & TRN & \\
\hline CHEMBL3670508 & 1527648 & 5.3084 & 5.5347 & TRN & \\
\hline CHEMBL3665629 & 1527648 & 5.4626 & 5.6822 & TST & \\
\hline CHEMBL 2413511 & 1527648 & 7.4815 & 7.3248 & TRN & \\
\hline CHEMBL3670615 & 1527648 & 6.2083 & 6.1606 & TRN & \\
\hline CHEMBL3670603 & 1527648 & 5.585 & 5.7774 & TST & \\
\hline CHEMBL 3670510 & 1527648 & 5.0605 & 5.4181 & TRN & \\
\hline CHEMBL3665644 & 1527648 & 6.8928 & 7.1239 & TRN & \\
\hline CHEMBL3639694 & 1527648 & 5.0 & 5.2619 & TRN & \\
\hline CHEMBL 3670528 & 1527648 & 7.4949 & 6.8713 & TST & \\
\hline CHEMBL3670522 & 1527648 & 5.7077 & 5.3413 & TRN & \\
\hline CHEMBL 3670542 & 1527648 & 6.2596 & 6.1897 & TRN & \\
\hline CHEMBL3665634 & 1527648 & 5.0 & 4.5867 & TRN & \\
\hline CHEMBL 3665628 & 1527648 & 5.4314 & 5.6527 & TRN & \\
\hline CHEMBL3670600 & 1527648 & 5.0 & 4.9607 & TRN & \\
\hline
\end{tabular}




\begin{tabular}{|c|c|c|c|c|c|}
\hline \multicolumn{6}{|c|}{ Supplemental Table S2.txt } \\
\hline CHEMBL3670598 & 1527648 & 5.0 & 5.093 & TRN & \\
\hline CHEMBL3670545 & 1527648 & 5.0 & 4.816 & TST & \\
\hline CHEMBL3670635 & 1527648 & 7.3279 & 7.0544 & TRN & \\
\hline CHEMBL3670618 & 1527648 & 6.8447 & 6.7218 & TRN & \\
\hline CHEMBL 3670524 & 1527648 & 5.0 & 4.7305 & TRN & \\
\hline CHEMBL3670511 & 1527648 & 5.1805 & 5.4039 & TRN & \\
\hline CHEMBL3670573 & 1527648 & 5.0 & 5.0908 & TRN & \\
\hline CHEMBL3665638 & 1527648 & 5.0 & 5.2151 & TRN & \\
\hline CHEMBL 3670617 & 1527648 & 7.284 & 6.7403 & TRN & \\
\hline CHEMBL3670622 & 1527648 & 6.0097 & 6.0282 & TRN & \\
\hline CHEMBL3670632 & 1527648 & 6.3233 & 6.4902 & TRN & \\
\hline CHEMBL 3670517 & 1527648 & 5.0 & 4.6134 & TRN & \\
\hline CHEMBL3670628 & 1527648 & 7.4949 & 7.6975 & TRN & \\
\hline CHEMBL 3670533 & 1527648 & 5.3822 & 5.7422 & TRN & \\
\hline CHEMBL 3670621 & 1527648 & 6.4881 & 6.3828 & TRN & \\
\hline CHEMBL3670526 & 1527648 & 7.6383 & 7.4039 & TRN & \\
\hline CHEMBL3670558 & 1527648 & 5.0 & 5.233 & TRN & \\
\hline CHEMBL3665652 & 1527648 & 5.2334 & 5.5972 & TRN & \\
\hline CHEMBL3670577 & 1527648 & 5.7989 & 6.0311 & TRN & \\
\hline CHEMBL 3670574 & 1527648 & 5.4156 & 5.7638 & TRN & \\
\hline CHEMBL 3670580 & 1527648 & 5.6678 & 6.0392 & TST & \\
\hline CHEMBL3670606 & 1527648 & 6.0 & 5.8011 & TRN & \\
\hline CHEMBL3670554 & 1527648 & 5.0458 & 5.3351 & TST & \\
\hline CHEMBL3670539 & 1527648 & 5.7657 & 5.8618 & TST & \\
\hline CHEMBL3670569 & 1527648 & 5.3468 & 5.1886 & TST & \\
\hline CHEMBL 3670572 & 1527648 & 5.4089 & 5.6564 & TST & \\
\hline CHEMBL3670604 & 1527648 & 7.1938 & 6.5311 & TST & \\
\hline CHEMBL3670631 & 1527648 & 6.3979 & 6.0576 & TST & \\
\hline CHEMBL3665619 & 1527648 & 6.3372 & 6.4963 & TST & \\
\hline CHEMBL3665645 & 1527648 & 5.0 & 4.9676 & TST & \\
\hline CHEMBL3665642 & 1527648 & 6.6478 & 6.6307 & TST & \\
\hline CHEMBL3670599 & 1527648 & 5.0 & 4.871 & TST & \\
\hline CHEMBL3665648 & 1527648 & 6.6576 & 6.4423 & TST & \\
\hline CHEMBL3670519 & 1527648 & 5.0 & 4.7314 & TST & \\
\hline CHEMBL3670549 & 1527648 & 5.9698 & 5.7918 & TST & \\
\hline CHEMBL3670571 & 1527648 & 5.0 & 4.5144 & TST & \\
\hline CHEMBL3665621 & 1527648 & 5.9179 & 6.3426 & TST & \\
\hline CHEMBL3670513 & 1527648 & 5.0 & 5.1255 & TST & \\
\hline CHEMBL131145 & 489239 & 5.2233 & 4.97199 & 99999999995 & TRN \\
\hline CHEMBL448576 & 489239 & 6.1952 & 6.1256 & TRN & \\
\hline CHEMBL477764 & 489239 & 5.5436 & 5.3954 & TRN & \\
\hline CHEMBL453206 & 489239 & 5.041 & 5.0278 & TRN & \\
\hline CHEMBL287047 & 489239 & 5.6968 & 5.7346 & TRN & \\
\hline CHEMBL509223 & 489239 & 5.8539 & 5.5619 & TST & \\
\hline CHEMBL508125 & 489239 & 5.1844 & 5.5222 & TRN & \\
\hline CHEMBL367501 & 489239 & 6.2118 & 6.2533 & TRN & \\
\hline CHEMBL449727 & 489239 & 5.8894 & 5.7615 & TRN & \\
\hline CHEMBL292821 & 489239 & 5.1433 & 5.35 & TRN & \\
\hline
\end{tabular}




\begin{tabular}{|c|c|c|c|c|c|c|}
\hline & & \multicolumn{5}{|c|}{ Supplemental Table S2.txt } \\
\hline CHEMBL451372 & 489239 & 6.4498 & 6.4451 & TRN & & \\
\hline CHEMBL147230 & 489239 & 5.4647 & 5.5869 & TRN & & \\
\hline CHEMBL476750 & 489239 & 5.9706 & 6.0426 & TRN & & \\
\hline CHEMBL124049 & 489239 & 5.1886 & 5.1655 & TRN & & \\
\hline CHEMBL274497 & 489239 & 6.7235 & 6.6102 & TRN & & \\
\hline CHEMBL124063 & 489239 & 5.1931 & 5.1132 & TRN & & \\
\hline CHEMBL474882 & 489239 & 2.2914 & 2.176 & TRN & & \\
\hline CHEMBL476107 & 489239 & 5.0022 & 5.8325 & TST & & \\
\hline CHEMBL505644 & 489239 & 6.4001 & 6.5107 & TRN & & \\
\hline CHEMBL45763 & 489239 & 6.4123 & 6.0702 & TRN & & \\
\hline CHEMBL476517 & 489239 & 6.9872 & 7.0511 & TRN & & \\
\hline CHEMBL453667 & 489239 & 6.7959 & 6.9118 & TRN & & \\
\hline CHEMBL313833 & 489239 & \multicolumn{3}{|c|}{5.821000000000001} & 6.5788 & TST \\
\hline CHEMBL450477 & 489239 & 6.1152 & 5.9288 & TST & & \\
\hline CHEMBL446131 & 489239 & 6.2757 & 6.3982 & TRN & & \\
\hline CHEMBL448523 & 489239 & 5.4034 & 5.7498 & TRN & & \\
\hline CHEMBL478845 & 489239 & \multicolumn{3}{|c|}{6.162999999999999} & 5.7468 & TRN \\
\hline CHEMBL10780 & 489239 & 5.4685 & 6.3857 & TST & & \\
\hline CHEMBL379916 & 489239 & 7.1871 & 7.3401 & TRN & & \\
\hline CHEMBL61251 & 489239 & 5.2967 & 6.6562 & TST & & \\
\hline CHEMBL478405 & 489239 & 4.9355 & 4.838 & TRN & & \\
\hline CHEMBL509695 & 489239 & 6.4237 & 6.3019 & TRN & & \\
\hline CHEMBL124733 & 489239 & 5.426 & 5.2412 & TRN & & \\
\hline CHEMBL442603 & 489239 & 5.9355 & 6.0989 & TRN & & \\
\hline CHEMBL420095 & 489239 & 5.2984 & 5.7765 & TST & & \\
\hline CHEMBL506244 & 489239 & 5.4609 & 5.6407 & TRN & & \\
\hline CHEMBL446560 & 489239 & 5.0809 & 4.8603 & TRN & & \\
\hline CHEMBL447753 & 489239 & 7.2441 & 7.184 & TRN & & \\
\hline CHEMBL46278 & 489239 & 4.0 & 4.725 & TRN & & \\
\hline CHEMBL476748 & 489239 & 4.6126 & 4.2585 & TRN & & \\
\hline CHEMBL11608 & 489239 & 6.1361 & 5.8546 & TRN & & \\
\hline CHEMBL407939 & 489239 & 7.1135 & 7.1804 & TRN & & \\
\hline CHEMBL450561 & 489239 & 5.3645 & 5.2141 & TRN & & \\
\hline CHEMBL443141 & 489239 & 6.9318 & 6.8649 & TRN & & \\
\hline CHEMBL445701 & 489239 & \multicolumn{3}{|c|}{ 4.718999999999999 } & 4.7916 & TRN \\
\hline CHEMBL452901 & 489239 & 6.5058 & 6.4548 & TRN & & \\
\hline CHEMBL103299 & 489239 & 5.3585 & 5.5277 & TRN & & \\
\hline CHEMBL101036 & 489239 & 5.2233 & 5.4284 & TRN & & \\
\hline CHEMBL476324 & 489239 & 5.983 & 6.0255 & TRN & & \\
\hline CHEMBL478847 & 489239 & 6.6882 & 6.7771 & TRN & & \\
\hline CHEMBL478846 & 489239 & 3.2007 & 3.6261 & TRN & & \\
\hline CHEMBL505110 & 489239 & 5.1035 & 4.6607 & TST & & \\
\hline CHEMBL145584 & 489239 & 5.7595 & 5.7528 & TRN & & \\
\hline CHEMBL452929 & 489239 & 5.129 & 4.9119 & TRN & & \\
\hline CHEMBL 610 & 489239 & 6.8894 & 6.5377 & TRN & & \\
\hline CHEMBL476516 & 489239 & 5.8125 & 5.9534 & TST & & \\
\hline CHEMBL217315 & 489239 & 6.1308 & 6.5047 & TST & & \\
\hline CHEMBL100635 & 489239 & 6.8416 & 6.4726 & TST & & \\
\hline
\end{tabular}


Supplemental Table S2.txt

\begin{tabular}{|c|c|c|c|c|}
\hline CHEMBL502343 & 489239 & 3.7763 & 5.3208 & TST \\
\hline CHEMBL130703 & 489239 & 6.3002 & 6.2089 & TST \\
\hline CHEMBL446238 & 489239 & 6.8239 & 6.8664 & TST \\
\hline CHEMBL510649 & 489239 & 7.2924 & 6.0487 & TST \\
\hline CHEMBL316698 & 489239 & 5.8404 & 5.8497 & TST \\
\hline CHEMBL148964 & 148444 & 6.5686 & 6.4803 & TST \\
\hline CHEMBL119073 & 148444 & 6.8239 & 7.3633 & TST \\
\hline CHEMBL146507 & 148444 & 7.3468 & 6.8005 & TRN \\
\hline CHEMBL119557 & 148444 & 6.4685 & 5.9182 & TRN \\
\hline CHEMBL149390 & 148444 & 5.301 & 6.4042 & TRN \\
\hline CHEMBL146916 & 148444 & 6.6383 & 6.5813 & TRN \\
\hline CHEMBL358520 & 148444 & 9.1938 & 7.3633 & TST \\
\hline CHEMBL147514 & 148444 & 6.4437 & 6.5027 & TRN \\
\hline CHEMBL147529 & 148444 & 3.9393 & \multicolumn{2}{|c|}{5.4879999999999995} \\
\hline CHEMBL149561 & 148444 & 6.2076 & 7.0393 & TST \\
\hline CHEMBL423209 & 148444 & 6.3665 & 5.4629 & TRN \\
\hline CHEMBL331107 & 148444 & 5.8239 & 5.9699 & TRN \\
\hline CHEMBL146237 & 148444 & 5.4145 & 6.0495 & TRN \\
\hline CHEMBL421897 & 148444 & 6.8239 & 6.2532 & TRN \\
\hline CHEMBL342090 & 148444 & 4.9666 & 6.1438 & TRN \\
\hline CHEMBL116717 & 148444 & 7.4815 & 6.3251 & TRN \\
\hline CHEMBL149489 & 148444 & 5.5229 & 6.8005 & TRN \\
\hline CHEMBL357621 & 148444 & 6.2676 & 6.8005 & TRN \\
\hline CHEMBL148729 & 148444 & 5.0132 & 6.0845 & TRN \\
\hline CHEMBL117619 & 148444 & 6.0757 & 6.103 & TRN \\
\hline CHEMBL148551 & 148444 & 6.7447 & 6.2424 & TRN \\
\hline CHEMBL110737 & 148444 & 6.8539 & 6.0845 & TRN \\
\hline CHEMBL148470 & 148444 & 6.5686 & 6.3378 & TRN \\
\hline CHEMBL149285 & 148444 & 6.1739 & 6.2248 & TST \\
\hline CHEMBL358063 & 148444 & 8.3098 & 6.7673 & TRN \\
\hline CHEMBL149119 & 148444 & 3.0969 & \multicolumn{2}{|c|}{6.747999999999999} \\
\hline CHEMBL148575 & 148444 & 6.3768 & 6.4803 & TST \\
\hline CHEMBL149118 & 148444 & 4.585 & 6.4803 & TST \\
\hline CHEMBL119701 & 148444 & 7.0458 & 7.3792 & TRN \\
\hline CHEMBL109873 & 148444 & 6.301 & 6.4042 & TRN \\
\hline CHEMBL146860 & 148444 & 6.8539 & 6.32 & TRN \\
\hline CHEMBL116718 & 148444 & 7.1938 & 6.0845 & TRN \\
\hline CHEMBL324402 & 148444 & 6.9586 & 6.2178 & TRN \\
\hline CHEMBL343452 & 148444 & 8.2757 & 6.8768 & TST \\
\hline CHEMBL146287 & 148444 & 6.6576 & 6.2424 & TRN \\
\hline CHEMBL147166 & 148444 & 6.4202 & 6.4648 & TRN \\
\hline CHEMBL149870 & 148444 & 6.5686 & 6.0845 & TST \\
\hline CHEMBL422319 & 148444 & 8.1192 & 7.4201 & TRN \\
\hline CHEMBL116428 & 148444 & 6.6778 & 6.1765 & TRN \\
\hline CHEMBL120016 & 148444 & 6.585 & 6.311 & TRN \\
\hline CHEMBL149661 & 148444 & 7.8861 & 7.3633 & TST \\
\hline CHEMBL332670 & 148444 & 6.1549 & 6.2424 & TRN \\
\hline CHEMBL151895 & 148444 & 8.3979 & 7.3792 & TRN \\
\hline
\end{tabular}

Page 18582 
Supplemental Table S2.txt

\begin{tabular}{|c|c|c|c|c|c|}
\hline CHEMBL357523 & 148444 & 8.7959 & 6.8005 & TST & \\
\hline CHEMBL119520 & 148444 & 6.3188 & 6.0495 & TRN & \\
\hline CHEMBL1202245 & 148444 & 5.7447 & 6.2424 & TRN & \\
\hline CHEMBL149894 & 148444 & 6.6576 & 6.4803 & TST & \\
\hline CHEMBL347545 & 148444 & 6.0915 & 6.0495 & TRN & \\
\hline CHEMBL423396 & 148444 & 8.9586 & 7.3633 & TST & \\
\hline CHEMBL175697 & 148444 & 7.3565 & 7.4942 & TRN & \\
\hline CHEMBL403227 & 468834 & 5.6778 & 5.3216 & TRN & \\
\hline CHEMBL257855 & 468834 & 6.4815 & 5.7836 & TRN & \\
\hline CHEMBL427900 & 468834 & 7.1675 & 5.9396 & TRN & \\
\hline CHEMBL402397 & 468834 & 6.4559 & 7.2047 & TST & \\
\hline CHEMBL402973 & 468834 & 3.301 & 4.9648 & TRN & \\
\hline CHEMBL 256656 & 468834 & 6.1871 & 6.0526 & TRN & \\
\hline CHEMBL 271741 & 468834 & 7.2218 & 6.3377 & TRN & \\
\hline CHEMBL398884 & 468834 & 6.8861 & 7.6823 & TRN & \\
\hline CHEMBL 271032 & 468834 & 3.301 & 3.8448 & TRN & \\
\hline CHEMBL257426 & 468834 & 4.8861 & 5.3673 & TRN & \\
\hline CHEMBL256655 & 468834 & 4.3565 & 3.8443 & TRN & \\
\hline CHEMBL269947 & 468834 & 3.301 & 5.7507 & TRN & \\
\hline CHEMBL438704 & 468834 & 5.7447 & 6.2893 & TRN & \\
\hline CHEMBL 257427 & 468834 & 3.301 & 5.3494 & TRN & \\
\hline CHEMBL255594 & 468834 & 6.7959 & 5.8761 & TRN & \\
\hline CHEMBL401750 & 468834 & 3.301 & 5.1466 & TRN & \\
\hline CHEMBL402354 & 468834 & 5.3468 & 4.0121 & TRN & \\
\hline CHEMBL411518 & 468834 & 6.8861 & 7.1738 & TST & \\
\hline CHEMBL437029 & 468834 & 7.2291 & 5.2901 & TST & \\
\hline CHEMBL270377 & 468834 & 6.6021 & 5.5105 & TRN & \\
\hline CHEMBL 255842 & 468834 & 6.8861 & 6.6111 & TRN & \\
\hline CHEMBL269935 & 468834 & 7.2366 & 6.5213 & TRN & \\
\hline CHEMBL403962 & 468834 & 6.1739 & 4.1892 & TRN & \\
\hline CHEMBL271949 & 468834 & 7.3188 & 7.7697 & TRN & \\
\hline CHEMBL 258128 & 468834 & 7.0 & 6.3293 & TST & \\
\hline CHEMBL402092 & 468834 & 3.301 & 3.9527 & TRN & \\
\hline CHEMBL257949 & 468834 & 3.301 & 5.6456 & TRN & \\
\hline CHEMBL405072 & 468834 & 5.6198 & 4.3249 & TRN & \\
\hline CHEMBL407560 & 468834 & 8.1549 & 7.42700 & 00000000005 & TRN \\
\hline CHEMBL269944 & 468834 & 3.301 & 4.4544 & TRN & \\
\hline CHEMBL272365 & 468834 & 3.301 & 3.4845 & TRN & \\
\hline CHEMBL256657 & 468834 & 5.3768 & 3.8801 & TST & \\
\hline CHEMBL 273153 & 468834 & 3.301 & 4.3873 & TRN & \\
\hline CHEMBL438736 & 468834 & 5.9208 & 5.8093 & TST & \\
\hline CHEMBL 273000 & 468834 & 6.2147 & 5.2679 & TRN & \\
\hline CHEMBL 270818 & 468834 & 3.301 & 3.8035 & TRN & \\
\hline CHEMBL 235842 & 468834 & 8.1549 & 7.8075 & TRN & \\
\hline CHEMBL 236678 & 468834 & 5.585 & 3.7956 & TRN & \\
\hline CHEMBL255985 & 468834 & 3.301 & 3.8416 & TRN & \\
\hline CHEMBL403256 & 468834 & 5.8861 & 4.8316 & TRN & \\
\hline CHEMBL 256441 & 468834 & 7.284 & 6.8566 & TRN & \\
\hline
\end{tabular}




\begin{tabular}{|c|c|c|c|c|c|}
\hline & & \multicolumn{4}{|c|}{ Supplemental Table s2.txt } \\
\hline CHEMBL401586 & 468834 & 3.301 & 3.9133 & TRN & \\
\hline CHEMBL403694 & 468834 & 6.3979 & 6.5244 & TRN & \\
\hline CHEMBL402117 & 468834 & 3.301 & 4.9312 & TRN & \\
\hline CHEMBL255805 & 468834 & 7.3188 & 5.8079 & TRN & \\
\hline CHEMBL255804 & 468834 & 6.0 & 4.1904 & TRN & \\
\hline CHEMBL256649 & 468834 & 3.301 & 5.1787 & TRN & \\
\hline CHEMBL257953 & 468834 & 5.8239 & 5.1927 & TRN & \\
\hline CHEMBL271498 & 468834 & 7.5528 & 6.3521 & TRN & \\
\hline CHEMBL403448 & 468834 & 5.2757 & 5.4857 & TRN & \\
\hline CHEMBL255737 & 468834 & 6.3565 & 6.3509 & TRN & \\
\hline CHEMBL256440 & 468834 & 7.1871 & 7.3241 & TRN & \\
\hline CHEMBL257656 & 468834 & 6.8539 & 5.6201 & TST & \\
\hline CHEMBL269945 & 468834 & 3.301 & 4.6538 & TST & \\
\hline CHEMBL272152 & 468834 & 3.301 & 3.7531 & TST & \\
\hline CHEMBL271497 & 468834 & 3.301 & 6.1253 & TST & \\
\hline CHEMBL403100 & 468834 & 7.7447 & 6.50899 & 99999999995 & TST \\
\hline CHEMBL428600 & 468834 & 3.301 & 5.5285 & TST & \\
\hline CHEMBL408755 & 468834 & 3.301 & 4.1029 & TST & \\
\hline CHEMBL269928 & 468834 & 5.3188 & 6.0467 & TST & \\
\hline CHEMBL270360 & 468834 & 6.5086 & 6.3999 & TST & \\
\hline CHEMBL257202 & 468834 & 7.1249 & 6.4868 & TST & \\
\hline CHEMBL1578252 & 688333 & 5.5634 & 4.9385 & TST & \\
\hline CHEMBL1530382 & 688333 & 5.0652 & 5.1458 & TRN & \\
\hline CHEMBL1347980 & 688333 & 4.99 & 5.3754 & TRN & \\
\hline CHEMBL3190415 & 688333 & 5.234 & 5.1053 & TRN & \\
\hline CHEMBL1478358 & 688333 & 4.9203 & 4.5738 & TRN & \\
\hline CHEMBL1505782 & 688333 & 4.3993 & 5.0982 & TRN & \\
\hline CHEMBL1495117 & 688333 & 4.2618 & 4.5151 & TRN & \\
\hline CHEMBL1502024 & 688333 & 4.7923 & 4.6046 & TRN & \\
\hline CHEMBL1333500 & 688333 & 4.7838 & 5.0433 & TRN & \\
\hline CHEMBL1361960 & 688333 & 4.8101 & 5.0073 & TRN & \\
\hline CHEMBL1379867 & 688333 & 4.2618 & 4.9829 & TRN & \\
\hline CHEMBL1361455 & 688333 & 2.8304 & 3.8139 & TRN & \\
\hline CHEMBL1471621 & 688333 & 4.7845 & 5.1525 & TRN & \\
\hline CHEMBL1483372 & 688333 & 4.2618 & 4.7335 & TRN & \\
\hline CHEMBL1307293 & 688333 & 5.1772 & 4.9059 & TRN & \\
\hline CHEMBL1508041 & 688333 & 5.7036 & 5.2671 & TRN & \\
\hline CHEMBL1415628 & 688333 & 4.7166 & 5.4352 & TRN & \\
\hline CHEMBL1476843 & 688333 & 5.3272 & 5.239 & TRN & \\
\hline CHEMBL1586752 & 688333 & 5.2297 & 4.6616 & TRN & \\
\hline CHEMBL1342681 & 688333 & 4.8829 & 4.801 & TST & \\
\hline CHEMBL1528266 & 688333 & 4.7754 & 4.6956 & TST & \\
\hline CHEMBL1403552 & 688333 & 4.6778 & 5.2297 & TRN & \\
\hline CHEMBL1578372 & 688333 & 5.2812 & 5.1418 & TRN & \\
\hline CHEMBL1469363 & 688333 & 4.4089 & 4.7724 & TRN & \\
\hline CHEMBL1374929 & 688333 & 5.216 & 5.0601 & TRN & \\
\hline CHEMBL3214012 & 688333 & 5.0891 & 4.5325 & TST & \\
\hline CHEMBL1578504 & 688333 & 5.0391 & 5.115 & TRN & \\
\hline
\end{tabular}




\begin{tabular}{|c|c|c|c|c|}
\hline & & & & \\
\hline ABL15 & 00 & 4. & 952 & TPA \\
\hline & & 4.7998 & & \\
\hline IEMBL: & & & & \\
\hline IEMBL: & 88333 & 8728 & & \\
\hline AEMBL1438044 & 88333 & 7922 & 296 & \\
\hline AEMBL1 & 88333 & 8245 & 366 & \\
\hline & & 1438 & & \\
\hline IEMB & & 228 & & \\
\hline AEMBL1983083 & 88333 & 8376 & & \\
\hline AEMBL1613601 & 88333 & 846 & 05 & \\
\hline 04942 & 33 & 303 & 39 & \\
\hline 84 & & 308 & & \\
\hline IEMBL & & 353 & & \\
\hline AEMBL: & 33 & 34 & & \\
\hline AEMBL: & 33 & 626 & & \\
\hline 070 & 3 & 156 & & \\
\hline & & & & \\
\hline IFMR & 33 & 645 & & \\
\hline 07 & 33 & 916 & & \\
\hline 01360 & 33 & & & \\
\hline 18 & & 91 & & \\
\hline & & & & \\
\hline 66 & & 04 & & \\
\hline 69 & & 967 & & \\
\hline EMBL & $68 \varepsilon$ & 818 & & \\
\hline 38 & & 38 & & \\
\hline & & & & \\
\hline & & & & \\
\hline & & & & \\
\hline 85742 & 33 & 304 & & \\
\hline 36 & & 37 & & \\
\hline & & & & \\
\hline & & & & \\
\hline & & & & \\
\hline MBL & 33 & 559 & & \\
\hline & & 64 & & \\
\hline & & & & \\
\hline & & & & \\
\hline EMBL & 3 & 843 & & \\
\hline$y$ & 3 & & & \\
\hline 166 & & & & \\
\hline & & & & \\
\hline EMBL & & 9461 & & $r R$ \\
\hline$M B L$ & & 018 & & \\
\hline & & & & \\
\hline CHEMBL1602399 & & & & \\
\hline EMBL & & 7869 & 4.1021 & \\
\hline I & 080 & 13 & 63 & \\
\hline
\end{tabular}

Page 18585 


\begin{tabular}{|c|c|c|c|c|}
\hline & & & pplement & al $\mathrm{T}$ \\
\hline CHEMBL1521983 & 688333 & 4.2618 & 4.6601 & TRN \\
\hline CHEMBL1602063 & 688333 & 5.564 & 5.1437 & TRN \\
\hline CHEMBL1352927 & 688333 & 5.2261 & 4.9777 & TRN \\
\hline CHEMBL3197332 & 688333 & 5.1406 & 4.9659 & TRN \\
\hline CHEMBL1513224 & 688333 & 5.2394 & 4.8979 & TRN \\
\hline CHEMBL1556594 & 688333 & 5.0232 & 4.871 & TRN \\
\hline CHEMBL1534191 & 688333 & 2.8304 & 4.1062 & TRN \\
\hline CHEMBL1328085 & 688333 & 5.2715 & 4.993 & TRN \\
\hline CHEMBL1353921 & 688333 & 4.6992 & 4.9639 & TST \\
\hline CHEMBL1588585 & 688333 & 4.2618 & 4.8087 & TRN \\
\hline CHEMBL1416638 & 688333 & 5.2761 & 4.7645 & TRN \\
\hline CHEMBL1385582 & 688333 & 4.7103 & 4.7782 & TRN \\
\hline CHEMBL1545747 & 688333 & 4.8701 & 5.0209 & TRN \\
\hline CHEMBL3212680 & 688333 & 4.2618 & 5.0617 & TST \\
\hline CHEMBL1504011 & 688333 & 5.2743 & 4.8272 & TRN \\
\hline CHEMBL1301532 & 688333 & 5.1367 & 4.9803 & TRN \\
\hline CHEMBL1463327 & 688333 & 4.8819 & 5.1365 & TST \\
\hline CHEMBL1508132 & 688333 & 5.1603 & 4.8308 & TRN \\
\hline CHEMBL1364577 & 688333 & 5.2498 & 4.6449 & TRN \\
\hline CHEMBL1517640 & 688333 & 5.3487 & 4.808 & TRN \\
\hline CHEMBL1450873 & 688333 & 4.8883 & 5.1722 & TST \\
\hline CHEMBL1504048 & 688333 & 5.6957 & 4.9588 & TRN \\
\hline CHEMBL1553362 & 688333 & 5.0382 & 5.1327 & TRN \\
\hline CHEMBL1420376 & 688333 & 5.2291 & 5.0655 & TRN \\
\hline CHEMBL3190959 & 688333 & 5.4418 & 4.9084 & TRN \\
\hline CHEMBL1606901 & 688333 & 4.7848 & 4.2619 & TRN \\
\hline CHEMBL1467170 & 688333 & 5.0049 & 5.2386 & TRN \\
\hline CHEMBL1455859 & 688333 & 4.7846 & 4.5221 & TRN \\
\hline CHEMBL1391307 & 688333 & 5.0424 & 4.9857 & TRN \\
\hline CHEMBL1417737 & 688333 & 4.8039 & 4.3853 & TRN \\
\hline CHEMBL1425472 & 688333 & 5.0137 & 5.0886 & TRN \\
\hline CHEMBL1393138 & 688333 & 4.8653 & 5.1738 & TRN \\
\hline CHEMBL1533736 & 688333 & 2.8304 & 4.0978 & TRN \\
\hline CHEMBL1516647 & 688333 & 5.1898 & 4.8258 & TRN \\
\hline CHEMBL1339034 & 688333 & 4.8279 & 4.667 & TST \\
\hline CHEMBL1584651 & 688333 & 4.8062 & 4.7894 & TST \\
\hline CHEMBL1488463 & 688333 & 4.2618 & 4.6576 & TST \\
\hline CHEMBL1481461 & 688333 & 4.8641 & 4.7323 & TST \\
\hline CHEMBL1460961 & 688333 & 5.2152 & 4.7768 & TST \\
\hline CHEMBL591148 & 688333 & 5.0463 & 5.4086 & TST \\
\hline CHEMBL1439562 & 688333 & 4.8877 & 4.4965 & TST \\
\hline CHEMBL1523416 & 688333 & 5.2579 & 4.8169 & TST \\
\hline CHEMBL1480176 & 688333 & 5.7242 & 4.7701 & TST \\
\hline CHEMBL1581004 & 688333 & 4.737 & 5.0895 & TST \\
\hline CHEMBL1568508 & 688333 & 2.8304 & 4.8439 & TST \\
\hline CHEMBL1447378 & 688333 & 4.8484 & 4.9978 & TST \\
\hline CHEMBL1542489 & 688333 & 5.3149 & 4.9808 & TST \\
\hline CHEMBL1377800 & 688333 & 4.9584 & 5.046 & TST \\
\hline
\end{tabular}




\begin{tabular}{|c|c|c|c|c|c|c|}
\hline & & \multicolumn{5}{|c|}{ Supplemental Table s2.txt } \\
\hline CHEMBL1468113 & 688333 & 4.7675 & 4.603 & TST & & \\
\hline CHEMBL1425498 & 688333 & $4.7810 e$ & 00000000 & & 5.1042 & TST \\
\hline CHEMBL1320538 & 688333 & 4.9317 & 4.8598 & TST & & \\
\hline CHEMBL1415356 & 688333 & 4.8125 & 5.3449 & TST & & \\
\hline CHEMBL 3664987 & 1527944 & 5.0044 & 4.4498 & TRN & & \\
\hline CHEMBL3669959 & 1527944 & 6.7212 & 5.7536 & TRN & & \\
\hline CHEMBL3670077 & 1527944 & 6.7959 & 6.6383 & TRN & & \\
\hline CHEMBL3669987 & 1527944 & 6.2441 & 5.7279 & TRN & & \\
\hline CHEMBL 3664940 & 1527944 & 3.301 & 4.4562 & TRN & & \\
\hline CHEMBL3669898 & 1527944 & 6.6021 & 5.7602 & TRN & & \\
\hline CHEMBL3670039 & 1527944 & 5.8539 & 6.3417 & TRN & & \\
\hline CHEMBL 3670003 & 1527944 & 3.699 & 4.3502 & TRN & & \\
\hline CHEMBL 3670044 & 1527944 & 6.6576 & 6.3798 & TRN & & \\
\hline CHEMBL 3664950 & 1527944 & 4.6021 & 5.7495 & TST & & \\
\hline CHEMBL3669971 & 1527944 & 5.1308 & 5.5909 & TRN & & \\
\hline CHEMBL3669914 & 1527944 & 4.8861 & 5.2609 & TRN & & \\
\hline CHEMBL3670068 & 1527944 & 6.7959 & 5.6788 & TRN & & \\
\hline CHEMBL 3664989 & 1527944 & 5.3665 & 4.8454 & TRN & & \\
\hline CHEMBL3669890 & 1527944 & 5.0555 & 5.6303 & TRN & & \\
\hline CHEMBL3665015 & 1527944 & 5.1549 & 4.8969 & TST & & \\
\hline CHEMBL3670040 & 1527944 & 6.7959 & 6.8588 & TRN & & \\
\hline CHEMBL3670053 & 1527944 & 3.699 & 3.9375 & TRN & & \\
\hline CHEMBL 3669891 & 1527944 & 6.4815 & 6.1115 & TRN & & \\
\hline CHEMBL 3674972 & 1527944 & 7.0706 & 6.3028 & TRN & & \\
\hline CHEMBL3669963 & 1527944 & 6.4437 & 5.3595 & TRN & & \\
\hline CHEMBL 3674971 & 1527944 & 6.585 & 5.9706 & TRN & & \\
\hline CHEMBL3669976 & 1527944 & 5.6576 & 5.7123 & TST & & \\
\hline CHEMBL 3670063 & 1527944 & 7.1308 & 7.3533 & TRN & & \\
\hline CHEMBL 3669867 & 1527944 & 6.9208 & 6.3764 & TRN & & \\
\hline CHEMBL3669908 & 1527944 & 5.5686 & 5.9654 & TRN & & \\
\hline CHEMBL 3664980 & 1527944 & 3.699 & 5.0622 & TRN & & \\
\hline CHEMBL 3669880 & 1527944 & 5.1308 & 5.8071 & TRN & & \\
\hline CHEMBL3664931 & 1527944 & 3.301 & 4.7171 & TRN & & \\
\hline CHEMBL3669871 & 1527944 & 6.7959 & 6.7813 & TRN & & \\
\hline CHEMBL3669902 & 1527944 & 5.0 & 6.0814 & TST & & \\
\hline CHEMBL3664908 & 1527944 & 4.9586 & 5.2351 & TRN & & \\
\hline CHEMBL3664995 & 1527944 & 3.699 & 4.5997 & TRN & & \\
\hline CHEMBL 3669864 & 1527944 & 4.8539 & 4.2684 & TST & & \\
\hline CHEMBL3669989 & 1527944 & 4.4949 & 5.6379 & TST & & \\
\hline CHEMBL3669924 & 1527944 & 6.6198 & 5.3822 & TRN & & \\
\hline CHEMBL3669892 & 1527944 & 6.2366 & 5.3488 & TRN & & \\
\hline CHEMBL3669943 & 1527944 & 6.2676 & 5.7247 & TRN & & \\
\hline CHEMBL3669998 & 1527944 & 6.1367 & 5.6101 & TRN & & \\
\hline CHEMBL3669888 & 1527944 & 5.8239 & 5.8659 & TRN & & \\
\hline CHEMBL3669907 & 1527944 & 6.2147 & 5.706 & TRN & & \\
\hline CHEMBL3670011 & 1527944 & 3.699 & 6.0475 & TRN & & \\
\hline CHEMBL 3670007 & 1527944 & 6.2218 & 5.829 & TRN & & \\
\hline CHEMBL 3664968 & 1527944 & 5.8239 & 4.5025 & TRN & & \\
\hline
\end{tabular}


Supplemental Table S2.txt

\begin{tabular}{|c|c|c|c|c|c|}
\hline CHEMBL3669920 & 1527944 & 5.6021 & 5.6685 & TST & \\
\hline CHEMBL3669936 & 1527944 & 4.8239 & 5.7169 & TRN & \\
\hline CHEMBL3664964 & 1527944 & 5.699 & 4.8264 & TST & \\
\hline CHEMBL3669952 & 1527944 & 5.5528 & \multicolumn{2}{|c|}{6.031000000000001} & TRN \\
\hline CHEMBL 3664977 & 1527944 & 5.5376 & 4.3804 & TRN & \\
\hline CHEMBL 3680032 & 1527944 & 6.0 & 6.5903 & TRN & \\
\hline CHEMBL3664917 & 1527944 & 3.301 & 5.73799 & 99999999995 & TST \\
\hline CHEMBL 3670038 & 1527944 & 6.8861 & 6.5134 & TRN & \\
\hline CHEMBL3669944 & 1527944 & 6.4202 & 6.0756 & TRN & \\
\hline CHEMBL 3665001 & 1527944 & 3.699 & 4.1614 & TST & \\
\hline CHEMBL 3664935 & 1527944 & 3.301 & 4.0196 & TRN & \\
\hline CHEMBL 3664937 & 1527944 & 5.6021 & 4.7594 & TST & \\
\hline CHEMBL3669859 & 1527944 & 3.699 & 5.4924 & TRN & \\
\hline CHEMBL3670062 & 1527944 & 7.0362 & 7.1834 & TRN & \\
\hline CHEMBL 3669994 & 1527944 & 6.699 & 5.9869 & TRN & \\
\hline CHEMBL 3669876 & 1527944 & 6.2924 & 6.1457 & TRN & \\
\hline CHEMBL3669981 & 1527944 & 6.5376 & 5.8107 & TRN & \\
\hline CHEMBL 3669980 & 1527944 & 6.1675 & 5.9017 & TST & \\
\hline CHEMBL3674969 & 1527944 & 7.0655 & 6.9134 & TRN & \\
\hline CHEMBL3670060 & 1527944 & 7.1871 & 6.1338 & TRN & \\
\hline CHEMBL3670019 & 1527944 & 6.3979 & 5.8922 & TRN & \\
\hline CHEMBL3664918 & 1527944 & 6.2518 & 6.0912 & TRN & \\
\hline CHEMBL 3664986 & 1527944 & 3.699 & 3.9243 & TST & \\
\hline CHEMBL3664976 & 1527944 & 6.5528 & 4.7303 & TST & \\
\hline CHEMBL 3670036 & 1527944 & 6.8239 & 6.4792 & TRN & \\
\hline CHEMBL3665002 & 1527944 & 5.7447 & 4.6054 & TST & \\
\hline CHEMBL 3670026 & 1527944 & 3.699 & 6.228 & TRN & \\
\hline CHEMBL3669910 & 1527944 & 5.7696 & 6.0701 & TRN & \\
\hline CHEMBL3669962 & 1527944 & 6.1549 & 5.9187 & TRN & \\
\hline CHEMBL 3669929 & 1527944 & 3.699 & 6.0289 & TRN & \\
\hline CHEMBL 3669927 & 1527944 & 5.7959 & 6.3851 & TRN & \\
\hline CHEMBL 3664942 & 1527944 & 3.301 & 3.8817 & TST & \\
\hline CHEMBL3669984 & 1527944 & 6.1805 & 6.0379 & TRN & \\
\hline CHEMBL3669913 & 1527944 & 3.699 & 5.1795 & TRN & \\
\hline CHEMBL 3669997 & 1527944 & 5.1938 & 6.0395 & TRN & \\
\hline CHEMBL3669965 & 1527944 & 7.1427 & 7.369 & TRN & \\
\hline CHEMBL3664927 & 1527944 & 3.301 & 3.56 & TST & \\
\hline CHEMBL3664992 & 1527944 & 3.699 & 4.1636 & TRN & \\
\hline CHEMBL 3670013 & 1527944 & 6.8539 & 6.9017 & TRN & \\
\hline CHEMBL3669931 & 1527944 & 6.2441 & 5.8338 & TST & \\
\hline CHEMBL 3664990 & 1527944 & 3.699 & 4.1954 & TRN & \\
\hline CHEMBL 3665000 & 1527944 & 5.301 & 4.5671 & TST & \\
\hline CHEMBL3670033 & 1527944 & 7.2076 & 6.4976 & TRN & \\
\hline CHEMBL3669975 & 1527944 & 6.1249 & 6.2739 & TRN & \\
\hline CHEMBL3664958 & 1527944 & 3.301 & 4.622 & TRN & \\
\hline CHEMBL3670059 & 1527944 & 6.4559 & 6.6083 & TRN & \\
\hline CHEMBL 3669872 & 1527944 & 6.8239 & 5.9109 & TRN & \\
\hline CHEMBL 3670025 & 1527944 & 3.699 & 5.3856 & TRN & \\
\hline
\end{tabular}


Supplemental Table S2.txt

\begin{tabular}{|c|c|c|c|c|}
\hline CHEMBL3670048 & 1527944 & 7.1612 & 6.375 & TRN \\
\hline CHEMBL3664910 & 1527944 & 6.7959 & 6.1904 & TRN \\
\hline CHEMBL3670027 & 1527944 & 6.7696 & 5.8209 & TRN \\
\hline CHEMBL3670012 & 1527944 & 6.5686 & 5.9494 & TRN \\
\hline CHEMBL3664969 & 1527944 & 6.4949 & 5.8668 & TRN \\
\hline CHEMBL3669885 & 1527944 & 5.2007 & 5.2904 & TRN \\
\hline CHEMBL3669938 & 1527944 & 6.9586 & 5.7495 & TRN \\
\hline CHEMBL 3670051 & 1527944 & 7.0 & 7.2095 & TRN \\
\hline CHEMBL3664943 & 1527944 & 3.301 & 3.8611 & TST \\
\hline CHEMBL3669946 & 1527944 & 6.284 & 5.9122 & TRN \\
\hline CHEMBL 3670024 & 1527944 & 3.699 & 6.7452 & TRN \\
\hline CHEMBL3664971 & 1527944 & 6.699 & 5.8021 & TRN \\
\hline CHEMBL3669863 & 1527944 & 3.699 & 5.9201 & TST \\
\hline CHEMBL3664944 & 1527944 & 4.3979 & 6.0121 & TST \\
\hline CHEMBL 3670070 & 1527944 & 6.585 & 6.0374 & TRN \\
\hline CHEMBL3665012 & 1527944 & 6.2924 & 4.3884 & TST \\
\hline CHEMBL3664928 & 1527944 & 4.585 & 4.3875 & TRN \\
\hline CHEMBL 3665003 & 1527944 & 5.7696 & 5.4973 & TST \\
\hline CHEMBL3670049 & 1527944 & 7.3098 & 7.3533 & TRN \\
\hline CHEMBL3664929 & 1527944 & 5.4318 & 3.9928 & TRN \\
\hline CHEMBL3670002 & 1527944 & 5.1549 & 5.8725 & TST \\
\hline CHEMBL 3664960 & 1527944 & 3.301 & 5.0324 & TRN \\
\hline CHEMBL3664893 & 1527944 & 3.301 & 5.178 & TRN \\
\hline CHEMBL3669882 & 1527944 & 5.7696 & 5.9885 & TRN \\
\hline CHEMBL3669934 & 1527944 & 5.1308 & 5.29700 & 0000000001 \\
\hline CHEMBL3669915 & 1527944 & 6.7696 & 6.5125 & TRN \\
\hline CHEMBL 3665008 & 1527944 & 3.699 & 3.4424 & TRN \\
\hline CHEMBL3669919 & 1527944 & 3.699 & 5.3579 & TRN \\
\hline CHEMBL3670055 & 1527944 & 6.4202 & 6.0821 & TRN \\
\hline CHEMBL3670018 & 1527944 & 6.1938 & 6.6958 & TRN \\
\hline CHEMBL3669983 & 1527944 & 7.0862 & 6.4163 & TRN \\
\hline CHEMBL3670034 & 1527944 & 7.1675 & 6.9257 & TRN \\
\hline CHEMBL3669889 & 1527944 & 5.5086 & 4.6184 & TRN \\
\hline CHEMBL 3670064 & 1527944 & 6.9208 & 6.1418 & TRN \\
\hline CHEMBL3664993 & 1527944 & 6.0223 & 4.6018 & TRN \\
\hline CHEMBL3669862 & 1527944 & 4.8239 & 5.5368 & TRN \\
\hline CHEMBL3669949 & 1527944 & 5.6383 & 5.8611 & TRN \\
\hline CHEMBL3669991 & 1527944 & 5.8239 & 5.4727 & TRN \\
\hline CHEMBL3664956 & 1527944 & 3.301 & 5.2393 & TRN \\
\hline CHEMBL3669875 & 1527944 & 6.6198 & 5.6356 & TRN \\
\hline CHEMBL3664970 & 1527944 & 6.7447 & 5.7697 & TRN \\
\hline CHEMBL3669916 & 1527944 & 3.699 & 5.95100 & 00000000005 \\
\hline CHEMBL3664947 & 1527944 & 4.6198 & 6.50799 & 9999999999 \\
\hline CHEMBL3669922 & 1527944 & 4.7959 & 4.7924 & TST \\
\hline CHEMBL 3670000 & 1527944 & 6.7959 & 7.0524 & TRN \\
\hline CHEMBL3670052 & 1527944 & 3.699 & 4.8411 & TST \\
\hline CHEMBL 3670050 & 1527944 & 7.0 & 6.9134 & TRN \\
\hline CHEMBL 3680022 & 1527944 & 5.5528 & 5.6874 & TRN \\
\hline
\end{tabular}


Supplemental Table S2.txt

\begin{tabular}{|c|c|c|c|c|}
\hline HEMBL & 527944 & 6.1938 & 6.6944 & \\
\hline רחת0 & 527944 & 6.1308 & 5.7537 & \\
\hline & 27944 & & & \\
\hline AEMBL & & & & \\
\hline HEMBL & 527944 & & 283 & \\
\hline HEMBL3669887 & 527944 & 5.9586 & 5683 & \\
\hline 66 & 44 & & 677 & \\
\hline 23 & & & & \\
\hline HEMBL & 527944 & 924 & 8736 & \\
\hline HEMBL3665016 & 527944 & & 5645 & \\
\hline HEMBL3664999 & 527944 & & 1387 & \\
\hline AEMBL: & 44 & 12 & 055 & \\
\hline AEMBL & & & & \\
\hline HEMBL3 & 14 & & .7848 & \\
\hline AEMBL3 & 44 & & 6696 & \\
\hline AEMBL3665013 & +4 & $4 . \varepsilon$ & 5857 & \\
\hline HEMBL & 44 & & 119 & \\
\hline HEMBL; & & & 454 & \\
\hline HEMBL3 & 44 & & 0421 & \\
\hline AEMBL: & & & & \\
\hline AEMIBL & 44 & & 38 & Intv \\
\hline HEMBL & & & 03 & RN \\
\hline HEMBL & & & 61 & \\
\hline 904 & & & & \\
\hline AEMBL3 & & & & TST \\
\hline HEMBL & 44 & 7. & ) & RN \\
\hline HEMBL & & & 51 & RN \\
\hline HFMRI & & & 05 & $C T$ \\
\hline HEMBL3 & & & 144 & IS \\
\hline HEMBL3669925 & & & 741 & $\Gamma \mathrm{RN}$ \\
\hline HEMBL3 & & 0 & 879 & RN \\
\hline HEMBL & T & 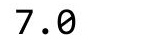 & 313 & RN \\
\hline HEMBL & 14 & 6 & 839 & sact \\
\hline HEMBL3E & & & 357 & IRN \\
\hline HEMBL3664991 & & 3. & 8815 & TST \\
\hline HEMBL3 & & & 555 & TRN \\
\hline HEMRI & & & 541 & $\Gamma \mathrm{RN}$ \\
\hline HEMBL & & 7. & 823 & ST \\
\hline HEMBL3669995 & 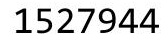 & 7. & 487 & TRN \\
\hline AEMBL3 & 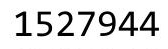 & & 245 & TST \\
\hline HEMBL3 & & & 382 & \\
\hline CHEMBL3 & & & 3987 & RN \\
\hline HEMBL 2 & 44 & 4. & 5468 & TRN \\
\hline HEMBL3669865 & 5279 & 6 & 8849 & TR \\
\hline - - & & & 1601 & - \\
\hline HEMBL3 & & & & \\
\hline CHEMBL3669886 & 527944 & .2441 & .7323 & \\
\hline CHEMBL3670071 & 1527944 & 6.4202 & 5.8047 & RN \\
\hline
\end{tabular}

Page 18590 
Supplemental Table S2.txt

\begin{tabular}{|c|c|c|c|c|c|}
\hline CHEMBL3669979 & 1527944 & 6.4202 & 4.8265 & TRN & \\
\hline CHEMBL3670016 & 1527944 & 6.7447 & 7.7294 & TRN & \\
\hline CHEMBL3664938 & 1527944 & 5.9208 & 5.1465 & TST & \\
\hline CHEMBL3669879 & 1527944 & 5.8861 & 5.4992 & TST & \\
\hline CHEMBL 3670074 & 1527944 & 6.6576 & 5.7335 & TRN & \\
\hline CHEMBL3664996 & 1527944 & 6.2218 & 4.9935 & TRN & \\
\hline CHEMBL3670075 & 1527944 & 7.0132 & 6.5378 & TRN & \\
\hline CHEMBL3664895 & 1527944 & 3.301 & 4.5838 & TRN & \\
\hline CHEMBL3669992 & 1527944 & 6.9208 & 6.3368 & TRN & \\
\hline CHEMBL3669960 & 1527944 & 6.6383 & 7.0868 & TRN & \\
\hline CHEMBL3680018 & 1527944 & 6.0 & 6.1949 & TRN & \\
\hline CHEMBL3665010 & 1527944 & 4.7212 & 4.4532 & TRN & \\
\hline CHEMBL3670015 & 1527944 & 6.7212 & 6.6656 & TRN & \\
\hline CHEMBL 3670001 & 1527944 & 3.699 & 6.6243 & TST & \\
\hline CHEMBL3669917 & 1527944 & 6.4202 & 6.4119 & TRN & \\
\hline CHEMBL3669935 & 1527944 & 5.0088 & 4.9167 & TRN & \\
\hline CHEMBL3670017 & 1527944 & 6.7447 & 7.1024 & TRN & \\
\hline CHEMBL3670046 & 1527944 & 6.0 & 7.2132 & TRN & \\
\hline CHEMBL3669911 & 1527944 & 6.0362 & 5.65799 & 99999999995 & TRN \\
\hline CHEMBL3680027 & 1527944 & 5.1612 & 5.3237 & TST & \\
\hline CHEMBL3664915 & 1527944 & 5.2518 & 5.7529 & TRN & \\
\hline CHEMBL3664967 & 1527944 & 6.6383 & 5.474 & TRN & \\
\hline CHEMBL3669901 & 1527944 & 5.4685 & 5.5914 & TST & \\
\hline CHEMBL3670057 & 1527944 & 5.7447 & 5.5997 & TRN & \\
\hline CHEMBL3664919 & 1527944 & 5.9208 & 5.905 & TRN & \\
\hline CHEMBL3665006 & 1527944 & 3.699 & 3.3718 & TRN & \\
\hline CHEMBL3669955 & 1527944 & 3.699 & 4.5708 & TRN & \\
\hline CHEMBL3669905 & 1527944 & 6.7447 & 5.7868 & TRN & \\
\hline CHEMBL3664903 & 1527944 & 5.1135 & 4.0156 & TRN & \\
\hline CHEMBL 3670006 & 1527944 & 5.1938 & 6.1804 & TRN & \\
\hline CHEMBL3669954 & 1527944 & 4.6778 & 4.3164 & TRN & \\
\hline CHEMBL3669937 & 1527944 & 5.699 & 6.0032 & TRN & \\
\hline CHEMBL3664921 & 1527944 & 5.1549 & 5.8924 & TRN & \\
\hline CHEMBL3669993 & 1527944 & 6.6198 & 5.9126 & TRN & \\
\hline CHEMBL3669972 & 1527944 & 7.0 & 7.2398 & TRN & \\
\hline CHEMBL3670035 & 1527944 & 7.1367 & 6.8241 & TRN & \\
\hline CHEMBL3664966 & 1527944 & 5.4089 & 4.0617 & TRN & \\
\hline CHEMBL3669909 & 1527944 & 6.7447 & 5.8743 & TST & \\
\hline CHEMBL3669945 & 1527944 & 6.4437 & 5.7808 & TST & \\
\hline CHEMBL3669964 & 1527944 & 6.4949 & 5.9961 & TRN & \\
\hline CHEMBL3680016 & 1527944 & 3.699 & 4.95100 & 00000000005 & TST \\
\hline CHEMBL3669957 & 1527944 & 6.9586 & 6.9647 & TRN & \\
\hline CHEMBL3669874 & 1527944 & 6.8861 & 6.3609 & TRN & \\
\hline CHEMBL3670030 & 1527944 & 5.4815 & 6.1038 & TST & \\
\hline CHEMBL3669912 & 1527944 & 6.4202 & 6.3635 & TRN & \\
\hline CHEMBL 3664983 & 1527944 & 4.6198 & 4.8448 & TST & \\
\hline CHEMBL3664907 & 1527944 & 5.3468 & 4.6902 & TST & \\
\hline CHEMBL3669857 & 1527944 & 5.4685 & 4.8738 & TRN & \\
\hline
\end{tabular}


Supplemental Table S2.txt

\begin{tabular}{|c|c|c|c|c|c|}
\hline CHEMBL3669856 & 1527944 & 6.1249 & 5.5061 & TST & \\
\hline CHEMBL 3670072 & 1527944 & 6.4559 & 6.226 & TRN & \\
\hline CHEMBL3670004 & 1527944 & 7.0969 & 6.5279 & TRN & \\
\hline CHEMBL 3664914 & 1527944 & 5.9208 & 5.4922 & TRN & \\
\hline CHEMBL 3669899 & 1527944 & 3.699 & 5.2937 & TRN & \\
\hline CHEMBL 3670056 & 1527944 & 6.5528 & 6.9663 & TRN & \\
\hline CHEMBL3669903 & 1527944 & 6.5229 & 5.3128 & TRN & \\
\hline CHEMBL 3664900 & 1527944 & 3.301 & 5.0654 & TRN & \\
\hline CHEMBL 3670028 & 1527944 & 3.699 & 5.5232 & TRN & \\
\hline CHEMBL 3664957 & 1527944 & 6.2291 & 6.1674 & TRN & \\
\hline CHEMBL 3664913 & 1527944 & 6.2924 & 5.3093 & TRN & \\
\hline CHEMBL3669918 & 1527944 & 5.9208 & 5.2557 & TRN & \\
\hline CHEMBL 3664905 & 1527944 & 3.301 & 6.0649 & TST & \\
\hline CHEMBL3669881 & 1527944 & 3.699 & 5.5719 & TRN & \\
\hline CHEMBL3669868 & 1527944 & 6.4685 & 6.3518 & TRN & \\
\hline CHEMBL3669869 & 1527944 & 6.6576 & 5.6718 & TRN & \\
\hline CHEMBL3669906 & 1527944 & 6.9208 & 5.7438 & TRN & \\
\hline CHEMBL 3664934 & 1527944 & 3.301 & 3.763 & TST & \\
\hline CHEMBL 3664904 & 1527944 & 5.5528 & 5.1137 & TRN & \\
\hline CHEMBL3664949 & 1527944 & 3.301 & 3.9747 & TST & \\
\hline CHEMBL 3670042 & 1527944 & 6.9208 & 5.683 & TRN & \\
\hline CHEMBL3664892 & 1527944 & 5.3872 & 4.5168 & TRN & \\
\hline CHEMBL 3669873 & 1527944 & 6.6383 & 5.2669 & TRN & \\
\hline CHEMBL 3669947 & 1527944 & 6.3979 & 6.50899 & 99999999995 & TRN \\
\hline CHEMBL3669942 & 1527944 & 6.5229 & 5.6768 & TST & \\
\hline CHEMBL 3664909 & 1527944 & 5.1805 & 5.1559 & TRN & \\
\hline CHEMBL3669923 & 1527944 & 6.0506 & 5.3289 & TRN & \\
\hline CHEMBL 3665014 & 1527944 & 6.5229 & 4.7875 & TST & \\
\hline CHEMBL 3669878 & 1527944 & 4.9586 & 5.4255 & TST & \\
\hline CHEMBL3670076 & 1527944 & 6.9208 & 6.7546 & TRN & \\
\hline CHEMBL3669921 & 1527944 & 6.0862 & 4.9914 & TRN & \\
\hline CHEMBL 2177757 & 1527944 & 6.699 & 5.7252 & TRN & \\
\hline CHEMBL 3670010 & 1527944 & 6.699 & 6.6025 & TRN & \\
\hline CHEMBL3669951 & 1527944 & 6.9208 & 6.3006 & TRN & \\
\hline CHEMBL 3664978 & 1527944 & 3.699 & 4.3846 & TST & \\
\hline CHEMBL3669932 & 1527944 & 5.4089 & 5.1831 & TST & \\
\hline CHEMBL 3665011 & 1527944 & 3.699 & 3.827 & TRN & \\
\hline CHEMBL3669948 & 1527944 & 6.7212 & 5.5526 & TRN & \\
\hline CHEMBL 3670058 & 1527944 & 3.699 & 5.1648 & TRN & \\
\hline CHEMBL 3664945 & 1527944 & 3.301 & 4.0477 & TRN & \\
\hline CHEMBL 3670041 & 1527944 & 6.7959 & 6.4091 & TRN & \\
\hline CHEMBL3669940 & 1527944 & 6.699 & 5.3935 & TRN & \\
\hline CHEMBL3665004 & 1527944 & 5.4559 & 4.9059 & TST & \\
\hline CHEMBL3669895 & 1527944 & 3.699 & 4.7508 & TRN & \\
\hline CHEMBL 3665005 & 1527944 & 4.9208 & 4.6889 & TST & \\
\hline CHEMBL3669978 & 1527944 & 3.699 & 4.9594 & TST & \\
\hline CHEMBL 3664963 & 1527944 & 6.0757 & 5.6059 & TST & \\
\hline CHEMBL3664939 & 1527944 & 5.0809 & 4.819 & TST & \\
\hline
\end{tabular}


Supplemental Table S2.txt

\begin{tabular}{|c|c|c|c|c|c|}
\hline CHEMBL3670073 & 1527944 & 6.5528 & 6.3109 & TRN & \\
\hline CHEMBL3664962 & 1527944 & 5.2147 & 5.3156 & TST & \\
\hline CHEMBL3664954 & 1527944 & 5.5229 & 5.7334 & TRN & \\
\hline CHEMBL3664936 & 1527944 & 4.4437 & 4.6297 & TRN & \\
\hline CHEMBL3669933 & 1527944 & 4.9208 & 4.9084 & TRN & \\
\hline CHEMBL 3664941 & 1527944 & 5.0362 & 4.9043 & TRN & \\
\hline CHEMBL3669928 & 1527944 & 3.699 & 5.6422 & TRN & \\
\hline CHEMBL3664920 & 1527944 & 3.301 & 4.9971 & TST & \\
\hline CHEMBL3664926 & 1527944 & 3.301 & 4.6673 & TST & \\
\hline CHEMBL3669990 & 1527944 & 6.0969 & 5.2721 & TRN & \\
\hline CHEMBL3669958 & 1527944 & 6.9208 & 6.2327 & TRN & \\
\hline CHEMBL3669926 & 1527944 & 6.7696 & 6.9131 & TRN & \\
\hline CHEMBL 3664988 & 1527944 & 3.699 & 5.423999 & 99999999995 & TRN \\
\hline CHEMBL3669870 & 1527944 & 6.9586 & 6.7452 & TRN & \\
\hline CHEMBL 3664898 & 1527944 & 3.301 & 6.3261 & TST & \\
\hline CHEMBL3669969 & 1527944 & 6.2218 & 5.7231 & TST & \\
\hline CHEMBL3669877 & 1527944 & 5.1308 & 5.3169 & TST & \\
\hline CHEMBL 3670022 & 1527944 & 5.3372 & 5.5161 & TRN & \\
\hline CHEMBL3670054 & 1527944 & 5.8539 & 6.1608 & TST & \\
\hline CHEMBL3669988 & 1527944 & 6.1739 & 5.8122 & TRN & \\
\hline CHEMBL3670065 & 1527944 & 6.9586 & 6.5134 & TRN & \\
\hline CHEMBL3664997 & 1527944 & 6.2076 & 5.3442 & TRN & \\
\hline CHEMBL3664896 & 1527944 & 3.301 & 5.7002 & TST & \\
\hline CHEMBL3664965 & 1527944 & 6.0969 & 5.4769 & TRN & \\
\hline CHEMBL 3664982 & 1527944 & 5.0915 & 5.2314 & TST & \\
\hline CHEMBL3664922 & 1527944 & 4.8861 & 5.7649 & TRN & \\
\hline CHEMBL3669985 & 1527944 & 3.699 & 5.931 & TRN & \\
\hline CHEMBL3674973 & 1527944 & 5.9208 & 6.6078 & TRN & \\
\hline CHEMBL3664973 & 1527944 & 3.699 & 4.0477 & TST & \\
\hline CHEMBL 3670043 & 1527944 & 6.8861 & 6.8721 & TRN & \\
\hline CHEMBL3669996 & 1527944 & 7.0 & 6.0621 & TRN & \\
\hline CHEMBL3669968 & 1527944 & 6.2147 & 5.6639 & TRN & \\
\hline CHEMBL3664894 & 1527944 & 4.8861 & 4.349 & TRN & \\
\hline CHEMBL3670066 & 1527944 & 6.5528 & 6.1259 & TRN & \\
\hline CHEMBL3670069 & 1527944 & 6.7696 & \multicolumn{2}{|c|}{6.122999999999999} & TRN \\
\hline CHEMBL3664961 & 1527944 & 3.301 & 5.3695 & TST & \\
\hline CHEMBL3664998 & 1527944 & 6.6198 & 5.352 & TRN & \\
\hline CHEMBL3664897 & 1527944 & 3.301 & 6.4638 & TST & \\
\hline CHEMBL3664951 & 1527944 & 5.8861 & 4.9409 & TST & \\
\hline CHEMBL 3664948 & 1527944 & 3.301 & 4.5644 & TRN & \\
\hline CHEMBL3670029 & 1527944 & 3.699 & 5.4409 & TRN & \\
\hline CHEMBL3639688 & 1527944 & 5.9208 & 5.8 & TRN & \\
\hline CHEMBL3664955 & 1527944 & 5.4685 & 5.9818 & TST & \\
\hline CHEMBL3664933 & 1527944 & 5.3098 & 5.3376 & TRN & \\
\hline CHEMBL3664912 & 1527944 & 3.301 & 3.6338 & TST & \\
\hline CHEMBL3665009 & 1527944 & 3.699 & 3.8391 & TRN & \\
\hline CHEMBL3669974 & 1527944 & 6.8539 & 6.1395 & TRN & \\
\hline CHEMBL3669894 & 1527944 & 3.699 & 5.0095 & TRN & \\
\hline
\end{tabular}




$$
\text { Supplemental Table S2.txt }
$$

\begin{tabular}{|c|c|c|c|c|c|}
\hline CHEMBL 3674970 & 1527944 & 7.0915 & 7.067 & TRN & \\
\hline CHEMBL3669893 & 1527944 & 3.699 & 4.7097 & TRN & \\
\hline CHEMBL3670045 & 1527944 & 6.0 & 6.2341 & TRN & \\
\hline CHEMBL3670009 & 1527944 & 7.0809 & 6.5303 & TRN & \\
\hline CHEMBL3664923 & 1527944 & 3.301 & 4.3443 & TRN & \\
\hline CHEMBL3670005 & 1527944 & 6.284 & 5.7054 & TRN & \\
\hline CHEMBL3664906 & 1527944 & 3.301 & 6.0608 & TST & \\
\hline CHEMBL3674974 & 1527944 & 6.6778 & 6.8677 & TRN & \\
\hline CHEMBL3669973 & 1527944 & 3.699 & 5.2222 & TRN & \\
\hline CHEMBL3670067 & 1527944 & 6.3665 & 6.0691 & TRN & \\
\hline CHEMBL3664932 & 1527944 & 5.6383 & 5.5123 & TRN & \\
\hline CHEMBL3664979 & 1527944 & 6.2518 & 5.7277 & TST & \\
\hline CHEMBL3669956 & 1527944 & 6.4202 & 6.50700 & 0000000001 & TRN \\
\hline CHEMBL3664953 & 1527944 & 6.0 & 5.5952 & TRN & \\
\hline CHEMBL3669986 & 1527944 & 6.7212 & 5.7362 & TRN & \\
\hline CHEMBL3664902 & 1527944 & 3.301 & 5.6308 & TST & \\
\hline CHEMBL3664916 & 1527944 & 3.301 & 5.9619 & TST & \\
\hline CHEMBL3669950 & 1527944 & 6.9208 & 6.8538 & TRN & \\
\hline CHEMBL3680036 & 1527944 & 3.699 & 6.0535 & TST & \\
\hline CHEMBL3669953 & 1527944 & 5.9208 & 5.91299 & 9999999999 & TRN \\
\hline CHEMBL3664911 & 1527944 & 3.301 & 3.6282 & TST & \\
\hline CHEMBL 3670020 & 1527944 & 5.6021 & 6.3321 & TRN & \\
\hline CHEMBL3664946 & 1527944 & 3.301 & 3.6723 & TST & \\
\hline CHEMBL1257989 & 1641446 & 7.2147 & 7.0835 & TRN & \\
\hline CHEMBL1258557 & 1641446 & 8.4685 & 8.6328 & TRN & \\
\hline CHEMBL1258107 & 1641446 & 6.8539 & 6.7277 & TRN & \\
\hline CHEMBL1257758 & 1641446 & 8.7447 & 8.9492 & TRN & \\
\hline CHEMBL214943 & 1641446 & 8.5528 & 8.4625 & TST & \\
\hline CHEMBL1258904 & 1641446 & 8.4318 & 8.4795 & TRN & \\
\hline CHEMBL1257634 & 1641446 & 8.5376 & 8.8031 & TRN & \\
\hline CHEMBL1258558 & 1641446 & 9.3979 & 8.8057 & TRN & \\
\hline CHEMBL1257518 & 1641446 & 9.301 & 9.3877 & TRN & \\
\hline CHEMBL1258448 & 1641446 & 6.5229 & 6.5819 & TRN & \\
\hline CHEMBL1257632 & 1641446 & 8.4089 & 8.6447 & TST & \\
\hline CHEMBL1258449 & 1641446 & 7.6778 & 8.0271 & TRN & \\
\hline CHEMBL1256165 & 1641446 & 5.4202 & 5.3197 & TRN & \\
\hline CHEMBL1258556 & 1641446 & 5.9586 & 6.2611 & TRN & \\
\hline CHEMBL1257169 & 1641446 & 9.1549 & 9.0548 & TRN & \\
\hline CHEMBL1258337 & 1641446 & 8.1427 & 8.1011 & TRN & \\
\hline CHEMBL1257759 & 1641446 & 9.3979 & 9.1303 & TRN & \\
\hline CHEMBL1257285 & 1641446 & 8.5086 & 8.5309 & TRN & \\
\hline CHEMBL1257516 & 1641446 & 8.5229 & 8.5938 & TRN & \\
\hline CHEMBL1257635 & 1641446 & 9.3979 & 9.0334 & TRN & \\
\hline CHEMBL1258785 & 1641446 & 9.3979 & 9.0774 & TRN & \\
\hline CHEMBL1257878 & 1641446 & 7.0605 & 6.977 & TRN & \\
\hline CHEMBL1257405 & 1641446 & 9.3979 & 9.3606 & TRN & \\
\hline CHEMBL 1257170 & 1641446 & 9.2218 & 9.332 & TRN & \\
\hline \multirow[t]{2}{*}{ CHEMBL1257633 } & 1641446 & 5.7696 & 5.74299 & 9999999999 & TRN \\
\hline & & \multicolumn{4}{|c|}{ Page 18594} \\
\hline
\end{tabular}


Supplemental Table S2.txt

\begin{tabular}{|c|c|c|c|c|}
\hline HEMBL & 1446 & & & \\
\hline HEMBL1258219 & 641446 & 6.4815 & 7038 & \\
\hline 90 & & & & \\
\hline AEMBL125 & 541446 & & 0209 & $\mathrm{MI}$ \\
\hline AEMBL1257877 & r & 28 & 5626 & \\
\hline HEMBL1256163 & 641446 & 6.8861 & 1551 & \\
\hline HEMBL125 & & & 2677 & \\
\hline IEMBL125 & & & & \\
\hline AEMBL1258220 & 446 & 7.8239 & .914 & \\
\hline HEMBL1258105 & 64 & 5.699 & 6903 & \\
\hline HEMBL1257514 & 16 & 949 & 6806 & \\
\hline AEMBL125 & 6 & 59 & 5975 & \\
\hline AEMBL125 & & & & \\
\hline HEMBL1258221 & 6 & 24 & 7.2244 & \\
\hline AEMBL1257517 & 6 & 79 & .465 & \\
\hline AEMBL125 & 6 & 8. & 8.4532 & \\
\hline HEMBL125 & $6<$ & & 186 & - \\
\hline HEMBL 125 & & & & \\
\hline HEMBL125 & & & 7.3205 & \\
\hline HEMBL125 & & & & \\
\hline UEMBLI2 & 6 & & 518 & 1SI \\
\hline AEMBL12 & & & 503 & ודים \\
\hline HEMBL 12 & & & & \\
\hline HEMBL125 & & & 99 & \\
\hline AEMBL125 & & & & 1د \\
\hline HEMBL12 & 6 & & & SI \\
\hline HEMBL12 & 0 & & & ST \\
\hline HEMBL13 & 52 & & 06 & RN \\
\hline HEMBL1359629 & & & & RIV \\
\hline HEMBL1573 & 52 & & 8843 & IRIN \\
\hline HEMBL132 & 2 & & 9569 & RN \\
\hline HEMBL1 & 2 & & 48 & RN \\
\hline HEMBL153 & 2 & & 3884 & RN \\
\hline HEMBL1335574 & 52 & & 669 & is \\
\hline HEMBL1605799 & 52 & & 9966 & 「RN \\
\hline HEMBL141 & 2 & & 214 & RN \\
\hline HEMRI 1 & & & 521 & $\Gamma \mathrm{RN}$ \\
\hline HEMBL13: & 73 & & & RN \\
\hline HEMBL1530865 & 37 & 4 & 6392 & TRN \\
\hline AEMBL136؟ & 2 & & 9615 & TRN \\
\hline HEMBL153 & & & 2137 & \\
\hline HEMBL 2448606 & & & 4.6585 & ГST \\
\hline HEMBL160 & 737 & & 0857 & ГST \\
\hline HEMBL1558517 & 37 & & 931 & TR \\
\hline MBL1 & & 4. & 3147 & RN \\
\hline CHEMBL1524111 & 37 & & 3.1786 & \\
\hline CHEMBL1601823 & 737 & 5.3565 & 4.449 & \\
\hline CHEMBL1595439 & 737062 & 6.0 & 6.1319 & 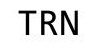 \\
\hline
\end{tabular}

Page 18595 


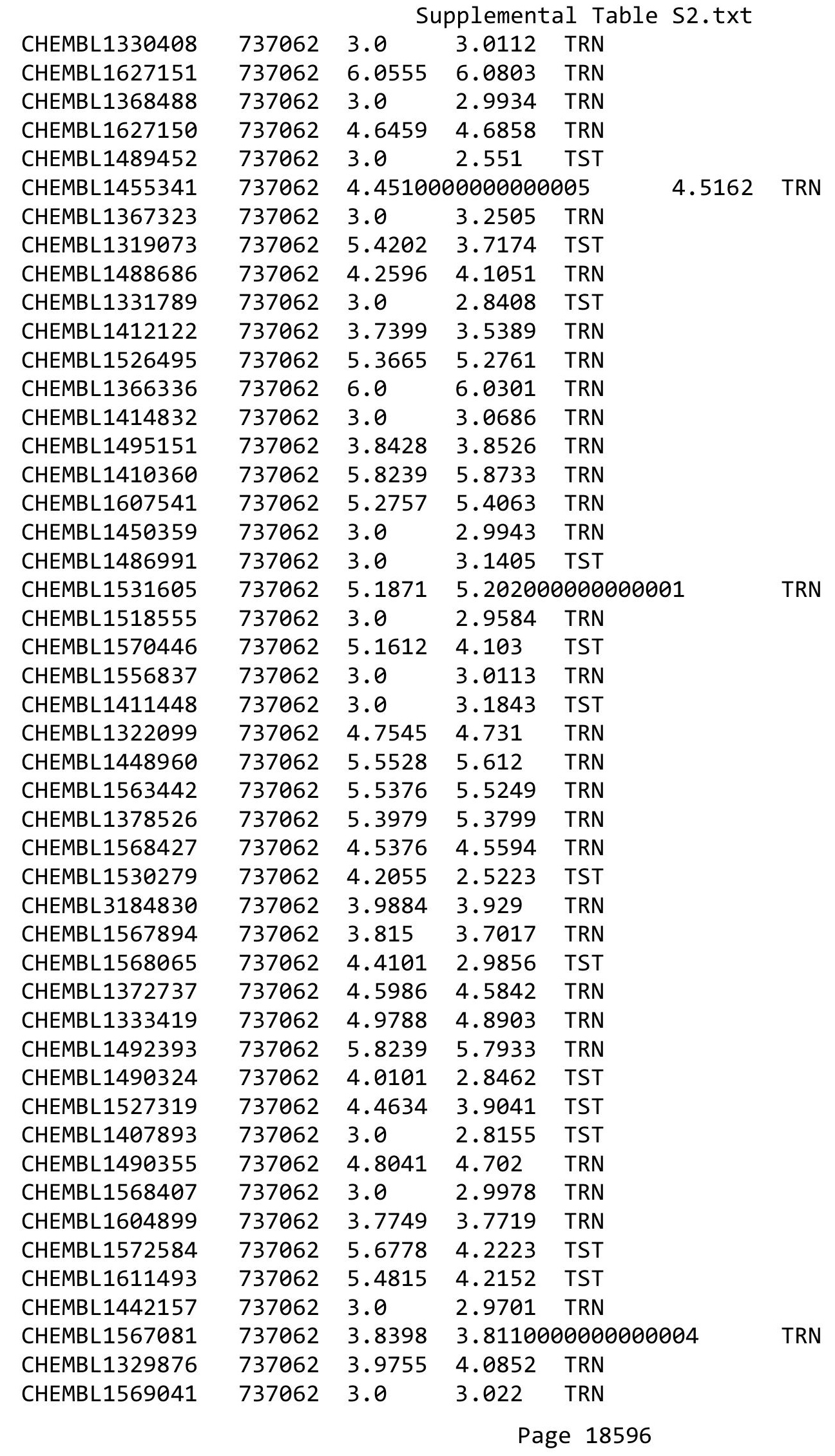




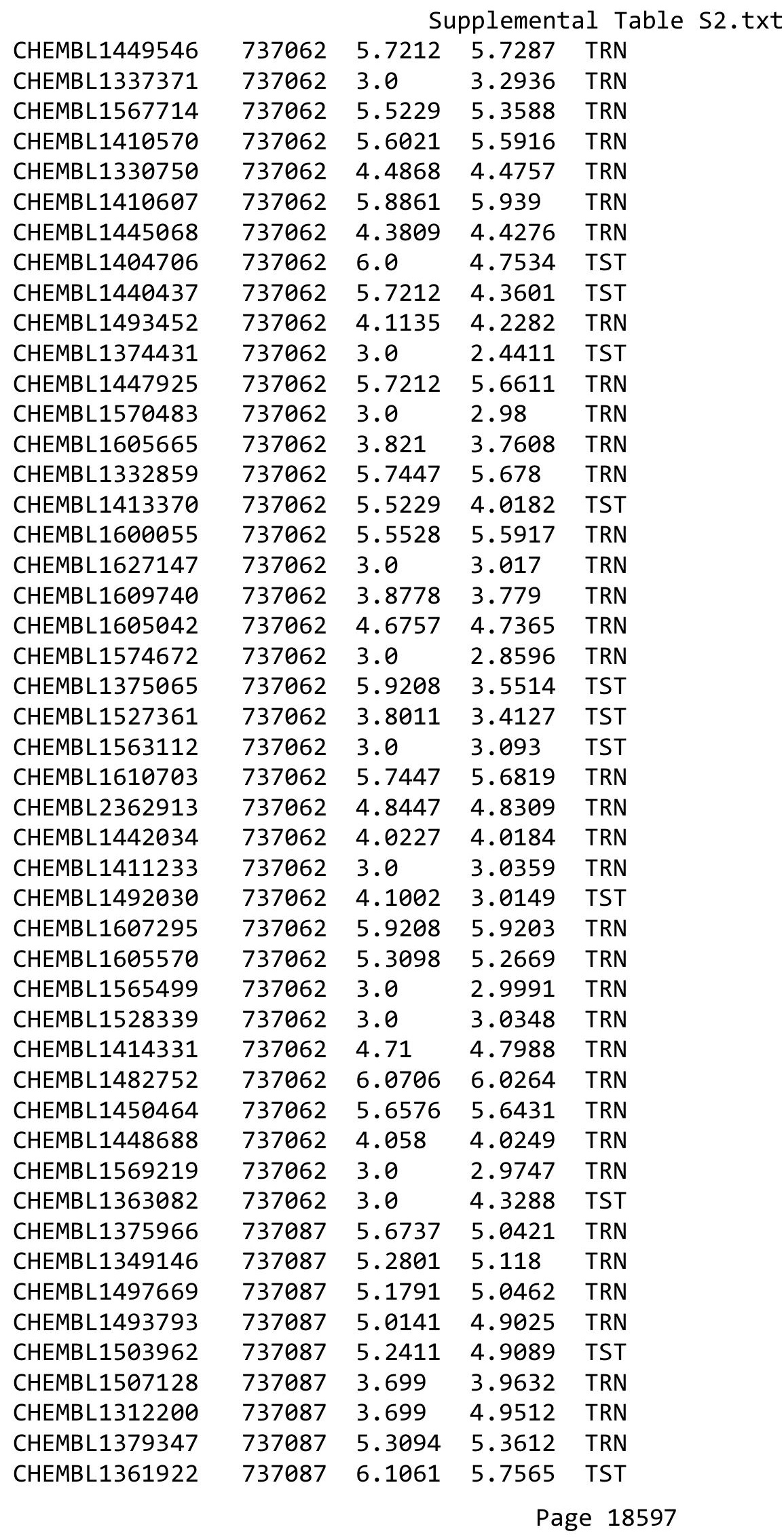


Supplemental Table S2.txt

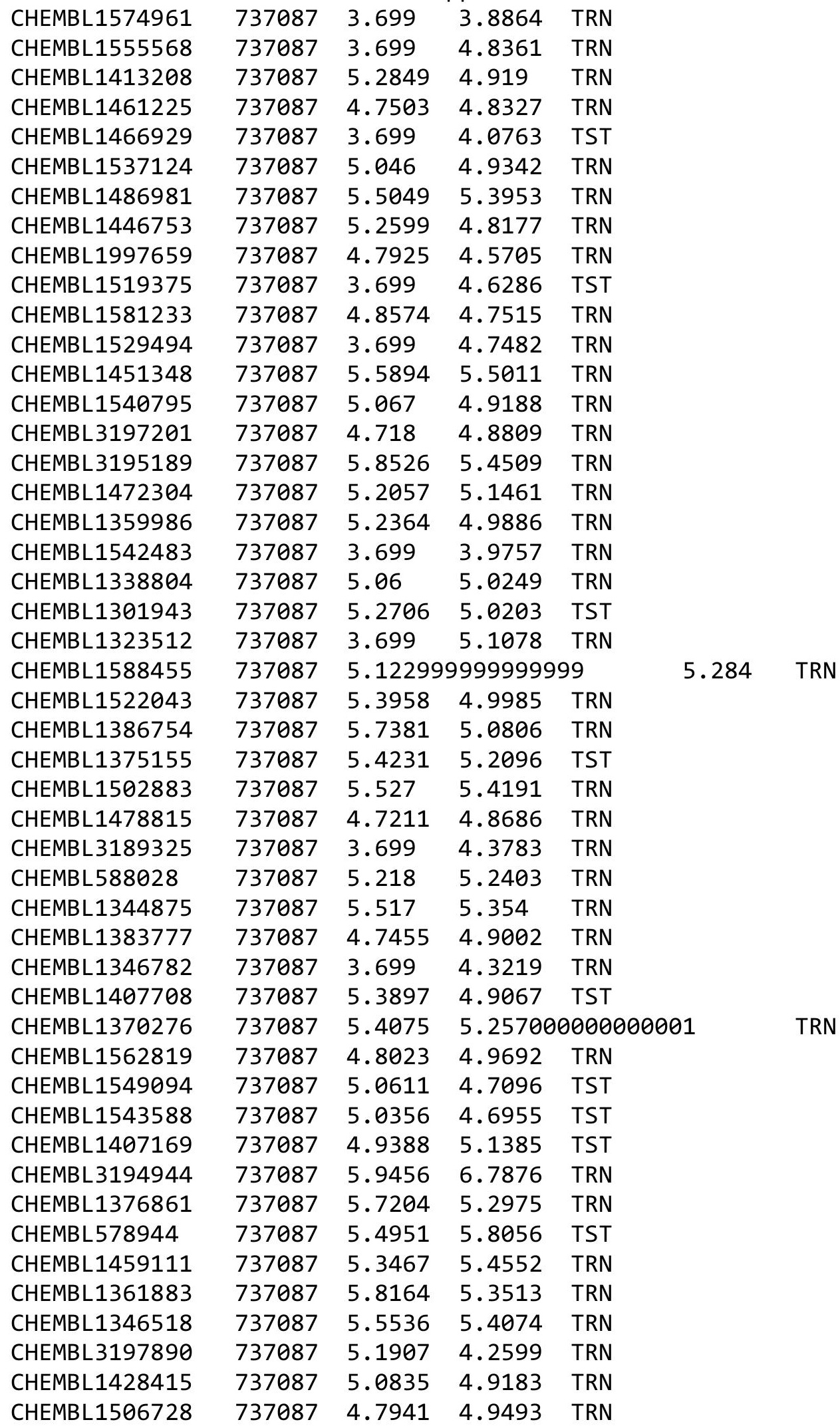

Page 18598 
Supplemental Table S2.txt

\begin{tabular}{|c|c|c|c|c|c|c|}
\hline CHEMBL1504170 & 737087 & 4.9974 & \multicolumn{3}{|c|}{ 4.718999999999999 } & TRN \\
\hline CHEMBL1501375 & 737087 & 4.9829 & 5.0367 & TRN & & \\
\hline CHEMBL1583186 & 737087 & 5.7752 & 5.534 & TRN & & \\
\hline CHEMBL1613298 & 737087 & 5.5291 & 4.9417 & TRN & & \\
\hline CHEMBL1313978 & 737087 & 5.5025 & 5.4069 & TRN & & \\
\hline CHEMBL1337226 & 737087 & 5.7917 & 5.7691 & TRN & & \\
\hline CHEMBL1462357 & 737087 & 5.4504 & 5.1234 & TRN & & \\
\hline CHEMBL1444822 & 737087 & 5.6308 & 4.5568 & TST & & \\
\hline CHEMBL1464490 & 737087 & 3.699 & 4.4612 & TRN & & \\
\hline CHEMBL1437979 & 737087 & 5.3544 & 5.5079 & TRN & & \\
\hline CHEMBL1478220 & 737087 & 4.8548 & 4.631 & TRN & & \\
\hline CHEMBL1425921 & 737087 & 5.1727 & 5.8496 & TRN & & \\
\hline CHEMBL1346232 & 737087 & 4.9262 & 4.8807 & TRN & & \\
\hline CHEMBL1431014 & 737087 & 4.9763 & 5.0737 & TRN & & \\
\hline CHEMBL257286 & 737087 & 5.5626 & 5.4596 & TRN & & \\
\hline CHEMBL1369879 & 737087 & 5.1981 & 5.4609 & TRN & & \\
\hline CHEMBL1439315 & 737087 & 5.3416 & 6.2372 & TRN & & \\
\hline CHEMBL1561275 & 737087 & 3.699 & 4.8173 & TST & & \\
\hline CHEMBL1364018 & 737087 & 5.6764 & 5.2864 & TST & & \\
\hline CHEMBL1361509 & 737087 & 5.2377 & 4.9255 & TRN & & \\
\hline CHEMBL1308276 & 737087 & 5.1122 & 5.0144 & TRN & & \\
\hline CHEMBL1571150 & 737087 & 5.0029 & 4.8787 & TST & & \\
\hline CHEMBL1310435 & 737087 & 7.5051 & 4.8467 & TRN & & \\
\hline CHEMBL1486619 & 737087 & 5.7426 & 5.5602 & TRN & & \\
\hline CHEMBL1579602 & 737087 & 5.1631 & 5.0371 & TST & & \\
\hline CHEMBL1306900 & 737087 & 5.2248 & 4.9882 & TST & & \\
\hline CHEMBL1565526 & 737087 & \multicolumn{3}{|c|}{5.7620000000000005} & 5.1278 & TRN \\
\hline CHEMBL1468596 & 737087 & 5.3683 & 5.2298 & TRN & & \\
\hline CHEMBL1306839 & 737087 & 4.8048 & 4.7961 & TRN & & \\
\hline CHEMBL1466636 & 737087 & 5.8899 & 5.3114 & TST & & \\
\hline CHEMBL 2006780 & 737087 & 5.4084 & 5.4438 & TRN & & \\
\hline CHEMBL1393096 & 737087 & 5.0692 & 5.3001 & TRN & & \\
\hline CHEMBL1600776 & 737087 & 5.3528 & 5.1752 & TRN & & \\
\hline CHEMBL1332060 & 737087 & 4.8287 & 4.9185 & TRN & & \\
\hline CHEMBL1538154 & 737087 & \multicolumn{3}{|c|}{5.5089999999999995} & 5.2965 & TRN \\
\hline CHEMBL1605213 & 737087 & 5.3784 & 4.9721 & TRN & & \\
\hline CHEMBL1505474 & 737087 & 5.8469 & 5.1122 & TRN & & \\
\hline CHEMBL1400385 & 737087 & 4.8891 & 4.9518 & TRN & & \\
\hline CHEMBL1586263 & 737087 & 5.334 & 5.2754 & TRN & & \\
\hline CHEMBL1526479 & 737087 & 5.2447 & 4.9212 & TST & & \\
\hline CHEMBL1387990 & 737087 & 3.699 & 4.6246 & TST & & \\
\hline CHEMBL1568877 & 737087 & 5.1659 & 5.1174 & TRN & & \\
\hline CHEMBL1473402 & 737087 & 4.9765 & 4.8295 & TRN & & \\
\hline CHEMBL1546267 & 737087 & 4.8031 & 4.7469 & TRN & & \\
\hline CHEMBL1586359 & 737087 & 5.2825 & 5.05399 & 999999999s & & ובן \\
\hline CHEMBL1328478 & 737087 & 3.699 & 4.2328 & TRN & & \\
\hline CHEMBL1306769 & 737087 & 3.699 & 4.4319 & TRN & & \\
\hline CHEMBL1424118 & 737087 & 5.2678 & 5.0589 & TST & & \\
\hline
\end{tabular}




\begin{tabular}{|c|c|c|c|c|}
\hline & & & pplement & al $\mathrm{T}$ \\
\hline CHEMBL1612423 & 737087 & 5.6755 & 4.8725 & TRN \\
\hline CHEMBL1549092 & 737087 & 3.699 & 4.9789 & TRN \\
\hline CHEMBL1542558 & 737087 & 3.699 & 4.0055 & TRN \\
\hline CHEMBL1612227 & 737087 & 5.2439 & 5.2188 & TRN \\
\hline CHEMBL1576555 & 737087 & 5.2534 & 5.1475 & TRN \\
\hline CHEMBL1388356 & 737087 & 3.699 & 4.1923 & TRN \\
\hline CHEMBL1480238 & 737087 & 6.1764 & 6.245 & TRN \\
\hline CHEMBL1466495 & 737087 & 3.699 & 4.8589 & TRN \\
\hline CHEMBL1536849 & 737087 & 4.8496 & 4.7354 & TRN \\
\hline CHEMBL1586285 & 737087 & 5.2202 & 5.1564 & TRN \\
\hline CHEMBL1452267 & 737087 & 5.1527 & 5.0378 & TRN \\
\hline CHEMBL1309874 & 737087 & 5.3622 & 5.34 & TRN \\
\hline CHEMBL1401026 & 737087 & 5.5144 & 5.1204 & TRN \\
\hline CHEMBL1457068 & 737087 & 3.699 & 4.0292 & TRN \\
\hline CHEMBL1598294 & 737087 & 4.7836 & 4.1274 & TRN \\
\hline CHEMBL3195226 & 737087 & 4.806 & 5.1013 & TRN \\
\hline CHEMBL1455542 & 737087 & 5.7371 & 5.612 & TST \\
\hline CHEMBL1320494 & 737087 & 5.0933 & 4.7334 & TRN \\
\hline CHEMBL1414053 & 737087 & 5.5103 & 5.3576 & TRN \\
\hline CHEMBL1521877 & 737087 & 3.699 & 5.1092 & TRN \\
\hline CHEMBL1414898 & 737087 & 5.4065 & 5.0652 & TRN \\
\hline CHEMBL1378118 & 737087 & 5.6626 & 4.7629 & TRN \\
\hline CHEMBL1603938 & 737087 & 3.699 & 4.8458 & TRN \\
\hline CHEMBL1495358 & 737087 & 5.1148 & 4.9113 & TRN \\
\hline CHEMBL1360862 & 737087 & 5.3306 & 5.059 & TRN \\
\hline CHEMBL1332684 & 737087 & 5.7932 & 5.0647 & TST \\
\hline CHEMBL1589670 & 737087 & 5.3128 & 4.8912 & TRN \\
\hline CHEMBL1528258 & 737087 & 5.0361 & 4.816 & TST \\
\hline CHEMBL1595790 & 737087 & 7.5051 & 6.3298 & TST \\
\hline CHEMBL1555482 & 737087 & 5.4438 & 5.0333 & TRN \\
\hline CHEMBL190346 & 737087 & 5.896 & 5.3356 & TRN \\
\hline CHEMBL3197098 & 737087 & 4.8016 & 4.8674 & TRN \\
\hline CHEMBL1580556 & 737087 & 6.3458 & 5.5428 & TRN \\
\hline CHEMBL1577792 & 737087 & 3.699 & 5.0002 & TST \\
\hline CHEMBL1611369 & 737087 & 5.3236 & 4.9355 & TRN \\
\hline CHEMBL1439435 & 737087 & 5.1622 & 4.6412 & TRN \\
\hline CHEMBL1423286 & 737087 & 4.8537 & 5.0801 & TRN \\
\hline CHEMBL1409963 & 737087 & 5.1591 & 4.9307 & TST \\
\hline CHEMBL1299319 & 737087 & 5.274 & 5.2533 & TRN \\
\hline CHEMBL1604919 & 737087 & 5.188 & 5.2937 & TST \\
\hline CHEMBL1470676 & 737087 & 5.1929 & 5.6925 & TRN \\
\hline CHEMBL1347270 & 737087 & 5.3203 & 5.5382 & TRN \\
\hline CHEMBL1332013 & 737087 & 5.3045 & 5.2622 & TRN \\
\hline CHEMBL1606583 & 737087 & 5.2053 & 5.2324 & TRN \\
\hline CHEMBL1310479 & 737087 & 4.9121 & 4.7496 & TRN \\
\hline CHEMBL1572157 & 737087 & 3.699 & 4.7318 & TRN \\
\hline CHEMBL1372398 & 737087 & 5.7657 & 5.6918 & TRN \\
\hline CHEMBL1426152 & 737087 & 4.9328 & 4.8805 & TRN \\
\hline
\end{tabular}




\begin{tabular}{|c|c|c|c|c|c|c|}
\hline & & \multicolumn{5}{|c|}{ Supplemental Table S2.txt } \\
\hline CHEMBL1400275 & 737087 & 5.4564 & 5.3788 & TRN & & \\
\hline CHEMBL1344292 & 737087 & 5.2884 & 5.2701 & TRN & & \\
\hline CHEMBL1495890 & 737087 & 5.2025 & 5.1471 & TST & & \\
\hline CHEMBL1427972 & 737087 & 3.699 & 3.967 & TRN & & \\
\hline CHEMBL1320446 & 737087 & 5.2697 & 4.9134 & TRN & & \\
\hline CHEMBL1337833 & 737087 & 5.1839 & 4.8449 & TRN & & \\
\hline CHEMBL1466286 & 737087 & 5.0888 & 4.9991 & TRN & & \\
\hline CHEMBL1547436 & 737087 & 5.3653 & 5.2562 & TST & & \\
\hline CHEMBL1490092 & 737087 & 5.1117 & 5.1254 & TRN & & \\
\hline CHEMBL1308674 & 737087 & 5.085 & 5.0524 & TRN & & \\
\hline CHEMBL1598561 & 737087 & 5.1589 & 5.2216 & TRN & & \\
\hline CHEMBL583558 & 737087 & 4.9767 & 4.8199 & TST & & \\
\hline CHEMBL1421574 & 737087 & 5.0402 & 4.7741 & TRN & & \\
\hline CHEMBL1611774 & 737087 & 4.8567 & 4.8631 & TST & & \\
\hline CHEMBL1573795 & 737087 & 3.699 & 3.7535 & TRN & & \\
\hline CHEMBL1385296 & 737087 & 5.0848 & 4.8535 & TRN & & \\
\hline CHEMBL1347274 & 737087 & 5.5417 & 5.5091 & TRN & & \\
\hline CHEMBL1489361 & 737087 & 5.1335 & 4.9353 & TST & & \\
\hline CHEMBL1498038 & 737087 & 5.3899 & 5.2416 & TRN & & \\
\hline CHEMBL1455507 & 737087 & 5.4662 & 4.881 & TRN & & \\
\hline CHEMBL1416848 & 737087 & 5.8126 & 5.4665 & TRN & & \\
\hline CHEMBL1484741 & 737087 & 5.6358 & 5.2668 & TST & & \\
\hline CHEMBL1374703 & 737087 & 3.699 & 4.3075 & TRN & & \\
\hline CHEMBL1407627 & 737087 & 5.2237 & 5.1702 & TRN & & \\
\hline CHEMBL3190198 & 737087 & 5.1857 & 5.0651 & TRN & & \\
\hline CHEMBL1481778 & 737087 & 5.2578 & 5.1271 & TRN & & \\
\hline CHEMBL3213107 & 737087 & $4.7010 e$ & 20000000 & 205 & 4.8131 & Tा \\
\hline CHEMBL1996376 & 737087 & 3.699 & 4.2799 & TST & & \\
\hline CHEMBL1388113 & 737087 & 5.222 & 5.5048 & TRN & & \\
\hline CHEMBL1481689 & 737087 & 5.1155 & 4.7516 & TRN & & \\
\hline CHEMBL1336374 & 737087 & 4.8909 & 4.7662 & TRN & & \\
\hline CHEMBL1542713 & 737087 & 5.6546 & 4.9398 & TRN & & \\
\hline CHEMBL1479888 & 737087 & 4.9731 & 5.3182 & TST & & \\
\hline CHEMBL1380813 & 737087 & 4.7093 & 5.2043 & TRN & & \\
\hline CHEMBL1339310 & 737087 & 4.8319 & 4.7731 & TRN & & \\
\hline CHEMBL1556086 & 737087 & 4.8375 & 4.0375 & TRN & & \\
\hline CHEMBL1460585 & 737087 & 3.699 & 4.9107 & TRN & & \\
\hline CHEMBL1457427 & 737087 & 4.7629 & 4.8107 & TRN & & \\
\hline CHEMBL1415786 & 737087 & 3.699 & 4.0755 & TST & & \\
\hline CHEMBL1440314 & 737087 & 5.1213 & 4.6084 & TRN & & \\
\hline CHEMBL1543504 & 737087 & 3.699 & 5.1588 & TST & & \\
\hline CHEMBL3197790 & 737087 & 4.7113 & 4.0072 & TRN & & \\
\hline CHEMBL1333821 & 737087 & 5.3203 & 5.6739 & TRN & & \\
\hline CHEMBL1436964 & 737087 & 4.8015 & 4.8617 & TRN & & \\
\hline CHEMBL1372308 & 737087 & 5.2383 & 5.0123 & TRN & & \\
\hline CHEMBL1501527 & 737087 & 5.0309 & 4.8816 & TRN & & \\
\hline CHEMBL1462451 & 737087 & 5.0308 & 5.0969 & TST & & \\
\hline CHEMBL1332003 & 737087 & 3.699 & 4.8374 & TRN & & \\
\hline
\end{tabular}




\begin{tabular}{|c|c|c|c|c|c|}
\hline & & \multicolumn{4}{|c|}{ Supplemental Table S2.txt } \\
\hline CHEMBL1478256 & 737087 & 3.699 & 4.6499 & TRN & \\
\hline CHEMBL1333757 & 737087 & 4.782 & 4.2232 & TST & \\
\hline CHEMBL1426978 & 737087 & 5.0201 & 5.0733 & TRN & \\
\hline CHEMBL1503006 & 737087 & 3.699 & 4.775 & TRN & \\
\hline CHEMBL1304363 & 737087 & 5.0764 & 5.193 & TRN & \\
\hline CHEMBL1318742 & 737087 & 5.1028 & 4.6934 & TRN & \\
\hline CHEMBL1384893 & 737087 & 5.0992 & 4.7525 & TRN & \\
\hline CHEMBL1409423 & 737087 & 5.4183 & 5.1996 & TRN & \\
\hline CHEMBL1509707 & 737087 & 4.9529 & \multicolumn{2}{|c|}{5.031000000000001} & TRN \\
\hline CHEMBL1570135 & 737087 & 5.2323 & 5.3736 & TRN & \\
\hline CHEMBL1556615 & 737087 & 5.2327 & 5.1142 & TRN & \\
\hline CHEMBL1597561 & 737087 & 7.5051 & 7.7511 & TRN & \\
\hline CHEMBL1528265 & 737087 & 5.0091 & 4.9188 & TRN & \\
\hline CHEMBL1445206 & 737087 & 3.699 & 4.7112 & TRN & \\
\hline CHEMBL1415184 & 737087 & 6.0355 & 5.7707 & TST & \\
\hline CHEMBL1608707 & 737087 & 4.7602 & 4.2641 & TRN & \\
\hline CHEMBL1354394 & 737087 & 3.699 & 4.8652 & TRN & \\
\hline CHEMBL1453730 & 737087 & 4.9541 & 5.3667 & TRN & \\
\hline CHEMBL1967099 & 737087 & 3.699 & 3.8626 & TRN & \\
\hline CHEMBL1449663 & 737087 & 3.699 & 4.4364 & TRN & \\
\hline CHEMBL1497803 & 737087 & 3.699 & 4.6266 & TRN & \\
\hline CHEMBL1520241 & 737087 & 5.9805 & 5.2953 & TRN & \\
\hline CHEMBL1599462 & 737087 & 5.2719 & 4.6828 & TRN & \\
\hline CHEMBL1499195 & 737087 & 5.2778 & 5.5342 & TRN & \\
\hline CHEMBL1593484 & 737087 & 3.699 & 4.4495 & TRN & \\
\hline CHEMBL1543473 & 737087 & 5.0389 & 4.7913 & TRN & \\
\hline CHEMBL1468750 & 737087 & 5.2458 & 5.1143 & TRN & \\
\hline CHEMBL1450208 & 737087 & 4.9511 & 4.8206 & TRN & \\
\hline CHEMBL1447831 & 737087 & 5.4737 & 5.1539 & TRN & \\
\hline CHEMBL1562608 & 737087 & 3.699 & \multicolumn{2}{|c|}{4.7780000000000005} & TRN \\
\hline CHEMBL1325227 & 737087 & 5.3889 & 5.4285 & TRN & \\
\hline CHEMBL1534959 & 737087 & 4.7571 & 3.9664 & TST & \\
\hline CHEMBL1489105 & 737087 & 3.699 & 4.8578 & TRN & \\
\hline CHEMBL1382640 & 737087 & 4.7319 & 4.7649 & TRN & \\
\hline CHEMBL600778 & 737087 & 4.9206 & 4.0106 & TRN & \\
\hline CHEMBL1299281 & 737087 & 5.0441 & 5.0325 & TRN & \\
\hline CHEMBL1462906 & 737087 & 3.699 & 5.1197 & TRN & \\
\hline CHEMBL1531328 & 737087 & 5.6266 & 5.5491 & TST & \\
\hline CHEMBL1364793 & 737087 & 5.5003 & 5.2139 & TRN & \\
\hline CHEMBL1418948 & 737087 & 5.1933 & 5.1244 & TST & \\
\hline CHEMBL1573242 & 737087 & 5.4291 & 4.9634 & TRN & \\
\hline CHEMBL1558928 & 737087 & 4.8816 & 4.7416 & TRN & \\
\hline CHEMBL1550184 & 737087 & 5.1404 & 4.6875 & TST & \\
\hline CHEMBL1351159 & 737087 & 5.0638 & 4.7351 & TRN & \\
\hline CHEMBL1327276 & 737087 & 5.0778 & 4.7833 & TRN & \\
\hline CHEMBL1384652 & 737087 & 3.699 & 4.90600 & 0000000001 & TRN \\
\hline CHEMBL1567973 & 737087 & 5.0897 & 4.9971 & TST & \\
\hline CHEMBL1495687 & 737087 & 5.4832 & 5.4407 & TST & \\
\hline
\end{tabular}




\begin{tabular}{|c|c|c|c|c|c|c|}
\hline \multirow[b]{2}{*}{ CHEMBL1394121 } & & \multicolumn{5}{|c|}{ Supplemental Table S2.txt } \\
\hline & 737087 & 3.699 & 4.3735 & TRN & & \\
\hline CHEMBL1560679 & 737087 & 4.9007 & 4.8395 & TRN & & \\
\hline CHEMBL1417054 & 737087 & 5.4481 & 5.35 & TRN & & \\
\hline CHEMBL1300239 & 737087 & 5.71399 & 99999999 & 995 & 5.2709 & TRN \\
\hline CHEMBL1586593 & 737087 & 4.9943 & 5.0928 & TRN & & \\
\hline CHEMBL1458660 & 737087 & 4.9288 & 4.7525 & TRN & & \\
\hline CHEMBL1330503 & 737087 & 4.8029 & 4.3015 & TRN & & \\
\hline CHEMBL1466121 & 737087 & 4.8931 & 4.8194 & TRN & & \\
\hline CHEMBL1444785 & 737087 & 5.2815 & 5.3058 & TRN & & \\
\hline CHEMBL1994623 & 737087 & 3.699 & 4.1623 & TRN & & \\
\hline CHEMBL1491541 & 737087 & 3.699 & 5.1777 & TRN & & \\
\hline CHEMBL1349185 & 737087 & 3.699 & 3.9053 & TRN & & \\
\hline CHEMBL1313090 & 737087 & 5.92299 & 79999999 & 99 & 5.0518 & TRN \\
\hline CHEMBL1991112 & 737087 & 3.699 & 4.6161 & TST & & \\
\hline CHEMBL1323456 & 737087 & 5.1047 & 4.9753 & TRN & & \\
\hline CHEMBL1332761 & 737087 & 4.9395 & 4.9253 & TRN & & \\
\hline CHEMBL1573929 & 737087 & 5.0708 & 4.2057 & TRN & & \\
\hline CHEMBL1344677 & 737087 & 5.0909 & 5.4783 & TST & & \\
\hline CHEMBL1457600 & 737087 & 4.8404 & 4.2101 & TRN & & \\
\hline CHEMBL1367597 & 737087 & 5.239 & 4.9485 & TRN & & \\
\hline CHEMBL1608077 & 737087 & 5.4025 & 5.2882 & TRN & & \\
\hline CHEMBL1568614 & 737087 & 3.699 & 4.0677 & TRN & & \\
\hline CHEMBL1514917 & 737087 & 5.3667 & 5.2526 & TST & & \\
\hline CHEMBL1493633 & 737087 & 5.2814 & 5.3207 & TRN & & \\
\hline CHEMBL1567424 & 737087 & 3.699 & 4.8359 & TRN & & \\
\hline CHEMBL1377693 & 737087 & 5.3648 & 5.0958 & TRN & & \\
\hline CHEMBL3189997 & 737087 & 3.699 & 4.7653 & TST & & \\
\hline CHEMBL1578700 & 737087 & 5.33799 & 99999999 & 99 & 5.2357 & TRN \\
\hline CHEMBL1323622 & 737087 & 4.876 & 5.3336 & TRN & & \\
\hline CHEMBL1571872 & 737087 & 3.699 & 5.0716 & TRN & & \\
\hline CHEMBL1599782 & 737087 & 3.699 & 5.1866 & TRN & & \\
\hline CHEMBL1568646 & 737087 & 5.6846 & 5.2877 & TRN & & \\
\hline CHEMBL1446570 & 737087 & 3.699 & 4.4611 & TRN & & \\
\hline CHEMBL1606309 & 737087 & 5.3383 & 5.0975 & TRN & & \\
\hline CHEMBL1505956 & 737087 & 6.0225 & 5.4731 & TRN & & \\
\hline CHEMBL1406480 & 737087 & 5.233 & 4.9929 & TRN & & \\
\hline CHEMBL1512575 & 737087 & 5.3814 & 5.3191 & TRN & & \\
\hline CHEMBL1571360 & 737087 & 3.699 & 4.6875 & TRN & & \\
\hline CHEMBL1325644 & 737087 & 3.699 & 4.8813 & TRN & & \\
\hline CHEMBL1418614 & 737087 & 5.1521 & 4.9213 & TRN & & \\
\hline CHEMBL1306524 & 737087 & 5.5845 & 5.4839 & TRN & & \\
\hline CHEMBL1391279 & 737087 & 4.9531 & 4.8044 & TST & & \\
\hline CHEMBL1588806 & 737087 & 5.0562 & 5.0963 & TRN & & \\
\hline CHEMBL1351128 & 737087 & 5.9183 & 5.1829 & TRN & & \\
\hline CHEMBL1550032 & 737087 & 5.0142 & 4.1636 & TRN & & \\
\hline CHEMBL1500227 & 737087 & 5.4923 & 5.3399 & TST & & \\
\hline CHEMBL1483308 & 737087 & 5.186 & 5.2513 & TRN & & \\
\hline CHEMBL1421446 & 737087 & 5.5062 & 5.0485 & TRN & & \\
\hline
\end{tabular}




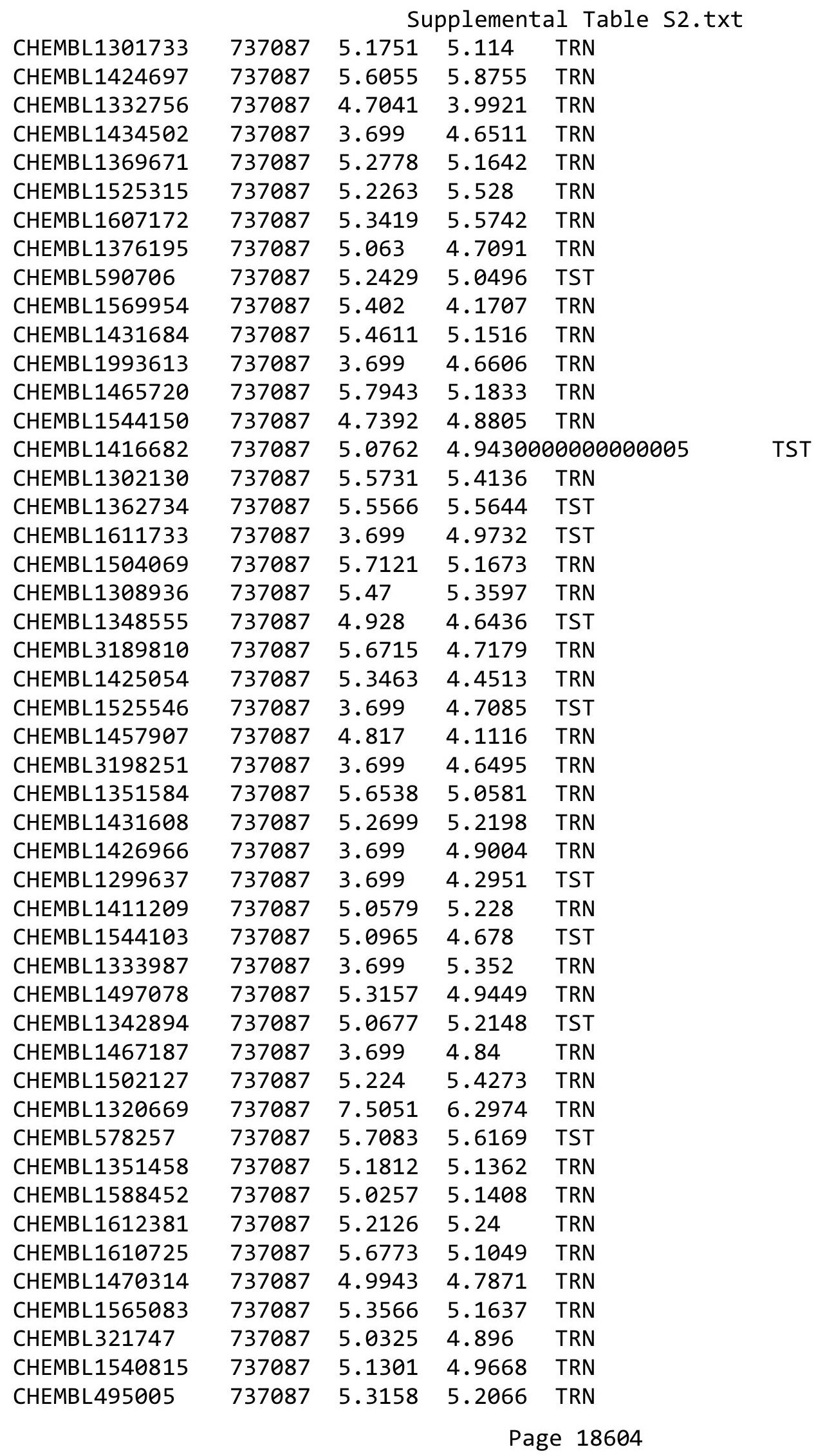




\begin{tabular}{|c|c|c|c|c|c|c|}
\hline \multirow{3}{*}{$\begin{array}{l}\text { CHEMBL } 1477197 \\
\text { CHEMBL1483105 }\end{array}$} & \multirow{2}{*}{737087} & & \multirow{2}{*}{\multicolumn{3}{|c|}{4.2330000000000005}} & \\
\hline & & 4.7805 & & & & TRN \\
\hline & 737087 & 4.8453 & 4.7317 & TRN & & \\
\hline CHEMBL1437053 & 737087 & 5.2187 & 5.0966 & TRN & & \\
\hline CHEMBL1401029 & 737087 & 3.699 & 3.9189 & TRN & & \\
\hline CHEMBL1525854 & 737087 & 3.699 & 3.9704 & TRN & & \\
\hline CHEMBL472646 & 737087 & 4.9634 & 5.1229 & TST & & \\
\hline CHEMBL 3189344 & 737087 & 3.699 & 4.0685 & TRN & & \\
\hline CHEMBL1546996 & 737087 & 5.0094 & 4.0723 & TRN & & \\
\hline CHEMBL1586616 & 737087 & 4.812 & 4.2936 & TST & & \\
\hline CHEMBL1504685 & 737087 & 5.4663 & 5.4804 & TST & & \\
\hline CHEMBL1525735 & 737087 & 5.565 & 5.6646 & TRN & & \\
\hline CHEMBL1604797 & 737087 & 5.1506 & 4.7708 & TRN & & \\
\hline CHEMBL1581425 & 737087 & 5.1847 & 5.3148 & TRN & & \\
\hline CHEMBL1385087 & 737087 & 4.7051 & 4.0768 & TRN & & \\
\hline CHEMBL1582794 & 737087 & 5.2652 & 5.1765 & TRN & & \\
\hline CHEMBL1494575 & 737087 & 5.2069 & 5.3403 & TRN & & \\
\hline CHEMBL1585147 & 737087 & 5.3543 & 5.3796 & TRN & & \\
\hline CHEMBL1531428 & 737087 & 5.103 & 4.9042 & TST & & \\
\hline CHEMBL1433943 & 737087 & 4.9548 & 4.8374 & TRN & & \\
\hline CHEMBL1528004 & 737087 & 5.4787 & 5.0369 & TRN & & \\
\hline CHEMBL1350780 & 737087 & 5.2832 & 5.364 & TRN & & \\
\hline CHEMBL3195760 & 737087 & 4.7536 & 5.2013 & TRN & & \\
\hline CHEMBL1442136 & 737087 & 5.37299 & 79999999 & 99 & 5.6367 & TRN \\
\hline CHEMBL3199216 & 737087 & 5.0376 & 5.0872 & TRN & & \\
\hline CHEMBL1540477 & 737087 & 5.73600 & 00000000 & $\partial 1$ & 5.2404 & TRN \\
\hline CHEMBL1569724 & 737087 & 5.2703 & 4.8875 & TRN & & \\
\hline CHEMBL1446989 & 737087 & 4.7312 & 5.0605 & TRN & & \\
\hline CHEMBL1446827 & 737087 & 3.699 & 4.9914 & TRN & & \\
\hline CHEMBL1569174 & 737087 & 7.5051 & 5.2351 & TRN & & \\
\hline CHEMBL1329385 & 737087 & 3.699 & 4.0335 & TRN & & \\
\hline CHEMBL1597042 & 737087 & 4.7903 & 3.9398 & TST & & \\
\hline CHEMBL1570111 & 737087 & 5.1434 & 5.1546 & TRN & & \\
\hline CHEMBL1424366 & 737087 & 4.7225 & 4.021 & TRN & & \\
\hline CHEMBL1400601 & 737087 & 3.699 & 4.6724 & TRN & & \\
\hline CHEMBL1454738 & 737087 & 5.3559 & 5.3291 & TRN & & \\
\hline CHEMBL3195658 & 737087 & 5.1857 & 5.1193 & TRN & & \\
\hline CHEMBL1302109 & 737087 & 5.2395 & 4.7794 & TRN & & \\
\hline CHEMBL1449912 & 737087 & 5.3006 & 4.9138 & TST & & \\
\hline CHEMBL1324011 & 737087 & 5.7238 & 5.3274 & TRN & & \\
\hline CHEMBL1520131 & 737087 & 5.0263 & 4.9413 & TRN & & \\
\hline CHEMBL1334593 & 737087 & 3.699 & 4.9514 & TST & & \\
\hline CHEMBL454580 & 737087 & 3.699 & 5.3371 & TST & & \\
\hline CHEMBL1464332 & 737087 & 3.699 & 4.6813 & TRN & & \\
\hline CHEMBL1472748 & 737087 & 4.8462 & 4.5387 & TRN & & \\
\hline CHEMBL1475198 & 737087 & 5.3257 & 5.4304 & TRN & & \\
\hline CHEMBL1529741 & 737087 & 5.0637 & 4.9555 & TST & & \\
\hline CHEMBL1321987 & 737087 & 5.2152 & 5.2002 & TRN & & \\
\hline CHEMBL1547420 & 737087 & 5.3654 & 4.9295 & TRN & & \\
\hline
\end{tabular}




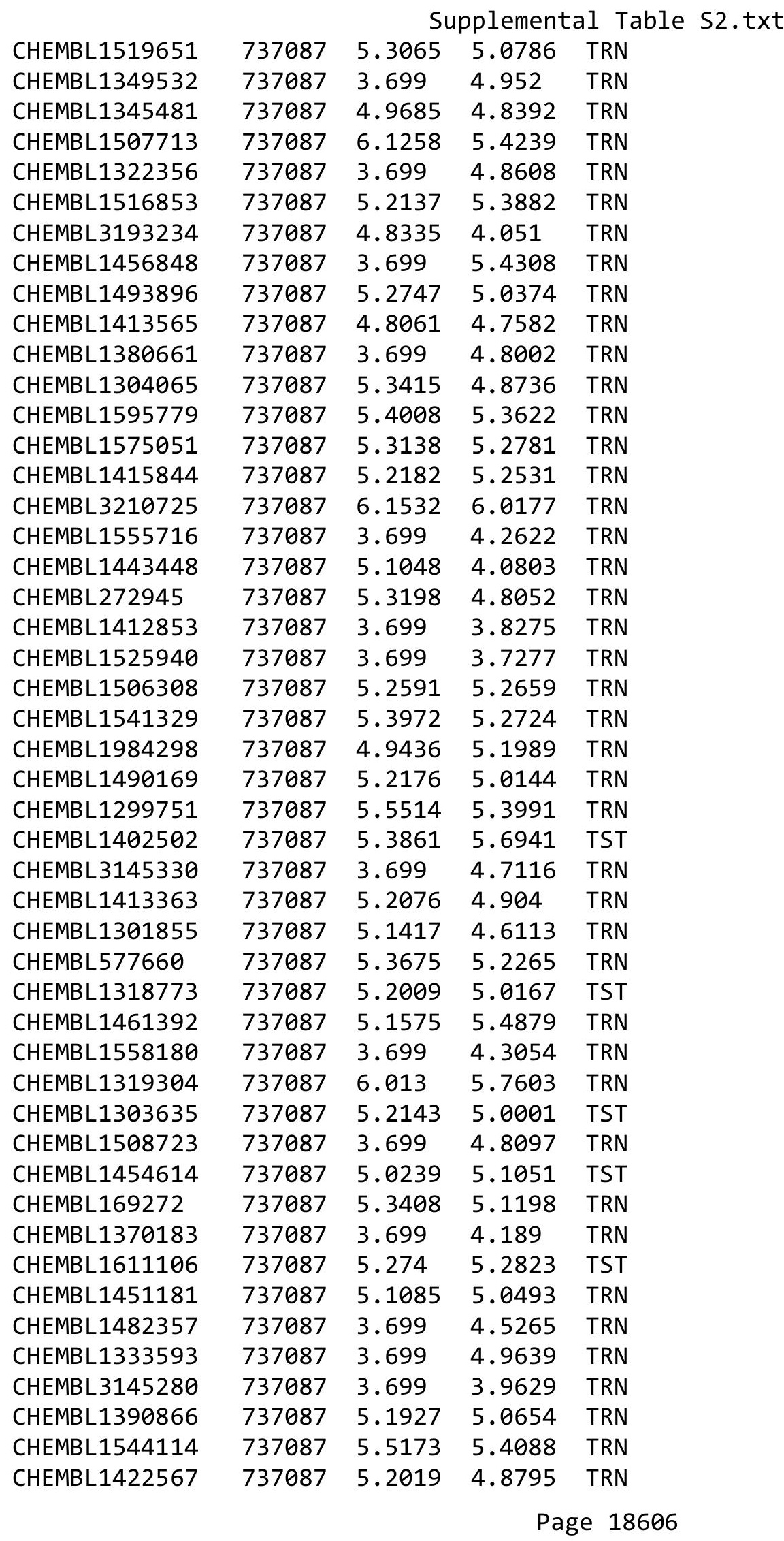




\begin{tabular}{|c|c|c|c|c|c|c|}
\hline & & \multicolumn{5}{|c|}{ Supplemental Table S2.txt } \\
\hline CHEMBL1374160 & 737087 & 5.6107 & 4.9734 & TRN & & \\
\hline CHEMBL1411639 & 737087 & 5.6265 & 5.0992 & TRN & & \\
\hline CHEMBL1556239 & 737087 & 3.699 & 4.8516 & TST & & \\
\hline CHEMBL1509029 & 737087 & 4.9617 & 4.8969 & TRN & & \\
\hline CHEMBL1544947 & 737087 & 5.4719 & 5.1168 & TRN & & \\
\hline CHEMBL1349713 & 737087 & 5.3559 & 5.2294 & TRN & & \\
\hline CHEMBL1308615 & 737087 & 4.7191 & 4.925 & TRN & & \\
\hline CHEMBL1497439 & 737087 & 3.699 & 3.7584 & TRN & & \\
\hline CHEMBL1550862 & 737087 & 5.7883 & 5.2008 & TRN & & \\
\hline CHEMBL1968085 & 737087 & 4.7574 & 4.1602 & TRN & & \\
\hline CHEMBL1580660 & 737087 & 4.9823 & 5.0952 & TRN & & \\
\hline CHEMBL1347256 & 737087 & 5.419 & 4.7746 & TRN & & \\
\hline CHEMBL1483975 & 737087 & 5.4669 & 5.3936 & TRN & & \\
\hline CHEMBL1444020 & 737087 & 5.24 & 5.4018 & TRN & & \\
\hline CHEMBL1366727 & 737087 & 5.5937 & 5.2833 & TRN & & \\
\hline CHEMBL3196263 & 737087 & 5.7531 & 5.2936 & TRN & & \\
\hline CHEMBL1299634 & 737087 & 5.3888 & 5.0862 & TRN & & \\
\hline CHEMBL1586401 & 737087 & 4.94 & 5.0966 & TRN & & \\
\hline CHEMBL1887153 & 737087 & 5.9352 & 4.2872 & TRN & & \\
\hline CHEMBL1567684 & 737087 & 4.7673 & 4.7851 & TRN & & \\
\hline CHEMBL1447125 & 737087 & 5.0398 & 5.0167 & TST & & \\
\hline CHEMBL1483882 & 737087 & 5.4089 & 5.0464 & TRN & & \\
\hline CHEMBL1468181 & 737087 & 7.5051 & 5.9252 & TRN & & \\
\hline CHEMBL1369425 & 737087 & 5.2185 & 5.1052 & TRN & & \\
\hline CHEMBL1445071 & 737087 & 3.699 & 4.0349 & TRN & & \\
\hline CHEMBL1347586 & 737087 & 4.7731 & 4.0316 & TST & & \\
\hline CHEMBL1421605 & 737087 & 5.1838 & 4.8732 & TST & & \\
\hline CHEMBL1498436 & 737087 & 5.2791 & 5.1499 & TRN & & \\
\hline CHEMBL1407401 & 737087 & 5.3713 & 5.2047 & TRN & & \\
\hline CHEMBL579621 & 737087 & 4.8491 & 4.8073 & TRN & & \\
\hline CHEMBL1484482 & 737087 & 5.1824 & 4.9229 & TRN & & \\
\hline CHEMBL1329069 & 737087 & 5.3221 & 5.2728 & TRN & & \\
\hline CHEMBL1306701 & 737087 & 3.699 & 4.1886 & TRN & & \\
\hline CHEMBL1982381 & 737087 & 5.2617 & 5.0309 & TRN & & \\
\hline CHEMBL3194040 & 737087 & 3.699 & 4.7869 & TRN & & \\
\hline CHEMBL1491893 & 737087 & 4.8934 & 4.8538 & TST & & \\
\hline CHEMBL1520276 & 737087 & 5.62299 & 99999999 & 99 & 5.5758 & TRN \\
\hline CHEMBL1477528 & 737087 & 5.0389 & 4.9779 & TRN & & \\
\hline CHEMBL1379291 & 737087 & 5.7385 & 5.0706 & TRN & & \\
\hline CHEMBL1536767 & 737087 & 5.2781 & 5.0568 & TRN & & \\
\hline CHEMBL1468075 & 737087 & 5.0343 & 4.5849 & TRN & & \\
\hline CHEMBL1490563 & 737087 & 3.699 & 4.7319 & TRN & & \\
\hline CHEMBL1457134 & 737087 & 5.23799 & 99999999 & 995 & 5.1598 & TRN \\
\hline CHEMBL1509539 & 737087 & 5.2983 & 5.1401 & TRN & & \\
\hline CHEMBL1374797 & 737087 & 4.9516 & 4.8558 & TRN & & \\
\hline CHEMBL1342784 & 737087 & 4.8968 & 4.8598 & TRN & & \\
\hline CHEMBL1407286 & 737087 & 5.28100 & jo00000e & & .2235 & TRN \\
\hline CHEMBL1379081 & 737087 & 3.699 & 4.2272 & TRN & & \\
\hline
\end{tabular}


Supplemental Table S2.txt

\begin{tabular}{|c|c|c|c|c|}
\hline CHEMBL599890 & 737087 & 3.699 & 3.7526 & TRN \\
\hline CHEMBL1496313 & 737087 & 5.2602 & 4.8528 & TST \\
\hline CHEMBL1351908 & 737087 & 6.3208 & 6.061 & TRN \\
\hline CHEMBL1426245 & 737087 & 4.9478 & 4.7497 & TST \\
\hline CHEMBL1431769 & 737087 & 5.0872 & 4.876 & TST \\
\hline CHEMBL1380946 & 737087 & 4.7972 & 4.0213 & TST \\
\hline CHEMBL1583914 & 737087 & 5.5786 & 5.4322 & TST \\
\hline CHEMBL1427059 & 737087 & 5.4319 & 5.432 & TST \\
\hline CHEMBL1393375 & 737087 & 3.699 & 4.7867 & TST \\
\hline CHEMBL1507251 & 737087 & 6.4625 & 5.8832 & TST \\
\hline CHEMBL3199186 & 737087 & 3.699 & 4.9721 & TST \\
\hline CHEMBL1444690 & 737087 & 5.4447 & 4.9991 & TST \\
\hline CHEMBL1335978 & 737087 & 3.699 & 4.7707 & TST \\
\hline CHEMBL1405985 & 737087 & 3.699 & 4.8724 & TST \\
\hline CHEMBL1586575 & 737087 & 5.3174 & 5.3096 & TST \\
\hline CHEMBL1570792 & 737087 & 5.3191 & 4.9874 & TST \\
\hline CHEMBL1560379 & 737087 & 5.4838 & 5.652 & TST \\
\hline CHEMBL1545677 & 737087 & 3.699 & 4.2081 & TST \\
\hline CHEMBL1408320 & 737087 & 4.7258 & 3.9485 & TST \\
\hline CHEMBL1510940 & 737087 & 5.1128 & 5.1783 & TST \\
\hline CHEMBL1560539 & 737087 & 4.8248 & 5.541 & TST \\
\hline CHEMBL1538692 & 737087 & 5.8207 & 5.6843 & TST \\
\hline CHEMBL1382232 & 737087 & 4.7232 & 4.8814 & TST \\
\hline CHEMBL1420606 & 737087 & 3.699 & 4.737 & TST \\
\hline CHEMBL1440735 & 737087 & 3.699 & 4.2504 & TST \\
\hline CHEMBL1311887 & 737087 & 5.1734 & 5.2231 & TST \\
\hline CHEMBL3197607 & 737087 & 3.699 & 4.3903 & TST \\
\hline CHEMBL1366153 & 737087 & 5.2381 & 4.6419 & TST \\
\hline CHEMBL1597716 & 737087 & 5.3421 & 5.0194 & TST \\
\hline CHEMBL1530557 & 737087 & 5.4999 & 5.55 & TST \\
\hline CHEMBL1377340 & 737087 & 3.699 & 4.9459 & TST \\
\hline CHEMBL1346468 & 737087 & 5.3246 & 4.9646 & TST \\
\hline CHEMBL1602150 & 737087 & 5.3398 & 5.17399 & 9999999995 \\
\hline CHEMBL1456373 & 737087 & 5.2009 & 5.20200 & 000000001 \\
\hline CHEMBL1986274 & 737087 & 5.4283 & 5.0855 & TST \\
\hline CHEMBL1523659 & 737087 & 5.0498 & 4.9715 & TST \\
\hline CHEMBL1442742 & 737087 & 5.4292 & 5.4372 & TST \\
\hline CHEMBL1375884 & 737087 & 4.9638 & 4.8749 & TST \\
\hline CHEMBL3195322 & 737087 & 5.7388 & 6.1164 & TST \\
\hline CHEMBL1398541 & 737087 & 4.7728 & 5.086 & TST \\
\hline CHEMBL3192230 & 737087 & 3.699 & 4.1752 & TST \\
\hline CHEMBL1309210 & 737087 & 5.2439 & 5.0089 & TST \\
\hline CHEMBL1305930 & 737087 & 5.7675 & 5.4376 & TST \\
\hline CHEMBL600100 & 737087 & 4.9671 & 4.7615 & TST \\
\hline CHEMBL1349428 & 737087 & 3.699 & 4.9006 & TST \\
\hline CHEMBL1467115 & 737087 & 5.021 & 5.0517 & TST \\
\hline CHEMBL1382616 & 737087 & 4.9399 & 5.046 & TST \\
\hline CHEMBL1583236 & 737087 & 5.3662 & 5.6761 & TST \\
\hline
\end{tabular}


Supplemental Table S2.txt

\begin{tabular}{|c|c|c|c|c|c|}
\hline CHEMBL1422976 & 737087 & 4.8282 & 5.2995 & TST & \\
\hline CHEMBL1427335 & 737087 & 6.0748 & 4.7528 & TST & \\
\hline CHEMBL1386337 & 737087 & 5.3826 & \multicolumn{2}{|c|}{5.297000000000001} & TST \\
\hline CHEMBL1373339 & 737087 & 5.0503 & 4.8247 & TST & \\
\hline CHEMBL1465119 & 737087 & 5.2682 & 5.2812 & TST & \\
\hline CHEMBL585502 & 737087 & 5.7209 & 5.5723 & TST & \\
\hline CHEMBL1341697 & 737087 & 4.9894 & 4.8568 & TST & \\
\hline CHEMBL1602759 & 737087 & 5.2577 & 5.0927 & TST & \\
\hline CHEMBL3589044 & 1503509 & 3.8239 & 5.0785 & TST & \\
\hline CHEMBL3589456 & 1503509 & 4.3979 & 4.3267 & TRN & \\
\hline CHEMBL3590284 & 1503509 & 5.6383 & 5.4034 & TRN & \\
\hline CHEMBL2347539 & 1503509 & 5.6778 & 6.1215 & TRN & \\
\hline CHEMBL3589457 & 1503509 & 3.8239 & 4.5083 & TRN & \\
\hline CHEMBL 3589450 & 1503509 & 5.699 & 5.7345 & TRN & \\
\hline CHEMBL3589430 & 1503509 & 5.4318 & 5.2606 & TRN & \\
\hline CHEMBL3589447 & 1503509 & 3.8239 & 3.7877 & TRN & \\
\hline CHEMBL3589452 & 1503509 & 5.7696 & 5.6055 & TRN & \\
\hline CHEMBL3589432 & 1503509 & 4.8239 & 4.7394 & TRN & \\
\hline CHEMBL3589454 & 1503509 & 4.3979 & 4.4299 & TRN & \\
\hline CHEMBL3589046 & 1503509 & 5.7212 & 5.5949 & TST & \\
\hline CHEMBL3589436 & 1503509 & 6.0506 & 6.2913 & TRN & \\
\hline CHEMBL3590282 & 1503509 & 3.8239 & 3.9209 & TRN & \\
\hline CHEMBL3590276 & 1503509 & 5.9586 & 5.5838 & TRN & \\
\hline CHEMBL3590277 & 1503509 & 3.8239 & 3.8242 & TRN & \\
\hline CHEMBL3588866 & 1503509 & 5.9747 & 6.5108 & TRN & \\
\hline CHEMBL3589444 & 1503509 & 5.3565 & 5.0686 & TRN & \\
\hline CHEMBL 3589448 & 1503509 & 3.8239 & 3.8198 & TRN & \\
\hline CHEMBL3589446 & 1503509 & 3.8239 & 3.7977 & TRN & \\
\hline CHEMBL3589045 & 1503509 & 5.6383 & 5.5717 & TST & \\
\hline CHEMBL3589455 & 1503509 & 3.8239 & 4.2366 & TST & \\
\hline CHEMBL3590281 & 1503509 & 3.8239 & 3.9068 & TRN & \\
\hline CHEMBL3589441 & 1503509 & 3.8239 & 4.0186 & TRN & \\
\hline CHEMBL3589440 & 1503509 & 4.5229 & 4.3235 & TST & \\
\hline CHEMBL3589433 & 1503509 & 5.699 & 5.38399 & 99999999995 & TRN \\
\hline CHEMBL3589443 & 1503509 & 5.6576 & 5.1755 & TRN & \\
\hline CHEMBL3589451 & 1503509 & 6.6198 & 6.3854 & TRN & \\
\hline CHEMBL3589445 & 1503509 & 3.8239 & 3.8545 & TRN & \\
\hline CHEMBL3589442 & 1503509 & 3.8239 & 4.0448 & TRN & \\
\hline CHEMBL3589429 & 1503509 & 5.3979 & 5.41 & TRN & \\
\hline CHEMBL3590283 & 1503509 & 5.7959 & 5.4416 & TRN & \\
\hline CHEMBL3590275 & 1503509 & 5.2518 & 5.44600 & 0000000001 & TRN \\
\hline CHEMBL3589439 & 1503509 & 3.8239 & 4.3121 & TST & \\
\hline CHEMBL3590288 & 1503509 & 3.8239 & 4.2719 & TST & \\
\hline CHEMBL3589431 & 1503509 & 5.4685 & 4.6911 & TST & \\
\hline CHEMBL3589453 & 1503509 & 5.6576 & 5.5303 & TRN & \\
\hline CHEMBL3590286 & 1503509 & 5.585 & 5.1237 & TST & \\
\hline CHEMBL3590278 & 1503509 & 3.8239 & 4.0132 & TRN & \\
\hline CHEMBL3589434 & 1503509 & 5.7959 & 5.6787 & TRN & \\
\hline
\end{tabular}


Supplemental Table S2.txt

\begin{tabular}{|c|c|c|c|c|}
\hline 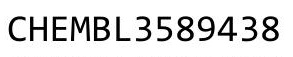 & 503509 & 5.6576 & 5.66 & TRN \\
\hline CHEMBL3589435 & 503509 & 5.6383 & 6.314 & \\
\hline HEMBL3589449 & 503509 & 5.7212 & 3723 & \\
\hline AEMBL3590287 & 503509 & 4.5229 & 3799 & \\
\hline IEMBL 2347404 & 503509 & 5.0969 & 5.1421 & \\
\hline AEMBL2347559 & 503509 & 3.8239 & 4.4367 & \\
\hline HEMBL3590289 & 503509 & 3.8239 & 5.2509 & \\
\hline CHEMBL 3590279 & 503509 & 3.8239 & & \\
\hline HEMBL3590280 & 503509 & 3.8239 & 3.9584 & \\
\hline AEMBL 3589437 & 503509 & 5.2218 & & \\
\hline AEMBL2347538 & 503509 & 5.7959 & 5.1737 & \\
\hline AEMBL3590285 & 1503509 & 5.2676 & & \\
\hline HEMBL 227323 & 438898 & 7.9172 & 68 & \\
\hline HEMBL3 & 38898 & 7.8761 & 44 & \\
\hline HEMBL 229320 & 38898 & 9.0458 & 95 & \\
\hline HEMBL 388311 & 38898 & 7.7959 & 8 . & \\
\hline AEMBL 227322 & 38898 & 208 & & \\
\hline HEMBL & 98 & 7.1079 & 7. & \\
\hline AEMBL & 98 & 8.6778 & & \\
\hline HEMBL: & 98 & 8.5376 & & \\
\hline HEMBL22 & 38898 & 9.2218 & 9. & \\
\hline HEMBL 227 & 438898 & 8.0 & & \\
\hline CHEMBL: & 438 & 7.3098 & & \\
\hline CHEMBL & 98 & 376 & & \\
\hline CHEMBL & 98 & 778 & & \\
\hline AEMBL2: & 98 & 208 & & \\
\hline CHEMBL 3 & 438898 & 7.5376 & & \\
\hline CHEMBL & 98 & 539 & & \\
\hline CHEME & 98 & 208 & & \\
\hline CHEMB & 98 & 886 & & \\
\hline CHEMBL 22 & 98 & 586 & & \\
\hline CHEMBL 2 & 438898 & 7.3279 & & \\
\hline $\mathrm{CHE}$ & 98 & & & T \\
\hline $\mathrm{CHE}$ & 98 & 27 & 65 & \\
\hline CHEMBL229917 & 98 & 437 & 8.469 & \\
\hline CHEMBL227367 & 438898 & 8.8861 & 8.3 & \\
\hline CHEMBL 2 & 438898 & 8.4089 & & \\
\hline & 438 & 539 & & IR \\
\hline $\mathrm{CHE}$ & 8 & 518 & 8. & \\
\hline CHEMBL389438 & 438898 & 7.7447 & 8.031 & TR \\
\hline CHEMBL226 & 438898 & 7.8861 & 54 & TS \\
\hline CHEMBL & 438898 & 8.8539 & & TS \\
\hline CHEMBL2 & 438898 & 5.5768 & & \\
\hline CHEMBL427422 & 438898 & 8.301 & 7.9566 & \\
\hline CHEMBL438483 & 438898 & 8.0706 & 8.0033 & TR \\
\hline CHEMBL229855 & 438898 & 8.301 & 8.0343 & TR \\
\hline $\mathrm{CH}$ & 438 & 8.2291 & 8.8899 & \\
\hline CHEMBL226745 & 438898 & 3.1675 & 7.6605 & \\
\hline
\end{tabular}

Page 18610 


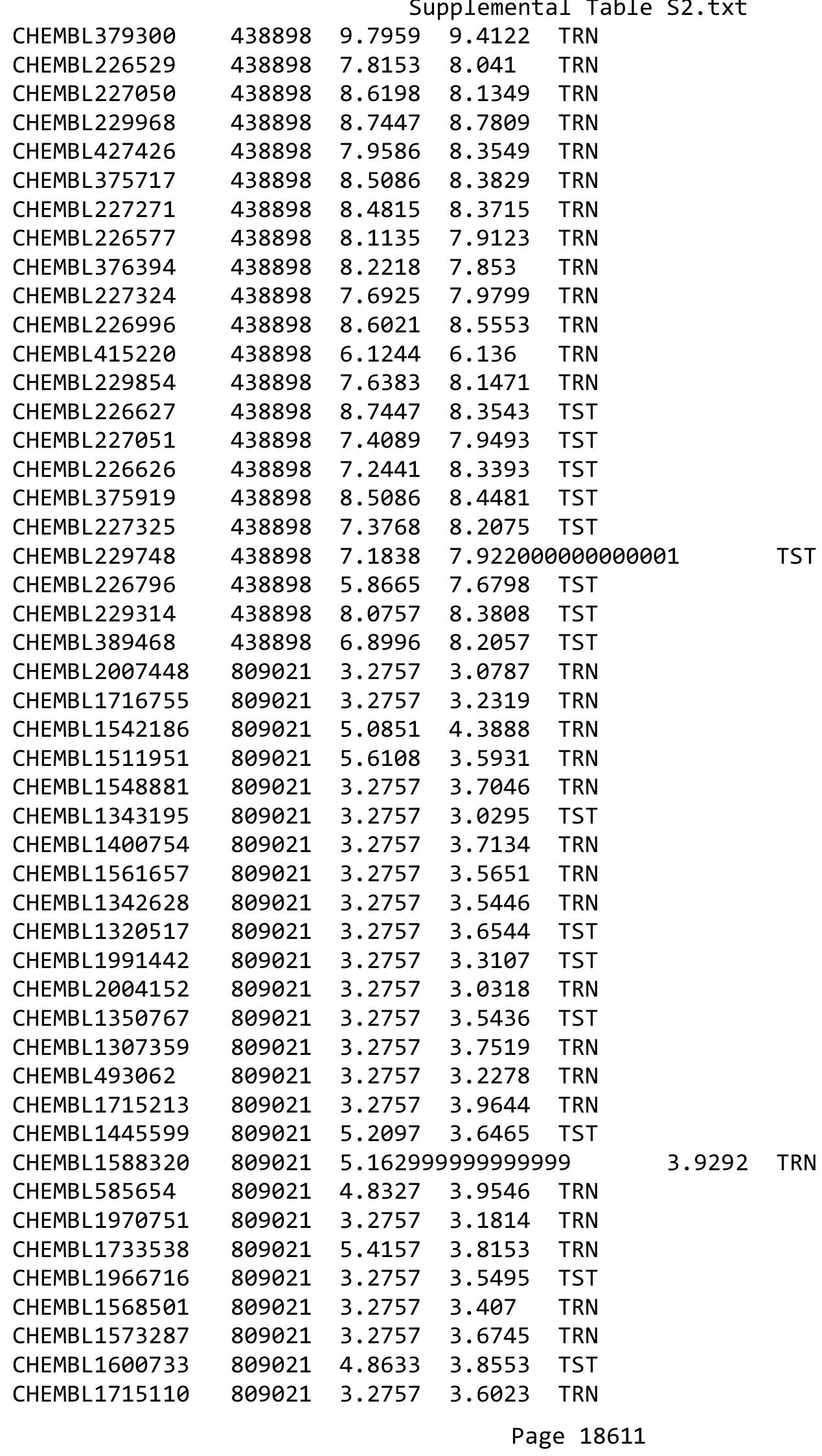


Supplemental Table S2.txt

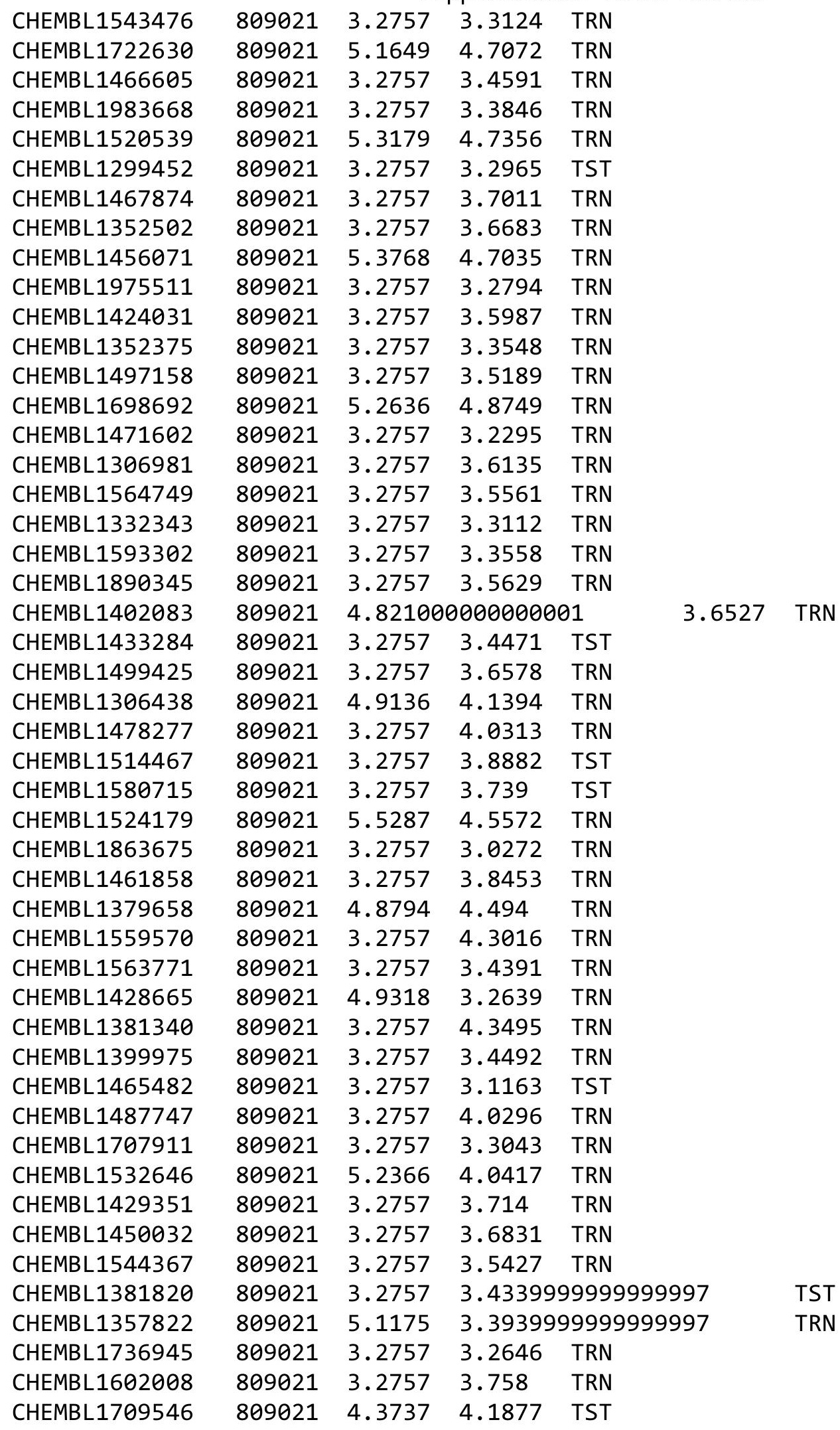

Page 18612 
Supplemental Table S2.txt

\begin{tabular}{|c|c|c|c|c|c|}
\hline CHEMBL1530938 & 809021 & 3.2757 & 3.7109 & TST & \\
\hline CHEMBL1383937 & 809021 & 3.2757 & 3.2654 & TST & \\
\hline CHEMBL3144954 & 809021 & 3.2757 & 3.8168 & TST & \\
\hline CHEMBL1585528 & 809021 & 3.2757 & 3.931 & TRN & \\
\hline CHEMBL1357484 & 809021 & 3.2757 & 3.7012 & TRN & \\
\hline CHEMBL1976163 & 809021 & 3.2757 & 3.3213 & TRN & \\
\hline CHEMBL1535443 & 809021 & 3.2757 & 3.5618 & TRN & \\
\hline CHEMBL1413464 & 809021 & 3.2757 & 3.2846 & TRN & \\
\hline CHEMBL1405032 & 809021 & 3.2757 & 4.0204 & TRN & \\
\hline CHEMBL1524924 & 809021 & 3.2757 & 3.3792 & TRN & \\
\hline CHEMBL1713997 & 809021 & 3.2757 & 3.5449 & TRN & \\
\hline CHEMBL1480530 & 809021 & 3.2757 & 3.4526 & TRN & \\
\hline CHEMBL236059 & 809021 & 3.2757 & 3.1514 & TRN & \\
\hline CHEMBL1887235 & 809021 & 3.2757 & 2.8291 & TRN & \\
\hline CHEMBL1304709 & 809021 & 3.2757 & 3.4808 & TST & \\
\hline CHEMBL1505875 & 809021 & 3.2757 & 4.0137 & TRN & \\
\hline CHEMBL1475698 & 809021 & 3.2757 & 4.1009 & TST & \\
\hline CHEMBL1527787 & 809021 & 3.2757 & 3.6736 & TRN & \\
\hline CHEMBL1544854 & 809021 & 3.2757 & 3.2081 & TRN & \\
\hline CHEMBL1893828 & 809021 & 3.2757 & 3.2624 & TRN & \\
\hline CHEMBL1382321 & 809021 & 3.2757 & 3.6551 & TST & \\
\hline CHEMBL1556958 & 809021 & 5.5702 & 3.5776 & TST & \\
\hline CHEMBL1713532 & 809021 & 3.2757 & 3.2974 & TRN & \\
\hline CHEMBL1720301 & 809021 & 3.2757 & 3.9756 & TRN & \\
\hline CHEMBL1992166 & 809021 & 3.2757 & 3.64 & TRN & \\
\hline CHEMBL1323891 & 809021 & 5.1198 & 4.115 & TRN & \\
\hline CHEMBL1307438 & 809021 & 3.2757 & 3.4268 & TRN & \\
\hline CHEMBL1442304 & 809021 & 3.2757 & 3.2665 & TRN & \\
\hline CHEMBL1468698 & 809021 & 5.1993 & 4.5482 & TRN & \\
\hline CHEMBL1731969 & 809021 & 3.2757 & 3.5548 & TRN & \\
\hline CHEMBL1863899 & 809021 & 3.2757 & 3.3954 & TRN & \\
\hline CHEMBL1703199 & 809021 & 5.0269 & 4.3414 & TST & \\
\hline CHEMBL1545363 & 809021 & 3.2757 & 3.4359 & TST & \\
\hline CHEMBL1571718 & 809021 & 5.3675 & 4.0626 & TRN & \\
\hline CHEMBL1393396 & 809021 & 5.1113 & 3.8784 & TRN & \\
\hline CHEMBL1410268 & 809021 & 3.2757 & 3.2664 & TRN & \\
\hline CHEMBL1904249 & 809021 & 3.2757 & 3.55800 & 00000000003 & TRN \\
\hline CHEMBL1359668 & 809021 & 3.2757 & 3.8913 & TST & \\
\hline CHEMBL1383148 & 809021 & 3.2757 & 3.4556 & TRN & \\
\hline CHEMBL1471863 & 809021 & 3.2757 & 3.8444 & TST & \\
\hline CHEMBL 2000650 & 809021 & 3.2757 & 3.5541 & TRN & \\
\hline CHEMBL1983302 & 809021 & 3.2757 & 3.9488 & TRN & \\
\hline CHEMBL1568582 & 809021 & 3.2757 & 3.6139 & TRN & \\
\hline CHEMBL1386528 & 809021 & 3.2757 & 3.65100 & 00000000002 & TRN \\
\hline CHEMBL1402675 & 809021 & 3.2757 & 2.7355 & TRN & \\
\hline CHEMBL1481185 & 809021 & 3.2757 & 3.7764 & TRN & \\
\hline CHEMBL1307821 & 809021 & 4.9208 & 3.8741 & TRN & \\
\hline CHEMBL1899267 & 809021 & 3.2757 & 3.4415 & TRN & \\
\hline
\end{tabular}


Supplemental Table S2.txt

\begin{tabular}{|c|c|c|c|c|}
\hline CHEMBL1719807 & 809021 & 4.7423 & 3.3575 & TRN \\
\hline CHEMBL1557730 & 809021 & 3.2757 & 3.8079 & TST \\
\hline CHEMBL1700097 & 809021 & 3.2757 & 3.4269 & TRN \\
\hline CHEMBL1422205 & 809021 & 3.2757 & 3.9224 & TST \\
\hline CHEMBL1597140 & 809021 & 3.2757 & 4.3498 & TRN \\
\hline CHEMBL1362871 & 809021 & 4.4214 & 3.8244 & TRN \\
\hline CHEMBL1483664 & 809021 & 3.2757 & 3.4082 & TRN \\
\hline CHEMBL1890858 & 809021 & 3.2757 & 3.9586 & TRN \\
\hline CHEMBL1518509 & 809021 & 5.1701 & 4.0539 & TRN \\
\hline CHEMBL1577167 & 809021 & 3.2757 & 3.0264 & TRN \\
\hline CHEMBL1478318 & 809021 & 3.2757 & 3.7173 & TRN \\
\hline CHEMBL1399164 & 809021 & 3.2757 & 4.2884 & TRN \\
\hline CHEMBL1972694 & 809021 & 3.2757 & 3.1494 & TRN \\
\hline CHEMBL1307329 & 809021 & 3.2757 & 4.5041 & TRN \\
\hline CHEMBL1977384 & 809021 & 5.5528 & 4.748 & TRN \\
\hline CHEMBL1486662 & 809021 & 3.2757 & 3.6518 & TRN \\
\hline CHEMBL1539781 & 809021 & 3.2757 & 2.9918 & TRN \\
\hline CHEMBL1493661 & 809021 & 4.9031 & 3.28899 & 99999999997 \\
\hline CHEMBL1415544 & 809021 & 3.2757 & 3.6579 & TRN \\
\hline CHEMBL1450131 & 809021 & 3.2757 & 3.3949 & TRN \\
\hline CHEMBL604100 & 809021 & 3.2757 & 3.0765 & TRN \\
\hline CHEMBL1603812 & 809021 & 3.2757 & 3.2525 & TRN \\
\hline CHEMBL1502719 & 809021 & 4.9957 & 3.6574 & TST \\
\hline CHEMBL1458175 & 809021 & 3.2757 & 4.0894 & TRN \\
\hline CHEMBL1893985 & 809021 & 3.2757 & 3.1657 & TST \\
\hline CHEMBL1522603 & 809021 & 3.2757 & 3.5016 & TRN \\
\hline CHEMBL1462154 & 809021 & 3.2757 & 3.6431 & TRN \\
\hline CHEMBL1458769 & 809021 & 3.2757 & 3.4839 & TRN \\
\hline CHEMBL1386484 & 809021 & 3.2757 & 3.7491 & TRN \\
\hline CHEMBL1573859 & 809021 & 3.2757 & 3.57800 & 00000000003 \\
\hline CHEMBL1698302 & 809021 & 3.2757 & 3.4774 & TRN \\
\hline CHEMBL1318567 & 809021 & 3.2757 & 3.5192 & TRN \\
\hline CHEMBL1575142 & 809021 & 3.2757 & 3.2847 & TST \\
\hline CHEMBL1406916 & 809021 & 3.2757 & 3.4999 & TRN \\
\hline CHEMBL1967399 & 809021 & 3.2757 & 3.0815 & TRN \\
\hline CHEMBL1446075 & 809021 & 3.2757 & 3.1463 & TRN \\
\hline CHEMBL1983899 & 809021 & 3.2757 & 3.1587 & TRN \\
\hline CHEMBL1556353 & 809021 & 3.2757 & 3.58699 & 99999999997 \\
\hline CHEMBL1889769 & 809021 & 3.2757 & 3.8862 & TRN \\
\hline CHEMBL 2002641 & 809021 & 3.2757 & 4.2325 & TST \\
\hline CHEMBL1369099 & 809021 & 4.4989 & 3.3864 & TRN \\
\hline CHEMBL1443529 & 809021 & 3.2757 & 3.7816 & TRN \\
\hline CHEMBL1976839 & 809021 & 5.3706 & 3.9539 & TST \\
\hline CHEMBL1305510 & 809021 & 3.2757 & 3.3035 & TRN \\
\hline CHEMBL1520053 & 809021 & 3.2757 & 3.9826 & TST \\
\hline CHEMBL1520888 & 809021 & 3.2757 & 3.3749 & TRN \\
\hline CHEMBL1548190 & 809021 & 5.1746 & 4.2163 & TRN \\
\hline CHEMBL1700989 & 809021 & 3.2757 & 3.76 & TRN \\
\hline
\end{tabular}


Supplemental Table S2.txt

\begin{tabular}{|c|c|c|c|c|}
\hline CHEMBL1365924 & 809021 & 3.2757 & 2.9187 & TRN \\
\hline CHEMBL1391097 & 809021 & 3.2757 & 4.4527 & TRN \\
\hline CHEMBL1442865 & 809021 & 3.2757 & 3.4643 & TRN \\
\hline CHEMBL1350179 & 809021 & 3.2757 & 3.5045 & TRN \\
\hline CHEMBL1964429 & 809021 & 3.2757 & 3.8751 & TST \\
\hline CHEMBL1331385 & 809021 & 5.1209 & 4.0686 & TST \\
\hline CHEMBL1497550 & 809021 & 3.2757 & 3.8345 & TRN \\
\hline CHEMBL1489935 & 809021 & 3.2757 & 3.8249 & TRN \\
\hline CHEMBL1507745 & 809021 & 3.2757 & 3.0449 & TRN \\
\hline CHEMBL1549656 & 809021 & 3.2757 & 3.66 & TST \\
\hline CHEMBL1407849 & 809021 & 3.2757 & 3.63100 & 0000000002 \\
\hline CHEMBL1998821 & 809021 & 3.2757 & 3.0705 & TRN \\
\hline CHEMBL1900331 & 809021 & 5.0535 & 3.9169 & TST \\
\hline CHEMBL1585090 & 809021 & 4.8356 & 3.9332 & TRN \\
\hline CHEMBL1470207 & 809021 & 3.2757 & 3.4029 & TST \\
\hline CHEMBL1988767 & 809021 & 3.2757 & 3.4599 & TRN \\
\hline CHEMBL1998555 & 809021 & 3.2757 & 3.4106 & TRN \\
\hline CHEMBL1172020 & 809021 & 5.3478 & 3.8021 & TRN \\
\hline CHEMBL1461975 & 809021 & 3.2757 & 3.4273 & TRN \\
\hline CHEMBL1301647 & 809021 & 5.2684 & 3.9245 & TST \\
\hline CHEMBL1528052 & 809021 & 3.2757 & 3.0614 & TRN \\
\hline CHEMBL1519061 & 809021 & 3.2757 & 3.458 & TRN \\
\hline CHEMBL1302687 & 809021 & 3.2757 & 3.4242 & TRN \\
\hline CHEMBL1480026 & 809021 & 4.6925 & 3.2296 & TST \\
\hline CHEMBL1449928 & 809021 & 3.2757 & 3.8403 & TST \\
\hline CHEMBL1500751 & 809021 & 5.2899 & 3.8978 & TST \\
\hline CHEMBL1599422 & 809021 & 3.2757 & 3.411 & TRN \\
\hline CHEMBL1454107 & 809021 & 3.2757 & 4.3588 & TRN \\
\hline CHEMBL1529093 & 809021 & 4.9547 & 4.0497 & TST \\
\hline CHEMBL578162 & 809021 & 3.2757 & 3.3741 & TRN \\
\hline CHEMBL1324073 & 809021 & 3.2757 & 3.471 & TRN \\
\hline CHEMBL1999610 & 809021 & 3.2757 & 3.2934 & TRN \\
\hline CHEMBL1710110 & 809021 & 3.2757 & 3.5415 & TRN \\
\hline CHEMBL1422936 & 809021 & 3.2757 & 3.4813 & TRN \\
\hline CHEMBL1400236 & 809021 & 5.2204 & 4.2761 & TRN \\
\hline CHEMBL1509520 & 809021 & 3.2757 & 3.5153 & TRN \\
\hline CHEMBL1409324 & 809021 & 3.2757 & 3.7662 & TRN \\
\hline CHEMBL1470702 & 809021 & 3.2757 & 2.9493 & TRN \\
\hline CHEMBL1504102 & 809021 & 3.2757 & 3.4314 & TRN \\
\hline CHEMBL1723000 & 809021 & 3.2757 & 3.1259 & TRN \\
\hline CHEMBL1982394 & 809021 & 5.2588 & 3.9689 & TRN \\
\hline CHEMBL1464771 & 809021 & 3.2757 & 3.5725 & TRN \\
\hline CHEMBL1720731 & 809021 & 3.2757 & 3.5729 & TRN \\
\hline CHEMBL1301228 & 809021 & 3.2757 & \multicolumn{2}{|c|}{ 3. 2969999999999997} \\
\hline CHEMBL1466793 & 809021 & 3.2757 & \multicolumn{2}{|c|}{3.5389999999999997} \\
\hline CHEMBL1712394 & 809021 & 3.2757 & 3.4019 & TRN \\
\hline CHEMBL1387503 & 809021 & 3.2757 & 3.3229 & TRN \\
\hline CHEMBL1444243 & 809021 & 3.2757 & 3.9249 & TRN \\
\hline
\end{tabular}

Page 18615 
Supplemental Table S2.txt

\begin{tabular}{|c|c|c|c|c|c|}
\hline CHEMBL1449957 & 809021 & 3.2757 & 3.2831 & TRN & \\
\hline CHEMBL1986582 & 809021 & 3.2757 & 3.7693 & TST & \\
\hline CHEMBL1885161 & 809021 & 3.2757 & 3.54600 & 20000000003 & TRN \\
\hline CHEMBL1346219 & 809021 & 4.6536 & 3.7862 & TRN & \\
\hline CHEMBL1375791 & 809021 & 3.2757 & 3.6128 & TRN & \\
\hline CHEMBL1397756 & 809021 & 3.2757 & 3.7021 & TRN & \\
\hline CHEMBL1994261 & 809021 & 3.2757 & 3.8774 & TRN & \\
\hline CHEMBL1875657 & 809021 & 3.2757 & 3.6025 & TRN & \\
\hline CHEMBL1587837 & 809021 & 3.2757 & 3.8004 & TRN & \\
\hline CHEMBL1457468 & 809021 & 3.2757 & 4.1041 & TRN & \\
\hline CHEMBL1444763 & 809021 & 3.2757 & 3.9522 & TRN & \\
\hline CHEMBL1446935 & 809021 & 3.2757 & 3.9502 & TRN & \\
\hline CHEMBL1342884 & 809021 & 3.2757 & 3.8442 & TRN & \\
\hline CHEMBL1393828 & 809021 & 3.2757 & 3.3903 & TRN & \\
\hline CHEMBL1362860 & 809021 & 3.2757 & 4.1369 & TRN & \\
\hline CHEMBL1572223 & 809021 & 3.2757 & 3.5796 & TRN & \\
\hline CHEMBL1592562 & 809021 & 5.2676 & 4.2849 & TRN & \\
\hline CHEMBL1375104 & 809021 & 3.2757 & $3.66300 t$ & 00000000003 & TRN \\
\hline CHEMBL1540243 & 809021 & 3.2757 & 3.0704 & TRN & \\
\hline CHEMBL1894417 & 809021 & 3.2757 & 3.8556 & TRN & \\
\hline CHEMBL1478678 & 809021 & 3.2757 & 3.5712 & TRN & \\
\hline CHEMBL1492709 & 809021 & 3.2757 & 3.1673 & TRN & \\
\hline CHEMBL1735078 & 809021 & 3.2757 & 3.3421 & TRN & \\
\hline CHEMBL1326182 & 809021 & 3.2757 & 3.6548 & TRN & \\
\hline CHEMBL1466463 & 809021 & 3.2757 & 3.4373 & TRN & \\
\hline CHEMBL1387446 & 809021 & 3.2757 & 3.3612 & TRN & \\
\hline CHEMBL1464557 & 809021 & 3.2757 & 3.4048 & TRN & \\
\hline CHEMBL1883812 & 809021 & \multicolumn{3}{|c|}{4.9830000000000005} & TRN \\
\hline CHEMBL1364242 & 809021 & 3.2757 & 3.7035 & TRN & \\
\hline CHEMBL1548099 & 809021 & 3.2757 & 3.6785 & TRN & \\
\hline CHEMBL1458071 & 809021 & 3.2757 & 3.3975 & TRN & \\
\hline CHEMBL1430122 & 809021 & 3.2757 & 3.5927 & TRN & \\
\hline CHEMBL1555083 & 809021 & 5.1656 & 4.24 & TRN & \\
\hline CHEMBL1973710 & 809021 & 3.2757 & 3.4105 & TRN & \\
\hline CHEMBL1467065 & 809021 & 3.2757 & \multicolumn{2}{|c|}{4.1819999999999995} & TRN \\
\hline CHEMBL1545864 & 809021 & 3.2757 & 3.1625 & TRN & \\
\hline CHEMBL1318855 & 809021 & 3.2757 & 3.8382 & TST & \\
\hline CHEMBL1712227 & 809021 & 3.2757 & 3.8815 & TRN & \\
\hline CHEMBL1414046 & 809021 & 3.2757 & 3.1391 & TRN & \\
\hline CHEMBL1994655 & 809021 & 3.2757 & 3.7577 & TRN & \\
\hline CHEMBL1576986 & 809021 & 5.3536 & 4.7091 & TRN & \\
\hline CHEMBL1532897 & 809021 & 4.8827 & \multicolumn{2}{|c|}{3.9760000000000004} & TRN \\
\hline CHEMBL 3144894 & 809021 & 3.2757 & 3.7481 & TRN & \\
\hline CHEMBL1698459 & 809021 & 5.2741 & 4.3259 & TST & \\
\hline CHEMBL1313600 & 809021 & 3.2757 & 3.4098 & TRN & \\
\hline CHEMBL1553122 & 809021 & 3.2757 & 3.3406 & TRN & \\
\hline CHEMBL1723182 & 809021 & 3.2757 & \multicolumn{2}{|c|}{3.5380000000000003} & TRN \\
\hline CHEMBL1445640 & 809021 & 3.2757 & 4.261 & TRN & \\
\hline
\end{tabular}




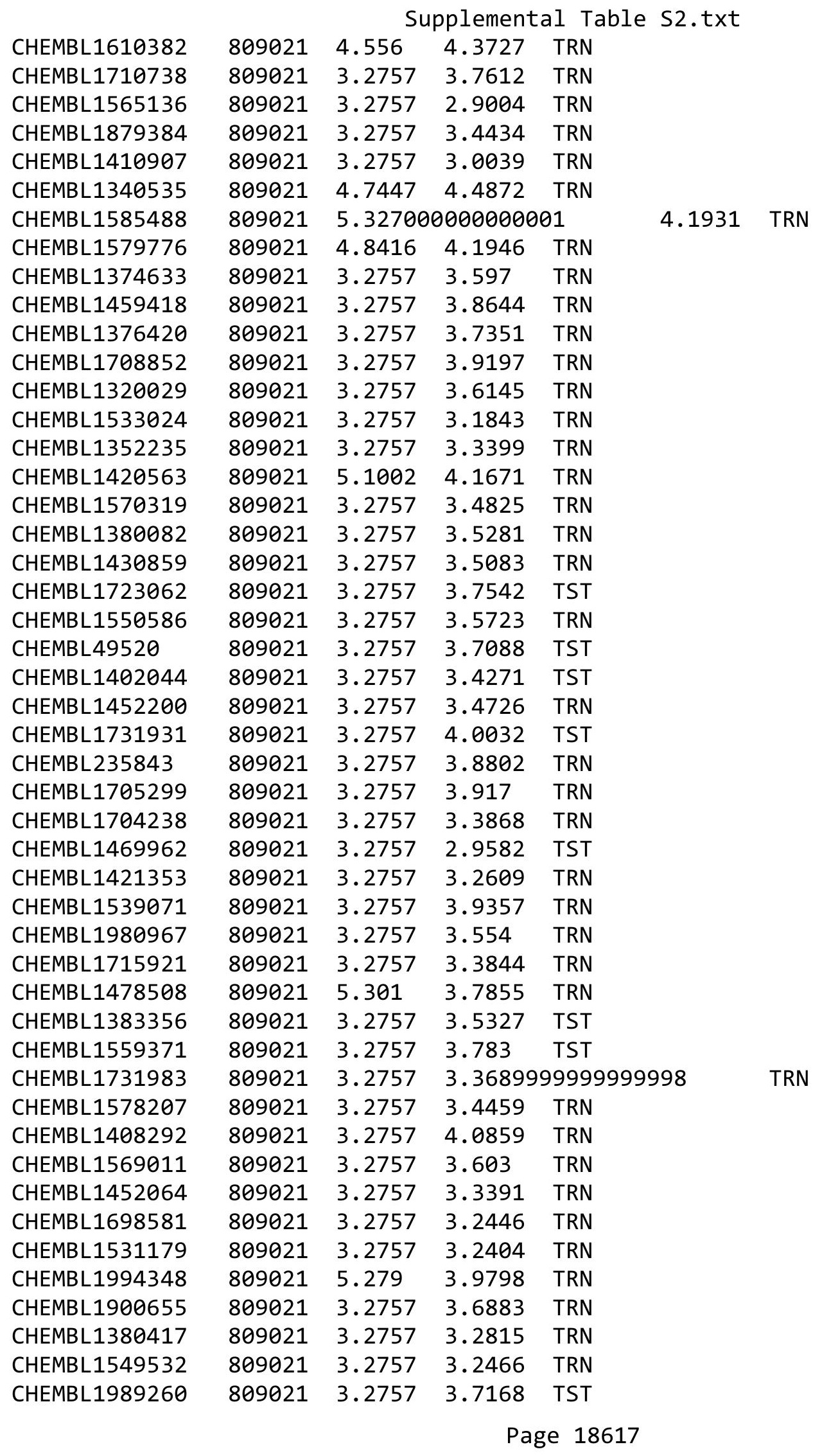


Supplemental Table S2.txt

\begin{tabular}{|c|c|c|c|c|c|}
\hline CHEMBL1979293 & 809021 & 3.2757 & 3.572 & TST & \\
\hline CHEMBL1568043 & 809021 & 3.2757 & 4.4242 & TRN & \\
\hline CHEMBL1306905 & 809021 & 3.2757 & 2.9192 & TRN & \\
\hline CHEMBL1702375 & 809021 & 5.2495 & 4.4462 & TRN & \\
\hline CHEMBL1386745 & 809021 & 3.2757 & 3.0767 & TRN & \\
\hline CHEMBL1443681 & 809021 & 3.2757 & 4.2216 & TRN & \\
\hline CHEMBL1343832 & 809021 & 3.2757 & 3.8579 & TRN & \\
\hline CHEMBL1483964 & 809021 & 3.2757 & 3.5966 & TRN & \\
\hline CHEMBL1500018 & 809021 & 3.2757 & 3.3028 & TRN & \\
\hline CHEMBL1903664 & 809021 & 3.2757 & 3.162 & TRN & \\
\hline CHEMBL1326929 & 809021 & \multicolumn{3}{|c|}{4.9830000000000005} & TRN \\
\hline CHEMBL1984373 & 809021 & 3.2757 & 3.0551 & TST & \\
\hline CHEMBL1310430 & 809021 & 3.2757 & 3.8011 & TRN & \\
\hline CHEMBL1407268 & 809021 & 3.2757 & 3.9687 & TRN & \\
\hline CHEMBL1578488 & 809021 & 3.2757 & 3.7366 & TST & \\
\hline CHEMBL1353938 & 809021 & 4.7852 & 3.2835 & TRN & \\
\hline CHEMBL1985591 & 809021 & 4.6517 & 3.7184 & TRN & \\
\hline CHEMBL1557071 & 809021 & 3.2757 & 2.8318 & TRN & \\
\hline CHEMBL1489194 & 809021 & 3.2757 & 3.2858 & TRN & \\
\hline CHEMBL 200965 & 809021 & 4.4413 & 4.1464 & TRN & \\
\hline CHEMBL1310406 & 809021 & 3.2757 & 3.8716 & TRN & \\
\hline CHEMBL1351559 & 809021 & 3.2757 & 3.70600 & 30000000004 & TRN \\
\hline CHEMBL1389286 & 809021 & 4.7122 & 4.0475 & TRN & \\
\hline CHEMBL1382633 & 809021 & 3.2757 & 3.3012 & TRN & \\
\hline CHEMBL1379439 & 809021 & 3.2757 & 3.4422 & TRN & \\
\hline CHEMBL1964398 & 809021 & 3.2757 & 3.8957 & TRN & \\
\hline CHEMBL1454788 & 809021 & 3.2757 & 3.235 & TRN & \\
\hline CHEMBL1381613 & 809021 & 3.2757 & 3.1624 & TRN & \\
\hline CHEMBL457723 & 809021 & 3.2757 & 3.5501 & TST & \\
\hline CHEMBL1563791 & 809021 & 5.556 & 4.6953 & TRN & \\
\hline CHEMBL1371722 & 809021 & 3.2757 & 3.3921 & TRN & \\
\hline CHEMBL1983549 & 809021 & 4.9957 & 3.6608 & TRN & \\
\hline CHEMBL1360428 & 809021 & 3.2757 & 3.43899 & 99999999996 & I KIV \\
\hline CHEMBL1428209 & 809021 & 3.2757 & 3.7982 & TRN & \\
\hline CHEMBL1308489 & 809021 & 3.2757 & 3.3145 & TRN & \\
\hline CHEMBL1720346 & 809021 & 3.2757 & 3.4891 & TRN & \\
\hline CHEMBL1442046 & 809021 & 3.2757 & 3.5694 & TRN & \\
\hline CHEMBL1506420 & 809021 & 3.2757 & 3.31600 & 30000000003 & I RIV \\
\hline CHEMBL1350499 & 809021 & 3.2757 & 3.6336 & TST & \\
\hline CHEMBL1874398 & 809021 & 3.2757 & 3.6026 & TST & \\
\hline CHEMBL1726324 & 809021 & 3.2757 & 3.5889 & TRN & \\
\hline CHEMBL1609933 & 809021 & 3.2757 & 3.661 & TRN & \\
\hline CHEMBL1377894 & 809021 & 3.2757 & 4.0353 & TRN & \\
\hline CHEMBL1722626 & 809021 & 3.2757 & 3.3592 & TRN & \\
\hline CHEMBL1516858 & 809021 & 4.9355 & 3.9397 & TRN & \\
\hline CHEMBL1608859 & 809021 & 3.2757 & 3.47300 & 00000000003 & KI \\
\hline CHEMBL1342544 & 809021 & 3.2757 & 3.8895 & TRN & \\
\hline CHEMBL1368669 & 809021 & 3.2757 & 3.7467 & TST & \\
\hline
\end{tabular}

Page 18618 
Supplemental Table S2.txt

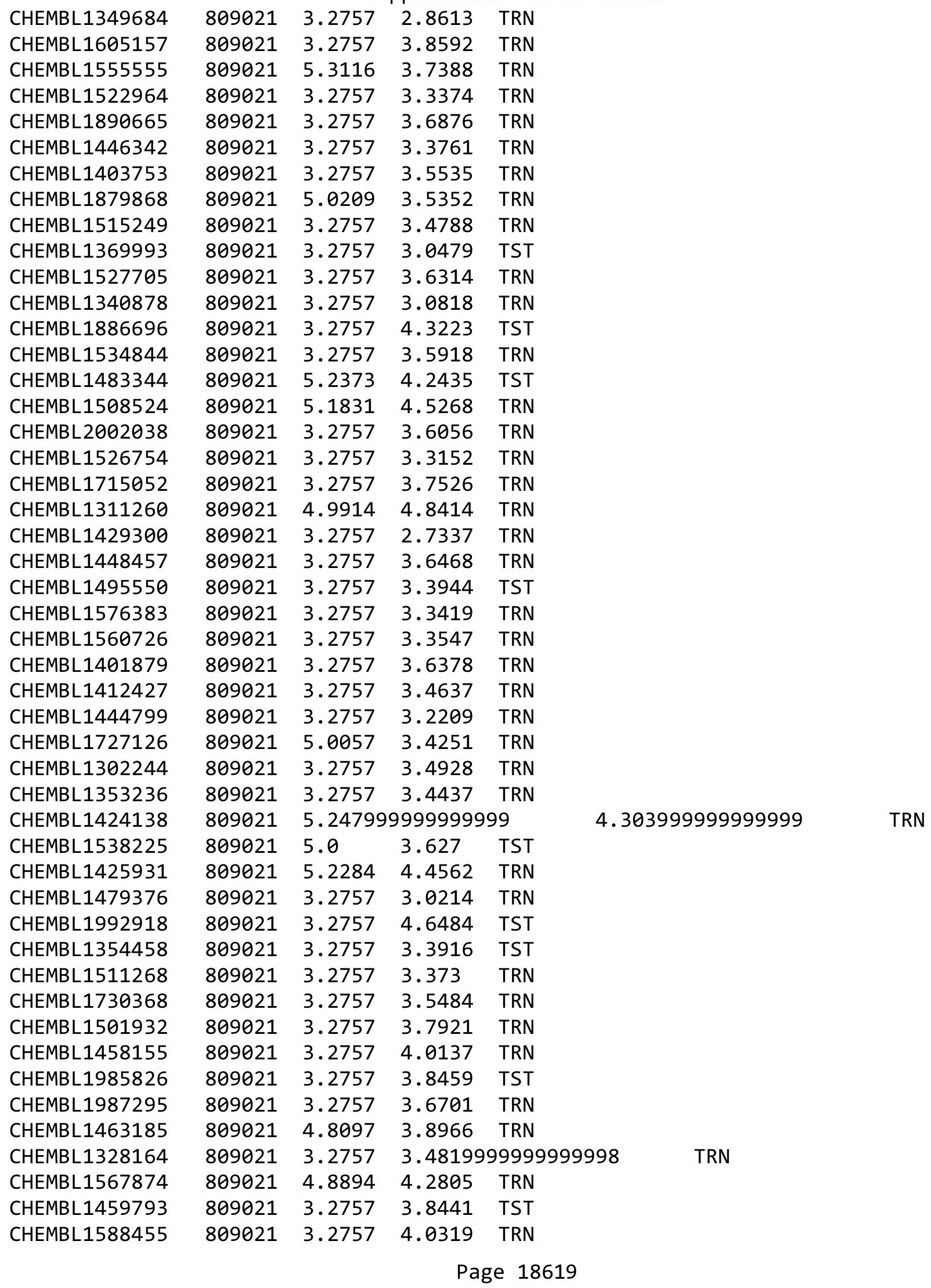


Supplemental Table S2.txt

\begin{tabular}{|c|c|c|c|c|c|}
\hline CHEMBL1540150 & 809021 & 3.2757 & 3.3739 & TRN & \\
\hline CHEMBL1725976 & 809021 & 3.2757 & 3.8253 & TST & \\
\hline CHEMBL1699645 & 809021 & 3.2757 & 3.1147 & TRN & \\
\hline CHEMBL1866538 & 809021 & 3.2757 & 3.5319 & TRN & \\
\hline CHEMBL 1454666 & 809021 & 3.2757 & 3.5273 & TRN & \\
\hline CHEMBL1448881 & 809021 & 3.2757 & 3.1716 & TRN & \\
\hline CHEMBL1409493 & 809021 & 3.2757 & 3.2843 & TRN & \\
\hline CHEMBL1573564 & 809021 & 3.2757 & 3.3256 & TRN & \\
\hline CHEMBL1527434 & 809021 & 3.2757 & \multicolumn{2}{|c|}{3.1660000000000004} & TRN \\
\hline CHEMBL1542486 & 809021 & 5.3372 & 3.7054 & TST & \\
\hline CHEMBL1365431 & 809021 & 4.9245 & 4.2449 & TRN & \\
\hline CHEMBL1327523 & 809021 & 4.8894 & \multicolumn{2}{|c|}{4.2860000000000005} & TRN \\
\hline CHEMBL1608884 & 809021 & 3.2757 & 3.1762 & TRN & \\
\hline CHEMBL1537947 & 809021 & 5.011 & 3.6691 & TRN & \\
\hline CHEMBL1988099 & 809021 & 3.2757 & 3.8389 & TST & \\
\hline CHEMBL1421625 & 809021 & 5.5391 & 4.4312 & TRN & \\
\hline CHEMBL1548706 & 809021 & 3.2757 & 3.5771 & TRN & \\
\hline CHEMBL1704208 & 809021 & 3.2757 & 3.5984 & TRN & \\
\hline CHEMBL1465893 & 809021 & 3.2757 & 3.4646 & TRN & \\
\hline CHEMBL1730260 & 809021 & 3.2757 & 3.5675 & TRN & \\
\hline CHEMBL1572346 & 809021 & 3.2757 & 3.8113 & TRN & \\
\hline CHEMBL1405942 & 809021 & 3.2757 & 3.8645 & TRN & \\
\hline CHEMBL1523372 & 809021 & 3.2757 & 3.3642 & TRN & \\
\hline CHEMBL1474802 & 809021 & 3.2757 & 3.7577 & TRN & \\
\hline CHEMBL1566464 & 809021 & 3.2757 & 3.7482 & TST & \\
\hline CHEMBL1456653 & 809021 & 3.2757 & 3.4794 & TRN & \\
\hline CHEMBL1382229 & 809021 & 3.2757 & 3.9162 & TRN & \\
\hline CHEMBL3195681 & 809021 & 5.6882 & 4.8363 & TRN & \\
\hline CHEMBL1581400 & 809021 & 3.2757 & 3.6808 & TRN & \\
\hline CHEMBL47047 & 809021 & 3.2757 & 3.2159 & TRN & \\
\hline CHEMBL1579621 & 809021 & 3.2757 & 3.7461 & TRN & \\
\hline CHEMBL1462394 & 809021 & 3.2757 & 2.9533 & TRN & \\
\hline CHEMBL1574806 & 809021 & 4.9469 & 3.7967 & TRN & \\
\hline CHEMBL1299242 & 809021 & 5.2958 & 4.3863 & TRN & \\
\hline CHEMBL1390651 & 809021 & 5.3179 & 4.9245 & TRN & \\
\hline CHEMBL1430624 & 809021 & 3.2757 & 3.7167 & TRN & \\
\hline CHEMBL1427197 & 809021 & 3.2757 & 3.299 & TRN & \\
\hline CHEMBL1605813 & 809021 & 3.2757 & 3.7204 & TRN & \\
\hline CHEMBL1594409 & 809021 & 3.2757 & 3.7063 & TRN & \\
\hline CHEMBL1973866 & 809021 & 4.8761 & 4.0922 & TRN & \\
\hline CHEMBL1319013 & 809021 & 5.1158 & 4.6489 & TRN & \\
\hline CHEMBL1438765 & 809021 & 3.2757 & 3.3733 & TRN & \\
\hline CHEMBL1406702 & 809021 & 5.2636 & 4.1384 & TRN & \\
\hline CHEMBL1606891 & 809021 & 3.2757 & 3.1848 & TRN & \\
\hline CHEMBL1380641 & 809021 & 3.2757 & 3.2157 & TRN & \\
\hline CHEMBL1503652 & 809021 & 3.2757 & 4.0681 & TRN & \\
\hline CHEMBL 1987762 & 809021 & 5.2255 & 4.05 & TRN & \\
\hline CHEMBL1863966 & 809021 & 3.2757 & 3.6874 & TRN & \\
\hline
\end{tabular}


Supplemental Table S2.txt

\begin{tabular}{|c|c|c|c|c|c|}
\hline CHEMBL1971715 & 809021 & 3.2757 & \multicolumn{2}{|c|}{3.2430000000000003} & TRN \\
\hline CHEMBL1521938 & 809021 & 5.2933 & 4.2444 & TRN & \\
\hline CHEMBL1439946 & 809021 & 3.2757 & \multicolumn{2}{|c|}{3.4939999999999998} & TRN \\
\hline CHEMBL1553295 & 809021 & 3.2757 & 3.3804 & TRN & \\
\hline CHEMBL1399081 & 809021 & 3.2757 & 3.2384 & TRN & \\
\hline CHEMBL1872930 & 809021 & 3.2757 & 3.3936 & TRN & \\
\hline CHEMBL1534038 & 809021 & 3.2757 & 3.1967 & TRN & \\
\hline CHEMBL1378580 & 809021 & 5.3125 & 3.89 & TRN & \\
\hline CHEMBL1373134 & 809021 & 3.2757 & 3.5054 & TRN & \\
\hline CHEMBL1726591 & 809021 & 3.2757 & 3.3405 & TRN & \\
\hline CHEMBL1408399 & 809021 & 3.2757 & 3.7264 & TST & \\
\hline CHEMBL1407945 & 809021 & 3.2757 & 3.5185 & TRN & \\
\hline CHEMBL1992804 & 809021 & 3.2757 & 3.8034 & TST & \\
\hline CHEMBL1548828 & 809021 & 4.6459 & 4.1534 & TRN & \\
\hline CHEMBL1904355 & 809021 & 3.2757 & 4.0207 & TRN & \\
\hline CHEMBL1389759 & 809021 & 3.2757 & 4.3795 & TST & \\
\hline CHEMBL1344412 & 809021 & 3.2757 & 3.6208 & TRN & \\
\hline CHEMBL1409093 & 809021 & 3.2757 & 3.4188 & TRN & \\
\hline CHEMBL1893192 & 809021 & 4.9957 & 3.325 & TRN & \\
\hline CHEMBL1583000 & 809021 & 3.2757 & 4.1299 & TRN & \\
\hline CHEMBL1369403 & 809021 & 3.2757 & 3.8964 & TST & \\
\hline CHEMBL1393211 & 809021 & 3.2757 & 3.577 & TRN & \\
\hline CHEMBL1870218 & 809021 & 3.2757 & 3.5981 & TRN & \\
\hline CHEMBL1478769 & 809021 & 3.2757 & 3.1152 & TRN & \\
\hline CHEMBL1325579 & 809021 & 3.2757 & 3.3745 & TRN & \\
\hline CHEMBL1371225 & 809021 & 3.2757 & 3.4952 & TRN & \\
\hline CHEMBL1483744 & 809021 & 3.2757 & 3.4929 & TRN & \\
\hline CHEMBL1312858 & 809021 & 3.2757 & \multicolumn{2}{|c|}{3.7460000000000004} & TRIV \\
\hline CHEMBL1532749 & 809021 & 3.2757 & 3.2838 & TRN & \\
\hline CHEMBL1529498 & 809021 & 3.2757 & 3.303 & TRN & \\
\hline CHEMBL1881661 & 809021 & 3.2757 & 3.2156 & TRN & \\
\hline CHEMBL1452079 & 809021 & 3.2757 & 3.9124 & TRN & \\
\hline CHEMBL1419090 & 809021 & 3.2757 & 3.7809 & TRN & \\
\hline CHEMBL 2000414 & 809021 & 3.2757 & 3.3435 & TRN & \\
\hline CHEMBL1865819 & 809021 & 3.2757 & 3.4755 & TRN & \\
\hline CHEMBL1479354 & 809021 & 3.2757 & 3.5413 & TRN & \\
\hline CHEMBL1313479 & 809021 & 3.2757 & 3.7281 & TRN & \\
\hline CHEMBL1385113 & 809021 & 3.2757 & 3.9007 & TST & \\
\hline CHEMBL1343246 & 809021 & 5.041 & 4.0326 & TST & \\
\hline CHEMBL1733884 & 809021 & 3.2757 & \multicolumn{2}{|c|}{3.5869999999999997} & TRN \\
\hline CHEMBL1505907 & 809021 & 3.2757 & 3.0956 & TRN & \\
\hline CHEMBL1877686 & 809021 & 3.2757 & 3.3776 & TRN & \\
\hline CHEMBL1894811 & 809021 & 3.2757 & 3.8205 & TRN & \\
\hline CHEMBL1308965 & 809021 & 3.2757 & 3.8355 & TRN & \\
\hline CHEMBL1395588 & 809021 & 3.2757 & 3.0272 & TRN & \\
\hline CHEMBL1986765 & 809021 & 3.2757 & 3.8758 & TST & \\
\hline CHEMBL1480560 & 809021 & 3.2757 & 3.4931 & TRN & \\
\hline CHEMBL1302890 & 809021 & 3.2757 & 2.9147 & TST & \\
\hline
\end{tabular}

Page 18621 


\begin{tabular}{|c|c|c|c|c|c|c|}
\hline & & \multicolumn{4}{|c|}{ Supplemental Table S2.txt } & \multirow[b]{2}{*}{ TRN } \\
\hline CHEMBL1490752 & 809021 & 5.1629 & 79999999 & & 4.9267 & \\
\hline CHEMBL1343279 & 809021 & 3.2757 & 3.7307 & TRN & & \\
\hline CHEMBL1445765 & 809021 & 3.2757 & 3.2925 & TRN & & \\
\hline CHEMBL1964936 & 809021 & 3.2757 & 3.3594 & TRN & & \\
\hline CHEMBL1420948 & 809021 & 3.2757 & 3.7372 & TRN & & \\
\hline CHEMBL1548456 & 809021 & 4.4461 & 3.7781 & TRN & & \\
\hline CHEMBL1467718 & 809021 & 3.2757 & 4.8398 & TRN & & \\
\hline CHEMBL1510007 & 809021 & 3.2757 & 3.8823 & TST & & \\
\hline CHEMBL1305899 & 809021 & 3.2757 & 3.409 & TRN & & \\
\hline CHEMBL1441618 & 809021 & 3.2757 & 3.6361 & TRN & & \\
\hline CHEMBL1339456 & 809021 & 4.3675 & 3.4078 & TRN & & \\
\hline CHEMBL1377025 & 809021 & 3.2757 & 3.1013 & TRN & & \\
\hline CHEMBL1409622 & 809021 & 3.2757 & 3.2021 & TRN & & \\
\hline CHEMBL1323512 & 809021 & 5.2381 & 3.8826 & TRN & & \\
\hline CHEMBL1742190 & 809021 & 3.2757 & 3.4181 & TRN & & \\
\hline CHEMBL1605046 & 809021 & 3.2757 & 3.6312 & TST & & \\
\hline CHEMBL507369 & 809021 & 3.2757 & 3.1936 & TST & & \\
\hline CHEMBL1456867 & 809021 & 4.9914 & 4.2371 & TRN & & \\
\hline CHEMBL 2006275 & 809021 & 3.2757 & 4.092 & TRN & & \\
\hline CHEMBL1351256 & 809021 & 3.2757 & 3.343 & TRN & & \\
\hline CHEMBL1729811 & 809021 & 3.2757 & 3.0983 & TRN & & \\
\hline CHEMBL1442733 & 809021 & \multicolumn{3}{|c|}{4.9830000000000005} & 3.865 & TRN \\
\hline CHEMBL1539574 & 809021 & 3.2757 & 3.4523 & TRN & & \\
\hline CHEMBL1906557 & 809021 & 3.2757 & 3.8066 & TRN & & \\
\hline CHEMBL1438515 & 809021 & 3.2757 & 2.9372 & TRN & & \\
\hline CHEMBL1338696 & 809021 & 3.2757 & 3.6024 & TRN & & \\
\hline CHEMBL1325638 & 809021 & 3.2757 & 3.23 & TRN & & \\
\hline CHEMBL1484743 & 809021 & 3.2757 & 3.3239 & TRN & & \\
\hline CHEMBL254071 & 809021 & 3.2757 & 4.0793 & TRN & & \\
\hline CHEMBL1990096 & 809021 & 3.2757 & 3.1535 & TRN & & \\
\hline CHEMBL1892881 & 809021 & 3.2757 & 3.7552 & TRN & & \\
\hline CHEMBL1403574 & 809021 & 3.2757 & 3.3288 & TRN & & \\
\hline CHEMBL1531930 & 809021 & 5.098 & 3.7906 & TRN & & \\
\hline CHEMBL1492819 & 809021 & 5.1765 & 3.687 & TST & & \\
\hline CHEMBL3191212 & 809021 & 3.2757 & 3.8484 & TRN & & \\
\hline CHEMBL1453993 & 809021 & 3.2757 & 2.5252 & TRN & & \\
\hline CHEMBL1418299 & 809021 & 3.2757 & 3.5934 & TRN & & \\
\hline CHEMBL1972190 & 809021 & 3.2757 & 3.6155 & TRN & & \\
\hline CHEMBL1341868 & 809021 & 3.2757 & 3.3108 & TRN & & \\
\hline CHEMBL1321140 & 809021 & 3.2757 & 2.7577 & TRN & & \\
\hline CHEMBL1489517 & 809021 & 3.2757 & 3.6936 & TRN & & \\
\hline CHEMBL458114 & 809021 & 3.2757 & 3.7252 & TRN & & \\
\hline CHEMBL1712230 & 809021 & 3.2757 & 3.7111 & TST & & \\
\hline CHEMBL1597481 & 809021 & 4.8601 & 3.9939 & TRN & & \\
\hline CHEMBL1539584 & 809021 & 3.2757 & 3.1962 & TRN & & \\
\hline CHEMBL1410321 & 809021 & 3.2757 & 3.4468 & TRN & & \\
\hline CHEMBL1490454 & 809021 & 3.2757 & 3.6316 & TRN & & \\
\hline CHEMBL1538757 & 809021 & 3.2757 & 3.3764 & TRN & & \\
\hline
\end{tabular}




\begin{tabular}{|c|c|c|c|c|c|c|}
\hline & & \multicolumn{5}{|c|}{ Supplemental Table S2.txt } \\
\hline CHEMBL1567636 & 809021 & 3.2757 & 3.0444 & TRN & & \\
\hline CHEMBL1546321 & 809021 & 3.2757 & 3.6091 & TRN & & \\
\hline CHEMBL 2000543 & 809021 & 3.2757 & 3.3684 & TRN & & \\
\hline CHEMBL1363649 & 809021 & 3.2757 & 3.3981 & TRN & & \\
\hline CHEMBL1600188 & 809021 & 3.2757 & 3.1599 & TRN & & \\
\hline CHEMBL1715050 & 809021 & 3.2757 & 3.387 & TRN & & \\
\hline CHEMBL1541929 & 809021 & 3.2757 & 3.347 & TRN & & \\
\hline CHEMBL1583989 & 809021 & 3.2757 & 3.4639 & TRN & & \\
\hline CHEMBL1364181 & 809021 & \multicolumn{3}{|c|}{4.9830000000000005} & 3.8907 & TRN \\
\hline CHEMBL1894795 & 809021 & 3.2757 & 3.2199 & TRN & & \\
\hline CHEMBL1310585 & 809021 & 5.5622 & 3.5329 & TST & & \\
\hline CHEMBL290077 & 809021 & 3.2757 & 3.6047 & TST & & \\
\hline CHEMBL1508769 & 809021 & 5.1669 & 5.0332 & TRN & & \\
\hline CHEMBL1464707 & 809021 & 3.2757 & 2.8925 & TRN & & \\
\hline CHEMBL1526909 & 809021 & 3.2757 & 3.4555 & TRN & & \\
\hline CHEMBL1377578 & 809021 & 3.2757 & 4.1649 & TRN & & \\
\hline CHEMBL1516543 & 809021 & 3.2757 & 3.5384 & TRN & & \\
\hline CHEMBL1599431 & 809021 & 3.2757 & 3.1172 & TRN & & \\
\hline CHEMBL 1576602 & 809021 & 4.9393 & 3.9265 & TST & & \\
\hline CHEMBL1982934 & 809021 & 5.289 & 3.9751 & TRN & & \\
\hline CHEMBL1864216 & 809021 & 3.2757 & 3.7605 & TRN & & \\
\hline CHEMBL1549432 & 809021 & 5.1457 & 3.4864 & TRN & & \\
\hline CHEMBL1390405 & 809021 & 3.2757 & 3.4717 & TRN & & \\
\hline CHEMBL1868573 & 809021 & 3.2757 & 3.2147 & TRN & & \\
\hline CHEMBL1970627 & 809021 & 3.2757 & 3.6559 & TRN & & \\
\hline CHEMBL1370400 & 809021 & 3.2757 & 3.4989 & TST & & \\
\hline CHEMBL1701141 & 809021 & 3.2757 & 3.3383 & TST & & \\
\hline CHEMBL1543573 & 809021 & 5.2226 & 4.2861 & TRN & & \\
\hline CHEMBL1733976 & 809021 & 3.2757 & 3.7859 & TRN & & \\
\hline CHEMBL1493417 & 809021 & 4.5031 & 3.5632 & TRN & & \\
\hline CHEMBL1993617 & 809021 & 3.2757 & 3.8539 & TRN & & \\
\hline CHEMBL1875872 & 809021 & 3.2757 & 3.3096 & TRN & & \\
\hline CHEMBL1497267 & 809021 & 5.1439 & 3.8765 & TRN & & \\
\hline CHEMBL1411251 & 809021 & 3.2757 & 3.4291 & TRN & & \\
\hline CHEMBL1347534 & 809021 & 3.2757 & 4.1044 & TRN & & \\
\hline CHEMBL1500419 & 809021 & 3.2757 & 3.457 & TST & & \\
\hline CHEMBL1611972 & 809021 & 3.2757 & 3.202 & TRN & & \\
\hline CHEMBL1967673 & 809021 & 3.2757 & 3.2483 & TST & & \\
\hline CHEMBL1464293 & 809021 & 3.2757 & 3.8464 & TRN & & \\
\hline CHEMBL1536902 & 809021 & 3.2757 & 3.7194 & TRN & & \\
\hline CHEMBL1406362 & 809021 & 3.2757 & 3.6158 & TRN & & \\
\hline CHEMBL1343816 & 809021 & 3.2757 & 3.7581 & TRN & & \\
\hline CHEMBL1365314 & 809021 & 3.2757 & 3.2378 & TRN & & \\
\hline CHEMBL1704748 & 809021 & 3.2757 & 3.4622 & TST & & \\
\hline CHEMBL1409229 & 809021 & 3.2757 & 3.2186 & TRN & & \\
\hline CHEMBL1588170 & 809021 & 3.2757 & 3.2651 & TRN & & \\
\hline CHEMBL1610096 & 809021 & 3.2757 & 3.6034 & TRN & & \\
\hline CHEMBL1872161 & 809021 & 3.2757 & 3.1885 & TRN & & \\
\hline
\end{tabular}


Supplemental Table S2.txt

\begin{tabular}{|c|c|c|c|c|c|}
\hline CHEMBL1730846 & 809021 & 3.2757 & 3.014 & TRN & \\
\hline CHEMBL1403377 & 809021 & 3.2757 & 3.8074 & TRN & \\
\hline CHEMBL1354386 & 809021 & 5.0595 & 4.0934 & TRN & \\
\hline CHEMBL1479892 & 809021 & 3.2757 & 3.4511 & TRN & \\
\hline CHEMBL1351355 & 809021 & 3.2757 & 3.6457 & TRN & \\
\hline CHEMBL1501584 & 809021 & 3.2757 & 3.597 & TRN & \\
\hline CHEMBL1370360 & 809021 & 3.2757 & 3.9533 & TRN & \\
\hline CHEMBL1458718 & 809021 & 3.2757 & 3.4475 & TRN & \\
\hline CHEMBL1493883 & 809021 & 3.2757 & 3.6912 & TST & \\
\hline CHEMBL1705012 & 809021 & 3.2757 & 3.0125 & TRN & \\
\hline CHEMBL1386414 & 809021 & 3.2757 & 3.6748 & TRN & \\
\hline CHEMBL1385236 & 809021 & 3.2757 & 3.6817 & TRN & \\
\hline CHEMBL1588110 & 809021 & 3.2757 & 3.6324 & TRN & \\
\hline CHEMBL1591662 & 809021 & 5.2588 & 4.6488 & TRN & \\
\hline CHEMBL1361846 & 809021 & 3.2757 & 3.4759 & TRN & \\
\hline CHEMBL1492295 & 809021 & 3.2757 & 3.5585 & TRN & \\
\hline CHEMBL1716105 & 809021 & 3.2757 & 4.1389 & TST & \\
\hline CHEMBL1711135 & 809021 & 3.2757 & 3.62399 & 99999999997 & TRN \\
\hline CHEMBL1875909 & 809021 & 3.2757 & 3.7529 & TRN & \\
\hline CHEMBL1375534 & 809021 & 3.2757 & 3.4701 & TRN & \\
\hline CHEMBL1411649 & 809021 & 3.2757 & 3.5706 & TRN & \\
\hline CHEMBL1561879 & 809021 & 3.2757 & 3.4621 & TRN & \\
\hline CHEMBL1313624 & 809021 & 3.2757 & 3.6136 & TRN & \\
\hline CHEMBL1332874 & 809021 & 3.2757 & 3.5894 & TRN & \\
\hline CHEMBL1887166 & 809021 & 3.2757 & \multicolumn{2}{|c|}{3.6430000000000002} & TRN \\
\hline CHEMBL3194207 & 809021 & 5.3098 & 4.1255 & TRN & \\
\hline CHEMBL 2000334 & 809021 & 3.2757 & 3.5788 & TRN & \\
\hline CHEMBL1711726 & 809021 & 3.2757 & 3.1082 & TRN & \\
\hline CHEMBL1304604 & 809021 & 3.2757 & 3.5949 & TRN & \\
\hline CHEMBL1462453 & 809021 & 5.0862 & 3.5343 & TRN & \\
\hline CHEMBL1504949 & 809021 & 5.1878 & 4.5631 & TRN & \\
\hline CHEMBL1510258 & 809021 & 3.2757 & 3.8608 & TRN & \\
\hline CHEMBL1731749 & 809021 & 5.2882 & 3.98 & TST & \\
\hline CHEMBL1325114 & 809021 & 3.2757 & 3.3268 & TRN & \\
\hline CHEMBL1888935 & 809021 & 3.2757 & 3.5239 & TRN & \\
\hline CHEMBL1996363 & 809021 & 4.7375 & 3.1895 & TST & \\
\hline CHEMBL1348539 & 809021 & 3.2757 & 3.43399 & 99999999997 & TRN \\
\hline CHEMBL1568987 & 809021 & 3.2757 & 3.4106 & TRN & \\
\hline CHEMBL1709228 & 809021 & 3.2757 & 3.4357 & TRN & \\
\hline CHEMBL 2002773 & 809021 & 3.2757 & 3.4101 & TRN & \\
\hline CHEMBL1558008 & 809021 & 3.2757 & 2.8956 & TRN & \\
\hline CHEMBL 2007095 & 809021 & 5.1512 & 3.8882 & TRN & \\
\hline CHEMBL1524366 & 809021 & 3.2757 & 3.9903 & TRN & \\
\hline CHEMBL1723695 & 809021 & 3.2757 & 3.0704 & TRN & \\
\hline CHEMBL1964836 & 809021 & 5.1752 & \multicolumn{2}{|c|}{4.321000000000001} & TST \\
\hline CHEMBL1874309 & 809021 & 3.2757 & 4.0404 & TST & \\
\hline CHEMBL1469111 & 809021 & 3.2757 & 3.2794 & TRN & \\
\hline CHEMBL1536745 & 809021 & 3.2757 & 3.7114 & TRN & \\
\hline
\end{tabular}


Supplemental Table S2.txt

\begin{tabular}{|c|c|c|c|c|c|c|}
\hline CHEMBL1698159 & 809021 & 3.2757 & 2.7991 & TRN & & \\
\hline CHEMBL1483881 & 809021 & 3.2757 & 2.9949 & TST & & \\
\hline CHEMBL1418647 & 809021 & 5.2366 & 4.2347 & TST & & \\
\hline CHEMBL1587306 & 809021 & 3.2757 & 3.1907 & TRN & & \\
\hline CHEMBL1467535 & 809021 & 5.2612 & 4.0315 & TRN & & \\
\hline CHEMBL1974033 & 809021 & 3.2757 & 3.1637 & TRN & & \\
\hline CHEMBL1598712 & 809021 & 3.2757 & 3.62 & TRN & & \\
\hline CHEMBL1302939 & 809021 & 3.2757 & 3.4158 & TRN & & \\
\hline CHEMBL1445195 & 809021 & \multicolumn{3}{|c|}{5.172000000000001} & 4.4564 & TRN \\
\hline CHEMBL1877350 & 809021 & 3.2757 & 3.4736 & TRN & & \\
\hline CHEMBL1393492 & 809021 & 3.2757 & 3.5498 & TRN & & \\
\hline CHEMBL 2000487 & 809021 & 3.2757 & 3.7717 & TRN & & \\
\hline CHEMBL1491621 & 809021 & 3.2757 & 3.0917 & TST & & \\
\hline CHEMBL1504683 & 809021 & 3.2757 & 3.5875 & TRN & & \\
\hline CHEMBL1521307 & 809021 & 5.3098 & 3.2017 & TRN & & \\
\hline CHEMBL1973500 & 809021 & 3.2757 & 3.7229 & TRN & & \\
\hline CHEMBL1978150 & 809021 & 3.2757 & 3.6689 & TRN & & \\
\hline CHEMBL 2005694 & 809021 & 5.4157 & 4.2657 & TRN & & \\
\hline CHEMBL1455113 & 809021 & 3.2757 & 3.3259 & TRN & & \\
\hline CHEMBL1973493 & 809021 & 3.2757 & 3.6888 & TRN & & \\
\hline CHEMBL1362082 & 809021 & 3.2757 & 3.9315 & TRN & & \\
\hline CHEMBL1981990 & 809021 & 5.2848 & 4.6421 & TRN & & \\
\hline CHEMBL1480708 & 809021 & 3.2757 & 3.8103 & TST & & \\
\hline CHEMBL1718149 & 809021 & 5.1851 & 4.1964 & TRN & & \\
\hline CHEMBL1558773 & 809021 & 3.2757 & 4.0739 & TST & & \\
\hline CHEMBL1597458 & 809021 & 5.7375 & 4.3519 & TRN & & \\
\hline CHEMBL1485894 & 809021 & 3.2757 & 2.9306 & TRN & & \\
\hline CHEMBL1478939 & 809021 & 3.2757 & 3.3061 & TRN & & \\
\hline CHEMBL1350251 & 809021 & 3.2757 & 3.4671 & TRN & & \\
\hline CHEMBL1577226 & 809021 & 3.2757 & 3.0624 & TRN & & \\
\hline CHEMBL1368214 & 809021 & 3.2757 & 4.3974 & TRN & & \\
\hline CHEMBL1598642 & 809021 & 3.2757 & 3.9638 & TRN & & \\
\hline CHEMBL1429233 & 809021 & 3.2757 & 3.5793 & TRN & & \\
\hline CHEMBL1427638 & 809021 & 3.2757 & 3.2102 & TRN & & \\
\hline CHEMBL1567718 & 809021 & 3.2757 & 2.9815 & TRN & & \\
\hline CHEMBL1589419 & 809021 & 5.5575 & 3.6596 & TRN & & \\
\hline CHEMBL1500670 & 809021 & 3.2757 & 3.7128 & TRN & & \\
\hline CHEMBL1699018 & 809021 & 3.2757 & 3.5539 & TRN & & \\
\hline CHEMBL1570445 & 809021 & 3.2757 & 3.1861 & TRN & & \\
\hline CHEMBL1443557 & 809021 & 3.2757 & 3.4926 & TRN & & \\
\hline CHEMBL1549531 & 809021 & 3.2757 & 3.5156 & TRN & & \\
\hline CHEMBL1980737 & 809021 & 3.2757 & 3.9844 & TRN & & \\
\hline CHEMBL1307172 & 809021 & 5.104 & 4.2573 & TRN & & \\
\hline CHEMBL1490486 & 809021 & 3.2757 & 4.0132 & TST & & \\
\hline CHEMBL 2002003 & 809021 & 3.2757 & 3.2537 & TST & & \\
\hline CHEMBL1548552 & 809021 & 3.2757 & 3.4832 & TRN & & \\
\hline CHEMBL1360105 & 809021 & 4.8069 & 3.4686 & TRN & & \\
\hline CHEMBL1520197 & 809021 & 3.2757 & 2.8848 & TRN & & \\
\hline
\end{tabular}

Page 18625 
Supplemental Table S2.txt

\begin{tabular}{|c|c|c|c|c|}
\hline CHEMBL1526013 & 809021 & 3.2757 & 3.3164 & TRN \\
\hline CHEMBL1559196 & 809021 & 3.2757 & 3.1361 & TST \\
\hline CHEMBL1714444 & 809021 & 3.2757 & 4.0299 & TRN \\
\hline CHEMBL1456097 & 809021 & 3.2757 & 3.138 & TRN \\
\hline CHEMBL1705440 & 809021 & 5.3316 & 4.5055 & TRN \\
\hline CHEMBL1716640 & 809021 & 5.2823 & 3.9007 & TRN \\
\hline CHEMBL1495868 & 809021 & 3.2757 & 3.5793 & TRN \\
\hline CHEMBL1492583 & 809021 & 3.2757 & 3.0013 & TRN \\
\hline CHEMBL1731729 & 809021 & 3.2757 & 3.642 & TRN \\
\hline CHEMBL1453190 & 809021 & 3.2757 & 3.5669 & TST \\
\hline CHEMBL1609057 & 809021 & 3.2757 & 3.4254 & TRN \\
\hline CHEMBL1719191 & 809021 & 3.2757 & 3.7096 & TRN \\
\hline CHEMBL1344918 & 809021 & 3.2757 & 4.1049 & TRN \\
\hline CHEMBL1501250 & 809021 & 3.2757 & 3.784 & TRN \\
\hline CHEMBL1456116 & 809021 & 3.2757 & 4.0768 & TRN \\
\hline CHEMBL1345007 & 809021 & 3.2757 & 3.2091 & TRN \\
\hline CHEMBL1378283 & 809021 & 3.2757 & 3.4548 & TRN \\
\hline CHEMBL1362036 & 809021 & 3.2757 & 3.1058 & TRN \\
\hline CHEMBL1559259 & 809021 & 3.2757 & 3.1969 & TRN \\
\hline CHEMBL1594700 & 809021 & 3.2757 & 3.1664 & TRN \\
\hline CHEMBL1504622 & 809021 & 3.2757 & 3.9265 & TRN \\
\hline CHEMBL1356720 & 809021 & 3.2757 & 3.236 & TRN \\
\hline CHEMBL1309373 & 809021 & 3.2757 & 3.3034 & TRN \\
\hline CHEMBL1871578 & 809021 & 3.2757 & 3.0312 & TRN \\
\hline CHEMBL1320606 & 809021 & 3.2757 & 3.3902 & TRN \\
\hline CHEMBL1465250 & 809021 & 3.2757 & 3.9566 & TRN \\
\hline CHEMBL1411304 & 809021 & 3.2757 & 3.6342 & TRN \\
\hline CHEMBL1724228 & 809021 & 3.2757 & 3.4944 & TRN \\
\hline CHEMBL1463570 & 809021 & 3.2757 & 3.0203 & TRN \\
\hline CHEMBL1703252 & 809021 & 3.2757 & 3.2569 & TRN \\
\hline CHEMBL1381553 & 809021 & 3.2757 & 3.9422 & TRN \\
\hline CHEMBL1400207 & 809021 & 3.2757 & 3.569 & TRN \\
\hline CHEMBL1311995 & 809021 & 3.2757 & 3.4934 & TST \\
\hline CHEMBL1424877 & 809021 & 3.2757 & 3.8198 & TST \\
\hline CHEMBL1459123 & 809021 & 3.2757 & 3.6426 & TRN \\
\hline CHEMBL1461547 & 809021 & 3.2757 & 3.9902 & TRN \\
\hline CHEMBL1377280 & 809021 & 3.2757 & 4.1418 & TRN \\
\hline CHEMBL1541239 & 809021 & 3.2757 & 3.6851 & TST \\
\hline CHEMBL1510679 & 809021 & 5.5031 & 3.87600 & 00000000003 \\
\hline CHEMBL1449516 & 809021 & 3.2757 & 3.3984 & TRN \\
\hline CHEMBL1434843 & 809021 & 5.1891 & 4.5881 & TRN \\
\hline CHEMBL1485554 & 809021 & 3.2757 & 3.0872 & TRN \\
\hline CHEMBL1452608 & 809021 & 3.2757 & 3.1857 & TRN \\
\hline CHEMBL1560765 & 809021 & 3.2757 & 3.0069 & TRN \\
\hline CHEMBL1526913 & 809021 & 3.2757 & 3.3649 & TST \\
\hline CHEMBL1459511 & 809021 & 3.2757 & 3.5368 & TRN \\
\hline CHEMBL1461925 & 809021 & 3.2757 & 3.8026 & TRN \\
\hline CHEMBL1561847 & 809021 & 5.3098 & 4.3207 & TRN \\
\hline
\end{tabular}

Page 18626 
Supplemental Table S2.txt

\begin{tabular}{|c|c|c|c|c|c|}
\hline CHEMBL1527203 & 809021 & 3.2757 & 3.3888 & TRN & \\
\hline CHEMBL1325211 & 809021 & 3.2757 & 3.3712 & TRN & \\
\hline CHEMBL1511045 & 809021 & 3.2757 & 3.5484 & TRN & \\
\hline CHEMBL1488101 & 809021 & 4.3851 & 3.8001 & TRN & \\
\hline CHEMBL1325862 & 809021 & 5.1506 & 4.1144 & TST & \\
\hline CHEMBL1587810 & 809021 & 4.7932 & 4.1301 & TRN & \\
\hline CHEMBL1572264 & 809021 & 3.2757 & 3.8149 & TRN & \\
\hline CHEMBL1537687 & 809021 & 3.2757 & 4.2373 & TRN & \\
\hline CHEMBL1362550 & 809021 & 3.2757 & 3.4963 & TRN & \\
\hline CHEMBL1439522 & 809021 & 5.1051 & 3.8852 & TRN & \\
\hline CHEMBL1365760 & 809021 & 3.2757 & 3.977 & TRN & \\
\hline CHEMBL1438361 & 809021 & 3.2757 & 3.5467 & TRN & \\
\hline CHEMBL1726441 & 809021 & 4.9666 & 4.4027 & TRN & \\
\hline CHEMBL1582765 & 809021 & 3.2757 & 3.6188 & TST & \\
\hline CHEMBL1970554 & 809021 & 3.2757 & 3.5588 & TRN & \\
\hline CHEMBL1452644 & 809021 & 3.2757 & 3.6637 & TRN & \\
\hline CHEMBL1874305 & 809021 & 3.2757 & 3.1268 & TRN & \\
\hline CHEMBL1734352 & 809021 & 3.2757 & 4.0661 & TRN & \\
\hline CHEMBL1702440 & 809021 & 3.2757 & 3.7789 & TRN & \\
\hline CHEMBL1714646 & 809021 & 4.9281 & 5.183 & TRN & \\
\hline CHEMBL 2007120 & 809021 & 3.2757 & 3.2203 & TRN & \\
\hline CHEMBL1561790 & 809021 & 5.1965 & 4.9744 & TRN & \\
\hline CHEMBL1490572 & 809021 & 3.2757 & 3.323 & TRN & \\
\hline CHEMBL1715787 & 809021 & 3.2757 & 3.2185 & TRN & \\
\hline CHEMBL1864139 & 809021 & 3.2757 & 3.6021 & TRN & \\
\hline CHEMBL1988039 & 809021 & 3.2757 & 3.4767 & TRN & \\
\hline CHEMBL1870302 & 809021 & 5.3063 & 4.0915 & TST & \\
\hline CHEMBL1418166 & 809021 & 3.2757 & 2.9877 & TRN & \\
\hline CHEMBL1470951 & 809021 & 3.2757 & 3.5224 & TST & \\
\hline CHEMBL1559794 & 809021 & 3.2757 & 3.1768 & TRN & \\
\hline CHEMBL1473316 & 809021 & 3.2757 & 3.9278 & TRN & \\
\hline CHEMBL1388885 & 809021 & 3.2757 & 3.4285 & TRN & \\
\hline CHEMBL1526404 & 809021 & 3.2757 & 3.7872 & TRN & \\
\hline CHEMBL1301337 & 809021 & 3.2757 & 3.9647 & TST & \\
\hline CHEMBL1355070 & 809021 & 3.2757 & 3.384 & TRN & \\
\hline CHEMBL1540293 & 809021 & 3.2757 & 3.97300 & 00000000003 & TRN \\
\hline CHEMBL1607098 & 809021 & 3.2757 & 3.8261 & TRN & \\
\hline CHEMBL1318873 & 809021 & 3.2757 & 3.4129 & TST & \\
\hline CHEMBL1985765 & 809021 & 5.06 & 4.4879 & TRN & \\
\hline CHEMBL1370397 & 809021 & 3.2757 & 3.7314 & TRN & \\
\hline CHEMBL1510100 & 809021 & 3.2757 & 3.45399 & 99999999997 & TRN \\
\hline CHEMBL1353787 & 809021 & 5.1904 & 3.2965 & TRN & \\
\hline CHEMBL1994316 & 809021 & 3.2757 & 3.4047 & TRN & \\
\hline CHEMBL1892065 & 809021 & 3.2757 & 3.2516 & TRN & \\
\hline CHEMBL1427147 & 809021 & 3.2757 & 3.0614 & TRN & \\
\hline CHEMBL1714749 & 809021 & 5.2733 & 4.1555 & TRN & \\
\hline CHEMBL1378201 & 809021 & 3.2757 & 3.8412 & TRN & \\
\hline CHEMBL1430478 & 809021 & 3.2757 & 3.5839 & TRN & \\
\hline
\end{tabular}

Page 18627 
Supplemental Table S2.txt

\begin{tabular}{|c|c|c|c|c|}
\hline CHEMBL548691 & 809021 & 3.2757 & 2.9022 & TRN \\
\hline CHEMBL1976917 & 809021 & 3.2757 & 3.3287 & TRN \\
\hline CHEMBL1565644 & 809021 & 5.5918 & 4.0917 & TRN \\
\hline CHEMBL1574884 & 809021 & 4.8125 & \multicolumn{2}{|c|}{3.2889999999999997} \\
\hline CHEMBL1327923 & 809021 & 3.2757 & 3.1212 & TRN \\
\hline CHEMBL1419407 & 809021 & 3.2757 & 3.4647 & TRN \\
\hline CHEMBL1548041 & 809021 & 3.2757 & 3.1219 & TRN \\
\hline CHEMBL1974381 & 809021 & 3.2757 & 3.1758 & TRN \\
\hline CHEMBL1312383 & 809021 & 3.2757 & 4.1022 & TRN \\
\hline CHEMBL 2005840 & 809021 & 3.2757 & 3.3778 & TRN \\
\hline CHEMBL1420195 & 809021 & 3.2757 & 3.4832 & TRN \\
\hline CHEMBL1716414 & 809021 & 3.2757 & 3.2021 & TRN \\
\hline CHEMBL1398879 & 809021 & 3.2757 & 3.8328 & TRN \\
\hline CHEMBL 2005553 & 809021 & 5.3233 & 4.1643 & TST \\
\hline CHEMBL1718088 & 809021 & 3.2757 & 3.2294 & TST \\
\hline CHEMBL1460794 & 809021 & 3.2757 & 3.5337 & TRN \\
\hline CHEMBL1725722 & 809021 & 4.3904 & 3.4925 & TST \\
\hline CHEMBL1301940 & 809021 & 3.2757 & 3.9123 & TRN \\
\hline CHEMBL1472321 & 809021 & 3.2757 & 3.7653 & TST \\
\hline CHEMBL1403387 & 809021 & 3.2757 & 3.8208 & TRN \\
\hline CHEMBL1560823 & 809021 & 5.0177 & 4.2535 & TRN \\
\hline CHEMBL1304685 & 809021 & 3.2757 & 3.2021 & TRN \\
\hline CHEMBL1377053 & 809021 & 3.2757 & 3.7129 & TRN \\
\hline CHEMBL1511149 & 809021 & 5.3439 & 3.6774 & TRN \\
\hline CHEMBL1482357 & 809021 & 3.2757 & 3.6623 & TRN \\
\hline CHEMBL1367530 & 809021 & 3.2757 & 3.4262 & TRN \\
\hline CHEMBL1413137 & 809021 & 5.1198 & 4.5455 & TRN \\
\hline CHEMBL1429338 & 809021 & 3.2757 & 3.7724 & TRN \\
\hline CHEMBL1573010 & 809021 & 3.2757 & 3.3318 & TRN \\
\hline CHEMBL1510052 & 809021 & 3.2757 & 3.4001 & TRN \\
\hline CHEMBL1471653 & 809021 & 3.2757 & 3.1812 & TRN \\
\hline CHEMBL1388546 & 809021 & 3.2757 & 3.2198 & TRN \\
\hline CHEMBL1551490 & 809021 & 3.2757 & \multicolumn{2}{|c|}{3.2569999999999997} \\
\hline CHEMBL1964945 & 809021 & 3.2757 & 4.1057 & TRN \\
\hline CHEMBL1526099 & 809021 & 5.3585 & 4.1077 & TRN \\
\hline CHEMBL1519870 & 809021 & 5.0799 & 4.0763 & TRN \\
\hline CHEMBL1373556 & 809021 & 4.9872 & 4.1977 & TRN \\
\hline CHEMBL1715025 & 809021 & 3.2757 & 3.2627 & TRN \\
\hline CHEMBL1386928 & 809021 & 5.2588 & 3.0736 & TRN \\
\hline CHEMBL1314067 & 809021 & 3.2757 & 3.3578 & TRN \\
\hline CHEMBL1336902 & 809021 & 3.2757 & 3.739 & TRN \\
\hline CHEMBL1721075 & 809021 & 3.2757 & 4.475 & TRN \\
\hline CHEMBL1975607 & 809021 & 3.2757 & 3.3689 & TRN \\
\hline CHEMBL1398190 & 809021 & 4.8125 & 4.4566 & TRN \\
\hline CHEMBL1373315 & 809021 & 3.2757 & 3.5011 & TRN \\
\hline CHEMBL1731103 & 809021 & 3.2757 & 2.8267 & TRN \\
\hline CHEMBL1905755 & 809021 & 3.2757 & 3.1361 & TRN \\
\hline CHEMBL1978075 & 809021 & 3.2757 & 3.5389 & TRN \\
\hline
\end{tabular}

Page 18628 
Supplemental Table S2.txt

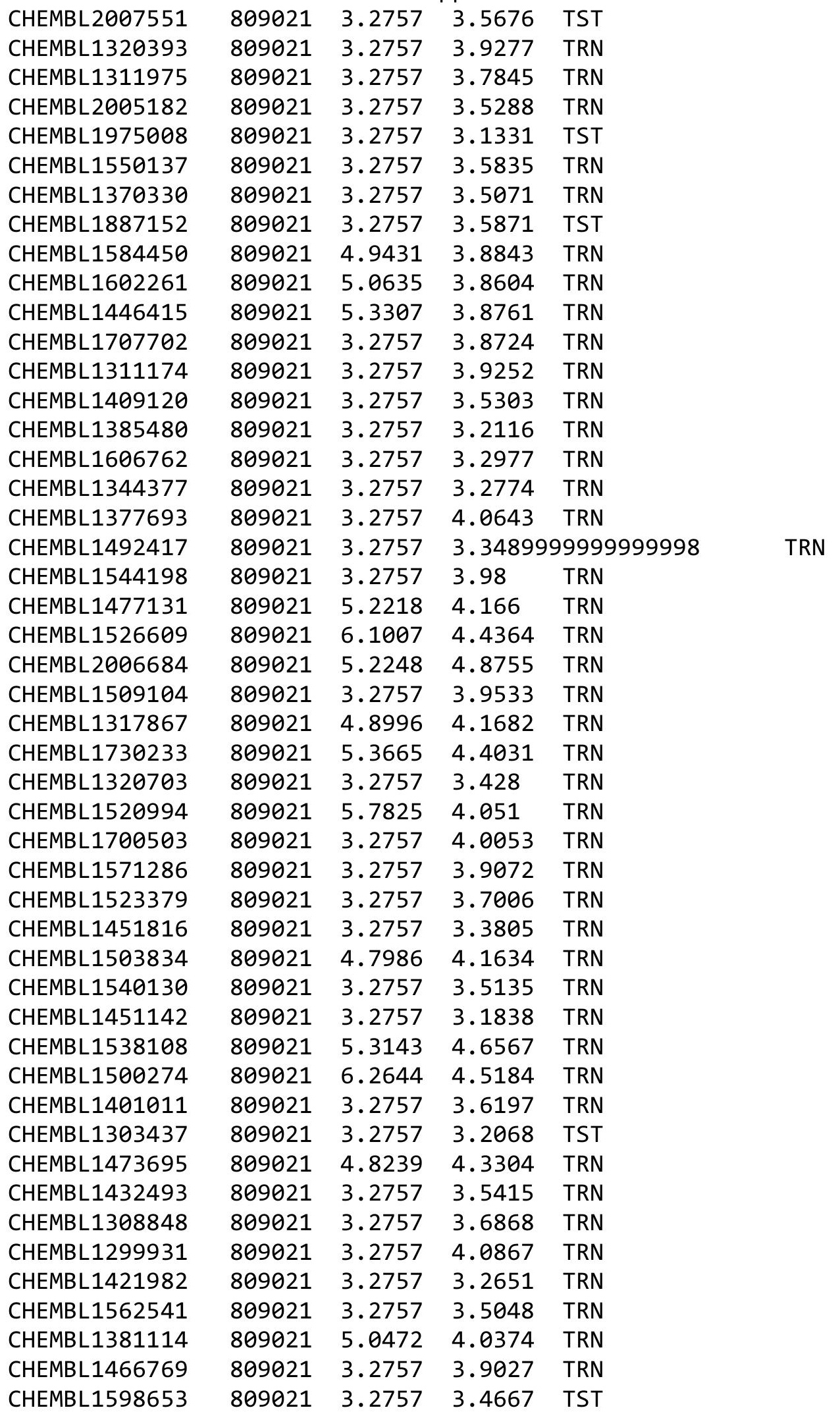

Page 18629 
Supplemental Table S2.txt

\begin{tabular}{|c|c|c|c|c|}
\hline W & & 2757 & & \\
\hline & & .2757 & 3.4496 & \\
\hline & 21 & & & \\
\hline AEMBL: & 021 & & & \\
\hline AEMBL1505493 & 29021 & .757 & & \\
\hline HEMBL1316870 & 09021 & 2757 & 1723 & \\
\hline & 29021 & & 778 & \\
\hline 18 & & & & \\
\hline AEMBL14 & 09021 & & & \\
\hline HEMBL1600229 & 09021 & 93 & 7106 & \\
\hline HEMBL1466865 & 09021 & & 8591 & \\
\hline IEMBL1 & 99021 & 57 & 718 & \\
\hline IEMBL: & & & & \\
\hline HEMBL1 & 09021 & & .2082 & \\
\hline AEMBL1 & 09021 & & & \\
\hline AEMBL1 & 09021 & 57 & 15 & \\
\hline AEMBL1 & 21 & & & \\
\hline HEMBL1 & & & & \\
\hline AEMBL1 & 21 & & 4672 & \\
\hline IEMBL1 & 1 & & & \\
\hline HEMBL: & 1 & & & \\
\hline AEMBL & 1 & & & \\
\hline AEMBL & & & & \\
\hline 134 & 1 & & & \\
\hline AEMBL1 & & & & \\
\hline HEMBL: & $\theta \mathrm{s}$ & & & KIV \\
\hline HEMBL & 1 & & 01 & 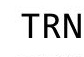 \\
\hline HFMRI & 1 & & & \\
\hline HEMBL1 & & & & 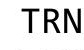 \\
\hline HEMBL146 & $0 s$ & & & s \\
\hline HEMBL5 & 1 & & & RIV \\
\hline HEMBL & 1 & & & RN \\
\hline HEMPI & 1 & & & \\
\hline HEMBL1. & 09 & & & R \\
\hline HEMBL1967015 & 09021 & & 471 & ГRN \\
\hline HEMBL: & 096 & & 08 & RN \\
\hline - & & & & $\Gamma \mathrm{RN}$ \\
\hline HEMBLI & & & & IRN \\
\hline HEMBL1569153 & 090 & & 337 & $\mathrm{TR}$ \\
\hline IEMBL1 & $\partial 9$ & & & RN \\
\hline HEMBL1 & 99 & & 76 & \\
\hline 1 & & & & וכ \\
\hline HEMBL1 & 809021 & & 3.2232 & RN \\
\hline AEMBL1710923 & 09021 & & 284 & rS \\
\hline MPI 1 & & & & \\
\hline HEMBL1 & 309021 & & & \\
\hline HEMBL1 & 309021 & & 3.2225 & \\
\hline HEMBL1487776 & 809021 & 5.1158 & 4.3969 & ГRN \\
\hline
\end{tabular}

Page 18630 
Supplemental Table S2.txt

\begin{tabular}{|c|c|c|c|c|}
\hline CHEMBL1299512 & 809021 & 3.2757 & 3.1367 & TST \\
\hline CHEMBL1323940 & 809021 & 3.2757 & 3.5061 & TST \\
\hline CHEMBL1486792 & 809021 & 3.2757 & 3.5525 & TRN \\
\hline CHEMBL1343918 & 809021 & 3.2757 & 3.9048 & TRN \\
\hline CHEMBL1979256 & 809021 & 3.2757 & 3.6329 & TRN \\
\hline CHEMBL 2001971 & 809021 & 3.2757 & 3.8389 & TST \\
\hline CHEMBL1347204 & 809021 & 5.6459 & 4.3291 & TRN \\
\hline CHEMBL1522372 & 809021 & 3.2757 & 3.5979 & TRN \\
\hline CHEMBL1417320 & 809021 & 3.2757 & 3.3269 & TRN \\
\hline CHEMBL 3145244 & 809021 & 3.2757 & 4.0399 & TRN \\
\hline CHEMBL1549538 & 809021 & 5.3179 & 4.1373 & TRN \\
\hline CHEMBL1342653 & 809021 & 3.2757 & 3.6691 & TRN \\
\hline CHEMBL1523577 & 809021 & 3.2757 & 4.0067 & TRN \\
\hline CHEMBL1569265 & 809021 & 3.2757 & 3.9785 & TRN \\
\hline CHEMBL1711327 & 809021 & 3.2757 & 3.54699 & \\
\hline CHEMBL1526794 & 809021 & 3.2757 & 2.8439 & TRN \\
\hline CHEMBL1596199 & 809021 & 3.2757 & 3.7726 & TRN \\
\hline CHEMBL1478737 & 809021 & 3.2757 & 3.5617 & TRN \\
\hline CHEMBL1585233 & 809021 & 3.2757 & 3.4932 & TRN \\
\hline CHEMBL1728967 & 809021 & 3.2757 & 3.9628 & TRN \\
\hline CHEMBL1499613 & 809021 & 3.2757 & 3.5771 & TRN \\
\hline CHEMBL1503528 & 809021 & 3.2757 & 3.2596 & TRN \\
\hline CHEMBL1578331 & 809021 & 3.2757 & 3.6958 & TST \\
\hline CHEMBL1308291 & 809021 & 3.2757 & 3.0784 & TRN \\
\hline CHEMBL1530418 & 809021 & 5.8539 & 4.1424 & TRN \\
\hline CHEMBL1449500 & 809021 & 4.8356 & 3.9415 & TRN \\
\hline CHEMBL1881506 & 809021 & 3.2757 & 3.9942 & TRN \\
\hline CHEMBL1733072 & 809021 & 3.2757 & 3.6845 & TRN \\
\hline CHEMBL1500567 & 809021 & 3.2757 & 4.1018 & TRN \\
\hline CHEMBL1704445 & 809021 & 3.2757 & 3.4006 & TRN \\
\hline CHEMBL1467207 & 809021 & 3.2757 & \multicolumn{2}{|c|}{3.3110000000000004} \\
\hline CHEMBL1529768 & 809021 & 3.2757 & 3.3168 & TST \\
\hline CHEMBL1863862 & 809021 & 3.2757 & 3.6332 & TRN \\
\hline CHEMBL1611742 & 809021 & 3.2757 & 3.9695 & TST \\
\hline CHEMBL1334115 & 809021 & 3.2757 & 3.444 & TRN \\
\hline CHEMBL1463801 & 809021 & 3.2757 & 3.5947 & TRN \\
\hline CHEMBL1977611 & 809021 & 5.2358 & 4.0681 & TRN \\
\hline CHEMBL1735370 & 809021 & 3.2757 & 3.4296 & TRN \\
\hline CHEMBL1402112 & 809021 & 3.2757 & 3.5391 & TRN \\
\hline CHEMBL1385288 & 809021 & 3.2757 & 3.7088 & TRN \\
\hline CHEMBL1498125 & 809021 & 4.4976 & 4.2336 & TRN \\
\hline CHEMBL1589282 & 809021 & 3.2757 & 3.3969 & TRN \\
\hline CHEMBL1990569 & 809021 & 3.2757 & 3.4379 & TRN \\
\hline CHEMBL1986726 & 809021 & 3.2757 & 3.6613 & TST \\
\hline CHEMBL1967050 & 809021 & 3.2757 & 3.801 & TRN \\
\hline CHEMBL1567826 & 809021 & 3.2757 & 3.4908 & TRN \\
\hline CHEMBL1996229 & 809021 & 3.2757 & 3.6915 & TRN \\
\hline CHEMBL1372192 & 809021 & 3.2757 & 3.8888 & TST \\
\hline
\end{tabular}

Page 18631 
Supplemental Table S2.txt

\begin{tabular}{|c|c|c|c|c|}
\hline CHEMBL1510844 & 809021 & 3.2757 & 3.6299 & TRN \\
\hline CHEMBL1301113 & 809021 & 3.2757 & 3.5624 & TST \\
\hline CHEMBL1472041 & 809021 & 3.2757 & 3.5196 & TRN \\
\hline CHEMBL1312376 & 809021 & 3.2757 & 3.6481 & TRN \\
\hline CHEMBL1995180 & 809021 & 3.2757 & 3.3372 & TST \\
\hline CHEMBL1517517 & 809021 & 3.2757 & 3.861 & TRN \\
\hline CHEMBL1968526 & 809021 & 3.2757 & 4.0926 & TST \\
\hline CHEMBL1498408 & 809021 & 3.2757 & 3.0368 & TRN \\
\hline CHEMBL1462114 & 809021 & 3.2757 & 3.2347 & TST \\
\hline CHEMBL1544694 & 809021 & 5.4001 & \multicolumn{2}{|c|}{3.8160000000000003} \\
\hline CHEMBL1894760 & 809021 & 5.4949 & 4.752 & TRN \\
\hline CHEMBL1958235 & 809021 & 3.2757 & 4.6732 & TRN \\
\hline CHEMBL1320969 & 809021 & 5.2441 & 4.0717 & TRN \\
\hline CHEMBL1470406 & 809021 & 3.2757 & 3.4525 & TRN \\
\hline CHEMBL1557372 & 809021 & 5.0773 & 3.497 & TRN \\
\hline CHEMBL1460452 & 809021 & 3.2757 & 3.5676 & TRN \\
\hline CHEMBL1306608 & 809021 & 3.2757 & 3.4146 & TRN \\
\hline CHEMBL1332851 & 809021 & 3.2757 & 3.4005 & TRN \\
\hline CHEMBL1568265 & 809021 & 3.2757 & 2.8939 & TST \\
\hline CHEMBL1506402 & 809021 & 3.2757 & 3.7569 & TRN \\
\hline CHEMBL1341499 & 809021 & 3.2757 & 3.2143 & TRN \\
\hline CHEMBL1708220 & 809021 & 3.2757 & 3.5847 & TRN \\
\hline CHEMBL1986734 & 809021 & 3.2757 & 3.423 & TRN \\
\hline CHEMBL1408146 & 809021 & 5.0218 & 4.648 & TRN \\
\hline CHEMBL1380796 & 809021 & 3.2757 & 3.6492 & TST \\
\hline CHEMBL1330067 & 809021 & 3.2757 & 3.9099 & TRN \\
\hline CHEMBL1307886 & 809021 & 3.2757 & 3.4458 & TRN \\
\hline CHEMBL1605800 & 809021 & 3.2757 & 3.6619 & TRN \\
\hline CHEMBL1534808 & 809021 & 3.2757 & 3.7032 & TRN \\
\hline CHEMBL1368499 & 809021 & 3.2757 & 3.6763 & TST \\
\hline CHEMBL1435209 & 809021 & 3.2757 & 3.2839 & TRN \\
\hline CHEMBL1989453 & 809021 & 4.8356 & 4.0062 & TRN \\
\hline CHEMBL1385066 & 809021 & 5.0482 & 3.7073 & TRN \\
\hline CHEMBL1699154 & 809021 & 3.2757 & 3.2398 & TRN \\
\hline CHEMBL1369339 & 809021 & 4.8539 & 4.1111 & TRN \\
\hline CHEMBL1349192 & 809021 & 3.2757 & 3.1919 & TRN \\
\hline CHEMBL1734544 & 809021 & 4.4134 & 3.7798 & TRN \\
\hline CHEMBL1728494 & 809021 & 3.2757 & 3.4823 & TRN \\
\hline CHEMBL1325341 & 809021 & 5.6778 & 4.7007 & TRN \\
\hline CHEMBL1454341 & 809021 & 3.2757 & 4.0327 & TRN \\
\hline CHEMBL1481422 & 809021 & 3.2757 & 3.7849 & TRN \\
\hline CHEMBL1407488 & 809021 & 3.2757 & 3.6274 & TRN \\
\hline CHEMBL1992447 & 809021 & 5.3179 & 4.3709 & TRN \\
\hline CHEMBL601994 & 809021 & 3.2757 & 3.6878 & TST \\
\hline CHEMBL1493739 & 809021 & 3.2757 & 3.563 & TST \\
\hline CHEMBL1466899 & 809021 & 3.2757 & 3.4531 & TRN \\
\hline CHEMBL1522824 & 809021 & 3.2757 & 2.968 & TRN \\
\hline CHEMBL1601295 & 809021 & 3.2757 & 3.1764 & TRN \\
\hline
\end{tabular}

\section{TST}


Supplemental Table S2.txt

\begin{tabular}{|c|c|c|c|c|c|}
\hline CHEMBL1556926 & 809021 & 3.2757 & 3.9512 & TRN & \\
\hline CHEMBL1581250 & 809021 & 3.2757 & 4.0075 & TRN & \\
\hline CHEMBL1549986 & 809021 & 3.2757 & 4.0206 & TRN & \\
\hline CHEMBL1562860 & 809021 & 3.2757 & 3.4514 & TRN & \\
\hline CHEMBL1385580 & 809021 & 3.2757 & 3.5197 & TRN & \\
\hline CHEMBL1502672 & 809021 & 3.2757 & 3.448 & TRN & \\
\hline CHEMBL1975932 & 809021 & 4.8697 & 3.438 & TRN & \\
\hline CHEMBL1907952 & 809021 & 3.2757 & 3.4886 & TRN & \\
\hline CHEMBL 2003332 & 809021 & 3.2757 & 3.7244 & TRN & \\
\hline CHEMBL1371902 & 809021 & 3.2757 & 3.6444 & TST & \\
\hline CHEMBL1353337 & 809021 & 3.2757 & 3.2374 & TRN & \\
\hline CHEMBL1384182 & 809021 & 3.2757 & 3.3572 & TRN & \\
\hline CHEMBL1710770 & 809021 & 3.2757 & 3.8628 & TRN & \\
\hline CHEMBL1990092 & 809021 & 3.2757 & 3.2606 & TRN & \\
\hline CHEMBL1875137 & 809021 & 3.2757 & 3.372 & TRN & \\
\hline CHEMBL1524620 & 809021 & 3.2757 & 3.6243 & TRN & \\
\hline CHEMBL1964667 & 809021 & 3.2757 & 3.8769 & TST & \\
\hline CHEMBL1584067 & 809021 & 3.2757 & 3.6993 & TRN & \\
\hline CHEMBL1606173 & 809021 & 3.2757 & 3.5233 & TRN & \\
\hline CHEMBL1364945 & 809021 & 3.2757 & 3.768999 & & TST \\
\hline CHEMBL1311736 & 809021 & 5.0057 & 3.7028 & TRN & \\
\hline CHEMBL1704588 & 809021 & 3.2757 & 3.878999 & 99999999996 & TIV \\
\hline CHEMBL1375673 & 809021 & 3.2757 & 3.6586 & TRN & \\
\hline CHEMBL1340114 & 809021 & 3.2757 & 3.5255 & TRN & \\
\hline CHEMBL1713500 & 809021 & 3.2757 & 3.34 & TRN & \\
\hline CHEMBL1900473 & 809021 & 3.2757 & 3.1479 & TRN & \\
\hline CHEMBL1483568 & 809021 & 4.8539 & 3.7991 & TRN & \\
\hline CHEMBL1428092 & 809021 & 3.2757 & 3.8104 & TRN & \\
\hline CHEMBL1438205 & 809021 & 5.3737 & 4.1433 & TRN & \\
\hline CHEMBL1515256 & 809021 & 4.9172 & 4.0154 & TRN & \\
\hline CHEMBL1732367 & 809021 & \multicolumn{3}{|c|}{5.2139999999999995} & RIV \\
\hline CHEMBL1312615 & 809021 & 3.2757 & 3.3765 & TRN & \\
\hline CHEMBL1451156 & 809021 & \multicolumn{3}{|c|}{4.821000000000001} & 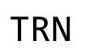 \\
\hline CHEMBL1386092 & 809021 & 3.2757 & 3.7145 & TST & \\
\hline CHEMBL1874188 & 809021 & 3.2757 & 3.4338 & TRN & \\
\hline CHEMBL1471789 & 809021 & 5.2967 & 4.6337 & TRN & \\
\hline CHEMBL1563028 & 809021 & 3.2757 & 3.6846 & TRN & \\
\hline CHEMBL1346004 & 809021 & 3.2757 & 3.1536 & TRN & \\
\hline CHEMBL1443801 & 809021 & 3.2757 & 3.7581 & TRN & \\
\hline CHEMBL1358911 & 809021 & 3.2757 & 3.2052 & TRN & \\
\hline CHEMBL1371089 & 809021 & 3.2757 & 3.1 & TRN & \\
\hline CHEMBL1974644 & 809021 & 3.2757 & 3.3025 & TST & \\
\hline CHEMBL1568079 & 809021 & 3.2757 & 3.0951 & TRN & \\
\hline CHEMBL1989074 & 809021 & 3.2757 & 3.5788 & TST & \\
\hline CHEMBL1369103 & 809021 & 3.2757 & 3.7877 & TRN & \\
\hline CHEMBL1310482 & 809021 & 3.2757 & 3.9225 & TST & \\
\hline CHEMBL1553778 & 809021 & 4.8539 & 3.3298 & TST & \\
\hline CHEMBL1416113 & 809021 & 3.2757 & 3.5799 & TRN & \\
\hline
\end{tabular}

Page 18633 


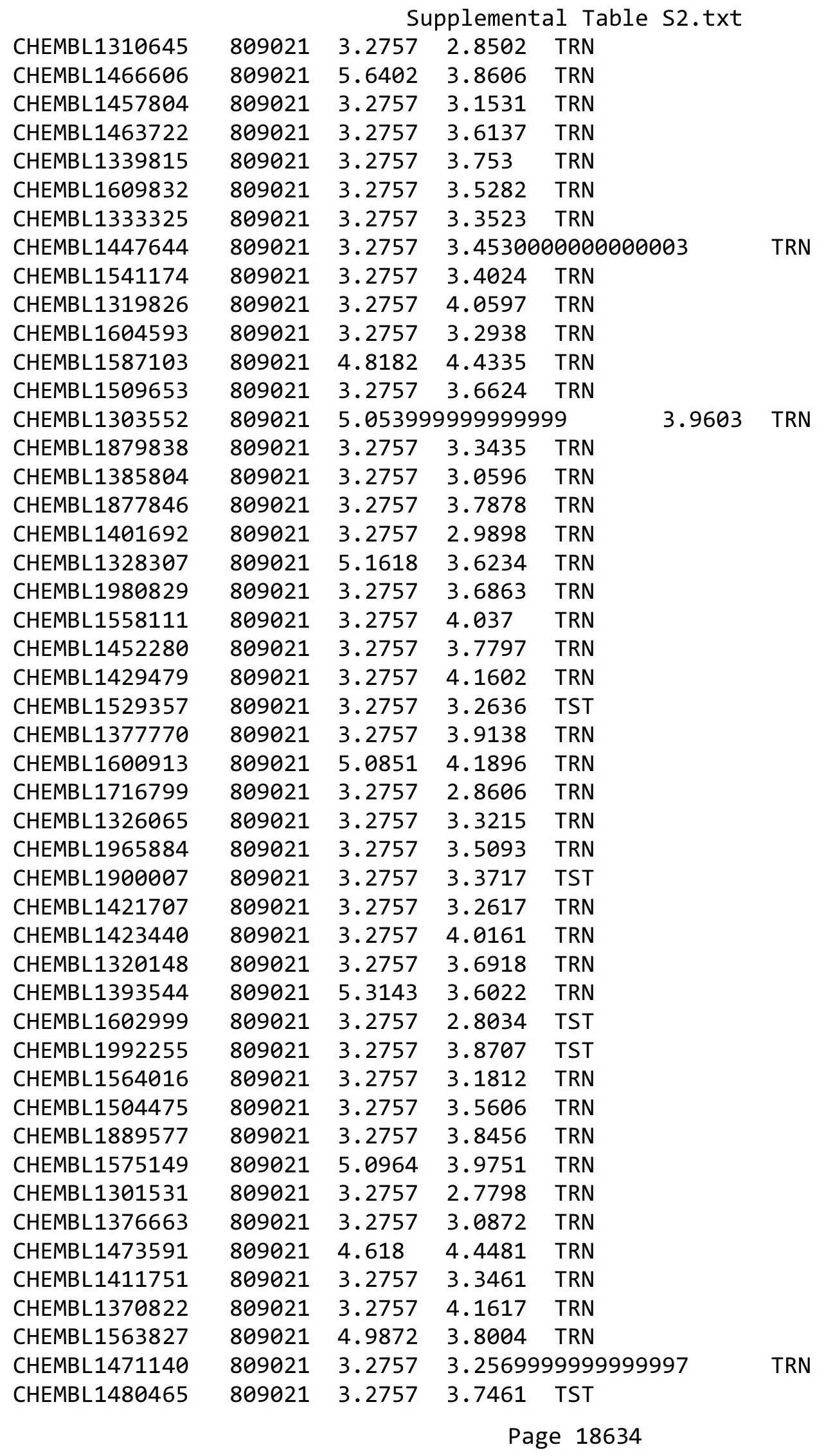


Supplemental Table S2.txt

\begin{tabular}{|c|c|c|c|c|c|}
\hline CHEMBL1485542 & 809021 & 3.2757 & 3.3537 & TRN & \\
\hline CHEMBL1332140 & 809021 & 3.2757 & 4.3095 & TRN & \\
\hline CHEMBL1996802 & 809021 & 3.2757 & 3.3474 & TRN & \\
\hline CHEMBL1600649 & 809021 & 3.2757 & 3.32899 & 99999999997 & TRN \\
\hline CHEMBL1380341 & 809021 & 3.2757 & 3.6987 & TRN & \\
\hline CHEMBL1400044 & 809021 & 3.2757 & 4.0772 & TRN & \\
\hline CHEMBL1983738 & 809021 & 4.9547 & 3.989 & TRN & \\
\hline CHEMBL1549488 & 809021 & 3.2757 & 3.2642 & TRN & \\
\hline CHEMBL1564012 & 809021 & 3.2757 & 3.4827 & TRN & \\
\hline CHEMBL1370144 & 809021 & 3.2757 & 3.2459 & TRN & \\
\hline CHEMBL1411241 & 809021 & 4.9747 & 4.5145 & TRN & \\
\hline CHEMBL1494284 & 809021 & 3.2757 & 3.7986 & TRN & \\
\hline CHEMBL1472052 & 809021 & 4.9706 & 3.4863 & TRN & \\
\hline CHEMBL1735745 & 809021 & 3.2757 & 3.49300 & 00000000003 & TRN \\
\hline CHEMBL1464772 & 809021 & 3.2757 & 3.4185 & TRN & \\
\hline CHEMBL1309395 & 809021 & 3.2757 & 3.759 & TRN & \\
\hline CHEMBL1462518 & 809021 & 3.2757 & 3.5242 & TRN & \\
\hline CHEMBL1604210 & 809021 & 3.2757 & 3.6995 & TRN & \\
\hline CHEMBL1442928 & 809021 & 3.2757 & 3.5705 & TRN & \\
\hline CHEMBL1889401 & 809021 & 3.2757 & 3.4912 & TRN & \\
\hline CHEMBL1549493 & 809021 & 4.7932 & 4.0374 & TST & \\
\hline CHEMBL1418504 & 809021 & 3.2757 & 3.6313 & TRN & \\
\hline CHEMBL1393746 & 809021 & 3.2757 & 3.2759 & TRN & \\
\hline CHEMBL1518424 & 809021 & 3.2757 & 3.8251 & TRN & \\
\hline CHEMBL1570103 & 809021 & 3.2757 & 3.3039 & TST & \\
\hline CHEMBL1353321 & 809021 & 5.041 & 3.4797 & TST & \\
\hline CHEMBL1299355 & 809021 & 3.2757 & 3.5985 & TRN & \\
\hline CHEMBL1490291 & 809021 & 3.2757 & 3.3932 & TRN & \\
\hline CHEMBL1537239 & 809021 & 3.2757 & 3.284 & TRN & \\
\hline CHEMBL1556611 & 809021 & 3.2757 & 3.7286 & TRN & \\
\hline CHEMBL1373829 & 809021 & 3.2757 & 4.4224 & TRN & \\
\hline CHEMBL1543210 & 809021 & \multicolumn{3}{|c|}{5.2620000000000005} & 10 \\
\hline CHEMBL1305513 & 809021 & 3.2757 & 3.1559 & TRN & \\
\hline CHEMBL1504692 & 809021 & 3.2757 & 3.8556 & TRN & \\
\hline CHEMBL1996536 & 809021 & 3.2757 & 3.7567 & TRN & \\
\hline CHEMBL1700323 & 809021 & 3.2757 & 3.6783 & TRN & \\
\hline CHEMBL1410862 & 809021 & 3.2757 & 3.9799 & TST & \\
\hline CHEMBL1377181 & 809021 & 3.2757 & 3.5109 & TST & \\
\hline CHEMBL1462692 & 809021 & 3.2757 & 3.8217 & TRN & \\
\hline CHEMBL1484379 & 809021 & 3.2757 & 3.9838 & TRN & \\
\hline CHEMBL1311578 & 809021 & 3.2757 & 3.1023 & TRN & \\
\hline CHEMBL1541844 & 809021 & 3.2757 & 3.6442 & TRN & \\
\hline CHEMBL1493964 & 809021 & 3.2757 & 3.4227 & TRN & \\
\hline CHEMBL1723613 & 809021 & 3.2757 & 4.2681 & TRN & \\
\hline CHEMBL1904654 & 809021 & 3.2757 & 3.3169 & TRN & \\
\hline CHEMBL1613198 & 809021 & 3.2757 & 3.0201 & TRN & \\
\hline CHEMBL1379214 & 809021 & 4.8697 & 3.767 & TRN & \\
\hline CHEMBL1561865 & 809021 & 3.2757 & 3.5819 & TRN & \\
\hline
\end{tabular}


Supplemental Table S2.txt

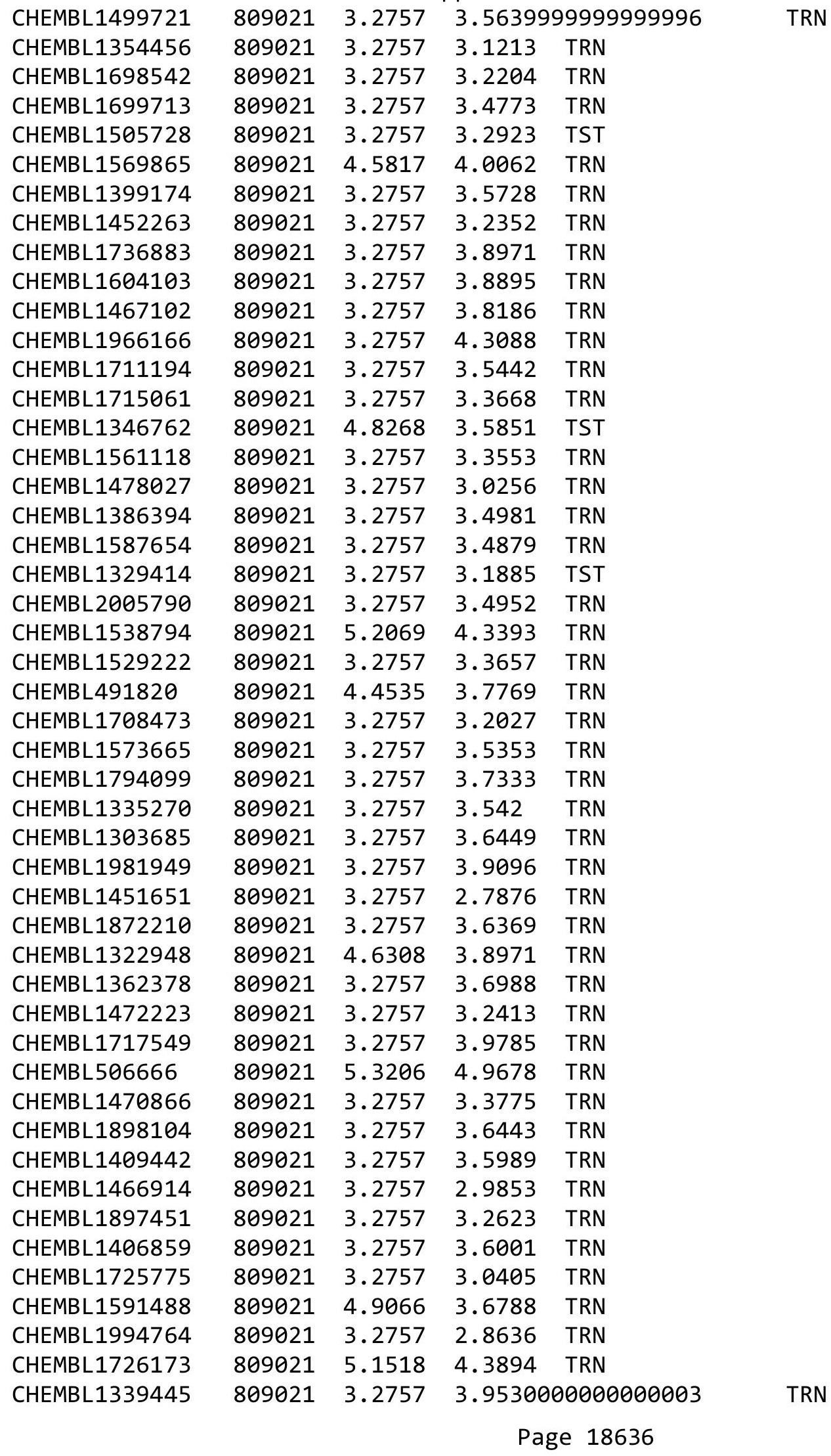


Supplemental Table S2.txt

\begin{tabular}{|c|c|c|c|c|}
\hline CHEMBL1462179 & 809021 & 3.2757 & 3.5867 & TRN \\
\hline CHEMBL1550694 & 809021 & 3.2757 & 3.7018 & TST \\
\hline CHEMBL1414980 & 809021 & 3.2757 & 4.2626 & TRN \\
\hline CHEMBL1547545 & 809021 & 3.2757 & 3.0525 & TRN \\
\hline CHEMBL1702337 & 809021 & 3.2757 & 3.8358 & TST \\
\hline CHEMBL1537016 & 809021 & 3.2757 & 3.4411 & TRN \\
\hline CHEMBL1308670 & 809021 & 3.2757 & 3.4265 & TRN \\
\hline CHEMBL1485638 & 809021 & 3.2757 & 3.1114 & TRN \\
\hline CHEMBL1613291 & 809021 & 3.2757 & 3.3709 & TRN \\
\hline CHEMBL1497417 & 809021 & 3.2757 & 3.4813 & TST \\
\hline CHEMBL1466828 & 809021 & 3.2757 & 3.1854 & TRN \\
\hline CHEMBL1717568 & 809021 & 3.2757 & 3.8329 & TRN \\
\hline CHEMBL1594237 & 809021 & 3.2757 & 3.4942 & TRN \\
\hline CHEMBL1415136 & 809021 & 5.1192 & 3.6145 & TRN \\
\hline CHEMBL1971705 & 809021 & 3.2757 & 3.5101 & TRN \\
\hline CHEMBL1418321 & 809021 & 3.2757 & 3.1508 & TRN \\
\hline CHEMBL1545742 & 809021 & 3.2757 & 3.0378 & TRN \\
\hline CHEMBL1986363 & 809021 & 3.2757 & 4.0943 & TST \\
\hline CHEMBL1377734 & 809021 & 3.2757 & 3.1987 & TRN \\
\hline CHEMBL1510057 & 809021 & 3.2757 & 3.235 & TRN \\
\hline CHEMBL1453613 & 809021 & 3.2757 & 3.4298 & TRN \\
\hline CHEMBL1431045 & 809021 & 3.2757 & 3.5666 & TST \\
\hline CHEMBL1472267 & 809021 & 3.2757 & 3.366 & TRN \\
\hline CHEMBL1733837 & 809021 & 3.2757 & 3.4624 & TST \\
\hline CHEMBL1302523 & 809021 & 3.2757 & 3.2755 & TRN \\
\hline CHEMBL1428459 & 809021 & 5.0788 & 3.9899 & TRN \\
\hline CHEMBL1995946 & 809021 & 3.2757 & 3.5293 & TRN \\
\hline CHEMBL1563699 & 809021 & 3.2757 & 3.6876 & TRN \\
\hline CHEMBL1492286 & 809021 & 3.2757 & 3.19100 & 00000000003 \\
\hline CHEMBL 2006470 & 809021 & 3.2757 & 3.2931 & TRN \\
\hline CHEMBL1732994 & 809021 & 3.2757 & 3.8239 & TRN \\
\hline CHEMBL1387734 & 809021 & 3.2757 & 3.1546 & TRN \\
\hline CHEMBL1524836 & 809021 & 3.2757 & 3.6216 & TRN \\
\hline CHEMBL1509144 & 809021 & 5.2725 & 4.4202 & TRN \\
\hline CHEMBL1379461 & 809021 & 3.2757 & 3.0533 & TRN \\
\hline CHEMBL1703419 & 809021 & 5.3862 & 4.7797 & TRN \\
\hline CHEMBL1996567 & 809021 & 3.2757 & 4.2596 & TRN \\
\hline CHEMBL1455852 & 809021 & 3.2757 & 3.8361 & TRN \\
\hline CHEMBL1392894 & 809021 & 5.0232 & 4.7811 & TST \\
\hline CHEMBL1341888 & 809021 & 3.2757 & 3.1337 & TRN \\
\hline CHEMBL1384559 & 809021 & 3.2757 & 3.8213 & TRN \\
\hline CHEMBL1467660 & 809021 & 3.2757 & 3.5427 & TRN \\
\hline CHEMBL1892675 & 809021 & 3.2757 & 3.0711 & TRN \\
\hline CHEMBL1499275 & 809021 & 3.2757 & 3.9652 & TRN \\
\hline CHEMBL1310342 & 809021 & 5.2534 & 3.7834 & TRN \\
\hline CHEMBL1429578 & 809021 & 5.4921 & 4.6738 & TRN \\
\hline CHEMBL1550439 & 809021 & 3.2757 & 3.0417 & TRN \\
\hline CHEMBL1349416 & 809021 & 3.2757 & 3.763 & TRN \\
\hline
\end{tabular}


Supplemental Table S2.txt

\begin{tabular}{|c|c|c|c|c|}
\hline CHEMBL 2006733 & 809021 & 3.2757 & 4.1484 & TST \\
\hline CHEMBL1892879 & 809021 & 3.2757 & 3.6835 & TRN \\
\hline CHEMBL1575690 & 809021 & 3.2757 & 3.6884 & TRN \\
\hline CHEMBL1495527 & 809021 & 3.2757 & 3.5156 & TST \\
\hline CHEMBL1570708 & 809021 & 3.2757 & 3.3815 & TRN \\
\hline CHEMBL1302710 & 809021 & 5.1931 & 3.9694 & TRN \\
\hline CHEMBL1577182 & 809021 & 3.2757 & 3.3276 & TRN \\
\hline CHEMBL1479434 & 809021 & 3.2757 & 4.0642 & TRN \\
\hline CHEMBL1449721 & 809021 & 3.2757 & 3.8982 & TRN \\
\hline CHEMBL1735984 & 809021 & 3.2757 & 3.5555 & TRN \\
\hline CHEMBL1987735 & 809021 & 3.2757 & 3.3508 & TRN \\
\hline CHEMBL1386981 & 809021 & 3.2757 & 3.4661 & TST \\
\hline CHEMBL1545743 & 809021 & 3.2757 & 3.9881 & TRN \\
\hline CHEMBL1359436 & 809021 & 3.2757 & 3.7829 & TRN \\
\hline CHEMBL1569544 & 809021 & 3.2757 & 3.8343 & TRN \\
\hline CHEMBL1715030 & 809021 & 5.2226 & 5.0315 & TRN \\
\hline CHEMBL1709601 & 809021 & 3.2757 & 3.1797 & TST \\
\hline CHEMBL1578629 & 809021 & 5.1993 & 4.875 & TRN \\
\hline CHEMBL1370968 & 809021 & 3.2757 & 3.2273 & TRN \\
\hline CHEMBL1733766 & 809021 & 5.2034 & 5.1902 & TRN \\
\hline CHEMBL1411122 & 809021 & 3.2757 & 3.0089 & TRN \\
\hline CHEMBL1548104 & 809021 & 3.2757 & 3.3632 & TST \\
\hline CHEMBL1970082 & 809021 & 3.2757 & 3.7334 & TRN \\
\hline CHEMBL1492959 & 809021 & 3.2757 & 3.7145 & TST \\
\hline CHEMBL1904030 & 809021 & 3.2757 & 3.7994 & TST \\
\hline CHEMBL1589457 & 809021 & 3.2757 & 3.8871 & TRN \\
\hline CHEMBL1601483 & 809021 & 3.2757 & 3.8909 & TST \\
\hline CHEMBL1469767 & 809021 & 3.2757 & 3.6313 & TRN \\
\hline CHEMBL1350340 & 809021 & 5.1152 & 3.987 & TRN \\
\hline CHEMBL1613653 & 809021 & 3.2757 & 3.885 & TRN \\
\hline CHEMBL1421097 & 809021 & 3.2757 & 3.5616 & TRN \\
\hline CHEMBL1429499 & 809021 & 3.2757 & 3.8372 & TRN \\
\hline CHEMBL1734867 & 809021 & 3.2757 & 3.5927 & TRN \\
\hline CHEMBL1390797 & 809021 & 5.1818 & 3.7403 & TRN \\
\hline CHEMBL1422869 & 809021 & 3.2757 & 4.3068 & TRN \\
\hline CHEMBL1999547 & 809021 & 3.2757 & 3.4032 & TRN \\
\hline CHEMBL1502448 & 809021 & 3.2757 & 3.7663 & TRN \\
\hline CHEMBL1345360 & 809021 & 3.2757 & 3.3748 & TRN \\
\hline CHEMBL1311234 & 809021 & 3.2757 & 3.2229 & TRN \\
\hline CHEMBL1411742 & 809021 & 3.2757 & 2.9406 & TRN \\
\hline CHEMBL 2000988 & 809021 & 3.2757 & 3.5655 & TST \\
\hline CHEMBL1443994 & 809021 & 3.2757 & 3.6286 & TRN \\
\hline CHEMBL1597974 & 809021 & 5.2612 & 4.141999 & 9999999995 \\
\hline CHEMBL1421539 & 809021 & 3.2757 & 4.0907 & TRN \\
\hline CHEMBL1699070 & 809021 & 3.2757 & 4.2791 & TRN \\
\hline CHEMBL1401343 & 809021 & 3.2757 & 3.4 & TRN \\
\hline CHEMBL1527784 & 809021 & 3.2757 & 3.5008 & TRN \\
\hline CHEMBL1303495 & 809021 & 3.2757 & 3.5019 & TRN \\
\hline
\end{tabular}




\begin{tabular}{|c|c|c|c|c|c|c|}
\hline & & \multicolumn{5}{|c|}{ Supplemental Table S2.txt } \\
\hline CHEMBL1607556 & 809021 & 4.4789 & 4.1121 & TRN & & \\
\hline CHEMBL1527358 & 809021 & 3.2757 & 4.6082 & TRN & & \\
\hline CHEMBL1702532 & 809021 & 3.2757 & 3.1599 & TRN & & \\
\hline CHEMBL458112 & 809021 & 3.2757 & 3.6604 & TRN & & \\
\hline CHEMBL1576217 & 809021 & 4.9469 & 3.8921 & TRN & & \\
\hline CHEMBL1494875 & 809021 & 5.3936 & 3.9458 & TRN & & \\
\hline CHEMBL1458493 & 809021 & 3.2757 & 3.3386 & TRN & & \\
\hline CHEMBL1311851 & 809021 & 3.2757 & 3.4038 & TST & & \\
\hline CHEMBL1729959 & 809021 & 3.2757 & 3.6073 & TRN & & \\
\hline CHEMBL1509434 & 809021 & 3.2757 & 3.4999 & TRN & & \\
\hline CHEMBL1545197 & 809021 & 3.2757 & 3.6746 & TRN & & \\
\hline CHEMBL1399679 & 809021 & 3.2757 & 3.3843 & TRN & & \\
\hline CHEMBL1975457 & 809021 & 3.2757 & 3.7181 & TRN & & \\
\hline CHEMBL1342237 & 809021 & 3.2757 & 4.5562 & TST & & \\
\hline CHEMBL1491798 & 809021 & \multicolumn{3}{|c|}{5.2620000000000005} & & TRN \\
\hline CHEMBL1583398 & 809021 & 3.2757 & 3.4905 & TRN & & \\
\hline CHEMBL1418086 & 809021 & 3.2757 & 3.7662 & TRN & & \\
\hline CHEMBL1519792 & 809021 & 3.2757 & 3.5089 & TRN & & \\
\hline CHEMBL1457774 & 809021 & 5.2815 & 3.7303 & TST & & \\
\hline CHEMBL1545155 & 809021 & 3.2757 & 3.8622 & TRN & & \\
\hline CHEMBL1459637 & 809021 & 3.2757 & 3.207 & TRN & & \\
\hline CHEMBL1966751 & 809021 & 3.2757 & 3.4691 & TRN & & \\
\hline CHEMBL1308433 & 809021 & 3.2757 & 3.0846 & TRN & & \\
\hline CHEMBL1304518 & 809021 & 3.2757 & 3.78 & TRN & & \\
\hline CHEMBL1704086 & 809021 & 4.567 & 3.6132 & TRN & & \\
\hline CHEMBL1610880 & 809021 & 3.2757 & 3.4386 & TRN & & \\
\hline CHEMBL1573421 & 809021 & 3.2757 & 3.4022 & TRN & & \\
\hline CHEMBL1892819 & 809021 & 3.2757 & 3.2958 & TRN & & \\
\hline CHEMBL1881383 & 809021 & 3.2757 & 3.7466 & TRN & & \\
\hline CHEMBL1519973 & 809021 & 3.2757 & 3.5999 & TRN & & \\
\hline CHEMBL 2000006 & 809021 & 3.2757 & 3.5447 & TRN & & \\
\hline CHEMBL1414305 & 809021 & 3.2757 & 3.388 & TRN & & \\
\hline CHEMBL1884623 & 809021 & 4.8508 & 4.4097 & TRN & & \\
\hline CHEMBL1453885 & 809021 & 3.2757 & 3.6712 & TRN & & \\
\hline CHEMBL1348645 & 809021 & 3.2757 & 3.7402 & TRN & & \\
\hline CHEMBL1877793 & 809021 & 3.2757 & 3.6079 & TRN & & \\
\hline CHEMBL1507535 & 809021 & 3.2757 & 3.8064 & TRN & & \\
\hline CHEMBL1596353 & 809021 & 5.104 & 4.5332 & TRN & & \\
\hline CHEMBL1471894 & 809021 & 3.2757 & 3.5261 & TRN & & \\
\hline CHEMBL 274499 & 809021 & 3.2757 & 3.2533 & TRN & & \\
\hline CHEMBL584031 & 809021 & 5.065 & 3.5069 & TRN & & \\
\hline CHEMBL1997195 & 809021 & 3.2757 & 3.7097 & TRN & & \\
\hline CHEMBL1888682 & 809021 & 3.2757 & 3.6853 & TRN & & \\
\hline CHEMBL1519574 & 809021 & 3.2757 & 3.57899 & 99999 & 997 & TRN \\
\hline CHEMBL1301825 & 809021 & 3.2757 & 3.6806 & TST & & \\
\hline CHEMBL1527480 & 809021 & 3.2757 & 3.2918 & TRN & & \\
\hline CHEMBL1539303 & 809021 & 3.2757 & 3.6124 & TRN & & \\
\hline CHEMBL1974913 & 809021 & 3.2757 & 3.3452 & TRN & & \\
\hline
\end{tabular}

Page 18639 
Supplemental Table S2.txt

\begin{tabular}{|c|c|c|c|c|c|}
\hline CHEMBL1967756 & 809021 & 3.2757 & 3.2602 & TRN & \\
\hline CHEMBL1461578 & 809021 & 3.2757 & 3.6199 & TRN & \\
\hline CHEMBL1454472 & 809021 & 3.2757 & 3.1658 & TRN & \\
\hline CHEMBL1469608 & 809021 & 3.2757 & 3.3199 & TRN & \\
\hline CHEMBL1469717 & 809021 & 3.2757 & 3.9959 & TRN & \\
\hline CHEMBL1455161 & 809021 & 3.2757 & 4.0589 & TRN & \\
\hline CHEMBL1339905 & 809021 & 5.1518 & 4.0814 & TRN & \\
\hline CHEMBL1331062 & 809021 & 3.2757 & 3.4184 & TRN & \\
\hline CHEMBL1409074 & 809021 & 3.2757 & 3.5349 & TRN & \\
\hline CHEMBL1332469 & 809021 & 3.2757 & 3.0148 & TRN & \\
\hline CHEMBL1335865 & 809021 & 3.2757 & 3.8954 & TRN & \\
\hline CHEMBL1469811 & 809021 & 3.2757 & 3.3266 & TRN & \\
\hline CHEMBL1453327 & 809021 & 5.2733 & 4.4894 & TRN & \\
\hline CHEMBL1490809 & 809021 & 3.2757 & 3.2485 & TRN & \\
\hline CHEMBL1717188 & 809021 & 3.2757 & 3.4777 & TRN & \\
\hline CHEMBL1878235 & 809021 & 3.2757 & 3.6767 & TRN & \\
\hline CHEMBL1319234 & 809021 & 3.2757 & 3.0474 & TRN & \\
\hline CHEMBL1459678 & 809021 & 3.2757 & 3.3108 & TRN & \\
\hline CHEMBL1724527 & 809021 & 3.2757 & 3.7638 & TRN & \\
\hline CHEMBL1416865 & 809021 & 3.2757 & 3.1924 & TRN & \\
\hline CHEMBL1864540 & 809021 & 5.1818 & 5.3056 & TRN & \\
\hline CHEMBL1386013 & 809021 & 3.2757 & 3.8132 & TRN & \\
\hline CHEMBL516954 & 809021 & 3.2757 & 4.0011 & TRN & \\
\hline CHEMBL1416158 & 809021 & 3.2757 & 3.2705 & TRN & \\
\hline CHEMBL1559894 & 809021 & 3.2757 & 3.6847 & TST & \\
\hline CHEMBL1506841 & 809021 & 3.2757 & 3.6851 & TRN & \\
\hline CHEMBL1430226 & 809021 & 3.2757 & 4.3148 & TRN & \\
\hline CHEMBL1468750 & 809021 & 3.2757 & 3.9408 & TRN & \\
\hline CHEMBL1324348 & 809021 & 3.2757 & 3.4149 & TST & \\
\hline CHEMBL1377960 & 809021 & 3.2757 & 4.2483 & TRN & \\
\hline CHEMBL1574323 & 809021 & 3.2757 & 3.9028 & TRN & \\
\hline CHEMBL1461213 & 809021 & 3.2757 & 3.1445 & TRN & \\
\hline CHEMBL1733230 & 809021 & 3.2757 & 3.8315 & TRN & \\
\hline CHEMBL1465349 & 809021 & 3.2757 & 3.64600 & 00000000004 & TRN \\
\hline CHEMBL3198643 & 809021 & 4.9666 & 4.4778 & TRN & \\
\hline CHEMBL1705963 & 809021 & 5.2644 & 3.7673 & TRN & \\
\hline CHEMBL1458095 & 809021 & 3.2757 & 2.9535 & TRN & \\
\hline CHEMBL1423516 & 809021 & 3.2757 & 3.3146 & TST & \\
\hline CHEMBL1448514 & 809021 & 3.2757 & 3.5401 & TRN & \\
\hline CHEMBL1375089 & 809021 & 3.2757 & 3.2218 & TRN & \\
\hline CHEMBL1428268 & 809021 & 3.2757 & 3.4736 & TST & \\
\hline CHEMBL1349479 & 809021 & 3.2757 & 3.4471 & TRN & \\
\hline CHEMBL1403507 & 809021 & 3.2757 & 3.0415 & TRN & \\
\hline CHEMBL1582229 & 809021 & 5.2182 & 3.6897 & TRN & \\
\hline CHEMBL1890417 & 809021 & 3.2757 & 3.5319 & TRN & \\
\hline CHEMBL1980826 & 809021 & 3.2757 & 4.1605 & TST & \\
\hline CHEMBL1323621 & 809021 & 3.2757 & 3.9746 & TRN & \\
\hline CHEMBL1353853 & 809021 & 3.2757 & 3.6497 & TST & \\
\hline
\end{tabular}

Page 18640 
Supplemental Table S2.txt

\begin{tabular}{|c|c|c|c|c|c|}
\hline CHEMBL1493712 & 809021 & 3.2757 & 2.9785 & TRN & \\
\hline CHEMBL1714053 & 809021 & 3.2757 & 3.6434 & TRN & \\
\hline CHEMBL1720673 & 809021 & 5.9547 & 4.5384 & TRN & \\
\hline CHEMBL1870358 & 809021 & 3.2757 & 3.5515 & TRN & \\
\hline CHEMBL1509029 & 809021 & 3.2757 & 3.469 & TRN & \\
\hline CHEMBL1094498 & 809021 & 3.2757 & 3.3115 & TRN & \\
\hline CHEMBL1505398 & 809021 & 3.2757 & 3.0653 & TST & \\
\hline CHEMBL1347041 & 809021 & 3.2757 & 3.3778 & TRN & \\
\hline CHEMBL1380457 & 809021 & 3.2757 & 3.5098 & TST & \\
\hline CHEMBL1711099 & 809021 & 5.3595 & 3.3321 & TRN & \\
\hline CHEMBL1971446 & 809021 & 3.2757 & 3.6738 & TST & \\
\hline CHEMBL1502712 & 809021 & 3.2757 & 3.5253 & TRN & \\
\hline CHEMBL1730548 & 809021 & 3.2757 & 3.6362 & TRN & \\
\hline CHEMBL1497226 & 809021 & 4.9245 & 4.1486 & TRN & \\
\hline CHEMBL1442604 & 809021 & 3.2757 & 3.531 & TRN & \\
\hline CHEMBL1422860 & 809021 & 3.2757 & 4.0129 & TST & \\
\hline CHEMBL1605906 & 809021 & 4.6162 & 3.6248 & TST & \\
\hline CHEMBL1484914 & 809021 & 3.2757 & 3.3207 & TRN & \\
\hline CHEMBL1596504 & 809021 & 3.2757 & 3.1949 & TST & \\
\hline CHEMBL1310744 & 809021 & 5.1694 & 4.529 & TRN & \\
\hline CHEMBL1490734 & 809021 & 5.15 & 4.0441 & TST & \\
\hline CHEMBL1327180 & 809021 & 5.1512 & 4.3502 & TRN & \\
\hline CHEMBL1535377 & 809021 & 3.2757 & 3.326 & TRN & \\
\hline CHEMBL1524084 & 809021 & 3.2757 & 3.68600 & 00000000004 & TRN \\
\hline CHEMBL1372921 & 809021 & 5.1506 & 3.9038 & TRN & \\
\hline CHEMBL1477639 & 809021 & 3.2757 & 3.4722 & TRN & \\
\hline CHEMBL1541480 & 809021 & 5.1308 & 3.7982 & TRN & \\
\hline CHEMBL1706502 & 809021 & 3.2757 & 3.3369 & TRN & \\
\hline CHEMBL1891811 & 809021 & 3.2757 & 3.6552 & TRN & \\
\hline CHEMBL 2007274 & 809021 & 5.1993 & 3.6497 & TRN & \\
\hline CHEMBL1370844 & 809021 & 4.6144 & 3.9634 & TRN & \\
\hline CHEMBL1724398 & 809021 & 3.2757 & 3.2982 & TRN & \\
\hline CHEMBL1581165 & 809021 & 3.2757 & 3.5445 & TRN & \\
\hline CHEMBL1459324 & 809021 & 3.2757 & 3.0679 & TRN & \\
\hline CHEMBL1587853 & 809021 & 5.3635 & 4.166 & TRN & \\
\hline CHEMBL1457805 & 809021 & 3.2757 & 3.6749 & TRN & \\
\hline CHEMBL1593521 & 809021 & 3.2757 & 3.9241 & TRN & \\
\hline CHEMBL1308990 & 809021 & 5.0937 & 4.3022 & TRN & \\
\hline CHEMBL1391386 & 809021 & 3.2757 & 3.5093 & TRN & \\
\hline CHEMBL1985679 & 809021 & 3.2757 & 3.9065 & TRN & \\
\hline CHEMBL1597620 & 809021 & 3.2757 & 3.3566 & TRN & \\
\hline CHEMBL1889431 & 809021 & 5.2182 & 3.8809 & TST & \\
\hline CHEMBL1413143 & 809021 & 3.2757 & 3.7918 & TRN & \\
\hline CHEMBL1329616 & 809021 & 3.2757 & 3.0703 & TST & \\
\hline CHEMBL1528114 & 809021 & 3.2757 & 2.6775 & TST & \\
\hline CHEMBL1570479 & 809021 & 5.0434 & 3.7599 & TRN & \\
\hline CHEMBL1874757 & 809021 & 3.2757 & 3.3127 & TST & \\
\hline CHEMBL1906117 & 809021 & 3.2757 & 3.5639 & TRN & \\
\hline
\end{tabular}

Page 18641 
Supplemental Table S2.txt

\begin{tabular}{|c|c|c|c|c|}
\hline CHEMBL1401975 & 809021 & 3.2757 & 3.5791 & TRN \\
\hline CHEMBL1715773 & 809021 & 4.7399 & 3.988 & TST \\
\hline CHEMBL1714612 & 809021 & 3.2757 & 3.3658 & TRN \\
\hline CHEMBL1484787 & 809021 & 3.2757 & 3.7917 & TST \\
\hline CHEMBL1703980 & 809021 & 3.2757 & 3.6209 & TRN \\
\hline CHEMBL1447555 & 809021 & 3.2757 & 3.3832 & TRN \\
\hline CHEMBL1519513 & 809021 & 4.5884 & 4.4059 & TRN \\
\hline CHEMBL1418017 & 809021 & 3.2757 & 3.4972 & TRN \\
\hline CHEMBL1568411 & 809021 & 3.2757 & 3.5123 & TRN \\
\hline CHEMBL1699207 & 809021 & 3.2757 & 3.4307 & TRN \\
\hline CHEMBL1990055 & 809021 & 3.2757 & 3.5804 & TRN \\
\hline CHEMBL1312135 & 809021 & 3.2757 & 3.7472 & TRN \\
\hline CHEMBL1539526 & 809021 & 3.2757 & 4.1209 & TST \\
\hline CHEMBL1904477 & 809021 & 3.2757 & 3.1041 & TST \\
\hline CHEMBL1577217 & 809021 & 3.2757 & 4.0145 & TST \\
\hline CHEMBL1531524 & 809021 & 3.2757 & 3.9924 & TRN \\
\hline CHEMBL1451237 & 809021 & 3.2757 & 3.1358 & TRN \\
\hline CHEMBL1545472 & 809021 & 3.2757 & 3.8545 & TRN \\
\hline CHEMBL1463227 & 809021 & 3.2757 & 3.1489 & TRN \\
\hline CHEMBL1409207 & 809021 & 5.5591 & 4.0267 & TRN \\
\hline CHEMBL1483550 & 809021 & 3.2757 & 3.641 & TRN \\
\hline CHEMBL1582739 & 809021 & 3.2757 & 3.2925 & TRN \\
\hline CHEMBL1714214 & 809021 & 3.2757 & 3.3177 & TRN \\
\hline CHEMBL1588406 & 809021 & 3.2757 & 3.6228 & TRN \\
\hline CHEMBL1486020 & 809021 & 3.2757 & 2.9137 & TRN \\
\hline CHEMBL1456300 & 809021 & 3.2757 & 4.0227 & TRN \\
\hline CHEMBL1418231 & 809021 & 3.2757 & 3.2293 & TRN \\
\hline CHEMBL1543203 & 809021 & 5.2993 & 3.6378 & TRN \\
\hline CHEMBL1487187 & 809021 & 3.2757 & 3.61800 & 30000000003 \\
\hline CHEMBL1521600 & 809021 & 3.2757 & 3.6287 & TRN \\
\hline CHEMBL1873465 & 809021 & 5.5638 & 4.3698 & TRN \\
\hline CHEMBL1343603 & 809021 & 3.2757 & 3.8539 & TST \\
\hline CHEMBL1518288 & 809021 & 3.2757 & 3.3475 & TRN \\
\hline CHEMBL1340852 & 809021 & 3.2757 & 3.1208 & TRN \\
\hline CHEMBL 245265 & 809021 & 3.2757 & 3.1557 & TRN \\
\hline CHEMBL1407258 & 809021 & 3.2757 & 3.7375 & TRN \\
\hline CHEMBL1975484 & 809021 & 3.2757 & 3.8614 & TRN \\
\hline CHEMBL1398060 & 809021 & 5.2874 & 4.4705 & TRN \\
\hline CHEMBL1889977 & 809021 & 5.1811 & 4.6317 & TRN \\
\hline CHEMBL1891535 & 809021 & 5.1612 & 4.0126 & TRN \\
\hline CHEMBL1558416 & 809021 & 3.2757 & 3.4082 & TST \\
\hline CHEMBL1463889 & 809021 & 3.2757 & 3.2146 & TRN \\
\hline CHEMBL1568876 & 809021 & 3.2757 & 3.9971 & TRN \\
\hline CHEMBL1974818 & 809021 & 3.2757 & 3.403 & TRN \\
\hline CHEMBL1463574 & 809021 & 5.2233 & 3.8301 & TRN \\
\hline CHEMBL1971946 & 809021 & 3.2757 & 3.822 & TRN \\
\hline CHEMBL1903930 & 809021 & 3.2757 & 3.6595 & TST \\
\hline CHEMBL1426192 & 809021 & 3.2757 & 3.5845 & TRN \\
\hline
\end{tabular}

Page 18642 
Supplemental Table S2.txt

\begin{tabular}{|c|c|c|c|c|}
\hline 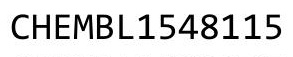 & & & & \\
\hline HEMBL1583907 & 99021 & 2757 & 3.6779 & \\
\hline HEMBL14 & 09021 & 2757 & 572 & \\
\hline IEMBL1 & & 2757 & 4173 & \\
\hline EMBL15 & 21 & 2757 & 7995 & \\
\hline HEMBL1343658 & 09021 & 2708 & 207 & \\
\hline HEMBL1509762 & 09021 & .2757 & .7442 & \\
\hline HEMBL14C & & & 5855 & \\
\hline EMBL18 & 21 & .2757 & 81 & \\
\hline IEMBL136 & 21 & .2757 & 464 & \\
\hline HEMBL1587868 & 09021 & .2299 & 43 & \\
\hline HEMBL1736939 & 09021 & .2757 & 6387 & \\
\hline HEMBL1301778 & 1 & 2757 & 7567 & \\
\hline AEMBL197 & 21 & 72 & 195 & \\
\hline HEMBL159 & 21 & 57 & 5851 & \\
\hline HEMBL155 & 21 & & 5862 & \\
\hline HEMBL 2002815 & 21 & & & \\
\hline HEMBL157 & 1 & 57 & 313 & \\
\hline HEMBL14 & & 57 & 74 & \\
\hline HEMBL15 & 1 & & 473 & \\
\hline HEMBL132 & 1 & & & \\
\hline HEMBL1440842 & 1 & & & \\
\hline HEMBL13 & 1 & & 362 & \\
\hline HEMBL14 & & & 31 & \\
\hline HEMBL17 & & & 183 & RN \\
\hline HEMBL15 & 1 & & & \\
\hline HEMBL189. & 1 & & & \\
\hline HEMBL18 & 1 & & & \\
\hline HEM & 1 & & 05 & \\
\hline HEM & 1 & & 208 & $\mathrm{RN}$ \\
\hline HEMBL158 & & & & ST \\
\hline HEMBL1891260 & 1 & & 463 & RN \\
\hline HEMBL13 & 1 & & & RIV \\
\hline 9 & & & 17 & RN \\
\hline HEMBL159 & & & & RN \\
\hline HEMBL1995565 & 21 & & & IST \\
\hline HEMBL1413263 & 1 & & 687 & $\Gamma \mathrm{RN}$ \\
\hline 0 & & & 343 & I RIV \\
\hline 1 19 & & & 228 & SI \\
\hline HEMBL1343599 & & & & RN \\
\hline HEMBL1870822 & 1 & & 996 & ГRN \\
\hline HEMBL170 & 1 & & 286 & \\
\hline 007 & & & & \\
\hline LHEMBL142 & & & & TRN \\
\hline HEMBL1424360 & & & 0589 & RN \\
\hline HEMBL157. & 1 & & 3095 & $N$ \\
\hline 196 & & & & \\
\hline 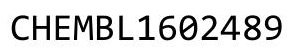 & & & & \\
\hline
\end{tabular}

Page 18643 


\begin{tabular}{|c|c|c|c|c|}
\hline & & & oplement & al Ta \\
\hline CHEMBL1709811 & 809021 & 5.098 & 3.6517 & TRN \\
\hline CHEMBL1367360 & 809021 & 3.2757 & 3.1622 & TRN \\
\hline CHEMBL1359004 & 809021 & 5.3242 & 3.8742 & TRN \\
\hline CHEMBL1508635 & 809021 & 3.2757 & 3.4876 & TRN \\
\hline CHEMBL1885384 & 809021 & 3.2757 & 4.0502 & TRN \\
\hline CHEMBL1590902 & 809021 & 3.2757 & 4.1066 & TST \\
\hline CHEMBL1561297 & 809021 & 3.2757 & 3.3529 & TRN \\
\hline CHEMBL1592246 & 809021 & 3.2757 & 3.3772 & TRN \\
\hline CHEMBL1964702 & 809021 & 3.2757 & 4.2416 & TRN \\
\hline CHEMBL1412955 & 809021 & 3.2757 & 4.189 & TRN \\
\hline CHEMBL1413942 & 809021 & 3.2757 & 3.6071 & TRN \\
\hline CHEMBL1426006 & 809021 & 5.3354 & 3.863 & TST \\
\hline CHEMBL1559175 & 809021 & 4.3372 & 3.805 & TRN \\
\hline CHEMBL1349774 & 809021 & 3.2757 & 3.9054 & TRN \\
\hline CHEMBL1726318 & 809021 & 3.2757 & 3.2428 & TRN \\
\hline CHEMBL1389773 & 809021 & 3.2757 & 3.3349 & TRN \\
\hline CHEMBL1448750 & 809021 & 3.2757 & 3.4877 & TRN \\
\hline CHEMBL1710757 & 809021 & 3.2757 & 3.4194 & TRN \\
\hline CHEMBL1403927 & 809021 & 3.2757 & 3.9875 & TST \\
\hline CHEMBL1587395 & 809021 & 3.2757 & 3.7969 & TST \\
\hline CHEMBL1494767 & 809021 & 3.2757 & 3.3657 & TRN \\
\hline CHEMBL1568515 & 809021 & 3.2757 & 3.5659 & TRN \\
\hline CHEMBL1583628 & 809021 & 3.2757 & 4.0141 & TST \\
\hline CHEMBL1518013 & 809021 & 5.0155 & 3.5565 & TRN \\
\hline CHEMBL1889382 & 809021 & 5.0128 & 3.8172 & TRN \\
\hline CHEMBL1725853 & 809021 & 3.2757 & 3.7967 & TST \\
\hline CHEMBL1482223 & 809021 & 3.2757 & 3.2932 & TRN \\
\hline CHEMBL1426270 & 809021 & 3.2757 & 3.6197 & TRN \\
\hline CHEMBL1602136 & 809021 & 3.2757 & 3.8465 & TST \\
\hline CHEMBL1439222 & 809021 & 3.2757 & 3.7212 & TRN \\
\hline CHEMBL1466708 & 809021 & 3.2757 & 3.1633 & TRN \\
\hline CHEMBL 2002522 & 809021 & 3.2757 & 3.4915 & TRN \\
\hline CHEMBL1602641 & 809021 & 3.2757 & 3.1961 & TRN \\
\hline CHEMBL1572156 & 809021 & 3.2757 & 3.5731 & TRN \\
\hline CHEMBL1371629 & 809021 & 3.2757 & 3.0813 & TRN \\
\hline CHEMBL1352413 & 809021 & 3.2757 & 3.6065 & TRN \\
\hline CHEMBL1349459 & 809021 & 3.2757 & 3.2125 & TRN \\
\hline CHEMBL1386206 & 809021 & 3.2757 & 3.5427 & TRN \\
\hline CHEMBL 2000442 & 809021 & 3.2757 & 3.4923 & TRN \\
\hline CHEMBL 2001226 & 809021 & 5.9066 & 4.3068 & TRN \\
\hline CHEMBL1572190 & 809021 & 3.2757 & 3.5921 & TRN \\
\hline CHEMBL1462271 & 809021 & 4.8069 & 3.7068 & TRN \\
\hline CHEMBL1450691 & 809021 & 3.2757 & 3.1279 & TRN \\
\hline CHEMBL1405622 & 809021 & 5.2013 & 4.4709 & TST \\
\hline CHEMBL1401174 & 809021 & 4.4802 & 3.3378 & TRN \\
\hline CHEMBL1731772 & 809021 & 3.2757 & 3.5025 & TRN \\
\hline CHEMBL1306917 & 809021 & 5.3585 & 3.9917 & TST \\
\hline CHEMBL1361498 & 809021 & 3.2757 & 4.137 & TRN \\
\hline
\end{tabular}


Supplemental Table S2.txt

\begin{tabular}{|c|c|c|c|c|}
\hline CHEMBL1979527 & 809021 & 3.2757 & 3.4291 & TRN \\
\hline CHEMBL1519346 & 809021 & 6.0799 & 4.1465 & TRN \\
\hline CHEMBL1700062 & 809021 & 3.2757 & 3.5937 & TRN \\
\hline CHEMBL1413736 & 809021 & 3.2757 & 3.5366 & TRN \\
\hline CHEMBL1418327 & 809021 & 3.2757 & 3.6178 & TRN \\
\hline CHEMBL1573690 & 809021 & 4.8477 & 4.5753 & TRN \\
\hline CHEMBL1718457 & 809021 & 3.2757 & 3.1238 & TRN \\
\hline CHEMBL1571584 & 809021 & 3.2757 & 3.3743 & TRN \\
\hline CHEMBL1453985 & 809021 & 3.2757 & 2.9297 & TRN \\
\hline CHEMBL1446271 & 809021 & 3.2757 & 3.2636 & TRN \\
\hline CHEMBL1303082 & 809021 & 3.2757 & 2.7366 & TRN \\
\hline CHEMBL1712433 & 809021 & 3.2757 & 3.1641 & TRN \\
\hline CHEMBL1384012 & 809021 & 4.9914 & 3.7441 & TRN \\
\hline CHEMBL1710908 & 809021 & 3.2757 & 3.7951 & TRN \\
\hline CHEMBL1322451 & 809021 & 5.2097 & 4.0218 & TRN \\
\hline CHEMBL1302378 & 809021 & 3.2757 & 3.4493 & TST \\
\hline CHEMBL1305430 & 809021 & 3.2757 & 3.9265 & TRN \\
\hline CHEMBL1469381 & 809021 & 3.2757 & 3.5944 & TRN \\
\hline CHEMBL1568105 & 809021 & 3.2757 & 3.7425 & TRN \\
\hline CHEMBL1576646 & 809021 & 3.2757 & 4.0596 & TRN \\
\hline CHEMBL1870778 & 809021 & 3.2757 & 3.6765 & TRN \\
\hline CHEMBL1897450 & 809021 & 3.2757 & 4.0368 & TRN \\
\hline CHEMBL1388462 & 809021 & 3.2757 & 3.2773 & TRN \\
\hline CHEMBL1967690 & 809021 & 3.2757 & 4.0443 & TST \\
\hline CHEMBL1578622 & 809021 & 3.2757 & 3.3609 & TRN \\
\hline CHEMBL1717845 & 809021 & 3.2757 & 4.2042 & TRN \\
\hline CHEMBL1308187 & 809021 & 5.2111 & 4.3832 & TRN \\
\hline CHEMBL1344002 & 809021 & 3.2757 & 3.6386 & TST \\
\hline CHEMBL1520048 & 809021 & 5.3686 & 3.7281 & TRN \\
\hline CHEMBL1458689 & 809021 & 5.0264 & 4.1712 & TRN \\
\hline CHEMBL1700473 & 809021 & 4.9136 & 3.4305 & TRN \\
\hline CHEMBL1467043 & 809021 & 3.2757 & 3.68899 & 99999999996 \\
\hline CHEMBL1528725 & 809021 & 3.2757 & 3.7764 & TRN \\
\hline CHEMBL1392211 & 809021 & 3.2757 & 3.3795 & TRN \\
\hline CHEMBL1411720 & 809021 & 3.2757 & 3.345 & TRN \\
\hline CHEMBL1313370 & 809021 & 3.2757 & 3.5029 & TRN \\
\hline CHEMBL1341582 & 809021 & 3.2757 & 3.4189 & TRN \\
\hline CHEMBL1611234 & 809021 & 3.2757 & 3.5294 & TRN \\
\hline CHEMBL1384298 & 809021 & 3.2757 & 3.6304 & TRN \\
\hline CHEMBL1728240 & 809021 & 3.2757 & 3.6967 & TRN \\
\hline CHEMBL1345630 & 809021 & 3.2757 & 4.0191 & TST \\
\hline CHEMBL1546025 & 809021 & 3.2757 & 3.1255 & TRN \\
\hline CHEMBL1698491 & 809021 & 3.2757 & 4.3923 & TRN \\
\hline CHEMBL1545345 & 809021 & 5.3969 & 4.3493 & TRN \\
\hline CHEMBL1351269 & 809021 & 5.3936 & 4.3139 & TRN \\
\hline CHEMBL1445654 & 809021 & 5.0814 & 4.0789 & TRN \\
\hline CHEMBL1505242 & 809021 & 3.2757 & 3.1969 & TRN \\
\hline CHEMBL1390210 & 809021 & 3.2757 & 3.0078 & TRN \\
\hline
\end{tabular}

Page 18645 
Supplemental Table S2.txt

\begin{tabular}{|c|c|c|c|c|}
\hline CHEMBL1887005 & 809021 & 3.2757 & 3.5216 & TRN \\
\hline CHEMBL1383372 & 809021 & 3.2757 & 2.9272 & TRN \\
\hline CHEMBL1603238 & 809021 & 3.2757 & 4.145 & TST \\
\hline CHEMBL1475287 & 809021 & 3.2757 & 3.8517 & TRN \\
\hline CHEMBL1352589 & 809021 & 3.2757 & 4.2482 & TRN \\
\hline CHEMBL1964415 & 809021 & 5.2358 & 4.6213 & TST \\
\hline CHEMBL1530277 & 809021 & 3.2757 & 3.2535 & TRN \\
\hline CHEMBL1584408 & 809021 & 3.2757 & 3.1341 & TRN \\
\hline CHEMBL1586600 & 809021 & 3.2757 & 3.6792 & TRN \\
\hline CHEMBL1546999 & 809021 & 3.2757 & 3.73100 & 00000000003 \\
\hline CHEMBL1518905 & 809021 & 5.4271 & 4.7988 & TRN \\
\hline CHEMBL1698099 & 809021 & 3.2757 & 3.2343 & TRN \\
\hline CHEMBL1883118 & 809021 & 3.2757 & 3.3364 & TRN \\
\hline CHEMBL1344594 & 809021 & 3.2757 & 3.0492 & TST \\
\hline CHEMBL1508418 & 809021 & 3.2757 & 3.839 & TRN \\
\hline CHEMBL1445253 & 809021 & 3.2757 & 3.6395 & TST \\
\hline CHEMBL1326080 & 809021 & 3.2757 & 3.4619 & TST \\
\hline CHEMBL1611094 & 809021 & 3.2757 & 3.4946 & TRN \\
\hline CHEMBL1533222 & 809021 & 3.2757 & 4.018 & TRN \\
\hline CHEMBL1868948 & 809021 & 4.9706 & 3.9113 & TRN \\
\hline CHEMBL1613285 & 809021 & 5.2125 & 4.2901 & TRN \\
\hline CHEMBL1415999 & 809021 & 5.5421 & 4.6428 & TRN \\
\hline CHEMBL1985295 & 809021 & 3.2757 & 3.6603 & TST \\
\hline CHEMBL1322166 & 809021 & 3.2757 & 3.1248 & TST \\
\hline CHEMBL1502194 & 809021 & 5.1688 & 4.0267 & TRN \\
\hline CHEMBL1530236 & 809021 & 3.2757 & 3.5409 & TRN \\
\hline CHEMBL1403977 & 809021 & 3.2757 & 3.0533 & TRN \\
\hline CHEMBL1545385 & 809021 & 3.2757 & 3.4831 & TRN \\
\hline CHEMBL3145316 & 809021 & 5.4034 & 4.0653 & TRN \\
\hline CHEMBL1342559 & 809021 & 3.2757 & 3.7652 & TRN \\
\hline CHEMBL1897551 & 809021 & 4.2993 & 3.6258 & TRN \\
\hline CHEMBL1433943 & 809021 & 3.2757 & 3.273 & TRN \\
\hline CHEMBL1421652 & 809021 & 3.2757 & 3.1066 & TRN \\
\hline CHEMBL1516953 & 809021 & 3.2757 & 3.3708 & TST \\
\hline CHEMBL1583719 & 809021 & 3.2757 & 3.7899 & TRN \\
\hline CHEMBL1342640 & 809021 & 5.266 & 3.6189 & TRN \\
\hline CHEMBL1431871 & 809021 & 3.2757 & 3.4537 & TST \\
\hline CHEMBL 2005764 & 809021 & 3.2757 & 3.5581 & TRN \\
\hline CHEMBL1539444 & 809021 & 3.2757 & 3.8744 & TRN \\
\hline CHEMBL1603709 & 809021 & 3.2757 & 3.6667 & TRN \\
\hline CHEMBL1890943 & 809021 & 3.2757 & 3.02 & TRN \\
\hline CHEMBL1521778 & 809021 & 3.2757 & 3.8974 & TRN \\
\hline CHEMBL1395368 & 809021 & 3.2757 & 3.5821 & TRN \\
\hline CHEMBL1429819 & 809021 & 3.2757 & 3.2065 & TRN \\
\hline CHEMBL1464962 & 809021 & 3.2757 & 3.3471 & TRN \\
\hline CHEMBL1588727 & 809021 & 3.2757 & 3.6345 & TRN \\
\hline CHEMBL1995825 & 809021 & 3.2757 & 3.6298 & TRN \\
\hline CHEMBL1362168 & 809021 & 3.2757 & 3.5152 & TRN \\
\hline
\end{tabular}


Supplemental Table S2.txt

\begin{tabular}{|c|c|c|c|c|c|}
\hline CHEMBL1496582 & 809021 & 4.7423 & 3.9069 & TRN & \\
\hline CHEMBL1389843 & 809021 & 3.2757 & 3.2686 & TRN & \\
\hline CHEMBL1510050 & 809021 & 3.2757 & 3.5358 & TRN & \\
\hline CHEMBL1484480 & 809021 & 3.2757 & 2.9578 & TST & \\
\hline CHEMBL579621 & 809021 & 3.2757 & 3.6907 & TRN & \\
\hline CHEMBL1496607 & 809021 & 5.1261 & 4.6289 & TRN & \\
\hline CHEMBL1995109 & 809021 & 3.2757 & 4.2179 & TRN & \\
\hline CHEMBL1882421 & 809021 & 3.2757 & 3.5823 & TST & \\
\hline CHEMBL137913 & 809021 & 5.2725 & 4.0802 & TRN & \\
\hline CHEMBL1399067 & 809021 & 3.2757 & 3.6769 & TRN & \\
\hline CHEMBL1447812 & 809021 & 3.2757 & 3.8712 & TRN & \\
\hline CHEMBL1451481 & 809021 & 3.2757 & 3.1743 & TRN & \\
\hline CHEMBL1891502 & 809021 & 3.2757 & 4.1299 & TRN & \\
\hline CHEMBL1715537 & 809021 & 5.5467 & 3.585 & TRN & \\
\hline CHEMBL1373597 & 809021 & 3.2757 & 3.8256 & TRN & \\
\hline CHEMBL579967 & 809021 & 3.2757 & 3.3284 & TRN & \\
\hline CHEMBL1432687 & 809021 & 3.2757 & 3.9742 & TRN & \\
\hline CHEMBL1547704 & 809021 & 3.2757 & 3.0034 & TRN & \\
\hline CHEMBL1577993 & 809021 & 3.2757 & 4.0202 & TRN & \\
\hline CHEMBL1403807 & 809021 & 3.2757 & 3.148 & TRN & \\
\hline CHEMBL1879609 & 809021 & 3.2757 & 3.6485 & TRN & \\
\hline CHEMBL1707693 & 809021 & 5.2062 & 4.312 & TST & \\
\hline CHEMBL1575832 & 809021 & 3.2757 & 3.43399 & 99999999997 & TRN \\
\hline CHEMBL1389073 & 809021 & 3.2757 & 4.1086 & TRN & \\
\hline CHEMBL1536683 & 809021 & 3.2757 & 3.5978 & TRN & \\
\hline CHEMBL1518362 & 809021 & 3.2757 & 3.3093 & TRN & \\
\hline CHEMBL1389929 & 809021 & 3.2757 & 4.1262 & TST & \\
\hline CHEMBL1310211 & 809021 & 3.2757 & 2.9824 & TRN & \\
\hline CHEMBL 2001481 & 809021 & 5.0991 & 4.4653 & TRN & \\
\hline CHEMBL1707960 & 809021 & 5.7721 & 4.1073 & TST & \\
\hline CHEMBL1904453 & 809021 & 3.2757 & 4.0179 & TRN & \\
\hline CHEMBL1367000 & 809021 & 3.2757 & 3.7644 & TRN & \\
\hline CHEMBL1967062 & 809021 & 3.2757 & 3.4779 & TRN & \\
\hline CHEMBL1574418 & 809021 & 3.2757 & 3.4166 & TRN & \\
\hline CHEMBL1715726 & 809021 & 3.2757 & 3.4286 & TRN & \\
\hline CHEMBL1997174 & 809021 & 3.2757 & 3.5317 & TRN & \\
\hline CHEMBL1467253 & 809021 & 3.2757 & 3.6916 & TRN & \\
\hline CHEMBL1446255 & 809021 & 3.2757 & 3.3898 & TRN & \\
\hline CHEMBL1577837 & 809021 & 3.2757 & 3.8096 & TST & \\
\hline CHEMBL1374927 & 809021 & 5.0443 & 4.0485 & TRN & \\
\hline CHEMBL1497720 & 809021 & 3.2757 & 4.2771 & TRN & \\
\hline CHEMBL1582859 & 809021 & 3.2757 & 3.6289 & TRN & \\
\hline CHEMBL1377330 & 809021 & 3.2757 & 3.426 & TRN & \\
\hline CHEMBL1319274 & 809021 & 3.2757 & 3.1846 & TRN & \\
\hline CHEMBL1709644 & 809021 & 3.2757 & 3.5491 & TRN & \\
\hline CHEMBL1725791 & 809021 & 3.2757 & 4.1168 & TST & \\
\hline CHEMBL1371231 & 809021 & 3.2757 & 4.0401 & TRN & \\
\hline CHEMBL1608409 & 809021 & 3.2757 & 3.5099 & TRN & \\
\hline
\end{tabular}

Page 18647 
Supplemental Table S2.txt

\begin{tabular}{|c|c|c|c|c|}
\hline CHEMBL1451060 & 809021 & 5.2741 & 4.6406 & TRN \\
\hline CHEMBL1888697 & 809021 & 5.5918 & 4.3172 & TST \\
\hline CHEMBL1886668 & 809021 & 3.2757 & 2.9613 & TRN \\
\hline CHEMBL1540040 & 809021 & 3.2757 & 3.1084 & TRN \\
\hline CHEMBL1437929 & 809021 & 3.2757 & 3.8397 & TST \\
\hline CHEMBL1719414 & 809021 & 5.2976 & 4.7973 & TRN \\
\hline CHEMBL1734383 & 809021 & 5.2865 & 4.4018 & TRN \\
\hline CHEMBL1904840 & 809021 & 3.2757 & 3.5115 & TRN \\
\hline CHEMBL1349183 & 809021 & 3.2757 & 3.2246 & TRN \\
\hline CHEMBL1482606 & 809021 & 3.2757 & 3.61899 & 99999999998 \\
\hline CHEMBL1971410 & 809021 & 3.2757 & 3.7607 & TRN \\
\hline CHEMBL1391473 & 809021 & 3.2757 & 3.4175 & TRN \\
\hline CHEMBL1313982 & 809021 & 5.1373 & 3.9569 & TRN \\
\hline CHEMBL1336833 & 809021 & 3.2757 & 3.7904 & TST \\
\hline CHEMBL1343586 & 809021 & 3.2757 & 4.0508 & TRN \\
\hline CHEMBL1307032 & 809021 & 3.2757 & 3.614 & TRN \\
\hline CHEMBL1701597 & 809021 & 3.2757 & 3.5796 & TRN \\
\hline CHEMBL1480837 & 809021 & 3.2757 & 3.2132 & TRN \\
\hline CHEMBL1725406 & 809021 & 5.27 & 5.0823 & TRN \\
\hline CHEMBL 2003272 & 809021 & 3.2757 & 3.1158 & TST \\
\hline CHEMBL1888181 & 809021 & 3.2757 & 3.3356 & TRN \\
\hline CHEMBL1412068 & 809021 & 3.2757 & 4.1582 & TRN \\
\hline CHEMBL1708730 & 809021 & 3.2757 & 3.466 & TRN \\
\hline CHEMBL 2001421 & 809021 & 3.2757 & 4.1083 & TRN \\
\hline CHEMBL1707812 & 809021 & 3.2757 & 4.3763 & TST \\
\hline CHEMBL1442335 & 809021 & 3.2757 & 3.7056 & TRN \\
\hline CHEMBL1354394 & 809021 & 3.2757 & 4.0608 & TST \\
\hline CHEMBL1389939 & 809021 & 3.2757 & 3.7727 & TRN \\
\hline CHEMBL1361290 & 809021 & 3.2757 & 3.4682 & TRN \\
\hline CHEMBL1573703 & 809021 & 3.2757 & 3.2031 & TRN \\
\hline CHEMBL1887983 & 809021 & 3.2757 & 3.4539 & TRN \\
\hline CHEMBL1903884 & 809021 & 3.2757 & 3.7723 & TST \\
\hline CHEMBL1402641 & 809021 & 5.1945 & 3.9612 & TRN \\
\hline CHEMBL 2004624 & 809021 & 3.2757 & 3.6745 & TRN \\
\hline CHEMBL1323094 & 809021 & 3.2757 & 3.7022 & TRN \\
\hline CHEMBL1330414 & 809021 & 3.2757 & 3.3627 & TRN \\
\hline CHEMBL1603355 & 809021 & 3.2757 & 3.0489 & TRN \\
\hline CHEMBL1428709 & 809021 & 3.2757 & 3.1715 & TRN \\
\hline CHEMBL1373496 & 809021 & 3.2757 & 3.5402 & TRN \\
\hline CHEMBL1321837 & 809021 & 3.2757 & 3.4182 & TRN \\
\hline CHEMBL1364137 & 809021 & 3.2757 & 3.3596 & TRN \\
\hline CHEMBL 2005664 & 809021 & 4.8729 & 3.7434 & TRN \\
\hline CHEMBL1489089 & 809021 & 3.2757 & 4.0486 & TRN \\
\hline CHEMBL1332060 & 809021 & 4.757 & 3.9634 & TRN \\
\hline CHEMBL1419598 & 809021 & 5.5143 & 4.2478 & TRN \\
\hline CHEMBL1462418 & 809021 & 3.2757 & 3.5158 & TRN \\
\hline CHEMBL1610675 & 809021 & 3.2757 & 3.4004 & TRN \\
\hline CHEMBL1550064 & 809021 & 5.3354 & 4.1411 & TRN \\
\hline
\end{tabular}


Supplemental Table S2.txt

\begin{tabular}{|c|c|c|c|c|}
\hline CHEMBL1310715 & 809021 & 3.2757 & 3.3859 & TRN \\
\hline CHEMBL1479108 & 809021 & 3.2757 & 3.7403 & TRN \\
\hline CHEMBL3392047 & 809021 & 4.9747 & 4.4701 & TST \\
\hline CHEMBL1508696 & 809021 & 5.2358 & 4.2573 & TRN \\
\hline CHEMBL1407195 & 809021 & 4.8962 & 3.411 & TRN \\
\hline CHEMBL1463504 & 809021 & 3.2757 & 2.9953 & TRN \\
\hline CHEMBL1485456 & 809021 & 3.2757 & 2.9422 & TRN \\
\hline CHEMBL1572650 & 809021 & 3.2757 & 3.6596 & TRN \\
\hline CHEMBL1468661 & 809021 & 3.2757 & 3.0555 & TRN \\
\hline CHEMBL1256959 & 809021 & 3.2757 & 3.7873 & TST \\
\hline CHEMBL1700111 & 809021 & 3.2757 & 3.1025 & TRN \\
\hline CHEMBL1526005 & 809021 & 3.2757 & 3.2984 & TRN \\
\hline CHEMBL1355452 & 809021 & 5.2865 & 4.0375 & TRN \\
\hline CHEMBL1418754 & 809021 & 5.1549 & 3.8663 & TRN \\
\hline CHEMBL1414869 & 809021 & 5.3635 & 4.0864 & TRN \\
\hline CHEMBL1306380 & 809021 & 3.2757 & 3.5484 & TRN \\
\hline CHEMBL1302234 & 809021 & 3.2757 & 3.6693 & TST \\
\hline CHEMBL1433246 & 809021 & 4.9508 & 4.19600 & 000000001 \\
\hline CHEMBL1559323 & 809021 & 3.2757 & 3.4401 & TRN \\
\hline CHEMBL1454950 & 809021 & 3.2757 & 3.7337 & TRN \\
\hline CHEMBL1586817 & 809021 & 3.2757 & 3.4867 & TRN \\
\hline CHEMBL1586928 & 809021 & 4.9355 & 4.1032 & TRN \\
\hline CHEMBL605752 & 809021 & 3.2757 & 4.0739 & TST \\
\hline CHEMBL1720735 & 809021 & 5.1433 & 4.3101 & TRN \\
\hline CHEMBL1500525 & 809021 & 3.2757 & 3.9324 & TRN \\
\hline CHEMBL1458398 & 809021 & 3.2757 & 3.3272 & TRN \\
\hline CHEMBL1400630 & 809021 & 5.2807 & 4.3074 & TRN \\
\hline CHEMBL1577691 & 809021 & 3.2757 & 3.4806 & TRN \\
\hline CHEMBL1359231 & 809021 & 3.2757 & 3.6544 & TRN \\
\hline CHEMBL1369232 & 809021 & 3.2757 & 3.1111 & TST \\
\hline CHEMBL1426832 & 809021 & 3.2757 & 3.2736 & TRN \\
\hline CHEMBL1365298 & 809021 & 3.2757 & 2.7151 & TRN \\
\hline CHEMBL1575025 & 809021 & 3.2757 & 3.1465 & TST \\
\hline CHEMBL1322928 & 809021 & 3.2757 & 3.5633 & TRN \\
\hline CHEMBL1389188 & 809021 & 3.2757 & 4.0685 & TRN \\
\hline CHEMBL1518781 & 809021 & 3.2757 & 3.7564 & TRN \\
\hline CHEMBL1899048 & 809021 & 3.2757 & 3.8714 & TRN \\
\hline CHEMBL1380999 & 809021 & 3.2757 & 2.957 & TRN \\
\hline CHEMBL1733654 & 809021 & 3.2757 & 3.9082 & TST \\
\hline CHEMBL1532970 & 809021 & 3.2757 & 2.9464 & TRN \\
\hline CHEMBL1417161 & 809021 & 3.2757 & 3.3191 & TRN \\
\hline CHEMBL1414569 & 809021 & 3.2757 & 2.8885 & TRN \\
\hline CHEMBL1322124 & 809021 & 3.2757 & 4.0988 & TRN \\
\hline CHEMBL1323917 & 809021 & 3.2757 & 3.5212 & TRN \\
\hline CHEMBL1348983 & 809021 & 3.2757 & 3.6816 & TRN \\
\hline CHEMBL1548549 & 809021 & 3.2757 & 3.8354 & TRN \\
\hline CHEMBL1996742 & 809021 & 3.2757 & 3.9263 & TRN \\
\hline CHEMBL1392985 & 809021 & 3.2757 & 3.9391 & TRN \\
\hline
\end{tabular}

Page 18649 
Supplemental Table S2.txt

\begin{tabular}{|c|c|c|c|c|c|}
\hline CHEMBL1899719 & 809021 & 3.2757 & \multicolumn{2}{|c|}{ 2.5989999999999998 } & TRN \\
\hline CHEMBL1365079 & 809021 & 3.2757 & 3.068 & TRN & \\
\hline CHEMBL582701 & 809021 & 3.2757 & 3.508 & TRN & \\
\hline CHEMBL 2005703 & 809021 & 3.2757 & 4.5303 & TRN & \\
\hline CHEMBL1509469 & 809021 & 3.2757 & 3.781 & TRN & \\
\hline CHEMBL1524681 & 809021 & 3.2757 & 3.6896 & TRN & \\
\hline CHEMBL1480809 & 809021 & 4.8633 & 3.5769 & TRN & \\
\hline CHEMBL1572432 & 809021 & 3.2757 & 3.6877 & TRN & \\
\hline CHEMBL1977221 & 809021 & 3.2757 & 3.4215 & TRN & \\
\hline CHEMBL1970761 & 809021 & 3.2757 & 3.5637 & TRN & \\
\hline CHEMBL1494993 & 809021 & 3.2757 & 3.8517 & TRN & \\
\hline CHEMBL1390144 & 809021 & 3.2757 & 3.5034 & TRN & \\
\hline CHEMBL1417479 & 809021 & 3.2757 & 4.1032 & TRN & \\
\hline CHEMBL1607637 & 809021 & 3.2757 & 3.3508 & TRN & \\
\hline CHEMBL1583560 & 809021 & 3.2757 & 3.9548 & TST & \\
\hline CHEMBL1471897 & 809021 & 3.2757 & 3.4022 & TRN & \\
\hline CHEMBL1484830 & 809021 & 5.4237 & 3.9846 & TRN & \\
\hline CHEMBL1390326 & 809021 & 5.3449 & 4.0329 & TRN & \\
\hline CHEMBL1865510 & 809021 & 5.1918 & 3.6434 & TST & \\
\hline CHEMBL1484968 & 809021 & 3.2757 & 3.8958 & TRN & \\
\hline CHEMBL1214033 & 809021 & 3.2757 & 4.5439 & TRN & \\
\hline CHEMBL1983860 & 809021 & 3.2757 & 3.8491 & TRN & \\
\hline CHEMBL1423919 & 809021 & 3.2757 & 4.1603 & TRN & \\
\hline CHEMBL1965196 & 809021 & 3.2757 & 3.6501 & TRN & \\
\hline CHEMBL1448380 & 809021 & 3.2757 & 3.5126 & TRN & \\
\hline CHEMBL1975512 & 809021 & 3.2757 & 3.8255 & TRN & \\
\hline CHEMBL1299959 & 809021 & 3.2757 & 3.553 & TRN & \\
\hline CHEMBL1483077 & 809021 & 3.2757 & 3.2721 & TRN & \\
\hline CHEMBL1607210 & 809021 & 3.2757 & 3.9317 & TRN & \\
\hline CHEMBL1415013 & 809021 & 5.7055 & 4.0039 & TRN & \\
\hline CHEMBL1401397 & 809021 & 5.2916 & 3.8246 & TST & \\
\hline CHEMBL1525088 & 809021 & 3.2757 & 3.5374 & TRN & \\
\hline CHEMBL1558725 & 809021 & 3.2757 & 3.7237 & TRN & \\
\hline CHEMBL1876097 & 809021 & 3.2757 & 3.5957 & TST & \\
\hline CHEMBL1598335 & 809021 & 5.5952 & 3.4341 & TRN & \\
\hline CHEMBL1346842 & 809021 & 3.2757 & 2.8807 & TRN & \\
\hline CHEMBL1576123 & 809021 & 3.2757 & 3.5636 & TRN & \\
\hline CHEMBL1361071 & 809021 & 3.2757 & 3.1275 & TRN & \\
\hline CHEMBL1734789 & 809021 & 3.2757 & 3.4616 & TRN & \\
\hline CHEMBL 2006764 & 809021 & 5.1475 & 3.6533 & TRN & \\
\hline CHEMBL1413726 & 809021 & 3.2757 & 4.0977 & TST & \\
\hline CHEMBL1470078 & 809021 & 3.2757 & 2.8111 & TRN & \\
\hline CHEMBL1453075 & 809021 & 3.2757 & 3.5131 & TRN & \\
\hline CHEMBL1577735 & 809021 & 3.2757 & 4.0611 & TRN & \\
\hline CHEMBL1710436 & 809021 & 3.2757 & 3.13100 & 30000000002 & TRN \\
\hline CHEMBL1334503 & 809021 & 5.7055 & 4.3771 & TRN & \\
\hline CHEMBL1906080 & 809021 & 3.2757 & 3.8839 & TRN & \\
\hline CHEMBL1469037 & 809021 & 3.2757 & 3.4924 & TRN & \\
\hline
\end{tabular}


Supplemental Table S2.txt

\begin{tabular}{|c|c|c|c|c|c|}
\hline CHEMBL1967041 & 809021 & 3.2757 & 3.3256 & TRN & \\
\hline CHEMBL1589539 & 809021 & 4.9172 & 3.9387 & TRN & \\
\hline CHEMBL1418574 & 809021 & 3.2757 & 4.0747 & TRN & \\
\hline CHEMBL1540674 & 809021 & 3.2757 & 3.5149 & TRN & \\
\hline CHEMBL1444612 & 809021 & 3.2757 & 4.5668 & TRN & \\
\hline CHEMBL1516761 & 809021 & 3.2757 & 3.4769 & TRN & \\
\hline CHEMBL 2006634 & 809021 & 3.2757 & 4.2348 & TRN & \\
\hline CHEMBL1406376 & 809021 & 3.2757 & 3.362 & TRN & \\
\hline CHEMBL1430681 & 809021 & 3.2757 & 3.903 & TRN & \\
\hline CHEMBL1584153 & 809021 & 4.9393 & 4.4272 & TRN & \\
\hline CHEMBL 2001857 & 809021 & 3.2757 & 3.4429 & TRN & \\
\hline CHEMBL1990978 & 809021 & 3.2757 & 2.9551 & TRN & \\
\hline CHEMBL1327017 & 809021 & 3.2757 & 3.7294 & TRN & \\
\hline CHEMBL1370068 & 809021 & 5.2596 & 4.2531 & TRN & \\
\hline CHEMBL1984169 & 809021 & 3.2757 & 3.9764 & TRN & \\
\hline CHEMBL1305020 & 809021 & 3.2757 & 3.5017 & TRN & \\
\hline CHEMBL1470679 & 809021 & 3.2757 & 2.8809 & TRN & \\
\hline CHEMBL1411839 & 809021 & 4.8069 & 4.0746 & TST & \\
\hline CHEMBL1366275 & 809021 & 3.2757 & 3.7264 & TRN & \\
\hline CHEMBL1382646 & 809021 & 3.2757 & 3.9165 & TRN & \\
\hline CHEMBL1330258 & 809021 & 3.2757 & 3.3326 & TRN & \\
\hline CHEMBL1303176 & 809021 & 3.2757 & 3.3416 & TRN & \\
\hline CHEMBL1456602 & 809021 & 3.2757 & 3.7446 & TRN & \\
\hline CHEMBL1583385 & 809021 & 3.2757 & 4.1456 & TRN & \\
\hline CHEMBL1997740 & 809021 & 5.2027 & 3.8922 & TRN & \\
\hline CHEMBL1985863 & 809021 & 3.2757 & 3.8416 & TRN & \\
\hline CHEMBL1411141 & 809021 & 3.2757 & 3.4847 & TRN & \\
\hline CHEMBL1606959 & 809021 & 3.2757 & 3.4236 & TRN & \\
\hline CHEMBL1322206 & 809021 & 5.0057 & 4.0613 & TRN & \\
\hline CHEMBL1448689 & 809021 & 3.2757 & 3.5375 & TRN & \\
\hline CHEMBL1978989 & 809021 & 3.2757 & 3.1243 & TRN & \\
\hline CHEMBL1711254 & 809021 & 3.2757 & 3.3169 & TRN & \\
\hline CHEMBL1491923 & 809021 & 3.2757 & 3.1065 & TRN & \\
\hline CHEMBL1409619 & 809021 & 3.2757 & 3.3833 & TRN & \\
\hline CHEMBL1581644 & 809021 & 3.2757 & 3.9027 & TRN & \\
\hline CHEMBL1318357 & 809021 & 4.5952 & 3.9214 & TRN & \\
\hline CHEMBL1872585 & 809021 & 3.2757 & 3.3683 & TRN & \\
\hline CHEMBL1719714 & 809021 & 3.2757 & 3.182 & TRN & \\
\hline CHEMBL1703698 & 809021 & 3.2757 & 3.6026 & TRN & \\
\hline CHEMBL1309071 & 809021 & 3.2757 & 3.7813 & TRN & \\
\hline CHEMBL1412335 & 809021 & 3.2757 & 3.819 & TRN & \\
\hline CHEMBL1415345 & 809021 & 3.2757 & 3.3646 & TRN & \\
\hline CHEMBL1887233 & 809021 & 3.2757 & 3.6507 & TRN & \\
\hline CHEMBL1353259 & 809021 & 4.6737 & 3.681 & TRN & \\
\hline CHEMBL1906017 & 809021 & 3.2757 & 3.0177 & TRN & \\
\hline CHEMBL1405773 & 809021 & $5.3820 e$ & 000000000 & $\partial 1$ & 3.4745 \\
\hline CHEMBL1979183 & 809021 & 5.8633 & 4.5451 & TRN & \\
\hline CHEMBL1344221 & 809021 & 3.2757 & 3.3177 & TRN & \\
\hline
\end{tabular}

Page 18651 
Supplemental Table S2.txt

\begin{tabular}{|c|c|c|c|c|c|}
\hline CHEMBL1424762 & 809021 & 3.2757 & 3.2817 & TST & \\
\hline CHEMBL1426795 & 809021 & 3.2757 & 3.6222 & TST & \\
\hline CHEMBL53738 & 809021 & 3.2757 & 3.4225 & TST & \\
\hline CHEMBL1996766 & 809021 & 3.2757 & 3.3174 & TST & \\
\hline CHEMBL1456699 & 809021 & 3.2757 & 3.8992 & TRN & \\
\hline CHEMBL1461296 & 809021 & 3.2757 & 4.173999 & و9999999995 & TRN \\
\hline CHEMBL1990571 & 809021 & 3.2757 & 4.0636 & TST & \\
\hline CHEMBL1325293 & 809021 & 5.2541 & 4.2512 & TRN & \\
\hline CHEMBL1565430 & 809021 & 3.2757 & 3.8137 & TST & \\
\hline CHEMBL1589496 & 809021 & 3.2757 & 3.8703 & TRN & \\
\hline CHEMBL1327987 & 809021 & 5.3372 & 4.0914 & TRN & \\
\hline CHEMBL1537866 & 809021 & 3.2757 & 3.1079 & TRN & \\
\hline CHEMBL1511541 & 809021 & 4.4685 & 3.7034 & TRN & \\
\hline CHEMBL1391209 & 809021 & 3.2757 & 3.5467 & TRN & \\
\hline CHEMBL1382689 & 809021 & 3.2757 & 3.5464 & TRN & \\
\hline CHEMBL1461142 & 809021 & 5.3089 & 4.8887 & TRN & \\
\hline CHEMBL1596152 & 809021 & 3.2757 & 3.9546 & TRN & \\
\hline CHEMBL1557059 & 809021 & 3.2757 & 3.0991 & TST & \\
\hline CHEMBL1506533 & 809021 & \multicolumn{2}{|c|}{5.053999999999999} & 3.44 & TRN \\
\hline CHEMBL255068 & 809021 & 3.2757 & 3.446 & TRN & \\
\hline CHEMBL1429539 & 809021 & 3.2757 & 4.0429 & TRN & \\
\hline CHEMBL1390056 & 809021 & 5.3036 & 3.8507 & TST & \\
\hline CHEMBL1901013 & 809021 & 3.2757 & 3.1682 & TRN & \\
\hline CHEMBL1422326 & 809021 & 3.2757 & 3.7319 & TRN & \\
\hline CHEMBL1711441 & 809021 & 3.2757 & 3.9387 & TRN & \\
\hline CHEMBL1573332 & 809021 & 3.2757 & 3.3874 & TRN & \\
\hline CHEMBL1557508 & 809021 & 3.2757 & 3.8409 & TRN & \\
\hline CHEMBL1709707 & 809021 & 4.9547 & 3.7332 & TRN & \\
\hline CHEMBL1430628 & 809021 & 3.2757 & 3.5442 & TST & \\
\hline CHEMBL1612213 & 809021 & 3.2757 & 3.9192 & TRN & \\
\hline CHEMBL1341456 & 809021 & 5.3969 & 4.1902 & TRN & \\
\hline CHEMBL1698481 & 809021 & 3.2757 & 3.4843 & TRN & \\
\hline CHEMBL1438154 & 809021 & 3.2757 & 4.613 & TRN & \\
\hline CHEMBL1582131 & 809021 & 3.2757 & 3.5964 & TRN & \\
\hline CHEMBL1976739 & 809021 & 5.3261 & 4.1403 & TST & \\
\hline CHEMBL1439560 & 809021 & 3.2757 & 3.5144 & TRN & \\
\hline CHEMBL1882047 & 809021 & 3.2757 & 3.5447 & TRN & \\
\hline CHEMBL1307289 & 809021 & 3.2757 & 3.2139 & TST & \\
\hline CHEMBL1317248 & 809021 & 3.2757 & 4.1234 & TRN & \\
\hline CHEMBL1569905 & 809021 & 3.2757 & 3.5674 & TRN & \\
\hline CHEMBL1508066 & 809021 & \multicolumn{2}{|c|}{5.202000000000001} & 4.0028 & $\mathrm{~T}$ \\
\hline CHEMBL1391337 & 809021 & 3.2757 & 4.2034 & TRN & \\
\hline CHEMBL1324718 & 809021 & 3.2757 & 3.4158 & TRN & \\
\hline CHEMBL1697912 & 809021 & 3.2757 & 3.6922 & TRN & \\
\hline CHEMBL1483134 & 809021 & 3.2757 & 3.9984 & TST & \\
\hline CHEMBL1987891 & 809021 & 3.2757 & 3.8882 & TRN & \\
\hline CHEMBL1431459 & 809021 & 4.4949 & 3.2675 & TRN & \\
\hline CHEMBL1558763 & 809021 & 3.2757 & 3.5095 & TRN & \\
\hline
\end{tabular}

Page 18652 
Supplemental Table S2.txt

\begin{tabular}{|c|c|c|c|c|}
\hline CHEMBL1489947 & 809021 & 3.2757 & 3.7547 & TRN \\
\hline CHEMBL1311961 & 809021 & 5.2993 & 3.5133 & TRN \\
\hline CHEMBL1321727 & 809021 & 3.2757 & 3.3158 & TRN \\
\hline CHEMBL1430340 & 809021 & 3.2757 & 3.4121 & TRN \\
\hline CHEMBL1728455 & 809021 & 3.2757 & 3.0401 & TRN \\
\hline CHEMBL1345541 & 809021 & 3.2757 & 3.5965 & TRN \\
\hline CHEMBL1331093 & 809021 & 3.2757 & 3.6214 & TRN \\
\hline CHEMBL399632 & 809021 & 3.2757 & 3.5317 & TRN \\
\hline CHEMBL1357808 & 809021 & 5.3458 & 4.0415 & TRN \\
\hline CHEMBL1423590 & 809021 & 3.2757 & 3.9279 & TST \\
\hline CHEMBL1566023 & 809021 & 3.2757 & 3.96199 & 99999999997 \\
\hline CHEMBL1986785 & 809021 & 3.2757 & 3.54 & TST \\
\hline CHEMBL1401190 & 809021 & 3.2757 & 3.4419 & TRN \\
\hline CHEMBL1364015 & 809021 & 3.2757 & 3.577 & TRN \\
\hline CHEMBL1320678 & 809021 & 3.2757 & 3.4423 & TST \\
\hline CHEMBL1869204 & 809021 & 3.2757 & 3.3303 & TRN \\
\hline CHEMBL1882956 & 809021 & 5.15799 & 99999999 & 3.7725 \\
\hline CHEMBL1484765 & 809021 & 3.2757 & 3.835 & TRN \\
\hline CHEMBL1717982 & 809021 & 3.2757 & 3.6478 & TRN \\
\hline CHEMBL1355120 & 809021 & 3.2757 & 3.7883 & TRN \\
\hline CHEMBL1455809 & 809021 & 3.2757 & 3.2149 & TRN \\
\hline CHEMBL1577205 & 809021 & 3.2757 & 3.3663 & TRN \\
\hline CHEMBL1876295 & 809021 & 3.2757 & 3.2088 & TRN \\
\hline CHEMBL1562790 & 809021 & 3.2757 & 3.4249 & TRN \\
\hline CHEMBL1546612 & 809021 & 3.2757 & 3.7114 & TRN \\
\hline CHEMBL1612672 & 809021 & 4.7447 & 3.8897 & TRN \\
\hline CHEMBL1597858 & 809021 & 4.6162 & 4.4668 & TRN \\
\hline CHEMBL1881465 & 809021 & 3.2757 & 3.4119 & TST \\
\hline CHEMBL1383832 & 809021 & 3.2757 & 3.6187 & TRN \\
\hline CHEMBL1521361 & 809021 & 4.8633 & 3.9609 & TRN \\
\hline CHEMBL1888652 & 809021 & 3.2757 & 2.8244 & TRN \\
\hline CHEMBL1873695 & 809021 & 3.2757 & 3.2734 & TRN \\
\hline CHEMBL1986086 & 809021 & 3.2757 & 3.5777 & TRN \\
\hline CHEMBL1732658 & 809021 & 3.2757 & 3.4645 & TRN \\
\hline CHEMBL1521935 & 809021 & 3.2757 & 3.1585 & TST \\
\hline CHEMBL1504948 & 809021 & 3.2757 & 4.5287 & TRN \\
\hline CHEMBL1870960 & 809021 & 5.1904 & 4.2973 & TRN \\
\hline CHEMBL1335494 & 809021 & 3.2757 & 3.7261 & TST \\
\hline CHEMBL1430256 & 809021 & 3.2757 & 3.8107 & TST \\
\hline CHEMBL1489121 & 809021 & 3.2757 & 3.4997 & TRN \\
\hline CHEMBL 2007414 & 809021 & 5.1451 & 3.7089 & TRN \\
\hline CHEMBL1541183 & 809021 & 3.2757 & 3.3419 & TRN \\
\hline CHEMBL1582516 & 809021 & 3.2757 & 3.9477 & TRN \\
\hline CHEMBL1302298 & 809021 & 3.2757 & 3.8066 & TRN \\
\hline CHEMBL1877673 & 809021 & 3.2757 & 3.4455 & TRN \\
\hline CHEMBL1731923 & 809021 & 3.2757 & 3.2684 & TRN \\
\hline CHEMBL1399666 & 809021 & 4.7328 & 3.9842 & TRN \\
\hline CHEMBL1470438 & 809021 & 3.2757 & 3.4486 & TRN \\
\hline
\end{tabular}

Page 18653 
Supplemental Table S2.txt

\begin{tabular}{|c|c|c|c|c|}
\hline CHEMBL1389157 & 809021 & 3.2757 & 3.8335 & TRN \\
\hline CHEMBL1875561 & 809021 & 5.289 & 3.5583 & TRN \\
\hline CHEMBL1990275 & 809021 & 3.2757 & 3.3059 & TRN \\
\hline CHEMBL1337325 & 809021 & 5.2782 & 3.8486 & TRN \\
\hline CHEMBL1428631 & 809021 & 3.2757 & 3.4017 & TRN \\
\hline CHEMBL1338083 & 809021 & 3.2757 & 3.3851 & TST \\
\hline CHEMBL1537193 & 809021 & 4.9626 & 3.9809 & TRN \\
\hline CHEMBL1545575 & 809021 & 3.2757 & 3.3241 & TRN \\
\hline CHEMBL1523000 & 809021 & 4.9914 & 4.0417 & TRN \\
\hline CHEMBL1439873 & 809021 & 3.2757 & 3.596 & TST \\
\hline CHEMBL1500116 & 809021 & 3.2757 & 3.1987 & TRN \\
\hline CHEMBL1731330 & 809021 & 6.0605 & 4.4797 & TRN \\
\hline CHEMBL1891903 & 809021 & 3.2757 & 3.0521 & TRN \\
\hline CHEMBL1466608 & 809021 & 3.2757 & 3.4472 & TST \\
\hline CHEMBL1510554 & 809021 & 3.2757 & 3.7434 & TST \\
\hline CHEMBL1516419 & 809021 & 3.2757 & 3.1823 & TRN \\
\hline CHEMBL1512198 & 809021 & 3.2757 & 4.9376 & TST \\
\hline CHEMBL1585801 & 809021 & 4.8239 & 3.8761 & TRN \\
\hline CHEMBL1988441 & 809021 & 3.2757 & 3.7586 & TST \\
\hline CHEMBL1412020 & 809021 & 3.2757 & 3.6102 & TRN \\
\hline CHEMBL1320332 & 809021 & 3.2757 & 4.0076 & TST \\
\hline CHEMBL1373367 & 809021 & 3.2757 & 3.2208 & TRN \\
\hline CHEMBL 2004242 & 809021 & 5.2526 & 3.3452 & TRN \\
\hline CHEMBL1873553 & 809021 & 3.2757 & 3.6304 & TRN \\
\hline CHEMBL1578625 & 809021 & 3.2757 & 3.2421 & TRN \\
\hline CHEMBL1487657 & 809021 & 5.0438 & 4.4268 & TRN \\
\hline CHEMBL1611775 & 809021 & 3.2757 & 3.3529 & TRN \\
\hline CHEMBL1698449 & 809021 & 5.0731 & 5.1046 & TRN \\
\hline CHEMBL1716916 & 809021 & 5.1325 & 4.4292 & TRN \\
\hline CHEMBL1376862 & 809021 & 3.2757 & 3.3623 & TRN \\
\hline CHEMBL1966869 & 809021 & 5.1107 & 3.84800 & 30000000003 \\
\hline CHEMBL1359784 & 809021 & 3.2757 & 3.3823 & TRN \\
\hline CHEMBL1713824 & 809021 & 3.2757 & 3.5765 & TRN \\
\hline CHEMBL1383895 & 809021 & 5.3645 & 4.355 & TRN \\
\hline CHEMBL1725641 & 809021 & 3.2757 & 3.8386 & TRN \\
\hline CHEMBL1528569 & 809021 & 3.2757 & 4.1231 & TRN \\
\hline CHEMBL1548199 & 809021 & 3.2757 & 2.9624 & TRN \\
\hline CHEMBL1541746 & 809021 & 3.2757 & 3.2965 & TRN \\
\hline CHEMBL1570188 & 809021 & 3.2757 & 3.3497 & TRN \\
\hline CHEMBL1400492 & 809021 & 3.2757 & 3.512 & TRN \\
\hline CHEMBL1577208 & 809021 & 3.2757 & 3.8267 & TRN \\
\hline CHEMBL1531482 & 809021 & 3.2757 & 3.2329 & TRN \\
\hline CHEMBL1576910 & 809021 & 3.2757 & 3.5538 & TRN \\
\hline CHEMBL1515236 & 809021 & 3.2757 & 3.1978 & TRN \\
\hline CHEMBL1891715 & 809021 & 3.2757 & 3.7552 & TRN \\
\hline CHEMBL1305625 & 809021 & 3.2757 & 3.2695 & TRN \\
\hline CHEMBL1557991 & 809021 & 3.2757 & 3.41600 & 00000000004 \\
\hline CHEMBL1474580 & 809021 & 3.2757 & 3.596 & TRN \\
\hline
\end{tabular}


Supplemental Table S2.txt

\begin{tabular}{|c|c|c|c|c|c|}
\hline CHEMBL1339626 & 809021 & 3.2757 & 3.6939 & TRN & \\
\hline CHEMBL1605776 & 809021 & 3.2757 & 3.0734 & TRN & \\
\hline CHEMBL1373053 & 809021 & 3.2757 & 2.9643 & TRN & \\
\hline CHEMBL1508157 & 809021 & 3.2757 & 3.8648 & TRN & \\
\hline CHEMBL1371272 & 809021 & 3.2757 & 3.3618 & TRN & \\
\hline CHEMBL1501720 & 809021 & 3.2757 & 3.9876 & TST & \\
\hline CHEMBL1521571 & 809021 & 3.2757 & 3.6559 & TRN & \\
\hline CHEMBL1414912 & 809021 & 3.2757 & 3.4384 & TRN & \\
\hline CHEMBL1370848 & 809021 & 5.5768 & 3.8989 & TRN & \\
\hline CHEMBL1366743 & 809021 & 3.2757 & 2.7357 & TRN & \\
\hline CHEMBL 2004640 & 809021 & 3.2757 & 3.9646 & TRN & \\
\hline CHEMBL1350574 & 809021 & 3.2757 & 3.8984 & TRN & \\
\hline CHEMBL1495386 & 809021 & 5.4078 & 3.7058 & TRN & \\
\hline CHEMBL1375451 & 809021 & 4.4584 & 4.2571 & TRN & \\
\hline CHEMBL1456403 & 809021 & 3.2757 & 3.9967 & TST & \\
\hline CHEMBL1428733 & 809021 & 3.2757 & 3.1062 & TRN & \\
\hline CHEMBL1894710 & 809021 & 3.2757 & 3.9194 & TRN & \\
\hline CHEMBL1599981 & 809021 & 3.2757 & 3.2946 & TRN & \\
\hline CHEMBL1329711 & 809021 & 3.2757 & 3.0257 & TRN & \\
\hline CHEMBL1432138 & 809021 & 3.2757 & 3.5719 & TRN & \\
\hline CHEMBL1490621 & 809021 & 5.0947 & 3.4022 & TRN & \\
\hline CHEMBL1527280 & 809021 & 5.1911 & 4.0698 & TRN & \\
\hline CHEMBL1888323 & 809021 & 3.2757 & 3.7209 & TST & \\
\hline CHEMBL1347512 & 809021 & 3.2757 & 3.82899 & 99999999997 & TRN \\
\hline CHEMBL1407565 & 809021 & 3.2757 & 3.9108 & TRN & \\
\hline CHEMBL1514279 & 809021 & 5.1002 & 3.7236 & TST & \\
\hline CHEMBL1578699 & 809021 & 4.7986 & 4.6813 & TST & \\
\hline CHEMBL1379767 & 809021 & 3.2757 & 3.3534 & TST & \\
\hline CHEMBL329706 & 809021 & 4.9245 & 3.6129 & TST & \\
\hline CHEMBL1589454 & 809021 & 3.2757 & 3.6831 & TST & \\
\hline CHEMBL1870458 & 809021 & 5.2976 & 3.9378 & TST & \\
\hline CHEMBL1540390 & 809021 & 3.2757 & 3.3145 & TST & \\
\hline CHEMBL1485528 & 809021 & 3.2757 & 4.1771 & TST & \\
\hline CHEMBL1712381 & 809021 & 3.2757 & 3.7768 & TST & \\
\hline CHEMBL1987895 & 809021 & 5.2255 & 4.1874 & TST & \\
\hline CHEMBL1727878 & 809021 & 3.2757 & 3.677 & TST & \\
\hline CHEMBL1580963 & 809021 & 3.2757 & 2.9181 & TST & \\
\hline CHEMBL1438067 & 809021 & 3.2757 & 3.7746 & TST & \\
\hline CHEMBL1573714 & 809021 & 3.2757 & 3.1892 & TST & \\
\hline CHEMBL1461633 & 809021 & 3.2757 & 3.755 & TST & \\
\hline CHEMBL1603027 & 809021 & 3.2757 & 4.1528 & TST & \\
\hline CHEMBL1353110 & 809021 & 3.2757 & 2.7097 & TST & \\
\hline CHEMBL1585011 & 809021 & 5.9508 & 3.6465 & TST & \\
\hline CHEMBL1883660 & 809021 & 3.2757 & 3.0908 & TST & \\
\hline CHEMBL1976940 & 809021 & 3.2757 & 3.9254 & TST & \\
\hline CHEMBL1596184 & 809021 & 5.0391 & 3.7301 & TST & \\
\hline CHEMBL1572094 & 809021 & 3.2757 & 3.7203 & TST & \\
\hline CHEMBL1464517 & 809021 & 3.2757 & 4.2652 & TST & \\
\hline
\end{tabular}


Supplemental Table S2.txt

\begin{tabular}{|c|c|c|c|c|}
\hline HEM & & 3.2757 & & בני \\
\hline & 09021 & & & \\
\hline ГMPI 1 & 21 & & & \\
\hline IEMBL1 & & 57 & & \\
\hline HEMBL1329882 & 09021 & 2757 & 3926 & \\
\hline HEMBL1 & 09 & .2757 & 6873 & \\
\hline HEMBL: & 21 & & 182 & \\
\hline AEMBL1 & & & & \\
\hline HEMBL1728659 & 309021 & 2757 & 6623 & \\
\hline HEMBL1900529 & 09021 & & 1231 & \\
\hline HEMBL1 & 09 & & & \\
\hline IEMBL] & 21 & & 415 & \\
\hline AEMBL1 & & & & \\
\hline HEMBL1873302 & 09021 & & 5436 & \\
\hline AEMBL14 & 21 & & & \\
\hline HEMBL1 & 1 & 57 & 097 & \\
\hline HEMBL1 & 1 & & 558 & \\
\hline HEMBL1 & 1 & & 552 & \\
\hline HEMBL1 & 1 & & 164 & \\
\hline AEMBL1 & & & 3486 & \\
\hline AEMBL & 1 & & 39 & SI \\
\hline HEM & 1 & & & \\
\hline AEMBL & 1 & & 06 & \\
\hline HEMBL1 & & & 979 & \\
\hline AEMBL1 & & & 3077 & IS \\
\hline AEMBL1 & 1 & 7 & 3821 & ST \\
\hline HEMBL' & & & 97 & \\
\hline IFM & & & 715 & \\
\hline AEMBL1 & & & & \\
\hline AEMBL1 & 09 & & 538 & TST \\
\hline HEMBL: & 1 & & 343 & ST \\
\hline HFM & & & 75 & \\
\hline & & & & \\
\hline HEMBL1 & & & 161 & IST \\
\hline HEMBL2C & 1 & & 996 & IST \\
\hline AFMRI 1 & 1 & & $\partial 24$ & \\
\hline 10 & & & & \\
\hline HEMBL1 & & & 3019 & TST \\
\hline HEMBL1 & 09 & & 578 & ГST \\
\hline Tht & & & 024 & ST \\
\hline HEMBL] & 1 & & 3278 & \\
\hline & & & 324 & ST \\
\hline HEMBL1. & & 2757 & 5217 & TS \\
\hline HEMBL1 & 1 & & & TS \\
\hline CHEMPI 1 & & & & \\
\hline HEMBL1 & & & 3082 & \\
\hline HEMBL1 & & 757 & 836 & \\
\hline CHEMBL1344304 & 809021 & 3.2757 & 3.6013 & \\
\hline
\end{tabular}

Page 18656 


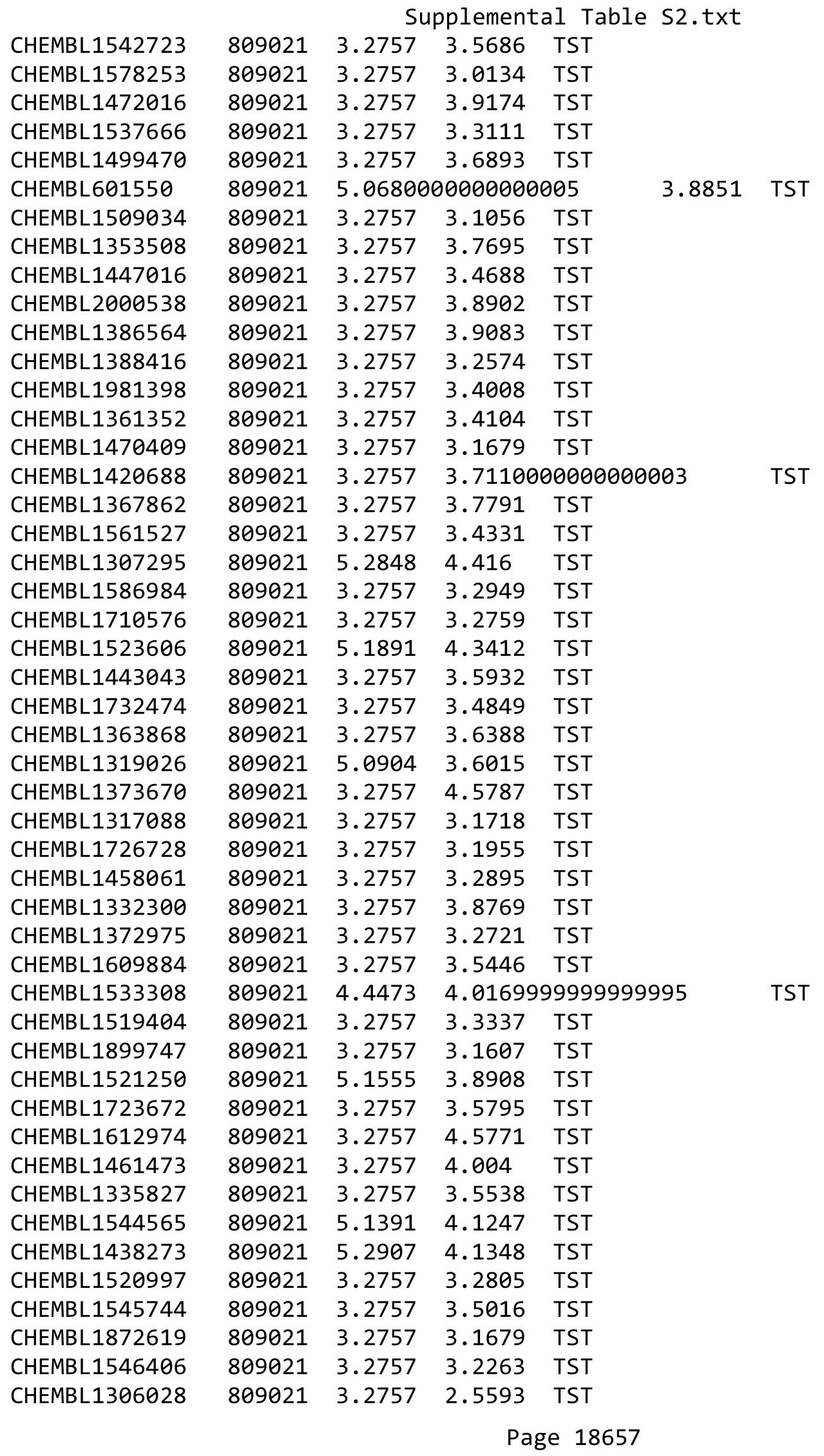


Supplemental Table S2.txt

\begin{tabular}{|c|c|c|c|c|}
\hline CHEMBL1588871 & 809021 & 3.2757 & 4.0267 & TST \\
\hline CHEMBL1543382 & 809021 & 3.2757 & 4.0446 & TST \\
\hline CHEMBL1965976 & 809021 & 3.2757 & 3.8497 & TST \\
\hline CHEMBL1589370 & 809021 & 3.2757 & 3.4622 & TST \\
\hline CHEMBL1701573 & 809021 & 3.2757 & 3.1136 & TST \\
\hline CHEMBL1326395 & 809021 & 3.2757 & 2.782 & TST \\
\hline CHEMBL1369775 & 809021 & 3.2757 & 3.4087 & TST \\
\hline CHEMBL1604220 & 809021 & 3.2757 & 3.7127 & TST \\
\hline CHEMBL1404787 & 809021 & 5.1918 & 4.7182 & TST \\
\hline CHEMBL1528669 & 809021 & 3.2757 & 3.2649 & TST \\
\hline CHEMBL1610388 & 809021 & 3.2757 & 3.7947 & TST \\
\hline CHEMBL1883622 & 809021 & 3.2757 & 3.4088 & TST \\
\hline CHEMBL1976321 & 809021 & 3.2757 & 3.3105 & TST \\
\hline CHEMBL1880561 & 809021 & 5.2457 & 4.3847 & TST \\
\hline CHEMBL1708151 & 809021 & 3.2757 & 4.0177 & TST \\
\hline CHEMBL1503247 & 809021 & 3.2757 & 3.4748 & TST \\
\hline CHEMBL1369524 & 809021 & 3.2757 & 3.1351 & TST \\
\hline CHEMBL1579984 & 809021 & 4.8041 & 4.1325 & TST \\
\hline CHEMBL1609782 & 809021 & 3.2757 & 3.2496 & TST \\
\hline CHEMBL1456577 & 809021 & 4.8962 & 3.60399 & \\
\hline CHEMBL1407214 & 809021 & 3.2757 & 3.7919 & TST \\
\hline CHEMBL1894266 & 809021 & 3.2757 & 3.7029 & TST \\
\hline CHEMBL1523011 & 809021 & 3.2757 & 4.13899 & 9999999999 \\
\hline CHEMBL1590944 & 809021 & 5.6234 & 3.3612 & TST \\
\hline CHEMBL1404229 & 809021 & 3.2757 & 3.8924 & TST \\
\hline CHEMBL1256362 & 809021 & 3.2757 & 3.1093 & TST \\
\hline CHEMBL1904763 & 809021 & 3.2757 & 3.1793 & TST \\
\hline CHEMBL1971428 & 809021 & 3.2757 & 3.8459 & TST \\
\hline CHEMBL1313525 & 809021 & 3.2757 & 3.1246 & TST \\
\hline CHEMBL1972106 & 809021 & 3.2757 & 4.0914 & TST \\
\hline CHEMBL1472456 & 809021 & 3.2757 & 3.9338 & TST \\
\hline CHEMBL1707844 & 809021 & 3.2757 & 3.6851 & TST \\
\hline CHEMBL 3902037 & 809021 & 3.2757 & 3.6733 & TST \\
\hline CHEMBL1480254 & 809021 & 3.2757 & 4.0133 & TST \\
\hline CHEMBL1448963 & 809021 & 5.3045 & 3.0285 & TST \\
\hline CHEMBL1706945 & 809021 & 3.2757 & 3.096 & TST \\
\hline CHEMBL1445625 & 809021 & 4.8356 & 3.5041 & TST \\
\hline CHEMBL1348050 & 809021 & 5.2007 & 4.2782 & TST \\
\hline CHEMBL1423337 & 809021 & 3.2757 & 3.2802 & TST \\
\hline CHEMBL1519192 & 809021 & 3.2757 & 3.6623 & TST \\
\hline CHEMBL1406404 & 809021 & 3.2757 & 3.5427 & TST \\
\hline CHEMBL1343738 & 809021 & 3.2757 & 3.3181 & TST \\
\hline CHEMBL1302934 & 809021 & 3.2757 & 3.4075 & TST \\
\hline CHEMBL1422335 & 809021 & 3.2757 & 3.7684 & TST \\
\hline CHEMBL1534572 & 809021 & 3.2757 & 3.5582 & TST \\
\hline CHEMBL1526763 & 809021 & 5.0 & 4.3155 & TST \\
\hline CHEMBL1455085 & 809021 & 3.2757 & 3.7475 & TST \\
\hline CHEMBL1425297 & 809021 & 4.7352 & 4.4811 & TST \\
\hline
\end{tabular}


Supplemental Table S2.txt

\begin{tabular}{|c|c|c|c|c|}
\hline CHEMBL1489218 & 809021 & 3.2757 & 3.6936 & TST \\
\hline CHEMBL1526494 & 809021 & 5.3215 & 3.6884 & TST \\
\hline CHEMBL1546530 & 809021 & 5.067 & 3.7026 & TST \\
\hline CHEMBL1504649 & 809021 & 3.2757 & 3.7787 & TST \\
\hline CHEMBL1502167 & 809021 & 3.2757 & 4.3659 & TST \\
\hline CHEMBL1395930 & 809021 & 3.2757 & 3.8085 & TST \\
\hline CHEMBL1435828 & 809021 & 3.2757 & 3.6304 & TST \\
\hline CHEMBL1385633 & 809021 & 3.2757 & 3.7408 & TST \\
\hline CHEMBL1416752 & 809021 & 5.2013 & 4.1662 & TST \\
\hline CHEMBL1416986 & 809021 & 3.2757 & 3.827 & TST \\
\hline CHEMBL1697975 & 809021 & 3.2757 & 4.2734 & TST \\
\hline CHEMBL1892848 & 809021 & 3.2757 & 3.353 & TST \\
\hline CHEMBL1361917 & 809021 & 3.2757 & 3.5665 & TST \\
\hline CHEMBL1965280 & 809021 & 4.5072 & 4.4838 & TST \\
\hline CHEMBL1572758 & 809021 & 3.2757 & 3.6979 & TST \\
\hline CHEMBL1308498 & 809021 & 4.7305 & 3.5809 & TST \\
\hline CHEMBL1528968 & 809021 & 3.2757 & 3.7937 & TST \\
\hline CHEMBL1549225 & 809021 & 3.2757 & 3.6202 & TST \\
\hline CHEMBL1361774 & 809021 & 3.2757 & 3.9878 & TST \\
\hline CHEMBL1312289 & 809021 & 5.118 & 3.1276 & TST \\
\hline CHEMBL1984510 & 809021 & 3.2757 & 3.865 & TST \\
\hline CHEMBL2005894 & 809021 & 3.2757 & 3.7575 & TST \\
\hline CHEMBL1575416 & 809021 & 5.0031 & 4.3292 & TST \\
\hline CHEMBL1556371 & 809021 & 3.2757 & 3.6463 & TST \\
\hline CHEMBL1516685 & 809021 & 3.2757 & 3.71199 & 99999999997 \\
\hline CHEMBL1502602 & 809021 & 5.6144 & 4.3387 & TST \\
\hline CHEMBL1736441 & 809021 & 3.2757 & 4.007 & TST \\
\hline CHEMBL1588956 & 809021 & 5.0857 & 4.0201 & TST \\
\hline CHEMBL1364899 & 809021 & 3.2757 & 3.1639 & TST \\
\hline CHEMBL1485786 & 809021 & 3.2757 & 3.3262 & TST \\
\hline CHEMBL1403593 & 809021 & 3.2757 & 3.1878 & TST \\
\hline CHEMBL1530471 & 809021 & 3.2757 & 3.5288 & TST \\
\hline CHEMBL1716557 & 809021 & 3.2757 & 4.2427 & TST \\
\hline CHEMBL1350467 & 809021 & 4.9586 & 3.7722 & TST \\
\hline CHEMBL1978211 & 809021 & 3.2757 & 2.7128 & TST \\
\hline CHEMBL1419816 & 809021 & 3.2757 & 3.3679 & TST \\
\hline CHEMBL1587482 & 809021 & 5.2396 & 3.7262 & TST \\
\hline CHEMBL1503606 & 809021 & 3.2757 & 3.7002 & TST \\
\hline CHEMBL1490388 & 809021 & 5.2757 & 3.3493 & TST \\
\hline CHEMBL1491493 & 809021 & 3.2757 & 2.8554 & TST \\
\hline CHEMBL 2005619 & 809021 & 3.2757 & 3.9435 & TST \\
\hline CHEMBL1540435 & 809021 & 3.2757 & 4.0822 & TST \\
\hline CHEMBL1731318 & 809021 & 5.2411 & 3.5641 & TST \\
\hline CHEMBL1356494 & 809021 & 3.2757 & 3.1393 & TST \\
\hline CHEMBL1330364 & 809021 & 3.2757 & 3.9901 & TST \\
\hline CHEMBL1896141 & 809021 & 3.2757 & 3.2038 & TST \\
\hline CHEMBL1707714 & 809021 & 3.2757 & 3.7605 & TST \\
\hline CHEMBL1999645 & 809021 & 3.2757 & 3.8587 & TST \\
\hline
\end{tabular}


Supplemental Table S2.txt

\begin{tabular}{|c|c|c|c|c|}
\hline CHEMBL1720455 & 809021 & 5.4045 & 4.1158 & TST \\
\hline CHEMBL1416615 & 809021 & 5.2449 & 4.4976 & TST \\
\hline CHEMBL1409450 & 809021 & 3.2757 & 3.4374 & TST \\
\hline CHEMBL1307629 & 809021 & 3.2757 & 4.1916 & TST \\
\hline CHEMBL1735667 & 809021 & 3.2757 & 3.6764 & TST \\
\hline CHEMBL1577332 & 809021 & 3.2757 & 3.5825 & TST \\
\hline CHEMBL1508389 & 809021 & 3.2757 & 4.1094 & TST \\
\hline CHEMBL1349325 & 809021 & 3.2757 & 3.7603 & TST \\
\hline CHEMBL1486410 & 809021 & 3.2757 & 3.1955 & TST \\
\hline CHEMBL1386864 & 809021 & 4.9788 & 3.7791 & TST \\
\hline CHEMBL1300114 & 809021 & 4.7991 & 3.7704 & TST \\
\hline CHEMBL1875477 & 809021 & 3.2757 & 3.3734 & TST \\
\hline CHEMBL1736615 & 809021 & 3.2757 & 3.4654 & TST \\
\hline CHEMBL1317462 & 809021 & 3.2757 & 3.3688 & TST \\
\hline CHEMBL1509203 & 809021 & 3.2757 & 3.6621 & TST \\
\hline CHEMBL1348506 & 809021 & 4.3625 & 3.43300 & 0000000003 \\
\hline CHEMBL1708485 & 809021 & 3.2757 & 3.0362 & TST \\
\hline CHEMBL1539096 & 809021 & 3.2757 & 3.5345 & TST \\
\hline CHEMBL1327614 & 809021 & 5.2457 & 3.4015 & TST \\
\hline CHEMBL1338833 & 809021 & 4.6253 & 3.97 & TST \\
\hline CHEMBL1887958 & 809021 & 3.2757 & 3.858 & TST \\
\hline CHEMBL1611640 & 809021 & 3.2757 & 3.4997 & TST \\
\hline CHEMBL1883373 & 809021 & 3.2757 & 3.5344 & TST \\
\hline CHEMBL488803 & 809021 & 3.2757 & 2.9997 & TST \\
\hline CHEMBL1432850 & 809021 & 5.1169 & 4.1573 & TST \\
\hline CHEMBL1886994 & 809021 & 3.2757 & 3.9796 & TST \\
\hline CHEMBL1405484 & 809021 & 3.2757 & 3.5329 & TST \\
\hline CHEMBL1560907 & 809021 & 3.2757 & 3.7741 & TST \\
\hline CHEMBL1458284 & 809021 & 3.2757 & 4.0009 & TST \\
\hline CHEMBL1448446 & 809021 & 3.2757 & 3.2583 & TST \\
\hline CHEMBL1606795 & 809021 & 5.3468 & 3.8719 & TST \\
\hline CHEMBL1597227 & 809021 & 3.2757 & 3.3063 & TST \\
\hline CHEMBL1991976 & 809021 & 5.1002 & 4.0635 & TST \\
\hline CHEMBL1357212 & 809021 & 3.2757 & 3.4807 & TST \\
\hline CHEMBL1710207 & 809021 & 3.2757 & 3.6631 & TST \\
\hline CHEMBL1400385 & 809021 & 3.2757 & 3.5271 & TST \\
\hline CHEMBL1903678 & 809021 & 4.9586 & 4.2098 & TST \\
\hline CHEMBL1990512 & 809021 & 4.6576 & 3.2869 & TST \\
\hline CHEMBL1388057 & 809021 & 3.2757 & 3.4031 & TST \\
\hline CHEMBL1448716 & 809021 & 3.2757 & 3.7993 & TST \\
\hline CHEMBL1457141 & 809021 & 3.2757 & 3.389 & TST \\
\hline CHEMBL1444699 & 809021 & 4.8794 & 4.0153 & TST \\
\hline CHEMBL1600680 & 809021 & 5.104 & 3.7451 & TST \\
\hline CHEMBL1432309 & 809021 & 5.2197 & 4.2918 & TST \\
\hline CHEMBL1609619 & 809021 & 3.2757 & 3.7025 & TST \\
\hline CHEMBL1983775 & 809021 & 3.2757 & 3.4982 & TST \\
\hline CHEMBL1371510 & 809021 & 3.2757 & 3.9365 & TST \\
\hline CHEMBL1712408 & 809021 & 4.3904 & 3.6176 & TST \\
\hline
\end{tabular}


Supplemental Table S2.txt

\begin{tabular}{|c|c|c|c|c|}
\hline 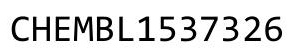 & & .2757 & 3.7187 & \\
\hline & & .2757 & 3.0723 & \\
\hline & 21 & & & \\
\hline IEMBL & 9021 & 2757 & & \\
\hline AEMBL1601531 & 29021 & 2757 & 8982 & \\
\hline HEMBL1519756 & 09021 & .2757 & 1815 & \\
\hline HEMBLI & 09021 & & & \\
\hline 219 & & & & \\
\hline AEMBL565862 & 309021 & & & \\
\hline HEMBL1455868 & 09021 & 57 & 15 & \\
\hline AEMBL1534293 & 09021 & & 92 & \\
\hline IEMBL189 & 09021 & 57 & & \\
\hline AEMBL142 & & & & \\
\hline HEMBL1388565 & 309021 & & & \\
\hline AEMBL1317849 & 09021 & & & \\
\hline IEMBL146 & 09021 & 7 & 66 & \\
\hline HEMBL13 & 21 & & 81 & \\
\hline HEMBL16 & 21 & & & \\
\hline AEMBL15e & 21 & & & \\
\hline AEMBL153 & 21 & & & \\
\hline HEMBLI & 1 & & & \\
\hline AEMBL14 & 1 & & & \\
\hline AEMBL13 & 1 & & & \\
\hline AEMBL14 & 21 & & & \\
\hline AEMBL198 & & & & \\
\hline HEMBL13 & 09 & & 24 & \\
\hline HEMBLI & 21 & & 72 & \\
\hline HFMBI 1 & 1 & & & \\
\hline HEMBL1328875 & & & & \\
\hline HEMBL 367 & 527 & & 33 & \\
\hline HEMBL367 & 52 & & 51 & \\
\hline AFMBI = & 3 & & & \\
\hline & & & & \\
\hline AEMBL367e & 527 & & & \\
\hline HEMBL3675032 & 527 & & 94 & RN \\
\hline JEMBL36 & 5 & & & \\
\hline HCMP - & 3 & & & \\
\hline HEMBL 367 & & & & RN \\
\hline HEMBL3939210 & 527943 & & 315 & ST \\
\hline IEMBL36 & 52 & & & RN \\
\hline HEMBL 367 & 43 & & 42 & \\
\hline HEMBL367 & & & & \\
\hline HEMBL368 & 527943 & & 9536 & IST \\
\hline AEMBL3675027 & 527943 & 49 & 366 & ГST \\
\hline MBL3 & $=0$ & & & 15 \\
\hline HEMBL 367 & & & .5061 & \\
\hline II & 43 & .9586 & .1307 & \\
\hline CHEMBL367517 & 1527943 & 8.301 & 8.2681 & ГRN \\
\hline
\end{tabular}

Page 18661 


$$
\text { Supplemental Table S2.txt }
$$

\begin{tabular}{|c|c|c|c|c|}
\hline CHEMBL 3675059 & 1527943 & 8.699 & 8.4991 & TRN \\
\hline CHEMBL 3675037 & 1527943 & 8.3979 & 8.3714 & TRN \\
\hline CHEMBL 3961766 & 1527943 & 5.2366 & 7.0352 & TST \\
\hline CHEMBL 3917101 & 1527943 & 8.301 & 7.2993 & TST \\
\hline CHEMBL 3675052 & 1527943 & 6.0 & 7.316 & TRN \\
\hline CHEMBL 3674978 & 1527943 & 7.0 & 7.6196 & TRN \\
\hline CHEMBL 3675031 & 1527943 & 7.9586 & 7.8609 & TRN \\
\hline CHEMBL 3674984 & 1527943 & 8.301 & 8.5837 & TRN \\
\hline CHEMBL 3680005 & 1527943 & 8.2218 & 8.1447 & TRN \\
\hline CHEMBL3679972 & 1527943 & 8.301 & 8.4731 & TRN \\
\hline CHEMBL 3675160 & 1527943 & 6.6576 & 6.8523 & TRN \\
\hline CHEMBL 3675127 & 1527943 & 8.0 & 8.5171 & TRN \\
\hline CHEMBL 3897907 & 1527943 & 6.9586 & 7.2211 & TST \\
\hline CHEMBL 3675099 & 1527943 & 8.5229 & 7.7556 & TST \\
\hline CHEMBL 3675094 & 1527943 & 6.2366 & 8.515 & TST \\
\hline CHEMBL 3679967 & 1527943 & 8.3979 & 7.9368 & TST \\
\hline CHEMBL 3675183 & 1527943 & 8.1549 & 7.9972 & TRN \\
\hline CHEMBL 3675131 & 1527943 & 3.699 & 7.9958 & TST \\
\hline CHEMBL 3674970 & 1527943 & 8.5229 & 8.5678 & TRN \\
\hline CHEMBL 3675038 & 1527943 & 8.5229 & 7.8072 & TRN \\
\hline CHEMBL3675159 & 1527943 & 8.301 & 7.9184 & TRN \\
\hline CHEMBL 3674980 & 1527943 & 8.3979 & 8.35 & TRN \\
\hline CHEMBL 3675062 & 1527943 & 8.301 & 8.6959 & TRN \\
\hline CHEMBL 3675006 & 1527943 & 6.5376 & 7.1727 & TRN \\
\hline CHEMBL 3675151 & 1527943 & 8.3979 & 8.2093 & TRN \\
\hline CHEMBL 3679970 & 1527943 & 3.699 & 7.6837 & TST \\
\hline CHEMBL3675156 & 1527943 & 8.301 & 8.0694 & TRN \\
\hline CHEMBL 3679974 & 1527943 & 8.1549 & 8.2212 & TRN \\
\hline CHEMBL 3675078 & 1527943 & 8.301 & 8.4959 & TRN \\
\hline CHEMBL 3675028 & 1527943 & 7.9586 & 8.2359 & TRN \\
\hline CHEMBL 3680003 & 1527943 & 8.3979 & 7.9672 & TRN \\
\hline CHEMBL 3675098 & 1527943 & 8.1549 & 8.1651 & TRN \\
\hline CHEMBL 3949363 & 1527943 & 6.0 & 7.4894 & TST \\
\hline CHEMBL 3679998 & 1527943 & 8.301 & 7.9396 & TRN \\
\hline CHEMBL 3675121 & 1527943 & 8.3979 & 8.4959 & TRN \\
\hline CHEMBL 3675110 & 1527943 & 8.2218 & 8.2035 & TRN \\
\hline CHEMBL3679959 & 1527943 & 8.0969 & 8.1553 & TRN \\
\hline CHEMBL 3675012 & 1527943 & 8.1549 & 7.6223 & TRN \\
\hline CHEMBL 3679980 & 1527943 & 8.3979 & 7.688 & TRN \\
\hline CHEMBL 3675135 & 1527943 & 8.301 & 7.9269 & TRN \\
\hline CHEMBL 3675148 & 1527943 & 6.3665 & 8.166 & TST \\
\hline CHEMBL 3675081 & 1527943 & 8.5229 & 8.6564 & TRN \\
\hline CHEMBL 3675009 & 1527943 & 8.2218 & 8.1654 & TRN \\
\hline CHEMBL 3675061 & 1527943 & 7.7447 & \multicolumn{2}{|c|}{7.952000000000001} \\
\hline CHEMBL 3675018 & 1527943 & 8.699 & 8.1709 & TRN \\
\hline CHEMBL 3669885 & 1527943 & 5.0809 & 6.9287 & TST \\
\hline CHEMBL 3675133 & 1527943 & 8.0969 & 8.0705 & TRN \\
\hline CHEMBL 3675130 & 1527943 & 8.0 & 8.0432 & TST \\
\hline
\end{tabular}


Supplemental Table S2.txt

\begin{tabular}{|c|c|c|c|c|}
\hline 104 & 527943 & & & \\
\hline & 527943 & 8.5229 & & \\
\hline & 27943 & & & \\
\hline EMBL & 27943 & 1549 & & \\
\hline AEMBL 3675001 & 527943 & 2596 & & \\
\hline AEMBL; & 527943 & 7.9208 & & \\
\hline 357 & 527943 & 8.699 & & \\
\hline EMBL & 527943 & 8.1549 & & \\
\hline IEMBL 3670043 & 527943 & 7.6198 & & \\
\hline AEMBL3675112 & 527943 & 8.1549 & & \\
\hline AEMBL; & 527943 & 8.301 & & \\
\hline IEMBL & 527943 & 8.301 & & \\
\hline IEMBL & 527943 & 229 & & \\
\hline AEMBL 3675080 & 527943 & 8.3979 & & \\
\hline AEMBL & 527943 & & & \\
\hline AEMBL & 527943 & 8 & & \\
\hline 033 & 527943 & 768 & & \\
\hline 978 & 527943 & 8.5229 & & \\
\hline IEMBL & 527943 & 7212 & & \\
\hline IEMBL & 43 & & & \\
\hline IEMB & +3 & 8 & & \\
\hline 81 & 7943 & 51 & & . \\
\hline 016 & 527943 & 549 & & \\
\hline 169 & 527943 & & & \\
\hline EMBL: & 3 & & & \\
\hline IEMBL & 7943 & 7. & & w \\
\hline 17 & 43 & & & $\cdots$ \\
\hline 971 & 43 & 49 & & \\
\hline 9986 & 7943 & & & $\mathrm{RI}$ \\
\hline 79960 & 13 & 7. & & IST \\
\hline 36 & 3 & 7 & & RI \\
\hline 3 & 3 & & & Tr \\
\hline & 3 & & & . \\
\hline IEMBL & 527943 & & & $S$ \\
\hline 75108 & 527943 & 7. & & $\mathrm{RI}$ \\
\hline$\llcorner 67$ & 7943 & & & $\Gamma R$ \\
\hline 2 & 13 & & & $\mathrm{R}$ \\
\hline 971 & 527943 & & & ST \\
\hline IEMBL & 527943 & & & $\Gamma R$ \\
\hline 074 & 943 & & & RI \\
\hline 999 & 527943 & & & 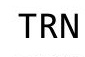 \\
\hline 979 & 527943 & 549 & 86 & $\Gamma R$ \\
\hline AEMBL: & 527943 & 8.301 & & $R$ \\
\hline AEMBL & 7943 & 7 & & $\mathrm{~F}$ \\
\hline 0 & & & & \\
\hline 75139 & 527943 & & 8.2761 & \\
\hline CHEMBL: & 527943 & & 8.2761 & \\
\hline CHEMBL3680013 & 1527943 & 5.7447 & 7.2308 & \\
\hline
\end{tabular}

Page 18663 
Supplemental Table S2.txt

\begin{tabular}{|c|c|c|c|c|}
\hline 政 & 527943 & & & \\
\hline CHEMBL3670071 & 1527943 & 8.301 & 8.1174 & \\
\hline HEMBL3680000 & 527943 & 8.3979 & 9396 & \\
\hline 578 & 527943 & 212 & & \\
\hline IEMBL3679991 & 527943 & 8.301 & 8932 & \\
\hline AEMBL3675128 & 527943 & 2218 & 4925 & \\
\hline HEMBL3679955 & 527943 & 0969 & 062 & \\
\hline 5036 & 527943 & 5229 & 815 & \\
\hline EMBL 3674975 & 527943 & 0757 & 3862 & \\
\hline AEMBL3675158 & 527943 & 8.301 & 2262 & \\
\hline AEMBL3675023 & 527943 & 1308 & .4817 & \\
\hline AEMBL36 & 527943 & 576 & & \\
\hline IEMBL: & 527943 & 3979 & 158 & \\
\hline IEMBL3674982 & 527943 & 969 & & \\
\hline AEMBL3675014 & 527943 & 8.3979 & .4484 & \\
\hline AEMBL3679963 & 527943 & 3979 & 3031 & \\
\hline HEMBL3680035 & 521943 & 58 & 7. & \\
\hline AEMBL36 & 527943 & & .1798 & \\
\hline 120 & 527943 & 79 & .5061 & \\
\hline AEMBL3 & 527943 & 3979 & .7531 & \\
\hline IEMBL 36 & 43 & & & \\
\hline AEMBL3 & $52 / 943$ & 8 & 8.4393 & \\
\hline AEMBL3 & 527943 & & 3.0231 & \\
\hline 124 & 527943 & 18 & 8.5812 & \\
\hline IEMBL: & 527943 & & 574 & \\
\hline EMBL3 & 43 & & & \\
\hline AEMBL36 & 1527943 & 18 & 8.0166 & \\
\hline 957 & 527943 & 59 & 7327 & \\
\hline 968 & 43 & 28 & 7.5791 & \\
\hline 5116 & 527943 & & & \\
\hline IEMBL3680024 & 5279 & & 0992 & \\
\hline 020 & 43 & 2 & 246 & \\
\hline 996 & 3 & 49 & 17 & \\
\hline 976 & 43 & & 7.9789 & \\
\hline IEMBL3680023 & 527943 & & 559 & \\
\hline IEMBL3 & 527943 & & 2639 & \\
\hline 051 & 527943 & 24 & 59 & \\
\hline 182 & 43 & 19 & 4087 & \\
\hline AEMBL3 & 1527943 & & 8.2821 & \\
\hline IEMBL36 & 5279 & 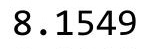 & 3523 & \\
\hline IEMBL3675039 & 527943 & 18 & 495 & \\
\hline HEMBL3674986 & 527943 & & & \\
\hline 9981 & 527943 & 8.3979 & 7.8205 & \\
\hline AEMBL3669995 & 527943 & 8.0 & 7.8946 & \\
\hline AEMBL3675145 & 5279 & $36-2$ & .0671 & \\
\hline CHEMBL & 15279 & & & \\
\hline & & & 8.2417 & \\
\hline CHEMBL 36 & גחרת & & 7.9042 & \\
\hline
\end{tabular}

Page 18664 
Supplemental Table S2.txt

\begin{tabular}{|c|c|c|c|c|}
\hline CHEMBL 3675022 & 1527943 & 7.1549 & 7.211 & TRN \\
\hline CHEMBL3680038 & 1527943 & 6.7696 & 7.1115 & TST \\
\hline CHEMBL3639740 & 1527943 & 8.2218 & 8.308 & TRN \\
\hline CHEMBL 3675184 & 1527943 & 8.1549 & 7.9562 & TRN \\
\hline CHEMBL3679997 & 1527943 & 8.301 & 8.2367 & TRN \\
\hline CHEMBL3680036 & 1527943 & 3.699 & 7.0118 & TST \\
\hline CHEMBL3675096 & 1527943 & 8.1549 & 7.8615 & TST \\
\hline CHEMBL3679966 & 1527943 & 8.3979 & 7.66299 & 9999999999 \\
\hline CHEMBL 3675179 & 1527943 & 8.0458 & 8.273 & TRN \\
\hline CHEMBL3675075 & 1527943 & 8.2218 & 8.3691 & TRN \\
\hline CHEMBL3675141 & 1527943 & 8.5229 & 8.5138 & TRN \\
\hline CHEMBL3670037 & 1527943 & 8.301 & 8.4569 & TRN \\
\hline CHEMBL3675034 & 1527943 & 7.9586 & 7.595 & TRN \\
\hline CHEMBL 3675065 & 1527943 & 8.1549 & 7.902 & TRN \\
\hline CHEMBL3675147 & 1527943 & 8.2218 & 8.1476 & TRN \\
\hline CHEMBL 3675144 & 1527943 & 8.2218 & 8.1983 & TRN \\
\hline CHEMBL3675107 & 1527943 & 8.1549 & 8.3048 & TRN \\
\hline CHEMBL3679973 & 1527943 & 8.0 & 7.6863 & TST \\
\hline CHEMBL 3675178 & 1527943 & 8.2218 & 8.2723 & TRN \\
\hline CHEMBL 3670022 & 1527943 & 7.9586 & 7.8178 & TRN \\
\hline CHEMBL 3675146 & 1527943 & 8.0458 & 8.249 & TRN \\
\hline CHEMBL3675058 & 1527943 & 8.5229 & 8.3803 & TRN \\
\hline CHEMBL3675102 & 1527943 & 8.0458 & 7.0803 & TST \\
\hline CHEMBL 3675053 & 1527943 & 8.1549 & 8.0359 & TRN \\
\hline CHEMBL3675067 & 1527943 & 8.5229 & 8.318 & TRN \\
\hline CHEMBL 3680027 & 1527943 & 5.5686 & 7.5545 & TST \\
\hline CHEMBL3669988 & 1527943 & 7.3979 & 7.3504 & TRN \\
\hline CHEMBL3675105 & 1527943 & 7.6383 & 8.2112 & TRN \\
\hline CHEMBL 3680037 & 1527943 & 6.3188 & 6.9909 & TST \\
\hline CHEMBL3670061 & 1527943 & 7.5229 & 7.7748 & TRN \\
\hline CHEMBL 3674985 & 1527943 & 7.8239 & 7.9677 & TRN \\
\hline CHEMBL3679994 & 1527943 & 8.1549 & 8.1183 & TRN \\
\hline CHEMBL3679990 & 1527943 & 6.6198 & 7.3965 & TRN \\
\hline CHEMBL 3680001 & 1527943 & 8.0458 & 8.2144 & TRN \\
\hline CHEMBL3675091 & 1527943 & 7.9586 & 8.4529 & TRN \\
\hline CHEMBL3670005 & 1527943 & 7.5086 & 7.2462 & TRN \\
\hline CHEMBL3985912 & 1527943 & 3.699 & 7.1126 & TST \\
\hline CHEMBL 3670038 & 1527943 & 7.8861 & 7.851 & TRN \\
\hline CHEMBL 3675163 & 1527943 & 8.1549 & 7.8198 & TRN \\
\hline CHEMBL 3675045 & 1527943 & 8.301 & 8.2131 & TRN \\
\hline CHEMBL 3680018 & 1527943 & 6.2076 & 7.2713 & TST \\
\hline CHEMBL 3680016 & 1527943 & 5.7696 & 6.8567 & TST \\
\hline CHEMBL 3675007 & 1527943 & 8.1549 & 8.2185 & TRN \\
\hline CHEMBL3664975 & 1527943 & 5.0 & 7.0252 & TST \\
\hline CHEMBL 3907500 & 1527943 & 7.0177 & 6.9077 & TST \\
\hline CHEMBL 3675175 & 1527943 & 8.0 & 8.3961 & TRN \\
\hline CHEMBL 3675132 & 1527943 & 8.301 & 8.3539 & TRN \\
\hline CHEMBL 3679965 & 1527943 & 8.3979 & 7.8655 & TST \\
\hline
\end{tabular}


Supplemental Table S2.txt

\begin{tabular}{|c|c|c|c|c|}
\hline TLTILL & & & 29 & \\
\hline HFMRI 3675020 & ה רמתרת & 8.5229 & 8.3245 & \\
\hline HEMBL & & 8.0 & 9296 & \\
\hline AEMBL3675086 & 021943 & 0969 & 9712 & \\
\hline HEMBL 3675084 & 527943 & 8.3979 & .186 & \\
\hline HEMBL; & 527943 & 6.8539 & 2194 & \\
\hline AEMBL & & 1549 & 6223 & \\
\hline HEMBL 3675140 & 43 & 8.5229 & 5138 & \\
\hline HEMBL3674988 & 527943 & 7.7447 & 5891 & \\
\hline HEMBL3675149 & 527943 & 7.9586 & .202 & \\
\hline HEMBL36 & 43 & 8.301 & 3979 & \\
\hline HEMBL; & & 208 & 5587 & \\
\hline HEMBL & 43 & 8.2218 & 3831 & \\
\hline HEMBL3675172 & +3 & 7.8239 & 8625 & \\
\hline AEMBL3675093 & 3 & 7.6576 & 1246 & \\
\hline AEMBL & 3 & 458 & 462 & \\
\hline AEMBL. & & 021 & 337 & RN \\
\hline HEMBL 2 & +3 & 7.0 & 4015 & \\
\hline HEMBL3 & & 18 & .75 & \\
\hline AEMBL3679989 & 3 & 47 & 304 & KIV \\
\hline AEMBL & 3 & 549 & 9 & $\mathrm{RN}$ \\
\hline AEMBL & & 79 & & RIV \\
\hline HEMBL & 13 & 229 & 41 & \\
\hline HEMBL & & 487 & & IST \\
\hline AEMBL36 & 3 & 229 & 97 & $R N$ \\
\hline IEMBL: & & 188 & 92 & $R N_{-}$ \\
\hline EM & & 79 & & ST \\
\hline 57 & & 586 & & RN \\
\hline IEMBL: & & 69 & & IRN \\
\hline AEMBL3675035 & 43 & 8.2218 & 037 & $\mathrm{RN}$ \\
\hline AEMBL & & & 18 & RN \\
\hline 0 & & & & ST \\
\hline & & 229 & & $\mathrm{RN}$ \\
\hline AEMBL3675143 & & & & 「RN \\
\hline AEMBL3674993 & +3 & 7.7447 & 108 & RN \\
\hline IEMPI: 7 & & 7. & 47 & 「RN \\
\hline & & & & ST \\
\hline HEMBL & & & & RN \\
\hline AEMBL3679971 & 43 & 8.3979 & & $\Gamma R$ \\
\hline IEMBL36 & 3 & 555 & 38 & RN \\
\hline HEMBL36 & & & 932 & \\
\hline HEMBL36 & & 8.0458 & 7.575 & RN \\
\hline HEMBL3675186 & & 8.301 & 1856 & 「RN \\
\hline AEMBL3675069 & +3 & 8.3979 & 97 & TR \\
\hline Not & & & & \\
\hline HEMBL 3674994 & & 8.0969 & & \\
\hline HEMBL 3639739 & & 7.7959 & 8.0468 & \\
\hline CHEMBL3675090 & 1527943 & 7.8861 & 8.0661 & \\
\hline
\end{tabular}

Page 18666 
Supplemental Table S2.txt

\begin{tabular}{|c|c|c|c|c|}
\hline ILT & נדלנו & 3861 & & \\
\hline & & 8.699 & & \\
\hline & & $\partial 21$ & & \\
\hline AEMBL & & 3979 & & \\
\hline HEMBL; & $52 / 943$ & 3979 & & \\
\hline HEMBL3675056 & 527943 & 8.2218 & 3699 & \\
\hline 164 & 13 & 969 & & \\
\hline 026 & & 9586 & & \\
\hline 79985 & 3 & 3979 & & \\
\hline HEMBL3675152 & 527 & 8.1549 & .1389 & \\
\hline AEMBL 3674997 & 13 & 7.5528 & 93 & \\
\hline EMBL: & 3 & 979 & 35 & \\
\hline AEMBL: & & 229 & & \\
\hline HEMBL3 & 3 & 8.301 & 7.3102 & \\
\hline AEMBL3 & 13 & 586 & & \\
\hline AEMBL3 & -3 & 3979 & 82 & \\
\hline AEMBL: & 3 & 218 & 55 & \\
\hline HEMBL; & & 549 & & \\
\hline HEMBL3 & 3 & 8.301 & & \\
\hline AEMBL3 & & 915 & & \\
\hline HEMBL. & 13 & 29 & 74 & RN \\
\hline AEMBL & & 18 & & $\mathrm{RN}$ \\
\hline HEMBL. & & 861 & 32 & \\
\hline 087 & & 8.1549 & & \\
\hline AEMBL36 & & & 25 & IRN \\
\hline HEMBL; & 3 & 969 & 8.4944 & ГST \\
\hline HEMBL & & 861 & 76 & KIV \\
\hline HFMRI & & 969 & 65 & \\
\hline HEMBL3 & & 518 & 7.881 & $\mid$ \\
\hline HEMBL 3675 & & 871 & 14 & $\mathrm{I}_{\mathrm{S}}$ \\
\hline HEMBL3 & & 229 & 36 & RN \\
\hline HEMBL & & 218 & 47 & $\mathrm{RN}$ \\
\hline AEMBL. & & 79 & 58 & TRN \\
\hline HEMBL3S & & 6 . & 7. & is \\
\hline HEMBL 39473 & 52 & 8.3979 & 7.1 & TST \\
\hline HEMBL3 & & 596 & 7. & RN \\
\hline יסוזות & & & 8 . & RN \\
\hline HEMBL & & 8 & & ST \\
\hline HEMBL3675176 & 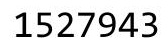 & 8.301 & .3699 & TRN \\
\hline EMBL3 & 52 & 949 & 377 & TST \\
\hline HEMBL $367 \angle$ & & 218 & 7.0734 & RN \\
\hline HEMBL3675137 & & 8.2218 & 7.6028 & 「RN \\
\hline HEMBL3 & 43 & 7.6778 & 7.8133 & $\Gamma R$ \\
\hline AEMBL3675097 & 52 & 8.0458 & 8.8076 & TC \\
\hline $1-7$ & & 915 & 7.7841 & TST \\
\hline HEMBL 3675 & & & 8.2483 & \\
\hline CHEMBL 3675 & & 7.7212 & 8.3826 & \\
\hline CHEMBL367505 & 1527943 & 8.5229 & 8.5574 & TST \\
\hline
\end{tabular}

Page 18667 
Supplemental Table S2.txt

\begin{tabular}{|c|c|c|c|c|c|}
\hline CHEMBL 3675040 & 1527943 & 8.5229 & 8.1672 & TST & \\
\hline CHEMBL3675047 & 1527943 & 8.2218 & 8.2899 & TST & \\
\hline CHEMBL3675088 & 1527943 & 8.0969 & 7.8095 & TST & \\
\hline CHEMBL3675082 & 1527943 & 8.0 & 7.9712 & TST & \\
\hline CHEMBL3675083 & 1527943 & 8.3979 & 8.35 & TST & \\
\hline CHEMBL 3675125 & 1527943 & 8.301 & 8.2475 & TST & \\
\hline CHEMBL 3675155 & 1527943 & 8.3979 & 8.2656 & TST & \\
\hline CHEMBL3675064 & 1527943 & 8.3979 & 8.3247 & TST & \\
\hline CHEMBL 3675173 & 1527943 & 8.301 & 8.3284 & TST & \\
\hline CHEMBL3674996 & 1527943 & 6.6576 & 6.8078 & TST & \\
\hline CHEMBL3675092 & 1527943 & 8.0 & 8.2624 & TST & \\
\hline CHEMBL3674995 & 1527943 & 8.0458 & 7.6095 & TST & \\
\hline CHEMBL3674977 & 1527943 & 7.8539 & 8.0666 & TST & \\
\hline CHEMBL3679969 & 1527943 & 7.5686 & 7.4794 & TST & \\
\hline CHEMBL3126915 & 1294972 & 5.2612 & 4.6078 & TST & \\
\hline CHEMBL3126865 & 1294972 & 5.0443 & 4.4749 & TST & \\
\hline CHEMBL3126867 & 1294972 & 3.699 & 3.6451 & TRN & \\
\hline CHEMBL 3127048 & 1294972 & 5.9393 & 4.283 & TST & \\
\hline CHEMBL3126876 & 1294972 & 3.699 & 3.9232 & TRN & \\
\hline CHEMBL3126889 & 1294972 & 3.699 & 4.1571 & TRN & \\
\hline CHEMBL3126874 & 1294972 & 4.7471 & 4.5448 & TRN & \\
\hline CHEMBL3126884 & 1294972 & 3.699 & 3.1893 & TRN & \\
\hline CHEMBL 3126888 & 1294972 & 3.699 & 3.8044 & TRN & \\
\hline CHEMBL3126877 & 1294972 & 3.0 & 3.4906 & TRN & \\
\hline CHEMBL3126914 & 1294972 & 5.2518 & 6.3985 & TST & \\
\hline CHEMBL3126882 & 1294972 & 3.0 & 3.4022 & TRN & \\
\hline CHEMBL3127059 & 1294972 & 3.699 & 3.8044 & TRN & \\
\hline CHEMBL3126893 & 1294972 & 3.699 & 3.3834 & TRN & \\
\hline CHEMBL3127065 & 1294972 & 7.699 & 7.7992 & TRN & \\
\hline CHEMBL3126883 & 1294972 & 3.699 & 3.9486 & TRN & \\
\hline CHEMBL3127055 & 1294972 & 3.699 & 5.87299 & 9999999999 & TST \\
\hline CHEMBL 3127068 & 1294972 & 5.5901 & 6.256 & TRN & \\
\hline CHEMBL 3127054 & 1294972 & 3.699 & 4.09699 & 99999999995 & TRN \\
\hline CHEMBL3126894 & 1294972 & 3.699 & 3.3475 & TRN & \\
\hline CHEMBL3126878 & 1294972 & 3.699 & 3.4493 & TRN & \\
\hline CHEMBL3126870 & 1294972 & 3.699 & 3.8313 & TRN & \\
\hline CHEMBL3127056 & 1294972 & 3.699 & 3.7197 & TST & \\
\hline CHEMBL3126908 & 1294972 & 7.3979 & 7.6949 & TRN & \\
\hline CHEMBL 3127047 & 1294972 & 3.699 & 5.4145 & TST & \\
\hline CHEMBL3126913 & 1294972 & 4.762 & 4.4147 & TRN & \\
\hline CHEMBL3126881 & 1294972 & 4.8386 & 3.8327 & TRN & \\
\hline CHEMBL3126886 & 1294972 & 3.699 & 3.678 & TRN & \\
\hline CHEMBL3127063 & 1294972 & 3.699 & 4.1027 & TRN & \\
\hline CHEMBL3126871 & 1294972 & 4.8962 & 4.9395 & TRN & \\
\hline CHEMBL3126901 & 1294972 & 3.699 & 4.0292 & TRN & \\
\hline CHEMBL3126899 & 1294972 & 5.5361 & 5.8133 & TRN & \\
\hline CHEMBL3126869 & 1294972 & 3.699 & 3.6389 & TRN & \\
\hline CHEMBL3126879 & 1294972 & 3.699 & 4.0333 & TRN & \\
\hline
\end{tabular}


Supplemental Table S2.txt

\begin{tabular}{|c|c|c|c|c|c|}
\hline CHEMBL3126892 & 1294972 & 3.699 & 3.3745 & TRN & \\
\hline CHEMBL3126911 & 1294972 & 4.9508 & 4.8133 & TRN & \\
\hline CHEMBL3126866 & 1294972 & 3.699 & 3.6727 & TRN & \\
\hline CHEMBL3126885 & 1294972 & 3.699 & \multicolumn{2}{|c|}{3.5869999999999997} & TRN \\
\hline CHEMBL3127046 & 1294972 & 5.27 & 5.1588 & TRN & \\
\hline CHEMBL 3127058 & 1294972 & 6.7447 & 6.1712 & TRN & \\
\hline CHEMBL319177 & 1294972 & 3.0 & \multicolumn{2}{|c|}{2.9739999999999998} & TST \\
\hline CHEMBL3126907 & 1294972 & 5.7986 & 6.4084 & TST & \\
\hline CHEMBL 3127061 & 1294972 & 3.699 & 3.8997 & TRN & \\
\hline CHEMBL3126890 & 1294972 & 3.0 & 3.0066 & TRN & \\
\hline CHEMBL 3126868 & 1294972 & 3.699 & 3.897 & TRN & \\
\hline CHEMBL403715 & 1294972 & 3.699 & 3.8976 & TST & \\
\hline CHEMBL1269812 & 1294972 & 8.0 & 7.9823 & TST & \\
\hline CHEMBL3126872 & 1294972 & 3.0 & 3.5115 & TST & \\
\hline CHEMBL3126895 & 1294972 & 3.699 & 3.8161 & TRN & \\
\hline CHEMBL3127067 & 1294972 & 7.0458 & 6.2979 & TRN & \\
\hline CHEMBL3127045 & 1294972 & 3.699 & 3.9738 & TRN & \\
\hline CHEMBL3124960 & 1294972 & 3.699 & 3.9439 & TRN & \\
\hline CHEMBL3126912 & 1294972 & 3.699 & 3.3727 & TRN & \\
\hline CHEMBL3126906 & 1294972 & 6.2007 & 5.4715 & TST & \\
\hline CHEMBL3126902 & 1294972 & 5.4584 & 4.7938 & TRN & \\
\hline CHEMBL3126910 & 1294972 & 3.699 & 3.6922 & TRN & \\
\hline CHEMBL3126896 & 1294972 & 3.699 & 3.3764 & TST & \\
\hline CHEMBL3127051 & 1294972 & 3.699 & 3.9187 & TRN & \\
\hline CHEMBL3126873 & 1294972 & 3.699 & \multicolumn{2}{|c|}{3.1289999999999996} & TRN \\
\hline CHEMBL3126904 & 1294972 & 3.699 & 3.8724 & TRN & \\
\hline CHEMBL3126875 & 1294972 & 3.699 & 3.6726 & TRN & \\
\hline CHEMBL3126900 & 1294972 & 4.8761 & 4.7185 & TRN & \\
\hline CHEMBL3126897 & 1294972 & 3.699 & 3.1831 & TST & \\
\hline CHEMBL3127050 & 1294972 & 4.8477 & 5.2548 & TRN & \\
\hline CHEMBL3127060 & 1294972 & 3.699 & 3.863 & TRN & \\
\hline CHEMBL 3127053 & 1294972 & 3.699 & 3.2546 & TRN & \\
\hline CHEMBL3126891 & 1294972 & 3.0 & 3.2072 & TRN & \\
\hline CHEMBL3126909 & 1294972 & 3.699 & 4.0919 & TRN & \\
\hline CHEMBL3126880 & 1294972 & 5.0443 & 4.2015 & TST & \\
\hline CHEMBL3127057 & 1294972 & 3.699 & 3.8568 & TST & \\
\hline CHEMBL1814768 & 1294972 & 7.699 & 7.5443 & TRN & \\
\hline CHEMBL3126903 & 1294972 & 3.699 & 3.6757 & TRN & \\
\hline CHEMBL1814767 & 1294972 & 7.3979 & \multicolumn{2}{|c|}{7.667999999999999} & TRN \\
\hline CHEMBL3127044 & 1294972 & 4.8239 & 4.1521 & TST & \\
\hline CHEMBL3126887 & 1294972 & 3.699 & 3.6358 & TRN & \\
\hline CHEMBL3127049 & 1294972 & 7.301 & 6.9602 & TRN & \\
\hline CHEMBL3127062 & 1294972 & 3.699 & 3.7048 & TRN & \\
\hline CHEMBL3127064 & 1294972 & 3.699 & 3.9983 & TST & \\
\hline CHEMBL3126898 & 1294972 & 3.699 & 4.1766 & TST & \\
\hline CHEMBL3127066 & 1294972 & 6.9586 & 6.3742 & TRN & \\
\hline CHEMBL3126905 & 1294972 & 7.0458 & 7.3871 & TST & \\
\hline CHEMBL3127052 & 1294972 & 3.699 & 4.3104 & TRN & \\
\hline
\end{tabular}


Supplemental Table S2.txt

\begin{tabular}{|c|c|c|c|c|}
\hline CHEMBL3127052 & 1294963 & 3.8239 & 3.9743 & TRN \\
\hline CHEMBL3127061 & 1294963 & 3.699 & 3.8973 & TRN \\
\hline CHEMBL3126903 & 1294963 & 3.699 & 3.4419 & TRN \\
\hline CHEMBL3126877 & 1294963 & 3.699 & 3.6277 & TRN \\
\hline CHEMBL3127048 & 1294963 & 3.699 & 4.73 & TST \\
\hline CHEMBL3127066 & 1294963 & 6.5376 & 5.8779 & TRN \\
\hline CHEMBL3126887 & 1294963 & 3.699 & 3.6919 & TRN \\
\hline CHEMBL3126899 & 1294963 & 3.8239 & 5.0528 & TRN \\
\hline CHEMBL3126870 & 1294963 & 3.699 & 3.5502 & TRN \\
\hline CHEMBL3126889 & 1294963 & 3.699 & 3.7577 & TRN \\
\hline CHEMBL 3127063 & 1294963 & 3.699 & 3.6885 & TRN \\
\hline CHEMBL3126913 & 1294963 & 3.699 & 4.09699 & 99999999995 \\
\hline CHEMBL3126895 & 1294963 & 3.699 & 3.8381 & TRN \\
\hline CHEMBL3126879 & 1294963 & 3.8239 & 4.0408 & TRN \\
\hline CHEMBL3126878 & 1294963 & 3.699 & 3.2203 & TRN \\
\hline CHEMBL3126897 & 1294963 & 3.699 & 3.9251 & TST \\
\hline CHEMBL3126901 & 1294963 & 3.699 & 3.4539 & TRN \\
\hline CHEMBL3126896 & 1294963 & 3.699 & 3.9991 & TST \\
\hline CHEMBL 3126880 & 1294963 & 4.9172 & 4.5253 & TRN \\
\hline CHEMBL3126904 & 1294963 & 3.699 & 3.127 & TRN \\
\hline CHEMBL3127065 & 1294963 & 6.5229 & 6.5351 & TRN \\
\hline CHEMBL3127051 & 1294963 & 3.699 & 3.6175 & TRN \\
\hline CHEMBL 3127054 & 1294963 & 3.699 & 3.4659 & TRN \\
\hline CHEMBL 3127056 & 1294963 & 3.699 & 4.2435 & TST \\
\hline CHEMBL3126866 & 1294963 & 3.699 & 3.6765 & TRN \\
\hline CHEMBL3127068 & 1294963 & 6.3665 & 5.6268 & TRN \\
\hline CHEMBL 3127062 & 1294963 & 3.699 & 3.6506 & TRN \\
\hline CHEMBL3126875 & 1294963 & 3.699 & 3.5919 & TRN \\
\hline CHEMBL3126871 & 1294963 & 3.699 & 3.7781 & TRN \\
\hline CHEMBL3126888 & 1294963 & 3.699 & 3.7035 & TRN \\
\hline CHEMBL3127046 & 1294963 & 3.699 & 4.4507 & TRN \\
\hline CHEMBL3126908 & 1294963 & 6.5229 & 6.5799 & TRN \\
\hline CHEMBL 3127047 & 1294963 & 4.8962 & 5.1528 & TST \\
\hline CHEMBL3126906 & 1294963 & 5.7423 & 5.0635 & TST \\
\hline CHEMBL3127059 & 1294963 & 3.699 & 4.1273 & TRN \\
\hline CHEMBL3127064 & 1294963 & 3.8239 & 4.3848 & TST \\
\hline CHEMBL3127067 & 1294963 & 4.857 & 5.2383 & TRN \\
\hline CHEMBL3126891 & 1294963 & 3.699 & 3.8462 & TRN \\
\hline CHEMBL319177 & 1294963 & 3.699 & 3.7443 & TST \\
\hline CHEMBL3126915 & 1294963 & 5.4609 & 5.0811 & TST \\
\hline CHEMBL3126881 & 1294963 & 3.8239 & 4.0529 & TRN \\
\hline CHEMBL3126886 & 1294963 & 3.699 & 3.6165 & TRN \\
\hline CHEMBL3127049 & 1294963 & 6.6576 & 5.8919 & TRN \\
\hline CHEMBL3126900 & 1294963 & 4.9031 & 4.2252 & TRN \\
\hline CHEMBL3126894 & 1294963 & 3.699 & 3.71 & TRN \\
\hline CHEMBL3127053 & 1294963 & 3.699 & 3.4985 & TRN \\
\hline CHEMBL3126869 & 1294963 & 3.699 & 3.7183 & TRN \\
\hline CHEMBL3127045 & 1294963 & 3.699 & 4.2576 & TRN \\
\hline
\end{tabular}


Supplemental Table S2.txt

\begin{tabular}{|c|c|c|c|c|}
\hline CHEMBL3126876 & 1294963 & 3.699 & 3.7761 & TRN \\
\hline CHEMBL3126890 & 1294963 & 3.699 & 3.5439 & TRN \\
\hline CHEMBL3126911 & 1294963 & 5.3261 & 5.1385 & TRN \\
\hline CHEMBL3126868 & 1294963 & 3.699 & 3.5186 & TRN \\
\hline CHEMBL3124960 & 1294963 & 3.699 & 3.5781 & TRN \\
\hline CHEMBL3126892 & 1294963 & 3.699 & 3.5671 & TRN \\
\hline CHEMBL3126867 & 1294963 & 3.699 & 3.842 & TRN \\
\hline CHEMBL1269812 & 1294963 & 7.2218 & 6.676 & TST \\
\hline CHEMBL 3127057 & 1294963 & 3.699 & 4.2168 & TST \\
\hline CHEMBL3126898 & 1294963 & 3.699 & 4.4926 & TST \\
\hline CHEMBL3126885 & 1294963 & 3.699 & 3.8935 & TRN \\
\hline CHEMBL 3126873 & 1294963 & 3.699 & 3.4219 & TRN \\
\hline CHEMBL3126872 & 1294963 & 3.699 & 3.5492 & TST \\
\hline CHEMBL 3126874 & 1294963 & 3.699 & 4.3885 & TRN \\
\hline CHEMBL3126883 & 1294963 & 3.699 & 3.5428 & TRN \\
\hline CHEMBL403715 & 1294963 & 3.699 & 4.3772 & TST \\
\hline CHEMBL3126884 & 1294963 & 3.699 & 3.5764 & TRN \\
\hline CHEMBL3126907 & 1294963 & 4.857 & 5.3034 & TST \\
\hline CHEMBL3126865 & 1294963 & 5.2 & 4.5484 & TST \\
\hline CHEMBL3126909 & 1294963 & 5.2741 & 4.7058 & TRN \\
\hline CHEMBL3126902 & 1294963 & 3.699 & 4.0185 & TRN \\
\hline CHEMBL3126893 & 1294963 & 3.699 & 3.8714 & TRN \\
\hline CHEMBL 3127044 & 1294963 & 5.2557 & 4.8557 & TST \\
\hline CHEMBL3126910 & 1294963 & 3.8239 & 4.1534 & TRN \\
\hline CHEMBL3127050 & 1294963 & 3.8239 & 4.7588 & TRN \\
\hline CHEMBL3127060 & 1294963 & 3.699 & 3.5666 & TRN \\
\hline CHEMBL3126905 & 1294963 & 5.8794 & 5.702999 & 9999999999 \\
\hline CHEMBL3127055 & 1294963 & 3.8239 & 5.1711 & TST \\
\hline CHEMBL 3127058 & 1294963 & 6.0706 & 5.5752 & TRN \\
\hline CHEMBL3126882 & 1294963 & 3.699 & 3.6821 & TRN \\
\hline CHEMBL3126912 & 1294963 & 3.699 & 4.1135 & TRN \\
\hline CHEMBL3126914 & 1294963 & 6.5376 & 5.5602 & TST \\
\hline CHEMBL1472459 & 688417 & 4.7122 & 4.5485 & TRN \\
\hline CHEMBL1550871 & 688417 & 4.5122 & 4.7529 & TRN \\
\hline CHEMBL1355519 & 688417 & 4.1122 & 4.1302 & TRN \\
\hline CHEMBL1448732 & 688417 & 4.95 & 4.8244 & TRN \\
\hline CHEMBL1550914 & 688417 & 5.7018 & 5.5167 & TRN \\
\hline CHEMBL1397967 & 688417 & 4.6122 & 4.208 & TRN \\
\hline CHEMBL1314118 & 688417 & 5.1122 & 5.2565 & TRN \\
\hline CHEMBL1210313 & 688417 & 6.5122 & 6.124 & TRN \\
\hline CHEMBL1566610 & 688417 & 6.0 & 5.9259 & TRN \\
\hline CHEMBL1569585 & 688417 & 5.4 & 5.6647 & TRN \\
\hline CHEMBL1447338 & 688417 & 5.0 & 5.4218 & TST \\
\hline CHEMBL1354214 & 688417 & 5.2122 & 4.6706 & TRN \\
\hline CHEMBL1354542 & 688417 & 4.3122 & 4.0759 & TRN \\
\hline CHEMBL1315412 & 688417 & 4.9122 & 4.8311 & TRN \\
\hline CHEMBL1354094 & 688417 & 5.4122 & 5.2926 & TRN \\
\hline CHEMBL1347105 & 688417 & 5.1 & 5.1057 & TRN \\
\hline
\end{tabular}




\begin{tabular}{|c|c|c|c|c|c|}
\hline \multicolumn{6}{|c|}{ Supplemental Table S2.txt } \\
\hline CHEMBL1475745 & 688417 & 5.3518 & 5.4588 & TRN & \\
\hline CHEMBL1476170 & 688417 & 4.95 & 6.0033 & TST & \\
\hline CHEMBL1433323 & 688417 & 6.1122 & 5.9954 & TRN & \\
\hline CHEMBL1301335 & 688417 & 5.1 & 5.6654 & TRN & \\
\hline CHEMBL1255837 & 688417 & 5.0 & 5.5876 & TST & \\
\hline CHEMBL1305540 & 688417 & 5.35 & 5.2977 & TST & \\
\hline CHEMBL1473112 & 688417 & 4.5018 & 4.3864 & TRN & \\
\hline CHEMBL1443332 & 688417 & 5.6 & 5.5438 & TRN & \\
\hline CHEMBL1467893 & 688417 & 5.15 & 5.37299 & 9999999999 & TST \\
\hline CHEMBL1385840 & 688417 & 5.4 & 6.4126 & TST & \\
\hline CHEMBL1511856 & 688417 & 5.0018 & 4.9604 & TRN & \\
\hline CHEMBL1354177 & 688417 & 4.0018 & 4.2822 & TRN & \\
\hline CHEMBL1476356 & 688417 & 4.5018 & 4.4563 & TRN & \\
\hline CHEMBL1314066 & 688417 & 3.6122 & 4.1473 & TRN & \\
\hline CHEMBL1341889 & 688417 & 4.3122 & 4.3574 & TRN & \\
\hline CHEMBL1433345 & 688417 & 4.7122 & 4.9227 & TRN & \\
\hline CHEMBL546170 & 688417 & 5.15 & 4.8026 & TRN & \\
\hline CHEMBL1333181 & 688417 & 5.0 & 4.8798 & TRN & \\
\hline CHEMBL1433349 & 688417 & 4.4122 & 4.8244 & TRN & \\
\hline CHEMBL1315807 & 688417 & 5.6017 & $5.6670 e$ & 0000000001 & TRN \\
\hline CHEMBL1433769 & 688417 & 4.9122 & 4.7979 & TRN & \\
\hline CHEMBL1436634 & 688417 & 4.7122 & 4.7677 & TRN & \\
\hline CHEMBL1433378 & 688417 & 4.1122 & 4.1065 & TRN & \\
\hline CHEMBL1978331 & 688417 & 5.3 & 5.2083 & TRN & \\
\hline CHEMBL1550915 & 688417 & 4.7122 & 4.8803 & TRN & \\
\hline CHEMBL1358475 & 688417 & 4.8122 & 4.8141 & TRN & \\
\hline CHEMBL1371924 & 688417 & 5.4 & 5.2176 & TRN & \\
\hline CHEMBL1162415 & 688417 & 4.9 & 5.0912 & TRN & \\
\hline CHEMBL1439938 & 688417 & 4.95 & 4.3794 & TRN & \\
\hline CHEMBL1511885 & 688417 & 5.2122 & 4.6062 & TRN & \\
\hline CHEMBL1474223 & 688417 & 4.3018 & 4.1959 & TRN & \\
\hline CHEMBL1511821 & 688417 & 4.7122 & 4.7951 & TRN & \\
\hline CHEMBL1354227 & 688417 & 4.9122 & 4.9416 & TRN & \\
\hline CHEMBL405110 & 688417 & 5.4 & 5.4554 & TST & \\
\hline CHEMBL1256686 & 688417 & 5.0 & $6.0820 e$ & 0000000001 & TST \\
\hline CHEMBL1499411 & 688417 & 5.55 & 5.2984 & TST & \\
\hline CHEMBL1314059 & 688417 & 4.8122 & 4.6979 & TRN & \\
\hline CHEMBL1317927 & 688417 & 4.9122 & 4.7382 & TRN & \\
\hline CHEMBL1368548 & 688417 & 5.7122 & 5.6665 & TRN & \\
\hline CHEMBL1393909 & 688417 & 4.3018 & 4.6291 & TRN & \\
\hline CHEMBL1474387 & 688417 & 6.4122 & 6.1362 & TRN & \\
\hline CHEMBL1314025 & 688417 & 2.7122 & 4.0838 & TRN & \\
\hline CHEMBL1511892 & 688417 & 5.0122 & 4.7558 & TRN & \\
\hline CHEMBL1541339 & 688417 & 5.35 & 5.7985 & TRN & \\
\hline CHEMBL1575588 & 688417 & 5.25 & 5.4323 & TRN & \\
\hline CHEMBL111750 & 688417 & 5.85 & 5.591 & TRN & \\
\hline CHEMBL1965415 & 688417 & 5.15 & 5.0191 & TRN & \\
\hline CHEMBL1433980 & 688417 & 4.6122 & 4.1076 & TRN & \\
\hline
\end{tabular}


Supplemental Table S2.txt

\begin{tabular}{|c|c|c|c|c|}
\hline CHEMBL1358834 & 688417 & 4.7122 & 4.4139 & TRN \\
\hline CHEMBL1433279 & 688417 & 4.8122 & 4.878 & TRN \\
\hline CHEMBL1514777 & 688417 & 4.6018 & 4.7329 & TRN \\
\hline CHEMBL1510118 & 688417 & 5.3 & 5.2576 & TRN \\
\hline CHEMBL1354113 & 688417 & 5.0122 & 4.7954 & TRN \\
\hline CHEMBL1474508 & 688417 & 4.1018 & 4.1951 & TRN \\
\hline CHEMBL1354083 & 688417 & 3.9122 & 4.5653 & TRN \\
\hline CHEMBL1403026 & 688417 & 4.95 & 4.8301 & TRN \\
\hline CHEMBL1533351 & 688417 & 5.0 & 5.7376 & TST \\
\hline CHEMBL1393978 & 688417 & 4.9122 & 4.829 & TRN \\
\hline CHEMBL1335099 & 688417 & 4.9 & 5.6549 & TST \\
\hline CHEMBL1589741 & 688417 & 4.5018 & 4.3947 & TRN \\
\hline CHEMBL1330510 & 688417 & 5.3 & 5.2163 & TRN \\
\hline CHEMBL1606167 & 688417 & 5.05 & 5.4387 & TRN \\
\hline CHEMBL1976308 & 688417 & 5.25 & 5.0875 & TRN \\
\hline CHEMBL1394107 & 688417 & 5.0122 & 4.762 & TRN \\
\hline CHEMBL1564250 & 688417 & 5.0 & 5.0875 & TRN \\
\hline CHEMBL1433350 & 688417 & 4.8122 & 4.6585 & TRN \\
\hline CHEMBL1456412 & 688417 & 5.25 & 5.6185 & TST \\
\hline CHEMBL1334291 & 688417 & 4.95 & 5.2536 & TRN \\
\hline CHEMBL1433364 & 688417 & 4.8122 & 4.8378 & TRN \\
\hline CHEMBL1395910 & 688417 & 4.3122 & 4.2434 & TRN \\
\hline CHEMBL1334062 & 688417 & 5.05 & 5.3162 & TRN \\
\hline CHEMBL428064 & 688417 & 5.35 & 4.9382 & TST \\
\hline CHEMBL1362856 & 688417 & 5.4 & 4.9724 & TRN \\
\hline CHEMBL1555096 & 688417 & 3.9122 & 4.7568 & TRN \\
\hline CHEMBL1354215 & 688417 & 4.5018 & 4.3861 & TST \\
\hline CHEMBL1436802 & 688417 & 4.0018 & 4.3043 & TST \\
\hline CHEMBL528694 & 688417 & 5.0 & 5.9409 & TST \\
\hline CHEMBL1354194 & 688417 & 4.6122 & 4.2303 & TST \\
\hline CHEMBL1314086 & 688417 & 5.2122 & 5.1835 & TST \\
\hline CHEMBL1522836 & 688417 & 7.6003 & 5.7748 & TST \\
\hline CHEMBL1435225 & 688417 & 4.7122 & 4.6773 & TST \\
\hline CHEMBL1316198 & 688417 & 4.9122 & 4.7666 & TST \\
\hline CHEMBL1448627 & 688417 & 5.3 & 6.0983 & TST \\
\hline CHEMBL1316872 & 688417 & 4.4018 & 4.3766 & TST \\
\hline CHEMBL1511805 & 688417 & 3.7122 & 4.7856 & TST \\
\hline CHEMBL1589783 & 688417 & 4.5018 & 4.2578 & TST \\
\hline CHEMBL1435265 & 688417 & 4.8122 & 4.999 & TST \\
\hline CHEMBL1938540 & 797766 & 6.2218 & 6.2254 & TRN \\
\hline CHEMBL1938670 & 797766 & 6.8239 & 6.8133 & TRN \\
\hline CHEMBL1938553 & 797766 & 5.6383 & 5.63899 & 9999999999 \\
\hline CHEMBL1941131 & 797766 & 6.9586 & 6.9629 & TRN \\
\hline CHEMBL1938665 & 797766 & 6.3979 & 6.3985 & TRN \\
\hline CHEMBL1938528 & 797766 & 6.699 & 6.7543 & TRN \\
\hline CHEMBL1938543 & 797766 & 5.4815 & 5.4913 & TRN \\
\hline CHEMBL1938557 & 797766 & 6.4685 & 6.4085 & TRN \\
\hline CHEMBL1938561 & 797766 & 6.5229 & 6.5224 & TRN \\
\hline
\end{tabular}




\begin{tabular}{|c|c|c|c|c|c|}
\hline \multicolumn{6}{|c|}{ Supplemental Table S2.txt } \\
\hline CHEMBL1938675 & 797766 & 7.5229 & 7.5159 & TRN & \\
\hline CHEMBL1938535 & 797766 & 7.2218 & 7.2005 & TRN & \\
\hline CHEMBL1938536 & 797766 & 7.699 & 7.1413 & TST & \\
\hline CHEMBL1938566 & 797766 & 6.6021 & 6.3439 & TST & \\
\hline CHEMBL1938531 & 797766 & 5.9208 & 6.5291 & TST & \\
\hline CHEMBL1941132 & 797766 & 6.5229 & 6.8662 & TST & \\
\hline CHEMBL1938545 & 797766 & 6.699 & 6.6997 & TRN & \\
\hline CHEMBL1938539 & 797766 & 5.7212 & 5.6949 & TRN & \\
\hline CHEMBL1938530 & 797766 & 7.0 & 6.731 & TST & \\
\hline CHEMBL1938533 & 797766 & 5.4202 & 6.9682 & TST & \\
\hline CHEMBL1938668 & 797766 & 7.699 & 7.7371 & TRN & \\
\hline CHEMBL1938547 & 797766 & 5.3768 & 5.3757 & TRN & \\
\hline CHEMBL1938664 & 797766 & 6.0969 & 6.1 & TRN & \\
\hline CHEMBL1938560 & 797766 & 7.0 & 6.9994 & TRN & \\
\hline CHEMBL1938563 & 797766 & 5.301 & 5.3115 & TRN & \\
\hline CHEMBL1941130 & 797766 & 6.4949 & 7.3918 & TST & \\
\hline CHEMBL1938666 & 797766 & 6.0458 & 6.0648 & TRN & \\
\hline CHEMBL1938558 & 797766 & 6.6383 & 6.6299 & TRN & \\
\hline CHEMBL1938541 & 797766 & 5.6021 & 5.5884 & TRN & \\
\hline CHEMBL1938549 & 797766 & 6.2218 & 6.2136 & TRN & \\
\hline CHEMBL1938537 & 797766 & 6.0458 & 6.0519 & TRN & \\
\hline CHEMBL1938562 & 797766 & 6.699 & 6.6874 & TRN & \\
\hline CHEMBL1938674 & 797766 & 8.0 & 7.981 & TRN & \\
\hline CHEMBL1938673 & 797766 & 7.699 & 7.6889 & TRN & \\
\hline CHEMBL1938554 & 797766 & 6.699 & 6.6913 & TRN & \\
\hline CHEMBL1938538 & 797766 & 5.7212 & 5.7597 & TRN & \\
\hline CHEMBL1938399 & 797766 & 6.301 & 6.7549 & TST & \\
\hline CHEMBL1938565 & 797766 & 5.7212 & 5.73600 & 0000000001 & TRN \\
\hline CHEMBL1938548 & 797766 & 5.2596 & 5.2586 & TRN & \\
\hline CHEMBL1938669 & 797766 & 7.1549 & 7.1351 & TRN & \\
\hline CHEMBL1938542 & 797766 & 6.9208 & 6.9104 & TRN & \\
\hline CHEMBL1938550 & 797766 & 5.4685 & 5.4499 & TRN & \\
\hline CHEMBL1938532 & 797766 & 6.2218 & 6.8403 & TST & \\
\hline CHEMBL1938544 & 797766 & 6.5229 & 6.5243 & TRN & \\
\hline CHEMBL1938663 & 797766 & 7.0 & 7.0036 & TRN & \\
\hline CHEMBL1938662 & 797766 & 6.8239 & 6.7259 & TST & \\
\hline CHEMBL1941133 & 797766 & 7.0 & 7.0675 & TST & \\
\hline CHEMBL1938671 & 797766 & 7.301 & 7.3122 & TRN & \\
\hline CHEMBL1938564 & 797766 & 6.699 & 6.7012 & TRN & \\
\hline CHEMBL1938661 & 797766 & 6.699 & 7.2616 & TST & \\
\hline CHEMBL1938672 & 797766 & 7.5229 & 7.5578 & TRN & \\
\hline CHEMBL1938555 & 797766 & 6.8539 & 6.8207 & TRN & \\
\hline CHEMBL1938534 & 797766 & 6.0458 & 7.2454 & TST & \\
\hline CHEMBL1938556 & 797766 & 6.7447 & 6.7785 & TRN & \\
\hline CHEMBL1938529 & 797766 & 7.1549 & 7.2676 & TST & \\
\hline CHEMBL1938559 & 797766 & 6.8861 & 6.8864 & TRN & \\
\hline CHEMBL1938398 & 797766 & 7.0 & 5.9292 & TST & \\
\hline CHEMBL1938667 & 797766 & 7.3979 & 7.3875 & TRN & \\
\hline
\end{tabular}




\begin{tabular}{|c|c|c|c|c|c|}
\hline \multicolumn{6}{|c|}{ Supplemental Table S2.txt } \\
\hline CHEMBL1938546 & 797766 & 6.301 & 6.3082 & TRN & \\
\hline CHEMBL1542804 & 688730 & 5.0945 & 5.1372 & TRN & \\
\hline CHEMBL3198933 & 688730 & 4.9528 & 4.9629 & TRN & \\
\hline CHEMBL3193133 & 688730 & 5.0172 & 5.0039 & TRN & \\
\hline CHEMBL3193986 & 688730 & 4.8482 & 4.8807 & TRN & \\
\hline CHEMBL1308255 & 688730 & 4.851 & 4.9351 & TRN & \\
\hline CHEMBL1545024 & 688730 & 4.7927 & 4.7402 & TST & \\
\hline CHEMBL1990214 & 688730 & 5.6544 & 5.466 & TRN & \\
\hline CHEMBL1303068 & 688730 & 5.2551 & 5.2684 & TRN & \\
\hline CHEMBL1437633 & 688730 & 3.9506 & 4.1305 & TRN & \\
\hline CHEMBL388978 & 688730 & 8.2291 & 7.2416 & TST & \\
\hline CHEMBL1367691 & 688730 & 4.631 & 4.6521 & TRN & \\
\hline CHEMBL1499027 & 688730 & 4.6898 & 4.7446 & TST & \\
\hline CHEMBL1506512 & 688730 & 5.0014 & 5.0162 & TRN & \\
\hline CHEMBL1444896 & 688730 & 4.1477 & 4.1771 & TRN & \\
\hline CHEMBL1602763 & 688730 & 3.8647 & 4.8989 & TRN & \\
\hline CHEMBL1441619 & 688730 & 5.1017 & 5.2394 & TRN & \\
\hline CHEMBL1507337 & 688730 & 4.9299 & 4.8477 & TRN & \\
\hline CHEMBL1433138 & 688730 & 4.2323 & 4.3754 & TRN & \\
\hline CHEMBL1501645 & 688730 & 5.0414 & 4.9349 & TRN & \\
\hline CHEMBL1467655 & 688730 & 6.2557 & 6.284 & TRN & \\
\hline CHEMBL1299464 & 688730 & 4.7789 & 4.8929 & TRN & \\
\hline CHEMBL3211998 & 688730 & 5.5281 & 5.4415 & TRN & \\
\hline CHEMBL1460871 & 688730 & 4.5548 & 5.2002 & TRN & \\
\hline CHEMBL1456753 & 688730 & 5.3909 & 5.3001 & TRN & \\
\hline CHEMBL 29711 & 688730 & 6.0762 & 5.6347 & TST & \\
\hline CHEMBL1336630 & 688730 & 4.9195 & 5.0767 & TRN & \\
\hline CHEMBL1483028 & 688730 & 4.8541 & 4.7985 & TRN & \\
\hline CHEMBL1497617 & 688730 & 4.6441 & 4.5795 & TRN & \\
\hline CHEMBL151946 & 688730 & 5.0071 & 4.5712 & TST & \\
\hline CHEMBL1446863 & 688730 & 4.5286 & 4.6981 & TST & \\
\hline CHEMBL1511371 & 688730 & 5.7261 & 5.71899 & 9999999999 & TRN \\
\hline CHEMBL3198581 & 688730 & 5.9634 & 6.0505 & TRN & \\
\hline CHEMBL1974389 & 688730 & 4.4539 & 4.59399 & 9999999999 & TRN \\
\hline CHEMBL1379143 & 688730 & 4.4735 & 4.7696 & TRN & \\
\hline CHEMBL1558920 & 688730 & 5.9393 & 6.0063 & TRN & \\
\hline CHEMBL 1313522 & 688730 & 5.7049 & 5.5826 & TRN & \\
\hline CHEMBL 2003873 & 688730 & 5.0238 & 4.879 & TRN & \\
\hline CHEMBL1518926 & 688730 & 5.0603 & 5.0175 & TRN & \\
\hline CHEMBL1327201 & 688730 & 4.6598 & 4.6008 & TST & \\
\hline CHEMBL1466897 & 688730 & 4.3655 & 4.1414 & TRN & \\
\hline CHEMBL3198004 & 688730 & 4.4447 & 4.3838 & TRN & \\
\hline CHEMBL1510981 & 688730 & 4.7212 & 4.7112 & TST & \\
\hline CHEMBL1578113 & 688730 & 4.4685 & 4.5951 & TRN & \\
\hline CHEMBL1462585 & 688730 & 5.2869 & 5.3389 & TRN & \\
\hline CHEMBL601757 & 688730 & 6.0857 & 5.8734 & TST & \\
\hline CHEMBL597251 & 688730 & 5.3559 & 5.2711 & TRN & \\
\hline CHEMBL1333511 & 688730 & 4.7447 & 4.7587 & TRN & \\
\hline
\end{tabular}




\begin{tabular}{|c|c|c|c|c|}
\hline & & & pplement & al $\mathrm{T}$ \\
\hline CHEMBL1559434 & 688730 & 4.8031 & 4.5922 & TRN \\
\hline CHEMBL1570958 & 688730 & 5.3161 & 5.322 & TRN \\
\hline CHEMBL1546678 & 688730 & 5.033 & 4.8752 & TRN \\
\hline CHEMBL1499017 & 688730 & 5.2409 & 5.2223 & TRN \\
\hline CHEMBL3193284 & 688730 & 4.323 & 4.4216 & TRN \\
\hline CHEMBL1988579 & 688730 & 5.0052 & 4.9922 & TRN \\
\hline CHEMBL1340787 & 688730 & 5.2788 & 5.0563 & TRN \\
\hline CHEMBL1345006 & 688730 & 4.6712 & 4.7187 & TRN \\
\hline CHEMBL3207697 & 688730 & 4.8931 & 4.803 & TRN \\
\hline CHEMBL530361 & 688730 & 5.3937 & 5.3246 & TRN \\
\hline CHEMBL1510261 & 688730 & 2.1484 & 4.8695 & TRN \\
\hline CHEMBL 3212304 & 688730 & 4.54 & 4.7157 & TST \\
\hline CHEMBL1362660 & 688730 & 8.2291 & 7.4242 & TRN \\
\hline CHEMBL1538035 & 688730 & 5.3436 & 5.3299 & TRN \\
\hline CHEMBL1993788 & 688730 & 5.5148 & 5.5251 & TRN \\
\hline CHEMBL1367899 & 688730 & 4.7513 & 4.681 & TRN \\
\hline CHEMBL1416769 & 688730 & 4.7048 & 4.6323 & TRN \\
\hline CHEMBL1581916 & 688730 & 4.3733 & 4.3859 & TST \\
\hline CHEMBL1337997 & 688730 & 4.5799 & 4.6847 & TRN \\
\hline CHEMBL1542833 & 688730 & 6.5952 & 6.0878 & TRN \\
\hline CHEMBL1432507 & 688730 & 8.2291 & 7.4018 & TRN \\
\hline CHEMBL1526325 & 688730 & 5.2201 & 5.1856 & TRN \\
\hline CHEMBL1543752 & 688730 & 4.7933 & 4.7575 & TST \\
\hline CHEMBL1573242 & 688730 & 4.7449 & 4.8112 & TRN \\
\hline CHEMBL1519014 & 688730 & 5.0033 & 5.1488 & TRN \\
\hline CHEMBL1310008 & 688730 & 5.8256 & 5.7464 & TRN \\
\hline CHEMBL1400909 & 688730 & 5.1438 & 5.1267 & TRN \\
\hline CHEMBL1533494 & 688730 & 4.2934 & 4.1826 & TRN \\
\hline CHEMBL1307474 & 688730 & 4.9396 & 4.981 & TRN \\
\hline CHEMBL1480101 & 688730 & 4.5844 & 4.515 & TRN \\
\hline CHEMBL1335358 & 688730 & 4.2117 & 4.0892 & TRN \\
\hline CHEMBL1324897 & 688730 & 4.9165 & 4.8235 & TRN \\
\hline CHEMBL1410029 & 688730 & 4.4265 & 4.4627 & TRN \\
\hline CHEMBL1325724 & 688730 & 4.1359 & 4.1165 & TRN \\
\hline CHEMBL1546832 & 688730 & 4.8324 & 5.0094 & TRN \\
\hline CHEMBL1536563 & 688730 & 4.7637 & 4.7683 & TRN \\
\hline CHEMBL1521425 & 688730 & 4.7503 & 4.7958 & TRN \\
\hline CHEMBL1541441 & 688730 & 5.1094 & 4.9571 & TST \\
\hline CHEMBL1323000 & 688730 & 5.5107 & 5.6008 & TRN \\
\hline CHEMBL1367572 & 688730 & 4.8988 & 4.9461 & TRN \\
\hline CHEMBL1978564 & 688730 & 4.3733 & 4.1663 & TRN \\
\hline CHEMBL3196691 & 688730 & 4.7459 & 4.7842 & TRN \\
\hline CHEMBL1525386 & 688730 & 4.8406 & 4.6491 & TRN \\
\hline CHEMBL1504634 & 688730 & 4.5865 & 4.6116 & TRN \\
\hline CHEMBL3192475 & 688730 & 5.2264 & 5.2641 & TRN \\
\hline CHEMBL1611684 & 688730 & 5.2314 & 5.105 & TRN \\
\hline CHEMBL1441024 & 688730 & 4.7665 & 4.7409 & TRN \\
\hline CHEMBL1534509 & 688730 & 4.649 & 4.755 & TRN \\
\hline
\end{tabular}


Supplemental Table S2.txt

\begin{tabular}{|c|c|c|c|c|c|c|}
\hline CHEMBL1986259 & 688730 & 4.8376 & 4.822 & TRN & & \\
\hline CHEMBL1485168 & 688730 & 5.7627 & 5.7291 & TRN & & \\
\hline CHEMBL1734063 & 688730 & 5.1312 & 5.1262 & TRN & & \\
\hline CHEMBL1432243 & 688730 & 4.9254 & 4.712 & TRN & & \\
\hline CHEMBL1388353 & 688730 & 4.6568 & 4.8908 & TRN & & \\
\hline CHEMBL1407174 & 688730 & 4.6054 & 4.63 & TST & & \\
\hline CHEMBL1503034 & 688730 & 5.8897 & 5.7322 & TRN & & \\
\hline CHEMBL1504303 & 688730 & 4.4475 & 4.6607 & TRN & & \\
\hline CHEMBL1984130 & 688730 & 5.2796 & 5.0672 & TRN & & \\
\hline CHEMBL494668 & 688730 & 5.1486 & 5.2962 & TRN & & \\
\hline CHEMBL1372952 & 688730 & 5.0254 & 5.1088 & TRN & & \\
\hline CHEMBL1459696 & 688730 & 4.8966 & 4.8283 & TRN & & \\
\hline CHEMBL1505788 & 688730 & 4.6652 & 4.7433 & TRN & & \\
\hline CHEMBL1438761 & 688730 & 4.8728 & 4.7008 & TRN & & \\
\hline CHEMBL1390516 & 688730 & 5.7572 & 5.9806 & TRN & & \\
\hline CHEMBL1360014 & 688730 & 4.6323 & 4.6518 & TRN & & \\
\hline CHEMBL1559825 & 688730 & 4.5276 & 4.5944 & TST & & \\
\hline CHEMBL1392894 & 688730 & 4.598 & 4.7922 & TST & & \\
\hline CHEMBL1344602 & 688730 & 4.5347 & 4.6018 & TRN & & \\
\hline CHEMBL1505158 & 688730 & 4.8932 & 5.0187 & TRN & & \\
\hline CHEMBL1568007 & 688730 & 4.9648 & 5.1587 & TST & & \\
\hline CHEMBL1502712 & 688730 & 4.7527 & 4.8724 & TRN & & \\
\hline CHEMBL1482389 & 688730 & 5.1199 & 5.1409 & TRN & & \\
\hline CHEMBL1991885 & 688730 & 4.4947 & 4.7547 & TRN & & \\
\hline CHEMBL1421466 & 688730 & 5.6461 & 5.5308 & TRN & & \\
\hline CHEMBL1540446 & 688730 & 4.9641 & 5.0202 & TRN & & \\
\hline CHEMBL1538775 & 688730 & 4.8103 & 4.6994 & TRN & & \\
\hline CHEMBL1604007 & 688730 & 5.8011 & 5.8151 & TRN & & \\
\hline CHEMBL1430931 & 688730 & 5.2343 & 5.0667 & TRN & & \\
\hline CHEMBL1494870 & 688730 & 4.7131 & 4.551 & TRN & & \\
\hline CHEMBL1570871 & 688730 & 4.8375 & 4.8896 & TRN & & \\
\hline CHEMBL1445171 & 688730 & 5.193 & 5.2149 & TRN & & \\
\hline CHEMBL1347975 & 688730 & 4.4098 & 4.5914 & TST & & \\
\hline CHEMBL1968355 & 688730 & 4.2812 & 4.6197 & TST & & \\
\hline CHEMBL1570025 & 688730 & 4.4549 & 4.5412 & TRN & & \\
\hline CHEMBL1504854 & 688730 & 4.6882 & 4.6978 & TRN & & \\
\hline CHEMBL1364787 & 688730 & \multicolumn{3}{|c|}{5.337000000000001} & 5.1852 & TST \\
\hline CHEMBL1327091 & 688730 & 4.8412 & 4.8887 & TST & & \\
\hline CHEMBL1389728 & 688730 & 5.3323 & 5.3253 & TRN & & \\
\hline CHEMBL 3192555 & 688730 & 5.9602 & 5.7207 & TRN & & \\
\hline CHEMBL1312486 & 688730 & 5.1611 & 5.3421 & TRN & & \\
\hline CHEMBL 3191590 & 688730 & 4.5201 & 4.5911 & TRN & & \\
\hline CHEMBL1439181 & 688730 & 4.7276 & 4.5913 & TRN & & \\
\hline CHEMBL1518508 & 688730 & 5.1488 & 5.2957 & TRN & & \\
\hline CHEMBL1340713 & 688730 & 5.6851 & 5.5601 & TRN & & \\
\hline CHEMBL1508896 & 688730 & 5.16799 & 999999999 & 99 & 5.2335 & TRN \\
\hline CHEMBL1565721 & 688730 & 4.743 & 4.7823 & TRN & & \\
\hline CHEMBL1416329 & 688730 & 5.0922 & 4.978 & TRN & & \\
\hline
\end{tabular}




\begin{tabular}{|c|c|c|c|c|}
\hline \multicolumn{5}{|c|}{ Supplemental Table s2.txt } \\
\hline CHEMBL1530525 & 688730 & 5.4624 & 5.3115 & TRN \\
\hline CHEMBL1576941 & 688730 & 4.7013 & 4.7519 & TRN \\
\hline CHEMBL1410536 & 688730 & 4.0068 & 4.4552 & TRN \\
\hline CHEMBL 3190262 & 688730 & 4.6019 & 4.5987 & TRN \\
\hline CHEMBL 3145322 & 688730 & 4.9511 & 4.8614 & TST \\
\hline CHEMBL577419 & 688730 & 4.6493 & 4.6151 & TRN \\
\hline CHEMBL1498603 & 688730 & 4.7179 & 4.7304 & TRN \\
\hline CHEMBL1406045 & 688730 & 4.5646 & 4.5596 & TRN \\
\hline CHEMBL 3190645 & 688730 & 4.8014 & 4.7692 & TRN \\
\hline CHEMBL1304902 & 688730 & 5.7975 & 5.9406 & TRN \\
\hline CHEMBL1976567 & 688730 & 5.3095 & 5.316 & TRN \\
\hline CHEMBL1365977 & 688730 & 4.547 & 4.5553 & TRN \\
\hline CHEMBL1312546 & 688730 & 4.7584 & 4.6577 & TRN \\
\hline CHEMBL1464031 & 688730 & 4.6535 & 4.6902 & TRN \\
\hline CHEMBL1463649 & 688730 & 5.1431 & 5.0798 & TRN \\
\hline CHEMBL1469035 & 688730 & 5.7956 & 5.9103 & TRN \\
\hline CHEMBL1310861 & 688730 & 5.7552 & 5.5934 & TRN \\
\hline CHEMBL1602290 & 688730 & 5.0995 & 5.1392 & TRN \\
\hline CHEMBL1556705 & 688730 & 4.8915 & 4.8479 & TRN \\
\hline CHEMBL1484063 & 688730 & 4.8659 & 4.8457 & TRN \\
\hline CHEMBL1506827 & 688730 & 5.0728 & 4.8696 & TRN \\
\hline CHEMBL1418676 & 688730 & 4.8506 & 4.8593 & TST \\
\hline CHEMBL3210099 & 688730 & 4.3862 & 4.3499 & TST \\
\hline CHEMBL1419587 & 688730 & 4.79 & 4.9143 & TST \\
\hline CHEMBL1420524 & 688730 & 4.7097 & 4.7389 & TRN \\
\hline CHEMBL1484332 & 688730 & 8.2291 & 8.0004 & TRN \\
\hline CHEMBL1306011 & 688730 & 5.0853 & 5.0351 & TRN \\
\hline CHEMBL1546134 & 688730 & 5.1316 & 5.0996 & TRN \\
\hline CHEMBL1504385 & 688730 & 4.2455 & 4.1884 & TST \\
\hline CHEMBL1392378 & 688730 & 4.0522 & 3.6249 & TRN \\
\hline CHEMBL1390575 & 688730 & 4.65 & 4.7554 & TRN \\
\hline CHEMBL1577745 & 688730 & 5.0786 & 4.8863 & TRN \\
\hline CHEMBL1595499 & 688730 & 4.8106 & 4.7421 & TST \\
\hline CHEMBL1324917 & 688730 & 5.1818 & 5.1105 & TST \\
\hline CHEMBL1405004 & 688730 & 4.7833 & 4.8472 & TRN \\
\hline CHEMBL1485515 & 688730 & 5.3567 & 5.4652 & TRN \\
\hline CHEMBL1544097 & 688730 & 4.7617 & 4.9118 & TRN \\
\hline CHEMBL1507490 & 688730 & 4.4102 & 4.6251 & TRN \\
\hline CHEMBL1442136 & 688730 & 5.4323 & 5.7373 & TRN \\
\hline CHEMBL1511409 & 688730 & 4.6612 & 4.6069 & TST \\
\hline CHEMBL1415310 & 688730 & 4.0273 & 4.386 & TRN \\
\hline CHEMBL1606504 & 688730 & 4.6366 & 4.7804 & TRN \\
\hline CHEMBL1511882 & 688730 & 4.6467 & 4.7868 & TRN \\
\hline CHEMBL1344292 & 688730 & 5.1244 & 5.0988 & TRN \\
\hline CHEMBL3191649 & 688730 & 4.8359 & 4.8008 & TST \\
\hline CHEMBL1563367 & 688730 & 4.6815 & 4.7445 & TRN \\
\hline CHEMBL1360308 & 688730 & 4.6725 & 4.6031 & TRN \\
\hline CHEMBL1421316 & 688730 & 4.8396 & 4.7199 & TRN \\
\hline
\end{tabular}


Supplemental Table S2.txt

\begin{tabular}{|c|c|c|c|c|}
\hline CHEMBL1450537 & 688730 & 4.6969 & 4.6561 & TRN \\
\hline CHEMBL1420268 & 688730 & 3.5587 & 2.4817 & TRN \\
\hline CHEMBL1456738 & 688730 & 5.1702 & 5.0403 & TRN \\
\hline CHEMBL1372491 & 688730 & 3.6786 & 4.6793 & TST \\
\hline CHEMBL1313121 & 688730 & 5.0086 & 5.0978 & TRN \\
\hline CHEMBL1538876 & 688730 & 3.3436 & 3.3932 & TRN \\
\hline CHEMBL1365340 & 688730 & 4.624 & 4.8499 & TRN \\
\hline CHEMBL1461188 & 688730 & 4.6105 & 4.5026 & TST \\
\hline CHEMBL3211667 & 688730 & 4.6497 & 4.65 & TRN \\
\hline CHEMBL1305537 & 688730 & 4.8164 & 4.7537 & TRN \\
\hline CHEMBL1508674 & 688730 & 4.6851 & 4.6757 & TRN \\
\hline CHEMBL1492232 & 688730 & 4.171 & 4.0687 & TRN \\
\hline CHEMBL1327351 & 688730 & 4.7069 & 4.618 & TRN \\
\hline CHEMBL1969164 & 688730 & 3.4603 & 3.8109 & TRN \\
\hline CHEMBL1399833 & 688730 & 2.5566 & 3.5959 & TRN \\
\hline CHEMBL1408774 & 688730 & 4.9781 & 4.8697 & TRN \\
\hline CHEMBL1383034 & 688730 & 4.4482 & 4.2402 & TRN \\
\hline CHEMBL1541335 & 688730 & 5.1087 & 4.9827 & TRN \\
\hline CHEMBL1549860 & 688730 & 5.2905 & 5.3513 & TRN \\
\hline CHEMBL1353518 & 688730 & 4.4047 & 4.5785 & TRN \\
\hline CHEMBL1540956 & 688730 & 5.4278 & 5.2747 & TRN \\
\hline CHEMBL1384265 & 688730 & 4.2678 & 4.3279 & TRN \\
\hline CHEMBL1370387 & 688730 & 4.5955 & 4.8362 & TRN \\
\hline CHEMBL1563861 & 688730 & 4.8769 & 4.9175 & TRN \\
\hline CHEMBL1455873 & 688730 & 5.3106 & 5.2643 & TRN \\
\hline CHEMBL1609419 & 688730 & 5.3086 & 5.23799 & 99999999995 \\
\hline CHEMBL1338041 & 688730 & 4.7635 & 4.9014 & TRN \\
\hline CHEMBL1543505 & 688730 & 4.7168 & 4.699 & TRN \\
\hline CHEMBL1320909 & 688730 & 4.9445 & 4.7818 & TRN \\
\hline CHEMBL1407885 & 688730 & 4.5995 & 4.7158 & TRN \\
\hline CHEMBL1363371 & 688730 & 4.5832 & 4.449 & TRN \\
\hline CHEMBL601547 & 688730 & 5.1212 & 5.0986 & TRN \\
\hline CHEMBL1461881 & 688730 & 5.0711 & 4.878 & TRN \\
\hline CHEMBL1362588 & 688730 & 5.0873 & 5.1255 & TST \\
\hline CHEMBL1585988 & 688730 & 4.7043 & 4.7002 & TST \\
\hline CHEMBL1493442 & 688730 & 6.6596 & 6.8276 & TRN \\
\hline CHEMBL1336887 & 688730 & 5.7897 & 5.3745 & TRN \\
\hline CHEMBL448741 & 688730 & 5.0622 & 5.0559 & TST \\
\hline CHEMBL1507036 & 688730 & 4.048 & 4.413 & TST \\
\hline CHEMBL1346421 & 688730 & 5.4624 & 5.2825 & TRN \\
\hline CHEMBL1324995 & 688730 & 5.2879 & 4.8222 & TRN \\
\hline CHEMBL 3183210 & 688730 & 5.4297 & 5.5558 & TRN \\
\hline CHEMBL3190733 & 688730 & 5.4742 & 5.4562 & TRN \\
\hline CHEMBL546597 & 688730 & 4.8625 & 4.8627 & TRN \\
\hline CHEMBL1523126 & 688730 & 4.7467 & 4.6476 & TRN \\
\hline CHEMBL1584754 & 688730 & 6.1871 & 5.9645 & TST \\
\hline CHEMBL1480847 & 688730 & 4.6239 & 4.6906 & TRN \\
\hline \multirow[t]{2}{*}{ CHEMBL1519658 } & 688730 & 4.0208 & 4.28600 & 20000000005 \\
\hline & & \multicolumn{3}{|c|}{ Page 18679} \\
\hline
\end{tabular}




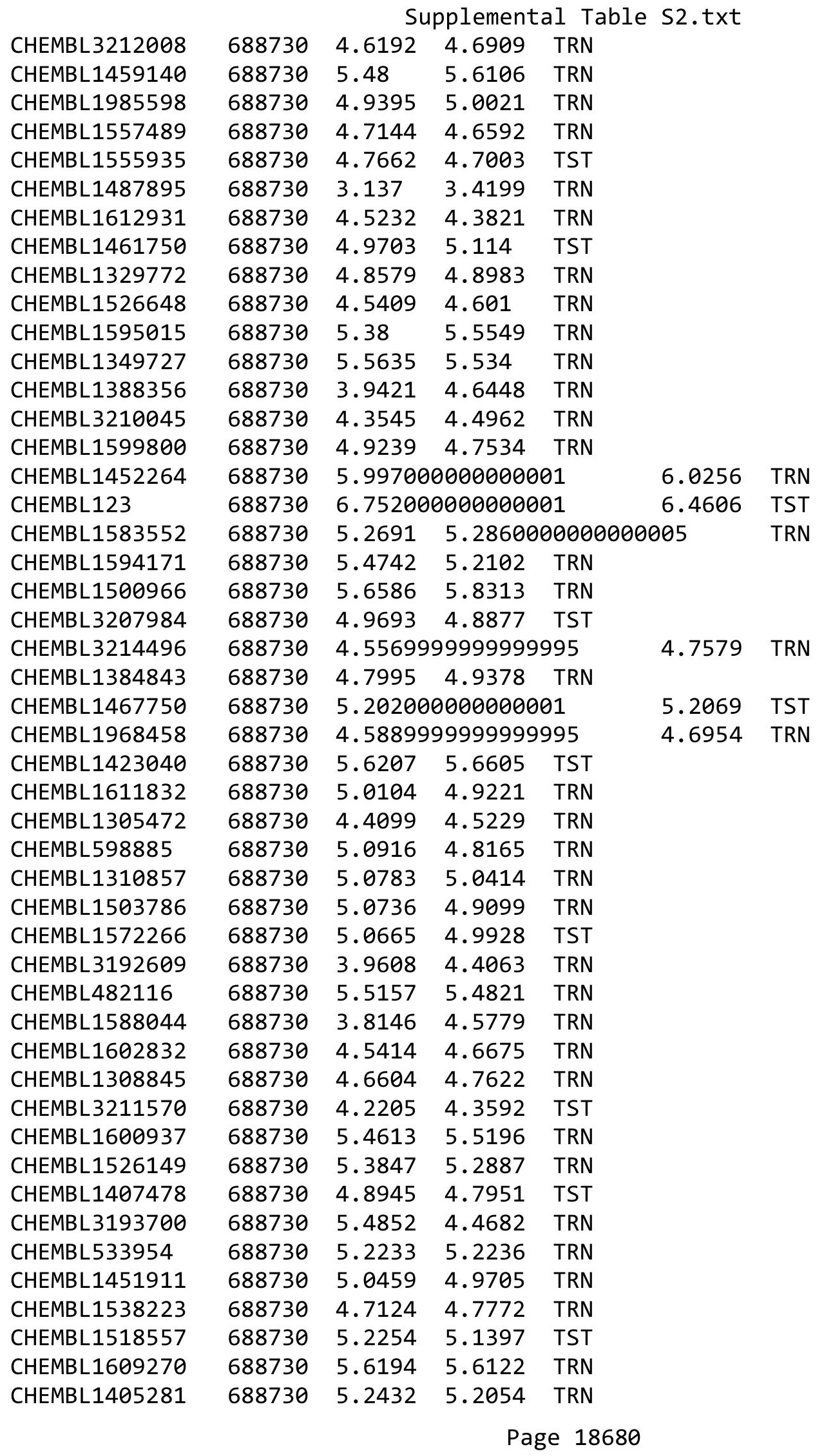




\begin{tabular}{|c|c|c|c|c|c|c|}
\hline & & \multicolumn{5}{|c|}{ Supplemental Table S2.txt } \\
\hline CHEMBL1502980 & 688730 & 4.9512 & 4.992 & TRN & & \\
\hline CHEMBL1481546 & 688730 & 4.7685 & 4.7363 & TRN & & \\
\hline CHEMBL1429418 & 688730 & 4.7692 & 4.851 & TRN & & \\
\hline CHEMBL1549594 & 688730 & 4.7919 & 4.6711 & TRN & & \\
\hline CHEMBL1518054 & 688730 & 5.8145 & 5.3884 & TRN & & \\
\hline CHEMBL1411379 & 688730 & 5.0672 & 5.0263 & TRN & & \\
\hline CHEMBL1305918 & 688730 & 4.5805 & 4.7143 & TRN & & \\
\hline CHEMBL1375001 & 688730 & 4.828 & 4.5422 & TRN & & \\
\hline CHEMBL1558822 & 688730 & 5.0284 & 4.9532 & TRN & & \\
\hline CHEMBL1368699 & 688730 & 4.7773 & 4.8207 & TRN & & \\
\hline CHEMBL1510394 & 688730 & 4.7382 & 4.7717 & TRN & & \\
\hline CHEMBL 3145030 & 688730 & 5.2658 & 5.2391 & TST & & \\
\hline CHEMBL1486335 & 688730 & 4.5671 & 4.768 & TRN & & \\
\hline CHEMBL1571208 & 688730 & 4.5153 & 4.6005 & TST & & \\
\hline CHEMBL1469733 & 688730 & 4.3007 & 4.1459 & TRN & & \\
\hline CHEMBL1531073 & 688730 & 5.3944 & 5.3878 & TRN & & \\
\hline CHEMBL1481903 & 688730 & 4.9324 & 4.8935 & TRN & & \\
\hline CHEMBL1326851 & 688730 & 5.0431 & 5.0018 & TRN & & \\
\hline CHEMBL1341762 & 688730 & 2.5914 & 4.919 & TRN & & \\
\hline CHEMBL1403351 & 688730 & 5.1015 & 5.3657 & TRN & & \\
\hline CHEMBL1453859 & 688730 & 5.2301 & 5.1906 & TRN & & \\
\hline CHEMBL1523242 & 688730 & 4.3104 & 4.6675 & TRN & & \\
\hline CHEMBL1423071 & 688730 & 4.5771 & 4.5388 & TRN & & \\
\hline CHEMBL1352313 & 688730 & 5.3798 & 5.3197 & TRN & & \\
\hline CHEMBL1486934 & 688730 & 5.1207 & 5.2152 & TRN & & \\
\hline CHEMBL3213876 & 688730 & 5.2289 & 5.3109 & TRN & & \\
\hline CHEMBL1404541 & 688730 & 4.8204 & 4.7416 & TRN & & \\
\hline CHEMBL1387593 & 688730 & 4.5519 & 4.1958 & TRN & & \\
\hline CHEMBL1493953 & 688730 & 4.9324 & 4.8593 & TRN & & \\
\hline CHEMBL1338466 & 688730 & 4.7549 & 4.8074 & TRN & & \\
\hline CHEMBL1544793 & 688730 & 5.4229 & 5.4135 & TST & & \\
\hline CHEMBL148072 & 688730 & 4.7865 & 4.9446 & TST & & \\
\hline CHEMBL1348067 & 688730 & 4.9985 & 4.8098 & TRN & & \\
\hline CHEMBL1462615 & 688730 & 4.6696 & 4.8153 & TRN & & \\
\hline CHEMBL1573851 & 688730 & 4.7962 & 4.7474 & TRN & & \\
\hline CHEMBL1419903 & 688730 & 4.6031 & 4.4108 & TST & & \\
\hline CHEMBL1418568 & 688730 & 4.9963 & 5.1746 & TST & & \\
\hline CHEMBL1604854 & 688730 & 4.5528 & 4.6352 & TRN & & \\
\hline CHEMBL1377813 & 688730 & 4.93199 & 99999999 & 995 & 5.0155 & TRN \\
\hline CHEMBL1578547 & 688730 & 4.6483 & 4.6608 & TRN & & \\
\hline CHEMBL3196039 & 688730 & 5.239 & 5.3324 & TRN & & \\
\hline CHEMBL1341030 & 688730 & 4.8007 & 4.7947 & TRN & & \\
\hline CHEMBL1375998 & 688730 & 5.4235 & 5.4771 & TRN & & \\
\hline CHEMBL1365226 & 688730 & 4.8813 & 4.8925 & TST & & \\
\hline CHEMBL1511795 & 688730 & 4.5113 & 4.5034 & TRN & & \\
\hline CHEMBL1303587 & 688730 & 4.812 & 5.1294 & TRN & & \\
\hline CHEMBL1532915 & 688730 & $4.4430 e$ & 30000000 & 205 & 4.6814 & TRN \\
\hline CHEMBL1596616 & 688730 & 5.1926 & 4.9197 & TRN & & \\
\hline
\end{tabular}




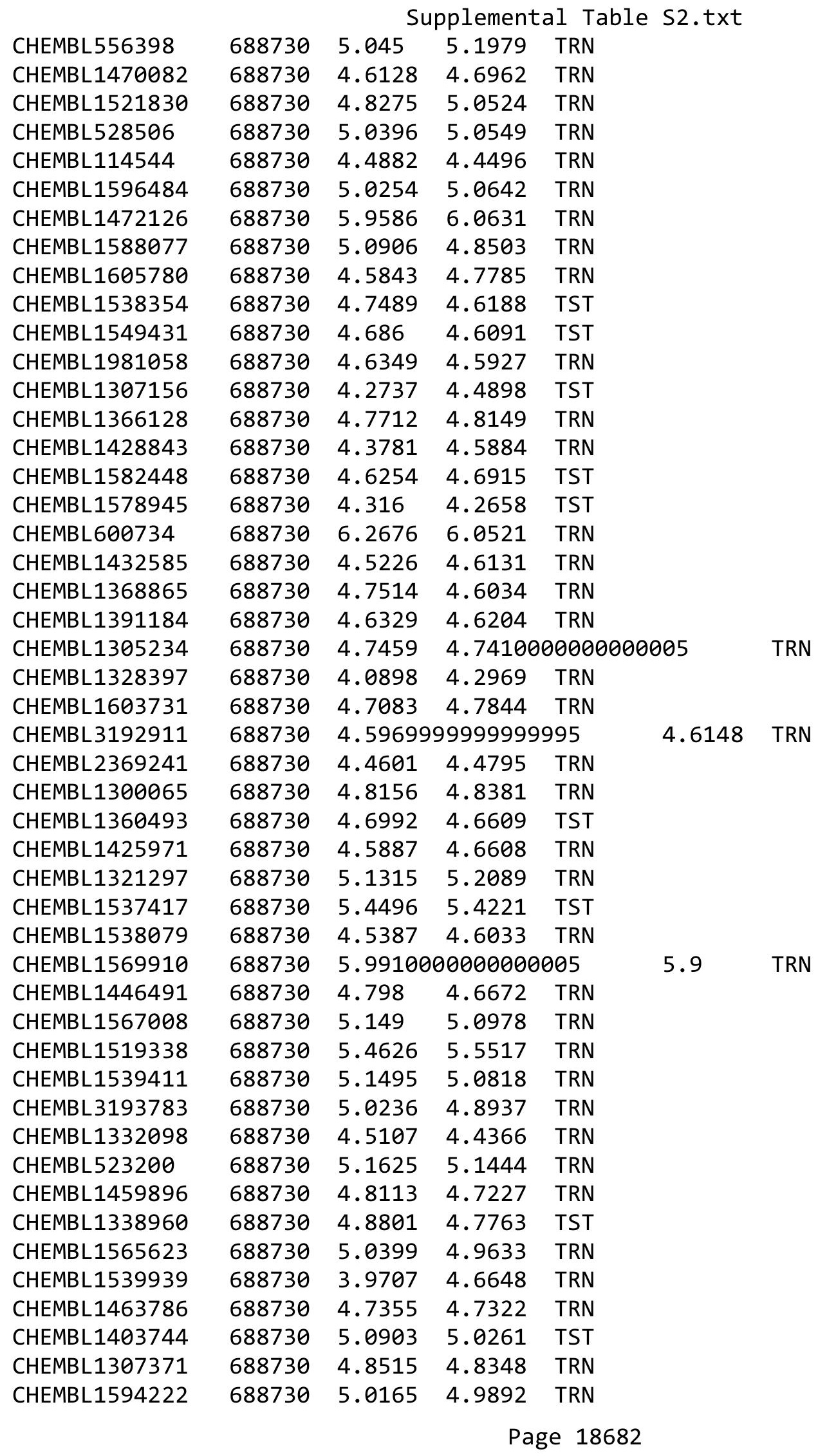




\begin{tabular}{|c|c|c|c|c|c|c|}
\hline & & \multicolumn{5}{|c|}{ Supplemental Table S2.txt } \\
\hline CHEMBL1454102 & 688730 & 4.8449 & 5.038 & TRN & & \\
\hline CHEMBL1382884 & 688730 & 5.19 & 5.3048 & TST & & \\
\hline CHEMBL1710 & 688730 & 4.9252 & 4.9432 & TST & & \\
\hline CHEMBL1411785 & 688730 & 4.467 & 4.5014 & TRN & & \\
\hline CHEMBL1432626 & 688730 & 5.2894 & 5.1951 & TRN & & \\
\hline CHEMBL45152 & 688730 & 4.3867 & 4.6233 & TRN & & \\
\hline CHEMBL1373255 & 688730 & 5.4779 & 5.5255 & TRN & & \\
\hline CHEMBL1331801 & 688730 & 4.7654 & 4.5545 & TRN & & \\
\hline CHEMBL1327880 & 688730 & 4.3273 & 3.7579 & TST & & \\
\hline CHEMBL1504020 & 688730 & 4.9275 & 4.8755 & TRN & & \\
\hline CHEMBL1351293 & 688730 & 4.8177 & 4.7169 & TRN & & \\
\hline CHEMBL1495592 & 688730 & 5.0364 & 4.9281 & TRN & & \\
\hline CHEMBL1999756 & 688730 & 5.205 & 5.316 & TRN & & \\
\hline CHEMBL1410009 & 688730 & 4.8373 & 4.8355 & TRN & & \\
\hline CHEMBL3190022 & 688730 & 4.9168 & 5.0955 & TRN & & \\
\hline CHEMBL1560561 & 688730 & 4.5903 & 4.6904 & TST & & \\
\hline CHEMBL3212953 & 688730 & 4.6123 & 4.6972 & TRN & & \\
\hline CHEMBL1598882 & 688730 & 4.812 & 4.8348 & TRN & & \\
\hline CHEMBL3190585 & 688730 & 4.8465 & 4.8984 & TRN & & \\
\hline CHEMBL1518562 & 688730 & 4.6101 & 4.599 & TRN & & \\
\hline CHEMBL1508591 & 688730 & 5.1245 & 5.0879 & TRN & & \\
\hline CHEMBL1571756 & 688730 & 5.6031 & 5.5841 & TRN & & \\
\hline CHEMBL3191503 & 688730 & 4.6151 & 4.6916 & TRN & & \\
\hline CHEMBL1483161 & 688730 & 5.228 & 5.3187 & TST & & \\
\hline CHEMBL1587286 & 688730 & 4.7339 & 4.7319 & TST & & \\
\hline CHEMBL1566424 & 688730 & 5.0479 & 5.1791 & TRN & & \\
\hline CHEMBL1346881 & 688730 & 5.0275 & 4.9494 & TST & & \\
\hline CHEMBL1541283 & 688730 & 5.3189 & 5.2465 & TRN & & \\
\hline CHEMBL1331050 & 688730 & 5.0215 & 4.94 & TRN & & \\
\hline CHEMBL1537481 & 688730 & 5.2847 & 5.1346 & TRN & & \\
\hline CHEMBL1414823 & 688730 & 4.2717 & 4.1829 & TRN & & \\
\hline CHEMBL1451772 & 688730 & 5.2013 & 5.2917 & TRN & & \\
\hline CHEMBL1327470 & 688730 & 4.8027 & 4.8216 & TST & & \\
\hline CHEMBL1379338 & 688730 & 4.9197 & 4.9632 & TRN & & \\
\hline CHEMBL1430757 & 688730 & 5.3028 & 5.3754 & TST & & \\
\hline CHEMBL1598694 & 688730 & 4.3981 & 4.4685 & TRN & & \\
\hline CHEMBL1346716 & 688730 & 4.5558 & 4.4255 & TRN & & \\
\hline CHEMBL1360203 & 688730 & 4.8598 & 4.8772 & TRN & & \\
\hline CHEMBL1323013 & 688730 & 4.8155 & 4.7081 & TRN & & \\
\hline CHEMBL1574219 & 688730 & 5.2328 & 5.2111 & TRN & & \\
\hline CHEMBL1482574 & 688730 & 4.6675 & 4.65 & TRN & & \\
\hline CHEMBL1500885 & 688730 & 4.3271 & 5.0073 & TRN & & \\
\hline CHEMBL1311572 & 688730 & 4.7929 & 4.8471 & TRN & & \\
\hline CHEMBL1345447 & 688730 & 4.9169 & 4.9768 & TRN & & \\
\hline CHEMBL1335607 & 688730 & 4.91100 & j000000e & 005 & 4.904 & TRI \\
\hline CHEMBL1468779 & 688730 & 5.8456 & 5.347 & TRN & & \\
\hline CHEMBL1529532 & 688730 & 4.8438 & 4.8372 & TRN & & \\
\hline CHEMBL1501412 & 688730 & 4.7985 & 4.8309 & TRN & & \\
\hline
\end{tabular}




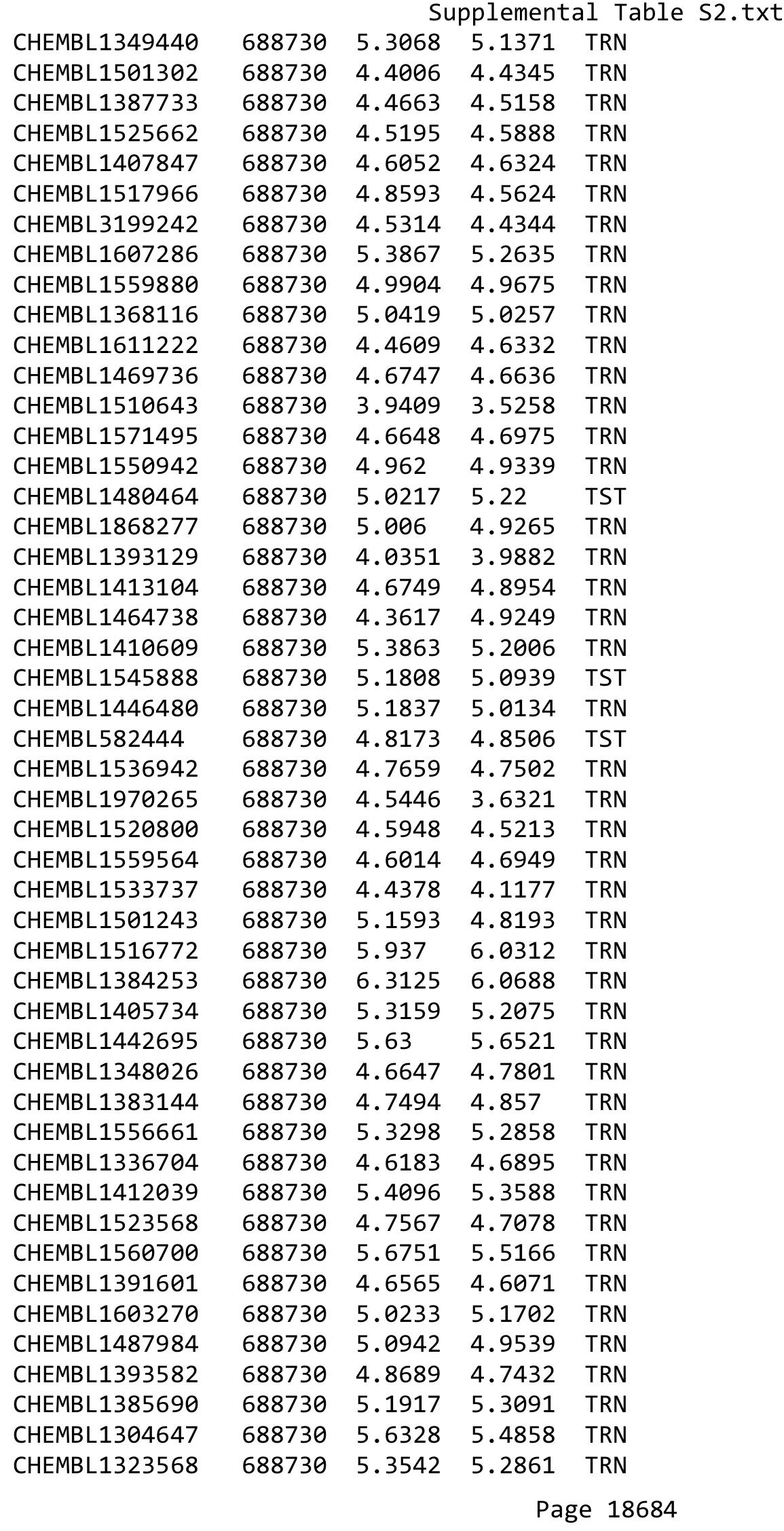




\begin{tabular}{|c|c|c|c|c|c|}
\hline & & \multicolumn{4}{|c|}{ Supplemental Table S2.txt } \\
\hline CHEMBL1976777 & 688730 & 4.7534 & 4.2316 & TST & \\
\hline CHEMBL1405668 & 688730 & 4.6595 & 4.666 & TST & \\
\hline CHEMBL1464853 & 688730 & 5.4626 & 5.4122 & TST & \\
\hline CHEMBL 3197899 & 688730 & 4.84 & 4.7543 & TRN & \\
\hline CHEMBL1400751 & 688730 & 4.7353 & 4.6531 & TRN & \\
\hline CHEMBL 3192837 & 688730 & 4.4521 & 4.5316 & TRN & \\
\hline CHEMBL 235891 & 688730 & 5.3388 & 5.2309 & TST & \\
\hline CHEMBL1380396 & 688730 & 4.209 & 4.9664 & TRN & \\
\hline CHEMBL1524365 & 688730 & 5.4215 & 5.1689 & TRN & \\
\hline CHEMBL1334984 & 688730 & 5.7503 & 5.6748 & TST & \\
\hline CHEMBL1336959 & 688730 & 4.5067 & 4.5767 & TRN & \\
\hline CHEMBL1350225 & 688730 & 4.8091 & 4.8918 & TRN & \\
\hline CHEMBL1382429 & 688730 & 4.9706 & 5.2965 & TRN & \\
\hline CHEMBL1371943 & 688730 & 4.6326 & 4.6689 & TRN & \\
\hline CHEMBL1461951 & 688730 & 4.9018 & 4.9051 & TST & \\
\hline CHEMBL1452379 & 688730 & 5.4401 & 5.3352 & TRN & \\
\hline CHEMBL3208118 & 688730 & 4.4913 & 4.5492 & TRN & \\
\hline CHEMBL1546223 & 688730 & 5.8567 & 5.6945 & TRN & \\
\hline CHEMBL1310703 & 688730 & 4.7344 & 4.7323 & TRN & \\
\hline CHEMBL1339245 & 688730 & 4.6963 & 5.0282 & TRN & \\
\hline CHEMBL1612627 & 688730 & 4.376 & 4.8191 & TRN & \\
\hline CHEMBL1573496 & 688730 & 4.8224 & 4.9733 & TRN & \\
\hline CHEMBL1378780 & 688730 & 4.6736 & 4.6639 & TRN & \\
\hline CHEMBL530049 & 688730 & 5.9087 & 5.7533 & TRN & \\
\hline CHEMBL3214332 & 688730 & 4.5375 & 4.5421 & TST & \\
\hline CHEMBL528181 & 688730 & 5.2422 & 5.1621 & TRN & \\
\hline CHEMBL1326180 & 688730 & 5.9027 & 5.6184 & TRN & \\
\hline CHEMBL1490404 & 688730 & 6.2248 & 6.2204 & TRN & \\
\hline CHEMBL1438881 & 688730 & 6.5302 & 6.49799 & 9999999999 & TST \\
\hline CHEMBL1532412 & 688730 & 4.9488 & 5.0189 & TRN & \\
\hline CHEMBL1417180 & 688730 & 5.0845 & 5.0431 & TRN & \\
\hline CHEMBL1972824 & 688730 & 4.6395 & 4.8451 & TRN & \\
\hline CHEMBL1453825 & 688730 & 4.5699 & 4.5587 & TRN & \\
\hline CHEMBL1351388 & 688730 & 4.7015 & 4.7625 & TRN & \\
\hline CHEMBL1421644 & 688730 & 4.89199 & 99999999 & 4.7323 & TRN \\
\hline CHEMBL1544947 & 688730 & 4.8852 & 4.933 & TST & \\
\hline CHEMBL1300414 & 688730 & 5.1746 & 5.2218 & TRN & \\
\hline CHEMBL1559813 & 688730 & 4.7716 & 4.6976 & TRN & \\
\hline CHEMBL1470135 & 688730 & 5.5779 & 5.7247 & TRN & \\
\hline CHEMBL1432593 & 688730 & 5.0114 & 4.8379 & TRN & \\
\hline CHEMBL1390145 & 688730 & 4.7441 & 4.6409 & TRN & \\
\hline CHEMBL1515852 & 688730 & 5.5717 & 5.49200 & $\partial 000000001$ & TRN \\
\hline CHEMBL1441938 & 688730 & 4.5629 & 4.5989 & TRN & \\
\hline CHEMBL1500910 & 688730 & 5.2861 & 5.3754 & TRN & \\
\hline CHEMBL1412429 & 688730 & 5.2343 & 5.0656 & TRN & \\
\hline CHEMBL1369125 & 688730 & 4.8142 & 4.7368 & TST & \\
\hline CHEMBL1545832 & 688730 & 4.9232 & 4.9359 & TST & \\
\hline CHEMBL1301709 & 688730 & 4.9992 & 5.002 & TRN & \\
\hline
\end{tabular}


Supplemental Table S2.txt

\begin{tabular}{|c|c|c|c|c|c|}
\hline CHEMBL1335633 & 688730 & 4.2877 & 4.3469 & TRN & \\
\hline CHEMBL1439210 & 688730 & 8.2291 & 8.2302 & TRN & \\
\hline CHEMBL1303908 & 688730 & 4.5236 & 4.6066 & TST & \\
\hline CHEMBL1570920 & 688730 & 5.3942 & 5.4554 & TRN & \\
\hline CHEMBL3197643 & 688730 & 4.5541 & 4.606 & TRN & \\
\hline CHEMBL1991908 & 688730 & 5.0507 & 5.062 & TRN & \\
\hline CHEMBL 2004157 & 688730 & 6.3851 & 6.0756 & TRN & \\
\hline CHEMBL1303626 & 688730 & 4.5134 & 4.6151 & TST & \\
\hline CHEMBL1465751 & 688730 & 5.2705 & 5.5124 & TRN & \\
\hline CHEMBL1611026 & 688730 & 5.0018 & 4.8992 & TRN & \\
\hline CHEMBL1538764 & 688730 & 5.1601 & 5.056 & TRN & \\
\hline CHEMBL166209 & 688730 & 4.7929 & 4.9444 & TRN & \\
\hline CHEMBL1393502 & 688730 & 4.1969 & 4.1881 & TRN & \\
\hline CHEMBL1540231 & 688730 & 5.0381 & 5.0998 & TST & \\
\hline CHEMBL1550246 & 688730 & 5.3333 & 5.0777 & TST & \\
\hline CHEMBL3198683 & 688730 & 4.7376 & 4.8304 & TRN & \\
\hline CHEMBL1092115 & 688730 & 4.8549 & 4.9585 & TRN & \\
\hline CHEMBL1574540 & 688730 & 5.3782 & 5.3416 & TRN & \\
\hline CHEMBL155563 & 688730 & 5.072 & 5.2904 & TRN & \\
\hline CHEMBL1360064 & 688730 & 4.7767 & 4.6363 & TRN & \\
\hline CHEMBL1303935 & 688730 & 4.3081 & 4.3536 & TRN & \\
\hline CHEMBL1426358 & 688730 & 4.7264 & 4.7953 & TRN & \\
\hline CHEMBL1310437 & 688730 & 3.9294 & 3.5635 & TRN & \\
\hline CHEMBL3189770 & 688730 & 5.4852 & 5.3969 & TRN & \\
\hline CHEMBL3191116 & 688730 & 5.3415 & 5.2372 & TRN & \\
\hline CHEMBL1310969 & 688730 & 5.1383 & 5.17700 & 00000000005 & TRN \\
\hline CHEMBL1610049 & 688730 & 5.3845 & 5.3271 & TRN & \\
\hline CHEMBL1306507 & 688730 & 5.0536 & 5.0025 & TRN & \\
\hline CHEMBL1588357 & 688730 & 4.4961 & 4.6202 & TRN & \\
\hline CHEMBL1360793 & 688730 & 6.2581 & 6.6741 & TRN & \\
\hline CHEMBL1424307 & 688730 & 4.8873 & 4.9116 & TRN & \\
\hline CHEMBL1564753 & 688730 & 4.3845 & 4.2494 & TRN & \\
\hline CHEMBL1547736 & 688730 & 4.7446 & 5.0305 & TST & \\
\hline CHEMBL1347497 & 688730 & 5.1413 & 5.0651 & TST & \\
\hline CHEMBL1998741 & 688730 & 4.5456 & 4.5756 & TRN & \\
\hline CHEMBL1385472 & 688730 & 4.5966 & 4.6302 & TRN & \\
\hline CHEMBL1462793 & 688730 & 4.989 & 4.8771 & TRN & \\
\hline CHEMBL1342257 & 688730 & 4.6837 & 4.7417 & TST & \\
\hline CHEMBL1511063 & 688730 & 5.9045 & 5.5644 & TRN & \\
\hline CHEMBL1350552 & 688730 & 4.527 & 4.5342 & TRN & \\
\hline CHEMBL1314100 & 688730 & 4.7529 & 4.6993 & TRN & \\
\hline CHEMBL3213238 & 688730 & 4.8726 & 4.7933 & TRN & \\
\hline CHEMBL1541146 & 688730 & 4.6143 & 4.605 & TST & \\
\hline CHEMBL1523114 & 688730 & 4.38 & 4.6563 & TRN & \\
\hline CHEMBL1311671 & 688730 & 4.7786 & 4.7978 & TST & \\
\hline CHEMBL1565290 & 688730 & 4.7792 & 4.7818 & TST & \\
\hline CHEMBL 2000338 & 688730 & 5.4231 & 5.0847 & TRN & \\
\hline CHEMBL1604884 & 688730 & 4.84699 & 99999999 & 4.7872 & TRN \\
\hline
\end{tabular}


Supplemental Table S2.txt

\begin{tabular}{|c|c|c|c|c|c|}
\hline CHEMBL1422690 & 688730 & 5.8844 & 5.9498 & TRN & \\
\hline CHEMBL1508699 & 688730 & 4.2027 & 4.5798 & TRN & \\
\hline CHEMBL1430845 & 688730 & 4.4452 & 4.7216 & TRN & \\
\hline CHEMBL1374947 & 688730 & 5.4394 & 5.4687 & TRN & \\
\hline CHEMBL1458253 & 688730 & 5.3379 & 5.0077 & TRN & \\
\hline CHEMBL1376371 & 688730 & 4.6015 & 4.6338 & TST & \\
\hline CHEMBL1344767 & 688730 & 5.0735 & 5.1174 & TRN & \\
\hline CHEMBL1535276 & 688730 & 4.6098 & 4.4433 & TRN & \\
\hline CHEMBL3195975 & 688730 & 4.8565 & 4.7872 & TRN & \\
\hline CHEMBL1412583 & 688730 & 4.9917 & 4.8984 & TRN & \\
\hline CHEMBL451574 & 688730 & 5.0869 & 5.0395 & TST & \\
\hline CHEMBL1386172 & 688730 & 4.9751 & 5.0116 & TRN & \\
\hline CHEMBL1578607 & 688730 & 4.6369 & 4.7001 & TRN & \\
\hline CHEMBL1321538 & 688730 & 5.3909 & 5.4158 & TRN & \\
\hline CHEMBL1452109 & 688730 & 4.7093 & 4.7177 & TRN & \\
\hline CHEMBL1309295 & 688730 & 5.1375 & 5.176 & TRN & \\
\hline CHEMBL1439352 & 688730 & 4.3831 & 4.9893 & TRN & \\
\hline CHEMBL1416184 & 688730 & 4.9534 & 4.9621 & TRN & \\
\hline CHEMBL1403058 & 688730 & 4.9621 & 4.9461 & TRN & \\
\hline CHEMBL1543295 & 688730 & 6.9318 & 6.48600 & 3000000001 & TST \\
\hline CHEMBL1450097 & 688730 & 4.0926 & 4.2705 & TRN & \\
\hline CHEMBL1200792 & 688730 & 5.0758 & 4.9756 & TST & \\
\hline CHEMBL1326118 & 688730 & 5.0227 & 4.8585 & TRN & \\
\hline CHEMBL1428762 & 688730 & 4.6803 & 4.8644 & TRN & \\
\hline CHEMBL3210329 & 688730 & 4.7678 & 4.9615 & TRN & \\
\hline CHEMBL1300736 & 688730 & 5.1077 & 5.1381 & TRN & \\
\hline CHEMBL1376749 & 688730 & 5.2559 & 5.6426 & TRN & \\
\hline CHEMBL1400568 & 688730 & 4.4704 & 4.3457 & TST & \\
\hline CHEMBL1443573 & 688730 & 4.7634 & 4.7544 & TRN & \\
\hline CHEMBL1325523 & 688730 & 4.4943 & 4.5665 & TST & \\
\hline CHEMBL1339905 & 688730 & 7.8539 & 4.6569 & TRN & \\
\hline CHEMBL1421559 & 688730 & 5.5804 & 5.693 & TRN & \\
\hline CHEMBL1331503 & 688730 & 4.9311 & 4.8346 & TRN & \\
\hline CHEMBL1410424 & 688730 & 5.2412 & 5.0477 & TRN & \\
\hline CHEMBL1582023 & 688730 & 4.629 & 4.6288 & TST & \\
\hline CHEMBL1576310 & 688730 & 5.0063 & 5.101 & TRN & \\
\hline CHEMBL1378745 & 688730 & 4.3152 & 4.3366 & TRN & \\
\hline CHEMBL1402807 & 688730 & 5.2408 & 5.048 & TRN & \\
\hline CHEMBL1443454 & 688730 & 5.5504 & 5.7871 & TRN & \\
\hline CHEMBL1538399 & 688730 & 5.6176 & 5.4153 & TRN & \\
\hline CHEMBL1977709 & 688730 & 4.7046 & 4.7401 & TRN & \\
\hline CHEMBL 3195749 & 688730 & 5.0988 & 5.1639 & TRN & \\
\hline CHEMBL1490048 & 688730 & 5.1315 & 5.2642 & TST & \\
\hline CHEMBL1479393 & 688730 & 5.0807 & 5.0716 & TRN & \\
\hline CHEMBL591126 & 688730 & 5.7104 & 5.6444 & TRN & \\
\hline CHEMBL1530513 & 688730 & 4.4968 & 4.2628 & TRN & \\
\hline CHEMBL1326664 & 688730 & 4.5947 & 4.2792 & TRN & \\
\hline CHEMBL1496432 & 688730 & 5.0418 & 4.8862 & TRN & \\
\hline
\end{tabular}


Supplemental Table S2.txt

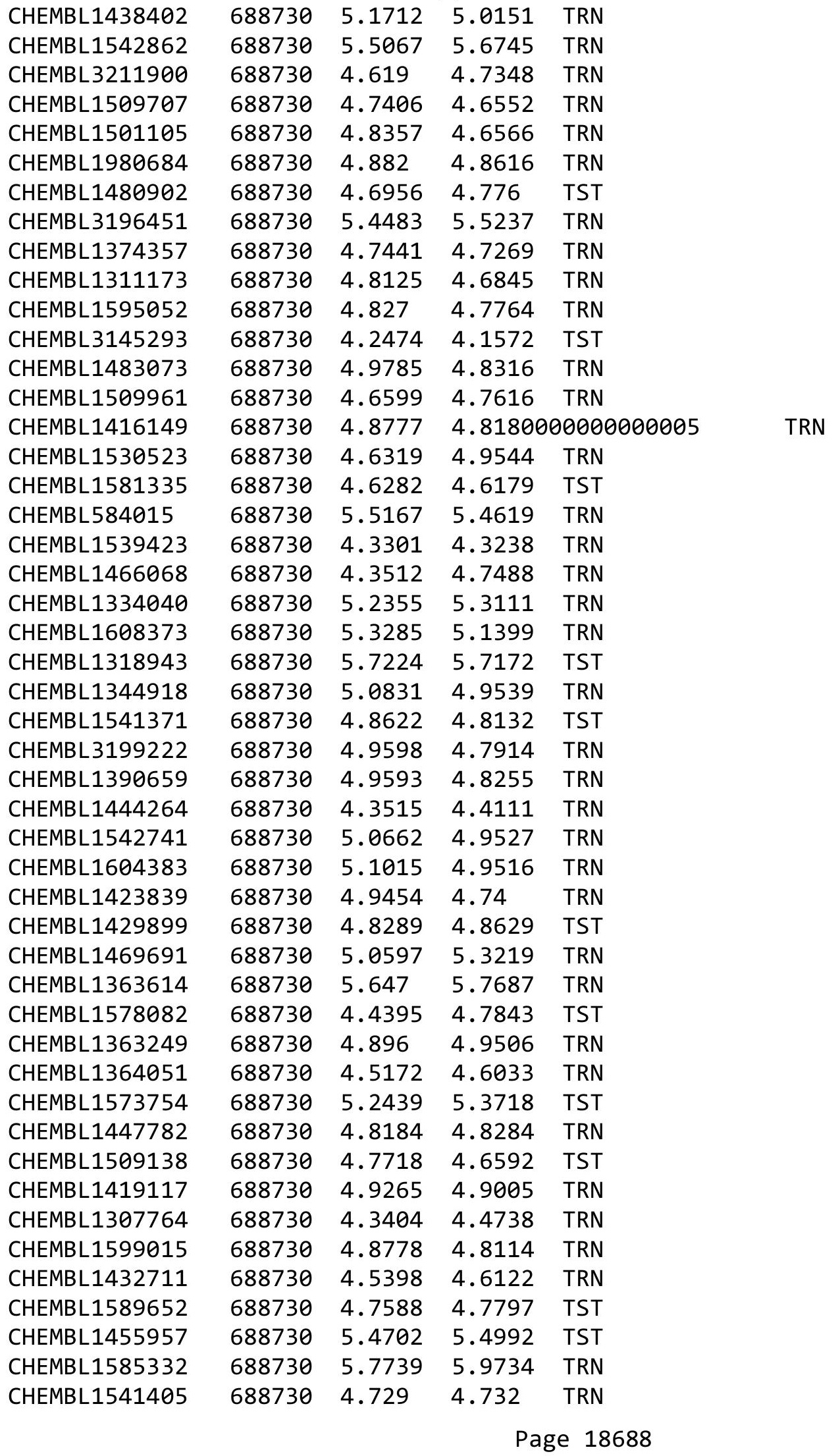




\begin{tabular}{|c|c|c|c|c|c|c|}
\hline & & \multicolumn{5}{|c|}{ Supplemental Table S2.txt } \\
\hline CHEMBL579503 & 688730 & 4.7894 & 4.852 & TRN & & \\
\hline CHEMBL1545873 & 688730 & 5.194 & 5.1426 & TRN & & \\
\hline CHEMBL1405259 & 688730 & 4.2938 & 4.5491 & TRN & & \\
\hline CHEMBL1418079 & 688730 & 5.4162 & 5.4293 & TST & & \\
\hline CHEMBL1504234 & 688730 & 4.7948 & 4.8409 & TRN & & \\
\hline CHEMBL1564158 & 688730 & 4.766 & 4.7906 & TRN & & \\
\hline CHEMBL2006338 & 688730 & 5.3036 & 5.0681 & TRN & & \\
\hline CHEMBL1601175 & 688730 & 4.1725 & 4.2535 & TST & & \\
\hline CHEMBL1503152 & 688730 & 5.0305 & 5.1283 & TRN & & \\
\hline CHEMBL1511191 & 688730 & 4.717 & 4.5304 & TRN & & \\
\hline CHEMBL1332277 & 688730 & 4.5996 & 4.6134 & TRN & & \\
\hline CHEMBL1588763 & 688730 & 4.819 & 4.7732 & TRN & & \\
\hline CHEMBL1611658 & 688730 & 4.867 & 4.8269 & TRN & & \\
\hline CHEMBL1337500 & 688730 & 5.2253 & 5.364 & TST & & \\
\hline CHEMBL260775 & 688730 & 5.1476 & 4.8372 & TRN & & \\
\hline CHEMBL1431928 & 688730 & 5.5674 & 5.6143 & TRN & & \\
\hline CHEMBL1971901 & 688730 & 5.1801 & 5.08 & TRN & & \\
\hline CHEMBL1308487 & 688730 & 4.5513 & 4.7161 & TRN & & \\
\hline CHEMBL1341317 & 688730 & 5.1171 & 5.0836 & TRN & & \\
\hline CHEMBL1349063 & 688730 & 6.3851 & 6.3636 & TRN & & \\
\hline CHEMBL1544046 & 688730 & 4.8084 & 4.8399 & TRN & & \\
\hline CHEMBL1343705 & 688730 & 5.7049 & 5.7048 & TRN & & \\
\hline CHEMBL1390645 & 688730 & 4.3618 & 3.4263 & TRN & & \\
\hline CHEMBL1494087 & 688730 & 5.12799 & 99999999 & 99 & 4.952 & TRN \\
\hline CHEMBL1300284 & 688730 & 4.9462 & 4.9143 & TST & & \\
\hline CHEMBL1978651 & 688730 & 4.7109 & 4.7415 & TRN & & \\
\hline CHEMBL1344703 & 688730 & 4.3895 & 4.337 & TST & & \\
\hline CHEMBL1500315 & 688730 & 4.8427 & 4.6361 & TRN & & \\
\hline CHEMBL1305478 & 688730 & 5.1109 & 4.9536 & TRN & & \\
\hline CHEMBL1496208 & 688730 & 4.3826 & 4.4708 & TRN & & \\
\hline CHEMBL1358604 & 688730 & 4.8765 & 4.8374 & TRN & & \\
\hline CHEMBL 3145321 & 688730 & 5.0551 & 4.8545 & TST & & \\
\hline CHEMBL1528634 & 688730 & 4.5461 & 4.5302 & TRN & & \\
\hline CHEMBL1588525 & 688730 & 6.5186 & 6.4192 & TRN & & \\
\hline CHEMBL1468192 & 688730 & 5.2908 & 5.2071 & TRN & & \\
\hline CHEMBL1379761 & 688730 & 5.1981 & 5.0954 & TST & & \\
\hline CHEMBL1343720 & 688730 & 4.6707 & 4.7203 & TRN & & \\
\hline CHEMBL1447148 & 688730 & 4.6483 & 4.7409 & TRN & & \\
\hline CHEMBL1343600 & 688730 & 4.3608 & 4.5844 & TRN & & \\
\hline CHEMBL1982308 & 688730 & 5.1908 & 5.306 & TRN & & \\
\hline CHEMBL1304034 & 688730 & 4.8537 & 4.7462 & TRN & & \\
\hline CHEMBL1495939 & 688730 & 4.4133 & 4.562 & TRN & & \\
\hline CHEMBL1462679 & 688730 & 4.572 & 4.678 & TRN & & \\
\hline CHEMBL1468793 & 688730 & 5.0328 & 5.1714 & TRN & & \\
\hline CHEMBL1983745 & 688730 & 5.3652 & 5.1655 & TRN & & \\
\hline CHEMBL1541834 & 688730 & 5.9863 & 5.8477 & TRN & & \\
\hline CHEMBL598679 & 688730 & 5.144 & 5.1837 & TRN & & \\
\hline CHEMBL1442795 & 688730 & 4.6215 & 4.7035 & TRN & & \\
\hline
\end{tabular}


Supplemental Table S2.txt

\begin{tabular}{|c|c|c|c|c|}
\hline & & & & \\
\hline AEMBL13 & 38730 & 6048 & & \\
\hline IEMBL1457704 & 8730 & 8461 & 8409 & \\
\hline AEMBL1348102 & 730 & 0727 & 09 & \\
\hline & 730 & 311 & & \\
\hline IEMBL1461574 & 730 & 428 & & \\
\hline AEMBL1503966 & 88730 & 3921 & 3247 & \\
\hline AEMBL1469709 & 88730 & 4.1135 & 798 & \\
\hline AEMBL1611370 & 730 & & 21 & \\
\hline AEMBL14 & 730 & & 838 & \\
\hline HEMBL160 & 730 & & & \\
\hline AEMBL1547646 & 688730 & 235 & & \\
\hline AEMBL1471698 & 730 & & 191 & \\
\hline IEMBL1348 & & & 01 & \\
\hline IEMBL58 & & & & \\
\hline AEMBL $14 \angle$ & & & & \\
\hline AEMBL1455802 & 730 & & 034 & RN \\
\hline AEMBL1366934 & & & & \\
\hline IEMBL14 & & & 94 & \\
\hline HEMBL13 & & & & \\
\hline AEMBL 13 & & & & $\mathrm{RN}$ \\
\hline AEMBL139 & & & & RN \\
\hline HEMBL134C & & & & \\
\hline IEMBL13 & & & & \\
\hline HEMBL 14 & & & & . \\
\hline AFMRI 1 & 30 & & 86 & $\mathrm{RN}$ \\
\hline HEMBL138 & & & & RN \\
\hline AEMBL1574687 & & & & $\mathrm{RI}$ \\
\hline AEMBL149e & & & 52 & $\mathrm{RN}$ \\
\hline HEMBL14 & & & 51 & . \\
\hline 12 & & & & - \\
\hline AEMBL1598093 & & & & ST \\
\hline AEMBL1518905 & & & & RN \\
\hline AEMBL1486 & & & 29 & RI \\
\hline AFMBI 14 & & & 24 & . \\
\hline HEMBL1451 & & & & $\mathrm{RN}$ \\
\hline AEMBL1336245 & & & & ST \\
\hline AEMBL1348057 & & & & $\Gamma \mathrm{R}$ \\
\hline IEMBL14 & & & & RI \\
\hline & & & & \\
\hline HEMBL 145 & & & 527 & RN \\
\hline AEMBL3197291 & 730 & & 9485 & rRN \\
\hline IEMBL1427 & & & & TS \\
\hline EMBL15 & & & & TS \\
\hline HEMBL155 & & & & \\
\hline CHEMBL17201 & & & 69 & RN \\
\hline AEMBL14891 & 8730 & 5.0948 & 5.2078 & $\mathrm{TR}$ \\
\hline HEMBL1305054 & 688730 & 3.9996 & 3.7796 & \\
\hline
\end{tabular}

Page 18690 
Supplemental Table S2.txt

\begin{tabular}{|c|c|c|c|c|c|}
\hline CHEMBL3207715 & 688730 & 5.2708 & 5.0686 & TRN & \\
\hline CHEMBL1408368 & 688730 & 4.0383 & 4.9042 & TRN & \\
\hline CHEMBL1417815 & 688730 & 4.4789 & 4.4485 & TRN & \\
\hline CHEMBL1362109 & 688730 & 5.2239 & 5.0782 & TRN & \\
\hline CHEMBL1510922 & 688730 & 4.7651 & 4.7862 & TRN & \\
\hline CHEMBL1507925 & 688730 & 4.842 & 4.71899 & 9999999999 & TRN \\
\hline CHEMBL1543384 & 688730 & 4.7758 & 4.5454 & TRN & \\
\hline CHEMBL1594205 & 688730 & 4.6953 & 4.5828 & TRN & \\
\hline CHEMBL3213359 & 688730 & 4.3144 & 4.4595 & TRN & \\
\hline CHEMBL1599610 & 688730 & 5.6662 & 5.5628 & TRN & \\
\hline CHEMBL1495072 & 688730 & 5.5077 & 5.4602 & TRN & \\
\hline CHEMBL1546412 & 688730 & 5.1915 & 5.2319 & TRN & \\
\hline CHEMBL1384702 & 688730 & 5.5518 & 5.6193 & TRN & \\
\hline CHEMBL1971532 & 688730 & 5.2355 & 5.0774 & TRN & \\
\hline CHEMBL1300968 & 688730 & 4.9853 & 4.9487 & TST & \\
\hline CHEMBL1327816 & 688730 & 5.0732 & 5.154 & TRN & \\
\hline CHEMBL1410678 & 688730 & 4.8968 & 4.9316 & TRN & \\
\hline CHEMBL1471931 & 688730 & 4.66 & 4.651 & TRN & \\
\hline CHEMBL1532375 & 688730 & 4.8086 & 4.762 & TRN & \\
\hline CHEMBL1549574 & 688730 & 5.2082 & 5.1125 & TRN & \\
\hline CHEMBL1584502 & 688730 & 5.272 & 5.5014 & TRN & \\
\hline CHEMBL1405111 & 688730 & 4.624 & 4.6678 & TRN & \\
\hline CHEMBL1458726 & 688730 & 4.7039 & 4.7501 & TRN & \\
\hline CHEMBL1508917 & 688730 & 4.7167 & 4.694 & TRN & \\
\hline CHEMBL1484321 & 688730 & 5.3099 & 5.1604 & TRN & \\
\hline CHEMBL1349146 & 688730 & 6.109 & 5.7599 & TST & \\
\hline CHEMBL1529687 & 688730 & 5.1348 & 5.2743 & TST & \\
\hline CHEMBL1319676 & 688730 & 4.7087 & 5.1154 & TRN & \\
\hline CHEMBL1328118 & 688730 & 4.836 & 4.8146 & TRN & \\
\hline CHEMBL1542070 & 688730 & 4.8693 & 4.7961 & TRN & \\
\hline CHEMBL1445372 & 688730 & 5.32299 & 99999999 & 5.1534 & W \\
\hline CHEMBL1353693 & 688730 & 4.7053 & 3.8287 & TRN & \\
\hline CHEMBL1427637 & 688730 & 5.604 & 5.69799 & 99999999995 & TST \\
\hline CHEMBL1376635 & 688730 & 4.7106 & 4.6206 & TRN & \\
\hline CHEMBL1407614 & 688730 & 4.8579 & 4.7004 & TRN & \\
\hline CHEMBL1303044 & 688730 & 4.48 & 4.5489 & TRN & \\
\hline CHEMBL1349590 & 688730 & 5.4237 & 5.5421 & TRN & \\
\hline CHEMBL1365720 & 688730 & 4.3988 & 4.46 & TRN & \\
\hline CHEMBL1338755 & 688730 & 4.5683 & 4.404 & TRN & \\
\hline CHEMBL1422217 & 688730 & 5.2601 & 5.2881 & TRN & \\
\hline CHEMBL1302139 & 688730 & 4.7454 & 4.7273 & TRN & \\
\hline CHEMBL1461419 & 688730 & 4.7933 & 4.8959 & TST & \\
\hline CHEMBL1508274 & 688730 & 5.1277 & 5.0372 & TRN & \\
\hline CHEMBL1455813 & 688730 & 4.8818 & 4.9465 & TRN & \\
\hline CHEMBL1426158 & 688730 & 5.2221 & 5.3562 & TRN & \\
\hline CHEMBL1338888 & 688730 & 4.7209 & 4.651 & TRN & \\
\hline CHEMBL1563156 & 688730 & 4.7068 & 4.6798 & TST & \\
\hline CHEMBL1530797 & 688730 & 5.3442 & 5.2401 & TRN & \\
\hline
\end{tabular}

Page 18691 


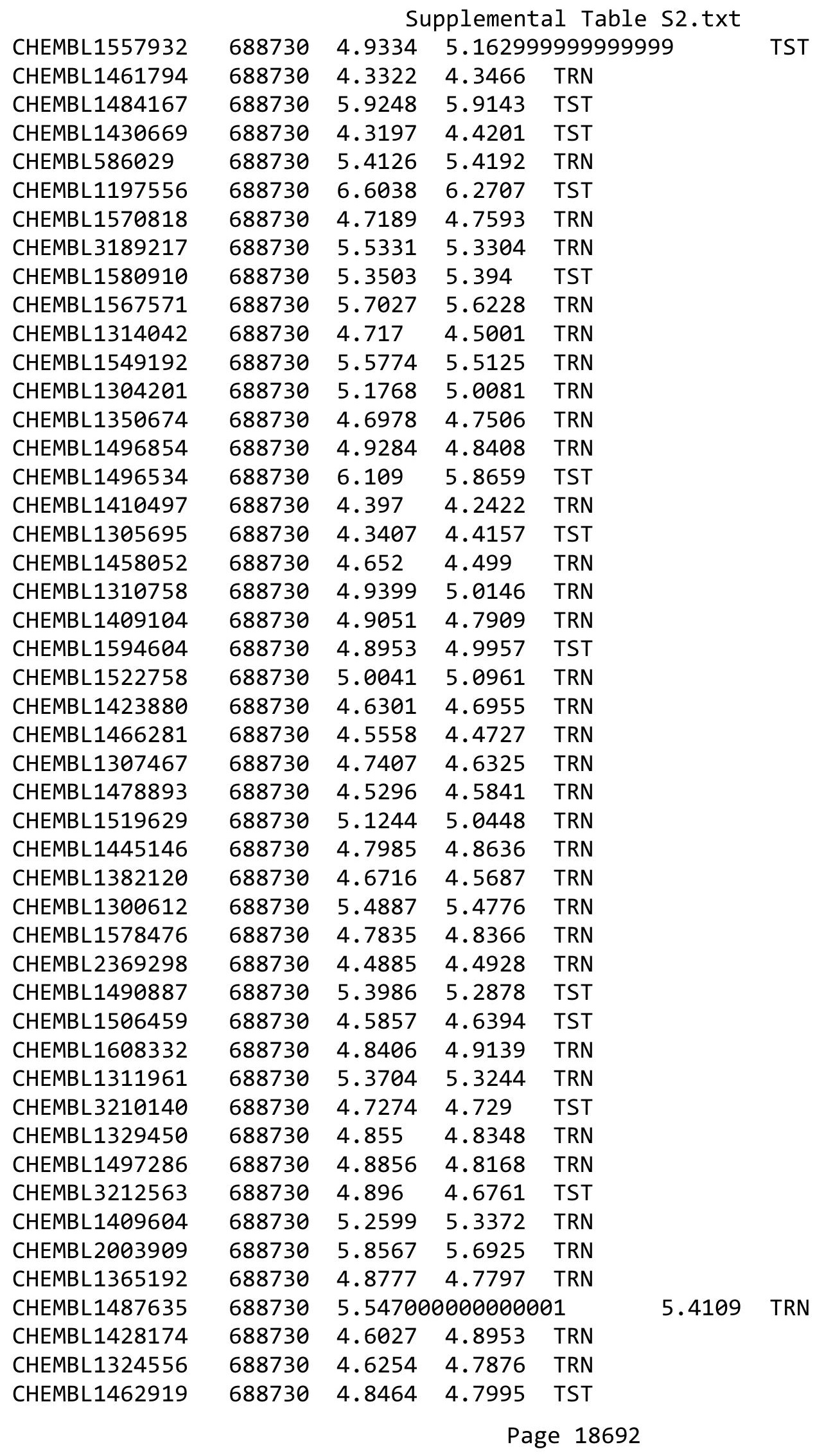




\begin{tabular}{|c|c|c|c|c|c|}
\hline & & \multicolumn{4}{|c|}{ Supplemental Table S2.txt } \\
\hline CHEMBL579105 & 688730 & 4.9549 & 5.0457 & TRN & \\
\hline CHEMBL1374533 & 688730 & 4.6671 & 4.874 & TRN & \\
\hline CHEMBL1425921 & 688730 & 6.6498 & 6.6806 & TRN & \\
\hline CHEMBL1543733 & 688730 & 4.9759 & 4.8434 & TRN & \\
\hline CHEMBL1598561 & 688730 & 5.2016 & 5.2928 & TRN & \\
\hline CHEMBL1599808 & 688730 & 4.7526 & 4.7654 & TRN & \\
\hline CHEMBL1351290 & 688730 & 5.3099 & 5.2605 & TST & \\
\hline CHEMBL1343568 & 688730 & \multicolumn{2}{|c|}{5.542000000000001} & 5.6371 & TRN \\
\hline CHEMBL 2095095 & 688730 & 5.3844 & 5.3082 & TRN & \\
\hline CHEMBL1973050 & 688730 & 5.7916 & 5.6536 & TRN & \\
\hline CHEMBL117966 & 688730 & 6.0066 & 5.9531 & TRN & \\
\hline CHEMBL1460352 & 688730 & 6.0969 & 5.6413 & TRN & \\
\hline CHEMBL1577857 & 688730 & 4.4278 & 4.2067 & TRN & \\
\hline CHEMBL3212479 & 688730 & 4.819 & 4.4942 & TST & \\
\hline CHEMBL1337246 & 688730 & 4.7292 & 4.8006 & TRN & \\
\hline CHEMBL1568173 & 688730 & 5.1354 & 5.1672 & TRN & \\
\hline CHEMBL1581337 & 688730 & 4.598 & 4.6115 & TRN & \\
\hline CHEMBL 2004056 & 688730 & 5.3087 & 5.3341 & TRN & \\
\hline CHEMBL3212224 & 688730 & 4.749 & \multicolumn{2}{|c|}{4.553999999999999} & TRN \\
\hline CHEMBL1425943 & 688730 & 4.8655 & 4.9523 & TRN & \\
\hline CHEMBL1537747 & 688730 & 4.1169 & 4.5347 & TRN & \\
\hline CHEMBL1484934 & 688730 & 5.5134 & 5.4838 & TRN & \\
\hline CHEMBL1506832 & 688730 & 4.914 & 4.905 & TRN & \\
\hline CHEMBL530664 & 688730 & 4.6496 & 4.8613 & TRN & \\
\hline CHEMBL1224757 & 688730 & 5.8447 & 5.8924 & TRN & \\
\hline CHEMBL1465920 & 688730 & 4.8244 & 4.7014 & TRN & \\
\hline CHEMBL1495763 & 688730 & 4.8604 & \multicolumn{2}{|c|}{4.9030000000000005} & TRN \\
\hline CHEMBL1388094 & 688730 & 5.0186 & 4.9441 & TST & \\
\hline CHEMBL1455524 & 688730 & 4.1849 & 4.1939 & TST & \\
\hline CHEMBL1449971 & 688730 & 4.4602 & 4.3378 & TST & \\
\hline CHEMBL1575748 & 688730 & 4.7703 & 4.7998 & TRN & \\
\hline CHEMBL1390555 & 688730 & 4.7316 & 4.6637 & TRN & \\
\hline CHEMBL1388241 & 688730 & 5.0338 & 5.0759 & TRN & \\
\hline CHEMBL1540229 & 688730 & 5.0476 & 4.709 & TRN & \\
\hline CHEMBL1494293 & 688730 & 5.3955 & 5.3171 & TRN & \\
\hline CHEMBL1389919 & 688730 & 5.4379 & 5.5482 & TRN & \\
\hline CHEMBL1466799 & 688730 & 3.9535 & 4.0959 & TRN & \\
\hline CHEMBL1410063 & 688730 & 5.2241 & 5.1626 & TRN & \\
\hline CHEMBL1510228 & 688730 & 5.0534 & 5.012 & TRN & \\
\hline CHEMBL1378489 & 688730 & 5.5337 & 5.5369 & TST & \\
\hline CHEMBL1600480 & 688730 & 4.6601 & 4.6595 & TRN & \\
\hline CHEMBL1415885 & 688730 & 6.0706 & 6.1482 & TRN & \\
\hline CHEMBL1581607 & 688730 & 4.9941 & 4.9659 & TRN & \\
\hline CHEMBL1562040 & 688730 & 5.5969 & 5.6031 & TRN & \\
\hline CHEMBL1342074 & 688730 & 4.9808 & 4.8616 & TRN & \\
\hline CHEMBL1304814 & 688730 & 4.8164 & 4.9833 & TST & \\
\hline CHEMBL1393341 & 688730 & 4.8657 & 4.885 & TRN & \\
\hline CHEMBL1568243 & 688730 & 5.0683 & 5.2736 & TRN & \\
\hline
\end{tabular}


Supplemental Table S2.txt

\begin{tabular}{|c|c|c|c|c|}
\hline CHEMBL1601781 & 688730 & 5.0171 & 4.9015 & TRN \\
\hline CHEMBL591404 & 688730 & 5.3775 & 5.4013 & TRN \\
\hline CHEMBL 3209649 & 688730 & 4.2139 & 4.3391 & TRN \\
\hline CHEMBL1546684 & 688730 & 4.9605 & 5.0033 & TRN \\
\hline CHEMBL1505006 & 688730 & 5.0504 & 4.8255 & TRN \\
\hline CHEMBL1574218 & 688730 & 5.6492 & 5.5658 & TRN \\
\hline CHEMBL1390139 & 688730 & 5.1412 & 5.2105 & TRN \\
\hline CHEMBL1322082 & 688730 & 5.1327 & 4.8519 & TRN \\
\hline CHEMBL1308346 & 688730 & 4.9756 & 4.9154 & TRN \\
\hline CHEMBL1698464 & 688730 & 5.7242 & 5.5586 & TRN \\
\hline CHEMBL1598791 & 688730 & 5.862 & 5.6494 & TST \\
\hline CHEMBL1450781 & 688730 & 4.3861 & 4.3455 & TRN \\
\hline CHEMBL1588256 & 688730 & 4.7344 & 4.7981 & TRN \\
\hline CHEMBL1431591 & 688730 & 4.463 & 4.5682 & TRN \\
\hline CHEMBL 3190637 & 688730 & 4.7087 & 4.6631 & TRN \\
\hline CHEMBL1531138 & 688730 & 5.0982 & 4.9501 & TRN \\
\hline CHEMBL1352852 & 688730 & 4.7252 & 4.6966 & TST \\
\hline CHEMBL1423338 & 688730 & 5.1364 & 5.1214 & TST \\
\hline CHEMBL 3210407 & 688730 & 4.67899 & 999999999 & 4.7251 \\
\hline CHEMBL1351463 & 688730 & 4.5769 & 4.556999 & 99999999995 \\
\hline CHEMBL1300063 & 688730 & 4.73300 & 000000000 & $005 \quad 4.628$ \\
\hline CHEMBL1438171 & 688730 & 5.4662 & 5.4382 & TST \\
\hline CHEMBL1607948 & 688730 & 5.2526 & 5.4342 & TRN \\
\hline CHEMBL1534756 & 688730 & 4.9403 & 4.9923 & TST \\
\hline CHEMBL1403738 & 688730 & 5.0803 & 4.9975 & TRN \\
\hline CHEMBL1311740 & 688730 & 5.2206 & 5.3231 & TRN \\
\hline CHEMBL1370757 & 688730 & 4.9176 & 4.8067 & TST \\
\hline CHEMBL1339227 & 688730 & 4.3215 & 4.252 & TRN \\
\hline CHEMBL1527929 & 688730 & 5.0537 & 5.1481 & TST \\
\hline CHEMBL1479249 & 688730 & 4.9471 & 4.9267 & TRN \\
\hline CHEMBL1607883 & 688730 & 4.4029 & 4.5788 & TRN \\
\hline CHEMBL1583276 & 688730 & 3.8726 & 4.0661 & TRN \\
\hline CHEMBL1967395 & 688730 & 5.1252 & 5.138 & TRN \\
\hline CHEMBL1607463 & 688730 & 4.6054 & 4.5 & TRN \\
\hline CHEMBL1481697 & 688730 & 5.1267 & 5.1327 & TRN \\
\hline CHEMBL1538643 & 688730 & 4.8744 & 4.9127 & TRN \\
\hline CHEMBL1308032 & 688730 & 4.5399 & 4.1779 & TST \\
\hline CHEMBL1570537 & 688730 & 4.0987 & 4.1337 & TRN \\
\hline CHEMBL1529086 & 688730 & 4.5546 & 4.5477 & TRN \\
\hline CHEMBL1452785 & 688730 & 4.833 & 4.8697 & TRN \\
\hline CHEMBL3196534 & 688730 & 4.4956 & 4.6272 & TRN \\
\hline CHEMBL1587655 & 688730 & 4.8027 & 4.7142 & TRN \\
\hline CHEMBL3194762 & 688730 & 4.5769 & 4.5867 & TRN \\
\hline CHEMBL1539616 & 688730 & 4.5932 & 4.5408 & TRN \\
\hline CHEMBL1382077 & 688730 & 4.7598 & 4.6891 & TRN \\
\hline CHEMBL1568641 & 688730 & 4.9301 & 4.9292 & TRN \\
\hline CHEMBL1429624 & 688730 & 4.9477 & 5.1484 & TRN \\
\hline CHEMBL1491541 & 688730 & 4.4743 & 4.5708 & TRN \\
\hline
\end{tabular}


Supplemental Table S2.txt

\begin{tabular}{|c|c|c|c|c|}
\hline CHEMBL1529127 & 688730 & 5.5183 & 5.5915 & TRN \\
\hline CHEMBL1528998 & 688730 & 4.6209 & 4.678 & TST \\
\hline CHEMBL1372307 & 688730 & 5.8752 & 5.3907 & TST \\
\hline CHEMBL1387003 & 688730 & 4.8514 & 4.4786 & TRN \\
\hline CHEMBL1336187 & 688730 & 5.6629 & 5.3508 & TRN \\
\hline CHEMBL1416808 & 688730 & 5.2367 & \multicolumn{2}{|c|}{5.5120000000000005} \\
\hline CHEMBL1430195 & 688730 & 5.0539 & 4.9947 & TRN \\
\hline CHEMBL2369168 & 688730 & 5.3827 & 5.3969 & TRN \\
\hline CHEMBL1351426 & 688730 & 4.6811 & 4.957 & TST \\
\hline CHEMBL1548869 & 688730 & 4.8273 & 4.7639 & TRN \\
\hline CHEMBL1449749 & 688730 & 5.3347 & 4.9901 & TRN \\
\hline CHEMBL3190534 & 688730 & 4.2125 & 4.3135 & TST \\
\hline CHEMBL1420457 & 688730 & 4.9718 & 5.0034 & TRN \\
\hline CHEMBL1569037 & 688730 & 5.5107 & 5.3263 & TRN \\
\hline CHEMBL589715 & 688730 & 5.2741 & 5.3761 & TRN \\
\hline CHEMBL3195193 & 688730 & 2.9592 & 3.9016 & TRN \\
\hline CHEMBL1376183 & 688730 & 4.7818 & 4.7832 & TRN \\
\hline CHEMBL1579805 & 688730 & 5.0546 & 4.8876 & TRN \\
\hline CHEMBL1313955 & 688730 & 4.6006 & 4.8213 & TRN \\
\hline CHEMBL1376704 & 688730 & 5.1389 & 5.4262 & TRN \\
\hline CHEMBL1359788 & 688730 & 4.6198 & 4.5975 & TRN \\
\hline CHEMBL1526457 & 688730 & 4.796 & 4.7475 & TRN \\
\hline CHEMBL1588509 & 688730 & 5.3112 & 5.1521 & TRN \\
\hline CHEMBL1525949 & 688730 & 4.7894 & 4.7195 & TRN \\
\hline CHEMBL1408215 & 688730 & 4.886 & 4.8372 & TRN \\
\hline CHEMBL1472199 & 688730 & 5.4571 & 5.2713 & TRN \\
\hline CHEMBL1576110 & 688730 & 4.5106 & 4.7447 & TRN \\
\hline CHEMBL1596681 & 688730 & 6.1379 & 5.976 & TST \\
\hline CHEMBL1424408 & 688730 & 4.5691 & 4.587 & TRN \\
\hline CHEMBL1519457 & 688730 & 4.9886 & 4.9978 & TRN \\
\hline CHEMBL1543421 & 688730 & 5.0658 & 4.9845 & TRN \\
\hline CHEMBL1373577 & 688730 & 5.1679 & 5.285 & TRN \\
\hline CHEMBL1587031 & 688730 & 5.564 & 5.3978 & TRN \\
\hline CHEMBL1367601 & 688730 & 4.7406 & 4.7933 & TRN \\
\hline CHEMBL1975458 & 688730 & 5.3564 & 5.194 & TRN \\
\hline CHEMBL1340447 & 688730 & 4.8819 & 4.8421 & TRN \\
\hline CHEMBL1499273 & 688730 & 5.025 & 4.79 & TRN \\
\hline CHEMBL533602 & 688730 & 6.6289 & 6.5617 & TST \\
\hline CHEMBL1582537 & 688730 & 4.7771 & 4.6649 & TRN \\
\hline CHEMBL1521989 & 688730 & 5.0475 & 5.0217 & TRN \\
\hline CHEMBL1388809 & 688730 & 4.6415 & 4.691 & TRN \\
\hline CHEMBL1479951 & 688730 & 4.6736 & 4.72 & TRN \\
\hline CHEMBL1498027 & 688730 & 5.2683 & 5.3562 & TRN \\
\hline CHEMBL1496095 & 688730 & 4.7592 & 4.7308 & TRN \\
\hline CHEMBL1498599 & 688730 & 4.8706 & 5.01399 & 9999999999 \\
\hline CHEMBL3214169 & 688730 & 3.5505 & 4.3947 & TRN \\
\hline CHEMBL1541809 & 688730 & 4.5823 & 4.6511 & TRN \\
\hline CHEMBL1411285 & 688730 & 4.8558 & 5.0103 & TRN \\
\hline
\end{tabular}




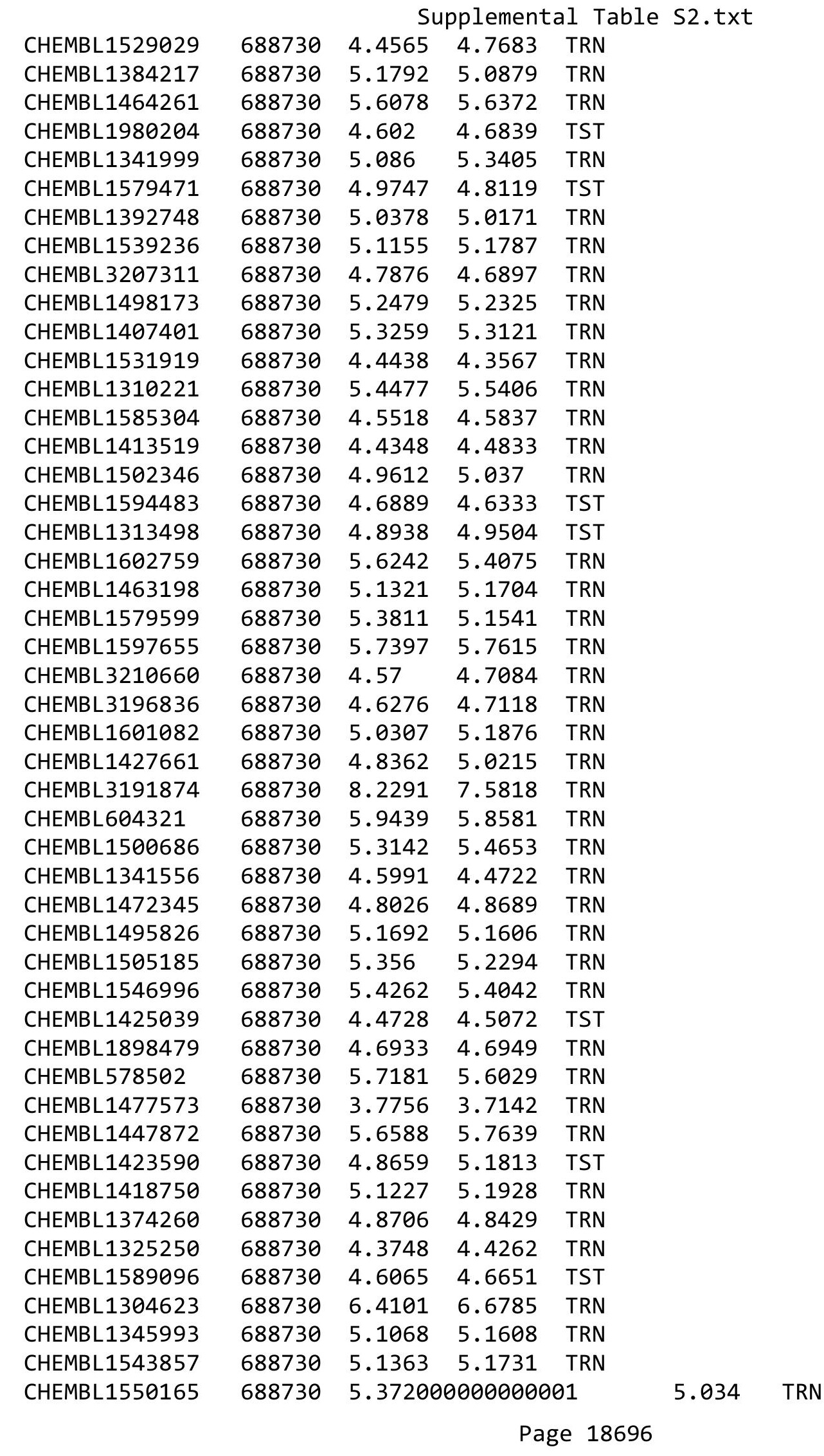




\begin{tabular}{|c|c|c|c|c|}
\hline & & & oplement & al $\mathrm{T}$ \\
\hline CHEMBL3210366 & 688730 & 4.9894 & 4.9048 & TRN \\
\hline CHEMBL3191251 & 688730 & 4.5163 & 4.6284 & TST \\
\hline CHEMBL1308329 & 688730 & 4.9737 & 4.8748 & TRN \\
\hline CHEMBL1371774 & 688730 & 4.494 & 4.7501 & TRN \\
\hline CHEMBL1479994 & 688730 & 4.6428 & 4.6803 & TRN \\
\hline CHEMBL1574879 & 688730 & 6.7055 & 6.3362 & TST \\
\hline CHEMBL1431763 & 688730 & 4.5717 & 4.5551 & TRN \\
\hline CHEMBL1388639 & 688730 & 4.75 & 4.8706 & TRN \\
\hline CHEMBL1461508 & 688730 & 4.9926 & 5.0033 & TST \\
\hline CHEMBL1523019 & 688730 & 5.2678 & 5.1778 & TRN \\
\hline CHEMBL1612392 & 688730 & 4.9079 & 4.7874 & TRN \\
\hline CHEMBL1481525 & 688730 & 4.9707 & 4.9545 & TRN \\
\hline CHEMBL1349390 & 688730 & 5.1765 & 5.2325 & TRN \\
\hline CHEMBL1328771 & 688730 & 4.4155 & 4.4083 & TRN \\
\hline CHEMBL1495237 & 688730 & 4.8372 & 5.0036 & TRN \\
\hline CHEMBL1528880 & 688730 & 4.7117 & 4.7479 & TST \\
\hline CHEMBL1310332 & 688730 & 4.7661 & 4.7809 & TRN \\
\hline CHEMBL248847 & 688730 & 4.7038 & 4.3678 & TRN \\
\hline CHEMBL1490873 & 688730 & 4.7439 & 4.7027 & TST \\
\hline CHEMBL1596115 & 688730 & 4.5989 & 4.602 & TRN \\
\hline CHEMBL1468664 & 688730 & 5.065 & 4.896 & TRN \\
\hline CHEMBL3208237 & 688730 & 4.7717 & 4.8011 & TRN \\
\hline CHEMBL1549430 & 688730 & 4.3102 & 4.5953 & TRN \\
\hline CHEMBL3208882 & 688730 & 4.1775 & 4.0296 & TRN \\
\hline CHEMBL1429289 & 688730 & 4.0999 & 4.2314 & TRN \\
\hline CHEMBL1499306 & 688730 & 5.9884 & 6.026 & TRN \\
\hline CHEMBL1430328 & 688730 & 4.7599 & 4.7726 & TRN \\
\hline CHEMBL1527872 & 688730 & 4.732 & 4.3889 & TRN \\
\hline CHEMBL1404345 & 688730 & 5.4562 & 5.5065 & TRN \\
\hline CHEMBL1347071 & 688730 & 6.0615 & 6.1015 & TST \\
\hline CHEMBL3190703 & 688730 & 5.0432 & 5.3337 & TRN \\
\hline CHEMBL1560954 & 688730 & 4.7013 & 4.6599 & TRN \\
\hline CHEMBL1333168 & 688730 & 4.9698 & 4.9502 & TST \\
\hline CHEMBL1550557 & 688730 & 5.0248 & 4.9047 & TRN \\
\hline CHEMBL3192856 & 688730 & 5.5284 & 5.3748 & TRN \\
\hline CHEMBL1382491 & 688730 & 4.3126 & 4.39 & TRN \\
\hline CHEMBL1342679 & 688730 & 4.706 & 4.6006 & TRN \\
\hline CHEMBL1429720 & 688730 & 4.7744 & 4.8294 & TRN \\
\hline CHEMBL1544502 & 688730 & 4.7607 & 4.7843 & TRN \\
\hline CHEMBL1453902 & 688730 & 4.5355 & 4.6237 & TRN \\
\hline CHEMBL1403470 & 688730 & 4.5397 & 4.5596 & TRN \\
\hline CHEMBL1526910 & 688730 & 5.0666 & 5.0981 & TST \\
\hline CHEMBL1510664 & 688730 & 4.9653 & 4.9765 & TRN \\
\hline CHEMBL1422720 & 688730 & 4.9746 & 4.9169 & TRN \\
\hline CHEMBL3195032 & 688730 & 4.8885 & 4.8512 & TST \\
\hline CHEMBL1341927 & 688730 & 5.5561 & 5.6433 & TRN \\
\hline CHEMBL1577981 & 688730 & 5.2282 & 5.1511 & TRN \\
\hline CHEMBL1572896 & 688730 & 5.249 & 5.183 & TRN \\
\hline
\end{tabular}




\begin{tabular}{|c|c|c|c|c|}
\hline \multicolumn{5}{|c|}{ Supplemental Table s2.txt } \\
\hline CHEMBL1451528 & 688730 & 4.3313 & 4.603 & TRN \\
\hline CHEMBL1606382 & 688730 & 4.7366 & 4.7819 & TRN \\
\hline CHEMBL1537070 & 688730 & 4.6747 & 4.7885 & TST \\
\hline CHEMBL1345523 & 688730 & 4.4931 & 4.5895 & TRN \\
\hline CHEMBL3194085 & 688730 & 5.021 & 5.1419 & TRN \\
\hline CHEMBL576208 & 688730 & 5.7176 & 5.6798 & TRN \\
\hline CHEMBL1510200 & 688730 & 4.7542 & 5.0476 & TRN \\
\hline CHEMBL1326229 & 688730 & 4.2821 & 3.9929 & TRN \\
\hline CHEMBL1310122 & 688730 & 4.5615 & 4.5823 & TRN \\
\hline CHEMBL1598311 & 688730 & 4.5587 & 4.7088 & TRN \\
\hline CHEMBL1403122 & 688730 & 5.2721 & 5.2038 & TST \\
\hline CHEMBL1559473 & 688730 & 4.3098 & 4.5785 & TRN \\
\hline CHEMBL1523537 & 688730 & 4.8072 & 4.8414 & TRN \\
\hline CHEMBL375905 & 688730 & 4.6455 & 4.8579 & TRN \\
\hline CHEMBL3209511 & 688730 & 4.998 & 5.1724 & TST \\
\hline CHEMBL1337592 & 688730 & 5.8652 & 5.8644 & TRN \\
\hline CHEMBL2369277 & 688730 & 5.4272 & 5.4624 & TRN \\
\hline CHEMBL1510634 & 688730 & 5.391 & 5.2511 & TRN \\
\hline CHEMBL3212447 & 688730 & 5.407 & 5.3141 & TRN \\
\hline CHEMBL1388457 & 688730 & 4.6202 & 4.6388 & TST \\
\hline CHEMBL1369328 & 688730 & 4.5125 & 4.4633 & TRN \\
\hline CHEMBL591613 & 688730 & 4.8329 & 4.8937 & TRN \\
\hline CHEMBL1333276 & 688730 & 4.6494 & 4.5837 & TRN \\
\hline CHEMBL1400132 & 688730 & 4.6296 & 4.8671 & TRN \\
\hline CHEMBL1463918 & 688730 & 4.4713 & 4.5607 & TRN \\
\hline CHEMBL1413724 & 688730 & 4.7021 & 4.5763 & TST \\
\hline CHEMBL1352555 & 688730 & 4.5576 & 4.561 & TRN \\
\hline CHEMBL1535134 & 688730 & 5.086 & 4.9234 & TRN \\
\hline CHEMBL1541657 & 688730 & 5.0122 & 5.0594 & TST \\
\hline CHEMBL1419967 & 688730 & 5.0372 & 4.9719 & TST \\
\hline CHEMBL1540346 & 688730 & 4.3994 & 4.6055 & TRN \\
\hline CHEMBL1339696 & 688730 & 5.2547 & 5.296 & TRN \\
\hline CHEMBL1501334 & 688730 & 4.3959 & 4.6158 & TRN \\
\hline CHEMBL1480192 & 688730 & 5.9052 & 6.315 & TRN \\
\hline CHEMBL1353015 & 688730 & 5.5885 & 5.5954 & TRN \\
\hline CHEMBL1451808 & 688730 & 5.1481 & 5.1245 & TRN \\
\hline CHEMBL1594642 & 688730 & 4.8357 & 4.8332 & TRN \\
\hline CHEMBL572994 & 688730 & 4.8865 & 4.8456 & TRN \\
\hline CHEMBL1407739 & 688730 & 4.7873 & 4.5628 & TRN \\
\hline CHEMBL1440017 & 688730 & 5.2481 & 4.9391 & TRN \\
\hline CHEMBL1328193 & 688730 & 4.9418 & 5.0648 & TST \\
\hline CHEMBL1306838 & 688730 & 4.7029 & 4.6514 & TRN \\
\hline CHEMBL3211050 & 688730 & 5.6078 & 5.3291 & TRN \\
\hline CHEMBL1585191 & 688730 & 4.3716 & 4.7115 & TRN \\
\hline CHEMBL1342907 & 688730 & 5.8639 & 5.5001 & TRN \\
\hline CHEMBL1408125 & 688730 & 4.3927 & 4.6639 & TST \\
\hline CHEMBL1483460 & 688730 & 4.252 & 4.4795 & TRN \\
\hline CHEMBL1416348 & 688730 & 4.5484 & 4.5345 & TRN \\
\hline
\end{tabular}




\begin{tabular}{|c|c|c|c|c|c|c|}
\hline & & \multicolumn{5}{|c|}{ Supplemental Table S2.txt } \\
\hline CHEMBL1428264 & 688730 & 4.6494 & 4.5776 & TRN & & \\
\hline CHEMBL1509152 & 688730 & 4.4644 & 4.5357 & TRN & & \\
\hline CHEMBL1453708 & 688730 & 5.2224 & 5.0919 & TRN & & \\
\hline CHEMBL1329138 & 688730 & 4.9447 & 4.9602 & TRN & & \\
\hline CHEMBL1458165 & 688730 & 4.8846 & 4.9308 & TRN & & \\
\hline CHEMBL1300625 & 688730 & 4.1497 & 4.4444 & TST & & \\
\hline CHEMBL1430531 & 688730 & 5.1407 & 5.2636 & TST & & \\
\hline CHEMBL1975257 & 688730 & 4.7543 & 4.7831 & TRN & & \\
\hline CHEMBL1341203 & 688730 & 5.351 & 5.4863 & TRN & & \\
\hline CHEMBL1430815 & 688730 & 4.5986 & 3.5973 & TRN & & \\
\hline CHEMBL1351519 & 688730 & 5.3079 & 5.249 & TRN & & \\
\hline CHEMBL581870 & 688730 & 5.3677 & 5.2969 & TRN & & \\
\hline CHEMBL1520214 & 688730 & 5.1623 & 5.2815 & TRN & & \\
\hline CHEMBL3191705 & 688730 & 5.1717 & 4.9898 & TRN & & \\
\hline CHEMBL1327548 & 688730 & 4.3596 & 3.9747 & TRN & & \\
\hline CHEMBL3193835 & 688730 & 6.1624 & 5.9225 & TRN & & \\
\hline CHEMBL1308313 & 688730 & 6.0 & 5.8471 & TRN & & \\
\hline CHEMBL1504567 & 688730 & 4.5411 & 4.6341 & TRN & & \\
\hline CHEMBL1352836 & 688730 & 5.4769 & 5.2516 & TRN & & \\
\hline CHEMBL1885024 & 688730 & 5.7073 & 5.6788 & TRN & & \\
\hline CHEMBL1350790 & 688730 & 5.2381 & 4.8997 & TRN & & \\
\hline CHEMBL1444691 & 688730 & 5.0625 & 4.9521 & TRN & & \\
\hline CHEMBL1389204 & 688730 & 4.5696 & 4.6981 & TRN & & \\
\hline CHEMBL1425768 & 688730 & 5.047 & 4.9835 & TRN & & \\
\hline CHEMBL1977568 & 688730 & 5.1012 & 5.1632 & TRN & & \\
\hline CHEMBL532160 & 688730 & 5.4504 & 5.45799 & 9999999999 & & TRN \\
\hline CHEMBL1413660 & 688730 & 5.5147 & 5.4287 & TRN & & \\
\hline CHEMBL1561181 & 688730 & 5.1876 & 4.7843 & TRN & & \\
\hline CHEMBL1524916 & 688730 & 5.2665 & 5.2051 & TST & & \\
\hline CHEMBL3195828 & 688730 & 4.2505 & 4.1859 & TRN & & \\
\hline CHEMBL1440558 & 688730 & 4.81800 & 00000000 & 005 & 5.0244 & TRN \\
\hline CHEMBL1471841 & 688730 & 4.6456 & 4.6597 & TRN & & \\
\hline CHEMBL1438624 & 688730 & 5.358 & 5.1528 & TRN & & \\
\hline CHEMBL1600768 & 688730 & 5.0758 & 5.0403 & TRN & & \\
\hline CHEMBL1375849 & 688730 & 5.0533 & 5.1612 & TRN & & \\
\hline CHEMBL1331809 & 688730 & 4.7254 & 4.872 & TST & & \\
\hline CHEMBL1577993 & 688730 & 4.3933 & 4.9765 & TRN & & \\
\hline CHEMBL 3197314 & 688730 & 6.1096 & 5.8416 & TRN & & \\
\hline CHEMBL1899958 & 688730 & 4.6587 & 4.7886 & TRN & & \\
\hline CHEMBL1585657 & 688730 & 4.5645 & 4.6592 & TST & & \\
\hline CHEMBL1444221 & 688730 & 5.0828 & 5.1809 & TRN & & \\
\hline CHEMBL1380459 & 688730 & 5.0356 & 4.9413 & TRN & & \\
\hline CHEMBL1499792 & 688730 & 5.8986 & 5.9341 & TST & & \\
\hline CHEMBL1611753 & 688730 & 4.56800 & 00000000 & 005 & 4.563 & TRN \\
\hline CHEMBL1499544 & 688730 & 5.8286 & 6.1138 & TRN & & \\
\hline CHEMBL1519279 & 688730 & 6.0575 & 5.9918 & TRN & & \\
\hline CHEMBL1304487 & 688730 & 4.7701 & 4.6623 & TRN & & \\
\hline CHEMBL1572904 & 688730 & 4.9924 & 4.9795 & TRN & & \\
\hline
\end{tabular}


Supplemental Table S2.txt

\begin{tabular}{|c|c|c|c|c|c|c|}
\hline CHEMBL1441782 & 688730 & 4.6856 & 4.7449 & TRN & & \\
\hline CHEMBL1596003 & 688730 & \multicolumn{3}{|c|}{5.257000000000001} & 5.1564 & TRN \\
\hline CHEMBL1558220 & 688730 & 4.5857 & 4.7379 & TRN & & \\
\hline CHEMBL1371805 & 688730 & 4.7987 & 4.7982 & TRN & & \\
\hline CHEMBL1485218 & 688730 & 4.6042 & 4.7316 & TRN & & \\
\hline CHEMBL1520852 & 688730 & 5.0555 & 5.1122 & TRN & & \\
\hline CHEMBL 3196561 & 688730 & 4.4091 & 4.3292 & TRN & & \\
\hline CHEMBL1508582 & 688730 & 5.0646 & 5.1739 & TRN & & \\
\hline CHEMBL1458565 & 688730 & 5.1677 & 4.97 & TRN & & \\
\hline CHEMBL1350167 & 688730 & 4.0721 & 3.883 & TRN & & \\
\hline CHEMBL602400 & 688730 & 5.3095 & 5.4105 & TRN & & \\
\hline CHEMBL1612169 & 688730 & 4.5623 & 4.7714 & TRN & & \\
\hline CHEMBL1539759 & 688730 & 4.6769 & 4.8464 & TRN & & \\
\hline CHEMBL 3208420 & 688730 & 4.1395 & 4.4381 & TRN & & \\
\hline CHEMBL1412370 & 688730 & 4.6483 & 4.6867 & TRN & & \\
\hline CHEMBL 3196469 & 688730 & 4.227 & 4.461 & TRN & & \\
\hline CHEMBL1606490 & 688730 & 4.5676 & 4.2187 & TRN & & \\
\hline CHEMBL 3198512 & 688730 & 5.2863 & 5.2591 & TRN & & \\
\hline CHEMBL1598230 & 688730 & 5.5887 & 5.4816 & TST & & \\
\hline CHEMBL1302406 & 688730 & 4.8824 & 4.6885 & TRN & & \\
\hline CHEMBL1541883 & 688730 & 4.7733 & 4.8439 & TRN & & \\
\hline CHEMBL1511007 & 688730 & 4.9795 & 4.8709 & TRN & & \\
\hline CHEMBL1479550 & 688730 & 4.80399 & 999999999 & 99 & 4.7583 & \\
\hline CHEMBL1372805 & 688730 & 4.7038 & 4.6605 & TRN & & \\
\hline CHEMBL1341586 & 688730 & 4.5008 & 4.552 & TST & & \\
\hline CHEMBL1441603 & 688730 & 4.6758 & 4.6915 & TRN & & \\
\hline CHEMBL1550862 & 688730 & 5.4057 & 5.4405 & TRN & & \\
\hline CHEMBL1305974 & 688730 & 4.2707 & 4.5892 & TRN & & \\
\hline CHEMBL1437208 & 688730 & 4.5322 & 4.6882 & TRN & & \\
\hline CHEMBL580819 & 688730 & 4.2373 & 4.4132 & TRN & & \\
\hline CHEMBL1536190 & 688730 & 5.4763 & 5.2294 & TRN & & \\
\hline CHEMBL1450086 & 688730 & 5.2076 & 5.2527 & TST & & \\
\hline CHEMBL1558739 & 688730 & 4.47199 & (999999999 & 995 & 4.7028 & \\
\hline CHEMBL112597 & 688730 & 5.2613 & 5.0542 & TST & & \\
\hline CHEMBL1428950 & 688730 & 5.8011 & 5.8782 & TST & & \\
\hline CHEMBL 3197094 & 688730 & 4.69300 & 000000000 & 205 & 4.7506 & ת \\
\hline CHEMBL1366992 & 688730 & 5.7781 & 5.6653 & TST & & \\
\hline CHEMBL1341815 & 688730 & 4.7988 & 4.7005 & TST & & \\
\hline CHEMBL1546347 & 688730 & 5.7007 & 5.4707 & TST & & \\
\hline CHEMBL1303916 & 688730 & 5.0414 & 5.1089 & TST & & \\
\hline CHEMBL1430872 & 688730 & 4.7615 & 4.5405 & TST & & \\
\hline CHEMBL1409389 & 688730 & 5.2868 & 5.1878 & TST & & \\
\hline CHEMBL1527739 & 688730 & 4.7625 & 4.7888 & TST & & \\
\hline CHEMBL1595841 & 688730 & 5.7162 & 5.5823 & TST & & \\
\hline CHEMBL1571639 & 688730 & 5.1439 & 5.1687 & TST & & \\
\hline CHEMBL1532453 & 688730 & 4.7306 & 4.7966 & TST & & \\
\hline CHEMBL1332524 & 688730 & 4.6324 & 4.5 & TST & & \\
\hline CHEMBL1471612 & 688730 & 4.8002 & 4.8662 & TST & & \\
\hline
\end{tabular}




\begin{tabular}{|c|c|c|c|c|c|}
\hline \multirow[b]{2}{*}{ CHEMBL 3194601} & \multicolumn{5}{|c|}{ Supplemental Table S2.txt } \\
\hline & 688730 & 4.31 & 4.7771 & TST & \\
\hline CHEMBL1517752 & 688730 & 5.3607 & 5.25700 & 0000000001 & TST \\
\hline CHEMBL1504139 & 688730 & 5.1249 & 5.0184 & TST & \\
\hline CHEMBL1335722 & 688730 & 5.1834 & 5.2599 & TST & \\
\hline CHEMBL1384094 & 688730 & 4.7158 & 4.7412 & TST & \\
\hline CHEMBL1303653 & 688730 & 5.4731 & 5.6156 & TST & \\
\hline CHEMBL1373720 & 688730 & 4.6695 & 4.3087 & TST & \\
\hline CHEMBL599291 & 688730 & 4.6028 & 4.6753 & TST & \\
\hline CHEMBL1379675 & 688730 & 5.95 & 5.8603 & TST & \\
\hline CHEMBL1974112 & 688730 & 4.9802 & 4.8817 & TST & \\
\hline CHEMBL1565991 & 688730 & 5.1339 & 5.0224 & TST & \\
\hline CHEMBL1586472 & 688730 & 5.0851 & 5.0487 & TST & \\
\hline CHEMBL1447076 & 688730 & 4.8497 & 4.801 & TST & \\
\hline CHEMBL1306267 & 688730 & 5.6482 & 5.6737 & TST & \\
\hline CHEMBL1504171 & 688730 & 4.9366 & 5.1745 & TST & \\
\hline CHEMBL1450507 & 688730 & 4.3476 & 4.4067 & TST & \\
\hline CHEMBL1601153 & 688730 & 4.7183 & 4.9107 & TST & \\
\hline CHEMBL3191811 & 688730 & 5.1322 & 4.9997 & TST & \\
\hline CHEMBL1558210 & 688730 & 5.2073 & 5.1378 & TST & \\
\hline CHEMBL1490042 & 688730 & 4.7637 & 4.7277 & TST & \\
\hline CHEMBL1517141 & 688730 & 5.8897 & 6.1887 & TST & \\
\hline CHEMBL1444381 & 688730 & 4.5178 & 4.577 & TST & \\
\hline CHEMBL1983234 & 688730 & 4.7256 & 4.7825 & TST & \\
\hline CHEMBL1451725 & 688730 & 4.982 & 4.7595 & TST & \\
\hline CHEMBL1417590 & 688730 & 4.2871 & 4.0078 & TST & \\
\hline CHEMBL512366 & 688730 & 4.7668 & 4.7744 & TST & \\
\hline CHEMBL1429966 & 688730 & 4.0603 & 4.2463 & TST & \\
\hline CHEMBL1511682 & 688730 & 4.4792 & 4.4482 & TST & \\
\hline CHEMBL1393358 & 688730 & 4.7067 & 4.5114 & TST & \\
\hline CHEMBL1311453 & 688730 & 5.7169 & 5.6906 & TST & \\
\hline CHEMBL1351385 & 688730 & 4.78 & 4.7501 & TST & \\
\hline CHEMBL3198098 & 688730 & 4.2786 & 4.0399 & TST & \\
\hline CHEMBL1605875 & 688730 & 4.1945 & 4.3231 & TST & \\
\hline CHEMBL1455824 & 688730 & 5.6405 & 5.6906 & TST & \\
\hline CHEMBL1405935 & 688730 & 5.0759 & 5.2734 & TST & \\
\hline CHEMBL3190941 & 688730 & 6.8601 & 6.4008 & TST & \\
\hline CHEMBL3213019 & 688730 & 5.2041 & 5.1366 & TST & \\
\hline CHEMBL1417120 & 688730 & 4.7566 & 4.7443 & TST & \\
\hline CHEMBL1464102 & 688730 & 4.7678 & 4.761 & TST & \\
\hline CHEMBL1466630 & 688730 & 4.5241 & 4.7554 & TST & \\
\hline CHEMBL1998502 & 688730 & 4.6833 & 4.5828 & TST & \\
\hline CHEMBL1300477 & 688730 & 4.7318 & 4.8141 & TST & \\
\hline CHEMBL1990659 & 688730 & 5.5203 & 5.3341 & TST & \\
\hline CHEMBL1588476 & 688730 & 5.046 & 5.1097 & TST & \\
\hline CHEMBL1985350 & 688730 & 4.8228 & 4.7775 & TST & \\
\hline CHEMBL3198030 & 688730 & 3.9371 & 4.6262 & TST & \\
\hline CHEMBL1362247 & 688730 & 4.8763 & 4.9992 & TST & \\
\hline CHEMBL1408465 & 688730 & 4.5463 & 4.4407 & TST & \\
\hline
\end{tabular}


Supplemental Table S2.txt

\begin{tabular}{|c|c|c|c|c|c|}
\hline CHEMBL1568168 & 688730 & 4.0806 & 4.5132 & TST & \\
\hline CHEMBL1485865 & 688730 & 5.2979 & 5.379 & TST & \\
\hline CHEMBL1601301 & 688730 & 4.9914 & 4.7508 & TST & \\
\hline CHEMBL1481776 & 688730 & 3.3036 & 4.25 & TST & \\
\hline CHEMBL436913 & 688730 & 5.0394 & 5.0149 & TST & \\
\hline CHEMBL1320274 & 688730 & 5.4634 & 5.5233 & TST & \\
\hline CHEMBL1418656 & 688730 & 5.2075 & 5.11100 & 0000000001 & TST \\
\hline CHEMBL1596661 & 688730 & 5.235 & 4.9937 & TST & \\
\hline CHEMBL1376851 & 688730 & 4.8573 & 4.7169 & TST & \\
\hline CHEMBL 3212190 & 688730 & 4.6962 & 4.4809 & TST & \\
\hline CHEMBL1457747 & 688730 & 4.9074 & 4.8369 & TST & \\
\hline CHEMBL1457929 & 688730 & 2.9387 & 3.9954 & TST & \\
\hline CHEMBL1447259 & 688730 & 4.7495 & 4.7955 & TST & \\
\hline CHEMBL3197459 & 688730 & 4.5837 & 4.6962 & TST & \\
\hline CHEMBL1599408 & 688730 & 4.3974 & 4.3225 & TST & \\
\hline CHEMBL1417269 & 688730 & 4.4841 & 4.6224 & TST & \\
\hline CHEMBL1498509 & 688730 & 5.9355 & 5.6501 & TST & \\
\hline CHEMBL1529236 & 688730 & 4.8177 & 4.8019 & TST & \\
\hline CHEMBL1497549 & 688730 & 6.6308 & 6.0987 & TST & \\
\hline CHEMBL1538234 & 688730 & 5.4743 & 5.3627 & TST & \\
\hline CHEMBL1565520 & 688730 & 4.9806 & 5.0705 & TST & \\
\hline CHEMBL1373985 & 688730 & 4.5087 & 3.6302 & TST & \\
\hline CHEMBL1533442 & 688730 & 4.7919 & 4.8117 & TST & \\
\hline CHEMBL1484502 & 688730 & 4.8955 & 4.6539 & TST & \\
\hline CHEMBL1579152 & 688730 & 5.3285 & 5.2488 & TST & \\
\hline CHEMBL1313978 & 688730 & 5.3409 & 5.1065 & TST & \\
\hline CHEMBL1499183 & 688730 & 4.8737 & 4.8699 & TST & \\
\hline CHEMBL577102 & 688730 & 5.3378 & 5.2795 & TST & \\
\hline CHEMBL1483847 & 688730 & 4.9226 & 4.9147 & TST & \\
\hline CHEMBL1428563 & 688730 & 4.5209 & 4.652 & TST & \\
\hline CHEMBL1458973 & 688730 & 3.7973 & 3.7082 & TST & \\
\hline CHEMBL1532880 & 688730 & 4.60800 & 00000000 & 4.7587 & TST \\
\hline CHEMBL1310629 & 688730 & 5.1297 & 5.1099 & TST & \\
\hline CHEMBL1444767 & 688730 & 4.9104 & 4.9316 & TST & \\
\hline CHEMBL1309229 & 688730 & 4.976 & 4.9424 & TST & \\
\hline CHEMBL1543341 & 688730 & 4.7692 & 4.8728 & TST & \\
\hline CHEMBL1538880 & 688730 & 4.0225 & 4.7337 & TST & \\
\hline CHEMBL1594535 & 688730 & 4.3995 & 4.4113 & TST & \\
\hline CHEMBL1538389 & 688730 & 4.9861 & 4.8431 & TST & \\
\hline CHEMBL1352733 & 688730 & 5.1727 & 5.23799 & 99999999995 & I \\
\hline CHEMBL1518765 & 688730 & 4.6179 & 4.5841 & TST & \\
\hline CHEMBL1389212 & 688730 & 4.5768 & 4.6953 & TST & \\
\hline CHEMBL1599520 & 688730 & 5.4707 & 5.5472 & TST & \\
\hline CHEMBL1377078 & 688730 & 5.2305 & 5.0686 & TST & \\
\hline CHEMBL1313167 & 688730 & 4.5015 & 4.6668 & TST & \\
\hline CHEMBL1328083 & 688730 & 5.0888 & 4.9505 & TST & \\
\hline CHEMBL1309785 & 688730 & 4.6659 & 5.1382 & TST & \\
\hline CHEMBL1472532 & 688730 & 4.4193 & 4.625 & TST & \\
\hline
\end{tabular}




\begin{tabular}{|c|c|c|c|c|c|}
\hline \multicolumn{6}{|c|}{ Supplemental Table S2.txt } \\
\hline CHEMBL 3195220 & 688730 & 5.0248 & 4.9833 & TST & \\
\hline CHEMBL1338862 & 688730 & 4.8295 & 4.6439 & TST & \\
\hline CHEMBL1331865 & 688730 & 4.164 & 4.4488 & TST & \\
\hline CHEMBL1480241 & 688730 & 5.3062 & 5.2191 & TST & \\
\hline CHEMBL1302028 & 688730 & 5.6121 & 5.7956 & TST & \\
\hline CHEMBL1449459 & 688730 & 4.3636 & 4.3455 & TST & \\
\hline CHEMBL1562333 & 688730 & 4.6566 & 4.73600 & 0000000001 & TST \\
\hline CHEMBL147514 & 688730 & 5.5381 & 5.1813 & TST & \\
\hline CHEMBL1392329 & 688730 & 4.5114 & 4.5778 & TST & \\
\hline CHEMBL3189458 & 688730 & 4.5781 & 4.7003 & TST & \\
\hline CHEMBL3208179 & 688730 & 5.4065 & 5.398 & TST & \\
\hline CHEMBL1574683 & 688730 & 4.4757 & 4.5514 & TST & \\
\hline CHEMBL1491019 & 688730 & 5.6313 & 5.6182 & TST & \\
\hline CHEMBL1431017 & 688730 & 4.6794 & 4.7232 & TST & \\
\hline CHEMBL1411210 & 688730 & 6.0841 & 5.8924 & TST & \\
\hline CHEMBL585840 & 688730 & 4.5054 & 4.7338 & TST & \\
\hline CHEMBL1550490 & 688730 & 4.8086 & 4.9122 & TST & \\
\hline CHEMBL1339613 & 688730 & 4.8143 & 4.8337 & TST & \\
\hline CHEMBL1036 & 688730 & 4.5327 & 4.5827 & TST & \\
\hline CHEMBL1388234 & 688730 & 4.8166 & 5.02 & TST & \\
\hline CHEMBL570400 & 688730 & 4.8101 & 5.1066 & TST & \\
\hline CHEMBL1347582 & 688730 & 4.582 & 4.7139 & TST & \\
\hline CHEMBL1464561 & 688730 & 5.2583 & 5.3808 & TST & \\
\hline CHEMBL1489113 & 688730 & 4.7603 & 4.7787 & TST & \\
\hline CHEMBL1533225 & 688730 & 4.9347 & 5.0357 & TST & \\
\hline CHEMBL 3613186 & 1514933 & 7.8861 & 7.9396 & TRN & \\
\hline CHEMBL3613198 & 1514933 & 9.0 & 8.8606 & TRN & \\
\hline CHEMBL3612648 & 1514933 & 3.6021 & 6.7178 & TST & \\
\hline CHEMBL3612079 & 1514933 & 6.7959 & 6.7719 & TRN & \\
\hline CHEMBL3612659 & 1514933 & 4.7959 & 6.6131 & TST & \\
\hline CHEMBL 3613195 & 1514933 & 7.301 & 7.5534 & TRN & \\
\hline CHEMBL 3612643 & 1514933 & 3.6021 & 5.6557 & TST & \\
\hline CHEMBL3613307 & 1514933 & 7.8861 & 7.904 & TRN & \\
\hline CHEMBL3612662 & 1514933 & 6.8996 & 6.9209 & TRN & \\
\hline CHEMBL3612655 & 1514933 & 5.2007 & 5.2607 & TRN & \\
\hline CHEMBL3613306 & 1514933 & 7.3979 & 7.5042 & TRN & \\
\hline CHEMBL3613309 & 1514933 & 7.7959 & 7.7396 & TRN & \\
\hline CHEMBL 3612663 & 1514933 & 6.8996 & 6.9395 & TRN & \\
\hline CHEMBL3613190 & 1514933 & 7.699 & 7.5885 & TRN & \\
\hline CHEMBL3612646 & 1514933 & 7.301 & 7.3088 & TRN & \\
\hline CHEMBL3613196 & 1514933 & 7.3979 & 7.189 & TRN & \\
\hline CHEMBL 3613184 & 1514933 & 7.6021 & 7.82299 & 99999999995 & TRN \\
\hline CHEMBL3612656 & 1514933 & 4.8861 & 5.572 & TST & \\
\hline CHEMBL3612642 & 1514933 & 5.4949 & 5.4134 & TRN & \\
\hline CHEMBL3613189 & 1514933 & 7.8861 & 7.8268 & TRN & \\
\hline CHEMBL 3613178 & 1514933 & 7.0 & 7.0121 & TRN & \\
\hline CHEMBL3612641 & 1514933 & 6.301 & 6.3246 & TRN & \\
\hline CHEMBL3613192 & 1514933 & 6.2007 & 6.2056 & TRN & \\
\hline
\end{tabular}


Supplemental Table S2.txt

\begin{tabular}{|c|c|c|c|c|c|}
\hline CHEMBL3613177 & 1514933 & 7.2007 & 7.2139 & TRN & \\
\hline CHEMBL 3612654 & 1514933 & 5.0969 & 5.0715 & TRN & \\
\hline CHEMBL3613199 & 1514933 & 7.8861 & 7.9503 & TRN & \\
\hline CHEMBL3613191 & 1514933 & 7.0 & 7.1508 & TST & \\
\hline CHEMBL3612645 & 1514933 & 4.7959 & \multicolumn{2}{|c|}{4.7330000000000005} & TRN \\
\hline CHEMBL3612660 & 1514933 & 6.6021 & 6.5977 & TRN & \\
\hline CHEMBL3612658 & 1514933 & 5.301 & 7.657 & TST & \\
\hline CHEMBL3613188 & 1514933 & 7.2007 & 7.2564 & TRN & \\
\hline CHEMBL 3613308 & 1514933 & 6.8996 & 7.0412 & TRN & \\
\hline CHEMBL3612666 & 1514933 & 7.4949 & 7.671 & TRN & \\
\hline CHEMBL3613182 & 1514933 & 7.0 & 7.0388 & TRN & \\
\hline CHEMBL3612647 & 1514933 & 7.0969 & 6.9491 & TRN & \\
\hline CHEMBL3613197 & 1514933 & 9.0 & 8.7327 & TRN & \\
\hline CHEMBL3613193 & 1514933 & 7.699 & 7.8331 & TRN & \\
\hline CHEMBL3613187 & 1514933 & 7.8861 & 7.8534 & TRN & \\
\hline CHEMBL3613180 & 1514933 & 7.0 & 7.0717 & TRN & \\
\hline CHEMBL3613179 & 1514933 & 7.301 & 7.2724 & TRN & \\
\hline CHEMBL 3612661 & 1514933 & 7.3979 & 7.5598 & TRN & \\
\hline CHEMBL3612651 & 1514933 & 5.699 & 5.7686 & TRN & \\
\hline CHEMBL3613176 & 1514933 & 7.3979 & 7.3179 & TRN & \\
\hline CHEMBL3613194 & 1514933 & 5.2007 & 5.1747 & TRN & \\
\hline CHEMBL 3613183 & 1514933 & 7.301 & 7.0056 & TRN & \\
\hline CHEMBL 3612667 & 1514933 & 7.3979 & 7.2888 & TRN & \\
\hline CHEMBL3612652 & 1514933 & 4.3979 & 4.3844 & TRN & \\
\hline CHEMBL3612644 & 1514933 & 5.0969 & 5.1222 & TRN & \\
\hline CHEMBL3613181 & 1514933 & 7.4949 & 7.5781 & TST & \\
\hline CHEMBL3612649 & 1514933 & 5.0969 & 6.1397 & TST & \\
\hline CHEMBL 3612650 & 1514933 & 6.3979 & 6.994 & TST & \\
\hline CHEMBL3612657 & 1514933 & 6.301 & 5.9055 & TST & \\
\hline CHEMBL3613305 & 1514933 & 9.0 & 8.1294 & TST & \\
\hline CHEMBL3613185 & 1514933 & 7.8861 & 7.1623 & TST & \\
\hline CHEMBL3612665 & 1514933 & 7.4949 & 7.5036 & TST & \\
\hline CHEMBL3612653 & 1514933 & 4.699 & 5.6922 & TST & \\
\hline CHEMBL 3612664 & 1514933 & 6.8996 & 7.6413 & TST & \\
\hline CHEMBL3935482 & 1640799 & 6.6696 & 6.6829 & TRN & \\
\hline CHEMBL3955207 & 1640799 & 7.6021 & 7.2354 & TST & \\
\hline CHEMBL3941613 & 1640799 & 6.3125 & 6.2961 & TST & \\
\hline CHEMBL3977049 & 1640799 & 7.3768 & 7.2849 & TRN & \\
\hline CHEMBL3945618 & 1640799 & 7.3665 & 7.4238 & TRN & \\
\hline CHEMBL 2419705 & 1640799 & 7.4559 & 7.4444 & TRN & \\
\hline CHEMBL3935111 & 1640799 & 7.7447 & 7.3965 & TRN & \\
\hline CHEMBL3941313 & 1640799 & 7.2596 & 7.2494 & TRN & \\
\hline CHEMBL3928549 & 1640799 & 5.8268 & 5.7743 & TST & \\
\hline CHEMBL3901978 & 1640799 & 7.3979 & 7.03299 & 99999999995 & TRN \\
\hline CHEMBL3914416 & 1640799 & 6.8601 & 6.9504 & TRN & \\
\hline CHEMBL3913243 & 1640799 & 7.2757 & 7.1797 & TRN & \\
\hline CHEMBL3946798 & 1640799 & 7.3098 & 7.24700 & 0000000001 & TRN \\
\hline CHEMBL 2419706 & 1640799 & 7.8097 & 7.6617 & TRN & \\
\hline
\end{tabular}


Supplemental Table S2.txt

\begin{tabular}{|c|c|c|c|c|}
\hline IEM & 799 & 528 & 79 & \\
\hline HEMBL3963547 & 640799 & 3.7212 & 7.2545 & \\
\hline$A F M B$ & 99 & 7696 & & \\
\hline HEMBL3949450 & 799 & 5.9245 & 0654 & \\
\hline HEMBL3975140 & 640799 & 7.3665 & 3313 & \\
\hline HEMBL3949925 & 640799 & 5.6478 & .9213 & \\
\hline HEMBL 2419700 & 799 & 6.9208 & .9373 & \\
\hline HEMBL3947374 & & & 409 & \\
\hline HEMBL3964642 & L640799 & 7.4318 & 7.2771 & \\
\hline HEMBL3940683 & 640799 & 7.4559 & 7.2998 & \\
\hline HEMBL3933577 & 640799 & 7.1135 & 7.2664 & \\
\hline AEMBL3956527 & 99 & 7.585 & . 7089 & \\
\hline HEMBL39 & & & .5766 & \\
\hline HEMBL3967549 & 799 & 7.4815 & 7.3905 & \\
\hline AEMBL3961412 & 99 & 86 & 6.8599 & \\
\hline HEMBL 3927814 & 64 & 5.9318 & 5.9117 & \\
\hline HEMBL3928915 & 99 & 83 & 7.5098 & \\
\hline HEMBL 3938947 & 99 & 805 & 7.1883 & \\
\hline AEMBL3932754 & 99 & 7.5452 & 6.4702 & \\
\hline HEMBL395 & 99 & & 7.1871 & \\
\hline HEMBL 2419 & 99 & 7. & 7.4645 & \\
\hline AEMBL3S & 9 & 7. & 78 & \\
\hline AEMBL3S & 99 & 739 & 7.1143 & \\
\hline HEMBL3946751 & 99 & 7.0 & 6.8635 & \\
\hline HEMBL3922251 & & 7. & & \\
\hline †EMBL39 & 64 & 7. & 6.9 & \\
\hline AEMBL3S & 164 & 8. & 64 & \\
\hline AEMBL3S & 99 & 76 & 177 & \\
\hline HEMBL396 & 99 & & 6.9412 & \\
\hline HEMBL3960803 & 99 & 7. & 7.3371 & \\
\hline HEMBL3933643 & 6 & 5. & 5.7521 & \\
\hline HEMBL3 & 9 & & 7.4 & \\
\hline HEMBL 2 & & & 7.1909 & \\
\hline HEMBL3956490 & 99 & 7. & 7.0912 & \\
\hline HEMBL3891789 & 64 & 7.4318 & 7.3845 & \\
\hline HEMBL3924532 & 64 & 6.0731 & 6.1885 & \\
\hline HEMBL3 & 9 & 38 & 7.2295 & \\
\hline HEMBL3942389 & 16 & 5.3 & 5.8684 & \\
\hline HEMBL3984137 & 640799 & 6.9788 & 6.8688 & \\
\hline HEMBL 3985156 & 64 & 7. & 7.0669 & \\
\hline HEMBL3925030 & 164 & 7.4 & 7.5563 & \\
\hline CHEMBL3898270 & 1640799 & 6.0 & 7.2121 & \\
\hline HEMBL3969046 & 1640799 & 5.52 & 5.4034 & \\
\hline HEMBL3935158 & 1640799 & 6.2612 & 6.2417 & \\
\hline EMBL394 & 64 & 6.2403 & 6.0654 & \\
\hline CHEMBL3916481 & 1640799 & 7.5086 & 7.535 & \\
\hline CHEMBL3983088 & 1640799 & 7.4318 & 7.4407 & \\
\hline CHEMBL3900771 & 1640799 & 6.3768 & 6.6599 & \\
\hline
\end{tabular}

Page 18705 


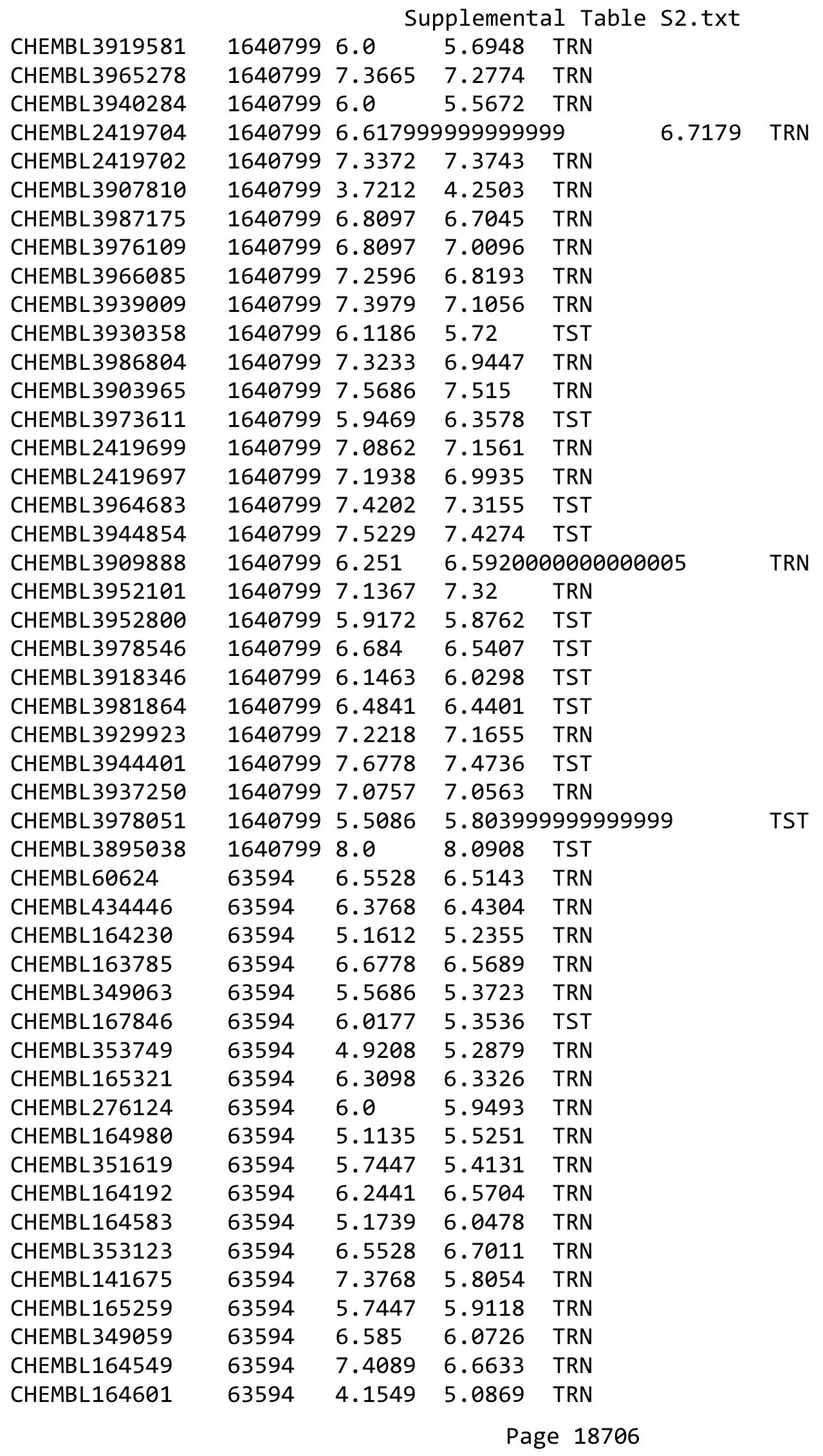




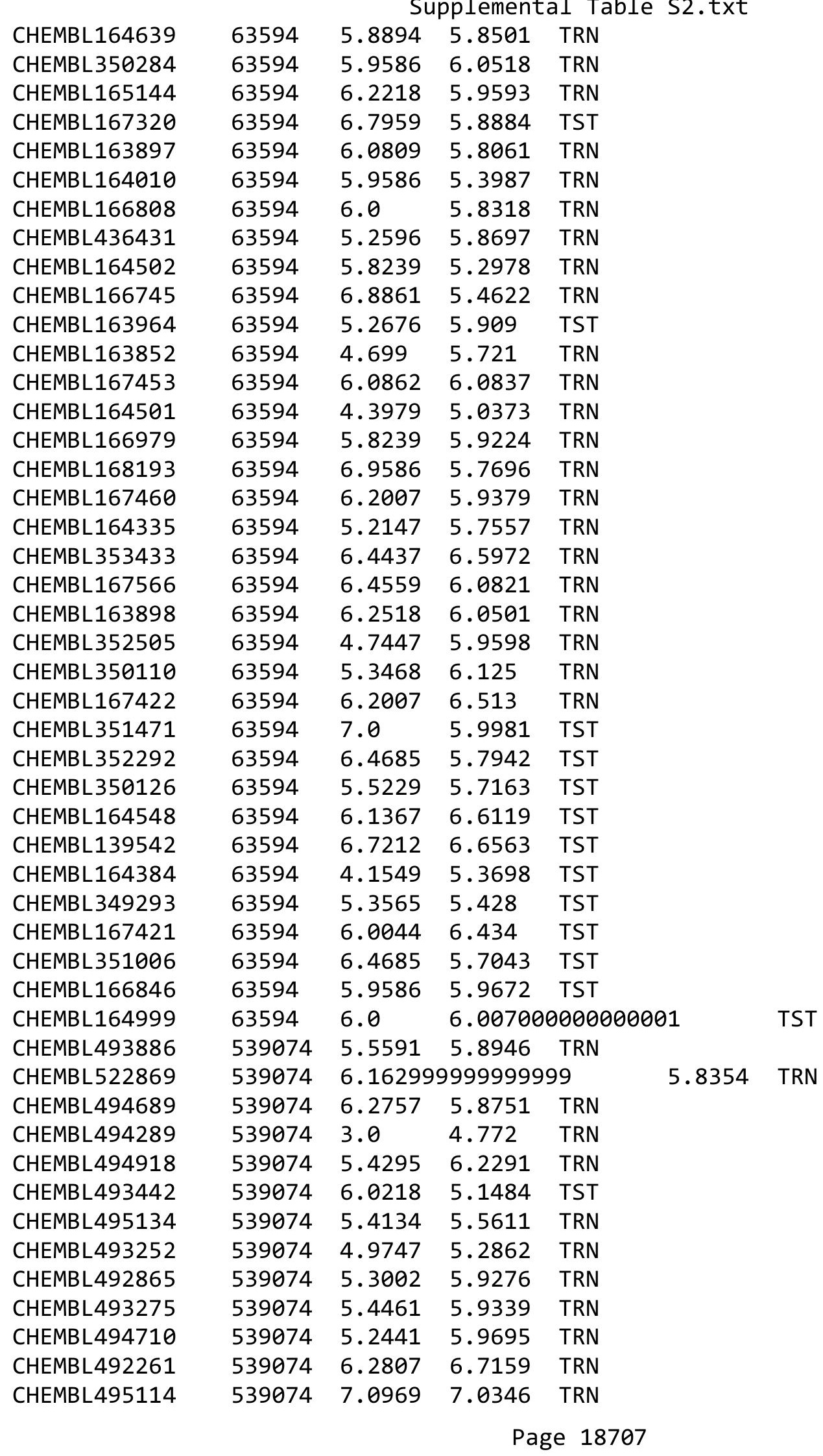




\begin{tabular}{|c|c|c|c|c|c|c|}
\hline & & \multicolumn{5}{|c|}{ Supplemental Table S2.txt } \\
\hline CHEMBL522541 & 539074 & 4.9245 & 5.4788 & TRN & & \\
\hline CHEMBL494894 & 539074 & 6.301 & 5.8111 & TRN & & \\
\hline CHEMBL492438 & 539074 & 6.0 & 5.8753 & TRN & & \\
\hline CHEMBL493071 & 539074 & 6.3197 & 6.1476 & TRN & & \\
\hline CHEMBL495486 & 539074 & 5.3595 & 5.3464 & TRN & & \\
\hline CHEMBL493453 & 539074 & 5.0278 & 5.6513 & TST & & \\
\hline CHEMBL494273 & 539074 & 6.20200 & 00000000 & & 5.8621 & TRN \\
\hline CHEMBL494085 & 539074 & 5.8386 & 5.6444 & TRN & & \\
\hline CHEMBL493053 & 539074 & 7.1675 & 6.8123 & TRN & & \\
\hline CHEMBL494105 & 539074 & 6.4318 & 6.1366 & TRN & & \\
\hline CHEMBL494690 & 539074 & 6.2299 & 6.1363 & TRN & & \\
\hline CHEMBL448888 & 539074 & 4.9208 & 5.6791 & TST & & \\
\hline CHEMBL493681 & 539074 & 6.2418 & 6.021 & TRN & & \\
\hline CHEMBL492425 & 539074 & 6.3675 & 5.6881 & TRN & & \\
\hline CHEMBL494061 & 539074 & 6.684 & 5.0393 & TRN & & \\
\hline CHEMBL524038 & 539074 & 6.1972 & 6.1497 & TRN & & \\
\hline CHEMBL492676 & 539074 & 6.8356 & 6.2816 & TRN & & \\
\hline CHEMBL492846 & 539074 & 6.9957 & 6.3103 & TRN & & \\
\hline CHEMBL493086 & 539074 & 5.007 & 5.6454 & TRN & & \\
\hline CHEMBL523345 & 539074 & 5.6351 & 6.2778 & TRN & & \\
\hline CHEMBL523502 & 539074 & 6.3696 & 6.8001 & TRN & & \\
\hline CHEMBL495334 & 539074 & 5.5544 & 5.4902 & TRN & & \\
\hline CHEMBL493901 & 539074 & 6.6038 & 6.8491 & TRN & & \\
\hline CHEMBL522320 & 539074 & 6.0 & 6.0948 & TRN & & \\
\hline CHEMBL494062 & 539074 & 5.295 & 5.0076 & TST & & \\
\hline CHEMBL523195 & 539074 & 6.5513 & 6.9793 & TRN & & \\
\hline CHEMBL493052 & 539074 & 6.4012 & 6.9197 & TRN & & \\
\hline CHEMBL493243 & 539074 & 3.0 & 5.0151 & TST & & \\
\hline CHEMBL494711 & 539074 & 5.2668 & 6.0725 & TRN & & \\
\hline CHEMBL492644 & 539074 & 5.699 & 4.8487 & TST & & \\
\hline CHEMBL493887 & 539074 & 6.556 & 6.1461 & TRN & & \\
\hline CHEMBL493913 & 539074 & 5.7399 & 5.9214 & TRN & & \\
\hline CHEMBL492620 & 539074 & 7.0177 & 6.1731 & TRN & & \\
\hline CHEMBL494288 & 539074 & 5.3536 & 4.9115 & TST & & \\
\hline CHEMBL523671 & 539074 & 6.4473 & 6.4206 & TST & & \\
\hline CHEMBL522185 & 539074 & 5.1403 & 5.0107 & TST & & \\
\hline CHEMBL494063 & 539074 & 4.8928 & 5.402 & TST & & \\
\hline CHEMBL524012 & 539074 & 6.2197 & 6.0566 & TRN & & \\
\hline CHEMBL495283 & 539074 & 6.2314 & 5.7813 & TST & & \\
\hline CHEMBL492441 & 539074 & 6.0691 & 5.9396 & TST & & \\
\hline CHEMBL451379 & 539074 & 5.1681 & 5.7838 & TST & & \\
\hline CHEMBL493087 & 539074 & $6.7520 e$ & 00000000 & 01 & 6.0875 & I RT \\
\hline CHEMBL494707 & 539074 & 6.1811 & 6.0876 & TRN & & \\
\hline CHEMBL493452 & 539074 & 5.0039 & 5.7929 & TST & & \\
\hline CHEMBL523843 & 539074 & 7.4202 & 6.3286 & TRN & & \\
\hline CHEMBL494064 & 539074 & 6.1221 & 5.9375 & TRN & & \\
\hline CHEMBL522510 & 539074 & 6.9469 & 6.0688 & TRN & & \\
\hline CHEMBL493902 & 539074 & 6.5607 & 6.9313 & TRN & & \\
\hline
\end{tabular}


Supplemental Table S2.txt

\begin{tabular}{|c|c|c|c|c|c|}
\hline CHEMBL492641 & 539074 & 7.1427 & 6.6106 & TST & \\
\hline CHEMBL492442 & 539074 & 6.1261 & 5.9875 & TST & \\
\hline CHEMBL495328 & 539074 & 6.0 & \multicolumn{2}{|c|}{5.9510000000000005} & TRN \\
\hline CHEMBL494260 & 539074 & 5.9431 & 5.1723 & TST & \\
\hline CHEMBL493078 & 539074 & 7.2924 & 7.2132 & TRN & \\
\hline CHEMBL522886 & 539074 & 5.2147 & 5.7844 & TST & \\
\hline CHEMBL523167 & 539074 & 6.0 & 6.093 & TRN & \\
\hline CHEMBL522516 & 539074 & 5.4547 & 6.0316 & TRN & \\
\hline CHEMBL3959013 & 1641311 & 5.0 & 5.0784 & TST & \\
\hline CHEMBL3890805 & 1641311 & 5.0 & 4.8175 & TRN & \\
\hline CHEMBL3946133 & 1641311 & 5.0 & 4.8307 & TRN & \\
\hline CHEMBL 3984444 & 1641311 & 5.0 & 5.1658 & TST & \\
\hline CHEMBL3963832 & 1641311 & 5.0 & 5.4604 & TST & \\
\hline CHEMBL3919742 & 1641311 & 5.0 & 4.9804 & TRN & \\
\hline CHEMBL3950928 & 1641311 & 5.0 & 4.8825 & TRN & \\
\hline CHEMBL3956195 & 1641311 & 5.0 & 5.3606 & TRN & \\
\hline CHEMBL3914621 & 1641311 & 5.0 & 5.3951 & TRN & \\
\hline CHEMBL3929687 & 1641311 & 5.0 & 5.3573 & TRN & \\
\hline CHEMBL3915257 & 1641311 & 5.0 & 5.2105 & TRN & \\
\hline CHEMBL3931327 & 1641311 & 5.0 & 5.8678 & TRN & \\
\hline CHEMBL3911495 & 1641311 & 6.2596 & 5.9527 & TRN & \\
\hline CHEMBL3961942 & 1641311 & 8.0 & 6.1769 & TRN & \\
\hline CHEMBL3983551 & 1641311 & 5.0 & 4.9204 & TRN & \\
\hline CHEMBL3940834 & 1641311 & 5.0 & 5.1386 & TRN & \\
\hline CHEMBL 3971322 & 1641311 & 5.0 & 5.0937 & TRN & \\
\hline CHEMBL3959485 & 1641311 & 5.0 & 4.8193 & TRN & \\
\hline CHEMBL3946382 & 1641311 & 5.0 & 4.8966 & TRN & \\
\hline CHEMBL 3891821 & 1641311 & 5.0 & 5.2389 & TRN & \\
\hline CHEMBL3943986 & 1641311 & 6.2596 & 5.7846 & TRN & \\
\hline CHEMBL3969543 & 1641311 & 5.0 & 5.1505 & TRN & \\
\hline CHEMBL3916345 & 1641311 & 5.0 & 5.4117 & TRN & \\
\hline CHEMBL3908150 & 1641311 & 5.0 & 5.2345 & TST & \\
\hline CHEMBL 3964884 & 1641311 & 8.0 & 6.0709 & TRN & \\
\hline CHEMBL3950633 & 1641311 & 5.0 & 5.157 & TRN & \\
\hline CHEMBL 3984727 & 1641311 & 5.0 & 4.8457 & TST & \\
\hline CHEMBL3902091 & 1641311 & 5.0 & 4.8383 & TST & \\
\hline CHEMBL3962520 & 1641311 & 5.0 & 5.9479 & TRN & \\
\hline CHEMBL 3894395 & 1641311 & 5.0 & 4.8516 & TRN & \\
\hline CHEMBL3906328 & 1641311 & 6.2596 & 5.4212 & TRN & \\
\hline CHEMBL3899091 & 1641311 & 5.0 & 4.9231 & TRN & \\
\hline CHEMBL3955573 & 1641311 & 5.0 & 4.8209 & TRN & \\
\hline CHEMBL3936315 & 1641311 & 5.0 & 4.8683 & TST & \\
\hline CHEMBL3914780 & 1641311 & 5.0 & 4.8966 & TST & \\
\hline CHEMBL3902512 & 1641311 & 5.0 & 4.8739 & TRN & \\
\hline CHEMBL3909257 & 1641311 & 5.0 & 4.9899 & TRN & \\
\hline CHEMBL3806228 & 1641311 & 5.0 & 5.1656 & TRN & \\
\hline CHEMBL3961122 & 1641311 & 6.2596 & 5.5122 & TRN & \\
\hline CHEMBL 3894743 & 1641311 & 6.2596 & 6.1901 & TRN & \\
\hline
\end{tabular}

Page 18709 
Supplemental Table S2.txt

\begin{tabular}{|c|c|c|c|c|}
\hline CHEMBL 3901264 & 641311 & 5.0 & 4.8995 & TS \\
\hline HEMBL 3969032 & 641311 & 5.0 & 4.8274 & \\
\hline HEMBL 392 & 641311 & 6.2596 & 8264 & $\mathrm{RN}$ \\
\hline HEMBL3960130 & 641311 & 5.0 & 1143 & RN \\
\hline HEMBL3932612 & 641311 & 5.0 & 0638 & N \\
\hline HEMBL3959531 & 641311 & 5.0 & .3691 & \\
\hline HEMBL3953484 & 311 & 5.0 & 7471 & RN \\
\hline HEMBL3902489 & 311 & 5.0 & .1421 & \\
\hline HEMBL3900390 & 311 & 5.0 & .2323 & RN \\
\hline HEMBL3935121 & 311 & 5.0 & 3751 & $2 \mathrm{~N}$ \\
\hline HEMBL3934086 & 311 & 5.0 & .3855 & \\
\hline HEMBL 3922 & 311 & 6.2596 & 8973 & \\
\hline HEMBL390 & 311 & 5.0 & 1425 & RN \\
\hline HEMBL3931513 & 311 & 5.0 & 827 & RN \\
\hline HEMBL3973117 & 311 & 5.0 & 9903 & ST \\
\hline HEMBL3945040 & 11 & 5.0 & 0023 & RN \\
\hline HEMBL392 & 11 & 5.0 & 8902 & RN \\
\hline HEMBL 395 & 11 & 6.2596 & 7167 & \\
\hline HEMBL3893512 & 311 & 5.0 & 5.1261 & $2 \mathrm{~N}$ \\
\hline HEMBL 390 & 311 & 5.0 & 3556 & N \\
\hline HEMBL390 & 164 & 5.0 & 9818 & ו \\
\hline HEMBL395 & 11 & 6.25 & 2876 & ST \\
\hline HEMBL 392 & 11 & 5.0 & 3271 & $\mathrm{RN}$ \\
\hline HEMBL 397 & 311 & 5.0 & 4.9272 & N \\
\hline HEMBL 398 & 11 & 5.0 & 169 & $\Gamma \mathrm{RN}$ \\
\hline HEMBL 394 & 16 & 5 . & 891 & RN \\
\hline HEMBL39e & 11 & 5.6 & 438 & RN \\
\hline HEMBL393 & 11 & 5.0 & 038 & RN \\
\hline HEMBL 390 & 311 & 5.0 & 9667 & TST \\
\hline HEMBL3963325 & 11 & 5.0 & & TRN \\
\hline HEMBL390 & 164 & 6.25 & 554 & $\mathrm{RN}$ \\
\hline HEMBL 391 & 11 & 5.0 & 895 & TRN \\
\hline HEMBL 39 & 11 & 5.0 & 324 & $\Gamma R N$ \\
\hline HEMBL395 & 11 & 5.0 & 5148 & TRN \\
\hline HEMBL3908658 & 311 & 5.0 & 0597 & TRN \\
\hline HEMBL390 & 11 & 6.25 & 2267 & TRN \\
\hline CHEMBL 39 & 16 & 5.0 & 1853 & IST \\
\hline CHEMBL394 & 16 & 5.0 & 3843 & TRN \\
\hline HEMBL3891379 & 311 & 5.0 & 4.8068 & TRN \\
\hline HEMBL 398 & 311 & 6.2596 & 5227 & TRN \\
\hline CHEMBL396 & 164 & 5.0 & 9909 & TRN \\
\hline CHEMBL3928621 & 164 & 5.0 & 4.918 & TRN \\
\hline CHEMBL3948382 & 16 & 5.0 & 5.0695 & TRN \\
\hline CHEMBL3962518 & 311 & 5.0 & 4.8074 & TRN \\
\hline CHEMBL 394 & 11 & 5 . & 3749 & TIV \\
\hline CHEMBL 389 & 164 & . & .8772 & \\
\hline CHEMBL3917559 & 1641311 & 5.0 & 5.8926 & RIV \\
\hline CHEMBL3954063 & 1641311 & 5.0 & 4.8523 & ГRN \\
\hline
\end{tabular}

Page 18710 
Supplemental Table S2.txt

\begin{tabular}{|c|c|c|c|c|c|}
\hline CHEMBL 3937519 & 1641311 & 6.2596 & 6.2429 & TST & \\
\hline CHEMBL3919058 & 1641311 & 5.0 & 4.8315 & TRN & \\
\hline CHEMBL3908612 & 1641311 & 5.0 & 4.9478 & TST & \\
\hline CHEMBL 3985786 & 1641311 & 5.0 & 5.6068 & TRN & \\
\hline CHEMBL3906875 & 1641311 & 5.0 & 5.521 & TRN & \\
\hline CHEMBL3910328 & 1641311 & 5.0 & 5.0708 & TRN & \\
\hline CHEMBL 3943275 & 1641311 & 8.0 & 6.2762 & TRN & \\
\hline CHEMBL 3943827 & 1641311 & 8.0 & 6.1143 & TRN & \\
\hline CHEMBL 3961581 & 1641311 & 5.0 & 4.8068 & TRN & \\
\hline CHEMBL3946520 & 1641311 & 5.0 & 5.2422 & TRN & \\
\hline CHEMBL3805061 & 1641311 & 6.2596 & 6.1393 & TRN & \\
\hline CHEMBL3922602 & 1641311 & 5.0 & 5.7961 & TRN & \\
\hline CHEMBL 3947550 & 1641311 & 5.0 & 4.922 & TRN & \\
\hline CHEMBL 3805337 & 1641311 & 6.2596 & 5.8069 & TRN & \\
\hline CHEMBL 3961281 & 1641311 & 5.0 & 4.9032 & TRN & \\
\hline CHEMBL3806195 & 1641311 & 6.2596 & 6.236006 & 0000000001 & TRN \\
\hline CHEMBL3907586 & 1641311 & 5.0 & 4.8988 & TRN & \\
\hline CHEMBL3979594 & 1641311 & 5.0 & 4.8267 & TRN & \\
\hline CHEMBL 3957723 & 1641311 & 5.0 & 4.812 & TRN & \\
\hline CHEMBL 3920650 & 1641311 & 5.0 & 4.8853 & TRN & \\
\hline CHEMBL 3919255 & 1641311 & 6.2596 & 6.1095 & TRN & \\
\hline CHEMBL 3937838 & 1641311 & 5.0 & 5.0906 & TRN & \\
\hline CHEMBL3903827 & 1641311 & 5.0 & 5.23 & TST & \\
\hline CHEMBL 3923649 & 1641311 & 5.0 & 5.1763 & TST & \\
\hline CHEMBL3952571 & 1641311 & 5.0 & 4.8778 & TRN & \\
\hline CHEMBL 3945844 & 1641311 & 5.0 & 5.5256 & TRN & \\
\hline CHEMBL 3898042 & 1641311 & 5.0 & 4.8164 & TRN & \\
\hline CHEMBL 3804882 & 1641311 & 5.0 & 5.8555 & TRN & \\
\hline CHEMBL3896111 & 1641311 & 5.0 & 5.3214 & TST & \\
\hline CHEMBL3944692 & 1641311 & 5.0 & 5.282 & TRN & \\
\hline CHEMBL3915903 & 1641311 & 5.0 & 4.8661 & TRN & \\
\hline CHEMBL3967978 & 1641311 & 6.2596 & 5.7289 & TRN & \\
\hline CHEMBL3964862 & 1641311 & 5.0 & 5.1701 & TRN & \\
\hline CHEMBL 3925201 & 1641311 & 5.0 & 5.1138 & TRN & \\
\hline CHEMBL3938430 & 1641311 & 5.0 & 5.4178 & TST & \\
\hline CHEMBL 3923690 & 1641311 & 8.0 & 6.2041 & TST & \\
\hline CHEMBL3917126 & 1641311 & 5.0 & 5.0409 & TST & \\
\hline CHEMBL3949799 & 1641311 & 5.0 & 5.0491 & TRN & \\
\hline CHEMBL3951359 & 1641311 & 5.0 & 5.0459 & TRN & \\
\hline CHEMBL3913035 & 1641311 & 5.0 & 4.855 & TRN & \\
\hline CHEMBL 3900762 & 1641311 & 5.0 & 4.8143 & TRN & \\
\hline CHEMBL3908064 & 1641311 & 5.0 & 5.3756 & TRN & \\
\hline CHEMBL3922388 & 1641311 & 5.0 & 4.8518 & TRN & \\
\hline CHEMBL3960691 & 1641311 & 5.0 & 4.9826 & TRN & \\
\hline CHEMBL3977922 & 1641311 & 5.0 & 5.8943 & TRN & \\
\hline CHEMBL3909896 & 1641311 & 5.0 & 4.8013 & TRN & \\
\hline CHEMBL 3973482 & 1641311 & 5.0 & 5.5866 & TRN & \\
\hline CHEMBL3981331 & 1641311 & 5.0 & 5.4323 & TRN & \\
\hline
\end{tabular}




\begin{tabular}{|c|c|c|c|c|}
\hline \multicolumn{5}{|c|}{ Supplemental Table s2.txt } \\
\hline CHEMBL3915079 & 1641311 & 5.0 & 5.1205 & TRN \\
\hline CHEMBL3952804 & 1641311 & 5.0 & 4.9913 & TRN \\
\hline CHEMBL3919714 & 1641311 & 5.0 & 4.8092 & TRN \\
\hline CHEMBL3896991 & 1641311 & 5.0 & 5.5396 & TRN \\
\hline CHEMBL3892931 & 1641311 & 6.2596 & 5.6754 & TRN \\
\hline CHEMBL3972988 & 1641311 & 5.0 & 5.1553 & TRN \\
\hline CHEMBL 3924120 & 1641311 & 5.0 & 4.9786 & TST \\
\hline CHEMBL3958476 & 1641311 & 6.2596 & 5.8932 & TRN \\
\hline CHEMBL 3965130 & 1641311 & 5.0 & 5.1245 & TST \\
\hline CHEMBL3972643 & 1641311 & 5.0 & 4.8586 & TRN \\
\hline CHEMBL3976500 & 1641311 & 5.0 & 5.1374 & TST \\
\hline CHEMBL 3805019 & 1641311 & 5.0 & 5.2996 & TST \\
\hline CHEMBL3930845 & 1641311 & 8.0 & 6.1743 & TST \\
\hline CHEMBL 3976222 & 1641311 & 6.2596 & 5.7076 & TST \\
\hline CHEMBL 3935531 & 1641311 & 6.2596 & 5.9632 & TST \\
\hline CHEMBL3984593 & 1641311 & 5.0 & 5.1647 & TST \\
\hline CHEMBL3892650 & 1641311 & 5.0 & 4.849 & TST \\
\hline CHEMBL3985129 & 1641311 & 5.0 & 4.8428 & TST \\
\hline CHEMBL 3907068 & 1641311 & 5.0 & 5.0431 & TST \\
\hline CHEMBL 3916948 & 1641311 & 5.0 & 4.8557 & TST \\
\hline CHEMBL 3926413 & 1641311 & 5.0 & 5.3837 & TST \\
\hline CHEMBL 3942778 & 1641311 & 5.0 & 4.8819 & TST \\
\hline CHEMBL 3960871 & 1641311 & 5.0 & 4.8806 & TST \\
\hline CHEMBL 3970101 & 1641311 & 5.0 & 5.4282 & TST \\
\hline CHEMBL 3747035 & 1545043 & 5.3002 & 5.2679 & TRN \\
\hline CHEMBL 3746560 & 1545043 & 3.699 & 3.8232 & TRN \\
\hline CHEMBL 3747384 & 1545043 & 3.699 & 3.8156 & TST \\
\hline CHEMBL 3746790 & 1545043 & 3.699 & 3.5622 & TRN \\
\hline CHEMBL3746023 & 1545043 & 3.699 & 3.7106 & TST \\
\hline CHEMBL3746061 & 1545043 & 5.1403 & 5.1824 & TRN \\
\hline CHEMBL 3746720 & 1545043 & 3.699 & 3.714 & TRN \\
\hline CHEMBL3745869 & 1545043 & 4.9952 & 5.0054 & TRN \\
\hline CHEMBL3747635 & 1545043 & 3.699 & 3.6855 & TST \\
\hline CHEMBL3746628 & 1545043 & 5.129 & 5.1015 & TRN \\
\hline CHEMBL3746933 & 1545043 & 5.7545 & 5.6244 & TRN \\
\hline CHEMBL3746704 & 1545043 & 3.699 & 3.8108 & TRN \\
\hline CHEMBL3747176 & 1545043 & 3.699 & 3.9525 & TRN \\
\hline CHEMBL3747164 & 1545043 & 5.7905 & 5.5952 & TRN \\
\hline CHEMBL 3747127 & 1545043 & 3.699 & 3.7964 & TST \\
\hline CHEMBL 3746767 & 1545043 & 3.699 & 3.7273 & TRN \\
\hline CHEMBL 3747725 & 1545043 & 5.1824 & 5.2712 & TRN \\
\hline CHEMBL 3746326 & 1545043 & 3.699 & 4.0839 & TRN \\
\hline CHEMBL3746987 & 1545043 & 3.699 & 3.625 & TRN \\
\hline CHEMBL 3746970 & 1545043 & 5.0526 & 5.2172 & TRN \\
\hline CHEMBL3746905 & 1545043 & 5.8508 & 5.6594 & TRN \\
\hline CHEMBL 3746744 & 1545043 & 5.0783 & 4.9242 & TRN \\
\hline CHEMBL 3747101 & 1545043 & 5.1972 & 5.2559 & TRN \\
\hline CHEMBL 3747374 & 1545043 & 3.699 & 3.4849 & TST \\
\hline
\end{tabular}


Supplemental Table S2.txt

\begin{tabular}{|c|c|c|c|c|c|c|}
\hline CHEMBL 3746500 & 1545043 & 3.699 & \multicolumn{3}{|c|}{3.8339999999999996} & TST \\
\hline CHEMBL 3747142 & 1545043 & 5.7852 & 5.8629 & TRN & & \\
\hline CHEMBL540 & 1545043 & 3.699 & 3.8754 & TST & & \\
\hline CHEMBL3747658 & 1545043 & 3.699 & 3.4595 & TST & & \\
\hline CHEMBL3746501 & 1545043 & 3.699 & 3.8521 & TRN & & \\
\hline CHEMBL3746403 & 1545043 & 5.1331 & 5.1022 & TRN & & \\
\hline CHEMBL 3747202 & 1545043 & 3.699 & 3.7749 & TRN & & \\
\hline CHEMBL3745820 & 1545043 & 5.0768 & 5.1255 & TRN & & \\
\hline CHEMBL3747572 & 1545043 & 3.699 & 3.628 & TST & & \\
\hline CHEMBL3746503 & 1545043 & 3.699 & 3.8187 & TRN & & \\
\hline CHEMBL3746813 & 1545043 & 5.1494 & 5.2862 & TRN & & \\
\hline CHEMBL 3747200 & 1545043 & 3.699 & 3.609 & TRN & & \\
\hline CHEMBL3746641 & 1545043 & 3.699 & 4.1619 & TST & & \\
\hline CHEMBL3746698 & 1545043 & 5.109 & 4.8061 & TRN & & \\
\hline CHEMBL3746903 & 1545043 & 3.699 & 3.9567 & TST & & \\
\hline CHEMBL3747242 & 1545043 & 3.699 & 3.9998 & TRN & & \\
\hline CHEMBL3746937 & 1545043 & 5.75200 & 000000006 & 01 & 5.8727 & TRN \\
\hline CHEMBL3746319 & 1545043 & 5.0742 & 4.9567 & TRN & & \\
\hline CHEMBL 3746684 & 1545043 & 5.8416 & 5.7901 & TRN & & \\
\hline CHEMBL3746020 & 1545043 & 3.699 & 3.6359 & TRN & & \\
\hline CHEMBL3746788 & 1545043 & 5.0696 & 5.0467 & TRN & & \\
\hline CHEMBL3746216 & 1545043 & 5.0675 & 4.6253 & TRN & & \\
\hline CHEMBL3747686 & 1545043 & 5.21399 & 99999999 & 995 & 5.1929 & TRN \\
\hline CHEMBL3747598 & 1545043 & 5.3354 & 5.1869 & TRN & & \\
\hline CHEMBL3746668 & 1545043 & 5.0804 & 5.2206 & TRN & & \\
\hline CHEMBL3746194 & 1545043 & 3.699 & 3.6602 & TST & & \\
\hline CHEMBL3746718 & 1545043 & 3.699 & 3.4742 & TRN & & \\
\hline CHEMBL3745908 & 1545043 & 5.3429 & 5.433 & TRN & & \\
\hline CHEMBL3746005 & 1545043 & 3.699 & 3.5898 & TRN & & \\
\hline CHEMBL3746688 & 1545043 & 5.0372 & 5.1891 & TRN & & \\
\hline CHEMBL3746132 & 1545043 & 5.0128 & 5.046 & TRN & & \\
\hline CHEMBL3747564 & 1545043 & 4.9539 & 4.9697 & TRN & & \\
\hline CHEMBL 3747745 & 1545043 & 3.699 & 3.2151 & TST & & \\
\hline CHEMBL3747671 & 1545043 & 3.699 & 3.7299 & TRN & & \\
\hline CHEMBL3747627 & 1545043 & 3.699 & 3.5321 & TRN & & \\
\hline CHEMBL3747163 & 1545043 & 3.699 & 3.7914 & TST & & \\
\hline CHEMBL3746367 & 1545043 & 3.699 & 3.736 & TRN & & \\
\hline CHEMBL3747409 & 1545043 & 5.0996 & 5.1994 & TRN & & \\
\hline CHEMBL3747251 & 1545043 & 3.699 & 3.6345 & TRN & & \\
\hline CHEMBL3747335 & 1545043 & 5.1209 & 5.0894 & TRN & & \\
\hline CHEMBL3745971 & 1545043 & 3.699 & 3.5751 & TRN & & \\
\hline CHEMBL3747731 & 1545043 & 3.699 & 3.7417 & TST & & \\
\hline CHEMBL3745972 & 1545043 & 3.699 & 3.7704 & TST & & \\
\hline CHEMBL3747665 & 1545043 & 5.7747 & 5.5263 & TRN & & \\
\hline CHEMBL3746360 & 1545043 & 3.699 & 3.7444 & TST & & \\
\hline CHEMBL3747232 & 1545043 & 5.1612 & 5.1795 & TRN & & \\
\hline CHEMBL3746811 & 1545043 & 5.1624 & 5.4302 & TRN & & \\
\hline CHEMBL3746096 & 1545043 & 5.8239 & 5.4061 & TST & & \\
\hline
\end{tabular}




\begin{tabular}{|c|c|c|c|c|c|}
\hline \\
\hline CHEMBL1964290 & 809149 & 4.8 & 4.8419 & TRN & \\
\hline CHEMBL213505 & 809149 & 4.8 & 4.8586 & TRN & \\
\hline CHEMBL202721 & 809149 & 4.5 & 4.6945 & TRN & \\
\hline CHEMBL1982880 & 809149 & 5.0 & 4.3097 & TRN & \\
\hline CHEMBL1987034 & 809149 & 7.7 & 7.3725 & TRN & \\
\hline CHEMBL1993941 & 809149 & 4.8 & 4.9717 & TRN & \\
\hline CHEMBL377383 & 809149 & 4.8 & 4.3386 & TRN & \\
\hline CHEMBL578061 & 809149 & 3.6 & 5.0386 & TRN & \\
\hline CHEMBL 2005886 & 809149 & 7.2 & 6.4979 & 9999999999 & TRN \\
\hline CHEMBL481491 & 809149 & 4.8 & 4.683 & TST & \\
\hline CHEMBL1682345 & 809149 & 5.9 & 5.7354 & TRN & \\
\hline CHEMBL1973142 & 809149 & 4.8 & 5.3413 & TRN & \\
\hline CHEMBL388311 & 809149 & 8.5 & 8.2538 & TRN & \\
\hline CHEMBL1973145 & 809149 & 4.2 & 3.9368 & TRN & \\
\hline CHEMBL1982924 & 809149 & 4.8 & 5.1233 & TRN & \\
\hline CHEMBL2005936 & 809149 & 4.8 & 5.9769 & TRN & \\
\hline CHEMBL1807515 & 809149 & 6.9 & 6.621 & TRN & \\
\hline CHEMBL1964948 & 809149 & 4.5 & 4.6271 & TRN & \\
\hline CHEMBL1971141 & 809149 & 4.8 & 4.0506 & TRN & \\
\hline CHEMBL1995813 & 809149 & 6.1 & 6.3488 & TRN & \\
\hline CHEMBL1979718 & 809149 & 4.0 & 5.0076 & TRN & \\
\hline CHEMBL206236 & 809149 & 4.8 & 4.6732 & TRN & \\
\hline CHEMBL1989834 & 809149 & 3.8 & 4.1393 & TRN & \\
\hline CHEMBL523823 & 809149 & 5.8 & 4.7399 & TST & \\
\hline CHEMBL1562756 & 809149 & 5.1 & 4.8356 & TST & \\
\hline CHEMBL1987430 & 809149 & 4.5 & 4.2817 & TRN & \\
\hline CHEMBL244378 & 809149 & 6.4 & 6.8899 & TRN & \\
\hline CHEMBL 2001957 & 809149 & 4.8 & 4.6295 & TRN & \\
\hline CHEMBL1969372 & 809149 & 4.8 & 4.6922 & TRN & \\
\hline CHEMBL1993413 & 809149 & 4.5 & 4.5552 & TRN & \\
\hline CHEMBL1986943 & 809149 & 6.9 & 6.8617 & TRN & \\
\hline CHEMBL 2006263 & 809149 & 6.7 & 5.0321 & TST & \\
\hline CHEMBL1993584 & 809149 & 5.9 & 4.6076 & TRN & \\
\hline CHEMBL1986263 & 809149 & 5.9 & 5.848 & TRN & \\
\hline CHEMBL 2000114 & 809149 & 4.8 & 5.2916 & TRN & \\
\hline CHEMBL210618 & 809149 & 4.2 & 3.6749 & TRN & \\
\hline CHEMBL1986265 & 809149 & 4.5 & 4.4422 & TRN & \\
\hline CHEMBL1975647 & 809149 & 5.9 & 4.7935 & TRN & \\
\hline CHEMBL1968380 & 809149 & 4.2 & 4.6712 & TRN & \\
\hline CHEMBL1964644 & 809149 & 4.8 & 4.852 & TRN & \\
\hline CHEMBL1991734 & 809149 & 6.3 & 5.7586 & TST & \\
\hline CHEMBL1981782 & 809149 & 6.4 & 5.8145 & TRN & \\
\hline CHEMBL1977681 & 809149 & 4.8 & 6.0139 & 9999999999 & TRN \\
\hline CHEMBL1970142 & 809149 & 4.8 & 4.801 & TRN & \\
\hline CHEMBL1990912 & 809149 & 4.8 & 4.6867 & TRN & \\
\hline CHEMBL1991782 & 809149 & 3.2 & 3.6349 & TRN & \\
\hline CHEMBL 2002105 & 809149 & 4.4 & 4.303 & TRN & \\
\hline CHEMBL1983348 & 809149 & 6.4 & 6.2944 & TRN & \\
\hline & & & & 18714 & \\
\hline
\end{tabular}




\begin{tabular}{|c|c|c|c|c|}
\hline & & & pplement & al $\mathrm{Ta}$ \\
\hline CHEMBL1988163 & 809149 & 6.8 & 6.7458 & TRN \\
\hline CHEMBL1995592 & 809149 & 4.0 & 4.8939 & TST \\
\hline CHEMBL1974480 & 809149 & 5.5 & 4.9596 & TRN \\
\hline CHEMBL 2000934 & 809149 & 4.5 & 4.3094 & TRN \\
\hline CHEMBL 2006493 & 809149 & 4.2 & 4.6306 & TST \\
\hline CHEMBL1986177 & 809149 & 4.5 & 4.6737 & TRN \\
\hline CHEMBL1982541 & 809149 & 5.1 & 4.2287 & TRN \\
\hline CHEMBL1996923 & 809149 & 4.2 & 4.5447 & TST \\
\hline CHEMBL1983449 & 809149 & 4.8 & 5.4418 & TRN \\
\hline CHEMBL1992323 & 809149 & 4.2 & 4.3546 & TRN \\
\hline CHEMBL1969735 & 809149 & 4.8 & 4.7589 & TRN \\
\hline CHEMBL 2003524 & 809149 & 5.5 & 4.8754 & TST \\
\hline CHEMBL2002649 & 809149 & 6.9 & 6.5014 & TRN \\
\hline CHEMBL1985367 & 809149 & 4.5 & 4.5002 & TRN \\
\hline CHEMBL1996510 & 809149 & 6.7 & 5.7666 & TST \\
\hline CHEMBL437747 & 809149 & 5.5 & 5.0382 & TRN \\
\hline CHEMBL2001584 & 809149 & 4.5 & 4.435 & TST \\
\hline CHEMBL507936 & 809149 & 4.0 & 3.7907 & TRN \\
\hline CHEMBL104264 & 809149 & 5.6 & 5.3086 & TST \\
\hline CHEMBL1967998 & 809149 & 7.0 & 7.0165 & TRN \\
\hline CHEMBL1994321 & 809149 & 4.2 & 4.5402 & TRN \\
\hline CHEMBL1978562 & 809149 & 5.8 & 5.1935 & TST \\
\hline CHEMBL1997129 & 809149 & 7.5 & 6.3054 & TRN \\
\hline CHEMBL451964 & 809149 & 4.0 & 4.335 & TRN \\
\hline CHEMBL1974875 & 809149 & 4.7 & 4.6156 & TST \\
\hline CHEMBL1964307 & 809149 & 4.0 & 4.602 & TRN \\
\hline CHEMBL1989471 & 809149 & 4.5 & 5.2774 & TST \\
\hline CHEMBL 2000508 & 809149 & 4.8 & 4.6255 & TRN \\
\hline CHEMBL1971694 & 809149 & 4.2 & 4.95 & TST \\
\hline CHEMBL 2001547 & 809149 & 4.8 & 4.579 & TRN \\
\hline CHEMBL 210928 & 809149 & 4.2 & 3.8762 & TRN \\
\hline CHEMBL1978195 & 809149 & 4.5 & 4.9456 & TRN \\
\hline CHEMBL1994361 & 809149 & 5.8 & 4.5299 & TRN \\
\hline CHEMBL1986603 & 809149 & 4.8 & 4.4789 & TST \\
\hline CHEMBL1972840 & 809149 & 5.7 & 5.4793 & TRN \\
\hline CHEMBL1977148 & 809149 & 4.8 & 4.3607 & TRN \\
\hline CHEMBL1966842 & 809149 & 4.5 & 4.6129 & TRN \\
\hline CHEMBL 2003286 & 809149 & 4.8 & 4.5198 & TRN \\
\hline CHEMBL1992306 & 809149 & 4.8 & 4.6348 & TRN \\
\hline CHEMBL2002165 & 809149 & 4.8 & 5.4267 & TRN \\
\hline CHEMBL 206382 & 809149 & 4.2 & 4.1331 & TRN \\
\hline CHEMBL1998585 & 809149 & 4.0 & 5.4581 & TRN \\
\hline CHEMBL127898 & 809149 & 4.8 & 4.5442 & TST \\
\hline CHEMBL519697 & 809149 & 5.9 & 5.2673 & TST \\
\hline CHEMBL 2004934 & 809149 & 4.8 & 5.1296 & TRN \\
\hline CHEMBL1996345 & 809149 & 4.5 & 4.3315 & TST \\
\hline CHEMBL1975128 & 809149 & 7.0 & 6.5483 & TRN \\
\hline CHEMBL 2004025 & 809149 & 5.9 & 5.2642 & TRN \\
\hline
\end{tabular}




\begin{tabular}{|c|c|c|c|c|c|}
\hline \multirow[b]{2}{*}{ CHEMBL1996048 } & \multirow[b]{2}{*}{809149} & \multirow[b]{2}{*}{6.8} & \\
\hline & & & 5.5024 & TST & \\
\hline CHEMBL461876 & 809149 & 4.5 & 5.1232 & TRN & \\
\hline CHEMBL1965033 & 809149 & 4.5 & 4.7836 & TRN & \\
\hline CHEMBL2001485 & 809149 & 4.8 & 4.8899 & TRN & \\
\hline CHEMBL504950 & 809149 & 4.0 & 4.3533 & TRN & \\
\hline CHEMBL1997335 & 809149 & 6.1 & 5.1947 & TRN & \\
\hline CHEMBL1966425 & 809149 & 6.2 & 5.3269 & TRN & \\
\hline CHEMBL1984363 & 809149 & 4.8 & 4.8168 & TRN & \\
\hline CHEMBL1978099 & 809149 & 5.8 & 6.2967 & TRN & \\
\hline CHEMBL1977041 & 809149 & 4.0 & 4.8945 & TRN & \\
\hline CHEMBL1968070 & 809149 & 5.6 & 5.3972 & TRN & \\
\hline CHEMBL1988608 & 809149 & 5.8 & \multicolumn{2}{|c|}{6.337000000000001} & TRN \\
\hline CHEMBL184847 & 809149 & 5.8 & 4.7623 & TRN & \\
\hline CHEMBL1984367 & 809149 & 4.8 & 5.9161 & TRN & \\
\hline CHEMBL226898 & 809149 & 7.9 & 7.1396 & TRN & \\
\hline CHEMBL1982563 & 809149 & 4.8 & 4.7128 & TRN & \\
\hline CHEMBL539474 & 809149 & 7.5 & 5.3253 & TST & \\
\hline CHEMBL575824 & 809149 & 4.5 & 5.1459 & TRN & \\
\hline CHEMBL1988387 & 809149 & 4.8 & 5.3662 & TRN & \\
\hline CHEMBL1973868 & 809149 & 4.5 & 4.1577 & TRN & \\
\hline CHEMBL1972462 & 809149 & 4.5 & 4.4421 & TRN & \\
\hline CHEMBL1990288 & 809149 & 4.8 & 4.7475 & TRN & \\
\hline CHEMBL1974803 & 809149 & 4.2 & 4.99 & TRN & \\
\hline CHEMBL1970074 & 809149 & 4.2 & 4.5835 & TRN & \\
\hline CHEMBL1984500 & 809149 & 3.2 & 3.8852 & TRN & \\
\hline CHEMBL1986970 & 809149 & 6.3 & 5.9276 & TRN & \\
\hline CHEMBL1958401 & 809149 & 4.8 & 4.3869 & TRN & \\
\hline CHEMBL1984044 & 809149 & 4.2 & 4.4144 & TRN & \\
\hline CHEMBL2003456 & 809149 & 4.8 & 4.9349 & TRN & \\
\hline CHEMBL1966816 & 809149 & 4.8 & 4.9288 & TRN & \\
\hline CHEMBL1972584 & 809149 & 5.8 & 5.1804 & TRN & \\
\hline CHEMBL2002992 & 809149 & 4.6 & 4.9285 & TRN & \\
\hline CHEMBL560813 & 809149 & 4.8 & 4.6927 & TRN & \\
\hline CHEMBL1890036 & 809149 & 4.0 & 4.6183 & TST & \\
\hline CHEMBL1982700 & 809149 & 4.5 & 4.6044 & TST & \\
\hline CHEMBL1968791 & 809149 & 4.2 & \multicolumn{2}{|c|}{4.0680000000000005} & TRN \\
\hline CHEMBL326282 & 809149 & 4.0 & 4.5635 & TST & \\
\hline CHEMBL1977634 & 809149 & 4.5 & 4.2144 & TRN & \\
\hline CHEMBL1992732 & 809149 & 4.0 & 4.2704 & TST & \\
\hline CHEMBL1971186 & 809149 & 4.8 & 4.8541 & TRN & \\
\hline CHEMBL 2003482 & 809149 & 4.8 & 4.9 & TRN & \\
\hline CHEMBL1973211 & 809149 & 4.2 & 4.4993 & TRN & \\
\hline CHEMBL1984700 & 809149 & 4.8 & 4.7085 & TRN & \\
\hline CHEMBL2007151 & 809149 & 4.0 & 4.0473 & TRN & \\
\hline CHEMBL1971606 & 809149 & 4.5 & 4.481 & TRN & \\
\hline CHEMBL1972125 & 809149 & 4.8 & 4.2692 & TRN & \\
\hline CHEMBL1999120 & 809149 & 4.3 & 4.3929 & TST & \\
\hline CHEMBL1976134 & 809149 & 4.8 & 5.3951 & TRN & \\
\hline & & & & 18716 & \\
\hline
\end{tabular}




\begin{tabular}{|c|c|c|c|c|}
\hline & & & 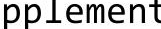 & al Ta \\
\hline CHEMBL1965131 & 809149 & 5.8 & 5.4164 & TRN \\
\hline CHEMBL1995448 & 809149 & 4.0 & 3.9758 & TRN \\
\hline CHEMBL1972158 & 809149 & 5.9 & 5.9231 & TRN \\
\hline CHEMBL1981215 & 809149 & 4.5 & 4.467 & TRN \\
\hline CHEMBL1974457 & 809149 & 4.0 & 4.9411 & TRN \\
\hline CHEMBL1999414 & 809149 & 5.8 & 5.1911 & TRN \\
\hline CHEMBL1967336 & 809149 & 4.5 & 4.4339 & TRN \\
\hline CHEMBL 2001228 & 809149 & 4.5 & 4.6878 & TRN \\
\hline CHEMBL 2006581 & 809149 & 4.0 & 4.3071 & TRN \\
\hline CHEMBL1979855 & 809149 & 4.8 & 4.4665 & TRN \\
\hline CHEMBL1970340 & 809149 & 3.6 & 3.6787 & TRN \\
\hline CHEMBL1967992 & 809149 & 4.5 & 4.4319 & TRN \\
\hline CHEMBL 2005186 & 809149 & 4.8 & 4.5284 & TRN \\
\hline CHEMBL 2006450 & 809149 & 4.5 & 4.0858 & TRN \\
\hline CHEMBL1975534 & 809149 & 4.8 & 4.5868 & TRN \\
\hline CHEMBL1993424 & 809149 & 6.4 & 6.4918 & TRN \\
\hline CHEMBL1966703 & 809149 & 4.8 & 4.9549 & TST \\
\hline CHEMBL 2001987 & 809149 & 4.5 & 4.4397 & TRN \\
\hline CHEMBL1969561 & 809149 & 6.5 & 6.1881 & TRN \\
\hline CHEMBL1994555 & 809149 & 4.5 & 5.0677 & TST \\
\hline CHEMBL1975121 & 809149 & 4.5 & 4.9016 & TRN \\
\hline CHEMBL1983640 & 809149 & 4.5 & 4.3279 & TRN \\
\hline CHEMBL1997023 & 809149 & 4.4 & 4.8008 & TST \\
\hline CHEMBL1964687 & 809149 & 5.5 & 5.3171 & TRN \\
\hline CHEMBL1971943 & 809149 & 4.6 & 4.4898 & TRN \\
\hline CHEMBL1999918 & 809149 & 6.2 & 5.8541 & TRN \\
\hline CHEMBL1974254 & 809149 & 4.8 & 4.7112 & TRN \\
\hline CHEMBL1997924 & 809149 & 8.4 & 6.8159 & TRN \\
\hline CHEMBL1988537 & 809149 & 4.8 & 5.5411 & TST \\
\hline CHEMBL1969049 & 809149 & 4.8 & 4.9796 & TRN \\
\hline CHEMBL 2005828 & 809149 & 6.0 & 4.7886 & TRN \\
\hline CHEMBL1978267 & 809149 & 4.5 & 4.3055 & TRN \\
\hline CHEMBL1998611 & 809149 & 6.2 & 5.046 & TRN \\
\hline CHEMBL485556 & 809149 & 4.0 & 5.0104 & TST \\
\hline CHEMBL1975900 & 809149 & 6.5 & 6.0185 & TRN \\
\hline CHEMBL 255822 & 809149 & 4.8 & 4.7199 & TRN \\
\hline CHEMBL1972221 & 809149 & 4.8 & 5.0625 & TRN \\
\hline CHEMBL 2006778 & 809149 & 4.2 & 5.0216 & TRN \\
\hline CHEMBL378627 & 809149 & 4.2 & 4.0752 & TRN \\
\hline CHEMBL1996979 & 809149 & 5.9 & 5.3159 & TRN \\
\hline CHEMBL1997025 & 809149 & 4.2 & 4.5922 & TRN \\
\hline CHEMBL1968406 & 809149 & 6.0 & 5.3599 & TRN \\
\hline CHEMBL1975921 & 809149 & 4.6 & 4.787 & TRN \\
\hline CHEMBL1982476 & 809149 & 5.1 & 4.9947 & TRN \\
\hline CHEMBL1984274 & 809149 & 4.3 & 4.7434 & TST \\
\hline CHEMBL1998545 & 809149 & 4.2 & 4.6992 & TRN \\
\hline CHEMBL1986869 & 809149 & 4.8 & 4.2298 & TRN \\
\hline CHEMBL1975923 & 809149 & 4.8 & 5.1577 & TST \\
\hline
\end{tabular}




\begin{tabular}{|c|c|c|c|c|c|}
\hline \multirow[b]{2}{*}{ CHEMBL 2005449} & \multirow[b]{2}{*}{809149} & \\
\hline & & 5.9 & 6.2118 & TRN & \\
\hline CHEMBL1987998 & 809149 & 4.5 & 4.3606 & TRN & \\
\hline CHEMBL1682558 & 809149 & 4.8 & 4.3414 & TRN & \\
\hline CHEMBL1971534 & 809149 & 4.5 & 4.5394 & TRN & \\
\hline CHEMBL1990496 & 809149 & 4.3 & 4.8657 & TRN & \\
\hline CHEMBL 242865 & 809149 & 5.8 & 5.9821 & TRN & \\
\hline CHEMBL1997623 & 809149 & 4.0 & 4.417 & TRN & \\
\hline CHEMBL2002479 & 809149 & 7.4 & 5.6284 & TRN & \\
\hline CHEMBL1993166 & 809149 & 4.0 & 5.7502 & TRN & \\
\hline CHEMBL1967094 & 809149 & 6.4 & 6.3269 & TRN & \\
\hline CHEMBL 2003341 & 809149 & 4.8 & 5.0296 & TRN & \\
\hline CHEMBL1992644 & 809149 & 3.6 & 4.4217 & TRN & \\
\hline CHEMBL1992645 & 809149 & 4.0 & 5.3681 & TST & \\
\hline CHEMBL1982992 & 809149 & 4.8 & 4.7172 & TRN & \\
\hline CHEMBL1998110 & 809149 & 4.5 & 4.5324 & TRN & \\
\hline CHEMBL1999590 & 809149 & 4.8 & 4.58 & TST & \\
\hline CHEMBL1981079 & 809149 & 4.8 & 5.2148 & TRN & \\
\hline CHEMBL1978166 & 809149 & 5.7 & 5.25799 & 9999999999 & TRN \\
\hline CHEMBL1980489 & 809149 & 6.2 & 5.8233 & TRN & \\
\hline CHEMBL 2000832 & 809149 & 6.5 & 6.5261 & TRN & \\
\hline CHEMBL1967116 & 809149 & 4.2 & 4.7141 & TRN & \\
\hline CHEMBL1990590 & 809149 & 4.5 & 4.585 & TRN & \\
\hline CHEMBL1977814 & 809149 & 4.2 & 4.4702 & TST & \\
\hline CHEMBL1970709 & 809149 & 4.8 & 5.1639 & TRN & \\
\hline CHEMBL1974617 & 809149 & 4.5 & 4.3941 & TRN & \\
\hline CHEMBL1965660 & 809149 & 4.8 & 5.4946 & TRN & \\
\hline CHEMBL1992125 & 809149 & 5.9 & 5.272 & TRN & \\
\hline CHEMBL1998112 & 809149 & 4.8 & 4.4756 & TRN & \\
\hline CHEMBL1969126 & 809149 & 4.8 & 4.8231 & TRN & \\
\hline CHEMBL1980896 & 809149 & 4.2 & 4.5565 & TRN & \\
\hline CHEMBL1970104 & 809149 & 6.9 & 6.5284 & TRN & \\
\hline CHEMBL1991429 & 809149 & 6.2 & 5.1023 & TRN & \\
\hline CHEMBL1967612 & 809149 & 4.3 & 4.9045 & TST & \\
\hline CHEMBL1971149 & 809149 & 4.8 & 4.8331 & TRN & \\
\hline CHEMBL1999714 & 809149 & 4.8 & 4.4188 & TRN & \\
\hline CHEMBL1987533 & 809149 & 4.2 & 4.76699 & 99999999995 & TRN \\
\hline CHEMBL1994040 & 809149 & 4.8 & 4.6695 & TRN & \\
\hline CHEMBL388978 & 809149 & 9.5 & 8.6562 & TST & \\
\hline CHEMBL579246 & 809149 & 5.9 & 5.6092 & TRN & \\
\hline CHEMBL398951 & 809149 & 4.6 & 4.4894 & TST & \\
\hline CHEMBL1982506 & 809149 & 4.6 & 4.8235 & TST & \\
\hline CHEMBL2004716 & 809149 & 4.9 & 5.2811 & TRN & \\
\hline CHEMBL1968127 & 809149 & 4.8 & 4.7288 & TRN & \\
\hline CHEMBL1975233 & 809149 & 4.3 & 4.4647 & TRN & \\
\hline CHEMBL1985406 & 809149 & 5.9 & 5.0964 & TRN & \\
\hline CHEMBL2007603 & 809149 & 4.5 & 4.4721 & TRN & \\
\hline CHEMBL207400 & 809149 & 4.2 & 4.3443 & TST & \\
\hline CHEMBL2000894 & 809149 & 4.8 & 4.9784 & TST & \\
\hline & & & & 18718 & \\
\hline
\end{tabular}




\begin{tabular}{|c|c|c|c|c|c|}
\hline & & & & & \\
\hline CHEMBL1421720 & 809149 & 5.8 & 5.517 & TRN & \\
\hline CHEMBL1968130 & 809149 & 4.7 & 4.2965 & TST & \\
\hline CHEMBL1982135 & 809149 & 4.8 & 5.15600 & 0000000001 & TRN \\
\hline CHEMBL1976090 & 809149 & 4.2 & 4.9102 & TRN & \\
\hline CHEMBL1993243 & 809149 & 4.8 & 4.6017 & TRN & \\
\hline CHEMBL2004771 & 809149 & 4.8 & 4.9871 & TRN & \\
\hline CHEMBL1992922 & 809149 & 6.0 & 5.5217 & TRN & \\
\hline CHEMBL399021 & 809149 & 4.0 & 4.1965 & TRN & \\
\hline CHEMBL1997597 & 809149 & 4.8 & 4.6591 & TRN & \\
\hline CHEMBL1969537 & 809149 & 5.9 & 5.2983 & TST & \\
\hline CHEMBL1976093 & 809149 & 4.8 & 4.6077 & TRN & \\
\hline CHEMBL 210032 & 809149 & 4.2 & 3.9776 & TRN & \\
\hline CHEMBL1996543 & 809149 & 4.0 & 4.8635 & TRN & \\
\hline CHEMBL1975256 & 809149 & 4.8 & 4.4388 & TST & \\
\hline CHEMBL508928 & 809149 & 4.2 & 4.3031 & TRN & \\
\hline CHEMBL 2004892 & 809149 & 4.8 & 4.6772 & TRN & \\
\hline CHEMBL116070 & 809149 & 4.4 & 4.5815 & TRN & \\
\hline CHEMBL1970314 & 809149 & 4.8 & 4.0373 & TRN & \\
\hline CHEMBL 2004871 & 809149 & 4.8 & 4.4453 & TRN & \\
\hline CHEMBL 2004872 & 809149 & 4.8 & 4.7046 & TRN & \\
\hline CHEMBL1727312 & 809149 & 3.8 & 4.2668 & TRN & \\
\hline CHEMBL1990223 & 809149 & 4.5 & 4.3095 & TRN & \\
\hline CHEMBL1969879 & 809149 & 4.8 & 4.4283 & TRN & \\
\hline CHEMBL1964382 & 809149 & 4.5 & 5.2174 & TST & \\
\hline CHEMBL101311 & 809149 & 4.5 & 5.2514 & TRN & \\
\hline CHEMBL1981720 & 809149 & 4.8 & 5.0179 & TRN & \\
\hline CHEMBL419932 & 809149 & 4.8 & 4.8605 & TRN & \\
\hline CHEMBL 262433 & 809149 & 4.8 & 4.6598 & TRN & \\
\hline CHEMBL 306380 & 809149 & 4.2 & 4.5546 & TRN & \\
\hline CHEMBL1966722 & 809149 & 6.4 & 5.624 & TST & \\
\hline CHEMBL1988581 & 809149 & 7.3 & 6.5073 & TST & \\
\hline CHEMBL2005699 & 809149 & 4.5 & 4.336 & TRN & \\
\hline CHEMBL1975500 & 809149 & 4.8 & 6.0273 & TRN & \\
\hline CHEMBL1976328 & 809149 & 4.0 & 4.2674 & TRN & \\
\hline CHEMBL394619 & 809149 & 4.2 & 4.3085 & TRN & \\
\hline CHEMBL2006564 & 809149 & 6.9 & 6.403 & TRN & \\
\hline CHEMBL1964399 & 809149 & 6.2 & 5.8877 & TRN & \\
\hline CHEMBL1996831 & 809149 & 6.4 & 4.8435 & TST & \\
\hline CHEMBL411903 & 809149 & 5.8 & 5.5841 & TRN & \\
\hline CHEMBL1978167 & 809149 & 5.8 & 4.9975 & TST & \\
\hline CHEMBL1965988 & 809149 & 4.2 & 4.9753 & TRN & \\
\hline CHEMBL418203 & 809149 & 4.6 & 5.2787 & TST & \\
\hline CHEMBL1989646 & 809149 & 4.8 & 5.7368 & TRN & \\
\hline CHEMBL1682357 & 809149 & 4.0 & 4.8908 & TRN & \\
\hline CHEMBL 225519 & 809149 & 4.9 & 5.2983 & TRN & \\
\hline CHEMBL209534 & 809149 & 4.0 & 3.89899 & 99999999996 & TRN \\
\hline CHEMBL1978200 & 809149 & 4.8 & 4.8862 & TRN & \\
\hline CHEMBL1970522 & 809149 & 4.2 & 4.5654 & TRN & \\
\hline & & & & 18719 & \\
\hline
\end{tabular}




\begin{tabular}{|c|c|c|c|c|c|}
\hline \\
\hline CHEMBL1966087 & 809149 & 4.2 & 4.2522 & TRN & \\
\hline CHEMBL1964692 & 809149 & 4.8 & 4.3917 & TRN & \\
\hline CHEMBL1996931 & 809149 & 4.8 & 4.784 & TRN & \\
\hline CHEMBL1964413 & 809149 & 4.2 & 4.4739 & TRN & \\
\hline CHEMBL1973483 & 809149 & 5.8 & 4.4926 & TRN & \\
\hline CHEMBL1998470 & 809149 & 4.5 & 4.4542 & TRN & \\
\hline CHEMBL1984432 & 809149 & 5.0 & 4.5465 & TRN & \\
\hline CHEMBL219722 & 809149 & 4.0 & 4.7532 & TRN & \\
\hline CHEMBL1975903 & 809149 & 4.5 & 4.9224 & TRN & \\
\hline CHEMBL1997340 & 809149 & 4.8 & 3.9995 & TRN & \\
\hline CHEMBL2004365 & 809149 & 6.2 & 4.6964 & TST & \\
\hline CHEMBL1522508 & 809149 & 4.8 & 3.9108 & TRN & \\
\hline CHEMBL1989474 & 809149 & 4.8 & 4.4504 & TRN & \\
\hline CHEMBL1090360 & 809149 & 4.8 & 4.5449 & TRN & \\
\hline CHEMBL210887 & 809149 & 4.8 & 4.8613 & TST & \\
\hline CHEMBL1988805 & 809149 & 4.5 & 4.1054 & TST & \\
\hline CHEMBL458997 & 809149 & 6.1 & 6.3144 & TRN & \\
\hline CHEMBL1971021 & 809149 & 4.8 & 4.4854 & TRN & \\
\hline CHEMBL227271 & 809149 & 7.4 & 7.3246 & TRN & \\
\hline CHEMBL583144 & 809149 & 4.3 & 4.9711 & TRN & \\
\hline CHEMBL1974310 & 809149 & 5.9 & 5.4279 & TRN & \\
\hline CHEMBL1969942 & 809149 & 4.5 & 4.7909 & TRN & \\
\hline CHEMBL1978567 & 809149 & 4.5 & 4.5324 & TRN & \\
\hline CHEMBL1982660 & 809149 & 4.8 & 4.80699 & 99999999995 & TRN \\
\hline CHEMBL1994693 & 809149 & 5.9 & 5.5266 & TRN & \\
\hline CHEMBL1982957 & 809149 & 6.9 & 5.8984 & TRN & \\
\hline CHEMBL1725279 & 809149 & 4.8 & 5.6931 & TST & \\
\hline CHEMBL1975138 & 809149 & 6.6 & 5.5937 & TST & \\
\hline CHEMBL424872 & 809149 & 4.4 & 4.0268 & TRN & \\
\hline CHEMBL 2006836 & 809149 & 4.2 & 4.7522 & TST & \\
\hline CHEMBL1971947 & 809149 & 4.0 & 4.2496 & TRN & \\
\hline CHEMBL412142 & 809149 & 4.4 & 5.0321 & TST & \\
\hline CHEMBL1980704 & 809149 & 4.8 & 4.5669 & TST & \\
\hline CHEMBL 2003271 & 809149 & 5.8 & 5.6061 & TRN & \\
\hline CHEMBL1966808 & 809149 & 4.8 & 4.4231 & TRN & \\
\hline CHEMBL 2004447 & 809149 & 4.2 & 4.2496 & TRN & \\
\hline CHEMBL1983111 & 809149 & 7.7 & 7.506 & TRN & \\
\hline CHEMBL1973860 & 809149 & 4.8 & 4.6759 & TRN & \\
\hline CHEMBL260135 & 809149 & 4.2 & 4.3115 & TRN & \\
\hline CHEMBL220241 & 809149 & 4.8 & 4.959 & TRN & \\
\hline CHEMBL 2004544 & 809149 & 6.4 & 5.1459 & TST & \\
\hline CHEMBL1988141 & 809149 & 6.4 & 6.1408 & TST & \\
\hline CHEMBL1982610 & 809149 & 4.8 & 4.5245 & TST & \\
\hline CHEMBL1977134 & 809149 & 4.5 & 4.1078 & TRN & \\
\hline CHEMBL1999496 & 809149 & 4.8 & 4.4963 & TRN & \\
\hline CHEMBL 2006933 & 809149 & 4.0 & 5.2684 & TST & \\
\hline CHEMBL1985206 & 809149 & 4.5 & 4.6607 & TST & \\
\hline CHEMBL1988300 & 809149 & 4.8 & 4.5033 & TRN & \\
\hline
\end{tabular}




\begin{tabular}{|c|c|c|c|c|c|}
\hline & & & & & \\
\hline CHEMBL1991078 & 809149 & 7.2 & 7.081 & TRN & \\
\hline CHEMBL1987359 & 809149 & 4.8 & 4.3359 & TST & \\
\hline CHEMBL1977749 & 809149 & 4.5 & 4.9601 & TST & \\
\hline CHEMBL 2000685 & 809149 & 6.7 & 6.0942 & TRN & \\
\hline CHEMBL2001613 & 809149 & 4.9 & 4.7947 & TRN & \\
\hline CHEMBL1997275 & 809149 & 4.5 & 5.2208 & TRN & \\
\hline CHEMBL1993904 & 809149 & 4.5 & 4.6862 & TRN & \\
\hline CHEMBL1967513 & 809149 & 4.5 & 4.2698 & TRN & \\
\hline CHEMBL 2000724 & 809149 & 4.5 & 4.3574 & TRN & \\
\hline CHEMBL1985311 & 809149 & 4.0 & 4.669 & TRN & \\
\hline CHEMBL1989265 & 809149 & 4.2 & 4.5916 & TST & \\
\hline CHEMBL1982413 & 809149 & 5.8 & 4.6789 & TST & \\
\hline CHEMBL1969502 & 809149 & 7.4 & 6.5182 & TRN & \\
\hline CHEMBL1965910 & 809149 & 4.0 & 4.2766 & TRN & \\
\hline CHEMBL1682553 & 809149 & 4.3 & 4.636 & TRN & \\
\hline CHEMBL1971430 & 809149 & 4.4 & 4.6432 & TRN & \\
\hline CHEMBL1983963 & 809149 & 4.2 & 4.5532 & TRN & \\
\hline CHEMBL1997764 & 809149 & 4.8 & 5.072 & TRN & \\
\hline CHEMBL 2000271 & 809149 & 6.2 & 6.6632 & TRN & \\
\hline CHEMBL1985042 & 809149 & 4.1 & 5.0732 & TST & \\
\hline CHEMBL1981792 & 809149 & 4.5 & 4.4752 & TRN & \\
\hline CHEMBL1987535 & 809149 & 5.7 & $5.3870 e$ & 00000000005 & TRN \\
\hline CHEMBL1985092 & 809149 & 4.8 & 5.3699 & TRN & \\
\hline CHEMBL2004692 & 809149 & 4.2 & 4.1586 & TST & \\
\hline CHEMBL1981410 & 809149 & 4.8 & 4.8183 & TRN & \\
\hline CHEMBL 2002586 & 809149 & 4.5 & 5.1049 & TRN & \\
\hline CHEMBL1987815 & 809149 & 4.0 & 4.0394 & TST & \\
\hline CHEMBL1996234 & 809149 & 4.8 & 3.9049 & TRN & \\
\hline CHEMBL383264 & 809149 & 5.8 & 5.1379 & TRN & \\
\hline CHEMBL2007421 & 809149 & 6.8 & 5.9678 & TST & \\
\hline CHEMBL1991434 & 809149 & 4.2 & 4.3749 & TST & \\
\hline CHEMBL1967544 & 809149 & 4.8 & 5.1151 & TRN & \\
\hline CHEMBL1973138 & 809149 & 4.5 & 4.4356 & TST & \\
\hline CHEMBL223367 & 809149 & 6.6 & 5.3298 & TST & \\
\hline CHEMBL1992673 & 809149 & 4.1 & 4.4603 & TRN & \\
\hline CHEMBL340384 & 809149 & 4.8 & 5.3877 & TST & \\
\hline CHEMBL1969151 & 809149 & 7.1 & 6.5369 & TRN & \\
\hline CHEMBL1996587 & 809149 & 4.8 & 4.8497 & TRN & \\
\hline CHEMBL1993335 & 809149 & 6.5 & 5.6664 & TST & \\
\hline CHEMBL1988692 & 809149 & 4.5 & 5.4394 & TRN & \\
\hline CHEMBL 2007574 & 809149 & 4.5 & 5.5288 & TRN & \\
\hline CHEMBL1964804 & 809149 & 4.8 & 4.8413 & TRN & \\
\hline CHEMBL443962 & 809149 & 4.2 & 4.6051 & TST & \\
\hline CHEMBL 2000354 & 809149 & 4.8 & 4.7401 & TRN & \\
\hline CHEMBL1965507 & 809149 & 5.0 & 5.9422 & TRN & \\
\hline CHEMBL1981107 & 809149 & 3.6 & 4.2413 & TST & \\
\hline CHEMBL 274064 & 809149 & 4.2 & 4.2456 & TRN & \\
\hline CHEMBL1998680 & 809149 & 4.5 & 4.3825 & TRN & \\
\hline & & & & 18721 & \\
\hline
\end{tabular}




\begin{tabular}{|c|c|c|c|c|c|}
\hline \multirow{2}{*}{ CHEMBL1967564 } & \multirow{2}{*}{809149} & \\
\hline & & 4.2 & 4.5198 & TRN & \\
\hline CHEMBL592030 & 809149 & 6.1 & 6.0574 & TST & \\
\hline CHEMBL 2000071 & 809149 & 5.8 & 5.6025 & TRN & \\
\hline CHEMBL1979176 & 809149 & 4.8 & 4.2527 & TRN & \\
\hline CHEMBL1970317 & 809149 & 4.5 & 5.1244 & TRN & \\
\hline CHEMBL 2000408 & 809149 & 4.8 & 4.8198 & TRN & \\
\hline CHEMBL248757 & 809149 & 4.8 & 5.2308 & TST & \\
\hline CHEMBL1978014 & 809149 & 4.8 & 4.5051 & TRN & \\
\hline CHEMBL1997007 & 809149 & 4.5 & 5.6184 & TRN & \\
\hline CHEMBL1994538 & 809149 & 4.4 & 4.4936 & TRN & \\
\hline CHEMBL1983195 & 809149 & 6.2 & 5.1686 & TST & \\
\hline CHEMBL1975490 & 809149 & 4.8 & 5.2398 & TRN & \\
\hline CHEMBL1964444 & 809149 & 4.6 & 4.5311 & TRN & \\
\hline CHEMBL 2002690 & 809149 & 4.5 & 4.3098 & TRN & \\
\hline CHEMBL 2006567 & 809149 & 4.0 & 4.0367 & TRN & \\
\hline CHEMBL1986139 & 809149 & 4.8 & 4.4849 & TRN & \\
\hline CHEMBL383527 & 809149 & 4.0 & 4.3226 & TRN & \\
\hline CHEMBL1980540 & 809149 & 4.8 & 4.473 & TRN & \\
\hline CHEMBL278041 & 809149 & 4.5 & 4.6603 & TRN & \\
\hline CHEMBL1979883 & 809149 & 4.2 & 4.6739 & 99999999995 & TRN \\
\hline CHEMBL1984162 & 809149 & 4.8 & 5.556 & TRN & \\
\hline CHEMBL1997051 & 809149 & 4.5 & 4.8856 & TRN & \\
\hline CHEMBL491758 & 809149 & 4.8 & 5.9919 & TRN & \\
\hline CHEMBL1986590 & 809149 & 4.5 & 5.4854 & TRN & \\
\hline CHEMBL549730 & 809149 & 4.1 & 4.9482 & TRN & \\
\hline CHEMBL1682360 & 809149 & 4.0 & 4.388 & TRN & \\
\hline CHEMBL1970189 & 809149 & 4.8 & 4.3581 & TRN & \\
\hline CHEMBL1870106 & 809149 & 4.5 & 4.7318 & TRN & \\
\hline CHEMBL1996791 & 809149 & 4.8 & 4.7259 & TRN & \\
\hline CHEMBL371206 & 809149 & 4.8 & 5.0497 & TRN & \\
\hline CHEMBL1974664 & 809149 & 4.8 & 4.7535 & TST & \\
\hline CHEMBL406845 & 809149 & 4.5 & 4.3994 & TRN & \\
\hline CHEMBL482538 & 809149 & 4.3 & 4.473 & TRN & \\
\hline CHEMBL1974288 & 809149 & 4.8 & 5.3677 & TRN & \\
\hline CHEMBL1984296 & 809149 & 5.7 & 5.4235 & TST & \\
\hline CHEMBL196363 & 809149 & 4.4 & 4.7301 & TRN & \\
\hline CHEMBL1190711 & 809149 & 4.8 & 4.648 & TRN & \\
\hline CHEMBL1990346 & 809149 & 4.0 & 4.1717 & TRN & \\
\hline CHEMBL1968705 & 809149 & 5.8 & 4.5205 & TRN & \\
\hline CHEMBL1964441 & 809149 & 4.5 & 4.4266 & TRN & \\
\hline CHEMBL1991410 & 809149 & 4.5 & 4.3255 & TRN & \\
\hline CHEMBL546797 & 809149 & 4.5 & 4.9946 & TRN & \\
\hline CHEMBL404367 & 809149 & 4.2 & 4.0273 & TRN & \\
\hline CHEMBL1966343 & 809149 & 4.8 & 4.9413 & TRN & \\
\hline CHEMBL1978271 & 809149 & 4.5 & 4.591 & TRN & \\
\hline CHEMBL1967887 & 809149 & 4.8 & 5.553 & TRN & \\
\hline CHEMBL 2007266 & 809149 & 4.5 & 3.8576 & TRN & \\
\hline CHEMBL 2000568 & 809149 & 4.6 & 4.8885 & TRN & \\
\hline & & & & 18722 & \\
\hline
\end{tabular}




\begin{tabular}{|c|c|c|c|c|c|}
\hline & & & & & \\
\hline CHEMBL1994308 & 809149 & 4.5 & 4.8766 & TST & \\
\hline CHEMBL 2000335 & 809149 & 6.4 & 5.5861 & TRN & \\
\hline CHEMBL2007097 & 809149 & 4.3 & 4.2427 & TRN & \\
\hline CHEMBL1988717 & 809149 & 5.8 & 4.2482 & TRN & \\
\hline CHEMBL1974328 & 809149 & 6.1 & 5.9704 & TRN & \\
\hline CHEMBL509032 & 809149 & 8.0 & 7.5344 & TRN & \\
\hline CHEMBL1973808 & 809149 & 4.8 & 4.8758 & TRN & \\
\hline CHEMBL 2000429 & 809149 & 4.8 & 4.8113 & TRN & \\
\hline CHEMBL1972576 & 809149 & 7.2 & 6.2161 & TRN & \\
\hline CHEMBL1992342 & 809149 & 4.8 & 4.7438 & TRN & \\
\hline CHEMBL1988173 & 809149 & 7.0 & 5.5686 & TST & \\
\hline CHEMBL1973013 & 809149 & 5.7 & 5.5803 & TST & \\
\hline CHEMBL1164265 & 809149 & 4.5 & 5.4537 & TST & \\
\hline CHEMBL1989805 & 809149 & 6.8 & 4.8204 & TST & \\
\hline CHEMBL1965423 & 809149 & 4.2 & 4.4426 & TRN & \\
\hline CHEMBL1983025 & 809149 & 4.2 & 4.7448 & TRN & \\
\hline CHEMBL1975927 & 809149 & 6.4 & 5.5058 & TRN & \\
\hline CHEMBL205415 & 809149 & 4.7 & 4.4939 & TRN & \\
\hline CHEMBL1977135 & 809149 & 4.8 & 5.1478 & TRN & \\
\hline CHEMBL 2001920 & 809149 & 5.8 & 5.4878 & TRN & \\
\hline CHEMBL 2002322 & 809149 & 4.0 & 4.6462 & TRN & \\
\hline CHEMBL1977138 & 809149 & 7.2 & 5.8795 & TST & \\
\hline CHEMBL 2002323 & 809149 & 4.0 & 3.8223 & TRN & \\
\hline CHEMBL1241473 & 809149 & 8.1 & 7.2003 & TRN & \\
\hline CHEMBL 2000879 & 809149 & 4.0 & 5.0412 & TST & \\
\hline CHEMBL1978448 & 809149 & 4.8 & 4.7857 & TST & \\
\hline CHEMBL1972258 & 809149 & 4.2 & 4.103 & TRN & \\
\hline CHEMBL1969483 & 809149 & 4.5 & 4.1265 & TRN & \\
\hline CHEMBL1980329 & 809149 & 6.8 & 6.5885 & TRN & \\
\hline CHEMBL 2004515 & 809149 & 5.2 & 4.7283 & TRN & \\
\hline CHEMBL 2001257 & 809149 & 4.3 & 4.381 & TRN & \\
\hline CHEMBL1992042 & 809149 & 5.5 & 5.5711 & TST & \\
\hline CHEMBL 2005548 & 809149 & 4.0 & 5.1213 & TRN & \\
\hline CHEMBL1992536 & 809149 & 4.8 & 5.1851 & TRN & \\
\hline CHEMBL 21156 & 809149 & 6.8 & 5.9185 & TST & \\
\hline CHEMBL1992740 & 809149 & 4.2 & 4.4872 & TRN & \\
\hline CHEMBL1994724 & 809149 & 4.5 & 4.9278 & TRN & \\
\hline CHEMBL1989267 & 809149 & 6.2 & 5.2097 & TRN & \\
\hline CHEMBL439340 & 809149 & 4.2 & 4.026 & TRN & \\
\hline CHEMBL 2006188 & 809149 & 4.8 & 4.9736 & TRN & \\
\hline CHEMBL1967531 & 809149 & 4.8 & 5.0888 & TRN & \\
\hline CHEMBL1970913 & 809149 & 4.2 & 4.4908 & TRN & \\
\hline CHEMBL1973893 & 809149 & 4.8 & 5.0935 & TRN & \\
\hline CHEMBL1997534 & 809149 & 4.8 & 5.7448 & TRN & \\
\hline CHEMBL1993877 & 809149 & 5.5 & 4.7243 & TRN & \\
\hline CHEMBL1996500 & 809149 & 4.5 & 4.6947 & TRN & \\
\hline CHEMBL1985095 & 809149 & 6.2 & 5.8343 & TST & \\
\hline CHEMBL1991180 & 809149 & 5.6 & $5.4570 e$ & 2000000001 & TST \\
\hline & & & & 18723 & \\
\hline
\end{tabular}




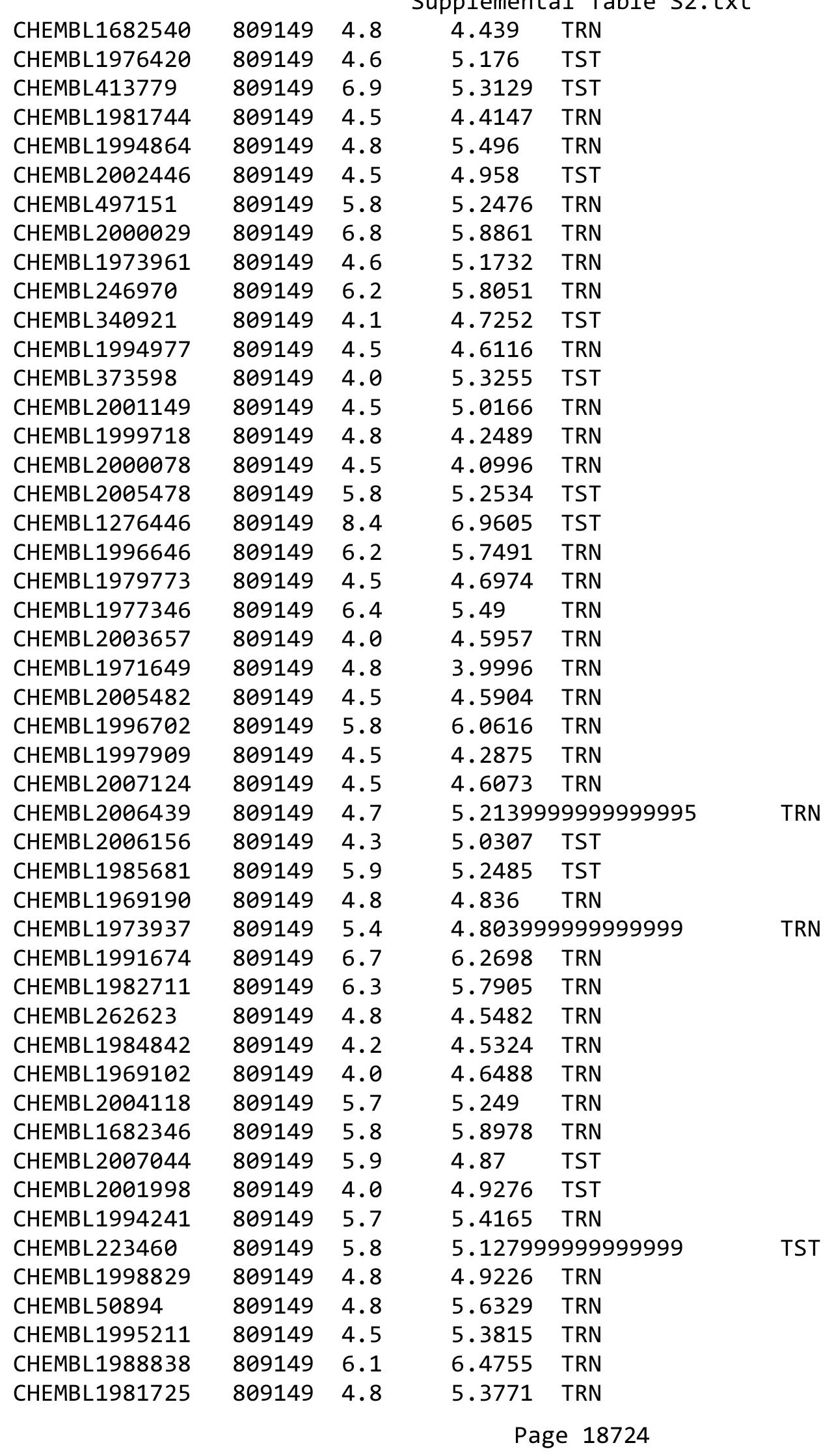




\begin{tabular}{|c|c|c|c|c|}
\hline & & & pplement & al $\mathrm{Ta}$ \\
\hline CHEMBL375284 & 809149 & 4.0 & 4.416 & TRN \\
\hline CHEMBL 2006299 & 809149 & 4.5 & 4.8339 & TRN \\
\hline CHEMBL1965169 & 809149 & 5.5 & 4.6733 & TST \\
\hline CHEMBL1081312 & 809149 & 5.6 & 4.8915 & TRN \\
\hline CHEMBL1965170 & 809149 & 4.5 & 4.7786 & TRN \\
\hline CHEMBL1982866 & 809149 & 4.8 & 4.2855 & TRN \\
\hline CHEMBL 2005792 & 809149 & 4.2 & 4.5459 & TRN \\
\hline CHEMBL1984206 & 809149 & 4.0 & 3.9599 & TRN \\
\hline CHEMBL462120 & 809149 & 4.2 & 4.294 & TRN \\
\hline CHEMBL1991577 & 809149 & 4.0 & 4.5564 & TRN \\
\hline CHEMBL1991867 & 809149 & 4.4 & 4.2157 & TST \\
\hline CHEMBL1965570 & 809149 & 4.8 & 4.8768 & TRN \\
\hline CHEMBL 2007592 & 809149 & 4.2 & 4.467 & TRN \\
\hline CHEMBL1972355 & 809149 & 6.1 & 5.7661 & TRN \\
\hline CHEMBL1997892 & 809149 & 4.5 & 4.8448 & TRN \\
\hline CHEMBL 2001641 & 809149 & 5.2 & 4.7482 & TRN \\
\hline CHEMBL1997193 & 809149 & 6.1 & 5.1673 & TST \\
\hline CHEMBL210963 & 809149 & 4.2 & 3.6899 & TRN \\
\hline CHEMBL1964902 & 809149 & 4.5 & 4.3291 & TRN \\
\hline CHEMBL1082440 & 809149 & 6.6 & 5.4434 & TST \\
\hline CHEMBL1614705 & 809149 & 4.2 & 4.5205 & TRN \\
\hline CHEMBL1972362 & 809149 & 4.0 & 4.968 & TRN \\
\hline CHEMBL1984633 & 809149 & 4.8 & 4.6003 & TRN \\
\hline CHEMBL1965845 & 809149 & 6.7 & 6.3389 & TRN \\
\hline CHEMBL1983715 & 809149 & 7.0 & 6.5166 & TRN \\
\hline CHEMBL1971017 & 809149 & 6.2 & 5.5764 & TRN \\
\hline CHEMBL 2006715 & 809149 & 6.0 & 5.3622 & TRN \\
\hline CHEMBL1986597 & 809149 & 4.8 & 4.6197 & TRN \\
\hline CHEMBL1990482 & 809149 & 4.1 & 4.5032 & TRN \\
\hline CHEMBL1990904 & 809149 & 4.8 & 4.7454 & TRN \\
\hline CHEMBL 2000104 & 809149 & 4.0 & 4.8043 & TRN \\
\hline CHEMBL 2005475 & 809149 & 5.9 & 5.9009 & TRN \\
\hline CHEMBL402846 & 809149 & 4.2 & 3.9741 & TRN \\
\hline CHEMBL1997349 & 809149 & 6.5 & 5.3548 & TST \\
\hline CHEMBL183844 & 809149 & 4.8 & 4.2498 & TRN \\
\hline CHEMBL220057 & 809149 & 4.2 & 4.5002 & TRN \\
\hline CHEMBL1682545 & 809149 & 4.2 & 4.3832 & TRN \\
\hline CHEMBL 383541 & 809149 & 4.2 & 4.7332 & TRN \\
\hline CHEMBL 2001224 & 809149 & 4.2 & 4.2503 & TRN \\
\hline CHEMBL10 & 809149 & 4.5 & 4.6116 & TRN \\
\hline CHEMBL1976732 & 809149 & 4.8 & 4.9816 & TRN \\
\hline CHEMBL1969506 & 809149 & 4.8 & 4.9898 & TRN \\
\hline CHEMBL1980763 & 809149 & 5.7 & 5.2224 & TRN \\
\hline CHEMBL1964937 & 809149 & 6.7 & 5.9869 & TRN \\
\hline CHEMBL1980163 & 809149 & 4.8 & 4.4115 & TRN \\
\hline CHEMBL590109 & 809149 & 6.4 & 5.994 & TST \\
\hline CHEMBL1970879 & 809149 & 4.0 & 4.8245 & TRN \\
\hline CHEMBL1989856 & 809149 & 4.0 & 4.7494 & TST \\
\hline
\end{tabular}




\begin{tabular}{|c|c|c|c|c|}
\hline & & & ient & al Ta \\
\hline CHEMBL 2005899 & 809149 & 4.2 & 4.9219 & TRN \\
\hline CHEMBL1682552 & 809149 & 4.1 & 4.3891 & TRN \\
\hline CHEMBL 259850 & 809149 & 4.0 & 4.7044 & TRN \\
\hline CHEMBL 2007479 & 809149 & 4.5 & 4.4402 & TRN \\
\hline CHEMBL1996155 & 809149 & 4.0 & 4.334 & TRN \\
\hline CHEMBL1986851 & 809149 & 4.5 & 4.888 & TRN \\
\hline CHEMBL229799 & 809149 & 8.0 & 7.6985 & TRN \\
\hline CHEMBL105739 & 809149 & 4.1 & 6.0786 & TRN \\
\hline CHEMBL1682359 & 809149 & 4.0 & 4.3624 & TRN \\
\hline CHEMBL1972220 & 809149 & 5.8 & 5.2752 & TRN \\
\hline CHEMBL 379300 & 809149 & 6.8 & 6.7036 & TRN \\
\hline CHEMBL 203673 & 809149 & 4.0 & 4.8075 & TRN \\
\hline CHEMBL 2003785 & 809149 & 4.8 & 4.9847 & TST \\
\hline CHEMBL1973720 & 809149 & 7.4 & 6.7798 & TRN \\
\hline CHEMBL1969523 & 809149 & 6.6 & 6.0298 & TRN \\
\hline CHEMBL 207995 & 809149 & 4.0 & 4.5432 & TRN \\
\hline CHEMBL 2001923 & 809149 & 4.2 & 4.4405 & TRN \\
\hline CHEMBL1986781 & 809149 & 4.8 & 4.808 & TRN \\
\hline CHEMBL1983070 & 809149 & 4.5 & 4.4466 & TRN \\
\hline CHEMBL526133 & 809149 & 6.1 & 4.9654 & TRN \\
\hline CHEMBL 2003514 & 809149 & 4.5 & 4.6527 & TRN \\
\hline CHEMBL1989043 & 809149 & 4.5 & 4.8609 & TRN \\
\hline CHEMBL1979057 & 809149 & 5.9 & 5.0813 & TRN \\
\hline CHEMBL1981045 & 809149 & 4.0 & 4.6981 & TRN \\
\hline CHEMBL 387971 & 809149 & 4.2 & 4.6562 & TST \\
\hline CHEMBL1975418 & 809149 & 6.1 & 6.1221 & TRN \\
\hline CHEMBL1992796 & 809149 & 4.0 & 4.6725 & TRN \\
\hline CHEMBL1164180 & 809149 & 6.1 & 5.4145 & TST \\
\hline CHEMBL223257 & 809149 & 6.0 & 5.1226 & TST \\
\hline CHEMBL1999428 & 809149 & 4.8 & 5.1699 & TRN \\
\hline CHEMBL1967560 & 809149 & 4.8 & 4.3822 & TRN \\
\hline CHEMBL1997611 & 809149 & 5.6 & 4.8217 & TST \\
\hline CHEMBL1516890 & 809149 & 5.8 & 5.6329 & TRN \\
\hline CHEMBL 211378 & 809149 & 4.2 & 4.3056 & TRN \\
\hline CHEMBL1982465 & 809149 & 4.2 & 4.2267 & TRN \\
\hline CHEMBL 2001751 & 809149 & 7.7 & 7.5023 & TRN \\
\hline CHEMBL 2003420 & 809149 & 4.8 & 4.6407 & TRN \\
\hline CHEMBL1984586 & 809149 & 4.8 & 4.644 & TRN \\
\hline CHEMBL1999774 & 809149 & 4.0 & 4.524 & TST \\
\hline CHEMBL1972659 & 809149 & 4.2 & 4.671 & TST \\
\hline CHEMBL 2002723 & 809149 & 5.9 & 5.3207 & TST \\
\hline CHEMBL1973395 & 809149 & 5.9 & 5.3042 & TRN \\
\hline CHEMBL 272453 & 809149 & 4.8 & 4.211 & TRN \\
\hline CHEMBL1970217 & 809149 & 4.8 & 5.1277 & TRN \\
\hline CHEMBL1971801 & 809149 & 4.0 & 5.1232 & TRN \\
\hline CHEMBL1968850 & 809149 & 5.4 & 5.3201 & TRN \\
\hline CHEMBL 2005528 & 809149 & 4.8 & 4.9039 & TRN \\
\hline CHEMBL1984686 & 809149 & 4.5 & 4.3931 & TRN \\
\hline
\end{tabular}




\begin{tabular}{|c|c|c|c|c|}
\hline & & & pplement & al $\mathrm{Ta}$ \\
\hline CHEMBL185569 & 809149 & 4.2 & 4.6171 & TRN \\
\hline CHEMBL1969843 & 809149 & 4.8 & 4.3589 & TRN \\
\hline CHEMBL2007002 & 809149 & 5.9 & 4.8772 & TRN \\
\hline CHEMBL1987007 & 809149 & 6.1 & 5.4234 & TRN \\
\hline CHEMBL1973793 & 809149 & 4.5 & 4.9468 & TST \\
\hline CHEMBL1969588 & 809149 & 8.4 & 6.7945 & TRN \\
\hline CHEMBL1984711 & 809149 & 4.2 & 4.5735 & TRN \\
\hline CHEMBL1992073 & 809149 & 5.7 & 5.3537 & TRN \\
\hline CHEMBL1990212 & 809149 & 4.0 & 4.3177 & TRN \\
\hline CHEMBL484390 & 809149 & 5.8 & 5.0236 & TST \\
\hline CHEMBL1979252 & 809149 & 6.0 & 5.6219 & TRN \\
\hline CHEMBL1986143 & 809149 & 4.5 & 5.0276 & TRN \\
\hline CHEMBL1972934 & 809149 & 4.3 & 4.2124 & TRN \\
\hline CHEMBL 2007559 & 809149 & 4.5 & 5.3306 & TRN \\
\hline CHEMBL1992581 & 809149 & 4.5 & 4.9122 & TRN \\
\hline CHEMBL1682341 & 809149 & 5.6 & 5.3911 & TRN \\
\hline CHEMBL2004290 & 809149 & 4.7 & 4.6737 & TRN \\
\hline CHEMBL1986499 & 809149 & 4.8 & 5.9927 & TRN \\
\hline CHEMBL1972937 & 809149 & 4.8 & 4.4404 & TRN \\
\hline CHEMBL1972250 & 809149 & 4.0 & 4.8109 & TST \\
\hline CHEMBL 2000393 & 809149 & 6.8 & 6.3269 & TST \\
\hline CHEMBL 2004072 & 809149 & 4.0 & 4.6135 & TRN \\
\hline CHEMBL 2004311 & 809149 & 4.8 & 4.7217 & TRN \\
\hline CHEMBL1992634 & 809149 & 4.8 & 5.4834 & TRN \\
\hline CHEMBL1242373 & 809149 & 6.4 & 5.3266 & TRN \\
\hline CHEMBL 2000433 & 809149 & 4.0 & 4.4158 & TST \\
\hline CHEMBL56543 & 809149 & 5.9 & 5.3609 & TRN \\
\hline CHEMBL1984847 & 809149 & 4.5 & 4.6028 & TST \\
\hline CHEMBL 316264 & 809149 & 4.8 & 4.5334 & TRN \\
\hline CHEMBL1988075 & 809149 & 5.8 & 4.8289 & TRN \\
\hline CHEMBL1996576 & 809149 & 4.5 & 4.7319 & TST \\
\hline CHEMBL1988076 & 809149 & 4.5 & 4.52 & TRN \\
\hline CHEMBL1991678 & 809149 & 4.5 & 4.7293 & TRN \\
\hline CHEMBL 2001239 & 809149 & 5.7 & 5.5515 & TST \\
\hline CHEMBL1988594 & 809149 & 7.0 & 6.2006 & TRN \\
\hline CHEMBL 2001288 & 809149 & 4.8 & 4.4499 & TRN \\
\hline CHEMBL260092 & 809149 & 4.0 & 5.2044 & TRN \\
\hline CHEMBL1999811 & 809149 & 4.8 & 5.2764 & TRN \\
\hline CHEMBL1965495 & 809149 & 4.0 & 4.9061 & TRN \\
\hline CHEMBL235157 & 809149 & 4.5 & 4.0838 & TST \\
\hline CHEMBL1985074 & 809149 & 6.4 & 4.8717 & TST \\
\hline CHEMBL 2000481 & 809149 & 4.8 & 5.2591 & TRN \\
\hline CHEMBL1982874 & 809149 & 4.8 & 4.5678 & TRN \\
\hline CHEMBL1991725 & 809149 & 4.8 & 4.7619 & TRN \\
\hline CHEMBL1992242 & 809149 & 4.2 & 4.1216 & TRN \\
\hline CHEMBL 2007296 & 809149 & 4.8 & 4.3869 & TRN \\
\hline CHEMBL 208637 & 809149 & 4.2 & 3.6489 & TRN \\
\hline CHEMBL396523 & 809149 & 6.3 & 6.8932 & TRN \\
\hline
\end{tabular}




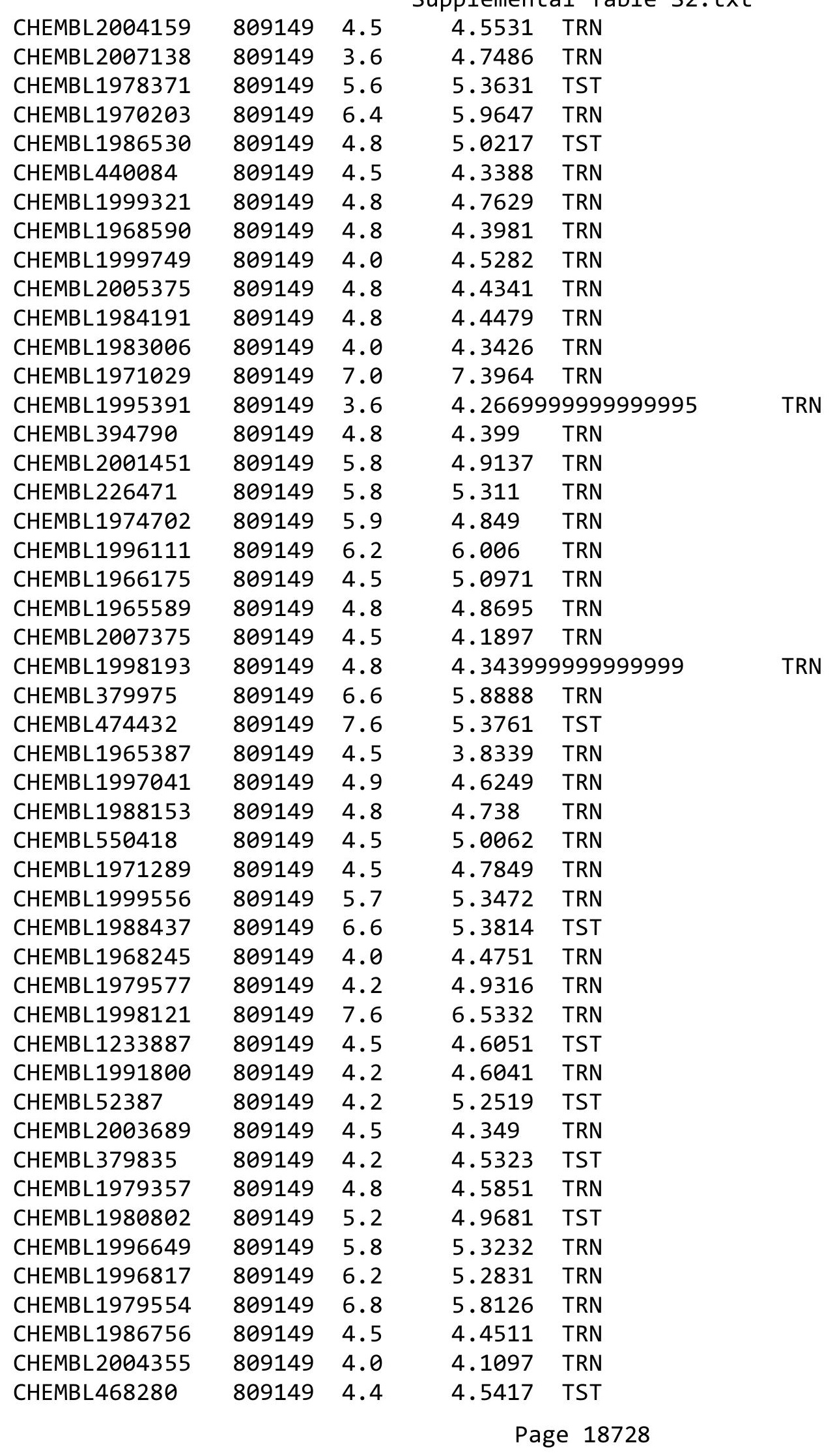




\begin{tabular}{|c|c|c|c|c|c|}
\hline \\
\hline CHEMBL1990884 & 809149 & 4.8 & 4.2654 & TRN & \\
\hline CHEMBL3109278 & 809149 & 7.2 & 6.7449 & TRN & \\
\hline CHEMBL256835 & 809149 & 4.5 & 4.4205 & TRN & \\
\hline CHEMBL1980142 & 809149 & 4.8 & 4.4447 & TRN & \\
\hline CHEMBL41783 & 809149 & 4.8 & 4.6385 & TRN & \\
\hline CHEMBL 2004438 & 809149 & 4.2 & 3.7339 & TRN & \\
\hline CHEMBL 2006276 & 809149 & 4.8 & 4.9249 & TRN & \\
\hline CHEMBL191003 & 809149 & 6.3 & 5.768 & TRN & \\
\hline CHEMBL 271381 & 809149 & 4.2 & 4.5194 & TRN & \\
\hline CHEMBL 2006785 & 809149 & 4.8 & 4.7276 & TRN & \\
\hline CHEMBL1982466 & 809149 & 4.8 & 4.6611 & TRN & \\
\hline CHEMBL1973359 & 809149 & 6.8 & 6.0287 & TST & \\
\hline CHEMBL1995740 & 809149 & 6.4 & 5.3863 & TRN & \\
\hline CHEMBL1996390 & 809149 & 4.0 & 4.8868 & TRN & \\
\hline CHEMBL1979690 & 809149 & 7.0 & 7.2247 & TRN & \\
\hline CHEMBL 234085 & 809149 & 4.5 & 4.4358 & TRN & \\
\hline CHEMBL1995832 & 809149 & 4.8 & 4.7411 & TRN & \\
\hline CHEMBL1969042 & 809149 & 4.8 & 5.4233 & TRN & \\
\hline CHEMBL 2000345 & 809149 & 6.0 & 5.5753 & TRN & \\
\hline CHEMBL1999931 & 809149 & 7.2 & 7.8412 & TRN & \\
\hline CHEMBL1976376 & 809149 & 4.5 & 4.3395 & TRN & \\
\hline CHEMBL1991640 & 809149 & 4.0 & 5.4898 & TST & \\
\hline CHEMBL1983575 & 809149 & 7.0 & 6.2124 & TRN & \\
\hline CHEMBL1968868 & 809149 & 4.5 & 4.3623 & TRN & \\
\hline CHEMBL1375418 & 809149 & 5.8 & 4.5726 & TRN & \\
\hline CHEMBL 2007064 & 809149 & 6.1 & 6.5263 & TRN & \\
\hline CHEMBL1981047 & 809149 & 7.8 & 6.5388 & TRN & \\
\hline CHEMBL229968 & 809149 & 7.5 & 7.7177 & TRN & \\
\hline CHEMBL1976196 & 809149 & 5.7 & 5.3032 & TST & \\
\hline CHEMBL1976240 & 809149 & 6.6 & $5.3670 e$ & 0000000001 & TRN \\
\hline CHEMBL1997197 & 809149 & 4.5 & 4.3047 & TRN & \\
\hline CHEMBL1983630 & 809149 & 4.3 & 4.5755 & TRN & \\
\hline CHEMBL1979093 & 809149 & 4.8 & 4.6468 & TRN & \\
\hline CHEMBL1968151 & 809149 & 4.8 & 4.3102 & TRN & \\
\hline CHEMBL1381197 & 809149 & 4.0 & 4.738 & TRN & \\
\hline CHEMBL1987009 & 809149 & 6.5 & 6.4809 & TRN & \\
\hline CHEMBL379218 & 809149 & 6.7 & 7.0556 & TRN & \\
\hline CHEMBL 2003817 & 809149 & 4.2 & 4.7066 & TRN & \\
\hline CHEMBL336961 & 809149 & 4.0 & 4.7355 & TRN & \\
\hline CHEMBL1994830 & 809149 & 4.8 & 4.5978 & TRN & \\
\hline CHEMBL1987054 & 809149 & 4.0 & 5.5837 & TRN & \\
\hline CHEMBL1970083 & 809149 & 4.0 & 5.1582 & TRN & \\
\hline CHEMBL 226403 & 809149 & 6.0 & 5.3935 & TRN & \\
\hline CHEMBL2005631 & 809149 & 4.3 & 4.9307 & TRN & \\
\hline CHEMBL1994938 & 809149 & 4.8 & 4.864 & TRN & \\
\hline CHEMBL1977223 & 809149 & 6.1 & 6.0842 & TRN & \\
\hline CHEMBL1995765 & 809149 & 4.8 & 4.2529 & TST & \\
\hline CHEMBL1966279 & 809149 & 4.8 & 5.1053 & TRN & \\
\hline
\end{tabular}




\begin{tabular}{|c|c|c|c|c|c|}
\hline \\
\hline CHEMBL1236126 & 809149 & 4.2 & 4.6602 & TST & \\
\hline CHEMBL1997846 & 809149 & 4.7 & 5.4739 & TRN & \\
\hline CHEMBL1984760 & 809149 & 5.5 & 5.5916 & TRN & \\
\hline CHEMBL 2004419 & 809149 & 4.8 & 4.4723 & TRN & \\
\hline CHEMBL1991728 & 809149 & 5.6 & 5.8184 & TRN & \\
\hline CHEMBL360847 & 809149 & 4.5 & 5.2213 & TST & \\
\hline CHEMBL1995811 & 809149 & 6.4 & 6.7474 & TRN & \\
\hline CHEMBL1975787 & 809149 & 5.7 & 5.6753 & TRN & \\
\hline CHEMBL 2002407 & 809149 & 4.0 & 4.436 & TRN & \\
\hline CHEMBL1972489 & 809149 & 4.8 & 4.7753 & TRN & \\
\hline CHEMBL1994074 & 809149 & 4.8 & 4.8552 & TRN & \\
\hline CHEMBL1992937 & 809149 & 4.3 & 5.0816 & TST & \\
\hline CHEMBL451401 & 809149 & 4.0 & 4.5462 & TRN & \\
\hline CHEMBL1985566 & 809149 & 4.0 & 4.4044 & TRN & \\
\hline CHEMBL536151 & 809149 & 4.0 & 4.8532 & TST & \\
\hline CHEMBL1972119 & 809149 & 4.8 & 4.1611 & TRN & \\
\hline CHEMBL1986328 & 809149 & 6.2 & 5.1684 & TST & \\
\hline CHEMBL95692 & 809149 & 4.2 & 4.3295 & TRN & \\
\hline CHEMBL1090356 & 809149 & 4.8 & 4.513 & TRN & \\
\hline CHEMBL 2002450 & 809149 & 4.1 & 3.8882 & TRN & \\
\hline CHEMBL1976455 & 809149 & 4.2 & 5.0394 & TRN & \\
\hline CHEMBL261849 & 809149 & 4.5 & 3.8527 & TST & \\
\hline CHEMBL1983923 & 809149 & 6.3 & 5.8744 & TRN & \\
\hline CHEMBL1983534 & 809149 & 4.8 & 4.8844 & TRN & \\
\hline CHEMBL1982361 & 809149 & 5.9 & 5.7126 & TRN & \\
\hline CHEMBL1999112 & 809149 & 4.8 & 4.6323 & TST & \\
\hline CHEMBL1982122 & 809149 & 4.8 & 4.97199 & 99999999995 & TRN \\
\hline CHEMBL 2000801 & 809149 & 4.8 & 4.3205 & TRN & \\
\hline CHEMBL1682546 & 809149 & 4.2 & 4.88899 & 9999999999 & TRN \\
\hline CHEMBL1991395 & 809149 & 4.4 & 4.591 & TRN & \\
\hline CHEMBL1971245 & 809149 & 4.8 & 4.6008 & TRN & \\
\hline CHEMBL1987648 & 809149 & 4.0 & 4.6167 & TRN & \\
\hline CHEMBL1996780 & 809149 & 4.0 & 4.4232 & TST & \\
\hline CHEMBL1972142 & 809149 & 4.8 & 5.4451 & TRN & \\
\hline CHEMBL1966514 & 809149 & 4.2 & 4.9372 & TRN & \\
\hline CHEMBL 2003638 & 809149 & 7.0 & 7.4548 & TST & \\
\hline CHEMBL 296586 & 809149 & 4.0 & 5.2612 & TST & \\
\hline CHEMBL1996066 & 809149 & 4.8 & 4.4406 & TST & \\
\hline CHEMBL1983393 & 809149 & 4.5 & 4.6441 & TST & \\
\hline CHEMBL516429 & 809149 & 6.5 & 5.8378 & TST & \\
\hline CHEMBL1993722 & 809149 & 4.2 & 4.7334 & TST & \\
\hline CHEMBL1970806 & 809149 & 4.2 & 4.21399 & 99999999995 & TST \\
\hline CHEMBL 2006674 & 809149 & 4.5 & 5.0592 & TST & \\
\hline CHEMBL1984236 & 809149 & 4.5 & 4.6186 & TST & \\
\hline CHEMBL1992371 & 809149 & 5.7 & 4.8276 & TST & \\
\hline CHEMBL202635 & 809149 & 5.5 & 4.2546 & TST & \\
\hline CHEMBL1375640 & 809149 & 4.8 & 4.4266 & TST & \\
\hline CHEMBL1979970 & 809149 & 4.4 & 4.5287 & TST & \\
\hline & & & & 87 & \\
\hline
\end{tabular}




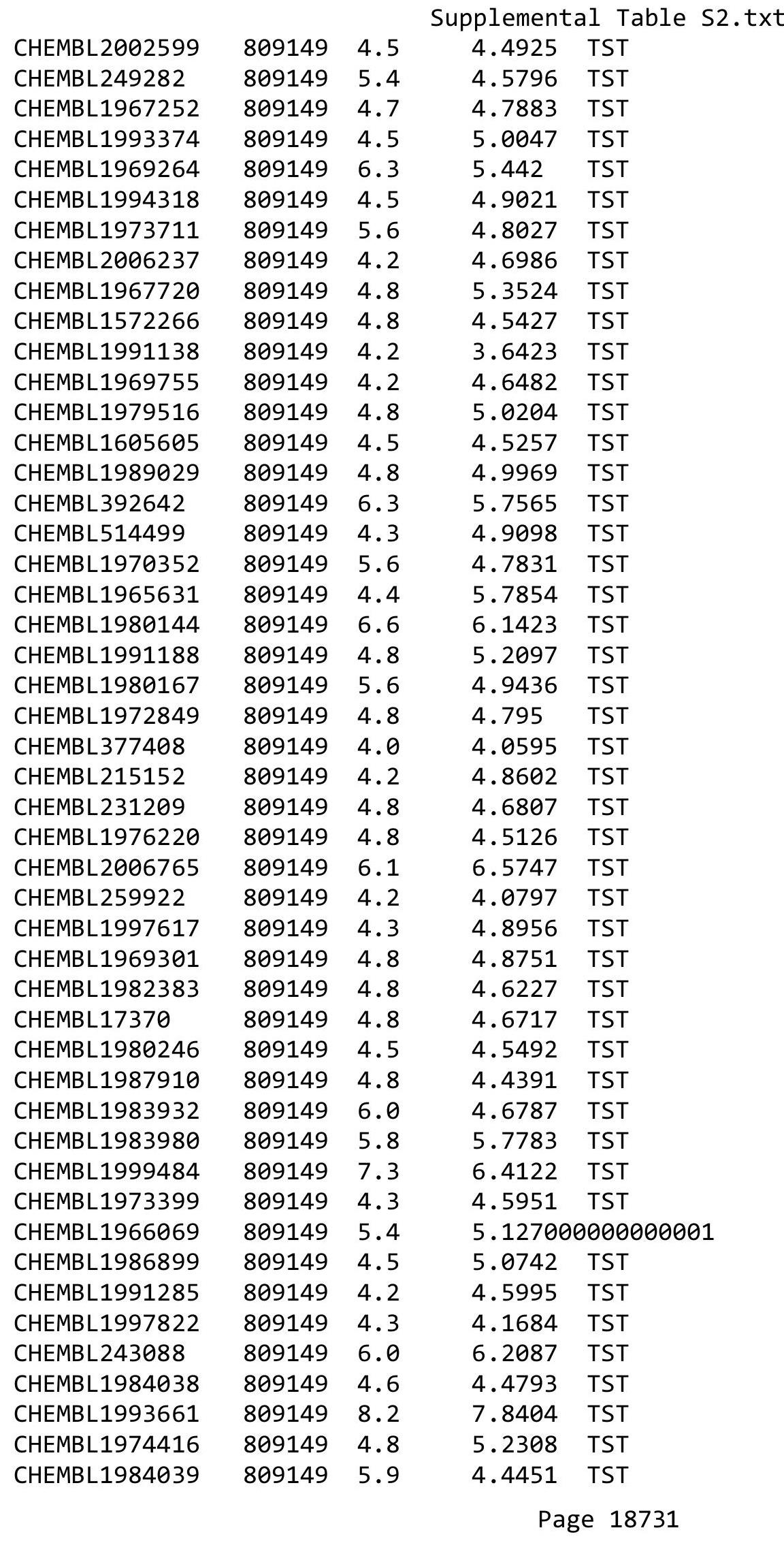




\begin{tabular}{|c|c|c|c|c|c|}
\hline \multicolumn{6}{|c|}{ Supplemental Table s2.txt } \\
\hline CHEMBL32096 & 45265 & 7.4437 & 7.2496 & TRN & \\
\hline CHEMBL34086 & 45265 & 7.5229 & 7.5629 & TRN & \\
\hline CHEMBL284732 & 45265 & 7.8861 & 7.7581 & TRN & \\
\hline CHEMBL36252 & 45265 & 7.7959 & 6.7533 & TST & \\
\hline CHEMBL416774 & 45265 & 6.8097 & 6.8485 & TRN & \\
\hline CHEMBL36322 & 45265 & 7.699 & 7.6034 & TRN & \\
\hline CHEMBL285170 & 45265 & 6.0315 & 6.0713 & TRN & \\
\hline CHEMBL6919 & 45265 & 6.2518 & 6.0896 & TST & \\
\hline CHEMBL416221 & 45265 & 7.1612 & 6.9845 & TRN & \\
\hline CHEMBL33478 & 45265 & 8.301 & 8.3208 & TRN & \\
\hline CHEMBL 34073 & 45265 & 7.0809 & 6.6333 & TRN & \\
\hline CHEMBL35595 & 45265 & 5.9066 & 6.0343 & TST & \\
\hline CHEMBL 2112274 & 45265 & 8.3979 & 8.1849 & TRN & \\
\hline CHEMBL35495 & 45265 & 6.0 & 6.4087 & TST & \\
\hline CHEMBL37958 & 45265 & 7.8861 & 7.6705 & TRN & \\
\hline CHEMBL284398 & 45265 & 7.5686 & 7.4845 & TRN & \\
\hline CHEMBL285239 & 45265 & 6.2636 & 6.3518 & TRN & \\
\hline CHEMBL6853 & 45265 & 6.7447 & 6.5143 & TST & \\
\hline CHEMBL1795051 & 45265 & 6.0 & 6.705 & TRN & \\
\hline CHEMBL 34013 & 45265 & 6.1249 & 6.1496 & TRN & \\
\hline CHEMBL1795064 & 45265 & 6.0 & 6.7044 & TRN & \\
\hline CHEMBL32735 & 45265 & 6.5901 & 6.5397 & TST & \\
\hline CHEMBL262651 & 45265 & 8.1549 & 7.6716 & TST & \\
\hline CHEMBL35021 & 45265 & 6.475 & 6.5734 & TRN & \\
\hline CHEMBL 34703 & 45265 & 7.3188 & 6.66799 & 9999999999 & TRN \\
\hline CHEMBL 34974 & 45265 & 6.5768 & 6.7642 & TRN & \\
\hline CHEMBL33914 & 45265 & 7.4949 & 7.6759 & TRN & \\
\hline CHEMBL35265 & 45265 & 6.6021 & 6.7525 & TRN & \\
\hline CHEMBL34809 & 45265 & 6.0 & 6.66799 & 9999999999 & TRN \\
\hline CHEMBL34969 & 45265 & 5.9208 & 6.0365 & TRN & \\
\hline CHEMBL36390 & 45265 & 7.0177 & 6.8485 & TRN & \\
\hline CHEMBL285516 & 45265 & 8.0969 & 8.1203 & TRN & \\
\hline CHEMBL35496 & 45265 & 7.0458 & 7.0431 & TRN & \\
\hline CHEMBL6852 & 45265 & 5.6576 & 5.9447 & TST & \\
\hline CHEMBL 34317 & 45265 & 8.2218 & 7.2818 & TRN & \\
\hline CHEMBL289888 & 45265 & 7.7212 & 6.7552 & TST & \\
\hline CHEMBL286131 & 45265 & 8.2218 & 8.423 & TRN & \\
\hline CHEMBL37730 & 45265 & 7.8861 & 7.726 & TRN & \\
\hline CHEMBL6705 & 45265 & 5.8827 & 5.9368 & TST & \\
\hline CHEMBL 35043 & 45265 & 6.7212 & 6.7344 & TRN & \\
\hline CHEMBL284617 & 45265 & 7.4437 & 7.5226 & TRN & \\
\hline CHEMBL284165 & 45265 & 7.2924 & 7.2958 & TRN & \\
\hline CHEMBL36452 & 45265 & 6.8097 & 6.9254 & TRN & \\
\hline CHEMBL34646 & 45265 & 6.9747 & 6.7644 & TST & \\
\hline CHEMBL1795055 & 45265 & 6.0 & 6.6333 & TRN & \\
\hline CHEMBL32157 & 45265 & 7.9208 & 7.727 & TRN & \\
\hline CHEMBL35189 & 45265 & 6.4559 & 6.4804 & TST & \\
\hline CHEMBL286338 & 45265 & 7.301 & 7.4836 & TRN & \\
\hline
\end{tabular}




\begin{tabular}{|c|c|c|c|c|c|}
\hline \multicolumn{6}{|c|}{ Supplemental Table S2.txt } \\
\hline CHEMBL6753 & 45265 & 6.4498 & 6.5281 & TST & \\
\hline CHEMBL35008 & 45265 & 7.6198 & 7.6034 & TRN & \\
\hline CHEMBL32198 & 45265 & 6.5918 & 6.5764 & TRN & \\
\hline CHEMBL 35710 & 45265 & 7.585 & 6.4087 & TST & \\
\hline CHEMBL35712 & 45265 & 6.6108 & 6.7215 & TST & \\
\hline CHEMBL 286666 & 45265 & 6.301 & 6.2851 & TRN & \\
\hline CHEMBL35113 & 45265 & 6.8861 & 6.7377 & TRN & \\
\hline CHEMBL 284354 & 45265 & 8.3979 & 8.2956 & TRN & \\
\hline CHEMBL154106 & 45265 & 6.0 & 6.7552 & TST & \\
\hline CHEMBL32606 & 45265 & 7.5528 & 7.5322 & TRN & \\
\hline CHEMBL6724 & 45265 & 7.1805 & 6.6062 & TST & \\
\hline CHEMBL34829 & 45265 & 6.1249 & 6.1686 & TRN & \\
\hline CHEMBL 36017 & 45265 & 6.0088 & 6.0514 & TST & \\
\hline CHEMBL408856 & 45265 & 6.0 & 7.2818 & TRN & \\
\hline CHEMBL285531 & 45265 & 6.8386 & 6.7206 & TST & \\
\hline CHEMBL34711 & 45265 & 6.8697 & 6.8313 & TST & \\
\hline CHEMBL 286328 & 45265 & 6.9872 & 7.0212 & TRN & \\
\hline CHEMBL34852 & 45265 & 8.301 & 8.2757 & TRN & \\
\hline CHEMBL 35050 & 45265 & 7.1024 & 7.0745 & TRN & \\
\hline CHEMBL 35410 & 45265 & 6.0655 & 6.1658 & TRN & \\
\hline CHEMBL415466 & 45265 & 8.0458 & 8.339 & TRN & \\
\hline CHEMBL35118 & 45265 & 7.7212 & 7.5074 & TST & \\
\hline CHEMBL 289672 & 45265 & 6.2596 & 6.3233 & TRN & \\
\hline CHEMBL 34488 & 45265 & 8.0969 & 7.9522 & TRN & \\
\hline CHEMBL 286108 & 45265 & 7.3188 & 7.6676 & TRN & \\
\hline CHEMBL32836 & 45265 & 6.7447 & 6.6997 & TRN & \\
\hline CHEMBL34262 & 45265 & 7.1871 & 7.3424 & TRN & \\
\hline CHEMBL 286549 & 45265 & 6.2007 & 6.3194 & TRN & \\
\hline CHEMBL 34710 & 45265 & 7.9586 & 7.9705 & TRN & \\
\hline CHEMBL32982 & 45265 & 7.5376 & 7.5783 & TRN & \\
\hline CHEMBL286297 & 45265 & 7.3979 & 7.2774 & TRN & \\
\hline CHEMBL35327 & 45265 & 6.4377 & 6.3237 & TST & \\
\hline CHEMBL 284061 & 45265 & 8.0 & 7.9522 & TRN & \\
\hline CHEMBL 32165 & 45265 & 7.301 & 7.169 & TRN & \\
\hline CHEMBL35421 & 45265 & 7.3468 & 7.6802 & TRN & \\
\hline CHEMBL284118 & 45265 & 6.8697 & 6.8227 & TRN & \\
\hline CHEMBL36334 & 45265 & 7.8539 & 7.8516 & TRN & \\
\hline CHEMBL284694 & 45265 & 6.8069 & 6.6997 & TRN & \\
\hline CHEMBL1795065 & 45265 & 6.0 & 6.7533 & TST & \\
\hline CHEMBL 32308 & 45265 & 8.1549 & 8.05600 & 3000000001 & TRN \\
\hline CHEMBL417321 & 45265 & 6.0757 & 6.1893 & TRN & \\
\hline CHEMBL284481 & 45265 & 6.0223 & 6.1696 & TST & \\
\hline CHEMBL 285238 & 45265 & 5.8239 & 6.0156 & TST & \\
\hline CHEMBL 34647 & 45265 & 6.9208 & 6.9652 & TST & \\
\hline CHEMBL435541 & 45265 & 6.5086 & 6.7344 & TRN & \\
\hline CHEMBL 34546 & 45265 & 6.0 & 6.5046 & TRN & \\
\hline CHEMBL285788 & 45265 & 6.9788 & 7.0708 & TRN & \\
\hline CHEMBL 34253 & 45265 & 8.0458 & 7.9705 & TRN & \\
\hline
\end{tabular}




\begin{tabular}{|c|c|c|c|c|}
\hline & & & oplement & al Ta \\
\hline CHEMBL32208 & 45265 & 7.6021 & 7.5226 & TRN \\
\hline CHEMBL34899 & 45265 & 7.6778 & 7.4694 & TRN \\
\hline CHEMBL36283 & 45265 & 6.7696 & 6.4009 & TRN \\
\hline CHEMBL35594 & 45265 & 6.3468 & 6.1788 & TST \\
\hline CHEMBL35315 & 45265 & 6.6021 & 6.6468 & TST \\
\hline CHEMBL34770 & 45265 & 6.5768 & 6.6315 & TRN \\
\hline CHEMBL34016 & 45265 & 6.0 & 6.3 & TRN \\
\hline CHEMBL34768 & 45265 & 7.5686 & 7.6946 & TRN \\
\hline CHEMBL262389 & 45265 & 6.3665 & 6.3194 & TRN \\
\hline CHEMBL 287470 & 45265 & 6.6198 & 6.5405 & TRN \\
\hline CHEMBL 285962 & 45265 & 6.2076 & 6.1496 & TRN \\
\hline CHEMBL 284500 & 45265 & 8.301 & 8.3208 & TRN \\
\hline CHEMBL33963 & 45265 & 6.699 & 6.5734 & TRN \\
\hline CHEMBL 7092 & 45265 & 6.4949 & 6.3563 & TST \\
\hline CHEMBL 286561 & 45265 & 6.4949 & 6.5542 & TRN \\
\hline CHEMBL 284071 & 45265 & 6.9788 & 6.8341 & TRN \\
\hline CHEMBL35262 & 45265 & 7.4949 & 6.705 & TRN \\
\hline CHEMBL 284610 & 45265 & 7.1192 & 7.0965 & TST \\
\hline CHEMBL34371 & 45265 & 6.8665 & 6.9827 & TRN \\
\hline CHEMBL442265 & 45265 & 6.8297 & 6.7662 & TRN \\
\hline CHEMBL 36525 & 45265 & 6.301 & 6.2982 & TRN \\
\hline CHEMBL418051 & 45265 & 6.1871 & 6.1643 & TRN \\
\hline CHEMBL35227 & 45265 & 8.1549 & 8.2956 & TRN \\
\hline CHEMBL414154 & 45265 & 8.0969 & 8.2757 & TRN \\
\hline CHEMBL286669 & 45265 & 6.8239 & 6.7525 & TRN \\
\hline CHEMBL 34314 & 45265 & 7.6778 & 6.7044 & TRN \\
\hline CHEMBL36253 & 45265 & 7.2757 & 7.125 & TRN \\
\hline CHEMBL417497 & 45265 & 6.9393 & 6.9674 & TRN \\
\hline CHEMBL 35338 & 45265 & 7.7447 & 7.6532 & TRN \\
\hline CHEMBL35528 & 45265 & 6.4815 & 6.3233 & TRN \\
\hline CHEMBL34608 & 45265 & 6.4949 & 6.3833 & TRN \\
\hline CHEMBL287316 & 45265 & 7.6778 & 7.6946 & TRN \\
\hline CHEMBL 2112275 & 45265 & 7.0 & 7.2784 & TRN \\
\hline CHEMBL35817 & 45265 & 6.9666 & 6.9664 & TRN \\
\hline CHEMBL 290348 & 45265 & 7.284 & 7.3784 & TRN \\
\hline CHEMBL35907 & 45265 & 7.3979 & 7.3071 & TRN \\
\hline CHEMBL 287117 & 45265 & 7.8239 & 7.8521 & TST \\
\hline CHEMBL418047 & 45265 & 7.8539 & 7.6681 & TRN \\
\hline CHEMBL 34520 & 45265 & 6.9431 & 6.8699 & TRN \\
\hline CHEMBL431112 & 45265 & 8.0 & 7.8942 & TRN \\
\hline CHEMBL 36003 & 45265 & 5.9978 & 6.1254 & TST \\
\hline CHEMBL 284831 & 45265 & 7.3872 & 7.3784 & TRN \\
\hline CHEMBL32848 & 45265 & 8.2218 & 8.0565 & TRN \\
\hline CHEMBL 285408 & 45265 & 6.4559 & 6.4217 & TRN \\
\hline CHEMBL35805 & 45265 & 7.5086 & 7.6025 & TRN \\
\hline CHEMBL35698 & 45265 & 6.3979 & 6.2957 & TRN \\
\hline CHEMBL35194 & 45265 & 6.4949 & 6.4997 & TRN \\
\hline CHEMBL 265674 & 45265 & 6.2676 & 6.2785 & TST \\
\hline
\end{tabular}




\begin{tabular}{|c|c|c|c|c|c|c|}
\hline & & \multicolumn{5}{|c|}{ Supplemental Table S2.txt } \\
\hline CHEMBL285435 & 45265 & 7.4559 & 7.4694 & TRN & & \\
\hline CHEMBL36451 & 45265 & 6.9586 & 7.0729 & TST & & \\
\hline CHEMBL418599 & 45265 & 6.9788 & 6.9845 & TRN & & \\
\hline CHEMBL287145 & 45265 & 6.3716 & 6.2982 & TRN & & \\
\hline CHEMBL35498 & 45265 & 7.9586 & 7.9173 & TRN & & \\
\hline CHEMBL34147 & 45265 & 6.2076 & 6.2957 & TRN & & \\
\hline CHEMBL35747 & 45265 & 7.1249 & 6.9252 & TRN & & \\
\hline CHEMBL34319 & 45265 & 7.1079 & 7.2799 & TRN & & \\
\hline CHEMBL35653 & 45265 & 7.2676 & 7.1901 & TRN & & \\
\hline CHEMBL286587 & 45265 & 6.4685 & 6.5298 & TST & & \\
\hline CHEMBL36447 & 45265 & 7.8861 & 8.0565 & TST & & \\
\hline CHEMBL432669 & 45265 & 7.6021 & 7.6759 & TRN & & \\
\hline CHEMBL7204 & 45265 & 5.4949 & 5.8768 & TST & & \\
\hline CHEMBL266240 & 45265 & 6.7959 & 6.275 & TST & & \\
\hline CHEMBL36567 & 45265 & 6.4559 & 6.585 & TST & & \\
\hline CHEMBL 7087 & 45265 & 5.6021 & 5.9988 & TST & & \\
\hline CHEMBL34012 & 45265 & 6.8239 & 6.8891 & TRN & & \\
\hline CHEMBL286831 & 45265 & 6.9101 & 6.8483 & TRN & & \\
\hline CHEMBL408857 & 45265 & 6.7696 & 6.7642 & TRN & & \\
\hline CHEMBL33967 & 45265 & 6.7825 & 6.8318 & TRN & & \\
\hline CHEMBL34998 & 45265 & 7.0177 & 7.2958 & TRN & & \\
\hline CHEMBL34354 & 45265 & 7.0 & 7.0298 & TRN & & \\
\hline CHEMBL285590 & 45265 & 7.7959 & 7.6025 & TRN & & \\
\hline CHEMBL 35420 & 45265 & 6.3468 & 6.2015 & TRN & & \\
\hline CHEMBL35240 & 45265 & 7.4685 & 7.4836 & TRN & & \\
\hline CHEMBL284711 & 45265 & 7.2518 & 7.2265 & TRN & & \\
\hline CHEMBL286602 & 45265 & 6.4949 & 6.3518 & TRN & & \\
\hline CHEMBL35186 & 45265 & 8.301 & 8.423 & TRN & & \\
\hline CHEMBL269628 & 45265 & $6.7570 e$ & 30000000 & $\partial 1$ & 6.5488 & TST \\
\hline CHEMBL 32732 & 45265 & 7.5376 & 7.6532 & TRN & & \\
\hline CHEMBL285266 & 45265 & 6.7825 & 6.7344 & TRN & & \\
\hline CHEMBL35132 & 45265 & 6.9586 & 6.9178 & TRN & & \\
\hline CHEMBL286449 & 45265 & 7.4318 & 7.2774 & TRN & & \\
\hline CHEMBL 35061 & 45265 & 7.4559 & 7.6731 & TST & & \\
\hline CHEMBL418402 & 45265 & 8.0458 & 7.9991 & TRN & & \\
\hline CHEMBL35484 & 45265 & 6.5229 & 6.6232 & TRN & & \\
\hline CHEMBL262650 & 45265 & 7.4437 & 7.3424 & TRN & & \\
\hline CHEMBL34582 & 45265 & 6.6676 & 6.7956 & TRN & & \\
\hline CHEMBL 34782 & 45265 & 7.9208 & 7.9111 & TRN & & \\
\hline CHEMBL32949 & 45265 & 6.0969 & 6.1643 & TRN & & \\
\hline CHEMBL35385 & 45265 & 6.9393 & 6.7344 & TRN & & \\
\hline CHEMBL 35474 & 45265 & 6.8386 & 6.8975 & TRN & & \\
\hline CHEMBL30168 & 45265 & 7.6198 & 7.5783 & TRN & & \\
\hline CHEMBL285688 & 45265 & 7.3468 & 7.2799 & TRN & & \\
\hline CHEMBL 35532 & 45265 & 7.2441 & 7.0727 & TRN & & \\
\hline CHEMBL 35746 & 45265 & 7.1612 & 7.169 & TRN & & \\
\hline CHEMBL 33088 & 45265 & 6.9706 & 6.9767 & TST & & \\
\hline CHEMBL286300 & 45265 & 6.2924 & 6.1686 & TRN & & \\
\hline
\end{tabular}




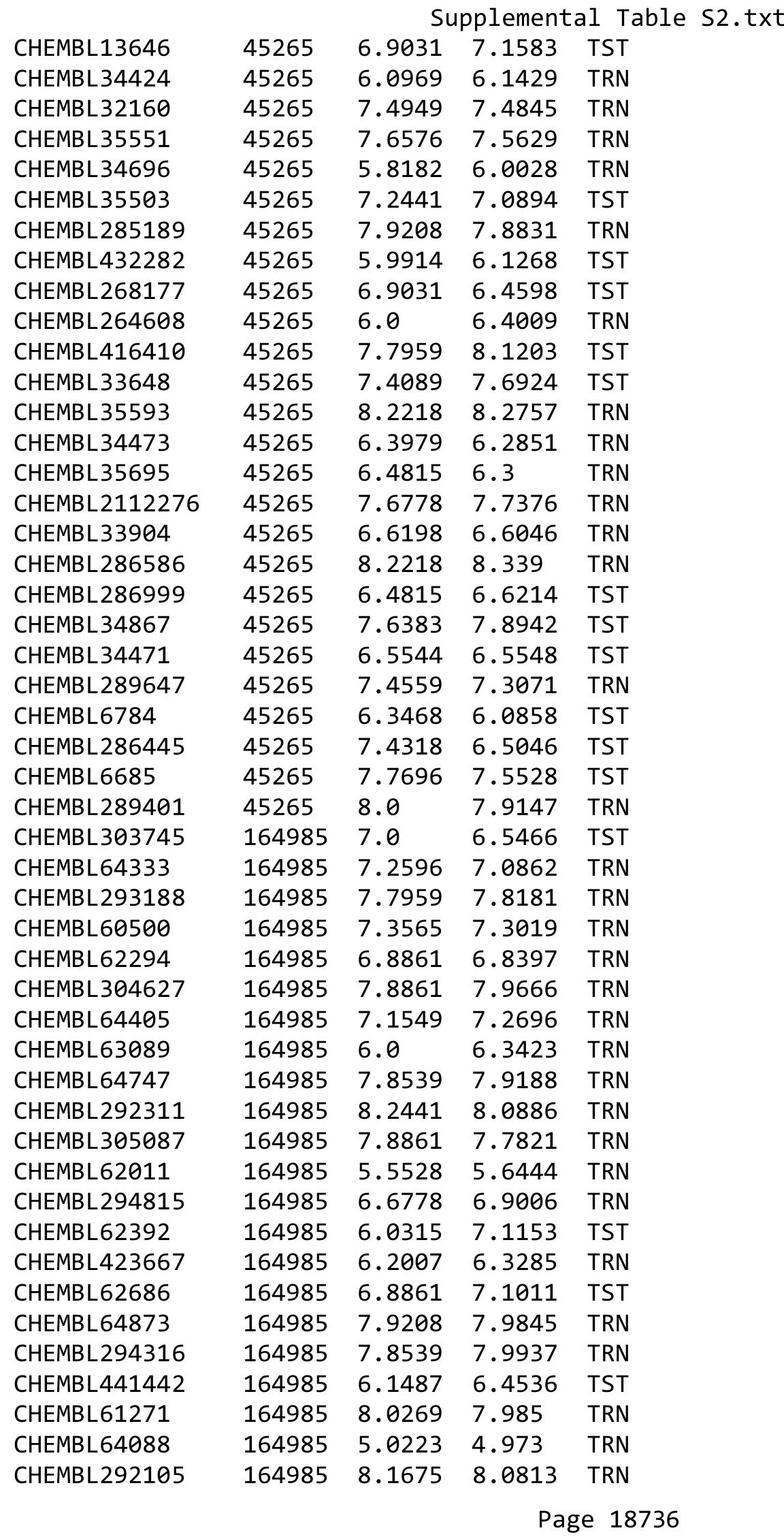




\begin{tabular}{|c|c|c|c|c|c|}
\hline \multirow[b]{2}{*}{ CHEMBL64141 } & \multicolumn{5}{|c|}{ Supplemental Table s2.txt } \\
\hline & 164985 & 7.6021 & 7.2991 & TRN & \\
\hline CHEMBL 304220 & 164985 & 7.2366 & 7.0073 & TST & \\
\hline CHEMBL302148 & 164985 & 7.0 & 6.8215 & TRN & \\
\hline CHEMBL62727 & 164985 & 6.5376 & 6.82299 & 99999999995 & TST \\
\hline CHEMBL423488 & 164985 & 7.6778 & 7.9103 & TST & \\
\hline CHEMBL62025 & 164985 & 7.6021 & 7.5507 & TRN & \\
\hline CHEMBL 304490 & 164985 & 7.0 & 7.1094 & TST & \\
\hline CHEMBL432724 & 164985 & 7.1249 & 7.4297 & TST & \\
\hline CHEMBL293395 & 164985 & 7.2366 & 7.2624 & TRN & \\
\hline CHEMBL61280 & 164985 & 7.5229 & 7.8448 & TRN & \\
\hline CHEMBL294330 & 164985 & 7.5686 & 7.749 & TRN & \\
\hline CHEMBL60249 & 164985 & 8.0555 & 8.1141 & TRN & \\
\hline CHEMBL65714 & 164985 & 7.6383 & 7.659 & TST & \\
\hline CHEMBL418505 & 164985 & 7.8539 & 8.0476 & TRN & \\
\hline CHEMBL446148 & 164985 & 7.7212 & 7.7133 & TRN & \\
\hline CHEMBL293446 & 164985 & 6.7959 & 6.7486 & TST & \\
\hline CHEMBL65165 & 164985 & 7.5686 & 7.4098 & TRN & \\
\hline CHEMBL291353 & 164985 & 7.7959 & 7.8665 & TRN & \\
\hline CHEMBL62271 & 164985 & 5.6576 & 7.1893 & TST & \\
\hline CHEMBL291658 & 164985 & 7.9586 & 7.6777 & TRN & \\
\hline CHEMBL60044 & 164985 & 7.6778 & 7.5646 & TRN & \\
\hline CHEMBL 302222 & 164985 & 8.0809 & 7.2744 & TST & \\
\hline CHEMBL62733 & 164985 & 6.8861 & 6.8978 & TRN & \\
\hline CHEMBL60138 & 164985 & 7.5229 & 7.5536 & TRN & \\
\hline CHEMBL60785 & 164985 & 7.6021 & 7.7253 & TST & \\
\hline CHEMBL60956 & 164985 & 7.3979 & 7.2594 & TRN & \\
\hline CHEMBL60216 & 164985 & 6.8539 & 7.0736 & TRN & \\
\hline CHEMBL60551 & 164985 & 8.2291 & 8.2019 & TRN & \\
\hline CHEMBL61057 & 164985 & 7.699 & 7.5088 & TRN & \\
\hline CHEMBL305166 & 164985 & 5.8861 & 6.8196 & TST & \\
\hline CHEMBL416314 & 164985 & 8.3188 & 8.2032 & TRN & \\
\hline CHEMBL62557 & 164985 & 7.1367 & 7.1645 & TRN & \\
\hline CHEMBL59613 & 164985 & 7.6021 & 7.6808 & TRN & \\
\hline CHEMBL62468 & 164985 & 6.7447 & 6.8379 & TRN & \\
\hline CHEMBL64359 & 164985 & 8.0 & 8.2659 & TRN & \\
\hline CHEMBL62771 & 164985 & 7.4437 & 7.3904 & TRN & \\
\hline CHEMBL62886 & 164985 & 7.3872 & 7.644 & TRN & \\
\hline CHEMBL64686 & 164985 & 7.3872 & 7.2361 & TRN & \\
\hline CHEMBL64485 & 164985 & 6.8239 & 6.7353 & TST & \\
\hline CHEMBL62469 & 164985 & 6.4202 & 6.4033 & TRN & \\
\hline CHEMBL61273 & 164985 & 6.5686 & 6.6472 & TRN & \\
\hline CHEMBL294310 & 164985 & 8.0088 & 8.0308 & TRN & \\
\hline CHEMBL61983 & 164985 & 7.7212 & 7.7057 & TRN & \\
\hline CHEMBL303297 & 164985 & 6.8539 & 6.6897 & TRN & \\
\hline CHEMBL302914 & 164985 & 7.8539 & 7.9091 & TRN & \\
\hline CHEMBL293887 & 164985 & 6.6576 & 6.7973 & TRN & \\
\hline CHEMBL302450 & 164985 & 8.0862 & 7.1865 & TST & \\
\hline CHEMBL62783 & 164985 & 7.4815 & 7.3984 & TST & \\
\hline
\end{tabular}


Supplemental Table S2.txt

\begin{tabular}{|c|c|c|c|c|}
\hline CHEMBL 293835 & 164985 & 7.3768 & 7.2786 & TRN \\
\hline CHEMBL64469 & 164985 & 7.7212 & 7.6846 & TRN \\
\hline CHEMBL64371 & 164985 & 6.7959 & 7.0384 & TRN \\
\hline CHEMBL64564 & 164985 & 7.5686 & 7.4554 & TRN \\
\hline CHEMBL63387 & 164985 & 7.1549 & 7.3769 & TRN \\
\hline CHEMBL64889 & 164985 & 8.699 & 8.6675 & TRN \\
\hline CHEMBL62299 & 164985 & 7.6778 & 7.6789 & TRN \\
\hline CHEMBL539413 & 164985 & 6.8239 & 6.6886 & TST \\
\hline CHEMBL64682 & 164985 & 6.4318 & 6.3832 & TRN \\
\hline CHEMBL62385 & 164985 & 7.9208 & 7.7761 & TRN \\
\hline CHEMBL64372 & 164985 & 7.1249 & 7.0118 & TRN \\
\hline CHEMBL 302634 & 164985 & 7.5686 & 7.5058 & TRN \\
\hline CHEMBL 303542 & 164985 & 6.7959 & 6.8286 & TRN \\
\hline CHEMBL64516 & 164985 & 7.6576 & 7.2089 & TST \\
\hline CHEMBL64380 & 164985 & 7.3565 & 7.1874 & TRN \\
\hline CHEMBL65166 & 164985 & 7.2218 & 7.3071 & TRN \\
\hline CHEMBL418648 & 164985 & 7.3468 & 7.3381 & TRN \\
\hline CHEMBL 293909 & 164985 & 6.8539 & 6.1296 & TST \\
\hline CHEMBL 303354 & 164985 & 8.0969 & 8.1901 & TRN \\
\hline CHEMBL59697 & 164985 & 8.2218 & 8.0406 & TRN \\
\hline CHEMBL61226 & 164985 & 7.1871 & 6.9032 & TRN \\
\hline CHEMBL59928 & 164985 & 7.7212 & 7.704 & TRN \\
\hline CHEMBL62889 & 164985 & 7.3098 & 6.7566 & TST \\
\hline CHEMBL64132 & 164985 & 7.7959 & 7.7524 & TRN \\
\hline CHEMBL62461 & 164985 & 8.0362 & 7.187 & TST \\
\hline CHEMBL 305111 & 164985 & 7.5528 & 7.3017 & TST \\
\hline CHEMBL 305578 & 164985 & 7.2007 & \multicolumn{2}{|c|}{7.4510000000000005} \\
\hline CHEMBL 292630 & 164985 & 7.4318 & 7.319 & TRN \\
\hline CHEMBL412450 & 164985 & 6.4685 & 5.9168 & TST \\
\hline CHEMBL60673 & 164985 & 7.4318 & 7.3848 & TRN \\
\hline CHEMBL62231 & 164985 & 6.8861 & 6.5161 & TST \\
\hline CHEMBL 304182 & 164985 & 7.284 & 7.4612 & TRN \\
\hline CHEMBL64049 & 164985 & 7.4318 & 7.2464 & TRN \\
\hline CHEMBL61220 & 164985 & 7.1192 & 7.1486 & TRN \\
\hline CHEMBL424229 & 164985 & 7.5528 & 7.532 & TRN \\
\hline CHEMBL61170 & 164985 & 6.7212 & 6.5031 & TST \\
\hline CHEMBL62785 & 164985 & 7.6383 & 7.5907 & TRN \\
\hline CHEMBL 291596 & 164985 & 7.5376 & 7.3702 & TRN \\
\hline CHEMBL62583 & 164985 & 7.5376 & 7.1652 & TST \\
\hline CHEMBL62556 & 164985 & 7.6576 & 7.789 & TRN \\
\hline CHEMBL64611 & 164985 & 7.9586 & 7.9029 & TRN \\
\hline CHEMBL 309124 & 75484 & 4.0 & 4.3598 & TST \\
\hline CHEMBL67383 & 75484 & 5.3565 & 4.9533 & TST \\
\hline CHEMBL66803 & 75484 & 4.0 & 3.8579 & TRN \\
\hline CHEMBL 306451 & 75484 & 4.0 & 3.7967 & TRN \\
\hline CHEMBL 304579 & 75484 & 4.0 & 4.3823 & TRN \\
\hline CHEMBL 302026 & 75484 & 5.8861 & 5.8029 & TRN \\
\hline CHEMBL 70039 & 75484 & 5.9586 & 5.8502 & TRN \\
\hline
\end{tabular}




\begin{tabular}{|c|c|c|c|c|c|}
\hline \multicolumn{6}{|c|}{ Supplemental Table S2.txt } \\
\hline CHEMBL67726 & 75484 & 5.1024 & 5.1213 & TRN & \\
\hline CHEMBL66291 & 75484 & 5.3665 & 4.2413 & TST & \\
\hline CHEMBL432349 & 75484 & 5.3768 & 5.4809 & TRN & \\
\hline CHEMBL66147 & 75484 & 4.0 & 5.5583 & TST & \\
\hline CHEMBL67632 & 75484 & 4.0 & 3.8659 & TRN & \\
\hline CHEMBL303682 & 75484 & 6.301 & 6.2551 & TRN & \\
\hline CHEMBL306192 & 75484 & 4.0 & 3.8562 & TRN & \\
\hline CHEMBL68836 & 75484 & 6.0 & 5.9285 & TRN & \\
\hline CHEMBL302726 & 75484 & 4.0 & 4.01399 & 9999999999 & TRN \\
\hline CHEMBL309139 & 75484 & 4.0 & 3.9506 & TRN & \\
\hline CHEMBL66509 & 75484 & 5.5086 & 4.6529 & TST & \\
\hline CHEMBL421674 & 75484 & 5.0706 & 5.0445 & TRN & \\
\hline CHEMBL66974 & 75484 & 5.2924 & 5.1637 & TRN & \\
\hline CHEMBL67317 & 75484 & 4.0 & 4.1015 & TRN & \\
\hline CHEMBL306901 & 75484 & 6.301 & 6.3612 & TRN & \\
\hline CHEMBL65965 & 75484 & 5.6021 & 5.1748 & TRN & \\
\hline CHEMBL66670 & 75484 & 5.9586 & 5.5347 & TRN & \\
\hline CHEMBL67347 & 75484 & 5.3872 & 5.4582 & TRN & \\
\hline CHEMBL65895 & 75484 & 4.9136 & 4.9417 & TRN & \\
\hline CHEMBL66372 & 75484 & 4.7696 & 5.2309 & TST & \\
\hline CHEMBL63206 & 75484 & 6.2218 & 6.2784 & TRN & \\
\hline CHEMBL304057 & 75484 & 5.041 & 5.0134 & TRN & \\
\hline CHEMBL68051 & 75484 & 4.0 & 3.9724 & TRN & \\
\hline CHEMBL 305788 & 75484 & 5.2596 & 5.3453 & TRN & \\
\hline CHEMBL417205 & 75484 & 5.8539 & 3.5919 & TST & \\
\hline CHEMBL302566 & 75484 & 5.1367 & 5.296 & TRN & \\
\hline CHEMBL 309140 & 75484 & 4.0 & 4.5921 & TST & \\
\hline CHEMBL68224 & 75484 & 4.0 & 4.5786 & TRN & \\
\hline CHEMBL66215 & 75484 & 5.0969 & 5.5407 & TRN & \\
\hline CHEMBL65953 & 75484 & 4.9031 & 4.9453 & TRN & \\
\hline CHEMBL 70058 & 75484 & 4.0 & 4.6095 & TST & \\
\hline CHEMBL66912 & 75484 & 5.585 & 5.3202 & TRN & \\
\hline CHEMBL65859 & 75484 & 5.4089 & 5.4455 & TRN & \\
\hline CHEMBL303929 & 75484 & 4.0 & 3.9845 & TRN & \\
\hline CHEMBL67849 & 75484 & 6.699 & 6.6382 & TRN & \\
\hline CHEMBL304959 & 75484 & 5.3279 & 4.8658 & TRN & \\
\hline CHEMBL65899 & 75484 & 4.0 & 4.0765 & TRN & \\
\hline CHEMBL68454 & 75484 & 6.0458 & 5.6734 & TRN & \\
\hline CHEMBL 304115 & 75484 & 5.4559 & 5.5003 & TRN & \\
\hline CHEMBL 66290 & 75484 & 4.0 & 4.7024 & TST & \\
\hline CHEMBL67035 & 75484 & 5.5086 & 5.521 & TRN & \\
\hline CHEMBL417057 & 75484 & 5.5086 & 5.8013 & TRN & \\
\hline CHEMBL67471 & 75484 & 4.0 & 4.1843 & TST & \\
\hline CHEMBL305211 & 75484 & 5.4559 & 5.6388 & TRN & \\
\hline CHEMBL 67202 & 75484 & 5.5086 & 5.5458 & TRN & \\
\hline CHEMBL66220 & 75484 & 5.3372 & 5.3666 & TRN & \\
\hline CHEMBL304296 & 75484 & 4.0 & 5.6305 & TST & \\
\hline CHEMBL66341 & 75484 & 5.699 & 4.3608 & TST & \\
\hline
\end{tabular}




\begin{tabular}{|c|c|c|c|c|c|}
\hline & & & pplement & al Table S & \\
\hline CHEMBL304299 & 75484 & 5.7447 & 5.7332 & TRN & \\
\hline CHEMBL304337 & 75484 & 5.0605 & 5.17700 & 30000000005 & TRN \\
\hline CHEMBL308467 & 75484 & 5.301 & 4.271 & TST & \\
\hline CHEMBL67316 & 75484 & 5.6198 & 5.5718 & TRN & \\
\hline CHEMBL67112 & 75484 & 5.4089 & 5.4155 & TRN & \\
\hline CHEMBL305581 & 75484 & 4.0 & 4.5267 & TST & \\
\hline CHEMBL67358 & 75484 & 6.699 & 6.726 & TRN & \\
\hline CHEMBL63827 & 75484 & 4.0 & 4.27 & TRN & \\
\hline CHEMBL303500 & 75484 & 6.1549 & 5.0276 & TST & \\
\hline CHEMBL3670494 & 1528050 & 8.5686 & 7.7858 & TRN & \\
\hline CHEMBL 3675367 & 1528050 & 6.1512 & 6.8079 & TRN & \\
\hline CHEMBL3680472 & 1528050 & 7.3546 & 6.8211 & TST & \\
\hline CHEMBL 3670422 & 1528050 & 7.041 & 6.7384 & TRN & \\
\hline CHEMBL3675418 & 1528050 & 9.0 & 8.8392 & TRN & \\
\hline CHEMBL3675514 & 1528050 & 7.8239 & 8.0712 & TRN & \\
\hline CHEMBL3675325 & 1528050 & 7.2211 & 7.0413 & TRN & \\
\hline CHEMBL3680588 & 1528050 & 6.7447 & 6.8759 & TRN & \\
\hline CHEMBL3675350 & 1528050 & 6.6144 & 6.8295 & TRN & \\
\hline CHEMBL 3680390 & 1528050 & 7.6778 & 6.8208 & TRN & \\
\hline CHEMBL3670407 & 1528050 & 6.0 & 7.3214 & TST & \\
\hline CHEMBL3680568 & 1528050 & 6.6383 & 7.2318 & TRN & \\
\hline CHEMBL3675409 & 1528050 & 9.1024 & 9.0838 & TRN & \\
\hline CHEMBL 3670404 & 1528050 & 9.2218 & 8.7524 & TRN & \\
\hline CHEMBL 3670460 & 1528050 & 8.5086 & 6.8317 & TRN & \\
\hline CHEMBL3680434 & 1528050 & 7.5086 & 7.5125 & TRN & \\
\hline CHEMBL3670458 & 1528050 & 7.3391 & 7.6076 & TRN & \\
\hline CHEMBL3685270 & 1528050 & 6.9208 & 7.3709 & TRN & \\
\hline CHEMBL3675492 & 1528050 & 8.0 & 8.14 & TRN & \\
\hline CHEMBL 3680428 & 1528050 & 7.5229 & 8.4102 & TRN & \\
\hline CHEMBL3680419 & 1528050 & 7.5686 & 7.4552 & TRN & \\
\hline CHEMBL3685296 & 1528050 & 6.041 & 6.6831 & TRN & \\
\hline CHEMBL 3680557 & 1528050 & 6.6778 & 7.4485 & TRN & \\
\hline CHEMBL 3675470 & 1528050 & 8.1487 & 7.7055 & TRN & \\
\hline CHEMBL 3675376 & 1528050 & 6.4045 & 6.7219 & TRN & \\
\hline CHEMBL3680435 & 1528050 & 7.5086 & 7.7278 & TRN & \\
\hline CHEMBL3680416 & 1528050 & 7.585 & 7.2226 & TRN & \\
\hline CHEMBL3685323 & 1528050 & 6.0 & 6.7656 & TST & \\
\hline CHEMBL3675353 & 1528050 & 7.5654 & 7.7695 & TRN & \\
\hline CHEMBL 3680602 & 1528050 & 6.5229 & 7.1084 & TRN & \\
\hline CHEMBL 3680481 & 1528050 & 7.2757 & 7.3321 & TRN & \\
\hline CHEMBL3670420 & 1528050 & 6.6383 & 6.2232 & TRN & \\
\hline CHEMBL3680484 & 1528050 & 7.2596 & 7.5026 & TRN & \\
\hline CHEMBL3670431 & 1528050 & 6.6108 & 6.8254 & TRN & \\
\hline CHEMBL 3685263 & 1528050 & 6.3372 & 7.1958 & TRN & \\
\hline CHEMBL3685330 & 1528050 & 7.8539 & 7.8296 & TRN & \\
\hline CHEMBL 3675434 & 1528050 & 8.5528 & 8.1442 & TRN & \\
\hline CHEMBL3675337 & 1528050 & 7.5003 & 7.1239 & TRN & \\
\hline CHEMBL3675419 & 1528050 & 8.9586 & 8.1317 & TRN & \\
\hline
\end{tabular}


Supplemental Table S2.txt

\begin{tabular}{|c|c|c|c|c|c|}
\hline CHEMBL3675358 & 1528050 & 5.3002 & 5.5267 & TRN & \\
\hline CHEMBL3670405 & 1528050 & 6.4248 & 6.8317 & TST & \\
\hline CHEMBL3670459 & 1528050 & 4.6737 & 6.2312 & TST & \\
\hline CHEMBL 3685320 & 1528050 & 5.0 & 6.7917 & TST & \\
\hline CHEMBL3675513 & 1528050 & 7.8239 & 7.6806 & TRN & \\
\hline CHEMBL3675512 & 1528050 & 7.8239 & 7.8855 & TRN & \\
\hline CHEMBL3670496 & 1528050 & 6.3645 & 6.3277 & TRN & \\
\hline CHEMBL3675491 & 1528050 & 8.0 & 7.8105 & TRN & \\
\hline CHEMBL3670427 & 1528050 & 7.0353 & 7.4847 & TRN & \\
\hline CHEMBL3675351 & 1528050 & 5.6108 & 6.499 & TRN & \\
\hline CHEMBL3680398 & 1528050 & 7.6576 & 7.4604 & TRN & \\
\hline CHEMBL3675387 & 1528050 & 5.7825 & 5.071006 & 0000000001 & TRN \\
\hline CHEMBL3675365 & 1528050 & 8.9208 & 7.5042 & TRN & \\
\hline CHEMBL 3675437 & 1528050 & 6.0 & 6.5546 & TRN & \\
\hline CHEMBL3675410 & 1528050 & 9.0969 & 8.967 & TRN & \\
\hline CHEMBL3670490 & 1528050 & 5.7825 & 6.4606 & TRN & \\
\hline CHEMBL3675482 & 1528050 & 6.0 & 6.5252 & TRN & \\
\hline CHEMBL3680510 & 1528050 & 7.1367 & 6.6251 & TRN & \\
\hline CHEMBL 3675452 & 1528050 & 8.3565 & 5.8922 & TST & \\
\hline CHEMBL3675460 & 1528050 & 8.283999 & 99999999 & 7.1779 & TRN \\
\hline CHEMBL3675505 & 1528050 & 7.8861 & 7.5685 & TRN & \\
\hline CHEMBL3685286 & 1528050 & 6.7212 & 6.4302 & TRN & \\
\hline CHEMBL3680475 & 1528050 & 7.3279 & 7.459 & TRN & \\
\hline CHEMBL3680593 & 1528050 & 6.5528 & 6.4377 & TRN & \\
\hline CHEMBL3680491 & 1528050 & 7.2218 & 6.9574 & TRN & \\
\hline CHEMBL3670461 & 1528050 & 5.9208 & 6.2601 & TRN & \\
\hline CHEMBL 3680534 & 1528050 & 7.0 & 7.489 & TRN & \\
\hline CHEMBL3675483 & 1528050 & 6.0 & 6.95 & TRN & \\
\hline CHEMBL3675531 & 1528050 & 7.7447 & 8.0662 & TRN & \\
\hline CHEMBL3675375 & 1528050 & 4.6091 & 6.3536 & TRN & \\
\hline CHEMBL3675407 & 1528050 & 6.0 & 7.5392 & TRN & \\
\hline CHEMBL3685209 & 1528050 & 6.8861 & 6.2739 & TRN & \\
\hline CHEMBL3680502 & 1528050 & 7.1739 & 7.4127 & TRN & \\
\hline CHEMBL 3680479 & 1528050 & 7.284 & 7.4584 & TRN & \\
\hline CHEMBL3680450 & 1528050 & 7.4437 & 6.7527 & TST & \\
\hline CHEMBL3680579 & 1528050 & 6.4815 & 7.3999 & TRN & \\
\hline CHEMBL3670482 & 1528050 & 8.7447 & 7.2734 & TRN & \\
\hline CHEMBL3675533 & 1528050 & 7.7212 & 7.6546 & TRN & \\
\hline CHEMBL3680477 & 1528050 & 7.3098 & 7.3202 & TRN & \\
\hline CHEMBL3675495 & 1528050 & 8.0 & 7.928 & TRN & \\
\hline CHEMBL3675366 & 1528050 & 6.5719 & 7.0634 & TRN & \\
\hline CHEMBL3675374 & 1528050 & 6.4306 & 6.2922 & TRN & \\
\hline CHEMBL3685311 & 1528050 & 6.2291 & 7.3396 & TST & \\
\hline CHEMBL3685222 & 1528050 & 6.4949 & 6.1969 & TST & \\
\hline CHEMBL3675485 & 1528050 & 8.0315 & 7.4837 & TRN & \\
\hline CHEMBL 3675527 & 1528050 & 7.7447 & 7.616006 & 00000000005 & TRN \\
\hline CHEMBL3680539 & 1528050 & 6.0 & 6.1291 & TRN & \\
\hline CHEMBL 3675402 & 1528050 & 9.2366 & 8.7431 & TRN & \\
\hline
\end{tabular}


Supplemental Table S2.txt

\begin{tabular}{|c|c|c|c|c|c|}
\hline CHEMBL 3675488 & 1528050 & 8.0269 & 7.818 & TRN & \\
\hline CHEMBL3675506 & 1528050 & 7.8539 & 8.0107 & TRN & \\
\hline CHEMBL3675416 & 1528050 & 9.0044 & 7.7859 & TRN & \\
\hline CHEMBL 3675471 & 1528050 & 8.1427 & 7.8256 & TRN & \\
\hline CHEMBL3680514 & 1528050 & 7.1192 & 7.6695 & TRN & \\
\hline CHEMBL 3680444 & 1528050 & 7.4685 & 7.3541 & TRN & \\
\hline CHEMBL3675432 & 1528050 & 8.5686 & 8.302 & TRN & \\
\hline CHEMBL3675450 & 1528050 & 8.3565 & 7.5682 & TST & \\
\hline CHEMBL3680396 & 1528050 & 7.6576 & 6.6453 & TST & \\
\hline CHEMBL3685205 & 1528050 & 5.301 & 6.7927 & TST & \\
\hline CHEMBL3680411 & 1528050 & 7.585 & 7.399 & TRN & \\
\hline CHEMBL3639742 & 1528050 & 6.9957 & 7.605 & TRN & \\
\hline CHEMBL3680461 & 1528050 & 7.4089 & \multicolumn{2}{|c|}{ 7.207000000000001 } & TRN \\
\hline CHEMBL3670485 & 1528050 & 7.9393 & 7.4528 & TRN & \\
\hline CHEMBL3675430 & 1528050 & 8.6198 & 8.5794 & TRN & \\
\hline CHEMBL3680547 & 1528050 & 6.7212 & 6.3121 & TRN & \\
\hline CHEMBL3685322 & 1528050 & 6.011 & 7.4862 & TST & \\
\hline CHEMBL3675352 & 1528050 & 6.3288 & 6.4412 & TRN & \\
\hline CHEMBL 3670429 & 1528050 & 7.8633 & 7.1918 & TRN & \\
\hline CHEMBL3685218 & 1528050 & 6.0605 & 7.0879 & TST & \\
\hline CHEMBL3670447 & 1528050 & 6.0 & 6.5382 & TRN & \\
\hline CHEMBL3675439 & 1528050 & 6.0 & 6.5069 & TRN & \\
\hline CHEMBL3675510 & 1528050 & 7.8239 & 7.3069 & TST & \\
\hline CHEMBL3670481 & 1528050 & 7.5346 & 7.4273 & TRN & \\
\hline CHEMBL3670438 & 1528050 & 5.51 & 6.1012 & TST & \\
\hline CHEMBL3680423 & 1528050 & 7.5528 & 7.1244 & TRN & \\
\hline CHEMBL3670423 & 1528050 & 6.8697 & 7.4163 & TRN & \\
\hline CHEMBL3675340 & 1528050 & 7.5229 & 7.3965 & TRN & \\
\hline CHEMBL3670415 & 1528050 & 8.1805 & 7.7719 & TRN & \\
\hline CHEMBL3680586 & 1528050 & 6.3979 & 6.3516 & TST & \\
\hline CHEMBL3675539 & 1528050 & 7.699 & 7.4382 & TRN & \\
\hline CHEMBL3964083 & 1528050 & 7.5229 & 6.9185 & TST & \\
\hline CHEMBL 3675403 & 1528050 & 9.2147 & 8.8105 & TRN & \\
\hline CHEMBL 3670419 & 1528050 & 7.9508 & 7.635 & TRN & \\
\hline CHEMBL3675328 & 1528050 & 7.6234 & 7.0515 & TRN & \\
\hline CHEMBL3675538 & 1528050 & 7.699 & 7.7503 & TRN & \\
\hline CHEMBL3675423 & 1528050 & 8.8861 & 7.3115 & TST & \\
\hline CHEMBL3680456 & 1528050 & 7.4202 & 7.3711 & TRN & \\
\hline CHEMBL3670492 & 1528050 & 5.4056 & 5.8259 & TRN & \\
\hline CHEMBL3680509 & 1528050 & 7.1427 & $7.58700 t$ & 0000000001 & TRN \\
\hline CHEMBL3680532 & 1528050 & 7.0 & 6.9804 & TRN & \\
\hline CHEMBL3685284 & 1528050 & 6.8239 & 6.7549 & TRN & \\
\hline CHEMBL3675517 & 1528050 & 7.7959 & 7.6358 & TRN & \\
\hline CHEMBL3675497 & 1528050 & 7.9586 & 7.1987 & TRN & \\
\hline CHEMBL3670452 & 1528050 & 5.8827 & 6.8483 & TRN & \\
\hline CHEMBL3685246 & 1528050 & 6.5086 & 6.5124 & TRN & \\
\hline CHEMBL3675526 & 1528050 & 7.7447 & 7.8939 & TRN & \\
\hline CHEMBL3685221 & 1528050 & 6.1675 & 6.2118 & TRN & \\
\hline
\end{tabular}


Supplemental Table S2.txt

\begin{tabular}{|c|c|c|c|c|c|}
\hline CHEMBL 3680500 & 1528050 & 7.1805 & 7.3718 & TRN & \\
\hline CHEMBL 3675357 & 1528050 & 6.9957 & 6.8185 & TRN & \\
\hline CHEMBL 3680458 & 1528050 & 7.4202 & 7.8549 & TRN & \\
\hline CHEMBL 3675401 & 1528050 & 9.2596 & 9.0823 & TRN & \\
\hline CHEMBL 3685325 & 1528050 & 6.4089 & 5.914 & TST & \\
\hline CHEMBL 3675384 & 1528050 & 4.4389 & 4.8179 & TRN & \\
\hline CHEMBL3680498 & 1528050 & 7.1871 & 7.5007 & TST & \\
\hline CHEMBL 3680528 & 1528050 & 7.0458 & 6.7629 & TRN & \\
\hline CHEMBL3670495 & 1528050 & 9.1549 & 8.6077 & TRN & \\
\hline CHEMBL 3670455 & 1528050 & 5.4949 & \multicolumn{2}{|c|}{5.712000000000001} & TRN \\
\hline CHEMBL 3680455 & 1528050 & 7.4202 & 7.6982 & TRN & \\
\hline CHEMBL 3680418 & 1528050 & 7.5686 & 7.1387 & TST & \\
\hline CHEMBL 3685297 & 1528050 & 6.0 & 6.1919 & TRN & \\
\hline CHEMBL 3680437 & 1528050 & 7.4949 & 7.5024 & TRN & \\
\hline CHEMBL 3675336 & 1528050 & 5.4584 & 6.4335 & TST & \\
\hline CHEMBL 3670475 & 1528050 & 7.2628 & 7.0814 & TRN & \\
\hline CHEMBL3680577 & 1528050 & 6.5528 & 6.7971 & TRN & \\
\hline CHEMBL3680599 & 1528050 & 6.8861 & 7.1224 & TRN & \\
\hline CHEMBL 3675383 & 1528050 & 5.5045 & 5.4111 & TRN & \\
\hline CHEMBL 3680582 & 1528050 & 6.6778 & 6.9192 & TRN & \\
\hline CHEMBL 3675473 & 1528050 & 8.1308 & 7.925 & TRN & \\
\hline CHEMBL3639693 & 1528050 & 7.9172 & 7.9968 & TRN & \\
\hline CHEMBL 3675493 & 1528050 & 8.0 & 7.197 & TRN & \\
\hline CHEMBL 3675474 & 1528050 & 8.0915 & 7.6654 & TRN & \\
\hline CHEMBL 3670464 & 1528050 & 9.2218 & 8.0598 & TRN & \\
\hline CHEMBL 3675486 & 1528050 & 8.0269 & 7.9674 & TRN & \\
\hline CHEMBL 3680518 & 1528050 & 7.1024 & 6.8609 & TRN & \\
\hline CHEMBL 3675414 & 1528050 & 9.0506 & 8.6714 & TRN & \\
\hline CHEMBL 3680596 & 1528050 & 6.1805 & 6.6017 & TRN & \\
\hline CHEMBL 3680417 & 1528050 & 7.5686 & 7.3359 & TRN & \\
\hline CHEMBL 3685226 & 1528050 & 5.7959 & 6.1762 & TST & \\
\hline CHEMBL 3675330 & 1528050 & \multicolumn{3}{|c|}{6.757000000000001} & TRN \\
\hline CHEMBL 3675363 & 1528050 & 7.6144 & 7.3426 & TRN & \\
\hline CHEMBL 3685213 & 1528050 & 5.7959 & 7.0023 & TST & \\
\hline CHEMBL 3675480 & 1528050 & 8.0458 & 8.0631 & TRN & \\
\hline CHEMBL3685299 & 1528050 & 6.0 & 6.5424 & TRN & \\
\hline CHEMBL 3675487 & 1528050 & 8.0269 & 8.1071 & TRN & \\
\hline CHEMBL 3670442 & 1528050 & 5.0757 & 4.4956 & TRN & \\
\hline CHEMBL 3670454 & 1528050 & 7.0809 & 7.8713 & TRN & \\
\hline CHEMBL3680409 & 1528050 & 7.5918 & 5.8033 & TST & \\
\hline CHEMBL 3670486 & 1528050 & 8.3372 & 7.5299 & TRN & \\
\hline CHEMBL 3675472 & 1528050 & 8.1367 & 6.8593 & TRN & \\
\hline CHEMBL 3675479 & 1528050 & 8.0506 & 8.5326 & TRN & \\
\hline CHEMBL 3685315 & 1528050 & 6.2757 & 6.5269 & TST & \\
\hline CHEMBL 3680427 & 1528050 & 7.5376 & 7.99100 & 00000000005 & TRN \\
\hline CHEMBL 3675406 & 1528050 & 9.1675 & 9.0733 & TRN & \\
\hline CHEMBL 3675503 & 1528050 & 7.8861 & 8.0964 & TRN & \\
\hline CHEMBL 3675320 & 1528050 & 6.7282 & 6.7982 & TRN & \\
\hline
\end{tabular}

Page 18743 
Supplemental Table S2.txt

\begin{tabular}{|c|c|c|c|c|}
\hline - & & & & \\
\hline & 528050 & 5.5528 & 6.1061 & \\
\hline & 28050 & & & \\
\hline AEMBL & 8050 & & & \\
\hline AEMBL3675449 & 528050 & 872 & 9629 & \\
\hline HEMBL3675329 & 528050 & 8.2441 & 0835 & \\
\hline 530 & 28050 & & & \\
\hline 414 & 528050 & & & \\
\hline AEMBL3 & 528050 & & 1025 & \\
\hline HEMBL3680499 & 528050 & 6.0 & 293 & \\
\hline AEMBL3675441 & 528050 & 8. & & \\
\hline IEMBL: & 28050 & & & \\
\hline IEMBL & & & & \\
\hline HEMBL3 & 528050 & 6 . & 2217 & \\
\hline AEMBL3 & 528050 & & & \\
\hline AEMBL3680505 & 528050 & 7. & & \\
\hline HEMBL & 28050 & & & \\
\hline HEMBL; & 8050 & & & \\
\hline HEMBL3 & 528050 & & & \\
\hline AEMBL: & 3050 & & & \\
\hline AEMIBL & 8050 & 8 & 22 & I RIV \\
\hline AEMBL & 8050 & & & RN \\
\hline HEMBL & 50 & & & \\
\hline 459 & 528050 & & & \\
\hline AEMBL3 & 50 & & & 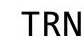 \\
\hline HEMBL & 8050 & & & RN \\
\hline HEME & 0 & & & ST \\
\hline HFMRI & 50 & & & \\
\hline HEMBL3 & 528050 & 6 & & in \\
\hline HEMBL3680388 & 50 & & & 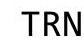 \\
\hline HEMBL3 & 8050 & & & RN \\
\hline HEMBL & 50 & & & RN \\
\hline HEMPI & 50 & 7. & & $\mathrm{~N}$ \\
\hline HEMBL3670493 & & & & IRN \\
\hline HEMBL3675338 & 528050 & & & TRN \\
\hline HEMBL & 28050 & & & \\
\hline HEMRI & 50 & 7. & & RN \\
\hline HEMBL & 50 & 6 & & RIN \\
\hline HEMBL3670489 & 528050 & & & TRN \\
\hline AEMBL & 528050 & & & RN \\
\hline HEMBL3 & 528050 & & & \\
\hline HEMBL3 & 1528050 & & & RN \\
\hline HEMBL3 & 528050 & & 2355 & RN \\
\hline AEMBL3675428 & 528050 & 8.6778 & 334 & TRN \\
\hline 1. & 3050 & & & \\
\hline HEMBL3 & 528050 & & & \\
\hline HEMBL3 & 528050 & & & \\
\hline HEMBL3680466 & 1528050 & 7.3768 & 7.1351 & IST \\
\hline
\end{tabular}

Page 18744 
Supplemental Table S2.txt

\begin{tabular}{|c|c|c|c|c|c|}
\hline CHEMBL3680432 & 1528050 & 7.5086 & 7.6739 & TRN & \\
\hline CHEMBL3685301 & 1528050 & 5.0 & 5.4172 & TST & \\
\hline CHEMBL3675322 & 1528050 & 6.8928 & 7.0266 & TRN & \\
\hline CHEMBL3685201 & 1528050 & 6.1192 & 6.1122 & TST & \\
\hline CHEMBL3675349 & 1528050 & 5.3655 & 6.9178 & TST & \\
\hline CHEMBL3670477 & 1528050 & 7.3354 & 6.8383 & TRN & \\
\hline CHEMBL3680506 & 1528050 & 7.1549 & 5.91799 & 9999999999 & TST \\
\hline CHEMBL3680529 & 1528050 & 7.041 & 7.343 & TRN & \\
\hline CHEMBL3675392 & 1528050 & 6.08200 & j00000006 & 6.1389 & TS \\
\hline CHEMBL3675523 & 1528050 & 7.7959 & 6.7371 & TST & \\
\hline CHEMBL3685313 & 1528050 & 6.4318 & 6.7462 & TST & \\
\hline CHEMBL3675532 & 1528050 & 7.7212 & 7.6623 & TRN & \\
\hline CHEMBL3685204 & 1528050 & 6.6198 & 6.0145 & TRN & \\
\hline CHEMBL 3675529 & 1528050 & 7.7447 & 7.8635 & TRN & \\
\hline CHEMBL 3675524 & 1528050 & 7.7696 & 7.9041 & TRN & \\
\hline CHEMBL3675368 & 1528050 & 7.8447 & 7.1996 & TRN & \\
\hline CHEMBL3675443 & 1528050 & 8.4318 & 7.2345 & TRN & \\
\hline CHEMBL3685312 & 1528050 & 6.041 & 6.9982 & TST & \\
\hline CHEMBL3675389 & 1528050 & 5.3507 & 5.4913 & TRN & \\
\hline CHEMBL 3680454 & 1528050 & 7.4318 & 8.1052 & TRN & \\
\hline CHEMBL3675446 & 1528050 & 8.3979 & 7.99200 & 0000000001 & TRN \\
\hline CHEMBL3680495 & 1528050 & 7.1938 & 7.5383 & TRN & \\
\hline CHEMBL3680533 & 1528050 & 7.0 & 7.3386 & TRN & \\
\hline CHEMBL3680394 & 1528050 & 7.6576 & 7.6142 & TRN & \\
\hline CHEMBL3685244 & 1528050 & 6.0 & 6.46299 & 9999999999 & TRN \\
\hline CHEMBL 3675345 & 1528050 & 6.4935 & 6.5969 & TRN & \\
\hline CHEMBL3685224 & 1528050 & 6.1612 & 6.7601 & TRN & \\
\hline CHEMBL3639792 & 1528050 & 7.6383 & 7.6278 & TRN & \\
\hline CHEMBL 3675440 & 1528050 & 8.4685 & 7.4528 & TRN & \\
\hline CHEMBL3680457 & 1528050 & 7.4202 & 7.0203 & TRN & \\
\hline CHEMBL3675326 & 1528050 & 9.301 & 8.2098 & TRN & \\
\hline CHEMBL 3670444 & 1528050 & 6.8827 & 6.152 & TRN & \\
\hline CHEMBL3680535 & 1528050 & 7.0 & 8.0945 & TST & \\
\hline CHEMBL3680467 & 1528050 & 7.3768 & 7.5552 & TST & \\
\hline CHEMBL3675394 & 1528050 & 9.8539 & 8.9435 & TRN & \\
\hline CHEMBL3670500 & 1528050 & 7.5361 & 7.5061 & TRN & \\
\hline CHEMBL3680527 & 1528050 & 7.0506 & 6.8827 & TRN & \\
\hline CHEMBL3675373 & 1528050 & 4.7747 & 5.9324 & TRN & \\
\hline CHEMBL 3670470 & 1528050 & 7.9318 & 7.9482 & TRN & \\
\hline CHEMBL3962025 & 1528050 & 5.0 & 6.3145 & TST & \\
\hline CHEMBL3680589 & 1528050 & 6.0506 & 7.0185 & TRN & \\
\hline CHEMBL3685317 & 1528050 & 6.4559 & 6.5296 & TST & \\
\hline CHEMBL3675370 & 1528050 & 6.2807 & 6.2723 & TRN & \\
\hline CHEMBL3680592 & 1528050 & 5.6383 & 6.6785 & TRN & \\
\hline CHEMBL3675436 & 1528050 & 8.4949 & 7.7454 & TRN & \\
\hline CHEMBL 3680448 & 1528050 & 7.4559 & 6.7719 & TST & \\
\hline CHEMBL 3670400 & 1528050 & 5.0 & 6.1602 & TRN & \\
\hline \multirow[t]{2}{*}{ CHEMBL3675535 } & 1528050 & 7.7212 & 6.21399 & 9999999 & 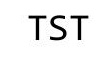 \\
\hline & & \multicolumn{3}{|c|}{ Page 18745} & \\
\hline
\end{tabular}


Supplemental Table S2.txt

\begin{tabular}{|c|c|c|c|c|c|}
\hline CHEMBL3680492 & 1528050 & 7.2147 & 6.9619 & TST & \\
\hline CHEMBL3680404 & 1528050 & 7.6198 & 7.5233 & TRN & \\
\hline CHEMBL3680485 & 1528050 & 7.2518 & 7.3441 & TRN & \\
\hline CHEMBL 3670474 & 1528050 & 6.9101 & 7.3226 & TRN & \\
\hline CHEMBL 3670428 & 1528050 & 6.8477 & 6.9757 & TRN & \\
\hline CHEMBL3675378 & 1528050 & 7.8477 & 6.7557 & TRN & \\
\hline CHEMBL 3675342 & 1528050 & 6.0 & \multicolumn{2}{|c|}{6.7170000000000005} & TRN \\
\hline CHEMBL3639743 & 1528050 & 6.0 & 6.5789 & TRN & \\
\hline CHEMBL 3675438 & 1528050 & 6.0 & 6.9568 & TRN & \\
\hline CHEMBL3670479 & 1528050 & 7.9281 & 6.8033 & TRN & \\
\hline CHEMBL3680536 & 1528050 & 7.0 & 6.6828 & TST & \\
\hline CHEMBL3670445 & 1528050 & 7.317 & 7.5326 & TRN & \\
\hline CHEMBL3680452 & 1528050 & 7.4437 & 7.5021 & TRN & \\
\hline CHEMBL3680504 & 1528050 & 7.1675 & 7.3744 & TRN & \\
\hline CHEMBL 3680413 & 1528050 & 7.585 & 7.0324 & TRN & \\
\hline CHEMBL 3670411 & 1528050 & 8.4685 & 8.5341 & TRN & \\
\hline CHEMBL3675502 & 1528050 & 7.9208 & \multicolumn{2}{|c|}{7.997000000000001} & TRN \\
\hline CHEMBL 3680522 & 1528050 & 7.0706 & 6.5569 & TST & \\
\hline CHEMBL3685292 & 1528050 & 6.5229 & 6.6346 & TST & \\
\hline CHEMBL 3675448 & 1528050 & 8.3979 & 7.7672 & TST & \\
\hline CHEMBL3675415 & 1528050 & 6.0 & 7.9233 & TRN & \\
\hline CHEMBL 3685214 & 1528050 & 6.1249 & 6.1913 & TRN & \\
\hline CHEMBL3670456 & 1528050 & 5.1911 & 6.4479 & TRN & \\
\hline CHEMBL3670466 & 1528050 & 6.0477 & 6.4115 & TRN & \\
\hline CHEMBL3680523 & 1528050 & 7.0655 & 7.0157 & TRN & \\
\hline CHEMBL3680538 & 1528050 & 7.0 & 7.5583 & TRN & \\
\hline CHEMBL 3675388 & 1528050 & 5.2557 & 6.0226 & TRN & \\
\hline CHEMBL3675454 & 1528050 & 8.3372 & 7.7972 & TRN & \\
\hline CHEMBL 3675347 & 1528050 & 6.7375 & 6.6166 & TRN & \\
\hline CHEMBL3675456 & 1528050 & 8.3098 & 7.3623 & TRN & \\
\hline CHEMBL 3680503 & 1528050 & 7.1739 & 6.4316 & TRN & \\
\hline CHEMBL3675522 & 1528050 & 7.7959 & \multicolumn{2}{|c|}{7.757000000000001} & TRN \\
\hline CHEMBL3685216 & 1528050 & 5.8539 & 6.7367 & TST & \\
\hline CHEMBL 3675540 & 1528050 & 7.6778 & 7.3793 & TRN & \\
\hline CHEMBL3670506 & 1528050 & 6.6021 & 6.6413 & TRN & \\
\hline CHEMBL3685239 & 1528050 & 6.0 & 5.9636 & TRN & \\
\hline CHEMBL 3675397 & 1528050 & 9.4089 & 8.2629 & TRN & \\
\hline CHEMBL 3675404 & 1528050 & 9.1871 & 9.0012 & TRN & \\
\hline CHEMBL 3675334 & 1528050 & 5.9508 & 5.9721 & TST & \\
\hline CHEMBL3680402 & 1528050 & 7.6198 & 7.1316 & TST & \\
\hline CHEMBL3685219 & 1528050 & 5.0044 & 5.8785 & TRN & \\
\hline CHEMBL 3675371 & 1528050 & 6.8182 & 6.8485 & TRN & \\
\hline CHEMBL3670505 & 1528050 & 6.8416 & 6.6952 & TRN & \\
\hline CHEMBL 3675468 & 1528050 & 8.1675 & 8.559 & TRN & \\
\hline CHEMBL3675477 & 1528050 & 8.0655 & 7.8042 & TRN & \\
\hline CHEMBL 3680520 & 1528050 & 7.0809 & 7.273 & TRN & \\
\hline CHEMBL3680476 & 1528050 & 7.3188 & 7.3657 & TRN & \\
\hline CHEMBL 3670491 & 1528050 & 5.9208 & 6.6209 & TRN & \\
\hline
\end{tabular}


Supplemental Table S2.txt

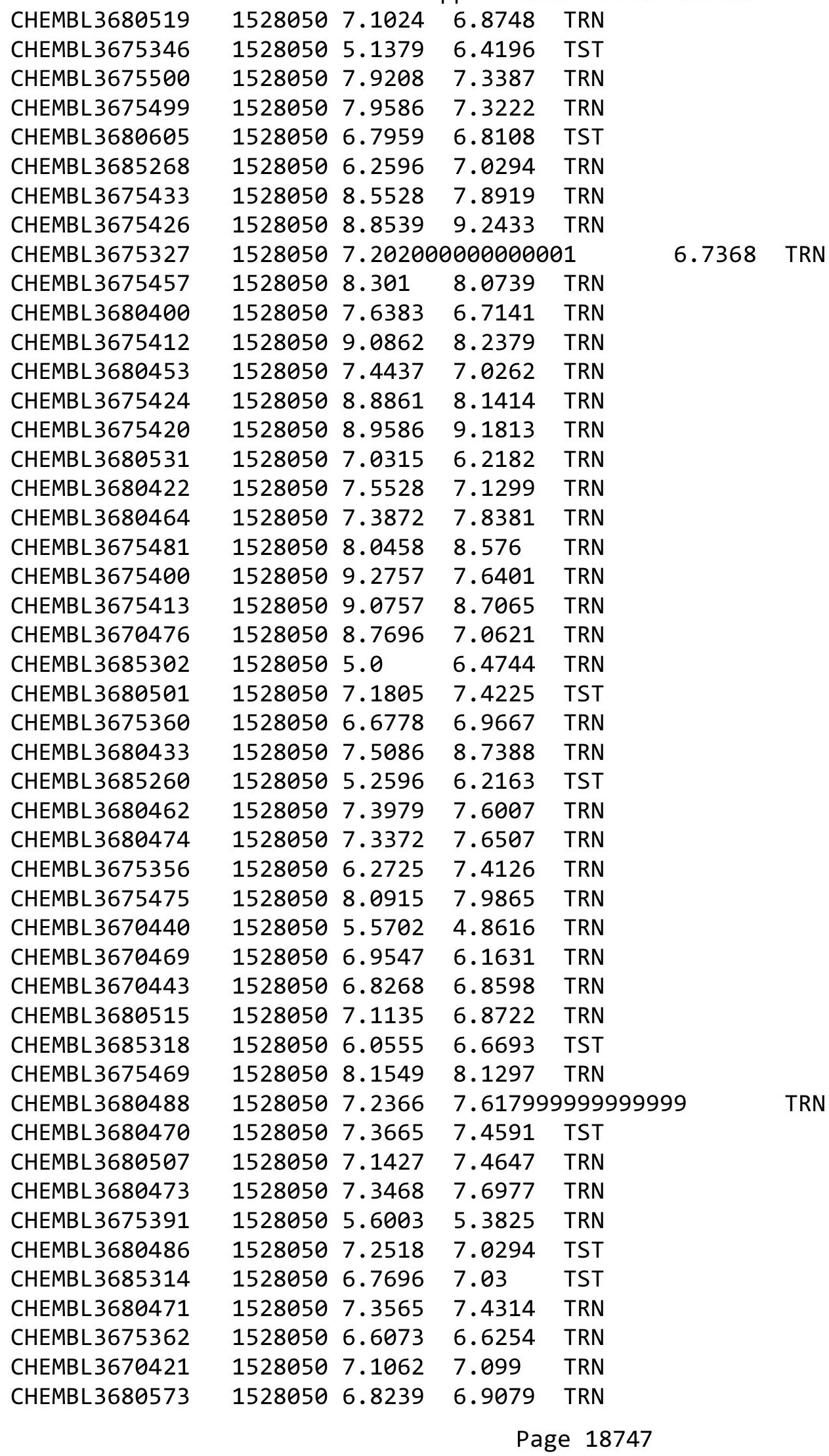


Supplemental Table S2.txt

\begin{tabular}{|c|c|c|c|c|}
\hline CHEMBL 3670465 & 1528050 & 6.7595 & 6.7586 & TRN \\
\hline CHEMBL 3680524 & 1528050 & 7.0655 & 7.2646 & TRN \\
\hline CHEMBL3685289 & 1528050 & 6.6778 & 6.9408 & TRN \\
\hline CHEMBL 3680511 & 1528050 & 7.1308 & 6.3623 & TST \\
\hline CHEMBL 3680436 & 1528050 & 7.4949 & 6.6585 & TRN \\
\hline CHEMBL 3670483 & 1528050 & 6.1851 & 6.648 & TRN \\
\hline CHEMBL 3680442 & 1528050 & 7.4685 & 7.6924 & TRN \\
\hline CHEMBL 3680451 & 1528050 & 7.4437 & 7.1977 & TRN \\
\hline CHEMBL 3670501 & 1528050 & 6.2668 & 6.1652 & TRN \\
\hline CHEMBL 3680395 & 1528050 & 7.6576 & 7.1504 & TRN \\
\hline CHEMBL 3680441 & 1528050 & 7.4815 & 6.7238 & TST \\
\hline CHEMBL 3675354 & 1528050 & 7.6253 & 7.1942 & TRN \\
\hline CHEMBL 3675364 & 1528050 & 6.5918 & 6.3384 & TRN \\
\hline CHEMBL 3675528 & 1528050 & 7.7447 & 8.4817 & TRN \\
\hline CHEMBL 3670426 & 1528050 & 6.7011 & 6.3406 & TRN \\
\hline CHEMBL 3675494 & 1528050 & 8.0 & 7.7643 & TRN \\
\hline CHEMBL 3680440 & 1528050 & 7.4815 & 7.6306 & TRN \\
\hline CHEMBL 3680424 & 1528050 & 7.5376 & 7.0007 & TRN \\
\hline CHEMBL 3680407 & 1528050 & 7.6021 & 7.1664 & TRN \\
\hline CHEMBL 3675478 & 1528050 & 8.0605 & 7.811 & TRN \\
\hline CHEMBL 3680574 & 1528050 & 6.5686 & 6.8503 & TRN \\
\hline CHEMBL 3685290 & 1528050 & 6.6383 & 6.2855 & TRN \\
\hline CHEMBL 3680517 & 1528050 & 7.1024 & 6.9164 & TRN \\
\hline CHEMBL 3680583 & 1528050 & 6.041 & 7.0906 & TST \\
\hline CHEMBL 3670418 & 1528050 & 6.8386 & 7.4715 & TST \\
\hline CHEMBL 3675451 & 1528050 & 8.3565 & 8.2015 & TRN \\
\hline CHEMBL 3675525 & 1528050 & 7.7696 & 7.62700 & 0000000001 \\
\hline CHEMBL 3675518 & 1528050 & 7.7959 & 7.6399 & TRN \\
\hline CHEMBL 3670480 & 1528050 & 7.4724 & 6.5579 & TRN \\
\hline CHEMBL 3680445 & 1528050 & 7.4685 & 7.404 & TRN \\
\hline CHEMBL 3675444 & 1528050 & 8.4318 & 7.0422 & TRN \\
\hline CHEMBL 3680575 & 1528050 & 6.5376 & 6.6775 & TRN \\
\hline CHEMBL 3675393 & 1528050 & 6.0 & 7.6681 & TRN \\
\hline CHEMBL 3680414 & 1528050 & 7.585 & 7.4628 & TRN \\
\hline CHEMBL 3670413 & 1528050 & 6.0 & 7.7931 & TRN \\
\hline CHEMBL 3685326 & 1528050 & 6.2924 & 6.0622 & TRN \\
\hline CHEMBL 3675385 & 1528050 & 6.4486 & 6.7727 & TRN \\
\hline CHEMBL 3680508 & 1528050 & 7.1427 & 6.9639 & TRN \\
\hline CHEMBL 3670502 & 1528050 & 6.6326 & 6.2903 & TRN \\
\hline CHEMBL 3685255 & 1528050 & 6.5686 & 7.6681 & TRN \\
\hline CHEMBL 3675361 & 1528050 & 5.7773 & 6.2858 & TRN \\
\hline CHEMBL 3670457 & 1528050 & 6.5969 & 7.4514 & TRN \\
\hline CHEMBL 3680415 & 1528050 & 7.585 & 7.3753 & TRN \\
\hline CHEMBL 3670446 & 1528050 & 6.7545 & 7.772 & TRN \\
\hline CHEMBL 3680405 & 1528050 & 7.6198 & 6.8944 & TST \\
\hline CHEMBL 3685223 & 1528050 & 6.0 & 5.4499 & TRN \\
\hline CHEMBL 3670410 & 1528050 & 6.6615 & 6.6912 & TST \\
\hline CHEMBL 3675395 & 1528050 & 9.5528 & 6.8206 & TST \\
\hline
\end{tabular}


Supplemental Table S2.txt

\begin{tabular}{|c|c|c|c|c|c|}
\hline CHEMBL 3670473 & 1528050 & 7.8356 & 7.6469 & TRN & \\
\hline CHEMBL3680410 & 1528050 & 7.585 & 7.3409 & TRN & \\
\hline CHEMBL 3680483 & 1528050 & 7.2596 & 6.441 & TRN & \\
\hline CHEMBL 3675417 & 1528050 & 9.0 & 9.3202 & TRN & \\
\hline CHEMBL3675520 & 1528050 & 6.0 & 7.29299 & 9999999999 & TRN \\
\hline CHEMBL3670434 & 1528050 & 6.9586 & 6.9005 & TRN & \\
\hline CHEMBL 3675489 & 1528050 & 8.0223 & 7.7152 & TRN & \\
\hline CHEMBL 3670499 & 1528050 & 7.6364 & 7.5384 & TRN & \\
\hline CHEMBL 3670433 & 1528050 & 7.0106 & 6.8951 & TRN & \\
\hline CHEMBL3675425 & 1528050 & 8.8539 & 7.1527 & TST & \\
\hline CHEMBL3670498 & 1528050 & 6.8665 & 7.6488 & TRN & \\
\hline CHEMBL 3680393 & 1528050 & 7.6778 & 6.6263 & TST & \\
\hline CHEMBL 3675507 & 1528050 & 7.8539 & 7.9037 & TRN & \\
\hline CHEMBL3680537 & 1528050 & 7.0 & 7.3556 & TRN & \\
\hline CHEMBL3670432 & 1528050 & 5.5229 & 4.9645 & TRN & \\
\hline CHEMBL3675422 & 1528050 & 8.8861 & 8.4356 & TRN & \\
\hline CHEMBL3680387 & 1528050 & 7.6778 & 7.7147 & TRN & \\
\hline CHEMBL 3670424 & 1528050 & 6.8069 & 6.7034 & TRN & \\
\hline CHEMBL3675466 & 1528050 & 8.1805 & 7.434 & TRN & \\
\hline CHEMBL3680443 & 1528050 & 7.4685 & 7.277 & TRN & \\
\hline CHEMBL3675458 & 1528050 & 8.301 & 7.954 & TRN & \\
\hline CHEMBL3685215 & 1528050 & 6.301 & 6.8442 & TST & \\
\hline CHEMBL 3680431 & 1528050 & 7.5229 & 7.8479 & TRN & \\
\hline CHEMBL3680425 & 1528050 & 7.5376 & 7.5067 & TRN & \\
\hline CHEMBL 3685321 & 1528050 & 6.0458 & 5.9208 & TST & \\
\hline CHEMBL3670478 & 1528050 & 7.0376 & 7.4198 & TRN & \\
\hline CHEMBL 3675427 & 1528050 & 8.6778 & 8.9323 & TRN & \\
\hline CHEMBL3670472 & 1528050 & 7.0878 & 6.6265 & TRN & \\
\hline CHEMBL3670439 & 1528050 & 7.3757 & 6.4836 & TRN & \\
\hline CHEMBL 3680463 & 1528050 & 7.3979 & 7.6545 & TRN & \\
\hline CHEMBL 3675453 & 1528050 & 8.3468 & 8.0195 & TRN & \\
\hline CHEMBL3670416 & 1528050 & 6.9547 & 7.6713 & TST & \\
\hline CHEMBL 3680468 & 1528050 & 7.3768 & 7.1981 & TRN & \\
\hline CHEMBL3675379 & 1528050 & 6.8794 & 7.1063 & TRN & \\
\hline CHEMBL 3685327 & 1528050 & 6.4202 & 6.5838 & TRN & \\
\hline CHEMBL3680403 & 1528050 & 7.6198 & 7.7895 & TRN & \\
\hline CHEMBL3670497 & 1528050 & 7.8297 & 7.6899 & TRN & \\
\hline CHEMBL 3675372 & 1528050 & 4.7328 & 6.0223 & TRN & \\
\hline CHEMBL3675435 & 1528050 & 8.5376 & 7.3432 & TST & \\
\hline CHEMBL 3675445 & 1528050 & 8.4089 & 8.1517 & TRN & \\
\hline CHEMBL3680465 & 1528050 & 7.3872 & 7.5401 & TRN & \\
\hline CHEMBL3675521 & 1528050 & 7.7959 & 8.2246 & TRN & \\
\hline CHEMBL3680426 & 1528050 & 7.5376 & 7.1518 & TRN & \\
\hline CHEMBL3685293 & 1528050 & 6.4815 & 7.6213 & TRN & \\
\hline CHEMBL 3685287 & 1528050 & 6.699 & 7.0637 & TRN & \\
\hline CHEMBL3670412 & 1528050 & 6.0 & 8.3936 & TRN & \\
\hline CHEMBL3680401 & 1528050 & 7.6383 & 7.3398 & TRN & \\
\hline CHEMBL3685324 & 1528050 & 6.0506 & 6.0897 & TRN & \\
\hline
\end{tabular}

Page 18749 
Supplemental Table S2.txt

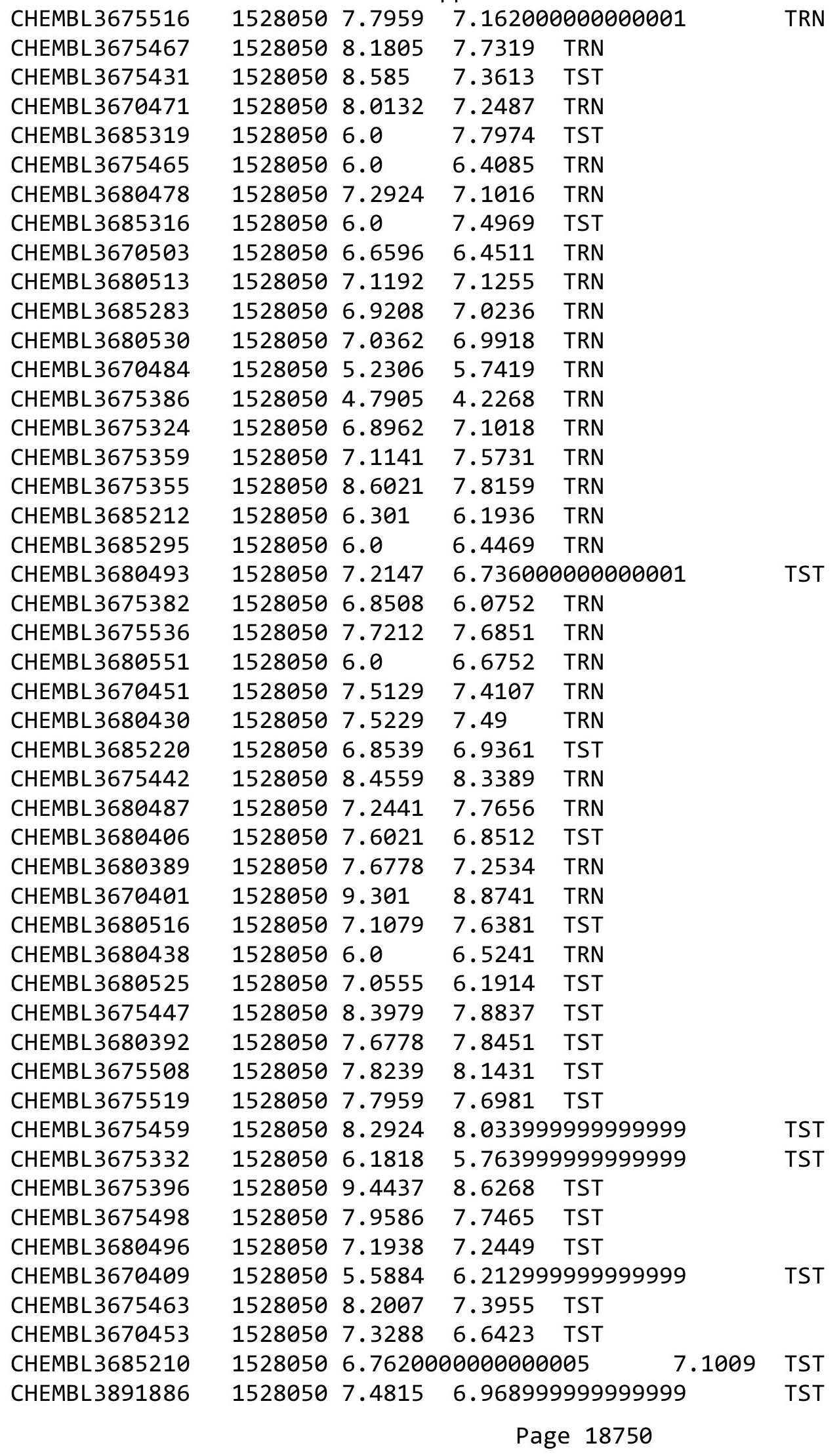


Supplemental Table S2.txt

\begin{tabular}{|c|c|c|c|c|c|}
\hline CHEMBL 3675405 & 1528050 & 9.1805 & 8.4339 & TST & \\
\hline CHEMBL 3675333 & 1528050 & 7.2111 & 6.3967 & TST & \\
\hline CHEMBL3670468 & 1528050 & 8.0458 & 7.852 & TST & \\
\hline CHEMBL 3685298 & 1528050 & 6.0 & 6.129 & TST & \\
\hline CHEMBL 3680570 & 1528050 & 6.7959 & 6.4342 & TST & \\
\hline CHEMBL 3675321 & 1528050 & 6.6904 & 7.1288 & TST & \\
\hline CHEMBL 3680526 & 1528050 & 7.0506 & 6.5591 & TST & \\
\hline CHEMBL 3680408 & 1528050 & 7.6021 & 7.7506 & TST & \\
\hline CHEMBL 3675461 & 1528050 & 8.2291 & 7.3486 & TST & \\
\hline CHEMBL3680460 & 1528050 & 6.0 & 6.3572 & TST & \\
\hline CHEMBL 3670408 & 1528050 & 5.4067 & 6.5136 & TST & \\
\hline CHEMBL3680591 & 1528050 & 6.4559 & 6.6574 & TST & \\
\hline CHEMBL 3675341 & 1528050 & 7.2111 & 6.8465 & TST & \\
\hline CHEMBL3670435 & 1528050 & 7.1701 & 7.0544 & TST & \\
\hline CHEMBL3685225 & 1528050 & 5.5528 & 6.4938 & TST & \\
\hline CHEMBL 3675534 & 1528050 & 7.7212 & 7.5972 & TST & \\
\hline CHEMBL 3680572 & 1528050 & 6.4089 & 6.9505 & TST & \\
\hline CHEMBL3670450 & 1528050 & 6.0 & 6.6683 & TST & \\
\hline CHEMBL3680497 & 1528050 & 7.1871 & 7.1886 & TST & \\
\hline CHEMBL3675369 & 1528050 & 6.5452 & 6.0401 & TST & \\
\hline CHEMBL3675411 & 1528050 & 9.0915 & 8.9209 & TST & \\
\hline CHEMBL 3670430 & 1528050 & 4.5346 & 5.2231 & TST & \\
\hline CHEMBL 3680449 & 1528050 & 7.4559 & 7.2827 & TST & \\
\hline CHEMBL3675339 & 1528050 & 8.7959 & 7.9193 & TST & \\
\hline CHEMBL 3675455 & 1528050 & 8.3188 & 7.3812 & TST & \\
\hline CHEMBL3680391 & 1528050 & 7.6778 & 7.5038 & TST & \\
\hline CHEMBL 3680412 & 1528050 & 7.585 & 7.8548 & TST & \\
\hline CHEMBL 3680490 & 1528050 & 7.2291 & 7.3995 & TST & \\
\hline CHEMBL 3670462 & 1528050 & 6.341 & 6.6362 & TST & \\
\hline CHEMBL 3675537 & 1528050 & 7.699 & 7.2357 & TST & \\
\hline CHEMBL 3670436 & 1528050 & 6.7212 & 7.1246 & TST & \\
\hline CHEMBL 3680482 & 1528050 & 7.2676 & 5.7975 & TST & \\
\hline CHEMBL 3670488 & 1528050 & 7.3107 & 6.7791 & TST & \\
\hline CHEMBL3675331 & 1528050 & 9.301 & 7.9241 & TST & \\
\hline CHEMBL 3680595 & 1528050 & 6.3188 & 7.2119 & TST & \\
\hline CHEMBL 3670467 & 1528050 & 7.6946 & 7.2642 & TST & \\
\hline CHEMBL 3670402 & 1528050 & 6.7055 & 6.7429 & TST & \\
\hline CHEMBL 3680489 & 1528050 & 7.2366 & 6.7391 & TST & \\
\hline CHEMBL 3675490 & 1528050 & 8.0177 & 7.6227 & TST & \\
\hline CHEMBL 3681166 & 1528485 & 8.7122 & 8.7215 & TRN & \\
\hline CHEMBL 3681167 & 1528485 & 8.6596 & 8.4311 & TRN & \\
\hline CHEMBL 2331667 & 1528485 & 9.2899 & 8.9161 & TST & \\
\hline CHEMBL3681110 & 1528485 & 8.9872 & 8.791 & TRN & \\
\hline CHEMBL 3681080 & 1528485 & 8.4584 & 8.4412 & TRN & \\
\hline CHEMBL 3681171 & 1528485 & $9.0910 e$ & 00000006 & & 8.988999999999999 \\
\hline CHEMBL3681152 & 1528485 & 7.2832 & 7.5875 & TRN & \\
\hline CHEMBL3681082 & 1528485 & 9.4698 & 9.2629 & TRN & \\
\hline CHEMBL3681090 & 1528485 & 8.9666 & 9.0797 & TRN & \\
\hline
\end{tabular}

Page 18751 
Supplemental Table S2.txt

\begin{tabular}{|c|c|c|c|c|}
\hline CHEMBL3681115 & 1528485 & 8.4056 & 8.3318 & TRN \\
\hline CHEMBL3681068 & 1528485 & 9.2684 & 8.5421 & TRN \\
\hline CHEMBL3681185 & 1528485 & 7.8697 & 8.0901 & TST \\
\hline CHEMBL3681188 & 1528485 & 8.7122 & 8.7771 & TRN \\
\hline CHEMBL3681169 & 1528485 & 7.7545 & 8.5803 & TST \\
\hline CHEMBL3681131 & 1528485 & 9.5513 & 9.2212 & TRN \\
\hline CHEMBL3681157 & 1528485 & 6.0 & 8.9113 & TST \\
\hline CHEMBL 3681173 & 1528485 & 8.98299 & 79999999 & 9.1276 \\
\hline CHEMBL3681181 & 1528485 & 8.1079 & 7.9418 & TST \\
\hline CHEMBL3681168 & 1528485 & 7.6162 & 8.0912 & TRN \\
\hline CHEMBL3681134 & 1528485 & 7.6126 & 7.4121 & TRN \\
\hline CHEMBL3681119 & 1528485 & 9.301 & 9.0099 & TRN \\
\hline CHEMBL3681111 & 1528485 & 9.4949 & 8.8647 & TRN \\
\hline CHEMBL3681160 & 1528485 & 8.3556 & 8.80600 & 0000000001 \\
\hline CHEMBL3681089 & 1528485 & 8.9208 & 8.844 & TRN \\
\hline CHEMBL3681137 & 1528485 & 8.3344 & 8.1235 & TRN \\
\hline CHEMBL3681127 & 1528485 & 8.0477 & 8.3576 & TRN \\
\hline CHEMBL3681097 & 1528485 & 7.6326 & 8.1099 & TRN \\
\hline CHEMBL3681063 & 1528485 & 7.1409 & 7.9348 & TST \\
\hline CHEMBL3681122 & 1528485 & 9.1192 & 9.2133 & TRN \\
\hline CHEMBL 2331669 & 1528485 & 9.1421 & 8.9517 & TST \\
\hline CHEMBL3681128 & 1528485 & 7.5482 & 8.5335 & TST \\
\hline CHEMBL3681107 & 1528485 & 7.6326 & 8.725 & TST \\
\hline CHEMBL 2331666 & 1528485 & 9.0353 & 9.1336 & TRN \\
\hline CHEMBL3681184 & 1528485 & 7.9136 & 7.6944 & TST \\
\hline CHEMBL3681180 & 1528485 & 8.2993 & 8.5053 & TST \\
\hline CHEMBL 2331664 & 1528485 & 9.0186 & 8.8698 & TRN \\
\hline CHEMBL3681067 & 1528485 & 8.4962 & 8.7385 & TRN \\
\hline CHEMBL3681106 & 1528485 & 8.3706 & 7.9638 & TRN \\
\hline CHEMBL 2331668 & 1528485 & 9.719 & 9.8114 & TRN \\
\hline CHEMBL3681148 & 1528485 & 6.4962 & 7.3258 & TRN \\
\hline CHEMBL3681155 & 1528485 & 7.8729 & 8.4499 & TST \\
\hline CHEMBL 3681143 & 1528485 & 7.5817 & 8.047 & TRN \\
\hline CHEMBL 3681064 & 1528485 & 8.1096 & 8.7523 & TST \\
\hline CHEMBL3681132 & 1528485 & 9.0958 & 8.8954 & TRN \\
\hline CHEMBL2331658 & 1528485 & 9.301 & 9.344 & TRN \\
\hline CHEMBL3681141 & 1528485 & 8.3307 & 7.9394 & TRN \\
\hline CHEMBL3681091 & 1528485 & 8.6799 & 8.6013 & TRN \\
\hline CHEMBL 3639800 & 1528485 & 8.6536 & 8.8127 & TRN \\
\hline CHEMBL3681142 & 1528485 & 9.2967 & 8.9568 & TRN \\
\hline CHEMBL3681138 & 1528485 & 7.8327 & 7.9913 & TRN \\
\hline CHEMBL3681153 & 1528485 & 8.7932 & 8.9249 & TRN \\
\hline CHEMBL3681179 & 1528485 & 9.5498 & 9.0974 & TRN \\
\hline CHEMBL 3681057 & 1528485 & 8.3516 & 9.0159 & TST \\
\hline CHEMBL3681076 & 1528485 & 8.2277 & 8.4481 & TRN \\
\hline CHEMBL3681182 & 1528485 & 9.8386 & 9.8644 & TRN \\
\hline CHEMBL3681190 & 1528485 & 8.6968 & 9.0273 & TRN \\
\hline CHEMBL3681054 & 1528485 & 8.7305 & 8.9254 & TST \\
\hline
\end{tabular}


Supplemental Table S2.txt

\begin{tabular}{|c|c|c|c|c|}
\hline TLI & & & 8232 & \\
\hline & & & & \\
\hline EN & 20 & & & \\
\hline IEMBL & & & & \\
\hline AEMBL3681056 & 528485 & & 927 & \\
\hline HEMBL3681059 & 52 & & .7664 & \\
\hline 060 & 35 & & 392 & \\
\hline AEMBL3681065 & & & & \\
\hline HEMBL3681087 & 528485 & & 8.6571 & \\
\hline HEMBL3681069 & 528485 & & 6134 & \\
\hline HEMBL3681158 & 35 & & & \\
\hline 101 & 35 & & .9713 & \\
\hline HEMBL; & & & 78 & \\
\hline HEMBL3681187 & 528485 & & 9.1902 & \\
\hline AEMBL3681177 & 185 & & & \\
\hline HEMBL36 & כ) & & & \\
\hline HEMBL & 3 & & & (1) \\
\hline HEMBL 2 & 35 & & & \\
\hline HEMBL3 & 85 & & 38 & \\
\hline HEMBL3681096 & & & 52 & I KIV \\
\hline HEMBL & 85 & & & RN \\
\hline 63 & & & & NIV \\
\hline AEMBL & 35 & & 03 & \\
\hline HEMBL & & & & \\
\hline AEMBL3 & 35 & & & RN \\
\hline HEMBL3 & & & 21 & RN \\
\hline 78 & & & & KIV \\
\hline 26 & & & 91 & \\
\hline AEMBL & & & & IRN \\
\hline HEMBL3681165 & 35 & & 32 & RN \\
\hline AEMBL & & & 37 & RN \\
\hline 66 & & & & \\
\hline 109 & & & & $\mathrm{RN}$ \\
\hline HEMBL3 & & & & $\mathrm{RN}$ \\
\hline HEMBL3681103 & -0 & & 391 & RN \\
\hline 183 & & & 74 & TRN \\
\hline 62 & & & & ST \\
\hline HEMBL36 & & & & 「RN \\
\hline HEMBL3 & 35 & & & TRN \\
\hline L02 & & & & RN \\
\hline HEMBL3 & & & 58 & RN \\
\hline HEMBL3 & & & 169 & RN \\
\hline HEMBL3681105 & 85 & & & RN \\
\hline HEMBL3 & 52 & & & TR \\
\hline 20 & & & & ST \\
\hline HEMBL3 & & & & \\
\hline CHEMBL3 & 5 & 8.4 & 1153 & \\
\hline CHEMBL3681174 & 1528485 & 9.2403 & 8.8461 & \\
\hline
\end{tabular}

Page 18753 
Supplemental Table S2.txt

\begin{tabular}{|c|c|c|c|c|c|}
\hline CHEMBL3681116 & 1528485 & 7.9245 & 7.9516 & TRN & \\
\hline CHEMBL 3681178 & 1528485 & 9.4949 & 9.2978 & TRN & \\
\hline CHEMBL3681075 & 1528485 & 8.5391 & 8.9852 & TRN & \\
\hline CHEMBL 3681092 & 1528485 & 8.0565 & 8.8618 & TRN & \\
\hline CHEMBL 3681098 & 1528485 & 8.3036 & 8.389 & TRN & \\
\hline CHEMBL 3681159 & 1528485 & 7.8097 & 8.752 & TST & \\
\hline CHEMBL 3681085 & 1528485 & 8.9393 & 9.3077 & TRN & \\
\hline CHEMBL 3681154 & 1528485 & 9.5638 & 9.2199 & TRN & \\
\hline CHEMBL 2331662 & 1528485 & 8.7055 & 8.7876 & TRN & \\
\hline CHEMBL3681170 & 1528485 & 8.3458 & 7.8652 & TST & \\
\hline CHEMBL 3681118 & 1528485 & 8.0888 & 8.1852 & TRN & \\
\hline CHEMBL3681099 & 1528485 & 8.3279 & 7.9224 & TRN & \\
\hline CHEMBL3681113 & 1528485 & 7.5607 & 7.8749 & TRN & \\
\hline CHEMBL3681095 & 1528485 & 8.5867 & 8.599 & TRN & \\
\hline CHEMBL3681125 & 1528485 & 7.9469 & 8.5654 & TRN & \\
\hline CHEMBL 3681084 & 1528485 & 7.6882 & 8.8507 & TRN & \\
\hline CHEMBL3681081 & 1528485 & 8.6517 & 8.7446 & TRN & \\
\hline CHEMBL3681077 & 1528485 & 8.6216 & 7.87 & TST & \\
\hline CHEMBL 3681144 & 1528485 & 7.3429 & 6.9578 & TRN & \\
\hline CHEMBL2331659 & 1528485 & 9.301 & 9.1754 & TRN & \\
\hline CHEMBL3681130 & 1528485 & 9.5258 & 8.8862 & TRN & \\
\hline CHEMBL3681055 & 1528485 & 7.4584 & 8.426 & TST & \\
\hline CHEMBL3681104 & 1528485 & 9.0114 & 8.4691 & TRN & \\
\hline CHEMBL2331665 & 1528485 & 8.4101 & 8.6062 & TRN & \\
\hline CHEMBL3681061 & 1528485 & 8.2154 & 8.318 & TST & \\
\hline CHEMBL3681172 & 1528485 & 9.0799 & 8.9793 & TST & \\
\hline CHEMBL 3681175 & 1528485 & 9.9586 & 9.8702 & TRN & \\
\hline CHEMBL3681135 & 1528485 & 9.5784 & 9.0641 & TRN & \\
\hline CHEMBL3681083 & 1528485 & 9.1752 & 9.0404 & TRN & \\
\hline CHEMBL3681129 & 1528485 & 8.2865 & 7.7468 & TRN & \\
\hline CHEMBL3681161 & 1528485 & 7.5287 & 8.2339 & TST & \\
\hline CHEMBL3681073 & 1528485 & 8.5935 & 8.5212 & TRN & \\
\hline CHEMBL 3681058 & 1528485 & 8.4191 & 9.7195 & TST & \\
\hline CHEMBL3681074 & 1528485 & 8.8601 & 8.9172 & TRN & \\
\hline CHEMBL11242 & 216035 & 6.0 & 6.3385 & TRN & \\
\hline CHEMBL11449 & 216035 & 5.6778 & 5.7371 & TRN & \\
\hline CHEMBL 275318 & 216035 & 6.6383 & 6.71200 & 0000000001 & TRN \\
\hline CHEMBL12104 & 216035 & 4.5528 & 4.7265 & TRN & \\
\hline CHEMBL267561 & 216035 & 4.6021 & 4.5615 & TST & \\
\hline CHEMBL12307 & 216035 & 5.4949 & 5.6101 & TRN & \\
\hline CHEMBL11543 & 216035 & 6.8539 & 6.7575 & TRN & \\
\hline CHEMBL3559635 & 216035 & 6.2441 & 6.1493 & TRN & \\
\hline CHEMBL1907818 & 216035 & 6.7447 & 6.7909 & TRN & \\
\hline CHEMBL12045 & 216035 & 4.4949 & 4.6439 & TRN & \\
\hline CHEMBL12226 & 216035 & 5.3979 & 4.9717 & TRN & \\
\hline CHEMBL 275349 & 216035 & 6.1308 & 6.241006 & 30000000005 & TRN \\
\hline CHEMBL12353 & 216035 & 6.6198 & 6.5152 & TRN & \\
\hline CHEMBL11661 & 216035 & 7.8239 & 7.6744 & TRN & \\
\hline
\end{tabular}




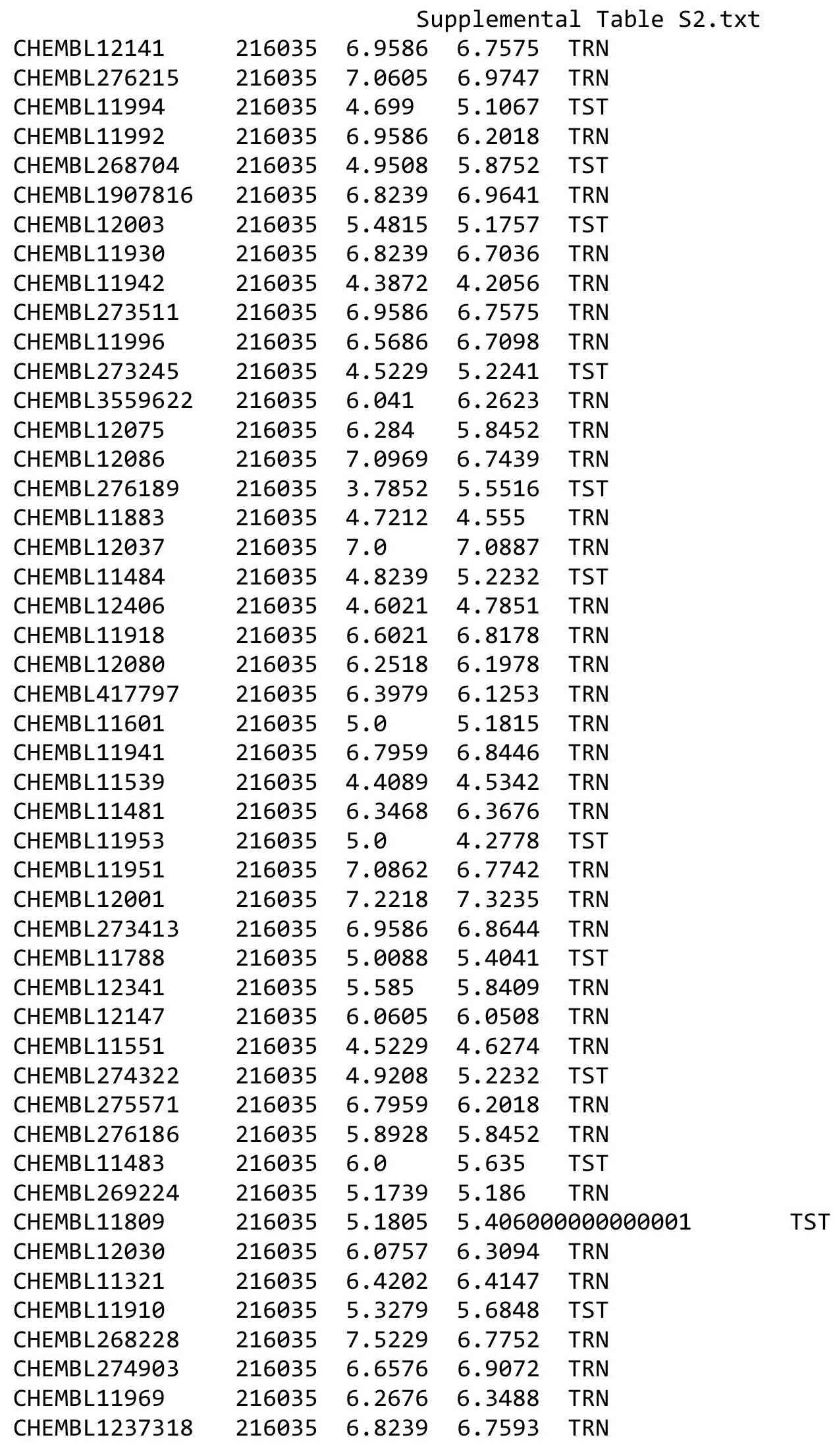

Page 18755 


\begin{tabular}{|c|c|c|c|c|c|}
\hline \multirow[b]{2}{*}{ CHEMBL11443 } & \multicolumn{5}{|c|}{ Supplemental Table S2.txt } \\
\hline & 216035 & 4.5528 & 5.2472 & TST & \\
\hline CHEMBL11602 & 216035 & 6.8861 & 7.38700 & 00000000005 & TRN \\
\hline CHEMBL12387 & 216035 & 5.3565 & 5.3389 & TRN & \\
\hline CHEMBL268486 & 216035 & 5.4622 & 5.9264 & TRN & \\
\hline CHEMBL12002 & 216035 & 5.3768 & 5.8688 & TST & \\
\hline CHEMBL 274108 & 216035 & 5.2218 & 4.9385 & TRN & \\
\hline CHEMBL11648 & 216035 & 6.0 & 6.3093 & TRN & \\
\hline CHEMBL 276187 & 216035 & 5.2076 & 5.1884 & TST & \\
\hline CHEMBL11747 & 216035 & 7.3979 & 7.4962 & TRN & \\
\hline CHEMBL11777 & 216035 & 6.8861 & 6.9774 & TRN & \\
\hline CHEMBL 276162 & 216035 & 6.699 & 6.8486 & TRN & \\
\hline CHEMBL11324 & 216035 & 6.6383 & 6.4728 & TRN & \\
\hline CHEMBL275227 & 216035 & 7.0177 & 6.7575 & TRN & \\
\hline CHEMBL 274418 & 216035 & 5.5229 & 5.8141 & TRN & \\
\hline CHEMBL11999 & 216035 & 4.585 & 4.555 & TRN & \\
\hline CHEMBL 267772 & 216035 & 4.284 & 6.2269 & TST & \\
\hline CHEMBL 276876 & 216035 & 5.301 & 5.7017 & TRN & \\
\hline CHEMBL267768 & 216035 & 6.2076 & 6.1463 & TST & \\
\hline CHEMBL1907817 & 216035 & 7.2218 & 7.1887 & TRN & \\
\hline CHEMBL11932 & 216035 & 6.1079 & 6.103 & TRN & \\
\hline CHEMBL11797 & 216035 & 4.4685 & 4.6592 & TRN & \\
\hline CHEMBL 273925 & 216035 & 6.7696 & 6.5711 & TRN & \\
\hline CHEMBL447179 & 216035 & 4.7447 & 4.4968 & TRN & \\
\hline CHEMBL 274527 & 216035 & 4.5086 & 5.22 & TST & \\
\hline CHEMBL12000 & 216035 & 4.8539 & 4.7159 & TRN & \\
\hline CHEMBL11744 & 216035 & 6.2366 & 6.2982 & TRN & \\
\hline CHEMBL11904 & 216035 & 4.5686 & 6.2018 & TRN & \\
\hline CHEMBL11961 & 216035 & 7.0362 & 6.6195 & TRN & \\
\hline CHEMBL12009 & 216035 & 6.1427 & 6.1749 & TRN & \\
\hline CHEMBL11700 & 216035 & 6.0655 & 5.8736 & TRN & \\
\hline CHEMBL3559630 & 216035 & 6.3468 & 5.9547 & TRN & \\
\hline CHEMBL417795 & 216035 & 3.9914 & 4.308 & TRN & \\
\hline CHEMBL 276493 & 216035 & 4.1549 & 4.5732 & TST & \\
\hline CHEMBL11924 & 216035 & 6.3979 & 6.1994 & TRN & \\
\hline CHEMBL11853 & 216035 & 5.5686 & 5.7561 & TST & \\
\hline CHEMBL11878 & 216035 & 5.3372 & 5.4949 & TST & \\
\hline CHEMBL 276692 & 216035 & 6.0655 & 6.2281 & TRN & \\
\hline CHEMBL 273954 & 216035 & 6.5229 & 6.3032 & TRN & \\
\hline CHEMBL 274188 & 216035 & 7.699 & 7.4887 & TRN & \\
\hline CHEMBL273926 & 216035 & 6.8239 & 6.2895 & TRN & \\
\hline CHEMBL11482 & 216035 & 6.9586 & 6.8223 & TRN & \\
\hline CHEMBL11734 & 216035 & 5.1427 & 5.4532 & TST & \\
\hline CHEMBL274139 & 216035 & 6.6383 & 6.5426 & TRN & \\
\hline CHEMBL429189 & 216035 & 4.4949 & 4.555 & TST & \\
\hline CHEMBL 274846 & 216035 & 7.3188 & 6.9389 & TRN & \\
\hline CHEMBL11704 & 216035 & 6.6576 & 6.5041 & TRN & \\
\hline CHEMBL11814 & 216035 & 4.6576 & 4.2296 & TST & \\
\hline CHEMBL11997 & 216035 & 6.5528 & 6.8596 & TRN & \\
\hline
\end{tabular}




\begin{tabular}{|c|c|c|c|c|c|}
\hline \multirow[b]{2}{*}{ CHEMBL 2092843} & \multicolumn{5}{|c|}{ plemental Table S } \\
\hline & 216035 & 6.0 & 6.8529 & TRN & \\
\hline CHEMBL11876 & 216035 & 6.3565 & 6.2248 & TRN & \\
\hline CHEMBL275319 & 216035 & 6.8239 & 6.58200 & 0000000001 & TRN \\
\hline CHEMBL11792 & 216035 & 6.6383 & 6.6863 & TRN & \\
\hline CHEMBL11830 & 216035 & 6.8539 & 6.7765 & TRN & \\
\hline CHEMBL11642 & 216035 & 4.5229 & 5.1411 & TST & \\
\hline CHEMBL417431 & 216035 & 6.7959 & 6.9417 & TRN & \\
\hline CHEMBL11764 & 216035 & 6.4815 & 6.4172 & TRN & \\
\hline CHEMBL12149 & 216035 & 5.1871 & 5.5655 & TST & \\
\hline CHEMBL 268273 & 216035 & 6.3979 & 6.4282 & TRN & \\
\hline CHEMBL12049 & 216035 & 4.9586 & 4.3005 & TST & \\
\hline CHEMBL11887 & 216035 & 6.5528 & 6.7276 & TRN & \\
\hline CHEMBL11763 & 216035 & 6.6778 & 6.8682 & TRN & \\
\hline CHEMBL12095 & 216035 & 7.2366 & 6.8929 & TRN & \\
\hline CHEMBL11554 & 216035 & 7.0458 & 7.1359 & TRN & \\
\hline CHEMBL 3559633 & 216035 & 5.9626 & 6.1814 & TRN & \\
\hline CHEMBL417981 & 216035 & 6.7959 & 6.7575 & TRN & \\
\hline CHEMBL11649 & 216035 & 6.301 & 6.6004 & TRN & \\
\hline CHEMBL12126 & 216035 & 6.7447 & 6.7519 & TRN & \\
\hline CHEMBL 276188 & 216035 & 4.6021 & 5.4094 & TST & \\
\hline CHEMBL11569 & 216035 & 6.4949 & 6.5287 & TRN & \\
\hline CHEMBL 274631 & 216035 & 5.5229 & 4.9975 & TST & \\
\hline CHEMBL 274526 & 216035 & 4.7212 & 4.0662 & TST & \\
\hline CHEMBL 276241 & 216035 & 5.7959 & 5.771 & TST & \\
\hline CHEMBL11462 & 216035 & 4.6576 & 5.3846 & TST & \\
\hline CHEMBL12008 & 216035 & 7.3565 & 7.1012 & TRN & \\
\hline CHEMBL12195 & 216035 & 6.7447 & 6.6181 & TRN & \\
\hline CHEMBL12148 & 216035 & 5.7959 & 6.0487 & TRN & \\
\hline CHEMBL12060 & 216035 & 5.0 & 4.5069 & TST & \\
\hline CHEMBL11967 & 216035 & 6.8239 & 6.9887 & TRN & \\
\hline CHEMBL11925 & 216035 & 6.6383 & 6.3235 & TRN & \\
\hline CHEMBL 267101 & 216035 & 6.4685 & 6.6546 & TRN & \\
\hline CHEMBL11971 & 216035 & 6.5376 & 6.1253 & TRN & \\
\hline CHEMBL267566 & 216035 & 5.301 & 5.7337 & TST & \\
\hline CHEMBL11556 & 216035 & 6.9208 & 7.0883 & TRN & \\
\hline CHEMBL12159 & 216035 & 4.284 & 4.3163 & TST & \\
\hline CHEMBL12017 & 216035 & 5.0458 & 5.0589 & TST & \\
\hline CHEMBL11576 & 216035 & 4.4559 & 4.555 & TST & \\
\hline CHEMBL11674 & 216035 & 6.7447 & 7.07700 & 0000000001 & TRN \\
\hline CHEMBL11837 & 216035 & 6.0915 & 6.3093 & TRN & \\
\hline CHEMBL1361173 & 1301765 & 5.3657 & 5.1913 & TRN & \\
\hline CHEMBL1729804 & 1301765 & 5.2798 & 5.4355 & TRN & \\
\hline CHEMBL3197208 & 1301765 & 4.8725 & 5.0004 & TRN & \\
\hline CHEMBL175434 & 1301765 & 5.3141 & 5.4558 & TRN & \\
\hline CHEMBL1458448 & 1301765 & 4.5554 & 4.7699 & TST & \\
\hline CHEMBL 3194086 & 1301765 & 5.4454 & 5.5263 & TRN & \\
\hline CHEMBL1735496 & 1301765 & 5.0098 & 4.9989 & TST & \\
\hline CHEMBL 3144856 & 1301765 & 4.331 & 4.1948 & TRN & \\
\hline
\end{tabular}


Supplemental Table S2.txt

\begin{tabular}{|c|c|c|c|c|c|}
\hline CHEMBL1713009 & 1301765 & 5.7506 & 5.5099 & TRN & \\
\hline CHEMBL600175 & 1301765 & 5.3224 & 5.2554 & TRN & \\
\hline CHEMBL1487660 & 1301765 & 4.1785 & 4.1852 & TRN & \\
\hline CHEMBL1326863 & 1301765 & 4.9781 & 5.1703 & TRN & \\
\hline CHEMBL1986381 & 1301765 & 4.7609 & 5.0828 & TRN & \\
\hline CHEMBL1535375 & 1301765 & 5.2896 & 5.1866 & TRN & \\
\hline CHEMBL1964407 & 1301765 & 5.803 & 5.4515 & TRN & \\
\hline CHEMBL1555938 & 1301765 & 5.3708 & 5.2178 & TRN & \\
\hline CHEMBL1331106 & 1301765 & 4.7248 & 3.9127 & TRN & \\
\hline CHEMBL1723945 & 1301765 & 5.2553 & 5.3852 & TRN & \\
\hline CHEMBL1438627 & 1301765 & 5.0517 & 5.178 & TRN & \\
\hline CHEMBL1988648 & 1301765 & 5.4618 & 5.3304 & TRN & \\
\hline CHEMBL1212972 & 1301765 & 5.4175 & 5.2453 & TRN & \\
\hline CHEMBL1495700 & 1301765 & 4.1622 & 4.585 & TST & \\
\hline CHEMBL1458444 & 1301765 & 5.0802 & 4.9648 & TRN & \\
\hline CHEMBL235504 & 1301765 & 5.2689 & \multicolumn{2}{|c|}{5.587000000000001} & TRN \\
\hline CHEMBL3190880 & 1301765 & 6.0793 & 6.0823 & TRN & \\
\hline CHEMBL1526391 & 1301765 & 5.1302 & 5.4463 & TRN & \\
\hline CHEMBL 3190083 & 1301765 & 5.2242 & 5.2064 & TRN & \\
\hline CHEMBL1598762 & 1301765 & 6.5689 & 5.9833 & TRN & \\
\hline CHEMBL1504710 & 1301765 & 5.1909 & 5.2237 & TRN & \\
\hline CHEMBL1469728 & 1301765 & 5.0017 & 5.2321 & TRN & \\
\hline CHEMBL1456440 & 1301765 & 5.1245 & 5.3798 & TRN & \\
\hline CHEMBL1324826 & 1301765 & 4.9859 & 4.8298 & TRN & \\
\hline CHEMBL1473428 & 1301765 & 5.1236 & 4.976 & TRN & \\
\hline CHEMBL1701533 & 1301765 & 5.5296 & 5.1746 & TST & \\
\hline CHEMBL1700996 & 1301765 & 5.4433 & 5.3817 & TRN & \\
\hline CHEMBL 2000633 & 1301765 & 5.0399 & 5.0745 & TRN & \\
\hline CHEMBL1541408 & 1301765 & 4.8168 & 5.0876 & TRN & \\
\hline CHEMBL578905 & 1301765 & 5.3432 & 5.271 & TRN & \\
\hline CHEMBL1881345 & 1301765 & 5.2915 & 5.1671 & TRN & \\
\hline CHEMBL1546172 & 1301765 & 6.1043 & 5.7501 & TRN & \\
\hline CHEMBL3187596 & 1301765 & 5.4756 & 5.3081 & TRN & \\
\hline CHEMBL1464949 & 1301765 & 5.0025 & 4.8799 & TRN & \\
\hline CHEMBL1702473 & 1301765 & 5.8626 & 5.6393 & TRN & \\
\hline CHEMBL1723968 & 1301765 & 5.495 & 5.4897 & TRN & \\
\hline CHEMBL1331912 & 1301765 & 5.945 & 6.0562 & TRN & \\
\hline CHEMBL1421377 & 1301765 & 4.9235 & 5.114 & TST & \\
\hline CHEMBL1706438 & 1301765 & 5.2517 & 5.2112 & TRN & \\
\hline CHEMBL1524233 & 1301765 & 5.1652 & 5.3274 & TRN & \\
\hline CHEMBL1463659 & 1301765 & 6.4363 & 6.0573 & TST & \\
\hline CHEMBL1605599 & 1301765 & 5.1801 & 5.1953 & TRN & \\
\hline CHEMBL1505552 & 1301765 & 5.1174 & 5.0297 & TST & \\
\hline CHEMBL1982305 & 1301765 & 6.1128 & 6.103 & TRN & \\
\hline CHEMBL1582771 & 1301765 & 5.0299 & 5.1157 & TRN & \\
\hline CHEMBL51931 & 1301765 & 5.6198 & 5.7439 & TRN & \\
\hline CHEMBL1301243 & 1301765 & 5.2815 & 5.5397 & TRN & \\
\hline CHEMBL1504853 & 1301765 & 4.9865 & 4.8945 & TRN & \\
\hline
\end{tabular}

Page 18758 
Supplemental Table S2.txt

\begin{tabular}{|c|c|c|c|c|c|}
\hline CHEMBL1735482 & 1301765 & 6.3613 & 6.1155 & TRN & \\
\hline CHEMBL604321 & 1301765 & 4.8944 & 4.7531 & TRN & \\
\hline CHEMBL1893320 & 1301765 & 4.6553 & 4.7812 & TST & \\
\hline CHEMBL1210769 & 1301765 & 6.4027 & 5.9962 & TRN & \\
\hline CHEMBL3199312 & 1301765 & 4.8315 & 5.0987 & TRN & \\
\hline CHEMBL1482180 & 1301765 & 2.9406 & 4.9166 & TRN & \\
\hline CHEMBL1362935 & 1301765 & 5.189 & 5.3571 & TRN & \\
\hline CHEMBL1607263 & 1301765 & 5.1167 & 5.229 & TRN & \\
\hline CHEMBL 2003651 & 1301765 & 6.4011 & 6.2928 & TRN & \\
\hline CHEMBL1384253 & 1301765 & 6.4908 & 6.1536 & TRN & \\
\hline CHEMBL1438881 & 1301765 & 4.99 & 5.3848 & TST & \\
\hline CHEMBL1360435 & 1301765 & 4.0468 & 4.122 & TST & \\
\hline CHEMBL1378508 & 1301765 & 4.6493 & 4.5972 & TST & \\
\hline CHEMBL1589737 & 1301765 & 5.3759 & 5.4103 & TRN & \\
\hline CHEMBL1698877 & 1301765 & 5.1702 & 5.4563 & TRN & \\
\hline CHEMBL1475961 & 1301765 & 5.1082 & 4.9052 & TRN & \\
\hline CHEMBL1530670 & 1301765 & 5.0567 & 4.9892 & TRN & \\
\hline CHEMBL1505544 & 1301765 & 5.8921 & 6.0292 & TRN & \\
\hline CHEMBL1508357 & 1301765 & 4.5917 & 4.8216 & TST & \\
\hline CHEMBL171632 & 1301765 & 5.7364 & 5.1488 & TST & \\
\hline CHEMBL1524916 & 1301765 & 4.6909 & 4.9909 & TRN & \\
\hline CHEMBL1403154 & 1301765 & 5.1681 & 5.2941 & TRN & \\
\hline CHEMBL1235966 & 1301765 & 5.1253 & 5.2171 & TST & \\
\hline CHEMBL 2137294 & 1301765 & 5.1861 & 5.1952 & TRN & \\
\hline CHEMBL1361392 & 1301765 & 5.1501 & 4.9472 & TRN & \\
\hline CHEMBL599924 & 1301765 & 6.5595 & 6.4137 & TST & \\
\hline CHEMBL1717890 & 1301765 & 5.4148 & 5.3923 & TRN & \\
\hline CHEMBL1380801 & 1301765 & 4.8492 & 5.0756 & TRN & \\
\hline CHEMBL1511226 & 1301765 & 4.8794 & 5.0308 & TST & \\
\hline CHEMBL1329140 & 1301765 & 5.357 & 5.3636 & TRN & \\
\hline CHEMBL586029 & 1301765 & 4.7934 & 4.7905 & TRN & \\
\hline CHEMBL1163377 & 1301765 & 6.5594 & 6.0219 & TRN & \\
\hline CHEMBL3193343 & 1301765 & 4.7387 & 4.84 & TST & \\
\hline CHEMBL1578029 & 1301765 & 5.0924 & 4.8223 & TRN & \\
\hline CHEMBL1707222 & 1301765 & 5.0256 & 5.2989 & TRN & \\
\hline CHEMBL1733422 & 1301765 & 5.6649 & 5.957006 & 0000000001 & TRN \\
\hline CHEMBL1526855 & 1301765 & 5.4515 & 5.3468 & TRN & \\
\hline CHEMBL1727228 & 1301765 & 5.1319 & 5.3207 & TRN & \\
\hline CHEMBL1373577 & 1301765 & 5.1465 & 5.3525 & TRN & \\
\hline CHEMBL1713097 & 1301765 & 4.4235 & 4.2147 & TST & \\
\hline CHEMBL1711432 & 1301765 & 5.4381 & 5.4375 & TRN & \\
\hline CHEMBL1530767 & 1301765 & 4.6785 & 3.9023 & TRN & \\
\hline CHEMBL1497838 & 1301765 & 4.9847 & 5.0972 & TRN & \\
\hline CHEMBL1302170 & 1301765 & 5.5907 & 5.2097 & TRN & \\
\hline CHEMBL1468658 & 1301765 & 4.777 & 5.0713 & TRN & \\
\hline CHEMBL1389066 & 1301765 & 4.6314 & 4.956 & TRN & \\
\hline CHEMBL1496231 & 1301765 & 5.4566 & 5.0485 & TRN & \\
\hline CHEMBL1998302 & 1301765 & 5.8035 & 6.2871 & TRN & \\
\hline
\end{tabular}


Supplemental Table S2.txt

\begin{tabular}{|c|c|c|c|c|c|}
\hline CHEMBL592115 & 1301765 & 5.3384 & 5.2783 & TRN & \\
\hline CHEMBL 2141749 & 1301765 & 5.5918 & 5.3694 & TST & \\
\hline CHEMBL1716155 & 1301765 & 5.3052 & 5.5146 & TRN & \\
\hline CHEMBL1383503 & 1301765 & 5.08 & 4.1895 & TRN & \\
\hline CHEMBL3191855 & 1301765 & 6.4259 & 6.2046 & TRN & \\
\hline CHEMBL3216654 & 1301765 & 5.5984 & 5.4751 & TRN & \\
\hline CHEMBL1890961 & 1301765 & 5.5635 & 5.6024 & TRN & \\
\hline CHEMBL1438567 & 1301765 & 4.794 & 5.0172 & TRN & \\
\hline CHEMBL1721855 & 1301765 & 6.0246 & 5.3574 & TRN & \\
\hline CHEMBL590186 & 1301765 & 4.9825 & 5.2052 & TRN & \\
\hline CHEMBL1698802 & 1301765 & 5.7133 & 5.7058 & TRN & \\
\hline CHEMBL3194415 & 1301765 & 4.9147 & 4.8422 & TRN & \\
\hline CHEMBL1570497 & 1301765 & 5.1991 & 5.3748 & TRN & \\
\hline CHEMBL1384339 & 1301765 & 4.9785 & 5.0595 & TRN & \\
\hline CHEMBL1376622 & 1301765 & 5.047 & 4.7034 & TRN & \\
\hline CHEMBL1339245 & 1301765 & 5.0863 & 5.1038 & TRN & \\
\hline CHEMBL1392394 & 1301765 & 4.7336 & 4.707 & TRN & \\
\hline CHEMBL1471498 & 1301765 & 5.9776 & 5.4802 & TRN & \\
\hline CHEMBL1359236 & 1301765 & 5.8722 & 5.8909 & TRN & \\
\hline CHEMBL339561 & 1301765 & 6.3397 & 5.6934 & TRN & \\
\hline CHEMBL1509380 & 1301765 & 4.8619 & 5.3205 & TST & \\
\hline CHEMBL1969046 & 1301765 & 6.0119 & \multicolumn{2}{|c|}{6.0889999999999995} & TRN \\
\hline CHEMBL1327596 & 1301765 & 2.9406 & 4.9483 & TST & \\
\hline CHEMBL1485159 & 1301765 & 5.2246 & 5.1486 & TRN & \\
\hline CHEMBL1732365 & 1301765 & 5.6002 & 5.3972 & TRN & \\
\hline CHEMBL3189714 & 1301765 & 6.6046 & 6.3991 & TRN & \\
\hline CHEMBL1468954 & 1301765 & 5.349 & 5.6651 & TRN & \\
\hline CHEMBL1331211 & 1301765 & 5.3514 & 5.3799 & TRN & \\
\hline CHEMBL1699398 & 1301765 & 5.1028 & \multicolumn{2}{|c|}{5.178999999999999} & TRN \\
\hline CHEMBL1698715 & 1301765 & 5.1084 & 5.3975 & TRN & \\
\hline CHEMBL156174 & 1301765 & 5.7317 & 5.7236 & TRN & \\
\hline CHEMBL1980681 & 1301765 & 4.7397 & 5.0318 & TRN & \\
\hline CHEMBL1430005 & 1301765 & 5.1931 & 5.2387 & TST & \\
\hline CHEMBL1330787 & 1301765 & 4.7004 & 4.0988 & TRN & \\
\hline CHEMBL1405964 & 1301765 & 2.9405 & 4.0109 & TRN & \\
\hline CHEMBL1569238 & 1301765 & 4.9772 & 4.9572 & TRN & \\
\hline CHEMBL1395907 & 1301765 & 5.1108 & 5.407 & TRN & \\
\hline CHEMBL1355280 & 1301765 & 5.1057 & 5.0032 & TRN & \\
\hline CHEMBL1706454 & 1301765 & 5.7282 & \multicolumn{2}{|c|}{5.5889999999999995} & TRN \\
\hline CHEMBL1709564 & 1301765 & 4.7753 & 5.4141 & TRN & \\
\hline CHEMBL1335953 & 1301765 & 5.0769 & 5.4036 & TRN & \\
\hline CHEMBL1335844 & 1301765 & 6.1499 & 5.5705 & TRN & \\
\hline CHEMBL1392911 & 1301765 & 5.1684 & 5.4621 & TRN & \\
\hline CHEMBL1899341 & 1301765 & 4.4347 & 5.0434 & TRN & \\
\hline CHEMBL1402117 & 1301765 & 4.7588 & 5.1397 & TST & \\
\hline CHEMBL1719244 & 1301765 & 5.9805 & 5.9706 & TRN & \\
\hline CHEMBL1472773 & 1301765 & 5.4342 & 5.2009 & TRN & \\
\hline CHEMBL1409603 & 1301765 & 5.0248 & 5.0397 & TRN & \\
\hline
\end{tabular}

Page 18760 
Supplemental Table S2.txt

\begin{tabular}{|c|c|c|c|c|}
\hline CHEMBL1983033 & 1301765 & 5.3441 & 5.0721 & TST \\
\hline CHEMBL 994 & 1301765 & 4.587 & 5.2733 & TRN \\
\hline CHEMBL1415312 & 1301765 & 4.5614 & 3.9454 & TRN \\
\hline CHEMBL1311500 & 1301765 & 4.4073 & 4.9137 & TST \\
\hline CHEMBL1491417 & 1301765 & 4.4075 & 4.8355 & TRN \\
\hline CHEMBL1484549 & 1301765 & 4.7979 & 5.0146 & TRN \\
\hline CHEMBL1709883 & 1301765 & 5.6015 & 5.416 & TST \\
\hline CHEMBL1999630 & 1301765 & 6.5905 & 6.5146 & TRN \\
\hline CHEMBL1438078 & 1301765 & 4.3286 & 4.9204 & TRN \\
\hline CHEMBL1451327 & 1301765 & 4.6183 & 4.8911 & TST \\
\hline CHEMBL3198994 & 1301765 & 4.8571 & 5.0738 & TRN \\
\hline CHEMBL1334670 & 1301765 & 5.2425 & 5.2035 & TRN \\
\hline CHEMBL1473955 & 1301765 & 5.1807 & 4.9786 & TRN \\
\hline CHEMBL1730252 & 1301765 & 5.2181 & 5.2553 & TRN \\
\hline CHEMBL1734152 & 1301765 & 5.2952 & 5.4278 & TRN \\
\hline CHEMBL1453503 & 1301765 & 5.9987 & 5.9571 & TRN \\
\hline CHEMBL429095 & 1301765 & 5.6676 & 5.4335 & TRN \\
\hline CHEMBL1470701 & 1301765 & 5.2793 & 5.3229 & TRN \\
\hline CHEMBL1728280 & 1301765 & 6.4021 & 5.9943 & TRN \\
\hline CHEMBL1379593 & 1301765 & 4.8028 & 4.9772 & TRN \\
\hline CHEMBL1452795 & 1301765 & 5.6284 & 5.3502 & TRN \\
\hline CHEMBL1417929 & 1301765 & 5.4055 & 5.1934 & TRN \\
\hline CHEMBL1344702 & 1301765 & 5.0398 & 5.0808 & TRN \\
\hline CHEMBL3191474 & 1301765 & 4.7656 & 5.058 & TRN \\
\hline CHEMBL1451931 & 1301765 & 5.2057 & 5.3822 & TRN \\
\hline CHEMBL1564699 & 1301765 & 5.301 & 5.3082 & TRN \\
\hline CHEMBL1527008 & 1301765 & 5.5119 & 5.3044 & TRN \\
\hline CHEMBL1454614 & 1301765 & 5.3752 & 5.4952 & TRN \\
\hline CHEMBL1383632 & 1301765 & 5.1686 & 5.3254 & TRN \\
\hline CHEMBL1734083 & 1301765 & 6.8954 & 6.3029 & TRN \\
\hline CHEMBL3187033 & 1301765 & 4.553 & 5.1388 & TST \\
\hline CHEMBL57013 & 1301765 & 6.0311 & 5.5673 & TRN \\
\hline CHEMBL1351369 & 1301765 & 4.6645 & 4.9041 & TST \\
\hline CHEMBL1329974 & 1301765 & 5.6119 & 5.3211 & TRN \\
\hline CHEMBL1412077 & 1301765 & 4.841 & 4.9899 & TRN \\
\hline CHEMBL1502234 & 1301765 & 4.8596 & 5.0655 & TRN \\
\hline CHEMBL1989853 & 1301765 & 5.4432 & 5.3641 & TRN \\
\hline CHEMBL1466516 & 1301765 & 5.8928 & 6.0816 & TRN \\
\hline CHEMBL1591913 & 1301765 & 5.0352 & 4.8573 & TRN \\
\hline CHEMBL1506756 & 1301765 & 5.0534 & 4.9241 & TST \\
\hline CHEMBL1445776 & 1301765 & 5.5704 & 5.48799 & 99999999995 \\
\hline CHEMBL1542809 & 1301765 & 4.711 & 4.7436 & TST \\
\hline CHEMBL299853 & 1301765 & 5.1628 & 5.3726 & TST \\
\hline CHEMBL1535503 & 1301765 & 4.3719 & 4.4205 & TST \\
\hline CHEMBL1448592 & 1301765 & 4.7826 & 5.1336 & TST \\
\hline CHEMBL1302524 & 1301765 & 5.5616 & 5.6111 & TST \\
\hline CHEMBL1709354 & 1301765 & 5.3707 & 5.1845 & TST \\
\hline CHEMBL3197091 & 1301765 & 5.7645 & 5.9331 & TST \\
\hline
\end{tabular}


Supplemental Table S2.txt

\begin{tabular}{|c|c|c|c|c|}
\hline CHEMBL3196451 & 1301765 & 6.3924 & 6.2239 & TST \\
\hline CHEMBL527336 & 1301765 & 5.3503 & 5.2028 & TST \\
\hline CHEMBL3192701 & 1301765 & 5.0744 & 5.1464 & TST \\
\hline CHEMBL1330558 & 1301765 & 4.6446 & 4.8304 & TST \\
\hline CHEMBL1304979 & 1301765 & 2.9406 & 4.2398 & TST \\
\hline CHEMBL1377824 & 1301765 & 4.1788 & 4.1396 & TST \\
\hline CHEMBL1506031 & 1301765 & 4.3396 & 4.7359 & TST \\
\hline CHEMBL1714348 & 1301765 & 5.4734 & 5.4316 & TST \\
\hline CHEMBL1402879 & 1301765 & 4.8957 & 5.0746 & TST \\
\hline CHEMBL1724452 & 1301765 & 4.9926 & 5.401 & TST \\
\hline CHEMBL1589837 & 1301765 & 5.2654 & 5.2651 & TST \\
\hline CHEMBL1308936 & 1301765 & 4.4047 & 4.8827 & TST \\
\hline CHEMBL1542693 & 1301765 & 5.6139 & 5.3314 & TST \\
\hline CHEMBL1389315 & 1301765 & 2.9406 & 3.9882 & TST \\
\hline CHEMBL1877709 & 1301765 & 6.4152 & 6.2942 & TST \\
\hline CHEMBL 2000196 & 1301765 & 4.782 & 5.0015 & TST \\
\hline CHEMBL3191689 & 1301765 & 6.1541 & 5.7332 & TST \\
\hline CHEMBL583244 & 596090 & 7.2596 & 7.2689 & TRN \\
\hline CHEMBL570690 & 596090 & 7.8539 & 7.8479 & TRN \\
\hline CHEMBL576920 & 596090 & 6.3565 & 6.3881 & TRN \\
\hline CHEMBL569082 & 596090 & 8.2218 & 8.2338 & TRN \\
\hline CHEMBL571342 & 596090 & 7.1549 & 7.1694 & TRN \\
\hline CHEMBL569994 & 596090 & 8.2218 & 8.2158 & TRN \\
\hline CHEMBL571330 & 596090 & \multicolumn{3}{|c|}{6.202000000000001} \\
\hline CHEMBL569993 & 596090 & 7.4559 & 7.4566 & TRN \\
\hline CHEMBL570907 & 596090 & 7.699 & 7.6757 & TRN \\
\hline CHEMBL571774 & 596090 & 7.0315 & 7.0173 & TRN \\
\hline CHEMBL584534 & 596090 & 6.0867 & 6.1602 & TRN \\
\hline CHEMBL571773 & 596090 & 7.5376 & 7.5469 & TRN \\
\hline CHEMBL584738 & 596090 & 7.0706 & 7.0595 & TRN \\
\hline CHEMBL571550 & 596090 & 8.301 & 8.3336 & TRN \\
\hline CHEMBL568807 & 596090 & 7.1549 & 7.11799 & 9999999999 \\
\hline CHEMBL571999 & 596090 & 8.1549 & 7.4579 & TST \\
\hline CHEMBL570876 & 596090 & 7.2518 & 6.644 & TRN \\
\hline CHEMBL571344 & 596090 & 4.0 & 3.9976 & TRN \\
\hline CHEMBL569524 & 596090 & 6.7905 & 6.7894 & TRN \\
\hline CHEMBL571559 & 596090 & 5.9914 & 6.644 & TRN \\
\hline CHEMBL570874 & 596090 & 7.0655 & 7.2689 & TRN \\
\hline CHEMBL583473 & 596090 & 7.1675 & 7.2607 & TST \\
\hline CHEMBL569299 & 596090 & 7.5686 & 7.5302 & TRN \\
\hline CHEMBL569301 & 596090 & 7.6576 & 7.6468 & TRN \\
\hline CHEMBL3085421 & 596090 & 7.3768 & 7.3798 & TRN \\
\hline CHEMBL262865 & 596090 & 7.7959 & 7.7886 & TRN \\
\hline CHEMBL570875 & 596090 & 5.817 & 5.8088 & TRN \\
\hline CHEMBL578178 & 596090 & 7.1249 & 7.1263 & TRN \\
\hline CHEMBL576706 & 596090 & 8.0969 & 8.1044 & TRN \\
\hline CHEMBL188 & 596090 & 7.0655 & 7.2259 & TST \\
\hline CHEMBL571776 & 596090 & 5.6576 & 5.6454 & TRN \\
\hline
\end{tabular}




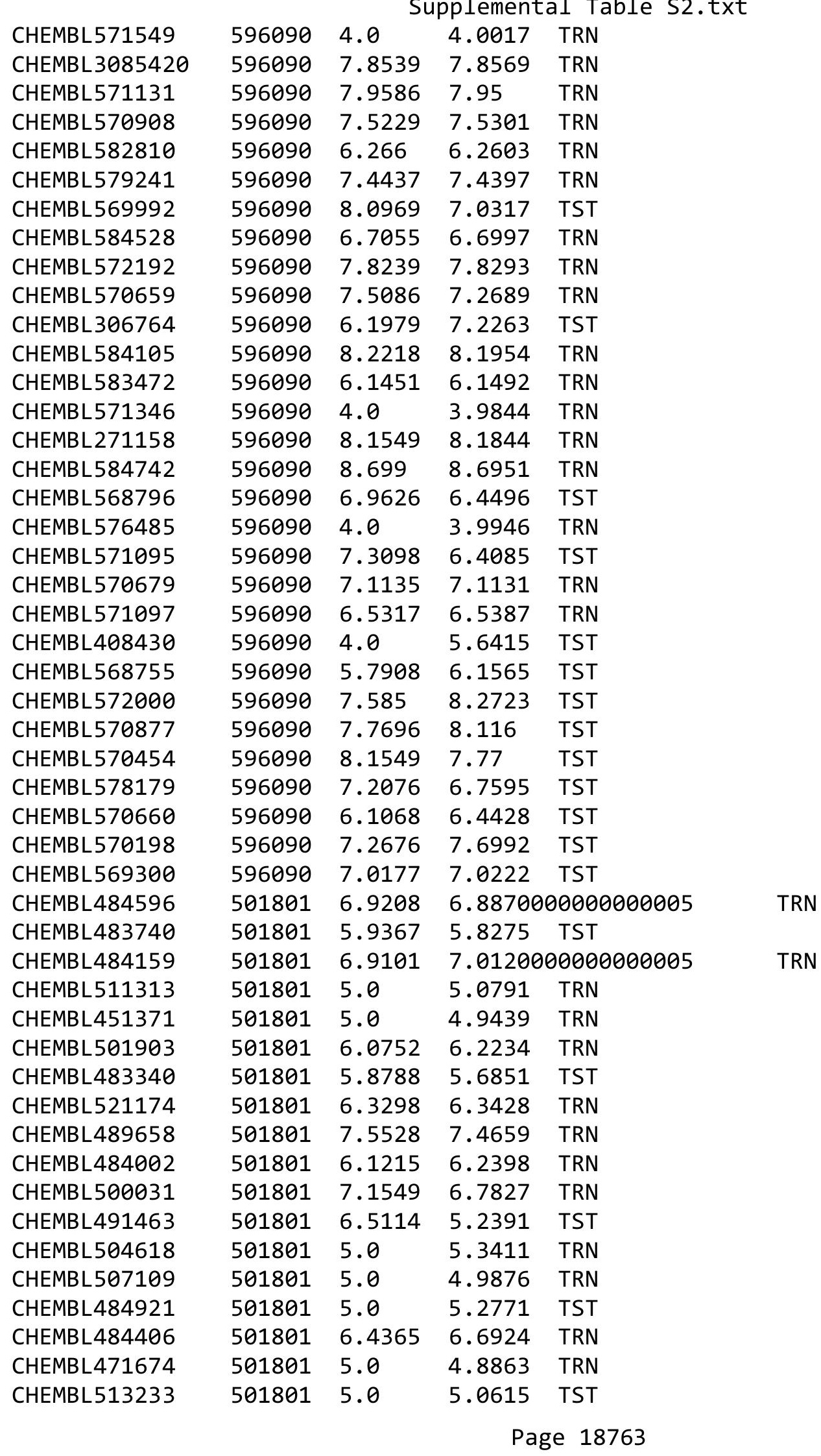




\begin{tabular}{|c|c|c|c|c|}
\hline & & & oplement & al Ta \\
\hline CHEMBL521492 & 501801 & 7.1249 & 7.2009 & TRN \\
\hline CHEMBL483361 & 501801 & 6.1965 & 6.1533 & TRN \\
\hline CHEMBL483739 & 501801 & 6.5702 & 6.6177 & TRN \\
\hline CHEMBL484591 & 501801 & 6.5591 & 6.5309 & TRN \\
\hline CHEMBL484920 & 501801 & 5.0 & 4.9162 & TRN \\
\hline CHEMBL489864 & 501801 & 7.2676 & 7.2817 & TRN \\
\hline CHEMBL521448 & 501801 & 6.4522 & 6.4911 & TRN \\
\hline CHEMBL509277 & 501801 & 5.9412 & 5.9918 & TRN \\
\hline CHEMBL522449 & 501801 & 7.1135 & 6.9947 & TRN \\
\hline CHEMBL521913 & 501801 & 7.5229 & 7.5827 & TRN \\
\hline CHEMBL490466 & 501801 & 5.0 & 5.0492 & TRN \\
\hline CHEMBL484004 & 501801 & 7.1805 & 7.2624 & TRN \\
\hline CHEMBL445540 & 501801 & 6.567 & 6.2622 & TRN \\
\hline CHEMBL489263 & 501801 & 7.3279 & 7.6228 & TRN \\
\hline CHEMBL451324 & 501801 & 6.8327 & 6.7295 & TRN \\
\hline CHEMBL484788 & 501801 & 7.0862 & 7.0434 & TRN \\
\hline CHEMBL505395 & 501801 & 6.3757 & 6.3937 & TRN \\
\hline CHEMBL483553 & 501801 & 5.0 & 5.2391 & TST \\
\hline CHEMBL471470 & 501801 & 6.7852 & 5.2457 & TST \\
\hline CHEMBL483738 & 501801 & 7.0862 & 7.0039 & TRN \\
\hline CHEMBL484003 & 501801 & 6.8097 & 6.7277 & TRN \\
\hline CHEMBL508076 & 501801 & 5.0 & 5.0241 & TRN \\
\hline CHEMBL485150 & 501801 & 6.0264 & 5.9861 & TRN \\
\hline CHEMBL446227 & 501801 & 6.2652 & 6.3049 & TRN \\
\hline CHEMBL483360 & 501801 & 6.4353 & 6.3532 & TRN \\
\hline CHEMBL490066 & 501801 & 5.0 & 5.0631 & TRN \\
\hline CHEMBL491073 & 501801 & 6.5436 & 6.4551 & TRN \\
\hline CHEMBL484157 & 501801 & 6.585 & 6.4447 & TRN \\
\hline CHEMBL499471 & 501801 & 5.0 & 5.1161 & TST \\
\hline CHEMBL484156 & 501801 & 6.8386 & 6.7218 & TST \\
\hline CHEMBL482560 & 501801 & 6.7423 & 6.439 & TST \\
\hline CHEMBL449550 & 501801 & 6.6596 & 6.9175 & TST \\
\hline CHEMBL484787 & 501801 & 6.2967 & 5.626 & TST \\
\hline CHEMBL482574 & 501801 & 6.9031 & 5.9421 & TST \\
\hline CHEMBL490465 & 501801 & 6.6882 & 5.0491 & TST \\
\hline CHEMBL2348939 & 949874 & 6.9957 & 7.2024 & TRN \\
\hline CHEMBL2348961 & 949874 & 5.4992 & 5.3979 & TRN \\
\hline CHEMBL2348941 & 949874 & 5.3752 & 5.4531 & TRN \\
\hline CHEMBL2348942 & 949874 & 5.4685 & 5.4218 & TRN \\
\hline CHEMBL2348959 & 949874 & 3.699 & 4.1203 & TRN \\
\hline CHEMBL2349089 & 949874 & 4.6021 & 4.6385 & TRN \\
\hline CHEMBL2348974 & 949874 & 6.4711 & 6.7165 & TST \\
\hline CHEMBL2348980 & 949874 & 3.0 & 2.988 & TRN \\
\hline CHEMBL 2348958 & 949874 & 3.699 & 3.9661 & TRN \\
\hline CHEMBL2348969 & 949874 & 6.7375 & 6.7273 & TRN \\
\hline CHEMBL 2348950 & 949874 & 6.6757 & 6.7068 & TRN \\
\hline CHEMBL2348968 & 949874 & 6.9318 & 6.6991 & TRN \\
\hline CHEMBL2348956 & 949874 & 6.0026 & 5.855 & TRN \\
\hline
\end{tabular}




\begin{tabular}{|c|c|c|c|c|c|}
\hline \multicolumn{6}{|c|}{ Supplemental Table S2.txt } \\
\hline CHEMBL 2348964 & 949874 & 6.7721 & 6.8731 & TRN & \\
\hline CHEMBL 2348945 & 949874 & 7.1308 & 7.1967 & TRN & \\
\hline CHEMBL 2348963 & 949874 & 7.5086 & 7.5982 & TRN & \\
\hline CHEMBL 2348949 & 949874 & 6.7852 & 6.6421 & TRN & \\
\hline CHEMBL 2348982 & 949874 & 3.0 & 3.0711 & TRN & \\
\hline CHEMBL 2348955 & 949874 & 6.1713 & 6.0381 & TRN & \\
\hline CHEMBL 2348971 & 949874 & 7.0088 & 7.2274 & TST & \\
\hline CHEMBL 2348946 & 949874 & 7.0555 & 7.1023 & TRN & \\
\hline CHEMBL 2348948 & 949874 & 6.2125 & 6.37299 & 9999999999 & TRN \\
\hline CHEMBL 2349092 & 949874 & 5.3251 & 5.2959 & TRN & \\
\hline CHEMBL 2348936 & 949874 & 6.6162 & 6.6464 & TRN & \\
\hline CHEMBL 2348952 & 949874 & 5.4808 & 5.4474 & TRN & \\
\hline CHEMBL 2348975 & 949874 & 5.8881 & 6.3551 & TST & \\
\hline CHEMBL 2348976 & 949874 & 5.6162 & 5.4962 & TST & \\
\hline CHEMBL 2348940 & 949874 & 4.9722 & 4.8169 & TRN & \\
\hline CHEMBL 2348951 & 949874 & 6.066 & 6.0453 & TRN & \\
\hline CHEMBL 2348984 & 949874 & 3.0 & 2.6305 & TRN & \\
\hline CHEMBL 2348944 & 949874 & 7.2757 & 7.0987 & TRN & \\
\hline CHEMBL 2348953 & 949874 & 6.5768 & 6.5588 & TRN & \\
\hline CHEMBL 2348938 & 949874 & 7.1249 & 6.8466 & TRN & \\
\hline CHEMBL 2348957 & 949874 & 5.2734 & 5.2247 & TRN & \\
\hline CHEMBL 2346687 & 949874 & 5.8099 & 5.8502 & TRN & \\
\hline CHEMBL 2348979 & 949874 & 4.3979 & 4.5113 & TRN & \\
\hline CHEMBL 2348983 & 949874 & 4.3979 & 4.4453 & TRN & \\
\hline CHEMBL 2349090 & 949874 & 4.585 & 3.6105 & TST & \\
\hline CHEMBL 2348947 & 949874 & 6.8539 & 6.88399 & 99999999995 & TRN \\
\hline CHEMBL 2348960 & 949874 & 5.2294 & 5.1587 & TRN & \\
\hline CHEMBL 2348966 & 949874 & 7.1249 & 7.1644 & TRN & \\
\hline CHEMBL 2348967 & 949874 & 6.5513 & 6.5572 & TRN & \\
\hline CHEMBL 2348954 & 949874 & 6.5031 & 6.6485 & TRN & \\
\hline CHEMBL 2348965 & 949874 & 6.8601 & 7.0627 & TST & \\
\hline CHEMBL 2348978 & 949874 & 5.7794 & 5.6281 & TST & \\
\hline CHEMBL 2348977 & 949874 & 6.4157 & 6.0767 & TST & \\
\hline CHEMBL 2348970 & 949874 & 6.7986 & 6.7527 & TST & \\
\hline CHEMBL 2348981 & 949874 & 3.0 & 3.8116 & TST & \\
\hline CHEMBL 2348943 & 949874 & 7.1192 & 7.89 & TST & \\
\hline CHEMBL 2349091 & 949874 & 5.5884 & 4.979 & TST & \\
\hline CHEMBL 2348962 & 949874 & 7.4949 & 7.8284 & TST & \\
\hline CHEMBL186742 & 302812 & 9.3979 & 9.1541 & TRN & \\
\hline CHEMBL185778 & 302812 & 7.7212 & 8.5241 & TST & \\
\hline CHEMBL185687 & 302812 & 7.5528 & 8.474 & TST & \\
\hline CHEMBL434903 & 302812 & 9.3372 & 9.3471 & TRN & \\
\hline CHEMBL186183 & 302812 & 9.6383 & 9.3619 & TRN & \\
\hline CHEMBL 365886 & 302812 & 8.699 & 8.7974 & TRN & \\
\hline CHEMBL 363550 & 302812 & 9.6198 & 7.5773 & TRN & \\
\hline CHEMBL186549 & 302812 & 9.0269 & 8.5746 & TRN & \\
\hline CHEMBL187114 & 302812 & 7.1487 & 7.3846 & TRN & \\
\hline CHEMBL185229 & 302812 & 8.8539 & 8.9865 & TRN & \\
\hline
\end{tabular}




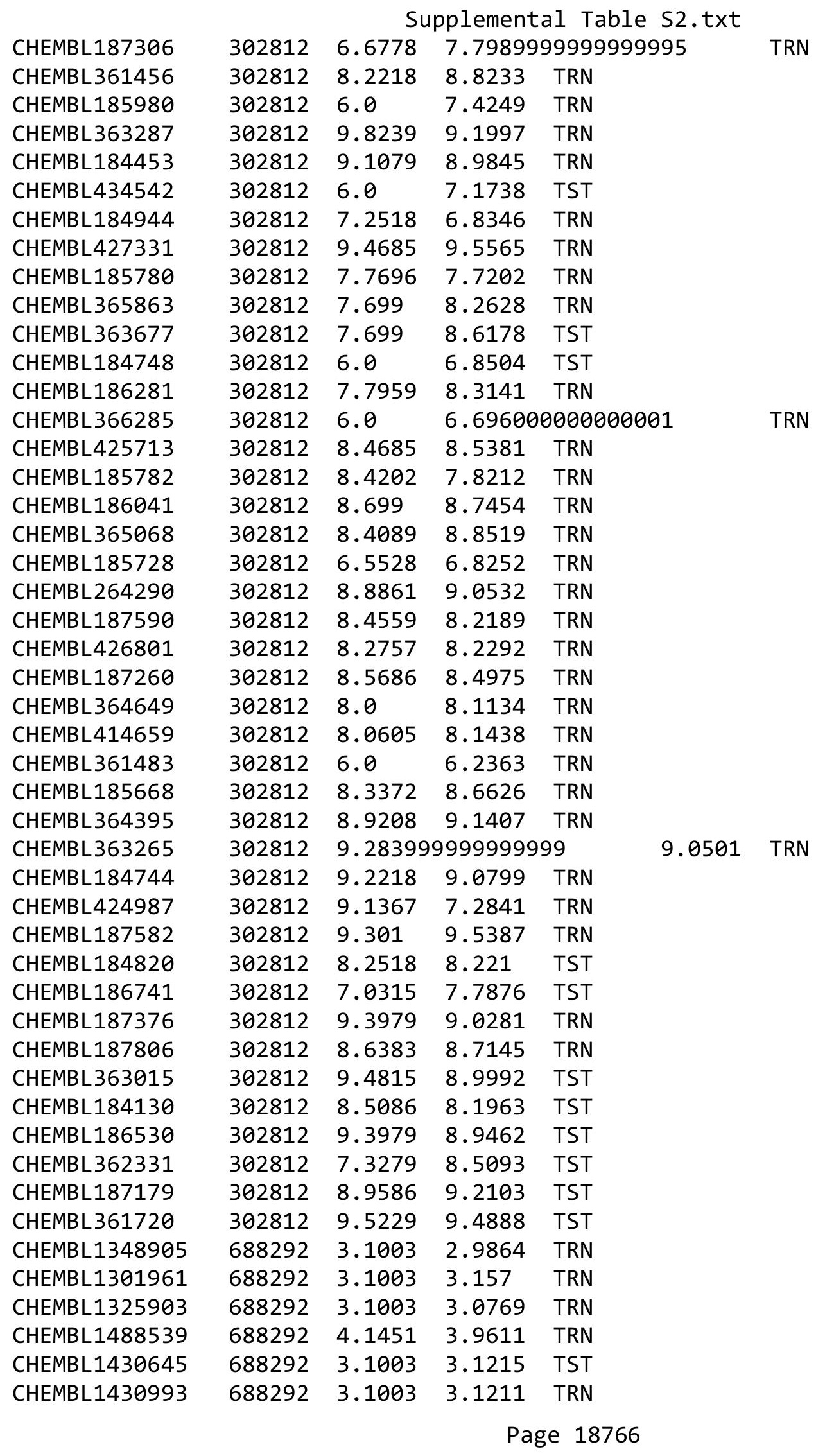




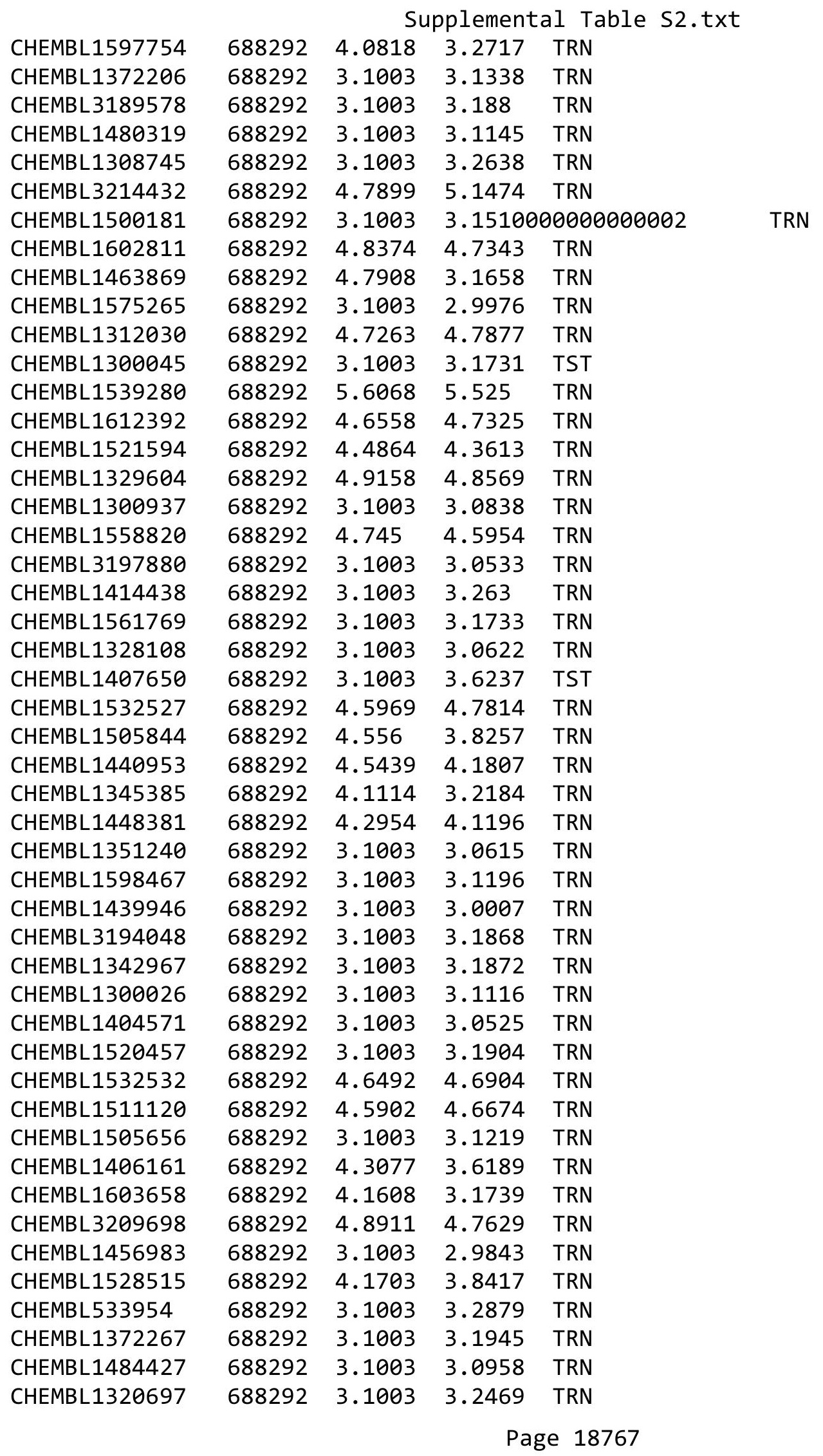




\begin{tabular}{|c|c|c|c|c|c|}
\hline & & & & & \\
\hline CHEMBL1495975 & 688292 & 4.2851 & 3.4283 & TRN & \\
\hline CHEMBL1341820 & 688292 & 3.1003 & 3.063 & TRN & \\
\hline CHEMBL1505538 & 688292 & 3.1003 & 3.2527 & TST & \\
\hline CHEMBL1346107 & 688292 & 3.1003 & 3.6462 & TRN & \\
\hline CHEMBL3195801 & 688292 & 4.5227 & 4.9244 & TRN & \\
\hline CHEMBL1540811 & 688292 & 4.4382 & 4.7778 & TRN & \\
\hline CHEMBL1306199 & 688292 & 3.5774 & 4.1078 & TRN & \\
\hline CHEMBL1479296 & 688292 & 4.3818 & 4.2492 & TRN & \\
\hline CHEMBL1352382 & 688292 & 3.1003 & 3.1047 & TRN & \\
\hline CHEMBL1373790 & 688292 & 4.2004 & 4.3432 & TRN & \\
\hline CHEMBL1380816 & 688292 & 5.0155 & 4.3737 & TRN & \\
\hline CHEMBL1320358 & 688292 & 3.1003 & 3.1046 & TRN & \\
\hline CHEMBL1335142 & 688292 & 4.1002 & 3.4939 & TRN & \\
\hline CHEMBL1362807 & 688292 & 3.1003 & 3.1728 & TRN & \\
\hline CHEMBL1399673 & 688292 & 3.1003 & 3.1297 & TRN & \\
\hline CHEMBL1601494 & 688292 & 3.1003 & 2.8869 & TRN & \\
\hline CHEMBL1579143 & 688292 & 3.1003 & 3.1079 & TST & \\
\hline CHEMBL1579477 & 688292 & 3.1003 & 3.2968 & TRN & \\
\hline CHEMBL1418035 & 688292 & 4.5224 & 4.3403 & TRN & \\
\hline CHEMBL1543421 & 688292 & 3.1003 & 3.1784 & TRN & \\
\hline CHEMBL1352863 & 688292 & 3.1003 & 3.0557 & TRN & \\
\hline CHEMBL1426581 & 688292 & 4.8483 & 5.3442 & TRN & \\
\hline CHEMBL1449055 & 688292 & 3.1003 & 3.10600 & 00000000003 & TRN \\
\hline CHEMBL1304179 & 688292 & 3.1003 & 3.1616 & TST & \\
\hline CHEMBL1417370 & 688292 & 3.1003 & 3.1576 & TST & \\
\hline CHEMBL3207839 & 688292 & 3.1003 & 3.657 & TRN & \\
\hline CHEMBL1583062 & 688292 & 3.1003 & 3.1239 & TRN & \\
\hline CHEMBL1400006 & 688292 & 4.6012 & 4.9067 & TRN & \\
\hline CHEMBL1300069 & 688292 & 4.6641 & 4.5309 & TST & \\
\hline CHEMBL1300592 & 688292 & 3.1003 & 3.2893 & TRN & \\
\hline CHEMBL1440467 & 688292 & 3.1003 & 3.27699 & 99999999997 & TRN \\
\hline CHEMBL1370690 & 688292 & 3.1003 & 3.0093 & TST & \\
\hline CHEMBL1531952 & 688292 & 3.1003 & 3.2424 & TRN & \\
\hline CHEMBL3193904 & 688292 & 3.1003 & 3.1396 & TRN & \\
\hline CHEMBL1602928 & 688292 & 3.1003 & 3.0792 & TRN & \\
\hline CHEMBL1449312 & 688292 & 3.1003 & 3.1211 & TST & \\
\hline CHEMBL1563940 & 688292 & 3.1003 & 3.2698 & TRN & \\
\hline CHEMBL1366259 & 688292 & 4.5456 & 4.686 & TRN & \\
\hline CHEMBL1425489 & 688292 & 3.1003 & 3.3243 & TST & \\
\hline CHEMBL3195359 & 688292 & 3.1003 & 3.1533 & TST & \\
\hline CHEMBL1389115 & 688292 & 3.1003 & 3.1341 & TRN & \\
\hline CHEMBL1608186 & 688292 & 3.1003 & 3.3849 & TRN & \\
\hline CHEMBL1488126 & 688292 & 3.1003 & 3.0023 & TRN & \\
\hline CHEMBL1524916 & 688292 & 3.1003 & 3.11 & TST & \\
\hline CHEMBL1563536 & 688292 & 3.1003 & 3.27699 & 99999999997 & TRN \\
\hline CHEMBL1968356 & 688292 & 3.1003 & 3.3215 & TRN & \\
\hline CHEMBL3189337 & 688292 & 3.1003 & 3.4973 & TRN & \\
\hline CHEMBL1595702 & 688292 & 4.871 & 4.6099 & TRN & \\
\hline
\end{tabular}


Supplemental Table S2.txt

\begin{tabular}{|c|c|c|c|c|}
\hline 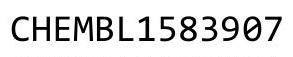 & & & & \\
\hline & & 3.1003 & & \\
\hline & & & & \\
\hline AEMBL13 & 292 & & & \\
\hline AEMBL1561316 & 8292 & 386 & 3176 & \\
\hline HEMBL1609957 & 88292 & 1003 & .2884 & \\
\hline HEMBL1986690 & 292 & & & \\
\hline IEMBL1451889 & & & & \\
\hline AEMBL1521729 & 88292 & 1003 & & \\
\hline HEMBL1438294 & 88292 & 1003 & .1424 & \\
\hline HEMBL1428286 & 88292 & .7289 & 0 & \\
\hline IEMBL1500513 & 92 & 23 & & \\
\hline AEMBL1459628 & & & & \\
\hline HEMBL1373371 & 292 & 003 & & \\
\hline AEMBL601578 & 92 & 33 & & \\
\hline AEMBL1470921 & 2 & 23 & $\partial 5$ & \\
\hline IEMBL19 & & & & \\
\hline HEMBL 144 & & & & \\
\hline HEMBL1373843 & & 57 & & \\
\hline AEMBL13e & & & & \\
\hline 化MBLI43 & & & & MT \\
\hline AEMBL1 & & & & 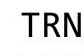 \\
\hline AEMBL15 & & & & \\
\hline AEMBL566064 & & & & \\
\hline AEMBL1522046 & & & & (3) \\
\hline HEMBL1 & & & & RN \\
\hline HEMBL: & & & & RN \\
\hline HFMBI 14 & & & & \\
\hline AEMBL1365995 & & & & I KIV \\
\hline HEMBL15794 & & & & r \\
\hline HEMBL1 & & & & RIV \\
\hline HEMBL & & & & RN \\
\hline ALMP & & 3 & & \\
\hline HEMBL1579409 & & & & $\mathrm{IR}$ \\
\hline HEMBL1484719 & & & & ГRN \\
\hline HEMBL152 & & & & RN \\
\hline HEMP I 1 & & & & $\Gamma \mathrm{RN}$ \\
\hline HEMBL1432295 & & & & IST \\
\hline HEMBL1601884 & 88292 & 3 & & TRN \\
\hline AEMBL31906 & & 003 & & TST \\
\hline HEMBL1507076 & & & 77 & \\
\hline HEMBL581929 & & & & \\
\hline HEMBL1352697 & & 1003 & & TST \\
\hline AEMBL1608327 & 8292 & 1003 & 344 & TS \\
\hline JEMBL141465 & & 1 & & $\mathrm{~h}$ \\
\hline HEMBL15 & & & & \\
\hline LHEMBL1478894 & & 3.1003 & 3.0098 & \\
\hline CHEMBL1605172 & 688292 & 3.1003 & 3.1693 & ГRN \\
\hline
\end{tabular}

Page 18769 
Supplemental Table S2.txt

\begin{tabular}{|c|c|c|c|c|c|}
\hline CHEMBL1320870 & 688292 & 3.1003 & 3.1685 & TRN & \\
\hline CHEMBL1565236 & 688292 & 4.5938 & 4.4924 & TRN & \\
\hline CHEMBL1321442 & 688292 & 3.1003 & 3.0559 & TRN & \\
\hline CHEMBL 235260 & 688292 & 3.1003 & 3.4252 & TRN & \\
\hline CHEMBL2369261 & 688292 & 3.1003 & 3.2054 & TRN & \\
\hline CHEMBL 3209557 & 688292 & 3.1003 & 3.1964 & TST & \\
\hline CHEMBL1471858 & 688292 & 3.1003 & 3.2971 & TRN & \\
\hline CHEMBL1336006 & 688292 & 3.1003 & 3.1668 & TRN & \\
\hline CHEMBL1447164 & 688292 & 5.0094 & 4.9053 & TRN & \\
\hline CHEMBL1462713 & 688292 & 5.2865 & 5.4429 & TRN & \\
\hline CHEMBL1492278 & 688292 & 3.1003 & \multicolumn{2}{|c|}{ 3.2739999999999996 } & TRN \\
\hline CHEMBL1468866 & 688292 & 3.1003 & 3.8518 & TRN & \\
\hline CHEMBL1390323 & 688292 & 3.1003 & 3.2521 & TRN & \\
\hline CHEMBL 3197588 & 688292 & 3.1003 & 3.2278 & TST & \\
\hline CHEMBL1609070 & 688292 & 3.1003 & 3.2077 & TRN & \\
\hline CHEMBL1468869 & 688292 & 4.9901 & 5.3265 & TRN & \\
\hline CHEMBL3210223 & 688292 & 3.1003 & 3.2157 & TRN & \\
\hline CHEMBL1351640 & 688292 & 3.1003 & \multicolumn{2}{|c|}{ 3. 2569999999999997} & TRN \\
\hline CHEMBL1457449 & 688292 & 3.1003 & 3.6411 & TRN & \\
\hline CHEMBL1575435 & 688292 & 4.7951 & 4.677 & TRN & \\
\hline CHEMBL 3189201 & 688292 & 4.9784 & 5.3551 & TRN & \\
\hline CHEMBL1506506 & 688292 & 4.9237 & 4.9051 & TRN & \\
\hline CHEMBL 3194630 & 688292 & 3.1003 & 3.2529 & TRN & \\
\hline CHEMBL1458535 & 688292 & 3.1003 & 3.1004 & TRN & \\
\hline CHEMBL1427125 & 688292 & 3.1003 & 3.1792 & TST & \\
\hline CHEMBL1518205 & 688292 & 3.1003 & 3.1994 & TRN & \\
\hline CHEMBL1444824 & 688292 & 3.1003 & 3.3213 & TRN & \\
\hline CHEMBL1542477 & 688292 & 4.5063 & 4.1803 & TRN & \\
\hline CHEMBL1432578 & 688292 & 3.1003 & 3.4024 & TRN & \\
\hline CHEMBL1385846 & 688292 & 3.1003 & 3.0243 & TRN & \\
\hline CHEMBL1439119 & 688292 & 3.1003 & 3.1539 & TRN & \\
\hline CHEMBL1405757 & 688292 & 3.1003 & 3.1529 & TST & \\
\hline CHEMBL1472426 & 688292 & 5.0048 & 4.8282 & TRN & \\
\hline CHEMBL1557326 & 688292 & 4.7503 & 4.5423 & TRN & \\
\hline CHEMBL1583115 & 688292 & 3.1003 & 3.116 & TRN & \\
\hline CHEMBL1565229 & 688292 & 3.1003 & 3.2514 & TRN & \\
\hline CHEMBL1519736 & 688292 & 3.1003 & 3.0147 & TRN & \\
\hline CHEMBL1581201 & 688292 & 3.1003 & 3.4021 & TRN & \\
\hline CHEMBL1415986 & 688292 & 3.1003 & 3.2175 & TRN & \\
\hline CHEMBL1465049 & 688292 & 3.1003 & 3.1225 & TRN & \\
\hline CHEMBL1405306 & 688292 & 4.9101 & 4.9084 & TRN & \\
\hline CHEMBL1567518 & 688292 & 4.8645 & 4.9442 & TRN & \\
\hline CHEMBL1564775 & 688292 & 3.1003 & 3.3787 & TRN & \\
\hline CHEMBL1381203 & 688292 & 3.1003 & 3.1034 & TRN & \\
\hline CHEMBL 3145293 & 688292 & 3.1003 & 3.2265 & TST & \\
\hline CHEMBL1387238 & 688292 & 4.7176 & 4.4244 & TRN & \\
\hline CHEMBL1359239 & 688292 & 3.1003 & 3.4533 & TRN & \\
\hline CHEMBL1362098 & 688292 & 3.1003 & 3.2111 & TST & \\
\hline
\end{tabular}


Supplemental Table S2.txt

\begin{tabular}{|c|c|c|c|c|}
\hline CHEMBL1368233 & 688292 & 3.1003 & 3.097 & TRN \\
\hline CHEMBL1507954 & 688292 & 4.567 & 4.4314 & TRN \\
\hline CHEMBL 2365639 & 688292 & 3.1003 & 3.1392 & TRN \\
\hline CHEMBL1445372 & 688292 & 4.6962 & 4.5083 & TST \\
\hline CHEMBL1351131 & 688292 & 5.2865 & 4.9868 & TRN \\
\hline CHEMBL 2000686 & 688292 & 3.1003 & 3.1569 & TRN \\
\hline CHEMBL1599069 & 688292 & 3.1003 & 3.1237 & TRN \\
\hline CHEMBL1420624 & 688292 & 3.1003 & 3.1718 & TST \\
\hline CHEMBL1607599 & 688292 & 4.6008 & 4.7262 & TST \\
\hline CHEMBL1439888 & 688292 & 4.5014 & 4.5042 & TRN \\
\hline CHEMBL546475 & 688292 & 3.1003 & 3.17 & TRN \\
\hline CHEMBL1543543 & 688292 & \multicolumn{3}{|c|}{5.031000000000001} \\
\hline CHEMBL1427163 & 688292 & 3.1003 & 3.1516 & TRN \\
\hline CHEMBL1471920 & 688292 & 4.5436 & 4.3705 & TRN \\
\hline CHEMBL1449791 & 688292 & 3.1003 & 3.0922 & TRN \\
\hline CHEMBL1529358 & 688292 & 3.1003 & 3.4401 & TRN \\
\hline CHEMBL1457704 & 688292 & 3.1003 & 3.2527 & TRN \\
\hline CHEMBL1461351 & 688292 & 4.7423 & 4.6987 & TRN \\
\hline CHEMBL1507486 & 688292 & 3.1003 & 3.271006 & 00000000004 \\
\hline CHEMBL1343936 & 688292 & 4.551 & 4.4334 & TRN \\
\hline CHEMBL1588102 & 688292 & 5.0509 & 5.0046 & TRN \\
\hline CHEMBL 3210083 & 688292 & 3.1003 & 3.1751 & TRN \\
\hline CHEMBL 3209573 & 688292 & 4.8542 & 4.9862 & TRN \\
\hline CHEMBL1301738 & 688292 & 3.1003 & 3.1431 & TRN \\
\hline CHEMBL 1328380 & 688292 & 3.1003 & 3.1682 & TRN \\
\hline CHEMBL1428087 & 688292 & 3.1003 & 3.4749 & TRN \\
\hline CHEMBL1339272 & 688292 & 3.1003 & 3.0361 & TRN \\
\hline CHEMBL1387439 & 688292 & 3.1003 & 3.0807 & TRN \\
\hline CHEMBL1608778 & 688292 & 3.1003 & 3.1967 & TST \\
\hline CHEMBL1370692 & 688292 & 3.1003 & 3.1455 & TRN \\
\hline CHEMBL1425135 & 688292 & 5.166 & 4.9061 & TRN \\
\hline CHEMBL1337316 & 688292 & 3.1003 & 3.2937 & TRN \\
\hline CHEMBL1333282 & 688292 & 3.1003 & 3.1865 & TRN \\
\hline CHEMBL1470283 & 688292 & 3.1003 & 3.0712 & TST \\
\hline CHEMBL1478573 & 688292 & 4.487 & 4.5079 & TRN \\
\hline CHEMBL1504012 & 688292 & 4.659 & 4.9688 & TRN \\
\hline CHEMBL1311094 & 688292 & 3.1003 & 3.2763 & TRN \\
\hline CHEMBL1458189 & 688292 & 3.1003 & 3.0943 & TRN \\
\hline CHEMBL1352206 & 688292 & 3.1003 & 3.2456 & TRN \\
\hline CHEMBL1382919 & 688292 & 3.1003 & 3.1212 & TRN \\
\hline CHEMBL1604006 & 688292 & 3.1003 & 3.2768 & TRN \\
\hline CHEMBL1353338 & 688292 & 3.1003 & 3.3725 & TRN \\
\hline CHEMBL1371533 & 688292 & 3.1003 & 3.2691 & TRN \\
\hline CHEMBL1557929 & 688292 & 3.1003 & 3.1212 & TRN \\
\hline CHEMBL1582123 & 688292 & 4.4731 & 4.6584 & TRN \\
\hline CHEMBL69086 & 688292 & 3.1003 & 3.1838 & TST \\
\hline CHEMBL1419387 & 688292 & 4.6321 & 3.3996 & TRN \\
\hline CHEMBL1606245 & 688292 & 3.1003 & 3.1908 & TRN \\
\hline
\end{tabular}




\begin{tabular}{|c|c|c|c|c|}
\hline \multicolumn{5}{|c|}{ Supplemental Table s2.txt } \\
\hline CHEMBL1407515 & 688292 & 4.0426 & 3.7259 & TRN \\
\hline CHEMBL1377287 & 688292 & 3.1003 & 3.1185 & TRN \\
\hline CHEMBL1454659 & 688292 & 3.1003 & 3.2639 & TRN \\
\hline CHEMBL1575331 & 688292 & 3.1003 & 3.2811 & TRN \\
\hline CHEMBL1562550 & 688292 & 4.4671 & 4.5269 & TRN \\
\hline CHEMBL3196561 & 688292 & 3.1003 & 3.1566 & TST \\
\hline CHEMBL1306142 & 688292 & 3.1003 & 3.1971 & TRN \\
\hline CHEMBL1560867 & 688292 & 3.1003 & 3.0615 & TRN \\
\hline CHEMBL1386483 & 688292 & 3.1003 & 3.1372 & TST \\
\hline CHEMBL1574032 & 688292 & 3.1003 & 3.2059 & TRN \\
\hline CHEMBL1339881 & 688292 & 3.1003 & 3.0442 & TRN \\
\hline CHEMBL1341675 & 688292 & 3.1003 & 3.1392 & TRN \\
\hline CHEMBL1321430 & 688292 & 4.6194 & 4.8281 & TRN \\
\hline CHEMBL1372549 & 688292 & 3.1003 & 3.1431 & TRN \\
\hline CHEMBL2143919 & 688292 & 4.9122 & 5.3782 & TRN \\
\hline CHEMBL1563782 & 688292 & 3.1003 & 3.2624 & TRN \\
\hline CHEMBL1506760 & 688292 & 3.1003 & 3.1392 & TRN \\
\hline CHEMBL1393451 & 688292 & 3.1003 & 3.2238 & TRN \\
\hline CHEMBL1584541 & 688292 & 3.1003 & 3.3503 & TRN \\
\hline CHEMBL1299851 & 688292 & 3.1003 & 3.1158 & TRN \\
\hline CHEMBL1495320 & 688292 & 4.5926 & 4.7483 & TRN \\
\hline CHEMBL1528496 & 688292 & 4.5837 & 4.5697 & TRN \\
\hline CHEMBL1538696 & 688292 & 3.1003 & 3.2914 & TRN \\
\hline CHEMBL1386273 & 688292 & 4.6741 & 4.5915 & TRN \\
\hline CHEMBL1432747 & 688292 & 3.1003 & 3.1906 & TST \\
\hline CHEMBL1488374 & 688292 & 4.3715 & 3.8548 & TRN \\
\hline CHEMBL1519059 & 688292 & 3.1003 & 3.255 & TRN \\
\hline CHEMBL1526968 & 688292 & 3.1003 & 3.1164 & TRN \\
\hline CHEMBL1526221 & 688292 & 3.1003 & 3.0644 & TRN \\
\hline CHEMBL1472502 & 688292 & 3.1003 & 3.2343 & TRN \\
\hline CHEMBL1423417 & 688292 & 4.3452 & 4.6663 & TRN \\
\hline CHEMBL1522598 & 688292 & 3.1003 & 3.1747 & TRN \\
\hline CHEMBL1411662 & 688292 & 3.1003 & 3.273 & TST \\
\hline CHEMBL1613102 & 688292 & 3.1003 & 3.1262 & TRN \\
\hline CHEMBL3192152 & 688292 & 3.1003 & 3.4255 & TRN \\
\hline CHEMBL1333009 & 688292 & 3.1003 & 3.2017 & TRN \\
\hline CHEMBL1312906 & 688292 & 3.1003 & 2.9946 & TRN \\
\hline CHEMBL1457789 & 688292 & 3.1003 & 3.1436 & TST \\
\hline CHEMBL1525574 & 688292 & 6.0546 & 5.1886 & TRN \\
\hline CHEMBL1310089 & 688292 & 3.1003 & 3.1044 & TRN \\
\hline CHEMBL1472393 & 688292 & 4.9905 & 4.7866 & TRN \\
\hline CHEMBL1421554 & 688292 & 3.1003 & 3.3362 & TRN \\
\hline CHEMBL1324080 & 688292 & 3.1003 & 3.4083 & TRN \\
\hline CHEMBL1544695 & 688292 & 3.1003 & 3.2055 & TRN \\
\hline CHEMBL1597380 & 688292 & 3.1003 & 3.1287 & TRN \\
\hline CHEMBL1492457 & 688292 & 4.4951 & 4.2426 & TRN \\
\hline CHEMBL 3208420 & 688292 & 5.099 & 5.1241 & TRN \\
\hline CHEMBL1490883 & 688292 & 3.1003 & 3.2559 & TRN \\
\hline
\end{tabular}


Supplemental Table S2.txt

\begin{tabular}{|c|c|c|c|c|c|}
\hline CHEMBL1329708 & 688292 & 3.1003 & 3.3068 & TRN & \\
\hline CHEMBL1398618 & 688292 & 4.6747 & \multicolumn{2}{|c|}{4.5360000000000005} & TRN \\
\hline CHEMBL 3191374 & 688292 & 3.1003 & 3.2622 & TST & \\
\hline CHEMBL1478352 & 688292 & 3.1003 & 3.1859 & TST & \\
\hline CHEMBL1336097 & 688292 & 3.1003 & 3.3209 & TRN & \\
\hline CHEMBL1324127 & 688292 & 3.1003 & 3.1242 & TRN & \\
\hline CHEMBL1508357 & 688292 & 3.1003 & 3.3781 & TST & \\
\hline CHEMBL1558616 & 688292 & 3.1003 & 3.2713 & TRN & \\
\hline CHEMBL1600402 & 688292 & 4.7305 & 3.3898 & TST & \\
\hline CHEMBL1334936 & 688292 & 3.1003 & 3.14 & TST & \\
\hline CHEMBL1367765 & 688292 & 5.0261 & 4.6549 & TST & \\
\hline CHEMBL1600071 & 688292 & 3.1003 & 3.2404 & TST & \\
\hline CHEMBL1578181 & 688292 & 4.8292 & 5.1881 & TST & \\
\hline CHEMBL1977734 & 688292 & 3.1003 & 3.2132 & TST & \\
\hline CHEMBL 3208768 & 688292 & 3.1003 & 3.2345 & TST & \\
\hline CHEMBL1450472 & 688292 & 3.1003 & 3.1896 & TST & \\
\hline CHEMBL1426120 & 688292 & 3.1003 & 3.0253 & TST & \\
\hline CHEMBL1492681 & 688292 & 3.1003 & 3.1153 & TST & \\
\hline CHEMBL1478908 & 688292 & 3.1003 & 3.155 & TST & \\
\hline CHEMBL1585187 & 688292 & 3.1003 & 3.1783 & TST & \\
\hline CHEMBL1542114 & 688292 & 3.1003 & 2.9742 & TST & \\
\hline CHEMBL1332063 & 688292 & 3.1003 & 3.0841 & TST & \\
\hline CHEMBL1505466 & 688292 & 4.5627 & 4.4829 & TST & \\
\hline CHEMBL1427319 & 688292 & 3.1003 & 3.5146 & TST & \\
\hline CHEMBL1595850 & 688292 & 3.1003 & 3.2299 & TST & \\
\hline CHEMBL1312133 & 688292 & 3.1003 & 3.2205 & TST & \\
\hline CHEMBL1306015 & 688292 & 3.1003 & 3.4325 & TST & \\
\hline CHEMBL 3190105 & 688292 & 3.1003 & 3.1756 & TST & \\
\hline CHEMBL1412254 & 688292 & 3.1003 & 3.2575 & TST & \\
\hline CHEMBL1334835 & 688292 & 3.1003 & 3.1156 & TST & \\
\hline CHEMBL1313434 & 688292 & 4.2062 & 3.4826 & TST & \\
\hline CHEMBL1470470 & 688292 & 3.8371 & 4.106 & TST & \\
\hline CHEMBL1379482 & 688292 & 3.1003 & 3.2108 & TST & \\
\hline CHEMBL1509978 & 688292 & 3.1003 & 3.4238 & TST & \\
\hline CHEMBL1489593 & 688292 & 4.6171 & 4.2765 & TST & \\
\hline CHEMBL1414445 & 688292 & 5.0853 & 5.3999 & TST & \\
\hline CHEMBL1433290 & 688292 & 4.7194 & 4.8703 & TST & \\
\hline CHEMBL1344196 & 688292 & 3.1003 & 3.1645 & TST & \\
\hline CHEMBL1374288 & 688292 & 3.1003 & 3.191999 & 99999999997 & TST \\
\hline CHEMBL1369422 & 688292 & 4.994 & 5.1611 & TST & \\
\hline CHEMBL1540443 & 688292 & 4.4006 & 3.8303 & TST & \\
\hline CHEMBL1528003 & 688292 & 3.1003 & 3.4165 & TST & \\
\hline CHEMBL1526244 & 688292 & 3.1003 & 3.0372 & TST & \\
\hline CHEMBL1606721 & 688292 & 3.1003 & 3.0906 & TST & \\
\hline CHEMBL1389672 & 688292 & 3.1003 & 2.944 & TST & \\
\hline CHEMBL1324769 & 688292 & 3.1003 & 3.1563 & TST & \\
\hline CHEMBL1999900 & 688292 & 3.1003 & 3.1889 & TST & \\
\hline CHEMBL1478329 & 688292 & 3.1003 & 3.3015 & TST & \\
\hline
\end{tabular}


Supplemental Table S2.txt

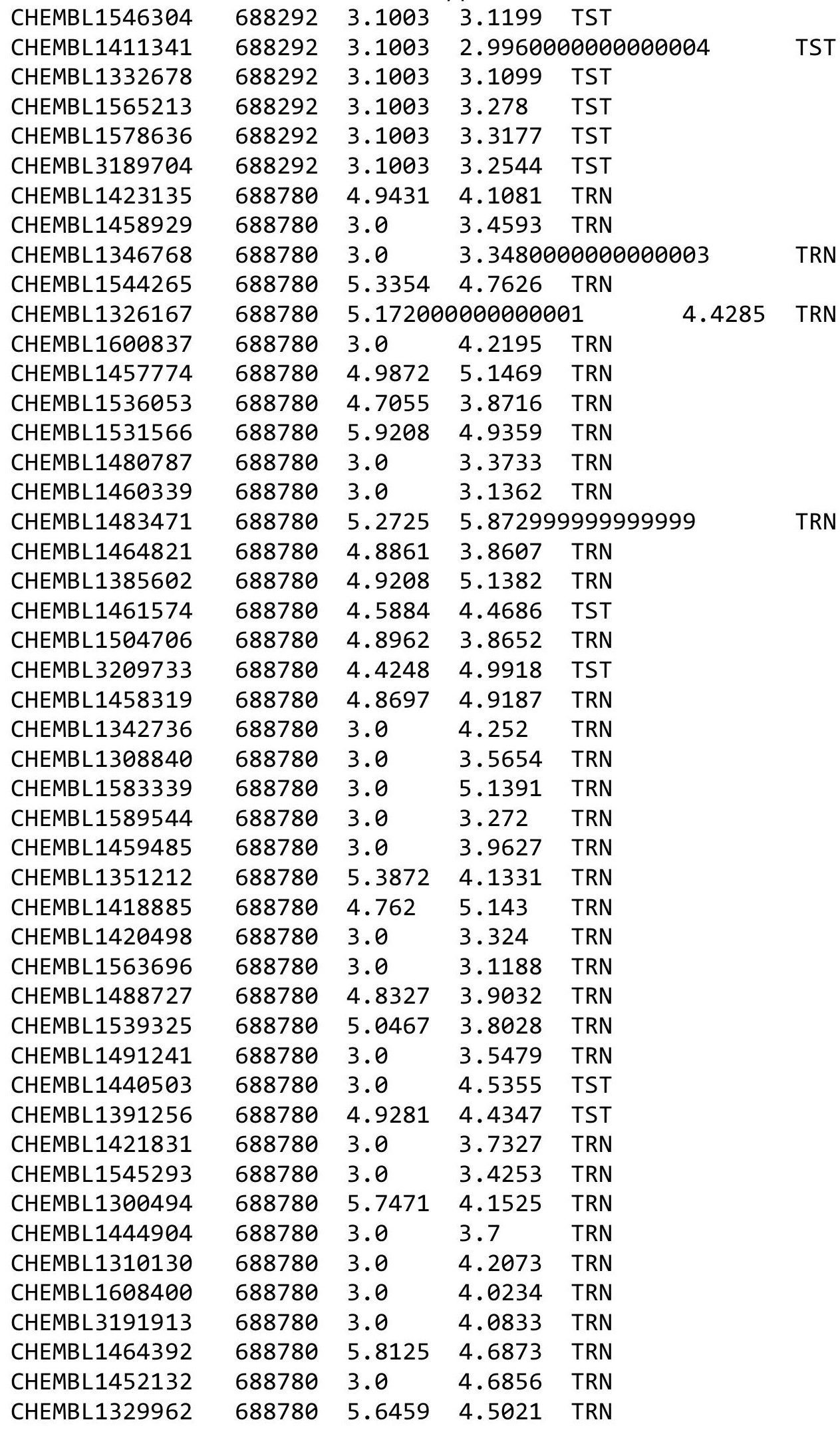

Page 18774 


\begin{tabular}{|c|c|c|c|c|c|}
\hline \multicolumn{6}{|c|}{ Supplemental Table S2.txt } \\
\hline CHEMBL1981303 & 688780 & 3.0 & 4.6184 & TST & \\
\hline CHEMBL1305648 & 688780 & 5.8697 & 4.6965 & TRN & \\
\hline CHEMBL1589300 & 688780 & 4.9245 & 5.0623 & TRN & \\
\hline CHEMBL1521960 & 688780 & 5.3054 & 5.3191 & TRN & \\
\hline CHEMBL1444164 & 688780 & 5.5784 & 4.9522 & TRN & \\
\hline CHEMBL1471965 & 688780 & 6.2218 & 5.7455 & TRN & \\
\hline CHEMBL1380232 & 688780 & 4.8013 & 3.0439 & TRN & \\
\hline CHEMBL3189669 & 688780 & 4.4034 & 4.4178 & TRN & \\
\hline CHEMBL1578409 & 688780 & 3.0 & 3.5809 & TRN & \\
\hline CHEMBL1540929 & 688780 & 5.1694 & 4.0278 & TRN & \\
\hline CHEMBL1347956 & 688780 & 5.4473 & 4.7742 & TRN & \\
\hline CHEMBL1340514 & 688780 & 5.2823 & 4.5292 & TRN & \\
\hline CHEMBL1478082 & 688780 & 3.0 & 4.2262 & TRN & \\
\hline CHEMBL1613004 & 688780 & 4.3737 & 4.7197 & TST & \\
\hline CHEMBL1537973 & 688780 & 3.0 & 3.8689 & TST & \\
\hline CHEMBL1305848 & 688780 & 5.5361 & 4.6936 & TRN & \\
\hline CHEMBL1444088 & 688780 & 3.0 & 3.9266 & TRN & \\
\hline CHEMBL1451902 & 688780 & 3.0 & 3.3304 & TRN & \\
\hline CHEMBL1468811 & 688780 & 5.6946 & 4.7964 & TRN & \\
\hline CHEMBL1578304 & 688780 & 4.7799 & 3.6671 & TRN & \\
\hline CHEMBL1471612 & 688780 & 5.6383 & 4.8861 & TRN & \\
\hline CHEMBL1384420 & 688780 & 5.0083 & 3.6509 & TRN & \\
\hline CHEMBL1308747 & 688780 & 5.289 & 4.6936 & TST & \\
\hline CHEMBL1508593 & 688780 & 4.5607 & 4.0012 & TST & \\
\hline CHEMBL1324935 & 688780 & 4.6676 & 4.1088 & TST & \\
\hline CHEMBL3196667 & 688780 & 5.8268 & 4.2947 & TRN & \\
\hline CHEMBL 3193270 & 688780 & 3.0 & 4.537 & TRN & \\
\hline CHEMBL1439640 & 688780 & 4.8665 & 3.3239 & TRN & \\
\hline CHEMBL1452020 & 688780 & 3.0 & $3.5460 e$ & 00000000003 & TRN \\
\hline CHEMBL1607455 & 688780 & 3.0 & 3.1148 & TRN & \\
\hline CHEMBL1351799 & 688780 & 5.5969 & 4.7749 & TRN & \\
\hline CHEMBL1530789 & 688780 & 4.4855 & 3.9593 & TRN & \\
\hline CHEMBL1346096 & 688780 & 4.7799 & 3.8825 & TRN & \\
\hline CHEMBL1583671 & 688780 & 3.0 & 3.7079 & TRN & \\
\hline CHEMBL1461953 & 688780 & 6.3979 & 5.2247 & TRN & \\
\hline CHEMBL1449724 & 688780 & 3.0 & 3.2182 & TRN & \\
\hline CHEMBL1311879 & 688780 & 4.8601 & 5.2167 & TRN & \\
\hline CHEMBL1341317 & 688780 & 3.0 & 3.33699 & 99999999997 & TRN \\
\hline CHEMBL1400332 & 688780 & 3.0 & 4.098 & TST & \\
\hline CHEMBL1446668 & 688780 & 4.9547 & 4.0818 & TRN & \\
\hline CHEMBL1570004 & 688780 & 4.618 & 4.474 & TRN & \\
\hline CHEMBL1483129 & 688780 & 3.0 & 4.1292 & TRN & \\
\hline CHEMBL1363734 & 688780 & 3.0 & 3.6707 & TRN & \\
\hline CHEMBL1341584 & 688780 & 5.2941 & 5.9032 & TRN & \\
\hline CHEMBL1448985 & 688780 & 4.6716 & 4.1053 & TRN & \\
\hline CHEMBL1509755 & 688780 & 3.0 & 3.4403 & TRN & \\
\hline CHEMBL1370844 & 688780 & 4.9666 & 4.5546 & TRN & \\
\hline CHEMBL1351229 & 688780 & 4.8827 & 5.1679 & TRN & \\
\hline
\end{tabular}




\begin{tabular}{|c|c|c|c|c|c|c|}
\hline \multicolumn{7}{|c|}{ Supplemental Table S2.txt } \\
\hline CHEMBL3194756 & 688780 & 3.0 & 3.5807 & TRN & & \\
\hline CHEMBL1487660 & 688780 & 4.6676 & 3.8209 & TRN & & \\
\hline CHEMBL1493604 & 688780 & 3.0 & 4.5118 & TRN & & \\
\hline CHEMBL1346952 & 688780 & 3.0 & 4.3823 & TST & & \\
\hline CHEMBL1612672 & 688780 & 5.0044 & 4.2448 & TRN & & \\
\hline CHEMBL1334591 & 688780 & 3.0 & 4.2733 & TRN & & \\
\hline CHEMBL1300534 & 688780 & 4.9469 & 3.906 & TRN & & \\
\hline CHEMBL1492819 & 688780 & 5.2636 & 5.0774 & TRN & & \\
\hline CHEMBL1477463 & 688780 & 3.0 & 3.7967 & TRN & & \\
\hline CHEMBL1605099 & 688780 & 5.4935 & 5.6874 & TRN & & \\
\hline CHEMBL1973866 & 688780 & 3.0 & 4.2439 & TRN & & \\
\hline CHEMBL1302425 & 688780 & 3.0 & 4.2838 & TRN & & \\
\hline CHEMBL1404792 & 688780 & 4.3556 & 5.2997 & TRN & & \\
\hline CHEMBL1549893 & 688780 & 3.0 & 4.96399 & 9999999999 & 95 & TRN \\
\hline CHEMBL1331573 & 688780 & 6.5229 & 4.8208 & TRN & & \\
\hline CHEMBL1370320 & 688780 & 3.0 & 3.7568 & TRN & & \\
\hline CHEMBL1336938 & 688780 & 5.24799 & 99999999 & 99 & 4.5974 & TRN \\
\hline CHEMBL1478345 & 688780 & 3.0 & 3.4567 & TRN & & \\
\hline CHEMBL1498596 & 688780 & 3.0 & 3.7504 & TRN & & \\
\hline CHEMBL1530630 & 688780 & 3.0 & 3.6122 & TRN & & \\
\hline CHEMBL 257359 & 688780 & 5.279 & 5.4536 & TRN & & \\
\hline CHEMBL1371777 & 688780 & 5.6091 & 4.4569 & TRN & & \\
\hline CHEMBL3392071 & 688780 & 5.4802 & 4.3233 & TST & & \\
\hline CHEMBL1420591 & 688780 & 5.5017 & 4.04899 & 9999999999 & 95 & TST \\
\hline CHEMBL1426947 & 688780 & 5.0434 & 3.6745 & TST & & \\
\hline CHEMBL1499091 & 688780 & 3.0 & 3.1313 & TST & & \\
\hline CHEMBL1523475 & 688780 & 4.3546 & 4.0296 & TST & & \\
\hline CHEMBL1559707 & 688780 & 5.0052 & 4.8863 & TST & & \\
\hline CHEMBL1903510 & 688780 & 5.0904 & 4.3453 & TST & & \\
\hline CHEMBL1302300 & 688780 & 4.7399 & 4.6566 & TST & & \\
\hline CHEMBL255881 & 688780 & 5.5544 & 5.426 & TST & & \\
\hline CHEMBL1564047 & 688780 & 4.98300 & 00000000 & 005 & 3.7728 & TST \\
\hline CHEMBL1576031 & 688780 & 3.0 & 4.2355 & TST & & \\
\hline CHEMBL1606403 & 688780 & 5.8386 & 4.6722 & TST & & \\
\hline CHEMBL1588992 & 688780 & 3.0 & 5.0459 & TST & & \\
\hline CHEMBL1393861 & 688780 & 4.8761 & 3.8823 & TST & & \\
\hline CHEMBL1311852 & 688780 & 3.0 & 3.8539 & TST & & \\
\hline CHEMBL1455556 & 688780 & 4.6126 & 4.2715 & TST & & \\
\hline CHEMBL1988401 & 688780 & 4.341 & 3.8537 & TST & & \\
\hline CHEMBL1362566 & 688780 & 5.4461 & 4.3716 & TST & & \\
\hline CHEMBL1390056 & 688780 & 5.21399 & 99999999 & 995 & 5.1166 & TST \\
\hline CHEMBL1581585 & 688780 & 5.4622 & 4.7489 & TST & & \\
\hline CHEMBL1305067 & 688780 & 3.0 & 4.3063 & TST & & \\
\hline CHEMBL1501158 & 688780 & 4.757 & 3.7506 & TST & & \\
\hline CHEMBL3969447 & 1637005 & 6.2596 & 6.2587 & TRN & & \\
\hline CHEMBL3930285 & 1637005 & 6.3872 & 6.3868 & TRN & & \\
\hline CHEMBL3930579 & 1637005 & 5.2676 & 5.2685 & TRN & & \\
\hline CHEMBL3951939 & 1637005 & 6.699 & 6.3815 & TST & & \\
\hline
\end{tabular}


Supplemental Table S2.txt

\begin{tabular}{|c|c|c|}
\hline & & \\
\hline HEMBL3968083 & 637005 & .3372 \\
\hline AEMBL 3944040 & 05 & 6.3665 \\
\hline 50 & & \\
\hline 3945 & 005 & \\
\hline AEMBL3981183 & 637005 & 2924 \\
\hline HEMBL3924129 & 637005 & 5.699 \\
\hline HEMBL3949870 & 205 & 426 \\
\hline AEMBL39 & 005 & 3.5229 \\
\hline IEMBL 3C & & \\
\hline HEMBL3914721 & 637005 & 7.2757 \\
\hline HEMBL3971296 & 637005 & 6.468 \\
\hline HEMBL3982510 & 205 & 6 \\
\hline AEMBL3S & 305 & 5 \\
\hline AEMBL3 & & \\
\hline HEMBL3955382 & 637005 & 6.2924 \\
\hline HEMBL3965662 & 005 & \\
\hline HEMBL3\& & 005 & 6.7447 \\
\hline HEMBL3 & 05 & 5.8239 \\
\hline HEMBL: & & \\
\hline HEMBL3898106 & 7005 & 5576 \\
\hline AEMBL3967823 & & 5.301 \\
\hline HEMBL3 & 163 & 7.1805 \\
\hline 377 & & 696 \\
\hline 552 & & 249 \\
\hline AEMBL3893648 & 637005 & 6.9208 \\
\hline AEMBL3947573 & & 6.187 \\
\hline HEMBL3952275 & 6 & 7. \\
\hline 33 & & 3 \\
\hline 643 & 05 & 29 \\
\hline AEMBL3918736 & & 7. \\
\hline HEMBL3942291 & 05 & 6.795 \\
\hline AEMBL3 & 05 & \\
\hline 228 & 5 & 69 \\
\hline 534 & 05 & 575 \\
\hline HEMBL3917255 & 637005 & 7.920 \\
\hline HEMBL3971765 & 637005 & 7.096 \\
\hline AEMBL & & \\
\hline HᄃMDI - & כנ & 7 \\
\hline HEMBL3 & 05 & 4.301 \\
\hline AEMBL3928916 & 1637005 & 6.431 \\
\hline HEMBL3907143 & 163700 & 3.522 \\
\hline LHEM & & \\
\hline CHEMBL 3900353 & & 5.795 \\
\hline HEMBL3961633 & 16 & $5 a$ \\
\hline AEMBL3913484 & 1637005 & $.0 s$ \\
\hline CHEMBL3920665 & 163700 & 0 \\
\hline 301 & & \\
\hline
\end{tabular}

$\begin{array}{ll}8.0464 & \text { TRN } \\ 7.3373 & \text { TRN } \\ 6.3663 & \text { TRN } \\ 7.3482 & \text { TRN } \\ 5.3001 & \text { TRN }\end{array}$

6.047000000000001

TST

5.6992 TRN

7.4186 TRN

3.5226 TRN

8.8522 TRN

7.2756 TRN

6.4688 TRN

4.0726 TST

7.0461 TRN

5.6201 TRN

6.2914 TRN

6.7457 TRN

6.7396 TRN

5.8226 TRN

8.5234 TRN

5.6587 TRN

5.3397 TST

7.1791 TRN

6.7702 TRN

6.1251 TRN

6.92 TRN

6.1884 TRN

7.774 TRN

3.5227 TRN

5.5687 TST

7.2221 TRN

6.7981 TRN

6.316 TST

6.0976 TRN

6.1669 TRN

7.9211 TRN

7.0978 TRN

5.818 TST

8.2538 TST

4.2999 TRN

6.431 TRN

5.6154 TST

5.8872 TRN

5.1071 TST

7.6659 TST

5.3676 TST

8.2222 TRN

7.625 TRN

Page 18777 
Supplemental Table S2.txt

\begin{tabular}{|c|c|c|c|c|}
\hline HEMBL 39 & 637005 & 7.3979 & 6.9734 & \\
\hline HEMBL 3968112 & 637005 & 7.2924 & 7.2903 & \\
\hline AEMBL3931655 & 637005 & 6.6778 & 768 & \\
\hline AEMBL3932326 & 637005 & 8.8861 & 3849 & \\
\hline HEMBL3935046 & 637005 & 6.585 & 5851 & \\
\hline HEMBL3903625 & 637005 & 5.699 & 5.7002 & \\
\hline HEMBL3980338 & 637005 & 7.2596 & .0046 & \\
\hline HEMBL3890861 & 637005 & 8.301 & 8.3001 & \\
\hline HEMBL3966655 & 1637005 & 6.4685 & 5.8711 & \\
\hline HEMBL3965696 & 637005 & 7.5229 & 7.5222 & \\
\hline HEMBL3971976 & 637005 & 5.7696 & 6.1447 & \\
\hline HEMBL3921169 & 637005 & 8.7447 & 8.7427 & \\
\hline HEMBL3980067 & & 5.4949 & 5.4755 & \\
\hline HEMBL3978819 & 637005 & 6.301 & 6.3018 & \\
\hline HEMBL 379300 & 63 & 1498 & 5.4489 & \\
\hline HEMBL1357247 & 55063 & 2.5831 & 2.5819 & \\
\hline AEMBL1190711 & 53 & 5.1134 & .1103 & \\
\hline HEMBL3392440 & 53 & 679 & 3.3678 & \\
\hline HEMBL 213100 & 63 & 3.1609 & 3.1579 & \\
\hline HEMBL1970879 & 3 & 4.3832 & 4.3867 & \\
\hline HEMBL4\& & 3 & 38 & 958 & \\
\hline JEMBL57 & 3 & 75 & 102 & \\
\hline HEMBL 65 & 3 & 569 & 8.5567 & \\
\hline HEMBL159 & 63 & 4.293 & 3.7194 & \\
\hline HEMBL 210618 & 3 & 926 & 4.2916 & \\
\hline HEMBL19 & 3 & 7. & 7.4846 & \\
\hline HEMBL92 & כ & 3. & 3.4523 & \\
\hline HEMBL19 & 3 & 24 & 097 & \\
\hline HEMBL258844 & 53 & 182 & 4.0137 & \\
\hline HEMBL1673039 & 3 & 308 & 5.3279 & \\
\hline HEMBL 222 & 3 & 565 & 4.4516 & \\
\hline HEMBL5E & ב & 4 . & 4. & \\
\hline HEMBL1\& & 3 & 42 & 775 & \\
\hline HEMBL209148 & 55063 & 4.8452 & 4.8503 & \\
\hline HEMBL259181 & 55063 & 4.6842 & 4.6814 & \\
\hline HEMBL1230020 & 55063 & 4.6552 & 4.6556 & \\
\hline HEMBL12 & 3 & 68 & 4.7445 & \\
\hline CHEMBL3349342 & 3 & 524 & 3.3552 & \\
\hline HEMBL 202721 & 55063 & 4.24 & 4.2386 & \\
\hline HEMBL515416 & 55063 & 3925 & 3.8931 & \\
\hline HEMBL2363137 & 55063 & 4.7862 & 4.7836 & \\
\hline CHEMBL300389 & & 6.7074 & 6.7068 & \\
\hline CHEMBL449158 & 955063 & 6.4067 & 5.7505 & \\
\hline CHEMBL412142 & 55063 & 3.3426 & 3.3419 & \\
\hline LHEMBL94 & & 5.75 & 4.9859 & \\
\hline CHEMBL2144069 & 55063 & 4.2483 & 4.2473 & \\
\hline CHEMBL392695 & 955063 & 5.6074 & 5.6088 & \\
\hline CHEMBL379975 & 955063 & 6.1128 & 6.1158 & \\
\hline
\end{tabular}

Page 18778 


\begin{tabular}{|c|c|c|c|c|}
\hline \multicolumn{5}{|c|}{ Supplemental Table S2.txt } \\
\hline CHEMBL1909414 & 955063 & 4.5838 & 4.582 & TRN \\
\hline CHEMBL180127 & 955063 & 4.2735 & 4.274 & TRN \\
\hline CHEMBL1256459 & 955063 & 6.396 & 6.3947 & TRN \\
\hline CHEMBL 373751 & 955063 & 3.365 & 3.3654 & TRN \\
\hline CHEMBL472940 & 955063 & 3.7333 & 3.7354 & TRN \\
\hline CHEMBL 2005886 & 955063 & 4.154 & 4.1536 & TRN \\
\hline CHEMBL585951 & 955063 & 5.5804 & 5.5799 & TRN \\
\hline CHEMBL1404918 & 955063 & 2.459 & 2.4579 & TRN \\
\hline CHEMBL483849 & 955063 & 3.3712 & 3.3716 & TRN \\
\hline CHEMBL135561 & 955063 & 3.8248 & 3.8238 & TRN \\
\hline CHEMBL393929 & 955063 & 4.4847 & 4.4832 & TRN \\
\hline CHEMBL188678 & 955063 & 4.8079 & 4.8159 & TRN \\
\hline CHEMBL577784 & 955063 & 5.003 & 5.0023 & TRN \\
\hline CHEMBL558642 & 955063 & 4.1133 & 4.1152 & TRN \\
\hline CHEMBL240954 & 955063 & 4.7733 & 4.2929 & TST \\
\hline CHEMBL1643959 & 955063 & 3.175 & 3.1783 & TRN \\
\hline CHEMBL3199475 & 955063 & 4.2225 & 4.6569 & TST \\
\hline CHEMBL3186408 & 955063 & 3.2129 & 4.0188 & TST \\
\hline CHEMBL221137 & 955063 & 4.4102 & 4.6102 & TST \\
\hline CHEMBL220241 & 955063 & 3.5059 & 3.9328 & TST \\
\hline CHEMBL102714 & 955063 & 3.492 & 3.95 & TST \\
\hline CHEMBL1516890 & 955063 & 4.0695 & 3.8498 & TST \\
\hline CHEMBL1788116 & 955063 & 4.2794 & 4.1399 & TST \\
\hline CHEMBL512504 & 955063 & 6.0823 & 6.0547 & TST \\
\hline CHEMBL514499 & 955063 & 7.7959 & 6.6621 & TST \\
\hline CHEMBL3786317 & 1565814 & 6.4737 & 6.6007 & TRN \\
\hline CHEMBL3786327 & 1565814 & 9.0 & 9.1006 & TRN \\
\hline CHEMBL3785178 & 1565814 & 9.0 & 9.2437 & TRN \\
\hline CHEMBL3786313 & 1565814 & 5.9935 & 6.1927 & TRN \\
\hline CHEMBL 3787257 & 1565814 & 6.6946 & 7.0065 & TRN \\
\hline CHEMBL3786996 & 1565814 & 7.0458 & 6.6772 & TRN \\
\hline CHEMBL3785514 & 1565814 & 6.7144 & 6.7339 & TRN \\
\hline CHEMBL3787178 & 1565814 & 7.041 & 7.1211 & TRN \\
\hline CHEMBL3787266 & 1565814 & 6.4271 & 6.8318 & TST \\
\hline CHEMBL3785689 & 1565814 & 9.0 & 9.3575 & TRN \\
\hline CHEMBL3787037 & 1565814 & 6.9245 & 6.7955 & TRN \\
\hline CHEMBL3785385 & 1565814 & 6.6003 & 6.4178 & TRN \\
\hline CHEMBL3785666 & 1565814 & 7.1805 & 7.4034 & TRN \\
\hline CHEMBL3786981 & 1565814 & 6.6799 & 6.8822 & TRN \\
\hline CHEMBL3786622 & 1565814 & 9.0 & 8.4225 & TRN \\
\hline CHEMBL3786092 & 1565814 & 7.2757 & 7.2991 & TRN \\
\hline CHEMBL3785851 & 1565814 & 6.6799 & 7.0084 & TRN \\
\hline CHEMBL3785823 & 1565814 & 7.7212 & 7.419 & TRN \\
\hline CHEMBL3786306 & 1565814 & 6.5258 & 6.5479 & TRN \\
\hline CHEMBL3786057 & 1565814 & 9.0 & 8.9026 & TRN \\
\hline CHEMBL3786947 & 1565814 & 7.7447 & 7.235 & TRN \\
\hline CHEMBL 2314209 & 1565814 & 7.2596 & 7.0162 & TST \\
\hline CHEMBL3786650 & 1565814 & 6.9355 & 6.9087 & TRN \\
\hline
\end{tabular}


Supplemental Table S2.txt

\begin{tabular}{|c|c|c|c|c|c|}
\hline CHEMBL3785950 & 1565814 & 6.1831 & 6.3497 & TRN & \\
\hline CHEMBL3787407 & 1565814 & 9.0 & 8.935 & TRN & \\
\hline CHEMBL3786945 & 1565814 & 9.0 & 9.0008 & TRN & \\
\hline CHEMBL3785312 & 1565814 & 6.4425 & 6.6005 & TRN & \\
\hline CHEMBL3786325 & 1565814 & 9.0 & 9.0747 & TRN & \\
\hline CHEMBL3786823 & 1565814 & 6.5072 & 6.7335 & TST & \\
\hline CHEMBL3787122 & 1565814 & 6.9355 & 7.237 & TRN & \\
\hline CHEMBL3785127 & 1565814 & 6.5114 & 7.4744 & TST & \\
\hline CHEMBL3787158 & 1565814 & 9.0 & 8.9672 & TST & \\
\hline CHEMBL3786244 & 1565814 & 7.0605 & 7.2002 & TRN & \\
\hline CHEMBL3785235 & 1565814 & 8.0 & 7.6197 & TRN & \\
\hline CHEMBL3785989 & 1565814 & 6.857 & 6.9272 & TRN & \\
\hline CHEMBL3786637 & 1565814 & 6.9281 & 6.6219 & TRN & \\
\hline CHEMBL3785629 & 1565814 & 6.5702 & 6.5402 & TRN & \\
\hline CHEMBL3786018 & 1565814 & 7.4437 & 7.1642 & TST & \\
\hline CHEMBL3785788 & 1565814 & 6.556 & 6.4098 & TRN & \\
\hline CHEMBL3786069 & 1565814 & 6.1838 & 6.2248 & TRN & \\
\hline CHEMBL3786746 & 1565814 & 9.0 & 8.8446 & TST & \\
\hline CHEMBL3786143 & 1565814 & 6.3665 & 6.4904 & TRN & \\
\hline CHEMBL3786582 & 1565814 & 7.0 & 6.7367 & TRN & \\
\hline CHEMBL3785461 & 1565814 & 9.0 & 9.1805 & TST & \\
\hline CHEMBL3785279 & 1565814 & 9.0 & 9.1668 & TST & \\
\hline CHEMBL3787690 & 1565814 & 6.3645 & 6.4127 & TRN & \\
\hline CHEMBL3785558 & 1565814 & 6.9318 & \multicolumn{2}{|c|}{6.787000000000001} & TRN \\
\hline CHEMBL3786051 & 1565814 & 7.8539 & 7.5468 & TST & \\
\hline CHEMBL3786147 & 1565814 & 9.0 & 7.7338 & TST & \\
\hline CHEMBL3785426 & 1565814 & 9.0 & 8.8736 & TST & \\
\hline CHEMBL3787127 & 1565814 & 6.475 & 6.4607 & TRN & \\
\hline CHEMBL3785228 & 1565814 & 7.1024 & 6.7406 & TRN & \\
\hline CHEMBL3787497 & 1565814 & 6.1068 & 6.8274 & TRN & \\
\hline CHEMBL3785313 & 1565814 & 9.0 & 8.6157 & TST & \\
\hline CHEMBL3785892 & 1565814 & 6.6364 & 6.4772 & TST & \\
\hline CHEMBL3786221 & 1565814 & 5.9594 & 6.2664 & TRN & \\
\hline CHEMBL3785155 & 1565814 & 7.2596 & 7.2364 & TRN & \\
\hline CHEMBL3785874 & 1565814 & 6.8297 & 6.8315 & TRN & \\
\hline CHEMBL3786848 & 1565814 & 6.4921 & 6.4248 & TRN & \\
\hline CHEMBL3786706 & 1565814 & 9.0 & 9.1056 & TST & \\
\hline CHEMBL3786233 & 1565814 & 9.0 & 8.5594 & TST & \\
\hline CHEMBL3787025 & 1565814 & 7.7959 & 7.3993 & TRN & \\
\hline CHEMBL3680746 & 1527683 & 8.8539 & 8.3754 & TRN & \\
\hline CHEMBL3680801 & 1527683 & 8.5229 & 8.1661 & TRN & \\
\hline CHEMBL3680725 & 1527683 & 8.6576 & 8.325 & TRN & \\
\hline CHEMBL3680707 & 1527683 & 6.0 & 5.976 & TRN & \\
\hline CHEMBL3680762 & 1527683 & 8.7696 & 7.8727 & TST & \\
\hline CHEMBL3680697 & 1527683 & 8.2218 & 8.1631 & TRN & \\
\hline CHEMBL3680731 & 1527683 & 8.8239 & 8.2036 & TRN & \\
\hline CHEMBL3680759 & 1527683 & 8.8861 & 8.6121 & TRN & \\
\hline CHEMBL3680723 & 1527683 & 8.585 & 7.9351 & TRN & \\
\hline
\end{tabular}


Supplemental Table S2.txt

\begin{tabular}{|c|c|c|c|c|}
\hline CHEMBL 3680793 & 1527683 & 7.1675 & 8.1863 & TRN \\
\hline CHEMBL 3680798 & 1527683 & 8.1871 & 7.6866 & TRN \\
\hline CHEMBL 3680764 & 1527683 & 8.2291 & 7.7902 & TST \\
\hline CHEMBL 3680712 & 1527683 & 7.4815 & 8.019 & TRN \\
\hline CHEMBL 3680743 & 1527683 & 8.5086 & 8.0299 & TST \\
\hline CHEMBL 3680702 & 1527683 & 8.2291 & 8.0187 & TST \\
\hline CHEMBL 3680730 & 1527683 & 7.7328 & 7.9687 & TRN \\
\hline CHEMBL 3680763 & 1527683 & 8.4202 & 8.1537 & TRN \\
\hline CHEMBL 3680696 & 1527683 & 8.699 & 8.2294 & TRN \\
\hline CHEMBL3680799 & 1527683 & 8.3188 & 7.7003 & TRN \\
\hline CHEMBL 3680758 & 1527683 & 7.6198 & 8.0021 & TRN \\
\hline CHEMBL3680718 & 1527683 & 6.0 & 5.8436 & TRN \\
\hline CHEMBL3680807 & 1527683 & 7.0655 & 7.9602 & TST \\
\hline CHEMBL 3680782 & 1527683 & 8.0223 & 7.9658 & TRN \\
\hline CHEMBL 3680797 & 1527683 & 7.0386 & 8.0477 & TRN \\
\hline CHEMBL 3680750 & 1527683 & 7.3279 & 7.9351 & TRN \\
\hline CHEMBL3680733 & 1527683 & 7.1925 & 8.163 & TRN \\
\hline CHEMBL 3680791 & 1527683 & 7.6478 & 8.3205 & TRN \\
\hline CHEMBL 3680749 & 1527683 & 8.7696 & 7.4836 & TST \\
\hline CHEMBL 3680720 & 1527683 & 8.7447 & 7.9996 & TST \\
\hline CHEMBL3680770 & 1527683 & 7.0969 & 8.1291 & TRN \\
\hline CHEMBL3680802 & 1527683 & 8.1612 & 7.8763 & TST \\
\hline CHEMBL3680706 & 1527683 & 8.0088 & 7.6672 & TRN \\
\hline CHEMBL 3680744 & 1527683 & 8.3872 & 8.0918 & TRN \\
\hline CHEMBL3680796 & 1527683 & 7.8386 & 8.0505 & TRN \\
\hline CHEMBL3639796 & 1527683 & 7.0915 & 8.0911 & TRN \\
\hline CHEMBL3639795 & 1527683 & 7.6478 & 7.7103 & TRN \\
\hline CHEMBL 3680747 & 1527683 & 8.4202 & 8.0638 & TRN \\
\hline CHEMBL3680781 & 1527683 & 8.7212 & 7.7832 & TST \\
\hline CHEMBL 3680754 & 1527683 & 7.8097 & 8.0245 & TRN \\
\hline CHEMBL 3680803 & 1527683 & 7.9245 & 7.6831 & TRN \\
\hline CHEMBL 3680745 & 1527683 & 8.0915 & 7.9548 & TRN \\
\hline CHEMBL 3680757 & 1527683 & 7.8386 & 8.2386 & TRN \\
\hline CHEMBL3680715 & 1527683 & 7.3615 & 8.0412 & TRN \\
\hline CHEMBL 3680722 & 1527683 & 7.4498 & 8.0997 & TST \\
\hline CHEMBL3680734 & 1527683 & 7.3516 & 8.1452 & TRN \\
\hline CHEMBL3680726 & 1527683 & 7.5528 & 7.6159 & TRN \\
\hline CHEMBL 3680739 & 1527683 & 8.8239 & 8.5765 & TRN \\
\hline CHEMBL3680721 & 1527683 & 8.7447 & 7.9944 & TST \\
\hline CHEMBL 3680742 & 1527683 & 7.3401 & 8.2543 & TST \\
\hline CHEMBL3680794 & 1527683 & 8.2441 & 7.8894 & TRN \\
\hline CHEMBL3680705 & 1527683 & 6.0 & 6.4065 & TST \\
\hline CHEMBL3680724 & 1527683 & 8.5376 & 8.0819 & TST \\
\hline CHEMBL3680695 & 1527683 & 8.3979 & 7.96200 & 0000000001 \\
\hline CHEMBL3680699 & 1527683 & 8.3188 & 7.8557 & TRN \\
\hline CHEMBL3680727 & 1527683 & 8.8861 & 8.5012 & TRN \\
\hline CHEMBL3680708 & 1527683 & 8.585 & 8.2479 & TRN \\
\hline CHEMBL3680736 & 1527683 & 8.8861 & 8.672 & TRN \\
\hline
\end{tabular}


Supplemental Table S2.txt

\begin{tabular}{|c|c|c|c|c|c|}
\hline CHEMBL3680700 & 1527683 & 7.7144 & 8.1414 & TST & \\
\hline CHEMBL3680737 & 1527683 & 8.9208 & 8.421 & TRN & \\
\hline CHEMBL3680703 & 1527683 & 8.2366 & 7.9592 & TRN & \\
\hline CHEMBL3680761 & 1527683 & 7.5607 & 8.042 & TST & \\
\hline CHEMBL 3680741 & 1527683 & 8.7696 & 8.5207 & TRN & \\
\hline CHEMBL3680717 & 1527683 & 8.3098 & 8.0742 & TRN & \\
\hline CHEMBL3680795 & 1527683 & 7.7447 & 8.162 & TRN & \\
\hline CHEMBL3680729 & 1527683 & 8.6778 & 8.451 & TRN & \\
\hline CHEMBL3680776 & 1527683 & 8.585 & 8.2759 & TRN & \\
\hline CHEMBL3680710 & 1527683 & 8.3372 & 8.0903 & TRN & \\
\hline CHEMBL3680800 & 1527683 & 7.4202 & 8.0433 & TST & \\
\hline CHEMBL3680711 & 1527683 & 6.0 & 6.0386 & TRN & \\
\hline CHEMBL3680732 & 1527683 & 8.6021 & 8.2575 & TST & \\
\hline CHEMBL 3680767 & 1527683 & 8.8861 & 8.4743 & TRN & \\
\hline CHEMBL 3680777 & 1527683 & 7.3072 & 8.0872 & TRN & \\
\hline CHEMBL 3238233 & 1338727 & 5.4318 & 5.3785 & TRN & \\
\hline CHEMBL3237885 & 1338727 & 6.2924 & 6.2724 & TRN & \\
\hline CHEMBL3237903 & 1338727 & 6.4559 & \multicolumn{2}{|c|}{6.337000000000001} & TRN \\
\hline CHEMBL3237897 & 1338727 & 6.7696 & 6.7805 & TRN & \\
\hline CHEMBL3238214 & 1338727 & 6.4318 & 6.6113 & TRN & \\
\hline CHEMBL3237923 & 1338727 & 6.6576 & 6.6485 & TRN & \\
\hline CHEMBL3237888 & 1338727 & 6.0969 & 5.9303 & TRN & \\
\hline CHEMBL3238223 & 1338727 & 6.7447 & 6.8926 & TRN & \\
\hline CHEMBL3238217 & 1338727 & 6.9586 & 7.0065 & TRN & \\
\hline CHEMBL 3237907 & 1338727 & 6.3098 & 6.269 & TRN & \\
\hline CHEMBL 3238215 & 1338727 & 7.0 & 7.02 & TRN & \\
\hline CHEMBL3238234 & 1338727 & 7.3188 & 7.7439 & TST & \\
\hline CHEMBL3238227 & 1338727 & 5.7959 & 6.7662 & TST & \\
\hline CHEMBL3237905 & 1338727 & 6.3565 & 6.2922 & TRN & \\
\hline CHEMBL 3238225 & 1338727 & 6.4437 & 6.5084 & TRN & \\
\hline CHEMBL3237889 & 1338727 & 5.8539 & 5.8838 & TRN & \\
\hline CHEMBL3237892 & 1338727 & 5.7212 & \multicolumn{2}{|c|}{5.9239999999999995} & TRN \\
\hline CHEMBL3238219 & 1338727 & 6.8539 & 6.7837 & TRN & \\
\hline CHEMBL 3237884 & 1338727 & 6.5376 & 6.5527 & TRN & \\
\hline CHEMBL3238241 & 1338727 & 5.5686 & 7.4723 & TST & \\
\hline CHEMBL3237899 & 1338727 & 6.8539 & 6.6123 & TST & \\
\hline CHEMBL3237917 & 1338727 & 6.7447 & 6.2814 & TST & \\
\hline CHEMBL3238232 & 1338727 & 6.2924 & 6.3499 & TRN & \\
\hline CHEMBL3238224 & 1338727 & 6.6383 & 6.6273 & TRN & \\
\hline CHEMBL3237891 & 1338727 & 5.7212 & 5.7094 & TRN & \\
\hline CHEMBL 3238221 & 1338727 & 6.6198 & 6.6666 & TRN & \\
\hline CHEMBL3237886 & 1338727 & 6.1367 & 6.0551 & TST & \\
\hline CHEMBL3237914 & 1338727 & 6.041 & \multicolumn{2}{|c|}{6.1739999999999995} & TRN \\
\hline CHEMBL3237902 & 1338727 & 6.4685 & 6.4571 & TRN & \\
\hline CHEMBL3237927 & 1338727 & 6.1192 & 6.194 & TRN & \\
\hline CHEMBL 3238246 & 1338727 & 7.3372 & 7.0887 & TRN & \\
\hline CHEMBL3237901 & 1338727 & 6.5528 & 6.4743 & TRN & \\
\hline CHEMBL 3238220 & 1338727 & 6.7959 & 6.6142 & TRN & \\
\hline
\end{tabular}


Supplemental Table S2.txt

\begin{tabular}{|c|c|c|c|c|c|}
\hline CHEMBL 3237928 & 1338727 & 6.8239 & 6.7703 & TRN & \\
\hline CHEMBL 3238229 & 1338727 & 7.284 & 7.2727 & TRN & \\
\hline CHEMBL3238228 & 1338727 & 5.9208 & 6.3826 & TST & \\
\hline CHEMBL 3237908 & 1338727 & 6.2596 & 6.1155 & TRN & \\
\hline CHEMBL 3237918 & 1338727 & 6.1249 & 6.1009 & TST & \\
\hline CHEMBL 3238218 & 1338727 & 6.8861 & 6.8805 & TRN & \\
\hline CHEMBL 3237924 & 1338727 & 6.4202 & 6.5041 & TRN & \\
\hline CHEMBL3238226 & 1338727 & 6.3188 & 6.1876 & TRN & \\
\hline CHEMBL3237906 & 1338727 & 6.3188 & 6.4306 & TRN & \\
\hline CHEMBL 3237887 & 1338727 & 6.1135 & 6.2806 & TST & \\
\hline CHEMBL 3238222 & 1338727 & 6.7447 & 6.7618 & TRN & \\
\hline CHEMBL 3238240 & 1338727 & 6.4559 & 7.5664 & TST & \\
\hline CHEMBL3237900 & 1338727 & 6.9586 & 7.0065 & TRN & \\
\hline CHEMBL3237911 & 1338727 & 6.2007 & 6.1759 & TRN & \\
\hline CHEMBL 3237894 & 1338727 & 5.1675 & 5.5198 & TST & \\
\hline CHEMBL3237904 & 1338727 & 6.3665 & 6.2299 & TRN & \\
\hline CHEMBL 3238242 & 1338727 & 5.0706 & 7.4761 & TST & \\
\hline CHEMBL3237913 & 1338727 & 6.0757 & 6.1632 & TRN & \\
\hline CHEMBL 3238243 & 1338727 & 6.0506 & 7.5543 & TST & \\
\hline CHEMBL 3238230 & 1338727 & 7.1805 & 7.2446 & TRN & \\
\hline CHEMBL3237890 & 1338727 & 5.7959 & 5.9583 & TST & \\
\hline CHEMBL 3237898 & 1338727 & 6.585 & 6.8567 & TST & \\
\hline CHEMBL 3237922 & 1338727 & 6.5686 & 6.4835 & TRN & \\
\hline CHEMBL 3238231 & 1338727 & 6.585 & 6.8535 & TRN & \\
\hline CHEMBL 3237912 & 1338727 & 6.1249 & 6.1688 & TRN & \\
\hline CHEMBL3237915 & 1338727 & 5.9586 & 5.9769 & TRN & \\
\hline CHEMBL 3237921 & 1338727 & 6.2676 & 6.2532 & TRN & \\
\hline CHEMBL 3237925 & 1338727 & 6.8861 & 6.6505 & TRN & \\
\hline CHEMBL3237926 & 1338727 & 5.6576 & 5.6979 & TRN & \\
\hline CHEMBL 3238235 & 1338727 & 6.0706 & 7.1866 & TST & \\
\hline CHEMBL3237916 & 1338727 & 5.5376 & 5.624 & TRN & \\
\hline CHEMBL 3237909 & 1338727 & 6.2518 & 6.2813 & TRN & \\
\hline CHEMBL3238216 & 1338727 & 7.3768 & 7.359 & TRN & \\
\hline CHEMBL3237910 & 1338727 & 6.2007 & 6.21700 & 00000000005 & TRN \\
\hline CHEMBL3237893 & 1338727 & 5.4949 & 5.982 & TST & \\
\hline CHEMBL1612106 & 1301756 & 3.284 & 4.2652 & TST & \\
\hline CHEMBL1389330 & 1301756 & 3.284 & 3.1615 & TST & \\
\hline CHEMBL1324944 & 1301756 & 5.341 & 5.0728 & TRN & \\
\hline CHEMBL1557405 & 1301756 & 3.284 & 3.1862 & TRN & \\
\hline CHEMBL1731938 & 1301756 & 4.5191 & 4.1195 & TRN & \\
\hline CHEMBL2355419 & 1301756 & 3.284 & 3.3907 & TRN & \\
\hline CHEMBL533082 & 1301756 & 4.9197 & 5.0697 & TRN & \\
\hline CHEMBL1301760 & 1301756 & 3.284 & 3.5767 & TRN & \\
\hline CHEMBL1356209 & 1301756 & 3.284 & 3.3775 & TST & \\
\hline CHEMBL1995197 & 1301756 & 3.284 & 3.5299 & TRN & \\
\hline CHEMBL531269 & 1301756 & 4.3189 & 3.5053 & TRN & \\
\hline CHEMBL1451016 & 1301756 & 4.768 & 4.9538 & TRN & \\
\hline CHEMBL1557704 & 1301756 & 4.3834 & 4.2186 & TRN & \\
\hline
\end{tabular}


Supplemental Table S2.txt

\begin{tabular}{|c|c|c|c|c|c|}
\hline CHEMBL1581250 & 1301756 & 4.2979 & 4.1903 & TRN & \\
\hline CHEMBL1612809 & 1301756 & 3.284 & 3.1233 & TRN & \\
\hline CHEMBL1319860 & 1301756 & 3.284 & 3.4327 & TRN & \\
\hline CHEMBL1466410 & 1301756 & 4.4159 & 4.1752 & TRN & \\
\hline CHEMBL1432335 & 1301756 & 3.284 & \multicolumn{2}{|c|}{3.1889999999999996} & TRN \\
\hline CHEMBL1301145 & 1301756 & 4.3937 & 4.2514 & TRN & \\
\hline CHEMBL1451888 & 1301756 & 3.284 & 3.7388 & TRN & \\
\hline CHEMBL3191057 & 1301756 & 3.284 & 3.1168 & TRN & \\
\hline CHEMBL1351626 & 1301756 & 3.284 & 3.4169 & TRN & \\
\hline CHEMBL3199935 & 1301756 & 3.284 & 3.3312 & TRN & \\
\hline CHEMBL1605568 & 1301756 & 3.284 & 3.5874 & TRN & \\
\hline CHEMBL1338805 & 1301756 & 4.7703 & 4.4823 & TRN & \\
\hline CHEMBL1381793 & 1301756 & 5.1002 & 4.8753 & TRN & \\
\hline CHEMBL1454195 & 1301756 & 3.284 & 4.1472 & TRN & \\
\hline CHEMBL1713546 & 1301756 & 3.284 & 3.6081 & TRN & \\
\hline CHEMBL1349892 & 1301756 & 3.284 & 3.262 & TRN & \\
\hline CHEMBL1508072 & 1301756 & 4.3908 & 3.8514 & TRN & \\
\hline CHEMBL1591647 & 1301756 & 3.284 & 2.8574 & TRN & \\
\hline CHEMBL1587065 & 1301756 & 3.284 & 3.1542 & TRN & \\
\hline CHEMBL1522563 & 1301756 & 3.284 & 3.7208 & TST & \\
\hline CHEMBL1301758 & 1301756 & 3.284 & \multicolumn{2}{|c|}{3.2260000000000004} & TRN \\
\hline CHEMBL1580664 & 1301756 & 3.284 & 3.6421 & TRN & \\
\hline CHEMBL 2354850 & 1301756 & 3.284 & \multicolumn{2}{|c|}{3.4760000000000004} & TRN \\
\hline CHEMBL3189676 & 1301756 & 3.284 & 3.1257 & TRN & \\
\hline CHEMBL1534106 & 1301756 & 3.284 & 3.4895 & TRN & \\
\hline CHEMBL3193659 & 1301756 & 3.284 & 3.1604 & TRN & \\
\hline CHEMBL1531133 & 1301756 & 4.8136 & 4.3483 & TRN & \\
\hline CHEMBL1343182 & 1301756 & 3.284 & 4.0386 & TRN & \\
\hline CHEMBL1736497 & 1301756 & 4.754 & 4.6915 & TRN & \\
\hline CHEMBL1462215 & 1301756 & 5.6615 & 5.0707 & TST & \\
\hline CHEMBL 269410 & 1301756 & 3.284 & 3.5307 & TST & \\
\hline CHEMBL1970965 & 1301756 & 3.284 & 3.2178 & TRN & \\
\hline CHEMBL1513630 & 1301756 & 3.284 & 3.265 & TRN & \\
\hline CHEMBL1436017 & 1301756 & 3.284 & 3.6852 & TRN & \\
\hline CHEMBL243861 & 1301756 & 3.284 & 3.3586 & TRN & \\
\hline CHEMBL 2356362 & 1301756 & 3.284 & 3.4287 & TST & \\
\hline CHEMBL1401272 & 1301756 & 3.284 & 3.1428 & TST & \\
\hline CHEMBL1403085 & 1301756 & 4.3033 & 3.4533 & TST & \\
\hline CHEMBL1698675 & 1301756 & 3.284 & 3.7108 & TST & \\
\hline CHEMBL1432801 & 1301756 & 5.1244 & 3.3255 & TST & \\
\hline CHEMBL1422429 & 1301756 & 4.8447 & 5.2365 & TST & \\
\hline CHEMBL1306033 & 1301756 & 4.9492 & 4.7883 & TST & \\
\hline CHEMBL1576924 & 1301756 & 4.3435 & 3.6048 & TST & \\
\hline CHEMBL1190711 & 955011 & 4.5476 & 4.5544 & TRN & \\
\hline CHEMBL209148 & 955011 & 4.018 & 4.0285 & TRN & \\
\hline CHEMBL188678 & 955011 & 3.8115 & 3.8397 & TRN & \\
\hline CHEMBL 2363137 & 955011 & 4.8377 & 4.8376 & TRN & \\
\hline CHEMBL102714 & 955011 & 4.521 & 4.5067 & TRN & \\
\hline
\end{tabular}


Supplemental Table S2.txt

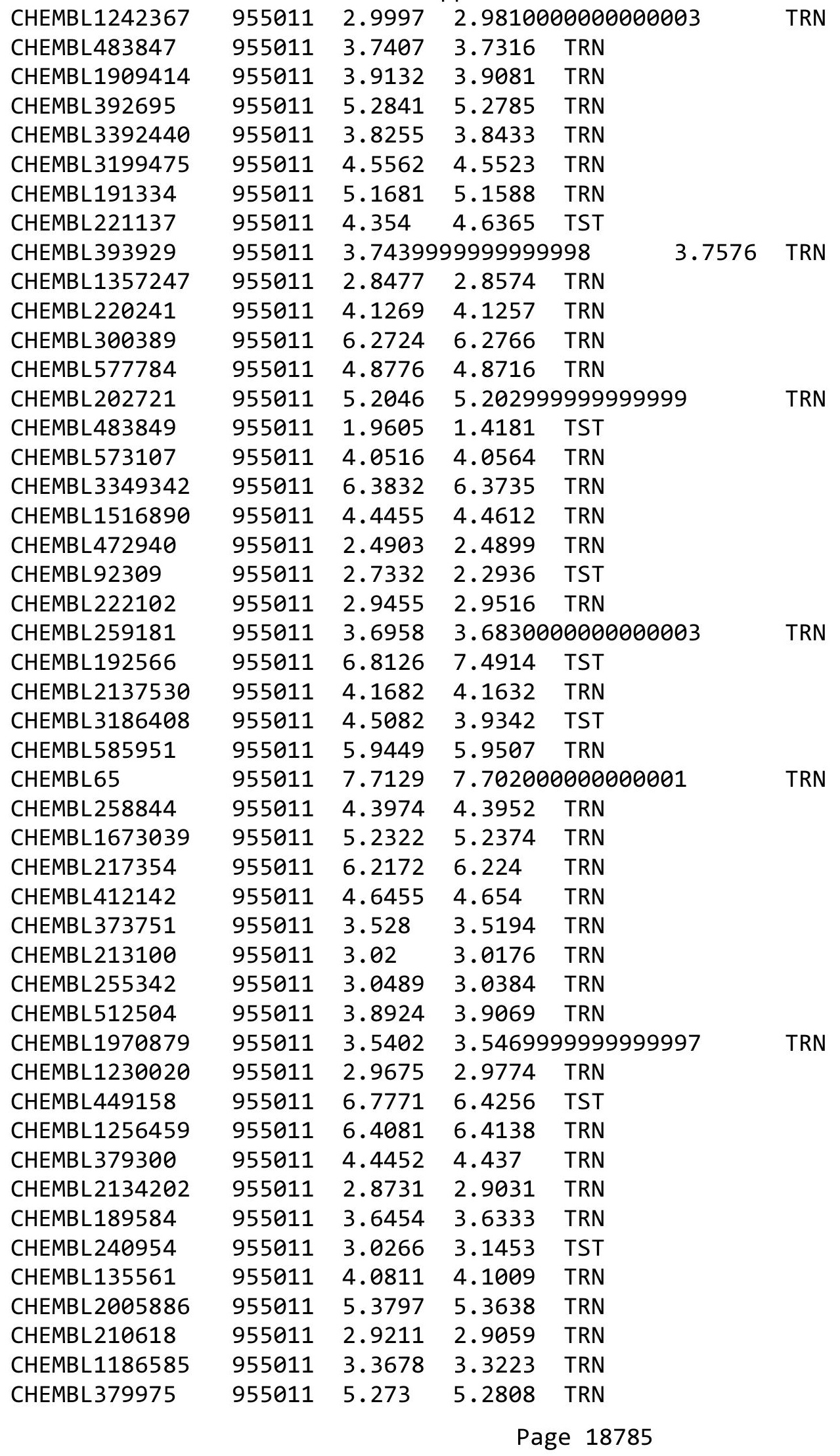




\begin{tabular}{|c|c|c|c|c|}
\hline \multicolumn{5}{|c|}{ Supplemental Table S2.txt } \\
\hline CHEMBL399530 & 955011 & 4.1024 & 4.0907 & TRN \\
\hline CHEMBL1590308 & 955011 & 4.9448 & 3.2783 & TST \\
\hline CHEMBL514499 & 955011 & 6.6746 & 6.6825 & TRN \\
\hline CHEMBL 2144069 & 955011 & 7.1299 & 5.3591 & TST \\
\hline CHEMBL515416 & 955011 & 2.2199 & 4.0423 & TST \\
\hline CHEMBL1404918 & 955011 & 2.8514 & 2.4087 & TST \\
\hline CHEMBL509032 & 955011 & 5.6531 & 6.0977 & TST \\
\hline CHEMBL1643959 & 955011 & 3.0574 & 2.4982 & TST \\
\hline CHEMBL558642 & 955011 & 3.0758 & 3.9379 & TST \\
\hline CHEMBL180127 & 955011 & 3.9289 & 4.1215 & TST \\
\hline CHEMBL1788116 & 955011 & 4.3526 & 4.2628 & TST \\
\hline CHEMBL9470 & 955011 & 5.8303 & 5.8149 & TST \\
\hline CHEMBL94176 & 36630 & 8.2366 & 8.3608 & TST \\
\hline CHEMBL 292150 & 36630 & 9.3468 & 9.4896 & TRN \\
\hline CHEMBL329858 & 36630 & 9.1675 & 8.7257 & TRN \\
\hline CHEMBL329942 & 36630 & 9.3188 & 9.6122 & TRN \\
\hline CHEMBL97446 & 36630 & 9.5686 & 9.7316 & TRN \\
\hline CHEMBL 329089 & 36630 & 9.3979 & 9.2051 & TRN \\
\hline CHEMBL330533 & 36630 & 9.8861 & 9.5513 & TRN \\
\hline CHEMBL321086 & 36630 & 8.4815 & 7.687 & TST \\
\hline CHEMBL328941 & 36630 & 9.6778 & 9.4143 & TRN \\
\hline CHEMBL97271 & 36630 & 8.585 & 9.3296 & TRN \\
\hline CHEMBL 330170 & 36630 & 8.9586 & 8.9453 & TRN \\
\hline CHEMBL 97465 & 36630 & 9.2218 & 8.9867 & TRN \\
\hline CHEMBL98426 & 36630 & 9.0757 & 9.1701 & TRN \\
\hline CHEMBL93956 & 36630 & 8.699 & 8.7275 & TRN \\
\hline CHEMBL94582 & 36630 & 8.9586 & 8.2284 & TRN \\
\hline CHEMBL94407 & 36630 & 8.3279 & 7.6315 & TST \\
\hline CHEMBL94910 & 36630 & 9.0969 & 9.0695 & TRN \\
\hline CHEMBL97500 & 36630 & 7.6778 & 8.0112 & TRN \\
\hline CHEMBL 327988 & 36630 & 9.3665 & 9.1486 & TRN \\
\hline CHEMBL95197 & 36630 & 8.301 & 8.9835 & TRN \\
\hline CHEMBL93606 & 36630 & 8.8861 & 9.0417 & TRN \\
\hline CHEMBL327191 & 36630 & 9.3979 & 9.235 & TRN \\
\hline CHEMBL329759 & 36630 & 9.0969 & 8.7851 & TRN \\
\hline CHEMBL316297 & 36630 & 8.7959 & 8.8425 & TRN \\
\hline CHEMBL327791 & 36630 & 8.2291 & 8.9632 & TRN \\
\hline CHEMBL319404 & 36630 & 8.3665 & 8.9573 & TRN \\
\hline CHEMBL318891 & 36630 & 8.1549 & 7.5853 & TST \\
\hline CHEMBL317368 & 36630 & 8.5528 & 8.8016 & TRN \\
\hline CHEMBL329693 & 36630 & 9.6576 & 9.485 & TRN \\
\hline CHEMBL330464 & 36630 & 9.4089 & 9.3285 & TST \\
\hline CHEMBL97273 & 36630 & 5.8861 & 6.9803 & TRN \\
\hline CHEMBL97068 & 36630 & 9.3768 & 9.0138 & TRN \\
\hline CHEMBL433375 & 36630 & 8.8861 & 8.9895 & TRN \\
\hline CHEMBL317547 & 36630 & 9.4437 & 9.0793 & TRN \\
\hline CHEMBL98140 & 36630 & 8.585 & 9.0822 & TRN \\
\hline CHEMBL407919 & 36630 & 9.5686 & 9.1951 & TRN \\
\hline
\end{tabular}




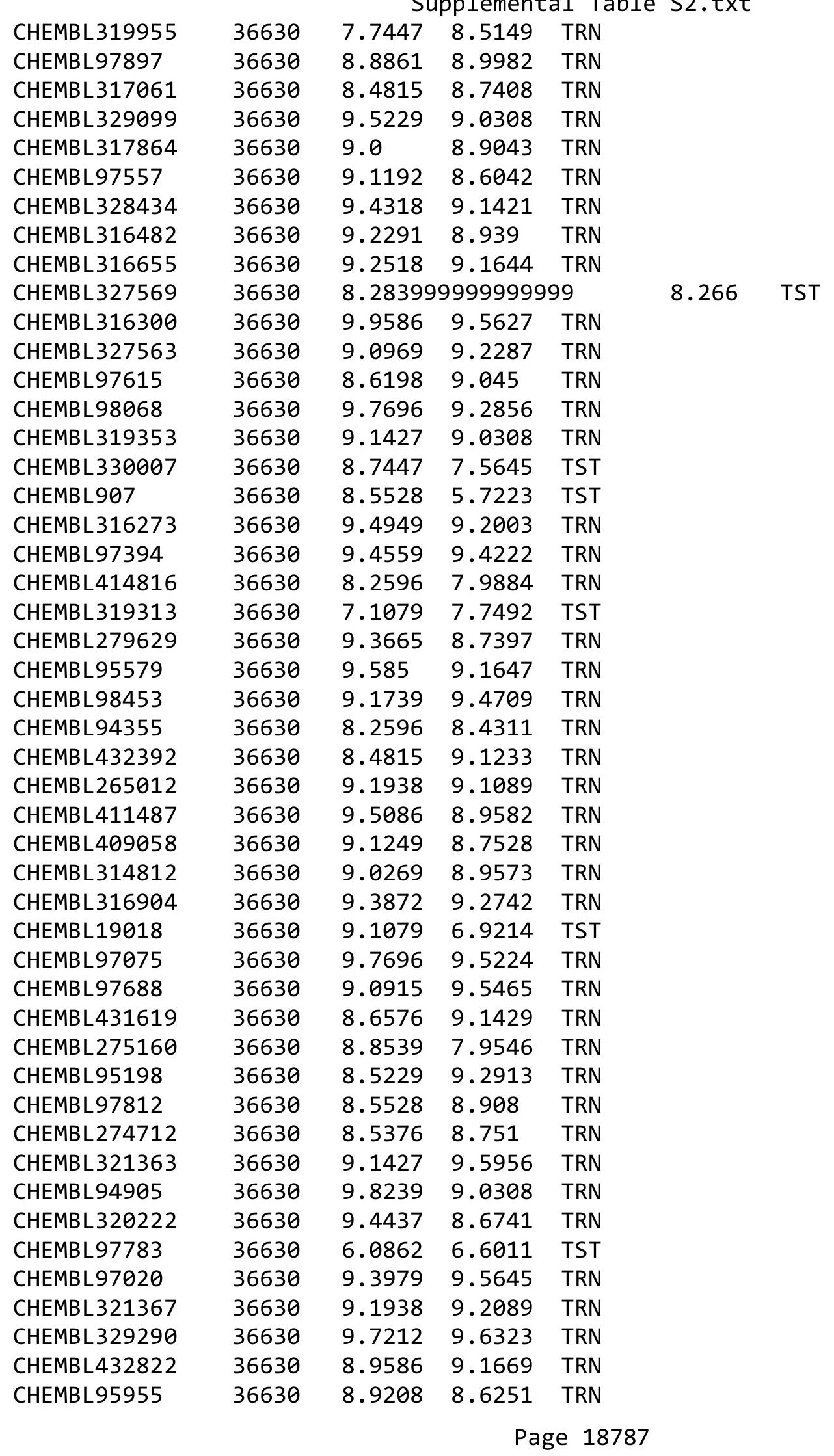




\begin{tabular}{|c|c|c|c|c|c|}
\hline \multicolumn{6}{|c|}{ Supplemental Table S2.txt } \\
\hline CHEMBL262296 & 36630 & 8.9586 & 9.5136 & TRN & \\
\hline CHEMBL97295 & 36630 & 7.8861 & 8.3458 & TRN & \\
\hline CHEMBL330165 & 36630 & 9.2518 & 9.3595 & TST & \\
\hline CHEMBL328176 & 36630 & 8.4202 & 8.5118 & TST & \\
\hline CHEMBL318042 & 36630 & 7.8861 & 7.3742 & TST & \\
\hline CHEMBL 274710 & 36630 & 8.7959 & 8.8332 & TST & \\
\hline CHEMBL97964 & 36630 & 8.4089 & 8.7212 & TST & \\
\hline CHEMBL97464 & 36630 & 9.0862 & 9.1175 & TST & \\
\hline CHEMBL330463 & 36630 & 9.1308 & 8.702 & TST & \\
\hline CHEMBL94145 & 36630 & 9.6576 & 9.224 & TST & \\
\hline CHEMBL97332 & 36630 & 9.699 & 7.8237 & TST & \\
\hline CHEMBL18606 & 36630 & 8.585 & 8.1055 & TST & \\
\hline CHEMBL 98126 & 36630 & 8.8239 & 9.1219 & TST & \\
\hline CHEMBL316706 & 36630 & 9.7959 & 7.8381 & TST & \\
\hline CHEMBL314514 & 36630 & 8.9208 & 8.6795 & TST & \\
\hline CHEMBL329255 & 36630 & 9.0 & 9.1208 & TST & \\
\hline CHEMBL3894163 & 1641781 & 6.5376 & 6.8605 & TRN & \\
\hline CHEMBL2031017 & 1641781 & 7.3979 & 7.61700 & 0000000001 & TRN \\
\hline CHEMBL 3927011 & 1641781 & 6.8861 & 7.0513 & TRN & \\
\hline CHEMBL3962772 & 1641781 & 7.5229 & 7.35 & TST & \\
\hline CHEMBL3947141 & 1641781 & 7.0969 & 7.4152 & TRN & \\
\hline CHEMBL 2031012 & 1641781 & 7.699 & 7.4383 & TRN & \\
\hline CHEMBL3917569 & 1641781 & 7.5229 & 7.2477 & TST & \\
\hline CHEMBL 3942482 & 1641781 & 6.6576 & 6.8155 & TRN & \\
\hline CHEMBL 2030856 & 1641781 & 8.2118 & 7.4138 & TRN & \\
\hline CHEMBL3931099 & 1641781 & 7.5229 & 7.0279 & TRN & \\
\hline CHEMBL3912610 & 1641781 & 8.1035 & 8.3138 & TRN & \\
\hline CHEMBL3945459 & 1641781 & 7.0969 & 6.90799 & 99999999995 & TRN \\
\hline CHEMBL 3984367 & 1641781 & 7.699 & 7.4052 & TRN & \\
\hline CHEMBL3904423 & 1641781 & 7.1549 & 7.6305 & TRN & \\
\hline CHEMBL3936947 & 1641781 & 7.301 & 7.4755 & TRN & \\
\hline CHEMBL 3978452 & 1641781 & 7.301 & 7.5157 & TRN & \\
\hline CHEMBL3981017 & 1641781 & 7.3979 & 7.5757 & TRN & \\
\hline CHEMBL3962921 & 1641781 & 7.699 & 7.7751 & TRN & \\
\hline CHEMBL 2030851 & 1641781 & 7.5229 & 7.5093 & TST & \\
\hline CHEMBL 3890787 & 1641781 & 7.3979 & 7.2639 & TRN & \\
\hline CHEMBL 2031021 & 1641781 & 8.0 & 7.5376 & TRN & \\
\hline CHEMBL 2031025 & 1641781 & 7.5229 & 8.0719 & TRN & \\
\hline CHEMBL3921891 & 1641781 & 7.5229 & 7.21200 & 0000000001 & TST \\
\hline CHEMBL3952199 & 1641781 & 7.3979 & 7.5011 & TRN & \\
\hline CHEMBL 2031008 & 1641781 & 7.699 & 7.5363 & TST & \\
\hline CHEMBL3893121 & 1641781 & 7.5229 & 7.29899 & 99999999995 & TRN \\
\hline CHEMBL 2030852 & 1641781 & 7.3979 & 7.4303 & TST & \\
\hline CHEMBL3891889 & 1641781 & 7.699 & 7.6828 & TST & \\
\hline CHEMBL 2031014 & 1641781 & 7.3979 & 7.8172 & TRN & \\
\hline CHEMBL3893805 & 1641781 & 7.2218 & 7.7007 & TST & \\
\hline CHEMBL3954559 & 1641781 & 7.5229 & 7.0067 & TRN & \\
\hline CHEMBL3936837 & 1641781 & 7.5229 & 7.4541 & TRN & \\
\hline
\end{tabular}


Supplemental Table S2.txt

\begin{tabular}{|c|c|c|c|c|}
\hline HEMBL 20 & 641781 & 7.2218 & 7.4832 & \\
\hline 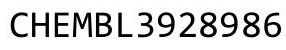 & 1641781 & 7.5229 & 6.9951 & \\
\hline HEMBL 39188 & 641781 & $\partial 969$ & 165 & \\
\hline HEMBL 3889549 & 641781 & 7.699 & 3846 & \\
\hline HEMBL3937806 & 641781 & 7.0969 & .0547 & \\
\hline HEMBL3960836 & 641781 & 7.0969 & 6.9531 & \\
\hline JEMBL396 & 781 & 7.0969 & 6123 & \\
\hline HEMBL396 & 781 & 7.3979 & 7.0657 & \\
\hline HEMBL2031009 & 1641781 & 8.0 & 7.5077 & \\
\hline HEMBL3901575 & L641781 & 8.0 & 7.7777 & \\
\hline HEMBL3955216 & 781 & 5.6108 & 6.5973 & \\
\hline HEMBL 203 & 781 & 8.0 & 7.5829 & \\
\hline HEMBL 397 & 781 & 8.0 & 7.7958 & \\
\hline HEMBL3986556 & 781 & 7.2218 & 7.0464 & \\
\hline HEMBL 2031024 & 781 & 8.2027 & 8.0477 & \\
\hline HEMBL 203 & 781 & 453 & 8. & \\
\hline JEMBL389 & 81 & 6.699 & 812 & \\
\hline HEMBL 203 & 781 & 8.0 & 8.0479 & \\
\hline HEMBL3982792 & 781 & 8.30 & 7.5792 & \\
\hline HEMBL3931548 & 781 & 8.0531 & 8.2118 & \\
\hline HEMBL 398 & 16 & 7.5229 & 6.4237 & \\
\hline HEMBL3 & 31 & 7. & 598 & \\
\hline HEMBL3 & 81 & 7.5229 & 7.3041 & \\
\hline HEMBL 396 & 81 & 7.699 & 7.4503 & \\
\hline HEMBL3980078 & 81 & 7.699 & 7.5221 & \\
\hline HEMBL3892056 & 81 & 7.0458 & 7.0951 & \\
\hline HEMBL3 & 81 & 01 & & \\
\hline HEMBL3 & & 218 & 7.1383 & \\
\hline HEMBL 389 & & 6. & 6.8711 & \\
\hline HEMBL3963300 & 81 & 8.1512 & 7.8165 & \\
\hline JEMBL 393 & 81 & 229 & 7.3999 & \\
\hline HEMBL3 & 31 & 1 & 24 & \\
\hline HEMBL3 & & & 7.149 & \\
\hline HEMBL3940231 & 31 & 6.7959 & 7.0844 & \\
\hline HEMBL3906577 & 81 & 7.301 & 7.5448 & \\
\hline HEMBL395 & 81 & 0 & 7.4504 & \\
\hline HEMBL3 & 31 & 99 & 314 & \\
\hline HEMBL3964058 & & 7.699 & 7.7976 & \\
\hline HEMBL3899265 & 16 & 7.3979 & 7.2608 & \\
\hline HEMBL395 & 16 & 979 & 7.3416 & \\
\hline CHEMBL395 & 16 & 969 & 7.3411 & \\
\hline CHEMBL3927392 & 16 & 7.3979 & 7.4245 & \\
\hline HEMBL3927598 & 781 & 6.6383 & 7.0285 & \\
\hline CHEMBL 389 & 16 & 5.4547 & 6.75 & \\
\hline CHEMBL391 & & & & \\
\hline CHEMBL3964186 & 164 & .1612 & 6.6603 & \\
\hline CHEMBL 2031022 & 1641781 & 7.3979 & 7.0967 & \\
\hline CHEMBL2030853 & 1641781 & 7.699 & 7.5192 & \\
\hline
\end{tabular}

Page 18789 
Supplemental Table S2.txt

\begin{tabular}{|c|c|c|c|c|c|}
\hline CHEMBL 2030850 & 1641781 & 7.2218 & 7.4481 & TST & \\
\hline CHEMBL3890311 & 1641781 & 7.1549 & 7.147 & TST & \\
\hline CHEMBL3890955 & 1641781 & 7.1549 & 7.2752 & TRN & \\
\hline CHEMBL 3901024 & 1641781 & 7.1549 & 7.1694 & TRN & \\
\hline CHEMBL 3965698 & 1641781 & 7.1549 & 6.9703 & TST & \\
\hline CHEMBL3912240 & 1641781 & 6.7959 & 6.7597 & TST & \\
\hline CHEMBL3963540 & 1641781 & 6.8861 & 7.0922 & TRN & \\
\hline CHEMBL 2030859 & 1641781 & 8.0964 & 7.8676 & TST & \\
\hline CHEMBL 3897725 & 1641781 & 8.0 & 7.9608 & TST & \\
\hline CHEMBL 3968982 & 1641781 & 6.2924 & 6.2764 & TRN & \\
\hline CHEMBL3912236 & 1641781 & 7.2218 & 6.991000 & 30000000005 & TRN \\
\hline CHEMBL3917408 & 1641781 & 7.5229 & 7.4981 & TRN & \\
\hline CHEMBL 2031018 & 1641781 & 7.301 & 7.4893 & TRN & \\
\hline CHEMBL 250988 & 455393 & 9.4815 & 9.6217 & TRN & \\
\hline CHEMBL250994 & 455393 & 10.585 & 10.0284 & TRN & \\
\hline CHEMBL249326 & 455393 & 10.0458 & 10.0129 & TRN & \\
\hline CHEMBL398334 & 455393 & 9.7959 & 9.8072 & TST & \\
\hline CHEMBL249730 & 455393 & 9.3979 & 9.8735 & TST & \\
\hline CHEMBL399258 & 455393 & 9.9208 & 9.8873 & TRN & \\
\hline CHEMBL425949 & 455393 & 9.6383 & 9.8084 & TST & \\
\hline CHEMBL251185 & 455393 & 9.6576 & 9.8734 & TRN & \\
\hline CHEMBL250344 & 455393 & 9.6778 & 9.3175 & TRN & \\
\hline CHEMBL399257 & 455393 & 9.9914 & 9.8822 & TRN & \\
\hline CHEMBL251184 & 455393 & 10.1938 & 9.9024 & TRN & \\
\hline CHEMBL 250549 & 455393 & 9.3468 & 9.2567 & TRN & \\
\hline CHEMBL400896 & 455393 & 9.8861 & 9.7754 & TRN & \\
\hline CHEMBL249980 & 455393 & 9.9208 & 10.0408 & TRN & \\
\hline CHEMBL398887 & 455393 & 9.9172 & 9.9675 & TRN & \\
\hline CHEMBL437588 & 455393 & 9.9586 & 9.9329 & TRN & \\
\hline CHEMBL251589 & 455393 & 10.0 & 9.7747 & TRN & \\
\hline CHEMBL249327 & 455393 & 9.7447 & 10.0212 & TRN & \\
\hline CHEMBL400908 & 455393 & 10.2218 & 9.9914 & TRN & \\
\hline CHEMBL401256 & 455393 & 9.5229 & 9.6481 & TRN & \\
\hline CHEMBL248768 & 455393 & 10.2518 & 10.0339 & TRN & \\
\hline CHEMBL 249526 & 455393 & 10.0809 & 10.0185 & TRN & \\
\hline CHEMBL250601 & 455393 & 10.0969 & 10.0097 & TRN & \\
\hline CHEMBL399645 & 455393 & 9.6021 & 9.7693 & TRN & \\
\hline CHEMBL205377 & 455393 & 9.8861 & 9.7965 & TRN & \\
\hline CHEMBL250140 & 455393 & 9.6021 & 9.1911 & TRN & \\
\hline CHEMBL 250550 & 455393 & 9.6383 & 9.7819 & TST & \\
\hline CHEMBL250548 & 455393 & 9.3468 & 9.7034 & TRN & \\
\hline CHEMBL399521 & 455393 & 8.7959 & 9.7213 & TST & \\
\hline CHEMBL401079 & 455393 & 9.6021 & 9.7514 & TRN & \\
\hline CHEMBL251382 & 455393 & 8.6696 & 9.7686 & TRN & \\
\hline CHEMBL400519 & 455393 & 9.6021 & 9.8582 & TST & \\
\hline CHEMBL401102 & 455393 & 10.0605 & 10.0665 & TRN & \\
\hline CHEMBL249527 & 455393 & 10.1805 & 9.9408 & TRN & \\
\hline CHEMBL250800 & 455393 & 9.8239 & 9.9699 & TRN & \\
\hline
\end{tabular}

Page 18790 


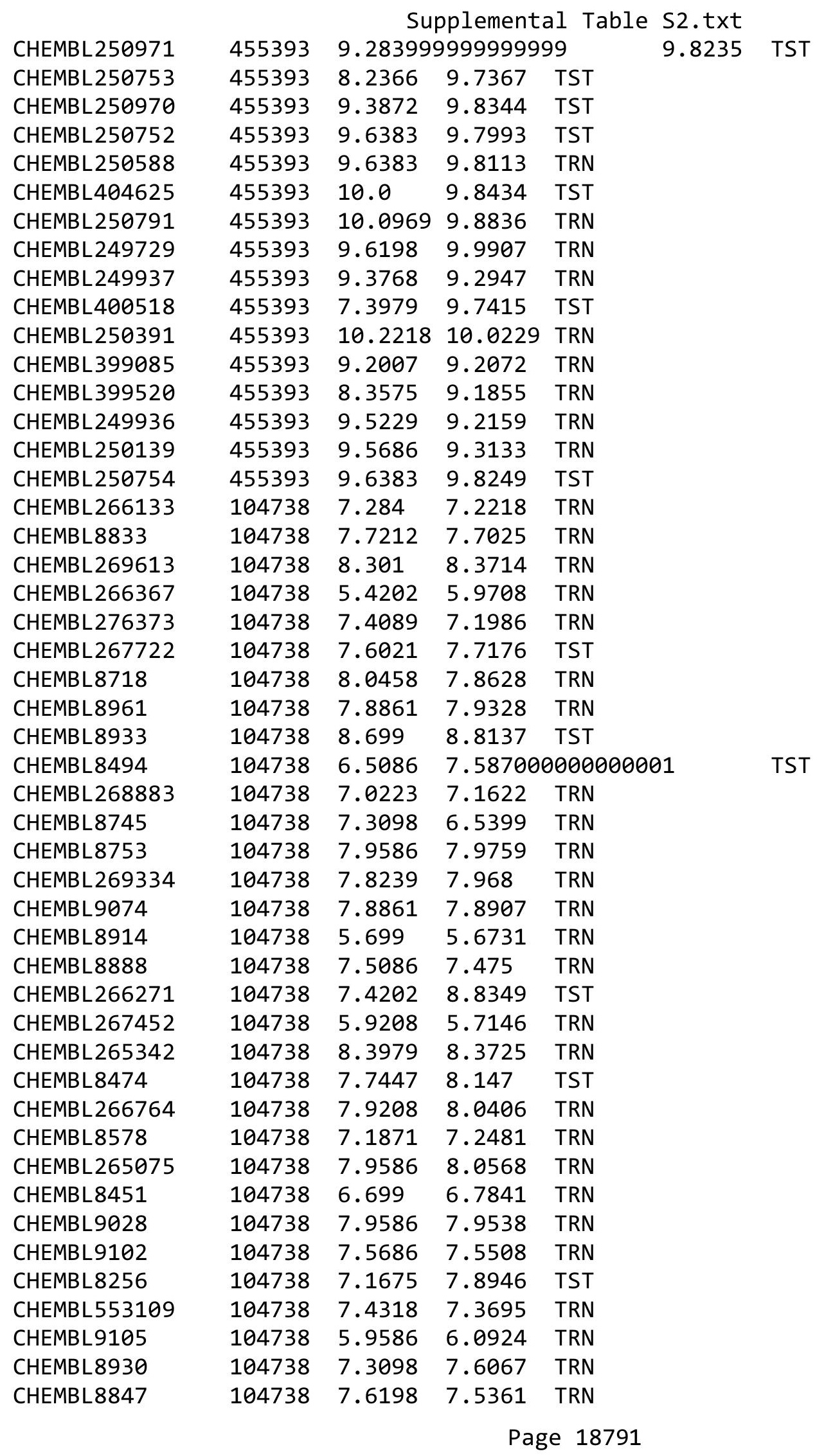




\begin{tabular}{|c|c|c|c|c|c|}
\hline \multirow[b]{2}{*}{ CHEMBL8984 } & \multicolumn{5}{|c|}{ Supplemental Table S2.txt } \\
\hline & 104738 & 6.4559 & 6.2813 & TRN & \\
\hline CHEMBL8828 & 104738 & 8.0 & 7.8995 & TRN & \\
\hline CHEMBL263717 & 104738 & 7.9208 & 7.9487 & TRN & \\
\hline CHEMBL8539 & 104738 & 5.8239 & 5.8007 & TRN & \\
\hline CHEMBL266294 & 104738 & 5.0269 & 5.45799 & 9999999999 & TRN \\
\hline CHEMBL251481 & 104738 & 6.6383 & 7.6978 & TST & \\
\hline CHEMBL418335 & 104738 & 7.0862 & 8.3632 & TST & \\
\hline CHEMBL267503 & 104738 & 8.0 & 7.9296 & TRN & \\
\hline CHEMBL268143 & 104738 & 6.9208 & 6.7653 & TRN & \\
\hline CHEMBL418521 & 104738 & 5.8539 & 5.732 & TRN & \\
\hline CHEMBL8634 & 104738 & 6.8539 & 6.9715 & TRN & \\
\hline CHEMBL267533 & 104738 & 8.699 & 8.7907 & TRN & \\
\hline CHEMBL266579 & 104738 & 7.8239 & 7.7203 & TRN & \\
\hline CHEMBL8868 & 104738 & 7.3979 & 7.5984 & TRN & \\
\hline CHEMBL268405 & 104738 & 7.6778 & 7.4944 & TRN & \\
\hline CHEMBL8917 & 104738 & 5.8239 & 7.4311 & TST & \\
\hline CHEMBL8282 & 104738 & 6.1612 & 7.3017 & TST & \\
\hline CHEMBL6216 & 104738 & 5.8539 & 7.1659 & TST & \\
\hline CHEMBL8761 & 104738 & 7.6778 & 7.2972 & TST & \\
\hline CHEMBL8580 & 104738 & 7.1308 & 7.5483 & TST & \\
\hline CHEMBL167423 & 688676 & 4.1 & 4.4422 & TRN & \\
\hline CHEMBL468037 & 688676 & 4.6 & 4.7456 & TRN & \\
\hline CHEMBL1308088 & 688676 & 4.9 & 5.0561 & TRN & \\
\hline CHEMBL289277 & 688676 & 4.2 & 4.584 & TRN & \\
\hline CHEMBL1524617 & 688676 & 5.3 & 5.3746 & TST & \\
\hline CHEMBL1558796 & 688676 & 4.8 & 4.7424 & TRN & \\
\hline CHEMBL329673 & 688676 & 4.3 & 4.5504 & TRN & \\
\hline CHEMBL1579130 & 688676 & 6.0 & 5.7802 & TRN & \\
\hline CHEMBL1569493 & 688676 & 6.2 & 6.1549 & TRN & \\
\hline CHEMBL1510786 & 688676 & 4.3 & 4.6869 & TST & \\
\hline CHEMBL1595845 & 688676 & 4.3 & 4.4921 & TST & \\
\hline CHEMBL1609459 & 688676 & 5.0 & 5.3851 & TRN & \\
\hline CHEMBL1344952 & 688676 & 4.1 & 4.4581 & TRN & \\
\hline CHEMBL105712 & 688676 & 5.1 & 5.2545 & TRN & \\
\hline CHEMBL1549844 & 688676 & 4.8 & 4.8314 & TST & \\
\hline CHEMBL1580759 & 688676 & 4.9 & 4.6092 & TRN & \\
\hline CHEMBL195953 & 688676 & 4.4 & 4.4265 & TRN & \\
\hline CHEMBL1393325 & 688676 & 4.3 & 4.5635 & TRN & \\
\hline CHEMBL1447588 & 688676 & 4.4 & $5.28100 t$ & 0000000001 & TST \\
\hline CHEMBL1569226 & 688676 & 5.4 & 5.4907 & TRN & \\
\hline CHEMBL1492978 & 688676 & 4.4 & 4.6584 & TST & \\
\hline CHEMBL1364985 & 688676 & 4.1 & 4.7172 & TRN & \\
\hline CHEMBL140 & 688676 & 4.7 & 4.5713 & TRN & \\
\hline CHEMBL1522486 & 688676 & 4.4 & 4.7665 & TRN & \\
\hline CHEMBL91732 & 688676 & 4.1 & 4.8309 & TRN & \\
\hline CHEMBL1338613 & 688676 & 4.5 & 4.5246 & TST & \\
\hline CHEMBL1600998 & 688676 & 5.6 & 5.6385 & TRN & \\
\hline CHEMBL1496957 & 688676 & 4.9 & 4.8964 & TRN & \\
\hline
\end{tabular}




\begin{tabular}{|c|c|c|c|c|c|}
\hline \\
\hline CHEMBL1448387 & 688676 & 4.7 & 4.7832 & TRN & \\
\hline CHEMBL1519327 & 688676 & 6.5 & 6.6291 & TRN & \\
\hline CHEMBL1309179 & 688676 & 5.1 & 5.013 & TRN & \\
\hline CHEMBL1450018 & 688676 & 4.4 & 4.5951 & TRN & \\
\hline CHEMBL468582 & 688676 & 4.4 & 4.5336 & TST & \\
\hline CHEMBL1304981 & 688676 & 4.3 & 4.4289 & TST & \\
\hline CHEMBL1406645 & 688676 & 4.5 & 4.6226 & TRN & \\
\hline CHEMBL15063 & 688676 & 5.1 & 4.7205 & TRN & \\
\hline CHEMBL1331245 & 688676 & 4.3 & 4.4379 & TRN & \\
\hline CHEMBL53330 & 688676 & 4.5 & 4.4597 & TRN & \\
\hline CHEMBL1452158 & 688676 & 4.1 & 4.5301 & TRN & \\
\hline CHEMBL1456906 & 688676 & 4.3 & 4.8486 & TST & \\
\hline CHEMBL39763 & 688676 & 5.4 & 4.5348 & TRN & \\
\hline CHEMBL1526319 & 688676 & 4.4 & 4.5672 & TRN & \\
\hline CHEMBL1499545 & 688676 & 5.4 & 5.4824 & TRN & \\
\hline CHEMBL443949 & 688676 & 4.3 & 4.5853 & TRN & \\
\hline CHEMBL334255 & 688676 & 5.0 & 5.1145 & TRN & \\
\hline CHEMBL1545634 & 688676 & 6.7001 & 6.7593 & TRN & \\
\hline CHEMBL1430204 & 688676 & 4.5 & 4.6276 & TRN & \\
\hline CHEMBL1527567 & 688676 & 4.5 & 4.4981 & TRN & \\
\hline CHEMBL 275626 & 688676 & 8.0 & 4.5526 & TRN & \\
\hline CHEMBL1585396 & 688676 & 4.3 & 4.5258 & TRN & \\
\hline CHEMBL1366408 & 688676 & 4.5 & 4.7571 & TRN & \\
\hline CHEMBL1421613 & 688676 & 4.7 & 4.5108 & TST & \\
\hline CHEMBL 28319 & 688676 & 4.4 & 4.5677 & TRN & \\
\hline CHEMBL486193 & 688676 & 4.3 & 4.9059 & TRN & \\
\hline CHEMBL1547989 & 688676 & 4.9 & 4.6185 & TRN & \\
\hline CHEMBL1333512 & 688676 & 4.4 & 4.7912 & TRN & \\
\hline CHEMBL1576086 & 688676 & 4.4 & 4.5887 & TRN & \\
\hline CHEMBL1529759 & 688676 & 4.1 & 4.6056 & TST & \\
\hline CHEMBL3391990 & 688676 & 4.4 & 4.668 & TST & \\
\hline CHEMBL454173 & 688676 & 6.0 & 4.8758 & TRN & \\
\hline CHEMBL1221925 & 688676 & 4.3 & 4.543 & TRN & \\
\hline CHEMBL1492884 & 688676 & 4.4 & 4.5754 & TRN & \\
\hline CHEMBL935 & 688676 & 4.3 & 4.5952 & TRN & \\
\hline CHEMBL 242080 & 688676 & 4.4 & 4.6669 & TRN & \\
\hline CHEMBL1530684 & 688676 & 4.5 & 4.6005 & TRN & \\
\hline CHEMBL1485974 & 688676 & 4.5 & 4.5419 & TRN & \\
\hline CHEMBL1200471 & 688676 & 6.7001 & 6.8937 & TRN & \\
\hline CHEMBL509531 & 688676 & 5.0 & 5.0337 & TST & \\
\hline CHEMBL1517425 & 688676 & 4.3 & 4.33899 & 99999999995 & TRN \\
\hline CHEMBL 389950 & 688676 & 4.3 & 4.4049 & TST & \\
\hline CHEMBL 220845 & 688676 & 4.5 & 4.4732 & TRN & \\
\hline CHEMBL1419151 & 688676 & 4.3 & 4.7844 & TRN & \\
\hline CHEMBL1485360 & 688676 & 5.0 & 4.7905 & TST & \\
\hline CHEMBL1330518 & 688676 & 4.4 & 4.5188 & TRN & \\
\hline CHEMBL1604283 & 688676 & 4.2 & 5.165 & TST & \\
\hline CHEMBL462576 & 688676 & 4.4 & 4.6174 & TRN & \\
\hline
\end{tabular}




\begin{tabular}{|c|c|c|c|c|c|}
\hline CHEMBL1428964 & 688676 & 4.1 & \multicolumn{2}{|c|}{4.531000000000001} & TRN \\
\hline CHEMBL1535689 & 688676 & 4.3 & 4.5382 & TRN & \\
\hline CHEMBL1328092 & 688676 & 4.1 & 4.8262 & TRN & \\
\hline CHEMBL36296 & 688676 & 4.3 & 4.4555 & TRN & \\
\hline CHEMBL1450607 & 688676 & 4.7 & 4.8198 & TRN & \\
\hline CHEMBL1451833 & 688676 & 4.5 & 4.6433 & TST & \\
\hline CHEMBL1369384 & 688676 & 4.1 & 4.6859 & TRN & \\
\hline CHEMBL175193 & 688676 & 4.0 & 4.363 & TRN & \\
\hline CHEMBL1518369 & 688676 & 4.4 & 4.5964 & TRN & \\
\hline CHEMBL1409985 & 688676 & 5.3 & 5.5189 & TRN & \\
\hline CHEMBL8320 & 688676 & 4.3 & 4.5357 & TRN & \\
\hline CHEMBL194399 & 688676 & 4.4 & 4.5142 & TRN & \\
\hline CHEMBL1559341 & 688676 & 4.4 & 4.6493 & TRN & \\
\hline CHEMBL162598 & 688676 & 4.5 & 4.4829 & TST & \\
\hline CHEMBL1142 & 688676 & 4.6 & 4.5618 & TRN & \\
\hline CHEMBL144530 & 688676 & 4.6 & 4.4867 & TRN & \\
\hline CHEMBL1442113 & 688676 & 7.0 & 5.2249 & TRN & \\
\hline CHEMBL230156 & 688676 & 4.3 & 4.4329 & TRN & \\
\hline CHEMBL440287 & 688676 & 4.4 & 4.6984 & TRN & \\
\hline CHEMBL31425 & 688676 & 4.3 & 4.55399 & 9999999999 & TRN \\
\hline CHEMBL1566504 & 688676 & 4.4 & 4.545 & TST & \\
\hline CHEMBL1414154 & 688676 & 4.4 & 4.3579 & TRN & \\
\hline CHEMBL 224282 & 688676 & 4.3 & 4.4215 & TRN & \\
\hline CHEMBL1462995 & 688676 & 4.4 & 4.7307 & TST & \\
\hline CHEMBL1479161 & 688676 & 7.699 & 4.6333 & TRN & \\
\hline CHEMBL70582 & 688676 & 5.0 & 4.6985 & TRN & \\
\hline CHEMBL1526721 & 688676 & 5.3 & 5.3279 & TRN & \\
\hline CHEMBL1612246 & 688676 & 4.5 & 4.6684 & TRN & \\
\hline CHEMBL1565705 & 688676 & 4.3 & 4.5111 & TRN & \\
\hline CHEMBL1492104 & 688676 & 5.0 & 4.8899 & TST & \\
\hline CHEMBL1449018 & 688676 & 4.9 & 4.7896 & TRN & \\
\hline CHEMBL552741 & 688676 & 4.9 & 4.8295 & TRN & \\
\hline CHEMBL57394 & 688676 & 4.6 & 4.6503 & TRN & \\
\hline CHEMBL192627 & 688676 & 4.9 & 4.7952 & TRN & \\
\hline CHEMBL346918 & 688676 & 4.1 & 4.5959 & TST & \\
\hline CHEMBL280998 & 688676 & 4.4 & 4.6075 & TRN & \\
\hline CHEMBL445957 & 688676 & 4.6 & 4.6111 & TRN & \\
\hline CHEMBL1408847 & 688676 & 5.4 & 5.5794 & TRN & \\
\hline CHEMBL540851 & 688676 & 4.6 & 4.643 & TST & \\
\hline CHEMBL1489064 & 688676 & 4.2 & 4.4417 & TRN & \\
\hline CHEMBL85811 & 688676 & 4.3 & 4.4001 & TRN & \\
\hline CHEMBL14068 & 688676 & 9.0969 & 4.7634 & TRN & \\
\hline CHEMBL402063 & 688676 & 6.0 & 5.5316 & TST & \\
\hline CHEMBL84685 & 688676 & 4.1 & 4.7072 & TRN & \\
\hline CHEMBL1391326 & 688676 & 4.8 & 4.6589 & TRN & \\
\hline CHEMBL1407826 & 688676 & 4.9 & 4.8968 & TST & \\
\hline CHEMBL1602699 & 688676 & 5.5 & 5.4876 & TRN & \\
\hline CHEMBL1236200 & 688676 & 4.5 & 4.5537 & TRN & \\
\hline
\end{tabular}




\begin{tabular}{|c|c|c|c|c|c|}
\hline \\
\hline CHEMBL8739 & 688676 & 4.3 & 4.4113 & TRN & \\
\hline CHEMBL44072 & 688676 & 4.4 & 4.5161 & TRN & \\
\hline CHEMBL284588 & 688676 & 4.4 & 4.7251 & TRN & \\
\hline CHEMBL194400 & 688676 & 4.1 & 4.4833 & TST & \\
\hline CHEMBL1471289 & 688676 & 4.4 & 4.6672 & TST & \\
\hline CHEMBL1303139 & 688676 & 5.5 & 5.4271 & TST & \\
\hline CHEMBL1562104 & 688676 & 5.7 & 5.6199 & TST & \\
\hline CHEMBL1319452 & 688676 & 4.9 & 4.717 & TST & \\
\hline CHEMBL70971 & 688676 & 4.9 & 4.7924 & TST & \\
\hline CHEMBL1324314 & 688676 & 4.3 & 4.6464 & TST & \\
\hline CHEMBL1594090 & 688676 & 5.3 & 4.6381 & TST & \\
\hline CHEMBL357097 & 63756 & 6.3372 & 6.9173 & TST & \\
\hline CHEMBL345988 & 63756 & 6.8327 & 9.1245 & TST & \\
\hline CHEMBL554983 & 63756 & 7.1427 & 8.3587 & TST & \\
\hline CHEMBL40734 & 63756 & 9.4089 & 9.4219 & TRN & \\
\hline CHEMBL544868 & 63756 & 7.2366 & 7.2488 & TRN & \\
\hline CHEMBL543457 & 63756 & 3.0 & 6.6923 & TST & \\
\hline CHEMBL544867 & 63756 & 7.9586 & 7.9061 & TRN & \\
\hline CHEMBL540082 & 63756 & 6.8013 & 6.7864 & TRN & \\
\hline CHEMBL553351 & 63756 & 7.9101 & 7.9418 & TRN & \\
\hline CHEMBL544865 & 63756 & 6.3526 & 6.3527 & TRN & \\
\hline CHEMBL347282 & 63756 & 7.3279 & 7.3313 & TRN & \\
\hline CHEMBL66031 & 63756 & 11.0969 & 11.0921 & TRN & \\
\hline CHEMBL153419 & 63756 & 6.71899 & 999999999 & 6.7212 & TST \\
\hline CHEMBL346863 & 63756 & 7.3979 & 7.4005 & TRN & \\
\hline CHEMBL415738 & 63756 & 9.0 & 8.4562 & TST & \\
\hline CHEMBL346846 & 63756 & 7.0969 & 7.0703 & TRN & \\
\hline CHEMBL29197 & 63756 & 10.6021 & 10.6006 & TRN & \\
\hline CHEMBL152905 & 63756 & 9.5686 & 9.5018 & TRN & \\
\hline CHEMBL152984 & 63756 & 6.1296 & 6.131 & TRN & \\
\hline CHEMBL448730 & 63756 & 5.3872 & 5.3725 & TRN & \\
\hline CHEMBL542755 & 63756 & 7.699 & 7.6844 & TRN & \\
\hline CHEMBL153409 & 63756 & 6.1355 & 6.1281 & TRN & \\
\hline CHEMBL153573 & 63756 & 9.0 & 9.0135 & TRN & \\
\hline CHEMBL553137 & 63756 & 6.8794 & 6.8872 & TRN & \\
\hline CHEMBL39337 & 63756 & 9.3565 & 9.3528 & TRN & \\
\hline CHEMBL329672 & 63756 & 7.6383 & 8.5599 & TST & \\
\hline CHEMBL357367 & 63756 & 8.0269 & 7.991000 & 00000000005 & TRN \\
\hline CHEMBL 3085277 & 63756 & 6.2692 & 6.8468 & TST & \\
\hline CHEMBL555921 & 63756 & 7.8996 & 7.9209 & TRN & \\
\hline CHEMBL153739 & 63756 & 7.7033 & 7.71 & TRN & \\
\hline CHEMBL539822 & 63756 & 9.3279 & 9.3397 & TRN & \\
\hline CHEMBL538814 & 63756 & 6.3372 & 6.3331 & TRN & \\
\hline CHEMBL149512 & 63756 & 6.1308 & 6.1556 & TRN & \\
\hline CHEMBL356850 & 63756 & 8.7447 & 8.7658 & TRN & \\
\hline CHEMBL155278 & 63756 & 8.6778 & 8.7555 & TRN & \\
\hline CHEMBL151593 & 63756 & 8.5686 & 8.5561 & TRN & \\
\hline CHEMBL357326 & 63756 & 4.0 & 6.4301 & TST & \\
\hline
\end{tabular}




\begin{tabular}{|c|c|c|c|c|c|c|}
\hline & & \multicolumn{5}{|c|}{ Supplemental Table S2.txt } \\
\hline CHEMBL150280 & 63756 & 6.5784 & 7.0786 & TST & & \\
\hline CHEMBL155100 & 63756 & 6.5654 & 6.5675 & TRN & & \\
\hline CHEMBL544640 & 63756 & 5.6757 & 7.1198 & TST & & \\
\hline CHEMBL53753 & 63756 & 11.0969 & 11.0919 & TRN & & \\
\hline CHEMBL540590 & 63756 & 7.3188 & 7.3392 & TRN & & \\
\hline CHEMBL153170 & 63756 & 7.5376 & 7.5405 & TRN & & \\
\hline CHEMBL153518 & 63756 & 5.3696 & 5.3739 & TRN & & \\
\hline CHEMBL345294 & 63756 & 7.9586 & 7.9545 & TRN & & \\
\hline CHEMBL153206 & 63756 & 8.9208 & 8.9314 & TRN & & \\
\hline CHEMBL358934 & 63756 & 8.9586 & 8.9758 & TRN & & \\
\hline CHEMBL153525 & 63756 & 8.9066 & 8.8967 & TRN & & \\
\hline CHEMBL357570 & 63756 & 8.1024 & 8.0938 & TRN & & \\
\hline CHEMBL150390 & 63756 & 5.0 & 5.0045 & TRN & & \\
\hline CHEMBL355982 & 63756 & 7.4559 & 7.4327 & TRN & & \\
\hline CHEMBL423224 & 63756 & 7.5086 & 8.1327 & TST & & \\
\hline CHEMBL555739 & 63756 & 4.0 & 8.055 & TST & & \\
\hline CHEMBL348003 & 63756 & 3.0 & 5.7393 & TST & & \\
\hline CHEMBL412142 & 954695 & 3.5584 & 3.7683 & TRN & & \\
\hline CHEMBL1186585 & 954695 & 3.0208 & 3.2567 & TRN & & \\
\hline CHEMBL472940 & 954695 & 4.0017 & 4.0871 & TRN & & \\
\hline CHEMBL558642 & 954695 & 4.8385 & 4.9668 & TRN & & \\
\hline CHEMBL3349342 & 954695 & 4.8106 & 5.072 & TRN & & \\
\hline CHEMBL188678 & 954695 & 4.2084 & 3.9605 & TRN & & \\
\hline CHEMBL 217354 & 954695 & 5.9086 & 6.0886 & TRN & & \\
\hline CHEMBL392695 & 954695 & 6.1365 & 5.8777 & TRN & & \\
\hline CHEMBL102714 & 954695 & 3.1571 & 3.0811 & TRN & & \\
\hline CHEMBL3392440 & 954695 & 4.1727 & 3.9626 & TRN & & \\
\hline CHEMBL1256459 & 954695 & 7.48 & 7.6654 & TRN & & \\
\hline CHEMBL191334 & 954695 & 3.3034 & 3.0892 & TRN & & \\
\hline CHEMBL240954 & 954695 & 3.3652 & 3.2174 & TST & & \\
\hline CHEMBL1643959 & 954695 & 4.0351 & 4.2605 & TRN & & \\
\hline CHEMBL3199475 & 954695 & 3.9808 & 4.087 & TRN & & \\
\hline CHEMBL1404918 & 954695 & 2.9303 & 2.8382 & TRN & & \\
\hline CHEMBL 2144069 & 954695 & 3.9914 & 4.3351 & TRN & & \\
\hline CHEMBL209148 & 954695 & 4.7955 & 4.7641 & TRN & & \\
\hline CHEMBL259181 & 954695 & 5.1242 & 5.317 & TRN & & \\
\hline CHEMBL180127 & 954695 & 4.5343 & 4.5783 & TRN & & \\
\hline CHEMBL483849 & 954695 & 2.82 & 2.1227 & TST & & \\
\hline CHEMBL1788116 & 954695 & 5.6525 & 5.5461 & TRN & & \\
\hline CHEMBL1230020 & 954695 & 2.9436 & 3.0285 & TRN & & \\
\hline CHEMBL393929 & 954695 & 3.5004 & 3.3939 & TRN & & \\
\hline CHEMBL573107 & 954695 & 5.2637 & 5.1648 & TRN & & \\
\hline CHEMBL585951 & 954695 & 6.5152 & 6.6265 & TRN & & \\
\hline CHEMBL 255342 & 954695 & 3.243990 & 79999999 & 998 & 3.1002 & TRN \\
\hline CHEMBL399530 & 954695 & 4.5683 & 4.5671 & TRN & & \\
\hline CHEMBL509032 & 954695 & 6.1457 & 5.9674 & TRN & & \\
\hline CHEMBL2137530 & 954695 & 4.6765 & 4.6312 & TRN & & \\
\hline CHEMBL515416 & 954695 & 4.079 & 4.1604 & TRN & & \\
\hline
\end{tabular}




\begin{tabular}{|c|c|c|c|c|c|}
\hline \multicolumn{6}{|c|}{ Supplemental Table S2.txt } \\
\hline CHEMBL1909414 & 954695 & 3.3005 & 3.1309 & TRN & \\
\hline CHEMBL 3186408 & 954695 & 4.0797 & 3.7385 & TST & \\
\hline CHEMBL202721 & 954695 & 4.5293 & 4.3055 & TRN & \\
\hline CHEMBL220241 & 954695 & 4.6413 & 4.7046 & TRN & \\
\hline CHEMBL512504 & 954695 & 4.2148 & 4.3885 & TRN & \\
\hline CHEMBL1673039 & 954695 & 5.1619 & 5.0756 & TRN & \\
\hline CHEMBL577784 & 954695 & 4.6983 & 4.793 & TRN & \\
\hline CHEMBL 379300 & 954695 & 7.0487 & 6.9806 & TRN & \\
\hline CHEMBL9470 & 954695 & 6.0061 & 6.0219 & TST & \\
\hline CHEMBL221137 & 954695 & 4.8757 & 5.1373 & TST & \\
\hline CHEMBL2363137 & 954695 & 5.3982 & 5.4842 & TRN & \\
\hline CHEMBL 213100 & 954695 & 5.3686 & 5.3014 & TRN & \\
\hline CHEMBL1970879 & 954695 & 5.6277 & 5.4953 & TRN & \\
\hline CHEMBL65 & 954695 & 6.8309 & 6.6888 & TRN & \\
\hline CHEMBL92309 & 954695 & 3.2015 & 3.1819 & TST & \\
\hline CHEMBL 2005886 & 954695 & 5.9206 & 5.7391 & TRN & \\
\hline CHEMBL483847 & 954695 & 4.7385 & 4.5582 & TRN & \\
\hline CHEMBL189584 & 954695 & 3.7487 & 3.7477 & TRN & \\
\hline CHEMBL449158 & 954695 & 6.1077 & 6.9007 & TST & \\
\hline CHEMBL1516890 & 954695 & 3.7262 & 3.8662 & TRN & \\
\hline CHEMBL135561 & 954695 & 5.1748 & 4.9885 & TRN & \\
\hline CHEMBL1242367 & 954695 & 5.3577 & 5.3334 & TRN & \\
\hline CHEMBL 373751 & 954695 & 3.5478 & 3.6814 & TRN & \\
\hline CHEMBL1590308 & 954695 & 2.9634 & 3.5652 & TST & \\
\hline CHEMBL1357247 & 954695 & 3.147 & 3.2532 & TRN & \\
\hline CHEMBL192566 & 954695 & 8.8033 & 8.9006 & TST & \\
\hline CHEMBL 258844 & 954695 & 5.0437 & 4.994 & TST & \\
\hline CHEMBL 379975 & 954695 & 4.7596 & 4.2348 & TST & \\
\hline CHEMBL 300389 & 954695 & 7.4176 & 7.3068 & TST & \\
\hline CHEMBL 2134202 & 954695 & 3.7689 & 3.7042 & TST & \\
\hline CHEMBL1190711 & 954695 & 5.7555 & 5.3029 & TST & \\
\hline CHEMBL210618 & 954695 & 2.9832 & 2.9109 & TST & \\
\hline CHEMBL514499 & 954695 & 7.8993 & 7.5494 & TST & \\
\hline CHEMBL 222102 & 954695 & 3.3712 & 3.5594 & TST & \\
\hline CHEMBL3931341 & 1641300 & 7.5528 & 6.99700 & 0000000001 & TRN \\
\hline CHEMBL3930614 & 1641300 & 6.1537 & 6.4515 & TRN & \\
\hline CHEMBL3912253 & 1641300 & 7.6576 & 7.4402 & TRN & \\
\hline CHEMBL3978993 & 1641300 & 3.8539 & 5.9224 & TRN & \\
\hline CHEMBL3957813 & 1641300 & 4.0 & 6.5173 & TST & \\
\hline CHEMBL3910177 & 1641300 & 8.0969 & 8.3655 & TRN & \\
\hline CHEMBL3903356 & 1641300 & 6.9136 & 7.5964 & TRN & \\
\hline CHEMBL3896898 & 1641300 & 6.1198 & 6.45799 & 9999999999 & TRN \\
\hline CHEMBL3911735 & 1641300 & 6.9469 & 6.6041 & TRN & \\
\hline CHEMBL3983001 & 1641300 & 5.8617 & 6.0605 & TRN & \\
\hline CHEMBL3958774 & 1641300 & 6.4921 & 6.0098 & TRN & \\
\hline CHEMBL 3932183 & 1641300 & 6.8928 & 7.0694 & TRN & \\
\hline CHEMBL3982394 & 1641300 & 6.4776 & 6.5465 & TRN & \\
\hline CHEMBL3934175 & 1641300 & 7.4437 & 7.066 & TRN & \\
\hline
\end{tabular}


Supplemental Table S2.txt

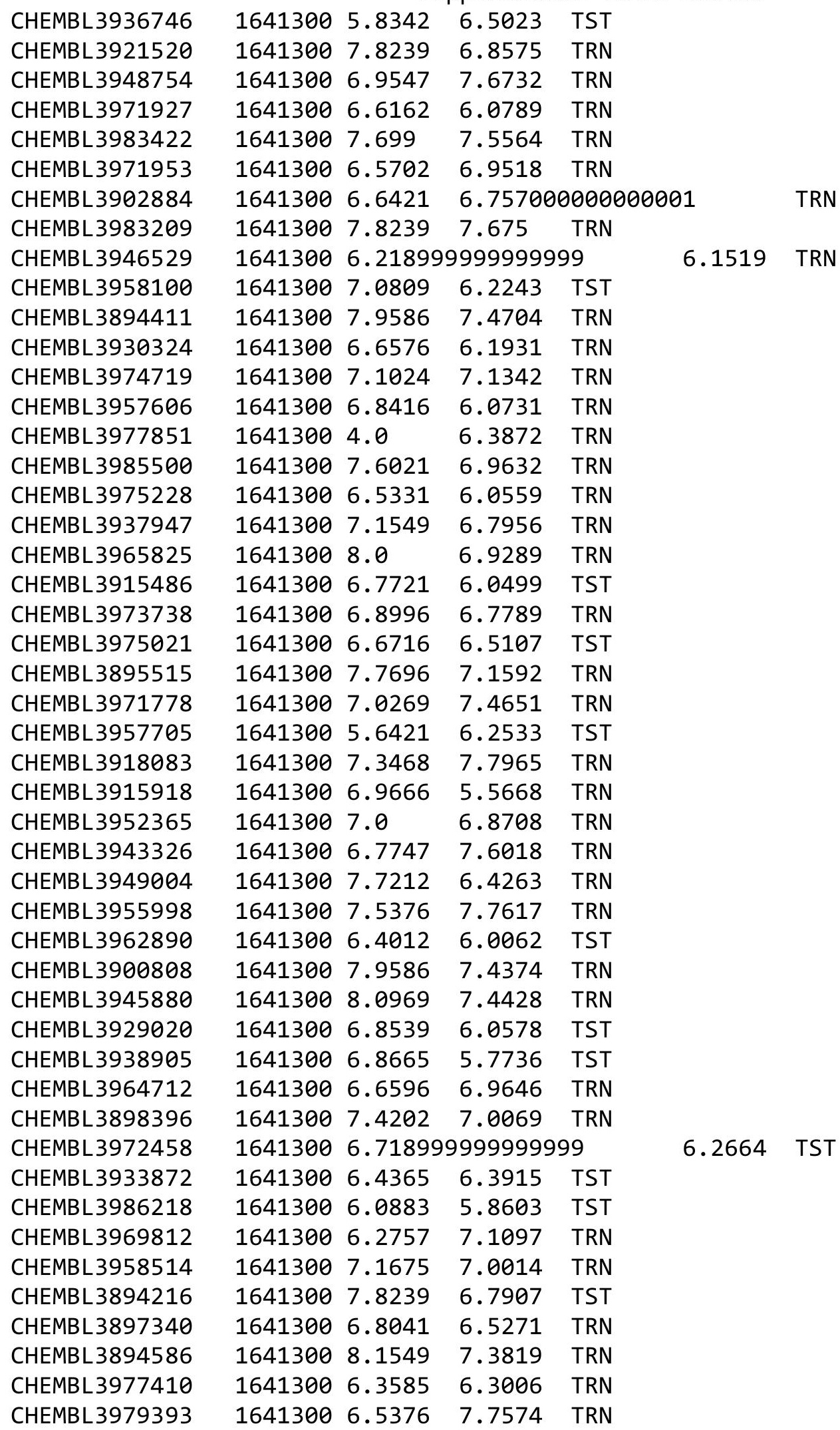

Page 18798 
Supplemental Table S2.txt

\begin{tabular}{|c|c|c|c|c|}
\hline 048 & 541300 & 2611 & 5.7907 & בו \\
\hline pror & 641300 & 7.2366 & 7.1767 & \\
\hline EN & 300 & 367 & 5942 & \\
\hline AEMBL & 300 & & 261 & \\
\hline AEMBL3902168 & 641300 & 7.6198 & 5795 & \\
\hline HEMBL3909733 & 300 & 4.0 & .7907 & \\
\hline 976 & 300 & 7.2291 & 083 & \\
\hline EMBL3 & 300 & & & \\
\hline HEMBL3915757 & 300 & 4.0 & 9251 & \\
\hline HEMBL3941184 & 300 & 7.284 & 8533 & \\
\hline HEMBL3939403 & 300 & 5.8225 & & \\
\hline AEMBL & 00 & 914 & 103 & \\
\hline AEMBL & & 177 & 902 & \\
\hline HEMBL3944268 & 300 & 5.6326 & 7896 & \\
\hline AEMBL3960295 & 300 & 6.4868 & 5822 & \\
\hline HEMBL3 & $\partial 0$ & 229 & 365 & \\
\hline HEMBL3 & & 596 & 207 & \\
\hline HEMBL3 & 00 & 7.5086 & 921 & \\
\hline HEMBL3920667 & 00 & 8.2218 & & \\
\hline HEMBL3913525 & 300 & 7.6021 & & I KIV \\
\hline HEMBL & $\partial 0$ & 8. & & RN \\
\hline IEM & & 1 & & MIV \\
\hline AEMBL & 00 & 4. & & \\
\hline AEMPI & & 4. & & IST \\
\hline AEMBL3955509 & 00 & 7. & 54 & I RIN \\
\hline HEMBL3 & 00 & 4 & 67 & SI \\
\hline HFM & & 7 & & RN \\
\hline 9 & & 721 & & \\
\hline AEMBL3893051 & & 223 & & IRN \\
\hline HEMBL3925964 & 00 & 7.5376 & 911 & TRN \\
\hline AEMBL & 00 & 4. & 172 & ST \\
\hline HFM & 30 & 16 & & 「RN \\
\hline 3 & & & & ST \\
\hline HEMBL3926390 & & 5 . & & $\mathrm{RN}$ \\
\hline HEMBL3901058 & 00 & 6.3947 & & ST \\
\hline 3 & 20 & 861 & 27 & TRN \\
\hline 8 & & & & ГRN \\
\hline HEMBL3 & & & & TRN \\
\hline HEMBL39278 & 00 & 7.2007 & & $\Gamma R$ \\
\hline U & & 86 & & RN \\
\hline HEMBL3 & & 8 . & 42 & RN \\
\hline HEMBL3968062 & & 6.3536 & & ST \\
\hline HEMBL3985485 & 300 & 7.8239 & 2555 & TRN \\
\hline HEMBL392. & 00 & 7.9586 & & TR \\
\hline CHEMBL3896261 & & & & \\
\hline HEMBL3936997 & & .2218 & & \\
\hline CHEMBL3957524 & 300 & .9172 & 6.1549 & ST \\
\hline CHEMBL3940006 & 1641300 & 6.0575 & 6.1636 & TST \\
\hline
\end{tabular}

Page 18799 
Supplemental Table S2.txt

\begin{tabular}{|c|c|c|c|c|}
\hline CHEMBL3894420 & 1641300 & 8.2218 & 7.6605 & TRN \\
\hline CHEMBL 3906870 & 1641300 & 6.5952 & 6.0144 & TST \\
\hline CHEMBL3952055 & 1641300 & 7.8539 & 7.9013 & TRN \\
\hline CHEMBL3915692 & 1641300 & 8.0 & 6.9778 & TRN \\
\hline CHEMBL3943139 & 1641300 & 7.4437 & 7.0758 & TRN \\
\hline CHEMBL3899289 & 1641300 & 6.0575 & 6.1515 & TRN \\
\hline CHEMBL 3904458 & 1641300 & 6.9872 & 6.5399 & TRN \\
\hline CHEMBL3941977 & 1641300 & 4.0 & 5.7465 & TRN \\
\hline CHEMBL3945637 & 1641300 & 5.4949 & 6.654 & TST \\
\hline CHEMBL3983864 & 1641300 & 4.0 & 6.21 & TST \\
\hline CHEMBL 3976944 & 1641300 & 4.0 & 5.9035 & TRN \\
\hline CHEMBL3931509 & 1641300 & 8.1549 & 7.6979 & TRN \\
\hline CHEMBL3952585 & 1641300 & 6.52 & 6.312 & TRN \\
\hline CHEMBL3986705 & 1641300 & 7.1938 & 7.8739 & TRN \\
\hline CHEMBL 3977520 & 1641300 & 7.4437 & 8.255 & TRN \\
\hline CHEMBL 3978476 & 1641300 & 7.5086 & 7.3709 & TRN \\
\hline CHEMBL3902769 & 1641300 & 6.2366 & 6.5565 & TST \\
\hline CHEMBL 3943652 & 1641300 & 7.9208 & 6.3406 & TRN \\
\hline CHEMBL3972302 & 1641300 & 7.0915 & 6.4703 & TRN \\
\hline CHEMBL 3973835 & 1641300 & 7.6383 & 6.9309 & TRN \\
\hline CHEMBL 3897394 & 1641300 & 6.3036 & 5.7001 & TST \\
\hline CHEMBL3893217 & 1641300 & 5.9492 & 6.9177 & TRN \\
\hline CHEMBL3926870 & 1641300 & 7.8239 & 7.3611 & TRN \\
\hline CHEMBL3900957 & 1641300 & 6.0 & 6.6838 & TRN \\
\hline CHEMBL3903362 & 1641300 & 7.284 & 7.3154 & TRN \\
\hline CHEMBL 3956243 & 1641300 & 4.0 & 7.0122 & TRN \\
\hline CHEMBL3896734 & 1641300 & 5.6059 & 6.1573 & TRN \\
\hline CHEMBL3905217 & 1641300 & 5.8105 & 6.3529 & TRN \\
\hline CHEMBL3948183 & 1641300 & 6.3706 & 7.4426 & TST \\
\hline CHEMBL3945371 & 1641300 & 7.2924 & 6.1541 & TRN \\
\hline CHEMBL3944623 & 1641300 & 7.6383 & 7.2369 & TRN \\
\hline CHEMBL3911785 & 1641300 & 5.3098 & 5.9089 & TRN \\
\hline CHEMBL 3974290 & 1641300 & 6.0825 & 7.0808 & TST \\
\hline CHEMBL3921148 & 1641300 & 6.4698 & 6.1234 & TRN \\
\hline CHEMBL3969848 & 1641300 & 5.9161 & 7.25200 & 0000000001 \\
\hline CHEMBL3943971 & 1641300 & 8.0 & 7.6901 & TRN \\
\hline CHEMBL3903264 & 1641300 & 5.0132 & 6.1034 & TRN \\
\hline CHEMBL 3907911 & 1641300 & 6.6003 & 6.7211 & TRN \\
\hline CHEMBL3953885 & 1641300 & 5.9948 & 6.0893 & TRN \\
\hline CHEMBL3948463 & 1641300 & 7.8239 & 7.8688 & TRN \\
\hline CHEMBL3936647 & 1641300 & 7.5686 & 6.9576 & TRN \\
\hline CHEMBL3906690 & 1641300 & 6.644 & 6.7428 & TST \\
\hline CHEMBL3985507 & 1641300 & 6.466 & 6.4752 & TST \\
\hline CHEMBL3957046 & 1641300 & 5.3833 & 5.9602 & TST \\
\hline CHEMBL3930097 & 1641300 & 6.9914 & 6.4111 & TRN \\
\hline CHEMBL3906198 & 1641300 & 6.9172 & 7.2793 & TRN \\
\hline CHEMBL 3892978 & 1641300 & 7.0362 & \multicolumn{2}{|c|}{6.287000000000001} \\
\hline CHEMBL3971941 & 1641300 & 5.6576 & 6.8613 & TRN \\
\hline
\end{tabular}


Supplemental Table S2.txt

\begin{tabular}{|c|c|c|c|c|}
\hline - & 300 & 861 & 44 & \\
\hline CHEMBL 3900016 & 641300 & 8.1549 & 609 & \\
\hline HEMBL3931268 & 641300 & 4.0 & 5834 & \\
\hline IEMBL: & 300 & & 581 & \\
\hline IEMBL 3924707 & 641300 & 904 & 719 & \\
\hline AEMBL3915356 & 641300 & 7.2676 & 7.9367 & \\
\hline AEMBL3916964 & 641300 & 7.6576 & 7.3575 & \\
\hline HEMBL3 & 300 & 8.0 & 242 & \\
\hline HEMBL1 & 46868 & 4.8539 & 778 & \\
\hline IEMBL2 & 68 & 4.3665 & 338 & \\
\hline HEMBL99340 & 68 & 4.8861 & 4.2323 & \\
\hline HEMBL 299079 & 68 & 4.5686 & 4.5872 & \\
\hline HEMBL12 & 68 & 4.301 & 891 & \\
\hline HEMBL2 & 58 & 4.0 & 156 & \\
\hline AEMBL] & 68 & 5.0458 & 168 & \\
\hline AEMBL52 & 68 & 4.6383 & 437 & \\
\hline HEMBL1 & 68 & & & \\
\hline HEMBL3 & 58 & 3.7 & 11 & \\
\hline HEMBLC & 58 & 5 . & 76 & \\
\hline HEMB & & 208 & 254 & \\
\hline HEMBL5 & & 279 & 123 & \\
\hline AEMBL: & 58 & 29 & & \\
\hline AEMBL: & 58 & 4. & 15 & \\
\hline AEMBL & 58 & 08 & 98 & \\
\hline AEMBL & 58 & 957 & 953 & \\
\hline 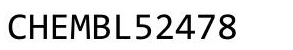 & & 4.0 & 914 & \\
\hline AEMBL] & 58 & 4. & 795 & \\
\hline AEMBL: & 58 & 4. & 139 & \\
\hline 8 & 8 & 4. & & \\
\hline 55 & & 86 & 427 & \\
\hline 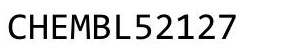 & & & & \\
\hline HEMBL9 & 58 & 884 & 554 & \\
\hline & & & & \\
\hline $\mathrm{Cr}$ & & 4. & & \\
\hline CHEMBL5 & & 29 & 891 & \\
\hline CHEMBL12 & & 4.9208 & 465 & \\
\hline CHEMBL 1 & 58 & 979 & 336 & \\
\hline & & & & \\
\hline CHEME & & 18 & 56 & \\
\hline CHEMBL1 & & 4.2147 & 4.1927 & \\
\hline CHEMBL1 & 68 & 4.3665 & 944 & \\
\hline CHEMB & 64 & & 039 & \\
\hline & & 4.3565 & & \\
\hline CHEMBL 5 & 646 & 4.0 & 3.9817 & \\
\hline CHEMBL51746 & & 5.301 & 5.3198 & $\Gamma R$ \\
\hline CHEMBL121350 & $64 \epsilon$ & 4.1024 & 167 & \\
\hline & 646 & & & \\
\hline CHEMBL1 & 646868 & 3.4168 & 3.4321 & \\
\hline
\end{tabular}

Page 18801 


\begin{tabular}{|c|c|c|c|c|c|}
\hline & & \multicolumn{4}{|c|}{ Supplemental Table s2.txt } \\
\hline CHEMBL299414 & 646868 & 4.301 & 4.3728 & TRN & \\
\hline CHEMBL134789 & 646868 & 3.8182 & 3.3614 & TST & \\
\hline CHEMBL54078 & 646868 & 4.0 & 4.1314 & TRN & \\
\hline CHEMBL335298 & 646868 & 4.585 & 4.5315 & TRN & \\
\hline CHEMBL54952 & 646868 & 4.4949 & 4.504 & TRN & \\
\hline CHEMBL52017 & 646868 & 4.0 & 4.206 & TST & \\
\hline CHEMBL51330 & 646868 & 4.2596 & 4.2959 & TRN & \\
\hline CHEMBL1213501 & 646868 & 4.7447 & 4.77 & TRN & \\
\hline CHEMBL1213587 & 646868 & 6.0 & 5.9657 & TRN & \\
\hline CHEMBL1213092 & 646868 & 3.6162 & 3.1142 & TST & \\
\hline CHEMBL52182 & 646868 & 4.4949 & 4.4909 & TRN & \\
\hline CHEMBL53586 & 646868 & 4.0 & 3.9641 & TRN & \\
\hline CHEMBL133958 & 646868 & 4.4202 & 3.6709 & TST & \\
\hline CHEMBL1213589 & 646868 & 4.3468 & 4.3936 & TRN & \\
\hline CHEMBL52905 & 646868 & 4.3188 & 4.1691 & TRN & \\
\hline CHEMBL136952 & 646868 & 5.301 & 5.3216 & TRN & \\
\hline CHEMBL222838 & 646868 & 3.6478 & 2.88100 & 00000000002 & TST \\
\hline CHEMBL1214498 & 646868 & 4.1871 & 3.3031 & TST & \\
\hline CHEMBL298564 & 646868 & 5.3979 & 5.4045 & TRN & \\
\hline CHEMBL1213547 & 646868 & 5.0969 & 4.9973 & TRN & \\
\hline CHEMBL1213464 & 646868 & 4.7696 & 4.823 & TRN & \\
\hline CHEMBL335105 & 646868 & 4.7696 & 4.7826 & TRN & \\
\hline CHEMBL 100210 & 646868 & 4.4437 & 4.4147 & TRN & \\
\hline CHEMBL431345 & 646868 & 4.301 & 4.3203 & TRN & \\
\hline CHEMBL2367467 & 646868 & 4.3279 & 3.679 & TST & \\
\hline CHEMBL 298557 & 646868 & 4.8861 & 4.8766 & TRN & \\
\hline CHEMBL135406 & 646868 & 5.3979 & 5.3597 & TRN & \\
\hline CHEMBL54094 & 646868 & 4.2218 & 4.1961 & TRN & \\
\hline CHEMBL 298794 & 646868 & 4.2676 & 4.2871 & TRN & \\
\hline CHEMBL99717 & 646868 & 4.9586 & 4.6383 & TST & \\
\hline CHEMBL 298774 & 646868 & 5.0969 & 5.0895 & TRN & \\
\hline CHEMBL53153 & 646868 & 5.301 & 5.2282 & TRN & \\
\hline CHEMBL54012 & 646868 & 4.3665 & 4.3079 & TST & \\
\hline CHEMBL 317528 & 646868 & 4.3872 & 3.897 & TST & \\
\hline CHEMBL1213178 & 646868 & 5.3979 & 2.9932 & TST & \\
\hline CHEMBL336114 & 646868 & 4.4815 & 4.5042 & TRN & \\
\hline CHEMBL1213505 & 646868 & 4.3468 & 4.4004 & TRN & \\
\hline CHEMBL1256031 & 671192 & 7.699 & 7.7134 & TRN & \\
\hline CHEMBL522672 & 671192 & 4.9208 & 4.919 & TRN & \\
\hline CHEMBL1256892 & 671192 & 5.0757 & 5.055 & TRN & \\
\hline CHEMBL479776 & 671192 & 5.3665 & 5.3771 & TRN & \\
\hline CHEMBL1256859 & 671192 & 5.8861 & 5.9027 & TRN & \\
\hline CHEMBL1256581 & 671192 & 6.8539 & 6.8559 & TRN & \\
\hline CHEMBL1256151 & 671192 & 7.3979 & 7.3991 & TRN & \\
\hline CHEMBL495042 & 671192 & 3.5436 & 4.9074 & TST & \\
\hline CHEMBL1256933 & 671192 & 7.8239 & 7.7866 & TRN & \\
\hline CHEMBL495287 & 671192 & 6.0 & 5.9941 & TRN & \\
\hline CHEMBL524053 & 671192 & 4.699 & 4.6864 & TRN & \\
\hline
\end{tabular}




\begin{tabular}{|c|c|c|c|c|c|}
\hline & & \multicolumn{4}{|c|}{ Supplemental Table S2.txt } \\
\hline CHEMBL495396 & 671192 & 5.1739 & 5.1802 & TRN & \\
\hline CHEMBL495489 & 671192 & 5.6778 & 5.6775 & TRN & \\
\hline CHEMBL1256731 & 671192 & 7.5376 & 7.5227 & TRN & \\
\hline CHEMBL1255971 & 671192 & 8.2076 & 7.5847 & TST & \\
\hline CHEMBL1256150 & 671192 & 7.2366 & 7.2677 & TRN & \\
\hline CHEMBL479787 & 671192 & 5.699 & 5.6683 & TRN & \\
\hline CHEMBL481517 & 671192 & 6.7447 & 6.7982 & TRN & \\
\hline CHEMBL523337 & 671192 & 5.6383 & 5.6349 & TRN & \\
\hline CHEMBL493456 & 671192 & 8.3565 & 8.3491 & TRN & \\
\hline CHEMBL443359 & 671192 & 4.399 & 5.2147 & TST & \\
\hline CHEMBL1256932 & 671192 & 6.9586 & 6.9338 & TRN & \\
\hline CHEMBL449677 & 671192 & 4.699 & 4.7075 & TRN & \\
\hline CHEMBL1256193 & 671192 & 4.7447 & 4.7491 & TST & \\
\hline CHEMBL1256893 & 671192 & 4.8827 & 4.8873 & TRN & \\
\hline CHEMBL261634 & 671192 & 5.2218 & 4.57100 & 0000000001 & TST \\
\hline CHEMBL521681 & 671192 & 6.1427 & 6.1632 & TRN & \\
\hline CHEMBL1256861 & 671192 & 4.1487 & 4.224 & TRN & \\
\hline CHEMBL527056 & 671192 & 3.9172 & 3.8717 & TRN & \\
\hline CHEMBL501060 & 671192 & 6.1249 & 6.1055 & TRN & \\
\hline CHEMBL479599 & 671192 & 4.3665 & 5.6033 & TST & \\
\hline CHEMBL1256582 & 671192 & 7.3768 & 7.3608 & TRN & \\
\hline CHEMBL442634 & 671192 & 5.4202 & 5.4027 & TRN & \\
\hline CHEMBL518314 & 671192 & 5.9208 & 5.9388 & TRN & \\
\hline CHEMBL1256829 & 671192 & 6.5086 & 6.4884 & TRN & \\
\hline CHEMBL1256828 & 671192 & 6.4318 & 6.3877 & TRN & \\
\hline CHEMBL1256524 & 671192 & 5.0223 & 5.0314 & TRN & \\
\hline CHEMBL480171 & 671192 & 6.0 & 5.9729 & TRN & \\
\hline CHEMBL480173 & 671192 & 7.2007 & 7.1966 & TRN & \\
\hline CHEMBL1256827 & 671192 & 7.8539 & 7.9689 & TRN & \\
\hline CHEMBL448024 & 671192 & 4.4949 & 4.5376 & TRN & \\
\hline CHEMBL482291 & 671192 & 5.4685 & 5.4714 & TRN & \\
\hline CHEMBL480001 & 671192 & 5.1249 & 5.1341 & TRN & \\
\hline CHEMBL1256860 & 671192 & 7.301 & 7.271 & TRN & \\
\hline CHEMBL495286 & 671192 & 6.1427 & 6.12299 & 9999999999 & TRN \\
\hline CHEMBL481518 & 671192 & 7.9586 & 7.9373 & TRN & \\
\hline CHEMBL505234 & 671192 & 5.1549 & 5.1376 & TRN & \\
\hline CHEMBL1256030 & 671192 & 7.7212 & 8.144 & TST & \\
\hline CHEMBL445249 & 671192 & 4.2366 & 4.7369 & TST & \\
\hline CHEMBL1256894 & 671192 & 3.7282 & 6.1103 & TST & \\
\hline CHEMBL453983 & 671192 & 4.5376 & 6.4199 & TST & \\
\hline CHEMBL481303 & 671192 & 4.6383 & 4.6913 & TST & \\
\hline CHEMBL493457 & 671192 & 8.3872 & 7.5703 & TST & \\
\hline CHEMBL504458 & 671192 & 4.585 & 5.86 & TST & \\
\hline CHEMBL480172 & 671192 & 5.9208 & 5.7712 & TST & \\
\hline CHEMBL1242198 & 654930 & 7.4815 & 7.6716 & TRN & \\
\hline CHEMBL1241949 & 654930 & 5.1192 & 5.3457 & TRN & \\
\hline CHEMBL1240554 & 654930 & 6.8477 & 6.6503 & TRN & \\
\hline CHEMBL1241390 & 654930 & 5.0605 & 4.8372 & TRN & \\
\hline
\end{tabular}


Supplemental Table S2.txt

\begin{tabular}{|c|c|c|c|c|c|}
\hline CHEMBL1241586 & 654930 & 5.4559 & 5.6059 & TRN & \\
\hline CHEMBL1241858 & 654930 & 6.8794 & 6.0806 & TRN & \\
\hline CHEMBL1242572 & 654930 & 7.3768 & 7.345 & TRN & \\
\hline CHEMBL1241482 & 654930 & 7.3768 & 6.6853 & TST & \\
\hline CHEMBL1242844 & 654930 & 6.1267 & 6.0059 & TRN & \\
\hline CHEMBL1242117 & 654930 & 4.8239 & 4.6691 & TRN & \\
\hline CHEMBL1242848 & 654930 & 7.3979 & 7.6933 & TRN & \\
\hline CHEMBL1242568 & 654930 & 9.2596 & 8.665 & TRN & \\
\hline CHEMBL1241587 & 654930 & 5.9872 & 5.985 & TST & \\
\hline CHEMBL1242664 & 654930 & 7.7696 & 7.681 & TRN & \\
\hline CHEMBL1242853 & 654930 & 6.7122 & 6.8887 & TRN & \\
\hline CHEMBL1242113 & 654930 & 7.1739 & 7.1358 & TRN & \\
\hline CHEMBL1242203 & 654930 & 6.61799 & 999999999 & 99 & 6.3967 \\
\hline CHEMBL1242477 & 654930 & 7.1612 & 7.2244 & TRN & \\
\hline CHEMBL1233882 & 654930 & 6.6198 & 6.5082 & TRN & \\
\hline CHEMBL1242379 & 654930 & 6.5331 & 6.3317 & TRN & \\
\hline CHEMBL1242377 & 654930 & 8.1612 & 8.0547 & TRN & \\
\hline CHEMBL1241863 & 654930 & 5.1427 & 5.0159 & TRN & \\
\hline CHEMBL1230790 & 654930 & 7.8239 & 7.4582 & TRN & \\
\hline CHEMBL1241950 & 654930 & 6.0969 & 5.499 & TRN & \\
\hline CHEMBL1241682 & 654930 & 4.0 & 5.3301 & TRN & \\
\hline CHEMBL1242757 & 654930 & 7.4318 & 5.9487 & TST & \\
\hline CHEMBL1241439 & 654930 & 5.284 & 5.269 & TST & \\
\hline CHEMBL1241767 & 654930 & 4.7696 & 5.0141 & TST & \\
\hline CHEMBL1242566 & 654930 & 7.6198 & 8.3412 & TRN & \\
\hline CHEMBL1242750 & 654930 & 7.8539 & 8.2005 & TRN & \\
\hline CHEMBL1241481 & 654930 & 10.0 & 9.7348 & TRN & \\
\hline CHEMBL1242286 & 654930 & 7.1427 & 7.2297 & TRN & \\
\hline CHEMBL1241862 & 654930 & 4.8239 & 5.2994 & TRN & \\
\hline CHEMBL1242665 & 654930 & 4.6383 & 4.7983 & TST & \\
\hline CHEMBL1241583 & 654930 & 5.5229 & 4.9934 & TRN & \\
\hline CHEMBL1241774 & 654930 & 6.0 & 6.0339 & TRN & \\
\hline CHEMBL1241484 & 654930 & 8.3979 & 8.4908 & TRN & \\
\hline CHEMBL1242662 & 654930 & 7.2596 & 7.2998 & TRN & \\
\hline CHEMBL1241864 & 654930 & 4.0 & 5.5972 & TRN & \\
\hline CHEMBL1241773 & 654930 & 5.6778 & 6.0224 & TRN & \\
\hline CHEMBL1242573 & 654930 & 6.9872 & 7.1927 & TRN & \\
\hline CHEMBL1242470 & 654930 & 7.7447 & 6.9689 & TST & \\
\hline CHEMBL1241769 & 654930 & 7.0177 & 6.6064 & TRN & \\
\hline CHEMBL1242847 & 654930 & 6.4202 & 6.1866 & TRN & \\
\hline CHEMBL1242114 & 654930 & 7.7696 & 7.7308 & TRN & \\
\hline CHEMBL1242295 & 654930 & 8.0969 & 7.3907 & TRN & \\
\hline CHEMBL1242476 & 654930 & 7.2366 & 7.1944 & TRN & \\
\hline CHEMBL1242475 & 654930 & 7.3098 & 7.0874 & TRN & \\
\hline CHEMBL1242758 & 654930 & 7.2441 & 6.8383 & TST & \\
\hline CHEMBL1241580 & 654930 & 7.9586 & 8.6728 & TRN & \\
\hline CHEMBL1241681 & 654930 & 6.0915 & 6.2875 & TRN & \\
\hline CHEMBL1242033 & 654930 & 4.9208 & 5.6117 & TRN & \\
\hline
\end{tabular}


Supplemental Table S2.txt

\begin{tabular}{|c|c|c|c|c|c|}
\hline CHEMBL1241684 & 654930 & 4.9208 & 4.6217 & TST & \\
\hline CHEMBL1242199 & 654930 & 8.301 & 8.2781 & TRN & \\
\hline CHEMBL1242753 & 654930 & 5.0088 & 4.9222 & TRN & \\
\hline CHEMBL1242656 & 654930 & 9.0 & 8.5271 & TRN & \\
\hline CHEMBL1242119 & 654930 & 6.2798 & 6.2135 & TRN & \\
\hline CHEMBL1241490 & 654930 & 6.6234 & 6.5804 & TRN & \\
\hline CHEMBL1241301 & 654930 & 6.2924 & 6.8183 & TRN & \\
\hline CHEMBL1242030 & 654930 & 5.6383 & 5.2962 & TRN & \\
\hline CHEMBL1241485 & 654930 & 7.6383 & 7.2863 & TRN & \\
\hline CHEMBL1242376 & 654930 & 7.9586 & 8.1615 & TRN & \\
\hline CHEMBL1242208 & 654930 & 4.9586 & 5.5508 & TRN & \\
\hline CHEMBL1242032 & 654930 & 4.9586 & 5.2691 & TRN & \\
\hline CHEMBL1242569 & 654930 & 4.8182 & 5.6171 & TRN & \\
\hline CHEMBL1242112 & 654930 & 6.9208 & 7.3518 & TRN & \\
\hline CHEMBL1242034 & 654930 & 5.5686 & 5.4739 & TRN & \\
\hline CHEMBL1242384 & 654930 & 6.8041 & 6.6286 & TRN & \\
\hline CHEMBL1242110 & 654930 & 7.6021 & 7.3387 & TRN & \\
\hline CHEMBL1241776 & 654930 & 6.8827 & 6.5359 & TRN & \\
\hline CHEMBL1242287 & 654930 & 8.0223 & 8.3046 & TRN & \\
\hline CHEMBL1241391 & 654930 & 4.301 & 4.7581 & TRN & \\
\hline CHEMBL1242751 & 654930 & 6.3019 & 5.6026 & TRN & \\
\hline CHEMBL1241772 & 654930 & 4.9208 & 4.8708 & TRN & \\
\hline CHEMBL1242202 & 654930 & 8.3979 & 8.1029 & TRN & \\
\hline CHEMBL1242471 & 654930 & 4.0 & 5.7372 & TST & \\
\hline CHEMBL1241486 & 654930 & 6.4672 & 6.2584 & TRN & \\
\hline CHEMBL1241771 & 654930 & 5.3565 & 5.5443 & TRN & \\
\hline CHEMBL1233881 & 654930 & 6.7696 & 7.2146 & TRN & \\
\hline CHEMBL1241860 & 654930 & 6.3098 & 6.1046 & TRN & \\
\hline CHEMBL1241861 & 654930 & 6.1169 & 6.0033 & TRN & \\
\hline CHEMBL1241578 & 654930 & 8.0 & 8.3676 & TRN & \\
\hline CHEMBL1242293 & 654930 & 7.699 & 7.7925 & TRN & \\
\hline CHEMBL1241492 & 654930 & 5.5229 & 5.7697 & TRN & \\
\hline CHEMBL1242031 & 654930 & 5.301 & 5.2752 & TRN & \\
\hline CHEMBL1241582 & 654930 & 6.2757 & 5.9831 & TRN & \\
\hline CHEMBL1242209 & 654930 & 6.2596 & 5.4022 & TRN & \\
\hline CHEMBL1242378 & 654930 & 6.0 & 6.6909 & TRN & \\
\hline CHEMBL1242755 & 654930 & 6.1451 & 6.4715 & TRN & \\
\hline CHEMBL1240566 & 654930 & 6.6021 & 6.5831 & TRN & \\
\hline CHEMBL1242109 & 654930 & 7.7959 & 7.4812 & TRN & \\
\hline CHEMBL1242748 & 654930 & 6.0 & 6.58299 & 9999999999 & TRN \\
\hline CHEMBL1241945 & 654930 & 7.3665 & 7.32799 & 9999999999 & TRN \\
\hline CHEMBL1241947 & 654930 & 5.8239 & 5.2965 & TST & \\
\hline CHEMBL1241679 & 654930 & 5.2291 & 4.8215 & TRN & \\
\hline CHEMBL1242115 & 654930 & 5.4949 & 5.6841 & TST & \\
\hline CHEMBL1234815 & 654930 & 5.9586 & 5.8942 & TRN & \\
\hline CHEMBL1242027 & 654930 & 6.3224 & 6.4892 & TRN & \\
\hline CHEMBL1241487 & 654930 & 7.9586 & 8.2153 & TRN & \\
\hline CHEMBL1241775 & 654930 & 4.5229 & 5.5044 & TRN & \\
\hline
\end{tabular}




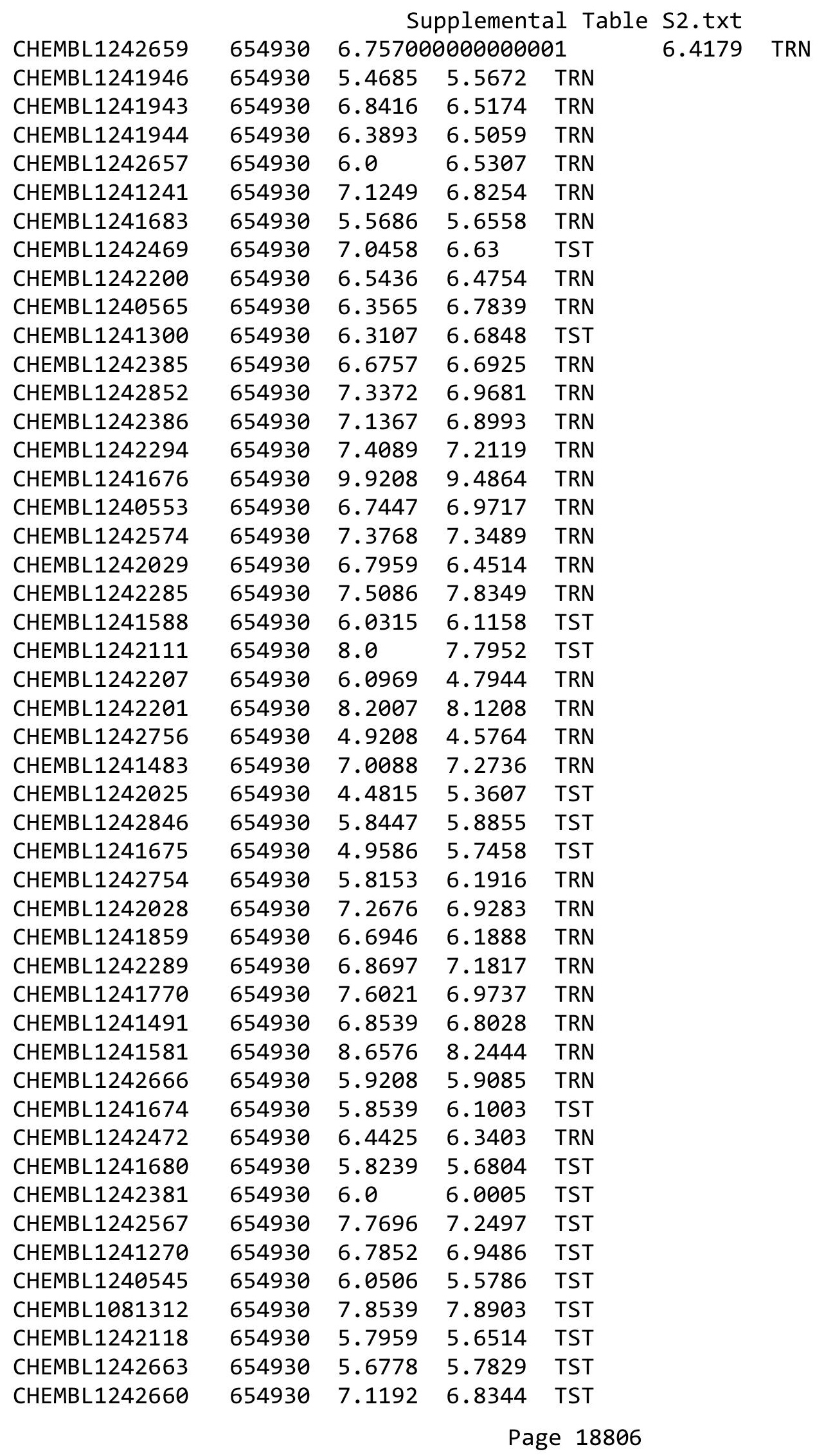


Supplemental Table S2.txt

\begin{tabular}{|c|c|c|}
\hline CHEMBL1242024 & & \\
\hline CHEMBL1241677 & 654930 & \\
\hline HEMBL1242290 & 54930 & \\
\hline HEMBL 1242752 & 554930 & \\
\hline HEMBL1242661 & 554930 & \\
\hline HEMBL1242026 & 654930 & \\
\hline HEMBL1241271 & 654930 & \\
\hline HEMBL1242845 & 654930 & \\
\hline HEMBL1242288 & 654930 & \\
\hline HEMBL1241299 & 654930 & \\
\hline HEMBL1241948 & 654930 & \\
\hline HEMBL3960514 & 1640384 & \\
\hline HEMBL3938656 & 1640384 & \\
\hline HEMBL 3897033 & 1640384 & \\
\hline HEMBL 3907537 & 1640384 & \\
\hline HEMBL1964288 & 1640384 & \\
\hline HEMBL3976347 & 1640384 & \\
\hline HEMBL3986570 & 1640384 & \\
\hline HEMBL1982400 & 164 & \\
\hline HEMBL 3979260 & 164 & \\
\hline CHEMBL 3914700 & 164 & \\
\hline HEMBL3909348 & 1640384 & \\
\hline CHEMBL 3968211 & 164 & \\
\hline HEMBL 2000029 & 164 & \\
\hline HEMBL398 & 164 & \\
\hline CHEMBL199 & 1640384 & \\
\hline CHEMBL3964735 & 1640384 & \\
\hline CHEMBL3923726 & 164 & \\
\hline CHEMBL3937279 & 1640384 & 6 . \\
\hline CHEMBL198 & 164 & \\
\hline CHEMBL391 & 164 & \\
\hline CHEMBL 3946172 & 1640384 & \\
\hline CHEMBL3941781 & 1640 & \\
\hline CHEMBL3953310 & 1640384 & \\
\hline CHEMBL197 & 164 & \\
\hline CHEMBL3970165 & 164 & \\
\hline CHEMBL 3890525 & 1640384 & 9.36 \\
\hline CHEMBL3964996 & 1640384 & \\
\hline CHEMBL1969221 & 164 & \\
\hline CHEMBL1972339 & 1640384 & \\
\hline CHEMBL3910678 & 1640384 & \\
\hline CHEMBL 3956257 & 1640384 & 6.4 \\
\hline CHEMBL3918627 & 1640384 & 6. \\
\hline CHEMBL3960629 & 164 & \\
\hline CHEMBL 3980762 & 1640384 & 7.2 \\
\hline CHEMBL3935067 & 1640384 & \\
\hline CHEMBL3959601 & 1640384 & \\
\hline CHEMBL3974914 & 1640384 & \\
\hline
\end{tabular}

7.3752 TST

7.2728 TST

6.374 TST

6.0474 TST

5.3874 TST

8.0479 TST

7.2281 TST

6.8574 TST

6.5795 TST

7.8375 TST

5.3144 TST

7.1693 TRN

7.7993 TRN

7.5365 TRN

7.192 TST

7.4697 TRN

8.1484 TST

6.6363 TRN

7.4949 TRN

6.3159 TRN

7.4074 TRN

6.8846 TRN

7.4933 TRN

9.0506 TRN

7.3491 TRN

8.4882 TRN

8.3856 TRN

6.0868 TRN

6.6587 TRN

8.9805 TRN

7.0934 TRN

6.7028 TRN

7.6321 TRN

7.2428 TRN

8.9652 TRN

8.0186 TRN

8.9445 TRN

5.5474 TRN

8.7272 TRN

9.2121 TRN

7.7811 TRN

6.3919 TRN

7.6382 TRN

6.4011 TRN

7.2505 TRN

8.7543 TST

8.5028 TRN

7.742999999999999 TST

Page 18807 
Supplemental Table S2.txt

\begin{tabular}{|c|c|c|c|c|}
\hline CHEMBL3966295 & 1640384 & 6.9586 & 7.7328 & TRN \\
\hline CHEMBL3975457 & 1640384 & 7.3872 & 7.2079 & TRN \\
\hline CHEMBL3902893 & 1640384 & 7.091 & 7.5685 & TRN \\
\hline CHEMBL3925088 & 1640384 & 7.3979 & 7.1478 & TRN \\
\hline CHEMBL3919634 & 1640384 & 6.8539 & 7.1648 & TRN \\
\hline CHEMBL3936503 & 1640384 & 7.1675 & 7.7315 & TRN \\
\hline CHEMBL3933614 & 1640384 & 6.6576 & 6.39 & TRN \\
\hline CHEMBL3968307 & 1640384 & 7.8962 & 7.3664 & TST \\
\hline CHEMBL3927401 & 1640384 & 7.8861 & 8.6645 & TRN \\
\hline CHEMBL3950878 & 1640384 & 8.0862 & 7.4684 & TRN \\
\hline CHEMBL 2003638 & 1640384 & 9.301 & 8.8366 & TRN \\
\hline CHEMBL3979653 & 1640384 & 6.0 & 5.6262 & TRN \\
\hline CHEMBL1682352 & 1640384 & 7.2495 & 7.572 & TST \\
\hline CHEMBL3960171 & 1640384 & 6.301 & 6.126 & TRN \\
\hline CHEMBL1682346 & 1640384 & 7.9208 & 7.8091 & TRN \\
\hline CHEMBL3891667 & 1640384 & 7.8239 & 7.2256 & TRN \\
\hline CHEMBL3912696 & 1640384 & 9.0458 & 9.1225 & TRN \\
\hline CHEMBL3891467 & 1640384 & 6.0088 & 5.3615 & TRN \\
\hline CHEMBL3928683 & 1640384 & 6.7167 & 8.0634 & TST \\
\hline CHEMBL3907396 & 1640384 & 7.8239 & 7.2516 & TRN \\
\hline CHEMBL3933471 & 1640384 & 8.7212 & 8.3582 & TRN \\
\hline CHEMBL3947423 & 1640384 & 6.7447 & 6.7291 & TST \\
\hline CHEMBL 2004631 & 1640384 & 7.4559 & 7.8413 & TST \\
\hline CHEMBL3902689 & 1640384 & 6.1669 & 7.6791 & TST \\
\hline CHEMBL1989646 & 1640384 & 7.6383 & 8.5486 & TST \\
\hline CHEMBL3936170 & 1640384 & 4.9101 & 6.2297 & TST \\
\hline CHEMBL3941943 & 1640384 & 6.9208 & 6.1997 & TST \\
\hline CHEMBL1969473 & 1640384 & 9.2211 & 8.542 & TST \\
\hline CHEMBL1986499 & 1640384 & 9.0969 & 9.2088 & TST \\
\hline CHEMBL3951439 & 1640384 & 7.1675 & 7.0063 & TST \\
\hline CHEMBL3964275 & 1640384 & 6.3107 & 7.3952 & TST \\
\hline CHEMBL27664 & 32524 & 6.44 & 5.7128 & TRN \\
\hline CHEMBL143953 & 32524 & 4.92 & 5.1192 & TRN \\
\hline CHEMBL118475 & 32524 & 6.09 & 6.3216 & TRN \\
\hline CHEMBL281864 & 32524 & 6.64 & 6.6999 & TRN \\
\hline CHEMBL11862 & 32524 & 6.32 & 6.2206 & TRN \\
\hline CHEMBL118310 & 32524 & 4.97 & 4.9517 & TRN \\
\hline CHEMBL342957 & 32524 & 0.15 & 5.1729 & TST \\
\hline CHEMBL323692 & 32524 & 5.58 & 5.6646 & TRN \\
\hline CHEMBL310736 & 32524 & 6.0 & 5.5729 & TRN \\
\hline CHEMBL26640 & 32524 & 6.33 & 6.185 & TRN \\
\hline CHEMBL28115 & 32524 & 4.74 & 4.6014 & TRN \\
\hline CHEMBL144182 & 32524 & 4.92 & 4.7528 & TRN \\
\hline CHEMBL27599 & 32524 & 4.47 & 4.7419 & TRN \\
\hline CHEMBL144750 & 32524 & 4.6 & 3.9955 & TRN \\
\hline CHEMBL14346 & 32524 & 6.45 & 6.3877 & TRN \\
\hline CHEMBL 71354 & 32524 & 6.52 & 6.8445 & TRN \\
\hline CHEMBL284257 & 32524 & 6.25 & 6.141 & TRN \\
\hline
\end{tabular}




\begin{tabular}{|c|c|c|c|c|c|}
\hline & & \multicolumn{4}{|c|}{ Supplemental Table s2.txt } \\
\hline CHEMBL38681 & 32524 & 5.39 & 5.0176 & TST & \\
\hline CHEMBL143615 & 32524 & 3.82 & 4.2647 & TRN & \\
\hline CHEMBL28390 & 32524 & 4.49 & 4.3382 & TRN & \\
\hline CHEMBL128633 & 32524 & 5.79 & 6.2495 & TST & \\
\hline CHEMBL144427 & 32524 & 5.04 & 4.9452 & TRN & \\
\hline CHEMBL280592 & 32524 & 4.02 & 3.9809 & TRN & \\
\hline CHEMBL68977 & 32524 & 5.85 & 6.0769 & TRN & \\
\hline CHEMBL26825 & 32524 & 5.34 & 5.2175 & TRN & \\
\hline CHEMBL287837 & 32524 & 7.66 & 6.3982 & TST & \\
\hline CHEMBL26711 & 32524 & 6.44 & 6.7424 & TRN & \\
\hline CHEMBL28431 & 32524 & 4.67 & 4.7796 & TRN & \\
\hline CHEMBL27730 & 32524 & 5.65 & 5.6495 & TRN & \\
\hline CHEMBL131174 & 32524 & 5.68 & 5.3358 & TST & \\
\hline CHEMBL 27776 & 32524 & 4.96 & 4.9726 & TRN & \\
\hline CHEMBL25316 & 32524 & 5.33 & 5.3016 & TRN & \\
\hline CHEMBL333343 & 32524 & 5.34 & 5.725 & TST & \\
\hline CHEMBL70546 & 32524 & 6.89 & 6.7722 & TRN & \\
\hline CHEMBL 308021 & 32524 & 6.11 & 6.0779 & TRN & \\
\hline CHEMBL522 & 32524 & 4.7 & 6.2582 & TST & \\
\hline CHEMBL141959 & 32524 & 3.96 & 4.0075 & TRN & \\
\hline CHEMBL26879 & 32524 & 5.21 & 5.1808 & TRN & \\
\hline CHEMBL144331 & 32524 & 5.05 & 5.2763 & TRN & \\
\hline CHEMBL286495 & 32524 & 5.64 & \multicolumn{2}{|c|}{5.5520000000000005} & TRN \\
\hline CHEMBL 27162 & 32524 & 5.14 & 5.3737 & TRN & \\
\hline CHEMBL441679 & 32524 & 4.57 & 4.605 & TRN & \\
\hline CHEMBL358495 & 32524 & 5.39 & 4.5459 & TST & \\
\hline CHEMBL131412 & 32524 & 5.34 & 6.211 & TST & \\
\hline CHEMBL26828 & 32524 & 6.66 & 6.6257 & TRN & \\
\hline CHEMBL39125 & 32524 & 3.88 & 4.4654 & TRN & \\
\hline CHEMBL144444 & 32524 & 4.18 & 4.1365 & TRN & \\
\hline CHEMBL281289 & 32524 & 5.37 & 5.4606 & TRN & \\
\hline CHEMBL145519 & 32524 & 4.11 & 4.6688 & TRN & \\
\hline CHEMBL344291 & 32524 & 3.82 & 3.5959 & TRN & \\
\hline CHEMBL 286497 & 32524 & 5.2 & 4.9766 & TRN & \\
\hline CHEMBL28340 & 32524 & 5.51 & \multicolumn{2}{|c|}{5.367999999999999} & TRN \\
\hline CHEMBL341882 & 32524 & 3.33 & 3.398 & TRN & \\
\hline CHEMBL27639 & 32524 & 3.72 & 3.7884 & TRN & \\
\hline CHEMBL118420 & 32524 & 5.39 & 5.535 & TST & \\
\hline CHEMBL69312 & 32524 & 6.14 & 5.9872 & TRN & \\
\hline CHEMBL22053 & 32524 & 6.62 & 5.426 & TST & \\
\hline CHEMBL338311 & 32524 & 6.08 & 5.8133 & TRN & \\
\hline CHEMBL116945 & 32524 & 4.81 & 4.918 & TRN & \\
\hline CHEMBL26717 & 32524 & 4.0 & 4.9739 & TST & \\
\hline CHEMBL 28228 & 32524 & 4.64 & 4.584 & TST & \\
\hline CHEMBL130744 & 32524 & 7.1 & 5.0078 & TST & \\
\hline CHEMBL28329 & 32524 & 6.39 & 6.1616 & TST & \\
\hline CHEMBL145494 & 32524 & 4.08 & 4.1011 & TST & \\
\hline CHEMBL27499 & 32524 & 5.89 & 5.6586 & TST & \\
\hline
\end{tabular}


Supplemental Table S2.txt

\begin{tabular}{|c|c|c|c|c|c|}
\hline CHEMBL 3423164 & 1474901 & 4.3737 & 3.9414 & TST & \\
\hline CHEMBL 3423162 & 1474901 & 5.3665 & 5.3213 & TRN & \\
\hline CHEMBL 3423178 & 1474901 & 4.4437 & 4.4566 & TRN & \\
\hline CHEMBL 3423185 & 1474901 & 5.2147 & 5.2637 & TRN & \\
\hline CHEMBL 3423169 & 1474901 & 3.0 & 4.0818 & TST & \\
\hline CHEMBL 3423146 & 1474901 & 3.0 & 3.0331 & TRN & \\
\hline CHEMBL 3423181 & 1474901 & 4.5719 & 4.5172 & TRN & \\
\hline CHEMBL 3423180 & 1474901 & 5.0809 & 5.0857 & TRN & \\
\hline CHEMBL 3423135 & 1474901 & 4.5229 & \multicolumn{2}{|c|}{4.593999999999999} & TRN \\
\hline CHEMBL 3423188 & 1474901 & 4.9586 & 4.8963 & TRN & \\
\hline CHEMBL 3423142 & 1474901 & 4.8633 & 4.8333 & TRN & \\
\hline CHEMBL 3423176 & 1474901 & 4.466 & 4.5982 & TRN & \\
\hline CHEMBL 3423153 & 1474901 & 3.0 & 2.8829 & TRN & \\
\hline CHEMBL 3423145 & 1474901 & 3.0 & 3.0275 & TRN & \\
\hline CHEMBL 3423175 & 1474901 & 4.7447 & 4.6199 & TRN & \\
\hline CHEMBL 3423179 & 1474901 & 4.5287 & 4.4773 & TRN & \\
\hline CHEMBL 3423173 & 1474901 & 4.8539 & 4.9711 & TRN & \\
\hline CHEMBL 3423186 & 1474901 & \multicolumn{3}{|c|}{4.9830000000000005} & TRN \\
\hline CHEMBL 3423189 & 1474901 & 3.0 & 2.8904 & TRN & \\
\hline CHEMBL 3423165 & 1474901 & 4.7986 & 5.2142 & TST & \\
\hline CHEMBL 3423174 & 1474901 & 4.4647 & 4.4874 & TRN & \\
\hline CHEMBL 3423155 & 1474901 & 4.4855 & 4.5137 & TRN & \\
\hline CHEMBL 3423171 & 1474901 & 4.4101 & 4.4653 & TRN & \\
\hline CHEMBL 3423143 & 1474901 & 3.0 & 3.1449 & TST & \\
\hline CHEMBL 3423191 & 1474901 & 4.3439 & 4.4438 & TRN & \\
\hline CHEMBL 3423182 & 1474901 & 5.0458 & 5.091 & TRN & \\
\hline CHEMBL 3423167 & 1474901 & 4.567 & 4.1222 & TST & \\
\hline CHEMBL 3423148 & 1474901 & 4.0788 & 3.8122 & TRN & \\
\hline CHEMBL 3423190 & 1474901 & 5.1739 & 5.1749 & TRN & \\
\hline CHEMBL 3423170 & 1474901 & 4.8386 & 4.7095 & TRN & \\
\hline CHEMBL 3423156 & 1474901 & 3.0 & 3.1751 & TRN & \\
\hline CHEMBL 3423144 & 1474901 & 3.0 & 3.1589 & TST & \\
\hline CHEMBL 3423168 & 1474901 & 4.2104 & 4.6314 & TST & \\
\hline CHEMBL 3423141 & 1474901 & 4.6198 & 4.7833 & TST & \\
\hline CHEMBL 3423138 & 1474901 & 4.8633 & 4.5472 & TST & \\
\hline CHEMBL 3423166 & 1474901 & 4.5702 & 4.2415 & TST & \\
\hline CHEMBL 3423147 & 1474901 & 3.0 & 3.1738 & TRN & \\
\hline CHEMBL 3423161 & 1474901 & 3.0 & 3.0402 & TRN & \\
\hline CHEMBL 3423163 & 1474901 & 5.1549 & 3.7472 & TST & \\
\hline CHEMBL 3423157 & 1474901 & 3.0 & 2.9772 & TRN & \\
\hline CHEMBL 3423150 & 1474901 & 3.0 & 3.5702 & TST & \\
\hline CHEMBL 3423172 & 1474901 & 4.7471 & 4.6564 & TRN & \\
\hline CHEMBL3423139 & 1474901 & 4.5528 & 4.5251 & TST & \\
\hline CHEMBL 3423154 & 1474901 & 3.0 & 4.44600 & 0000000001 & IJ \\
\hline CHEMBL 3423151 & 1474901 & 3.0 & 3.0625 & TRN & \\
\hline CHEMBL 3423152 & 1474901 & 3.0 & 3.0145 & TRN & \\
\hline CHEMBL 3423158 & 1474901 & 3.0 & 2.9081 & TRN & \\
\hline CHEMBL 3423187 & 1474901 & 4.251 & 4.401 & TRN & \\
\hline
\end{tabular}


Supplemental Table S2.txt

\begin{tabular}{|c|c|c|c|c|}
\hline CHEMBL 3423184 & 1474901 & 4.9281 & 4.8167 & TRN \\
\hline CHEMBL 3421648 & 1474901 & 3.0 & 3.0458 & TRN \\
\hline CHEMBL3423160 & 1474901 & 3.0 & 2.9628 & TRN \\
\hline CHEMBL3423159 & 1474901 & 3.0 & 3.0363 & TRN \\
\hline CHEMBL3423149 & 1474901 & 3.0 & 2.9116 & TRN \\
\hline CHEMBL 3423183 & 1474901 & 4.1543 & 4.3224 & TRN \\
\hline CHEMBL 3423177 & 1474901 & 4.51 & 4.502 & TRN \\
\hline CHEMBL 3087847 & 1474901 & 6.0 & 6.0242 & TRN \\
\hline CHEMBL 3423140 & 1474901 & 4.5258 & 5.6112 & TST \\
\hline CHEMBL189727 & 303260 & 3.0 & 3.0 & TST \\
\hline CHEMBL189988 & 303260 & 3.0 & 3.0 & TRN \\
\hline CHEMBL192039 & 303260 & 3.0 & 3.0 & TRN \\
\hline CHEMBL193180 & 303260 & 3.0 & 3.0 & TRN \\
\hline CHEMBL365129 & 303260 & 3.0 & 3.0 & TRN \\
\hline CHEMBL192809 & 303260 & 3.0 & 3.0 & TRN \\
\hline CHEMBL365809 & 303260 & 3.0 & 3.0 & TRN \\
\hline CHEMBL191688 & 303260 & 3.0 & 3.0 & TST \\
\hline CHEMBL365161 & 303260 & 3.0 & 3.0 & TST \\
\hline CHEMBL371858 & 303260 & 3.0 & 3.0 & TRN \\
\hline CHEMBL191676 & 303260 & 3.0 & 3.0 & TRN \\
\hline CHEMBL195713 & 303260 & 3.0 & 3.0 & TRN \\
\hline CHEMBL192648 & 303260 & 3.0 & 3.0 & TRN \\
\hline CHEMBL365392 & 303260 & 3.0 & 3.0 & TRN \\
\hline CHEMBL370059 & 303260 & 3.0 & 3.0 & TRN \\
\hline CHEMBL192180 & 303260 & 3.0 & 3.0 & TRN \\
\hline CHEMBL364734 & 303260 & 3.0 & 3.0 & TRN \\
\hline CHEMBL192410 & 303260 & 3.0 & 3.0 & TRN \\
\hline CHEMBL192627 & 303260 & 6.572 & 3.0 & TST \\
\hline CHEMBL191513 & 303260 & 3.0 & 3.0 & TRN \\
\hline CHEMBL192595 & 303260 & 3.0 & 3.0 & TRN \\
\hline CHEMBL363186 & 303260 & 3.0 & 3.0 & TST \\
\hline CHEMBL435109 & 303260 & 3.0 & 3.0 & TRN \\
\hline CHEMBL192474 & 303260 & 3.0 & 3.0 & TRN \\
\hline CHEMBL191625 & 303260 & 3.0 & 3.0 & TRN \\
\hline CHEMBL284028 & 303260 & 3.0 & 3.0 & TST \\
\hline CHEMBL191822 & 303260 & 3.0 & 3.0 & TRN \\
\hline CHEMBL189886 & 303260 & 3.0 & 3.0 & TRN \\
\hline CHEMBL365517 & 303260 & 3.0 & 3.0 & TRN \\
\hline CHEMBL363855 & 303260 & 3.0 & 3.0 & TRN \\
\hline CHEMBL366205 & 303260 & 3.0 & 3.0 & TRN \\
\hline CHEMBL370299 & 303260 & 3.0 & 3.0 & TRN \\
\hline CHEMBL192712 & 303260 & 3.0 & 3.0 & TST \\
\hline CHEMBL191800 & 303260 & 3.0 & 3.0 & TST \\
\hline CHEMBL371371 & 303260 & 3.0 & 3.0 & TST \\
\hline CHEMBL192657 & 303260 & 3.0 & 3.0 & TRN \\
\hline CHEMBL364588 & 303260 & 3.0 & 3.0 & TRN \\
\hline CHEMBL90039 & 303260 & 3.0 & 3.0 & TRN \\
\hline CHEMBL193140 & 303260 & 3.0 & 3.0 & TRN \\
\hline
\end{tabular}




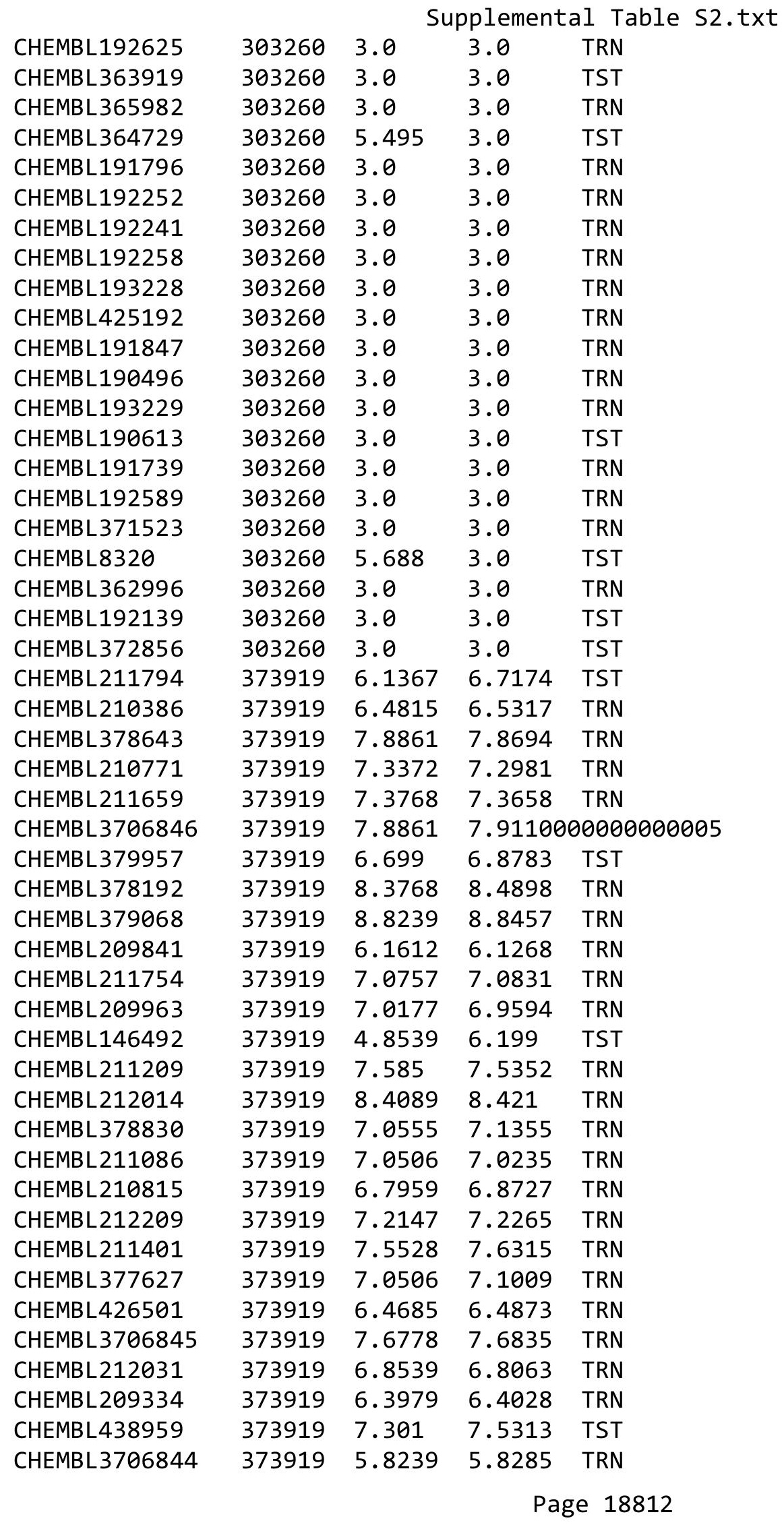

TRN 


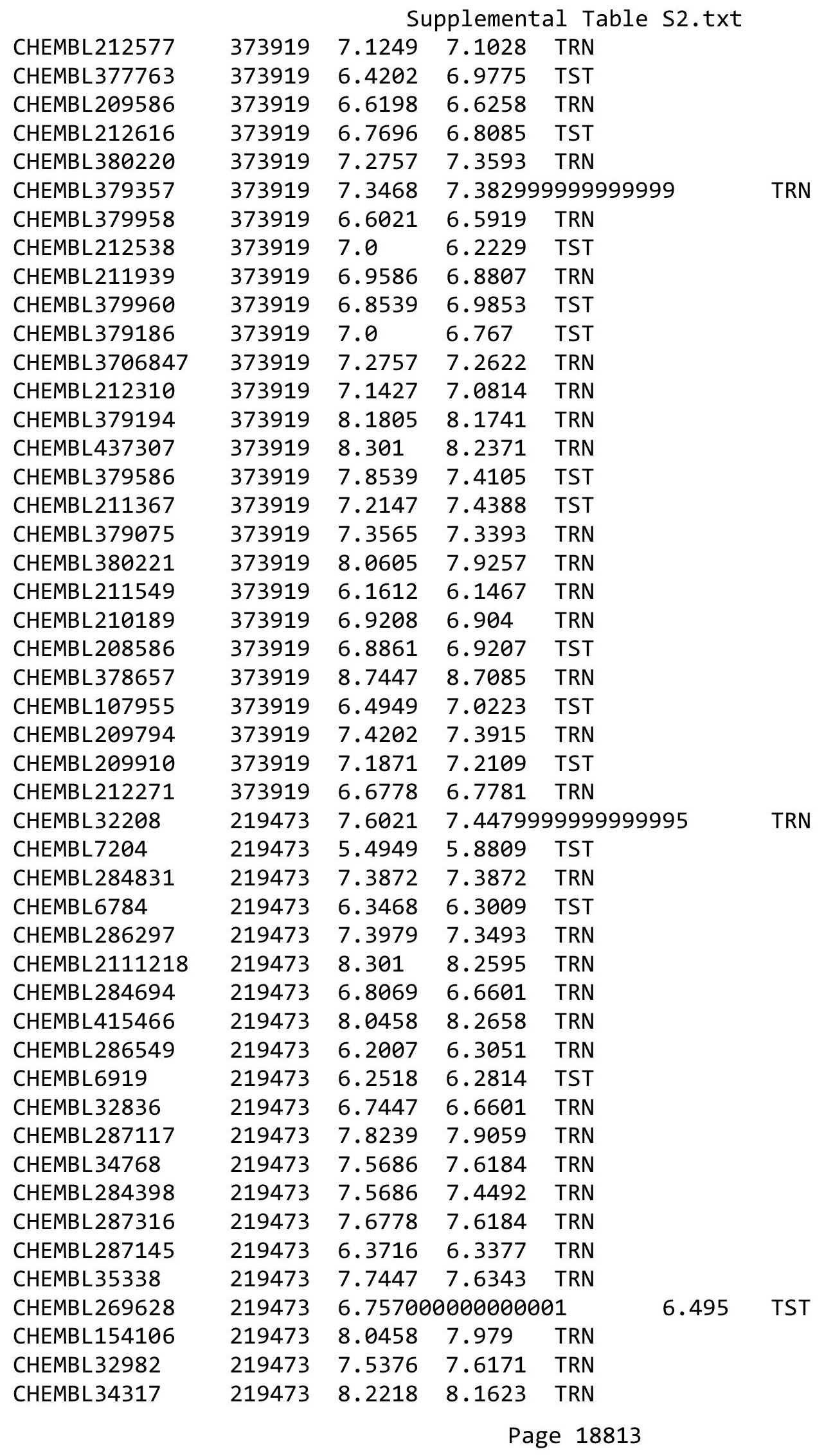




\begin{tabular}{|c|c|c|c|c|c|}
\hline \multicolumn{6}{|c|}{ Supplemental Table S2.txt } \\
\hline CHEMBL286586 & 219473 & 8.2218 & 8.2658 & TRN & \\
\hline CHEMBL416410 & 219473 & 7.7959 & 7.9701 & TRN & \\
\hline CHEMBL6685 & 219473 & 7.7696 & 7.6658 & TRN & \\
\hline CHEMBL289672 & 219473 & 6.2596 & 6.2546 & TRN & \\
\hline CHEMBL268177 & 219473 & 6.9031 & 6.6446 & TST & \\
\hline CHEMBL 290348 & 219473 & 7.284 & 7.3872 & TRN & \\
\hline CHEMBL 6852 & 219473 & 5.6576 & 6.0118 & TST & \\
\hline CHEMBL35528 & 219473 & 6.4815 & 6.2546 & TRN & \\
\hline CHEMBL 2112274 & 219473 & 8.3979 & 8.0849 & TRN & \\
\hline CHEMBL35118 & 219473 & 7.7212 & 7.6747 & TRN & \\
\hline CHEMBL35043 & 219473 & 6.7212 & 7.0175 & TRN & \\
\hline CHEMBL7092 & 219473 & 6.4949 & 6.4613 & TST & \\
\hline CHEMBL408857 & 219473 & 6.7696 & 6.8965 & TRN & \\
\hline CHEMBL6753 & 219473 & 6.4498 & 7.029 & TST & \\
\hline CHEMBL 6724 & 219473 & 7.1805 & 6.6812 & TST & \\
\hline CHEMBL 286449 & 219473 & 7.4318 & 7.3493 & TRN & \\
\hline CHEMBL36525 & 219473 & 6.301 & 6.3377 & TRN & \\
\hline CHEMBL32606 & 219473 & 7.5528 & 7.7658 & TRN & \\
\hline CHEMBL 32732 & 219473 & 7.5376 & 7.6343 & TRN & \\
\hline CHEMBL 266240 & 219473 & 6.7959 & 6.3833 & TST & \\
\hline CHEMBL284617 & 219473 & 7.4437 & 7.44799 & 99999999995 & TRN \\
\hline CHEMBL 2112276 & 219473 & 7.6778 & 7.7181 & TRN & \\
\hline CHEMBL34974 & 219473 & 6.5768 & 6.8965 & TRN & \\
\hline CHEMBL32096 & 219473 & 7.4437 & 7.2776 & TRN & \\
\hline CHEMBL35385 & 219473 & 6.9393 & 7.0175 & TRN & \\
\hline CHEMBL6705 & 219473 & 5.8827 & 5.8263 & TST & \\
\hline CHEMBL 7087 & 219473 & 5.6021 & 6.20100 & 00000000005 & TST \\
\hline CHEMBL432083 & 219473 & 8.1549 & 7.7658 & TRN & \\
\hline CHEMBL346691 & 219473 & 8.3979 & 8.3995 & TRN & \\
\hline CHEMBL408856 & 219473 & 8.301 & 8.1623 & TRN & \\
\hline CHEMBL 265674 & 219473 & 6.2676 & 6.6536 & TST & \\
\hline CHEMBL13646 & 219473 & 6.9031 & 7.0372 & TRN & \\
\hline CHEMBL 289888 & 219473 & 7.7212 & 7.979 & TRN & \\
\hline CHEMBL262389 & 219473 & 6.3665 & 6.3051 & TRN & \\
\hline CHEMBL2112275 & 219473 & 7.0 & 7.0241 & TRN & \\
\hline CHEMBL6853 & 219473 & 6.7447 & 6.6713 & TST & \\
\hline CHEMBL34852 & 219473 & 8.301 & 8.3995 & TRN & \\
\hline CHEMBL285516 & 219473 & 8.0969 & 7.9701 & TRN & \\
\hline CHEMBL 32160 & 219473 & 7.4949 & 7.4492 & TST & \\
\hline CHEMBL30168 & 219473 & 7.6198 & 7.6171 & TST & \\
\hline CHEMBL141478 & 45431 & 5.983 & 5.4764 & TRN & \\
\hline CHEMBL141868 & 45431 & 8.0458 & 7.8252 & TRN & \\
\hline CHEMBL343047 & 45431 & 6.8861 & 6.7871 & TRN & \\
\hline CHEMBL140095 & 45431 & 8.0458 & 7.9897 & TRN & \\
\hline CHEMBL 262561 & 45431 & 7.4815 & 7.5892 & TRN & \\
\hline CHEMBL344887 & 45431 & 6.0809 & 6.0183 & TRN & \\
\hline CHEMBL 342485 & 45431 & 7.3468 & 7.1598 & TRN & \\
\hline CHEMBL140169 & 45431 & 6.3872 & 5.8793 & TST & \\
\hline
\end{tabular}


Supplemental Table S2.txt

\begin{tabular}{|c|c|c|c|c|}
\hline CHEMBL433685 & 45431 & 5.9208 & 5.4807 & TST \\
\hline CHEMBI 341548 & 45431 & 6.1675 & 6.1152 & TRN \\
\hline CHEMBL140389 & 45431 & .2596 & 6.3538 & \\
\hline HEMBL 344889 & 45431 & 7.6021 & 7.6003 & RN \\
\hline CHEMBL143294 & 45431 & 7.5086 & 7.7963 & \\
\hline CHEMBL 281794 & 45431 & .0706 & 6.2335 & \\
\hline HEMBL140880 & 45431 & .0915 & 6.0281 & ST \\
\hline IHEMBL94836 & 45431 & 8.2218 & 8.1668 & RN \\
\hline HEMBL138115 & 45431 & 4.3279 & 4.4008 & RN \\
\hline CHEMBL140221 & 45431 & 6.5935 & 6.5434 & \\
\hline CHEMBL69149 & 45431 & .0969 & 7.6623 & \\
\hline CHEMBL 96361 & 45431 & .7328 & 6.6536 & \\
\hline CHEMBL140696 & 45431 & 7.2076 & 7.1842 & RN \\
\hline HEMBL140391 & 45431 & .5229 & 7.5561 & \\
\hline CHEMBL 336249 & 45431 & 6.1871 & 6.2189 & RN \\
\hline HEMBL139023 & 45431 & .301 & 4.3327 & RN \\
\hline CHEMBL14 & 45431 & .0458 & 5.4878 & ST \\
\hline CHEMBL138530 & 45431 & 6.2218 & 6.3033 & $\mathrm{RN}$ \\
\hline CHEMBL140975 & 45431 & .2162 & 4.0696 & r \\
\hline CHEMBL422639 & 45431 & .301 & 6.1398 & RN \\
\hline HEMBL141965 & 454 & 1518 & 6.5442 & ST \\
\hline CHEMBL42 & 454 & 959 & 7.7192 & RN \\
\hline CHEMBL138847 & 45431 & 7.9208 & 7.8248 & TRN \\
\hline CHEMBL140879 & 45431 & 0 & 8.2443 & TST \\
\hline CHEMBL 341600 & 45431 & .9101 & 4.6823 & TST \\
\hline HEMBL 343048 & 454 & .8861 & 7.8888 & TRN \\
\hline CHEMBL14 & 452 & 218 & 8.4327 & TRN \\
\hline CHEMBL34 & 45431 & 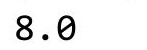 & 8.0189 & TRN \\
\hline CHEMBL142078 & 454 & 18 & 4.0545 & TST \\
\hline CHEMBL342038 & 45431 & .983 & 5.9091 & TRN \\
\hline CHEMBL142541 & 454 & 086 & 6.415 & TST \\
\hline CHEMBL14 & 452 & 549 & 8.0906 & TRN \\
\hline CHEMBL1 14 & 454 & 707 & 5.7116 & TST \\
\hline CHEMBL336691 & 45431 & .3768 & 4.4789 & TRN \\
\hline CHEMBL 342610 & 45431 & .0969 & 8.1747 & TRN \\
\hline CHEMBL138920 & 45431 & 9458 & 7.9988 & TRN \\
\hline CHEMBL 33 & 45431 & 98 & 6.4616 & IST \\
\hline CHEMBL139700 & 45431 & 4.9872 & 5.3028 & TRN \\
\hline CHEMBL344055 & 45431 & 7.3979 & 7.216 & TRN \\
\hline CHEMBL14 & 454 & 4.5376 & 4.7833 & TRN \\
\hline CHEMBL 344861 & 45431 & 6.3279 & 5.8482 & TST \\
\hline CHEMBL139539 & 45431 & 7.4437 & 7.7497 & TRN \\
\hline CHEMBL141363 & 45431 & 7.4815 & 7.3972 & TRN \\
\hline CHEMBL443483 & 45431 & 6.0605 & 6.0233 & TRN \\
\hline CHEMBL139563 & 45431 & 6.063 & 6.1301 & TRN \\
\hline CHEMBL 335353 & 45431 & 4.8239 & 5.2507 & RIN \\
\hline CHEMBL343268 & 45431 & 6.2676 & 5.8547 & ГST \\
\hline CHEMBL 342679 & 45431 & 6.301 & 6.3843 & TRN \\
\hline
\end{tabular}

Page 18815 
Supplemental Table S2.txt

\begin{tabular}{|c|c|c|c|c|}
\hline CHEMBL337771 & 45431 & 7.5376 & 7.4638 & TRN \\
\hline CHEMBL344941 & 45431 & 6.4559 & 6.2753 & TST \\
\hline CHEMBL140973 & 5431 & .0132 & 3.9002 & ГST \\
\hline CHEMBL140820 & 45431 & .3468 & 4.3968 & ST \\
\hline CHEMBL138603 & 45431 & 8.0458 & 8.0317 & RIV \\
\hline CHEMBL140252 & 45431 & 6.8239 & 6.6398 & TRN \\
\hline CHEMBL343944 & 45431 & 7.6198 & 7.6343 & RN \\
\hline CHEMBL264879 & 45431 & 8.0969 & 7.9546 & RN \\
\hline CHEMBL141899 & 45431 & 8.1549 & 8.336 & RN \\
\hline HEMBL344888 & 45431 & 6.8097 & 6.8681 & RIV \\
\hline CHEMBL139939 & 45431 & 7.8861 & 7.9145 & ITV \\
\hline IHEMBL336247 & 45431 & 4.3098 & 4.3494 & RN \\
\hline CHEMBL140938 & 45431 & 4.0209 & 4.1265 & RN \\
\hline IHEMBL140428 & 45431 & 6.8539 & 6.6195 & -CT \\
\hline HEMBL139549 & 45431 & 6.2218 & 6.2507 & $\mathrm{RI}$ \\
\hline CHEMBL139946 & 45431 & 8.1549 & 8.1033 & NIV \\
\hline CHEMBL140116 & 45431 & 55 & 256 & RN \\
\hline CHEMBL141130 & 45431 & 98 & 441 & $\mathrm{RN}$ \\
\hline CHEMBL139668 & 45431 & 7.6021 & 7.545 & 「RN \\
\hline CHEMBL141618 & 45431 & 4.9208 & 594 & ו \\
\hline CHEMBL141624 & 45431 & 8.7 & 8.2 & RIN \\
\hline CHEMBL140379 & 45431 & 88 & 6. & RN \\
\hline CHEMBL336483 & 45431 & 6.7959 & 269 & TRN \\
\hline HEMBL140452 & 45431 & 6.1675 & 5.8427 & $T$ \\
\hline CHEMBL141052 & 45431 & 6.2218 & 6.2772 & TRN \\
\hline CHEMBL436573 & 45431 & 6.6383 & 372 & ST \\
\hline CHEMBL335337 & 45431 & 7.5229 & 7.7231 & TRN \\
\hline CHEMBL343098 & 45431 & 7.585 & 7.2834 & TST \\
\hline CHEMBL344056 & 45431 & 6.1249 & 6.0425 & TRN \\
\hline CHEMBL141108 & 45431 & 7.5376 & 7.5533 & TRN \\
\hline CHEMBL342146 & 45431 & 6.699 & 47 & TRN \\
\hline CHEMBL142142 & 45431 & 84 & 6. & TRN \\
\hline CHEMBL140805 & 45431 & 69 & 8.1551 & TRN \\
\hline CHEMBL337369 & 45431 & 8.0458 & 8.1424 & TRN \\
\hline CHEMBL341760 & 45431 & 8.0 & 8.0785 & TRN \\
\hline CHEMBL14 & 45431 & 8.0458 & 518 & TRN \\
\hline CHEMBL14 & 45431 & 7.4949 & 7.4561 & TRN \\
\hline CHEMBL337136 & 45431 & 6.0088 & 6.0514 & TRN \\
\hline CHEMBL141408 & 45431 & 6.2596 & 5.8367 & TST \\
\hline CHEMBL141028 & 45431 & 4.1898 & 4.2887 & TRN \\
\hline CHEMBL141757 & 45431 & 7.4437 & 7.4127 & TRN \\
\hline CHEMBL342668 & 45431 & 6.2291 & 6.0321 & TRN \\
\hline CHEMBL139649 & 45431 & 7.4089 & 7.3562 & TRN \\
\hline CHEMBL141410 & 45431 & 7.4685 & 7.4027 & TRN \\
\hline CHEMBL141898 & 45431 & 7.8539 & 7.8209 & TST \\
\hline CHEMBL138812 & 45431 & 7.9586 & 8.1553 & TRI \\
\hline CHEMBL141255 & 45431 & 7.2676 & 7.1161 & 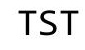 \\
\hline CHEMBL141049 & 45431 & 6.0555 & 5.5935 & TR \\
\hline
\end{tabular}

Page 18816 


\begin{tabular}{|c|c|c|c|c|}
\hline & & & pplement & al $\mathrm{T}$ \\
\hline CHEMBL140554 & 45431 & 6.3768 & 6.6325 & TST \\
\hline CHEMBL 344034 & 45431 & 7.7696 & 7.9456 & TRN \\
\hline CHEMBL141562 & 45431 & 6.301 & 6.2905 & TRN \\
\hline CHEMBL138309 & 45431 & 4.9586 & 5.0156 & TST \\
\hline CHEMBL140110 & 45431 & 8.301 & 8.1495 & TRN \\
\hline CHEMBL140643 & 45431 & 4.9031 & 5.3849 & TRN \\
\hline CHEMBL 344001 & 45431 & 7.8239 & 7.7472 & TRN \\
\hline CHEMBL342407 & 45431 & 7.3665 & 7.5342 & TRN \\
\hline CHEMBL138972 & 45431 & 4.6108 & 4.7509 & TST \\
\hline CHEMBL141753 & 45431 & 8.2218 & 8.5045 & TRN \\
\hline CHEMBL141756 & 45431 & 7.6021 & 7.4061 & TRN \\
\hline CHEMBL337328 & 45431 & 7.8539 & 7.7677 & TRN \\
\hline CHEMBL344382 & 45431 & 8.0 & 8.0068 & TRN \\
\hline CHEMBL140941 & 45431 & 7.4949 & 7.3686 & TST \\
\hline CHEMBL142067 & 45431 & 6.1397 & 6.0998 & TRN \\
\hline CHEMBL141346 & 45431 & 7.3979 & 7.2455 & TRN \\
\hline CHEMBL343046 & 45431 & 7.6778 & 7.5812 & TRN \\
\hline CHEMBL140942 & 45431 & 6.2218 & 6.472 & TRN \\
\hline CHEMBL265112 & 45431 & 6.1163 & 6.2941 & TRN \\
\hline CHEMBL140370 & 45431 & 8.1549 & 8.1223 & TRN \\
\hline CHEMBL138009 & 45431 & 6.0757 & 6.0723 & TRN \\
\hline CHEMBL140791 & 45431 & 7.9208 & 7.6926 & TRN \\
\hline CHEMBL342622 & 45431 & 6.3872 & 6.5862 & TRN \\
\hline CHEMBL436400 & 45431 & 5.0362 & 5.1097 & TST \\
\hline CHEMBL139940 & 45431 & 7.2596 & 7.2499 & TRN \\
\hline CHEMBL344181 & 45431 & 6.0458 & 5.5882 & TRN \\
\hline CHEMBL142132 & 45431 & 8.2218 & 8.2295 & TRN \\
\hline CHEMBL141425 & 45431 & 7.7447 & 7.6957 & TST \\
\hline CHEMBL343916 & 45431 & 8.0969 & 8.1254 & TRN \\
\hline CHEMBL141351 & 45431 & 8.0969 & 8.1505 & TRN \\
\hline CHEMBL344709 & 45431 & 6.3979 & 5.773 & TST \\
\hline CHEMBL138178 & 45431 & 5.8239 & 5.754 & TRN \\
\hline CHEMBL140692 & 45431 & 6.9872 & 6.1001 & TST \\
\hline CHEMBL344237 & 45431 & 4.9767 & 5.119 & TST \\
\hline CHEMBL141526 & 45431 & 6.0292 & 6.0256 & TRN \\
\hline CHEMBL342390 & 45431 & 4.9626 & 4.7423 & TST \\
\hline CHEMBL343590 & 45431 & 6.8477 & 6.7308 & TST \\
\hline CHEMBL342026 & 45431 & 8.301 & 8.0885 & TRN \\
\hline CHEMBL138253 & 45431 & 8.0458 & 8.0196 & TRN \\
\hline CHEMBL140616 & 45431 & 7.9586 & 7.9103 & TRN \\
\hline CHEMBL140933 & 45431 & 6.2076 & 6.2468 & TRN \\
\hline CHEMBL140007 & 45431 & 7.4089 & 7.3547 & TRN \\
\hline CHEMBL140544 & 45431 & 6.2291 & 6.2421 & TRN \\
\hline CHEMBL139763 & 45431 & 7.0 & 6.1655 & TST \\
\hline CHEMBL344030 & 45431 & 6.1192 & 6.0457 & TRN \\
\hline CHEMBL343332 & 45431 & 6.6198 & 5.8424 & TST \\
\hline CHEMBL 3704630 & 1528930 & 9.0969 & 8.7147 & TRN \\
\hline CHEMBL3704646 & 1528930 & 8.1739 & 8.0461 & TST \\
\hline
\end{tabular}


Supplemental Table S2.txt

\begin{tabular}{|c|c|c|c|c|c|c|}
\hline CHEMBL 3704588 & 1528930 & 7.7212 & 7.2725 & TRN & & \\
\hline CHEMBL3704641 & 1528930 & 7.3979 & 7.7727 & TRN & & \\
\hline CHEMBL3943176 & 1528930 & 6.1612 & 6.5882 & TRN & & \\
\hline CHEMBL3704644 & 1528930 & 8.2218 & 8.2487 & TRN & & \\
\hline CHEMBL3704613 & 1528930 & 8.5719 & 8.5563 & TRN & & \\
\hline CHEMBL3704609 & 1528930 & 7.6498 & 7.6016 & TST & & \\
\hline CHEMBL3704591 & 1528930 & 7.3625 & 7.3155 & TRN & & \\
\hline CHEMBL3704589 & 1528930 & 6.0 & 6.5359 & TRN & & \\
\hline CHEMBL3704595 & 1528930 & 7.3696 & 7.4528 & TRN & & \\
\hline CHEMBL3954436 & 1528930 & 8.0706 & 7.8686 & TST & & \\
\hline CHEMBL3704606 & 1528930 & 7.1805 & 7.2994 & TRN & & \\
\hline CHEMBL3704597 & 1528930 & 7.8477 & 7.5536 & TRN & & \\
\hline CHEMBL 3704618 & 1528930 & 8.9393 & 8.3032 & TRN & & \\
\hline CHEMBL 3704627 & 1528930 & 8.2118 & 8.2349 & TRN & & \\
\hline CHEMBL3704596 & 1528930 & 7.0362 & 7.4561 & TRN & & \\
\hline CHEMBL 3704580 & 1528930 & 8.3251 & 7.7412 & TRN & & \\
\hline CHEMBL3704626 & 1528930 & 7.9393 & 7.9005 & TRN & & \\
\hline CHEMBL 3891288 & 1528930 & 7.0137 & 6.6881 & TRN & & \\
\hline CHEMBL3704628 & 1528930 & 7.3197 & 7.2206 & TRN & & \\
\hline CHEMBL 3704582 & 1528930 & 8.7212 & 8.2942 & TST & & \\
\hline CHEMBL3704625 & 1528930 & 7.4437 & 7.5042 & TRN & & \\
\hline CHEMBL3704642 & 1528930 & 8.1487 & 8.2872 & TRN & & \\
\hline CHEMBL 3704647 & 1528930 & 7.6819 & 8.0687 & TRN & & \\
\hline CHEMBL3704634 & 1528930 & 7.7011 & 6.9179 & TRN & & \\
\hline CHEMBL3704583 & 1528930 & 6.0 & 6.5184 & TRN & & \\
\hline CHEMBL3704640 & 1528930 & 7.6655 & 8.2082 & TRN & & \\
\hline CHEMBL3704607 & 1528930 & 7.75700 & 0000000 & 91 & 7.621 & TST \\
\hline CHEMBL 3704620 & 1528930 & 7.8268 & 7.5975 & TRN & & \\
\hline CHEMBL3704601 & 1528930 & 6.2967 & 5.77 & TRN & & \\
\hline CHEMBL3704629 & 1528930 & 7.8013 & 7.546 & TRN & & \\
\hline CHEMBL3704598 & 1528930 & 7.6289 & 7.5517 & TRN & & \\
\hline CHEMBL3704645 & 1528930 & 8.3098 & 8.3874 & TRN & & \\
\hline CHEMBL3704624 & 1528930 & 6.9318 & 7.1637 & TRN & & \\
\hline CHEMBL3704617 & 1528930 & 8.699 & 8.4398 & TRN & & \\
\hline CHEMBL3704602 & 1528930 & 6.0 & 6.0764 & TRN & & \\
\hline CHEMBL3704643 & 1528930 & 8.3768 & 8.1068 & TRN & & \\
\hline CHEMBL3704603 & 1528930 & 6.6003 & 6.6165 & TRN & & \\
\hline CHEMBL 3704587 & 1528930 & 7.0655 & 7.5523 & TRN & & \\
\hline CHEMBL 3704621 & 1528930 & 6.777 & 6.9086 & TRN & & \\
\hline CHEMBL3704593 & 1528930 & 7.8041 & 7.8733 & TRN & & \\
\hline CHEMBL 3704623 & 1528930 & 6.0 & 6.7204 & TRN & & \\
\hline CHEMBL3704611 & 1528930 & 7.1871 & 7.3002 & TRN & & \\
\hline CHEMBL3704637 & 1528930 & 8.4202 & 8.5283 & TRN & & \\
\hline CHEMBL 3704622 & 1528930 & 6.9208 & 7.1807 & TRN & & \\
\hline CHEMBL 3704610 & 1528930 & 7.4306 & 7.5352 & TST & & \\
\hline CHEMBL 3704608 & 1528930 & 7.4353 & 7.2103 & TST & & \\
\hline CHEMBL 3704592 & 1528930 & 7.0655 & 7.2899 & TRN & & \\
\hline CHEMBL3704605 & 1528930 & 7.5575 & 7.2979 & TRN & & \\
\hline
\end{tabular}

Page 18818 
Supplemental Table S2.txt

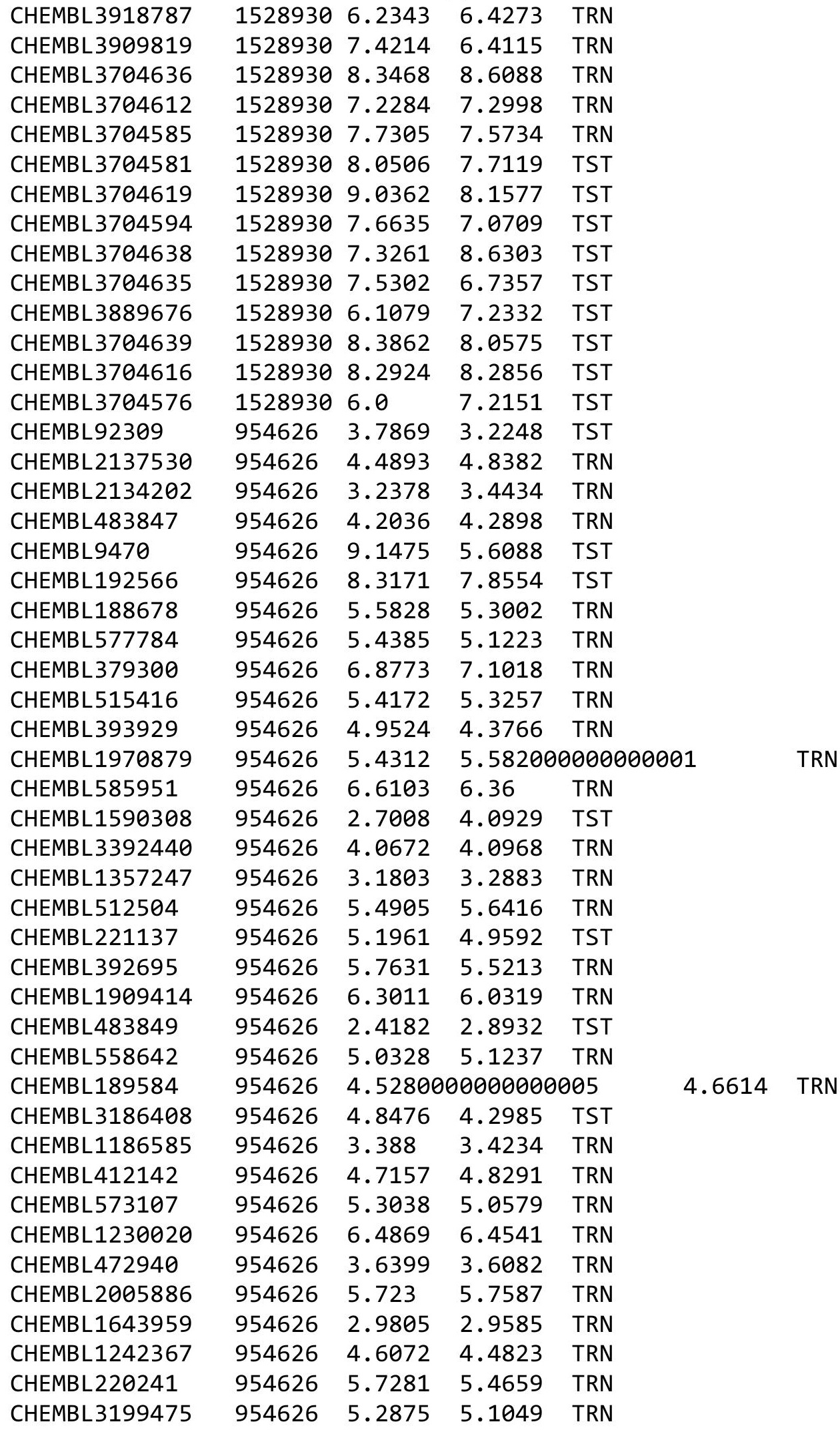

Page 18819 
Supplemental Table S2.txt

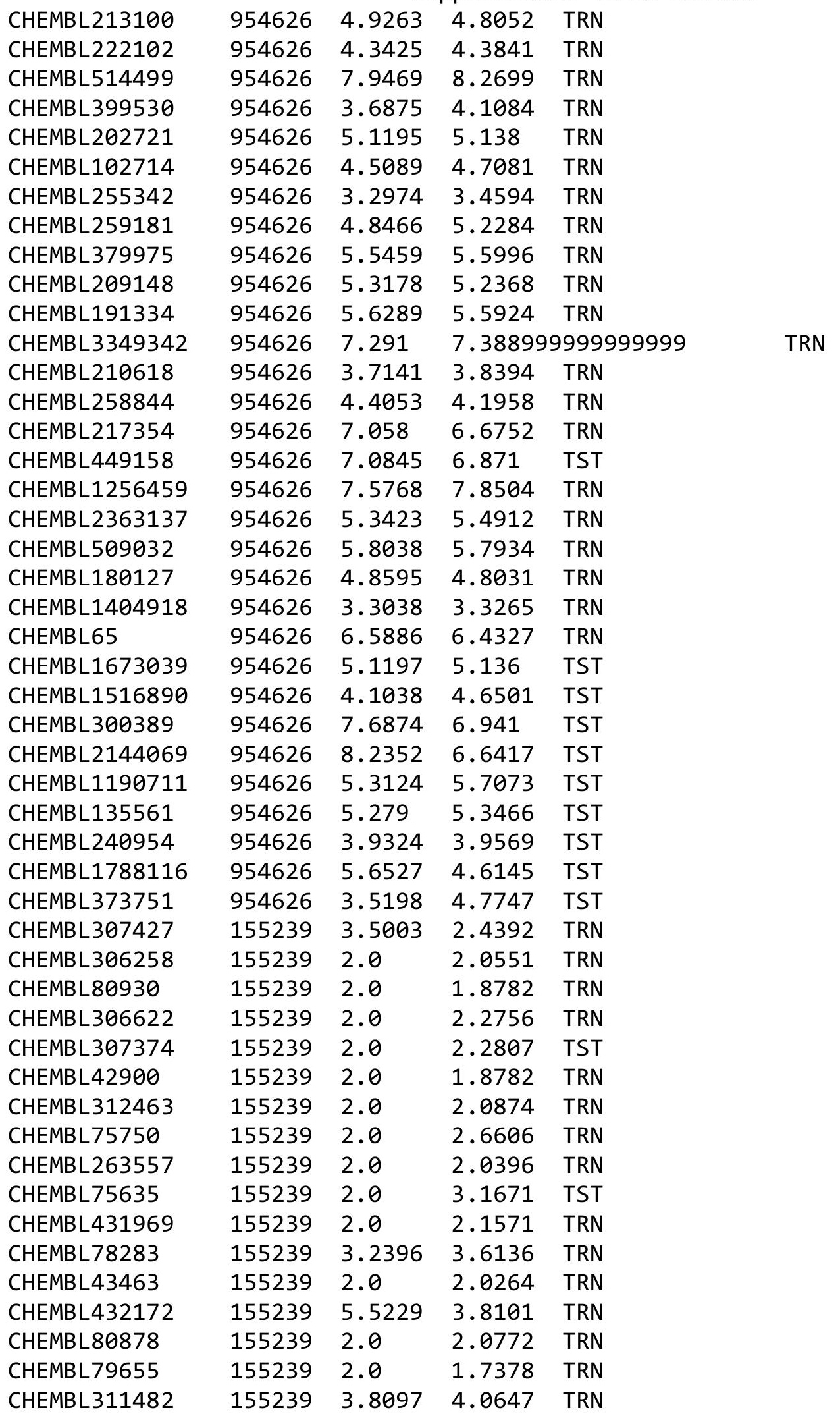

Page 18820 


\begin{tabular}{|c|c|c|c|c|c|}
\hline \multicolumn{6}{|c|}{ Supplemental Table S2.txt } \\
\hline CHEMBL 308764 & 155239 & 2.0 & 2.3886 & TST & \\
\hline CHEMBL 310760 & 155239 & 4.2218 & 4.6344 & TRN & \\
\hline CHEMBL 263454 & 155239 & 2.0 & 2.5033 & TST & \\
\hline CHEMBL406737 & 155239 & 2.0 & 2.0499 & TRN & \\
\hline CHEMBL 308632 & 155239 & 2.0 & 2.4799 & TRN & \\
\hline CHEMBL310412 & 155239 & 2.0 & 2.0669 & TRN & \\
\hline CHEMBL309395 & 155239 & 2.0 & 2.7055 & TST & \\
\hline CHEMBL 263244 & 155239 & 2.0 & 2.3315 & TRN & \\
\hline CHEMBL311043 & 155239 & 2.0 & 1.922 & TRN & \\
\hline CHEMBL 77326 & 155239 & 2.0 & 2.6351 & TST & \\
\hline CHEMBL 306620 & 155239 & 3.1549 & 3.08699 & 99999999997 & TRN \\
\hline CHEMBL 76967 & 155239 & 2.0 & 2.2262 & TRN & \\
\hline CHEMBL77074 & 155239 & 2.0 & 2.1771 & TRN & \\
\hline CHEMBL 75679 & 155239 & 2.0 & 2.0686 & TRN & \\
\hline CHEMBL77998 & 155239 & 2.0 & 1.8855 & TRN & \\
\hline CHEMBL77361 & 155239 & 2.0 & 2.2916 & TRN & \\
\hline CHEMBL77043 & 155239 & 3.1993 & 3.2257 & TST & \\
\hline CHEMBL77183 & 155239 & 2.0 & 2.3886 & TST & \\
\hline CHEMBL 75624 & 155239 & 2.0 & 1.9645 & TST & \\
\hline CHEMBL76796 & 155239 & 2.0 & 2.1627 & TRN & \\
\hline CHEMBL307479 & 155239 & 2.0 & 2.075 & TRN & \\
\hline CHEMBL46809 & 155239 & 3.3063 & 2.3243 & TRN & \\
\hline CHEMBL80502 & 155239 & 2.0 & 2.0396 & TRN & \\
\hline CHEMBL448786 & 155239 & 4.1805 & 4.205 & TRN & \\
\hline CHEMBL 76070 & 155239 & 2.0 & 2.2672 & TST & \\
\hline CHEMBL 298256 & 155239 & 3.8729 & 4.1386 & TRN & \\
\hline CHEMBL 77949 & 155239 & 2.0 & 3.2596 & TST & \\
\hline CHEMBL75972 & 155239 & 2.0 & 2.1627 & TRN & \\
\hline CHEMBL 307597 & 155239 & 3.2441 & 2.6265 & TRN & \\
\hline CHEMBL 312023 & 155239 & 2.0 & 2.9372 & TST & \\
\hline CHEMBL76424 & 155239 & 2.0 & 2.9736 & TST & \\
\hline CHEMBL 78173 & 155239 & 2.0 & 1.9707 & TRN & \\
\hline CHEMBL77007 & 155239 & 3.1549 & 3.043 & TRN & \\
\hline CHEMBL 308074 & 155239 & 2.0 & 2.449 & TRN & \\
\hline CHEMBL 309830 & 155239 & 2.0 & 2.1713 & TRN & \\
\hline CHEMBL 307927 & 155239 & 2.0 & 2.3886 & TST & \\
\hline CHEMBL307637 & 155239 & 2.0 & 1.9884 & TRN & \\
\hline CHEMBL311655 & 155239 & 2.0 & 2.1627 & TRN & \\
\hline CHEMBL 308630 & 155239 & 2.0 & 1.6666 & TRN & \\
\hline CHEMBL 76883 & 155239 & 2.0 & 2.1627 & TST & \\
\hline CHEMBL1863508 & 774025 & 4.0757 & 4.1105 & TRN & \\
\hline CHEMBL1863294 & 774025 & 3.0 & 3.4368 & TRN & \\
\hline CHEMBL1862943 & 774025 & 3.1185 & 3.6296 & TRN & \\
\hline CHEMBL1863130 & 774025 & 3.0 & 3.2123 & TST & \\
\hline CHEMBL1863069 & 774025 & 4.2637 & 4.4083 & TRN & \\
\hline CHEMBL1863052 & 774025 & 3.0 & 2.5899 & TRN & \\
\hline CHEMBL1863475 & 774025 & 4.1259 & 4.2248 & TRN & \\
\hline CHEMBL1863353 & 774025 & 4.3361 & 3.8255 & TRN & \\
\hline
\end{tabular}




\begin{tabular}{|c|c|c|c|c|c|c|}
\hline \multirow[b]{2}{*}{ CHEMBL1863507 } & & \multicolumn{5}{|c|}{ Supplemental Table S2.txt } \\
\hline & 774025 & 4.0744 & 3.8689 & TRN & & \\
\hline CHEMBL1863444 & 774025 & 4.2875 & 4.3083 & TRN & & \\
\hline CHEMBL1863479 & 774025 & 3.0 & 2.8788 & TRN & & \\
\hline CHEMBL1863079 & 774025 & 3.0 & 3.3613 & TRN & & \\
\hline CHEMBL1863156 & 774025 & 3.0 & 2.7971 & TRN & & \\
\hline CHEMBL1862873 & 774025 & 4.0662 & 3.8558 & TST & & \\
\hline CHEMBL1862905 & 774025 & 4.2199 & 3.6517 & TRN & & \\
\hline CHEMBL1863348 & 774025 & 3.0 & 3.0763 & TRN & & \\
\hline CHEMBL1862808 & 774025 & 3.0 & 3.3747 & TRN & & \\
\hline CHEMBL1863060 & 774025 & \multicolumn{3}{|c|}{4.236000000000001} & 3.1766 & TRN \\
\hline CHEMBL1863332 & 774025 & 4.2043 & 4.0046 & TRN & & \\
\hline CHEMBL1863318 & 774025 & 3.0 & 2.4811 & TRN & & \\
\hline CHEMBL1862822 & 774025 & 3.0 & 2.5654 & TRN & & \\
\hline CHEMBL1863396 & 774025 & 3.0 & 3.446 & TST & & \\
\hline CHEMBL1863150 & 774025 & 3.0 & 4.0162 & TRN & & \\
\hline CHEMBL1862938 & 774025 & 3.0 & 3.2894 & TRN & & \\
\hline CHEMBL1863167 & 774025 & 4.2092 & 4.2327 & TRN & & \\
\hline CHEMBL1863502 & 774025 & 4.1805 & 4.1303 & TRN & & \\
\hline CHEMBL1863427 & 774025 & 4.2153 & 3.9527 & TRN & & \\
\hline CHEMBL1863037 & 774025 & 4.2493 & 3.7456 & TRN & & \\
\hline CHEMBL1862875 & 774025 & 4.537 & 3.7506 & TRN & & \\
\hline CHEMBL1862841 & 774025 & 4.2486 & 3.5651 & TRN & & \\
\hline CHEMBL1863157 & 774025 & 3.0 & 3.6167 & TRN & & \\
\hline CHEMBL1863204 & 774025 & 3.0 & 4.3057 & TST & & \\
\hline CHEMBL1863014 & 774025 & 3.0 & 3.6948 & TRN & & \\
\hline CHEMBL1863136 & 774025 & 4.2098 & 4.2947 & TST & & \\
\hline CHEMBL1863141 & 774025 & 4.2031 & 3.8291 & TRN & & \\
\hline CHEMBL1863122 & 774025 & 3.0 & 3.1696 & TRN & & \\
\hline CHEMBL1863287 & 774025 & 3.0 & 3.3296 & TRN & & \\
\hline CHEMBL1863382 & 774025 & 3.0 & 3.3257 & TRN & & \\
\hline CHEMBL1863084 & 774025 & 6.0 & 3.7572 & TST & & \\
\hline CHEMBL1863082 & 774025 & 4.2669 & 4.2216 & TRN & & \\
\hline CHEMBL1863309 & 774025 & 4.1519 & 3.5881 & TRN & & \\
\hline CHEMBL1862914 & 774025 & 4.2587 & 3.9307 & TRN & & \\
\hline CHEMBL1863030 & 774025 & 4.2237 & 4.3077 & TRN & & \\
\hline CHEMBL1862843 & 774025 & 3.0 & 3.1376 & TRN & & \\
\hline CHEMBL1863263 & 774025 & 3.0 & 2.8912 & TRN & & \\
\hline CHEMBL1863000 & 774025 & 4.2444 & 4.2881 & TRN & & \\
\hline CHEMBL1863186 & 774025 & 3.0 & 3.4945 & TRN & & \\
\hline CHEMBL1863339 & 774025 & 4.2649 & 3.0977 & TRN & & \\
\hline CHEMBL1863035 & 774025 & 3.0 & 3.5922 & TRN & & \\
\hline CHEMBL1863207 & 774025 & 3.0 & 3.342 & TRN & & \\
\hline CHEMBL1863437 & 774025 & 4.1754 & 4.1535 & TRN & & \\
\hline CHEMBL1863046 & 774025 & 4.3616 & 4.169 & TRN & & \\
\hline CHEMBL1863044 & 774025 & 3.0 & 2.8822 & TRN & & \\
\hline CHEMBL1863058 & 774025 & 3.0 & 2.8389 & TRN & & \\
\hline CHEMBL1863120 & 774025 & 3.0 & 3.2115 & TRN & & \\
\hline CHEMBL1863452 & 774025 & 3.0 & 3.4949 & TRN & & \\
\hline
\end{tabular}




\begin{tabular}{|c|c|c|c|c|}
\hline \multicolumn{5}{|c|}{ Supplemental Table S2.txt } \\
\hline CHEMBL1862922 & 774025 & 3.0 & 3.5449 & TRN \\
\hline CHEMBL1862975 & 774025 & 3.0 & 3.1325 & TRN \\
\hline CHEMBL1863413 & 774025 & 3.0 & 3.4753 & TST \\
\hline CHEMBL1862871 & 774025 & 3.0 & 3.6095 & TRN \\
\hline CHEMBL1863108 & 774025 & 4.4653 & 4.3518 & TRN \\
\hline CHEMBL1863243 & 774025 & 3.0 & 2.8462 & TRN \\
\hline CHEMBL280558 & 774025 & 3.0 & 3.3247 & TST \\
\hline CHEMBL1862925 & 774025 & 4.2223 & 3.7466 & TRN \\
\hline CHEMBL1863433 & 774025 & 4.254 & 4.3329 & TRN \\
\hline CHEMBL1863032 & 774025 & 4.249 & 4.113 & TRN \\
\hline CHEMBL1863023 & 774025 & 3.0 & 3.2568 & TRN \\
\hline CHEMBL1863465 & 774025 & 3.0 & 3.1748 & TRN \\
\hline CHEMBL1862876 & 774025 & 3.0 & 3.1937 & TRN \\
\hline CHEMBL1863445 & 774025 & 4.3389 & 4.0407 & TRN \\
\hline CHEMBL1862934 & 774025 & 3.0 & 3.208 & TRN \\
\hline CHEMBL1862959 & 774025 & 3.0 & 2.6675 & TST \\
\hline CHEMBL1863214 & 774025 & 3.0 & 3.3133 & TRN \\
\hline CHEMBL1863356 & 774025 & 3.0 & 2.7744 & TRN \\
\hline CHEMBL1863013 & 774025 & 4.1083 & 4.1403 & TRN \\
\hline CHEMBL1863303 & 774025 & 4.1315 & 4.0688 & TRN \\
\hline CHEMBL1862848 & 774025 & 4.2229 & 4.4744 & TRN \\
\hline CHEMBL1862935 & 774025 & 3.0 & 3.2625 & TRN \\
\hline CHEMBL1863316 & 774025 & 3.0 & 3.2194 & TRN \\
\hline CHEMBL1863127 & 774025 & 3.0 & 3.1598 & TRN \\
\hline CHEMBL1863090 & 774025 & 3.0 & 3.0801 & TRN \\
\hline CHEMBL1863270 & 774025 & 3.0 & 3.0152 & TRN \\
\hline CHEMBL1863123 & 774025 & 4.7452 & 4.6158 & TRN \\
\hline CHEMBL1863357 & 774025 & 3.0 & 3.2641 & TRN \\
\hline CHEMBL1862828 & 774025 & 4.1746 & 3.955 & TRN \\
\hline CHEMBL1863443 & 774025 & 3.0 & 3.3843 & TST \\
\hline CHEMBL1863064 & 774025 & 4.7418 & 4.1296 & TRN \\
\hline CHEMBL1863061 & 774025 & 4.0819 & 3.1941 & TST \\
\hline CHEMBL1863400 & 774025 & 4.2748 & 4.2365 & TRN \\
\hline CHEMBL1862887 & 774025 & 3.0 & 2.7348 & TST \\
\hline CHEMBL1863038 & 774025 & 3.0 & 3.0193 & TRN \\
\hline CHEMBL1863320 & 774025 & 3.0 & 3.0179 & TRN \\
\hline CHEMBL1863253 & 774025 & 3.0 & 2.9569 & TRN \\
\hline CHEMBL1863036 & 774025 & 3.0 & 2.9838 & TST \\
\hline CHEMBL1863258 & 774025 & 3.0 & 3.9456 & TRN \\
\hline CHEMBL138538 & 774025 & 4.2135 & 3.9339 & TRN \\
\hline CHEMBL1863187 & 774025 & 3.0 & 3.0767 & TRN \\
\hline CHEMBL1863196 & 774025 & 4.1492 & 3.5595 & TRN \\
\hline CHEMBL1863217 & 774025 & 3.0 & 3.0244 & TRN \\
\hline CHEMBL1862990 & 774025 & 4.2543 & 4.3542 & TRN \\
\hline CHEMBL1863078 & 774025 & 4.2531 & 3.2614 & TST \\
\hline CHEMBL1229721 & 774025 & 3.0 & 2.7991 & TST \\
\hline CHEMBL1862904 & 774025 & 3.0 & 3.5238 & TRN \\
\hline CHEMBL1863274 & 774025 & 3.0 & 3.4677 & TST \\
\hline
\end{tabular}




\begin{tabular}{|c|c|c|c|c|c|}
\hline \multicolumn{6}{|c|}{ Supplemental Table S2.txt } \\
\hline CHEMBL1863183 & 774025 & 3.0 & 3.4918 & TRN & \\
\hline CHEMBL573221 & 774025 & 3.0 & 3.1163 & TST & \\
\hline CHEMBL1862986 & 774025 & 3.0 & 3.0534 & TRN & \\
\hline CHEMBL1862862 & 774025 & 4.2028 & 4.1871 & TRN & \\
\hline CHEMBL1863334 & 774025 & 4.2507 & 4.2458 & TRN & \\
\hline CHEMBL1862806 & 774025 & 4.2962 & 3.8605 & TRN & \\
\hline CHEMBL1862864 & 774025 & 4.1166 & 2.7891 & TST & \\
\hline CHEMBL1862833 & 774025 & 3.0 & 3.7887 & TRN & \\
\hline CHEMBL1863292 & 774025 & 3.0 & 3.2252 & TRN & \\
\hline CHEMBL1862882 & 774025 & 3.0 & 3.28 & TRN & \\
\hline CHEMBL1862886 & 774025 & 4.2466 & 4.4436 & TRN & \\
\hline CHEMBL1863451 & 774025 & 3.0 & 3.6476 & TRN & \\
\hline CHEMBL337750 & 774025 & 4.21899 & 99999999 & 4.4896 & TRN \\
\hline CHEMBL1863020 & 774025 & 4.2871 & 4.5233 & TRN & \\
\hline CHEMBL1862852 & 774025 & 3.0 & 3.0776 & TRN & \\
\hline CHEMBL1863477 & 774025 & 4.7196 & 3.8093 & TRN & \\
\hline CHEMBL1863289 & 774025 & 4.1473 & 4.0702 & TRN & \\
\hline CHEMBL1863126 & 774025 & 3.0 & 3.81399 & 99999999996 & TRN \\
\hline CHEMBL1863208 & 774025 & 3.0 & $2.7460 e$ & 00000000004 & TRN \\
\hline CHEMBL1863004 & 774025 & 4.3225 & 4.6311 & TRN & \\
\hline CHEMBL1863467 & 774025 & 3.0 & 3.123 & TRN & \\
\hline CHEMBL1863237 & 774025 & 4.249 & 3.8893 & TRN & \\
\hline CHEMBL1862810 & 774025 & 3.0 & 3.4966 & TRN & \\
\hline CHEMBL1863366 & 774025 & 3.0 & 3.1805 & TRN & \\
\hline CHEMBL1863218 & 774025 & 3.0 & 3.7895 & TRN & \\
\hline CHEMBL1863397 & 774025 & 3.0 & 3.3701 & TRN & \\
\hline CHEMBL1862846 & 774025 & 3.0 & 2.9437 & TRN & \\
\hline CHEMBL1862913 & 774025 & 3.0 & 3.4715 & TRN & \\
\hline CHEMBL1862893 & 774025 & 3.0 & 3.3564 & TRN & \\
\hline CHEMBL1862821 & 774025 & 4.0391 & 3.9387 & TST & \\
\hline CHEMBL1862945 & 774025 & 3.0 & 3.395 & TRN & \\
\hline CHEMBL230001 & 774025 & 4.2983 & 2.8776 & TST & \\
\hline CHEMBL1863057 & 774025 & 4.0138 & 3.5949 & TRN & \\
\hline CHEMBL1863449 & 774025 & 4.2349 & 3.9497 & TRN & \\
\hline CHEMBL1862989 & 774025 & 4.2185 & 3.8248 & TRN & \\
\hline CHEMBL1863343 & 774025 & 4.5194 & 4.2034 & TRN & \\
\hline CHEMBL1863100 & 774025 & 3.0 & 2.6546 & TRN & \\
\hline CHEMBL1862951 & 774025 & 3.0 & 2.9809 & TRN & \\
\hline CHEMBL1862936 & 774025 & 3.0 & 3.0167 & TRN & \\
\hline CHEMBL1862854 & 774025 & 3.0 & 2.9755 & TRN & \\
\hline CHEMBL1863071 & 774025 & 4.0422 & 3.5648 & TRN & \\
\hline CHEMBL1863241 & 774025 & 3.0 & 3.5992 & TRN & \\
\hline CHEMBL1862958 & 774025 & 3.0 & 3.7933 & TRN & \\
\hline CHEMBL1863442 & 774025 & 3.0 & 2.9054 & TRN & \\
\hline CHEMBL1863469 & 774025 & 3.0 & 3.5199 & TRN & \\
\hline CHEMBL1863066 & 774025 & 4.3621 & 4.266 & TRN & \\
\hline CHEMBL1863478 & 774025 & 4.6584 & 4.0924 & TRN & \\
\hline CHEMBL1863245 & 774025 & 4.2038 & 3.7407 & TRN & \\
\hline
\end{tabular}




\begin{tabular}{|c|c|c|c|c|c|}
\hline & & \multicolumn{4}{|c|}{ Supplemental Table S2.txt } \\
\hline CHEMBL1863161 & 774025 & 4.3036 & 4.3826 & TRN & \\
\hline CHEMBL1863168 & 774025 & 4.2214 & 3.8123 & TRN & \\
\hline CHEMBL1863047 & 774025 & 6.0 & 4.7198 & TRN & \\
\hline CHEMBL281217 & 774025 & 3.0 & 3.5265 & TRN & \\
\hline CHEMBL1863205 & 774025 & 4.3197 & 4.5754 & TRN & \\
\hline CHEMBL1863501 & 774025 & 3.0 & 3.1856 & TRN & \\
\hline CHEMBL1863405 & 774025 & 4.2372 & 3.9405 & TRN & \\
\hline CHEMBL1862809 & 774025 & 4.0421 & 3.2528 & TRN & \\
\hline CHEMBL1862827 & 774025 & 4.1013 & 4.2073 & TRN & \\
\hline CHEMBL1863496 & 774025 & 3.0 & 3.0473 & TRN & \\
\hline CHEMBL1863059 & 774025 & 3.0 & 3.3456 & TRN & \\
\hline CHEMBL137192 & 774025 & 6.0 & 3.51899 & 99999999997 & TRN \\
\hline CHEMBL1862908 & 774025 & 4.3989 & 4.6388 & TRN & \\
\hline CHEMBL1863067 & 774025 & 4.2473 & 3.5699 & TST & \\
\hline CHEMBL1863065 & 774025 & 3.0 & 3.1769 & TST & \\
\hline CHEMBL1863434 & 774025 & 3.0 & 3.5945 & TST & \\
\hline CHEMBL1862872 & 774025 & 4.157 & 3.4615 & TRN & \\
\hline CHEMBL1863176 & 774025 & 4.1054 & 3.642 & TRN & \\
\hline CHEMBL1863300 & 774025 & 4.1437 & 3.7097 & TRN & \\
\hline CHEMBL1712057 & 774025 & 3.0 & 2.6447 & TST & \\
\hline CHEMBL1863180 & 774025 & 4.2303 & 3.9793 & TRN & \\
\hline CHEMBL1863033 & 774025 & 4.2057 & 3.5354 & TRN & \\
\hline CHEMBL1863135 & 774025 & 4.2622 & 4.185 & TRN & \\
\hline CHEMBL1862829 & 774025 & 3.0 & 3.5879 & TRN & \\
\hline CHEMBL1863420 & 774025 & 3.0 & 3.7192 & TRN & \\
\hline CHEMBL1863019 & 774025 & 3.0 & 3.1141 & TRN & \\
\hline CHEMBL1863230 & 774025 & 4.2237 & 4.3648 & TRN & \\
\hline CHEMBL1862814 & 774025 & 3.0 & 3.2158 & TRN & \\
\hline CHEMBL1862885 & 774025 & 4.2048 & 3.5713 & TRN & \\
\hline CHEMBL1863271 & 774025 & 4.0779 & 3.7371 & TST & \\
\hline CHEMBL1863483 & 774025 & 3.0 & 3.5294 & TRN & \\
\hline CHEMBL1862898 & 774025 & 4.1651 & 3.5561 & TRN & \\
\hline CHEMBL1863370 & 774025 & 4.0916 & 3.6389 & TRN & \\
\hline CHEMBL1862994 & 774025 & 4.2191 & 3.5914 & TRN & \\
\hline CHEMBL1863367 & 774025 & 4.6236 & 4.6455 & TST & \\
\hline CHEMBL1862842 & 774025 & 4.2314 & 3.7766 & TST & \\
\hline CHEMBL1862880 & 774025 & 4.1379 & 3.4048 & TRN & \\
\hline CHEMBL1863146 & 774025 & 3.0 & 3.5607 & TRN & \\
\hline CHEMBL1863461 & 774025 & 4.2031 & 3.4782 & TRN & \\
\hline CHEMBL1863329 & 774025 & 3.0 & 3.5789 & TRN & \\
\hline CHEMBL1862820 & 774025 & 4.2523 & 3.975 & TRN & \\
\hline CHEMBL1863144 & 774025 & 3.0 & 3.8188 & TRN & \\
\hline CHEMBL1863269 & 774025 & 3.0 & 3.0485 & TST & \\
\hline CHEMBL1862825 & 774025 & 4.3264 & 4.5372 & TRN & \\
\hline CHEMBL1863029 & 774025 & 4.1578 & 3.5567 & TRN & \\
\hline CHEMBL1863439 & 774025 & 4.3135 & 4.2547 & TRN & \\
\hline CHEMBL1863350 & 774025 & 3.0 & 2.9144 & TRN & \\
\hline CHEMBL1863096 & 774025 & 4.2489 & 4.5217 & TRN & \\
\hline
\end{tabular}




\begin{tabular}{|c|c|c|c|c|c|}
\hline & & \multicolumn{4}{|c|}{ Supplemental Table S2.txt } \\
\hline CHEMBL1863392 & 774025 & 4.2397 & 4.0349 & TRN & \\
\hline CHEMBL1863195 & 774025 & 3.0 & 3.157 & TRN & \\
\hline CHEMBL1862971 & 774025 & 4.1043 & 4.0139 & TRN & \\
\hline CHEMBL1863007 & 774025 & 4.048 & 3.9349 & TRN & \\
\hline CHEMBL1863045 & 774025 & 3.0 & 3.6892 & TRN & \\
\hline CHEMBL1863116 & 774025 & 4.208 & 4.3612 & TRN & \\
\hline CHEMBL1863081 & 774025 & 3.0 & 2.9779 & TRN & \\
\hline CHEMBL1863250 & 774025 & 4.724 & 4.7653 & TRN & \\
\hline CHEMBL1863401 & 774025 & 3.0 & 3.1044 & TRN & \\
\hline CHEMBL1862797 & 774025 & 3.0 & 3.3705 & TRN & \\
\hline CHEMBL1863252 & 774025 & 4.2622 & 3.702 & TRN & \\
\hline CHEMBL1862999 & 774025 & 4.244 & 4.2446 & TRN & \\
\hline CHEMBL1862857 & 774025 & 4.6772 & 4.4219 & TRN & \\
\hline CHEMBL1863355 & 774025 & 4.3668 & 3.8799 & TRN & \\
\hline CHEMBL1862910 & 774025 & 4.2497 & 3.8916 & TRN & \\
\hline CHEMBL1862845 & 774025 & 4.1534 & 3.5287 & TST & \\
\hline CHEMBL1863117 & 774025 & 4.2583 & 3.8448 & TRN & \\
\hline CHEMBL1863244 & 774025 & 4.2671 & 3.673 & TRN & \\
\hline CHEMBL1863286 & 774025 & 6.0 & 4.8232 & TRN & \\
\hline CHEMBL1863509 & 774025 & 3.0 & 2.63100 & 00000000002 & TRN \\
\hline CHEMBL1863488 & 774025 & 3.0 & 2.9527 & TRN & \\
\hline CHEMBL1863293 & 774025 & 4.1293 & 3.7264 & TRN & \\
\hline CHEMBL1862978 & 774025 & 4.0769 & 3.4705 & TRN & \\
\hline CHEMBL1863089 & 774025 & 3.0 & 3.2722 & TRN & \\
\hline CHEMBL1863227 & 774025 & 3.0 & 3.304 & TRN & \\
\hline CHEMBL1862906 & 774025 & 3.0 & 3.3518 & TRN & \\
\hline CHEMBL1863500 & 774025 & 3.0 & 3.4872 & TRN & \\
\hline CHEMBL1863054 & 774025 & 4.0549 & 3.5741 & TRN & \\
\hline CHEMBL1863422 & 774025 & 3.0 & 3.25 & TRN & \\
\hline CHEMBL1863419 & 774025 & 3.0 & 3.2669 & TRN & \\
\hline CHEMBL1863175 & 774025 & 3.0 & 3.0365 & TRN & \\
\hline CHEMBL1863188 & 774025 & 4.1766 & 4.2247 & TRN & \\
\hline CHEMBL1863297 & 774025 & 3.0 & 3.6189 & TRN & \\
\hline CHEMBL1862985 & 774025 & 4.2369 & 3.5881 & TRN & \\
\hline CHEMBL1862863 & 774025 & 3.0 & 3.37100 & 00000000004 & TRN \\
\hline CHEMBL1863189 & 774025 & 4.5751 & 4.6148 & TRN & \\
\hline CHEMBL1863324 & 774025 & 3.0 & 3.2967 & TRN & \\
\hline CHEMBL1863072 & 774025 & 3.0 & 3.5756 & TRN & \\
\hline CHEMBL1863386 & 774025 & 4.2738 & 3.8697 & TRN & \\
\hline CHEMBL1863221 & 774025 & 3.0 & 3.1473 & TRN & \\
\hline CHEMBL1863051 & 774025 & 3.0 & 2.9484 & TRN & \\
\hline CHEMBL1863349 & 774025 & 3.0 & 3.373 & TRN & \\
\hline CHEMBL1863110 & 774025 & 4.346 & 4.4486 & TRN & \\
\hline CHEMBL1863310 & 774025 & 4.1188 & 3.4529 & TRN & \\
\hline CHEMBL1862957 & 774025 & 4.2619 & 3.3947 & TST & \\
\hline CHEMBL1863376 & 774025 & 4.1822 & 4.0267 & TRN & \\
\hline CHEMBL1863354 & 774025 & 3.0 & 3.5741 & TRN & \\
\hline CHEMBL1863266 & 774025 & 3.0 & 3.2386 & TRN & \\
\hline
\end{tabular}




\begin{tabular}{|c|c|c|c|c|c|c|}
\hline & & \multicolumn{5}{|c|}{ Supplemental Table S2.txt } \\
\hline CHEMBL1862874 & 774025 & 3.0 & 2.9575 & TRN & & \\
\hline CHEMBL1862911 & 774025 & 3.0 & 3.3649 & TRN & & \\
\hline CHEMBL1863155 & 774025 & \multicolumn{3}{|c|}{4.111000000000001} & 4.4631 & TRN \\
\hline CHEMBL1863369 & 774025 & 3.0 & 3.236 & TRN & & \\
\hline CHEMBL1862869 & 774025 & 3.0 & 3.0464 & TRN & & \\
\hline CHEMBL1863368 & 774025 & 4.2443 & 4.3682 & TRN & & \\
\hline CHEMBL1862855 & 774025 & 3.0 & 3.208 & TRN & & \\
\hline CHEMBL1863387 & 774025 & 3.0 & 2.8437 & TRN & & \\
\hline CHEMBL1863403 & 774025 & 3.0 & 3.5047 & TRN & & \\
\hline CHEMBL1863177 & 774025 & 4.2708 & 3.4245 & TST & & \\
\hline CHEMBL1863133 & 774025 & 3.0 & \multicolumn{3}{|c|}{3.2310000000000003} & TRN \\
\hline CHEMBL1863464 & 774025 & 3.0 & 3.8421 & TRN & & \\
\hline CHEMBL1863313 & 774025 & 3.0 & 4.5578 & TRN & & \\
\hline CHEMBL 2028156 & 774025 & 4.2605 & 4.2878 & TRN & & \\
\hline CHEMBL1863112 & 774025 & 4.2658 & 4.0665 & TRN & & \\
\hline CHEMBL1863101 & 774025 & 3.0 & 3.1464 & TRN & & \\
\hline CHEMBL1862940 & 774025 & 4.1175 & 4.9418 & TST & & \\
\hline CHEMBL1863239 & 774025 & 3.0 & 3.0861 & TRN & & \\
\hline CHEMBL1862901 & 774025 & 3.0 & 3.7905 & TST & & \\
\hline CHEMBL1862881 & 774025 & 3.0 & 3.4713 & TRN & & \\
\hline CHEMBL1863327 & 774025 & 4.2749 & 4.1368 & TRN & & \\
\hline CHEMBL1862960 & 774025 & 4.3188 & 5.1604 & TRN & & \\
\hline CHEMBL1862832 & 774025 & 3.0 & 3.3659 & TRN & & \\
\hline CHEMBL1863097 & 774025 & 4.1497 & 3.4991 & TRN & & \\
\hline CHEMBL1863473 & 774025 & 3.0 & 3.2974 & TRN & & \\
\hline CHEMBL1863301 & 774025 & 3.0 & 3.4583 & TST & & \\
\hline CHEMBL1863302 & 774025 & 3.0 & 3.18300 & 0000000000 & 03 & TRN \\
\hline CHEMBL1863358 & 774025 & 4.2602 & 3.1175 & TST & & \\
\hline CHEMBL1863379 & 774025 & 6.0 & 3.9726 & TRN & & \\
\hline CHEMBL1862976 & 774025 & \multicolumn{3}{|c|}{4.1530000000000005} & 3.4746 & TST \\
\hline CHEMBL1862813 & 774025 & 4.2031 & 3.7334 & TRN & & \\
\hline CHEMBL1862897 & 774025 & 3.0 & 3.0892 & TRN & & \\
\hline CHEMBL1863149 & 774025 & 4.2551 & 3.8837 & TST & & \\
\hline CHEMBL1862791 & 774025 & 4.1311 & 3.9733 & TRN & & \\
\hline CHEMBL282325 & 774025 & 3.0 & 3.6291 & TRN & & \\
\hline CHEMBL1862812 & 774025 & 4.2479 & 4.1058 & TRN & & \\
\hline CHEMBL1863001 & 774025 & 4.2737 & 4.249 & TRN & & \\
\hline CHEMBL1863017 & 774025 & 4.2138 & 4.5054 & TRN & & \\
\hline CHEMBL1862870 & 774025 & 3.0 & 3.053 & TRN & & \\
\hline CHEMBL1863281 & 774025 & 3.0 & 3.7339 & TRN & & \\
\hline CHEMBL1863288 & 774025 & 4.1144 & 3.39399 & 9999999999 & 97 & TRN \\
\hline CHEMBL1863265 & 774025 & 4.2223 & 3.7663 & TRN & & \\
\hline CHEMBL1863423 & 774025 & 3.0 & 3.2124 & TRN & & \\
\hline CHEMBL1862991 & 774025 & 4.2833 & 4.0067 & TRN & & \\
\hline CHEMBL1862907 & 774025 & 4.246 & 3.4489 & TST & & \\
\hline CHEMBL1863498 & 774025 & 3.0 & 3.2671 & TRN & & \\
\hline CHEMBL1862956 & 774025 & 4.2032 & 4.29 & TRN & & \\
\hline CHEMBL1862826 & 774025 & 3.0 & 3.3665 & TST & & \\
\hline
\end{tabular}




\begin{tabular}{|c|c|c|c|c|}
\hline \multicolumn{5}{|c|}{ Supplemental Table S2.txt } \\
\hline CHEMBL1863018 & 774025 & 3.0 & 3.2983 & TRN \\
\hline CHEMBL1863104 & 774025 & 4.2497 & 3.9594 & TST \\
\hline CHEMBL1863166 & 774025 & 4.1637 & 3.6276 & TRN \\
\hline CHEMBL1863296 & 774025 & 4.2461 & 3.8819 & TRN \\
\hline CHEMBL1231667 & 774025 & 3.0 & 2.7598 & TST \\
\hline CHEMBL1863280 & 774025 & 4.1443 & 3.4208 & TRN \\
\hline CHEMBL1862961 & 774025 & 4.2008 & 3.5404 & TRN \\
\hline CHEMBL1863330 & 774025 & 3.0 & 3.2994 & TRN \\
\hline CHEMBL1862802 & 774025 & 4.2299 & 4.6522 & TRN \\
\hline CHEMBL1862926 & 774025 & 3.0 & 2.7296 & TRN \\
\hline CHEMBL1863076 & 774025 & 3.0 & 3.2854 & TRN \\
\hline CHEMBL1863476 & 774025 & 3.0 & 2.9541 & TRN \\
\hline CHEMBL 1863040 & 774025 & 4.1724 & 4.4732 & TRN \\
\hline CHEMBL1863182 & 774025 & 4.7359 & 4.3179 & TRN \\
\hline CHEMBL1863393 & 774025 & 4.2097 & 3.8603 & TRN \\
\hline CHEMBL1862972 & 774025 & 3.0 & 3.1976 & TRN \\
\hline CHEMBL1863171 & 774025 & 3.0 & 3.1683 & TRN \\
\hline CHEMBL1863251 & 774025 & 3.0 & 3.4979 & TRN \\
\hline CHEMBL1862949 & 774025 & 3.0 & 3.3281 & TRN \\
\hline CHEMBL1863264 & 774025 & 3.0 & 2.8047 & TRN \\
\hline CHEMBL1862964 & 774025 & 4.2524 & 4.1726 & TRN \\
\hline CHEMBL1863431 & 774025 & 3.0 & 3.258 & TRN \\
\hline CHEMBL1862982 & 774025 & 4.2495 & 4.2573 & TRN \\
\hline CHEMBL1862996 & 774025 & 3.0 & 3.8556 & TRN \\
\hline CHEMBL1863406 & 774025 & 3.0 & 3.4954 & TST \\
\hline CHEMBL1863493 & 774025 & 3.0 & 3.2812 & TRN \\
\hline CHEMBL1863458 & 774025 & 4.1545 & 3.8447 & TRN \\
\hline CHEMBL1863163 & 774025 & 4.2492 & 4.0714 & TRN \\
\hline CHEMBL1863345 & 774025 & 3.0 & 3.7494 & TRN \\
\hline CHEMBL1863347 & 774025 & 3.0 & 2.7069 & TRN \\
\hline CHEMBL1862839 & 774025 & 3.0 & 3.2057 & TST \\
\hline CHEMBL1862970 & 774025 & 4.2562 & 4.341 & TRN \\
\hline CHEMBL1863360 & 774025 & 4.2894 & 4.1178 & TRN \\
\hline CHEMBL1863484 & 774025 & 3.0 & 3.5252 & TRN \\
\hline CHEMBL1863394 & 774025 & 4.1268 & 4.3824 & TRN \\
\hline CHEMBL1863377 & 774025 & 3.0 & 3.2876 & TRN \\
\hline CHEMBL1863381 & 774025 & 4.4439 & 4.3409 & TRN \\
\hline CHEMBL1862921 & 774025 & 3.0 & 3.5915 & TRN \\
\hline CHEMBL1863011 & 774025 & 3.0 & 3.6265 & TRN \\
\hline CHEMBL1863206 & 774025 & 4.1981 & 3.1893 & TST \\
\hline CHEMBL1863474 & 774025 & 4.2536 & 4.0516 & TRN \\
\hline CHEMBL1863505 & 774025 & 3.0 & 3.7568 & TRN \\
\hline CHEMBL29904 & 774025 & 4.3213 & 3.5286 & TRN \\
\hline CHEMBL1862950 & 774025 & 4.2435 & 4.33899 & 99999999995 \\
\hline CHEMBL1863190 & 774025 & 3.0 & 3.5112 & TRN \\
\hline CHEMBL1863118 & 774025 & 3.0 & 3.9593 & TRN \\
\hline CHEMBL1863111 & 774025 & 3.0 & 2.7976 & TST \\
\hline CHEMBL1863415 & 774025 & 3.0 & 2.7366 & TRN \\
\hline
\end{tabular}

TRN 


\begin{tabular}{|c|c|c|c|c|}
\hline \multicolumn{5}{|c|}{ Supplemental Table S2.txt } \\
\hline CHEMBL1862955 & 774025 & 4.2813 & 4.1453 & TST \\
\hline CHEMBL1862892 & 774025 & 3.0 & 3.3519 & TRN \\
\hline CHEMBL1863362 & 774025 & 4.1135 & 4.1616 & TRN \\
\hline CHEMBL1863198 & 774025 & 3.0 & 3.2469 & TST \\
\hline CHEMBL1863224 & 774025 & 3.0 & 4.189 & TST \\
\hline CHEMBL1863485 & 774025 & 4.0711 & 4.3726 & TRN \\
\hline CHEMBL1862984 & 774025 & 3.0 & 3.1498 & TRN \\
\hline CHEMBL1862979 & 774025 & 3.0 & 2.7918 & TRN \\
\hline CHEMBL1863333 & 774025 & 4.194 & 3.8993 & TST \\
\hline CHEMBL1863306 & 774025 & 4.1942 & 3.9038 & TRN \\
\hline CHEMBL1863185 & 774025 & 3.0 & 3.4044 & TRN \\
\hline CHEMBL1863235 & 774025 & 4.033 & 3.2343 & TRN \\
\hline CHEMBL421035 & 774025 & 3.0 & 3.2721 & TST \\
\hline CHEMBL1863184 & 774025 & 4.706 & 4.3281 & TRN \\
\hline CHEMBL1863352 & 774025 & 4.2602 & 3.7167 & TRN \\
\hline CHEMBL1862891 & 774025 & 4.1691 & 4.2456 & TST \\
\hline CHEMBL1863365 & 774025 & 4.115 & 3.8756 & TRN \\
\hline CHEMBL1863124 & 774025 & 4.2274 & 4.2607 & TRN \\
\hline CHEMBL1863275 & 774025 & 3.0 & 3.0655 & TRN \\
\hline CHEMBL1863364 & 774025 & 4.0801 & 3.5462 & TRN \\
\hline CHEMBL1863460 & 774025 & 4.2483 & 3.3734 & TST \\
\hline CHEMBL1863248 & 774025 & 3.0 & 3.2162 & TRN \\
\hline CHEMBL1863068 & 774025 & 3.0 & 3.7069 & TST \\
\hline CHEMBL1862894 & 774025 & 4.1853 & 3.4679 & TRN \\
\hline CHEMBL1863005 & 774025 & 4.2116 & 3.63 & TRN \\
\hline CHEMBL1862834 & 774025 & 4.3123 & 3.9 & TST \\
\hline CHEMBL1862850 & 774025 & 3.0 & 2.6667 & TST \\
\hline CHEMBL1863470 & 774025 & 3.0 & 3.4409 & TRN \\
\hline CHEMBL1863178 & 774025 & 3.0 & 4.6434 & TST \\
\hline CHEMBL1863238 & 774025 & 3.0 & 3.4352 & TRN \\
\hline CHEMBL1862942 & 774025 & 4.0347 & 3.5422 & TST \\
\hline CHEMBL1862903 & 774025 & 3.0 & 3.9346 & TST \\
\hline CHEMBL1862995 & 774025 & 3.0 & 3.5873 & TRN \\
\hline CHEMBL1862927 & 774025 & 3.0 & 3.5695 & TST \\
\hline CHEMBL1863487 & 774025 & 4.1717 & 4.4237 & TRN \\
\hline CHEMBL1863328 & 774025 & 4.2057 & 3.5167 & TRN \\
\hline CHEMBL1863107 & 774025 & 4.2565 & 4.4924 & TRN \\
\hline CHEMBL1863277 & 774025 & 3.0 & 3.1303 & TRN \\
\hline CHEMBL29400 & 774025 & 4.2423 & 3.6513 & TST \\
\hline CHEMBL1863212 & 774025 & 4.2306 & 4.3063 & TRN \\
\hline CHEMBL1863147 & 774025 & 3.0 & 3.3087 & TRN \\
\hline CHEMBL1863359 & 774025 & 3.0 & 3.0261 & TRN \\
\hline CHEMBL1863331 & 774025 & 3.0 & 3.5536 & TST \\
\hline CHEMBL1863272 & 774025 & 3.0 & 3.7908 & TST \\
\hline CHEMBL1863455 & 774025 & 4.2317 & 3.6621 & TRN \\
\hline CHEMBL1863471 & 774025 & 4.0397 & 3.4629 & TST \\
\hline CHEMBL1862930 & 774025 & 4.2132 & 3.5636 & TRN \\
\hline CHEMBL1863338 & 774025 & 4.2538 & 3.6718 & TRN \\
\hline
\end{tabular}




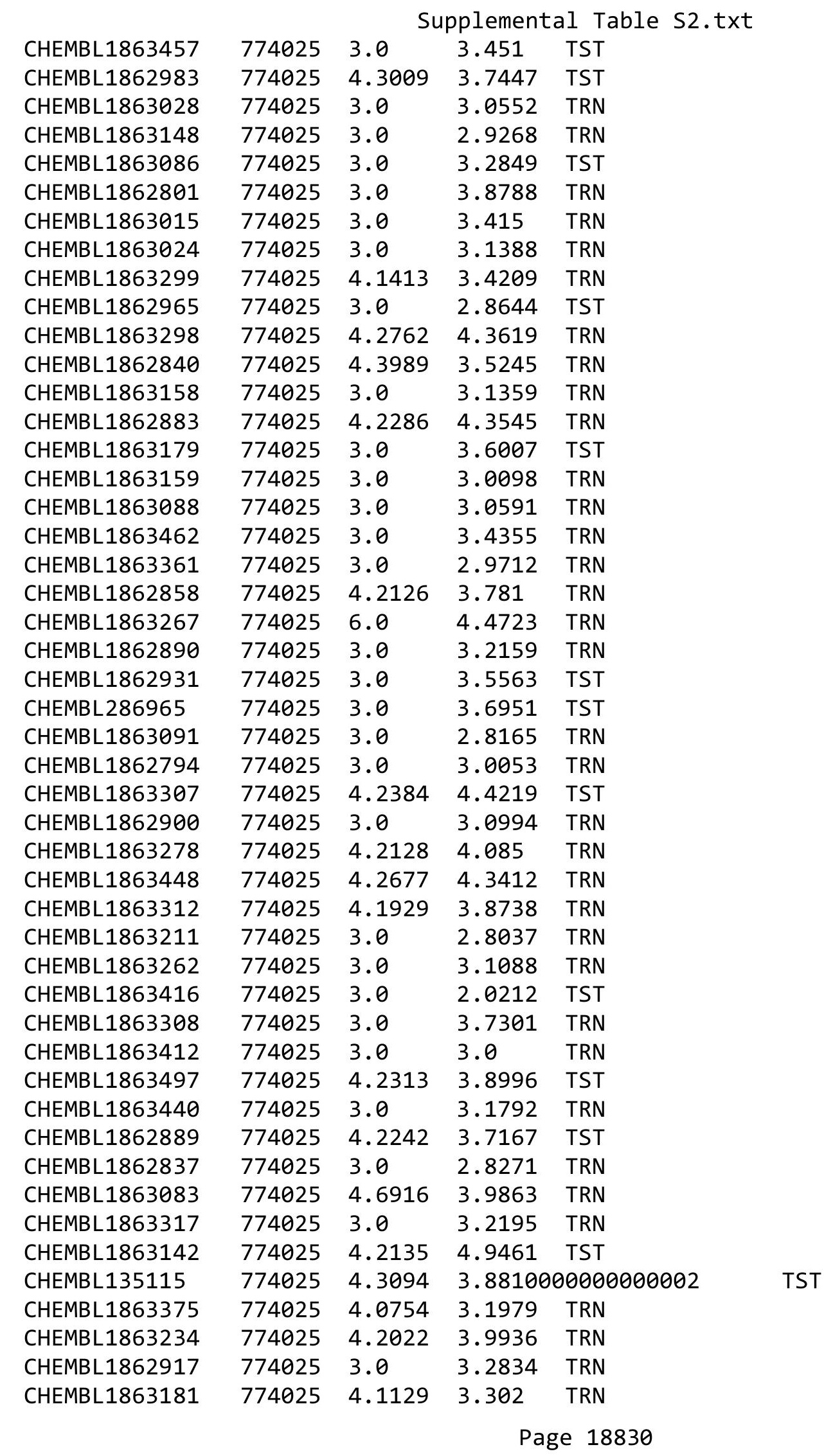




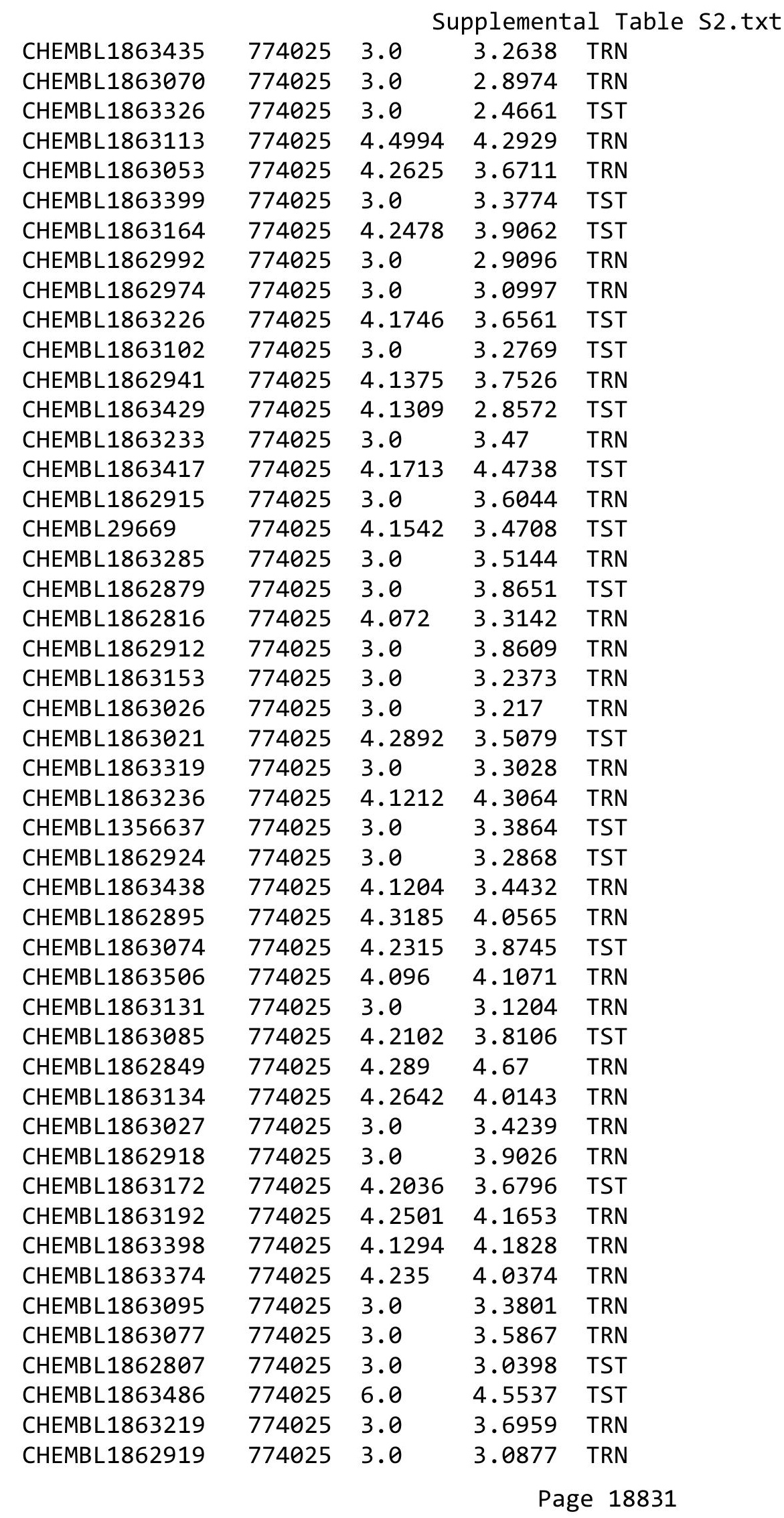




\begin{tabular}{|c|c|c|c|c|c|}
\hline \multirow[b]{2}{*}{ CHEMBL1862977 } & \multicolumn{5}{|c|}{ Supplemental Table S2.txt } \\
\hline & 774025 & 4.2209 & 4.2844 & TST & \\
\hline CHEMBL1862947 & 774025 & 4.1957 & 4.1603 & TRN & \\
\hline CHEMBL1863109 & 774025 & 3.0 & 2.90199 & 99999999997 & TRN \\
\hline CHEMBL1863257 & 774025 & 4.5309 & 4.28 & TRN & \\
\hline CHEMBL1862973 & 774025 & 3.0 & 3.3032 & TRN & \\
\hline CHEMBL1862896 & 774025 & 4.1003 & 3.4787 & TST & \\
\hline CHEMBL1863194 & 774025 & 4.2215 & 3.9226 & TRN & \\
\hline CHEMBL1862817 & 774025 & 4.216 & 4.0201 & TST & \\
\hline CHEMBL1863254 & 774025 & 3.0 & 2.9091 & TRN & \\
\hline CHEMBL1863418 & 774025 & 4.2641 & 4.4068 & TST & \\
\hline CHEMBL1863268 & 774025 & 3.0 & 3.5645 & TST & \\
\hline CHEMBL1863031 & 774025 & 4.2489 & 4.449 & TRN & \\
\hline CHEMBL1863441 & 774025 & 3.0 & 2.5407 & TST & \\
\hline CHEMBL1863481 & 774025 & 3.0 & 2.8039 & TRN & \\
\hline CHEMBL1863260 & 774025 & 3.0 & 3.0662 & TRN & \\
\hline CHEMBL1863450 & 774025 & 4.2273 & 3.7558 & TST & \\
\hline CHEMBL1863173 & 774025 & 3.0 & 3.815 & TRN & \\
\hline CHEMBL1863395 & 774025 & 4.0771 & 4.1493 & TRN & \\
\hline CHEMBL1863504 & 774025 & 3.0 & 4.2673 & TST & \\
\hline CHEMBL1863240 & 774025 & 3.0 & 3.8273 & TST & \\
\hline CHEMBL1862969 & 774025 & 6.0 & 3.6189 & TRN & \\
\hline CHEMBL1862831 & 774025 & 3.0 & 3.3658 & TRN & \\
\hline CHEMBL1863295 & 774025 & 4.2813 & 4.4514 & TRN & \\
\hline CHEMBL415725 & 774025 & 4.0721 & 3.7171 & TST & \\
\hline CHEMBL1863050 & 774025 & 3.0 & 4.3519 & TST & \\
\hline CHEMBL1862824 & 774025 & 3.0 & 2.6045 & TST & \\
\hline CHEMBL1862909 & 774025 & 4.2286 & 3.7236 & TST & \\
\hline CHEMBL1863225 & 774025 & 3.0 & 3.5787 & TST & \\
\hline CHEMBL1863228 & 774025 & 4.1409 & 3.8827 & TST & \\
\hline CHEMBL1863025 & 774025 & 3.0 & 3.2898 & TRN & \\
\hline CHEMBL1862859 & 774025 & 4.216 & 4.0824 & TRN & \\
\hline CHEMBL1863170 & 774025 & 3.0 & 3.7463 & TST & \\
\hline CHEMBL1863137 & 774025 & 4.2388 & 3.8739 & TRN & \\
\hline CHEMBL1863231 & 774025 & 4.135 & 4.0103 & TRN & \\
\hline CHEMBL1862803 & 774025 & 4.2076 & 3.4654 & TST & \\
\hline CHEMBL1863197 & 774025 & 4.0676 & 4.4586 & TST & \\
\hline CHEMBL1863305 & 774025 & 3.0 & 3.0081 & TRN & \\
\hline CHEMBL1863138 & 774025 & 3.0 & 3.4778 & TST & \\
\hline CHEMBL1862835 & 774025 & 3.0 & 3.3339 & TRN & \\
\hline CHEMBL1863426 & 774025 & 3.0 & 3.1642 & TRN & \\
\hline CHEMBL1862818 & 774025 & 3.0 & 3.2069 & TRN & \\
\hline CHEMBL1863407 & 774025 & 3.0 & 3.5821 & TST & \\
\hline CHEMBL1862920 & 774025 & 4.1929 & 4.0923 & TRN & \\
\hline CHEMBL1862815 & 774025 & 3.0 & 3.3027 & TRN & \\
\hline CHEMBL1863247 & 774025 & 3.0 & 3.25 & TST & \\
\hline CHEMBL1863321 & 774025 & 4.2036 & 4.3801 & TST & \\
\hline CHEMBL1863193 & 774025 & 3.0 & 2.9961 & TST & \\
\hline CHEMBL1863223 & 774025 & 4.1191 & 3.6018 & TST & \\
\hline
\end{tabular}




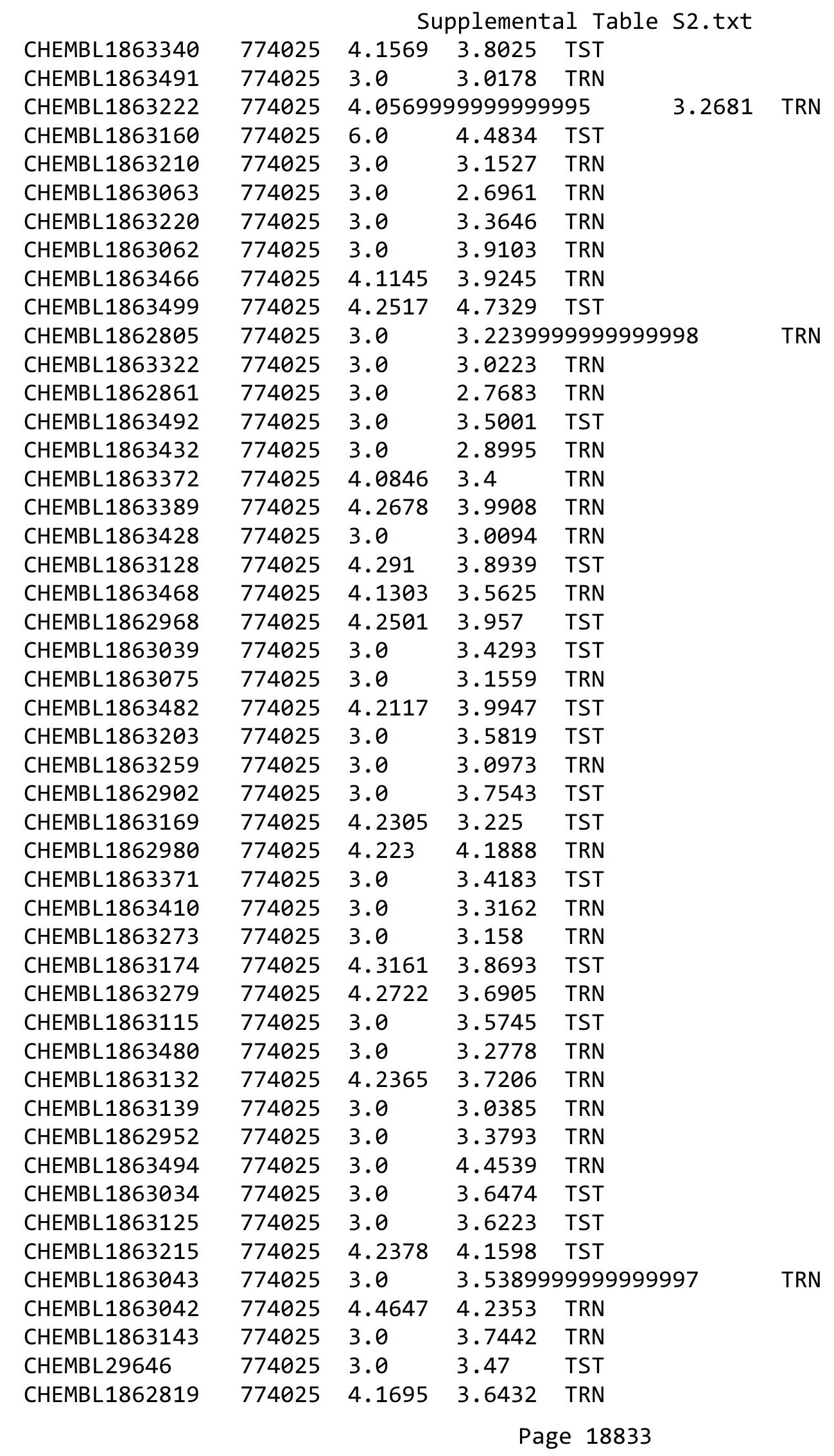




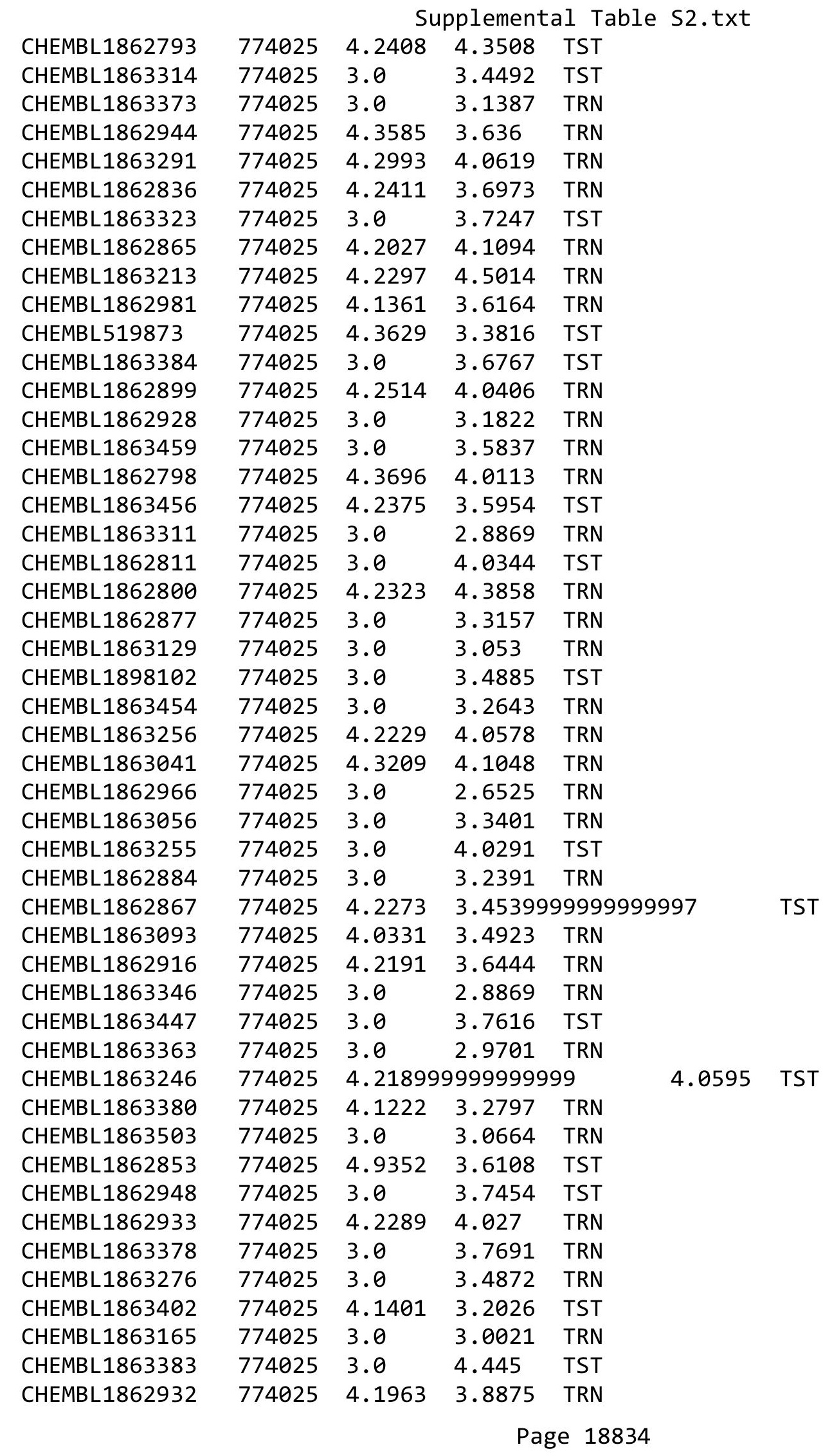




\begin{tabular}{|c|c|c|c|c|}
\hline \multicolumn{5}{|c|}{ Supplemental Table S2.txt } \\
\hline CHEMBL1862799 & 774025 & 3.0 & 2.7071 & TST \\
\hline CHEMBL1863232 & 774025 & 4.2587 & 4.0445 & TRN \\
\hline CHEMBL1862967 & 774025 & 3.0 & 3.7908 & TST \\
\hline CHEMBL1862962 & 774025 & 3.0 & 3.2815 & TRN \\
\hline CHEMBL1863201 & 774025 & 4.2669 & 4.0718 & TRN \\
\hline CHEMBL1863080 & 774025 & 3.0 & 3.3621 & TRN \\
\hline CHEMBL1862988 & 774025 & 4.0716 & 3.4797 & TST \\
\hline CHEMBL1863002 & 774025 & 4.4738 & 4.4146 & TRN \\
\hline CHEMBL1862804 & 774025 & 3.0 & 3.5772 & TRN \\
\hline CHEMBL1863121 & 774025 & 3.0 & 3.397 & TRN \\
\hline CHEMBL1863119 & 774025 & 4.0842 & 3.6224 & TRN \\
\hline CHEMBL1863337 & 774025 & 4.2031 & 4.1202 & TST \\
\hline CHEMBL1863154 & 774025 & 4.3241 & 3.8252 & TRN \\
\hline CHEMBL1863152 & 774025 & 3.0 & 3.1852 & TRN \\
\hline CHEMBL1863012 & 774025 & 3.0 & 2.5161 & TST \\
\hline CHEMBL1863411 & 774025 & 4.2132 & 3.5767 & TRN \\
\hline CHEMBL1863489 & 774025 & 6.0 & 3.4841 & TST \\
\hline CHEMBL1862998 & 774025 & 4.2864 & 3.9334 & TST \\
\hline CHEMBL1862937 & 774025 & 4.1671 & 4.5254 & TST \\
\hline CHEMBL1863105 & 774025 & 4.4161 & 4.6561 & TRN \\
\hline CHEMBL1863216 & 774025 & 4.1538 & 4.1327 & TST \\
\hline CHEMBL1862923 & 774025 & 4.2094 & 4.2494 & TRN \\
\hline CHEMBL1863304 & 774025 & 4.1464 & 3.7407 & TRN \\
\hline CHEMBL1863463 & 774025 & 3.0 & 3.2587 & TRN \\
\hline CHEMBL1863446 & 774025 & 3.0 & 2.9509 & TRN \\
\hline CHEMBL1862963 & 774025 & 3.0 & 3.4353 & TRN \\
\hline CHEMBL1863106 & 774025 & 4.2716 & 4.9432 & TRN \\
\hline CHEMBL1863016 & 774025 & 6.0 & 4.0419 & TRN \\
\hline CHEMBL1862929 & 774025 & 4.3879 & 3.9273 & TRN \\
\hline CHEMBL 1863453 & 774025 & 3.0 & 2.9557 & TRN \\
\hline CHEMBL1862823 & 774025 & 3.0 & 3.4612 & TRN \\
\hline CHEMBL1863209 & 774025 & 3.0 & 3.4363 & TRN \\
\hline CHEMBL1863390 & 774025 & 4.7106 & 4.4146 & TRN \\
\hline CHEMBL1862860 & 774025 & 3.0 & 2.8765 & TRN \\
\hline CHEMBL1863290 & 774025 & 3.0 & 3.4383 & TRN \\
\hline CHEMBL1863099 & 774025 & 3.0 & 3.088 & TRN \\
\hline CHEMBL1863199 & 774025 & 3.0 & 3.409 & TST \\
\hline CHEMBL1863336 & 774025 & 3.0 & 2.6524 & TST \\
\hline CHEMBL1863342 & 774025 & 3.0 & 3.5735 & TST \\
\hline CHEMBL1863424 & 774025 & 4.2812 & 4.5827 & TRN \\
\hline CHEMBL1862878 & 774025 & 3.0 & 3.4601 & TRN \\
\hline CHEMBL1863010 & 774025 & 3.0 & 2.8767 & TRN \\
\hline CHEMBL1863490 & 774025 & 3.0 & 3.3483 & TRN \\
\hline CHEMBL1862844 & 774025 & 3.0 & 4.1139 & TST \\
\hline CHEMBL1863006 & 774025 & 4.232 & 3.4374 & TRN \\
\hline CHEMBL1862795 & 774025 & 3.0 & 3.7826 & TRN \\
\hline CHEMBL1863009 & 774025 & 3.0 & 3.1797 & TRN \\
\hline CHEMBL1863202 & 774025 & 4.5928 & 4.0414 & TRN \\
\hline
\end{tabular}




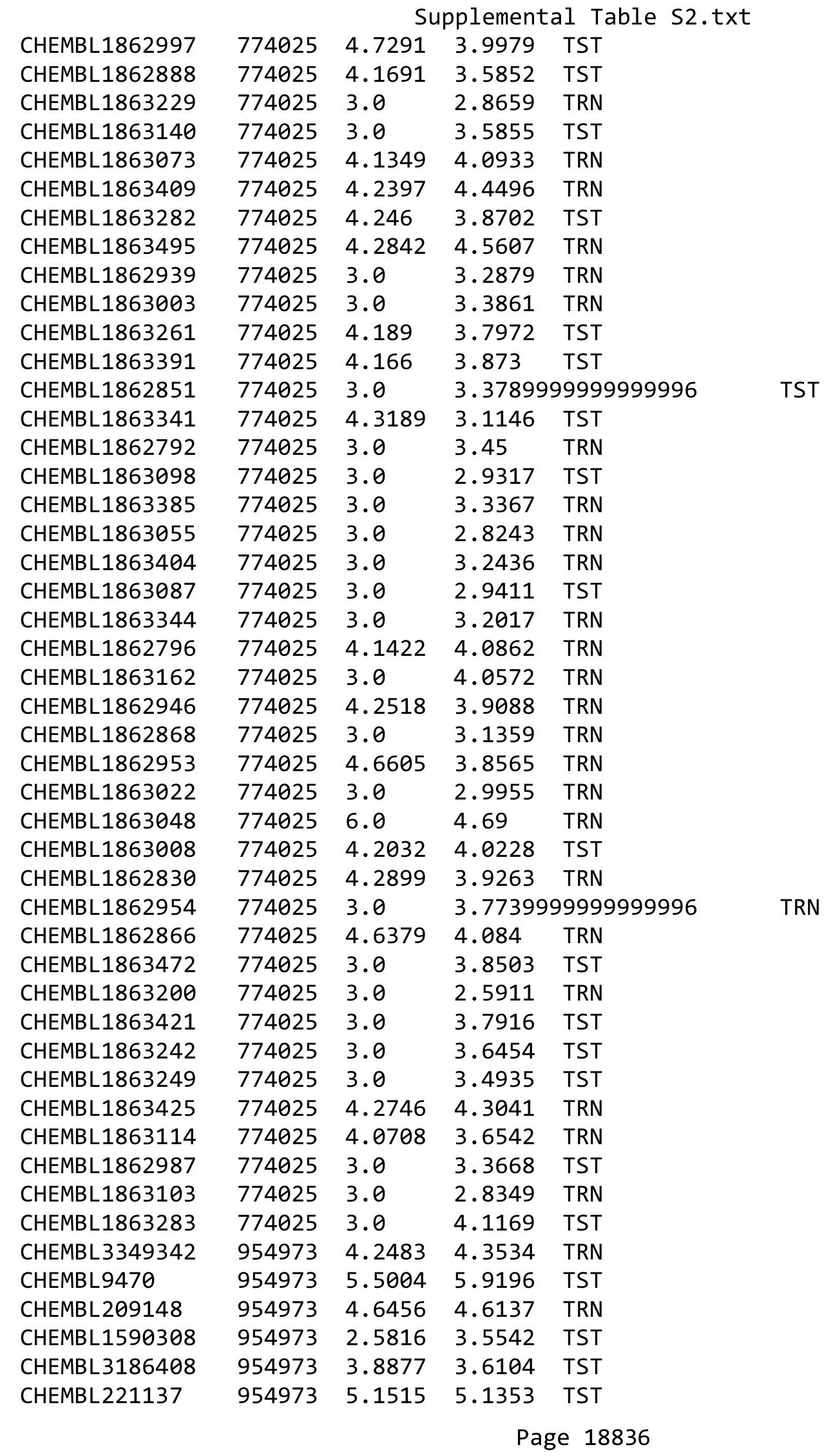




\begin{tabular}{|c|c|c|c|c|c|c|}
\hline & & \multicolumn{5}{|c|}{ Supplemental Table S2.txt } \\
\hline CHEMBL573107 & 954973 & 4.4604 & 4.5121 & TRN & & \\
\hline CHEMBL 379300 & 954973 & 6.6122 & 6.7322 & TRN & & \\
\hline CHEMBL1230020 & 954973 & 3.8269 & 3.8033 & TRN & & \\
\hline CHEMBL 217354 & 954973 & 5.7133 & 6.0005 & TRN & & \\
\hline CHEMBL393929 & 954973 & 3.2217 & 3.2848 & TRN & & \\
\hline CHEMBL1909414 & 954973 & 3.3766 & 3.3073 & TRN & & \\
\hline CHEMBL483849 & 954973 & 2.0857 & 2.3102 & TST & & \\
\hline CHEMBL220241 & 954973 & 4.2882 & 4.1457 & TRN & & \\
\hline CHEMBL 399530 & 954973 & 4.7204 & 4.4561 & TRN & & \\
\hline CHEMBL585951 & 954973 & 6.2232 & 6.4751 & TRN & & \\
\hline CHEMBL472940 & 954973 & 3.9255 & 4.2409 & TRN & & \\
\hline CHEMBL191334 & 954973 & 2.9404 & 2.8145 & TRN & & \\
\hline CHEMBL1516890 & 954973 & 3.8097 & 3.9456 & TRN & & \\
\hline CHEMBL1788116 & 954973 & 5.455 & 5.3822 & TRN & & \\
\hline CHEMBL412142 & 954973 & 4.6438 & 4.327 & TRN & & \\
\hline CHEMBL189584 & 954973 & 3.6173 & 3.8693 & TRN & & \\
\hline CHEMBL2144069 & 954973 & 4.6829 & 4.3007 & TRN & & \\
\hline CHEMBL1190711 & 954973 & 5.1301 & 5.3143 & TRN & & \\
\hline CHEMBL1643959 & 954973 & 4.176 & 4.4043 & TRN & & \\
\hline CHEMBL180127 & 954973 & 4.2147 & 4.2681 & TRN & & \\
\hline CHEMBL192566 & 954973 & 8.2641 & 8.69700 & 0000000001 & & TST \\
\hline CHEMBL 240954 & 954973 & 2.9497 & 3.5052 & TST & & \\
\hline CHEMBL 2134202 & 954973 & 3.4779 & 3.5894 & TRN & & \\
\hline CHEMBL1186585 & 954973 & 3.1409 & 3.4546 & TRN & & \\
\hline CHEMBL515416 & 954973 & 4.7113 & 4.7522 & TRN & & \\
\hline CHEMBL 213100 & 954973 & 5.6493 & 5.4047 & TRN & & \\
\hline CHEMBL558642 & 954973 & 4.2171 & 4.8509 & TRN & & \\
\hline CHEMBL 2363137 & 954973 & 5.8773 & 5.4138 & TRN & & \\
\hline CHEMBL300389 & 954973 & 7.2232 & 7.0635 & TRN & & \\
\hline CHEMBL392695 & 954973 & 5.2812 & 5.2491 & TRN & & \\
\hline CHEMBL1357247 & 954973 & 3.3679 & 3.5268 & TRN & & \\
\hline CHEMBL210618 & 954973 & 3.0711 & 3.2309 & TRN & & \\
\hline CHEMBL1242367 & 954973 & 5.2017 & 5.0788 & TRN & & \\
\hline CHEMBL 255342 & 954973 & 3.0734 & 3.0828 & TRN & & \\
\hline CHEMBL509032 & 954973 & 5.7706 & 5.3784 & TRN & & \\
\hline CHEMBL1256459 & 954973 & 7.6173 & 7.8025 & TRN & & \\
\hline CHEMBL259181 & 954973 & 5.4183 & 5.2941 & TRN & & \\
\hline CHEMBL102714 & 954973 & 2.9911 & 3.1459 & TRN & & \\
\hline CHEMBL1673039 & 954973 & 4.2949 & 4.5518 & TRN & & \\
\hline CHEMBL222102 & 954973 & 3.9379 & 3.6733 & TRN & & \\
\hline CHEMBL135561 & 954973 & 4.5613 & 4.7133 & TRN & & \\
\hline CHEMBL3199475 & 954973 & 5.2272 & 5.0554 & TRN & & \\
\hline CHEMBL483847 & 954973 & 4.48600 & 30000000 & $\partial 1$ & 4.5151 & $\mathrm{TR}$ \\
\hline CHEMBL577784 & 954973 & 4.5602 & 4.5991 & TRN & & \\
\hline CHEMBL3392440 & 954973 & 3.9078 & 4.0649 & TRN & & \\
\hline CHEMBL1404918 & 954973 & 3.2862 & 3.1127 & TRN & & \\
\hline CHEMBL258844 & 954973 & 5.6369 & 5.3978 & TRN & & \\
\hline CHEMBL188678 & 954973 & 4.7967 & 4.0686 & TRN & & \\
\hline
\end{tabular}


Supplemental Table S2.txt

\begin{tabular}{|c|c|c|c|c|}
\hline HEMBL & & & $\partial 5$ & $T R$ \\
\hline HEMPI 511190 & & 7.3004 & 70947 & \\
\hline HEMBL1 & & & 5146 & \\
\hline HEMBL449158 & 54973 & 883 & 644 & \\
\hline HEMBL65 & 54973 & 5.4396 & 9608 & \\
\hline HEMBL & & 029 & 1321 & \\
\hline AEMBL & & & 171 & \\
\hline HEMBL2 & 73 & 436 & 5809 & \\
\hline HEMBL 2005886 & 73 & 5.3976 & 6381 & \\
\hline HEMBL92309 & 73 & 2.8043 & 3248 & \\
\hline HEMBL3 & 73 & 3344 & 3796 & \\
\hline HEMBL & & 6.5767 & 617 & \\
\hline HEMBL3 & 70 & 7.2973 & 3317 & \\
\hline HEMBL3 & 70 & 7.2525 & 368 & \\
\hline AEMBL3927878 & 70 & 6.9446 & 3416 & \\
\hline AEMBL & 70 & 7.4852 & 042 & \\
\hline AEMBL & & 184 & & \\
\hline HEMBL & 70 & 6.024 & 203 & \\
\hline HEMBL3 & & 395 & 26 & \\
\hline AEMBL3 & 70 & 7.9097 & 95 & \\
\hline AEMBL & & 312 & 54 & \\
\hline HEME & & 65 & & \\
\hline HEMBL. & & 313 & 582 & \\
\hline HEMBL; & & 995 & & \\
\hline AEMBL 3 & 70 & 6.2987 & 417 & TST \\
\hline IEMBL: & & 738 & 75 & RN \\
\hline HEM & & 74 & & \\
\hline 19 & & 41 & 573 & \\
\hline AEMBL: & & & & ГST \\
\hline AEMBL3 & 70 & 9.2076 & 022 & RN \\
\hline IFMBI & & 642 & 219 & RN \\
\hline 25 & & 28 & 35 & \\
\hline & & & & RN \\
\hline AEMBL3 & & 6.7966 & 88 & ГRN \\
\hline HEMBL3 & 70 & 6.2356 & 771 & $\mathrm{RN}$ \\
\hline$A F M R I=$ & & 582 & 803 & . \\
\hline & & & & RN \\
\hline HEMBL3 & & 7.2987 & & RN \\
\hline AEMBL3 & & 7.1002 & 069 & 「RN \\
\hline EMBL; & 0 & 6.0583 & 711 & 「RN \\
\hline HEMBL3 & & 586 & 587 & \\
\hline HEMBL3 & & 7.2979 & 885 & RN \\
\hline HEMBL3 & & 6.5984 & 4621 & TRN \\
\hline AEMBL3 & 70 & 7.6546 & 704 & $\mathrm{R}$ \\
\hline 10 & & & 221 & \\
\hline HEMBL3 & & 8.0353 & 8.1781 & \\
\hline HEMBL3 & & 6.8951 & 6.7116 & \\
\hline CHEMBL3909419 & 1641070 & 7.2222 & 6.9369 & \\
\hline
\end{tabular}

Page 18838 
Supplemental Table S2.txt

\begin{tabular}{|c|c|c|c|c|c|}
\hline CHEMBL 3933218 & 1641070 & 6.0653 & 6.6903 & TRN & \\
\hline CHEMBL 3948050 & 1641070 & 6.9893 & 7.2955 & TRN & \\
\hline CHEMBL 3943062 & 1641070 & 8.0953 & 7.395 & TRN & \\
\hline CHEMBL 3907607 & 1641070 & 7.7284 & 7.2175 & TRN & \\
\hline CHEMBL 3969184 & 1641070 & 7.62799 & 999999999 & 7.5843 & TRN \\
\hline CHEMBL 3902466 & 1641070 & 7.2752 & 7.3617 & TRN & \\
\hline CHEMBL 3938866 & 1641070 & 6.187 & 6.1481 & TRN & \\
\hline CHEMBL 3911178 & 1641070 & 7.9442 & 7.74 & TRN & \\
\hline CHEMBL 3964356 & 1641070 & 5.8651 & 5.7595 & TRN & \\
\hline CHEMBL 3910267 & 1641070 & 6.6668 & 6.9638 & TRN & \\
\hline CHEMBL 3962378 & 1641070 & 5.8207 & 6.2169 & TRN & \\
\hline CHEMBL 3984591 & 1641070 & 6.0077 & 5.8941 & TRN & \\
\hline CHEMBL 3960438 & 1641070 & 6.04899 & 999999999 & 6.7671 & TST \\
\hline CHEMBL 3944959 & 1641070 & 7.0152 & 6.9594 & TST & \\
\hline CHEMBL 3985467 & 1641070 & 8.2328 & 8.0519 & TST & \\
\hline CHEMBL 3979649 & 1641070 & 8.0306 & 7.1278 & TST & \\
\hline CHEMBL 3933635 & 1641070 & 6.8562 & 7.0935 & TST & \\
\hline CHEMBL 3936020 & 1641070 & 7.1009 & 6.6945 & TST & \\
\hline CHEMBL 3895580 & 1641070 & 6.4901 & 6.2284 & TST & \\
\hline CHEMBL 3951909 & 1641070 & 5.6666 & 6.6326 & TST & \\
\hline CHEMBL 3935949 & 1641070 & 5.888 & 6.1455 & TST & \\
\hline CHEMBL1161065 & 62394 & 7.301 & 7.4584 & TRN & \\
\hline CHEMBL543905 & 62394 & 8.0 & 7.6147 & TRN & \\
\hline CHEMBL1161049 & 62394 & 6.0 & 6.1159 & TRN & \\
\hline CHEMBL1161046 & 62394 & 5.0 & 5.2695 & TRN & \\
\hline CHEMBL1161047 & 62394 & 6.5229 & 6.7322 & TRN & \\
\hline CHEMBL1161043 & 62394 & 5.8444 & 6.1816 & TRN & \\
\hline CHEMBL1161050 & 62394 & 5.0 & 4.4272 & TRN & \\
\hline CHEMBL1161074 & 62394 & 7.301 & 7.2106 & TRN & \\
\hline CHEMBL1161069 & 62394 & 6.0 & 5.72 & TRN & \\
\hline CHEMBL 334889 & 62394 & 5.0 & 4.6646 & TRN & \\
\hline CHEMBL1161068 & 62394 & 7.0 & 7.0044 & TRN & \\
\hline CHEMBL538280 & 62394 & 7.5229 & 7.6287 & TRN & \\
\hline CHEMBL1161052 & 62394 & 6.5229 & 6.5793 & TRN & \\
\hline CHEMBL 1161056 & 62394 & 5.0 & 5.8851 & TRN & \\
\hline CHEMBL435198 & 62394 & 8.0 & 7.5624 & TRN & \\
\hline CHEMBL553555 & 62394 & 5.6171 & 5.641 & TRN & \\
\hline CHEMBL1161060 & 62394 & 6.8861 & 7.3042 & TRN & \\
\hline CHEMBL538529 & 62394 & 5.0 & 5.004 & TRN & \\
\hline CHEMBL1161095 & 62394 & 6.7773 & 6.1816 & TRN & \\
\hline CHEMBL1161053 & 62394 & 6.5229 & 6.7497 & TRN & \\
\hline CHEMBL544373 & 62394 & 7.5528 & 7.609 & TRN & \\
\hline CHEMBL1161045 & 62394 & 5.0 & 5.282999 & 99999999995 & RN \\
\hline CHEMBL544371 & 62394 & 5.0 & 6.4163 & TST & \\
\hline CHEMBL1161073 & 62394 & 6.5229 & 6.7144 & TRN & \\
\hline CHEMBL133765 & 62394 & 5.0 & 5.6959 & TST & \\
\hline CHEMBL1161066 & 62394 & 5.0 & 5.3821 & TRN & \\
\hline CHEMBL1161061 & 62394 & 7.585 & 7.3595 & TRN & \\
\hline
\end{tabular}




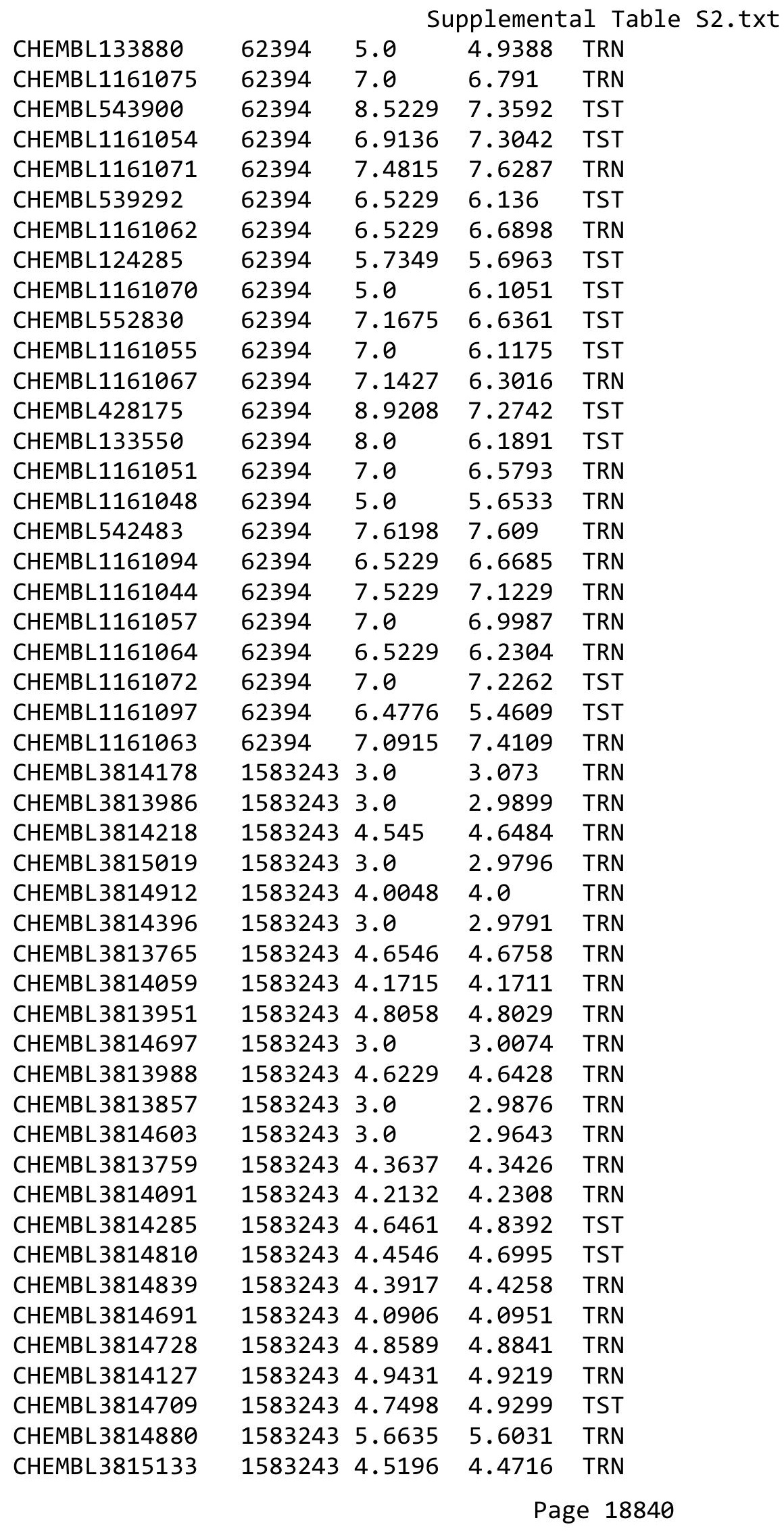


Supplemental Table S2.txt

\begin{tabular}{|c|c|c|c|c|}
\hline HEMBL 3814464 & 583243 & 5.3372 & 3275 & \\
\hline & 583243 & 3.0 & 2.9735 & \\
\hline 1479 & 83243 & 4.3512 & & \\
\hline AEMBL 3813800 & 583243 & 3.0 & & \\
\hline AEMBL 3814488 & 583243 & 4.8216 & 072 & \\
\hline AEMBL 3813893 & 583243 & 4.9935 & 943 & \\
\hline 15047 & 583243 & 3.0 & 116 & \\
\hline 35192 & 583243 & 4.5795 & & \\
\hline AEMBL 3814439 & 583243 & 5.0605 & 379 & \\
\hline AEMBL3814989 & .583243 & 4.164 & 667 & \\
\hline 14622 & 243 & 4.2064 & & \\
\hline 14930 & 583243 & 4.1846 & 92 & \\
\hline 127 & 243 & 748 & & \\
\hline AEMBL3814984 & 1583243 & 4.3516 & 387 & \\
\hline AEMBL3813816 & 583243 & 3.0 & 36 & \\
\hline 886 & 158 & 4.7873 & 57 & \\
\hline 246 & 243 & 4.7093 & & \\
\hline 4344 & 243 & 3.0 & & \\
\hline 13749 & 1583243 & 3.0 & 25 & \\
\hline 2333 & & 802 & & \\
\hline 24 & 158 & 3. & 65 & \\
\hline 1 & 243 & 3.0 & & \\
\hline 50 & 243 & 3.0 & & \\
\hline 14312 & 1583243 & 3.0 & & \\
\hline 15035 & 43 & 4. & & \\
\hline $\mathrm{CHE}$ & 243 & 4.1041 & & \\
\hline 7 & 43 & 3. & & \\
\hline 37 & 243 & 3.0 & 77 & \\
\hline 862 & 69 & 8.3979 & & \\
\hline 070 & 304 & & & \\
\hline CH & 304 & 6. & & \\
\hline & 30 & 6. & & \\
\hline 2 & 9 & 7. & & \\
\hline 1733 & 304 & 7.3665 & & \\
\hline CHEMBL 1 & 304869 & 6.5528 & & \\
\hline & & & & \\
\hline $\mathrm{CH}$ & 30 & 8. & & \\
\hline $\mathrm{CHE}$ & 304 & 71 & & \\
\hline CHEMBL180448 & 304869 & 6.6021 & 03 & 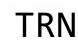 \\
\hline - $-2+2$ & 304869 & 7.0044 & & \\
\hline $\mathrm{CHE}$ & 304 & 7.4 & & \\
\hline CHEMB & 304 & 8.1549 & 79 & \\
\hline CHEMBL & 304869 & 7.6383 & 7.7643 & 11 \\
\hline CHEMBL & 304869 & 3.301 & 426 & $\mathrm{TR}$ \\
\hline Sur & 304869 & 4.4089 & 03 & \\
\hline CHEMBL & 304 & 6.0088 & & \\
\hline CHEMB & 304869 & 7.3279 & 7.2681 & \\
\hline CHEMBL181233 & 304869 & 8.0458 & 7.5625 & \\
\hline
\end{tabular}

Page 18841 


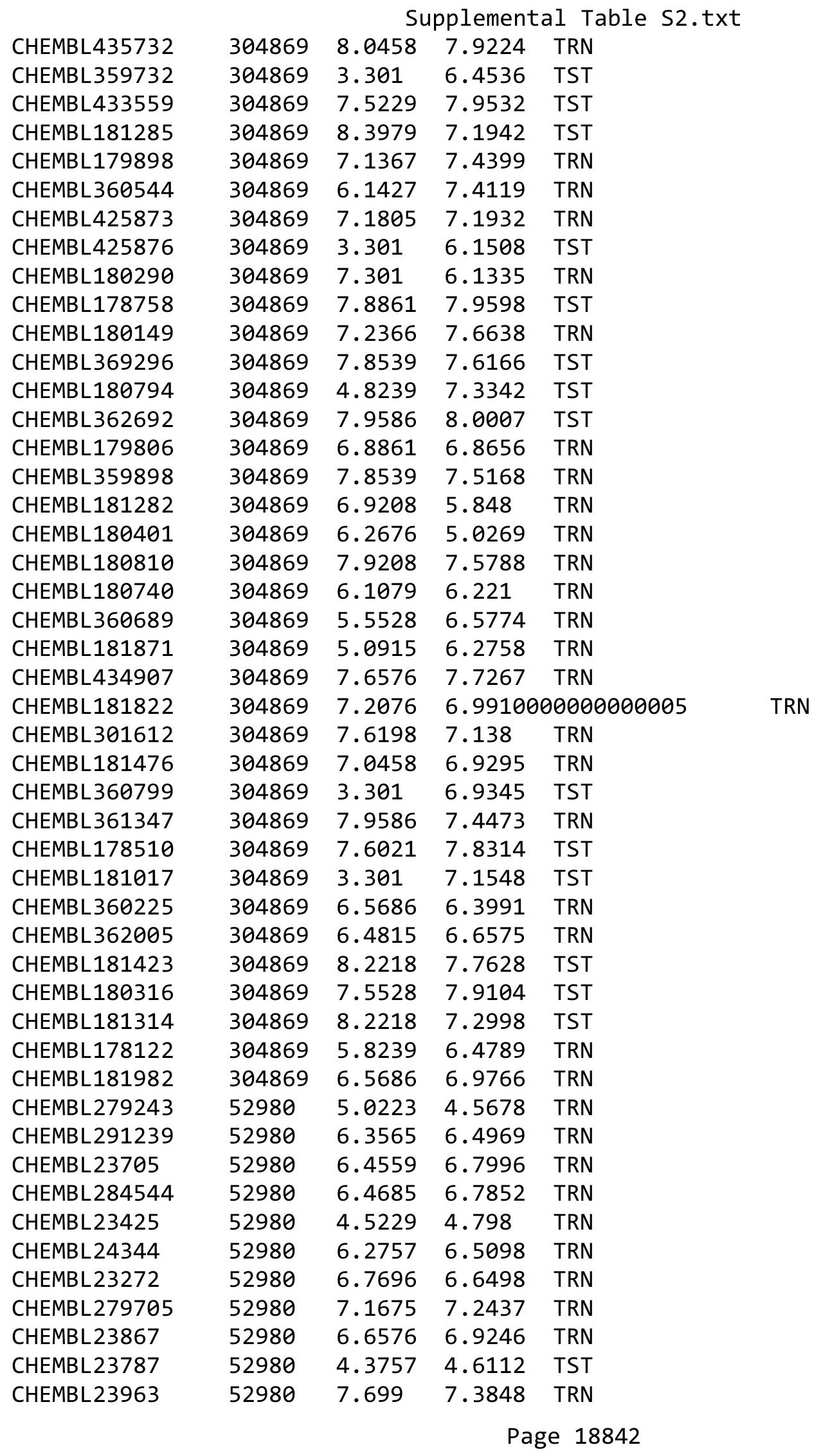




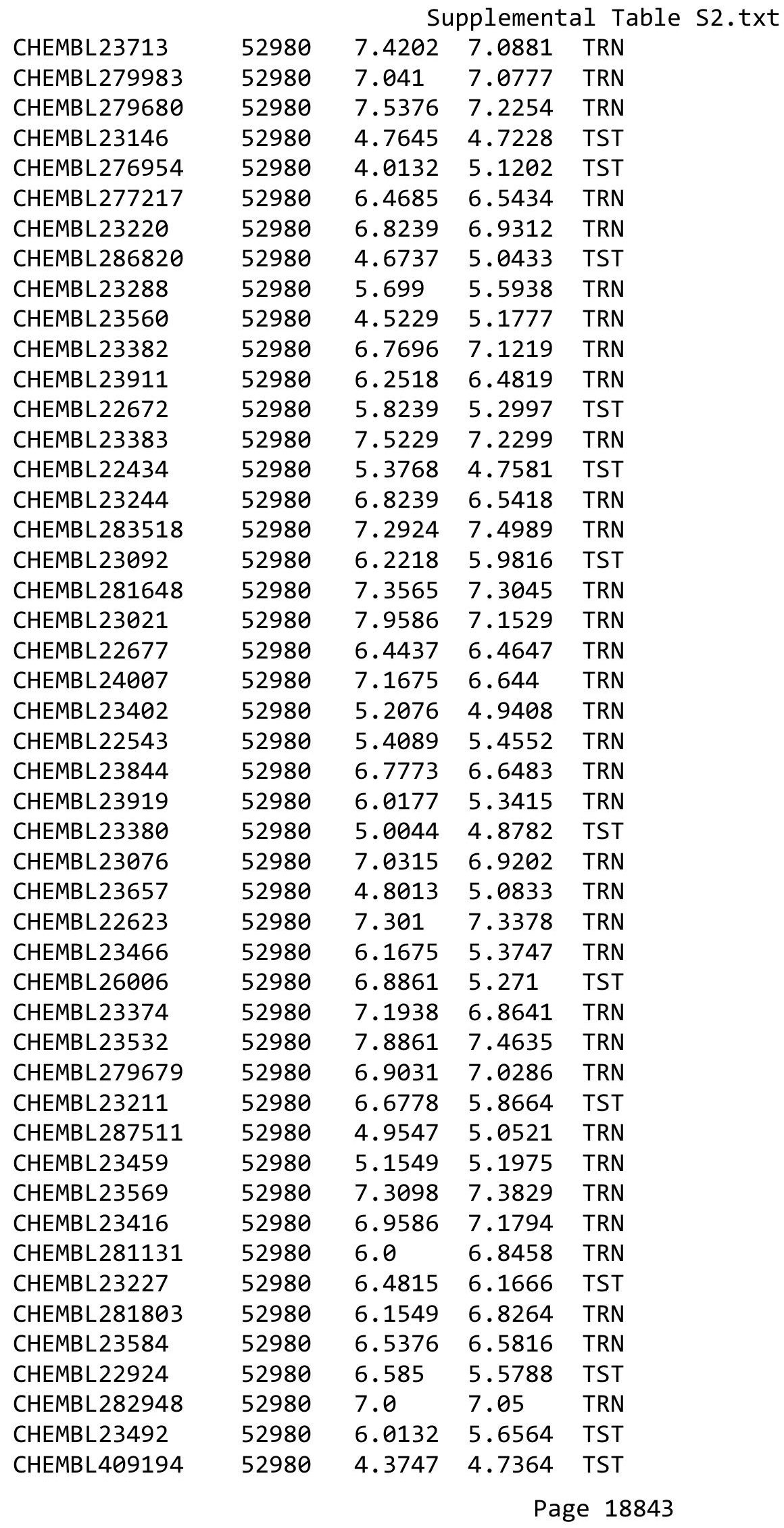




\begin{tabular}{|c|c|c|c|c|c|c|}
\hline \multirow[b]{2}{*}{ CHEMBL23454 } & \multirow[b]{2}{*}{52980} & \multicolumn{5}{|c|}{ Supplemental Table S2.txt } \\
\hline & & 6.1249 & 5.7424 & TST & & \\
\hline CHEMBL 23286 & 52980 & 4.2351 & 4.7294 & TST & & \\
\hline CHEMBL23495 & 52980 & 4.6778 & 5.1282 & TRN & & \\
\hline CHEMBL26836 & 2187 & 6.45 & 6.4462 & TRN & & \\
\hline CHEMBL27025 & 2187 & 7.349 & 7.2234 & TRN & & \\
\hline CHEMBL417470 & 2187 & \multicolumn{3}{|c|}{5.9670000000000005} & 5.9342 & TRN \\
\hline CHEMBL 27719 & 2187 & 5.44 & 5.4862 & TRN & & \\
\hline CHEMBL26972 & 2187 & 5.89 & 5.9716 & TRN & & \\
\hline CHEMBL27998 & 2187 & 6.254 & 6.3112 & TRN & & \\
\hline CHEMBL128544 & 2187 & 6.228 & 6.0412 & TST & & \\
\hline CHEMBL285777 & 2187 & \multicolumn{3}{|c|}{6.047000000000001} & 6.0389 & TRN \\
\hline CHEMBL 26868 & 2187 & 4.967 & 4.9809 & TRN & & \\
\hline CHEMBL283397 & 2187 & 6.4 & 6.4244 & TRN & & \\
\hline CHEMBL281434 & 2187 & 5.87 & 5.9191 & TRN & & \\
\hline CHEMBL26655 & 2187 & \multicolumn{3}{|c|}{7.1739999999999995} & 7.1154 & TRN \\
\hline CHEMBL28105 & 2187 & \multicolumn{3}{|c|}{5.6160000000000005} & 5.5563 & TRN \\
\hline CHEMBL283185 & 2187 & \multicolumn{3}{|c|}{7.292000000000001} & 7.2931 & TRN \\
\hline CHEMBL 25812 & 2187 & 5.84 & 5.8707 & TRN & & \\
\hline CHEMBL281432 & 2187 & 5.29 & 5.0016 & TRN & & \\
\hline CHEMBL 26850 & 2187 & 6.061 & 6.0463 & TRN & & \\
\hline CHEMBL130159 & 2187 & 5.83 & 6.7525 & TST & & \\
\hline CHEMBL282799 & 2187 & \multicolumn{3}{|c|}{5.537000000000001} & 5.4922 & TRN \\
\hline CHEMBL285157 & 2187 & \multicolumn{3}{|c|}{7.361000000000001} & 7.3958 & TRN \\
\hline CHEMBL26322 & 2187 & 5.0 & 4.7627 & TRN & & \\
\hline CHEMBL283257 & 2187 & 6.785 & 6.885 & TRN & & \\
\hline CHEMBL283398 & 2187 & 4.774 & 5.061 & TRN & & \\
\hline CHEMBL27643 & 2187 & \multicolumn{3}{|c|}{6.007000000000001} & 6.0032 & TRN \\
\hline CHEMBL287576 & 2187 & 6.921 & 6.9176 & TRN & & \\
\hline CHEMBL287655 & 2187 & 5.2 & 5.2272 & TRN & & \\
\hline CHEMBL131203 & 2187 & 5.301 & 5.2775 & TRN & & \\
\hline CHEMBL26900 & 2187 & \multicolumn{3}{|c|}{5.5520000000000005} & 5.5267 & TRN \\
\hline CHEMBL341485 & 2187 & \multicolumn{3}{|c|}{7.7139999999999995} & 6.9534 & TST \\
\hline CHEMBL287441 & 2187 & \multicolumn{3}{|c|}{5.7620000000000005} & 5.7335 & TRN \\
\hline CHEMBL340175 & 2187 & 6.7 & 6.7136 & TRN & & \\
\hline CHEMBL283899 & 2187 & 6.02 & 6.0321 & TRN & & \\
\hline CHEMBL337381 & 2187 & \multicolumn{3}{|c|}{6.542999999999999} & 6.7051 & TST \\
\hline CHEMBL280779 & 2187 & \multicolumn{3}{|c|}{5.5089999999999995} & 5.5688 & TRN \\
\hline CHEMBL26921 & 2187 & 6.836 & 6.8825 & TRN & & \\
\hline CHEMBL27227 & 2187 & 7.32 & 7.2906 & TRN & & \\
\hline CHEMBL18785 & 2187 & 6.04 & 6.0278 & TRN & & \\
\hline CHEMBL287097 & 2187 & 4.301 & 4.5201 & TRN & & \\
\hline CHEMBL128288 & 2187 & 6.66 & 6.6491 & TRN & & \\
\hline CHEMBL26311 & 2187 & 5.36 & 5.2985 & TRN & & \\
\hline CHEMBL281937 & 2187 & 7.81 & 6.5765 & TST & & \\
\hline CHEMBL284107 & 2187 & \multicolumn{3}{|c|}{5.957000000000001} & 5.9679 & TRN \\
\hline CHEMBL284447 & 2187 & 5.36 & 5.3176 & TRN & & \\
\hline CHEMBL27811 & 2187 & 6.691 & 7.4059 & TST & & \\
\hline CHEMBL442534 & 2187 & 6.9 & 6.393 & TST & & \\
\hline
\end{tabular}




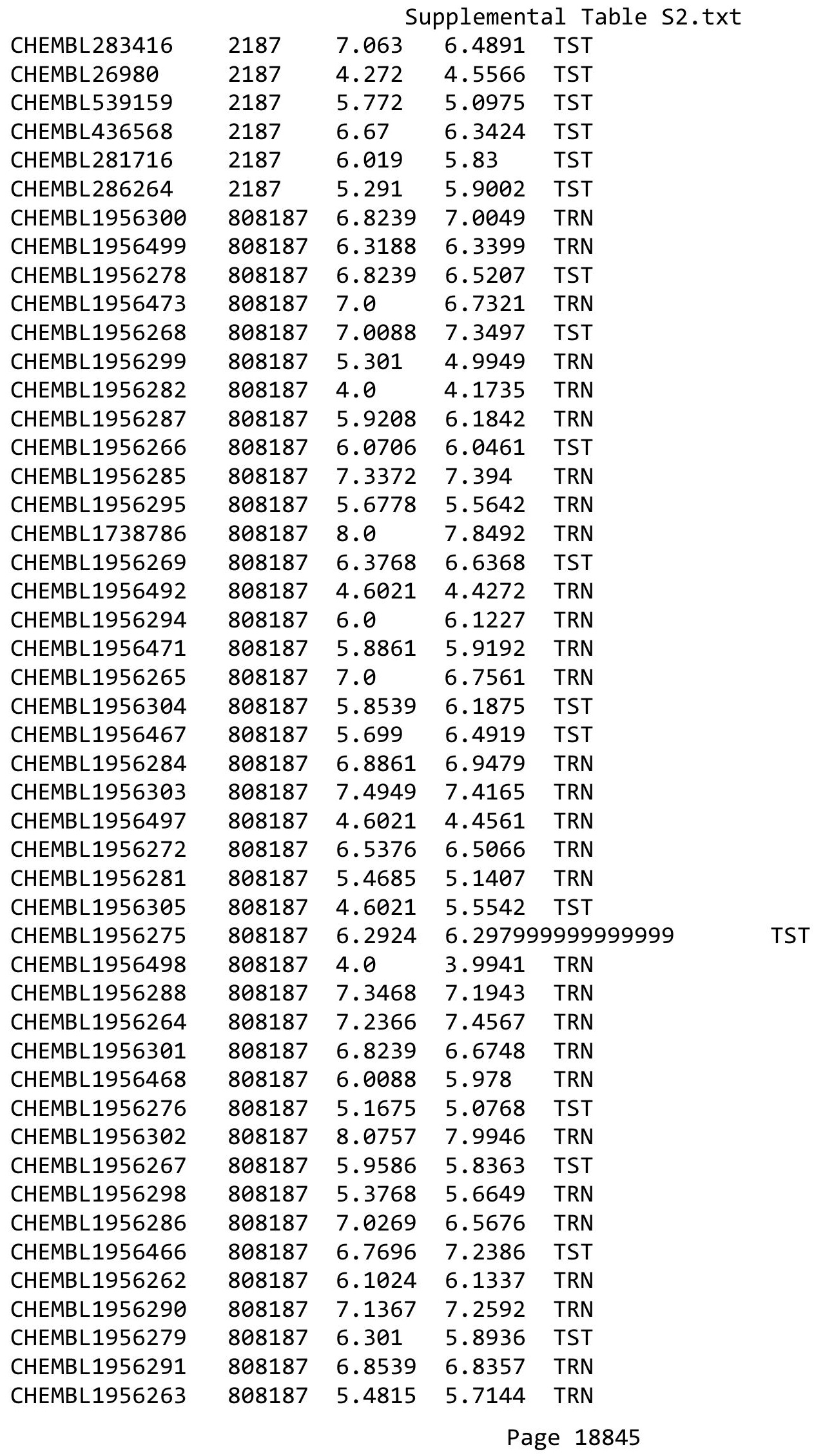




\begin{tabular}{|c|c|c|c|c|c|}
\hline & & \multicolumn{4}{|c|}{ Supplemental Table S2.txt } \\
\hline CHEMBL1956470 & 808187 & 5.3565 & 5.5337 & TRN & \\
\hline CHEMBL1956472 & 808187 & 7.2366 & 7.3166 & TRN & \\
\hline CHEMBL1956488 & 808187 & 4.6021 & 4.8348 & TRN & \\
\hline CHEMBL1956283 & 808187 & 7.301 & 7.3959 & TRN & \\
\hline CHEMBL1956289 & 808187 & 6.2596 & 6.5059 & TRN & \\
\hline CHEMBL1956469 & 808187 & 6.2291 & 6.1783 & TRN & \\
\hline CHEMBL1956274 & 808187 & 6.5686 & 6.9148 & TST & \\
\hline CHEMBL1956273 & 808187 & 5.6383 & 5.7866 & TRN & \\
\hline CHEMBL387348 & 428502 & 7.3768 & 7.3768 & TRN & \\
\hline CHEMBL222364 & 428502 & 8.3098 & 8.3098 & TRN & \\
\hline CHEMBL266768 & 428502 & 6.2882 & 6.2883 & TRN & \\
\hline CHEMBL221208 & 428502 & 7.6021 & 7.4887 & TST & \\
\hline CHEMBL223047 & 428502 & 5.4815 & 5.4815 & TRN & \\
\hline CHEMBL375404 & 428502 & 8.0 & 8.0 & TRN & \\
\hline CHEMBL385325 & 428502 & 8.0 & 7.37200 & 2000000001 & TST \\
\hline CHEMBL223634 & 428502 & 7.8861 & 7.8861 & TRN & \\
\hline CHEMBL373919 & 428502 & 6.9208 & 6.9208 & TRN & \\
\hline CHEMBL219792 & 428502 & 6.4685 & 6.4866 & TST & \\
\hline CHEMBL385334 & 428502 & 7.0706 & 7.0706 & TRN & \\
\hline CHEMBL374486 & 428502 & 6.0269 & 6.0268 & TRN & \\
\hline CHEMBL223045 & 428502 & 6.6108 & 6.6109 & TRN & \\
\hline CHEMBL223840 & 428502 & 6.4949 & 6.4949 & TRN & \\
\hline CHEMBL 223515 & 428502 & 6.6576 & 6.6575 & TRN & \\
\hline CHEMBL373881 & 428502 & 7.1308 & 7.1307 & TRN & \\
\hline CHEMBL223788 & 428502 & 8.0458 & 8.0458 & TRN & \\
\hline CHEMBL222619 & 428502 & 6.3768 & 7.1847 & TST & \\
\hline CHEMBL426377 & 428502 & 5.0 & 5.0001 & TRN & \\
\hline CHEMBL220632 & 428502 & 8.2291 & 8.2297 & TRN & \\
\hline CHEMBL223782 & 428502 & 7.3188 & 7.3187 & TRN & \\
\hline CHEMBL424928 & 428502 & 7.8861 & 7.886 & TRN & \\
\hline CHEMBL373868 & 428502 & 6.585 & 6.5849 & TRN & \\
\hline CHEMBL223839 & 428502 & 6.301 & 6.3011 & TRN & \\
\hline CHEMBL373546 & 428502 & 6.4318 & 6.4319 & TRN & \\
\hline CHEMBL387349 & 428502 & 6.6383 & 6.6382 & TRN & \\
\hline CHEMBL220559 & 428502 & 5.9586 & 6.0992 & TST & \\
\hline CHEMBL223385 & 428502 & 7.7959 & 7.7959 & TRN & \\
\hline CHEMBL221264 & 428502 & 7.7959 & 7.7953 & TRN & \\
\hline CHEMBL374681 & 428502 & 7.6383 & 7.6382 & TRN & \\
\hline CHEMBL424756 & 428502 & 5.0 & 6.4231 & TST & \\
\hline CHEMBL376733 & 428502 & 8.2518 & 8.2512 & TRN & \\
\hline CHEMBL442041 & 428502 & 8.1549 & 8.1556 & TRN & \\
\hline CHEMBL223044 & 428502 & 5.0 & 5.0 & TRN & \\
\hline CHEMBL223615 & 428502 & 6.1675 & 6.1675 & TRN & \\
\hline CHEMBL223043 & 428502 & 6.5622 & 6.5622 & TRN & \\
\hline CHEMBL220121 & 428502 & 6.9586 & 6.9585 & TRN & \\
\hline CHEMBL220269 & 428502 & 6.3565 & 6.3565 & TRN & \\
\hline CHEMBL411343 & 428502 & 7.1549 & 7.1549 & TRN & \\
\hline CHEMBL376632 & 428502 & 7.699 & 7.4989 & TST & \\
\hline
\end{tabular}




\begin{tabular}{|c|c|c|c|c|}
\hline & & & & \\
\hline CHEMBL 223614 & 428502 & 5.7447 & 47 & $\mathrm{TH}$ \\
\hline HEMBL 374552 & 428502 & 7.0 & 7.0 & \\
\hline CHEMBL374319 & 428502 & 7.6021 & 7.602 & \\
\hline HEMBL436535 & 428502 & 6.6778 & 6.6778 & \\
\hline HEMBL 374132 & 428502 & 6.4949 & 6.4947 & \\
\hline HEMBL376237 & 428502 & 6.7959 & 7.3739 & \\
\hline HEMBL 220270 & 428502 & 6.8539 & 7.2213 & \\
\hline HEMBL 220880 & 428502 & 8.1249 & 8.1248 & \\
\hline HEMBL 376713 & 428502 & 7.5528 & 7.5529 & \\
\hline HEMBL37 & 428502 & 6.0269 & 5.7121 & \\
\hline HEMBL427062 & 428502 & 7.6021 & 7.5545 & \\
\hline HEMBL 373623 & 428502 & 7.9586 & 7.9585 & \\
\hline CHEMBL 2 & 428502 & 7.6198 & 7.62 & \\
\hline HEMBL2 & 42 & 6.585 & 6.2827 & \\
\hline HEMBL2 & 42 & 6.3468 & 58 & \\
\hline HEMBL 22 & 428502 & 7.4685 & 7.4686 & \\
\hline CHEMBL223792 & 428502 & 7.7447 & 7.7447 & \\
\hline CHEMBL 22 & 502 & 6.7959 & 6.7098 & \\
\hline HEMBL2 & 42 & 685 & 95 & \\
\hline CHEMBL 2 & 42 & 706 & 6. & \\
\hline CHEMBL 221320 & 428502 & 5.0 & 544 & \\
\hline CHEMBL 22 & 502 & 7.1427 & 7.1428 & \\
\hline CHEMBL 2 & 428502 & 6.3468 & 6.3468 & \\
\hline CHEMBL3 & 113 & 9.3098 & 16 & \\
\hline CHEMBL 3 & 113 & 9.0044 & 8. & \\
\hline CHEMBL 36 & 5113 & 9.9586 & 9.7307 & \\
\hline CHEMBL3699299 & 6113 & 7.7948 & 9525 & \\
\hline CHEMBL 3 & 113 & 9.8239 & 9.7666 & \\
\hline CHEMBL & 113 & 8.8794 & 9. & \\
\hline CHEMBL 3 & 113 & 7.6801 & 7.61 & \\
\hline CHEMBL 3 & 6113 & 9.2147 & 19 & \\
\hline CHEMBL3699298 & 1536113 & 7.7053 & 7.7421 & \\
\hline CHEMBL 36 & 6113 & 9.7959 & 9.8174 & RIV \\
\hline CHEMBL3 & 113 & 8.3439 & 8 . & \\
\hline CHEMBL3 & 113 & 10.5229 & 9.8415 & \\
\hline CHEMBL 3699297 & 1536113 & 9.0862 & 9.305 & RN \\
\hline CHEMBL3699236 & 1536113 & 9.0605 & 9.1532 & \\
\hline CHEMBL 3 & & 18 & & \\
\hline CHEMBL3 & 15 & 383 & 9. & \\
\hline CHEMBL3 & 6113 & 10.1549 & 9.8055 & \\
\hline CHEMBL 3699240 & 1536113 & 9.0315 & 9.0391 & $\mathrm{R}$ \\
\hline CHEMBL3699271 & 1536113 & 8.3261 & 8.5187 & \\
\hline CHEMBL3 & & & 7.8079 & \\
\hline CHEMBL 3 & 1536113 & 9.3098 & 9.0167 & \\
\hline CHEMBL 39 & 1536113 & 9.1938 & 9.1795 & \\
\hline CHEMBL 3699243 & 1536113 & 7.8088 & 8.0442 & \\
\hline CHEMBL3699270 & 1536113 & 8.2248 & 8.4313 & \\
\hline CHEMBL3699255 & 1536113 & 9.5686 & 9.8026 & \\
\hline
\end{tabular}




$$
\text { Supplemental Table S2.txt }
$$

\begin{tabular}{|c|c|c|c|c|}
\hline CHEMBL 3699300 & 1536113 & 8.8447 & 7.9165 & TST \\
\hline CHEMBL 3699250 & 1536113 & 9.2676 & 9.4887 & TRN \\
\hline CHEMBL 3699275 & 1536113 & 8.5214 & 8.5562 & TRN \\
\hline CHEMBL 3699247 & 1536113 & 6.8136 & 7.0654 & TRN \\
\hline CHEMBL3699291 & 1536113 & 6.0 & 7.0962 & TST \\
\hline CHEMBL 3699278 & 1536113 & 9.6778 & 9.7551 & TRN \\
\hline CHEMBL 3699280 & 1536113 & 9.6021 & 9.7079 & TRN \\
\hline CHEMBL3699234 & 1536113 & 10.0458 & 9.4545 & TST \\
\hline CHEMBL 3699296 & 1536113 & 9.6383 & 9.2836 & TRN \\
\hline CHEMBL 3699295 & 1536113 & 9.9586 & 9.9703 & TRN \\
\hline CHEMBL 3699269 & 1536113 & 9.3279 & 8.9775 & TRN \\
\hline CHEMBL 3699248 & 1536113 & 7.0672 & 7.2114 & TRN \\
\hline CHEMBL3699267 & 1536113 & 9.5686 & 9.1729 & TRN \\
\hline CHEMBL 3916092 & 1536113 & 10.0458 & 9.415 & TRN \\
\hline CHEMBL3699283 & 1536113 & 7.0882 & 7.4992 & TST \\
\hline CHEMBL 3699249 & 1536113 & 7.6029 & 7.6615 & TRN \\
\hline CHEMBL 3699264 & 1536113 & 9.1192 & 9.3033 & TRN \\
\hline CHEMBL 3979154 & 1536113 & 9.585 & 9.2599 & TRN \\
\hline CHEMBL 3699272 & 1536113 & 8.4935 & 8.3684 & TRN \\
\hline CHEMBL3699245 & 1536113 & 8.8153 & 8.9751 & TRN \\
\hline CHEMBL 3914263 & 1536113 & 8.0872 & 8.7877 & TST \\
\hline CHEMBL 3699293 & 1536113 & 9.0269 & 8.4728 & TST \\
\hline CHEMBL 3923258 & 1536113 & 9.283999 & 99999999 & 9.2133 \\
\hline CHEMBL 3699238 & 1536113 & 9.699 & 9.5857 & TRN \\
\hline CHEMBL 3699251 & 1536113 & 8.7932 & 8.812006 & 0000000001 \\
\hline CHEMBL 3699284 & 1536113 & 9.1192 & 9.2515 & TST \\
\hline CHEMBL 3954645 & 1536113 & 8.6073 & 8.7075 & TST \\
\hline CHEMBL 3699287 & 1536113 & 9.2147 & 9.6814 & TRN \\
\hline CHEMBL 3699274 & 1536113 & 9.1249 & 9.0945 & TRN \\
\hline CHEMBL 3923466 & 1536113 & 7.2132 & 7.6178 & TST \\
\hline CHEMBL 3699301 & 1536113 & 7.3317 & 7.5174 & TST \\
\hline CHEMBL 3699294 & 1536113 & 9.7959 & 10.003 & TRN \\
\hline CHEMBL 3699237 & 1536113 & 9.9586 & 9.7909 & TRN \\
\hline CHEMBL 3699277 & 1536113 & 9.3468 & 9.5432 & TRN \\
\hline CHEMBL 3699242 & 1536113 & 9.1549 & 9.2417 & TRN \\
\hline CHEMBL 3699273 & 1536113 & 8.5003 & 8.2194 & TRN \\
\hline CHEMBL 3890962 & 1536113 & 9.5528 & 9.8556 & TST \\
\hline CHEMBL 3699304 & 1536113 & 8.2924 & 7.9542 & TST \\
\hline CHEMBL 3699253 & 1536113 & 9.5086 & 9.6916 & TRN \\
\hline CHEMBL 3699303 & 1536113 & 9.1308 & 9.0269 & TRN \\
\hline CHEMBL 3699265 & 1536113 & 8.6882 & 8.4674 & TRN \\
\hline CHEMBL 3651035 & 1528713 & 8.699 & 9.1004 & TRN \\
\hline CHEMBL 3703485 & 1528713 & 8.2596 & 8.3057 & TRN \\
\hline CHEMBL 3650998 & 1528713 & 9.9586 & 10.3249 & TRN \\
\hline CHEMBL 3651024 & 1528713 & 8.699 & 9.0318 & TRN \\
\hline CHEMBL 3651007 & 1528713 & 8.8239 & 9.3196 & TRN \\
\hline CHEMBL 3651055 & 1528713 & 8.7447 & 8.1489 & TRN \\
\hline CHEMBL 3703490 & 1528713 & 8.2218 & 8.5625 & TST \\
\hline
\end{tabular}


Supplemental Table S2.txt

\begin{tabular}{|c|c|c|c|c|c|}
\hline CHEMBL3703489 & 1528713 & 8.3372 & 8.2986 & TRN & \\
\hline CHEMBL 3651062 & 1528713 & 8.0969 & 8.1854 & TRN & \\
\hline CHEMBL3651059 & 1528713 & 8.8539 & 7.4217 & TST & \\
\hline CHEMBL 3650977 & 1528713 & 8.8239 & 8.2466 & TST & \\
\hline CHEMBL 3703488 & 1528713 & 8.4559 & 8.5126 & TRN & \\
\hline CHEMBL 3651004 & 1528713 & 9.9586 & 9.6255 & TRN & \\
\hline CHEMBL3703491 & 1528713 & 8.1249 & 8.4307 & TRN & \\
\hline CHEMBL 3651034 & 1528713 & 9.3979 & 9.3322 & TRN & \\
\hline CHEMBL 3703493 & 1528713 & 8.3372 & 8.2027 & TST & \\
\hline CHEMBL 3650987 & 1528713 & 10.3098 & 9.8369 & TRN & \\
\hline CHEMBL 3651021 & 1528713 & 10.8861 & 10.2242 & TRN & \\
\hline CHEMBL 3651006 & 1528713 & 9.8539 & 9.8287 & TRN & \\
\hline CHEMBL 3651017 & 1528713 & 10.3665 & 9.9325 & TRN & \\
\hline CHEMBL 3650979 & 1528713 & 8.1871 & 7.8819 & TRN & \\
\hline CHEMBL 3703500 & 1528713 & 8.3768 & 8.1949 & TRN & \\
\hline CHEMBL 3650981 & 1528713 & 8.0132 & 8.0519 & TRN & \\
\hline CHEMBL 3650990 & 1528713 & 9.2147 & 10.0818 & TRN & \\
\hline CHEMBL 3650996 & 1528713 & 10.1549 & 10.0876 & TRN & \\
\hline CHEMBL 3650991 & 1528713 & 10.8861 & 10.11399 & 99999999999 & TRN \\
\hline CHEMBL 3650992 & 1528713 & 9.8239 & 9.7885 & TRN & \\
\hline CHEMBL 3651060 & 1528713 & 10.6990 & 00000006 & 9.4098 & TRN \\
\hline CHEMBL 3651045 & 1528713 & 9.0177 & 8.8353 & TRN & \\
\hline CHEMBL 3651044 & 1528713 & 9.2291 & 8.8516 & TRN & \\
\hline CHEMBL 3703496 & 1528713 & 8.0757 & 8.6133 & TRN & \\
\hline CHEMBL 3703486 & 1528713 & 8.1427 & 7.7153 & TRN & \\
\hline CHEMBL 3650997 & 1528713 & 9.9586 & 9.8908 & TRN & \\
\hline CHEMBL3703497 & 1528713 & 8.0555 & 8.1405 & TRN & \\
\hline CHEMBL 3639498 & 1528713 & 9.9586 & 9.8425 & TRN & \\
\hline CHEMBL3703492 & 1528713 & 8.0915 & 8.0736 & TRN & \\
\hline CHEMBL 3651026 & 1528713 & 8.7212 & 9.5242 & TRN & \\
\hline CHEMBL 3651037 & 1528713 & 10.284 & 10.1889 & TRN & \\
\hline CHEMBL 3651019 & 1528713 & 8.6778 & 9.4861 & TRN & \\
\hline CHEMBL 3703494 & 1528713 & 8.0809 & 8.1529 & TRN & \\
\hline CHEMBL 3651003 & 1528713 & 10.1675 & 10.1737 & TRN & \\
\hline CHEMBL 3651029 & 1528713 & 9.1805 & 9.8926 & TRN & \\
\hline CHEMBL 3651028 & 1528713 & 8.4089 & 8.8651 & TRN & \\
\hline CHEMBL3651009 & 1528713 & 8.8239 & 9.375 & TRN & \\
\hline CHEMBL 3651008 & 1528713 & 10.0605 & 9.9039 & TRN & \\
\hline CHEMBL3703501 & 1528713 & 8.2518 & 8.3296 & TRN & \\
\hline CHEMBL 3651005 & 1528713 & 9.7212 & 10.1476 & TRN & \\
\hline CHEMBL 3651002 & 1528713 & 9.4685 & 8.7388 & TST & \\
\hline CHEMBL 3651022 & 1528713 & 8.2757 & 9.4286 & TRN & \\
\hline CHEMBL 3650982 & 1528713 & 8.1249 & 8.0998 & TRN & \\
\hline CHEMBL 3651054 & 1528713 & 7.9872 & 8.4647 & TRN & \\
\hline CHEMBL 3703506 & 1528713 & 8.4815 & 8.363999 & 9999999999 & TRI \\
\hline CHEMBL 3651000 & 1528713 & 10.0915 & 8.8558 & TST & \\
\hline CHEMBL 3651061 & 1528713 & 8.1805 & 9.4615 & TRN & \\
\hline CHEMBL 3651050 & 1528713 & 10.7959 & 8.3294 & TST & \\
\hline
\end{tabular}

Page 18849 
Supplemental Table S2.txt

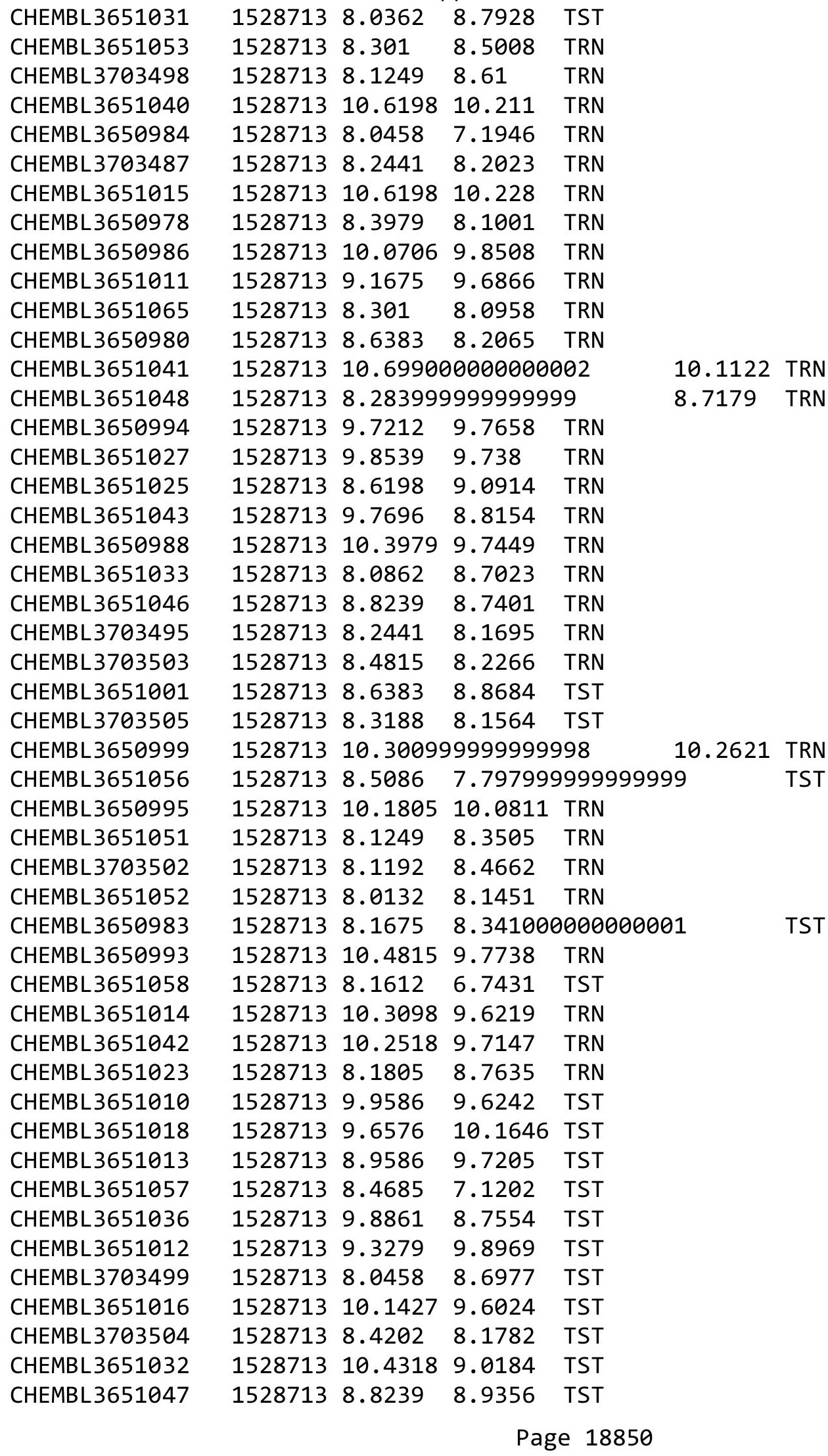


Supplemental Table S2.txt

\begin{tabular}{|c|c|c|c|c|c|c|}
\hline CHEMBL3651030 & 1528713 & 10.6021 & 9.9103 & TST & & \\
\hline CHEMBL3651049 & 1528713 & 8.2676 & 8.641 & TST & & \\
\hline CHEMBL3651063 & 1528713 & 8.0809 & 8.6738 & TST & & \\
\hline CHEMBL3781913 & 1565336 & 8.3979 & 8.6568 & TRN & & \\
\hline CHEMBL3781994 & 1565336 & 6.5376 & 6.9355 & TRN & & \\
\hline CHEMBL3781573 & 1565336 & 4.0 & 4.1745 & TRN & & \\
\hline CHEMBL3781347 & 1565336 & 8.0 & 7.2679 & TRN & & \\
\hline CHEMBL3781086 & 1565336 & 4.0 & 4.3875 & TST & & \\
\hline CHEMBL3781535 & 1565336 & 7.0969 & 7.0872 & TRN & & \\
\hline CHEMBL3781893 & 1565336 & 4.0 & 3.69 & TRN & & \\
\hline CHEMBL3781331 & 1565336 & 8.301 & 8.2267 & TRN & & \\
\hline CHEMBL 3780235 & 1565336 & 7.301 & 7.4897 & TRN & & \\
\hline CHEMBL3781797 & 1565336 & 6.1249 & 6.3085 & TRN & & \\
\hline CHEMBL3781161 & 1565336 & 5.6198 & 5.3755 & TRN & & \\
\hline CHEMBL3780372 & 1565336 & 8.0458 & 7.6306 & TRN & & \\
\hline CHEMBL3781827 & 1565336 & 6.7447 & 6.6828 & TRN & & \\
\hline CHEMBL3781183 & 1565336 & 6.8239 & 7.4159 & TRN & & \\
\hline CHEMBL3781548 & 1565336 & 8.1549 & 8.1209 & TRN & & \\
\hline CHEMBL3781447 & 1565336 & 5.9208 & 6.2747 & TRN & & \\
\hline CHEMBL3780729 & 1565336 & 6.3872 & 6.6228 & TRN & & \\
\hline CHEMBL3781308 & 1565336 & 7.8539 & 7.4792 & TRN & & \\
\hline CHEMBL3781290 & 1565336 & 6.3279 & 5.8769 & TRN & & \\
\hline CHEMBL3781094 & 1565336 & 5.7423 & 6.0058 & TRN & & \\
\hline CHEMBL 3780470 & 1565336 & 7.5229 & 7.5236 & TRN & & \\
\hline CHEMBL3780144 & 1565336 & 7.699 & 8.0524 & TRN & & \\
\hline CHEMBL3780785 & 1565336 & 7.5686 & 7.5041 & TST & & \\
\hline CHEMBL3780459 & 1565336 & 6.5686 & 6.4234 & TRN & & \\
\hline CHEMBL3780239 & 1565336 & 9.0 & 8.9206 & TRN & & \\
\hline CHEMBL3781625 & 1565336 & 6.6383 & 7.0075 & TRN & & \\
\hline CHEMBL3780972 & 1565336 & 8.0 & 7.9677 & TRN & & \\
\hline CHEMBL3781149 & 1565336 & 8.1549 & 7.5613 & TRN & & \\
\hline CHEMBL3781757 & 1565336 & 5.3979 & 5.4768 & TRN & & \\
\hline CHEMBL3781157 & 1565336 & 7.6021 & 7.1413 & TRN & & \\
\hline CHEMBL 3780054 & 1565336 & 7.2757 & 6.7205 & TST & & \\
\hline CHEMBL3781194 & 1565336 & 7.7696 & 7.2293 & TRN & & \\
\hline CHEMBL3781847 & 1565336 & 6.6383 & 6.3559 & TRN & & \\
\hline CHEMBL3780527 & 1565336 & 7.3979 & 7.352 & TST & & \\
\hline CHEMBL3780153 & 1565336 & 5.3565 & 5.6868 & TRN & & \\
\hline CHEMBL3780772 & 1565336 & 6.699 & 7.2151 & TRN & & \\
\hline CHEMBL3781835 & 1565336 & 7.2218 & 7.4949 & TRN & & \\
\hline CHEMBL3780765 & 1565336 & 7.4815 & 7.1132 & TRN & & \\
\hline CHEMBL3780717 & 1565336 & 7.4089 & 7.5498 & TRN & & \\
\hline CHEMBL3781741 & 1565336 & 7.4559 & 7.7063 & TRN & & \\
\hline CHEMBL 3780460 & 1565336 & 8.0969 & 7.8749 & TRN & & \\
\hline CHEMBL3780534 & 1565336 & 5.752000 & 000000000 & $\partial 1$ & 6.0945 & TRN \\
\hline CHEMBL3780764 & 1565336 & 6.7447 & 6.5448 & TRN & & \\
\hline CHEMBL3781633 & 1565336 & 6.9208 & 6.8944 & TRN & & \\
\hline CHEMBL 3780349 & 1565336 & 6.2924 & 6.6466 & TRN & & \\
\hline
\end{tabular}


Supplemental Table S2.txt

\begin{tabular}{|c|c|c|c|c|c|}
\hline CHEMBL3781384 & 1565336 & 7.3098 & 6.6747 & TST & \\
\hline CHEMBL3780756 & 1565336 & 6.5229 & 5.1819 & TST & \\
\hline CHEMBL3781151 & 1565336 & 7.7696 & 7.9729 & TST & \\
\hline CHEMBL3780043 & 1565336 & 7.301 & 7.4369 & TST & \\
\hline CHEMBL1551510 & 1565336 & 5.8239 & 6.1736 & TST & \\
\hline CHEMBL3780595 & 1565336 & 7.0 & 6.9735 & TST & \\
\hline CHEMBL3780845 & 1565336 & 5.9208 & 6.2478 & TST & \\
\hline CHEMBL3781668 & 1565336 & 5.7212 & 4.564 & TST & \\
\hline CHEMBL3780403 & 1565336 & 4.0 & 4.2915 & TST & \\
\hline CHEMBL3781654 & 1565336 & 6.9586 & 6.2672 & TST & \\
\hline CHEMBL270987 & 472997 & 4.0 & 3.72899 & 99999999996 & TRN \\
\hline CHEMBL411674 & 472997 & 8.0 & 8.3137 & TRN & \\
\hline CHEMBL1203961 & 472997 & 6.644 & 5.8653 & TST & \\
\hline CHEMBL262865 & 472997 & 7.8539 & 6.8595 & TRN & \\
\hline CHEMBL409231 & 472997 & 4.0 & 4.39 & TRN & \\
\hline CHEMBL270546 & 472997 & 6.8697 & 5.7205 & TRN & \\
\hline CHEMBL259463 & 472997 & 6.5528 & 5.2936 & TRN & \\
\hline CHEMBL409265 & 472997 & 4.0 & 4.2592 & TRN & \\
\hline CHEMBL271527 & 472997 & 4.0 & 4.2864 & TRN & \\
\hline CHEMBL272868 & 472997 & 7.7447 & 8.0286 & TRN & \\
\hline CHEMBL409647 & 472997 & 6.6459 & 6.7718 & TRN & \\
\hline CHEMBL410313 & 472997 & 7.1367 & 6.9833 & TRN & \\
\hline CHEMBL270125 & 472997 & 4.0 & 4.5526 & TRN & \\
\hline CHEMBL410655 & 472997 & 7.3468 & 6.5739 & TRN & \\
\hline CHEMBL271838 & 472997 & 4.0 & \multicolumn{2}{|c|}{4.946000000000001} & TRN \\
\hline CHEMBL272189 & 472997 & 4.0 & 4.0704 & TRN & \\
\hline CHEMBL408174 & 472997 & 4.0 & 4.0946 & TRN & \\
\hline CHEMBL270968 & 472997 & 4.0 & 3.8368 & TRN & \\
\hline CHEMBL409491 & 472997 & 7.8239 & 8.1177 & TRN & \\
\hline CHEMBL406399 & 472997 & 7.3872 & 7.1826 & TRN & \\
\hline CHEMBL271837 & 472997 & 6.7305 & \multicolumn{2}{|c|}{5.9510000000000005} & TRN \\
\hline CHEMBL271839 & 472997 & 4.0 & 3.7215 & TRN & \\
\hline CHEMBL406918 & 472997 & 4.0 & 3.5066 & TRN & \\
\hline CHEMBL411888 & 472997 & 4.0 & 3.9975 & TRN & \\
\hline CHEMBL271553 & 472997 & 4.0 & 4.2648 & TRN & \\
\hline CHEMBL271158 & 472997 & 8.1549 & 8.8413 & TRN & \\
\hline CHEMBL272882 & 472997 & 7.2147 & 6.6602 & TRN & \\
\hline CHEMBL271805 & 472997 & 4.0 & 4.2272 & TRN & \\
\hline CHEMBL272658 & 472997 & 4.0 & 4.0024 & TRN & \\
\hline CHEMBL410842 & 472997 & 6.4168 & 6.8507 & TRN & \\
\hline CHEMBL272176 & 472997 & 7.6778 & 7.5119 & TRN & \\
\hline CHEMBL306764 & 472997 & 6.1979 & 6.9215 & TST & \\
\hline CHEMBL188 & 472997 & 7.0655 & 5.5253 & TST & \\
\hline CHEMBL 259462 & 472997 & 8.0 & 7.862 & TRN & \\
\hline CHEMBL272876 & 472997 & 4.0 & 5.6721 & TRN & \\
\hline CHEMBL411673 & 472997 & 4.0 & 5.5439 & TRN & \\
\hline CHEMBL411631 & 472997 & 4.0 & 3.6965 & TRN & \\
\hline CHEMBL408964 & 472997 & 7.0915 & 6.8574 & TRN & \\
\hline
\end{tabular}



Supplemental Table S2.txt

\begin{tabular}{|c|c|c|c|c|c|}
\hline CHEMBL3103669 & 1285820 & 6.6345 & 6.9979 & TRN & \\
\hline CHEMBL3105249 & 1285820 & 9.1549 & 7.9842 & TST & \\
\hline CHEMBL3105486 & 1285820 & 7.7496 & 8.1271 & TRN & \\
\hline CHEMBL3103661 & 1285820 & 7.8239 & 7.3226 & TRN & \\
\hline CHEMBL3105485 & 1285820 & 6.5229 & 8.0722 & TRN & \\
\hline CHEMBL3102988 & 1285820 & 8.9586 & 8.2909 & TRN & \\
\hline CHEMBL3103671 & 1285820 & 7.0132 & 5.1774 & TST & \\
\hline CHEMBL3102985 & 1285820 & 8.9586 & 8.4813 & TRN & \\
\hline CHEMBL3105483 & 1285820 & 9.0458 & 8.4173 & TRN & \\
\hline CHEMBL3105489 & 1285820 & 8.585 & 8.2806 & TRN & \\
\hline CHEMBL3105478 & 1285820 & 8.8861 & 7.9667 & TST & \\
\hline CHEMBL3103657 & 1285820 & 8.2007 & 8.4823 & TRN & \\
\hline CHEMBL3105484 & 1285820 & 8.8861 & 8.4504 & TRN & \\
\hline CHEMBL3105488 & 1285820 & 8.4685 & 8.1271 & TRN & \\
\hline CHEMBL3103658 & 1285820 & 8.8539 & 8.472006 & 000000001 & TRN \\
\hline CHEMBL3102992 & 1285820 & 8.3279 & 8.4817 & TRN & \\
\hline CHEMBL3103660 & 1285820 & 6.5498 & 5.3479 & TRN & \\
\hline CHEMBL3105250 & 1285820 & 9.0 & 8.1726 & TST & \\
\hline CHEMBL3103679 & 1285820 & 4.0 & 4.8024 & TRN & \\
\hline CHEMBL3103673 & 1285820 & 5.067 & 4.7718 & TST & \\
\hline CHEMBL3105248 & 1285820 & 9.1549 & 8.1858 & TST & \\
\hline CHEMBL3103662 & 1285820 & 8.3372 & 6.4371 & TRN & \\
\hline CHEMBL3103664 & 1285820 & 5.5072 & 6.4868 & TRN & \\
\hline CHEMBL3102989 & 1285820 & 8.7447 & 8.5292 & TRN & \\
\hline CHEMBL3103680 & 1285820 & 4.0 & 5.2999 & TRN & \\
\hline CHEMBL3102990 & 1285820 & 8.3565 & 8.0969 & TRN & \\
\hline CHEMBL3105247 & 1285820 & 8.9586 & 8.084 & TST & \\
\hline CHEMBL3105246 & 1285820 & 8.4815 & 8.3246 & TRN & \\
\hline CHEMBL3105481 & 1285820 & 8.8239 & 8.5333 & TST & \\
\hline CHEMBL 3102987 & 1285820 & 8.585 & 8.1876 & TST & \\
\hline CHEMBL137669 & 143676 & 5.0315 & 6.0409 & TST & \\
\hline CHEMBL137356 & 143676 & 5.284 & 4.5815 & TST & \\
\hline CHEMBL341563 & 143676 & 9.1549 & 7.3789 & TRN & \\
\hline CHEMBL138435 & 143676 & 6.0655 & 5.8754 & TRN & \\
\hline CHEMBL336711 & 143676 & 11.0 & 10.4075 & TRN & \\
\hline CHEMBL137619 & 143676 & 5.9586 & 6.9735 & TRN & \\
\hline CHEMBL137427 & 143676 & 7.2757 & 6.0793 & TRN & \\
\hline CHEMBL136974 & 143676 & 11.0 & 10.4269 & TRN & \\
\hline CHEMBL133032 & 143676 & 7.5229 & 7.2225 & TST & \\
\hline CHEMBL435825 & 143676 & 5.0862 & 5.3659 & TRN & \\
\hline CHEMBL343330 & 143676 & 5.0809 & 5.8888 & TRN & \\
\hline CHEMBL 2111927 & 143676 & 6.041 & 5.7383 & TRN & \\
\hline CHEMBL136650 & 143676 & 7.5376 & 6.445 & TRN & \\
\hline CHEMBL137378 & 143676 & 9.3979 & 8.5199 & TRN & \\
\hline CHEMBL341993 & 143676 & 6.8239 & 7.3014 & TRN & \\
\hline CHEMBL137302 & 143676 & 11.0 & 8.7931 & TRN & \\
\hline CHEMBL138118 & 143676 & 8.2757 & 6.4133 & TRN & \\
\hline CHEMBL335604 & 143676 & 11.0 & 10.8189 & TRN & \\
\hline
\end{tabular}




\begin{tabular}{|c|c|c|c|c|}
\hline \multicolumn{5}{|c|}{ Supplemental Table s2.txt } \\
\hline CHEMBL135262 & 143676 & 8.6576 & 7.928 & TRN \\
\hline CHEMBL344820 & 143676 & 7.1024 & 7.9375 & TRN \\
\hline CHEMBL335569 & 143676 & 4.0 & 4.4642 & TRN \\
\hline CHEMBL337105 & 143676 & 5.9208 & 6.3666 & TRN \\
\hline CHEMBL342153 & 143676 & 6.9208 & 6.6357 & TRN \\
\hline CHEMBL137008 & 143676 & 7.3565 & 7.4177 & TRN \\
\hline CHEMBL343766 & 143676 & 6.2366 & 7.933 & TRN \\
\hline CHEMBL139270 & 143676 & 5.1249 & 5.1018 & TRN \\
\hline CHEMBL342818 & 143676 & 6.2291 & 7.0306 & TRN \\
\hline CHEMBL137724 & 143676 & 6.2518 & 5.9854 & TST \\
\hline CHEMBL137428 & 143676 & 5.3979 & 6.6291 & TRN \\
\hline CHEMBL337305 & 143676 & 6.6576 & 7.5015 & TST \\
\hline CHEMBL424283 & 143676 & 11.0 & 10.8287 & TRN \\
\hline CHEMBL138278 & 143676 & 6.5528 & 6.7387 & TRN \\
\hline CHEMBL344692 & 143676 & 6.2676 & 5.78 & TRN \\
\hline CHEMBL423720 & 143676 & 5.8539 & 6.9906 & TRN \\
\hline CHEMBL136959 & 143676 & 5.0706 & 4.093 & TST \\
\hline CHEMBL137260 & 143676 & 6.8539 & 7.1122 & TRN \\
\hline CHEMBL343318 & 143676 & 9.301 & 8.9797 & TRN \\
\hline CHEMBL342042 & 143676 & 5.6198 & 6.9578 & TRN \\
\hline CHEMBL335861 & 143676 & 6.4815 & 6.3616 & TRN \\
\hline CHEMBL337815 & 143676 & 5.3979 & 6.1186 & TRN \\
\hline CHEMBL137236 & 143676 & 6.6021 & 6.6909 & TRN \\
\hline CHEMBL138379 & 143676 & 9.5229 & 8.4227 & TRN \\
\hline CHEMBL345082 & 143676 & 7.699 & 7.8055 & TRN \\
\hline CHEMBL138383 & 143676 & 5.6383 & 6.4283 & TST \\
\hline CHEMBL137538 & 143676 & 7.7696 & 5.6998 & TST \\
\hline CHEMBL422816 & 143676 & 7.3872 & 8.1525 & TRN \\
\hline CHEMBL137290 & 143676 & 6.1805 & 8.1562 & TRN \\
\hline CHEMBL139483 & 143676 & 7.0 & 6.8288 & TRN \\
\hline CHEMBL137557 & 143676 & 6.1367 & 5.2338 & TST \\
\hline CHEMBL343394 & 143676 & 6.7959 & 6.2763 & TRN \\
\hline CHEMBL137258 & 143676 & 7.1805 & 6.9192 & TRN \\
\hline CHEMBL137403 & 143676 & 6.8239 & 6.6064 & TRN \\
\hline CHEMBL137638 & 143676 & 8.0 & 6.9833 & TRN \\
\hline CHEMBL343817 & 143676 & 9.5229 & 9.2999 & TRN \\
\hline CHEMBL137530 & 143676 & 7.4949 & 5.0753 & TST \\
\hline CHEMBL137613 & 143676 & 7.284 & 5.2349 & TST \\
\hline CHEMBL135485 & 143676 & 6.1367 & 5.3674 & TRN \\
\hline CHEMBL341791 & 143676 & 4.0 & 5.6988 & TST \\
\hline CHEMBL137350 & 143676 & 6.4202 & 8.4251 & TRN \\
\hline CHEMBL137404 & 143676 & 7.0 & 7.0162 & TRN \\
\hline CHEMBL137086 & 143676 & 9.1549 & 8.3474 & TRN \\
\hline CHEMBL343564 & 143676 & 5.8539 & 8.7422 & TRN \\
\hline CHEMBL343924 & 143676 & 6.7696 & 7.3722 & TRN \\
\hline CHEMBL337152 & 143676 & 7.4437 & 5.4853 & TST \\
\hline CHEMBL335039 & 143676 & 8.9586 & 7.4917 & TRN \\
\hline CHEMBL137296 & 143676 & 5.3279 & 6.0732 & TRN \\
\hline
\end{tabular}




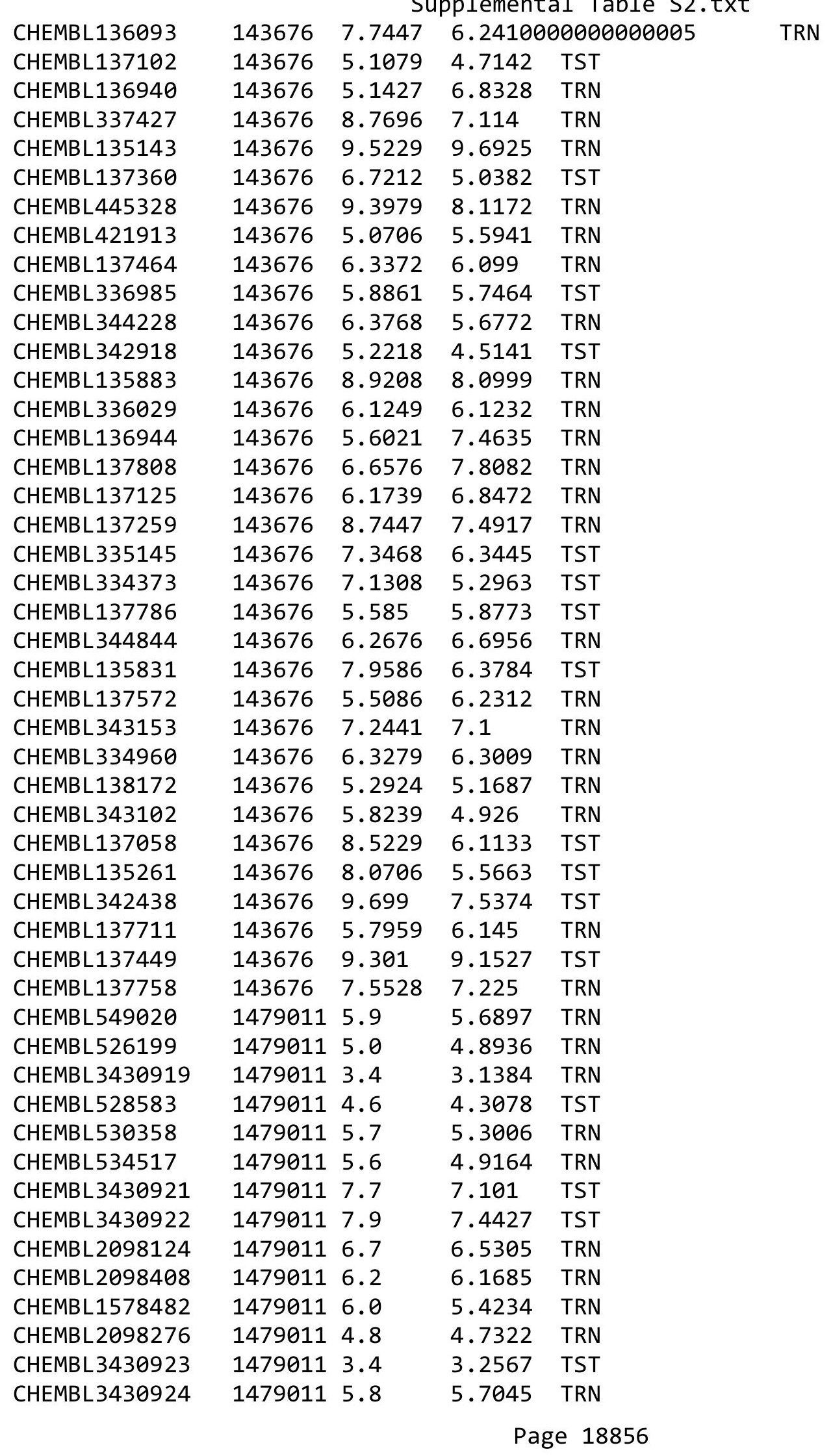




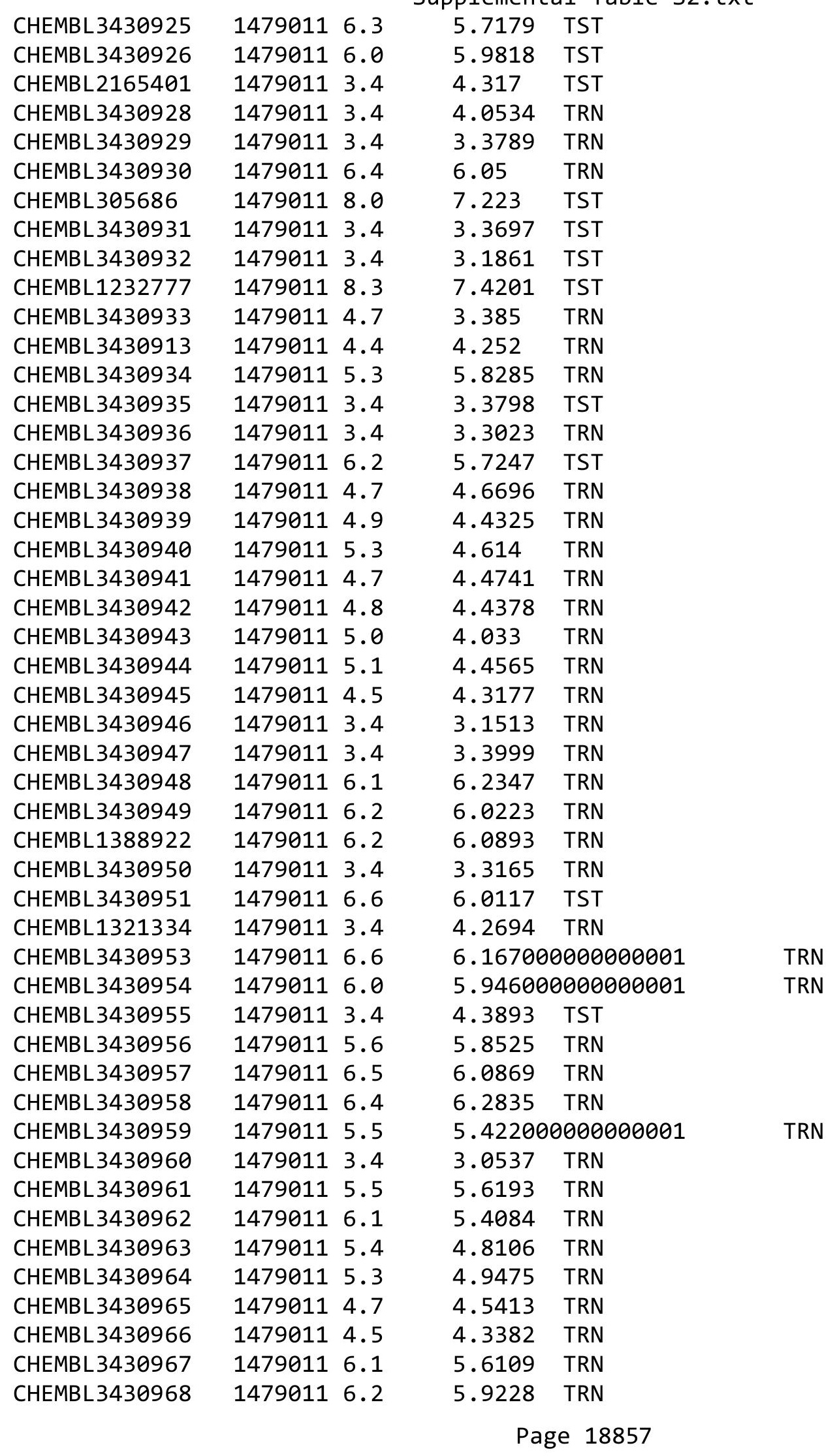




\begin{tabular}{|c|c|c|c|c|}
\hline \\
\hline CHEMBL3430969 & 14790116.2 & 6.2157 & TRN & \\
\hline CHEMBL3430970 & 14790114.9 & 5.0665 & TRN & \\
\hline CHEMBL1482137 & 14790116.7 & 6.2796 & TRN & \\
\hline CHEMBL3430971 & 14790113.4 & 4.3133 & TRN & \\
\hline CHEMBL3430972 & 14790113.4 & 3.2646 & TRN & \\
\hline CHEMBL3430973 & 14790116.0 & 5.8476 & TRN & \\
\hline CHEMBL3430974 & 14790113.4 & 3.4468 & TRN & \\
\hline CHEMBL3430975 & 14790116.3 & 6.0806 & TRN & \\
\hline CHEMBL3430976 & 14790116.1 & 5.9291 & TRN & \\
\hline CHEMBL3430977 & 14790116.7 & 6.3374 & TST & \\
\hline CHEMBL164422 & 14790116.0 & 5.83899 & 99999999995 & TRN \\
\hline CHEMBL3430978 & 14790116.0 & 5.8444 & TRN & \\
\hline CHEMBL3430979 & 14790113.4 & 4.8838 & TRN & \\
\hline CHEMBL3430980 & 14790115.3 & 4.8552 & TRN & \\
\hline CHEMBL1487481 & 14790115.6 & 5.6707 & TRN & \\
\hline CHEMBL1487467 & 14790116.2 & 6.0214 & TRN & \\
\hline CHEMBL3430981 & 14790114.6 & 4.5595 & TRN & \\
\hline CHEMBL3430982 & 14790114.7 & 4.5102 & TRN & \\
\hline CHEMBL3430983 & 14790114.8 & 4.7286 & TRN & \\
\hline CHEMBL592827 & 14790113.4 & 3.9837 & TRN & \\
\hline CHEMBL3430984 & 14790115.5 & 5.2186 & TRN & \\
\hline CHEMBL3430985 & 14790115.7 & 5.182 & TRN & \\
\hline CHEMBL1466712 & 14790115.2 & 3.6692 & TRN & \\
\hline CHEMBL3430986 & 14790116.2 & 6.1423 & TRN & \\
\hline CHEMBL3430987 & 14790114.7 & 4.3354 & TST & \\
\hline CHEMBL3430988 & 14790113.4 & 3.19 & TRN & \\
\hline CHEMBL3430989 & 14790113.4 & 3.2863 & TRN & \\
\hline CHEMBL3430990 & 14790114.8 & 4.9481 & TRN & \\
\hline CHEMBL3430991 & 14790113.4 & 4.4209 & TRN & \\
\hline CHEMBL3430992 & 14790114.6 & 4.4527 & TRN & \\
\hline CHEMBL3430993 & 14790115.0 & 4.843 & TRN & \\
\hline CHEMBL3430994 & 14790116.1 & 5.6522 & TRN & \\
\hline CHEMBL3430995 & 14790113.4 & 3.3003 & TST & \\
\hline CHEMBL3430996 & 14790115.5 & 5.3936 & TRN & \\
\hline CHEMBL3430997 & 14790113.4 & 3.4585 & TRN & \\
\hline CHEMBL3430998 & 14790116.4 & 6.05399 & 9999999999 & TRN \\
\hline CHEMBL3430999 & 14790114.8 & 4.0516 & TRN & \\
\hline CHEMBL 3431001 & 14790113.4 & 3.0855 & TRN & \\
\hline CHEMBL3431002 & 14790113.4 & 3.2175 & TST & \\
\hline CHEMBL3431003 & 14790116.9 & 6.9358 & TRN & \\
\hline CHEMBL3431004 & 14790116.8 & 7.4027 & TRN & \\
\hline CHEMBL3431005 & 14790115.0 & 6.1758 & TRN & \\
\hline CHEMBL3431006 & 14790115.3 & 6.5011 & TRN & \\
\hline CHEMBL3431007 & 14790116.2 & 5.6165 & TRN & \\
\hline CHEMBL3431008 & 14790115.3 & 4.7706 & TST & \\
\hline CHEMBL3431009 & 14790116.7 & 6.5327 & TRN & \\
\hline CHEMBL2355685 & 14790114.9 & 4.6257 & TST & \\
\hline CHEMBL3431010 & 14790115.3 & 5.0637 & TRN & \\
\hline
\end{tabular}




\begin{tabular}{|c|c|c|c|c|}
\hline CHEMBL3431011 & 14790116.1 & 5.7976 & TRN & \\
\hline CHEMBL3431012 & 14790116.2 & 5.4847 & TST & \\
\hline CHEMBL1731664 & 14790114.5 & 5.0426 & TRN & \\
\hline CHEMBL3431013 & 14790115.5 & 5.2479 & TRN & \\
\hline CHEMBL3431014 & 14790116.0 & 6.2706 & TRN & \\
\hline CHEMBL3431015 & 14790116.6 & 6.6753 & TRN & \\
\hline CHEMBL3431016 & 14790113.4 & 3.0422 & TRN & \\
\hline CHEMBL3431017 & 14790113.4 & 3.4998 & TRN & \\
\hline CHEMBL3431018 & 14790116.1 & 5.7809 & TRN & \\
\hline CHEMBL3431019 & 14790115.7 & 5.9344 & TRN & \\
\hline CHEMBL3431020 & 14790114.5 & 4.19 & TRN & \\
\hline CHEMBL3431021 & 14790117.2 & 6.7893 & TRN & \\
\hline CHEMBL3431022 & 14790113.4 & 4.5217 & TRN & \\
\hline CHEMBL3431023 & 14790114.9 & 4.5688 & TST & \\
\hline CHEMBL3431024 & 14790113.4 & 4.8177 & TRN & \\
\hline CHEMBL3431025 & 14790113.4 & 4.9538 & TRN & \\
\hline CHEMBL3431026 & 14790115.4 & 4.6183 & TST & \\
\hline CHEMBL3431027 & 14790116.3 & 5.9917 & TRN & \\
\hline CHEMBL3431028 & 14790113.4 & 3.9931 & TRN & \\
\hline CHEMBL3431029 & 14790113.4 & 3.8808 & TRN & \\
\hline CHEMBL3431030 & 14790116.1 & 6.0699 & TRN & \\
\hline CHEMBL3431031 & 14790114.6 & 4.4782 & TRN & \\
\hline CHEMBL3431032 & 14790116.2 & 5.9253 & TRN & \\
\hline CHEMBL1527364 & 14790116.2 & 6.0628 & TRN & \\
\hline CHEMBL3430914 & 14790115.7 & 5.6925 & TRN & \\
\hline CHEMBL3431033 & 14790113.4 & 3.9322 & TRN & \\
\hline CHEMBL3431034 & 14790116.5 & 6.0945 & TRN & \\
\hline CHEMBL3431035 & 14790116.6 & 6.1199 & TRN & \\
\hline CHEMBL3431036 & 14790115.2 & 4.8858 & TRN & \\
\hline CHEMBL3431037 & 14790113.4 & 4.0249 & TRN & \\
\hline CHEMBL3431038 & 14790114.4 & 4.2506 & TRN & \\
\hline CHEMBL3431039 & 14790113.4 & 4.3073 & TRN & \\
\hline CHEMBL3431040 & 14790116.6 & 7.0033 & TRN & \\
\hline CHEMBL1354075 & 14790116.4 & 6.4707 & TRN & \\
\hline CHEMBL 3431041 & 14790116.3 & 6.3512 & TRN & \\
\hline CHEMBL3431042 & 14790113.4 & 3.6527 & TRN & \\
\hline CHEMBL3431043 & 14790114.7 & 4.459 & TST & \\
\hline CHEMBL3431044 & 14790115.0 & 4.559 & TST & \\
\hline CHEMBL 3431045 & 14790116.6 & 6.3138 & TRN & \\
\hline CHEMBL3431046 & 14790114.9 & 4.5732 & TRN & \\
\hline CHEMBL3431047 & 14790114.9 & 4.4042 & TRN & \\
\hline CHEMBL3431048 & 14790115.0 & \multicolumn{2}{|c|}{4.5489999999999995} & TRN \\
\hline CHEMBL3431049 & 14790115.2 & 5.1579 & TRN & \\
\hline CHEMBL 3431050 & 14790115.5 & 5.2645 & TRN & \\
\hline CHEMBL3431051 & 14790114.9 & 5.1671 & TRN & \\
\hline CHEMBL 3431052 & 14790115.2 & \multicolumn{2}{|c|}{5.172000000000001} & TRN \\
\hline CHEMBL3431053 & 14790115.5 & 5.5872 & TRN & \\
\hline CHEMBL2356808 & 14790116.3 & 6.157 & TRN & \\
\hline
\end{tabular}




\begin{tabular}{|c|c|c|c|c|}
\hline \multirow{2}{*}{\multicolumn{5}{|c|}{ CHFMRI 3431954}} \\
\hline CHEMBL3431054 & 14790116.1 & & & \\
\hline CHEMBL3431055 & 14790114.8 & 4.6284 & TST & \\
\hline CHEMBL3431056 & 14790113.4 & 3.0882 & TRN & \\
\hline CHEMBL3431057 & 14790113.4 & 4.9322 & TST & \\
\hline CHEMBL 2093320 & 14790113.4 & 5.0251 & TRN & \\
\hline CHEMBL3431058 & 14790116.0 & 5.8216 & TRN & \\
\hline CHEMBL3431059 & 14790116.1 & 6.0013 & TRN & \\
\hline CHEMBL3431060 & 14790116.0 & 5.9741 & TRN & \\
\hline CHEMBL3431061 & 14790116.3 & 6.1314 & TRN & \\
\hline CHEMBL3431062 & 14790116.3 & 6.0668 & TRN & \\
\hline CHEMBL3431063 & 14790116.6 & 6.1825 & TRN & \\
\hline CHEMBL3431064 & 14790116.3 & 5.6011 & TRN & \\
\hline CHEMBL3431065 & 14790114.6 & 4.2804 & TST & \\
\hline CHEMBL3431066 & 14790116.3 & 5.9708 & TRN & \\
\hline CHEMBL3431067 & 14790116.1 & 6.4569 & TRN & \\
\hline CHEMBL3431068 & 14790113.4 & 3.8518 & TRN & \\
\hline CHEMBL3431069 & 14790114.8 & 4.7299 & TRN & \\
\hline CHEMBL3431070 & 14790113.4 & 3.9785 & TRN & \\
\hline CHEMBL3431071 & 14790115.1 & 5.7764 & TST & \\
\hline CHEMBL3431072 & 14790116.0 & 5.5943 & TRN & \\
\hline CHEMBL3431073 & 14790116.1 & 5.3283 & TST & \\
\hline CHEMBL3431074 & 14790113.4 & 5.2424 & TRN & \\
\hline CHEMBL3431075 & 14790116.3 & 5.8576 & TST & \\
\hline CHEMBL3431076 & 14790116.0 & 5.2622 & TRN & \\
\hline CHEMBL3431077 & 14790114.4 & 3.3385 & TRN & \\
\hline CHEMBL3431078 & 14790114.6 & 4.2371 & TRN & \\
\hline CHEMBL3431079 & 14790113.4 & 4.3227 & TRN & \\
\hline CHEMBL3431080 & 14790114.6 & 3.86899 & 99999999998 & TRN \\
\hline CHEMBL3431081 & 14790113.4 & 4.496 & TRN & \\
\hline CHEMBL3431082 & 14790115.2 & 5.0607 & TRN & \\
\hline CHEMBL3431083 & 14790116.3 & 5.7679 & TRN & \\
\hline CHEMBL3431084 & 14790116.5 & 6.1875 & TST & \\
\hline CHEMBL1585368 & 14790113.4 & 4.6423 & TRN & \\
\hline CHEMBL 3431085 & 14790113.4 & 4.0562 & TRN & \\
\hline CHEMBL 3431086 & 14790116.4 & 6.7346 & TRN & \\
\hline CHEMBL3431087 & 14790114.4 & 4.1269 & TRN & \\
\hline CHEMBL3431088 & 14790114.5 & 4.7609 & TRN & \\
\hline CHEMBL3431089 & 14790116.3 & 6.3424 & TRN & \\
\hline CHEMBL3431090 & 14790114.6 & 4.4988 & TRN & \\
\hline CHEMBL3431091 & 14790114.6 & 4.6048 & TRN & \\
\hline CHEMBL3431092 & 14790114.7 & 5.2582 & TRN & \\
\hline CHEMBL3431093 & 14790115.2 & 4.8882 & TRN & \\
\hline CHEMBL3431094 & 14790113.4 & 4.3216 & TRN & \\
\hline CHEMBL3431095 & 14790116.2 & 6.1513 & TRN & \\
\hline CHEMBL3431096 & 14790116.6 & 6.1416 & TRN & \\
\hline CHEMBL3431097 & 14790116.4 & 6.1244 & TRN & \\
\hline CHEMBL3431098 & 14790113.4 & 3.069 & TRN & \\
\hline CHEMBL3431099 & 14790116.1 & 5.9857 & TST & \\
\hline
\end{tabular}




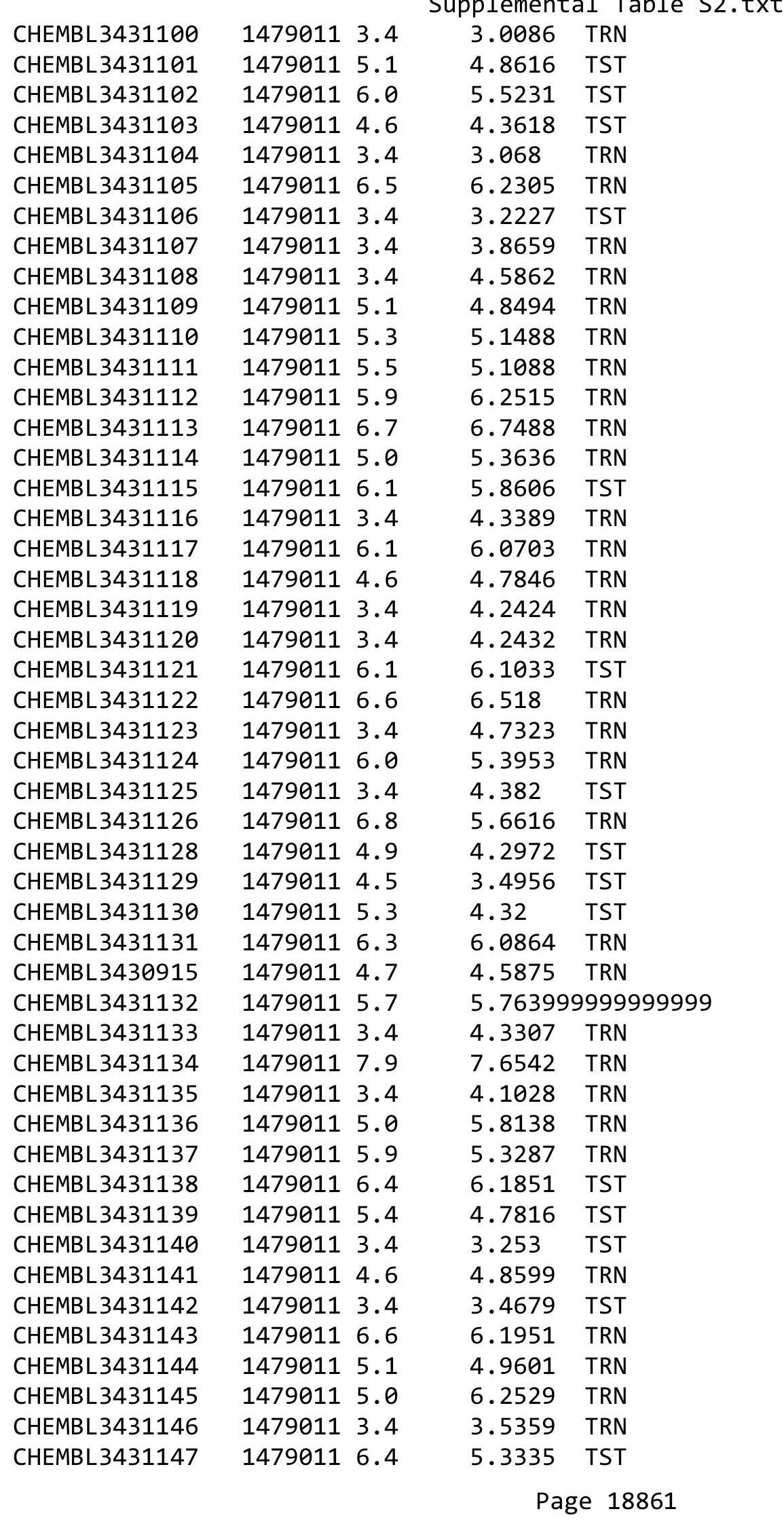

TRN 


\begin{tabular}{|c|c|c|c|c|}
\hline & & & & \\
\hline CHEMBL3431148 & 14790113.4 & 3.595 & TRN & \\
\hline CHEMBL3431149 & 14790116.5 & 6.1617 & TRN & \\
\hline CHEMBL3431150 & 14790113.4 & 3.7559 & TRN & \\
\hline CHEMBL3431151 & 14790117.0 & 6.7186 & TRN & \\
\hline CHEMBL3431152 & 14790113.4 & 2.7107 & TRN & \\
\hline CHEMBL3431153 & 14790113.4 & 2.9045 & TRN & \\
\hline CHEMBL3431154 & 14790116.1 & 5.7073 & TST & \\
\hline CHEMBL3431155 & 14790113.4 & 3.1599 & TRN & \\
\hline CHEMBL3431156 & 14790113.4 & 4.1345 & TRN & \\
\hline CHEMBL3431157 & 14790117.5 & 6.7111 & TST & \\
\hline CHEMBL3431158 & 14790113.4 & 5.3439 & TST & \\
\hline CHEMBL3431159 & 14790113.4 & 4.7269 & TST & \\
\hline CHEMBL1593679 & 14790114.7 & 4.1959 & TRN & \\
\hline CHEMBL3431160 & 14790116.2 & 6.1784 & TRN & \\
\hline CHEMBL3431161 & 14790113.4 & 4.4395 & TST & \\
\hline CHEMBL3431162 & 14790114.5 & 4.2181 & TST & \\
\hline CHEMBL3431163 & 14790114.5 & 4.1083 & TRN & \\
\hline CHEMBL3431164 & 14790113.4 & 2.9367 & TRN & \\
\hline CHEMBL3431165 & 14790116.0 & 5.5869 & TRN & \\
\hline CHEMBL1458931 & 14790113.4 & 3.3032 & TRN & \\
\hline CHEMBL3431166 & 14790116.4 & 6.1161 & TRN & \\
\hline CHEMBL3431167 & 14790113.4 & 4.4686 & TRN & \\
\hline CHEMBL3431168 & 14790116.4 & 6.3093 & TRN & \\
\hline CHEMBL3431169 & 14790113.4 & 4.1796 & TRN & \\
\hline CHEMBL3431170 & 14790117.2 & 7.3157 & TRN & \\
\hline CHEMBL3431171 & 14790116.1 & 5.8676 & TRN & \\
\hline CHEMBL3431172 & 14790116.9 & 7.1158 & TRN & \\
\hline CHEMBL3431173 & 14790114.7 & 4.4299 & TRN & \\
\hline CHEMBL3431174 & 14790114.5 & 4.7718 & TRN & \\
\hline CHEMBL3431175 & 14790113.4 & 4.2032 & TST & \\
\hline CHEMBL3431176 & 14790115.0 & 4.6893 & TRN & \\
\hline CHEMBL3431177 & 14790113.3 & 4.13399 & 99999999995 & TRN \\
\hline CHEMBL3431178 & 14790113.3 & 3.24 & TRN & \\
\hline CHEMBL3431179 & 14790113.4 & 3.6168 & TRN & \\
\hline CHEMBL 3431180 & 14790114.7 & 4.6459 & TRN & \\
\hline CHEMBL3431181 & 14790116.3 & 6.165 & TRN & \\
\hline CHEMBL3431182 & 14790115.2 & 4.8095 & TST & \\
\hline CHEMBL 3431183 & 14790113.4 & 4.1429 & TRN & \\
\hline CHEMBL3431184 & 14790113.4 & 3.1998 & TRN & \\
\hline CHEMBL3431185 & 14790116.0 & 6.223 & TRN & \\
\hline CHEMBL3431186 & 14790116.8 & 7.0031 & TRN & \\
\hline CHEMBL3431187 & 14790113.4 & 3.0283 & TRN & \\
\hline CHEMBL3431188 & 14790116.7 & 6.4676 & TRN & \\
\hline CHEMBL3431189 & 14790116.1 & 5.6005 & TST & \\
\hline CHEMBL3431190 & 14790116.7 & 6.0983 & TRN & \\
\hline CHEMBL3431191 & 14790114.6 & 4.5071 & TRN & \\
\hline CHEMBL3431192 & 14790117.2 & 6.9781 & TRN & \\
\hline CHEMBL3431193 & 14790117.2 & 7.6297 & TRN & \\
\hline
\end{tabular}




\begin{tabular}{|c|c|c|c|}
\hline & & & $a \perp 1 a$ \\
\hline CHEMBL 3431194 & 14790117.8 & 7.6844 & TRN \\
\hline CHEMBL3431195 & 14790116.5 & 7.1931 & TRN \\
\hline CHEMBL3431196 & 14790113.4 & 4.4208 & TRN \\
\hline CHEMBL3431197 & 14790116.2 & 6.8415 & TRN \\
\hline CHEMBL3431198 & 14790116.6 & 7.1094 & TRN \\
\hline CHEMBL3431199 & 14790116.1 & 5.5344 & TST \\
\hline CHEMBL3431200 & 14790113.4 & 3.2174 & TRN \\
\hline CHEMBL3431201 & 14790113.4 & 3.55 & TRN \\
\hline CHEMBL 3431202 & 14790116.3 & 6.1623 & TRN \\
\hline CHEMBL3431203 & 14790116.2 & 6.6811 & TRN \\
\hline CHEMBL3431204 & 14790115.4 & 5.0711 & TRN \\
\hline CHEMBL3431206 & 14790117.0 & 7.0819 & TRN \\
\hline CHEMBL3431207 & 14790117.1 & 6.9366 & TRN \\
\hline CHEMBL3431209 & 14790116.9 & 7.1572 & TRN \\
\hline CHEMBL3431210 & 14790113.4 & 3.5415 & TRN \\
\hline CHEMBL3431211 & 14790116.5 & 6.4418 & TRN \\
\hline CHEMBL3431212 & 14790115.2 & 5.5723 & TRN \\
\hline CHEMBL3431213 & 14790115.6 & 5.7552 & TRN \\
\hline CHEMBL3431214 & 14790113.4 & 4.1136 & TRN \\
\hline CHEMBL3431215 & 14790116.2 & 6.3926 & TRN \\
\hline CHEMBL3431216 & 14790115.4 & 5.5739 & TRN \\
\hline CHEMBL3431217 & 14790114.9 & 4.8431 & TRN \\
\hline CHEMBL3431218 & 14790113.4 & 4.0589 & TRN \\
\hline CHEMBL3431219 & 14790117.2 & 6.0954 & TRN \\
\hline CHEMBL 3431220 & 14790115.8 & 5.8422 & TRN \\
\hline CHEMBL 3431221 & 14790116.7 & 6.521 & TRN \\
\hline CHEMBL3431222 & 14790117.3 & 6.5345 & TRN \\
\hline CHEMBL3431223 & 14790116.2 & 5.4997 & TST \\
\hline CHEMBL 3431224 & 14790117.0 & 6.3489 & TRN \\
\hline CHEMBL3431225 & 14790116.0 & 6.097 & TRN \\
\hline CHEMBL3431226 & 14790116.8 & 6.4638 & TRN \\
\hline CHEMBL3431227 & 14790113.4 & 4.8239 & TRN \\
\hline CHEMBL3431228 & 14790116.4 & 6.5613 & TRN \\
\hline CHEMBL3431229 & 14790117.0 & 7.1367 & TRN \\
\hline CHEMBL3431230 & 14790117.0 & 7.0737 & TRN \\
\hline CHEMBL2441267 & 14790117.4 & 7.3129 & TRN \\
\hline CHEMBL3430916 & 14790115.7 & 5.4626 & TRN \\
\hline CHEMBL3431231 & 14790113.4 & 3.4578 & TRN \\
\hline CHEMBL 3431232 & 14790113.4 & 4.5404 & TRN \\
\hline CHEMBL 3431233 & 14790115.1 & 4.8216 & TRN \\
\hline CHEMBL 3431234 & 14790115.2 & 3.4505 & TRN \\
\hline CHEMBL3431236 & 14790114.5 & 4.2137 & TST \\
\hline CHEMBL3431237 & 14790115.3 & 5.3336 & TRN \\
\hline CHEMBL 3431238 & 14790113.4 & 4.2935 & TRN \\
\hline CHEMBL3431239 & 14790116.3 & 6.1524 & TRN \\
\hline CHEMBL 3431240 & 14790115.6 & 5.2316 & TST \\
\hline CHEMBL 3431241 & 14790113.4 & 4.7239 & TRN \\
\hline CHEMBL3431242 & 14790113.4 & 3.1315 & TRN \\
\hline
\end{tabular}




\begin{tabular}{|c|c|c|c|c|}
\hline & & & & \\
\hline CHEMBL3431243 & 14790113.4 & 3.1419 & TST & \\
\hline CHEMBL3431244 & 14790114.4 & 5.0339 & TRN & \\
\hline CHEMBL3431245 & 14790115.4 & 4.8117 & TRN & \\
\hline CHEMBL3431246 & 14790114.9 & 4.9164 & TRN & \\
\hline CHEMBL 3431247 & 14790116.2 & 5.5952 & TRN & \\
\hline CHEMBL3431248 & 14790113.4 & 3.1465 & TRN & \\
\hline CHEMBL3431249 & 14790113.4 & 3.73 & TRN & \\
\hline CHEMBL 3431251 & 14790116.1 & 5.6514 & TRN & \\
\hline CHEMBL3431252 & 14790116.0 & 5.4687 & TRN & \\
\hline CHEMBL3431253 & 14790114.5 & 4.548 & TST & \\
\hline CHEMBL3431254 & 14790114.8 & 4.3072 & TRN & \\
\hline CHEMBL3431255 & 14790116.5 & 5.4444 & TST & \\
\hline CHEMBL3431257 & 14790113.4 & 4.3091 & TRN & \\
\hline CHEMBL 3431258 & 14790113.4 & 3.1874 & TRN & \\
\hline CHEMBL3431259 & 14790113.4 & 3.1245 & TRN & \\
\hline CHEMBL3431260 & 14790113.4 & 3.4707 & TRN & \\
\hline CHEMBL3431261 & 14790114.5 & 4.3505 & TRN & \\
\hline CHEMBL2356920 & 14790116.1 & 5.7244 & TRN & \\
\hline CHEMBL3431262 & 14790116.6 & 5.6057 & TRN & \\
\hline CHEMBL3431263 & 14790114.4 & 4.1043 & TRN & \\
\hline CHEMBL3431264 & 14790116.0 & 5.3449 & TRN & \\
\hline CHEMBL3431265 & 14790113.4 & 3.1822 & TST & \\
\hline CHEMBL3431268 & 14790115.2 & 4.8903 & TST & \\
\hline CHEMBL3431269 & 14790114.8 & 4.9724 & TRN & \\
\hline CHEMBL3431270 & 14790116.1 & 6.2951 & TST & \\
\hline CHEMBL 3431271 & 14790116.4 & 6.0461 & TRN & \\
\hline CHEMBL3431272 & 14790116.6 & 6.3717 & TRN & \\
\hline CHEMBL3431273 & 14790115.6 & 5.4905 & TRN & \\
\hline CHEMBL3431274 & 14790114.6 & 4.82600 & 00000000005 & TRN \\
\hline CHEMBL3431275 & 14790116.2 & 5.9012 & TRN & \\
\hline CHEMBL3431277 & 14790115.1 & 5.1791 & TRN & \\
\hline CHEMBL3431278 & 14790116.6 & 5.8835 & TRN & \\
\hline CHEMBL3431279 & 14790116.6 & 7.3398 & TST & \\
\hline CHEMBL 3431280 & 14790116.2 & 6.5667 & TST & \\
\hline CHEMBL3431281 & 14790115.0 & 4.9985 & TST & \\
\hline CHEMBL3431282 & 14790116.1 & 5.4749 & TST & \\
\hline CHEMBL3431283 & 14790116.2 & 5.53600 & 00000000005 & TST \\
\hline CHEMBL 3431284 & 14790116.1 & 5.9598 & TRN & \\
\hline CHEMBL3431285 & 14790115.0 & 5.2303 & TRN & \\
\hline CHEMBL 3431286 & 14790116.6 & 6.3146 & TST & \\
\hline CHEMBL 3431287 & 14790113.4 & 4.2524 & TST & \\
\hline CHEMBL 3431288 & 14790116.3 & 5.9184 & TRN & \\
\hline CHEMBL3431289 & 14790113.4 & 4.5342 & TST & \\
\hline CHEMBL3431290 & 14790113.4 & 3.1296 & TRN & \\
\hline CHEMBL3431291 & 14790113.4 & 3.0759 & TRN & \\
\hline CHEMBL3431292 & 14790116.0 & 5.94 & TRN & \\
\hline CHEMBL3431293 & 14790113.4 & 3.0793 & TRN & \\
\hline CHEMBL3431294 & 14790116.5 & 5.6694 & TRN & \\
\hline
\end{tabular}




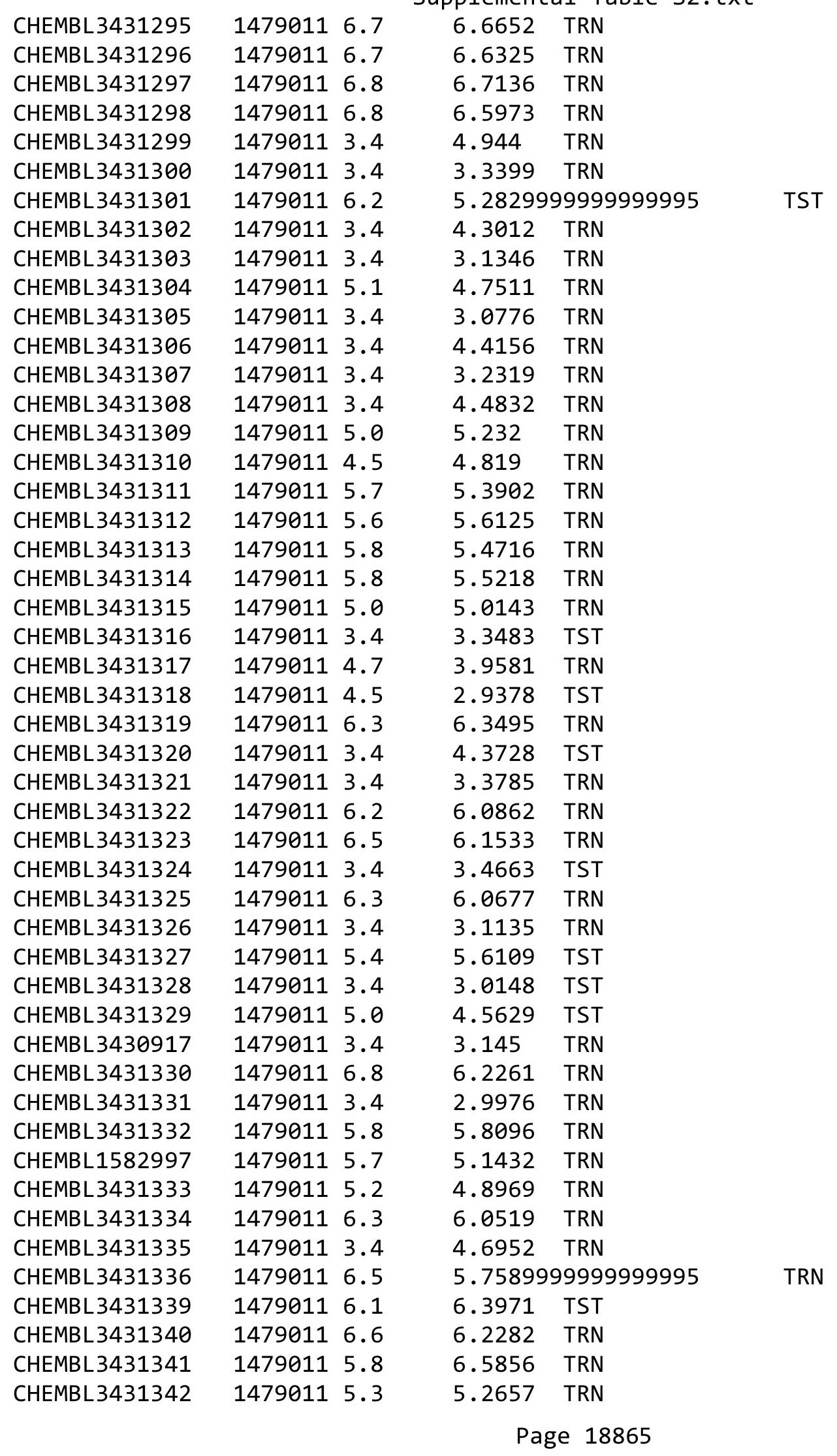




\begin{tabular}{|c|c|c|c|}
\hline & & גpplement & $a \perp T a$ \\
\hline CHEMBL3431343 & 14790113.4 & 4.5376 & TRN \\
\hline CHEMBL3431344 & 14790113.4 & 4.3892 & TRN \\
\hline CHEMBL3431345 & 14790115.9 & 6.7748 & TRN \\
\hline CHEMBL3431346 & 14790116.1 & 6.9977 & TRN \\
\hline CHEMBL1430615 & 14790113.4 & 3.2629 & TRN \\
\hline CHEMBL3431347 & 14790116.0 & 5.6551 & TRN \\
\hline CHEMBL3431348 & 14790116.2 & 6.1867 & TRN \\
\hline CHEMBL3431349 & 14790116.2 & 5.9549 & TRN \\
\hline CHEMBL3431350 & 14790116.3 & 6.3876 & TRN \\
\hline CHEMBL465227 & 14790114.7 & 4.931 & TRN \\
\hline CHEMBL3431351 & 14790113.4 & 3.1946 & TRN \\
\hline CHEMBL1611993 & 14790114.8 & 4.3283 & TRN \\
\hline CHEMBL3431352 & 14790113.4 & 3.2783 & TRN \\
\hline CHEMBL1393829 & 14790116.2 & 5.8468 & TST \\
\hline CHEMBL3431354 & 14790116.2 & 6.903 & TRN \\
\hline CHEMBL3431355 & 14790114.7 & 4.8094 & TRN \\
\hline CHEMBL3431356 & 14790114.8 & 4.4159 & TRN \\
\hline CHEMBL3431357 & 14790114.4 & 4.1302 & TRN \\
\hline CHEMBL3431358 & 14790116.5 & 6.7196 & TRN \\
\hline CHEMBL3431359 & 14790113.4 & 3.8647 & TRN \\
\hline CHEMBL3431360 & 14790116.3 & 5.5843 & TRN \\
\hline CHEMBL3431361 & 14790115.4 & 5.7485 & TRN \\
\hline CHEMBL1535535 & 14790113.4 & 3.1374 & TRN \\
\hline CHEMBL3431362 & 14790116.0 & 5.1074 & TRN \\
\hline CHEMBL 3431363 & 14790116.4 & 6.0096 & TRN \\
\hline CHEMBL3431364 & 14790113.4 & 3.3091 & TRN \\
\hline CHEMBL3431365 & 14790113.4 & 4.4518 & TRN \\
\hline CHEMBL3431366 & 14790116.3 & 5.9446 & TST \\
\hline CHEMBL3431367 & 14790114.6 & 4.827 & TST \\
\hline CHEMBL3431368 & 14790115.5 & 5.113 & TRN \\
\hline CHEMBL3431369 & 14790113.4 & 4.5613 & TRN \\
\hline CHEMBL1447267 & 14790116.2 & 6.0278 & TRN \\
\hline CHEMBL3431370 & 14790113.4 & 4.5904 & TRN \\
\hline CHEMBL1325144 & 14790114.7 & 4.2276 & TRN \\
\hline CHEMBL1429841 & 14790114.6 & 4.6294 & TRN \\
\hline CHEMBL3431371 & 14790113.4 & 4.1301 & TRN \\
\hline CHEMBL1308225 & 14790116.2 & 6.0286 & TST \\
\hline CHEMBL2441359 & 14790114.6 & 4.5346 & TRN \\
\hline CHEMBL1517284 & 14790116.3 & 5.3441 & TRN \\
\hline CHEMBL3431372 & 14790113.4 & 3.4343 & TRN \\
\hline CHEMBL3431373 & 14790116.0 & 5.7383 & TRN \\
\hline CHEMBL3431374 & 14790115.2 & 4.3813 & TRN \\
\hline CHEMBL3431375 & 14790114.4 & 4.1296 & TST \\
\hline CHEMBL3431376 & 14790116.4 & 6.7045 & TRN \\
\hline CHEMBL1365653 & 14790113.4 & 4.9235 & TRN \\
\hline CHEMBL3431377 & 14790116.0 & 5.449 & TRN \\
\hline CHEMBL3431378 & 14790114.6 & 4.7677 & TRN \\
\hline CHEMBL3431379 & 14790115.1 & 4.3936 & TRN \\
\hline
\end{tabular}




\begin{tabular}{|c|c|c|c|}
\hline & & & \\
\hline CHEMBL1478826 & 14790115.2 & 4.8709 & TRN \\
\hline CHEMBL1872842 & 14790116.5 & 6.3678 & TRN \\
\hline CHEMBL3431380 & 14790116.4 & 6.3811 & TRN \\
\hline CHEMBL 3431381 & 14790115.8 & 6.5257 & TRN \\
\hline CHEMBL3431382 & 14790117.2 & 7.0504 & TRN \\
\hline CHEMBL 3431383 & 14790114.6 & 4.2151 & TRN \\
\hline CHEMBL3431384 & 14790114.8 & 4.4142 & TRN \\
\hline CHEMBL3431385 & 14790116.3 & 6.0221 & TRN \\
\hline CHEMBL3431386 & 14790113.4 & 4.122 & TRN \\
\hline CHEMBL1730515 & 14790116.1 & 6.4171 & TRN \\
\hline CHEMBL 3431387 & 14790116.2 & 6.2065 & TRN \\
\hline CHEMBL3431388 & 14790116.6 & 6.4167 & TRN \\
\hline CHEMBL1566898 & 14790116.5 & 6.46 & TRN \\
\hline CHEMBL3431389 & 14790116.2 & 6.4134 & TRN \\
\hline CHEMBL3431390 & 14790116.1 & 6.1795 & TST \\
\hline CHEMBL3431391 & 14790116.1 & 5.6554 & TRN \\
\hline CHEMBL1489081 & 14790116.2 & 6.2741 & TRN \\
\hline CHEMBL3431392 & 14790116.1 & 5.6606 & TRN \\
\hline CHEMBL3431393 & 14790114.7 & 4.4084 & TRN \\
\hline CHEMBL 3431394 & 14790116.1 & 5.8218 & TST \\
\hline CHEMBL3431395 & 14790114.9 & 4.6555 & TRN \\
\hline CHEMBL3431396 & 14790116.0 & 6.0968 & TRN \\
\hline CHEMBL3431397 & 14790114.7 & 4.4109 & TRN \\
\hline CHEMBL3431398 & 14790113.4 & 4.6252 & TST \\
\hline CHEMBL 3431400 & 14790113.4 & 3.8659 & TRN \\
\hline CHEMBL1418463 & 14790113.4 & 4.5416 & TRN \\
\hline CHEMBL3431401 & 14790116.1 & 5.7296 & TST \\
\hline CHEMBL3431402 & 14790116.1 & 6.1842 & TST \\
\hline CHEMBL3431403 & 14790116.0 & 5.5119 & TST \\
\hline CHEMBL 3431404 & 14790114.8 & 4.6915 & TST \\
\hline CHEMBL3431405 & 14790113.4 & 4.4228 & TST \\
\hline CHEMBL3431406 & 14790115.1 & 5.1224 & TST \\
\hline CHEMBL3431407 & 14790113.9 & 4.7684 & TST \\
\hline CHEMBL 3431408 & 14790113.4 & 4.0731 & TST \\
\hline CHEMBL3431409 & 14790114.7 & 4.8349 & TST \\
\hline CHEMBL3431410 & 14790114.5 & 4.0122 & TST \\
\hline CHEMBL3431411 & 14790113.4 & 3.1994 & TST \\
\hline CHEMBL 3431412 & 14790114.6 & 4.4591 & TST \\
\hline CHEMBL3431413 & 14790114.7 & 4.3253 & TST \\
\hline CHEMBL 3431414 & 14790118.3 & 7.3406 & TST \\
\hline CHEMBL3431415 & 14790116.7 & 6.4453 & TST \\
\hline CHEMBL3431416 & 14790113.4 & 4.4137 & TST \\
\hline CHEMBL291721 & 14790115.3 & 4.9887 & TST \\
\hline CHEMBL3431417 & 14790115.9 & 5.6152 & TST \\
\hline CHEMBL3431418 & 14790113.4 & 4.2942 & TST \\
\hline CHEMBL487186 & 14790113.4 & 3.3296 & TST \\
\hline CHEMBL3431419 & 14790115.0 & 4.8578 & TST \\
\hline CHEMBL 3431420 & 14790114.5 & 4.5137 & TST \\
\hline
\end{tabular}




\begin{tabular}{|c|c|c|c|c|c|}
\hline & & & & & \\
\hline CHEMBL3431422 & 1479011 & 4.6 & 4.4869 & TST & \\
\hline CHEMBL3431423 & 1479011 & 6.3 & 6.249 & TST & \\
\hline CHEMBL3431424 & 1479011 & 4.7 & 3.0573 & TST & \\
\hline CHEMBL3431425 & 1479011 & 3.4 & 3.5513 & TST & \\
\hline CHEMBL3431426 & 1479011 & 4.6 & 4.154 & TST & \\
\hline CHEMBL3431427 & 1479011 & 4.5 & 4.2506 & TST & \\
\hline CHEMBL3431428 & 1479011 & 6.3 & 5.5791 & TST & \\
\hline CHEMBL1725748 & 1479011 & 4.8 & 4.1717 & TST & \\
\hline CHEMBL3430918 & 1479011 & 4.6 & 4.5113 & TST & \\
\hline CHEMBL3431429 & 1479011 & 3.4 & 3.6293 & TST & \\
\hline CHEMBL3431430 & 1479011 & 3.4 & 4.2276 & TST & \\
\hline CHEMBL128672 & 1479011 & 3.4 & 4.7826 & TST & \\
\hline CHEMBL491149 & 1479011 & 5.8 & 5.7435 & TST & \\
\hline CHEMBL 3431431 & 1479011 & 6.8 & 7.1672 & TST & \\
\hline CHEMBL3431432 & 1479011 & 6.7 & 6.8657 & TST & \\
\hline CHEMBL3431433 & 1479011 & 7.3 & 7.4164 & TST & \\
\hline CHEMBL3431434 & 1479011 & 4.6 & 4.3767 & TST & \\
\hline CHEMBL3431435 & 1479011 & 7.7 & 8.2266 & TST & \\
\hline CHEMBL3431436 & 1479011 & 4.6 & 4.3641 & TST & \\
\hline CHEMBL3431437 & 1479011 & 7.0 & 6.6279 & TST & \\
\hline CHEMBL 3431438 & 1479011 & 7.0 & 6.5055 & TST & \\
\hline CHEMBL3431439 & 1479011 & 6.1 & 5.9623 & TST & \\
\hline CHEMBL3431440 & 1479011 & 7.0 & 6.9499 & TST & \\
\hline CHEMBL3431441 & 1479011 & 6.4 & 5.6781 & TST & \\
\hline CHEMBL3431442 & 1479011 & 6.4 & 6.4982 & TST & \\
\hline CHEMBL3431443 & 1479011 & 6.3 & 6.0027 & TST & \\
\hline CHEMBL3431444 & 1479011 & 6.7 & 5.8746 & TST & \\
\hline CHEMBL3431445 & 1479011 & 6.3 & 5.7867 & TST & \\
\hline CHEMBL1519531 & 752538 & 3.0969 & 3.3144 & TST & \\
\hline CHEMBL1324104 & 752538 & 3.0969 & 3.1584 & TST & \\
\hline CHEMBL1723607 & 752538 & 4.6498 & 4.2632 & TRN & \\
\hline CHEMBL1337166 & 752538 & 3.0969 & 3.3108 & TRN & \\
\hline CHEMBL1355212 & 752538 & 4.1798 & 3.4263 & TST & \\
\hline CHEMBL3199870 & 752538 & 3.0969 & 2.83100 & 00000000004 & TST \\
\hline CHEMBL1411556 & 752538 & 3.0969 & 2.9558 & TRN & \\
\hline CHEMBL1335844 & 752538 & 3.0969 & 3.3045 & TRN & \\
\hline CHEMBL1556634 & 752538 & 4.3098 & 3.7775 & TRN & \\
\hline CHEMBL1342570 & 752538 & 3.0969 & 3.362 & TRN & \\
\hline CHEMBL1725665 & 752538 & 3.0969 & 3.3909 & TRN & \\
\hline CHEMBL131037 & 752538 & 4.6326 & 3.7554 & TRN & \\
\hline CHEMBL1598737 & 752538 & 4.2041 & 3.7768 & TRN & \\
\hline CHEMBL1698608 & 752538 & 3.0969 & 2.8328 & TRN & \\
\hline CHEMBL1257041 & 752538 & 3.0969 & 3.1653 & TST & \\
\hline CHEMBL1509082 & 752538 & 3.0969 & 3.9375 & TRN & \\
\hline CHEMBL1714283 & 752538 & 3.0969 & 3.2179 & TRN & \\
\hline CHEMBL1466201 & 752538 & 3.0969 & 3.3713 & TRN & \\
\hline CHEMBL1392034 & 752538 & 3.0969 & 3.6121 & TRN & \\
\hline CHEMBL1716493 & 752538 & 3.0969 & 3.55 & TRN & \\
\hline
\end{tabular}


Supplemental Table S2.txt

\begin{tabular}{|c|c|c|c|c|c|}
\hline CHEMBL1504429 & 752538 & 3.0969 & 3.2785 & TRN & \\
\hline CHEMBL1473548 & 752538 & 3.0969 & 3.3793 & TRN & \\
\hline CHEMBL1703976 & 752538 & 3.0969 & 3.2745 & TRN & \\
\hline CHEMBL1609529 & 752538 & 3.0969 & 2.8788 & TRN & \\
\hline CHEMBL1518503 & 752538 & 3.0969 & 3.3298 & TRN & \\
\hline CHEMBL1504286 & 752538 & 3.0969 & 3.6922 & TRN & \\
\hline CHEMBL1366328 & 752538 & 3.0969 & 3.3449 & TRN & \\
\hline CHEMBL1390710 & 752538 & 3.0969 & 3.2587 & TRN & \\
\hline CHEMBL1380844 & 752538 & 3.0969 & 2.9073 & TRN & \\
\hline CHEMBL1599312 & 752538 & 3.0969 & 3.4994 & TRN & \\
\hline CHEMBL1364723 & 752538 & 3.0969 & 3.4497 & TST & \\
\hline CHEMBL1736502 & 752538 & 3.0969 & 3.3384 & TRN & \\
\hline CHEMBL441433 & 752538 & 4.1713 & 3.9024 & TRN & \\
\hline CHEMBL1479190 & 752538 & 3.0969 & 3.444 & TST & \\
\hline CHEMBL1426134 & 752538 & 4.308 & 3.7488 & TRN & \\
\hline CHEMBL483531 & 752538 & 3.0969 & 3.4857 & TRN & \\
\hline CHEMBL1347600 & 752538 & 3.0969 & 3.103 & TST & \\
\hline CHEMBL1563951 & 752538 & 3.0969 & 3.0731 & TRN & \\
\hline CHEMBL1560740 & 752538 & 3.0969 & 3.03899 & 99999999997 & TRN \\
\hline CHEMBL1393611 & 752538 & 3.0969 & 2.9765 & TRN & \\
\hline CHEMBL1364896 & 752538 & 3.0969 & 3.1772 & TRN & \\
\hline CHEMBL1700880 & 752538 & 3.0969 & 2.9474 & TST & \\
\hline CHEMBL3213086 & 752538 & 3.0969 & 3.0636 & TRN & \\
\hline CHEMBL1998566 & 752538 & 3.0969 & 3.2443 & TRN & \\
\hline CHEMBL1514534 & 752538 & 3.0969 & 3.2019 & TRN & \\
\hline CHEMBL1255656 & 752538 & 4.5607 & 3.5465 & TRN & \\
\hline CHEMBL1718737 & 752538 & 3.0969 & 3.7275 & TRN & \\
\hline CHEMBL1423667 & 752538 & 3.0969 & 2.8632 & TRN & \\
\hline CHEMBL1707960 & 752538 & 3.0969 & 3.7476 & TRN & \\
\hline CHEMBL1452103 & 752538 & 3.0969 & 3.3418 & TRN & \\
\hline CHEMBL1398142 & 752538 & 3.0969 & 3.4205 & TRN & \\
\hline CHEMBL1594545 & 752538 & 3.0969 & 2.8415 & TRN & \\
\hline CHEMBL 225230 & 752538 & 3.0969 & 3.0092 & TST & \\
\hline CHEMBL1569991 & 752538 & 3.0969 & 3.263 & TST & \\
\hline CHEMBL1720128 & 752538 & 4.8239 & \multicolumn{2}{|c|}{ 4. 3919999999999995} & TRN \\
\hline CHEMBL1564355 & 752538 & 3.0969 & 3.3212 & TRN & \\
\hline CHEMBL1718398 & 752538 & 3.0969 & 3.6335 & TRN & \\
\hline CHEMBL510515 & 752538 & 3.0969 & 3.3365 & TRN & \\
\hline CHEMBL1589526 & 752538 & 3.0969 & 3.4003 & TST & \\
\hline CHEMBL1484167 & 752538 & 3.0969 & 3.4738 & TST & \\
\hline CHEMBL1608402 & 752538 & 3.0969 & 3.194 & TRN & \\
\hline CHEMBL1717071 & 752538 & 4.4112 & 3.9229 & TRN & \\
\hline CHEMBL1365064 & 752538 & 3.0969 & 3.135 & TST & \\
\hline CHEMBL3197242 & 752538 & 4.1391 & \multicolumn{2}{|c|}{ 3. 3989999999999996} & TRN \\
\hline CHEMBL 220845 & 752538 & 4.2612 & 3.5987 & TRN & \\
\hline CHEMBL1489664 & 752538 & 3.0969 & 3.7358 & TRN & \\
\hline CHEMBL1732317 & 752538 & 3.0969 & 3.3216 & TST & \\
\hline CHEMBL512216 & 752538 & 3.0969 & 3.3934 & TST & \\
\hline
\end{tabular}


Supplemental Table S2.txt

\begin{tabular}{|c|c|c|c|c|c|}
\hline CHEMBL1523225 & 752538 & 3.0969 & 3.5222 & TST & \\
\hline CHEMBL1477787 & 752538 & 3.0969 & 3.0465 & TRN & \\
\hline CHEMBL1449785 & 752538 & 3.0969 & 3.1838 & TRN & \\
\hline CHEMBL1702248 & 752538 & 4.2218 & 3.5856 & TST & \\
\hline CHEMBL1557622 & 752538 & 4.2749 & 3.458 & TRN & \\
\hline CHEMBL 3208664 & 752538 & 3.0969 & 2.6993 & TRN & \\
\hline CHEMBL1509648 & 752538 & 4.4737 & 3.2749 & TRN & \\
\hline CHEMBL1529325 & 752538 & 3.0969 & 3.5382 & TRN & \\
\hline CHEMBL1465837 & 752538 & 3.0969 & 3.2915 & TRN & \\
\hline CHEMBL1707429 & 752538 & 4.4737 & 3.8336 & TRN & \\
\hline CHEMBL527584 & 752538 & 3.0969 & 3.1319 & TRN & \\
\hline CHEMBL1601716 & 752538 & 4.9788 & 4.6768 & TRN & \\
\hline CHEMBL1703892 & 752538 & 3.0969 & 3.9148 & TRN & \\
\hline CHEMBL1427925 & 752538 & 3.0969 & 2.8476 & TRN & \\
\hline CHEMBL1475746 & 752538 & 3.0969 & 3.5107 & TRN & \\
\hline CHEMBL1698153 & 752538 & 3.0969 & 2.94199 & 99999999997 & TRN \\
\hline CHEMBL1560188 & 752538 & 3.0969 & 2.9876 & TRN & \\
\hline CHEMBL1324935 & 752538 & 3.0969 & 3.3683 & TRN & \\
\hline CHEMBL118678 & 752538 & 4.2161 & 3.5323 & TST & \\
\hline CHEMBL3191533 & 752538 & 3.0969 & 3.2881 & TRN & \\
\hline CHEMBL1539384 & 752538 & 3.0969 & 3.1067 & TRN & \\
\hline CHEMBL1390450 & 752538 & 3.0969 & 3.6034 & TRN & \\
\hline CHEMBL542493 & 752538 & 3.0969 & 2.99 & TST & \\
\hline CHEMBL1465511 & 752538 & 3.0969 & 3.4956 & TRN & \\
\hline CHEMBL1366942 & 752538 & 3.0969 & 3.315 & TRN & \\
\hline CHEMBL3189238 & 752538 & 3.0969 & 2.8581 & TRN & \\
\hline CHEMBL3194593 & 752538 & 3.0969 & 2.8954 & TRN & \\
\hline CHEMBL1465938 & 752538 & 3.0969 & 3.32899 & 99999999997 & TRN \\
\hline CHEMBL1410860 & 752538 & 3.0969 & 3.2578 & TRN & \\
\hline CHEMBL1700720 & 752538 & 3.0969 & 3.3165 & TST & \\
\hline CHEMBL1702711 & 752538 & 4.8182 & 4.6389 & TRN & \\
\hline CHEMBL1703200 & 752538 & 4.8386 & 4.7235 & TRN & \\
\hline CHEMBL1440703 & 752538 & 3.0969 & 3.2304 & TST & \\
\hline CHEMBL1527929 & 752538 & 3.0969 & 3.5048 & TST & \\
\hline CHEMBL1415566 & 752538 & 4.2464 & 3.7442 & TRN & \\
\hline CHEMBL1353285 & 752538 & 3.0969 & 3.4379 & TRN & \\
\hline CHEMBL1709906 & 752538 & 4.8069 & 4.4416 & TRN & \\
\hline CHEMBL452751 & 752538 & 3.0969 & 3.077 & TST & \\
\hline CHEMBL1441874 & 752538 & 3.0969 & 3.156 & TRN & \\
\hline CHEMBL1580845 & 752538 & 3.0969 & 3.6805 & TRN & \\
\hline CHEMBL3197134 & 752538 & 3.0969 & 3.0906 & TRN & \\
\hline CHEMBL1487368 & 752538 & 5.1878 & 3.3884 & TRN & \\
\hline CHEMBL1319596 & 752538 & 4.1938 & 3.9346 & TRN & \\
\hline CHEMBL1442252 & 752538 & 3.0969 & 2.7787 & TRN & \\
\hline CHEMBL1702253 & 752538 & 3.0969 & 3.0352 & TRN & \\
\hline CHEMBL1613004 & 752538 & 3.0969 & 3.2868 & TST & \\
\hline CHEMBL1576254 & 752538 & 3.0969 & 3.4366 & TST & \\
\hline CHEMBL1379740 & 752538 & 3.0969 & 3.1553 & TRN & \\
\hline
\end{tabular}


Supplemental Table S2.txt

\begin{tabular}{|c|c|c|c|c|c|}
\hline CHEMBL3192682 & 752538 & 3.0969 & 3.1712 & TRN & \\
\hline CHEMBL536950 & 752538 & 4.8761 & 3.9709 & TRN & \\
\hline CHEMBL1345026 & 752538 & 3.0969 & 3.2707 & TST & \\
\hline CHEMBL1553163 & 752538 & 4.5935 & 4.8124 & TRN & \\
\hline CHEMBL1537984 & 752538 & 3.0969 & 3.4526 & TRN & \\
\hline CHEMBL1414687 & 752538 & 3.0969 & 2.924 & TRN & \\
\hline CHEMBL1463638 & 752538 & 4.2933 & 3.7961 & TRN & \\
\hline CHEMBL1698737 & 752538 & 3.0969 & 3.0452 & TRN & \\
\hline CHEMBL1432204 & 752538 & 3.0969 & 2.9077 & TST & \\
\hline CHEMBL1385949 & 752538 & 3.0969 & 3.1646 & TRN & \\
\hline CHEMBL1969672 & 752538 & 3.0969 & 3.1698 & TRN & \\
\hline CHEMBL1414595 & 752538 & 3.0969 & 3.0073 & TST & \\
\hline CHEMBL1531200 & 752538 & 3.0969 & 3.0065 & TRN & \\
\hline CHEMBL1096834 & 752538 & 3.0969 & 2.8192 & TRN & \\
\hline CHEMBL327502 & 752538 & 4.8761 & 4.4873 & TRN & \\
\hline CHEMBL1348445 & 752538 & 3.0969 & 3.5637 & TRN & \\
\hline CHEMBL1377465 & 752538 & 3.0969 & 3.1565 & TRN & \\
\hline CHEMBL1736537 & 752538 & 4.6253 & 3.7124 & TRN & \\
\hline CHEMBL3190002 & 752538 & 3.0969 & 3.02600 & 00000000002 & TRN \\
\hline CHEMBL 257286 & 752538 & 3.0969 & 3.33399 & 99999999996 & TRN \\
\hline CHEMBL1504939 & 752538 & 4.1681 & 3.4611 & TRN & \\
\hline CHEMBL1480186 & 752538 & 3.0969 & 3.3637 & TST & \\
\hline CHEMBL1600326 & 752538 & 3.0969 & 3.08399 & 99999999996 & TRN \\
\hline CHEMBL1463161 & 752538 & 3.0969 & 3.1425 & TRN & \\
\hline CHEMBL1342337 & 752538 & 3.0969 & 3.4022 & TRN & \\
\hline CHEMBL477855 & 752538 & 3.0969 & 3.5687 & TST & \\
\hline CHEMBL1514916 & 752538 & 3.0969 & 3.3152 & TST & \\
\hline CHEMBL1558563 & 752538 & 3.0969 & 3.1397 & TRN & \\
\hline CHEMBL1548507 & 752538 & 4.2396 & 3.573 & TRN & \\
\hline CHEMBL3198590 & 752538 & 3.0969 & 3.1882 & TRN & \\
\hline CHEMBL1729008 & 752538 & 3.0969 & 3.1864 & TST & \\
\hline CHEMBL1424911 & 752538 & 3.0969 & 3.1371 & TRN & \\
\hline CHEMBL1727678 & 752538 & 3.0969 & 2.9201 & TRN & \\
\hline CHEMBL1322745 & 752538 & 3.0969 & 3.1339 & TRN & \\
\hline CHEMBL1385889 & 752538 & 3.0969 & 2.764 & TRN & \\
\hline CHEMBL1380069 & 752538 & 3.0969 & 3.5823 & TRN & \\
\hline CHEMBL1699137 & 752538 & 3.0969 & 3.1849 & TRN & \\
\hline CHEMBL1318818 & 752538 & 3.0969 & 3.0252 & TRN & \\
\hline CHEMBL1572924 & 752538 & 3.0969 & 3.2057 & TRN & \\
\hline CHEMBL1566805 & 752538 & 3.0969 & 2.9953 & TRN & \\
\hline CHEMBL1348432 & 752538 & 3.0969 & 2.8327 & TRN & \\
\hline CHEMBL1595227 & 752538 & 3.0969 & 3.0964 & TST & \\
\hline CHEMBL1613270 & 752538 & 3.0969 & 2.9965 & TST & \\
\hline CHEMBL1320696 & 752538 & 4.2604 & 3.6478 & TRN & \\
\hline CHEMBL1300266 & 752538 & 3.0969 & 3.5083 & TRN & \\
\hline CHEMBL1993855 & 752538 & 3.0969 & 3.1189 & TRN & \\
\hline CHEMBL3199003 & 752538 & 3.0969 & 2.9984 & TRN & \\
\hline CHEMBL1566068 & 752538 & 3.0969 & 3.0465 & TRN & \\
\hline
\end{tabular}


Supplemental Table S2.txt

\begin{tabular}{|c|c|c|c|c|}
\hline CHEMBL 3197910 & 752538 & 3.0969 & 3.228 & TRN \\
\hline CHEMBL1570127 & 752538 & 3.0969 & 3.0639 & TRN \\
\hline CHEMBL1465049 & 752538 & 3.0969 & 3.1458 & TRN \\
\hline CHEMBL1713817 & 752538 & 4.2182 & 3.4429 & TST \\
\hline CHEMBL1564773 & 752538 & 3.0969 & 2.963 & TRN \\
\hline CHEMBL1699355 & 752538 & 4.7721 & 4.5396 & TRN \\
\hline CHEMBL1339349 & 752538 & 3.0969 & 3.6109 & TRN \\
\hline CHEMBL1320096 & 752538 & 3.0969 & 3.9234 & TRN \\
\hline CHEMBL1388125 & 752538 & 3.0969 & \multicolumn{2}{|c|}{3.1510000000000002} \\
\hline CHEMBL1444986 & 752538 & 3.0969 & 2.9349 & TRN \\
\hline CHEMBL1447124 & 752538 & 4.308 & \multicolumn{2}{|c|}{3.6919999999999997} \\
\hline CHEMBL1470492 & 752538 & 3.0969 & 3.0504 & TRN \\
\hline CHEMBL1698123 & 752538 & 4.8633 & 4.7663 & TRN \\
\hline CHEMBL1431126 & 752538 & 3.0969 & 3.327 & TRN \\
\hline CHEMBL1312502 & 752538 & 3.0969 & 3.1004 & TRN \\
\hline CHEMBL1989090 & 752538 & 3.0969 & 2.8297 & TRN \\
\hline CHEMBL119878 & 752538 & 3.0969 & 3.7701 & TST \\
\hline CHEMBL1351333 & 752538 & 3.0969 & 3.3423 & TRN \\
\hline CHEMBL1405717 & 752538 & 3.0969 & 3.6859 & TRN \\
\hline CHEMBL3195177 & 752538 & 3.0969 & 3.2864 & TRN \\
\hline CHEMBL1456393 & 752538 & 3.0969 & 3.2773 & TRN \\
\hline CHEMBL1701533 & 752538 & 3.0969 & 3.1236 & TRN \\
\hline CHEMBL1719734 & 752538 & 3.0969 & 3.4142 & TRN \\
\hline CHEMBL1410383 & 752538 & 3.0969 & 3.2219 & TRN \\
\hline CHEMBL1486503 & 752538 & 3.0969 & 3.3512 & TRN \\
\hline CHEMBL1701411 & 752538 & 3.0969 & 3.8422 & TRN \\
\hline CHEMBL1712663 & 752538 & 4.5421 & 3.5736 & TST \\
\hline CHEMBL1579380 & 752538 & 3.0969 & 3.3695 & TRN \\
\hline CHEMBL1393447 & 752538 & 3.0969 & 3.0383 & TRN \\
\hline CHEMBL1308549 & 752538 & 3.0969 & 2.5959 & TRN \\
\hline CHEMBL1546332 & 752538 & 3.0969 & 3.4071 & TRN \\
\hline CHEMBL1427185 & 752538 & 4.1844 & 3.42 & TRN \\
\hline CHEMBL 3197161 & 752538 & 3.0969 & 3.3153 & TRN \\
\hline CHEMBL1582210 & 752538 & 3.0969 & 3.0826 & TST \\
\hline CHEMBL1719817 & 752538 & 3.0969 & 2.9943 & TRN \\
\hline CHEMBL1478652 & 752538 & 3.0969 & 3.3175 & TST \\
\hline CHEMBL1506351 & 752538 & 3.0969 & 3.3577 & TST \\
\hline CHEMBL1411593 & 752538 & 3.0969 & 3.1396 & TRN \\
\hline CHEMBL1310865 & 752538 & 3.0969 & 3.2106 & TRN \\
\hline CHEMBL1736559 & 752538 & 3.0969 & 3.3362 & TRN \\
\hline CHEMBL1334300 & 752538 & 3.0969 & 3.3551 & TRN \\
\hline CHEMBL1571835 & 752538 & 4.4202 & 3.8905 & TRN \\
\hline CHEMBL 3210640 & 752538 & 3.0969 & 2.9472 & TRN \\
\hline CHEMBL1574351 & 752538 & 5.0535 & 3.6636 & TRN \\
\hline CHEMBL1715446 & 752538 & 3.0969 & 3.7393 & TRN \\
\hline CHEMBL1531345 & 752538 & 3.0969 & 3.3217 & TRN \\
\hline CHEMBL1709419 & 752538 & 4.6596 & 4.4927 & TRN \\
\hline CHEMBL1329615 & 752538 & 3.0969 & 3.2779 & TRN \\
\hline
\end{tabular}

Page 18872 


\begin{tabular}{|c|c|c|c|c|c|}
\hline \multirow[b]{2}{*}{ CHEMBL 82134} & \multicolumn{5}{|c|}{ Supplemental Table S2.txt } \\
\hline & 752538 & 3.0969 & 3.1896 & TST & \\
\hline CHEMBL3198697 & 752538 & 3.0969 & 3.1677 & TRN & \\
\hline CHEMBL 2000342 & 752538 & 3.0969 & 3.3418 & TRN & \\
\hline CHEMBL1581385 & 752538 & 3.0969 & 3.41600 & 00000000004 & TRN \\
\hline CHEMBL1708363 & 752538 & 3.0969 & 3.5879 & TRN & \\
\hline CHEMBL1707641 & 752538 & 3.0969 & 3.5038 & TRN & \\
\hline CHEMBL1310318 & 752538 & 5.091 & 4.5062 & TRN & \\
\hline CHEMBL1391746 & 752538 & 3.0969 & 3.3916 & TRN & \\
\hline CHEMBL3213331 & 752538 & 3.0969 & 3.0215 & TRN & \\
\hline CHEMBL1412489 & 752538 & 4.6517 & 3.6243 & TRN & \\
\hline CHEMBL1734268 & 752538 & 4.699 & 3.5047 & TRN & \\
\hline CHEMBL1438567 & 752538 & 3.0969 & 3.3021 & TRN & \\
\hline CHEMBL3192179 & 752538 & 3.0969 & 3.2812 & TRN & \\
\hline CHEMBL1567159 & 752538 & 4.6198 & 3.2487 & TRN & \\
\hline CHEMBL1336386 & 752538 & 3.0969 & 2.932 & TRN & \\
\hline CHEMBL1332203 & 752538 & 3.0969 & 3.1625 & TRN & \\
\hline CHEMBL1605172 & 752538 & 4.2581 & 3.5213 & TRN & \\
\hline CHEMBL1481042 & 752538 & 3.0969 & 3.3089 & TST & \\
\hline CHEMBL288096 & 752538 & 3.0969 & 3.0034 & TST & \\
\hline CHEMBL1497146 & 752538 & 3.0969 & 3.603 & TRN & \\
\hline CHEMBL1287980 & 752538 & 4.4789 & 3.7785 & TRN & \\
\hline CHEMBL3192006 & 752538 & 3.0969 & 2.965 & TST & \\
\hline CHEMBL1461413 & 752538 & 3.0969 & 3.2738 & TST & \\
\hline CHEMBL1728065 & 752538 & 3.0969 & 3.5233 & TRN & \\
\hline CHEMBL1698802 & 752538 & 3.0969 & 3.1461 & TRN & \\
\hline CHEMBL1548574 & 752538 & 3.0969 & 3.2728 & TRN & \\
\hline CHEMBL1716105 & 752538 & 3.0969 & 3.0705 & TST & \\
\hline CHEMBL1336825 & 752538 & 3.0969 & 3.3162 & TRN & \\
\hline CHEMBL1477845 & 752538 & 3.0969 & 2.8468 & TRN & \\
\hline CHEMBL3197471 & 752538 & 3.0969 & 2.9613 & TRN & \\
\hline CHEMBL1562104 & 752538 & 4.3372 & 3.7907 & TRN & \\
\hline CHEMBL1721015 & 752538 & 4.3439 & 4.0746 & TRN & \\
\hline CHEMBL1703189 & 752538 & 4.857 & 4.7567 & TRN & \\
\hline CHEMBL1600114 & 752538 & 5.0615 & 3.6718 & TRN & \\
\hline CHEMBL1310862 & 752538 & 3.0969 & 3.0471 & TRN & \\
\hline CHEMBL3190856 & 752538 & 3.0969 & 3.0361 & TRN & \\
\hline CHEMBL3196050 & 752538 & 4.7011 & 3.1966 & TRN & \\
\hline CHEMBL1705412 & 752538 & 3.0969 & 3.2314 & TRN & \\
\hline CHEMBL1380659 & 752538 & 3.0969 & 2.9559 & TRN & \\
\hline CHEMBL1432420 & 752538 & 3.0969 & 3.3338 & TRN & \\
\hline CHEMBL1717420 & 752538 & 4.9136 & 4.5597 & TRN & \\
\hline CHEMBL1489399 & 752538 & 3.0969 & 3.0877 & TRN & \\
\hline CHEMBL1411806 & 752538 & 4.3002 & 3.7226 & TRN & \\
\hline CHEMBL1498754 & 752538 & 3.0969 & 3.2104 & TRN & \\
\hline CHEMBL1092115 & 752538 & 3.0969 & 3.298 & TRN & \\
\hline CHEMBL1707222 & 752538 & 3.0969 & 3.3644 & TST & \\
\hline CHEMBL1597427 & 752538 & 3.0969 & 2.9399 & TRN & \\
\hline CHEMBL1480480 & 752538 & 3.0969 & 3.2556 & TRN & \\
\hline
\end{tabular}




\begin{tabular}{|c|c|c|c|c|}
\hline & & & pplement & al $\mathrm{T}$ \\
\hline CHEMBL1972037 & 752538 & 4.4401 & 3.3227 & TRN \\
\hline CHEMBL1384702 & 752538 & 3.0969 & 3.1057 & TRN \\
\hline CHEMBL572994 & 752538 & 4.2534 & 3.9072 & TRN \\
\hline CHEMBL1722096 & 752538 & 3.0969 & 3.1985 & TRN \\
\hline CHEMBL1713376 & 752538 & 3.0969 & 3.2932 & TRN \\
\hline CHEMBL1401342 & 752538 & 4.5045 & 3.4651 & TRN \\
\hline CHEMBL1715126 & 752538 & 3.0969 & 3.1177 & TRN \\
\hline CHEMBL1714971 & 752538 & 3.0969 & 3.1942 & TRN \\
\hline CHEMBL1361252 & 752538 & 4.2248 & 3.8737 & TRN \\
\hline CHEMBL3196864 & 752538 & 3.0969 & 3.362 & TRN \\
\hline CHEMBL3195749 & 752538 & 3.0969 & 3.28 & TRN \\
\hline CHEMBL3214350 & 752538 & 3.0969 & 3.1388 & TRN \\
\hline CHEMBL1485717 & 752538 & 3.0969 & 3.1577 & TRN \\
\hline CHEMBL1583540 & 752538 & 3.0969 & 3.0224 & TRN \\
\hline CHEMBL1968789 & 752538 & 3.0969 & 3.1988 & TRN \\
\hline CHEMBL1465240 & 752538 & 3.0969 & 3.6208 & TRN \\
\hline CHEMBL1309134 & 752538 & 3.0969 & 2.9026 & TRN \\
\hline CHEMBL1734152 & 752538 & 3.0969 & 3.5675 & TRN \\
\hline CHEMBL1368578 & 752538 & 3.0969 & 2.9816 & TRN \\
\hline CHEMBL1698845 & 752538 & 4.4023 & 3.681 & TST \\
\hline CHEMBL3190599 & 752538 & 3.0969 & 3.2658 & TRN \\
\hline CHEMBL1428615 & 752538 & 3.0969 & 3.0007 & TST \\
\hline CHEMBL3191855 & 752538 & 3.0969 & 2.7614 & TRN \\
\hline CHEMBL1521312 & 752538 & 3.0969 & 2.99 & TRN \\
\hline CHEMBL1385230 & 752538 & 3.0969 & 3.3406 & TRN \\
\hline CHEMBL1318998 & 752538 & 3.0969 & 3.4132 & TRN \\
\hline CHEMBL1480663 & 752538 & 3.0969 & 3.3904 & TRN \\
\hline CHEMBL1466117 & 752538 & 3.0969 & 3.5822 & TRN \\
\hline CHEMBL45152 & 752538 & 5.1024 & 4.916 & TRN \\
\hline CHEMBL1375198 & 752538 & 3.0969 & 3.6039 & TST \\
\hline CHEMBL1277060 & 752538 & 3.0969 & 2.7678 & TRN \\
\hline CHEMBL1477734 & 752538 & 3.0969 & 3.1942 & TRN \\
\hline CHEMBL1340352 & 752538 & 3.0969 & 3.0727 & TST \\
\hline CHEMBL1319020 & 752538 & 3.0969 & 3.3793 & TRN \\
\hline CHEMBL1533008 & 752538 & 3.0969 & 2.9778 & TRN \\
\hline CHEMBL1706062 & 752538 & 4.1911 & 3.7854 & TRN \\
\hline CHEMBL1368818 & 752538 & 3.0969 & 3.5323 & TRN \\
\hline CHEMBL1713097 & 752538 & 3.0969 & 3.1806 & TST \\
\hline CHEMBL1416184 & 752538 & 3.0969 & 3.2021 & TRN \\
\hline CHEMBL1370221 & 752538 & 3.0969 & 3.7352 & TRN \\
\hline CHEMBL1453822 & 752538 & 3.0969 & 3.3862 & TRN \\
\hline CHEMBL1491019 & 752538 & 3.0969 & 3.0407 & TRN \\
\hline CHEMBL1471841 & 752538 & 3.0969 & 3.5509 & TRN \\
\hline CHEMBL3189691 & 752538 & 3.0969 & 3.0151 & TRN \\
\hline CHEMBL1703503 & 752538 & 3.0969 & 4.4766 & TRN \\
\hline CHEMBL1587245 & 752538 & 3.0969 & 3.4595 & TRN \\
\hline CHEMBL1503768 & 752538 & 3.0969 & 3.2315 & TRN \\
\hline CHEMBL1735740 & 752538 & 3.0969 & 3.0037 & TRN \\
\hline
\end{tabular}




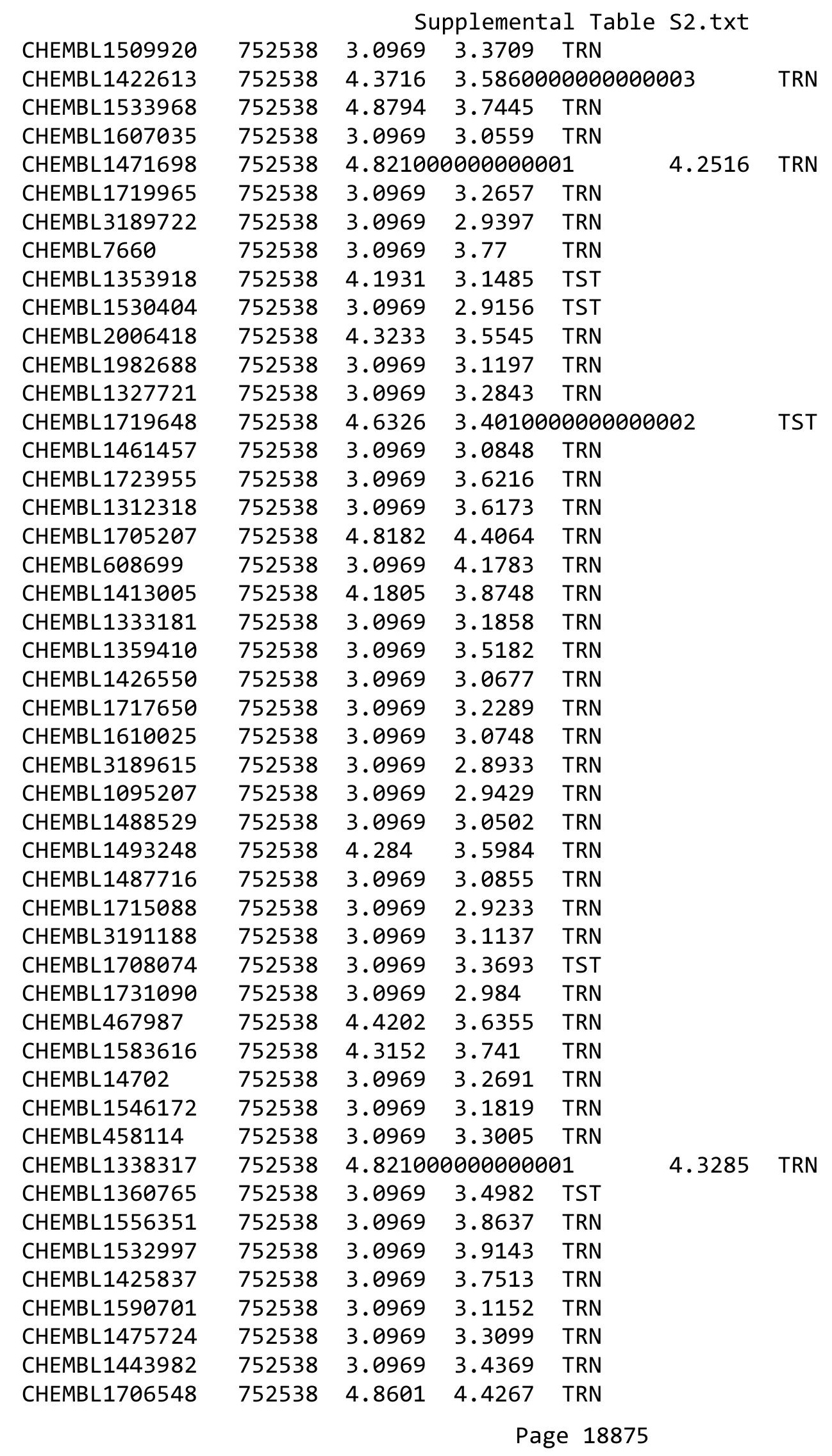


Supplemental Table S2.txt

\begin{tabular}{|c|c|c|c|c|c|}
\hline CHEMBL1409586 & 752538 & 3.0969 & 3.1722 & TRN & \\
\hline CHEMBL1501009 & 752538 & 3.0969 & 3.3237 & TRN & \\
\hline CHEMBL1343630 & 752538 & 3.0969 & 3.0726 & TRN & \\
\hline CHEMBL1537872 & 752538 & 3.0969 & 3.3522 & TST & \\
\hline CHEMBL 3196881 & 752538 & 3.0969 & 3.1188 & TRN & \\
\hline CHEMBL1442120 & 752538 & 3.0969 & 3.2971 & TST & \\
\hline CHEMBL1406389 & 752538 & 3.0969 & 3.4086 & TRN & \\
\hline CHEMBL1579122 & 752538 & 3.0969 & 2.9496 & TRN & \\
\hline CHEMBL1609490 & 752538 & 3.0969 & 3.7926 & TRN & \\
\hline CHEMBL1523343 & 752538 & 3.0969 & 3.3637 & TRN & \\
\hline CHEMBL1481150 & 752538 & 3.0969 & 3.3222 & TRN & \\
\hline CHEMBL1313139 & 752538 & 3.0969 & 3.3618 & TRN & \\
\hline CHEMBL1712082 & 752538 & 3.0969 & 3.3931 & TST & \\
\hline CHEMBL1333250 & 752538 & 3.0969 & 4.3446 & TRN & \\
\hline CHEMBL244649 & 752538 & 3.0969 & 3.4064 & TRN & \\
\hline CHEMBL1385343 & 752538 & 4.2197 & 3.5227 & TRN & \\
\hline CHEMBL1392885 & 752538 & 4.4935 & 3.2531 & TST & \\
\hline CHEMBL1370822 & 752538 & 3.0969 & 3.3447 & TRN & \\
\hline CHEMBL3197607 & 752538 & 3.0969 & 3.227 & TRN & \\
\hline CHEMBL1503335 & 752538 & 3.0969 & 3.0332 & TRN & \\
\hline CHEMBL1447350 & 752538 & 4.4763 & 3.7442 & TRN & \\
\hline CHEMBL1305916 & 752538 & 3.0969 & 3.1621 & TRN & \\
\hline CHEMBL1339993 & 752538 & 3.0969 & 3.3543 & TRN & \\
\hline CHEMBL1722539 & 752538 & 4.2757 & 3.63199 & 99999999997 & TRN \\
\hline CHEMBL1427539 & 752538 & 3.0969 & 3.2901 & TRN & \\
\hline CHEMBL1724452 & 752538 & 3.0969 & 3.8034 & TRN & \\
\hline CHEMBL1699398 & 752538 & 3.0969 & 3.142 & TRN & \\
\hline CHEMBL1408718 & 752538 & 3.0969 & 3.1695 & TRN & \\
\hline CHEMBL1555928 & 752538 & 4.1475 & 3.2657 & TRN & \\
\hline CHEMBL1412731 & 752538 & 3.0969 & 3.862 & TRN & \\
\hline CHEMBL1606460 & 752538 & 3.0969 & 3.2028 & TST & \\
\hline CHEMBL 3193252 & 752538 & 3.0969 & 3.4442 & TRN & \\
\hline CHEMBL1472879 & 752538 & 4.7545 & 3.9467 & TRN & \\
\hline CHEMBL1704186 & 752538 & 3.0969 & 3.3638 & TRN & \\
\hline CHEMBL1578299 & 752538 & 3.0969 & 3.5398 & TRN & \\
\hline CHEMBL1391552 & 752538 & 4.5817 & 4.3449 & TRN & \\
\hline CHEMBL1564699 & 752538 & 3.0969 & 3.5273 & TRN & \\
\hline CHEMBL1351081 & 752538 & 3.0969 & 3.4434 & TRN & \\
\hline CHEMBL1599257 & 752538 & 3.0969 & 3.03899 & 99999999997 & TRN \\
\hline CHEMBL1323484 & 752538 & 3.0969 & 3.1538 & TRN & \\
\hline CHEMBL1397145 & 752538 & 3.0969 & 3.2984 & TRN & \\
\hline CHEMBL1346883 & 752538 & 3.0969 & 3.188 & TRN & \\
\hline CHEMBL 3197706 & 752538 & 3.0969 & 3.2317 & TRN & \\
\hline CHEMBL1312836 & 752538 & 3.0969 & 3.3334 & TRN & \\
\hline CHEMBL1342666 & 752538 & 3.0969 & 3.3637 & TRN & \\
\hline CHEMBL1710047 & 752538 & 4.2815 & 4.3526 & TRN & \\
\hline CHEMBL1699069 & 752538 & 4.1278 & 3.5486 & TRN & \\
\hline CHEMBL1419121 & 752538 & 4.3152 & 3.8354 & TRN & \\
\hline
\end{tabular}


Supplemental Table S2.txt

\begin{tabular}{|c|c|c|c|c|}
\hline CHEMBL1462764 & 752538 & 3.0969 & 3.0849 & TRN \\
\hline CHEMBL1324790 & 752538 & 3.0969 & 3.023 & TRN \\
\hline CHEMBL1720314 & 752538 & 4.6234 & 4.0041 & TRN \\
\hline CHEMBL1312788 & 752538 & 4.3768 & 3.6262 & TRN \\
\hline CHEMBL1735864 & 752538 & 4.2924 & 3.7061 & TRN \\
\hline CHEMBL1378223 & 752538 & 3.0969 & 3.5804 & TST \\
\hline CHEMBL1462691 & 752538 & 3.0969 & 3.3425 & TRN \\
\hline CHEMBL1472466 & 752538 & 4.3595 & 3.0092 & TST \\
\hline CHEMBL1092816 & 752538 & 3.0969 & 3.1488 & TRN \\
\hline CHEMBL1966224 & 752538 & 4.1713 & 3.4602 & TRN \\
\hline CHEMBL 3212746 & 752538 & 3.0969 & 3.0577 & TRN \\
\hline CHEMBL1542413 & 752538 & 3.0969 & 3.2661 & TST \\
\hline CHEMBL1489240 & 752538 & 3.0969 & 3.2449 & TRN \\
\hline CHEMBL1971154 & 752538 & 3.0969 & 3.0116 & TRN \\
\hline CHEMBL1394863 & 752538 & 3.0969 & 2.9594 & TRN \\
\hline CHEMBL1730100 & 752538 & 3.0969 & 3.4715 & TST \\
\hline CHEMBL1408295 & 752538 & 3.0969 & 3.6698 & TRN \\
\hline CHEMBL1572332 & 752538 & 3.0969 & 3.8018 & TRN \\
\hline CHEMBL1330951 & 752538 & 3.0969 & 3.0553 & TST \\
\hline CHEMBL1401754 & 752538 & 3.0969 & 3.2811 & TST \\
\hline CHEMBL1721597 & 752538 & 4.3507 & 3.7858 & TRN \\
\hline CHEMBL1510664 & 752538 & 4.2503 & 3.6367 & TST \\
\hline CHEMBL1402473 & 752538 & 3.0969 & 3.0538 & TRN \\
\hline CHEMBL1529183 & 752538 & 3.0969 & 3.1777 & TRN \\
\hline CHEMBL 3214079 & 752538 & 3.0969 & 2.9051 & TRN \\
\hline CHEMBL1982454 & 752538 & 3.0969 & 3.12600 & 30000000003 \\
\hline CHEMBL445304 & 752538 & 3.0969 & 3.6858 & TST \\
\hline CHEMBL1590378 & 752538 & 3.0969 & 3.471 & TST \\
\hline CHEMBL1565164 & 752538 & 3.0969 & 3.4636 & TRN \\
\hline CHEMBL1427991 & 752538 & 3.0969 & 3.3173 & TRN \\
\hline CHEMBL1504634 & 752538 & 3.0969 & 3.4516 & TRN \\
\hline CHEMBL1309972 & 752538 & 3.0969 & 3.3196 & TRN \\
\hline CHEMBL1717300 & 752538 & 3.0969 & 3.3219 & TRN \\
\hline CHEMBL1304584 & 752538 & 3.0969 & 3.3459 & TST \\
\hline CHEMBL1572324 & 752538 & 3.0969 & 3.2419 & TRN \\
\hline CHEMBL75913 & 752538 & 4.2676 & 3.642 & TRN \\
\hline CHEMBL 3189811 & 752538 & 3.0969 & 3.0918 & TRN \\
\hline CHEMBL1527565 & 752538 & 3.0969 & 3.7254 & TRN \\
\hline CHEMBL1533931 & 752538 & 3.0969 & 3.3816 & TRN \\
\hline CHEMBL1330954 & 752538 & 4.4214 & 3.6884 & TRN \\
\hline CHEMBL103583 & 752538 & 3.0969 & 3.7381 & TST \\
\hline CHEMBL1396393 & 752538 & 3.0969 & 3.6037 & TRN \\
\hline CHEMBL1302099 & 752538 & 3.0969 & 3.1351 & TRN \\
\hline CHEMBL1703714 & 752538 & 3.0969 & 3.3229 & TRN \\
\hline CHEMBL1706151 & 752538 & 3.0969 & 3.3175 & TRN \\
\hline CHEMBL1567962 & 752538 & 3.0969 & 3.3575 & TST \\
\hline CHEMBL1374979 & 752538 & 3.0969 & 3.3208 & TST \\
\hline CHEMBL1432396 & 752538 & 3.0969 & 3.2229 & TRN \\
\hline
\end{tabular}

Page 18877 
Supplemental Table S2.txt

\begin{tabular}{|c|c|c|c|c|}
\hline 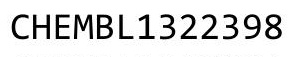 & & 59 & & \\
\hline HEMBL1348294 & 2538 & 0969 & 1123 & \\
\hline HEMBL1469008 & 52538 & 3969 & 7308 & \\
\hline IEMBL1 & & 969 & 28 & \\
\hline EMBL14 & 538 & 969 & 9413 & \\
\hline HEMBL1372495 & 52538 & 969 & 1034 & \\
\hline HEMBL1736254 & 52538 & 969 & 013 & \\
\hline HEMBL498373 & & 969 & 1851 & \\
\hline AEMBL16 & 52538 & 601 & 532 & \\
\hline IEMBL13 & 52538 & 969 & 3932 & \\
\hline HEMBL3194574 & 52538 & 969 & 0994 & \\
\hline HEMBL1370704 & 52538 & 969 & .7131 & \\
\hline HEMBL1397665 & 38 & 486 & 8128 & \\
\hline HEMBL 36 & 38 & 969 & 1001 & \\
\hline HEMBL17 & 38 & 969 & .4558 & \\
\hline HEMBL 31 & 38 & 969 & 4279 & \\
\hline HEMBL14 & 38 & 969 & 5346 & \\
\hline HEMBL17 & 38 & 399 & 4627 & \\
\hline HEMBL1: & & 827 & 8718 & \\
\hline HEMBL17 & 38 & 969 & 3488 & RN \\
\hline HEMBL1 & 38 & 969 & 5705 & RN \\
\hline HEMBL15 & 38 & 969 & 782 & RN \\
\hline HEMBL15 & 38 & 969 & 916 & 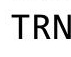 \\
\hline HEMBL3: & & 59 & 43 & RN \\
\hline HEMBL3. & 38 & 969 & 9021 & RN \\
\hline HEMBL13 & & 969 & & RN \\
\hline AEMBL19 & 38 & 969 & 923 & ST \\
\hline HEMBL15 & 38 & 969 & 119 & RN \\
\hline 312 & 38 & 59 & 8 & RN \\
\hline 996 & 38 & 969 & 4189 & RN \\
\hline HEMBL14 & & 969 & & RN \\
\hline HEMBL1336959 & 38 & 055 & 75 & RN \\
\hline HEMBL1 & 38 & 969 & 183 & RN \\
\hline 8 & 38 & 35 & & RN \\
\hline HEMBL15 & & & 5862 & RN \\
\hline HEMBL3189803 & 38 & 969 & 9052 & RN \\
\hline HEMBL463563 & 38 & 969 & .2857 & RN \\
\hline HEMBL15 & 38 & 969 & 1889 & RN \\
\hline 9 & & & & RN \\
\hline HEMBL13 & & & 104 & RN \\
\hline HEMBL1966295 & 52538 & 969 & 948 & RN \\
\hline HEMBL4€ & 38 & 969 & & RN \\
\hline HEMBL15 & & 969 & 799 & \\
\hline HEMBL13 & & & & RN \\
\hline HEMBL1391094 & 52538 & .0969 & .4858 & RN \\
\hline HEMBL17C & 52538 & $\partial 969$ & 2724 & RN \\
\hline EM & & & & \\
\hline 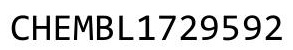 & & & & \\
\hline
\end{tabular}

Page 18878 


\begin{tabular}{|c|c|c|c|c|}
\hline & & & oplement & al Ta \\
\hline CHEMBL1392315 & 752538 & 4.4365 & 4.2242 & TRN \\
\hline CHEMBL1451538 & 752538 & 3.0969 & 3.013 & TRN \\
\hline CHEMBL1718995 & 752538 & 4.3072 & 3.7836 & TRN \\
\hline CHEMBL1716217 & 752538 & 3.0969 & 3.4021 & TST \\
\hline CHEMBL1389498 & 752538 & 3.0969 & 2.9845 & TRN \\
\hline CHEMBL1717890 & 752538 & 3.0969 & 3.7071 & TRN \\
\hline CHEMBL1413554 & 752538 & 3.0969 & 2.965 & TST \\
\hline CHEMBL1557018 & 752538 & 3.0969 & 3.1984 & TRN \\
\hline CHEMBL1607263 & 752538 & 3.0969 & 3.4394 & TRN \\
\hline CHEMBL1381271 & 752538 & 4.1838 & 3.7925 & TRN \\
\hline CHEMBL1409735 & 752538 & 3.0969 & 3.1651 & TRN \\
\hline CHEMBL1319488 & 752538 & 3.0969 & 3.1081 & TRN \\
\hline CHEMBL1412451 & 752538 & 3.0969 & 3.3231 & TRN \\
\hline CHEMBL1409836 & 752538 & 3.0969 & 3.4464 & TRN \\
\hline CHEMBL 3192578 & 752538 & 3.0969 & 3.4353 & TRN \\
\hline CHEMBL1460878 & 752538 & 3.0969 & 2.5799 & TRN \\
\hline CHEMBL1468193 & 752538 & 3.0969 & 3.0153 & TST \\
\hline CHEMBL1702473 & 752538 & 3.0969 & 3.3561 & TST \\
\hline CHEMBL1331149 & 752538 & 3.0969 & 3.0973 & TST \\
\hline CHEMBL1362714 & 752538 & 3.0969 & 3.2078 & TST \\
\hline CHEMBL1585485 & 752538 & 3.0969 & 3.1798 & TST \\
\hline CHEMBL1449479 & 752538 & 3.0969 & 3.1257 & TST \\
\hline CHEMBL1728153 & 752538 & 3.0969 & 3.7149 & TST \\
\hline CHEMBL1542003 & 752538 & 3.0969 & 3.238 & TST \\
\hline CHEMBL1479427 & 752538 & 3.0969 & 2.7996 & TST \\
\hline CHEMBL1374016 & 752538 & 3.0969 & 3.4611 & TST \\
\hline CHEMBL1553409 & 752538 & 4.2503 & 3.6966 & TST \\
\hline CHEMBL1441974 & 752538 & 3.0969 & 3.491 & TST \\
\hline CHEMBL1449018 & 752538 & 3.0969 & 3.4094 & TST \\
\hline CHEMBL1702981 & 752538 & 4.8268 & 4.689 & TST \\
\hline CHEMBL1304359 & 752538 & 3.0969 & 2.9633 & TST \\
\hline CHEMBL3208936 & 752538 & 3.0969 & 3.193 & TST \\
\hline CHEMBL3196863 & 752538 & 3.0969 & 2.9856 & TST \\
\hline CHEMBL51085 & 752538 & 4.8697 & 4.3311 & TST \\
\hline CHEMBL1705503 & 752538 & 3.0969 & 3.1245 & TST \\
\hline CHEMBL1481413 & 752538 & 3.0969 & 3.0475 & TST \\
\hline CHEMBL1524916 & 752538 & 3.0969 & 3.4418 & TST \\
\hline CHEMBL1449526 & 752538 & 3.0969 & 3.0275 & TST \\
\hline CHEMBL1387028 & 752538 & 3.0969 & 3.6415 & TST \\
\hline CHEMBL1542823 & 752538 & 3.0969 & 3.0098 & TST \\
\hline CHEMBL1426299 & 752538 & 3.0969 & 3.1846 & TST \\
\hline CHEMBL1418971 & 752538 & 3.0969 & 3.5659 & TST \\
\hline CHEMBL1536873 & 752538 & 3.0969 & 3.0234 & TST \\
\hline CHEMBL1477589 & 752538 & 3.0969 & 2.8487 & TST \\
\hline CHEMBL1609871 & 752538 & 4.2366 & 3.258 & TST \\
\hline CHEMBL1454269 & 752538 & 3.0969 & 3.0486 & TST \\
\hline CHEMBL1566610 & 752538 & 3.0969 & 3.1174 & TST \\
\hline CHEMBL1448440 & 752538 & 3.0969 & 3.1035 & TST \\
\hline
\end{tabular}


Supplemental Table S2.txt

\begin{tabular}{|c|c|c|c|c|c|}
\hline CHEMBL1339149 & 752538 & 4.8697 & 4.5221 & TST & \\
\hline CHEMBL1726592 & 752538 & 4.5817 & 4.4728 & TST & \\
\hline CHEMBL1423122 & 752538 & 3.0969 & 2.6302 & TST & \\
\hline CHEMBL1723964 & 752538 & 4.3536 & 3.2314 & TST & \\
\hline CHEMBL1727570 & 752538 & 3.0969 & 3.4956 & TST & \\
\hline CHEMBL1481364 & 752538 & 3.0969 & 3.0255 & TST & \\
\hline CHEMBL3191304 & 752538 & 3.0969 & 3.4865 & TST & \\
\hline CHEMBL1471361 & 752538 & 3.0969 & 3.1817 & TST & \\
\hline CHEMBL1729300 & 752538 & 4.52 & 3.568 & TST & \\
\hline CHEMBL52 & 752538 & 4.1649 & 3.5177 & TST & \\
\hline CHEMBL1329974 & 752538 & 3.0969 & 3.6201 & TST & \\
\hline CHEMBL1496195 & 752538 & 3.0969 & 3.5135 & TST & \\
\hline CHEMBL1422971 & 752538 & 4.1681 & 3.8755 & TST & \\
\hline CHEMBL1352170 & 752538 & 3.0969 & 3.5956 & TST & \\
\hline CHEMBL1318817 & 752538 & 4.5346 & 3.6208 & TST & \\
\hline CHEMBL1556561 & 752538 & 3.0969 & 3.7351 & TST & \\
\hline CHEMBL3195533 & 752538 & 3.0969 & 2.97399 & 99999999998 & TST \\
\hline CHEMBL1444730 & 752538 & 3.0969 & 3.5905 & TST & \\
\hline CHEMBL1304193 & 752538 & 4.2628 & 3.5482 & TST & \\
\hline CHEMBL3192506 & 752538 & 3.0969 & 3.2277 & TST & \\
\hline CHEMBL98386 & 752538 & 4.7645 & 4.8481 & TST & \\
\hline CHEMBL1528757 & 752538 & 3.0969 & 3.4757 & TST & \\
\hline CHEMBL1790039 & 752538 & 3.0969 & 3.3895 & TST & \\
\hline CHEMBL1565767 & 752538 & 3.0969 & 3.6934 & TST & \\
\hline CHEMBL 225903 & 752538 & 3.0969 & 3.182 & TST & \\
\hline CHEMBL1710816 & 752538 & 4.7825 & 3.7432 & TST & \\
\hline CHEMBL1524715 & 752538 & 3.0969 & 3.1289 & TST & \\
\hline CHEMBL1501723 & 752538 & 3.0969 & 3.338 & TST & \\
\hline CHEMBL1549039 & 752538 & 3.0969 & 3.2235 & TST & \\
\hline CHEMBL1545058 & 752538 & 3.0969 & 3.089 & TST & \\
\hline CHEMBL392695 & 955016 & 5.194 & 5.1915 & TRN & \\
\hline CHEMBL1909414 & 955016 & 4.7489 & 4.7493 & TRN & \\
\hline CHEMBL213100 & 955016 & 3.2815 & 3.2809 & TRN & \\
\hline CHEMBL509032 & 955016 & 5.4333 & 5.4358 & TRN & \\
\hline CHEMBL393929 & 955016 & 3.4969 & 3.4975 & TRN & \\
\hline CHEMBL514499 & 955016 & 5.9618 & 5.96399 & 99999999995 & TRN \\
\hline CHEMBL373751 & 955016 & 3.2833 & 3.283 & TRN & \\
\hline CHEMBL 2144069 & 955016 & 4.7306 & 4.7288 & TRN & \\
\hline CHEMBL379975 & 955016 & 3.9118 & 3.9122 & TRN & \\
\hline CHEMBL 3349342 & 955016 & 5.4847 & 5.4845 & TRN & \\
\hline CHEMBL558642 & 955016 & \multicolumn{3}{|c|}{3.7760000000000002} & $1 \mathrm{KT}$ \\
\hline CHEMBL3199475 & 955016 & 4.0888 & 4.0891 & TRN & \\
\hline CHEMBL1230020 & 955016 & 4.6603 & 4.6615 & TRN & \\
\hline CHEMBL1590308 & 955016 & 2.8307 & 2.6826 & TST & \\
\hline CHEMBL 240954 & 955016 & 3.9951 & 3.5462 & TST & \\
\hline CHEMBL209148 & 955016 & 3.6817 & 3.6823 & TRN & \\
\hline CHEMBL300389 & 955016 & 6.2611 & 6.2601 & TRN & \\
\hline CHEMBL1190711 & 955016 & 5.6532 & 5.6539 & TRN & \\
\hline
\end{tabular}




\begin{tabular}{|c|c|c|c|c|c|c|}
\hline & & \multicolumn{5}{|c|}{ Supplemental Table S2.txt } \\
\hline CHEMBL 2005886 & 955016 & 5.3469 & 5.3492 & TRN & & \\
\hline CHEMBL449158 & 955016 & 6.4064 & 6.2263 & TST & & \\
\hline CHEMBL92309 & 955016 & 2.6264 & 2.5428 & TST & & \\
\hline CHEMBL210618 & 955016 & 3.1 & 3.0976 & TRN & & \\
\hline CHEMBL1404918 & 955016 & 2.7392 & 2.742 & TRN & & \\
\hline CHEMBL483849 & 955016 & 1.7703 & 1.7709 & TRN & & \\
\hline CHEMBL1970879 & 955016 & 2.6276 & 2.62899 & 9999 & 996 & TRN \\
\hline CHEMBL585951 & 955016 & 5.7798 & 5.7793 & TRN & & \\
\hline CHEMBL202721 & 955016 & 4.5769 & 4.5782 & TRN & & \\
\hline CHEMBL180127 & 955016 & 3.4248 & 3.4272 & TRN & & \\
\hline CHEMBL1357247 & 955016 & 3.3023 & 3.3001 & TRN & & \\
\hline CHEMBL1643959 & 955016 & 3.3349 & 3.3352 & TRN & & \\
\hline CHEMBL 258844 & 955016 & 4.0059 & 4.0067 & TRN & & \\
\hline CHEMBL191334 & 955016 & 4.0164 & 4.018 & TRN & & \\
\hline CHEMBL259181 & 955016 & 4.5844 & 4.5819 & TRN & & \\
\hline CHEMBL 220241 & 955016 & 3.4955 & 3.4959 & TRN & & \\
\hline CHEMBL9470 & 955016 & 3.6555 & 5.6525 & TST & & \\
\hline CHEMBL512504 & 955016 & 6.2839 & 6.284 & TRN & & \\
\hline CHEMBL221137 & 955016 & 4.1978 & 4.3199 & TST & & \\
\hline CHEMBL1516890 & 955016 & 3.714 & 3.7164 & TRN & & \\
\hline CHEMBL573107 & 955016 & 4.7351 & 4.7333 & TRN & & \\
\hline CHEMBL1673039 & 955016 & 3.3324 & 3.333 & TRN & & \\
\hline CHEMBL3186408 & 955016 & 3.2937 & 3.4505 & TST & & \\
\hline CHEMBL135561 & 955016 & 3.8594 & 3.8615 & TRN & & \\
\hline CHEMBL483847 & 955016 & 3.4726 & 3.4684 & TRN & & \\
\hline CHEMBL1242367 & 955016 & 3.0727 & 3.0703 & TRN & & \\
\hline CHEMBL379300 & 955016 & 4.8571 & 4.8554 & TRN & & \\
\hline CHEMBL65 & 955016 & 6.5586 & 6.558 & TRN & & \\
\hline CHEMBL1256459 & 955016 & 5.3856 & 5.386 & TRN & & \\
\hline CHEMBL1788116 & 955016 & 4.766 & 4.7653 & TRN & & \\
\hline CHEMBL3392440 & 955016 & 3.5152 & 3.5139 & TRN & & \\
\hline CHEMBL192566 & 955016 & 8.071 & 7.8866 & TST & & \\
\hline CHEMBL189584 & 955016 & 4.7868 & 4.5154 & TST & & \\
\hline CHEMBL 2363137 & 955016 & 4.497 & 4.60800 & 00006 & 005 & TST \\
\hline CHEMBL472940 & 955016 & 3.3808 & 3.7164 & TST & & \\
\hline CHEMBL102714 & 955016 & 3.5485 & 3.6998 & TST & & \\
\hline CHEMBL412142 & 955016 & 3.9953 & 4.1085 & TST & & \\
\hline CHEMBL515416 & 955016 & 3.5372 & 3.8649 & TST & & \\
\hline CHEMBL 2024643 & 816440 & 4.3264 & 4.5804 & TRN & & \\
\hline CHEMBL 2022392 & 816440 & 3.7662 & 4.3494 & TRN & & \\
\hline CHEMBL1341255 & 816440 & 3.7228 & 4.1036 & TST & & \\
\hline CHEMBL 2024638 & 816440 & 3.52600 & 30000000 & 002 & 4.2012 & TRN \\
\hline CHEMBL 2024632 & 816440 & 4.048 & 3.9487 & TRN & & \\
\hline CHEMBL 2022385 & 816440 & 5.2708 & 3.5082 & TRN & & \\
\hline CHEMBL 2023711 & 816440 & 2.627 & 3.137 & TST & & \\
\hline CHEMBL 1271483 & 816440 & 2.353 & 3.2291 & TRN & & \\
\hline CHEMBL 2024636 & 816440 & 3.70300 & 30000000 & 203 & 4.0887 & TRN \\
\hline CHEMBL 2024628 & 816440 & 4.1795 & 3.1072 & TRN & & \\
\hline
\end{tabular}




\begin{tabular}{|c|c|c|c|c|c|}
\hline \multicolumn{6}{|c|}{ Supplemental Table S2.txt } \\
\hline CHEMBL2022389 & 816440 & 3.7967 & 3.5485 & TRN & \\
\hline CHEMBL 2024639 & 816440 & 4.3217 & 4.7461 & TRN & \\
\hline CHEMBL 2022380 & 816440 & 4.7091 & 4.0475 & TRN & \\
\hline CHEMBL 2022394 & 816440 & 5.0419 & 4.71 & TST & \\
\hline CHEMBL 2023712 & 816440 & 4.7359 & 4.465 & TST & \\
\hline CHEMBL 2024633 & 816440 & 2.32 & 3.2016 & TRN & \\
\hline CHEMBL 2022386 & 816440 & 2.371 & 3.0904 & TRN & \\
\hline CHEMBL 2022401 & 816440 & 2.5332 & 2.8912 & TST & \\
\hline CHEMBL 2024631 & 816440 & 4.1738 & 3.9448 & TRN & \\
\hline CHEMBL 2023706 & 816440 & 2.6012 & 2.3644 & TRN & \\
\hline CHEMBL 2022395 & 816440 & 2.426 & 3.0697 & TRN & \\
\hline CHEMBL 2024630 & 816440 & 2.5902 & 3.1072 & TRN & \\
\hline CHEMBL 2024626 & 816440 & 2.608 & 3.2179 & TRN & \\
\hline CHEMBL 2024640 & 816440 & 4.8784 & 4.7461 & TRN & \\
\hline CHEMBL 2022398 & 816440 & 4.1877 & 4.0823 & TRN & \\
\hline CHEMBL 2024642 & 816440 & 4.5105 & 4.812 & TRN & \\
\hline CHEMBL 2022390 & 816440 & 3.7096 & 3.6426 & TRN & \\
\hline CHEMBL 2024629 & 816440 & 2.4417 & 3.1072 & TRN & \\
\hline CHEMBL2022384 & 816440 & 4.7418 & 3.3189 & TRN & \\
\hline CHEMBL 2024635 & 816440 & 4.8486 & 4.9212 & TRN & \\
\hline CHEMBL 2022399 & 816440 & 2.6078 & 2.46599 & 99999999997 & TRN \\
\hline CHEMBL 2024625 & 816440 & 2.2383 & 3.1287 & TRN & \\
\hline CHEMBL 2024627 & 816440 & 3.4788 & 3.2008 & TRN & \\
\hline CHEMBL2022381 & 816440 & 3.2763 & 3.3867 & TRN & \\
\hline CHEMBL 2024637 & 816440 & 4.5412 & 4.762 & TRN & \\
\hline CHEMBL 2024623 & 816440 & 4.3168 & 3.9492 & TST & \\
\hline CHEMBL 2023710 & 816440 & 2.9197 & 3.1679 & TRN & \\
\hline CHEMBL 2022391 & 816440 & 4.8153 & 3.9693 & TRN & \\
\hline CHEMBL 2022387 & 816440 & 4.6728 & 4.958 & TRN & \\
\hline CHEMBL 2022393 & 816440 & 4.6245 & 4.6049 & TRN & \\
\hline CHEMBL 2022388 & 816440 & 5.0506 & 4.4894 & TRN & \\
\hline CHEMBL 2024624 & 816440 & 3.9205 & 2.8141 & TST & \\
\hline CHEMBL 2023707 & 816440 & 2.5672 & 2.6942 & TST & \\
\hline CHEMBL450046 & 816440 & 4.3526 & 3.7395 & TST & \\
\hline CHEMBL 2024634 & 816440 & 4.5438 & 3.5288 & TRN & \\
\hline CHEMBL 2022402 & 816440 & 2.5873 & 2.2439 & TRN & \\
\hline CHEMBL 2022383 & 816440 & 2.5123 & 3.3328 & TRN & \\
\hline CHEMBL 2023709 & 816440 & 2.5319 & 2.909 & TST & \\
\hline CHEMBL2023708 & 816440 & 2.5129 & 2.5414 & TRN & \\
\hline CHEMBL1269516 & 816440 & 3.8151 & 3.8889 & TRN & \\
\hline CHEMBL 2022382 & 816440 & 5.2434 & 3.8737 & TRN & \\
\hline CHEMBL 2022396 & 816440 & 2.4184 & 2.7428 & TRN & \\
\hline CHEMBL 2024641 & 816440 & 3.8584 & 3.7485 & TST & \\
\hline CHEMBL2022397 & 816440 & 2.5343 & 3.9257 & TST & \\
\hline CHEMBL 2022400 & 816440 & 2.6484 & 2.5326 & TST & \\
\hline CHEMBL487933 & 816440 & 4.3279 & 4.2158 & TST & \\
\hline CHEMBL1964290 & 809262 & 5.9 & 6.4677 & TRN & \\
\hline CHEMBL 2001398 & 809262 & 6.2 & 5.598 & TRN & \\
\hline
\end{tabular}




\begin{tabular}{|c|c|c|c|c|c|}
\hline & & & & & \\
\hline CHEMBL2003768 & 809262 & 5.1 & 5.0543 & TRN & \\
\hline CHEMBL 213505 & 809262 & 5.6 & 5.6931 & TRN & \\
\hline CHEMBL 202721 & 809262 & 4.4 & 5.4178 & TRN & \\
\hline CHEMBL1982880 & 809262 & 4.0 & 4.0667 & TRN & \\
\hline CHEMBL1987034 & 809262 & 6.1 & 7.0104 & TRN & \\
\hline CHEMBL1993941 & 809262 & 6.3 & 6.3263 & TRN & \\
\hline CHEMBL 377383 & 809262 & 4.0 & 4.1097 & TRN & \\
\hline CHEMBL 2005886 & 809262 & 6.1 & 5.715 & TRN & \\
\hline CHEMBL481491 & 809262 & 4.0 & 4.2595 & TST & \\
\hline CHEMBL1682345 & 809262 & 6.8 & 7.26399 & 9999999999 & TRN \\
\hline CHEMBL1973142 & 809262 & 6.2 & 6.1316 & TRN & \\
\hline CHEMBL 388311 & 809262 & 8.4 & 7.3926 & TRN & \\
\hline CHEMBL1973145 & 809262 & 4.0 & 4.8516 & TRN & \\
\hline CHEMBL1982924 & 809262 & 5.1 & 5.7301 & TRN & \\
\hline CHEMBL2005936 & 809262 & 6.5 & 7.0933 & TRN & \\
\hline CHEMBL1971141 & 809262 & 4.0 & 4.5254 & TRN & \\
\hline CHEMBL1995813 & 809262 & 8.3 & 7.7652 & TRN & \\
\hline CHEMBL1979718 & 809262 & 6.1 & 6.2502 & TRN & \\
\hline CHEMBL206236 & 809262 & 5.8 & 6.6599 & TRN & \\
\hline CHEMBL1989834 & 809262 & 3.8 & 4.3978 & TRN & \\
\hline CHEMBL523823 & 809262 & 4.0 & 4.335 & TST & \\
\hline CHEMBL1562756 & 809262 & 5.2 & 4.6701 & TST & \\
\hline CHEMBL1987430 & 809262 & 4.4 & 4.283 & TRN & \\
\hline CHEMBL 244378 & 809262 & 6.6 & 6.5467 & TRN & \\
\hline CHEMBL 2001957 & 809262 & 4.0 & 3.9116 & TRN & \\
\hline CHEMBL1969372 & 809262 & 4.0 & 3.8729 & TRN & \\
\hline CHEMBL1993413 & 809262 & 5.5 & 5.8154 & TRN & \\
\hline CHEMBL1990583 & 809262 & 7.4 & 4.4731 & TRN & \\
\hline CHEMBL1986943 & 809262 & 8.1 & 8.3247 & TRN & \\
\hline CHEMBL289959 & 809262 & 4.5 & 4.0411 & TRN & \\
\hline CHEMBL 2006263 & 809262 & 4.0 & 4.4858 & TST & \\
\hline CHEMBL1993584 & 809262 & 6.3 & 6.5064 & TRN & \\
\hline CHEMBL1986263 & 809262 & 6.0 & 5.4507 & TRN & \\
\hline CHEMBL 2000114 & 809262 & 4.0 & 5.1788 & TRN & \\
\hline CHEMBL210618 & 809262 & 4.0 & 4.118 & TRN & \\
\hline CHEMBL1986265 & 809262 & 4.4 & 4.9532 & TRN & \\
\hline CHEMBL1975647 & 809262 & 4.0 & 4.0468 & TRN & \\
\hline CHEMBL1968380 & 809262 & 4.0 & 4.2263 & TRN & \\
\hline CHEMBL1964644 & 809262 & 4.0 & 4.0568 & TRN & \\
\hline CHEMBL1991734 & 809262 & 6.1 & 4.882 & TST & \\
\hline CHEMBL1981782 & 809262 & 6.9 & 7.1488 & TRN & \\
\hline CHEMBL1977681 & 809262 & 5.3 & 4.3904 & TRN & \\
\hline CHEMBL1970142 & 809262 & 7.0 & 6.1301 & TRN & \\
\hline CHEMBL1990912 & 809262 & 4.0 & 4.7357 & TRN & \\
\hline CHEMBL1991782 & 809262 & 3.1 & 4.8578 & TRN & \\
\hline CHEMBL 2002105 & 809262 & 4.2 & 5.0132 & TRN & \\
\hline CHEMBL1983348 & 809262 & 6.0 & 5.2987 & TRN & \\
\hline CHEMBL1988163 & 809262 & 5.5 & 6.0941 & TRN & \\
\hline & & & & 18883 & \\
\hline
\end{tabular}




\begin{tabular}{|c|c|c|c|c|c|}
\hline \\
\hline CHEMBL1995592 & 809262 & 5.6 & 5.8639 & TST & \\
\hline CHEMBL 2000934 & 809262 & 4.4 & 4.2722 & TRN & \\
\hline CHEMBL1980671 & 809262 & 5.1 & 4.651 & TRN & \\
\hline CHEMBL 2006493 & 809262 & 4.0 & 4.0865 & TST & \\
\hline CHEMBL1986177 & 809262 & 4.4 & 5.138 & TRN & \\
\hline CHEMBL1996923 & 809262 & 4.0 & 4.0551 & TST & \\
\hline CHEMBL1983449 & 809262 & 6.3 & 6.4398 & TRN & \\
\hline CHEMBL1992323 & 809262 & 4.0 & 4.2773 & TRN & \\
\hline CHEMBL1969735 & 809262 & 4.0 & 3.9 & TRN & \\
\hline CHEMBL 2003524 & 809262 & 4.0 & 4.3062 & TST & \\
\hline CHEMBL2002649 & 809262 & 5.2 & 5.3866 & TRN & \\
\hline CHEMBL1983589 & 809262 & 8.2 & 8.4767 & TRN & \\
\hline CHEMBL1989423 & 809262 & 4.3 & 4.3672 & TST & \\
\hline CHEMBL1985367 & 809262 & 4.4 & 4.755 & TST & \\
\hline CHEMBL1996510 & 809262 & 4.7 & 5.48799 & 99999999995 & TST \\
\hline CHEMBL437747 & 809262 & 5.6 & 4.6852 & TRN & \\
\hline CHEMBL2005718 & 809262 & 7.4 & 7.7223 & TRN & \\
\hline CHEMBL1995172 & 809262 & 4.2 & 4.2144 & TST & \\
\hline CHEMBL 2001584 & 809262 & 4.4 & 5.1059 & TRN & \\
\hline CHEMBL507936 & 809262 & 4.0 & 5.5466 & TRN & \\
\hline CHEMBL104264 & 809262 & 6.7 & 7.0816 & TRN & \\
\hline CHEMBL1967998 & 809262 & 6.6 & 6.7635 & TRN & \\
\hline CHEMBL1994321 & 809262 & 6.9 & 6.7903 & TRN & \\
\hline CHEMBL1978562 & 809262 & 4.4 & 5.2565 & TST & \\
\hline CHEMBL1997129 & 809262 & 6.6 & 5.9715 & TRN & \\
\hline CHEMBL1984788 & 809262 & 4.0 & 4.1479 & TRN & \\
\hline CHEMBL451964 & 809262 & 4.0 & 4.147 & TRN & \\
\hline CHEMBL1974875 & 809262 & 4.2 & 4.6685 & TST & \\
\hline CHEMBL1996604 & 809262 & 4.0 & 4.0731 & TRN & \\
\hline CHEMBL1964307 & 809262 & 6.5 & 6.4177 & TRN & \\
\hline CHEMBL1989471 & 809262 & 4.4 & 5.1078 & TST & \\
\hline CHEMBL 2000508 & 809262 & 4.0 & 4.0361 & TRN & \\
\hline CHEMBL1971694 & 809262 & 4.0 & 4.1447 & TST & \\
\hline CHEMBL 2001547 & 809262 & 4.0 & 3.9102 & TRN & \\
\hline CHEMBL 210928 & 809262 & 4.0 & 4.05699 & 99999999995 & TRN \\
\hline CHEMBL1978195 & 809262 & 5.5 & 5.3157 & TRN & \\
\hline CHEMBL1994361 & 809262 & 5.4 & 4.7764 & TRN & \\
\hline CHEMBL1986603 & 809262 & 4.0 & 4.1923 & TST & \\
\hline CHEMBL1972840 & 809262 & 6.6 & 7.8244 & TRN & \\
\hline CHEMBL1977148 & 809262 & 4.0 & 4.5577 & TRN & \\
\hline CHEMBL1966842 & 809262 & 4.4 & 4.3617 & TRN & \\
\hline CHEMBL 2003286 & 809262 & 4.0 & 4.0872 & TRN & \\
\hline CHEMBL1992306 & 809262 & 4.0 & 4.3775 & TRN & \\
\hline CHEMBL 2002165 & 809262 & 6.5 & 6.4493 & TRN & \\
\hline CHEMBL 2001668 & 809262 & 4.0 & 4.181 & TST & \\
\hline CHEMBL1979318 & 809262 & 4.0 & 4.0275 & TRN & \\
\hline CHEMBL 206382 & 809262 & 6.2 & 6.1655 & TRN & \\
\hline CHEMBL1998585 & 809262 & 6.7 & 6.0144 & TRN & \\
\hline
\end{tabular}




\begin{tabular}{|c|c|c|c|c|}
\hline & & & & al Table s \\
\hline CHEMBL127898 & 809262 & 4.0 & 4.3817 & TST \\
\hline CHEMBL519697 & 809262 & 4.0 & 4.4404 & TST \\
\hline CHEMBL 2004934 & 809262 & 7.8 & 6.9615 & TRN \\
\hline CHEMBL1973516 & 809262 & 4.4 & 6.3574 & TRN \\
\hline CHEMBL1996345 & 809262 & 4.4 & 4.5 & TST \\
\hline CHEMBL1975128 & 809262 & 6.6 & 7.5627 & TRN \\
\hline CHEMBL 2004025 & 809262 & 5.7 & 5.1595 & TRN \\
\hline CHEMBL1996048 & 809262 & 6.6 & 5.57799 & 9999999999 \\
\hline CHEMBL1970369 & 809262 & 4.0 & 5.0765 & TRN \\
\hline CHEMBL461876 & 809262 & 5.7 & 5.2382 & TST \\
\hline CHEMBL1965033 & 809262 & 4.4 & 5.159 & TRN \\
\hline CHEMBL 2001485 & 809262 & 6.4 & 6.1521 & TRN \\
\hline CHEMBL1971519 & 809262 & 6.3 & 5.6136 & TRN \\
\hline CHEMBL504950 & 809262 & 6.4 & 6.2755 & TRN \\
\hline CHEMBL1997335 & 809262 & 6.3 & 4.9089 & TRN \\
\hline CHEMBL1966425 & 809262 & 6.3 & 6.1728 & TRN \\
\hline CHEMBL1984363 & 809262 & 6.3 & 6.2337 & TRN \\
\hline CHEMBL1978099 & 809262 & 4.0 & 4.9383 & TRN \\
\hline CHEMBL1977041 & 809262 & 6.6 & 6.2505 & TRN \\
\hline CHEMBL1968070 & 809262 & 4.0 & 4.1753 & TRN \\
\hline CHEMBL1988608 & 809262 & 7.5 & 7.4974 & TRN \\
\hline CHEMBL184847 & 809262 & 6.4 & 5.894 & TRN \\
\hline CHEMBL1984367 & 809262 & 4.0 & 4.4372 & TRN \\
\hline CHEMBL1985723 & 809262 & 7.6 & 7.3687 & TRN \\
\hline CHEMBL178737 & 809262 & 4.0 & 4.6427 & TST \\
\hline CHEMBL226898 & 809262 & 8.1 & 8.0094 & TRN \\
\hline CHEMBL1982563 & 809262 & 4.0 & 3.9309 & TRN \\
\hline CHEMBL539474 & 809262 & 4.0 & 4.434 & TST \\
\hline CHEMBL575824 & 809262 & 6.7 & 7.3452 & TRN \\
\hline CHEMBL1988387 & 809262 & 6.9 & 6.0969 & TRN \\
\hline CHEMBL1973868 & 809262 & 6.5 & 5.539 & TRN \\
\hline CHEMBL1972462 & 809262 & 4.4 & 4.587 & TRN \\
\hline CHEMBL1977128 & 809262 & 6.3 & 5.6385 & TRN \\
\hline CHEMBL1997759 & 809262 & 4.0 & 4.1557 & TRN \\
\hline CHEMBL1990288 & 809262 & 4.0 & 4.0287 & TRN \\
\hline CHEMBL1974803 & 809262 & 4.0 & 4.3142 & TST \\
\hline CHEMBL1970074 & 809262 & 5.8 & 4.6875 & TRN \\
\hline CHEMBL1965702 & 809262 & 7.5 & 7.8362 & TRN \\
\hline CHEMBL1984500 & 809262 & 4.7 & 4.7497 & TRN \\
\hline CHEMBL1986970 & 809262 & 6.9 & 7.4937 & TRN \\
\hline CHEMBL 2005112 & 809262 & 4.0 & 4.0009 & TST \\
\hline CHEMBL1958401 & 809262 & 6.0 & 5.5921 & TRN \\
\hline CHEMBL1984044 & 809262 & 4.0 & 4.1696 & TRN \\
\hline CHEMBL 2003456 & 809262 & 4.0 & 4.1665 & TRN \\
\hline CHEMBL1966816 & 809262 & 4.0 & 3.9978 & TRN \\
\hline CHEMBL 2002992 & 809262 & 6.8 & 6.9405 & TRN \\
\hline CHEMBL560813 & 809262 & 4.0 & 4.0836 & TRN \\
\hline CHEMBL207253 & 809262 & 4.0 & 3.9841 & TST \\
\hline
\end{tabular}




\begin{tabular}{|c|c|c|c|c|}
\hline & & & pplement & al $\mathrm{Ta}$ \\
\hline CHEMBL1890036 & 809262 & 5.2 & 5.2853 & TST \\
\hline CHEMBL1982700 & 809262 & 4.4 & 5.0632 & TST \\
\hline CHEMBL1968791 & 809262 & 6.3 & 5.5939 & TRN \\
\hline CHEMBL326282 & 809262 & 4.0 & 4.3115 & TST \\
\hline CHEMBL2002682 & 809262 & 5.5 & 4.3722 & TST \\
\hline CHEMBL1977634 & 809262 & 4.4 & 4.9396 & TRN \\
\hline CHEMBL1992732 & 809262 & 4.0 & 4.4126 & TST \\
\hline CHEMBL1971186 & 809262 & 4.0 & 4.0027 & TRN \\
\hline CHEMBL 2003482 & 809262 & 4.0 & 4.4446 & TRN \\
\hline CHEMBL1969156 & 809262 & 4.3 & 4.845 & TRN \\
\hline CHEMBL1973211 & 809262 & 6.6 & 6.7345 & TRN \\
\hline CHEMBL1984700 & 809262 & 4.0 & 3.8989 & TRN \\
\hline CHEMBL2007151 & 809262 & 6.0 & 5.3345 & TRN \\
\hline CHEMBL1998953 & 809262 & 4.4 & 5.235 & TRN \\
\hline CHEMBL1971606 & 809262 & 9.1 & 6.5598 & TRN \\
\hline CHEMBL1972125 & 809262 & 4.0 & 4.697 & TRN \\
\hline CHEMBL1461728 & 809262 & 5.2 & 5.2218 & TRN \\
\hline CHEMBL1976134 & 809262 & 6.5 & 5.4862 & TRN \\
\hline CHEMBL1965131 & 809262 & 5.9 & 6.2497 & TRN \\
\hline CHEMBL1995448 & 809262 & 6.1 & 5.6761 & TRN \\
\hline CHEMBL1972158 & 809262 & 7.1 & 7.8664 & TRN \\
\hline CHEMBL1981215 & 809262 & 4.4 & 4.2719 & TRN \\
\hline CHEMBL1974457 & 809262 & 4.0 & 4.1215 & TRN \\
\hline CHEMBL2006580 & 809262 & 4.0 & 4.114 & TRN \\
\hline CHEMBL1999414 & 809262 & 6.4 & 6.3035 & TRN \\
\hline CHEMBL1967336 & 809262 & 4.4 & 4.3147 & TRN \\
\hline CHEMBL2001228 & 809262 & 4.4 & 4.6406 & TRN \\
\hline CHEMBL2006581 & 809262 & 4.0 & 4.2126 & TRN \\
\hline CHEMBL2006481 & 809262 & 4.0 & 5.0584 & TRN \\
\hline CHEMBL1979855 & 809262 & 4.0 & 4.4595 & TRN \\
\hline CHEMBL1970340 & 809262 & 6.0 & 5.8241 & TRN \\
\hline CHEMBL1967992 & 809262 & 5.9 & 5.6023 & TRN \\
\hline CHEMBL2005186 & 809262 & 6.3 & 5.8592 & TRN \\
\hline CHEMBL1995927 & 809262 & 4.0 & 4.0606 & TST \\
\hline CHEMBL 2006450 & 809262 & 6.5 & 6.937 & TRN \\
\hline CHEMBL1975534 & 809262 & 5.4 & 5.2711 & TRN \\
\hline CHEMBL1993424 & 809262 & 4.0 & 5.6829 & TRN \\
\hline CHEMBL1966703 & 809262 & 4.0 & 4.2788 & TST \\
\hline CHEMBL2001987 & 809262 & 4.4 & 4.1814 & TRN \\
\hline CHEMBL1969561 & 809262 & 6.5 & 7.6244 & TRN \\
\hline CHEMBL1994555 & 809262 & 4.4 & 4.7601 & TST \\
\hline CHEMBL1983640 & 809262 & 6.2 & 5.9356 & TRN \\
\hline CHEMBL1997023 & 809262 & 4.0 & 5.1705 & TST \\
\hline CHEMBL1980003 & 809262 & 4.2 & 4.4823 & TRN \\
\hline CHEMBL1964687 & 809262 & 6.0 & 6.4551 & TRN \\
\hline CHEMBL1999918 & 809262 & 5.7 & 5.2565 & TRN \\
\hline CHEMBL1974254 & 809262 & 6.4 & 4.9181 & TRN \\
\hline CHEMBL1997924 & 809262 & 6.3 & 5.4412 & TRN \\
\hline
\end{tabular}




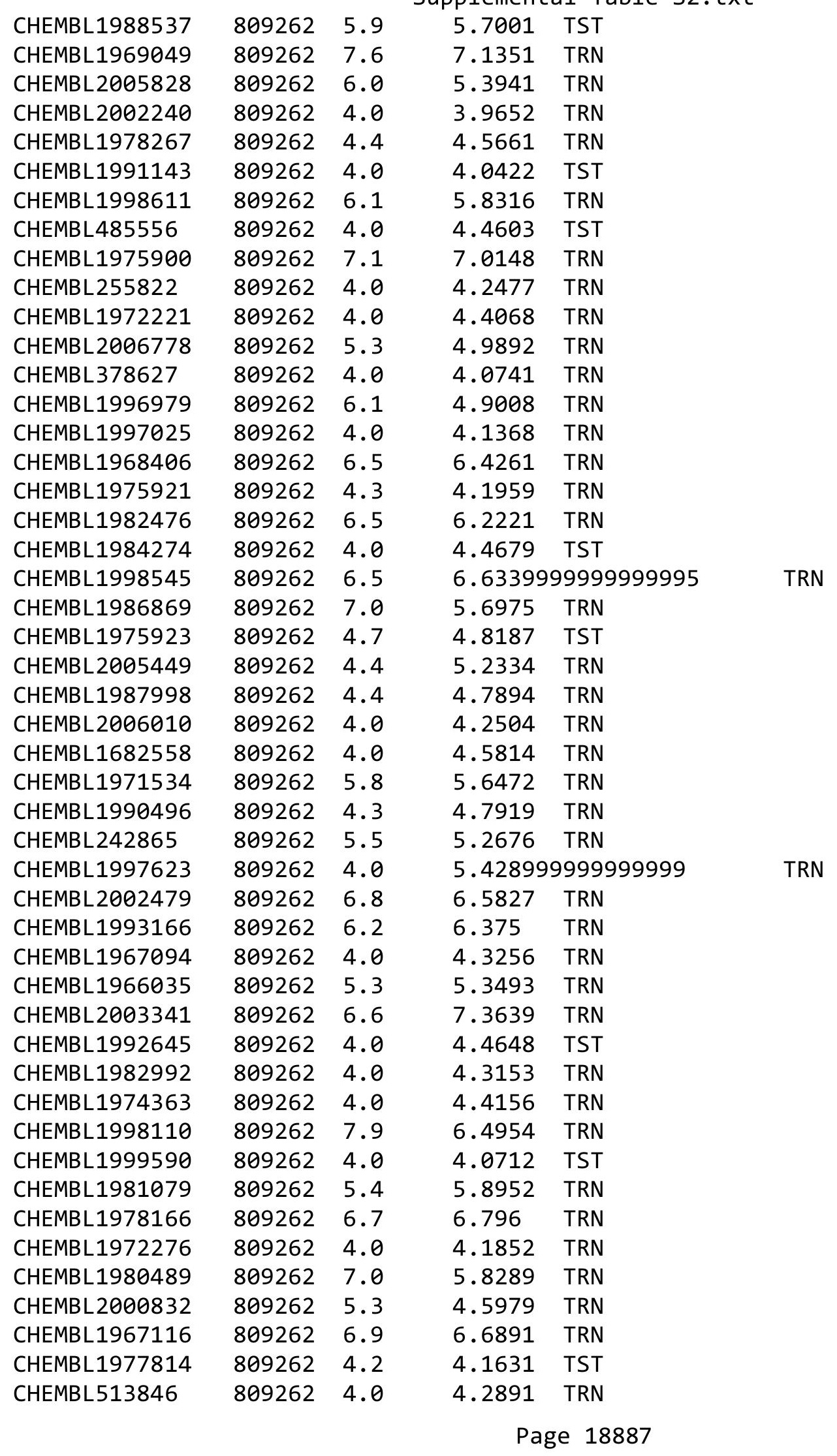




\begin{tabular}{|c|c|c|c|c|}
\hline & & & Supplement & \\
\hline CHEMBL86755 & 809262 & 4.4 & 4.9747 & TRN \\
\hline CHEMBL1970709 & 809262 & 6.4 & 6.3586 & TRN \\
\hline CHEMBL1974617 & 809262 & 6.4 & 6.0986 & TRN \\
\hline CHEMBL1965660 & 809262 & 6.9 & 6.6261 & TRN \\
\hline CHEMBL1992125 & 809262 & 5.5 & 5.1657 & TRN \\
\hline CHEMBL1998112 & 809262 & 4.0 & 4.7237 & TRN \\
\hline CHEMBL1972290 & 809262 & 7.5 & 7.9308 & TRN \\
\hline CHEMBL1969126 & 809262 & 4.0 & 3.9959 & TRN \\
\hline CHEMBL1980896 & 809262 & 4.0 & 4.5223 & TRN \\
\hline CHEMBL1975208 & 809262 & 4.0 & 4.0983 & TST \\
\hline CHEMBL1970104 & 809262 & 6.3 & 5.6635 & TRN \\
\hline CHEMBL1991429 & 809262 & 4.0 & 4.0439 & TRN \\
\hline CHEMBL1964777 & 809262 & 4.0 & 5.1615 & TRN \\
\hline CHEMBL1971149 & 809262 & 4.0 & 3.9507 & TRN \\
\hline CHEMBL1999714 & 809262 & 4.0 & 4.032 & TRN \\
\hline CHEMBL1987533 & 809262 & 4.0 & 4.4284 & TRN \\
\hline CHEMBL1994040 & 809262 & 4.0 & 3.9502 & TRN \\
\hline CHEMBL 388978 & 809262 & 9.1 & 8.7124 & TST \\
\hline CHEMBL579246 & 809262 & 6.8 & 7.3284 & TRN \\
\hline CHEMBL398951 & 809262 & 4.3 & 4.3348 & TST \\
\hline CHEMBL1982506 & 809262 & 4.0 & 4.2361 & TST \\
\hline CHEMBL2004716 & 809262 & 6.9 & 6.6878 & TRN \\
\hline CHEMBL1968127 & 809262 & 4.0 & 3.9124 & TRN \\
\hline CHEMBL1975233 & 809262 & 4.0 & 4.1478 & TRN \\
\hline CHEMBL1985406 & 809262 & 4.0 & 4.1547 & TRN \\
\hline CHEMBL 2007603 & 809262 & 4.4 & 4.1889 & TRN \\
\hline CHEMBL 207400 & 809262 & 4.0 & 3.9468 & TST \\
\hline CHEMBL 2000894 & 809262 & 7.3 & 7.5288 & TST \\
\hline CHEMBL1421720 & 809262 & 5.5 & 4.9148 & TRN \\
\hline CHEMBL 2002553 & 809262 & 4.0 & 4.3885 & TST \\
\hline CHEMBL1982135 & 809262 & 4.0 & 4.5572 & TRN \\
\hline CHEMBL1976090 & 809262 & 6.5 & 6.1152 & TRN \\
\hline CHEMBL1993243 & 809262 & 4.0 & 4.5071 & TRN \\
\hline CHEMBL2004771 & 809262 & 7.1 & 6.3177 & TRN \\
\hline CHEMBL1992922 & 809262 & 5.7 & 5.9388 & TRN \\
\hline CHEMBL399021 & 809262 & 5.8 & 5.5751 & TRN \\
\hline CHEMBL1997597 & 809262 & 5.4 & 5.6184 & TRN \\
\hline CHEMBL1969537 & 809262 & 4.0 & 4.7233 & TST \\
\hline CHEMBL1976093 & 809262 & 4.0 & 3.8798 & TRN \\
\hline CHEMBL 210032 & 809262 & 4.0 & 3.8761 & TRN \\
\hline CHEMBL1996543 & 809262 & 5.4 & 5.9375 & TRN \\
\hline CHEMBL1975256 & 809262 & 5.6 & 5.3279 & TST \\
\hline CHEMBL508928 & 809262 & 5.8 & 5.4203 & TRN \\
\hline CHEMBL1991356 & 809262 & 4.0 & 4.0584 & TST \\
\hline CHEMBL1983309 & 809262 & 4.0 & 4.1562 & TRN \\
\hline CHEMBL2004892 & 809262 & 5.5 & 5.6482 & TRN \\
\hline CHEMBL1999126 & 809262 & 4.0 & 3.8391 & TST \\
\hline CHEMBL1997503 & 809262 & 4.0 & 4.4624 & TST \\
\hline
\end{tabular}




\begin{tabular}{|c|c|c|c|c|}
\hline & & & pplement & al $\mathrm{Ta}$ \\
\hline CHEMBL116070 & 809262 & 5.9 & 5.4186 & TRN \\
\hline CHEMBL1990821 & 809262 & 4.0 & 4.1879 & TST \\
\hline CHEMBL1970314 & 809262 & 4.0 & 4.3615 & TRN \\
\hline CHEMBL 2004871 & 809262 & 4.0 & 4.1108 & TRN \\
\hline CHEMBL 2004872 & 809262 & 7.0 & 6.4846 & TRN \\
\hline CHEMBL1727312 & 809262 & 4.0 & 3.9683 & TRN \\
\hline CHEMBL1990223 & 809262 & 5.5 & 4.7654 & TRN \\
\hline CHEMBL1969879 & 809262 & 4.0 & 4.7 & TRN \\
\hline CHEMBL1964382 & 809262 & 4.4 & 5.0022 & TST \\
\hline CHEMBL101311 & 809262 & 5.9 & 5.2776 & TRN \\
\hline CHEMBL1981720 & 809262 & 4.0 & 4.1784 & TRN \\
\hline CHEMBL419932 & 809262 & 6.6 & 6.7675 & TRN \\
\hline CHEMBL262433 & 809262 & 5.4 & 5.3889 & TRN \\
\hline CHEMBL 306380 & 809262 & 5.3 & 5.5176 & TRN \\
\hline CHEMBL1966722 & 809262 & 4.0 & 4.5333 & TST \\
\hline CHEMBL1983595 & 809262 & 6.3 & 5.2937 & TRN \\
\hline CHEMBL1988581 & 809262 & 6.8 & 4.9196 & TST \\
\hline CHEMBL2005699 & 809262 & 4.4 & 4.667 & TRN \\
\hline CHEMBL1975500 & 809262 & 4.0 & 4.3414 & TRN \\
\hline CHEMBL1976328 & 809262 & 6.5 & 6.1792 & TRN \\
\hline CHEMBL394619 & 809262 & 6.6 & 6.2091 & TRN \\
\hline CHEMBL 2006564 & 809262 & 6.5 & 5.9996 & TRN \\
\hline CHEMBL1964399 & 809262 & 6.0 & 5.4596 & TRN \\
\hline CHEMBL1996831 & 809262 & 4.0 & 4.1614 & TST \\
\hline CHEMBL411903 & 809262 & 6.4 & 6.0199 & TRN \\
\hline CHEMBL1978167 & 809262 & 5.5 & 5.1195 & TST \\
\hline CHEMBL1965988 & 809262 & 6.4 & 6.8304 & TRN \\
\hline CHEMBL418203 & 809262 & 4.2 & 4.7802 & TST \\
\hline CHEMBL1989646 & 809262 & 6.2 & 7.2874 & TRN \\
\hline CHEMBL1682357 & 809262 & 6.7 & 6.7886 & TRN \\
\hline CHEMBL225519 & 809262 & 7.0 & 6.766 & TRN \\
\hline CHEMBL 209534 & 809262 & 4.0 & 4.6298 & TRN \\
\hline CHEMBL1978200 & 809262 & 4.0 & 3.9279 & TRN \\
\hline CHEMBL1994159 & 809262 & 4.3 & 4.7139 & TRN \\
\hline CHEMBL 2006631 & 809262 & 4.0 & 5.0287 & TRN \\
\hline CHEMBL1970522 & 809262 & 5.2 & 4.052 & TRN \\
\hline CHEMBL1990415 & 809262 & 4.0 & 4.4763 & TRN \\
\hline CHEMBL1966087 & 809262 & 6.3 & 6.1327 & TRN \\
\hline CHEMBL1996931 & 809262 & 5.7 & 6.4283 & TRN \\
\hline CHEMBL1964692 & 809262 & 6.4 & 6.0895 & TRN \\
\hline CHEMBL1964413 & 809262 & 5.8 & 6.5019 & TRN \\
\hline CHEMBL1973483 & 809262 & 4.0 & 3.9001 & TRN \\
\hline CHEMBL1998470 & 809262 & 6.5 & 7.2637 & TRN \\
\hline CHEMBL1996980 & 809262 & 8.4 & 8.3269 & TRN \\
\hline CHEMBL1984432 & 809262 & 6.9 & 6.9785 & TRN \\
\hline CHEMBL1970735 & 809262 & 4.0 & 4.0323 & TRN \\
\hline CHEMBL 219722 & 809262 & 6.0 & 6.1035 & TRN \\
\hline CHEMBL1975903 & 809262 & 4.4 & 5.1265 & TRN \\
\hline
\end{tabular}




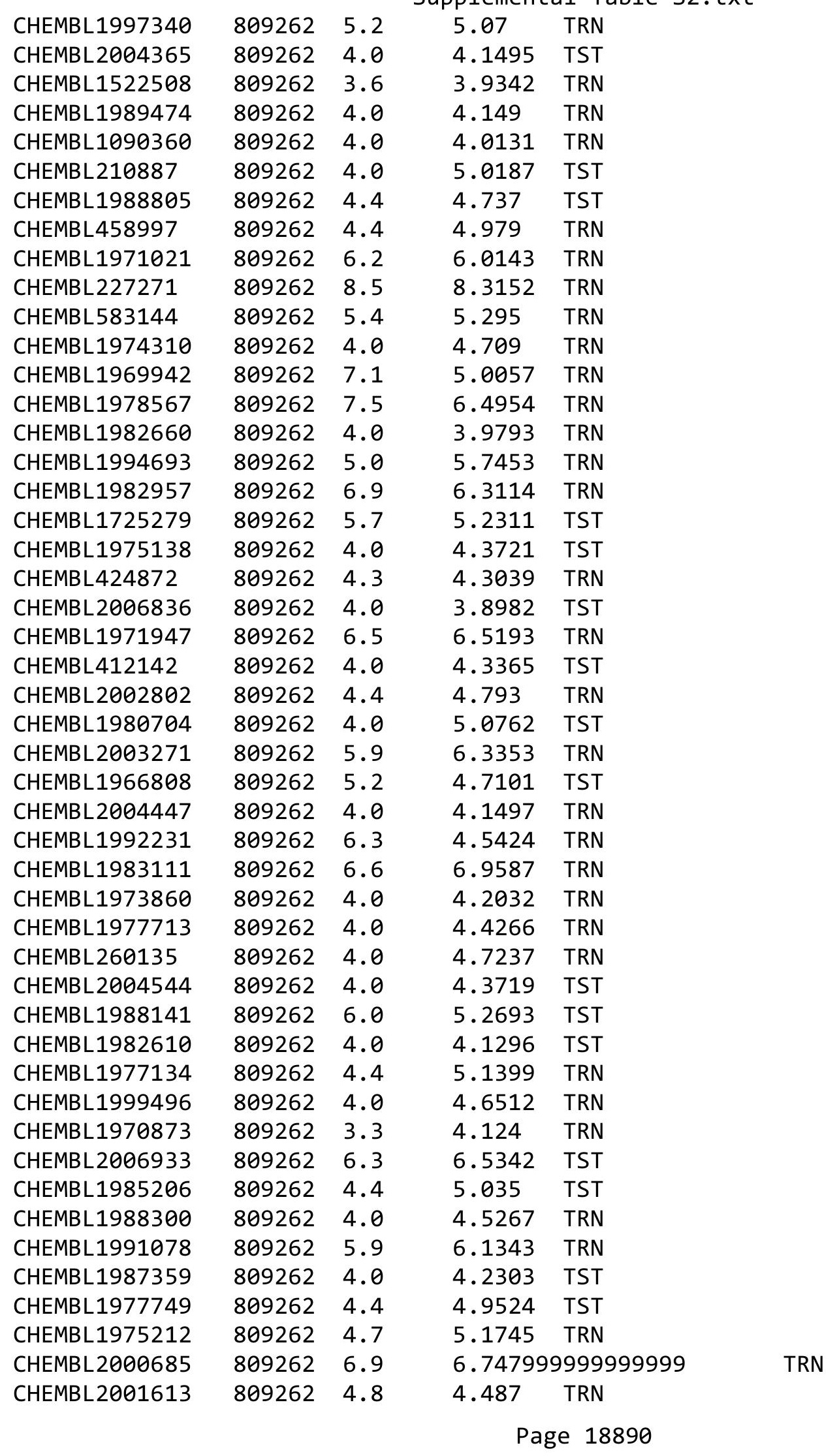




\begin{tabular}{|c|c|c|c|c|c|}
\hline \multirow{2}{*}{ CHEMBL1997275 } & \multirow{2}{*}{809262} & \\
\hline & & 4.4 & 4.995 & TRN & \\
\hline CHEMBL1993904 & 809262 & 6.5 & 6.0206 & TRN & \\
\hline CHEMBL1994438 & 809262 & 7.9 & 8.0628 & TRN & \\
\hline CHEMBL1980376 & 809262 & 5.0 & 5.5916 & TRN & \\
\hline CHEMBL1967513 & 809262 & 4.4 & 4.1219 & TRN & \\
\hline CHEMBL1985311 & 809262 & 6.1 & 6.0325 & TRN & \\
\hline CHEMBL1989265 & 809262 & 4.0 & 4.2158 & TST & \\
\hline CHEMBL1982413 & 809262 & 5.7 & 4.9072 & TRN & \\
\hline CHEMBL 2004647 & 809262 & 4.0 & 4.2639 & TST & \\
\hline CHEMBL1969502 & 809262 & 6.3 & 6.3563 & TRN & \\
\hline CHEMBL1965910 & 809262 & 5.1 & 5.106 & TRN & \\
\hline CHEMBL1682553 & 809262 & 7.0 & 6.91200 & 2000000001 & TRN \\
\hline CHEMBL1971430 & 809262 & 4.0 & 4.4595 & TRN & \\
\hline CHEMBL1983963 & 809262 & 6.1 & 6.0531 & TRN & \\
\hline CHEMBL1997764 & 809262 & 5.5 & 5.4433 & TRN & \\
\hline CHEMBL 2000271 & 809262 & 8.2 & 8.1412 & TRN & \\
\hline CHEMBL1981792 & 809262 & 4.4 & 4.2757 & TRN & \\
\hline CHEMBL1987535 & 809262 & 7.2 & 6.9096 & TRN & \\
\hline CHEMBL1985092 & 809262 & 6.7 & 6.8968 & TRN & \\
\hline CHEMBL 2004692 & 809262 & 5.3 & 5.1588 & TST & \\
\hline CHEMBL1981410 & 809262 & 5.8 & 5.2055 & TRN & \\
\hline CHEMBL 2002586 & 809262 & 5.9 & 5.5793 & TRN & \\
\hline CHEMBL1996234 & 809262 & 6.2 & 5.191 & TRN & \\
\hline CHEMBL 2007421 & 809262 & 5.7 & 5.0001 & TST & \\
\hline CHEMBL1991434 & 809262 & 4.0 & 4.1745 & TRN & \\
\hline CHEMBL1967544 & 809262 & 7.4 & 7.6576 & TRN & \\
\hline CHEMBL1973138 & 809262 & 4.4 & 5.0183 & TRN & \\
\hline CHEMBL223367 & 809262 & 4.0 & 4.8947 & TST & \\
\hline CHEMBL340384 & 809262 & 7.9 & 8.0489 & TST & \\
\hline CHEMBL1969151 & 809262 & 8.9 & 8.6683 & TRN & \\
\hline CHEMBL1996587 & 809262 & 4.0 & 3.87 & TRN & \\
\hline CHEMBL1981492 & 809262 & 4.4 & 4.8406 & TRN & \\
\hline CHEMBL1993335 & 809262 & 5.9 & 5.1483 & TST & \\
\hline CHEMBL1988692 & 809262 & 4.4 & 4.9691 & TRN & \\
\hline CHEMBL 2007574 & 809262 & 8.5 & 7.5871 & TRN & \\
\hline CHEMBL1964804 & 809262 & 6.6 & 6.4994 & TRN & \\
\hline CHEMBL443962 & 809262 & 4.0 & 4.119 & TST & \\
\hline CHEMBL 2000354 & 809262 & 5.1 & 4.1774 & TRN & \\
\hline CHEMBL1965507 & 809262 & 5.7 & 4.4422 & TRN & \\
\hline CHEMBL274064 & 809262 & 4.0 & 4.322 & TRN & \\
\hline CHEMBL1998680 & 809262 & 4.4 & 4.92899 & 9999999999 & TRN \\
\hline CHEMBL1967564 & 809262 & 4.0 & 3.951 & TRN & \\
\hline CHEMBL592030 & 809262 & 7.1 & 7.0441 & TST & \\
\hline CHEMBL 2000071 & 809262 & 5.4 & 5.6993 & TRN & \\
\hline CHEMBL1979176 & 809262 & 4.0 & 3.8467 & TRN & \\
\hline CHEMBL1970317 & 809262 & 5.7 & 6.12799 & 9999999999 & TRN \\
\hline CHEMBL 2000408 & 809262 & 4.0 & 3.9347 & TRN & \\
\hline CHEMBL248757 & 809262 & 4.0 & 4.4453 & TST & \\
\hline
\end{tabular}




\begin{tabular}{|c|c|c|c|c|c|}
\hline \multicolumn{6}{|c|}{ Supplemental Table S2.txt } \\
\hline CHEMBL1978014 & 809262 & 4.0 & 5.2623 & TRN & \\
\hline CHEMBL 2002736 & 809262 & 5.8 & 5.4877 & TRN & \\
\hline CHEMBL1997007 & 809262 & 5.5 & 5.3885 & TRN & \\
\hline CHEMBL1994538 & 809262 & 4.0 & 3.9213 & TRN & \\
\hline CHEMBL1983195 & 809262 & 4.0 & 4.1128 & TST & \\
\hline CHEMBL1975490 & 809262 & 6.4 & 6.4923 & TRN & \\
\hline CHEMBL1964444 & 809262 & 4.2 & 4.0122 & TRN & \\
\hline CHEMBL1989957 & 809262 & 4.0 & 4.1183 & TRN & \\
\hline CHEMBL 2002690 & 809262 & 4.4 & 4.6377 & TRN & \\
\hline CHEMBL 2006567 & 809262 & 4.0 & 3.971 & TRN & \\
\hline CHEMBL1986139 & 809262 & 4.0 & 3.9505 & TRN & \\
\hline CHEMBL1975503 & 809262 & 4.9 & 4.7957 & TRN & \\
\hline CHEMBL 383527 & 809262 & 7.0 & 7.00299 & 9999999999 & TRN \\
\hline CHEMBL1980540 & 809262 & 4.0 & 3.93 & TRN & \\
\hline CHEMBL 278041 & 809262 & 4.4 & 4.4172 & TRN & \\
\hline CHEMBL1979883 & 809262 & 6.7 & 6.6995 & TRN & \\
\hline CHEMBL1984162 & 809262 & 6.5 & 6.8067 & TRN & \\
\hline CHEMBL1997051 & 809262 & 5.5 & 4.4091 & TRN & \\
\hline CHEMBL491758 & 809262 & 4.0 & 4.7938 & TRN & \\
\hline CHEMBL1986590 & 809262 & 5.9 & 4.9659 & TRN & \\
\hline CHEMBL549730 & 809262 & 6.5 & 5.83 & TRN & \\
\hline CHEMBL1682360 & 809262 & 6.2 & 6.1533 & TRN & \\
\hline CHEMBL1970189 & 809262 & 4.0 & 3.9997 & TRN & \\
\hline CHEMBL1870106 & 809262 & 9.1 & 7.6077 & TST & \\
\hline CHEMBL1996791 & 809262 & 4.0 & 4.6933 & TRN & \\
\hline CHEMBL371206 & 809262 & 6.4 & 6.2659 & TRN & \\
\hline CHEMBL1974664 & 809262 & 4.0 & 4.6041 & TST & \\
\hline CHEMBL406845 & 809262 & 4.4 & 5.0139 & TRN & \\
\hline CHEMBL482538 & 809262 & 6.6 & 5.6701 & TRN & \\
\hline CHEMBL1974288 & 809262 & 7.3 & 8.0858 & TRN & \\
\hline CHEMBL1984296 & 809262 & 4.4 & 4.6316 & TST & \\
\hline CHEMBL196363 & 809262 & 6.3 & 6.3492 & TRN & \\
\hline CHEMBL1996837 & 809262 & 4.9 & 4.9634 & TRN & \\
\hline CHEMBL1190711 & 809262 & 6.7 & 5.6468 & TRN & \\
\hline CHEMBL1990346 & 809262 & 6.1 & 5.8692 & TRN & \\
\hline CHEMBL1968705 & 809262 & 6.8 & 6.5058 & TRN & \\
\hline CHEMBL1991410 & 809262 & 7.1 & 6.1833 & TRN & \\
\hline CHEMBL1964441 & 809262 & 7.3 & 6.8282 & TRN & \\
\hline CHEMBL546797 & 809262 & 5.7 & 4.7473 & TRN & \\
\hline CHEMBL404367 & 809262 & 6.1 & 5.9556 & TRN & \\
\hline CHEMBL1966343 & 809262 & 6.3 & 6.3218 & TRN & \\
\hline CHEMBL1967887 & 809262 & 7.3 & 7.3696 & TRN & \\
\hline CHEMBL 2007266 & 809262 & 4.4 & 5.683 & TRN & \\
\hline CHEMBL 2000568 & 809262 & 5.6 & 4.7152 & TRN & \\
\hline CHEMBL1994308 & 809262 & 4.4 & 5.1611 & TRN & \\
\hline CHEMBL 2000335 & 809262 & 6.9 & 6.2801 & TRN & \\
\hline CHEMBL1977604 & 809262 & 4.0 & 4.064 & TST & \\
\hline CHEMBL1988717 & 809262 & 4.0 & 4.7976 & TRN & \\
\hline
\end{tabular}




\begin{tabular}{|c|c|c|c|c|c|}
\hline \\
\hline CHEMBL1974328 & 809262 & 7.2 & 7.0348 & TRN & \\
\hline CHEMBL509032 & 809262 & 7.2 & 6.855 & TRN & \\
\hline CHEMBL1973808 & 809262 & 5.6 & 5.4325 & TRN & \\
\hline CHEMBL 2000429 & 809262 & 4.0 & 3.8908 & TRN & \\
\hline CHEMBL1972576 & 809262 & 4.0 & 4.5329 & TRN & \\
\hline CHEMBL1992555 & 809262 & 6.3 & 5.4756 & TST & \\
\hline CHEMBL1992342 & 809262 & 6.1 & 5.9146 & TRN & \\
\hline CHEMBL1988173 & 809262 & 4.0 & 4.8994 & TST & \\
\hline CHEMBL1973013 & 809262 & 4.4 & 5.4044 & TST & \\
\hline CHEMBL1164265 & 809262 & 4.4 & 4.8914 & TST & \\
\hline CHEMBL535331 & 809262 & 4.0 & 4.2915 & TRN & \\
\hline CHEMBL1989805 & 809262 & 4.0 & 3.8419 & TST & \\
\hline CHEMBL1966204 & 809262 & 6.3 & 5.8622 & TRN & \\
\hline CHEMBL1982980 & 809262 & 4.0 & 4.1542 & TST & \\
\hline CHEMBL1965423 & 809262 & 4.0 & 3.8846 & TRN & \\
\hline CHEMBL1983025 & 809262 & 6.3 & 6.7698 & TRN & \\
\hline CHEMBL 205415 & 809262 & 7.8 & 7.9614 & TRN & \\
\hline CHEMBL1977135 & 809262 & 6.8 & 6.7393 & TRN & \\
\hline CHEMBL 2001920 & 809262 & 5.3 & 5.1931 & TRN & \\
\hline CHEMBL 2002322 & 809262 & 4.0 & 4.3848 & TRN & \\
\hline CHEMBL1997119 & 809262 & 4.5 & 4.9062 & TRN & \\
\hline CHEMBL1977138 & 809262 & 6.1 & 5.1405 & TST & \\
\hline CHEMBL 2002323 & 809262 & 4.0 & 4.3027 & TST & \\
\hline CHEMBL1241473 & 809262 & 6.8 & 6.6599 & TRN & \\
\hline CHEMBL2000879 & 809262 & 5.1 & 4.8196 & TST & \\
\hline CHEMBL1978448 & 809262 & 4.2 & 4.4789 & TST & \\
\hline CHEMBL1972258 & 809262 & 6.6 & 6.1017 & TRN & \\
\hline CHEMBL 2004513 & 809262 & 5.6 & 4.9441 & TRN & \\
\hline CHEMBL1991251 & 809262 & 4.4 & 5.0819 & TST & \\
\hline CHEMBL1969483 & 809262 & 4.4 & 4.579 & TRN & \\
\hline CHEMBL1980329 & 809262 & 4.4 & 5.4416 & TRN & \\
\hline CHEMBL 2004515 & 809262 & 6.4 & 5.57706 & 0000000001 & TRN \\
\hline CHEMBL 2001257 & 809262 & 6.4 & 6.3766 & TRN & \\
\hline CHEMBL1992042 & 809262 & 4.4 & 5.2887 & TST & \\
\hline CHEMBL 2005548 & 809262 & 6.8 & 6.6479 & TRN & \\
\hline CHEMBL1987793 & 809262 & 5.0 & 4.3174 & TST & \\
\hline CHEMBL1992536 & 809262 & 6.3 & 5.7984 & TRN & \\
\hline CHEMBL21156 & 809262 & 6.3 & 4.9779 & TST & \\
\hline CHEMBL1992740 & 809262 & 4.0 & 4.0331 & TRN & \\
\hline CHEMBL1994724 & 809262 & 8.9 & 6.9571 & TRN & \\
\hline CHEMBL1989267 & 809262 & 6.3 & 5.0947 & TRN & \\
\hline CHEMBL 2002373 & 809262 & 4.0 & 4.1531 & TRN & \\
\hline CHEMBL439340 & 809262 & 4.0 & 4.4874 & TRN & \\
\hline CHEMBL 2006188 & 809262 & 7.4 & 7.1871 & TRN & \\
\hline CHEMBL1967531 & 809262 & 5.7 & 5.8586 & TRN & \\
\hline CHEMBL1970913 & 809262 & 4.0 & 3.9662 & TRN & \\
\hline CHEMBL1973893 & 809262 & 4.0 & 4.3866 & TRN & \\
\hline CHEMBL1995736 & 809262 & 4.0 & 4.2168 & TRN & \\
\hline & & & & 885 & \\
\hline
\end{tabular}




\begin{tabular}{|c|c|c|c|c|c|}
\hline \multicolumn{6}{|c|}{ Supplemental Table S2.txt } \\
\hline CHEMBL1997534 & 809262 & 7.7 & 6.8817 & TRN & \\
\hline CHEMBL1993877 & 809262 & 6.0 & 5.0929 & TRN & \\
\hline CHEMBL1985095 & 809262 & 5.8 & 6.438 & TST & \\
\hline CHEMBL1996500 & 809262 & 4.5 & 3.9646 & TRN & \\
\hline CHEMBL1998551 & 809262 & 4.0 & 3.9163 & TRN & \\
\hline CHEMBL1977374 & 809262 & 4.0 & 3.9358 & TRN & \\
\hline CHEMBL1973363 & 809262 & 6.0 & 5.2876 & TRN & \\
\hline CHEMBL1991180 & 809262 & 6.3 & 6.5675 & TST & \\
\hline CHEMBL1682540 & 809262 & 6.0 & 6.2241 & TRN & \\
\hline CHEMBL1978656 & 809262 & 4.0 & 4.0434 & TRN & \\
\hline CHEMBL1976420 & 809262 & 5.0 & 4.3804 & TST & \\
\hline CHEMBL1998253 & 809262 & 4.4 & 4.5752 & TST & \\
\hline CHEMBL413779 & 809262 & 4.0 & 4.9289 & TST & \\
\hline CHEMBL1994864 & 809262 & 6.7 & 5.6808 & TRN & \\
\hline CHEMBL1981744 & 809262 & 4.4 & 4.1117 & TRN & \\
\hline CHEMBL 2002446 & 809262 & 4.0 & 4.7713 & TST & \\
\hline CHEMBL497151 & 809262 & 5.2 & 5.3944 & TRN & \\
\hline CHEMBL 2000029 & 809262 & 8.4 & 7.6589 & TRN & \\
\hline CHEMBL1973961 & 809262 & 4.6 & 4.8731 & TRN & \\
\hline CHEMBL246970 & 809262 & 4.0 & 5.0544 & TRN & \\
\hline CHEMBL340921 & 809262 & 7.0 & 7.4913 & TST & \\
\hline CHEMBL373598 & 809262 & 4.0 & 4.8169 & TST & \\
\hline CHEMBL 2001149 & 809262 & 5.9 & 4.9955 & TRN & \\
\hline CHEMBL1999718 & 809262 & 4.0 & 3.9295 & TRN & \\
\hline CHEMBL1987073 & 809262 & 6.3 & 5.24100 & 00000000005 & TRN \\
\hline CHEMBL 2000078 & 809262 & 4.4 & 4.5706 & TRN & \\
\hline CHEMBL1276446 & 809262 & 6.5 & 6.968 & TST & \\
\hline CHEMBL 2005478 & 809262 & 4.4 & 5.3242 & TST & \\
\hline CHEMBL1996646 & 809262 & 5.8 & 5.0592 & TRN & \\
\hline CHEMBL1995712 & 809262 & 6.2 & 7.0273 & TRN & \\
\hline CHEMBL1977346 & 809262 & 4.0 & 3.9222 & TRN & \\
\hline CHEMBL 2003657 & 809262 & 4.0 & 3.9986 & TRN & \\
\hline CHEMBL1971649 & 809262 & 5.1 & 5.284 & TRN & \\
\hline CHEMBL1992723 & 809262 & 5.2 & 4.3432 & TRN & \\
\hline CHEMBL 2005482 & 809262 & 4.4 & 4.6705 & TRN & \\
\hline CHEMBL1996702 & 809262 & 5.7 & 4.6619 & TRN & \\
\hline CHEMBL1997909 & 809262 & 4.4 & 4.3045 & TRN & \\
\hline CHEMBL 2007124 & 809262 & 4.4 & 5.3097 & TRN & \\
\hline CHEMBL1998435 & 809262 & 5.1 & 4.9984 & TRN & \\
\hline CHEMBL 2006439 & 809262 & 7.8 & 7.4548 & TRN & \\
\hline CHEMBL 2006156 & 809262 & 4.0 & 4.0254 & TST & \\
\hline CHEMBL1985681 & 809262 & 5.7 & 4.8439 & TST & \\
\hline CHEMBL1969190 & 809262 & 5.9 & 5.9138 & TRN & \\
\hline CHEMBL1973937 & 809262 & 5.4 & 5.888 & TRN & \\
\hline CHEMBL1991674 & 809262 & 7.5 & 8.1021 & TRN & \\
\hline CHEMBL1982711 & 809262 & 6.4 & 6.6356 & TRN & \\
\hline CHEMBL 262623 & 809262 & 4.6 & 5.2478 & TRN & \\
\hline CHEMBL1987982 & 809262 & 4.0 & 4.4721 & TST & \\
\hline
\end{tabular}




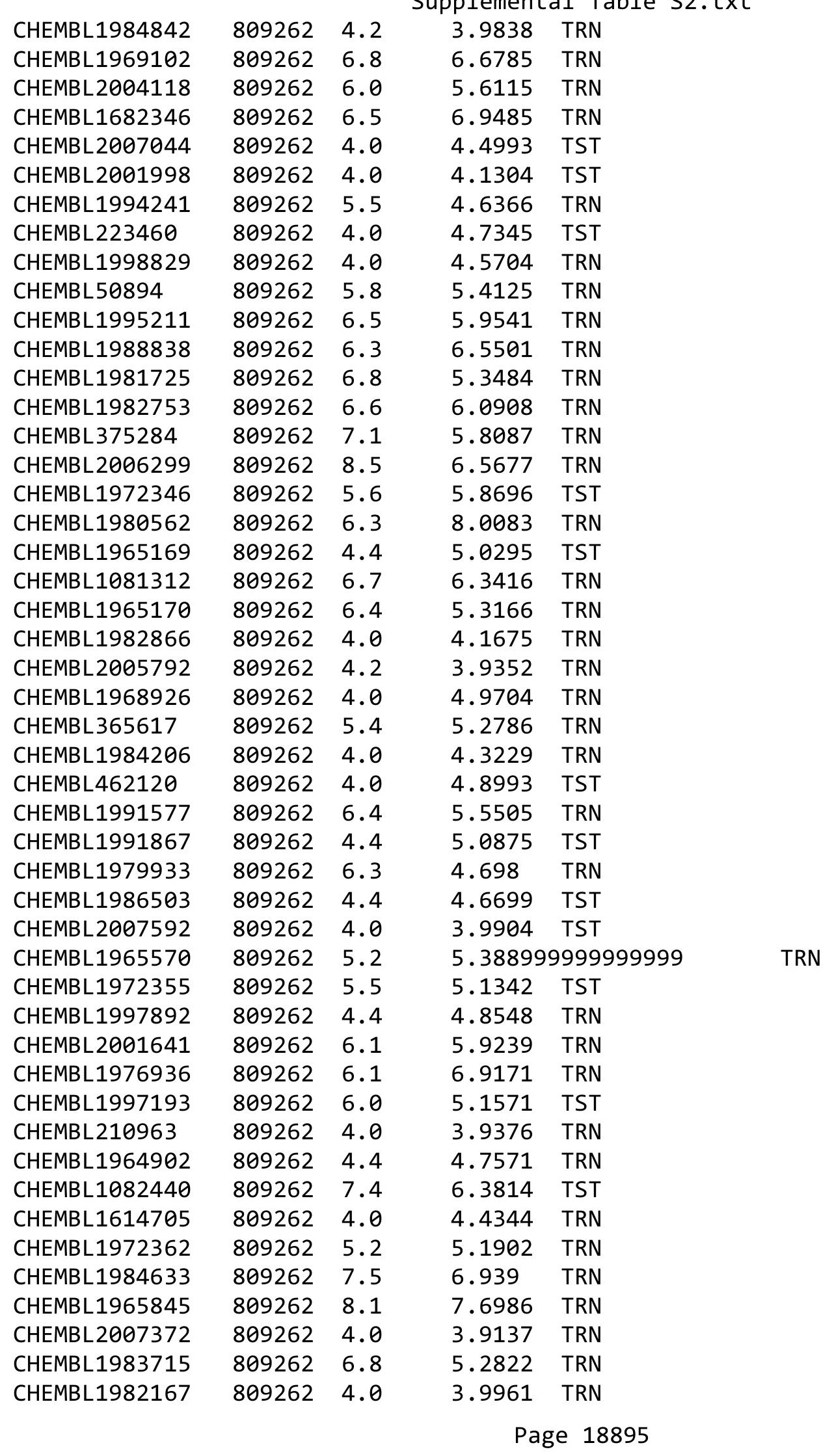




\begin{tabular}{|c|c|c|c|c|}
\hline & & & & \\
\hline CHEMBL1971017 & 809262 & 5.3 & 4.8363 & TRN \\
\hline CHEMBL2006715 & 809262 & 4.0 & 4.2194 & TRN \\
\hline CHEMBL1986597 & 809262 & 5.8 & 5.7992 & TRN \\
\hline CHEMBL1990482 & 809262 & 6.4 & 6.0483 & TRN \\
\hline CHEMBL1990904 & 809262 & 4.0 & 3.9076 & TRN \\
\hline CHEMBL 2000104 & 809262 & 5.4 & 5.0135 & TRN \\
\hline CHEMBL2005475 & 809262 & 4.0 & 4.1126 & TRN \\
\hline CHEMBL1987448 & 809262 & 8.3 & 7.7267 & TRN \\
\hline CHEMBL402846 & 809262 & 5.9 & 5.5387 & TRN \\
\hline CHEMBL1997349 & 809262 & 4.0 & 4.0451 & TST \\
\hline CHEMBL183844 & 809262 & 4.0 & 5.4828 & TRN \\
\hline CHEMBL220057 & 809262 & 6.7 & 6.4309 & TRN \\
\hline CHEMBL1682545 & 809262 & 6.4 & 5.7756 & TRN \\
\hline CHEMBL 383541 & 809262 & 7.6 & 7.8001 & TRN \\
\hline CHEMBL 2001224 & 809262 & 4.0 & 4.379 & TRN \\
\hline CHEMBL10 & 809262 & 4.4 & 4.2282 & TRN \\
\hline CHEMBL1976732 & 809262 & 4.0 & 3.9261 & TRN \\
\hline CHEMBL2005216 & 809262 & 7.4 & 7.7732 & TRN \\
\hline CHEMBL1969506 & 809262 & 6.1 & 5.6399 & TRN \\
\hline CHEMBL1980763 & 809262 & 5.9 & 5.7138 & TRN \\
\hline CHEMBL1964937 & 809262 & 6.6 & 7.4846 & TRN \\
\hline CHEMBL1980163 & 809262 & 4.0 & 4.0662 & TRN \\
\hline CHEMBL590109 & 809262 & 6.4 & 6.7438 & TST \\
\hline CHEMBL1970879 & 809262 & 6.4 & 4.6901 & TRN \\
\hline CHEMBL1989856 & 809262 & 4.0 & 4.2152 & TST \\
\hline CHEMBL 2005899 & 809262 & 6.8 & 6.1281 & TRN \\
\hline CHEMBL1972568 & 809262 & 5.4 & 5.7517 & TRN \\
\hline CHEMBL1682552 & 809262 & 6.6 & 6.6334 & TRN \\
\hline CHEMBL 259850 & 809262 & 4.0 & 4.1455 & TRN \\
\hline CHEMBL 2007479 & 809262 & 4.4 & 4.9068 & TRN \\
\hline CHEMBL1996155 & 809262 & 6.2 & 5.3899 & TRN \\
\hline CHEMBL105739 & 809262 & 5.3 & 4.9674 & TRN \\
\hline CHEMBL1682359 & 809262 & 6.3 & 6.1694 & TRN \\
\hline CHEMBL1972220 & 809262 & 6.7 & 5.6693 & TRN \\
\hline CHEMBL 379300 & 809262 & 8.1 & 8.6087 & TRN \\
\hline CHEMBL203673 & 809262 & 6.7 & 6.7394 & TRN \\
\hline CHEMBL 2003785 & 809262 & 5.3 & 4.7659 & TST \\
\hline CHEMBL1973720 & 809262 & 8.9 & 8.8864 & TRN \\
\hline CHEMBL1969523 & 809262 & 6.2 & $5.4620 e$ & 0000000001 \\
\hline CHEMBL1988995 & 809262 & 4.0 & 3.8801 & TRN \\
\hline CHEMBL207995 & 809262 & 5.3 & 4.1528 & TRN \\
\hline CHEMBL 2001923 & 809262 & 4.2 & 5.2776 & TRN \\
\hline CHEMBL1986781 & 809262 & 4.0 & 3.9572 & TRN \\
\hline CHEMBL526133 & 809262 & 5.8 & 5.9251 & TRN \\
\hline CHEMBL 2003514 & 809262 & 8.4 & 7.0416 & TRN \\
\hline CHEMBL1989043 & 809262 & 4.4 & 5.3173 & TRN \\
\hline CHEMBL 2002470 & 809262 & 5.1 & 4.6106 & TST \\
\hline CHEMBL1979057 & 809262 & 6.7 & 5.5988 & TRN \\
\hline
\end{tabular}




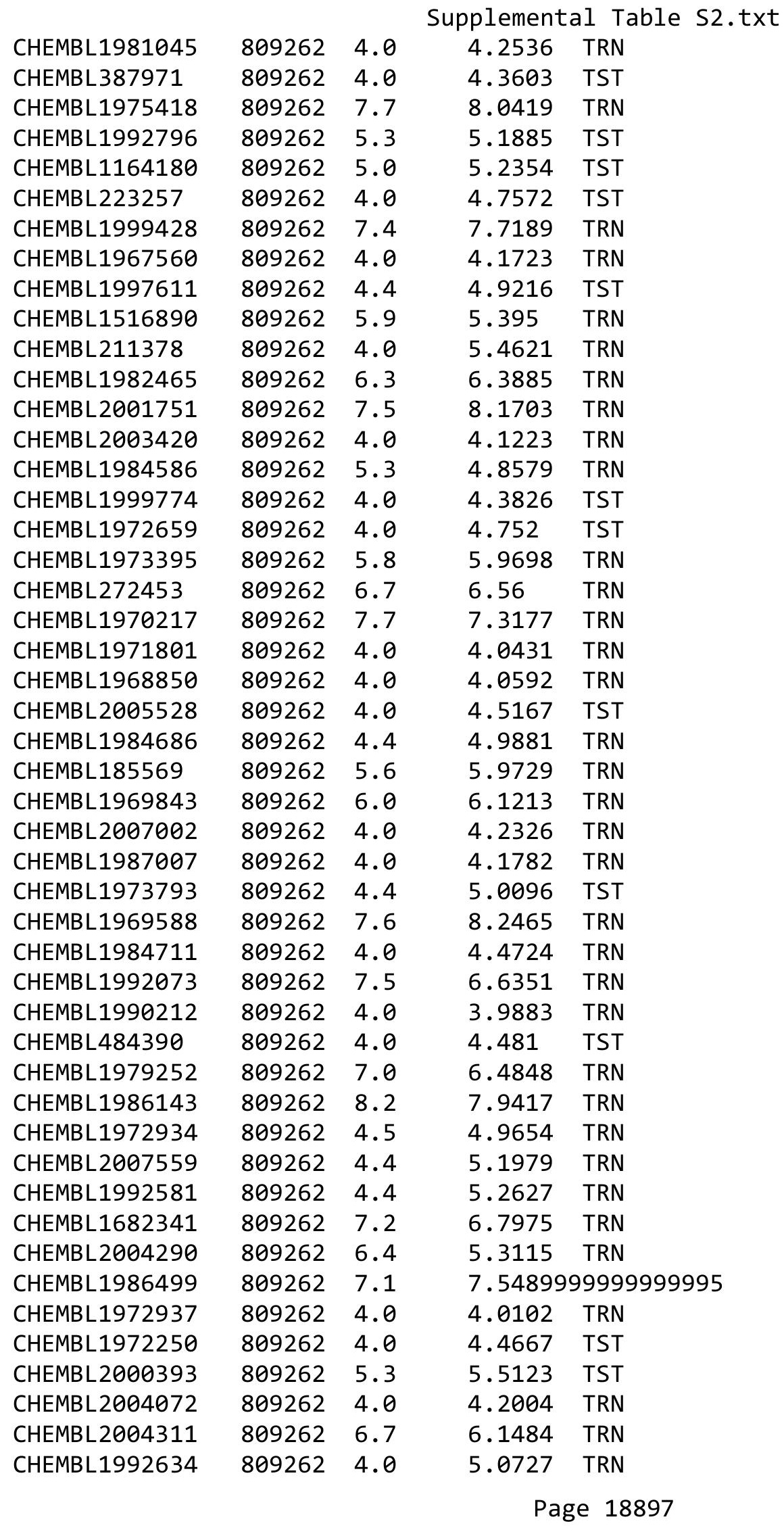

TRN 


\begin{tabular}{|c|c|c|c|c|c|}
\hline \\
\hline CHEMBL1242373 & 809262 & 6.1 & 6.4562 & TRN & \\
\hline CHEMBL 2000433 & 809262 & 4.0 & 4.2054 & TST & \\
\hline CHEMBL56543 & 809262 & 4.0 & 4.1944 & TRN & \\
\hline CHEMBL316264 & 809262 & 4.0 & 4.0255 & TRN & \\
\hline CHEMBL1988075 & 809262 & 6.0 & 5.7977 & TRN & \\
\hline CHEMBL1996576 & 809262 & 4.4 & 4.8588 & TST & \\
\hline CHEMBL1988076 & 809262 & 4.4 & 4.382 & TRN & \\
\hline CHEMBL1991678 & 809262 & 4.4 & 3.9818 & TRN & \\
\hline CHEMBL 2001239 & 809262 & 5.7 & 5.8188 & TRN & \\
\hline CHEMBL1988594 & 809262 & 4.0 & 4.3131 & TRN & \\
\hline CHEMBL 2001288 & 809262 & 4.0 & 4.3799 & TRN & \\
\hline CHEMBL1992363 & 809262 & 6.3 & 6.3133 & TRN & \\
\hline CHEMBL260092 & 809262 & 6.2 & 5.8338 & TRN & \\
\hline CHEMBL1999811 & 809262 & 5.6 & 5.7815 & TRN & \\
\hline CHEMBL1965495 & 809262 & 5.7 & 5.2233 & TRN & \\
\hline CHEMBL1985074 & 809262 & 4.0 & 4.1396 & TST & \\
\hline CHEMBL 2000481 & 809262 & 7.0 & 6.8135 & TRN & \\
\hline CHEMBL1982874 & 809262 & 4.0 & 3.9434 & TRN & \\
\hline CHEMBL1991725 & 809262 & 6.8 & 6.8285 & TRN & \\
\hline CHEMBL1992242 & 809262 & 4.0 & 4.6016 & TRN & \\
\hline CHEMBL1982271 & 809262 & 8.3 & 8.1922 & TRN & \\
\hline CHEMBL 2007296 & 809262 & 7.6 & 6.8914 & TRN & \\
\hline CHEMBL208637 & 809262 & 4.0 & 4.0047 & TRN & \\
\hline CHEMBL 2004159 & 809262 & 7.6 & 5.8403 & TRN & \\
\hline CHEMBL396523 & 809262 & 6.7 & 6.7671 & TRN & \\
\hline CHEMBL1978371 & 809262 & 5.8 & 4.7627 & TST & \\
\hline CHEMBL1970203 & 809262 & 4.0 & 4.3119 & TRN & \\
\hline CHEMBL1986530 & 809262 & 4.0 & 4.3461 & TST & \\
\hline CHEMBL440084 & 809262 & 4.4 & 4.8455 & TRN & \\
\hline CHEMBL1999321 & 809262 & 4.0 & 4.5175 & TRN & \\
\hline CHEMBL1968590 & 809262 & 4.0 & 4.3991 & TRN & \\
\hline CHEMBL1999749 & 809262 & 4.0 & 4.3841 & TRN & \\
\hline CHEMBL 2005375 & 809262 & 4.0 & 4.1986 & TRN & \\
\hline CHEMBL1984191 & 809262 & 4.0 & 4.5878 & TRN & \\
\hline CHEMBL1983006 & 809262 & 4.0 & 4.0972 & TRN & \\
\hline CHEMBL1972183 & 809262 & 4.0 & 4.3982 & TRN & \\
\hline CHEMBL1971029 & 809262 & 6.0 & 6.1012 & TRN & \\
\hline CHEMBL 394790 & 809262 & 6.3 & 6.3013 & TRN & \\
\hline CHEMBL 2001451 & 809262 & 5.8 & 5.0057 & TRN & \\
\hline CHEMBL226471 & 809262 & 4.0 & 4.4186 & TRN & \\
\hline CHEMBL1974702 & 809262 & 4.0 & 4.2401 & TRN & \\
\hline CHEMBL1996111 & 809262 & 6.7 & 7.54899 & 99999999995 & TRN \\
\hline CHEMBL1966175 & 809262 & 7.6 & 5.7065 & TRN & \\
\hline CHEMBL1965589 & 809262 & 4.0 & 4.0387 & TRN & \\
\hline CHEMBL 2007375 & 809262 & 4.4 & 4.2072 & TRN & \\
\hline CHEMBL1998193 & 809262 & 4.0 & 4.2535 & TRN & \\
\hline CHEMBL379975 & 809262 & 4.7 & 5.4266 & TST & \\
\hline CHEMBL474432 & 809262 & 4.0 & 4.4488 & TST & \\
\hline
\end{tabular}




\begin{tabular}{|c|c|c|c|c|c|}
\hline \multicolumn{6}{|c|}{ Supplemental Table S2.txt } \\
\hline CHEMBL1973016 & 809262 & 4.4 & 4.881 & TST & \\
\hline CHEMBL1965387 & 809262 & 4.4 & 5.9215 & TRN & \\
\hline CHEMBL 2001539 & 809262 & 5.8 & 4.5118 & TST & \\
\hline CHEMBL1997041 & 809262 & 5.6 & 5.3471 & TRN & \\
\hline CHEMBL1988153 & 809262 & 4.0 & 4.0159 & TRN & \\
\hline CHEMBL550418 & 809262 & 4.4 & 4.5796 & TRN & \\
\hline CHEMBL1972584 & 809262 & 6.2 & 5.6069 & TRN & \\
\hline CHEMBL1971289 & 809262 & 4.4 & 4.7733 & TRN & \\
\hline CHEMBL1999556 & 809262 & 5.3 & 4.9219 & TRN & \\
\hline CHEMBL1988437 & 809262 & 4.3 & 5.5806 & TST & \\
\hline CHEMBL1968245 & 809262 & 6.9 & 7.5957 & TRN & \\
\hline CHEMBL1979577 & 809262 & 6.8 & 7.1689 & TRN & \\
\hline CHEMBL1998121 & 809262 & 8.4 & 8.1437 & TRN & \\
\hline CHEMBL1991800 & 809262 & 4.0 & 3.9004 & TRN & \\
\hline CHEMBL52387 & 809262 & 4.0 & 4.2838 & TST & \\
\hline CHEMBL1985566 & 809262 & 4.0 & 4.2824 & TRN & \\
\hline CHEMBL2003689 & 809262 & 4.4 & 4.6445 & TRN & \\
\hline CHEMBL379835 & 809262 & 4.0 & 3.895 & TST & \\
\hline CHEMBL1979357 & 809262 & 6.5 & 6.7229 & TRN & \\
\hline CHEMBL1980802 & 809262 & 4.0 & 4.3675 & TST & \\
\hline CHEMBL1996649 & 809262 & 5.9 & 5.9464 & TRN & \\
\hline CHEMBL1996817 & 809262 & 6.3 & 6.2758 & TRN & \\
\hline CHEMBL1979554 & 809262 & 7.9 & 7.9183 & TRN & \\
\hline CHEMBL1986756 & 809262 & 4.4 & 4.2178 & TRN & \\
\hline CHEMBL3197315 & 809262 & 4.0 & 5.1158 & TST & \\
\hline CHEMBL 2004355 & 809262 & 4.0 & 4.8092 & TRN & \\
\hline CHEMBL468280 & 809262 & 4.0 & 4.1476 & TST & \\
\hline CHEMBL1990884 & 809262 & 5.8 & 5.2619 & TRN & \\
\hline CHEMBL3109278 & 809262 & 4.6 & 5.7761 & TRN & \\
\hline CHEMBL 256835 & 809262 & 4.0 & 4.1017 & TRN & \\
\hline CHEMBL1970006 & 809262 & 4.0 & 5.1826 & TST & \\
\hline CHEMBL1980142 & 809262 & 4.0 & 3.8943 & TRN & \\
\hline CHEMBL41783 & 809262 & 4.0 & 4.1045 & TRN & \\
\hline CHEMBL2004438 & 809262 & 4.3 & 5.4543 & TRN & \\
\hline CHEMBL 2006276 & 809262 & 5.6 & 4.7977 & TRN & \\
\hline CHEMBL191003 & 809262 & 6.9 & $6.1220 e$ & 0000000001 & TRN \\
\hline CHEMBL 271381 & 809262 & 5.6 & 5.8637 & TRN & \\
\hline CHEMBL 2006785 & 809262 & 4.0 & 4.2628 & TRN & \\
\hline CHEMBL1982466 & 809262 & 7.0 & 6.1097 & TRN & \\
\hline CHEMBL1973359 & 809262 & 6.0 & 5.2216 & TST & \\
\hline CHEMBL1995740 & 809262 & 4.0 & 4.8169 & TRN & \\
\hline CHEMBL1996390 & 809262 & 4.0 & 4.4779 & TRN & \\
\hline CHEMBL1990162 & 809262 & 6.3 & 5.6029 & TRN & \\
\hline CHEMBL1979690 & 809262 & 6.6 & 6.55 & TRN & \\
\hline CHEMBL 234085 & 809262 & 6.6 & 5.4555 & TRN & \\
\hline CHEMBL1998414 & 809262 & 4.0 & 4.2472 & TRN & \\
\hline CHEMBL1995832 & 809262 & 4.0 & $3.9010 e$ & 00000000002 & TRN \\
\hline CHEMBL1969042 & 809262 & 6.3 & 6.7097 & TRN & \\
\hline
\end{tabular}





\begin{tabular}{|c|c|c|c|c|}
\hline & & & pl & \\
\hline CHEMBL95692 & 809262 & 4.0 & 4.1916 & TRN \\
\hline CHEMBL1090356 & 809262 & 4.0 & 4.0778 & TRN \\
\hline CHEMBL1976455 & 809262 & 4.0 & 4.2248 & TRN \\
\hline CHEMBL261849 & 809262 & 4.4 & 5.1677 & TST \\
\hline CHEMBL1983923 & 809262 & 4.5 & 4.6301 & TRN \\
\hline CHEMBL1983534 & 809262 & 7.1 & 7.1544 & TRN \\
\hline CHEMBL1982361 & 809262 & 7.0 & 5.71 & TRN \\
\hline CHEMBL1999112 & 809262 & 4.0 & 3.9617 & TST \\
\hline CHEMBL1982122 & 809262 & 7.7 & 7.2959 & TRN \\
\hline CHEMBL 2000801 & 809262 & 4.0 & 4.2561 & TRN \\
\hline CHEMBL1682546 & 809262 & 6.2 & 6.3194 & TRN \\
\hline CHEMBL1988872 & 809262 & 5.8 & 5.5933 & TRN \\
\hline CHEMBL1991395 & 809262 & 4.0 & 3.8795 & TRN \\
\hline CHEMBL1971245 & 809262 & 4.0 & 4.338 & TRN \\
\hline CHEMBL1987648 & 809262 & 4.0 & 3.9787 & TRN \\
\hline CHEMBL1996780 & 809262 & 6.8 & 7.0932 & TST \\
\hline CHEMBL1972142 & 809262 & 6.1 & 4.5354 & TRN \\
\hline CHEMBL1966514 & 809262 & 5.6 & 5.6043 & TRN \\
\hline CHEMBL 2003638 & 809262 & 4.9 & 5.7743 & TRN \\
\hline CHEMBL296586 & 809262 & 5.7 & 5.0294 & TRN \\
\hline CHEMBL1996066 & 809262 & 4.0 & 4.0361 & TST \\
\hline CHEMBL1983393 & 809262 & 4.4 & 5.1048 & TRN \\
\hline CHEMBL516429 & 809262 & 7.7 & 8.4332 & TRN \\
\hline CHEMBL1972152 & 809262 & 4.0 & 4.6261 & TST \\
\hline CHEMBL1970806 & 809262 & 4.0 & 4.1697 & TST \\
\hline CHEMBL1993722 & 809262 & 5.5 & 5.5824 & TRN \\
\hline CHEMBL 2006674 & 809262 & 4.4 & 5.0599 & TST \\
\hline CHEMBL1984236 & 809262 & 4.4 & 5.346 & TST \\
\hline CHEMBL1992371 & 809262 & 4.4 & 4.4632 & TRN \\
\hline CHEMBL 202635 & 809262 & 4.0 & 4.4328 & TRN \\
\hline CHEMBL1375640 & 809262 & 6.4 & 5.8796 & TST \\
\hline CHEMBL1979970 & 809262 & 4.0 & 3.9422 & TRN \\
\hline CHEMBL 2002599 & 809262 & 4.4 & 4.5212 & TRN \\
\hline CHEMBL249282 & 809262 & 4.0 & 4.4236 & TST \\
\hline CHEMBL1967252 & 809262 & 6.6 & 5.8149 & TRN \\
\hline CHEMBL1993374 & 809262 & 4.4 & 5.409 & TST \\
\hline CHEMBL1969264 & 809262 & 4.0 & 4.419 & TRN \\
\hline CHEMBL1994318 & 809262 & 6.1 & 4.9274 & TRN \\
\hline CHEMBL1973711 & 809262 & 4.0 & 4.1214 & TST \\
\hline CHEMBL 2006237 & 809262 & 4.0 & 4.059 & TST \\
\hline CHEMBL1967719 & 809262 & 5.5 & 5.858 & TST \\
\hline CHEMBL1967720 & 809262 & 6.8 & 6.4209 & TST \\
\hline CHEMBL1572266 & 809262 & 4.0 & 4.3108 & TST \\
\hline CHEMBL1991138 & 809262 & 5.9 & 5.5238 & TST \\
\hline CHEMBL1979516 & 809262 & 5.2 & 5.739 & TST \\
\hline CHEMBL1969755 & 809262 & 5.9 & 5.9919 & TST \\
\hline CHEMBL1972820 & 809262 & 4.0 & 4.2044 & TST \\
\hline CHEMBL1605605 & 809262 & 8.7 & 6.2224 & TST \\
\hline
\end{tabular}




\begin{tabular}{|c|c|c|c|c|c|}
\hline \\
\hline CHEMBL1996208 & 809262 & 4.2 & 4.4338 & TST & \\
\hline CHEMBL1989029 & 809262 & 4.0 & 4.3341 & TST & \\
\hline CHEMBL392642 & 809262 & 4.0 & 5.0242 & TST & \\
\hline CHEMBL514499 & 809262 & 4.0 & 4.2202 & TST & \\
\hline CHEMBL1970352 & 809262 & 4.4 & 4.8413 & TST & \\
\hline CHEMBL1965631 & 809262 & 5.3 & 5.402 & TST & \\
\hline CHEMBL1980144 & 809262 & 5.3 & 4.3486 & TST & \\
\hline CHEMBL1991188 & 809262 & 7.7 & 6.6637 & TST & \\
\hline CHEMBL1980167 & 809262 & 4.4 & 5.5477 & TST & \\
\hline CHEMBL1972849 & 809262 & 4.0 & 3.87100 & 00000000004 & TST \\
\hline CHEMBL377408 & 809262 & 5.5 & 5.0287 & TST & \\
\hline CHEMBL215152 & 809262 & 4.2 & 4.69 & TST & \\
\hline CHEMBL231209 & 809262 & 6.1 & 5.8768 & TST & \\
\hline CHEMBL1975357 & 809262 & 4.0 & 4.2945 & TST & \\
\hline CHEMBL1976220 & 809262 & 6.4 & 6.3513 & TST & \\
\hline CHEMBL 2006765 & 809262 & 6.8 & 5.6355 & TST & \\
\hline CHEMBL259922 & 809262 & 4.0 & 4.2568 & TST & \\
\hline CHEMBL1997617 & 809262 & 5.2 & 4.686 & TST & \\
\hline CHEMBL1969301 & 809262 & 4.0 & 4.4473 & TST & \\
\hline CHEMBL1982383 & 809262 & 4.0 & 3.9637 & TST & \\
\hline CHEMBL17370 & 809262 & 5.1 & 4.2539 & TST & \\
\hline CHEMBL1980246 & 809262 & 4.4 & 5.3238 & TST & \\
\hline CHEMBL1987910 & 809262 & 6.1 & 5.1504 & TST & \\
\hline CHEMBL1983932 & 809262 & 4.0 & 4.0278 & TST & \\
\hline CHEMBL1983980 & 809262 & 6.0 & 5.3614 & TST & \\
\hline CHEMBL1999484 & 809262 & 7.0 & 5.3936 & TST & \\
\hline CHEMBL1966069 & 809262 & 7.3 & 6.7595 & TST & \\
\hline CHEMBL1986899 & 809262 & 5.8 & 4.8593 & TST & \\
\hline CHEMBL1991285 & 809262 & 4.0 & 4.2745 & TST & \\
\hline CHEMBL1997822 & 809262 & 5.9 & 4.9783 & TST & \\
\hline CHEMBL 243088 & 809262 & 5.4 & 5.7025 & TST & \\
\hline CHEMBL1984038 & 809262 & 4.3 & 4.3275 & TST & \\
\hline CHEMBL1965683 & 809262 & 4.7 & 5.0105 & TST & \\
\hline CHEMBL1968606 & 809262 & 5.6 & 5.3224 & TST & \\
\hline CHEMBL1974416 & 809262 & 5.4 & 5.5616 & TST & \\
\hline CHEMBL1993661 & 809262 & 7.9 & 7.1719 & TST & \\
\hline CHEMBL 2004615 & 809262 & 5.2 & 5.0127 & TST & \\
\hline CHEMBL1984039 & 809262 & 4.0 & 4.0589 & TST & \\
\hline CHEMBL1997872 & 809262 & 5.6 & 4.3192 & TST & \\
\hline CHEMBL 2165049 & 860485 & 7.2076 & 7.20700 & 2000000001 & TRN \\
\hline CHEMBL 2165268 & 860485 & 7.6021 & 7.6019 & TRN & \\
\hline CHEMBL 2165043 & 860485 & 4.0 & 4.6762 & TST & \\
\hline CHEMBL 2165007 & 860485 & 9.0 & 8.9998 & TRN & \\
\hline CHEMBL 2165011 & 860485 & 7.2007 & 7.2006 & TRN & \\
\hline CHEMBL 2165023 & 860485 & 7.0362 & 7.0359 & TRN & \\
\hline CHEMBL 2165032 & 860485 & 8.1549 & 8.1557 & TRN & \\
\hline CHEMBL2165269 & 860485 & 7.4318 & 7.4319 & TRN & \\
\hline CHEMBL1615182 & 860485 & 7.284 & 6.9634 & TST & \\
\hline
\end{tabular}




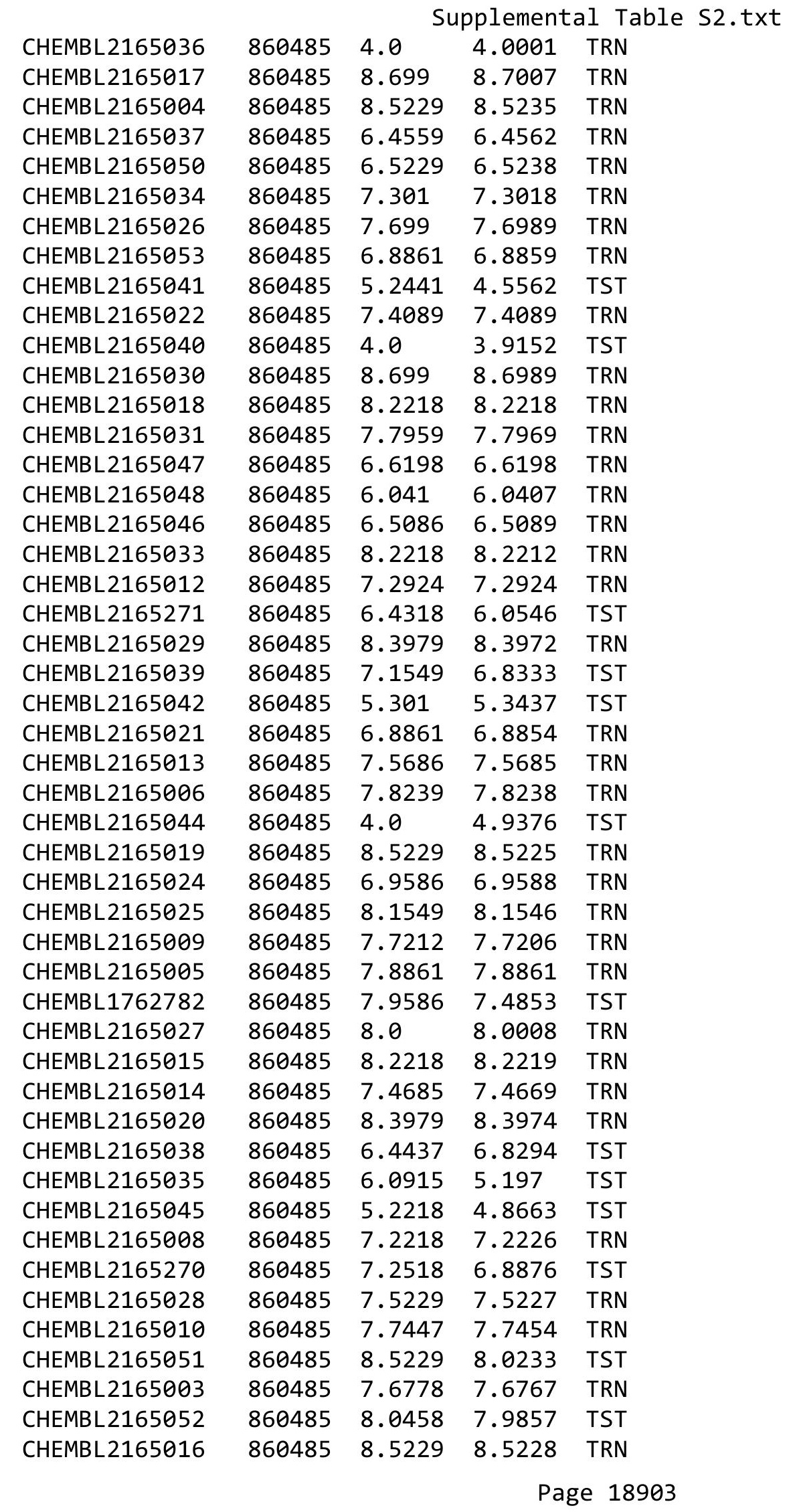


Supplemental Table S2.txt

\begin{tabular}{|c|c|c|c|c|c|}
\hline CHEMBL 3601718 & 1509386 & 5.96299 & 9999999 & 6.21 & TRN \\
\hline CHEMBL3601115 & 1509386 & 7.7212 & 7.4465 & TRN & \\
\hline CHEMBL 3601242 & 1509386 & 8.0 & 7.9781 & TRN & \\
\hline CHEMBL 3601117 & 1509386 & 7.4089 & 7.7945 & TRN & \\
\hline CHEMBL 3601728 & 1509386 & 5.5913 & 5.5569 & TRN & \\
\hline CHEMBL 3601711 & 1509386 & 6.3635 & 6.2504 & TRN & \\
\hline CHEMBL 3601237 & 1509386 & 7.4559 & 7.5166 & TRN & \\
\hline CHEMBL 3601111 & 1509386 & 7.1739 & 7.0494 & TRN & \\
\hline CHEMBL1229592 & 1509386 & 5.0 & 5.0458 & TRN & \\
\hline CHEMBL 3601861 & 1509386 & 5.2054 & 5.1674 & TRN & \\
\hline CHEMBL 3601232 & 1509386 & 7.5376 & 7.5043 & TRN & \\
\hline CHEMBL 3601120 & 1509386 & 7.4685 & 7.5839 & TRN & \\
\hline CHEMBL 3601724 & 1509386 & 5.3057 & 6.8976 & TST & \\
\hline CHEMBL 3601707 & 1509386 & 6.3325 & 6.2102 & TRN & \\
\hline CHEMBL 3601118 & 1509386 & 7.3468 & 7.5352 & TRN & \\
\hline CHEMBL 3601709 & 1509386 & 6.3575 & 6.2135 & TRN & \\
\hline CHEMBL 3601113 & 1509386 & 7.7696 & 7.7221 & TRN & \\
\hline CHEMBL 3601233 & 1509386 & 7.9586 & 7.6631 & TRN & \\
\hline CHEMBL 3601239 & 1509386 & 5.2634 & 7.0197 & TST & \\
\hline CHEMBL 3601862 & 1509386 & 5.8861 & 7.2266 & TST & \\
\hline CHEMBL 3601231 & 1509386 & 8.1549 & 8.1524 & TRN & \\
\hline CHEMBL 3601244 & 1509386 & 6.9431 & 7.6102 & TST & \\
\hline CHEMBL 3601710 & 1509386 & 7.2441 & \multicolumn{2}{|c|}{7.361000000000001} & TRN \\
\hline CHEMBL3601106 & 1509386 & 7.6778 & 7.8411 & TRN & \\
\hline CHEMBL 3601224 & 1509386 & 5.8844 & 5.9547 & TRN & \\
\hline CHEMBL 3601123 & 1509386 & 6.0237 & 6.1112 & TRN & \\
\hline CHEMBL 3601723 & 1509386 & 8.0969 & 7.7557 & TST & \\
\hline CHEMBL 3601108 & 1509386 & 7.7959 & 7.7029 & TRN & \\
\hline CHEMBL 3601228 & 1509386 & 7.699 & 7.7152 & TRN & \\
\hline CHEMBL 3601114 & 1509386 & 7.6198 & 7.6347 & TRN & \\
\hline CHEMBL 3601234 & 1509386 & 6.3206 & 6.6417 & TRN & \\
\hline CHEMBL 3601226 & 1509386 & 7.9586 & 8.0261 & TRN & \\
\hline CHEMBL3601109 & 1509386 & 6.8447 & 6.6264 & TRN & \\
\hline CHEMBL 3601725 & 1509386 & 6.6778 & 7.4742 & TST & \\
\hline CHEMBL 3601121 & 1509386 & 7.0362 & 7.2049 & TRN & \\
\hline CHEMBL3601706 & 1509386 & 7.7447 & 7.4287 & TRN & \\
\hline CHEMBL 3601107 & 1509386 & 7.9586 & 7.8551 & TRN & \\
\hline CHEMBL 3601235 & 1509386 & 7.0044 & 7.1751 & TRN & \\
\hline CHEMBL 3601714 & 1509386 & 6.1221 & 6.3961 & TRN & \\
\hline CHEMBL 3601713 & 1509386 & 6.9508 & 7.4906 & TST & \\
\hline CHEMBL3601236 & 1509386 & 7.6383 & 7.5485 & TRN & \\
\hline CHEMBL 3601223 & 1509386 & 7.1612 & 6.4919 & TRN & \\
\hline CHEMBL 3601726 & 1509386 & 6.7986 & 7.3922 & TST & \\
\hline CHEMBL 3601112 & 1509386 & 6.9245 & 6.9225 & TRN & \\
\hline CHEMBL 3601243 & 1509386 & 6.9626 & 6.9714 & TRN & \\
\hline CHEMBL 3601705 & 1509386 & 7.7696 & 7.6832 & TRN & \\
\hline CHEMBL 3601715 & 1509386 & 6.9706 & 7.0072 & TRN & \\
\hline CHEMBL 3601716 & 1509386 & 6.5129 & 6.597 & TRN & \\
\hline
\end{tabular}


Supplemental Table S2.txt

\begin{tabular}{|c|c|c|c|c|c|}
\hline CHEMBL 3601722 & 1509386 & 5.8735 & 6.7811 & TST & \\
\hline CHEMBL 3601110 & 1509386 & 6.9586 & 6.8867 & TRN & \\
\hline CHEMBL 3601122 & 1509386 & 5.1003 & 5.0774 & TRN & \\
\hline CHEMBL3601116 & 1509386 & 7.6576 & 7.6862 & TRN & \\
\hline CHEMBL 3601727 & 1509386 & 6.8416 & 7.4082 & TST & \\
\hline CHEMBL 3600393 & 1509386 & 7.5528 & 7.6877 & TRN & \\
\hline CHEMBL 3601704 & 1509386 & 5.6265 & 5.7936 & TRN & \\
\hline CHEMBL 3601227 & 1509386 & 7.8239 & 7.6929 & TRN & \\
\hline CHEMBL 3601708 & 1509386 & 6.8827 & 6.9089 & TRN & \\
\hline CHEMBL 3601127 & 1509386 & 6.9914 & \multicolumn{2}{|c|}{7.047000000000001} & TRN \\
\hline CHEMBL 3601712 & 1509386 & 7.4815 & 7.6515 & TST & \\
\hline CHEMBL3601119 & 1509386 & 6.9066 & 7.3466 & TST & \\
\hline CHEMBL 3601238 & 1509386 & 7.2676 & 7.3326 & TST & \\
\hline CHEMBL 3601125 & 1509386 & 4.8342 & 5.7437 & TST & \\
\hline CHEMBL 3601230 & 1509386 & 6.9031 & 6.8061 & TST & \\
\hline CHEMBL 3601229 & 1509386 & 7.1249 & 7.4766 & TST & \\
\hline CHEMBL 3905610 & 1641071 & 6.022 & 6.4789 & TRN & \\
\hline CHEMBL 3960438 & 1641071 & 6.83 & 6.3315 & TRN & \\
\hline CHEMBL3959095 & 1641071 & 6.1781 & 6.114 & TRN & \\
\hline CHEMBL 3948050 & 1641071 & 7.8771 & \multicolumn{2}{|c|}{7.928999999999999} & TRN \\
\hline CHEMBL 3911178 & 1641071 & 8.8239 & 8.5794 & TRN & \\
\hline CHEMBL 3907239 & 1641071 & \multicolumn{3}{|c|}{4.986000000000001} & TST \\
\hline CHEMBL3902466 & 1641071 & 7.9416 & 7.6903 & TRN & \\
\hline CHEMBL 3896260 & 1641071 & 6.0455 & \multicolumn{2}{|c|}{5.667999999999999} & TRN \\
\hline CHEMBL 3938757 & 1641071 & 8.4045 & 7.7439 & TST & \\
\hline CHEMBL 3974588 & 1641071 & 6.2302 & 6.6345 & TRN & \\
\hline CHEMBL 3923805 & 1641071 & 6.2898 & 6.0575 & TRN & \\
\hline CHEMBL 3965843 & 1641071 & 5.9044 & 6.0499 & TRN & \\
\hline CHEMBL3915085 & 1641071 & 5.2624 & 6.9426 & TST & \\
\hline CHEMBL 3924271 & 1641071 & 5.8405 & 6.0365 & TRN & \\
\hline CHEMBL3960194 & 1641071 & 8.0241 & 7.8535 & TRN & \\
\hline CHEMBL 3938649 & 1641071 & 8.118 & 7.4763 & TST & \\
\hline CHEMBL3916122 & 1641071 & 8.3696 & 8.4911 & TRN & \\
\hline CHEMBL3976519 & 1641071 & 6.6908 & 6.6091 & TRN & \\
\hline CHEMBL 3909928 & 1641071 & 7.0847 & \multicolumn{2}{|c|}{7.236000000000001} & TRN \\
\hline CHEMBL3899017 & 1641071 & 6.2194 & \multicolumn{2}{|c|}{6.0889999999999995} & TRN \\
\hline CHEMBL3914777 & 1641071 & 6.726 & 6.5204 & TRN & \\
\hline CHEMBL 3978134 & 1641071 & 7.3938 & 7.8827 & TRN & \\
\hline CHEMBL 3920595 & 1641071 & 7.1952 & 6.9857 & TST & \\
\hline CHEMBL 3933635 & 1641071 & 7.6478 & 7.8132 & TST & \\
\hline CHEMBL3910267 & 1641071 & 7.5577 & 7.6531 & TRN & \\
\hline CHEMBL 3962378 & 1641071 & 7.2847 & 6.8484 & TRN & \\
\hline CHEMBL3956960 & 1641071 & 7.0216 & 6.7224 & TRN & \\
\hline CHEMBL3946475 & 1641071 & 6.0879 & 6.114 & TRN & \\
\hline CHEMBL3907582 & 1641071 & 9.2366 & 8.8849 & TRN & \\
\hline CHEMBL3914891 & 1641071 & 5.7854 & 6.4567 & TRN & \\
\hline CHEMBL 3969293 & 1641071 & 5.7377 & 7.0149 & TST & \\
\hline CHEMBL 3916653 & 1641071 & 6.2866 & 6.24100 & 00000000005 & TRN \\
\hline & & & & 18905 & \\
\hline
\end{tabular}


Supplemental Table S2.txt

\begin{tabular}{|c|c|c|c|c|}
\hline 6 & 541071 & 6.8908 & & \\
\hline & 641071 & & & \\
\hline$E A$ & & & & \\
\hline IEMBL & 071 & 6662 & & \\
\hline AEMBL3909419 & 641071 & 5167 & 8148 & \\
\hline HEMBL & $\partial 71$ & 842 & 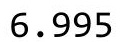 & \\
\hline 77 & 971 & & & \\
\hline AEMBL & & 506 & 239 & \\
\hline HEMBL3976894 & 641071 & 8.6402 & 1559 & \\
\hline HEMBL3938819 & 071 & 7.6757 & 7433 & \\
\hline HEMBL & 971 & 7.3223 & 9704 & \\
\hline IEME & 71 & 788 & 295 & \\
\hline AEMBL3 & 71 & & & \\
\hline HEMBL3974171 & $\partial 71$ & 6.8077 & 5824 & \\
\hline HEMBL3933629 & $\partial 71$ & & & \\
\hline HEMBL3 & 6 & 6 & 572 & \\
\hline AEMBL & & & 794 & s \\
\hline HEMBL & 71 & 904 & 3686 & \\
\hline HEMBL3 & 971 & 747 & 5799 & \\
\hline AEMBL3 & & 37 & & \\
\hline HEMBL & 6 & 5. & 76 & 31 \\
\hline IEM & & & & RN \\
\hline AEMBL & 71 & 744 & 03 & RN \\
\hline AEMP & & 1 & 74 & IRIV \\
\hline AEMBL3 & & & 55 & I RN \\
\hline HEMBL3 & & 8 & 994 & ГR/ \\
\hline HEM & & 8 & 18 & DI \\
\hline 1 & & $\partial 6$ & 069 & $-c T$ \\
\hline AEMBL3 & & & & $\Gamma \mathrm{RN}$ \\
\hline AEMBL 3964 & 71 & 5.6202 & 3403 & RN \\
\hline AEMBL & & 7 & 839 & RN \\
\hline JEN & & & 81 & 「RN \\
\hline$-M$ & & & & 「RN \\
\hline HEMBL 394 & & & 02 & 「RN \\
\hline HEMBL3921651 & 71 & 8.7375 & 3509 & ГRN \\
\hline JFMPI - & 1 & & 314 & TRN \\
\hline 7 & & 6. & 07 & ГRN \\
\hline HEMBL3 & & & 944 & TRN \\
\hline HEMBL391S & & 6 . & 997 & $\Gamma R$ \\
\hline TID & & & 383 & IST \\
\hline HEMBL3 & & 6 . & 529 & TRN \\
\hline HEMBL3 & & 6.8055 & 682 & 「RN \\
\hline HEMBL3925010 & 071 & 6.016 & 6425 & {$[R$} \\
\hline HEMBL 392 & 71 & 9.0177 & 513 & TR \\
\hline CHEMPI 39256 & & & 7242 & \\
\hline HEMBL3952490 & & .2676 & 9. 1724 & \\
\hline HEMBL3908063 & 971 & 7.1776 & .4322 & \\
\hline CHEMBL3971535 & 1641071 & 8.6126 & 7.8663 & \\
\hline
\end{tabular}

Page 18906 
Supplemental Table S2.txt

\begin{tabular}{|c|c|c|c|c|c|}
\hline CHEMBL3930729 & 1641071 & 6.8909 & 7.3213 & TST & \\
\hline CHEMBL3977810 & 1641071 & 6.7178 & 6.479 & TST & \\
\hline CHEMBL3984591 & 1641071 & 6.3786 & 6.1105 & TST & \\
\hline CHEMBL3921264 & 1641071 & 8.6383 & 8.4517 & TST & \\
\hline CHEMBL3939745 & 1641071 & 8.5867 & \multicolumn{2}{|c|}{8.466000000000001} & TST \\
\hline CHEMBL3977305 & 1641071 & 9.0757 & 8.792 & TST & \\
\hline CHEMBL3979649 & 1641071 & 6.8883 & 7.9255 & TST & \\
\hline CHEMBL3985625 & 1641071 & 6.6946 & 6.0326 & TST & \\
\hline CHEMBL3604176 & 1509999 & 5.5072 & 5.6109 & TRN & \\
\hline CHEMBL 3604163 & 1509999 & 6.6655 & 6.6994 & TRN & \\
\hline CHEMBL3604157 & 1509999 & 6.2588 & 6.2904 & TRN & \\
\hline CHEMBL3604155 & 1509999 & 7.4089 & 7.42 & TRN & \\
\hline CHEMBL3604170 & 1509999 & 7.0132 & 7.0492 & TRN & \\
\hline CHEMBL1587607 & 1509999 & 6.209 & \multicolumn{2}{|c|}{6.361000000000001} & TRN \\
\hline CHEMBL 3604149 & 1509999 & 7.3768 & 7.3747 & TRN & \\
\hline CHEMBL3604173 & 1509999 & 7.1675 & 7.2938 & TRN & \\
\hline CHEMBL3604131 & 1509999 & 5.8794 & 5.9233 & TRN & \\
\hline CHEMBL3604143 & 1509999 & 6.3915 & \multicolumn{2}{|c|}{6.6339999999999995} & TST \\
\hline CHEMBL3604145 & 1509999 & 5.8761 & 5.9019 & TRN & \\
\hline CHEMBL 3604140 & 1509999 & 5.4271 & 5.5594 & TST & \\
\hline CHEMBL3604139 & 1509999 & 6.8861 & 7.5632 & TST & \\
\hline CHEMBL 3604154 & 1509999 & 7.3768 & \multicolumn{2}{|c|}{7.343999999999999} & TRN \\
\hline CHEMBL3604177 & 1509999 & 5.9914 & 6.0262 & TRN & \\
\hline CHEMBL3604156 & 1509999 & 8.0 & 7.9407 & TRN & \\
\hline CHEMBL 3604142 & 1509999 & 6.0773 & 6.0858 & TRN & \\
\hline CHEMBL3604174 & 1509999 & 7.2518 & 7.2227 & TRN & \\
\hline CHEMBL3604185 & 1509999 & 7.4685 & 7.0948 & TST & \\
\hline CHEMBL3604135 & 1509999 & 5.4672 & 5.4475 & TRN & \\
\hline CHEMBL3604184 & 1509999 & 6.8827 & 7.0006 & TST & \\
\hline CHEMBL3604175 & 1509999 & 7.1024 & 7.099 & TRN & \\
\hline CHEMBL3604160 & 1509999 & 6.9508 & 6.9318 & TRN & \\
\hline CHEMBL3604162 & 1509999 & 7.4318 & 7.4372 & TRN & \\
\hline CHEMBL3604133 & 1509999 & 6.2848 & 6.276 & TRN & \\
\hline CHEMBL 3604179 & 1509999 & 6.1952 & 6.1468 & TST & \\
\hline CHEMBL3604167 & 1509999 & 6.4763 & 6.4594 & TRN & \\
\hline CHEMBL3604181 & 1509999 & 6.9066 & 6.8937 & TST & \\
\hline CHEMBL 3604130 & 1509999 & 6.5686 & 6.4858 & TRN & \\
\hline CHEMBL3604148 & 1509999 & 6.068 & 6.0553 & TRN & \\
\hline CHEMBL3604178 & 1509999 & 6.2248 & 6.204 & TRN & \\
\hline CHEMBL3604132 & 1509999 & 7.6198 & 7.6211 & TRN & \\
\hline CHEMBL3604172 & 1509999 & 6.4067 & 6.1764 & TRN & \\
\hline CHEMBL3604141 & 1509999 & 7.0362 & 7.0093 & TRN & \\
\hline CHEMBL3604182 & 1509999 & 6.1451 & 6.2202 & TST & \\
\hline CHEMBL3604152 & 1509999 & 7.6576 & 7.7203 & TRN & \\
\hline CHEMBL3604134 & 1509999 & 7.0269 & 7.0118 & TRN & \\
\hline CHEMBL3604137 & 1509999 & 6.9281 & 6.8258 & TRN & \\
\hline CHEMBL3604183 & 1509999 & 4.6529 & 6.5067 & TST & \\
\hline CHEMBL3604153 & 1509999 & 7.8539 & 7.8476 & TRN & \\
\hline
\end{tabular}


Supplemental Table S2.txt

\begin{tabular}{|c|c|c|c|c|}
\hline W & 509999 & 6.5544 & & \\
\hline & & 7.5686 & & \\
\hline & & & & \\
\hline AEMBL & & & & \\
\hline HEMBL360 & 509999 & 612 & 065 & \\
\hline HEMBL3604151 & 509999 & 7.4815 & 4399 & \\
\hline HEMBL & 999 & & & \\
\hline 0 & 999 & & & \\
\hline AEMBL3604165 & 509999 & & & \\
\hline AEMBL3604138 & 509999 & 665 & 196 & \\
\hline HEMBL3604164 & 509999 & 7.4089 & 584 & \\
\hline IEMBL36e & 509999 & 75 & 126 & \\
\hline IEMBL: & & & & \\
\hline JEMBL360 & 509999 & 861 & 7945 & \\
\hline AEMBL311 & 290460 & 88 & 975 & \\
\hline AEMBL 31 & 290460 & 528 & 42 & \\
\hline AEMBL3 & 50 & 66 & 25 & \\
\hline AEMBL3 & 50 & & & \\
\hline HEMBL311 & 290460 & 212 & 3392 & \\
\hline AEMBL311 & 60 & & & \\
\hline AEMBL: & 290 & 72 & 58 & 15 \\
\hline AEMBL & 290 & & 69 & RN \\
\hline HEMBL; & 50 & & & \\
\hline 80 & 290460 & & & \\
\hline AEMBL311 & & & & I RIV \\
\hline AEMBL3 & 290 & & & RN \\
\hline HEM & 90 & & & Niv \\
\hline AFMBI 3 & 50 & 37 & 36 & \\
\hline HEMBL311 & 460 & & & TRIV \\
\hline HEMBL 311 & 290 & & & 15 \\
\hline HEMBL31 & 290460 & & & RN \\
\hline HEMBL & 90 & & 07 & KIV \\
\hline AEMBL31 & 60 & 91 & 44 & 3 \\
\hline AEMBL 311 & 290 & & 132 & $\mathrm{IR}$ \\
\hline HEMBL3112825 & 290460 & 086 & 9132 & TST \\
\hline HEMBL31 & 290460 & 383 & 23 & TRN \\
\hline HFMRI & 0 & 29 & 82 & $\Gamma \mathrm{RN}$ \\
\hline HEMBL3 & 50 & & 482 & ST \\
\hline HEMBL 3112 & 290460 & 12 & 386 & TST \\
\hline IEMBL 311 & 290460 & & 98 & TRN \\
\hline HEMBL31 & 290460 & 91 & 521 & D \\
\hline HEMBL311 & 290460 & & & RIV \\
\hline HEMBL311 & 290460 & 5.8539 & & ГST \\
\hline AEMBL 311 & 290460 & 5.8539 & 574 & TST \\
\hline $\mathrm{MBL}=$ & 90 & 18 & & $\mathrm{~N}$ \\
\hline HEMBL31 & 290460 & 676 & & \\
\hline HEMBL311 & 290460 & .6576 & .8159 & \\
\hline HEMBL3112803 & 1290460 & 3.301 & 4.8232 & RN \\
\hline
\end{tabular}

Page 18908 
Supplemental Table S2.txt

\begin{tabular}{|c|c|c|c|c|c|}
\hline CHEMBL3112807 & 1290460 & 6.4202 & 6.1723 & TRN & \\
\hline CHEMBL3112779 & 1290460 & 5.284 & 5.1087 & TRN & \\
\hline CHEMBL3112800 & 1290460 & 5.8239 & 5.2584 & TST & \\
\hline CHEMBL3112796 & 1290460 & 4.4089 & 5.3326 & TRN & \\
\hline CHEMBL3112792 & 1290460 & 4.4559 & 5.0716 & TRN & \\
\hline CHEMBL3112798 & 1290460 & 5.4318 & 5.2452 & TRN & \\
\hline CHEMBL3112787 & 1290460 & 4.4815 & 4.7861 & TRN & \\
\hline CHEMBL3112826 & 1290460 & 4.301 & 4.8121 & TST & \\
\hline CHEMBL3112815 & 1290460 & 5.1871 & 5.0379 & TRN & \\
\hline CHEMBL3112784 & 1290460 & 5.8539 & 5.126 & TRN & \\
\hline CHEMBL3112793 & 1290460 & 5.3768 & 5.2005 & TRN & \\
\hline CHEMBL3112813 & 1290460 & 6.2007 & 6.4306 & TRN & \\
\hline CHEMBL3112782 & 1290460 & 5.7212 & 5.1361 & TRN & \\
\hline CHEMBL 3112783 & 1290460 & 5.5376 & 5.1971 & TRN & \\
\hline CHEMBL3112802 & 1290460 & 6.2518 & 5.5542 & TST & \\
\hline CHEMBL3112828 & 1290460 & 4.6778 & 5.2505 & TST & \\
\hline CHEMBL3112795 & 1290460 & 4.9208 & 5.0967 & TST & \\
\hline CHEMBL1802875 & 756581 & 7.0462 & 6.9086 & TRN & \\
\hline CHEMBL1802647 & 756581 & 5.7011 & 5.6819 & TRN & \\
\hline CHEMBL1802937 & 756581 & 7.4584 & 7.1402 & TRN & \\
\hline CHEMBL1802665 & 756581 & 5.8356 & 5.9782 & TRN & \\
\hline CHEMBL1802942 & 756581 & 5.32700 & 000000006 & 5.8468 & TRN \\
\hline CHEMBL1802662 & 756581 & 4.0123 & 4.2327 & TRN & \\
\hline CHEMBL1802926 & 756581 & 5.5702 & 5.7557 & TRN & \\
\hline CHEMBL1802887 & 756581 & 6.3478 & 6.4097 & TRN & \\
\hline CHEMBL602366 & 756581 & 6.1433 & 6.7827 & TST & \\
\hline CHEMBL1802940 & 756581 & 4.0004 & 5.2396 & TST & \\
\hline CHEMBL1802933 & 756581 & 7.58 & 6.9261 & TRN & \\
\hline CHEMBL1800102 & 756581 & 6.5817 & 6.6569 & TRN & \\
\hline CHEMBL586279 & 756581 & 6.8633 & 7.0531 & TRN & \\
\hline CHEMBL1802878 & 756581 & 5.6345 & 6.2186 & TRN & \\
\hline CHEMBL1802889 & 756581 & 5.8697 & 5.2441 & TRN & \\
\hline CHEMBL1802710 & 756581 & 5.9706 & 5.531006 & $\partial 000000001$ & TST \\
\hline CHEMBL1802939 & 756581 & 6.1759 & 5.7167 & TRN & \\
\hline CHEMBL1802702 & 756581 & 7.1096 & 6.9921 & TRN & \\
\hline CHEMBL117217 & 756581 & 8.06 & 6.3152 & TST & \\
\hline CHEMBL1802934 & 756581 & 7.1152 & 7.2447 & TRN & \\
\hline CHEMBL1802713 & 756581 & 4.0159 & 3.8141 & TRN & \\
\hline CHEMBL1802931 & 756581 & 7.5143 & 7.2432 & TRN & \\
\hline CHEMBL1802701 & 756581 & 6.4225 & 6.3534 & TRN & \\
\hline CHEMBL1802879 & 756581 & 6.9208 & 6.6781 & TRN & \\
\hline CHEMBL1802720 & 756581 & 7.4449 & 7.4919 & TRN & \\
\hline CHEMBL1802712 & 756581 & 5.4067 & 5.5182 & TRN & \\
\hline CHEMBL1802938 & 756581 & 6.9469 & 6.9831 & TRN & \\
\hline CHEMBL1802876 & 756581 & 6.767 & 6.7893 & TRN & \\
\hline CHEMBL1802649 & 756581 & 5.0757 & 4.5645 & TRN & \\
\hline CHEMBL1802929 & 756581 & 6.8894 & 6.7599 & TRN & \\
\hline \multirow[t]{2}{*}{ CHEMBL1802886 } & 756581 & 6.8239 & 6.98799 & 99999999995 & TRN \\
\hline & & \multicolumn{4}{|c|}{ Page 18909} \\
\hline
\end{tabular}


Supplemental Table S2.txt

\begin{tabular}{|c|c|c|c|c|c|}
\hline CHEMBL1802925 & 756581 & 6.0947 & 5.0352 & TST & \\
\hline CHEMBL1802936 & 756581 & 6.4647 & 6.4891 & TRN & \\
\hline CHEMBL1802722 & 756581 & 7.2351 & 7.0488 & TRN & \\
\hline CHEMBL1802696 & 756581 & 5.5243 & 5.2956 & TRN & \\
\hline CHEMBL1802718 & 756581 & 6.8894 & 6.9992 & TRN & \\
\hline CHEMBL1802881 & 756581 & 5.3242 & 5.3237 & TRN & \\
\hline CHEMBL1802949 & 756581 & 7.3883 & 7.3995 & TRN & \\
\hline CHEMBL1802703 & 756581 & 4.0092 & 4.4125 & TRN & \\
\hline CHEMBL1802930 & 756581 & 7.4535 & 7.2997 & TRN & \\
\hline CHEMBL1802922 & 756581 & 7.0565 & 6.432 & TRN & \\
\hline CHEMBL1802645 & 756581 & 6.4342 & 6.3215 & TRN & \\
\hline CHEMBL1802885 & 756581 & 5.6576 & 6.0318 & TRN & \\
\hline CHEMBL1802928 & 756581 & 5.9788 & 5.6947 & TRN & \\
\hline CHEMBL1802941 & 756581 & 6.7721 & 7.1676 & TRN & \\
\hline CHEMBL1802659 & 756581 & 5.7282 & 6.1266 & TRN & \\
\hline CHEMBL1802935 & 756581 & 6.8297 & 6.5657 & TRN & \\
\hline CHEMBL1802877 & 756581 & 6.8356 & 6.7893 & TRN & \\
\hline CHEMBL1802716 & 756581 & 5.1979 & 4.9618 & TRN & \\
\hline CHEMBL1802668 & 756581 & 5.1739 & 4.738 & TRN & \\
\hline CHEMBL1802874 & 756581 & 5.9469 & 6.4133 & TRN & \\
\hline CHEMBL1802661 & 756581 & 6.4498 & 6.1016 & TRN & \\
\hline CHEMBL1802884 & 756581 & 5.0472 & 4.9653 & TRN & \\
\hline CHEMBL1802944 & 756581 & 5.2069 & 5.3355 & TRN & \\
\hline CHEMBL1802700 & 756581 & 7.1694 & 6.9858 & TRN & \\
\hline CHEMBL1802658 & 756581 & 6.4283 & 6.1318 & TRN & \\
\hline CHEMBL1802650 & 756581 & 5.2807 & 4.9782 & TRN & \\
\hline CHEMBL1802919 & 756581 & 5.0472 & 5.9491 & TRN & \\
\hline CHEMBL1802706 & 756581 & 6.056 & 6.1667 & TRN & \\
\hline CHEMBL1802715 & 756581 & 4.1373 & 4.6193 & TRN & \\
\hline CHEMBL1802708 & 756581 & 6.8153 & 7.0885 & TRN & \\
\hline CHEMBL1802694 & 756581 & 5.9666 & 6.0117 & TRN & \\
\hline CHEMBL1802709 & 756581 & 5.5129 & 4.9948 & TST & \\
\hline CHEMBL1802663 & 756581 & 4.0123 & 4.4284 & TRN & \\
\hline CHEMBL1802725 & 756581 & 7.0035 & 7.0329 & TRN & \\
\hline CHEMBL1802651 & 756581 & 6.1018 & 6.2611 & TRN & \\
\hline CHEMBL1802927 & 756581 & 7.7825 & 6.1373 & TST & \\
\hline CHEMBL1802655 & 756581 & 5.3307 & 5.7037 & TRN & \\
\hline CHEMBL1802943 & 756581 & 5.32700 & 100000000 & $\partial 1$ & 5.4019 \\
\hline CHEMBL1802924 & 756581 & 6.4935 & 6.9633 & TRN & \\
\hline CHEMBL1802948 & 756581 & 7.0218 & 7.1959 & TRN & \\
\hline CHEMBL1802888 & 756581 & 5.2041 & 5.3944 & TRN & \\
\hline CHEMBL1802945 & 756581 & 5.118 & 4.9649 & TRN & \\
\hline CHEMBL1802654 & 756581 & 5.52 & 5.2416 & TRN & \\
\hline CHEMBL1802656 & 756581 & 6.6198 & 6.3703 & TRN & \\
\hline CHEMBL1802664 & 756581 & 5.6253 & 5.5596 & TRN & \\
\hline CHEMBL1487406 & 756581 & 6.7055 & 6.4865 & TST & \\
\hline CHEMBL1802714 & 756581 & 4.0159 & 4.3956 & TRN & \\
\hline CHEMBL1802707 & 756581 & 6.5768 & 6.5827 & TRN & \\
\hline
\end{tabular}

Page 18910 
Supplemental Table S2.txt

\begin{tabular}{|c|c|c|c|c|}
\hline 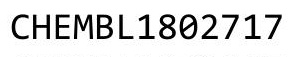 & 56581 & 575 & 7.4099 & \\
\hline HEMBL1802667 & 56581 & 0004 & 4.3057 & \\
\hline HEMBL1802646 & 56581 & 3757 & 401 & \\
\hline 2920 & & 306 & 3585 & \\
\hline HEMBL1802697 & 81 & 788 & 1001 & \\
\hline HEMBL1802719 & 56581 & 3516 & .3585 & \\
\hline HEMBL1802946 & 56581 & .7144 & 6.9291 & \\
\hline HEMBL1802726 & 56581 & .9136 & 2558 & \\
\hline HEMBL1802721 & 81 & 957 & 5.5584 & \\
\hline AEMBL1802698 & 81 & & .9511 & \\
\hline HEMBL1802705 & 756581 & 292 & 4.0563 & \\
\hline HEMBL1802880 & 56581 & . 3107 & 5.3237 & \\
\hline HEMBL1802723 & 756581 & 7.4572 & 7.6595 & \\
\hline HEMBL180 & 31 & 708 & .7911 & \\
\hline HEMBL 180 & 81 & & & \\
\hline HEMBL1802660 & 756581 & 844 & 4.9612 & \\
\hline HEMBL1802648 & 56581 & & & \\
\hline HEMBL180 & 756 & $\partial 6$ & 4.7375 & \\
\hline HEMBL 18 & 31 & 45 & & \\
\hline HEMBL18 & & 16 & & \\
\hline HEMBL1802923 & 756581 & 86 & 4.7008 & \\
\hline AEMBL1802652 & 56 & & & \\
\hline HEMBL116 & 756 & 21 & 67 & \\
\hline HEMBL18 & 31 & 99 & 89 & \\
\hline HEMBL18 & 31 & 42 & 195 & \\
\hline HEMBL180 & 756581 & & 8437 & ST \\
\hline HEMBL1802695 & 56581 & & & ST \\
\hline HEMBL180 & 56 & $\partial 9$ & 291 & ST \\
\hline HEMBL1\& & 31 & 26 & 24 & ST \\
\hline HEMBL18€ & 31 & 18 & 6.3859 & ST \\
\hline HEMBL180 & 31 & & 01 & ST \\
\hline HEMBL1802883 & 756581 & 66 & 393 & TST \\
\hline HEMBL 27 & 07 & & & RN \\
\hline HEMBL 23 & 30 & 18 & & ST \\
\hline HEMBL 234 & 07 & 18 & 69 & ST \\
\hline HEMBL 23374 & 07930 & & 27 & RN \\
\hline HEMBL 23286 & 07930 & & 7537 & RN \\
\hline HEMBL 27 & 30 & & 274 & RN \\
\hline HEMBL 23 & 207 & 18 & 49 & RN \\
\hline HEMBL 23146 & 207930 & 5.5229 & 5.2606 & RN \\
\hline HEMBL 23560 & 207930 & & 8871 & RN \\
\hline HEMBL 23584 & 207 & & & RN \\
\hline CHEMBL 22677 & 207930 & 29 & & \\
\hline CHEMBL 23466 & 207930 & & 8658 & RN \\
\hline IHEMBL 23402 & 207930 & 5.30 & & RN \\
\hline HEMBL 281803 & 207930 & 99 & 3165 & RN \\
\hline CHEMBL 23 & 207 & 4 & & \\
\hline CHEMBL 23416 & 207930 & 6.823 & 7.0856 & \\
\hline
\end{tabular}

Page 18911 


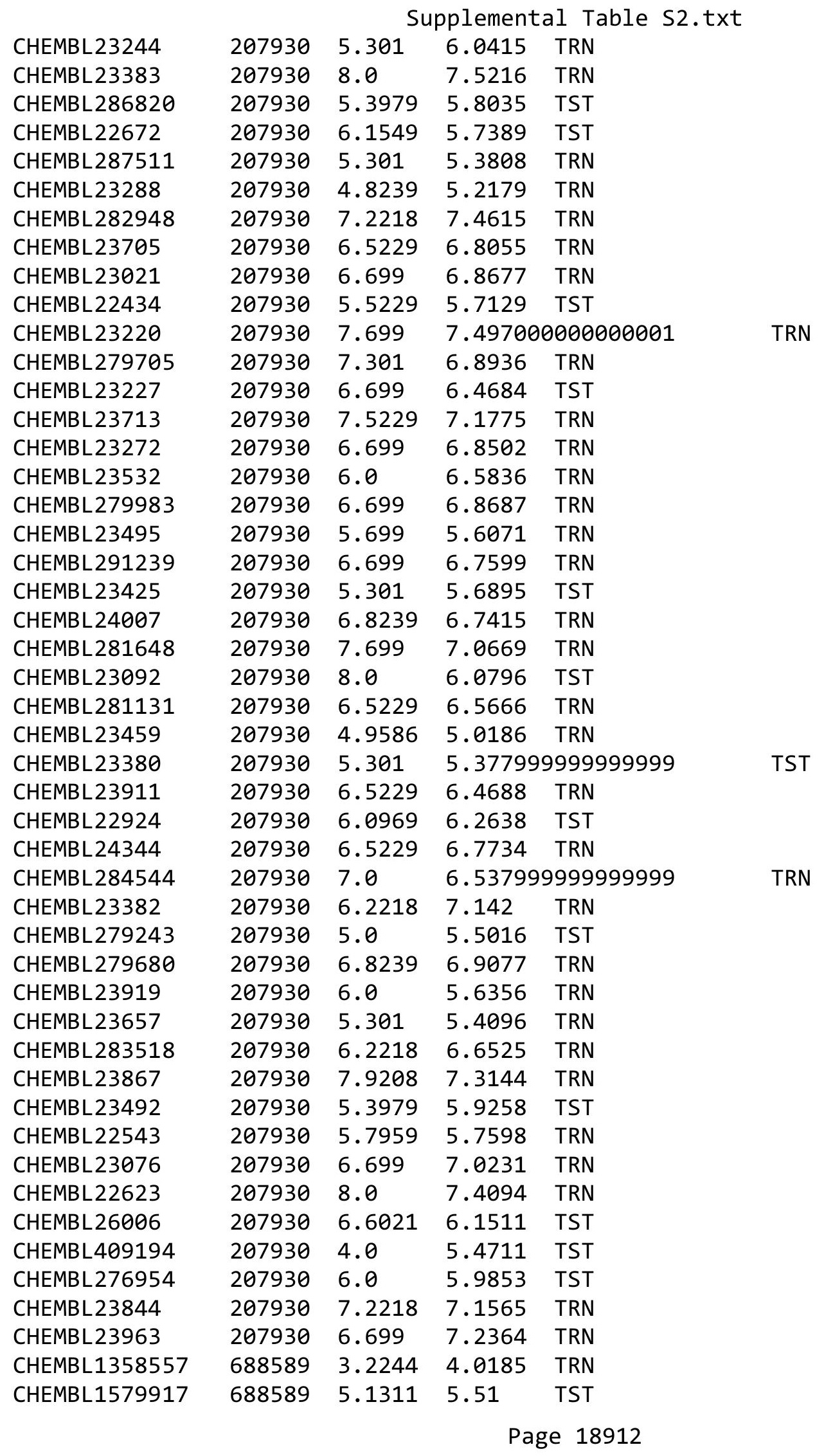




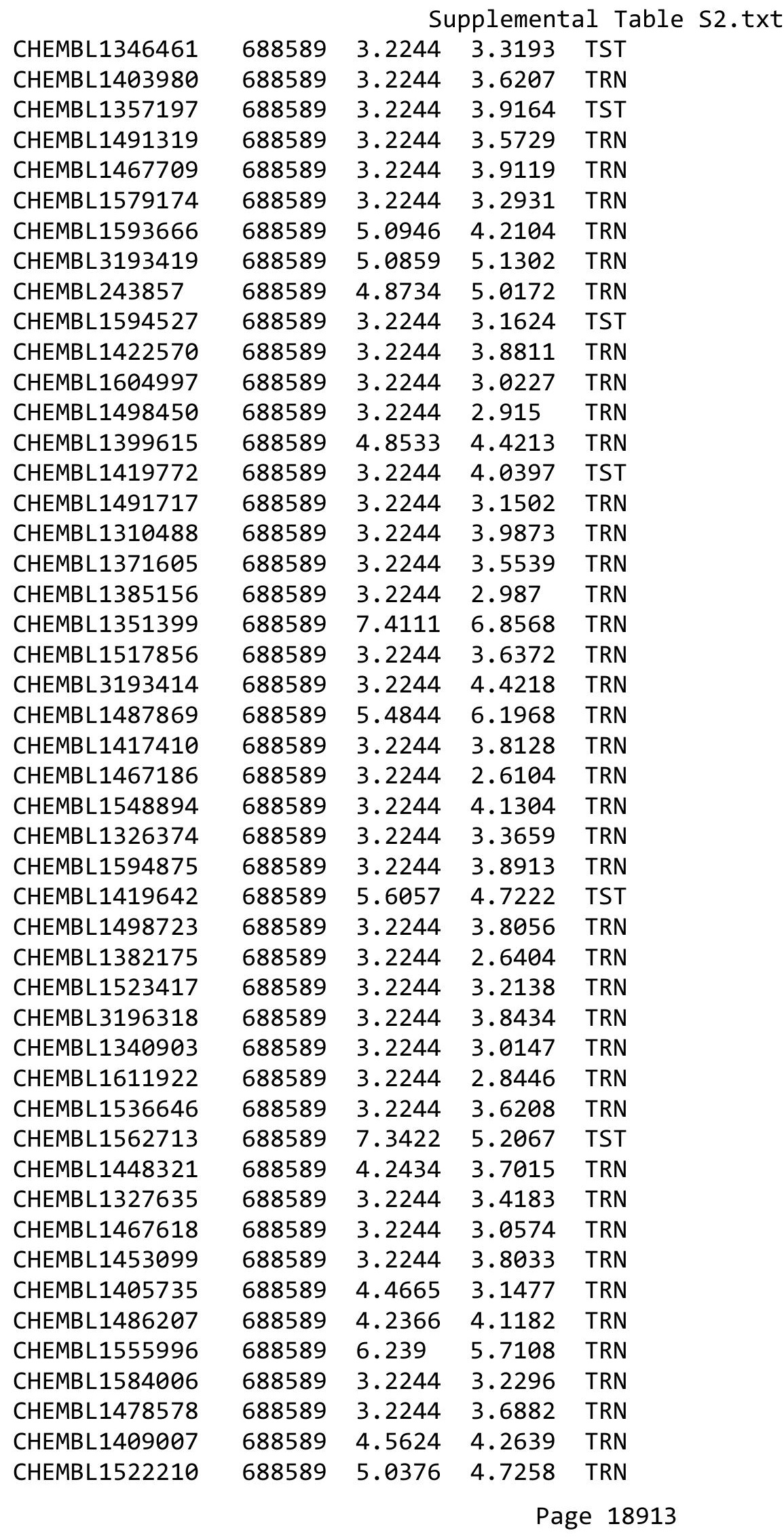




\begin{tabular}{|c|c|c|c|c|c|}
\hline & & & & & \\
\hline CHEMBL1488035 & 688589 & 6.7825 & 4.0108 & TRN & \\
\hline CHEMBL1338157 & 688589 & 7.2019 & 6.4735 & TRN & \\
\hline CHEMBL1378567 & 688589 & 3.2244 & 3.5594 & TST & \\
\hline CHEMBL1367838 & 688589 & 3.2244 & 3.4382 & TRN & \\
\hline CHEMBL1346745 & 688589 & 3.2244 & 3.0379 & TRN & \\
\hline CHEMBL1318749 & 688589 & 3.2244 & 4.029 & TRN & \\
\hline CHEMBL1562516 & 688589 & 3.2244 & 3.9274 & TRN & \\
\hline CHEMBL1301700 & 688589 & 3.2244 & 3.5212 & TRN & \\
\hline CHEMBL 3207442 & 688589 & 3.2244 & 3.548 & TRN & \\
\hline CHEMBL1430538 & 688589 & 3.2244 & 2.7878 & TRN & \\
\hline CHEMBL1588059 & 688589 & 5.6084 & 4.6192 & TRN & \\
\hline CHEMBL1542071 & 688589 & 3.2244 & 3.1395 & TRN & \\
\hline CHEMBL1366838 & 688589 & 3.2244 & 3.79399 & 99999999996 & TRN \\
\hline CHEMBL1450675 & 688589 & 5.63899 & 99999999 & 4.7938 & TRN \\
\hline CHEMBL3199236 & 688589 & 4.9239 & 4.3332 & TRN & \\
\hline CHEMBL1520448 & 688589 & 3.2244 & 4.2908 & TRN & \\
\hline CHEMBL 203543 & 688589 & 5.4014 & 4.6989 & TRN & \\
\hline CHEMBL1555775 & 688589 & 3.2244 & 2.8681 & TRN & \\
\hline CHEMBL1486196 & 688589 & 5.0404 & 5.4312 & TRN & \\
\hline CHEMBL1553293 & 688589 & 5.794 & 4.9823 & TRN & \\
\hline CHEMBL1564801 & 688589 & 6.2245 & 3.7763 & TST & \\
\hline CHEMBL1473747 & 688589 & 3.2244 & 3.8109 & TRN & \\
\hline CHEMBL1575183 & 688589 & 3.2244 & 2.7104 & TRN & \\
\hline CHEMBL1465537 & 688589 & 3.2244 & 3.8878 & TST & \\
\hline CHEMBL1346278 & 688589 & 3.2244 & 3.9534 & TRN & \\
\hline CHEMBL1496905 & 688589 & 3.2244 & 3.1456 & TRN & \\
\hline CHEMBL1449349 & 688589 & 3.2244 & 3.2538 & TRN & \\
\hline CHEMBL1322436 & 688589 & 3.2244 & 2.6111 & TRN & \\
\hline CHEMBL1441932 & 688589 & 4.2961 & 4.0413 & TRN & \\
\hline CHEMBL 1344648 & 688589 & 3.2244 & 3.2754 & TRN & \\
\hline CHEMBL1607173 & 688589 & 4.5236 & 4.5236 & TRN & \\
\hline CHEMBL1439783 & 688589 & 3.2244 & 3.8151 & TRN & \\
\hline CHEMBL1328547 & 688589 & 4.4028 & 3.9719 & TRN & \\
\hline CHEMBL1413348 & 688589 & 4.4318 & 4.2882 & TRN & \\
\hline CHEMBL1564543 & 688589 & 3.2244 & 3.4902 & TRN & \\
\hline CHEMBL1556438 & 688589 & 5.0977 & 5.2102 & TST & \\
\hline CHEMBL1532443 & 688589 & 3.2244 & 3.1018 & TST & \\
\hline CHEMBL1341756 & 688589 & 4.5848 & 3.6132 & TST & \\
\hline CHEMBL1583409 & 688589 & 3.2244 & 3.4524 & TST & \\
\hline CHEMBL1537296 & 688589 & 3.2244 & 4.2744 & TST & \\
\hline CHEMBL1344788 & 688589 & 3.2244 & 5.4309 & TST & \\
\hline CHEMBL1438161 & 688589 & 3.2244 & 3.0056 & TST & \\
\hline CHEMBL1345387 & 688589 & 3.2244 & 3.8356 & TST & \\
\hline CHEMBL1540795 & 688589 & 3.2244 & 3.0165 & TST & \\
\hline CHEMBL1302463 & 688589 & 3.2244 & 3.1421 & TST & \\
\hline CHEMBL1545792 & 688589 & 3.2244 & 3.2224 & TST & \\
\hline CHEMBL1552290 & 688589 & 3.2244 & 3.3989 & TST & \\
\hline CHEMBL1334062 & 688589 & 6.9546 & 4.2992 & TST & \\
\hline
\end{tabular}




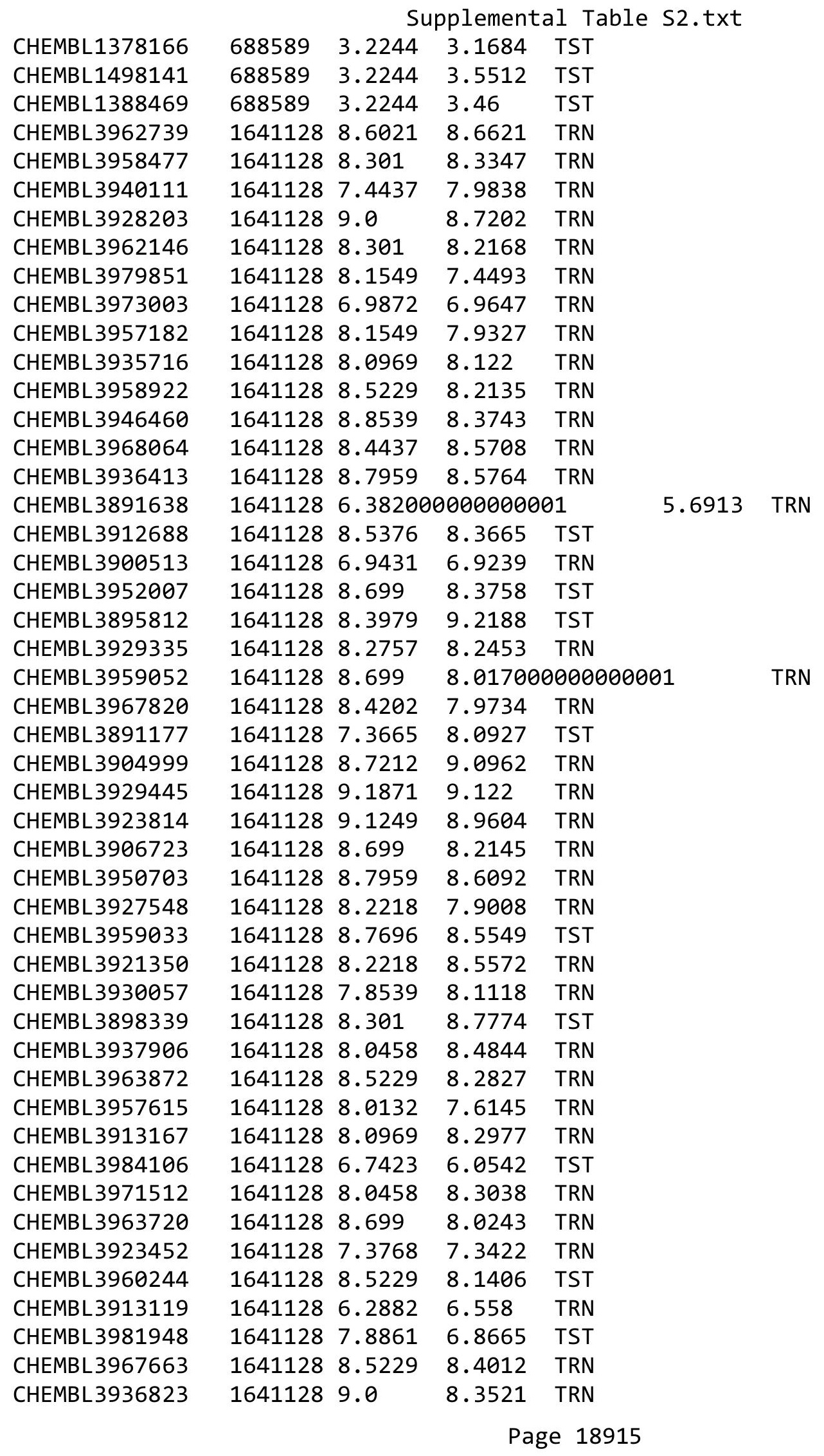


Supplemental Table S2.txt

\begin{tabular}{|c|c|c|c|c|}
\hline CHEMBL3940779 & 1641128 & 8.3979 & 8.7157 & TRN \\
\hline CHEMBL3986676 & 1641128 & 7.9586 & 8.2205 & TRN \\
\hline CHEMBL3980912 & 1641128 & 8.699 & 8.6471 & TST \\
\hline CHEMBL 3891185 & 1641128 & 8.2218 & 8.4398 & TST \\
\hline CHEMBL3960361 & 1641128 & 7.6576 & 8.2559 & TRN \\
\hline CHEMBL 3977803 & 1641128 & 8.1871 & 7.9829 & TST \\
\hline CHEMBL3978618 & 1641128 & 8.3979 & 8.3835 & TRN \\
\hline CHEMBL3967939 & 1641128 & 9.0 & 8.8753 & TRN \\
\hline CHEMBL3964529 & 1641128 & 7.0362 & 6.5361 & TRN \\
\hline CHEMBL3911350 & 1641128 & 8.8861 & 8.3375 & TRN \\
\hline CHEMBL3969541 & 1641128 & 8.3979 & \multicolumn{2}{|c|}{8.392000000000001} \\
\hline CHEMBL3983770 & 1641128 & 7.4559 & 8.2421 & TRN \\
\hline CHEMBL 3940945 & 1641128 & 5.0 & 7.5769 & TRN \\
\hline CHEMBL3951173 & 1641128 & 7.4949 & \multicolumn{2}{|c|}{7.257000000000001} \\
\hline CHEMBL3972631 & 1641128 & 8.5086 & 8.8713 & TRN \\
\hline CHEMBL 3896189 & 1641128 & 7.0862 & 8.0523 & TST \\
\hline CHEMBL3905596 & 1641128 & 8.5229 & 8.2554 & TST \\
\hline CHEMBL3895937 & 1641128 & 7.3565 & 7.483 & TST \\
\hline CHEMBL3983885 & 1641128 & 6.4437 & 7.0776 & TRN \\
\hline CHEMBL3891695 & 1641128 & 8.1549 & 8.2517 & TST \\
\hline CHEMBL3973506 & 1641128 & 7.4881 & 7.5148 & TRN \\
\hline CHEMBL3930318 & 1641128 & 6.0835 & 5.9728 & TRN \\
\hline CHEMBL 3943034 & 1641128 & 8.9208 & 8.8163 & TRN \\
\hline CHEMBL3958017 & 1641128 & 7.4815 & 7.1485 & TST \\
\hline CHEMBL3892930 & 1641128 & 8.5229 & 8.0194 & TST \\
\hline CHEMBL3967108 & 1641128 & 8.699 & 8.5626 & TRN \\
\hline CHEMBL3968916 & 1641128 & 5.0 & 5.9625 & TRN \\
\hline CHEMBL3982806 & 1641128 & 9.0 & 8.5812 & TRN \\
\hline CHEMBL3926871 & 1641128 & 7.3872 & 7.4667 & TRN \\
\hline CHEMBL3928043 & 1641128 & 5.0 & 6.3765 & TST \\
\hline CHEMBL3951652 & 1641128 & 8.4685 & 8.3734 & TRN \\
\hline CHEMBL 3904110 & 1641128 & 7.8861 & 7.147 & TST \\
\hline CHEMBL3959907 & 1641128 & 7.2924 & 6.8937 & TRN \\
\hline CHEMBL 3948372 & 1641128 & 6.209 & 8.9598 & TST \\
\hline CHEMBL3918651 & 1641128 & 8.0969 & 7.941 & TRN \\
\hline CHEMBL3903267 & 1641128 & 6.9393 & 7.1966 & TRN \\
\hline CHEMBL 3952062 & 1641128 & 8.0 & 7.2632 & TST \\
\hline CHEMBL3918358 & 1641128 & 8.9393 & 8.9927 & TST \\
\hline CHEMBL 3944128 & 1641128 & 8.5086 & 8.5152 & TST \\
\hline CHEMBL3965546 & 1641128 & 8.4559 & 8.3256 & TST \\
\hline CHEMBL3919488 & 1641128 & 8.8239 & 8.8305 & TRN \\
\hline CHEMBL 3891434 & 1641128 & 8.0 & 8.1736 & TRN \\
\hline CHEMBL3955997 & 1641128 & 8.7696 & 8.6006 & TRN \\
\hline CHEMBL3930105 & 1641128 & 5.0 & 7.0639 & TST \\
\hline CHEMBL 3976070 & 1641128 & 8.3979 & 8.2343 & TRN \\
\hline CHEMBL3950134 & 1641128 & 7.699 & 7.4348 & TRN \\
\hline CHEMBL3921994 & 1641128 & 8.0458 & 8.0706 & TST \\
\hline CHEMBL 3900184 & 1641128 & 8.5229 & 8.3033 & TRN \\
\hline
\end{tabular}

Page 18916 
Supplemental Table S2.txt

\begin{tabular}{|c|c|c|}
\hline 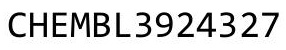 & & \\
\hline CHEMBL3901691 & 1641128 & 5.0 \\
\hline HEMBL3914067 & 641128 & \\
\hline HEMBL 3966506 & 641128 & \\
\hline HEMBL 3958000 & 641128 & \\
\hline HEMBL3894094 & 1641128 & \\
\hline HEMBL3909430 & 1641128 & \\
\hline HEMBL3898737 & 1641128 & \\
\hline HEMBL3921953 & 1641128 & \\
\hline HEMBL3929529 & 1641128 & \\
\hline HEMBL3957625 & 1641128 & \\
\hline HEMBL3984930 & 1641128 & \\
\hline HEMBL3970328 & 1641128 & \\
\hline HEMBL3962290 & 1641128 & \\
\hline HEMBL 3958033 & 1641128 & \\
\hline HEMBL 3987117 & 1641128 & \\
\hline HEMBL3906165 & 1641128 & \\
\hline HEMBL 3967515 & 1641128 & \\
\hline HEMBL3952971 & 1641128 & \\
\hline HEMBL3895833 & 1641128 & \\
\hline CHEMBL 3958502 & 1641128 & \\
\hline HEMBL 3974246 & 1641128 & \\
\hline CHEMBL 3980662 & 1641128 & \\
\hline CHEMBL 3904399 & 1641128 & \\
\hline HEMBL3982709 & 1641128 & \\
\hline CHEMBL3941978 & 128 & \\
\hline CHEMBL 3922230 & 1641128 & 8 . \\
\hline CHEMBL3948209 & 1641128 & \\
\hline CHEMBL3954122 & 1641128 & \\
\hline CHEMBL3966597 & 1641128 & \\
\hline CHEMBL3975009 & 1641128 & \\
\hline CHEMBL3953196 & 1641128 & 8.3 \\
\hline CHEMBL 3967425 & 1641128 & \\
\hline CHEMBL 3900430 & 1641128 & \\
\hline CHEMBL3928390 & 1641128 & 8 . \\
\hline CHEMBL3907763 & 1641128 & \\
\hline CHEMBL3979659 & 1641128 & $8 . \varepsilon$ \\
\hline CHEMBL3949342 & 1641128 & \\
\hline CHEMBL3931607 & 1641128 & \\
\hline CHEMBL3942801 & 1641128 & 8 . \\
\hline CHEMBL3901371 & 1641128 & \\
\hline CHEMBL3957396 & 1641128 & 9.0 \\
\hline CHEMBL3966346 & 1641128 & 7.6 \\
\hline CHEMBL3949916 & 1641128 & \\
\hline CHEMBL 3976332 & 1641128 & \\
\hline CHEMBL3937490 & 1641128 & \\
\hline CHEMBL3968892 & 1641128 & \\
\hline CHEMBL3950770 & 1641128 & \\
\hline
\end{tabular}

7.9439 TRN

6.6332 TST

7.0453 TRN

6.8385 TRN

6.6317 TRN

7.5461 TRN

8.4288 TRN

8.2459 TRN

8.8768 TRN

7.9745 TRN

8.3449 TRN

8.2512 TRN

8.5828 TRN

8.4731 TST

7.0984 TRN

7.6269 TRN

7.0104 TST

8.875 TRN

8.712 TRN

7.0005 TRN

5.2573 TRN

7.412999999999999 TRN

8.1387 TRN

8.2066 TRN

8.3019 TST

8.8625 TST

8.3651 TRN

7.3031 TRN

8.873 TRN

7.2162 TRN

6.2216 TRN

8.3745 TST

7.8685 TRN

8.3715 TRN

8.6806 TRN

8.0369 TRN

8.4258 TRN

6.6664 TRN

8.3841 TRN

8.1444 TST

8.3904 TRN

8.9833 TRN

8.3678 TRN

7.9118 TRN

7.7406 TST

7.2264 TRN

8.1521 TRN

8.0698 TRN

Page 18917 
Supplemental Table S2.txt

\begin{tabular}{|c|c|c|c|c|}
\hline HEMBL3956789 & 641128 & 8.5229 & 7.8874 & TRN \\
\hline HEMBL3946872 & L641128 & 5.0 & 4.9193 & TR \\
\hline HEMBL85716 & 0099 & 5.0 & & RN \\
\hline JEMBL59180 & 0099 & 7.9957 & 7418 & D \\
\hline HEMBL10483 & 0099 & 9.8539 & 9.2474 & \\
\hline HEMBL6814 & 0099 & 7.767 & 7.7714 & \\
\hline HEMBL431973 & 0099 & 6.3645 & 6.8316 & \\
\hline AEMBL 314788 & 0099 & .4377 & 5.1662 & \\
\hline HEMBL84668 & 0099 & 5.0 & 5.5762 & \\
\hline HEMBL59181 & 0099 & 6.9172 & 6.7327 & \\
\hline HEMBL133272 & 0099 & 8.0809 & 8.2304 & \\
\hline HEMBL 295277 & 0099 & 5.5229 & 5.6972 & \\
\hline HEMBL84921 & 0099 & 7.3468 & 6.9532 & RN \\
\hline HEMBL341398 & 0099 & 7.7696 & 8.0605 & \\
\hline HEMBL 335888 & 0099 & 7.1367 & 7.0678 & \\
\hline JEMBL52750 & 0099 & 8.2757 & 7.7431 & \\
\hline HEMBL6659 & 0099 & 8.0 & 8.1289 & \\
\hline HEMBL17468 & 0099 & 8.2441 & 7.7372 & Tाष \\
\hline HEMBL 3144697 & 0099 & 10.2218 & 11.1831 & $C T$ \\
\hline AEMBL420044 & 0099 & 7.5918 & 6.8729 & TST \\
\hline HEMBL49141 & 70099 & 9.3098 & 8.5382 & II \\
\hline HEMBL369358 & 0099 & 6.8508 & 6.6415 & RI \\
\hline HEMBL10195 & 0099 & 8.699 & 8.9879 & \\
\hline AEMBL87331 & 0099 & 6. & 5.8959 & הN \\
\hline AEMBL44784 & 0099 & & 931 & $1 \mathrm{~K}$ \\
\hline HEMBL 314484 & 70099 & 9. & 10.9546 & TST \\
\hline HEMBL416450 & 0099 & 7.5 & 7.794 & RN \\
\hline HEMBL173082 & 0099 & 67 & 8.3404 & RN \\
\hline IEMBL273464 & 0099 & 7 . & 7.8073 & TRN \\
\hline HEMBL13458 & 0099 & 6.5 & 6.7457 & 15 \\
\hline HEMBL43718 & 0099 & 6.3 & 5.6693 & rRN \\
\hline IEMBL408797 & $\partial 099$ & 7. & 8.53 & ות \\
\hline IEMBL $2 \varepsilon$ & 099 & 7. & 7.6566 & RN \\
\hline IEMBL69719 & 0099 & 8.6 & 8.7215 & 11 \\
\hline HEMBL 368919 & 0099 & 8.6383 & 8.6025 & $\mathrm{TR}$ \\
\hline IEMBL43725 & 0099 & 4. & 5.5274 & RI \\
\hline AEMBL58570 & 0099 & 7.8 & 7.7203 & RI \\
\hline HEMBL366789 & $\partial 099$ & 4.5 & 6.0569 & TST \\
\hline HEMBL 307783 & 70099 & 9.1427 & 8.8597 & TRA \\
\hline HEMBL10534 & 0099 & 9.2 & 9.2189 & TR \\
\hline CHEMBL133705 & 70099 & 6.8069 & 6.9071 & RI \\
\hline CHEMBL173347 & 70099 & 7.0269 & 6.819 & $\mathrm{RI}$ \\
\hline HEMBL7290 & 70099 & 7.8928 & 8.1223 & rR \\
\hline HEMBL133219 & 0099 & 7.585 & 8.1145 & rR \\
\hline MBL314804 & 70099 & 5.5229 & 5.7357 & RI \\
\hline CHEMBL53651 & 70099 & 7.1726 & 7.8021 & $\mathrm{RI}$ \\
\hline CHEMBL17453 & 70099 & 7.1175 & 7.3153 & $\mathrm{RI}$ \\
\hline CHEMBL367051 & 70099 & 5.5229 & 6.2399 & $1 n$ \\
\hline
\end{tabular}

Page 18918 


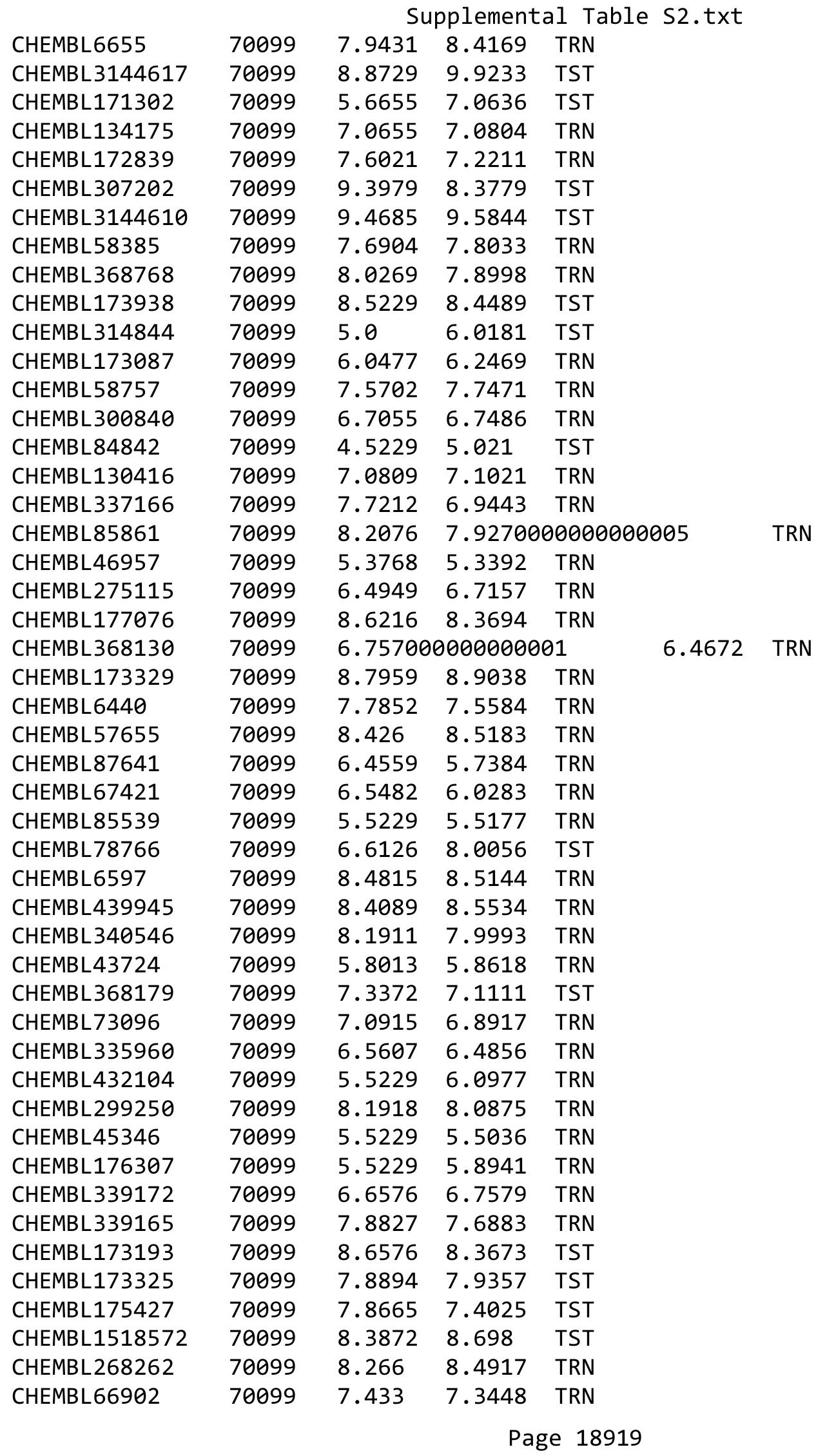




\begin{tabular}{|c|c|c|c|c|c|c|}
\hline & & \multicolumn{5}{|c|}{ Supplemental Table s2.txt } \\
\hline CHEMBL10597 & 70099 & 8.1427 & 7.6597 & TRN & & \\
\hline CHEMBL415290 & 70099 & 8.1675 & 8.007 & TRN & & \\
\hline CHEMBL3144795 & 70099 & 8.5229 & 9.7749 & TST & & \\
\hline CHEMBL415293 & 70099 & \multicolumn{3}{|c|}{7.7620000000000005} & 7.7887 & TRN \\
\hline CHEMBL367639 & 70099 & 6.9788 & 7.5465 & TST & & \\
\hline CHEMBL13662 & 70099 & 7.2441 & 6.1811 & TST & & \\
\hline CHEMBL 295981 & 70099 & 5.5229 & 5.4662 & TRN & & \\
\hline CHEMBL1269093 & 70099 & 7.6038 & 7.8262 & TST & & \\
\hline CHEMBL6421 & 70099 & 8.1397 & 8.1011 & TRN & & \\
\hline CHEMBL130609 & 70099 & 8.8239 & 8.7258 & TRN & & \\
\hline CHEMBL132529 & 70099 & 8.0 & 7.7294 & TRN & & \\
\hline CHEMBL173219 & 70099 & 8.4672 & 8.1512 & TRN & & \\
\hline CHEMBL141039 & 70099 & 8.4685 & 8.7693 & TRN & & \\
\hline CHEMBL 298561 & 70099 & \multicolumn{3}{|c|}{7.218999999999999} & 7.7434 & TRN \\
\hline CHEMBL3144753 & 70099 & 9.699 & 10.2654 & TST & & \\
\hline CHEMBL3144696 & 70099 & 10.0969 & 11.3283 & TST & & \\
\hline CHEMBL172866 & 70099 & 7.5528 & 8.048 & TST & & \\
\hline CHEMBL435550 & 70099 & 6.7375 & 7.2213 & TRN & & \\
\hline CHEMBL 3144698 & 70099 & 9.7447 & 10.9437 & TST & & \\
\hline CHEMBL173339 & 70099 & 7.7167 & 7.6468 & TRN & & \\
\hline CHEMBL45174 & 70099 & 5.6882 & 5.6216 & TRN & & \\
\hline CHEMBL133049 & 70099 & 8.1713 & 8.2143 & TRN & & \\
\hline CHEMBL19732 & 70099 & \multicolumn{3}{|c|}{10.300999999999998} & 9.8125 & TST \\
\hline CHEMBL176457 & 70099 & 7.8125 & 7.6178 & TRN & & \\
\hline CHEMBL11709 & 70099 & 8.9208 & 9.1408 & TRN & & \\
\hline CHEMBL 301605 & 70099 & 8.9586 & 9.2845 & TST & & \\
\hline CHEMBL 267665 & 70099 & 8.9208 & 8.8617 & TRN & & \\
\hline CHEMBL79945 & 70099 & 8.2924 & 8.4846 & TRN & & \\
\hline CHEMBL131977 & 70099 & 8.2366 & 8.0139 & TRN & & \\
\hline CHEMBL3144849 & 70099 & 10.1549 & 11.1596 & TST & & \\
\hline CHEMBL3144615 & 70099 & 9.6383 & 10.7384 & TST & & \\
\hline CHEMBL170808 & 70099 & 9.3098 & 8.7812 & TRN & & \\
\hline CHEMBL47853 & 70099 & 5.0232 & 5.0528 & TRN & & \\
\hline CHEMBL336728 & 70099 & 7.6778 & 7.7774 & TRN & & \\
\hline CHEMBL368171 & 70099 & 7.5129 & 7.8219 & TRN & & \\
\hline CHEMBL83581 & 70099 & 7.6091 & 7.0896 & TST & & \\
\hline CHEMBL52030 & 70099 & 7.3143 & 7.9443 & TRN & & \\
\hline CHEMBL3980992 & 1641036 & 6.0555 & 5.7573 & TRN & & \\
\hline CHEMBL3971373 & 1641036 & 6.8539 & 6.8084 & TRN & & \\
\hline CHEMBL3894474 & 1641036 & 7.3565 & 7.4447 & TRN & & \\
\hline CHEMBL3934580 & 1641036 & 7.3565 & 7.361006 & 0000000001 & & TRN \\
\hline CHEMBL3906776 & 1641036 & 6.4318 & 6.4272 & TRN & & \\
\hline CHEMBL3978366 & 1641036 & 5.0 & 5.3189 & TRN & & \\
\hline CHEMBL3963532 & 1641036 & 6.2291 & 6.4967 & TST & & \\
\hline CHEMBL3906967 & 1641036 & 6.0 & 6.1073 & TRN & & \\
\hline CHEMBL3962364 & 1641036 & 5.0 & 5.0882 & TRN & & \\
\hline CHEMBL3961357 & 1641036 & 6.1135 & 6.0147 & TRN & & \\
\hline CHEMBL3921202 & 1641036 & 5.0 & 4.7773 & TRN & & \\
\hline
\end{tabular}




$$
\text { Supplemental Table S2.txt }
$$

\begin{tabular}{|c|c|c|c|c|c|}
\hline CHEMBL3914847 & 1641036 & 6.2924 & 6.3214 & TRN & \\
\hline CHEMBL3986686 & 1641036 & 6.0 & 6.3146 & TRN & \\
\hline CHEMBL3965307 & 1641036 & 6.9208 & 6.652 & TRN & \\
\hline CHEMBL3949195 & 1641036 & 5.0 & 4.8335 & TRN & \\
\hline CHEMBL3952261 & 1641036 & 6.4949 & 6.8695 & TRN & \\
\hline CHEMBL3926817 & 1641036 & 7.2757 & 7.2357 & TRN & \\
\hline CHEMBL3929096 & 1641036 & 6.7959 & 6.5934 & TRN & \\
\hline CHEMBL3903353 & 1641036 & 5.0 & 5.5765 & TRN & \\
\hline CHEMBL3909793 & 1641036 & 5.0 & 5.3681 & TRN & \\
\hline CHEMBL3975399 & 1641036 & 6.8861 & 6.5516 & TRN & \\
\hline CHEMBL3891204 & 1641036 & 6.3872 & 6.7907 & TRN & \\
\hline CHEMBL3984424 & 1641036 & 6.0 & 5.7772 & TRN & \\
\hline CHEMBL3981443 & 1641036 & 6.3372 & 6.0723 & TRN & \\
\hline CHEMBL3904186 & 1641036 & 6.4815 & 6.2902 & TRN & \\
\hline CHEMBL3942424 & 1641036 & 6.0 & 6.1346 & TRN & \\
\hline CHEMBL3954454 & 1641036 & 8.5528 & 8.3918 & TRN & \\
\hline CHEMBL3910017 & 1641036 & 5.0 & 6.25 & TRN & \\
\hline CHEMBL3945964 & 1641036 & 6.5528 & 6.1513 & TRN & \\
\hline CHEMBL3931093 & 1641036 & 6.9586 & 6.8328 & TRN & \\
\hline CHEMBL3927316 & 1641036 & 5.0 & 5.4311 & TRN & \\
\hline CHEMBL3929398 & 1641036 & 5.0 & 4.6791 & TRN & \\
\hline CHEMBL3965217 & 1641036 & 6.1024 & 6.0025 & TRN & \\
\hline CHEMBL3969811 & 1641036 & 5.0 & 5.055 & TRN & \\
\hline CHEMBL3940644 & 1641036 & 6.1308 & 6.1961 & TRN & \\
\hline CHEMBL3986660 & 1641036 & 8.3098 & 8.2186 & TRN & \\
\hline CHEMBL3902123 & 1641036 & 6.8539 & 6.8149 & TRN & \\
\hline CHEMBL3935408 & 1641036 & 6.3468 & 6.9202 & TST & \\
\hline CHEMBL3910680 & 1641036 & 5.0 & 5.5596 & TRN & \\
\hline CHEMBL3913565 & 1641036 & 6.2366 & 6.1484 & TRN & \\
\hline CHEMBL3927682 & 1641036 & 5.0 & 5.1145 & TST & \\
\hline CHEMBL3896777 & 1641036 & 6.8239 & 6.8501 & TRN & \\
\hline CHEMBL3951230 & 1641036 & 6.6778 & 6.7706 & TRN & \\
\hline CHEMBL3911142 & 1641036 & 6.8539 & 7.1514 & TRN & \\
\hline CHEMBL3911362 & 1641036 & 7.0969 & 7.0237 & TRN & \\
\hline CHEMBL3939325 & 1641036 & 6.3188 & 6.2102 & TRN & \\
\hline CHEMBL3898818 & 1641036 & 6.6198 & 7.067 & TRN & \\
\hline CHEMBL3981542 & 1641036 & 6.8239 & 6.206 & TRN & \\
\hline CHEMBL3983127 & 1641036 & 6.5086 & 6.1307 & TRN & \\
\hline CHEMBL3954894 & 1641036 & 8.9208 & 8.4737 & TRN & \\
\hline CHEMBL3906460 & 1641036 & 5.0 & 5.4065 & TRN & \\
\hline CHEMBL3976885 & 1641036 & 5.0 & $5.48600 t$ & 0000000001 & TRN \\
\hline CHEMBL3930389 & 1641036 & 7.1739 & 7.0991 & TRN & \\
\hline CHEMBL3980120 & 1641036 & 5.0 & 5.7401 & TRN & \\
\hline CHEMBL3956450 & 1641036 & 6.7696 & 6.7651 & TRN & \\
\hline CHEMBL3931226 & 1641036 & 6.0088 & 6.2695 & TRN & \\
\hline CHEMBL3916457 & 1641036 & 6.2076 & 6.5885 & TRN & \\
\hline CHEMBL3934116 & 1641036 & 8.1367 & 8.0171 & TRN & \\
\hline CHEMBL3918943 & 1641036 & 6.0757 & 5.6642 & TRN & \\
\hline
\end{tabular}


Supplemental Table S2.txt

\begin{tabular}{|c|c|c|c|c|c|}
\hline CHEMBL3953486 & 1641036 & 6.3098 & 6.2896 & TRN & \\
\hline CHEMBL3931435 & 1641036 & 5.0 & 5.6022 & TST & \\
\hline CHEMBL3913693 & 1641036 & 5.0 & 5.6425 & TRN & \\
\hline CHEMBL3969473 & 1641036 & 7.3372 & 7.709 & TRN & \\
\hline CHEMBL3902992 & 1641036 & 6.0 & 6.0039 & TRN & \\
\hline CHEMBL3973302 & 1641036 & 7.3872 & 7.3853 & TRN & \\
\hline CHEMBL3948605 & 1641036 & 7.2291 & 7.7989 & TST & \\
\hline CHEMBL3896712 & 1641036 & 5.585 & 5.5173 & TRN & \\
\hline CHEMBL3956611 & 1641036 & 6.0 & 5.7766 & TRN & \\
\hline CHEMBL3912192 & 1641036 & 5.0 & 5.5097 & TRN & \\
\hline CHEMBL3889588 & 1641036 & 6.1079 & 6.1913 & TST & \\
\hline CHEMBL3946125 & 1641036 & 6.6198 & 6.6191 & TRN & \\
\hline CHEMBL3941680 & 1641036 & 5.0 & 5.1373 & TRN & \\
\hline CHEMBL3941598 & 1641036 & 6.4815 & 6.71399 & 99999999995 & TRN \\
\hline CHEMBL3916636 & 1641036 & 6.5686 & 6.4545 & TRN & \\
\hline CHEMBL3964008 & 1641036 & 6.2441 & 6.1205 & TRN & \\
\hline CHEMBL3972033 & 1641036 & 6.4318 & 6.066 & TRN & \\
\hline CHEMBL3986588 & 1641036 & 5.0 & 5.0604 & TRN & \\
\hline CHEMBL3915165 & 1641036 & 5.0 & 5.572 & TRN & \\
\hline CHEMBL3957921 & 1641036 & 7.1675 & 7.0994 & TRN & \\
\hline CHEMBL3949285 & 1641036 & 7.2441 & 7.1926 & TRN & \\
\hline CHEMBL3907944 & 1641036 & 6.7447 & 6.229 & TRN & \\
\hline CHEMBL3968423 & 1641036 & 6.0 & 5.9857 & TRN & \\
\hline CHEMBL3939232 & 1641036 & 6.2596 & 6.271 & TRN & \\
\hline CHEMBL3979340 & 1641036 & 7.0088 & 7.0952 & TRN & \\
\hline CHEMBL3902205 & 1641036 & 6.4318 & 6.5438 & TRN & \\
\hline CHEMBL3962117 & 1641036 & 6.5686 & 6.3597 & TRN & \\
\hline CHEMBL3892138 & 1641036 & 6.3372 & 6.4583 & TRN & \\
\hline CHEMBL3934943 & 1641036 & 5.0 & 4.9226 & TRN & \\
\hline CHEMBL3947889 & 1641036 & 6.7959 & 6.9252 & TRN & \\
\hline CHEMBL3943994 & 1641036 & 8.0605 & 8.0955 & TRN & \\
\hline CHEMBL3963480 & 1641036 & 5.0 & 6.2664 & TST & \\
\hline CHEMBL3917030 & 1641036 & 6.4949 & 6.5169 & TRN & \\
\hline CHEMBL3950399 & 1641036 & 6.1938 & 6.2013 & TRN & \\
\hline CHEMBL3985391 & 1641036 & 6.7447 & 6.496 & TRN & \\
\hline CHEMBL3973060 & 1641036 & 6.2676 & 5.9072 & TST & \\
\hline CHEMBL3974289 & 1641036 & 6.0 & 5.6579 & TRN & \\
\hline CHEMBL3900724 & 1641036 & 5.0 & 4.6431 & TRN & \\
\hline CHEMBL3983078 & 1641036 & 6.9208 & 6.7513 & TRN & \\
\hline CHEMBL3942459 & 1641036 & 6.9586 & 6.1975 & TRN & \\
\hline CHEMBL3896798 & 1641036 & 5.0 & 4.9329 & TST & \\
\hline CHEMBL3916687 & 1641036 & 6.4949 & 6.5953 & TRN & \\
\hline CHEMBL3935714 & 1641036 & 7.4437 & 7.0907 & TST & \\
\hline CHEMBL3899650 & 1641036 & 6.3279 & 5.7774 & TRN & \\
\hline CHEMBL3968041 & 1641036 & 7.5229 & 7.2215 & TRN & \\
\hline CHEMBL3899634 & 1641036 & 6.8239 & 7.1295 & TRN & \\
\hline CHEMBL3928338 & 1641036 & 6.6778 & 6.0496 & TST & \\
\hline CHEMBL3939331 & 1641036 & 5.0 & 5.1872 & TRN & \\
\hline
\end{tabular}


Supplemental Table S2.txt

\begin{tabular}{|c|c|c|c|c|c|}
\hline CHEMBL3898786 & 1641036 & 6.6383 & 6.8928 & TST & \\
\hline CHEMBL3965670 & 1641036 & 7.3468 & 6.1899 & TST & \\
\hline CHEMBL3943768 & 1641036 & 5.0 & 5.0732 & TST & \\
\hline CHEMBL3923802 & 1641036 & 6.4949 & 6.3993 & TRN & \\
\hline CHEMBL3934192 & 1641036 & 6.2076 & 6.3265 & TRN & \\
\hline CHEMBL3949040 & 1641036 & 7.0132 & 7.0086 & TRN & \\
\hline CHEMBL3953550 & 1641036 & 6.7696 & 6.5237 & TRN & \\
\hline CHEMBL3972962 & 1641036 & 5.0 & 4.8643 & TRN & \\
\hline CHEMBL3900631 & 1641036 & 6.4815 & 6.5627 & TRN & \\
\hline CHEMBL3919034 & 1641036 & 6.2147 & 5.4236 & TST & \\
\hline CHEMBL3902333 & 1641036 & 6.3872 & 6.644 & TRN & \\
\hline CHEMBL3942304 & 1641036 & 5.0 & 5.234 & TRN & \\
\hline CHEMBL3963387 & 1641036 & 6.4089 & 6.5337 & TRN & \\
\hline CHEMBL3975255 & 1641036 & 5.0 & 4.2669 & TRN & \\
\hline CHEMBL3935688 & 1641036 & 6.7212 & 6.7452 & TRN & \\
\hline CHEMBL3937827 & 1641036 & 6.4318 & 5.9057 & TRN & \\
\hline CHEMBL3907394 & 1641036 & 5.0 & 5.2509 & TRN & \\
\hline CHEMBL3892562 & 1641036 & 5.0 & 5.5518 & TRN & \\
\hline CHEMBL 3896784 & 1641036 & 6.0 & 5.6152 & TRN & \\
\hline CHEMBL3922240 & 1641036 & 7.0 & 6.4687 & TRN & \\
\hline CHEMBL3970198 & 1641036 & 5.0 & 5.3622 & TRN & \\
\hline CHEMBL3979623 & 1641036 & 6.5229 & 6.2987 & TRN & \\
\hline CHEMBL3963443 & 1641036 & 6.0 & 5.8072 & TRN & \\
\hline CHEMBL3905617 & 1641036 & 6.1487 & 5.4076 & TST & \\
\hline CHEMBL3911186 & 1641036 & 6.2596 & 5.78 & TRN & \\
\hline CHEMBL3937326 & 1641036 & 5.0 & 5.3985 & TRN & \\
\hline CHEMBL3967397 & 1641036 & 8.2596 & 8.4453 & TRN & \\
\hline CHEMBL3965965 & 1641036 & 6.699 & 6.394 & TRN & \\
\hline CHEMBL3922180 & 1641036 & 5.0 & 5.0513 & TRN & \\
\hline CHEMBL3907648 & 1641036 & 6.4685 & 6.6812 & TRN & \\
\hline CHEMBL3902428 & 1641036 & 6.2757 & 6.3466 & TRN & \\
\hline CHEMBL3947749 & 1641036 & 5.0 & 4.9109 & TRN & \\
\hline CHEMBL3922303 & 1641036 & 6.1739 & \multicolumn{2}{|c|}{6.297000000000001} & TRN \\
\hline CHEMBL3909146 & 1641036 & 6.9208 & 7.0502 & TRN & \\
\hline CHEMBL3897798 & 1641036 & 6.4437 & 6.4621 & TRN & \\
\hline CHEMBL3980246 & 1641036 & 6.0757 & 6.1203 & TRN & \\
\hline CHEMBL3953381 & 1641036 & 6.6778 & 6.4065 & TRN & \\
\hline CHEMBL3945740 & 1641036 & 6.8861 & 6.4535 & TST & \\
\hline CHEMBL3933612 & 1641036 & 5.0 & 5.4261 & TST & \\
\hline CHEMBL3926894 & 1641036 & 6.6778 & 6.3625 & TRN & \\
\hline CHEMBL3957421 & 1641036 & 6.0 & 6.2637 & TRN & \\
\hline CHEMBL3959556 & 1641036 & 6.5686 & 6.4197 & TRN & \\
\hline CHEMBL3986377 & 1641036 & 6.5229 & 6.2579 & TRN & \\
\hline CHEMBL3963319 & 1641036 & 5.3872 & 5.9094 & TST & \\
\hline CHEMBL3935174 & 1641036 & 6.1249 & 5.8292 & TRN & \\
\hline CHEMBL3977017 & 1641036 & 6.5376 & 6.4175 & TRN & \\
\hline CHEMBL3908040 & 1641036 & 8.2291 & 8.2678 & TRN & \\
\hline CHEMBL3940483 & 1641036 & 5.0 & 4.9511 & TRN & \\
\hline
\end{tabular}


Supplemental Table S2.txt

\begin{tabular}{|c|c|c|c|c|}
\hline CHEMBL3971898 & 1641036 & 5.0 & 5.8514 & TRN \\
\hline CHEMBL3985390 & 1641036 & 6.2291 & 6.4402 & TRN \\
\hline CHEMBL3985603 & 1641036 & 6.2366 & 6.097 & TRN \\
\hline CHEMBL3973072 & 1641036 & 6.1249 & 6.1839 & TRN \\
\hline CHEMBL3905358 & 1641036 & 5.0 & 5.5033 & TST \\
\hline CHEMBL3897849 & 1641036 & 6.2366 & 6.2591 & TRN \\
\hline CHEMBL3927649 & 1641036 & 6.8239 & 6.5367 & TRN \\
\hline CHEMBL 3923513 & 1641036 & 6.7959 & 6.9023 & TRN \\
\hline CHEMBL3913228 & 1641036 & 5.0 & 4.8201 & TRN \\
\hline CHEMBL3962451 & 1641036 & 6.0132 & 5.9823 & TRN \\
\hline CHEMBL3918854 & 1641036 & 5.0 & 5.8963 & TRN \\
\hline CHEMBL3963994 & 1641036 & 5.0 & 5.6457 & TRN \\
\hline CHEMBL3940316 & 1641036 & 5.0 & 5.1743 & TRN \\
\hline CHEMBL3983344 & 1641036 & 6.5376 & 6.813 & TRN \\
\hline CHEMBL 3924171 & 1641036 & 5.0 & 4.7677 & TRN \\
\hline CHEMBL3949323 & 1641036 & 7.5528 & 7.3824 & TRN \\
\hline CHEMBL3966425 & 1641036 & 6.0 & 6.0523 & TRN \\
\hline CHEMBL3920329 & 1641036 & 6.2757 & 6.7284 & TRN \\
\hline CHEMBL3892296 & 1641036 & 7.4949 & 7.6369 & TRN \\
\hline CHEMBL 3957937 & 1641036 & 6.4089 & 5.9868 & TRN \\
\hline CHEMBL3901676 & 1641036 & 6.0605 & 5.54799 & 9999999999 \\
\hline CHEMBL3926766 & 1641036 & 7.6021 & 7.4108 & TST \\
\hline CHEMBL3900189 & 1641036 & 5.0 & 5.2928 & TST \\
\hline CHEMBL3918875 & 1641036 & 5.0 & 5.2547 & TST \\
\hline CHEMBL 3908073 & 1641036 & 6.6021 & 6.0811 & TST \\
\hline CHEMBL3902447 & 1641036 & 6.0555 & 5.5643 & TRN \\
\hline CHEMBL3967735 & 1641036 & 6.0 & 5.8812 & TRN \\
\hline CHEMBL3936565 & 1641036 & 5.0 & 5.4291 & TRN \\
\hline CHEMBL3931713 & 1641036 & 6.0458 & 5.8951 & TRN \\
\hline CHEMBL3976356 & 1641036 & 5.0 & 4.9831 & TRN \\
\hline CHEMBL3985597 & 1641036 & 5.2757 & 5.0577 & TST \\
\hline CHEMBL3909814 & 1641036 & 6.3279 & 6.1219 & TRN \\
\hline CHEMBL3944831 & 1641036 & 6.0044 & 5.943 & TRN \\
\hline CHEMBL3917774 & 1641036 & 7.5686 & 7.709 & TRN \\
\hline CHEMBL3970109 & 1641036 & 6.3768 & 6.4251 & TRN \\
\hline CHEMBL3949242 & 1641036 & 6.3565 & 6.2945 & TRN \\
\hline CHEMBL3950680 & 1641036 & 8.4815 & 8.0352 & TRN \\
\hline CHEMBL3985119 & 1641036 & 6.3768 & 6.3739 & TRN \\
\hline CHEMBL3890660 & 1641036 & 5.0 & 5.2143 & TRN \\
\hline CHEMBL3945787 & 1641036 & 6.3565 & 6.7225 & TRN \\
\hline CHEMBL3955496 & 1641036 & 7.1079 & 6.9658 & TST \\
\hline CHEMBL3940267 & 1641036 & 6.8539 & 6.778 & TRN \\
\hline CHEMBL3926516 & 1641036 & 6.3665 & \multicolumn{2}{|c|}{6.917000000000001} \\
\hline CHEMBL3972475 & 1641036 & 7.3279 & 7.3925 & TRN \\
\hline CHEMBL3971389 & 1641036 & 6.2441 & 6.0224 & TST \\
\hline CHEMBL3978620 & 1641036 & 6.3565 & 6.3097 & TRN \\
\hline CHEMBL 3984562 & 1641036 & 7.7959 & 7.8687 & TRN \\
\hline CHEMBL3981130 & 1641036 & 6.0655 & 6.0933 & TRN \\
\hline
\end{tabular}


Supplemental Table S2.txt

\begin{tabular}{|c|c|c|c|c|}
\hline CHEMBL 3969865 & 1641036 & 6.699 & 6.0538 & TST \\
\hline CHEMBL 3922488 & 1641036 & 6.2147 & 6.0193 & TRN \\
\hline CHEMBL 3973486 & 1641036 & 6.0605 & 5.3462 & TRN \\
\hline CHEMBL 3937067 & 1641036 & 7.2076 & 7.0796 & TRN \\
\hline CHEMBL 3900738 & 1641036 & 5.0 & 4.8503 & TRN \\
\hline CHEMBL3985243 & 1641036 & 7.0 & 7.5297 & TRN \\
\hline CHEMBL 3957659 & 1641036 & 6.585 & 6.499 & TRN \\
\hline CHEMBL 3909024 & 1641036 & 6.6198 & 6.6369 & TST \\
\hline CHEMBL 3966840 & 1641036 & 6.0 & 5.3858 & TRN \\
\hline CHEMBL 3899570 & 1641036 & 6.1549 & 5.89 & TRN \\
\hline CHEMBL 3955720 & 1641036 & 7.4318 & 7.3669 & TRN \\
\hline CHEMBL 3899587 & 1641036 & 5.0 & 4.7146 & TST \\
\hline CHEMBL 3973429 & 1641036 & 5.0 & 4.9643 & TRN \\
\hline CHEMBL 3937822 & 1641036 & 5.0 & 5.0036 & TST \\
\hline CHEMBL 3943501 & 1641036 & 6.8861 & 6.2515 & TRN \\
\hline CHEMBL 3893196 & 1641036 & 5.0 & 5.0365 & TRN \\
\hline CHEMBL 3956966 & 1641036 & 6.5086 & 5.1755 & TST \\
\hline CHEMBL 3933397 & 1641036 & 6.699 & 6.3941 & TST \\
\hline CHEMBL 3924291 & 1641036 & 5.0 & 6.4352 & TST \\
\hline CHEMBL 3969516 & 1641036 & 6.041 & 6.1579 & TRN \\
\hline CHEMBL 3983856 & 1641036 & 6.2518 & 5.9172 & TRN \\
\hline CHEMBL 3900746 & 1641036 & 8.585 & 8.5643 & TRN \\
\hline CHEMBL 3954249 & 1641036 & 5.0 & 5.6734 & TST \\
\hline CHEMBL 3891947 & 1641036 & 8.4437 & 7.9903 & TRN \\
\hline CHEMBL 3979988 & 1641036 & 7.0 & 7.0856 & TRN \\
\hline CHEMBL 3974904 & 1641036 & 5.0 & 4.796 & TRN \\
\hline CHEMBL 3977496 & 1641036 & 5.0 & 5.09399 & 9999999999 \\
\hline CHEMBL 3932581 & 1641036 & 5.0 & 5.7446 & TST \\
\hline CHEMBL 3955793 & 1641036 & 5.0 & 5.83200 & 0000000001 \\
\hline CHEMBL 3983447 & 1641036 & 7.0 & 6.5981 & TRN \\
\hline CHEMBL 3941925 & 1641036 & 6.1024 & 6.6208 & TST \\
\hline CHEMBL 3934426 & 1641036 & 6.4437 & 6.70299 & 9999999999 \\
\hline CHEMBL 3958797 & 1641036 & 5.8239 & 5.7907 & TRN \\
\hline CHEMBL 3896461 & 1641036 & 6.3665 & 6.2009 & TRN \\
\hline CHEMBL 3920352 & 1641036 & 5.0 & 5.1092 & TRN \\
\hline CHEMBL 3894366 & 1641036 & 5.0 & 5.307 & TRN \\
\hline CHEMBL 3979388 & 1641036 & 5.0 & 4.907 & TRN \\
\hline CHEMBL 3985220 & 1641036 & 7.4685 & 6.9719 & TST \\
\hline CHEMBL 3978202 & 1641036 & 7.2007 & 7.675 & TRN \\
\hline CHEMBL 3940782 & 1641036 & 7.1871 & 6.5789 & TRN \\
\hline CHEMBL 3947422 & 1641036 & 5.0 & 4.7449 & TRN \\
\hline CHEMBL 3975158 & 1641036 & 6.8539 & 6.7677 & TRN \\
\hline CHEMBL 3920091 & 1641036 & 7.3565 & 6.6833 & TST \\
\hline CHEMBL 3962138 & 1641036 & 6.4089 & 6.515 & TRN \\
\hline CHEMBL 3904453 & 1641036 & 6.1487 & 5.8072 & TRN \\
\hline CHEMBL 3909751 & 1641036 & 5.0 & 5.3933 & TRN \\
\hline CHEMBL 3911874 & 1641036 & 6.8861 & 6.042006 & 0000000001 \\
\hline CHEMBL 3938956 & 1641036 & 5.0 & 5.7804 & TRN \\
\hline
\end{tabular}


Supplemental Table S2.txt

\begin{tabular}{|c|c|c|c|c|}
\hline CHEMBL3894161 & 1641036 & 6.9586 & 6.5756 & TRN \\
\hline CHEMBL3978189 & 1641036 & 6.5086 & 6.0778 & TRN \\
\hline CHEMBL3941241 & 1641036 & 6.0 & 6.0386 & TRN \\
\hline CHEMBL3896766 & 1641036 & 6.3098 & 6.4007 & TRN \\
\hline CHEMBL3953229 & 1641036 & 7.5528 & 7.8415 & TRN \\
\hline CHEMBL3936877 & 1641036 & 6.2147 & 6.0863 & TRN \\
\hline CHEMBL3975123 & 1641036 & 5.0 & 4.7627 & TRN \\
\hline CHEMBL3973102 & 1641036 & 6.0 & 5.6973 & TRN \\
\hline CHEMBL3960109 & 1641036 & 6.699 & 6.5154 & TST \\
\hline CHEMBL3973453 & 1641036 & 5.0 & 5.2684 & TRN \\
\hline CHEMBL3895546 & 1641036 & 6.0 & 5.7213 & TRN \\
\hline CHEMBL3896566 & 1641036 & 5.0 & 5.8953 & TRN \\
\hline CHEMBL3954819 & 1641036 & 6.0 & 5.6875 & TRN \\
\hline CHEMBL3981393 & 1641036 & 6.3872 & 6.6209 & TRN \\
\hline CHEMBL3949257 & 1641036 & 6.0223 & 6.5072 & TRN \\
\hline CHEMBL3941431 & 1641036 & 6.4202 & 6.5182 & TRN \\
\hline CHEMBL3975439 & 1641036 & 6.7447 & 6.50899 & 99999999995 \\
\hline CHEMBL3938593 & 1641036 & 6.2366 & 6.3149 & TRN \\
\hline CHEMBL3947711 & 1641036 & 6.3468 & 6.5566 & TRN \\
\hline CHEMBL3890951 & 1641036 & 5.0 & 5.4709 & TST \\
\hline CHEMBL3962689 & 1641036 & 5.0 & 4.8889 & TRN \\
\hline CHEMBL3972067 & 1641036 & 6.2076 & 6.0553 & TRN \\
\hline CHEMBL3978777 & 1641036 & 6.4685 & 6.5532 & TRN \\
\hline CHEMBL3986618 & 1641036 & 6.6778 & 6.3692 & TRN \\
\hline CHEMBL3945676 & 1641036 & 5.0 & 5.9499 & TRN \\
\hline CHEMBL3902431 & 1641036 & 7.284 & 6.4184 & TST \\
\hline CHEMBL3960910 & 1641036 & 6.5376 & 6.67200 & 0000000001 \\
\hline CHEMBL3942741 & 1641036 & 7.9586 & 7.9271 & TRN \\
\hline CHEMBL3912553 & 1641036 & 7.041 & 7.0801 & TRN \\
\hline CHEMBL3964133 & 1641036 & 5.0 & 5.394 & TRN \\
\hline CHEMBL3948921 & 1641036 & 6.6778 & 6.9538 & TRN \\
\hline CHEMBL3951710 & 1641036 & 6.0269 & 6.0046 & TRN \\
\hline CHEMBL3958508 & 1641036 & 6.2366 & 5.8919 & TRN \\
\hline CHEMBL3906687 & 1641036 & 5.0 & 5.0827 & TRN \\
\hline CHEMBL3965520 & 1641036 & 5.0 & 5.5754 & TST \\
\hline CHEMBL3900224 & 1641036 & 7.3872 & 6.8431 & TRN \\
\hline CHEMBL3925854 & 1641036 & 6.4685 & 6.2805 & TRN \\
\hline CHEMBL3927827 & 1641036 & 5.3768 & 6.1002 & TST \\
\hline CHEMBL3983303 & 1641036 & 5.0 & 5.2458 & TRN \\
\hline CHEMBL3973276 & 1641036 & 5.0 & 5.1898 & TRN \\
\hline CHEMBL3934440 & 1641036 & 6.0655 & 6.0834 & TRN \\
\hline CHEMBL3923184 & 1641036 & 6.7447 & 7.0639 & TRN \\
\hline CHEMBL3977129 & 1641036 & 6.8861 & 6.2711 & TRN \\
\hline CHEMBL3957990 & 1641036 & 7.1427 & 6.8269 & TRN \\
\hline CHEMBL3911332 & 1641036 & 5.0 & 4.2694 & TST \\
\hline CHEMBL3897131 & 1641036 & 5.0 & 5.2551 & TST \\
\hline CHEMBL3905498 & 1641036 & 6.1871 & 6.5312 & TRN \\
\hline CHEMBL3967749 & 1641036 & 6.9586 & 6.8161 & TRN \\
\hline
\end{tabular}


Supplemental Table S2.txt

\begin{tabular}{|c|c|c|c|c|}
\hline & 036 & & & 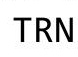 \\
\hline HEMBL3958601 & 641036 & 6.301 & 5.1369 & \\
\hline 89 & 036 & & & \\
\hline 516 & 1036 & 7959 & & \\
\hline IEMBL 3931368 & 541036 & 6.1249 & & \\
\hline AEMBL3905627 & 641036 & 7.5528 & 222 & \\
\hline EMBL3896324 & 036 & 6.5686 & 881 & \\
\hline 07774 & 036 & 5 & & \\
\hline EMBL3922520 & 1036 & 6.3372 & 88 & \\
\hline AEMBL3917954 & 641036 & 6.284 & 575 & \\
\hline AEMBL3897850 & 641036 & 5.0 & 99 & \\
\hline EMBL3917783 & 036 & . & 59 & \\
\hline EMBL3971717 & & & & $\mathrm{RN}$ \\
\hline AEMBL3967880 & 036 & 6.3979 & & \\
\hline IEMBL 3956418 & 641036 & 7.0 & & \\
\hline IEMBL 3944859 & 036 & 7. & & \\
\hline IEMBL 3972353 & 36 & 0 & & \\
\hline IEMBL 3965485 & 36 & & & RN \\
\hline IEMBL 3972506 & 036 & 7. & & \\
\hline EMBL 3973343 & 036 & & & \\
\hline EMBL3975090 & 16 & 5. & 02 & \\
\hline EMBL3943946 & 6 & 5 . & 25 & \\
\hline EMBL3942120 & 6 & & & \\
\hline 124 & 036 & & & \\
\hline EMBL3S & 36 & & & KIV \\
\hline EMBL3926748 & 16 & 6 & & KI \\
\hline EMBL3915844 & 6 & & & -8 \\
\hline 3936356 & 6 & 8 & & \\
\hline 2456 & 336 & & & $\mathrm{R}$ \\
\hline 4960 & 36 & & & RN \\
\hline MBL3906210 & 036 & 6. & & RI \\
\hline 3904571 & 16 & 6. & & RN \\
\hline 277 & 6 & & & \\
\hline & & & & $\mathrm{RN}$ \\
\hline IEMBL 3973017 & 936 & & & R \\
\hline 93 & 36 & & & $S T$ \\
\hline 915 & 6 & 6 . & & RN \\
\hline & 36 & & & RN \\
\hline EMBL3918308 & 641036 & 8.58 & 77 & $\mathrm{RN}$ \\
\hline EMBL 3934664 & 036 & & & $\mathrm{R}$ \\
\hline EMBL 3975250 & 16 & . & & RI \\
\hline HEMBL3921442 & 36 & & & RI \\
\hline IEMBL3929124 & 036 & 7. & & RN \\
\hline MBL 3975088 & 641036 & 6.4685 & 153 & RI \\
\hline IBL3930431 & 036 & & & $\mathrm{k}$ \\
\hline AEMBL3986443 & 1641036 & & & \\
\hline CHEMBL3917860 & 1641036 & 6.2007 & 5.3523 & \\
\hline CHEMBL3956311 & 1641036 & 5.0 & 5.2438 & \\
\hline
\end{tabular}

Page 18927 
Supplemental Table S2.txt

\begin{tabular}{|c|c|c|c|c|}
\hline CHEMBL3949461 & 1641036 & 6.6383 & 6.5213 & TRN \\
\hline CHEMBL3945378 & 1641036 & 6.2676 & 5.671 & TRN \\
\hline CHEMBL3891030 & 1641036 & 6.7696 & 6.7323 & TRN \\
\hline CHEMBL 3897648 & 1641036 & 6.0969 & 6.4678 & TRN \\
\hline CHEMBL3946758 & 1641036 & 6.699 & 6.5304 & TRN \\
\hline CHEMBL3896215 & 1641036 & 6.3768 & 6.7812 & TST \\
\hline CHEMBL3959692 & 1641036 & 6.1249 & 6.1866 & TST \\
\hline CHEMBL3963555 & 1641036 & 6.1487 & 6.1895 & TST \\
\hline CHEMBL3951107 & 1641036 & 7.6576 & 7.5598 & TRN \\
\hline CHEMBL3912419 & 1641036 & 7.0044 & 6.9541 & TST \\
\hline CHEMBL3933671 & 1641036 & 5.0 & 5.2588 & TST \\
\hline CHEMBL3892159 & 1641036 & 6.8539 & 6.3475 & TST \\
\hline CHEMBL3981338 & 1641036 & 6.5086 & 6.2773 & TST \\
\hline CHEMBL3962051 & 1641036 & 7.3468 & 6.6415 & TST \\
\hline CHEMBL3902770 & 1641036 & 5.0 & 5.1015 & TST \\
\hline CHEMBL3956945 & 1641036 & 6.4318 & 6.6697 & TST \\
\hline CHEMBL3908624 & 1641036 & 6.1871 & 5.7049 & TST \\
\hline CHEMBL3913397 & 1641036 & 6.9586 & 6.6037 & TST \\
\hline CHEMBL3923711 & 1641036 & 6.8539 & 6.4806 & TST \\
\hline CHEMBL3936616 & 1641036 & 5.0 & 5.7454 & TST \\
\hline CHEMBL3974989 & 1641036 & 6.5086 & 6.4013 & TST \\
\hline CHEMBL3919766 & 1641036 & 6.7212 & 5.9834 & TST \\
\hline CHEMBL3980369 & 1641036 & 5.0 & 4.7252 & TST \\
\hline CHEMBL3933458 & 1641036 & 5.0 & 5.6767 & TST \\
\hline CHEMBL3904312 & 1641036 & 7.0269 & 7.2522 & TST \\
\hline CHEMBL3948691 & 1641036 & 7.7959 & 8.2374 & TST \\
\hline CHEMBL3956550 & 1641036 & 5.0 & 5.5033 & TST \\
\hline CHEMBL3935532 & 1641036 & 6.5686 & 6.8333 & TST \\
\hline CHEMBL 3947782 & 1641036 & 6.1675 & 6.4074 & TST \\
\hline CHEMBL3894535 & 1641036 & 6.4202 & 5.88700 & 20000000005 \\
\hline CHEMBL3927252 & 1641036 & 8.0132 & 8.2204 & TST \\
\hline CHEMBL3954792 & 1641036 & 6.2924 & 5.419 & TST \\
\hline CHEMBL3976587 & 1641036 & 6.2291 & 5.6804 & TST \\
\hline CHEMBL3902256 & 1641036 & 5.0 & 5.2763 & TST \\
\hline CHEMBL3906872 & 1641036 & 5.6576 & 6.419 & TST \\
\hline CHEMBL3907503 & 1641036 & 6.9208 & 6.5203 & TST \\
\hline CHEMBL3919050 & 1641036 & 8.3188 & 7.7718 & TST \\
\hline CHEMBL3936927 & 1641036 & 5.0 & 5.1396 & TST \\
\hline CHEMBL3898916 & 1641036 & 5.0 & 5.5955 & TST \\
\hline CHEMBL 3907227 & 1641036 & 5.0 & 4.7096 & TST \\
\hline CHEMBL3962300 & 1641036 & 6.4815 & 5.9675 & TST \\
\hline CHEMBL3907770 & 1641036 & 6.5376 & 6.2132 & TST \\
\hline CHEMBL3959789 & 1641036 & 5.0 & 4.8672 & TST \\
\hline CHEMBL3949248 & 1641036 & 6.4437 & 5.9482 & TST \\
\hline CHEMBL3924572 & 1641036 & 6.4437 & 6.5659 & TST \\
\hline CHEMBL3962232 & 1641036 & 5.0 & 4.4372 & TST \\
\hline CHEMBL3940421 & 1641036 & 6.3372 & 5.1149 & TST \\
\hline CHEMBL3906986 & 1641036 & 5.0 & 5.6556 & TST \\
\hline
\end{tabular}




\begin{tabular}{|c|c|c|c|c|c|}
\hline & & \multicolumn{4}{|c|}{ Supplemental Table S2.txt } \\
\hline CHEMBL1518665 & 688182 & 5.8674 & 5.0389 & TRN & \\
\hline CHEMBL1376802 & 688182 & 3.2541 & 4.1207 & TRN & \\
\hline CHEMBL1369131 & 688182 & 4.8389 & 4.775 & TRN & \\
\hline CHEMBL1526414 & 688182 & 5.7368 & 5.7461 & TRN & \\
\hline CHEMBL1300161 & 688182 & 3.2541 & 4.2199 & TST & \\
\hline CHEMBL1391810 & 688182 & 3.2541 & 4.7297 & TRN & \\
\hline CHEMBL1389016 & 688182 & 5.6402 & 4.9202 & TRN & \\
\hline CHEMBL1368375 & 688182 & 5.2369 & 4.9136 & TRN & \\
\hline CHEMBL1558283 & 688182 & 3.2541 & 4.0613 & TRN & \\
\hline CHEMBL1386224 & 688182 & 5.3172 & 4.6675 & TRN & \\
\hline CHEMBL1472198 & 688182 & 3.2541 & 3.2491 & TRN & \\
\hline CHEMBL1454972 & 688182 & 4.5909 & 4.4439 & TST & \\
\hline CHEMBL1506434 & 688182 & 5.3029 & 5.3005 & TRN & \\
\hline CHEMBL1349451 & 688182 & 3.2541 & 4.2357 & TRN & \\
\hline CHEMBL1504503 & 688182 & 5.0699 & 4.1791 & TRN & \\
\hline CHEMBL1341945 & 688182 & 4.9259 & 5.2843 & TRN & \\
\hline CHEMBL1430610 & 688182 & 5.6402 & 4.7634 & TRN & \\
\hline CHEMBL1336909 & 688182 & 3.2541 & 4.3153 & TRN & \\
\hline CHEMBL1544647 & 688182 & 5.4229 & 3.2363 & TRN & \\
\hline CHEMBL1549714 & 688182 & 3.2541 & 4.672 & TRN & \\
\hline CHEMBL1430058 & 688182 & 4.5552 & 3.3713 & TRN & \\
\hline CHEMBL1351615 & 688182 & 5.5456 & 4.734 & TRN & \\
\hline CHEMBL1328233 & 688182 & 6.3298 & 5.2026 & TRN & \\
\hline CHEMBL1323798 & 688182 & 5.7277 & 4.7514 & TRN & \\
\hline CHEMBL1539238 & 688182 & 4.6857 & 5.0718 & TRN & \\
\hline CHEMBL1432151 & 688182 & 4.8239 & 4.6788 & TRN & \\
\hline CHEMBL1547935 & 688182 & 5.5258 & 4.7403 & TRN & \\
\hline CHEMBL1558246 & 688182 & 5.4781 & 5.28799 & 7999999999 & TRN \\
\hline CHEMBL1525574 & 688182 & 3.7314 & 4.508 & TRN & \\
\hline CHEMBL1457224 & 688182 & 5.2083 & 5.0024 & TRN & \\
\hline CHEMBL1559225 & 688182 & 5.6936 & 5.1955 & TRN & \\
\hline CHEMBL1542426 & 688182 & 3.2541 & 4.6389 & TRN & \\
\hline CHEMBL1303262 & 688182 & 4.8633 & 4.5222 & TRN & \\
\hline CHEMBL1509017 & 688182 & 5.7667 & 4.9516 & TRN & \\
\hline CHEMBL1379838 & 688182 & 4.2083 & 3.4371 & TRN & \\
\hline CHEMBL1364109 & 688182 & 4.8864 & 4.5344 & TST & \\
\hline CHEMBL1414300 & 688182 & 5.0812 & 4.6106 & TRN & \\
\hline CHEMBL1467246 & 688182 & 5.2819 & 4.6514 & TRN & \\
\hline CHEMBL1481853 & 688182 & 3.2541 & 4.4513 & TRN & \\
\hline CHEMBL1362522 & 688182 & 5.6402 & 5.5098 & TRN & \\
\hline CHEMBL1399590 & 688182 & 3.2541 & 4.7445 & TRN & \\
\hline CHEMBL 3144975 & 688182 & 3.2541 & 4.8052 & TST & \\
\hline CHEMBL1482268 & 688182 & 3.2541 & 4.2573 & TRN & \\
\hline CHEMBL1430550 & 688182 & 6.7595 & 5.0928 & TRN & \\
\hline CHEMBL1325801 & 688182 & 3.2541 & 4.121 & TRN & \\
\hline CHEMBL1450225 & 688182 & 3.2541 & 4.2247 & TRN & \\
\hline CHEMBL1588761 & 688182 & 5.1109 & 4.8117 & TRN & \\
\hline CHEMBL1572697 & 688182 & 6.1192 & 5.0495 & TRN & \\
\hline
\end{tabular}




\begin{tabular}{|c|c|c|c|c|}
\hline & & & oplement & al Ta \\
\hline CHEMBL1539619 & 688182 & 4.2083 & 4.6145 & TRN \\
\hline CHEMBL1489951 & 688182 & 4.961 & 4.9762 & TRN \\
\hline CHEMBL1528519 & 688182 & 3.2541 & 4.6421 & TRN \\
\hline CHEMBL1558140 & 688182 & 3.2541 & 3.3819 & TRN \\
\hline CHEMBL1503154 & 688182 & 4.8586 & 4.6926 & TRN \\
\hline CHEMBL1431924 & 688182 & 3.2541 & 4.1072 & TRN \\
\hline CHEMBL1386595 & 688182 & 5.2289 & 3.7866 & TST \\
\hline CHEMBL1410782 & 688182 & 4.9846 & 4.8851 & TRN \\
\hline CHEMBL1416896 & 688182 & 3.2541 & 4.3046 & TRN \\
\hline CHEMBL1605444 & 688182 & 6.2832 & 4.9315 & TRN \\
\hline CHEMBL1340119 & 688182 & 3.2541 & 4.6877 & TST \\
\hline CHEMBL1304983 & 688182 & 5.4487 & 4.2374 & TRN \\
\hline CHEMBL1482737 & 688182 & 4.7703 & 4.8638 & TRN \\
\hline CHEMBL1545665 & 688182 & 3.2541 & 4.7934 & TRN \\
\hline CHEMBL1485511 & 688182 & 3.2541 & 4.5352 & TST \\
\hline CHEMBL1541958 & 688182 & 3.2541 & 4.5498 & TRN \\
\hline CHEMBL530664 & 688182 & 5.1627 & 3.4948 & TRN \\
\hline CHEMBL1341345 & 688182 & 5.2929 & 5.051 & TRN \\
\hline CHEMBL1367683 & 688182 & 4.2083 & 4.7735 & TST \\
\hline CHEMBL1410722 & 688182 & 6.1911 & 4.0002 & TRN \\
\hline CHEMBL1535939 & 688182 & 3.2541 & 4.1261 & TRN \\
\hline CHEMBL1353526 & 688182 & 3.2541 & 4.5456 & TRN \\
\hline CHEMBL1443482 & 688182 & 5.09 & 4.9664 & TRN \\
\hline CHEMBL1385195 & 688182 & 5.6128 & 5.2643 & TRN \\
\hline CHEMBL1570104 & 688182 & 3.2541 & 3.9344 & TST \\
\hline CHEMBL1369090 & 688182 & 5.2469 & 5.1484 & TRN \\
\hline CHEMBL1322557 & 688182 & 5.6402 & 5.1757 & TST \\
\hline CHEMBL1337042 & 688182 & 5.0107 & 4.9731 & TRN \\
\hline CHEMBL1301345 & 688182 & 5.4782 & 4.9386 & TRN \\
\hline CHEMBL1322173 & 688182 & 5.2125 & 3.812 & TRN \\
\hline CHEMBL1301223 & 688182 & 5.3774 & 5.1533 & TRN \\
\hline CHEMBL1362841 & 688182 & 5.0936 & 5.0107 & TRN \\
\hline CHEMBL1390963 & 688182 & 5.1624 & 4.4181 & TRN \\
\hline CHEMBL1301794 & 688182 & 3.2541 & 3.3038 & TRN \\
\hline CHEMBL1353939 & 688182 & 5.8867 & 5.5134 & TRN \\
\hline CHEMBL1548996 & 688182 & 6.1972 & 4.546 & TST \\
\hline CHEMBL1300243 & 688182 & 4.6286 & 4.6152 & TST \\
\hline CHEMBL1338665 & 688182 & 3.2541 & 4.3583 & TRN \\
\hline CHEMBL1418188 & 688182 & 4.8321 & 5.2078 & TRN \\
\hline CHEMBL1611185 & 688182 & 5.4689 & 5.3451 & TRN \\
\hline CHEMBL1312229 & 688182 & 3.2541 & 4.2193 & TST \\
\hline CHEMBL1334718 & 688182 & 3.2541 & 4.3771 & TRN \\
\hline CHEMBL1556610 & 688182 & 5.6759 & 5.4096 & TRN \\
\hline CHEMBL1580974 & 688182 & 5.2461 & 4.6081 & TRN \\
\hline CHEMBL1437930 & 688182 & 5.13 & 4.4673 & TRN \\
\hline CHEMBL1384888 & 688182 & 5.0097 & 4.9755 & TRN \\
\hline CHEMBL1338485 & 688182 & 3.2541 & 4.2066 & TRN \\
\hline CHEMBL1464509 & 688182 & 3.2541 & 4.7524 & TRN \\
\hline
\end{tabular}




\begin{tabular}{|c|c|c|c|c|}
\hline & & & oplement & al $\mathrm{T}$ \\
\hline CHEMBL1372949 & 688182 & 5.1624 & 4.3044 & TRN \\
\hline CHEMBL258089 & 688182 & 3.2541 & 3.7312 & TRN \\
\hline CHEMBL1570764 & 688182 & 5.6028 & 4.8367 & TRN \\
\hline CHEMBL1367459 & 688182 & 4.9454 & 5.087 & TRN \\
\hline CHEMBL1378470 & 688182 & 3.2541 & 4.1484 & TRN \\
\hline CHEMBL1600680 & 688182 & 3.2541 & 4.3573 & TRN \\
\hline CHEMBL1584884 & 688182 & 5.1624 & 5.0419 & TRN \\
\hline CHEMBL1610497 & 688182 & 3.2541 & 4.4389 & TST \\
\hline CHEMBL1406413 & 688182 & 3.2541 & 4.5862 & TRN \\
\hline CHEMBL1449962 & 688182 & 6.1192 & 4.8124 & TST \\
\hline CHEMBL1407470 & 688182 & 6.5935 & 5.3732 & TST \\
\hline CHEMBL1483112 & 688182 & 4.2083 & 4.754 & TST \\
\hline CHEMBL1299373 & 688182 & 6.0857 & 4.9977 & TST \\
\hline CHEMBL1582302 & 688182 & 3.7314 & 4.7514 & TST \\
\hline CHEMBL1323935 & 688182 & 4.6861 & 4.3322 & TST \\
\hline CHEMBL1368342 & 688182 & 7.0711 & 5.0169 & TST \\
\hline CHEMBL1560912 & 688182 & 5.2362 & 4.5993 & TST \\
\hline CHEMBL1392618 & 688182 & 5.6131 & 4.6688 & TST \\
\hline CHEMBL1524075 & 688182 & 4.83 & 5.0338 & TST \\
\hline CHEMBL1389728 & 688182 & 4.2083 & 3.1783 & TST \\
\hline CHEMBL1360680 & 688182 & 5.2195 & 5.4808 & TST \\
\hline CHEMBL1452439 & 688182 & 4.2083 & 4.8714 & TST \\
\hline CHEMBL1448413 & 688182 & 4.9714 & 5.0363 & TST \\
\hline CHEMBL1412524 & 688182 & 3.2541 & 4.4417 & TST \\
\hline CHEMBL442581 & 688182 & 4.6861 & 4.9107 & TST \\
\hline CHEMBL1490917 & 688182 & 6.2434 & 4.4275 & TST \\
\hline CHEMBL 2448545 & 327342 & 5.6459 & 5.3381 & TST \\
\hline CHEMBL380657 & 327342 & 6.0506 & 5.8777 & TRN \\
\hline CHEMBL437138 & 327342 & 5.1586 & 5.1396 & TRN \\
\hline CHEMBL 382802 & 327342 & 5.1046 & 5.1034 & TRN \\
\hline CHEMBL201487 & 327342 & 5.2111 & 5.2777 & TRN \\
\hline CHEMBL 381044 & 327342 & 5.3575 & 5.46 & TRN \\
\hline CHEMBL 201345 & 327342 & 5.6778 & 5.8611 & TRN \\
\hline CHEMBL199601 & 327342 & 6.0177 & 5.9785 & TRN \\
\hline CHEMBL 380413 & 327342 & 4.3371 & 4.5061 & TST \\
\hline CHEMBL200132 & 327342 & 6.0969 & 6.2212 & TRN \\
\hline CHEMBL199556 & 327342 & 5.0899 & 5.1906 & TRN \\
\hline CHEMBL201123 & 327342 & 6.0 & 5.3863 & TST \\
\hline CHEMBL 203140 & 327342 & 5.6968 & 5.1379 & TST \\
\hline CHEMBL199889 & 327342 & 5.1203 & 5.178 & TRN \\
\hline CHEMBL370376 & 327342 & 5.0937 & 5.2755 & TRN \\
\hline CHEMBL413570 & 327342 & 5.5638 & 5.5867 & TRN \\
\hline CHEMBL201590 & 327342 & 5.7496 & 5.7773 & TRN \\
\hline CHEMBL 202975 & 327342 & 5.1361 & 5.1321 & TRN \\
\hline CHEMBL201356 & 327342 & 5.4881 & 5.5003 & TRN \\
\hline CHEMBL437511 & 327342 & 5.2708 & 5.2122 & TRN \\
\hline CHEMBL 369978 & 327342 & 5.2441 & 5.3874 & TRN \\
\hline CHEMBL381737 & 327342 & 5.4101 & 5.4513 & TRN \\
\hline
\end{tabular}




\begin{tabular}{|c|c|c|c|c|c|c|}
\hline \multirow[b]{2}{*}{ CHEMBL201503 } & \multicolumn{6}{|c|}{ Supplemental Table s2.txt } \\
\hline & 327342 & 3.2596 & 4.0949 & TST & & \\
\hline CHEMBL383494 & 327342 & 3.2291 & 4.2538 & TST & & \\
\hline CHEMBL377948 & 327342 & 5.1024 & 5.2407 & TRN & & \\
\hline CHEMBL202978 & 327342 & 6.1079 & 6.0235 & TRN & & \\
\hline CHEMBL198407 & 327342 & 5.3045 & 5.4165 & TRN & & \\
\hline CHEMBL380751 & 327342 & 4.9772 & 4.9373 & TRN & & \\
\hline CHEMBL201078 & 327342 & 5.3737 & 5.2947 & TRN & & \\
\hline CHEMBL199953 & 327342 & 5.9318 & 5.6033 & TRN & & \\
\hline CHEMBL201319 & 327342 & 5.0747 & 5.0671 & TRN & & \\
\hline CHEMBL201637 & 327342 & 5.0232 & 5.1798 & TST & & \\
\hline CHEMBL201238 & 327342 & 6.1024 & 6.0529 & TRN & & \\
\hline CHEMBL202976 & 327342 & 5.0731 & 5.0212 & TRN & & \\
\hline CHEMBL382137 & 327342 & 5.5918 & 5.8116 & TRN & & \\
\hline CHEMBL197594 & 327342 & 4.8719 & 4.9643 & TRN & & \\
\hline CHEMBL380823 & 327342 & 6.2441 & 6.2217 & TRN & & \\
\hline CHEMBL201734 & 327342 & 5.2604 & 5.0244 & TRN & & \\
\hline CHEMBL199604 & 327342 & 6.1367 & 5.9603 & TRN & & \\
\hline CHEMBL201704 & 327342 & 5.9788 & 5.8603 & TRN & & \\
\hline CHEMBL383608 & 327342 & 5.6021 & 5.7957 & TRN & & \\
\hline CHEMBL199942 & 327342 & 5.4306 & 5.3959 & TRN & & \\
\hline CHEMBL383534 & 327342 & 5.0953 & 5.0118 & TRN & & \\
\hline CHEMBL201545 & 327342 & 5.5317 & 5.4293 & TRN & & \\
\hline CHEMBL201380 & 327342 & 6.4318 & 6.3809 & TRN & & \\
\hline CHEMBL201682 & 327342 & 4.8962 & 4.9037 & TRN & & \\
\hline CHEMBL199332 & 327342 & 6.1549 & 6.2563 & TRN & & \\
\hline CHEMBL202664 & 327342 & 5.0721 & 5.0717 & TRN & & \\
\hline CHEMBL440759 & 327342 & 5.8069 & 5.6385 & TRN & & \\
\hline CHEMBL202379 & 327342 & 5.0872 & 5.7608 & TST & & \\
\hline CHEMBL201579 & 327342 & 4.4757 & 4.787 & TST & & \\
\hline CHEMBL382849 & 327342 & 5.8697 & 5.5156 & TST & & \\
\hline CHEMBL201134 & 327342 & 5.1938 & 4.9342 & TST & & \\
\hline CHEMBL383649 & 327342 & 5.7905 & 5.6802 & TST & & \\
\hline CHEMBL381989 & 327342 & 5.1124 & 5.6522 & TST & & \\
\hline CHEMBL202778 & 327342 & 5.0516 & 5.404 & TST & & \\
\hline CHEMBL455521 & 556838 & 10.3009 & 99999999 & 998 & 10.3045 & TRN \\
\hline CHEMBL502262 & 556838 & 10.0 & 8.4599 & TST & & \\
\hline CHEMBL520303 & 556838 & 9.301 & 9.3091 & TRN & & \\
\hline CHEMBL501180 & 556838 & 10.0 & 8.9423 & TST & & \\
\hline CHEMBL520634 & 556838 & 9.301 & 9.2509 & TRN & & \\
\hline CHEMBL501207 & 556838 & 10.0 & 8.5405 & TST & & \\
\hline CHEMBL489861 & 556838 & 9.301 & 9.2743 & TRN & & \\
\hline CHEMBL303130 & 556838 & 10.3009 & 99999999 & 998 & 10.3145 & TRN \\
\hline CHEMBL482502 & 556838 & 9.301 & 9.3111 & TRN & & \\
\hline CHEMBL523285 & 556838 & 9.301 & 9.2645 & TRN & & \\
\hline CHEMBL300092 & 556838 & 10.3009 & 99999999 & 998 & 10.2831 & TRN \\
\hline CHEMBL121894 & 556838 & 9.699 & 9.6817 & TRN & & \\
\hline CHEMBL489862 & 556838 & 10.3009 & 99999999 & 998 & 10.3111 & TRN \\
\hline CHEMBL482533 & 556838 & 9.301 & 9.34799 & 9999999999 & & TRN \\
\hline
\end{tabular}




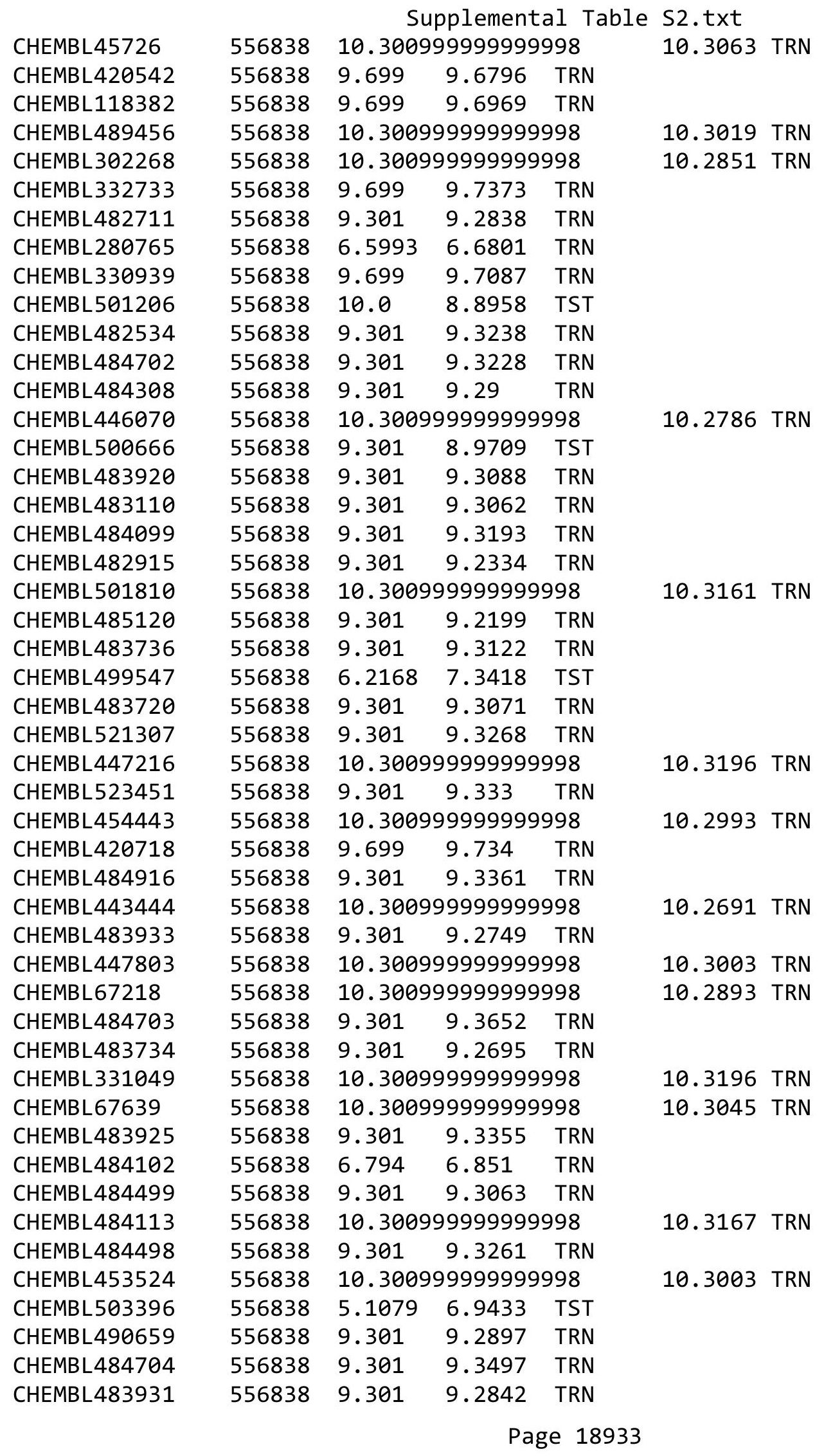




\begin{tabular}{|c|c|c|c|c|c|c|c|}
\hline \multicolumn{8}{|c|}{ Supplemental } \\
\hline CHEMBL500266 & 556838 & 6.9834 & 6.9298 & TST & & & \\
\hline CHEMBL331867 & 556838 & 9.699 & 9.7183 & TRN & & & \\
\hline CHEMBL453002 & 556838 & 10.3009 & 999999999 & 998 & 10.2945 & TRN & \\
\hline CHEMBL502261 & 556838 & 10.0 & 8.8087 & TST & & & \\
\hline CHEMBL449130 & 556838 & 10.3009 & 999999999 & 998 & 10.2804 & TRN & \\
\hline CHEMBL 304783 & 556838 & 10.3009 & 99999999 & 998 & 10.32406 & 00000000002 & TRN \\
\hline CHEMBL506483 & 556838 & 10.3009 & 999999999 & 998 & 10.2861 & TRN & \\
\hline CHEMBL484517 & 556838 & 10.0 & 8.5557 & TST & & & \\
\hline CHEMBL525996 & 556838 & 10.0 & 8.8987 & TST & & & \\
\hline CHEMBL505778 & 556838 & 10.3009 & 999999999 & 998 & 10.3148 & TRN & \\
\hline CHEMBL503479 & 556838 & 10.3009 & 999999999 & 998 & 10.3063 & TRN & \\
\hline CHEMBL483924 & 556838 & 9.301 & 9.3237 & TRN & & & \\
\hline CHEMBL500794 & 556838 & 5.5086 & 6.8566 & TST & & & \\
\hline CHEMBL483724 & 556838 & 9.301 & 9.312006 & 000000000 & & TRN & \\
\hline CHEMBL450004 & 556838 & 10.3009 & 999999999 & 998 & 10.2859 & TRN & \\
\hline CHEMBL121844 & 556838 & 9.699 & 9.7008 & TRN & & & \\
\hline CHEMBL500913 & 556838 & 10.0 & 8.5202 & TST & & & \\
\hline CHEMBL483109 & 556838 & 9.301 & 9.2998 & TRN & & & \\
\hline CHEMBL483923 & 556838 & 9.301 & 9.3072 & TRN & & & \\
\hline CHEMBL483111 & 556838 & 9.301 & 9.3159 & TRN & & & \\
\hline CHEMBL520132 & 556838 & 9.301 & 9.3371 & TRN & & & \\
\hline CHEMBL507908 & 556838 & 10.3009 & 999999999 & 998 & 10.3026 & TRN & \\
\hline CHEMBL484309 & 556838 & 9.301 & 9.3064 & TRN & & & \\
\hline CHEMBL502270 & 556838 & 10.0 & 9.0157 & TST & & & \\
\hline CHEMBL521936 & 556838 & 10.3009 & 999999995 & 998 & 10.2977 & TRN & \\
\hline CHEMBL483097 & 556838 & 9.301 & 9.2996 & TRN & & & \\
\hline CHEMBL520511 & 556838 & 10.0 & 8.4698 & TST & & & \\
\hline CHEMBL482503 & 556838 & 9.301 & 9.3116 & TRN & & & \\
\hline CHEMBL444167 & 556838 & 10.3009 & 999999995 & 998 & 10.2954 & TRN & \\
\hline CHEMBL490059 & 556838 & 9.301 & 9.3039 & TRN & & & \\
\hline CHEMBL519027 & 556838 & 9.301 & 9.2339 & TRN & & & \\
\hline CHEMBL483301 & 556838 & 9.301 & 9.2827 & TRN & & & \\
\hline CHEMBL502327 & 556838 & 10.3009 & 999999999 & 998 & 10.3159 & 99999999999 & TRN \\
\hline CHEMBL120543 & 556838 & 9.699 & 9.656 & TRN & & & \\
\hline CHEMBL 331263 & 556838 & 9.699 & 9.7373 & TRN & & & \\
\hline CHEMBL331692 & 556838 & 9.699 & 9.7373 & TRN & & & \\
\hline CHEMBL519026 & 556838 & 9.301 & 9.2833 & TRN & & & \\
\hline CHEMBL500672 & 556838 & 10.0 & 8.975 & TST & & & \\
\hline CHEMBL499875 & 556838 & 9.699 & 9.7733 & TST & & & \\
\hline CHEMBL333356 & 556838 & 9.699 & 9.729 & TST & & & \\
\hline CHEMBL484310 & 556838 & 10.0 & 8.2732 & TST & & & \\
\hline CHEMBL118764 & 556838 & 9.699 & 9.6931 & TRN & & & \\
\hline CHEMBL491070 & 556838 & 9.301 & 9.2767 & TRN & & & \\
\hline CHEMBL483541 & 556838 & 9.301 & 9.3073 & TRN & & & \\
\hline CHEMBL490063 & 556838 & 10.3009 & 99999999 & 998 & 10.3076 & TRN & \\
\hline CHEMBL482713 & 556838 & 9.301 & 9.2965 & TRN & & & \\
\hline CHEMBL331389 & 556838 & 9.699 & 9.7177 & TST & & & \\
\hline CHEMBL451389 & 556838 & 10.3009 & 999999995 & 998 & 10.2947 & TRN & \\
\hline
\end{tabular}




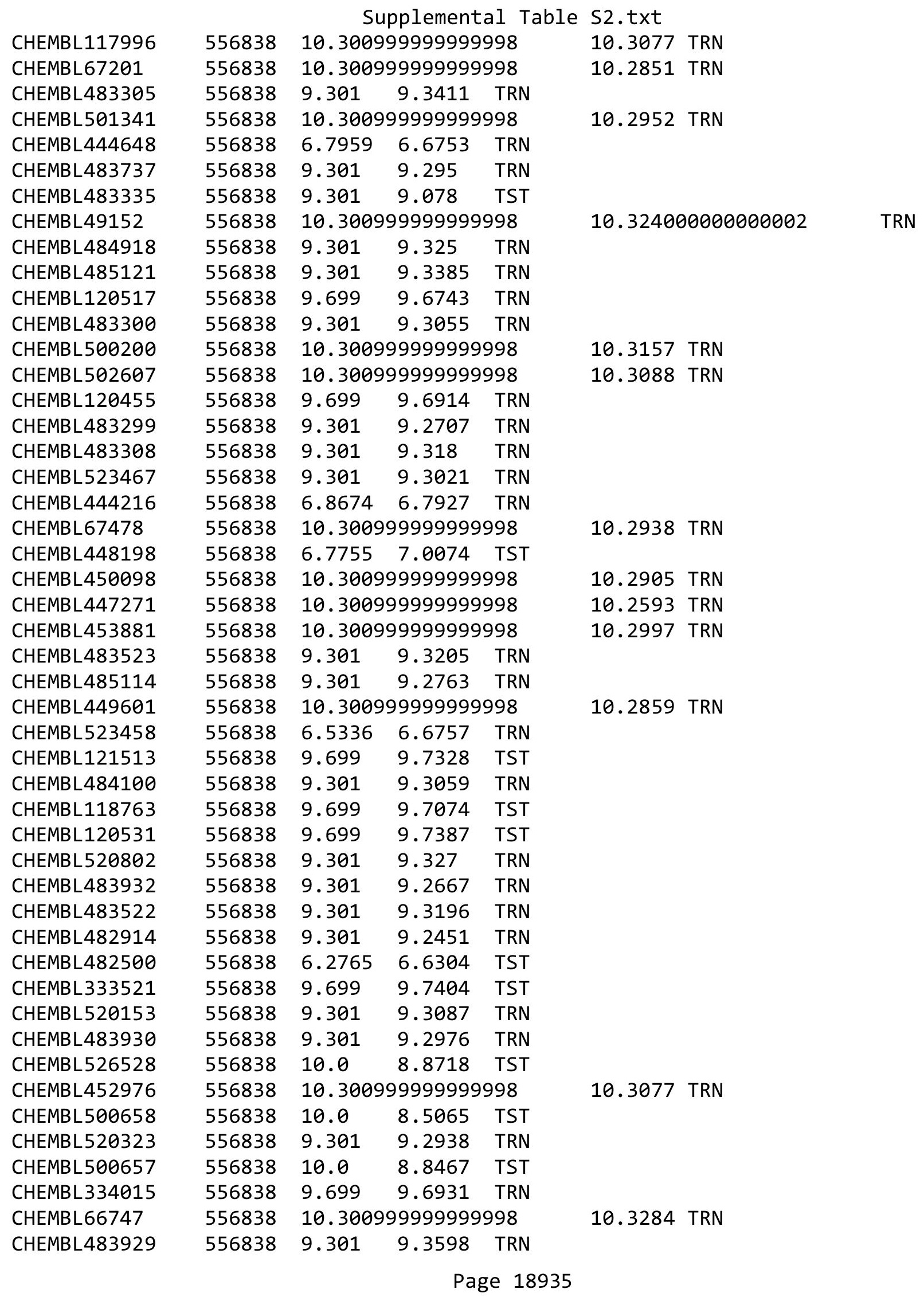




\begin{tabular}{|c|c|c|c|c|c|c|c|}
\hline \multicolumn{8}{|c|}{ Supplemental Table S2.txt } \\
\hline CHEMBL489656 & 556838 & 9.301 & 9.3605 & TRN & & & \\
\hline CHEMBL482909 & 556838 & 9.301 & 9.2955 & TRN & & & \\
\hline CHEMBL500671 & 556838 & 10.0 & 8.4454 & TST & & & \\
\hline CHEMBL120938 & 556838 & 9.699 & 9.7387 & TST & & & \\
\hline CHEMBL67162 & 556838 & \multicolumn{3}{|c|}{10.300999999999998} & 10.2748 & TRN & \\
\hline CHEMBL483727 & 556838 & 9.301 & 9.3002 & TRN & & & \\
\hline CHEMBL526748 & 556838 & 10.0 & 8.6795 & TST & & & \\
\hline CHEMBL484117 & 556838 & 9.301 & 9.2522 & TRN & & & \\
\hline CHEMBL482712 & 556838 & 9.301 & 9.2794 & TRN & & & \\
\hline CHEMBL483512 & 556838 & 9.301 & 9.2357 & TRN & & & \\
\hline CHEMBL499414 & 556838 & 5.2518 & 6.9397 & TST & & & \\
\hline CHEMBL120331 & 556838 & 9.699 & 9.7008 & TRN & & & \\
\hline CHEMBL519177 & 556838 & 9.301 & 9.2497 & TRN & & & \\
\hline CHEMBL482899 & 556838 & 9.301 & 9.3361 & TRN & & & \\
\hline CHEMBL501726 & 556838 & 9.699 & 9.7733 & TST & & & \\
\hline CHEMBL483511 & 556838 & 9.301 & 9.3518 & TRN & & & \\
\hline CHEMBL504347 & 556838 & \multicolumn{3}{|c|}{10.300999999999998} & 10.2831 & TRN & \\
\hline CHEMBL324570 & 556838 & 9.699 & 9.7212 & TST & & & \\
\hline CHEMBL123871 & 556838 & 9.699 & 9.7008 & TRN & & & \\
\hline CHEMBL447351 & 556838 & \multicolumn{3}{|c|}{10.300999999999998} & 10.3077 & TRN & \\
\hline CHEMBL482901 & 556838 & 9.301 & 9.3148 & TRN & & & \\
\hline CHEMBL484120 & 556838 & 9.301 & 9.3108 & TRN & & & \\
\hline CHEMBL450125 & 556838 & \multicolumn{3}{|c|}{10.300999999999998} & 10.3095 & TRN & \\
\hline CHEMBL483704 & 556838 & 9.301 & 9.2396 & TRN & & & \\
\hline CHEMBL483906 & 556838 & 9.301 & 9.3072 & TRN & & & \\
\hline CHEMBL66172 & 556838 & \multicolumn{3}{|c|}{10.300999999999998} & \multirow{2}{*}{\multicolumn{2}{|c|}{10.324000000000002}} & TRN \\
\hline CHEMBL490263 & 556838 & 9.301 & 9.2688 & TRN & & & \\
\hline CHEMBL121562 & 556838 & 9.699 & 9.7387 & TST & & & \\
\hline CHEMBL331927 & 556838 & 9.699 & 9.7263 & TRN & & & \\
\hline CHEMBL483735 & 556838 & 9.301 & 9.3049 & TRN & & & \\
\hline CHEMBL520123 & 556838 & 3.0 & 7.245 & TST & & & \\
\hline CHEMBL452779 & 556838 & \multicolumn{3}{|c|}{10.300999999999998} & 10.3063 & TRN & \\
\hline CHEMBL444520 & 556838 & \multicolumn{3}{|c|}{10.300999999999998} & 10.2887 & TRN & \\
\hline CHEMBL300094 & 556838 & \multicolumn{3}{|c|}{10.300999999999998} & 10.2859 & TRN & \\
\hline CHEMBL500931 & 556838 & 10.0 & 8.5685 & TST & & & \\
\hline CHEMBL502524 & 556838 & 9.699 & 9.7731 & TST & & & \\
\hline CHEMBL300093 & 556838 & \multicolumn{3}{|c|}{10.300999999999998} & 10.3026 & TRN & \\
\hline CHEMBL499605 & 556838 & 9.699 & 9.7714 & TST & & & \\
\hline CHEMBL491460 & 556838 & 5.9586 & 7.2389 & TST & & & \\
\hline CHEMBL490865 & 556838 & 6.9151 & 6.9218 & TRN & & & \\
\hline CHEMBL499604 & 556838 & 9.699 & 9.7762 & TST & & & \\
\hline CHEMBL483524 & 556838 & 9.301 & 9.267999 & 999999999 & & TRN & \\
\hline CHEMBL519798 & 556838 & 9.301 & 9.3076 & TRN & & & \\
\hline CHEMBL482507 & 556838 & 10.0 & 8.7642 & TST & & & \\
\hline CHEMBL484110 & 556838 & 10.0 & 8.8311 & TST & & & \\
\hline CHEMBL116323 & 556838 & 10.3009 & 999999999 & 998 & 10.2905 & TRN & \\
\hline CHEMBL483505 & 556838 & 9.301 & 9.2783 & TRN & & & \\
\hline CHEMBL454867 & 556838 & 10.3009 & 999999995 & 998 & 10.2905 & TRN & \\
\hline
\end{tabular}




\begin{tabular}{|c|c|c|c|c|c|c|c|}
\hline \multicolumn{8}{|c|}{ Supplemental Table S2.txt } \\
\hline CHEMBL452850 & 556838 & \multicolumn{3}{|c|}{10.300999999999998} & 10.3196 & TRN & \\
\hline CHEMBL483539 & 556838 & 9.301 & 9.0001 & TST & & & \\
\hline CHEMBL489860 & 556838 & 9.301 & 9.3012 & TRN & & & \\
\hline CHEMBL500912 & 556838 & 10.0 & 8.8479 & TST & & & \\
\hline CHEMBL46172 & 556838 & \multicolumn{3}{|c|}{ 10.300999999999998 } & 10.2851 & TRN & \\
\hline CHEMBL483304 & 556838 & 10.0 & 8.3033 & TST & & & \\
\hline CHEMBL520294 & 556838 & 10.0 & 8.3446 & TST & & & \\
\hline CHEMBL445455 & 556838 & \multicolumn{3}{|c|}{10.300999999999998} & 10.31599 & 99999999999 & TRN \\
\hline CHEMBL499892 & 556838 & 10.0 & 8.9037 & TST & & & \\
\hline CHEMBL458786 & 556838 & \multicolumn{3}{|c|}{ 10.300999999999998 } & 10.3026 & TRN & \\
\hline CHEMBL420544 & 556838 & 9.699 & 9.7183 & TST & & & \\
\hline CHEMBL483732 & 556838 & 9.699 & 9.7733 & TST & & & \\
\hline CHEMBL47792 & 556838 & \multicolumn{3}{|c|}{10.300999999999998} & 10.3003 & TRN & \\
\hline CHEMBL483733 & 556838 & 9.301 & 9.3154 & TRN & & & \\
\hline CHEMBL119929 & 556838 & 9.699 & 9.7183 & TST & & & \\
\hline CHEMBL483306 & 556838 & 9.301 & 9.3345 & TRN & & & \\
\hline CHEMBL483508 & 556838 & 10.0 & 8.8846 & TST & & & \\
\hline CHEMBL489260 & 556838 & 9.301 & 9.3393 & TRN & & & \\
\hline CHEMBL524500 & 556838 & 10.0 & 8.5786 & TST & & & \\
\hline CHEMBL483540 & 556838 & 9.301 & 9.1158 & TST & & & \\
\hline CHEMBL503007 & 556838 & 6.7038 & 6.6233 & TRN & & & \\
\hline CHEMBL505223 & 556838 & \multicolumn{3}{|c|}{10.300999999999998} & 10.2698 & TRN & \\
\hline CHEMBL454265 & 556838 & \multicolumn{3}{|c|}{10.300999999999998} & 10.2924 & TRN & \\
\hline CHEMBL510759 & 556838 & \multicolumn{3}{|c|}{10.300999999999998} & 10.3095 & TRN & \\
\hline CHEMBL444712 & 556838 & \multicolumn{3}{|c|}{10.300999999999998} & 10.3055 & TRN & \\
\hline CHEMBL483907 & 556838 & 9.301 & 9.2948 & TRN & & & \\
\hline CHEMBL450042 & 556838 & \multicolumn{3}{|c|}{10.300999999999998} & 10.2939 & TRN & \\
\hline CHEMBL489455 & 556838 & 9.301 & 9.3404 & TRN & & & \\
\hline CHEMBL482696 & 556838 & 10.0 & 8.9084 & TST & & & \\
\hline CHEMBL482705 & 556838 & 10.0 & 8.8186 & TST & & & \\
\hline CHEMBL123870 & 556838 & 9.699 & 9.6931 & TRN & & & \\
\hline CHEMBL452931 & 556838 & \multicolumn{3}{|c|}{10.300999999999998} & 10.2831 & TRN & \\
\hline CHEMBL502499 & 556838 & \multicolumn{3}{|c|}{10.300999999999998} & 10.298 & TRN & \\
\hline CHEMBL483311 & 556838 & 10.0 & 8.4001 & TST & & & \\
\hline CHEMBL48163 & 556838 & \multicolumn{3}{|c|}{10.300999999999998} & 10.3095 & TRN & \\
\hline CHEMBL526865 & 556838 & 10.0 & 8.6156 & TST & & & \\
\hline CHEMBL447694 & 556838 & \multicolumn{3}{|c|}{ 10.300999999999998 } & 10.287 & TRN & \\
\hline CHEMBL447200 & 556838 & \multicolumn{3}{|c|}{10.300999999999998} & 10.31599 & 99999999999 & TRN \\
\hline CHEMBL447092 & 556838 & \multicolumn{3}{|c|}{10.300999999999998} & 10.286 & TRN & \\
\hline CHEMBL518977 & 556838 & 10.0 & 8.372 & TST & & & \\
\hline CHEMBL482490 & 556838 & 6.16 & 7.52 & TST & & & \\
\hline CHEMBL483905 & 556838 & 9.301 & 9.2738 & TRN & & & \\
\hline CHEMBL483719 & 556838 & 9.301 & 9.26700 & 000000000 & & TRN & \\
\hline CHEMBL520633 & 556838 & 10.0 & 8.8469 & TST & & & \\
\hline CHEMBL444213 & 556838 & 10.3009 & 99999999 & 998 & 10.2856 & TRN & \\
\hline CHEMBL1436598 & 688612 & 4.6 & 4.5716 & TRN & & & \\
\hline CHEMBL1496389 & 688612 & 5.5 & 4.6564 & TRN & & & \\
\hline CHEMBL343409 & 688612 & 6.5501 & 4.6124 & TST & & & \\
\hline
\end{tabular}




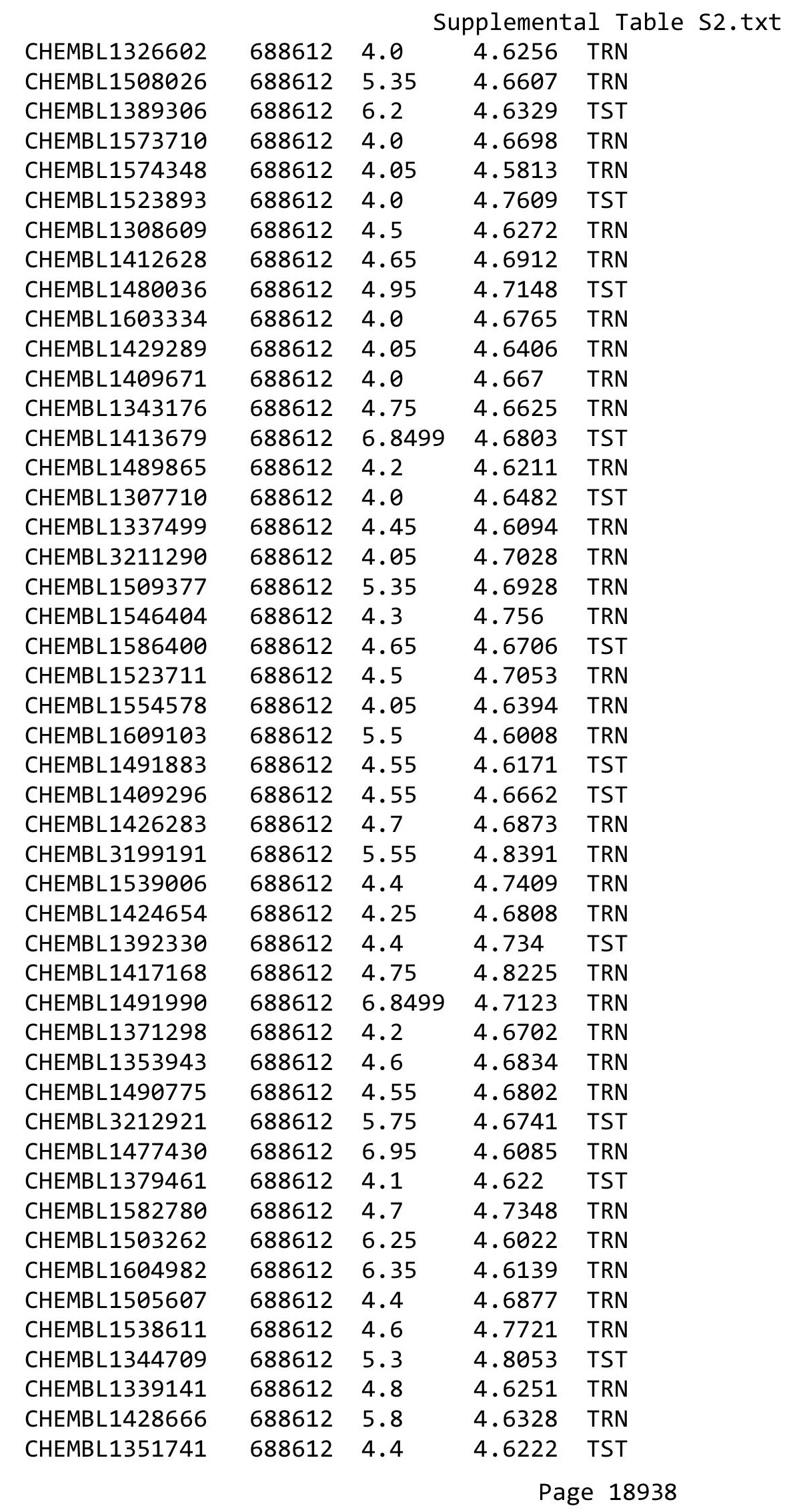




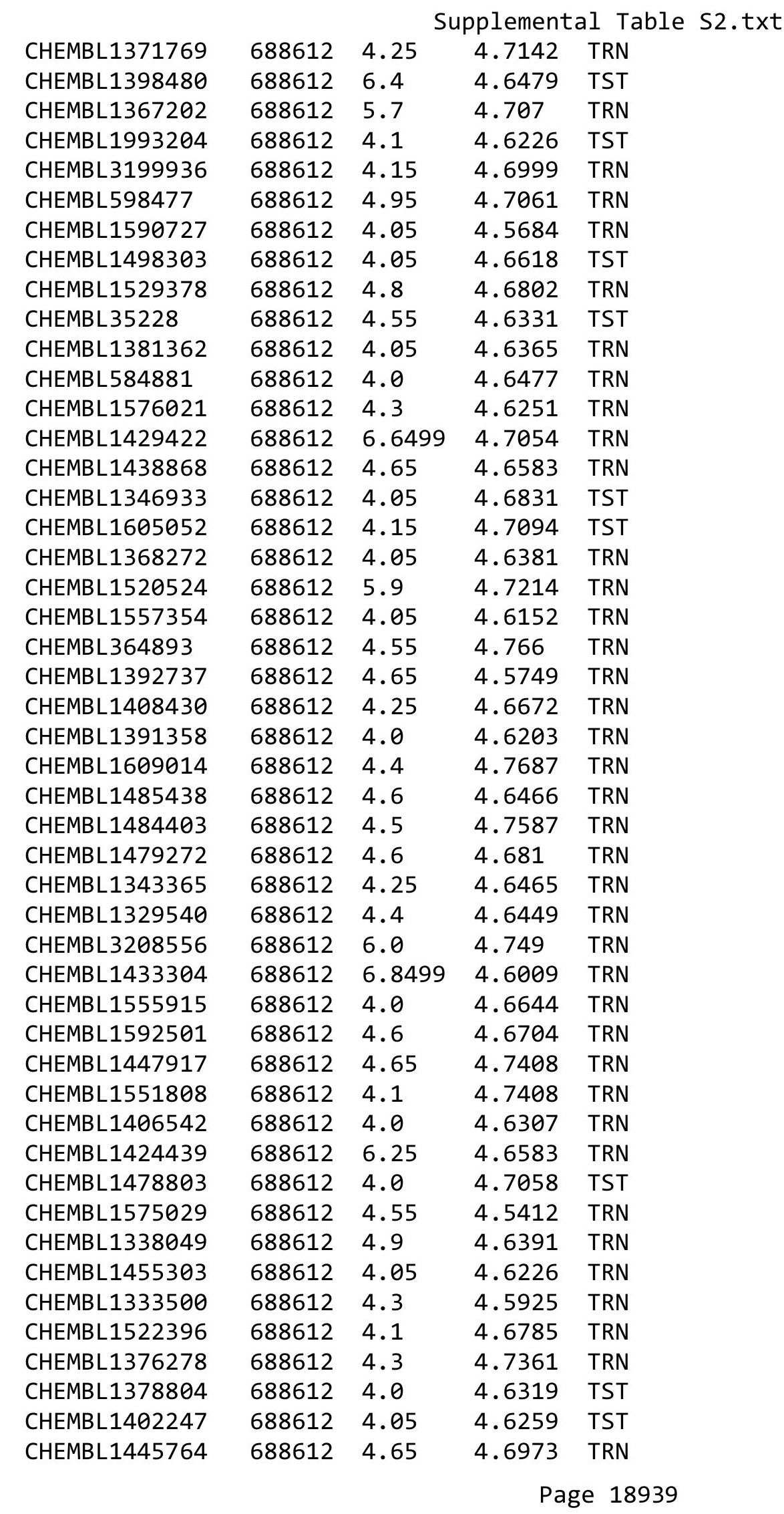




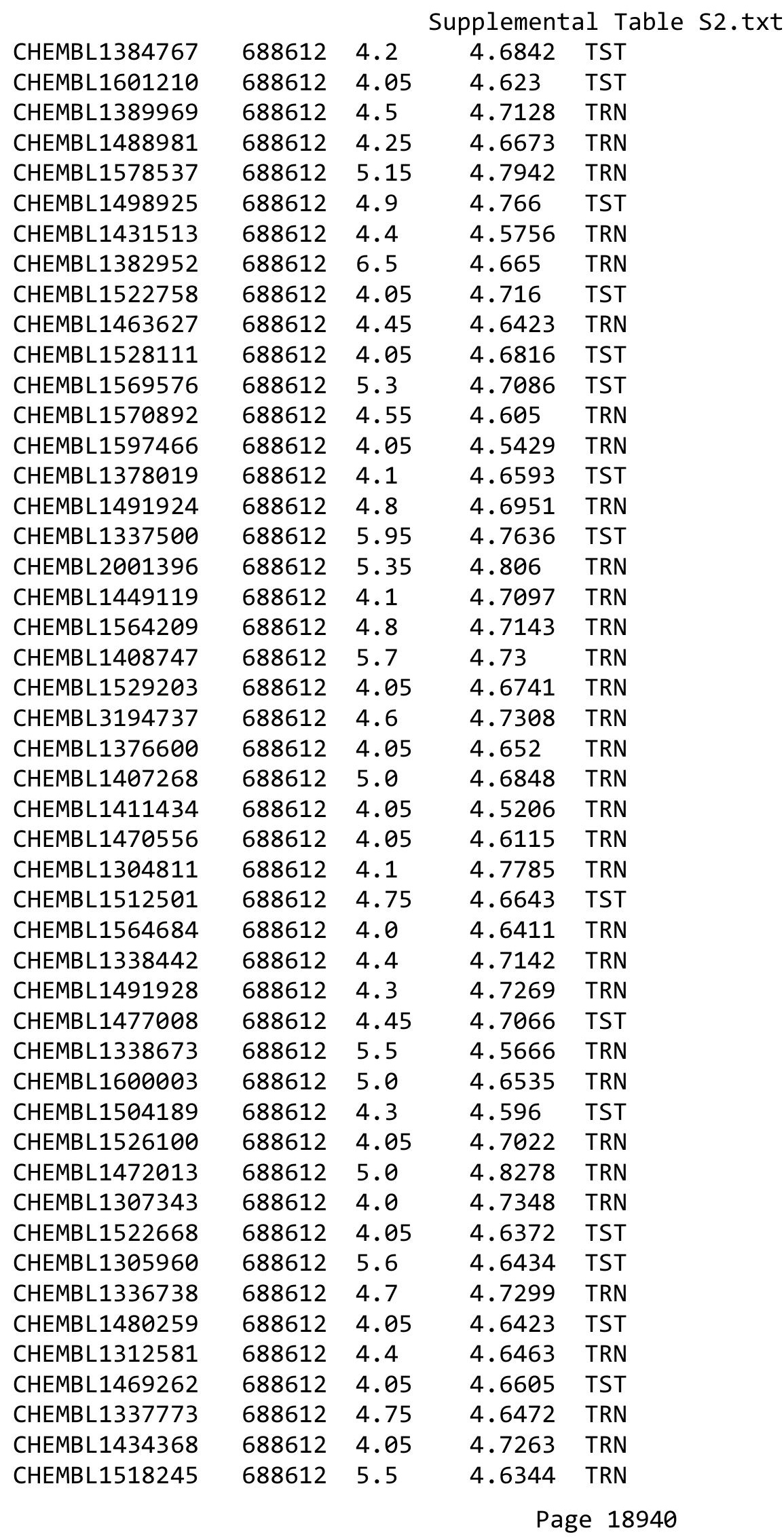




\begin{tabular}{|c|c|c|c|c|c|}
\hline \multicolumn{6}{|c|}{ Supplemental Table S2.txt } \\
\hline CHEMBL1590482 & 688612 & 4.05 & 4.6399 & TRN & \\
\hline CHEMBL1537025 & 688612 & 5.4 & 4.7789 & TST & \\
\hline CHEMBL1383544 & 688612 & 4.8 & 4.7403 & TST & \\
\hline CHEMBL1326893 & 688612 & 4.6 & 4.5918 & TRN & \\
\hline CHEMBL1417901 & 688612 & 4.95 & 4.6802 & TST & \\
\hline CHEMBL1583089 & 688612 & 4.05 & 4.6737 & TRN & \\
\hline CHEMBL576932 & 688612 & 4.6 & 4.8201 & TRN & \\
\hline CHEMBL1437589 & 688612 & 4.0 & 4.5667 & TRN & \\
\hline CHEMBL1598520 & 688612 & 4.1 & 4.6873 & TST & \\
\hline CHEMBL1540331 & 688612 & 4.05 & 4.628 & TRN & \\
\hline CHEMBL1491782 & 688612 & 4.6 & 4.7098 & TRN & \\
\hline CHEMBL1458134 & 688612 & 4.35 & 4.662 & TRN & \\
\hline CHEMBL1989426 & 688612 & 4.3 & 4.7126 & TST & \\
\hline CHEMBL1330684 & 688612 & 6.05 & 4.7017 & TST & \\
\hline CHEMBL1507397 & 688612 & 6.1 & 4.6833 & TRN & \\
\hline CHEMBL151946 & 688612 & 4.45 & 4.7175 & TRN & \\
\hline CHEMBL1479228 & 688612 & 4.05 & 4.6322 & TRN & \\
\hline CHEMBL1444373 & 688612 & 4.35 & 4.6992 & TRN & \\
\hline CHEMBL1346623 & 688612 & 4.35 & 4.6699 & TRN & \\
\hline CHEMBL1991357 & 688612 & 4.55 & 4.6296 & TRN & \\
\hline CHEMBL1592918 & 688612 & 4.0 & 4.596 & TRN & \\
\hline CHEMBL1510983 & 688612 & 4.65 & 4.6958 & TRN & \\
\hline CHEMBL3207477 & 688612 & 5.4 & 4.7483 & TRN & \\
\hline CHEMBL1591250 & 688612 & 4.0 & 4.6553 & TRN & \\
\hline CHEMBL3191607 & 688612 & 4.05 & 4.7512 & TST & \\
\hline CHEMBL1495078 & 688612 & 5.55 & 4.7015 & TST & \\
\hline CHEMBL1491508 & 688612 & 4.25 & 4.5717 & TRN & \\
\hline CHEMBL173530 & 688612 & 5.1 & 4.7312 & TST & \\
\hline CHEMBL1432636 & 688612 & 6.5501 & 4.6965 & TRN & \\
\hline CHEMBL3192783 & 688612 & 4.05 & 4.7412 & TRN & \\
\hline CHEMBL1530553 & 688612 & 4.75 & 4.7176 & TRN & \\
\hline CHEMBL1571904 & 688612 & 6.0 & 4.6599 & TRN & \\
\hline CHEMBL1400523 & 688612 & 5.55 & 4.6889 & TRN & \\
\hline CHEMBL1310954 & 688612 & 4.05 & 4.6923 & TRN & \\
\hline CHEMBL1348391 & 688612 & 4.9 & 4.7613 & TRN & \\
\hline CHEMBL1406404 & 688612 & 4.55 & 4.6862 & TST & \\
\hline CHEMBL3145149 & 688612 & 4.1 & 4.637 & TRN & \\
\hline CHEMBL1526302 & 688612 & 4.05 & 4.6719 & TRN & \\
\hline CHEMBL1558838 & 688612 & 4.0 & 4.6918 & TRN & \\
\hline CHEMBL1446341 & 688612 & 4.75 & 4.6312 & TRN & \\
\hline CHEMBL1528787 & 688612 & 4.65 & 4.7244 & TRN & \\
\hline CHEMBL1455258 & 688612 & 4.85 & $4.6560 e$ & 0000000001 & TRN \\
\hline CHEMBL1444840 & 688612 & 4.45 & 4.6208 & TRN & \\
\hline CHEMBL1367339 & 688612 & 4.1 & 4.7021 & TRN & \\
\hline CHEMBL1315392 & 688612 & 4.05 & 4.6171 & TRN & \\
\hline CHEMBL1586689 & 688612 & 4.1 & 4.7187 & TRN & \\
\hline CHEMBL1582201 & 688612 & 6.8 & 4.6164 & TST & \\
\hline CHEMBL1495685 & 688612 & 4.7 & 4.7377 & TRN & \\
\hline
\end{tabular}




\begin{tabular}{|c|c|c|c|c|}
\hline & & & pplement & al Ta \\
\hline CHEMBL1400512 & 688612 & 4.35 & 4.6382 & TRN \\
\hline CHEMBL1978424 & 688612 & 4.95 & 4.723 & TRN \\
\hline CHEMBL1396586 & 688612 & 5.0 & 4.6424 & TRN \\
\hline CHEMBL1581751 & 688612 & 5.5 & 4.6078 & TRN \\
\hline CHEMBL1425545 & 688612 & 6.1 & 4.7224 & TRN \\
\hline CHEMBL1301238 & 688612 & 4.4 & 4.6649 & TRN \\
\hline CHEMBL1539309 & 688612 & 5.35 & 4.6549 & TRN \\
\hline CHEMBL1357342 & 688612 & 4.8 & 4.6869 & TST \\
\hline CHEMBL1483871 & 688612 & 6.0 & 4.7202 & TRN \\
\hline CHEMBL1552965 & 688612 & 4.4 & 4.6434 & TRN \\
\hline CHEMBL1453945 & 688612 & 4.05 & 4.6327 & TST \\
\hline CHEMBL1566994 & 688612 & 4.75 & 4.648 & TRN \\
\hline CHEMBL3195663 & 688612 & 4.4 & 4.6411 & TST \\
\hline CHEMBL1538615 & 688612 & 4.2 & 4.6224 & TRN \\
\hline CHEMBL1301312 & 688612 & 5.4 & 4.6899 & TRN \\
\hline CHEMBL1528247 & 688612 & 4.05 & 4.7316 & TST \\
\hline CHEMBL1494136 & 688612 & 4.3 & 4.6304 & TRN \\
\hline CHEMBL3189202 & 688612 & 4.0 & 4.6941 & TRN \\
\hline CHEMBL1588999 & 688612 & 4.1 & 4.5994 & TRN \\
\hline CHEMBL1496008 & 688612 & 4.25 & 4.7345 & TRN \\
\hline CHEMBL1575761 & 688612 & 4.0 & 4.6934 & TRN \\
\hline CHEMBL1394720 & 688612 & 4.55 & 4.6508 & TRN \\
\hline CHEMBL1977247 & 688612 & 4.5 & 4.6659 & TRN \\
\hline CHEMBL1501245 & 688612 & 4.05 & 4.6537 & TRN \\
\hline CHEMBL1600230 & 688612 & 4.5 & 4.6659 & TST \\
\hline CHEMBL1429282 & 688612 & 4.85 & 4.684 & TST \\
\hline CHEMBL1470473 & 688612 & 4.05 & 4.6333 & TRN \\
\hline CHEMBL1315007 & 688612 & 4.6 & 4.6154 & TRN \\
\hline CHEMBL1477640 & 688612 & 4.65 & 4.7158 & TST \\
\hline CHEMBL1554231 & 688612 & 5.05 & 4.6991 & TST \\
\hline CHEMBL1334004 & 688612 & 4.05 & 4.6539 & TRN \\
\hline CHEMBL1437098 & 688612 & 4.9 & 4.5967 & TRN \\
\hline CHEMBL 2374080 & 688612 & 5.8 & 4.7773 & TRN \\
\hline CHEMBL1527231 & 688612 & 4.65 & 4.7888 & TRN \\
\hline CHEMBL1600038 & 688612 & 5.35 & 4.5947 & TRN \\
\hline CHEMBL3209928 & 688612 & 4.1 & 4.6459 & TST \\
\hline CHEMBL1398955 & 688612 & 4.05 & 4.5694 & TST \\
\hline CHEMBL1316716 & 688612 & 4.7 & 4.664 & TRN \\
\hline CHEMBL1541342 & 688612 & 4.05 & 4.6161 & TRN \\
\hline CHEMBL1358877 & 688612 & 4.25 & 4.6233 & TRN \\
\hline CHEMBL1368901 & 688612 & 4.95 & 4.7789 & TRN \\
\hline CHEMBL1608659 & 688612 & 4.05 & 4.6319 & TRN \\
\hline CHEMBL1602648 & 688612 & 4.05 & 4.6079 & TRN \\
\hline CHEMBL1419788 & 688612 & 4.9 & 4.6616 & TST \\
\hline CHEMBL1368122 & 688612 & 4.05 & 4.6218 & TRN \\
\hline CHEMBL1549418 & 688612 & 4.4 & 4.6659 & TST \\
\hline CHEMBL1381623 & 688612 & 4.4 & 4.6657 & TST \\
\hline CHEMBL1493904 & 688612 & 4.05 & 4.6362 & TST \\
\hline
\end{tabular}




\begin{tabular}{|c|c|c|c|c|c|}
\hline \multicolumn{6}{|c|}{ Supplemental Table S2.txt } \\
\hline CHEMBL1446353 & 688612 & 4.95 & 4.6902 & TRN & \\
\hline CHEMBL1353130 & 688612 & 4.65 & 4.665 & TRN & \\
\hline CHEMBL1417964 & 688612 & 5.45 & 4.7201 & TRN & \\
\hline CHEMBL1594348 & 688612 & 4.7 & 4.6319 & TST & \\
\hline CHEMBL1346234 & 688612 & 4.0 & 4.6663 & TRN & \\
\hline CHEMBL1473907 & 688612 & 6.8499 & 4.6167 & TST & \\
\hline CHEMBL1390930 & 688612 & 4.3 & 4.7057 & TRN & \\
\hline CHEMBL1430319 & 688612 & 4.25 & 4.7194 & TRN & \\
\hline CHEMBL1580660 & 688612 & 4.5 & 4.6899 & TRN & \\
\hline CHEMBL1604715 & 688612 & 5.55 & 4.6583 & TRN & \\
\hline CHEMBL1379506 & 688612 & 4.2 & 4.6504 & TRN & \\
\hline CHEMBL1572860 & 688612 & 4.05 & 4.6515 & TST & \\
\hline CHEMBL3193834 & 688612 & 4.05 & 4.613 & TRN & \\
\hline CHEMBL 2001761 & 688612 & 4.45 & 4.7913 & TRN & \\
\hline CHEMBL1476572 & 688612 & 4.1 & 4.647 & TRN & \\
\hline CHEMBL1546596 & 688612 & 6.45 & 4.6628 & TRN & \\
\hline CHEMBL1565907 & 688612 & 4.05 & 4.655 & TRN & \\
\hline CHEMBL1339531 & 688612 & 4.1 & 4.6752 & TRN & \\
\hline CHEMBL 1344856 & 688612 & 7.6003 & 4.6333 & TRN & \\
\hline CHEMBL1492585 & 688612 & 4.55 & 4.713 & TRN & \\
\hline CHEMBL1437053 & 688612 & 5.0 & 4.6961 & TRN & \\
\hline CHEMBL1987622 & 688612 & 4.05 & 4.7061 & TST & \\
\hline CHEMBL1534339 & 688612 & 4.05 & 4.6837 & TRN & \\
\hline CHEMBL1329961 & 688612 & 4.1 & 4.6874 & TRN & \\
\hline CHEMBL1469502 & 688612 & 4.4 & 4.6492 & TRN & \\
\hline CHEMBL1491176 & 688612 & 4.0 & 4.5909 & TRN & \\
\hline CHEMBL1577724 & 688612 & 4.6 & 4.5907 & TRN & \\
\hline CHEMBL1508560 & 688612 & 4.45 & 4.7012 & TRN & \\
\hline CHEMBL1526478 & 688612 & 4.4 & 4.7148 & TST & \\
\hline CHEMBL1429517 & 688612 & 4.05 & 4.6332 & TRN & \\
\hline CHEMBL1332219 & 688612 & 4.7 & 4.622 & TST & \\
\hline CHEMBL1363329 & 688612 & 4.2 & 4.61100 & 0000000001 & TRN \\
\hline CHEMBL1370199 & 688612 & 4.75 & 4.6726 & TRN & \\
\hline CHEMBL1489471 & 688612 & 4.05 & 4.7535 & TST & \\
\hline CHEMBL1433829 & 688612 & 4.0 & 4.5945 & TRN & \\
\hline CHEMBL1516851 & 688612 & 6.8499 & 4.6789 & TRN & \\
\hline CHEMBL1570368 & 688612 & 4.4 & 4.7094 & TRN & \\
\hline CHEMBL1389272 & 688612 & 6.0 & 4.6171 & TRN & \\
\hline CHEMBL1460189 & 688612 & 5.65 & 4.7026 & TRN & \\
\hline CHEMBL1576808 & 688612 & 4.0 & 4.6677 & TST & \\
\hline CHEMBL1446592 & 688612 & 4.4 & 4.603 & TRN & \\
\hline CHEMBL1533350 & 688612 & 4.2 & 4.6635 & TRN & \\
\hline CHEMBL1540512 & 688612 & 4.1 & 4.6453 & TRN & \\
\hline CHEMBL3208868 & 688612 & 4.3 & 4.6646 & TRN & \\
\hline CHEMBL1581664 & 688612 & 4.1 & 4.6975 & TST & \\
\hline CHEMBL1367879 & 688612 & 4.25 & 4.7454 & TST & \\
\hline CHEMBL1326029 & 688612 & 4.05 & 4.6229 & TRN & \\
\hline CHEMBL1408218 & 688612 & 4.05 & 4.6362 & TRN & \\
\hline
\end{tabular}




\begin{tabular}{|c|c|c|c|c|c|}
\hline \multirow[b]{2}{*}{ CHEMBL1299224 } & \multirow[b]{2}{*}{688612} & \multicolumn{4}{|c|}{ Supplemental Table S2.txt } \\
\hline & & 4.0 & 4.6443 & TRN & \\
\hline CHEMBL1448854 & 688612 & 5.0 & 4.7793 & TRN & \\
\hline CHEMBL1557655 & 688612 & 4.6 & 4.6673 & TRN & \\
\hline CHEMBL 3190022 & 688612 & 4.7 & 4.7064 & TST & \\
\hline CHEMBL1469981 & 688612 & 4.3 & 4.6987 & TRN & \\
\hline CHEMBL1410068 & 688612 & 4.95 & 4.81800 & 00000000005 & TST \\
\hline CHEMBL1344222 & 688612 & 5.75 & 4.5905 & TRN & \\
\hline CHEMBL1428540 & 688612 & 4.05 & 4.6517 & TST & \\
\hline CHEMBL3198222 & 688612 & 4.1 & 4.673 & TRN & \\
\hline CHEMBL1300812 & 688612 & 4.05 & 4.6837 & TRN & \\
\hline CHEMBL1516758 & 688612 & 5.45 & 4.6766 & TST & \\
\hline CHEMBL1579664 & 688612 & 4.25 & 4.7459 & TST & \\
\hline CHEMBL3214023 & 688612 & 5.0 & 4.6002 & TRN & \\
\hline CHEMBL1473870 & 688612 & 4.05 & 4.5922 & TRN & \\
\hline CHEMBL1504798 & 688612 & 4.0 & 4.6261 & TRN & \\
\hline CHEMBL1348310 & 688612 & 4.4 & 4.63399 & 99999999995 & TRN \\
\hline CHEMBL1338541 & 688612 & 4.0 & 4.6176 & TRN & \\
\hline CHEMBL1416840 & 688612 & 4.5 & 4.617 & TRN & \\
\hline CHEMBL1479501 & 688612 & 4.65 & 4.6055 & TRN & \\
\hline CHEMBL1369841 & 688612 & 4.6 & 4.6308 & TRN & \\
\hline CHEMBL399043 & 688612 & 4.6 & 4.7802 & TST & \\
\hline CHEMBL1342796 & 688612 & 5.95 & 4.6314 & TRN & \\
\hline CHEMBL1387923 & 688612 & 4.4 & 4.7067 & TRN & \\
\hline CHEMBL3193794 & 688612 & 4.8 & 4.7299 & TRN & \\
\hline CHEMBL1975525 & 688612 & 4.2 & 4.751 & TRN & \\
\hline CHEMBL1358677 & 688612 & 4.05 & 4.6712 & TRN & \\
\hline CHEMBL1533133 & 688612 & 5.45 & 4.6792 & TRN & \\
\hline CHEMBL1374358 & 688612 & 6.3 & 4.6375 & TRN & \\
\hline CHEMBL1357513 & 688612 & 4.05 & 4.6297 & TRN & \\
\hline CHEMBL1419301 & 688612 & 4.65 & 4.7001 & TRN & \\
\hline CHEMBL1462933 & 688612 & 4.65 & 4.7257 & TST & \\
\hline CHEMBL1999515 & 688612 & 4.4 & 4.6986 & TRN & \\
\hline CHEMBL1365766 & 688612 & 4.05 & 4.6563 & TST & \\
\hline CHEMBL1473739 & 688612 & 4.35 & 4.5822 & TST & \\
\hline CHEMBL1355309 & 688612 & 4.6 & 4.5622 & TRN & \\
\hline CHEMBL1546136 & 688612 & 4.65 & 4.7087 & TRN & \\
\hline CHEMBL1598753 & 688612 & 4.5 & 4.6306 & TRN & \\
\hline CHEMBL1374733 & 688612 & 4.45 & 4.5984 & TRN & \\
\hline CHEMBL1428426 & 688612 & 6.8499 & 4.6464 & TRN & \\
\hline CHEMBL1505648 & 688612 & 4.4 & 4.5458 & TRN & \\
\hline CHEMBL1417932 & 688612 & 4.4 & 4.6833 & TRN & \\
\hline CHEMBL1384773 & 688612 & 4.7 & 4.7059 & TRN & \\
\hline CHEMBL1574923 & 688612 & 4.0 & 4.7145 & TRN & \\
\hline CHEMBL 1425710 & 688612 & 4.9 & 4.7327 & TRN & \\
\hline CHEMBL590427 & 688612 & 4.1 & 4.6503 & TST & \\
\hline CHEMBL1496441 & 688612 & 5.0 & 4.6689 & TRN & \\
\hline CHEMBL1340632 & 688612 & 4.4 & 4.5914 & TRN & \\
\hline CHEMBL1389840 & 688612 & 4.1 & 4.65600 & 000000 & TRN \\
\hline & & & & 1894 & \\
\hline
\end{tabular}




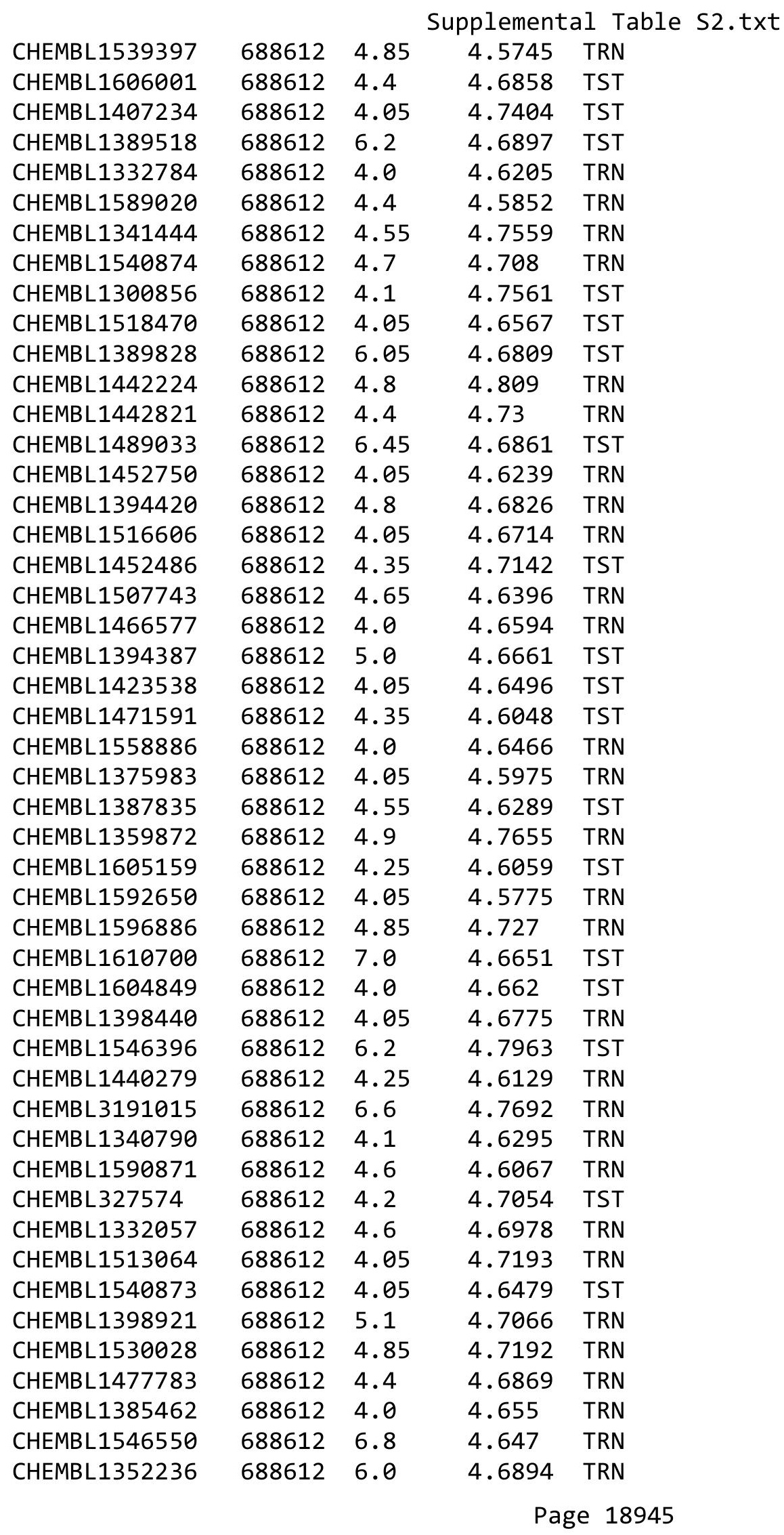




\begin{tabular}{|c|c|c|c|c|}
\hline \multicolumn{5}{|c|}{ Supplemental Table S2.txt } \\
\hline CHEMBL1309643 & 688612 & 4.95 & 4.7538 & TRN \\
\hline CHEMBL1585740 & 688612 & 4.05 & 4.734 & TST \\
\hline CHEMBL1395495 & 688612 & 4.25 & 4.6138 & TRN \\
\hline CHEMBL1406250 & 688612 & 4.4 & 4.7114 & TRN \\
\hline CHEMBL1375621 & 688612 & 4.4 & 4.6354 & TST \\
\hline CHEMBL1413056 & 688612 & 5.0 & 4.6828 & TST \\
\hline CHEMBL1368133 & 688612 & 4.4 & 4.6796 & TST \\
\hline CHEMBL1495645 & 688612 & 4.1 & 4.6564 & TRN \\
\hline CHEMBL1542798 & 688612 & 4.1 & 4.5695 & TRN \\
\hline CHEMBL1503523 & 688612 & 4.1 & 4.678 & TRN \\
\hline CHEMBL1435421 & 688612 & 4.1 & 4.6234 & TRN \\
\hline CHEMBL1416980 & 688612 & 4.0 & 4.5799 & TRN \\
\hline CHEMBL1509091 & 688612 & 4.35 & 4.7211 & TST \\
\hline CHEMBL1300235 & 688612 & 4.7 & 4.7155 & TRN \\
\hline CHEMBL1431715 & 688612 & 4.4 & 4.6008 & TRN \\
\hline CHEMBL3211246 & 688612 & 4.75 & 4.7128 & TRN \\
\hline CHEMBL66854 & 688612 & 6.5 & 4.8177 & TRN \\
\hline CHEMBL1573558 & 688612 & 4.7 & 4.6385 & TRN \\
\hline CHEMBL3192637 & 688612 & 4.7 & 4.7631 & TRN \\
\hline CHEMBL1412192 & 688612 & 4.0 & 4.6853 & TST \\
\hline CHEMBL1582630 & 688612 & 4.25 & 4.7213 & TST \\
\hline CHEMBL1424371 & 688612 & 6.8499 & 4.7389 & TRN \\
\hline CHEMBL1546414 & 688612 & 4.8 & 4.7294 & TRN \\
\hline CHEMBL1416046 & 688612 & 4.4 & 4.6201 & TRN \\
\hline CHEMBL1303025 & 688612 & 4.3 & 4.6338 & TRN \\
\hline CHEMBL1601600 & 688612 & 5.5 & 4.6801 & TRN \\
\hline CHEMBL1579062 & 688612 & 4.05 & 4.6369 & TRN \\
\hline CHEMBL1440428 & 688612 & 4.05 & 4.6238 & TRN \\
\hline CHEMBL3195382 & 688612 & 5.0 & 4.6927 & TRN \\
\hline CHEMBL1318345 & 688612 & 4.05 & 4.5741 & TRN \\
\hline CHEMBL1431996 & 688612 & 4.5 & 4.7265 & TRN \\
\hline CHEMBL1486653 & 688612 & 6.95 & 4.6987 & TRN \\
\hline CHEMBL1343998 & 688612 & 5.45 & 4.5806 & TRN \\
\hline CHEMBL1505990 & 688612 & 4.65 & 4.6598 & TRN \\
\hline CHEMBL1312690 & 688612 & 4.05 & 4.6467 & TST \\
\hline CHEMBL1492187 & 688612 & 4.4 & 4.6107 & TRN \\
\hline CHEMBL3195575 & 688612 & 4.25 & 4.7492 & TRN \\
\hline CHEMBL1419890 & 688612 & 4.4 & 4.6148 & TRN \\
\hline CHEMBL1415545 & 688612 & 4.9 & 4.6911 & TRN \\
\hline CHEMBL 2374083 & 688612 & 5.0 & 4.7712 & TST \\
\hline CHEMBL1611421 & 688612 & 4.05 & 4.7173 & TST \\
\hline CHEMBL1439668 & 688612 & 4.8 & 4.7701 & TRN \\
\hline CHEMBL1537686 & 688612 & 6.0 & 4.82 & TRN \\
\hline CHEMBL1517042 & 688612 & 4.0 & 4.6603 & TRN \\
\hline CHEMBL1349934 & 688612 & 5.05 & 4.6361 & TRN \\
\hline CHEMBL1597924 & 688612 & 4.85 & 4.6731 & TST \\
\hline CHEMBL1544166 & 688612 & 4.1 & 4.6782 & TST \\
\hline CHEMBL1561757 & 688612 & 4.05 & 4.66100 & 00000000005 \\
\hline & & & & 18946 \\
\hline
\end{tabular}




\begin{tabular}{|c|c|c|c|c|}
\hline \multicolumn{5}{|c|}{ Supplemental Table S2.txt } \\
\hline CHEMBL3194432 & 688612 & 4.4 & 4.7071 & TRN \\
\hline CHEMBL3207326 & 688612 & 4.3 & 4.7177 & TRN \\
\hline CHEMBL1479295 & 688612 & 4.4 & 4.6449 & TRN \\
\hline CHEMBL1585273 & 688612 & 4.85 & 4.7209 & TRN \\
\hline CHEMBL1479517 & 688612 & 4.05 & 4.6999 & TST \\
\hline CHEMBL1325310 & 688612 & 5.6 & 4.6189 & TRN \\
\hline CHEMBL1553385 & 688612 & 6.8499 & 4.6308 & TRN \\
\hline CHEMBL574779 & 688612 & 4.6 & 4.6893 & TRN \\
\hline CHEMBL1559571 & 688612 & 4.1 & 4.6789 & TRN \\
\hline CHEMBL1601496 & 688612 & 5.0 & 4.6337 & TRN \\
\hline CHEMBL1322110 & 688612 & 4.5 & 4.7984 & TRN \\
\hline CHEMBL1369696 & 688612 & 4.15 & 4.5617 & TRN \\
\hline CHEMBL1562080 & 688612 & 4.05 & 4.6648 & TRN \\
\hline CHEMBL1564888 & 688612 & 5.6 & 4.6719 & TRN \\
\hline CHEMBL1599162 & 688612 & 4.2 & 4.6447 & TST \\
\hline CHEMBL1495089 & 688612 & 4.1 & 4.5901 & TRN \\
\hline CHEMBL1380145 & 688612 & 4.7 & 4.7593 & TRN \\
\hline CHEMBL1412528 & 688612 & 5.3 & 4.5852 & TRN \\
\hline CHEMBL1365215 & 688612 & 4.05 & 4.6821 & TST \\
\hline CHEMBL1412087 & 688612 & 5.0 & 4.7511 & TRN \\
\hline CHEMBL1314259 & 688612 & 4.1 & 4.6593 & TST \\
\hline CHEMBL1473471 & 688612 & 4.9 & 4.7064 & TRN \\
\hline CHEMBL1563585 & 688612 & 6.2 & 4.7039 & TST \\
\hline CHEMBL1405283 & 688612 & 4.4 & 4.5625 & TRN \\
\hline CHEMBL1471099 & 688612 & 4.15 & 4.6586 & TRN \\
\hline CHEMBL1559159 & 688612 & 4.85 & 4.7237 & TST \\
\hline CHEMBL1578551 & 688612 & 4.1 & 4.6878 & TRN \\
\hline CHEMBL1487253 & 688612 & 4.8 & 4.6841 & TRN \\
\hline CHEMBL1363878 & 688612 & 4.4 & 4.6379 & TRN \\
\hline CHEMBL1406168 & 688612 & 5.1 & 4.6547 & TRN \\
\hline CHEMBL1188912 & 688612 & 4.55 & 4.7173 & TST \\
\hline CHEMBL1442764 & 688612 & 4.85 & 4.7443 & TRN \\
\hline CHEMBL1525188 & 688612 & 4.65 & 4.6052 & TRN \\
\hline CHEMBL1533094 & 688612 & 4.4 & 4.8094 & TRN \\
\hline CHEMBL1480934 & 688612 & 4.65 & 4.5796 & TRN \\
\hline CHEMBL1606497 & 688612 & 4.45 & 4.7243 & TRN \\
\hline CHEMBL1346845 & 688612 & 5.45 & 4.6776 & TST \\
\hline CHEMBL1588348 & 688612 & 4.6 & 4.5513 & TRN \\
\hline CHEMBL1611221 & 688612 & 4.05 & 4.5771 & TRN \\
\hline CHEMBL1476285 & 688612 & 4.0 & 4.6637 & TRN \\
\hline CHEMBL1335658 & 688612 & 5.55 & 4.6961 & TST \\
\hline CHEMBL1393145 & 688612 & 4.4 & 4.7142 & TST \\
\hline CHEMBL1552117 & 688612 & 5.5 & 4.6083 & TRN \\
\hline CHEMBL1595390 & 688612 & 4.05 & 4.6604 & TRN \\
\hline CHEMBL1997376 & 688612 & 4.1 & 4.6118 & TST \\
\hline CHEMBL1537418 & 688612 & 4.05 & 4.711 & TRN \\
\hline CHEMBL1560577 & 688612 & 4.65 & 4.7144 & TRN \\
\hline CHEMBL1397012 & 688612 & 4.65 & 4.6058 & TRN \\
\hline
\end{tabular}




\begin{tabular}{|c|c|c|c|c|c|}
\hline \multirow[b]{2}{*}{ CHEMBL1351479 } & \multirow[b]{2}{*}{688612} & \multicolumn{4}{|c|}{ Supplemental Table S2.txt } \\
\hline & & 4.5 & 4.677 & TST & \\
\hline CHEMBL1510393 & 688612 & 4.2 & 4.6996 & TRN & \\
\hline CHEMBL1513190 & 688612 & 4.2 & 4.6189 & TRN & \\
\hline CHEMBL3190387 & 688612 & 5.55 & 4.6191 & TRN & \\
\hline CHEMBL1587395 & 688612 & 5.0 & 4.7184 & TST & \\
\hline CHEMBL3190923 & 688612 & 4.1 & 4.6527 & TRN & \\
\hline CHEMBL1433718 & 688612 & 4.4 & 4.6458 & TST & \\
\hline CHEMBL1313886 & 688612 & 6.3 & 4.6391 & TST & \\
\hline CHEMBL1496635 & 688612 & 4.0 & 4.706 & TST & \\
\hline CHEMBL1562979 & 688612 & 4.2 & 4.6784 & TRN & \\
\hline CHEMBL1411803 & 688612 & 4.55 & 4.6751 & TRN & \\
\hline CHEMBL1417675 & 688612 & 6.0 & 4.7214 & TRN & \\
\hline CHEMBL1421651 & 688612 & 4.05 & 4.6633 & TRN & \\
\hline CHEMBL1519855 & 688612 & 5.95 & 4.6946 & TRN & \\
\hline CHEMBL1536224 & 688612 & 4.05 & 4.6819 & TRN & \\
\hline CHEMBL1383834 & 688612 & 4.2 & 4.6471 & TST & \\
\hline CHEMBL1460604 & 688612 & 6.2 & 4.6772 & TST & \\
\hline CHEMBL1582573 & 688612 & 4.35 & 4.7489 & TST & \\
\hline CHEMBL1592810 & 688612 & 4.1 & 4.6867 & TRN & \\
\hline CHEMBL1472521 & 688612 & 4.05 & 4.64199 & 99999999995 & TRN \\
\hline CHEMBL1463703 & 688612 & 4.6 & 4.6693 & TRN & \\
\hline CHEMBL1466650 & 688612 & 4.0 & 4.6036 & TRN & \\
\hline CHEMBL1336255 & 688612 & 6.5 & 4.6931 & TST & \\
\hline CHEMBL1326994 & 688612 & 4.65 & 4.6613 & TST & \\
\hline CHEMBL1431650 & 688612 & 4.35 & 4.7235 & TRN & \\
\hline CHEMBL1584125 & 688612 & 4.1 & 4.7101 & TRN & \\
\hline CHEMBL1524490 & 688612 & 6.9 & 4.6569 & TST & \\
\hline CHEMBL1436690 & 688612 & 5.35 & 4.6048 & TRN & \\
\hline CHEMBL3194001 & 688612 & 4.1 & 4.6475 & TST & \\
\hline CHEMBL1329093 & 688612 & 4.05 & 4.5635 & TRN & \\
\hline CHEMBL1346987 & 688612 & 4.0 & 4.6251 & TRN & \\
\hline CHEMBL1299509 & 688612 & 4.05 & 4.5861 & TST & \\
\hline CHEMBL1603056 & 688612 & 5.05 & 4.6733 & TRN & \\
\hline CHEMBL1442721 & 688612 & 4.05 & 4.5943 & TRN & \\
\hline CHEMBL1442105 & 688612 & 4.45 & 4.63 & TST & \\
\hline CHEMBL1376492 & 688612 & 5.05 & 4.6994 & TST & \\
\hline CHEMBL1572430 & 688612 & 4.0 & 4.7543 & TST & \\
\hline CHEMBL1595693 & 688612 & 4.0 & 4.6472 & TRN & \\
\hline CHEMBL1552452 & 688612 & 4.85 & 4.5752 & TRN & \\
\hline CHEMBL1334525 & 688612 & 4.05 & 4.67899 & 9999999999 & TST \\
\hline CHEMBL1544671 & 688612 & 4.15 & 4.6336 & TRN & \\
\hline CHEMBL1502722 & 688612 & 5.2 & 4.6046 & TST & \\
\hline CHEMBL1384066 & 688612 & 4.2 & 4.6879 & TRN & \\
\hline CHEMBL1415223 & 688612 & 4.05 & 4.7004 & TST & \\
\hline CHEMBL1613033 & 688612 & 4.6 & 4.6941 & TRN & \\
\hline CHEMBL3211554 & 688612 & 4.05 & 4.6404 & TST & \\
\hline CHEMBL1358225 & 688612 & 4.25 & 4.6876 & TRN & \\
\hline CHEMBL3196509 & 688612 & 4.4 & 4.7182 & TRN & \\
\hline
\end{tabular}




\begin{tabular}{|c|c|c|c|c|}
\hline & & \multicolumn{3}{|c|}{ Supplemental Table S2.txt } \\
\hline CHEMBL1549530 & 688612 & 4.45 & 4.6143 & TRN \\
\hline CHEMBL1394293 & 688612 & 4.9 & 4.6202 & TRN \\
\hline CHEMBL1369148 & 688612 & 4.6 & 4.678 & TRN \\
\hline CHEMBL1450236 & 688612 & 4.9 & 4.6961 & TRN \\
\hline CHEMBL1528668 & 688612 & 5.45 & 4.7091 & TRN \\
\hline CHEMBL1552387 & 688612 & 4.8 & 4.691 & TRN \\
\hline CHEMBL1366181 & 688612 & 5.0 & 4.6336 & TST \\
\hline CHEMBL2374071 & 688612 & 5.0 & 4.7762 & TRN \\
\hline CHEMBL1299695 & 688612 & 4.1 & 4.7209 & TST \\
\hline CHEMBL1566982 & 688612 & 4.1 & 4.6678 & TST \\
\hline CHEMBL1415806 & 688612 & 4.05 & 4.5748 & TRN \\
\hline CHEMBL1328509 & 688612 & 4.0 & 4.6906 & TRN \\
\hline CHEMBL1568852 & 688612 & 6.1 & 4.6441 & TRN \\
\hline CHEMBL1492875 & 688612 & 4.1 & 4.5666 & TST \\
\hline CHEMBL1454323 & 688612 & 5.95 & 4.6634 & TRN \\
\hline CHEMBL1425233 & 688612 & 4.05 & 4.7046 & TST \\
\hline CHEMBL3198535 & 688612 & 4.8 & 4.7021 & TRN \\
\hline CHEMBL1500850 & 688612 & 4.45 & 4.797 & TRN \\
\hline CHEMBL1307138 & 688612 & 4.1 & 4.7063 & TST \\
\hline CHEMBL1520338 & 688612 & 4.05 & 4.5479 & TRN \\
\hline CHEMBL3190097 & 688612 & 4.1 & 4.7488 & TRN \\
\hline CHEMBL3209729 & 688612 & 4.45 & 4.5767 & TRN \\
\hline CHEMBL1351854 & 688612 & 4.35 & 4.7463 & TRN \\
\hline CHEMBL1562974 & 688612 & 4.95 & 4.648 & TRN \\
\hline CHEMBL1471454 & 688612 & 4.0 & 4.6005 & TRN \\
\hline CHEMBL1347144 & 688612 & 4.2 & 4.6785 & TRN \\
\hline CHEMBL1322076 & 688612 & 4.3 & 4.6232 & TRN \\
\hline CHEMBL3199580 & 688612 & 4.95 & 4.7097 & TST \\
\hline CHEMBL1342317 & 688612 & 4.15 & 4.6507 & TST \\
\hline CHEMBL1458068 & 688612 & 4.5 & 4.6644 & TST \\
\hline CHEMBL1506139 & 688612 & 4.5 & 4.6578 & TRN \\
\hline CHEMBL1464853 & 688612 & 5.25 & 4.6688 & TST \\
\hline CHEMBL1539157 & 688612 & 4.3 & 4.6156 & TRN \\
\hline CHEMBL1302682 & 688612 & 4.4 & 4.703 & TRN \\
\hline CHEMBL1520905 & 688612 & 5.95 & 4.6941 & TRN \\
\hline CHEMBL1589252 & 688612 & 4.0 & 4.7334 & TST \\
\hline CHEMBL1571285 & 688612 & 4.05 & 4.7258 & TRN \\
\hline CHEMBL3213062 & 688612 & 4.1 & 4.7041 & TST \\
\hline CHEMBL1302969 & 688612 & 4.25 & 4.6817 & TRN \\
\hline CHEMBL1326207 & 688612 & 4.35 & 4.6817 & TRN \\
\hline CHEMBL1197556 & 688612 & 4.8 & 4.7295 & TRN \\
\hline CHEMBL1361272 & 688612 & 5.35 & 4.6551 & TRN \\
\hline CHEMBL1397968 & 688612 & 4.05 & 4.6912 & TST \\
\hline CHEMBL1529736 & 688612 & 5.3 & 4.6751 & TRN \\
\hline CHEMBL1586824 & 688612 & 5.3 & 4.6304 & TST \\
\hline CHEMBL1338474 & 688612 & 5.2 & 4.8228 & TRN \\
\hline CHEMBL 2000633 & 688612 & 5.0 & 4.7584 & TRN \\
\hline CHEMBL1390709 & 688612 & 4.4 & 4.6796 & TST \\
\hline
\end{tabular}




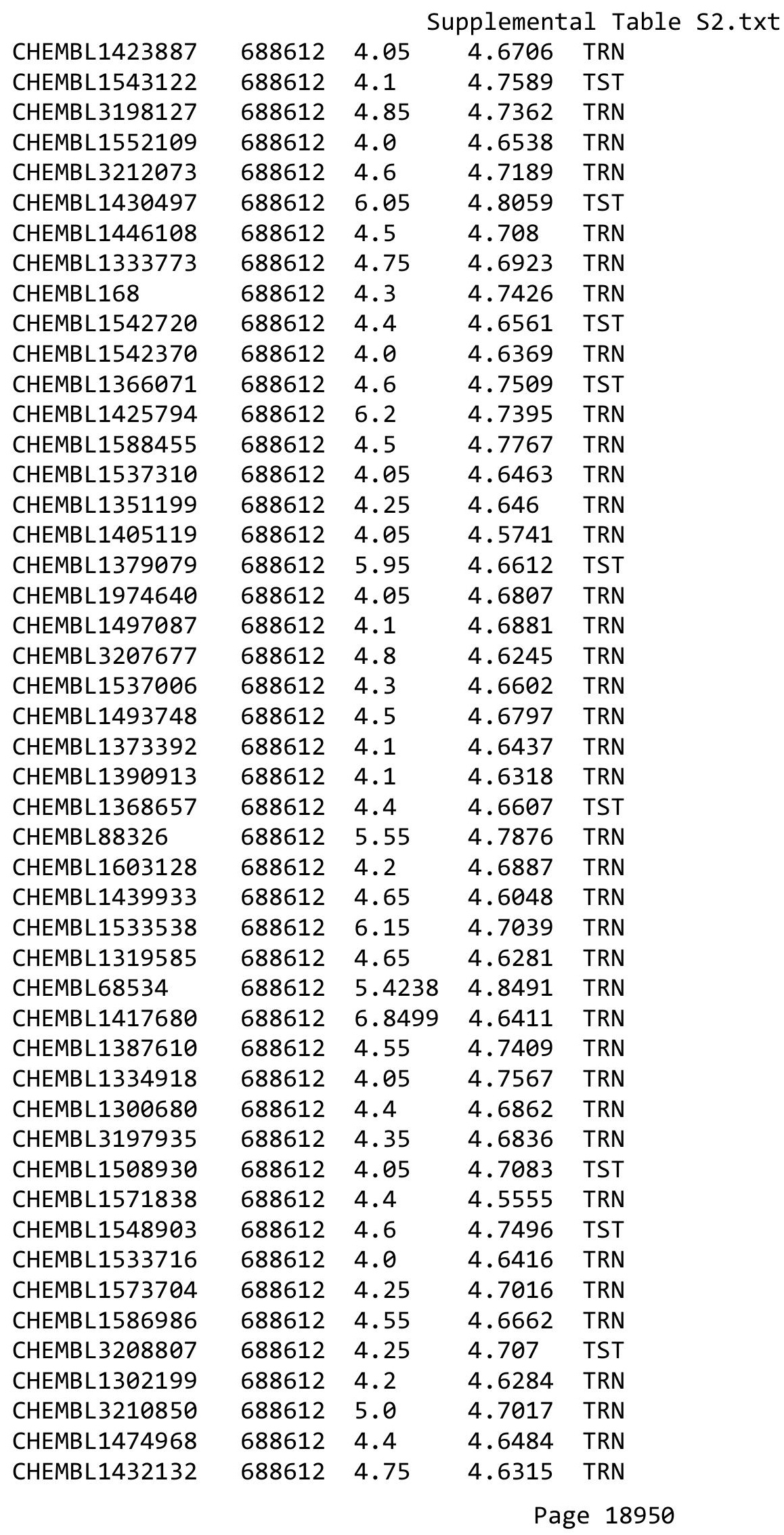




\begin{tabular}{|c|c|c|c|c|c|}
\hline \multirow[b]{2}{*}{ CHEMBL1501195 } & \multirow[b]{2}{*}{688612} & \multicolumn{4}{|c|}{ Supplemental Table S2.txt } \\
\hline & & 5.4 & 4.6749 & TST & \\
\hline CHEMBL3196410 & 688612 & 4.15 & 4.6771 & TRN & \\
\hline CHEMBL1331111 & 688612 & 4.3 & 4.7199 & TRN & \\
\hline CHEMBL3194109 & 688612 & 4.7 & 4.7602 & TRN & \\
\hline CHEMBL1475046 & 688612 & 4.0 & 4.6011 & TRN & \\
\hline CHEMBL1454948 & 688612 & 4.05 & 4.56800 & 00000000005 & TRN \\
\hline CHEMBL1398469 & 688612 & 4.65 & 4.6816 & TST & \\
\hline CHEMBL1989897 & 688612 & 4.4 & 4.7896 & TST & \\
\hline CHEMBL1982713 & 688612 & 4.75 & 4.7752 & TRN & \\
\hline CHEMBL1358220 & 688612 & 5.5 & 4.5855 & TRN & \\
\hline CHEMBL1304817 & 688612 & 4.8 & 4.6991 & TST & \\
\hline CHEMBL1578773 & 688612 & 4.0 & 4.5723 & TRN & \\
\hline CHEMBL1452939 & 688612 & 4.7 & 4.7044 & TRN & \\
\hline CHEMBL1409437 & 688612 & 4.0 & 4.687 & TST & \\
\hline CHEMBL1476863 & 688612 & 4.0 & 4.6096 & TRN & \\
\hline CHEMBL1480932 & 688612 & 4.05 & 4.687 & TST & \\
\hline CHEMBL209101 & 688612 & 4.7 & 4.5895 & TRN & \\
\hline CHEMBL1541754 & 688612 & 4.2 & 4.7143 & TST & \\
\hline CHEMBL3195409 & 688612 & 4.8 & 4.7562 & TST & \\
\hline CHEMBL1374676 & 688612 & 5.1 & 4.6616 & TRN & \\
\hline CHEMBL1325639 & 688612 & 4.05 & 4.6502 & TRN & \\
\hline CHEMBL1520320 & 688612 & 4.0 & 4.7027 & TST & \\
\hline CHEMBL1595362 & 688612 & 4.0 & 4.6593 & TRN & \\
\hline CHEMBL1612430 & 688612 & 4.05 & 4.6772 & TST & \\
\hline CHEMBL1304445 & 688612 & 4.3 & 4.8183 & TRN & \\
\hline CHEMBL1393847 & 688612 & 4.5 & 4.6892 & TRN & \\
\hline CHEMBL1379623 & 688612 & 6.15 & 4.5788 & TRN & \\
\hline CHEMBL 3214426 & 688612 & 4.25 & 4.7652 & TST & \\
\hline CHEMBL1591420 & 688612 & 5.5 & 4.6116 & TRN & \\
\hline CHEMBL1443539 & 688612 & 4.05 & 4.6963 & TST & \\
\hline CHEMBL1546860 & 688612 & 4.1 & 4.6153 & TRN & \\
\hline CHEMBL1342851 & 688612 & 4.35 & 4.6545 & TRN & \\
\hline CHEMBL1581375 & 688612 & 4.2 & 4.5558 & TST & \\
\hline CHEMBL1447948 & 688612 & 4.85 & 4.6004 & TRN & \\
\hline CHEMBL1365175 & 688612 & 5.3 & 4.6114 & TRN & \\
\hline CHEMBL1570852 & 688612 & 4.95 & 4.6855 & TRN & \\
\hline CHEMBL1327136 & 688612 & 4.1 & 4.6623 & TRN & \\
\hline CHEMBL118175 & 688612 & 4.65 & 4.7563 & TST & \\
\hline CHEMBL3198620 & 688612 & 4.65 & 4.7676 & TRN & \\
\hline CHEMBL1483908 & 688612 & 4.1 & 4.6959 & TRN & \\
\hline CHEMBL1434854 & 688612 & 4.05 & 4.7084 & TRN & \\
\hline CHEMBL1476914 & 688612 & 4.05 & 4.6133 & TRN & \\
\hline CHEMBL1540110 & 688612 & 4.05 & 4.5485 & TRN & \\
\hline CHEMBL1404826 & 688612 & 4.2 & 4.6891 & TST & \\
\hline CHEMBL1590778 & 688612 & 4.0 & 4.6333 & TRN & \\
\hline CHEMBL1334161 & 688612 & 4.1 & 4.6642 & TRN & \\
\hline CHEMBL1320493 & 688612 & 4.0 & 4.6703 & TRN & \\
\hline CHEMBL1588358 & 688612 & 4.3 & 4.5977 & TRN & \\
\hline
\end{tabular}




\begin{tabular}{|c|c|c|c|c|c|}
\hline \multicolumn{6}{|c|}{ Supplemental Table S2.txt } \\
\hline CHEMBL1968085 & 688612 & 4.4 & 4.7718 & TRN & \\
\hline CHEMBL1372591 & 688612 & 4.15 & 4.6658 & TRN & \\
\hline CHEMBL297453 & 688612 & 6.35 & 4.8055 & TST & \\
\hline CHEMBL244090 & 688612 & 4.5 & 4.7365 & TST & \\
\hline CHEMBL1542833 & 688612 & 6.1 & 4.6151 & TRN & \\
\hline CHEMBL1591595 & 688612 & 4.65 & 4.6175 & TRN & \\
\hline CHEMBL1388764 & 688612 & 4.2 & 4.6282 & TRN & \\
\hline CHEMBL1331134 & 688612 & 5.1 & $4.7780 e$ & 00000000005 & TRN \\
\hline CHEMBL1310804 & 688612 & 4.5 & 4.63399 & 99999999995 & TST \\
\hline CHEMBL1336978 & 688612 & 4.0 & 4.6642 & TST & \\
\hline CHEMBL1496785 & 688612 & 4.4 & 4.6035 & TST & \\
\hline CHEMBL1595173 & 688612 & 4.4 & 4.5787 & TRN & \\
\hline CHEMBL1524994 & 688612 & 4.7 & 4.6659 & TRN & \\
\hline CHEMBL1381265 & 688612 & 6.5501 & 4.7046 & TRN & \\
\hline CHEMBL1605026 & 688612 & 4.7 & 4.7501 & TRN & \\
\hline CHEMBL 2000992 & 688612 & 4.05 & 4.6682 & TRN & \\
\hline CHEMBL1331279 & 688612 & 4.6 & 4.6749 & TRN & \\
\hline CHEMBL3210215 & 688612 & 4.5 & 4.6072 & TRN & \\
\hline CHEMBL1498684 & 688612 & 4.0 & 4.6635 & TRN & \\
\hline CHEMBL1377478 & 688612 & 4.05 & 4.6837 & TST & \\
\hline CHEMBL1469133 & 688612 & 4.05 & $4.6960 e$ & 0000000001 & TST \\
\hline CHEMBL1582927 & 688612 & 4.6 & 4.7499 & TRN & \\
\hline CHEMBL1346482 & 688612 & 5.75 & 4.702 & TRN & \\
\hline CHEMBL1478195 & 688612 & 4.15 & 4.681 & TST & \\
\hline CHEMBL1583273 & 688612 & 5.1 & 4.6954 & TRN & \\
\hline CHEMBL1469467 & 688612 & 4.7 & 4.6828 & TST & \\
\hline CHEMBL1549675 & 688612 & 4.2 & 4.5863 & TST & \\
\hline CHEMBL1580361 & 688612 & 4.1 & 4.6421 & TRN & \\
\hline CHEMBL1393087 & 688612 & 4.8 & 4.6978 & TRN & \\
\hline CHEMBL3209058 & 688612 & 5.35 & 4.6593 & TRN & \\
\hline CHEMBL1494515 & 688612 & 4.05 & 4.6475 & TRN & \\
\hline CHEMBL1402846 & 688612 & 5.5 & 4.7124 & TRN & \\
\hline CHEMBL1342469 & 688612 & 4.4 & 4.6853 & TRN & \\
\hline CHEMBL348436 & 688612 & 4.05 & 4.7541 & TRN & \\
\hline CHEMBL1521144 & 688612 & 5.3 & 4.6917 & TRN & \\
\hline CHEMBL3211815 & 688612 & 4.3 & 4.7691 & TRN & \\
\hline CHEMBL1483332 & 688612 & 4.0 & 4.6004 & TRN & \\
\hline CHEMBL 374374 & 688612 & 6.8 & 4.6819 & TST & \\
\hline CHEMBL1546272 & 688612 & 6.05 & 4.5942 & TST & \\
\hline CHEMBL3195829 & 688612 & 4.0 & 4.6602 & TRN & \\
\hline CHEMBL1471685 & 688612 & 4.05 & 4.6692 & TRN & \\
\hline CHEMBL2357911 & 688612 & 4.45 & 4.7072 & TRN & \\
\hline CHEMBL1343830 & 688612 & 4.45 & 4.7139 & TRN & \\
\hline CHEMBL1573044 & 688612 & 5.5 & 4.71 & TRN & \\
\hline CHEMBL1392949 & 688612 & 4.4 & 4.6904 & TST & \\
\hline CHEMBL1977678 & 688612 & 4.3 & 4.6967 & TRN & \\
\hline CHEMBL1521410 & 688612 & 4.5 & 4.7326 & TRN & \\
\hline CHEMBL3198186 & 688612 & 4.55 & 4.6501 & TRN & \\
\hline
\end{tabular}




\begin{tabular}{|c|c|c|c|c|c|}
\hline \multicolumn{6}{|c|}{ Supplemental Table S2.txt } \\
\hline CHEMBL1334182 & 688612 & 4.4 & 4.6858 & TST & \\
\hline CHEMBL1607217 & 688612 & 6.0 & 4.5759 & TST & \\
\hline CHEMBL1323967 & 688612 & 4.45 & 4.6852 & TST & \\
\hline CHEMBL1539325 & 688612 & 6.35 & 4.7522 & TRN & \\
\hline CHEMBL1302537 & 688612 & 4.0 & 4.6075 & TRN & \\
\hline CHEMBL1343023 & 688612 & 4.45 & 4.6473 & TRN & \\
\hline CHEMBL1343475 & 688612 & 4.0 & 4.6005 & TRN & \\
\hline CHEMBL3198304 & 688612 & 4.3 & 4.6064 & TRN & \\
\hline CHEMBL600554 & 688612 & 4.05 & 4.671 & TRN & \\
\hline CHEMBL1399166 & 688612 & 4.1 & 4.6971 & TST & \\
\hline CHEMBL1398763 & 688612 & 4.05 & 4.7357 & TST & \\
\hline CHEMBL1380979 & 688612 & 4.05 & 4.6377 & TST & \\
\hline CHEMBL1546338 & 688612 & 4.05 & 4.6346 & TRN & \\
\hline CHEMBL1515418 & 688612 & 4.25 & 4.7097 & TRN & \\
\hline CHEMBL1365725 & 688612 & 4.7 & 4.6361 & TRN & \\
\hline CHEMBL3198266 & 688612 & 4.1 & 4.7206 & TRN & \\
\hline CHEMBL1490822 & 688612 & 4.4 & 4.6536 & TST & \\
\hline CHEMBL1356289 & 688612 & 6.1 & 4.588 & TRN & \\
\hline CHEMBL1359301 & 688612 & 4.05 & 4.6764 & TRN & \\
\hline CHEMBL1316561 & 688612 & 5.6 & 4.6744 & TRN & \\
\hline CHEMBL3213206 & 688612 & 4.75 & 4.6581 & TST & \\
\hline CHEMBL1421152 & 688612 & 4.05 & 4.7192 & TRN & \\
\hline CHEMBL1531961 & 688612 & 5.65 & 4.6211 & TRN & \\
\hline CHEMBL1974392 & 688612 & 4.45 & 4.7011 & TRN & \\
\hline CHEMBL1466492 & 688612 & 4.45 & 4.7661 & TRN & \\
\hline CHEMBL1421887 & 688612 & 5.15 & 4.647 & TRN & \\
\hline CHEMBL1570277 & 688612 & 4.1 & 4.6526 & TRN & \\
\hline CHEMBL1422458 & 688612 & 4.05 & 4.6138 & TRN & \\
\hline CHEMBL1363048 & 688612 & 4.1 & 4.5891 & TRN & \\
\hline CHEMBL1393994 & 688612 & 4.25 & 4.7741 & TST & \\
\hline CHEMBL1510323 & 688612 & 4.25 & 4.6279 & TRN & \\
\hline CHEMBL3191438 & 688612 & 5.6 & 4.6978 & TRN & \\
\hline CHEMBL1425379 & 688612 & 4.25 & 4.7268 & TRN & \\
\hline CHEMBL1593482 & 688612 & 4.0 & 4.5744 & TRN & \\
\hline CHEMBL1432015 & 688612 & 6.8499 & 4.7082 & TRN & \\
\hline CHEMBL1352782 & 688612 & 4.0 & 4.615 & TST & \\
\hline CHEMBL1302652 & 688612 & 4.0 & 4.5714 & TRN & \\
\hline CHEMBL1537679 & 688612 & 4.25 & 4.6556 & TRN & \\
\hline CHEMBL1999548 & 688612 & 4.9 & 4.8003 & TRN & \\
\hline CHEMBL1494689 & 688612 & 7.1002 & 4.652 & TRN & \\
\hline CHEMBL1537868 & 688612 & 4.0 & 4.7043 & TRN & \\
\hline CHEMBL 3211134 & 688612 & 4.1 & 4.6596 & TRN & \\
\hline CHEMBL1347712 & 688612 & 4.0 & 4.6192 & TRN & \\
\hline CHEMBL1570418 & 688612 & 6.95 & 4.7244 & TRN & \\
\hline CHEMBL1462092 & 688612 & 4.55 & 4.723 & TST & \\
\hline CHEMBL1556668 & 688612 & 6.7001 & 4.6831 & TST & \\
\hline CHEMBL1586082 & 688612 & 4.2 & 4.63399 & 99999999995 & TRN \\
\hline CHEMBL1384976 & 688612 & 5.25 & 4.672 & TRN & \\
\hline
\end{tabular}




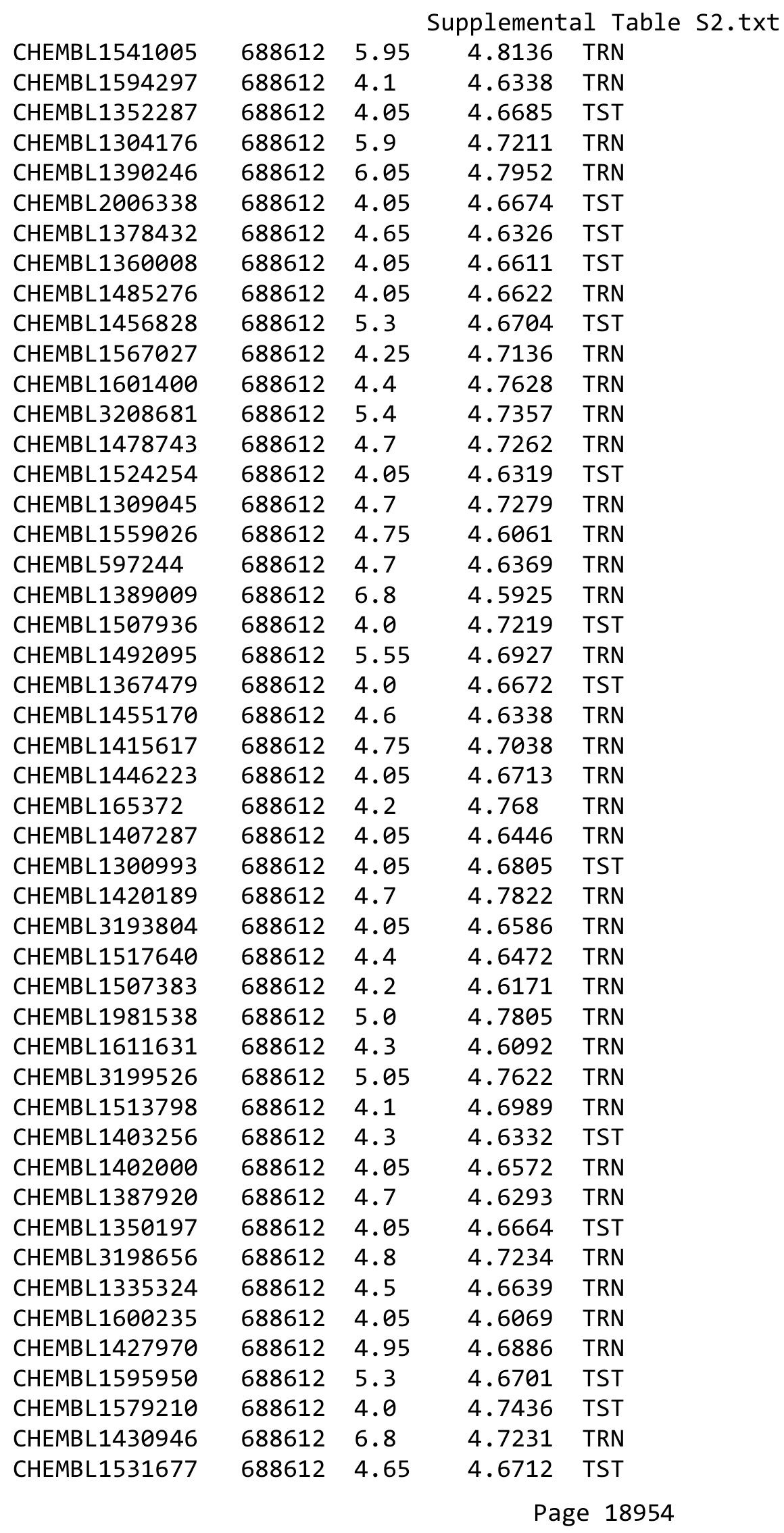




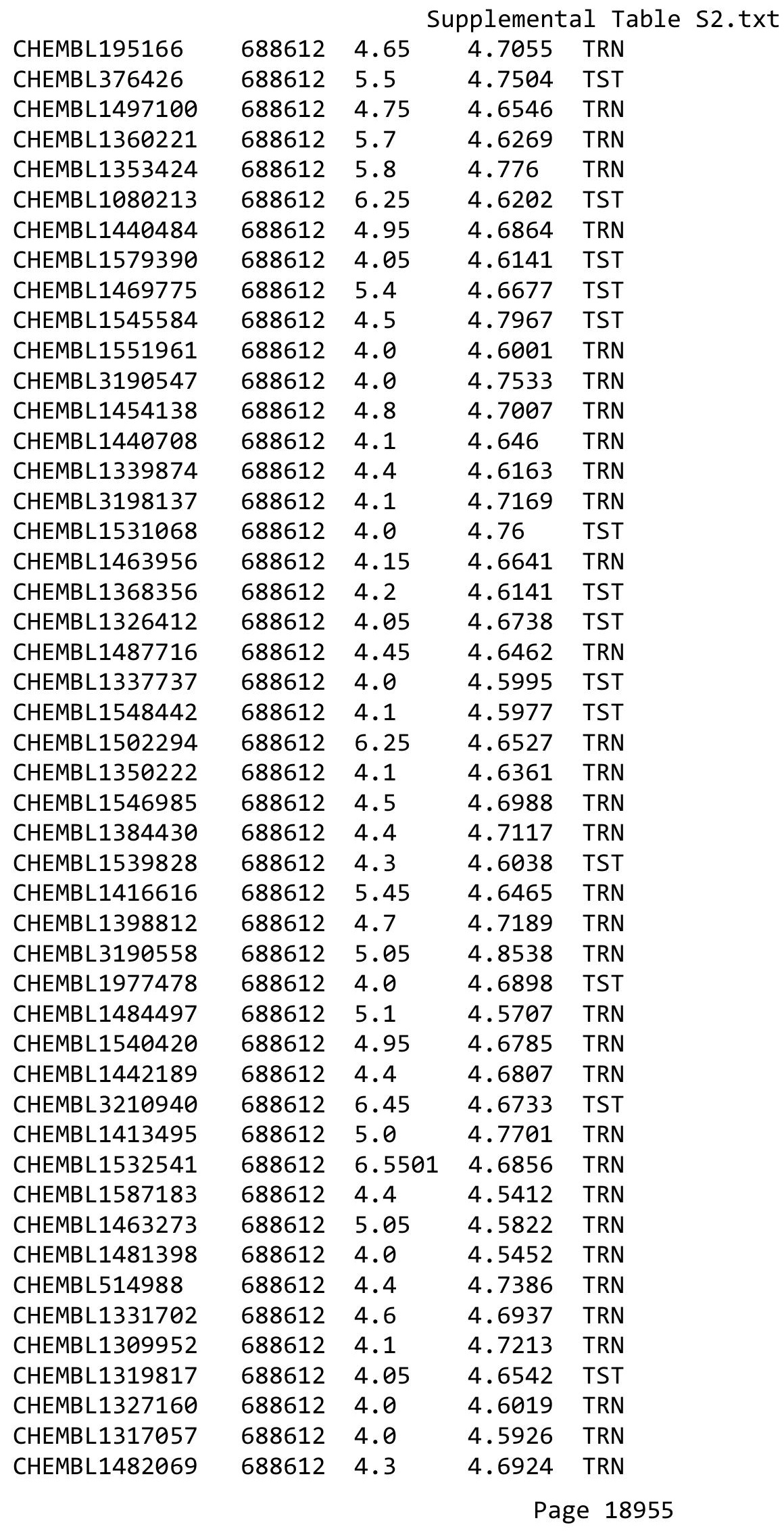




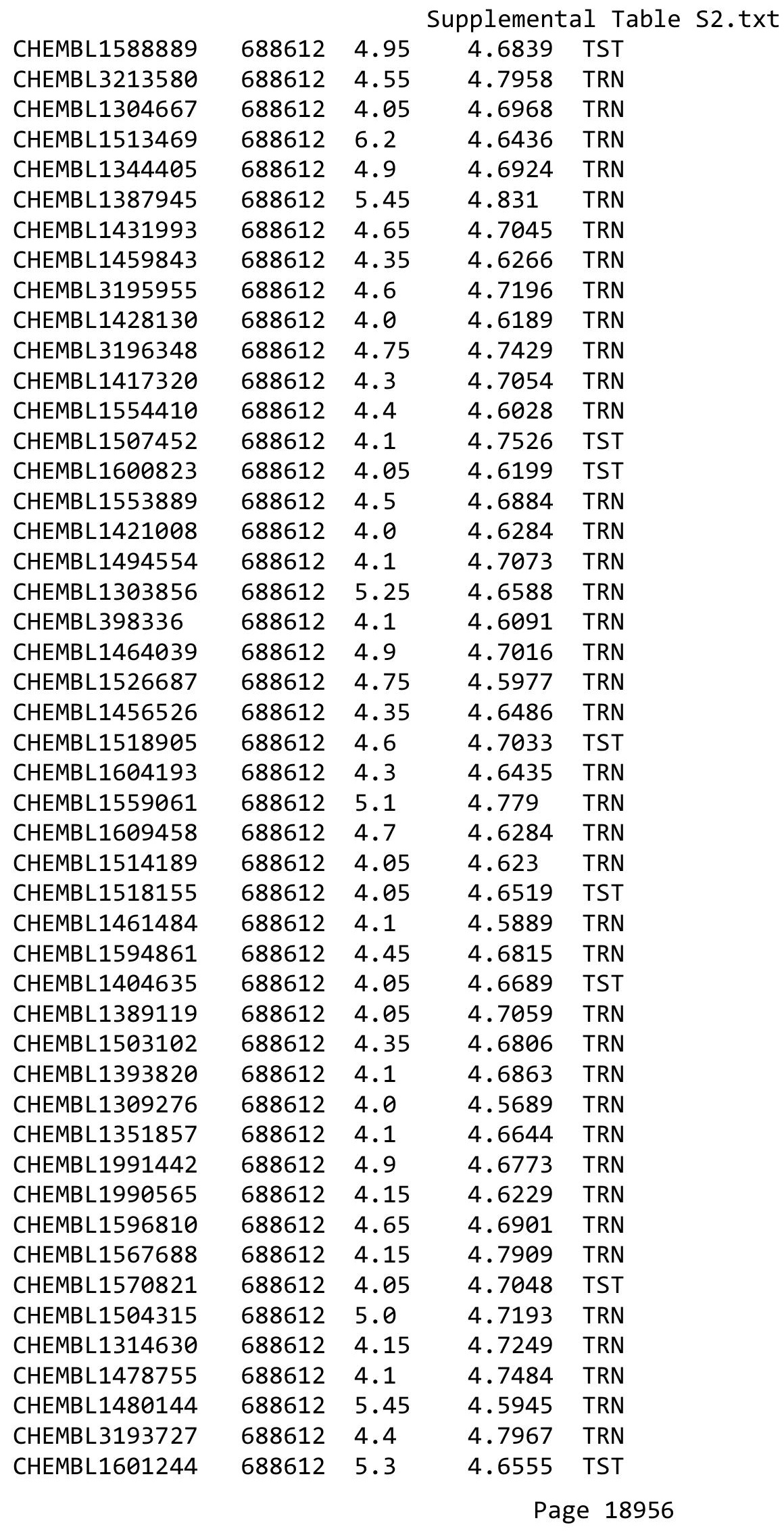




\begin{tabular}{|c|c|c|c|c|c|}
\hline & & \multicolumn{4}{|c|}{ Supplemental Table S2.txt } \\
\hline CHEMBL1375130 & 688612 & 4.4 & 4.6713 & TRN & \\
\hline CHEMBL1385676 & 688612 & 4.15 & 4.6356 & TRN & \\
\hline CHEMBL1506788 & 688612 & 5.0 & 4.6491 & TRN & \\
\hline CHEMBL1369492 & 688612 & 4.35 & 4.6363 & TRN & \\
\hline CHEMBL1969992 & 688612 & 4.75 & 4.7117 & TRN & \\
\hline CHEMBL1474796 & 688612 & 4.1 & 4.6857 & TRN & \\
\hline CHEMBL1518827 & 688612 & 4.55 & 4.5947 & TST & \\
\hline CHEMBL1528982 & 688612 & 4.55 & 4.6168 & TRN & \\
\hline CHEMBL1545036 & 688612 & 4.45 & 4.6307 & TRN & \\
\hline CHEMBL1337644 & 688612 & 5.05 & 4.7053 & TST & \\
\hline CHEMBL358546 & 688612 & 4.8 & 4.795 & TRN & \\
\hline CHEMBL 3193563 & 688612 & 4.2 & 4.73600 & 0000000001 & TRN \\
\hline CHEMBL3196603 & 688612 & 4.4 & 4.7688 & TST & \\
\hline CHEMBL1557376 & 688612 & 6.2 & 4.6113 & TRN & \\
\hline CHEMBL1397010 & 688612 & 4.0 & 4.6087 & TRN & \\
\hline CHEMBL1382695 & 688612 & 4.85 & 4.7148 & TRN & \\
\hline CHEMBL1538131 & 688612 & 4.05 & 4.6602 & TST & \\
\hline CHEMBL1336753 & 688612 & 5.3 & 4.7007 & TRN & \\
\hline CHEMBL1394618 & 688612 & 5.4 & 4.6787 & TRN & \\
\hline CHEMBL1459839 & 688612 & 4.4 & 4.6531 & TRN & \\
\hline CHEMBL1388051 & 688612 & 5.25 & 4.7242 & TST & \\
\hline CHEMBL1433213 & 688612 & 4.0 & 4.692 & TST & \\
\hline CHEMBL1367419 & 688612 & 4.4 & 4.6118 & TRN & \\
\hline CHEMBL247336 & 688612 & 4.0 & 4.7129 & TRN & \\
\hline CHEMBL1582133 & 688612 & 5.0 & 4.7454 & TRN & \\
\hline CHEMBL3193748 & 688612 & 4.2 & 4.7344 & TRN & \\
\hline CHEMBL1411867 & 688612 & 4.45 & 4.6692 & TRN & \\
\hline CHEMBL1503276 & 688612 & 4.05 & 4.6356 & TRN & \\
\hline CHEMBL1388024 & 688612 & 4.0 & 4.6728 & TRN & \\
\hline CHEMBL3189489 & 688612 & 5.05 & 4.7208 & TRN & \\
\hline CHEMBL1328130 & 688612 & 4.35 & 4.7142 & TRN & \\
\hline CHEMBL1328853 & 688612 & 4.4 & 4.6549 & TRN & \\
\hline CHEMBL1413708 & 688612 & 4.05 & 4.6525 & TRN & \\
\hline CHEMBL1514471 & 688612 & 6.8 & 4.6626 & TRN & \\
\hline CHEMBL1556298 & 688612 & 4.1 & 4.6219 & TST & \\
\hline CHEMBL1452705 & 688612 & 5.9 & 4.5666 & TRN & \\
\hline CHEMBL1422795 & 688612 & 5.85 & 4.6726 & TST & \\
\hline CHEMBL1494016 & 688612 & 4.0 & 4.6862 & TST & \\
\hline CHEMBL1572088 & 688612 & 4.4 & 4.5988 & TST & \\
\hline CHEMBL1558607 & 688612 & 4.95 & 4.7074 & TRN & \\
\hline CHEMBL1447450 & 688612 & 5.25 & 4.6482 & TRN & \\
\hline CHEMBL1432884 & 688612 & 4.3 & 4.6519 & TRN & \\
\hline CHEMBL1346073 & 688612 & 5.0 & 4.6646 & TRN & \\
\hline CHEMBL1598884 & 688612 & 5.35 & 4.7061 & TRN & \\
\hline CHEMBL1469519 & 688612 & 4.0 & 4.643 & TST & \\
\hline CHEMBL1550539 & 688612 & 4.5 & 4.6408 & TRN & \\
\hline CHEMBL1551104 & 688612 & 4.0 & 4.6676 & TRN & \\
\hline CHEMBL1567029 & 688612 & 4.2 & 4.6829 & TRN & \\
\hline
\end{tabular}




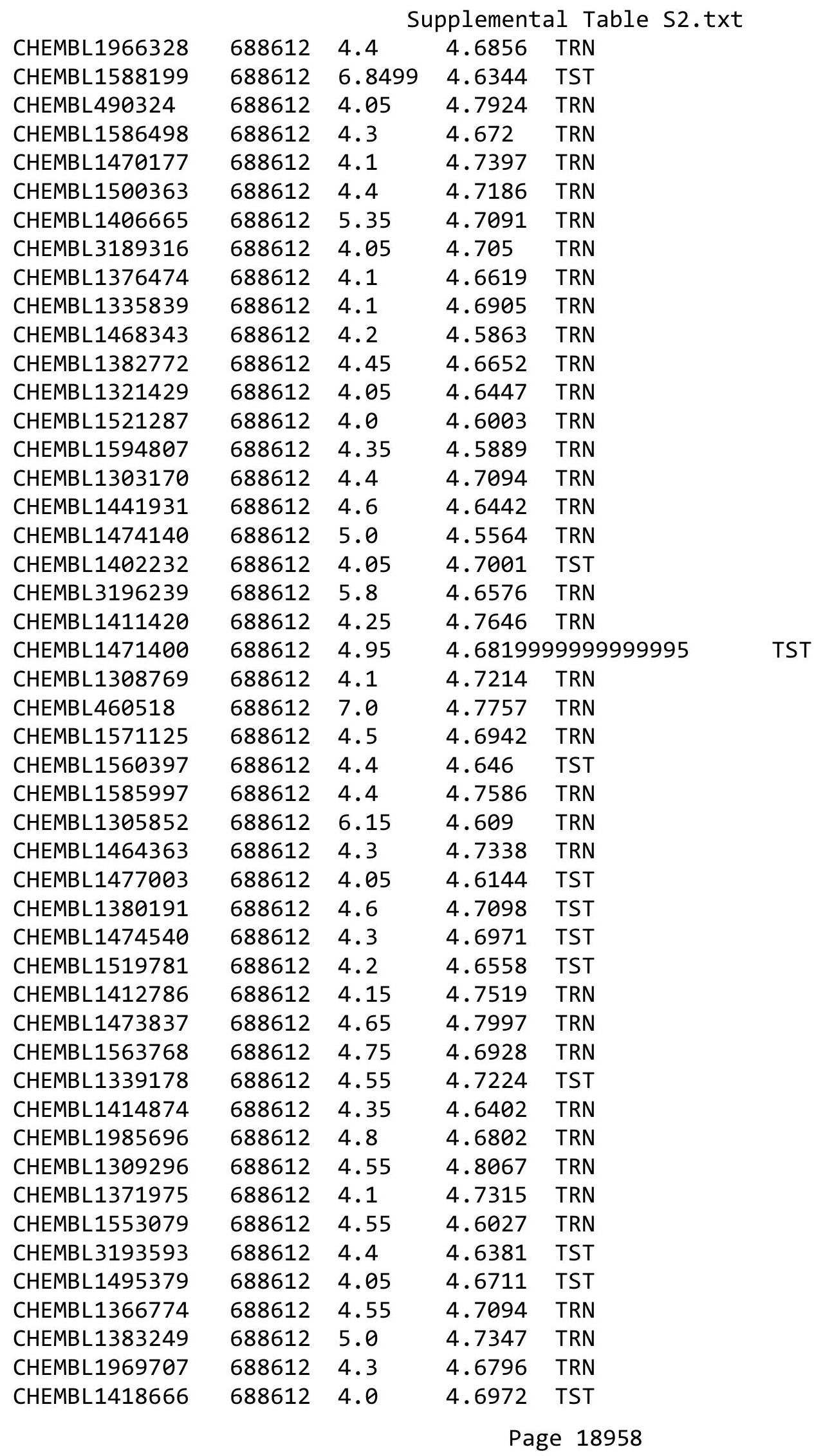




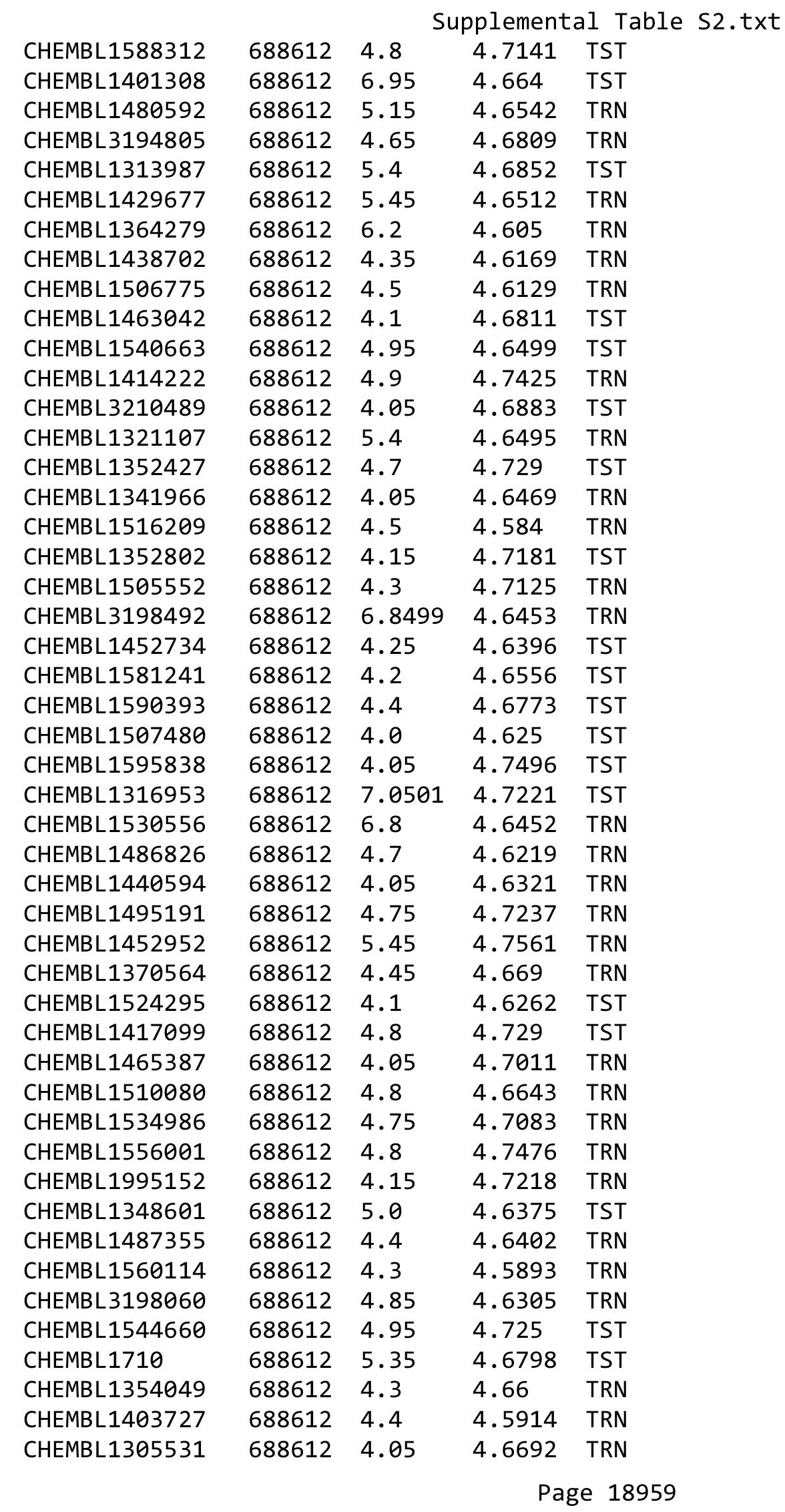




\begin{tabular}{|c|c|c|c|c|c|}
\hline \multicolumn{6}{|c|}{ Supplemental Table S2.txt } \\
\hline CHEMBL1520504 & 688612 & 4.0 & 4.6537 & TST & \\
\hline CHEMBL1332855 & 688612 & 4.1 & 4.6912 & TRN & \\
\hline CHEMBL1360263 & 688612 & 4.4 & 4.6954 & TST & \\
\hline CHEMBL1556341 & 688612 & 4.05 & 4.6064 & TRN & \\
\hline CHEMBL1334108 & 688612 & 4.0 & 4.6574 & TRN & \\
\hline CHEMBL1359538 & 688612 & 4.3 & 4.621 & TRN & \\
\hline CHEMBL1379646 & 688612 & 4.1 & 4.6344 & TRN & \\
\hline CHEMBL1309614 & 688612 & 4.4 & 4.6768 & TRN & \\
\hline CHEMBL1354844 & 688612 & 4.9 & 4.6253 & TRN & \\
\hline CHEMBL1479665 & 688612 & 4.4 & 4.6667 & TRN & \\
\hline CHEMBL1341660 & 688612 & 4.35 & 4.6871 & TRN & \\
\hline CHEMBL1312953 & 688612 & 4.3 & 4.6819 & TST & \\
\hline CHEMBL1345491 & 688612 & 4.1 & 4.6666 & TST & \\
\hline CHEMBL1493396 & 688612 & 4.35 & 4.7452 & TST & \\
\hline CHEMBL1306526 & 688612 & 4.05 & 4.5965 & TRN & \\
\hline CHEMBL1426490 & 688612 & 4.4 & 4.6631 & TRN & \\
\hline CHEMBL1591234 & 688612 & 4.4 & 4.5957 & TRN & \\
\hline CHEMBL1444231 & 688612 & 6.0 & 4.6717 & TRN & \\
\hline CHEMBL1312700 & 688612 & 4.2 & 4.5899 & TRN & \\
\hline CHEMBL1426344 & 688612 & 6.9 & 4.6485 & TST & \\
\hline CHEMBL1494387 & 688612 & 4.65 & 4.7619 & TRN & \\
\hline CHEMBL1429292 & 688612 & 6.25 & 4.6938 & TRN & \\
\hline CHEMBL3197309 & 688612 & 5.05 & 4.6491 & TRN & \\
\hline CHEMBL1546030 & 688612 & 4.5 & 4.76699 & 99999999995 & TST \\
\hline CHEMBL1556267 & 688612 & 4.05 & 4.7359 & TRN & \\
\hline CHEMBL1324211 & 688612 & 4.05 & 4.5821 & TRN & \\
\hline CHEMBL1309765 & 688612 & 4.5 & 4.7387 & TRN & \\
\hline CHEMBL1575715 & 688612 & 5.0 & 4.7089 & TST & \\
\hline CHEMBL1400390 & 688612 & 4.1 & 4.6266 & TST & \\
\hline CHEMBL3199604 & 688612 & 4.05 & 4.6604 & TST & \\
\hline CHEMBL1351708 & 688612 & 6.2 & 4.7036 & TRN & \\
\hline CHEMBL1486603 & 688612 & 4.45 & 4.6476 & TRN & \\
\hline CHEMBL1383140 & 688612 & 4.75 & 4.6299 & TRN & \\
\hline CHEMBL1605464 & 688612 & 4.4 & 4.6366 & TRN & \\
\hline CHEMBL1425086 & 688612 & 6.8499 & 4.6193 & TRN & \\
\hline CHEMBL3197887 & 688612 & 4.7 & 4.8027 & TRN & \\
\hline CHEMBL1320672 & 688612 & 4.5 & 4.6328 & TRN & \\
\hline CHEMBL1588372 & 688612 & 4.55 & 4.6037 & TRN & \\
\hline CHEMBL1375111 & 688612 & 4.15 & 4.7346 & TRN & \\
\hline CHEMBL1588485 & 688612 & 4.8 & 4.6459 & TRN & \\
\hline CHEMBL1418647 & 688612 & 4.4 & 4.745 & TRN & \\
\hline CHEMBL1469246 & 688612 & 4.6 & 4.61100 & $\partial 000000001$ & TRN \\
\hline CHEMBL1420653 & 688612 & 6.1 & 4.6473 & TST & \\
\hline CHEMBL1501269 & 688612 & 4.8 & 4.7196 & TRN & \\
\hline CHEMBL1603459 & 688612 & 4.55 & 4.6499 & TRN & \\
\hline CHEMBL1484167 & 688612 & 4.25 & 4.6612 & TST & \\
\hline CHEMBL1368212 & 688612 & 4.3 & 4.7022 & TST & \\
\hline CHEMBL1379278 & 688612 & 4.3 & 4.7371 & TRN & \\
\hline
\end{tabular}




\begin{tabular}{|c|c|c|c|c|c|}
\hline \multicolumn{6}{|c|}{ Supplemental Table S2.txt } \\
\hline CHEMBL1384041 & 688612 & 5.0 & 4.6626 & TST & \\
\hline CHEMBL1463851 & 688612 & 4.1 & 4.7043 & TRN & \\
\hline CHEMBL1325064 & 688612 & 4.0 & 4.6062 & TRN & \\
\hline CHEMBL1406824 & 688612 & 4.35 & 4.6073 & TRN & \\
\hline CHEMBL1471937 & 688612 & 4.75 & 4.6991 & TRN & \\
\hline CHEMBL1471076 & 688612 & 4.05 & 4.6307 & TRN & \\
\hline CHEMBL1306929 & 688612 & 5.6 & 4.6354 & TRN & \\
\hline CHEMBL1965814 & 688612 & 5.15 & 4.752 & TRN & \\
\hline CHEMBL 1474560 & 688612 & 4.35 & 4.6086 & TRN & \\
\hline CHEMBL1357107 & 688612 & 4.0 & 4.6583 & TRN & \\
\hline CHEMBL1453770 & 688612 & 4.6 & 4.5851 & TRN & \\
\hline CHEMBL1493254 & 688612 & 4.65 & 4.6389 & TST & \\
\hline CHEMBL1331126 & 688612 & 4.4 & 4.598 & TRN & \\
\hline CHEMBL3189552 & 688612 & 5.3 & 4.6656 & TST & \\
\hline CHEMBL1403839 & 688612 & 4.0 & 4.6676 & TRN & \\
\hline CHEMBL1567374 & 688612 & 4.05 & 4.6742 & TST & \\
\hline CHEMBL1590754 & 688612 & 4.0 & 4.618 & TST & \\
\hline CHEMBL1369960 & 688612 & 4.85 & 4.6327 & TST & \\
\hline CHEMBL1419115 & 688612 & 4.05 & 4.66100 & 00000000005 & TRN \\
\hline CHEMBL1483882 & 688612 & 5.4 & 4.6254 & TRN & \\
\hline CHEMBL1424300 & 688612 & 4.5 & 4.6981 & TRN & \\
\hline CHEMBL1416708 & 688612 & 4.1 & 4.6526 & TRN & \\
\hline CHEMBL1556215 & 688612 & 5.0 & 4.6965 & TRN & \\
\hline CHEMBL1613300 & 688612 & 6.6 & 4.7267 & TST & \\
\hline CHEMBL1406100 & 688612 & 5.5 & 4.6663 & TST & \\
\hline CHEMBL1526464 & 688612 & 4.4 & 4.7057 & TRN & \\
\hline CHEMBL1377856 & 688612 & 6.5 & 4.7027 & TRN & \\
\hline CHEMBL1445800 & 688612 & 4.1 & 4.6453 & TRN & \\
\hline CHEMBL1308603 & 688612 & 4.25 & 4.6126 & TRN & \\
\hline CHEMBL1374578 & 688612 & 4.1 & 4.6941 & TRN & \\
\hline CHEMBL1324374 & 688612 & 5.3 & 4.699 & TST & \\
\hline CHEMBL1572667 & 688612 & 4.95 & 4.5903 & TRN & \\
\hline CHEMBL1385027 & 688612 & 4.85 & 4.7294 & TRN & \\
\hline CHEMBL1589115 & 688612 & 4.4 & 4.6026 & TST & \\
\hline CHEMBL1516326 & 688612 & 4.15 & 4.6671 & TRN & \\
\hline CHEMBL1304879 & 688612 & 4.05 & 4.6348 & TRN & \\
\hline CHEMBL1305631 & 688612 & 4.55 & 4.6009 & TRN & \\
\hline CHEMBL1521414 & 688612 & 4.25 & 4.6123 & TRN & \\
\hline CHEMBL1563225 & 688612 & 4.95 & 4.6552 & TRN & \\
\hline CHEMBL1419116 & 688612 & 4.35 & 4.7377 & TRN & \\
\hline CHEMBL1359190 & 688612 & 4.8 & 4.7129 & TRN & \\
\hline CHEMBL1537048 & 688612 & 4.15 & 4.5804 & TRN & \\
\hline CHEMBL1307145 & 688612 & 4.6 & 4.6317 & TRN & \\
\hline CHEMBL1389334 & 688612 & 5.0 & 4.6288 & TRN & \\
\hline CHEMBL1359281 & 688612 & 4.9 & 4.6379 & TRN & \\
\hline CHEMBL1339797 & 688612 & 7.0 & 4.7778 & TRN & \\
\hline CHEMBL1447399 & 688612 & 4.0 & 4.6952 & TRN & \\
\hline CHEMBL1607126 & 688612 & 4.15 & 4.7112 & TRN & \\
\hline
\end{tabular}




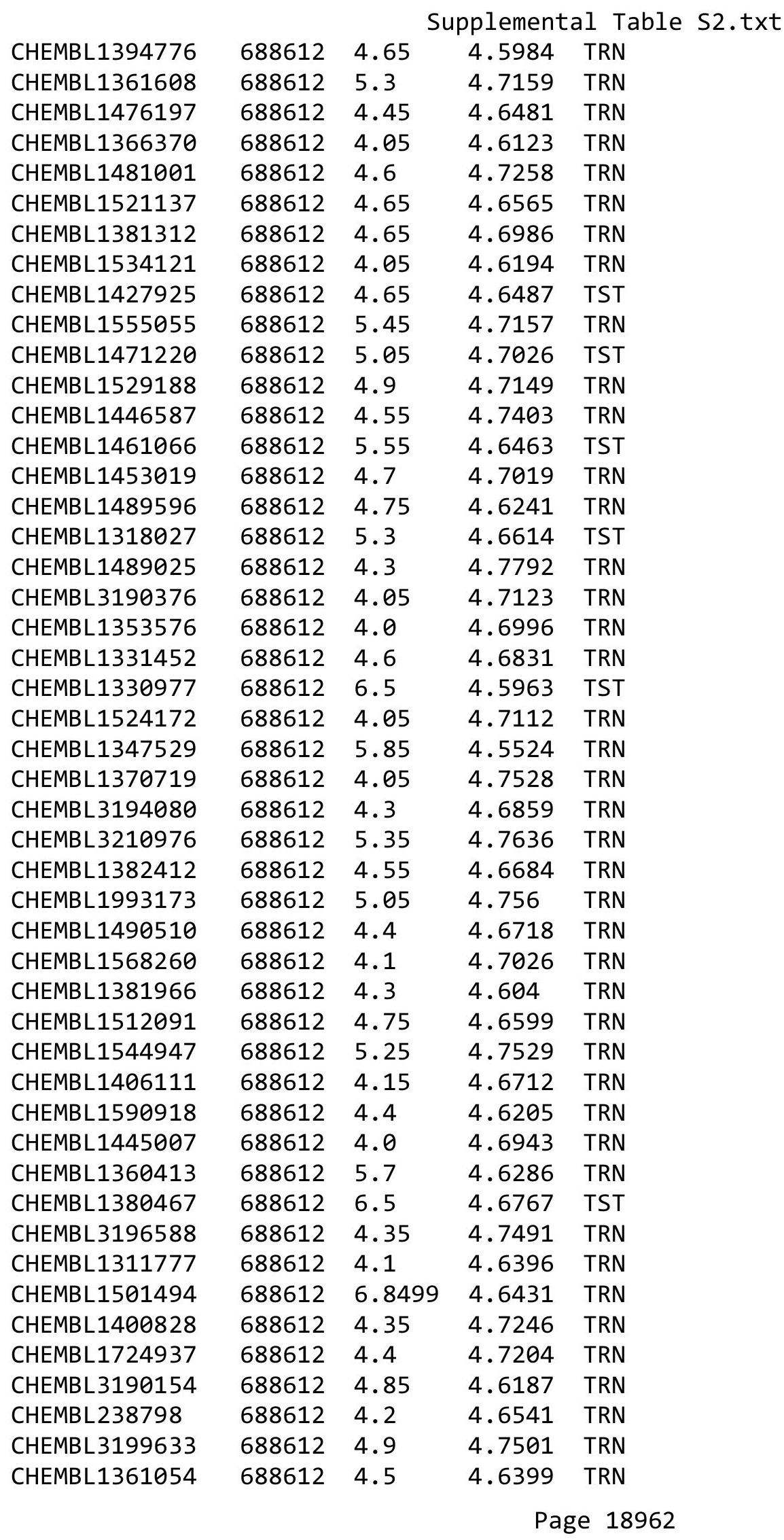




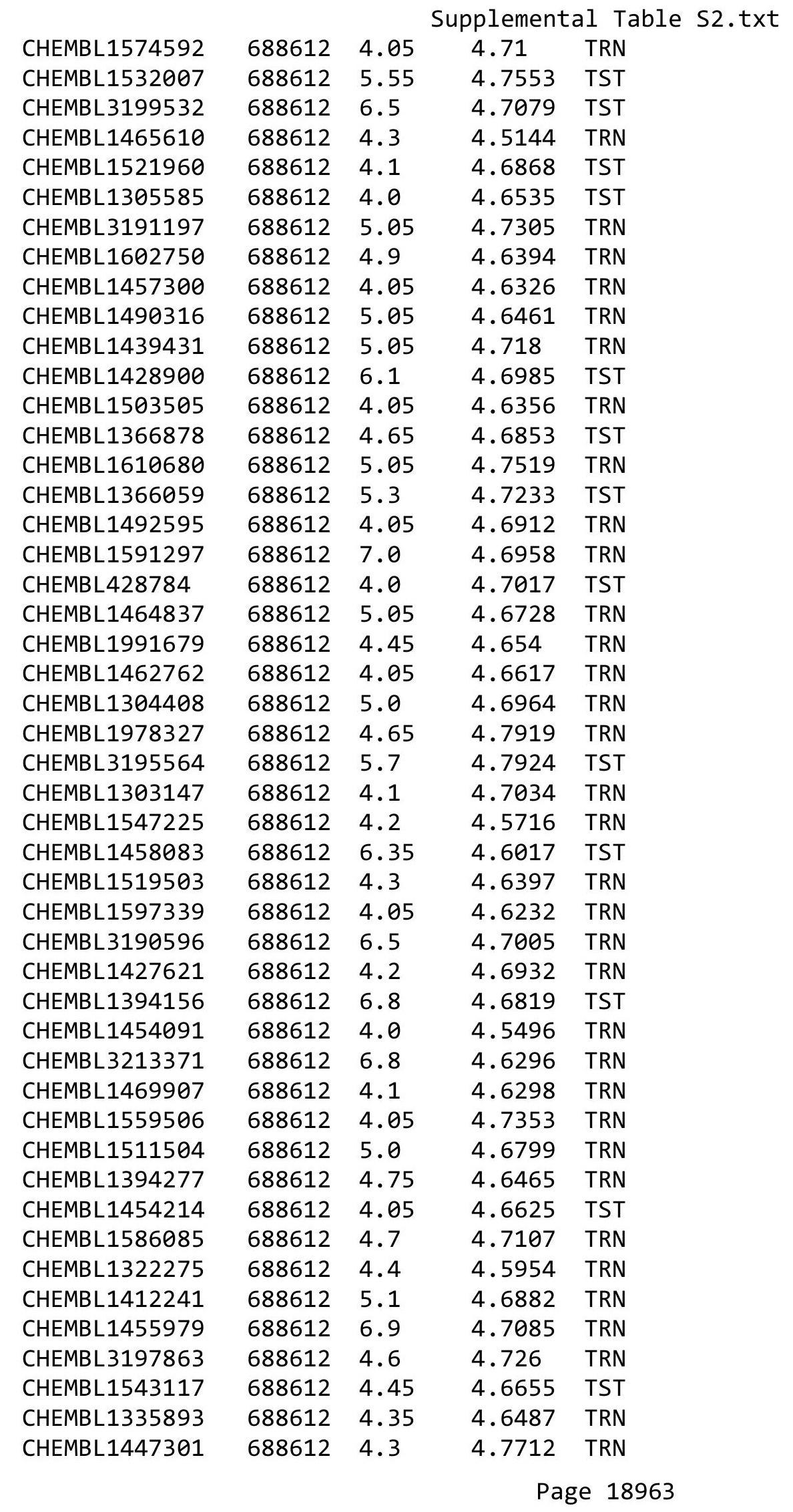




\begin{tabular}{|c|c|c|c|c|c|}
\hline \multicolumn{6}{|c|}{ Supplemental Table S2.txt } \\
\hline CHEMBL1306199 & 688612 & 4.15 & 4.625 & TRN & \\
\hline CHEMBL1501148 & 688612 & 5.6 & 4.7333 & TRN & \\
\hline CHEMBL1502830 & 688612 & 4.05 & 4.5781 & TRN & \\
\hline CHEMBL1338791 & 688612 & 4.05 & 4.6647 & TRN & \\
\hline CHEMBL1427805 & 688612 & 4.05 & 4.6201 & TRN & \\
\hline CHEMBL1336680 & 688612 & 5.7 & 4.6948 & TRN & \\
\hline CHEMBL1441560 & 688612 & 6.9 & 4.7375 & TRN & \\
\hline CHEMBL1550816 & 688612 & 4.45 & 4.7625 & TST & \\
\hline CHEMBL1503359 & 688612 & 4.3 & 4.7257 & TST & \\
\hline CHEMBL1306466 & 688612 & 5.25 & 4.66100 & 00000000005 & TRN \\
\hline CHEMBL1541890 & 688612 & 4.5 & 4.7056 & TST & \\
\hline CHEMBL1593285 & 688612 & 4.05 & 4.6682 & TRN & \\
\hline CHEMBL1559043 & 688612 & 4.65 & 4.6775 & TRN & \\
\hline CHEMBL1451925 & 688612 & 4.3 & 4.7161 & TRN & \\
\hline CHEMBL1360118 & 688612 & 4.55 & 4.6446 & TRN & \\
\hline CHEMBL1327903 & 688612 & 4.05 & 4.6233 & TRN & \\
\hline CHEMBL1384541 & 688612 & 4.1 & 4.6674 & TST & \\
\hline CHEMBL1421033 & 688612 & 4.05 & 4.7467 & TST & \\
\hline CHEMBL3210985 & 688612 & 6.35 & 4.7123 & TRN & \\
\hline CHEMBL1477479 & 688612 & 4.1 & 4.6523 & TRN & \\
\hline CHEMBL1568537 & 688612 & 4.5 & 4.7609 & TRN & \\
\hline CHEMBL1557268 & 688612 & 4.9 & 4.6507 & TRN & \\
\hline CHEMBL1523429 & 688612 & 5.45 & 4.655 & TRN & \\
\hline CHEMBL1322650 & 688612 & 4.2 & 4.5506 & TRN & \\
\hline CHEMBL1585635 & 688612 & 4.55 & 4.7288 & TST & \\
\hline CHEMBL1451288 & 688612 & 4.05 & 4.6747 & TRN & \\
\hline CHEMBL1313225 & 688612 & 6.5501 & 4.6479 & TRN & \\
\hline CHEMBL1437070 & 688612 & 4.55 & 4.654 & TRN & \\
\hline CHEMBL1491818 & 688612 & 6.5 & 4.7466 & TST & \\
\hline CHEMBL1368472 & 688612 & 4.2 & 4.6167 & TRN & \\
\hline CHEMBL1310477 & 688612 & 6.8499 & 4.6614 & TRN & \\
\hline CHEMBL1573782 & 688612 & 4.8 & 4.6088 & TRN & \\
\hline CHEMBL1394718 & 688612 & 4.0 & 4.6076 & TRN & \\
\hline CHEMBL3192873 & 688612 & 4.05 & 4.6502 & TRN & \\
\hline CHEMBL1507032 & 688612 & 4.05 & 4.6486 & TRN & \\
\hline CHEMBL1462274 & 688612 & 5.05 & 4.6887 & TRN & \\
\hline CHEMBL1380160 & 688612 & 4.05 & 4.6255 & TRN & \\
\hline CHEMBL1430405 & 688612 & 4.2 & 4.7167 & TRN & \\
\hline CHEMBL1444394 & 688612 & 4.4 & 4.6423 & TRN & \\
\hline CHEMBL1488962 & 688612 & 5.0 & 4.6937 & TRN & \\
\hline CHEMBL3145118 & 688612 & 4.0 & 4.7556 & TST & \\
\hline CHEMBL 2006357 & 688612 & 4.75 & 4.7825 & TRN & \\
\hline CHEMBL1503871 & 688612 & 4.0 & 4.64199 & 99999999995 & TST \\
\hline CHEMBL1979957 & 688612 & 5.35 & 4.7888 & TRN & \\
\hline CHEMBL1532800 & 688612 & 4.75 & 4.6154 & TRN & \\
\hline CHEMBL1356272 & 688612 & 4.05 & 4.6544 & TRN & \\
\hline CHEMBL1416423 & 688612 & 4.8 & 4.6575 & TRN & \\
\hline CHEMBL1307141 & 688612 & 4.1 & 4.5657 & TRN & \\
\hline
\end{tabular}




\begin{tabular}{|c|c|c|c|c|c|}
\hline & & \multicolumn{4}{|c|}{ Supplemental Table S2.txt } \\
\hline CHEMBL1450375 & 688612 & 4.05 & 4.7055 & TRN & \\
\hline CHEMBL1403991 & 688612 & 4.0 & 4.5942 & TRN & \\
\hline CHEMBL1419335 & 688612 & 5.75 & 4.7494 & TRN & \\
\hline CHEMBL1578166 & 688612 & 4.1 & 4.6254 & TRN & \\
\hline CHEMBL1345780 & 688612 & 4.05 & 4.6479 & TRN & \\
\hline CHEMBL1976388 & 688612 & 5.5 & 4.7224 & TRN & \\
\hline CHEMBL1487945 & 688612 & 4.35 & 4.7099 & TRN & \\
\hline CHEMBL1467492 & 688612 & 4.05 & 4.6539 & TRN & \\
\hline CHEMBL1579137 & 688612 & 4.6 & 4.73300 & 00000000005 & TRN \\
\hline CHEMBL1530561 & 688612 & 4.05 & 4.6522 & TRN & \\
\hline CHEMBL1419563 & 688612 & 4.5 & 4.6777 & TRN & \\
\hline CHEMBL1523026 & 688612 & 4.05 & 4.5571 & TRN & \\
\hline CHEMBL1362277 & 688612 & 4.05 & 4.5628 & TRN & \\
\hline CHEMBL1336622 & 688612 & 4.05 & 4.6781 & TRN & \\
\hline CHEMBL584841 & 688612 & 4.05 & 4.6684 & TST & \\
\hline CHEMBL1477738 & 688612 & 4.05 & 4.6701 & TST & \\
\hline CHEMBL1498068 & 688612 & 4.0 & 4.6824 & TRN & \\
\hline CHEMBL1399386 & 688612 & 4.95 & 4.7264 & TRN & \\
\hline CHEMBL1509650 & 688612 & 5.45 & 4.8 & TRN & \\
\hline CHEMBL1440732 & 688612 & 4.0 & 4.7025 & TRN & \\
\hline CHEMBL1441899 & 688612 & 4.3 & 4.5588 & TST & \\
\hline CHEMBL1449435 & 688612 & 4.9 & 4.6015 & TRN & \\
\hline CHEMBL1473237 & 688612 & 4.0 & 4.6823 & TST & \\
\hline CHEMBL1439122 & 688612 & 4.6 & 4.7152 & TRN & \\
\hline CHEMBL1436932 & 688612 & 4.05 & 4.652 & TRN & \\
\hline CHEMBL1311191 & 688612 & 4.2 & 4.6972 & TRN & \\
\hline CHEMBL1563767 & 688612 & 4.25 & 4.7231 & TRN & \\
\hline CHEMBL3214553 & 688612 & 5.45 & 4.631 & TRN & \\
\hline CHEMBL 1454210 & 688612 & 4.05 & 4.7125 & TRN & \\
\hline CHEMBL1493636 & 688612 & 4.4 & 4.625 & TRN & \\
\hline CHEMBL332686 & 688612 & 4.15 & 4.7419 & TRN & \\
\hline CHEMBL1308029 & 688612 & 5.5 & 4.5855 & TRN & \\
\hline CHEMBL1589320 & 688612 & 4.7 & 4.628 & TRN & \\
\hline CHEMBL1390989 & 688612 & 4.05 & 4.6912 & TST & \\
\hline CHEMBL1512402 & 688612 & 4.05 & 4.6584 & TRN & \\
\hline CHEMBL1563520 & 688612 & 4.05 & 4.6162 & TST & \\
\hline CHEMBL1553449 & 688612 & 4.65 & 4.6742 & TRN & \\
\hline CHEMBL1506499 & 688612 & 4.6 & 4.7992 & TRN & \\
\hline CHEMBL1429416 & 688612 & 6.15 & 4.7166 & TRN & \\
\hline CHEMBL1374603 & 688612 & 4.7 & 4.6307 & TRN & \\
\hline CHEMBL1407036 & 688612 & 4.55 & 4.6356 & TRN & \\
\hline CHEMBL1451460 & 688612 & 4.35 & 4.6742 & TST & \\
\hline CHEMBL1376551 & 688612 & 4.35 & 4.7238 & TRN & \\
\hline CHEMBL 1426212 & 688612 & 5.15 & 4.7089 & TRN & \\
\hline CHEMBL1527832 & 688612 & 4.7 & 4.7858 & TST & \\
\hline CHEMBL1611950 & 688612 & 4.05 & 4.6357 & TRN & \\
\hline CHEMBL1312918 & 688612 & 4.65 & 4.7273 & TRN & \\
\hline CHEMBL1991599 & 688612 & 5.0 & 4.8185 & TRN & \\
\hline
\end{tabular}




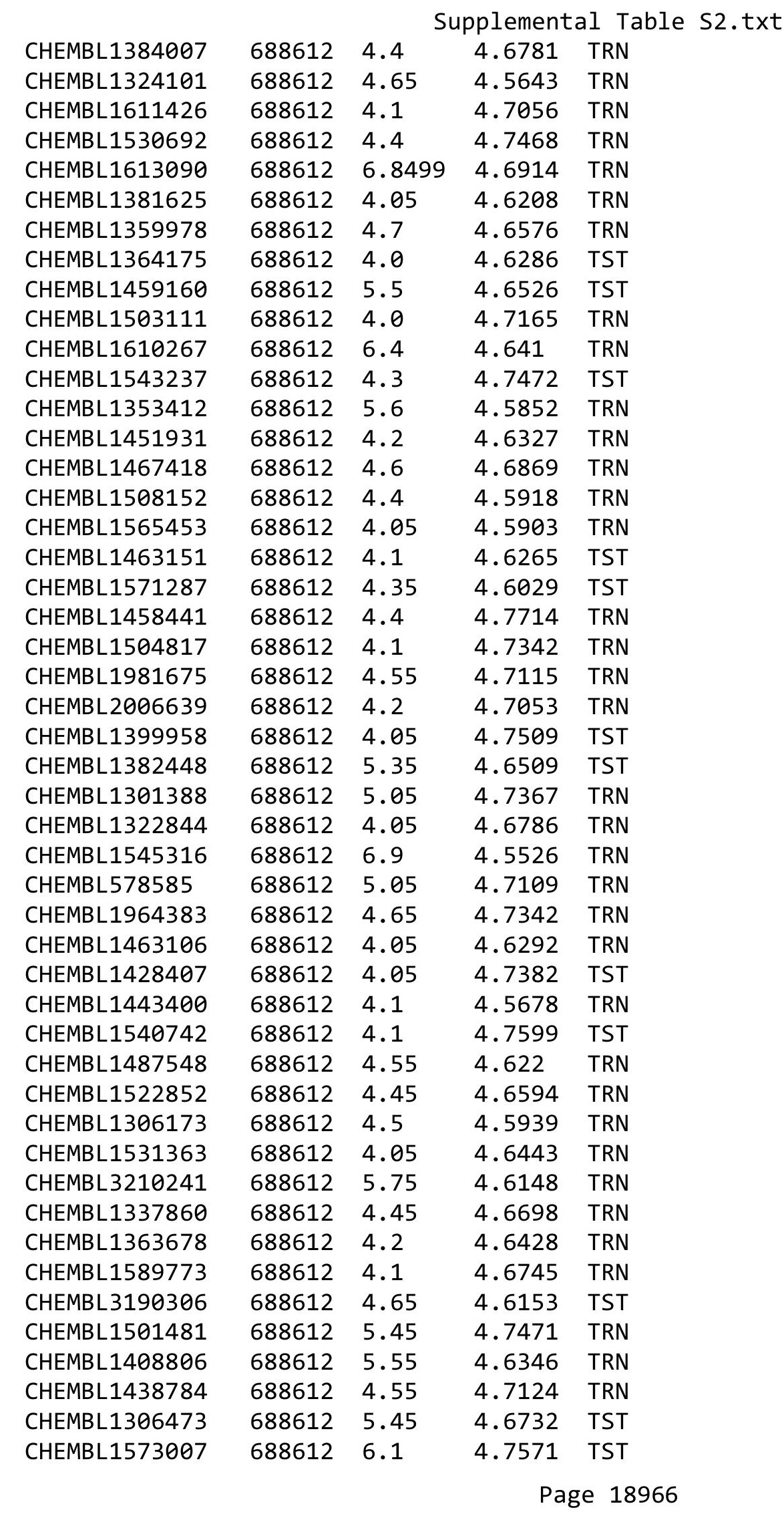




\begin{tabular}{|c|c|c|c|c|c|}
\hline \multicolumn{6}{|c|}{ Supplemental Table S2.txt } \\
\hline CHEMBL1534173 & 688612 & 4.7 & 4.6667 & TRN & \\
\hline CHEMBL1584577 & 688612 & 6.8499 & 4.6991 & TRN & \\
\hline CHEMBL1352925 & 688612 & 4.05 & 4.6056 & TST & \\
\hline CHEMBL3196378 & 688612 & 4.1 & 4.7013 & TRN & \\
\hline CHEMBL369513 & 688612 & 4.4 & 4.6718 & TRN & \\
\hline CHEMBL1599840 & 688612 & 6.5501 & 4.7179 & TRN & \\
\hline CHEMBL1385808 & 688612 & 5.25 & 4.8261 & TRN & \\
\hline CHEMBL1559014 & 688612 & 4.7 & 4.6912 & TRN & \\
\hline CHEMBL1550183 & 688612 & 6.05 & 4.6668 & TRN & \\
\hline CHEMBL1487870 & 688612 & 4.7 & 4.7071 & TRN & \\
\hline CHEMBL1420438 & 688612 & 4.5 & 4.6743 & TRN & \\
\hline CHEMBL1432023 & 688612 & 4.0 & 4.6147 & TRN & \\
\hline CHEMBL1477255 & 688612 & 4.05 & 4.641 & TRN & \\
\hline CHEMBL1304708 & 688612 & 4.0 & 4.7042 & TRN & \\
\hline CHEMBL1457328 & 688612 & 4.55 & 4.7144 & TRN & \\
\hline CHEMBL1326803 & 688612 & 4.65 & 4.7603 & TRN & \\
\hline CHEMBL1578788 & 688612 & 4.5 & 4.6828 & TST & \\
\hline CHEMBL1572319 & 688612 & 5.35 & 4.6871 & TST & \\
\hline CHEMBL1370469 & 688612 & 6.5501 & 4.698 & TRN & \\
\hline CHEMBL1397271 & 688612 & 4.1 & 4.64 & TRN & \\
\hline CHEMBL1503309 & 688612 & 4.85 & 4.648 & TRN & \\
\hline CHEMBL3193805 & 688612 & 4.2 & 4.725 & TST & \\
\hline CHEMBL1427730 & 688612 & 4.55 & 4.6931 & TRN & \\
\hline CHEMBL1342347 & 688612 & 4.05 & 4.6287 & TRN & \\
\hline CHEMBL1447169 & 688612 & 5.5 & 4.6588 & TRN & \\
\hline CHEMBL1349071 & 688612 & 4.05 & 4.6572 & TRN & \\
\hline CHEMBL1605469 & 688612 & 4.05 & 4.6876 & TRN & \\
\hline CHEMBL1320070 & 688612 & 4.85 & 4.6046 & TST & \\
\hline CHEMBL1307087 & 688612 & 4.05 & 4.5997 & TST & \\
\hline CHEMBL1368812 & 688612 & 4.05 & 4.6382 & TST & \\
\hline CHEMBL1379337 & 688612 & 4.4 & 4.6344 & TST & \\
\hline CHEMBL3197906 & 688612 & 4.8 & 4.78600 & 00000000005 & TRN \\
\hline CHEMBL1477178 & 688612 & 4.25 & 4.6756 & TRN & \\
\hline CHEMBL1538775 & 688612 & 4.9 & 4.7546 & TRN & \\
\hline CHEMBL1406945 & 688612 & 4.35 & 4.7323 & TRN & \\
\hline CHEMBL3192608 & 688612 & 4.1 & 4.6328 & TRN & \\
\hline CHEMBL1488973 & 688612 & 4.9 & 4.6926 & TST & \\
\hline CHEMBL1407922 & 688612 & 4.5 & 4.6583 & TST & \\
\hline CHEMBL1471872 & 688612 & 4.2 & 4.6613 & TRN & \\
\hline CHEMBL1497983 & 688612 & 4.45 & 4.746 & TRN & \\
\hline CHEMBL1456026 & 688612 & 4.25 & 4.6779 & TRN & \\
\hline CHEMBL1319645 & 688612 & 5.0 & 4.7845 & TRN & \\
\hline CHEMBL3196834 & 688612 & 5.5 & 4.7941 & TST & \\
\hline CHEMBL1524521 & 688612 & 4.05 & 4.6674 & TRN & \\
\hline CHEMBL1560496 & 688612 & 4.6 & 4.7511 & TRN & \\
\hline CHEMBL1302756 & 688612 & 4.7 & 4.8442 & TST & \\
\hline CHEMBL1387967 & 688612 & 6.0 & 4.6869 & TRN & \\
\hline CHEMBL1471907 & 688612 & 4.45 & 4.6873 & TRN & \\
\hline
\end{tabular}




\begin{tabular}{|c|c|c|c|c|c|}
\hline \multicolumn{6}{|c|}{ Supplemental Table S2.txt } \\
\hline CHEMBL1548361 & 688612 & 4.55 & 4.6983 & TST & \\
\hline CHEMBL1543210 & 688612 & 4.35 & 4.7016 & TRN & \\
\hline CHEMBL1468789 & 688612 & 4.05 & 4.6174 & TRN & \\
\hline CHEMBL1542378 & 688612 & 4.05 & 4.6777 & TRN & \\
\hline CHEMBL1478316 & 688612 & 4.6 & 4.7123 & TRN & \\
\hline CHEMBL1471583 & 688612 & 5.3 & 4.70100 & 00000000005 & TRN \\
\hline CHEMBL1345538 & 688612 & 4.3 & 4.6709 & TRN & \\
\hline CHEMBL1339510 & 688612 & 4.3 & 4.6143 & TRN & \\
\hline CHEMBL1607651 & 688612 & 4.6 & 4.6126 & TST & \\
\hline CHEMBL1522927 & 688612 & 4.35 & 4.7146 & TRN & \\
\hline CHEMBL1477167 & 688612 & 4.3 & 4.7612 & TST & \\
\hline CHEMBL1381627 & 688612 & 6.05 & 4.7603 & TRN & \\
\hline CHEMBL1419731 & 688612 & 4.05 & 4.6017 & TST & \\
\hline CHEMBL1563519 & 688612 & 4.05 & 4.6779 & TST & \\
\hline CHEMBL1503702 & 688612 & 5.5 & 4.6423 & TRN & \\
\hline CHEMBL1352625 & 688612 & 4.05 & 4.7102 & TRN & \\
\hline CHEMBL3192009 & 688612 & 4.3 & 4.6958 & TRN & \\
\hline CHEMBL1359520 & 688612 & 4.85 & 4.6553 & TRN & \\
\hline CHEMBL1440608 & 688612 & 4.05 & 4.6087 & TRN & \\
\hline CHEMBL1360281 & 688612 & 4.0 & 4.6714 & TRN & \\
\hline CHEMBL1528581 & 688612 & 4.5 & 4.8138 & TRN & \\
\hline CHEMBL1601103 & 688612 & 4.05 & 4.7071 & TRN & \\
\hline CHEMBL1323000 & 688612 & 4.95 & 4.6938 & TRN & \\
\hline CHEMBL1584172 & 688612 & 4.2 & 4.6232 & TRN & \\
\hline CHEMBL1457083 & 688612 & 4.45 & 4.5954 & TRN & \\
\hline CHEMBL1446827 & 688612 & 4.4 & 4.7199 & TRN & \\
\hline CHEMBL1498462 & 688612 & 4.8 & 4.6133 & TRN & \\
\hline CHEMBL1344099 & 688612 & 5.95 & 4.7386 & TRN & \\
\hline CHEMBL3190842 & 688612 & 4.45 & 4.6889 & TST & \\
\hline CHEMBL3192872 & 688612 & 5.75 & 4.742 & TRN & \\
\hline CHEMBL1427984 & 688612 & 4.05 & 4.6488 & TST & \\
\hline CHEMBL1398558 & 688612 & 5.3 & 4.5632 & TRN & \\
\hline CHEMBL1545381 & 688612 & 6.0 & 4.6752 & TRN & \\
\hline CHEMBL1542696 & 688612 & 6.9 & 4.6681 & TRN & \\
\hline CHEMBL496729 & 688612 & 4.4 & 4.7501 & TRN & \\
\hline CHEMBL1403686 & 688612 & 4.75 & 4.645 & TRN & \\
\hline CHEMBL1412001 & 688612 & 4.5 & 4.6521 & TST & \\
\hline CHEMBL3197605 & 688612 & 4.0 & 4.6136 & TRN & \\
\hline CHEMBL1466436 & 688612 & 4.2 & 4.6422 & TST & \\
\hline CHEMBL1401379 & 688612 & 4.45 & 4.5644 & TRN & \\
\hline CHEMBL1533951 & 688612 & 4.05 & 4.7183 & TRN & \\
\hline CHEMBL1358874 & 688612 & 4.45 & 4.7108 & TRN & \\
\hline CHEMBL1467581 & 688612 & 5.7 & 4.7126 & TST & \\
\hline CHEMBL1577187 & 688612 & 4.6 & 4.6988 & TRN & \\
\hline CHEMBL3190218 & 688612 & 4.45 & 4.7398 & TST & \\
\hline CHEMBL1600481 & 688612 & 4.85 & 4.6543 & TRN & \\
\hline CHEMBL1552575 & 688612 & 5.6 & 4.7025 & TRN & \\
\hline CHEMBL1541295 & 688612 & 4.7 & 4.7413 & TRN & \\
\hline
\end{tabular}




\begin{tabular}{|c|c|c|c|c|}
\hline \multicolumn{5}{|c|}{ Supplemental Table S2.txt } \\
\hline CHEMBL1558438 & 688612 & 4.05 & 4.5808 & TST \\
\hline CHEMBL1599125 & 688612 & 4.65 & 4.6244 & TRN \\
\hline CHEMBL1441302 & 688612 & 4.2 & 4.5799 & TRN \\
\hline CHEMBL1432904 & 688612 & 4.05 & 4.5727 & TRN \\
\hline CHEMBL1455531 & 688612 & 4.1 & 4.5764 & TRN \\
\hline CHEMBL1611018 & 688612 & 6.25 & 4.7534 & TRN \\
\hline CHEMBL1448177 & 688612 & 4.3 & 4.7137 & TRN \\
\hline CHEMBL3199039 & 688612 & 4.25 & 4.6382 & TRN \\
\hline CHEMBL1579510 & 688612 & 4.2 & 4.7262 & TRN \\
\hline CHEMBL1998946 & 688612 & 5.05 & 4.7632 & TRN \\
\hline CHEMBL1372681 & 688612 & 4.4 & 4.6958 & TRN \\
\hline CHEMBL1539412 & 688612 & 5.1 & 4.643 & TRN \\
\hline CHEMBL1357949 & 688612 & 6.0 & 4.5656 & TRN \\
\hline CHEMBL1510471 & 688612 & 4.35 & 4.6496 & TRN \\
\hline CHEMBL1476347 & 688612 & 4.65 & 4.6932 & TRN \\
\hline CHEMBL1589144 & 688612 & 4.35 & 4.6309 & TRN \\
\hline CHEMBL1381781 & 688612 & 4.1 & 4.6871 & TST \\
\hline CHEMBL1536326 & 688612 & 4.65 & 4.6801 & TRN \\
\hline CHEMBL1584544 & 688612 & 4.4 & 4.5898 & TRN \\
\hline CHEMBL1320660 & 688612 & 4.05 & 4.5863 & TRN \\
\hline CHEMBL1543964 & 688612 & 4.3 & 4.6241 & TRN \\
\hline CHEMBL1401821 & 688612 & 4.15 & 4.6405 & TRN \\
\hline CHEMBL1334780 & 688612 & 4.75 & 4.5716 & TRN \\
\hline CHEMBL448328 & 688612 & 5.1 & 4.6972 & TRN \\
\hline CHEMBL1381264 & 688612 & 4.95 & 4.7456 & TRN \\
\hline CHEMBL1496181 & 688612 & 4.65 & 4.6993 & TRN \\
\hline CHEMBL579919 & 688612 & 4.45 & 4.5739 & TRN \\
\hline CHEMBL1339860 & 688612 & 4.45 & 4.6416 & TRN \\
\hline CHEMBL1305339 & 688612 & 4.05 & 4.6752 & TST \\
\hline CHEMBL1396844 & 688612 & 7.0 & 4.6444 & TRN \\
\hline CHEMBL1611359 & 688612 & 4.0 & 4.6459 & TRN \\
\hline CHEMBL1321854 & 688612 & 4.2 & 4.615 & TRN \\
\hline CHEMBL1354366 & 688612 & 4.05 & 4.7464 & TST \\
\hline CHEMBL1578360 & 688612 & 4.4 & 4.6445 & TRN \\
\hline CHEMBL1481990 & 688612 & 4.1 & 4.6078 & TRN \\
\hline CHEMBL1607599 & 688612 & 4.05 & 4.7119 & TRN \\
\hline CHEMBL3189564 & 688612 & 4.05 & 4.7351 & TRN \\
\hline CHEMBL1398500 & 688612 & 5.4 & 4.6548 & TRN \\
\hline CHEMBL1563481 & 688612 & 4.95 & 4.6833 & TRN \\
\hline CHEMBL1367450 & 688612 & 4.05 & 4.6831 & TST \\
\hline CHEMBL1469387 & 688612 & 4.05 & 4.6385 & TST \\
\hline CHEMBL1302767 & 688612 & 6.5501 & 4.6485 & TRN \\
\hline CHEMBL1366112 & 688612 & 4.95 & 4.691 & TRN \\
\hline CHEMBL1965976 & 688612 & 4.0 & 4.7529 & TRN \\
\hline CHEMBL1507172 & 688612 & 4.3 & 4.6038 & TRN \\
\hline CHEMBL1510511 & 688612 & 5.35 & 4.6579 & TST \\
\hline CHEMBL1508761 & 688612 & 4.65 & 4.6474 & TST \\
\hline CHEMBL3211375 & 688612 & 4.5 & 4.7159 & TRN \\
\hline
\end{tabular}




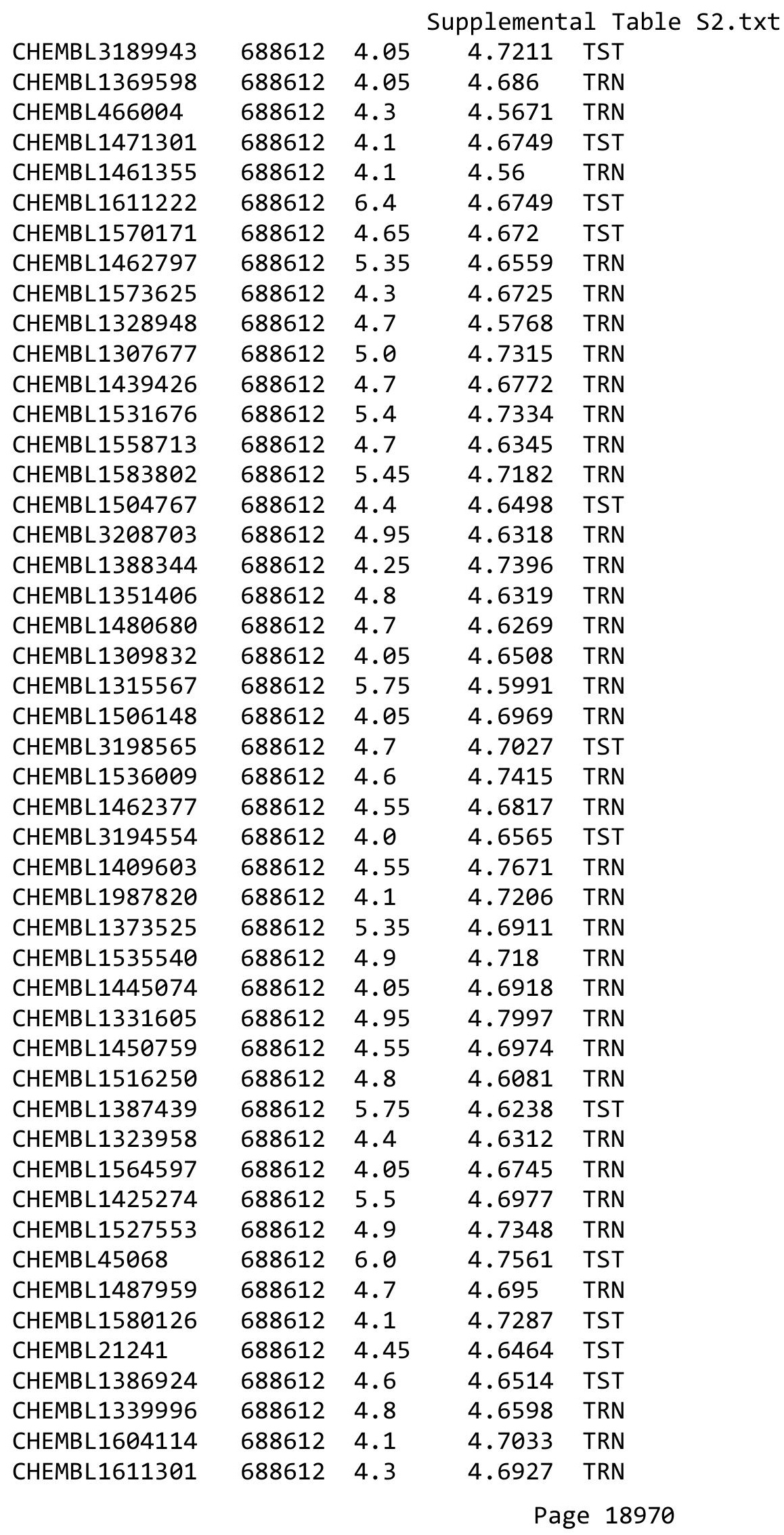




\begin{tabular}{|c|c|c|c|c|c|}
\hline \multicolumn{6}{|c|}{ Supplemental Table S2.txt } \\
\hline CHEMBL1613240 & 688612 & 4.8 & 4.6929 & TRN & \\
\hline CHEMBL1329925 & 688612 & 4.1 & 4.6148 & TRN & \\
\hline CHEMBL1401174 & 688612 & 4.05 & 4.6087 & TRN & \\
\hline CHEMBL1406612 & 688612 & 4.05 & 4.5993 & TRN & \\
\hline CHEMBL1301994 & 688612 & 4.95 & 4.6771 & TRN & \\
\hline CHEMBL1396415 & 688612 & 4.35 & 4.66100 & 00000000005 & TST \\
\hline CHEMBL1425833 & 688612 & 6.0 & 4.7117 & TST & \\
\hline CHEMBL1584952 & 688612 & 4.05 & 4.5723 & TRN & \\
\hline CHEMBL1329472 & 688612 & 5.5 & 4.6159 & TST & \\
\hline CHEMBL1452169 & 688612 & 4.05 & 4.6027 & TRN & \\
\hline CHEMBL1309191 & 688612 & 4.05 & 4.6805 & TST & \\
\hline CHEMBL1554321 & 688612 & 4.0 & 4.6108 & TRN & \\
\hline CHEMBL1419212 & 688612 & 4.05 & 4.6574 & TRN & \\
\hline CHEMBL1327603 & 688612 & 4.1 & 4.6378 & TRN & \\
\hline CHEMBL1470218 & 688612 & 5.1 & 4.6355 & TRN & \\
\hline CHEMBL1428857 & 688612 & 4.4 & 4.629 & TRN & \\
\hline CHEMBL1524993 & 688612 & 4.2 & 4.7021 & TRN & \\
\hline CHEMBL1374302 & 688612 & 4.65 & 4.6824 & TRN & \\
\hline CHEMBL1570828 & 688612 & 4.8 & 4.695 & TRN & \\
\hline CHEMBL1462027 & 688612 & 4.15 & 4.6157 & TRN & \\
\hline CHEMBL1566820 & 688612 & 4.9 & 4.6551 & TRN & \\
\hline CHEMBL1567663 & 688612 & 5.45 & 4.681 & TRN & \\
\hline CHEMBL1458490 & 688612 & 4.05 & 4.6255 & TRN & \\
\hline CHEMBL1302175 & 688612 & 4.45 & 4.7049 & TST & \\
\hline CHEMBL1484743 & 688612 & 4.9 & 4.6868 & TRN & \\
\hline CHEMBL1367766 & 688612 & 4.2 & 4.694 & TST & \\
\hline CHEMBL1429933 & 688612 & 6.0 & 4.6613 & TRN & \\
\hline CHEMBL1350435 & 688612 & 5.05 & 4.7679 & TRN & \\
\hline CHEMBL1336784 & 688612 & 4.6 & 4.7405 & TRN & \\
\hline CHEMBL1565944 & 688612 & 4.4 & 4.6349 & TRN & \\
\hline CHEMBL1494151 & 688612 & 4.05 & 4.7187 & TST & \\
\hline CHEMBL1395113 & 688612 & 4.1 & 4.6808 & TRN & \\
\hline CHEMBL1474285 & 688612 & 6.8 & 4.6076 & TRN & \\
\hline CHEMBL258893 & 688612 & 4.55 & 4.6599 & TST & \\
\hline CHEMBL1602655 & 688612 & 5.6 & 4.6835 & TST & \\
\hline CHEMBL1578454 & 688612 & 4.7 & 4.543 & TRN & \\
\hline CHEMBL1388113 & 688612 & 4.05 & 4.6983 & TST & \\
\hline CHEMBL1464184 & 688612 & 4.7 & 4.6467 & TRN & \\
\hline CHEMBL164747 & 688612 & 4.45 & 4.7289 & TST & \\
\hline CHEMBL1402056 & 688612 & 4.9 & 4.7758 & TST & \\
\hline CHEMBL1333250 & 688612 & 4.05 & 4.6318 & TRN & \\
\hline CHEMBL1345991 & 688612 & 4.05 & 4.7 & TRN & \\
\hline CHEMBL1335405 & 688612 & 4.1 & 4.6595 & TST & \\
\hline CHEMBL1408816 & 688612 & 4.05 & 4.7332 & TST & \\
\hline CHEMBL1379376 & 688612 & 4.4 & 4.6962 & TST & \\
\hline CHEMBL1408965 & 688612 & 4.3 & 4.7339 & TRN & \\
\hline CHEMBL1346464 & 688612 & 5.25 & 4.6665 & TRN & \\
\hline CHEMBL1373519 & 688612 & 4.1 & 4.7786 & TST & \\
\hline
\end{tabular}




\begin{tabular}{|c|c|c|c|c|}
\hline \multicolumn{5}{|c|}{ Supplemental Table S2.txt } \\
\hline CHEMBL 3208515 & 688612 & 6.25 & 4.7957 & TST \\
\hline CHEMBL1491010 & 688612 & 4.75 & 4.6745 & TST \\
\hline CHEMBL1541914 & 688612 & 6.1 & 4.6629 & TRN \\
\hline CHEMBL1347583 & 688612 & 5.55 & 4.6664 & TST \\
\hline CHEMBL1426135 & 688612 & 4.0 & 4.5964 & TRN \\
\hline CHEMBL1331620 & 688612 & 4.0 & 4.7271 & TRN \\
\hline CHEMBL1545810 & 688612 & 4.4 & 4.6246 & TRN \\
\hline CHEMBL1428897 & 688612 & 4.05 & 4.6862 & TRN \\
\hline CHEMBL1320100 & 688612 & 5.5 & 4.5626 & TRN \\
\hline CHEMBL1332151 & 688612 & 5.45 & 4.7033 & TST \\
\hline CHEMBL1446623 & 688612 & 4.4 & 4.6772 & TST \\
\hline CHEMBL1586147 & 688612 & 5.15 & 4.6771 & TRN \\
\hline CHEMBL1527837 & 688612 & 4.1 & 4.6642 & TRN \\
\hline CHEMBL1304289 & 688612 & 5.2 & 4.6237 & TRN \\
\hline CHEMBL1562551 & 688612 & 4.1 & 4.6555 & TST \\
\hline CHEMBL1316031 & 688612 & 4.1 & 4.628 & TST \\
\hline CHEMBL1564093 & 688612 & 4.0 & 4.7097 & TST \\
\hline CHEMBL1515075 & 688612 & 4.1 & 4.6063 & TRN \\
\hline CHEMBL1441023 & 688612 & 5.3 & 4.6378 & TRN \\
\hline CHEMBL1519945 & 688612 & 6.5 & 4.6594 & TRN \\
\hline CHEMBL3190651 & 688612 & 4.35 & 4.708 & TRN \\
\hline CHEMBL3197388 & 688612 & 4.3 & 4.7561 & TRN \\
\hline CHEMBL1414465 & 688612 & 5.1 & 4.6422 & TST \\
\hline CHEMBL1374796 & 688612 & 4.45 & 4.6116 & TRN \\
\hline CHEMBL1480257 & 688612 & 5.0 & 4.5951 & TRN \\
\hline CHEMBL1339675 & 688612 & 6.95 & 4.6517 & TST \\
\hline CHEMBL1394612 & 688612 & 4.1 & 4.6605 & TRN \\
\hline CHEMBL1530039 & 688612 & 5.05 & 4.6697 & TRN \\
\hline CHEMBL1417935 & 688612 & 4.6 & 4.607 & TRN \\
\hline CHEMBL1345803 & 688612 & 4.0 & 4.6377 & TRN \\
\hline CHEMBL1543944 & 688612 & 5.45 & 4.7275 & TRN \\
\hline CHEMBL1412540 & 688612 & 5.45 & 4.686 & TRN \\
\hline CHEMBL1584314 & 688612 & 5.5 & 4.6416 & TRN \\
\hline CHEMBL1375776 & 688612 & 5.45 & 4.6716 & TRN \\
\hline CHEMBL1472118 & 688612 & 4.8 & 4.6375 & TRN \\
\hline CHEMBL1429756 & 688612 & 4.8 & 4.6537 & TST \\
\hline CHEMBL1592942 & 688612 & 4.4 & 4.6844 & TST \\
\hline CHEMBL3211535 & 688612 & 4.1 & 4.6978 & TRN \\
\hline CHEMBL1300124 & 688612 & 4.65 & 4.6736 & TST \\
\hline CHEMBL1412597 & 688612 & 4.05 & 4.6776 & TST \\
\hline CHEMBL1528722 & 688612 & 4.55 & 4.6786 & TRN \\
\hline CHEMBL1454108 & 688612 & 4.1 & 4.7618 & TST \\
\hline CHEMBL1363805 & 688612 & 4.35 & 4.6871 & TRN \\
\hline CHEMBL1426885 & 688612 & 4.05 & 4.6592 & TRN \\
\hline CHEMBL1509927 & 688612 & 4.1 & 4.7327 & TRN \\
\hline CHEMBL1455790 & 688612 & 4.0 & 4.6007 & TRN \\
\hline CHEMBL1519528 & 688612 & 4.4 & 4.71 & TST \\
\hline CHEMBL1607944 & 688612 & 5.75 & 4.7246 & TRN \\
\hline
\end{tabular}




\begin{tabular}{|c|c|c|c|c|c|}
\hline \multicolumn{6}{|c|}{ Supplemental Table S2.txt } \\
\hline CHEMBL1354466 & 688612 & 5.15 & 4.6335 & TRN & \\
\hline CHEMBL1493247 & 688612 & 5.15 & 4.7459 & TST & \\
\hline CHEMBL1355876 & 688612 & 4.05 & 4.5686 & TRN & \\
\hline CHEMBL1451327 & 688612 & 4.3 & 4.7892 & TST & \\
\hline CHEMBL1310886 & 688612 & 4.8 & 4.7013 & TRN & \\
\hline CHEMBL588919 & 688612 & 4.05 & 4.7201 & TRN & \\
\hline CHEMBL1385812 & 688612 & 4.1 & 4.6665 & TRN & \\
\hline CHEMBL1354230 & 688612 & 6.6 & 4.6209 & TRN & \\
\hline CHEMBL1476865 & 688612 & 4.05 & 4.6237 & TRN & \\
\hline CHEMBL1590015 & 688612 & 4.1 & 4.6187 & TRN & \\
\hline CHEMBL1575104 & 688612 & 4.3 & 4.6502 & TST & \\
\hline CHEMBL1389931 & 688612 & 4.35 & 4.6818 & TRN & \\
\hline CHEMBL1573724 & 688612 & 4.25 & 4.6007 & TRN & \\
\hline CHEMBL1507356 & 688612 & 4.1 & 4.643 & TRN & \\
\hline CHEMBL1461991 & 688612 & 4.2 & 4.6442 & TRN & \\
\hline CHEMBL1320602 & 688612 & 4.7 & 4.7118 & TST & \\
\hline CHEMBL1496955 & 688612 & 4.0 & 4.6205 & TRN & \\
\hline CHEMBL1485184 & 688612 & 4.0 & 4.5756 & TRN & \\
\hline CHEMBL1447211 & 688612 & 5.0 & 4.7456 & TST & \\
\hline CHEMBL1373091 & 688612 & 4.7 & 4.6543 & TRN & \\
\hline CHEMBL1518002 & 688612 & 6.0 & 4.7128 & TRN & \\
\hline CHEMBL1587501 & 688612 & 4.05 & 4.6778 & TST & \\
\hline CHEMBL1391330 & 688612 & 4.4 & 4.7091 & TRN & \\
\hline CHEMBL 3207890 & 688612 & 5.35 & 4.6949 & TRN & \\
\hline CHEMBL1338974 & 688612 & 4.0 & 4.6634 & TRN & \\
\hline CHEMBL1340782 & 688612 & 4.3 & 4.7239 & TST & \\
\hline CHEMBL1476617 & 688612 & 4.05 & 4.6571 & TRN & \\
\hline CHEMBL3197462 & 688612 & 4.55 & 4.7192 & TRN & \\
\hline CHEMBL1379495 & 688612 & 6.5501 & 4.5772 & TRN & \\
\hline CHEMBL 3189280 & 688612 & 6.4 & 4.7884 & TRN & \\
\hline CHEMBL1401441 & 688612 & 4.7 & 4.6801 & TRN & \\
\hline CHEMBL1490789 & 688612 & 4.5 & 4.6161 & TRN & \\
\hline CHEMBL1466085 & 688612 & 4.1 & 4.6638 & TRN & \\
\hline CHEMBL1436755 & 688612 & 6.05 & 4.6624 & TRN & \\
\hline CHEMBL305978 & 688612 & 4.75 & 4.8005 & TRN & \\
\hline CHEMBL1536769 & 688612 & 4.0 & 4.5877 & TRN & \\
\hline CHEMBL1330070 & 688612 & 4.1 & 4.65600 & 0000000001 & TRN \\
\hline CHEMBL1323040 & 688612 & 4.0 & 4.7388 & TRN & \\
\hline CHEMBL1872457 & 688612 & 6.05 & 4.7705 & TRN & \\
\hline CHEMBL1575086 & 688612 & 5.4 & 4.7484 & TST & \\
\hline CHEMBL1343825 & 688612 & 4.05 & 4.6597 & TST & \\
\hline CHEMBL1444604 & 688612 & 4.05 & 4.7166 & TST & \\
\hline CHEMBL1451846 & 688612 & 4.65 & 4.6148 & TRN & \\
\hline CHEMBL1384417 & 688612 & 5.6 & 4.6307 & TST & \\
\hline CHEMBL1584610 & 688612 & 5.4 & 4.6405 & TRN & \\
\hline CHEMBL1500691 & 688612 & 4.6 & 4.6977 & TST & \\
\hline CHEMBL1550385 & 688612 & 4.0 & 4.7882 & TRN & \\
\hline CHEMBL1522133 & 688612 & 4.55 & 4.7253 & TRN & \\
\hline
\end{tabular}




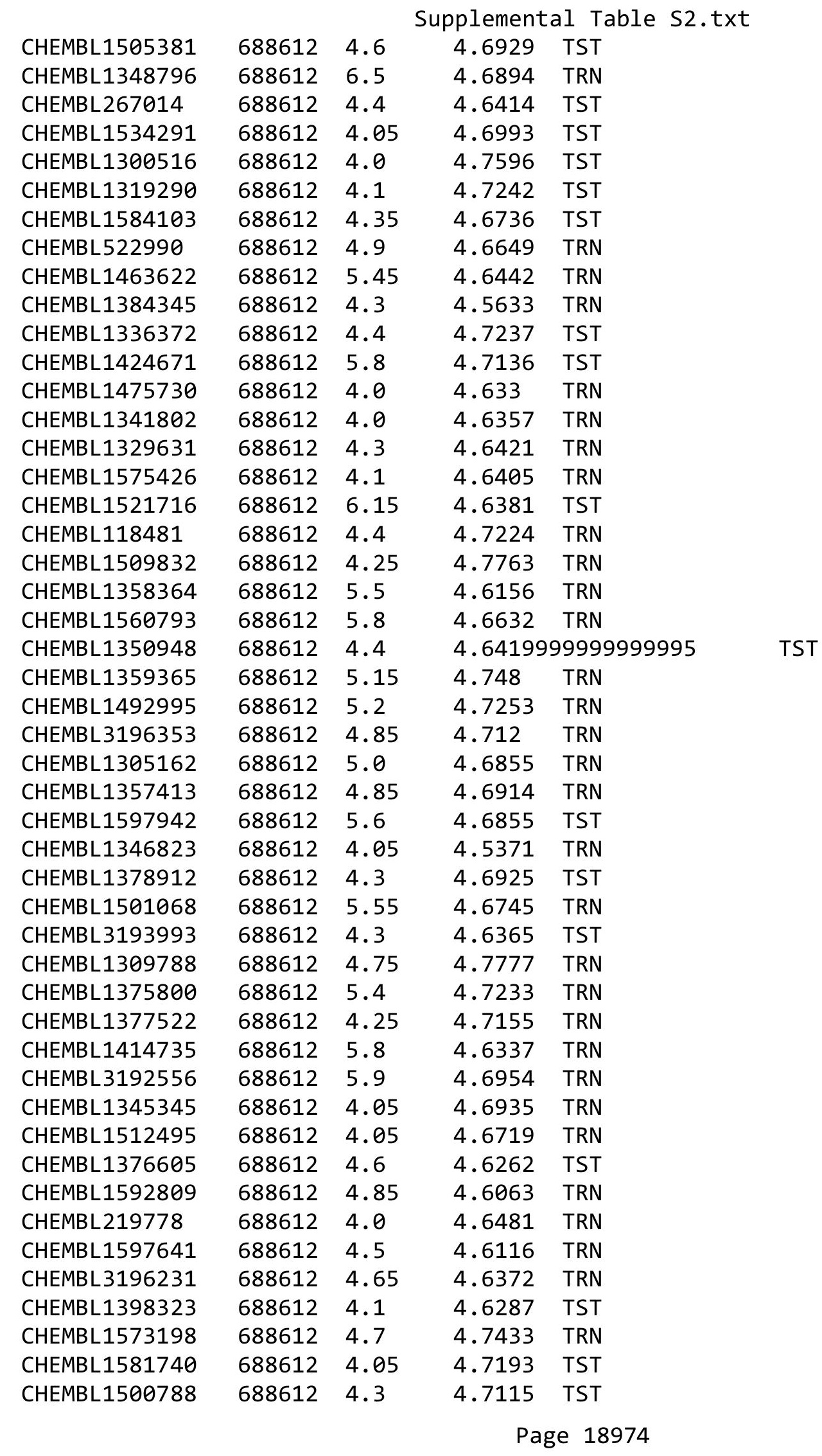




\begin{tabular}{|c|c|c|c|c|}
\hline \multicolumn{5}{|c|}{ Supplemental Table S2.txt } \\
\hline CHEMBL 2003178 & 688612 & 5.55 & 4.7393 & TRN \\
\hline CHEMBL1568118 & 688612 & 4.75 & 4.7519 & TRN \\
\hline CHEMBL1394832 & 688612 & 5.75 & 4.6393 & TRN \\
\hline CHEMBL1492163 & 688612 & 4.4 & 4.6872 & TST \\
\hline CHEMBL1302473 & 688612 & 4.45 & 4.6781 & TST \\
\hline CHEMBL1401156 & 688612 & 4.05 & 4.6647 & TST \\
\hline CHEMBL1302595 & 688612 & 4.55 & 4.692 & TRN \\
\hline CHEMBL1489775 & 688612 & 4.2 & 4.6674 & TST \\
\hline CHEMBL1443822 & 688612 & 4.85 & 4.7308 & TRN \\
\hline CHEMBL1345763 & 688612 & 4.3 & 4.6941 & TRN \\
\hline CHEMBL1547829 & 688612 & 6.15 & 4.6862 & TRN \\
\hline CHEMBL1528058 & 688612 & 4.35 & 4.6635 & TRN \\
\hline CHEMBL1426408 & 688612 & 4.0 & 4.7369 & TST \\
\hline CHEMBL1345724 & 688612 & 4.65 & 4.8204 & TRN \\
\hline CHEMBL1565657 & 688612 & 5.15 & 4.6661 & TST \\
\hline CHEMBL1403449 & 688612 & 4.4 & 4.7246 & TRN \\
\hline CHEMBL1367613 & 688612 & 4.1 & 4.6088 & TRN \\
\hline CHEMBL1460134 & 688612 & 4.4 & 4.7299 & TST \\
\hline CHEMBL1431603 & 688612 & 4.05 & 4.6552 & TRN \\
\hline CHEMBL3208880 & 688612 & 4.65 & 4.74 & TRN \\
\hline CHEMBL1415852 & 688612 & 4.3 & 4.7273 & TRN \\
\hline CHEMBL1462770 & 688612 & 4.4 & 4.7381 & TRN \\
\hline CHEMBL1359564 & 688612 & 5.0 & 4.738 & TRN \\
\hline CHEMBL1359175 & 688612 & 6.0 & 4.5795 & TRN \\
\hline CHEMBL1504868 & 688612 & 4.8 & 4.5503 & TRN \\
\hline CHEMBL1397222 & 688612 & 4.05 & 4.605 & TRN \\
\hline CHEMBL1391238 & 688612 & 4.1 & 4.7642 & TST \\
\hline CHEMBL1572021 & 688612 & 4.0 & 4.7212 & TRN \\
\hline CHEMBL1539442 & 688612 & 4.25 & 4.5922 & TRN \\
\hline CHEMBL1550779 & 688612 & 5.0 & 4.5943 & TRN \\
\hline CHEMBL3191433 & 688612 & 4.2 & 4.6497 & TST \\
\hline CHEMBL3207537 & 688612 & 5.15 & 4.6967 & TRN \\
\hline CHEMBL1583962 & 688612 & 6.8499 & 4.6904 & TRN \\
\hline CHEMBL1543675 & 688612 & 4.55 & 4.5425 & TRN \\
\hline CHEMBL391997 & 688612 & 4.55 & 4.6672 & TST \\
\hline CHEMBL388025 & 688612 & 4.6 & 4.743 & TRN \\
\hline CHEMBL1606333 & 688612 & 6.7001 & 4.659 & TRN \\
\hline CHEMBL1569264 & 688612 & 4.05 & 4.6036 & TRN \\
\hline CHEMBL1591032 & 688612 & 6.8499 & 4.6187 & TST \\
\hline CHEMBL3191468 & 688612 & 4.8 & 4.7001 & TRN \\
\hline CHEMBL3213629 & 688612 & 6.05 & 4.6303 & TST \\
\hline CHEMBL1398403 & 688612 & 5.05 & 4.6498 & TRN \\
\hline CHEMBL1468122 & 688612 & 4.1 & 4.7453 & TST \\
\hline CHEMBL1583172 & 688612 & 5.05 & 4.706 & TRN \\
\hline CHEMBL1396856 & 688612 & 4.05 & 4.6107 & TRN \\
\hline CHEMBL1356516 & 688612 & 4.05 & 4.5903 & TRN \\
\hline CHEMBL1580543 & 688612 & 4.3 & 4.7103 & TRN \\
\hline CHEMBL1496130 & 688612 & 4.65 & 4.6808 & TRN \\
\hline
\end{tabular}




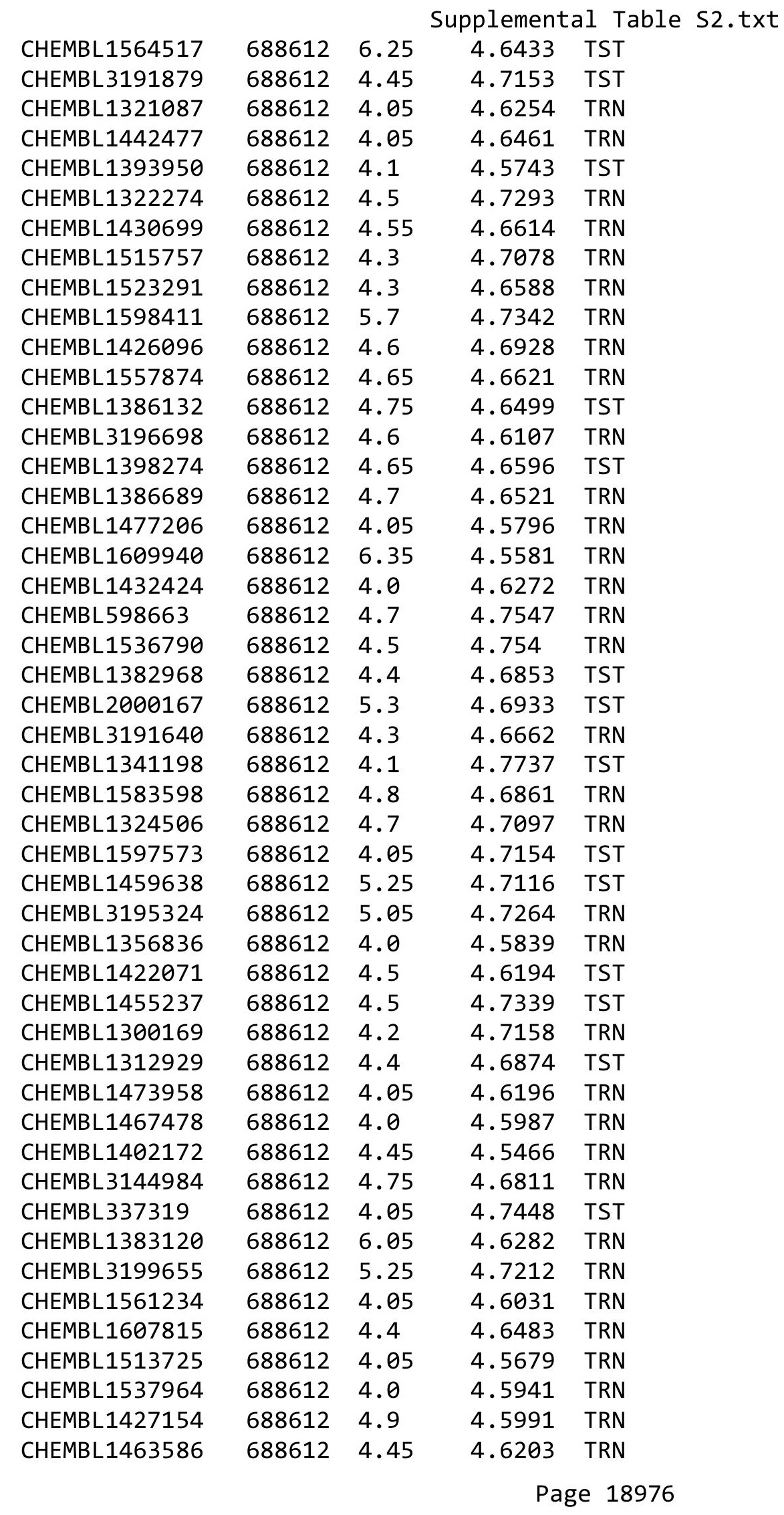




\begin{tabular}{|c|c|c|c|c|c|}
\hline \multicolumn{6}{|c|}{ Supplemental Table s2.txt } \\
\hline CHEMBL1426102 & 688612 & 4.05 & 4.671 & TRN & \\
\hline CHEMBL1574645 & 688612 & 4.1 & 4.5792 & TST & \\
\hline CHEMBL1590893 & 688612 & 5.1 & 4.6056 & TRN & \\
\hline CHEMBL3189643 & 688612 & 4.6 & 4.712 & TRN & \\
\hline CHEMBL1572292 & 688612 & 6.4 & 4.7238 & TRN & \\
\hline CHEMBL1587944 & 688612 & 4.0 & 4.698 & TST & \\
\hline CHEMBL1310952 & 688612 & 5.45 & 4.6845 & TRN & \\
\hline CHEMBL1463091 & 688612 & 4.25 & 4.614 & TRN & \\
\hline CHEMBL1603185 & 688612 & 4.0 & 4.5835 & TRN & \\
\hline CHEMBL1369475 & 688612 & 6.0 & 4.6542 & TRN & \\
\hline CHEMBL1377319 & 688612 & 4.15 & 4.5897 & TRN & \\
\hline CHEMBL1342063 & 688612 & 4.7 & 4.66100 & 00000000005 & TRN \\
\hline CHEMBL3192083 & 688612 & 4.65 & 4.626 & TRN & \\
\hline CHEMBL1406922 & 688612 & 4.05 & 4.6211 & TRN & \\
\hline CHEMBL1541715 & 688612 & 4.85 & 4.5897 & TRN & \\
\hline CHEMBL1409063 & 688612 & 4.05 & 4.7142 & TRN & \\
\hline CHEMBL1975834 & 688612 & 4.65 & 4.7434 & TRN & \\
\hline CHEMBL1607821 & 688612 & 6.7501 & 4.6812 & TRN & \\
\hline CHEMBL1308993 & 688612 & 4.1 & 4.6865 & TST & \\
\hline CHEMBL1461887 & 688612 & 6.9 & 4.5064 & TRN & \\
\hline CHEMBL1472798 & 688612 & 4.35 & 4.6561 & TRN & \\
\hline CHEMBL1370601 & 688612 & 4.6 & 4.6703 & TRN & \\
\hline CHEMBL3208709 & 688612 & 4.7 & 4.7129 & TRN & \\
\hline CHEMBL1306274 & 688612 & 4.55 & 4.7023 & TST & \\
\hline CHEMBL1567539 & 688612 & 6.15 & 4.6982 & TST & \\
\hline CHEMBL1374057 & 688612 & 4.0 & 4.6566 & TRN & \\
\hline CHEMBL1612165 & 688612 & 4.35 & 4.6979 & TRN & \\
\hline CHEMBL1305496 & 688612 & 4.3 & 4.6523 & TRN & \\
\hline CHEMBL1480047 & 688612 & 4.0 & 4.637 & TRN & \\
\hline CHEMBL1448094 & 688612 & 4.0 & 4.6834 & TRN & \\
\hline CHEMBL596271 & 688612 & 5.55 & 4.6305 & TRN & \\
\hline CHEMBL1610543 & 688612 & 4.05 & 4.6144 & TRN & \\
\hline CHEMBL1564200 & 688612 & 4.6 & 4.7086 & TST & \\
\hline CHEMBL1347318 & 688612 & 6.95 & 4.7018 & TRN & \\
\hline CHEMBL1299301 & 688612 & 4.05 & 4.6043 & TST & \\
\hline CHEMBL1374955 & 688612 & 5.0 & 4.669 & TRN & \\
\hline CHEMBL1576847 & 688612 & 6.0 & 4.6361 & TRN & \\
\hline CHEMBL1320792 & 688612 & 4.45 & 4.7076 & TRN & \\
\hline CHEMBL1353879 & 688612 & 4.65 & 4.6787 & TRN & \\
\hline CHEMBL1337352 & 688612 & 6.15 & 4.7073 & TRN & \\
\hline CHEMBL1556428 & 688612 & 4.05 & 4.7411 & TRN & \\
\hline CHEMBL1611627 & 688612 & 4.05 & 4.6426 & TRN & \\
\hline CHEMBL3211555 & 688612 & 4.5 & 4.6527 & TRN & \\
\hline CHEMBL1465322 & 688612 & 4.4 & 4.7307 & TRN & \\
\hline CHEMBL1400876 & 688612 & 4.0 & 4.586 & TRN & \\
\hline CHEMBL1590158 & 688612 & 4.45 & 4.6601 & TRN & \\
\hline CHEMBL1583636 & 688612 & 5.25 & 4.7075 & TRN & \\
\hline CHEMBL1525485 & 688612 & 4.6 & 4.6403 & TRN & \\
\hline
\end{tabular}




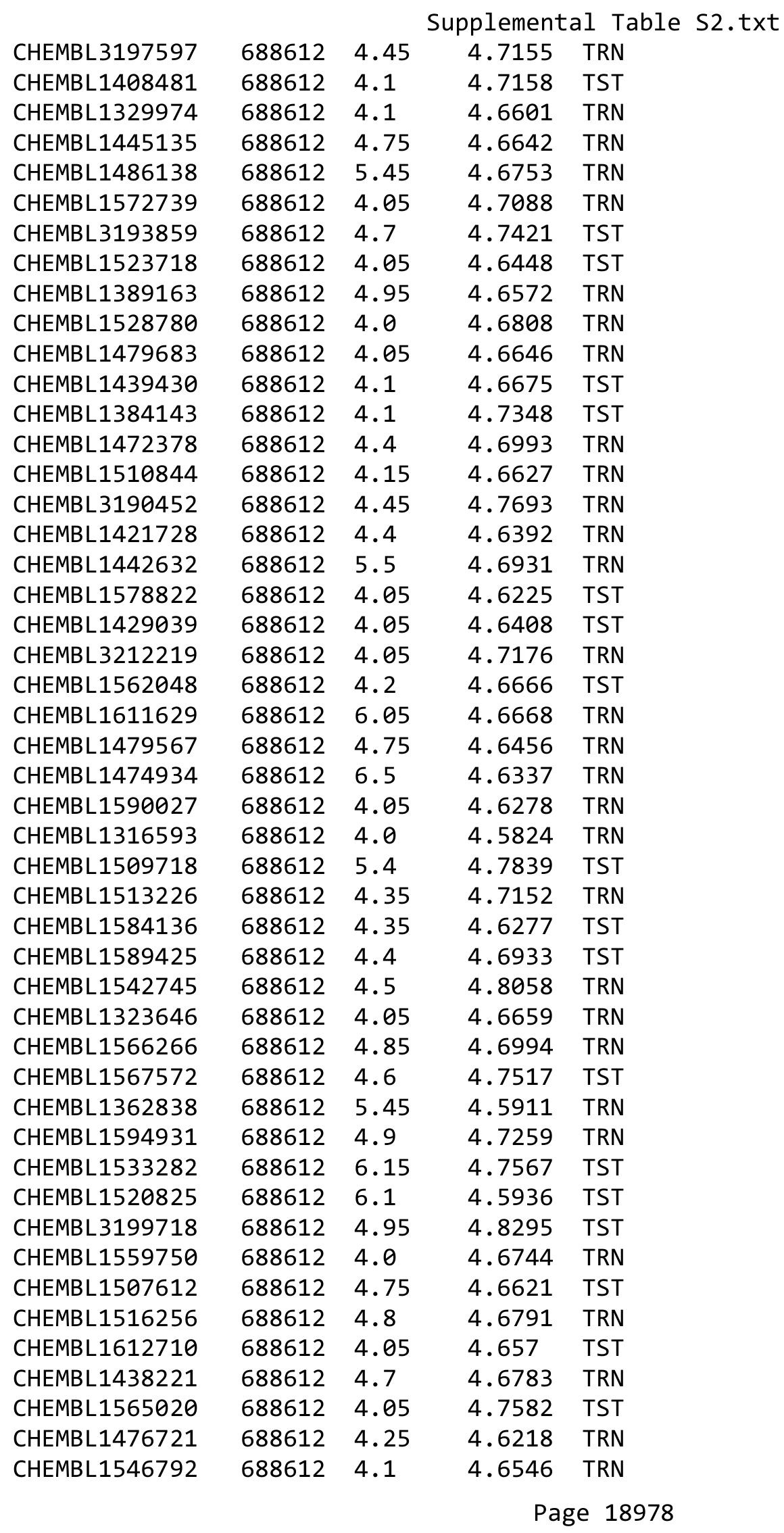




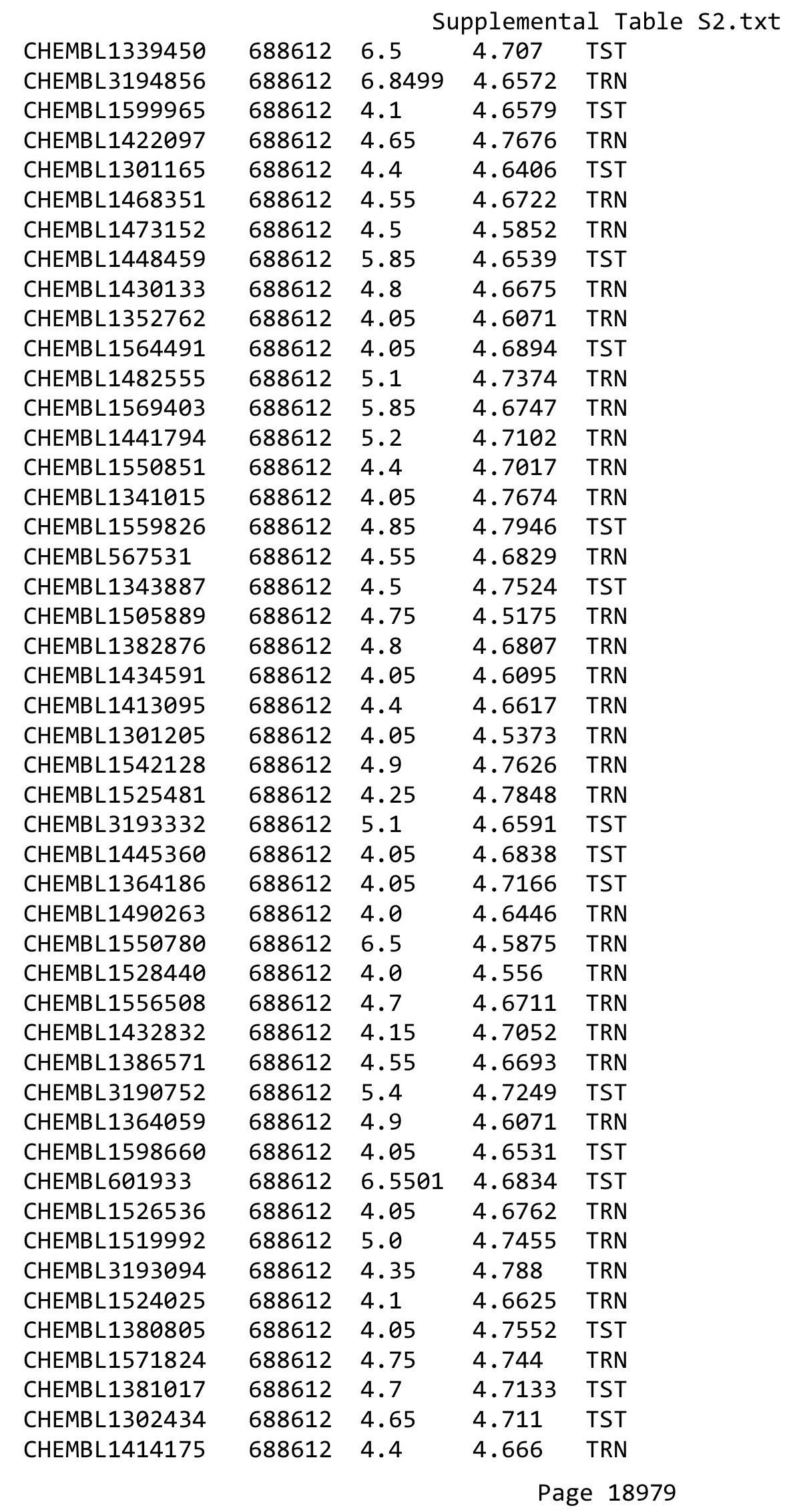




\begin{tabular}{|c|c|c|c|c|}
\hline \multicolumn{5}{|c|}{ Supplemental Table S2.txt } \\
\hline CHEMBL1476246 & 688612 & 5.4 & 4.6492 & TST \\
\hline CHEMBL1471629 & 688612 & 4.2 & 4.5961 & TST \\
\hline CHEMBL1325227 & 688612 & 4.6 & 4.6717 & TST \\
\hline CHEMBL1304092 & 688612 & 4.15 & 4.7168 & TRN \\
\hline CHEMBL1474782 & 688612 & 4.45 & 4.7284 & TRN \\
\hline CHEMBL1548501 & 688612 & 4.2 & 4.6545 & TRN \\
\hline CHEMBL1470756 & 688612 & 4.1 & 4.6431 & TRN \\
\hline CHEMBL1608662 & 688612 & 4.9 & 4.7079 & TRN \\
\hline CHEMBL1368867 & 688612 & 5.8 & 4.6769 & TRN \\
\hline CHEMBL1498262 & 688612 & 4.8 & 4.6435 & TRN \\
\hline CHEMBL1408678 & 688612 & 4.05 & 4.5893 & TRN \\
\hline CHEMBL1558131 & 688612 & 4.35 & 4.6457 & TST \\
\hline CHEMBL 3196130 & 688612 & 4.05 & 4.8124 & TRN \\
\hline CHEMBL1449668 & 688612 & 4.1 & 4.5948 & TRN \\
\hline CHEMBL1371451 & 688612 & 4.05 & 4.678 & TST \\
\hline CHEMBL1305388 & 688612 & 4.1 & 4.6765 & TRN \\
\hline CHEMBL1508084 & 688612 & 4.25 & 4.6726 & TRN \\
\hline CHEMBL1531335 & 688612 & 4.55 & 4.7209 & TRN \\
\hline CHEMBL1575966 & 688612 & 4.3 & 4.6288 & TRN \\
\hline CHEMBL1330464 & 688612 & 4.75 & 4.7512 & TRN \\
\hline CHEMBL1565003 & 688612 & 4.1 & 4.6532 & TRN \\
\hline CHEMBL1419414 & 688612 & 4.05 & 4.7369 & TRN \\
\hline CHEMBL1312167 & 688612 & 4.5 & 4.6873 & TRN \\
\hline CHEMBL1602306 & 688612 & 4.0 & 4.6471 & TRN \\
\hline CHEMBL1561551 & 688612 & 5.0 & 4.6145 & TST \\
\hline CHEMBL1451215 & 688612 & 5.45 & 4.6911 & TRN \\
\hline CHEMBL3211707 & 688612 & 5.05 & 4.6482 & TRN \\
\hline CHEMBL1427243 & 688612 & 4.3 & 4.6321 & TRN \\
\hline CHEMBL1570004 & 688612 & 5.15 & 4.7527 & TRN \\
\hline CHEMBL1447962 & 688612 & 4.0 & 4.6203 & TST \\
\hline CHEMBL1485637 & 688612 & 6.6 & 4.6825 & TRN \\
\hline CHEMBL1445897 & 688612 & 4.75 & 4.7406 & TRN \\
\hline CHEMBL1978101 & 688612 & 4.3 & 4.6915 & TRN \\
\hline CHEMBL1340486 & 688612 & 5.35 & 4.6303 & TRN \\
\hline CHEMBL 3198754 & 688612 & 4.05 & 4.7347 & TST \\
\hline CHEMBL563577 & 688612 & 4.05 & 4.7095 & TRN \\
\hline CHEMBL3198943 & 688612 & 4.6 & 4.7092 & TRN \\
\hline CHEMBL1432114 & 688612 & 4.5 & 4.6615 & TRN \\
\hline CHEMBL1987894 & 688612 & 4.25 & 4.6502 & TRN \\
\hline CHEMBL1393889 & 688612 & 4.25 & 4.6148 & TRN \\
\hline CHEMBL1492088 & 688612 & 4.95 & 4.7133 & TRN \\
\hline CHEMBL1425762 & 688612 & 6.8 & 4.6142 & TRN \\
\hline CHEMBL1510676 & 688612 & 4.5 & 4.8102 & TST \\
\hline CHEMBL1554566 & 688612 & 4.95 & 4.6348 & TST \\
\hline CHEMBL1426772 & 688612 & 6.45 & 4.6612 & TRN \\
\hline CHEMBL1336557 & 688612 & 4.0 & 4.6839 & TST \\
\hline CHEMBL1408983 & 688612 & 4.05 & 4.5998 & TST \\
\hline CHEMBL1314189 & 688612 & 6.15 & 4.613 & TRN \\
\hline
\end{tabular}




\begin{tabular}{|c|c|c|c|c|c|}
\hline \multicolumn{6}{|c|}{ Supplemental Table S2.txt } \\
\hline CHEMBL1390521 & 688612 & 5.5 & 4.7725 & TST & \\
\hline CHEMBL1457225 & 688612 & 5.25 & 4.5727 & TRN & \\
\hline CHEMBL1409250 & 688612 & 4.05 & 4.6738 & TRN & \\
\hline CHEMBL1522583 & 688612 & 4.0 & 4.6603 & TST & \\
\hline CHEMBL3191412 & 688612 & 5.75 & 4.80699 & 99999999995 & TRN \\
\hline CHEMBL1317783 & 688612 & 4.55 & 4.7904 & TRN & \\
\hline CHEMBL 3190727 & 688612 & 4.05 & 4.6974 & TRN & \\
\hline CHEMBL1344422 & 688612 & 4.95 & 4.8161 & TRN & \\
\hline CHEMBL1314037 & 688612 & 5.1 & 4.7566 & TRN & \\
\hline CHEMBL1458231 & 688612 & 4.45 & 4.6655 & TST & \\
\hline CHEMBL1528973 & 688612 & 4.0 & 4.6515 & TRN & \\
\hline CHEMBL1309943 & 688612 & 4.2 & 4.6777 & TRN & \\
\hline CHEMBL1611552 & 688612 & 4.5 & 4.7449 & TST & \\
\hline CHEMBL1445864 & 688612 & 5.25 & 4.6254 & TST & \\
\hline CHEMBL1557575 & 688612 & 4.1 & 4.6509 & TRN & \\
\hline CHEMBL1340705 & 688612 & 4.05 & 4.7186 & TRN & \\
\hline CHEMBL1381559 & 688612 & 4.7 & 4.7619 & TRN & \\
\hline CHEMBL1464948 & 688612 & 4.05 & 4.7045 & TST & \\
\hline CHEMBL492418 & 688612 & 4.7 & 4.6979 & TST & \\
\hline CHEMBL1421517 & 688612 & 4.6 & 4.6649 & TRN & \\
\hline CHEMBL1371301 & 688612 & 5.15 & 4.633 & TRN & \\
\hline CHEMBL1395914 & 688612 & 4.3 & 4.5773 & TRN & \\
\hline CHEMBL493698 & 688612 & 5.1 & 4.6839 & TRN & \\
\hline CHEMBL1386336 & 688612 & 6.8499 & 4.6756 & TST & \\
\hline CHEMBL1308037 & 688612 & 4.15 & 4.6386 & TRN & \\
\hline CHEMBL1333346 & 688612 & 4.1 & 4.7263 & TST & \\
\hline CHEMBL1313524 & 688612 & 4.05 & 4.7491 & TST & \\
\hline CHEMBL1553584 & 688612 & 5.05 & 4.689 & TRN & \\
\hline CHEMBL1431059 & 688612 & 6.8499 & 4.7101 & TST & \\
\hline CHEMBL1383459 & 688612 & 4.5 & 4.6779 & TRN & \\
\hline CHEMBL1535440 & 688612 & 6.05 & 4.6159 & TRN & \\
\hline CHEMBL1507759 & 688612 & 6.4 & 4.7758 & TST & \\
\hline CHEMBL1592234 & 688612 & 5.75 & 4.6975 & TRN & \\
\hline CHEMBL1365759 & 688612 & 4.7 & 4.7016 & TST & \\
\hline CHEMBL1411129 & 688612 & 4.0 & 4.65 & TRN & \\
\hline CHEMBL1525133 & 688612 & 4.4 & 4.5736 & TRN & \\
\hline CHEMBL1443910 & 688612 & 4.05 & 4.7139 & TST & \\
\hline CHEMBL1367738 & 688612 & 4.05 & 4.7083 & TST & \\
\hline CHEMBL1327797 & 688612 & 4.55 & 4.66 & TRN & \\
\hline CHEMBL1411074 & 688612 & 6.25 & 4.6394 & TRN & \\
\hline CHEMBL3189985 & 688612 & 4.35 & 4.7803 & TRN & \\
\hline CHEMBL1526824 & 688612 & 6.6 & 4.6673 & TST & \\
\hline CHEMBL1433525 & 688612 & 5.7 & 4.5971 & TRN & \\
\hline CHEMBL1563797 & 688612 & 4.7 & 4.6674 & TRN & \\
\hline CHEMBL3145185 & 688612 & 4.85 & 4.7686 & TST & \\
\hline CHEMBL1525158 & 688612 & 4.1 & 4.5869 & TRN & \\
\hline CHEMBL1223397 & 688612 & 4.4 & 4.6929 & TRN & \\
\hline CHEMBL1465597 & 688612 & 4.0 & 4.7175 & TRN & \\
\hline
\end{tabular}




\begin{tabular}{|c|c|c|c|c|c|}
\hline \multirow[b]{2}{*}{ CHEMBL3192725 } & \multicolumn{5}{|c|}{ Supplemental Table S2.txt } \\
\hline & 688612 & 4.9 & 4.7192 & TRN & \\
\hline CHEMBL1503224 & 688612 & 6.9 & $4.7010 e$ & 00000000005 & TRN \\
\hline CHEMBL1506829 & 688612 & 4.05 & 4.6645 & TST & \\
\hline CHEMBL1481970 & 688612 & 4.3 & 4.6103 & TRN & \\
\hline CHEMBL3192116 & 688612 & 4.6 & 4.6786 & TRN & \\
\hline CHEMBL3193295 & 688612 & 4.8 & 4.6732 & TRN & \\
\hline CHEMBL 2448463 & 688612 & 4.1 & 4.6679 & TRN & \\
\hline CHEMBL1359984 & 688612 & 4.35 & 4.6013 & TST & \\
\hline CHEMBL 3195250 & 688612 & 7.15 & 4.6664 & TRN & \\
\hline CHEMBL1300836 & 688612 & 5.4 & 4.8074 & TRN & \\
\hline CHEMBL1592863 & 688612 & 5.05 & 4.6204 & TRN & \\
\hline CHEMBL1603296 & 688612 & 5.65 & $4.6160 e$ & 00000000005 & TST \\
\hline CHEMBL1416609 & 688612 & 4.5 & 4.6352 & TRN & \\
\hline CHEMBL1527746 & 688612 & 4.1 & 4.7261 & TRN & \\
\hline CHEMBL1360824 & 688612 & 4.05 & 4.6668 & TRN & \\
\hline CHEMBL1531571 & 688612 & 4.7 & 4.6764 & TST & \\
\hline CHEMBL1515923 & 688612 & 4.45 & 4.6142 & TRN & \\
\hline CHEMBL1442121 & 688612 & 5.45 & 4.5834 & TRN & \\
\hline CHEMBL1420550 & 688612 & 4.7 & 4.7115 & TRN & \\
\hline CHEMBL1306565 & 688612 & 5.3 & 4.6738 & TST & \\
\hline CHEMBL1509087 & 688612 & 4.55 & 4.6963 & TST & \\
\hline CHEMBL1561199 & 688612 & 4.85 & 4.6377 & TRN & \\
\hline CHEMBL1586592 & 688612 & 6.9 & 4.716 & TRN & \\
\hline CHEMBL1530776 & 688612 & 4.15 & 4.6846 & TRN & \\
\hline CHEMBL1494694 & 688612 & 6.5 & 4.7094 & TST & \\
\hline CHEMBL1415682 & 688612 & 4.0 & 4.7184 & TST & \\
\hline CHEMBL241657 & 688612 & 4.15 & 4.6038 & TRN & \\
\hline CHEMBL1571615 & 688612 & 6.8499 & 4.7339 & TRN & \\
\hline CHEMBL1341978 & 688612 & 4.4 & 4.6677 & TRN & \\
\hline CHEMBL1546745 & 688612 & 4.45 & 4.6358 & TST & \\
\hline CHEMBL1325641 & 688612 & 4.05 & 4.6516 & TRN & \\
\hline CHEMBL1420728 & 688612 & 6.0 & 4.7113 & TRN & \\
\hline CHEMBL1325210 & 688612 & 5.0 & 4.6393 & TRN & \\
\hline CHEMBL1554496 & 688612 & 4.05 & 4.7054 & TST & \\
\hline CHEMBL1442260 & 688612 & 4.1 & 4.5941 & TST & \\
\hline CHEMBL1340146 & 688612 & 4.1 & 4.6617 & TST & \\
\hline CHEMBL1316221 & 688612 & 4.05 & 4.603 & TRN & \\
\hline CHEMBL252417 & 688612 & 4.85 & 4.7489 & TRN & \\
\hline CHEMBL1320894 & 688612 & 4.35 & 4.6479 & TRN & \\
\hline CHEMBL3145192 & 688612 & 4.35 & 4.6912 & TRN & \\
\hline CHEMBL1565371 & 688612 & 4.05 & 4.6507 & TST & \\
\hline CHEMBL1490524 & 688612 & 4.8 & 4.6459 & TRN & \\
\hline CHEMBL1446868 & 688612 & 4.05 & 4.6355 & TRN & \\
\hline CHEMBL1550618 & 688612 & 5.9 & 4.6988 & TRN & \\
\hline CHEMBL3198910 & 688612 & 4.3 & 4.8039 & TRN & \\
\hline CHEMBL1390068 & 688612 & 4.6 & 4.6515 & TRN & \\
\hline CHEMBL1465490 & 688612 & 4.1 & 4.6422 & TST & \\
\hline CHEMBL1370356 & 688612 & 5.5 & 4.7098 & TRN & \\
\hline
\end{tabular}




\begin{tabular}{|c|c|c|c|c|c|}
\hline \multicolumn{6}{|c|}{ Supplemental Table S2.txt } \\
\hline CHEMBL3209659 & 688612 & 4.5 & 4.6332 & TST & \\
\hline CHEMBL1312944 & 688612 & 4.75 & 4.6677 & TRN & \\
\hline CHEMBL1477445 & 688612 & 5.55 & 4.6139 & TRN & \\
\hline CHEMBL1532063 & 688612 & 5.35 & 4.6417 & TRN & \\
\hline CHEMBL1300086 & 688612 & 4.4 & 4.724 & TST & \\
\hline CHEMBL3191271 & 688612 & 5.95 & 4.6867 & TST & \\
\hline CHEMBL374632 & 688612 & 4.0 & 4.7364 & TRN & \\
\hline CHEMBL1395478 & 688612 & 4.1 & 4.6689 & TRN & \\
\hline CHEMBL1365005 & 688612 & 4.4 & 4.6779 & TST & \\
\hline CHEMBL1359961 & 688612 & 4.05 & 4.5982 & TRN & \\
\hline CHEMBL1529161 & 688612 & 4.65 & 4.6884 & TST & \\
\hline CHEMBL1516290 & 688612 & 4.7 & 4.5926 & TRN & \\
\hline CHEMBL1440342 & 688612 & 4.05 & 4.6548 & TST & \\
\hline CHEMBL1411396 & 688612 & 5.0 & 4.7014 & TRN & \\
\hline CHEMBL3191987 & 688612 & 4.05 & 4.7051 & TST & \\
\hline CHEMBL1432402 & 688612 & 5.3 & 4.7115 & TST & \\
\hline CHEMBL1462918 & 688612 & 4.4 & 4.7922 & TRN & \\
\hline CHEMBL1445891 & 688612 & 4.05 & 4.7411 & TST & \\
\hline CHEMBL1561171 & 688612 & 5.3 & 4.7072 & TRN & \\
\hline CHEMBL1418840 & 688612 & 6.0 & 4.6084 & TST & \\
\hline CHEMBL1381156 & 688612 & 5.5 & 4.6392 & TST & \\
\hline CHEMBL3208704 & 688612 & 4.05 & 4.6402 & TST & \\
\hline CHEMBL1571714 & 688612 & 4.35 & 4.6623 & TST & \\
\hline CHEMBL1357538 & 688612 & 4.0 & 4.6481 & TRN & \\
\hline CHEMBL1417775 & 688612 & 4.0 & 4.6141 & TRN & \\
\hline CHEMBL1559370 & 688612 & 5.15 & 4.7248 & TST & \\
\hline CHEMBL1372615 & 688612 & 4.3 & 4.6341 & TRN & \\
\hline CHEMBL1425198 & 688612 & 4.15 & 4.6591 & TST & \\
\hline CHEMBL1417279 & 688612 & 4.05 & 4.5949 & TRN & \\
\hline CHEMBL393037 & 688612 & 4.3 & 4.6546 & TRN & \\
\hline CHEMBL1348642 & 688612 & 4.65 & 4.6775 & TST & \\
\hline CHEMBL1601853 & 688612 & 4.7 & 4.6119 & TRN & \\
\hline CHEMBL1377671 & 688612 & 6.3 & 4.5301 & TST & \\
\hline CHEMBL1336840 & 688612 & 5.7 & 4.6847 & TST & \\
\hline CHEMBL1506195 & 688612 & 5.05 & 4.72199 & 99999999995 & TRN \\
\hline CHEMBL1567745 & 688612 & 4.7 & 4.6664 & TRN & \\
\hline CHEMBL1368786 & 688612 & 5.2 & 4.669 & TRN & \\
\hline CHEMBL1540467 & 688612 & 4.1 & 4.6159 & TRN & \\
\hline CHEMBL1524134 & 688612 & 6.3 & 4.6468 & TRN & \\
\hline CHEMBL1502007 & 688612 & 4.35 & 4.6224 & TRN & \\
\hline CHEMBL1492696 & 688612 & 4.2 & 4.667 & TRN & \\
\hline CHEMBL3194553 & 688612 & 4.1 & 4.713 & TST & \\
\hline CHEMBL1601740 & 688612 & 4.1 & 4.6029 & TRN & \\
\hline CHEMBL1581580 & 688612 & 4.8 & 4.6347 & TRN & \\
\hline CHEMBL1543475 & 688612 & 5.3 & 4.54899 & 99999999995 & TRN \\
\hline CHEMBL1568994 & 688612 & 5.8 & 4.6959 & TST & \\
\hline CHEMBL1494765 & 688612 & 4.4 & 4.7335 & TRN & \\
\hline CHEMBL1389429 & 688612 & 4.45 & 4.7281 & TST & \\
\hline
\end{tabular}




\begin{tabular}{|c|c|c|c|c|c|}
\hline \multicolumn{6}{|c|}{ Supplemental Table S2.txt } \\
\hline CHEMBL1370791 & 688612 & 4.0 & 4.5911 & TRN & \\
\hline CHEMBL1510502 & 688612 & 6.6499 & 4.6288 & TST & \\
\hline CHEMBL1496820 & 688612 & 4.2 & 4.7451 & TST & \\
\hline CHEMBL1410122 & 688612 & 4.45 & 4.6581 & TRN & \\
\hline CHEMBL1496305 & 688612 & 4.95 & 4.60800 & 00000000005 & TST \\
\hline CHEMBL3195659 & 688612 & 4.6 & 4.6933 & TST & \\
\hline CHEMBL1492046 & 688612 & 4.05 & 4.6236 & TRN & \\
\hline CHEMBL1389414 & 688612 & 4.1 & 4.6594 & TRN & \\
\hline CHEMBL1360697 & 688612 & 5.0 & 4.7089 & TRN & \\
\hline CHEMBL1597948 & 688612 & 4.05 & 4.5621 & TRN & \\
\hline CHEMBL1334844 & 688612 & 4.0 & 4.6965 & TRN & \\
\hline CHEMBL1404757 & 688612 & 4.3 & 4.6602 & TRN & \\
\hline CHEMBL1321313 & 688612 & 4.8 & 4.5437 & TST & \\
\hline CHEMBL1609566 & 688612 & 5.5 & 4.74100 & 00000000005 & TRN \\
\hline CHEMBL1336764 & 688612 & 4.45 & 4.6424 & TRN & \\
\hline CHEMBL1465620 & 688612 & 4.05 & 4.6165 & TRN & \\
\hline CHEMBL1361136 & 688612 & 4.05 & 4.6605 & TRN & \\
\hline CHEMBL1603057 & 688612 & 4.55 & 4.6766 & TST & \\
\hline CHEMBL1382467 & 688612 & 6.25 & 4.5844 & TST & \\
\hline CHEMBL1506859 & 688612 & 4.05 & 4.5871 & TRN & \\
\hline CHEMBL1497838 & 688612 & 4.55 & 4.7155 & TRN & \\
\hline CHEMBL1343033 & 688612 & 4.05 & 4.672 & TRN & \\
\hline CHEMBL1528901 & 688612 & 4.7 & 4.6854 & TRN & \\
\hline CHEMBL3195386 & 688612 & 4.15 & 4.7623 & TRN & \\
\hline CHEMBL1407935 & 688612 & 4.05 & 4.6702 & TST & \\
\hline CHEMBL1493120 & 688612 & 4.55 & 4.699 & TRN & \\
\hline CHEMBL1508765 & 688612 & 4.4 & 4.6812 & TRN & \\
\hline CHEMBL 3197820 & 688612 & 6.8 & 4.7265 & TST & \\
\hline CHEMBL1372804 & 688612 & 5.1 & 4.6568 & TST & \\
\hline CHEMBL1518895 & 688612 & 5.0 & 4.6979 & TRN & \\
\hline CHEMBL1330897 & 688612 & 4.05 & 4.6362 & TRN & \\
\hline CHEMBL1428448 & 688612 & 5.95 & 4.6826 & TRN & \\
\hline CHEMBL1318405 & 688612 & 4.1 & 4.6286 & TST & \\
\hline CHEMBL1540086 & 688612 & 6.1 & 4.6281 & TST & \\
\hline CHEMBL1494675 & 688612 & 4.0 & 4.6531 & TRN & \\
\hline CHEMBL1306960 & 688612 & 5.45 & 4.6508 & TRN & \\
\hline CHEMBL1573119 & 688612 & 4.0 & 4.6463 & TST & \\
\hline CHEMBL1393755 & 688612 & 4.3 & 4.6249 & TRN & \\
\hline CHEMBL1411916 & 688612 & 7.0 & 4.6879 & TST & \\
\hline CHEMBL1593381 & 688612 & 4.1 & 4.65600 & 0000000001 & TRN \\
\hline CHEMBL1980335 & 688612 & 4.4 & 4.6501 & TRN & \\
\hline CHEMBL1513442 & 688612 & 4.1 & 4.5757 & TRN & \\
\hline CHEMBL1429871 & 688612 & 4.25 & 4.711 & TRN & \\
\hline CHEMBL1365608 & 688612 & 4.55 & 4.673 & TRN & \\
\hline CHEMBL1973626 & 688612 & 4.7 & 4.658 & TRN & \\
\hline CHEMBL1382620 & 688612 & 5.6 & 4.7405 & TRN & \\
\hline CHEMBL1401357 & 688612 & 4.45 & 4.6526 & TST & \\
\hline CHEMBL1323433 & 688612 & 4.8 & 4.6775 & TRN & \\
\hline
\end{tabular}




\begin{tabular}{|c|c|c|c|c|c|}
\hline \multicolumn{6}{|c|}{ Supplemental Table s2.txt } \\
\hline CHEMBL 3192884 & 688612 & 4.3 & 4.6563 & TRN & \\
\hline CHEMBL1971234 & 688612 & 4.7 & 4.7157 & TST & \\
\hline CHEMBL1390031 & 688612 & 4.05 & 4.658 & TRN & \\
\hline CHEMBL432608 & 688612 & 4.55 & 4.6673 & TST & \\
\hline CHEMBL1586999 & 688612 & 4.0 & 4.622 & TRN & \\
\hline CHEMBL1445821 & 688612 & 4.55 & 4.6384 & TRN & \\
\hline CHEMBL1401409 & 688612 & 4.3 & 4.5682 & TRN & \\
\hline CHEMBL1435600 & 688612 & 4.35 & 4.6163 & TRN & \\
\hline CHEMBL1421583 & 688612 & 4.4 & 4.7121 & TRN & \\
\hline CHEMBL1308751 & 688612 & 4.35 & 4.6808 & TRN & \\
\hline CHEMBL1495451 & 688612 & 6.15 & 4.699 & TST & \\
\hline CHEMBL3197212 & 688612 & 5.75 & 4.7301 & TST & \\
\hline CHEMBL1347858 & 688612 & 5.5 & 4.6619 & TST & \\
\hline CHEMBL1608260 & 688612 & 4.5 & 4.6153 & TRN & \\
\hline CHEMBL1581101 & 688612 & 4.7 & 4.5479 & TRN & \\
\hline CHEMBL1578069 & 688612 & 4.05 & 4.6705 & TST & \\
\hline CHEMBL1576176 & 688612 & 4.55 & 4.7038 & TRN & \\
\hline CHEMBL1394385 & 688612 & 4.0 & 4.6695 & TRN & \\
\hline CHEMBL1531349 & 688612 & 4.05 & 4.6448 & TRN & \\
\hline CHEMBL1303212 & 688612 & 5.0 & 4.7382 & TRN & \\
\hline CHEMBL1511443 & 688612 & 4.05 & 4.6884 & TST & \\
\hline CHEMBL1412169 & 688612 & 4.9 & 4.7079 & TST & \\
\hline CHEMBL1466558 & 688612 & 5.1 & 4.73300 & 00000000005 & TST \\
\hline CHEMBL1545260 & 688612 & 4.4 & 4.6711 & TST & \\
\hline CHEMBL1466097 & 688612 & 4.55 & 4.6387 & TRN & \\
\hline CHEMBL1300851 & 688612 & 4.8 & 4.6424 & TRN & \\
\hline CHEMBL1585420 & 688612 & 5.4 & 4.7278 & TST & \\
\hline CHEMBL1362669 & 688612 & 5.05 & 4.572 & TST & \\
\hline CHEMBL1480895 & 688612 & 4.3 & 4.7052 & TRN & \\
\hline CHEMBL192566 & 688612 & 4.65 & 4.7283 & TST & \\
\hline CHEMBL1343466 & 688612 & 4.2 & 4.6552 & TST & \\
\hline CHEMBL1377291 & 688612 & 4.45 & 4.5761 & TRN & \\
\hline CHEMBL1342054 & 688612 & 5.75 & 4.6983 & TRN & \\
\hline CHEMBL1443358 & 688612 & 4.05 & 4.6467 & TRN & \\
\hline CHEMBL1400757 & 688612 & 5.8 & 4.7021 & TRN & \\
\hline CHEMBL1527862 & 688612 & 4.45 & 4.6451 & TRN & \\
\hline CHEMBL1465487 & 688612 & 4.2 & 4.5568 & TRN & \\
\hline CHEMBL1423711 & 688612 & 6.0 & 4.635 & TST & \\
\hline CHEMBL3199737 & 688612 & 4.05 & 4.7263 & TST & \\
\hline CHEMBL1429556 & 688612 & 4.75 & 4.7503 & TRN & \\
\hline CHEMBL1503465 & 688612 & 4.05 & 4.6239 & TST & \\
\hline CHEMBL1349331 & 688612 & 4.65 & 4.6324 & TRN & \\
\hline CHEMBL1406328 & 688612 & 4.05 & 4.6351 & TRN & \\
\hline CHEMBL3213486 & 688612 & 5.7 & 4.6618 & TRN & \\
\hline CHEMBL1554586 & 688612 & 6.6499 & 4.6179 & TRN & \\
\hline CHEMBL580727 & 688612 & 4.75 & 4.6984 & TRN & \\
\hline CHEMBL1302276 & 688612 & 4.05 & 4.7332 & TRN & \\
\hline CHEMBL1464662 & 688612 & 4.85 & 4.6349 & TRN & \\
\hline
\end{tabular}




\begin{tabular}{|c|c|c|c|c|c|}
\hline \multicolumn{6}{|c|}{ Supplemental Table S2.txt } \\
\hline CHEMBL1314463 & 688612 & 4.0 & 4.5605 & TRN & \\
\hline CHEMBL1588698 & 688612 & 4.4 & 4.7475 & TRN & \\
\hline CHEMBL1346343 & 688612 & 6.0 & 4.8124 & TRN & \\
\hline CHEMBL1430839 & 688612 & 5.05 & 4.7339 & TRN & \\
\hline CHEMBL1456334 & 688612 & 4.85 & 4.7142 & TST & \\
\hline CHEMBL1555635 & 688612 & 4.05 & 4.6595 & TRN & \\
\hline CHEMBL1500249 & 688612 & 6.8 & 4.7928 & TST & \\
\hline CHEMBL1315702 & 688612 & 4.0 & 4.5321 & TRN & \\
\hline CHEMBL 1347848 & 688612 & 4.5 & 4.7232 & TST & \\
\hline CHEMBL1386340 & 688612 & 4.65 & 4.6294 & TRN & \\
\hline CHEMBL1375490 & 688612 & 4.5 & 4.7687 & TRN & \\
\hline CHEMBL1396905 & 688612 & 4.05 & 4.6879 & TST & \\
\hline CHEMBL1992551 & 688612 & 4.6 & 4.779 & TRN & \\
\hline CHEMBL1403097 & 688612 & 4.7 & 4.65300 & 00000000005 & TRN \\
\hline CHEMBL1380420 & 688612 & 6.5501 & 4.5812 & TRN & \\
\hline CHEMBL1428662 & 688612 & 4.65 & 4.6772 & TRN & \\
\hline CHEMBL1314032 & 688612 & 5.0 & 4.6615 & TST & \\
\hline CHEMBL1539701 & 688612 & 6.8499 & 4.6802 & TST & \\
\hline CHEMBL1404459 & 688612 & 4.35 & 4.6924 & TRN & \\
\hline CHEMBL1451830 & 688612 & 4.3 & 4.6424 & TRN & \\
\hline CHEMBL1489096 & 688612 & 4.0 & 4.5917 & TRN & \\
\hline CHEMBL1511858 & 688612 & 4.85 & 4.7176 & TRN & \\
\hline CHEMBL1452656 & 688612 & 4.3 & 4.6393 & TST & \\
\hline CHEMBL 1352246 & 688612 & 6.3 & 4.5618 & TRN & \\
\hline CHEMBL1467504 & 688612 & 4.75 & 4.6922 & TRN & \\
\hline CHEMBL1515230 & 688612 & 4.05 & 4.6317 & TRN & \\
\hline CHEMBL1408142 & 688612 & 4.6 & 4.6788 & TRN & \\
\hline CHEMBL1472352 & 688612 & 4.8 & 4.6458 & TRN & \\
\hline CHEMBL1507455 & 688612 & 6.8499 & 4.6645 & TRN & \\
\hline CHEMBL 2007077 & 688612 & 4.65 & 4.7491 & TRN & \\
\hline CHEMBL1511121 & 688612 & 4.15 & 4.6186 & TST & \\
\hline CHEMBL1357894 & 688612 & 4.55 & 4.7281 & TST & \\
\hline CHEMBL1556028 & 688612 & 4.05 & 4.7427 & TRN & \\
\hline CHEMBL1522129 & 688612 & 4.45 & 4.7512 & TRN & \\
\hline CHEMBL1560519 & 688612 & 5.0 & 4.71399 & э9999999995 & TRN \\
\hline CHEMBL1369825 & 688612 & 4.0 & 4.7006 & TST & \\
\hline CHEMBL1463322 & 688612 & 5.7 & 4.8162 & TST & \\
\hline CHEMBL1375063 & 688612 & 4.05 & 4.6544 & TRN & \\
\hline CHEMBL1357554 & 688612 & 5.1 & 4.6286 & TRN & \\
\hline CHEMBL1543089 & 688612 & 4.05 & 4.5464 & TST & \\
\hline CHEMBL3210499 & 688612 & 6.05 & 4.7545 & TRN & \\
\hline CHEMBL1514490 & 688612 & 4.35 & 4.6145 & TRN & \\
\hline CHEMBL1375149 & 688612 & 4.2 & 4.7806 & TST & \\
\hline CHEMBL1412315 & 688612 & 5.35 & 4.7488 & TRN & \\
\hline CHEMBL1335844 & 688612 & 4.65 & 4.6735 & TRN & \\
\hline CHEMBL1482786 & 688612 & 4.7 & 4.6954 & TRN & \\
\hline CHEMBL1423046 & 688612 & 4.95 & 4.6629 & TRN & \\
\hline CHEMBL1584173 & 688612 & 4.4 & 4.7781 & TRN & \\
\hline
\end{tabular}




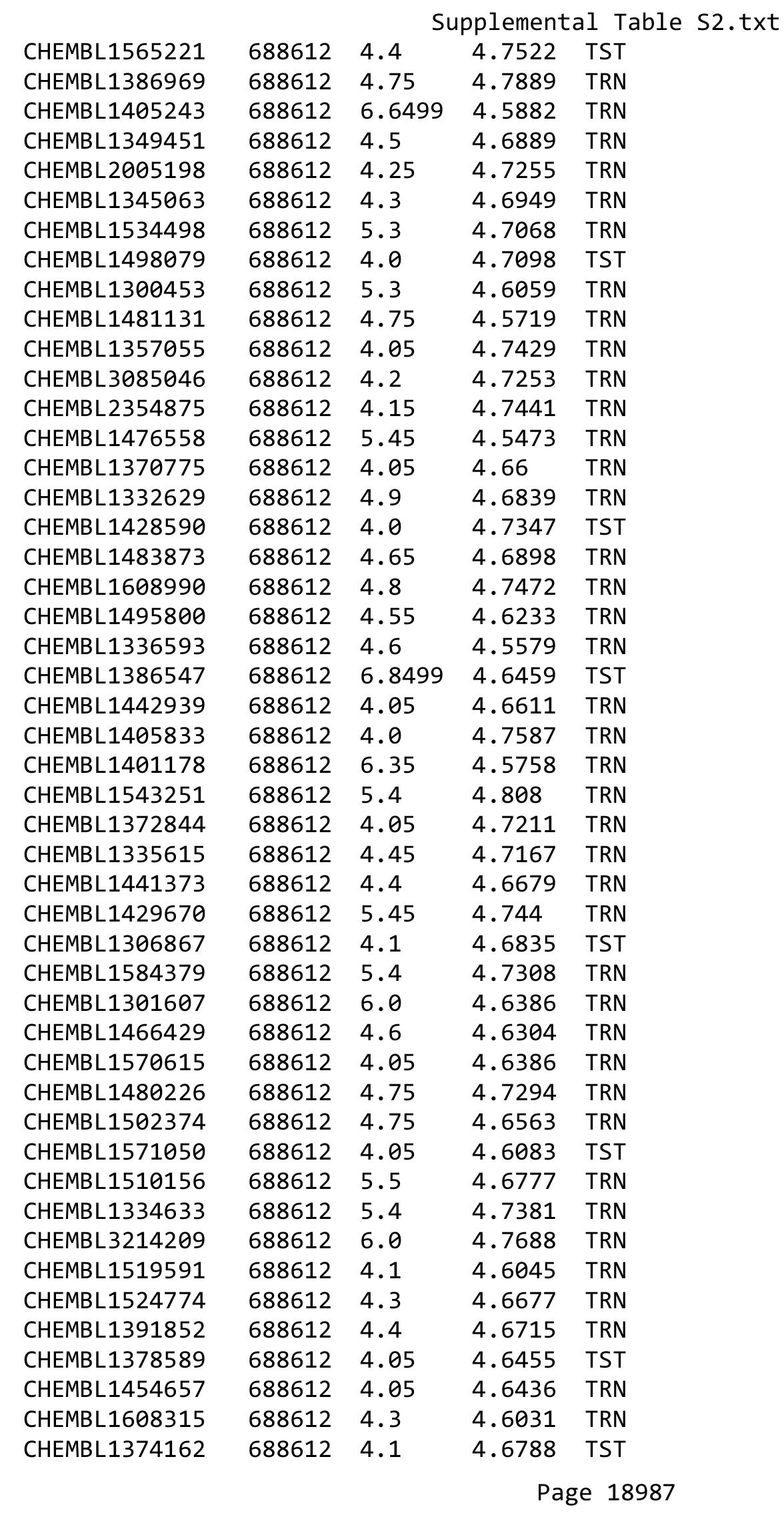




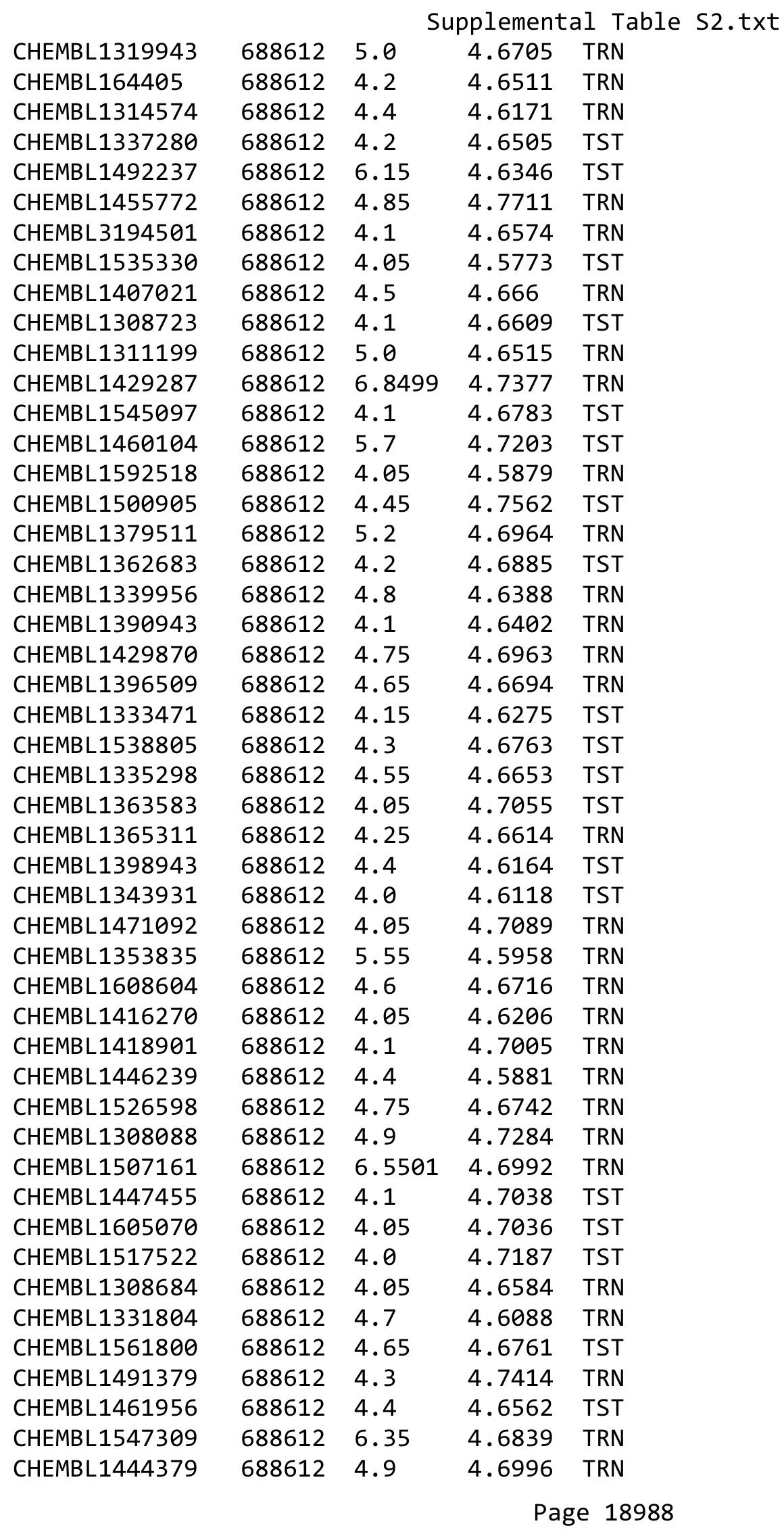




\begin{tabular}{|c|c|c|c|c|}
\hline & & & pplement & $\mathrm{T}$ \\
\hline CHEMBL1340068 & 688612 & 4.95 & 4.6954 & TST \\
\hline CHEMBL1307815 & 688612 & 5.5 & 4.7164 & TRN \\
\hline CHEMBL1422429 & 688612 & 4.45 & 4.6657 & TRN \\
\hline CHEMBL1357262 & 688612 & 4.1 & 4.5943 & TRN \\
\hline CHEMBL 3208352 & 688612 & 4.65 & 4.6606 & TST \\
\hline CHEMBL1489384 & 688612 & 4.9 & 4.686 & TST \\
\hline CHEMBL1461910 & 688612 & 5.05 & 4.6539 & TRN \\
\hline CHEMBL1376029 & 688612 & 4.0 & 4.6991 & TST \\
\hline CHEMBL1399343 & 688612 & 4.1 & 4.7158 & TRN \\
\hline CHEMBL1605701 & 688612 & 4.85 & 4.7235 & TST \\
\hline CHEMBL1344944 & 688612 & 4.65 & 4.7405 & TRN \\
\hline CHEMBL1379740 & 688612 & 4.5 & 4.6496 & TST \\
\hline CHEMBL1507531 & 688612 & 4.65 & 4.6429 & TRN \\
\hline CHEMBL1367558 & 688612 & 6.8499 & 4.6238 & TRN \\
\hline CHEMBL1453926 & 688612 & 4.05 & 4.657 & TRN \\
\hline CHEMBL1467730 & 688612 & 5.0 & 4.6271 & TRN \\
\hline CHEMBL1312549 & 688612 & 5.55 & 4.5873 & TRN \\
\hline CHEMBL1498952 & 688612 & 4.35 & 4.6729 & TRN \\
\hline CHEMBL1312051 & 688612 & 4.7 & 4.6736 & TST \\
\hline CHEMBL1987510 & 688612 & 4.9 & 4.6862 & TRN \\
\hline CHEMBL1556256 & 688612 & 4.3 & 4.6301 & TRN \\
\hline CHEMBL1469066 & 688612 & 4.55 & 4.6393 & TRN \\
\hline CHEMBL1603655 & 688612 & 4.9 & 4.6624 & TST \\
\hline CHEMBL1548573 & 688612 & 4.0 & 4.6736 & TRN \\
\hline CHEMBL3199221 & 688612 & 4.25 & 4.6893 & TST \\
\hline CHEMBL1537375 & 688612 & 5.3 & 4.7028 & TRN \\
\hline CHEMBL1613403 & 688612 & 4.75 & 4.658 & TRN \\
\hline CHEMBL1301305 & 688612 & 5.9 & 4.6124 & TRN \\
\hline CHEMBL1315228 & 688612 & 4.9 & 4.6876 & TRN \\
\hline CHEMBL1425993 & 688612 & 5.55 & 4.6465 & TRN \\
\hline CHEMBL1353435 & 688612 & 4.05 & 4.5887 & TRN \\
\hline CHEMBL3197943 & 688612 & 4.8 & 4.6853 & TRN \\
\hline CHEMBL1405185 & 688612 & 4.0 & 4.7701 & TST \\
\hline CHEMBL1469622 & 688612 & 4.1 & 4.6469 & TRN \\
\hline CHEMBL1379048 & 688612 & 4.6 & 4.6868 & TST \\
\hline CHEMBL1436857 & 688612 & 5.25 & 4.7405 & TRN \\
\hline CHEMBL1575382 & 688612 & 4.7 & 4.6405 & TRN \\
\hline CHEMBL1606284 & 688612 & 4.05 & 4.6765 & TRN \\
\hline CHEMBL3199376 & 688612 & 5.05 & 4.5677 & TRN \\
\hline CHEMBL1600063 & 688612 & 4.05 & 4.7118 & TRN \\
\hline CHEMBL1586766 & 688612 & 4.35 & 4.7176 & TRN \\
\hline CHEMBL1610490 & 688612 & 4.0 & 4.6572 & TRN \\
\hline CHEMBL1489529 & 688612 & 4.3 & 4.6605 & TRN \\
\hline CHEMBL3198782 & 688612 & 4.55 & 4.7391 & TRN \\
\hline CHEMBL1580852 & 688612 & 4.35 & 4.7409 & TST \\
\hline CHEMBL1492020 & 688612 & 4.8 & 4.7535 & TRN \\
\hline CHEMBL1403752 & 688612 & 4.05 & 4.6697 & TRN \\
\hline CHEMBL1354151 & 688612 & 4.05 & 4.659 & TST \\
\hline
\end{tabular}




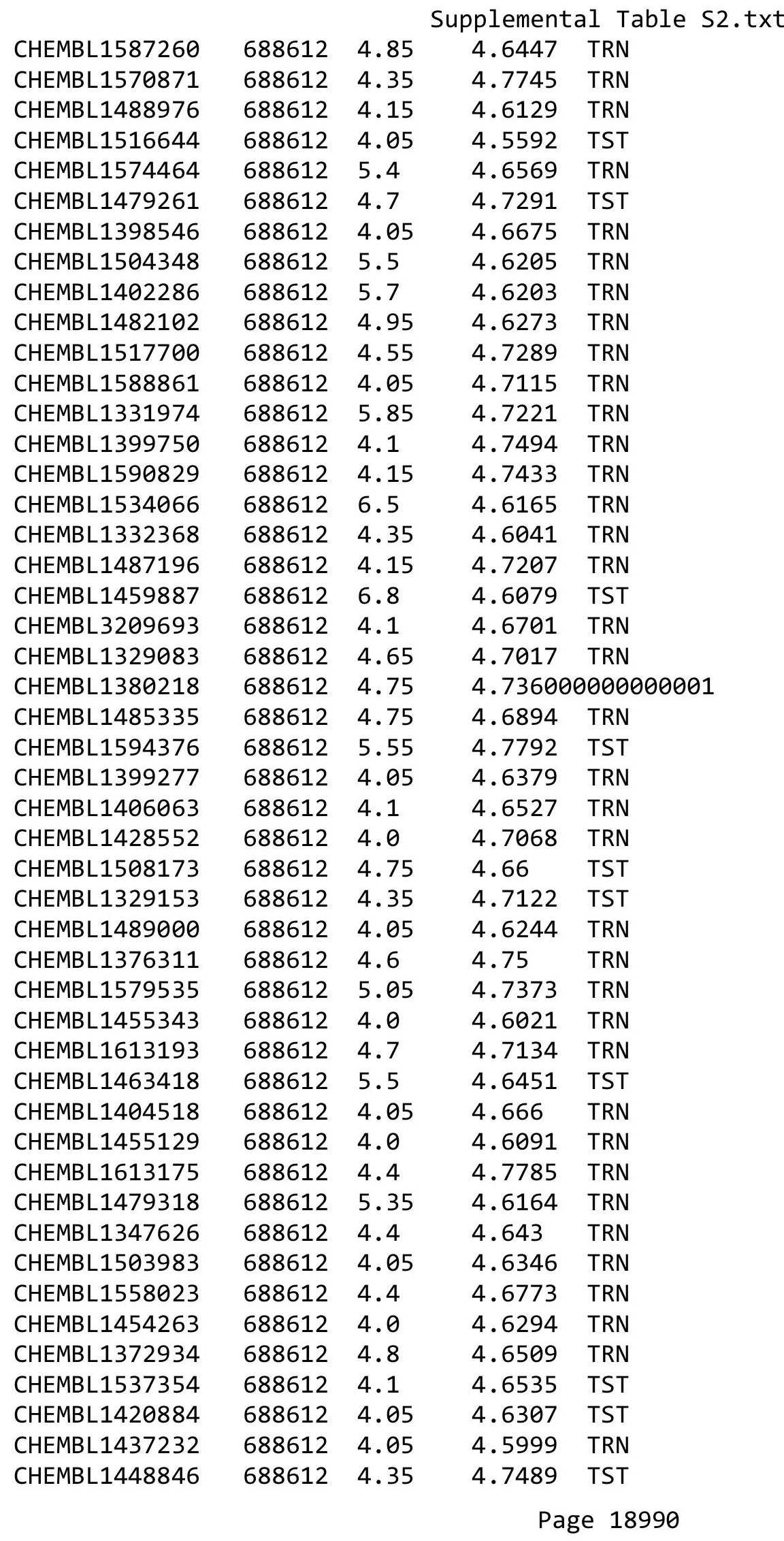




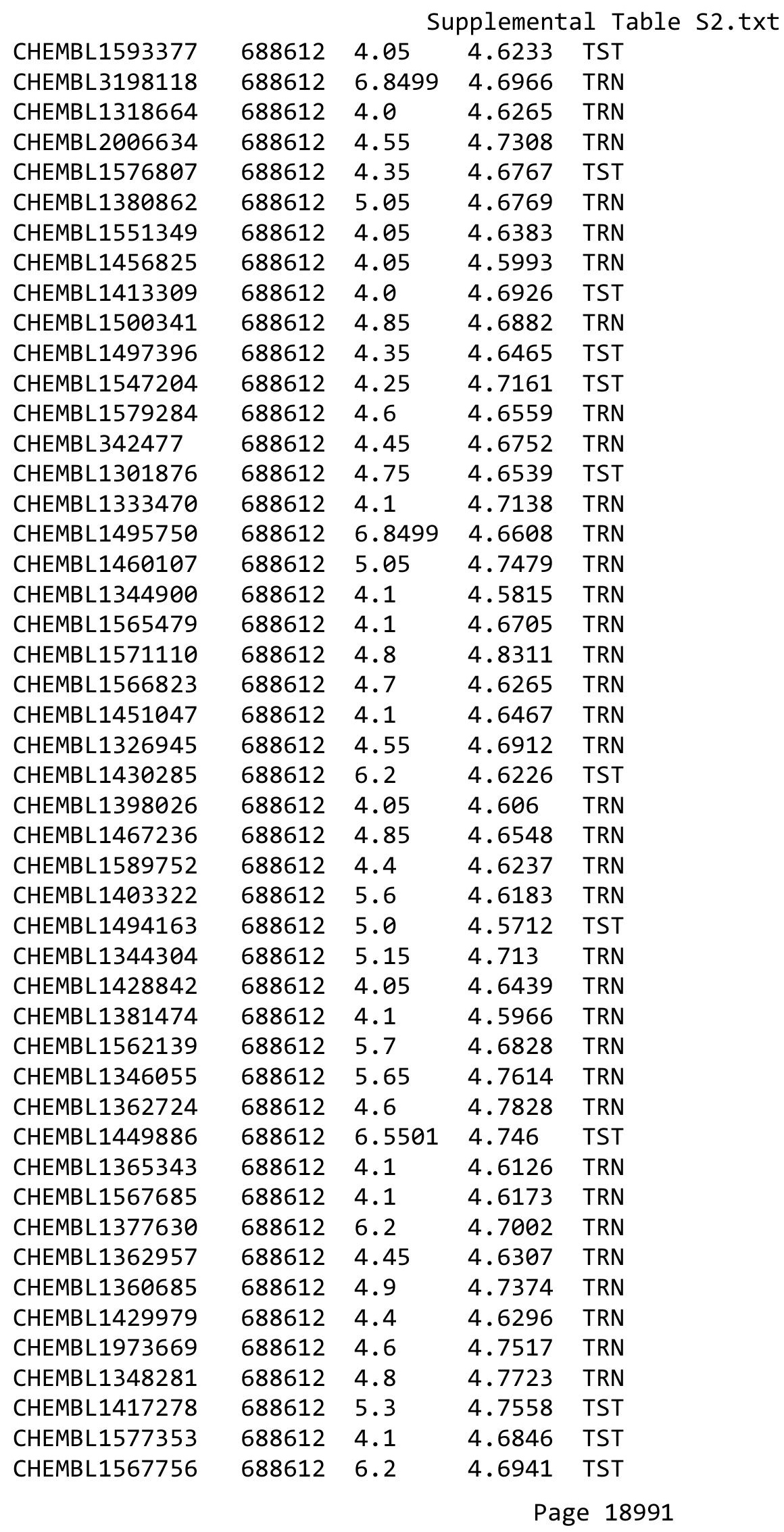




\begin{tabular}{|c|c|c|c|c|c|}
\hline \multicolumn{6}{|c|}{ Supplemental Table S2.txt } \\
\hline CHEMBL1577929 & 688612 & 4.4 & 4.6788 & TRN & \\
\hline CHEMBL1496143 & 688612 & 5.35 & 4.6606 & TRN & \\
\hline CHEMBL1583467 & 688612 & 4.5 & 4.6659 & TRN & \\
\hline CHEMBL1471708 & 688612 & 5.3 & 4.6354 & TST & \\
\hline CHEMBL1612000 & 688612 & 4.05 & 4.6276 & TRN & \\
\hline CHEMBL1513518 & 688612 & 4.0 & 4.66 & TST & \\
\hline CHEMBL1544009 & 688612 & 5.35 & 4.6602 & TRN & \\
\hline CHEMBL3192546 & 688612 & 4.45 & 4.6927 & TRN & \\
\hline CHEMBL1376458 & 688612 & 4.05 & \multicolumn{2}{|c|}{4.611000000000001} & TRN \\
\hline CHEMBL1465249 & 688612 & 5.1 & 4.6394 & TRN & \\
\hline CHEMBL1338464 & 688612 & 4.1 & 4.6187 & TRN & \\
\hline CHEMBL57013 & 688612 & 5.0 & 4.6476 & TST & \\
\hline CHEMBL1363707 & 688612 & 4.85 & 4.6486 & TRN & \\
\hline CHEMBL1505881 & 688612 & 4.05 & 4.5545 & TRN & \\
\hline CHEMBL1601725 & 688612 & 4.1 & 4.6949 & TRN & \\
\hline CHEMBL1493954 & 688612 & 4.65 & 4.6546 & TST & \\
\hline CHEMBL1324973 & 688612 & 6.15 & 4.5991 & TRN & \\
\hline CHEMBL1483828 & 688612 & 5.5 & 4.5887 & TRN & \\
\hline CHEMBL1462919 & 688612 & 6.35 & 4.6623 & TST & \\
\hline CHEMBL3190287 & 688612 & 4.75 & 4.7919 & TRN & \\
\hline CHEMBL1335863 & 688612 & 4.65 & 4.6753 & TRN & \\
\hline CHEMBL1411229 & 688612 & 4.25 & 4.6567 & TRN & \\
\hline CHEMBL1571463 & 688612 & 6.8499 & 4.6398 & TRN & \\
\hline CHEMBL1407474 & 688612 & 6.15 & 4.6969 & TST & \\
\hline CHEMBL1546688 & 688612 & 4.5 & 4.7366 & TST & \\
\hline CHEMBL1320663 & 688612 & 4.7 & 4.6187 & TRN & \\
\hline CHEMBL1600815 & 688612 & 4.05 & 4.6142 & TRN & \\
\hline CHEMBL1357053 & 688612 & 6.5501 & 4.6145 & TRN & \\
\hline CHEMBL1378076 & 688612 & 6.45 & 4.6508 & TST & \\
\hline CHEMBL1341056 & 688612 & 4.4 & 4.6774 & TST & \\
\hline CHEMBL1571560 & 688612 & 4.95 & 4.8165 & TRN & \\
\hline CHEMBL1562364 & 688612 & 4.85 & 4.59699 & 99999999995 & TST \\
\hline CHEMBL 2006078 & 688612 & 4.75 & 4.7727 & TRN & \\
\hline CHEMBL1447158 & 688612 & 5.1 & 4.6508 & TST & \\
\hline CHEMBL1554416 & 688612 & 4.65 & 4.6196 & TRN & \\
\hline CHEMBL1507911 & 688612 & 4.0 & 4.7208 & TST & \\
\hline CHEMBL1511381 & 688612 & 4.35 & 4.6284 & TST & \\
\hline CHEMBL1538897 & 688612 & 5.5 & 4.5708 & TRN & \\
\hline CHEMBL1335373 & 688612 & 4.5 & 4.5987 & TRN & \\
\hline CHEMBL1301028 & 688612 & 4.75 & 4.7293 & TST & \\
\hline CHEMBL1561102 & 688612 & 4.5 & 4.6989 & TRN & \\
\hline CHEMBL1340437 & 688612 & 4.05 & 4.7013 & TRN & \\
\hline CHEMBL1588731 & 688612 & 4.1 & 4.6124 & TRN & \\
\hline CHEMBL1564402 & 688612 & 4.3 & 4.6574 & TRN & \\
\hline CHEMBL1326914 & 688612 & 4.5 & 4.6587 & TRN & \\
\hline CHEMBL1538589 & 688612 & 4.1 & 4.6895 & TRN & \\
\hline CHEMBL1378944 & 688612 & 4.0 & 4.731 & TST & \\
\hline CHEMBL1572882 & 688612 & 5.1 & 4.698 & TRN & \\
\hline
\end{tabular}




\begin{tabular}{|c|c|c|c|c|}
\hline \multicolumn{5}{|c|}{ Supplemental Table S2.txt } \\
\hline CHEMBL1319885 & 688612 & 4.4 & 4.6322 & TST \\
\hline CHEMBL1356153 & 688612 & 4.55 & 4.6507 & TRN \\
\hline CHEMBL1348243 & 688612 & 5.0 & 4.6809 & TST \\
\hline CHEMBL1553091 & 688612 & 4.1 & 4.6082 & TRN \\
\hline CHEMBL1601116 & 688612 & 4.0 & 4.6729 & TST \\
\hline CHEMBL1974740 & 688612 & 4.65 & 4.6983 & TRN \\
\hline CHEMBL1460804 & 688612 & 4.05 & 4.6494 & TRN \\
\hline CHEMBL1551215 & 688612 & 4.35 & 4.5978 & TRN \\
\hline CHEMBL1303939 & 688612 & 4.65 & 4.7409 & TRN \\
\hline CHEMBL1993662 & 688612 & 4.1 & 4.704 & TRN \\
\hline CHEMBL1453598 & 688612 & 4.65 & 4.5216 & TRN \\
\hline CHEMBL1543976 & 688612 & 5.35 & 4.6844 & TRN \\
\hline CHEMBL1567690 & 688612 & 4.05 & 4.7349 & TRN \\
\hline CHEMBL1467130 & 688612 & 4.1 & 4.5893 & TRN \\
\hline CHEMBL1958246 & 688612 & 4.1 & 4.7659 & TRN \\
\hline CHEMBL 214321 & 688612 & 4.4 & 4.805 & TRN \\
\hline CHEMBL1398372 & 688612 & 4.15 & 4.6681 & TST \\
\hline CHEMBL1421980 & 688612 & 4.5 & 4.694 & TRN \\
\hline CHEMBL1500722 & 688612 & 5.55 & 4.6099 & TRN \\
\hline CHEMBL1414628 & 688612 & 4.05 & 4.6842 & TST \\
\hline CHEMBL1595465 & 688612 & 4.05 & 4.7865 & TRN \\
\hline CHEMBL187266 & 688612 & 4.65 & 4.7482 & TRN \\
\hline CHEMBL1613538 & 688612 & 4.1 & 4.7017 & TRN \\
\hline CHEMBL1533038 & 688612 & 4.1 & 4.6334 & TST \\
\hline CHEMBL1391159 & 688612 & 4.45 & 4.7144 & TRN \\
\hline CHEMBL1300870 & 688612 & 4.55 & 4.6638 & TST \\
\hline CHEMBL1544739 & 688612 & 4.5 & 4.6448 & TRN \\
\hline CHEMBL1471171 & 688612 & 4.55 & 4.6856 & TRN \\
\hline CHEMBL1362723 & 688612 & 4.65 & 4.7308 & TST \\
\hline CHEMBL1428894 & 688612 & 4.3 & 4.6448 & TST \\
\hline CHEMBL 3210405 & 688612 & 4.6 & 4.7063 & TRN \\
\hline CHEMBL1593911 & 688612 & 5.75 & 4.6171 & TST \\
\hline CHEMBL1408840 & 688612 & 5.45 & 4.7107 & TRN \\
\hline CHEMBL1336054 & 688612 & 5.45 & 4.7514 & TRN \\
\hline CHEMBL3212905 & 688612 & 6.05 & 4.7375 & TST \\
\hline CHEMBL1321972 & 688612 & 4.05 & 4.6734 & TST \\
\hline CHEMBL3213794 & 688612 & 4.2 & 4.7198 & TRN \\
\hline CHEMBL1569927 & 688612 & 4.15 & 4.6918 & TRN \\
\hline CHEMBL1454925 & 688612 & 4.6 & 4.5432 & TRN \\
\hline CHEMBL1531549 & 688612 & 6.5501 & 4.5536 & TST \\
\hline CHEMBL1421076 & 688612 & 4.55 & 4.6547 & TRN \\
\hline CHEMBL1477073 & 688612 & 4.05 & 4.5865 & TRN \\
\hline CHEMBL1369307 & 688612 & 4.25 & 4.6429 & TRN \\
\hline CHEMBL1570412 & 688612 & 4.25 & 4.6219 & TRN \\
\hline CHEMBL1574232 & 688612 & 5.1 & 4.5529 & TRN \\
\hline CHEMBL1528770 & 688612 & 6.25 & 4.6062 & TRN \\
\hline CHEMBL1455190 & 688612 & 4.65 & 4.5978 & TRN \\
\hline CHEMBL1573455 & 688612 & 4.15 & 4.7055 & TST \\
\hline
\end{tabular}




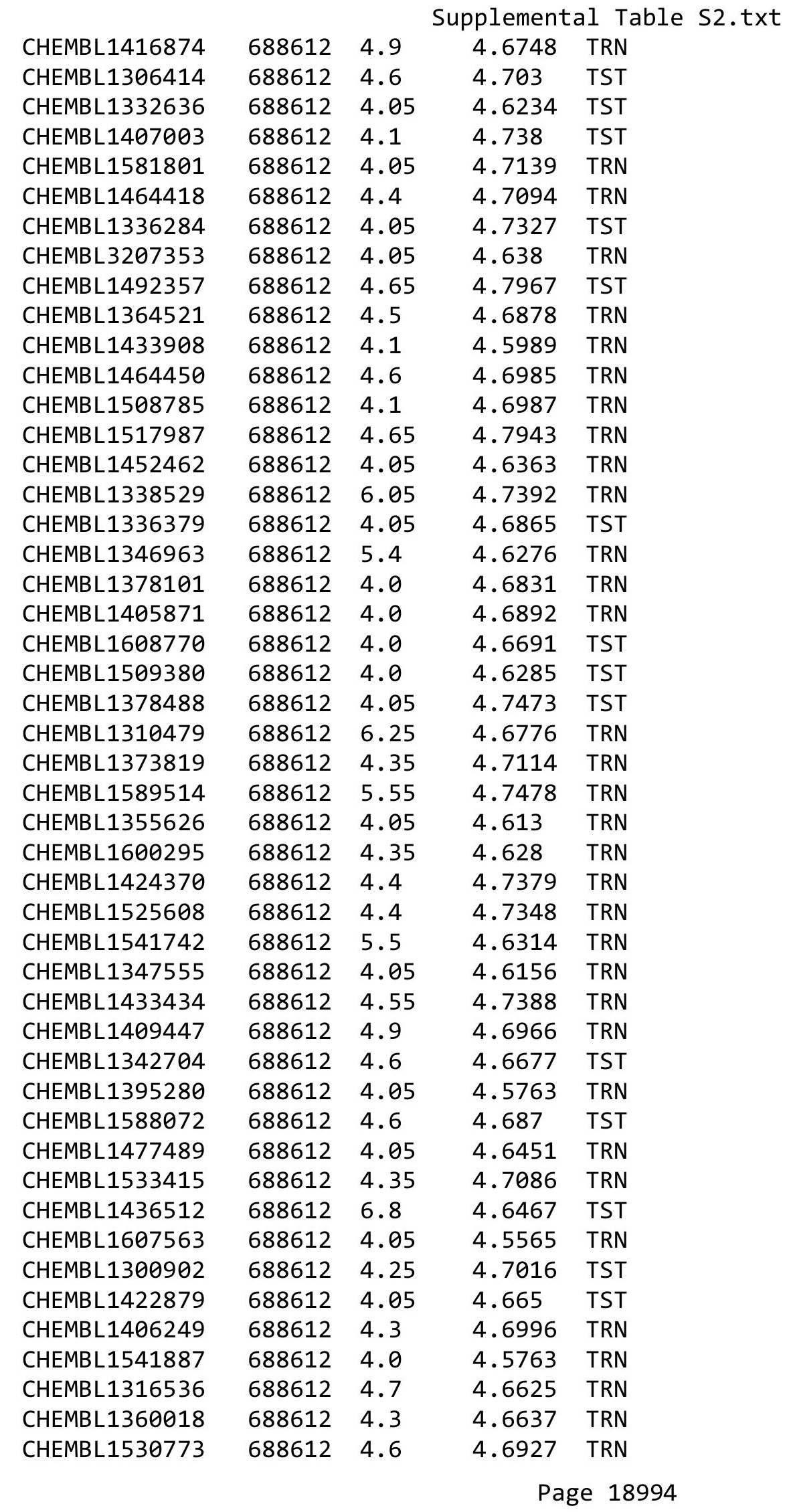




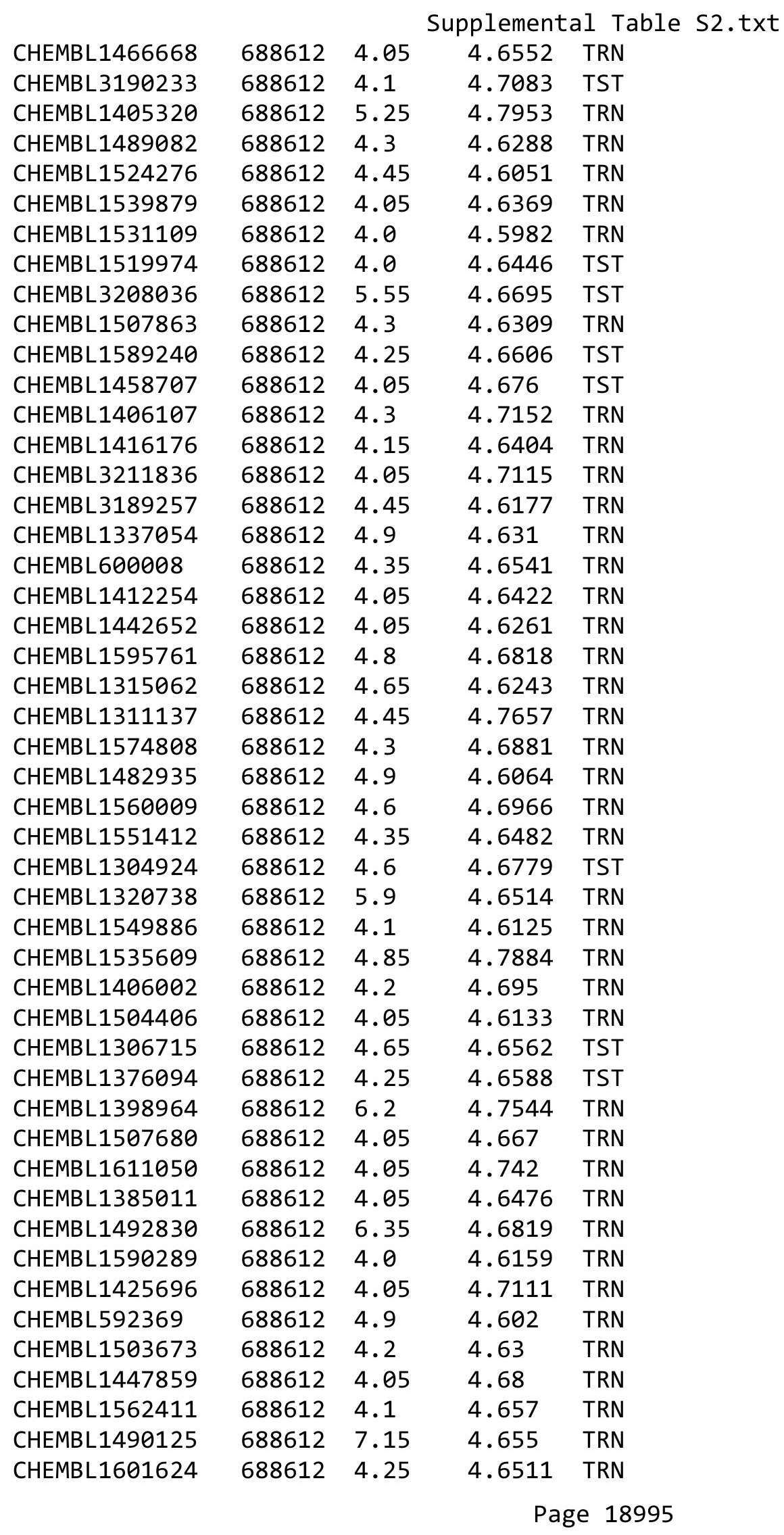




\begin{tabular}{|c|c|c|c|c|}
\hline \multicolumn{5}{|c|}{ Supplemental Table S2.txt } \\
\hline CHEMBL1302827 & 688612 & 4.4 & 4.785 & TRN \\
\hline CHEMBL1502818 & 688612 & 4.5 & 4.7121 & TST \\
\hline CHEMBL1500886 & 688612 & 7.0 & 4.5909 & TRN \\
\hline CHEMBL1521448 & 688612 & 4.3 & 4.6481 & TRN \\
\hline CHEMBL1463442 & 688612 & 4.1 & 4.6899 & TRN \\
\hline CHEMBL1432593 & 688612 & 4.4 & 4.6488 & TRN \\
\hline CHEMBL1443689 & 688612 & 4.25 & 4.6153 & TST \\
\hline CHEMBL1379672 & 688612 & 4.05 & 4.5479 & TRN \\
\hline CHEMBL1571678 & 688612 & 6.8 & 4.5705 & TRN \\
\hline CHEMBL1376834 & 688612 & 4.2 & 4.5392 & TRN \\
\hline CHEMBL1493191 & 688612 & 5.5 & 4.8647 & TRN \\
\hline CHEMBL1423496 & 688612 & 4.6 & 4.8017 & TRN \\
\hline CHEMBL1549546 & 688612 & 4.75 & 4.7903 & TRN \\
\hline CHEMBL1307247 & 688612 & 4.6 & 4.7029 & TRN \\
\hline CHEMBL1452197 & 688612 & 6.0 & 4.6306 & TRN \\
\hline CHEMBL1398576 & 688612 & 6.1 & 4.5779 & TRN \\
\hline CHEMBL1407868 & 688612 & 4.45 & 4.6724 & TST \\
\hline CHEMBL1471925 & 688612 & 4.4 & 4.6697 & TRN \\
\hline CHEMBL1499040 & 688612 & 4.05 & 4.6434 & TRN \\
\hline CHEMBL1423524 & 688612 & 5.55 & 4.797 & TST \\
\hline CHEMBL1543094 & 688612 & 4.4 & 4.7328 & TST \\
\hline CHEMBL1552143 & 688612 & 4.65 & 4.6741 & TRN \\
\hline CHEMBL1499404 & 688612 & 4.45 & 4.6695 & TST \\
\hline CHEMBL1527258 & 688612 & 4.55 & 4.6772 & TST \\
\hline CHEMBL1397485 & 688612 & 4.8 & 4.6146 & TRN \\
\hline CHEMBL1431135 & 688612 & 4.05 & 4.7557 & TST \\
\hline CHEMBL1528830 & 688612 & 4.1 & 4.7356 & TRN \\
\hline CHEMBL1471381 & 688612 & 6.3 & 4.6584 & TRN \\
\hline CHEMBL1325208 & 688612 & 4.1 & 4.7707 & TST \\
\hline CHEMBL1475987 & 688612 & 5.2 & 4.7171 & TST \\
\hline CHEMBL1526796 & 688612 & 4.1 & 4.6554 & TRN \\
\hline CHEMBL1609690 & 688612 & 4.3 & 4.8193 & TST \\
\hline CHEMBL1390036 & 688612 & 4.95 & 4.6682 & TRN \\
\hline CHEMBL1539251 & 688612 & 4.85 & 4.6812 & TRN \\
\hline CHEMBL1484978 & 688612 & 4.05 & 4.702 & TRN \\
\hline CHEMBL1546791 & 688612 & 4.45 & 4.7879 & TST \\
\hline CHEMBL1324900 & 688612 & 5.55 & 4.6342 & TRN \\
\hline CHEMBL1459571 & 688612 & 4.85 & 4.6675 & TRN \\
\hline CHEMBL1367742 & 688612 & 4.8 & 4.6491 & TRN \\
\hline CHEMBL1585790 & 688612 & 5.4 & 4.6411 & TRN \\
\hline CHEMBL1333337 & 688612 & 5.5 & 4.629 & TRN \\
\hline CHEMBL1341867 & 688612 & 4.45 & 4.7899 & TRN \\
\hline CHEMBL1449413 & 688612 & 4.05 & 4.6444 & TRN \\
\hline CHEMBL1342716 & 688612 & 4.3 & 4.7194 & TRN \\
\hline CHEMBL1543239 & 688612 & 4.05 & 4.6022 & TRN \\
\hline CHEMBL1410633 & 688612 & 5.0 & 4.6411 & TRN \\
\hline CHEMBL1334803 & 688612 & 6.8499 & 4.6995 & TRN \\
\hline CHEMBL1391235 & 688612 & 4.3 & 4.7315 & TST \\
\hline
\end{tabular}




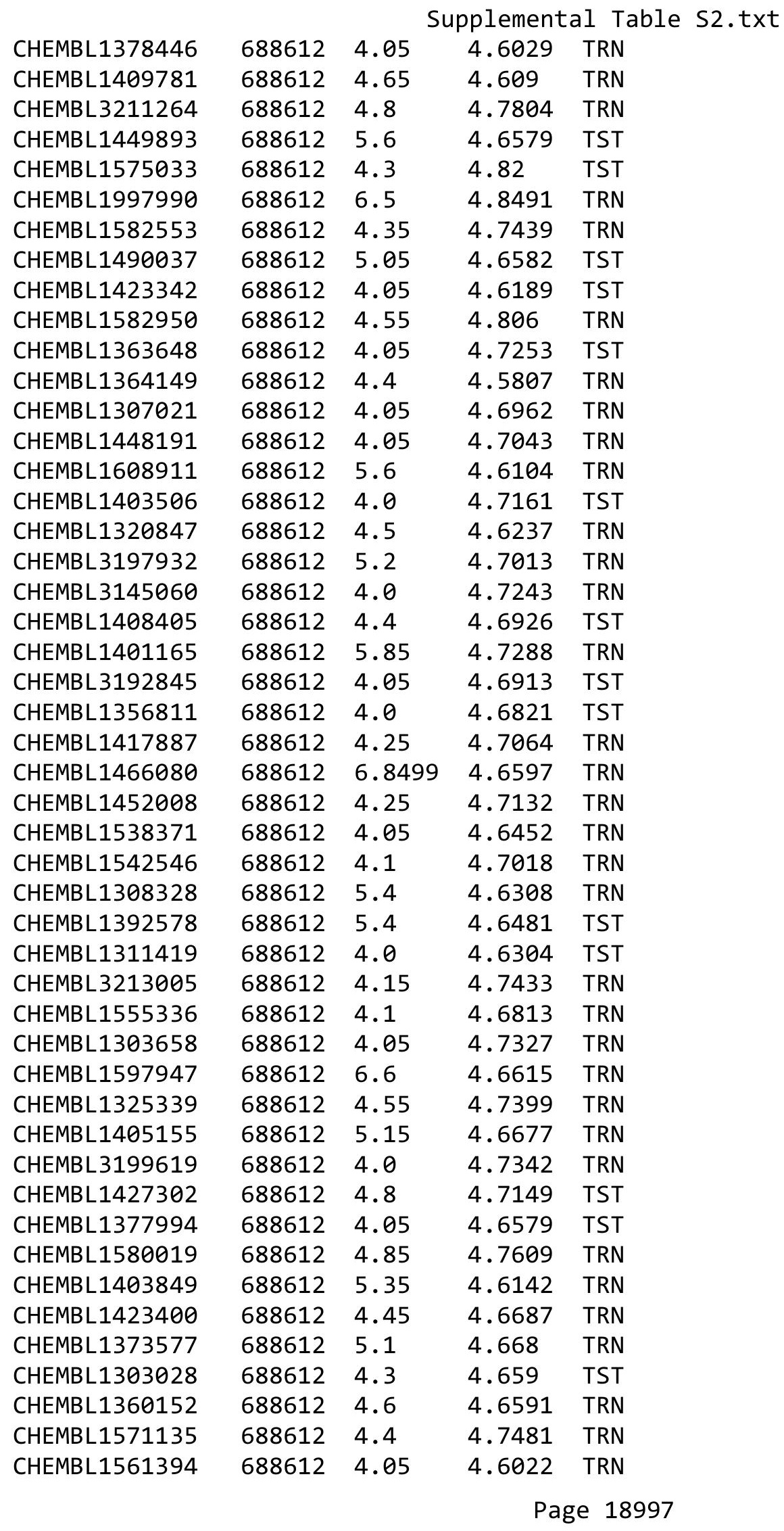




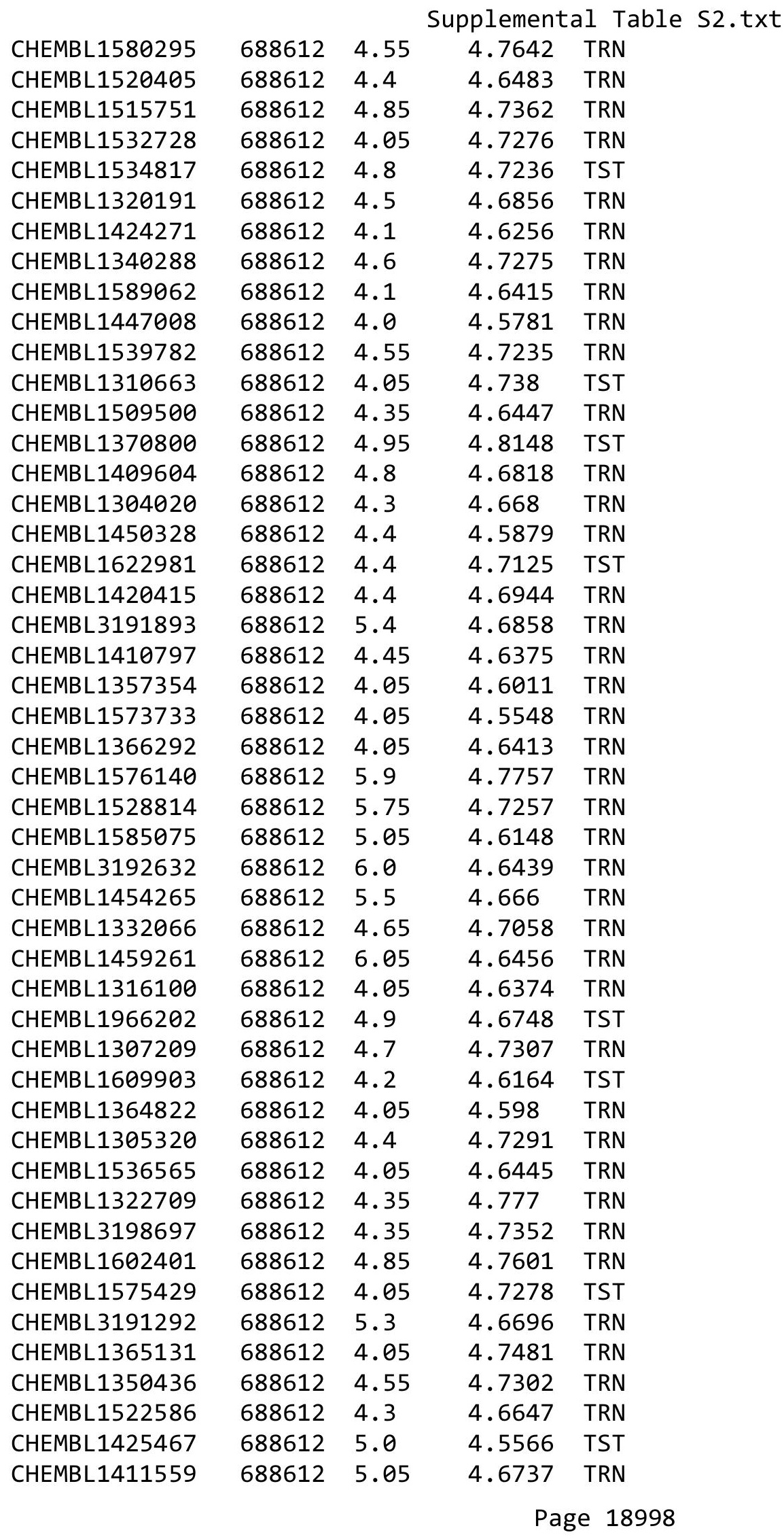




\begin{tabular}{|c|c|c|c|c|c|}
\hline & & \multicolumn{4}{|c|}{ Supplemental Table S2.txt } \\
\hline CHEMBL1452185 & 688612 & 5.0 & 4.7253 & TRN & \\
\hline CHEMBL1335669 & 688612 & 5.05 & 4.6609 & TST & \\
\hline CHEMBL1436891 & 688612 & 4.05 & 4.6468 & TRN & \\
\hline CHEMBL1312836 & 688612 & 4.65 & 4.721 & TRN & \\
\hline CHEMBL1576282 & 688612 & 4.05 & 4.651 & TRN & \\
\hline CHEMBL1309006 & 688612 & 6.15 & 4.6349 & TRN & \\
\hline CHEMBL1484234 & 688612 & 4.65 & 4.7411 & TST & \\
\hline CHEMBL1320319 & 688612 & 4.75 & 4.7722 & TRN & \\
\hline CHEMBL1331372 & 688612 & 4.75 & 4.7122 & TRN & \\
\hline CHEMBL1383729 & 688612 & 4.05 & 4.6752 & TRN & \\
\hline CHEMBL1319908 & 688612 & 4.9 & 4.7155 & TRN & \\
\hline CHEMBL1311631 & 688612 & 4.75 & 4.6499 & TRN & \\
\hline CHEMBL1564716 & 688612 & 4.7 & 4.7164 & TRN & \\
\hline CHEMBL1491865 & 688612 & 6.6499 & 4.7437 & TST & \\
\hline CHEMBL1590807 & 688612 & 4.0 & 4.6501 & TST & \\
\hline CHEMBL1488373 & 688612 & 4.2 & 4.6224 & TRN & \\
\hline CHEMBL1594770 & 688612 & 4.1 & 4.6212 & TRN & \\
\hline CHEMBL1576730 & 688612 & 4.4 & 4.6995 & TRN & \\
\hline CHEMBL1548822 & 688612 & 5.0 & 4.7973 & TRN & \\
\hline CHEMBL1415426 & 688612 & 5.05 & 4.7208 & TRN & \\
\hline CHEMBL1981200 & 688612 & 5.45 & 4.7342 & TRN & \\
\hline CHEMBL244948 & 688612 & 4.85 & 4.856 & TST & \\
\hline CHEMBL1536738 & 688612 & 4.05 & 4.7386 & TST & \\
\hline CHEMBL3191746 & 688612 & 6.8499 & 4.7198 & TST & \\
\hline CHEMBL1554097 & 688612 & 4.2 & 4.64 & TRN & \\
\hline CHEMBL1340470 & 688612 & 6.5501 & 4.7014 & TST & \\
\hline CHEMBL1478133 & 688612 & 4.1 & 4.7341 & TST & \\
\hline CHEMBL1318940 & 688612 & 4.3 & 4.6821 & TST & \\
\hline CHEMBL1337286 & 688612 & 4.4 & 4.6197 & TRN & \\
\hline CHEMBL1313051 & 688612 & 4.1 & 4.7169 & TST & \\
\hline CHEMBL1389647 & 688612 & 4.05 & 4.6474 & TRN & \\
\hline CHEMBL1507527 & 688612 & 4.05 & 4.6539 & TST & \\
\hline CHEMBL1558573 & 688612 & 6.5 & 4.6911 & TRN & \\
\hline CHEMBL3208806 & 688612 & 4.0 & 4.669 & TRN & \\
\hline CHEMBL1481366 & 688612 & 4.55 & 4.6133 & TRN & \\
\hline CHEMBL1567877 & 688612 & 4.05 & 4.6823 & TST & \\
\hline CHEMBL1482647 & 688612 & 4.05 & 4.5906 & TRN & \\
\hline CHEMBL3207386 & 688612 & 4.0 & 4.7602 & TST & \\
\hline CHEMBL1482137 & 688612 & 4.0 & 4.7152 & TRN & \\
\hline CHEMBL1511344 & 688612 & 4.25 & 4.6593 & TRN & \\
\hline CHEMBL1600306 & 688612 & 4.45 & 4.79899 & 99999999995 & TRN \\
\hline CHEMBL1586636 & 688612 & 4.3 & 4.6546 & TST & \\
\hline CHEMBL1371033 & 688612 & 6.1 & 4.7107 & TRN & \\
\hline CHEMBL1392259 & 688612 & 4.3 & 4.6724 & TRN & \\
\hline CHEMBL601757 & 688612 & 6.25 & 4.717 & TRN & \\
\hline CHEMBL 3213422 & 688612 & 6.0 & 4.6633 & TRN & \\
\hline CHEMBL1532111 & 688612 & 4.4 & 4.7377 & TST & \\
\hline CHEMBL3197607 & 688612 & 4.7 & 4.6938 & TST & \\
\hline
\end{tabular}




\begin{tabular}{|c|c|c|c|c|}
\hline \multicolumn{5}{|c|}{ Supplemental Table S2.txt } \\
\hline CHEMBL1344498 & 688612 & 4.8 & 4.6993 & TRN \\
\hline CHEMBL1343244 & 688612 & 4.1 & 4.758 & TST \\
\hline CHEMBL1514546 & 688612 & 7.1002 & 4.738 & TRN \\
\hline CHEMBL1596526 & 688612 & 4.05 & 4.7154 & TST \\
\hline CHEMBL1588052 & 688612 & 5.5 & 4.7697 & TRN \\
\hline CHEMBL1482944 & 688612 & 4.0 & 4.7318 & TRN \\
\hline CHEMBL1503211 & 688612 & 4.05 & 4.7212 & TRN \\
\hline CHEMBL1530364 & 688612 & 4.5 & 4.63 & TST \\
\hline CHEMBL1572171 & 688612 & 4.4 & 4.6053 & TRN \\
\hline CHEMBL1520101 & 688612 & 4.95 & 4.6691 & TRN \\
\hline CHEMBL1515203 & 688612 & 4.8 & 4.74 & TST \\
\hline CHEMBL1564677 & 688612 & 6.15 & 4.6295 & TRN \\
\hline CHEMBL1525874 & 688612 & 4.0 & 4.613 & TRN \\
\hline CHEMBL3193188 & 688612 & 6.8499 & 4.6372 & TST \\
\hline CHEMBL1485038 & 688612 & 4.05 & 4.6493 & TRN \\
\hline CHEMBL1457139 & 688612 & 4.3 & 4.7479 & TST \\
\hline CHEMBL1358062 & 688612 & 4.0 & 4.6145 & TRN \\
\hline CHEMBL1576742 & 688612 & 4.3 & 4.6749 & TRN \\
\hline CHEMBL1601217 & 688612 & 4.4 & 4.7712 & TRN \\
\hline CHEMBL1495138 & 688612 & 4.1 & 4.7566 & TRN \\
\hline CHEMBL1560509 & 688612 & 4.3 & 4.6922 & TRN \\
\hline CHEMBL3190375 & 688612 & 4.65 & 4.6681 & TST \\
\hline CHEMBL1560395 & 688612 & 4.05 & 4.5865 & TRN \\
\hline CHEMBL1556190 & 688612 & 5.35 & 4.6486 & TRN \\
\hline CHEMBL1350637 & 688612 & 4.95 & 4.789 & TRN \\
\hline CHEMBL1407151 & 688612 & 4.55 & 4.6877 & TRN \\
\hline CHEMBL1301374 & 688612 & 4.05 & 4.6739 & TST \\
\hline CHEMBL1555271 & 688612 & 4.05 & 4.6319 & TRN \\
\hline CHEMBL3197491 & 688612 & 4.05 & 4.7822 & TRN \\
\hline CHEMBL 357170 & 688612 & 4.15 & 4.6937 & TRN \\
\hline CHEMBL1422139 & 688612 & 4.45 & 4.7458 & TST \\
\hline CHEMBL1553852 & 688612 & 5.05 & 4.6522 & TRN \\
\hline CHEMBL1988686 & 688612 & 4.65 & 4.635 & TRN \\
\hline CHEMBL1539063 & 688612 & 4.3 & 4.7713 & TST \\
\hline CHEMBL1336604 & 688612 & 4.45 & 4.6878 & TRN \\
\hline CHEMBL1396059 & 688612 & 5.0 & 4.6635 & TST \\
\hline CHEMBL1324556 & 688612 & 4.65 & 4.6957 & TRN \\
\hline CHEMBL1448340 & 688612 & 5.55 & 4.7241 & TRN \\
\hline CHEMBL1334586 & 688612 & 4.75 & 4.6996 & TRN \\
\hline CHEMBL1376051 & 688612 & 5.25 & 4.6359 & TRN \\
\hline CHEMBL1308530 & 688612 & 4.45 & 4.6741 & TRN \\
\hline CHEMBL1438705 & 688612 & 4.05 & 4.6706 & TRN \\
\hline CHEMBL1471405 & 688612 & 4.35 & 4.6801 & TRN \\
\hline CHEMBL1426512 & 688612 & 4.8 & 4.6833 & TRN \\
\hline CHEMBL1520667 & 688612 & 4.6 & 4.7673 & TRN \\
\hline CHEMBL1328041 & 688612 & 5.05 & 4.6381 & TRN \\
\hline CHEMBL1594651 & 688612 & 4.4 & 4.6614 & TRN \\
\hline CHEMBL1500543 & 688612 & 4.05 & 4.6911 & TST \\
\hline
\end{tabular}




\begin{tabular}{|c|c|c|c|c|c|}
\hline \multirow[b]{2}{*}{ CHEMBL1348962 } & \multicolumn{5}{|c|}{ Supplemental Table S2.txt } \\
\hline & 688612 & 6.5501 & 4.7193 & TRN & \\
\hline CHEMBL3193530 & 688612 & 4.3 & 4.7057 & TST & \\
\hline CHEMBL1317991 & 688612 & 4.85 & 4.675 & TST & \\
\hline CHEMBL1593674 & 688612 & 4.3 & 4.63899 & 9999999999 & TRN \\
\hline CHEMBL1501520 & 688612 & 6.05 & 4.6272 & TRN & \\
\hline CHEMBL1597346 & 688612 & 4.0 & 4.67 & TRN & \\
\hline CHEMBL1964393 & 688612 & 5.8 & 4.8162 & TST & \\
\hline CHEMBL1529467 & 688612 & 6.4 & 4.6548 & TRN & \\
\hline CHEMBL1385609 & 688612 & 4.4 & 4.7059 & TST & \\
\hline CHEMBL1315619 & 688612 & 4.25 & 4.6359 & TRN & \\
\hline CHEMBL1528508 & 688612 & 4.05 & 4.6543 & TST & \\
\hline CHEMBL1575894 & 688612 & 4.05 & 4.6619 & TRN & \\
\hline CHEMBL1492622 & 688612 & 4.55 & 4.7087 & TRN & \\
\hline CHEMBL1416077 & 688612 & 4.4 & 4.6901 & TRN & \\
\hline CHEMBL1377537 & 688612 & 4.05 & 4.64199 & 99999999995 & TST \\
\hline CHEMBL1404514 & 688612 & 5.45 & 4.609 & TRN & \\
\hline CHEMBL1373060 & 688612 & 4.5 & 4.6273 & TRN & \\
\hline CHEMBL1574673 & 688612 & 4.05 & 4.5651 & TRN & \\
\hline CHEMBL3208993 & 688612 & 4.05 & 4.6999 & TRN & \\
\hline CHEMBL1412412 & 688612 & 4.4 & 4.61 & TST & \\
\hline CHEMBL1449940 & 688612 & 4.8 & 4.5835 & TRN & \\
\hline CHEMBL1491858 & 688612 & 4.0 & 4.6586 & TST & \\
\hline CHEMBL1581302 & 688612 & 6.05 & 4.708 & TST & \\
\hline CHEMBL1601616 & 688612 & 4.05 & 4.6503 & TRN & \\
\hline CHEMBL1412226 & 688612 & 4.25 & 4.7526 & TRN & \\
\hline CHEMBL3193768 & 688612 & 5.65 & 4.6411 & TRN & \\
\hline CHEMBL1536762 & 688612 & 4.0 & 4.7098 & TRN & \\
\hline CHEMBL1587704 & 688612 & 6.15 & 4.6566 & TRN & \\
\hline CHEMBL1593975 & 688612 & 4.05 & 4.6336 & TRN & \\
\hline CHEMBL1320710 & 688612 & 4.05 & 4.6164 & TRN & \\
\hline CHEMBL1467293 & 688612 & 4.8 & 4.5713 & TRN & \\
\hline CHEMBL1374596 & 688612 & 4.05 & 4.6655 & TRN & \\
\hline CHEMBL1494656 & 688612 & 4.6 & 4.7935 & TRN & \\
\hline CHEMBL1566829 & 688612 & 4.2 & 4.5364 & TRN & \\
\hline CHEMBL1996757 & 688612 & 4.4 & 4.7117 & TRN & \\
\hline CHEMBL1541229 & 688612 & 4.7 & 4.6352 & TRN & \\
\hline CHEMBL1573639 & 688612 & 4.0 & 4.7231 & TRN & \\
\hline CHEMBL1543865 & 688612 & 4.65 & 4.6417 & TRN & \\
\hline CHEMBL1589300 & 688612 & 5.25 & 4.7672 & TST & \\
\hline CHEMBL1329538 & 688612 & 4.05 & 4.6504 & TST & \\
\hline CHEMBL1376663 & 688612 & 4.5 & 4.6627 & TRN & \\
\hline CHEMBL1405559 & 688612 & 5.0 & 4.662 & TRN & \\
\hline CHEMBL1377475 & 688612 & 4.05 & 4.7137 & TRN & \\
\hline CHEMBL1554075 & 688612 & 5.65 & 4.5865 & TST & \\
\hline CHEMBL1529703 & 688612 & 4.05 & 4.6356 & TRN & \\
\hline CHEMBL1969593 & 688612 & 4.65 & 4.6691 & TRN & \\
\hline CHEMBL1510086 & 688612 & 4.15 & 4.7381 & TRN & \\
\hline CHEMBL1609499 & 688612 & 4.8 & 4.7404 & TST & \\
\hline
\end{tabular}




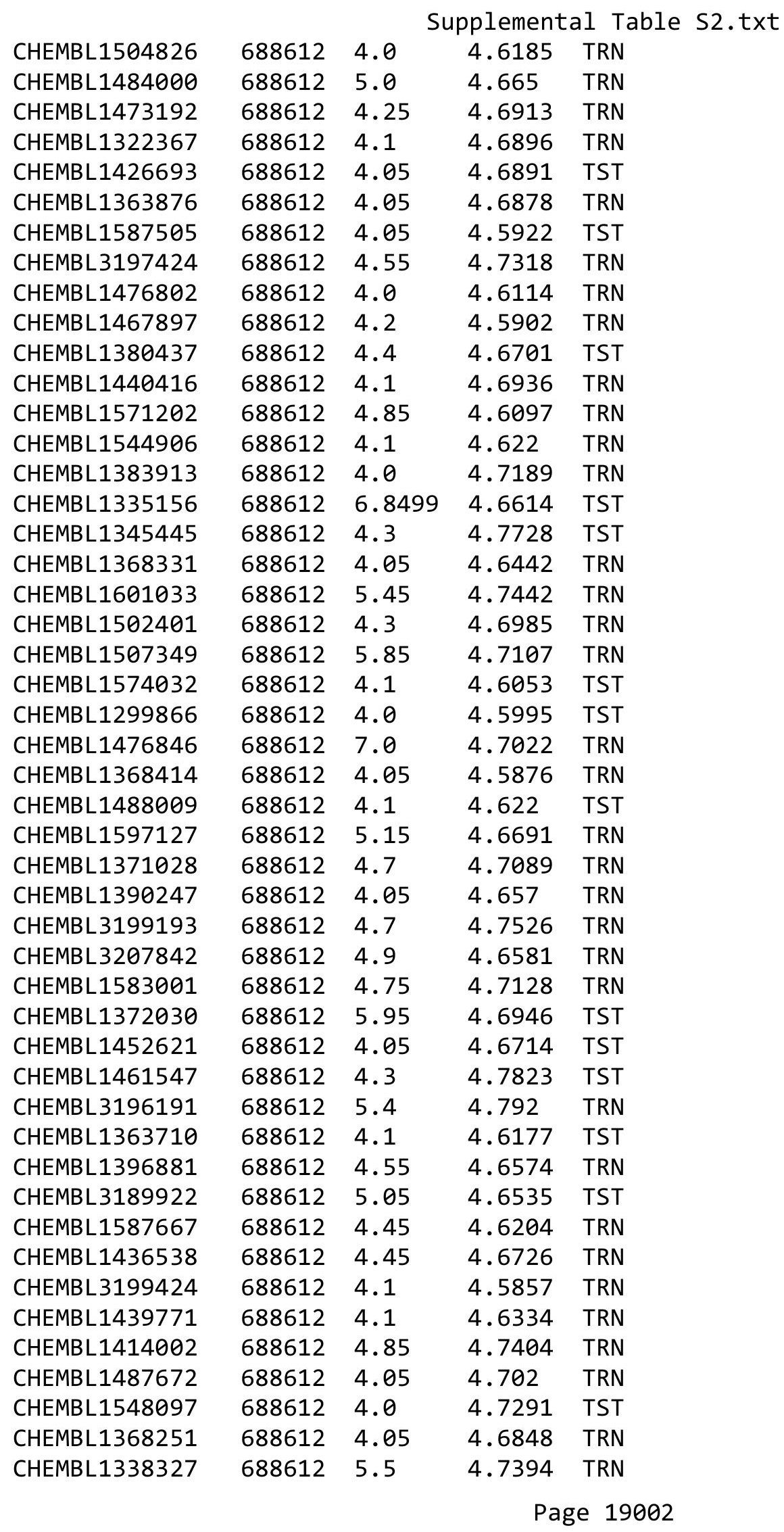




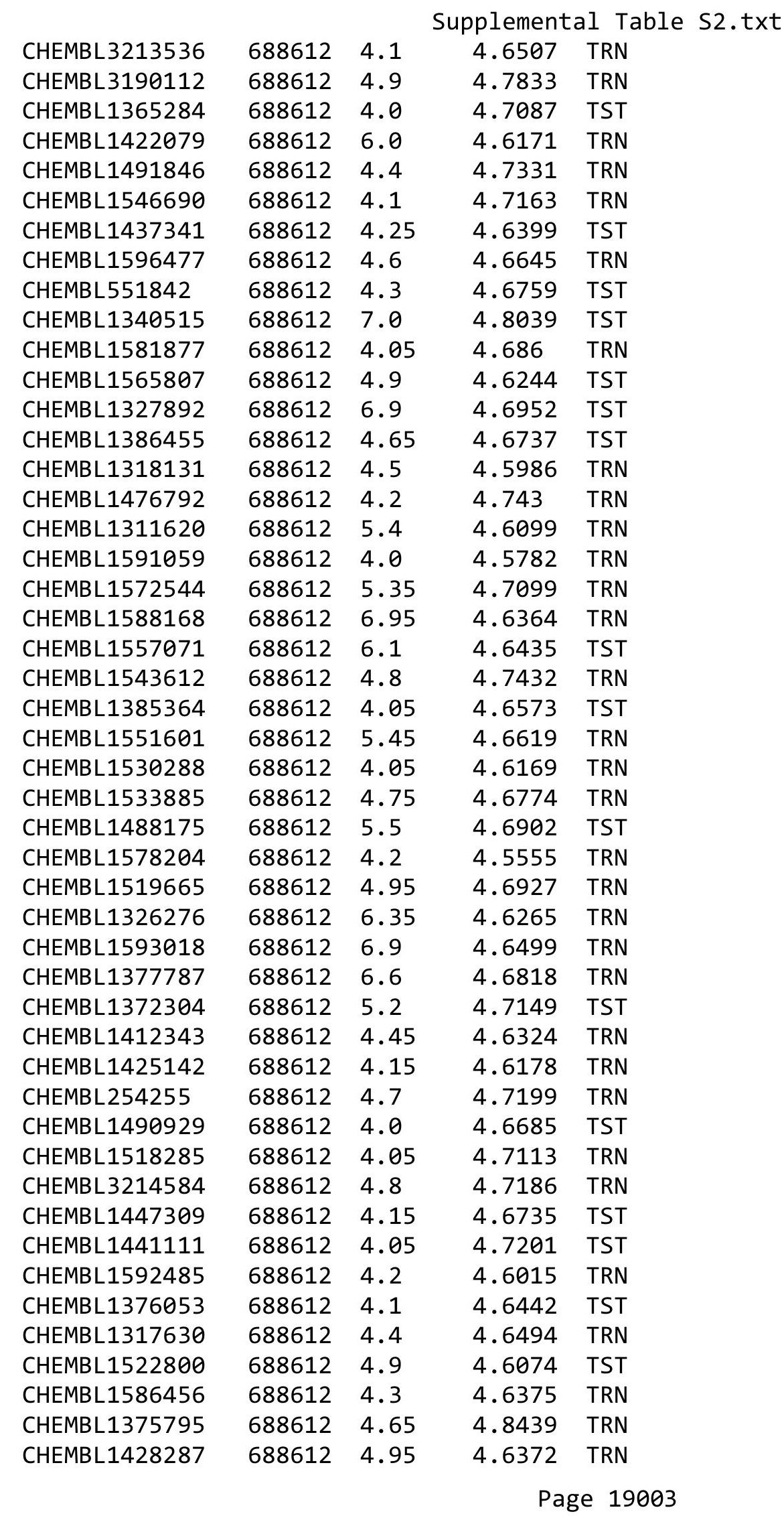




\begin{tabular}{|c|c|c|c|c|c|}
\hline \multicolumn{6}{|c|}{ Supplemental Table s2.txt } \\
\hline CHEMBL1566216 & 688612 & 4.6 & 4.6766 & TRN & \\
\hline CHEMBL1594479 & 688612 & 7.0 & 4.651 & TRN & \\
\hline CHEMBL609606 & 688612 & 4.65 & 4.703 & TRN & \\
\hline CHEMBL3198927 & 688612 & 4.6 & 4.6766 & TST & \\
\hline CHEMBL1568782 & 688612 & 5.15 & 4.6705 & TRN & \\
\hline CHEMBL1545869 & 688612 & 4.05 & 4.6841 & TST & \\
\hline CHEMBL1483841 & 688612 & 4.05 & 4.6268 & TRN & \\
\hline CHEMBL1534959 & 688612 & 6.0 & 4.7561 & TRN & \\
\hline CHEMBL1998061 & 688612 & 4.05 & 4.7861 & TST & \\
\hline CHEMBL578512 & 688612 & 4.05 & 4.723 & TRN & \\
\hline CHEMBL1522018 & 688612 & 4.1 & 4.6886 & TRN & \\
\hline CHEMBL1439545 & 688612 & 6.4 & 4.6684 & TRN & \\
\hline CHEMBL1528328 & 688612 & 4.4 & 4.6585 & TRN & \\
\hline CHEMBL1502555 & 688612 & 4.05 & 4.643 & TST & \\
\hline CHEMBL1461389 & 688612 & 4.7 & 4.6596 & TRN & \\
\hline CHEMBL1348155 & 688612 & 4.0 & 4.6235 & TST & \\
\hline CHEMBL1561728 & 688612 & 4.2 & 4.6073 & TST & \\
\hline CHEMBL236615 & 688612 & 5.55 & 4.8232 & TRN & \\
\hline CHEMBL1347158 & 688612 & 4.3 & 4.6045 & TRN & \\
\hline CHEMBL1603144 & 688612 & 5.95 & 4.7206 & TST & \\
\hline CHEMBL1452948 & 688612 & 5.05 & 4.6357 & TRN & \\
\hline CHEMBL1430914 & 688612 & 4.6 & 4.5886 & TRN & \\
\hline CHEMBL1443228 & 688612 & 4.55 & 4.6541 & TRN & \\
\hline CHEMBL1422983 & 688612 & 6.05 & 4.59699 & 99999999995 & TRN \\
\hline CHEMBL1528630 & 688612 & 4.05 & 4.6327 & TRN & \\
\hline CHEMBL1424422 & 688612 & 4.05 & 4.6468 & TST & \\
\hline CHEMBL1558749 & 688612 & 4.2 & 4.6718 & TRN & \\
\hline CHEMBL1604516 & 688612 & 4.4 & 4.7525 & TST & \\
\hline CHEMBL1384323 & 688612 & 4.7 & 4.6456 & TST & \\
\hline CHEMBL1566723 & 688612 & 4.05 & 4.6708 & TRN & \\
\hline CHEMBL1306217 & 688612 & 4.85 & 4.6411 & TRN & \\
\hline CHEMBL1503290 & 688612 & 4.05 & 4.7126 & TRN & \\
\hline CHEMBL1589110 & 688612 & 5.95 & 4.5943 & TST & \\
\hline CHEMBL1363116 & 688612 & 4.55 & 4.7093 & TRN & \\
\hline CHEMBL269277 & 688612 & 5.5 & 4.7237 & TST & \\
\hline CHEMBL1479051 & 688612 & 6.5 & 4.6261 & TRN & \\
\hline CHEMBL1300411 & 688612 & 4.1 & 4.7131 & TRN & \\
\hline CHEMBL1600245 & 688612 & 6.5 & 4.6996 & TRN & \\
\hline CHEMBL1312803 & 688612 & 5.05 & 4.609 & TST & \\
\hline CHEMBL1586910 & 688612 & 4.2 & 4.6075 & TRN & \\
\hline CHEMBL1331753 & 688612 & 5.45 & 4.7154 & TRN & \\
\hline CHEMBL1314680 & 688612 & 4.05 & 4.6422 & TST & \\
\hline CHEMBL1510726 & 688612 & 6.8 & 4.6455 & TST & \\
\hline CHEMBL1300484 & 688612 & 4.6 & 4.6788 & TST & \\
\hline CHEMBL1565098 & 688612 & 4.6 & 4.6766 & TRN & \\
\hline CHEMBL1581245 & 688612 & 4.7 & 4.6886 & TRN & \\
\hline CHEMBL3199013 & 688612 & 4.9 & 4.7949 & TRN & \\
\hline CHEMBL1601864 & 688612 & 4.55 & 4.6762 & TRN & \\
\hline
\end{tabular}




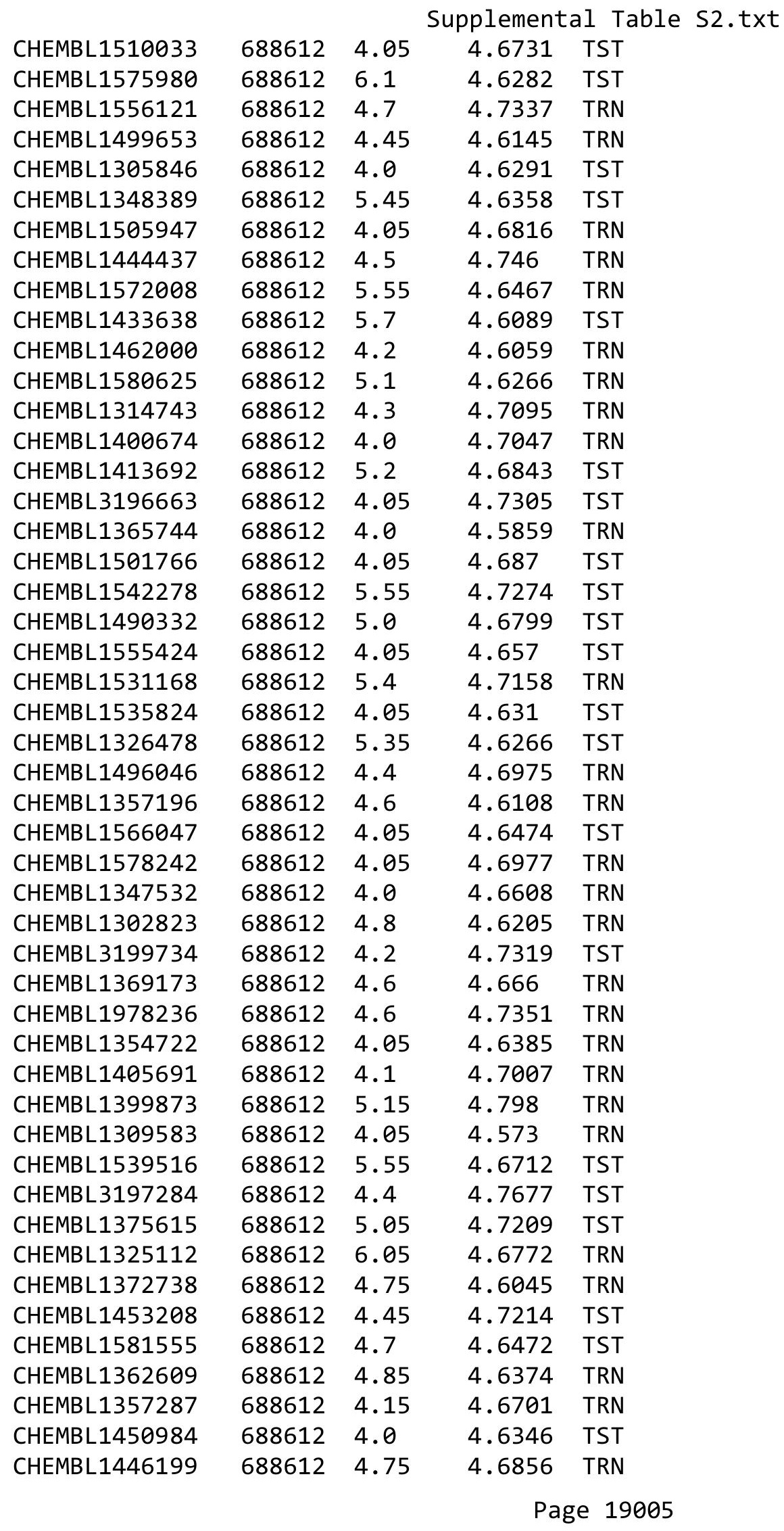




\begin{tabular}{|c|c|c|c|c|}
\hline \multicolumn{5}{|c|}{ Supplemental Table s2.txt } \\
\hline CHEMBL1172405 & 688612 & 4.5 & 4.6461 & TRN \\
\hline CHEMBL1306737 & 688612 & 4.6 & 4.6504 & TRN \\
\hline CHEMBL1528674 & 688612 & 5.1 & 4.6615 & TRN \\
\hline CHEMBL 3212102 & 688612 & 5.3 & 4.6669 & TRN \\
\hline CHEMBL1300246 & 688612 & 4.65 & 4.6161 & TRN \\
\hline CHEMBL1401221 & 688612 & 4.75 & 4.694 & TST \\
\hline CHEMBL1450318 & 688612 & 4.9 & 4.65306 & 00000000005 \\
\hline CHEMBL1533815 & 688612 & 4.8 & 4.6704 & TRN \\
\hline CHEMBL1488214 & 688612 & 5.95 & 4.7078 & TST \\
\hline CHEMBL1426796 & 688612 & 5.05 & 4.604 & TRN \\
\hline CHEMBL1314922 & 688612 & 4.6 & 4.6946 & TRN \\
\hline CHEMBL1329357 & 688612 & 4.2 & 4.6719 & TST \\
\hline CHEMBL1501261 & 688612 & 4.45 & 4.6344 & TRN \\
\hline CHEMBL1429248 & 688612 & 4.05 & 4.7025 & TST \\
\hline CHEMBL1505634 & 688612 & 4.5 & 4.7332 & TRN \\
\hline CHEMBL1487623 & 688612 & 4.1 & 4.7083 & TST \\
\hline CHEMBL1468231 & 688612 & 4.2 & 4.6295 & TRN \\
\hline CHEMBL1414537 & 688612 & 5.55 & 4.614 & TRN \\
\hline CHEMBL1513784 & 688612 & 6.7001 & 4.5589 & TRN \\
\hline CHEMBL3190841 & 688612 & 4.0 & 4.7572 & TRN \\
\hline CHEMBL1361152 & 688612 & 6.5501 & 4.5592 & TRN \\
\hline CHEMBL1332865 & 688612 & 4.8 & 4.6236 & TRN \\
\hline CHEMBL1344091 & 688612 & 5.55 & 4.7407 & TRN \\
\hline CHEMBL1599731 & 688612 & 4.3 & 4.6382 & TST \\
\hline CHEMBL1405054 & 688612 & 4.7 & 4.766 & TRN \\
\hline CHEMBL3192198 & 688612 & 4.35 & 4.7189 & TRN \\
\hline CHEMBL3191145 & 688612 & 4.4 & 4.8017 & TRN \\
\hline CHEMBL566474 & 688612 & 4.4 & 4.7227 & TRN \\
\hline CHEMBL1609016 & 688612 & 5.25 & 4.7747 & TST \\
\hline CHEMBL1359923 & 688612 & 4.55 & 4.6285 & TRN \\
\hline CHEMBL1586928 & 688612 & 4.0 & 4.6844 & TRN \\
\hline CHEMBL1378036 & 688612 & 4.6 & 4.6771 & TST \\
\hline CHEMBL1526990 & 688612 & 4.5 & 4.6055 & TRN \\
\hline CHEMBL1523097 & 688612 & 4.1 & 4.5975 & TRN \\
\hline CHEMBL1552903 & 688612 & 4.0 & 4.6071 & TRN \\
\hline CHEMBL1566424 & 688612 & 4.4 & 4.6916 & TST \\
\hline CHEMBL1492797 & 688612 & 4.4 & 4.6852 & TST \\
\hline CHEMBL1173475 & 688612 & 6.0 & 4.9128 & TRN \\
\hline CHEMBL1469996 & 688612 & 4.35 & 4.7124 & TST \\
\hline CHEMBL1601656 & 688612 & 4.2 & 4.6697 & TST \\
\hline CHEMBL1375676 & 688612 & 4.05 & 4.6234 & TST \\
\hline CHEMBL3194406 & 688612 & 5.0 & 4.6698 & TRN \\
\hline CHEMBL1527542 & 688612 & 4.05 & 4.7025 & TST \\
\hline CHEMBL1370817 & 688612 & 4.1 & 4.7159 & TST \\
\hline CHEMBL1400701 & 688612 & 4.4 & 4.7219 & TRN \\
\hline CHEMBL1519773 & 688612 & 4.7 & 4.6687 & TST \\
\hline CHEMBL1997827 & 688612 & 5.35 & 4.729 & TST \\
\hline CHEMBL1574401 & 688612 & 4.1 & 4.612 & TRN \\
\hline
\end{tabular}




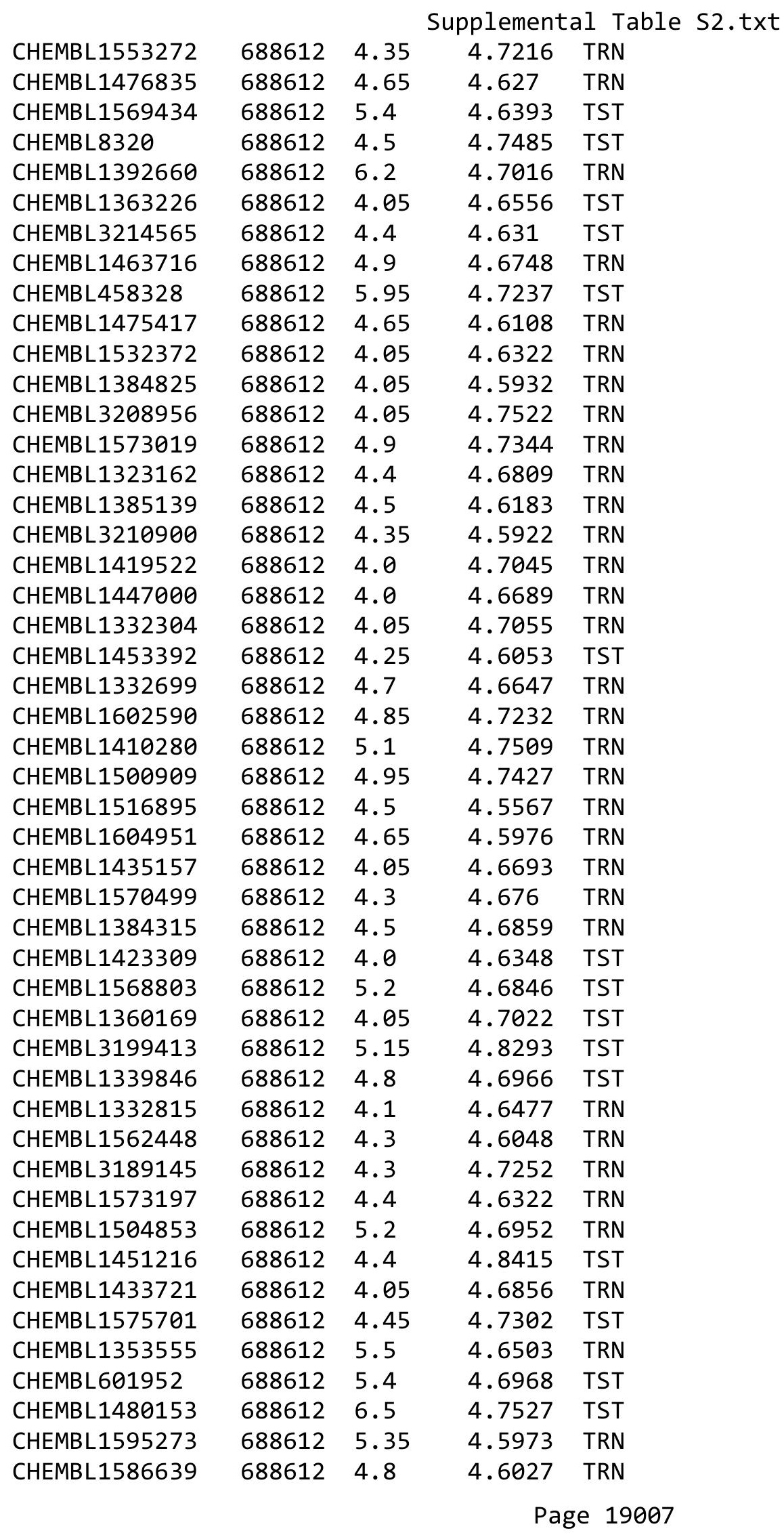




\begin{tabular}{|c|c|c|c|c|}
\hline \multicolumn{5}{|c|}{ Supplemental Table S2.txt } \\
\hline CHEMBL1357911 & 688612 & 5.5 & 4.7133 & TRN \\
\hline CHEMBL1550533 & 688612 & 4.0 & 4.6962 & TRN \\
\hline CHEMBL1422634 & 688612 & 6.15 & 4.6396 & TST \\
\hline CHEMBL1410196 & 688612 & 4.05 & 4.6195 & TRN \\
\hline CHEMBL1314418 & 688612 & 6.5 & 4.5556 & TST \\
\hline CHEMBL1401823 & 688612 & 4.05 & 4.7399 & TST \\
\hline CHEMBL 3195082 & 688612 & 4.05 & 4.6629 & TRN \\
\hline CHEMBL1422640 & 688612 & 6.45 & 4.6634 & TRN \\
\hline CHEMBL1578345 & 688612 & 4.5 & 4.6904 & TRN \\
\hline CHEMBL1467917 & 688612 & 4.0 & 4.6731 & TST \\
\hline CHEMBL 3189828 & 688612 & 4.6 & 4.6689 & TRN \\
\hline CHEMBL 3212742 & 688612 & 4.45 & 4.6768 & TST \\
\hline CHEMBL1613571 & 688612 & 4.0 & 4.7528 & TRN \\
\hline CHEMBL1500130 & 688612 & 6.5 & 4.6241 & TRN \\
\hline CHEMBL1543827 & 688612 & 4.05 & 4.6371 & TRN \\
\hline CHEMBL1554583 & 688612 & 4.1 & 4.5933 & TRN \\
\hline CHEMBL1340171 & 688612 & 6.1 & 4.7148 & TRN \\
\hline CHEMBL1597375 & 688612 & 4.5 & 4.7509 & TRN \\
\hline CHEMBL1410130 & 688612 & 4.2 & 4.605 & TRN \\
\hline CHEMBL1308111 & 688612 & 3.95 & 4.663 & TRN \\
\hline CHEMBL1375790 & 688612 & 5.4 & 4.7976 & TST \\
\hline CHEMBL1568145 & 688612 & 4.1 & 4.6612 & TRN \\
\hline CHEMBL1381815 & 688612 & 4.05 & 4.6241 & TRN \\
\hline CHEMBL1425251 & 688612 & 4.25 & 4.6089 & TRN \\
\hline CHEMBL1351141 & 688612 & 4.0 & 4.6576 & TRN \\
\hline CHEMBL1427866 & 688612 & 4.0 & 4.6396 & TRN \\
\hline CHEMBL1498338 & 688612 & 6.4 & 4.65 & TRN \\
\hline CHEMBL1469597 & 688612 & 4.2 & 4.6331 & TST \\
\hline CHEMBL1443688 & 688612 & 5.6 & 4.6293 & TRN \\
\hline CHEMBL1372650 & 688612 & 4.95 & 4.768 & TRN \\
\hline CHEMBL3198581 & 688612 & 4.6 & 4.7295 & TRN \\
\hline CHEMBL1455671 & 688612 & 4.1 & 4.5419 & TRN \\
\hline CHEMBL1592935 & 688612 & 4.05 & 4.5867 & TRN \\
\hline CHEMBL3198398 & 688612 & 6.8499 & 4.6492 & TST \\
\hline CHEMBL1397330 & 688612 & 4.1 & 4.6516 & TRN \\
\hline CHEMBL1576393 & 688612 & 4.35 & 4.6858 & TRN \\
\hline CHEMBL1596550 & 688612 & 5.4 & 4.6403 & TST \\
\hline CHEMBL1471644 & 688612 & 4.0 & 4.6403 & TRN \\
\hline CHEMBL1332143 & 688612 & 4.25 & 4.6889 & TRN \\
\hline CHEMBL1445574 & 688612 & 4.05 & 4.5621 & TRN \\
\hline CHEMBL1572899 & 688612 & 4.0 & 4.6369 & TRN \\
\hline CHEMBL1406367 & 688612 & 4.3 & 4.8094 & TRN \\
\hline CHEMBL 2002166 & 688612 & 4.85 & 4.6759 & TRN \\
\hline CHEMBL1340216 & 688612 & 4.9 & 4.7182 & TRN \\
\hline CHEMBL1411043 & 688612 & 6.8499 & 4.6084 & TRN \\
\hline CHEMBL1439414 & 688612 & 4.5 & 4.7882 & TRN \\
\hline CHEMBL1381391 & 688612 & 5.1 & 4.7266 & TRN \\
\hline CHEMBL1366320 & 688612 & 4.4 & 4.6184 & TST \\
\hline
\end{tabular}




\begin{tabular}{|c|c|c|c|c|c|}
\hline & & \multicolumn{4}{|c|}{ Supplemental Table S2.txt } \\
\hline CHEMBL1398942 & 688612 & 4.1 & 4.6579 & TST & \\
\hline CHEMBL1471043 & 688612 & 4.3 & 4.7277 & TST & \\
\hline CHEMBL1419046 & 688612 & 4.05 & 4.646 & TRN & \\
\hline CHEMBL1340625 & 688612 & 5.5 & 4.7188 & TST & \\
\hline CHEMBL1319465 & 688612 & 4.05 & 4.7342 & TST & \\
\hline CHEMBL1531650 & 688612 & 4.4 & 4.6977 & TRN & \\
\hline CHEMBL1414415 & 688612 & 4.4 & 4.6188 & TRN & \\
\hline CHEMBL1387896 & 688612 & 4.0 & 4.7044 & TST & \\
\hline CHEMBL1445081 & 688612 & 4.05 & 4.6529 & TST & \\
\hline CHEMBL1344323 & 688612 & 4.05 & 4.6032 & TRN & \\
\hline CHEMBL1541523 & 688612 & 4.0 & 4.5957 & TRN & \\
\hline CHEMBL1327905 & 688612 & 4.05 & 4.6208 & TST & \\
\hline CHEMBL1564567 & 688612 & 4.65 & 4.72199 & 99999999995 & TST \\
\hline CHEMBL1577881 & 688612 & 6.05 & 4.63 & TST & \\
\hline CHEMBL1426615 & 688612 & 4.7 & 4.6715 & TRN & \\
\hline CHEMBL1473779 & 688612 & 6.25 & 4.7197 & TRN & \\
\hline CHEMBL1508776 & 688612 & 4.0 & 4.7502 & TST & \\
\hline CHEMBL1574614 & 688612 & 4.05 & 4.7207 & TRN & \\
\hline CHEMBL1592842 & 688612 & 4.0 & 4.6638 & TRN & \\
\hline CHEMBL1497824 & 688612 & 4.0 & 4.7211 & TRN & \\
\hline CHEMBL1558372 & 688612 & 4.3 & 4.5794 & TRN & \\
\hline CHEMBL1509585 & 688612 & 4.35 & 4.7407 & TRN & \\
\hline CHEMBL1521123 & 688612 & 4.9 & 4.7268 & TRN & \\
\hline CHEMBL1494492 & 688612 & 6.4 & 4.6442 & TST & \\
\hline CHEMBL1503248 & 688612 & 4.85 & 4.6798 & TRN & \\
\hline CHEMBL1329762 & 688612 & 5.8 & 4.7015 & TST & \\
\hline CHEMBL1560549 & 688612 & 4.25 & 4.72 & TRN & \\
\hline CHEMBL1421758 & 688612 & 4.6 & 4.6491 & TST & \\
\hline CHEMBL1519408 & 688612 & 5.5 & 4.7231 & TRN & \\
\hline CHEMBL1531245 & 688612 & 4.3 & 4.6826 & TST & \\
\hline CHEMBL1335851 & 688612 & 7.0 & 4.7653 & TRN & \\
\hline CHEMBL1527452 & 688612 & 4.95 & 4.6772 & TRN & \\
\hline CHEMBL1410104 & 688612 & 4.05 & 4.5856 & TRN & \\
\hline CHEMBL1459750 & 688612 & 5.35 & 4.6691 & TRN & \\
\hline CHEMBL1485916 & 688612 & 4.7 & 4.7419 & TRN & \\
\hline CHEMBL1973504 & 688612 & 5.15 & 4.7412 & TRN & \\
\hline CHEMBL3196342 & 688612 & 5.05 & 4.6574 & TST & \\
\hline CHEMBL1445082 & 688612 & 6.3 & 4.6688 & TRN & \\
\hline CHEMBL1413375 & 688612 & 4.15 & 4.6547 & TRN & \\
\hline CHEMBL1439879 & 688612 & 4.35 & 4.6889 & TRN & \\
\hline CHEMBL3198576 & 688612 & 4.05 & 4.7176 & TRN & \\
\hline CHEMBL1579522 & 688612 & 4.05 & 4.5674 & TRN & \\
\hline CHEMBL1588023 & 688612 & 4.0 & 4.7808 & TRN & \\
\hline CHEMBL1533137 & 688612 & 4.05 & 4.6748 & TST & \\
\hline CHEMBL1542073 & 688612 & 6.0 & 4.6169 & TRN & \\
\hline CHEMBL1408395 & 688612 & 4.8 & 4.704 & TST & \\
\hline CHEMBL1607873 & 688612 & 4.5 & 4.6304 & TRN & \\
\hline CHEMBL1465518 & 688612 & 4.4 & 4.6479 & TRN & \\
\hline
\end{tabular}




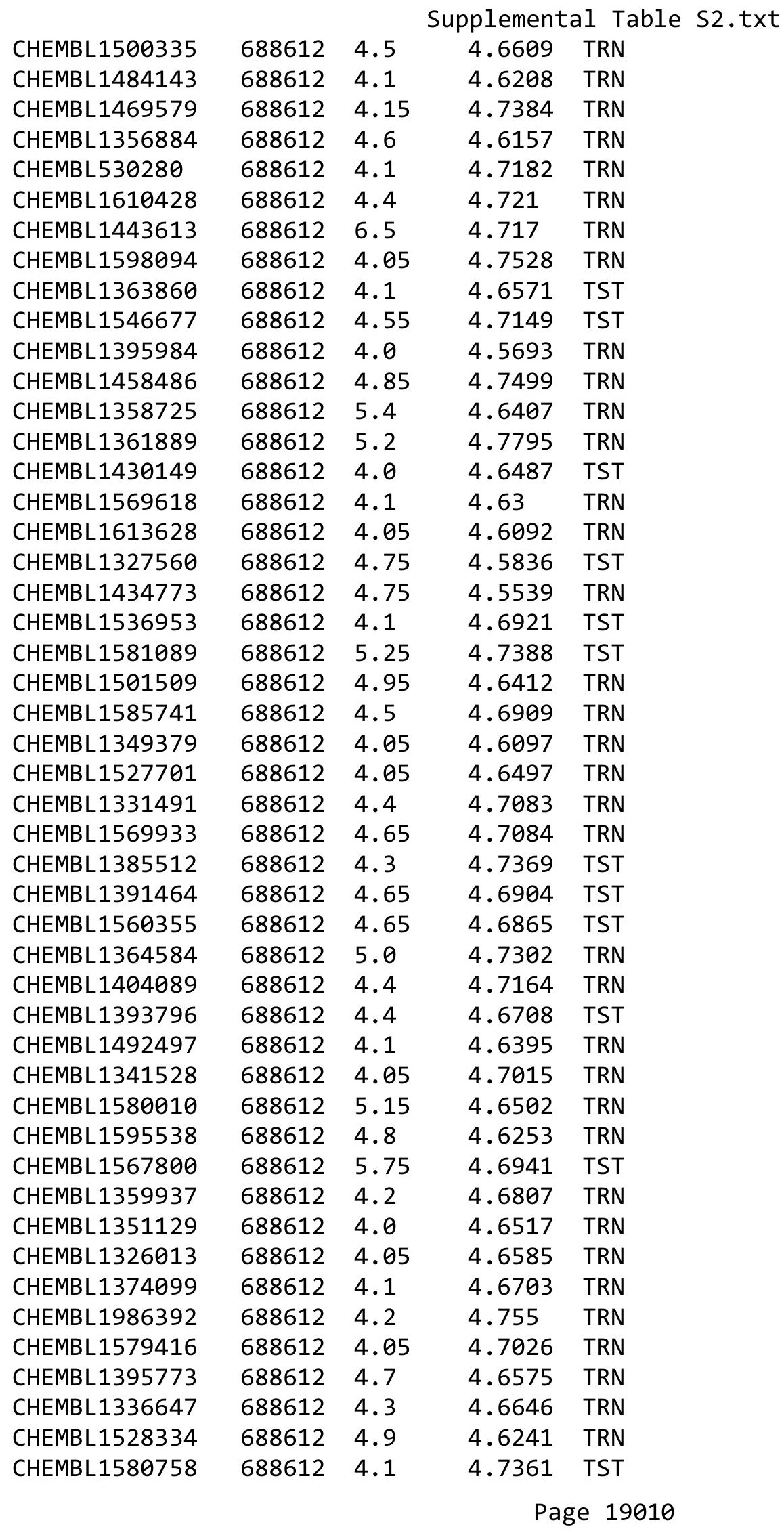




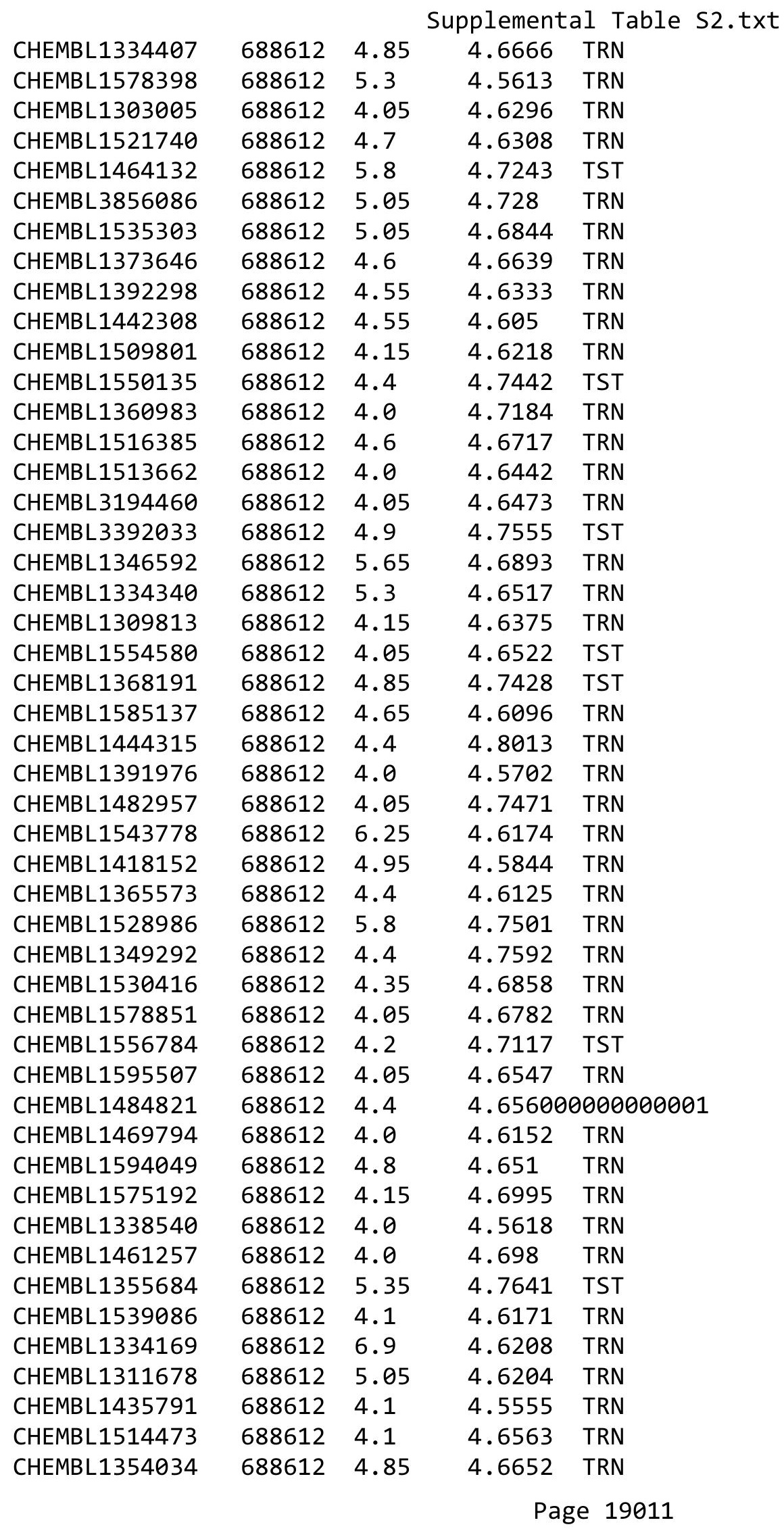




\begin{tabular}{|c|c|c|c|c|c|}
\hline \multirow{3}{*}{$\begin{array}{l}\text { CHEMBL1451565 } \\
\text { CHEMBL } 1578178\end{array}$} & \multirow[b]{2}{*}{688612} & \multicolumn{4}{|c|}{ Supplemental Table s2.txt } \\
\hline & & 4.05 & 4.65600 & 0000000001 & TRN \\
\hline & 688612 & 4.6 & 4.8161 & TRN & \\
\hline CHEMBL1569781 & 688612 & 4.7 & 4.7222 & TRN & \\
\hline CHEMBL1458460 & 688612 & 6.15 & 4.6255 & TRN & \\
\hline CHEMBL1356384 & 688612 & 4.7 & 4.5533 & TRN & \\
\hline CHEMBL1508786 & 688612 & 5.5 & 4.6009 & TRN & \\
\hline CHEMBL1380958 & 688612 & 4.6 & 4.6236 & TRN & \\
\hline CHEMBL1510672 & 688612 & 4.05 & 4.6718 & TRN & \\
\hline CHEMBL1391157 & 688612 & 4.05 & 4.7125 & TST & \\
\hline CHEMBL1433245 & 688612 & 4.05 & 4.5392 & TRN & \\
\hline CHEMBL1611255 & 688612 & 4.0 & 4.6198 & TRN & \\
\hline CHEMBL1421541 & 688612 & 6.25 & 4.6194 & TRN & \\
\hline CHEMBL1355920 & 688612 & 4.05 & 4.6432 & TRN & \\
\hline CHEMBL1585746 & 688612 & 4.9 & 4.67 & TRN & \\
\hline CHEMBL1470128 & 688612 & 4.1 & 4.6811 & TRN & \\
\hline CHEMBL1422284 & 688612 & 4.6 & 4.6389 & TST & \\
\hline CHEMBL1444360 & 688612 & 4.6 & 4.6587 & TRN & \\
\hline CHEMBL1494313 & 688612 & 4.05 & 4.6719 & TRN & \\
\hline CHEMBL1580151 & 688612 & 4.05 & 4.6675 & TRN & \\
\hline CHEMBL1500167 & 688612 & 4.65 & 4.6547 & TRN & \\
\hline CHEMBL1499099 & 688612 & 4.05 & 4.6456 & TST & \\
\hline CHEMBL1423537 & 688612 & 5.55 & 4.6685 & TRN & \\
\hline CHEMBL3195542 & 688612 & 6.5 & 4.7016 & TRN & \\
\hline CHEMBL1564792 & 688612 & 6.5 & 4.692 & TRN & \\
\hline CHEMBL1360941 & 688612 & 4.55 & 4.5734 & TRN & \\
\hline CHEMBL1378798 & 688612 & 4.05 & 4.758 & TRN & \\
\hline CHEMBL1497641 & 688612 & 4.0 & 4.6981 & TST & \\
\hline CHEMBL1505777 & 688612 & 4.6 & 4.7195 & TRN & \\
\hline CHEMBL1584869 & 688612 & 4.35 & 4.5805 & TRN & \\
\hline CHEMBL1393011 & 688612 & 4.0 & 4.68199 & 99999999995 & TST \\
\hline CHEMBL1416711 & 688612 & 4.35 & 4.6209 & TRN & \\
\hline CHEMBL1323529 & 688612 & 4.5 & 4.6904 & TRN & \\
\hline CHEMBL1330964 & 688612 & 6.0 & 4.5868 & TRN & \\
\hline CHEMBL1343643 & 688612 & 4.4 & 4.7815 & TST & \\
\hline CHEMBL1985664 & 688612 & 6.25 & 4.6876 & TRN & \\
\hline CHEMBL1523438 & 688612 & 4.05 & 4.6978 & TST & \\
\hline CHEMBL1553024 & 688612 & 4.8 & 4.657 & TRN & \\
\hline CHEMBL3196837 & 688612 & 4.75 & 4.7906 & TRN & \\
\hline CHEMBL1372323 & 688612 & 4.1 & 4.6553 & TRN & \\
\hline CHEMBL1603570 & 688612 & 4.05 & 4.6591 & TRN & \\
\hline CHEMBL1333049 & 688612 & 4.05 & 4.6913 & TRN & \\
\hline CHEMBL1549333 & 688612 & 7.0 & 4.7127 & TRN & \\
\hline CHEMBL1443620 & 688612 & 4.2 & 4.5928 & TRN & \\
\hline CHEMBL1327901 & 688612 & 4.05 & 4.6406 & TST & \\
\hline CHEMBL1301354 & 688612 & 4.1 & 4.6765 & TST & \\
\hline CHEMBL1310862 & 688612 & 4.6 & 4.7145 & TRN & \\
\hline CHEMBL1511593 & 688612 & 4.05 & 4.734 & TST & \\
\hline CHEMBL1314088 & 688612 & 4.9 & 4.6699 & TRN & \\
\hline
\end{tabular}




\begin{tabular}{|c|c|c|c|c|c|}
\hline \multicolumn{6}{|c|}{ Supplemental Table S2.txt } \\
\hline CHEMBL1601667 & 688612 & 4.35 & 4.6377 & TRN & \\
\hline CHEMBL1332521 & 688612 & 4.0 & 4.6326 & TRN & \\
\hline CHEMBL1580052 & 688612 & 4.55 & 4.5694 & TRN & \\
\hline CHEMBL1450923 & 688612 & 4.05 & 4.5696 & TRN & \\
\hline CHEMBL1567412 & 688612 & 4.4 & 4.6507 & TST & \\
\hline CHEMBL1546258 & 688612 & 6.05 & 4.6805 & TRN & \\
\hline CHEMBL1560108 & 688612 & 4.05 & 4.7096 & TST & \\
\hline CHEMBL1359228 & 688612 & 4.4 & 4.7245 & TST & \\
\hline CHEMBL1343163 & 688612 & 4.85 & 4.7133 & TRN & \\
\hline CHEMBL1375874 & 688612 & 4.65 & 4.6141 & TRN & \\
\hline CHEMBL1545006 & 688612 & 4.1 & 4.7356 & TRN & \\
\hline CHEMBL1525827 & 688612 & 4.05 & 4.6143 & TRN & \\
\hline CHEMBL1479494 & 688612 & 4.0 & 4.6791 & TRN & \\
\hline CHEMBL 3194581 & 688612 & 5.55 & 4.7279 & TST & \\
\hline CHEMBL1485368 & 688612 & 4.1 & 4.6987 & TRN & \\
\hline CHEMBL3198515 & 688612 & 4.4 & 4.6727 & TRN & \\
\hline CHEMBL 2374042 & 688612 & 5.55 & 4.8003 & TRN & \\
\hline CHEMBL3211377 & 688612 & 6.15 & 4.6906 & TRN & \\
\hline CHEMBL1551451 & 688612 & 5.25 & 4.567 & TRN & \\
\hline CHEMBL1443946 & 688612 & 4.0 & 4.7164 & TRN & \\
\hline CHEMBL1324007 & 688612 & 4.1 & 4.731 & TRN & \\
\hline CHEMBL1496607 & 688612 & 4.4 & 4.6264 & TRN & \\
\hline CHEMBL1545757 & 688612 & 5.05 & 4.6295 & TRN & \\
\hline CHEMBL1566069 & 688612 & 4.65 & 4.6734 & TRN & \\
\hline CHEMBL1534645 & 688612 & 4.45 & 4.7063 & TRN & \\
\hline CHEMBL1310375 & 688612 & 4.3 & 4.6923 & TRN & \\
\hline CHEMBL1530217 & 688612 & 4.3 & 4.7296 & TST & \\
\hline CHEMBL1359354 & 688612 & 4.7 & 4.7410 & 00000000005 & TRN \\
\hline CHEMBL3210902 & 688612 & 4.1 & 4.6565 & TST & \\
\hline CHEMBL1340626 & 688612 & 4.85 & 4.6342 & TRN & \\
\hline CHEMBL1527756 & 688612 & 6.15 & 4.6817 & TRN & \\
\hline CHEMBL1537509 & 688612 & 4.6 & 4.7292 & TST & \\
\hline CHEMBL1521564 & 688612 & 5.25 & 4.6691 & TRN & \\
\hline CHEMBL1597778 & 688612 & 4.2 & 4.7296 & TST & \\
\hline CHEMBL3199451 & 688612 & 5.4 & 4.8218 & TRN & \\
\hline CHEMBL1378735 & 688612 & 4.6 & 4.6877 & TRN & \\
\hline CHEMBL3190795 & 688612 & 4.8 & 4.7489 & TST & \\
\hline CHEMBL1484510 & 688612 & 6.8499 & 4.5719 & TST & \\
\hline CHEMBL1569742 & 688612 & 4.7 & 4.6414 & TRN & \\
\hline CHEMBL1419810 & 688612 & 4.65 & 4.6553 & TRN & \\
\hline CHEMBL1407205 & 688612 & 4.4 & 4.6683 & TRN & \\
\hline CHEMBL1986073 & 688612 & 4.3 & 4.6706 & TST & \\
\hline CHEMBL1353123 & 688612 & 4.1 & 4.6704 & TRN & \\
\hline CHEMBL1448593 & 688612 & 4.0 & 4.5795 & TRN & \\
\hline CHEMBL1318003 & 688612 & 4.0 & 4.695 & TRN & \\
\hline CHEMBL1326236 & 688612 & 4.6 & 4.6751 & TRN & \\
\hline CHEMBL3207650 & 688612 & 5.45 & 4.7306 & TST & \\
\hline CHEMBL1976940 & 688612 & 4.65 & 4.7431 & TRN & \\
\hline
\end{tabular}




\begin{tabular}{|c|c|c|c|c|c|}
\hline & & \multicolumn{4}{|c|}{ Supplemental Table S2.txt } \\
\hline CHEMBL1332456 & 688612 & 4.25 & 4.7225 & TRN & \\
\hline CHEMBL 3199324 & 688612 & 4.95 & 4.6563 & TRN & \\
\hline CHEMBL1308104 & 688612 & 5.5 & 4.7549 & TST & \\
\hline CHEMBL1384301 & 688612 & 5.2 & 4.6837 & TRN & \\
\hline CHEMBL3214580 & 688612 & 4.05 & 4.6699 & TRN & \\
\hline CHEMBL1301716 & 688612 & 4.45 & 4.6565 & TRN & \\
\hline CHEMBL1433947 & 688612 & 4.0 & 4.5793 & TRN & \\
\hline CHEMBL1576856 & 688612 & 4.1 & 4.6536 & TRN & \\
\hline CHEMBL1387598 & 688612 & 4.3 & 4.6475 & TRN & \\
\hline CHEMBL576038 & 688612 & 4.35 & 4.7909 & TRN & \\
\hline CHEMBL1372907 & 688612 & 6.5 & 4.6986 & TST & \\
\hline CHEMBL1452292 & 688612 & 4.05 & 4.6741 & TRN & \\
\hline CHEMBL1390860 & 688612 & 6.0 & 4.7331 & TRN & \\
\hline CHEMBL1446472 & 688612 & 4.05 & 4.6275 & TRN & \\
\hline CHEMBL1612072 & 688612 & 4.45 & 4.662 & TST & \\
\hline CHEMBL1605292 & 688612 & 4.5 & 4.6808 & TST & \\
\hline CHEMBL1444099 & 688612 & 4.0 & 4.6536 & TRN & \\
\hline CHEMBL1994988 & 688612 & 4.3 & 4.6913 & TRN & \\
\hline CHEMBL1613332 & 688612 & 4.4 & 4.6084 & TRN & \\
\hline CHEMBL392673 & 688612 & 4.6 & 4.7538 & TRN & \\
\hline CHEMBL3210624 & 688612 & 4.5 & 4.7184 & TRN & \\
\hline CHEMBL1502698 & 688612 & 5.05 & 4.619 & TST & \\
\hline CHEMBL1440756 & 688612 & 4.1 & 4.6814 & TST & \\
\hline CHEMBL1365410 & 688612 & 4.1 & 4.7081 & TST & \\
\hline CHEMBL1488797 & 688612 & 5.45 & 4.6137 & TST & \\
\hline CHEMBL1302545 & 688612 & 4.95 & 4.7971 & TRN & \\
\hline CHEMBL1354704 & 688612 & 5.05 & 4.6155 & TRN & \\
\hline CHEMBL1569662 & 688612 & 4.4 & 4.6756 & TST & \\
\hline CHEMBL1405595 & 688612 & 4.35 & 4.6782 & TRN & \\
\hline CHEMBL1319981 & 688612 & 6.2 & 4.7139 & TRN & \\
\hline CHEMBL1600632 & 688612 & 4.0 & 4.6938 & TST & \\
\hline CHEMBL1410274 & 688612 & 4.8 & 4.6817 & TRN & \\
\hline CHEMBL1503016 & 688612 & 4.0 & 4.6365 & TRN & \\
\hline CHEMBL583555 & 688612 & 4.6 & 4.7174 & TRN & \\
\hline CHEMBL1382804 & 688612 & 6.1 & 4.6619 & TRN & \\
\hline CHEMBL1352965 & 688612 & 4.9 & 4.6736 & TST & \\
\hline CHEMBL1537216 & 688612 & 4.6 & 4.6639 & TRN & \\
\hline CHEMBL1467477 & 688612 & 4.4 & 4.6306 & TRN & \\
\hline CHEMBL1378299 & 688612 & 4.3 & 4.6186 & TRN & \\
\hline CHEMBL1414064 & 688612 & 4.05 & 4.6325 & TRN & \\
\hline CHEMBL1361213 & 688612 & 4.1 & 4.6753 & TRN & \\
\hline CHEMBL1557554 & 688612 & 4.9 & 4.6402 & TRN & \\
\hline CHEMBL1457979 & 688612 & 4.8 & 4.6530 & 00000000005 & TRN \\
\hline CHEMBL1469245 & 688612 & 5.05 & 4.6806 & TRN & \\
\hline CHEMBL1408615 & 688612 & 5.6 & 4.7386 & TRN & \\
\hline CHEMBL 2374049 & 688612 & 4.8 & 4.7338 & TRN & \\
\hline CHEMBL1355221 & 688612 & 4.6 & 4.7104 & TRN & \\
\hline CHEMBL3208250 & 688612 & 4.0 & 4.6637 & TST & \\
\hline
\end{tabular}




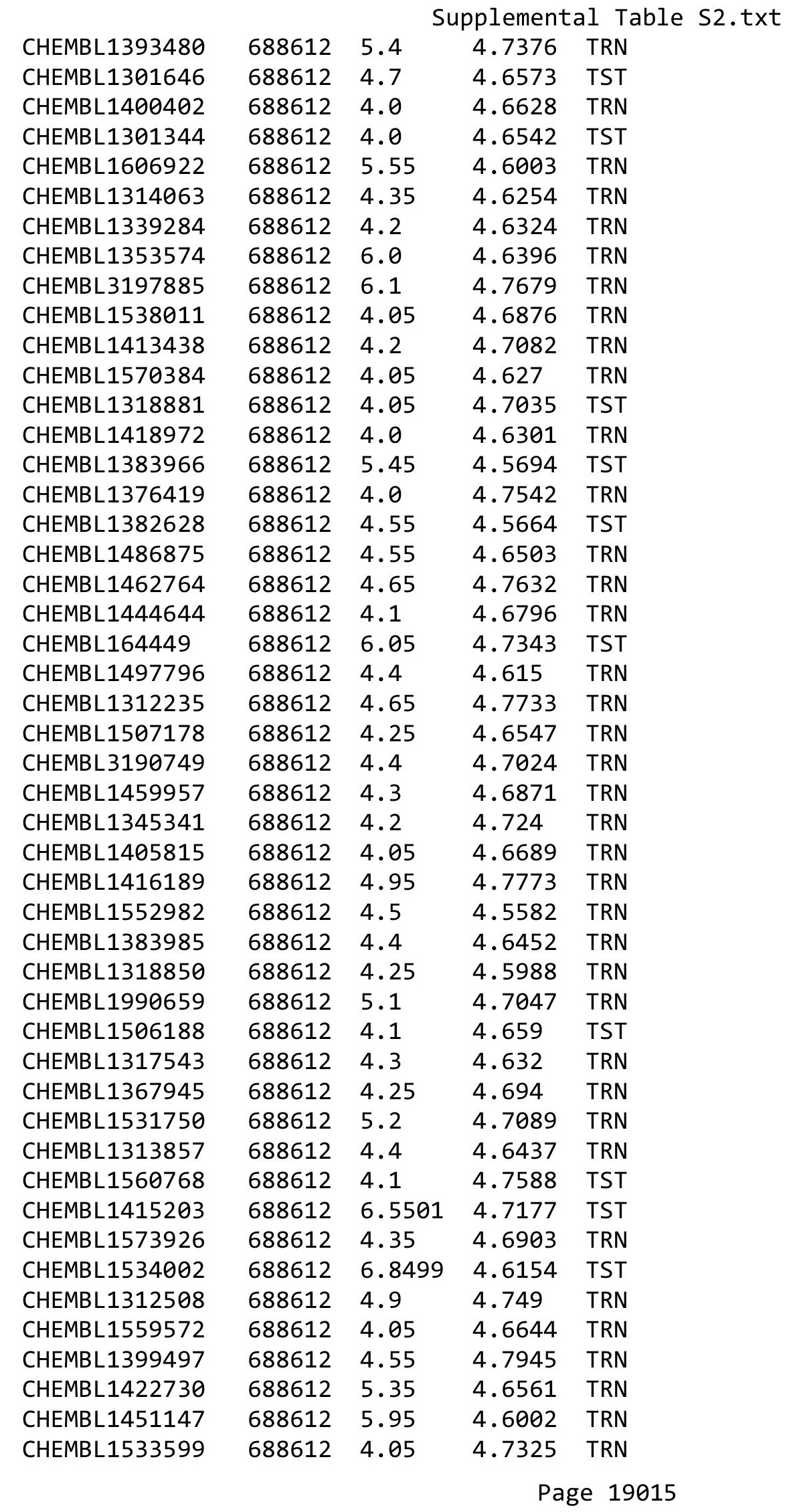




\begin{tabular}{|c|c|c|c|c|}
\hline \multicolumn{5}{|c|}{ Supplemental Table S2.txt } \\
\hline CHEMBL1388189 & 688612 & 6.3 & 4.6806 & TRN \\
\hline CHEMBL1441129 & 688612 & 4.0 & 4.6938 & TST \\
\hline CHEMBL1573155 & 688612 & 4.65 & 4.6518 & TRN \\
\hline CHEMBL1316067 & 688612 & 4.0 & 4.6029 & TRN \\
\hline CHEMBL476513 & 688612 & 6.15 & 4.7107 & TST \\
\hline CHEMBL1468755 & 688612 & 4.05 & 4.5843 & TRN \\
\hline CHEMBL1533701 & 688612 & 5.65 & 4.7273 & TRN \\
\hline CHEMBL1602089 & 688612 & 6.15 & 4.6212 & TRN \\
\hline CHEMBL1365444 & 688612 & 4.7 & 4.6919 & TRN \\
\hline CHEMBL1334656 & 688612 & 4.25 & 4.7273 & TRN \\
\hline CHEMBL1434818 & 688612 & 4.2 & 4.6665 & TST \\
\hline CHEMBL1318579 & 688612 & 4.6 & 4.7182 & TRN \\
\hline CHEMBL1538232 & 688612 & 4.2 & 4.6901 & TST \\
\hline CHEMBL1553715 & 688612 & 4.05 & 4.6108 & TRN \\
\hline CHEMBL1549326 & 688612 & 4.4 & 4.6479 & TRN \\
\hline CHEMBL1373412 & 688612 & 4.15 & 4.6782 & TRN \\
\hline CHEMBL1548680 & 688612 & 4.35 & 4.7257 & TRN \\
\hline CHEMBL1356033 & 688612 & 5.8 & 4.7026 & TRN \\
\hline CHEMBL57978 & 688612 & 5.65 & 4.7859 & TST \\
\hline CHEMBL3197780 & 688612 & 4.9 & 4.6709 & TRN \\
\hline CHEMBL1312699 & 688612 & 6.5 & 4.64 & TRN \\
\hline CHEMBL1493248 & 688612 & 6.7501 & 4.8456 & TST \\
\hline CHEMBL1491957 & 688612 & 4.45 & 4.7506 & TRN \\
\hline CHEMBL1475056 & 688612 & 4.05 & 4.6682 & TRN \\
\hline CHEMBL1369771 & 688612 & 4.5 & 4.6993 & TRN \\
\hline CHEMBL1589350 & 688612 & 4.1 & 4.7279 & TRN \\
\hline CHEMBL1342020 & 688612 & 6.6 & 4.7001 & TRN \\
\hline CHEMBL1302298 & 688612 & 4.3 & 4.6748 & TRN \\
\hline CHEMBL1355594 & 688612 & 5.0 & 4.6066 & TRN \\
\hline CHEMBL1571696 & 688612 & 4.2 & 4.6972 & TST \\
\hline CHEMBL1575932 & 688612 & 4.7 & 4.7496 & TRN \\
\hline CHEMBL1473401 & 688612 & 4.05 & 4.6359 & TRN \\
\hline CHEMBL1372066 & 688612 & 5.4 & 4.6524 & TST \\
\hline CHEMBL1507308 & 688612 & 4.9 & 4.6963 & TRN \\
\hline CHEMBL1972015 & 688612 & 4.05 & 4.6821 & TRN \\
\hline CHEMBL1536866 & 688612 & 4.0 & 4.6101 & TRN \\
\hline CHEMBL1591672 & 688612 & 6.8499 & 4.6363 & TRN \\
\hline CHEMBL1591952 & 688612 & 4.4 & 4.7601 & TRN \\
\hline CHEMBL1405654 & 688612 & 4.05 & 4.6178 & TRN \\
\hline CHEMBL1337112 & 688612 & 4.5 & 4.687 & TRN \\
\hline CHEMBL1368423 & 688612 & 4.8 & 4.5986 & TRN \\
\hline CHEMBL1566794 & 688612 & 4.1 & 4.6923 & TST \\
\hline CHEMBL1370706 & 688612 & 6.0 & 4.6956 & TST \\
\hline CHEMBL1506365 & 688612 & 4.7 & 4.7114 & TRN \\
\hline CHEMBL1501376 & 688612 & 4.85 & 4.7731 & TRN \\
\hline CHEMBL1474341 & 688612 & 4.8 & 4.7112 & TRN \\
\hline CHEMBL1409552 & 688612 & 4.8 & 4.7786 & TRN \\
\hline CHEMBL1394871 & 688612 & 4.55 & 4.6486 & TRN \\
\hline
\end{tabular}




\begin{tabular}{|c|c|c|c|c|c|}
\hline \multirow{2}{*}{ CHEMBL1524550 } & \\
\hline & 688612 & 4.3 & 4.6646 & TRN & \\
\hline CHEMBL1501514 & 688612 & 4.0 & $4.6960 e$ & 0000000001 & TST \\
\hline CHEMBL1439621 & 688612 & 4.85 & 4.6578 & TRN & \\
\hline CHEMBL1338476 & 688612 & 4.05 & 4.6568 & TRN & \\
\hline CHEMBL1606571 & 688612 & 5.05 & 4.6681 & TST & \\
\hline CHEMBL1441026 & 688612 & 6.9 & 4.71399 & 99999999995 & TST \\
\hline CHEMBL1309376 & 688612 & 4.15 & 4.6031 & TRN & \\
\hline CHEMBL1371781 & 688612 & 4.5 & 4.7077 & TRN & \\
\hline CHEMBL1333508 & 688612 & 4.1 & 4.7155 & TST & \\
\hline CHEMBL1326580 & 688612 & 4.0 & 4.6789 & 9999999999 & TRN \\
\hline CHEMBL1471129 & 688612 & 6.8 & 4.7159 & TST & \\
\hline CHEMBL1314318 & 688612 & 4.7 & 4.5899 & TRN & \\
\hline CHEMBL1574629 & 688612 & 4.5 & 4.69306 & 00000000005 & TRN \\
\hline CHEMBL1406356 & 688612 & 4.05 & 4.6997 & TRN & \\
\hline CHEMBL1322341 & 688612 & 4.05 & 4.6551 & TRN & \\
\hline CHEMBL1443693 & 688612 & 4.15 & 4.5688 & TRN & \\
\hline CHEMBL1324343 & 688612 & 4.1 & 4.6819 & TST & \\
\hline CHEMBL1367503 & 688612 & 4.3 & 4.691 & TRN & \\
\hline CHEMBL1338882 & 688612 & 5.45 & 4.6324 & TST & \\
\hline CHEMBL1453953 & 688612 & 4.1 & 4.6689 & TST & \\
\hline CHEMBL3190827 & 688612 & 4.45 & 4.7388 & TST & \\
\hline CHEMBL1083123 & 688612 & 4.05 & 4.7177 & TRN & \\
\hline CHEMBL3199679 & 688612 & 4.85 & 4.771 & TRN & \\
\hline CHEMBL1405950 & 688612 & 4.0 & 4.6334 & TRN & \\
\hline CHEMBL1344893 & 688612 & 4.4 & 4.6359 & TRN & \\
\hline CHEMBL1535698 & 688612 & 4.05 & 4.6155 & TST & \\
\hline CHEMBL1315994 & 688612 & 4.4 & 4.6161 & TRN & \\
\hline CHEMBL1429425 & 688612 & 4.35 & 4.7347 & TRN & \\
\hline CHEMBL1736377 & 688612 & 4.7 & 4.7211 & TRN & \\
\hline CHEMBL1467900 & 688612 & 4.4 & 4.673 & TRN & \\
\hline CHEMBL592842 & 688612 & 4.35 & 4.6269 & TRN & \\
\hline CHEMBL1340194 & 688612 & 5.35 & 4.6371 & TRN & \\
\hline CHEMBL340807 & 688612 & 4.45 & 4.6861 & TRN & \\
\hline CHEMBL1564717 & 688612 & 4.5 & 4.7373 & TST & \\
\hline CHEMBL1490631 & 688612 & 5.6 & 4.6908 & TST & \\
\hline CHEMBL1557237 & 688612 & 4.95 & 4.6779 & TST & \\
\hline CHEMBL1409412 & 688612 & 5.8 & 4.6408 & TRN & \\
\hline CHEMBL1454319 & 688612 & 7.0 & 4.6546 & TRN & \\
\hline CHEMBL1458215 & 688612 & 5.45 & 4.7067 & TRN & \\
\hline CHEMBL1977034 & 688612 & 4.1 & 4.7356 & TRN & \\
\hline CHEMBL1608263 & 688612 & 4.0 & 4.6457 & TRN & \\
\hline CHEMBL1473977 & 688612 & 4.0 & 4.6439 & TRN & \\
\hline CHEMBL1446400 & 688612 & 4.0 & 4.6459 & TST & \\
\hline CHEMBL1400439 & 688612 & 4.3 & 4.7662 & TST & \\
\hline CHEMBL1351643 & 688612 & 4.05 & 4.602 & TRN & \\
\hline CHEMBL1396948 & 688612 & 4.5 & 4.6679 & TST & \\
\hline CHEMBL1426226 & 688612 & 6.8499 & 4.6989 & TST & \\
\hline CHEMBL1597850 & 688612 & 4.7 & 4.7061 & TRN & \\
\hline
\end{tabular}




\begin{tabular}{|c|c|c|c|c|}
\hline \multicolumn{5}{|c|}{ Supplemental Table s2.txt } \\
\hline CHEMBL1303507 & 688612 & 4.1 & 4.6743 & TST \\
\hline CHEMBL1548928 & 688612 & 4.95 & 4.6682 & TST \\
\hline CHEMBL1341791 & 688612 & 5.95 & 4.6747 & TST \\
\hline CHEMBL3210695 & 688612 & 4.55 & 4.7372 & TRN \\
\hline CHEMBL1438428 & 688612 & 4.5 & 4.6634 & TRN \\
\hline CHEMBL1422133 & 688612 & 4.55 & 4.6496 & TRN \\
\hline CHEMBL 3214324 & 688612 & 5.1 & 4.6777 & TST \\
\hline CHEMBL1319652 & 688612 & 6.2 & 4.7268 & TRN \\
\hline CHEMBL1524564 & 688612 & 4.9 & 4.694 & TRN \\
\hline CHEMBL1605095 & 688612 & 6.2 & 4.607 & TST \\
\hline CHEMBL1515065 & 688612 & 5.05 & 4.5801 & TRN \\
\hline CHEMBL222759 & 688612 & 4.3 & 4.7501 & TRN \\
\hline CHEMBL1307620 & 688612 & 5.4 & 4.7093 & TRN \\
\hline CHEMBL3194266 & 688612 & 4.3 & 4.742 & TRN \\
\hline CHEMBL1536878 & 688612 & 5.05 & 4.8122 & TRN \\
\hline CHEMBL3196098 & 688612 & 5.05 & 4.7607 & TST \\
\hline CHEMBL1469466 & 688612 & 4.05 & 4.7704 & TRN \\
\hline CHEMBL1497556 & 688612 & 5.45 & 4.5779 & TRN \\
\hline CHEMBL1408537 & 688612 & 4.25 & 4.5979 & TRN \\
\hline CHEMBL1447488 & 688612 & 4.1 & 4.6278 & TRN \\
\hline CHEMBL1375293 & 688612 & 4.4 & 4.6248 & TST \\
\hline CHEMBL3190188 & 688612 & 4.05 & 4.7744 & TRN \\
\hline CHEMBL1611675 & 688612 & 4.05 & 4.7844 & TRN \\
\hline CHEMBL1999149 & 688612 & 4.75 & 4.6788 & TRN \\
\hline CHEMBL1512064 & 688612 & 4.65 & 4.6078 & TRN \\
\hline CHEMBL1476478 & 688612 & 4.0 & 4.6781 & TRN \\
\hline CHEMBL3209746 & 688612 & 4.4 & 4.7124 & TRN \\
\hline CHEMBL1391901 & 688612 & 4.4 & 4.7209 & TRN \\
\hline CHEMBL1339365 & 688612 & 4.2 & 4.7171 & TRN \\
\hline CHEMBL1505994 & 688612 & 4.45 & 4.7417 & TRN \\
\hline CHEMBL3191172 & 688612 & 5.9 & 4.678 & TRN \\
\hline CHEMBL1491488 & 688612 & 4.9 & 4.6024 & TRN \\
\hline CHEMBL1508952 & 688612 & 6.05 & 4.6832 & TST \\
\hline CHEMBL1313922 & 688612 & 6.8499 & 4.5536 & TRN \\
\hline CHEMBL3197637 & 688612 & 4.5 & 4.6184 & TRN \\
\hline CHEMBL1326980 & 688612 & 4.85 & 4.6687 & TRN \\
\hline CHEMBL1345201 & 688612 & 4.05 & 4.645 & TRN \\
\hline CHEMBL1495196 & 688612 & 4.05 & 4.6467 & TRN \\
\hline CHEMBL1373629 & 688612 & 4.0 & 4.6833 & TRN \\
\hline CHEMBL1540526 & 688612 & 4.85 & 4.7026 & TRN \\
\hline CHEMBL1464730 & 688612 & 4.05 & 4.5985 & TST \\
\hline CHEMBL1332617 & 688612 & 5.0 & 4.7269 & TRN \\
\hline CHEMBL1405183 & 688612 & 6.1 & 4.5958 & TRN \\
\hline CHEMBL1494708 & 688612 & 4.05 & 4.7001 & TRN \\
\hline CHEMBL1334793 & 688612 & 4.05 & 4.6277 & TRN \\
\hline CHEMBL1609008 & 688612 & 5.8 & 4.6624 & TRN \\
\hline CHEMBL1376396 & 688612 & 4.05 & 4.6211 & TRN \\
\hline CHEMBL1550010 & 688612 & 5.2 & 4.6327 & TRN \\
\hline
\end{tabular}




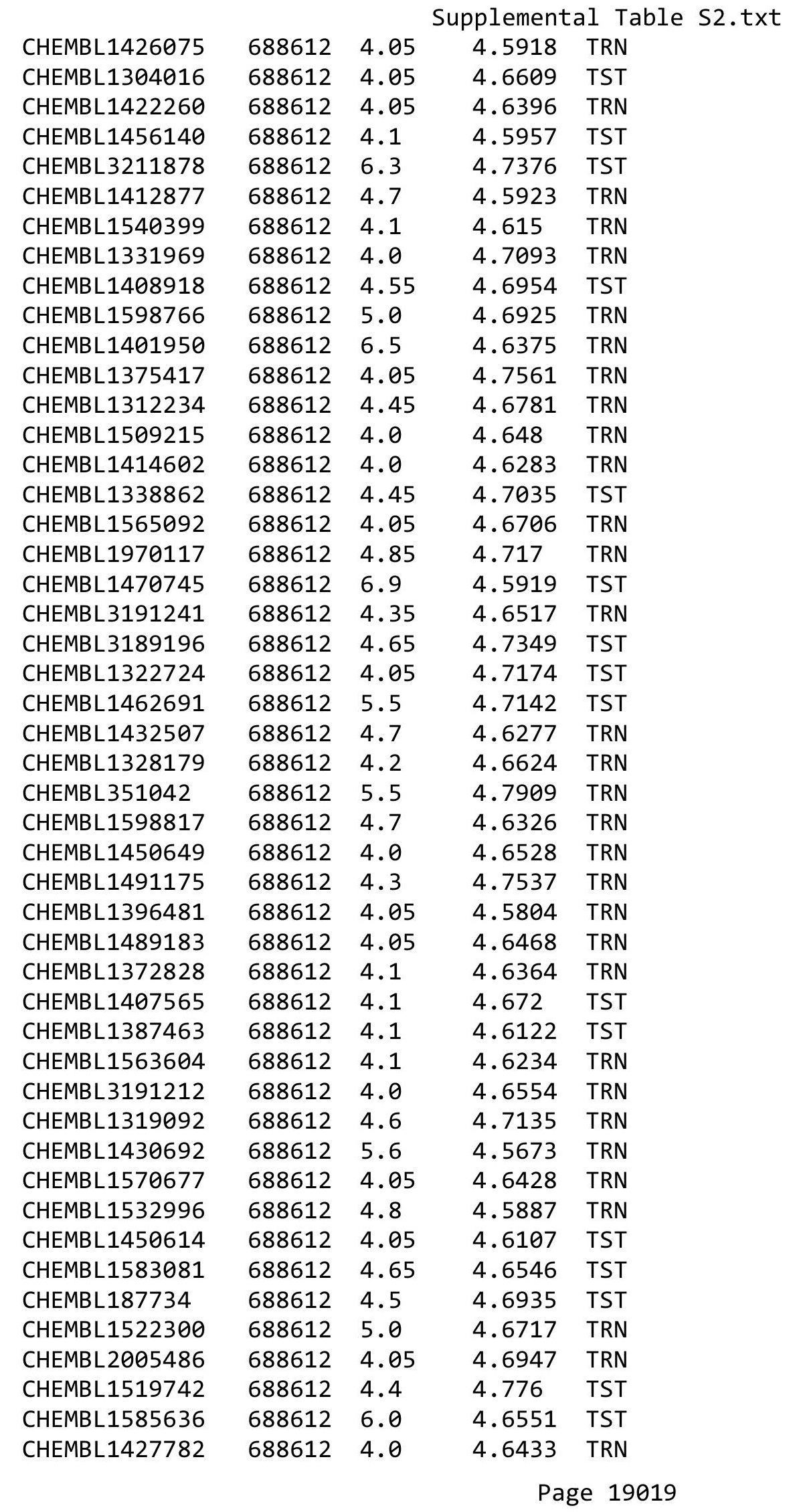




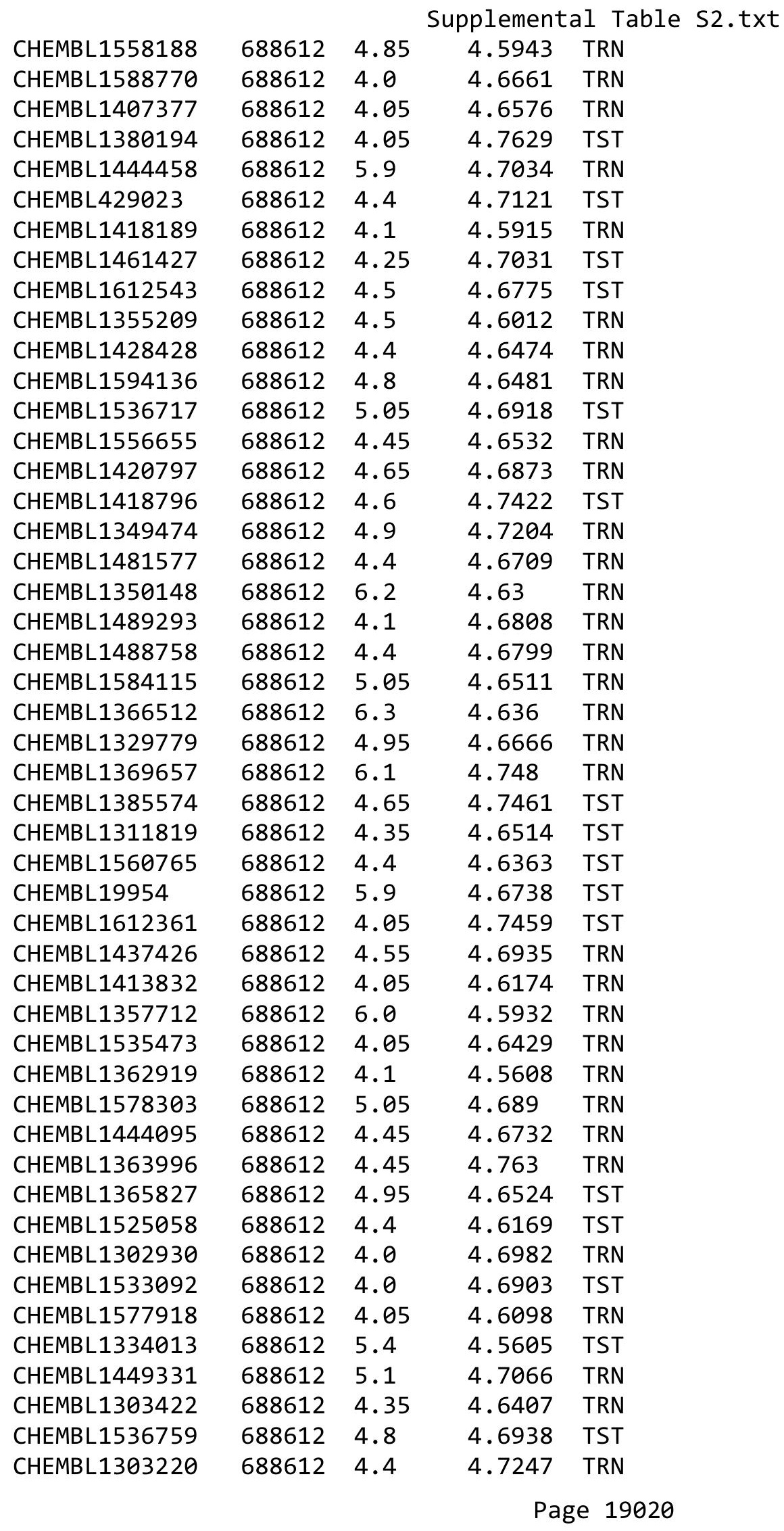




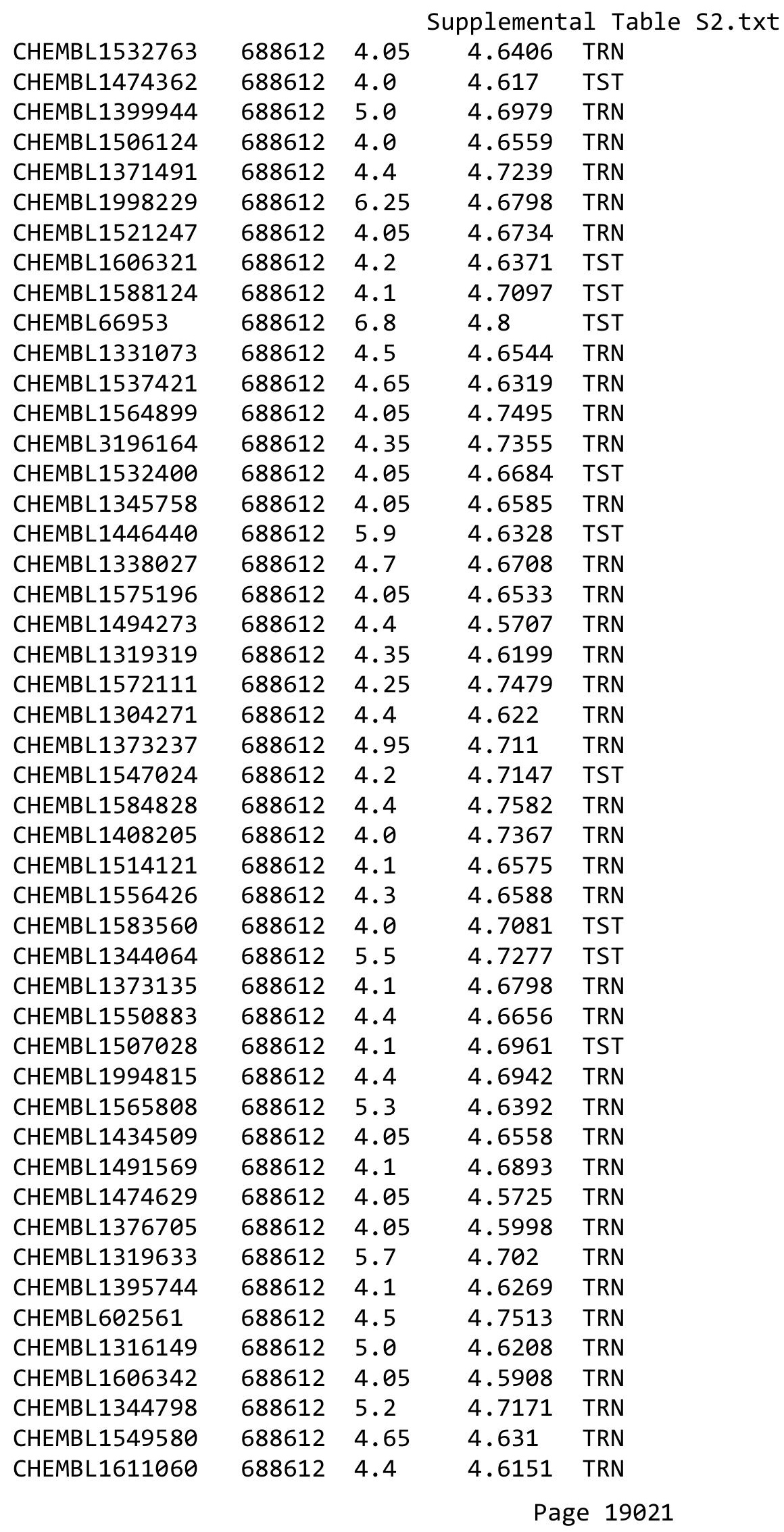




\begin{tabular}{|c|c|c|c|c|c|}
\hline \multicolumn{6}{|c|}{ Supplemental Table S2.txt } \\
\hline CHEMBL580819 & 688612 & 4.9 & 4.7662 & TRN & \\
\hline CHEMBL1581306 & 688612 & 4.05 & 4.6375 & TRN & \\
\hline CHEMBL1390881 & 688612 & 4.25 & 4.6239 & TST & \\
\hline CHEMBL1572624 & 688612 & 6.6499 & 4.6309 & TRN & \\
\hline CHEMBL3189614 & 688612 & 4.1 & 4.6411 & TRN & \\
\hline CHEMBL1357503 & 688612 & 5.4 & 4.5996 & TRN & \\
\hline CHEMBL1558182 & 688612 & 5.4 & 4.6292 & TRN & \\
\hline CHEMBL1479329 & 688612 & 4.05 & 4.5716 & TRN & \\
\hline CHEMBL1505757 & 688612 & 5.3 & 4.6913 & TRN & \\
\hline CHEMBL1447734 & 688612 & 6.1 & 4.6222 & TRN & \\
\hline CHEMBL1417340 & 688612 & 4.05 & 4.7045 & TRN & \\
\hline CHEMBL1321569 & 688612 & 6.2 & 4.5686 & TST & \\
\hline CHEMBL1521195 & 688612 & 4.8 & 4.6783 & TRN & \\
\hline CHEMBL1504364 & 688612 & 4.05 & 4.7036 & TST & \\
\hline CHEMBL1464581 & 688612 & 4.05 & 4.6932 & TRN & \\
\hline CHEMBL356061 & 688612 & 5.25 & 4.6404 & TRN & \\
\hline CHEMBL1355290 & 688612 & 6.5 & 4.6721 & TRN & \\
\hline CHEMBL1356086 & 688612 & 4.85 & 4.6154 & TRN & \\
\hline CHEMBL1514543 & 688612 & 4.0 & 4.6506 & TRN & \\
\hline CHEMBL1562783 & 688612 & 4.05 & 4.5439 & TST & \\
\hline CHEMBL1420871 & 688612 & 4.85 & 4.6891 & TRN & \\
\hline CHEMBL1378371 & 688612 & 4.4 & 4.6488 & TRN & \\
\hline CHEMBL1582096 & 688612 & 5.5 & 4.5837 & TST & \\
\hline CHEMBL1383932 & 688612 & 4.15 & 4.7156 & TRN & \\
\hline CHEMBL1315525 & 688612 & 4.0 & 4.6032 & TRN & \\
\hline CHEMBL1373228 & 688612 & 4.65 & 4.73600 & 0000000001 & TRN \\
\hline CHEMBL1338001 & 688612 & 5.95 & 4.6613 & TRN & \\
\hline CHEMBL1312441 & 688612 & 4.1 & 4.6971 & TST & \\
\hline CHEMBL1582472 & 688612 & 4.7 & 4.7232 & TRN & \\
\hline CHEMBL1323914 & 688612 & 5.0 & 4.6262 & TRN & \\
\hline CHEMBL1324949 & 688612 & 5.3 & 4.6472 & TST & \\
\hline CHEMBL1349430 & 688612 & 4.4 & 4.6486 & TRN & \\
\hline CHEMBL 2006451 & 688612 & 4.05 & 4.744 & TST & \\
\hline CHEMBL1472059 & 688612 & 4.05 & 4.6778 & TRN & \\
\hline CHEMBL1520016 & 688612 & 4.55 & 4.6088 & TRN & \\
\hline CHEMBL1563650 & 688612 & 5.5 & 4.5917 & TRN & \\
\hline CHEMBL1432290 & 688612 & 4.1 & 4.6417 & TST & \\
\hline CHEMBL1327350 & 688612 & 4.15 & 4.7239 & TST & \\
\hline CHEMBL1594016 & 688612 & 4.4 & 4.6383 & TRN & \\
\hline CHEMBL1544978 & 688612 & 6.05 & 4.7489 & TRN & \\
\hline CHEMBL1308985 & 688612 & 4.05 & 4.6852 & TRN & \\
\hline CHEMBL1419683 & 688612 & 4.05 & 4.6993 & TRN & \\
\hline CHEMBL1492860 & 688612 & 4.15 & 4.5889 & TRN & \\
\hline CHEMBL1565089 & 688612 & 4.4 & 4.8031 & TRN & \\
\hline CHEMBL1503374 & 688612 & 4.05 & 4.6566 & TRN & \\
\hline CHEMBL1339849 & 688612 & 5.45 & 4.6498 & TST & \\
\hline CHEMBL1546925 & 688612 & 4.1 & 4.6348 & TRN & \\
\hline CHEMBL1532539 & 688612 & 4.4 & 4.6774 & TST & \\
\hline
\end{tabular}




\begin{tabular}{|c|c|c|c|c|c|}
\hline & & \multicolumn{4}{|c|}{ Supplemental Table S2.txt } \\
\hline CHEMBL1426684 & 688612 & 6.5501 & 4.6654 & TST & \\
\hline CHEMBL1320225 & 688612 & 4.2 & 4.6206 & TRN & \\
\hline CHEMBL1521877 & 688612 & 4.5 & 4.6833 & TRN & \\
\hline CHEMBL1392418 & 688612 & 4.0 & 4.5907 & TRN & \\
\hline CHEMBL1335896 & 688612 & 4.1 & 4.6776 & TRN & \\
\hline CHEMBL1352903 & 688612 & 4.5 & 4.7181 & TST & \\
\hline CHEMBL1305499 & 688612 & 4.2 & 4.6708 & TRN & \\
\hline CHEMBL1307740 & 688612 & 4.4 & 4.6725 & TRN & \\
\hline CHEMBL1590926 & 688612 & 4.05 & 4.7114 & TRN & \\
\hline CHEMBL1457359 & 688612 & 4.05 & 4.6467 & TRN & \\
\hline CHEMBL1352570 & 688612 & 4.1 & 4.7039 & TRN & \\
\hline CHEMBL1500751 & 688612 & 5.05 & 4.7862 & TST & \\
\hline CHEMBL1474219 & 688612 & 4.0 & 4.61100 & 0000000001 & TRN \\
\hline CHEMBL1355808 & 688612 & 4.65 & 4.6236 & TRN & \\
\hline CHEMBL1330719 & 688612 & 4.1 & 4.6415 & TRN & \\
\hline CHEMBL1401854 & 688612 & 4.05 & 4.7128 & TST & \\
\hline CHEMBL1507989 & 688612 & 4.0 & 4.6775 & TST & \\
\hline CHEMBL1377641 & 688612 & 4.1 & 4.618 & TST & \\
\hline CHEMBL1427600 & 688612 & 4.05 & 4.6904 & TRN & \\
\hline CHEMBL1345629 & 688612 & 4.5 & 4.6661 & TST & \\
\hline CHEMBL1540098 & 688612 & 4.1 & 4.7066 & TST & \\
\hline CHEMBL1591713 & 688612 & 4.05 & 4.6227 & TRN & \\
\hline CHEMBL1597481 & 688612 & 4.3 & 4.7149 & TRN & \\
\hline CHEMBL1511661 & 688612 & 4.5 & 4.7481 & TRN & \\
\hline CHEMBL1573521 & 688612 & 4.6 & 4.7151 & TRN & \\
\hline CHEMBL1595015 & 688612 & 4.8 & 4.7152 & TRN & \\
\hline CHEMBL1499891 & 688612 & 5.35 & 4.664 & TRN & \\
\hline CHEMBL1360098 & 688612 & 4.7 & 4.7101 & TRN & \\
\hline CHEMBL1546129 & 688612 & 4.05 & 4.6343 & TRN & \\
\hline CHEMBL1467075 & 688612 & 5.2 & 4.6552 & TRN & \\
\hline CHEMBL1455066 & 688612 & 5.55 & 4.6183 & TST & \\
\hline CHEMBL3212560 & 688612 & 4.1 & 4.6454 & TRN & \\
\hline CHEMBL1323641 & 688612 & 4.05 & 4.58 & TRN & \\
\hline CHEMBL1354491 & 688612 & 4.1 & 4.6104 & TRN & \\
\hline CHEMBL1349475 & 688612 & 6.0 & 4.749 & TRN & \\
\hline CHEMBL1502167 & 688612 & 4.1 & 4.7031 & TRN & \\
\hline CHEMBL1484989 & 688612 & 4.55 & 4.7084 & TRN & \\
\hline CHEMBL1471626 & 688612 & 6.35 & 4.6626 & TRN & \\
\hline CHEMBL1337024 & 688612 & 4.05 & 4.6457 & TRN & \\
\hline CHEMBL 3213507 & 688612 & 7.0 & 4.7384 & TRN & \\
\hline CHEMBL1422192 & 688612 & 4.5 & 4.6671 & TST & \\
\hline CHEMBL1595736 & 688612 & 4.3 & 4.6659 & TRN & \\
\hline CHEMBL1500355 & 688612 & 6.35 & 4.6373 & TRN & \\
\hline CHEMBL1322801 & 688612 & 4.0 & 4.6338 & TRN & \\
\hline CHEMBL3197250 & 688612 & 5.35 & 4.6902 & TST & \\
\hline CHEMBL1448142 & 688612 & 4.05 & 4.593 & TRN & \\
\hline CHEMBL1352579 & 688612 & 6.8499 & 4.7034 & TRN & \\
\hline CHEMBL1991021 & 688612 & 4.3 & 4.6312 & TRN & \\
\hline
\end{tabular}




\begin{tabular}{|c|c|c|c|c|c|}
\hline \multicolumn{6}{|c|}{ Supplemental Table s2.txt } \\
\hline CHEMBL1360570 & 688612 & 4.6 & 4.6674 & TRN & \\
\hline CHEMBL1389057 & 688612 & 4.45 & 4.7121 & TRN & \\
\hline CHEMBL1320023 & 688612 & 4.05 & 4.7395 & TST & \\
\hline CHEMBL289716 & 688612 & 5.4 & 4.7668 & TRN & \\
\hline CHEMBL1363977 & 688612 & 4.5 & 4.71399 & 99999999995 & TRN \\
\hline CHEMBL1499658 & 688612 & 5.5 & 4.7079 & TRN & \\
\hline CHEMBL1592955 & 688612 & 4.05 & 4.6054 & TRN & \\
\hline CHEMBL1460732 & 688612 & 4.1 & 4.6595 & TRN & \\
\hline CHEMBL1390878 & 688612 & 4.2 & 4.6683 & TST & \\
\hline CHEMBL1526027 & 688612 & 4.05 & 4.6904 & TRN & \\
\hline CHEMBL1386789 & 688612 & 4.6 & 4.6842 & TRN & \\
\hline CHEMBL1545554 & 688612 & 4.4 & 4.7575 & TRN & \\
\hline CHEMBL1308068 & 688612 & 5.15 & 4.6506 & TRN & \\
\hline CHEMBL1553755 & 688612 & 4.6 & 4.7149 & TST & \\
\hline CHEMBL1340123 & 688612 & 5.8 & 4.6732 & TRN & \\
\hline CHEMBL1563592 & 688612 & 4.8 & 4.6714 & TRN & \\
\hline CHEMBL1335704 & 688612 & 6.45 & 4.6035 & TST & \\
\hline CHEMBL1584099 & 688612 & 6.7501 & 4.7076 & TST & \\
\hline CHEMBL1361855 & 688612 & 4.9 & 4.6748 & TST & \\
\hline CHEMBL1448090 & 688612 & 4.4 & 4.7032 & TRN & \\
\hline CHEMBL1430289 & 688612 & 5.05 & 4.6486 & TST & \\
\hline CHEMBL 3207814 & 688612 & 4.1 & 4.6525 & TRN & \\
\hline CHEMBL1256869 & 688612 & 4.4 & 4.7342 & TST & \\
\hline CHEMBL1539579 & 688612 & 5.05 & 4.6918 & TRN & \\
\hline CHEMBL1466658 & 688612 & 4.1 & 4.7554 & TRN & \\
\hline CHEMBL1427281 & 688612 & 5.05 & 4.6672 & TST & \\
\hline CHEMBL1336326 & 688612 & 6.3 & 4.6628 & TRN & \\
\hline CHEMBL1573855 & 688612 & 4.95 & 4.6621 & TRN & \\
\hline CHEMBL1510320 & 688612 & 5.35 & 4.6599 & TRN & \\
\hline CHEMBL3191806 & 688612 & 4.2 & 4.7741 & TRN & \\
\hline CHEMBL1550037 & 688612 & 4.6 & 4.6409 & TRN & \\
\hline CHEMBL1305407 & 688612 & 4.0 & 4.7287 & TRN & \\
\hline CHEMBL1500515 & 688612 & 4.1 & 4.66100 & 00000000005 & TRN \\
\hline CHEMBL1323775 & 688612 & 6.35 & 4.6032 & TRN & \\
\hline CHEMBL1326097 & 688612 & 6.1 & 4.6127 & TRN & \\
\hline CHEMBL1387827 & 688612 & 4.9 & 4.6712 & TRN & \\
\hline CHEMBL1594499 & 688612 & 5.3 & 4.6553 & TST & \\
\hline CHEMBL1493058 & 688612 & 4.35 & 4.7217 & TRN & \\
\hline CHEMBL1362915 & 688612 & 4.05 & 4.6506 & TRN & \\
\hline CHEMBL1474582 & 688612 & 4.25 & 4.6554 & TRN & \\
\hline CHEMBL 216504 & 688612 & 5.6238 & 4.6887 & TST & \\
\hline CHEMBL1497496 & 688612 & 4.55 & 4.6173 & TST & \\
\hline CHEMBL1508177 & 688612 & 4.25 & 4.7208 & TRN & \\
\hline CHEMBL1331995 & 688612 & 4.3 & 4.7181 & TRN & \\
\hline CHEMBL1569156 & 688612 & 4.05 & 4.6969 & TRN & \\
\hline CHEMBL1540706 & 688612 & 4.05 & 4.677 & TST & \\
\hline CHEMBL1387960 & 688612 & 4.5 & 4.7333 & TST & \\
\hline CHEMBL1351828 & 688612 & 4.05 & 4.6827 & TST & \\
\hline
\end{tabular}




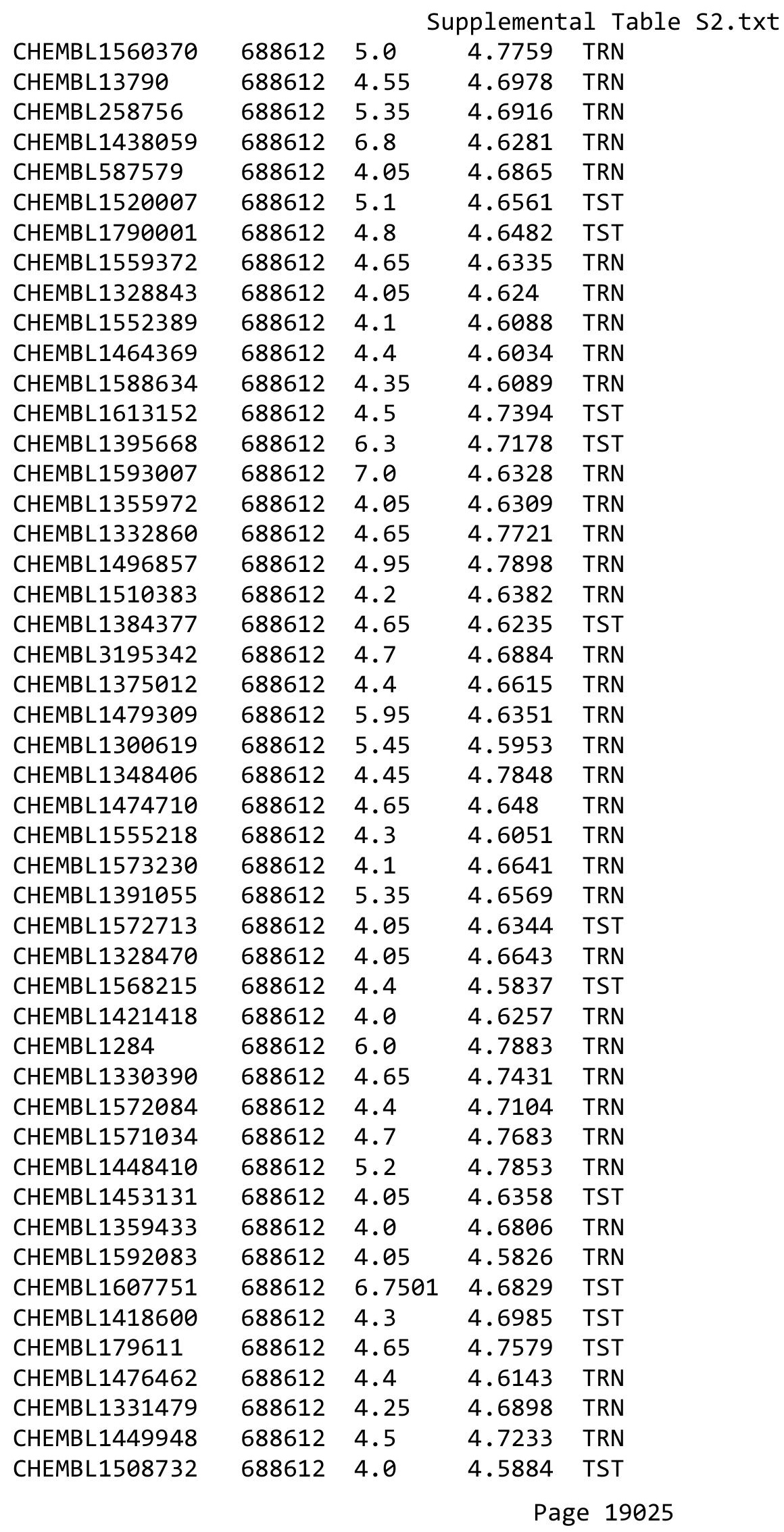




\begin{tabular}{|c|c|c|c|c|}
\hline \multicolumn{5}{|c|}{ Supplemental Table S2.txt } \\
\hline CHEMBL1505440 & 688612 & 4.5 & 4.5911 & TRN \\
\hline CHEMBL1990571 & 688612 & 4.3 & 4.6457 & TRN \\
\hline CHEMBL1524900 & 688612 & 4.85 & 4.6568 & TRN \\
\hline CHEMBL 3198425 & 688612 & 4.05 & 4.725 & TST \\
\hline CHEMBL1554849 & 688612 & 4.1 & 4.6063 & TRN \\
\hline CHEMBL1397432 & 688612 & 4.45 & 4.5977 & TRN \\
\hline CHEMBL442925 & 688612 & 4.05 & 4.7365 & TRN \\
\hline CHEMBL1409749 & 688612 & 4.95 & 4.6372 & TRN \\
\hline CHEMBL1456118 & 688612 & 4.8 & 4.6384 & TRN \\
\hline CHEMBL1345080 & 688612 & 4.05 & 4.6429 & TST \\
\hline CHEMBL1567682 & 688612 & 4.7 & 4.7371 & TRN \\
\hline CHEMBL1363582 & 688612 & 4.4 & 4.6636 & TST \\
\hline CHEMBL1517769 & 688612 & 4.05 & 4.6168 & TRN \\
\hline CHEMBL1363349 & 688612 & 4.0 & 4.6201 & TST \\
\hline CHEMBL1577423 & 688612 & 4.1 & 4.6353 & TST \\
\hline CHEMBL1512969 & 688612 & 4.6 & 4.6348 & TRN \\
\hline CHEMBL1549828 & 688612 & 4.65 & 4.5757 & TRN \\
\hline CHEMBL1559315 & 688612 & 5.9 & 4.7076 & TST \\
\hline CHEMBL179642 & 688612 & 4.15 & 4.7687 & TRN \\
\hline CHEMBL3195832 & 688612 & 4.9 & 4.6998 & TRN \\
\hline CHEMBL1607897 & 688612 & 4.65 & 4.7105 & TST \\
\hline CHEMBL1455634 & 688612 & 4.7 & 4.7069 & TRN \\
\hline CHEMBL1300008 & 688612 & 4.5 & 4.7084 & TRN \\
\hline CHEMBL1466181 & 688612 & 4.8 & 4.8001 & TST \\
\hline CHEMBL1343573 & 688612 & 4.45 & 4.6393 & TRN \\
\hline CHEMBL1374207 & 688612 & 4.2 & 4.6375 & TRN \\
\hline CHEMBL1485598 & 688612 & 4.3 & 4.6563 & TRN \\
\hline CHEMBL1523840 & 688612 & 4.1 & 4.5672 & TRN \\
\hline CHEMBL 88453 & 688612 & 4.1 & 4.7697 & TRN \\
\hline CHEMBL1456139 & 688612 & 6.8499 & 4.6666 & TST \\
\hline CHEMBL592869 & 688612 & 5.35 & 4.7742 & TRN \\
\hline CHEMBL1606005 & 688612 & 4.1 & 4.5729 & TRN \\
\hline CHEMBL1336097 & 688612 & 4.15 & 4.6276 & TRN \\
\hline CHEMBL1373368 & 688612 & 4.0 & 4.5873 & TRN \\
\hline CHEMBL1520003 & 688612 & 4.2 & 4.6819 & TRN \\
\hline CHEMBL1332780 & 688612 & 4.75 & 4.6548 & TRN \\
\hline CHEMBL1588434 & 688612 & 4.65 & 4.7253 & TRN \\
\hline CHEMBL1560833 & 688612 & 5.0 & 4.7564 & TRN \\
\hline CHEMBL1425998 & 688612 & 4.05 & 4.6643 & TRN \\
\hline CHEMBL1515603 & 688612 & 4.8 & 4.6273 & TRN \\
\hline CHEMBL1402811 & 688612 & 6.9 & 4.6197 & TRN \\
\hline CHEMBL1322904 & 688612 & 4.6 & 4.7078 & TRN \\
\hline CHEMBL1328863 & 688612 & 4.05 & 4.6714 & TRN \\
\hline CHEMBL1487831 & 688612 & 5.0 & 4.6784 & TRN \\
\hline CHEMBL1522512 & 688612 & 4.0 & 4.6752 & TRN \\
\hline CHEMBL578939 & 688612 & 4.5 & 4.6451 & TST \\
\hline CHEMBL1344971 & 688612 & 4.1 & 4.6986 & TRN \\
\hline CHEMBL1377760 & 688612 & 4.1 & 4.5681 & TRN \\
\hline
\end{tabular}




\begin{tabular}{|c|c|c|c|c|c|}
\hline & & \multicolumn{4}{|c|}{ Supplemental Table S2.txt } \\
\hline CHEMBL 2001933 & 688612 & 4.7 & 4.7878 & TRN & \\
\hline CHEMBL1315149 & 688612 & 4.35 & 4.5853 & TRN & \\
\hline CHEMBL1350506 & 688612 & 4.7 & 4.6278 & TST & \\
\hline CHEMBL1549788 & 688612 & 6.1 & 4.6153 & TRN & \\
\hline CHEMBL1483318 & 688612 & 6.45 & 4.6311 & TRN & \\
\hline CHEMBL1534097 & 688612 & 4.65 & 4.6792 & TRN & \\
\hline CHEMBL1552739 & 688612 & 4.0 & 4.6138 & TRN & \\
\hline CHEMBL1367548 & 688612 & 4.0 & 4.6002 & TRN & \\
\hline CHEMBL609438 & 688612 & 4.15 & 4.7205 & TRN & \\
\hline CHEMBL1349770 & 688612 & 4.0 & 4.6908 & TRN & \\
\hline CHEMBL1612258 & 688612 & 5.5 & 4.6122 & TRN & \\
\hline CHEMBL1382392 & 688612 & 6.95 & 4.6871 & TST & \\
\hline CHEMBL1457944 & 688612 & 4.45 & 4.6951 & TRN & \\
\hline CHEMBL1526265 & 688612 & 4.55 & 4.6949 & TRN & \\
\hline CHEMBL1389241 & 688612 & 5.9 & 4.6692 & TRN & \\
\hline CHEMBL1597494 & 688612 & 4.1 & 4.6561 & TST & \\
\hline CHEMBL1459709 & 688612 & 4.5 & 4.7433 & TRN & \\
\hline CHEMBL1608218 & 688612 & 4.35 & 4.6915 & TRN & \\
\hline CHEMBL1607067 & 688612 & 4.3 & 4.63899 & 9999999999 & TST \\
\hline CHEMBL1496959 & 688612 & 4.4 & 4.7122 & TRN & \\
\hline CHEMBL3196704 & 688612 & 5.0 & 4.7442 & TRN & \\
\hline CHEMBL1603748 & 688612 & 4.1 & 4.7312 & TRN & \\
\hline CHEMBL1343398 & 688612 & 6.25 & 4.6756 & TRN & \\
\hline CHEMBL1384039 & 688612 & 4.1 & 4.6688 & TST & \\
\hline CHEMBL1603330 & 688612 & 4.0 & 4.6661 & TST & \\
\hline CHEMBL1518714 & 688612 & 6.9 & 4.6595 & TST & \\
\hline CHEMBL1449660 & 688612 & 4.65 & 4.6658 & TRN & \\
\hline CHEMBL3196385 & 688612 & 6.1 & 4.637 & TRN & \\
\hline CHEMBL1395593 & 688612 & 5.1 & 4.6218 & TRN & \\
\hline CHEMBL1398043 & 688612 & 4.05 & 4.6333 & TST & \\
\hline CHEMBL1434477 & 688612 & 6.05 & 4.6706 & TRN & \\
\hline CHEMBL1604687 & 688612 & 4.5 & 4.7487 & TST & \\
\hline CHEMBL1525109 & 688612 & 4.0 & 4.6654 & TRN & \\
\hline CHEMBL1511771 & 688612 & 4.05 & 4.6048 & TRN & \\
\hline CHEMBL1301694 & 688612 & 4.4 & 4.5771 & TRN & \\
\hline CHEMBL1438597 & 688612 & 4.65 & 4.6241 & TRN & \\
\hline CHEMBL1586975 & 688612 & 4.4 & 4.7026 & TST & \\
\hline CHEMBL1409194 & 688612 & 4.65 & 4.5984 & TRN & \\
\hline CHEMBL1472867 & 688612 & 4.45 & 4.6268 & TRN & \\
\hline CHEMBL1399230 & 688612 & 7.0 & 4.7317 & TRN & \\
\hline CHEMBL1410186 & 688612 & 5.15 & 4.7076 & TRN & \\
\hline CHEMBL1519012 & 688612 & 6.8499 & 4.6519 & TST & \\
\hline CHEMBL1405485 & 688612 & 4.05 & 4.6917 & TST & \\
\hline CHEMBL1364160 & 688612 & 4.55 & 4.6872 & TRN & \\
\hline CHEMBL1355790 & 688612 & 4.7 & 4.6019 & TRN & \\
\hline CHEMBL1335867 & 688612 & 4.55 & 4.7427 & TST & \\
\hline CHEMBL1506071 & 688612 & 4.0 & 4.6321 & TRN & \\
\hline CHEMBL1464399 & 688612 & 4.6 & 4.7003 & TRN & \\
\hline
\end{tabular}




\begin{tabular}{|c|c|c|c|c|c|}
\hline \multicolumn{6}{|c|}{ Supplemental Table S2.txt } \\
\hline CHEMBL3192885 & 688612 & 4.75 & 4.6177 & TRN & \\
\hline CHEMBL1375714 & 688612 & 6.8 & 4.5533 & TRN & \\
\hline CHEMBL1455701 & 688612 & 4.55 & 4.6965 & TRN & \\
\hline CHEMBL1502851 & 688612 & 5.0 & 4.7744 & TST & \\
\hline CHEMBL1414554 & 688612 & 4.45 & 4.6618 & TRN & \\
\hline CHEMBL 3213477 & 688612 & 4.15 & 4.7052 & TRN & \\
\hline CHEMBL1486713 & 688612 & 4.0 & 4.64 & TRN & \\
\hline CHEMBL1372271 & 688612 & 4.05 & 4.6549 & TRN & \\
\hline CHEMBL1309113 & 688612 & 4.4 & 4.5787 & TRN & \\
\hline CHEMBL1567174 & 688612 & 5.35 & 4.6984 & TRN & \\
\hline CHEMBL1426446 & 688612 & 4.05 & 4.7351 & TRN & \\
\hline CHEMBL1431748 & 688612 & 5.15 & 4.6854 & TRN & \\
\hline CHEMBL1533050 & 688612 & 4.15 & 4.5995 & TRN & \\
\hline CHEMBL1494120 & 688612 & 4.35 & $4.6110 e$ & 2000000001 & TST \\
\hline CHEMBL1582394 & 688612 & 5.4 & 4.7599 & TRN & \\
\hline CHEMBL1552414 & 688612 & 4.3 & $4.6160 e$ & 30000000005 & TRN \\
\hline CHEMBL3191585 & 688612 & 5.05 & 4.6444 & TST & \\
\hline CHEMBL1481948 & 688612 & 6.8499 & 4.6817 & TRN & \\
\hline CHEMBL 3197853 & 688612 & 4.2 & 4.7462 & TRN & \\
\hline CHEMBL1460828 & 688612 & 4.0 & 4.6822 & TRN & \\
\hline CHEMBL1306493 & 688612 & 4.2 & 4.6643 & TST & \\
\hline CHEMBL1464900 & 688612 & 4.1 & 4.63 & TRN & \\
\hline CHEMBL1403039 & 688612 & 4.05 & 4.6694 & TRN & \\
\hline CHEMBL1473647 & 688612 & 4.35 & 4.6792 & TRN & \\
\hline CHEMBL1346664 & 688612 & 4.75 & 4.6707 & TRN & \\
\hline CHEMBL1307390 & 688612 & 4.1 & 4.5686 & TRN & \\
\hline CHEMBL1994460 & 688612 & 4.6 & 4.6566 & TST & \\
\hline CHEMBL1582433 & 688612 & 4.05 & 4.542 & TRN & \\
\hline CHEMBL3193120 & 688612 & 6.15 & 4.6602 & TRN & \\
\hline CHEMBL1560393 & 688612 & 4.15 & 4.6289 & TRN & \\
\hline CHEMBL1436455 & 688612 & 6.6499 & 4.637 & TRN & \\
\hline CHEMBL1515465 & 688612 & 4.6 & 4.6215 & TRN & \\
\hline CHEMBL1535798 & 688612 & 4.7 & 4.6652 & TRN & \\
\hline CHEMBL1423186 & 688612 & 4.85 & 4.6746 & TRN & \\
\hline CHEMBL1501583 & 688612 & 4.6 & 4.601 & TRN & \\
\hline CHEMBL1532420 & 688612 & 4.3 & 4.6868 & TST & \\
\hline CHEMBL1504875 & 688612 & 5.0 & 4.6969 & TRN & \\
\hline CHEMBL1561719 & 688612 & 4.1 & 4.6174 & TRN & \\
\hline CHEMBL1445030 & 688612 & 5.55 & 4.7178 & TRN & \\
\hline CHEMBL1479837 & 688612 & 6.5501 & 4.6205 & TST & \\
\hline CHEMBL1590409 & 688612 & 4.1 & 4.6211 & TRN & \\
\hline CHEMBL1599597 & 688612 & 4.7 & 4.6042 & TRN & \\
\hline CHEMBL1981446 & 688612 & 5.85 & 4.7047 & TRN & \\
\hline CHEMBL1516944 & 688612 & 4.05 & 4.5855 & TRN & \\
\hline CHEMBL1340249 & 688612 & 6.15 & 4.6238 & TRN & \\
\hline CHEMBL1396458 & 688612 & 4.5 & 4.627 & TRN & \\
\hline CHEMBL1409844 & 688612 & 4.4 & 4.7579 & TST & \\
\hline CHEMBL1350286 & 688612 & 4.4 & 4.6011 & TRN & \\
\hline
\end{tabular}




\begin{tabular}{|c|c|c|c|c|}
\hline \multicolumn{5}{|c|}{ Supplemental Table S2.txt } \\
\hline CHEMBL3199636 & 688612 & 4.05 & 4.6331 & TRN \\
\hline CHEMBL1497166 & 688612 & 4.35 & 4.6335 & TRN \\
\hline CHEMBL1341114 & 688612 & 4.1 & 4.7055 & TST \\
\hline CHEMBL 3198401 & 688612 & 4.6 & 4.7106 & TRN \\
\hline CHEMBL1381632 & 688612 & 4.5 & 4.6242 & TRN \\
\hline CHEMBL1480798 & 688612 & 5.75 & 4.7981 & TRN \\
\hline CHEMBL1341933 & 688612 & 4.05 & 4.5463 & TST \\
\hline CHEMBL3191892 & 688612 & 4.85 & 4.7952 & TRN \\
\hline CHEMBL1424167 & 688612 & 5.25 & 4.7304 & TRN \\
\hline CHEMBL1518628 & 688612 & 4.9 & 4.7122 & TST \\
\hline CHEMBL1578657 & 688612 & 4.25 & 4.7366 & TRN \\
\hline CHEMBL1504218 & 688612 & 4.05 & 4.6271 & TST \\
\hline CHEMBL1486462 & 688612 & 4.95 & 4.6718 & TST \\
\hline CHEMBL1468655 & 688612 & 4.05 & 4.633 & TST \\
\hline CHEMBL1388602 & 688612 & 6.3 & 4.6325 & TST \\
\hline CHEMBL1454090 & 688612 & 4.6 & 4.6269 & TRN \\
\hline CHEMBL1510444 & 688612 & 4.05 & 4.6432 & TST \\
\hline CHEMBL1435085 & 688612 & 4.15 & 4.6553 & TST \\
\hline CHEMBL1405167 & 688612 & 6.8 & 4.6349 & TRN \\
\hline CHEMBL1505830 & 688612 & 4.4 & 4.6457 & TST \\
\hline CHEMBL1329411 & 688612 & 4.65 & 4.788 & TRN \\
\hline CHEMBL1548256 & 688612 & 4.1 & 4.6728 & TRN \\
\hline CHEMBL1417329 & 688612 & 4.7 & 4.6417 & TRN \\
\hline CHEMBL1559494 & 688612 & 5.05 & 4.6171 & TRN \\
\hline CHEMBL1502638 & 688612 & 4.0 & 4.7318 & TST \\
\hline CHEMBL1334637 & 688612 & 4.0 & 4.7192 & TRN \\
\hline CHEMBL1330644 & 688612 & 4.1 & 4.6937 & TST \\
\hline CHEMBL1388213 & 688612 & 5.55 & 4.6771 & TRN \\
\hline CHEMBL1408237 & 688612 & 4.45 & 4.6853 & TRN \\
\hline CHEMBL1363427 & 688612 & 4.4 & 4.7376 & TST \\
\hline CHEMBL1492872 & 688612 & 4.45 & 4.6151 & TRN \\
\hline CHEMBL1609369 & 688612 & 6.95 & 4.6828 & TST \\
\hline CHEMBL1543589 & 688612 & 4.25 & 4.6222 & TST \\
\hline CHEMBL1308055 & 688612 & 4.55 & 4.6687 & TRN \\
\hline CHEMBL1524713 & 688612 & 5.0 & 4.5805 & TRN \\
\hline CHEMBL1601165 & 688612 & 5.5 & 4.6838 & TST \\
\hline CHEMBL1305667 & 688612 & 4.0 & 4.6841 & TRN \\
\hline CHEMBL1383596 & 688612 & 4.5 & 4.6707 & TST \\
\hline CHEMBL1531888 & 688612 & 4.2 & 4.5938 & TRN \\
\hline CHEMBL1364875 & 688612 & 4.05 & 4.6699 & TRN \\
\hline CHEMBL1342186 & 688612 & 4.1 & 4.6469 & TST \\
\hline CHEMBL1313635 & 688612 & 5.0 & 4.5956 & TRN \\
\hline CHEMBL1360980 & 688612 & 4.4 & 4.7011 & TST \\
\hline CHEMBL1568623 & 688612 & 4.0 & 4.5254 & TRN \\
\hline CHEMBL1577840 & 688612 & 5.4 & 4.7372 & TST \\
\hline CHEMBL1541286 & 688612 & 6.8 & 4.7044 & TRN \\
\hline CHEMBL3194356 & 688612 & 5.5 & 4.8051 & TRN \\
\hline CHEMBL1518139 & 688612 & 4.05 & 4.6323 & TRN \\
\hline
\end{tabular}




\begin{tabular}{|c|c|c|c|c|}
\hline \multicolumn{5}{|c|}{ Supplemental Table S2.txt } \\
\hline CHEMBL1577191 & 688612 & 4.8 & 4.6484 & TRN \\
\hline CHEMBL1588413 & 688612 & 6.8 & 4.6676 & TRN \\
\hline CHEMBL1527194 & 688612 & 4.75 & 4.6847 & TRN \\
\hline CHEMBL1382981 & 688612 & 6.5501 & 4.7517 & TST \\
\hline CHEMBL1344122 & 688612 & 6.35 & 4.638 & TST \\
\hline CHEMBL1346879 & 688612 & 4.85 & 4.7462 & TRN \\
\hline CHEMBL1416169 & 688612 & 4.8 & 4.6618 & TRN \\
\hline CHEMBL1324102 & 688612 & 4.55 & 4.73 & TST \\
\hline CHEMBL1402708 & 688612 & 4.25 & 4.6963 & TRN \\
\hline CHEMBL546257 & 688612 & 6.0 & 4.5876 & TST \\
\hline CHEMBL1336823 & 688612 & 4.85 & 4.7343 & TST \\
\hline CHEMBL3199623 & 688612 & 5.0 & 4.7236 & TRN \\
\hline CHEMBL1402519 & 688612 & 4.05 & 4.6733 & TRN \\
\hline CHEMBL1509563 & 688612 & 5.5 & 4.5712 & TST \\
\hline CHEMBL1495280 & 688612 & 4.85 & 4.6372 & TRN \\
\hline CHEMBL1530127 & 688612 & 5.1 & 4.6135 & TRN \\
\hline CHEMBL1534266 & 688612 & 4.1 & 4.6853 & TRN \\
\hline CHEMBL1529346 & 688612 & 6.8499 & 4.6469 & TRN \\
\hline CHEMBL1453375 & 688612 & 4.65 & 4.6369 & TRN \\
\hline CHEMBL1965791 & 688612 & 4.95 & 4.7746 & TRN \\
\hline CHEMBL1464959 & 688612 & 4.05 & 4.6263 & TRN \\
\hline CHEMBL1324809 & 688612 & 4.05 & 4.6518 & TRN \\
\hline CHEMBL1355373 & 688612 & 5.35 & 4.6841 & TST \\
\hline CHEMBL1497375 & 688612 & 5.35 & 4.6469 & TST \\
\hline CHEMBL1378792 & 688612 & 5.8 & 4.7571 & TST \\
\hline CHEMBL1584749 & 688612 & 4.1 & 4.7323 & TST \\
\hline CHEMBL1470578 & 688612 & 6.35 & 4.7151 & TRN \\
\hline CHEMBL1487139 & 688612 & 4.05 & 4.6469 & TRN \\
\hline CHEMBL1518838 & 688612 & 4.75 & 4.6904 & TRN \\
\hline CHEMBL1335384 & 688612 & 4.05 & 4.636 & TRN \\
\hline CHEMBL1482927 & 688612 & 4.05 & 4.6621 & TRN \\
\hline CHEMBL1317303 & 688612 & 4.05 & 4.6816 & TRN \\
\hline CHEMBL1484692 & 688612 & 4.4 & 4.6798 & TRN \\
\hline CHEMBL1394174 & 688612 & 4.05 & 4.6563 & TRN \\
\hline CHEMBL495123 & 688612 & 4.25 & 4.8317 & TRN \\
\hline CHEMBL1465684 & 688612 & 4.1 & 4.6573 & TRN \\
\hline CHEMBL1316608 & 688612 & 4.0 & 4.6893 & TRN \\
\hline CHEMBL1345155 & 688612 & 4.05 & 4.6984 & TRN \\
\hline CHEMBL1462469 & 688612 & 5.15 & 4.6428 & TST \\
\hline CHEMBL1448958 & 688612 & 4.05 & 4.7137 & TST \\
\hline CHEMBL1324024 & 688612 & 4.1 & 4.5875 & TRN \\
\hline CHEMBL1442416 & 688612 & 4.95 & 4.673 & TRN \\
\hline CHEMBL1300730 & 688612 & 6.0 & 4.7303 & TRN \\
\hline CHEMBL1336417 & 688612 & 4.05 & 4.6666 & TRN \\
\hline CHEMBL1481651 & 688612 & 4.3 & 4.6726 & TRN \\
\hline CHEMBL1972480 & 688612 & 4.4 & 4.6029 & TRN \\
\hline CHEMBL1594349 & 688612 & 4.1 & 4.6341 & TRN \\
\hline CHEMBL1347042 & 688612 & 5.05 & 4.7506 & TST \\
\hline
\end{tabular}




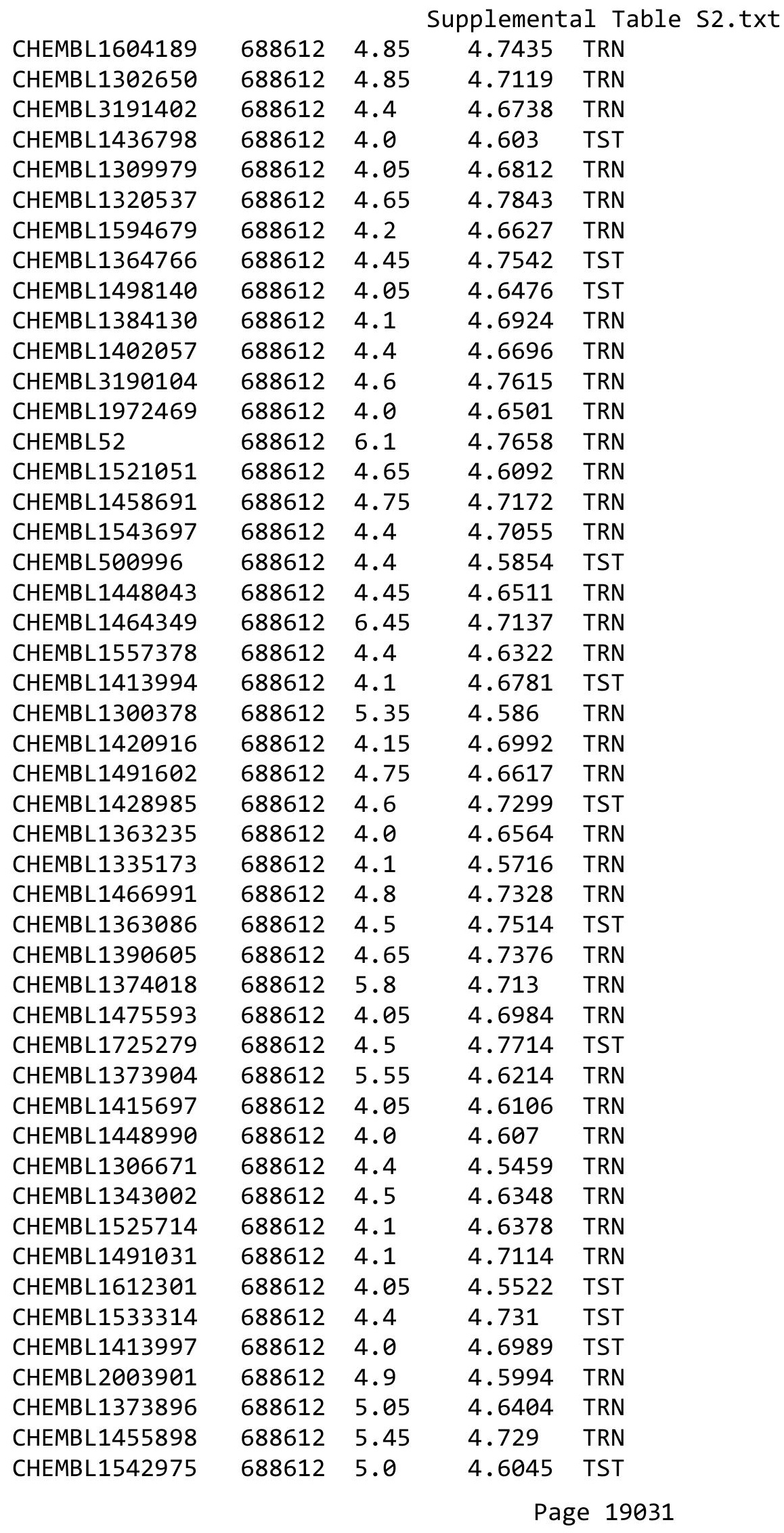




\begin{tabular}{|c|c|c|c|c|c|}
\hline \multicolumn{6}{|c|}{ Supplemental Table S2.txt } \\
\hline CHEMBL1483479 & 688612 & 4.6 & 4.6667 & TST & \\
\hline CHEMBL1464699 & 688612 & 4.05 & 4.646 & TRN & \\
\hline CHEMBL1555752 & 688612 & 4.3 & 4.7044 & TRN & \\
\hline CHEMBL1394997 & 688612 & 5.45 & 4.6188 & TRN & \\
\hline CHEMBL1400176 & 688612 & 4.75 & 4.6936 & TRN & \\
\hline CHEMBL1479582 & 688612 & 4.85 & 4.6136 & TRN & \\
\hline CHEMBL3192691 & 688612 & 4.65 & 4.6189 & TRN & \\
\hline CHEMBL1564267 & 688612 & 4.05 & 4.6453 & TRN & \\
\hline CHEMBL1348176 & 688612 & 4.1 & 4.7147 & TRN & \\
\hline CHEMBL1608453 & 688612 & 4.1 & 4.6897 & TRN & \\
\hline CHEMBL1345796 & 688612 & 5.25 & 4.6839 & TRN & \\
\hline CHEMBL1525940 & 688612 & 4.4 & 4.7091 & TRN & \\
\hline CHEMBL1420252 & 688612 & 4.85 & 4.706 & TRN & \\
\hline CHEMBL1486633 & 688612 & 4.0 & 4.6113 & TRN & \\
\hline CHEMBL1304093 & 688612 & 4.95 & 4.6219 & TST & \\
\hline CHEMBL1582022 & 688612 & 4.9 & 4.6296 & TRN & \\
\hline CHEMBL1585550 & 688612 & 6.9 & 4.6513 & TRN & \\
\hline CHEMBL1416601 & 688612 & 4.1 & 4.635 & TRN & \\
\hline CHEMBL1439235 & 688612 & 4.05 & 4.6889 & TRN & \\
\hline CHEMBL1307160 & 688612 & 4.75 & 4.7313 & TST & \\
\hline CHEMBL1598523 & 688612 & 6.0 & 4.6836 & TRN & \\
\hline CHEMBL1602972 & 688612 & 4.35 & 4.6276 & TRN & \\
\hline CHEMBL1486341 & 688612 & 4.4 & 4.6646 & TRN & \\
\hline CHEMBL1510380 & 688612 & 4.4 & 4.6127 & TRN & \\
\hline CHEMBL1505177 & 688612 & 4.5 & 4.7867 & TRN & \\
\hline CHEMBL1560542 & 688612 & 4.1 & 4.6001 & TRN & \\
\hline CHEMBL1537042 & 688612 & 4.1 & 4.6653 & TRN & \\
\hline CHEMBL1437135 & 688612 & 4.7 & 4.6715 & TST & \\
\hline CHEMBL1967770 & 688612 & 4.0 & 4.7964 & TST & \\
\hline CHEMBL3392068 & 688612 & 4.8 & 4.7589 & TST & \\
\hline CHEMBL1447311 & 688612 & 4.65 & 4.6397 & TRN & \\
\hline CHEMBL1303559 & 688612 & 4.6 & 4.6644 & TST & \\
\hline CHEMBL1613124 & 688612 & 4.85 & 4.6414 & TRN & \\
\hline CHEMBL1432627 & 688612 & 4.65 & 4.7885 & TRN & \\
\hline CHEMBL1539621 & 688612 & 4.4 & 4.7025 & TRN & \\
\hline CHEMBL1403547 & 688612 & 6.0 & 4.6379 & TRN & \\
\hline CHEMBL1347211 & 688612 & 4.4 & 4.58899 & 99999999995 & TRN \\
\hline CHEMBL1444498 & 688612 & 4.6 & 4.5839 & TRN & \\
\hline CHEMBL1512997 & 688612 & 6.5501 & 4.666 & TRN & \\
\hline CHEMBL1314400 & 688612 & 4.4 & 4.6297 & TRN & \\
\hline CHEMBL3198496 & 688612 & 5.55 & 4.8544 & TRN & \\
\hline CHEMBL1466887 & 688612 & 4.65 & 4.7436 & TST & \\
\hline CHEMBL1446687 & 688612 & 6.3 & 4.6345 & TRN & \\
\hline CHEMBL1327371 & 688612 & 6.5 & 4.6832 & TRN & \\
\hline CHEMBL1356890 & 688612 & 4.0 & 4.5889 & TRN & \\
\hline CHEMBL1560713 & 688612 & 4.95 & 4.629 & TRN & \\
\hline CHEMBL1588550 & 688612 & 4.35 & 4.5831 & TRN & \\
\hline CHEMBL1594641 & 688612 & 6.1 & 4.6832 & TRN & \\
\hline
\end{tabular}




\begin{tabular}{|c|c|c|c|c|c|}
\hline \multicolumn{6}{|c|}{ Supplemental Table S2.txt } \\
\hline CHEMBL1568511 & 688612 & 4.05 & 4.6136 & TRN & \\
\hline CHEMBL1599843 & 688612 & 5.35 & 4.7009 & TST & \\
\hline CHEMBL1594699 & 688612 & 4.5 & 4.78 & TRN & \\
\hline CHEMBL1457840 & 688612 & 6.8499 & 4.6712 & TST & \\
\hline CHEMBL3209049 & 688612 & 4.1 & 4.6298 & TRN & \\
\hline CHEMBL3197564 & 688612 & 4.45 & 4.80699 & 99999999995 & TRN \\
\hline CHEMBL1412030 & 688612 & 4.05 & 4.7014 & TRN & \\
\hline CHEMBL1596328 & 688612 & 4.1 & 4.6164 & TST & \\
\hline CHEMBL1489994 & 688612 & 4.4 & 4.6242 & TRN & \\
\hline CHEMBL1427775 & 688612 & 6.25 & 4.7198 & TRN & \\
\hline CHEMBL1584643 & 688612 & 4.2 & 4.6745 & TST & \\
\hline CHEMBL1501496 & 688612 & 4.0 & 4.6442 & TRN & \\
\hline CHEMBL1541303 & 688612 & 4.25 & 4.7749 & TRN & \\
\hline CHEMBL1302938 & 688612 & 4.4 & 4.6882 & TST & \\
\hline CHEMBL1342734 & 688612 & 4.25 & 4.7395 & TRN & \\
\hline CHEMBL1327961 & 688612 & 6.05 & 4.5629 & TRN & \\
\hline CHEMBL3192303 & 688612 & 5.75 & 4.7659 & TST & \\
\hline CHEMBL1348487 & 688612 & 6.3 & 4.6348 & TRN & \\
\hline CHEMBL1605138 & 688612 & 4.1 & 4.6794 & TST & \\
\hline CHEMBL3208998 & 688612 & 4.6 & 4.7132 & TST & \\
\hline CHEMBL1361191 & 688612 & 4.7 & 4.6375 & TRN & \\
\hline CHEMBL1480196 & 688612 & 4.15 & 4.6265 & TRN & \\
\hline CHEMBL1707275 & 688612 & 4.95 & 4.7051 & TRN & \\
\hline CHEMBL1544628 & 688612 & 6.1 & 4.6468 & TRN & \\
\hline CHEMBL1310717 & 688612 & 4.5 & 4.6943 & TRN & \\
\hline CHEMBL1433086 & 688612 & 4.1 & 4.7433 & TST & \\
\hline CHEMBL1320561 & 688612 & 4.05 & 4.5778 & TRN & \\
\hline CHEMBL1447002 & 688612 & 5.0 & 4.7178 & TRN & \\
\hline CHEMBL1468112 & 688612 & 4.65 & 4.6625 & TRN & \\
\hline CHEMBL1610522 & 688612 & 4.05 & 4.6243 & TRN & \\
\hline CHEMBL1539857 & 688612 & 4.2 & 4.7457 & TST & \\
\hline CHEMBL3199060 & 688612 & 5.3 & 4.794 & TST & \\
\hline CHEMBL1548074 & 688612 & 4.1 & 4.7039 & TRN & \\
\hline CHEMBL1552045 & 688612 & 4.05 & 4.5898 & TRN & \\
\hline CHEMBL157351 & 688612 & 4.65 & 4.7835 & TST & \\
\hline CHEMBL1447678 & 688612 & 4.85 & 4.7705 & TRN & \\
\hline CHEMBL1552908 & 688612 & 4.0 & 4.6256 & TST & \\
\hline CHEMBL1391171 & 688612 & 4.2 & 4.6999 & TST & \\
\hline CHEMBL1402058 & 688612 & 4.0 & 4.6865 & TRN & \\
\hline CHEMBL365327 & 688612 & 4.7 & 4.7294 & TRN & \\
\hline CHEMBL1348005 & 688612 & 4.15 & 4.6908 & TRN & \\
\hline CHEMBL1526526 & 688612 & 4.2 & 4.6084 & TST & \\
\hline CHEMBL1431726 & 688612 & 4.5 & 4.6731 & TST & \\
\hline CHEMBL1425729 & 688612 & 4.85 & 4.6646 & TRN & \\
\hline CHEMBL1539720 & 688612 & 5.7 & 4.7444 & TST & \\
\hline CHEMBL1590756 & 688612 & 4.05 & 4.6593 & TRN & \\
\hline CHEMBL 1607528 & 688612 & 4.4 & 4.6712 & TRN & \\
\hline CHEMBL1580484 & 688612 & 4.05 & 4.6741 & TRN & \\
\hline
\end{tabular}




\begin{tabular}{|c|c|c|c|c|c|}
\hline \multirow{3}{*}{$\begin{array}{l}\text { CHEMBL1612422 } \\
\text { CHEMBL1440857 }\end{array}$} & \multirow{3}{*}{$\begin{array}{l}688612 \\
688612\end{array}$} & \multicolumn{4}{|c|}{ Supplemental Table S2.txt } \\
\hline & & 4.2 & 4.67899 & 9999999999 & TST \\
\hline & & 5.2238 & 4.7328 & TST & \\
\hline CHEMBL1469463 & 688612 & 4.8 & 4.7361 & TRN & \\
\hline CHEMBL1339865 & 688612 & 4.0 & 4.6203 & TRN & \\
\hline CHEMBL1374521 & 688612 & 4.65 & 4.5848 & TRN & \\
\hline CHEMBL1469647 & 688612 & 4.45 & 4.6737 & TRN & \\
\hline CHEMBL1612791 & 688612 & 4.05 & 4.6253 & TRN & \\
\hline CHEMBL1372779 & 688612 & 4.2 & 4.6667 & TST & \\
\hline CHEMBL1367748 & 688612 & 4.1 & 4.6325 & TRN & \\
\hline CHEMBL1509952 & 688612 & 4.1 & 4.6162 & TRN & \\
\hline CHEMBL1591620 & 688612 & 5.5 & 4.6643 & TRN & \\
\hline CHEMBL1342622 & 688612 & 4.85 & 4.7773 & TRN & \\
\hline CHEMBL1354029 & 688612 & 4.05 & 4.7101 & TST & \\
\hline CHEMBL 3210473 & 688612 & 4.1 & 4.6776 & TRN & \\
\hline CHEMBL1393355 & 688612 & 4.3 & 4.627 & TRN & \\
\hline CHEMBL3214036 & 688612 & 4.1 & 4.6718 & TST & \\
\hline CHEMBL1335491 & 688612 & 4.2 & 4.6599 & TST & \\
\hline CHEMBL1577586 & 688612 & 6.6 & 4.732 & TST & \\
\hline CHEMBL1507865 & 688612 & 4.0 & 4.7048 & TST & \\
\hline CHEMBL1326704 & 688612 & 4.35 & 4.6957 & TRN & \\
\hline CHEMBL1346843 & 688612 & 4.45 & 4.6504 & TRN & \\
\hline CHEMBL363535 & 688612 & 4.7 & 4.7232 & TRN & \\
\hline CHEMBL1476191 & 688612 & 6.8499 & 4.5515 & TRN & \\
\hline CHEMBL3191783 & 688612 & 4.7 & 4.6679 & TRN & \\
\hline CHEMBL1417353 & 688612 & 5.5 & 4.5943 & TRN & \\
\hline CHEMBL1450008 & 688612 & 4.4 & 4.7018 & TRN & \\
\hline CHEMBL1542162 & 688612 & 5.05 & 4.6793 & TRN & \\
\hline CHEMBL1447680 & 688612 & 4.4 & 4.593 & TRN & \\
\hline CHEMBL1554606 & 688612 & 4.25 & 4.6322 & TRN & \\
\hline CHEMBL1548225 & 688612 & 5.3 & 4.7698 & TRN & \\
\hline CHEMBL1581354 & 688612 & 6.4 & 4.6273 & TRN & \\
\hline CHEMBL576544 & 688612 & 4.05 & 4.6102 & TST & \\
\hline CHEMBL1397720 & 688612 & 4.15 & 4.621 & TRN & \\
\hline CHEMBL1457729 & 688612 & 4.4 & 4.6799 & TRN & \\
\hline CHEMBL1329243 & 688612 & 4.05 & 4.7011 & TRN & \\
\hline CHEMBL1318302 & 688612 & 4.05 & 4.6194 & TRN & \\
\hline CHEMBL1429365 & 688612 & 4.1 & 4.7486 & TRN & \\
\hline CHEMBL3195065 & 688612 & 4.3 & 4.7956 & TRN & \\
\hline CHEMBL1510371 & 688612 & 4.4 & 4.6977 & TST & \\
\hline CHEMBL1397992 & 688612 & 4.05 & 4.7361 & TRN & \\
\hline CHEMBL1443219 & 688612 & 4.55 & 4.6422 & TRN & \\
\hline CHEMBL 3213202 & 688612 & 4.05 & 4.684 & TST & \\
\hline CHEMBL1598563 & 688612 & 5.35 & 4.6223 & TRN & \\
\hline CHEMBL1460369 & 688612 & 4.25 & 4.7858 & TST & \\
\hline CHEMBL1599786 & 688612 & 4.0 & 4.5165 & TRN & \\
\hline CHEMBL1586176 & 688612 & 4.0 & 4.6167 & TRN & \\
\hline CHEMBL1474198 & 688612 & 4.55 & 4.6519 & TRN & \\
\hline CHEMBL1302702 & 688612 & 4.2 & 4.6519 & TST & \\
\hline
\end{tabular}




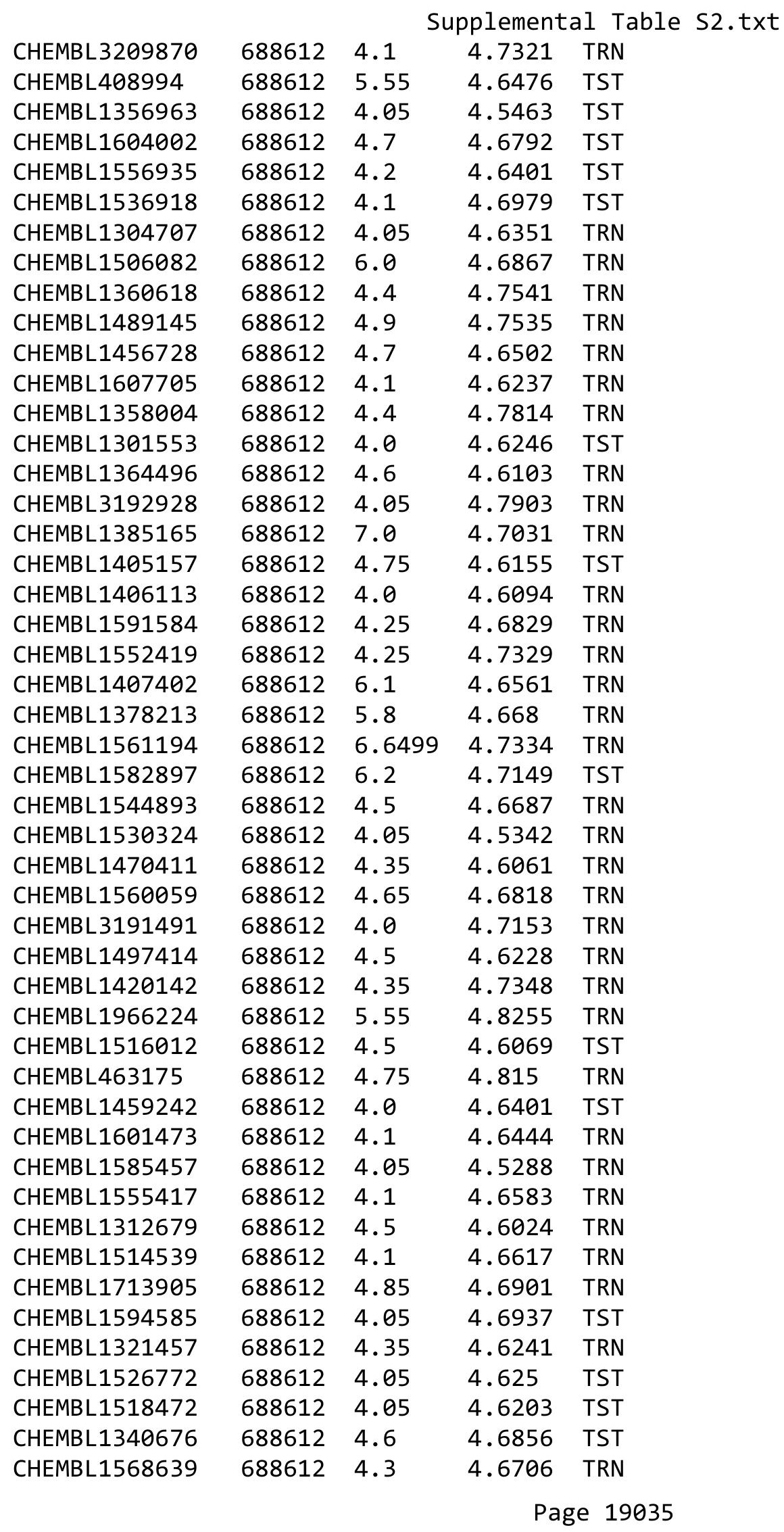




\begin{tabular}{|c|c|c|c|c|c|}
\hline \multicolumn{6}{|c|}{ Supplemental Table S2.txt } \\
\hline CHEMBL3194374 & 688612 & 5.15 & 4.7134 & TRN & \\
\hline CHEMBL1479123 & 688612 & 4.35 & 4.7651 & TRN & \\
\hline CHEMBL1509423 & 688612 & 4.05 & 4.7063 & TRN & \\
\hline CHEMBL1575212 & 688612 & 4.05 & 4.6702 & TRN & \\
\hline CHEMBL1523393 & 688612 & 4.5 & 4.6872 & TRN & \\
\hline CHEMBL1488292 & 688612 & 5.1 & 4.6582 & TST & \\
\hline CHEMBL1445702 & 688612 & 4.4 & 4.65600 & 0000000001 & TRN \\
\hline CHEMBL1520153 & 688612 & 6.95 & 4.7236 & TRN & \\
\hline CHEMBL1546709 & 688612 & 4.05 & 4.7361 & TRN & \\
\hline CHEMBL1546864 & 688612 & 5.35 & 4.6176 & TRN & \\
\hline CHEMBL1542713 & 688612 & 6.8499 & 4.6667 & TRN & \\
\hline CHEMBL1372139 & 688612 & 4.0 & 4.6475 & TRN & \\
\hline CHEMBL3209719 & 688612 & 4.05 & 4.7542 & TRN & \\
\hline CHEMBL1569435 & 688612 & 4.5 & 4.7059 & TRN & \\
\hline CHEMBL1383450 & 688612 & 4.0 & 4.7326 & TST & \\
\hline CHEMBL1406684 & 688612 & 4.05 & 4.5861 & TRN & \\
\hline CHEMBL1375956 & 688612 & 4.0 & 4.6131 & TST & \\
\hline CHEMBL1345146 & 688612 & 4.05 & 4.6277 & TST & \\
\hline CHEMBL1386497 & 688612 & 6.9 & 4.7031 & TRN & \\
\hline CHEMBL1415676 & 688612 & 7.0 & 4.6823 & TRN & \\
\hline CHEMBL1465281 & 688612 & 4.05 & 4.6405 & TST & \\
\hline CHEMBL236059 & 688612 & 4.4 & 4.7148 & TRN & \\
\hline CHEMBL1529747 & 688612 & 4.3 & 4.6833 & TRN & \\
\hline CHEMBL1380354 & 688612 & 4.55 & 4.5821 & TRN & \\
\hline CHEMBL1446190 & 688612 & 4.5 & 4.7301 & TST & \\
\hline CHEMBL1346387 & 688612 & 4.4 & 4.685 & TRN & \\
\hline CHEMBL1613684 & 688612 & 6.9 & 4.7675 & TST & \\
\hline CHEMBL1419063 & 688612 & 4.05 & 4.5605 & TRN & \\
\hline CHEMBL1461947 & 688612 & 4.5 & 4.6773 & TST & \\
\hline CHEMBL220869 & 688612 & 7.0 & 4.5562 & TRN & \\
\hline CHEMBL1329038 & 688612 & 5.05 & 4.6162 & TST & \\
\hline CHEMBL1381234 & 688612 & 4.0 & 4.6346 & TRN & \\
\hline CHEMBL1478319 & 688612 & 4.5 & 4.711 & TRN & \\
\hline CHEMBL3197628 & 688612 & 6.2 & 4.7484 & TRN & \\
\hline CHEMBL1538396 & 688612 & 4.7 & 4.8572 & TRN & \\
\hline CHEMBL1481712 & 688612 & 4.65 & 4.6505 & TRN & \\
\hline CHEMBL1391437 & 688612 & 4.05 & 4.5242 & TRN & \\
\hline CHEMBL1571059 & 688612 & 4.1 & 4.5869 & TRN & \\
\hline CHEMBL1412636 & 688612 & 4.0 & 4.5773 & TRN & \\
\hline CHEMBL1521333 & 688612 & 4.7 & 4.6498 & TRN & \\
\hline CHEMBL1386003 & 688612 & 4.6 & 4.6576 & TRN & \\
\hline CHEMBL1328357 & 688612 & 6.45 & 4.6589 & TST & \\
\hline CHEMBL1477363 & 688612 & 6.5 & 4.5994 & TST & \\
\hline CHEMBL 1358176 & 688612 & 4.2 & 4.5959 & TRN & \\
\hline CHEMBL1424381 & 688612 & 4.55 & 4.7028 & TRN & \\
\hline CHEMBL3199160 & 688612 & 4.8 & 4.7491 & TRN & \\
\hline CHEMBL1359806 & 688612 & 5.0 & 4.7132 & TRN & \\
\hline CHEMBL1337605 & 688612 & 5.55 & 4.7831 & TST & \\
\hline
\end{tabular}




\begin{tabular}{|c|c|c|c|c|c|}
\hline \multicolumn{6}{|c|}{ Supplemental Table S2.txt } \\
\hline CHEMBL1589930 & 688612 & 4.1 & 4.6205 & TRN & \\
\hline CHEMBL1380490 & 688612 & 4.8 & 4.7048 & TRN & \\
\hline CHEMBL1574682 & 688612 & 5.6 & 4.6636 & TRN & \\
\hline CHEMBL1464646 & 688612 & 4.05 & 4.67 & TRN & \\
\hline CHEMBL1610708 & 688612 & 5.05 & 4.63399 & 99999999995 & TRN \\
\hline CHEMBL1606060 & 688612 & 4.85 & 4.721 & TRN & \\
\hline CHEMBL 1408140 & 688612 & 5.25 & 4.6269 & TRN & \\
\hline CHEMBL1346762 & 688612 & 4.55 & 4.7162 & TRN & \\
\hline CHEMBL1498133 & 688612 & 4.05 & 4.6561 & TST & \\
\hline CHEMBL1394705 & 688612 & 4.05 & 4.6756 & TRN & \\
\hline CHEMBL1299683 & 688612 & 5.2 & 4.5968 & TRN & \\
\hline CHEMBL1308971 & 688612 & 4.4 & 4.726 & TRN & \\
\hline CHEMBL1511691 & 688612 & 4.4 & 4.6923 & TST & \\
\hline CHEMBL1475385 & 688612 & 4.85 & 4.6717 & TRN & \\
\hline CHEMBL1506153 & 688612 & 4.05 & 4.717 & TST & \\
\hline CHEMBL524376 & 688612 & 5.35 & 4.6706 & TRN & \\
\hline CHEMBL1446904 & 688612 & 4.85 & 4.7961 & TST & \\
\hline CHEMBL1320322 & 688612 & 4.4 & 4.7147 & TRN & \\
\hline CHEMBL1510501 & 688612 & 4.1 & 4.6684 & TRN & \\
\hline CHEMBL1557079 & 688612 & 4.05 & 4.6478 & TRN & \\
\hline CHEMBL1340557 & 688612 & 4.2 & 4.6148 & TRN & \\
\hline CHEMBL1592473 & 688612 & 6.9 & 4.6549 & TST & \\
\hline CHEMBL1318943 & 688612 & 5.95 & 4.7018 & TST & \\
\hline CHEMBL1498987 & 688612 & 5.5 & 4.6792 & TRN & \\
\hline CHEMBL1538544 & 688612 & 4.1 & 4.705 & TST & \\
\hline CHEMBL1395543 & 688612 & 4.05 & 4.6004 & TRN & \\
\hline CHEMBL1324829 & 688612 & 4.1 & 4.7192 & TST & \\
\hline CHEMBL1525111 & 688612 & 6.8499 & 4.7085 & TRN & \\
\hline CHEMBL1337895 & 688612 & 4.0 & 4.7413 & TST & \\
\hline CHEMBL 1457077 & 688612 & 4.5 & 4.7592 & TRN & \\
\hline CHEMBL1353608 & 688612 & 5.0 & 4.6568 & TRN & \\
\hline CHEMBL1531369 & 688612 & 4.05 & 4.7084 & TRN & \\
\hline CHEMBL1612203 & 688612 & 4.05 & 4.6573 & TST & \\
\hline CHEMBL1383633 & 688612 & 4.05 & 4.6639 & TRN & \\
\hline CHEMBL1376421 & 688612 & 4.4 & 4.7171 & TRN & \\
\hline CHEMBL1432050 & 688612 & 5.4 & 4.7371 & TRN & \\
\hline CHEMBL1586258 & 688612 & 4.05 & 4.6769 & TRN & \\
\hline CHEMBL1368496 & 688612 & 5.0 & 4.7512 & TRN & \\
\hline CHEMBL1429986 & 688612 & 5.15 & 4.5662 & TRN & \\
\hline CHEMBL1356362 & 688612 & 4.05 & 4.6014 & TRN & \\
\hline CHEMBL1308372 & 688612 & 6.9 & 4.7271 & TRN & \\
\hline CHEMBL1305441 & 688612 & 4.85 & 4.7967 & TRN & \\
\hline CHEMBL3199263 & 688612 & 4.45 & 4.7201 & TST & \\
\hline CHEMBL3193896 & 688612 & 4.65 & 4.6804 & TRN & \\
\hline CHEMBL1325233 & 688612 & 4.65 & 4.6781 & TRN & \\
\hline CHEMBL1345322 & 688612 & 4.0 & 4.6619 & TRN & \\
\hline CHEMBL1604955 & 688612 & 4.85 & 4.6644 & TRN & \\
\hline CHEMBL1431144 & 688612 & 4.0 & 4.6623 & TRN & \\
\hline
\end{tabular}




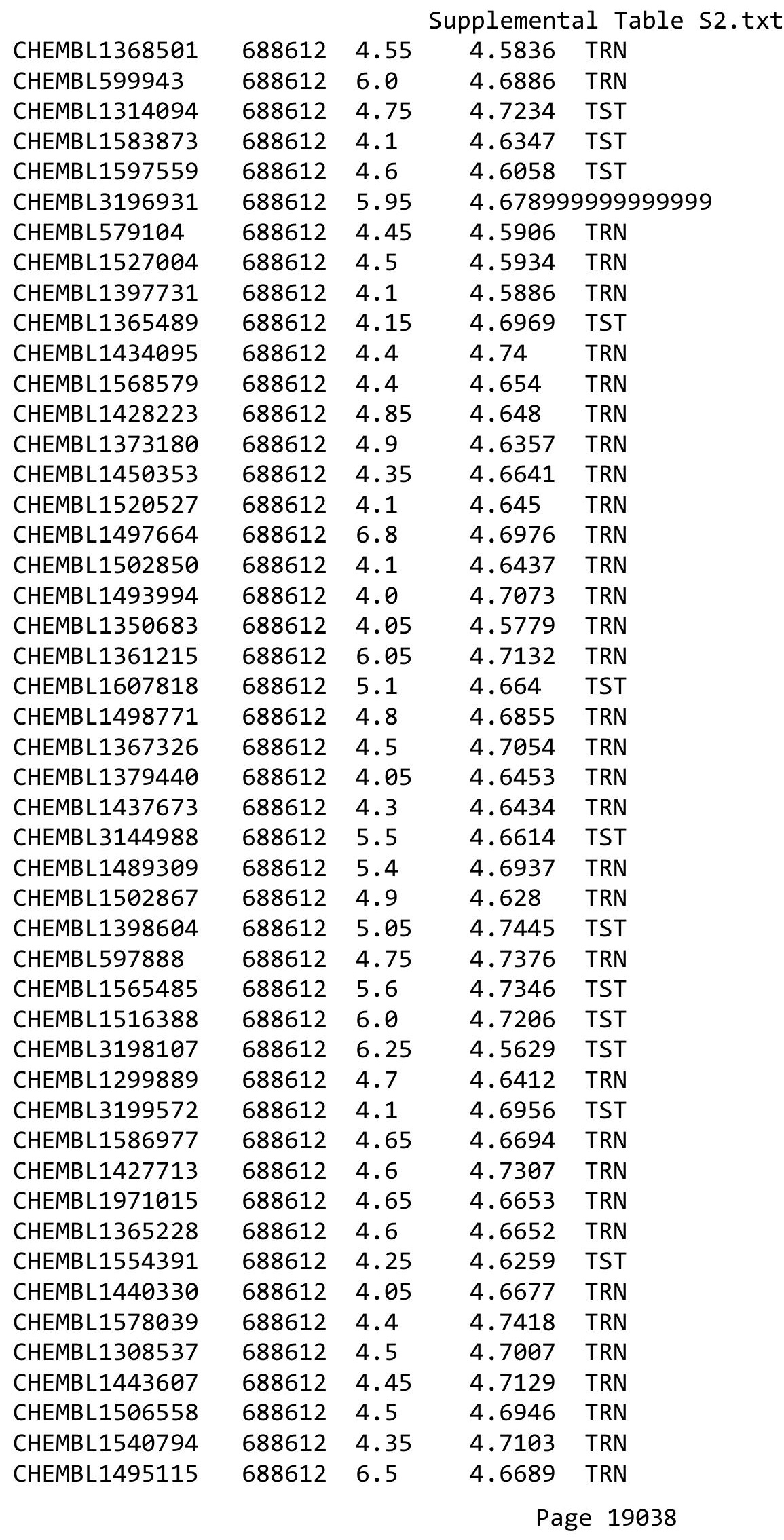




\begin{tabular}{|c|c|c|c|c|}
\hline \multicolumn{5}{|c|}{ Supplemental Table S2.txt } \\
\hline CHEMBL1405206 & 688612 & 4.3 & 4.6333 & TRN \\
\hline CHEMBL 3207518 & 688612 & 4.05 & 4.7222 & TRN \\
\hline CHEMBL1573961 & 688612 & 4.3 & 4.7028 & TRN \\
\hline CHEMBL1447978 & 688612 & 4.7 & 4.6491 & TST \\
\hline CHEMBL1481631 & 688612 & 4.0 & 4.5974 & TRN \\
\hline CHEMBL1528361 & 688612 & 5.0 & 4.5578 & TRN \\
\hline CHEMBL1552781 & 688612 & 4.1 & 4.6488 & TRN \\
\hline CHEMBL1416292 & 688612 & 4.85 & 4.7522 & TST \\
\hline CHEMBL1594352 & 688612 & 4.05 & 4.7071 & TRN \\
\hline CHEMBL1556958 & 688612 & 4.5 & 4.7528 & TRN \\
\hline CHEMBL1606509 & 688612 & 4.05 & 4.5674 & TRN \\
\hline CHEMBL1591043 & 688612 & 4.6 & 4.5956 & TRN \\
\hline CHEMBL1440499 & 688612 & 4.05 & 4.6478 & TRN \\
\hline CHEMBL1393327 & 688612 & 6.35 & 4.6981 & TRN \\
\hline CHEMBL1322550 & 688612 & 5.0 & 4.6294 & TRN \\
\hline CHEMBL1477354 & 688612 & 4.35 & 4.6245 & TRN \\
\hline CHEMBL1514426 & 688612 & 4.1 & 4.7217 & TST \\
\hline CHEMBL1427447 & 688612 & 4.55 & 4.6961 & TRN \\
\hline CHEMBL1443541 & 688612 & 6.8499 & 4.5388 & TRN \\
\hline CHEMBL1312576 & 688612 & 5.3 & 4.7532 & TST \\
\hline CHEMBL1462906 & 688612 & 4.1 & 4.7293 & TRN \\
\hline CHEMBL1566878 & 688612 & 4.45 & 4.6627 & TRN \\
\hline CHEMBL1422572 & 688612 & 4.0 & 4.5585 & TRN \\
\hline CHEMBL1518820 & 688612 & 4.4 & 4.7352 & TST \\
\hline CHEMBL1312523 & 688612 & 5.15 & 4.8341 & TST \\
\hline CHEMBL1365492 & 688612 & 4.6 & 4.6776 & TST \\
\hline CHEMBL1400414 & 688612 & 4.3 & 4.6263 & TRN \\
\hline CHEMBL1519140 & 688612 & 4.9 & 4.7056 & TRN \\
\hline CHEMBL1580318 & 688612 & 4.65 & 4.789 & TRN \\
\hline CHEMBL1590395 & 688612 & 4.9 & 4.7588 & TRN \\
\hline CHEMBL 2234807 & 688612 & 4.05 & 4.6718 & TRN \\
\hline CHEMBL1580321 & 688612 & 4.05 & 4.7154 & TRN \\
\hline CHEMBL1470775 & 688612 & 4.65 & 4.6506 & TRN \\
\hline CHEMBL1574622 & 688612 & 6.0 & 4.6132 & TRN \\
\hline CHEMBL1581674 & 688612 & 4.6 & 4.6187 & TST \\
\hline CHEMBL1329921 & 688612 & 4.3 & 4.5828 & TRN \\
\hline CHEMBL1578022 & 688612 & 4.7 & 4.7104 & TRN \\
\hline CHEMBL1581735 & 688612 & 4.6 & 4.6398 & TRN \\
\hline CHEMBL1461304 & 688612 & 4.05 & 4.70100 & 00000000005 \\
\hline CHEMBL1340539 & 688612 & 4.0 & 4.6177 & TRN \\
\hline CHEMBL1350751 & 688612 & 4.5 & 4.5557 & TRN \\
\hline CHEMBL1314040 & 688612 & 6.2 & 4.779 & TST \\
\hline CHEMBL1525364 & 688612 & 5.1 & 4.6818 & TRN \\
\hline CHEMBL 259355 & 688612 & 5.0 & 4.6533 & TRN \\
\hline CHEMBL1485018 & 688612 & 4.2 & 4.6766 & TRN \\
\hline CHEMBL1333771 & 688612 & 4.0 & 4.6266 & TRN \\
\hline CHEMBL1461644 & 688612 & 4.6 & 4.7986 & TST \\
\hline CHEMBL1501132 & 688612 & 5.65 & 4.7109 & TRN \\
\hline
\end{tabular}




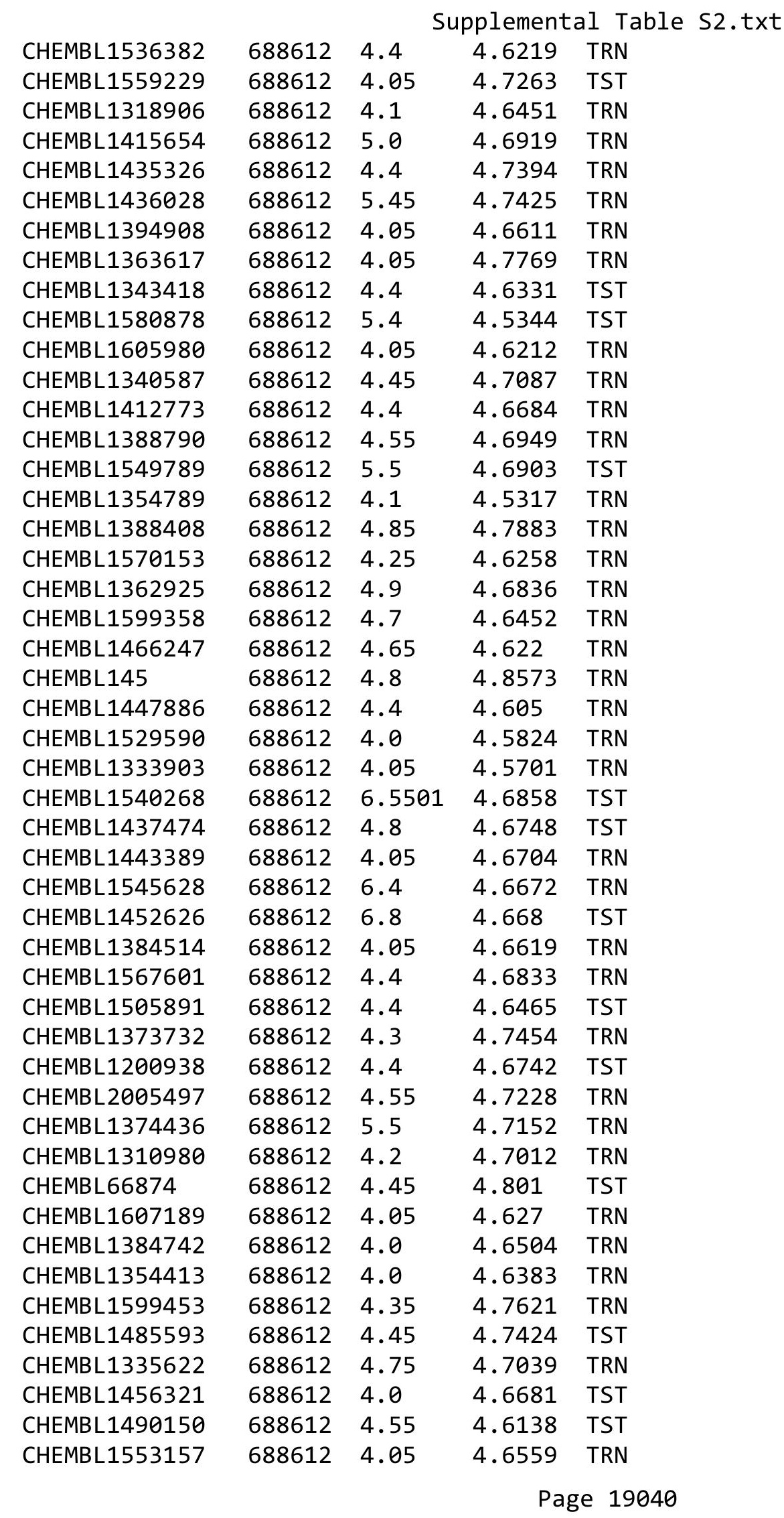




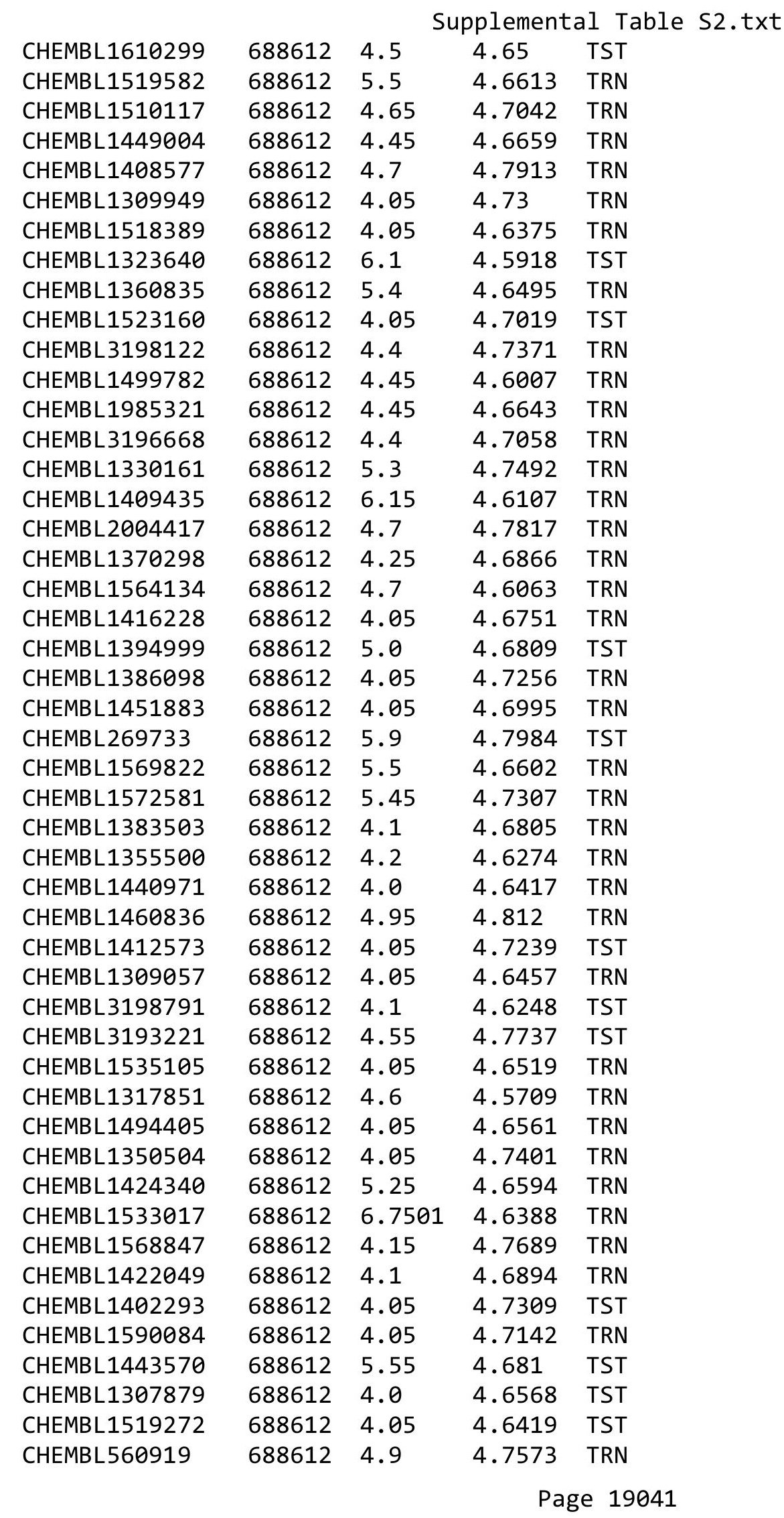




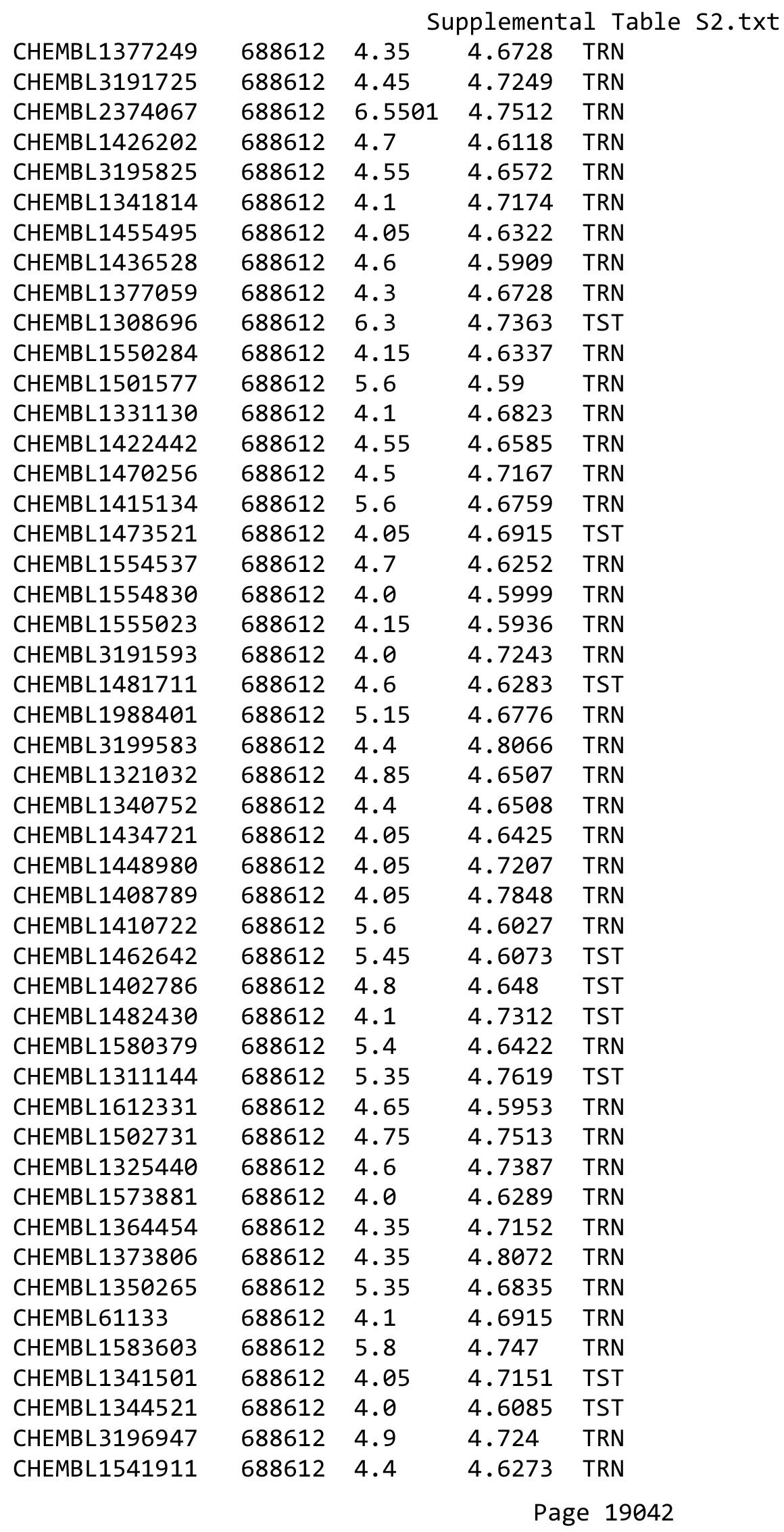




\begin{tabular}{|c|c|c|c|c|c|}
\hline CHEMBL3191383 & 688612 & 4.45 & \multicolumn{2}{|c|}{ 4.7219999999999995 } & TST \\
\hline CHEMBL1548000 & 688612 & 5.65 & 4.6347 & TRN & \\
\hline CHEMBL1455292 & 688612 & 4.6 & 4.7775 & TST & \\
\hline CHEMBL1562476 & 688612 & 4.45 & 4.6634 & TST & \\
\hline CHEMBL1398504 & 688612 & 4.05 & 4.6635 & TRN & \\
\hline CHEMBL50175 & 688612 & 6.9 & 4.7092 & TRN & \\
\hline CHEMBL1364192 & 688612 & 4.65 & 4.6684 & TRN & \\
\hline CHEMBL1474990 & 688612 & 4.95 & \multicolumn{2}{|c|}{4.638999999999999} & TRN \\
\hline CHEMBL1404146 & 688612 & 4.55 & 4.71 & TRN & \\
\hline CHEMBL3197141 & 688612 & 5.05 & 4.7407 & TRN & \\
\hline CHEMBL1474052 & 688612 & 4.05 & 4.638 & TRN & \\
\hline CHEMBL1301659 & 688612 & 4.0 & 4.6767 & TRN & \\
\hline CHEMBL1409402 & 688612 & 4.45 & 4.7204 & TST & \\
\hline CHEMBL1593860 & 688612 & 4.8 & 4.6393 & TRN & \\
\hline CHEMBL1553220 & 688612 & 5.4 & 4.6437 & TRN & \\
\hline CHEMBL1379430 & 688612 & 4.85 & 4.6467 & TRN & \\
\hline CHEMBL1567289 & 688612 & 5.55 & 4.6718 & TRN & \\
\hline CHEMBL3182716 & 688612 & 4.15 & 4.6369 & TRN & \\
\hline CHEMBL1429728 & 688612 & 4.4 & 4.7501 & TST & \\
\hline CHEMBL1579667 & 688612 & 4.35 & 4.6221 & TRN & \\
\hline CHEMBL1415694 & 688612 & 4.0 & 4.6921 & TRN & \\
\hline CHEMBL1336119 & 688612 & 4.65 & 4.7334 & TST & \\
\hline CHEMBL1326939 & 688612 & 4.85 & 4.6214 & TRN & \\
\hline CHEMBL1325708 & 688612 & 4.05 & 4.6169 & TST & \\
\hline CHEMBL1299712 & 688612 & 4.05 & 4.6309 & TRN & \\
\hline CHEMBL1382077 & 688612 & 4.1 & 4.6692 & TRN & \\
\hline CHEMBL1442780 & 688612 & 4.95 & 4.6197 & TRN & \\
\hline CHEMBL1329497 & 688612 & 5.25 & 4.7442 & TRN & \\
\hline CHEMBL1414236 & 688612 & 4.85 & 4.6961 & TST & \\
\hline CHEMBL1576268 & 688612 & 4.1 & 4.6609 & TRN & \\
\hline CHEMBL1415733 & 688612 & 6.0 & 4.6969 & TRN & \\
\hline CHEMBL3191401 & 688612 & 4.05 & 4.7088 & TRN & \\
\hline CHEMBL1463438 & 688612 & 4.05 & 4.6021 & TST & \\
\hline CHEMBL3197385 & 688612 & 4.2 & 4.8047 & TRN & \\
\hline CHEMBL1397061 & 688612 & 4.05 & 4.6488 & TRN & \\
\hline CHEMBL1352424 & 688612 & 5.05 & 4.6351 & TRN & \\
\hline CHEMBL1503347 & 688612 & 7.0 & 4.6284 & TRN & \\
\hline CHEMBL1440464 & 688612 & 4.9 & 4.6251 & TRN & \\
\hline CHEMBL1365568 & 688612 & 4.75 & 4.7094 & TRN & \\
\hline CHEMBL3198768 & 688612 & 4.0 & 4.7277 & TRN & \\
\hline CHEMBL1426153 & 688612 & 5.35 & 4.6858 & TST & \\
\hline CHEMBL1446090 & 688612 & 6.8 & 4.5663 & TRN & \\
\hline CHEMBL1558469 & 688612 & 4.05 & 4.6925 & TRN & \\
\hline CHEMBL1335104 & 688612 & 6.9 & 4.5839 & TRN & \\
\hline CHEMBL1389650 & 688612 & 4.1 & 4.6076 & TRN & \\
\hline CHEMBL1528144 & 688612 & 4.75 & 4.7692 & TRN & \\
\hline CHEMBL3190747 & 688612 & 5.35 & 4.7802 & TST & \\
\hline CHEMBL1573158 & 688612 & 4.0 & 4.6196 & TST & \\
\hline
\end{tabular}




\begin{tabular}{|c|c|c|c|c|c|}
\hline \multicolumn{6}{|c|}{ Supplemental Table S2.txt } \\
\hline CHEMBL1568245 & 688612 & 4.55 & 4.6422 & TRN & \\
\hline CHEMBL1506266 & 688612 & 4.55 & 4.6493 & TRN & \\
\hline CHEMBL1516963 & 688612 & 4.05 & 4.6322 & TRN & \\
\hline CHEMBL1378103 & 688612 & 4.1 & 4.7 & TRN & \\
\hline CHEMBL1539894 & 688612 & 4.1 & 4.71399 & 99999999995 & TST \\
\hline CHEMBL1546548 & 688612 & 5.6 & 4.6313 & TST & \\
\hline CHEMBL1342485 & 688612 & 4.1 & 4.7089 & TST & \\
\hline CHEMBL1384410 & 688612 & 5.9 & 4.6773 & TRN & \\
\hline CHEMBL1429064 & 688612 & 5.35 & 4.7138 & TRN & \\
\hline CHEMBL1583051 & 688612 & 6.15 & 4.6987 & TRN & \\
\hline CHEMBL1548326 & 688612 & 5.3 & 4.7319 & TRN & \\
\hline CHEMBL1565853 & 688612 & 4.7 & 4.5964 & TRN & \\
\hline CHEMBL1328334 & 688612 & 4.0 & 4.6432 & TST & \\
\hline CHEMBL1443145 & 688612 & 5.0 & 4.6109 & TRN & \\
\hline CHEMBL1355826 & 688612 & 4.8 & 4.6231 & TRN & \\
\hline CHEMBL1372338 & 688612 & 4.75 & 4.6155 & TRN & \\
\hline CHEMBL1390593 & 688612 & 4.7 & 4.7681 & TRN & \\
\hline CHEMBL1397418 & 688612 & 4.45 & 4.6359 & TRN & \\
\hline CHEMBL1581649 & 688612 & 4.6 & 4.7385 & TRN & \\
\hline CHEMBL1397982 & 688612 & 4.05 & 4.6226 & TRN & \\
\hline CHEMBL1463881 & 688612 & 4.05 & 4.647 & TST & \\
\hline CHEMBL1513325 & 688612 & 4.35 & 4.6936 & TRN & \\
\hline CHEMBL1459278 & 688612 & 4.05 & 4.6191 & TRN & \\
\hline CHEMBL1517128 & 688612 & 4.4 & 4.7328 & TRN & \\
\hline CHEMBL1576602 & 688612 & 4.2 & 4.6982 & TST & \\
\hline CHEMBL1577036 & 688612 & 6.0 & 4.7034 & TST & \\
\hline CHEMBL1354805 & 688612 & 7.0 & 4.6311 & TRN & \\
\hline CHEMBL1514197 & 688612 & 4.15 & 4.5896 & TRN & \\
\hline CHEMBL1557415 & 688612 & 4.0 & 4.612 & TRN & \\
\hline CHEMBL3190699 & 688612 & 4.1 & 4.6623 & TRN & \\
\hline CHEMBL1432897 & 688612 & 4.05 & 4.6403 & TRN & \\
\hline CHEMBL3209772 & 688612 & 4.25 & 4.7418 & TRN & \\
\hline CHEMBL1309432 & 688612 & 6.25 & 4.7075 & TRN & \\
\hline CHEMBL1333956 & 688612 & 4.1 & 4.6627 & TRN & \\
\hline CHEMBL1456155 & 688612 & 4.05 & 4.7138 & TRN & \\
\hline CHEMBL1492150 & 688612 & 4.2 & 4.7386 & TST & \\
\hline CHEMBL1525254 & 688612 & 4.0 & 4.6679 & TST & \\
\hline CHEMBL3192060 & 688612 & 4.2 & 4.6975 & TRN & \\
\hline CHEMBL1475281 & 688612 & 4.65 & 4.6696 & TRN & \\
\hline CHEMBL1464280 & 688612 & 5.95 & 4.7652 & TRN & \\
\hline CHEMBL1422166 & 688612 & 4.0 & 4.582 & TRN & \\
\hline CHEMBL1545930 & 688612 & 4.05 & 4.6922 & TST & \\
\hline CHEMBL1419534 & 688612 & 4.0 & 4.6683 & TST & \\
\hline CHEMBL3211661 & 688612 & 6.8499 & 4.7262 & TRN & \\
\hline CHEMBL1536814 & 688612 & 6.5501 & 4.6394 & TST & \\
\hline CHEMBL1977596 & 688612 & 4.75 & 4.7343 & TRN & \\
\hline CHEMBL3211105 & 688612 & 4.8 & 4.7417 & TRN & \\
\hline CHEMBL1588286 & 688612 & 4.85 & 4.7893 & TRN & \\
\hline
\end{tabular}




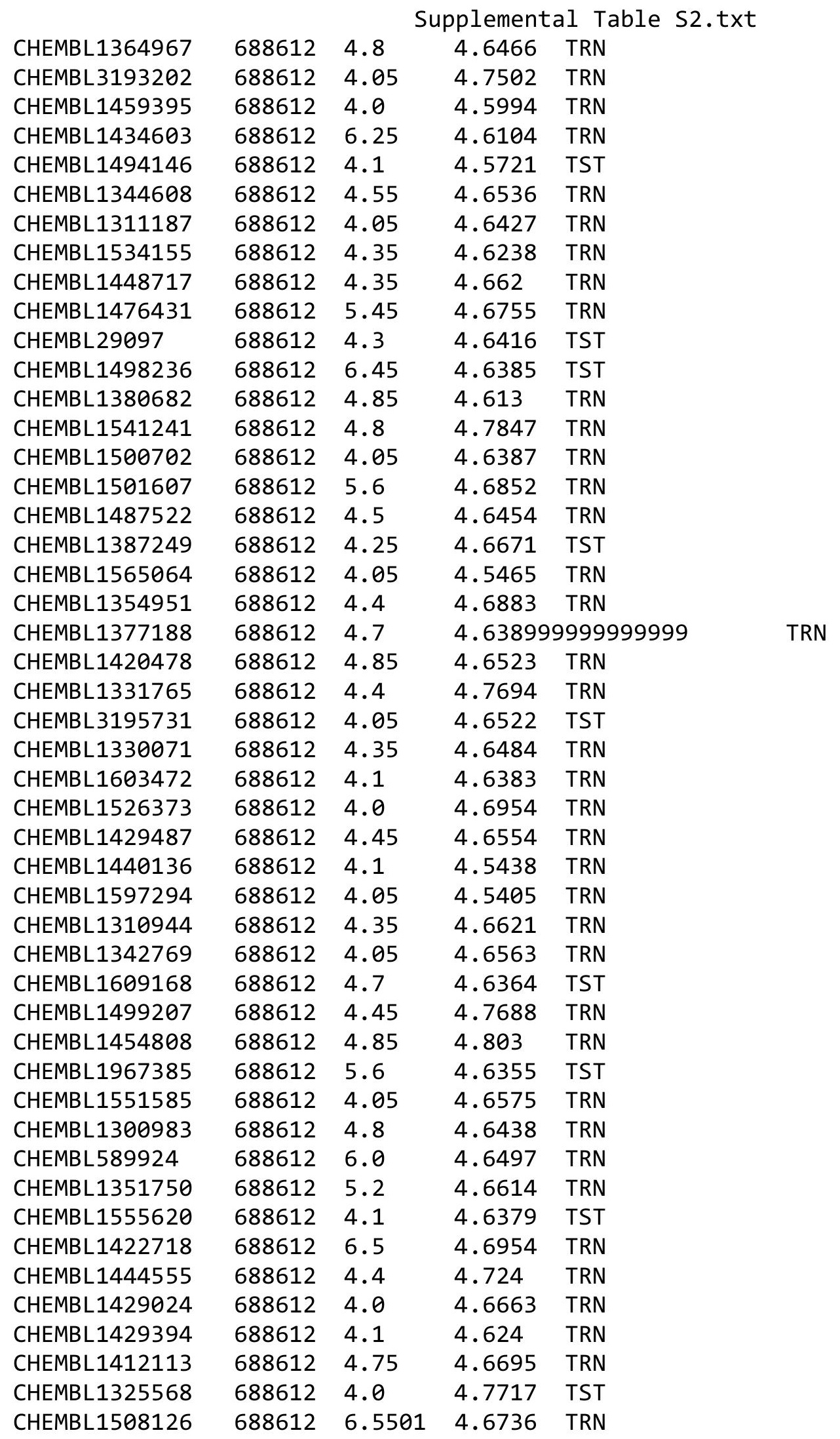

Page 19045 


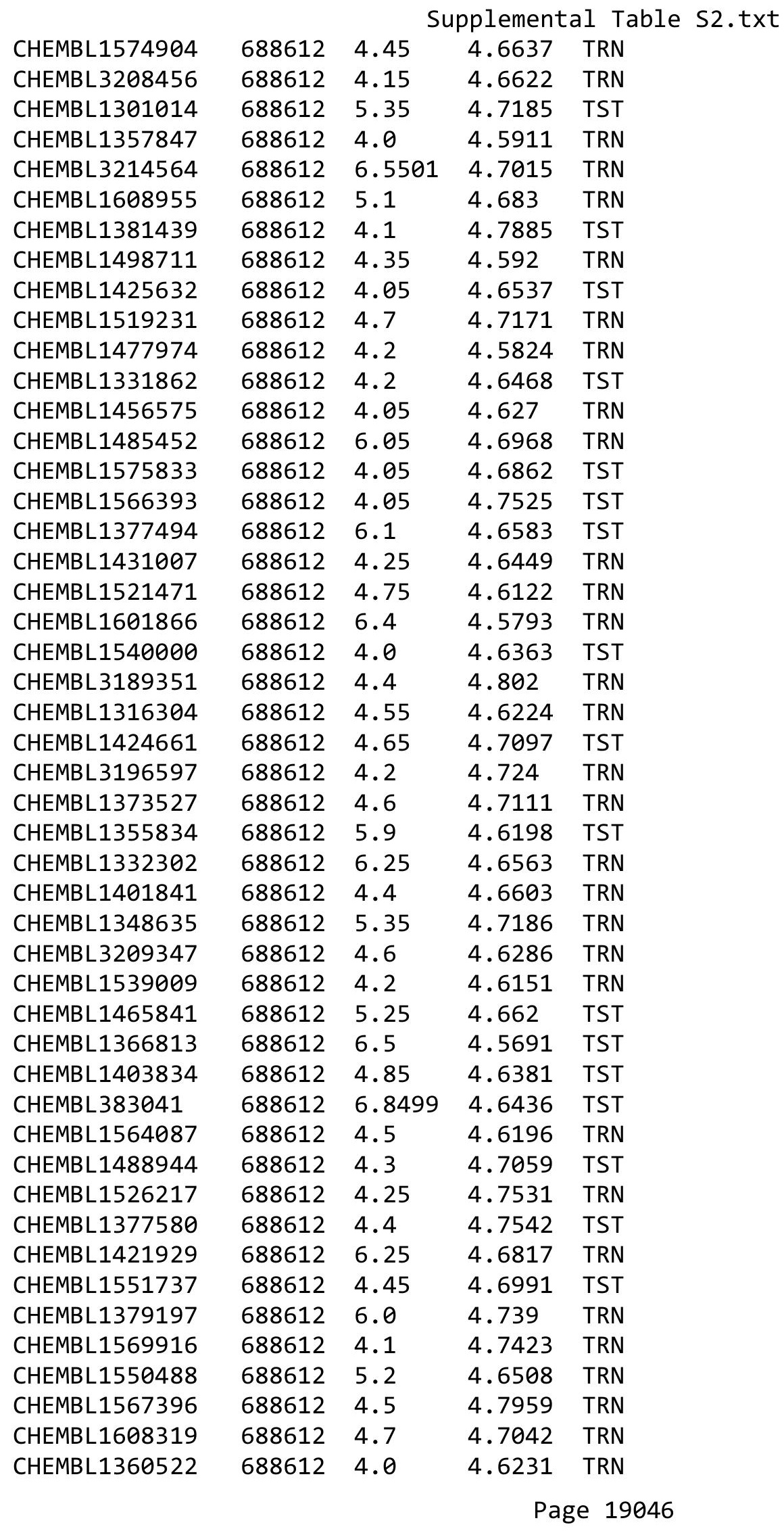




\begin{tabular}{|c|c|c|c|c|c|}
\hline \multicolumn{6}{|c|}{ Supplemental Table S2.txt } \\
\hline CHEMBL3190552 & 688612 & 4.3 & 4.7311 & TRN & \\
\hline CHEMBL1402432 & 688612 & 4.25 & 4.6381 & TRN & \\
\hline CHEMBL1383011 & 688612 & 4.75 & 4.695 & TRN & \\
\hline CHEMBL3190857 & 688612 & 4.1 & 4.6971 & TRN & \\
\hline CHEMBL1450866 & 688612 & 4.55 & 4.5918 & TRN & \\
\hline CHEMBL1573507 & 688612 & 6.0 & 4.6828 & TST & \\
\hline CHEMBL1587754 & 688612 & 4.0 & 4.5671 & TST & \\
\hline CHEMBL1383242 & 688612 & 4.65 & 4.6761 & TST & \\
\hline CHEMBL1542062 & 688612 & 4.2 & 4.5844 & TST & \\
\hline CHEMBL1433126 & 688612 & 4.3 & 4.7485 & TRN & \\
\hline CHEMBL1501007 & 688612 & 4.05 & 4.6561 & TRN & \\
\hline CHEMBL1316736 & 688612 & 4.15 & 4.5786 & TRN & \\
\hline CHEMBL1538712 & 688612 & 4.05 & 4.6536 & TRN & \\
\hline CHEMBL1474610 & 688612 & 6.8499 & 4.6289 & TRN & \\
\hline CHEMBL1365476 & 688612 & 4.3 & 4.6823 & TRN & \\
\hline CHEMBL1494805 & 688612 & 4.8 & 4.6855 & TRN & \\
\hline CHEMBL1578494 & 688612 & 4.85 & 4.6347 & TRN & \\
\hline CHEMBL1308880 & 688612 & 4.05 & 4.6849 & TRN & \\
\hline CHEMBL1352790 & 688612 & 5.2 & 4.6853 & TRN & \\
\hline CHEMBL1336112 & 688612 & 4.1 & 4.5646 & TRN & \\
\hline CHEMBL1411791 & 688612 & 5.4 & 4.6189 & TRN & \\
\hline CHEMBL3193260 & 688612 & 4.3 & 4.7254 & TRN & \\
\hline CHEMBL1533211 & 688612 & 4.05 & 4.7357 & TST & \\
\hline CHEMBL1451223 & 688612 & 4.05 & 4.6192 & TRN & \\
\hline CHEMBL1409064 & 688612 & 4.95 & 4.7579 & TST & \\
\hline CHEMBL 3212478 & 688612 & 4.65 & 4.6922 & TRN & \\
\hline CHEMBL1408354 & 688612 & 4.75 & 4.6543 & TST & \\
\hline CHEMBL1406915 & 688612 & 6.15 & 4.6342 & TRN & \\
\hline CHEMBL1452880 & 688612 & 4.0 & 4.65300 & 00000000005 & TST \\
\hline CHEMBL1435676 & 688612 & 4.05 & 4.6273 & TST & \\
\hline CHEMBL1352272 & 688612 & 4.1 & 4.6132 & TRN & \\
\hline CHEMBL1454030 & 688612 & 4.0 & 4.7155 & TST & \\
\hline CHEMBL1511663 & 688612 & 5.75 & 4.7513 & TRN & \\
\hline CHEMBL1479015 & 688612 & 4.45 & 4.6696 & TRN & \\
\hline CHEMBL1528525 & 688612 & 4.4 & 4.6698 & TRN & \\
\hline CHEMBL1404018 & 688612 & 4.1 & 4.6703 & TRN & \\
\hline CHEMBL1341521 & 688612 & 6.3 & 4.6308 & TRN & \\
\hline CHEMBL1400183 & 688612 & 4.05 & 4.6703 & TRN & \\
\hline CHEMBL1506910 & 688612 & 4.6 & 4.6442 & TST & \\
\hline CHEMBL 2003794 & 688612 & 5.6 & 4.7 & TRN & \\
\hline CHEMBL1510849 & 688612 & 4.2 & 4.7517 & TRN & \\
\hline CHEMBL1527087 & 688612 & 4.4 & 4.65600 & 0000000001 & TRN \\
\hline CHEMBL1495079 & 688612 & 4.25 & 4.6909 & TST & \\
\hline CHEMBL1445797 & 688612 & 6.8499 & 4.7064 & TST & \\
\hline CHEMBL1409410 & 688612 & 5.6 & 4.6138 & TRN & \\
\hline CHEMBL1410014 & 688612 & 5.85 & 4.6395 & TRN & \\
\hline CHEMBL1461779 & 688612 & 4.05 & 4.6561 & TST & \\
\hline CHEMBL3190140 & 688612 & 4.25 & 4.6912 & TRN & \\
\hline
\end{tabular}




\begin{tabular}{|c|c|c|c|c|c|}
\hline \multicolumn{6}{|c|}{ Supplemental Table s2.txt } \\
\hline CHEMBL1571063 & 688612 & 4.6 & 4.6496 & TRN & \\
\hline CHEMBL1498189 & 688612 & 4.05 & 4.5312 & TRN & \\
\hline CHEMBL1517732 & 688612 & 5.35 & 4.6439 & TRN & \\
\hline CHEMBL1450791 & 688612 & 4.35 & 4.7174 & TRN & \\
\hline CHEMBL1457804 & 688612 & 4.0 & 4.6173 & TST & \\
\hline CHEMBL1611641 & 688612 & 6.45 & 4.5981 & TRN & \\
\hline CHEMBL1355555 & 688612 & 4.05 & 4.6375 & TRN & \\
\hline CHEMBL1493208 & 688612 & 4.0 & 4.7388 & TST & \\
\hline CHEMBL1530319 & 688612 & 4.75 & 4.5641 & TRN & \\
\hline CHEMBL1579570 & 688612 & 4.4 & 4.6943 & TRN & \\
\hline CHEMBL1446366 & 688612 & 4.05 & 4.7467 & TST & \\
\hline CHEMBL1414210 & 688612 & 4.5 & 4.6183 & TRN & \\
\hline CHEMBL1580581 & 688612 & 4.3 & 4.6668 & TRN & \\
\hline CHEMBL1446573 & 688612 & 4.0 & 4.747 & TST & \\
\hline CHEMBL1547165 & 688612 & 4.35 & 4.68199 & 99999999995 & TRN \\
\hline CHEMBL1579235 & 688612 & 4.2 & 4.6813 & TRN & \\
\hline CHEMBL1472020 & 688612 & 6.5 & 4.6875 & TST & \\
\hline CHEMBL1497606 & 688612 & 4.0 & 4.7036 & TST & \\
\hline CHEMBL1356702 & 688612 & 4.7 & 4.6013 & TRN & \\
\hline CHEMBL1445117 & 688612 & 4.4 & 4.6759 & TRN & \\
\hline CHEMBL1488885 & 688612 & 4.2 & 4.7152 & TRN & \\
\hline CHEMBL1536900 & 688612 & 4.25 & 4.6061 & TRN & \\
\hline CHEMBL1475998 & 688612 & 4.05 & 4.6183 & TST & \\
\hline CHEMBL1312246 & 688612 & 4.05 & 4.6866 & TRN & \\
\hline CHEMBL3197936 & 688612 & 4.8 & 4.7092 & TRN & \\
\hline CHEMBL1365109 & 688612 & 4.0 & 4.7203 & TRN & \\
\hline CHEMBL1397827 & 688612 & 4.5 & 4.643 & TRN & \\
\hline CHEMBL1304766 & 688612 & 5.3 & 4.7037 & TRN & \\
\hline CHEMBL1591165 & 688612 & 4.2 & 4.5996 & TRN & \\
\hline CHEMBL1429321 & 688612 & 4.0 & 4.6149 & TRN & \\
\hline CHEMBL1301759 & 688612 & 4.4 & 4.6322 & TST & \\
\hline CHEMBL1449319 & 688612 & 4.0 & 4.7178 & TST & \\
\hline CHEMBL1372611 & 688612 & 4.95 & 4.6033 & TRN & \\
\hline CHEMBL1406228 & 688612 & 4.05 & 4.5997 & TRN & \\
\hline CHEMBL1315457 & 688612 & 5.0 & 4.6806 & TST & \\
\hline CHEMBL1316551 & 688612 & 4.0 & 4.6433 & TST & \\
\hline CHEMBL1334125 & 688612 & 6.9 & 4.6693 & TRN & \\
\hline CHEMBL1426947 & 688612 & 5.15 & 4.64199 & 99999999995 & TRN \\
\hline CHEMBL1487909 & 688612 & 4.05 & 4.6485 & TRN & \\
\hline CHEMBL1475901 & 688612 & 4.1 & 4.6113 & TRN & \\
\hline CHEMBL1445289 & 688612 & 4.4 & 4.6959 & TST & \\
\hline CHEMBL1408148 & 688612 & 4.0 & 4.7298 & TST & \\
\hline CHEMBL1377571 & 688612 & 4.7 & 4.6908 & TRN & \\
\hline CHEMBL1332184 & 688612 & 4.05 & 4.7766 & TRN & \\
\hline CHEMBL1352694 & 688612 & 4.0 & 4.6394 & TRN & \\
\hline CHEMBL1492909 & 688612 & 4.15 & 4.7495 & TST & \\
\hline CHEMBL1488694 & 688612 & 5.55 & 4.7499 & TST & \\
\hline CHEMBL1388059 & 688612 & 4.0 & 4.6544 & TST & \\
\hline
\end{tabular}




\begin{tabular}{|c|c|c|c|c|c|}
\hline & & \multicolumn{4}{|c|}{ Supplemental Table s2.txt } \\
\hline CHEMBL1323544 & 688612 & 4.05 & 4.7134 & TST & \\
\hline CHEMBL1365784 & 688612 & 4.35 & 4.6449 & TRN & \\
\hline CHEMBL1568762 & 688612 & 4.0 & 4.7405 & TRN & \\
\hline CHEMBL1540929 & 688612 & 4.65 & 4.6276 & TRN & \\
\hline CHEMBL1364755 & 688612 & 4.1 & 4.6263 & TRN & \\
\hline CHEMBL1521028 & 688612 & 4.1 & 4.6378 & TRN & \\
\hline CHEMBL1471849 & 688612 & 6.9 & 4.6587 & TST & \\
\hline CHEMBL1468410 & 688612 & 5.0 & 4.7266 & TST & \\
\hline CHEMBL1999595 & 688612 & 4.05 & 4.6915 & TRN & \\
\hline CHEMBL3192551 & 688612 & 4.3 & 4.7185 & TRN & \\
\hline CHEMBL1346476 & 688612 & 5.3 & 4.5843 & TRN & \\
\hline CHEMBL1493871 & 688612 & 4.0 & 4.6553 & TRN & \\
\hline CHEMBL1522196 & 688612 & 4.4 & 4.5402 & TST & \\
\hline CHEMBL1338322 & 688612 & 4.3 & 4.7566 & TST & \\
\hline CHEMBL1577000 & 688612 & 6.1 & 4.7128 & TST & \\
\hline CHEMBL1347597 & 688612 & 5.9 & 4.6529 & TRN & \\
\hline CHEMBL1477490 & 688612 & 4.1 & 4.6759 & TST & \\
\hline CHEMBL1313927 & 688612 & 5.4 & 4.6841 & TRN & \\
\hline CHEMBL 1423432 & 688612 & 4.05 & 4.6637 & TRN & \\
\hline CHEMBL1336283 & 688612 & 4.05 & 4.588 & TST & \\
\hline CHEMBL1411969 & 688612 & 6.15 & 4.6717 & TST & \\
\hline CHEMBL1589707 & 688612 & 4.05 & 4.6792 & TRN & \\
\hline CHEMBL1537302 & 688612 & 4.05 & 4.70100 & 00000000005 & TRN \\
\hline CHEMBL 1404588 & 688612 & 4.1 & 4.6089 & TRN & \\
\hline CHEMBL1597658 & 688612 & 4.6 & 4.6837 & TRN & \\
\hline CHEMBL1307765 & 688612 & 4.2 & 4.6083 & TST & \\
\hline CHEMBL1523139 & 688612 & 5.35 & 4.6193 & TRN & \\
\hline CHEMBL1532174 & 688612 & 4.45 & 4.7288 & TST & \\
\hline CHEMBL1392299 & 688612 & 4.0 & 4.7651 & TST & \\
\hline CHEMBL1547522 & 688612 & 4.45 & 4.6672 & TRN & \\
\hline CHEMBL1369710 & 688612 & 4.45 & 4.5988 & TRN & \\
\hline CHEMBL1323825 & 688612 & 4.0 & 4.6335 & TRN & \\
\hline CHEMBL1447836 & 688612 & 4.3 & 4.7006 & TRN & \\
\hline CHEMBL1344015 & 688612 & 4.75 & 4.664 & TRN & \\
\hline CHEMBL1521281 & 688612 & 4.2 & 4.6792 & TRN & \\
\hline CHEMBL1450350 & 688612 & 4.7 & 4.7006 & TRN & \\
\hline CHEMBL1555295 & 688612 & 4.05 & 4.6032 & TST & \\
\hline CHEMBL1384797 & 688612 & 5.95 & 4.7228 & TRN & \\
\hline CHEMBL1485731 & 688612 & 4.6 & 4.6909 & TRN & \\
\hline CHEMBL1516536 & 688612 & 4.05 & 4.6895 & TRN & \\
\hline CHEMBL1466656 & 688612 & 4.85 & 4.6656 & TRN & \\
\hline CHEMBL1334105 & 688612 & 4.05 & 4.6557 & TRN & \\
\hline CHEMBL1559196 & 688612 & 4.05 & 4.6314 & TRN & \\
\hline CHEMBL 1256360 & 688612 & 6.0 & 4.7555 & TRN & \\
\hline CHEMBL1319280 & 688612 & 4.45 & 4.7504 & TST & \\
\hline CHEMBL1561405 & 688612 & 4.05 & 4.6622 & TRN & \\
\hline CHEMBL1402640 & 688612 & 4.6 & 4.7043 & TRN & \\
\hline CHEMBL1366319 & 688612 & 4.9 & 4.715 & TRN & \\
\hline
\end{tabular}




\begin{tabular}{|c|c|c|c|c|c|}
\hline & & \multicolumn{4}{|c|}{ Supplemental Table S2.txt } \\
\hline CHEMBL1386235 & 688612 & 4.35 & 4.6656 & TST & \\
\hline CHEMBL1428953 & 688612 & 4.35 & 4.702 & TRN & \\
\hline CHEMBL1510039 & 688612 & 4.8 & 4.7443 & TRN & \\
\hline CHEMBL1544343 & 688612 & 6.8 & 4.651 & TRN & \\
\hline CHEMBL177991 & 688612 & 4.1 & 4.7272 & TST & \\
\hline CHEMBL1412423 & 688612 & 5.4 & 4.8224 & TRN & \\
\hline CHEMBL589207 & 688612 & 4.45 & 4.663 & TRN & \\
\hline CHEMBL3192495 & 688612 & 4.4 & 4.6942 & TRN & \\
\hline CHEMBL1492501 & 688612 & 4.2 & 4.6813 & TRN & \\
\hline CHEMBL1406151 & 688612 & 4.4 & 4.6808 & TRN & \\
\hline CHEMBL1533117 & 688612 & 5.1 & 4.636 & TRN & \\
\hline CHEMBL1587868 & 688612 & 4.4 & 4.6999 & TST & \\
\hline CHEMBL1344635 & 688612 & 4.05 & 4.659 & TRN & \\
\hline CHEMBL1608660 & 688612 & 4.65 & 4.677 & TST & \\
\hline CHEMBL1317813 & 688612 & 4.0 & 4.6013 & TRN & \\
\hline CHEMBL1462044 & 688612 & 6.15 & 4.6529 & TRN & \\
\hline CHEMBL1329268 & 688612 & 7.1002 & 4.6781 & TRN & \\
\hline CHEMBL 242515 & 688612 & 4.75 & 4.7774 & TST & \\
\hline CHEMBL1551908 & 688612 & 4.1 & 4.6361 & TST & \\
\hline CHEMBL1383684 & 688612 & 5.6 & 4.6566 & TRN & \\
\hline CHEMBL1312698 & 688612 & 4.3 & 4.6904 & TRN & \\
\hline CHEMBL1558547 & 688612 & 4.1 & 4.6846 & TST & \\
\hline CHEMBL1524843 & 688612 & 4.0 & 4.6193 & TST & \\
\hline CHEMBL1505826 & 688612 & 4.0 & 4.6682 & TST & \\
\hline CHEMBL1474765 & 688612 & 4.1 & 4.6416 & TRN & \\
\hline CHEMBL1332343 & 688612 & 4.05 & 4.7221 & TRN & \\
\hline CHEMBL1439197 & 688612 & 4.05 & 4.6263 & TRN & \\
\hline CHEMBL1404190 & 688612 & 4.8 & 4.7291 & TRN & \\
\hline CHEMBL3190625 & 688612 & 4.95 & 4.698 & TST & \\
\hline CHEMBL1577430 & 688612 & 4.05 & 4.7441 & TRN & \\
\hline CHEMBL3192957 & 688612 & 6.0 & 4.7143 & TRN & \\
\hline CHEMBL1454195 & 688612 & 4.5 & 4.7065 & TRN & \\
\hline CHEMBL1408157 & 688612 & 4.05 & 4.7398 & TRN & \\
\hline CHEMBL1439367 & 688612 & 4.7 & 4.7274 & TST & \\
\hline CHEMBL1500776 & 688612 & 4.0 & 4.6735 & TRN & \\
\hline CHEMBL1575257 & 688612 & 4.45 & 4.6624 & TST & \\
\hline CHEMBL1609726 & 688612 & 4.0 & 4.6753 & TRN & \\
\hline CHEMBL1338441 & 688612 & 4.3 & 4.7333 & TRN & \\
\hline CHEMBL1602206 & 688612 & 4.0 & 4.7124 & TST & \\
\hline CHEMBL1446660 & 688612 & 4.7 & 4.6507 & TRN & \\
\hline CHEMBL1427525 & 688612 & 4.0 & 4.63899 & 9999999999 & TRN \\
\hline CHEMBL1531032 & 688612 & 4.0 & 4.6414 & TRN & \\
\hline CHEMBL1479382 & 688612 & 4.8 & 4.7571 & TST & \\
\hline CHEMBL1331175 & 688612 & 4.05 & 4.6443 & TRN & \\
\hline CHEMBL1522332 & 688612 & 4.05 & 4.69600 & 0000000001 & TRN \\
\hline CHEMBL1364118 & 688612 & 4.9 & 4.7127 & TRN & \\
\hline CHEMBL1352143 & 688612 & 4.1 & 4.717 & TST & \\
\hline CHEMBL1425718 & 688612 & 4.3 & 4.6141 & TRN & \\
\hline
\end{tabular}




\begin{tabular}{|c|c|c|c|c|c|}
\hline & & \multicolumn{4}{|c|}{ Supplemental Table S2.txt } \\
\hline CHEMBL3199566 & 688612 & 4.05 & 4.7279 & TRN & \\
\hline CHEMBL1455832 & 688612 & 4.65 & 4.6587 & TST & \\
\hline CHEMBL1376232 & 688612 & 4.6 & 4.6712 & TRN & \\
\hline CHEMBL1585390 & 688612 & 4.05 & 4.7137 & TRN & \\
\hline CHEMBL1431777 & 688612 & 5.5 & 4.6318 & TST & \\
\hline CHEMBL1447534 & 688612 & 6.0 & 4.6584 & TRN & \\
\hline CHEMBL3189532 & 688612 & 4.05 & 4.7424 & TRN & \\
\hline CHEMBL1613238 & 688612 & 4.35 & 4.7147 & TRN & \\
\hline CHEMBL1327413 & 688612 & 5.75 & 4.7318 & TST & \\
\hline CHEMBL1302114 & 688612 & 4.4 & 4.6716 & TRN & \\
\hline CHEMBL3211910 & 688612 & 4.3 & 4.6397 & TRN & \\
\hline CHEMBL1477826 & 688612 & 4.4 & 4.5947 & TRN & \\
\hline CHEMBL1588553 & 688612 & 6.2 & 4.6582 & TST & \\
\hline CHEMBL1499996 & 688612 & 4.4 & 4.6605 & TST & \\
\hline CHEMBL3195556 & 688612 & 5.55 & 4.6903 & TST & \\
\hline CHEMBL1305226 & 688612 & 5.0 & 4.7041 & TST & \\
\hline CHEMBL1494882 & 688612 & 7.0 & 4.6297 & TRN & \\
\hline CHEMBL1608223 & 688612 & 5.1 & 4.7487 & TRN & \\
\hline CHEMBL1568882 & 688612 & 4.05 & 4.6335 & TRN & \\
\hline CHEMBL1601438 & 688612 & 5.4 & 4.6435 & TST & \\
\hline CHEMBL1313720 & 688612 & 4.7 & 4.6119 & TRN & \\
\hline CHEMBL1966252 & 688612 & 4.85 & 4.7226 & TRN & \\
\hline CHEMBL1507738 & 688612 & 4.05 & 4.7168 & TRN & \\
\hline CHEMBL3189177 & 688612 & 4.6 & 4.7447 & TRN & \\
\hline CHEMBL1556552 & 688612 & 5.0 & 4.6725 & TRN & \\
\hline CHEMBL1601089 & 688612 & 4.1 & 4.6956 & TST & \\
\hline CHEMBL1403749 & 688612 & 5.85 & 4.6305 & TST & \\
\hline CHEMBL1597797 & 688612 & 4.05 & 4.6377 & TST & \\
\hline CHEMBL1462570 & 688612 & 5.45 & 4.74100 & 00000000005 & TST \\
\hline CHEMBL1360774 & 688612 & 6.0 & 4.6842 & TRN & \\
\hline CHEMBL1465553 & 688612 & 4.4 & 4.6086 & TST & \\
\hline CHEMBL1529492 & 688612 & 4.05 & 4.6211 & TST & \\
\hline CHEMBL3190755 & 688612 & 4.1 & 4.768 & TRN & \\
\hline CHEMBL1441130 & 688612 & 4.2 & 4.5977 & TRN & \\
\hline CHEMBL1569239 & 688612 & 4.25 & 4.7388 & TRN & \\
\hline CHEMBL1460349 & 688612 & 4.1 & 4.6579 & TST & \\
\hline CHEMBL1390582 & 688612 & 4.75 & 4.6603 & TST & \\
\hline CHEMBL1335198 & 688612 & 4.25 & 4.6239 & TRN & \\
\hline CHEMBL1484206 & 688612 & 5.3 & 4.5703 & TRN & \\
\hline CHEMBL1349161 & 688612 & 4.3 & 4.718 & TRN & \\
\hline CHEMBL1543396 & 688612 & 4.35 & 4.6553 & TRN & \\
\hline CHEMBL1535656 & 688612 & 4.05 & 4.7124 & TRN & \\
\hline CHEMBL1445521 & 688612 & 4.7 & 4.6873 & TST & \\
\hline CHEMBL1432118 & 688612 & 4.05 & 4.6843 & TRN & \\
\hline CHEMBL1377220 & 688612 & 4.3 & 4.6564 & TRN & \\
\hline CHEMBL1443557 & 688612 & 4.1 & 4.7047 & TST & \\
\hline CHEMBL1370422 & 688612 & 4.0 & 4.6769 & TRN & \\
\hline CHEMBL1427723 & 688612 & 4.65 & 4.6412 & TRN & \\
\hline
\end{tabular}




\begin{tabular}{|c|c|c|c|c|}
\hline \multicolumn{5}{|c|}{ Supplemental Table S2.txt } \\
\hline CHEMBL1457027 & 688612 & 6.5 & 4.6187 & TRN \\
\hline CHEMBL1340803 & 688612 & 4.0 & 4.5857 & TRN \\
\hline CHEMBL1390754 & 688612 & 6.05 & 4.6068 & TRN \\
\hline CHEMBL1439006 & 688612 & 4.05 & 4.7121 & TRN \\
\hline CHEMBL1607935 & 688612 & 4.3 & 4.7772 & TRN \\
\hline CHEMBL1982888 & 688612 & 5.4 & 4.7686 & TRN \\
\hline CHEMBL1604803 & 688612 & 4.5 & 4.7639 & TRN \\
\hline CHEMBL1606765 & 688612 & 5.05 & 4.7238 & TRN \\
\hline CHEMBL1362266 & 688612 & 6.5501 & 4.6998 & TRN \\
\hline CHEMBL1384365 & 688612 & 4.55 & 4.6753 & TRN \\
\hline CHEMBL3196903 & 688612 & 4.65 & 4.7117 & TST \\
\hline CHEMBL1549028 & 688612 & 4.4 & 4.6817 & TRN \\
\hline CHEMBL1490919 & 688612 & 5.55 & 4.7339 & TST \\
\hline CHEMBL1423457 & 688612 & 4.3 & 4.7494 & TRN \\
\hline CHEMBL1475097 & 688612 & 4.4 & 4.6306 & TRN \\
\hline CHEMBL1482275 & 688612 & 4.65 & 4.7184 & TRN \\
\hline CHEMBL1408713 & 688612 & 4.0 & 4.6887 & TST \\
\hline CHEMBL1424528 & 688612 & 5.45 & 4.6437 & TRN \\
\hline CHEMBL1460225 & 688612 & 5.9 & 4.7012 & TRN \\
\hline CHEMBL1511852 & 688612 & 5.7 & 4.6556 & TST \\
\hline CHEMBL1302563 & 688612 & 6.45 & 4.675 & TST \\
\hline CHEMBL1458913 & 688612 & 4.05 & 4.6585 & TRN \\
\hline CHEMBL1573517 & 688612 & 4.05 & 4.592 & TRN \\
\hline CHEMBL3213779 & 688612 & 6.8499 & 4.6938 & TST \\
\hline CHEMBL1595720 & 688612 & 4.2 & 4.6175 & TRN \\
\hline CHEMBL1572427 & 688612 & 4.4 & 4.6553 & TRN \\
\hline CHEMBL1402480 & 688612 & 6.95 & 4.6453 & TRN \\
\hline CHEMBL1423122 & 688612 & 4.95 & 4.6483 & TRN \\
\hline CHEMBL 3208384 & 688612 & 5.2 & 4.7208 & TRN \\
\hline CHEMBL1545298 & 688612 & 4.0 & 4.6789 & TRN \\
\hline CHEMBL1544371 & 688612 & 4.05 & 4.6955 & TRN \\
\hline CHEMBL 1405878 & 688612 & 4.05 & 4.7505 & TRN \\
\hline CHEMBL 263972 & 688612 & 5.6238 & 4.7165 & TRN \\
\hline CHEMBL1383777 & 688612 & 4.75 & 4.7196 & TRN \\
\hline CHEMBL1446306 & 688612 & 4.25 & 4.6675 & TRN \\
\hline CHEMBL1533772 & 688612 & 4.0 & 4.7855 & TRN \\
\hline CHEMBL1441406 & 688612 & 5.9 & 4.669 & TST \\
\hline CHEMBL1485328 & 688612 & 4.4 & 4.6182 & TRN \\
\hline CHEMBL1412171 & 688612 & 4.05 & 4.6058 & TRN \\
\hline CHEMBL1461753 & 688612 & 4.55 & 4.7094 & TST \\
\hline CHEMBL1337591 & 688612 & 4.05 & 4.6996 & TST \\
\hline CHEMBL1446940 & 688612 & 4.1 & 4.6028 & TST \\
\hline CHEMBL1549380 & 688612 & 4.95 & 4.6612 & TRN \\
\hline CHEMBL1333845 & 688612 & 4.4 & 4.6861 & TST \\
\hline CHEMBL3191635 & 688612 & 4.45 & 4.6608 & TST \\
\hline CHEMBL1398580 & 688612 & 4.0 & 4.69 & TRN \\
\hline CHEMBL578257 & 688612 & 4.3 & 4.7082 & TRN \\
\hline CHEMBL1398946 & 688612 & 5.45 & 4.6632 & TST \\
\hline
\end{tabular}




\begin{tabular}{|c|c|c|c|c|c|}
\hline \multicolumn{6}{|c|}{ Supplemental Table S2.txt } \\
\hline CHEMBL1547230 & 688612 & 4.0 & 4.6231 & TRN & \\
\hline CHEMBL1314456 & 688612 & 4.5 & 4.5937 & TRN & \\
\hline CHEMBL1493201 & 688612 & 4.05 & 4.596 & TRN & \\
\hline CHEMBL1469163 & 688612 & 4.5 & 4.7451 & TRN & \\
\hline CHEMBL1565377 & 688612 & 4.95 & 4.6301 & TRN & \\
\hline CHEMBL1384209 & 688612 & 4.4 & 4.7433 & TRN & \\
\hline CHEMBL1496697 & 688612 & 6.25 & 4.6623 & TST & \\
\hline CHEMBL1375218 & 688612 & 5.25 & 4.7588 & TST & \\
\hline CHEMBL1595682 & 688612 & 4.0 & 4.6405 & TST & \\
\hline CHEMBL1508606 & 688612 & 4.9 & 4.6346 & TRN & \\
\hline CHEMBL1319081 & 688612 & 4.1 & 4.6179 & TRN & \\
\hline CHEMBL1400629 & 688612 & 4.05 & 4.7035 & TRN & \\
\hline CHEMBL1468680 & 688612 & 5.05 & 4.6253 & TRN & \\
\hline CHEMBL 3196465 & 688612 & 4.05 & 4.6693 & TST & \\
\hline CHEMBL1344691 & 688612 & 5.7 & 4.66100 & 00000000005 & TST \\
\hline CHEMBL1301169 & 688612 & 5.15 & 4.7578 & TRN & \\
\hline CHEMBL1478912 & 688612 & 4.8 & 4.6218 & TRN & \\
\hline CHEMBL1440107 & 688612 & 4.4 & 4.658 & TRN & \\
\hline CHEMBL1311804 & 688612 & 5.05 & 4.63899 & 9999999999 & TST \\
\hline CHEMBL1580684 & 688612 & 4.5 & 4.6881 & TST & \\
\hline CHEMBL1900055 & 688612 & 4.05 & 4.6797 & TST & \\
\hline CHEMBL1328409 & 688612 & 4.05 & 4.6681 & TST & \\
\hline CHEMBL1584180 & 688612 & 4.3 & 4.6828 & TRN & \\
\hline CHEMBL1499479 & 688612 & 4.1 & 4.7352 & TST & \\
\hline CHEMBL1443419 & 688612 & 4.05 & 4.7279 & TST & \\
\hline CHEMBL1514118 & 688612 & 4.5 & 4.6221 & TRN & \\
\hline CHEMBL1511509 & 688612 & 6.8 & 4.6397 & TRN & \\
\hline CHEMBL1410109 & 688612 & 4.9 & 4.7129 & TST & \\
\hline CHEMBL1304359 & 688612 & 5.1 & 4.6612 & TRN & \\
\hline CHEMBL1460700 & 688612 & 4.75 & 4.6185 & TRN & \\
\hline CHEMBL1513502 & 688612 & 4.7 & 4.5517 & TRN & \\
\hline CHEMBL1305142 & 688612 & 4.05 & 4.6299 & TST & \\
\hline CHEMBL1489230 & 688612 & 4.7 & 4.7217 & TRN & \\
\hline CHEMBL1373645 & 688612 & 5.35 & 4.6407 & TST & \\
\hline CHEMBL1306284 & 688612 & 4.35 & 4.7559 & TST & \\
\hline CHEMBL1496573 & 688612 & 4.45 & 4.7121 & TRN & \\
\hline CHEMBL1466462 & 688612 & 4.4 & 4.711 & TRN & \\
\hline CHEMBL1545411 & 688612 & 5.4 & 4.6764 & TRN & \\
\hline CHEMBL1300956 & 688612 & 4.3 & 4.691 & TRN & \\
\hline CHEMBL69086 & 688612 & 5.4 & 4.7337 & TST & \\
\hline CHEMBL1594374 & 688612 & 5.75 & 4.7264 & TST & \\
\hline CHEMBL1612094 & 688612 & 4.1 & 4.6613 & TRN & \\
\hline CHEMBL1336520 & 688612 & 4.6 & 4.6493 & TRN & \\
\hline CHEMBL1500349 & 688612 & 4.05 & 4.6704 & TRN & \\
\hline CHEMBL1349624 & 688612 & 4.15 & 4.6508 & TRN & \\
\hline CHEMBL3190804 & 688612 & 5.0 & 4.7547 & TST & \\
\hline CHEMBL1487521 & 688612 & 5.15 & 4.5753 & TRN & \\
\hline CHEMBL1337094 & 688612 & 4.0 & 4.6498 & TRN & \\
\hline
\end{tabular}




\begin{tabular}{|c|c|c|c|c|c|}
\hline \multicolumn{6}{|c|}{ Supplemental Table s2.txt } \\
\hline CHEMBL1426393 & 688612 & 6.8 & 4.6347 & TRN & \\
\hline CHEMBL1576435 & 688612 & 4.0 & 4.5618 & TRN & \\
\hline CHEMBL1356208 & 688612 & 4.05 & 4.61100 & 0000000001 & TRN \\
\hline CHEMBL1364205 & 688612 & 4.05 & 4.6809 & TRN & \\
\hline CHEMBL1430264 & 688612 & 6.8499 & 4.7082 & TRN & \\
\hline CHEMBL1555362 & 688612 & 5.45 & 4.6914 & TRN & \\
\hline CHEMBL1502762 & 688612 & 6.0 & 4.6457 & TRN & \\
\hline CHEMBL1423164 & 688612 & 4.1 & 4.7758 & TRN & \\
\hline CHEMBL1372751 & 688612 & 4.95 & 4.7529 & TRN & \\
\hline CHEMBL1478538 & 688612 & 4.2 & 4.6085 & TRN & \\
\hline CHEMBL1508297 & 688612 & 4.55 & 4.6324 & TRN & \\
\hline CHEMBL1593892 & 688612 & 6.5 & 4.6024 & TRN & \\
\hline CHEMBL1998648 & 688612 & 6.5 & 4.6742 & TRN & \\
\hline CHEMBL1366681 & 688612 & 4.55 & 4.8078 & TST & \\
\hline CHEMBL1441740 & 688612 & 4.25 & 4.703 & TRN & \\
\hline CHEMBL1388369 & 688612 & 4.6 & 4.6481 & TRN & \\
\hline CHEMBL267160 & 688612 & 4.4 & 4.7186 & TRN & \\
\hline CHEMBL1540592 & 688612 & 4.05 & 4.702 & TRN & \\
\hline CHEMBL1599158 & 688612 & 4.55 & 4.7207 & TRN & \\
\hline CHEMBL1481495 & 688612 & 4.6 & 4.6972 & TRN & \\
\hline CHEMBL1603945 & 688612 & 4.0 & 4.6526 & TRN & \\
\hline CHEMBL1441006 & 688612 & 4.05 & 4.7048 & TRN & \\
\hline CHEMBL1608714 & 688612 & 4.45 & 4.6155 & TRN & \\
\hline CHEMBL 1426340 & 688612 & 4.7 & 4.7431 & TST & \\
\hline CHEMBL1580341 & 688612 & 4.6 & 4.6134 & TRN & \\
\hline CHEMBL1507700 & 688612 & 5.8 & 4.6524 & TRN & \\
\hline CHEMBL1978623 & 688612 & 4.9 & 4.7682 & TRN & \\
\hline CHEMBL1335063 & 688612 & 4.4 & 4.663 & TST & \\
\hline CHEMBL42288 & 688612 & 4.05 & 4.7016 & TRN & \\
\hline CHEMBL1361223 & 688612 & 4.0 & 4.7313 & TST & \\
\hline CHEMBL1431126 & 688612 & 4.4 & 4.7449 & TRN & \\
\hline CHEMBL1407322 & 688612 & 4.0 & 4.6399 & TST & \\
\hline CHEMBL1401637 & 688612 & 4.05 & 4.6582 & TST & \\
\hline CHEMBL1330231 & 688612 & 5.35 & 4.6548 & TST & \\
\hline CHEMBL1568659 & 688612 & 6.5 & 4.6734 & TST & \\
\hline CHEMBL1564660 & 688612 & 4.25 & 4.7245 & TST & \\
\hline CHEMBL1606322 & 688612 & 4.4 & 4.6158 & TST & \\
\hline CHEMBL1542777 & 688612 & 4.05 & 4.6582 & TRN & \\
\hline CHEMBL1574031 & 688612 & 4.1 & 4.6595 & TST & \\
\hline CHEMBL1496906 & 688612 & 4.05 & 4.6642 & TST & \\
\hline CHEMBL1524017 & 688612 & 4.45 & 4.6293 & TRN & \\
\hline CHEMBL1400107 & 688612 & 4.05 & 4.5655 & TST & \\
\hline CHEMBL1576977 & 688612 & 6.05 & 4.6839 & TRN & \\
\hline CHEMBL 1604680 & 688612 & 6.5501 & 4.6479 & TRN & \\
\hline CHEMBL1600017 & 688612 & 5.75 & 4.6163 & TRN & \\
\hline CHEMBL1340593 & 688612 & 4.05 & 4.7077 & TRN & \\
\hline CHEMBL1454417 & 688612 & 4.75 & 4.6286 & TRN & \\
\hline CHEMBL1498281 & 688612 & 4.3 & 4.7168 & TRN & \\
\hline
\end{tabular}




\begin{tabular}{|c|c|c|c|c|c|}
\hline \multicolumn{6}{|c|}{ Supplemental Table S2.txt } \\
\hline CHEMBL1342081 & 688612 & 4.4 & 4.7062 & TRN & \\
\hline CHEMBL401588 & 688612 & 4.05 & 4.6163 & TRN & \\
\hline CHEMBL1566751 & 688612 & 4.2 & 4.7378 & TST & \\
\hline CHEMBL1392542 & 688612 & 4.35 & 4.6981 & TST & \\
\hline CHEMBL1535951 & 688612 & 4.65 & 4.6535 & TRN & \\
\hline CHEMBL1575162 & 688612 & 5.8 & 4.6496 & TRN & \\
\hline CHEMBL1398788 & 688612 & 4.75 & 4.6427 & TRN & \\
\hline CHEMBL1598139 & 688612 & 4.2 & 4.6713 & TRN & \\
\hline CHEMBL1503724 & 688612 & 4.5 & 4.7829 & TRN & \\
\hline CHEMBL1319991 & 688612 & 4.6 & 4.6118 & TRN & \\
\hline CHEMBL1526088 & 688612 & 4.8 & 4.652 & TRN & \\
\hline CHEMBL1335636 & 688612 & 4.05 & 4.6426 & TST & \\
\hline CHEMBL1496644 & 688612 & 4.8 & 4.6857 & TST & \\
\hline CHEMBL1363714 & 688612 & 6.15 & 4.6367 & TRN & \\
\hline CHEMBL1591716 & 688612 & 4.05 & 4.5889 & TRN & \\
\hline CHEMBL3209934 & 688612 & 4.05 & 4.6431 & TRN & \\
\hline CHEMBL1990772 & 688612 & 4.55 & 4.7302 & TRN & \\
\hline CHEMBL1351293 & 688612 & 4.45 & 4.6029 & TST & \\
\hline CHEMBL1974201 & 688612 & 4.55 & 4.7401 & TRN & \\
\hline CHEMBL1586266 & 688612 & 4.95 & 4.6745 & TRN & \\
\hline CHEMBL1515251 & 688612 & 4.65 & 4.7371 & TRN & \\
\hline CHEMBL1544163 & 688612 & 6.0 & 4.67899 & 9999999999 & TRN \\
\hline CHEMBL1315394 & 688612 & 5.35 & 4.6225 & TRN & \\
\hline CHEMBL1542847 & 688612 & 4.35 & 4.6409 & TST & \\
\hline CHEMBL1536910 & 688612 & 4.9 & 4.8169 & TRN & \\
\hline CHEMBL1459067 & 688612 & 6.35 & 4.6378 & TRN & \\
\hline CHEMBL1410069 & 688612 & 4.45 & 4.6479 & TRN & \\
\hline CHEMBL1360995 & 688612 & 4.1 & 4.6557 & TST & \\
\hline CHEMBL1303996 & 688612 & 5.0 & 4.6339 & TRN & \\
\hline CHEMBL1545897 & 688612 & 5.1 & 4.7152 & TRN & \\
\hline CHEMBL1474260 & 688612 & 4.05 & 4.5761 & TST & \\
\hline CHEMBL1368265 & 688612 & 4.35 & 4.6916 & TST & \\
\hline CHEMBL1444096 & 688612 & 5.15 & 4.6625 & TST & \\
\hline CHEMBL1542040 & 688612 & 4.7 & 4.6285 & TRN & \\
\hline CHEMBL1528030 & 688612 & 4.05 & 4.6432 & TRN & \\
\hline CHEMBL3192002 & 688612 & 4.25 & 4.76 & TST & \\
\hline CHEMBL1566275 & 688612 & 4.4 & 4.587 & TST & \\
\hline CHEMBL1551944 & 688612 & 4.7 & 4.5895 & TRN & \\
\hline CHEMBL1455406 & 688612 & 4.1 & 4.58899 & 99999999995 & TRN \\
\hline CHEMBL1578224 & 688612 & 6.8 & 4.7289 & TST & \\
\hline CHEMBL1402821 & 688612 & 4.9 & 4.615 & TRN & \\
\hline CHEMBL1338879 & 688612 & 4.6 & 4.7237 & TRN & \\
\hline CHEMBL1480254 & 688612 & 4.05 & 4.5965 & TRN & \\
\hline CHEMBL1548904 & 688612 & 4.3 & 4.6687 & TST & \\
\hline CHEMBL1364076 & 688612 & 4.0 & 4.7602 & TST & \\
\hline CHEMBL1357424 & 688612 & 4.0 & 4.6602 & TRN & \\
\hline CHEMBL1498266 & 688612 & 4.05 & 4.6723 & TST & \\
\hline CHEMBL1530393 & 688612 & 4.25 & 4.7017 & TRN & \\
\hline
\end{tabular}




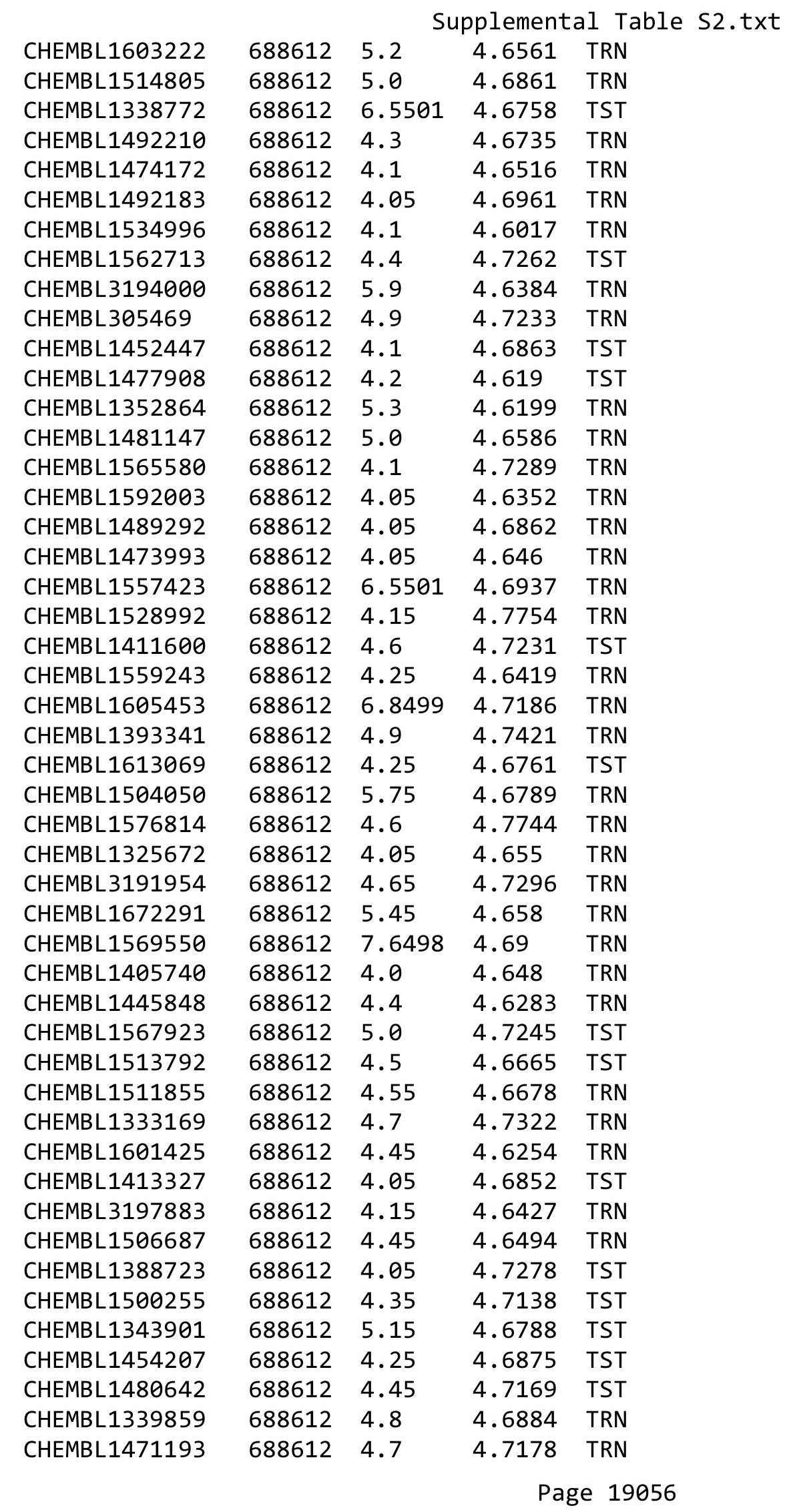




\begin{tabular}{|c|c|c|c|c|}
\hline \multicolumn{5}{|c|}{ Supplemental Table s2.txt } \\
\hline CHEMBL1577661 & 688612 & 4.9 & 4.7127 & TST \\
\hline CHEMBL1495342 & 688612 & 5.55 & 4.6848 & TRN \\
\hline CHEMBL1411446 & 688612 & 6.8499 & 4.647 & TRN \\
\hline CHEMBL1322674 & 688612 & 4.7 & 4.6355 & TRN \\
\hline CHEMBL1512283 & 688612 & 4.05 & 4.5729 & TST \\
\hline CHEMBL1495102 & 688612 & 4.0 & 4.6872 & TST \\
\hline CHEMBL1601890 & 688612 & 4.9 & 4.5728 & TRN \\
\hline CHEMBL3192956 & 688612 & 6.5501 & 4.6078 & TRN \\
\hline CHEMBL1593151 & 688612 & 4.45 & 4.5718 & TRN \\
\hline CHEMBL1390877 & 688612 & 4.4 & 4.5756 & TRN \\
\hline CHEMBL1375224 & 688612 & 4.1 & 4.6402 & TRN \\
\hline CHEMBL1474606 & 688612 & 5.35 & 4.5699 & TRN \\
\hline CHEMBL1576614 & 688612 & 4.65 & 4.7006 & TRN \\
\hline CHEMBL1364338 & 688612 & 4.3 & 4.6845 & TRN \\
\hline CHEMBL1995193 & 688612 & 4.4 & 4.769 & TRN \\
\hline CHEMBL1559598 & 688612 & 4.05 & 4.6406 & TRN \\
\hline CHEMBL1494540 & 688612 & 4.1 & 4.605 & TRN \\
\hline CHEMBL1511242 & 688612 & 4.0 & 4.5999 & TRN \\
\hline CHEMBL1414448 & 688612 & 4.65 & 4.7306 & TST \\
\hline CHEMBL1485876 & 688612 & 4.45 & 4.6896 & TRN \\
\hline CHEMBL1391376 & 688612 & 6.5 & 4.6604 & TRN \\
\hline CHEMBL1543764 & 688612 & 4.65 & 4.6443 & TST \\
\hline CHEMBL1461867 & 688612 & 4.35 & 4.6747 & TST \\
\hline CHEMBL1611166 & 688612 & 4.0 & 4.6573 & TRN \\
\hline CHEMBL1558087 & 688612 & 4.6 & 4.72199 & 99999999995 \\
\hline CHEMBL1535432 & 688612 & 4.0 & 4.6644 & TRN \\
\hline CHEMBL1322883 & 688612 & 4.45 & 4.6395 & TRN \\
\hline CHEMBL1510259 & 688612 & 4.4 & 4.6549 & TST \\
\hline CHEMBL1462924 & 688612 & 4.35 & 4.7392 & TRN \\
\hline CHEMBL1481538 & 688612 & 4.2 & 4.6406 & TRN \\
\hline CHEMBL1431157 & 688612 & 6.0 & 4.718 & TST \\
\hline CHEMBL1355828 & 688612 & 4.1 & 4.6791 & TRN \\
\hline CHEMBL1526194 & 688612 & 6.8499 & 4.6231 & TRN \\
\hline CHEMBL 289277 & 688612 & 4.95 & 4.798 & TRN \\
\hline CHEMBL1432535 & 688612 & 4.9 & 4.6176 & TRN \\
\hline CHEMBL1575184 & 688612 & 4.25 & 4.7094 & TST \\
\hline CHEMBL1563171 & 688612 & 4.7 & 4.7635 & TRN \\
\hline CHEMBL1520122 & 688612 & 4.4 & 4.6303 & TRN \\
\hline CHEMBL1386233 & 688612 & 4.4 & 4.6317 & TRN \\
\hline CHEMBL1546317 & 688612 & 4.05 & 4.6422 & TRN \\
\hline CHEMBL1416360 & 688612 & 5.35 & 4.6549 & TRN \\
\hline CHEMBL1326534 & 688612 & 4.4 & 4.7182 & TRN \\
\hline CHEMBL1343454 & 688612 & 4.05 & 4.6439 & TST \\
\hline CHEMBL1519608 & 688612 & 4.4 & 4.6652 & TRN \\
\hline CHEMBL1399380 & 688612 & 4.9 & 4.7245 & TST \\
\hline CHEMBL 3189634 & 688612 & 4.05 & 4.6901 & TRN \\
\hline CHEMBL1448892 & 688612 & 4.05 & 4.6933 & TRN \\
\hline CHEMBL1467599 & 688612 & 4.05 & 4.6087 & TRN \\
\hline
\end{tabular}




\begin{tabular}{|c|c|c|c|c|c|}
\hline \multicolumn{6}{|c|}{ Supplemental Table S2.txt } \\
\hline CHEMBL1559168 & 688612 & 4.05 & 4.6559 & TRN & \\
\hline CHEMBL1432715 & 688612 & 5.05 & 4.7027 & TRN & \\
\hline CHEMBL1613421 & 688612 & 4.6 & 4.6425 & TRN & \\
\hline CHEMBL1707818 & 688612 & 4.8 & 4.763 & TST & \\
\hline CHEMBL1362772 & 688612 & 5.15 & 4.6168 & TRN & \\
\hline CHEMBL1397959 & 688612 & 4.05 & 4.6314 & TRN & \\
\hline CHEMBL1605982 & 688612 & 5.25 & 4.614 & TRN & \\
\hline CHEMBL1536190 & 688612 & 4.95 & 4.7298 & TRN & \\
\hline CHEMBL1543601 & 688612 & 6.5501 & 4.8275 & TRN & \\
\hline CHEMBL1415813 & 688612 & 4.25 & 4.7459 & TST & \\
\hline CHEMBL 3209038 & 688612 & 4.85 & 4.6359 & TST & \\
\hline CHEMBL 3193078 & 688612 & 4.4 & 4.6766 & TRN & \\
\hline CHEMBL1414796 & 688612 & 4.4 & 4.7446 & TRN & \\
\hline CHEMBL1587927 & 688612 & 4.7 & 4.7033 & TRN & \\
\hline CHEMBL1435900 & 688612 & 4.4 & 4.5976 & TRN & \\
\hline CHEMBL1446808 & 688612 & 4.05 & 4.6396 & TRN & \\
\hline CHEMBL1366547 & 688612 & 5.4 & 4.6215 & TRN & \\
\hline CHEMBL1381248 & 688612 & 4.1 & 4.6996 & TRN & \\
\hline CHEMBL1442633 & 688612 & 4.35 & 4.7345 & TRN & \\
\hline CHEMBL1587986 & 688612 & 4.0 & 4.5643 & TRN & \\
\hline CHEMBL1437600 & 688612 & 4.0 & 4.6318 & TRN & \\
\hline CHEMBL1552796 & 688612 & 4.1 & 4.7037 & TRN & \\
\hline CHEMBL1571573 & 688612 & 4.3 & 4.6955 & TRN & \\
\hline CHEMBL 3194819 & 688612 & 4.05 & 4.7684 & TRN & \\
\hline CHEMBL1567847 & 688612 & 6.45 & 4.6775 & TRN & \\
\hline CHEMBL1603843 & 688612 & 4.8 & 4.6234 & TRN & \\
\hline CHEMBL1399410 & 688612 & 5.15 & 4.6424 & TRN & \\
\hline CHEMBL1326289 & 688612 & 4.65 & 4.6646 & TST & \\
\hline CHEMBL1309516 & 688612 & 4.75 & $4.6610 €$ & 00000000005 & TRN \\
\hline CHEMBL1486510 & 688612 & 4.8 & 4.7212 & TST & \\
\hline CHEMBL1445734 & 688612 & 4.05 & 4.6276 & TRN & \\
\hline CHEMBL1516065 & 688612 & 4.05 & 4.6041 & TRN & \\
\hline CHEMBL1337241 & 688612 & 4.1 & 4.5635 & TST & \\
\hline CHEMBL3210061 & 688612 & 4.4 & 4.7134 & TRN & \\
\hline CHEMBL1557939 & 688612 & 4.7 & 4.7672 & TRN & \\
\hline CHEMBL1975219 & 688612 & 4.4 & 4.6848 & TRN & \\
\hline CHEMBL 1472376 & 688612 & 4.65 & 4.6071 & TRN & \\
\hline CHEMBL1441143 & 688612 & 4.45 & 4.7101 & TRN & \\
\hline CHEMBL1362445 & 688612 & 4.5 & 4.7313 & TST & \\
\hline CHEMBL1375126 & 688612 & 4.4 & 4.6559 & TRN & \\
\hline CHEMBL1305050 & 688612 & 5.35 & 4.7057 & TRN & \\
\hline CHEMBL3209096 & 688612 & 4.4 & 4.6903 & TRN & \\
\hline CHEMBL1449081 & 688612 & 6.8 & 4.631 & TRN & \\
\hline CHEMBL1372109 & 688612 & 5.0 & 4.79 & TRN & \\
\hline CHEMBL1547421 & 688612 & 4.4 & 4.7555 & TST & \\
\hline CHEMBL1406204 & 688612 & 4.05 & 4.7241 & TST & \\
\hline CHEMBL1574184 & 688612 & 4.05 & 4.6122 & TRN & \\
\hline CHEMBL1539740 & 688612 & 4.4 & 4.6435 & TRN & \\
\hline
\end{tabular}




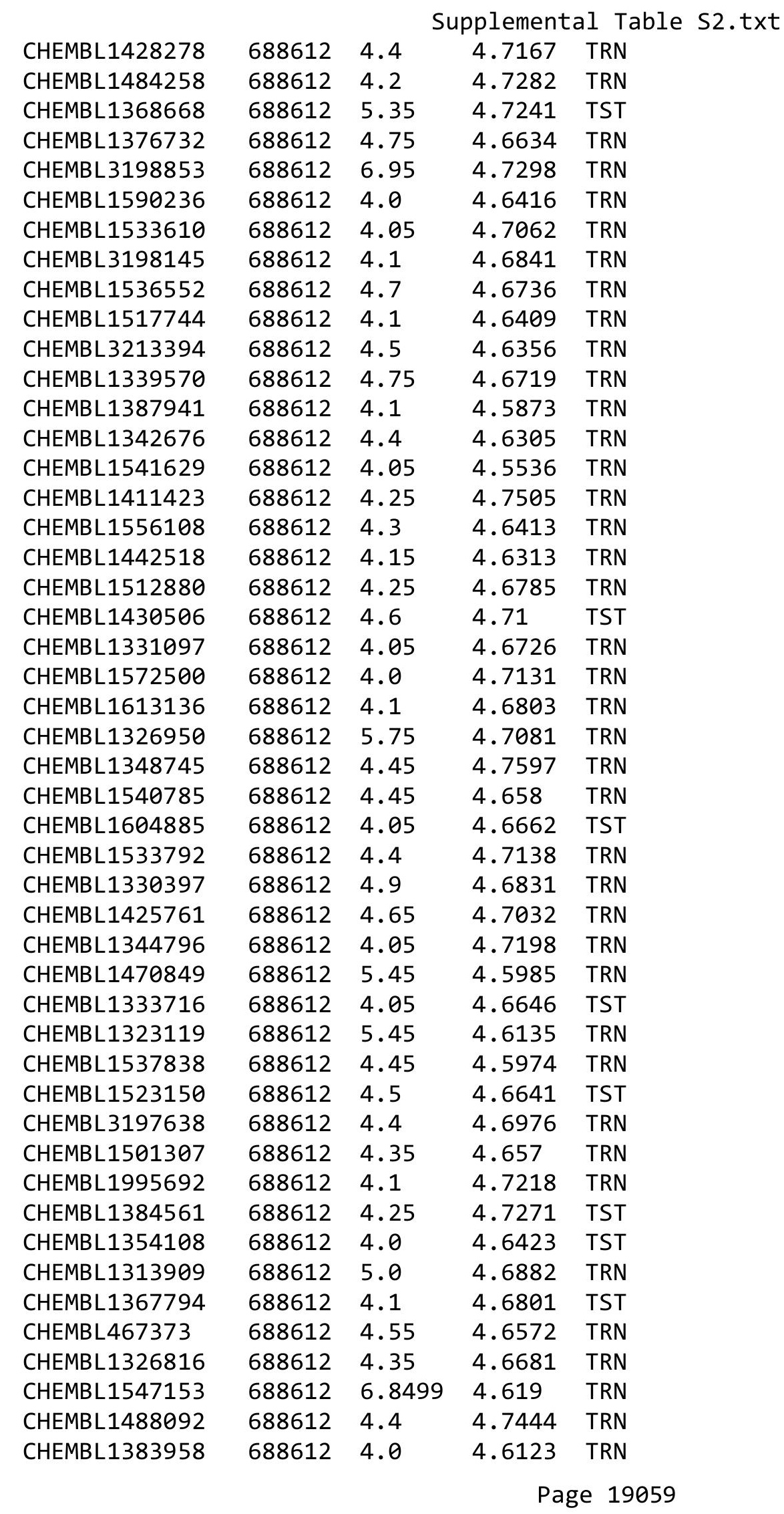




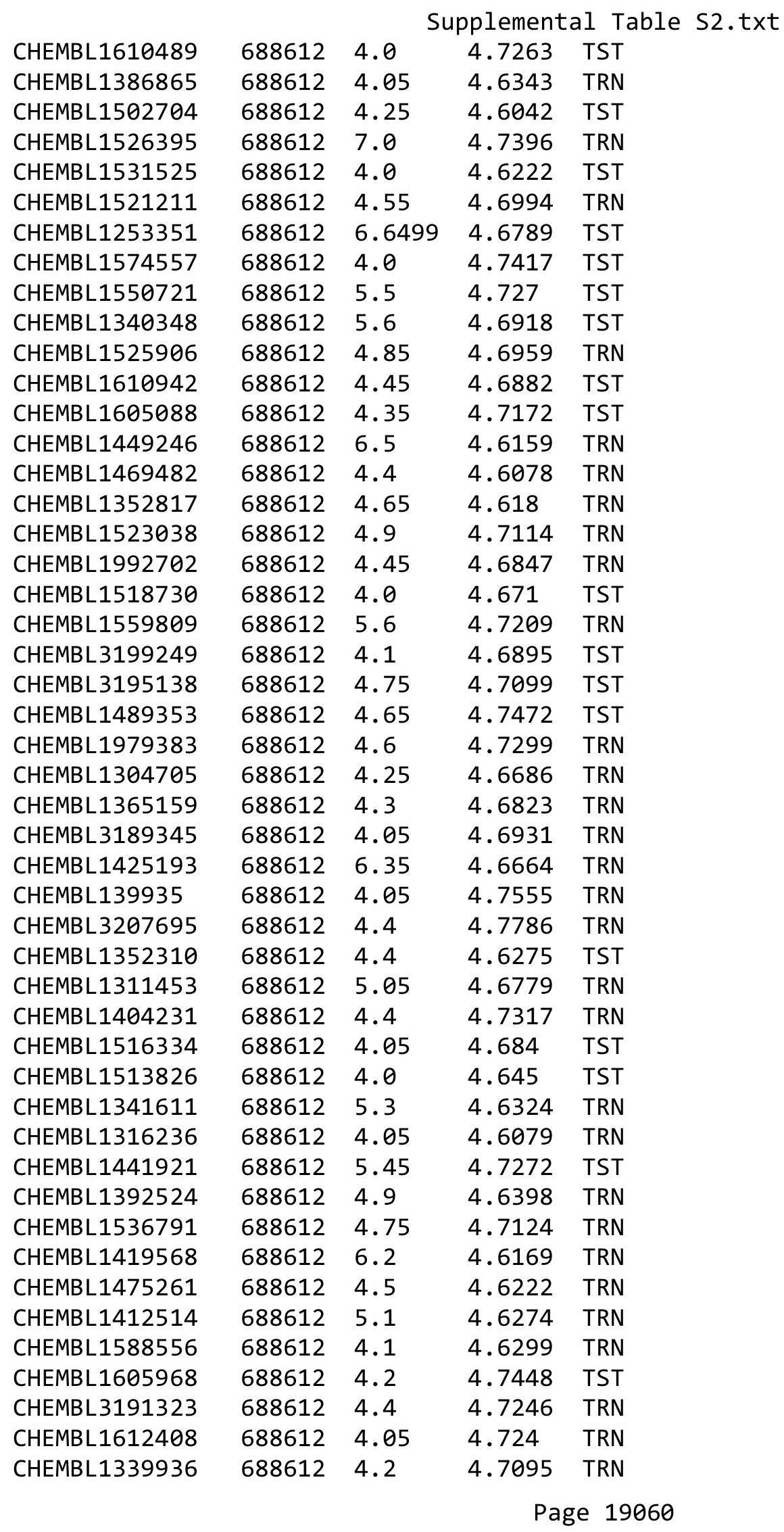




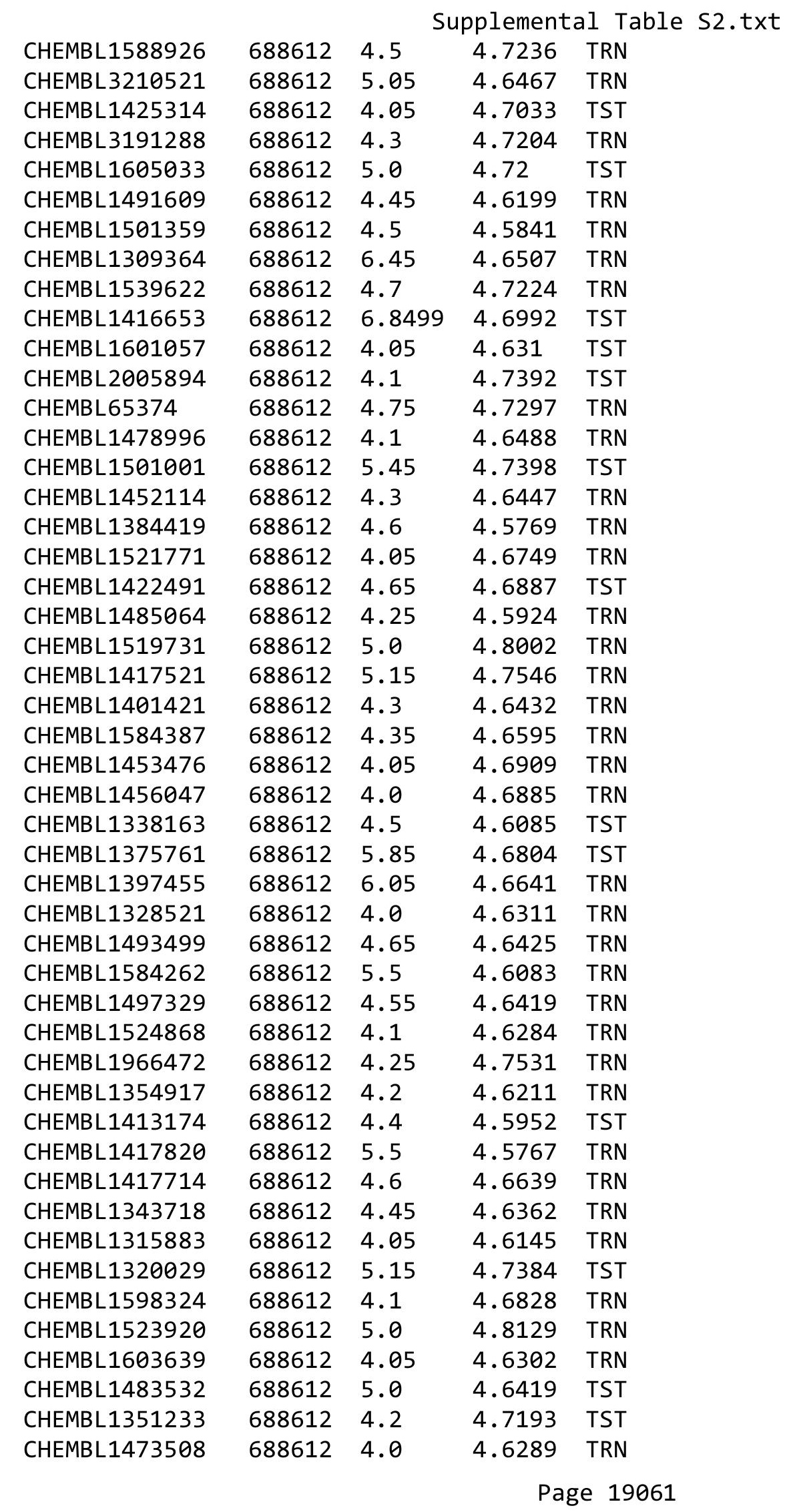




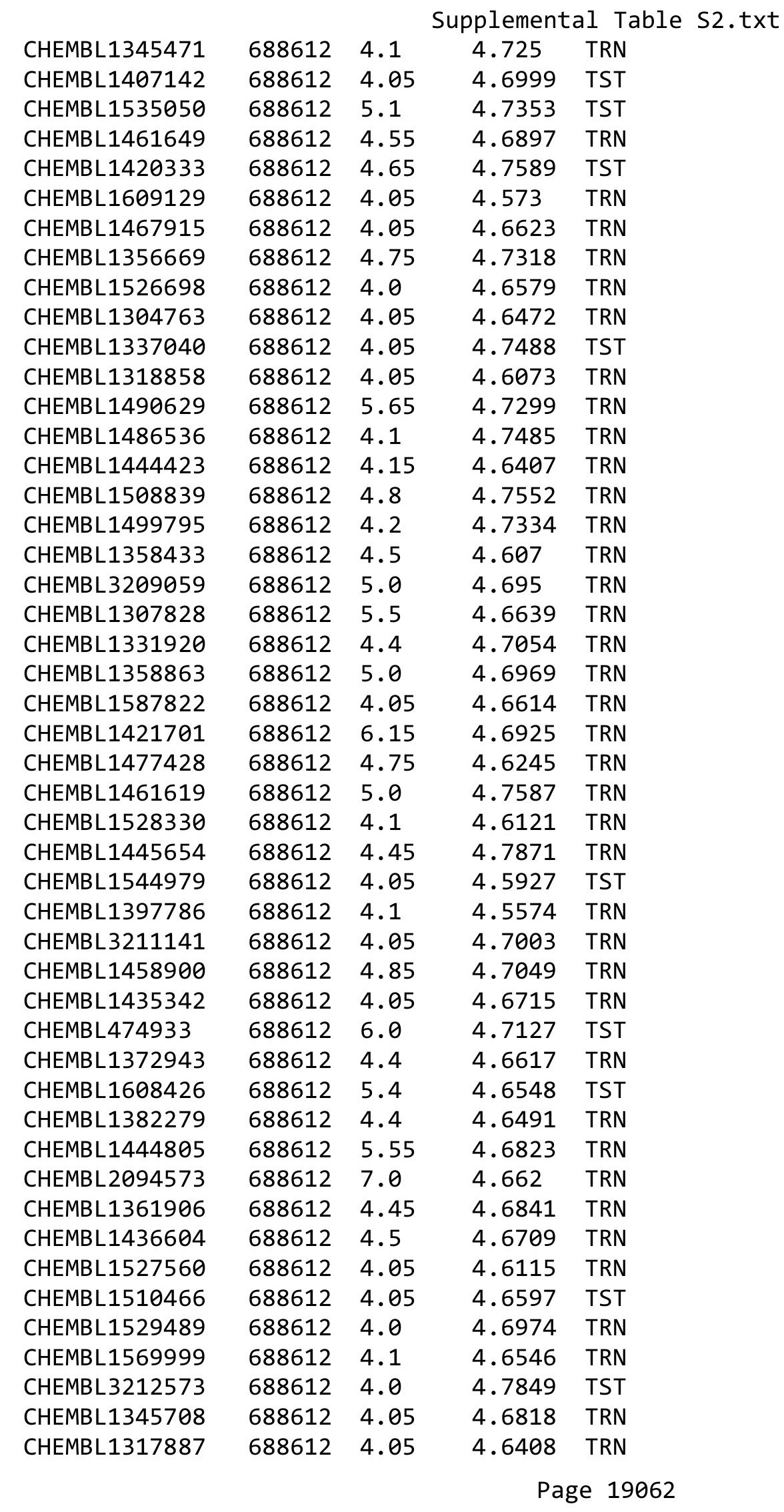




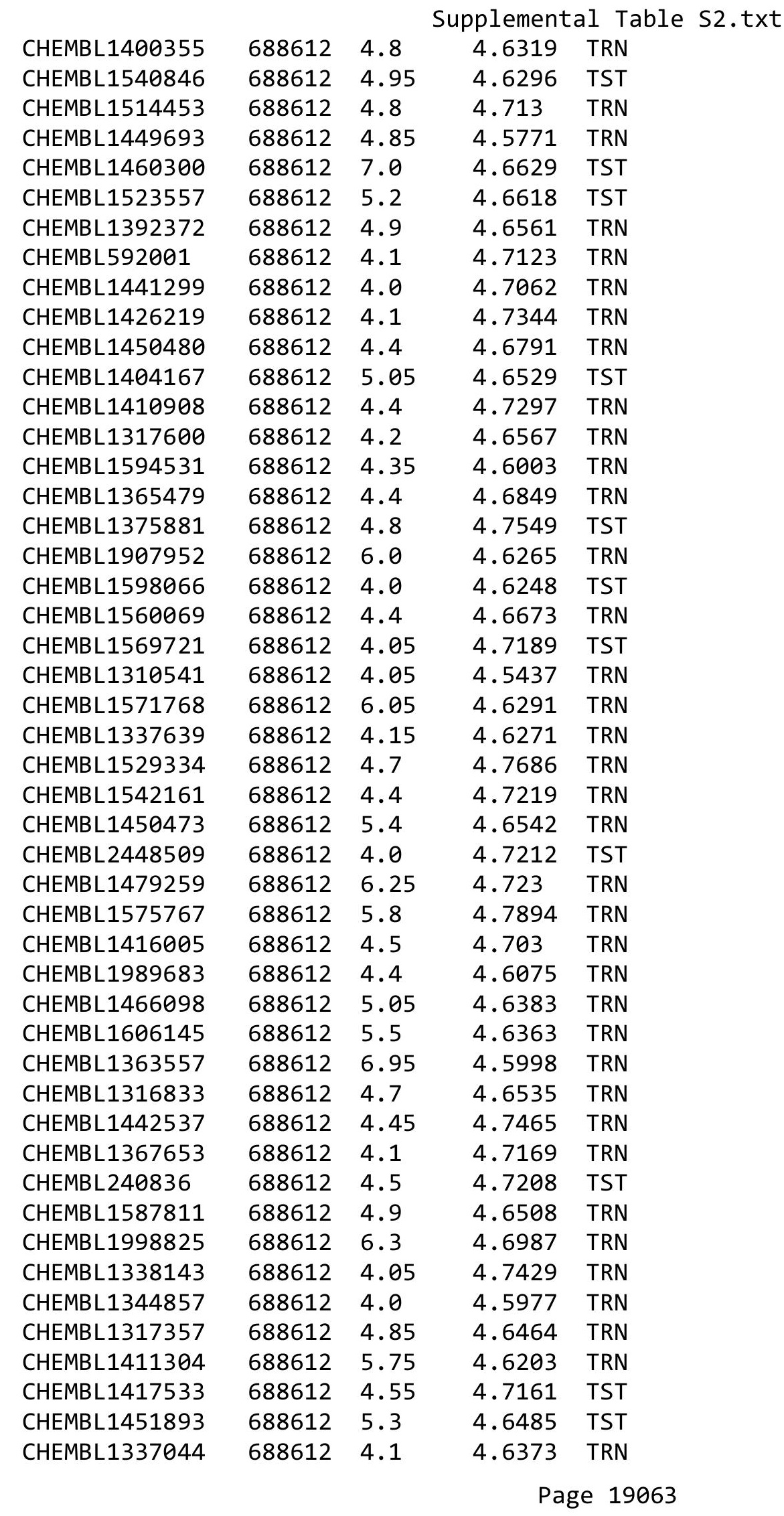




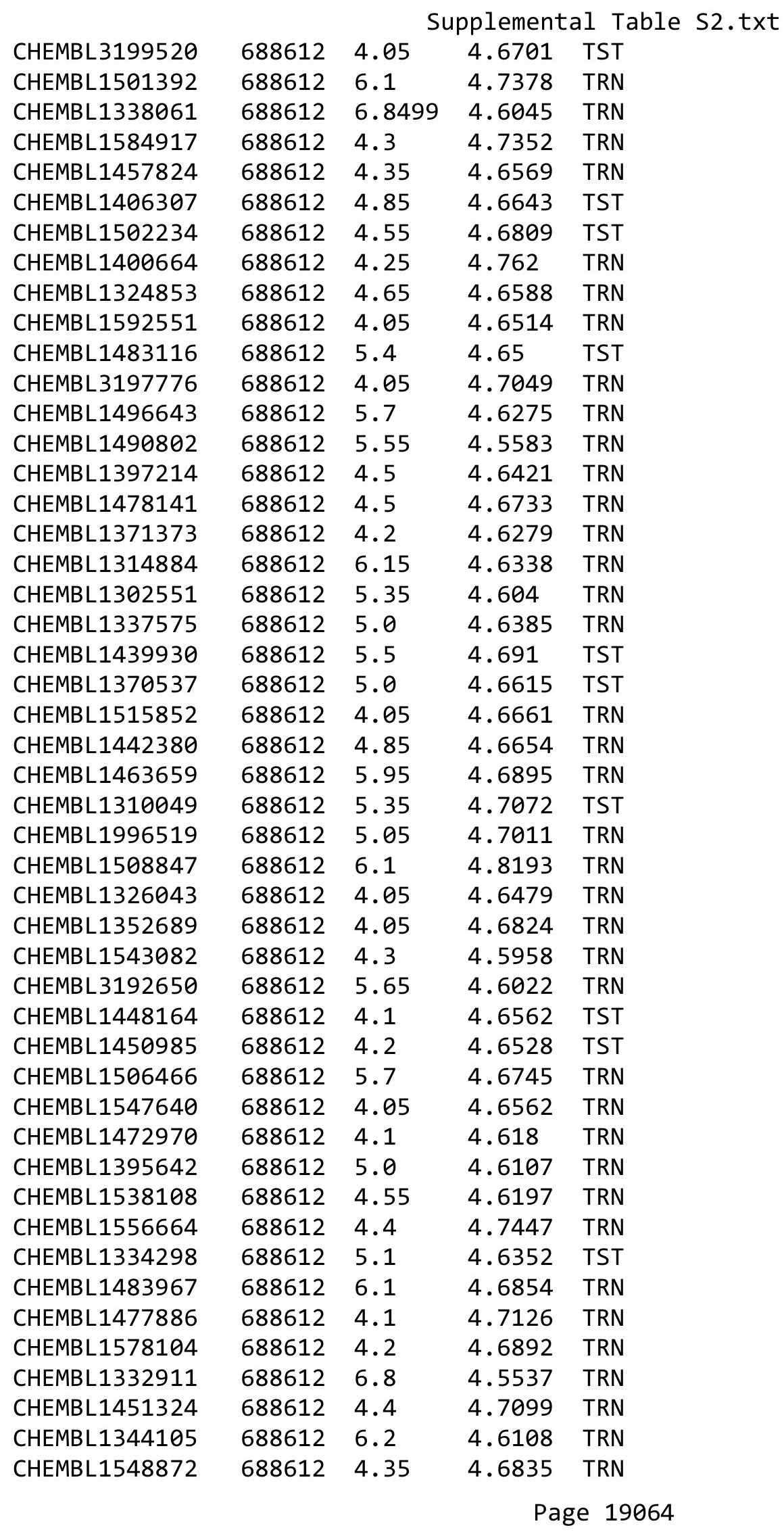




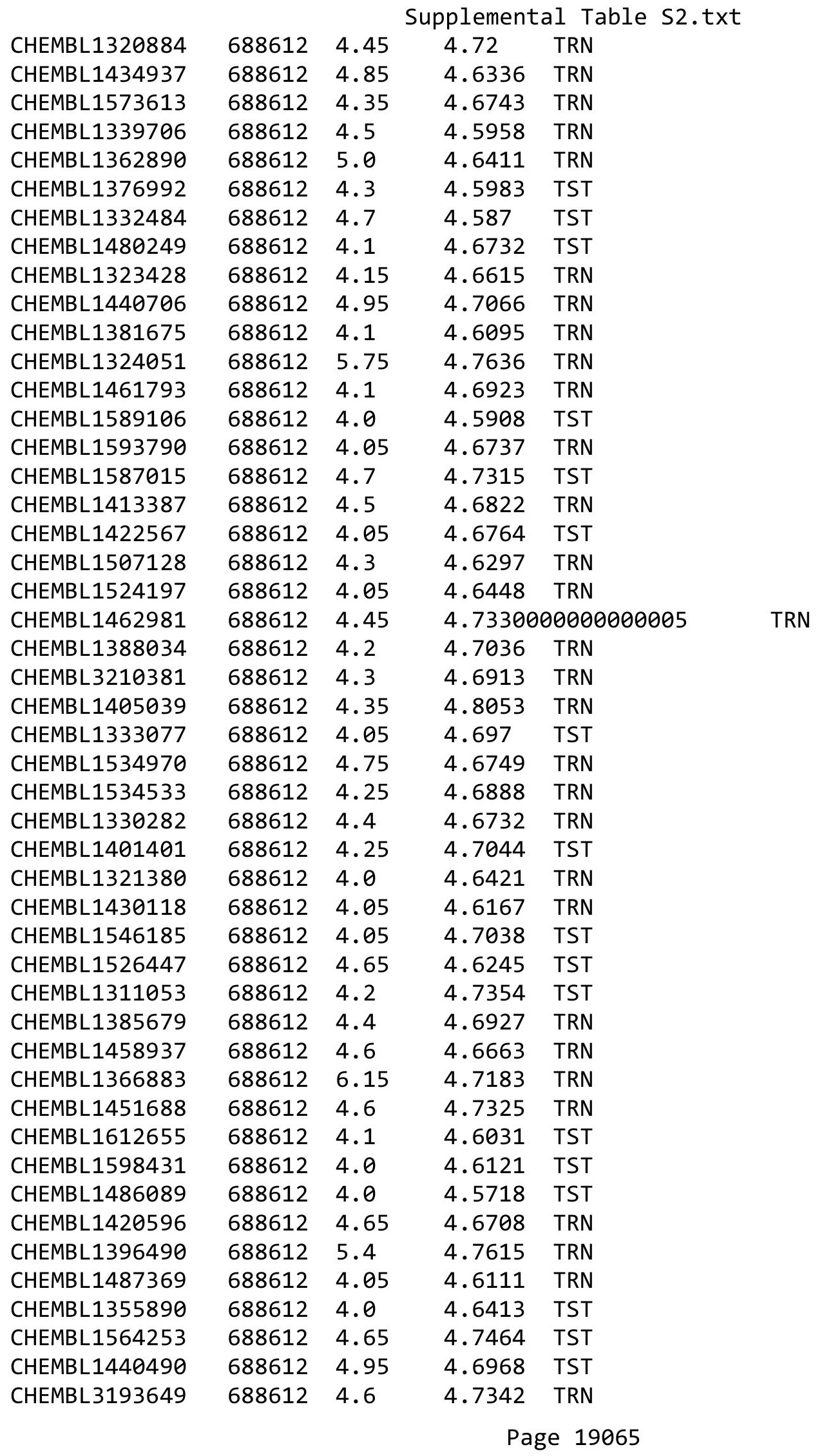




\begin{tabular}{|c|c|c|c|c|}
\hline \multicolumn{5}{|c|}{ Supplemental Table s2.txt } \\
\hline CHEMBL1532753 & 688612 & 6.3 & 4.6215 & TST \\
\hline CHEMBL1524016 & 688612 & 4.85 & 4.6831 & TRN \\
\hline CHEMBL1475660 & 688612 & 4.0 & 4.6202 & TRN \\
\hline CHEMBL1438370 & 688612 & 5.2 & 4.6278 & TRN \\
\hline CHEMBL86464 & 688612 & 4.3 & 4.6718 & TST \\
\hline CHEMBL1386963 & 688612 & 4.7 & 4.7496 & TRN \\
\hline CHEMBL1492202 & 688612 & 4.0 & 4.6867 & TRN \\
\hline CHEMBL1502303 & 688612 & 4.7 & 4.8125 & TST \\
\hline CHEMBL1487669 & 688612 & 4.75 & 4.5969 & TRN \\
\hline CHEMBL1531100 & 688612 & 6.2 & 4.666 & TRN \\
\hline CHEMBL1602950 & 688612 & 4.35 & 4.7799 & TST \\
\hline CHEMBL1539911 & 688612 & 4.65 & 4.6983 & TST \\
\hline CHEMBL1598474 & 688612 & 4.75 & 4.6544 & TST \\
\hline CHEMBL 3195483 & 688612 & 5.15 & 4.8027 & TRN \\
\hline CHEMBL1595830 & 688612 & 4.05 & 4.6047 & TST \\
\hline CHEMBL1315878 & 688612 & 4.65 & 4.6226 & TRN \\
\hline CHEMBL1551397 & 688612 & 4.3 & 4.6052 & TRN \\
\hline CHEMBL1428015 & 688612 & 4.4 & 4.6562 & TRN \\
\hline CHEMBL1516726 & 688612 & 6.15 & 4.771 & TRN \\
\hline CHEMBL1348138 & 688612 & 4.1 & 4.6869 & TST \\
\hline CHEMBL1489480 & 688612 & 4.0 & 4.6916 & TRN \\
\hline CHEMBL1601234 & 688612 & 4.4 & 4.5889 & TRN \\
\hline CHEMBL1522033 & 688612 & 4.8 & 4.6838 & TRN \\
\hline CHEMBL1480810 & 688612 & 6.3 & 4.6076 & TRN \\
\hline CHEMBL1572735 & 688612 & 5.05 & 4.5918 & TRN \\
\hline CHEMBL1572042 & 688612 & 4.05 & 4.6879 & TST \\
\hline CHEMBL3198665 & 688612 & 4.05 & 4.6709 & TRN \\
\hline CHEMBL3193933 & 688612 & 3.95 & 4.6618 & TST \\
\hline CHEMBL1482013 & 688612 & 4.1 & 4.6461 & TRN \\
\hline CHEMBL1544961 & 688612 & 4.6 & 4.7416 & TRN \\
\hline CHEMBL1420095 & 688612 & 5.1 & 4.5955 & TRN \\
\hline CHEMBL1353091 & 688612 & 4.2 & 4.6699 & TST \\
\hline CHEMBL1498876 & 688612 & 4.4 & 4.7281 & TRN \\
\hline CHEMBL3192736 & 688612 & 4.2 & 4.6874 & TRN \\
\hline CHEMBL1435875 & 688612 & 5.0 & 4.6347 & TST \\
\hline CHEMBL1413085 & 688612 & 4.2 & 4.6785 & TRN \\
\hline CHEMBL3209255 & 688612 & 4.5 & 4.706 & TRN \\
\hline CHEMBL3189857 & 688612 & 4.6 & 4.7208 & TST \\
\hline CHEMBL1320982 & 688612 & 6.8499 & 4.7513 & TRN \\
\hline CHEMBL1358973 & 688612 & 4.1 & 4.5822 & TRN \\
\hline CHEMBL1342905 & 688612 & 4.65 & 4.6967 & TRN \\
\hline CHEMBL3209601 & 688612 & 4.3 & 4.6902 & TRN \\
\hline CHEMBL1550002 & 688612 & 5.6 & 4.6817 & TST \\
\hline CHEMBL1381658 & 688612 & 4.6 & 4.7248 & TRN \\
\hline CHEMBL1416493 & 688612 & 4.85 & 4.73 & TRN \\
\hline CHEMBL3196610 & 688612 & 5.6 & 4.6981 & TRN \\
\hline CHEMBL1492885 & 688612 & 4.3 & 4.5658 & TRN \\
\hline CHEMBL1580101 & 688612 & 5.95 & 4.7053 & TST \\
\hline
\end{tabular}




\begin{tabular}{|c|c|c|c|c|c|}
\hline \multicolumn{6}{|c|}{ Supplemental Table s2.txt } \\
\hline CHEMBL541847 & 688612 & 4.4 & 4.7108 & TRN & \\
\hline CHEMBL1359908 & 688612 & 5.1 & 4.7131 & TRN & \\
\hline CHEMBL1505833 & 688612 & 4.05 & 4.6504 & TRN & \\
\hline CHEMBL1507888 & 688612 & 4.2 & 4.7083 & TST & \\
\hline CHEMBL1307931 & 688612 & 4.1 & 4.7632 & TST & \\
\hline CHEMBL1472283 & 688612 & 4.95 & 4.708 & TRN & \\
\hline CHEMBL1377721 & 688612 & 4.95 & 4.5995 & TRN & \\
\hline CHEMBL1310148 & 688612 & 5.55 & 4.6904 & TRN & \\
\hline CHEMBL1572378 & 688612 & 4.4 & 4.658 & TRN & \\
\hline CHEMBL1457514 & 688612 & 4.6 & 4.7339 & TRN & \\
\hline CHEMBL1364172 & 688612 & 4.05 & 4.6555 & TRN & \\
\hline CHEMBL1352053 & 688612 & 4.05 & 4.6409 & TRN & \\
\hline CHEMBL1604567 & 688612 & 4.0 & 4.7258 & TST & \\
\hline CHEMBL1509714 & 688612 & 4.05 & 4.6156 & TRN & \\
\hline CHEMBL1578967 & 688612 & 4.1 & 4.6679 & TRN & \\
\hline CHEMBL1365424 & 688612 & 4.2 & 4.6953 & TRN & \\
\hline CHEMBL1583209 & 688612 & 4.45 & 4.6261 & TRN & \\
\hline CHEMBL1581590 & 688612 & 4.4 & 4.7095 & TST & \\
\hline CHEMBL1563569 & 688612 & 5.75 & 4.7055 & TRN & \\
\hline CHEMBL1377349 & 688612 & 4.3 & 4.6221 & TRN & \\
\hline CHEMBL3192475 & 688612 & 4.95 & 4.8056 & TRN & \\
\hline CHEMBL1340117 & 688612 & 5.45 & 4.7459 & TRN & \\
\hline CHEMBL1455911 & 688612 & 6.9 & 4.5962 & TRN & \\
\hline CHEMBL1564268 & 688612 & 5.45 & 4.691 & TRN & \\
\hline CHEMBL1476278 & 688612 & 5.25 & $4.6560 e$ & 0000000001 & TRN \\
\hline CHEMBL1343742 & 688612 & 4.1 & 4.7799 & TRN & \\
\hline CHEMBL1580329 & 688612 & 4.1 & 4.6251 & TRN & \\
\hline CHEMBL1583097 & 688612 & 4.05 & 4.5812 & TST & \\
\hline CHEMBL1392079 & 688612 & 4.65 & 4.6664 & TRN & \\
\hline CHEMBL1509643 & 688612 & 4.15 & 4.6543 & TRN & \\
\hline CHEMBL1419476 & 688612 & 4.5 & 4.7574 & TRN & \\
\hline CHEMBL3190905 & 688612 & 4.2 & 4.6645 & TRN & \\
\hline CHEMBL1601336 & 688612 & 4.3 & 4.673 & TRN & \\
\hline CHEMBL1300585 & 688612 & 4.0 & 4.6703 & TRN & \\
\hline CHEMBL1517598 & 688612 & 4.1 & 4.6525 & TRN & \\
\hline CHEMBL1437704 & 688612 & 4.75 & 4.6304 & TRN & \\
\hline CHEMBL1374373 & 688612 & 5.5 & 4.7053 & TST & \\
\hline CHEMBL1587239 & 688612 & 4.05 & 4.6488 & TST & \\
\hline CHEMBL1502537 & 688612 & 4.15 & 4.605 & TRN & \\
\hline CHEMBL1608221 & 688612 & 4.2 & 4.5377 & TRN & \\
\hline CHEMBL1445436 & 688612 & 4.1 & 4.6956 & TRN & \\
\hline CHEMBL1382030 & 688612 & 4.1 & 4.6002 & TRN & \\
\hline CHEMBL1599756 & 688612 & 4.05 & 4.6399 & TST & \\
\hline CHEMBL1557400 & 688612 & 6.1 & 4.6374 & TST & \\
\hline CHEMBL1503464 & 688612 & 4.1 & $4.6560 e$ & 2000000001 & TST \\
\hline CHEMBL1368934 & 688612 & 4.75 & 4.6099 & TRN & \\
\hline CHEMBL1511770 & 688612 & 4.4 & 4.686 & TST & \\
\hline CHEMBL1365118 & 688612 & 4.1 & 4.6645 & TRN & \\
\hline
\end{tabular}




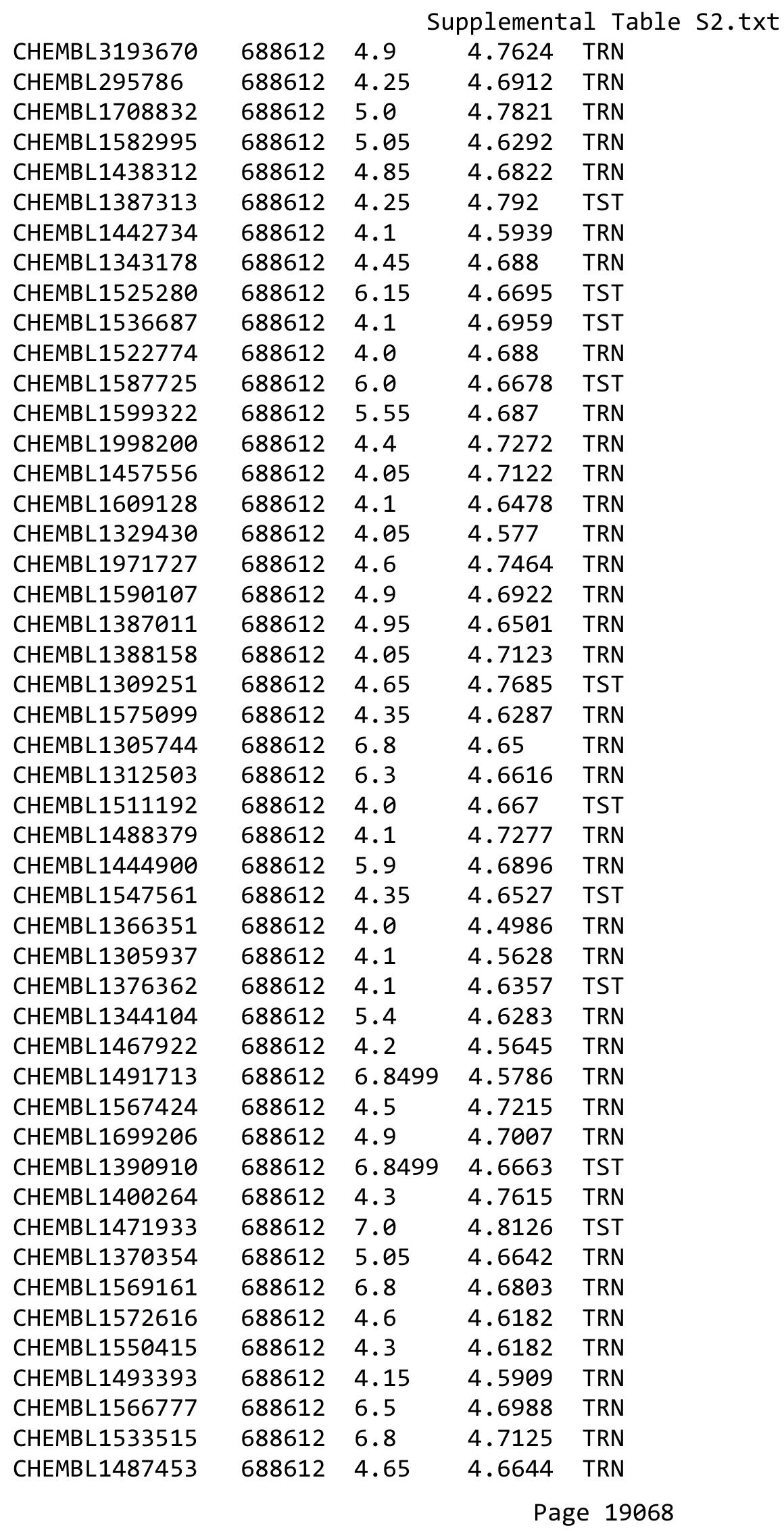




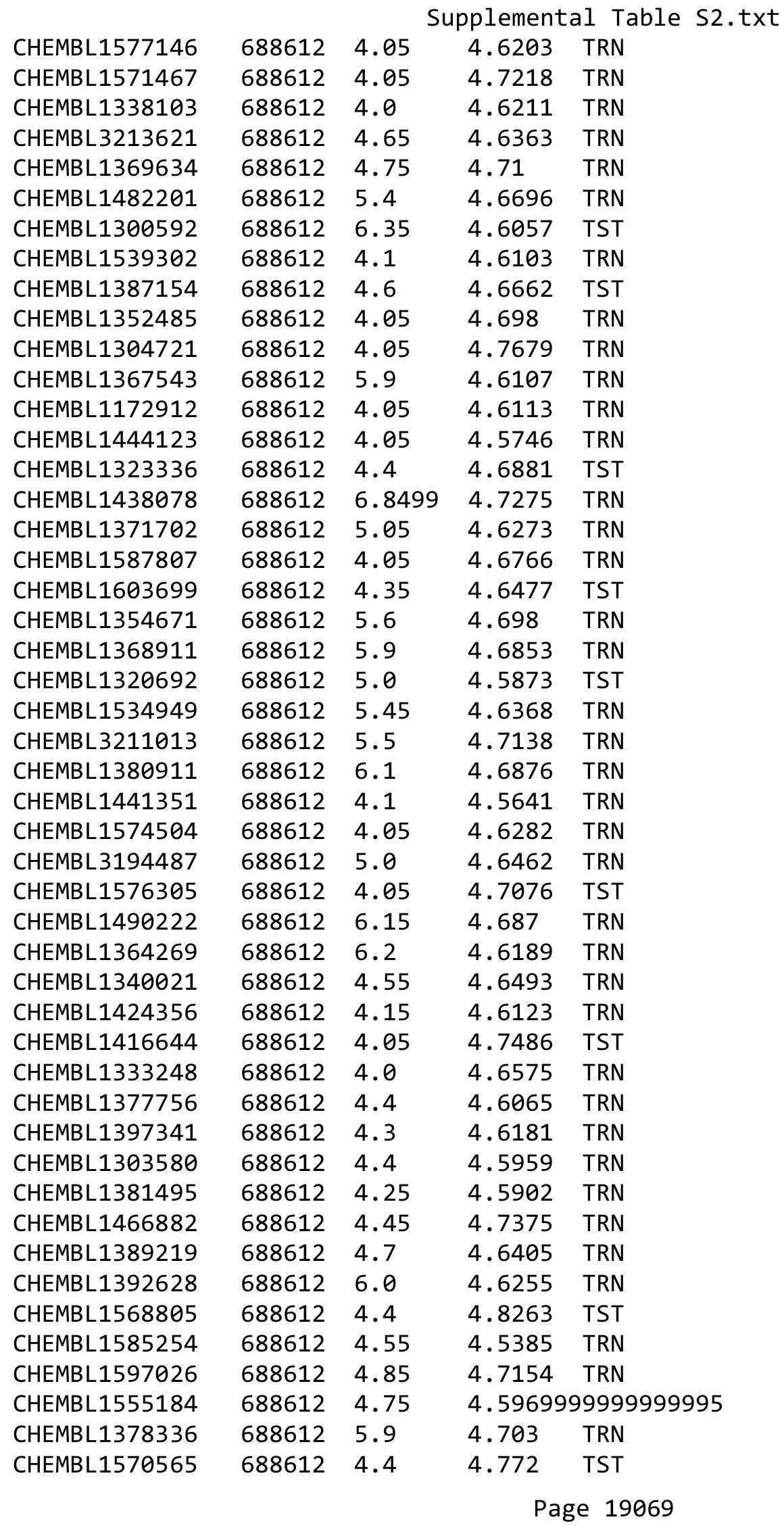

TRN 


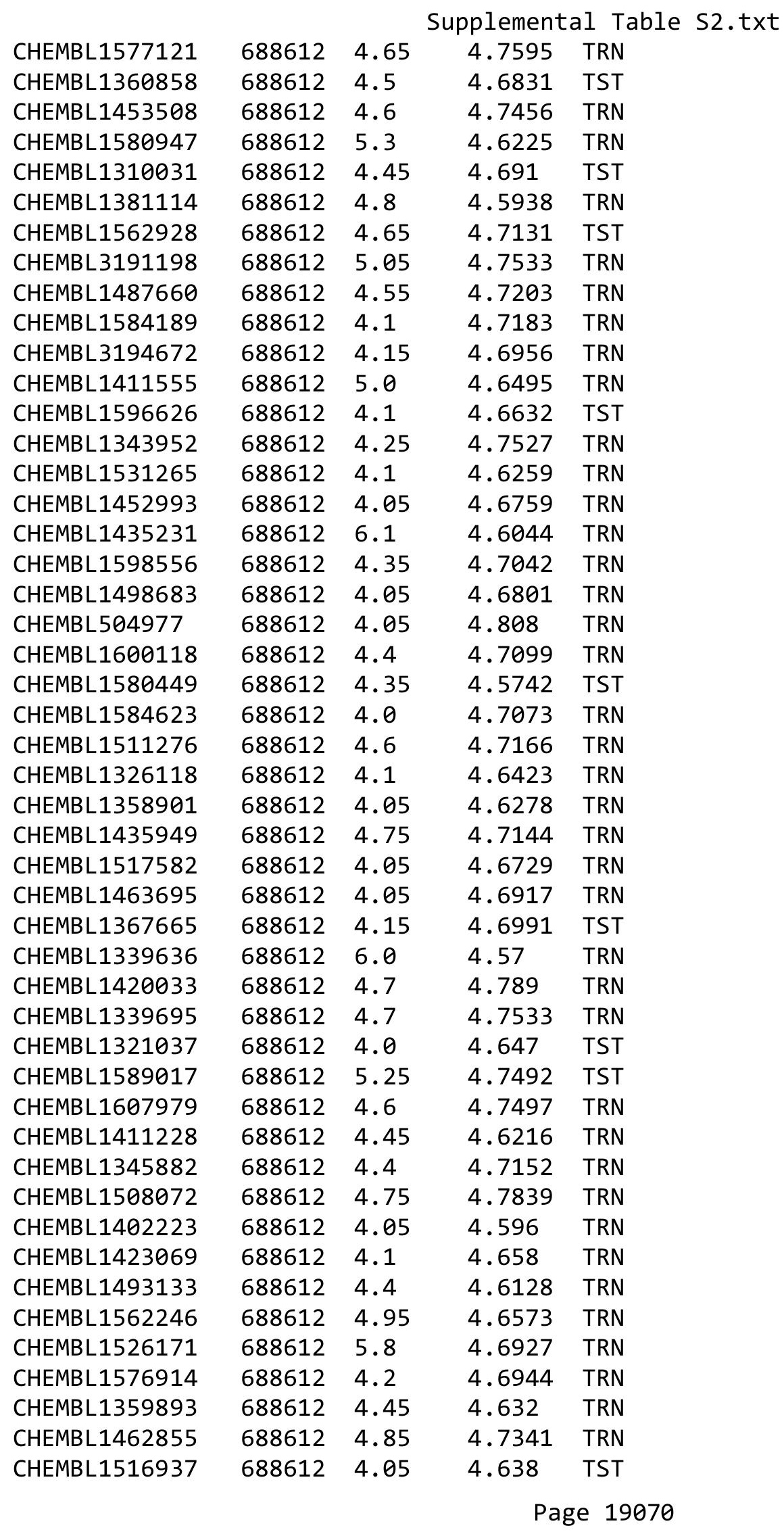




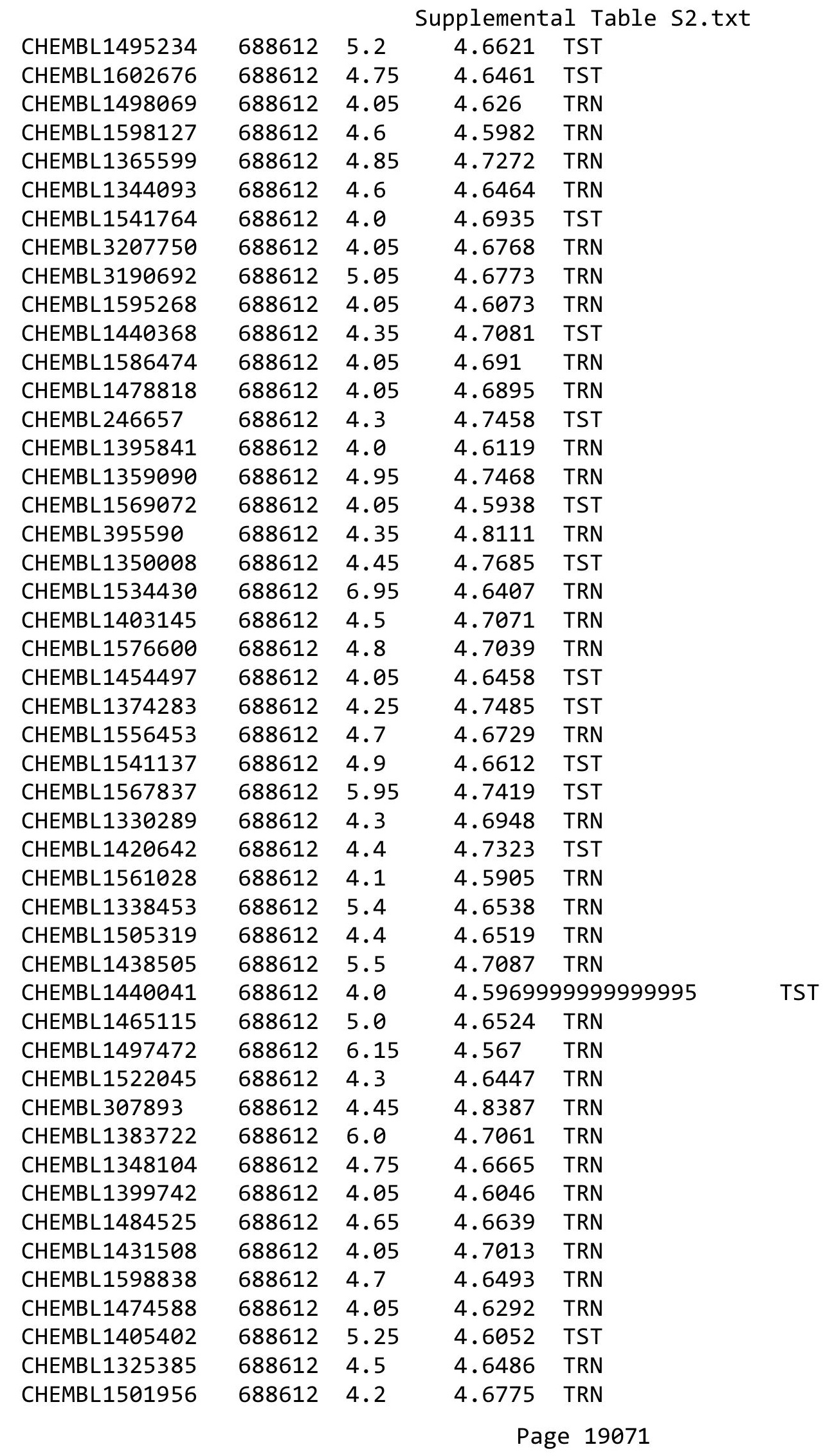




\begin{tabular}{|c|c|c|c|c|}
\hline \multicolumn{5}{|c|}{ Supplemental Table S2.txt } \\
\hline CHEMBL1423323 & 688612 & 4.45 & 4.6492 & TST \\
\hline CHEMBL1978479 & 688612 & 6.45 & $4.7360 e$ & 0000000001 \\
\hline CHEMBL1361025 & 688612 & 4.1 & 4.6297 & TRN \\
\hline CHEMBL 3194798 & 688612 & 4.2 & 4.5978 & TRN \\
\hline CHEMBL1381123 & 688612 & 4.25 & 4.6175 & TRN \\
\hline CHEMBL1512345 & 688612 & 4.25 & 4.7153 & TRN \\
\hline CHEMBL1527203 & 688612 & 4.4 & 4.5896 & TRN \\
\hline CHEMBL1554263 & 688612 & 4.1 & 4.5951 & TRN \\
\hline CHEMBL1459366 & 688612 & 4.05 & 4.5587 & TRN \\
\hline CHEMBL1496156 & 688612 & 4.0 & 4.7425 & TRN \\
\hline CHEMBL1894168 & 688612 & 5.1 & 4.688 & TRN \\
\hline CHEMBL 3197204 & 688612 & 4.05 & 4.6819 & TST \\
\hline CHEMBL1453528 & 688612 & 4.2 & 4.6057 & TRN \\
\hline CHEMBL1597463 & 688612 & 4.1 & 4.6404 & TRN \\
\hline CHEMBL1350188 & 688612 & 5.85 & 4.694 & TST \\
\hline CHEMBL1340059 & 688612 & 4.7 & 4.6487 & TRN \\
\hline CHEMBL1595952 & 688612 & 4.35 & 4.6627 & TRN \\
\hline CHEMBL1337197 & 688612 & 4.1 & 4.6634 & TRN \\
\hline CHEMBL1567910 & 688612 & 4.0 & 4.7217 & TST \\
\hline CHEMBL1445600 & 688612 & 4.1 & 4.7035 & TRN \\
\hline CHEMBL1380010 & 688612 & 5.7 & 4.6283 & TRN \\
\hline CHEMBL1575138 & 688612 & 4.4 & 4.6684 & TRN \\
\hline CHEMBL1511609 & 688612 & 4.05 & 4.6705 & TST \\
\hline CHEMBL1495805 & 688612 & 4.55 & 4.7407 & TRN \\
\hline CHEMBL 1481716 & 688612 & 5.5 & 4.7307 & TRN \\
\hline CHEMBL578716 & 688612 & 4.3 & 4.7417 & TST \\
\hline CHEMBL1435728 & 688612 & 4.0 & 4.6095 & TRN \\
\hline CHEMBL1461270 & 688612 & 5.0 & 4.6077 & TRN \\
\hline CHEMBL1581320 & 688612 & 4.4 & 4.7326 & TRN \\
\hline CHEMBL 1403154 & 688612 & 6.15 & 4.6691 & TST \\
\hline CHEMBL1478969 & 688612 & 4.85 & 4.6537 & TRN \\
\hline CHEMBL3197576 & 688612 & 4.4 & 4.6902 & TRN \\
\hline CHEMBL1404686 & 688612 & 4.6 & 4.6926 & TRN \\
\hline CHEMBL1343046 & 688612 & 4.1 & 4.6923 & TST \\
\hline CHEMBL1310970 & 688612 & 4.7 & 4.6212 & TRN \\
\hline CHEMBL1513100 & 688612 & 4.35 & 4.5741 & TRN \\
\hline CHEMBL1612668 & 688612 & 5.1 & 4.5981 & TRN \\
\hline CHEMBL1531788 & 688612 & 4.55 & 4.6445 & TRN \\
\hline CHEMBL1397747 & 688612 & 4.9 & 4.6409 & TRN \\
\hline CHEMBL1545065 & 688612 & 4.75 & 4.6673 & TRN \\
\hline CHEMBL1528194 & 688612 & 4.5 & 4.6846 & TRN \\
\hline CHEMBL1467855 & 688612 & 4.05 & 4.6075 & TST \\
\hline CHEMBL1524394 & 688612 & 4.6 & 4.635 & TRN \\
\hline CHEMBL1539004 & 688612 & 5.65 & 4.7235 & TRN \\
\hline CHEMBL1611962 & 688612 & 5.2 & 4.6426 & TRN \\
\hline CHEMBL1433382 & 688612 & 4.0 & 4.6386 & TRN \\
\hline CHEMBL1470034 & 688612 & 4.0 & 4.6357 & TRN \\
\hline CHEMBL1561238 & 688612 & 4.2 & 4.6131 & TRN \\
\hline
\end{tabular}




\begin{tabular}{|c|c|c|c|c|c|}
\hline \multicolumn{6}{|c|}{ Supplemental Table s2.txt } \\
\hline CHEMBL1419609 & 688612 & 4.7 & 4.6846 & TRN & \\
\hline CHEMBL492193 & 688612 & 4.8 & 4.715 & TST & \\
\hline CHEMBL1578578 & 688612 & 4.65 & 4.6768 & TRN & \\
\hline CHEMBL1442855 & 688612 & 4.65 & 4.6724 & TRN & \\
\hline CHEMBL1425650 & 688612 & 4.05 & 4.6281 & TRN & \\
\hline CHEMBL1309632 & 688612 & 4.45 & 4.7653 & TST & \\
\hline CHEMBL1966952 & 688612 & 4.8 & 4.7006 & TRN & \\
\hline CHEMBL1384371 & 688612 & 7.0 & 4.6191 & TST & \\
\hline CHEMBL1479146 & 688612 & 6.0 & \multicolumn{2}{|c|}{4.6610000000000005} & TRN \\
\hline CHEMBL1382732 & 688612 & 4.15 & 4.5617 & TRN & \\
\hline CHEMBL1551282 & 688612 & 4.9 & 4.6161 & TRN & \\
\hline CHEMBL1526821 & 688612 & 5.95 & 4.613 & TRN & \\
\hline CHEMBL1494814 & 688612 & 4.75 & 4.6487 & TRN & \\
\hline CHEMBL 250450 & 688612 & 6.0 & 4.8752 & TRN & \\
\hline CHEMBL1479571 & 688612 & 4.6 & 4.6367 & TRN & \\
\hline CHEMBL1572723 & 688612 & 4.05 & 4.5915 & TST & \\
\hline CHEMBL1411383 & 688612 & 6.0 & 4.6222 & TRN & \\
\hline CHEMBL1472364 & 688612 & 4.45 & 4.6184 & TRN & \\
\hline CHEMBL1613285 & 688612 & 4.95 & 4.7043 & TRN & \\
\hline CHEMBL1550445 & 688612 & 4.8 & 4.798 & TRN & \\
\hline CHEMBL1458386 & 688612 & 6.3 & 4.6528 & TST & \\
\hline CHEMBL1442102 & 688612 & 4.4 & 4.6896 & TRN & \\
\hline CHEMBL1566523 & 688612 & 4.65 & 4.7637 & TRN & \\
\hline CHEMBL1598946 & 688612 & 4.65 & 4.7211 & TRN & \\
\hline CHEMBL1508086 & 688612 & 4.1 & 4.797 & TST & \\
\hline CHEMBL3212910 & 688612 & 4.0 & 4.7082 & TST & \\
\hline CHEMBL1331192 & 688612 & 4.95 & 4.6815 & TRN & \\
\hline CHEMBL1415659 & 688612 & 4.05 & 4.6875 & TRN & \\
\hline CHEMBL1595023 & 688612 & 4.4 & 4.6203 & TRN & \\
\hline CHEMBL1544074 & 688612 & 4.4 & 4.6754 & TRN & \\
\hline CHEMBL1344496 & 688612 & 4.1 & 4.6748 & TRN & \\
\hline CHEMBL1609842 & 688612 & 4.75 & 4.6697 & TRN & \\
\hline CHEMBL1498655 & 688612 & 4.4 & 4.6646 & TST & \\
\hline CHEMBL1526270 & 688612 & 4.4 & 4.7768 & TST & \\
\hline CHEMBL1305101 & 688612 & 4.0 & 4.6089 & TST & \\
\hline CHEMBL1335525 & 688612 & 4.25 & $4.6160 e$ & 00000000005 & TRN \\
\hline CHEMBL1485671 & 688612 & 4.7 & 4.6649 & TRN & \\
\hline CHEMBL3209355 & 688612 & 5.05 & 4.6482 & TRN & \\
\hline CHEMBL1358343 & 688612 & 4.05 & 4.4996 & TRN & \\
\hline CHEMBL30707 & 688612 & 4.45 & 4.8184 & TST & \\
\hline CHEMBL1448159 & 688612 & 4.05 & 4.5973 & TRN & \\
\hline CHEMBL1570554 & 688612 & 4.4 & 4.6995 & TST & \\
\hline CHEMBL1442811 & 688612 & 7.0 & 4.6963 & TRN & \\
\hline CHEMBL1450078 & 688612 & 4.95 & 4.6608 & TRN & \\
\hline CHEMBL3190020 & 688612 & 4.4 & 4.7946 & TRN & \\
\hline CHEMBL1467962 & 688612 & 4.0 & 4.6531 & TST & \\
\hline CHEMBL1496594 & 688612 & 4.4 & 4.7232 & TRN & \\
\hline CHEMBL1447576 & 688612 & 4.1 & 4.5885 & TRN & \\
\hline
\end{tabular}




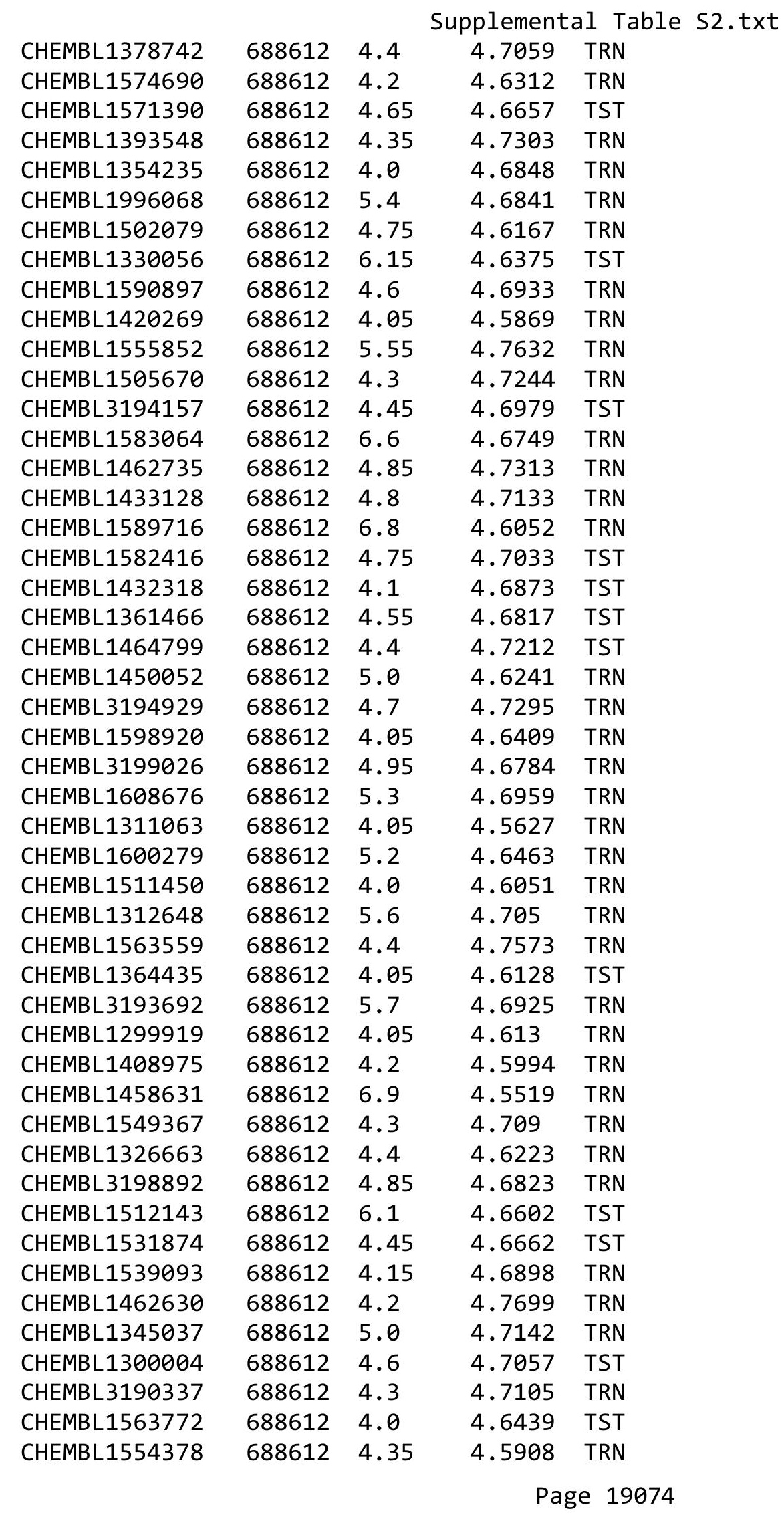




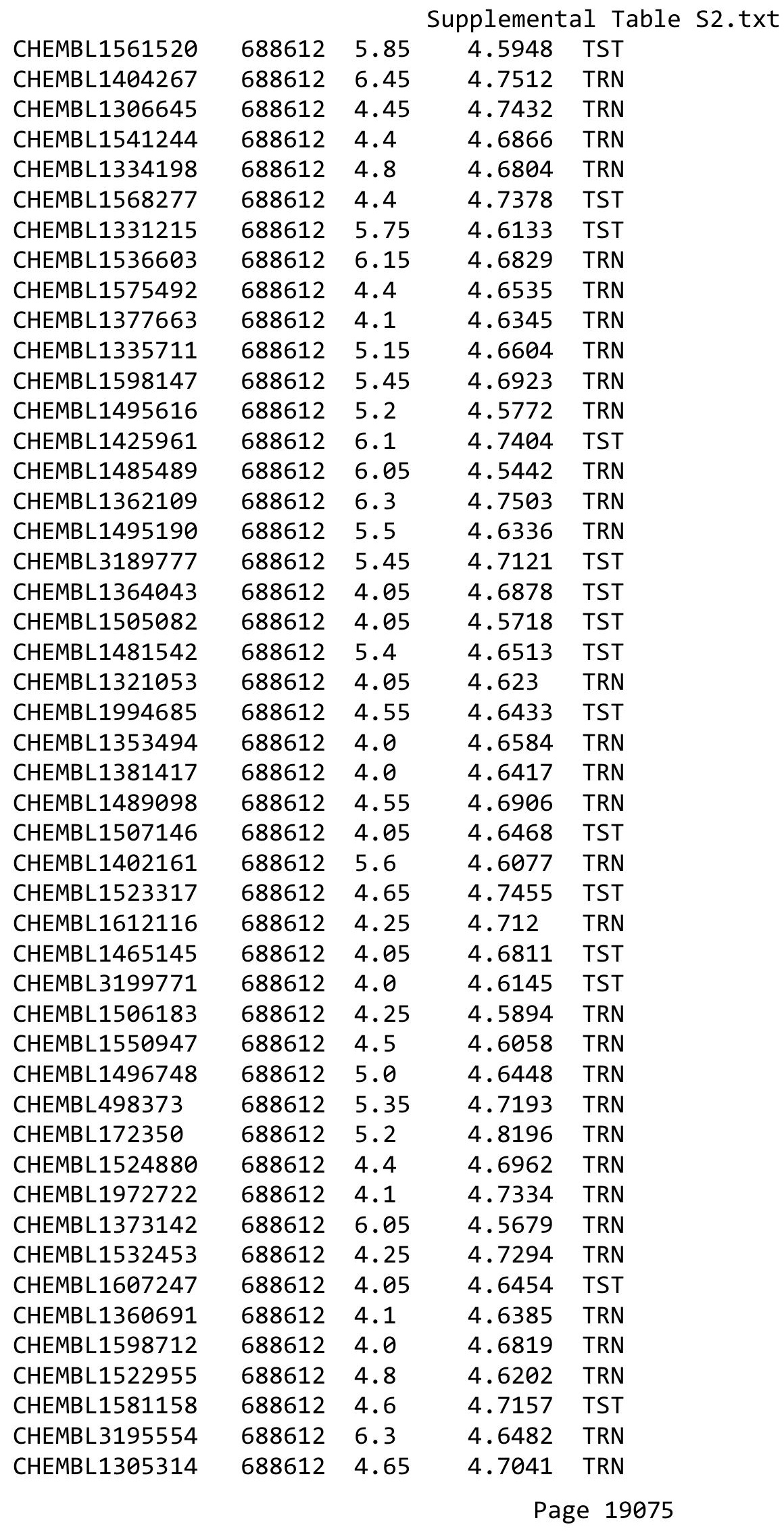




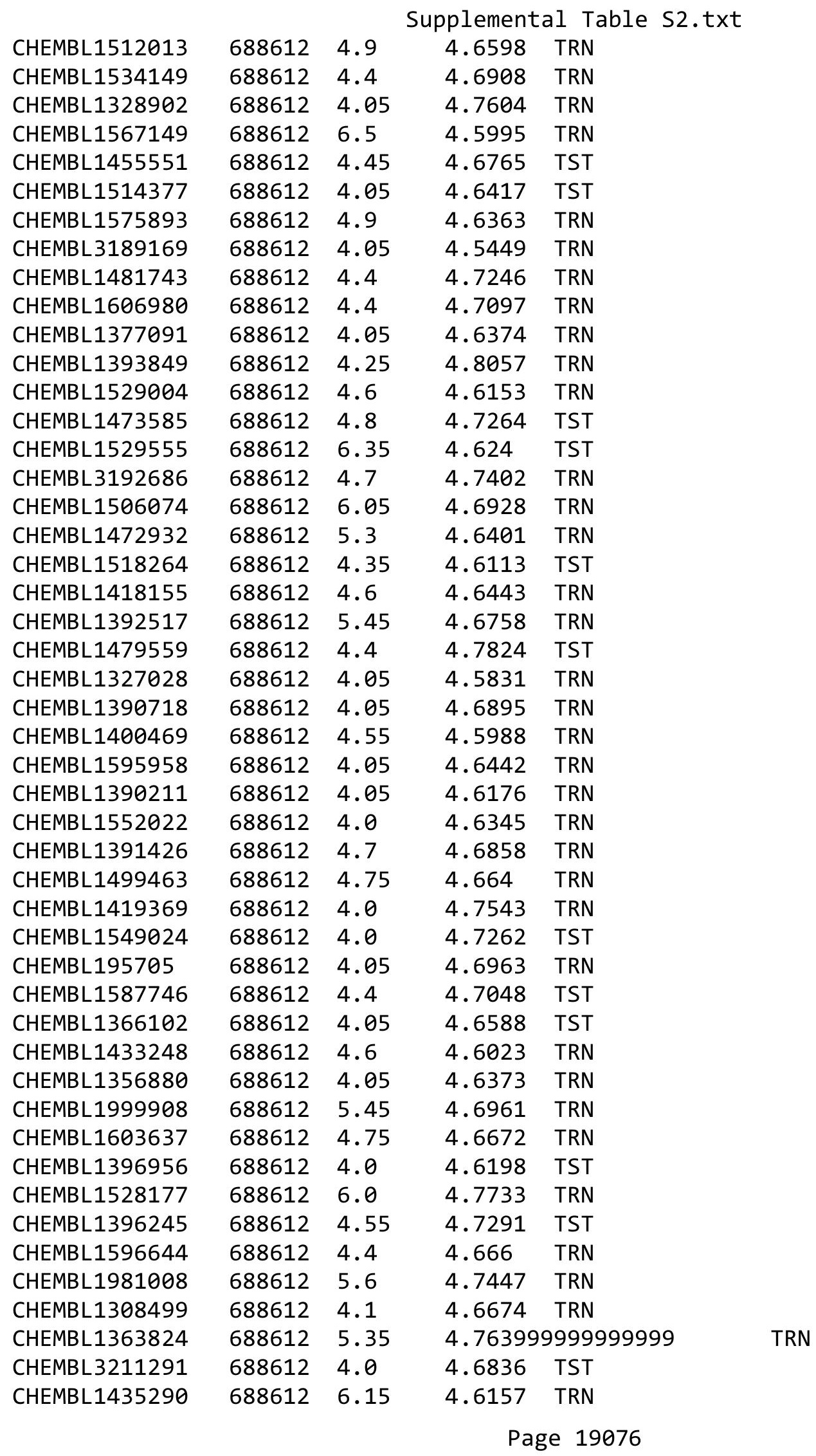




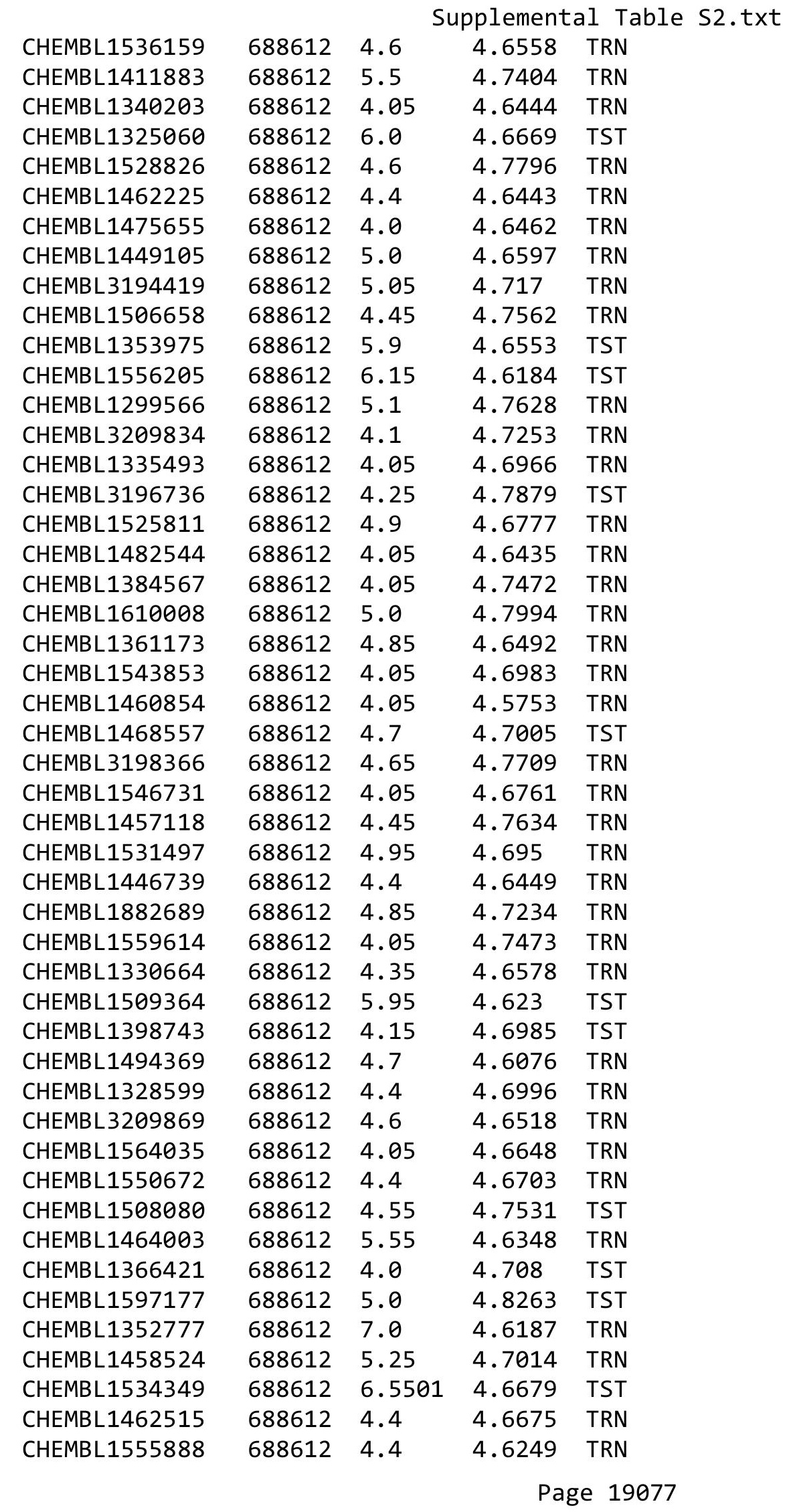




\begin{tabular}{|c|c|c|c|c|}
\hline \multicolumn{5}{|c|}{ Supplemental Table S2.txt } \\
\hline CHEMBL1372404 & 688612 & 4.9 & 4.6206 & TRN \\
\hline CHEMBL3196005 & 688612 & 4.2 & 4.631 & TST \\
\hline CHEMBL1342723 & 688612 & 6.0 & 4.731 & TRN \\
\hline CHEMBL1520859 & 688612 & 6.05 & 4.6654 & TRN \\
\hline CHEMBL1302385 & 688612 & 4.0 & 4.6611 & TRN \\
\hline CHEMBL1474754 & 688612 & 4.2 & 4.6395 & TRN \\
\hline CHEMBL1556492 & 688612 & 5.45 & 4.6348 & TRN \\
\hline CHEMBL1568866 & 688612 & 5.8 & 4.6329 & TRN \\
\hline CHEMBL1332109 & 688612 & 5.5 & 4.6737 & TRN \\
\hline CHEMBL1378061 & 688612 & 6.9 & 4.703 & TST \\
\hline CHEMBL1347186 & 688612 & 5.85 & 4.7024 & TRN \\
\hline CHEMBL1489720 & 688612 & 4.0 & 4.65 & TST \\
\hline CHEMBL1405704 & 688612 & 5.3 & 4.6357 & TRN \\
\hline CHEMBL1340125 & 688612 & 4.45 & 4.7006 & TST \\
\hline CHEMBL1332482 & 688612 & 5.1 & 4.6194 & TRN \\
\hline CHEMBL1428537 & 688612 & 6.8499 & 4.6507 & TRN \\
\hline CHEMBL1964407 & 688612 & 4.45 & 4.6893 & TST \\
\hline CHEMBL1331950 & 688612 & 4.0 & 4.5877 & TRN \\
\hline CHEMBL1359647 & 688612 & 4.05 & 4.6628 & TRN \\
\hline CHEMBL1463326 & 688612 & 4.55 & 4.687 & TRN \\
\hline CHEMBL1999069 & 688612 & 4.05 & 4.7335 & TRN \\
\hline CHEMBL1599175 & 688612 & 4.7 & 4.796 & TRN \\
\hline CHEMBL1342821 & 688612 & 4.8 & 4.7883 & TRN \\
\hline CHEMBL1543099 & 688612 & 6.15 & 4.6343 & TRN \\
\hline CHEMBL1319258 & 688612 & 4.35 & 4.7277 & TRN \\
\hline CHEMBL1576442 & 688612 & 4.0 & 4.5662 & TRN \\
\hline CHEMBL1502484 & 688612 & 4.4 & 4.6922 & TRN \\
\hline CHEMBL1494628 & 688612 & 4.3 & 4.7545 & TRN \\
\hline CHEMBL1596515 & 688612 & 4.05 & 4.6481 & TST \\
\hline CHEMBL1348636 & 688612 & 4.4 & 4.6182 & TRN \\
\hline CHEMBL1364557 & 688612 & 5.3 & 4.6658 & TRN \\
\hline CHEMBL1603640 & 688612 & 4.5 & 4.6757 & TRN \\
\hline CHEMBL1541032 & 688612 & 4.05 & 4.6894 & TST \\
\hline CHEMBL1420978 & 688612 & 4.05 & 4.6807 & TRN \\
\hline CHEMBL1469912 & 688612 & 4.2 & 4.6808 & TRN \\
\hline CHEMBL1305825 & 688612 & 4.3 & 4.6571 & TRN \\
\hline CHEMBL3192697 & 688612 & 4.65 & 4.7163 & TRN \\
\hline CHEMBL1376723 & 688612 & 4.95 & 4.845 & TST \\
\hline CHEMBL1597856 & 688612 & 4.05 & 4.6972 & TST \\
\hline CHEMBL1399429 & 688612 & 4.05 & 4.6352 & TRN \\
\hline CHEMBL1299856 & 688612 & 4.5 & 4.672 & TST \\
\hline CHEMBL1565207 & 688612 & 4.0 & 4.7164 & TST \\
\hline CHEMBL1321332 & 688612 & 4.1 & 4.7195 & TRN \\
\hline CHEMBL1430973 & 688612 & 6.5501 & 4.5801 & TRN \\
\hline CHEMBL1363146 & 688612 & 4.4 & 4.6589 & TST \\
\hline CHEMBL1597146 & 688612 & 4.05 & 4.761 & TRN \\
\hline CHEMBL1468323 & 688612 & 4.65 & 4.6574 & TRN \\
\hline CHEMBL1451969 & 688612 & 6.1 & 4.7402 & TRN \\
\hline
\end{tabular}




\begin{tabular}{|c|c|c|c|c|c|}
\hline \multicolumn{6}{|c|}{ Supplemental Table S2.txt } \\
\hline CHEMBL1338266 & 688612 & 4.4 & 4.7218 & TRN & \\
\hline CHEMBL1310635 & 688612 & 5.5 & 4.5394 & TRN & \\
\hline CHEMBL1603005 & 688612 & 5.25 & 4.7184 & TRN & \\
\hline CHEMBL1453559 & 688612 & 4.55 & 4.6296 & TRN & \\
\hline CHEMBL1541409 & 688612 & 4.2 & 4.6018 & TRN & \\
\hline CHEMBL1522075 & 688612 & 4.05 & 4.7497 & TST & \\
\hline CHEMBL1533003 & 688612 & 4.05 & 4.7679 & TST & \\
\hline CHEMBL3199850 & 688612 & 4.65 & 4.6126 & TST & \\
\hline CHEMBL1532558 & 688612 & 5.2 & 4.6746 & TRN & \\
\hline CHEMBL1312152 & 688612 & 4.4 & 4.6704 & TRN & \\
\hline CHEMBL1552751 & 688612 & 4.75 & 4.562 & TRN & \\
\hline CHEMBL1586630 & 688612 & 4.55 & 4.7538 & TRN & \\
\hline CHEMBL1369402 & 688612 & 5.0 & 4.7066 & TRN & \\
\hline CHEMBL1397389 & 688612 & 6.8499 & 4.5713 & TRN & \\
\hline CHEMBL1303604 & 688612 & 4.45 & 4.7334 & TRN & \\
\hline CHEMBL1978383 & 688612 & 4.0 & 4.7084 & TST & \\
\hline CHEMBL1350028 & 688612 & 4.95 & 4.7262 & TRN & \\
\hline CHEMBL1304024 & 688612 & 5.5 & 4.7486 & TST & \\
\hline CHEMBL2374030 & 688612 & 5.0 & 4.7953 & TRN & \\
\hline CHEMBL1570278 & 688612 & 5.85 & 4.6784 & TRN & \\
\hline CHEMBL1393167 & 688612 & 4.9 & 4.6662 & TRN & \\
\hline CHEMBL1428783 & 688612 & 4.4 & 4.6745 & TRN & \\
\hline CHEMBL1480762 & 688612 & 4.4 & 4.6372 & TST & \\
\hline CHEMBL3198723 & 688612 & 5.95 & 4.7338 & TRN & \\
\hline CHEMBL1321228 & 688612 & 4.95 & 4.6941 & TRN & \\
\hline CHEMBL1566610 & 688612 & 4.7 & 4.742 & TRN & \\
\hline CHEMBL1560629 & 688612 & 5.0 & 4.7201 & TRN & \\
\hline CHEMBL1531774 & 688612 & 4.25 & 4.7068 & TRN & \\
\hline CHEMBL1527663 & 688612 & 4.65 & 4.6135 & TRN & \\
\hline CHEMBL1403961 & 688612 & 4.1 & 4.6608 & TST & \\
\hline CHEMBL1327760 & 688612 & 4.0 & 4.6459 & TRN & \\
\hline CHEMBL1333909 & 688612 & 4.05 & 4.6814 & TRN & \\
\hline CHEMBL1536122 & 688612 & 4.6 & 4.72199 & 99999999995 & TRN \\
\hline CHEMBL1423391 & 688612 & 4.55 & 4.6143 & TRN & \\
\hline CHEMBL1405129 & 688612 & 4.0 & 4.6405 & TRN & \\
\hline CHEMBL1588073 & 688612 & 6.15 & 4.6557 & TRN & \\
\hline CHEMBL1485280 & 688612 & 4.85 & 4.671 & TRN & \\
\hline CHEMBL1472938 & 688612 & 4.05 & 4.6048 & TST & \\
\hline CHEMBL1399653 & 688612 & 4.4 & 4.7104 & TRN & \\
\hline CHEMBL1611388 & 688612 & 4.0 & 4.5996 & TRN & \\
\hline CHEMBL3208179 & 688612 & 4.1 & 4.6441 & TRN & \\
\hline CHEMBL 297323 & 688612 & 4.1 & 4.6686 & TRN & \\
\hline CHEMBL3192831 & 688612 & 5.6 & 4.7444 & TRN & \\
\hline CHEMBL1578728 & 688612 & 5.05 & 4.676 & TST & \\
\hline CHEMBL1438650 & 688612 & 5.0 & 4.5653 & TRN & \\
\hline CHEMBL1409096 & 688612 & 6.0 & 4.6227 & TRN & \\
\hline CHEMBL1613444 & 688612 & 4.1 & 4.7102 & TRN & \\
\hline CHEMBL1459591 & 688612 & 4.0 & 4.662 & TRN & \\
\hline
\end{tabular}




\begin{tabular}{|c|c|c|c|c|c|}
\hline \multicolumn{6}{|c|}{ Supplemental Table S2.txt } \\
\hline CHEMBL1552723 & 688612 & 4.6 & 4.7011 & TRN & \\
\hline CHEMBL1449742 & 688612 & 4.45 & 4.6721 & TST & \\
\hline CHEMBL1462826 & 688612 & 4.0 & 4.7214 & TST & \\
\hline CHEMBL1602360 & 688612 & 4.45 & 4.6348 & TRN & \\
\hline CHEMBL1499718 & 688612 & 4.4 & 4.7144 & TRN & \\
\hline CHEMBL1533540 & 688612 & 4.05 & 4.5622 & TRN & \\
\hline CHEMBL1350147 & 688612 & 4.05 & 4.6998 & TRN & \\
\hline CHEMBL1611106 & 688612 & 4.4 & 4.7774 & TST & \\
\hline CHEMBL1454704 & 688612 & 6.8499 & 4.6463 & TRN & \\
\hline CHEMBL1480190 & 688612 & 6.5 & 4.7174 & TRN & \\
\hline CHEMBL1553974 & 688612 & 4.45 & 4.7769 & TRN & \\
\hline CHEMBL1320230 & 688612 & 5.95 & 4.8192 & TRN & \\
\hline CHEMBL1313127 & 688612 & 4.95 & 4.7585 & TRN & \\
\hline CHEMBL 1376772 & 688612 & 4.8 & 4.6778 & TRN & \\
\hline CHEMBL1378760 & 688612 & 4.05 & 4.6107 & TRN & \\
\hline CHEMBL1568494 & 688612 & 4.0 & 4.6193 & TRN & \\
\hline CHEMBL1447245 & 688612 & 4.25 & 4.7771 & TST & \\
\hline CHEMBL1534561 & 688612 & 4.1 & 4.7089 & TRN & \\
\hline CHEMBL1601867 & 688612 & 4.05 & 4.7039 & TST & \\
\hline CHEMBL1327274 & 688612 & 4.4 & 4.7205 & TRN & \\
\hline CHEMBL1609515 & 688612 & 4.05 & 4.64199 & 99999999995 & TRN \\
\hline CHEMBL1554627 & 688612 & 6.2 & 4.5835 & TRN & \\
\hline CHEMBL1545093 & 688612 & 4.1 & 4.7443 & TRN & \\
\hline CHEMBL1374529 & 688612 & 4.3 & 4.5762 & TRN & \\
\hline CHEMBL1557115 & 688612 & 4.9 & 4.7063 & TRN & \\
\hline CHEMBL1366536 & 688612 & 4.1 & 4.5999 & TRN & \\
\hline CHEMBL1449251 & 688612 & 4.1 & 4.6169 & TRN & \\
\hline CHEMBL1329271 & 688612 & 4.95 & 4.613 & TRN & \\
\hline CHEMBL1369618 & 688612 & 4.3 & 4.7255 & TRN & \\
\hline CHEMBL3208684 & 688612 & 6.15 & 4.7109 & TRN & \\
\hline CHEMBL1301275 & 688612 & 4.4 & 4.7082 & TST & \\
\hline CHEMBL1367590 & 688612 & 4.75 & 4.6515 & TRN & \\
\hline CHEMBL1303204 & 688612 & 4.4 & 4.6142 & TRN & \\
\hline CHEMBL1441888 & 688612 & 4.0 & 4.6412 & TRN & \\
\hline CHEMBL1547860 & 688612 & 5.55 & 4.6005 & TST & \\
\hline CHEMBL1419900 & 688612 & 5.0 & 4.6379 & TRN & \\
\hline CHEMBL1371584 & 688612 & 4.05 & 4.5971 & TRN & \\
\hline CHEMBL1318014 & 688612 & 4.6 & 4.6339 & TRN & \\
\hline CHEMBL1372345 & 688612 & 4.65 & 4.69 & TST & \\
\hline CHEMBL3197824 & 688612 & 4.5 & 4.7141 & TRN & \\
\hline CHEMBL1303693 & 688612 & 4.1 & 4.5764 & TRN & \\
\hline CHEMBL1446882 & 688612 & 4.4 & 4.618 & TRN & \\
\hline CHEMBL1471827 & 688612 & 4.55 & 4.6795 & TRN & \\
\hline CHEMBL1328361 & 688612 & 4.75 & 4.7175 & TST & \\
\hline CHEMBL1608053 & 688612 & 4.1 & 4.5601 & TRN & \\
\hline CHEMBL1548087 & 688612 & 4.65 & 4.5989 & TRN & \\
\hline CHEMBL1465092 & 688612 & 5.05 & 4.598 & TRN & \\
\hline CHEMBL1598935 & 688612 & 4.35 & 4.7381 & TRN & \\
\hline
\end{tabular}




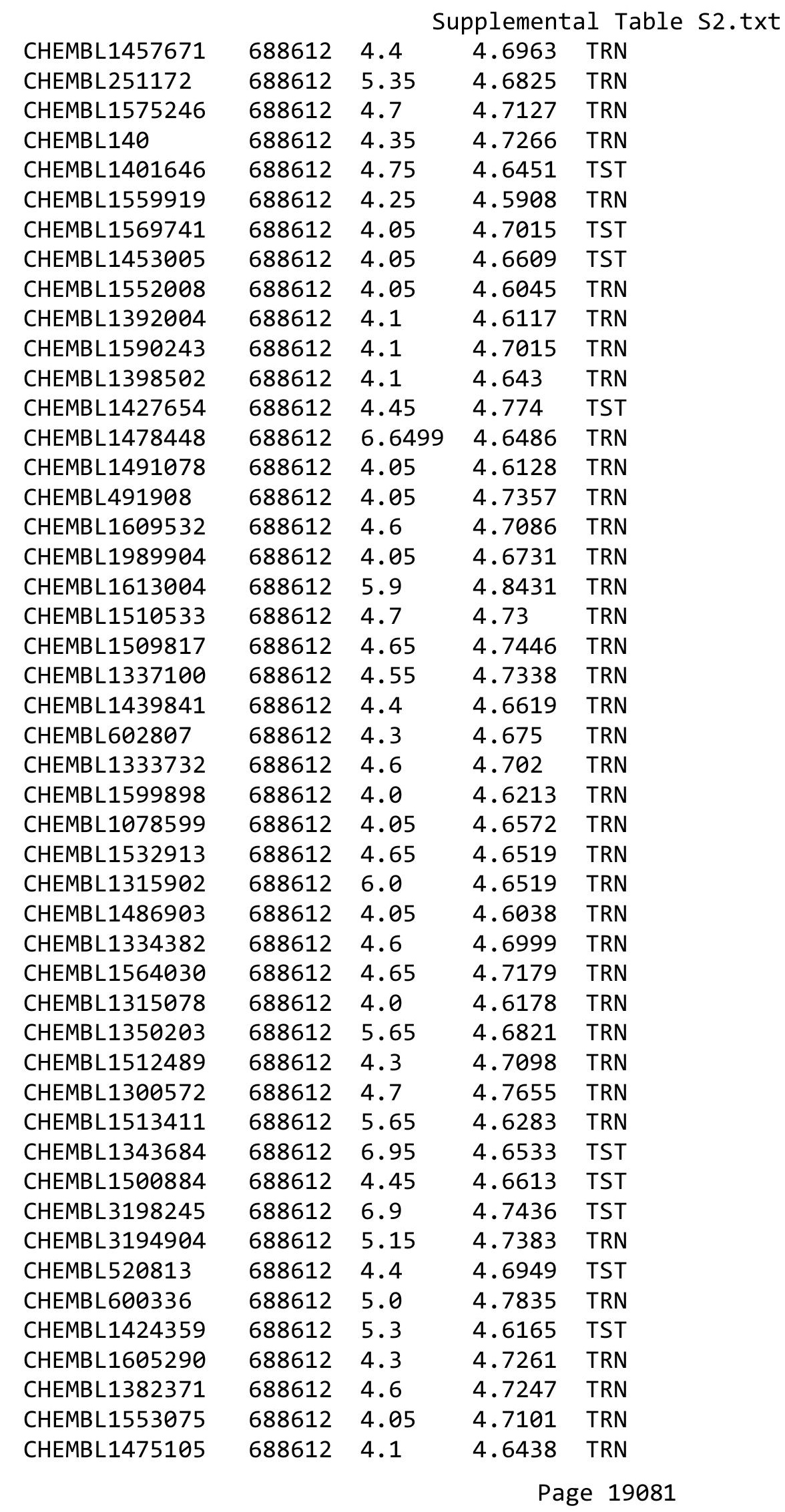




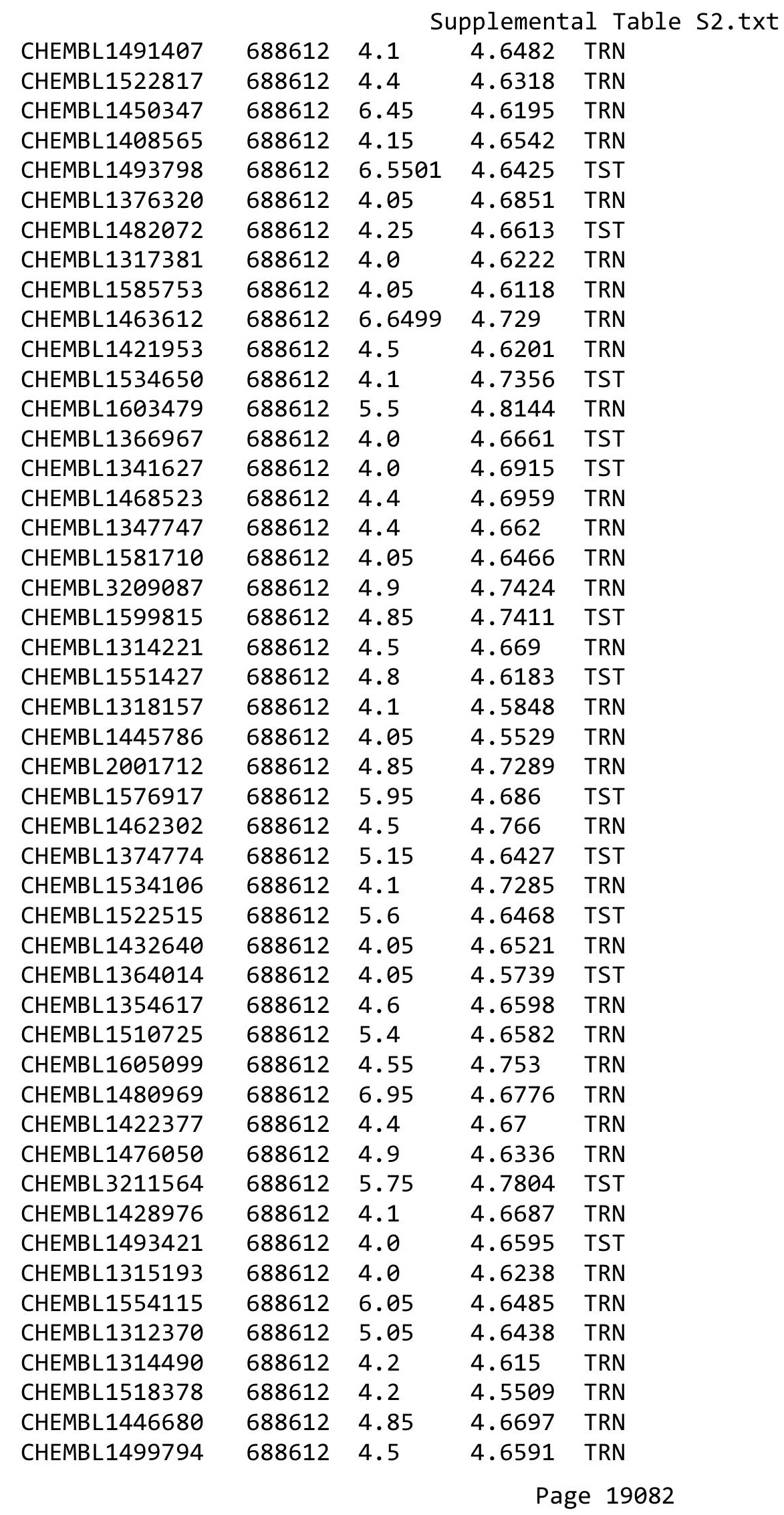




\begin{tabular}{|c|c|c|c|c|c|}
\hline \multicolumn{6}{|c|}{ Supplemental Table S2.txt } \\
\hline CHEMBL1969704 & 688612 & 4.45 & 4.6969 & TST & \\
\hline CHEMBL1602581 & 688612 & 5.05 & 4.6801 & TST & \\
\hline CHEMBL1080505 & 688612 & 4.55 & 4.6025 & TRN & \\
\hline CHEMBL1438824 & 688612 & 4.35 & 4.6561 & TST & \\
\hline CHEMBL1460721 & 688612 & 4.65 & 4.7031 & TRN & \\
\hline CHEMBL1368503 & 688612 & 4.05 & 4.6643 & TST & \\
\hline CHEMBL1451192 & 688612 & 6.8499 & 4.6592 & TRN & \\
\hline CHEMBL1558369 & 688612 & 4.65 & 4.6396 & TST & \\
\hline CHEMBL1502084 & 688612 & 4.2 & 4.5626 & TRN & \\
\hline CHEMBL1325172 & 688612 & 4.05 & 4.6866 & TST & \\
\hline CHEMBL1990081 & 688612 & 4.7 & 4.6427 & TRN & \\
\hline CHEMBL1609172 & 688612 & 4.3 & 4.7149 & TST & \\
\hline CHEMBL1533846 & 688612 & 6.0 & 4.6795 & TRN & \\
\hline CHEMBL1518953 & 688612 & 4.4 & 4.6022 & TST & \\
\hline CHEMBL1457977 & 688612 & 4.05 & 4.6182 & TRN & \\
\hline CHEMBL1558563 & 688612 & 4.7 & 4.7508 & TST & \\
\hline CHEMBL1564528 & 688612 & 4.5 & 4.666 & TRN & \\
\hline CHEMBL1382501 & 688612 & 6.15 & 4.5961 & TST & \\
\hline CHEMBL 3208264 & 688612 & 4.1 & 4.664 & TRN & \\
\hline CHEMBL1527700 & 688612 & 4.05 & 4.687 & TST & \\
\hline CHEMBL1430546 & 688612 & 4.0 & 4.6637 & TST & \\
\hline CHEMBL486706 & 688612 & 4.65 & 4.6211 & TRN & \\
\hline CHEMBL1333010 & 688612 & 4.3 & 4.8096 & TRN & \\
\hline CHEMBL1455876 & 688612 & 4.0 & 4.6605 & TRN & \\
\hline CHEMBL1372621 & 688612 & 4.05 & 4.676 & TST & \\
\hline CHEMBL395808 & 688612 & 4.75 & 4.7688 & TRN & \\
\hline CHEMBL1355415 & 688612 & 4.55 & 4.6559 & TRN & \\
\hline CHEMBL1409564 & 688612 & 5.0 & 4.6815 & TST & \\
\hline CHEMBL1603750 & 688612 & 4.3 & 4.708 & TRN & \\
\hline CHEMBL1423284 & 688612 & 4.4 & 4.6754 & TRN & \\
\hline CHEMBL1530402 & 688612 & 5.15 & 4.8026 & TRN & \\
\hline CHEMBL1440505 & 688612 & 4.85 & 4.6872 & TRN & \\
\hline CHEMBL1592801 & 688612 & 4.15 & 4.637 & TRN & \\
\hline CHEMBL1325117 & 688612 & 4.5 & 4.6998 & TRN & \\
\hline CHEMBL3212667 & 688612 & 4.8 & 4.6413 & TRN & \\
\hline CHEMBL1480077 & 688612 & 4.4 & 4.6391 & TRN & \\
\hline CHEMBL1332137 & 688612 & 4.2 & 4.6005 & TRN & \\
\hline CHEMBL1385995 & 688612 & 4.4 & 4.7548 & TRN & \\
\hline CHEMBL1505922 & 688612 & 5.0 & 4.681 & TST & \\
\hline CHEMBL1441784 & 688612 & 6.8499 & 4.63399 & 99999999995 & TST \\
\hline CHEMBL1330781 & 688612 & 6.15 & 4.7181 & TRN & \\
\hline CHEMBL1372229 & 688612 & 4.45 & 4.6928 & TRN & \\
\hline CHEMBL1349989 & 688612 & 4.6 & 4.6353 & TRN & \\
\hline CHEMBL1575410 & 688612 & 4.0 & 4.5991 & TRN & \\
\hline CHEMBL1546881 & 688612 & 6.0 & 4.6235 & TST & \\
\hline CHEMBL1355735 & 688612 & 5.1 & 4.7071 & TRN & \\
\hline CHEMBL3210191 & 688612 & 4.4 & 4.7321 & TRN & \\
\hline CHEMBL1441838 & 688612 & 4.3 & 4.7172 & TRN & \\
\hline
\end{tabular}




\begin{tabular}{|c|c|c|c|c|c|}
\hline \multicolumn{6}{|c|}{ Supplemental Table S2.txt } \\
\hline CHEMBL1443867 & 688612 & 4.3 & 4.6789 & TRN & \\
\hline CHEMBL1608616 & 688612 & 4.75 & 4.6667 & TST & \\
\hline CHEMBL1476998 & 688612 & 4.0 & 4.5897 & TRN & \\
\hline CHEMBL1501117 & 688612 & 4.65 & 4.7666 & TRN & \\
\hline CHEMBL1527812 & 688612 & 6.1 & 4.6306 & TST & \\
\hline CHEMBL1576388 & 688612 & 6.8499 & 4.6597 & TST & \\
\hline CHEMBL1427885 & 688612 & 4.05 & 4.6355 & TRN & \\
\hline CHEMBL1580572 & 688612 & 4.75 & 4.6713 & TRN & \\
\hline CHEMBL1563612 & 688612 & 4.7 & 4.6914 & TRN & \\
\hline CHEMBL1569771 & 688612 & 4.8 & 4.6318 & TRN & \\
\hline CHEMBL1545261 & 688612 & 4.0 & 4.7125 & TRN & \\
\hline CHEMBL1570861 & 688612 & 4.6 & 4.6839 & TRN & \\
\hline CHEMBL1551368 & 688612 & 5.1 & 4.5747 & TRN & \\
\hline CHEMBL1340950 & 688612 & 4.85 & 4.6954 & TRN & \\
\hline CHEMBL1551483 & 688612 & 4.4 & 4.6233 & TRN & \\
\hline CHEMBL1545215 & 688612 & 4.3 & 4.6392 & TRN & \\
\hline CHEMBL1317659 & 688612 & 4.0 & 4.7076 & TRN & \\
\hline CHEMBL1162110 & 688612 & 4.5 & 4.6042 & TRN & \\
\hline CHEMBL1416361 & 688612 & 4.35 & 4.6337 & TRN & \\
\hline CHEMBL1590488 & 688612 & 5.0 & 4.6283 & TST & \\
\hline CHEMBL1509550 & 688612 & 4.95 & 4.6892 & TRN & \\
\hline CHEMBL1355291 & 688612 & 4.05 & 4.7056 & TRN & \\
\hline CHEMBL1355194 & 688612 & 4.95 & 4.5476 & TRN & \\
\hline CHEMBL1556531 & 688612 & 4.95 & 4.7853 & TRN & \\
\hline CHEMBL1473790 & 688612 & 4.05 & 4.6064 & TRN & \\
\hline CHEMBL1517037 & 688612 & 4.0 & 4.7664 & TST & \\
\hline CHEMBL1981638 & 688612 & 4.45 & 4.7116 & TRN & \\
\hline CHEMBL1446535 & 688612 & 6.0 & 4.5379 & TRN & \\
\hline CHEMBL1438166 & 688612 & 4.05 & 4.6723 & TST & \\
\hline CHEMBL1513101 & 688612 & 4.95 & 4.7213 & TRN & \\
\hline CHEMBL1488495 & 688612 & 4.45 & 4.6708 & TRN & \\
\hline CHEMBL1441289 & 688612 & 4.35 & 4.7477 & TST & \\
\hline CHEMBL1337846 & 688612 & 4.75 & 4.6988 & TRN & \\
\hline CHEMBL1600246 & 688612 & 4.7 & 4.792 & TRN & \\
\hline CHEMBL1409391 & 688612 & 4.05 & 4.6159 & TST & \\
\hline CHEMBL1497302 & 688612 & 4.4 & 4.6294 & TRN & \\
\hline CHEMBL1588203 & 688612 & 4.05 & 4.5489 & TRN & \\
\hline CHEMBL1469229 & 688612 & 4.35 & 4.7332 & TRN & \\
\hline CHEMBL1446483 & 688612 & 4.8 & 4.6749 & TRN & \\
\hline CHEMBL1433214 & 688612 & 4.7 & 4.6873 & TRN & \\
\hline CHEMBL1432165 & 688612 & 4.2 & $4.7010 e$ & 00000000005 & TST \\
\hline CHEMBL3208922 & 688612 & 4.05 & 4.7053 & TRN & \\
\hline CHEMBL1332935 & 688612 & 5.5 & 4.6355 & TRN & \\
\hline CHEMBL1362643 & 688612 & 4.65 & 4.63399 & 99999999995 & TRN \\
\hline CHEMBL1988660 & 688612 & 4.05 & 4.6571 & TRN & \\
\hline CHEMBL1457098 & 688612 & 6.8499 & 4.6596 & TST & \\
\hline CHEMBL1532876 & 688612 & 6.95 & 4.6289 & TRN & \\
\hline CHEMBL1581754 & 688612 & 6.05 & 4.6804 & TRN & \\
\hline
\end{tabular}




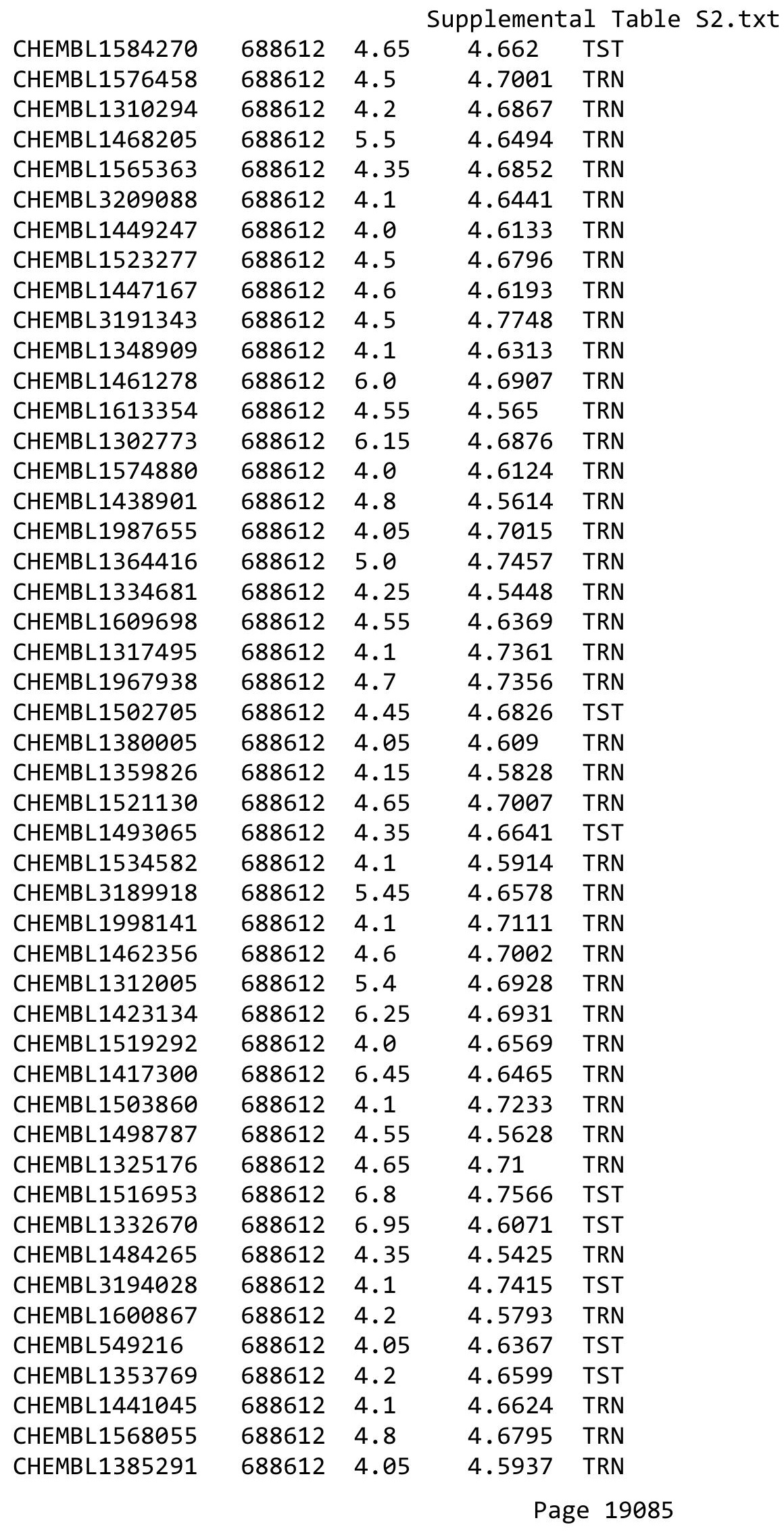




\begin{tabular}{|c|c|c|c|c|c|}
\hline \multicolumn{6}{|c|}{ Supplemental Table S2.txt } \\
\hline CHEMBL1410551 & 688612 & 4.65 & 4.6131 & TRN & \\
\hline CHEMBL1442123 & 688612 & 5.0 & 4.7012 & TST & \\
\hline CHEMBL1489952 & 688612 & 4.45 & 4.613 & TRN & \\
\hline CHEMBL1537017 & 688612 & 4.95 & 4.6743 & TRN & \\
\hline CHEMBL1580205 & 688612 & 4.1 & 4.5851 & TRN & \\
\hline CHEMBL1399736 & 688612 & 6.45 & 4.7482 & TRN & \\
\hline CHEMBL1455873 & 688612 & 5.25 & 4.6034 & TRN & \\
\hline CHEMBL1307953 & 688612 & 5.55 & 4.6662 & TRN & \\
\hline CHEMBL1338876 & 688612 & 5.6 & 4.6137 & TRN & \\
\hline CHEMBL1479218 & 688612 & 4.4 & 4.6113 & TST & \\
\hline CHEMBL1384502 & 688612 & 4.4 & 4.7175 & TRN & \\
\hline CHEMBL1506142 & 688612 & 4.05 & 4.5914 & TRN & \\
\hline CHEMBL1498729 & 688612 & 4.05 & 4.7709 & TRN & \\
\hline CHEMBL1462449 & 688612 & 4.05 & 4.5791 & TST & \\
\hline CHEMBL1398408 & 688612 & 4.4 & 4.6293 & TRN & \\
\hline CHEMBL1302355 & 688612 & 5.7 & 4.6072 & TRN & \\
\hline CHEMBL1416736 & 688612 & 4.05 & 4.712 & TST & \\
\hline CHEMBL1594542 & 688612 & 5.05 & 4.6884 & TRN & \\
\hline CHEMBL1404276 & 688612 & 4.05 & 4.6166 & TRN & \\
\hline CHEMBL1499525 & 688612 & 4.4 & 4.5866 & TRN & \\
\hline CHEMBL1421601 & 688612 & 5.3 & 4.5644 & TRN & \\
\hline CHEMBL1304177 & 688612 & 4.25 & 4.6966 & TRN & \\
\hline CHEMBL1551690 & 688612 & 4.05 & 4.6172 & TST & \\
\hline CHEMBL1303403 & 688612 & 4.1 & 4.6726 & TRN & \\
\hline CHEMBL1387230 & 688612 & 4.2 & 4.5562 & TRN & \\
\hline CHEMBL1478098 & 688612 & 4.0 & 4.6378 & TRN & \\
\hline CHEMBL1554103 & 688612 & 4.2 & 4.6077 & TRN & \\
\hline CHEMBL1567207 & 688612 & 7.0 & 4.7397 & TRN & \\
\hline CHEMBL1456360 & 688612 & 4.05 & 4.76399 & 9999999999 & TST \\
\hline CHEMBL1444771 & 688612 & 4.1 & 4.7388 & TRN & \\
\hline CHEMBL1493936 & 688612 & 5.05 & 4.7982 & TRN & \\
\hline CHEMBL1608345 & 688612 & 4.0 & 4.5953 & TRN & \\
\hline CHEMBL1564110 & 688612 & 4.45 & 4.6536 & TRN & \\
\hline CHEMBL1543316 & 688612 & 6.1 & 4.7419 & TST & \\
\hline CHEMBL1411856 & 688612 & 4.1 & 4.5225 & TRN & \\
\hline CHEMBL1347107 & 688612 & 4.7 & 4.7552 & TRN & \\
\hline CHEMBL1402276 & 688612 & 4.9 & 4.6882 & TRN & \\
\hline CHEMBL 3210895 & 688612 & 6.3 & 4.6222 & TRN & \\
\hline CHEMBL448741 & 688612 & 4.4 & 4.7185 & TST & \\
\hline CHEMBL1531959 & 688612 & 4.05 & 4.753 & TRN & \\
\hline CHEMBL1419952 & 688612 & 4.4 & 4.6259 & TRN & \\
\hline CHEMBL1417517 & 688612 & 5.0 & 4.7781 & TST & \\
\hline CHEMBL1586805 & 688612 & 4.3 & 4.6205 & TST & \\
\hline CHEMBL1366126 & 688612 & 4.25 & 4.7344 & TRN & \\
\hline CHEMBL1469048 & 688612 & 4.35 & 4.6617 & TST & \\
\hline CHEMBL1451178 & 688612 & 4.4 & 4.6554 & TRN & \\
\hline CHEMBL1573701 & 688612 & 4.65 & 4.6345 & TST & \\
\hline CHEMBL1458319 & 688612 & 4.05 & 4.7315 & TRN & \\
\hline
\end{tabular}




\begin{tabular}{|c|c|c|c|c|}
\hline \multicolumn{5}{|c|}{ Supplemental Table S2.txt } \\
\hline CHEMBL1517639 & 688612 & 4.9 & 4.57 & TST \\
\hline CHEMBL1361590 & 688612 & 4.05 & 4.6617 & TRN \\
\hline CHEMBL1594130 & 688612 & 5.7 & 4.6279 & TRN \\
\hline CHEMBL1592329 & 688612 & 4.3 & 4.729 & TRN \\
\hline CHEMBL1977709 & 688612 & 4.3 & 4.7324 & TST \\
\hline CHEMBL 3190400 & 688612 & 4.05 & 4.7779 & TST \\
\hline CHEMBL1540339 & 688612 & 4.7 & 4.6547 & TRN \\
\hline CHEMBL1393242 & 688612 & 4.0 & 4.7133 & TRN \\
\hline CHEMBL1495539 & 688612 & 4.1 & 4.6962 & TRN \\
\hline CHEMBL1467882 & 688612 & 4.25 & 4.7043 & TRN \\
\hline CHEMBL 2000340 & 688612 & 4.9 & 4.7464 & TRN \\
\hline CHEMBL1415859 & 688612 & 4.9 & 4.6121 & TRN \\
\hline CHEMBL1428409 & 688612 & 4.65 & 4.6859 & TST \\
\hline CHEMBL1417729 & 688612 & 5.9 & 4.6549 & TRN \\
\hline CHEMBL1332039 & 688612 & 4.35 & 4.6518 & TRN \\
\hline CHEMBL3189868 & 688612 & 4.6 & 4.7828 & TRN \\
\hline CHEMBL1299746 & 688612 & 4.8 & 4.6455 & TST \\
\hline CHEMBL1419884 & 688612 & 4.65 & 4.6811 & TRN \\
\hline CHEMBL1408715 & 688612 & 4.15 & 4.7907 & TRN \\
\hline CHEMBL1306692 & 688612 & 5.2 & 4.7106 & TRN \\
\hline CHEMBL1404179 & 688612 & 4.05 & 4.6997 & TRN \\
\hline CHEMBL1565187 & 688612 & 5.0 & 4.7618 & TRN \\
\hline CHEMBL1429083 & 688612 & 4.75 & 4.7678 & TRN \\
\hline CHEMBL3191465 & 688612 & 6.2 & 4.7533 & TRN \\
\hline CHEMBL1374166 & 688612 & 4.05 & 4.7551 & TRN \\
\hline CHEMBL1424878 & 688612 & 4.9 & 4.7958 & TRN \\
\hline CHEMBL3189236 & 688612 & 4.75 & 4.7287 & TRN \\
\hline CHEMBL1430846 & 688612 & 5.0 & 4.6344 & TRN \\
\hline CHEMBL1375952 & 688612 & 4.3 & 4.635 & TRN \\
\hline CHEMBL1409791 & 688612 & 4.45 & 4.6343 & TRN \\
\hline CHEMBL1478566 & 688612 & 4.05 & 4.6051 & TST \\
\hline CHEMBL1423032 & 688612 & 4.9 & 4.694 & TRN \\
\hline CHEMBL1390234 & 688612 & 5.45 & 4.6707 & TRN \\
\hline CHEMBL1404171 & 688612 & 4.05 & 4.6358 & TRN \\
\hline CHEMBL 1372748 & 688612 & 4.05 & 4.7037 & TST \\
\hline CHEMBL1428580 & 688612 & 4.05 & 4.6831 & TRN \\
\hline CHEMBL1598833 & 688612 & 4.4 & 4.6995 & TRN \\
\hline CHEMBL1545104 & 688612 & 5.5 & 4.703 & TRN \\
\hline CHEMBL1499881 & 688612 & 4.45 & 4.7147 & TRN \\
\hline CHEMBL3199033 & 688612 & 4.65 & 4.7838 & TRN \\
\hline CHEMBL1576702 & 688612 & 4.8 & 4.782 & TST \\
\hline CHEMBL1510143 & 688612 & 4.05 & 4.6473 & TRN \\
\hline CHEMBL1570980 & 688612 & 4.05 & 4.7321 & TST \\
\hline CHEMBL1582884 & 688612 & 6.45 & 4.6661 & TRN \\
\hline CHEMBL1318953 & 688612 & 4.3 & 4.7042 & TRN \\
\hline CHEMBL1362047 & 688612 & 4.05 & 4.7882 & TRN \\
\hline CHEMBL1461709 & 688612 & 4.0 & 4.6204 & TRN \\
\hline CHEMBL1317109 & 688612 & 4.1 & 4.5989 & TRN \\
\hline
\end{tabular}




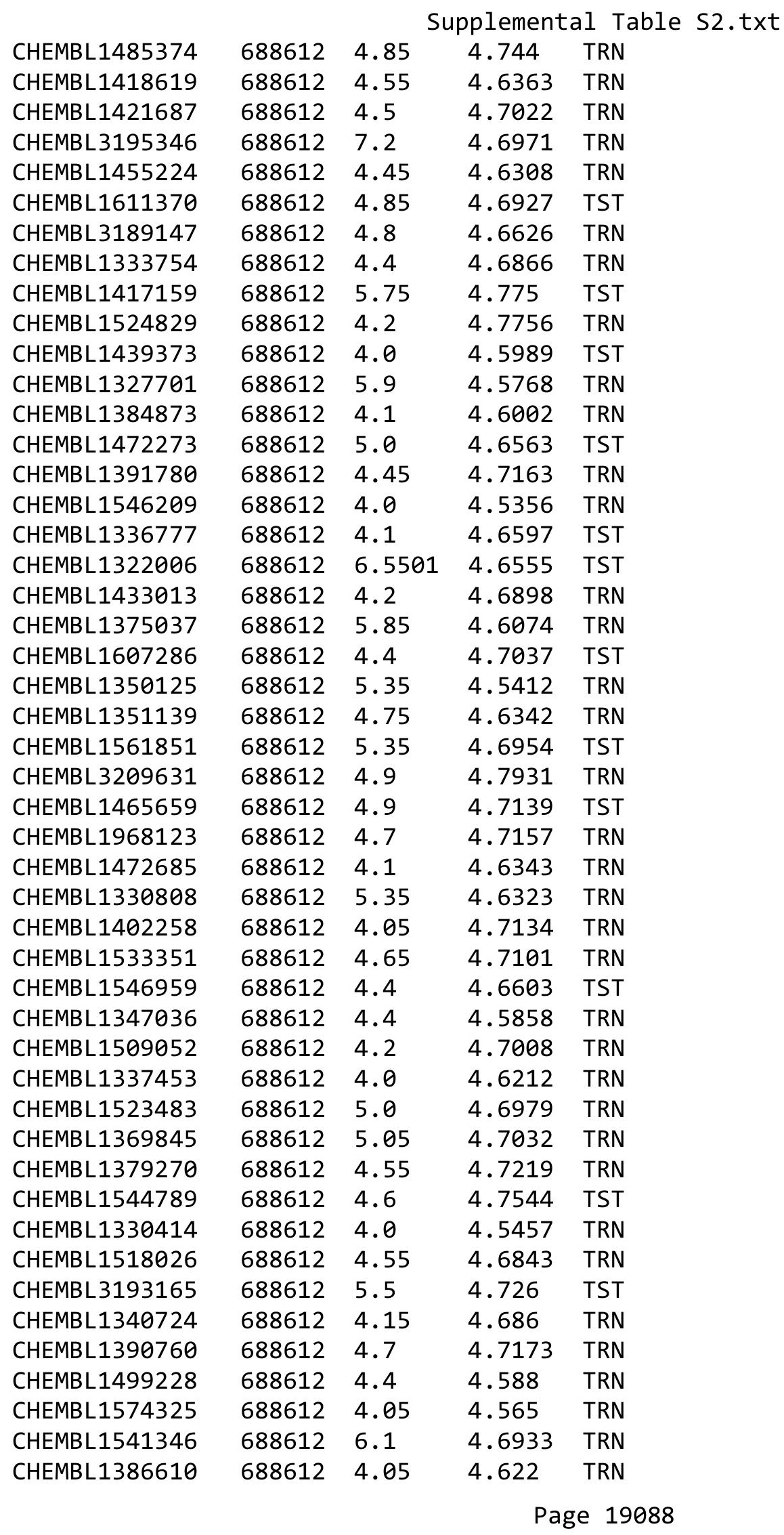




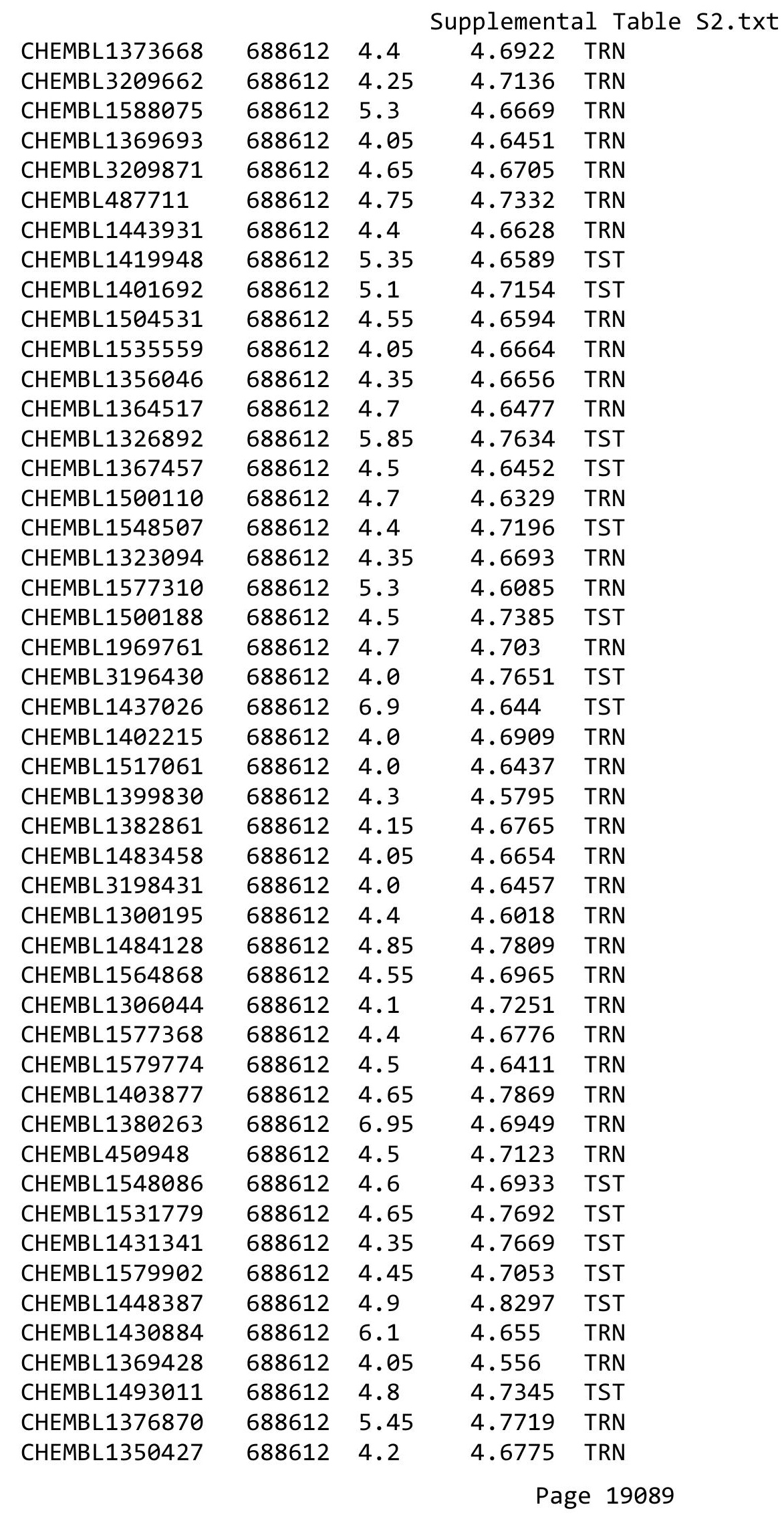




\begin{tabular}{|c|c|c|c|c|}
\hline \multicolumn{5}{|c|}{ Supplemental Table S2.txt } \\
\hline CHEMBL1583517 & 688612 & 4.6 & 4.7108 & TST \\
\hline CHEMBL1605193 & 688612 & 4.1 & 4.7061 & TST \\
\hline CHEMBL1496115 & 688612 & 4.1 & 4.6031 & TRN \\
\hline CHEMBL1494951 & 688612 & 4.1 & 4.5982 & TRN \\
\hline CHEMBL1497484 & 688612 & 5.3 & 4.6718 & TST \\
\hline CHEMBL1608758 & 688612 & 4.4 & 4.72 & TST \\
\hline CHEMBL1405683 & 688612 & 5.6 & 4.6306 & TST \\
\hline CHEMBL1545928 & 688612 & 4.0 & 4.6573 & TRN \\
\hline CHEMBL 3212021 & 688612 & 5.65 & 4.6554 & TST \\
\hline CHEMBL592588 & 688612 & 4.8 & 4.7336 & TRN \\
\hline CHEMBL1395818 & 688612 & 4.0 & 4.7157 & TRN \\
\hline CHEMBL1508508 & 688612 & 4.65 & 4.7258 & TRN \\
\hline CHEMBL1535232 & 688612 & 6.8499 & 4.6369 & TRN \\
\hline CHEMBL191750 & 688612 & 4.05 & 4.7247 & TRN \\
\hline CHEMBL1546890 & 688612 & 6.6499 & 4.657 & TRN \\
\hline CHEMBL1444898 & 688612 & 4.35 & 4.6591 & TRN \\
\hline CHEMBL1356313 & 688612 & 4.35 & 4.6618 & TRN \\
\hline CHEMBL313938 & 688612 & 4.65 & 4.7663 & TST \\
\hline CHEMBL1422647 & 688612 & 4.6 & 4.6999 & TST \\
\hline CHEMBL1312958 & 688612 & 5.15 & 4.5785 & TRN \\
\hline CHEMBL1309842 & 688612 & 5.85 & 4.7115 & TST \\
\hline CHEMBL1461629 & 688612 & 4.7 & 4.7823 & TST \\
\hline CHEMBL1331168 & 688612 & 4.0 & 4.5756 & TRN \\
\hline CHEMBL1300312 & 688612 & 5.45 & 4.7158 & TRN \\
\hline CHEMBL1521402 & 688612 & 4.05 & 4.6524 & TRN \\
\hline CHEMBL1320902 & 688612 & 5.75 & 4.8088 & TRN \\
\hline CHEMBL3197986 & 688612 & 4.5 & 4.7636 & TST \\
\hline CHEMBL3211838 & 688612 & 6.8499 & 4.7025 & TRN \\
\hline CHEMBL1610460 & 688612 & 4.25 & 4.5666 & TRN \\
\hline CHEMBL1484254 & 688612 & 5.05 & 4.6461 & TRN \\
\hline CHEMBL1518016 & 688612 & 4.1 & 4.6672 & TST \\
\hline CHEMBL1593194 & 688612 & 4.55 & 4.6567 & TRN \\
\hline CHEMBL1531097 & 688612 & 4.0 & 4.7009 & TRN \\
\hline CHEMBL1484151 & 688612 & 5.7 & 4.5766 & TRN \\
\hline CHEMBL1336762 & 688612 & 4.1 & 4.6378 & TRN \\
\hline CHEMBL1494807 & 688612 & 4.2 & 4.6909 & TRN \\
\hline CHEMBL1299825 & 688612 & 4.6 & 4.6471 & TRN \\
\hline CHEMBL1410688 & 688612 & 6.7001 & 4.7579 & TRN \\
\hline CHEMBL1537538 & 688612 & 4.2 & 4.5971 & TST \\
\hline CHEMBL3192784 & 688612 & 6.9 & 4.6813 & TRN \\
\hline CHEMBL1545288 & 688612 & 4.5 & 4.7441 & TRN \\
\hline CHEMBL1417645 & 688612 & 4.05 & 4.6249 & TST \\
\hline CHEMBL1508189 & 688612 & 4.55 & 4.6601 & TRN \\
\hline CHEMBL1373377 & 688612 & 4.4 & 4.5907 & TRN \\
\hline CHEMBL1310406 & 688612 & 4.0 & 4.5767 & TRN \\
\hline CHEMBL1371007 & 688612 & 4.45 & 4.7093 & TRN \\
\hline CHEMBL1471920 & 688612 & 4.55 & 4.6647 & TRN \\
\hline CHEMBL1510409 & 688612 & 6.9 & 4.6951 & TST \\
\hline
\end{tabular}




\begin{tabular}{|c|c|c|c|c|c|}
\hline \multicolumn{6}{|c|}{ Supplemental Table S2.txt } \\
\hline CHEMBL1600122 & 688612 & 5.35 & 4.6962 & TRN & \\
\hline CHEMBL1511131 & 688612 & 6.7501 & 4.7013 & TRN & \\
\hline CHEMBL596633 & 688612 & 6.0 & 4.6807 & TRN & \\
\hline CHEMBL1374226 & 688612 & 4.1 & 4.6893 & TRN & \\
\hline CHEMBL1566002 & 688612 & 4.7 & 4.6893 & TST & \\
\hline CHEMBL1600851 & 688612 & 4.05 & 4.6404 & TRN & \\
\hline CHEMBL1515135 & 688612 & 4.05 & 4.5796 & TRN & \\
\hline CHEMBL1496444 & 688612 & 4.1 & 4.5888 & TRN & \\
\hline CHEMBL1472145 & 688612 & 4.0 & 4.5601 & TRN & \\
\hline CHEMBL1504679 & 688612 & 5.0 & 4.8673 & TRN & \\
\hline CHEMBL1542640 & 688612 & 4.05 & 4.6217 & TST & \\
\hline CHEMBL1569737 & 688612 & 4.1 & 4.5778 & TRN & \\
\hline CHEMBL1331327 & 688612 & 4.1 & 4.601 & TRN & \\
\hline CHEMBL1592347 & 688612 & 4.45 & 4.6451 & TST & \\
\hline CHEMBL1460445 & 688612 & 4.9 & 4.6984 & TRN & \\
\hline CHEMBL1479209 & 688612 & 4.1 & 4.6186 & TRN & \\
\hline CHEMBL1530403 & 688612 & 6.9 & 4.6777 & TST & \\
\hline CHEMBL1407136 & 688612 & 4.95 & 4.7506 & TRN & \\
\hline CHEMBL1456591 & 688612 & 4.4 & 4.621 & TRN & \\
\hline CHEMBL1443298 & 688612 & 6.8499 & 4.6668 & TRN & \\
\hline CHEMBL1449291 & 688612 & 4.4 & 4.5929 & TRN & \\
\hline CHEMBL1490724 & 688612 & 4.05 & 4.6603 & TRN & \\
\hline CHEMBL1557108 & 688612 & 6.8499 & 4.6023 & TRN & \\
\hline CHEMBL1379774 & 688612 & 4.2 & 4.6708 & TST & \\
\hline CHEMBL1524636 & 688612 & 4.05 & 4.6037 & TRN & \\
\hline CHEMBL1500022 & 688612 & 4.1 & 4.6972 & TST & \\
\hline CHEMBL1557442 & 688612 & 5.55 & 4.617 & TRN & \\
\hline CHEMBL1406321 & 688612 & 4.15 & 4.6317 & TRN & \\
\hline CHEMBL1483840 & 688612 & 4.3 & 4.7705 & TST & \\
\hline CHEMBL1502492 & 688612 & 4.6 & 4.6996 & TST & \\
\hline CHEMBL1454848 & 688612 & 4.0 & 4.775 & TRN & \\
\hline CHEMBL1403825 & 688612 & 4.65 & 4.6769 & TRN & \\
\hline CHEMBL1470483 & 688612 & 5.5 & 4.7829 & TRN & \\
\hline CHEMBL1578415 & 688612 & 4.1 & 4.717 & TST & \\
\hline CHEMBL1443224 & 688612 & 4.55 & 4.5833 & TRN & \\
\hline CHEMBL1550948 & 688612 & 6.9 & 4.5653 & TRN & \\
\hline CHEMBL1450883 & 688612 & 4.0 & 4.60800 & 00000000005 & TRN \\
\hline CHEMBL1521451 & 688612 & 4.05 & 4.6684 & TST & \\
\hline CHEMBL582473 & 688612 & 4.35 & 4.5616 & TRN & \\
\hline CHEMBL1374051 & 688612 & 4.75 & 4.7335 & TRN & \\
\hline CHEMBL 1470010 & 688612 & 4.05 & 4.6819 & TRN & \\
\hline CHEMBL1536225 & 688612 & 4.1 & 4.6616 & TST & \\
\hline CHEMBL1577834 & 688612 & 4.05 & 4.6728 & TST & \\
\hline CHEMBL1421105 & 688612 & 5.35 & 4.6058 & TRN & \\
\hline CHEMBL1414378 & 688612 & 4.05 & 4.6649 & TRN & \\
\hline CHEMBL1322725 & 688612 & 6.8499 & 4.6831 & TRN & \\
\hline CHEMBL1552306 & 688612 & 4.45 & 4.6837 & TRN & \\
\hline CHEMBL1378257 & 688612 & 4.6 & 4.6333 & TST & \\
\hline
\end{tabular}




\begin{tabular}{|c|c|c|c|c|c|}
\hline \multicolumn{6}{|c|}{ Supplemental Table S2.txt } \\
\hline CHEMBL1333412 & 688612 & 4.6 & 4.702 & TST & \\
\hline CHEMBL1502014 & 688612 & 5.35 & 4.7471 & TST & \\
\hline CHEMBL1498971 & 688612 & 4.6 & 4.7207 & TRN & \\
\hline CHEMBL1300612 & 688612 & 5.55 & 4.6042 & TST & \\
\hline CHEMBL1337806 & 688612 & 5.35 & 4.6908 & TRN & \\
\hline CHEMBL1375545 & 688612 & 5.3 & 4.61600 & 00000000005 & TST \\
\hline CHEMBL1588274 & 688612 & 6.3 & 4.7988 & TRN & \\
\hline CHEMBL1520373 & 688612 & 4.6 & 4.7214 & TRN & \\
\hline CHEMBL3197706 & 688612 & 4.4 & 4.6545 & TRN & \\
\hline CHEMBL1346506 & 688612 & 4.55 & 4.6709 & TRN & \\
\hline CHEMBL1494817 & 688612 & 3.95 & 4.7127 & TST & \\
\hline CHEMBL1576658 & 688612 & 6.25 & 4.8179 & TST & \\
\hline CHEMBL3190350 & 688612 & 4.7 & 4.6569 & TRN & \\
\hline CHEMBL1319415 & 688612 & 4.05 & 4.6041 & TST & \\
\hline CHEMBL1461732 & 688612 & 4.45 & 4.6419 & TRN & \\
\hline CHEMBL1403304 & 688612 & 6.95 & 4.6957 & TRN & \\
\hline CHEMBL1358497 & 688612 & 4.15 & 4.5816 & TRN & \\
\hline CHEMBL1430296 & 688612 & 5.4 & 4.6004 & TRN & \\
\hline CHEMBL303846 & 688612 & 4.1 & 4.7731 & TST & \\
\hline CHEMBL1336219 & 688612 & 4.1 & 4.6429 & TST & \\
\hline CHEMBL1447511 & 688612 & 4.85 & 4.688 & TRN & \\
\hline CHEMBL1333611 & 688612 & 4.25 & 4.6845 & TST & \\
\hline CHEMBL3145316 & 688612 & 5.55 & 4.7253 & TRN & \\
\hline CHEMBL1508677 & 688612 & 5.0 & 4.6008 & TRN & \\
\hline CHEMBL1541882 & 688612 & 4.0 & 4.6492 & TRN & \\
\hline CHEMBL1556879 & 688612 & 4.45 & 4.6372 & TRN & \\
\hline CHEMBL1426062 & 688612 & 4.4 & 4.6853 & TST & \\
\hline CHEMBL1517993 & 688612 & 4.6 & 4.6871 & TRN & \\
\hline CHEMBL1494370 & 688612 & 4.4 & 4.6032 & TST & \\
\hline CHEMBL1527749 & 688612 & 4.6 & 4.63 & TRN & \\
\hline CHEMBL1446630 & 688612 & 4.05 & 4.6831 & TST & \\
\hline CHEMBL1575299 & 688612 & 4.5 & 4.6313 & TRN & \\
\hline CHEMBL1585505 & 688612 & 4.55 & 4.6062 & TRN & \\
\hline CHEMBL1542978 & 688612 & 4.65 & 4.7361 & TRN & \\
\hline CHEMBL1605251 & 688612 & 4.05 & 4.6361 & TRN & \\
\hline CHEMBL1545345 & 688612 & 4.0 & 4.6368 & TRN & \\
\hline CHEMBL1467354 & 688612 & 4.35 & 4.6947 & TST & \\
\hline CHEMBL1463594 & 688612 & 4.1 & 4.5767 & TST & \\
\hline CHEMBL1415650 & 688612 & 4.0 & 4.6904 & TST & \\
\hline CHEMBL3191124 & 688612 & 4.05 & 4.698 & TRN & \\
\hline CHEMBL1521742 & 688612 & 4.05 & 4.6839 & TRN & \\
\hline CHEMBL1504700 & 688612 & 4.05 & 4.6153 & TRN & \\
\hline CHEMBL3213107 & 688612 & 5.35 & 4.7347 & TRN & \\
\hline CHEMBL1501987 & 688612 & 5.25 & 4.6948 & TRN & \\
\hline CHEMBL1494221 & 688612 & 6.8499 & 4.6439 & TST & \\
\hline CHEMBL1528774 & 688612 & 4.4 & 4.606 & TRN & \\
\hline CHEMBL1389510 & 688612 & 4.45 & 4.7186 & TRN & \\
\hline CHEMBL1322730 & 688612 & 5.05 & 4.6635 & TST & \\
\hline
\end{tabular}




\begin{tabular}{|c|c|c|c|c|c|}
\hline \multicolumn{6}{|c|}{ Supplemental Table S2.txt } \\
\hline CHEMBL1418501 & 688612 & 4.65 & 4.6123 & TRN & \\
\hline CHEMBL3192204 & 688612 & 4.2 & 4.6403 & TRN & \\
\hline CHEMBL1316282 & 688612 & 4.0 & 4.6285 & TST & \\
\hline CHEMBL1563004 & 688612 & 4.15 & 4.7331 & TST & \\
\hline CHEMBL1538209 & 688612 & 4.55 & 4.8084 & TRN & \\
\hline CHEMBL1350479 & 688612 & 4.0 & 4.6735 & TRN & \\
\hline CHEMBL1423506 & 688612 & 4.1 & 4.6589 & TRN & \\
\hline CHEMBL1426811 & 688612 & 4.85 & 4.6128 & TRN & \\
\hline CHEMBL1302986 & 688612 & 4.4 & 4.7086 & TRN & \\
\hline CHEMBL1311378 & 688612 & 4.05 & 4.74100 & 00000000005 & TRN \\
\hline CHEMBL1605483 & 688612 & 4.05 & 4.6232 & TRN & \\
\hline CHEMBL1480512 & 688612 & 4.65 & 4.5422 & TRN & \\
\hline CHEMBL1570839 & 688612 & 5.1 & 4.5965 & TST & \\
\hline CHEMBL1382688 & 688612 & 4.8 & 4.6138 & TST & \\
\hline CHEMBL1457267 & 688612 & 6.8499 & 4.7189 & TST & \\
\hline CHEMBL1322044 & 688612 & 4.5 & 4.665 & TRN & \\
\hline CHEMBL3198534 & 688612 & 4.1 & 4.7149 & TRN & \\
\hline CHEMBL1556649 & 688612 & 4.3 & 4.628 & TRN & \\
\hline CHEMBL 2003485 & 688612 & 4.35 & 4.7181 & TRN & \\
\hline CHEMBL1416076 & 688612 & 4.4 & 4.676 & TRN & \\
\hline CHEMBL1976414 & 688612 & 5.0 & 4.7419 & TRN & \\
\hline CHEMBL1373849 & 688612 & 5.0 & 4.7276 & TRN & \\
\hline CHEMBL1412701 & 688612 & 4.05 & 4.5565 & TRN & \\
\hline CHEMBL1501986 & 688612 & 4.6 & 4.6729 & TRN & \\
\hline CHEMBL1416013 & 688612 & 4.05 & 4.6144 & TRN & \\
\hline CHEMBL3192591 & 688612 & 4.4 & 4.7105 & TRN & \\
\hline CHEMBL1974521 & 688612 & 6.0 & 4.8268 & TRN & \\
\hline CHEMBL1523907 & 688612 & 4.4 & 4.6297 & TRN & \\
\hline CHEMBL1583198 & 688612 & 4.7 & 4.6581 & TRN & \\
\hline CHEMBL1529637 & 688612 & 4.5 & 4.6286 & TRN & \\
\hline CHEMBL1575053 & 688612 & 4.05 & 4.6715 & TRN & \\
\hline CHEMBL1508863 & 688612 & 5.45 & 4.6674 & TST & \\
\hline CHEMBL1477142 & 688612 & 4.25 & 4.5753 & TRN & \\
\hline CHEMBL1320897 & 688612 & 4.55 & 4.6838 & TST & \\
\hline CHEMBL1608090 & 688612 & 4.25 & 4.588 & TRN & \\
\hline CHEMBL1596594 & 688612 & 5.8 & 4.7265 & TRN & \\
\hline CHEMBL1473788 & 688612 & 4.0 & 4.6207 & TST & \\
\hline CHEMBL 238236 & 688612 & 6.05 & 4.7456 & TRN & \\
\hline CHEMBL1556550 & 688612 & 4.4 & 4.6522 & TST & \\
\hline CHEMBL1524181 & 688612 & 5.9 & 4.6761 & TST & \\
\hline CHEMBL1538934 & 688612 & 4.0 & 4.7483 & TST & \\
\hline CHEMBL578136 & 688612 & 4.95 & 4.7141 & TRN & \\
\hline CHEMBL1437202 & 688612 & 4.05 & 4.6397 & TRN & \\
\hline CHEMBL1428214 & 688612 & 4.2 & 4.6537 & TRN & \\
\hline CHEMBL1439892 & 688612 & 4.0 & 4.6937 & TRN & \\
\hline CHEMBL3212030 & 688612 & 4.7 & 4.6577 & TRN & \\
\hline CHEMBL1364761 & 688612 & 4.1 & 4.6374 & TRN & \\
\hline CHEMBL3192297 & 688612 & 5.05 & 4.6903 & TRN & \\
\hline
\end{tabular}




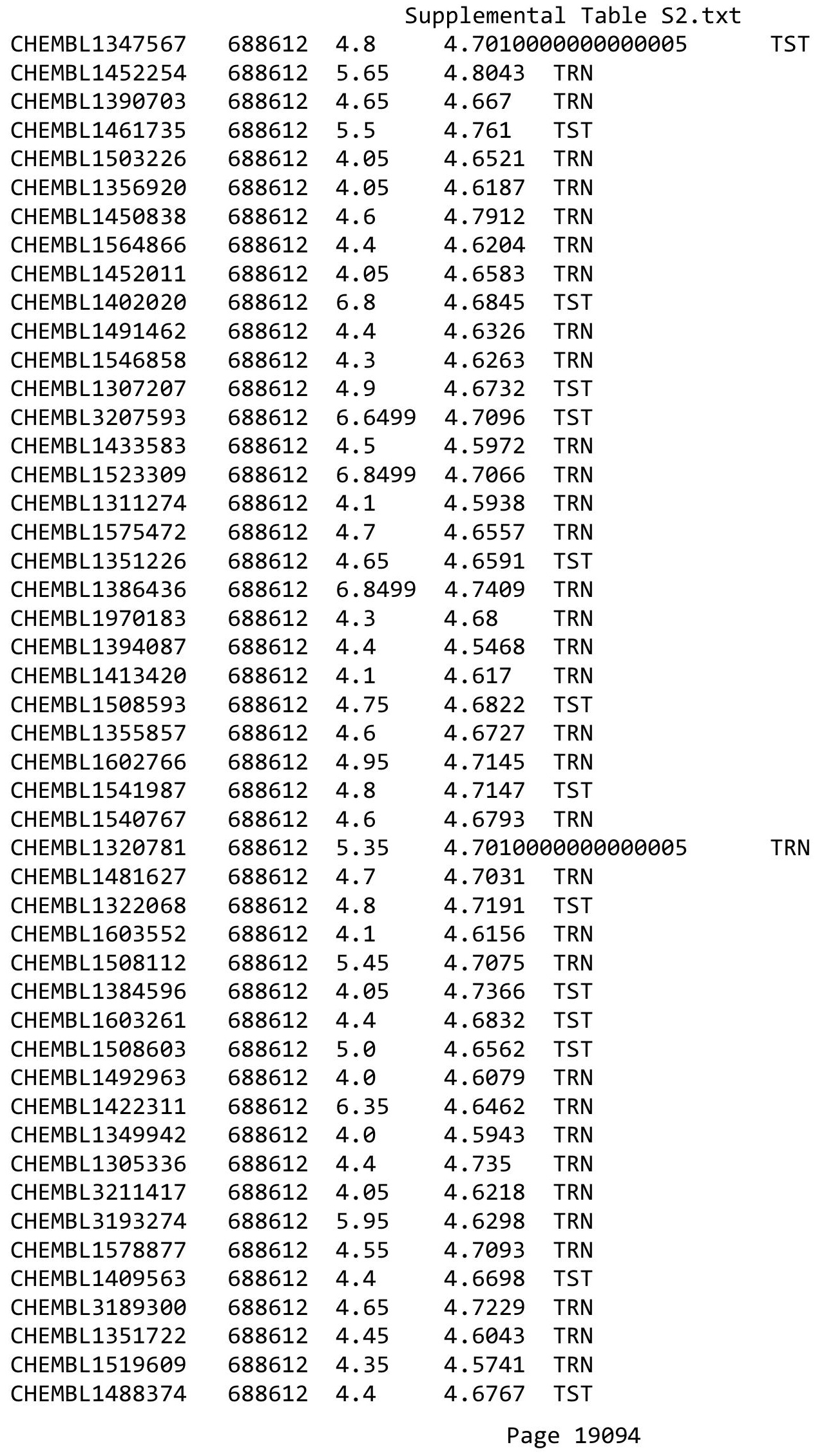




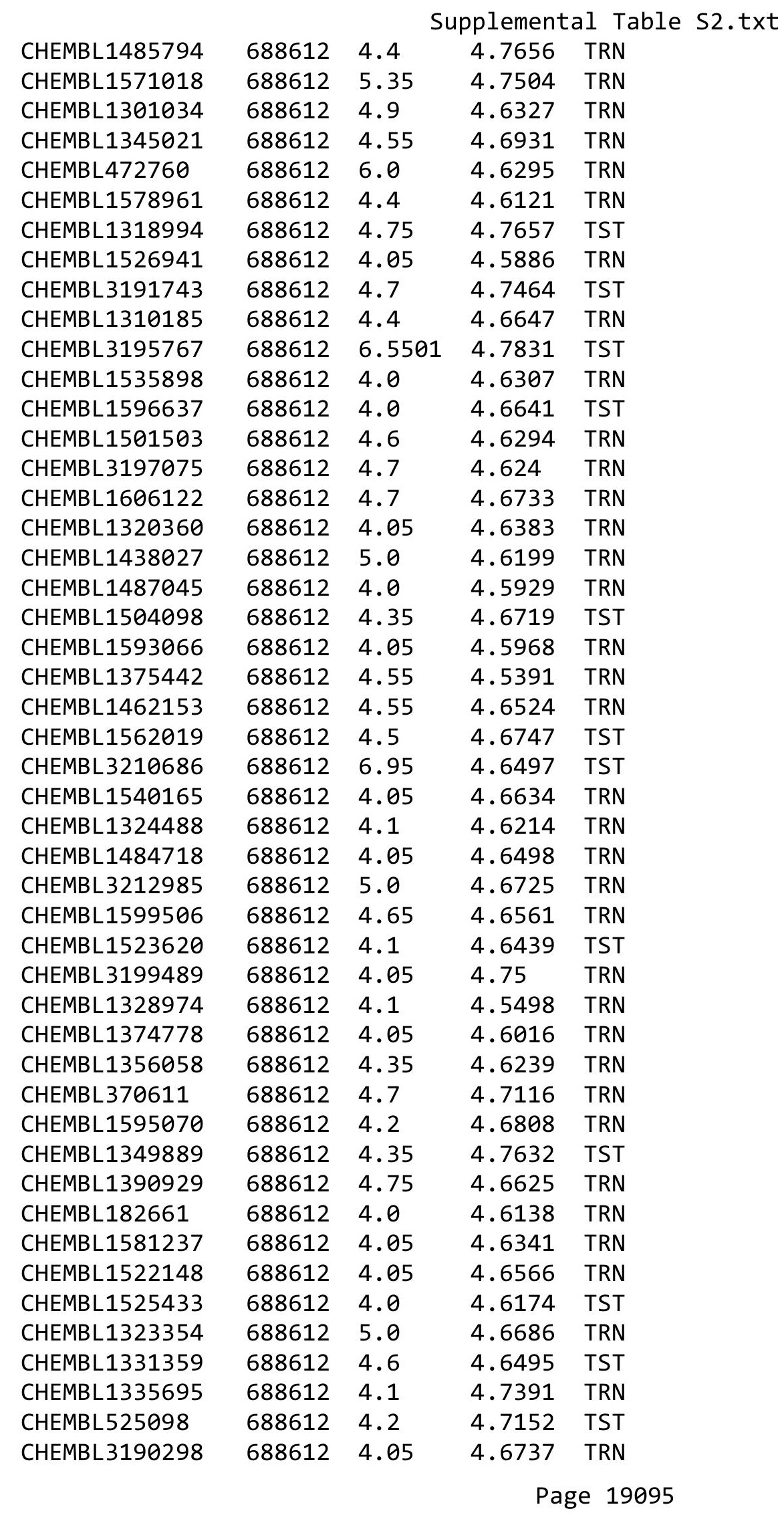




\begin{tabular}{|c|c|c|c|c|}
\hline \multicolumn{5}{|c|}{ Supplemental Table S2.txt } \\
\hline CHEMBL1371880 & 688612 & 4.0 & 4.7636 & TRN \\
\hline CHEMBL1523795 & 688612 & 4.4 & 4.7208 & TST \\
\hline CHEMBL1325053 & 688612 & 4.05 & 4.7214 & TST \\
\hline CHEMBL3191205 & 688612 & 4.5 & 4.7182 & TRN \\
\hline CHEMBL3191543 & 688612 & 4.7 & 4.8211 & TRN \\
\hline CHEMBL1409928 & 688612 & 4.05 & 4.6165 & TST \\
\hline CHEMBL1459271 & 688612 & 4.05 & 4.6359 & TST \\
\hline CHEMBL1453751 & 688612 & 6.8499 & 4.6751 & TST \\
\hline CHEMBL1493615 & 688612 & 4.5 & 4.6158 & TRN \\
\hline CHEMBL1332310 & 688612 & 4.7 & 4.5892 & TRN \\
\hline CHEMBL1387069 & 688612 & 4.65 & 4.6638 & TRN \\
\hline CHEMBL1383577 & 688612 & 4.4 & 4.649 & TRN \\
\hline CHEMBL1514960 & 688612 & 5.05 & 4.6441 & TRN \\
\hline CHEMBL1414935 & 688612 & 6.9 & 4.6227 & TRN \\
\hline CHEMBL503470 & 688612 & 4.7 & 4.7085 & TST \\
\hline CHEMBL1454051 & 688612 & 6.0 & 4.6404 & TRN \\
\hline CHEMBL1567693 & 688612 & 4.05 & 4.6868 & TST \\
\hline CHEMBL1497051 & 688612 & 4.1 & 4.6492 & TRN \\
\hline CHEMBL1323312 & 688612 & 4.45 & 4.7457 & TST \\
\hline CHEMBL1459813 & 688612 & 4.05 & 4.6935 & TRN \\
\hline CHEMBL1375421 & 688612 & 4.6 & 4.6786 & TRN \\
\hline CHEMBL1590466 & 688612 & 4.6 & 4.6605 & TRN \\
\hline CHEMBL1451749 & 688612 & 4.65 & 4.7367 & TST \\
\hline CHEMBL1487460 & 688612 & 4.6 & 4.6978 & TRN \\
\hline CHEMBL1314355 & 688612 & 4.5 & 4.6215 & TRN \\
\hline CHEMBL1341147 & 688612 & 4.05 & 4.6819 & TST \\
\hline CHEMBL1391621 & 688612 & 4.05 & 4.6897 & TRN \\
\hline CHEMBL1403942 & 688612 & 4.05 & 4.6302 & TRN \\
\hline CHEMBL1497153 & 688612 & 4.45 & 4.7161 & TRN \\
\hline CHEMBL1333630 & 688612 & 4.6 & 4.6427 & TRN \\
\hline CHEMBL 2004756 & 688612 & 4.25 & 4.7238 & TRN \\
\hline CHEMBL1461667 & 688612 & 4.05 & 4.6694 & TRN \\
\hline CHEMBL1316094 & 688612 & 4.75 & 4.631 & TRN \\
\hline CHEMBL1339167 & 688612 & 4.0 & 4.6892 & TST \\
\hline CHEMBL1558592 & 688612 & 4.1 & 4.69 & TST \\
\hline CHEMBL1313891 & 688612 & 6.15 & 4.7593 & TRN \\
\hline CHEMBL1362990 & 688612 & 4.1 & 4.5929 & TST \\
\hline CHEMBL1390131 & 688612 & 4.05 & 4.7431 & TST \\
\hline CHEMBL1455187 & 688612 & 4.0 & 4.6943 & TST \\
\hline CHEMBL1479940 & 688612 & 4.35 & 4.7127 & TRN \\
\hline CHEMBL1383076 & 688612 & 5.5 & 4.6406 & TST \\
\hline CHEMBL1565114 & 688612 & 4.75 & 4.7066 & TRN \\
\hline CHEMBL1406997 & 688612 & 4.95 & 4.6008 & TST \\
\hline CHEMBL1389399 & 688612 & 4.5 & 4.6528 & TST \\
\hline CHEMBL1309110 & 688612 & 4.9 & 4.6399 & TRN \\
\hline CHEMBL1382373 & 688612 & 4.0 & 4.6833 & TRN \\
\hline CHEMBL1326194 & 688612 & 4.5 & 4.7185 & TRN \\
\hline CHEMBL1591997 & 688612 & 4.55 & 4.6459 & TRN \\
\hline
\end{tabular}




\begin{tabular}{|c|c|c|c|c|c|}
\hline \multicolumn{6}{|c|}{ Supplemental Table s2.txt } \\
\hline CHEMBL1359009 & 688612 & 4.05 & 4.6686 & TRN & \\
\hline CHEMBL 2000172 & 688612 & 4.55 & 4.7507 & TRN & \\
\hline CHEMBL1537178 & 688612 & 4.1 & 4.6939 & TRN & \\
\hline CHEMBL1964614 & 688612 & 5.05 & 4.7009 & TRN & \\
\hline CHEMBL3197557 & 688612 & 5.8 & 4.7741 & TRN & \\
\hline CHEMBL1300599 & 688612 & 4.85 & 4.6356 & TRN & \\
\hline CHEMBL1549883 & 688612 & 4.05 & 4.6569 & TRN & \\
\hline CHEMBL3208413 & 688612 & 4.1 & 4.7432 & TST & \\
\hline CHEMBL1505816 & 688612 & 6.4 & 4.8449 & TRN & \\
\hline CHEMBL3208397 & 688612 & 4.05 & 4.6825 & TST & \\
\hline CHEMBL1445235 & 688612 & 4.15 & 4.627 & TRN & \\
\hline CHEMBL 2004087 & 688612 & 4.75 & 4.6556 & TRN & \\
\hline CHEMBL1366819 & 688612 & 4.0 & 4.6823 & TRN & \\
\hline CHEMBL1563177 & 688612 & 4.1 & 4.5965 & TRN & \\
\hline CHEMBL1401904 & 688612 & 4.45 & 4.692 & TRN & \\
\hline CHEMBL1524318 & 688612 & 4.65 & 4.6522 & TRN & \\
\hline CHEMBL1357159 & 688612 & 4.05 & 4.6165 & TRN & \\
\hline CHEMBL1304623 & 688612 & 4.55 & 4.6469 & TRN & \\
\hline CHEMBL1312682 & 688612 & 5.45 & 4.7181 & TRN & \\
\hline CHEMBL1464693 & 688612 & 5.1 & 4.6303 & TRN & \\
\hline CHEMBL1506329 & 688612 & 4.05 & 4.6491 & TRN & \\
\hline CHEMBL1417032 & 688612 & 4.05 & 4.5439 & TRN & \\
\hline CHEMBL1301650 & 688612 & 4.05 & 4.6145 & TRN & \\
\hline CHEMBL1422046 & 688612 & 5.1 & 4.801 & TRN & \\
\hline CHEMBL1571480 & 688612 & 4.05 & 4.6865 & TRN & \\
\hline CHEMBL1551877 & 688612 & 4.05 & 4.6461 & TRN & \\
\hline CHEMBL1578710 & 688612 & 4.05 & 4.6143 & TST & \\
\hline CHEMBL1468850 & 688612 & 4.55 & 4.6848 & TRN & \\
\hline CHEMBL518292 & 688612 & 4.7 & 4.7273 & TST & \\
\hline CHEMBL1411518 & 688612 & 4.05 & 4.6975 & TRN & \\
\hline CHEMBL1385267 & 688612 & 4.1 & 4.6503 & TRN & \\
\hline CHEMBL1376639 & 688612 & 5.5 & 4.6216 & TST & \\
\hline CHEMBL1521611 & 688612 & 6.8499 & 4.6806 & TRN & \\
\hline CHEMBL1440718 & 688612 & 4.6 & 4.6423 & TRN & \\
\hline CHEMBL1578675 & 688612 & 4.4 & 4.6752 & TRN & \\
\hline CHEMBL1315199 & 688612 & 5.15 & 4.6882 & TST & \\
\hline CHEMBL1339737 & 688612 & 4.4 & 4.6834 & TST & \\
\hline CHEMBL1570027 & 688612 & 6.4 & 4.6945 & TRN & \\
\hline CHEMBL1364662 & 688612 & 4.8 & 4.6343 & TST & \\
\hline CHEMBL1310339 & 688612 & 4.45 & 4.6438 & TRN & \\
\hline CHEMBL1367414 & 688612 & 4.4 & 4.6415 & TRN & \\
\hline CHEMBL1560609 & 688612 & 4.4 & 4.6182 & TRN & \\
\hline CHEMBL3190315 & 688612 & 4.05 & 4.6676 & TST & \\
\hline CHEMBL1336224 & 688612 & 4.05 & 4.6376 & TRN & \\
\hline CHEMBL1452552 & 688612 & 6.6499 & 4.5544 & TRN & \\
\hline CHEMBL1392670 & 688612 & 4.65 & 4.678 & TST & \\
\hline CHEMBL1423303 & 688612 & 4.4 & 4.6635 & TRN & \\
\hline CHEMBL1461574 & 688612 & 4.45 & 4.61100 & 0000000001 & TRN \\
\hline & & & & 19097 & \\
\hline
\end{tabular}




\begin{tabular}{|c|c|c|c|c|}
\hline \multicolumn{5}{|c|}{ Supplemental Table S2.txt } \\
\hline CHEMBL1506689 & 688612 & 4.45 & 4.6579 & TRN \\
\hline CHEMBL1569472 & 688612 & 4.3 & 4.8002 & TRN \\
\hline CHEMBL2007318 & 688612 & 5.45 & 4.7748 & TRN \\
\hline CHEMBL1479325 & 688612 & 4.35 & 4.7192 & TRN \\
\hline CHEMBL1562005 & 688612 & 4.0 & 4.6745 & TST \\
\hline CHEMBL 1455640 & 688612 & 4.25 & 4.7306 & TRN \\
\hline CHEMBL1367408 & 688612 & 4.45 & 4.678 & TRN \\
\hline CHEMBL1308699 & 688612 & 6.5501 & 4.6229 & TRN \\
\hline CHEMBL 1409888 & 688612 & 4.05 & 4.6482 & TRN \\
\hline CHEMBL1599723 & 688612 & 5.0 & 4.7321 & TRN \\
\hline CHEMBL1530621 & 688612 & 6.15 & 4.6748 & TRN \\
\hline CHEMBL1484998 & 688612 & 4.05 & 4.7059 & TRN \\
\hline CHEMBL3195206 & 688612 & 4.05 & 4.7047 & TRN \\
\hline CHEMBL1522978 & 688612 & 4.1 & 4.6368 & TRN \\
\hline CHEMBL1988987 & 688612 & 4.05 & 4.6501 & TRN \\
\hline CHEMBL1355620 & 688612 & 6.0 & 4.6898 & TST \\
\hline CHEMBL1448529 & 688612 & 4.9 & 4.6633 & TRN \\
\hline CHEMBL1510679 & 688612 & 6.3 & 4.7162 & TST \\
\hline CHEMBL1530697 & 688612 & 5.75 & 4.6497 & TST \\
\hline CHEMBL1564994 & 688612 & 4.65 & 4.584 & TST \\
\hline CHEMBL1255936 & 688612 & 4.55 & 4.6636 & TST \\
\hline CHEMBL1427459 & 688612 & 6.1 & 4.7067 & TRN \\
\hline CHEMBL 85139 & 688612 & 4.35 & 4.7053 & TRN \\
\hline CHEMBL1486346 & 688612 & 4.05 & 4.6878 & TRN \\
\hline CHEMBL1419365 & 688612 & 4.25 & 4.664 & TST \\
\hline CHEMBL1315025 & 688612 & 4.2 & 4.6045 & TRN \\
\hline CHEMBL1556638 & 688612 & 5.25 & 4.5948 & TST \\
\hline CHEMBL1463980 & 688612 & 5.75 & 4.6592 & TRN \\
\hline CHEMBL1388371 & 688612 & 5.1 & 4.6176 & TST \\
\hline CHEMBL 1502030 & 688612 & 4.8 & 4.6504 & TRN \\
\hline CHEMBL1367594 & 688612 & 5.0 & 4.6387 & TRN \\
\hline CHEMBL1366987 & 688612 & 4.15 & 4.7364 & TST \\
\hline CHEMBL1363286 & 688612 & 4.05 & 4.5751 & TRN \\
\hline CHEMBL1357389 & 688612 & 4.0 & 4.655 & TST \\
\hline CHEMBL1301983 & 688612 & 4.0 & 4.6476 & TRN \\
\hline CHEMBL1356852 & 688612 & 4.45 & 4.7189 & TRN \\
\hline CHEMBL1465820 & 688612 & 5.45 & 4.5927 & TRN \\
\hline CHEMBL1481788 & 688612 & 6.5 & 4.6782 & TST \\
\hline CHEMBL1349968 & 688612 & 4.05 & $4.6560 e$ & 0000000001 \\
\hline CHEMBL1352358 & 688612 & 4.0 & 4.7319 & TRN \\
\hline CHEMBL1379963 & 688612 & 6.8499 & 4.7563 & TRN \\
\hline CHEMBL1457099 & 688612 & 4.0 & 4.5722 & TRN \\
\hline CHEMBL1605743 & 688612 & 5.1 & 4.7891 & TRN \\
\hline CHEMBL1482865 & 688612 & 4.0 & 4.7292 & TRN \\
\hline CHEMBL1612170 & 688612 & 6.45 & 4.5968 & TRN \\
\hline CHEMBL1390647 & 688612 & 4.05 & 4.6768 & TRN \\
\hline CHEMBL1334312 & 688612 & 4.25 & 4.6552 & TRN \\
\hline CHEMBL1557199 & 688612 & 4.6 & 4.6067 & TST \\
\hline
\end{tabular}




\begin{tabular}{|c|c|c|c|c|}
\hline \multicolumn{5}{|c|}{ Supplemental Table S2.txt } \\
\hline CHEMBL1364277 & 688612 & 4.4 & 4.7635 & TST \\
\hline CHEMBL1392035 & 688612 & 4.1 & 4.663 & TST \\
\hline CHEMBL1593938 & 688612 & 4.1 & 4.6398 & TRN \\
\hline CHEMBL 1444780 & 688612 & 4.05 & 4.6955 & TRN \\
\hline CHEMBL1341987 & 688612 & 4.9 & 4.5606 & TRN \\
\hline CHEMBL1334710 & 688612 & 5.0 & 4.7406 & TRN \\
\hline CHEMBL1306155 & 688612 & 4.5 & 4.5928 & TRN \\
\hline CHEMBL1408177 & 688612 & 6.8499 & 4.6552 & TRN \\
\hline CHEMBL3197761 & 688612 & 4.1 & 4.6669 & TRN \\
\hline CHEMBL1731995 & 688612 & 5.5 & 4.7392 & TRN \\
\hline CHEMBL1462118 & 688612 & 6.95 & 4.7109 & TST \\
\hline CHEMBL1613422 & 688612 & 4.3 & 4.7128 & TST \\
\hline CHEMBL1447322 & 688612 & 4.65 & 4.6037 & TRN \\
\hline CHEMBL1381278 & 688612 & 4.05 & 4.6552 & TRN \\
\hline CHEMBL1511181 & 688612 & 4.55 & 4.6935 & TRN \\
\hline CHEMBL1537608 & 688612 & 5.0 & 4.6559 & TRN \\
\hline CHEMBL1576811 & 688612 & 4.1 & 4.6052 & TRN \\
\hline CHEMBL1543343 & 688612 & 4.25 & 4.7581 & TST \\
\hline CHEMBL1360580 & 688612 & 4.05 & 4.7101 & TST \\
\hline CHEMBL1301328 & 688612 & 4.7 & 4.6098 & TRN \\
\hline CHEMBL3197565 & 688612 & 4.1 & 4.7128 & TRN \\
\hline CHEMBL1600608 & 688612 & 4.1 & 4.6024 & TRN \\
\hline CHEMBL1544707 & 688612 & 4.4 & 4.6397 & TST \\
\hline CHEMBL1351620 & 688612 & 4.05 & 4.5817 & TRN \\
\hline CHEMBL1494528 & 688612 & 6.0 & 4.6863 & TST \\
\hline CHEMBL1412666 & 688612 & 5.6 & 4.6983 & TST \\
\hline CHEMBL1475528 & 688612 & 5.3 & 4.6615 & TRN \\
\hline CHEMBL1502839 & 688612 & 4.05 & 4.6705 & TRN \\
\hline CHEMBL1547264 & 688612 & 4.55 & 4.695 & TRN \\
\hline CHEMBL1400949 & 688612 & 4.05 & 4.6576 & TST \\
\hline CHEMBL1421731 & 688612 & 5.5 & 4.6236 & TRN \\
\hline CHEMBL1309877 & 688612 & 4.95 & 4.716 & TRN \\
\hline CHEMBL3208526 & 688612 & 4.0 & 4.6943 & TRN \\
\hline CHEMBL1568068 & 688612 & 4.0 & 4.7 & TST \\
\hline CHEMBL1322751 & 688612 & 4.0 & 4.6249 & TST \\
\hline CHEMBL1533230 & 688612 & 5.7 & 4.6553 & TST \\
\hline CHEMBL1380309 & 688612 & 4.5 & 4.7107 & TST \\
\hline CHEMBL1362783 & 688612 & 4.25 & 4.668 & TRN \\
\hline CHEMBL1403541 & 688612 & 4.55 & 4.789 & TRN \\
\hline CHEMBL1507982 & 688612 & 4.05 & 4.7806 & TRN \\
\hline CHEMBL1581543 & 688612 & 4.85 & 4.7314 & TRN \\
\hline CHEMBL1402632 & 688612 & 4.7 & 4.6614 & TRN \\
\hline CHEMBL1602781 & 688612 & 5.1 & 4.6329 & TRN \\
\hline CHEMBL1335789 & 688612 & 4.1 & 4.6639 & TRN \\
\hline CHEMBL1354369 & 688612 & 4.05 & 4.541 & TRN \\
\hline CHEMBL1524046 & 688612 & 4.35 & 4.6346 & TRN \\
\hline CHEMBL1431050 & 688612 & 5.3 & 4.5947 & TST \\
\hline CHEMBL1389544 & 688612 & 5.05 & 4.6168 & TRN \\
\hline
\end{tabular}




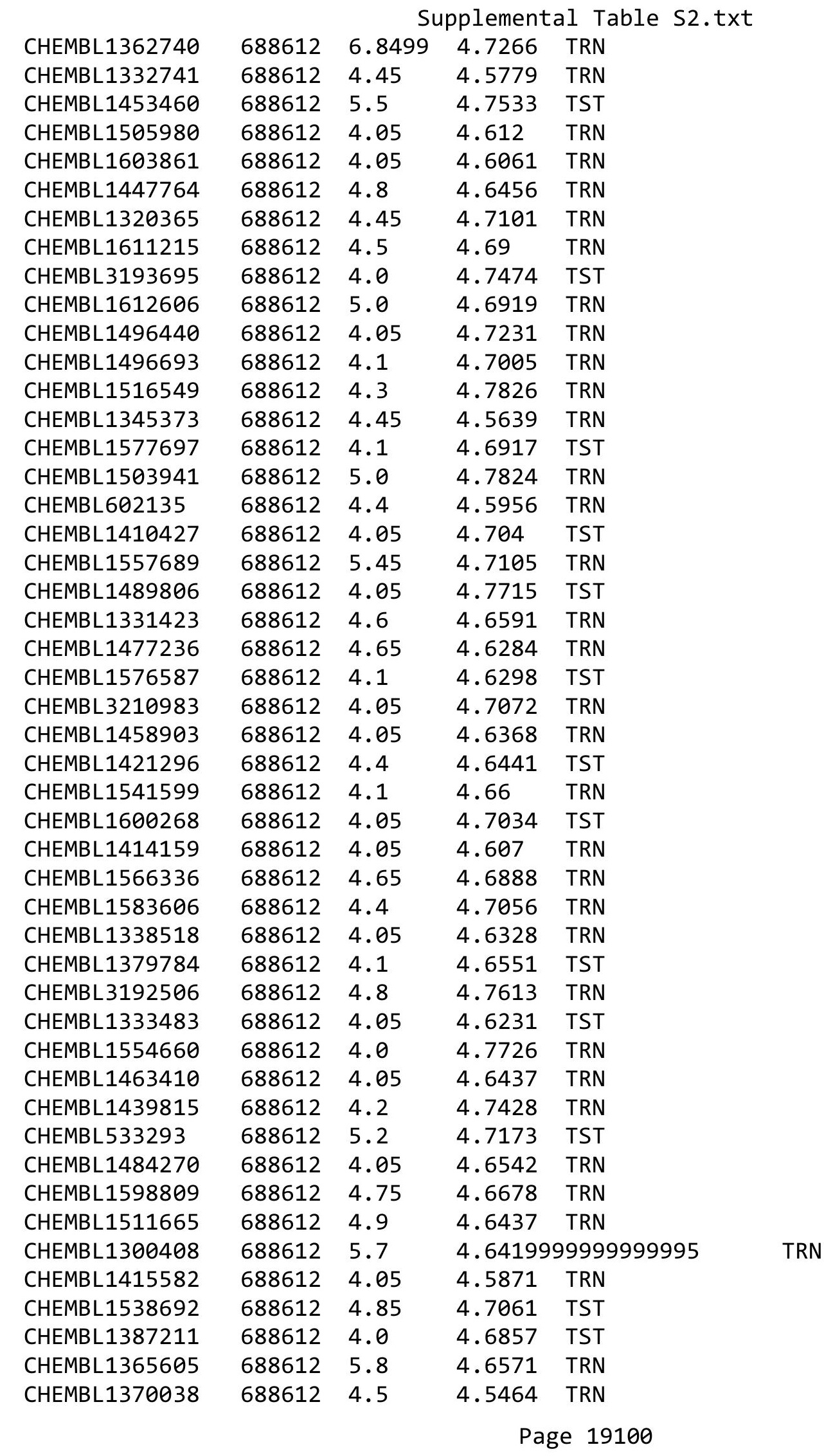




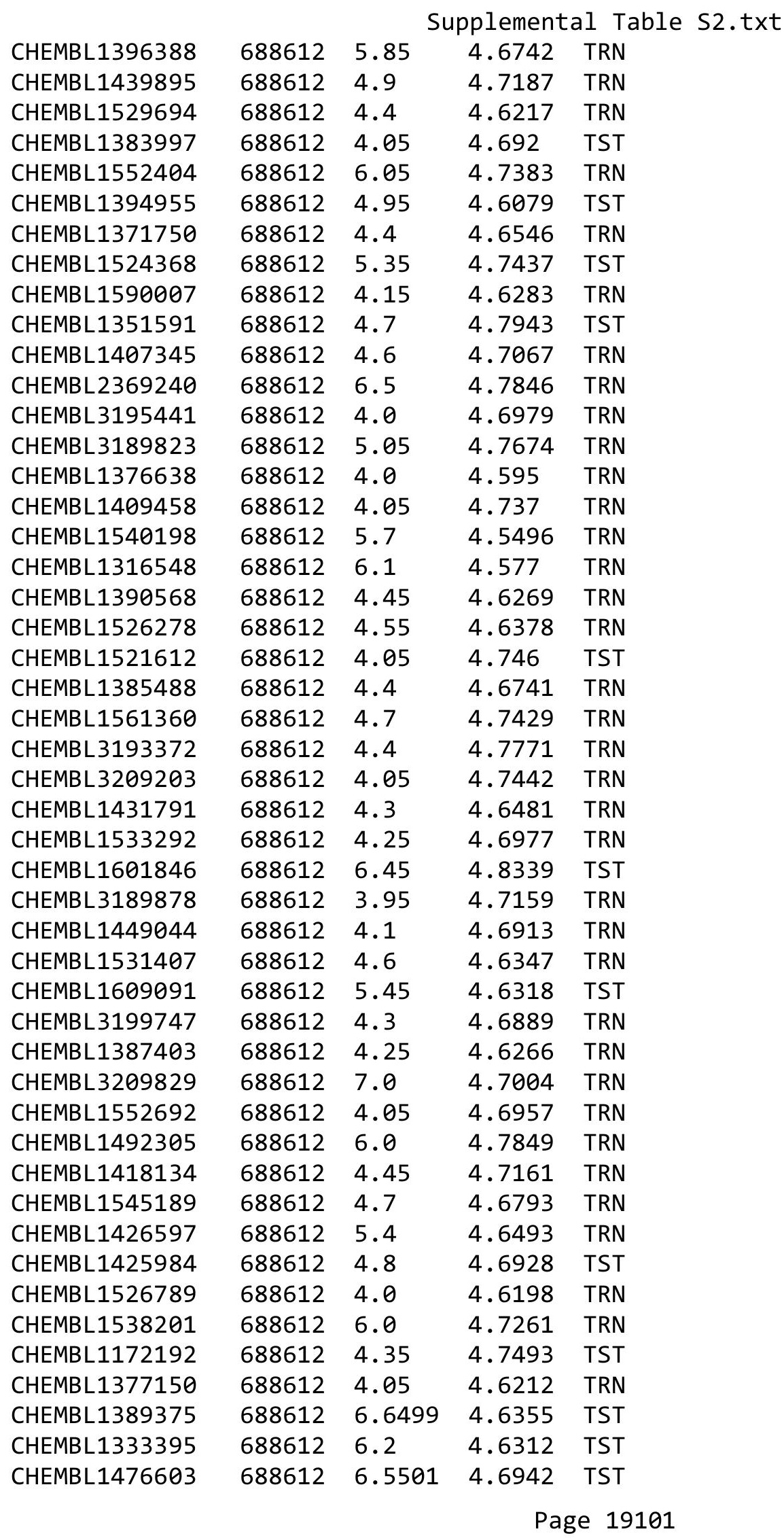




\begin{tabular}{|c|c|c|c|c|c|}
\hline \multicolumn{6}{|c|}{ Supplemental Table s2.txt } \\
\hline CHEMBL3189286 & 688612 & 6.15 & 4.6483 & TST & \\
\hline CHEMBL1392536 & 688612 & 4.6 & 4.7365 & TST & \\
\hline CHEMBL1516965 & 688612 & 5.4 & 4.6461 & TRN & \\
\hline CHEMBL1505610 & 688612 & 4.1 & 4.6578 & TRN & \\
\hline CHEMBL1588403 & 688612 & 6.1 & 4.6523 & TRN & \\
\hline CHEMBL1406808 & 688612 & 5.3 & 4.6003 & TRN & \\
\hline CHEMBL1403644 & 688612 & 4.6 & 4.6965 & TRN & \\
\hline CHEMBL1394890 & 688612 & 4.05 & 4.5944 & TRN & \\
\hline CHEMBL1587393 & 688612 & 4.1 & 4.7104 & TRN & \\
\hline CHEMBL1469489 & 688612 & 4.25 & 4.6824 & TRN & \\
\hline CHEMBL1380450 & 688612 & 4.4 & 4.6603 & TRN & \\
\hline CHEMBL1338404 & 688612 & 4.05 & 4.6556 & TRN & \\
\hline CHEMBL1457361 & 688612 & 4.8 & 4.5588 & TRN & \\
\hline CHEMBL51931 & 688612 & 4.8 & 4.7085 & TRN & \\
\hline CHEMBL1369200 & 688612 & 4.35 & 4.6515 & TRN & \\
\hline CHEMBL3199894 & 688612 & 4.3 & 4.7035 & TRN & \\
\hline CHEMBL1473350 & 688612 & 7.699 & 4.7142 & TRN & \\
\hline CHEMBL1361562 & 688612 & 4.2 & 4.6416 & TRN & \\
\hline CHEMBL1299937 & 688612 & 4.0 & 4.6741 & TRN & \\
\hline CHEMBL1561460 & 688612 & 4.0 & 4.6457 & TST & \\
\hline CHEMBL 2003240 & 688612 & 4.2 & 4.6956 & TRN & \\
\hline CHEMBL3211470 & 688612 & 4.1 & 4.73300 & 00000000005 & TRN \\
\hline CHEMBL1441346 & 688612 & 4.5 & 4.6979 & TRN & \\
\hline CHEMBL1566544 & 688612 & 4.05 & 4.6855 & TRN & \\
\hline CHEMBL1505129 & 688612 & 4.7 & 4.6179 & TRN & \\
\hline CHEMBL1358171 & 688612 & 5.1 & 4.6727 & TRN & \\
\hline CHEMBL1413761 & 688612 & 4.05 & 4.6552 & TRN & \\
\hline CHEMBL1467794 & 688612 & 4.3 & 4.6486 & TRN & \\
\hline CHEMBL1458769 & 688612 & 4.4 & 4.6735 & TRN & \\
\hline CHEMBL1486865 & 688612 & 5.3 & 4.6415 & TRN & \\
\hline CHEMBL1553972 & 688612 & 4.05 & 4.6357 & TRN & \\
\hline CHEMBL1487833 & 688612 & 4.7 & 4.7056 & TRN & \\
\hline CHEMBL1466573 & 688612 & 4.05 & 4.6318 & TST & \\
\hline CHEMBL1379288 & 688612 & 4.05 & 4.6525 & TRN & \\
\hline CHEMBL1388881 & 688612 & 4.5 & 4.72 & TRN & \\
\hline CHEMBL1596702 & 688612 & 4.7 & 4.7384 & TRN & \\
\hline CHEMBL1577593 & 688612 & 4.4 & 4.615 & TST & \\
\hline CHEMBL1483497 & 688612 & 6.8499 & 4.6501 & TRN & \\
\hline CHEMBL1583266 & 688612 & 4.6 & 4.6728 & TRN & \\
\hline CHEMBL1497594 & 688612 & 4.1 & 4.6377 & TST & \\
\hline CHEMBL1393232 & 688612 & 4.3 & 4.6403 & TRN & \\
\hline CHEMBL1344523 & 688612 & 4.1 & 4.6444 & TRN & \\
\hline CHEMBL 276727 & 688612 & 4.4 & 4.7415 & TST & \\
\hline CHEMBL1370065 & 688612 & 4.7 & 4.5975 & TRN & \\
\hline CHEMBL1375955 & 688612 & 6.0 & 4.6762 & TRN & \\
\hline CHEMBL1499390 & 688612 & 4.8 & 4.7419 & TST & \\
\hline CHEMBL1382693 & 688612 & 4.35 & 4.6789 & TRN & \\
\hline CHEMBL1466395 & 688612 & 6.5501 & 4.6918 & TRN & \\
\hline
\end{tabular}




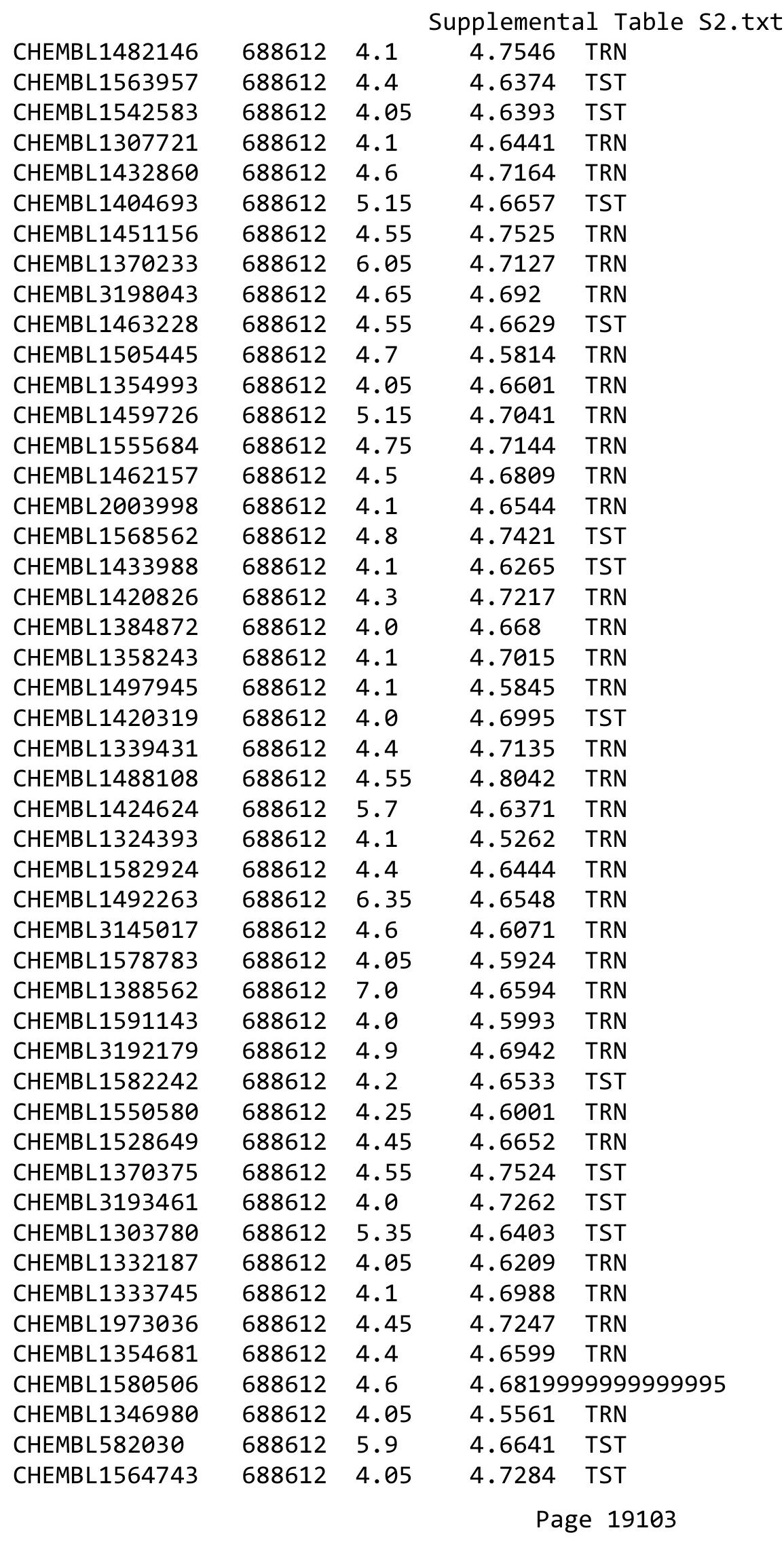




\begin{tabular}{|c|c|c|c|c|c|}
\hline \multirow[b]{2}{*}{ CHEMBL1595609 } & \multicolumn{5}{|c|}{ Supplemental Table s2.txt } \\
\hline & 688612 & 4.05 & 4.6411 & TRN & \\
\hline CHEMBL1479098 & 688612 & 6.6 & 4.64199 & 99999999995 & TST \\
\hline CHEMBL1530984 & 688612 & 4.0 & 4.6515 & TRN & \\
\hline CHEMBL1378824 & 688612 & 4.4 & 4.6451 & TST & \\
\hline CHEMBL1561272 & 688612 & 4.75 & 4.6609 & TRN & \\
\hline CHEMBL1969672 & 688612 & 4.6 & 4.6411 & TRN & \\
\hline CHEMBL1301682 & 688612 & 4.0 & 4.6453 & TRN & \\
\hline CHEMBL1435910 & 688612 & 4.05 & 4.6845 & TRN & \\
\hline CHEMBL1400161 & 688612 & 4.0 & 4.6401 & TST & \\
\hline CHEMBL1436034 & 688612 & 4.25 & 4.6312 & TRN & \\
\hline CHEMBL1610373 & 688612 & 4.05 & 4.6643 & TRN & \\
\hline CHEMBL1443274 & 688612 & 4.05 & 4.5909 & TRN & \\
\hline CHEMBL1301514 & 688612 & 6.1 & 4.5694 & TRN & \\
\hline CHEMBL1519166 & 688612 & 5.4 & 4.6863 & TRN & \\
\hline CHEMBL1413557 & 688612 & 4.75 & 4.6864 & TRN & \\
\hline CHEMBL1502107 & 688612 & 6.8 & 4.6186 & TRN & \\
\hline CHEMBL1575977 & 688612 & 4.2 & 4.7518 & TRN & \\
\hline CHEMBL1532547 & 688612 & 4.9 & 4.784 & TRN & \\
\hline CHEMBL1472389 & 688612 & 4.1 & 4.657 & TST & \\
\hline CHEMBL1570398 & 688612 & 4.55 & 4.6563 & TRN & \\
\hline CHEMBL1405648 & 688612 & 4.4 & 4.6947 & TRN & \\
\hline CHEMBL1361241 & 688612 & 5.8 & 4.6395 & TRN & \\
\hline CHEMBL1376991 & 688612 & 4.6 & 4.6853 & TRN & \\
\hline CHEMBL 3189852 & 688612 & 4.05 & 4.6883 & TST & \\
\hline CHEMBL1302318 & 688612 & 4.75 & 4.7189 & TST & \\
\hline CHEMBL1595676 & 688612 & 5.15 & 4.586 & TRN & \\
\hline CHEMBL1603603 & 688612 & 4.4 & 4.6314 & TRN & \\
\hline CHEMBL1561733 & 688612 & 4.05 & 4.5081 & TRN & \\
\hline CHEMBL3198161 & 688612 & 4.65 & 4.6788 & TRN & \\
\hline CHEMBL1465413 & 688612 & 4.05 & 4.5588 & TRN & \\
\hline CHEMBL1412594 & 688612 & 6.5501 & 4.6118 & TRN & \\
\hline CHEMBL3194670 & 688612 & 4.0 & 4.6927 & TRN & \\
\hline CHEMBL1500890 & 688612 & 4.65 & 4.7329 & TRN & \\
\hline CHEMBL3198979 & 688612 & 4.55 & 4.6567 & TRN & \\
\hline CHEMBL1352328 & 688612 & 4.35 & 4.6696 & TRN & \\
\hline CHEMBL1481455 & 688612 & 5.0 & 4.7154 & TRN & \\
\hline CHEMBL1353907 & 688612 & 4.65 & 4.7062 & TRN & \\
\hline CHEMBL1548353 & 688612 & 4.7 & 4.7053 & TRN & \\
\hline CHEMBL1562604 & 688612 & 6.5501 & 4.7568 & TST & \\
\hline CHEMBL1443547 & 688612 & 4.05 & 4.7039 & TRN & \\
\hline CHEMBL589835 & 688612 & 4.25 & 4.6798 & TRN & \\
\hline CHEMBL3208823 & 688612 & 4.1 & 4.6648 & TST & \\
\hline CHEMBL1310509 & 688612 & 4.5 & 4.6027 & TST & \\
\hline CHEMBL1368717 & 688612 & 5.3 & 4.7007 & TST & \\
\hline CHEMBL1486121 & 688612 & 4.35 & 4.69600 & 0000000001 & TRN \\
\hline CHEMBL1560828 & 688612 & 6.05 & 4.6397 & TRN & \\
\hline CHEMBL1349640 & 688612 & 4.8 & 4.6908 & TRN & \\
\hline CHEMBL1335703 & 688612 & 4.25 & 4.6877 & TST & \\
\hline
\end{tabular}




\begin{tabular}{|c|c|c|c|c|c|}
\hline \multicolumn{6}{|c|}{ Supplemental Table s2.txt } \\
\hline CHEMBL1444176 & 688612 & 6.25 & 4.7212 & TST & \\
\hline CHEMBL1507285 & 688612 & 6.8 & 4.6596 & TRN & \\
\hline CHEMBL1504991 & 688612 & 5.45 & 4.6445 & TRN & \\
\hline CHEMBL1332103 & 688612 & 4.0 & 4.6441 & TST & \\
\hline CHEMBL1363210 & 688612 & 4.05 & 4.6353 & TRN & \\
\hline CHEMBL1451659 & 688612 & 4.1 & 4.705 & TST & \\
\hline CHEMBL1390780 & 688612 & 4.85 & 4.7277 & TRN & \\
\hline CHEMBL1612535 & 688612 & 4.5 & 4.6214 & TRN & \\
\hline CHEMBL1548470 & 688612 & 4.0 & 4.6202 & TRN & \\
\hline CHEMBL1387330 & 688612 & 4.05 & 4.6535 & TST & \\
\hline CHEMBL1540519 & 688612 & 4.05 & 4.7016 & TRN & \\
\hline CHEMBL1437377 & 688612 & 4.0 & 4.5276 & TRN & \\
\hline CHEMBL 1455340 & 688612 & 4.1 & 4.7007 & TRN & \\
\hline CHEMBL1532072 & 688612 & 6.0 & 4.7435 & TRN & \\
\hline CHEMBL1347385 & 688612 & 4.7 & 4.7595 & TRN & \\
\hline CHEMBL1471807 & 688612 & 4.05 & 4.6433 & TRN & \\
\hline CHEMBL1357032 & 688612 & 6.6 & 4.6726 & TRN & \\
\hline CHEMBL1468011 & 688612 & 4.3 & 4.7599 & TRN & \\
\hline CHEMBL1560526 & 688612 & 6.6 & 4.6715 & TST & \\
\hline CHEMBL3211402 & 688612 & 4.05 & 4.6507 & TRN & \\
\hline CHEMBL1495400 & 688612 & 4.0 & 4.6285 & TRN & \\
\hline CHEMBL1380954 & 688612 & 4.45 & 4.69 & TRN & \\
\hline CHEMBL1551317 & 688612 & 4.0 & 4.6887 & TST & \\
\hline CHEMBL 3193592 & 688612 & 4.85 & 4.7444 & TRN & \\
\hline CHEMBL3207804 & 688612 & 6.1 & 4.6578 & TRN & \\
\hline CHEMBL1408208 & 688612 & 5.4 & 4.6614 & TRN & \\
\hline CHEMBL1329033 & 688612 & 4.7 & 4.73300 & 00000000005 & TST \\
\hline CHEMBL1590575 & 688612 & 4.1 & 4.6969 & TST & \\
\hline CHEMBL1551779 & 688612 & 4.1 & 4.6725 & TRN & \\
\hline CHEMBL1546374 & 688612 & 4.3 & 4.7151 & TST & \\
\hline CHEMBL1424819 & 688612 & 4.6 & 4.7357 & TRN & \\
\hline CHEMBL1570051 & 688612 & 4.45 & 4.7523 & TRN & \\
\hline CHEMBL1435287 & 688612 & 4.25 & 4.6153 & TRN & \\
\hline CHEMBL3194655 & 688612 & 4.55 & 4.6588 & TRN & \\
\hline CHEMBL1528413 & 688612 & 4.2 & 4.6935 & TST & \\
\hline CHEMBL1487745 & 688612 & 6.9 & 4.6438 & TRN & \\
\hline CHEMBL1458844 & 688612 & 6.05 & 4.6186 & TST & \\
\hline CHEMBL1461421 & 688612 & 4.9 & 4.6251 & TST & \\
\hline CHEMBL1488104 & 688612 & 4.85 & 4.6874 & TRN & \\
\hline CHEMBL 3198017 & 688612 & 4.4 & 4.7221 & TST & \\
\hline CHEMBL1519821 & 688612 & 4.5 & 4.6731 & TRN & \\
\hline CHEMBL1429989 & 688612 & 6.95 & 4.6223 & TRN & \\
\hline CHEMBL3191779 & 688612 & 4.4 & 4.7517 & TST & \\
\hline CHEMBL1545603 & 688612 & 4.05 & 4.7638 & TST & \\
\hline CHEMBL 3212947 & 688612 & 4.6 & 4.7403 & TST & \\
\hline CHEMBL1327906 & 688612 & 4.45 & 4.59 & TRN & \\
\hline CHEMBL 3192328 & 688612 & 4.0 & 4.678 & TRN & \\
\hline CHEMBL1484370 & 688612 & 4.8 & 4.7217 & TRN & \\
\hline
\end{tabular}




\begin{tabular}{|c|c|c|c|c|c|}
\hline \multicolumn{6}{|c|}{ Supplemental Table S2.txt } \\
\hline CHEMBL1337238 & 688612 & 4.05 & 4.5732 & TRN & \\
\hline CHEMBL1313361 & 688612 & 6.35 & 4.5983 & TRN & \\
\hline CHEMBL1533529 & 688612 & 4.4 & 4.6749 & TRN & \\
\hline CHEMBL1580190 & 688612 & 4.0 & 4.6772 & TRN & \\
\hline CHEMBL1441941 & 688612 & 4.05 & 4.6155 & TRN & \\
\hline CHEMBL1475504 & 688612 & 4.95 & 4.6356 & TRN & \\
\hline CHEMBL1381564 & 688612 & 4.75 & 4.6914 & TRN & \\
\hline CHEMBL1540381 & 688612 & 4.4 & 4.6209 & TST & \\
\hline CHEMBL1973707 & 688612 & 4.1 & 4.7187 & TRN & \\
\hline CHEMBL1349626 & 688612 & 4.4 & 4.6481 & TRN & \\
\hline CHEMBL1572000 & 688612 & 4.0 & 4.6275 & TRN & \\
\hline CHEMBL1382648 & 688612 & 4.8 & 4.7332 & TRN & \\
\hline CHEMBL1559523 & 688612 & 4.3 & 4.7392 & TRN & \\
\hline CHEMBL1409045 & 688612 & 4.4 & 4.6211 & TRN & \\
\hline CHEMBL1577582 & 688612 & 4.4 & 4.598 & TRN & \\
\hline CHEMBL1404059 & 688612 & 4.0 & 4.6361 & TRN & \\
\hline CHEMBL3207648 & 688612 & 4.35 & 4.7274 & TRN & \\
\hline CHEMBL1402580 & 688612 & 4.1 & 4.61100 & 0000000001 & TRN \\
\hline CHEMBL1388711 & 688612 & 4.0 & 4.7203 & TRN & \\
\hline CHEMBL1523017 & 688612 & 4.0 & 4.6431 & TRN & \\
\hline CHEMBL1430989 & 688612 & 4.05 & 4.7437 & TRN & \\
\hline CHEMBL1420727 & 688612 & 4.4 & 4.7044 & TST & \\
\hline CHEMBL1367521 & 688612 & 4.05 & 4.6699 & TST & \\
\hline CHEMBL1377457 & 688612 & 4.35 & 4.6889 & TRN & \\
\hline CHEMBL1528709 & 688612 & 4.7 & 4.6848 & TRN & \\
\hline CHEMBL1426896 & 688612 & 4.1 & 4.76 & TST & \\
\hline CHEMBL1574979 & 688612 & 4.4 & 4.7635 & TRN & \\
\hline CHEMBL1542112 & 688612 & 5.1 & 4.5941 & TST & \\
\hline CHEMBL1480770 & 688612 & 4.55 & 4.6619 & TRN & \\
\hline CHEMBL1435796 & 688612 & 4.05 & 4.6372 & TRN & \\
\hline CHEMBL1606973 & 688612 & 4.4 & 4.7147 & TRN & \\
\hline CHEMBL1596439 & 688612 & 4.5 & 4.5197 & TRN & \\
\hline CHEMBL 1458120 & 688612 & 4.4 & 4.6961 & TRN & \\
\hline CHEMBL1564185 & 688612 & 4.1 & 4.6122 & TRN & \\
\hline CHEMBL1599000 & 688612 & 6.15 & 4.6671 & TRN & \\
\hline CHEMBL1309895 & 688612 & 5.05 & 4.7075 & TRN & \\
\hline CHEMBL3196712 & 688612 & 6.5501 & 4.7175 & TRN & \\
\hline CHEMBL1455212 & 688612 & 4.1 & 4.7329 & TRN & \\
\hline CHEMBL1533566 & 688612 & 4.65 & 4.5873 & TRN & \\
\hline CHEMBL1345338 & 688612 & 5.15 & 4.6764 & TRN & \\
\hline CHEMBL1421493 & 688612 & 4.2 & 4.7104 & TRN & \\
\hline CHEMBL1498796 & 688612 & 4.0 & 4.6507 & TRN & \\
\hline CHEMBL1988918 & 688612 & 4.05 & 4.7187 & TST & \\
\hline CHEMBL1508582 & 688612 & 5.05 & 4.6136 & TRN & \\
\hline CHEMBL1478408 & 688612 & 5.45 & 4.6852 & TST & \\
\hline CHEMBL1381892 & 688612 & 5.2 & 4.6367 & TRN & \\
\hline CHEMBL1497933 & 688612 & 4.35 & 4.6708 & TST & \\
\hline CHEMBL1975615 & 688612 & 5.65 & 4.7047 & TRN & \\
\hline
\end{tabular}




\begin{tabular}{|c|c|c|c|c|}
\hline \multicolumn{5}{|c|}{ Supplemental Table S2.txt } \\
\hline CHEMBL1373537 & 688612 & 4.3 & 4.6382 & TRN \\
\hline CHEMBL1705092 & 688612 & 4.05 & 4.7163 & TST \\
\hline CHEMBL1487901 & 688612 & 4.05 & 4.6989 & TST \\
\hline CHEMBL 1485170 & 688612 & 4.7 & 4.6782 & TRN \\
\hline CHEMBL1381136 & 688612 & 4.7 & 4.7849 & TRN \\
\hline CHEMBL1518976 & 688612 & 4.5 & 4.7178 & TRN \\
\hline CHEMBL3191831 & 688612 & 4.6 & 4.7767 & TRN \\
\hline CHEMBL1495113 & 688612 & 5.35 & 4.6622 & TRN \\
\hline CHEMBL1597650 & 688612 & 6.5 & 4.7406 & TRN \\
\hline CHEMBL3195664 & 688612 & 4.05 & 4.7491 & TST \\
\hline CHEMBL 3145049 & 688612 & 4.75 & 4.6937 & TRN \\
\hline CHEMBL1598222 & 688612 & 4.05 & 4.7156 & TRN \\
\hline CHEMBL1317845 & 688612 & 4.6 & 4.6001 & TRN \\
\hline CHEMBL1375934 & 688612 & 4.75 & 4.6749 & TST \\
\hline CHEMBL1409364 & 688612 & 4.05 & 4.6312 & TRN \\
\hline CHEMBL1508503 & 688612 & 4.9 & 4.7186 & TRN \\
\hline CHEMBL1392892 & 688612 & 5.8 & 4.6801 & TRN \\
\hline CHEMBL1458664 & 688612 & 4.2 & 4.6941 & TRN \\
\hline CHEMBL1332857 & 688612 & 5.45 & 4.6715 & TRN \\
\hline CHEMBL1334724 & 688612 & 4.0 & 4.675 & TRN \\
\hline CHEMBL1452195 & 688612 & 5.35 & 4.6755 & TRN \\
\hline CHEMBL1305751 & 688612 & 4.15 & 4.5682 & TRN \\
\hline CHEMBL1365170 & 688612 & 5.1 & 4.7245 & TRN \\
\hline CHEMBL1540993 & 688612 & 4.9 & 4.668 & TRN \\
\hline CHEMBL3209293 & 688612 & 4.95 & 4.7419 & TRN \\
\hline CHEMBL512261 & 688612 & 4.8 & 4.6956 & TRN \\
\hline CHEMBL1351397 & 688612 & 4.45 & 4.6886 & TRN \\
\hline CHEMBL1610559 & 688612 & 5.25 & 4.7192 & TRN \\
\hline CHEMBL3198420 & 688612 & 4.05 & 4.6627 & TRN \\
\hline CHEMBL1482962 & 688612 & 4.0 & 4.6498 & TRN \\
\hline CHEMBL1531104 & 688612 & 6.5 & 4.624 & TRN \\
\hline CHEMBL1432216 & 688612 & 4.05 & 4.7915 & TST \\
\hline CHEMBL1510927 & 688612 & 4.0 & 4.6606 & TRN \\
\hline CHEMBL1354269 & 688612 & 5.55 & 4.6128 & TRN \\
\hline CHEMBL1405078 & 688612 & 4.75 & 4.7894 & TRN \\
\hline CHEMBL1564012 & 688612 & 4.05 & 4.7476 & TST \\
\hline CHEMBL1343291 & 688612 & 4.4 & 4.6405 & TRN \\
\hline CHEMBL1444512 & 688612 & 6.9 & 4.6435 & TRN \\
\hline CHEMBL1583406 & 688612 & 4.6 & 4.7526 & TRN \\
\hline CHEMBL1547684 & 688612 & 6.4 & 4.7348 & TST \\
\hline CHEMBL1378648 & 688612 & 6.8499 & 4.5841 & TRN \\
\hline CHEMBL1462176 & 688612 & 4.2 & 4.6901 & TRN \\
\hline CHEMBL1426623 & 688612 & 6.45 & 4.6606 & TRN \\
\hline CHEMBL1391279 & 688612 & 4.35 & 4.6728 & TRN \\
\hline CHEMBL3192017 & 688612 & 4.8 & 4.71 & TRN \\
\hline CHEMBL1385788 & 688612 & 4.1 & 4.6735 & TRN \\
\hline CHEMBL1340261 & 688612 & 4.1 & 4.6137 & TRN \\
\hline CHEMBL1526379 & 688612 & 4.5 & 4.6719 & TST \\
\hline
\end{tabular}




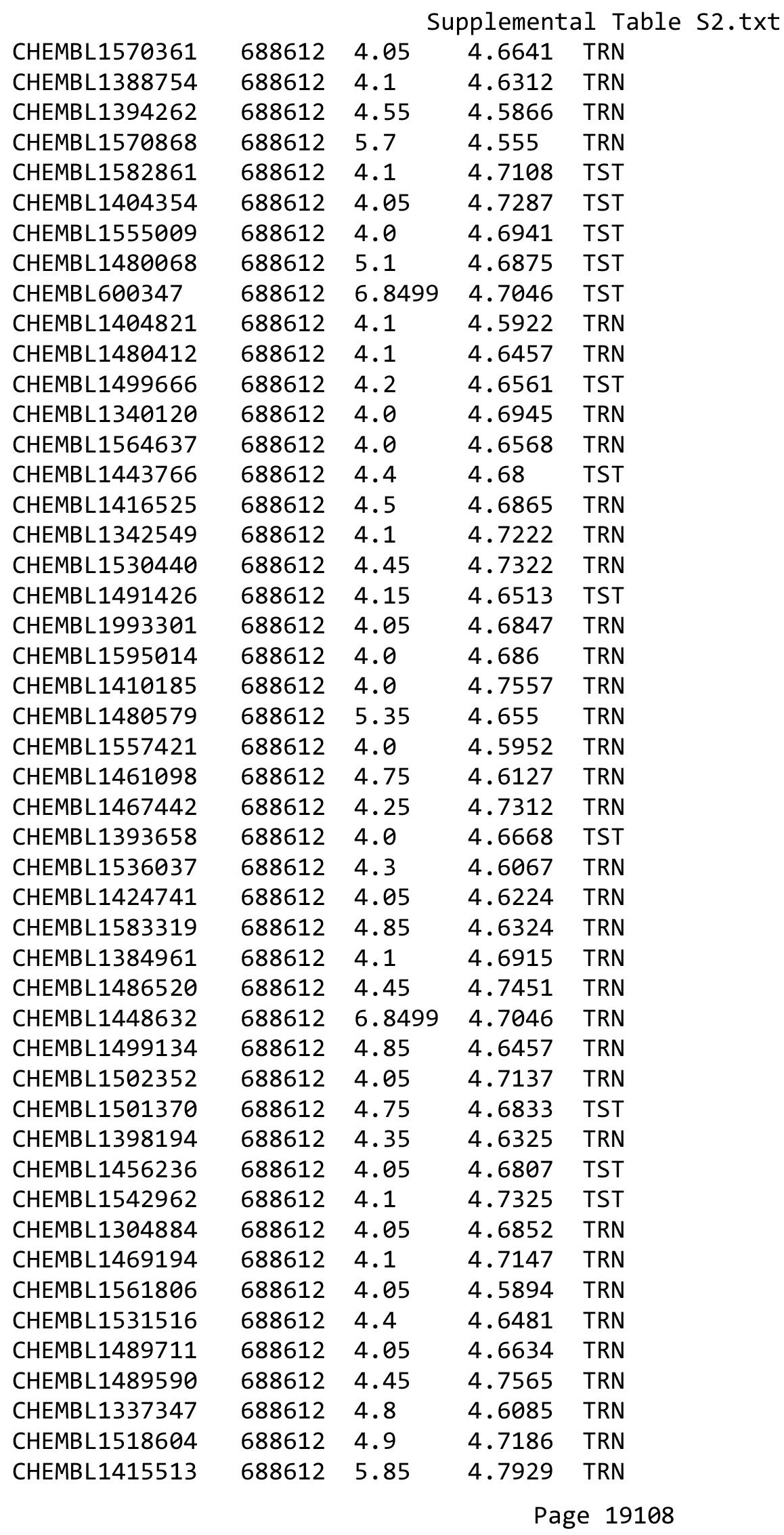




\begin{tabular}{|c|c|c|c|c|}
\hline \multicolumn{5}{|c|}{ Supplemental Table } \\
\hline CHEMBL1464827 & 688612 & 6.6499 & 4.6996 & TRN \\
\hline CHEMBL1529090 & 688612 & 4.75 & 4.7445 & TRN \\
\hline CHEMBL1368667 & 688612 & 4.85 & 4.7406 & TRN \\
\hline CHEMBL1460583 & 688612 & 4.45 & 4.6357 & TRN \\
\hline CHEMBL1588221 & 688612 & 4.05 & 4.6918 & TST \\
\hline CHEMBL1313799 & 688612 & 4.25 & 4.7029 & TRN \\
\hline CHEMBL 3194341 & 688612 & 6.5501 & 4.7318 & TRN \\
\hline CHEMBL1588406 & 688612 & 4.0 & 4.692 & TRN \\
\hline CHEMBL1510101 & 688612 & 6.6499 & 4.6179 & TRN \\
\hline CHEMBL1706619 & 688612 & 4.75 & 4.7427 & TRN \\
\hline CHEMBL1391308 & 688612 & 4.1 & 4.6769 & TRN \\
\hline CHEMBL1338052 & 688612 & 6.9 & 4.6136 & TRN \\
\hline CHEMBL1331531 & 688612 & 3.95 & 4.6131 & TST \\
\hline CHEMBL1524942 & 688612 & 4.7 & 4.743 & TRN \\
\hline CHEMBL1309685 & 688612 & 4.3 & 4.6285 & TRN \\
\hline CHEMBL1604557 & 688612 & 4.05 & 4.6159 & TST \\
\hline CHEMBL1983886 & 688612 & 4.25 & 4.6477 & TRN \\
\hline CHEMBL1336927 & 688612 & 4.35 & 4.7914 & TRN \\
\hline CHEMBL1548357 & 688612 & 4.3 & 4.7268 & TRN \\
\hline CHEMBL1489200 & 688612 & 4.0 & 4.6996 & TST \\
\hline CHEMBL1488551 & 688612 & 4.5 & 4.8138 & TRN \\
\hline CHEMBL1512884 & 688612 & 4.55 & 4.6089 & TRN \\
\hline CHEMBL1417848 & 688612 & 4.6 & 4.7297 & TRN \\
\hline CHEMBL1609550 & 688612 & 5.8 & 4.8031 & TRN \\
\hline CHEMBL1547938 & 688612 & 4.45 & 4.8201 & TRN \\
\hline CHEMBL1532590 & 688612 & 4.1 & 4.7078 & TST \\
\hline CHEMBL1594027 & 688612 & 4.25 & 4.6137 & TRN \\
\hline CHEMBL1457034 & 688612 & 4.05 & 4.7224 & TRN \\
\hline CHEMBL1386352 & 688612 & 4.5 & 4.7178 & TRN \\
\hline CHEMBL1437305 & 688612 & 4.4 & 4.6313 & TRN \\
\hline CHEMBL1459394 & 688612 & 4.05 & 4.7164 & TRN \\
\hline CHEMBL1493370 & 688612 & 4.0 & 4.6593 & TRN \\
\hline CHEMBL1338804 & 688612 & 4.1 & 4.6602 & TST \\
\hline CHEMBL1558865 & 688612 & 4.05 & 4.5981 & TRN \\
\hline CHEMBL1578048 & 688612 & 4.1 & 4.6603 & TRN \\
\hline CHEMBL1571627 & 688612 & 4.95 & 4.7454 & TST \\
\hline CHEMBL1542956 & 688612 & 4.55 & 4.5868 & TRN \\
\hline CHEMBL1466912 & 688612 & 4.85 & 4.7244 & TRN \\
\hline CHEMBL1349532 & 688612 & 4.4 & 4.5897 & TST \\
\hline CHEMBL1410200 & 688612 & 4.5 & 4.6718 & TRN \\
\hline CHEMBL1358385 & 688612 & 4.25 & 4.6378 & TRN \\
\hline CHEMBL1385771 & 688612 & 4.3 & 4.6674 & TRN \\
\hline CHEMBL1389829 & 688612 & 4.55 & 4.7217 & TST \\
\hline CHEMBL1317981 & 688612 & 4.1 & 4.5807 & TRN \\
\hline CHEMBL1472272 & 688612 & 4.05 & 4.7233 & TST \\
\hline CHEMBL1477260 & 688612 & 4.5 & 4.5604 & TRN \\
\hline CHEMBL 3195243 & 688612 & 4.05 & 4.6709 & TRN \\
\hline CHEMBL1423852 & 688612 & 5.45 & 4.7662 & TST \\
\hline
\end{tabular}




\begin{tabular}{|c|c|c|c|c|c|}
\hline & & \multicolumn{4}{|c|}{ Supplemental Table s2.txt } \\
\hline CHEMBL1310925 & 688612 & 4.45 & 4.6344 & TST & \\
\hline CHEMBL1565428 & 688612 & 5.45 & 4.6403 & TRN & \\
\hline CHEMBL1563483 & 688612 & 4.95 & 4.6869 & TST & \\
\hline CHEMBL1613455 & 688612 & 4.0 & 4.5889 & TRN & \\
\hline CHEMBL1327390 & 688612 & 6.8 & 4.6267 & TRN & \\
\hline CHEMBL1450845 & 688612 & 4.0 & 4.6046 & TRN & \\
\hline CHEMBL1312179 & 688612 & 5.95 & 4.6299 & TRN & \\
\hline CHEMBL1457160 & 688612 & 4.35 & 4.6222 & TRN & \\
\hline CHEMBL1357612 & 688612 & 4.35 & 4.6249 & TRN & \\
\hline CHEMBL438909 & 688612 & 4.1 & 4.7287 & TRN & \\
\hline CHEMBL1469720 & 688612 & 4.0 & 4.6799 & TRN & \\
\hline CHEMBL3194772 & 688612 & 4.8 & 4.7869 & TRN & \\
\hline CHEMBL1520131 & 688612 & 4.85 & 4.6925 & TRN & \\
\hline CHEMBL3211121 & 688612 & 6.15 & 4.6999 & TRN & \\
\hline CHEMBL1396798 & 688612 & 4.4 & 4.6201 & TRN & \\
\hline CHEMBL1435736 & 688612 & 4.7 & 4.6075 & TRN & \\
\hline CHEMBL1332243 & 688612 & 5.45 & 4.6508 & TRN & \\
\hline CHEMBL1438931 & 688612 & 4.05 & 4.7082 & TRN & \\
\hline CHEMBL1490174 & 688612 & 4.1 & 4.6466 & TRN & \\
\hline CHEMBL1482347 & 688612 & 4.95 & 4.5881 & TRN & \\
\hline CHEMBL1441402 & 688612 & 4.05 & 4.6467 & TRN & \\
\hline CHEMBL1484936 & 688612 & 5.7 & 4.6512 & TST & \\
\hline CHEMBL1576377 & 688612 & 4.25 & 4.6635 & TRN & \\
\hline CHEMBL3198313 & 688612 & 4.25 & 4.7129 & TRN & \\
\hline CHEMBL1408463 & 688612 & 4.65 & 4.77800 & 00000000005 & TRN \\
\hline CHEMBL1407370 & 688612 & 7.0501 & 4.6929 & TST & \\
\hline CHEMBL1594365 & 688612 & 6.8 & 4.6548 & TRN & \\
\hline CHEMBL1362841 & 688612 & 4.8 & 4.7136 & TRN & \\
\hline CHEMBL1475587 & 688612 & 4.05 & 4.6088 & TRN & \\
\hline CHEMBL1419493 & 688612 & 4.05 & 4.6262 & TRN & \\
\hline CHEMBL1459559 & 688612 & 4.05 & 4.6214 & TRN & \\
\hline CHEMBL1596218 & 688612 & 4.1 & 4.6884 & TRN & \\
\hline CHEMBL3189151 & 688612 & 4.7 & 4.7991 & TRN & \\
\hline CHEMBL1418481 & 688612 & 5.45 & 4.7138 & TRN & \\
\hline CHEMBL 3210808 & 688612 & 4.85 & 4.7121 & TRN & \\
\hline CHEMBL1446936 & 688612 & 5.1 & 4.6452 & TST & \\
\hline CHEMBL1602624 & 688612 & 4.4 & 4.6772 & TRN & \\
\hline CHEMBL1544111 & 688612 & 6.45 & 4.7244 & TST & \\
\hline CHEMBL3199523 & 688612 & 4.45 & 4.6998 & TST & \\
\hline CHEMBL1479948 & 688612 & 4.05 & 4.734 & TRN & \\
\hline CHEMBL1373289 & 688612 & 5.15 & 4.798 & TST & \\
\hline CHEMBL1490029 & 688612 & 4.85 & 4.6761 & TRN & \\
\hline CHEMBL1317088 & 688612 & 6.15 & 4.6061 & TRN & \\
\hline CHEMBL1412239 & 688612 & 5.95 & 4.598 & TST & \\
\hline CHEMBL1596208 & 688612 & 4.05 & 4.6532 & TRN & \\
\hline CHEMBL1583228 & 688612 & 5.35 & 4.6485 & TRN & \\
\hline CHEMBL1353632 & 688612 & 4.55 & 4.5842 & TRN & \\
\hline CHEMBL1575202 & 688612 & 4.0 & 4.6452 & TST & \\
\hline
\end{tabular}




\begin{tabular}{|c|c|c|c|c|c|}
\hline \multicolumn{6}{|c|}{ Supplemental Table S2.txt } \\
\hline CHEMBL1576032 & 688612 & 6.5 & 4.6841 & TRN & \\
\hline CHEMBL1490007 & 688612 & 4.55 & 4.6765 & TRN & \\
\hline CHEMBL1512180 & 688612 & 4.1 & 4.6229 & TRN & \\
\hline CHEMBL3199590 & 688612 & 6.0 & 4.742 & TRN & \\
\hline CHEMBL1333617 & 688612 & 4.0 & 4.7292 & TST & \\
\hline CHEMBL1501032 & 688612 & 4.65 & 4.702 & TRN & \\
\hline CHEMBL1405834 & 688612 & 5.65 & 4.8243 & TRN & \\
\hline CHEMBL1470350 & 688612 & 4.3 & 4.6957 & TRN & \\
\hline CHEMBL1333782 & 688612 & 4.2 & 4.6808 & TRN & \\
\hline CHEMBL1538297 & 688612 & 5.0 & 4.6099 & TST & \\
\hline CHEMBL1409829 & 688612 & 4.7 & 4.683 & TRN & \\
\hline CHEMBL1341602 & 688612 & 4.65 & 4.7374 & TST & \\
\hline CHEMBL1539706 & 688612 & 6.9 & 4.6937 & TST & \\
\hline CHEMBL1535238 & 688612 & 4.05 & 4.7489 & TRN & \\
\hline CHEMBL1587137 & 688612 & 4.5 & 4.6096 & TST & \\
\hline CHEMBL1475342 & 688612 & 4.85 & 4.6374 & TRN & \\
\hline CHEMBL1518982 & 688612 & 4.4 & 4.7431 & TRN & \\
\hline CHEMBL3198859 & 688612 & 4.15 & 4.7781 & TRN & \\
\hline CHEMBL1358869 & 688612 & 4.6 & 4.6951 & TRN & \\
\hline CHEMBL1969464 & 688612 & 4.35 & 4.7397 & TRN & \\
\hline CHEMBL1576254 & 688612 & 4.75 & 4.7444 & TST & \\
\hline CHEMBL1353351 & 688612 & 6.9 & 4.6822 & TRN & \\
\hline CHEMBL3196278 & 688612 & 4.1 & 4.7372 & TST & \\
\hline CHEMBL1403234 & 688612 & 6.15 & 4.6028 & TST & \\
\hline CHEMBL1476620 & 688612 & 4.05 & 4.6147 & TRN & \\
\hline CHEMBL1441152 & 688612 & 4.1 & 4.5513 & TRN & \\
\hline CHEMBL1610127 & 688612 & 4.05 & 4.5913 & TRN & \\
\hline CHEMBL1587715 & 688612 & 4.85 & 4.7339 & TRN & \\
\hline CHEMBL1377885 & 688612 & 4.05 & 4.7108 & TST & \\
\hline CHEMBL1548075 & 688612 & 4.2 & 4.7474 & TST & \\
\hline CHEMBL1406554 & 688612 & 4.4 & 4.71399 & 99999999995 & \\
\hline CHEMBL 3194752 & 688612 & 4.6 & 4.6879 & TRN & \\
\hline CHEMBL1366479 & 688612 & 5.05 & 4.726 & TRN & \\
\hline CHEMBL1610883 & 688612 & 4.45 & 4.6375 & TRN & \\
\hline CHEMBL3192559 & 688612 & 5.0 & 4.6656 & TST & \\
\hline CHEMBL1494220 & 688612 & 5.35 & 4.7101 & TRN & \\
\hline CHEMBL1326180 & 688612 & 4.4 & 4.7298 & TST & \\
\hline CHEMBL1499948 & 688612 & 4.25 & 4.7709 & TRN & \\
\hline CHEMBL1376584 & 688612 & 5.3 & 4.6713 & TRN & \\
\hline CHEMBL1503793 & 688612 & 5.25 & 4.7757 & TRN & \\
\hline CHEMBL1995800 & 688612 & 4.1 & 4.7185 & TST & \\
\hline CHEMBL1512591 & 688612 & 4.4 & 4.5574 & TRN & \\
\hline CHEMBL1587737 & 688612 & 4.4 & 4.6777 & TRN & \\
\hline CHEMBL 1490580 & 688612 & 6.95 & 4.689 & TRN & \\
\hline CHEMBL1567657 & 688612 & 4.2 & 4.5925 & TRN & \\
\hline CHEMBL1465531 & 688612 & 4.1 & 4.7483 & TST & \\
\hline CHEMBL1352552 & 688612 & 4.2 & 4.6737 & TRN & \\
\hline CHEMBL1399676 & 688612 & 4.5 & 4.7389 & TST & \\
\hline
\end{tabular}




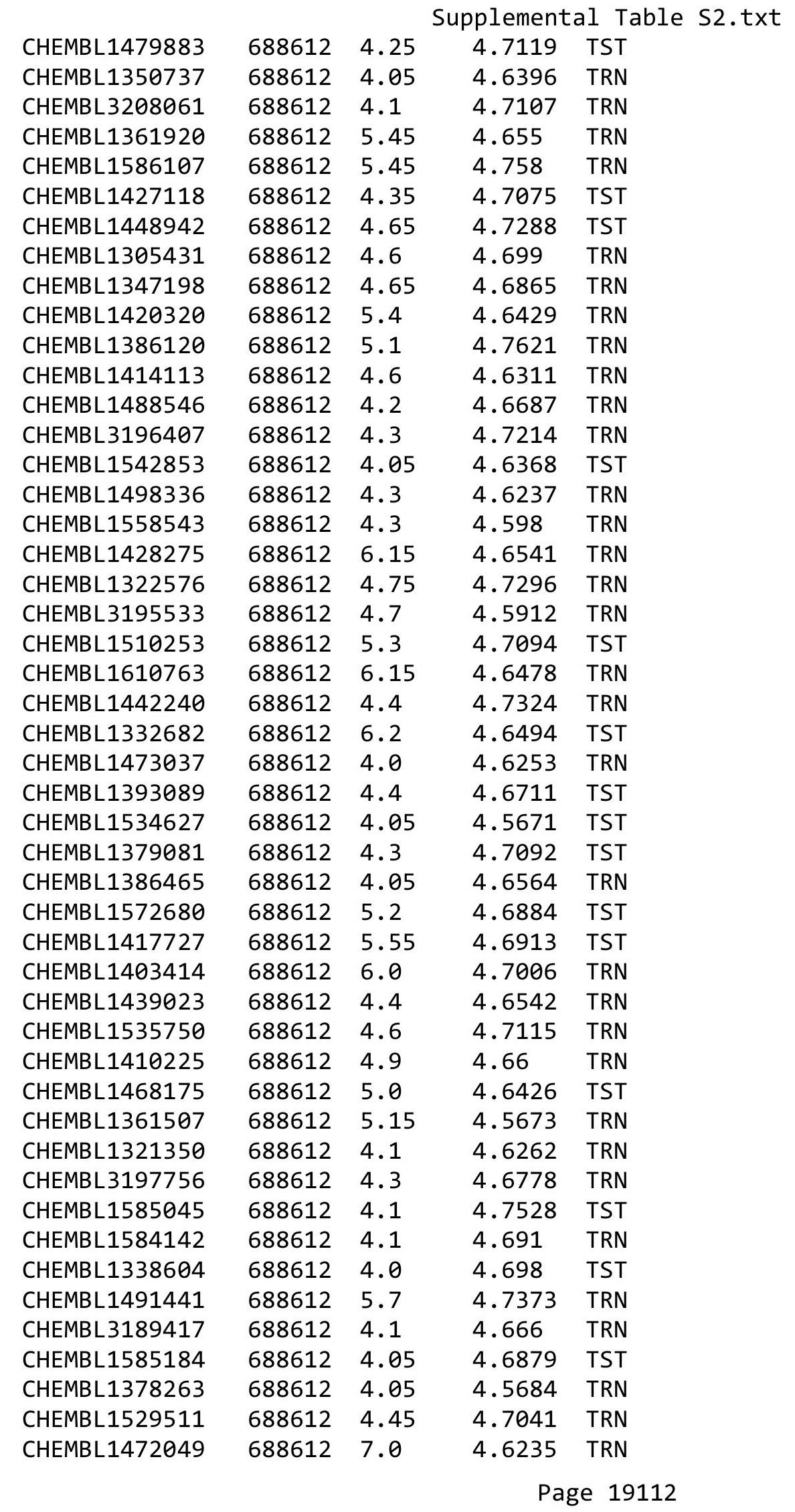




\begin{tabular}{|c|c|c|c|c|c|}
\hline \multicolumn{6}{|c|}{ Supplemental Table S2.txt } \\
\hline CHEMBL1416847 & 688612 & 4.0 & 4.632 & TRN & \\
\hline CHEMBL1334591 & 688612 & 4.5 & 4.7397 & TST & \\
\hline CHEMBL1432939 & 688612 & 4.05 & 4.6535 & TRN & \\
\hline CHEMBL1562824 & 688612 & 5.6 & 4.7349 & TRN & \\
\hline CHEMBL1335220 & 688612 & 5.5 & 4.6829 & TRN & \\
\hline CHEMBL1421529 & 688612 & 5.0 & 4.7346 & TRN & \\
\hline CHEMBL 1445973 & 688612 & 4.05 & 4.5733 & TRN & \\
\hline CHEMBL1492716 & 688612 & 5.35 & 4.7204 & TST & \\
\hline CHEMBL1305974 & 688612 & 4.6 & 4.6483 & TRN & \\
\hline CHEMBL1468742 & 688612 & 5.7 & 4.6021 & TRN & \\
\hline CHEMBL1388427 & 688612 & 4.25 & 4.7071 & TRN & \\
\hline CHEMBL1393307 & 688612 & 4.25 & 4.6674 & TRN & \\
\hline CHEMBL1613606 & 688612 & 4.5 & 4.742 & TRN & \\
\hline CHEMBL1384606 & 688612 & 6.0 & 4.6292 & TRN & \\
\hline CHEMBL1398716 & 688612 & 4.15 & 4.7116 & TRN & \\
\hline CHEMBL584442 & 688612 & 4.65 & 4.7149 & TRN & \\
\hline CHEMBL1510832 & 688612 & 4.9 & 4.7257 & TRN & \\
\hline CHEMBL1415666 & 688612 & 5.45 & 4.6358 & TRN & \\
\hline CHEMBL1400601 & 688612 & 6.8499 & 4.6389 & TRN & \\
\hline CHEMBL1557043 & 688612 & 4.75 & 4.6825 & TRN & \\
\hline CHEMBL3198418 & 688612 & 4.45 & 4.6822 & TRN & \\
\hline CHEMBL 1382674 & 688612 & 4.4 & 4.7 & TRN & \\
\hline CHEMBL1562180 & 688612 & 4.1 & 4.7558 & TRN & \\
\hline CHEMBL1421672 & 688612 & 6.2 & 4.6002 & TRN & \\
\hline CHEMBL1545518 & 688612 & 4.35 & 4.6533 & TRN & \\
\hline CHEMBL1333085 & 688612 & 4.2 & 4.7211 & TRN & \\
\hline CHEMBL3197739 & 688612 & 4.05 & 4.742 & TST & \\
\hline CHEMBL1609397 & 688612 & 6.15 & 4.6735 & TRN & \\
\hline CHEMBL1591340 & 688612 & 4.05 & 4.6075 & TRN & \\
\hline CHEMBL1517271 & 688612 & 4.7 & 4.658 & TRN & \\
\hline CHEMBL1438557 & 688612 & 5.35 & 4.6271 & TRN & \\
\hline CHEMBL1343542 & 688612 & 4.7 & 4.7162 & TST & \\
\hline CHEMBL1326392 & 688612 & 4.05 & 4.5535 & TRN & \\
\hline CHEMBL1429255 & 688612 & 4.1 & 4.7408 & TST & \\
\hline CHEMBL1581445 & 688612 & 4.5 & 4.7476 & TST & \\
\hline CHEMBL3191707 & 688612 & 6.8499 & 4.7459 & TST & \\
\hline CHEMBL1319628 & 688612 & 4.15 & 4.6595 & TST & \\
\hline CHEMBL 22062 & 688612 & 4.75 & 4.6772 & TRN & \\
\hline CHEMBL1386010 & 688612 & 4.0 & 4.6005 & TRN & \\
\hline CHEMBL1481605 & 688612 & 5.0 & 4.7619 & TRN & \\
\hline CHEMBL1481012 & 688612 & 4.95 & 4.6938 & TRN & \\
\hline CHEMBL1536715 & 688612 & 5.0 & 4.647 & TRN & \\
\hline CHEMBL1432377 & 688612 & 4.55 & 4.7333 & TRN & \\
\hline CHEMBL1418365 & 688612 & 5.6 & 4.6937 & TST & \\
\hline CHEMBL1543826 & 688612 & 4.1 & $4.6530 e$ & 00000000005 & TRN \\
\hline CHEMBL1384221 & 688612 & 4.3 & 4.6949 & TRN & \\
\hline CHEMBL1355870 & 688612 & 4.05 & 4.6726 & TRN & \\
\hline CHEMBL3193435 & 688612 & 5.65 & 4.7276 & TRN & \\
\hline
\end{tabular}




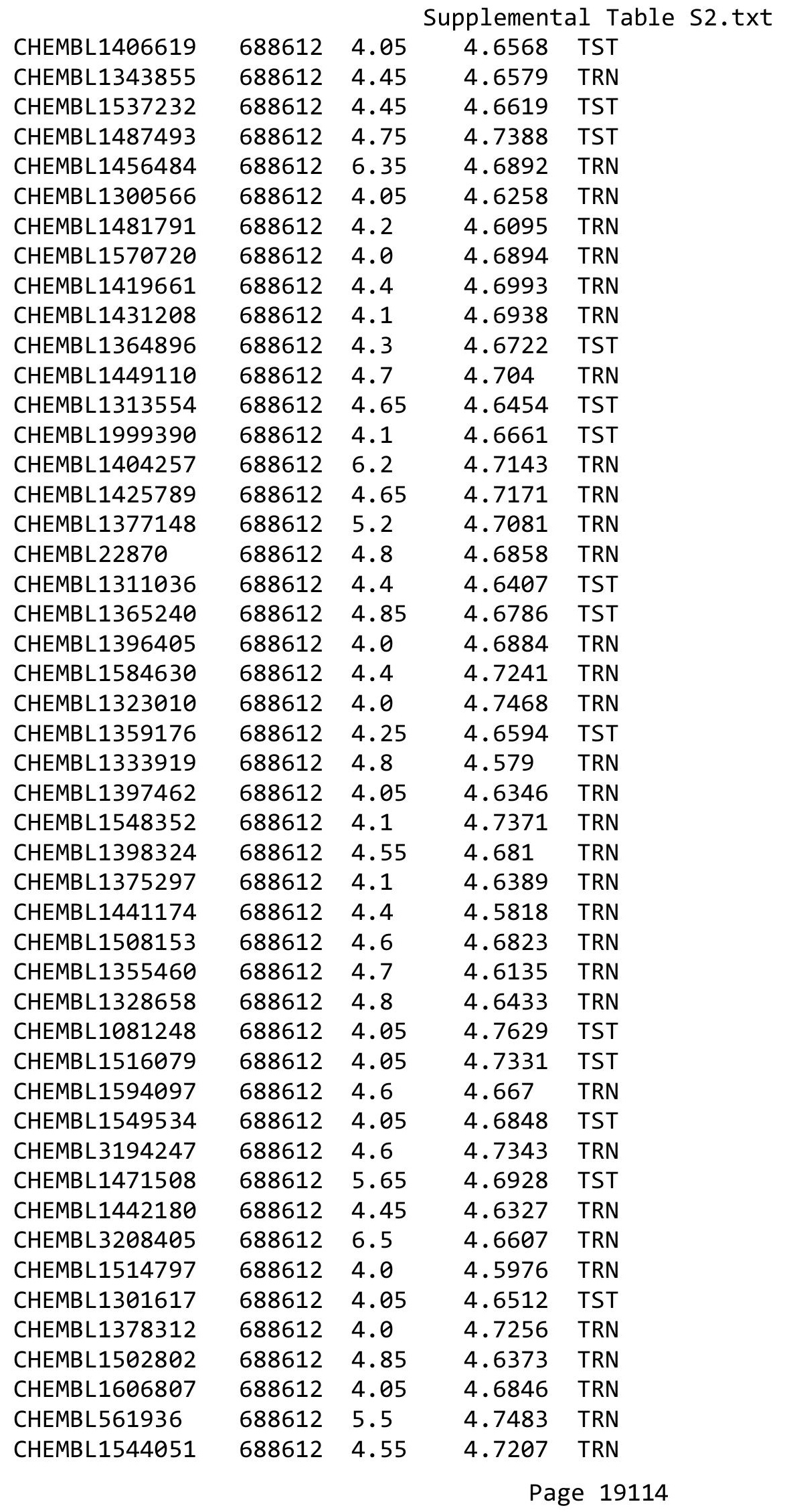




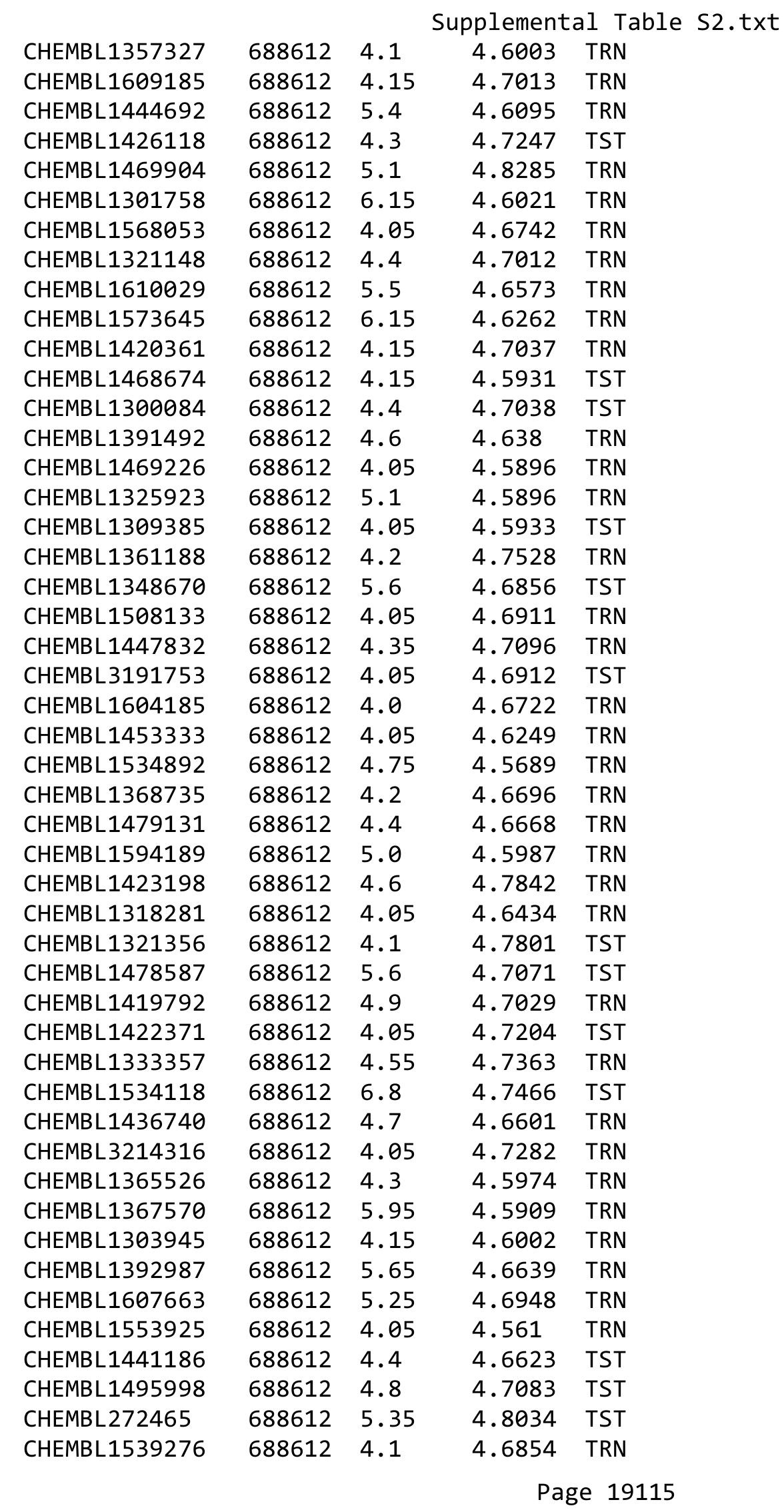




\begin{tabular}{|c|c|c|c|c|c|}
\hline & & \multicolumn{4}{|c|}{ Supplemental Table S2.txt } \\
\hline CHEMBL1360242 & 688612 & 4.4 & 4.5721 & TRN & \\
\hline CHEMBL1477830 & 688612 & 4.1 & 4.7094 & TST & \\
\hline CHEMBL1371636 & 688612 & 4.05 & 4.7077 & TST & \\
\hline CHEMBL1408103 & 688612 & 4.05 & 4.6547 & TRN & \\
\hline CHEMBL1508359 & 688612 & 4.6 & 4.6764 & TST & \\
\hline CHEMBL1480845 & 688612 & 4.0 & 4.5962 & TST & \\
\hline CHEMBL1318806 & 688612 & 5.55 & 4.6703 & TRN & \\
\hline CHEMBL1335772 & 688612 & 4.75 & 4.6331 & TRN & \\
\hline CHEMBL1464803 & 688612 & 4.55 & 4.7377 & TRN & \\
\hline CHEMBL1384801 & 688612 & 4.4 & 4.6421 & TRN & \\
\hline CHEMBL1478549 & 688612 & 4.0 & 4.6013 & TRN & \\
\hline CHEMBL1343672 & 688612 & 4.05 & 4.6746 & TRN & \\
\hline CHEMBL484640 & 688612 & 5.9 & 4.7873 & TRN & \\
\hline CHEMBL1443472 & 688612 & 4.0 & 4.6056 & TST & \\
\hline CHEMBL1986027 & 688612 & 4.1 & 4.6279 & TRN & \\
\hline CHEMBL1528813 & 688612 & 4.05 & 4.6178 & TRN & \\
\hline CHEMBL1714669 & 688612 & 5.75 & 4.6869 & TRN & \\
\hline CHEMBL1489838 & 688612 & 5.55 & 4.6594 & TST & \\
\hline CHEMBL1359782 & 688612 & 4.75 & 4.8385 & TRN & \\
\hline CHEMBL1349290 & 688612 & 6.6 & 4.7567 & TRN & \\
\hline CHEMBL1542376 & 688612 & 4.65 & 4.6535 & TRN & \\
\hline CHEMBL1335541 & 688612 & 4.0 & 4.6712 & TRN & \\
\hline CHEMBL1481572 & 688612 & 6.1 & 4.6986 & TRN & \\
\hline CHEMBL1313470 & 688612 & 5.6 & 4.6955 & TST & \\
\hline CHEMBL1447034 & 688612 & 6.0 & 4.7595 & TRN & \\
\hline CHEMBL1411470 & 688612 & 4.65 & 4.6957 & TST & \\
\hline CHEMBL1471703 & 688612 & 5.1 & 4.6322 & TRN & \\
\hline CHEMBL1311955 & 688612 & 4.8 & 4.6792 & TST & \\
\hline CHEMBL1384575 & 688612 & 4.5 & 4.66 & TRN & \\
\hline CHEMBL1433124 & 688612 & 4.05 & 4.8086 & TRN & \\
\hline CHEMBL1354780 & 688612 & 4.0 & 4.6206 & TRN & \\
\hline CHEMBL1411469 & 688612 & 4.5 & 4.6728 & TRN & \\
\hline CHEMBL1488271 & 688612 & 4.05 & 4.6562 & TRN & \\
\hline CHEMBL1330148 & 688612 & 4.0 & 4.5566 & TRN & \\
\hline CHEMBL1524856 & 688612 & 4.05 & 4.6385 & TRN & \\
\hline CHEMBL1609956 & 688612 & 4.05 & 4.6819 & TST & \\
\hline CHEMBL1490844 & 688612 & 4.0 & 4.6547 & TRN & \\
\hline CHEMBL1521712 & 688612 & 4.6 & 4.6911 & TRN & \\
\hline CHEMBL1416394 & 688612 & 6.8499 & 4.6909 & TRN & \\
\hline CHEMBL1312609 & 688612 & 4.35 & 4.7364 & TRN & \\
\hline CHEMBL1527477 & 688612 & 4.75 & 4.6612 & TRN & \\
\hline CHEMBL1579758 & 688612 & 4.0 & 4.63399 & 99999999995 & TRN \\
\hline CHEMBL1464499 & 688612 & 4.55 & 4.7887 & TRN & \\
\hline CHEMBL1371801 & 688612 & 4.5 & 4.6812 & TRN & \\
\hline CHEMBL1612571 & 688612 & 5.4 & 4.6621 & TRN & \\
\hline CHEMBL1331001 & 688612 & 6.5 & 4.6309 & TRN & \\
\hline CHEMBL1412155 & 688612 & 4.8 & 4.6387 & TRN & \\
\hline CHEMBL1355542 & 688612 & 4.05 & 4.6017 & TRN & \\
\hline
\end{tabular}




\begin{tabular}{|c|c|c|c|c|c|}
\hline & & \multicolumn{4}{|c|}{ Supplemental Table s2.txt } \\
\hline CHEMBL1462885 & 688612 & 4.45 & 4.603 & TRN & \\
\hline CHEMBL1587181 & 688612 & 5.9 & 4.683 & TST & \\
\hline CHEMBL1444389 & 688612 & 4.05 & 4.6584 & TST & \\
\hline CHEMBL 2000316 & 688612 & 4.2 & 4.5925 & TRN & \\
\hline CHEMBL1512950 & 688612 & 4.4 & 4.69300 & 00000000005 & TRN \\
\hline CHEMBL1461349 & 688612 & 6.5501 & 4.6182 & TRN & \\
\hline CHEMBL1387557 & 688612 & 4.0 & 4.675 & TST & \\
\hline CHEMBL1360358 & 688612 & 5.35 & 4.7159 & TST & \\
\hline CHEMBL1538165 & 688612 & 5.05 & 4.6661 & TST & \\
\hline CHEMBL1563824 & 688612 & 3.95 & 4.6964 & TRN & \\
\hline CHEMBL1458746 & 688612 & 5.35 & 4.7833 & TRN & \\
\hline CHEMBL1530375 & 688612 & 4.35 & 4.6625 & TRN & \\
\hline CHEMBL1311058 & 688612 & 4.65 & 4.6318 & TRN & \\
\hline CHEMBL1334889 & 688612 & 4.9 & 4.7199 & TST & \\
\hline CHEMBL1454904 & 688612 & 6.1 & 4.6114 & TRN & \\
\hline CHEMBL1489151 & 688612 & 4.05 & 4.729 & TRN & \\
\hline CHEMBL1467002 & 688612 & 5.55 & 4.6987 & TRN & \\
\hline CHEMBL1391377 & 688612 & 4.05 & 4.6139 & TRN & \\
\hline CHEMBL1563802 & 688612 & 4.05 & 4.6409 & TRN & \\
\hline CHEMBL1383482 & 688612 & 4.8 & 4.7605 & TST & \\
\hline CHEMBL1494945 & 688612 & 6.8499 & 4.675 & TST & \\
\hline CHEMBL1608251 & 688612 & 6.25 & 4.6894 & TST & \\
\hline CHEMBL1558542 & 688612 & 5.5 & 4.6494 & TST & \\
\hline CHEMBL1353165 & 688612 & 4.1 & 4.7108 & TST & \\
\hline CHEMBL3189718 & 688612 & 4.4 & 4.7498 & TRN & \\
\hline CHEMBL1375232 & 688612 & 4.1 & 4.5806 & TRN & \\
\hline CHEMBL1415277 & 688612 & 5.6 & 4.6655 & TST & \\
\hline CHEMBL1376712 & 688612 & 4.75 & 4.689 & TRN & \\
\hline CHEMBL1517325 & 688612 & 4.6 & 4.7365 & TRN & \\
\hline CHEMBL1978791 & 688612 & 4.2 & 4.6546 & TRN & \\
\hline CHEMBL1315095 & 688612 & 4.05 & 4.6096 & TRN & \\
\hline CHEMBL1609381 & 688612 & 6.45 & 4.6518 & TRN & \\
\hline CHEMBL1554166 & 688612 & 4.05 & 4.5957 & TRN & \\
\hline CHEMBL1459218 & 688612 & 4.35 & 4.6495 & TRN & \\
\hline CHEMBL1350132 & 688612 & 4.9 & 4.7505 & TRN & \\
\hline CHEMBL1546561 & 688612 & 5.9 & 4.6658 & TRN & \\
\hline CHEMBL1588707 & 688612 & 5.0 & 4.6362 & TRN & \\
\hline CHEMBL1441862 & 688612 & 4.0 & 4.5955 & TST & \\
\hline CHEMBL1525407 & 688612 & 4.05 & 4.6488 & TRN & \\
\hline CHEMBL1515919 & 688612 & 4.6 & 4.5776 & TRN & \\
\hline CHEMBL1465317 & 688612 & 4.0 & 4.6935 & TST & \\
\hline CHEMBL1546671 & 688612 & 6.5501 & 4.6131 & TRN & \\
\hline CHEMBL1522429 & 688612 & 5.75 & 4.6618 & TRN & \\
\hline CHEMBL1307933 & 688612 & 4.8 & 4.7076 & TRN & \\
\hline CHEMBL1308646 & 688612 & 4.4 & 4.6216 & TRN & \\
\hline CHEMBL1345911 & 688612 & 4.95 & 4.7363 & TRN & \\
\hline CHEMBL1308747 & 688612 & 4.4 & 4.7409 & TRN & \\
\hline CHEMBL1975754 & 688612 & 4.55 & 4.7218 & TRN & \\
\hline
\end{tabular}




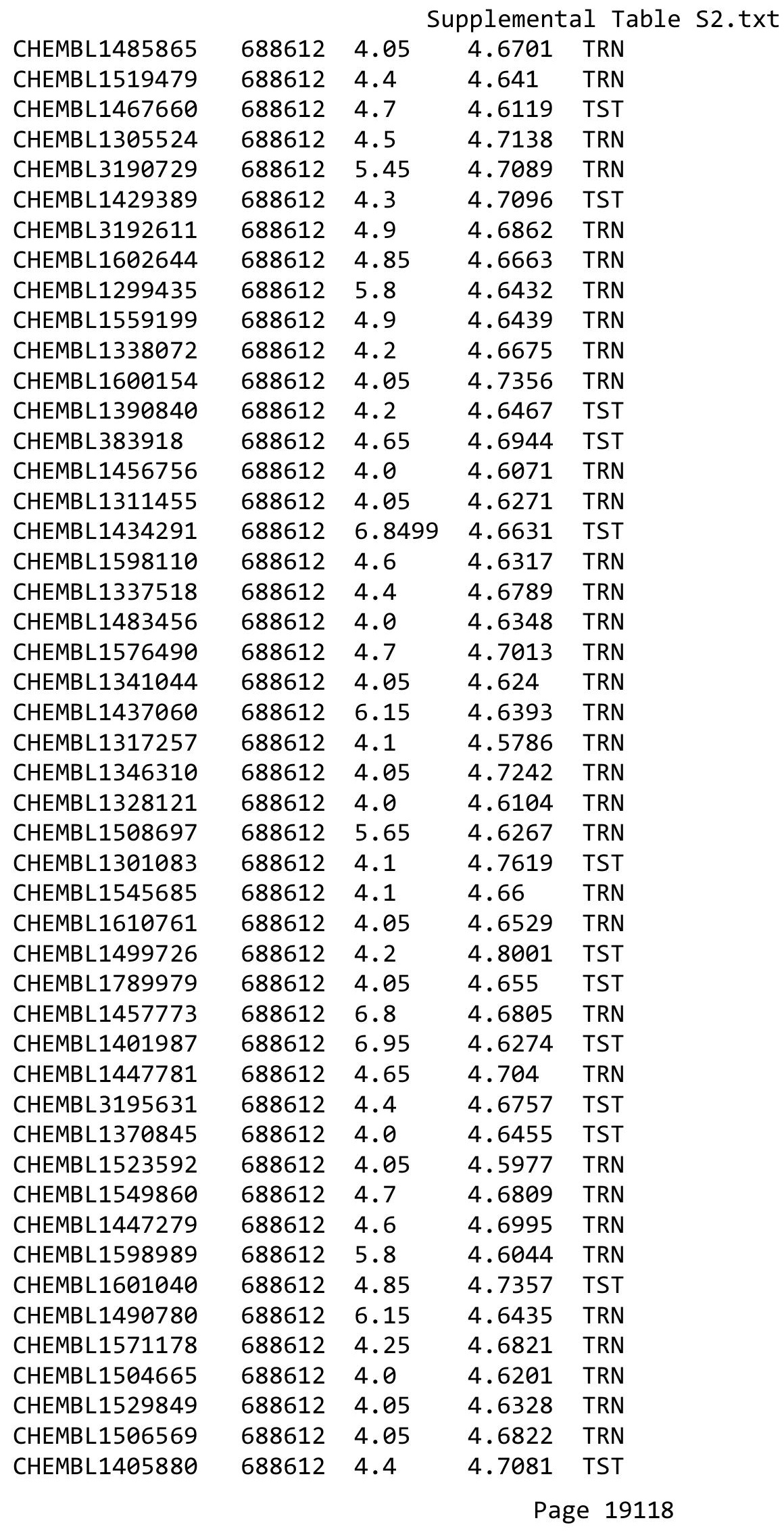




\begin{tabular}{|c|c|c|c|c|}
\hline \multicolumn{5}{|c|}{ Supplemental Table S2.txt } \\
\hline CHEMBL1382911 & 688612 & 6.8499 & 4.6725 & TRN \\
\hline CHEMBL1413526 & 688612 & 4.45 & 4.655 & TRN \\
\hline CHEMBL1385130 & 688612 & 4.0 & 4.6462 & TST \\
\hline CHEMBL1316605 & 688612 & 4.05 & 4.5971 & TRN \\
\hline CHEMBL1421229 & 688612 & 6.4 & 4.5958 & TRN \\
\hline CHEMBL1438054 & 688612 & 5.3 & 4.6606 & TST \\
\hline CHEMBL1606132 & 688612 & 4.1 & 4.7314 & TRN \\
\hline CHEMBL1477877 & 688612 & 4.4 & 4.6396 & TRN \\
\hline CHEMBL1601615 & 688612 & 4.05 & 4.6722 & TRN \\
\hline CHEMBL3211453 & 688612 & 6.95 & 4.6547 & TST \\
\hline CHEMBL1422825 & 688612 & 4.05 & 4.6005 & TRN \\
\hline CHEMBL1506992 & 688612 & 4.05 & 4.6482 & TRN \\
\hline CHEMBL1497909 & 688612 & 4.65 & 4.644 & TRN \\
\hline CHEMBL1579454 & 688612 & 4.1 & 4.6325 & TRN \\
\hline CHEMBL1330489 & 688612 & 4.3 & 4.6567 & TRN \\
\hline CHEMBL1599223 & 688612 & 6.8499 & 4.6835 & TRN \\
\hline CHEMBL1327229 & 688612 & 4.05 & 4.6959 & TRN \\
\hline CHEMBL1339640 & 688612 & 4.05 & 4.6128 & TRN \\
\hline CHEMBL1573690 & 688612 & 4.6 & 4.6756 & TRN \\
\hline CHEMBL1336921 & 688612 & 4.4 & 4.6377 & TRN \\
\hline CHEMBL1553221 & 688612 & 4.1 & 4.6089 & TRN \\
\hline CHEMBL1527822 & 688612 & 4.6 & 4.6362 & TRN \\
\hline CHEMBL1383693 & 688612 & 5.35 & 4.6617 & TRN \\
\hline CHEMBL1495907 & 688612 & 4.05 & 4.6191 & TST \\
\hline CHEMBL1590950 & 688612 & 4.7 & 4.6367 & TRN \\
\hline CHEMBL478754 & 688612 & 4.25 & 4.6872 & TRN \\
\hline CHEMBL1606812 & 688612 & 4.05 & 4.635 & TST \\
\hline CHEMBL1444318 & 688612 & 5.4 & 4.6191 & TRN \\
\hline CHEMBL1514353 & 688612 & 4.05 & 4.6526 & TRN \\
\hline CHEMBL1486971 & 688612 & 4.1 & 4.6326 & TRN \\
\hline CHEMBL1410048 & 688612 & 4.45 & 4.6733 & TRN \\
\hline CHEMBL1492876 & 688612 & 6.1 & 4.6582 & TST \\
\hline CHEMBL1592116 & 688612 & 4.05 & 4.6118 & TRN \\
\hline CHEMBL1490643 & 688612 & 5.0 & 4.6282 & TRN \\
\hline CHEMBL 1385340 & 688612 & 4.0 & 4.732 & TRN \\
\hline CHEMBL1346555 & 688612 & 4.4 & 4.6645 & TST \\
\hline CHEMBL1463023 & 688612 & 4.95 & 4.7596 & TRN \\
\hline CHEMBL1558022 & 688612 & 4.05 & 4.5623 & TRN \\
\hline CHEMBL1344189 & 688612 & 4.0 & 4.8245 & TST \\
\hline CHEMBL1394813 & 688612 & 5.65 & 4.6256 & TRN \\
\hline CHEMBL1388069 & 688612 & 4.4 & 4.7409 & TRN \\
\hline CHEMBL1978925 & 688612 & 5.2 & 4.703 & TRN \\
\hline CHEMBL3196459 & 688612 & 4.85 & 4.8014 & TRN \\
\hline CHEMBL1399355 & 688612 & 4.5 & 4.6757 & TRN \\
\hline CHEMBL1486180 & 688612 & 4.6 & 4.6418 & TRN \\
\hline CHEMBL1506491 & 688612 & 6.15 & 4.5882 & TRN \\
\hline CHEMBL1421530 & 688612 & 4.65 & 4.7095 & TRN \\
\hline CHEMBL1342252 & 688612 & 4.4 & 4.658 & TRN \\
\hline
\end{tabular}




\begin{tabular}{|c|c|c|c|c|c|}
\hline \multicolumn{6}{|c|}{ Supplemental Table S2.txt } \\
\hline CHEMBL1491562 & 688612 & 4.45 & 4.7565 & TRN & \\
\hline CHEMBL1536956 & 688612 & 6.8 & 4.663 & TRN & \\
\hline CHEMBL1399432 & 688612 & 4.05 & 4.6057 & TRN & \\
\hline CHEMBL3191714 & 688612 & 6.5 & 4.7167 & TST & \\
\hline CHEMBL1348098 & 688612 & 4.05 & 4.7519 & TST & \\
\hline CHEMBL1304724 & 688612 & 4.95 & 4.6244 & TRN & \\
\hline CHEMBL1339591 & 688612 & 4.35 & 4.6555 & TST & \\
\hline CHEMBL1547363 & 688612 & 5.45 & 4.743 & TST & \\
\hline CHEMBL1471194 & 688612 & 4.05 & 4.7142 & TRN & \\
\hline CHEMBL1596753 & 688612 & 5.15 & 4.8058 & TST & \\
\hline CHEMBL1301488 & 688612 & 4.15 & 4.7243 & TRN & \\
\hline CHEMBL1544175 & 688612 & 4.4 & 4.5811 & TST & \\
\hline CHEMBL1461636 & 688612 & 4.9 & 4.65 & TRN & \\
\hline CHEMBL1473981 & 688612 & 4.45 & 4.5901 & TRN & \\
\hline CHEMBL1327780 & 688612 & 4.5 & 4.7364 & TRN & \\
\hline CHEMBL3191929 & 688612 & 4.4 & 4.7296 & TRN & \\
\hline CHEMBL1418483 & 688612 & 5.4 & 4.6691 & TST & \\
\hline CHEMBL1306333 & 688612 & 4.1 & 4.6032 & TRN & \\
\hline CHEMBL1566550 & 688612 & 4.4 & 4.6341 & TST & \\
\hline CHEMBL1507015 & 688612 & 4.1 & 4.6355 & TRN & \\
\hline CHEMBL1465872 & 688612 & 4.4 & 4.6619 & TRN & \\
\hline CHEMBL1462955 & 688612 & 4.05 & 4.6997 & TRN & \\
\hline CHEMBL1346087 & 688612 & 6.8499 & 4.7129 & TST & \\
\hline CHEMBL1345025 & 688612 & 4.0 & 4.6449 & TST & \\
\hline CHEMBL1403014 & 688612 & 6.6 & 4.6812 & TST & \\
\hline CHEMBL1430092 & 688612 & 4.05 & 4.5963 & TST & \\
\hline CHEMBL3197532 & 688612 & 4.2 & 4.7045 & TRN & \\
\hline CHEMBL1587422 & 688612 & 4.45 & 4.7325 & TST & \\
\hline CHEMBL3186069 & 688612 & 4.8 & 4.72199 & 99999999995 & TRN \\
\hline CHEMBL1434005 & 688612 & 4.3 & 4.6922 & TRN & \\
\hline CHEMBL1595715 & 688612 & 4.05 & 4.6795 & TST & \\
\hline CHEMBL1556559 & 688612 & 5.05 & 4.6983 & TRN & \\
\hline CHEMBL1534503 & 688612 & 4.2 & 4.5844 & TRN & \\
\hline CHEMBL3197709 & 688612 & 4.45 & 4.6622 & TRN & \\
\hline CHEMBL1343458 & 688612 & 4.7 & 4.7298 & TRN & \\
\hline CHEMBL1583671 & 688612 & 4.55 & 4.7047 & TRN & \\
\hline CHEMBL1310738 & 688612 & 5.3 & 4.6798 & TST & \\
\hline CHEMBL1441448 & 688612 & 5.7 & 4.6058 & TRN & \\
\hline CHEMBL1575909 & 688612 & 5.45 & 4.583 & TRN & \\
\hline CHEMBL1596237 & 688612 & 6.8499 & 4.6095 & TST & \\
\hline CHEMBL1322389 & 688612 & 4.6 & 4.638 & TRN & \\
\hline CHEMBL1412529 & 688612 & 4.5 & 4.6707 & TRN & \\
\hline CHEMBL1322221 & 688612 & 4.8 & 4.6875 & TST & \\
\hline CHEMBL1594874 & 688612 & 4.05 & 4.6541 & TRN & \\
\hline CHEMBL1439062 & 688612 & 4.5 & 4.5596 & TRN & \\
\hline CHEMBL3198873 & 688612 & 4.0 & 4.6969 & TST & \\
\hline CHEMBL1610823 & 688612 & 4.05 & 4.6699 & TST & \\
\hline CHEMBL1579933 & 688612 & 4.4 & 4.7176 & TST & \\
\hline
\end{tabular}




\begin{tabular}{|c|c|c|c|c|c|}
\hline & & \multicolumn{4}{|c|}{ Supplemental Table S2.txt } \\
\hline CHEMBL1393377 & 688612 & 4.05 & 4.6484 & TRN & \\
\hline CHEMBL1587666 & 688612 & 4.35 & 4.5871 & TRN & \\
\hline CHEMBL1595287 & 688612 & 4.2 & 4.5908 & TRN & \\
\hline CHEMBL1520255 & 688612 & 4.6 & 4.6212 & TST & \\
\hline CHEMBL1606671 & 688612 & 4.4 & 4.7323 & TRN & \\
\hline CHEMBL1517496 & 688612 & 4.05 & 4.637 & TRN & \\
\hline CHEMBL1536896 & 688612 & 5.55 & 4.686 & TRN & \\
\hline CHEMBL1572277 & 688612 & 4.7 & 4.6058 & TRN & \\
\hline CHEMBL1438273 & 688612 & 4.05 & 4.6111 & TRN & \\
\hline CHEMBL3199352 & 688612 & 4.45 & 4.78100 & 0000000001 & TRN \\
\hline CHEMBL1541040 & 688612 & 4.3 & 4.6726 & TRN & \\
\hline CHEMBL1325878 & 688612 & 4.4 & 4.6054 & TRN & \\
\hline CHEMBL1333485 & 688612 & 6.95 & 4.68199 & 99999999995 & TST \\
\hline CHEMBL3197903 & 688612 & 5.0 & 4.7173 & TRN & \\
\hline CHEMBL1463566 & 688612 & 4.1 & 4.779 & TRN & \\
\hline CHEMBL1358174 & 688612 & 4.0 & 4.6389 & TRN & \\
\hline CHEMBL1492165 & 688612 & 5.5 & 4.6536 & TST & \\
\hline CHEMBL1482428 & 688612 & 4.1 & 4.6576 & TRN & \\
\hline CHEMBL1388653 & 688612 & 6.6 & 4.6629 & TRN & \\
\hline CHEMBL1497996 & 688612 & 4.05 & 4.6451 & TRN & \\
\hline CHEMBL1537744 & 688612 & 4.4 & 4.7543 & TRN & \\
\hline CHEMBL1537472 & 688612 & 4.6 & 4.7109 & TRN & \\
\hline CHEMBL1510447 & 688612 & 4.05 & 4.7071 & TRN & \\
\hline CHEMBL3207795 & 688612 & 5.0 & 4.7111 & TRN & \\
\hline CHEMBL1534460 & 688612 & 4.3 & 4.7034 & TRN & \\
\hline CHEMBL1448744 & 688612 & 4.45 & 4.7128 & TRN & \\
\hline CHEMBL1310865 & 688612 & 4.05 & 4.5726 & TRN & \\
\hline CHEMBL3196869 & 688612 & 4.55 & 4.6194 & TRN & \\
\hline CHEMBL1325295 & 688612 & 4.25 & 4.6355 & TRN & \\
\hline CHEMBL3199715 & 688612 & 4.3 & 4.7313 & TRN & \\
\hline CHEMBL1302005 & 688612 & 4.65 & 4.6932 & TRN & \\
\hline CHEMBL1358278 & 688612 & 4.45 & 4.7301 & TRN & \\
\hline CHEMBL1410091 & 688612 & 4.6 & 4.7761 & TRN & \\
\hline CHEMBL1525832 & 688612 & 4.6 & 4.6115 & TRN & \\
\hline CHEMBL1561483 & 688612 & 4.05 & 4.5568 & TST & \\
\hline CHEMBL1554512 & 688612 & 4.3 & 4.6769 & TRN & \\
\hline CHEMBL 3198324 & 688612 & 4.35 & 4.6547 & TRN & \\
\hline CHEMBL1403970 & 688612 & 4.55 & 4.7471 & TST & \\
\hline CHEMBL1506648 & 688612 & 4.0 & 4.6772 & TRN & \\
\hline CHEMBL1461413 & 688612 & 4.65 & 4.8186 & TRN & \\
\hline CHEMBL1470020 & 688612 & 6.25 & 4.6467 & TRN & \\
\hline CHEMBL1544614 & 688612 & 5.85 & 4.6274 & TRN & \\
\hline CHEMBL1504676 & 688612 & 4.4 & 4.7509 & TRN & \\
\hline CHEMBL1340411 & 688612 & 4.65 & 4.6295 & TRN & \\
\hline CHEMBL1481603 & 688612 & 4.8 & 4.7169 & TST & \\
\hline CHEMBL1985165 & 688612 & 4.9 & 4.7691 & TRN & \\
\hline CHEMBL1404467 & 688612 & 4.1 & 4.6332 & TRN & \\
\hline CHEMBL1396149 & 688612 & 5.05 & 4.7619 & TRN & \\
\hline
\end{tabular}




\begin{tabular}{|c|c|c|c|c|c|}
\hline \multirow[b]{2}{*}{ CHEMBL1400102 } & \multirow[b]{2}{*}{688612} & \multicolumn{4}{|c|}{ Supplemental Table S2.txt } \\
\hline & & 5.1 & 4.6208 & TRN & \\
\hline CHEMBL1385904 & 688612 & 4.65 & 4.6930 & 00000000005 & TST \\
\hline CHEMBL1440782 & 688612 & 4.2 & 4.5825 & TRN & \\
\hline CHEMBL1303213 & 688612 & 4.0 & 4.6245 & TRN & \\
\hline CHEMBL1451814 & 688612 & 4.4 & 4.713 & TRN & \\
\hline CHEMBL1302593 & 688612 & 4.05 & 4.6751 & TRN & \\
\hline CHEMBL1547416 & 688612 & 5.45 & 4.7023 & TRN & \\
\hline CHEMBL1433168 & 688612 & 4.25 & 4.6648 & TST & \\
\hline CHEMBL1613447 & 688612 & 4.65 & 4.7731 & TRN & \\
\hline CHEMBL1461690 & 688612 & 4.85 & 4.6342 & TRN & \\
\hline CHEMBL151 & 688612 & 5.15 & 4.8983 & TRN & \\
\hline CHEMBL1567976 & 688612 & 4.05 & 4.6072 & TRN & \\
\hline CHEMBL1508386 & 688612 & 4.05 & 4.6953 & TRN & \\
\hline CHEMBL1390941 & 688612 & 4.05 & 4.654 & TST & \\
\hline CHEMBL1410365 & 688612 & 4.75 & 4.5959 & TRN & \\
\hline CHEMBL1527143 & 688612 & 5.3 & 4.7096 & TRN & \\
\hline CHEMBL1472297 & 688612 & 4.2 & 4.7231 & TRN & \\
\hline CHEMBL1498351 & 688612 & 4.75 & 4.6876 & TRN & \\
\hline CHEMBL417727 & 688612 & 5.3 & 4.7276 & TRN & \\
\hline CHEMBL1490728 & 688612 & 5.4 & 4.5936 & TRN & \\
\hline CHEMBL1500006 & 688612 & 6.1 & 4.7107 & TRN & \\
\hline CHEMBL1419388 & 688612 & 4.6 & 4.6394 & TRN & \\
\hline CHEMBL1580068 & 688612 & 4.3 & 4.6659 & TST & \\
\hline CHEMBL1549960 & 688612 & 4.2 & 4.6887 & TST & \\
\hline CHEMBL1517202 & 688612 & 4.05 & 4.5939 & TRN & \\
\hline CHEMBL1310336 & 688612 & 4.3 & 4.6088 & TRN & \\
\hline CHEMBL1327397 & 688612 & 4.0 & 4.6993 & TRN & \\
\hline CHEMBL1567590 & 688612 & 4.7 & 4.6977 & TRN & \\
\hline CHEMBL1970784 & 688612 & 4.1 & 4.7177 & TST & \\
\hline CHEMBL1354591 & 688612 & 4.45 & 4.6152 & TRN & \\
\hline CHEMBL1379509 & 688612 & 4.6 & 4.7049 & TRN & \\
\hline CHEMBL1542693 & 688612 & 4.65 & 4.7007 & TRN & \\
\hline CHEMBL1489377 & 688612 & 4.05 & 4.6056 & TRN & \\
\hline CHEMBL1485267 & 688612 & 4.8 & 4.6247 & TST & \\
\hline CHEMBL1597376 & 688612 & 4.0 & 4.6148 & TRN & \\
\hline CHEMBL1505915 & 688612 & 4.35 & 4.7003 & TRN & \\
\hline CHEMBL1375321 & 688612 & 4.2 & 4.7186 & TST & \\
\hline CHEMBL1403687 & 688612 & 4.05 & 4.6962 & TST & \\
\hline CHEMBL1573936 & 688612 & 4.05 & 4.613 & TRN & \\
\hline CHEMBL1475187 & 688612 & 4.05 & 4.6196 & TST & \\
\hline CHEMBL1317184 & 688612 & 4.95 & 4.7831 & TRN & \\
\hline CHEMBL1333183 & 688612 & 5.45 & 4.6452 & TRN & \\
\hline CHEMBL1456959 & 688612 & 4.2 & 4.7141 & TRN & \\
\hline CHEMBL1439849 & 688612 & 4.05 & 4.6769 & TRN & \\
\hline CHEMBL1546212 & 688612 & 4.05 & 4.6759 & TRN & \\
\hline CHEMBL1423005 & 688612 & 4.5 & 4.7065 & TRN & \\
\hline CHEMBL1588436 & 688612 & 4.4 & 4.7744 & TRN & \\
\hline CHEMBL3213887 & 688612 & 4.4 & 4.6786 & TRN & \\
\hline
\end{tabular}




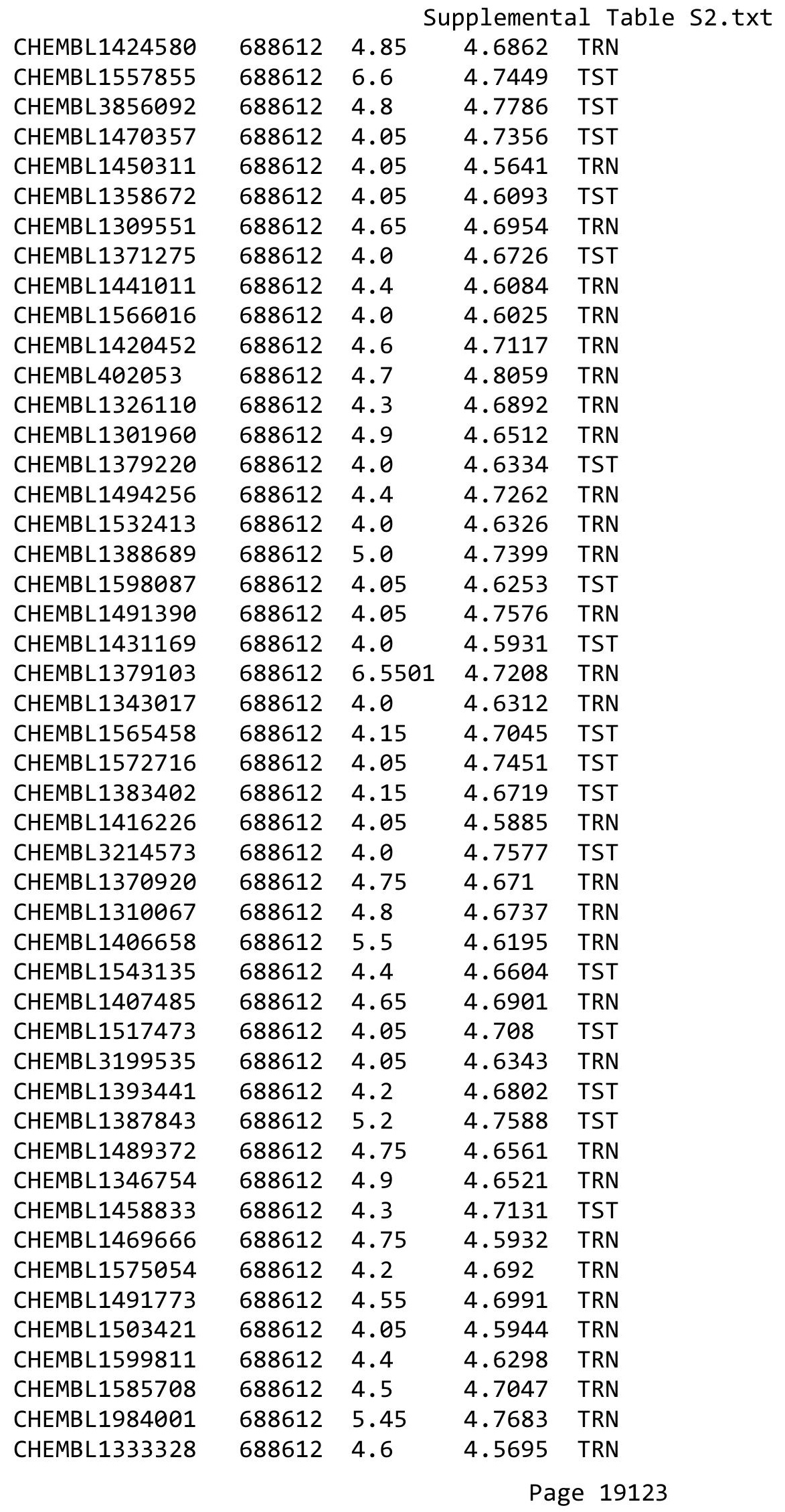




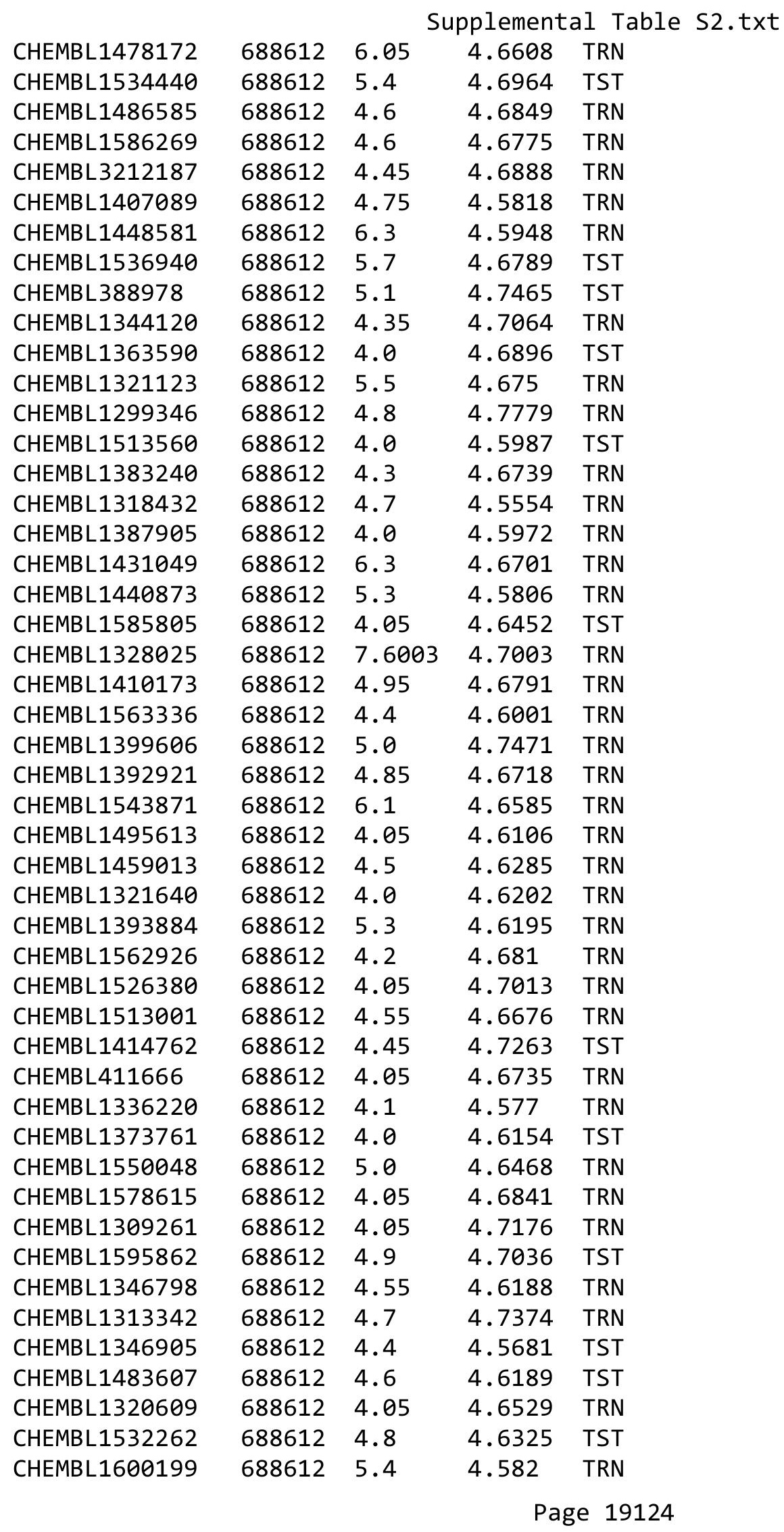




\begin{tabular}{|c|c|c|c|c|}
\hline \multicolumn{5}{|c|}{ Supplemental Table S2.txt } \\
\hline CHEMBL1433188 & 688612 & 5.85 & 4.6828 & TRN \\
\hline CHEMBL1605134 & 688612 & 4.05 & 4.6865 & TRN \\
\hline CHEMBL1486910 & 688612 & 4.35 & 4.6544 & TRN \\
\hline CHEMBL1340663 & 688612 & 4.7 & 4.729 & TRN \\
\hline CHEMBL1343536 & 688612 & 4.1 & 4.8072 & TST \\
\hline CHEMBL1469738 & 688612 & 4.1 & 4.6511 & TST \\
\hline CHEMBL1351888 & 688612 & 5.35 & 4.6977 & TST \\
\hline CHEMBL1325203 & 688612 & 4.8 & 4.6159 & TRN \\
\hline CHEMBL1420077 & 688612 & 4.6 & 4.7177 & TRN \\
\hline CHEMBL1462540 & 688612 & 4.95 & 4.6538 & TRN \\
\hline CHEMBL 3207580 & 688612 & 6.8499 & 4.708 & TRN \\
\hline CHEMBL1344339 & 688612 & 4.05 & 4.7569 & TST \\
\hline CHEMBL1459274 & 688612 & 4.05 & 4.6421 & TRN \\
\hline CHEMBL1326175 & 688612 & 4.05 & 4.6089 & TRN \\
\hline CHEMBL1554604 & 688612 & 6.5501 & 4.6589 & TRN \\
\hline CHEMBL1383629 & 688612 & 4.85 & 4.5941 & TRN \\
\hline CHEMBL1450165 & 688612 & 5.05 & 4.8147 & TRN \\
\hline CHEMBL1328224 & 688612 & 4.5 & 4.7465 & TST \\
\hline CHEMBL1450839 & 688612 & 4.05 & 4.6206 & TRN \\
\hline CHEMBL1551046 & 688612 & 4.05 & 4.6164 & TRN \\
\hline CHEMBL1329548 & 688612 & 4.4 & 4.6837 & TRN \\
\hline CHEMBL1402476 & 688612 & 4.5 & 4.728 & TRN \\
\hline CHEMBL1472773 & 688612 & 4.6 & 4.7341 & TST \\
\hline CHEMBL3190894 & 688612 & 4.5 & 4.6494 & TRN \\
\hline CHEMBL1575230 & 688612 & 4.25 & 4.7755 & TRN \\
\hline CHEMBL1341869 & 688612 & 4.1 & 4.6418 & TRN \\
\hline CHEMBL1522293 & 688612 & 6.8499 & 4.6158 & TRN \\
\hline CHEMBL1468371 & 688612 & 5.3 & 4.7372 & TRN \\
\hline CHEMBL1552328 & 688612 & 5.05 & 4.6195 & TRN \\
\hline CHEMBL1447336 & 688612 & 6.8 & 4.7305 & TRN \\
\hline CHEMBL1476665 & 688612 & 4.05 & 4.6174 & TST \\
\hline CHEMBL1602334 & 688612 & 4.4 & 4.7128 & TRN \\
\hline CHEMBL1550294 & 688612 & 4.85 & 4.6274 & TRN \\
\hline CHEMBL1551858 & 688612 & 4.6 & 4.685 & TST \\
\hline CHEMBL1532691 & 688612 & 4.7 & 4.6831 & TST \\
\hline CHEMBL1513434 & 688612 & 4.3 & 4.6296 & TRN \\
\hline CHEMBL1481770 & 688612 & 4.55 & 4.6736 & TRN \\
\hline CHEMBL1605282 & 688612 & 4.1 & 4.665 & TRN \\
\hline CHEMBL1476144 & 688612 & 4.8 & 4.7082 & TRN \\
\hline CHEMBL1518548 & 688612 & 4.1 & 4.7104 & TRN \\
\hline CHEMBL1555897 & 688612 & 4.6 & 4.7074 & TST \\
\hline CHEMBL1418391 & 688612 & 4.05 & 4.6936 & TRN \\
\hline CHEMBL1435493 & 688612 & 4.45 & 4.7356 & TRN \\
\hline CHEMBL1523736 & 688612 & 4.7 & 4.7742 & TRN \\
\hline CHEMBL1351342 & 688612 & 4.35 & 4.7304 & TRN \\
\hline CHEMBL1401282 & 688612 & 4.0 & 4.6811 & TRN \\
\hline CHEMBL1347116 & 688612 & 4.05 & 4.7039 & TST \\
\hline CHEMBL1312858 & 688612 & 4.0 & 4.6676 & TRN \\
\hline
\end{tabular}




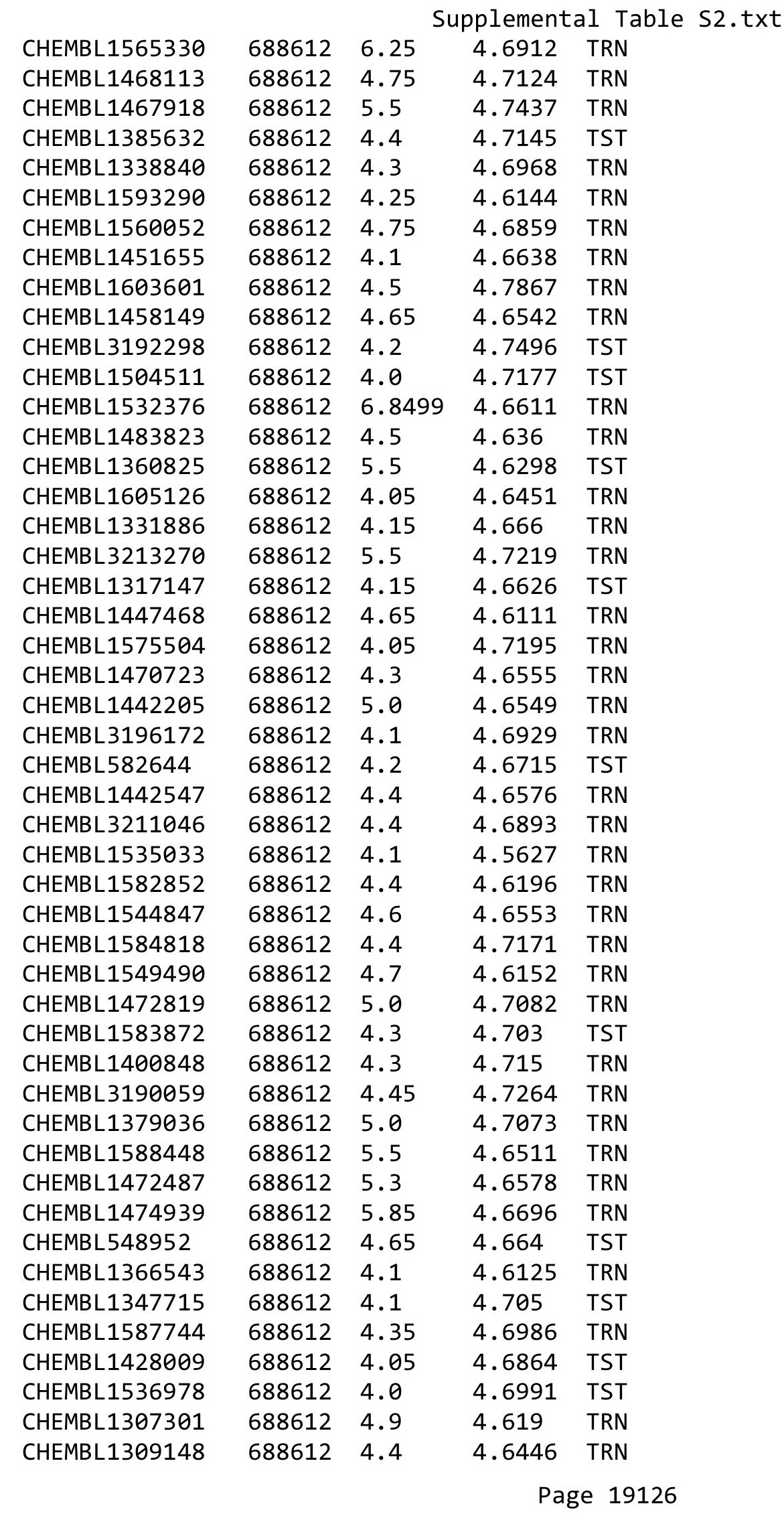




\begin{tabular}{|c|c|c|c|c|}
\hline \multicolumn{5}{|c|}{ Supplemental Table S2.txt } \\
\hline CHEMBL1422862 & 688612 & 4.9 & 4.7441 & TRN \\
\hline CHEMBL1604540 & 688612 & 4.05 & 4.7164 & TRN \\
\hline CHEMBL164 & 688612 & 6.7001 & 4.8769 & TRN \\
\hline CHEMBL1310699 & 688612 & 4.3 & 4.7746 & TRN \\
\hline CHEMBL1421172 & 688612 & 5.45 & 4.7856 & TRN \\
\hline CHEMBL1484085 & 688612 & 4.05 & 4.6295 & TRN \\
\hline CHEMBL1522112 & 688612 & 4.3 & 4.6463 & TRN \\
\hline CHEMBL1457412 & 688612 & 4.75 & 4.7179 & TRN \\
\hline CHEMBL1611892 & 688612 & 4.75 & 4.7256 & TRN \\
\hline CHEMBL1508843 & 688612 & 5.5 & 4.6472 & TRN \\
\hline CHEMBL 3192944 & 688612 & 4.65 & 4.7171 & TST \\
\hline CHEMBL1425597 & 688612 & 5.0 & 4.6716 & TRN \\
\hline CHEMBL1482703 & 688612 & 6.0 & 4.7284 & TRN \\
\hline CHEMBL1548556 & 688612 & 4.05 & 4.734 & TST \\
\hline CHEMBL1306200 & 688612 & 5.3 & 4.67 & TRN \\
\hline CHEMBL1722566 & 688612 & 5.05 & 4.7547 & TRN \\
\hline CHEMBL1583888 & 688612 & 4.1 & 4.7141 & TST \\
\hline CHEMBL1343834 & 688612 & 4.05 & 4.6463 & TRN \\
\hline CHEMBL1311202 & 688612 & 6.5 & 4.6305 & TRN \\
\hline CHEMBL1469900 & 688612 & 4.3 & 4.7153 & TRN \\
\hline CHEMBL1610589 & 688612 & 4.3 & 4.6991 & TRN \\
\hline CHEMBL1445386 & 688612 & 4.2 & 4.7367 & TST \\
\hline CHEMBL1488460 & 688612 & 4.05 & 4.7145 & TST \\
\hline CHEMBL1322157 & 688612 & 6.3 & 4.7165 & TRN \\
\hline CHEMBL1493204 & 688612 & 4.35 & 4.7509 & TST \\
\hline CHEMBL1346131 & 688612 & 6.7001 & 4.6706 & TST \\
\hline CHEMBL1475984 & 688612 & 4.1 & 4.6742 & TST \\
\hline CHEMBL1426122 & 688612 & 4.0 & 4.7133 & TST \\
\hline CHEMBL1558431 & 688612 & 4.9 & 4.7049 & TRN \\
\hline CHEMBL3195537 & 688612 & 4.0 & 4.676 & TRN \\
\hline CHEMBL1579927 & 688612 & 4.8 & 4.7144 & TRN \\
\hline CHEMBL1353365 & 688612 & 4.1 & 4.6769 & TRN \\
\hline CHEMBL3191647 & 688612 & 4.05 & 4.6395 & TRN \\
\hline CHEMBL1568618 & 688612 & 4.65 & 4.711 & TRN \\
\hline CHEMBL1570744 & 688612 & 4.0 & 4.6753 & TRN \\
\hline CHEMBL1337030 & 688612 & 4.05 & 4.6733 & TST \\
\hline CHEMBL1438886 & 688612 & 4.35 & 4.6348 & TRN \\
\hline CHEMBL1394688 & 688612 & 4.05 & 4.5761 & TRN \\
\hline CHEMBL1574521 & 688612 & 4.0 & 4.6965 & TST \\
\hline CHEMBL1304030 & 688612 & 5.3 & 4.7007 & TRN \\
\hline CHEMBL 3856088 & 688612 & 4.3 & 4.7762 & TRN \\
\hline CHEMBL3194762 & 688612 & 4.15 & 4.6912 & TRN \\
\hline CHEMBL1385224 & 688612 & 4.65 & 4.7294 & TRN \\
\hline CHEMBL1409433 & 688612 & 4.55 & 4.7573 & TRN \\
\hline CHEMBL1551882 & 688612 & 4.75 & 4.5425 & TRN \\
\hline CHEMBL1560690 & 688612 & 4.7 & 4.6361 & TST \\
\hline CHEMBL1346206 & 688612 & 4.1 & 4.5969 & TST \\
\hline CHEMBL1565837 & 688612 & 4.6 & 4.6745 & TRN \\
\hline
\end{tabular}




\begin{tabular}{|c|c|c|c|c|}
\hline \multicolumn{5}{|c|}{ Supplemental Table S2.txt } \\
\hline CHEMBL1301318 & 688612 & 4.0 & 4.5424 & TRN \\
\hline CHEMBL1452648 & 688612 & 4.6 & 4.654 & TRN \\
\hline CHEMBL1445636 & 688612 & 5.0 & 4.6282 & TRN \\
\hline CHEMBL1456343 & 688612 & 4.35 & 4.6292 & TRN \\
\hline CHEMBL1362799 & 688612 & 4.6 & 4.721 & TRN \\
\hline CHEMBL1428250 & 688612 & 6.35 & 4.7028 & TST \\
\hline CHEMBL1465974 & 688612 & 4.35 & 4.6125 & TRN \\
\hline CHEMBL1398937 & 688612 & 4.4 & 4.6991 & TRN \\
\hline CHEMBL1407263 & 688612 & 4.8 & 4.7288 & TRN \\
\hline CHEMBL1474183 & 688612 & 4.1 & 4.579 & TRN \\
\hline CHEMBL1587828 & 688612 & 5.05 & 4.698 & TRN \\
\hline CHEMBL1541779 & 688612 & 5.0 & 4.7485 & TRN \\
\hline CHEMBL1314951 & 688612 & 6.5 & 4.6861 & TRN \\
\hline CHEMBL1505788 & 688612 & 5.4 & 4.6364 & TRN \\
\hline CHEMBL1413941 & 688612 & 4.4 & 4.6503 & TRN \\
\hline CHEMBL280065 & 688612 & 4.5 & 4.6708 & TRN \\
\hline CHEMBL1348007 & 688612 & 4.1 & 4.6108 & TST \\
\hline CHEMBL1611905 & 688612 & 4.95 & 4.6112 & TRN \\
\hline CHEMBL1593520 & 688612 & 4.0 & 4.6308 & TRN \\
\hline CHEMBL1419711 & 688612 & 4.05 & 4.6301 & TRN \\
\hline CHEMBL144472 & 688612 & 5.0 & 4.7218 & TST \\
\hline CHEMBL1493819 & 688612 & 4.0 & 4.5513 & TRN \\
\hline CHEMBL1417508 & 688612 & 4.4 & 4.6012 & TST \\
\hline CHEMBL1459430 & 688612 & 4.4 & 4.6522 & TRN \\
\hline CHEMBL1392271 & 688612 & 4.05 & 4.6584 & TRN \\
\hline CHEMBL1380004 & 688612 & 4.0 & 4.6453 & TST \\
\hline CHEMBL1401965 & 688612 & 3.95 & 4.588 & TRN \\
\hline CHEMBL1340541 & 688612 & 4.4 & 4.6509 & TRN \\
\hline CHEMBL1609118 & 688612 & 5.5 & 4.6316 & TST \\
\hline CHEMBL1500636 & 688612 & 5.45 & 4.7773 & TST \\
\hline CHEMBL1459002 & 688612 & 4.45 & 4.6719 & TRN \\
\hline CHEMBL1459655 & 688612 & 4.45 & 4.699 & TRN \\
\hline CHEMBL1332293 & 688612 & 4.4 & 4.632 & TRN \\
\hline CHEMBL1333101 & 688612 & 4.05 & 4.7781 & TRN \\
\hline CHEMBL1397275 & 688612 & 4.0 & 4.6167 & TST \\
\hline CHEMBL1575652 & 688612 & 4.7 & 4.7725 & TST \\
\hline CHEMBL1611321 & 688612 & 4.05 & 4.6145 & TST \\
\hline CHEMBL1403481 & 688612 & 6.05 & 4.6925 & TRN \\
\hline CHEMBL1582429 & 688612 & 4.1 & 4.6529 & TRN \\
\hline CHEMBL1602234 & 688612 & 4.15 & 4.7068 & TRN \\
\hline CHEMBL1545983 & 688612 & 4.05 & 4.6153 & TRN \\
\hline CHEMBL1406499 & 688612 & 4.4 & 4.6832 & TST \\
\hline CHEMBL1317745 & 688612 & 6.0 & 4.562 & TRN \\
\hline CHEMBL1460470 & 688612 & 6.5 & 4.6944 & TST \\
\hline CHEMBL1544802 & 688612 & 4.05 & 4.7303 & TRN \\
\hline CHEMBL1979455 & 688612 & 4.4 & 4.7618 & TRN \\
\hline CHEMBL1444282 & 688612 & 5.8 & 4.6369 & TRN \\
\hline CHEMBL1584150 & 688612 & 5.25 & 4.7412 & TST \\
\hline
\end{tabular}




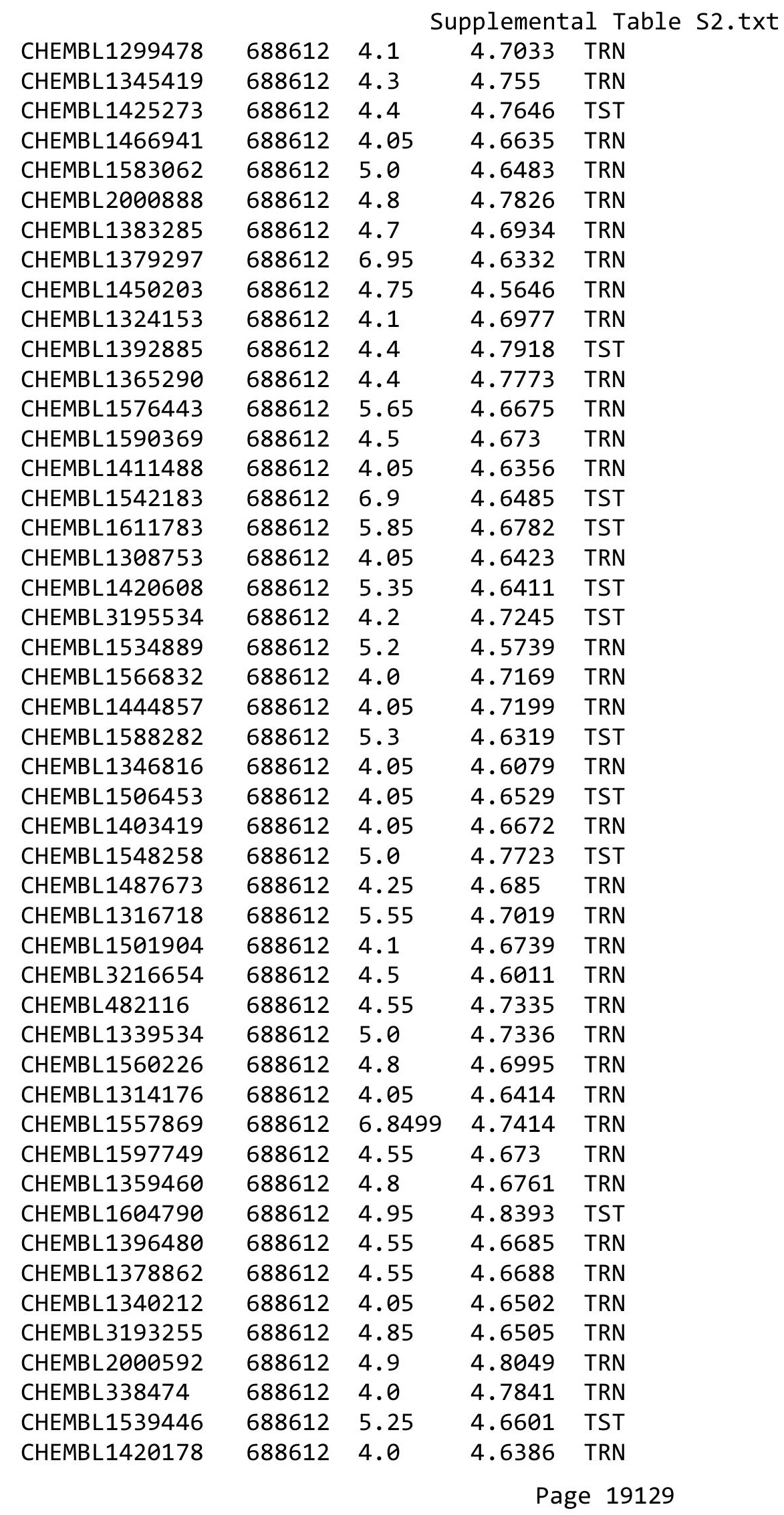




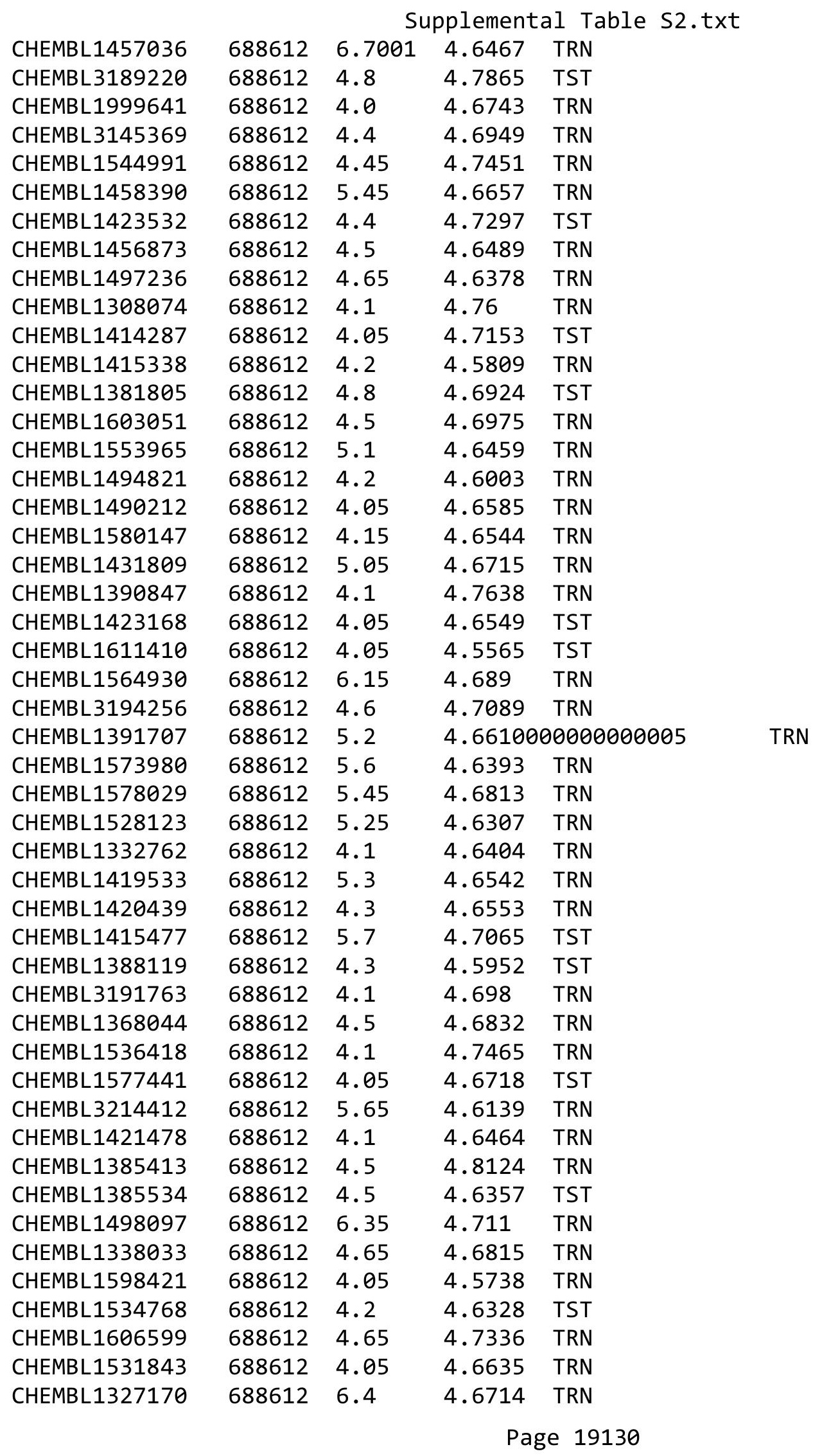




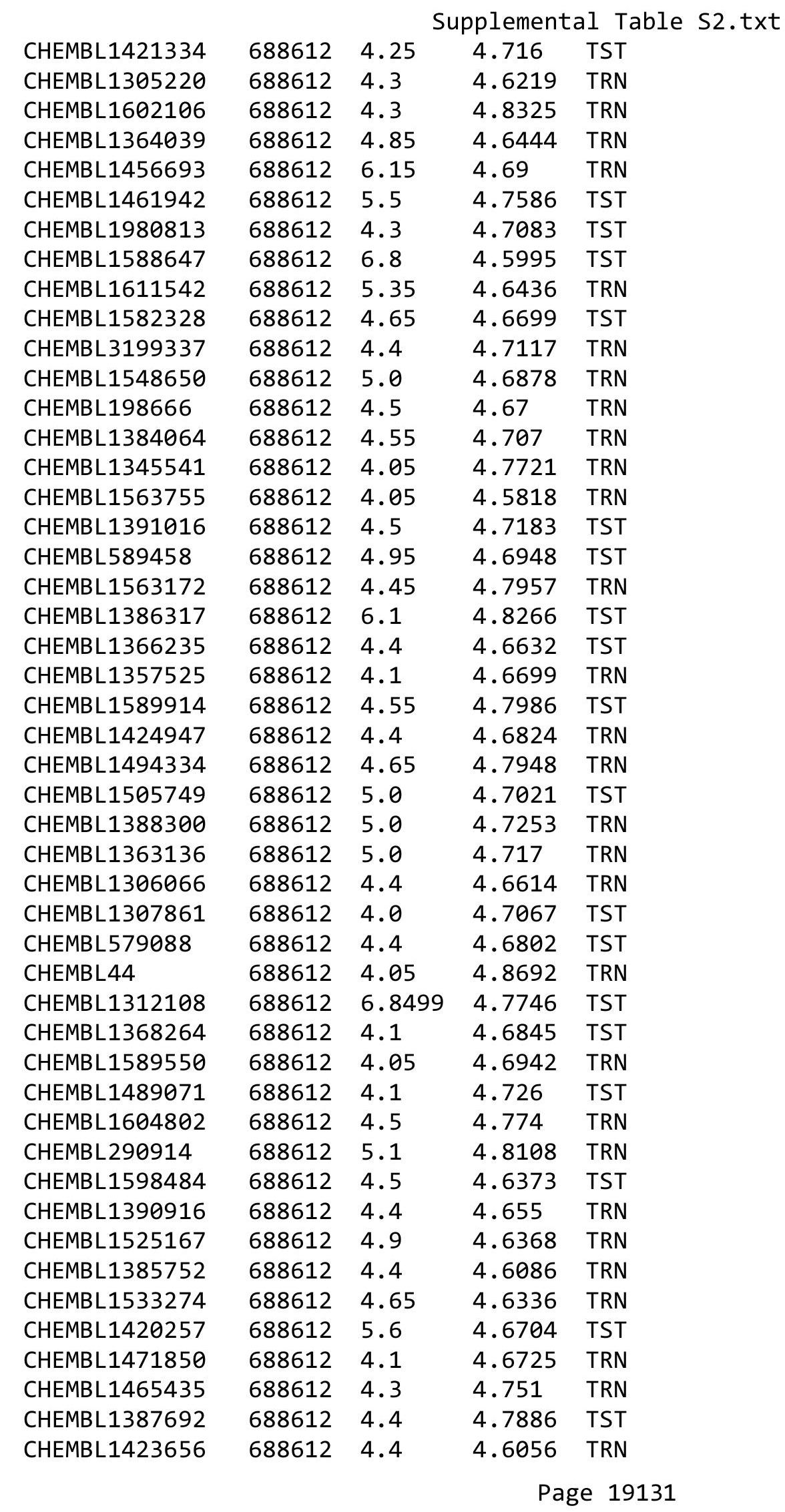




\begin{tabular}{|c|c|c|c|c|c|}
\hline \multicolumn{6}{|c|}{ Supplemental Table S2.txt } \\
\hline CHEMBL1580481 & 688612 & 5.05 & 4.6994 & TRN & \\
\hline CHEMBL1488648 & 688612 & 4.4 & 4.7587 & TRN & \\
\hline CHEMBL1502647 & 688612 & 5.5 & 4.6716 & TST & \\
\hline CHEMBL1378300 & 688612 & 4.6 & 4.7185 & TST & \\
\hline CHEMBL1424803 & 688612 & 4.7 & 4.7381 & TRN & \\
\hline CHEMBL1481240 & 688612 & 4.05 & 4.7181 & TST & \\
\hline CHEMBL1576938 & 688612 & 4.65 & 4.6537 & TRN & \\
\hline CHEMBL1415864 & 688612 & 5.5 & 4.7006 & TST & \\
\hline CHEMBL1309000 & 688612 & 4.05 & 4.7812 & TRN & \\
\hline CHEMBL1586625 & 688612 & 4.1 & 4.6518 & TST & \\
\hline CHEMBL1573405 & 688612 & 5.2 & 4.6427 & TRN & \\
\hline CHEMBL1344927 & 688612 & 4.05 & 4.7456 & TRN & \\
\hline CHEMBL1605157 & 688612 & 4.55 & 4.7618 & TST & \\
\hline CHEMBL1341010 & 688612 & 4.6 & 4.7662 & TRN & \\
\hline CHEMBL1525242 & 688612 & 5.65 & 4.6559 & TRN & \\
\hline CHEMBL1403611 & 688612 & 4.2 & 4.7011 & TST & \\
\hline CHEMBL1439033 & 688612 & 6.1 & 4.6708 & TRN & \\
\hline CHEMBL1335652 & 688612 & 4.4 & 4.6012 & TST & \\
\hline CHEMBL1318301 & 688612 & 4.1 & 4.6129 & TST & \\
\hline CHEMBL1471812 & 688612 & 4.1 & 4.6523 & TRN & \\
\hline CHEMBL1305450 & 688612 & 4.65 & 4.7434 & TRN & \\
\hline CHEMBL1418946 & 688612 & 6.5501 & 4.71399 & 99999999995 & TST \\
\hline CHEMBL1337192 & 688612 & 4.1 & 4.6488 & TRN & \\
\hline CHEMBL1406688 & 688612 & 4.05 & 4.672 & TST & \\
\hline CHEMBL1409507 & 688612 & 4.1 & 4.6701 & TRN & \\
\hline CHEMBL1604156 & 688612 & 4.45 & 4.6374 & TRN & \\
\hline CHEMBL1332263 & 688612 & 6.0 & 4.7364 & TRN & \\
\hline CHEMBL1405006 & 688612 & 5.5 & 4.6195 & TRN & \\
\hline CHEMBL1322509 & 688612 & 4.25 & 4.6369 & TST & \\
\hline CHEMBL533082 & 688612 & 4.85 & 4.6483 & TRN & \\
\hline CHEMBL1404155 & 688612 & 4.6 & 4.681 & TRN & \\
\hline CHEMBL1430328 & 688612 & 5.2 & 4.6301 & TRN & \\
\hline CHEMBL1468251 & 688612 & 5.15 & 4.6433 & TRN & \\
\hline CHEMBL1468376 & 688612 & 4.0 & 4.6431 & TST & \\
\hline CHEMBL1506083 & 688612 & 4.75 & 4.6912 & TRN & \\
\hline CHEMBL1471039 & 688612 & 4.7 & 4.7637 & TRN & \\
\hline CHEMBL1523996 & 688612 & 6.35 & 4.5534 & TRN & \\
\hline CHEMBL1516394 & 688612 & 4.0 & 4.7546 & TRN & \\
\hline CHEMBL1303974 & 688612 & 6.6499 & 4.584 & TRN & \\
\hline CHEMBL1558645 & 688612 & 4.6 & 4.6991 & TST & \\
\hline CHEMBL1347493 & 688612 & 4.3 & 4.7421 & TRN & \\
\hline CHEMBL1469623 & 688612 & 4.05 & 4.6847 & TRN & \\
\hline CHEMBL1389681 & 688612 & 4.7 & 4.643 & TRN & \\
\hline CHEMBL3195077 & 688612 & 4.05 & 4.7491 & TRN & \\
\hline CHEMBL1529556 & 688612 & 4.2 & 4.6385 & TRN & \\
\hline CHEMBL1593675 & 688612 & 4.55 & 4.6324 & TRN & \\
\hline CHEMBL1475164 & 688612 & 4.25 & 4.6978 & TRN & \\
\hline CHEMBL1450705 & 688612 & 4.0 & 4.6607 & TRN & \\
\hline
\end{tabular}




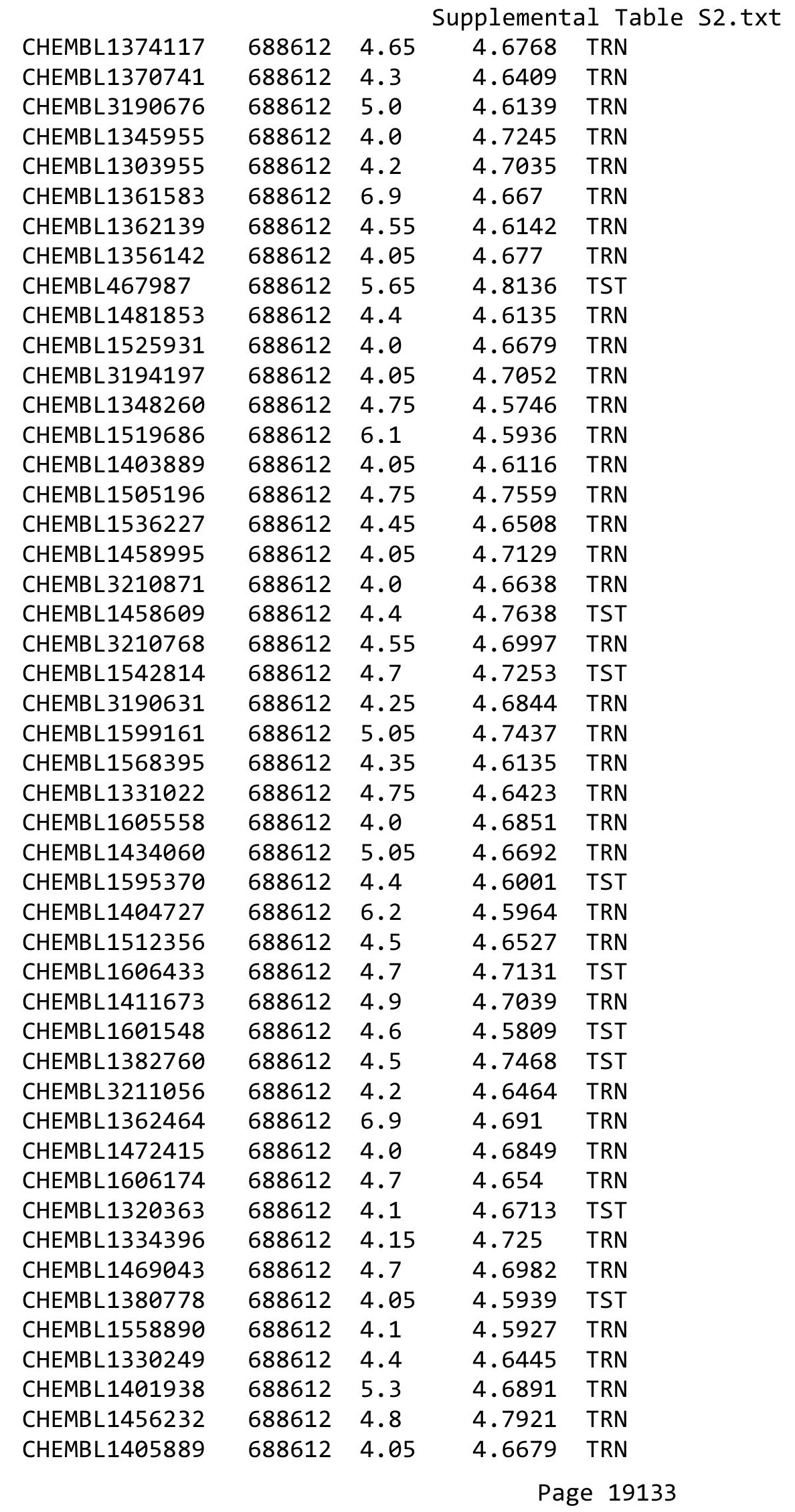




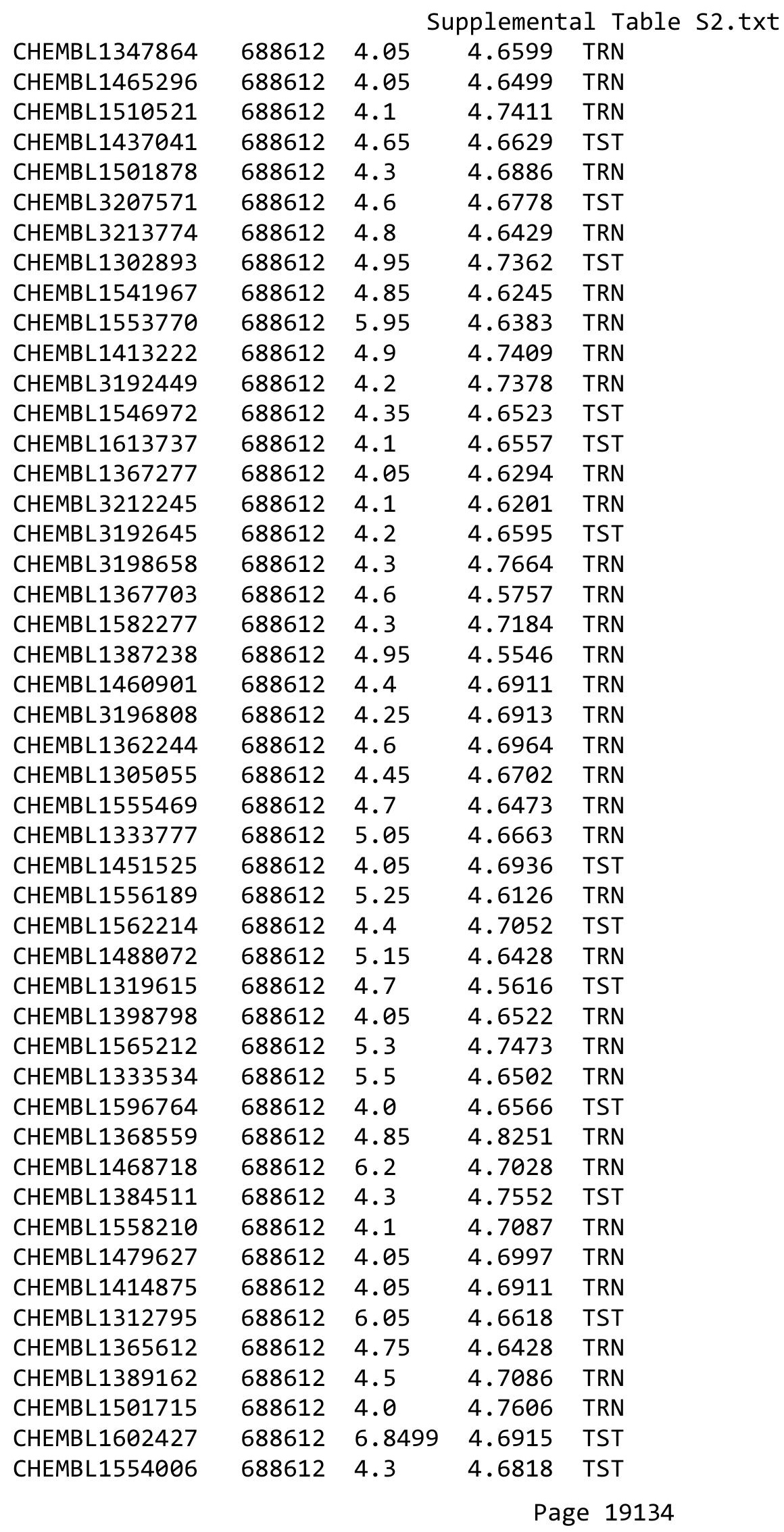




\begin{tabular}{|c|c|c|c|c|c|}
\hline \multicolumn{6}{|c|}{ Supplemental Table S2.txt } \\
\hline CHEMBL1432668 & 688612 & 4.45 & 4.6698 & TST & \\
\hline CHEMBL1333826 & 688612 & 4.1 & 4.619 & TRN & \\
\hline CHEMBL1490194 & 688612 & 4.9 & 4.6592 & TRN & \\
\hline CHEMBL1460902 & 688612 & 4.1 & 4.6507 & TRN & \\
\hline CHEMBL578878 & 688612 & 4.8 & 4.6888 & TRN & \\
\hline CHEMBL1575437 & 688612 & 4.05 & 4.6335 & TST & \\
\hline CHEMBL1589010 & 688612 & 6.1 & 4.671 & TRN & \\
\hline CHEMBL3189716 & 688612 & 4.05 & 4.7509 & TRN & \\
\hline CHEMBL1493705 & 688612 & 5.4 & 4.6907 & TST & \\
\hline CHEMBL3189262 & 688612 & 4.65 & 4.6819 & TRN & \\
\hline CHEMBL1479518 & 688612 & 4.35 & 4.7151 & TRN & \\
\hline CHEMBL1334017 & 688612 & 5.15 & 4.687 & TST & \\
\hline CHEMBL1340938 & 688612 & 4.4 & 4.6414 & TST & \\
\hline CHEMBL1496880 & 688612 & 4.4 & 4.6505 & TRN & \\
\hline CHEMBL1500027 & 688612 & 4.8 & 4.5979 & TST & \\
\hline CHEMBL1327079 & 688612 & 4.05 & 4.71399 & 99999999995 & TST \\
\hline CHEMBL1437973 & 688612 & 4.1 & 4.6106 & TRN & \\
\hline CHEMBL1611569 & 688612 & 4.1 & 4.6561 & TRN & \\
\hline CHEMBL1299186 & 688612 & 4.3 & 4.7535 & TRN & \\
\hline CHEMBL1580723 & 688612 & 5.15 & 4.6429 & TRN & \\
\hline CHEMBL1367986 & 688612 & 6.05 & 4.7632 & TRN & \\
\hline CHEMBL1431149 & 688612 & 4.55 & 4.6805 & TRN & \\
\hline CHEMBL1543147 & 688612 & 5.15 & 4.6747 & TRN & \\
\hline CHEMBL1412123 & 688612 & 4.85 & 4.6428 & TRN & \\
\hline CHEMBL1413583 & 688612 & 4.55 & 4.6126 & TRN & \\
\hline CHEMBL1351439 & 688612 & 4.05 & 4.7204 & TST & \\
\hline CHEMBL1527190 & 688612 & 4.05 & 4.7021 & TRN & \\
\hline CHEMBL1991234 & 688612 & 4.8 & 4.8812 & TRN & \\
\hline CHEMBL1584158 & 688612 & 4.05 & 4.5665 & TRN & \\
\hline CHEMBL1397917 & 688612 & 4.1 & 4.5961 & TRN & \\
\hline CHEMBL1408143 & 688612 & 4.8 & 4.6883 & TRN & \\
\hline CHEMBL1478941 & 688612 & 4.05 & 4.6712 & TRN & \\
\hline CHEMBL3190269 & 688612 & 4.15 & 4.6837 & TRN & \\
\hline CHEMBL1419035 & 688612 & 4.75 & 4.7059 & TST & \\
\hline CHEMBL1437513 & 688612 & 4.1 & 4.7173 & TRN & \\
\hline CHEMBL3199927 & 688612 & 4.05 & 4.624 & TRN & \\
\hline CHEMBL1393005 & 688612 & 4.1 & 4.7306 & TRN & \\
\hline CHEMBL1307641 & 688612 & 4.05 & 4.6403 & TRN & \\
\hline CHEMBL1495622 & 688612 & 5.5 & 4.5938 & TRN & \\
\hline CHEMBL1415266 & 688612 & 4.4 & 4.6328 & TRN & \\
\hline CHEMBL1566720 & 688612 & 5.25 & 4.643 & TRN & \\
\hline CHEMBL1308094 & 688612 & 6.8499 & 4.6621 & TRN & \\
\hline CHEMBL1532997 & 688612 & 4.05 & 4.7529 & TST & \\
\hline CHEMBL3208797 & 688612 & 4.0 & 4.61600 & 00000000005 & TRN \\
\hline CHEMBL1416884 & 688612 & 4.05 & 4.628 & TST & \\
\hline CHEMBL1383849 & 688612 & 4.3 & 4.6785 & TRN & \\
\hline CHEMBL1612269 & 688612 & 4.05 & 4.6231 & TRN & \\
\hline CHEMBL1351171 & 688612 & 4.1 & 4.6324 & TRN & \\
\hline
\end{tabular}




\begin{tabular}{|c|c|c|c|c|}
\hline \multicolumn{5}{|c|}{ Supplemental Table S2.txt } \\
\hline CHEMBL1358767 & 688612 & 4.4 & 4.6567 & TRN \\
\hline CHEMBL1447011 & 688612 & 5.05 & 4.6829 & TRN \\
\hline CHEMBL1572943 & 688612 & 4.7 & 4.6015 & TST \\
\hline CHEMBL1389085 & 688612 & 6.8499 & 4.6568 & TRN \\
\hline CHEMBL1474106 & 688612 & 4.0 & 4.6405 & TRN \\
\hline CHEMBL1599076 & 688612 & 4.05 & 4.6673 & TRN \\
\hline CHEMBL1467399 & 688612 & 4.5 & 4.7142 & TRN \\
\hline CHEMBL1446226 & 688612 & 4.0 & 4.6722 & TRN \\
\hline CHEMBL3199889 & 688612 & 5.05 & 4.633 & TRN \\
\hline CHEMBL1556609 & 688612 & 5.55 & 4.629 & TRN \\
\hline CHEMBL1594984 & 688612 & 4.3 & 4.8054 & TRN \\
\hline CHEMBL1551562 & 688612 & 4.05 & 4.6002 & TRN \\
\hline CHEMBL3197021 & 688612 & 5.45 & 4.7004 & TRN \\
\hline CHEMBL1979696 & 688612 & 4.7 & 4.6827 & TST \\
\hline CHEMBL1379897 & 688612 & 4.65 & 4.7031 & TRN \\
\hline CHEMBL1999648 & 688612 & 4.75 & 4.7159 & TST \\
\hline CHEMBL162783 & 688612 & 4.45 & 4.827 & TRN \\
\hline CHEMBL1608829 & 688612 & 4.2 & 4.6466 & TRN \\
\hline CHEMBL1509444 & 688612 & 6.2 & 4.6232 & TST \\
\hline CHEMBL1480782 & 688612 & 4.05 & 4.6991 & TST \\
\hline CHEMBL1545976 & 688612 & 4.1 & 4.6221 & TRN \\
\hline CHEMBL1452706 & 688612 & 4.05 & 4.7348 & TST \\
\hline CHEMBL1352733 & 688612 & 4.1 & 4.6342 & TRN \\
\hline CHEMBL1350986 & 688612 & 4.25 & 4.6086 & TRN \\
\hline CHEMBL1520344 & 688612 & 4.1 & 4.609 & TST \\
\hline CHEMBL 3199440 & 688612 & 5.6 & 4.7127 & TRN \\
\hline CHEMBL1424717 & 688612 & 4.75 & 4.584 & TRN \\
\hline CHEMBL1581479 & 688612 & 4.25 & 4.6196 & TRN \\
\hline CHEMBL1586655 & 688612 & 4.5 & 4.6457 & TRN \\
\hline CHEMBL1430874 & 688612 & 6.1 & 4.5651 & TRN \\
\hline CHEMBL1519036 & 688612 & 5.45 & 4.6312 & TRN \\
\hline CHEMBL1560131 & 688612 & 4.05 & 4.7802 & TST \\
\hline CHEMBL1456448 & 688612 & 4.6 & 4.6959 & TRN \\
\hline CHEMBL403419 & 688612 & 4.0 & 4.7125 & TRN \\
\hline CHEMBL1446203 & 688612 & 7.0 & 4.655 & TST \\
\hline CHEMBL1517686 & 688612 & 5.5 & 4.725 & TRN \\
\hline CHEMBL576175 & 688612 & 4.45 & 4.6133 & TRN \\
\hline CHEMBL589694 & 688612 & 4.05 & 4.6408 & TRN \\
\hline CHEMBL1597699 & 688612 & 4.1 & 4.6598 & TST \\
\hline CHEMBL1590465 & 688612 & 4.7 & 4.6138 & TRN \\
\hline CHEMBL3210147 & 688612 & 4.05 & 4.7136 & TRN \\
\hline CHEMBL3195365 & 688612 & 4.6 & 4.7358 & TRN \\
\hline CHEMBL159895 & 688612 & 4.2 & 4.8162 & TRN \\
\hline CHEMBL1333647 & 688612 & 4.05 & 4.6561 & TST \\
\hline CHEMBL1550550 & 688612 & 4.4 & 4.6551 & TST \\
\hline CHEMBL1497463 & 688612 & 4.6 & 4.7358 & TRN \\
\hline CHEMBL1380530 & 688612 & 4.45 & 4.7051 & TRN \\
\hline CHEMBL3193663 & 688612 & 4.75 & 4.6514 & TST \\
\hline
\end{tabular}




\begin{tabular}{|c|c|c|c|c|}
\hline \multicolumn{5}{|c|}{ Supplemental Table S2.txt } \\
\hline CHEMBL1605624 & 688612 & 4.4 & 4.5909 & TRN \\
\hline CHEMBL1985257 & 688612 & 4.95 & 4.667 & TRN \\
\hline CHEMBL1327940 & 688612 & 5.45 & 4.6557 & TST \\
\hline CHEMBL3198362 & 688612 & 4.4 & 4.7136 & TRN \\
\hline CHEMBL1497894 & 688612 & 5.0 & 4.7133 & TRN \\
\hline CHEMBL1473936 & 688612 & 4.05 & 4.628 & TRN \\
\hline CHEMBL1411840 & 688612 & 4.05 & 4.646 & TRN \\
\hline CHEMBL1436312 & 688612 & 4.3 & 4.6311 & TRN \\
\hline CHEMBL1545664 & 688612 & 4.4 & 4.7664 & TRN \\
\hline CHEMBL1520892 & 688612 & 4.55 & 4.6615 & TRN \\
\hline CHEMBL1370396 & 688612 & 6.2 & 4.6294 & TST \\
\hline CHEMBL1596703 & 688612 & 4.0 & 4.677 & TRN \\
\hline CHEMBL3191670 & 688612 & 5.45 & 4.7352 & TRN \\
\hline CHEMBL1576621 & 688612 & 4.65 & 4.6415 & TRN \\
\hline CHEMBL1437881 & 688612 & 6.2 & 4.7356 & TRN \\
\hline CHEMBL 3210583 & 688612 & 4.15 & 4.7179 & TRN \\
\hline CHEMBL1427512 & 688612 & 5.3 & 4.5875 & TRN \\
\hline CHEMBL3190597 & 688612 & 4.25 & 4.7766 & TRN \\
\hline CHEMBL1566467 & 688612 & 4.1 & 4.6255 & TST \\
\hline CHEMBL1318890 & 688612 & 4.7 & 4.629 & TRN \\
\hline CHEMBL1406118 & 688612 & 4.8 & 4.6629 & TRN \\
\hline CHEMBL1525782 & 688612 & 5.0 & 4.6479 & TRN \\
\hline CHEMBL1485367 & 688612 & 4.0 & 4.5956 & TRN \\
\hline CHEMBL1516335 & 688612 & 4.55 & 4.7006 & TRN \\
\hline CHEMBL1329759 & 688612 & 6.8499 & 4.6553 & TRN \\
\hline CHEMBL1561111 & 688612 & 4.1 & 4.7695 & TRN \\
\hline CHEMBL1553788 & 688612 & 4.05 & 4.631 & TRN \\
\hline CHEMBL1420623 & 688612 & 4.05 & 4.7157 & TST \\
\hline CHEMBL1514689 & 688612 & 4.1 & 4.6463 & TRN \\
\hline CHEMBL 1484530 & 688612 & 4.4 & 4.6059 & TRN \\
\hline CHEMBL1300583 & 688612 & 4.45 & 4.6413 & TST \\
\hline CHEMBL1395489 & 688612 & 4.8 & 4.5831 & TST \\
\hline CHEMBL1343747 & 688612 & 6.5501 & 4.619 & TRN \\
\hline CHEMBL1340183 & 688612 & 4.7 & 4.6976 & TRN \\
\hline CHEMBL1311193 & 688612 & 4.3 & 4.6726 & TRN \\
\hline CHEMBL1406561 & 688612 & 4.05 & 4.6146 & TRN \\
\hline CHEMBL1579122 & 688612 & 4.4 & 4.6415 & TST \\
\hline CHEMBL1324221 & 688612 & 4.35 & 4.7124 & TRN \\
\hline CHEMBL 3210451 & 688612 & 5.65 & 4.6909 & TRN \\
\hline CHEMBL 3210332 & 688612 & 4.7 & 4.7179 & TRN \\
\hline CHEMBL3213596 & 688612 & 4.05 & 4.6391 & TRN \\
\hline CHEMBL1386161 & 688612 & 4.55 & 4.7316 & TRN \\
\hline CHEMBL1575837 & 688612 & 4.4 & 4.6743 & TRN \\
\hline CHEMBL1491595 & 688612 & 4.4 & 4.724 & TST \\
\hline CHEMBL1463012 & 688612 & 5.45 & 4.6637 & TRN \\
\hline CHEMBL1303940 & 688612 & 4.4 & 4.6363 & TRN \\
\hline CHEMBL1334007 & 688612 & 4.65 & 4.7147 & TST \\
\hline CHEMBL1497636 & 688612 & 5.85 & 4.6152 & TRN \\
\hline
\end{tabular}




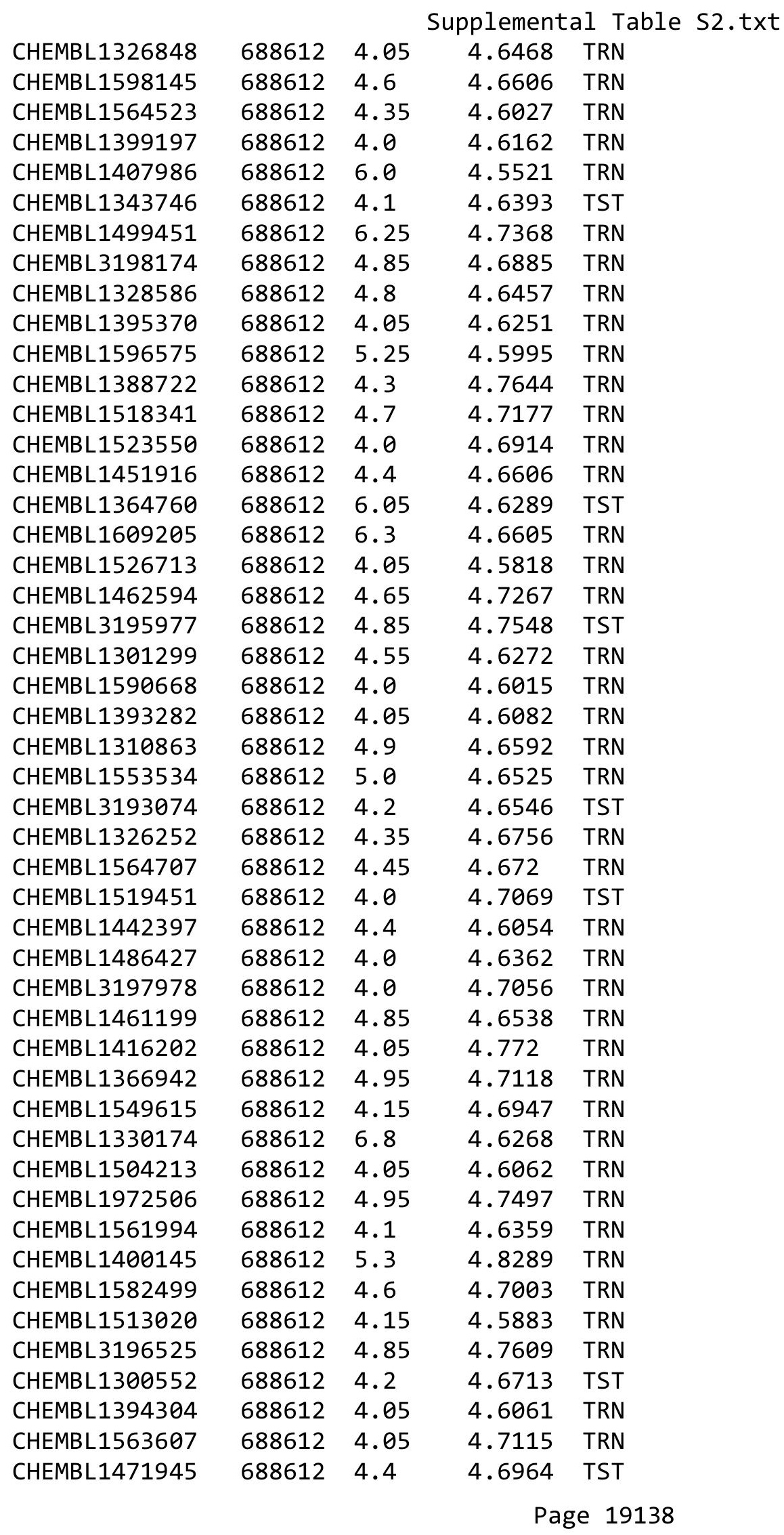




\begin{tabular}{|c|c|c|c|c|c|}
\hline \multicolumn{6}{|c|}{ Supplemental Table S2.txt } \\
\hline CHEMBL1321359 & 688612 & 4.95 & 4.636 & TRN & \\
\hline CHEMBL1454404 & 688612 & 4.05 & 4.63 & TRN & \\
\hline CHEMBL 251670 & 688612 & 4.05 & 4.7024 & TST & \\
\hline CHEMBL 3208028 & 688612 & 5.05 & 4.6975 & TST & \\
\hline CHEMBL1554635 & 688612 & 5.45 & 4.6969 & TRN & \\
\hline CHEMBL1545565 & 688612 & 4.65 & 4.6117 & TRN & \\
\hline CHEMBL1374385 & 688612 & 4.1 & 4.6763 & TRN & \\
\hline CHEMBL1339402 & 688612 & 4.05 & 4.6548 & TRN & \\
\hline CHEMBL1538773 & 688612 & 5.35 & 4.6849 & TRN & \\
\hline CHEMBL1601440 & 688612 & 6.9 & 4.6835 & TRN & \\
\hline CHEMBL1524286 & 688612 & 4.55 & 4.7371 & TRN & \\
\hline CHEMBL1322854 & 688612 & 6.5 & 4.7089 & TRN & \\
\hline CHEMBL1568422 & 688612 & 6.6 & 4.7363 & TST & \\
\hline CHEMBL1494282 & 688612 & 4.0 & 4.6636 & TRN & \\
\hline CHEMBL1580541 & 688612 & 4.2 & 4.7294 & TRN & \\
\hline CHEMBL1348201 & 688612 & 7.0 & 4.7077 & TST & \\
\hline CHEMBL1522760 & 688612 & 4.6 & 4.7051 & TRN & \\
\hline CHEMBL1541070 & 688612 & 4.85 & 4.6597 & TRN & \\
\hline CHEMBL1557403 & 688612 & 4.0 & 4.6696 & TRN & \\
\hline CHEMBL 1574527 & 688612 & 4.05 & 4.7094 & TST & \\
\hline CHEMBL1517022 & 688612 & 4.0 & 4.6466 & TST & \\
\hline CHEMBL1486429 & 688612 & 4.8 & 4.7091 & TRN & \\
\hline CHEMBL1534783 & 688612 & 4.3 & 4.762 & TRN & \\
\hline CHEMBL1333959 & 688612 & 4.05 & 4.6563 & TRN & \\
\hline CHEMBL1464953 & 688612 & 5.35 & 4.6916 & TRN & \\
\hline CHEMBL1484810 & 688612 & 5.7 & 4.7263 & TST & \\
\hline CHEMBL1365168 & 688612 & 4.05 & 4.7116 & TST & \\
\hline CHEMBL1363666 & 688612 & 4.1 & 4.65600 & 0000000001 & TRN \\
\hline CHEMBL1395406 & 688612 & 4.1 & 4.6886 & TST & \\
\hline CHEMBL1509755 & 688612 & 4.5 & 4.6244 & TRN & \\
\hline CHEMBL1518121 & 688612 & 4.05 & 4.5709 & TRN & \\
\hline CHEMBL1478911 & 688612 & 4.2 & 4.6584 & TRN & \\
\hline CHEMBL1532604 & 688612 & 4.55 & 4.5664 & TRN & \\
\hline CHEMBL14192 & 688612 & 4.75 & 4.6327 & TST & \\
\hline CHEMBL1605587 & 688612 & 4.05 & 4.6972 & TRN & \\
\hline CHEMBL1529896 & 688612 & 4.1 & 4.6499 & TST & \\
\hline CHEMBL1449627 & 688612 & 4.75 & 4.7703 & TRN & \\
\hline CHEMBL1466371 & 688612 & 6.15 & 4.6268 & TRN & \\
\hline CHEMBL1994371 & 688612 & 4.25 & 4.726 & TRN & \\
\hline CHEMBL 3190250 & 688612 & 5.5 & 4.6546 & TRN & \\
\hline CHEMBL1437272 & 688612 & 4.95 & 4.6158 & TRN & \\
\hline CHEMBL 1558752 & 688612 & 4.05 & 4.711 & TST & \\
\hline CHEMBL3212420 & 688612 & 4.05 & 4.6743 & TRN & \\
\hline CHEMBL1403094 & 688612 & 4.4 & 4.6395 & TRN & \\
\hline CHEMBL1343254 & 688612 & 6.8 & 4.6294 & TST & \\
\hline CHEMBL1369668 & 688612 & 4.05 & 4.5684 & TRN & \\
\hline CHEMBL 1425918 & 688612 & 5.4 & 4.6461 & TRN & \\
\hline CHEMBL1435377 & 688612 & 4.75 & 4.6437 & TRN & \\
\hline
\end{tabular}




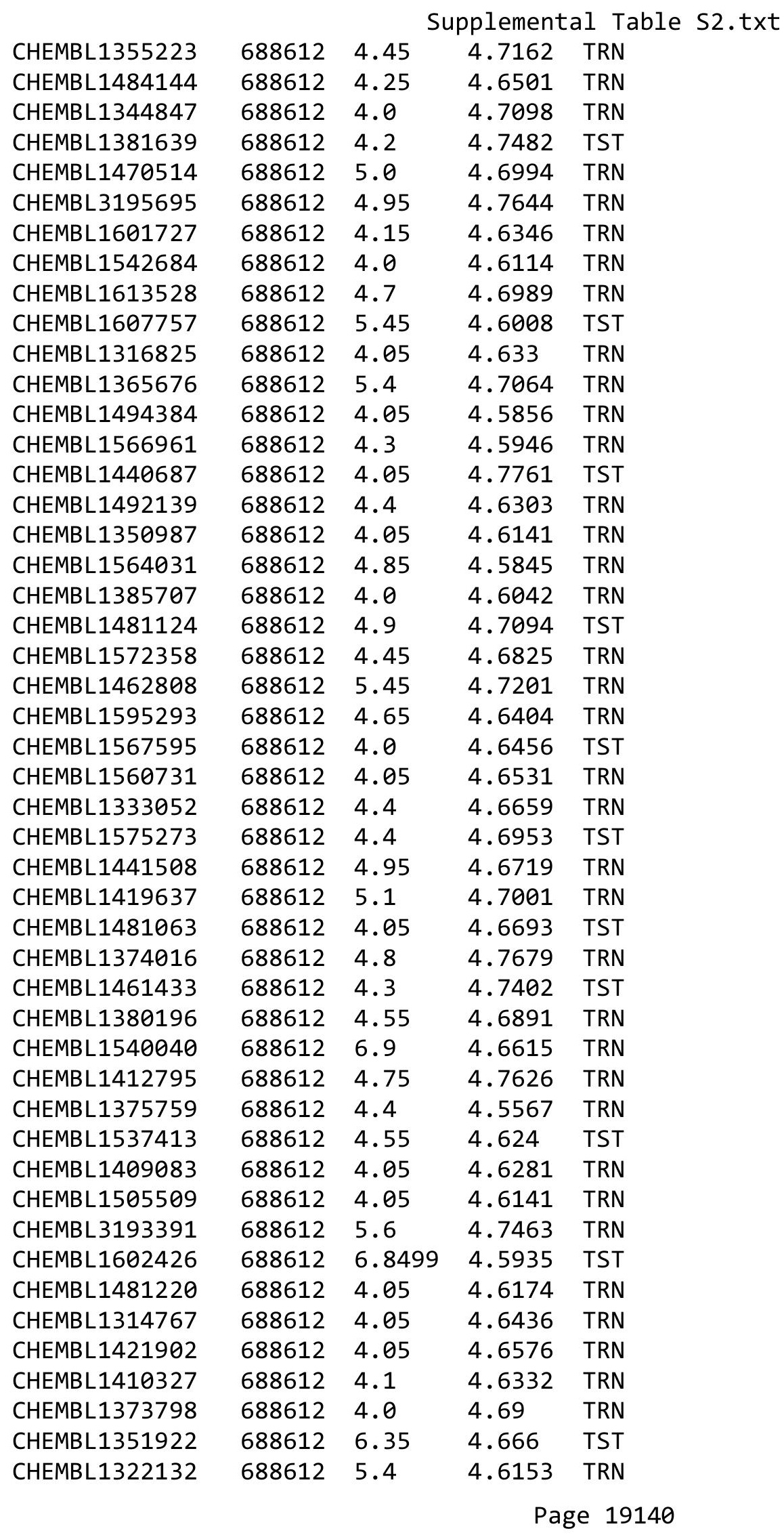




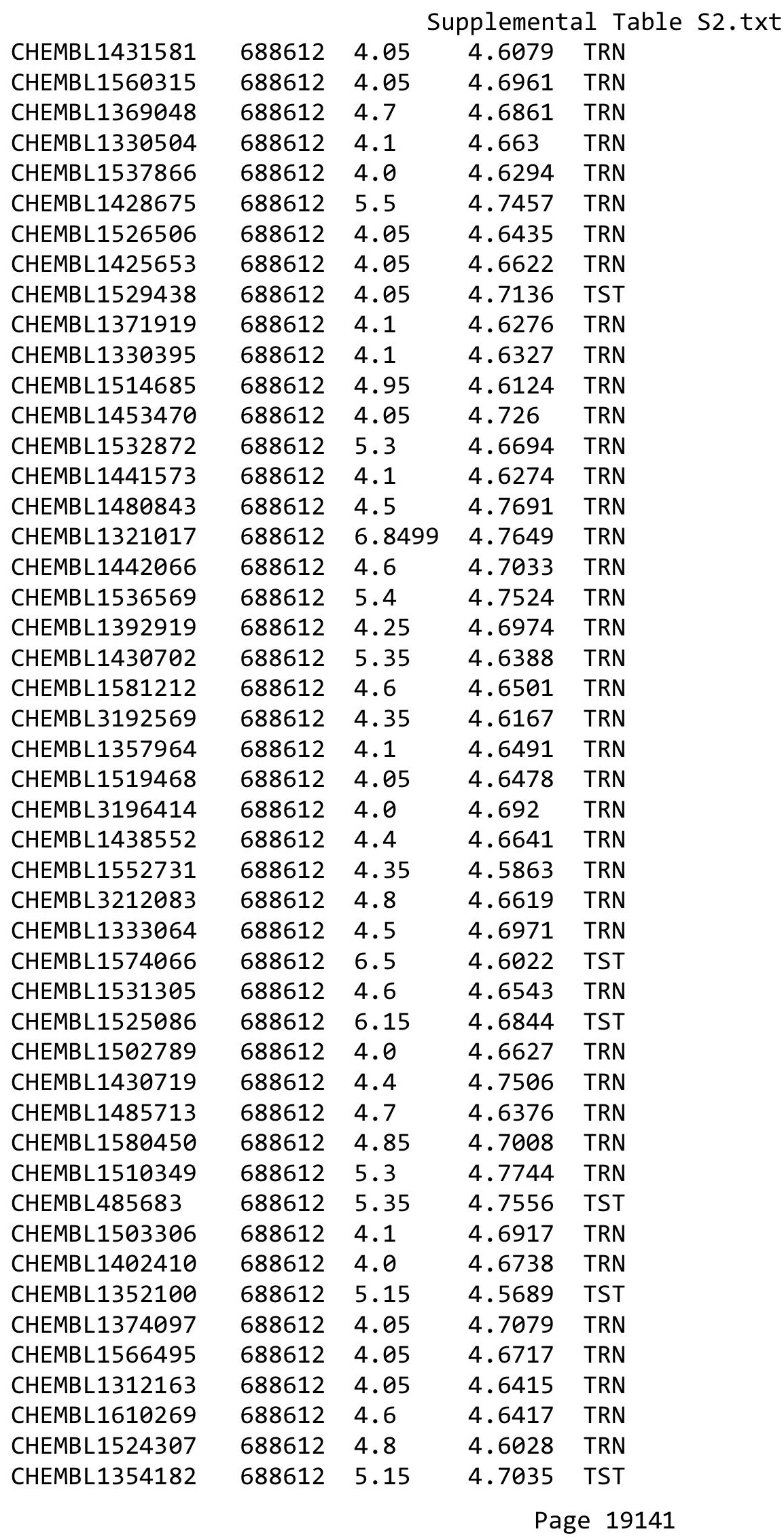




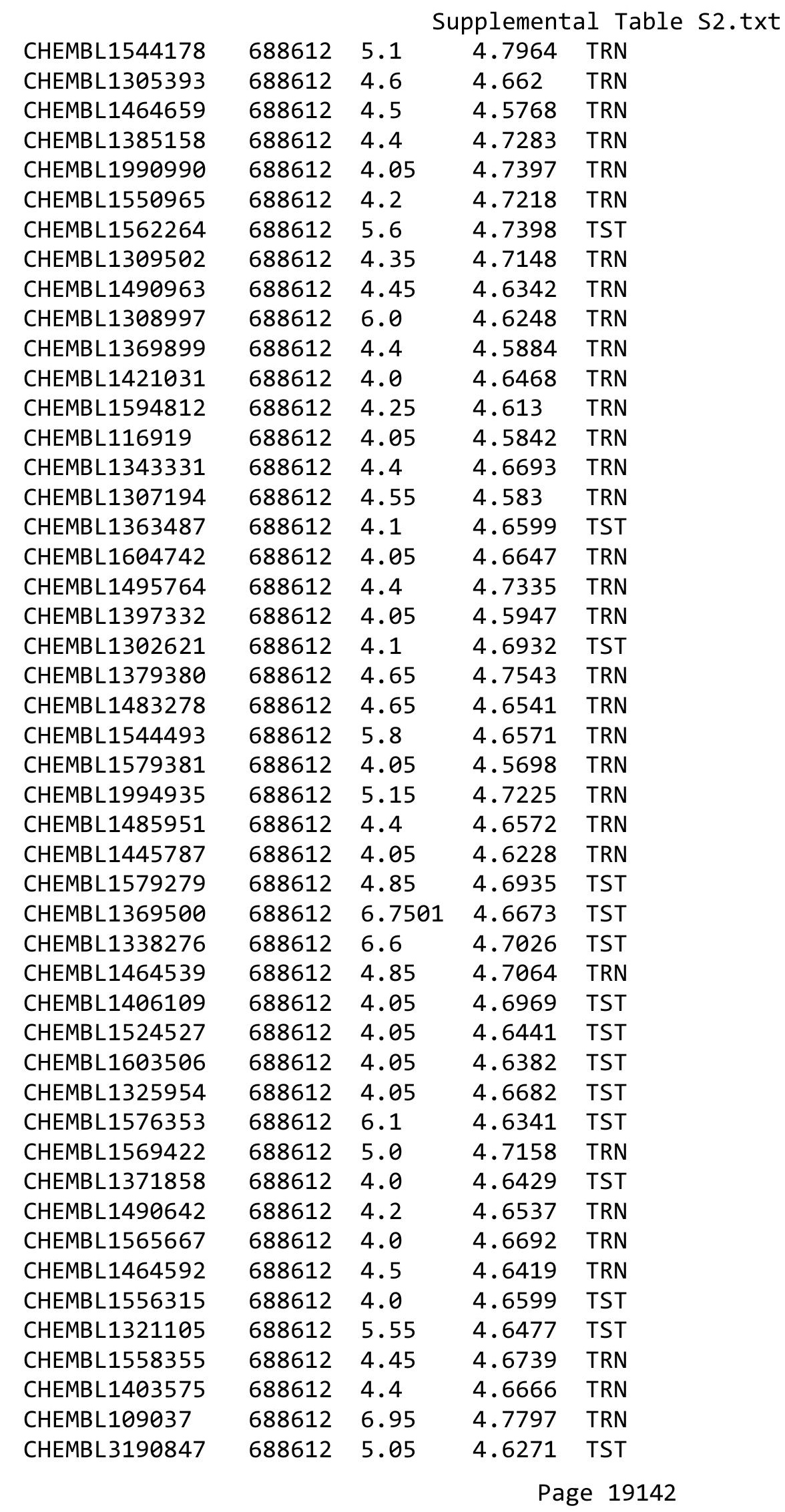




\begin{tabular}{|c|c|c|c|c|c|}
\hline \multicolumn{6}{|c|}{ Supplemental Table S2.txt } \\
\hline CHEMBL1469839 & 688612 & 4.8 & 4.7038 & TST & \\
\hline CHEMBL1560881 & 688612 & 4.35 & 4.7028 & TRN & \\
\hline CHEMBL1554650 & 688612 & 4.05 & 4.644 & TRN & \\
\hline CHEMBL1516035 & 688612 & 5.3 & 4.7407 & TRN & \\
\hline CHEMBL1430661 & 688612 & 6.35 & 4.6274 & TRN & \\
\hline CHEMBL1312797 & 688612 & 4.5 & 4.6377 & TRN & \\
\hline CHEMBL1517926 & 688612 & 4.6 & 4.6238 & TST & \\
\hline CHEMBL1432386 & 688612 & 4.5 & 4.6365 & TRN & \\
\hline CHEMBL1502787 & 688612 & 7.0 & 4.6427 & TST & \\
\hline CHEMBL1371197 & 688612 & 4.05 & 4.6376 & TRN & \\
\hline CHEMBL225852 & 688612 & 4.3 & 4.6733 & TST & \\
\hline CHEMBL1352564 & 688612 & 4.4 & 4.7428 & TRN & \\
\hline CHEMBL1432141 & 688612 & 4.05 & 4.6748 & TRN & \\
\hline CHEMBL86966 & 688612 & 4.1 & 4.74100 & 00000000005 & TRN \\
\hline CHEMBL1407418 & 688612 & 4.7 & 4.6671 & TRN & \\
\hline CHEMBL1551035 & 688612 & 4.7 & 4.5905 & TRN & \\
\hline CHEMBL1570644 & 688612 & 4.05 & 4.7148 & TST & \\
\hline CHEMBL1442453 & 688612 & 4.8 & 4.6498 & TRN & \\
\hline CHEMBL11475 & 688612 & 5.75 & 4.7914 & TST & \\
\hline CHEMBL1587008 & 688612 & 4.05 & 4.687 & TST & \\
\hline CHEMBL1350431 & 688612 & 4.55 & 4.7006 & TRN & \\
\hline CHEMBL1968290 & 688612 & 4.7 & 4.7424 & TST & \\
\hline CHEMBL1314390 & 688612 & 4.9 & 4.5772 & TRN & \\
\hline CHEMBL1421797 & 688612 & 4.0 & 4.5896 & TRN & \\
\hline CHEMBL1587558 & 688612 & 4.85 & 4.6207 & TRN & \\
\hline CHEMBL1988731 & 688612 & 4.35 & 4.7271 & TRN & \\
\hline CHEMBL1382662 & 688612 & 5.35 & 4.7337 & TRN & \\
\hline CHEMBL1347080 & 688612 & 4.55 & 4.7964 & TRN & \\
\hline CHEMBL1517288 & 688612 & 4.35 & 4.7298 & TRN & \\
\hline CHEMBL1343000 & 688612 & 4.1 & 4.6334 & TRN & \\
\hline CHEMBL3191149 & 688612 & 4.6 & 4.6503 & TRN & \\
\hline CHEMBL1590504 & 688612 & 4.05 & 4.5942 & TRN & \\
\hline CHEMBL1583585 & 688612 & 4.45 & 4.7313 & TRN & \\
\hline CHEMBL3192124 & 688612 & 4.75 & 4.6727 & TRN & \\
\hline CHEMBL1578008 & 688612 & 4.7 & 4.6284 & TRN & \\
\hline CHEMBL1464965 & 688612 & 5.4 & 4.6804 & TST & \\
\hline CHEMBL1451589 & 688612 & 5.45 & 4.6121 & TRN & \\
\hline CHEMBL1300307 & 688612 & 4.2 & 4.729 & TRN & \\
\hline CHEMBL1536364 & 688612 & 4.1 & 4.56800 & 00000000005 & TRN \\
\hline CHEMBL1504577 & 688612 & 4.55 & 4.7311 & TRN & \\
\hline CHEMBL1376975 & 688612 & 4.0 & 4.6964 & TST & \\
\hline CHEMBL1510708 & 688612 & 4.4 & 4.6252 & TRN & \\
\hline CHEMBL1386901 & 688612 & 5.4 & 4.662 & TRN & \\
\hline CHEMBL1349449 & 688612 & 4.55 & 4.757 & TRN & \\
\hline CHEMBL1429713 & 688612 & 4.4 & 4.7288 & TRN & \\
\hline CHEMBL1446782 & 688612 & 6.5 & 4.6625 & TST & \\
\hline CHEMBL1522786 & 688612 & 4.45 & 4.6169 & TRN & \\
\hline CHEMBL1419589 & 688612 & 4.4 & 4.628 & TRN & \\
\hline
\end{tabular}




\begin{tabular}{|c|c|c|c|c|c|}
\hline \multicolumn{6}{|c|}{ Supplemental Table S2.txt } \\
\hline CHEMBL1576144 & 688612 & 4.9 & 4.7713 & TRN & \\
\hline CHEMBL1496320 & 688612 & 4.5 & 4.6826 & TRN & \\
\hline CHEMBL1336373 & 688612 & 4.55 & 4.7258 & TRN & \\
\hline CHEMBL1478290 & 688612 & 4.0 & 4.6128 & TRN & \\
\hline CHEMBL1392027 & 688612 & 4.0 & 4.6849 & TST & \\
\hline CHEMBL1392492 & 688612 & 4.1 & 4.7286 & TRN & \\
\hline CHEMBL1350811 & 688612 & 4.6 & 4.625 & TRN & \\
\hline CHEMBL1469927 & 688612 & 4.4 & 4.6404 & TRN & \\
\hline CHEMBL1586803 & 688612 & 4.35 & 4.66100 & 00000000005 & TST \\
\hline CHEMBL1451747 & 688612 & 4.45 & 4.6661 & TST & \\
\hline CHEMBL1388044 & 688612 & 5.15 & 4.7562 & TRN & \\
\hline CHEMBL1385287 & 688612 & 4.8 & 4.7085 & TRN & \\
\hline CHEMBL1416330 & 688612 & 4.1 & 4.6439 & TST & \\
\hline CHEMBL1533591 & 688612 & 4.0 & 4.7569 & TRN & \\
\hline CHEMBL1482850 & 688612 & 4.6 & 4.6877 & TST & \\
\hline CHEMBL1545719 & 688612 & 4.5 & 4.7449 & TRN & \\
\hline CHEMBL1472210 & 688612 & 4.55 & 4.6971 & TRN & \\
\hline CHEMBL1377640 & 688612 & 5.4 & 4.6037 & TRN & \\
\hline CHEMBL608699 & 688612 & 7.0 & 4.7065 & TST & \\
\hline CHEMBL1546048 & 688612 & 5.0 & 4.7771 & TRN & \\
\hline CHEMBL1299544 & 688612 & 6.8499 & 4.6749 & TRN & \\
\hline CHEMBL1471441 & 688612 & 4.05 & 4.655 & TST & \\
\hline CHEMBL1429234 & 688612 & 5.8 & 4.6572 & TRN & \\
\hline CHEMBL1556560 & 688612 & 6.95 & 4.601 & TRN & \\
\hline CHEMBL1521668 & 688612 & 4.25 & 4.7073 & TRN & \\
\hline CHEMBL1598306 & 688612 & 4.75 & 4.6643 & TST & \\
\hline CHEMBL 73288 & 688612 & 4.0 & 4.6282 & TRN & \\
\hline CHEMBL438298 & 688612 & 6.8499 & 4.6815 & TRN & \\
\hline CHEMBL1344569 & 688612 & 5.3 & 4.6122 & TRN & \\
\hline CHEMBL1302802 & 688612 & 4.85 & 4.7147 & TRN & \\
\hline CHEMBL1304345 & 688612 & 5.05 & 4.68 & TRN & \\
\hline CHEMBL1497427 & 688612 & 4.65 & 4.6867 & TRN & \\
\hline CHEMBL1400683 & 688612 & 4.0 & 4.6112 & TRN & \\
\hline CHEMBL1485923 & 688612 & 5.15 & 4.7369 & TRN & \\
\hline CHEMBL1579280 & 688612 & 5.75 & 4.6933 & TRN & \\
\hline CHEMBL1304496 & 688612 & 4.1 & 4.6592 & TST & \\
\hline CHEMBL3194729 & 688612 & 4.2 & 4.6887 & TRN & \\
\hline CHEMBL1525368 & 688612 & 4.05 & 4.7031 & TRN & \\
\hline CHEMBL1506627 & 688612 & 4.0 & 4.668 & TRN & \\
\hline CHEMBL1395836 & 688612 & 4.45 & 4.6288 & TRN & \\
\hline CHEMBL1400903 & 688612 & 4.0 & 4.6271 & TST & \\
\hline CHEMBL1299835 & 688612 & 5.95 & 4.6581 & TRN & \\
\hline CHEMBL302753 & 688612 & 4.4 & 4.6582 & TST & \\
\hline CHEMBL1494366 & 688612 & 4.1 & 4.622 & TST & \\
\hline CHEMBL1508048 & 688612 & 4.05 & 4.6287 & TRN & \\
\hline CHEMBL1553684 & 688612 & 4.1 & 4.6056 & TRN & \\
\hline CHEMBL1302599 & 688612 & 4.4 & 4.7295 & TRN & \\
\hline CHEMBL1433003 & 688612 & 4.3 & 4.6468 & TRN & \\
\hline
\end{tabular}




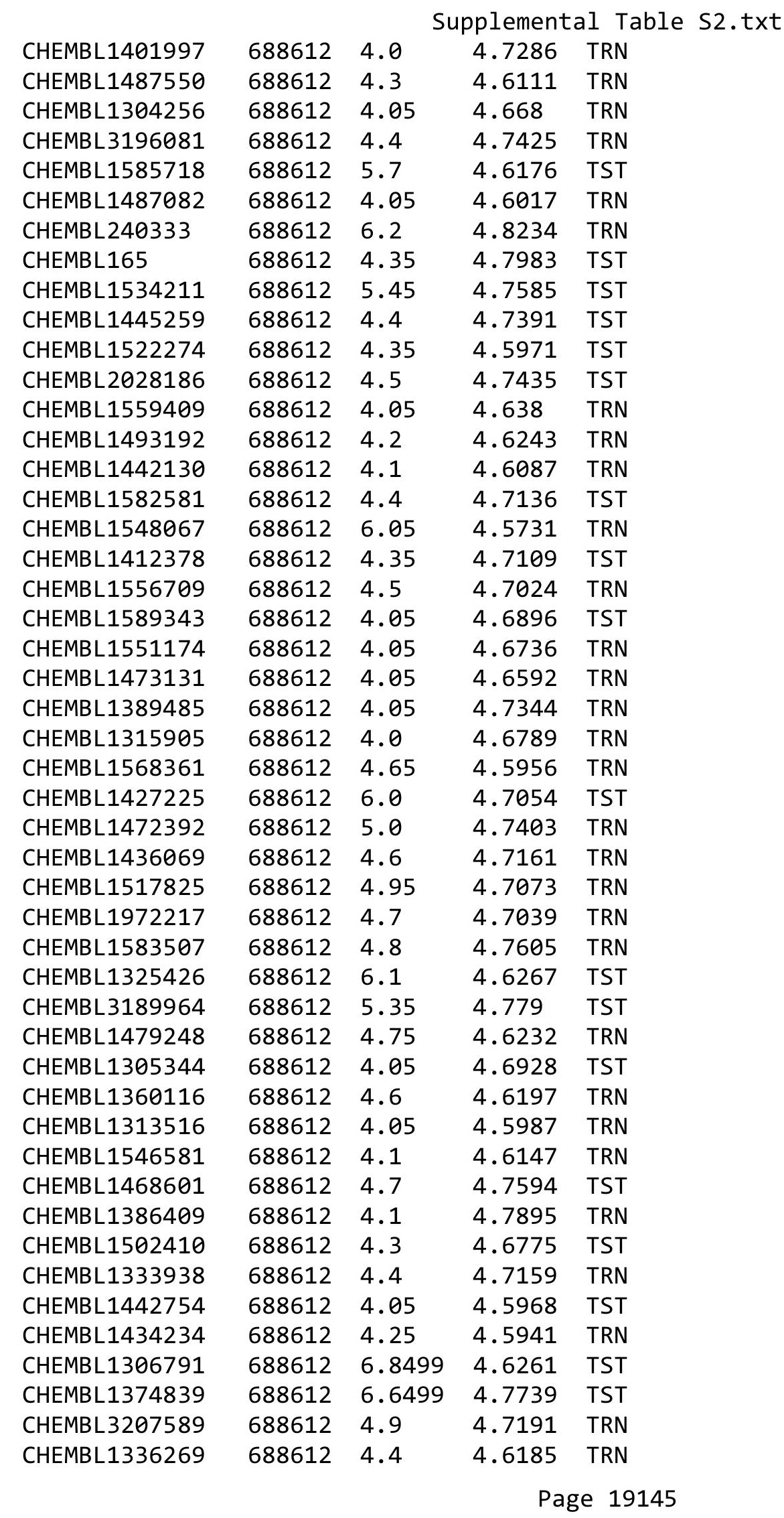




\begin{tabular}{|c|c|c|c|c|c|}
\hline \multicolumn{6}{|c|}{ Supplemental Table S2.txt } \\
\hline CHEMBL1398233 & 688612 & 4.6 & 4.5861 & TRN & \\
\hline CHEMBL1369530 & 688612 & 6.25 & 4.6921 & TRN & \\
\hline CHEMBL1565403 & 688612 & 4.1 & 4.6243 & TRN & \\
\hline CHEMBL1369669 & 688612 & 5.0 & 4.6348 & TST & \\
\hline CHEMBL1441363 & 688612 & 4.7 & 4.6776 & TRN & \\
\hline CHEMBL1346492 & 688612 & 4.1 & 4.7429 & TST & \\
\hline CHEMBL1501716 & 688612 & 4.05 & 4.5941 & TRN & \\
\hline CHEMBL1382196 & 688612 & 4.05 & 4.6774 & TRN & \\
\hline CHEMBL1377873 & 688612 & 4.25 & 4.7094 & TRN & \\
\hline CHEMBL1526452 & 688612 & 4.45 & 4.7283 & TRN & \\
\hline CHEMBL1578736 & 688612 & 5.1 & 4.6723 & TST & \\
\hline CHEMBL1339889 & 688612 & 4.0 & 4.6523 & TRN & \\
\hline CHEMBL1430390 & 688612 & 4.05 & 4.6787 & TRN & \\
\hline CHEMBL1337712 & 688612 & 4.6 & 4.6859 & TRN & \\
\hline CHEMBL1392520 & 688612 & 4.4 & 4.71899 & 9999999999 & TRN \\
\hline CHEMBL1347028 & 688612 & 5.2 & 4.7217 & TRN & \\
\hline CHEMBL1582771 & 688612 & 5.1 & 4.809 & TST & \\
\hline CHEMBL1412661 & 688612 & 5.1 & 4.6042 & TRN & \\
\hline CHEMBL1378795 & 688612 & 4.6 & 4.5556 & TRN & \\
\hline CHEMBL1578562 & 688612 & 6.8 & 4.6842 & TRN & \\
\hline CHEMBL1495519 & 688612 & 6.2 & 4.604 & TRN & \\
\hline CHEMBL1456723 & 688612 & 4.3 & 4.5718 & TST & \\
\hline CHEMBL1483348 & 688612 & 5.75 & 4.6352 & TRN & \\
\hline CHEMBL1599681 & 688612 & 4.7 & 4.6481 & TRN & \\
\hline CHEMBL1387525 & 688612 & 4.5 & 4.6365 & TRN & \\
\hline CHEMBL1325897 & 688612 & 5.05 & 4.7647 & TRN & \\
\hline CHEMBL1975975 & 688612 & 4.75 & 4.658 & TRN & \\
\hline CHEMBL1410264 & 688612 & 4.05 & 4.7243 & TST & \\
\hline CHEMBL229012 & 688612 & 5.85 & 4.7134 & TRN & \\
\hline CHEMBL1434596 & 688612 & 4.05 & 4.5799 & TRN & \\
\hline CHEMBL1579106 & 688612 & 4.6 & 4.6367 & TRN & \\
\hline CHEMBL1489361 & 688612 & 5.3 & 4.7461 & TST & \\
\hline CHEMBL1976312 & 688612 & 5.75 & 4.7517 & TRN & \\
\hline CHEMBL1360523 & 688612 & 4.1 & 4.7419 & TST & \\
\hline CHEMBL1428551 & 688612 & 5.05 & 4.6384 & TRN & \\
\hline CHEMBL1472278 & 688612 & 4.4 & 4.65600 & 0000000001 & TRN \\
\hline CHEMBL1599331 & 688612 & 6.9 & 4.619 & TRN & \\
\hline CHEMBL1476485 & 688612 & 4.0 & 4.7058 & TRN & \\
\hline CHEMBL1539094 & 688612 & 5.7 & 4.6555 & TRN & \\
\hline CHEMBL1331464 & 688612 & 5.45 & 4.5864 & TRN & \\
\hline CHEMBL1365905 & 688612 & 4.05 & 4.6294 & TRN & \\
\hline CHEMBL3214083 & 688612 & 4.45 & 4.6949 & TRN & \\
\hline CHEMBL1394760 & 688612 & 4.05 & 4.6579 & TST & \\
\hline CHEMBL3190370 & 688612 & 4.85 & 4.7491 & TRN & \\
\hline CHEMBL1350685 & 688612 & 4.4 & 4.6291 & TRN & \\
\hline CHEMBL1431052 & 688612 & 4.7 & 4.6451 & TRN & \\
\hline CHEMBL1572364 & 688612 & 4.7 & 4.76399 & 9999999999 & TRN \\
\hline CHEMBL1331692 & 688612 & 4.3 & 4.609 & TRN & \\
\hline
\end{tabular}




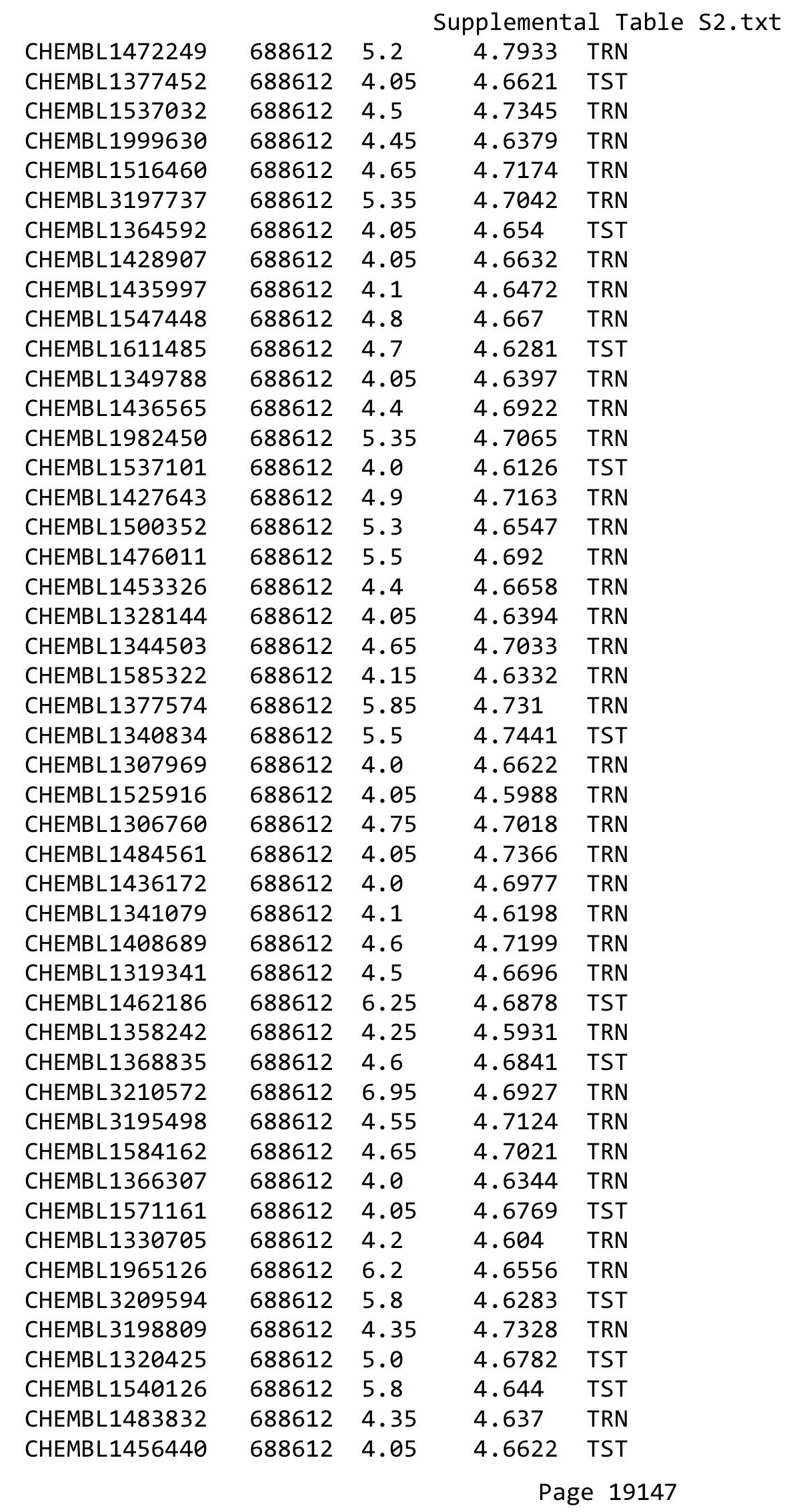




\begin{tabular}{|c|c|c|c|c|c|}
\hline \multicolumn{6}{|c|}{ Supplemental Table S2.txt } \\
\hline CHEMBL1392651 & 688612 & 4.9 & 4.6254 & TST & \\
\hline CHEMBL1477518 & 688612 & 5.5 & 4.5773 & TRN & \\
\hline CHEMBL1371665 & 688612 & 4.6 & 4.6835 & TST & \\
\hline CHEMBL1428106 & 688612 & 4.4 & 4.6225 & TRN & \\
\hline CHEMBL1334782 & 688612 & 4.45 & 4.6175 & TRN & \\
\hline CHEMBL1417924 & 688612 & 5.05 & 4.7241 & TRN & \\
\hline CHEMBL3209553 & 688612 & 4.7 & 4.6798 & TRN & \\
\hline CHEMBL1351868 & 688612 & 4.4 & 4.6377 & TRN & \\
\hline CHEMBL1363078 & 688612 & 4.05 & 4.6016 & TRN & \\
\hline CHEMBL1380787 & 688612 & 4.1 & 4.6405 & TRN & \\
\hline CHEMBL1360891 & 688612 & 4.05 & 4.5902 & TRN & \\
\hline CHEMBL1484883 & 688612 & 4.15 & 4.6802 & TRN & \\
\hline CHEMBL1380570 & 688612 & 4.0 & 4.6606 & TRN & \\
\hline CHEMBL1526996 & 688612 & 4.1 & 4.7274 & TST & \\
\hline CHEMBL1530381 & 688612 & 4.25 & 4.63399 & 99999999995 & TST \\
\hline CHEMBL586465 & 688612 & 4.4 & 4.7059 & TRN & \\
\hline CHEMBL1343498 & 688612 & 6.5501 & 4.5712 & TRN & \\
\hline CHEMBL1488347 & 688612 & 4.25 & 4.6174 & TRN & \\
\hline CHEMBL 1486572 & 688612 & 5.95 & 4.61 & TRN & \\
\hline CHEMBL1438480 & 688612 & 4.1 & 4.5963 & TRN & \\
\hline CHEMBL1474589 & 688612 & 6.0 & 4.7226 & TRN & \\
\hline CHEMBL1319277 & 688612 & 4.05 & 4.6354 & TRN & \\
\hline CHEMBL1369784 & 688612 & 4.3 & 4.687 & TRN & \\
\hline CHEMBL1582834 & 688612 & 4.4 & 4.7832 & TRN & \\
\hline CHEMBL1464414 & 688612 & 4.05 & 4.6529 & TST & \\
\hline CHEMBL1477099 & 688612 & 4.05 & 4.6656 & TST & \\
\hline CHEMBL1311319 & 688612 & 4.05 & 4.6772 & TRN & \\
\hline CHEMBL1319867 & 688612 & 4.75 & 4.7371 & TRN & \\
\hline CHEMBL449392 & 688612 & 6.8 & 4.8159 & TST & \\
\hline CHEMBL1303972 & 688612 & 4.4 & 4.6396 & TRN & \\
\hline CHEMBL1341744 & 688612 & 4.5 & 4.6593 & TST & \\
\hline CHEMBL3189537 & 688612 & 4.9 & 4.6548 & TRN & \\
\hline CHEMBL1608242 & 688612 & 4.4 & 4.6732 & TRN & \\
\hline CHEMBL1459846 & 688612 & 4.85 & 4.6575 & TST & \\
\hline CHEMBL1390206 & 688612 & 4.5 & 4.6686 & TRN & \\
\hline CHEMBL1308590 & 688612 & 4.35 & 4.5618 & TRN & \\
\hline CHEMBL1537568 & 688612 & 4.05 & 4.6615 & TRN & \\
\hline CHEMBL1361286 & 688612 & 4.05 & 4.5567 & TRN & \\
\hline CHEMBL1359099 & 688612 & 4.5 & 4.7217 & TRN & \\
\hline CHEMBL1425999 & 688612 & 4.05 & 4.7146 & TRN & \\
\hline CHEMBL1539824 & 688612 & 4.45 & 4.6341 & TRN & \\
\hline CHEMBL1519469 & 688612 & 6.95 & 4.7154 & TRN & \\
\hline CHEMBL1509835 & 688612 & 4.1 & 4.7419 & TST & \\
\hline CHEMBL1384243 & 688612 & 4.1 & 4.5848 & TRN & \\
\hline CHEMBL1355376 & 688612 & 4.15 & 4.7055 & TRN & \\
\hline CHEMBL1556269 & 688612 & 4.7 & 4.6243 & TRN & \\
\hline CHEMBL1986541 & 688612 & 4.45 & 4.7407 & TRN & \\
\hline CHEMBL1554471 & 688612 & 4.7 & 4.6491 & TRN & \\
\hline
\end{tabular}




\begin{tabular}{|c|c|c|c|c|c|}
\hline \multicolumn{6}{|c|}{ Supplemental Table S2.txt } \\
\hline CHEMBL1583238 & 688612 & 4.6 & 4.7164 & TRN & \\
\hline CHEMBL1374248 & 688612 & 4.4 & 4.5939 & TRN & \\
\hline CHEMBL1605244 & 688612 & 5.45 & 4.6043 & TST & \\
\hline CHEMBL1502985 & 688612 & 4.4 & 4.6682 & TST & \\
\hline CHEMBL1527629 & 688612 & 4.1 & 4.6267 & TRN & \\
\hline CHEMBL1396541 & 688612 & 6.45 & 4.6842 & TST & \\
\hline CHEMBL1565270 & 688612 & 4.4 & 4.6327 & TRN & \\
\hline CHEMBL1375190 & 688612 & 4.85 & 4.6861 & TRN & \\
\hline CHEMBL1381308 & 688612 & 5.9 & 4.6366 & TST & \\
\hline CHEMBL 3190834 & 688612 & 4.85 & 4.7728 & TST & \\
\hline CHEMBL1503700 & 688612 & 4.05 & 4.5851 & TRN & \\
\hline CHEMBL1540335 & 688612 & 6.8499 & 4.6221 & TRN & \\
\hline CHEMBL1551532 & 688612 & 4.5 & 4.6697 & TRN & \\
\hline CHEMBL1376340 & 688612 & 4.85 & 4.6244 & TRN & \\
\hline CHEMBL1594069 & 688612 & 4.05 & 4.6271 & TRN & \\
\hline CHEMBL1568987 & 688612 & 4.1 & 4.6832 & TRN & \\
\hline CHEMBL1439302 & 688612 & 4.35 & 4.6658 & TST & \\
\hline CHEMBL1403936 & 688612 & 4.0 & 4.6819 & TST & \\
\hline CHEMBL1543615 & 688612 & 4.15 & 4.723 & TRN & \\
\hline CHEMBL1524921 & 688612 & 4.65 & 4.7773 & TRN & \\
\hline CHEMBL1573371 & 688612 & 4.4 & 4.6317 & TST & \\
\hline CHEMBL1441736 & 688612 & 4.55 & 4.7245 & TRN & \\
\hline CHEMBL1415861 & 688612 & 4.45 & 4.6748 & TRN & \\
\hline CHEMBL1522344 & 688612 & 4.3 & 4.6768 & TST & \\
\hline CHEMBL1320793 & 688612 & 4.65 & 4.66100 & 00000000005 & TRN \\
\hline CHEMBL3198990 & 688612 & 6.6499 & 4.6624 & TRN & \\
\hline CHEMBL1586970 & 688612 & 4.4 & 4.7862 & TST & \\
\hline CHEMBL1332984 & 688612 & 4.3 & 4.724 & TRN & \\
\hline CHEMBL1375393 & 688612 & 4.9 & 4.7936 & TRN & \\
\hline CHEMBL3189623 & 688612 & 4.4 & 4.7412 & TST & \\
\hline CHEMBL1581250 & 688612 & 4.55 & 4.7126 & TRN & \\
\hline CHEMBL1482585 & 688612 & 4.05 & 4.6191 & TRN & \\
\hline CHEMBL 3208876 & 688612 & 4.75 & 4.7634 & TRN & \\
\hline CHEMBL1391362 & 688612 & 4.05 & 4.6313 & TRN & \\
\hline CHEMBL1408050 & 688612 & 4.05 & 4.6838 & TST & \\
\hline CHEMBL1476385 & 688612 & 5.35 & 4.5449 & TRN & \\
\hline CHEMBL 257359 & 688612 & 5.8 & 4.8173 & TRN & \\
\hline CHEMBL1430476 & 688612 & 4.05 & 4.6383 & TRN & \\
\hline CHEMBL3196713 & 688612 & 4.05 & 4.7325 & TRN & \\
\hline CHEMBL1542638 & 688612 & 5.75 & 4.6588 & TST & \\
\hline CHEMBL1440291 & 688612 & 5.05 & 4.6345 & TRN & \\
\hline CHEMBL1572254 & 688612 & 5.45 & 4.7491 & TRN & \\
\hline CHEMBL1606408 & 688612 & 4.55 & 4.7352 & TST & \\
\hline CHEMBL1505684 & 688612 & 4.05 & 4.6628 & TRN & \\
\hline CHEMBL1343096 & 688612 & 5.3 & 4.6809 & TST & \\
\hline CHEMBL1408547 & 688612 & 4.45 & 4.6357 & TRN & \\
\hline CHEMBL1542156 & 688612 & 7.0 & 4.6054 & TRN & \\
\hline CHEMBL1517266 & 688612 & 5.0 & 4.5999 & TRN & \\
\hline
\end{tabular}




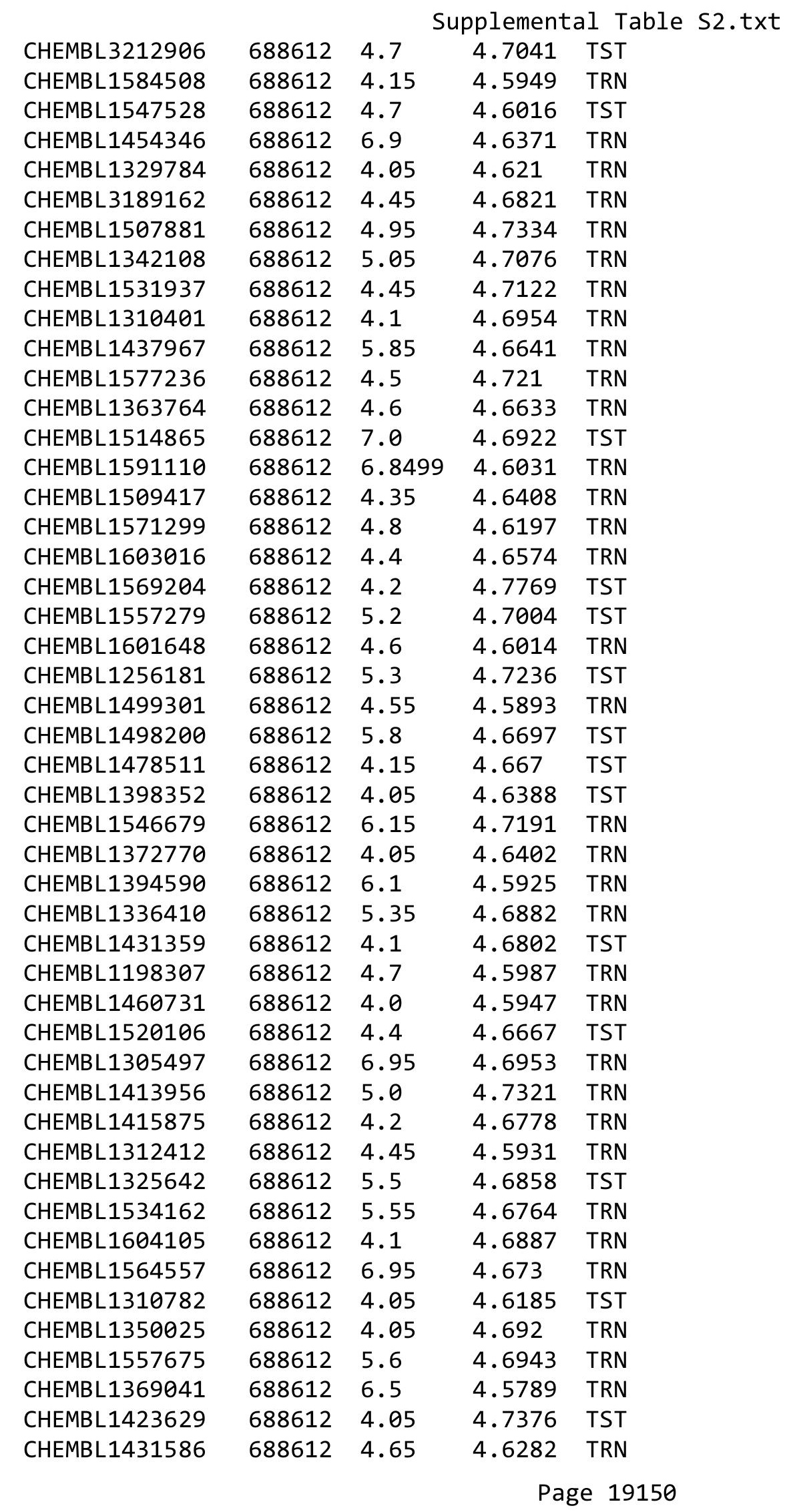




\begin{tabular}{|c|c|c|c|c|c|}
\hline \multicolumn{6}{|c|}{ Supplemental Table S2.txt } \\
\hline CHEMBL1411292 & 688612 & 4.9 & 4.6614 & TRN & \\
\hline CHEMBL 85500 & 688612 & 6.6 & 4.7416 & TST & \\
\hline CHEMBL1976000 & 688612 & 4.2 & 4.7471 & TRN & \\
\hline CHEMBL1417934 & 688612 & 4.6 & 4.6257 & TRN & \\
\hline CHEMBL1994456 & 688612 & 4.65 & 4.7244 & TRN & \\
\hline CHEMBL1368292 & 688612 & 4.05 & 4.6059 & TRN & \\
\hline CHEMBL1414281 & 688612 & 6.6499 & 4.5917 & TRN & \\
\hline CHEMBL1467579 & 688612 & 4.45 & 4.7402 & TST & \\
\hline CHEMBL1309987 & 688612 & 4.55 & 4.7338 & TST & \\
\hline CHEMBL145867 & 688612 & 4.05 & 4.6149 & TRN & \\
\hline CHEMBL3196993 & 688612 & 5.75 & 4.7753 & TRN & \\
\hline CHEMBL1460743 & 688612 & 5.3 & 4.5748 & TST & \\
\hline CHEMBL1453605 & 688612 & 5.0 & 4.7116 & TRN & \\
\hline CHEMBL1304793 & 688612 & 6.1 & 4.6103 & TST & \\
\hline CHEMBL1486241 & 688612 & 4.9 & 4.6071 & TRN & \\
\hline CHEMBL1337697 & 688612 & 4.1 & 4.5787 & TRN & \\
\hline CHEMBL1416917 & 688612 & 4.0 & 4.6339 & TRN & \\
\hline CHEMBL1317440 & 688612 & 4.05 & 4.6083 & TRN & \\
\hline CHEMBL1609574 & 688612 & 4.1 & 4.6433 & TRN & \\
\hline CHEMBL1581078 & 688612 & 4.65 & 4.6913 & TRN & \\
\hline CHEMBL1484713 & 688612 & 5.75 & 4.649 & TST & \\
\hline CHEMBL1601652 & 688612 & 5.0 & 4.6523 & TRN & \\
\hline CHEMBL1303737 & 688612 & 4.15 & 4.7692 & TRN & \\
\hline CHEMBL1384015 & 688612 & 4.0 & 4.70100 & 00000000005 & TST \\
\hline CHEMBL1578304 & 688612 & 4.4 & 4.7012 & TRN & \\
\hline CHEMBL1470879 & 688612 & 4.2 & 4.6824 & TRN & \\
\hline CHEMBL1445942 & 688612 & 4.55 & 4.7128 & TRN & \\
\hline CHEMBL1366215 & 688612 & 4.1 & 4.7236 & TST & \\
\hline CHEMBL1499111 & 688612 & 4.65 & 4.7682 & TRN & \\
\hline CHEMBL1592322 & 688612 & 5.2 & 4.6386 & TRN & \\
\hline CHEMBL1443631 & 688612 & 4.6 & 4.6245 & TST & \\
\hline CHEMBL1564738 & 688612 & 6.4 & 4.6696 & TRN & \\
\hline CHEMBL3191790 & 688612 & 4.8 & 4.7333 & TRN & \\
\hline CHEMBL1410686 & 688612 & 4.3 & 4.7823 & TRN & \\
\hline CHEMBL3211589 & 688612 & 4.55 & 4.6521 & TRN & \\
\hline CHEMBL1429325 & 688612 & 4.05 & 4.6894 & TRN & \\
\hline CHEMBL599100 & 688612 & 4.05 & 4.6378 & TRN & \\
\hline CHEMBL1554266 & 688612 & 4.9 & 4.6836 & TRN & \\
\hline CHEMBL1309683 & 688612 & 4.6 & 4.7551 & TRN & \\
\hline CHEMBL1552091 & 688612 & 4.4 & 4.592 & TRN & \\
\hline CHEMBL1609120 & 688612 & 4.8 & 4.7057 & TRN & \\
\hline CHEMBL3197264 & 688612 & 4.6 & 4.7548 & TRN & \\
\hline CHEMBL1527054 & 688612 & 4.9 & 4.6591 & TRN & \\
\hline CHEMBL600968 & 688612 & 4.4 & 4.8185 & TRN & \\
\hline CHEMBL1599396 & 688612 & 4.7 & 4.7203 & TRN & \\
\hline CHEMBL1420171 & 688612 & 4.15 & 4.6755 & TST & \\
\hline CHEMBL1401696 & 688612 & 4.1 & 4.6332 & TST & \\
\hline CHEMBL1561123 & 688612 & 4.65 & 4.6972 & TST & \\
\hline
\end{tabular}




\begin{tabular}{|c|c|c|c|c|c|}
\hline \multicolumn{6}{|c|}{ Supplemental Table S2.txt } \\
\hline CHEMBL1486804 & 688612 & 4.05 & 4.5971 & TRN & \\
\hline CHEMBL1452046 & 688612 & 4.05 & 4.5537 & TRN & \\
\hline CHEMBL1482801 & 688612 & 5.45 & 4.6936 & TRN & \\
\hline CHEMBL1559516 & 688612 & 4.2 & 4.6618 & TRN & \\
\hline CHEMBL1304387 & 688612 & 4.8 & 4.6599 & TRN & \\
\hline CHEMBL1469881 & 688612 & 4.1 & 4.6743 & TRN & \\
\hline CHEMBL1425289 & 688612 & 4.4 & 4.6352 & TRN & \\
\hline CHEMBL1458514 & 688612 & 5.2 & 4.7133 & TRN & \\
\hline CHEMBL1593142 & 688612 & 5.05 & 4.57 & TRN & \\
\hline CHEMBL1575292 & 688612 & 4.5 & 4.6976 & TRN & \\
\hline CHEMBL1399879 & 688612 & 5.25 & 4.6544 & TRN & \\
\hline CHEMBL1571069 & 688612 & 4.05 & 4.7105 & TST & \\
\hline CHEMBL1535723 & 688612 & 5.0 & 4.6898 & TRN & \\
\hline CHEMBL1458253 & 688612 & 4.4 & 4.75 & TRN & \\
\hline CHEMBL1410962 & 688612 & 4.0 & 4.6677 & TRN & \\
\hline CHEMBL1608136 & 688612 & 4.05 & 4.7198 & TRN & \\
\hline CHEMBL1995948 & 688612 & 4.9 & 4.7476 & TRN & \\
\hline CHEMBL1341038 & 688612 & 4.95 & 4.7023 & TRN & \\
\hline CHEMBL1587402 & 688612 & 5.4 & 4.681 & TST & \\
\hline CHEMBL 2448510 & 688612 & 6.8 & 4.6764 & TRN & \\
\hline CHEMBL 28626 & 688612 & 6.0 & 4.873 & TRN & \\
\hline CHEMBL1381868 & 688612 & 5.05 & 4.8306 & TRN & \\
\hline CHEMBL1345641 & 688612 & 4.05 & 4.7286 & TRN & \\
\hline CHEMBL1553314 & 688612 & 4.65 & 4.6756 & TRN & \\
\hline CHEMBL1583687 & 688612 & 4.85 & 4.69600 & 000000001 & TRN \\
\hline CHEMBL1348074 & 688612 & 4.45 & 4.7511 & TST & \\
\hline CHEMBL1488779 & 688612 & 4.75 & 4.7535 & TST & \\
\hline CHEMBL 3207726 & 688612 & 4.4 & 4.7128 & TRN & \\
\hline CHEMBL1456457 & 688612 & 4.05 & 4.6101 & TST & \\
\hline CHEMBL1463405 & 688612 & 4.3 & 4.6926 & TST & \\
\hline CHEMBL1364376 & 688612 & 6.05 & 4.6818 & TRN & \\
\hline CHEMBL1341527 & 688612 & 4.65 & 4.5959 & TRN & \\
\hline CHEMBL1348278 & 688612 & 4.7 & 4.8131 & TRN & \\
\hline CHEMBL1566513 & 688612 & 4.35 & 4.7656 & TRN & \\
\hline CHEMBL1371606 & 688612 & 4.4 & 4.6265 & TST & \\
\hline CHEMBL1348397 & 688612 & 4.4 & 4.7423 & TST & \\
\hline CHEMBL1456550 & 688612 & 4.75 & 4.6598 & TRN & \\
\hline CHEMBL1535311 & 688612 & 4.0 & 4.6143 & TRN & \\
\hline CHEMBL1568965 & 688612 & 4.05 & 4.585 & TRN & \\
\hline CHEMBL1354384 & 688612 & 4.75 & 4.5679 & TRN & \\
\hline CHEMBL1345205 & 688612 & 5.0 & 4.6564 & TRN & \\
\hline CHEMBL1363614 & 688612 & 6.8499 & 4.7374 & TST & \\
\hline CHEMBL1542664 & 688612 & 4.4 & 4.6818 & TRN & \\
\hline CHEMBL 299228 & 688612 & 4.05 & 4.6172 & TRN & \\
\hline CHEMBL1345666 & 688612 & 5.3 & 4.5688 & TST & \\
\hline CHEMBL3199428 & 688612 & 4.3 & 4.6763 & TRN & \\
\hline CHEMBL1436266 & 688612 & 4.55 & 4.6053 & TRN & \\
\hline CHEMBL3208975 & 688612 & 4.95 & 4.6882 & TRN & \\
\hline
\end{tabular}




\begin{tabular}{|c|c|c|c|c|c|}
\hline \multicolumn{6}{|c|}{ Supplemental Table S2.txt } \\
\hline CHEMBL1532542 & 688612 & 5.6 & 4.6626 & TRN & \\
\hline CHEMBL1429821 & 688612 & 5.3 & 4.7063 & TRN & \\
\hline CHEMBL1605133 & 688612 & 4.05 & 4.5792 & TRN & \\
\hline CHEMBL1555636 & 688612 & 4.4 & 4.6344 & TRN & \\
\hline CHEMBL1436170 & 688612 & 4.7 & 4.6385 & TRN & \\
\hline CHEMBL1306377 & 688612 & 4.6 & 4.7582 & TRN & \\
\hline CHEMBL1575160 & 688612 & 4.05 & 4.5952 & TRN & \\
\hline CHEMBL1336264 & 688612 & 4.4 & 4.6286 & TRN & \\
\hline CHEMBL1364185 & 688612 & 4.0 & 4.78 & TST & \\
\hline CHEMBL1411862 & 688612 & 5.35 & 4.7592 & TRN & \\
\hline CHEMBL1390762 & 688612 & 4.25 & 4.7089 & TST & \\
\hline CHEMBL1533146 & 688612 & 4.05 & 4.7351 & TST & \\
\hline CHEMBL1443240 & 688612 & 4.05 & 4.6297 & TST & \\
\hline CHEMBL150924 & 688612 & 4.75 & 4.7625 & TRN & \\
\hline CHEMBL1498341 & 688612 & 5.5 & 4.6815 & TRN & \\
\hline CHEMBL1444595 & 688612 & 4.45 & 4.6156 & TRN & \\
\hline CHEMBL1573473 & 688612 & 6.8499 & 4.6688 & TRN & \\
\hline CHEMBL1539079 & 688612 & 5.0 & 4.6387 & TRN & \\
\hline CHEMBL1387016 & 688612 & 4.8 & 4.7135 & TST & \\
\hline CHEMBL1426266 & 688612 & 4.8 & 4.6509 & TRN & \\
\hline CHEMBL1444338 & 688612 & 4.7 & 4.6222 & TRN & \\
\hline CHEMBL2003964 & 688612 & 5.55 & 4.8973 & TRN & \\
\hline CHEMBL1349908 & 688612 & 4.0 & 4.71399 & 99999999995 & TST \\
\hline CHEMBL1469208 & 688612 & 4.3 & 4.7286 & TST & \\
\hline CHEMBL1468426 & 688612 & 4.1 & 4.6838 & TRN & \\
\hline CHEMBL1418579 & 688612 & 4.0 & 4.6479 & TRN & \\
\hline CHEMBL1424811 & 688612 & 4.0 & 4.6958 & TRN & \\
\hline CHEMBL1399169 & 688612 & 6.35 & 4.5552 & TRN & \\
\hline CHEMBL1506363 & 688612 & 5.8 & 4.6995 & TRN & \\
\hline CHEMBL1420694 & 688612 & 4.05 & 4.68199 & 99999999995 & TRN \\
\hline CHEMBL1531688 & 688612 & 4.4 & 4.7309 & TRN & \\
\hline CHEMBL1436486 & 688612 & 6.25 & 4.7174 & TRN & \\
\hline CHEMBL1400852 & 688612 & 4.45 & 4.7152 & TRN & \\
\hline CHEMBL1460076 & 688612 & 4.0 & $4.7330 e$ & 00000000005 & TST \\
\hline CHEMBL1304529 & 688612 & 4.2 & 4.6917 & TRN & \\
\hline CHEMBL1357987 & 688612 & 4.3 & 4.6863 & TRN & \\
\hline CHEMBL1566448 & 688612 & 4.0 & 4.73 & TRN & \\
\hline CHEMBL1541530 & 688612 & 4.05 & 4.6448 & TRN & \\
\hline CHEMBL1375514 & 688612 & 4.0 & 4.727 & TRN & \\
\hline CHEMBL1517799 & 688612 & 5.7 & 4.7217 & TRN & \\
\hline CHEMBL1486288 & 688612 & 4.2 & 4.5788 & TRN & \\
\hline CHEMBL1361049 & 688612 & 4.75 & 4.6668 & TRN & \\
\hline CHEMBL1401029 & 688612 & 4.5 & $4.6080 e$ & 00000000005 & TRN \\
\hline CHEMBL1580703 & 688612 & 4.15 & 4.6783 & TRN & \\
\hline CHEMBL1533940 & 688612 & 4.0 & 4.6911 & TRN & \\
\hline CHEMBL1361099 & 688612 & 4.35 & 4.6816 & TRN & \\
\hline CHEMBL3193143 & 688612 & 6.25 & 4.7042 & TST & \\
\hline CHEMBL1342271 & 688612 & 6.5 & 4.7455 & TRN & \\
\hline
\end{tabular}




\begin{tabular}{|c|c|c|c|c|c|}
\hline \multirow[b]{2}{*}{ CHEMBL1492422 } & & \multicolumn{4}{|c|}{ Supplemental Table S2.txt } \\
\hline & 688612 & 4.05 & 4.6972 & TRN & \\
\hline CHEMBL1526359 & 688612 & 4.0 & 4.6530 & 00000000005 & TRN \\
\hline CHEMBL1557556 & 688612 & 4.05 & 4.7719 & TST & \\
\hline CHEMBL1538137 & 688612 & 4.3 & 4.6267 & TRN & \\
\hline CHEMBL1359102 & 688612 & 5.1 & 4.6746 & TRN & \\
\hline CHEMBL1424086 & 688612 & 4.55 & 4.7103 & TRN & \\
\hline CHEMBL3197958 & 688612 & 5.15 & 4.7943 & TRN & \\
\hline CHEMBL1498640 & 688612 & 4.0 & 4.5844 & TRN & \\
\hline CHEMBL 1473230 & 688612 & 4.65 & 4.655 & TRN & \\
\hline CHEMBL1442097 & 688612 & 4.05 & 4.6667 & TST & \\
\hline CHEMBL1350238 & 688612 & 4.55 & 4.6523 & TST & \\
\hline CHEMBL1420591 & 688612 & 4.75 & 4.7627 & TST & \\
\hline CHEMBL1328125 & 688612 & 4.4 & 4.6488 & TST & \\
\hline CHEMBL1540624 & 688612 & 4.3 & 4.6656 & TRN & \\
\hline CHEMBL1323764 & 688612 & 4.65 & 4.713 & TRN & \\
\hline CHEMBL1605955 & 688612 & 4.4 & 4.6182 & TRN & \\
\hline CHEMBL1485558 & 688612 & 4.3 & 4.6146 & TRN & \\
\hline CHEMBL1404201 & 688612 & 5.0 & 4.6757 & TRN & \\
\hline CHEMBL1553561 & 688612 & 4.85 & 4.645 & TRN & \\
\hline CHEMBL576186 & 688612 & 5.0 & 4.7031 & TRN & \\
\hline CHEMBL1445608 & 688612 & 6.2 & 4.6379 & TRN & \\
\hline CHEMBL1331603 & 688612 & 4.4 & 4.646 & TRN & \\
\hline CHEMBL1377384 & 688612 & 4.75 & 4.7174 & TRN & \\
\hline CHEMBL1332487 & 688612 & 4.8 & 4.6215 & TRN & \\
\hline CHEMBL1361853 & 688612 & 4.3 & 4.7074 & TST & \\
\hline CHEMBL1582521 & 688612 & 4.05 & 4.7367 & TRN & \\
\hline CHEMBL1371955 & 688612 & 4.05 & 4.6929 & TST & \\
\hline CHEMBL1344564 & 688612 & 4.1 & 4.6599 & TRN & \\
\hline CHEMBL1465938 & 688612 & 4.05 & 4.5769 & TRN & \\
\hline CHEMBL1373913 & 688612 & 5.7 & 4.6666 & TRN & \\
\hline CHEMBL1542061 & 688612 & 4.4 & 4.6725 & TRN & \\
\hline CHEMBL1568073 & 688612 & 4.6 & 4.6358 & TRN & \\
\hline CHEMBL3196497 & 688612 & 5.0 & 4.6898 & TRN & \\
\hline CHEMBL1339765 & 688612 & 4.6 & 4.6423 & TRN & \\
\hline CHEMBL1578235 & 688612 & 4.05 & 4.7432 & TRN & \\
\hline CHEMBL1391970 & 688612 & 4.35 & 4.6787 & TRN & \\
\hline CHEMBL1340902 & 688612 & 4.75 & 4.6337 & TRN & \\
\hline CHEMBL1470858 & 688612 & 4.9 & 4.6472 & TRN & \\
\hline CHEMBL1515185 & 688612 & 4.1 & 4.652 & TRN & \\
\hline CHEMBL1398974 & 688612 & 5.35 & 4.6328 & TST & \\
\hline CHEMBL1340310 & 688612 & 4.1 & 4.7134 & TST & \\
\hline CHEMBL1556894 & 688612 & 4.05 & 4.5725 & TRN & \\
\hline CHEMBL1398142 & 688612 & 4.05 & 4.757 & TRN & \\
\hline CHEMBL1374675 & 688612 & 4.0 & 4.5645 & TST & \\
\hline CHEMBL1303290 & 688612 & 4.3 & 4.6106 & TRN & \\
\hline CHEMBL1580984 & 688612 & 4.05 & 4.6144 & TRN & \\
\hline CHEMBL1503683 & 688612 & 4.3 & 4.7262 & TST & \\
\hline CHEMBL3210991 & 688612 & 4.05 & 4.6882 & TRN & \\
\hline
\end{tabular}




\begin{tabular}{|c|c|c|c|c|c|}
\hline \multicolumn{6}{|c|}{ Supplemental Table S2.txt } \\
\hline CHEMBL1414887 & 688612 & 5.6 & 4.6789 & TRN & \\
\hline CHEMBL1359231 & 688612 & 4.4 & 4.6936 & TRN & \\
\hline CHEMBL1363697 & 688612 & 4.45 & 4.6378 & TRN & \\
\hline CHEMBL1569215 & 688612 & 5.0 & 4.791 & TRN & \\
\hline CHEMBL1446800 & 688612 & 4.1 & 4.6884 & TRN & \\
\hline CHEMBL1564764 & 688612 & 6.5 & 4.57100 & 0000000001 & TRN \\
\hline CHEMBL1363927 & 688612 & 4.75 & 4.6528 & TRN & \\
\hline CHEMBL1359070 & 688612 & 6.0 & 4.7787 & TST & \\
\hline CHEMBL 3198206 & 688612 & 4.4 & 4.6815 & TRN & \\
\hline CHEMBL1490310 & 688612 & 4.7 & 4.7111 & TST & \\
\hline CHEMBL1419844 & 688612 & 4.05 & 4.5869 & TRN & \\
\hline CHEMBL1450458 & 688612 & 4.95 & 4.7381 & TRN & \\
\hline CHEMBL3194007 & 688612 & 4.2 & 4.6658 & TRN & \\
\hline CHEMBL1498996 & 688612 & 6.8499 & 4.6671 & TRN & \\
\hline CHEMBL1468963 & 688612 & 4.15 & 4.7174 & TRN & \\
\hline CHEMBL1603040 & 688612 & 6.0 & 4.6205 & TRN & \\
\hline CHEMBL1299384 & 688612 & 4.2 & 4.7357 & TST & \\
\hline CHEMBL1433007 & 688612 & 6.0 & 4.6356 & TRN & \\
\hline CHEMBL1477947 & 688612 & 4.25 & 4.6698 & TRN & \\
\hline CHEMBL1601797 & 688612 & 4.05 & 4.745 & TST & \\
\hline CHEMBL3191860 & 688612 & 4.0 & 4.6206 & TRN & \\
\hline CHEMBL1576800 & 688612 & 4.05 & 4.6814 & TST & \\
\hline CHEMBL1407368 & 688612 & 4.3 & 4.6473 & TRN & \\
\hline CHEMBL1333195 & 688612 & 4.1 & 4.7418 & TST & \\
\hline CHEMBL1488308 & 688612 & 6.8499 & 4.6957 & TRN & \\
\hline CHEMBL1471188 & 688612 & 4.4 & 4.6085 & TRN & \\
\hline CHEMBL1457701 & 688612 & 4.6 & 4.7056 & TRN & \\
\hline CHEMBL1493703 & 688612 & 4.6 & 4.6466 & TRN & \\
\hline CHEMBL1390506 & 688612 & 4.55 & 4.6769 & TRN & \\
\hline CHEMBL1373106 & 688612 & 4.4 & 4.8077 & TST & \\
\hline CHEMBL1595566 & 688612 & 4.1 & 4.6849 & TRN & \\
\hline CHEMBL1306991 & 688612 & 4.05 & 4.6269 & TRN & \\
\hline CHEMBL1990425 & 688612 & 5.8 & 4.6515 & TST & \\
\hline CHEMBL1553725 & 688612 & 6.8499 & 4.6357 & TRN & \\
\hline CHEMBL1575464 & 688612 & 4.0 & 4.6831 & TRN & \\
\hline CHEMBL1526851 & 688612 & 4.4 & 4.8481 & TRN & \\
\hline CHEMBL1329199 & 688612 & 6.45 & 4.7238 & TST & \\
\hline CHEMBL1607333 & 688612 & 4.75 & 4.6224 & TRN & \\
\hline CHEMBL1440508 & 688612 & 6.3 & 4.7181 & TST & \\
\hline CHEMBL1422006 & 688612 & 4.05 & 4.6085 & TRN & \\
\hline CHEMBL1365136 & 688612 & 4.0 & 4.7728 & TST & \\
\hline CHEMBL1346178 & 688612 & 4.05 & 4.6509 & TRN & \\
\hline CHEMBL1378104 & 688612 & 4.95 & 4.7261 & TST & \\
\hline CHEMBL1344966 & 688612 & 4.65 & 4.7081 & TRN & \\
\hline CHEMBL1371885 & 688612 & 4.1 & 4.6615 & TRN & \\
\hline CHEMBL1449836 & 688612 & 5.1 & 4.7499 & TRN & \\
\hline CHEMBL1408569 & 688612 & 4.4 & 4.6633 & TST & \\
\hline CHEMBL1528089 & 688612 & 4.05 & 4.641 & TRN & \\
\hline
\end{tabular}




\begin{tabular}{|c|c|c|c|c|c|}
\hline \multicolumn{6}{|c|}{ Supplemental Table S2.txt } \\
\hline CHEMBL1396078 & 688612 & 4.5 & 4.6503 & TRN & \\
\hline CHEMBL1453704 & 688612 & 4.1 & 4.6356 & TRN & \\
\hline CHEMBL1520738 & 688612 & 4.4 & 4.5957 & TRN & \\
\hline CHEMBL1368319 & 688612 & 5.5 & 4.6707 & TRN & \\
\hline CHEMBL1467073 & 688612 & 6.8499 & 4.7481 & TRN & \\
\hline CHEMBL1402568 & 688612 & 4.35 & 4.6014 & TRN & \\
\hline CHEMBL1424486 & 688612 & 4.3 & 4.8123 & TRN & \\
\hline CHEMBL3194468 & 688612 & 6.2 & 4.6828 & TRN & \\
\hline CHEMBL1574264 & 688612 & 4.05 & 4.6342 & TRN & \\
\hline CHEMBL3198429 & 688612 & 4.05 & 4.7344 & TRN & \\
\hline CHEMBL224844 & 688612 & 4.7 & 4.6224 & TRN & \\
\hline CHEMBL1501459 & 688612 & 4.05 & 4.6249 & TST & \\
\hline CHEMBL1472115 & 688612 & 5.5 & 4.6824 & TRN & \\
\hline CHEMBL1566741 & 688612 & 4.65 & 4.7161 & TRN & \\
\hline CHEMBL1453783 & 688612 & 4.4 & 4.7209 & TRN & \\
\hline CHEMBL1491750 & 688612 & 4.05 & 4.8166 & TST & \\
\hline CHEMBL1583383 & 688612 & 6.6 & 4.6039 & TRN & \\
\hline CHEMBL1372361 & 688612 & 4.0 & 4.7492 & TRN & \\
\hline CHEMBL1510358 & 688612 & 4.6 & 4.59399 & 9999999999 & TRN \\
\hline CHEMBL1418414 & 688612 & 4.05 & 4.6477 & TRN & \\
\hline CHEMBL1321665 & 688612 & 6.5501 & 4.6619 & TRN & \\
\hline CHEMBL1480616 & 688612 & 4.0 & 4.6837 & TST & \\
\hline CHEMBL1560476 & 688612 & 4.05 & 4.6964 & TRN & \\
\hline CHEMBL1304317 & 688612 & 5.1 & 4.6734 & TRN & \\
\hline CHEMBL1534626 & 688612 & 5.2 & 4.6375 & TST & \\
\hline CHEMBL1533308 & 688612 & 4.05 & 4.7219 & 99999999995 & TRN \\
\hline CHEMBL1354019 & 688612 & 4.1 & 4.6208 & TRN & \\
\hline CHEMBL1591748 & 688612 & 4.1 & 4.6361 & TRN & \\
\hline CHEMBL1557171 & 688612 & 5.6 & 4.6778 & TST & \\
\hline CHEMBL1329850 & 688612 & 4.35 & 4.6842 & TRN & \\
\hline CHEMBL3208795 & 688612 & 4.6 & 4.7543 & TRN & \\
\hline CHEMBL1538637 & 688612 & 4.4 & 4.6942 & TST & \\
\hline CHEMBL1391256 & 688612 & 5.2 & 4.76699 & 99999999995 & TRN \\
\hline CHEMBL1584552 & 688612 & 5.4 & 4.6406 & TST & \\
\hline CHEMBL3190748 & 688612 & 5.0 & 4.7151 & TRN & \\
\hline CHEMBL1404913 & 688612 & 4.55 & 4.7004 & TRN & \\
\hline CHEMBL1610647 & 688612 & 4.05 & 4.6985 & TRN & \\
\hline CHEMBL1543157 & 688612 & 4.3 & 4.6974 & TST & \\
\hline CHEMBL1449667 & 688612 & 4.35 & 4.6762 & TRN & \\
\hline CHEMBL1419479 & 688612 & 4.0 & 4.6939 & TST & \\
\hline CHEMBL1367938 & 688612 & 4.6 & 4.6507 & TRN & \\
\hline CHEMBL236897 & 688612 & 4.45 & 4.757 & TRN & \\
\hline CHEMBL1496630 & 688612 & 5.1 & 4.6764 & TRN & \\
\hline CHEMBL1367553 & 688612 & 4.35 & 4.6593 & TRN & \\
\hline CHEMBL1498789 & 688612 & 4.0 & 4.7046 & TST & \\
\hline CHEMBL1409173 & 688612 & 4.4 & 4.7056 & TRN & \\
\hline CHEMBL1491120 & 688612 & 4.05 & 4.7646 & TRN & \\
\hline CHEMBL1492705 & 688612 & 6.1 & 4.6668 & TRN & \\
\hline
\end{tabular}




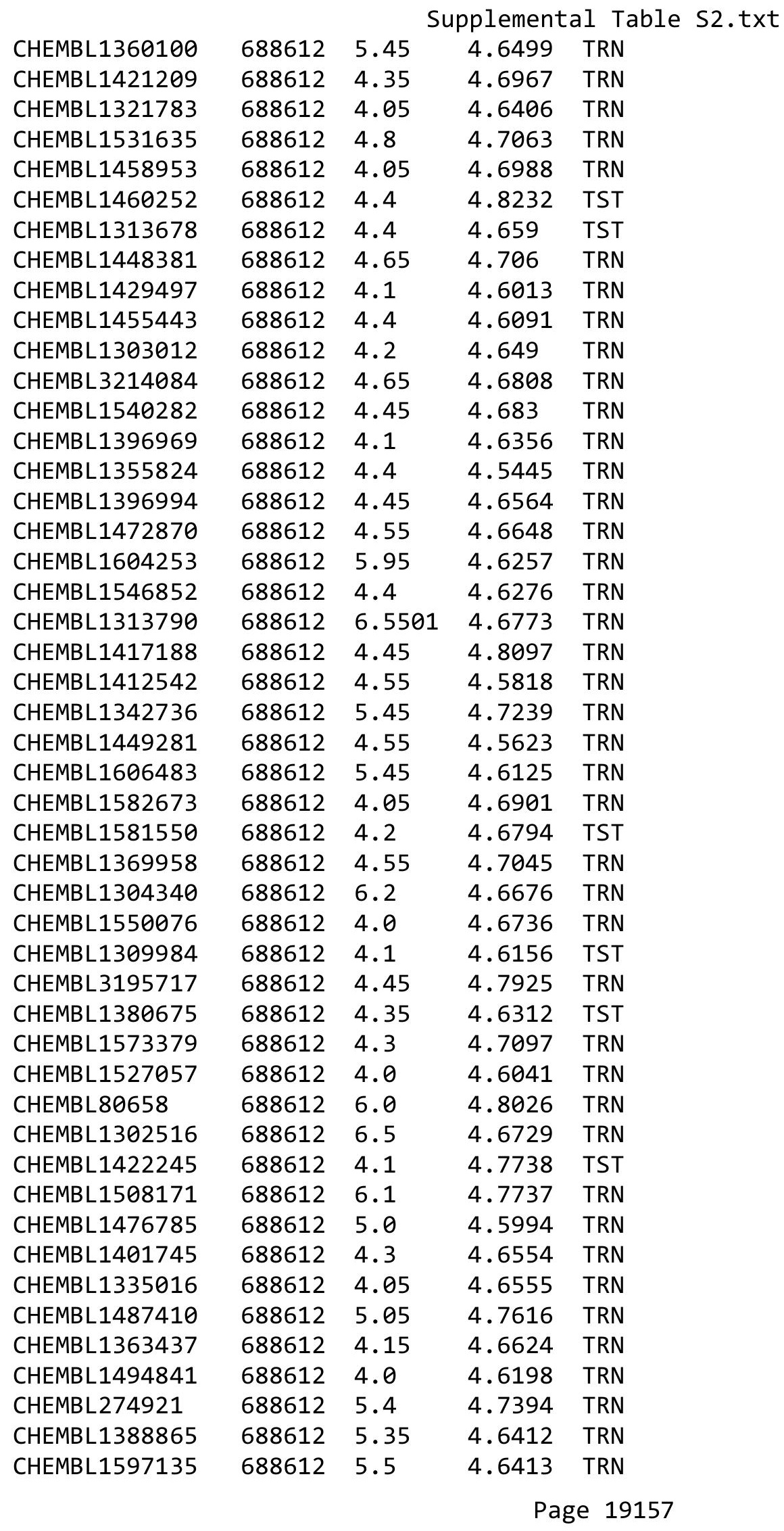




\begin{tabular}{|c|c|c|c|c|}
\hline \multicolumn{5}{|c|}{ Supplemental Table S2.txt } \\
\hline CHEMBL1383805 & 688612 & 4.05 & 4.7049 & TRN \\
\hline CHEMBL1460099 & 688612 & 5.4 & 4.6434 & TST \\
\hline CHEMBL1491203 & 688612 & 4.05 & 4.6372 & TRN \\
\hline CHEMBL1516596 & 688612 & 4.15 & 4.6788 & TRN \\
\hline CHEMBL1370104 & 688612 & 4.05 & 4.6687 & TRN \\
\hline CHEMBL1316534 & 688612 & 4.8 & 4.618 & TRN \\
\hline CHEMBL1544871 & 688612 & 4.7 & 4.6505 & TRN \\
\hline CHEMBL1323106 & 688612 & 4.4 & 4.6637 & TRN \\
\hline CHEMBL1388970 & 688612 & 4.05 & 4.5871 & TRN \\
\hline CHEMBL1510236 & 688612 & 4.0 & 4.6116 & TRN \\
\hline CHEMBL1560516 & 688612 & 4.0 & 4.7128 & TRN \\
\hline CHEMBL1332087 & 688612 & 4.2 & 4.6922 & TST \\
\hline CHEMBL1312302 & 688612 & 4.45 & 4.6272 & TRN \\
\hline CHEMBL1307104 & 688612 & 4.7 & 4.5941 & TRN \\
\hline CHEMBL1509165 & 688612 & 4.3 & 4.7244 & TRN \\
\hline CHEMBL1339576 & 688612 & 4.6 & 4.68 & TRN \\
\hline CHEMBL1474031 & 688612 & 4.0 & 4.6494 & TRN \\
\hline CHEMBL1464899 & 688612 & 4.05 & 4.6899 & TRN \\
\hline CHEMBL1305422 & 688612 & 4.15 & 4.6707 & TST \\
\hline CHEMBL1403355 & 688612 & 5.4 & 4.6526 & TRN \\
\hline CHEMBL1524475 & 688612 & 4.8 & 4.6673 & TRN \\
\hline CHEMBL1982071 & 688612 & 6.6499 & 4.6222 & TRN \\
\hline CHEMBL1540309 & 688612 & 6.1 & 4.6747 & TRN \\
\hline CHEMBL1559622 & 688612 & 4.4 & 4.6671 & TRN \\
\hline CHEMBL1337265 & 688612 & 4.4 & 4.7469 & TST \\
\hline CHEMBL1451290 & 688612 & 4.6 & 4.7061 & TRN \\
\hline CHEMBL1465124 & 688612 & 4.4 & 4.6196 & TRN \\
\hline CHEMBL1516296 & 688612 & 4.25 & 4.6045 & TST \\
\hline CHEMBL1564723 & 688612 & 6.8499 & 4.633 & TRN \\
\hline CHEMBL1302252 & 688612 & 6.0 & 4.6501 & TRN \\
\hline CHEMBL1336015 & 688612 & 4.3 & 4.6326 & TRN \\
\hline CHEMBL1996954 & 688612 & 4.35 & 4.6895 & TRN \\
\hline CHEMBL1543874 & 688612 & 4.05 & 4.6718 & TRN \\
\hline CHEMBL1348554 & 688612 & 4.0 & 4.6176 & TRN \\
\hline CHEMBL1315798 & 688612 & 4.95 & 4.5801 & TRN \\
\hline CHEMBL1554561 & 688612 & 4.2 & 4.6199 & TRN \\
\hline CHEMBL 3195254 & 688612 & 4.0 & 4.7476 & TST \\
\hline CHEMBL1368345 & 688612 & 4.75 & 4.6688 & TRN \\
\hline CHEMBL1550075 & 688612 & 5.5 & 4.6625 & TRN \\
\hline CHEMBL3191622 & 688612 & 4.75 & 4.8072 & TRN \\
\hline CHEMBL1600414 & 688612 & 4.65 & 4.6736 & TRN \\
\hline CHEMBL1303130 & 688612 & 4.25 & 4.5874 & TRN \\
\hline CHEMBL1388643 & 688612 & 4.05 & 4.5928 & TRN \\
\hline CHEMBL1362648 & 688612 & 4.05 & 4.7094 & TST \\
\hline CHEMBL1597793 & 688612 & 5.6 & 4.6507 & TRN \\
\hline CHEMBL1405448 & 688612 & 4.25 & 4.6254 & TRN \\
\hline CHEMBL1441542 & 688612 & 4.8 & 4.5599 & TRN \\
\hline CHEMBL51085 & 688612 & 5.5 & 4.7144 & TST \\
\hline
\end{tabular}




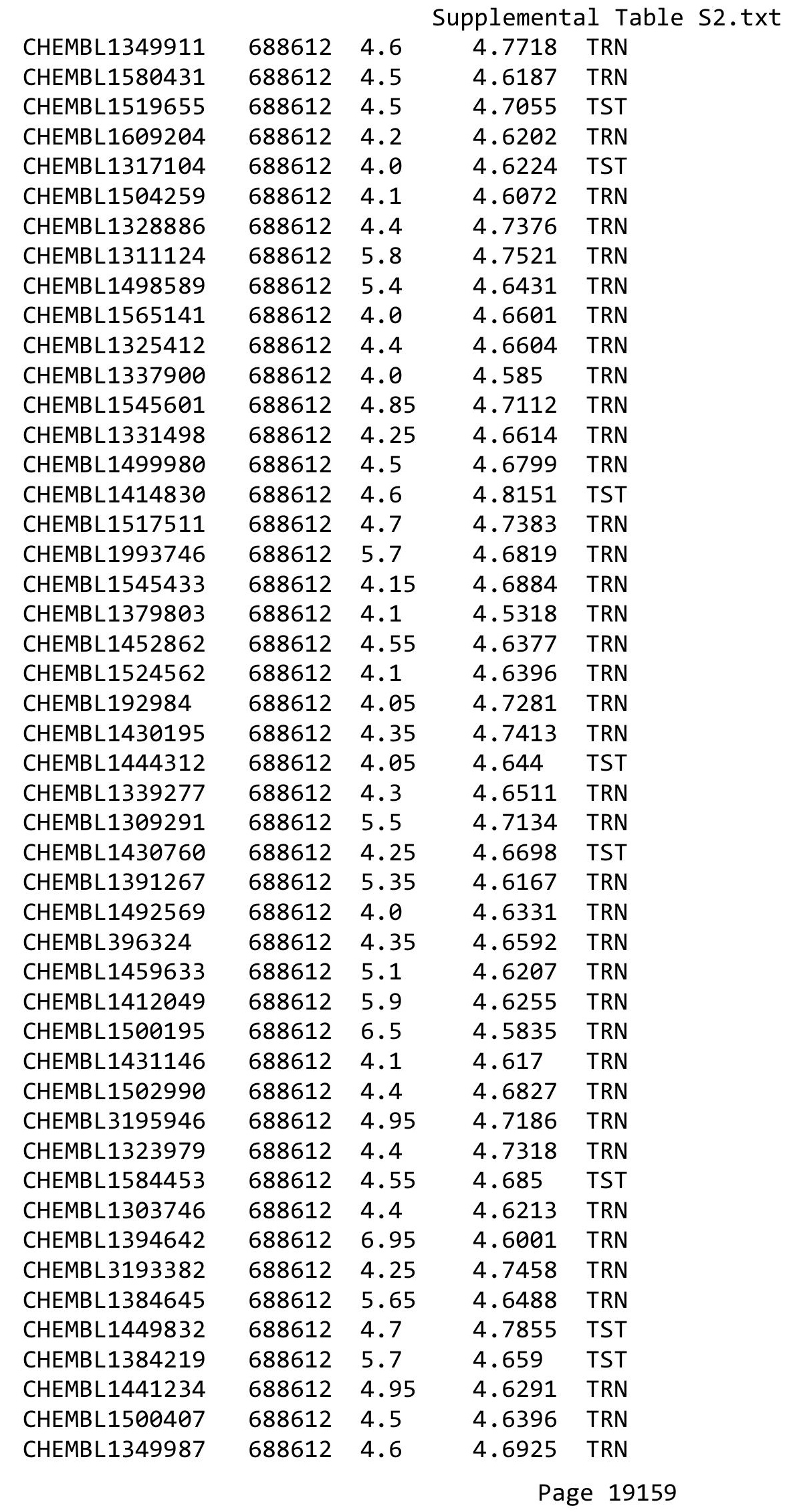




\begin{tabular}{|c|c|c|c|c|c|}
\hline \multicolumn{6}{|c|}{ Supplemental Table S2.txt } \\
\hline CHEMBL1334709 & 688612 & 4.0 & 4.6496 & TST & \\
\hline CHEMBL1385125 & 688612 & 4.3 & 4.7024 & TST & \\
\hline CHEMBL1549283 & 688612 & 6.5 & 4.7301 & TST & \\
\hline CHEMBL1326687 & 688612 & 4.05 & 4.6487 & TRN & \\
\hline CHEMBL1605788 & 688612 & 4.65 & 4.6701 & TRN & \\
\hline CHEMBL1560505 & 688612 & 6.45 & 4.6706 & TRN & \\
\hline CHEMBL1324561 & 688612 & 4.4 & 4.6405 & TRN & \\
\hline CHEMBL1335286 & 688612 & 4.45 & 4.7619 & TRN & \\
\hline CHEMBL1469781 & 688612 & 4.6 & 4.6523 & TRN & \\
\hline CHEMBL1326328 & 688612 & 4.4 & 4.6964 & TRN & \\
\hline CHEMBL1387701 & 688612 & 5.55 & 4.6829 & TRN & \\
\hline CHEMBL1307163 & 688612 & 4.5 & 4.7094 & TST & \\
\hline CHEMBL1576087 & 688612 & 4.35 & 4.5896 & TRN & \\
\hline CHEMBL1519183 & 688612 & 4.5 & 4.6218 & TRN & \\
\hline CHEMBL1536825 & 688612 & 4.1 & 4.6359 & TST & \\
\hline CHEMBL3198916 & 688612 & 4.75 & 4.6986 & TRN & \\
\hline CHEMBL1603907 & 688612 & 4.4 & 4.6607 & TRN & \\
\hline CHEMBL1468428 & 688612 & 4.05 & 4.63899 & 9999999999 & TST \\
\hline CHEMBL3194778 & 688612 & 4.4 & 4.6753 & TRN & \\
\hline CHEMBL1424264 & 688612 & 5.0 & 4.7082 & TRN & \\
\hline CHEMBL1374993 & 688612 & 4.05 & 4.6987 & TST & \\
\hline CHEMBL1559122 & 688612 & 4.0 & 4.6095 & TRN & \\
\hline CHEMBL3191063 & 688612 & 5.45 & 4.7873 & TRN & \\
\hline CHEMBL579761 & 688612 & 6.15 & 4.7122 & TRN & \\
\hline CHEMBL1450904 & 688612 & 6.35 & 4.6724 & TRN & \\
\hline CHEMBL1453553 & 688612 & 4.05 & 4.6198 & TRN & \\
\hline CHEMBL1439640 & 688612 & 5.7 & 4.6767 & TRN & \\
\hline CHEMBL3190258 & 688612 & 4.25 & 4.6718 & TRN & \\
\hline CHEMBL1414569 & 688612 & 6.9 & 4.6573 & TRN & \\
\hline CHEMBL1571442 & 688612 & 5.1 & 4.6305 & TRN & \\
\hline CHEMBL1321628 & 688612 & 4.0 & 4.6229 & TRN & \\
\hline CHEMBL1375627 & 688612 & 4.05 & 4.5659 & TST & \\
\hline CHEMBL1498364 & 688612 & 4.65 & 4.6717 & TRN & \\
\hline CHEMBL1459684 & 688612 & 4.55 & 4.6689 & TRN & \\
\hline CHEMBL1375381 & 688612 & 4.05 & 4.5823 & TRN & \\
\hline CHEMBL3190760 & 688612 & 5.05 & 4.6465 & TST & \\
\hline CHEMBL1578768 & 688612 & 5.05 & 4.7266 & TRN & \\
\hline CHEMBL1551623 & 688612 & 4.4 & 4.6595 & TRN & \\
\hline CHEMBL1601629 & 688612 & 4.0 & 4.6042 & TRN & \\
\hline CHEMBL1595909 & 688612 & 5.0 & 4.7593 & TRN & \\
\hline CHEMBL3193362 & 688612 & 4.15 & 4.7171 & TST & \\
\hline CHEMBL1409610 & 688612 & 4.55 & 4.6703 & TRN & \\
\hline CHEMBL1348993 & 688612 & 4.0 & 4.5939 & TRN & \\
\hline CHEMBL3209841 & 688612 & 6.7001 & 4.6413 & TRN & \\
\hline CHEMBL3192289 & 688612 & 6.45 & 4.686 & TRN & \\
\hline CHEMBL3193813 & 688612 & 5.1 & 4.6824 & TST & \\
\hline CHEMBL1327501 & 688612 & 4.4 & 4.6371 & TRN & \\
\hline CHEMBL1530246 & 688612 & 4.35 & 4.6798 & TRN & \\
\hline
\end{tabular}




\begin{tabular}{|c|c|c|c|c|c|}
\hline \multicolumn{6}{|c|}{ Supplemental Table S2.txt } \\
\hline CHEMBL1468796 & 688612 & 4.7 & 4.8686 & TRN & \\
\hline CHEMBL1537909 & 688612 & 6.5 & 4.6595 & TRN & \\
\hline CHEMBL1572777 & 688612 & 4.5 & 4.7507 & TRN & \\
\hline CHEMBL1376811 & 688612 & 6.3 & 4.6685 & TRN & \\
\hline CHEMBL1312980 & 688612 & 5.35 & 4.6826 & TRN & \\
\hline CHEMBL1613017 & 688612 & 4.1 & 4.681 & TRN & \\
\hline CHEMBL1509273 & 688612 & 4.3 & 4.6749 & TRN & \\
\hline CHEMBL1602132 & 688612 & 4.4 & 4.6775 & TRN & \\
\hline CHEMBL1472881 & 688612 & 4.05 & 4.548 & TRN & \\
\hline CHEMBL3197819 & 688612 & 4.55 & 4.6831 & TST & \\
\hline CHEMBL1461385 & 688612 & 4.05 & 4.6357 & TST & \\
\hline CHEMBL1309826 & 688612 & 6.0 & 4.5568 & TRN & \\
\hline CHEMBL1456380 & 688612 & 4.3 & 4.6364 & TRN & \\
\hline CHEMBL 3210471 & 688612 & 4.35 & 4.7429 & TST & \\
\hline CHEMBL1341078 & 688612 & 4.5 & 4.7428 & TRN & \\
\hline CHEMBL1584661 & 688612 & 4.05 & 4.7155 & TRN & \\
\hline CHEMBL1483048 & 688612 & 4.05 & 4.6576 & TRN & \\
\hline CHEMBL1486939 & 688612 & 5.25 & 4.7231 & TRN & \\
\hline CHEMBL1533618 & 688612 & 4.05 & 4.5844 & TRN & \\
\hline CHEMBL1609615 & 688612 & 4.9 & 4.7097 & TRN & \\
\hline CHEMBL3193467 & 688612 & 4.05 & 4.7108 & TRN & \\
\hline CHEMBL1473050 & 688612 & 4.05 & 4.499 & TRN & \\
\hline CHEMBL1308225 & 688612 & 6.5501 & 4.7387 & TRN & \\
\hline CHEMBL1523068 & 688612 & 4.4 & 4.6678 & TRN & \\
\hline CHEMBL1517626 & 688612 & 4.35 & 4.7072 & TST & \\
\hline CHEMBL3190929 & 688612 & 4.1 & 4.6661 & TRN & \\
\hline CHEMBL3194789 & 688612 & 4.1 & 4.6693 & TRN & \\
\hline CHEMBL1456537 & 688612 & 4.35 & $4.6560 e$ & 0000000001 & TRN \\
\hline CHEMBL1492575 & 688612 & 5.35 & 4.6798 & TRN & \\
\hline CHEMBL1980657 & 688612 & 5.4 & 4.7046 & TRN & \\
\hline CHEMBL1548176 & 688612 & 4.3 & 4.7194 & TST & \\
\hline CHEMBL3198445 & 688612 & 4.9 & 4.7648 & TST & \\
\hline CHEMBL1412196 & 688612 & 4.0 & 4.6939 & TST & \\
\hline CHEMBL1509572 & 688612 & 6.0 & 4.5842 & TRN & \\
\hline CHEMBL611661 & 688612 & 4.4 & 4.6954 & TST & \\
\hline CHEMBL1349070 & 688612 & 4.0 & 4.7685 & TRN & \\
\hline CHEMBL1405097 & 688612 & 4.45 & 4.6964 & TRN & \\
\hline CHEMBL1584913 & 688612 & 4.05 & 4.6523 & TRN & \\
\hline CHEMBL251963 & 688612 & 4.05 & 4.711 & TRN & \\
\hline CHEMBL1559969 & 688612 & 4.8 & 4.6712 & TST & \\
\hline CHEMBL1453577 & 688612 & 5.0 & 4.6345 & TRN & \\
\hline CHEMBL1478321 & 688612 & 5.05 & 4.5847 & TRN & \\
\hline CHEMBL1377204 & 688612 & 4.35 & 4.5654 & TRN & \\
\hline CHEMBL1552196 & 688612 & 4.1 & 4.7022 & TRN & \\
\hline CHEMBL1361700 & 688612 & 5.35 & 4.6032 & TRN & \\
\hline CHEMBL1509590 & 688612 & 4.55 & 4.7288 & TRN & \\
\hline CHEMBL1442043 & 688612 & 4.05 & 4.6384 & TRN & \\
\hline CHEMBL1563711 & 688612 & 6.8499 & 4.5842 & TST & \\
\hline
\end{tabular}




\begin{tabular}{|c|c|c|c|c|c|}
\hline & & \multicolumn{4}{|c|}{ Supplemental Table s2.txt } \\
\hline CHEMBL1360837 & 688612 & 4.55 & 4.6162 & TRN & \\
\hline CHEMBL1339157 & 688612 & 4.55 & 4.7359 & TRN & \\
\hline CHEMBL1351344 & 688612 & 4.25 & 4.6597 & TST & \\
\hline CHEMBL1422308 & 688612 & 4.3 & 4.7199 & TST & \\
\hline CHEMBL1418723 & 688612 & 4.3 & 4.7427 & TST & \\
\hline CHEMBL3191795 & 688612 & 4.05 & 4.7307 & TRN & \\
\hline CHEMBL1493103 & 688612 & 4.4 & 4.7335 & TRN & \\
\hline CHEMBL1463605 & 688612 & 5.7 & 4.6969 & TST & \\
\hline CHEMBL1608015 & 688612 & 4.1 & 4.6552 & TRN & \\
\hline CHEMBL1541462 & 688612 & 4.85 & 4.6534 & TRN & \\
\hline CHEMBL1340653 & 688612 & 4.05 & 4.6667 & TST & \\
\hline CHEMBL1529985 & 688612 & 6.35 & 4.61 & TRN & \\
\hline CHEMBL1308820 & 688612 & 5.5 & 4.5506 & TRN & \\
\hline CHEMBL1322375 & 688612 & 4.75 & 4.7568 & TRN & \\
\hline CHEMBL1568481 & 688612 & 4.5 & 4.65 & TRN & \\
\hline CHEMBL3199693 & 688612 & 5.2 & 4.7047 & TRN & \\
\hline CHEMBL1506704 & 688612 & 4.0 & 4.663 & TRN & \\
\hline CHEMBL3196247 & 688612 & 4.65 & 4.6906 & TRN & \\
\hline CHEMBL1328170 & 688612 & 4.05 & 4.6477 & TRN & \\
\hline CHEMBL1380079 & 688612 & 4.05 & 4.6347 & TST & \\
\hline CHEMBL 2016647 & 688612 & 4.3 & 4.7625 & TRN & \\
\hline CHEMBL1304416 & 688612 & 4.6 & 4.6395 & TRN & \\
\hline CHEMBL1523660 & 688612 & 4.85 & 4.7348 & TST & \\
\hline CHEMBL1401492 & 688612 & 4.05 & 4.6572 & TRN & \\
\hline CHEMBL1510687 & 688612 & 5.4 & 4.6503 & TRN & \\
\hline CHEMBL1548107 & 688612 & 4.0 & 4.7152 & TST & \\
\hline CHEMBL1594100 & 688612 & 4.4 & 4.6389 & TRN & \\
\hline CHEMBL1310022 & 688612 & 5.1 & 4.57100 & 0000000001 & TRN \\
\hline CHEMBL1789994 & 688612 & 4.15 & 4.65600 & 3000000001 & TST \\
\hline CHEMBL1351531 & 688612 & 4.05 & 4.5931 & TRN & \\
\hline CHEMBL1396835 & 688612 & 4.9 & 4.6761 & TRN & \\
\hline CHEMBL1547422 & 688612 & 4.6 & 4.6659 & TST & \\
\hline CHEMBL1388238 & 688612 & 4.4 & 4.6599 & TRN & \\
\hline CHEMBL1586706 & 688612 & 5.0 & 4.6143 & TRN & \\
\hline CHEMBL1364785 & 688612 & 4.85 & 4.584 & TRN & \\
\hline CHEMBL1361940 & 688612 & 4.45 & 4.6944 & TRN & \\
\hline CHEMBL1535916 & 688612 & 4.4 & 4.7023 & TRN & \\
\hline CHEMBL1464053 & 688612 & 4.4 & 4.7365 & TRN & \\
\hline CHEMBL1532757 & 688612 & 4.15 & 4.5639 & TRN & \\
\hline CHEMBL1445002 & 688612 & 4.7 & 4.7033 & TST & \\
\hline CHEMBL3197508 & 688612 & 5.0 & 4.7056 & TRN & \\
\hline CHEMBL1976525 & 688612 & 4.05 & 4.8349 & TST & \\
\hline CHEMBL1479888 & 688612 & 4.65 & 4.7282 & TST & \\
\hline CHEMBL1441733 & 688612 & 5.35 & 4.5962 & TST & \\
\hline CHEMBL3197017 & 688612 & 4.4 & 4.716 & TST & \\
\hline CHEMBL1559609 & 688612 & 4.3 & 4.7411 & TRN & \\
\hline CHEMBL1489134 & 688612 & 4.05 & 4.6199 & TRN & \\
\hline CHEMBL1599542 & 688612 & 6.0 & 4.7695 & TRN & \\
\hline
\end{tabular}




\begin{tabular}{|c|c|c|c|c|}
\hline \multicolumn{5}{|c|}{ Supplemental Table S2.txt } \\
\hline CHEMBL1373205 & 688612 & 6.5501 & 4.723 & TST \\
\hline CHEMBL1563754 & 688612 & 6.5 & 4.7194 & TRN \\
\hline CHEMBL1370986 & 688612 & 4.5 & 4.6316 & TRN \\
\hline CHEMBL1470205 & 688612 & 4.4 & 4.7124 & TRN \\
\hline CHEMBL 3199148 & 688612 & 4.0 & 4.7093 & TST \\
\hline CHEMBL1588725 & 688612 & 4.35 & 4.6042 & TRN \\
\hline CHEMBL175266 & 688612 & 4.95 & 4.8153 & TRN \\
\hline CHEMBL1449203 & 688612 & 4.7 & 4.5593 & TST \\
\hline CHEMBL1574068 & 688612 & 4.55 & 4.6187 & TRN \\
\hline CHEMBL1370259 & 688612 & 4.4 & 4.704 & TRN \\
\hline CHEMBL1461549 & 688612 & 4.1 & 4.6524 & TRN \\
\hline CHEMBL1346486 & 688612 & 5.55 & 4.8186 & TRN \\
\hline CHEMBL3210376 & 688612 & 4.2 & 4.7288 & TST \\
\hline CHEMBL1978733 & 688612 & 4.5 & 4.6528 & TRN \\
\hline CHEMBL1510469 & 688612 & 4.05 & 4.6722 & TST \\
\hline CHEMBL1540523 & 688612 & 6.45 & 4.6034 & TRN \\
\hline CHEMBL1420549 & 688612 & 4.05 & 4.6209 & TRN \\
\hline CHEMBL1556936 & 688612 & 4.05 & 4.7114 & TST \\
\hline CHEMBL1585310 & 688612 & 6.05 & 4.6883 & TRN \\
\hline CHEMBL 213432 & 688612 & 6.0 & 4.6988 & TRN \\
\hline CHEMBL1561602 & 688612 & 4.0 & 4.6667 & TST \\
\hline CHEMBL1557987 & 688612 & 4.4 & 4.6209 & TRN \\
\hline CHEMBL1403896 & 688612 & 6.3 & 4.7489 & TRN \\
\hline CHEMBL1560672 & 688612 & 4.65 & 4.7258 & TRN \\
\hline CHEMBL1549325 & 688612 & 4.0 & 4.6026 & TST \\
\hline CHEMBL1418885 & 688612 & 4.75 & 4.7664 & TRN \\
\hline CHEMBL1305187 & 688612 & 6.1 & 4.6186 & TRN \\
\hline CHEMBL1429627 & 688612 & 4.3 & 4.6414 & TRN \\
\hline CHEMBL1415408 & 688612 & 4.55 & 4.5965 & TRN \\
\hline CHEMBL 246446 & 688612 & 5.45 & 4.8038 & TRN \\
\hline CHEMBL1386849 & 688612 & 5.3 & 4.7375 & TRN \\
\hline CHEMBL1390963 & 688612 & 4.9 & 4.7106 & TRN \\
\hline CHEMBL1317552 & 688612 & 4.3 & 4.6888 & TRN \\
\hline CHEMBL1447162 & 688612 & 4.55 & 4.7941 & TST \\
\hline CHEMBL1608356 & 688612 & 4.0 & 4.6756 & TRN \\
\hline CHEMBL1527971 & 688612 & 5.4 & 4.6815 & TRN \\
\hline CHEMBL1530652 & 688612 & 4.4 & 4.7272 & TRN \\
\hline CHEMBL1603812 & 688612 & 4.0 & 4.6419 & TRN \\
\hline CHEMBL3192990 & 688612 & 4.4 & 4.6763 & TST \\
\hline CHEMBL1526230 & 688612 & 4.4 & 4.6523 & TRN \\
\hline CHEMBL1534527 & 688612 & 4.65 & 4.6099 & TRN \\
\hline CHEMBL1464077 & 688612 & 4.4 & 4.7015 & TRN \\
\hline CHEMBL1373500 & 688612 & 6.0 & 4.6333 & TST \\
\hline CHEMBL1345233 & 688612 & 6.95 & 4.7306 & TST \\
\hline CHEMBL1437300 & 688612 & 4.05 & 4.6274 & TRN \\
\hline CHEMBL1470758 & 688612 & 4.1 & 4.6793 & TST \\
\hline CHEMBL1406680 & 688612 & 4.0 & 4.6236 & TRN \\
\hline CHEMBL1565043 & 688612 & 4.15 & 4.5433 & TST \\
\hline
\end{tabular}




\begin{tabular}{|c|c|c|c|c|c|}
\hline \multicolumn{6}{|c|}{ Supplemental Table S2.txt } \\
\hline CHEMBL1310714 & 688612 & 5.9 & 4.6555 & TST & \\
\hline CHEMBL1541948 & 688612 & 4.25 & 4.739 & TST & \\
\hline CHEMBL1591173 & 688612 & 4.05 & 4.5702 & TRN & \\
\hline CHEMBL1980588 & 688612 & 4.15 & 4.7793 & TRN & \\
\hline CHEMBL1304920 & 688612 & 5.4 & 4.6552 & TRN & \\
\hline CHEMBL1485442 & 688612 & 6.7501 & 4.71399 & 99999999995 & TST \\
\hline CHEMBL1498284 & 688612 & 4.45 & 4.7008 & TST & \\
\hline CHEMBL1467903 & 688612 & 4.05 & 4.7051 & TRN & \\
\hline CHEMBL1363989 & 688612 & 4.5 & 4.8115 & TRN & \\
\hline CHEMBL1352624 & 688612 & 4.7 & 4.7509 & TRN & \\
\hline CHEMBL1458189 & 688612 & 4.65 & 4.6579 & TRN & \\
\hline CHEMBL1336617 & 688612 & 4.9 & 4.7065 & TRN & \\
\hline CHEMBL1341590 & 688612 & 4.65 & 4.6479 & TRN & \\
\hline CHEMBL 2001914 & 688612 & 4.5 & 4.6905 & TRN & \\
\hline CHEMBL1442725 & 688612 & 4.15 & 4.6414 & TRN & \\
\hline CHEMBL1391833 & 688612 & 5.5 & 4.6563 & TRN & \\
\hline CHEMBL1538468 & 688612 & 4.4 & 4.7402 & TRN & \\
\hline CHEMBL1574311 & 688612 & 6.3 & 4.6742 & TST & \\
\hline CHEMBL1352343 & 688612 & 4.4 & 4.6925 & TRN & \\
\hline CHEMBL1508860 & 688612 & 4.1 & 4.7668 & TRN & \\
\hline CHEMBL1432030 & 688612 & 4.3 & 4.6563 & TRN & \\
\hline CHEMBL1601774 & 688612 & 4.05 & 4.5788 & TRN & \\
\hline CHEMBL1390677 & 688612 & 4.7 & 4.6573 & TRN & \\
\hline CHEMBL1348583 & 688612 & 4.05 & 4.6317 & TST & \\
\hline CHEMBL1443884 & 688612 & 4.4 & 4.8072 & TRN & \\
\hline CHEMBL1429604 & 688612 & 4.4 & 4.6882 & TST & \\
\hline CHEMBL1418440 & 688612 & 4.45 & 4.7084 & TRN & \\
\hline CHEMBL1472673 & 688612 & 5.95 & 4.6616 & TRN & \\
\hline CHEMBL1508968 & 688612 & 4.4 & 4.7116 & TST & \\
\hline CHEMBL1457362 & 688612 & 5.45 & 4.698 & TRN & \\
\hline CHEMBL1409467 & 688612 & 4.05 & 4.6586 & TRN & \\
\hline CHEMBL1380455 & 688612 & 5.5 & 4.6724 & TST & \\
\hline CHEMBL1302972 & 688612 & 4.4 & 4.6257 & TRN & \\
\hline CHEMBL1572403 & 688612 & 4.6 & 4.6483 & TRN & \\
\hline CHEMBL1535503 & 688612 & 5.0 & 4.6932 & TRN & \\
\hline CHEMBL1480065 & 688612 & 4.1 & 4.6713 & TRN & \\
\hline CHEMBL1543689 & 688612 & 4.5 & 4.6764 & TRN & \\
\hline CHEMBL1418258 & 688612 & 6.7001 & 4.6186 & TRN & \\
\hline CHEMBL3210216 & 688612 & 4.45 & 4.7229 & TST & \\
\hline CHEMBL1536501 & 688612 & 4.4 & 4.6698 & TRN & \\
\hline CHEMBL1485014 & 688612 & 5.55 & 4.7331 & TST & \\
\hline CHEMBL1601417 & 688612 & 4.75 & 4.6394 & TRN & \\
\hline CHEMBL1537145 & 688612 & 4.05 & 4.7038 & TST & \\
\hline CHEMBL416615 & 688612 & 6.8 & 4.8344 & TST & \\
\hline CHEMBL1465752 & 688612 & 5.05 & 4.6677 & TRN & \\
\hline CHEMBL1471272 & 688612 & 4.4 & 4.7105 & TRN & \\
\hline CHEMBL1464107 & 688612 & 4.85 & 4.712 & TRN & \\
\hline CHEMBL1446168 & 688612 & 4.05 & 4.6211 & TST & \\
\hline
\end{tabular}




\begin{tabular}{|c|c|c|c|c|}
\hline & & \multicolumn{3}{|c|}{ Supplemental Table S2.txt } \\
\hline CHEMBL1593763 & 688612 & 4.05 & 4.6266 & TST \\
\hline CHEMBL1509007 & 688612 & 4.15 & 4.6884 & TRN \\
\hline CHEMBL1418235 & 688612 & 5.0 & 4.6466 & TRN \\
\hline CHEMBL1531641 & 688612 & 4.75 & 4.7457 & TRN \\
\hline CHEMBL478323 & 688612 & 4.9 & 4.6972 & TRN \\
\hline CHEMBL1372214 & 688612 & 4.05 & 4.7104 & TRN \\
\hline CHEMBL1334904 & 688612 & 4.25 & 4.7543 & TRN \\
\hline CHEMBL1339694 & 688612 & 4.35 & 4.5993 & TRN \\
\hline CHEMBL600287 & 688612 & 5.0 & 4.6668 & TRN \\
\hline CHEMBL1483965 & 688612 & 4.85 & 4.6894 & TRN \\
\hline CHEMBL1539288 & 688612 & 4.9 & 4.6811 & TRN \\
\hline CHEMBL1381049 & 688612 & 5.05 & 4.6411 & TST \\
\hline CHEMBL1521921 & 688612 & 4.25 & 4.6039 & TRN \\
\hline CHEMBL1526126 & 688612 & 5.25 & 4.7869 & TRN \\
\hline CHEMBL1531199 & 688612 & 4.05 & 4.6613 & TST \\
\hline CHEMBL1489910 & 688612 & 5.0 & 4.6121 & TRN \\
\hline CHEMBL1323335 & 688612 & 4.4 & 4.6366 & TRN \\
\hline CHEMBL1559994 & 688612 & 4.0 & 4.6948 & TRN \\
\hline CHEMBL1401150 & 688612 & 4.0 & 4.6035 & TRN \\
\hline CHEMBL1306420 & 688612 & 4.35 & 4.6319 & TRN \\
\hline CHEMBL1564810 & 688612 & 5.2 & 4.7293 & TRN \\
\hline CHEMBL1541965 & 688612 & 4.1 & 4.6258 & TRN \\
\hline CHEMBL1552163 & 688612 & 4.6 & 4.6883 & TRN \\
\hline CHEMBL1571005 & 688612 & 5.35 & 4.6327 & TRN \\
\hline CHEMBL1583534 & 688612 & 5.2 & 4.7787 & TRN \\
\hline CHEMBL1416876 & 688612 & 4.7 & 4.6061 & TRN \\
\hline CHEMBL1519014 & 688612 & 4.4 & 4.7181 & TRN \\
\hline CHEMBL3192969 & 688612 & 5.6 & 4.6777 & TRN \\
\hline CHEMBL1541874 & 688612 & 6.1 & 4.63899 & 9999999999 \\
\hline CHEMBL585591 & 688612 & 4.1 & 4.751 & TST \\
\hline CHEMBL1482208 & 688612 & 4.05 & 4.7101 & TRN \\
\hline CHEMBL1612107 & 688612 & 4.9 & 4.6421 & TST \\
\hline CHEMBL1583768 & 688612 & 4.05 & 4.6084 & TST \\
\hline CHEMBL1441788 & 688612 & 5.35 & 4.6124 & TST \\
\hline CHEMBL1507450 & 688612 & 4.3 & 4.6266 & TST \\
\hline CHEMBL1519529 & 688612 & 4.0 & 4.6583 & TRN \\
\hline CHEMBL1441261 & 688612 & 4.4 & 4.7092 & TRN \\
\hline CHEMBL1450442 & 688612 & 4.6 & 4.6587 & TRN \\
\hline CHEMBL1301873 & 688612 & 4.05 & 4.6546 & TRN \\
\hline CHEMBL1996724 & 688612 & 5.65 & 4.6981 & TRN \\
\hline CHEMBL1547290 & 688612 & 4.45 & 4.7334 & TRN \\
\hline CHEMBL1394208 & 688612 & 4.4 & 4.6434 & TRN \\
\hline CHEMBL1254746 & 688612 & 4.3 & 4.6973 & TRN \\
\hline CHEMBL1522862 & 688612 & 6.15 & 4.6675 & TRN \\
\hline CHEMBL1561898 & 688612 & 4.05 & 4.7249 & TST \\
\hline CHEMBL1553633 & 688612 & 4.2 & 4.6078 & TRN \\
\hline CHEMBL1583475 & 688612 & 5.1 & 4.724 & TRN \\
\hline CHEMBL1513969 & 688612 & 5.0 & 4.6192 & TRN \\
\hline
\end{tabular}




\begin{tabular}{|c|c|c|c|c|c|}
\hline \multicolumn{6}{|c|}{ Supplemental Table S2.txt } \\
\hline CHEMBL1612731 & 688612 & 5.4 & 4.5894 & TRN & \\
\hline CHEMBL1371199 & 688612 & 6.35 & 4.6356 & TRN & \\
\hline CHEMBL1301576 & 688612 & 4.15 & 4.5953 & TRN & \\
\hline CHEMBL1498887 & 688612 & 4.2 & 4.598 & TRN & \\
\hline CHEMBL1345580 & 688612 & 4.4 & 4.7242 & TST & \\
\hline CHEMBL1397956 & 688612 & 4.8 & 4.58899 & 99999999995 & TRN \\
\hline CHEMBL1528102 & 688612 & 4.1 & 4.6611 & TRN & \\
\hline CHEMBL1353909 & 688612 & 5.35 & 4.6861 & TRN & \\
\hline CHEMBL1362847 & 688612 & 4.05 & 4.6496 & TRN & \\
\hline CHEMBL1396482 & 688612 & 4.05 & 4.6185 & TRN & \\
\hline CHEMBL1395042 & 688612 & 4.7 & 4.61100 & 0000000001 & TST \\
\hline CHEMBL1999551 & 688612 & 4.75 & 4.7422 & TST & \\
\hline CHEMBL1337468 & 688612 & 4.5 & 4.6281 & TST & \\
\hline CHEMBL1572661 & 688612 & 4.5 & 4.7372 & TRN & \\
\hline CHEMBL1398217 & 688612 & 4.55 & 4.7021 & TRN & \\
\hline CHEMBL1392541 & 688612 & 4.9 & 4.6933 & TRN & \\
\hline CHEMBL1373003 & 688612 & 4.25 & 4.5983 & TRN & \\
\hline CHEMBL1538186 & 688612 & 4.0 & 4.6007 & TRN & \\
\hline CHEMBL1531053 & 688612 & 4.05 & 4.6554 & TRN & \\
\hline CHEMBL1470303 & 688612 & 4.4 & 4.7332 & TRN & \\
\hline CHEMBL1459380 & 688612 & 4.1 & 4.5169 & TRN & \\
\hline CHEMBL1492778 & 688612 & 4.7 & 4.6663 & TRN & \\
\hline CHEMBL1332899 & 688612 & 4.95 & 4.6297 & TRN & \\
\hline CHEMBL1488814 & 688612 & 4.85 & 4.6143 & TRN & \\
\hline CHEMBL1504737 & 688612 & 6.2 & 4.6254 & TRN & \\
\hline CHEMBL1436432 & 688612 & 4.1 & 4.6065 & TRN & \\
\hline CHEMBL1365950 & 688612 & 4.2 & 4.6278 & TRN & \\
\hline CHEMBL1413605 & 688612 & 4.1 & 4.6321 & TRN & \\
\hline CHEMBL1322781 & 688612 & 4.4 & 4.6321 & TRN & \\
\hline CHEMBL1500587 & 688612 & 6.5 & 4.658 & TRN & \\
\hline CHEMBL1472162 & 688612 & 4.2 & 4.6997 & TST & \\
\hline CHEMBL1481888 & 688612 & 4.4 & 4.6507 & TRN & \\
\hline CHEMBL3194089 & 688612 & 4.8 & 4.6501 & TRN & \\
\hline CHEMBL1300077 & 688612 & 4.05 & 4.6606 & TRN & \\
\hline CHEMBL1544912 & 688612 & 4.05 & 4.6654 & TRN & \\
\hline CHEMBL1350496 & 688612 & 6.8499 & 4.5727 & TRN & \\
\hline CHEMBL1547311 & 688612 & 5.0 & 4.7282 & TRN & \\
\hline CHEMBL1425446 & 688612 & 4.7 & 4.7031 & TST & \\
\hline CHEMBL1556534 & 688612 & 4.4 & 4.6903 & TRN & \\
\hline CHEMBL3198466 & 688612 & 4.75 & 4.7176 & TRN & \\
\hline CHEMBL1495918 & 688612 & 4.3 & 4.6687 & TST & \\
\hline CHEMBL1394173 & 688612 & 4.5 & 4.6879 & TRN & \\
\hline CHEMBL1347956 & 688612 & 5.65 & 4.6697 & TST & \\
\hline CHEMBL1559715 & 688612 & 4.75 & 4.7573 & TRN & \\
\hline CHEMBL1465044 & 688612 & 4.05 & 4.7686 & TRN & \\
\hline CHEMBL1427726 & 688612 & 6.0 & 4.7606 & TRN & \\
\hline CHEMBL1508869 & 688612 & 5.15 & 4.7225 & TRN & \\
\hline CHEMBL1371188 & 688612 & 4.05 & 4.6833 & TRN & \\
\hline
\end{tabular}




\begin{tabular}{|c|c|c|c|c|c|}
\hline \multicolumn{6}{|c|}{ Supplemental Table S2.txt } \\
\hline CHEMBL1412735 & 688612 & 4.1 & 4.6831 & TRN & \\
\hline CHEMBL1365420 & 688612 & 4.8 & 4.6401 & TRN & \\
\hline CHEMBL1511539 & 688612 & 4.75 & 4.6243 & TRN & \\
\hline CHEMBL1436874 & 688612 & 5.55 & 4.5969 & TRN & \\
\hline CHEMBL1389559 & 688612 & 5.35 & 4.7029 & TRN & \\
\hline CHEMBL1430005 & 688612 & 4.55 & 4.7133 & TST & \\
\hline CHEMBL1494514 & 688612 & 5.0 & 4.7141 & TST & \\
\hline CHEMBL1420181 & 688612 & 4.3 & 4.6609 & TRN & \\
\hline CHEMBL1470973 & 688612 & 6.8499 & 4.6796 & TRN & \\
\hline CHEMBL1527843 & 688612 & 4.05 & 4.6742 & TRN & \\
\hline CHEMBL1427121 & 688612 & 4.05 & 4.7424 & TST & \\
\hline CHEMBL1493749 & 688612 & 5.45 & 4.7452 & TRN & \\
\hline CHEMBL1509666 & 688612 & 5.5 & 4.7147 & TST & \\
\hline CHEMBL1339549 & 688612 & 4.05 & 4.6411 & TST & \\
\hline CHEMBL1600636 & 688612 & 4.1 & 4.6376 & TRN & \\
\hline CHEMBL1383939 & 688612 & 5.35 & 4.67399 & 99999999995 & TRN \\
\hline CHEMBL1578990 & 688612 & 4.05 & 4.6362 & TRN & \\
\hline CHEMBL236614 & 688612 & 6.25 & 4.78 & TRN & \\
\hline CHEMBL1568305 & 688612 & 4.55 & 4.6851 & TRN & \\
\hline CHEMBL1462107 & 688612 & 4.35 & 4.7141 & TRN & \\
\hline CHEMBL1426093 & 688612 & 4.55 & 4.6959 & TST & \\
\hline CHEMBL1588606 & 688612 & 4.1 & 4.6371 & TRN & \\
\hline CHEMBL1994556 & 688612 & 4.85 & 4.7301 & TRN & \\
\hline CHEMBL1348205 & 688612 & 5.95 & 4.6203 & TST & \\
\hline CHEMBL1370935 & 688612 & 5.6 & 4.7193 & TRN & \\
\hline CHEMBL1348047 & 688612 & 4.65 & 4.6021 & TRN & \\
\hline CHEMBL1532818 & 688612 & 4.75 & 4.6278 & TRN & \\
\hline CHEMBL1572230 & 688612 & 4.1 & 4.7361 & TRN & \\
\hline CHEMBL1596058 & 688612 & 4.1 & 4.6133 & TRN & \\
\hline CHEMBL1488541 & 688612 & 6.05 & 4.6397 & TST & \\
\hline CHEMBL1493390 & 688612 & 4.6 & 4.6882 & TRN & \\
\hline CHEMBL1534939 & 688612 & 4.1 & 4.7182 & TST & \\
\hline CHEMBL1364266 & 688612 & 5.15 & 4.7618 & TRN & \\
\hline CHEMBL1423505 & 688612 & 4.6 & 4.6814 & TST & \\
\hline CHEMBL1476827 & 688612 & 4.65 & 4.6612 & TRN & \\
\hline CHEMBL1301997 & 688612 & 6.2 & 4.6367 & TRN & \\
\hline CHEMBL 3212807 & 688612 & 4.4 & 4.7054 & TRN & \\
\hline CHEMBL3195683 & 688612 & 6.1 & 4.7349 & TRN & \\
\hline CHEMBL1438889 & 688612 & 5.8 & 4.6821 & TRN & \\
\hline CHEMBL1360557 & 688612 & 6.8499 & 4.7007 & TRN & \\
\hline CHEMBL1400248 & 688612 & 4.05 & 4.6552 & TRN & \\
\hline CHEMBL1514113 & 688612 & 4.4 & 4.6631 & TRN & \\
\hline CHEMBL1481874 & 688612 & 4.4 & 4.6709 & TRN & \\
\hline CHEMBL1332402 & 688612 & 5.15 & 4.7234 & TRN & \\
\hline CHEMBL1582563 & 688612 & 4.45 & 4.6748 & TRN & \\
\hline CHEMBL1347992 & 688612 & 4.1 & 4.6244 & TST & \\
\hline CHEMBL1482256 & 688612 & 4.75 & 4.6636 & TST & \\
\hline CHEMBL1420256 & 688612 & 4.1 & 4.6124 & TRN & \\
\hline
\end{tabular}




\begin{tabular}{|c|c|c|c|c|c|}
\hline \multicolumn{6}{|c|}{ Supplemental Table S2.txt } \\
\hline CHEMBL1455769 & 688612 & 4.05 & 4.6681 & TRN & \\
\hline CHEMBL1444783 & 688612 & 4.0 & 4.6425 & TRN & \\
\hline CHEMBL1363991 & 688612 & 4.05 & 4.6852 & TRN & \\
\hline CHEMBL1345115 & 688612 & 4.15 & 4.5471 & TRN & \\
\hline CHEMBL1524420 & 688612 & 4.65 & 4.7072 & TRN & \\
\hline CHEMBL1336723 & 688612 & 4.1 & 4.7682 & TST & \\
\hline CHEMBL3213530 & 688612 & 4.0 & 4.6653 & TRN & \\
\hline CHEMBL 2373660 & 688612 & 4.05 & 4.7143 & TRN & \\
\hline CHEMBL1493092 & 688612 & 4.15 & 4.5557 & TRN & \\
\hline CHEMBL1495785 & 688612 & 4.05 & 4.7349 & TST & \\
\hline CHEMBL1308655 & 688612 & 4.05 & 4.6589 & TRN & \\
\hline CHEMBL1385629 & 688612 & 4.15 & 4.6518 & TRN & \\
\hline CHEMBL1324857 & 688612 & 4.3 & 4.6252 & TRN & \\
\hline CHEMBL1456681 & 688612 & 4.05 & 4.6315 & TRN & \\
\hline CHEMBL1419660 & 688612 & 4.05 & 4.6151 & TRN & \\
\hline CHEMBL1566026 & 688612 & 6.05 & 4.6634 & TRN & \\
\hline CHEMBL1477873 & 688612 & 4.8 & 4.5707 & TRN & \\
\hline CHEMBL3196469 & 688612 & 5.0 & 4.7254 & TRN & \\
\hline CHEMBL578741 & 688612 & 5.85 & 4.7913 & TRN & \\
\hline CHEMBL1528737 & 688612 & 5.1 & 4.7197 & TRN & \\
\hline CHEMBL1487392 & 688612 & 4.6 & 4.7571 & TRN & \\
\hline CHEMBL1552485 & 688612 & 6.2 & 4.6473 & TRN & \\
\hline CHEMBL1325906 & 688612 & 4.05 & 4.6948 & TRN & \\
\hline CHEMBL1429451 & 688612 & 4.05 & 4.7292 & TRN & \\
\hline CHEMBL1520941 & 688612 & 4.5 & 4.6813 & TST & \\
\hline CHEMBL1372352 & 688612 & 6.1 & 4.621 & TRN & \\
\hline CHEMBL1452989 & 688612 & 4.05 & 4.7197 & TST & \\
\hline CHEMBL1500056 & 688612 & 4.2 & 4.6544 & TST & \\
\hline CHEMBL1606226 & 688612 & 4.0 & 4.66100 & 00000000005 & TRN \\
\hline CHEMBL1522828 & 688612 & 4.05 & 4.6574 & TRN & \\
\hline CHEMBL1335856 & 688612 & 4.05 & 4.6611 & TRN & \\
\hline CHEMBL405857 & 688612 & 4.9 & 4.705 & TRN & \\
\hline CHEMBL1610733 & 688612 & 5.9 & 4.7259 & TST & \\
\hline CHEMBL1389935 & 688612 & 4.05 & 4.6322 & TRN & \\
\hline CHEMBL1383057 & 688612 & 6.2 & 4.7085 & TRN & \\
\hline CHEMBL1569784 & 688612 & 6.8499 & 4.6303 & TST & \\
\hline CHEMBL1549266 & 688612 & 4.5 & 4.6171 & TRN & \\
\hline CHEMBL1355316 & 688612 & 4.55 & 4.5875 & TRN & \\
\hline CHEMBL1497854 & 688612 & 5.45 & 4.6505 & TST & \\
\hline CHEMBL1426178 & 688612 & 4.1 & 4.6062 & TST & \\
\hline CHEMBL1372274 & 688612 & 4.85 & 4.6875 & TRN & \\
\hline CHEMBL1407273 & 688612 & 4.05 & 4.6851 & TRN & \\
\hline CHEMBL1592103 & 688612 & 4.05 & 4.5936 & TRN & \\
\hline CHEMBL1384518 & 688612 & 6.45 & 4.6469 & TRN & \\
\hline CHEMBL1568218 & 688612 & 4.8 & 4.5946 & TRN & \\
\hline CHEMBL1325298 & 688612 & 4.6 & 4.62 & TRN & \\
\hline CHEMBL3187659 & 688612 & 4.6 & 4.7526 & TRN & \\
\hline CHEMBL1393935 & 688612 & 4.55 & 4.6665 & TRN & \\
\hline
\end{tabular}




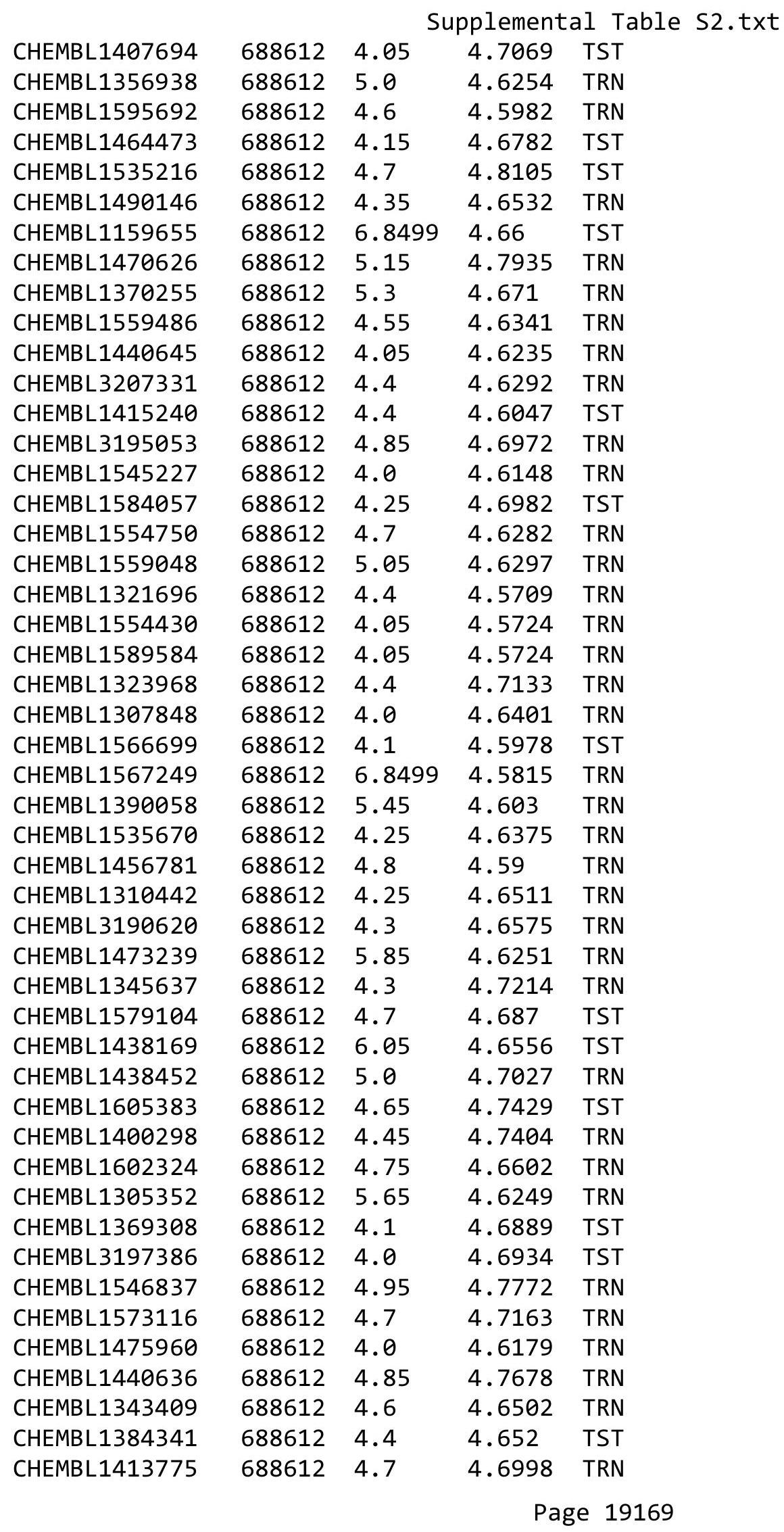




\begin{tabular}{|c|c|c|c|c|c|}
\hline \multicolumn{6}{|c|}{ Supplemental Table S2.txt } \\
\hline CHEMBL1600446 & 688612 & 4.05 & 4.7143 & TST & \\
\hline CHEMBL1394143 & 688612 & 4.85 & 4.6726 & TRN & \\
\hline CHEMBL 3193844 & 688612 & 5.0 & 4.7106 & TRN & \\
\hline CHEMBL1409326 & 688612 & 4.0 & 4.6048 & TRN & \\
\hline CHEMBL1322618 & 688612 & 4.05 & 4.6562 & TRN & \\
\hline CHEMBL1486335 & 688612 & 4.3 & 4.7201 & TRN & \\
\hline CHEMBL1597409 & 688612 & 4.0 & 4.5703 & TRN & \\
\hline CHEMBL1312971 & 688612 & 4.05 & 4.5845 & TRN & \\
\hline CHEMBL1507379 & 688612 & 6.6 & 4.7395 & TRN & \\
\hline CHEMBL1469425 & 688612 & 4.05 & 4.6185 & TRN & \\
\hline CHEMBL1481914 & 688612 & 5.05 & 4.7627 & TRN & \\
\hline CHEMBL1528829 & 688612 & 4.05 & 4.6923 & TRN & \\
\hline CHEMBL1456894 & 688612 & 4.6 & 4.6411 & TRN & \\
\hline CHEMBL1495579 & 688612 & 4.3 & 4.6428 & TRN & \\
\hline CHEMBL1984628 & 688612 & 4.7 & 4.7166 & TST & \\
\hline CHEMBL1599931 & 688612 & 4.9 & 4.6617 & TRN & \\
\hline CHEMBL1583966 & 688612 & 4.75 & 4.676 & TRN & \\
\hline CHEMBL1508226 & 688612 & 4.6 & 4.7018 & TST & \\
\hline CHEMBL1309472 & 688612 & 4.55 & 4.8075 & TRN & \\
\hline CHEMBL1993847 & 688612 & 4.55 & 4.7053 & TRN & \\
\hline CHEMBL1561790 & 688612 & 4.4 & 4.6925 & TRN & \\
\hline CHEMBL1453883 & 688612 & 4.0 & 4.7284 & TRN & \\
\hline CHEMBL1396976 & 688612 & 6.5501 & 4.7332 & TRN & \\
\hline CHEMBL1440101 & 688612 & 4.05 & 4.6642 & TRN & \\
\hline CHEMBL1578626 & 688612 & 4.05 & 4.6639 & TRN & \\
\hline CHEMBL1584109 & 688612 & 4.3 & 4.7664 & TRN & \\
\hline CHEMBL1560830 & 688612 & 4.95 & 4.6524 & TRN & \\
\hline CHEMBL1425721 & 688612 & 4.85 & 4.6763 & TRN & \\
\hline CHEMBL 3198134 & 688612 & 4.35 & 4.744 & TRN & \\
\hline CHEMBL1576312 & 688612 & 4.6 & 4.6653 & TRN & \\
\hline CHEMBL1396884 & 688612 & 4.9 & 4.7252 & TRN & \\
\hline CHEMBL1374456 & 688612 & 6.6 & 4.675 & TRN & \\
\hline CHEMBL1595855 & 688612 & 4.0 & 4.7023 & TST & \\
\hline CHEMBL1410260 & 688612 & 4.4 & 4.7582 & TRN & \\
\hline CHEMBL1494416 & 688612 & 4.25 & 4.5952 & TRN & \\
\hline CHEMBL1545505 & 688612 & 4.0 & 4.7296 & TRN & \\
\hline CHEMBL1532620 & 688612 & 4.2 & 4.6569 & TST & \\
\hline CHEMBL1495948 & 688612 & 6.6 & 4.7003 & TST & \\
\hline CHEMBL1321832 & 688612 & 4.05 & 4.6625 & TRN & \\
\hline CHEMBL1428288 & 688612 & 6.3 & 4.6308 & TRN & \\
\hline CHEMBL1543334 & 688612 & 5.5 & 4.63899 & 9999999999 & TRN \\
\hline CHEMBL1340152 & 688612 & 4.05 & 4.6206 & TRN & \\
\hline CHEMBL1354111 & 688612 & 4.05 & 4.667 & TRN & \\
\hline CHEMBL1562343 & 688612 & 4.05 & 4.6027 & TRN & \\
\hline CHEMBL1533643 & 688612 & 4.35 & 4.6527 & TRN & \\
\hline CHEMBL1477394 & 688612 & 4.5 & 4.624 & TRN & \\
\hline CHEMBL1394198 & 688612 & 6.4 & 4.5977 & TRN & \\
\hline CHEMBL1304325 & 688612 & 4.5 & 4.6529 & TRN & \\
\hline
\end{tabular}




\begin{tabular}{|c|c|c|c|c|c|}
\hline \multicolumn{6}{|c|}{ Supplemental Table S2.txt } \\
\hline CHEMBL1422680 & 688612 & 4.25 & 4.6962 & TRN & \\
\hline CHEMBL1606888 & 688612 & 4.35 & 4.6155 & TRN & \\
\hline CHEMBL1414792 & 688612 & 6.0 & 4.6373 & TRN & \\
\hline CHEMBL1596268 & 688612 & 4.1 & 4.651 & TRN & \\
\hline CHEMBL1536003 & 688612 & 4.0 & 4.6415 & TST & \\
\hline CHEMBL1468951 & 688612 & 4.05 & 4.6323 & TRN & \\
\hline CHEMBL1486503 & 688612 & 4.75 & 4.76699 & 99999999995 & TRN \\
\hline CHEMBL1499624 & 688612 & 4.6 & 4.64199 & 99999999995 & TRN \\
\hline CHEMBL1458694 & 688612 & 4.0 & 4.6169 & TRN & \\
\hline CHEMBL1328788 & 688612 & 4.8 & 4.6739 & TST & \\
\hline CHEMBL1312849 & 688612 & 4.4 & 4.7262 & TST & \\
\hline CHEMBL1377558 & 688612 & 4.75 & 4.6884 & TRN & \\
\hline CHEMBL1568340 & 688612 & 4.05 & 4.6923 & TRN & \\
\hline CHEMBL1442849 & 688612 & 4.05 & 4.6669 & TST & \\
\hline CHEMBL1878162 & 688612 & 5.15 & 4.8529 & TRN & \\
\hline CHEMBL1478258 & 688612 & 4.85 & 4.7204 & TRN & \\
\hline CHEMBL1406990 & 688612 & 5.75 & 4.6619 & TRN & \\
\hline CHEMBL1391393 & 688612 & 4.05 & 4.7464 & TRN & \\
\hline CHEMBL1491495 & 688612 & 4.3 & 4.6091 & TRN & \\
\hline CHEMBL1375585 & 688612 & 4.65 & 4.586 & TRN & \\
\hline CHEMBL1558993 & 688612 & 4.45 & 4.7233 & TRN & \\
\hline CHEMBL1449337 & 688612 & 4.1 & 4.7127 & TRN & \\
\hline CHEMBL1331911 & 688612 & 4.1 & 4.6821 & TRN & \\
\hline CHEMBL3210420 & 688612 & 4.85 & 4.6559 & TRN & \\
\hline CHEMBL1392461 & 688612 & 4.4 & 4.6474 & TRN & \\
\hline CHEMBL1435515 & 688612 & 4.6 & 4.6573 & TRN & \\
\hline CHEMBL1362431 & 688612 & 4.05 & 4.6657 & TST & \\
\hline CHEMBL3192187 & 688612 & 6.8499 & 4.7389 & TRN & \\
\hline CHEMBL1532708 & 688612 & 4.45 & 4.6077 & TRN & \\
\hline CHEMBL1309573 & 688612 & 4.0 & 4.6902 & TRN & \\
\hline CHEMBL1307459 & 688612 & 5.1 & 4.6797 & TST & \\
\hline CHEMBL1578515 & 688612 & 4.75 & 4.7863 & TRN & \\
\hline CHEMBL1312545 & 688612 & 4.7 & 4.6475 & TST & \\
\hline CHEMBL1471223 & 688612 & 4.0 & 4.5866 & TRN & \\
\hline CHEMBL1353612 & 688612 & 4.0 & 4.6034 & TST & \\
\hline CHEMBL1328966 & 688612 & 5.5 & 4.7061 & TRN & \\
\hline CHEMBL1304174 & 688612 & 4.9 & 4.6784 & TST & \\
\hline CHEMBL1433863 & 688612 & 4.05 & 4.6441 & TST & \\
\hline CHEMBL1312431 & 688612 & 4.85 & 4.729 & TRN & \\
\hline CHEMBL1372023 & 688612 & 4.35 & 4.6621 & TRN & \\
\hline CHEMBL1303815 & 688612 & 4.2 & 4.6452 & TST & \\
\hline CHEMBL1332879 & 688612 & 4.3 & 4.7215 & TRN & \\
\hline CHEMBL1463290 & 688612 & 6.8 & 4.5938 & TRN & \\
\hline CHEMBL1359203 & 688612 & 4.05 & 4.6156 & TRN & \\
\hline CHEMBL1463538 & 688612 & 5.4 & 4.6302 & TRN & \\
\hline CHEMBL1474284 & 688612 & 4.15 & 4.6715 & TRN & \\
\hline CHEMBL1423633 & 688612 & 4.5 & 4.7209 & TRN & \\
\hline CHEMBL1490179 & 688612 & 4.05 & 4.5559 & TRN & \\
\hline
\end{tabular}




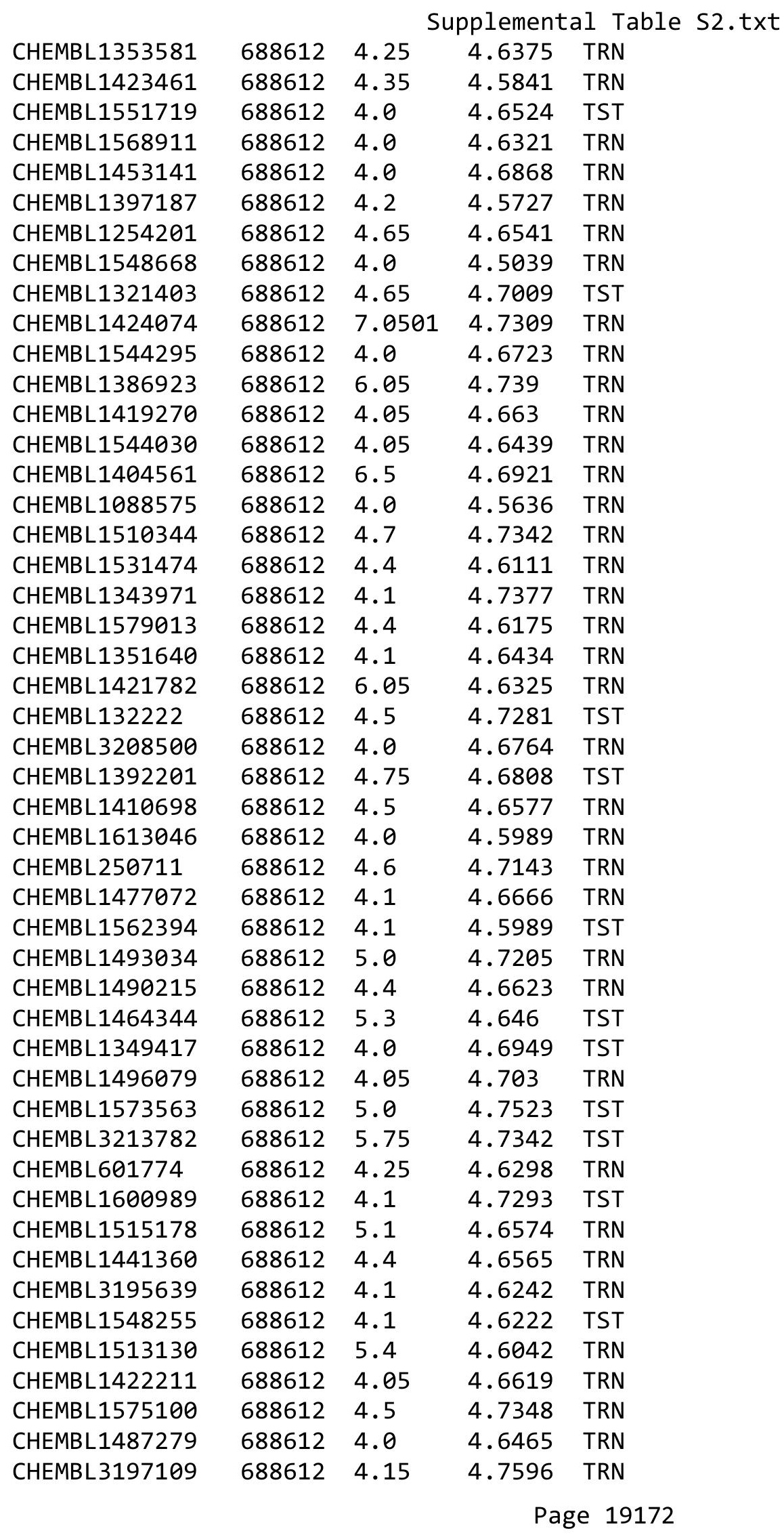




\begin{tabular}{|c|c|c|c|c|c|}
\hline \multicolumn{6}{|c|}{ Supplemental Table S2.txt } \\
\hline CHEMBL1443758 & 688612 & 4.4 & 4.6127 & TRN & \\
\hline CHEMBL1330381 & 688612 & 5.0 & 4.6212 & TRN & \\
\hline CHEMBL1506981 & 688612 & 6.5 & 4.6483 & TRN & \\
\hline CHEMBL1489024 & 688612 & 5.0 & 4.7166 & TST & \\
\hline CHEMBL1596745 & 688612 & 4.45 & 4.6628 & TRN & \\
\hline CHEMBL1345270 & 688612 & 4.05 & 4.56800 & 00000000005 & TRN \\
\hline CHEMBL1579753 & 688612 & 4.0 & 4.6551 & TRN & \\
\hline CHEMBL1316878 & 688612 & 4.1 & 4.6343 & TRN & \\
\hline CHEMBL591876 & 688612 & 4.25 & 4.6702 & TRN & \\
\hline CHEMBL1552056 & 688612 & 4.7 & 4.7017 & TRN & \\
\hline CHEMBL1481374 & 688612 & 4.05 & 4.6165 & TRN & \\
\hline CHEMBL1406128 & 688612 & 5.8 & 4.6649 & TRN & \\
\hline CHEMBL1597033 & 688612 & 4.05 & 4.6987 & TRN & \\
\hline CHEMBL1438975 & 688612 & 4.05 & 4.6525 & TST & \\
\hline CHEMBL1535553 & 688612 & 4.65 & 4.6856 & TST & \\
\hline CHEMBL3193247 & 688612 & 5.0 & 4.7229 & TRN & \\
\hline CHEMBL1569129 & 688612 & 4.05 & 4.6348 & TRN & \\
\hline CHEMBL1376146 & 688612 & 4.05 & 4.6375 & TRN & \\
\hline CHEMBL3211107 & 688612 & 4.05 & 4.6234 & TRN & \\
\hline CHEMBL 227726 & 688612 & 5.5 & 4.6569 & TRN & \\
\hline CHEMBL1305122 & 688612 & 6.8499 & 4.6291 & TRN & \\
\hline CHEMBL1409276 & 688612 & 4.1 & 4.6152 & TRN & \\
\hline CHEMBL1415532 & 688612 & 4.9 & 4.6845 & TRN & \\
\hline CHEMBL1330483 & 688612 & 5.25 & 4.5842 & TST & \\
\hline CHEMBL1359104 & 688612 & 4.7 & 4.6345 & TRN & \\
\hline CHEMBL1418617 & 688612 & 6.8499 & 4.6378 & TST & \\
\hline CHEMBL1564091 & 688612 & 4.55 & 4.6642 & TRN & \\
\hline CHEMBL1530785 & 688612 & 4.05 & 4.628 & TRN & \\
\hline CHEMBL1574595 & 688612 & 4.05 & 4.6836 & TRN & \\
\hline CHEMBL1533819 & 688612 & 4.15 & 4.6733 & TRN & \\
\hline CHEMBL1335653 & 688612 & 4.2 & 4.6064 & TRN & \\
\hline CHEMBL1360593 & 688612 & 4.2 & 4.6856 & TRN & \\
\hline CHEMBL1419670 & 688612 & 4.0 & 4.7048 & TRN & \\
\hline CHEMBL1371651 & 688612 & 6.0 & 4.6778 & TRN & \\
\hline CHEMBL1600629 & 688612 & 4.05 & 4.6086 & TRN & \\
\hline CHEMBL1980184 & 688612 & 4.0 & 4.7821 & TRN & \\
\hline CHEMBL3145067 & 688612 & 4.4 & 4.7246 & TST & \\
\hline CHEMBL1535368 & 688612 & 4.05 & 4.6601 & TRN & \\
\hline CHEMBL1595581 & 688612 & 4.5 & 4.6628 & TRN & \\
\hline CHEMBL1417193 & 688612 & 4.3 & 4.6234 & TRN & \\
\hline CHEMBL1606918 & 688612 & 4.05 & 4.6478 & TRN & \\
\hline CHEMBL1496995 & 688612 & 4.55 & 4.7828 & TRN & \\
\hline CHEMBL1520245 & 688612 & 4.45 & 4.7527 & TST & \\
\hline CHEMBL1402810 & 688612 & 4.05 & 4.6505 & TST & \\
\hline CHEMBL3196919 & 688612 & 4.3 & 4.7358 & TRN & \\
\hline CHEMBL1428067 & 688612 & 4.65 & 4.6407 & TRN & \\
\hline CHEMBL1601764 & 688612 & 4.05 & 4.6911 & TRN & \\
\hline CHEMBL1364369 & 688612 & 4.2 & 4.6942 & TRN & \\
\hline
\end{tabular}




\begin{tabular}{|c|c|c|c|c|c|}
\hline \multicolumn{6}{|c|}{ Supplemental Table S2.txt } \\
\hline CHEMBL1461169 & 688612 & 5.0 & 4.6373 & TRN & \\
\hline CHEMBL1303767 & 688612 & 5.05 & 4.695 & TST & \\
\hline CHEMBL1511185 & 688612 & 4.15 & 4.66 & TRN & \\
\hline CHEMBL1392192 & 688612 & 4.65 & 4.5692 & TRN & \\
\hline CHEMBL1461196 & 688612 & 4.75 & 4.7855 & TRN & \\
\hline CHEMBL1450906 & 688612 & 4.05 & 4.6065 & TRN & \\
\hline CHEMBL1390923 & 688612 & 4.15 & 4.7549 & TRN & \\
\hline CHEMBL1490111 & 688612 & 4.05 & 4.6993 & TRN & \\
\hline CHEMBL1347598 & 688612 & 4.35 & 4.7154 & TRN & \\
\hline CHEMBL1569456 & 688612 & 5.8 & 4.6916 & TRN & \\
\hline CHEMBL1601049 & 688612 & 4.2 & 4.6367 & TRN & \\
\hline CHEMBL1372076 & 688612 & 5.0 & 4.7534 & TRN & \\
\hline CHEMBL1461351 & 688612 & 4.0 & 4.646 & TRN & \\
\hline CHEMBL1508989 & 688612 & 4.65 & 4.709 & TRN & \\
\hline CHEMBL1992164 & 688612 & 5.3 & 4.6985 & TRN & \\
\hline CHEMBL1465114 & 688612 & 6.0 & 4.6869 & TRN & \\
\hline CHEMBL1511298 & 688612 & 4.05 & 4.739 & TST & \\
\hline CHEMBL1460423 & 688612 & 4.1 & 4.61600 & 00000000005 & TRN \\
\hline CHEMBL1341913 & 688612 & 4.05 & 4.652 & TST & \\
\hline CHEMBL1509334 & 688612 & 4.1 & 4.5504 & TRN & \\
\hline CHEMBL1364917 & 688612 & 6.9 & 4.641 & TRN & \\
\hline CHEMBL582471 & 688612 & 4.6 & 4.6539 & TRN & \\
\hline CHEMBL1412170 & 688612 & 4.35 & 4.6729 & TRN & \\
\hline CHEMBL1518941 & 688612 & 4.6 & 4.6842 & TRN & \\
\hline CHEMBL1603442 & 688612 & 5.0 & 4.7163 & TRN & \\
\hline CHEMBL1431269 & 688612 & 4.05 & 4.5792 & TRN & \\
\hline CHEMBL233896 & 688612 & 4.35 & 4.6812 & TRN & \\
\hline CHEMBL1406079 & 688612 & 4.1 & 4.6766 & TRN & \\
\hline CHEMBL1448499 & 688612 & 4.1 & 4.6139 & TST & \\
\hline CHEMBL1308619 & 688612 & 4.25 & 4.6717 & TRN & \\
\hline CHEMBL1320367 & 688612 & 4.55 & 4.7626 & TRN & \\
\hline CHEMBL1522155 & 688612 & 4.5 & 4.7746 & TRN & \\
\hline CHEMBL1604666 & 688612 & 6.5501 & 4.7393 & TRN & \\
\hline CHEMBL1462076 & 688612 & 5.45 & 4.6911 & TST & \\
\hline CHEMBL1369716 & 688612 & 4.1 & 4.6238 & TST & \\
\hline CHEMBL1584411 & 688612 & 6.35 & 4.6212 & TRN & \\
\hline CHEMBL1422155 & 688612 & 5.05 & 4.6459 & TRN & \\
\hline CHEMBL1427619 & 688612 & 6.95 & 4.704 & TRN & \\
\hline CHEMBL1449293 & 688612 & 4.4 & 4.6245 & TST & \\
\hline CHEMBL1544112 & 688612 & 4.05 & 4.5475 & TRN & \\
\hline CHEMBL1412620 & 688612 & 4.05 & 4.6173 & TRN & \\
\hline CHEMBL1358196 & 688612 & 4.6 & 4.6236 & TRN & \\
\hline CHEMBL1389157 & 688612 & 4.3 & 4.6052 & TRN & \\
\hline CHEMBL1514226 & 688612 & 4.75 & 4.6613 & TRN & \\
\hline CHEMBL1093246 & 688612 & 4.05 & 4.8753 & TRN & \\
\hline CHEMBL1585716 & 688612 & 4.05 & 4.63899 & 9999999999 & TRN \\
\hline CHEMBL1413866 & 688612 & 5.4 & 4.7788 & TRN & \\
\hline CHEMBL1571540 & 688612 & 4.4 & 4.6738 & TRN & \\
\hline
\end{tabular}




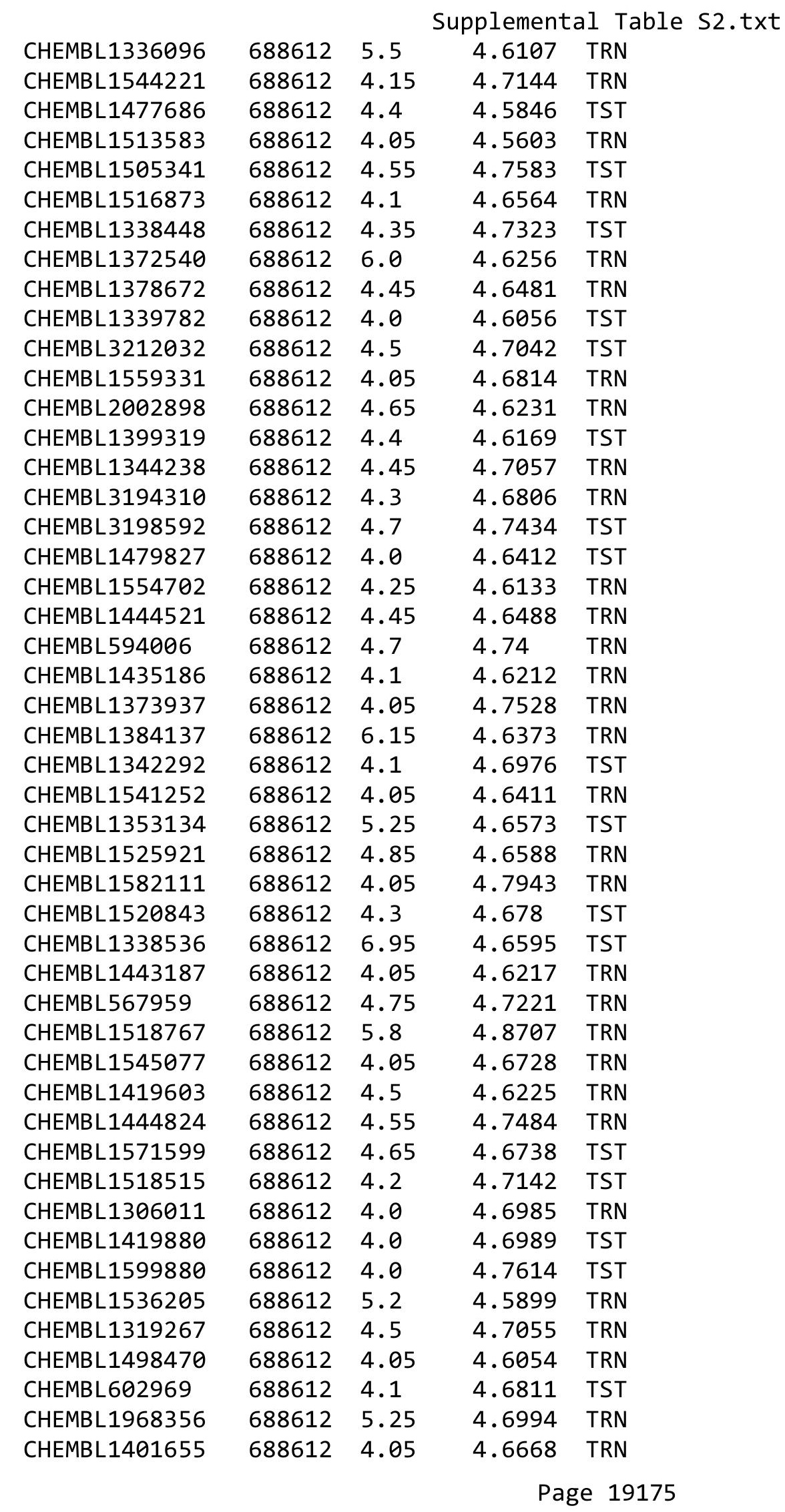




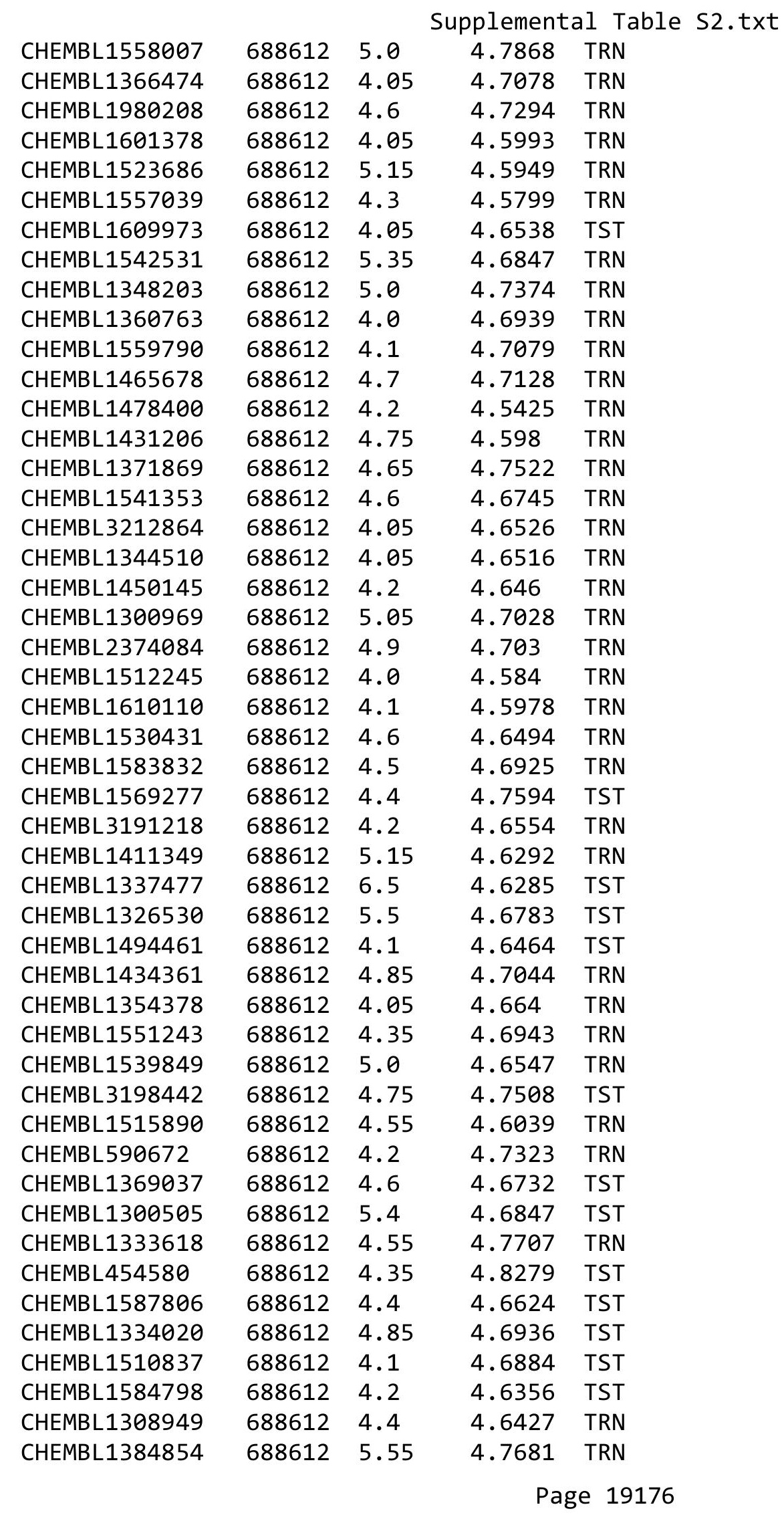




\begin{tabular}{|c|c|c|c|c|c|}
\hline & & \multicolumn{4}{|c|}{ Supplemental Table S2.txt } \\
\hline CHEMBL1329450 & 688612 & 4.1 & 4.5938 & TRN & \\
\hline CHEMBL1352164 & 688612 & 4.4 & 4.6733 & TRN & \\
\hline CHEMBL1459256 & 688612 & 4.05 & 4.6495 & TST & \\
\hline CHEMBL1358697 & 688612 & 4.35 & 4.6383 & TRN & \\
\hline CHEMBL1342431 & 688612 & 4.1 & 4.5754 & TRN & \\
\hline CHEMBL1603899 & 688612 & 5.05 & 4.637 & TRN & \\
\hline CHEMBL1526408 & 688612 & 4.35 & 4.6669 & TRN & \\
\hline CHEMBL122334 & 688612 & 4.2 & 4.7578 & TST & \\
\hline CHEMBL1397824 & 688612 & 4.1 & 4.5876 & TRN & \\
\hline CHEMBL1435183 & 688612 & 5.15 & 4.7086 & TRN & \\
\hline CHEMBL1569246 & 688612 & 5.0 & 4.5791 & TRN & \\
\hline CHEMBL1374495 & 688612 & 5.05 & 4.613 & TRN & \\
\hline CHEMBL1581747 & 688612 & 4.3 & 4.6571 & TRN & \\
\hline CHEMBL1465338 & 688612 & 4.4 & 4.7516 & TRN & \\
\hline CHEMBL1301692 & 688612 & 4.7 & 4.7276 & TRN & \\
\hline CHEMBL1517844 & 688612 & 4.0 & 4.7092 & TRN & \\
\hline CHEMBL2004847 & 688612 & 5.5 & 4.7656 & TRN & \\
\hline CHEMBL1510793 & 688612 & 6.45 & 4.7107 & TRN & \\
\hline CHEMBL1486834 & 688612 & 4.25 & 4.6858 & TRN & \\
\hline CHEMBL1403434 & 688612 & 5.6 & 4.7381 & TRN & \\
\hline CHEMBL1389045 & 688612 & 4.6 & 4.6265 & TRN & \\
\hline CHEMBL1309208 & 688612 & 4.9 & 4.7068 & TST & \\
\hline CHEMBL1330800 & 688612 & 4.7 & 4.6726 & TRN & \\
\hline CHEMBL1495592 & 688612 & 4.4 & 4.6766 & TST & \\
\hline CHEMBL1310838 & 688612 & 4.3 & 4.7104 & TST & \\
\hline CHEMBL1391916 & 688612 & 4.85 & 4.675 & TRN & \\
\hline CHEMBL1526116 & 688612 & 5.9 & 4.6037 & TRN & \\
\hline CHEMBL1568786 & 688612 & 5.4 & 4.6781 & TRN & \\
\hline CHEMBL1433885 & 688612 & 4.85 & 4.6326 & TRN & \\
\hline CHEMBL1334708 & 688612 & 4.05 & 4.6192 & TRN & \\
\hline CHEMBL1329487 & 688612 & 4.15 & 4.7064 & TRN & \\
\hline CHEMBL2001408 & 688612 & 6.05 & 4.7505 & TST & \\
\hline CHEMBL1419532 & 688612 & 4.05 & 4.52800 & 00000000005 & TRN \\
\hline CHEMBL1461478 & 688612 & 4.05 & 4.6691 & TRN & \\
\hline CHEMBL1435269 & 688612 & 4.65 & 4.6437 & TRN & \\
\hline CHEMBL1547578 & 688612 & 4.65 & 4.707 & TRN & \\
\hline CHEMBL1447752 & 688612 & 6.8499 & 4.5995 & TRN & \\
\hline CHEMBL1560145 & 688612 & 4.0 & 4.6365 & TRN & \\
\hline CHEMBL1586826 & 688612 & 4.05 & 4.626 & TRN & \\
\hline CHEMBL1407335 & 688612 & 6.3 & 4.7434 & TRN & \\
\hline CHEMBL1319798 & 688612 & 5.0 & 4.6275 & TRN & \\
\hline CHEMBL1407316 & 688612 & 4.05 & 4.6777 & TRN & \\
\hline CHEMBL3214195 & 688612 & 4.5 & 4.6923 & TRN & \\
\hline CHEMBL1307643 & 688612 & 6.8 & 4.6276 & TRN & \\
\hline CHEMBL1502157 & 688612 & 4.0 & 4.6168 & TRN & \\
\hline CHEMBL1572399 & 688612 & 4.4 & 4.6921 & TRN & \\
\hline CHEMBL1603130 & 688612 & 4.35 & 4.7027 & TRN & \\
\hline CHEMBL1546661 & 688612 & 4.05 & 4.6509 & TRN & \\
\hline
\end{tabular}




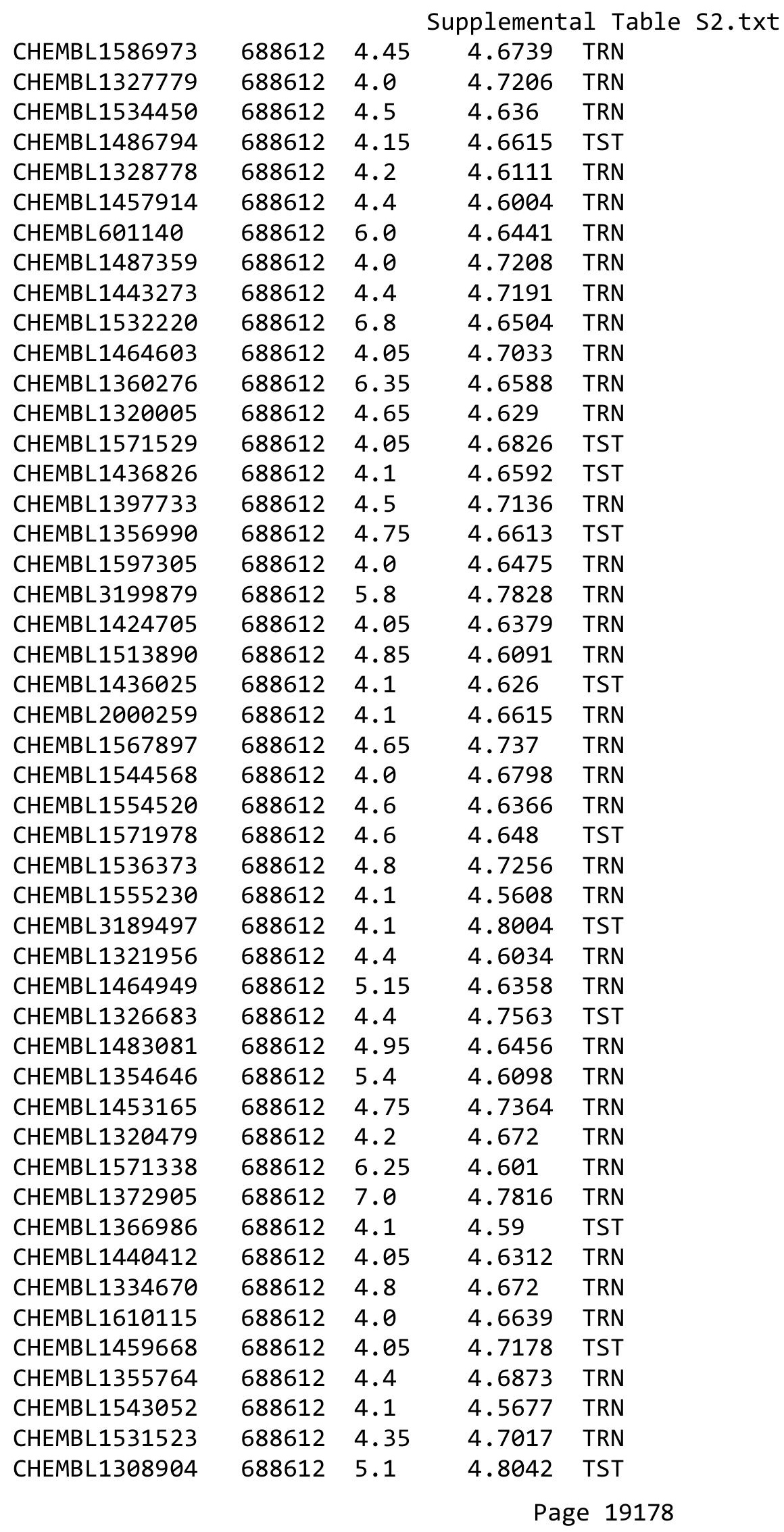




\begin{tabular}{|c|c|c|c|c|}
\hline \multicolumn{5}{|c|}{ Supplemental Table S2.txt } \\
\hline CHEMBL1528373 & 688612 & 7.0 & 4.6409 & TRN \\
\hline CHEMBL1603719 & 688612 & 6.5501 & 4.6165 & TRN \\
\hline CHEMBL1514461 & 688612 & 6.5501 & 4.7078 & TST \\
\hline CHEMBL1329425 & 688612 & 4.3 & 4.6095 & TRN \\
\hline CHEMBL1574641 & 688612 & 5.05 & 4.6392 & TRN \\
\hline CHEMBL1568594 & 688612 & 4.05 & 4.6539 & TST \\
\hline CHEMBL1530810 & 688612 & 4.55 & 4.717 & TRN \\
\hline CHEMBL1506806 & 688612 & 4.85 & 4.7274 & TST \\
\hline CHEMBL3194324 & 688612 & 4.3 & 4.7245 & TRN \\
\hline CHEMBL3195371 & 688612 & 4.9 & 4.7164 & TST \\
\hline CHEMBL3213159 & 688612 & 4.05 & 4.6952 & TST \\
\hline CHEMBL1577371 & 688612 & 5.35 & 4.6475 & TST \\
\hline CHEMBL1407274 & 688612 & 4.4 & 4.7982 & TRN \\
\hline CHEMBL1443088 & 688612 & 4.65 & 4.7861 & TRN \\
\hline CHEMBL1531982 & 688612 & 4.05 & 4.6713 & TST \\
\hline CHEMBL1509065 & 688612 & 5.55 & 4.7011 & TRN \\
\hline CHEMBL1493432 & 688612 & 4.3 & 4.7338 & TRN \\
\hline CHEMBL1604487 & 688612 & 4.55 & 4.7021 & TRN \\
\hline CHEMBL1584216 & 688612 & 4.7 & 4.6537 & TRN \\
\hline CHEMBL1595141 & 688612 & 6.8499 & 4.6312 & TST \\
\hline CHEMBL1482554 & 688612 & 5.0 & 4.7634 & TRN \\
\hline CHEMBL1516808 & 688612 & 7.0 & 4.6706 & TRN \\
\hline CHEMBL1533288 & 688612 & 6.0 & 4.7503 & TST \\
\hline CHEMBL1422752 & 688612 & 4.55 & 4.78 & TST \\
\hline CHEMBL1543960 & 688612 & 5.05 & 4.6947 & TRN \\
\hline CHEMBL1389565 & 688612 & 4.15 & 4.6718 & TRN \\
\hline CHEMBL1367952 & 688612 & 4.3 & 4.7401 & TRN \\
\hline CHEMBL89697 & 688612 & 4.0 & 4.7615 & TRN \\
\hline CHEMBL1430175 & 688612 & 5.5 & 4.7767 & TRN \\
\hline CHEMBL1576198 & 688612 & 4.0 & 4.6575 & TRN \\
\hline CHEMBL1549720 & 688612 & 4.05 & 4.6532 & TRN \\
\hline CHEMBL1502002 & 688612 & 4.85 & 4.6627 & TST \\
\hline CHEMBL1457346 & 688612 & 4.4 & 4.6386 & TRN \\
\hline CHEMBL1426571 & 688612 & 4.65 & 4.6874 & TRN \\
\hline CHEMBL1976046 & 688612 & 4.6 & 4.7888 & TRN \\
\hline CHEMBL1339823 & 688612 & 4.0 & 4.6135 & TST \\
\hline CHEMBL1484903 & 688612 & 6.05 & 4.6535 & TRN \\
\hline CHEMBL1573389 & 688612 & 4.7 & 4.6798 & TRN \\
\hline CHEMBL1609527 & 688612 & 4.05 & 4.5502 & TRN \\
\hline CHEMBL1322573 & 688612 & 4.0 & 4.5898 & TRN \\
\hline CHEMBL1481417 & 688612 & 4.1 & 4.7481 & TRN \\
\hline CHEMBL1370186 & 688612 & 6.0 & 4.5668 & TRN \\
\hline CHEMBL1541894 & 688612 & 4.6 & 4.6775 & TRN \\
\hline CHEMBL1607314 & 688612 & 4.05 & 4.6127 & TRN \\
\hline CHEMBL3212606 & 688612 & 4.85 & 4.7446 & TRN \\
\hline CHEMBL1577934 & 688612 & 4.2 & 4.7124 & TST \\
\hline CHEMBL3198135 & 688612 & 4.45 & 4.7418 & TRN \\
\hline CHEMBL1432440 & 688612 & 4.0 & 4.7121 & TRN \\
\hline
\end{tabular}




\begin{tabular}{|c|c|c|c|c|c|}
\hline & & \multicolumn{4}{|c|}{ Supplemental Table S2.txt } \\
\hline CHEMBL1607445 & 688612 & 4.35 & 4.7225 & TRN & \\
\hline CHEMBL1407324 & 688612 & 4.65 & 4.7507 & TST & \\
\hline CHEMBL1372094 & 688612 & 4.65 & 4.721 & TRN & \\
\hline CHEMBL1471533 & 688612 & 4.1 & 4.6251 & TST & \\
\hline CHEMBL1382577 & 688612 & 4.05 & 4.6605 & TRN & \\
\hline CHEMBL1450570 & 688612 & 4.4 & 4.7091 & TST & \\
\hline CHEMBL1528613 & 688612 & 4.0 & 4.7016 & TST & \\
\hline CHEMBL3196328 & 688612 & 4.05 & 4.689 & TRN & \\
\hline CHEMBL1303731 & 688612 & 4.0 & 4.7191 & TRN & \\
\hline CHEMBL1583807 & 688612 & 4.25 & 4.6308 & TRN & \\
\hline CHEMBL1979432 & 688612 & 4.7 & 4.71899 & 9999999999 & TRN \\
\hline CHEMBL 306783 & 688612 & 4.4 & 4.6388 & TST & \\
\hline CHEMBL1519093 & 688612 & 4.05 & 4.6429 & TRN & \\
\hline CHEMBL1419443 & 688612 & 4.4 & 4.7353 & TRN & \\
\hline CHEMBL1561353 & 688612 & 6.25 & 4.6032 & TRN & \\
\hline CHEMBL1455007 & 688612 & 4.05 & 4.6003 & TST & \\
\hline CHEMBL3194615 & 688612 & 4.05 & 4.672 & TST & \\
\hline CHEMBL1450534 & 688612 & 4.4 & 4.7634 & TRN & \\
\hline CHEMBL1573531 & 688612 & 5.9 & 4.6645 & TRN & \\
\hline CHEMBL1523598 & 688612 & 4.3 & 4.5356 & TRN & \\
\hline CHEMBL1453608 & 688612 & 4.95 & 4.7477 & TST & \\
\hline CHEMBL1342388 & 688612 & 4.8 & 4.7596 & TST & \\
\hline CHEMBL1366048 & 688612 & 4.6 & 4.6694 & TRN & \\
\hline CHEMBL1967220 & 688612 & 6.95 & 4.7353 & TST & \\
\hline CHEMBL1590099 & 688612 & 4.05 & 4.5853 & TRN & \\
\hline CHEMBL1478468 & 688612 & 4.45 & 4.6542 & TRN & \\
\hline CHEMBL1302012 & 688612 & 5.4 & 4.7523 & TRN & \\
\hline CHEMBL1371004 & 688612 & 4.25 & 4.7227 & TRN & \\
\hline CHEMBL3197777 & 688612 & 4.5 & 4.7543 & TRN & \\
\hline CHEMBL1393427 & 688612 & 5.4 & 4.6692 & TRN & \\
\hline CHEMBL1306666 & 688612 & 4.3 & 4.6958 & TST & \\
\hline CHEMBL1974348 & 688612 & 4.8 & 4.6186 & TST & \\
\hline CHEMBL1403450 & 688612 & 4.5 & 4.6428 & TRN & \\
\hline CHEMBL1401801 & 688612 & 4.05 & 4.7431 & TRN & \\
\hline CHEMBL1544615 & 688612 & 5.5 & 4.6836 & TRN & \\
\hline CHEMBL149322 & 688612 & 4.05 & 4.7687 & TRN & \\
\hline CHEMBL1327550 & 688612 & 4.0 & 4.6485 & TST & \\
\hline CHEMBL1453071 & 688612 & 5.0 & 4.6615 & TRN & \\
\hline CHEMBL1323500 & 688612 & 4.1 & 4.6744 & TST & \\
\hline CHEMBL1369659 & 688612 & 6.25 & 4.6344 & TRN & \\
\hline CHEMBL1554634 & 688612 & 6.5 & 4.7465 & TRN & \\
\hline CHEMBL1341911 & 688612 & 4.3 & 4.6679 & TRN & \\
\hline CHEMBL3196071 & 688612 & 4.75 & 4.7346 & TST & \\
\hline CHEMBL1436177 & 688612 & 4.05 & 4.6383 & TRN & \\
\hline CHEMBL1577155 & 688612 & 4.1 & 4.678 & TRN & \\
\hline CHEMBL1398626 & 688612 & 5.55 & 4.6806 & TRN & \\
\hline CHEMBL1493801 & 688612 & 4.0 & 4.7513 & TST & \\
\hline CHEMBL1567533 & 688612 & 6.35 & 4.6932 & TST & \\
\hline
\end{tabular}




\begin{tabular}{|c|c|c|c|c|c|}
\hline \multirow{3}{*}{$\begin{array}{l}\text { CHEMBL1490019 } \\
\text { CHEMBL } 1556675\end{array}$} & \multirow{3}{*}{$\begin{array}{l}688612 \\
688612\end{array}$} & \multicolumn{4}{|c|}{ Supplemental Table s2.txt } \\
\hline & & 4.35 & \multicolumn{2}{|c|}{4.656000000000001} & TRN \\
\hline & & 4.05 & 4.6483 & TST & \\
\hline CHEMBL1578953 & 688612 & 4.6 & 4.7887 & TRN & \\
\hline CHEMBL1403540 & 688612 & 4.65 & 4.6484 & TST & \\
\hline CHEMBL1435197 & 688612 & 4.05 & 4.6186 & TRN & \\
\hline CHEMBL1404816 & 688612 & 4.1 & 4.5854 & TRN & \\
\hline CHEMBL1462524 & 688612 & 4.05 & 4.708 & TRN & \\
\hline CHEMBL1347789 & 688612 & 5.05 & 4.7354 & TRN & \\
\hline CHEMBL1968421 & 688612 & 4.75 & 4.6738 & TRN & \\
\hline CHEMBL 1402782 & 688612 & 4.4 & 4.5832 & TRN & \\
\hline CHEMBL1608839 & 688612 & 4.55 & 4.5902 & TST & \\
\hline CHEMBL1439233 & 688612 & 5.0 & 4.6725 & TRN & \\
\hline CHEMBL3209083 & 688612 & 4.05 & 4.6786 & TRN & \\
\hline CHEMBL1526211 & 688612 & 4.4 & 4.72 & TST & \\
\hline CHEMBL1361107 & 688612 & 4.0 & 4.6619 & TRN & \\
\hline CHEMBL1382558 & 688612 & 4.6 & 4.6722 & TRN & \\
\hline CHEMBL1313324 & 688612 & 6.0 & 4.7838 & TST & \\
\hline CHEMBL1308951 & 688612 & 5.45 & 4.6391 & TRN & \\
\hline CHEMBL1589874 & 688612 & 4.4 & 4.6117 & TRN & \\
\hline CHEMBL 2006260 & 688612 & 5.35 & 4.6572 & TST & \\
\hline CHEMBL1367123 & 688612 & 6.1 & 4.6302 & TRN & \\
\hline CHEMBL1388454 & 688612 & 5.7 & 4.7212 & TRN & \\
\hline CHEMBL1593769 & 688612 & 4.4 & 4.5582 & TRN & \\
\hline CHEMBL1593357 & 688612 & 5.0 & 4.6215 & TRN & \\
\hline CHEMBL1608789 & 688612 & 4.65 & 4.7003 & TST & \\
\hline CHEMBL1418274 & 688612 & 4.0 & 4.7205 & TST & \\
\hline CHEMBL3196280 & 688612 & 4.4 & 4.6689 & TRN & \\
\hline CHEMBL1554709 & 688612 & 6.0 & 4.6302 & TST & \\
\hline CHEMBL1573334 & 688612 & 4.3 & 4.7373 & TRN & \\
\hline CHEMBL 3212370 & 688612 & 4.3 & 4.65600 & 0000000001 & TRN \\
\hline CHEMBL 2028179 & 688612 & 4.95 & 4.7164 & TST & \\
\hline CHEMBL1498647 & 688612 & 4.05 & 4.6493 & TST & \\
\hline CHEMBL1539171 & 688612 & 4.3 & 4.7975 & TST & \\
\hline CHEMBL1477530 & 688612 & 4.15 & 4.6564 & TRN & \\
\hline CHEMBL3144869 & 688612 & 5.5 & 4.6858 & TRN & \\
\hline CHEMBL1580372 & 688612 & 4.7 & 4.7141 & TRN & \\
\hline CHEMBL420539 & 688612 & 5.35 & 4.6609 & TRN & \\
\hline CHEMBL1504841 & 688612 & 4.05 & 4.6717 & TST & \\
\hline CHEMBL1380496 & 688612 & 4.0 & 4.7046 & TST & \\
\hline CHEMBL595648 & 688612 & 4.6 & 4.7964 & TRN & \\
\hline CHEMBL1477517 & 688612 & 6.0 & 4.6673 & TRN & \\
\hline CHEMBL1546326 & 688612 & 4.35 & 4.5845 & TRN & \\
\hline CHEMBL1999768 & 688612 & 4.1 & 4.5914 & TRN & \\
\hline CHEMBL1578456 & 688612 & 4.8 & 4.7171 & TRN & \\
\hline CHEMBL1380542 & 688612 & 4.1 & 4.6692 & TST & \\
\hline CHEMBL1334662 & 688612 & 4.05 & 4.6456 & TRN & \\
\hline CHEMBL1540596 & 688612 & 5.05 & 4.6954 & TRN & \\
\hline CHEMBL1319634 & 688612 & 4.55 & 4.567 & TRN & \\
\hline
\end{tabular}




\begin{tabular}{|c|c|c|c|c|}
\hline \multicolumn{5}{|c|}{ Supplemental Table S2.txt } \\
\hline CHEMBL1393131 & 688612 & 5.5 & 4.7799 & TRN \\
\hline CHEMBL1416382 & 688612 & 4.5 & 4.7398 & TRN \\
\hline CHEMBL1583911 & 688612 & 4.4 & 4.6699 & TRN \\
\hline CHEMBL1594853 & 688612 & 5.65 & 4.6452 & TRN \\
\hline CHEMBL1330761 & 688612 & 5.05 & 4.6247 & TRN \\
\hline CHEMBL1366353 & 688612 & 5.8 & 4.6714 & TRN \\
\hline CHEMBL1544870 & 688612 & 4.65 & 4.6889 & TRN \\
\hline CHEMBL1590790 & 688612 & 4.05 & 4.5762 & TRN \\
\hline CHEMBL1526463 & 688612 & 4.05 & 4.6921 & TRN \\
\hline CHEMBL1464281 & 688612 & 4.05 & 4.7163 & TST \\
\hline CHEMBL1966612 & 688612 & 5.05 & 4.6741 & TRN \\
\hline CHEMBL1425591 & 688612 & 5.1 & 4.6367 & TRN \\
\hline CHEMBL1552858 & 688612 & 4.1 & 4.6091 & TRN \\
\hline CHEMBL1384568 & 688612 & 4.05 & 4.6142 & TRN \\
\hline CHEMBL1476832 & 688612 & 4.4 & 4.6772 & TST \\
\hline CHEMBL1543253 & 688612 & 4.3 & 4.6756 & TRN \\
\hline CHEMBL1311200 & 688612 & 5.2 & 4.6814 & TST \\
\hline CHEMBL1484322 & 688612 & 4.2 & 4.6627 & TRN \\
\hline CHEMBL1538755 & 688612 & 4.0 & 4.6385 & TRN \\
\hline CHEMBL1386676 & 688612 & 4.95 & 4.7108 & TRN \\
\hline CHEMBL1416704 & 688612 & 5.75 & 4.6971 & TRN \\
\hline CHEMBL1404559 & 688612 & 4.95 & 4.6763 & TRN \\
\hline CHEMBL1552564 & 688612 & 4.05 & 4.6179 & TRN \\
\hline CHEMBL1596161 & 688612 & 4.2 & 4.6606 & TRN \\
\hline CHEMBL1390242 & 688612 & 4.4 & 4.6907 & TRN \\
\hline CHEMBL1302885 & 688612 & 6.1 & 4.6944 & TRN \\
\hline CHEMBL1391508 & 688612 & 4.0 & 4.6304 & TST \\
\hline CHEMBL1429971 & 688612 & 6.0 & 4.6887 & TST \\
\hline CHEMBL1496088 & 688612 & 6.25 & 4.6146 & TRN \\
\hline CHEMBL1519354 & 688612 & 4.35 & 4.6707 & TRN \\
\hline CHEMBL1508694 & 688612 & 4.45 & 4.7011 & TRN \\
\hline CHEMBL1517441 & 688612 & 6.1 & 4.7228 & TRN \\
\hline CHEMBL1404260 & 688612 & 4.5 & 4.6733 & TRN \\
\hline CHEMBL1482317 & 688612 & 4.35 & 4.6853 & TRN \\
\hline CHEMBL1403893 & 688612 & 4.05 & 4.5808 & TRN \\
\hline CHEMBL1406195 & 688612 & 6.3 & 4.7478 & TRN \\
\hline CHEMBL 1422226 & 688612 & 4.0 & 4.6241 & TRN \\
\hline CHEMBL1491528 & 688612 & 4.3 & 4.6355 & TST \\
\hline CHEMBL1477715 & 688612 & 4.05 & 4.7047 & TRN \\
\hline CHEMBL1561980 & 688612 & 5.4 & 4.6206 & TRN \\
\hline CHEMBL1585285 & 688612 & 4.2 & 4.7768 & TRN \\
\hline CHEMBL1546625 & 688612 & 6.8499 & 4.5856 & TRN \\
\hline CHEMBL1438343 & 688612 & 4.6 & 4.6731 & TRN \\
\hline CHEMBL1612490 & 688612 & 4.25 & 4.7237 & TRN \\
\hline CHEMBL1361317 & 688612 & 4.45 & 4.7156 & TRN \\
\hline CHEMBL1477769 & 688612 & 4.45 & 4.5955 & TRN \\
\hline CHEMBL1392623 & 688612 & 6.7001 & 4.7145 & TRN \\
\hline CHEMBL1470983 & 688612 & 4.05 & 4.6916 & TRN \\
\hline
\end{tabular}




\begin{tabular}{|c|c|c|c|c|}
\hline \multicolumn{5}{|c|}{ Supplemental Table S2.txt } \\
\hline CHEMBL1336084 & 688612 & 4.05 & 4.6639 & TRN \\
\hline CHEMBL1302527 & 688612 & 5.95 & 4.6637 & TRN \\
\hline CHEMBL1430143 & 688612 & 6.2 & 4.6918 & TRN \\
\hline CHEMBL1563930 & 688612 & 4.4 & 4.6455 & TST \\
\hline CHEMBL1483175 & 688612 & 4.65 & 4.7294 & TRN \\
\hline CHEMBL1594285 & 688612 & 4.1 & 4.5685 & TRN \\
\hline CHEMBL1569436 & 688612 & 4.1 & 4.6355 & TRN \\
\hline CHEMBL1541592 & 688612 & 4.95 & 4.7732 & TRN \\
\hline CHEMBL582276 & 688612 & 4.05 & 4.6339 & TST \\
\hline CHEMBL 1437782 & 688612 & 4.35 & 4.6896 & TRN \\
\hline CHEMBL1574720 & 688612 & 4.5 & 4.6931 & TRN \\
\hline CHEMBL1600223 & 688612 & 4.2 & 4.6545 & TRN \\
\hline CHEMBL1491700 & 688612 & 4.65 & 4.6108 & TRN \\
\hline CHEMBL1974456 & 688612 & 4.5 & 4.7396 & TRN \\
\hline CHEMBL1537051 & 688612 & 4.05 & 4.7259 & TRN \\
\hline CHEMBL3197368 & 688612 & 4.5 & 4.671 & TRN \\
\hline CHEMBL1558805 & 688612 & 5.0 & 4.7036 & TST \\
\hline CHEMBL1458436 & 688612 & 4.05 & 4.7094 & TRN \\
\hline CHEMBL1563562 & 688612 & 4.4 & 4.5871 & TST \\
\hline CHEMBL1327977 & 688612 & 4.4 & 4.6389 & TRN \\
\hline CHEMBL1360981 & 688612 & 5.1 & 4.6281 & TRN \\
\hline CHEMBL1334402 & 688612 & 4.1 & 4.6555 & TRN \\
\hline CHEMBL1380550 & 688612 & 4.65 & 4.6391 & TRN \\
\hline CHEMBL1449334 & 688612 & 5.05 & 4.7952 & TRN \\
\hline CHEMBL3189255 & 688612 & 4.7 & 4.6373 & TRN \\
\hline CHEMBL1562648 & 688612 & 4.05 & 4.6942 & TST \\
\hline CHEMBL1477216 & 688612 & 6.5 & 4.6199 & TRN \\
\hline CHEMBL1554896 & 688612 & 6.35 & 4.7177 & TRN \\
\hline CHEMBL1571760 & 688612 & 6.4 & 4.6368 & TRN \\
\hline CHEMBL1384194 & 688612 & 4.7 & 4.5996 & TRN \\
\hline CHEMBL1366929 & 688612 & 4.05 & 4.6205 & TRN \\
\hline CHEMBL1426839 & 688612 & 4.5 & 4.5949 & TRN \\
\hline CHEMBL1446502 & 688612 & 4.65 & 4.7275 & TRN \\
\hline CHEMBL1505447 & 688612 & 4.0 & 4.5954 & TRN \\
\hline CHEMBL1997922 & 688612 & 4.85 & 4.7452 & TRN \\
\hline CHEMBL1608409 & 688612 & 4.05 & 4.6271 & TRN \\
\hline CHEMBL1312723 & 688612 & 4.25 & 4.7949 & TST \\
\hline CHEMBL1299492 & 688612 & 5.55 & 4.6494 & TRN \\
\hline CHEMBL1369417 & 688612 & 4.2 & 4.6898 & TST \\
\hline CHEMBL1307905 & 688612 & 4.05 & 4.6882 & TRN \\
\hline CHEMBL1310171 & 688612 & 4.7 & 4.6798 & TRN \\
\hline CHEMBL3207430 & 688612 & 5.1 & 4.7199 & TST \\
\hline CHEMBL1471883 & 688612 & 4.65 & 4.6343 & TRN \\
\hline CHEMBL1502228 & 688612 & 4.05 & 4.6988 & TRN \\
\hline CHEMBL1322821 & 688612 & 4.65 & 4.7473 & TRN \\
\hline CHEMBL1382962 & 688612 & 4.0 & 4.625 & TRN \\
\hline CHEMBL3191436 & 688612 & 4.6 & 4.68 & TRN \\
\hline CHEMBL3189251 & 688612 & 4.7 & 4.7812 & TRN \\
\hline
\end{tabular}




\begin{tabular}{|c|c|c|c|c|}
\hline & & & pplement & al Ta \\
\hline CHEMBL1505850 & 688612 & 4.7 & 4.6298 & TRN \\
\hline CHEMBL1555955 & 688612 & 5.5 & 4.577 & TRN \\
\hline CHEMBL1597241 & 688612 & 4.1 & 4.667 & TST \\
\hline CHEMBL1551015 & 688612 & 4.5 & 4.6951 & TRN \\
\hline CHEMBL1547543 & 688612 & 4.05 & 4.6757 & TST \\
\hline CHEMBL1552775 & 688612 & 6.35 & 4.6287 & TRN \\
\hline CHEMBL1373946 & 688612 & 4.0 & 4.6437 & TST \\
\hline CHEMBL1451892 & 688612 & 4.4 & 4.6728 & TRN \\
\hline CHEMBL1578561 & 688612 & 4.65 & 4.7341 & TRN \\
\hline CHEMBL1580282 & 688612 & 6.15 & 4.6632 & TRN \\
\hline CHEMBL1301232 & 688612 & 4.8 & 4.6483 & TRN \\
\hline CHEMBL1977191 & 688612 & 4.85 & 4.7734 & TRN \\
\hline CHEMBL1353256 & 688612 & 4.0 & 4.6589 & TRN \\
\hline CHEMBL1316981 & 688612 & 4.05 & 4.5977 & TRN \\
\hline CHEMBL1998525 & 688612 & 4.45 & 4.7372 & TRN \\
\hline CHEMBL1613210 & 688612 & 4.5 & 4.6293 & TRN \\
\hline CHEMBL1364573 & 688612 & 4.85 & 4.6812 & TST \\
\hline CHEMBL1467244 & 688612 & 4.85 & 4.7488 & TRN \\
\hline CHEMBL1590196 & 688612 & 4.05 & 4.6572 & TRN \\
\hline CHEMBL1536950 & 688612 & 4.8 & 4.6416 & TRN \\
\hline CHEMBL1364042 & 688612 & 4.6 & 4.6381 & TRN \\
\hline CHEMBL3208366 & 688612 & 4.85 & 4.7468 & TRN \\
\hline CHEMBL1407176 & 688612 & 4.05 & 4.6963 & TRN \\
\hline CHEMBL1590525 & 688612 & 4.85 & 4.6106 & TRN \\
\hline CHEMBL1343352 & 688612 & 5.55 & 4.6425 & TRN \\
\hline CHEMBL1300885 & 688612 & 4.05 & 4.6421 & TRN \\
\hline CHEMBL1613412 & 688612 & 4.1 & 4.6591 & TRN \\
\hline CHEMBL1545451 & 688612 & 7.0 & 4.7132 & TRN \\
\hline CHEMBL1496325 & 688612 & 4.3 & 4.699 & TRN \\
\hline CHEMBL 3207715 & 688612 & 5.2 & 4.7296 & TRN \\
\hline CHEMBL1357213 & 688612 & 5.05 & 4.6499 & TRN \\
\hline CHEMBL1353788 & 688612 & 4.1 & 4.6058 & TST \\
\hline CHEMBL1400505 & 688612 & 4.3 & 4.7436 & TRN \\
\hline CHEMBL1318465 & 688612 & 5.1 & 4.615 & TRN \\
\hline CHEMBL1445795 & 688612 & 4.65 & 4.6977 & TRN \\
\hline CHEMBL1589594 & 688612 & 5.4 & 4.6262 & TRN \\
\hline CHEMBL1449026 & 688612 & 4.0 & 4.5785 & TRN \\
\hline CHEMBL1590310 & 688612 & 4.5 & 4.613 & TST \\
\hline CHEMBL1525911 & 688612 & 4.05 & 4.6672 & TRN \\
\hline CHEMBL1351487 & 688612 & 4.3 & 4.7246 & TRN \\
\hline CHEMBL1325762 & 688612 & 5.1 & 4.704 & TST \\
\hline CHEMBL549640 & 688612 & 4.65 & 4.7752 & TRN \\
\hline CHEMBL1543214 & 688612 & 4.75 & 4.62 & TRN \\
\hline CHEMBL1517788 & 688612 & 5.0 & 4.6441 & TRN \\
\hline CHEMBL1367865 & 688612 & 5.35 & 4.602 & TRN \\
\hline CHEMBL1499285 & 688612 & 4.0 & 4.6595 & TRN \\
\hline CHEMBL1310928 & 688612 & 4.55 & 4.7438 & TST \\
\hline CHEMBL1577959 & 688612 & 4.0 & 4.7396 & TST \\
\hline
\end{tabular}




\begin{tabular}{|c|c|c|c|c|c|}
\hline \multicolumn{6}{|c|}{ Supplemental Table S2.txt } \\
\hline CHEMBL1583199 & 688612 & 5.5 & 4.7162 & TRN & \\
\hline CHEMBL1606450 & 688612 & 4.55 & 4.6824 & TST & \\
\hline CHEMBL1559463 & 688612 & 4.3 & 4.7135 & TRN & \\
\hline CHEMBL1421043 & 688612 & 4.15 & 4.7027 & TRN & \\
\hline CHEMBL 3193740 & 688612 & 4.9 & 4.6364 & TRN & \\
\hline CHEMBL1531476 & 688612 & 4.55 & 4.6139 & TRN & \\
\hline CHEMBL1997450 & 688612 & 4.25 & 4.7998 & TRN & \\
\hline CHEMBL1522991 & 688612 & 4.6 & 4.646 & TRN & \\
\hline CHEMBL1537466 & 688612 & 4.05 & 4.6791 & TRN & \\
\hline CHEMBL1362234 & 688612 & 4.7 & 4.7297 & TRN & \\
\hline CHEMBL1387319 & 688612 & 4.5 & 4.665 & TRN & \\
\hline CHEMBL1583368 & 688612 & 6.8 & 4.7311 & TRN & \\
\hline CHEMBL1300253 & 688612 & 5.1 & 4.667 & TRN & \\
\hline CHEMBL1491192 & 688612 & 4.1 & 4.68 & TST & \\
\hline CHEMBL1322535 & 688612 & 5.1 & 4.5608 & TRN & \\
\hline CHEMBL3190253 & 688612 & 4.35 & 4.7308 & TST & \\
\hline CHEMBL1413192 & 688612 & 4.4 & 4.6692 & TST & \\
\hline CHEMBL1368591 & 688612 & 5.1 & 4.7002 & TRN & \\
\hline CHEMBL 212414 & 688612 & 5.4 & 4.724 & TRN & \\
\hline CHEMBL 2005518 & 688612 & 4.95 & 4.7002 & TRN & \\
\hline CHEMBL1359563 & 688612 & 4.5 & 4.7232 & TRN & \\
\hline CHEMBL 3207448 & 688612 & 4.25 & 4.6701 & TRN & \\
\hline CHEMBL1339008 & 688612 & 4.45 & 4.7127 & TST & \\
\hline CHEMBL1369691 & 688612 & 6.0 & 4.7874 & TRN & \\
\hline CHEMBL1497229 & 688612 & 5.9 & 4.705 & TRN & \\
\hline CHEMBL1394060 & 688612 & 4.15 & 4.6779 & TRN & \\
\hline CHEMBL1574071 & 688612 & 4.0 & 4.6866 & TST & \\
\hline CHEMBL1354748 & 688612 & 4.05 & 4.5518 & TRN & \\
\hline CHEMBL3194899 & 688612 & 5.55 & 4.6933 & TRN & \\
\hline CHEMBL1605235 & 688612 & 4.55 & 4.7899 & TST & \\
\hline CHEMBL1382526 & 688612 & 6.1 & 4.7351 & TST & \\
\hline CHEMBL1312017 & 688612 & 4.45 & 4.6286 & TST & \\
\hline CHEMBL1442893 & 688612 & 4.05 & 4.7261 & TRN & \\
\hline CHEMBL1321176 & 688612 & 4.65 & 4.65300 & 00000000005 & TRN \\
\hline CHEMBL1604007 & 688612 & 4.3 & 4.7575 & TST & \\
\hline CHEMBL1404493 & 688612 & 6.0 & 4.6946 & TRN & \\
\hline CHEMBL1384172 & 688612 & 5.6 & 4.806 & TRN & \\
\hline CHEMBL1377973 & 688612 & 4.7 & 4.7195 & TRN & \\
\hline CHEMBL3214588 & 688612 & 4.4 & 4.7291 & TRN & \\
\hline CHEMBL1327948 & 688612 & 4.4 & 4.6897 & TRN & \\
\hline CHEMBL1361318 & 688612 & 4.05 & 4.587 & TRN & \\
\hline CHEMBL3194039 & 688612 & 5.0 & 4.6648 & TRN & \\
\hline CHEMBL1579790 & 688612 & 4.0 & 4.7197 & TST & \\
\hline CHEMBL1520481 & 688612 & 4.5 & 4.6444 & TRN & \\
\hline CHEMBL1538128 & 688612 & 4.05 & 4.6688 & TRN & \\
\hline CHEMBL1570914 & 688612 & 5.0 & 4.6593 & TRN & \\
\hline CHEMBL1537207 & 688612 & 4.8 & 4.665 & TRN & \\
\hline CHEMBL1530417 & 688612 & 4.05 & 4.5879 & TST & \\
\hline
\end{tabular}




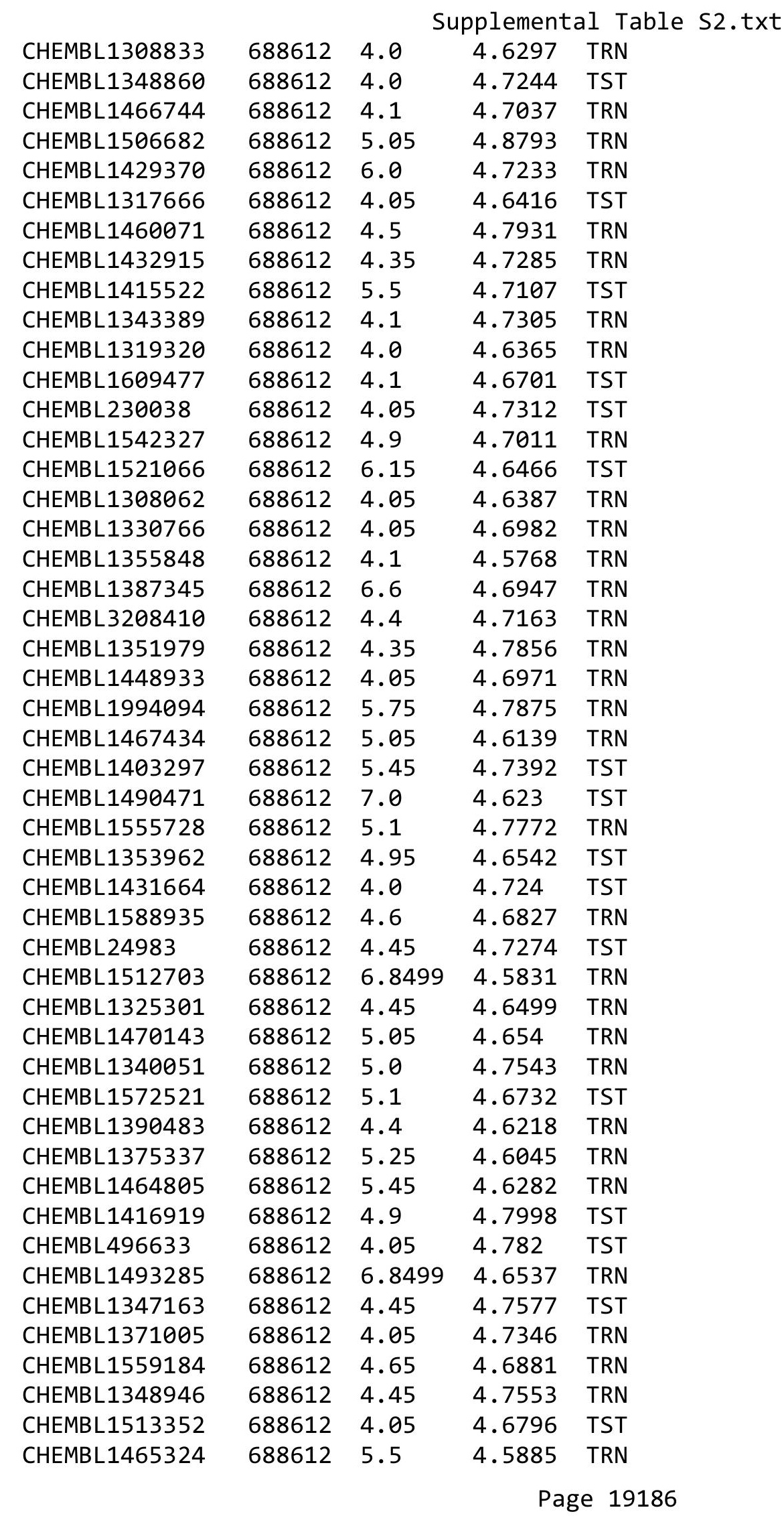




\begin{tabular}{|c|c|c|c|c|}
\hline \multicolumn{5}{|c|}{ Supplemental Table S2.txt } \\
\hline CHEMBL1382110 & 688612 & 4.1 & 4.7709 & TRN \\
\hline CHEMBL1505663 & 688612 & 4.95 & 4.6276 & TRN \\
\hline CHEMBL1556291 & 688612 & 4.05 & 4.5936 & TRN \\
\hline CHEMBL1595235 & 688612 & 5.6 & 4.7939 & TRN \\
\hline CHEMBL1370605 & 688612 & 4.45 & 4.6533 & TST \\
\hline CHEMBL1595321 & 688612 & 4.35 & 4.6771 & TRN \\
\hline CHEMBL1385425 & 688612 & 4.55 & 4.6264 & TRN \\
\hline CHEMBL1446724 & 688612 & 6.8499 & 4.6666 & TRN \\
\hline CHEMBL1341381 & 688612 & 4.6 & 4.5757 & TRN \\
\hline CHEMBL1591819 & 688612 & 4.4 & 4.629 & TRN \\
\hline CHEMBL1388287 & 688612 & 4.8 & 4.684 & TRN \\
\hline CHEMBL1433764 & 688612 & 4.05 & 4.6598 & TRN \\
\hline CHEMBL1364903 & 688612 & 4.45 & 4.6707 & TST \\
\hline CHEMBL1554119 & 688612 & 4.05 & 4.5894 & TRN \\
\hline CHEMBL236899 & 688612 & 4.3 & 4.7292 & TRN \\
\hline CHEMBL1601599 & 688612 & 4.4 & 4.7644 & TRN \\
\hline CHEMBL1597071 & 688612 & 5.4 & 4.6686 & TRN \\
\hline CHEMBL1302343 & 688612 & 4.0 & 4.6796 & TRN \\
\hline CHEMBL1538344 & 688612 & 4.05 & 4.6607 & TST \\
\hline CHEMBL1590761 & 688612 & 5.2 & 4.7031 & TRN \\
\hline CHEMBL1548422 & 688612 & 4.5 & 4.7377 & TRN \\
\hline CHEMBL1507486 & 688612 & 4.6 & 4.7656 & TRN \\
\hline CHEMBL1315465 & 688612 & 4.05 & 4.6178 & TRN \\
\hline CHEMBL1517284 & 688612 & 4.1 & 4.6983 & TRN \\
\hline CHEMBL1354688 & 688612 & 4.05 & 4.6944 & TST \\
\hline CHEMBL1602714 & 688612 & 4.4 & 4.7056 & TRN \\
\hline CHEMBL1613060 & 688612 & 4.0 & 4.6172 & TRN \\
\hline CHEMBL1443506 & 688612 & 4.7 & 4.6957 & TST \\
\hline CHEMBL1515569 & 688612 & 4.6 & 4.5899 & TRN \\
\hline CHEMBL1350277 & 688612 & 4.0 & 4.6905 & TST \\
\hline CHEMBL1350316 & 688612 & 6.9 & 4.7081 & TST \\
\hline CHEMBL1603293 & 688612 & 4.1 & 4.6777 & TRN \\
\hline CHEMBL1597469 & 688612 & 4.65 & 4.7616 & TST \\
\hline CHEMBL1992105 & 688612 & 4.8 & 4.5893 & TRN \\
\hline CHEMBL1429584 & 688612 & 4.7 & 4.6823 & TRN \\
\hline CHEMBL1372101 & 688612 & 4.1 & 4.6503 & TRN \\
\hline CHEMBL1375252 & 688612 & 4.05 & 4.6517 & TRN \\
\hline CHEMBL1477979 & 688612 & 4.65 & 4.637 & TST \\
\hline CHEMBL1319751 & 688612 & 6.8499 & 4.5463 & TRN \\
\hline CHEMBL1305100 & 688612 & 4.8 & 4.6654 & TRN \\
\hline CHEMBL1309269 & 688612 & 6.95 & 4.6552 & TST \\
\hline CHEMBL1511982 & 688612 & 4.4 & 4.6319 & TRN \\
\hline CHEMBL3189890 & 688612 & 4.4 & 4.6541 & TST \\
\hline CHEMBL1532923 & 688612 & 4.1 & 4.6466 & TRN \\
\hline CHEMBL1560258 & 688612 & 4.8 & 4.6776 & TRN \\
\hline CHEMBL1537344 & 688612 & 5.35 & 4.7913 & TRN \\
\hline CHEMBL1399717 & 688612 & 4.65 & 4.6942 & TST \\
\hline CHEMBL 3145371 & 688612 & 6.8499 & 4.7189 & TRN \\
\hline
\end{tabular}




\begin{tabular}{|c|c|c|c|c|}
\hline \multicolumn{5}{|c|}{ Supplemental Table S2.txt } \\
\hline CHEMBL1489187 & 688612 & 4.7 & 4.6604 & TRN \\
\hline CHEMBL 2005317 & 688612 & 4.2 & 4.7062 & TRN \\
\hline CHEMBL1572040 & 688612 & 4.05 & 4.6688 & TST \\
\hline CHEMBL1578829 & 688612 & 4.15 & 4.5959 & TST \\
\hline CHEMBL 267373 & 688612 & 4.1 & 4.7562 & TRN \\
\hline CHEMBL1510956 & 688612 & 5.0 & 4.6429 & TRN \\
\hline CHEMBL1587988 & 688612 & 5.3 & 4.5883 & TRN \\
\hline CHEMBL1336525 & 688612 & 4.7 & 4.6182 & TRN \\
\hline CHEMBL1612013 & 688612 & 4.05 & 4.6694 & TRN \\
\hline CHEMBL1351146 & 688612 & 5.95 & 4.6041 & TRN \\
\hline CHEMBL1461423 & 688612 & 4.25 & 4.6008 & TRN \\
\hline CHEMBL1335424 & 688612 & 4.1 & 4.6606 & TRN \\
\hline CHEMBL1518073 & 688612 & 6.0 & 4.712 & TRN \\
\hline CHEMBL 3197586 & 688612 & 4.85 & 4.7625 & TRN \\
\hline CHEMBL3194943 & 688612 & 4.2 & 4.6352 & TST \\
\hline CHEMBL1613404 & 688612 & 4.35 & 4.6306 & TRN \\
\hline CHEMBL1415789 & 688612 & 4.0 & 4.6336 & TRN \\
\hline CHEMBL1536269 & 688612 & 4.0 & 4.6723 & TRN \\
\hline CHEMBL1343100 & 688612 & 4.65 & 4.7882 & TST \\
\hline CHEMBL1451276 & 688612 & 4.6 & 4.6275 & TRN \\
\hline CHEMBL1505170 & 688612 & 4.1 & 4.6686 & TST \\
\hline CHEMBL1480162 & 688612 & 4.05 & 4.6287 & TRN \\
\hline CHEMBL1577611 & 688612 & 4.05 & 4.5634 & TRN \\
\hline CHEMBL 3198000 & 688612 & 4.3 & 4.7548 & TRN \\
\hline CHEMBL1610713 & 688612 & 5.7 & 4.6144 & TRN \\
\hline CHEMBL1556846 & 688612 & 6.25 & 4.6809 & TRN \\
\hline CHEMBL1518137 & 688612 & 6.2 & 4.6132 & TST \\
\hline CHEMBL1515790 & 688612 & 4.05 & 4.6814 & TRN \\
\hline CHEMBL1440130 & 688612 & 4.85 & 4.6116 & TRN \\
\hline CHEMBL1449687 & 688612 & 5.85 & 4.5986 & TRN \\
\hline CHEMBL3210023 & 688612 & 4.5 & 4.6938 & TRN \\
\hline CHEMBL1528391 & 688612 & 4.05 & 4.6043 & TRN \\
\hline CHEMBL1380697 & 688612 & 5.15 & 4.5971 & TRN \\
\hline CHEMBL1467222 & 688612 & 5.35 & 4.779 & TRN \\
\hline CHEMBL1585819 & 688612 & 4.6 & 4.6142 & TST \\
\hline CHEMBL1567951 & 688612 & 4.9 & 4.6752 & TRN \\
\hline CHEMBL1482766 & 688612 & 4.4 & 4.6142 & TRN \\
\hline CHEMBL 2006418 & 688612 & 5.35 & 4.7576 & TRN \\
\hline CHEMBL1463484 & 688612 & 5.4 & 4.6741 & TRN \\
\hline CHEMBL1476305 & 688612 & 4.05 & 4.5877 & TRN \\
\hline CHEMBL1611580 & 688612 & 4.7 & 4.6202 & TRN \\
\hline CHEMBL1582126 & 688612 & 4.1 & 4.7285 & TRN \\
\hline CHEMBL1321040 & 688612 & 5.95 & 4.6112 & TRN \\
\hline CHEMBL1449454 & 688612 & 6.8 & 4.7112 & TRN \\
\hline CHEMBL1337343 & 688612 & 5.4 & 4.6143 & TRN \\
\hline CHEMBL1486931 & 688612 & 4.35 & 4.7598 & TRN \\
\hline CHEMBL1393495 & 688612 & 5.0 & 4.6439 & TRN \\
\hline CHEMBL1466664 & 688612 & 4.3 & 4.7093 & TRN \\
\hline
\end{tabular}




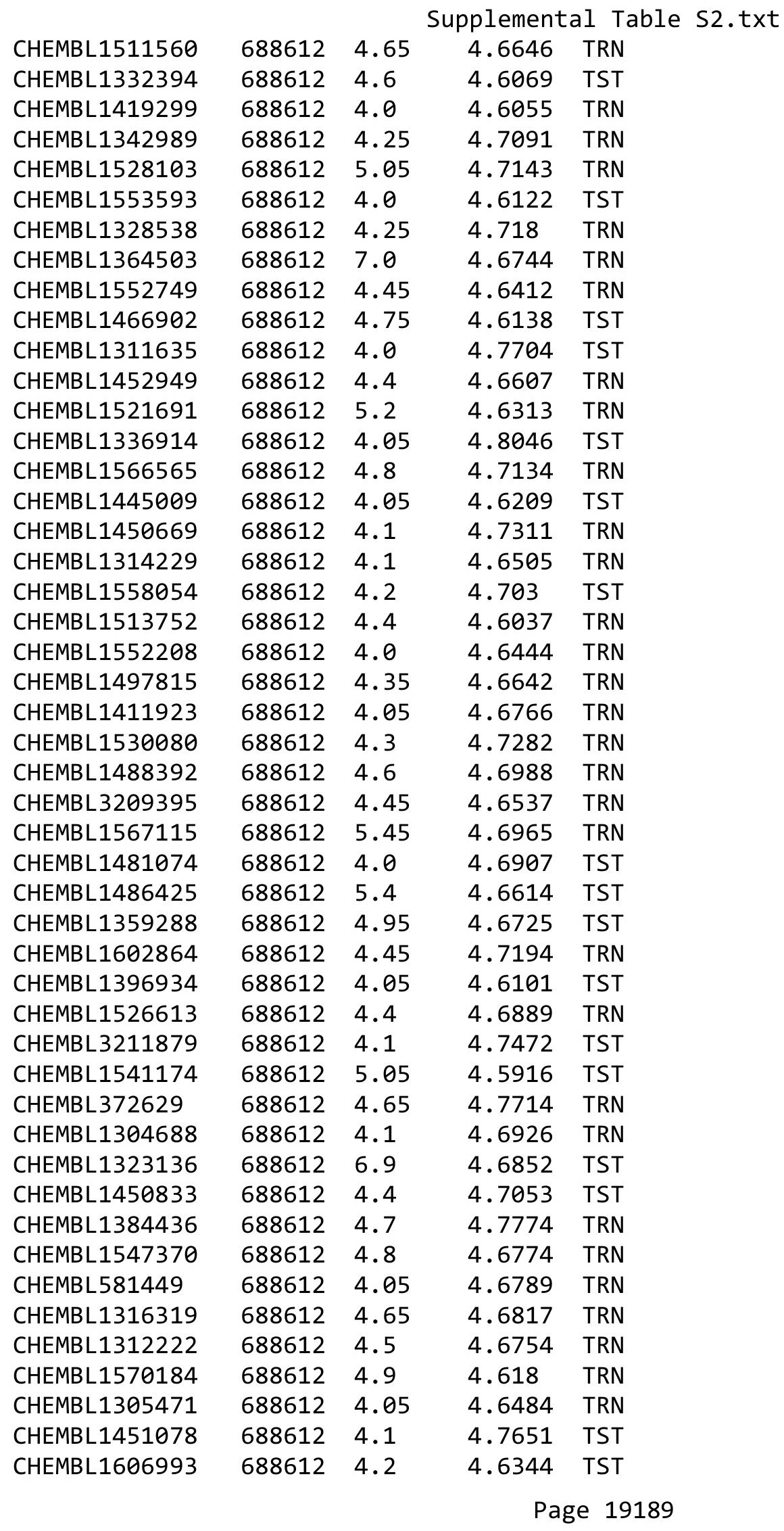




\begin{tabular}{|c|c|c|c|c|c|}
\hline & & \multicolumn{4}{|c|}{ Supplemental Table S2.txt } \\
\hline CHEMBL1515472 & 688612 & 4.75 & 4.707 & TRN & \\
\hline CHEMBL1357600 & 688612 & 4.6 & 4.622 & TRN & \\
\hline CHEMBL1422953 & 688612 & 4.45 & 4.7357 & TST & \\
\hline CHEMBL1499823 & 688612 & 4.95 & 4.7281 & TRN & \\
\hline CHEMBL1564636 & 688612 & 4.2 & 4.6364 & TRN & \\
\hline CHEMBL1488747 & 688612 & 4.0 & 4.6683 & TST & \\
\hline CHEMBL1477682 & 688612 & 4.1 & 4.5932 & TRN & \\
\hline CHEMBL1313460 & 688612 & 4.45 & 4.6765 & TRN & \\
\hline CHEMBL1334143 & 688612 & 4.2 & 4.6172 & TST & \\
\hline CHEMBL1373038 & 688612 & 4.2 & 4.7104 & TST & \\
\hline CHEMBL1421586 & 688612 & 4.7 & 4.6053 & TRN & \\
\hline CHEMBL1994007 & 688612 & 4.3 & 4.6527 & TRN & \\
\hline CHEMBL1447029 & 688612 & 5.3 & 4.6571 & TST & \\
\hline CHEMBL1567885 & 688612 & 4.1 & 4.6543 & TRN & \\
\hline CHEMBL1565902 & 688612 & 4.45 & 4.6506 & TST & \\
\hline CHEMBL1460261 & 688612 & 5.9 & 4.6353 & TRN & \\
\hline CHEMBL1385721 & 688612 & 4.05 & 4.6481 & TRN & \\
\hline CHEMBL1454685 & 688612 & 4.05 & 4.7173 & TST & \\
\hline CHEMBL1510757 & 688612 & 4.85 & 4.6475 & TRN & \\
\hline CHEMBL1566083 & 688612 & 4.75 & 4.6787 & TRN & \\
\hline CHEMBL1984086 & 688612 & 4.9 & 4.6402 & TRN & \\
\hline CHEMBL1597217 & 688612 & 4.45 & 4.6806 & TRN & \\
\hline CHEMBL1479440 & 688612 & 6.8499 & 4.6604 & TRN & \\
\hline CHEMBL1440977 & 688612 & 4.6 & 4.6643 & TST & \\
\hline CHEMBL1383950 & 688612 & 5.75 & 4.63399 & 99999999995 & TRN \\
\hline CHEMBL1604076 & 688612 & 4.3 & 4.6458 & TRN & \\
\hline CHEMBL1338363 & 688612 & 4.05 & 4.622 & TRN & \\
\hline CHEMBL1461321 & 688612 & 4.65 & 4.7478 & TRN & \\
\hline CHEMBL3194370 & 688612 & 4.05 & 4.6568 & TRN & \\
\hline CHEMBL1476065 & 688612 & 4.6 & 4.63399 & 99999999995 & TRN \\
\hline CHEMBL1968462 & 688612 & 4.15 & 4.713 & TRN & \\
\hline CHEMBL1378636 & 688612 & 5.5 & 4.6978 & TST & \\
\hline CHEMBL1468954 & 688612 & 4.3 & 4.7156 & TRN & \\
\hline CHEMBL1505845 & 688612 & 4.05 & 4.6327 & TRN & \\
\hline CHEMBL1453134 & 688612 & 4.3 & 4.7386 & TRN & \\
\hline CHEMBL1321072 & 688612 & 4.1 & 4.6691 & TRN & \\
\hline CHEMBL1422017 & 688612 & 4.65 & 4.6647 & TST & \\
\hline CHEMBL1556331 & 688612 & 4.55 & 4.6584 & TRN & \\
\hline CHEMBL1308536 & 688612 & 5.55 & 4.6783 & TST & \\
\hline CHEMBL1416645 & 688612 & 4.0 & 4.7211 & TST & \\
\hline CHEMBL1388937 & 688612 & 4.85 & 4.6025 & TRN & \\
\hline CHEMBL1404587 & 688612 & 4.75 & 4.6693 & TRN & \\
\hline CHEMBL1305449 & 688612 & 4.05 & 4.5966 & TRN & \\
\hline CHEMBL3193553 & 688612 & 4.75 & 4.80699 & 99999999995 & TRN \\
\hline CHEMBL600070 & 688612 & 5.9 & 4.6765 & TST & \\
\hline CHEMBL1500471 & 688612 & 4.1 & 4.6511 & TRN & \\
\hline CHEMBL1500225 & 688612 & 4.7 & 4.7508 & TST & \\
\hline CHEMBL1517463 & 688612 & 4.05 & 4.624 & TRN & \\
\hline
\end{tabular}




\begin{tabular}{|c|c|c|c|c|c|}
\hline \multicolumn{6}{|c|}{ Supplemental Table S2.txt } \\
\hline CHEMBL1375350 & 688612 & 4.4 & 4.6464 & TRN & \\
\hline CHEMBL1412130 & 688612 & 5.3 & 4.635 & TRN & \\
\hline CHEMBL1604719 & 688612 & 4.4 & 4.7252 & TRN & \\
\hline CHEMBL1580870 & 688612 & 4.6 & 4.7849 & TRN & \\
\hline CHEMBL 34241 & 688612 & 4.65 & 4.7468 & TST & \\
\hline CHEMBL1379186 & 688612 & 5.3 & 4.6994 & TST & \\
\hline CHEMBL1452180 & 688612 & 5.0 & 4.6597 & TRN & \\
\hline CHEMBL3212421 & 688612 & 5.0 & 4.7553 & TRN & \\
\hline CHEMBL1555041 & 688612 & 4.85 & 4.689 & TRN & \\
\hline CHEMBL1401426 & 688612 & 4.7 & 4.6486 & TRN & \\
\hline CHEMBL1414915 & 688612 & 4.4 & 4.6714 & TRN & \\
\hline CHEMBL1500997 & 688612 & 4.35 & 4.71899 & 9999999999 & TRN \\
\hline CHEMBL1501049 & 688612 & 4.6 & 4.6275 & TST & \\
\hline CHEMBL494668 & 688612 & 4.95 & 4.6092 & TRN & \\
\hline CHEMBL1406091 & 688612 & 4.65 & 4.7445 & TRN & \\
\hline CHEMBL1424064 & 688612 & 4.15 & 4.7245 & TRN & \\
\hline CHEMBL1360068 & 688612 & 5.5 & 4.6154 & TRN & \\
\hline CHEMBL1303208 & 688612 & 6.8499 & 4.6099 & TRN & \\
\hline CHEMBL1371210 & 688612 & 4.1 & 4.6962 & TST & \\
\hline CHEMBL1589344 & 688612 & 5.0 & 4.7335 & TRN & \\
\hline CHEMBL1312514 & 688612 & 5.5 & 4.6731 & TRN & \\
\hline CHEMBL1338776 & 688612 & 4.6 & 4.7185 & TRN & \\
\hline CHEMBL1569747 & 688612 & 5.6 & 4.5751 & TRN & \\
\hline CHEMBL1568880 & 688612 & 4.05 & 4.632 & TRN & \\
\hline CHEMBL3193667 & 688612 & 4.4 & 4.6115 & TRN & \\
\hline CHEMBL1420114 & 688612 & 4.45 & 4.6907 & TRN & \\
\hline CHEMBL1594992 & 688612 & 5.5 & 4.6086 & TRN & \\
\hline CHEMBL1309010 & 688612 & 4.05 & 4.6916 & TRN & \\
\hline CHEMBL1974269 & 688612 & 4.35 & 4.6867 & TRN & \\
\hline CHEMBL1405684 & 688612 & 4.55 & 4.7333 & TRN & \\
\hline CHEMBL1419986 & 688612 & 4.3 & 4.5889 & TRN & \\
\hline CHEMBL1493337 & 688612 & 5.45 & 4.6532 & TRN & \\
\hline CHEMBL1451968 & 688612 & 4.9 & 4.663 & TRN & \\
\hline CHEMBL1516293 & 688612 & 5.4 & 4.7062 & TRN & \\
\hline CHEMBL1443475 & 688612 & 4.1 & 4.5823 & TRN & \\
\hline CHEMBL1418573 & 688612 & 4.0 & 4.7399 & TST & \\
\hline CHEMBL3191236 & 688612 & 4.05 & 4.7538 & TRN & \\
\hline CHEMBL1575900 & 688612 & 4.0 & 4.6673 & TRN & \\
\hline CHEMBL1333129 & 688612 & 7.0 & 4.6502 & TRN & \\
\hline CHEMBL1389886 & 688612 & 4.4 & 4.6083 & TRN & \\
\hline CHEMBL1300007 & 688612 & 4.4 & 4.8097 & TRN & \\
\hline CHEMBL1435013 & 688612 & 4.95 & 4.678 & TRN & \\
\hline CHEMBL1313522 & 688612 & 4.7 & 4.5729 & TRN & \\
\hline CHEMBL1528096 & 688612 & 4.05 & 4.6698 & TRN & \\
\hline CHEMBL1421864 & 688612 & 4.5 & 4.6793 & TRN & \\
\hline CHEMBL1426071 & 688612 & 4.35 & 4.6888 & TRN & \\
\hline CHEMBL1609749 & 688612 & 4.6 & 4.7314 & TST & \\
\hline CHEMBL1304692 & 688612 & 4.45 & 4.6594 & TRN & \\
\hline
\end{tabular}




\begin{tabular}{|c|c|c|c|c|c|}
\hline \multicolumn{6}{|c|}{ Supplemental Table S2.txt } \\
\hline CHEMBL1978364 & 688612 & 5.35 & 4.7454 & TRN & \\
\hline CHEMBL1445239 & 688612 & 6.05 & 4.6348 & TRN & \\
\hline CHEMBL1597580 & 688612 & 5.6 & 4.6629 & TRN & \\
\hline CHEMBL1320759 & 688612 & 4.5 & 4.5417 & TRN & \\
\hline CHEMBL1504580 & 688612 & 4.6 & 4.7102 & TRN & \\
\hline CHEMBL1395381 & 688612 & 4.35 & 4.5808 & TRN & \\
\hline CHEMBL1588263 & 688612 & 4.4 & 4.7651 & TST & \\
\hline CHEMBL 2374060 & 688612 & 5.45 & 4.6962 & TST & \\
\hline CHEMBL1975756 & 688612 & 4.95 & 4.7606 & TRN & \\
\hline CHEMBL1380497 & 688612 & 4.25 & 4.7267 & TRN & \\
\hline CHEMBL1446798 & 688612 & 4.05 & 4.7052 & TST & \\
\hline CHEMBL1528726 & 688612 & 4.55 & 4.6937 & TRN & \\
\hline CHEMBL1513186 & 688612 & 4.0 & 4.59399 & 9999999999 & TST \\
\hline CHEMBL1475707 & 688612 & 4.4 & 4.5899 & TRN & \\
\hline CHEMBL 274070 & 688612 & 4.3 & 4.7805 & TST & \\
\hline CHEMBL1171436 & 688612 & 5.55 & 4.6322 & TRN & \\
\hline CHEMBL1505098 & 688612 & 4.1 & 4.6279 & TRN & \\
\hline CHEMBL1426294 & 688612 & 6.8499 & 4.5727 & TRN & \\
\hline CHEMBL1319612 & 688612 & 6.1 & 4.7205 & TRN & \\
\hline CHEMBL1401988 & 688612 & 4.1 & 4.6808 & TRN & \\
\hline CHEMBL1525240 & 688612 & 4.3 & 4.7684 & TRN & \\
\hline CHEMBL1499097 & 688612 & 4.0 & 4.5952 & TRN & \\
\hline CHEMBL1521985 & 688612 & 4.4 & 4.6866 & TRN & \\
\hline CHEMBL1379978 & 688612 & 4.05 & 4.5276 & TRN & \\
\hline CHEMBL1568776 & 688612 & 4.1 & 4.7449 & TRN & \\
\hline CHEMBL1513667 & 688612 & 4.1 & 4.6093 & TRN & \\
\hline CHEMBL1509777 & 688612 & 6.0 & 4.6205 & TST & \\
\hline CHEMBL1496434 & 688612 & 4.6 & 4.6919 & TRN & \\
\hline CHEMBL1341093 & 688612 & 4.4 & 4.6807 & TST & \\
\hline CHEMBL1339264 & 688612 & 4.4 & 4.6639 & TRN & \\
\hline CHEMBL1501374 & 688612 & 6.8499 & 4.7352 & TRN & \\
\hline CHEMBL1414197 & 688612 & 4.35 & 4.6788 & TRN & \\
\hline CHEMBL1459632 & 688612 & 4.6 & 4.6746 & TST & \\
\hline CHEMBL1499214 & 688612 & 4.05 & 4.7712 & TRN & \\
\hline CHEMBL1407220 & 688612 & 5.2 & 4.7031 & TST & \\
\hline CHEMBL1569019 & 688612 & 4.0 & 4.5854 & TST & \\
\hline CHEMBL1494137 & 688612 & 4.5 & 4.7623 & TST & \\
\hline CHEMBL1527129 & 688612 & 4.4 & 4.6649 & TRN & \\
\hline CHEMBL1487018 & 688612 & 4.05 & 4.6615 & TRN & \\
\hline CHEMBL1578962 & 688612 & 4.65 & 4.72199 & 99999999995 & TRN \\
\hline CHEMBL1611174 & 688612 & 4.05 & 4.6888 & TRN & \\
\hline CHEMBL1585367 & 688612 & 4.4 & 4.6758 & TST & \\
\hline CHEMBL1602572 & 688612 & 4.55 & 4.6563 & TRN & \\
\hline CHEMBL1509357 & 688612 & 4.3 & 4.7543 & TRN & \\
\hline CHEMBL1577181 & 688612 & 4.05 & 4.6039 & TRN & \\
\hline CHEMBL1371043 & 688612 & 6.1 & 4.6542 & TRN & \\
\hline CHEMBL1495862 & 688612 & 4.7 & 4.8038 & TST & \\
\hline CHEMBL1371052 & 688612 & 6.0 & 4.7092 & TRN & \\
\hline
\end{tabular}




\begin{tabular}{|c|c|c|c|c|c|}
\hline & & \multicolumn{4}{|c|}{ Supplemental Table S2.txt } \\
\hline CHEMBL1385640 & 688612 & 4.2 & 4.7124 & TRN & \\
\hline CHEMBL1539087 & 688612 & 4.05 & 4.6746 & TST & \\
\hline CHEMBL1358299 & 688612 & 4.1 & 4.6563 & TRN & \\
\hline CHEMBL1347106 & 688612 & 4.4 & 4.7006 & TRN & \\
\hline CHEMBL1411305 & 688612 & 4.05 & 4.5729 & TRN & \\
\hline CHEMBL1352629 & 688612 & 6.8 & 4.6467 & TRN & \\
\hline CHEMBL1494533 & 688612 & 4.4 & 4.7448 & TST & \\
\hline CHEMBL1484379 & 688612 & 4.1 & 4.6523 & TRN & \\
\hline CHEMBL1338766 & 688612 & 5.3 & 4.6478 & TST & \\
\hline CHEMBL1335402 & 688612 & 6.15 & 4.7153 & TRN & \\
\hline CHEMBL1414574 & 688612 & 4.4 & 4.5539 & TRN & \\
\hline CHEMBL1579763 & 688612 & 6.0 & 4.7568 & TRN & \\
\hline CHEMBL1462859 & 688612 & 5.05 & 4.6523 & TRN & \\
\hline CHEMBL1481533 & 688612 & 4.1 & 4.6761 & TRN & \\
\hline CHEMBL1606907 & 688612 & 4.0 & 4.7865 & TRN & \\
\hline CHEMBL3195511 & 688612 & 4.0 & 4.6973 & TRN & \\
\hline CHEMBL1315688 & 688612 & 4.55 & 4.5994 & TRN & \\
\hline CHEMBL1483685 & 688612 & 4.05 & 4.7017 & TRN & \\
\hline CHEMBL1335838 & 688612 & 4.8 & 4.6184 & TRN & \\
\hline CHEMBL1450422 & 688612 & 4.5 & 4.7353 & TRN & \\
\hline CHEMBL1608914 & 688612 & 4.55 & 4.67899 & 9999999999 & TRN \\
\hline CHEMBL1479236 & 688612 & 4.05 & 4.6638 & TRN & \\
\hline CHEMBL1399711 & 688612 & 5.65 & 4.7354 & TST & \\
\hline CHEMBL1543572 & 688612 & 4.4 & 4.6642 & TRN & \\
\hline CHEMBL1329367 & 688612 & 4.25 & 4.7195 & TRN & \\
\hline CHEMBL1507971 & 688612 & 4.75 & 4.794 & TST & \\
\hline CHEMBL1982025 & 688612 & 4.4 & 4.824 & TRN & \\
\hline CHEMBL1459125 & 688612 & 5.1 & 4.7428 & TRN & \\
\hline CHEMBL1394634 & 688612 & 5.45 & 4.6545 & TST & \\
\hline CHEMBL3199809 & 688612 & 4.3 & 4.7362 & TST & \\
\hline CHEMBL1324135 & 688612 & 4.4 & 4.7151 & TRN & \\
\hline CHEMBL1505045 & 688612 & 4.35 & 4.6399 & TRN & \\
\hline CHEMBL1571452 & 688612 & 4.05 & 4.6782 & TST & \\
\hline CHEMBL1596021 & 688612 & 4.05 & 4.7047 & TRN & \\
\hline CHEMBL1327040 & 688612 & 4.6 & 4.6863 & TRN & \\
\hline CHEMBL1351149 & 688612 & 4.05 & 4.6348 & TRN & \\
\hline CHEMBL3195081 & 688612 & 4.45 & 4.6876 & TRN & \\
\hline CHEMBL1572288 & 688612 & 4.35 & 4.6896 & TRN & \\
\hline CHEMBL1509225 & 688612 & 4.95 & 4.6196 & TRN & \\
\hline CHEMBL1470856 & 688612 & 4.85 & 4.7304 & TRN & \\
\hline CHEMBL1441545 & 688612 & 4.4 & 4.6273 & TRN & \\
\hline CHEMBL1482914 & 688612 & 4.6 & 4.6601 & TRN & \\
\hline CHEMBL1316438 & 688612 & 4.4 & 4.663 & TRN & \\
\hline CHEMBL1378026 & 688612 & 4.0 & 4.7627 & TST & \\
\hline CHEMBL1301586 & 688612 & 4.4 & 4.7121 & TST & \\
\hline CHEMBL1561738 & 688612 & 4.1 & 4.7404 & TRN & \\
\hline CHEMBL1607263 & 688612 & 5.0 & 4.6012 & TRN & \\
\hline CHEMBL1577286 & 688612 & 4.6 & 4.6399 & TST & \\
\hline
\end{tabular}




\begin{tabular}{|c|c|c|c|c|c|}
\hline \multirow{3}{*}{$\begin{array}{l}\text { CHEMBL1457011 } \\
\text { CHEMBL } 1436671\end{array}$} & \multirow{3}{*}{$\begin{array}{l}688612 \\
688612\end{array}$} & \multicolumn{4}{|c|}{ Supplemental Table S2.txt } \\
\hline & & 4.7 & 4.71899 & 9999999999 & TRN \\
\hline & & 4.3 & 4.7286 & TRN & \\
\hline CHEMBL1370230 & 688612 & 6.1 & 4.6954 & TRN & \\
\hline CHEMBL1567370 & 688612 & 4.1 & 4.6776 & TST & \\
\hline CHEMBL1504007 & 688612 & 4.05 & 4.5813 & TST & \\
\hline CHEMBL1571398 & 688612 & 5.25 & 4.6875 & TRN & \\
\hline CHEMBL1305529 & 688612 & 4.05 & 4.6844 & TRN & \\
\hline CHEMBL1611521 & 688612 & 4.1 & 4.7313 & TRN & \\
\hline CHEMBL1388117 & 688612 & 4.2 & 4.7562 & TST & \\
\hline CHEMBL1540144 & 688612 & 4.95 & 4.681 & TRN & \\
\hline CHEMBL1550775 & 688612 & 4.0 & 4.6543 & TRN & \\
\hline CHEMBL1522996 & 688612 & 6.0 & 4.6911 & TRN & \\
\hline CHEMBL1432537 & 688612 & 4.05 & 4.6108 & TRN & \\
\hline CHEMBL1420921 & 688612 & 4.0 & 4.6459 & TRN & \\
\hline CHEMBL1498383 & 688612 & 4.7 & 4.6876 & TST & \\
\hline CHEMBL1344800 & 688612 & 6.8499 & 4.6971 & TST & \\
\hline CHEMBL1554287 & 688612 & 4.9 & 4.6037 & TRN & \\
\hline CHEMBL1362734 & 688612 & 4.25 & 4.7105 & TST & \\
\hline CHEMBL1319682 & 688612 & 5.3 & 4.6772 & TRN & \\
\hline CHEMBL1301421 & 688612 & 4.05 & 4.7219 & TRN & \\
\hline CHEMBL1468018 & 688612 & 4.4 & 4.7297 & TST & \\
\hline CHEMBL1581777 & 688612 & 4.45 & 4.744 & TST & \\
\hline CHEMBL1386276 & 688612 & 4.1 & 4.721 & TST & \\
\hline CHEMBL 2006594 & 688612 & 4.65 & 4.6933 & TRN & \\
\hline CHEMBL1348134 & 688612 & 4.8 & 4.6893 & TRN & \\
\hline CHEMBL1432248 & 688612 & 4.5 & 4.6247 & TRN & \\
\hline CHEMBL1563546 & 688612 & 4.2 & 4.668 & TST & \\
\hline CHEMBL1539909 & 688612 & 5.2 & 4.6261 & TRN & \\
\hline CHEMBL1578127 & 688612 & 4.1 & 4.7071 & TRN & \\
\hline CHEMBL 2006274 & 688612 & 5.35 & 4.6879 & TRN & \\
\hline CHEMBL1417952 & 688612 & 4.9 & 4.6551 & TRN & \\
\hline CHEMBL3207592 & 688612 & 4.95 & 4.6083 & TRN & \\
\hline CHEMBL1375040 & 688612 & 4.5 & 4.7142 & TST & \\
\hline CHEMBL1509438 & 688612 & 4.15 & 4.6169 & TRN & \\
\hline CHEMBL1542053 & 688612 & 6.8499 & 4.6905 & TRN & \\
\hline CHEMBL1507396 & 688612 & 4.7 & 4.6451 & TST & \\
\hline CHEMBL1530437 & 688612 & 4.55 & 4.7155 & TRN & \\
\hline CHEMBL1481897 & 688612 & 6.9 & 4.667 & TRN & \\
\hline CHEMBL1526229 & 688612 & 5.45 & 4.7139 & TST & \\
\hline CHEMBL1510357 & 688612 & 4.05 & 4.6855 & TST & \\
\hline CHEMBL1306629 & 688612 & 4.05 & 4.6308 & TST & \\
\hline CHEMBL1486913 & 688612 & 4.2 & 4.7282 & TST & \\
\hline CHEMBL1401117 & 688612 & 5.6 & 4.5545 & TRN & \\
\hline CHEMBL1337952 & 688612 & 5.25 & 4.625 & TRN & \\
\hline CHEMBL1357579 & 688612 & 4.05 & 4.5933 & TRN & \\
\hline CHEMBL3208140 & 688612 & 5.5 & 4.7152 & TRN & \\
\hline CHEMBL 1584542 & 688612 & 6.5 & 4.6496 & TRN & \\
\hline CHEMBL1589472 & 688612 & 4.4 & 4.5635 & TST & \\
\hline
\end{tabular}




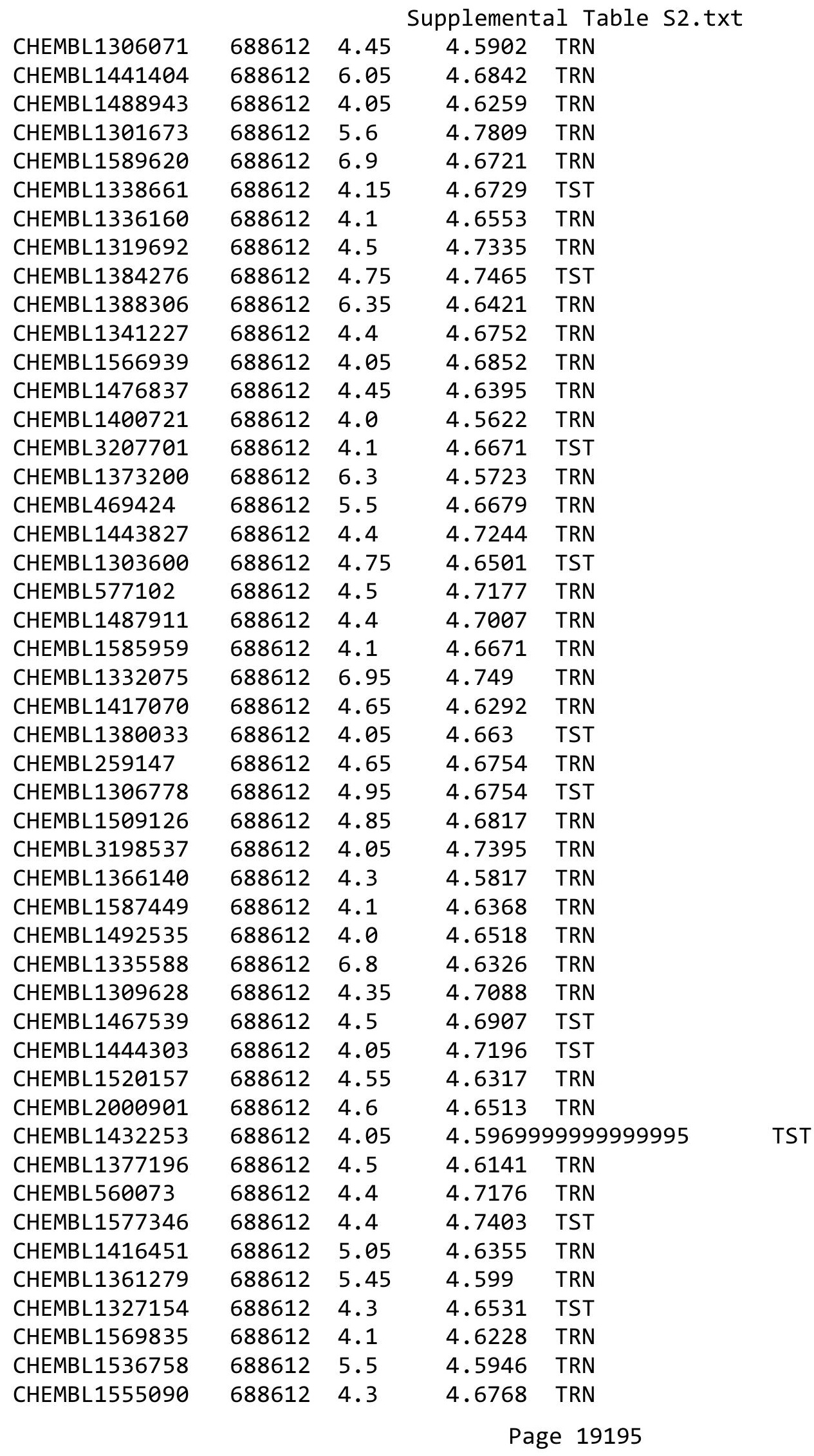




\begin{tabular}{|c|c|c|c|c|c|}
\hline \multicolumn{6}{|c|}{ Supplemental Table s2.txt } \\
\hline CHEMBL1402902 & 688612 & 4.85 & 4.7146 & TRN & \\
\hline CHEMBL1403168 & 688612 & 5.35 & 4.6548 & TRN & \\
\hline CHEMBL1383216 & 688612 & 4.0 & 4.5214 & TRN & \\
\hline CHEMBL1390198 & 688612 & 4.9 & 4.7104 & TRN & \\
\hline CHEMBL1493244 & 688612 & 4.05 & 4.6441 & TST & \\
\hline CHEMBL3191066 & 688612 & 4.05 & 4.6491 & TRN & \\
\hline CHEMBL1518888 & 688612 & 4.5 & 4.6921 & TRN & \\
\hline CHEMBL1350546 & 688612 & 4.0 & 4.7132 & TST & \\
\hline CHEMBL3196877 & 688612 & 4.5 & 4.7497 & TRN & \\
\hline CHEMBL1301289 & 688612 & 4.6 & 4.6271 & TRN & \\
\hline CHEMBL3197868 & 688612 & 4.0 & 4.6548 & TRN & \\
\hline CHEMBL3198903 & 688612 & 4.1 & 4.6999 & TRN & \\
\hline CHEMBL1361894 & 688612 & 4.55 & 4.641 & TRN & \\
\hline CHEMBL1591470 & 688612 & 4.05 & 4.6191 & TRN & \\
\hline CHEMBL1601394 & 688612 & 5.05 & 4.8459 & TRN & \\
\hline CHEMBL1324795 & 688612 & 6.7001 & 4.609 & TRN & \\
\hline CHEMBL1362298 & 688612 & 4.0 & 4.7249 & TRN & \\
\hline CHEMBL1418586 & 688612 & 4.1 & 4.6372 & TRN & \\
\hline CHEMBL1528208 & 688612 & 5.05 & 4.6605 & TRN & \\
\hline CHEMBL1366562 & 688612 & 4.35 & 4.6391 & TRN & \\
\hline CHEMBL1549137 & 688612 & 4.25 & 4.6246 & TRN & \\
\hline CHEMBL1320991 & 688612 & 4.25 & 4.6996 & TRN & \\
\hline CHEMBL1341352 & 688612 & 6.8499 & 4.5915 & TRN & \\
\hline CHEMBL1580292 & 688612 & 5.7 & 4.6234 & TRN & \\
\hline CHEMBL1386851 & 688612 & 5.0 & 4.6316 & TRN & \\
\hline CHEMBL1558285 & 688612 & 4.0 & 4.7021 & TST & \\
\hline CHEMBL1351611 & 688612 & 4.7 & 4.7718 & TRN & \\
\hline CHEMBL1508758 & 688612 & 4.1 & 4.6809 & TRN & \\
\hline CHEMBL1579003 & 688612 & 4.4 & 4.6905 & TRN & \\
\hline CHEMBL1393605 & 688612 & 5.1 & 4.7557 & TRN & \\
\hline CHEMBL1443237 & 688612 & 6.25 & 4.66100 & 00000000005 & TRN \\
\hline CHEMBL1594286 & 688612 & 4.8 & 4.7129 & TRN & \\
\hline CHEMBL1356626 & 688612 & 4.05 & 4.6448 & TRN & \\
\hline CHEMBL3210411 & 688612 & 4.8 & 4.7292 & TRN & \\
\hline CHEMBL1317139 & 688612 & 4.05 & 4.6401 & TRN & \\
\hline CHEMBL3197845 & 688612 & 4.8 & 4.6833 & TRN & \\
\hline CHEMBL3191969 & 688612 & 4.8 & 4.79 & TRN & \\
\hline CHEMBL1302776 & 688612 & 4.4 & 4.6113 & TRN & \\
\hline CHEMBL1485180 & 688612 & 4.1 & 4.6354 & TRN & \\
\hline CHEMBL1591359 & 688612 & 6.7501 & 4.6461 & TRN & \\
\hline CHEMBL1438401 & 688612 & 4.45 & 4.7372 & TRN & \\
\hline CHEMBL1387693 & 688612 & 5.25 & 4.7424 & TRN & \\
\hline CHEMBL1367354 & 688612 & 5.55 & 4.6743 & TRN & \\
\hline CHEMBL1549687 & 688612 & 4.7 & 4.7798 & TRN & \\
\hline CHEMBL1329318 & 688612 & 4.4 & 4.6723 & TRN & \\
\hline CHEMBL1407693 & 688612 & 4.1 & 4.6256 & TST & \\
\hline CHEMBL73451 & 688612 & 4.2 & 4.6752 & TST & \\
\hline CHEMBL1367248 & 688612 & 4.45 & 4.6651 & TRN & \\
\hline
\end{tabular}




\begin{tabular}{|c|c|c|c|c|c|}
\hline & & \multicolumn{4}{|c|}{ Supplemental Table S2.txt } \\
\hline CHEMBL1307328 & 688612 & 5.45 & 4.6731 & TRN & \\
\hline CHEMBL1576610 & 688612 & 4.4 & 4.6694 & TRN & \\
\hline CHEMBL1587644 & 688612 & 4.3 & 4.6523 & TRN & \\
\hline CHEMBL1575072 & 688612 & 4.7 & 4.67899 & 9999999999 & TRN \\
\hline CHEMBL1486156 & 688612 & 4.25 & 4.6518 & TRN & \\
\hline CHEMBL1611199 & 688612 & 5.05 & 4.7219 & TRN & \\
\hline CHEMBL1173206 & 688612 & 6.1 & 4.6533 & TST & \\
\hline CHEMBL1480850 & 688612 & 4.4 & 4.6693 & TRN & \\
\hline CHEMBL1432950 & 688612 & 4.05 & 4.6982 & TST & \\
\hline CHEMBL1379821 & 688612 & 4.15 & 4.683 & TRN & \\
\hline CHEMBL1452055 & 688612 & 4.4 & 4.7242 & TRN & \\
\hline CHEMBL1470508 & 688612 & 4.1 & 4.6507 & TRN & \\
\hline CHEMBL1523721 & 688612 & 6.1 & 4.7107 & TST & \\
\hline CHEMBL1496380 & 688612 & 4.05 & 4.67 & TRN & \\
\hline CHEMBL1983302 & 688612 & 4.3 & 4.6438 & TRN & \\
\hline CHEMBL3197136 & 688612 & 5.5 & 4.7199 & TRN & \\
\hline CHEMBL1475171 & 688612 & 4.05 & 4.598 & TRN & \\
\hline CHEMBL1412131 & 688612 & 4.4 & 4.6533 & TRN & \\
\hline CHEMBL1528596 & 688612 & 4.0 & 4.6422 & TRN & \\
\hline CHEMBL1480877 & 688612 & 4.7 & 4.6783 & TRN & \\
\hline CHEMBL1587577 & 688612 & 4.0 & 4.6252 & TRN & \\
\hline CHEMBL1501234 & 688612 & 4.2 & 4.668 & TST & \\
\hline CHEMBL1321082 & 688612 & 4.5 & 4.7156 & TST & \\
\hline CHEMBL1545801 & 688612 & 3.95 & 4.605 & TRN & \\
\hline CHEMBL1366142 & 688612 & 4.05 & 4.7012 & TRN & \\
\hline CHEMBL3191786 & 688612 & 4.6 & 4.7358 & TST & \\
\hline CHEMBL1569290 & 688612 & 4.65 & 4.7073 & TRN & \\
\hline CHEMBL1610417 & 688612 & 5.05 & 4.6743 & TRN & \\
\hline CHEMBL529361 & 688612 & 5.35 & 4.6522 & TST & \\
\hline CHEMBL1464114 & 688612 & 4.65 & 4.614 & TRN & \\
\hline CHEMBL1341727 & 688612 & 4.4 & 4.5823 & TRN & \\
\hline CHEMBL1420957 & 688612 & 4.7 & 4.7239 & TST & \\
\hline CHEMBL1560401 & 688612 & 4.3 & 4.6059 & TST & \\
\hline CHEMBL1596826 & 688612 & 6.25 & 4.7205 & TRN & \\
\hline CHEMBL1394362 & 688612 & 4.25 & 4.5518 & TRN & \\
\hline CHEMBL1314571 & 688612 & 4.9 & 4.6009 & TRN & \\
\hline CHEMBL1366149 & 688612 & 4.05 & 4.7242 & TST & \\
\hline CHEMBL1339398 & 688612 & 4.9 & 4.774 & TST & \\
\hline CHEMBL505734 & 688612 & 5.85 & 4.7196 & TST & \\
\hline CHEMBL1353805 & 688612 & 4.2 & 4.732 & TST & \\
\hline CHEMBL1312212 & 688612 & 4.05 & 4.6333 & TRN & \\
\hline CHEMBL1412044 & 688612 & 4.5 & 4.7012 & TST & \\
\hline CHEMBL1525589 & 688612 & 6.45 & 4.6352 & TRN & \\
\hline CHEMBL1319048 & 688612 & 4.05 & 4.6074 & TRN & \\
\hline CHEMBL1391735 & 688612 & 5.75 & 4.6439 & TRN & \\
\hline CHEMBL3192599 & 688612 & 5.0 & 4.6796 & TRN & \\
\hline CHEMBL1421400 & 688612 & 4.4 & 4.7936 & TRN & \\
\hline CHEMBL1554328 & 688612 & 4.4 & 4.6477 & TST & \\
\hline
\end{tabular}




\begin{tabular}{|c|c|c|c|c|c|}
\hline \multicolumn{6}{|c|}{ Supplemental Table S2.txt } \\
\hline CHEMBL1352286 & 688612 & 5.5 & 4.6539 & TRN & \\
\hline CHEMBL1415038 & 688612 & 4.4 & 4.6201 & TRN & \\
\hline CHEMBL1344792 & 688612 & 4.05 & 4.6891 & TST & \\
\hline CHEMBL1408414 & 688612 & 5.45 & 4.7261 & TRN & \\
\hline CHEMBL1578214 & 688612 & 4.0 & 4.6763 & TST & \\
\hline CHEMBL1531657 & 688612 & 4.4 & 4.5852 & TRN & \\
\hline CHEMBL1420270 & 688612 & 6.15 & 4.6457 & TRN & \\
\hline CHEMBL1322810 & 688612 & 4.75 & 4.7185 & TST & \\
\hline CHEMBL3207495 & 688612 & 5.75 & 4.6197 & TRN & \\
\hline CHEMBL1389942 & 688612 & 4.05 & 4.6875 & TST & \\
\hline CHEMBL1456717 & 688612 & 6.8499 & 4.6594 & TRN & \\
\hline CHEMBL1419337 & 688612 & 4.5 & 4.6377 & TRN & \\
\hline CHEMBL1581025 & 688612 & 4.5 & 4.7171 & TST & \\
\hline CHEMBL1513822 & 688612 & 4.05 & 4.6367 & TRN & \\
\hline CHEMBL3209377 & 688612 & 4.4 & 4.6832 & TRN & \\
\hline CHEMBL1533718 & 688612 & 4.4 & 4.6832 & TRN & \\
\hline CHEMBL1328177 & 688612 & 5.55 & 4.6713 & TRN & \\
\hline CHEMBL1357027 & 688612 & 5.65 & 4.729 & TRN & \\
\hline CHEMBL1362526 & 688612 & 4.6 & 4.7715 & TRN & \\
\hline CHEMBL1499296 & 688612 & 4.25 & 4.7142 & TRN & \\
\hline CHEMBL1471532 & 688612 & 4.0 & 4.6329 & TRN & \\
\hline CHEMBL1518886 & 688612 & 4.4 & 4.703 & TST & \\
\hline CHEMBL 2004141 & 688612 & 4.85 & 4.7175 & TRN & \\
\hline CHEMBL545900 & 688612 & 6.3 & 4.6394 & TRN & \\
\hline CHEMBL1363129 & 688612 & 4.85 & 4.6864 & TRN & \\
\hline CHEMBL1460639 & 688612 & 4.4 & 4.7212 & TST & \\
\hline CHEMBL1449342 & 688612 & 4.2 & 4.6419 & TST & \\
\hline CHEMBL1469265 & 688612 & 4.55 & 4.6612 & TRN & \\
\hline CHEMBL1515272 & 688612 & 4.05 & 4.6788 & TRN & \\
\hline CHEMBL1468838 & 688612 & 4.8 & 4.7683 & TRN & \\
\hline CHEMBL1319400 & 688612 & 4.05 & 4.6747 & TRN & \\
\hline CHEMBL1307944 & 688612 & 4.05 & 4.6017 & TST & \\
\hline CHEMBL3198395 & 688612 & 4.4 & 4.7229 & TST & \\
\hline CHEMBL1341057 & 688612 & 4.85 & 4.6721 & TRN & \\
\hline CHEMBL1353838 & 688612 & 4.6 & 4.6541 & TST & \\
\hline CHEMBL3209258 & 688612 & 4.1 & 4.5822 & TRN & \\
\hline CHEMBL1326949 & 688612 & 4.05 & 4.574 & TRN & \\
\hline CHEMBL3190728 & 688612 & 5.5 & 4.6606 & TRN & \\
\hline CHEMBL1583628 & 688612 & 4.0 & 4.6948 & TST & \\
\hline CHEMBL1431725 & 688612 & 4.7 & $4.7860 e$ & 00000000005 & TRN \\
\hline CHEMBL1509676 & 688612 & 4.65 & 4.7324 & TRN & \\
\hline CHEMBL1454041 & 688612 & 4.4 & 4.6644 & TRN & \\
\hline CHEMBL1521776 & 688612 & 5.3 & 4.7199 & TST & \\
\hline CHEMBL1312290 & 688612 & 4.05 & 4.6775 & TRN & \\
\hline CHEMBL1516270 & 688612 & 4.05 & 4.6392 & TRN & \\
\hline CHEMBL1468258 & 688612 & 4.55 & 4.5779 & TST & \\
\hline CHEMBL1465246 & 688612 & 4.1 & 4.6557 & TST & \\
\hline CHEMBL1503589 & 688612 & 4.2 & 4.6153 & TRN & \\
\hline
\end{tabular}




\begin{tabular}{|c|c|c|c|c|c|}
\hline \multicolumn{6}{|c|}{ Supplemental Table S2.txt } \\
\hline CHEMBL1498725 & 688612 & 4.65 & 4.6892 & TST & \\
\hline CHEMBL1565957 & 688612 & 4.1 & 4.6803 & TRN & \\
\hline CHEMBL1435971 & 688612 & 4.05 & 4.7078 & TRN & \\
\hline CHEMBL1478006 & 688612 & 4.8 & 4.7082 & TRN & \\
\hline CHEMBL 1374450 & 688612 & 5.0 & 4.6185 & TRN & \\
\hline CHEMBL1305398 & 688612 & 4.05 & 4.6942 & TRN & \\
\hline CHEMBL1307404 & 688612 & 4.0 & 4.7387 & TST & \\
\hline CHEMBL1327230 & 688612 & 4.55 & 4.686 & TRN & \\
\hline CHEMBL1300534 & 688612 & 4.75 & 4.7058 & TRN & \\
\hline CHEMBL1491757 & 688612 & 4.05 & 4.6848 & TRN & \\
\hline CHEMBL1503882 & 688612 & 4.4 & 4.71399 & 99999999995 & TRN \\
\hline CHEMBL1574724 & 688612 & 5.5 & 4.7326 & TST & \\
\hline CHEMBL1335649 & 688612 & 4.2 & 4.5881 & TRN & \\
\hline CHEMBL1316985 & 688612 & 5.1 & 4.5637 & TRN & \\
\hline CHEMBL1427691 & 688612 & 4.05 & 4.5814 & TRN & \\
\hline CHEMBL1514618 & 688612 & 4.1 & 4.6804 & TRN & \\
\hline CHEMBL1335352 & 688612 & 4.55 & 4.6753 & TRN & \\
\hline CHEMBL1507671 & 688612 & 4.6 & 4.6189 & TRN & \\
\hline CHEMBL1389291 & 688612 & 4.0 & 4.5931 & TST & \\
\hline CHEMBL1427761 & 688612 & 4.05 & 4.6935 & TST & \\
\hline CHEMBL1597715 & 688612 & 4.05 & 4.6586 & TRN & \\
\hline CHEMBL1898790 & 688612 & 4.55 & 4.7005 & TST & \\
\hline CHEMBL1348307 & 688612 & 4.25 & 4.6746 & TRN & \\
\hline CHEMBL1721986 & 688612 & 4.65 & 4.6694 & TRN & \\
\hline CHEMBL1607898 & 688612 & 4.0 & 4.6482 & TST & \\
\hline CHEMBL1406349 & 688612 & 4.05 & 4.7314 & TRN & \\
\hline CHEMBL1327266 & 688612 & 5.35 & 4.7181 & TRN & \\
\hline CHEMBL1455361 & 688612 & 4.25 & 4.8071 & TRN & \\
\hline CHEMBL1531070 & 688612 & 4.25 & 4.6234 & TST & \\
\hline CHEMBL1416014 & 688612 & 4.05 & 4.6937 & TRN & \\
\hline CHEMBL1348038 & 688612 & 4.1 & 4.6786 & TST & \\
\hline CHEMBL1305292 & 688612 & 4.65 & 4.73600 & 0000000001 & TRN \\
\hline CHEMBL1400127 & 688612 & 4.7 & 4.6574 & TRN & \\
\hline CHEMBL1420184 & 688612 & 4.35 & 4.6766 & TRN & \\
\hline CHEMBL1608334 & 688612 & 4.6 & 4.6842 & TRN & \\
\hline CHEMBL3195011 & 688612 & 4.55 & 4.6436 & TRN & \\
\hline CHEMBL 1257003 & 688612 & 6.2238 & 4.8029 & TRN & \\
\hline CHEMBL1503482 & 688612 & 5.55 & 4.6336 & TRN & \\
\hline CHEMBL1458223 & 688612 & 6.8 & 4.5845 & TRN & \\
\hline CHEMBL1421610 & 688612 & 4.1 & 4.6884 & TRN & \\
\hline CHEMBL1473902 & 688612 & 4.05 & 4.6484 & TRN & \\
\hline CHEMBL1372649 & 688612 & 4.8 & 4.6684 & TRN & \\
\hline CHEMBL1578037 & 688612 & 4.05 & 4.6405 & TRN & \\
\hline CHEMBL1352929 & 688612 & 6.3 & 4.6355 & TRN & \\
\hline CHEMBL1412275 & 688612 & 4.1 & 4.6608 & TRN & \\
\hline CHEMBL1585999 & 688612 & 4.4 & 4.7495 & TST & \\
\hline CHEMBL1466751 & 688612 & 4.1 & 4.6779 & TRN & \\
\hline CHEMBL1444601 & 688612 & 4.05 & 4.7075 & TRN & \\
\hline
\end{tabular}




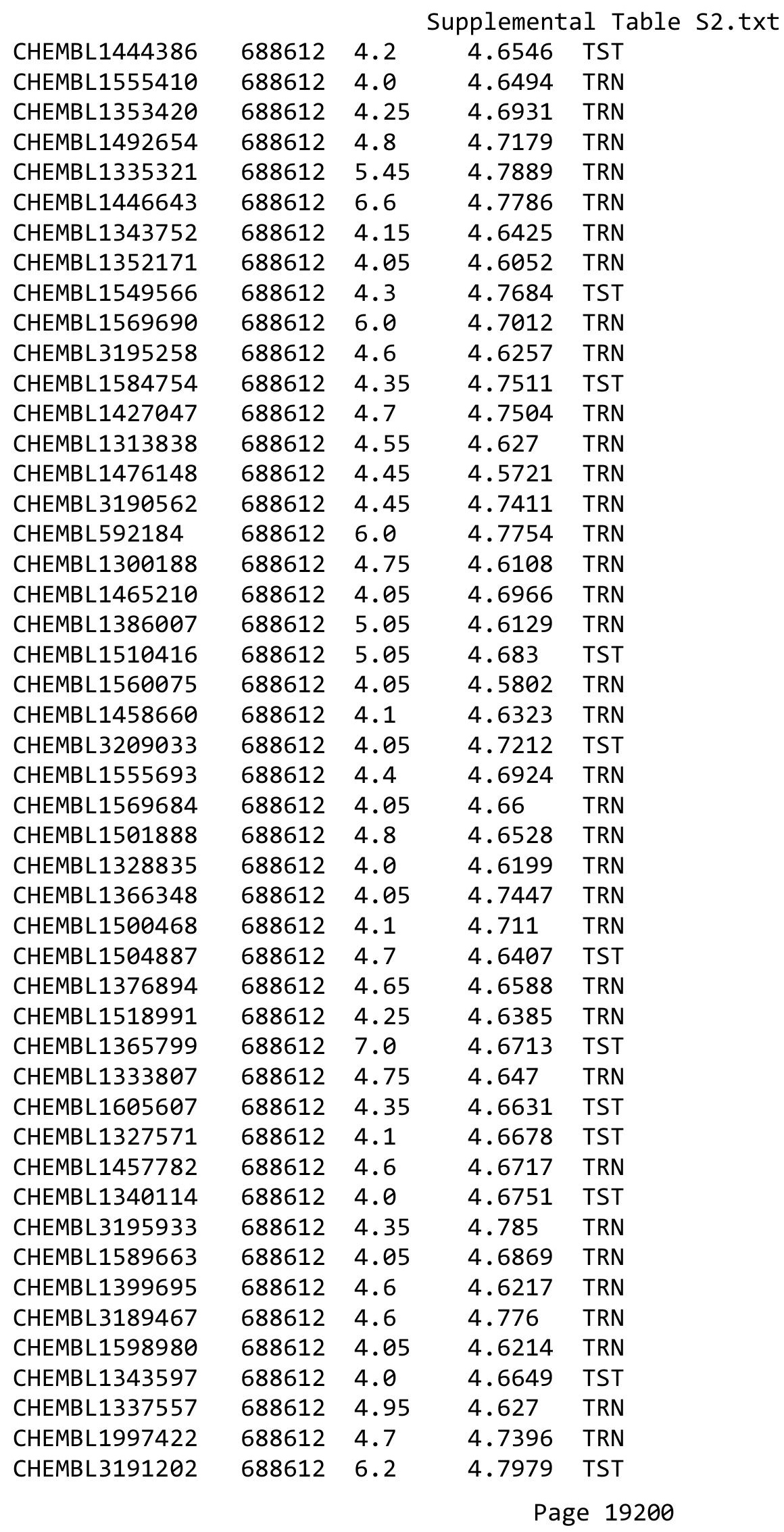




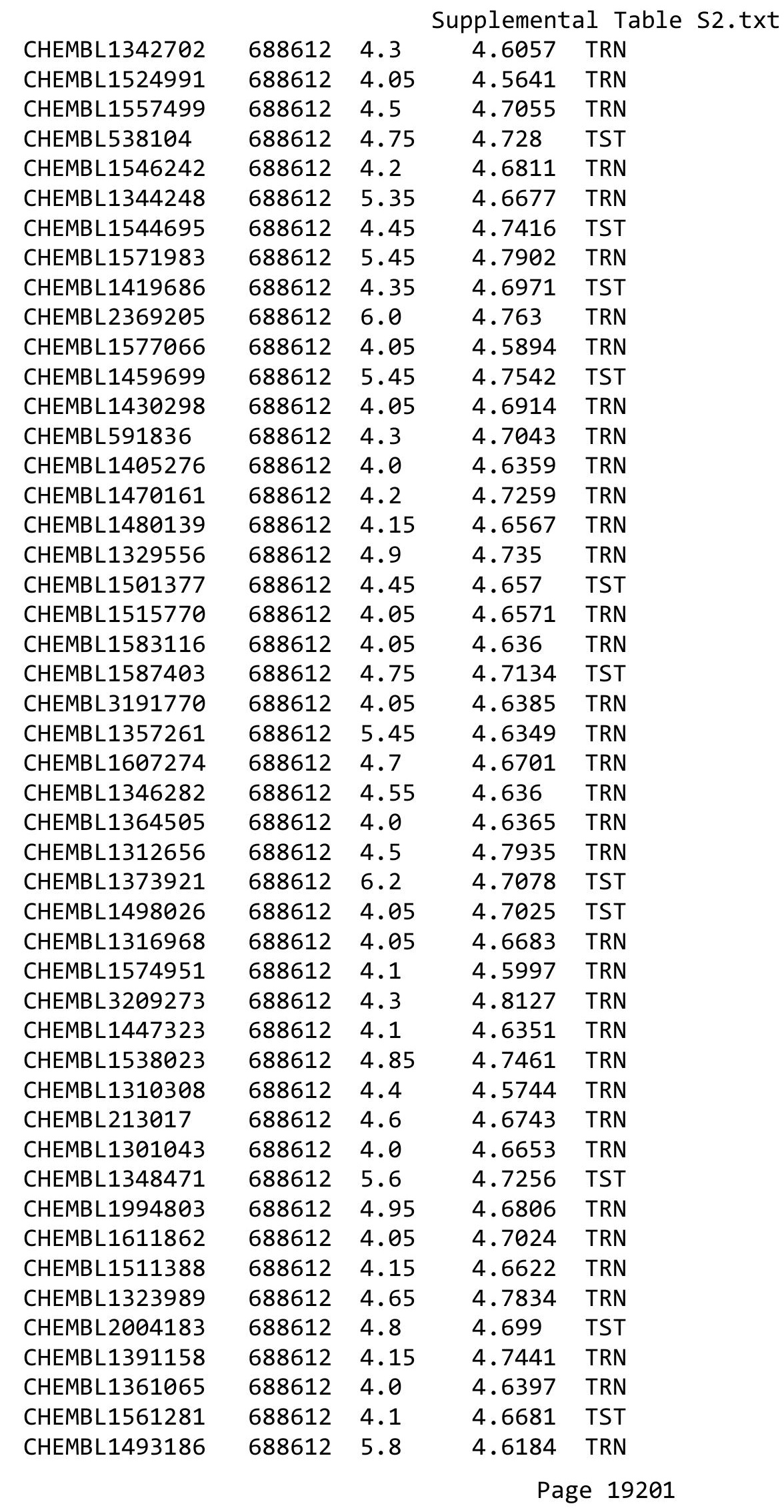




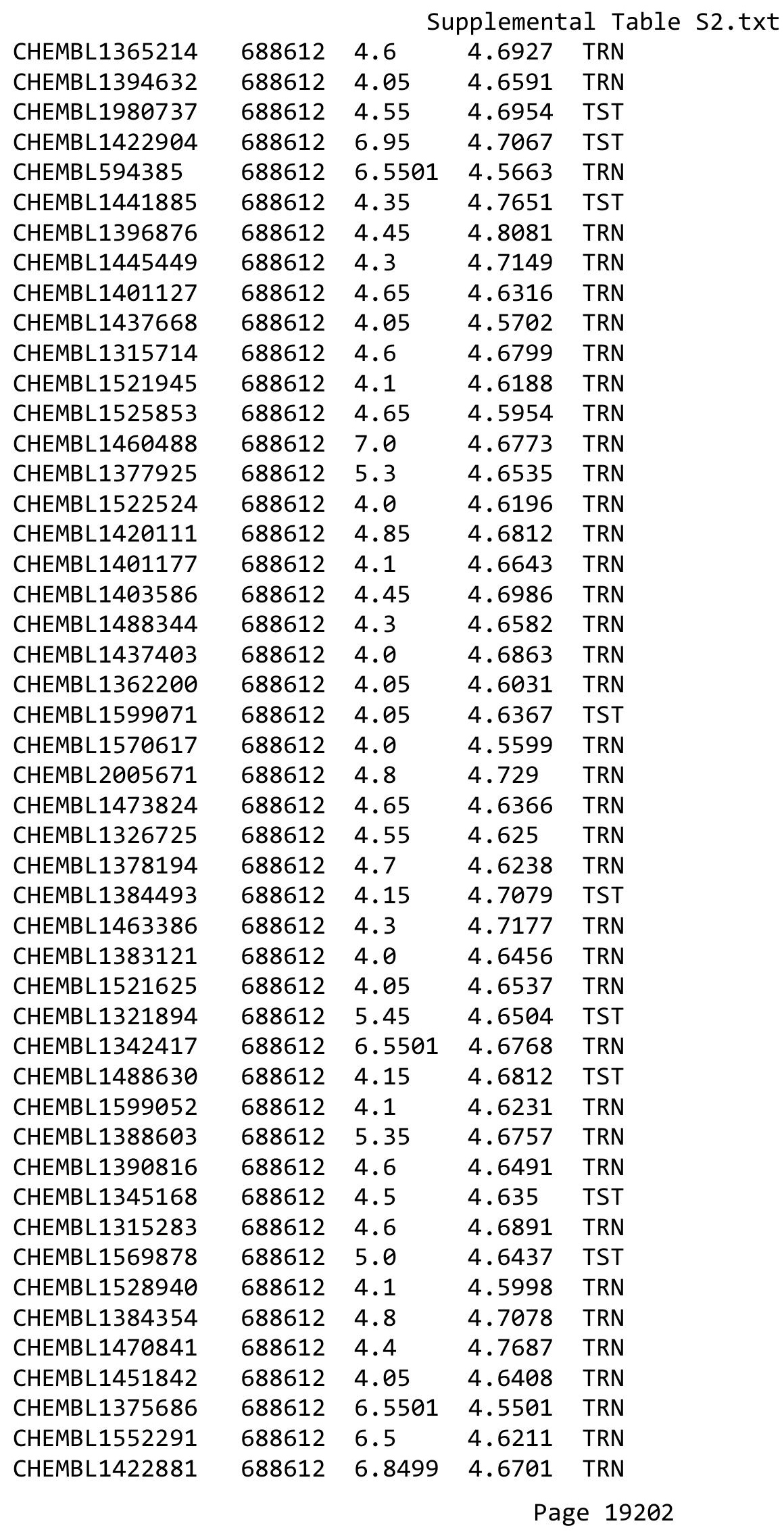




\begin{tabular}{|c|c|c|c|c|c|}
\hline \multicolumn{6}{|c|}{ Supplemental Table S2.txt } \\
\hline CHEMBL1487033 & 688612 & 4.1 & 4.6674 & TRN & \\
\hline CHEMBL 3196283 & 688612 & 4.5 & 4.7313 & TRN & \\
\hline CHEMBL1594591 & 688612 & 4.85 & 4.7121 & TRN & \\
\hline CHEMBL1399472 & 688612 & 5.0 & 4.6347 & TRN & \\
\hline CHEMBL1490680 & 688612 & 4.1 & 4.7949 & TST & \\
\hline CHEMBL1604129 & 688612 & 4.4 & 4.6461 & TRN & \\
\hline CHEMBL1414413 & 688612 & 4.1 & 4.6634 & TRN & \\
\hline CHEMBL1597423 & 688612 & 4.05 & 4.5937 & TRN & \\
\hline CHEMBL 3208853 & 688612 & 4.4 & 4.6206 & TRN & \\
\hline CHEMBL1369906 & 688612 & 4.05 & 4.5341 & TRN & \\
\hline CHEMBL3194906 & 688612 & 4.15 & 4.6952 & TRN & \\
\hline CHEMBL3191950 & 688612 & 5.85 & 4.6862 & TRN & \\
\hline CHEMBL1300265 & 688612 & 4.2 & 4.6111 & TRN & \\
\hline CHEMBL1520133 & 688612 & 5.05 & 4.7086 & TRN & \\
\hline CHEMBL3196182 & 688612 & 4.75 & 4.7645 & TST & \\
\hline CHEMBL1990993 & 688612 & 5.2 & 4.7489 & TRN & \\
\hline CHEMBL1513087 & 688612 & 4.4 & $4.6610 e$ & 00000000005 & TRN \\
\hline CHEMBL1421184 & 688612 & 5.45 & 4.6208 & TRN & \\
\hline CHEMBL1452899 & 688612 & 4.05 & 4.6297 & TRN & \\
\hline CHEMBL1530299 & 688612 & 4.35 & 4.6695 & TRN & \\
\hline CHEMBL1401900 & 688612 & 4.55 & 4.6413 & TRN & \\
\hline CHEMBL1993491 & 688612 & 4.3 & 4.712 & TST & \\
\hline CHEMBL1585431 & 688612 & 4.3 & 4.6874 & TRN & \\
\hline CHEMBL1444110 & 688612 & 4.4 & 4.6681 & TRN & \\
\hline CHEMBL1497935 & 688612 & 4.5 & 4.6633 & TST & \\
\hline CHEMBL1362334 & 688612 & 5.55 & 4.6077 & TRN & \\
\hline CHEMBL1581368 & 688612 & 4.6 & 4.6812 & TST & \\
\hline CHEMBL1538587 & 688612 & 4.05 & 4.718 & TST & \\
\hline CHEMBL1539155 & 688612 & 4.8 & 4.6043 & TRN & \\
\hline CHEMBL1421553 & 688612 & 6.95 & 4.6803 & TRN & \\
\hline CHEMBL1971613 & 688612 & 5.55 & 4.7203 & TST & \\
\hline CHEMBL1351969 & 688612 & 4.85 & 4.7297 & TST & \\
\hline CHEMBL1438417 & 688612 & 6.0 & $4.7780 e$ & 00000000005 & TRN \\
\hline CHEMBL9632 & 688612 & 4.7 & 4.6843 & TST & \\
\hline CHEMBL1527541 & 688612 & 4.0 & 4.6482 & TRN & \\
\hline CHEMBL1404349 & 688612 & 4.7 & 4.6579 & TRN & \\
\hline CHEMBL1563486 & 688612 & 4.05 & 4.5984 & TRN & \\
\hline CHEMBL1997392 & 688612 & 4.05 & 4.7362 & TRN & \\
\hline CHEMBL1327600 & 688612 & 4.0 & 4.583 & TST & \\
\hline CHEMBL3194107 & 688612 & 4.7 & 4.7304 & TRN & \\
\hline CHEMBL1400492 & 688612 & 4.15 & 4.6678 & TRN & \\
\hline CHEMBL1462478 & 688612 & 4.05 & $4.6560 e$ & $\partial 000000001$ & TST \\
\hline CHEMBL1465136 & 688612 & 4.15 & 4.6397 & TRN & \\
\hline CHEMBL1378688 & 688612 & 5.45 & 4.6171 & TST & \\
\hline CHEMBL1347424 & 688612 & 4.15 & 4.6283 & TRN & \\
\hline CHEMBL1438154 & 688612 & 6.1 & 4.6621 & TRN & \\
\hline CHEMBL1380528 & 688612 & 4.55 & 4.5919 & TRN & \\
\hline CHEMBL3196484 & 688612 & 4.3 & 4.7483 & TRN & \\
\hline
\end{tabular}




\begin{tabular}{|c|c|c|c|c|c|}
\hline \multicolumn{6}{|c|}{ Supplemental Table S2.txt } \\
\hline CHEMBL1460649 & 688612 & 5.05 & 4.7143 & TST & \\
\hline CHEMBL1438494 & 688612 & 4.2 & 4.6998 & TRN & \\
\hline CHEMBL1576354 & 688612 & 4.8 & 4.6336 & TRN & \\
\hline CHEMBL1568078 & 688612 & 4.05 & 4.6153 & TRN & \\
\hline CHEMBL1607325 & 688612 & 4.25 & 4.8031 & TRN & \\
\hline CHEMBL1568304 & 688612 & 6.5 & 4.5955 & TRN & \\
\hline CHEMBL1422383 & 688612 & 5.3 & 4.6035 & TST & \\
\hline CHEMBL1554423 & 688612 & 4.05 & 4.581 & TST & \\
\hline CHEMBL1377491 & 688612 & 4.6 & 4.6563 & TST & \\
\hline CHEMBL1572228 & 688612 & 4.0 & 4.6561 & TRN & \\
\hline CHEMBL1578670 & 688612 & 4.95 & 4.7291 & TST & \\
\hline CHEMBL1486387 & 688612 & 4.8 & 4.6881 & TRN & \\
\hline CHEMBL1359163 & 688612 & 4.05 & 4.6174 & TRN & \\
\hline CHEMBL1510625 & 688612 & 6.45 & 4.6356 & TRN & \\
\hline CHEMBL1518687 & 688612 & 5.5 & 4.6791 & TRN & \\
\hline CHEMBL1495159 & 688612 & 4.2 & 4.6113 & TRN & \\
\hline CHEMBL1351069 & 688612 & 4.9 & 4.6438 & TRN & \\
\hline CHEMBL1502852 & 688612 & 5.0 & 4.6562 & TST & \\
\hline CHEMBL1398877 & 688612 & 4.3 & 4.7594 & TRN & \\
\hline CHEMBL1418326 & 688612 & 6.8499 & 4.6754 & TST & \\
\hline CHEMBL1304734 & 688612 & 4.05 & 4.6372 & TRN & \\
\hline CHEMBL1549173 & 688612 & 4.0 & 4.68199 & 99999999995 & TRN \\
\hline CHEMBL1389724 & 688612 & 4.65 & 4.6996 & TRN & \\
\hline CHEMBL1303527 & 688612 & 4.1 & 4.6761 & TST & \\
\hline CHEMBL1458710 & 688612 & 6.1 & 4.6733 & TRN & \\
\hline CHEMBL1372272 & 688612 & 4.5 & 4.7414 & TRN & \\
\hline CHEMBL1526281 & 688612 & 4.7 & 4.5742 & TRN & \\
\hline CHEMBL1354351 & 688612 & 4.0 & 4.6596 & TST & \\
\hline CHEMBL1481688 & 688612 & 5.05 & 4.595 & TRN & \\
\hline CHEMBL1463102 & 688612 & 4.0 & 4.6764 & TST & \\
\hline CHEMBL1585608 & 688612 & 4.05 & 4.6347 & TRN & \\
\hline CHEMBL1543864 & 688612 & 6.95 & 4.727 & TRN & \\
\hline CHEMBL1558015 & 688612 & 5.0 & 4.6233 & TRN & \\
\hline CHEMBL1309178 & 688612 & 4.45 & 4.6791 & TRN & \\
\hline CHEMBL1996233 & 688612 & 4.7 & 4.837 & TRN & \\
\hline CHEMBL1305518 & 688612 & 4.1 & 4.5894 & TRN & \\
\hline CHEMBL1537028 & 688612 & 5.3 & 4.5923 & TST & \\
\hline CHEMBL3192206 & 688612 & 5.55 & 4.6832 & TST & \\
\hline CHEMBL1475915 & 688612 & 5.4 & 4.6736 & TRN & \\
\hline CHEMBL3196884 & 688612 & 4.8 & 4.7422 & TRN & \\
\hline CHEMBL1411060 & 688612 & 4.05 & 4.625 & TST & \\
\hline CHEMBL1334293 & 688612 & 4.35 & 4.6797 & TRN & \\
\hline CHEMBL1573223 & 688612 & 4.05 & 4.6083 & TRN & \\
\hline CHEMBL1579514 & 688612 & 4.4 & 4.6699 & TST & \\
\hline CHEMBL1480092 & 688612 & 5.05 & 4.6354 & TRN & \\
\hline CHEMBL1560045 & 688612 & 4.4 & 4.718 & TRN & \\
\hline CHEMBL1334820 & 688612 & 4.5 & 4.6778 & TST & \\
\hline CHEMBL155161 & 688612 & 4.0 & 4.7063 & TST & \\
\hline
\end{tabular}




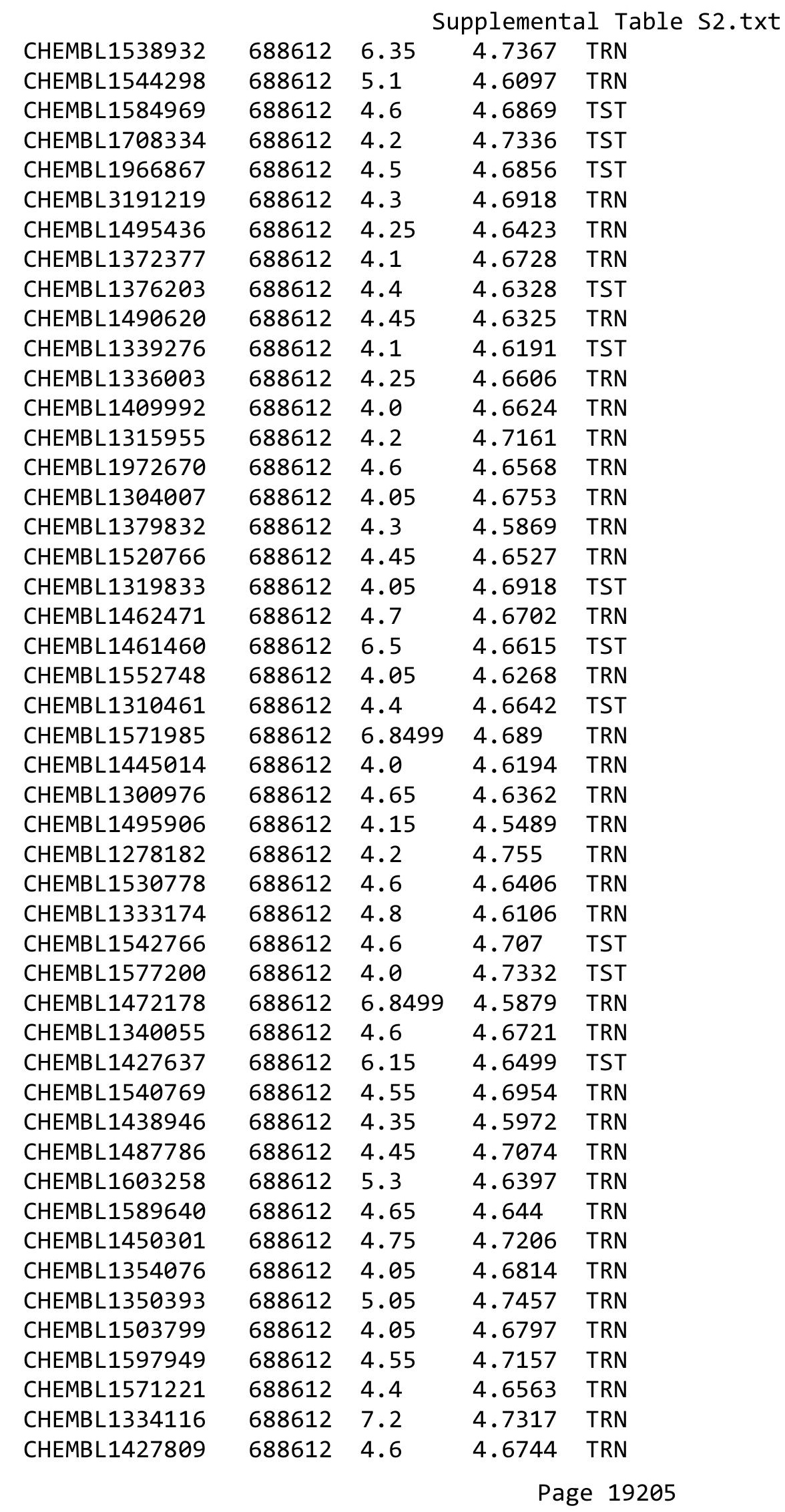




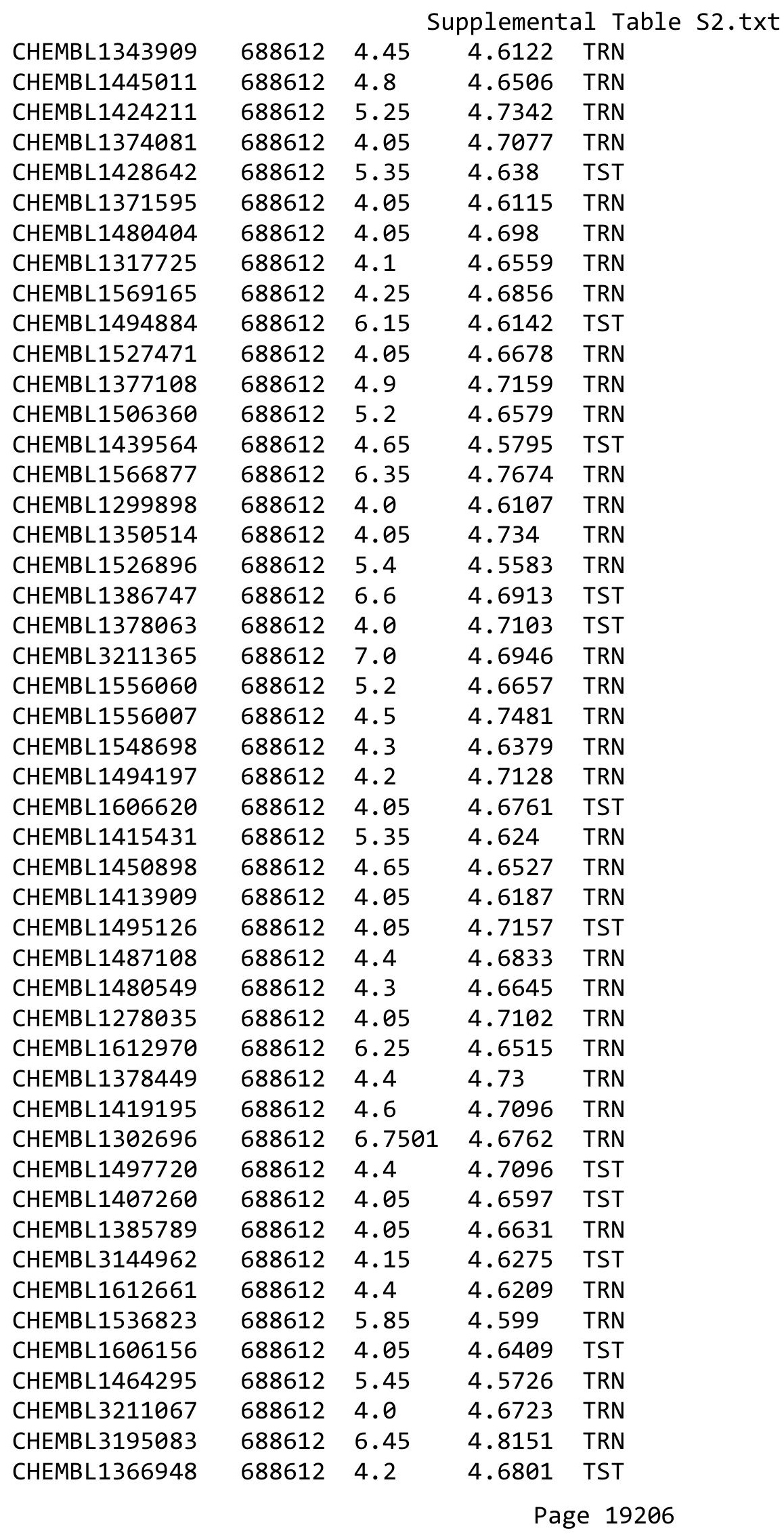




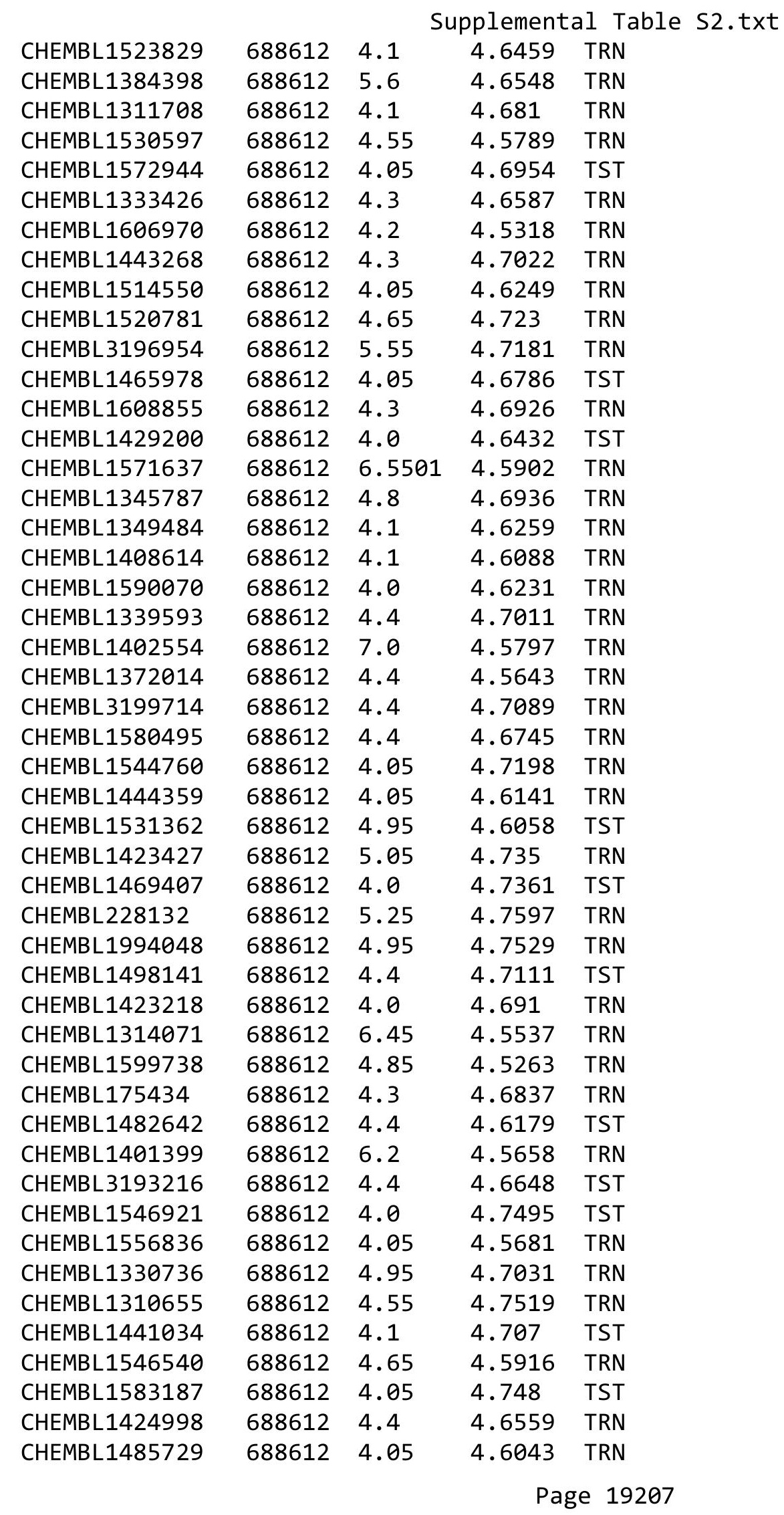




\begin{tabular}{|c|c|c|c|c|}
\hline \multicolumn{5}{|c|}{ Supplemental Table S2.txt } \\
\hline CHEMBL1320256 & 688612 & 6.5 & 4.6756 & TRN \\
\hline CHEMBL1586877 & 688612 & 4.05 & 4.5869 & TRN \\
\hline CHEMBL1594873 & 688612 & 4.45 & 4.6424 & TRN \\
\hline CHEMBL1454400 & 688612 & 4.8 & 4.618 & TST \\
\hline CHEMBL1391580 & 688612 & 4.7 & 4.6459 & TRN \\
\hline CHEMBL1548669 & 688612 & 4.65 & 4.7841 & TRN \\
\hline CHEMBL1362310 & 688612 & 4.55 & 4.6296 & TRN \\
\hline CHEMBL1593446 & 688612 & 4.65 & 4.6152 & TRN \\
\hline CHEMBL1365382 & 688612 & 4.75 & 4.6361 & TRN \\
\hline CHEMBL1331592 & 688612 & 4.0 & 4.6191 & TST \\
\hline CHEMBL1498116 & 688612 & 4.05 & 4.532 & TRN \\
\hline CHEMBL1538536 & 688612 & 4.65 & 4.6388 & TRN \\
\hline CHEMBL 3194254 & 688612 & 4.05 & 4.7161 & TST \\
\hline CHEMBL1605719 & 688612 & 4.25 & 4.6097 & TRN \\
\hline CHEMBL3190612 & 688612 & 6.95 & 4.6706 & TST \\
\hline CHEMBL1393740 & 688612 & 4.4 & 4.6482 & TRN \\
\hline CHEMBL3199772 & 688612 & 4.25 & 4.7204 & TST \\
\hline CHEMBL578905 & 688612 & 4.65 & 4.6334 & TRN \\
\hline CHEMBL1324956 & 688612 & 4.05 & 4.699 & TRN \\
\hline CHEMBL1429280 & 688612 & 4.4 & 4.6074 & TRN \\
\hline CHEMBL1323252 & 688612 & 4.25 & 4.6655 & TRN \\
\hline CHEMBL1530432 & 688612 & 4.05 & 4.7127 & TRN \\
\hline CHEMBL1556511 & 688612 & 4.65 & 4.6914 & TRN \\
\hline CHEMBL1495411 & 688612 & 4.7 & 4.6847 & TRN \\
\hline CHEMBL1463746 & 688612 & 7.0 & 4.5999 & TRN \\
\hline CHEMBL3214469 & 688612 & 4.7 & 4.6583 & TRN \\
\hline CHEMBL1544143 & 688612 & 4.2 & 4.5969 & TRN \\
\hline CHEMBL3193578 & 688612 & 4.65 & 4.6137 & TRN \\
\hline CHEMBL1597292 & 688612 & 5.0 & 4.728 & TRN \\
\hline CHEMBL1440558 & 688612 & 4.3 & 4.7004 & TST \\
\hline CHEMBL1403439 & 688612 & 6.05 & 4.6485 & TST \\
\hline CHEMBL1549849 & 688612 & 4.05 & 4.619 & TRN \\
\hline CHEMBL1352022 & 688612 & 6.1 & 4.6469 & TRN \\
\hline CHEMBL1359054 & 688612 & 4.45 & 4.8071 & TRN \\
\hline CHEMBL1421888 & 688612 & 4.8 & 4.6111 & TRN \\
\hline CHEMBL1610413 & 688612 & 4.4 & 4.583 & TRN \\
\hline CHEMBL1433091 & 688612 & 6.7001 & 4.6648 & TRN \\
\hline CHEMBL1469281 & 688612 & 4.05 & 4.5923 & TRN \\
\hline CHEMBL1380702 & 688612 & 4.05 & 4.6287 & TST \\
\hline CHEMBL1591593 & 688612 & 4.05 & 4.5972 & TRN \\
\hline CHEMBL1256813 & 688612 & 4.5 & 4.7266 & TST \\
\hline CHEMBL1472597 & 688612 & 4.1 & 4.6449 & TST \\
\hline CHEMBL1316937 & 688612 & 4.2 & 4.668 & TRN \\
\hline CHEMBL1351362 & 688612 & 4.4 & 4.6993 & TRN \\
\hline CHEMBL1562213 & 688612 & 4.5 & 4.60800 & 00000000005 \\
\hline CHEMBL1305699 & 688612 & 5.4 & 4.6012 & TRN \\
\hline CHEMBL1390355 & 688612 & 5.75 & 4.7605 & TRN \\
\hline CHEMBL1541795 & 688612 & 4.85 & 4.7824 & TRN \\
\hline
\end{tabular}




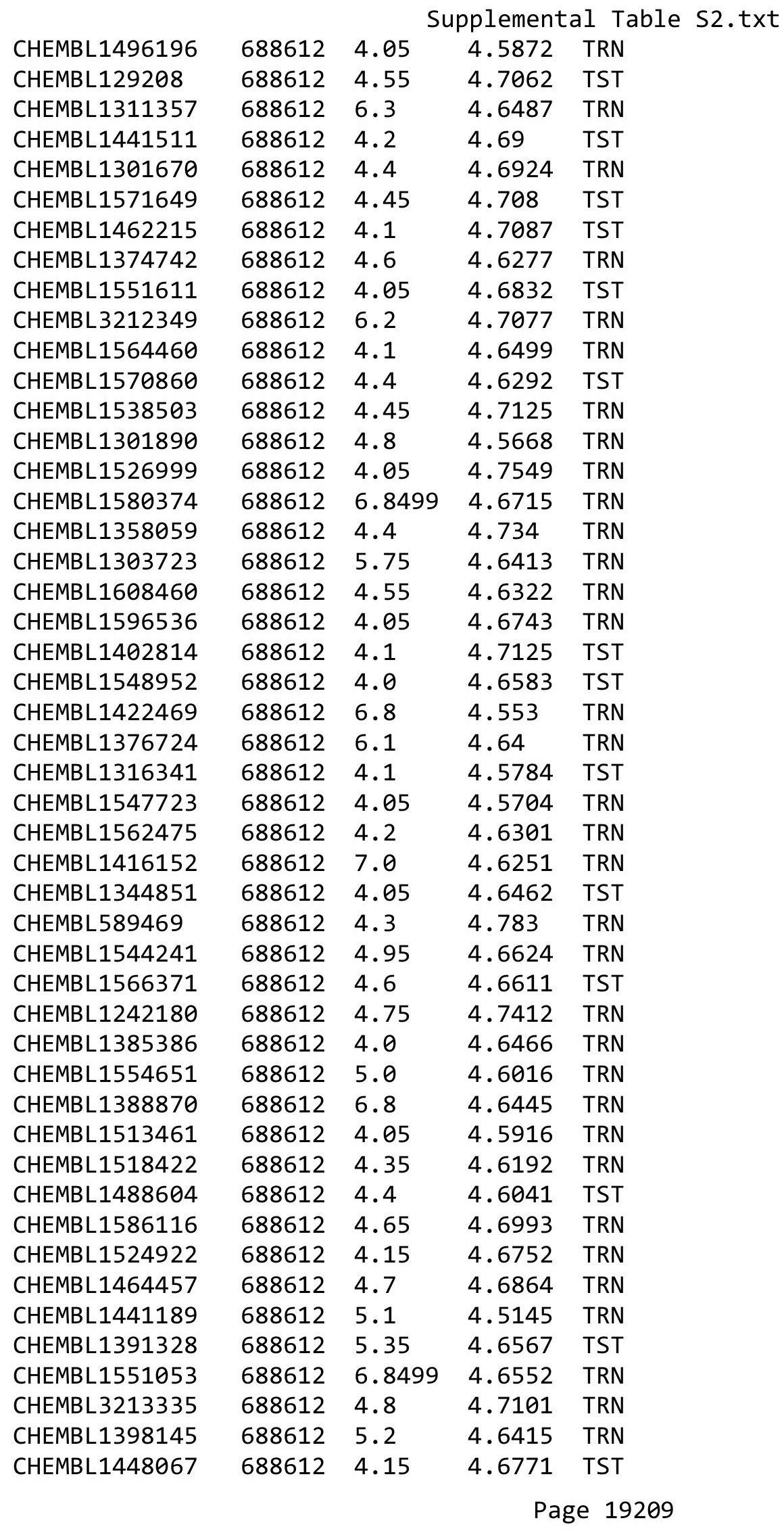




\begin{tabular}{|c|c|c|c|c|}
\hline \multicolumn{5}{|c|}{ Supplemental Table } \\
\hline CHEMBL1498546 & 688612 & 5.05 & 4.5458 & TST \\
\hline CHEMBL1338096 & 688612 & 5.05 & 4.6658 & TRN \\
\hline CHEMBL1600861 & 688612 & 4.4 & 4.7139 & TST \\
\hline CHEMBL1547392 & 688612 & 4.2 & 4.6776 & TRN \\
\hline CHEMBL 1304218 & 688612 & 6.4 & 4.6639 & TRN \\
\hline CHEMBL3192914 & 688612 & 4.55 & 4.6159 & TRN \\
\hline CHEMBL1416827 & 688612 & 6.8499 & 4.6751 & TRN \\
\hline CHEMBL1539651 & 688612 & 5.95 & 4.654 & TRN \\
\hline CHEMBL1509433 & 688612 & 4.3 & 4.6629 & TRN \\
\hline CHEMBL1306907 & 688612 & 4.2 & 4.7025 & TRN \\
\hline CHEMBL3191592 & 688612 & 4.1 & 4.7102 & TRN \\
\hline CHEMBL1384665 & 688612 & 4.1 & 4.7275 & TRN \\
\hline CHEMBL1383670 & 688612 & 4.05 & 4.6444 & TRN \\
\hline CHEMBL1366225 & 688612 & 4.0 & 4.6911 & TRN \\
\hline CHEMBL1478526 & 688612 & 4.4 & 4.6966 & TST \\
\hline CHEMBL1525212 & 688612 & 6.25 & 4.7074 & TRN \\
\hline CHEMBL1490640 & 688612 & 4.05 & 4.5722 & TRN \\
\hline CHEMBL1391094 & 688612 & 4.6 & 4.6907 & TRN \\
\hline CHEMBL1976499 & 688612 & 4.55 & 4.7916 & TRN \\
\hline CHEMBL3197971 & 688612 & 4.1 & 4.6979 & TST \\
\hline CHEMBL1304265 & 688612 & 4.8 & 4.6917 & TRN \\
\hline CHEMBL1339423 & 688612 & 4.0 & 4.6704 & TRN \\
\hline CHEMBL1369517 & 688612 & 4.5 & 4.6449 & TRN \\
\hline CHEMBL3192313 & 688612 & 4.2 & 4.6863 & TRN \\
\hline CHEMBL1503652 & 688612 & 4.45 & 4.7855 & TRN \\
\hline CHEMBL1440229 & 688612 & 5.4 & 4.7157 & TRN \\
\hline CHEMBL1471215 & 688612 & 4.05 & 4.703 & TRN \\
\hline CHEMBL1448431 & 688612 & 6.8499 & 4.5895 & TST \\
\hline CHEMBL1558200 & 688612 & 4.0 & 4.7111 & TRN \\
\hline CHEMBL1469314 & 688612 & 4.05 & 4.7778 & TST \\
\hline CHEMBL1488820 & 688612 & 4.5 & 4.6147 & TRN \\
\hline CHEMBL1603605 & 688612 & 4.15 & 4.6712 & TRN \\
\hline CHEMBL1510189 & 688612 & 4.0 & 4.664 & TRN \\
\hline CHEMBL1509707 & 688612 & 4.35 & 4.7323 & TRN \\
\hline CHEMBL1535118 & 688612 & 4.7 & 4.6746 & TRN \\
\hline CHEMBL1577795 & 688612 & 4.1 & 4.6091 & TRN \\
\hline CHEMBL1456627 & 688612 & 4.2 & 4.7574 & TST \\
\hline CHEMBL1421564 & 688612 & 4.55 & 4.5952 & TRN \\
\hline CHEMBL1300360 & 688612 & 4.85 & 4.7639 & TRN \\
\hline CHEMBL1563769 & 688612 & 4.8 & 4.7147 & TST \\
\hline CHEMBL1464985 & 688612 & 5.5 & 4.5979 & TRN \\
\hline CHEMBL1465297 & 688612 & 4.4 & 4.7263 & TRN \\
\hline CHEMBL1451308 & 688612 & 4.1 & 4.7094 & TRN \\
\hline CHEMBL1312268 & 688612 & 4.45 & 4.8108 & TST \\
\hline CHEMBL1410410 & 688612 & 4.4 & 4.7065 & TRN \\
\hline CHEMBL3212869 & 688612 & 4.05 & 4.6633 & TRN \\
\hline CHEMBL1392264 & 688612 & 4.0 & 4.6757 & TST \\
\hline CHEMBL1443113 & 688612 & 4.3 & 4.7404 & TRN \\
\hline
\end{tabular}




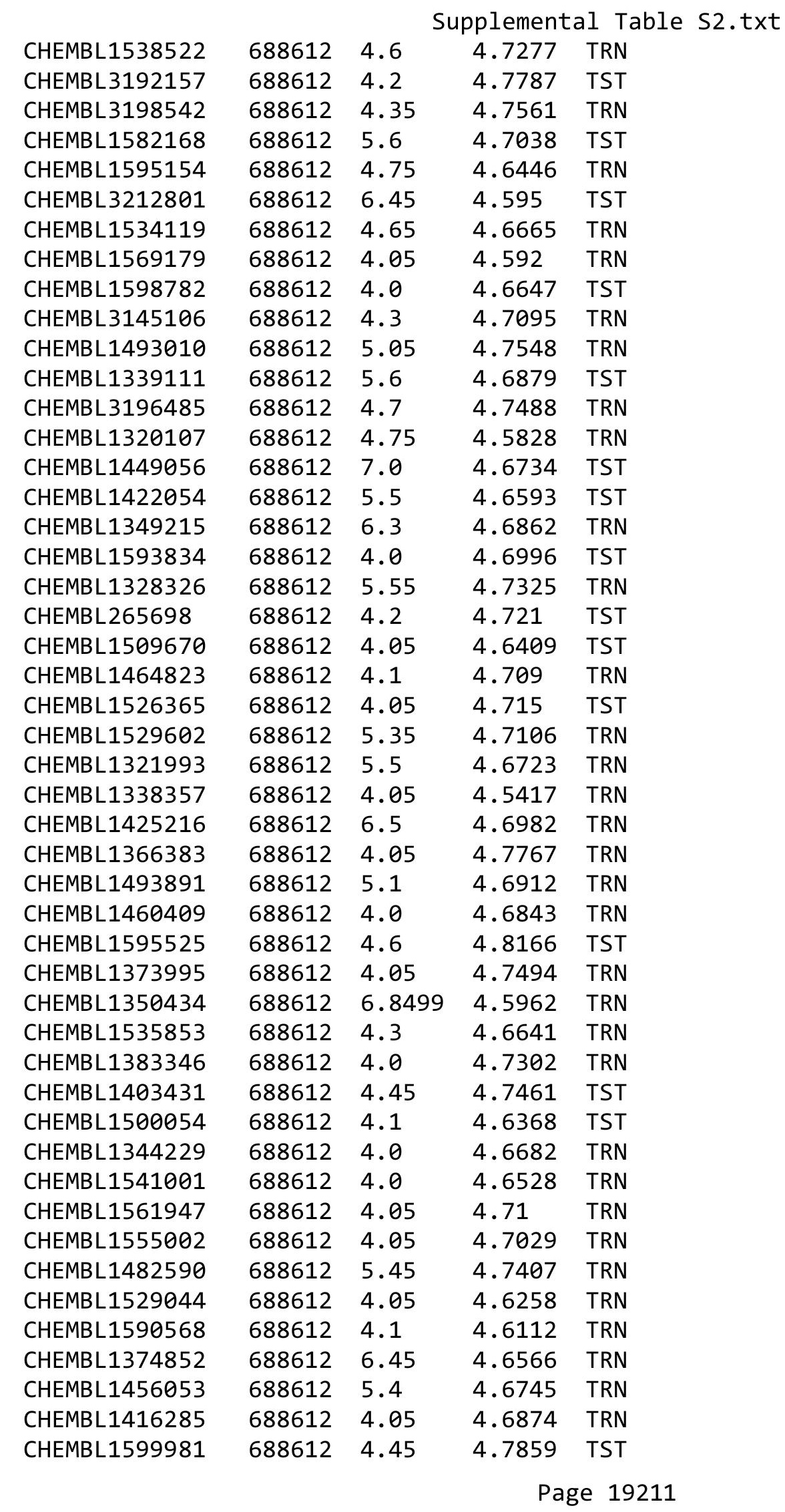




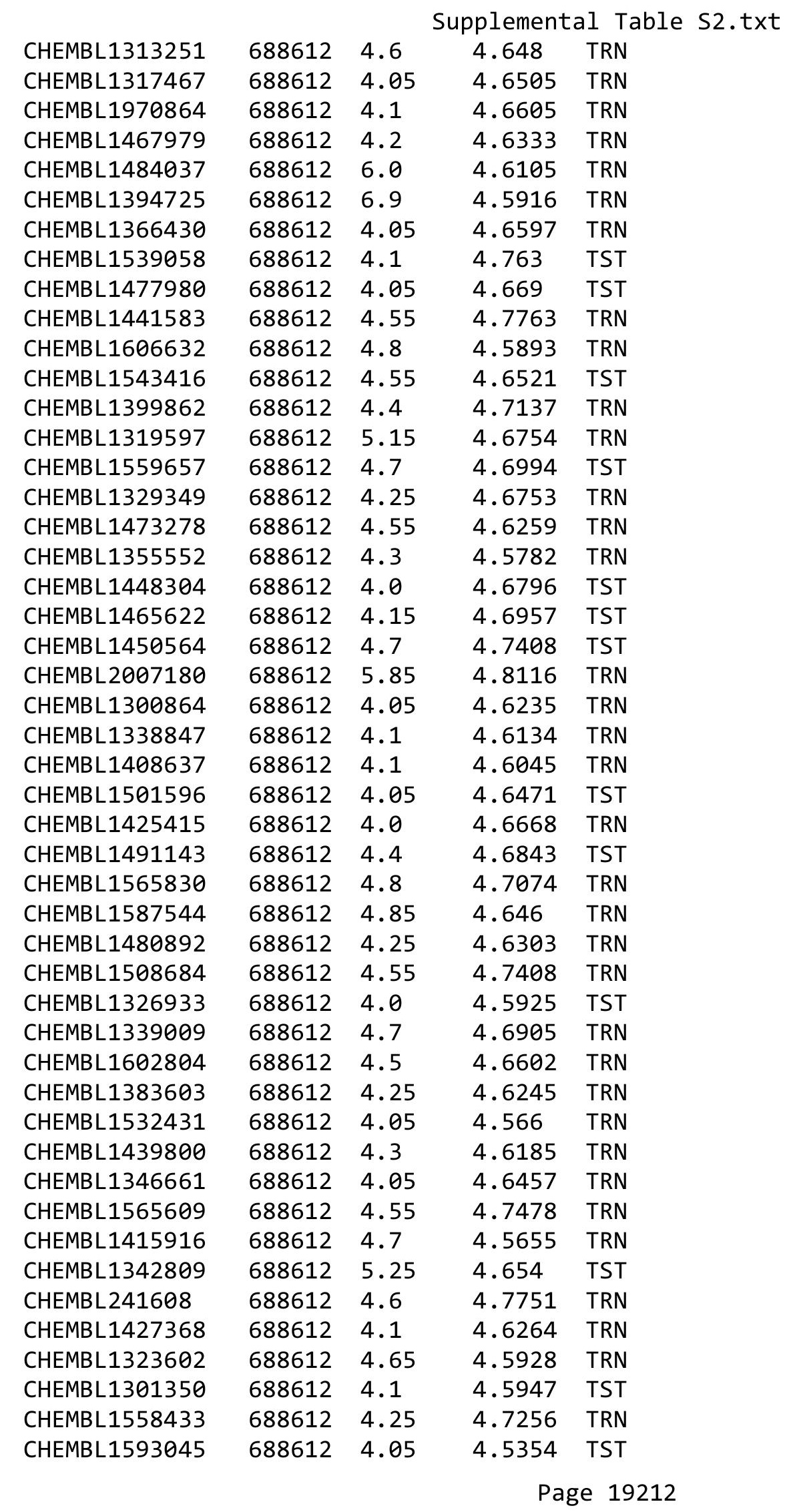




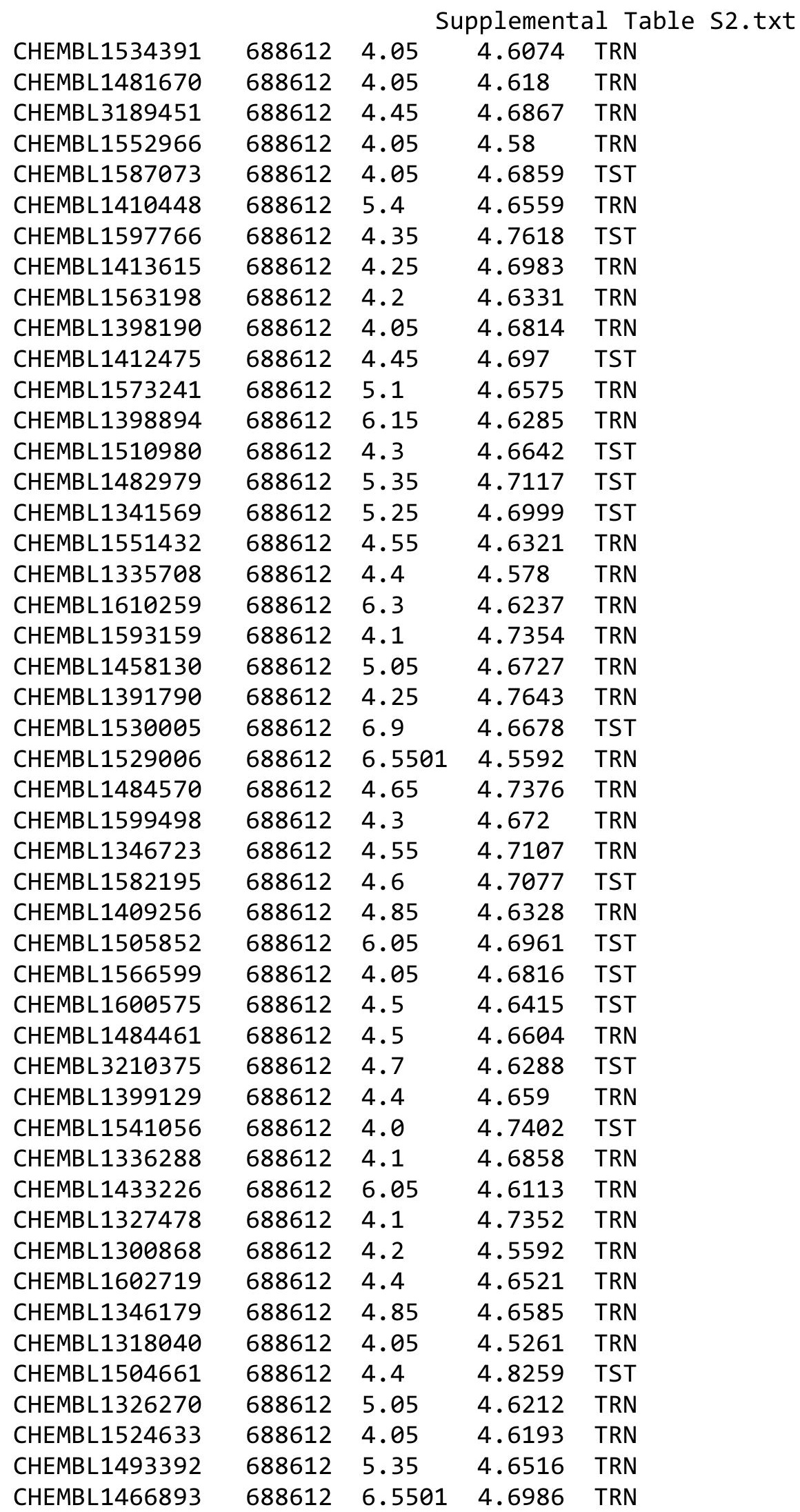

Page 19213 


\begin{tabular}{|c|c|c|c|c|c|}
\hline & & \multicolumn{4}{|c|}{ Supplemental Table S2.txt } \\
\hline CHEMBL1455542 & 688612 & 4.55 & 4.7872 & TRN & \\
\hline CHEMBL1445716 & 688612 & 4.45 & 4.6093 & TRN & \\
\hline CHEMBL1342961 & 688612 & 6.45 & 4.6347 & TRN & \\
\hline CHEMBL1393368 & 688612 & 4.75 & 4.6069 & TRN & \\
\hline CHEMBL1400684 & 688612 & 4.1 & 4.6624 & TRN & \\
\hline CHEMBL1350680 & 688612 & 4.05 & 4.7105 & TST & \\
\hline CHEMBL1515865 & 688612 & 4.05 & 4.5535 & TRN & \\
\hline CHEMBL1451063 & 688612 & 4.0 & 4.6421 & TRN & \\
\hline CHEMBL1988756 & 688612 & 4.4 & 4.6459 & TRN & \\
\hline CHEMBL387744 & 688612 & 4.05 & 4.675 & TST & \\
\hline CHEMBL1377629 & 688612 & 4.65 & 4.7141 & TST & \\
\hline CHEMBL1574206 & 688612 & 4.8 & 4.6313 & TRN & \\
\hline CHEMBL1387950 & 688612 & 4.95 & 4.6896 & TRN & \\
\hline CHEMBL1414384 & 688612 & 4.1 & 4.7376 & TST & \\
\hline CHEMBL1578115 & 688612 & 4.2 & 4.6399 & TRN & \\
\hline CHEMBL1421433 & 688612 & 4.15 & 4.73300 & 00000000005 & TST \\
\hline CHEMBL1421839 & 688612 & 5.5 & 4.7276 & TRN & \\
\hline CHEMBL1483565 & 688612 & 4.7 & 4.763 & TRN & \\
\hline CHEMBL1575389 & 688612 & 4.2 & 4.7258 & TST & \\
\hline CHEMBL1530741 & 688612 & 4.7 & 4.7686 & TRN & \\
\hline CHEMBL1350069 & 688612 & 4.3 & 4.7101 & TRN & \\
\hline CHEMBL1483540 & 688612 & 4.05 & 4.6295 & TRN & \\
\hline CHEMBL1526934 & 688612 & 4.15 & 4.7723 & TRN & \\
\hline CHEMBL1425564 & 688612 & 4.6 & 4.6049 & TRN & \\
\hline CHEMBL1526342 & 688612 & 5.0 & 4.7293 & TRN & \\
\hline CHEMBL1535683 & 688612 & 4.0 & 4.6975 & TRN & \\
\hline CHEMBL1371164 & 688612 & 6.05 & 4.6612 & TRN & \\
\hline CHEMBL1601491 & 688612 & 4.4 & 4.6602 & TRN & \\
\hline CHEMBL1477294 & 688612 & 4.05 & 4.5972 & TST & \\
\hline CHEMBL1441225 & 688612 & 4.15 & 4.706 & TST & \\
\hline CHEMBL1468005 & 688612 & 4.45 & 4.6166 & TRN & \\
\hline CHEMBL596847 & 688612 & 7.0 & 4.5797 & TST & \\
\hline CHEMBL1524371 & 688612 & 4.6 & 4.66 & TST & \\
\hline CHEMBL1612391 & 688612 & 5.5 & 4.7619 & TST & \\
\hline CHEMBL1562898 & 688612 & 4.0 & 4.6723 & TRN & \\
\hline CHEMBL1460566 & 688612 & 4.05 & 4.6493 & TRN & \\
\hline CHEMBL1536572 & 688612 & 4.05 & 4.7391 & TRN & \\
\hline CHEMBL3191900 & 688612 & 4.9 & 4.6995 & TRN & \\
\hline CHEMBL1613477 & 688612 & 4.6 & 4.7407 & TST & \\
\hline CHEMBL1326397 & 688612 & 4.6 & 4.7015 & TRN & \\
\hline CHEMBL1329188 & 688612 & 4.05 & 4.725 & TST & \\
\hline CHEMBL3199253 & 688612 & 4.0 & 4.7001 & TST & \\
\hline CHEMBL1512633 & 688612 & 4.5 & 4.5836 & TRN & \\
\hline CHEMBL1404034 & 688612 & 4.4 & 4.7334 & TRN & \\
\hline CHEMBL1459529 & 688612 & 4.5 & 4.6974 & TST & \\
\hline CHEMBL3195552 & 688612 & 5.9 & 4.7223 & TRN & \\
\hline CHEMBL1396827 & 688612 & 4.4 & 4.6024 & TST & \\
\hline CHEMBL1437537 & 688612 & 5.55 & 4.609 & TRN & \\
\hline
\end{tabular}




\begin{tabular}{|c|c|c|c|c|}
\hline \multicolumn{5}{|c|}{ Supplemental Table S2.txt } \\
\hline CHEMBL1318115 & 688612 & 4.45 & 4.6121 & TRN \\
\hline CHEMBL1302558 & 688612 & 4.9 & 4.6319 & TST \\
\hline CHEMBL1453095 & 688612 & 5.5 & 4.7447 & TST \\
\hline CHEMBL1337377 & 688612 & 4.65 & 4.7025 & TRN \\
\hline CHEMBL1461369 & 688612 & 4.1 & 4.5915 & TRN \\
\hline CHEMBL1576756 & 688612 & 4.05 & 4.6343 & TRN \\
\hline CHEMBL1301115 & 688612 & 4.9 & 4.6398 & TRN \\
\hline CHEMBL1337039 & 688612 & 4.75 & 4.6884 & TST \\
\hline CHEMBL1429408 & 688612 & 4.2 & 4.6788 & TRN \\
\hline CHEMBL1540463 & 688612 & 6.6499 & 4.7108 & TST \\
\hline CHEMBL1494249 & 688612 & 5.4 & 4.6807 & TRN \\
\hline CHEMBL1491822 & 688612 & 4.55 & 4.6994 & TRN \\
\hline CHEMBL1419228 & 688612 & 5.4 & 4.843 & TRN \\
\hline CHEMBL1485399 & 688612 & 5.45 & 4.6297 & TRN \\
\hline CHEMBL577758 & 688612 & 4.85 & 4.7299 & TRN \\
\hline CHEMBL1317538 & 688612 & 4.5 & 4.6583 & TST \\
\hline CHEMBL1549282 & 688612 & 4.6 & 4.5992 & TRN \\
\hline CHEMBL1377040 & 688612 & 4.0 & 4.6444 & TRN \\
\hline CHEMBL1364797 & 688612 & 4.05 & 4.6973 & TRN \\
\hline CHEMBL1362342 & 688612 & 4.1 & 4.7343 & TST \\
\hline CHEMBL1498348 & 688612 & 5.3 & 4.5979 & TRN \\
\hline CHEMBL1570302 & 688612 & 4.35 & 4.6445 & TRN \\
\hline CHEMBL1307350 & 688612 & 4.1 & 4.7279 & TST \\
\hline CHEMBL1487077 & 688612 & 4.05 & 4.6767 & TRN \\
\hline CHEMBL36654 & 688612 & 4.8 & 4.7247 & TRN \\
\hline CHEMBL1336603 & 688612 & 4.4 & 4.6037 & TST \\
\hline CHEMBL3191918 & 688612 & 4.7 & 4.7056 & TRN \\
\hline CHEMBL1465122 & 688612 & 4.95 & 4.6836 & TST \\
\hline CHEMBL1549697 & 688612 & 4.4 & 4.6454 & TRN \\
\hline CHEMBL1601524 & 688612 & 4.75 & 4.5858 & TRN \\
\hline CHEMBL1529565 & 688612 & 4.35 & 4.6355 & TRN \\
\hline CHEMBL1586790 & 688612 & 4.05 & 4.6884 & TRN \\
\hline CHEMBL1432619 & 688612 & 6.15 & 4.6376 & TST \\
\hline CHEMBL1329285 & 688612 & 5.1 & 4.6659 & TRN \\
\hline CHEMBL1331695 & 688612 & 4.6 & 4.6633 & TRN \\
\hline CHEMBL1413249 & 688612 & 4.05 & 4.6282 & TRN \\
\hline CHEMBL1312494 & 688612 & 5.45 & 4.7111 & TST \\
\hline CHEMBL1541942 & 688612 & 4.85 & 4.6839 & TRN \\
\hline CHEMBL1358245 & 688612 & 5.4 & 4.6691 & TRN \\
\hline CHEMBL1608056 & 688612 & 4.75 & 4.632 & TST \\
\hline CHEMBL1393719 & 688612 & 6.5 & 4.6192 & TRN \\
\hline CHEMBL1399786 & 688612 & 6.2 & 4.6341 & TRN \\
\hline CHEMBL1603356 & 688612 & 4.05 & 4.6530 & 20000000005 \\
\hline CHEMBL533954 & 688612 & 4.45 & 4.6828 & TRN \\
\hline CHEMBL 1299622 & 688612 & 4.7 & 4.7054 & TST \\
\hline CHEMBL1497812 & 688612 & 6.1 & 4.6704 & TRN \\
\hline CHEMBL1503307 & 688612 & 4.75 & 4.6678 & TRN \\
\hline CHEMBL1549045 & 688612 & 6.8 & 4.7107 & TST \\
\hline
\end{tabular}




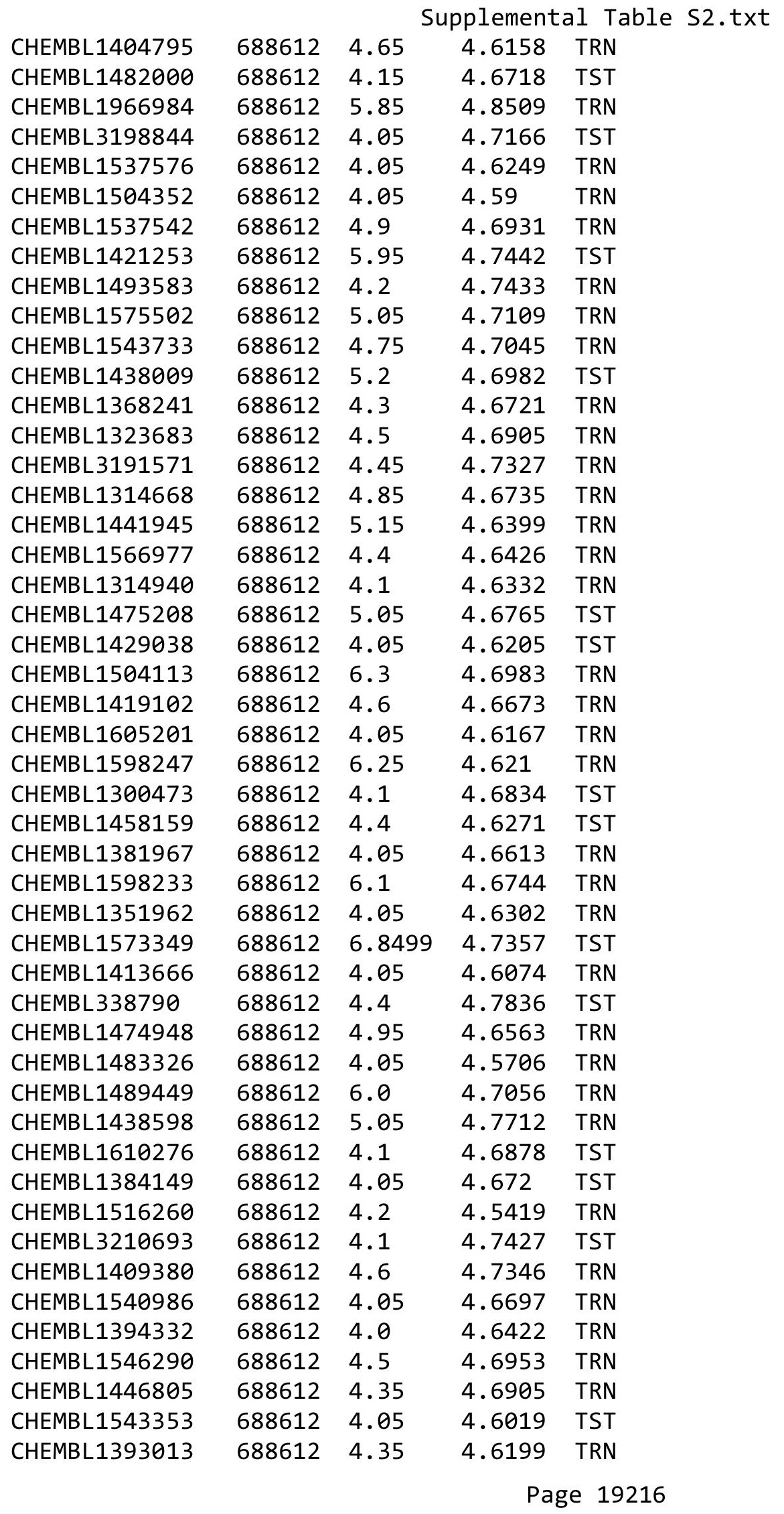




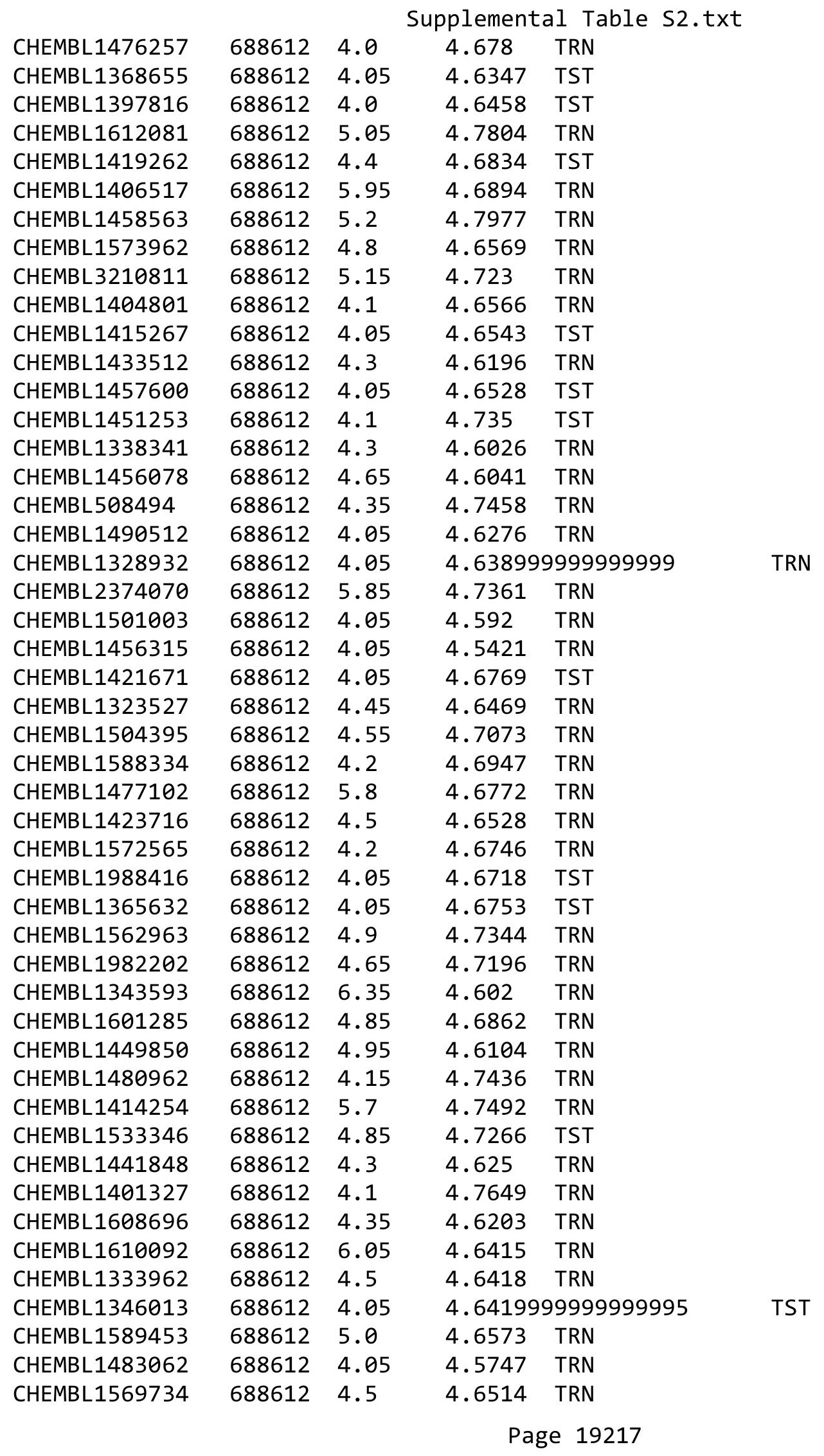




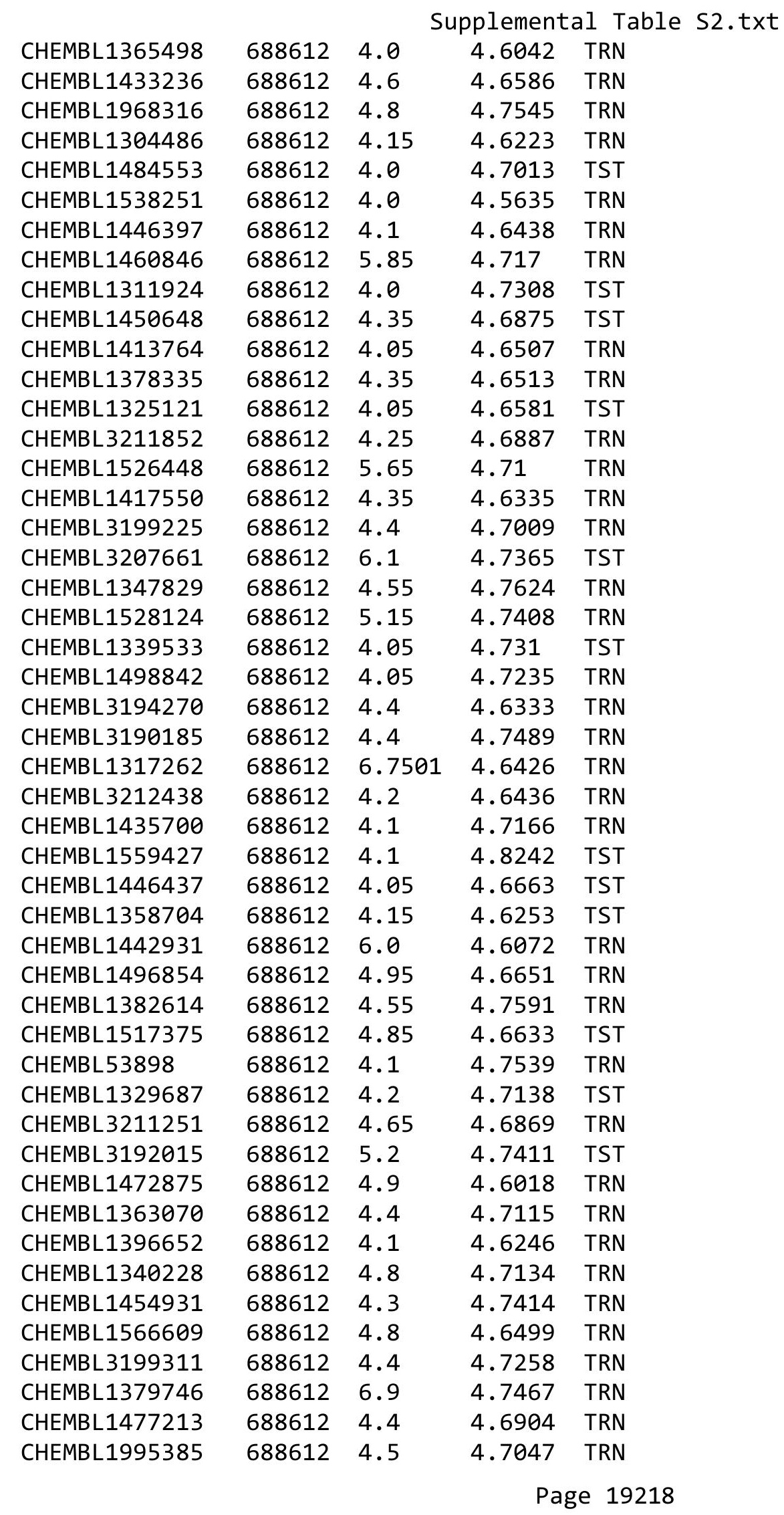




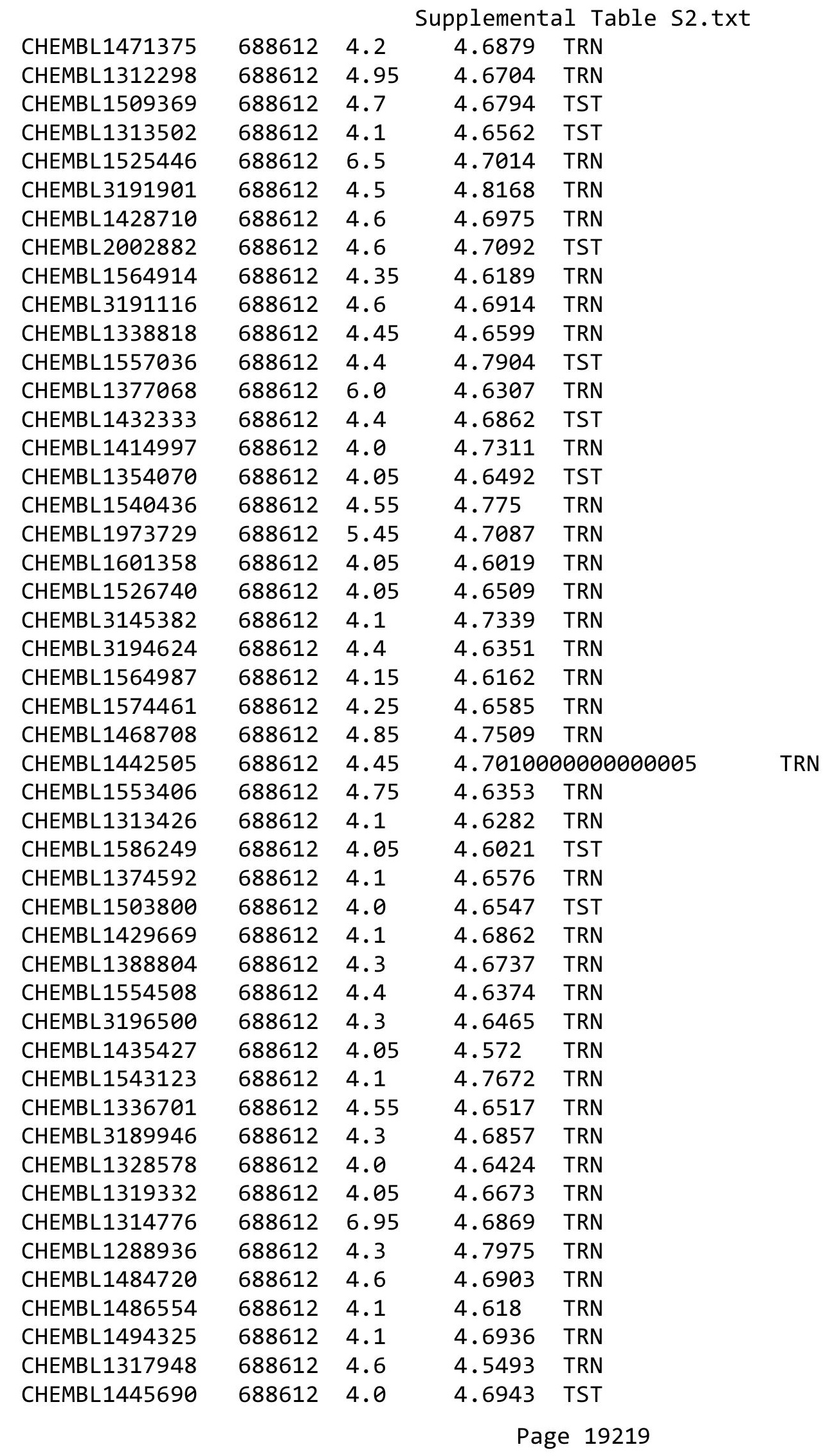




\begin{tabular}{|c|c|c|c|c|c|}
\hline \multicolumn{6}{|c|}{ Supplemental Table S2.txt } \\
\hline CHEMBL1314664 & 688612 & 4.2 & 4.5754 & TRN & \\
\hline CHEMBL1501082 & 688612 & 5.05 & 4.5883 & TRN & \\
\hline CHEMBL3196086 & 688612 & 4.0 & 4.6675 & TST & \\
\hline CHEMBL1379677 & 688612 & 4.6 & 4.6624 & TRN & \\
\hline CHEMBL1442243 & 688612 & 4.0 & 4.6732 & TRN & \\
\hline CHEMBL1590169 & 688612 & 4.4 & 4.6347 & TRN & \\
\hline CHEMBL1367581 & 688612 & 4.3 & 4.6664 & TRN & \\
\hline CHEMBL1603993 & 688612 & 6.95 & 4.6394 & TRN & \\
\hline CHEMBL1561341 & 688612 & 6.5501 & 4.6968 & TRN & \\
\hline CHEMBL1314599 & 688612 & 4.0 & 4.6783 & TRN & \\
\hline CHEMBL3194392 & 688612 & 4.1 & 4.6992 & TRN & \\
\hline CHEMBL1560674 & 688612 & 4.05 & 4.6758 & TRN & \\
\hline CHEMBL1362666 & 688612 & 4.65 & 4.6787 & TST & \\
\hline CHEMBL1487415 & 688612 & 5.4 & 4.6825 & TRN & \\
\hline CHEMBL1539112 & 688612 & 4.05 & 4.6504 & TST & \\
\hline CHEMBL1416367 & 688612 & 4.1 & 4.5669 & TRN & \\
\hline CHEMBL1560036 & 688612 & 5.5 & 4.657 & TRN & \\
\hline CHEMBL1351655 & 688612 & 5.8 & 4.6701 & TST & \\
\hline CHEMBL1351656 & 688612 & 4.1 & 4.6831 & TRN & \\
\hline CHEMBL1299904 & 688612 & 4.7 & 4.6447 & TRN & \\
\hline CHEMBL1406387 & 688612 & 4.05 & 4.6383 & TRN & \\
\hline CHEMBL1562089 & 688612 & 5.8 & 4.7343 & TST & \\
\hline CHEMBL1306748 & 688612 & 4.1 & 4.6248 & TRN & \\
\hline CHEMBL1567438 & 688612 & 6.5501 & 4.6616 & TRN & \\
\hline CHEMBL1464824 & 688612 & 5.55 & 4.6471 & TRN & \\
\hline CHEMBL1585777 & 688612 & 4.8 & 4.7423 & TRN & \\
\hline CHEMBL1343745 & 688612 & 4.05 & 4.6891 & TST & \\
\hline CHEMBL1452818 & 688612 & 5.0 & 4.6235 & TRN & \\
\hline CHEMBL1351763 & 688612 & 4.6 & 4.7032 & TRN & \\
\hline CHEMBL1320237 & 688612 & 4.4 & 4.6204 & TRN & \\
\hline CHEMBL1532723 & 688612 & 4.8 & 4.6547 & TST & \\
\hline CHEMBL1483845 & 688612 & 4.0 & 4.8043 & TRN & \\
\hline CHEMBL1442741 & 688612 & 4.85 & 4.5849 & TRN & \\
\hline CHEMBL1356253 & 688612 & 4.05 & 4.6489 & TRN & \\
\hline CHEMBL1550180 & 688612 & 4.3 & 4.7122 & TRN & \\
\hline CHEMBL1418720 & 688612 & 4.4 & 4.6444 & TST & \\
\hline CHEMBL1551995 & 688612 & 4.2 & 4.6261 & TRN & \\
\hline CHEMBL1590819 & 688612 & 4.55 & 4.6387 & TRN & \\
\hline CHEMBL3191304 & 688612 & 4.6 & 4.773 & TRN & \\
\hline CHEMBL1313140 & 688612 & 4.7 & 4.6492 & TRN & \\
\hline CHEMBL1525260 & 688612 & 4.6 & 4.66100 & 00000000005 & TRN \\
\hline CHEMBL1988376 & 688612 & 4.75 & 4.7062 & TST & \\
\hline CHEMBL1605542 & 688612 & 4.05 & 4.629 & TRN & \\
\hline CHEMBL1309382 & 688612 & 4.6 & 4.79899 & 99999999995 & TRN \\
\hline CHEMBL1553504 & 688612 & 4.05 & 4.6171 & TRN & \\
\hline CHEMBL1555301 & 688612 & 4.0 & 4.6707 & TRN & \\
\hline CHEMBL1500799 & 688612 & 4.15 & 4.6906 & TST & \\
\hline CHEMBL1408398 & 688612 & 4.6 & 4.6595 & TRN & \\
\hline
\end{tabular}




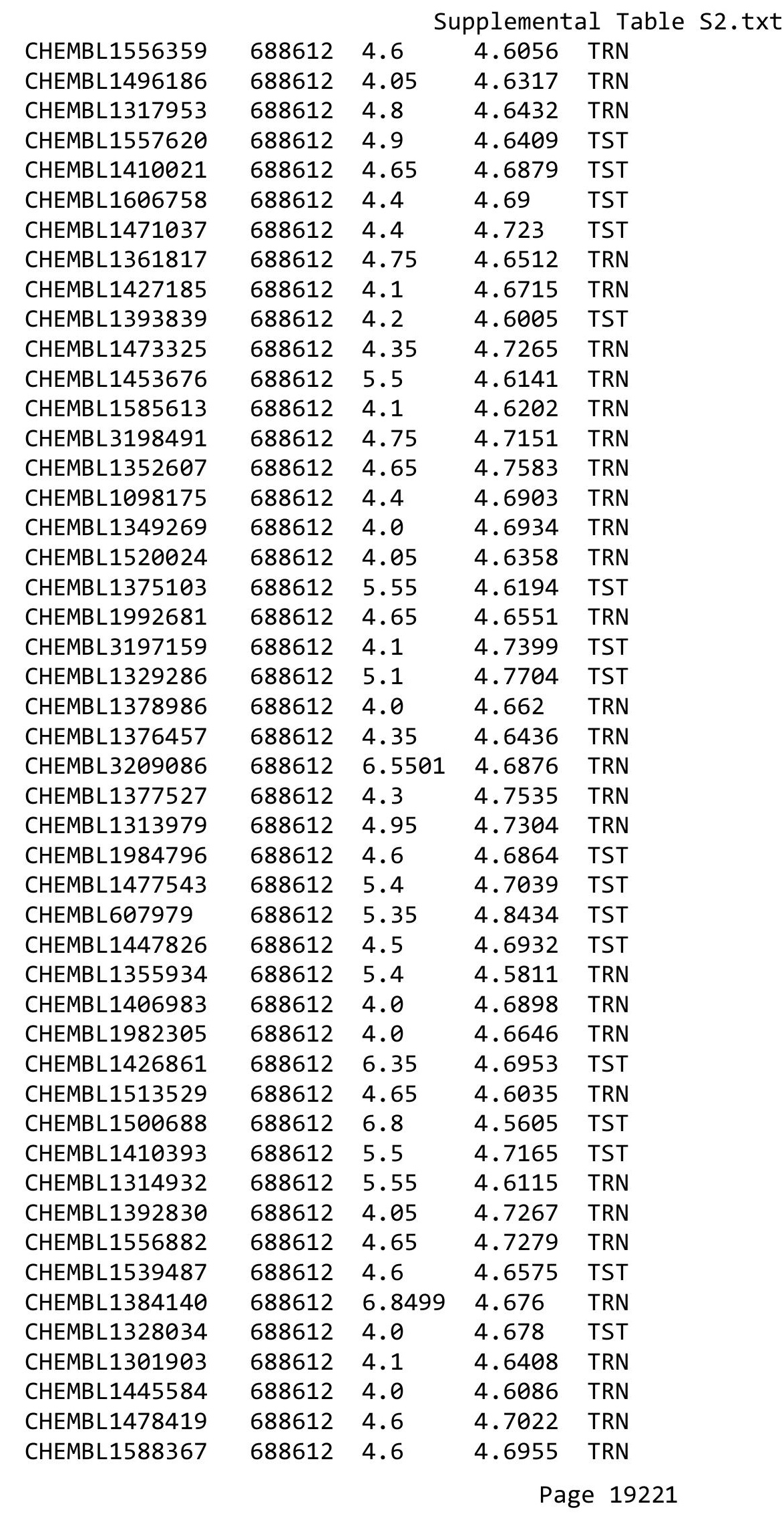




\begin{tabular}{|c|c|c|c|c|c|}
\hline \multicolumn{6}{|c|}{ Supplemental Table S2.txt } \\
\hline CHEMBL1478521 & 688612 & 4.0 & 4.6012 & TRN & \\
\hline CHEMBL1346451 & 688612 & 4.45 & 4.7322 & TRN & \\
\hline CHEMBL3198958 & 688612 & 5.2 & 4.6791 & TRN & \\
\hline CHEMBL1570760 & 688612 & 4.05 & 4.6531 & TRN & \\
\hline CHEMBL1517539 & 688612 & 4.05 & 4.7183 & TRN & \\
\hline CHEMBL1481681 & 688612 & 5.8 & 4.6237 & TRN & \\
\hline CHEMBL1350917 & 688612 & 4.0 & 4.6332 & TRN & \\
\hline CHEMBL1538161 & 688612 & 4.85 & 4.6878 & TRN & \\
\hline CHEMBL1465079 & 688612 & 5.0 & 4.6556 & TST & \\
\hline CHEMBL1604093 & 688612 & 5.45 & 4.6092 & TRN & \\
\hline CHEMBL1473621 & 688612 & 4.1 & 4.6246 & TST & \\
\hline CHEMBL1567943 & 688612 & 4.05 & 4.7152 & TST & \\
\hline CHEMBL1337207 & 688612 & 6.5 & 4.5895 & TST & \\
\hline CHEMBL1525749 & 688612 & 4.8 & 4.6598 & TRN & \\
\hline CHEMBL1510175 & 688612 & 4.05 & 4.6357 & TRN & \\
\hline CHEMBL1436948 & 688612 & 4.0 & 4.654 & TST & \\
\hline CHEMBL1475505 & 688612 & 4.05 & 4.6639 & TRN & \\
\hline CHEMBL1325658 & 688612 & 4.85 & 4.7463 & TRN & \\
\hline CHEMBL1543701 & 688612 & 4.05 & 4.6414 & TST & \\
\hline CHEMBL1578765 & 688612 & 4.1 & 4.67399 & 99999999995 & TRN \\
\hline CHEMBL1983142 & 688612 & 4.3 & 4.7246 & TST & \\
\hline CHEMBL 3194357 & 688612 & 4.2 & 4.7484 & TRN & \\
\hline CHEMBL1533452 & 688612 & 4.95 & 4.68 & TRN & \\
\hline CHEMBL1340564 & 688612 & 4.2 & 4.6394 & TRN & \\
\hline CHEMBL1536613 & 688612 & 4.05 & 4.6714 & TST & \\
\hline CHEMBL1407197 & 688612 & 4.3 & 4.7595 & TRN & \\
\hline CHEMBL1501714 & 688612 & 6.8499 & 4.659 & TRN & \\
\hline CHEMBL1549049 & 688612 & 4.3 & 4.7106 & TST & \\
\hline CHEMBL3198269 & 688612 & 4.4 & 4.7672 & TRN & \\
\hline CHEMBL1497829 & 688612 & 5.65 & 4.6194 & TST & \\
\hline CHEMBL1565911 & 688612 & 4.2 & 4.6991 & TRN & \\
\hline CHEMBL1580102 & 688612 & 5.35 & 4.6644 & TRN & \\
\hline CHEMBL1606811 & 688612 & 4.05 & 4.5667 & TRN & \\
\hline CHEMBL1334684 & 688612 & 5.65 & 4.7739 & TRN & \\
\hline CHEMBL1514004 & 688612 & 4.3 & 4.6764 & TRN & \\
\hline CHEMBL1366688 & 688612 & 4.0 & 4.6652 & TRN & \\
\hline CHEMBL1520210 & 688612 & 4.2 & 4.6657 & TRN & \\
\hline CHEMBL1467007 & 688612 & 4.9 & 4.7501 & TRN & \\
\hline CHEMBL1470748 & 688612 & 4.9 & 4.7256 & TRN & \\
\hline CHEMBL175822 & 688612 & 4.1 & 4.7406 & TRN & \\
\hline CHEMBL1578142 & 688612 & 4.7 & 4.6763 & TRN & \\
\hline CHEMBL1318486 & 688612 & 6.8 & 4.618 & TRN & \\
\hline CHEMBL1967837 & 688612 & 4.1 & 4.6912 & TRN & \\
\hline CHEMBL3198447 & 688612 & 5.3 & 4.7085 & TST & \\
\hline CHEMBL1533108 & 688612 & 5.3 & 4.6918 & TRN & \\
\hline CHEMBL1386105 & 688612 & 4.2 & 4.6301 & TRN & \\
\hline CHEMBL1482899 & 688612 & 4.6 & 4.7014 & TRN & \\
\hline CHEMBL1302389 & 688612 & 6.15 & 4.5996 & TRN & \\
\hline
\end{tabular}




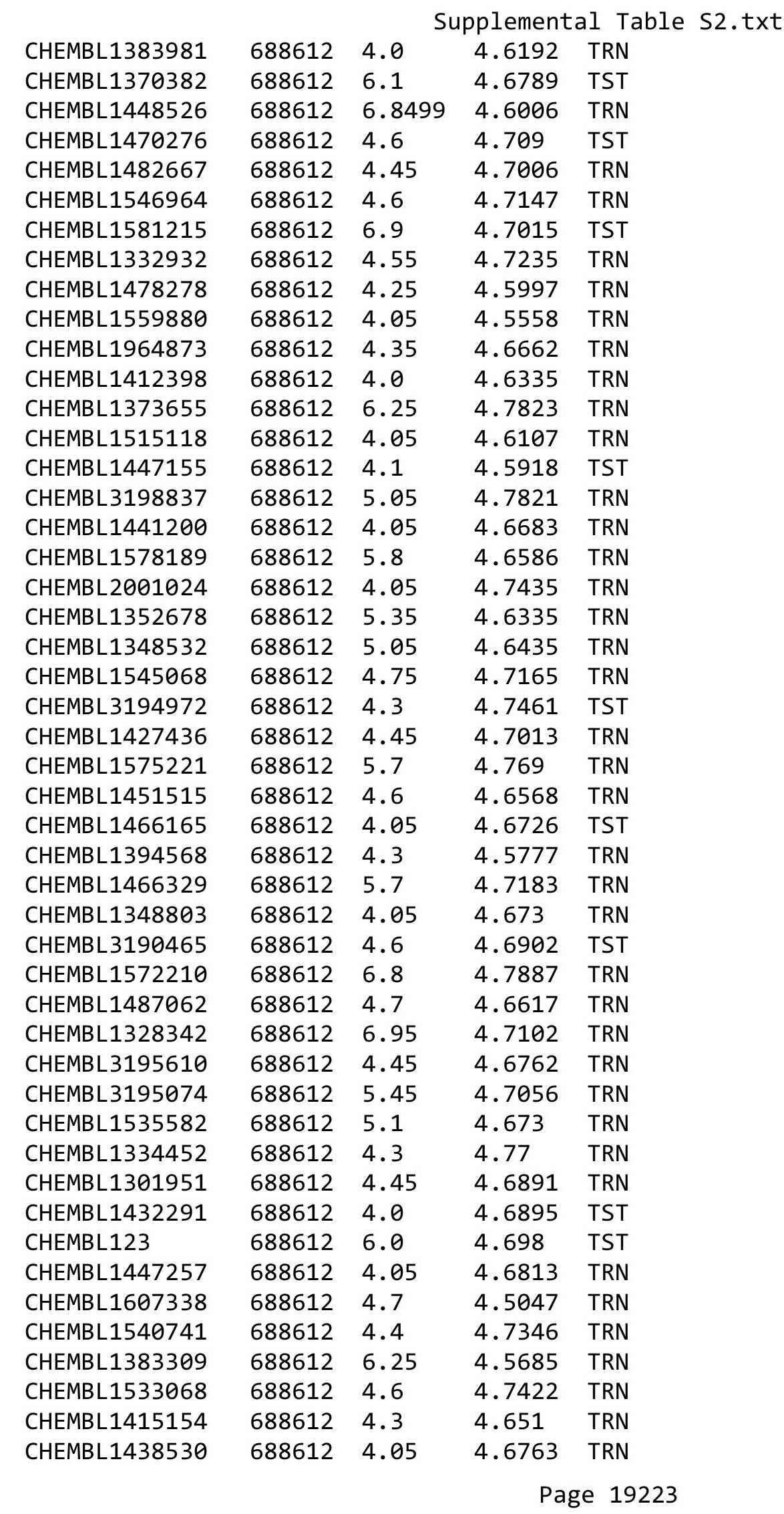




\begin{tabular}{|c|c|c|c|c|c|}
\hline \multicolumn{6}{|c|}{ Supplemental Table s2.txt } \\
\hline CHEMBL 3197142 & 688612 & 4.65 & 4.6756 & TRN & \\
\hline CHEMBL1386518 & 688612 & 4.05 & 4.6404 & TRN & \\
\hline CHEMBL3214011 & 688612 & 4.0 & 4.6913 & TST & \\
\hline CHEMBL1587159 & 688612 & 4.65 & 4.7294 & TRN & \\
\hline CHEMBL1533345 & 688612 & 4.2 & 4.6767 & TRN & \\
\hline CHEMBL1574642 & 688612 & 6.9 & 4.6259 & TRN & \\
\hline CHEMBL1377555 & 688612 & 4.05 & 4.6939 & TST & \\
\hline CHEMBL1421276 & 688612 & 5.05 & 4.712 & TST & \\
\hline CHEMBL1444417 & 688612 & 4.05 & 4.7139 & TRN & \\
\hline CHEMBL1345354 & 688612 & 4.1 & 4.5918 & TRN & \\
\hline CHEMBL1322874 & 688612 & 4.1 & 4.6496 & TRN & \\
\hline CHEMBL3197091 & 688612 & 4.65 & 4.6563 & TRN & \\
\hline CHEMBL3193559 & 688612 & 4.75 & 4.7107 & TRN & \\
\hline CHEMBL1303404 & 688612 & 4.4 & 4.6717 & TRN & \\
\hline CHEMBL1468913 & 688612 & 4.35 & 4.6841 & TRN & \\
\hline CHEMBL1314353 & 688612 & 4.4 & 4.6802 & TRN & \\
\hline CHEMBL1573309 & 688612 & 4.85 & 4.6734 & TRN & \\
\hline CHEMBL 7973 & 688612 & 4.2 & 4.7989 & TRN & \\
\hline CHEMBL1305632 & 688612 & 4.05 & 4.6667 & TRN & \\
\hline CHEMBL1575174 & 688612 & 4.65 & 4.5807 & TRN & \\
\hline CHEMBL1589849 & 688612 & 4.4 & 4.6598 & TRN & \\
\hline CHEMBL1358464 & 688612 & 4.4 & 4.6765 & TST & \\
\hline CHEMBL1970734 & 688612 & 6.5 & 4.6172 & TST & \\
\hline CHEMBL1450240 & 688612 & 4.0 & 4.7055 & TRN & \\
\hline CHEMBL1322741 & 688612 & 4.05 & 4.6634 & TRN & \\
\hline CHEMBL1485070 & 688612 & 4.05 & 4.6062 & TRN & \\
\hline CHEMBL3189963 & 688612 & 4.05 & 4.7057 & TST & \\
\hline CHEMBL1537528 & 688612 & 4.85 & 4.5742 & TRN & \\
\hline CHEMBL1473500 & 688612 & 4.05 & 4.6928 & TST & \\
\hline CHEMBL1367772 & 688612 & 4.45 & 4.6483 & TST & \\
\hline CHEMBL1424262 & 688612 & 4.55 & 4.7175 & TST & \\
\hline CHEMBL1539044 & 688612 & 4.05 & 4.6117 & TRN & \\
\hline CHEMBL1448793 & 688612 & 6.05 & 4.7208 & TRN & \\
\hline CHEMBL1407495 & 688612 & 4.3 & 4.6637 & TRN & \\
\hline CHEMBL1610430 & 688612 & 4.6 & 4.6943 & TRN & \\
\hline CHEMBL1582788 & 688612 & 4.1 & 4.6837 & TRN & \\
\hline CHEMBL1494704 & 688612 & 4.05 & 4.5969 & TST & \\
\hline CHEMBL1381318 & 688612 & 4.3 & 4.7874 & TRN & \\
\hline CHEMBL1467862 & 688612 & 4.2 & 4.6405 & TST & \\
\hline CHEMBL1335945 & 688612 & 4.25 & 4.7183 & TST & \\
\hline CHEMBL1526825 & 688612 & 4.05 & 4.7561 & TST & \\
\hline CHEMBL1597288 & 688612 & 4.5 & 4.65600 & 0000000001 & TRN \\
\hline CHEMBL1563377 & 688612 & 4.1 & 4.6022 & TRN & \\
\hline CHEMBL1560194 & 688612 & 4.3 & 4.605 & TRN & \\
\hline CHEMBL1601703 & 688612 & 4.65 & 4.6665 & TRN & \\
\hline CHEMBL1491599 & 688612 & 4.35 & 4.8039 & TRN & \\
\hline CHEMBL1553891 & 688612 & 4.05 & 4.5906 & TRN & \\
\hline CHEMBL1314633 & 688612 & 4.85 & 4.65600 & 0000000001 & TRN \\
\hline & & & & 19224 & \\
\hline
\end{tabular}




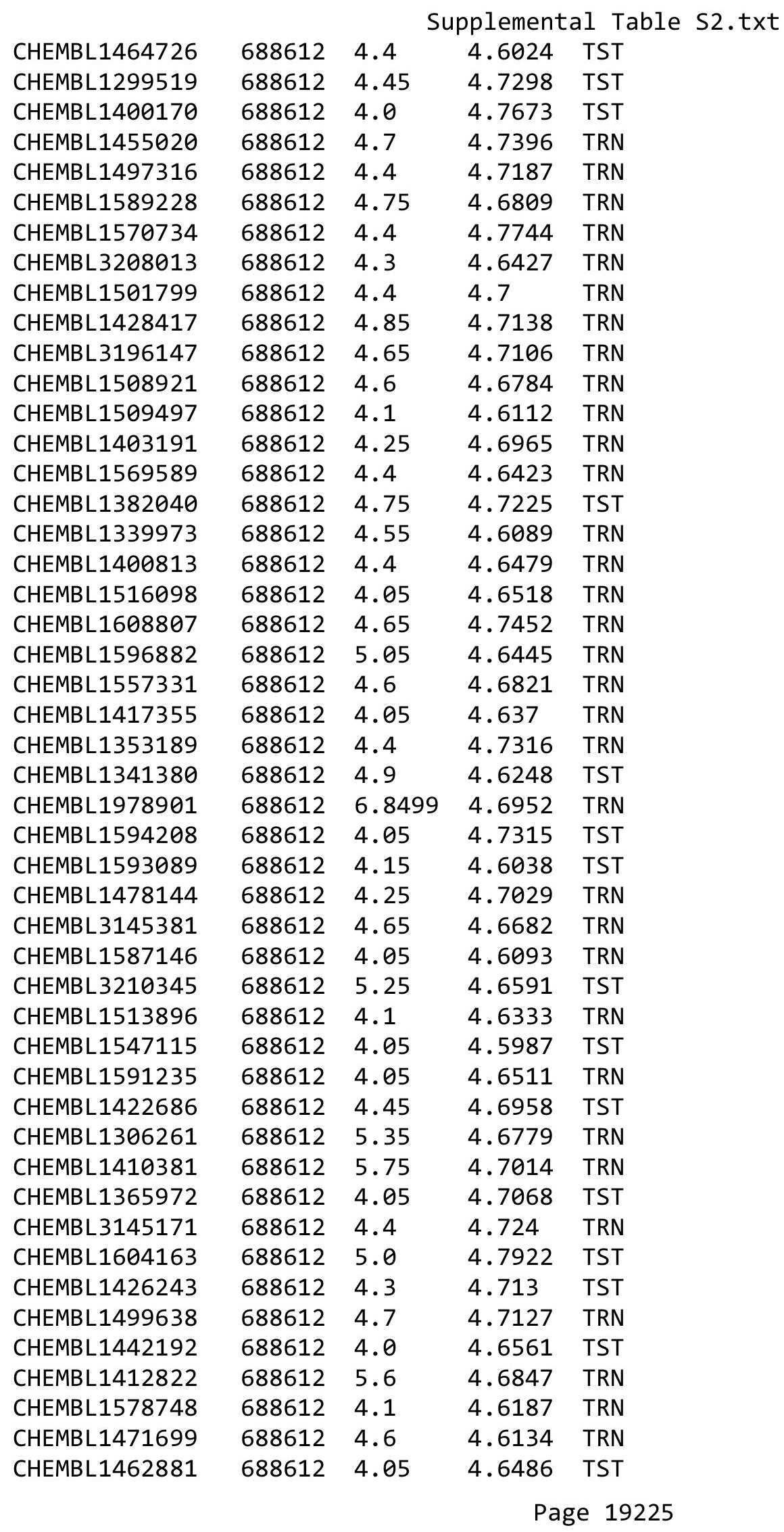




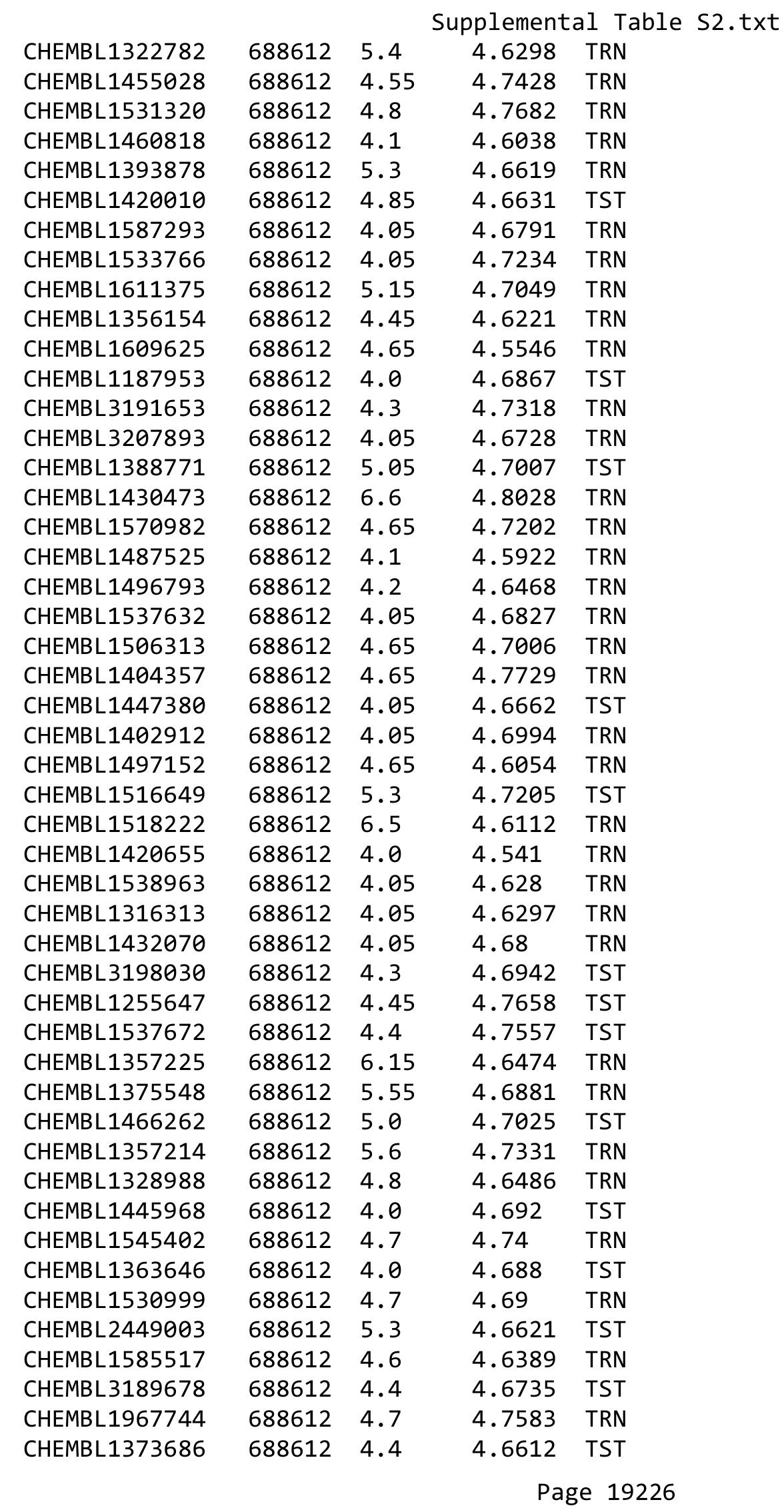




\begin{tabular}{|c|c|c|c|c|}
\hline \multicolumn{5}{|c|}{ Supplemental Table S2.txt } \\
\hline CHEMBL1599270 & 688612 & 4.1 & 4.683 & TRN \\
\hline CHEMBL1419644 & 688612 & 4.4 & 4.663 & TRN \\
\hline CHEMBL1355049 & 688612 & 4.05 & 4.6326 & TRN \\
\hline CHEMBL1318586 & 688612 & 5.3 & 4.6101 & TRN \\
\hline CHEMBL1402094 & 688612 & 4.05 & 4.5613 & TRN \\
\hline CHEMBL1581699 & 688612 & 4.1 & 4.6703 & TRN \\
\hline CHEMBL1442465 & 688612 & 5.1 & 4.6513 & TRN \\
\hline CHEMBL1470159 & 688612 & 4.65 & 4.6873 & TRN \\
\hline CHEMBL574189 & 688612 & 4.0 & 4.7104 & TST \\
\hline CHEMBL1592841 & 688612 & 4.1 & 4.5934 & TRN \\
\hline CHEMBL522504 & 688612 & 4.15 & 4.5953 & TRN \\
\hline CHEMBL1526877 & 688612 & 4.0 & 4.659 & TRN \\
\hline CHEMBL1547565 & 688612 & 4.3 & 4.7386 & TST \\
\hline CHEMBL1588851 & 688612 & 6.5501 & 4.7031 & TRN \\
\hline CHEMBL1601243 & 688612 & 4.1 & 4.6747 & TRN \\
\hline CHEMBL1557679 & 688612 & 4.0 & 4.6687 & TST \\
\hline CHEMBL1527597 & 688612 & 5.4 & 4.6753 & TRN \\
\hline CHEMBL1322494 & 688612 & 4.1 & 4.6438 & TST \\
\hline CHEMBL3198925 & 688612 & 4.6 & 4.7043 & TRN \\
\hline CHEMBL1411046 & 688612 & 5.5 & 4.6572 & TRN \\
\hline CHEMBL1556391 & 688612 & 5.15 & 4.6904 & TRN \\
\hline CHEMBL1417141 & 688612 & 5.1 & 4.6893 & TRN \\
\hline CHEMBL1572145 & 688612 & 4.35 & 4.6135 & TRN \\
\hline CHEMBL1393349 & 688612 & 4.05 & 4.7069 & TRN \\
\hline CHEMBL1577950 & 688612 & 4.1 & 4.613 & TRN \\
\hline CHEMBL1540725 & 688612 & 4.6 & 4.6936 & TST \\
\hline CHEMBL1381506 & 688612 & 4.4 & 4.7146 & TRN \\
\hline CHEMBL1603012 & 688612 & 4.4 & 4.6799 & TRN \\
\hline CHEMBL1410684 & 688612 & 4.2 & 4.6705 & TRN \\
\hline CHEMBL1409918 & 688612 & 5.4 & 4.5438 & TRN \\
\hline CHEMBL 3212647 & 688612 & 6.1 & 4.6662 & TST \\
\hline CHEMBL1397168 & 688612 & 4.05 & 4.6134 & TRN \\
\hline CHEMBL1600844 & 688612 & 4.4 & 4.6954 & TRN \\
\hline CHEMBL1400392 & 688612 & 4.2 & 4.6184 & TRN \\
\hline CHEMBL 26655 & 688612 & 5.75 & 4.7036 & TST \\
\hline CHEMBL1385349 & 688612 & 5.05 & 4.7042 & TST \\
\hline CHEMBL1365025 & 688612 & 4.45 & 4.6598 & TRN \\
\hline CHEMBL1374960 & 688612 & 6.6499 & 4.6352 & TRN \\
\hline CHEMBL1391099 & 688612 & 4.75 & 4.7298 & TRN \\
\hline CHEMBL1550067 & 688612 & 5.65 & 4.6527 & TRN \\
\hline CHEMBL1369416 & 688612 & 4.4 & 4.6983 & TRN \\
\hline CHEMBL1503033 & 688612 & 4.75 & 4.8286 & TRN \\
\hline CHEMBL1458522 & 688612 & 4.4 & 4.6662 & TRN \\
\hline CHEMBL1536256 & 688612 & 4.5 & 4.7014 & TRN \\
\hline CHEMBL1578504 & 688612 & 4.5 & 4.7081 & TRN \\
\hline CHEMBL1417929 & 688612 & 4.55 & 4.6991 & TRN \\
\hline CHEMBL1507038 & 688612 & 4.0 & 4.6226 & TRN \\
\hline CHEMBL1583401 & 688612 & 4.0 & 4.7327 & TST \\
\hline
\end{tabular}




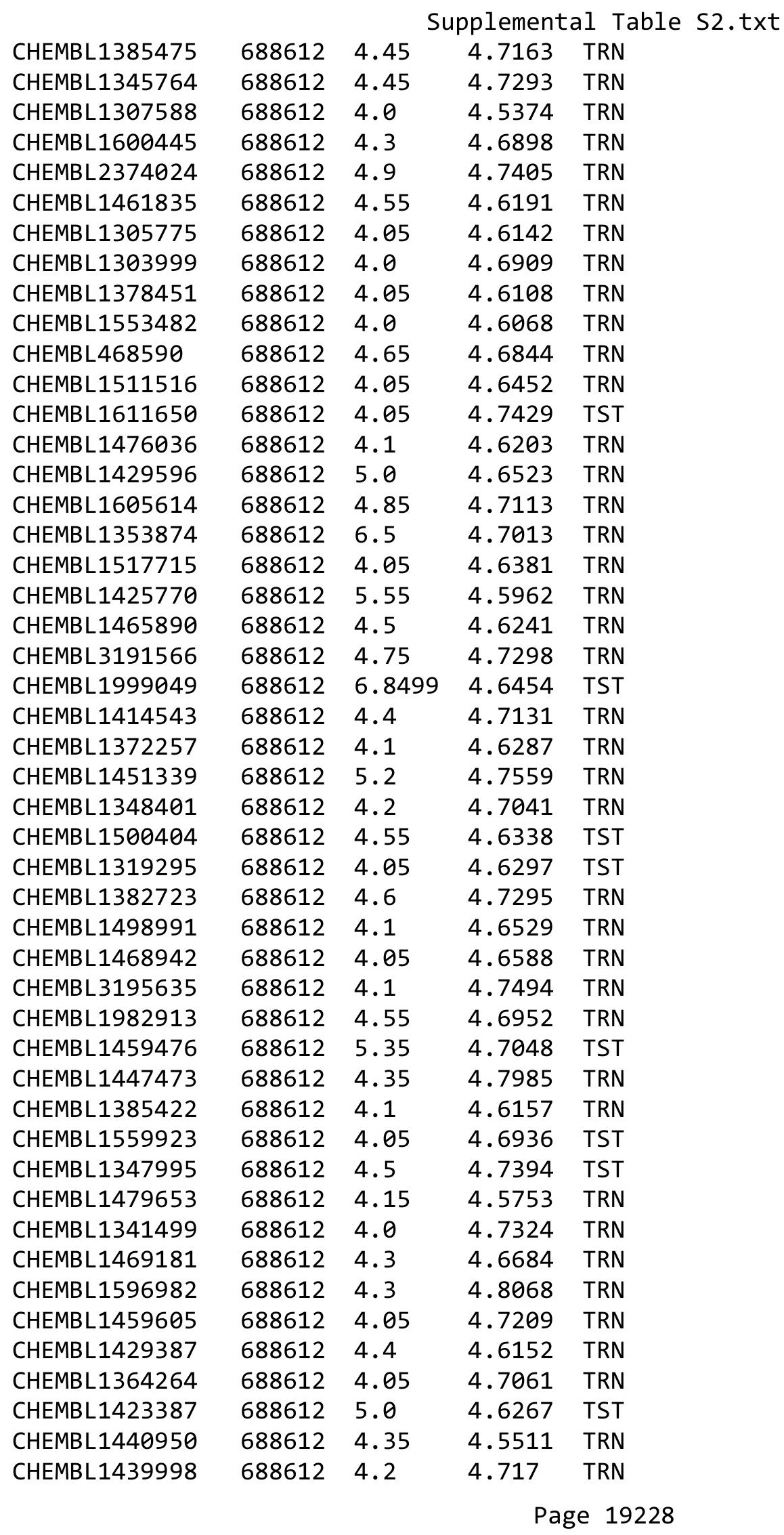




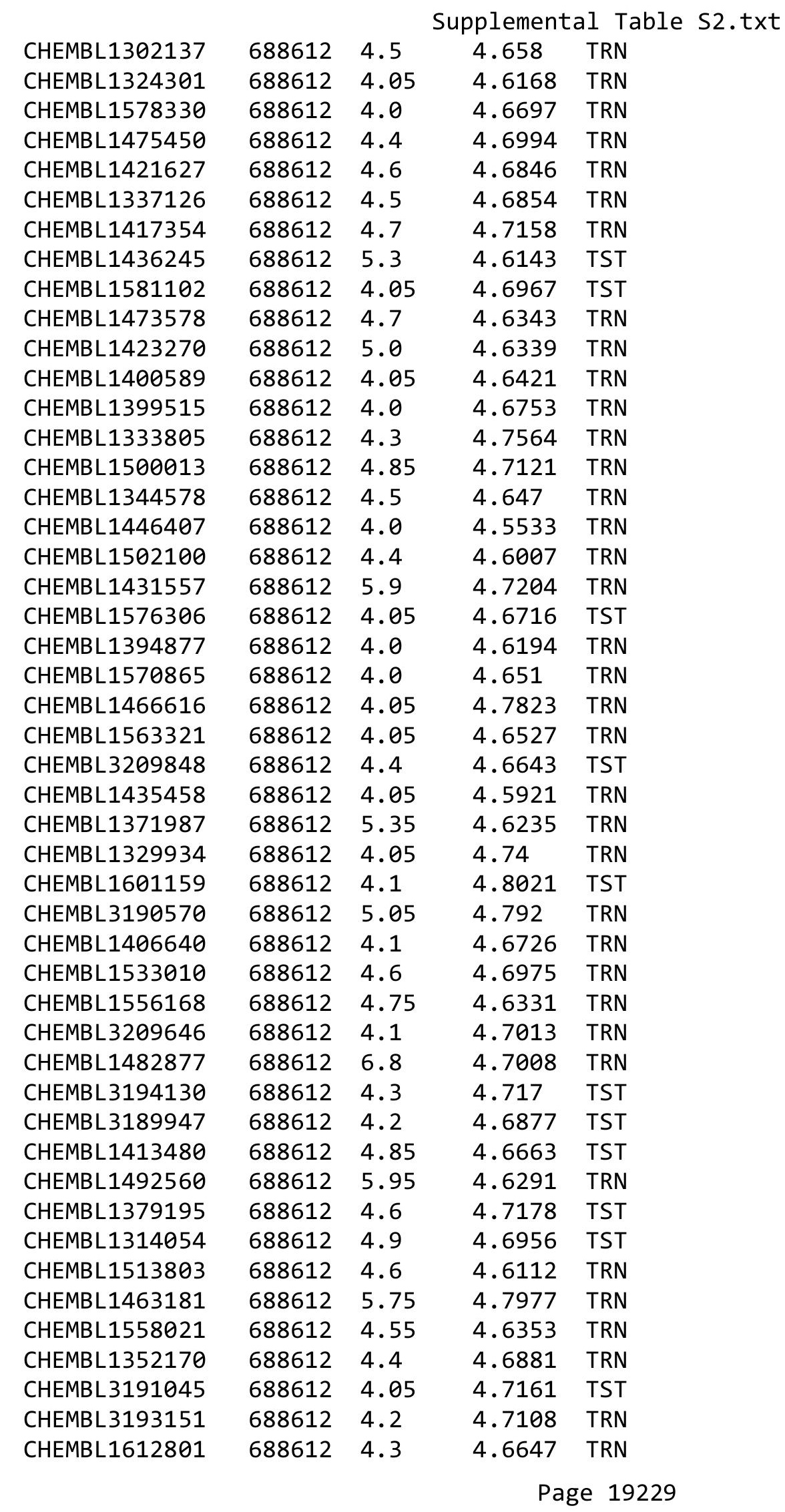




\begin{tabular}{|c|c|c|c|c|c|}
\hline \multicolumn{6}{|c|}{ Supplemental Table S2.txt } \\
\hline CHEMBL1477147 & 688612 & 4.25 & 4.6226 & TST & \\
\hline CHEMBL1426853 & 688612 & 6.9 & 4.6934 & TST & \\
\hline CHEMBL1342539 & 688612 & 5.4 & 4.5985 & TRN & \\
\hline CHEMBL1447093 & 688612 & 4.7 & 4.7092 & TRN & \\
\hline CHEMBL1328641 & 688612 & 4.3 & 4.7078 & TST & \\
\hline CHEMBL1475387 & 688612 & 4.4 & 4.5445 & TRN & \\
\hline CHEMBL1401725 & 688612 & 4.05 & 4.61 & TST & \\
\hline CHEMBL1443825 & 688612 & 4.75 & 4.7098 & TRN & \\
\hline CHEMBL1316307 & 688612 & 5.05 & 4.6227 & TRN & \\
\hline CHEMBL1534393 & 688612 & 4.4 & 4.6304 & TRN & \\
\hline CHEMBL3209597 & 688612 & 4.65 & 4.6917 & TRN & \\
\hline CHEMBL1383006 & 688612 & 4.65 & 4.7669 & TRN & \\
\hline CHEMBL1544326 & 688612 & 4.85 & 4.7142 & TRN & \\
\hline CHEMBL1320799 & 688612 & 5.2 & 4.7742 & TRN & \\
\hline CHEMBL1454366 & 688612 & 4.8 & 4.5932 & TST & \\
\hline CHEMBL1330084 & 688612 & 4.4 & 4.6579 & TST & \\
\hline CHEMBL1581151 & 688612 & 5.0 & 4.6254 & TRN & \\
\hline CHEMBL1549540 & 688612 & 4.95 & 4.6761 & TRN & \\
\hline CHEMBL1309944 & 688612 & 5.7 & 4.6443 & TST & \\
\hline CHEMBL1318217 & 688612 & 4.3 & 4.5797 & TRN & \\
\hline CHEMBL1310832 & 688612 & 4.1 & 4.6073 & TRN & \\
\hline CHEMBL1475440 & 688612 & 4.85 & 4.6524 & TRN & \\
\hline CHEMBL1366513 & 688612 & 5.9 & 4.63899 & 7999999999 & TST \\
\hline CHEMBL1418616 & 688612 & 6.8499 & 4.6215 & TRN & \\
\hline CHEMBL39879 & 688612 & 4.05 & 4.7117 & TST & \\
\hline CHEMBL1578128 & 688612 & 5.25 & 4.7079 & TRN & \\
\hline CHEMBL1539496 & 688612 & 4.7 & 4.7189 & & TST \\
\hline CHEMBL3209188 & 688612 & 4.05 & 4.6865 & TRN & \\
\hline CHEMBL1391873 & 688612 & 4.05 & 4.6798 & TRN & \\
\hline CHEMBL1519066 & 688612 & 4.2 & 4.6894 & TRN & \\
\hline CHEMBL1481285 & 688612 & 4.45 & 4.6686 & TST & \\
\hline CHEMBL1517167 & 688612 & 4.05 & 4.6181 & TRN & \\
\hline CHEMBL1528591 & 688612 & 4.6 & 4.6396 & TRN & \\
\hline CHEMBL133576 & 688612 & 4.7 & 4.6564 & TRN & \\
\hline CHEMBL1428050 & 688612 & 4.05 & 4.6488 & TRN & \\
\hline CHEMBL1329388 & 688612 & 4.1 & 4.6713 & TRN & \\
\hline CHEMBL1432907 & 688612 & 4.65 & 4.6329 & TST & \\
\hline CHEMBL1461928 & 688612 & 4.05 & 4.7139 & TRN & \\
\hline CHEMBL1450538 & 688612 & 4.0 & 4.6697 & TRN & \\
\hline CHEMBL1382537 & 688612 & 4.6 & $4.6560 e$ & 0000000001 & TRI \\
\hline CHEMBL1478119 & 688612 & 5.0 & 4.6393 & TRN & \\
\hline CHEMBL1303651 & 688612 & 4.3 & 4.7994 & TRN & \\
\hline CHEMBL1586866 & 688612 & 5.0 & 4.6645 & TRN & \\
\hline CHEMBL1533488 & 688612 & 4.4 & 4.6812 & TRN & \\
\hline CHEMBL1403614 & 688612 & 4.0 & 4.6494 & TRN & \\
\hline CHEMBL1487052 & 688612 & 6.8499 & 4.6486 & TRN & \\
\hline CHEMBL1408913 & 688612 & 4.1 & 4.647 & TRN & \\
\hline CHEMBL1580706 & 688612 & 4.55 & 4.7213 & TRN & \\
\hline
\end{tabular}




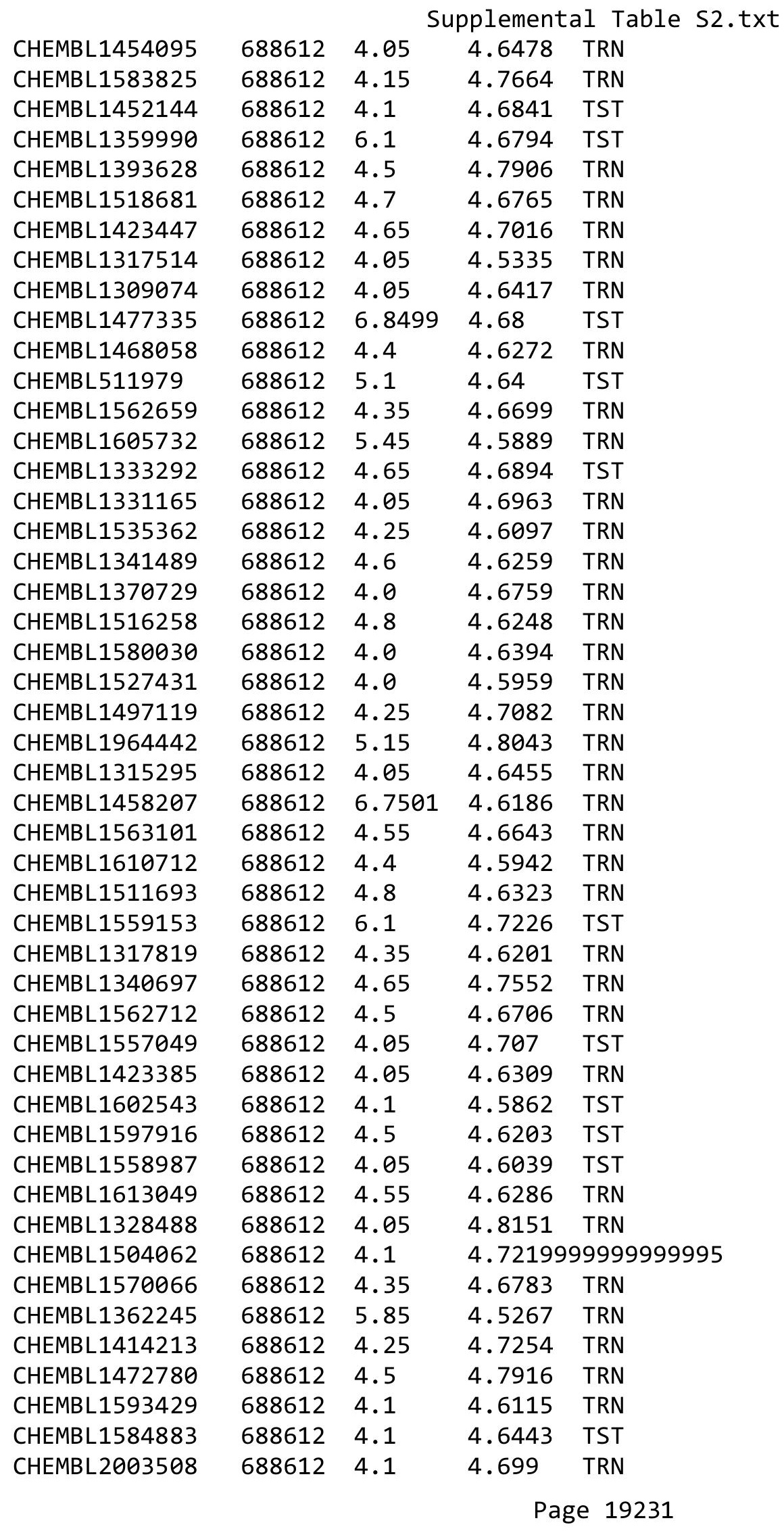




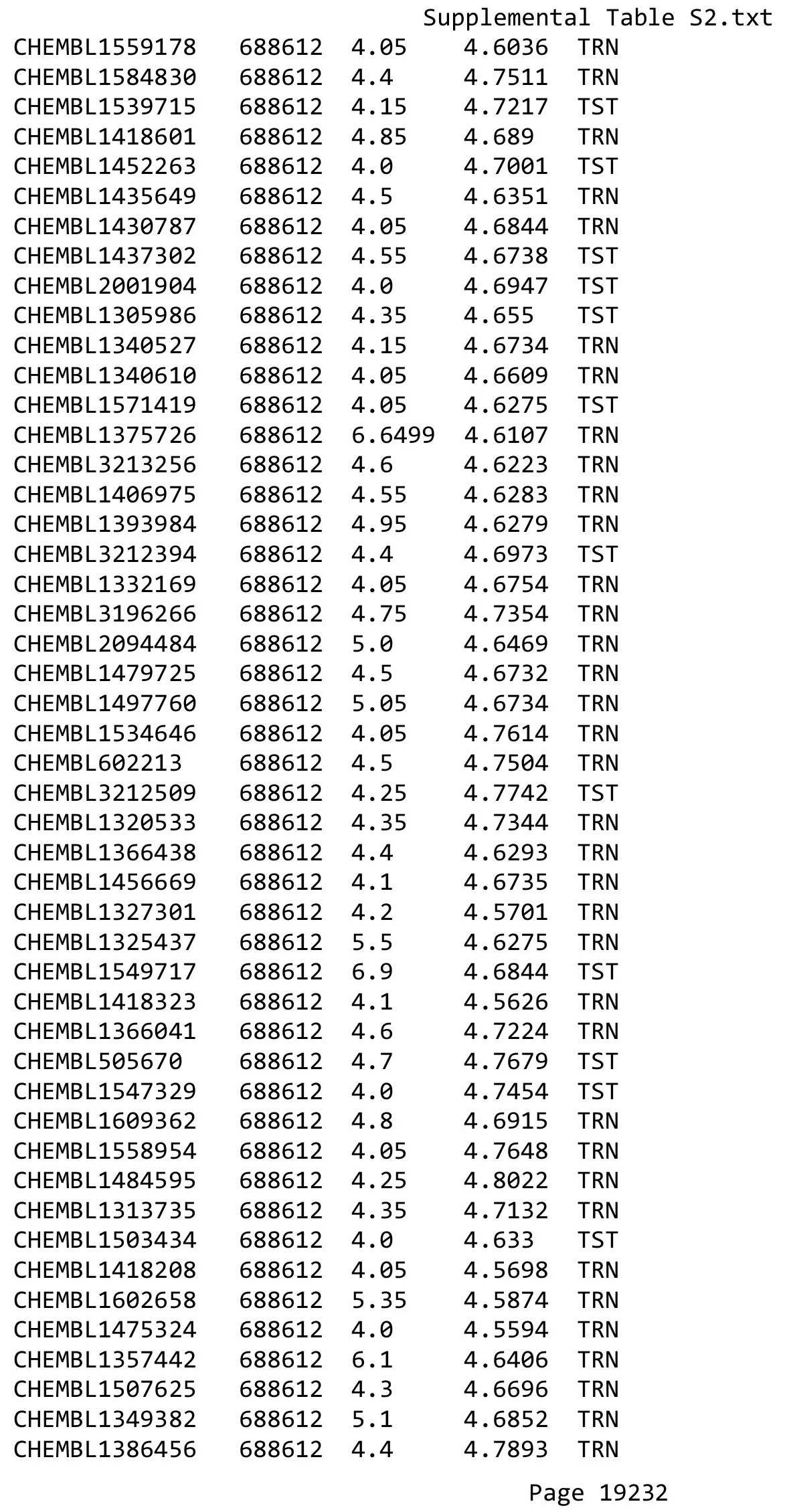




\begin{tabular}{|c|c|c|c|c|c|}
\hline & & \multicolumn{4}{|c|}{ Supplemental Table S2.txt } \\
\hline CHEMBL1460238 & 688612 & 4.45 & 4.5578 & TRN & \\
\hline CHEMBL1320878 & 688612 & 5.0 & 4.6029 & TRN & \\
\hline CHEMBL1399534 & 688612 & 4.0 & 4.6048 & TRN & \\
\hline CHEMBL1447223 & 688612 & 5.05 & 4.8369 & TST & \\
\hline CHEMBL1559531 & 688612 & 4.7 & 4.6778 & TRN & \\
\hline CHEMBL1542492 & 688612 & 4.4 & 4.7289 & TRN & \\
\hline CHEMBL1597524 & 688612 & 5.05 & 4.7764 & TRN & \\
\hline CHEMBL1478964 & 688612 & 4.2 & 4.6688 & TRN & \\
\hline CHEMBL1567763 & 688612 & 4.7 & 4.5896 & TRN & \\
\hline CHEMBL1398855 & 688612 & 4.95 & 4.686 & TST & \\
\hline CHEMBL1564039 & 688612 & 5.4 & 4.6588 & TRN & \\
\hline CHEMBL1358848 & 688612 & 5.3 & 4.7664 & TRN & \\
\hline CHEMBL1598010 & 688612 & 4.3 & 4.7565 & TST & \\
\hline CHEMBL3209441 & 688612 & 4.85 & 4.6925 & TRN & \\
\hline CHEMBL1403968 & 688612 & 5.55 & 4.6306 & TRN & \\
\hline CHEMBL1580418 & 688612 & 4.1 & 4.6095 & TRN & \\
\hline CHEMBL1533277 & 688612 & 4.9 & 4.676 & TRN & \\
\hline CHEMBL1374533 & 688612 & 6.15 & 4.6462 & TRN & \\
\hline CHEMBL3213455 & 688612 & 4.05 & 4.6822 & TRN & \\
\hline CHEMBL1394320 & 688612 & 4.7 & 4.68199 & 99999999995 & TRN \\
\hline CHEMBL1590611 & 688612 & 5.7 & 4.6138 & TRN & \\
\hline CHEMBL1557278 & 688612 & 4.4 & 4.7033 & TRN & \\
\hline CHEMBL3183979 & 688612 & 4.1 & 4.7497 & TRN & \\
\hline CHEMBL1397401 & 688612 & 4.1 & 4.6717 & TRN & \\
\hline CHEMBL1530557 & 688612 & 4.3 & 4.6272 & TRN & \\
\hline CHEMBL1373860 & 688612 & 4.05 & 4.6893 & TRN & \\
\hline CHEMBL 2016645 & 688612 & 4.9 & 4.6733 & TRN & \\
\hline CHEMBL1442787 & 688612 & 6.0 & 4.6029 & TRN & \\
\hline CHEMBL1319738 & 688612 & 4.0 & 4.6297 & TRN & \\
\hline CHEMBL3196670 & 688612 & 4.1 & 4.7313 & TRN & \\
\hline CHEMBL1322154 & 688612 & 5.4 & 4.7704 & TST & \\
\hline CHEMBL1335577 & 688612 & 5.0 & 4.6816 & TRN & \\
\hline CHEMBL3195562 & 688612 & 4.3 & 4.777 & TRN & \\
\hline CHEMBL1507666 & 688612 & 4.1 & 4.6745 & TRN & \\
\hline CHEMBL1469811 & 688612 & 4.1 & 4.65 & TRN & \\
\hline CHEMBL3207848 & 688612 & 4.95 & 4.6943 & TRN & \\
\hline CHEMBL3211310 & 688612 & 5.45 & 4.6501 & TST & \\
\hline CHEMBL1369513 & 688612 & 4.45 & 4.7399 & TRN & \\
\hline CHEMBL1527670 & 688612 & 4.2 & 4.5805 & TST & \\
\hline CHEMBL3192304 & 688612 & 4.95 & 4.6453 & TRN & \\
\hline CHEMBL1975120 & 688612 & 4.6 & 4.8117 & TRN & \\
\hline CHEMBL1344729 & 688612 & 4.1 & 4.6271 & TRN & \\
\hline CHEMBL1430148 & 688612 & 4.1 & 4.6479 & TRN & \\
\hline CHEMBL1527508 & 688612 & 4.1 & 4.5869 & TST & \\
\hline CHEMBL3211956 & 688612 & 4.05 & 4.7373 & TRN & \\
\hline CHEMBL 2005302 & 688612 & 4.75 & 4.6533 & TRN & \\
\hline CHEMBL1405192 & 688612 & 4.9 & 4.6601 & TRN & \\
\hline CHEMBL1396959 & 688612 & 4.35 & 4.6089 & TRN & \\
\hline
\end{tabular}




\begin{tabular}{|c|c|c|c|c|c|}
\hline \multicolumn{6}{|c|}{ Supplemental Table S2.txt } \\
\hline CHEMBL547924 & 688612 & 4.0 & 4.6661 & TRN & \\
\hline CHEMBL1517879 & 688612 & 4.05 & 4.6653 & TRN & \\
\hline CHEMBL1602853 & 688612 & 4.05 & 4.63399 & 99999999995 & TRN \\
\hline CHEMBL1323786 & 688612 & 4.55 & 4.7301 & TRN & \\
\hline CHEMBL1587849 & 688612 & 4.75 & 4.7638 & TRN & \\
\hline CHEMBL1540089 & 688612 & 4.85 & 4.7377 & TRN & \\
\hline CHEMBL1342383 & 688612 & 4.65 & 4.6401 & TRN & \\
\hline CHEMBL1580407 & 688612 & 4.55 & 4.7245 & TRN & \\
\hline CHEMBL 3212553 & 688612 & 4.05 & 4.705 & TRN & \\
\hline CHEMBL1412400 & 688612 & 4.5 & 4.603 & TRN & \\
\hline CHEMBL1311353 & 688612 & 4.6 & 4.6717 & TST & \\
\hline CHEMBL1314626 & 688612 & 4.7 & 4.6849 & TRN & \\
\hline CHEMBL1531483 & 688612 & 4.0 & 4.6989 & TRN & \\
\hline CHEMBL 212827 & 688612 & 5.5 & 4.6995 & TRN & \\
\hline CHEMBL1510325 & 688612 & 4.75 & 4.7306 & TRN & \\
\hline CHEMBL1304521 & 688612 & 4.0 & 4.6203 & TRN & \\
\hline CHEMBL1352844 & 688612 & 5.15 & 4.7134 & TRN & \\
\hline CHEMBL1387597 & 688612 & 4.4 & 4.729 & TRN & \\
\hline CHEMBL1333663 & 688612 & 4.05 & 4.7094 & TST & \\
\hline CHEMBL1385660 & 688612 & 4.85 & 4.7243 & TRN & \\
\hline CHEMBL1392018 & 688612 & 4.0 & 4.6116 & TRN & \\
\hline CHEMBL1360880 & 688612 & 4.3 & 4.5915 & TRN & \\
\hline CHEMBL1299613 & 688612 & 4.0 & 4.6056 & TRN & \\
\hline CHEMBL1347094 & 688612 & 4.05 & 4.7496 & TRN & \\
\hline CHEMBL1362042 & 688612 & 4.05 & 4.629 & TRN & \\
\hline CHEMBL1432733 & 688612 & 5.45 & 4.6276 & TST & \\
\hline CHEMBL3190951 & 688612 & 4.85 & 4.7725 & TRN & \\
\hline CHEMBL1342698 & 688612 & 4.45 & 4.7366 & TRN & \\
\hline CHEMBL1464746 & 688612 & 4.9 & 4.5511 & TRN & \\
\hline CHEMBL3210622 & 688612 & 4.0 & 4.7482 & TST & \\
\hline CHEMBL1374465 & 688612 & 4.7 & 4.7663 & TRN & \\
\hline CHEMBL1407956 & 688612 & 4.2 & 4.6336 & TST & \\
\hline CHEMBL 3194549 & 688612 & 6.0 & 4.6539 & TRN & \\
\hline CHEMBL1321499 & 688612 & 4.0 & 4.6416 & TRN & \\
\hline CHEMBL1977082 & 688612 & 4.95 & 4.728 & TRN & \\
\hline CHEMBL193054 & 688612 & 4.1 & 4.6015 & TRN & \\
\hline CHEMBL1357532 & 688612 & 5.15 & 4.6527 & TRN & \\
\hline CHEMBL1469293 & 688612 & 6.35 & 4.5742 & TRN & \\
\hline CHEMBL1506843 & 688612 & 4.9 & 4.6344 & TRN & \\
\hline CHEMBL483531 & 688612 & 4.7 & 4.6974 & TRN & \\
\hline CHEMBL1352633 & 688612 & 4.3 & 4.77800 & 00000000005 & TST \\
\hline CHEMBL1307020 & 688612 & 4.6 & 4.6499 & TRN & \\
\hline CHEMBL1416942 & 688612 & 4.4 & 4.5958 & TRN & \\
\hline CHEMBL1523843 & 688612 & 5.25 & 4.6944 & TST & \\
\hline CHEMBL1406585 & 688612 & 5.4 & 4.7086 & TRN & \\
\hline CHEMBL1390111 & 688612 & 4.65 & 4.7024 & TST & \\
\hline CHEMBL1305289 & 688612 & 4.55 & 4.7664 & TST & \\
\hline CHEMBL1435473 & 688612 & 4.0 & 4.6408 & TRN & \\
\hline
\end{tabular}




\begin{tabular}{|c|c|c|c|c|c|}
\hline \multicolumn{6}{|c|}{ Supplemental Table S2.txt } \\
\hline CHEMBL1611461 & 688612 & 4.05 & 4.6614 & TRN & \\
\hline CHEMBL1538977 & 688612 & 4.55 & 4.6693 & TRN & \\
\hline CHEMBL1301690 & 688612 & 6.8 & 4.6032 & TRN & \\
\hline CHEMBL1418313 & 688612 & 6.45 & 4.6661 & TRN & \\
\hline CHEMBL1483738 & 688612 & 4.45 & 4.7033 & TRN & \\
\hline CHEMBL1416795 & 688612 & 4.4 & 4.5808 & TRN & \\
\hline CHEMBL1545172 & 688612 & 4.4 & 4.6671 & TRN & \\
\hline CHEMBL3190219 & 688612 & 4.45 & 4.6157 & TRN & \\
\hline CHEMBL1348054 & 688612 & 5.05 & 4.7648 & TRN & \\
\hline CHEMBL1316118 & 688612 & 4.3 & 4.6029 & TRN & \\
\hline CHEMBL1410664 & 688612 & 4.25 & 4.7015 & TRN & \\
\hline CHEMBL1337587 & 688612 & 4.5 & 4.7089 & TRN & \\
\hline CHEMBL1313829 & 688612 & 4.0 & 4.6985 & TRN & \\
\hline CHEMBL 1455556 & 688612 & 4.1 & 4.6948 & TST & \\
\hline CHEMBL1310746 & 688612 & 4.7 & 4.7126 & TRN & \\
\hline CHEMBL1532655 & 688612 & 4.1 & 4.6314 & TRN & \\
\hline CHEMBL1439679 & 688612 & 4.45 & 4.7328 & TST & \\
\hline CHEMBL 3210964 & 688612 & 4.2 & 4.6315 & TRN & \\
\hline CHEMBL3144871 & 688612 & 4.4 & 4.7164 & TST & \\
\hline CHEMBL1572510 & 688612 & 4.25 & 4.6051 & TRN & \\
\hline CHEMBL3195862 & 688612 & 4.1 & 4.7063 & TRN & \\
\hline CHEMBL1408688 & 688612 & 6.25 & 4.614 & TRN & \\
\hline CHEMBL1587957 & 688612 & 4.2 & 4.6781 & TRN & \\
\hline CHEMBL1313485 & 688612 & 5.95 & 4.7419 & TRN & \\
\hline CHEMBL1427247 & 688612 & 4.1 & 4.6079 & TRN & \\
\hline CHEMBL1989234 & 688612 & 4.6 & 4.6969 & TRN & \\
\hline CHEMBL1588774 & 688612 & 6.9 & 4.6468 & TST & \\
\hline CHEMBL1612473 & 688612 & 4.45 & 4.6439 & TST & \\
\hline CHEMBL1443351 & 688612 & 5.0 & 4.7716 & TRN & \\
\hline CHEMBL1520410 & 688612 & 4.0 & 4.5635 & TRN & \\
\hline CHEMBL1481305 & 688612 & 4.1 & 4.6234 & TST & \\
\hline CHEMBL512761 & 688612 & 4.4 & 4.6873 & TRN & \\
\hline CHEMBL1511286 & 688612 & 4.3 & 4.7087 & TRN & \\
\hline CHEMBL1373040 & 688612 & 5.3 & 4.6545 & TRN & \\
\hline CHEMBL1306708 & 688612 & 6.6499 & 4.76699 & 99999999995 & TST \\
\hline CHEMBL1556294 & 688612 & 4.0 & 4.6481 & TRN & \\
\hline CHEMBL1477564 & 688612 & 7.0 & 4.6355 & TRN & \\
\hline CHEMBL3192188 & 688612 & 5.6 & 4.8157 & TRN & \\
\hline CHEMBL 1463272 & 688612 & 4.25 & 4.7544 & TRN & \\
\hline CHEMBL1353455 & 688612 & 4.15 & 4.6763 & TRN & \\
\hline CHEMBL1398090 & 688612 & 6.9 & 4.6474 & TRN & \\
\hline CHEMBL1521735 & 688612 & 4.65 & 4.6664 & TRN & \\
\hline CHEMBL1477210 & 688612 & 4.0 & 4.5919 & TRN & \\
\hline CHEMBL1368203 & 688612 & 4.15 & 4.7582 & TST & \\
\hline CHEMBL1586897 & 688612 & 4.8 & 4.6592 & TRN & \\
\hline CHEMBL1377126 & 688612 & 4.9 & 4.6396 & TRN & \\
\hline CHEMBL1561916 & 688612 & 4.5 & 4.6742 & TRN & \\
\hline CHEMBL1609121 & 688612 & 5.15 & 4.6927 & TST & \\
\hline
\end{tabular}




\begin{tabular}{|c|c|c|c|c|}
\hline \multicolumn{5}{|c|}{ Supplemental Table S2.txt } \\
\hline CHEMBL3191915 & 688612 & 4.1 & 4.7725 & TRN \\
\hline CHEMBL1604810 & 688612 & 4.4 & 4.6273 & TRN \\
\hline CHEMBL3198507 & 688612 & 4.1 & 4.6664 & TRN \\
\hline CHEMBL1409876 & 688612 & 4.4 & 4.6876 & TRN \\
\hline CHEMBL1334507 & 688612 & 4.85 & 4.6609 & TRN \\
\hline CHEMBL1600939 & 688612 & 4.1 & 4.6675 & TST \\
\hline CHEMBL1422700 & 688612 & 4.4 & 4.6677 & TRN \\
\hline CHEMBL1364919 & 688612 & 4.0 & 4.5938 & TST \\
\hline CHEMBL1472817 & 688612 & 4.65 & 4.7956 & TST \\
\hline CHEMBL1610734 & 688612 & 4.05 & 4.6715 & TRN \\
\hline CHEMBL1528035 & 688612 & 4.1 & 4.6215 & TRN \\
\hline CHEMBL1543000 & 688612 & 6.15 & 4.7499 & TST \\
\hline CHEMBL1463935 & 688612 & 4.4 & 4.7274 & TRN \\
\hline CHEMBL1503034 & 688612 & 4.35 & 4.7462 & TRN \\
\hline CHEMBL1306205 & 688612 & 4.4 & 4.5727 & TRN \\
\hline CHEMBL3189764 & 688612 & 4.65 & 4.7765 & TRN \\
\hline CHEMBL1581949 & 688612 & 4.75 & 4.6078 & TRN \\
\hline CHEMBL224916 & 688612 & 5.15 & 4.7913 & TRN \\
\hline CHEMBL1304744 & 688612 & 4.6 & 4.7736 & TST \\
\hline CHEMBL1390040 & 688612 & 4.2 & 4.663 & TRN \\
\hline CHEMBL1527364 & 688612 & 6.5501 & 4.584 & TRN \\
\hline CHEMBL1322303 & 688612 & 4.05 & 4.6513 & TRN \\
\hline CHEMBL1308547 & 688612 & 4.3 & 4.7146 & TRN \\
\hline CHEMBL1550366 & 688612 & 4.25 & 4.7624 & TST \\
\hline CHEMBL1526120 & 688612 & 4.0 & 4.7136 & TST \\
\hline CHEMBL1519673 & 688612 & 4.1 & 4.6026 & TRN \\
\hline CHEMBL1509325 & 688612 & 4.05 & 4.6797 & TST \\
\hline CHEMBL1384919 & 688612 & 4.95 & 4.7525 & TRN \\
\hline CHEMBL1388036 & 688612 & 4.7 & 4.6999 & TST \\
\hline CHEMBL1336387 & 688612 & 4.25 & 4.6027 & TRN \\
\hline CHEMBL1399921 & 688612 & 4.1 & 4.6682 & TRN \\
\hline CHEMBL1428947 & 688612 & 5.95 & 4.694 & TRN \\
\hline CHEMBL1360615 & 688612 & 4.5 & 4.6787 & TST \\
\hline CHEMBL1411425 & 688612 & 4.05 & 4.6298 & TRN \\
\hline CHEMBL1389172 & 688612 & 4.1 & 4.5924 & TRN \\
\hline CHEMBL1312657 & 688612 & 4.5 & 4.6424 & TRN \\
\hline CHEMBL2369172 & 688612 & 4.1 & 4.6702 & TRN \\
\hline CHEMBL1479406 & 688612 & 4.2 & 4.6334 & TRN \\
\hline CHEMBL1594634 & 688612 & 4.3 & 4.7623 & TST \\
\hline CHEMBL1543994 & 688612 & 4.35 & 4.588 & TRN \\
\hline CHEMBL1329086 & 688612 & 4.0 & 4.6592 & TST \\
\hline CHEMBL1397291 & 688612 & 6.0 & 4.5936 & TRN \\
\hline CHEMBL1492648 & 688612 & 4.05 & 4.6687 & TRN \\
\hline CHEMBL1374100 & 688612 & 4.1 & 4.6696 & TRN \\
\hline CHEMBL1396319 & 688612 & 4.05 & 4.5656 & TRN \\
\hline CHEMBL1445482 & 688612 & 4.1 & 4.5349 & TRN \\
\hline CHEMBL1357441 & 688612 & 4.65 & 4.6661 & TRN \\
\hline CHEMBL1432508 & 688612 & 4.7 & 4.716 & TST \\
\hline
\end{tabular}




\begin{tabular}{|c|c|c|c|c|c|}
\hline \multicolumn{6}{|c|}{ Supplemental Table S2.txt } \\
\hline CHEMBL1534135 & 688612 & 4.8 & 4.7701 & TST & \\
\hline CHEMBL1495531 & 688612 & 5.4 & 4.6877 & TRN & \\
\hline CHEMBL1303385 & 688612 & 6.5 & 4.7124 & TRN & \\
\hline CHEMBL1435583 & 688612 & 4.8 & 4.6007 & TRN & \\
\hline CHEMBL586163 & 688612 & 4.75 & 4.6965 & TST & \\
\hline CHEMBL1532277 & 688612 & 4.25 & 4.6112 & TRN & \\
\hline CHEMBL1501349 & 688612 & 6.6 & 4.6846 & TRN & \\
\hline CHEMBL1464282 & 688612 & 4.0 & 4.68 & TST & \\
\hline CHEMBL1967099 & 688612 & 5.0 & 4.7582 & TRN & \\
\hline CHEMBL1429021 & 688612 & 4.0 & 4.6886 & TST & \\
\hline CHEMBL1382605 & 688612 & 6.8499 & 4.5955 & TRN & \\
\hline CHEMBL1466829 & 688612 & 5.35 & 4.6615 & TST & \\
\hline CHEMBL1331534 & 688612 & 4.7 & 4.6885 & TRN & \\
\hline CHEMBL1445923 & 688612 & 6.3 & 4.6896 & TRN & \\
\hline CHEMBL3192689 & 688612 & 5.0 & 4.7323 & TRN & \\
\hline CHEMBL1354279 & 688612 & 4.55 & 4.7625 & TRN & \\
\hline CHEMBL1364011 & 688612 & 4.65 & 4.6885 & TRN & \\
\hline CHEMBL1557557 & 688612 & 4.85 & 4.6098 & TRN & \\
\hline CHEMBL1561001 & 688612 & 4.05 & 4.64199 & 99999999995 & TRN \\
\hline CHEMBL1334880 & 688612 & 4.05 & 4.6075 & TRN & \\
\hline CHEMBL1578546 & 688612 & 5.0 & 4.6609 & TRN & \\
\hline CHEMBL1383954 & 688612 & 4.15 & 4.6339 & TRN & \\
\hline CHEMBL1560176 & 688612 & 5.35 & 4.6259 & TRN & \\
\hline CHEMBL1426768 & 688612 & 4.9 & 4.7432 & TRN & \\
\hline CHEMBL1380871 & 688612 & 6.35 & 4.6871 & TRN & \\
\hline CHEMBL1371693 & 688612 & 4.0 & 4.6386 & TRN & \\
\hline CHEMBL1500403 & 688612 & 4.1 & 4.6649 & TRN & \\
\hline CHEMBL1557815 & 688612 & 5.4 & 4.6729 & TRN & \\
\hline CHEMBL1399709 & 688612 & 6.8 & 4.6074 & TRN & \\
\hline CHEMBL1500967 & 688612 & 4.55 & 4.56800 & 00000000005 & TRN \\
\hline CHEMBL1578693 & 688612 & 4.7 & 4.6814 & TRN & \\
\hline CHEMBL1354201 & 688612 & 4.65 & 4.7067 & TST & \\
\hline CHEMBL1419822 & 688612 & 4.1 & 4.6597 & TRN & \\
\hline CHEMBL1519276 & 688612 & 4.5 & 4.7428 & TRN & \\
\hline CHEMBL1501978 & 688612 & 4.4 & 4.6567 & TRN & \\
\hline CHEMBL1377426 & 688612 & 4.05 & 4.6239 & TRN & \\
\hline CHEMBL1410176 & 688612 & 6.35 & 4.6141 & TST & \\
\hline CHEMBL1542655 & 688612 & 6.9 & 4.6634 & TRN & \\
\hline CHEMBL1425499 & 688612 & 5.0 & 4.5884 & TRN & \\
\hline CHEMBL1464268 & 688612 & 4.05 & 4.6432 & TST & \\
\hline CHEMBL1491256 & 688612 & 5.45 & 4.6042 & TRN & \\
\hline CHEMBL1969010 & 688612 & 4.05 & 4.6455 & TRN & \\
\hline CHEMBL1526578 & 688612 & 4.55 & 4.7821 & TST & \\
\hline CHEMBL1564427 & 688612 & 4.05 & 4.6251 & TST & \\
\hline CHEMBL1574269 & 688612 & 6.0 & 4.6743 & TRN & \\
\hline CHEMBL1467793 & 688612 & 4.2 & 4.7563 & TRN & \\
\hline CHEMBL1439606 & 688612 & 5.35 & 4.6939 & TRN & \\
\hline CHEMBL1341561 & 688612 & 5.5 & 4.6627 & TRN & \\
\hline
\end{tabular}




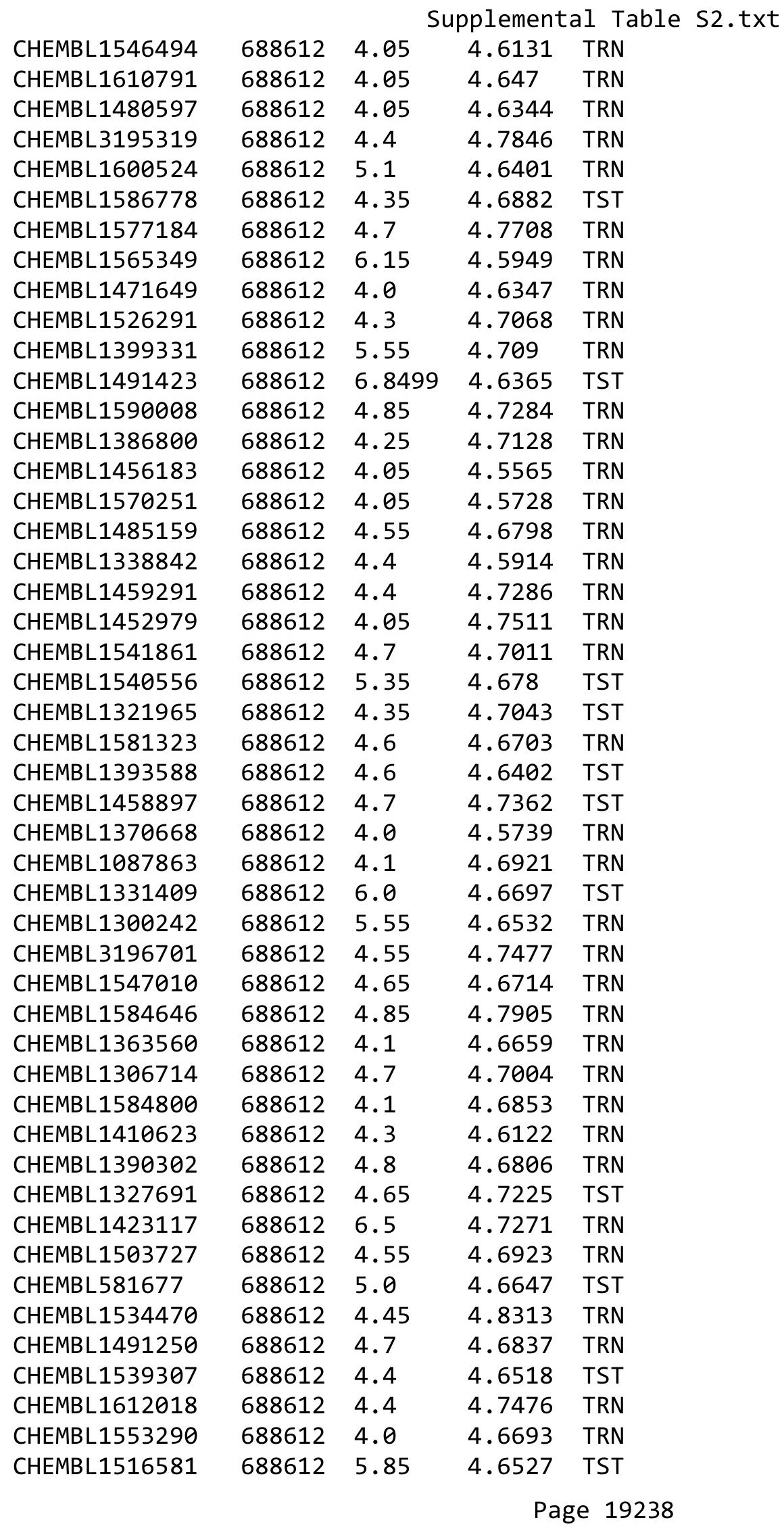




\begin{tabular}{|c|c|c|c|c|c|}
\hline \multicolumn{6}{|c|}{ Supplemental Table S2.txt } \\
\hline CHEMBL1319501 & 688612 & 4.6 & 4.6135 & TRN & \\
\hline CHEMBL1577545 & 688612 & 4.05 & 4.6465 & TRN & \\
\hline CHEMBL1302956 & 688612 & 4.4 & 4.5935 & TRN & \\
\hline CHEMBL1482479 & 688612 & 4.6 & 4.6366 & TRN & \\
\hline CHEMBL1317046 & 688612 & 5.05 & 4.6267 & TRN & \\
\hline CHEMBL1400846 & 688612 & 4.1 & 4.6866 & TST & \\
\hline CHEMBL1376782 & 688612 & 4.1 & 4.6564 & TRN & \\
\hline CHEMBL1371780 & 688612 & 4.45 & 4.7166 & TRN & \\
\hline CHEMBL1469518 & 688612 & 5.35 & 4.6098 & TRN & \\
\hline CHEMBL1483128 & 688612 & 6.9 & 4.6735 & TST & \\
\hline CHEMBL1451235 & 688612 & 4.2 & 4.5983 & TRN & \\
\hline CHEMBL1488875 & 688612 & 4.6 & 4.7274 & TRN & \\
\hline CHEMBL1586589 & 688612 & 4.6 & 4.651 & TRN & \\
\hline CHEMBL1478463 & 688612 & 4.05 & 4.5361 & TRN & \\
\hline CHEMBL1501573 & 688612 & 4.35 & 4.8213 & TRN & \\
\hline CHEMBL1317433 & 688612 & 5.15 & 4.657 & TRN & \\
\hline CHEMBL1507651 & 688612 & 5.1 & 4.6158 & TRN & \\
\hline CHEMBL1356130 & 688612 & 6.15 & 4.6271 & TST & \\
\hline CHEMBL1584403 & 688612 & 6.8499 & 4.6458 & TRN & \\
\hline CHEMBL1301797 & 688612 & 4.7 & 4.6869 & TRN & \\
\hline CHEMBL1424327 & 688612 & 4.05 & 4.6774 & TRN & \\
\hline CHEMBL494891 & 688612 & 4.7 & $4.7330 e$ & 00000000005 & \\
\hline CHEMBL1579351 & 688612 & 4.1 & 4.6664 & TRN & \\
\hline CHEMBL3190977 & 688612 & 4.05 & 4.6515 & TRN & \\
\hline CHEMBL1364093 & 688612 & 4.65 & 4.7181 & TST & \\
\hline CHEMBL1407804 & 688612 & 5.0 & 4.662 & TRN & \\
\hline CHEMBL1494978 & 688612 & 4.4 & 4.6142 & TRN & \\
\hline CHEMBL1498965 & 688612 & 5.35 & 4.5832 & TRN & \\
\hline CHEMBL1462625 & 688612 & 5.8 & 4.6776 & TST & \\
\hline CHEMBL1376190 & 688612 & 4.05 & 4.5894 & TRN & \\
\hline CHEMBL1371268 & 688612 & 4.4 & 4.5988 & TRN & \\
\hline CHEMBL1611824 & 688612 & 4.55 & 4.7157 & TRN & \\
\hline CHEMBL1306954 & 688612 & 4.4 & 4.68 & TRN & \\
\hline CHEMBL1520858 & 688612 & 5.35 & 4.7566 & TRN & \\
\hline CHEMBL1601531 & 688612 & 4.4 & 4.6575 & TRN & \\
\hline CHEMBL1549245 & 688612 & 4.05 & 4.6393 & TRN & \\
\hline CHEMBL1514232 & 688612 & 4.4 & 4.6197 & TRN & \\
\hline CHEMBL1419158 & 688612 & 4.55 & 4.6272 & TST & \\
\hline CHEMBL1494021 & 688612 & 4.05 & 4.7008 & TRN & \\
\hline CHEMBL1584615 & 688612 & 5.5 & 4.6674 & TST & \\
\hline CHEMBL3189187 & 688612 & 4.7 & 4.668 & TRN & \\
\hline CHEMBL1460084 & 688612 & 4.4 & 4.7523 & TRN & \\
\hline CHEMBL1534864 & 688612 & 4.5 & 4.7183 & TRN & \\
\hline CHEMBL1535364 & 688612 & 4.05 & 4.6013 & TRN & \\
\hline CHEMBL1309071 & 688612 & 4.25 & 4.5236 & TRN & \\
\hline CHEMBL1489458 & 688612 & 4.65 & 4.6638 & TRN & \\
\hline CHEMBL1343791 & 688612 & 4.4 & 4.6598 & TRN & \\
\hline CHEMBL1361975 & 688612 & 4.75 & 4.7007 & TRN & \\
\hline
\end{tabular}




\begin{tabular}{|c|c|c|c|c|}
\hline \multicolumn{5}{|c|}{ Supplemental Table S2.txt } \\
\hline CHEMBL1484029 & 688612 & 6.2 & 4.658 & TRN \\
\hline CHEMBL1387008 & 688612 & 4.3 & 4.7489 & TRN \\
\hline CHEMBL1333510 & 688612 & 4.35 & 4.6473 & TST \\
\hline CHEMBL3194509 & 688612 & 5.0 & 4.6765 & TRN \\
\hline CHEMBL1517976 & 688612 & 4.7 & 4.6159 & TST \\
\hline CHEMBL1323006 & 688612 & 4.65 & 4.7031 & TRN \\
\hline CHEMBL1381473 & 688612 & 4.5 & 4.7268 & TRN \\
\hline CHEMBL1522210 & 688612 & 4.1 & 4.7496 & TRN \\
\hline CHEMBL1319381 & 688612 & 5.4 & 4.7118 & TST \\
\hline CHEMBL1425184 & 688612 & 4.85 & 4.6639 & TRN \\
\hline CHEMBL1346829 & 688612 & 5.3 & 4.655 & TRN \\
\hline CHEMBL1473082 & 688612 & 4.05 & 4.6166 & TRN \\
\hline CHEMBL1316748 & 688612 & 4.0 & 4.5967 & TRN \\
\hline CHEMBL1503109 & 688612 & 4.05 & 4.6549 & TRN \\
\hline CHEMBL1482764 & 688612 & 5.4 & 4.6402 & TRN \\
\hline CHEMBL1581714 & 688612 & 4.05 & 4.6053 & TST \\
\hline CHEMBL1399144 & 688612 & 4.05 & 4.6945 & TST \\
\hline CHEMBL1345598 & 688612 & 6.05 & 4.7158 & TRN \\
\hline CHEMBL1412812 & 688612 & 4.1 & 4.657 & TST \\
\hline CHEMBL1591077 & 688612 & 4.95 & 4.5793 & TRN \\
\hline CHEMBL1575781 & 688612 & 4.2 & 4.6819 & TST \\
\hline CHEMBL1462054 & 688612 & 4.05 & 4.6913 & TRN \\
\hline CHEMBL1965860 & 688612 & 4.85 & 4.6108 & TST \\
\hline CHEMBL3189473 & 688612 & 4.05 & 4.6788 & TST \\
\hline CHEMBL1498192 & 688612 & 4.1 & 4.6952 & TST \\
\hline CHEMBL1411364 & 688612 & 4.25 & 4.7073 & TRN \\
\hline CHEMBL3208257 & 688612 & 6.25 & 4.6616 & TST \\
\hline CHEMBL1375683 & 688612 & 6.6 & 4.6072 & TRN \\
\hline CHEMBL1506938 & 688612 & 4.4 & 4.6852 & TST \\
\hline CHEMBL1602396 & 688612 & 4.05 & 4.6907 & TRN \\
\hline CHEMBL1526037 & 688612 & 4.05 & 4.624 & TRN \\
\hline CHEMBL1574714 & 688612 & 4.45 & 4.6455 & TST \\
\hline CHEMBL1373010 & 688612 & 4.35 & 4.6812 & TRN \\
\hline CHEMBL1330778 & 688612 & 4.1 & 4.6633 & TST \\
\hline CHEMBL1590718 & 688612 & 4.65 & 4.6241 & TRN \\
\hline CHEMBL1534680 & 688612 & 4.05 & 4.6243 & TST \\
\hline CHEMBL1442966 & 688612 & 5.05 & 4.6809 & TRN \\
\hline CHEMBL3194666 & 688612 & 4.75 & 4.7793 & TRN \\
\hline CHEMBL1369472 & 688612 & 4.35 & 4.7329 & TRN \\
\hline CHEMBL1416073 & 688612 & 4.8 & 4.6381 & TRN \\
\hline CHEMBL56393 & 688612 & 7.2 & 4.8919 & TRN \\
\hline CHEMBL1309157 & 688612 & 4.3 & 4.8021 & TRN \\
\hline CHEMBL1472849 & 688612 & 5.05 & 4.7135 & TRN \\
\hline CHEMBL1315275 & 688612 & 4.2 & 4.6911 & TRN \\
\hline CHEMBL67535 & 688612 & 6.9 & 4.8168 & TRN \\
\hline CHEMBL1364104 & 688612 & 4.45 & 4.5836 & TRN \\
\hline CHEMBL1514807 & 688612 & 4.0 & 4.6113 & TST \\
\hline CHEMBL1523510 & 688612 & 4.65 & 4.6931 & TRN \\
\hline
\end{tabular}




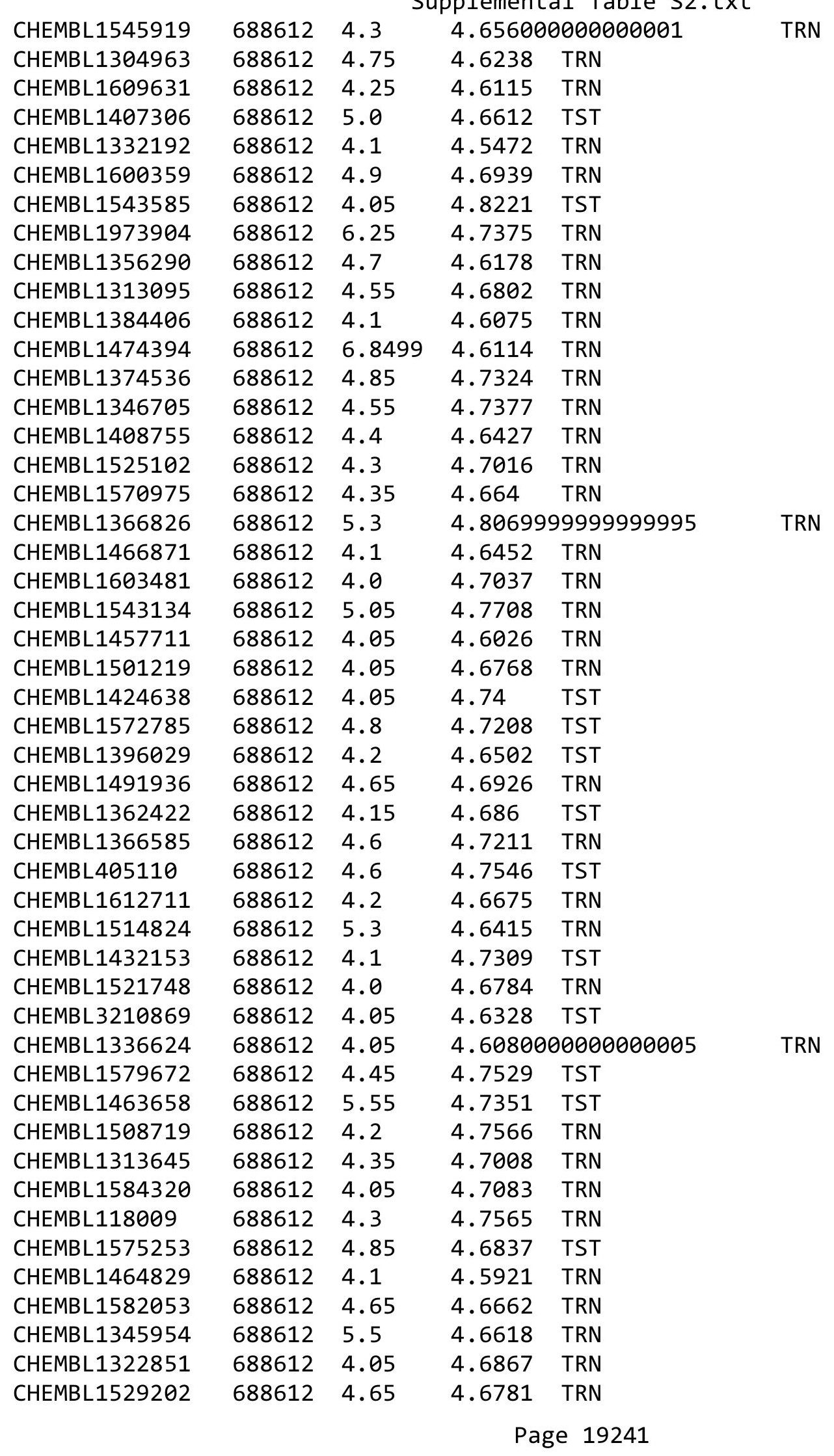




\begin{tabular}{|c|c|c|c|c|c|}
\hline \multicolumn{6}{|c|}{ Supplemental Table S2.txt } \\
\hline CHEMBL1424600 & 688612 & 4.6 & 4.6559 & TRN & \\
\hline CHEMBL1607552 & 688612 & 4.2 & 4.6501 & TRN & \\
\hline CHEMBL1339477 & 688612 & 4.1 & 4.5675 & TRN & \\
\hline CHEMBL1364610 & 688612 & 5.3 & 4.6848 & TRN & \\
\hline CHEMBL1429439 & 688612 & 5.55 & 4.6731 & TRN & \\
\hline CHEMBL1346814 & 688612 & 5.4 & 4.6706 & TRN & \\
\hline CHEMBL1345628 & 688612 & 4.05 & 4.7696 & TRN & \\
\hline CHEMBL1455137 & 688612 & 4.65 & 4.7722 & TRN & \\
\hline CHEMBL1984240 & 688612 & 5.55 & 4.81800 & 00000000005 & TRN \\
\hline CHEMBL1534102 & 688612 & 4.45 & 4.6511 & TST & \\
\hline CHEMBL1381380 & 688612 & 6.7001 & 4.676 & TRN & \\
\hline CHEMBL1313220 & 688612 & 4.05 & 4.5676 & TST & \\
\hline CHEMBL1327584 & 688612 & 4.75 & 4.6862 & TRN & \\
\hline CHEMBL1310291 & 688612 & 4.1 & 4.6627 & TST & \\
\hline CHEMBL1352839 & 688612 & 6.1 & 4.7028 & TRN & \\
\hline CHEMBL1359081 & 688612 & 4.4 & 4.7327 & TST & \\
\hline CHEMBL1318922 & 688612 & 4.5 & 4.6941 & TRN & \\
\hline CHEMBL3208568 & 688612 & 5.45 & 4.704 & TRN & \\
\hline CHEMBL1388823 & 688612 & 4.05 & 4.582 & TRN & \\
\hline CHEMBL1533949 & 688612 & 4.6 & 4.7057 & TRN & \\
\hline CHEMBL1391337 & 688612 & 4.05 & 4.6718 & TRN & \\
\hline CHEMBL1396888 & 688612 & 4.05 & 4.6424 & TRN & \\
\hline CHEMBL1351548 & 688612 & 6.5501 & 4.6535 & TRN & \\
\hline CHEMBL1579836 & 688612 & 4.05 & 4.6409 & TRN & \\
\hline CHEMBL1335299 & 688612 & 4.45 & 4.7692 & TRN & \\
\hline CHEMBL1591473 & 688612 & 4.0 & 4.6187 & TRN & \\
\hline CHEMBL1385761 & 688612 & 4.05 & 4.5707 & TRN & \\
\hline CHEMBL1517036 & 688612 & 4.05 & 4.7453 & TRN & \\
\hline CHEMBL1464914 & 688612 & 6.2 & 4.6688 & TRN & \\
\hline CHEMBL1506511 & 688612 & 4.1 & 4.6856 & TRN & \\
\hline CHEMBL3198930 & 688612 & 5.3 & 4.7204 & TRN & \\
\hline CHEMBL1443844 & 688612 & 4.8 & 4.6642 & TST & \\
\hline CHEMBL1541151 & 688612 & 5.05 & 4.6741 & TST & \\
\hline CHEMBL1507021 & 688612 & 4.7 & 4.7236 & TRN & \\
\hline CHEMBL1523231 & 688612 & 4.2 & 4.6407 & TST & \\
\hline CHEMBL1369728 & 688612 & 4.05 & 4.6593 & TST & \\
\hline CHEMBL1442757 & 688612 & 5.5 & 4.6877 & TRN & \\
\hline CHEMBL1588920 & 688612 & 4.4 & 4.5823 & TRN & \\
\hline CHEMBL1384202 & 688612 & 6.2 & 4.7392 & TST & \\
\hline CHEMBL1382917 & 688612 & 4.6 & 4.71899 & 9999999999 & TRN \\
\hline CHEMBL1479432 & 688612 & 4.9 & 4.69600 & 0000000001 & TRN \\
\hline CHEMBL1549425 & 688612 & 4.05 & 4.665 & TRN & \\
\hline CHEMBL1309218 & 688612 & 5.3 & 4.6597 & TRN & \\
\hline CHEMBL1434959 & 688612 & 6.6499 & 4.6973 & TRN & \\
\hline CHEMBL1340981 & 688612 & 6.5501 & 4.7131 & TRN & \\
\hline CHEMBL3191310 & 688612 & 4.05 & 4.6772 & TRN & \\
\hline CHEMBL1502716 & 688612 & 4.4 & 4.6924 & TST & \\
\hline CHEMBL1465409 & 688612 & 4.4 & 4.6678 & TRN & \\
\hline
\end{tabular}




\begin{tabular}{|c|c|c|c|c|c|}
\hline \multicolumn{6}{|c|}{ Supplemental Table s2.txt } \\
\hline CHEMBL1526967 & 688612 & 5.3 & 4.6046 & TST & \\
\hline CHEMBL1368811 & 688612 & 4.05 & 4.6289 & TRN & \\
\hline CHEMBL1540730 & 688612 & 5.5 & 4.7051 & TST & \\
\hline CHEMBL1433970 & 688612 & 4.1 & 4.605 & TRN & \\
\hline CHEMBL1452574 & 688612 & 4.1 & 4.694 & TRN & \\
\hline CHEMBL1299502 & 688612 & 4.85 & 4.7041 & TRN & \\
\hline CHEMBL3192409 & 688612 & 4.05 & 4.7281 & TRN & \\
\hline CHEMBL1538976 & 688612 & 4.7 & 4.6996 & TRN & \\
\hline CHEMBL1379958 & 688612 & 4.0 & 4.6537 & TST & \\
\hline CHEMBL1501830 & 688612 & 4.1 & 4.7036 & TRN & \\
\hline CHEMBL1309221 & 688612 & 4.0 & 4.6488 & TRN & \\
\hline CHEMBL1790008 & 688612 & 4.05 & 4.7092 & TRN & \\
\hline CHEMBL1574977 & 688612 & 4.1 & 4.6735 & TRN & \\
\hline CHEMBL1493400 & 688612 & 4.45 & 4.6507 & TRN & \\
\hline CHEMBL1413104 & 688612 & 4.05 & 4.6504 & TST & \\
\hline CHEMBL3193909 & 688612 & 4.4 & 4.6687 & TRN & \\
\hline CHEMBL1416544 & 688612 & 4.9 & 4.6024 & TRN & \\
\hline CHEMBL1595798 & 688612 & 4.05 & 4.5794 & TRN & \\
\hline CHEMBL3195110 & 688612 & 4.6 & 4.7 & TRN & \\
\hline CHEMBL3195591 & 688612 & 4.25 & 4.8179 & TRN & \\
\hline CHEMBL1343370 & 688612 & 4.05 & 4.6719 & TRN & \\
\hline CHEMBL1323955 & 688612 & 6.25 & 4.613 & TRN & \\
\hline CHEMBL3189261 & 688612 & 4.75 & 4.6618 & TST & \\
\hline CHEMBL1496953 & 688612 & 7.0501 & 4.6455 & TST & \\
\hline CHEMBL1600121 & 688612 & 4.85 & 4.7403 & TRN & \\
\hline CHEMBL1532028 & 688612 & 6.95 & 4.5744 & TRN & \\
\hline CHEMBL1323413 & 688612 & 4.55 & 4.5754 & TRN & \\
\hline CHEMBL1537716 & 688612 & 5.3 & 4.6545 & TRN & \\
\hline CHEMBL1573207 & 688612 & 4.2 & 4.6613 & TRN & \\
\hline CHEMBL1542241 & 688612 & 4.7 & 4.6316 & TRN & \\
\hline CHEMBL1446668 & 688612 & 4.4 & 4.7205 & TRN & \\
\hline CHEMBL1559754 & 688612 & 4.7 & 4.6674 & TRN & \\
\hline CHEMBL1300462 & 688612 & 5.85 & 4.7281 & TST & \\
\hline CHEMBL1371148 & 688612 & 4.4 & 4.7318 & TRN & \\
\hline CHEMBL1613097 & 688612 & 4.05 & 4.61600 & 00000000005 & TRN \\
\hline CHEMBL1311629 & 688612 & 4.9 & 4.6689 & TST & \\
\hline CHEMBL1507756 & 688612 & 4.0 & 4.6082 & TRN & \\
\hline CHEMBL1324128 & 688612 & 6.45 & 4.7014 & TRN & \\
\hline CHEMBL1403855 & 688612 & 4.25 & 4.7152 & TRN & \\
\hline CHEMBL1349094 & 688612 & 4.2 & 4.6578 & TRN & \\
\hline CHEMBL1482644 & 688612 & 4.05 & 4.6438 & TRN & \\
\hline CHEMBL1390946 & 688612 & 4.05 & 4.6281 & TRN & \\
\hline CHEMBL3212897 & 688612 & 4.55 & 4.6591 & TRN & \\
\hline CHEMBL1589817 & 688612 & 4.3 & 4.6778 & TRN & \\
\hline CHEMBL1594818 & 688612 & 5.0 & 4.6467 & TRN & \\
\hline CHEMBL1478602 & 688612 & 4.35 & 4.6426 & TRN & \\
\hline CHEMBL1506845 & 688612 & 4.0 & 4.7498 & TST & \\
\hline CHEMBL1502247 & 688612 & 4.55 & 4.7087 & TRN & \\
\hline
\end{tabular}




\begin{tabular}{|c|c|c|c|c|c|}
\hline \multicolumn{6}{|c|}{ Supplemental Table S2.txt } \\
\hline CHEMBL1453420 & 688612 & 4.9 & 4.6238 & TST & \\
\hline CHEMBL1325124 & 688612 & 4.05 & 4.6605 & TRN & \\
\hline CHEMBL1582121 & 688612 & 4.7 & 4.6877 & TRN & \\
\hline CHEMBL1336706 & 688612 & 4.1 & 4.7851 & TRN & \\
\hline CHEMBL1529152 & 688612 & 4.0 & 4.6665 & TRN & \\
\hline CHEMBL1506637 & 688612 & 4.55 & 4.7833 & TRN & \\
\hline CHEMBL1394018 & 688612 & 4.3 & 4.6604 & TRN & \\
\hline CHEMBL1559707 & 688612 & 4.55 & 4.6368 & TST & \\
\hline CHEMBL1318334 & 688612 & 4.05 & 4.6365 & TRN & \\
\hline CHEMBL1590925 & 688612 & 4.35 & 4.724 & TST & \\
\hline CHEMBL1325709 & 688612 & 4.0 & 4.6642 & TRN & \\
\hline CHEMBL1517763 & 688612 & 4.0 & 4.6116 & TRN & \\
\hline CHEMBL87189 & 688612 & 4.05 & 4.7464 & TRN & \\
\hline CHEMBL1576434 & 688612 & 4.05 & 4.7454 & TRN & \\
\hline CHEMBL1418118 & 688612 & 4.1 & 4.6701 & TRN & \\
\hline CHEMBL1317907 & 688612 & 4.0 & 4.6371 & TRN & \\
\hline CHEMBL1466898 & 688612 & 4.15 & 4.6602 & TRN & \\
\hline CHEMBL1365542 & 688612 & 6.6499 & 4.6942 & TRN & \\
\hline CHEMBL1395400 & 688612 & 4.05 & 4.6627 & TRN & \\
\hline CHEMBL486817 & 688612 & 4.55 & 4.7347 & TST & \\
\hline CHEMBL1531077 & 688612 & 4.35 & 4.6755 & TRN & \\
\hline CHEMBL1456371 & 688612 & 5.2 & 4.6735 & TST & \\
\hline CHEMBL1597519 & 688612 & 4.35 & 4.6435 & TST & \\
\hline CHEMBL1519664 & 688612 & 4.4 & 4.6376 & TST & \\
\hline CHEMBL1398950 & 688612 & 4.4 & 4.7008 & TRN & \\
\hline CHEMBL1527851 & 688612 & 4.55 & 4.6387 & TRN & \\
\hline CHEMBL1399952 & 688612 & 4.85 & 4.6459 & TRN & \\
\hline CHEMBL1442271 & 688612 & 4.8 & 4.6627 & TST & \\
\hline CHEMBL 1440188 & 688612 & 4.95 & 4.6513 & TRN & \\
\hline CHEMBL3191587 & 688612 & 4.05 & 4.7376 & TST & \\
\hline CHEMBL1367596 & 688612 & 6.95 & 4.7459 & TST & \\
\hline CHEMBL1529958 & 688612 & 5.1 & 4.6553 & TRN & \\
\hline CHEMBL1530637 & 688612 & 5.0 & 4.5745 & TST & \\
\hline CHEMBL1571290 & 688612 & 4.65 & $4.6560 e$ & 3000000001 & TRN \\
\hline CHEMBL1565216 & 688612 & 5.7 & 4.6315 & TST & \\
\hline CHEMBL3207683 & 688612 & 4.6 & 4.5687 & TRN & \\
\hline CHEMBL1422687 & 688612 & 5.4 & 4.6959 & TRN & \\
\hline CHEMBL1351010 & 688612 & 4.45 & 4.637 & TST & \\
\hline CHEMBL1404055 & 688612 & 4.9 & 4.6972 & TST & \\
\hline CHEMBL1354291 & 688612 & 4.4 & 4.6764 & TRN & \\
\hline CHEMBL1432156 & 688612 & 4.35 & 4.7332 & TRN & \\
\hline CHEMBL1398914 & 688612 & 4.25 & 4.603 & TRN & \\
\hline CHEMBL1366293 & 688612 & 4.05 & 4.7412 & TRN & \\
\hline CHEMBL1594155 & 688612 & 5.55 & 4.596 & TRN & \\
\hline CHEMBL1493257 & 688612 & 4.45 & 4.6042 & TRN & \\
\hline CHEMBL3194710 & 688612 & 4.2 & 4.7608 & TRN & \\
\hline CHEMBL1299697 & 688612 & 4.05 & 4.6551 & TST & \\
\hline CHEMBL1349079 & 688612 & 4.1 & 4.7155 & TST & \\
\hline
\end{tabular}




\begin{tabular}{|c|c|c|c|c|c|}
\hline \multicolumn{6}{|c|}{ Supplemental Table s2.txt } \\
\hline CHEMBL1579445 & 688612 & 4.2 & 4.6286 & TST & \\
\hline CHEMBL1573376 & 688612 & 5.2 & 4.6452 & TRN & \\
\hline CHEMBL589062 & 688612 & 4.2 & 4.6692 & TRN & \\
\hline CHEMBL1554733 & 688612 & 4.65 & 4.7247 & TRN & \\
\hline CHEMBL1448768 & 688612 & 6.05 & 4.6686 & TRN & \\
\hline CHEMBL1322279 & 688612 & 4.05 & 4.7077 & TRN & \\
\hline CHEMBL1323305 & 688612 & 4.05 & 4.6727 & TRN & \\
\hline CHEMBL1391821 & 688612 & 4.1 & 4.5777 & TRN & \\
\hline CHEMBL1509951 & 688612 & 4.05 & 4.6585 & TRN & \\
\hline CHEMBL1503478 & 688612 & 5.4 & 4.6117 & TST & \\
\hline CHEMBL1351021 & 688612 & 4.05 & 4.6271 & TRN & \\
\hline CHEMBL1413356 & 688612 & 4.6 & 4.572 & TRN & \\
\hline CHEMBL1537750 & 688612 & 4.05 & 4.6691 & TRN & \\
\hline CHEMBL1359797 & 688612 & 4.8 & 4.7556 & TRN & \\
\hline CHEMBL1583264 & 688612 & 4.9 & 4.7558 & TST & \\
\hline CHEMBL 2007120 & 688612 & 4.9 & 4.6744 & TRN & \\
\hline CHEMBL1305903 & 688612 & 4.0 & 4.63899 & 9999999999 & TST \\
\hline CHEMBL1497215 & 688612 & 4.1 & 4.6795 & TRN & \\
\hline CHEMBL1544048 & 688612 & 4.1 & 4.6768 & TRN & \\
\hline CHEMBL515252 & 688612 & 5.5 & 4.8883 & TRN & \\
\hline CHEMBL1568184 & 688612 & 4.6 & 4.6892 & TRN & \\
\hline CHEMBL1469243 & 688612 & 4.35 & 4.7496 & TRN & \\
\hline CHEMBL1482096 & 688612 & 4.05 & 4.6695 & TST & \\
\hline CHEMBL1440170 & 688612 & 4.2 & 4.5818 & TRN & \\
\hline CHEMBL1502646 & 688612 & 6.0 & 4.6864 & TST & \\
\hline CHEMBL1414340 & 688612 & 4.0 & 4.6299 & TRN & \\
\hline CHEMBL1339853 & 688612 & 4.2 & 4.6954 & TST & \\
\hline CHEMBL192600 & 688612 & 5.05 & 4.6451 & TST & \\
\hline CHEMBL1604848 & 688612 & 5.3 & 4.6759 & TRN & \\
\hline CHEMBL1520380 & 688612 & 4.0 & 4.7079 & TRN & \\
\hline CHEMBL1490189 & 688612 & 4.1 & 4.6767 & TRN & \\
\hline CHEMBL1589024 & 688612 & 4.95 & 4.6908 & TRN & \\
\hline CHEMBL1486487 & 688612 & 5.45 & 4.6116 & TRN & \\
\hline CHEMBL1464640 & 688612 & 6.2 & 4.6729 & TRN & \\
\hline CHEMBL1573086 & 688612 & 4.0 & 4.6464 & TRN & \\
\hline CHEMBL1170688 & 688612 & 4.75 & 4.6477 & TRN & \\
\hline CHEMBL1330042 & 688612 & 4.65 & 4.7219 & TRN & \\
\hline CHEMBL1592607 & 688612 & 4.05 & 4.6911 & TRN & \\
\hline CHEMBL1515898 & 688612 & 4.05 & 4.6656 & TRN & \\
\hline CHEMBL1572481 & 688612 & 4.0 & 4.6627 & TST & \\
\hline CHEMBL3197448 & 688612 & 4.2 & 4.697 & TRN & \\
\hline CHEMBL1482441 & 688612 & 4.6 & 4.7602 & TST & \\
\hline CHEMBL1332026 & 688612 & 4.05 & 4.6233 & TRN & \\
\hline CHEMBL1434542 & 688612 & 6.6 & 4.6991 & TRN & \\
\hline CHEMBL1369875 & 688612 & 4.55 & 4.7074 & TST & \\
\hline CHEMBL1428681 & 688612 & 4.35 & 4.6877 & TRN & \\
\hline CHEMBL1599949 & 688612 & 5.6 & 4.6841 & TRN & \\
\hline CHEMBL1464792 & 688612 & 4.0 & 4.691 & TRN & \\
\hline
\end{tabular}




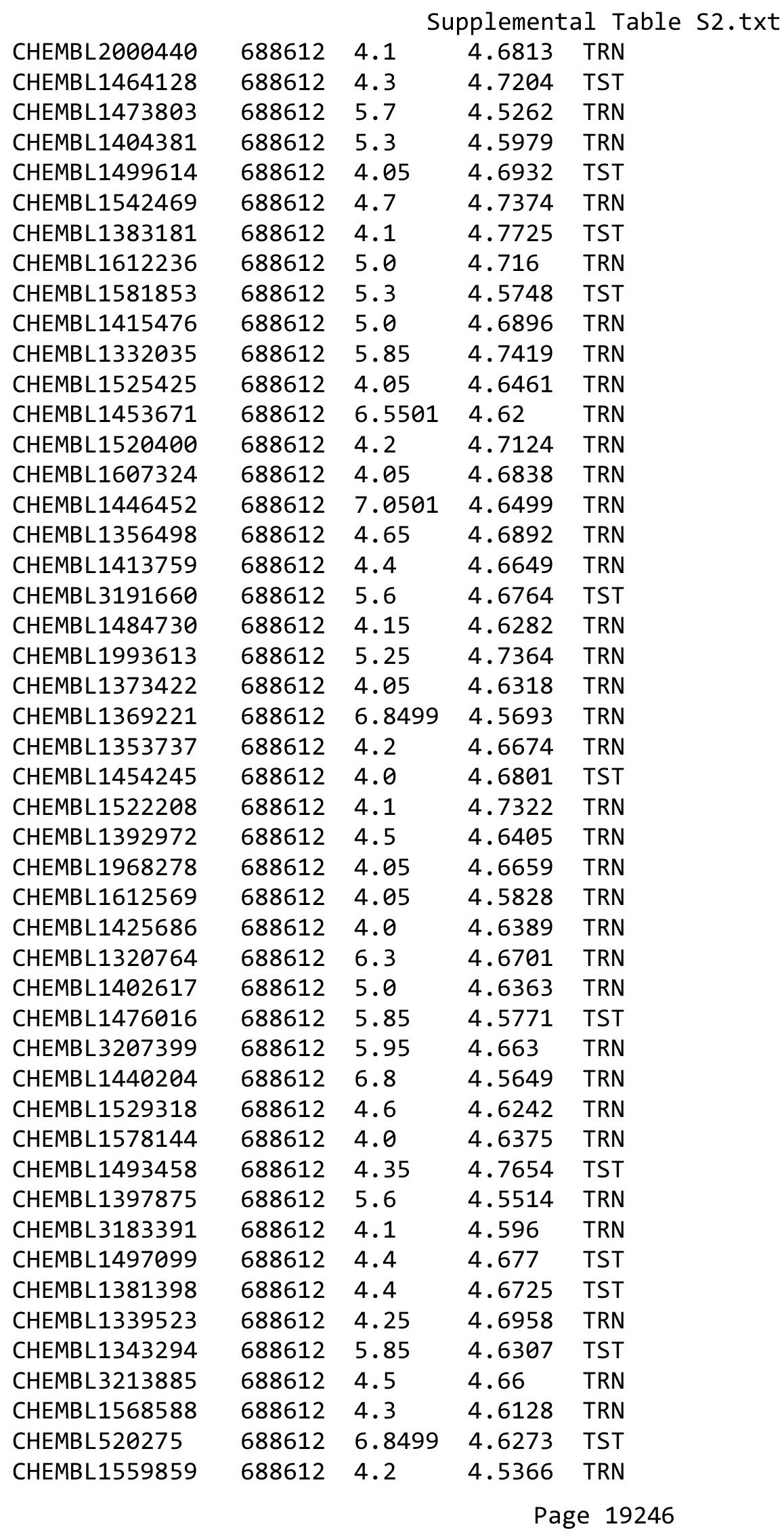




\begin{tabular}{|c|c|c|c|c|c|}
\hline \multicolumn{6}{|c|}{ Supplemental Table S2.txt } \\
\hline CHEMBL1528261 & 688612 & 5.45 & 4.6658 & TRN & \\
\hline CHEMBL1443895 & 688612 & 4.95 & 4.7081 & TST & \\
\hline CHEMBL1498127 & 688612 & 4.4 & 4.7446 & TRN & \\
\hline CHEMBL1478873 & 688612 & 5.15 & 4.7497 & TRN & \\
\hline CHEMBL1364734 & 688612 & 4.05 & 4.5659 & TST & \\
\hline CHEMBL1476338 & 688612 & 4.05 & 4.637 & TRN & \\
\hline CHEMBL1351102 & 688612 & 4.4 & 4.7141 & TRN & \\
\hline CHEMBL1500535 & 688612 & 4.1 & 4.6998 & TST & \\
\hline CHEMBL1335895 & 688612 & 5.5 & 4.6281 & TST & \\
\hline CHEMBL1599422 & 688612 & 4.2 & 4.6554 & TST & \\
\hline CHEMBL1481310 & 688612 & 4.05 & 4.5901 & TRN & \\
\hline CHEMBL1336972 & 688612 & 4.65 & 4.5967 & TST & \\
\hline CHEMBL1526619 & 688612 & 4.0 & 4.6527 & TST & \\
\hline CHEMBL1358189 & 688612 & 4.05 & 4.566 & TRN & \\
\hline CHEMBL1520833 & 688612 & 5.55 & 4.5611 & TRN & \\
\hline CHEMBL1349173 & 688612 & 4.05 & 4.6232 & TST & \\
\hline CHEMBL1366627 & 688612 & 5.05 & 4.8041 & TRN & \\
\hline CHEMBL1577383 & 688612 & 7.0 & 4.6892 & TST & \\
\hline CHEMBL1329610 & 688612 & 4.35 & 4.6755 & TRN & \\
\hline CHEMBL1442644 & 688612 & 5.75 & 4.6545 & TST & \\
\hline CHEMBL1386500 & 688612 & 4.0 & 4.6004 & TRN & \\
\hline CHEMBL1537012 & 688612 & 4.75 & 4.8213 & TRN & \\
\hline CHEMBL1326038 & 688612 & 4.05 & 4.7063 & TRN & \\
\hline CHEMBL1444370 & 688612 & 4.75 & 4.7289 & TRN & \\
\hline CHEMBL1315812 & 688612 & 5.65 & 4.7009 & TRN & \\
\hline CHEMBL 2002221 & 688612 & 4.15 & 4.6623 & TST & \\
\hline CHEMBL1473412 & 688612 & 4.05 & 4.6582 & TST & \\
\hline CHEMBL1352491 & 688612 & 5.05 & 4.7346 & TRN & \\
\hline CHEMBL1479512 & 688612 & 4.5 & 4.6462 & TRN & \\
\hline CHEMBL1256646 & 688612 & 4.65 & 4.8164 & TST & \\
\hline CHEMBL1464922 & 688612 & 4.6 & 4.6681 & TRN & \\
\hline CHEMBL1367090 & 688612 & 4.05 & 4.6838 & TST & \\
\hline CHEMBL1521077 & 688612 & 4.0 & 4.53106 & 3000000001 & TRN \\
\hline CHEMBL1377205 & 688612 & 6.5501 & 4.6146 & TRN & \\
\hline CHEMBL1474627 & 688612 & 4.05 & 4.6048 & TRN & \\
\hline CHEMBL1517470 & 688612 & 4.65 & 4.6854 & TRN & \\
\hline CHEMBL1601396 & 688612 & 4.05 & 4.6618 & TST & \\
\hline CHEMBL1574670 & 688612 & 5.35 & 4.6497 & TRN & \\
\hline CHEMBL3193785 & 688612 & 4.7 & 4.7391 & TRN & \\
\hline CHEMBL1347519 & 688612 & 4.1 & 4.7197 & TRN & \\
\hline CHEMBL3213144 & 688612 & 4.25 & 4.6254 & TRN & \\
\hline CHEMBL1461446 & 688612 & 4.35 & 4.753 & TRN & \\
\hline CHEMBL1500107 & 688612 & 4.05 & 4.5899 & TST & \\
\hline CHEMBL1519144 & 688612 & 5.45 & 4.692 & TRN & \\
\hline CHEMBL1373840 & 688612 & 4.4 & 4.6466 & TST & \\
\hline CHEMBL1428163 & 688612 & 4.0 & 4.6354 & TRN & \\
\hline CHEMBL1449814 & 688612 & 4.0 & 4.6422 & TRN & \\
\hline CHEMBL1382389 & 688612 & 6.5501 & 4.6506 & TST & \\
\hline
\end{tabular}




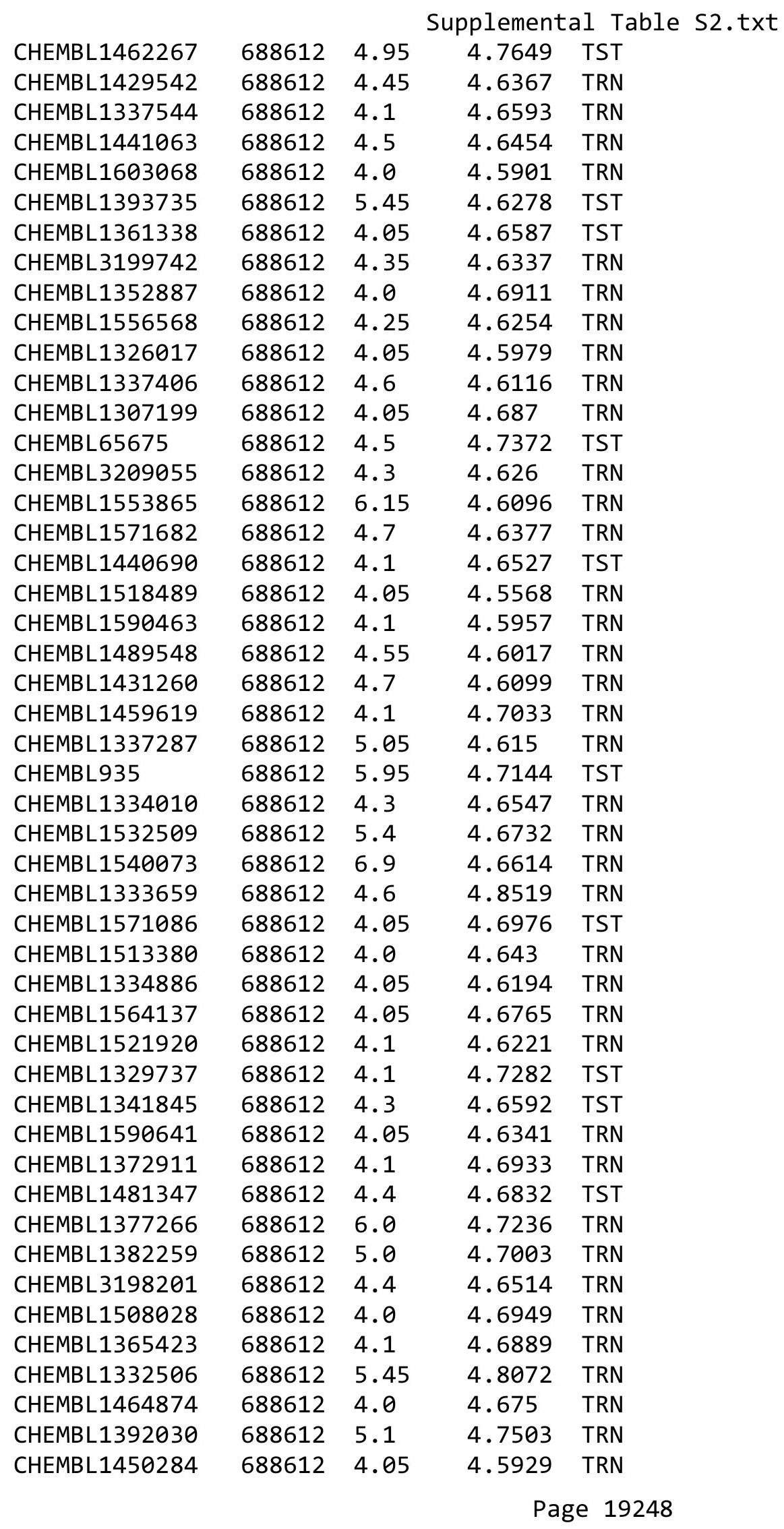




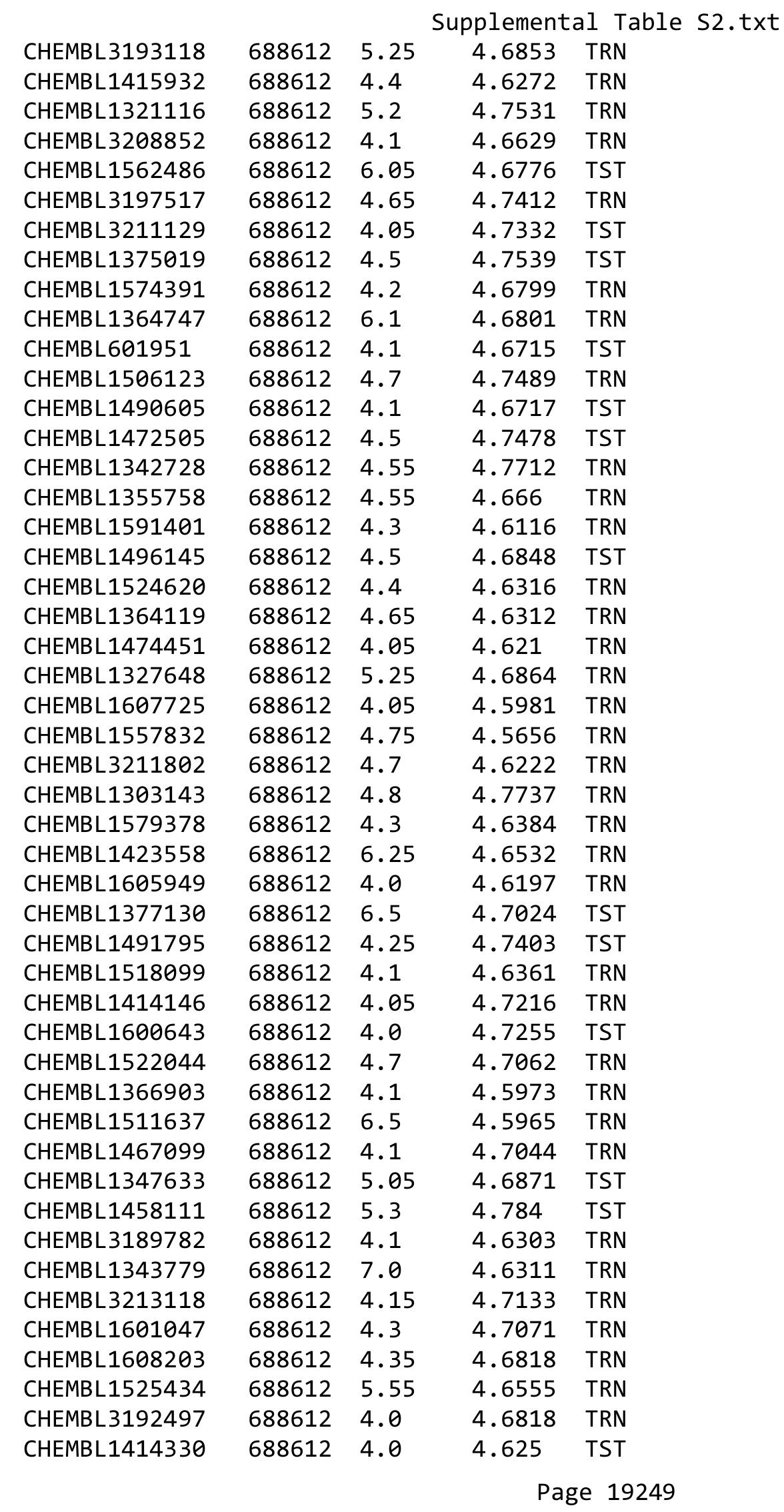




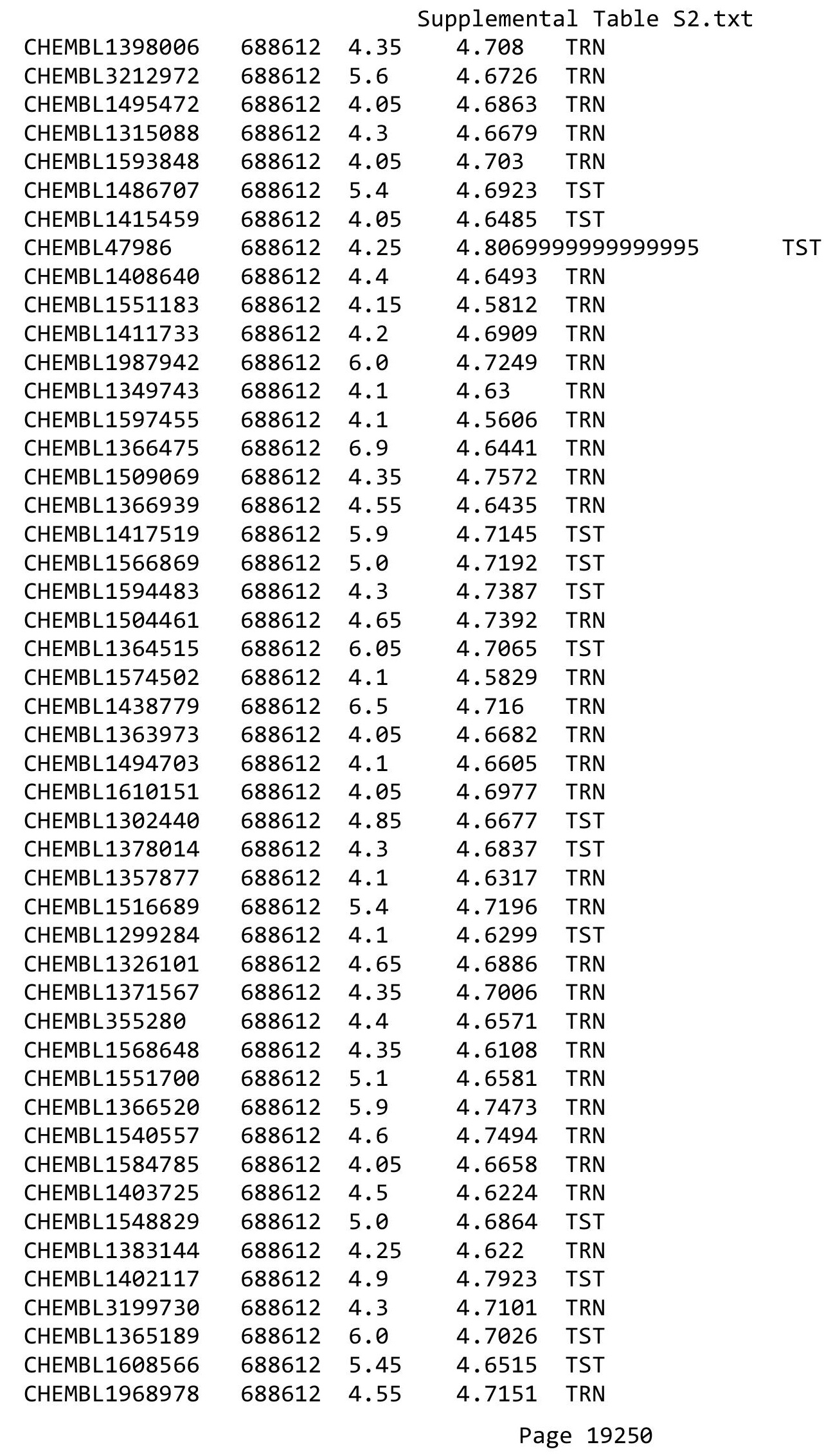




\begin{tabular}{|c|c|c|c|c|c|}
\hline \multicolumn{6}{|c|}{ Supplemental Table S2.txt } \\
\hline CHEMBL1370073 & 688612 & 4.4 & 4.6626 & TRN & \\
\hline CHEMBL1436949 & 688612 & 5.35 & 4.6923 & TST & \\
\hline CHEMBL1403448 & 688612 & 4.45 & 4.7672 & TRN & \\
\hline CHEMBL1559256 & 688612 & 4.45 & 4.7288 & TRN & \\
\hline CHEMBL1397947 & 688612 & 5.05 & 4.5732 & TRN & \\
\hline CHEMBL1464021 & 688612 & 4.85 & 4.6342 & TRN & \\
\hline CHEMBL3198550 & 688612 & 6.15 & 4.7529 & TRN & \\
\hline CHEMBL1586267 & 688612 & 4.05 & 4.6887 & TRN & \\
\hline CHEMBL1504361 & 688612 & 4.7 & 4.6457 & TST & \\
\hline CHEMBL1371816 & 688612 & 4.5 & 4.6656 & TRN & \\
\hline CHEMBL1982441 & 688612 & 4.7 & 4.713 & TRN & \\
\hline CHEMBL 3194343 & 688612 & 4.2 & 4.7375 & TRN & \\
\hline CHEMBL1599077 & 688612 & 4.7 & 4.6253 & TRN & \\
\hline CHEMBL1368625 & 688612 & 5.4 & 4.613 & TRN & \\
\hline CHEMBL1511558 & 688612 & 4.05 & 4.6329 & TRN & \\
\hline CHEMBL1571381 & 688612 & 4.2 & 4.7033 & TRN & \\
\hline CHEMBL546747 & 688612 & 4.7 & 4.6766 & TST & \\
\hline CHEMBL1430818 & 688612 & 4.05 & 4.5371 & TRN & \\
\hline CHEMBL1526919 & 688612 & 4.05 & 4.6467 & TRN & \\
\hline CHEMBL1602747 & 688612 & 6.8499 & 4.6864 & TST & \\
\hline CHEMBL1588660 & 688612 & 4.85 & 4.7636 & TRN & \\
\hline CHEMBL1471878 & 688612 & 4.6 & 4.6348 & TRN & \\
\hline CHEMBL1301282 & 688612 & 4.4 & 4.6859 & TRN & \\
\hline CHEMBL3190880 & 688612 & 4.05 & 4.6245 & TRN & \\
\hline CHEMBL1394907 & 688612 & 6.15 & 4.6785 & TST & \\
\hline CHEMBL1468388 & 688612 & 4.0 & 4.6381 & TST & \\
\hline CHEMBL1545569 & 688612 & 5.25 & 4.6754 & TRN & \\
\hline CHEMBL1492946 & 688612 & 5.5 & 4.6976 & TRN & \\
\hline CHEMBL1310747 & 688612 & 5.35 & 4.6895 & TRN & \\
\hline CHEMBL1474658 & 688612 & 4.4 & 4.6629 & TRN & \\
\hline CHEMBL1330129 & 688612 & 4.4 & 4.7825 & TRN & \\
\hline CHEMBL1459178 & 688612 & 5.0 & 4.758 & TRN & \\
\hline CHEMBL1434750 & 688612 & 4.15 & 4.7009 & TRN & \\
\hline CHEMBL1333249 & 688612 & 4.8 & 4.7446 & TRN & \\
\hline CHEMBL405927 & 688612 & 5.1 & 4.7039 & TRN & \\
\hline CHEMBL1402560 & 688612 & 7.4001 & 4.6547 & TRN & \\
\hline CHEMBL1587145 & 688612 & 5.05 & 4.757 & TRN & \\
\hline CHEMBL1448030 & 688612 & 4.35 & 4.6161 & TRN & \\
\hline CHEMBL1322977 & 688612 & 4.95 & 4.6533 & TRN & \\
\hline CHEMBL1346189 & 688612 & 4.1 & 4.5985 & TRN & \\
\hline CHEMBL 237442 & 688612 & 4.05 & 4.6316 & TRN & \\
\hline CHEMBL1379505 & 688612 & 6.2 & 4.6637 & TRN & \\
\hline CHEMBL1545126 & 688612 & 4.0 & 4.7198 & TST & \\
\hline CHEMBL1594754 & 688612 & 4.05 & 4.7131 & TST & \\
\hline CHEMBL1339250 & 688612 & 4.4 & 4.67899 & 9999999999 & TRN \\
\hline CHEMBL1367141 & 688612 & 4.05 & 4.7158 & TRN & \\
\hline CHEMBL1594581 & 688612 & 5.15 & 4.644 & TRN & \\
\hline CHEMBL1597816 & 688612 & 4.4 & 4.7458 & TRN & \\
\hline
\end{tabular}




\begin{tabular}{|c|c|c|c|c|c|}
\hline & & \multicolumn{4}{|c|}{ Supplemental Table S2.txt } \\
\hline CHEMBL1599394 & 688612 & 4.05 & 4.6537 & TST & \\
\hline CHEMBL47814 & 688612 & 4.25 & 4.6689 & TST & \\
\hline CHEMBL1392012 & 688612 & 4.4 & 4.7117 & TRN & \\
\hline CHEMBL1545142 & 688612 & 5.25 & 4.6926 & TST & \\
\hline CHEMBL1463954 & 688612 & 4.95 & 4.6713 & TRN & \\
\hline CHEMBL1560307 & 688612 & 5.3 & 4.7642 & TST & \\
\hline CHEMBL1302238 & 688612 & 4.7 & 4.7697 & TRN & \\
\hline CHEMBL1396495 & 688612 & 4.45 & 4.624 & TST & \\
\hline CHEMBL1506502 & 688612 & 4.05 & 4.614 & TRN & \\
\hline CHEMBL1410465 & 688612 & 4.75 & 4.6849 & TRN & \\
\hline CHEMBL1563788 & 688612 & 4.2 & 4.7403 & TST & \\
\hline CHEMBL1569416 & 688612 & 4.25 & 4.6928 & TRN & \\
\hline CHEMBL1333628 & 688612 & 5.4 & 4.6469 & TST & \\
\hline CHEMBL1965758 & 688612 & 4.0 & 4.6423 & TRN & \\
\hline CHEMBL1488898 & 688612 & 4.55 & 4.7167 & TRN & \\
\hline CHEMBL1304297 & 688612 & 4.7 & 4.7103 & TRN & \\
\hline CHEMBL1571733 & 688612 & 6.95 & 4.7367 & TST & \\
\hline CHEMBL1550742 & 688612 & 4.05 & 4.6364 & TRN & \\
\hline CHEMBL 3192879 & 688612 & 4.5 & 4.758 & TRN & \\
\hline CHEMBL1375027 & 688612 & 4.4 & 4.64199 & 99999999995 & TRN \\
\hline CHEMBL1978117 & 688612 & 4.85 & 4.715 & TRN & \\
\hline CHEMBL1528502 & 688612 & 4.05 & 4.7267 & TRN & \\
\hline CHEMBL1366858 & 688612 & 4.6 & 4.643 & TRN & \\
\hline CHEMBL1323985 & 688612 & 5.3 & 4.7078 & TRN & \\
\hline CHEMBL1560260 & 688612 & 5.4 & 4.6042 & TST & \\
\hline CHEMBL1577316 & 688612 & 4.4 & 4.7134 & TRN & \\
\hline CHEMBL525103 & 688612 & 4.9 & 4.7723 & TRN & \\
\hline CHEMBL 2003564 & 688612 & 5.7 & 4.7416 & TRN & \\
\hline CHEMBL1458132 & 688612 & 4.8 & 4.746 & TRN & \\
\hline CHEMBL1381932 & 688612 & 4.45 & 4.6452 & TRN & \\
\hline CHEMBL1598351 & 688612 & 4.1 & 4.5602 & TRN & \\
\hline CHEMBL1309417 & 688612 & 4.3 & 4.6542 & TST & \\
\hline CHEMBL1451209 & 688612 & 5.35 & 4.6598 & TRN & \\
\hline CHEMBL1399090 & 688612 & 4.05 & 4.7122 & TST & \\
\hline CHEMBL1448309 & 688612 & 4.55 & 4.6574 & TST & \\
\hline CHEMBL1966366 & 688612 & 4.75 & 4.6955 & TST & \\
\hline CHEMBL1408471 & 688612 & 4.05 & 4.6651 & TRN & \\
\hline CHEMBL1463399 & 688612 & 4.6 & 4.6764 & TRN & \\
\hline CHEMBL1319617 & 688612 & 4.65 & 4.6407 & TRN & \\
\hline CHEMBL1350736 & 688612 & 4.05 & 4.614 & TRN & \\
\hline CHEMBL1544915 & 688612 & 4.85 & 4.7193 & TRN & \\
\hline CHEMBL1362967 & 688612 & 4.8 & 4.6427 & TRN & \\
\hline CHEMBL1463185 & 688612 & 5.4 & 4.6076 & TST & \\
\hline CHEMBL1484853 & 688612 & 4.05 & 4.6017 & TRN & \\
\hline CHEMBL1341196 & 688612 & 4.4 & 4.5644 & TRN & \\
\hline CHEMBL1315849 & 688612 & 4.05 & 4.6094 & TRN & \\
\hline CHEMBL1362512 & 688612 & 4.65 & 4.6177 & TRN & \\
\hline CHEMBL1415258 & 688612 & 4.4 & 4.6681 & TRN & \\
\hline
\end{tabular}




\begin{tabular}{|c|c|c|c|c|c|}
\hline \multicolumn{6}{|c|}{ Supplemental Table S2.txt } \\
\hline CHEMBL1567642 & 688612 & 4.1 & 4.7381 & TST & \\
\hline CHEMBL1466951 & 688612 & 4.05 & 4.6382 & TRN & \\
\hline CHEMBL1471867 & 688612 & 4.7 & 4.7055 & TRN & \\
\hline CHEMBL1380732 & 688612 & 4.0 & 4.6893 & TRN & \\
\hline CHEMBL1535204 & 688612 & 4.55 & 4.6934 & TRN & \\
\hline CHEMBL1317470 & 688612 & 5.4 & 4.6911 & TST & \\
\hline CHEMBL176125 & 688612 & 4.5 & 4.7396 & TRN & \\
\hline CHEMBL1546947 & 688612 & 4.55 & 4.7785 & TRN & \\
\hline CHEMBL1531325 & 688612 & 4.05 & 4.6921 & TST & \\
\hline CHEMBL1401378 & 688612 & 5.45 & 4.6373 & TRN & \\
\hline CHEMBL1504492 & 688612 & 4.05 & 4.729 & TRN & \\
\hline CHEMBL1500707 & 688612 & 4.4 & 4.7727 & TST & \\
\hline CHEMBL1357346 & 688612 & 4.05 & 4.5848 & TRN & \\
\hline CHEMBL1525830 & 688612 & 4.55 & 4.6905 & TRN & \\
\hline CHEMBL1542726 & 688612 & 7.0 & 4.7105 & TRN & \\
\hline CHEMBL3199817 & 688612 & 4.65 & 4.7264 & TRN & \\
\hline CHEMBL 1454753 & 688612 & 4.5 & 4.7 & TRN & \\
\hline CHEMBL1428002 & 688612 & 4.85 & 4.6778 & TRN & \\
\hline CHEMBL1417038 & 688612 & 4.05 & 4.6335 & TRN & \\
\hline CHEMBL1589819 & 688612 & 5.05 & 4.59699 & 99999999995 & TRN \\
\hline CHEMBL1457241 & 688612 & 4.35 & 4.6867 & TRN & \\
\hline CHEMBL171626 & 688612 & 6.8 & 4.6346 & TRN & \\
\hline CHEMBL1375912 & 688612 & 4.45 & 4.6358 & TRN & \\
\hline CHEMBL1406629 & 688612 & 4.05 & 4.6079 & TRN & \\
\hline CHEMBL1392579 & 688612 & 4.15 & 4.6646 & TRN & \\
\hline CHEMBL1317491 & 688612 & 4.05 & 4.6624 & TRN & \\
\hline CHEMBL1376066 & 688612 & 4.1 & 4.7834 & TRN & \\
\hline CHEMBL1449954 & 688612 & 4.05 & 4.7458 & TRN & \\
\hline CHEMBL1510063 & 688612 & 4.05 & 4.672 & TRN & \\
\hline CHEMBL 3190010 & 688612 & 6.8499 & 4.665 & TST & \\
\hline CHEMBL1327573 & 688612 & 4.1 & 4.6542 & TRN & \\
\hline CHEMBL1487019 & 688612 & 4.1 & 4.7213 & TRN & \\
\hline CHEMBL1391839 & 688612 & 4.05 & 4.6353 & TRN & \\
\hline CHEMBL1359379 & 688612 & 5.1 & 4.6827 & TRN & \\
\hline CHEMBL1519377 & 688612 & 4.75 & 4.7126 & TRN & \\
\hline CHEMBL1300470 & 688612 & 4.05 & 4.7089 & TRN & \\
\hline CHEMBL1511149 & 688612 & 4.65 & 4.7372 & TRN & \\
\hline CHEMBL1411451 & 688612 & 4.0 & 4.6354 & TST & \\
\hline CHEMBL1451362 & 688612 & 6.05 & 4.6888 & TRN & \\
\hline CHEMBL1402589 & 688612 & 4.05 & 4.6931 & TRN & \\
\hline CHEMBL1587527 & 688612 & 4.45 & 4.6215 & TRN & \\
\hline CHEMBL1429479 & 688612 & 4.0 & 4.7978 & TRN & \\
\hline CHEMBL1388322 & 688612 & 4.45 & 4.6046 & TRN & \\
\hline CHEMBL1503874 & 688612 & 5.0 & 4.7473 & TRN & \\
\hline CHEMBL3192181 & 688612 & 4.5 & 4.7288 & TRN & \\
\hline CHEMBL1496575 & 688612 & 4.05 & 4.7284 & TST & \\
\hline CHEMBL 3189847 & 688612 & 4.0 & 4.6938 & TRN & \\
\hline CHEMBL1401584 & 688612 & 4.05 & 4.7127 & TRN & \\
\hline
\end{tabular}




\begin{tabular}{|c|c|c|c|c|}
\hline \multicolumn{5}{|c|}{ Supplemental Table S2.txt } \\
\hline CHEMBL1408885 & 688612 & 4.1 & 4.6781 & TRN \\
\hline CHEMBL1491400 & 688612 & 4.05 & 4.7278 & TRN \\
\hline CHEMBL1399430 & 688612 & 4.4 & 4.5952 & TRN \\
\hline CHEMBL1448770 & 688612 & 4.5 & 4.7 & TRN \\
\hline CHEMBL3213160 & 688612 & 5.45 & 4.5571 & TST \\
\hline CHEMBL1316573 & 688612 & 4.1 & 4.5806 & TST \\
\hline CHEMBL1377097 & 688612 & 4.05 & 4.5736 & TRN \\
\hline CHEMBL1484320 & 688612 & 4.0 & 4.581 & TRN \\
\hline CHEMBL1539409 & 688612 & 4.3 & 4.6969 & TRN \\
\hline CHEMBL1562340 & 688612 & 4.05 & 4.7666 & TRN \\
\hline CHEMBL1557727 & 688612 & 4.4 & 4.6495 & TRN \\
\hline CHEMBL1301952 & 688612 & 4.05 & 4.7231 & TRN \\
\hline CHEMBL1345553 & 688612 & 4.4 & 4.6761 & TRN \\
\hline CHEMBL1331218 & 688612 & 4.05 & 4.7077 & TRN \\
\hline CHEMBL1542215 & 688612 & 4.0 & 4.7478 & TRN \\
\hline CHEMBL1549372 & 688612 & 4.0 & 4.6195 & TRN \\
\hline CHEMBL600334 & 688612 & 6.5 & 4.6995 & TST \\
\hline CHEMBL1383754 & 688612 & 4.5 & 4.7548 & TRN \\
\hline CHEMBL1603018 & 688612 & 4.1 & 4.6593 & TRN \\
\hline CHEMBL1557295 & 688612 & 6.8499 & 4.7018 & TRN \\
\hline CHEMBL1303044 & 688612 & 4.2 & 4.6682 & TST \\
\hline CHEMBL1376242 & 688612 & 6.35 & 4.5911 & TRN \\
\hline CHEMBL1456682 & 688612 & 4.5 & 4.6171 & TRN \\
\hline CHEMBL1484395 & 688612 & 4.65 & 4.7743 & TRN \\
\hline CHEMBL1412483 & 688612 & 4.45 & 4.6461 & TRN \\
\hline CHEMBL1325945 & 688612 & 4.3 & 4.6722 & TRN \\
\hline CHEMBL1580065 & 688612 & 4.35 & 4.6918 & TRN \\
\hline CHEMBL1534453 & 688612 & 5.45 & 4.7096 & TRN \\
\hline CHEMBL1348369 & 688612 & 4.3 & 4.584 & TRN \\
\hline CHEMBL1414686 & 688612 & 4.1 & 4.7419 & TST \\
\hline CHEMBL1317601 & 688612 & 4.8 & 4.7298 & TRN \\
\hline CHEMBL3212652 & 688612 & 4.45 & 4.7233 & TRN \\
\hline CHEMBL1599540 & 688612 & 6.25 & 4.6858 & TRN \\
\hline CHEMBL3197921 & 688612 & 4.1 & 4.6019 & TRN \\
\hline CHEMBL1543820 & 688612 & 4.05 & 4.6712 & TRN \\
\hline CHEMBL1496547 & 688612 & 4.1 & 4.623 & TRN \\
\hline CHEMBL1430960 & 688612 & 5.4 & 4.5551 & TRN \\
\hline CHEMBL1442395 & 688612 & 4.35 & 4.6329 & TRN \\
\hline CHEMBL1517474 & 688612 & 4.0 & 4.6624 & TST \\
\hline CHEMBL1477011 & 688612 & 4.85 & 4.6663 & TRN \\
\hline CHEMBL3208485 & 688612 & 4.8 & 4.6642 & TST \\
\hline CHEMBL1565048 & 688612 & 4.65 & 4.614 & TRN \\
\hline CHEMBL1397996 & 688612 & 4.15 & 4.6121 & TRN \\
\hline CHEMBL1490882 & 688612 & 6.8499 & 4.7057 & TRN \\
\hline CHEMBL1560769 & 688612 & 4.45 & 4.6931 & TST \\
\hline CHEMBL1517966 & 688612 & 4.05 & 4.6946 & TRN \\
\hline CHEMBL1355045 & 688612 & 4.05 & 4.7026 & TRN \\
\hline CHEMBL1526774 & 688612 & 4.7 & 4.6398 & TRN \\
\hline
\end{tabular}




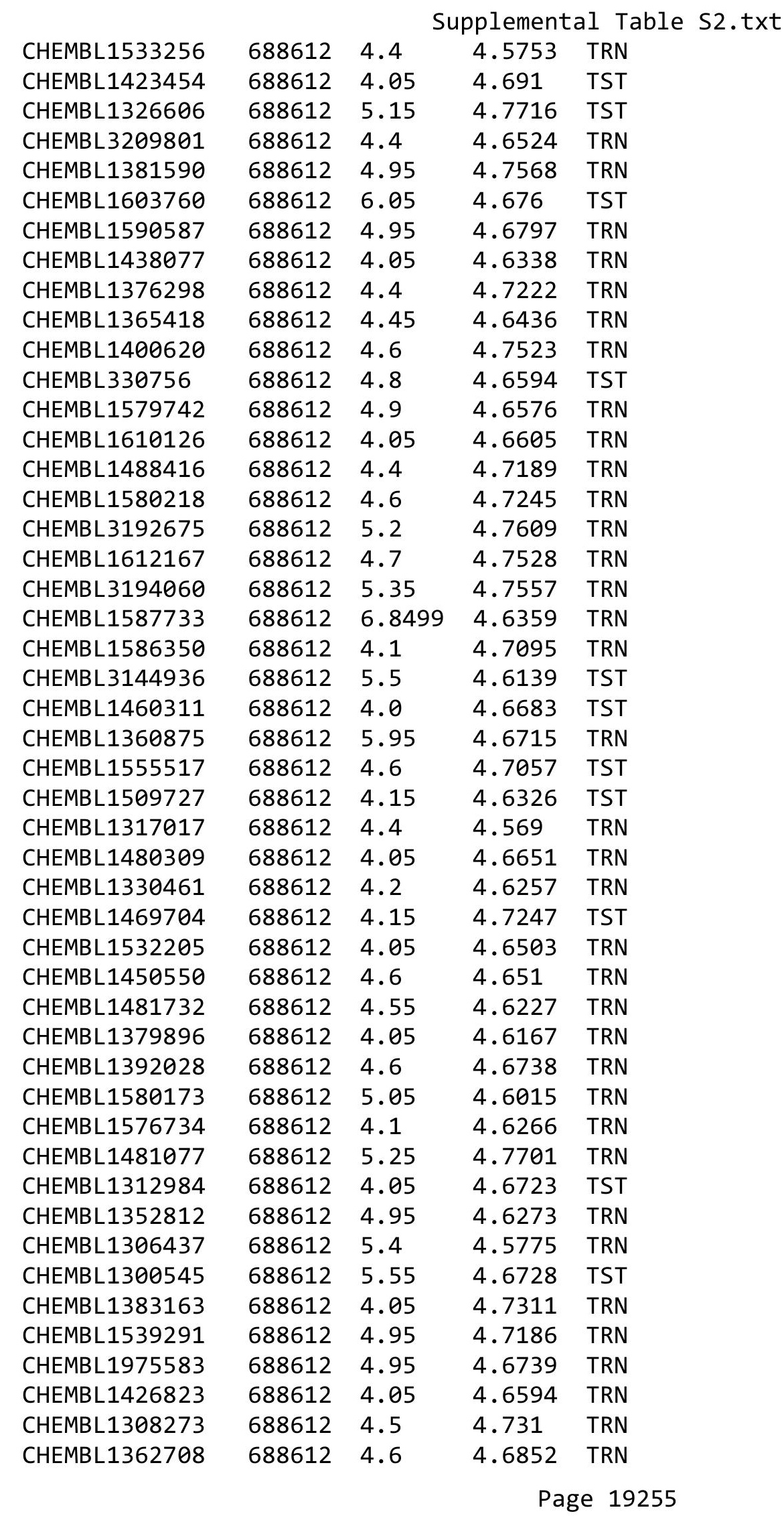




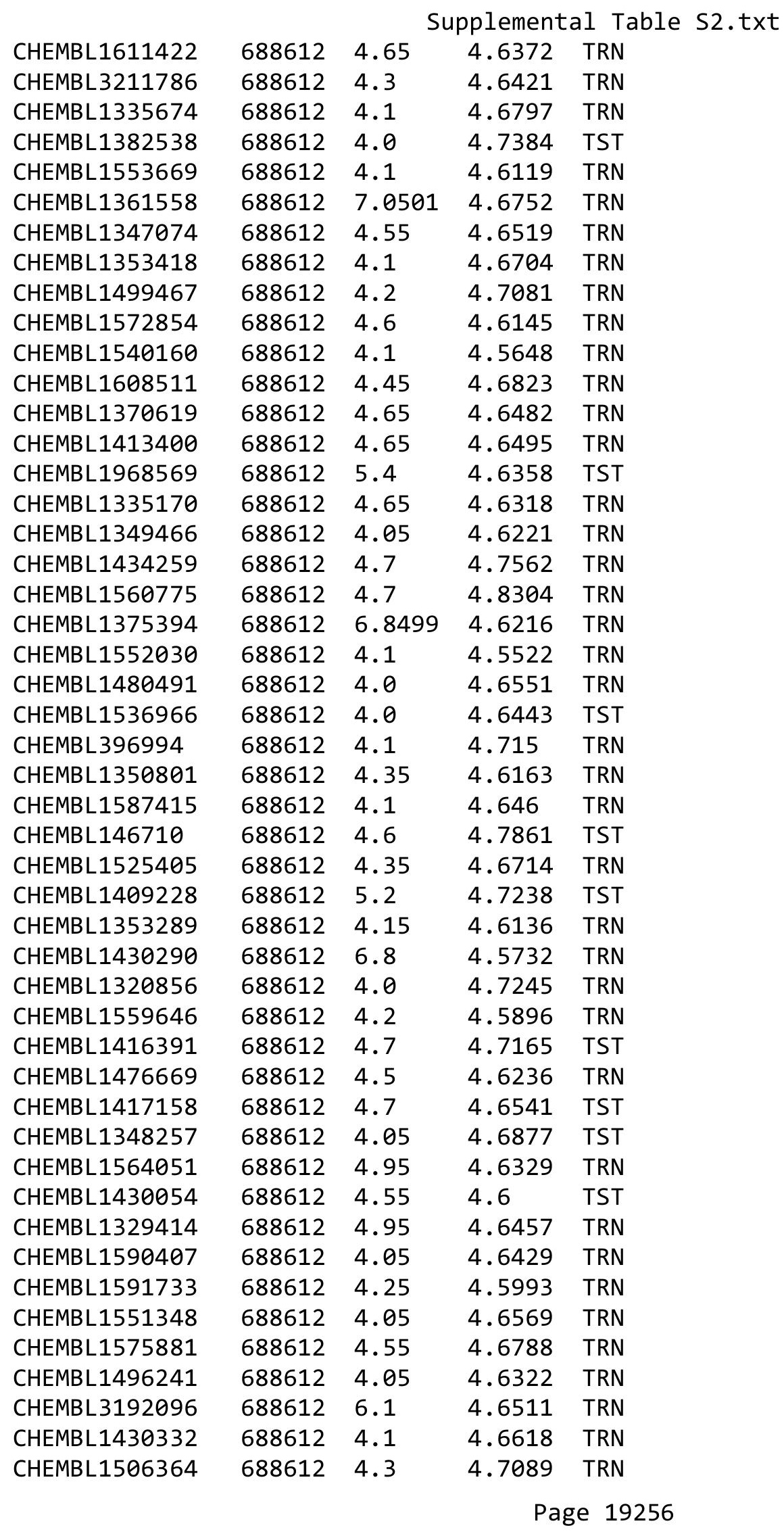




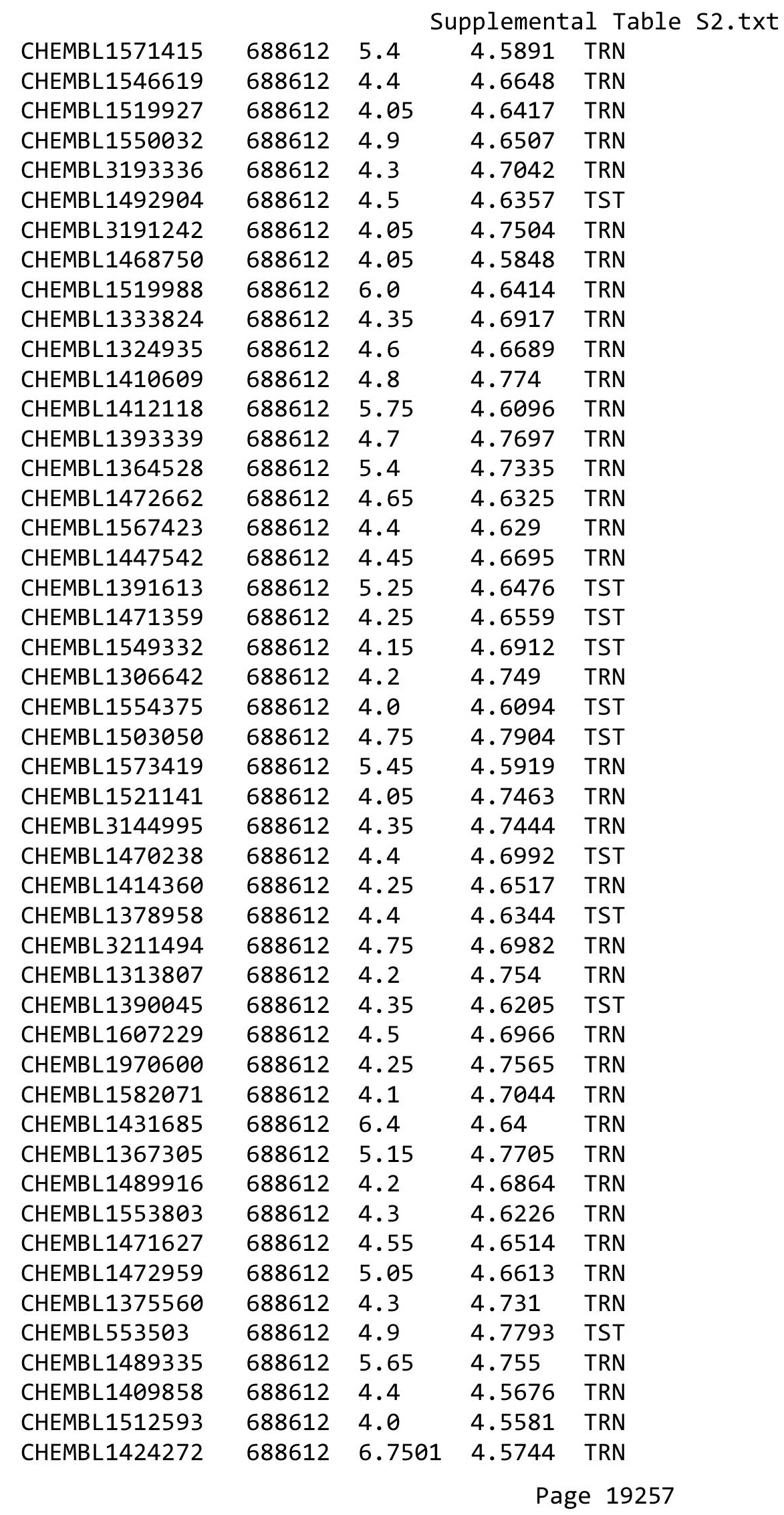




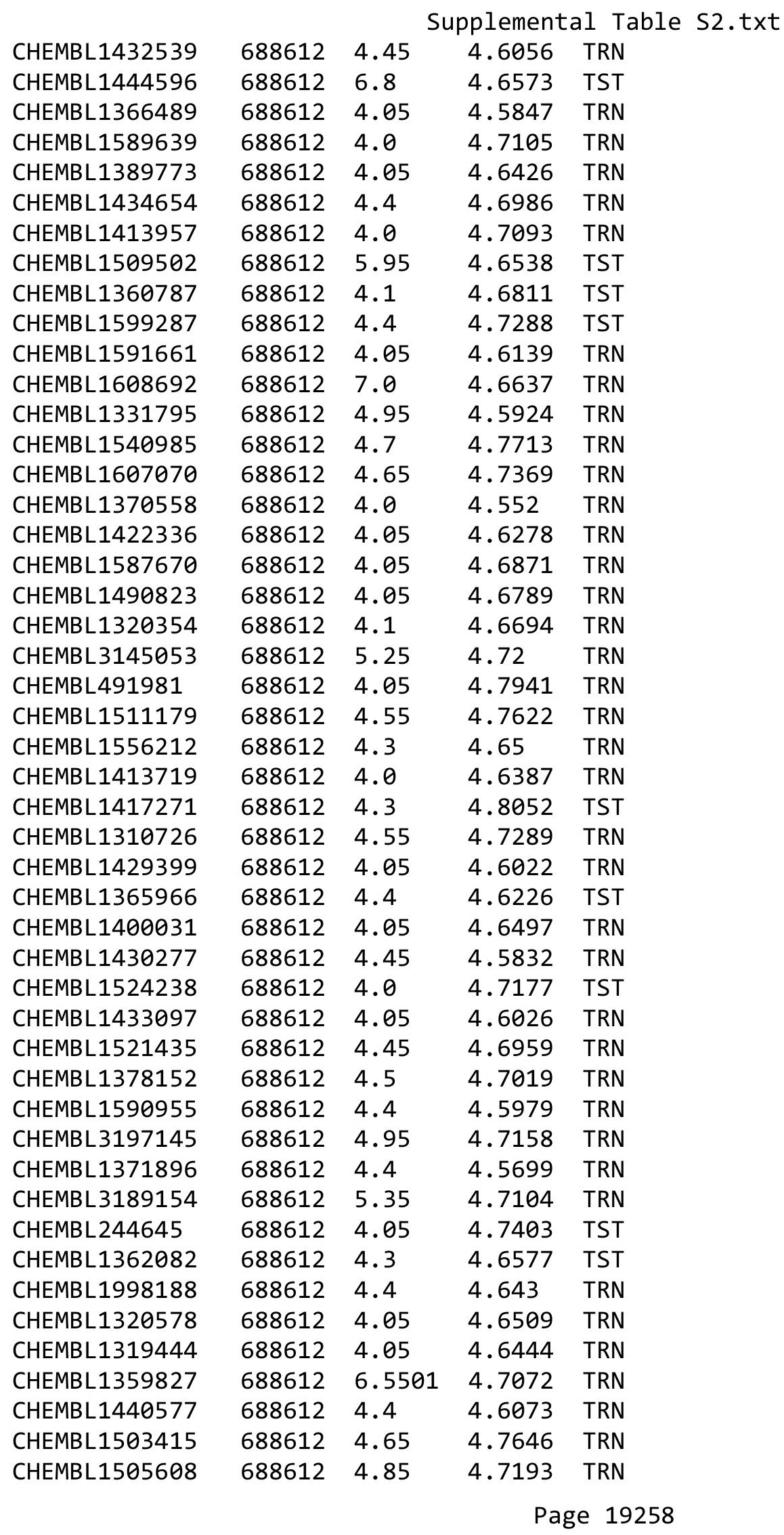




\begin{tabular}{|c|c|c|c|c|c|}
\hline & & \multicolumn{4}{|c|}{ Supplemental Table S2.txt } \\
\hline CHEMBL344344 & 688612 & 4.75 & 4.6311 & TRN & \\
\hline CHEMBL1573672 & 688612 & 4.0 & 4.7036 & TST & \\
\hline CHEMBL1611722 & 688612 & 4.1 & 4.6402 & TRN & \\
\hline CHEMBL1464449 & 688612 & 4.05 & 4.6152 & TRN & \\
\hline CHEMBL1499660 & 688612 & 4.1 & 4.7049 & TRN & \\
\hline CHEMBL1361216 & 688612 & 6.6 & 4.6148 & TRN & \\
\hline CHEMBL3199404 & 688612 & 4.6 & 4.7003 & TRN & \\
\hline CHEMBL1391427 & 688612 & 4.65 & 4.7161 & TRN & \\
\hline CHEMBL1417035 & 688612 & 4.3 & 4.6419 & TST & \\
\hline CHEMBL1532811 & 688612 & 5.5 & 4.7065 & TST & \\
\hline CHEMBL1329872 & 688612 & 5.7 & 4.6491 & TST & \\
\hline CHEMBL1478159 & 688612 & 4.45 & 4.632 & TRN & \\
\hline CHEMBL1521089 & 688612 & 4.4 & 4.607 & TRN & \\
\hline CHEMBL1576746 & 688612 & 4.4 & 4.7381 & TRN & \\
\hline CHEMBL3213075 & 688612 & 4.25 & 4.681999 & 99999999995 & TRN \\
\hline CHEMBL1539606 & 688612 & 4.7 & 4.7244 & TRN & \\
\hline CHEMBL3208120 & 688612 & 4.0 & 4.646 & TST & \\
\hline CHEMBL1509851 & 688612 & 4.75 & 4.6687 & TRN & \\
\hline CHEMBL 1437950 & 688612 & 4.25 & 4.6816 & TST & \\
\hline CHEMBL1422253 & 688612 & 4.55 & 4.6735 & TRN & \\
\hline CHEMBL1525576 & 688612 & 4.7 & 4.6544 & TRN & \\
\hline CHEMBL1612407 & 688612 & 5.05 & 4.5985 & TRN & \\
\hline CHEMBL1458734 & 688612 & 4.6 & 4.6612 & TRN & \\
\hline CHEMBL1390626 & 688612 & 4.4 & 4.6069 & TRN & \\
\hline CHEMBL3194161 & 688612 & 5.45 & 4.6839 & TRN & \\
\hline CHEMBL1580152 & 688612 & 6.0 & 4.8065 & TRN & \\
\hline CHEMBL1315816 & 688612 & 4.1 & 4.6597 & TRN & \\
\hline CHEMBL1408870 & 688612 & 4.45 & 4.6834 & TST & \\
\hline CHEMBL1446611 & 688612 & 7.0 & 4.7034 & TST & \\
\hline CHEMBL1576603 & 688612 & 6.0 & 4.6792 & TRN & \\
\hline CHEMBL1571430 & 688612 & 4.05 & 4.7214 & TRN & \\
\hline CHEMBL3145365 & 688612 & 4.05 & 4.7164 & TRN & \\
\hline CHEMBL1463624 & 688612 & 4.55 & 4.7407 & TRN & \\
\hline CHEMBL1413968 & 688612 & 4.0 & 4.5487 & TRN & \\
\hline CHEMBL1337622 & 688612 & 6.5 & 4.6088 & TRN & \\
\hline CHEMBL1443960 & 688612 & 6.05 & 4.6472 & TRN & \\
\hline CHEMBL1513207 & 688612 & 4.4 & 4.6179 & TRN & \\
\hline CHEMBL1965679 & 688612 & 4.65 & 4.7072 & TRN & \\
\hline CHEMBL1421944 & 688612 & 4.05 & 4.6441 & TRN & \\
\hline CHEMBL1479300 & 688612 & 4.35 & 4.7033 & TST & \\
\hline CHEMBL1368994 & 688612 & 4.6 & 4.612 & TRN & \\
\hline CHEMBL1604799 & 688612 & 4.0 & 4.6359 & TRN & \\
\hline CHEMBL1507428 & 688612 & 4.7 & 4.7235 & TST & \\
\hline CHEMBL1542390 & 688612 & 4.45 & 4.6788 & TRN & \\
\hline CHEMBL1559785 & 688612 & 5.05 & 4.681 & TRN & \\
\hline CHEMBL1377119 & 688612 & 4.05 & 4.6874 & TRN & \\
\hline CHEMBL1496610 & 688612 & 4.75 & 4.6545 & TRN & \\
\hline CHEMBL1357523 & 688612 & 5.45 & 4.6199 & TRN & \\
\hline
\end{tabular}




\begin{tabular}{|c|c|c|c|c|c|}
\hline & & \multicolumn{4}{|c|}{ Supplemental Table S2.txt } \\
\hline CHEMBL3191617 & 688612 & 4.4 & 4.7253 & TRN & \\
\hline CHEMBL1309044 & 688612 & 4.5 & 4.603 & TRN & \\
\hline CHEMBL1356651 & 688612 & 4.05 & 4.6745 & TRN & \\
\hline CHEMBL1514567 & 688612 & 4.9 & 4.658 & TRN & \\
\hline CHEMBL1457173 & 688612 & 4.1 & 4.6618 & TST & \\
\hline CHEMBL1465103 & 688612 & 5.35 & 4.6399 & TST & \\
\hline CHEMBL1435543 & 688612 & 4.9 & 4.7035 & TRN & \\
\hline CHEMBL1487251 & 688612 & 4.3 & 4.6402 & TRN & \\
\hline CHEMBL1381413 & 688612 & 5.85 & 4.7329 & TRN & \\
\hline CHEMBL581860 & 688612 & 4.0 & 4.645 & TRN & \\
\hline CHEMBL1381676 & 688612 & 5.35 & 4.6557 & TRN & \\
\hline CHEMBL1537358 & 688612 & 4.1 & 4.6623 & TST & \\
\hline CHEMBL1610184 & 688612 & 4.65 & 4.7201 & TST & \\
\hline CHEMBL1586683 & 688612 & 5.55 & 4.6907 & TRN & \\
\hline CHEMBL1305942 & 688612 & 4.0 & 4.6088 & TST & \\
\hline CHEMBL1607586 & 688612 & 5.2 & 4.7131 & TRN & \\
\hline CHEMBL1565201 & 688612 & 4.05 & 4.6995 & TRN & \\
\hline CHEMBL1305391 & 688612 & 4.85 & 4.6898 & TRN & \\
\hline CHEMBL1510042 & 688612 & 5.05 & 4.7031 & TRN & \\
\hline CHEMBL1733605 & 688612 & 4.7 & 4.6406 & TRN & \\
\hline CHEMBL1339651 & 688612 & 4.4 & 4.6584 & TRN & \\
\hline CHEMBL2373672 & 688612 & 4.05 & 4.7657 & TRN & \\
\hline CHEMBL3207959 & 688612 & 4.1 & 4.7445 & TST & \\
\hline CHEMBL1307979 & 688612 & 4.8 & 4.7301 & TRN & \\
\hline CHEMBL1343648 & 688612 & 4.0 & 4.6681 & TRN & \\
\hline CHEMBL1605663 & 688612 & 4.05 & 4.6960 & 0000000001 & TST \\
\hline CHEMBL1410092 & 688612 & 6.35 & 4.6921 & TRN & \\
\hline CHEMBL1331512 & 688612 & 4.1 & 4.6534 & TRN & \\
\hline CHEMBL1353716 & 688612 & 4.3 & 4.6325 & TRN & \\
\hline CHEMBL1587652 & 688612 & 7.0 & 4.6869 & TST & \\
\hline CHEMBL3192715 & 688612 & 5.65 & 4.8301 & TRN & \\
\hline CHEMBL1331052 & 688612 & 4.1 & 4.6518 & TST & \\
\hline CHEMBL1506055 & 688612 & 4.7 & 4.7902 & TRN & \\
\hline CHEMBL1558277 & 688612 & 5.25 & 4.7352 & TRN & \\
\hline CHEMBL1315327 & 688612 & 4.1 & 4.6069 & TRN & \\
\hline CHEMBL1481795 & 688612 & 4.8 & 4.7242 & TRN & \\
\hline CHEMBL3192804 & 688612 & 4.35 & 4.7860 & 00000000005 & TRN \\
\hline CHEMBL1514312 & 688612 & 4.85 & 4.6375 & TRN & \\
\hline CHEMBL1383387 & 688612 & 4.05 & 4.6065 & TRN & \\
\hline CHEMBL1345754 & 688612 & 4.8 & 4.7336 & TRN & \\
\hline CHEMBL1345825 & 688612 & 4.5 & 4.7285 & TRN & \\
\hline CHEMBL1439912 & 688612 & 4.05 & 4.6256 & TRN & \\
\hline CHEMBL1469053 & 688612 & 4.4 & 4.6698 & TRN & \\
\hline CHEMBL1405482 & 688612 & 4.6 & 4.7447 & TST & \\
\hline CHEMBL1385381 & 688612 & 4.1 & 4.6998 & TRN & \\
\hline CHEMBL1397186 & 688612 & 5.5 & 4.7337 & TRN & \\
\hline CHEMBL1356109 & 688612 & 4.1 & 4.6478 & TRN & \\
\hline CHEMBL1363851 & 688612 & 5.2 & 4.6229 & TRN & \\
\hline
\end{tabular}




\begin{tabular}{|c|c|c|c|c|c|}
\hline \multicolumn{6}{|c|}{ Supplemental Table S2.txt } \\
\hline CHEMBL1579645 & 688612 & 5.7 & 4.6083 & TRN & \\
\hline CHEMBL1570388 & 688612 & 4.6 & 4.6547 & TRN & \\
\hline CHEMBL1414009 & 688612 & 4.3 & 4.7063 & TRN & \\
\hline CHEMBL1488035 & 688612 & 4.25 & 4.6818 & TRN & \\
\hline CHEMBL109772 & 688612 & 4.0 & 4.6854 & TST & \\
\hline CHEMBL 3197786 & 688612 & 4.15 & 4.7319 & TRN & \\
\hline CHEMBL1444876 & 688612 & 4.1 & 4.68199 & 99999999995 & TRN \\
\hline CHEMBL1532402 & 688612 & 4.05 & 4.5767 & TRN & \\
\hline CHEMBL1306640 & 688612 & 4.5 & 4.64 & TST & \\
\hline CHEMBL3194567 & 688612 & 4.15 & 4.7465 & TRN & \\
\hline CHEMBL1452649 & 688612 & 4.5 & 4.7089 & TRN & \\
\hline CHEMBL 232148 & 688612 & 4.45 & 4.8362 & TRN & \\
\hline CHEMBL1473265 & 688612 & 4.2 & 4.7273 & TRN & \\
\hline CHEMBL1513505 & 688612 & 5.15 & 4.5974 & TST & \\
\hline CHEMBL1302266 & 688612 & 4.05 & 4.6904 & TRN & \\
\hline CHEMBL1479289 & 688612 & 4.05 & 4.6917 & TRN & \\
\hline CHEMBL1358370 & 688612 & 5.5 & 4.5704 & TRN & \\
\hline CHEMBL1421023 & 688612 & 5.05 & 4.6361 & TRN & \\
\hline CHEMBL1491303 & 688612 & 4.75 & 4.6897 & TST & \\
\hline CHEMBL1312885 & 688612 & 4.05 & 4.7528 & TST & \\
\hline CHEMBL1493223 & 688612 & 4.05 & 4.6403 & TRN & \\
\hline CHEMBL1503681 & 688612 & 4.1 & 4.6825 & TST & \\
\hline CHEMBL3193326 & 688612 & 5.65 & 4.6694 & TRN & \\
\hline CHEMBL1367765 & 688612 & 4.05 & 4.6644 & TRN & \\
\hline CHEMBL463563 & 688612 & 5.15 & 4.791 & TRN & \\
\hline CHEMBL1309831 & 688612 & 4.45 & 4.6838 & TRN & \\
\hline CHEMBL1426647 & 688612 & 5.0 & 4.7676 & TRN & \\
\hline CHEMBL1479971 & 688612 & 6.8499 & 4.6297 & TRN & \\
\hline CHEMBL1459970 & 688612 & 4.5 & 4.6505 & TRN & \\
\hline CHEMBL1461840 & 688612 & 4.6 & 4.6043 & TST & \\
\hline CHEMBL1313737 & 688612 & 4.05 & 4.5948 & TRN & \\
\hline CHEMBL1383473 & 688612 & 4.85 & 4.6751 & TRN & \\
\hline CHEMBL1488919 & 688612 & 4.05 & 4.6692 & TRN & \\
\hline CHEMBL1404929 & 688612 & 4.65 & 4.7292 & TRN & \\
\hline CHEMBL1360857 & 688612 & 5.6 & 4.7219 & TRN & \\
\hline CHEMBL1430617 & 688612 & 4.0 & 4.6486 & TRN & \\
\hline CHEMBL1451645 & 688612 & 4.0 & 4.5771 & TRN & \\
\hline CHEMBL1562237 & 688612 & 4.05 & 4.6571 & TRN & \\
\hline CHEMBL1419363 & 688612 & 6.4 & 4.7037 & TRN & \\
\hline CHEMBL1517269 & 688612 & 4.2 & 4.5897 & TST & \\
\hline CHEMBL1403264 & 688612 & 5.45 & 4.6849 & TRN & \\
\hline CHEMBL1503386 & 688612 & 4.85 & 4.7868 & TRN & \\
\hline CHEMBL1376435 & 688612 & 4.0 & 4.6361 & TST & \\
\hline CHEMBL1519439 & 688612 & 5.7 & 4.7612 & TST & \\
\hline CHEMBL1484400 & 688612 & 7.0 & 4.7323 & TST & \\
\hline CHEMBL1434949 & 688612 & 4.0 & 4.6518 & TST & \\
\hline CHEMBL1410302 & 688612 & 6.2 & 4.6158 & TRN & \\
\hline CHEMBL1565622 & 688612 & 4.05 & 4.6344 & TRN & \\
\hline
\end{tabular}




\begin{tabular}{|c|c|c|c|c|c|}
\hline \multicolumn{6}{|c|}{ Supplemental Table S2.txt } \\
\hline CHEMBL3193504 & 688612 & 4.9 & 4.6822 & TRN & \\
\hline CHEMBL1545213 & 688612 & 4.7 & 4.7061 & TRN & \\
\hline CHEMBL1387343 & 688612 & 4.6 & 4.7053 & TRN & \\
\hline CHEMBL1591493 & 688612 & 4.1 & 4.6584 & TRN & \\
\hline CHEMBL1589127 & 688612 & 4.55 & 4.6791 & TRN & \\
\hline CHEMBL1424957 & 688612 & 6.95 & 4.614 & TRN & \\
\hline CHEMBL1405136 & 688612 & 4.75 & 4.5602 & TRN & \\
\hline CHEMBL1436263 & 688612 & 4.0 & 4.6044 & TRN & \\
\hline CHEMBL 3189775 & 688612 & 4.55 & 4.7285 & TRN & \\
\hline CHEMBL1497927 & 688612 & 4.1 & 4.617 & TRN & \\
\hline CHEMBL1468510 & 688612 & 4.1 & 4.6167 & TRN & \\
\hline CHEMBL1461998 & 688612 & 4.05 & 4.7103 & TRN & \\
\hline CHEMBL1387587 & 688612 & 4.05 & 4.7756 & TRN & \\
\hline CHEMBL1343957 & 688612 & 4.05 & 4.599 & TRN & \\
\hline CHEMBL1316642 & 688612 & 4.05 & 4.5378 & TRN & \\
\hline CHEMBL1465280 & 688612 & 4.4 & 4.6756 & TRN & \\
\hline CHEMBL1455402 & 688612 & 4.75 & 4.8545 & TRN & \\
\hline CHEMBL1413947 & 688612 & 4.1 & 4.601 & TRN & \\
\hline CHEMBL1377232 & 688612 & 4.4 & 4.6064 & TRN & \\
\hline CHEMBL1573688 & 688612 & 6.0 & 4.6549 & TRN & \\
\hline CHEMBL1429397 & 688612 & 4.45 & 4.7381 & TRN & \\
\hline CHEMBL1558096 & 688612 & 4.65 & 4.67899 & 9999999999 & TRN \\
\hline CHEMBL1585294 & 688612 & 4.3 & 4.6817 & TST & \\
\hline CHEMBL1969419 & 688612 & 4.25 & 4.6548 & TRN & \\
\hline CHEMBL1470471 & 688612 & 4.05 & 4.7784 & TST & \\
\hline CHEMBL1502719 & 688612 & 6.05 & 4.7585 & TRN & \\
\hline CHEMBL1489686 & 688612 & 4.9 & 4.738 & TST & \\
\hline CHEMBL3391890 & 688612 & 4.6 & 4.6922 & TRN & \\
\hline CHEMBL1574520 & 688612 & 4.0 & 4.7469 & TRN & \\
\hline CHEMBL3193904 & 688612 & 5.25 & 4.6905 & TRN & \\
\hline CHEMBL1459441 & 688612 & 5.4 & 4.69 & TST & \\
\hline CHEMBL1449796 & 688612 & 4.2 & 4.6542 & TRN & \\
\hline CHEMBL1561815 & 688612 & 4.0 & 4.6542 & TRN & \\
\hline CHEMBL1583696 & 688612 & 4.95 & 4.7039 & TRN & \\
\hline CHEMBL1556821 & 688612 & 4.0 & 4.7204 & TRN & \\
\hline CHEMBL1598871 & 688612 & 4.1 & 4.6811 & TRN & \\
\hline CHEMBL1355498 & 688612 & 4.3 & 4.6831 & TST & \\
\hline CHEMBL1515904 & 688612 & 6.9 & 4.6991 & TST & \\
\hline CHEMBL1331630 & 688612 & 4.0 & 4.6665 & TRN & \\
\hline CHEMBL1996867 & 688612 & 4.5 & 4.7333 & TST & \\
\hline CHEMBL1329829 & 688612 & 4.05 & 4.6511 & TST & \\
\hline CHEMBL1589768 & 688612 & 4.05 & 4.6455 & TST & \\
\hline CHEMBL1527167 & 688612 & 6.5501 & 4.6321 & TRN & \\
\hline CHEMBL1517300 & 688612 & 4.8 & 4.6372 & TST & \\
\hline CHEMBL1319762 & 688612 & 4.0 & 4.6851 & TST & \\
\hline CHEMBL1401458 & 688612 & 5.0 & 4.7264 & TRN & \\
\hline CHEMBL 2374032 & 688612 & 5.5 & 4.7566 & TRN & \\
\hline CHEMBL1346724 & 688612 & 5.2 & 4.6747 & TRN & \\
\hline
\end{tabular}




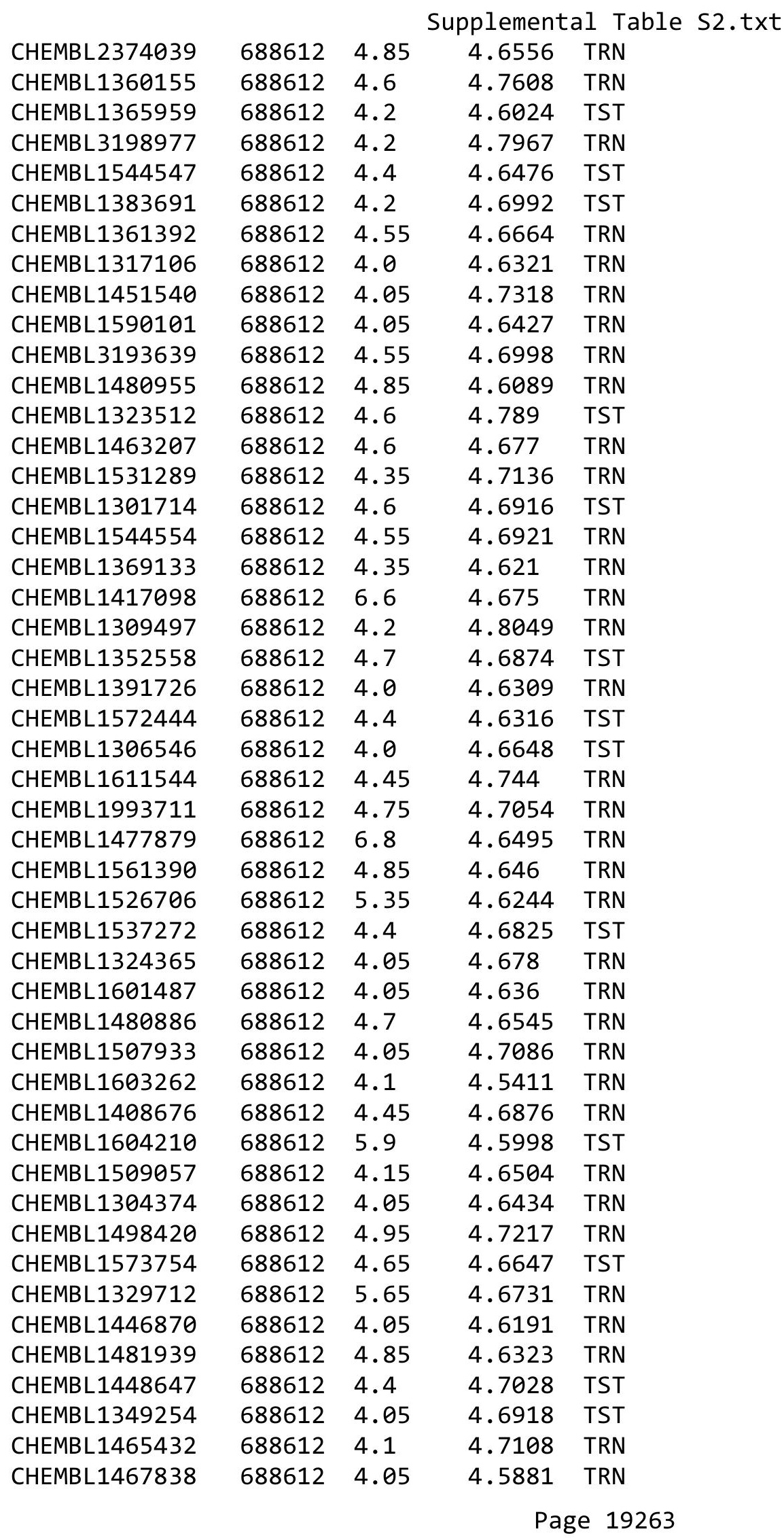




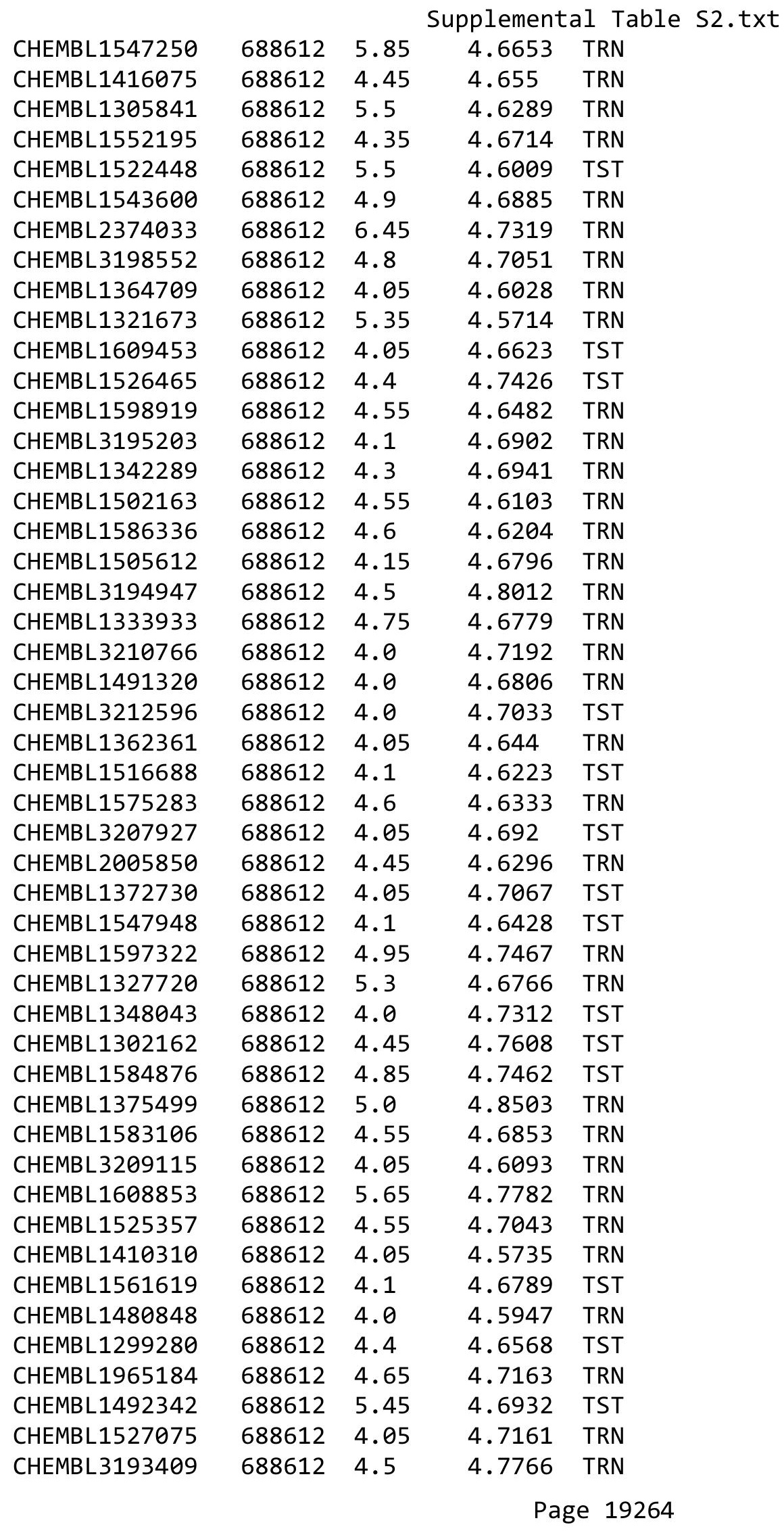




\begin{tabular}{|c|c|c|c|c|c|}
\hline \multicolumn{6}{|c|}{ Supplemental Table S2.txt } \\
\hline CHEMBL1348416 & 688612 & 5.5 & 4.6636 & TRN & \\
\hline CHEMBL1555938 & 688612 & 4.4 & 4.6719 & TRN & \\
\hline CHEMBL1462209 & 688612 & 4.05 & 4.7198 & TRN & \\
\hline CHEMBL1420798 & 688612 & 4.2 & 4.614 & TRN & \\
\hline CHEMBL1451212 & 688612 & 4.3 & 4.6901 & TRN & \\
\hline CHEMBL3198770 & 688612 & 4.7 & 4.6357 & TRN & \\
\hline CHEMBL3198618 & 688612 & 4.65 & 4.7221 & TRN & \\
\hline CHEMBL1360171 & 688612 & 5.75 & 4.602 & TRN & \\
\hline CHEMBL 1476087 & 688612 & 4.1 & 4.6513 & TRN & \\
\hline CHEMBL1385524 & 688612 & 5.0 & 4.7039 & TRN & \\
\hline CHEMBL1327860 & 688612 & 6.05 & 4.64 & TST & \\
\hline CHEMBL1462900 & 688612 & 4.1 & 4.6607 & TRN & \\
\hline CHEMBL1600264 & 688612 & 4.75 & 4.7401 & TRN & \\
\hline CHEMBL1538030 & 688612 & 6.25 & 4.7236 & TST & \\
\hline CHEMBL1469220 & 688612 & 4.05 & 4.6045 & TRN & \\
\hline CHEMBL1415018 & 688612 & 4.05 & 4.6166 & TRN & \\
\hline CHEMBL1453479 & 688612 & 4.1 & 4.6639 & TST & \\
\hline CHEMBL1400087 & 688612 & 4.55 & 4.5755 & TRN & \\
\hline CHEMBL1463096 & 688612 & 4.05 & 4.6382 & TRN & \\
\hline CHEMBL1430849 & 688612 & 4.55 & 4.6239 & TRN & \\
\hline CHEMBL1315003 & 688612 & 5.05 & 4.7434 & TST & \\
\hline CHEMBL3198487 & 688612 & 4.05 & 4.6824 & TRN & \\
\hline CHEMBL1506069 & 688612 & 4.05 & 4.6383 & TRN & \\
\hline CHEMBL 1450293 & 688612 & 4.1 & 4.6514 & TRN & \\
\hline CHEMBL1371954 & 688612 & 4.9 & 4.6243 & TRN & \\
\hline CHEMBL3194273 & 688612 & 4.1 & 4.7065 & TST & \\
\hline CHEMBL1376511 & 688612 & 4.4 & 4.67399 & 99999999995 & $1 \mathrm{~K}$ \\
\hline CHEMBL1468081 & 688612 & 4.8 & 4.6303 & TRN & \\
\hline CHEMBL1601646 & 688612 & 4.3 & 4.7191 & TST & \\
\hline CHEMBL1531217 & 688612 & 4.65 & 4.7052 & TRN & \\
\hline CHEMBL1520089 & 688612 & 4.65 & 4.6959 & TRN & \\
\hline CHEMBL1579841 & 688612 & 4.75 & 4.6901 & TRN & \\
\hline CHEMBL1410137 & 688612 & 4.05 & 4.6443 & TRN & \\
\hline CHEMBL1354657 & 688612 & 5.3 & 4.709 & TRN & \\
\hline CHEMBL1565285 & 688612 & 4.45 & 4.6514 & TRN & \\
\hline CHEMBL1548770 & 688612 & 4.55 & 4.7482 & TRN & \\
\hline CHEMBL1336270 & 688612 & 4.65 & 4.6776 & TRN & \\
\hline CHEMBL1429635 & 688612 & 4.4 & 4.7789 & TRN & \\
\hline CHEMBL3191425 & 688612 & 4.05 & 4.6684 & TRN & \\
\hline CHEMBL1379190 & 688612 & 4.0 & 4.6315 & TRN & \\
\hline CHEMBL3209966 & 688612 & 4.0 & 4.6673 & TRN & \\
\hline CHEMBL1334453 & 688612 & 4.55 & 4.6288 & TRN & \\
\hline CHEMBL1368698 & 688612 & 4.25 & 4.5958 & TRN & \\
\hline CHEMBL1573082 & 688612 & 5.0 & 4.6649 & TRN & \\
\hline CHEMBL1603490 & 688612 & 4.4 & 4.5304 & TRN & \\
\hline CHEMBL3192621 & 688612 & 4.4 & 4.5945 & TRN & \\
\hline CHEMBL1366498 & 688612 & 4.2 & 4.6543 & TRN & \\
\hline CHEMBL1521618 & 688612 & 4.6 & 4.681 & TRN & \\
\hline
\end{tabular}




\begin{tabular}{|c|c|c|c|c|}
\hline \multicolumn{5}{|c|}{ Supplemental Table S2.txt } \\
\hline CHEMBL1344568 & 688612 & 5.45 & 4.7083 & TRN \\
\hline CHEMBL1358721 & 688612 & 4.05 & 4.5906 & TRN \\
\hline CHEMBL3191785 & 688612 & 4.7 & 4.7749 & TRN \\
\hline CHEMBL1445308 & 688612 & 4.0 & 4.6231 & TRN \\
\hline CHEMBL1560276 & 688612 & 4.2 & 4.7604 & TST \\
\hline CHEMBL3189821 & 688612 & 4.35 & 4.7476 & TST \\
\hline CHEMBL1529342 & 688612 & 4.45 & 4.7184 & TRN \\
\hline CHEMBL1406844 & 688612 & 4.35 & 4.6934 & TRN \\
\hline CHEMBL1554101 & 688612 & 4.75 & 4.647 & TRN \\
\hline CHEMBL1490989 & 688612 & 6.95 & 4.6069 & TRN \\
\hline CHEMBL1322181 & 688612 & 4.0 & 4.7519 & TRN \\
\hline CHEMBL3199508 & 688612 & 4.6 & 4.62 & TRN \\
\hline CHEMBL1522475 & 688612 & 4.4 & 4.7441 & TST \\
\hline CHEMBL418068 & 688612 & 4.95 & 4.8006 & TRN \\
\hline CHEMBL1603938 & 688612 & 5.0 & 4.6974 & TRN \\
\hline CHEMBL1594565 & 688612 & 4.7 & 4.7093 & TST \\
\hline CHEMBL1583879 & 688612 & 4.6 & 4.7047 & TST \\
\hline CHEMBL1613089 & 688612 & 5.0 & 4.665 & TRN \\
\hline CHEMBL1442738 & 688612 & 5.0 & 4.654 & TST \\
\hline CHEMBL1364477 & 688612 & 4.25 & 4.6181 & TRN \\
\hline CHEMBL1582631 & 688612 & 5.45 & 4.6388 & TRN \\
\hline CHEMBL1339571 & 688612 & 6.8499 & 4.7274 & TST \\
\hline CHEMBL1611440 & 688612 & 4.95 & 4.7625 & TRN \\
\hline CHEMBL1301352 & 688612 & 4.0 & 4.6346 & TRN \\
\hline CHEMBL1378078 & 688612 & 4.05 & 4.6209 & TST \\
\hline CHEMBL3191926 & 688612 & 4.8 & 4.7517 & TRN \\
\hline CHEMBL1577636 & 688612 & 4.35 & 4.7331 & TST \\
\hline CHEMBL1592405 & 688612 & 4.1 & 4.6562 & TST \\
\hline CHEMBL1443054 & 688612 & 4.1 & 4.6977 & TST \\
\hline CHEMBL 3211140 & 688612 & 4.7 & 4.625 & TRN \\
\hline CHEMBL3190756 & 688612 & 4.05 & 4.7893 & TRN \\
\hline CHEMBL1533429 & 688612 & 4.5 & 4.7328 & TRN \\
\hline CHEMBL1397135 & 688612 & 4.05 & 4.7023 & TRN \\
\hline CHEMBL1542422 & 688612 & 4.3 & 4.7006 & TRN \\
\hline CHEMBL1574650 & 688612 & 4.4 & 4.6781 & TST \\
\hline CHEMBL1447137 & 688612 & 4.75 & 4.7858 & TRN \\
\hline CHEMBL1368127 & 688612 & 4.3 & 4.6741 & TRN \\
\hline CHEMBL1415880 & 688612 & 4.05 & 4.5795 & TRN \\
\hline CHEMBL1568214 & 688612 & 4.2 & 4.665 & TST \\
\hline CHEMBL1320511 & 688612 & 4.2 & 4.6164 & TRN \\
\hline CHEMBL1577579 & 688612 & 4.5 & 4.7172 & TST \\
\hline CHEMBL1308275 & 688612 & 6.1 & 4.7239 & TRN \\
\hline CHEMBL1583619 & 688612 & 4.45 & 4.6232 & TRN \\
\hline CHEMBL1422707 & 688612 & 4.65 & 4.6637 & TRN \\
\hline CHEMBL1472549 & 688612 & 4.6 & 4.5294 & TRN \\
\hline CHEMBL1580070 & 688612 & 4.05 & 4.7101 & TRN \\
\hline CHEMBL1524334 & 688612 & 4.3 & 4.6354 & TRN \\
\hline CHEMBL1566883 & 688612 & 4.05 & 4.5927 & TST \\
\hline
\end{tabular}




\begin{tabular}{|c|c|c|c|c|c|}
\hline \multicolumn{6}{|c|}{ Supplemental Table S2.txt } \\
\hline CHEMBL1991440 & 688612 & 5.2 & 4.6678 & TRN & \\
\hline CHEMBL1497368 & 688612 & 6.2 & 4.6841 & TRN & \\
\hline CHEMBL1558541 & 688612 & 5.5 & 4.5789 & TRN & \\
\hline CHEMBL3199921 & 688612 & 4.1 & 4.7224 & TRN & \\
\hline CHEMBL1400571 & 688612 & 6.15 & 4.751 & TST & \\
\hline CHEMBL66966 & 688612 & 6.0 & 4.8148 & TRN & \\
\hline CHEMBL1510860 & 688612 & 4.5 & 4.7396 & TRN & \\
\hline CHEMBL1381723 & 688612 & 4.85 & 4.6845 & TRN & \\
\hline CHEMBL1396875 & 688612 & 4.35 & 4.6736 & TRN & \\
\hline CHEMBL1354691 & 688612 & 4.6 & 4.6281 & TRN & \\
\hline CHEMBL1981657 & 688612 & 5.45 & 4.8401 & TRN & \\
\hline CHEMBL1470731 & 688612 & 5.4 & 4.6952 & TST & \\
\hline CHEMBL1547325 & 688612 & 4.1 & 4.6961 & TRN & \\
\hline CHEMBL1304003 & 688612 & 4.05 & 4.633 & TST & \\
\hline CHEMBL1427833 & 688612 & 4.0 & 4.7113 & TRN & \\
\hline CHEMBL1463882 & 688612 & 4.0 & 4.6424 & TST & \\
\hline CHEMBL1503936 & 688612 & 4.45 & 4.6618 & TST & \\
\hline CHEMBL1570284 & 688612 & 6.8499 & 4.6616 & TRN & \\
\hline CHEMBL1610795 & 688612 & 4.1 & 4.6694 & TRN & \\
\hline CHEMBL1589254 & 688612 & 4.6 & 4.6817 & TRN & \\
\hline CHEMBL1426692 & 688612 & 4.45 & 4.6862 & TRN & \\
\hline CHEMBL1482335 & 688612 & 4.4 & 4.6084 & TRN & \\
\hline CHEMBL1599278 & 688612 & 5.05 & 4.6611 & TRN & \\
\hline CHEMBL1430463 & 688612 & 4.45 & 4.6864 & TRN & \\
\hline CHEMBL1360482 & 688612 & 5.25 & 4.6928 & TRN & \\
\hline CHEMBL1568470 & 688612 & 4.55 & 4.6054 & TRN & \\
\hline CHEMBL1992394 & 688612 & 4.2 & 4.6364 & TRN & \\
\hline CHEMBL1421246 & 688612 & 4.45 & 4.7992 & TRN & \\
\hline CHEMBL1588379 & 688612 & 4.6 & 4.6934 & TST & \\
\hline CHEMBL1519057 & 688612 & 4.6 & 4.687 & TRN & \\
\hline CHEMBL1332183 & 688612 & 5.9 & 4.7101 & TRN & \\
\hline CHEMBL1353369 & 688612 & 4.85 & 4.7777 & TRN & \\
\hline CHEMBL1588148 & 688612 & 6.0 & 4.6863 & TST & \\
\hline CHEMBL1389670 & 688612 & 4.0 & 4.6459 & TRN & \\
\hline CHEMBL3193997 & 688612 & 4.6 & 4.7904 & TRN & \\
\hline CHEMBL1540510 & 688612 & 4.2 & 4.65306 & 00000000005 & TRN \\
\hline CHEMBL1414967 & 688612 & 4.1 & 4.613 & TRN & \\
\hline CHEMBL1401312 & 688612 & 4.55 & 4.7429 & TRN & \\
\hline CHEMBL1456904 & 688612 & 4.15 & 4.6514 & TST & \\
\hline CHEMBL1489613 & 688612 & 4.05 & 4.6325 & TRN & \\
\hline CHEMBL1463595 & 688612 & 4.55 & 4.8101 & TRN & \\
\hline CHEMBL1577171 & 688612 & 4.0 & 4.6958 & TRN & \\
\hline CHEMBL1339266 & 688612 & 4.2 & 4.665 & TRN & \\
\hline CHEMBL1567285 & 688612 & 4.95 & 4.738 & TST & \\
\hline CHEMBL1986232 & 688612 & 4.7 & 4.7051 & TRN & \\
\hline CHEMBL1319680 & 688612 & 4.6 & 4.6029 & TRN & \\
\hline CHEMBL1338421 & 688612 & 4.65 & 4.6013 & TRN & \\
\hline CHEMBL1349915 & 688612 & 4.75 & 4.6996 & TRN & \\
\hline
\end{tabular}




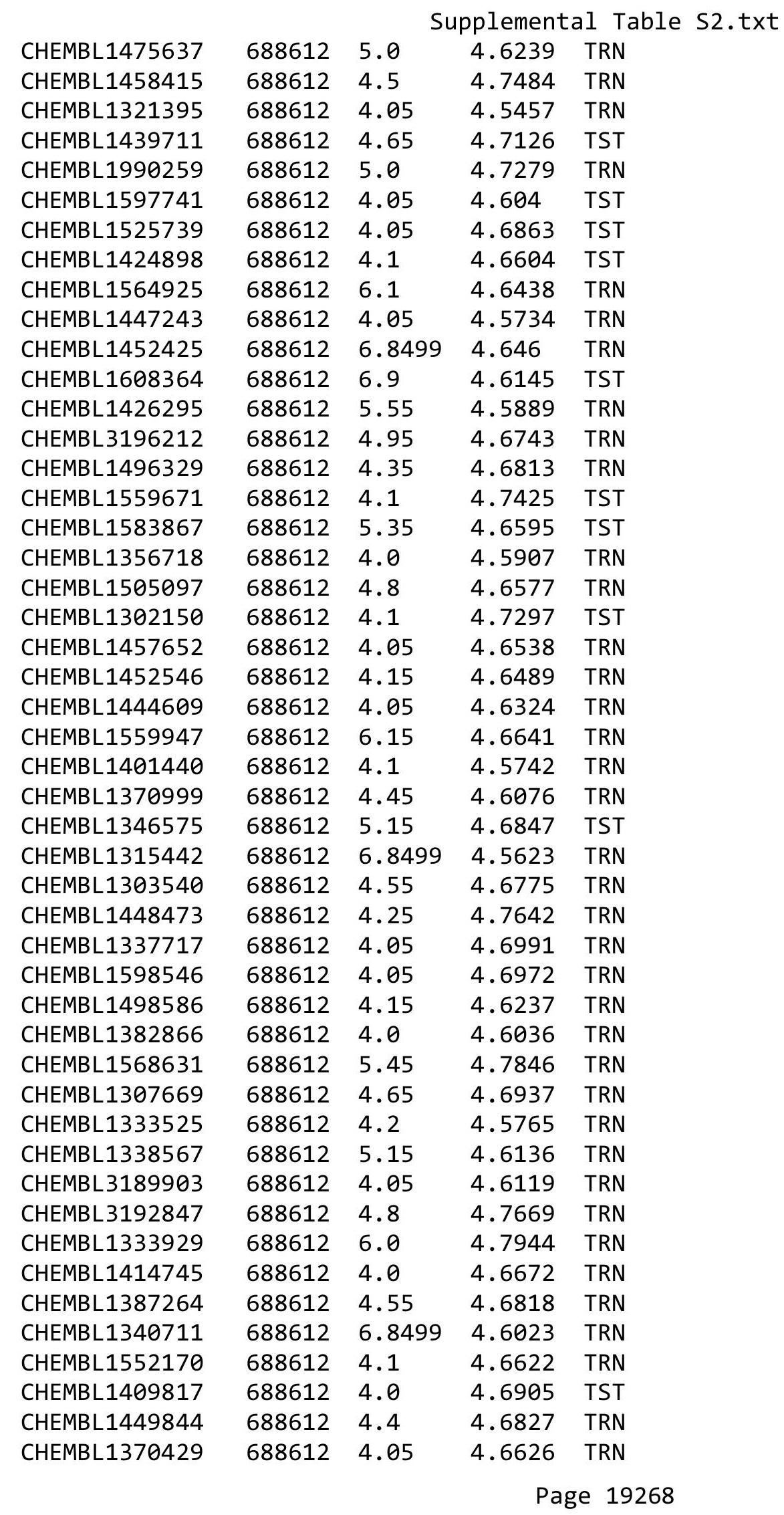




\begin{tabular}{|c|c|c|c|c|c|}
\hline & & \multicolumn{4}{|c|}{ Supplemental Table S2.txt } \\
\hline CHEMBL3195435 & 688612 & 4.9 & 4.6588 & TRN & \\
\hline CHEMBL1534616 & 688612 & 4.1 & 4.6383 & TRN & \\
\hline CHEMBL1439189 & 688612 & 4.4 & 4.6497 & TST & \\
\hline CHEMBL1613480 & 688612 & 4.55 & 4.7395 & TRN & \\
\hline CHEMBL1469721 & 688612 & 4.05 & 4.6664 & TRN & \\
\hline CHEMBL1988684 & 688612 & 4.1 & 4.7268 & TRN & \\
\hline CHEMBL1440082 & 688612 & 5.4 & 4.6072 & TRN & \\
\hline CHEMBL1328982 & 688612 & 4.05 & 4.628 & TRN & \\
\hline CHEMBL1548678 & 688612 & 5.8 & 4.8191 & TST & \\
\hline CHEMBL1332043 & 688612 & 5.1 & 4.7065 & TRN & \\
\hline CHEMBL3199506 & 688612 & 4.05 & 4.5946 & TRN & \\
\hline CHEMBL1458801 & 688612 & 4.2 & 4.7252 & TRN & \\
\hline CHEMBL460601 & 688612 & 4.05 & 4.7141 & TST & \\
\hline CHEMBL1416771 & 688612 & 4.05 & 4.7222 & TRN & \\
\hline CHEMBL1386083 & 688612 & 4.45 & 4.7465 & TST & \\
\hline CHEMBL 3856095 & 688612 & 5.2 & 4.7885 & TRN & \\
\hline CHEMBL1413175 & 688612 & 4.5 & 4.6004 & TST & \\
\hline CHEMBL 3207385 & 688612 & 4.3 & 4.7105 & TRN & \\
\hline CHEMBL1597406 & 688612 & 4.4 & 4.7727 & TRN & \\
\hline CHEMBL3199178 & 688612 & 5.0 & 4.7216 & TST & \\
\hline CHEMBL1382977 & 688612 & 4.65 & 4.6709 & TRN & \\
\hline CHEMBL1347276 & 688612 & 4.9 & 4.6774 & TRN & \\
\hline CHEMBL1465507 & 688612 & 5.35 & 4.76699 & 99999999995 & TRN \\
\hline CHEMBL1969543 & 688612 & 4.75 & 4.7633 & TRN & \\
\hline CHEMBL1483829 & 688612 & 4.05 & 4.7517 & TST & \\
\hline CHEMBL1363396 & 688612 & 5.4 & 4.7079 & TST & \\
\hline CHEMBL1557515 & 688612 & 6.35 & 4.6303 & TRN & \\
\hline CHEMBL606675 & 688612 & 4.3 & 4.7818 & TST & \\
\hline CHEMBL1413670 & 688612 & 4.5 & 4.7335 & TRN & \\
\hline CHEMBL1428986 & 688612 & 4.65 & 4.6162 & TST & \\
\hline CHEMBL1520420 & 688612 & 4.1 & 4.7432 & TRN & \\
\hline CHEMBL1449995 & 688612 & 4.6 & 4.7031 & TRN & \\
\hline CHEMBL1368555 & 688612 & 4.5 & 4.6858 & TRN & \\
\hline CHEMBL1464936 & 688612 & 4.55 & 4.7653 & TST & \\
\hline CHEMBL1560511 & 688612 & 5.3 & 4.71 & TST & \\
\hline CHEMBL1465256 & 688612 & 4.1 & 4.5977 & TRN & \\
\hline CHEMBL1432220 & 688612 & 6.0 & 4.5741 & TST & \\
\hline CHEMBL1608387 & 688612 & 5.4 & 4.6022 & TST & \\
\hline CHEMBL1501761 & 688612 & 6.8499 & 4.7565 & TST & \\
\hline CHEMBL1361621 & 688612 & 4.05 & 4.5778 & TRN & \\
\hline CHEMBL1388533 & 688612 & 4.35 & 4.7458 & TST & \\
\hline CHEMBL1435153 & 688612 & 4.05 & 4.6115 & TRN & \\
\hline CHEMBL1595994 & 688612 & 5.1 & 4.6737 & TRN & \\
\hline CHEMBL1588351 & 688612 & 4.05 & 4.5994 & TRN & \\
\hline CHEMBL457835 & 688612 & 6.45 & 4.7733 & TST & \\
\hline CHEMBL1444535 & 688612 & 4.0 & 4.6192 & TST & \\
\hline CHEMBL1395087 & 688612 & 4.05 & 4.711 & TRN & \\
\hline CHEMBL1432339 & 688612 & 4.25 & 4.6612 & TRN & \\
\hline
\end{tabular}




\begin{tabular}{|c|c|c|c|c|c|}
\hline \multicolumn{6}{|c|}{ Supplemental Table S2.txt } \\
\hline CHEMBL1443441 & 688612 & 4.5 & 4.6503 & TRN & \\
\hline CHEMBL1529812 & 688612 & 4.6 & 4.663 & TST & \\
\hline CHEMBL1547172 & 688612 & 4.6 & 4.7424 & TRN & \\
\hline CHEMBL 3197723 & 688612 & 5.0 & 4.6732 & TRN & \\
\hline CHEMBL1560518 & 688612 & 6.25 & 4.6207 & TST & \\
\hline CHEMBL1560616 & 688612 & 4.35 & 4.6798 & TST & \\
\hline CHEMBL1601352 & 688612 & 4.1 & 4.6928 & TRN & \\
\hline CHEMBL1552668 & 688612 & 4.4 & 4.6154 & TRN & \\
\hline CHEMBL1343959 & 688612 & 4.25 & 4.6553 & TRN & \\
\hline CHEMBL1461916 & 688612 & 5.4 & 4.6041 & TRN & \\
\hline CHEMBL1305830 & 688612 & 4.4 & 4.6723 & TRN & \\
\hline CHEMBL1389703 & 688612 & 4.3 & 4.74 & TRN & \\
\hline CHEMBL1512215 & 688612 & 6.1 & 4.6598 & TRN & \\
\hline CHEMBL1607114 & 688612 & 4.35 & 4.6441 & TRN & \\
\hline CHEMBL3212568 & 688612 & 4.65 & 4.6371 & TRN & \\
\hline CHEMBL1349552 & 688612 & 6.8499 & 4.6868 & TRN & \\
\hline CHEMBL1494390 & 688612 & 4.05 & 4.7022 & TRN & \\
\hline CHEMBL1465102 & 688612 & 4.1 & 4.6394 & TRN & \\
\hline CHEMBL1318923 & 688612 & 4.25 & 4.7588 & TRN & \\
\hline CHEMBL1531409 & 688612 & 4.0 & 4.6995 & TRN & \\
\hline CHEMBL1428051 & 688612 & 6.05 & 4.5755 & TRN & \\
\hline CHEMBL1483777 & 688612 & 5.3 & 4.6225 & TRN & \\
\hline CHEMBL1539820 & 688612 & 5.4 & 4.6499 & TRN & \\
\hline CHEMBL1587075 & 688612 & 4.1 & 4.6538 & TST & \\
\hline CHEMBL1501898 & 688612 & 4.05 & 4.7621 & TRN & \\
\hline CHEMBL1357677 & 688612 & 5.35 & 4.6889 & TST & \\
\hline CHEMBL1391844 & 688612 & 5.0 & 4.6184 & TRN & \\
\hline CHEMBL1349922 & 688612 & 4.05 & 4.67399 & 99999999995 & TRN \\
\hline CHEMBL1393962 & 688612 & 4.0 & 4.6475 & TRN & \\
\hline CHEMBL1354837 & 688612 & 5.45 & 4.6868 & TST & \\
\hline CHEMBL1604248 & 688612 & 4.1 & 4.6723 & TRN & \\
\hline CHEMBL1537248 & 688612 & 6.8499 & 4.7245 & TRN & \\
\hline CHEMBL1534819 & 688612 & 4.05 & 4.6331 & TRN & \\
\hline CHEMBL1360477 & 688612 & 4.25 & 4.6529 & TRN & \\
\hline CHEMBL1979780 & 688612 & 6.95 & 4.7129 & TST & \\
\hline CHEMBL1578872 & 688612 & 4.8 & 4.6454 & TRN & \\
\hline CHEMBL1551315 & 688612 & 4.05 & 4.6436 & TRN & \\
\hline CHEMBL1490799 & 688612 & 4.95 & 4.6238 & TRN & \\
\hline CHEMBL1524730 & 688612 & 4.0 & 4.626 & TRN & \\
\hline CHEMBL1519543 & 688612 & 4.2 & 4.5722 & TRN & \\
\hline CHEMBL3212725 & 688612 & 4.65 & 4.7153 & TRN & \\
\hline CHEMBL1572805 & 688612 & 4.6 & 4.664 & TST & \\
\hline CHEMBL1492839 & 688612 & 4.8 & 4.7229 & TRN & \\
\hline CHEMBL1510626 & 688612 & 5.4 & 4.706 & TRN & \\
\hline CHEMBL1421468 & 688612 & 4.5 & 4.7377 & TRN & \\
\hline CHEMBL1502443 & 688612 & 5.7 & 4.6184 & TRN & \\
\hline CHEMBL3193106 & 688612 & 4.4 & 4.6571 & TRN & \\
\hline CHEMBL1419536 & 688612 & 4.6 & 4.7687 & TRN & \\
\hline
\end{tabular}




\begin{tabular}{|c|c|c|c|c|c|}
\hline \multicolumn{6}{|c|}{ Supplemental Table S2.txt } \\
\hline CHEMBL1492188 & 688612 & 4.05 & 4.6498 & TRN & \\
\hline CHEMBL1520666 & 688612 & 4.1 & 4.6911 & TRN & \\
\hline CHEMBL1342434 & 688612 & 4.1 & 4.6597 & TRN & \\
\hline CHEMBL1332222 & 688612 & 4.0 & 4.6149 & TST & \\
\hline CHEMBL3199876 & 688612 & 4.85 & 4.6653 & TRN & \\
\hline CHEMBL1328373 & 688612 & 4.15 & 4.6809 & TRN & \\
\hline CHEMBL3207983 & 688612 & 4.6 & 4.7151 & TRN & \\
\hline CHEMBL1331511 & 688612 & 6.05 & 4.6406 & TRN & \\
\hline CHEMBL1544107 & 688612 & 4.55 & 4.6724 & TRN & \\
\hline CHEMBL1310003 & 688612 & 6.5501 & 4.66100 & 00000000005 & TRN \\
\hline CHEMBL3209598 & 688612 & 6.8499 & 4.7839 & TST & \\
\hline CHEMBL1394669 & 688612 & 4.65 & 4.703 & TRN & \\
\hline CHEMBL1466539 & 688612 & 5.3 & 4.6427 & TRN & \\
\hline CHEMBL1323320 & 688612 & 4.95 & 4.7336 & TRN & \\
\hline CHEMBL1561605 & 688612 & 4.75 & 4.5896 & TRN & \\
\hline CHEMBL1476621 & 688612 & 4.05 & 4.5961 & TRN & \\
\hline CHEMBL1560423 & 688612 & 4.05 & 4.6558 & TRN & \\
\hline CHEMBL1498875 & 688612 & 4.6 & 4.71899 & э999999999 & TRN \\
\hline CHEMBL1423606 & 688612 & 5.25 & 4.6194 & TRN & \\
\hline CHEMBL1324560 & 688612 & 4.6 & 4.7348 & TRN & \\
\hline CHEMBL1404779 & 688612 & 4.95 & 4.6166 & TRN & \\
\hline CHEMBL1392532 & 688612 & 4.05 & 4.6549 & TRN & \\
\hline CHEMBL1422122 & 688612 & 6.25 & 4.6473 & TST & \\
\hline CHEMBL579075 & 688612 & 4.95 & 4.6322 & TRN & \\
\hline CHEMBL1499938 & 688612 & 4.8 & 4.6331 & TRN & \\
\hline CHEMBL1455821 & 688612 & 4.1 & 4.73 & TST & \\
\hline CHEMBL1568263 & 688612 & 4.05 & 4.59699 & 99999999995 & TRN \\
\hline CHEMBL1572807 & 688612 & 4.55 & 4.8116 & TRN & \\
\hline CHEMBL1446186 & 688612 & 4.05 & 4.70100 & 00000000005 & TST \\
\hline CHEMBL1503634 & 688612 & 4.25 & 4.7116 & TRN & \\
\hline CHEMBL1310687 & 688612 & 6.8499 & 4.6054 & TRN & \\
\hline CHEMBL1452960 & 688612 & 4.05 & 4.6578 & TRN & \\
\hline CHEMBL1442915 & 688612 & 4.3 & 4.6378 & TRN & \\
\hline CHEMBL1308345 & 688612 & 4.5 & 4.7239 & TRN & \\
\hline CHEMBL1407862 & 688612 & 4.05 & 4.7233 & TRN & \\
\hline CHEMBL1507237 & 688612 & 4.05 & 4.5837 & TRN & \\
\hline CHEMBL1449590 & 688612 & 4.0 & 4.7067 & TRN & \\
\hline CHEMBL1370158 & 688612 & 4.8 & 4.6731 & TRN & \\
\hline CHEMBL1445049 & 688612 & 6.1 & 4.6397 & TRN & \\
\hline CHEMBL1362279 & 688612 & 4.8 & 4.7372 & TRN & \\
\hline CHEMBL1565174 & 688612 & 4.0 & 4.5803 & TRN & \\
\hline CHEMBL146525 & 688612 & 5.05 & 4.7335 & TRN & \\
\hline CHEMBL1495826 & 688612 & 4.55 & 4.6908 & TRN & \\
\hline CHEMBL1451666 & 688612 & 5.1 & 4.6814 & TST & \\
\hline CHEMBL1320725 & 688612 & 4.55 & 4.7116 & TRN & \\
\hline CHEMBL1481529 & 688612 & 5.7 & 4.6992 & TRN & \\
\hline CHEMBL1309854 & 688612 & 4.75 & 4.6164 & TRN & \\
\hline CHEMBL1578653 & 688612 & 5.55 & 4.7318 & TST & \\
\hline
\end{tabular}




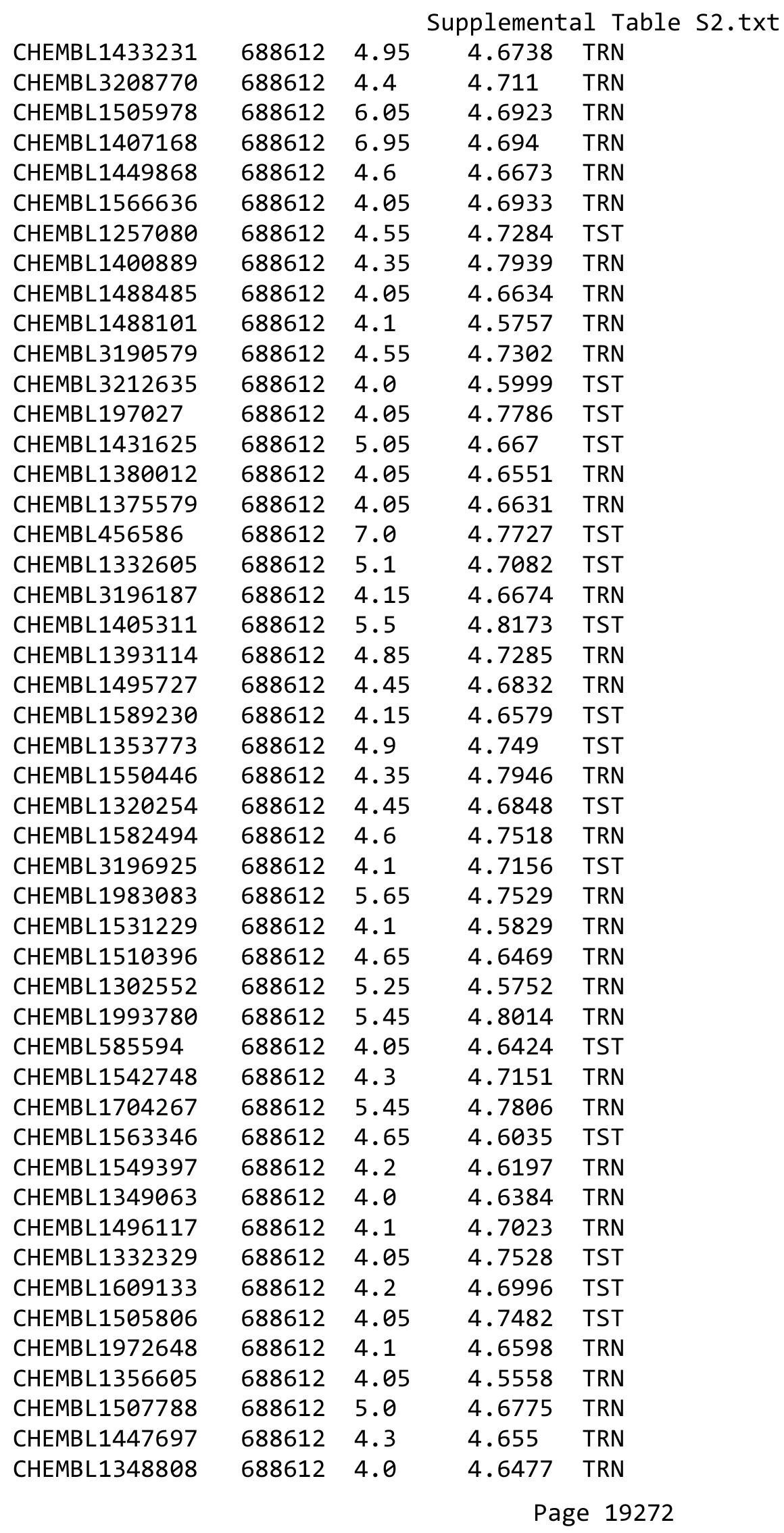




\begin{tabular}{|c|c|c|c|c|}
\hline \multicolumn{5}{|c|}{ Supplemental Table S2.txt } \\
\hline CHEMBL3192031 & 688612 & 6.3 & 4.7607 & TRN \\
\hline CHEMBL1436628 & 688612 & 6.5501 & 4.6866 & TRN \\
\hline CHEMBL1607983 & 688612 & 4.05 & 4.6512 & TRN \\
\hline CHEMBL1440716 & 688612 & 4.1 & 4.6818 & TRN \\
\hline CHEMBL1504136 & 688612 & 4.05 & 4.6845 & TRN \\
\hline CHEMBL1590563 & 688612 & 4.05 & 4.7245 & TST \\
\hline CHEMBL1475104 & 688612 & 4.65 & 4.6083 & TRN \\
\hline CHEMBL1317876 & 688612 & 4.0 & 4.6439 & TRN \\
\hline CHEMBL1417438 & 688612 & 4.7 & 4.6092 & TRN \\
\hline CHEMBL1487430 & 688612 & 6.5501 & 4.6676 & TRN \\
\hline CHEMBL1328746 & 688612 & 4.35 & 4.6294 & TRN \\
\hline CHEMBL1497617 & 688612 & 4.05 & 4.6252 & TRN \\
\hline CHEMBL1968928 & 688612 & 6.35 & 4.8555 & TRN \\
\hline CHEMBL1504335 & 688612 & 4.0 & 4.6758 & TRN \\
\hline CHEMBL1426603 & 688612 & 4.6 & 4.651 & TRN \\
\hline CHEMBL1417562 & 688612 & 4.05 & 4.6162 & TRN \\
\hline CHEMBL1396500 & 688612 & 5.5 & 4.6508 & TRN \\
\hline CHEMBL1541656 & 688612 & 4.6 & 4.6609 & TRN \\
\hline CHEMBL1415853 & 688612 & 4.4 & 4.6854 & TRN \\
\hline CHEMBL1524961 & 688612 & 4.6 & 4.6006 & TST \\
\hline CHEMBL1574249 & 688612 & 4.3 & 4.6329 & TRN \\
\hline CHEMBL1358049 & 688612 & 4.0 & 4.6371 & TST \\
\hline CHEMBL1545406 & 688612 & 4.4 & 4.7135 & TRN \\
\hline CHEMBL1401137 & 688612 & 4.05 & 4.7077 & TRN \\
\hline CHEMBL1430928 & 688612 & 6.8 & 4.6143 & TRN \\
\hline CHEMBL1345363 & 688612 & 4.05 & 4.6696 & TRN \\
\hline CHEMBL1475815 & 688612 & 4.6 & 4.5952 & TRN \\
\hline CHEMBL1386557 & 688612 & 4.3 & 4.5746 & TRN \\
\hline CHEMBL1332241 & 688612 & 4.65 & 4.7339 & TRN \\
\hline CHEMBL1478805 & 688612 & 4.05 & 4.644 & TRN \\
\hline CHEMBL1540099 & 688612 & 4.4 & 4.7318 & TRN \\
\hline CHEMBL1418009 & 688612 & 4.35 & 4.6864 & TRN \\
\hline CHEMBL1537336 & 688612 & 5.0 & 4.6327 & TRN \\
\hline CHEMBL 2001262 & 688612 & 4.35 & 4.659 & TRN \\
\hline CHEMBL1430335 & 688612 & 5.0 & 4.631 & TRN \\
\hline CHEMBL1545407 & 688612 & 5.45 & 4.6855 & TRN \\
\hline CHEMBL1369264 & 688612 & 4.75 & 4.6667 & TRN \\
\hline CHEMBL1379363 & 688612 & 4.45 & 4.7132 & TRN \\
\hline CHEMBL 85826 & 688612 & 4.1 & 4.6503 & TRN \\
\hline CHEMBL1434222 & 688612 & 4.45 & 4.6364 & TRN \\
\hline CHEMBL1317550 & 688612 & 4.95 & 4.6109 & TRN \\
\hline CHEMBL1607045 & 688612 & 4.05 & 4.6739 & TRN \\
\hline CHEMBL1387612 & 688612 & 5.05 & 4.6389 & TRN \\
\hline CHEMBL1502962 & 688612 & 4.05 & 4.6323 & TRN \\
\hline CHEMBL1596568 & 688612 & 4.5 & 4.7573 & TST \\
\hline CHEMBL1404049 & 688612 & 5.05 & 4.6804 & TST \\
\hline CHEMBL1299545 & 688612 & 4.7 & 4.6736 & TRN \\
\hline CHEMBL1502034 & 688612 & 4.55 & 4.7674 & TRN \\
\hline
\end{tabular}




\begin{tabular}{|c|c|c|c|c|c|}
\hline & & \multicolumn{4}{|c|}{ Supplemental Table s2.txt } \\
\hline CHEMBL3191481 & 688612 & 4.65 & 4.6469 & TRN & \\
\hline CHEMBL1302861 & 688612 & 4.05 & 4.6647 & TRN & \\
\hline CHEMBL1438783 & 688612 & 4.25 & 4.6245 & TRN & \\
\hline CHEMBL1578505 & 688612 & 4.05 & 4.5692 & TRN & \\
\hline CHEMBL1205406 & 688612 & 4.65 & 4.7393 & TST & \\
\hline CHEMBL1360241 & 688612 & 4.9 & 4.7072 & TRN & \\
\hline CHEMBL1453334 & 688612 & 4.05 & 4.6516 & TRN & \\
\hline CHEMBL1376616 & 688612 & 4.05 & 4.6458 & TRN & \\
\hline CHEMBL1387003 & 688612 & 4.65 & 4.6919 & TRN & \\
\hline CHEMBL1536782 & 688612 & 4.65 & 4.6942 & TRN & \\
\hline CHEMBL1532292 & 688612 & 4.05 & 4.563 & TRN & \\
\hline CHEMBL 3214488 & 688612 & 5.2 & 4.7333 & TRN & \\
\hline CHEMBL1428941 & 688612 & 4.2 & 4.667 & TRN & \\
\hline CHEMBL1404343 & 688612 & 4.05 & 4.5747 & TRN & \\
\hline CHEMBL1326257 & 688612 & 4.3 & 4.6949 & TRN & \\
\hline CHEMBL1470135 & 688612 & 4.25 & 4.7146 & TST & \\
\hline CHEMBL1441401 & 688612 & 4.9 & 4.7784 & TRN & \\
\hline CHEMBL1462034 & 688612 & 4.4 & 4.6127 & TRN & \\
\hline CHEMBL1966168 & 688612 & 5.05 & 4.6878 & TRN & \\
\hline CHEMBL1336500 & 688612 & 4.85 & 4.6395 & TRN & \\
\hline CHEMBL1589770 & 688612 & 4.45 & 4.5994 & TRN & \\
\hline CHEMBL1576044 & 688612 & 4.05 & 4.6635 & TRN & \\
\hline CHEMBL1541863 & 688612 & 5.0 & 4.7162 & TRN & \\
\hline CHEMBL1376228 & 688612 & 4.0 & 4.5816 & TRN & \\
\hline CHEMBL1600383 & 688612 & 5.1 & 4.6983 & TRN & \\
\hline CHEMBL1477098 & 688612 & 4.5 & 4.6469 & TRN & \\
\hline CHEMBL1613066 & 688612 & 4.55 & 4.7334 & TRN & \\
\hline CHEMBL1990932 & 688612 & 7.0 & 4.7735 & TRN & \\
\hline CHEMBL1553442 & 688612 & 4.6 & 4.6392 & TRN & \\
\hline CHEMBL1502811 & 688612 & 4.4 & 4.6754 & TRN & \\
\hline CHEMBL1336490 & 688612 & 4.0 & 4.7107 & TST & \\
\hline CHEMBL1428422 & 688612 & 4.0 & 4.6718 & TRN & \\
\hline CHEMBL1474072 & 688612 & 4.35 & 4.6212 & TRN & \\
\hline CHEMBL1472052 & 688612 & 4.1 & 4.6610 & 00000000005 & TRN \\
\hline CHEMBL1582029 & 688612 & 4.85 & 4.7198 & TRN & \\
\hline CHEMBL1555746 & 688612 & 6.6 & 4.548 & TRN & \\
\hline CHEMBL1537782 & 688612 & 4.4 & 4.6752 & TRN & \\
\hline CHEMBL1362803 & 688612 & 4.1 & 4.6567 & TRN & \\
\hline CHEMBL1457665 & 688612 & 4.05 & 4.6671 & TRN & \\
\hline CHEMBL1373997 & 688612 & 4.7 & 4.6278 & TRN & \\
\hline CHEMBL1348662 & 688612 & 5.15 & 4.5680 & 00000000005 & TRN \\
\hline CHEMBL1589991 & 688612 & 4.45 & 4.6756 & TRN & \\
\hline CHEMBL1502229 & 688612 & 4.1 & 4.7447 & TST & \\
\hline CHEMBL3189960 & 688612 & 4.1 & 4.6935 & TRN & \\
\hline CHEMBL1460945 & 688612 & 4.7 & 4.6536 & TST & \\
\hline CHEMBL1442697 & 688612 & 5.1 & 4.6303 & TRN & \\
\hline CHEMBL1330214 & 688612 & 4.35 & 4.8116 & TRN & \\
\hline CHEMBL1584243 & 688612 & 4.05 & 4.6724 & TRN & \\
\hline
\end{tabular}




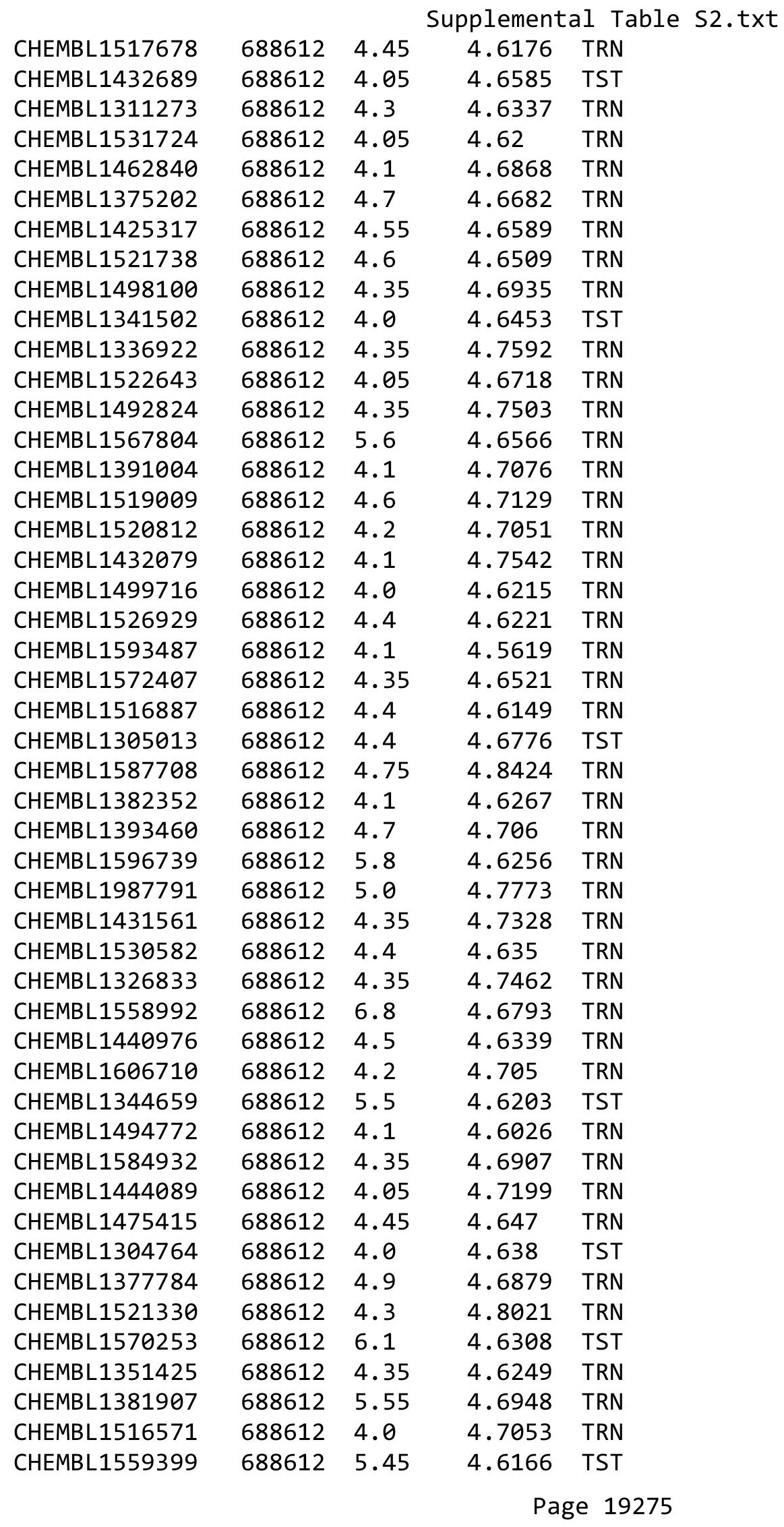




\begin{tabular}{|c|c|c|c|c|c|}
\hline \multicolumn{6}{|c|}{ Supplemental Table S2.txt } \\
\hline CHEMBL1439583 & 688612 & 4.0 & 4.609 & TRN & \\
\hline CHEMBL1491029 & 688612 & 6.9 & 4.6366 & TST & \\
\hline CHEMBL1539299 & 688612 & 6.25 & 4.6475 & TST & \\
\hline CHEMBL1499581 & 688612 & 4.1 & 4.6419 & 99999999995 & TRN \\
\hline CHEMBL1309448 & 688612 & 4.15 & 4.6080 & 00000000005 & TST \\
\hline CHEMBL1348345 & 688612 & 4.7 & 4.7368 & TRN & \\
\hline CHEMBL245264 & 688612 & 5.75 & 4.6942 & TRN & \\
\hline CHEMBL 2374081 & 688612 & 4.9 & 4.7832 & TRN & \\
\hline CHEMBL3190807 & 688612 & 4.4 & 4.7813 & TRN & \\
\hline CHEMBL1414491 & 688612 & 4.05 & 4.5869 & TST & \\
\hline CHEMBL1564114 & 688612 & 4.55 & 4.6416 & TST & \\
\hline CHEMBL1355065 & 688612 & 4.65 & 4.6219 & TRN & \\
\hline CHEMBL1345135 & 688612 & 4.7 & 4.678 & TRN & \\
\hline CHEMBL1409717 & 688612 & 4.4 & 4.7822 & TRN & \\
\hline CHEMBL1465739 & 688612 & 5.05 & 4.6804 & TRN & \\
\hline CHEMBL1326593 & 688612 & 5.2 & 4.612 & TRN & \\
\hline CHEMBL1392848 & 688612 & 4.35 & 4.7937 & TST & \\
\hline CHEMBL1589116 & 688612 & 5.4 & 4.6808 & TRN & \\
\hline CHEMBL 1374874 & 688612 & 4.05 & 4.7369 & TRN & \\
\hline CHEMBL1373347 & 688612 & 4.5 & 4.7342 & TRN & \\
\hline CHEMBL1362493 & 688612 & 4.1 & 4.6266 & TRN & \\
\hline CHEMBL1489010 & 688612 & 4.1 & 4.5988 & TRN & \\
\hline CHEMBL1408425 & 688612 & 5.8 & 4.6131 & TRN & \\
\hline CHEMBL 1402752 & 688612 & 4.05 & 4.5813 & TRN & \\
\hline CHEMBL1517097 & 688612 & 4.55 & 4.6964 & TRN & \\
\hline CHEMBL1437867 & 688612 & 4.35 & 4.7045 & TST & \\
\hline CHEMBL1537228 & 688612 & 4.85 & 4.6792 & TST & \\
\hline CHEMBL1462418 & 688612 & 4.2 & 4.6094 & TRN & \\
\hline CHEMBL1572703 & 688612 & 4.3 & 4.6771 & TRN & \\
\hline CHEMBL1401798 & 688612 & 4.4 & 4.7543 & TRN & \\
\hline CHEMBL1527498 & 688612 & 4.7 & 4.6902 & TRN & \\
\hline CHEMBL1485397 & 688612 & 4.35 & 4.6713 & TRN & \\
\hline CHEMBL1452482 & 688612 & 4.4 & 4.6433 & TST & \\
\hline CHEMBL1578549 & 688612 & 4.65 & 4.7472 & TRN & \\
\hline CHEMBL3207824 & 688612 & 6.5 & 4.6803 & TST & \\
\hline CHEMBL1322260 & 688612 & 6.35 & 4.6608 & TRN & \\
\hline CHEMBL1431104 & 688612 & 4.4 & 4.6765 & TST & \\
\hline CHEMBL1488638 & 688612 & 4.05 & 4.648 & TRN & \\
\hline CHEMBL1319107 & 688612 & 4.75 & 4.6289 & TRN & \\
\hline CHEMBL1579393 & 688612 & 5.85 & 4.7279 & TST & \\
\hline CHEMBL1506094 & 688612 & 6.8 & 4.6932 & TRN & \\
\hline CHEMBL3194811 & 688612 & 4.05 & 4.7993 & TRN & \\
\hline CHEMBL1439368 & 688612 & 4.8 & 4.6707 & TST & \\
\hline CHEMBL1346456 & 688612 & 5.85 & 4.7242 & TST & \\
\hline CHEMBL1367252 & 688612 & 4.85 & 4.6631 & TRN & \\
\hline CHEMBL1603555 & 688612 & 4.1 & 4.6712 & TRN & \\
\hline CHEMBL1368745 & 688612 & 4.1 & 4.6848 & TRN & \\
\hline CHEMBL1334194 & 688612 & 4.5 & 4.6683 & TRN & \\
\hline
\end{tabular}




\begin{tabular}{|c|c|c|c|c|}
\hline \multicolumn{5}{|c|}{ Supplemental Table S2.txt } \\
\hline CHEMBL1552373 & 688612 & 4.0 & 4.5881 & TRN \\
\hline CHEMBL1579973 & 688612 & 4.6 & 4.7593 & TRN \\
\hline CHEMBL1458551 & 688612 & 4.75 & 4.637 & TRN \\
\hline CHEMBL1548010 & 688612 & 4.9 & 4.671 & TRN \\
\hline CHEMBL1376163 & 688612 & 4.25 & 4.5797 & TRN \\
\hline CHEMBL1502732 & 688612 & 4.05 & 4.6239 & TRN \\
\hline CHEMBL1606494 & 688612 & 4.3 & 4.6625 & TST \\
\hline CHEMBL1587620 & 688612 & 4.95 & 4.7022 & TRN \\
\hline CHEMBL1503175 & 688612 & 5.1 & 4.7613 & TRN \\
\hline CHEMBL1375251 & 688612 & 4.4 & 4.6818 & TRN \\
\hline CHEMBL1580671 & 688612 & 4.6 & 4.7694 & TRN \\
\hline CHEMBL1406423 & 688612 & 5.3 & 4.6597 & TRN \\
\hline CHEMBL1512965 & 688612 & 4.85 & 4.6791 & TRN \\
\hline CHEMBL1303571 & 688612 & 4.2 & 4.6131 & TRN \\
\hline CHEMBL1567938 & 688612 & 4.1 & 4.6051 & TRN \\
\hline CHEMBL1323508 & 688612 & 6.5 & 4.6991 & TST \\
\hline CHEMBL1429158 & 688612 & 4.7 & 4.7945 & TRN \\
\hline CHEMBL1518175 & 688612 & 4.05 & 4.5719 & TRN \\
\hline CHEMBL1586909 & 688612 & 4.05 & 4.7623 & TRN \\
\hline CHEMBL1388129 & 688612 & 5.4 & 4.6504 & TRN \\
\hline CHEMBL1513675 & 688612 & 4.4 & 4.691 & TST \\
\hline CHEMBL1492143 & 688612 & 5.4 & 4.8062 & TRN \\
\hline CHEMBL1335650 & 688612 & 4.1 & 4.7598 & TST \\
\hline CHEMBL1335816 & 688612 & 4.0 & 4.7217 & TRN \\
\hline CHEMBL1564601 & 688612 & 4.0 & 4.7157 & TST \\
\hline CHEMBL1462729 & 688612 & 4.05 & 4.6579 & TST \\
\hline CHEMBL1354158 & 688612 & 4.0 & 4.6515 & TRN \\
\hline CHEMBL1307017 & 688612 & 4.0 & 4.6712 & TST \\
\hline CHEMBL3190092 & 688612 & 4.3 & 4.7111 & TRN \\
\hline CHEMBL1443207 & 688612 & 6.8499 & 4.6926 & TST \\
\hline CHEMBL1503188 & 688612 & 4.55 & 4.7497 & TRN \\
\hline CHEMBL1372692 & 688612 & 4.4 & 4.7244 & TST \\
\hline CHEMBL1522413 & 688612 & 5.5 & 4.7761 & TRN \\
\hline CHEMBL1499344 & 688612 & 4.5 & 4.7519 & TST \\
\hline CHEMBL1490060 & 688612 & 4.05 & 4.7322 & TST \\
\hline CHEMBL1331582 & 688612 & 4.05 & 4.6403 & TRN \\
\hline CHEMBL1527180 & 688612 & 4.05 & 4.6573 & TST \\
\hline CHEMBL1595048 & 688612 & 4.2 & 4.6534 & TRN \\
\hline CHEMBL1408725 & 688612 & 4.5 & 4.6398 & TRN \\
\hline CHEMBL1326488 & 688612 & 4.0 & 4.6656 & TRN \\
\hline CHEMBL1595597 & 688612 & 4.05 & 4.6724 & TRN \\
\hline CHEMBL1375922 & 688612 & 4.2 & 4.6612 & TRN \\
\hline CHEMBL1448867 & 688612 & 4.3 & 4.7231 & TRN \\
\hline CHEMBL1528083 & 688612 & 4.05 & 4.7222 & TST \\
\hline CHEMBL3192201 & 688612 & 4.75 & 4.7655 & TRN \\
\hline CHEMBL1397658 & 688612 & 5.05 & 4.6646 & TRN \\
\hline CHEMBL1494209 & 688612 & 4.0 & 4.6932 & TRN \\
\hline CHEMBL1513319 & 688612 & 4.05 & 4.7915 & TST \\
\hline
\end{tabular}




\begin{tabular}{|c|c|c|c|c|c|}
\hline \multicolumn{6}{|c|}{ Supplemental Table S2.txt } \\
\hline CHEMBL1434545 & 688612 & 4.3 & 4.586 & TRN & \\
\hline CHEMBL1336294 & 688612 & 4.05 & 4.6202 & TST & \\
\hline CHEMBL1453881 & 688612 & 4.7 & 4.599 & TRN & \\
\hline CHEMBL1494414 & 688612 & 4.55 & 4.6689 & TST & \\
\hline CHEMBL1426867 & 688612 & 5.8 & 4.5656 & TRN & \\
\hline CHEMBL1412369 & 688612 & 4.45 & 4.7206 & TST & \\
\hline CHEMBL1352808 & 688612 & 6.0 & 4.6298 & TRN & \\
\hline CHEMBL1492668 & 688612 & 5.95 & 4.7423 & TRN & \\
\hline CHEMBL1567272 & 688612 & 4.25 & 4.6706 & TRN & \\
\hline CHEMBL1379966 & 688612 & 4.75 & 4.624 & TST & \\
\hline CHEMBL 3213423 & 688612 & 6.35 & 4.626 & TST & \\
\hline CHEMBL3211491 & 688612 & 4.0 & 4.6521 & TRN & \\
\hline CHEMBL1484705 & 688612 & 5.4 & 4.7566 & TRN & \\
\hline CHEMBL1981243 & 688612 & 5.55 & 4.7699 & TRN & \\
\hline CHEMBL1367718 & 688612 & 4.05 & 4.7167 & TRN & \\
\hline CHEMBL1462447 & 688612 & 6.05 & 4.7488 & TRN & \\
\hline CHEMBL1380333 & 688612 & 4.05 & 4.7345 & TRN & \\
\hline CHEMBL1599319 & 688612 & 4.5 & 4.666 & TRN & \\
\hline CHEMBL1446378 & 688612 & 5.45 & 4.6423 & TRN & \\
\hline CHEMBL1354093 & 688612 & 4.6 & 4.67399 & 99999999995 & TRN \\
\hline CHEMBL1512129 & 688612 & 4.4 & 4.6917 & TRN & \\
\hline CHEMBL1457029 & 688612 & 4.15 & 4.6554 & TRN & \\
\hline CHEMBL3196390 & 688612 & 4.2 & 4.7078 & TRN & \\
\hline CHEMBL1401331 & 688612 & 4.05 & 4.6728 & TRN & \\
\hline CHEMBL1501265 & 688612 & 4.65 & 4.7485 & TRN & \\
\hline CHEMBL1538950 & 688612 & 4.45 & 4.6935 & TST & \\
\hline CHEMBL1466256 & 688612 & 4.85 & 4.65 & TRN & \\
\hline CHEMBL1605419 & 688612 & 4.5 & 4.8006 & TRN & \\
\hline CHEMBL1445732 & 688612 & 4.2 & 4.7008 & TST & \\
\hline CHEMBL1514287 & 688612 & 4.0 & 4.6733 & TRN & \\
\hline CHEMBL1457591 & 688612 & 4.05 & 4.6813 & TST & \\
\hline CHEMBL1479600 & 688612 & 6.3 & 4.6648 & TRN & \\
\hline CHEMBL1533944 & 688612 & 4.65 & 4.7131 & TST & \\
\hline CHEMBL1568910 & 688612 & 4.75 & 4.6469 & TRN & \\
\hline CHEMBL1502833 & 688612 & 4.6 & 4.6548 & TRN & \\
\hline CHEMBL1491213 & 688612 & 6.0 & 4.7012 & TRN & \\
\hline CHEMBL1525963 & 688612 & 4.2 & 4.5857 & TRN & \\
\hline CHEMBL1355746 & 688612 & 6.0 & 4.6033 & TRN & \\
\hline CHEMBL235453 & 688612 & 4.35 & 4.64199 & 99999999995 & TRN \\
\hline CHEMBL1409444 & 688612 & 4.75 & 4.637 & TRN & \\
\hline CHEMBL1528221 & 688612 & 4.3 & 4.6808 & TRN & \\
\hline CHEMBL1589911 & 688612 & 4.1 & 4.6334 & TRN & \\
\hline CHEMBL1553128 & 688612 & 5.4 & 4.7125 & TRN & \\
\hline CHEMBL1565687 & 688612 & 4.45 & 4.6915 & TRN & \\
\hline CHEMBL1496303 & 688612 & 4.6 & 4.7204 & TRN & \\
\hline CHEMBL1403179 & 688612 & 4.05 & 4.672 & TRN & \\
\hline CHEMBL1467977 & 688612 & 5.85 & 4.7074 & TST & \\
\hline CHEMBL1353819 & 688612 & 4.05 & 4.6587 & TRN & \\
\hline
\end{tabular}




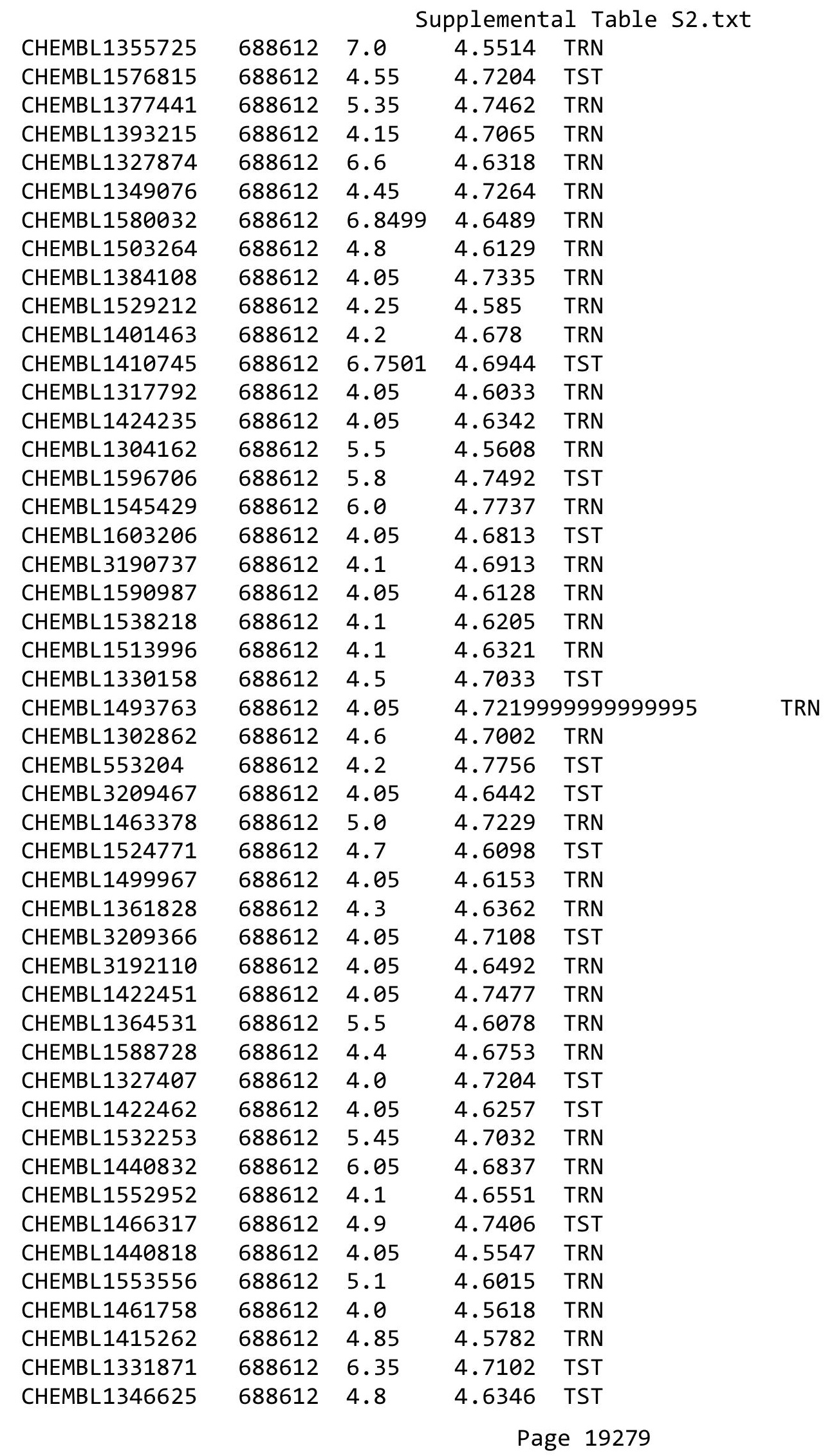




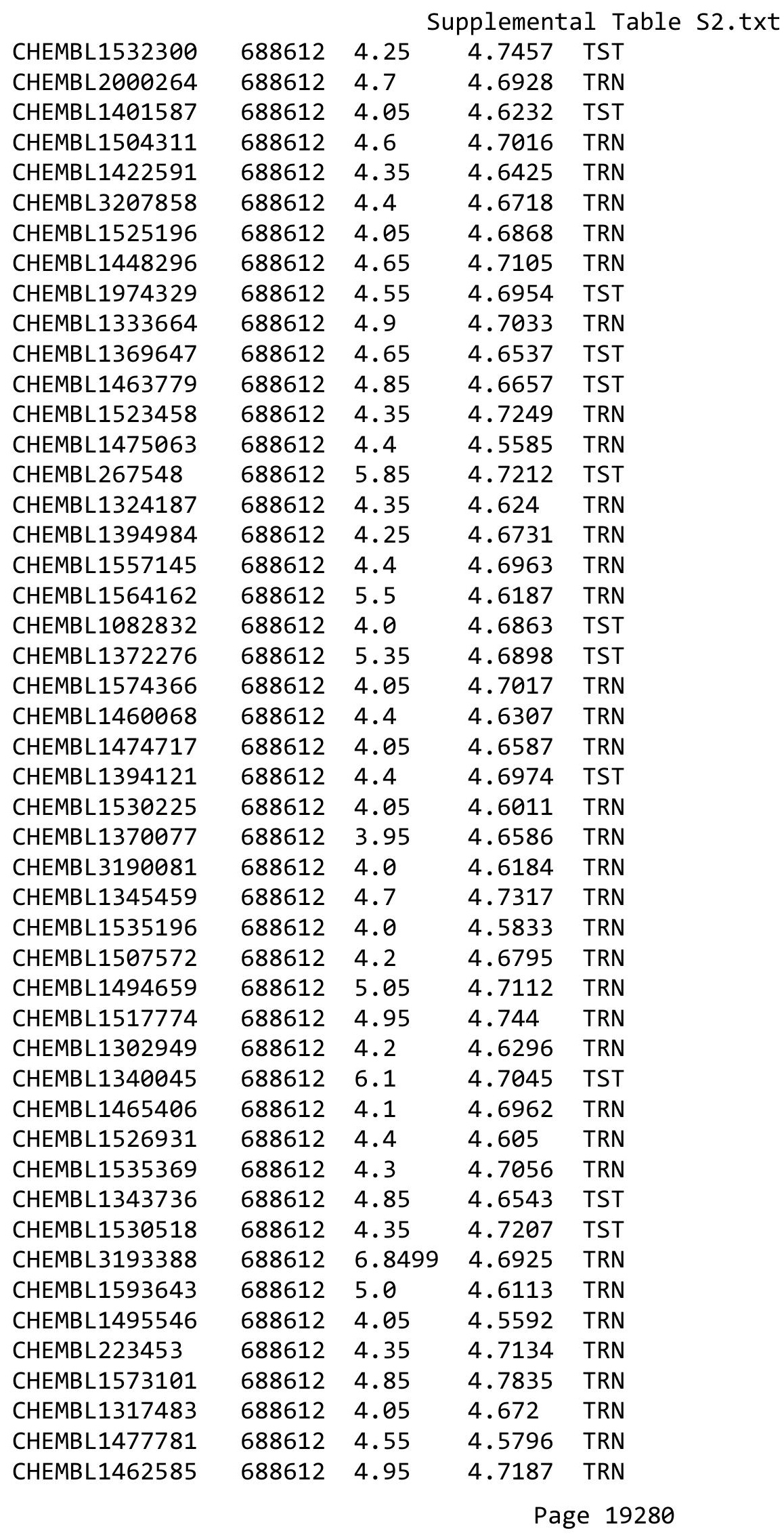




\begin{tabular}{|c|c|c|c|c|c|}
\hline & & \multicolumn{4}{|c|}{ Supplemental Table S2.txt } \\
\hline CHEMBL1319350 & 688612 & 4.45 & 4.6622 & TRN & \\
\hline CHEMBL1563204 & 688612 & 5.45 & 4.64199 & 99999999995 & TRN \\
\hline CHEMBL1361696 & 688612 & 4.2 & 4.7795 & TRN & \\
\hline CHEMBL1302855 & 688612 & 4.1 & 4.6966 & TST & \\
\hline CHEMBL1323846 & 688612 & 4.5 & 4.6317 & TRN & \\
\hline CHEMBL1499728 & 688612 & 4.05 & 4.662 & TRN & \\
\hline CHEMBL1526106 & 688612 & 4.05 & 4.5249 & TRN & \\
\hline CHEMBL1437694 & 688612 & 4.65 & 4.5873 & TRN & \\
\hline CHEMBL1586297 & 688612 & 4.1 & 4.6912 & TST & \\
\hline CHEMBL1390954 & 688612 & 5.45 & 4.6189 & TRN & \\
\hline CHEMBL1389065 & 688612 & 4.05 & 4.584 & TRN & \\
\hline CHEMBL1346188 & 688612 & 5.6 & 4.6444 & TRN & \\
\hline CHEMBL1337319 & 688612 & 4.05 & 4.6433 & TST & \\
\hline CHEMBL1406588 & 688612 & 4.0 & 4.6188 & TRN & \\
\hline CHEMBL1353169 & 688612 & 4.05 & 4.7493 & TST & \\
\hline CHEMBL1325722 & 688612 & 5.7 & 4.7405 & TRN & \\
\hline CHEMBL1357564 & 688612 & 4.65 & 4.6104 & TRN & \\
\hline CHEMBL3214153 & 688612 & 4.05 & 4.6981 & TST & \\
\hline CHEMBL1400136 & 688612 & 5.95 & 4.6358 & TRN & \\
\hline CHEMBL1594580 & 688612 & 4.1 & 4.625 & TRN & \\
\hline CHEMBL3198157 & 688612 & 5.3 & 4.617 & TRN & \\
\hline CHEMBL1371549 & 688612 & 5.25 & 4.7388 & TRN & \\
\hline CHEMBL1419623 & 688612 & 4.05 & 4.7181 & TST & \\
\hline CHEMBL1594848 & 688612 & 5.0 & 4.67 & TRN & \\
\hline CHEMBL1543956 & 688612 & 5.0 & 4.7277 & TST & \\
\hline CHEMBL1409322 & 688612 & 4.4 & 4.596 & TRN & \\
\hline CHEMBL3210131 & 688612 & 4.4 & 4.68 & TRN & \\
\hline CHEMBL1572390 & 688612 & 4.05 & 4.6266 & TRN & \\
\hline CHEMBL1433592 & 688612 & 4.0 & 4.6571 & TRN & \\
\hline CHEMBL1436536 & 688612 & 4.05 & 4.6244 & TST & \\
\hline CHEMBL1349341 & 688612 & 6.95 & 4.7309 & TRN & \\
\hline CHEMBL1979574 & 688612 & 4.25 & 4.7352 & TST & \\
\hline CHEMBL1401138 & 688612 & 4.1 & 4.718 & TRN & \\
\hline CHEMBL1488582 & 688612 & 4.65 & 4.6995 & TST & \\
\hline CHEMBL1321750 & 688612 & 4.4 & 4.7171 & TST & \\
\hline CHEMBL1354075 & 688612 & 4.5 & 4.6393 & TRN & \\
\hline CHEMBL1365033 & 688612 & 4.55 & 4.6639 & TRN & \\
\hline CHEMBL1600988 & 688612 & 7.0 & 4.6548 & TRN & \\
\hline CHEMBL1608658 & 688612 & 4.05 & 4.633 & TRN & \\
\hline CHEMBL1378604 & 688612 & 4.5 & 4.641 & TRN & \\
\hline CHEMBL3197662 & 688612 & 4.5 & 4.6974 & TRN & \\
\hline CHEMBL3199382 & 688612 & 4.1 & 4.7619 & TST & \\
\hline CHEMBL1557513 & 688612 & 4.0 & 4.6649 & TRN & \\
\hline CHEMBL3192164 & 688612 & 5.05 & 4.7563 & TRN & \\
\hline CHEMBL1605583 & 688612 & 4.95 & 4.7465 & TRN & \\
\hline CHEMBL1336468 & 688612 & 6.15 & 4.7106 & TST & \\
\hline CHEMBL1323944 & 688612 & 4.7 & 4.7015 & TRN & \\
\hline CHEMBL1493733 & 688612 & 4.0 & 4.6148 & TRN & \\
\hline
\end{tabular}




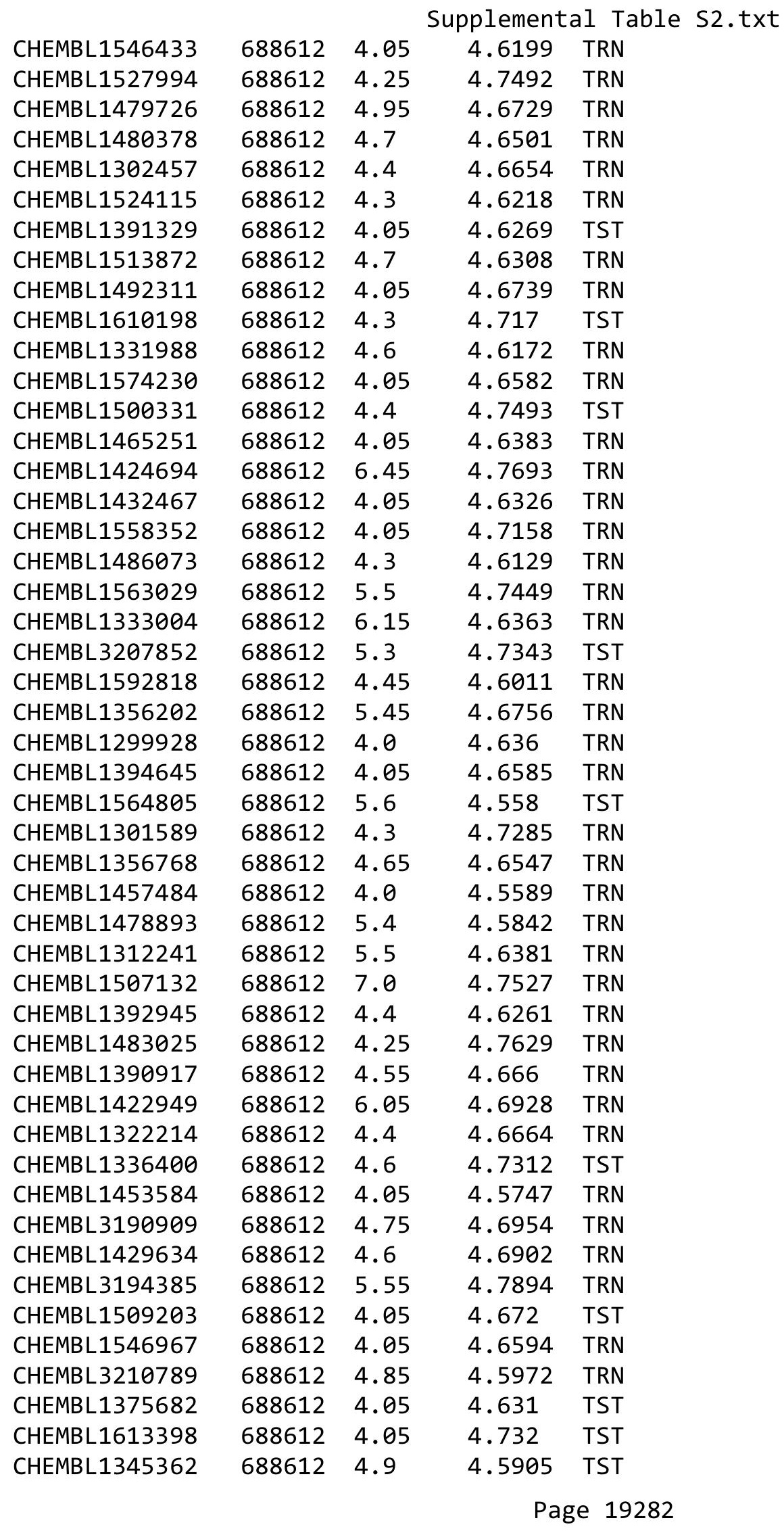




\begin{tabular}{|c|c|c|c|c|c|}
\hline \multicolumn{6}{|c|}{ Supplemental Table S2.txt } \\
\hline CHEMBL1324870 & 688612 & 4.05 & 4.6426 & TRN & \\
\hline CHEMBL3192070 & 688612 & 4.1 & 4.6445 & TRN & \\
\hline CHEMBL1382266 & 688612 & 4.8 & 4.5994 & TRN & \\
\hline CHEMBL1321207 & 688612 & 4.8 & 4.66 & TRN & \\
\hline CHEMBL1548186 & 688612 & 4.25 & $4.6610 e$ & 00000000005 & TRN \\
\hline CHEMBL1356705 & 688612 & 4.05 & 4.6301 & TRN & \\
\hline CHEMBL1523335 & 688612 & 4.0 & 4.7102 & TST & \\
\hline CHEMBL1394282 & 688612 & 4.3 & 4.6475 & TRN & \\
\hline CHEMBL1522163 & 688612 & 5.65 & 4.6453 & TRN & \\
\hline CHEMBL1430461 & 688612 & 5.45 & 4.6067 & TRN & \\
\hline CHEMBL1584376 & 688612 & 4.25 & 4.7297 & TRN & \\
\hline CHEMBL1309785 & 688612 & 6.8499 & 4.7599 & TRN & \\
\hline CHEMBL1452551 & 688612 & 4.25 & 4.6789 & TRN & \\
\hline CHEMBL1348831 & 688612 & 4.0 & 4.7097 & TST & \\
\hline CHEMBL1587920 & 688612 & 5.05 & 4.6802 & TRN & \\
\hline CHEMBL1613311 & 688612 & 4.0 & 4.6959 & TRN & \\
\hline CHEMBL1311773 & 688612 & 5.6 & 4.6706 & TST & \\
\hline CHEMBL1444349 & 688612 & 5.7 & 4.8042 & TRN & \\
\hline CHEMBL1547733 & 688612 & 4.1 & 4.6341 & TST & \\
\hline CHEMBL1578157 & 688612 & 4.65 & 4.6375 & TST & \\
\hline CHEMBL1449766 & 688612 & 4.0 & 4.6809 & TRN & \\
\hline CHEMBL3190990 & 688612 & 5.45 & 4.7322 & TRN & \\
\hline CHEMBL1512784 & 688612 & 4.05 & 4.6925 & TRN & \\
\hline CHEMBL1515872 & 688612 & 5.15 & 4.6037 & TRN & \\
\hline CHEMBL1967497 & 688612 & 4.8 & 4.6731 & TRN & \\
\hline CHEMBL1377525 & 688612 & 4.55 & 4.5462 & TRN & \\
\hline CHEMBL1389335 & 688612 & 4.9 & 4.7229 & TRN & \\
\hline CHEMBL1573883 & 688612 & 4.7 & 4.632 & TRN & \\
\hline CHEMBL1554810 & 688612 & 5.35 & 4.694 & TRN & \\
\hline CHEMBL1557816 & 688612 & 4.65 & 4.6852 & TRN & \\
\hline CHEMBL3197134 & 688612 & 4.05 & 4.6998 & TST & \\
\hline CHEMBL1334813 & 688612 & 5.5 & 4.6959 & TST & \\
\hline CHEMBL1521882 & 688612 & 4.05 & 4.6683 & TRN & \\
\hline CHEMBL1548039 & 688612 & 4.3 & 4.6064 & TRN & \\
\hline CHEMBL1382314 & 688612 & 4.1 & 4.7162 & TST & \\
\hline CHEMBL1999461 & 688612 & 4.15 & 4.5825 & TRN & \\
\hline CHEMBL1366051 & 688612 & 4.0 & 4.6368 & TRN & \\
\hline CHEMBL1529101 & 688612 & 4.0 & 4.7249 & TST & \\
\hline CHEMBL1544150 & 688612 & 4.95 & 4.6971 & TRN & \\
\hline CHEMBL1528906 & 688612 & 4.4 & 4.6568 & TRN & \\
\hline CHEMBL1303616 & 688612 & 4.65 & 4.6422 & TRN & \\
\hline CHEMBL 1487744 & 688612 & 6.5 & 4.6956 & TRN & \\
\hline CHEMBL1496318 & 688612 & 4.7 & 4.6356 & TRN & \\
\hline CHEMBL1364749 & 688612 & 4.55 & 4.7153 & TRN & \\
\hline CHEMBL1448038 & 688612 & 6.5501 & 4.7023 & TRN & \\
\hline CHEMBL1523158 & 688612 & 4.65 & 4.5955 & TRN & \\
\hline CHEMBL 1377263 & 688612 & 4.4 & 4.7103 & TRN & \\
\hline CHEMBL1387915 & 688612 & 4.2 & 4.5935 & TRN & \\
\hline
\end{tabular}




\begin{tabular}{|c|c|c|c|c|}
\hline \multicolumn{5}{|c|}{ Supplemental Table S2.txt } \\
\hline CHEMBL1432830 & 688612 & 4.4 & 4.703 & TRN \\
\hline CHEMBL1500840 & 688612 & 5.0 & 4.7126 & TRN \\
\hline CHEMBL1375160 & 688612 & 4.45 & 4.555 & TST \\
\hline CHEMBL1464214 & 688612 & 4.65 & 4.6791 & TRN \\
\hline CHEMBL1520962 & 688612 & 4.55 & 4.7947 & TST \\
\hline CHEMBL1500717 & 688612 & 4.4 & 4.6279 & TRN \\
\hline CHEMBL1526723 & 688612 & 4.4 & 4.6602 & TRN \\
\hline CHEMBL1576206 & 688612 & 4.1 & 4.7195 & TRN \\
\hline CHEMBL1345565 & 688612 & 4.0 & 4.6935 & TRN \\
\hline CHEMBL1584983 & 688612 & 4.0 & 4.6316 & TRN \\
\hline CHEMBL1406497 & 688612 & 5.85 & 4.7292 & TRN \\
\hline CHEMBL1551159 & 688612 & 4.0 & 4.6342 & TRN \\
\hline CHEMBL1486827 & 688612 & 6.25 & 4.7304 & TST \\
\hline CHEMBL1463671 & 688612 & 4.0 & 4.6958 & TRN \\
\hline CHEMBL1379494 & 688612 & 5.4 & 4.4932 & TRN \\
\hline CHEMBL3212538 & 688612 & 4.95 & 4.694 & TRN \\
\hline CHEMBL1588712 & 688612 & 6.3 & 4.6547 & TRN \\
\hline CHEMBL1433516 & 688612 & 4.4 & 4.7617 & TST \\
\hline CHEMBL1370829 & 688612 & 6.3 & 4.6248 & TRN \\
\hline CHEMBL1422472 & 688612 & 5.05 & 4.6905 & TRN \\
\hline CHEMBL1371008 & 688612 & 4.1 & 4.7223 & TST \\
\hline CHEMBL1386507 & 688612 & 4.95 & 4.6951 & TRN \\
\hline CHEMBL1587064 & 688612 & 4.65 & 4.7261 & TRN \\
\hline CHEMBL1480252 & 688612 & 6.05 & 4.7534 & TST \\
\hline CHEMBL1532909 & 688612 & 4.3 & 4.6282 & TST \\
\hline CHEMBL1337572 & 688612 & 5.4 & 4.6903 & TRN \\
\hline CHEMBL1384294 & 688612 & 5.35 & 4.6494 & TST \\
\hline CHEMBL1454907 & 688612 & 4.05 & 4.6411 & TRN \\
\hline CHEMBL1448421 & 688612 & 4.45 & 4.6302 & TRN \\
\hline CHEMBL1351985 & 688612 & 4.0 & 4.6803 & TRN \\
\hline CHEMBL1497504 & 688612 & 4.4 & 4.6644 & TRN \\
\hline CHEMBL1344074 & 688612 & 4.65 & 4.766 & TRN \\
\hline CHEMBL1532436 & 688612 & 4.05 & 4.5668 & TRN \\
\hline CHEMBL1576571 & 688612 & 4.35 & 4.7058 & TRN \\
\hline CHEMBL1591609 & 688612 & 5.2 & 4.6912 & TRN \\
\hline CHEMBL1601262 & 688612 & 5.6 & 4.6168 & TST \\
\hline CHEMBL1393615 & 688612 & 4.75 & 4.6761 & TRN \\
\hline CHEMBL1531831 & 688612 & 4.1 & 4.6686 & TRN \\
\hline CHEMBL1590047 & 688612 & 4.9 & 4.6559 & TRN \\
\hline CHEMBL1476923 & 688612 & 4.0 & 4.5985 & TRN \\
\hline CHEMBL1335733 & 688612 & 5.45 & 4.6529 & TRN \\
\hline CHEMBL1448669 & 688612 & 5.7 & 4.5517 & TRN \\
\hline CHEMBL1589307 & 688612 & 4.0 & 4.6564 & TRN \\
\hline CHEMBL1311754 & 688612 & 5.0 & 4.7839 & TRN \\
\hline CHEMBL1363788 & 688612 & 4.05 & 4.7515 & TRN \\
\hline CHEMBL1418226 & 688612 & 5.05 & 4.6446 & TRN \\
\hline CHEMBL3208964 & 688612 & 4.4 & 4.6704 & TRN \\
\hline CHEMBL1350334 & 688612 & 4.35 & 4.5414 & TRN \\
\hline
\end{tabular}




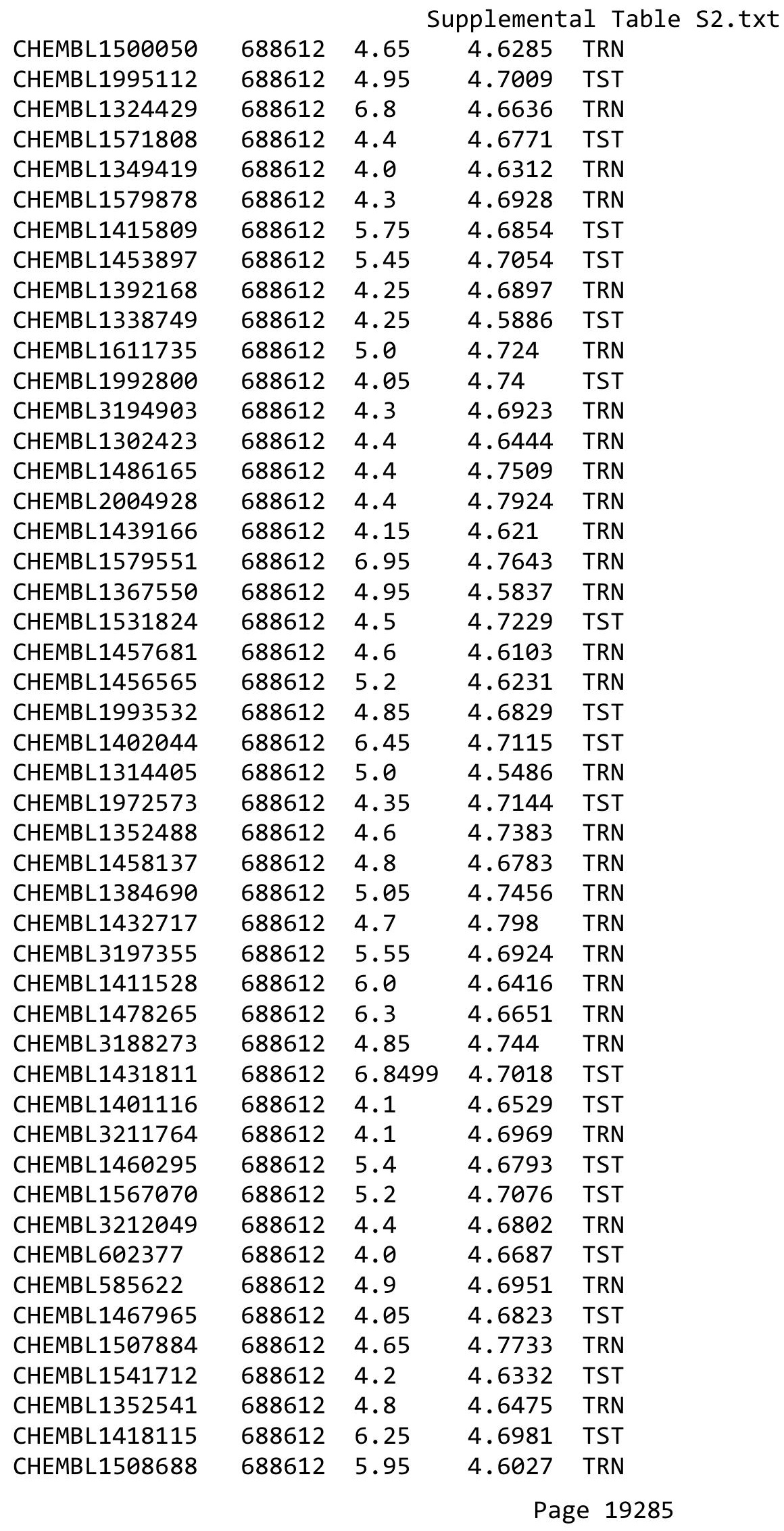




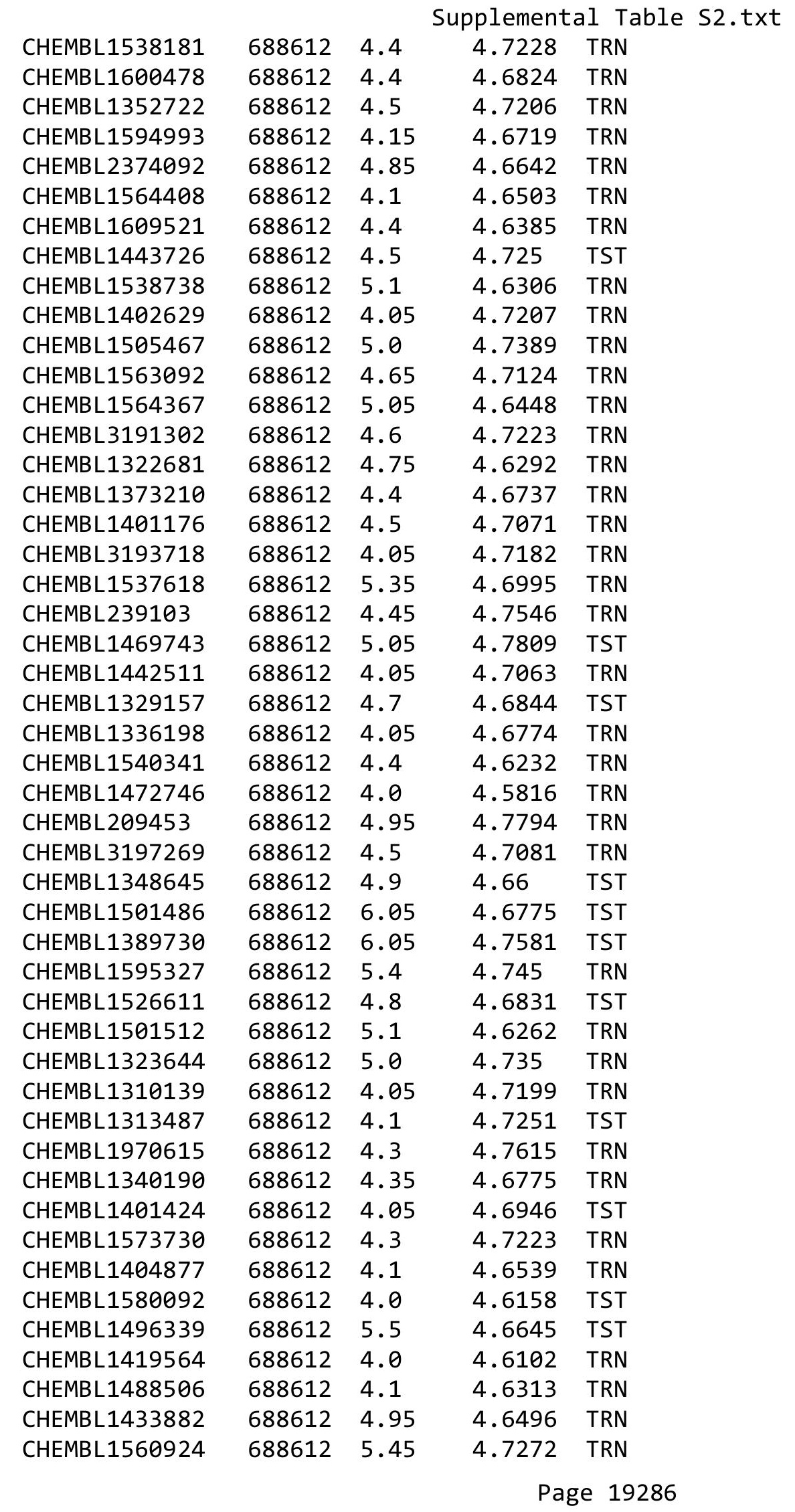




\begin{tabular}{|c|c|c|c|c|}
\hline \multicolumn{5}{|c|}{ Supplemental Table S2.txt } \\
\hline CHEMBL1318207 & 688612 & 4.1 & 4.6054 & TRN \\
\hline CHEMBL1449361 & 688612 & 4.2 & 4.6475 & TST \\
\hline CHEMBL3190043 & 688612 & 4.0 & 4.8145 & TRN \\
\hline CHEMBL236268 & 688612 & 5.45 & 4.7324 & TRN \\
\hline CHEMBL1313832 & 688612 & 4.1 & 4.6311 & TST \\
\hline CHEMBL1593398 & 688612 & 4.6 & 4.6244 & TST \\
\hline CHEMBL1415688 & 688612 & 4.0 & 4.5939 & TRN \\
\hline CHEMBL1577660 & 688612 & 4.4 & 4.6945 & TRN \\
\hline CHEMBL1381774 & 688612 & 4.05 & 4.6449 & TRN \\
\hline CHEMBL1556704 & 688612 & 5.35 & 4.6528 & TRN \\
\hline CHEMBL1349509 & 688612 & 5.4 & 4.6931 & TRN \\
\hline CHEMBL1421623 & 688612 & 4.1 & 4.6631 & TST \\
\hline CHEMBL1550189 & 688612 & 4.1 & 4.7075 & TST \\
\hline CHEMBL1587416 & 688612 & 4.4 & 4.615 & TRN \\
\hline CHEMBL 72365 & 688612 & 4.5 & 4.8123 & TST \\
\hline CHEMBL1518574 & 688612 & 4.1 & 4.6784 & TST \\
\hline CHEMBL1486191 & 688612 & 4.35 & 4.7134 & TST \\
\hline CHEMBL1513571 & 688612 & 4.05 & 4.6774 & TST \\
\hline CHEMBL1358102 & 688612 & 4.4 & 4.5993 & TRN \\
\hline CHEMBL1426754 & 688612 & 4.45 & 4.8084 & TRN \\
\hline CHEMBL1345523 & 688612 & 5.0 & 4.6092 & TRN \\
\hline CHEMBL1321909 & 688612 & 4.95 & 4.6171 & TRN \\
\hline CHEMBL1483491 & 688612 & 5.35 & 4.675 & TRN \\
\hline CHEMBL78010 & 688612 & 4.65 & 4.7691 & TRN \\
\hline CHEMBL1341398 & 688612 & 4.1 & 4.6699 & TST \\
\hline CHEMBL1491565 & 688612 & 4.4 & 4.5863 & TRN \\
\hline CHEMBL1370976 & 688612 & 5.0 & 4.6955 & TRN \\
\hline CHEMBL1327684 & 688612 & 4.8 & 4.6987 & TST \\
\hline CHEMBL1554116 & 688612 & 4.0 & 4.6409 & TRN \\
\hline CHEMBL1548374 & 688612 & 5.0 & 4.7894 & TRN \\
\hline CHEMBL1494795 & 688612 & 6.0 & 4.5569 & TRN \\
\hline CHEMBL1572749 & 688612 & 4.1 & 4.6739 & TRN \\
\hline CHEMBL1313405 & 688612 & 4.1 & 4.606 & TRN \\
\hline CHEMBL1495881 & 688612 & 4.0 & 4.6154 & TST \\
\hline CHEMBL3191093 & 688612 & 4.4 & 4.6335 & TRN \\
\hline CHEMBL1519064 & 688612 & 4.45 & 4.5648 & TRN \\
\hline CHEMBL1422590 & 688612 & 4.45 & 4.7106 & TRN \\
\hline CHEMBL1506276 & 688612 & 4.4 & 4.7121 & TST \\
\hline CHEMBL1994910 & 688612 & 4.05 & 4.6715 & TRN \\
\hline CHEMBL1382247 & 688612 & 4.5 & 4.6886 & TRN \\
\hline CHEMBL1607776 & 688612 & 4.05 & 4.6438 & TRN \\
\hline CHEMBL1342580 & 688612 & 4.05 & 4.5796 & TRN \\
\hline CHEMBL1585345 & 688612 & 6.25 & 4.6042 & TRN \\
\hline CHEMBL1562870 & 688612 & 4.6 & 4.6071 & TRN \\
\hline CHEMBL1562714 & 688612 & 4.45 & 4.6589 & TRN \\
\hline CHEMBL1519852 & 688612 & 4.05 & 4.6941 & TRN \\
\hline CHEMBL1470356 & 688612 & 4.4 & 4.7323 & TST \\
\hline CHEMBL1468933 & 688612 & 7.0501 & 4.5667 & TRN \\
\hline
\end{tabular}




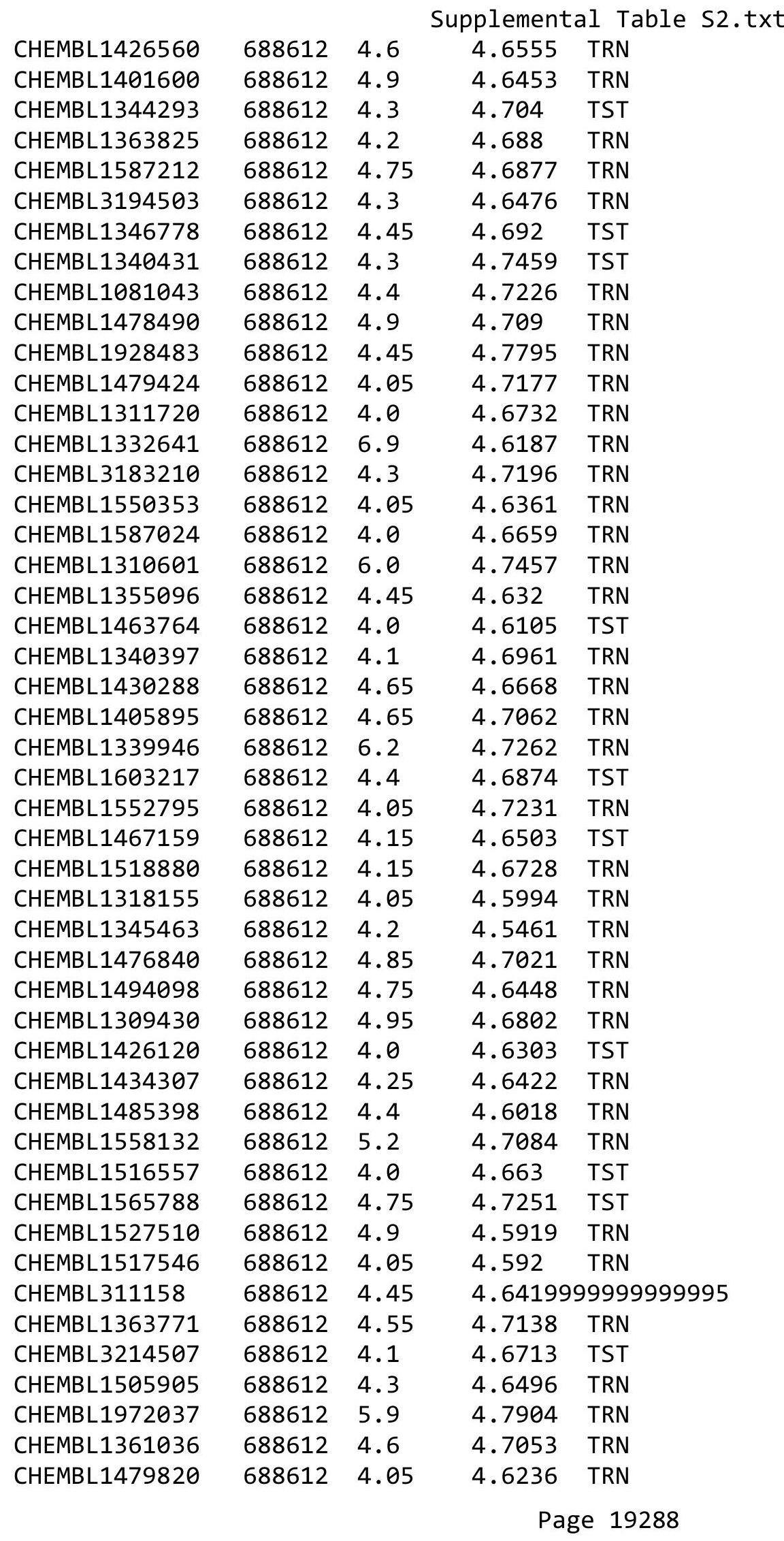




\begin{tabular}{|c|c|c|c|c|c|}
\hline & & \multicolumn{4}{|c|}{ Supplemental Table s2.txt } \\
\hline CHEMBL1370563 & 688612 & 4.05 & 4.7069 & TST & \\
\hline CHEMBL1423493 & 688612 & 4.2 & 4.5969 & 99999999995 & TST \\
\hline CHEMBL1507585 & 688612 & 5.45 & 4.698 & TST & \\
\hline CHEMBL1333105 & 688612 & 5.05 & 4.6455 & TRN & \\
\hline CHEMBL1489835 & 688612 & 4.05 & 4.6421 & TST & \\
\hline CHEMBL3207998 & 688612 & 4.55 & 4.6934 & TRN & \\
\hline CHEMBL1386866 & 688612 & 4.05 & 4.666 & TST & \\
\hline CHEMBL1326485 & 688612 & 4.9 & 4.8061 & TRN & \\
\hline CHEMBL1497457 & 688612 & 4.1 & 4.7028 & TRN & \\
\hline CHEMBL1546773 & 688612 & 4.65 & 4.6558 & TRN & \\
\hline CHEMBL1481324 & 688612 & 4.4 & 4.6159 & TRN & \\
\hline CHEMBL1498690 & 688612 & 4.65 & 4.7232 & TRN & \\
\hline CHEMBL1368871 & 688612 & 5.05 & 4.6239 & TST & \\
\hline CHEMBL1594109 & 688612 & 4.35 & 4.6205 & TRN & \\
\hline CHEMBL1968986 & 688612 & 4.85 & 4.7226 & TRN & \\
\hline CHEMBL1422545 & 688612 & 5.1 & 4.5593 & TRN & \\
\hline CHEMBL1531310 & 688612 & 4.35 & 4.6698 & TRN & \\
\hline CHEMBL1464304 & 688612 & 4.25 & 4.7466 & TRN & \\
\hline CHEMBL3144987 & 688612 & 4.5 & 4.7201 & TST & \\
\hline CHEMBL1549607 & 688612 & 4.7 & 4.7494 & TRN & \\
\hline CHEMBL1344355 & 688612 & 4.65 & 4.5710 & 0000000001 & TRN \\
\hline CHEMBL1299447 & 688612 & 4.9 & 4.6942 & TST & \\
\hline CHEMBL1461633 & 688612 & 5.0 & 4.6751 & TRN & \\
\hline CHEMBL1334863 & 688612 & 4.45 & 4.646 & TST & \\
\hline CHEMBL1437277 & 688612 & 5.0 & 4.5825 & TRN & \\
\hline CHEMBL1468868 & 688612 & 4.8 & 4.5931 & TRN & \\
\hline CHEMBL1428610 & 688612 & 4.05 & 4.558 & TRN & \\
\hline CHEMBL1312353 & 688612 & 5.6 & 4.7834 & TRN & \\
\hline CHEMBL1390869 & 688612 & 4.6 & 4.5922 & TRN & \\
\hline CHEMBL1455950 & 688612 & 4.05 & 4.7339 & TRN & \\
\hline CHEMBL1311065 & 688612 & 4.05 & 4.6883 & TRN & \\
\hline CHEMBL1484592 & 688612 & 4.5 & 4.6944 & TRN & \\
\hline CHEMBL1524294 & 688612 & 4.6 & 4.7742 & TRN & \\
\hline CHEMBL1612232 & 688612 & 4.5 & 4.6518 & TST & \\
\hline CHEMBL504791 & 688612 & 4.5 & 4.8223 & TRN & \\
\hline CHEMBL3189327 & 688612 & 4.55 & 4.7157 & TRN & \\
\hline CHEMBL1412175 & 688612 & 4.4 & 4.6129 & TRN & \\
\hline CHEMBL1311219 & 688612 & 4.15 & 4.6579 & TRN & \\
\hline CHEMBL1392107 & 688612 & 4.05 & 4.6219 & TRN & \\
\hline CHEMBL1575584 & 688612 & 4.65 & 4.6349 & TRN & \\
\hline CHEMBL1364008 & 688612 & 4.75 & 4.5969 & TRN & \\
\hline CHEMBL1394875 & 688612 & 4.05 & 4.6222 & TRN & \\
\hline CHEMBL1343486 & 688612 & 5.4 & 4.6107 & TRN & \\
\hline CHEMBL1404718 & 688612 & 4.0 & 4.6077 & TST & \\
\hline CHEMBL1591225 & 688612 & 6.8 & 4.6243 & TRN & \\
\hline CHEMBL1509408 & 688612 & 4.4 & 4.5438 & TRN & \\
\hline CHEMBL1362547 & 688612 & 4.65 & 4.7166 & TRN & \\
\hline CHEMBL1470083 & 688612 & 4.1 & 4.6599 & TST & \\
\hline
\end{tabular}




\begin{tabular}{|c|c|c|c|c|c|}
\hline & & \multicolumn{4}{|c|}{ Supplemental Table S2.txt } \\
\hline CHEMBL1381034 & 688612 & 4.15 & 4.6792 & TST & \\
\hline CHEMBL1360978 & 688612 & 4.05 & 4.617 & TRN & \\
\hline CHEMBL1343739 & 688612 & 4.0 & 4.6745 & TRN & \\
\hline CHEMBL1360585 & 688612 & 5.85 & 4.758 & TRN & \\
\hline CHEMBL1607968 & 688612 & 5.6 & 4.7094 & TRN & \\
\hline CHEMBL1412997 & 688612 & 5.5 & 4.6122 & TRN & \\
\hline CHEMBL1327542 & 688612 & 4.1 & 4.6785 & TST & \\
\hline CHEMBL1463930 & 688612 & 4.75 & 4.6945 & TST & \\
\hline CHEMBL 2004776 & 688612 & 4.05 & 4.6118 & TST & \\
\hline CHEMBL1341092 & 688612 & 4.05 & 4.6068 & TST & \\
\hline CHEMBL1463903 & 688612 & 4.3 & 4.7079 & TRN & \\
\hline CHEMBL1300151 & 688612 & 4.05 & 4.631 & TRN & \\
\hline CHEMBL1494391 & 688612 & 4.0 & 4.6695 & TRN & \\
\hline CHEMBL1592089 & 688612 & 4.15 & 4.6055 & TRN & \\
\hline CHEMBL1611246 & 688612 & 4.5 & 4.7325 & TRN & \\
\hline CHEMBL1433078 & 688612 & 4.8 & 4.6754 & TST & \\
\hline CHEMBL1431304 & 688612 & 4.0 & 4.7037 & TST & \\
\hline CHEMBL1302295 & 688612 & 4.0 & 4.6428 & TRN & \\
\hline CHEMBL1606858 & 688612 & 4.25 & 4.5623 & TRN & \\
\hline CHEMBL 253989 & 688612 & 4.05 & 4.728 & TST & \\
\hline CHEMBL1586927 & 688612 & 4.05 & 4.69300 & 00000000005 & TST \\
\hline CHEMBL1511067 & 688612 & 4.9 & 4.7484 & TRN & \\
\hline CHEMBL1352916 & 688612 & 5.15 & 4.6601 & TST & \\
\hline CHEMBL1351833 & 688612 & 4.65 & 4.6185 & TRN & \\
\hline CHEMBL1530600 & 688612 & 4.1 & 4.6544 & TRN & \\
\hline CHEMBL1526580 & 688612 & 4.1 & 4.6784 & TST & \\
\hline CHEMBL1361435 & 688612 & 4.4 & 4.7016 & TST & \\
\hline CHEMBL1413350 & 688612 & 4.0 & 4.7152 & TST & \\
\hline CHEMBL1360315 & 688612 & 4.5 & 4.7181 & TRN & \\
\hline CHEMBL1506070 & 688612 & 4.05 & 4.613 & TRN & \\
\hline CHEMBL1416348 & 688612 & 4.55 & 4.709 & TRN & \\
\hline CHEMBL1579665 & 688612 & 6.15 & 4.6991 & TST & \\
\hline CHEMBL1580289 & 688612 & 5.1 & 4.6554 & TRN & \\
\hline CHEMBL1535185 & 688612 & 4.6 & 4.5717 & TRN & \\
\hline CHEMBL1378484 & 688612 & 5.45 & 4.6101 & TRN & \\
\hline CHEMBL1314787 & 688612 & 4.65 & 4.7707 & TRN & \\
\hline CHEMBL1562163 & 688612 & 4.0 & 4.6093 & TRN & \\
\hline CHEMBL1592991 & 688612 & 4.6 & 4.6748 & TRN & \\
\hline CHEMBL 1422642 & 688612 & 6.8 & 4.6058 & TRN & \\
\hline CHEMBL1411344 & 688612 & 4.6 & 4.8088 & TRN & \\
\hline CHEMBL3191602 & 688612 & 4.6 & 4.7658 & TRN & \\
\hline CHEMBL1471480 & 688612 & 4.05 & 4.6964 & TRN & \\
\hline CHEMBL1348863 & 688612 & 5.95 & 4.6469 & TRN & \\
\hline CHEMBL1531710 & 688612 & 4.6 & 4.59 & TST & \\
\hline CHEMBL1418410 & 688612 & 5.1 & 4.6348 & TRN & \\
\hline CHEMBL1413246 & 688612 & 5.05 & 4.6263 & TRN & \\
\hline CHEMBL1424138 & 688612 & 4.0 & 4.6571 & TST & \\
\hline CHEMBL1387577 & 688612 & 4.2 & 4.6933 & TRN & \\
\hline
\end{tabular}




\begin{tabular}{|c|c|c|c|c|}
\hline \multicolumn{5}{|c|}{ Supplemental Table s2.txt } \\
\hline CHEMBL1565410 & 688612 & 4.4 & 4.6717 & TRN \\
\hline CHEMBL3199765 & 688612 & 4.0 & 4.6889 & TRN \\
\hline CHEMBL1404086 & 688612 & 4.05 & 4.7407 & TRN \\
\hline CHEMBL1586874 & 688612 & 6.8499 & 4.6575 & TRN \\
\hline CHEMBL1512636 & 688612 & 4.3 & 4.66 & TST \\
\hline CHEMBL1401264 & 688612 & 4.1 & 4.7359 & TRN \\
\hline CHEMBL1540754 & 688612 & 4.6 & 4.6571 & TRN \\
\hline CHEMBL1560206 & 688612 & 4.05 & 4.6493 & TRN \\
\hline CHEMBL1428623 & 688612 & 4.1 & 4.7639 & TRN \\
\hline CHEMBL1568394 & 688612 & 4.05 & 4.62 & TRN \\
\hline CHEMBL1601809 & 688612 & 4.1 & 4.6383 & TST \\
\hline CHEMBL1594025 & 688612 & 5.35 & 4.6388 & TRN \\
\hline CHEMBL1525775 & 688612 & 4.05 & 4.7061 & TRN \\
\hline CHEMBL1442279 & 688612 & 4.85 & 4.5441 & TRN \\
\hline CHEMBL1321493 & 688612 & 4.05 & 4.5955 & TST \\
\hline CHEMBL1446496 & 688612 & 4.35 & 4.6823 & TRN \\
\hline CHEMBL1672292 & 688612 & 4.65 & 4.6613 & TRN \\
\hline CHEMBL1524752 & 688612 & 4.5 & 4.6813 & TRN \\
\hline CHEMBL1588063 & 688612 & 5.5 & 4.5972 & TRN \\
\hline CHEMBL1496483 & 688612 & 4.1 & 4.7245 & TST \\
\hline CHEMBL1361577 & 688612 & 4.05 & 4.6129 & TRN \\
\hline CHEMBL1573347 & 688612 & 5.65 & 4.6586 & TRN \\
\hline CHEMBL1290699 & 688612 & 4.55 & 4.6203 & TRN \\
\hline CHEMBL3212600 & 688612 & 5.4 & 4.737 & TRN \\
\hline CHEMBL 3189422 & 688612 & 4.8 & 4.6841 & TST \\
\hline CHEMBL1339042 & 688612 & 4.05 & 4.6288 & TRN \\
\hline CHEMBL1300613 & 688612 & 4.0 & 4.6507 & TRN \\
\hline CHEMBL1460896 & 688612 & 4.85 & 4.7128 & TRN \\
\hline CHEMBL1601684 & 688612 & 4.15 & 4.6457 & TST \\
\hline CHEMBL1429375 & 688612 & 5.5 & 4.6631 & TRN \\
\hline CHEMBL1602954 & 688612 & 4.55 & 4.6793 & TST \\
\hline CHEMBL 3192643 & 688612 & 6.15 & 4.7328 & TRN \\
\hline CHEMBL1581312 & 688612 & 4.45 & 4.6804 & TRN \\
\hline CHEMBL1331576 & 688612 & 4.8 & 4.7384 & TRN \\
\hline CHEMBL1600862 & 688612 & 4.05 & 4.648 & TRN \\
\hline CHEMBL1420157 & 688612 & 5.6 & 4.7344 & TRN \\
\hline CHEMBL1578557 & 688612 & 4.05 & 4.6551 & TST \\
\hline CHEMBL1487633 & 688612 & 4.2 & 4.6569 & TRN \\
\hline CHEMBL1200847 & 688612 & 5.05 & 4.8398 & TST \\
\hline CHEMBL3194221 & 688612 & 4.45 & 4.724 & TRN \\
\hline CHEMBL1420156 & 688612 & 5.7 & 4.6789 & TST \\
\hline CHEMBL1443315 & 688612 & 5.7 & 4.6242 & TRN \\
\hline CHEMBL1444978 & 688612 & 7.1002 & 4.672 & TRN \\
\hline CHEMBL1514915 & 688612 & 6.2 & 4.7086 & TRN \\
\hline CHEMBL1379839 & 688612 & 4.6 & 4.6674 & TRN \\
\hline CHEMBL1351359 & 688612 & 4.2 & 4.6529 & TRN \\
\hline CHEMBL1518766 & 688612 & 4.1 & 4.6535 & TST \\
\hline CHEMBL3196055 & 688612 & 4.4 & 4.7499 & TRN \\
\hline
\end{tabular}




\begin{tabular}{|c|c|c|c|c|c|}
\hline & & \multicolumn{4}{|c|}{ Supplemental Table S2.txt } \\
\hline CHEMBL1543848 & 688612 & 6.8499 & 4.665 & TST & \\
\hline CHEMBL1471665 & 688612 & 4.35 & 4.7544 & TRN & \\
\hline CHEMBL1299359 & 688612 & 5.4 & 4.5884 & TRN & \\
\hline CHEMBL1385356 & 688612 & 4.9 & 4.7609 & TRN & \\
\hline CHEMBL 255881 & 688612 & 5.9 & 4.8113 & TRN & \\
\hline CHEMBL1353809 & 688612 & 4.05 & 4.7369 & TRN & \\
\hline CHEMBL1524270 & 688612 & 4.4 & 4.6607 & TST & \\
\hline CHEMBL1380656 & 688612 & 4.0 & 4.7088 & TST & \\
\hline CHEMBL1507635 & 688612 & 5.3 & 4.6393 & TRN & \\
\hline CHEMBL1392137 & 688612 & 4.55 & 4.6856 & TRN & \\
\hline CHEMBL76887 & 688612 & 4.1 & 4.7749 & TRN & \\
\hline CHEMBL1459282 & 688612 & 5.15 & 4.6269 & TST & \\
\hline CHEMBL1612952 & 688612 & 5.0 & 4.6667 & TRN & \\
\hline CHEMBL1464261 & 688612 & 4.6 & 4.592 & TRN & \\
\hline CHEMBL1556971 & 688612 & 4.65 & 4.6575 & TRN & \\
\hline CHEMBL1602480 & 688612 & 6.05 & 4.6655 & TRN & \\
\hline CHEMBL1369353 & 688612 & 5.1 & 4.6684 & TST & \\
\hline CHEMBL1501420 & 688612 & 4.05 & 4.6515 & TRN & \\
\hline CHEMBL3197595 & 688612 & 4.1 & 4.6419 & TRN & \\
\hline CHEMBL1591315 & 688612 & 4.0 & 4.6382 & TRN & \\
\hline CHEMBL1478831 & 688612 & 4.0 & 4.7128 & TRN & \\
\hline CHEMBL1308199 & 688612 & 4.0 & 4.5929 & TRN & \\
\hline CHEMBL1452415 & 688612 & 4.05 & 4.7166 & TST & \\
\hline CHEMBL1512943 & 688612 & 4.55 & 4.6478 & TRN & \\
\hline CHEMBL1613151 & 688612 & 4.35 & 4.6268 & TST & \\
\hline CHEMBL1462889 & 688612 & 4.45 & 4.7163 & TST & \\
\hline CHEMBL1361421 & 688612 & 5.3 & 4.5706 & TRN & \\
\hline CHEMBL1442002 & 688612 & 4.95 & 4.6127 & TRN & \\
\hline CHEMBL1458444 & 688612 & 5.15 & 4.7046 & TRN & \\
\hline CHEMBL1569992 & 688612 & 5.0 & 4.7237 & TRN & \\
\hline CHEMBL1599657 & 688612 & 4.3 & 4.7192 & TST & \\
\hline CHEMBL1390395 & 688612 & 6.8499 & 4.6534 & TST & \\
\hline CHEMBL1418864 & 688612 & 6.8 & 4.6405 & TRN & \\
\hline CHEMBL1335683 & 688612 & 4.35 & 4.6961 & TST & \\
\hline CHEMBL1458092 & 688612 & 4.1 & 4.6337 & TST & \\
\hline CHEMBL1506994 & 688612 & 5.5 & 4.65300 & 00000000005 & TRN \\
\hline CHEMBL1492220 & 688612 & 4.1 & 4.6444 & TST & \\
\hline CHEMBL1588461 & 688612 & 4.1 & 4.606 & TST & \\
\hline CHEMBL1589563 & 688612 & 4.45 & 4.7435 & TST & \\
\hline CHEMBL1369817 & 688612 & 4.05 & 4.7183 & TRN & \\
\hline CHEMBL1603283 & 688612 & 4.7 & 4.6731 & TRN & \\
\hline CHEMBL1512153 & 688612 & 4.0 & 4.6974 & TRN & \\
\hline CHEMBL1488363 & 688612 & 4.75 & 4.5444 & TRN & \\
\hline CHEMBL1573430 & 688612 & 6.8499 & 4.6336 & TRN & \\
\hline CHEMBL1371330 & 688612 & 5.15 & 4.6335 & TRN & \\
\hline CHEMBL1419143 & 688612 & 4.0 & 4.6723 & TST & \\
\hline CHEMBL3189665 & 688612 & 4.8 & 4.7635 & TRN & \\
\hline CHEMBL1344063 & 688612 & 4.05 & 4.6354 & TRN & \\
\hline
\end{tabular}




\begin{tabular}{|c|c|c|c|c|c|}
\hline \multicolumn{6}{|c|}{ Supplemental Table S2.txt } \\
\hline CHEMBL1477786 & 688612 & 4.7 & 4.6362 & TRN & \\
\hline CHEMBL1471482 & 688612 & 4.0 & 4.5909 & TRN & \\
\hline CHEMBL1369858 & 688612 & 4.15 & 4.6258 & TRN & \\
\hline CHEMBL1604815 & 688612 & 4.0 & 4.6906 & TST & \\
\hline CHEMBL1412488 & 688612 & 4.1 & 4.654 & TST & \\
\hline CHEMBL1560062 & 688612 & 4.7 & 4.7627 & TRN & \\
\hline CHEMBL1584863 & 688612 & 5.7 & 4.6791 & TST & \\
\hline CHEMBL1581471 & 688612 & 4.9 & 4.6693 & TRN & \\
\hline CHEMBL1452132 & 688612 & 4.45 & 4.7562 & TRN & \\
\hline CHEMBL1471546 & 688612 & 4.0 & 4.72199 & 99999999995 & TST \\
\hline CHEMBL1313746 & 688612 & 4.9 & 4.6295 & TRN & \\
\hline CHEMBL 3235884 & 688612 & 4.5 & 4.7489 & TRN & \\
\hline CHEMBL1337078 & 688612 & 6.0 & 4.6474 & TRN & \\
\hline CHEMBL1478595 & 688612 & 4.7 & 4.6209 & TRN & \\
\hline CHEMBL1584902 & 688612 & 4.45 & 4.7388 & TRN & \\
\hline CHEMBL1435561 & 688612 & 4.5 & 4.7417 & TRN & \\
\hline CHEMBL1304185 & 688612 & 5.35 & 4.6333 & TST & \\
\hline CHEMBL1372492 & 688612 & 5.1 & 4.5818 & TRN & \\
\hline CHEMBL1479463 & 688612 & 4.15 & 4.7627 & TRN & \\
\hline CHEMBL3191780 & 688612 & 5.3 & 4.8366 & TRN & \\
\hline CHEMBL3191858 & 688612 & 4.05 & 4.7323 & TRN & \\
\hline CHEMBL1446678 & 688612 & 6.5 & 4.6242 & TRN & \\
\hline CHEMBL1531125 & 688612 & 5.0 & 4.7611 & TRN & \\
\hline CHEMBL1509648 & 688612 & 4.95 & 4.7441 & TST & \\
\hline CHEMBL1441874 & 688612 & 4.05 & 4.64199 & 99999999995 & TRN \\
\hline CHEMBL1439904 & 688612 & 4.25 & 4.7559 & TST & \\
\hline CHEMBL3194229 & 688612 & 4.05 & 4.6328 & TRN & \\
\hline CHEMBL1439540 & 688612 & 4.3 & 4.7218 & TRN & \\
\hline CHEMBL1363207 & 688612 & 4.25 & 4.7157 & TRN & \\
\hline CHEMBL 1450682 & 688612 & 5.6 & 4.6052 & TRN & \\
\hline CHEMBL1440403 & 688612 & 4.45 & 4.715 & TST & \\
\hline CHEMBL1551883 & 688612 & 4.05 & 4.6204 & TST & \\
\hline CHEMBL1581898 & 688612 & 4.0 & 4.6241 & TRN & \\
\hline CHEMBL1565813 & 688612 & 4.35 & 4.627 & TRN & \\
\hline CHEMBL1612112 & 688612 & 5.05 & 4.6133 & TRN & \\
\hline CHEMBL1402742 & 688612 & 6.8499 & 4.6908 & TRN & \\
\hline CHEMBL1357058 & 688612 & 4.05 & 4.6276 & TST & \\
\hline CHEMBL1422276 & 688612 & 4.35 & 4.7541 & TRN & \\
\hline CHEMBL1602293 & 688612 & 4.3 & 4.74 & TST & \\
\hline CHEMBL1564388 & 688612 & 4.45 & 4.754 & TRN & \\
\hline CHEMBL1393428 & 688612 & 4.85 & 4.755 & TRN & \\
\hline CHEMBL1449237 & 688612 & 4.4 & 4.6024 & TRN & \\
\hline CHEMBL1577635 & 688612 & 4.6 & 4.6235 & TRN & \\
\hline CHEMBL1500317 & 688612 & 4.3 & 4.7102 & TRN & \\
\hline CHEMBL1453706 & 688612 & 5.1 & 4.7378 & TST & \\
\hline CHEMBL1459094 & 688612 & 4.55 & 4.7021 & TRN & \\
\hline CHEMBL3191972 & 688612 & 4.4 & 4.7269 & TRN & \\
\hline CHEMBL1355190 & 688612 & 4.4 & 4.6416 & TRN & \\
\hline
\end{tabular}




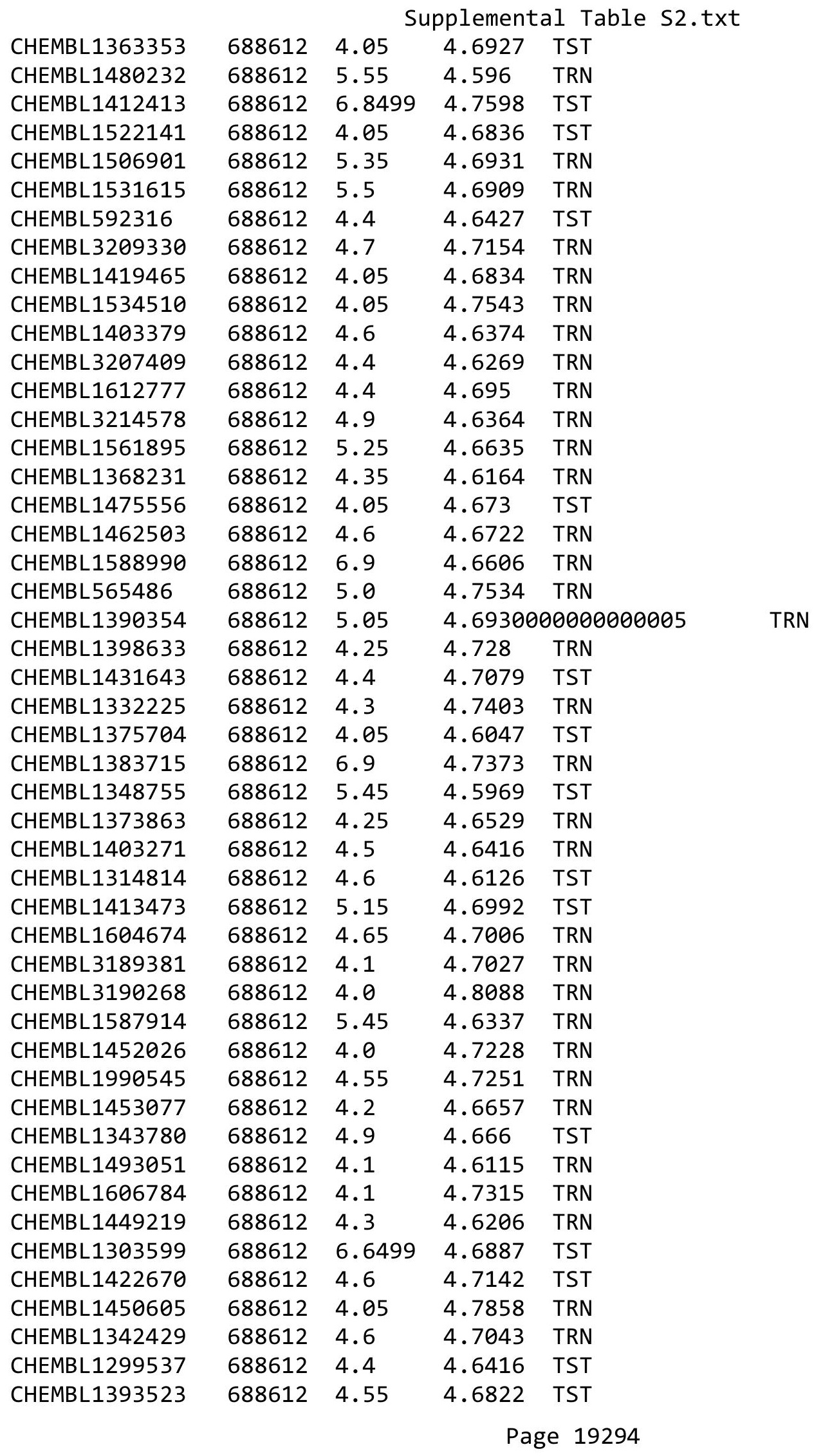




\begin{tabular}{|c|c|c|c|c|}
\hline \multicolumn{5}{|c|}{ Supplemental Table S2.txt } \\
\hline CHEMBL1413007 & 688612 & 4.7 & 4.7018 & TRN \\
\hline CHEMBL3191275 & 688612 & 4.35 & 4.7462 & TRN \\
\hline CHEMBL1594566 & 688612 & 4.4 & 4.6749 & TRN \\
\hline CHEMBL1432988 & 688612 & 4.9 & 4.6224 & TRN \\
\hline CHEMBL1575858 & 688612 & 4.1 & 4.6376 & TRN \\
\hline CHEMBL1344618 & 688612 & 4.1 & 4.6501 & TRN \\
\hline CHEMBL1470234 & 688612 & 4.0 & 4.7293 & TRN \\
\hline CHEMBL1396434 & 688612 & 5.45 & 4.5909 & TRN \\
\hline CHEMBL1426194 & 688612 & 6.8 & 4.6186 & TRN \\
\hline CHEMBL1411203 & 688612 & 5.0 & 4.6565 & TRN \\
\hline CHEMBL1480604 & 688612 & 4.3 & 4.6729 & TRN \\
\hline CHEMBL1577389 & 688612 & 4.05 & 4.6942 & TST \\
\hline CHEMBL1572424 & 688612 & 4.55 & 4.5457 & TRN \\
\hline CHEMBL1564036 & 688612 & 4.35 & 4.7088 & TRN \\
\hline CHEMBL1387227 & 688612 & 4.4 & 4.6434 & TRN \\
\hline CHEMBL 293776 & 688612 & 4.05 & 4.8014 & TRN \\
\hline CHEMBL1386015 & 688612 & 4.85 & 4.7313 & TRN \\
\hline CHEMBL1574743 & 688612 & 4.6 & 4.7241 & TST \\
\hline CHEMBL1340623 & 688612 & 4.05 & 4.6586 & TRN \\
\hline CHEMBL1398966 & 688612 & 6.8499 & 4.6744 & TRN \\
\hline CHEMBL395209 & 688612 & 4.0 & 4.6358 & TST \\
\hline CHEMBL1551535 & 688612 & 4.0 & 4.7003 & TRN \\
\hline CHEMBL1406018 & 688612 & 4.6 & 4.654 & TRN \\
\hline CHEMBL1537423 & 688612 & 4.0 & 4.6369 & TRN \\
\hline CHEMBL1476340 & 688612 & 4.4 & 4.6439 & TRN \\
\hline CHEMBL1579347 & 688612 & 4.65 & 4.783 & TRN \\
\hline CHEMBL1338413 & 688612 & 4.7 & 4.7455 & TRN \\
\hline CHEMBL1442841 & 688612 & 4.5 & 4.7101 & TRN \\
\hline CHEMBL1444035 & 688612 & 4.4 & 4.702 & TRN \\
\hline CHEMBL1423051 & 688612 & 4.7 & 4.6339 & TRN \\
\hline CHEMBL3199127 & 688612 & 4.55 & 4.7913 & TRN \\
\hline CHEMBL1318718 & 688612 & 4.5 & 4.6305 & TRN \\
\hline CHEMBL1489380 & 688612 & 5.15 & 4.6029 & TRN \\
\hline CHEMBL1562688 & 688612 & 4.75 & 4.6866 & TST \\
\hline CHEMBL1362415 & 688612 & 4.3 & 4.6618 & TRN \\
\hline CHEMBL1586096 & 688612 & 4.35 & 4.7152 & TRN \\
\hline CHEMBL1473291 & 688612 & 4.05 & 4.7198 & TRN \\
\hline CHEMBL1327548 & 688612 & 6.9 & 4.6607 & TST \\
\hline CHEMBL1395426 & 688612 & 4.85 & 4.6467 & TRN \\
\hline CHEMBL1613453 & 688612 & 4.3 & 4.5673 & TRN \\
\hline CHEMBL1368052 & 688612 & 4.05 & 4.675 & TRN \\
\hline CHEMBL3194794 & 688612 & 4.9 & 4.6916 & TST \\
\hline CHEMBL1384304 & 688612 & 4.05 & 4.7133 & TRN \\
\hline CHEMBL1404207 & 688612 & 4.9 & 4.6498 & TRN \\
\hline CHEMBL1991311 & 688612 & 4.4 & 4.70100 & 00000000005 \\
\hline CHEMBL193872 & 688612 & 4.45 & 4.7273 & TRN \\
\hline CHEMBL1520676 & 688612 & 4.05 & 4.6637 & TRN \\
\hline CHEMBL1612772 & 688612 & 4.05 & 4.6189 & TRN \\
\hline
\end{tabular}




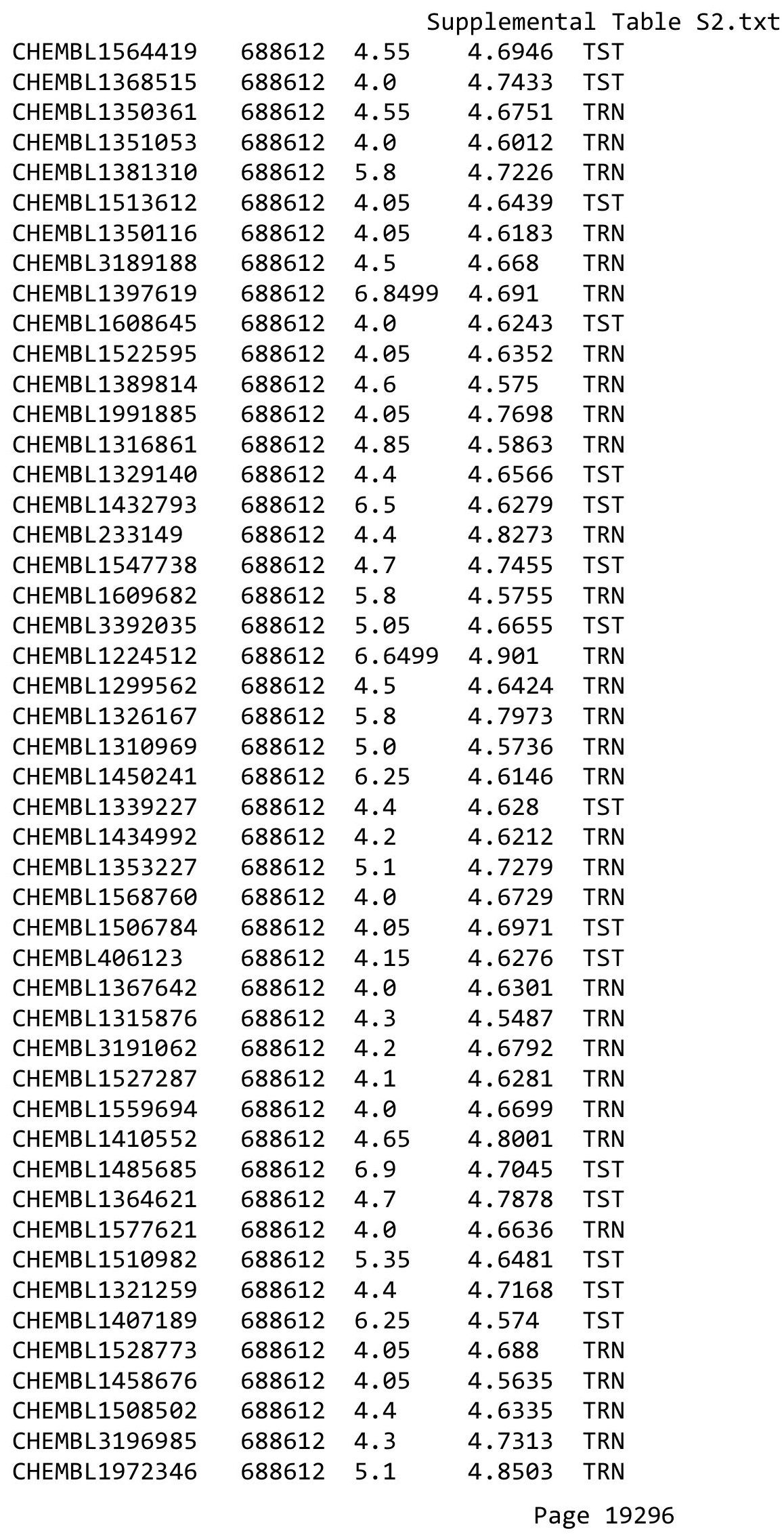




\begin{tabular}{|c|c|c|c|c|}
\hline \multicolumn{5}{|c|}{ Supplemental Table S2.txt } \\
\hline CHEMBL1317129 & 688612 & 5.3 & 4.6576 & TRN \\
\hline CHEMBL1579630 & 688612 & 5.4 & 4.6551 & TST \\
\hline CHEMBL1462884 & 688612 & 4.55 & 4.6714 & TRN \\
\hline CHEMBL1546205 & 688612 & 4.4 & 4.7459 & TST \\
\hline CHEMBL1562002 & 688612 & 6.2 & 4.5963 & TRN \\
\hline CHEMBL1342048 & 688612 & 6.1 & 4.6918 & TRN \\
\hline CHEMBL1475606 & 688612 & 4.1 & 4.6095 & TRN \\
\hline CHEMBL1487374 & 688612 & 4.4 & 4.7275 & TRN \\
\hline CHEMBL1533621 & 688612 & 4.1 & 4.6643 & TST \\
\hline CHEMBL1565849 & 688612 & 6.25 & 4.5989 & TRN \\
\hline CHEMBL1466225 & 688612 & 4.55 & 4.6671 & TRN \\
\hline CHEMBL1479140 & 688612 & 4.55 & 4.6663 & TRN \\
\hline CHEMBL1456574 & 688612 & 4.0 & 4.7134 & TRN \\
\hline CHEMBL1321419 & 688612 & 4.05 & 4.5976 & TRN \\
\hline CHEMBL1381799 & 688612 & 4.3 & 4.6082 & TST \\
\hline CHEMBL1437420 & 688612 & 4.0 & 4.6848 & TRN \\
\hline CHEMBL1540819 & 688612 & 6.15 & 4.6084 & TST \\
\hline CHEMBL1421449 & 688612 & 4.4 & 4.6398 & TRN \\
\hline CHEMBL1378198 & 688612 & 4.05 & 4.5504 & TRN \\
\hline CHEMBL1316111 & 688612 & 4.05 & 4.6725 & TRN \\
\hline CHEMBL1422505 & 688612 & 4.1 & 4.6151 & TRN \\
\hline CHEMBL1360516 & 688612 & 4.1 & 4.5907 & TRN \\
\hline CHEMBL1469754 & 688612 & 4.05 & 4.6411 & TRN \\
\hline CHEMBL1313044 & 688612 & 4.4 & 4.6148 & TRN \\
\hline CHEMBL1395397 & 688612 & 4.0 & 4.6578 & TRN \\
\hline CHEMBL1522593 & 688612 & 4.05 & 4.6457 & TRN \\
\hline CHEMBL1314773 & 688612 & 4.05 & 4.5964 & TRN \\
\hline CHEMBL1407033 & 688612 & 4.35 & 4.7049 & TRN \\
\hline CHEMBL3197914 & 688612 & 4.45 & 4.6957 & TRN \\
\hline CHEMBL1594041 & 688612 & 4.6 & 4.6275 & TRN \\
\hline CHEMBL1430429 & 688612 & 4.0 & 4.6787 & TST \\
\hline CHEMBL1573323 & 688612 & 5.1 & 4.708 & TST \\
\hline CHEMBL3194919 & 688612 & 4.55 & 4.7524 & TRN \\
\hline CHEMBL1406708 & 688612 & 5.2 & 4.7123 & TST \\
\hline CHEMBL1453652 & 688612 & 4.15 & 4.7484 & TRN \\
\hline CHEMBL1539099 & 688612 & 5.6 & 4.6239 & TRN \\
\hline CHEMBL3198063 & 688612 & 4.05 & 4.7454 & TST \\
\hline CHEMBL1586294 & 688612 & 4.4 & 4.6959 & TRN \\
\hline CHEMBL1577574 & 688612 & 4.05 & 4.7064 & TRN \\
\hline CHEMBL1302769 & 688612 & 4.4 & 4.636 & TRN \\
\hline CHEMBL1425483 & 688612 & 4.5 & 4.7052 & TRN \\
\hline CHEMBL1414580 & 688612 & 4.05 & 4.664 & TST \\
\hline CHEMBL1321933 & 688612 & 4.3 & 4.7027 & TRN \\
\hline CHEMBL1346822 & 688612 & 5.6 & 4.7063 & TST \\
\hline CHEMBL1311226 & 688612 & 4.55 & 4.726 & TRN \\
\hline CHEMBL1473574 & 688612 & 5.05 & 4.6342 & TRN \\
\hline CHEMBL1554475 & 688612 & 4.45 & 4.615 & TRN \\
\hline CHEMBL1583898 & 688612 & 5.05 & 4.7134 & TST \\
\hline
\end{tabular}




\begin{tabular}{|c|c|c|c|c|c|}
\hline & & \multicolumn{4}{|c|}{ Supplemental Table S2.txt } \\
\hline CHEMBL1447385 & 688612 & 5.05 & 4.6233 & TRN & \\
\hline CHEMBL1347984 & 688612 & 4.15 & 4.8107 & TRN & \\
\hline CHEMBL1457293 & 688612 & 4.6 & 4.6207 & TRN & \\
\hline CHEMBL1495435 & 688612 & 6.3 & 4.5856 & TRN & \\
\hline CHEMBL1503489 & 688612 & 4.4 & 4.6639 & TRN & \\
\hline CHEMBL1505576 & 688612 & 4.65 & 4.6275 & TRN & \\
\hline CHEMBL1572331 & 688612 & 4.05 & 4.6925 & TST & \\
\hline CHEMBL1415759 & 688612 & 4.0 & 4.6047 & TRN & \\
\hline CHEMBL1372508 & 688612 & 4.1 & 4.7038 & TRN & \\
\hline CHEMBL1300887 & 688612 & 5.0 & 4.6559 & TST & \\
\hline CHEMBL1548730 & 688612 & 4.6 & 4.6599 & TRN & \\
\hline CHEMBL1558353 & 688612 & 4.05 & 4.5412 & TRN & \\
\hline CHEMBL3211680 & 688612 & 4.0 & 4.6564 & TRN & \\
\hline CHEMBL1427419 & 688612 & 6.05 & 4.6904 & TRN & \\
\hline CHEMBL1383746 & 688612 & 4.7 & 4.80399 & 9999999999 & TRN \\
\hline CHEMBL1441675 & 688612 & 4.95 & 4.6413 & TST & \\
\hline CHEMBL1377223 & 688612 & 5.45 & 4.5795 & TRN & \\
\hline CHEMBL1421103 & 688612 & 4.35 & 4.6769 & TRN & \\
\hline CHEMBL1968694 & 688612 & 4.2 & 4.6417 & TRN & \\
\hline CHEMBL1453021 & 688612 & 5.4 & 4.5856 & TST & \\
\hline CHEMBL3191235 & 688612 & 4.0 & 4.7037 & TST & \\
\hline CHEMBL1606489 & 688612 & 4.65 & 4.6735 & TRN & \\
\hline CHEMBL1344042 & 688612 & 4.4 & 4.7771 & TRN & \\
\hline CHEMBL1559883 & 688612 & 4.5 & 4.7913 & TRN & \\
\hline CHEMBL1538753 & 688612 & 5.0 & 4.6725 & TRN & \\
\hline CHEMBL1525205 & 688612 & 4.05 & 4.59399 & 9999999999 & TRN \\
\hline CHEMBL1581624 & 688612 & 5.5 & 4.5829 & TRN & \\
\hline CHEMBL3209403 & 688612 & 4.3 & 4.716 & TRN & \\
\hline CHEMBL1566078 & 688612 & 4.75 & 4.7165 & TRN & \\
\hline CHEMBL1608479 & 688612 & 4.05 & 4.6641 & TST & \\
\hline CHEMBL1350054 & 688612 & 5.05 & 4.7446 & TRN & \\
\hline CHEMBL1495699 & 688612 & 4.0 & 4.6402 & TRN & \\
\hline CHEMBL1336358 & 688612 & 4.7 & 4.6076 & TST & \\
\hline CHEMBL1448434 & 688612 & 7.0 & 4.6998 & TST & \\
\hline CHEMBL1378108 & 688612 & 6.95 & 4.61100 & 0000000001 & TRN \\
\hline CHEMBL1408970 & 688612 & 5.0 & 4.7591 & TST & \\
\hline CHEMBL1308964 & 688612 & 4.1 & 4.6584 & TRN & \\
\hline CHEMBL1998234 & 688612 & 4.35 & 4.7155 & TRN & \\
\hline CHEMBL1383837 & 688612 & 4.1 & 4.6735 & TRN & \\
\hline CHEMBL1348023 & 688612 & 4.05 & 4.6611 & TRN & \\
\hline CHEMBL1421869 & 688612 & 4.85 & 4.6661 & TRN & \\
\hline CHEMBL1586475 & 688612 & 6.8 & 4.6747 & TST & \\
\hline CHEMBL1506439 & 688612 & 4.05 & 4.6993 & TRN & \\
\hline CHEMBL1468477 & 688612 & 4.4 & 4.6968 & TRN & \\
\hline CHEMBL1580090 & 688612 & 4.15 & 4.6354 & TRN & \\
\hline CHEMBL1346726 & 688612 & 4.05 & 4.6294 & TST & \\
\hline CHEMBL1377466 & 688612 & 4.65 & 4.6898 & TRN & \\
\hline CHEMBL3194664 & 688612 & 6.05 & 4.7417 & TST & \\
\hline
\end{tabular}




\begin{tabular}{|c|c|c|c|c|}
\hline \multicolumn{5}{|c|}{ Supplemental Table s2.txt } \\
\hline CHEMBL1359327 & 688612 & 4.3 & 4.7073 & TRN \\
\hline CHEMBL1359614 & 688612 & 4.4 & 4.729 & TRN \\
\hline CHEMBL1306048 & 688612 & 4.05 & 4.5514 & TRN \\
\hline CHEMBL1556259 & 688612 & 5.05 & 4.6003 & TRN \\
\hline CHEMBL1534034 & 688612 & 5.65 & 4.7462 & TRN \\
\hline CHEMBL1419273 & 688612 & 4.7 & 4.7172 & TRN \\
\hline CHEMBL1418210 & 688612 & 5.0 & 4.6996 & TRN \\
\hline CHEMBL1360057 & 688612 & 4.1 & 4.6368 & TST \\
\hline CHEMBL1597395 & 688612 & 4.05 & 4.6064 & TRN \\
\hline CHEMBL1572482 & 688612 & 6.6 & 4.7181 & TRN \\
\hline CHEMBL1484666 & 688612 & 4.05 & 4.5758 & TRN \\
\hline CHEMBL1504359 & 688612 & 5.5 & 4.6475 & TST \\
\hline CHEMBL1497306 & 688612 & 4.05 & 4.6212 & TRN \\
\hline CHEMBL1435124 & 688612 & 4.05 & 4.6486 & TRN \\
\hline CHEMBL1430193 & 688612 & 4.1 & 4.669 & TRN \\
\hline CHEMBL1334995 & 688612 & 4.05 & 4.6776 & TRN \\
\hline CHEMBL1483075 & 688612 & 4.05 & 4.7229 & TST \\
\hline CHEMBL1462966 & 688612 & 5.25 & 4.6456 & TST \\
\hline CHEMBL1389305 & 688612 & 4.05 & 4.6361 & TRN \\
\hline CHEMBL1594863 & 688612 & 5.5 & 4.7196 & TST \\
\hline CHEMBL1357245 & 688612 & 4.3 & 4.6431 & TRN \\
\hline CHEMBL1579735 & 688612 & 5.5 & 4.5826 & TST \\
\hline CHEMBL1429984 & 688612 & 5.0 & 4.5681 & TRN \\
\hline CHEMBL1564303 & 688612 & 4.6 & 4.6362 & TRN \\
\hline CHEMBL1562542 & 688612 & 4.5 & 4.6573 & TRN \\
\hline CHEMBL3190935 & 688612 & 4.05 & 4.6944 & TST \\
\hline CHEMBL1313811 & 688612 & 4.05 & 4.6833 & TRN \\
\hline CHEMBL1456075 & 688612 & 6.8 & 4.6298 & TST \\
\hline CHEMBL3189416 & 688612 & 4.55 & 4.7929 & TRN \\
\hline CHEMBL1596355 & 688612 & 4.0 & 4.6613 & TRN \\
\hline CHEMBL1604150 & 688612 & 4.1 & 4.6182 & TRN \\
\hline CHEMBL1483194 & 688612 & 4.1 & 4.6622 & TST \\
\hline CHEMBL1424255 & 688612 & 5.5 & 4.6471 & TST \\
\hline CHEMBL1604485 & 688612 & 4.05 & 4.7126 & TST \\
\hline CHEMBL1511353 & 688612 & 4.05 & 4.7063 & TST \\
\hline CHEMBL1994902 & 688612 & 4.05 & 4.7404 & TST \\
\hline CHEMBL1400706 & 688612 & 4.1 & 4.6521 & TRN \\
\hline CHEMBL1310120 & 688612 & 5.2 & 4.7733 & TRN \\
\hline CHEMBL1583009 & 688612 & 4.05 & 4.6704 & TRN \\
\hline CHEMBL1397753 & 688612 & 4.7 & 4.6962 & TRN \\
\hline CHEMBL1392649 & 688612 & 4.05 & 4.6567 & TRN \\
\hline CHEMBL1549792 & 688612 & 5.1 & 4.7113 & TST \\
\hline CHEMBL1511705 & 688612 & 4.1 & 4.7351 & TST \\
\hline CHEMBL1317464 & 688612 & 4.45 & 4.6204 & TRN \\
\hline CHEMBL1544703 & 688612 & 4.05 & 4.7435 & TST \\
\hline CHEMBL3191411 & 688612 & 5.95 & 4.6131 & TRN \\
\hline CHEMBL1365061 & 688612 & 4.75 & 4.7903 & TRN \\
\hline CHEMBL3190828 & 688612 & 4.85 & 4.6554 & TRN \\
\hline
\end{tabular}




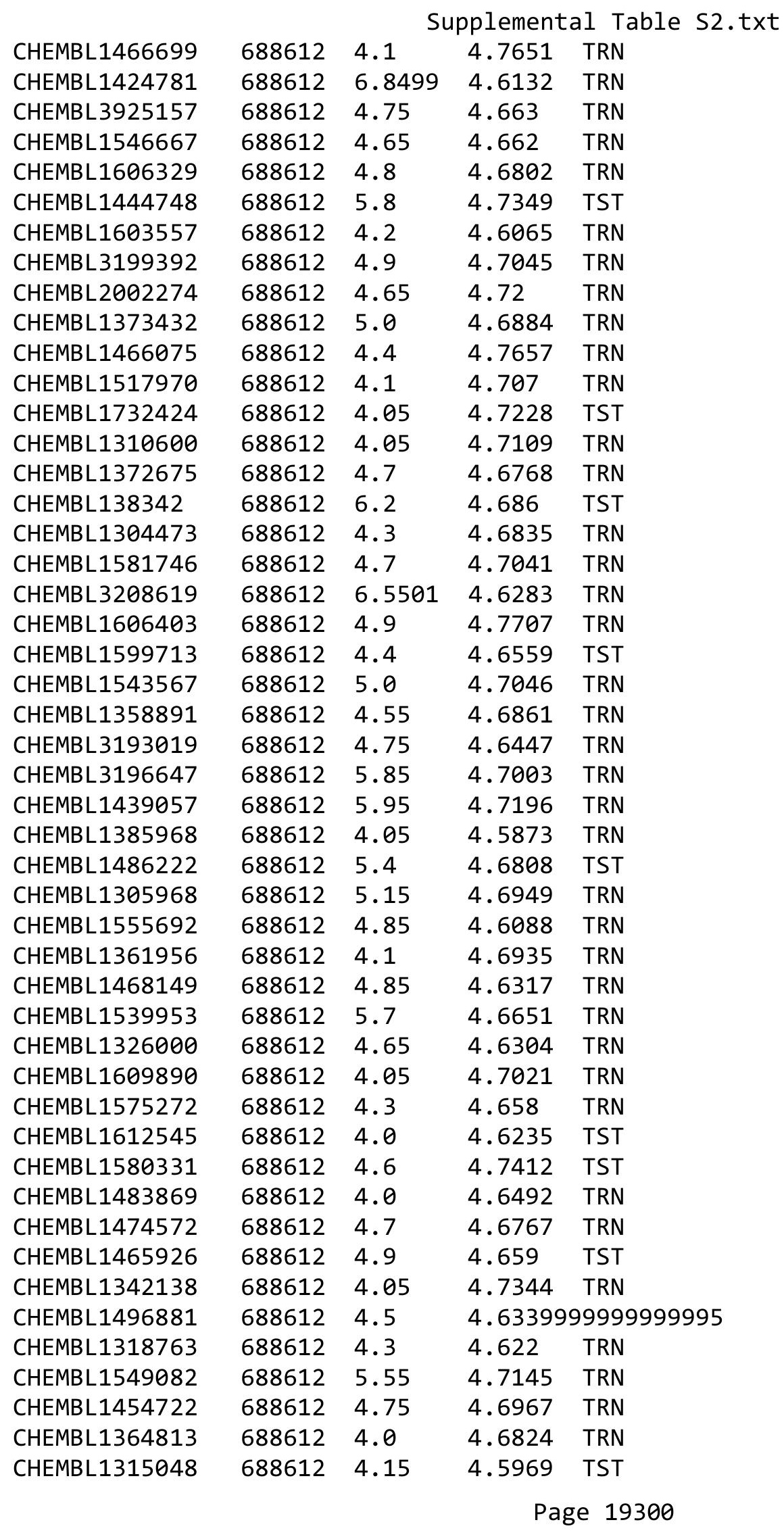




\begin{tabular}{|c|c|c|c|c|c|}
\hline \multicolumn{6}{|c|}{ Supplemental Table S2.txt } \\
\hline CHEMBL1408583 & 688612 & 4.55 & 4.7666 & TRN & \\
\hline CHEMBL1457983 & 688612 & 4.1 & 4.6464 & TRN & \\
\hline CHEMBL1479602 & 688612 & 4.1 & 4.6279 & TRN & \\
\hline CHEMBL1349825 & 688612 & 5.6 & 4.681 & TRN & \\
\hline CHEMBL 3197788 & 688612 & 6.5501 & 4.7169 & TRN & \\
\hline CHEMBL1526055 & 688612 & 5.1 & 4.7377 & TST & \\
\hline CHEMBL1440181 & 688612 & 4.05 & 4.632 & TRN & \\
\hline CHEMBL1432032 & 688612 & 4.8 & 4.6991 & TRN & \\
\hline CHEMBL1341065 & 688612 & 4.45 & 4.6945 & TRN & \\
\hline CHEMBL1542206 & 688612 & 4.05 & 4.7382 & TRN & \\
\hline CHEMBL1313195 & 688612 & 5.3 & 4.6983 & TRN & \\
\hline CHEMBL1407039 & 688612 & 5.7 & 4.6451 & TRN & \\
\hline CHEMBL1455444 & 688612 & 5.0 & 4.628 & TRN & \\
\hline CHEMBL1310568 & 688612 & 5.3 & 4.6807 & TRN & \\
\hline CHEMBL1406996 & 688612 & 4.6 & 4.5934 & TRN & \\
\hline CHEMBL1322935 & 688612 & 4.4 & 4.7339 & TRN & \\
\hline CHEMBL1522007 & 688612 & 4.4 & 4.72199 & 99999999995 & TST \\
\hline CHEMBL1469318 & 688612 & 4.75 & 4.7292 & TRN & \\
\hline CHEMBL 1403812 & 688612 & 4.05 & 4.6017 & TRN & \\
\hline CHEMBL3198131 & 688612 & 4.8 & 4.673 & TRN & \\
\hline CHEMBL1345012 & 688612 & 4.05 & 4.7083 & TST & \\
\hline CHEMBL1399010 & 688612 & 4.8 & 4.7006 & TRN & \\
\hline CHEMBL1603200 & 688612 & 4.05 & 4.6272 & TRN & \\
\hline CHEMBL1460906 & 688612 & 4.55 & 4.6799 & TRN & \\
\hline CHEMBL1438820 & 688612 & 4.0 & 4.6521 & TRN & \\
\hline CHEMBL1382177 & 688612 & 4.05 & 4.6921 & TRN & \\
\hline CHEMBL1319077 & 688612 & 4.3 & 4.6167 & TRN & \\
\hline CHEMBL1391551 & 688612 & 4.1 & 4.6927 & TRN & \\
\hline CHEMBL1323523 & 688612 & 4.6 & 4.7373 & TRN & \\
\hline CHEMBL1393919 & 688612 & 6.5501 & 4.7371 & TRN & \\
\hline CHEMBL1527646 & 688612 & 4.45 & 4.6424 & TRN & \\
\hline CHEMBL1446455 & 688612 & 4.05 & 4.7678 & TRN & \\
\hline CHEMBL1394878 & 688612 & 4.05 & 4.6429 & TRN & \\
\hline CHEMBL3197042 & 688612 & 5.05 & 4.6854 & TRN & \\
\hline CHEMBL1342234 & 688612 & 4.6 & 4.6699 & TRN & \\
\hline CHEMBL1366505 & 688612 & 4.1 & 4.6301 & TRN & \\
\hline CHEMBL1501816 & 688612 & 6.8499 & 4.6424 & TRN & \\
\hline CHEMBL1583212 & 688612 & 4.1 & 4.6703 & TST & \\
\hline CHEMBL1328313 & 688612 & 4.3 & 4.5896 & TRN & \\
\hline CHEMBL1449402 & 688612 & 6.5501 & 4.652 & TRN & \\
\hline CHEMBL1459398 & 688612 & 4.95 & 4.6552 & TRN & \\
\hline CHEMBL1410198 & 688612 & 4.1 & 4.5566 & TRN & \\
\hline CHEMBL249987 & 688612 & 4.4 & 4.6504 & TRN & \\
\hline CHEMBL1516788 & 688612 & 4.6 & 4.6989 & TRN & \\
\hline CHEMBL1450243 & 688612 & 4.2 & 4.7362 & TST & \\
\hline CHEMBL1343424 & 688612 & 5.7 & 4.6774 & TRN & \\
\hline CHEMBL1515854 & 688612 & 4.05 & 4.6615 & TRN & \\
\hline CHEMBL1322912 & 688612 & 4.25 & 4.7523 & TRN & \\
\hline
\end{tabular}




\begin{tabular}{|c|c|c|c|c|c|}
\hline \multicolumn{6}{|c|}{ Supplemental Table S2.txt } \\
\hline CHEMBL1446926 & 688612 & 4.45 & 4.6378 & TRN & \\
\hline CHEMBL3192312 & 688612 & 4.5 & 4.7307 & TRN & \\
\hline CHEMBL1551221 & 688612 & 4.4 & 4.6146 & TRN & \\
\hline CHEMBL1494054 & 688612 & 4.05 & 4.5991 & TRN & \\
\hline CHEMBL1506640 & 688612 & 4.4 & 4.7129 & TRN & \\
\hline CHEMBL1305091 & 688612 & 4.65 & 4.7258 & TRN & \\
\hline CHEMBL1354274 & 688612 & 4.3 & 4.6488 & TRN & \\
\hline CHEMBL1306438 & 688612 & 4.05 & 4.7531 & TRN & \\
\hline CHEMBL1603311 & 688612 & 4.5 & 4.6882 & TST & \\
\hline CHEMBL1470221 & 688612 & 4.05 & 4.672 & TRN & \\
\hline CHEMBL1434045 & 688612 & 6.25 & 4.6573 & TRN & \\
\hline CHEMBL1384965 & 688612 & 6.5501 & 4.6654 & TRN & \\
\hline CHEMBL1335687 & 688612 & 4.55 & 4.8018 & TRN & \\
\hline CHEMBL3193888 & 688612 & 4.35 & 4.7831 & TST & \\
\hline CHEMBL1335262 & 688612 & 4.05 & 4.7138 & TST & \\
\hline CHEMBL1226 & 688612 & 4.1 & 4.6736 & TRN & \\
\hline CHEMBL1546789 & 688612 & 4.65 & 4.6041 & TRN & \\
\hline CHEMBL1305972 & 688612 & 4.05 & 4.6409 & TST & \\
\hline CHEMBL1321921 & 688612 & 4.4 & 4.6503 & TST & \\
\hline CHEMBL1456205 & 688612 & 4.35 & 4.6884 & TRN & \\
\hline CHEMBL1554613 & 688612 & 5.1 & 4.7103 & TST & \\
\hline CHEMBL1342079 & 688612 & 5.3 & 4.6939 & TST & \\
\hline CHEMBL3213591 & 688612 & 5.8 & 4.6756 & TRN & \\
\hline CHEMBL1591292 & 688612 & 4.25 & 4.6405 & TRN & \\
\hline CHEMBL1331453 & 688612 & 4.2 & 4.6172 & TRN & \\
\hline CHEMBL1463431 & 688612 & 6.8 & 4.74100 & 00000000005 & TST \\
\hline CHEMBL3196120 & 688612 & 5.0 & 4.6363 & TRN & \\
\hline CHEMBL1426674 & 688612 & 4.5 & 4.6397 & TRN & \\
\hline CHEMBL1329239 & 688612 & 4.5 & 4.6681 & TRN & \\
\hline CHEMBL1467321 & 688612 & 4.5 & 4.6489 & TRN & \\
\hline CHEMBL1319618 & 688612 & 4.4 & 4.7139 & TRN & \\
\hline CHEMBL1340634 & 688612 & 4.6 & 4.7095 & TRN & \\
\hline CHEMBL1401019 & 688612 & 4.1 & 4.5838 & TRN & \\
\hline CHEMBL1458616 & 688612 & 4.1 & 4.6529 & TRN & \\
\hline CHEMBL1502860 & 688612 & 5.1 & 4.7204 & TRN & \\
\hline CHEMBL1349060 & 688612 & 4.0 & 4.5578 & TRN & \\
\hline CHEMBL1534835 & 688612 & 4.05 & 4.6908 & TST & \\
\hline CHEMBL1429173 & 688612 & 5.5 & 4.6478 & TRN & \\
\hline CHEMBL1383812 & 688612 & 4.4 & 4.7288 & TST & \\
\hline CHEMBL3194211 & 688612 & 4.8 & 4.7367 & TRN & \\
\hline CHEMBL3195481 & 688612 & 4.8 & 4.749 & TRN & \\
\hline CHEMBL1510345 & 688612 & 4.45 & 4.6047 & TRN & \\
\hline CHEMBL1563908 & 688612 & 4.55 & 4.6289 & TRN & \\
\hline CHEMBL1586890 & 688612 & 4.5 & 4.6341 & TRN & \\
\hline CHEMBL1476806 & 688612 & 4.05 & 4.6443 & TRN & \\
\hline CHEMBL1409893 & 688612 & 4.65 & 4.6489 & TST & \\
\hline CHEMBL1586610 & 688612 & 4.55 & 4.7051 & TRN & \\
\hline CHEMBL1465663 & 688612 & 5.5 & 4.655 & TRN & \\
\hline
\end{tabular}




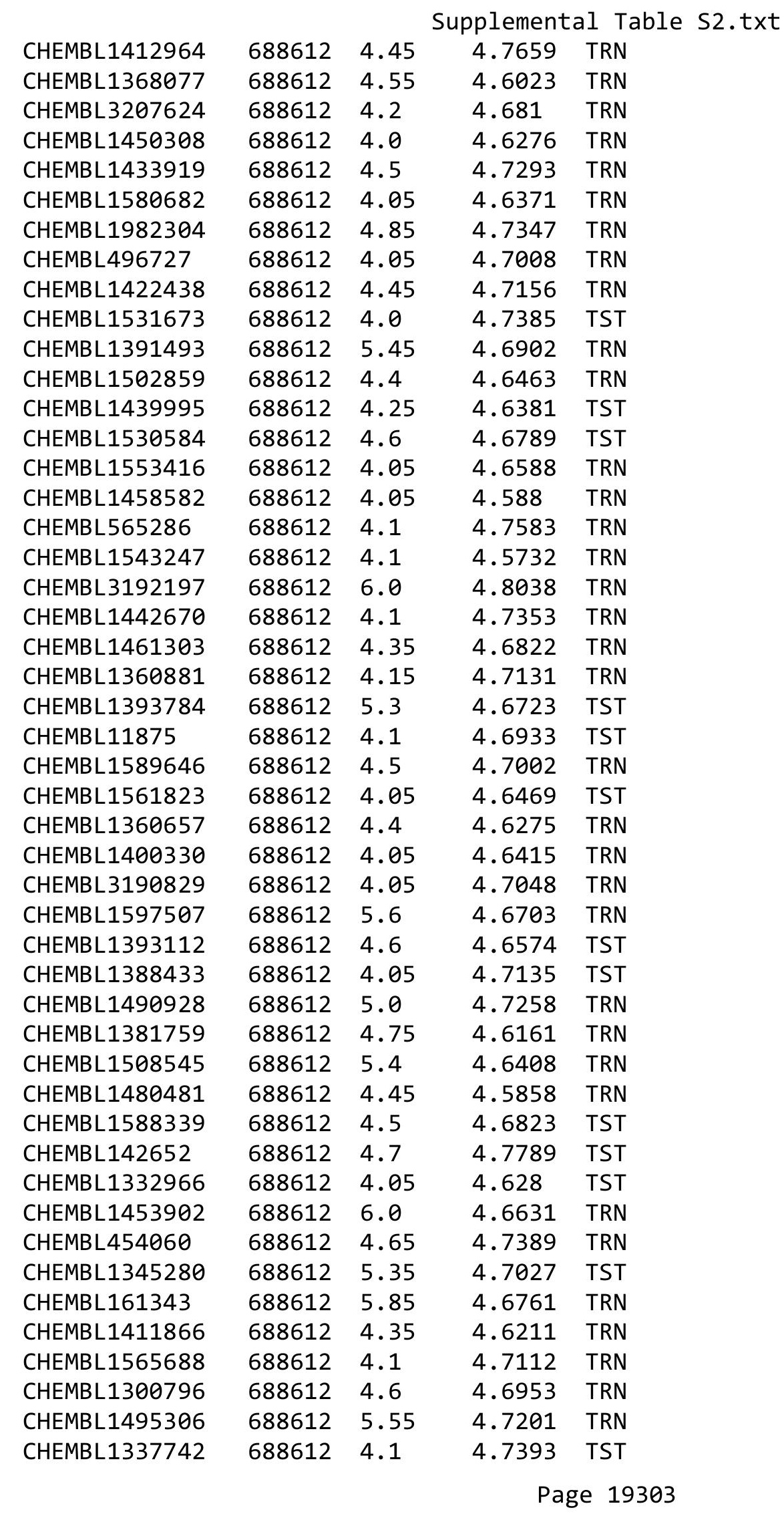




\begin{tabular}{|c|c|c|c|c|}
\hline & & & upplement & $\mathrm{T}$ \\
\hline CHEMBL1557305 & 688612 & 4.25 & 4.6256 & TRN \\
\hline CHEMBL1569630 & 688612 & 4.05 & 4.6956 & TST \\
\hline CHEMBL1508176 & 688612 & 4.1 & 4.6461 & TRN \\
\hline CHEMBL1412223 & 688612 & 4.4 & 4.7214 & TRN \\
\hline CHEMBL1435513 & 688612 & 4.05 & 4.6104 & TRN \\
\hline CHEMBL1543029 & 688612 & 4.15 & 4.7737 & TRN \\
\hline CHEMBL1382785 & 688612 & 4.05 & 4.586 & TRN \\
\hline CHEMBL 3190518 & 688612 & 4.0 & 4.6825 & TRN \\
\hline CHEMBL1314510 & 688612 & 4.7 & 4.6339 & TRN \\
\hline CHEMBL1509978 & 688612 & 4.75 & 4.613 & TRN \\
\hline CHEMBL1537659 & 688612 & 4.05 & 4.7056 & TRN \\
\hline CHEMBL1583580 & 688612 & 5.15 & 4.677 & TRN \\
\hline CHEMBL 3196406 & 688612 & 4.7 & 4.7557 & TRN \\
\hline CHEMBL1521428 & 688612 & 5.15 & 4.6137 & TRN \\
\hline CHEMBL1438177 & 688612 & 4.0 & 4.6218 & TST \\
\hline CHEMBL1413898 & 688612 & 4.8 & 4.683 & TRN \\
\hline CHEMBL1404649 & 688612 & 4.7 & 4.7195 & TRN \\
\hline CHEMBL1515173 & 688612 & 4.1 & 4.6603 & TRN \\
\hline CHEMBL1395468 & 688612 & 5.0 & 4.6558 & TRN \\
\hline CHEMBL 2018847 & 688612 & 4.75 & 4.7597 & TRN \\
\hline CHEMBL1351370 & 688612 & 4.2 & 4.7542 & TST \\
\hline CHEMBL1349324 & 688612 & 6.1 & 4.6715 & TRN \\
\hline CHEMBL1386552 & 688612 & 5.4 & 4.6121 & TRN \\
\hline CHEMBL1318339 & 688612 & 4.5 & 4.6166 & TRN \\
\hline CHEMBL 3212480 & 688612 & 4.8 & 4.6624 & TRN \\
\hline CHEMBL1509744 & 688612 & 4.4 & 4.6347 & TRN \\
\hline CHEMBL1536928 & 688612 & 4.05 & 4.6961 & TRN \\
\hline CHEMBL1468542 & 688612 & 4.1 & 4.6792 & TRN \\
\hline CHEMBL1533317 & 688612 & 4.75 & 4.5985 & TRN \\
\hline CHEMBL1528122 & 688612 & 4.0 & 4.6794 & TRN \\
\hline CHEMBL503254 & 688612 & 4.75 & 4.6982 & TRN \\
\hline CHEMBL1493516 & 688612 & 4.35 & 4.7239 & TST \\
\hline CHEMBL3199400 & 688612 & 4.0 & 4.7319 & TRN \\
\hline CHEMBL1514132 & 688612 & 4.5 & 4.6462 & TRN \\
\hline CHEMBL1302578 & 688612 & 4.0 & 4.5973 & TRN \\
\hline CHEMBL1452889 & 688612 & 5.5 & 4.6152 & TRN \\
\hline CHEMBL3193394 & 688612 & 4.5 & 4.7314 & TRN \\
\hline CHEMBL1381489 & 688612 & 4.95 & 4.6494 & TRN \\
\hline CHEMBL1510317 & 688612 & 4.0 & 4.7097 & TST \\
\hline CHEMBL1607367 & 688612 & 4.45 & 4.6616 & TRN \\
\hline CHEMBL1593419 & 688612 & 4.25 & 4.6708 & TRN \\
\hline CHEMBL1599316 & 688612 & 4.0 & 4.6617 & TST \\
\hline CHEMBL 2003651 & 688612 & 4.35 & 4.6584 & TRN \\
\hline CHEMBL1352818 & 688612 & 4.0 & 4.6678 & TRN \\
\hline CHEMBL1416262 & 688612 & 4.5 & 4.6855 & TRN \\
\hline CHEMBL1421054 & 688612 & 4.1 & 4.6722 & TRN \\
\hline CHEMBL1387044 & 688612 & 4.45 & 4.7037 & TST \\
\hline CHEMBL1331195 & 688612 & 4.45 & 4.716 & TST \\
\hline
\end{tabular}




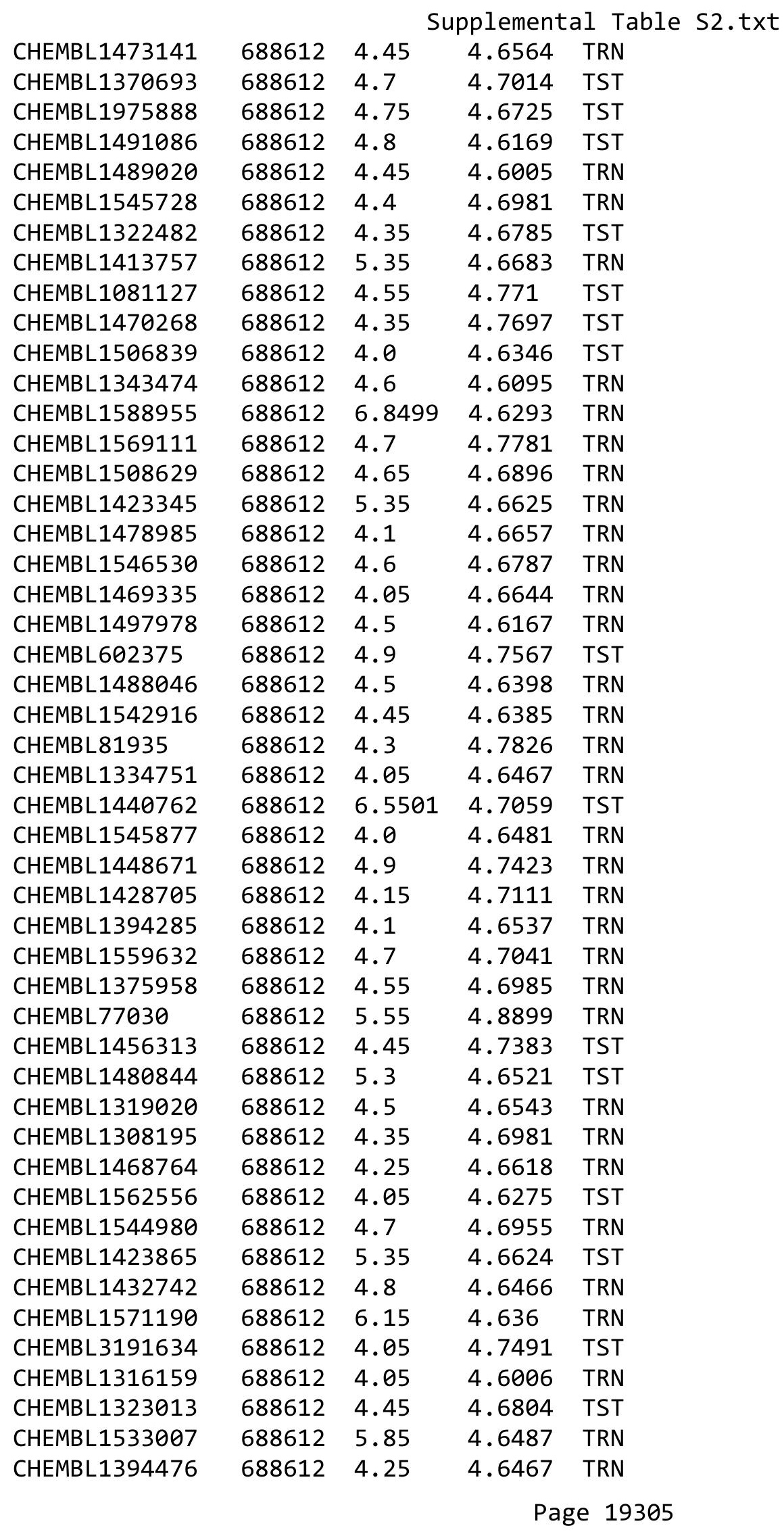




\begin{tabular}{|c|c|c|c|c|}
\hline \multicolumn{5}{|c|}{ Supplemental Table S2.txt } \\
\hline CHEMBL1449115 & 688612 & 4.4 & 4.5948 & TRN \\
\hline CHEMBL1984703 & 688612 & 5.0 & 4.7306 & TRN \\
\hline CHEMBL1302261 & 688612 & 4.8 & 4.6599 & TRN \\
\hline CHEMBL1973265 & 688612 & 4.55 & 4.7395 & TRN \\
\hline CHEMBL1561066 & 688612 & 6.05 & 4.6542 & TRN \\
\hline CHEMBL1414757 & 688612 & 5.45 & 4.6508 & TST \\
\hline CHEMBL1515766 & 688612 & 4.35 & 4.6509 & TRN \\
\hline CHEMBL1311317 & 688612 & 4.05 & 4.685 & TRN \\
\hline CHEMBL1511209 & 688612 & 4.1 & 4.6308 & TRN \\
\hline CHEMBL1602691 & 688612 & 4.7 & 4.6909 & TRN \\
\hline CHEMBL1439611 & 688612 & 4.1 & 4.6002 & TST \\
\hline CHEMBL1387595 & 688612 & 4.4 & 4.6402 & TRN \\
\hline CHEMBL1427053 & 688612 & 6.15 & 4.537 & TRN \\
\hline CHEMBL1421625 & 688612 & 4.1 & 4.7371 & TRN \\
\hline CHEMBL1304014 & 688612 & 5.5 & 4.6828 & TRN \\
\hline CHEMBL1577622 & 688612 & 4.5 & 4.7041 & TRN \\
\hline CHEMBL1356821 & 688612 & 4.4 & 4.6413 & TRN \\
\hline CHEMBL1552094 & 688612 & 5.4 & 4.6482 & TST \\
\hline CHEMBL1412284 & 688612 & 4.05 & 4.7141 & TRN \\
\hline CHEMBL1539461 & 688612 & 4.05 & 4.6905 & TRN \\
\hline CHEMBL1511646 & 688612 & 4.55 & 4.5885 & TST \\
\hline CHEMBL3193714 & 688612 & 4.5 & 4.773 & TRN \\
\hline CHEMBL1601475 & 688612 & 4.4 & 4.6602 & TST \\
\hline CHEMBL1491483 & 688612 & 4.4 & 4.6237 & TRN \\
\hline CHEMBL1393023 & 688612 & 5.35 & 4.7073 & TST \\
\hline CHEMBL1325401 & 688612 & 4.5 & 4.6065 & TRN \\
\hline CHEMBL591613 & 688612 & 4.8 & 4.6271 & TRN \\
\hline CHEMBL1326544 & 688612 & 4.5 & 4.6957 & TRN \\
\hline CHEMBL1586083 & 688612 & 4.4 & 4.7111 & TRN \\
\hline CHEMBL240331 & 688612 & 4.7 & 4.769 & TRN \\
\hline CHEMBL1499497 & 688612 & 4.45 & 4.6537 & TST \\
\hline CHEMBL 1440380 & 688612 & 4.1 & 4.6495 & TRN \\
\hline CHEMBL1396430 & 688612 & 4.2 & 4.6311 & TRN \\
\hline CHEMBL1480005 & 688612 & 4.1 & 4.7431 & TRN \\
\hline CHEMBL1552852 & 688612 & 4.0 & 4.59 & TST \\
\hline CHEMBL1434908 & 688612 & 4.05 & 4.6566 & TRN \\
\hline CHEMBL1595299 & 688612 & 4.0 & 4.6732 & TRN \\
\hline CHEMBL1391063 & 688612 & 6.7501 & 4.8164 & TST \\
\hline CHEMBL1465062 & 688612 & 4.05 & 4.6865 & TRN \\
\hline CHEMBL1316455 & 688612 & 4.35 & 4.6163 & TRN \\
\hline CHEMBL1308131 & 688612 & 4.15 & 4.7497 & TRN \\
\hline CHEMBL1507354 & 688612 & 5.3 & 4.655 & TRN \\
\hline CHEMBL1321690 & 688612 & 4.2 & 4.732 & TST \\
\hline CHEMBL1302278 & 688612 & 4.0 & 4.6483 & TRN \\
\hline CHEMBL1337275 & 688612 & 4.0 & 4.7073 & TRN \\
\hline CHEMBL1547371 & 688612 & 4.9 & 4.713 & TST \\
\hline CHEMBL 215553 & 688612 & 5.05 & 4.7978 & TRN \\
\hline CHEMBL1582406 & 688612 & 4.4 & 4.7139 & TST \\
\hline
\end{tabular}




\begin{tabular}{|c|c|c|c|c|c|}
\hline & & \multicolumn{4}{|c|}{ Supplemental Table S2.txt } \\
\hline CHEMBL3211851 & 688612 & 4.25 & 4.7298 & TRN & \\
\hline CHEMBL1474329 & 688612 & 5.15 & 4.6106 & TRN & \\
\hline CHEMBL1548996 & 688612 & 5.4 & 4.7565 & TST & \\
\hline CHEMBL1557107 & 688612 & 4.95 & 4.6546 & TST & \\
\hline CHEMBL1321936 & 688612 & 4.0 & 4.5433 & TRN & \\
\hline CHEMBL1508239 & 688612 & 4.0 & 4.6619 & TST & \\
\hline CHEMBL1443883 & 688612 & 4.05 & 4.6388 & TST & \\
\hline CHEMBL1362650 & 688612 & 5.3 & 4.6217 & TRN & \\
\hline CHEMBL3199188 & 688612 & 4.45 & 4.6357 & TRN & \\
\hline CHEMBL1524461 & 688612 & 4.7 & 4.7125 & TRN & \\
\hline CHEMBL1381419 & 688612 & 5.0 & 4.7972 & TRN & \\
\hline CHEMBL1373719 & 688612 & 4.55 & 4.7408 & TST & \\
\hline CHEMBL1486062 & 688612 & 6.15 & 4.6398 & TRN & \\
\hline CHEMBL1439117 & 688612 & 4.05 & 4.575 & TST & \\
\hline CHEMBL1581073 & 688612 & 6.8 & 4.6968 & TRN & \\
\hline CHEMBL1426966 & 688612 & 4.1 & 4.71 & TRN & \\
\hline CHEMBL1493427 & 688612 & 4.3 & 4.6323 & TRN & \\
\hline CHEMBL1489786 & 688612 & 4.8 & 4.7036 & TRN & \\
\hline CHEMBL1600933 & 688612 & 4.0 & 4.7128 & TRN & \\
\hline CHEMBL1481289 & 688612 & 4.25 & 4.6876 & TRN & \\
\hline CHEMBL1365553 & 688612 & 5.95 & 4.6645 & TRN & \\
\hline CHEMBL1489847 & 688612 & 4.4 & 4.6085 & TRN & \\
\hline CHEMBL1587584 & 688612 & 5.1 & 4.6544 & TRN & \\
\hline CHEMBL1430869 & 688612 & 5.25 & 4.6794 & TRN & \\
\hline CHEMBL1519929 & 688612 & 4.15 & 4.6689 & TRN & \\
\hline CHEMBL1532884 & 688612 & 4.1 & 4.6273 & TST & \\
\hline CHEMBL1603546 & 688612 & 4.45 & 4.5805 & TST & \\
\hline CHEMBL1301718 & 688612 & 4.05 & 4.6142 & TST & \\
\hline CHEMBL1461940 & 688612 & 4.0 & 4.6936 & TST & \\
\hline CHEMBL1542690 & 688612 & 6.25 & 4.6076 & TRN & \\
\hline CHEMBL1451501 & 688612 & 4.1 & 4.6577 & TST & \\
\hline CHEMBL1391298 & 688612 & 4.2 & 4.6682 & TRN & \\
\hline CHEMBL1448466 & 688612 & 4.35 & 4.6516 & TRN & \\
\hline CHEMBL1334412 & 688612 & 4.05 & 4.7616 & TRN & \\
\hline CHEMBL536950 & 688612 & 4.45 & 4.7086 & TST & \\
\hline CHEMBL1350833 & 688612 & 4.45 & 4.7673 & TRN & \\
\hline CHEMBL1609603 & 688612 & 4.5 & 4.72199 & 99999999995 & TRN \\
\hline CHEMBL1570218 & 688612 & 4.05 & 4.6246 & TST & \\
\hline CHEMBL1353657 & 688612 & 4.4 & 4.6916 & TRN & \\
\hline CHEMBL 2374035 & 688612 & 4.95 & 4.8134 & TRN & \\
\hline CHEMBL3209102 & 688612 & 4.9 & 4.6273 & TRN & \\
\hline CHEMBL1500096 & 688612 & 4.6 & 4.6003 & TRN & \\
\hline CHEMBL1540672 & 688612 & 4.05 & 4.6606 & TRN & \\
\hline CHEMBL1342410 & 688612 & 4.1 & 4.6177 & TRN & \\
\hline CHEMBL1374950 & 688612 & 4.5 & 4.7632 & TRN & \\
\hline CHEMBL1481020 & 688612 & 6.5 & 4.6268 & TRN & \\
\hline CHEMBL410525 & 688612 & 4.4 & 4.7352 & TRN & \\
\hline CHEMBL1407872 & 688612 & 4.05 & 4.601 & TRN & \\
\hline
\end{tabular}




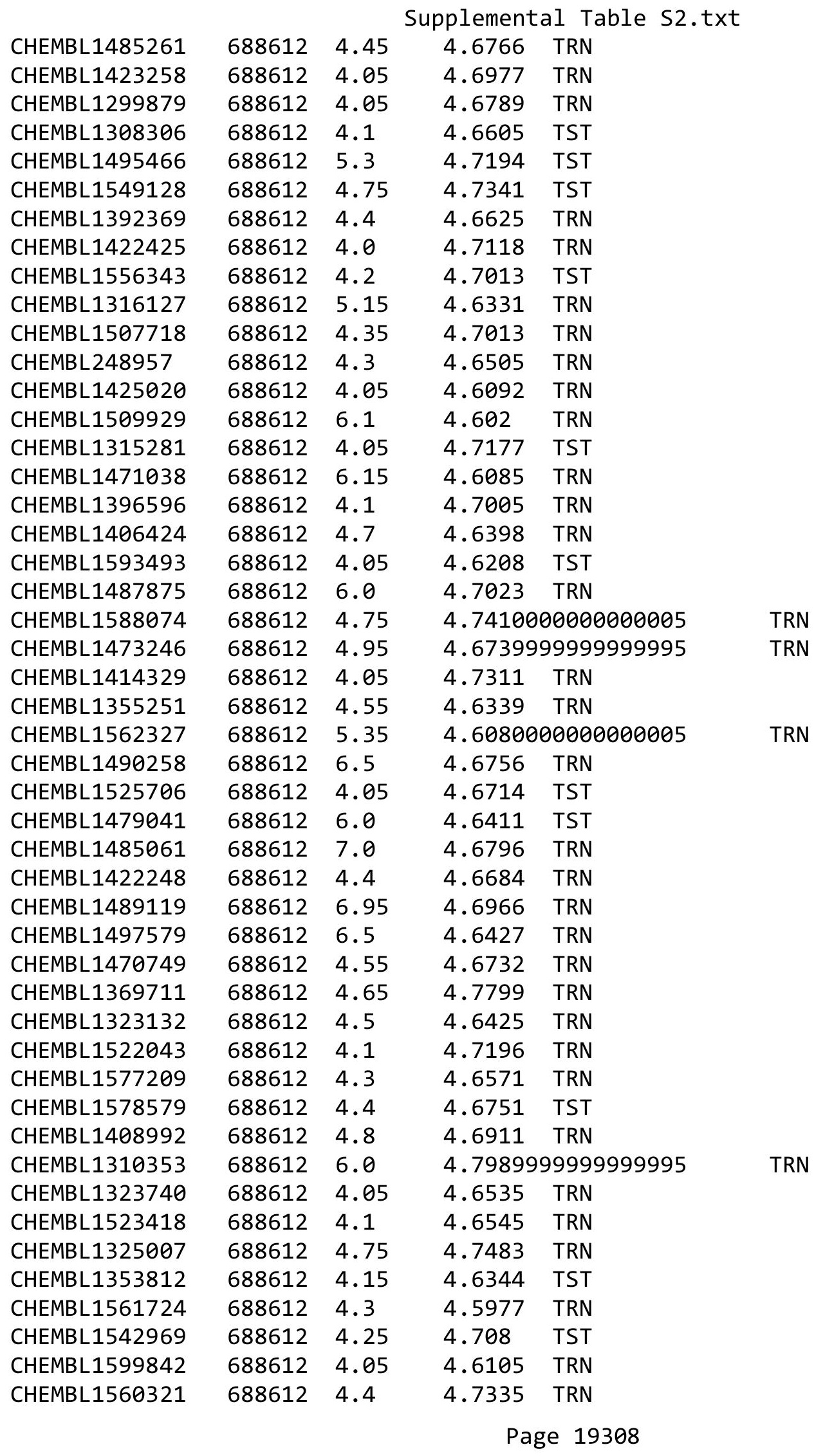




\begin{tabular}{|c|c|c|c|c|}
\hline \multicolumn{5}{|c|}{ Supplemental Table S2.txt } \\
\hline CHEMBL1589975 & 688612 & 4.35 & 4.6209 & TRN \\
\hline CHEMBL1566669 & 688612 & 4.0 & 4.5377 & TST \\
\hline CHEMBL1339659 & 688612 & 4.25 & 4.6573 & TRN \\
\hline CHEMBL580168 & 688612 & 4.05 & 4.5862 & TST \\
\hline CHEMBL1301164 & 688612 & 4.9 & 4.6687 & TRN \\
\hline CHEMBL1511092 & 688612 & 5.45 & 4.6801 & TST \\
\hline CHEMBL1312728 & 688612 & 4.05 & 4.637 & TRN \\
\hline CHEMBL1408662 & 688612 & 4.9 & 4.7415 & TRN \\
\hline CHEMBL1496969 & 688612 & 4.9 & 4.6462 & TST \\
\hline CHEMBL 259840 & 688612 & 4.4 & 4.5941 & TST \\
\hline CHEMBL1384217 & 688612 & 5.75 & 4.6676 & TST \\
\hline CHEMBL1533851 & 688612 & 5.3 & 4.6369 & TRN \\
\hline CHEMBL1462663 & 688612 & 6.45 & 4.7217 & TRN \\
\hline CHEMBL1405455 & 688612 & 4.95 & 4.6761 & TRN \\
\hline CHEMBL1567392 & 688612 & 4.35 & 4.7057 & TST \\
\hline CHEMBL1988303 & 688612 & 4.75 & 4.7388 & TST \\
\hline CHEMBL1604274 & 688612 & 4.05 & 4.699 & TRN \\
\hline CHEMBL1574723 & 688612 & 4.1 & 4.7154 & TST \\
\hline CHEMBL1589118 & 688612 & 4.85 & 4.7529 & TRN \\
\hline CHEMBL1329566 & 688612 & 4.05 & 4.6961 & TRN \\
\hline CHEMBL 275311 & 688612 & 4.45 & 4.7409 & TST \\
\hline CHEMBL1538959 & 688612 & 4.65 & 4.6654 & TRN \\
\hline CHEMBL1429925 & 688612 & 4.5 & 4.6504 & TRN \\
\hline CHEMBL1525333 & 688612 & 4.95 & 4.7502 & TST \\
\hline CHEMBL1336532 & 688612 & 5.25 & 4.7156 & TST \\
\hline CHEMBL1434444 & 688612 & 4.0 & 4.6534 & TRN \\
\hline CHEMBL1496973 & 688612 & 4.35 & 4.6336 & TRN \\
\hline CHEMBL1402586 & 688612 & 4.5 & 4.6692 & TRN \\
\hline CHEMBL1404502 & 688612 & 4.4 & 4.7469 & TST \\
\hline CHEMBL1508011 & 688612 & 4.05 & 4.6865 & TRN \\
\hline CHEMBL1455522 & 688612 & 4.05 & 4.7266 & TRN \\
\hline CHEMBL1522288 & 688612 & 4.7 & 4.6772 & TRN \\
\hline CHEMBL1565973 & 688612 & 4.0 & 4.6359 & TST \\
\hline CHEMBL1482975 & 688612 & 4.75 & 4.6953 & TRN \\
\hline CHEMBL1496217 & 688612 & 4.4 & 4.6077 & TRN \\
\hline CHEMBL1492945 & 688612 & 4.45 & 4.6862 & TRN \\
\hline CHEMBL 1370576 & 688612 & 5.8 & 4.6899 & TRN \\
\hline CHEMBL1424060 & 688612 & 4.05 & 4.7038 & TST \\
\hline CHEMBL1567048 & 688612 & 5.95 & 4.6147 & TRN \\
\hline CHEMBL1311802 & 688612 & 4.0 & 4.7007 & TRN \\
\hline CHEMBL1561148 & 688612 & 4.65 & 4.7109 & TST \\
\hline CHEMBL1537289 & 688612 & 4.1 & 4.678 & TRN \\
\hline CHEMBL1588262 & 688612 & 4.25 & 4.6023 & TRN \\
\hline CHEMBL1309139 & 688612 & 4.1 & 4.5856 & TRN \\
\hline CHEMBL1339826 & 688612 & 4.0 & 4.6243 & TRN \\
\hline CHEMBL1540637 & 688612 & 5.8 & 4.6702 & TRN \\
\hline CHEMBL1304322 & 688612 & 4.05 & 4.6954 & TRN \\
\hline CHEMBL1613274 & 688612 & 4.7 & 4.7001 & TRN \\
\hline
\end{tabular}




\begin{tabular}{|c|c|c|c|c|c|}
\hline \multirow{2}{*}{ CHEMBL1526404 } & \multirow[b]{2}{*}{688612} & \multicolumn{4}{|c|}{ Supplemental Table S2.txt } \\
\hline & & 4.0 & 4.6655 & TRN & \\
\hline CHEMBL1506756 & 688612 & 4.5 & $4.6930 e$ & 00000000005 & TRN \\
\hline CHEMBL1441062 & 688612 & 4.7 & 4.5986 & TRN & \\
\hline CHEMBL 3195042 & 688612 & 4.05 & 4.6852 & TST & \\
\hline CHEMBL1389728 & 688612 & 4.3 & 4.6524 & TRN & \\
\hline CHEMBL493863 & 688612 & 4.85 & 4.6512 & TRN & \\
\hline CHEMBL1548641 & 688612 & 4.15 & 4.6137 & TRN & \\
\hline CHEMBL1500756 & 688612 & 4.1 & 4.6107 & TRN & \\
\hline CHEMBL1334129 & 688612 & 4.6 & 4.6492 & TRN & \\
\hline CHEMBL1609026 & 688612 & 4.05 & 4.6621 & TRN & \\
\hline CHEMBL3191072 & 688612 & 4.4 & 4.6335 & TRN & \\
\hline CHEMBL1327774 & 688612 & 4.15 & 4.6614 & TRN & \\
\hline CHEMBL1332760 & 688612 & 4.6 & 4.677 & TRN & \\
\hline CHEMBL1424412 & 688612 & 5.5 & 4.6042 & TRN & \\
\hline CHEMBL1542185 & 688612 & 4.05 & 4.6971 & TST & \\
\hline CHEMBL1492565 & 688612 & 6.0 & 4.7801 & TRN & \\
\hline CHEMBL1319191 & 688612 & 4.6 & $4.7360 e$ & 0000000001 & TRN \\
\hline CHEMBL1409195 & 688612 & 4.4 & 4.6745 & TRN & \\
\hline CHEMBL1491887 & 688612 & 5.45 & 4.7056 & TRN & \\
\hline CHEMBL1497269 & 688612 & 4.65 & 4.7278 & TRN & \\
\hline CHEMBL1519514 & 688612 & 4.65 & 4.5918 & TRN & \\
\hline CHEMBL1344813 & 688612 & 5.9 & 4.6605 & TRN & \\
\hline CHEMBL3198522 & 688612 & 4.6 & 4.6664 & TRN & \\
\hline CHEMBL3191643 & 688612 & 7.0 & 4.7157 & TST & \\
\hline CHEMBL1495962 & 688612 & 4.1 & 4.5911 & TRN & \\
\hline CHEMBL1611517 & 688612 & 4.75 & 4.545 & TRN & \\
\hline CHEMBL1548007 & 688612 & 5.9 & 4.766 & TST & \\
\hline CHEMBL1426296 & 688612 & 4.05 & 4.6566 & TRN & \\
\hline CHEMBL 3189365 & 688612 & 4.7 & 4.6931 & TRN & \\
\hline CHEMBL1535636 & 688612 & 5.7 & 4.7275 & TRN & \\
\hline CHEMBL1560361 & 688612 & 4.2 & 4.6693 & TRN & \\
\hline CHEMBL1602945 & 688612 & 4.65 & 4.5831 & TRN & \\
\hline CHEMBL1532226 & 688612 & 4.05 & 4.5749 & TRN & \\
\hline CHEMBL1522277 & 688612 & 4.1 & 4.6055 & TRN & \\
\hline CHEMBL1353810 & 688612 & 4.05 & 4.6061 & TRN & \\
\hline CHEMBL3194498 & 688612 & 4.4 & 4.6722 & TST & \\
\hline CHEMBL1992447 & 688612 & 4.05 & 4.7197 & TRN & \\
\hline CHEMBL1330321 & 688612 & 4.4 & 4.7003 & TRN & \\
\hline CHEMBL1603620 & 688612 & 6.15 & 4.707 & TRN & \\
\hline CHEMBL1608264 & 688612 & 4.25 & 4.7364 & TRN & \\
\hline CHEMBL124006 & 688612 & 5.65 & 4.6269 & TRN & \\
\hline CHEMBL1402576 & 688612 & 5.5 & 4.7827 & TST & \\
\hline CHEMBL1442843 & 688612 & 4.1 & 4.63 & TRN & \\
\hline CHEMBL1493910 & 688612 & 4.4 & 4.6895 & TRN & \\
\hline CHEMBL1585859 & 688612 & 4.7 & 4.6261 & TRN & \\
\hline CHEMBL1431875 & 688612 & 4.5 & 4.7001 & TRN & \\
\hline CHEMBL1417906 & 688612 & 4.0 & 4.5943 & TST & \\
\hline CHEMBL1397761 & 688612 & 4.65 & 4.6872 & TST & \\
\hline
\end{tabular}




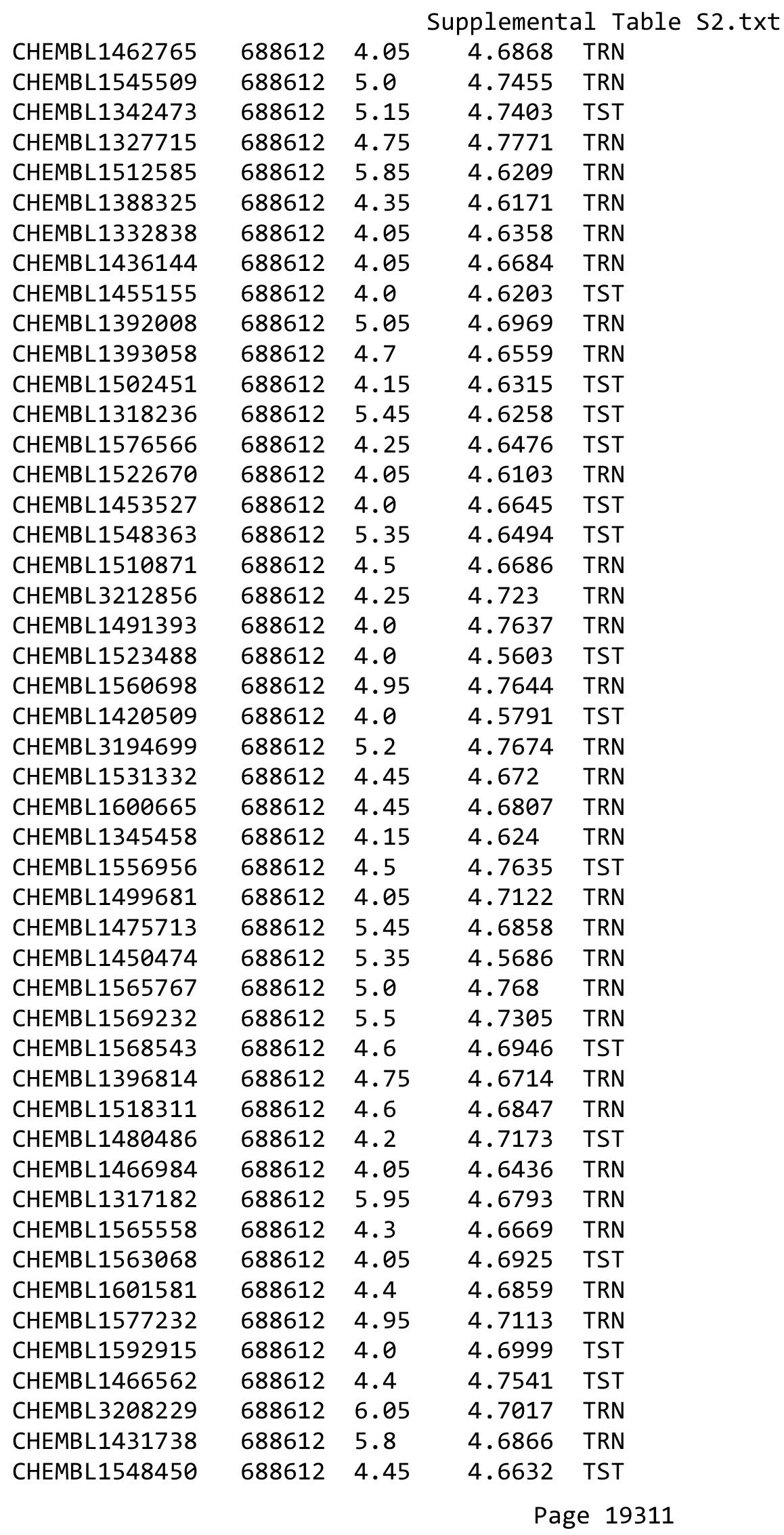




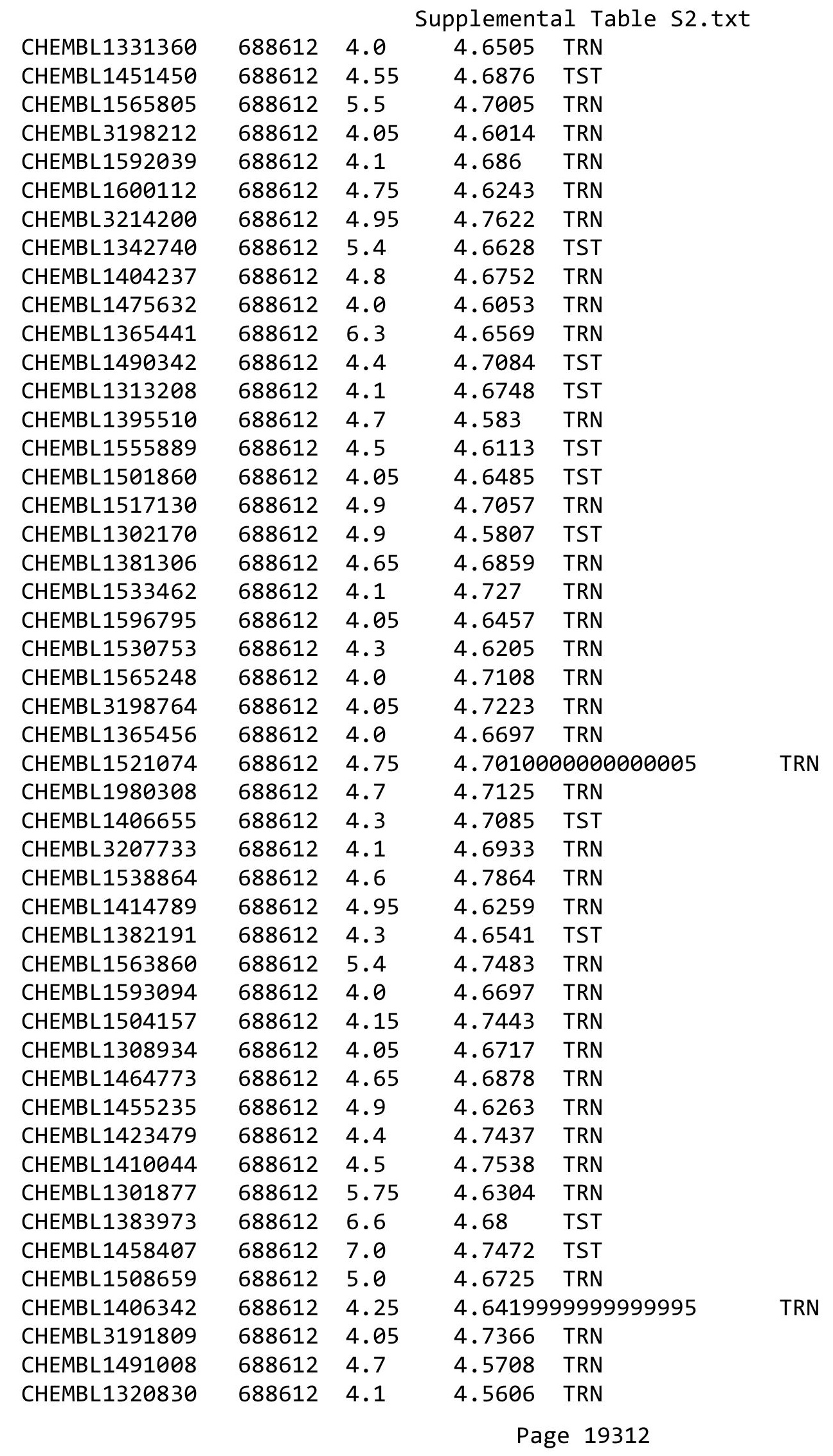




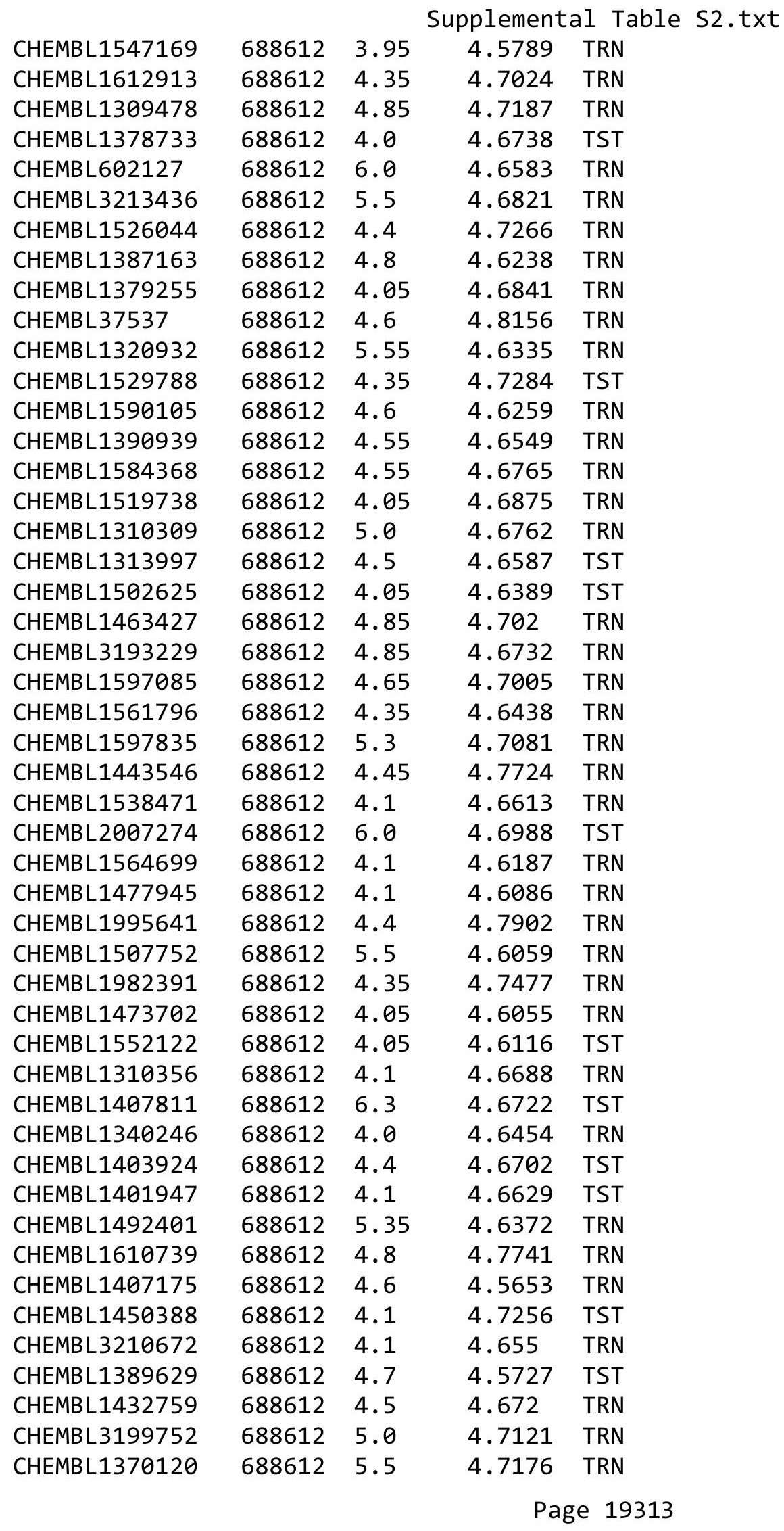




\begin{tabular}{|c|c|c|c|c|c|}
\hline & & \multicolumn{4}{|c|}{ Supplemental Table S2.txt } \\
\hline CHEMBL1568409 & 688612 & 6.8499 & 4.6493 & TRN & \\
\hline CHEMBL1450025 & 688612 & 4.25 & 4.7216 & TRN & \\
\hline CHEMBL1301027 & 688612 & 4.4 & 4.6527 & TRN & \\
\hline CHEMBL1984772 & 688612 & 5.0 & 4.6554 & TRN & \\
\hline CHEMBL1578895 & 688612 & 4.05 & 4.7418 & TRN & \\
\hline CHEMBL1604490 & 688612 & 4.4 & 4.6555 & TRN & \\
\hline CHEMBL1607856 & 688612 & 4.0 & 4.5596 & TRN & \\
\hline CHEMBL1550628 & 688612 & 4.45 & 4.6617 & TRN & \\
\hline CHEMBL 2007057 & 688612 & 4.4 & 4.7788 & TRN & \\
\hline CHEMBL1330295 & 688612 & 5.55 & 4.5642 & TRN & \\
\hline CHEMBL1547955 & 688612 & 4.2 & 4.6368 & TRN & \\
\hline CHEMBL1552509 & 688612 & 4.5 & 4.6058 & TRN & \\
\hline CHEMBL1368510 & 688612 & 4.0 & 4.6281 & TRN & \\
\hline CHEMBL1577542 & 688612 & 4.0 & 4.6151 & TRN & \\
\hline CHEMBL1325505 & 688612 & 4.35 & 4.8395 & TST & \\
\hline CHEMBL1376656 & 688612 & 5.5 & 4.7304 & TRN & \\
\hline CHEMBL3145285 & 688612 & 4.75 & 4.7003 & TRN & \\
\hline CHEMBL1350426 & 688612 & 4.95 & 4.7294 & TRN & \\
\hline CHEMBL3190368 & 688612 & 4.7 & 4.6938 & TST & \\
\hline CHEMBL1448748 & 688612 & 4.05 & 4.6249 & TRN & \\
\hline CHEMBL1370398 & 688612 & 4.05 & 4.705 & TST & \\
\hline CHEMBL1342028 & 688612 & 4.4 & 4.6351 & TRN & \\
\hline CHEMBL1576220 & 688612 & 5.45 & 4.6088 & TRN & \\
\hline CHEMBL1506575 & 688612 & 4.05 & 4.6508 & TST & \\
\hline CHEMBL605499 & 688612 & 4.05 & 4.5915 & TRN & \\
\hline CHEMBL1419843 & 688612 & 6.8499 & 4.6713 & TRN & \\
\hline CHEMBL1544948 & 688612 & 6.6499 & 4.6856 & TRN & \\
\hline CHEMBL1569293 & 688612 & 6.5 & 4.6555 & TST & \\
\hline CHEMBL3191363 & 688612 & 5.15 & 4.6939 & TRN & \\
\hline CHEMBL 1352270 & 688612 & 5.85 & 4.6866 & TRN & \\
\hline CHEMBL1491296 & 688612 & 4.4 & 4.6784 & TRN & \\
\hline CHEMBL1315715 & 688612 & 4.1 & 4.6207 & TRN & \\
\hline CHEMBL1454086 & 688612 & 4.4 & 4.6272 & TRN & \\
\hline CHEMBL1556488 & 688612 & 4.95 & 4.6036 & TRN & \\
\hline CHEMBL1602278 & 688612 & 4.0 & 4.6511 & TRN & \\
\hline CHEMBL1469718 & 688612 & 3.95 & 4.6259 & TRN & \\
\hline CHEMBL1594527 & 688612 & 4.35 & 4.6475 & TST & \\
\hline CHEMBL1302308 & 688612 & 5.35 & 4.8667 & TRN & \\
\hline CHEMBL1375894 & 688612 & 5.25 & 4.6805 & TST & \\
\hline CHEMBL1506716 & 688612 & 4.65 & 4.7574 & TST & \\
\hline CHEMBL1407070 & 688612 & 4.0 & 4.67899 & 9999999999 & TRN \\
\hline CHEMBL1549262 & 688612 & 6.8 & 4.684 & TRN & \\
\hline CHEMBL1420084 & 688612 & 5.75 & 4.5989 & TRN & \\
\hline CHEMBL1583537 & 688612 & 4.3 & 4.8215 & TRN & \\
\hline CHEMBL1479270 & 688612 & 5.4 & 4.6278 & TRN & \\
\hline CHEMBL1439735 & 688612 & 5.0 & 4.8096 & TRN & \\
\hline CHEMBL1545000 & 688612 & 4.0 & 4.6298 & TST & \\
\hline CHEMBL1590981 & 688612 & 5.7 & 4.6754 & TRN & \\
\hline
\end{tabular}




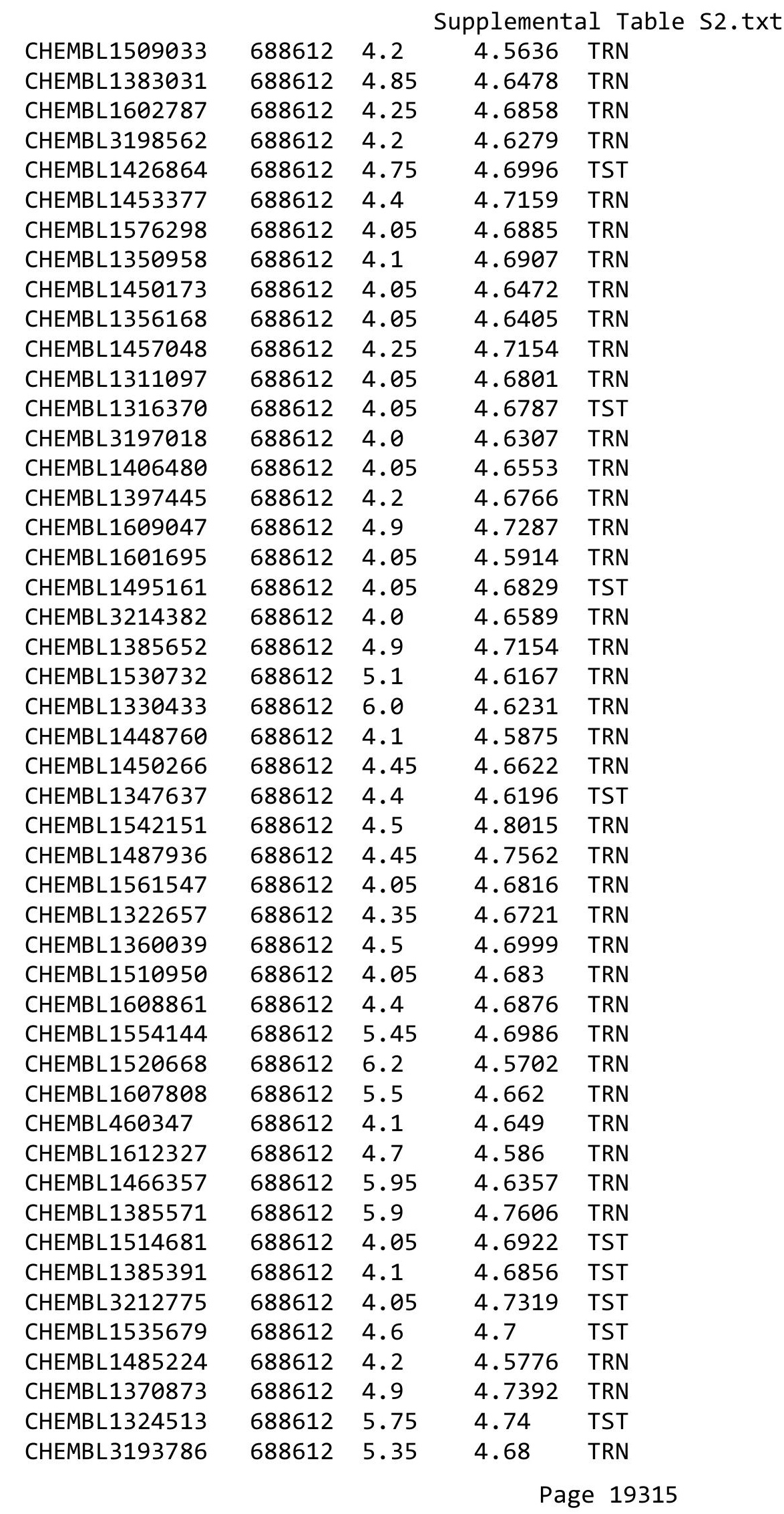




\begin{tabular}{|c|c|c|c|c|}
\hline \multicolumn{5}{|c|}{ Supplemental Table S2.txt } \\
\hline CHEMBL534047 & 688612 & 4.8 & 4.7342 & TRN \\
\hline CHEMBL1545971 & 688612 & 4.5 & 4.6594 & TRN \\
\hline CHEMBL1504182 & 688612 & 6.8 & 4.728 & TST \\
\hline CHEMBL 3210584 & 688612 & 5.55 & 4.6558 & TRN \\
\hline CHEMBL1573442 & 688612 & 4.1 & 4.6097 & TRN \\
\hline CHEMBL1321446 & 688612 & 4.0 & 4.7824 & TRN \\
\hline CHEMBL1375717 & 688612 & 4.05 & 4.6575 & TRN \\
\hline CHEMBL 3214001 & 688612 & 4.65 & 4.6816 & TRN \\
\hline CHEMBL1542115 & 688612 & 4.3 & 4.6438 & TRN \\
\hline CHEMBL1412487 & 688612 & 4.4 & 4.6755 & TRN \\
\hline CHEMBL1357100 & 688612 & 5.2 & 4.7329 & TST \\
\hline CHEMBL1305105 & 688612 & 4.1 & 4.7319 & TRN \\
\hline CHEMBL1343878 & 688612 & 5.7 & 4.7226 & TST \\
\hline CHEMBL1574448 & 688612 & 5.05 & 4.6324 & TRN \\
\hline CHEMBL1411303 & 688612 & 4.6 & 4.6644 & TRN \\
\hline CHEMBL3196844 & 688612 & 4.75 & 4.7828 & TRN \\
\hline CHEMBL1306057 & 688612 & 6.2 & 4.6242 & TRN \\
\hline CHEMBL1344116 & 688612 & 5.65 & 4.6297 & TRN \\
\hline CHEMBL1546149 & 688612 & 4.0 & 4.6024 & TRN \\
\hline CHEMBL3198701 & 688612 & 4.9 & 4.6665 & TRN \\
\hline CHEMBL1502238 & 688612 & 5.8 & 4.6095 & TRN \\
\hline CHEMBL1441513 & 688612 & 4.4 & 4.6205 & TRN \\
\hline CHEMBL1301297 & 688612 & 4.85 & 4.7311 & TRN \\
\hline CHEMBL1509222 & 688612 & 4.4 & 4.6289 & TRN \\
\hline CHEMBL1389405 & 688612 & 4.35 & 4.6416 & TRN \\
\hline CHEMBL1307967 & 688612 & 4.4 & 4.7288 & TRN \\
\hline CHEMBL1529956 & 688612 & 4.05 & 4.6823 & TST \\
\hline CHEMBL1597164 & 688612 & 4.6 & 4.6048 & TRN \\
\hline CHEMBL1580036 & 688612 & 5.0 & 4.6664 & TRN \\
\hline CHEMBL1463330 & 688612 & 6.15 & 4.5931 & TRN \\
\hline CHEMBL1484907 & 688612 & 4.1 & 4.6417 & TRN \\
\hline CHEMBL1529341 & 688612 & 4.95 & 4.7124 & TRN \\
\hline CHEMBL1495778 & 688612 & 5.85 & 4.7517 & TRN \\
\hline CHEMBL1382425 & 688612 & 4.2 & 4.6713 & TRN \\
\hline CHEMBL1969929 & 688612 & 4.45 & 4.6448 & TRN \\
\hline CHEMBL1565451 & 688612 & 5.95 & 4.6428 & TRN \\
\hline CHEMBL1449470 & 688612 & 4.3 & 4.7148 & TRN \\
\hline CHEMBL1612212 & 688612 & 4.0 & 4.6726 & TRN \\
\hline CHEMBL1573979 & 688612 & 4.05 & 4.6632 & TRN \\
\hline CHEMBL1332082 & 688612 & 4.65 & 4.783 & TRN \\
\hline CHEMBL1543913 & 688612 & 4.4 & 4.5768 & TRN \\
\hline CHEMBL1552548 & 688612 & 4.05 & 4.5564 & TRN \\
\hline CHEMBL1411822 & 688612 & 4.2 & 4.5011 & TRN \\
\hline CHEMBL1536001 & 688612 & 4.1 & 4.7112 & TST \\
\hline CHEMBL1583277 & 688612 & 5.0 & 4.6474 & TRN \\
\hline CHEMBL1436000 & 688612 & 4.6 & 4.6303 & TRN \\
\hline CHEMBL1405067 & 688612 & 4.45 & 4.737 & TRN \\
\hline CHEMBL1574857 & 688612 & 5.95 & 4.8172 & TRN \\
\hline
\end{tabular}




\begin{tabular}{|c|c|c|c|c|c|}
\hline & & \multicolumn{4}{|c|}{ Supplemental Table S2.txt } \\
\hline CHEMBL1378290 & 688612 & 6.8499 & 4.5785 & TRN & \\
\hline CHEMBL3189395 & 688612 & 4.9 & 4.6819 & TRN & \\
\hline CHEMBL1598723 & 688612 & 4.0 & 4.6465 & TRN & \\
\hline CHEMBL1519441 & 688612 & 4.4 & 4.7529 & TRN & \\
\hline CHEMBL1513264 & 688612 & 4.55 & 4.5874 & TRN & \\
\hline CHEMBL1466605 & 688612 & 4.3 & 4.6405 & TRN & \\
\hline CHEMBL1519229 & 688612 & 4.45 & 4.70100 & 00000000005 & TRN \\
\hline CHEMBL1510327 & 688612 & 4.05 & 4.7455 & TRN & \\
\hline CHEMBL1611254 & 688612 & 4.6 & 4.7815 & TST & \\
\hline CHEMBL1596165 & 688612 & 4.9 & 4.5979 & TRN & \\
\hline CHEMBL1315771 & 688612 & 4.95 & 4.615 & TRN & \\
\hline CHEMBL1532515 & 688612 & 4.8 & 4.7057 & TRN & \\
\hline CHEMBL1508300 & 688612 & 4.05 & 4.648 & TRN & \\
\hline CHEMBL1538803 & 688612 & 6.8 & 4.6513 & TRN & \\
\hline CHEMBL1546859 & 688612 & 4.35 & 4.685 & TRN & \\
\hline CHEMBL1335481 & 688612 & 4.85 & 4.6277 & TST & \\
\hline CHEMBL1433110 & 688612 & 4.3 & 4.6341 & TRN & \\
\hline CHEMBL1596864 & 688612 & 4.35 & 4.6627 & TRN & \\
\hline CHEMBL1468671 & 688612 & 4.0 & 4.7173 & TRN & \\
\hline CHEMBL1409304 & 688612 & 4.1 & 4.6352 & TRN & \\
\hline CHEMBL1459513 & 688612 & 4.6 & 4.6674 & TRN & \\
\hline CHEMBL1323243 & 688612 & 4.3 & 4.7413 & TST & \\
\hline CHEMBL1508102 & 688612 & 4.0 & 4.5949 & TRN & \\
\hline CHEMBL1536035 & 688612 & 4.3 & 4.6087 & TST & \\
\hline CHEMBL1391372 & 688612 & 6.7001 & 4.6887 & TST & \\
\hline CHEMBL1991736 & 688612 & 5.45 & 4.7108 & TRN & \\
\hline CHEMBL1529545 & 688612 & 4.5 & 4.6953 & TRN & \\
\hline CHEMBL 3214447 & 688612 & 4.1 & 4.7574 & TST & \\
\hline CHEMBL 1370314 & 688612 & 4.65 & 4.6736 & TRN & \\
\hline CHEMBL1498247 & 688612 & 4.4 & 4.7578 & TRN & \\
\hline CHEMBL1434493 & 688612 & 4.0 & 4.6578 & TRN & \\
\hline CHEMBL1495571 & 688612 & 4.05 & 4.6749 & TRN & \\
\hline CHEMBL1403988 & 688612 & 4.1 & 4.5157 & TRN & \\
\hline CHEMBL1352801 & 688612 & 4.8 & 4.7497 & TST & \\
\hline CHEMBL1457067 & 688612 & 4.3 & 4.6158 & TRN & \\
\hline CHEMBL1387467 & 688612 & 4.2 & 4.6758 & TRN & \\
\hline CHEMBL1444592 & 688612 & 4.0 & 4.6131 & TRN & \\
\hline CHEMBL1512769 & 688612 & 4.4 & 4.5705 & TRN & \\
\hline CHEMBL1527034 & 688612 & 6.8499 & 4.5869 & TST & \\
\hline CHEMBL1301220 & 688612 & 4.05 & 4.6234 & TRN & \\
\hline CHEMBL1413321 & 688612 & 4.1 & 4.6761 & TRN & \\
\hline CHEMBL3199121 & 688612 & 4.95 & 4.8041 & TRN & \\
\hline CHEMBL1417122 & 688612 & 4.3 & 4.7652 & TRN & \\
\hline CHEMBL1472174 & 688612 & 4.6 & 4.5587 & TRN & \\
\hline CHEMBL1367091 & 688612 & 4.05 & 4.5285 & TRN & \\
\hline CHEMBL1475413 & 688612 & 4.4 & 4.5586 & TRN & \\
\hline CHEMBL1350866 & 688612 & 4.7 & 4.6857 & TST & \\
\hline CHEMBL1577838 & 688612 & 4.05 & 4.6088 & TRN & \\
\hline
\end{tabular}




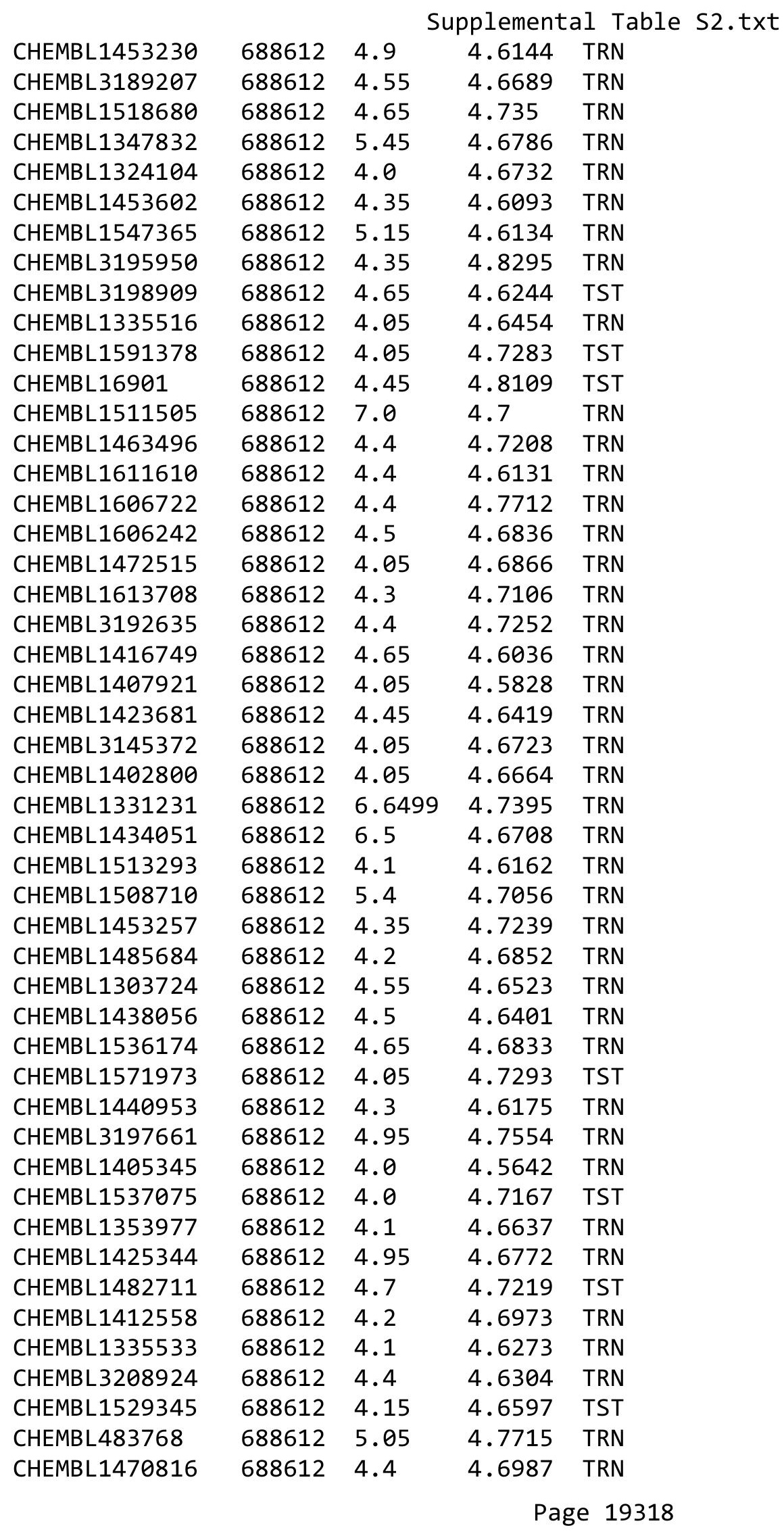




\begin{tabular}{|c|c|c|c|c|}
\hline \multicolumn{5}{|c|}{ Supplemental Table S2.txt } \\
\hline CHEMBL1385049 & 688612 & 4.5 & 4.6634 & TRN \\
\hline CHEMBL1492611 & 688612 & 4.2 & 4.6424 & TST \\
\hline CHEMBL1347427 & 688612 & 4.2 & 4.6899 & TRN \\
\hline CHEMBL 3191655 & 688612 & 4.95 & 4.7291 & TRN \\
\hline CHEMBL1432769 & 688612 & 5.7 & 4.6663 & TRN \\
\hline CHEMBL1448985 & 688612 & 5.1 & 4.7245 & TRN \\
\hline CHEMBL585408 & 688612 & 4.0 & 4.5502 & TRN \\
\hline CHEMBL1605920 & 688612 & 4.0 & 4.6295 & TST \\
\hline CHEMBL1448721 & 688612 & 4.55 & 4.5675 & TRN \\
\hline CHEMBL1548815 & 688612 & 5.2 & 4.6387 & TST \\
\hline CHEMBL1520692 & 688612 & 4.6 & 4.6617 & TRN \\
\hline CHEMBL1455196 & 688612 & 4.3 & 4.6968 & TST \\
\hline CHEMBL1518480 & 688612 & 5.4 & 4.6285 & TST \\
\hline CHEMBL1575794 & 688612 & 6.4 & 4.5785 & TRN \\
\hline CHEMBL1594587 & 688612 & 6.05 & 4.6745 & TST \\
\hline CHEMBL 210572 & 688612 & 4.05 & 4.6518 & TRN \\
\hline CHEMBL1606789 & 688612 & 4.3 & 4.7177 & TRN \\
\hline CHEMBL1315372 & 688612 & 6.05 & 4.7626 & TRN \\
\hline CHEMBL1359218 & 688612 & 4.0 & 4.6196 & TST \\
\hline CHEMBL1459606 & 688612 & 6.6 & 4.6689 & TRN \\
\hline CHEMBL 3190075 & 688612 & 4.25 & 4.7328 & TRN \\
\hline CHEMBL1447622 & 688612 & 4.0 & 4.6261 & TST \\
\hline CHEMBL1491694 & 688612 & 4.1 & 4.6486 & TRN \\
\hline CHEMBL 3193756 & 688612 & 4.55 & 4.6387 & TRN \\
\hline CHEMBL1530824 & 688612 & 5.15 & 4.705 & TRN \\
\hline CHEMBL1413241 & 688612 & 4.0 & 4.5956 & TRN \\
\hline CHEMBL1389920 & 688612 & 5.05 & 4.7339 & TST \\
\hline CHEMBL1431616 & 688612 & 4.55 & 4.6548 & TRN \\
\hline CHEMBL118378 & 688612 & 4.05 & 4.665 & TRN \\
\hline CHEMBL1496134 & 688612 & 6.8499 & 4.665 & TST \\
\hline CHEMBL1333481 & 688612 & 5.55 & 4.5813 & TRN \\
\hline CHEMBL1486847 & 688612 & 4.25 & 4.6676 & TRN \\
\hline CHEMBL1502547 & 688612 & 4.4 & 4.6913 & TST \\
\hline CHEMBL1568867 & 688612 & 4.25 & 4.6005 & TRN \\
\hline CHEMBL1572827 & 688612 & 5.3 & 4.6738 & TST \\
\hline CHEMBL1600403 & 688612 & 4.05 & 4.7023 & TRN \\
\hline CHEMBL 2005657 & 688612 & 4.1 & 4.8024 & TRN \\
\hline CHEMBL1405124 & 688612 & 4.1 & 4.5796 & TRN \\
\hline CHEMBL1343556 & 688612 & 4.05 & 4.6838 & TRN \\
\hline CHEMBL1610120 & 688612 & 4.2 & 4.6338 & TRN \\
\hline CHEMBL1583378 & 688612 & 4.05 & 4.5696 & TRN \\
\hline CHEMBL 1536072 & 688612 & 4.5 & 4.66 & TRN \\
\hline CHEMBL1388703 & 688612 & 5.05 & 4.6327 & TRN \\
\hline CHEMBL1345309 & 688612 & 4.7 & 4.6637 & TRN \\
\hline CHEMBL1536196 & 688612 & 4.3 & 4.7397 & TST \\
\hline CHEMBL1390043 & 688612 & 4.4 & 4.5591 & TRN \\
\hline CHEMBL1347387 & 688612 & 4.95 & 4.6687 & TRN \\
\hline CHEMBL1438851 & 688612 & 5.35 & 4.6299 & TST \\
\hline
\end{tabular}




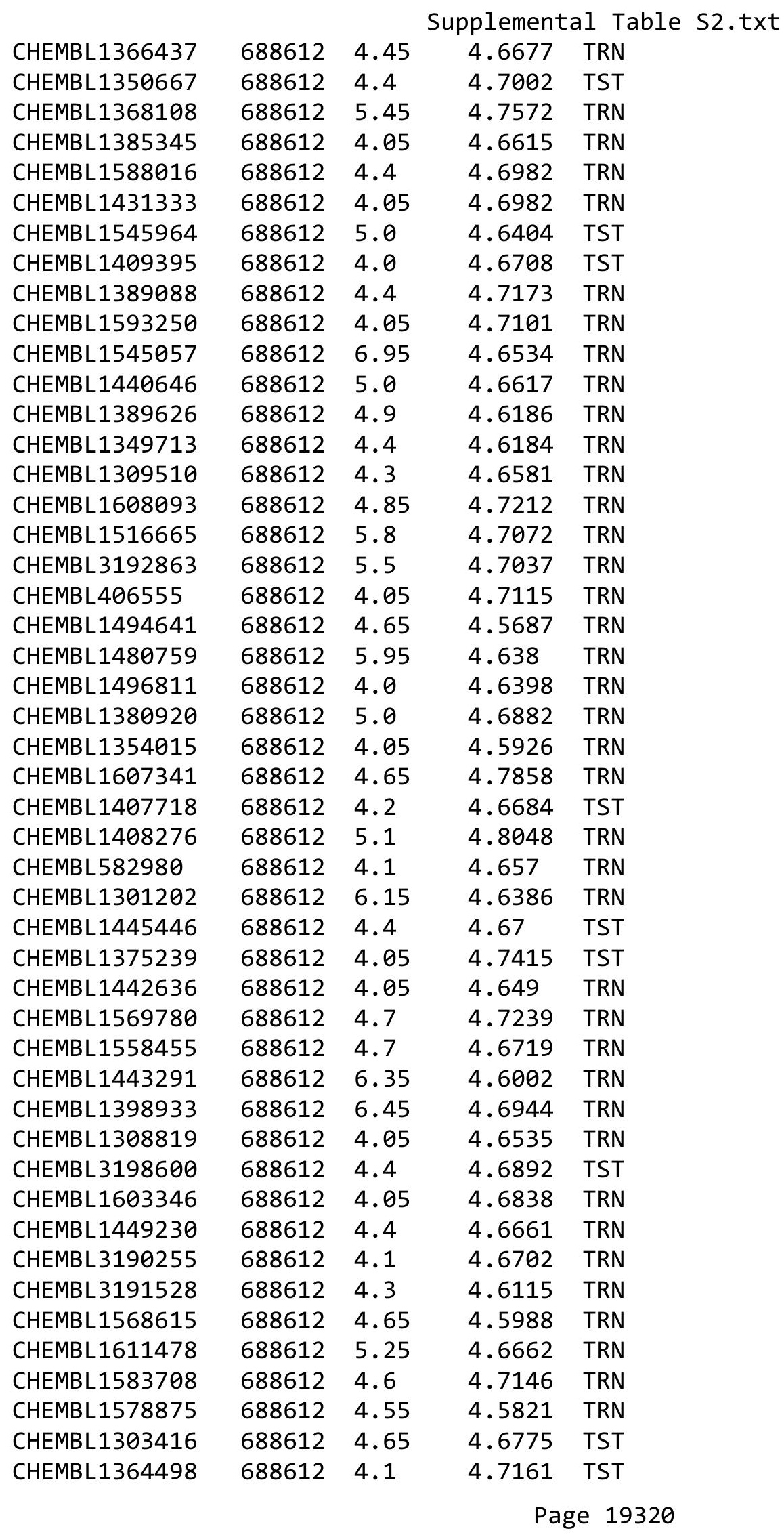




\begin{tabular}{|c|c|c|c|c|c|}
\hline \multicolumn{6}{|c|}{ Supplemental Table S2.txt } \\
\hline CHEMBL1375187 & 688612 & 4.4 & 4.6538 & TRN & \\
\hline CHEMBL1316648 & 688612 & 4.05 & 4.6175 & TRN & \\
\hline CHEMBL1478924 & 688612 & 5.05 & 4.684 & TRN & \\
\hline CHEMBL 377295 & 688612 & 5.05 & 4.67899 & 9999999999 & TRN \\
\hline CHEMBL1373385 & 688612 & 6.5501 & 4.688 & TST & \\
\hline CHEMBL1538505 & 688612 & 5.1 & 4.7183 & TRN & \\
\hline CHEMBL1496435 & 688612 & 4.75 & 4.6724 & TRN & \\
\hline CHEMBL1331211 & 688612 & 4.05 & 4.6485 & TRN & \\
\hline CHEMBL1382036 & 688612 & 4.0 & 4.6517 & TST & \\
\hline CHEMBL1565196 & 688612 & 4.6 & 4.5727 & TST & \\
\hline CHEMBL1487674 & 688612 & 4.45 & 4.6734 & TRN & \\
\hline CHEMBL1981770 & 688612 & 5.1 & 4.7365 & TRN & \\
\hline CHEMBL1325162 & 688612 & 5.0 & 4.7159 & TRN & \\
\hline CHEMBL1337204 & 688612 & 4.1 & 4.5109 & TRN & \\
\hline CHEMBL1386264 & 688612 & 4.0 & 4.6154 & TRN & \\
\hline CHEMBL1363104 & 688612 & 4.7 & 4.7129 & TRN & \\
\hline CHEMBL1328733 & 688612 & 5.0 & 4.8062 & TRN & \\
\hline CHEMBL1377708 & 688612 & 4.75 & 4.7038 & TRN & \\
\hline CHEMBL3208242 & 688612 & 4.7 & 4.5878 & TST & \\
\hline CHEMBL1378470 & 688612 & 6.8499 & 4.6777 & TST & \\
\hline CHEMBL1433302 & 688612 & 4.0 & 4.668 & TRN & \\
\hline CHEMBL1539123 & 688612 & 4.75 & 4.6888 & TRN & \\
\hline CHEMBL327209 & 688612 & 4.55 & 4.816 & TRN & \\
\hline CHEMBL1596685 & 688612 & 4.1 & 4.558 & TRN & \\
\hline CHEMBL1552039 & 688612 & 4.35 & 4.5954 & TRN & \\
\hline CHEMBL1456143 & 688612 & 4.3 & 4.7237 & TRN & \\
\hline CHEMBL1318353 & 688612 & 4.2 & 4.6559 & TST & \\
\hline CHEMBL1457215 & 688612 & 4.1 & 4.6474 & TRN & \\
\hline CHEMBL1488916 & 688612 & 4.2 & 4.6631 & TRN & \\
\hline CHEMBL1336933 & 688612 & 6.0 & 4.6442 & TST & \\
\hline CHEMBL1396663 & 688612 & 4.1 & 4.6595 & TRN & \\
\hline CHEMBL1540272 & 688612 & 5.1 & 4.6624 & TRN & \\
\hline CHEMBL1981058 & 688612 & 4.7 & 4.6419 & TRN & \\
\hline CHEMBL3191651 & 688612 & 4.0 & 4.746 & TRN & \\
\hline CHEMBL1347435 & 688612 & 4.6 & 4.6555 & TST & \\
\hline CHEMBL1417631 & 688612 & 4.3 & 4.6372 & TRN & \\
\hline CHEMBL1477607 & 688612 & 4.05 & 4.5848 & TRN & \\
\hline CHEMBL1603687 & 688612 & 4.1 & 4.6293 & TRN & \\
\hline CHEMBL1472131 & 688612 & 4.3 & 4.6598 & TRN & \\
\hline CHEMBL1592006 & 688612 & 4.6 & 4.624 & TRN & \\
\hline CHEMBL1350705 & 688612 & 4.6 & 4.695 & TRN & \\
\hline CHEMBL1562780 & 688612 & 4.1 & 4.605 & TRN & \\
\hline CHEMBL1585500 & 688612 & 6.35 & 4.6756 & TRN & \\
\hline CHEMBL1410809 & 688612 & 4.1 & 4.6135 & TRN & \\
\hline CHEMBL1564831 & 688612 & 4.05 & 4.5762 & TRN & \\
\hline CHEMBL1465513 & 688612 & 4.25 & 4.6595 & TRN & \\
\hline CHEMBL1543621 & 688612 & 5.3 & 4.7002 & TRN & \\
\hline CHEMBL1416591 & 688612 & 4.9 & 4.6617 & TST & \\
\hline
\end{tabular}




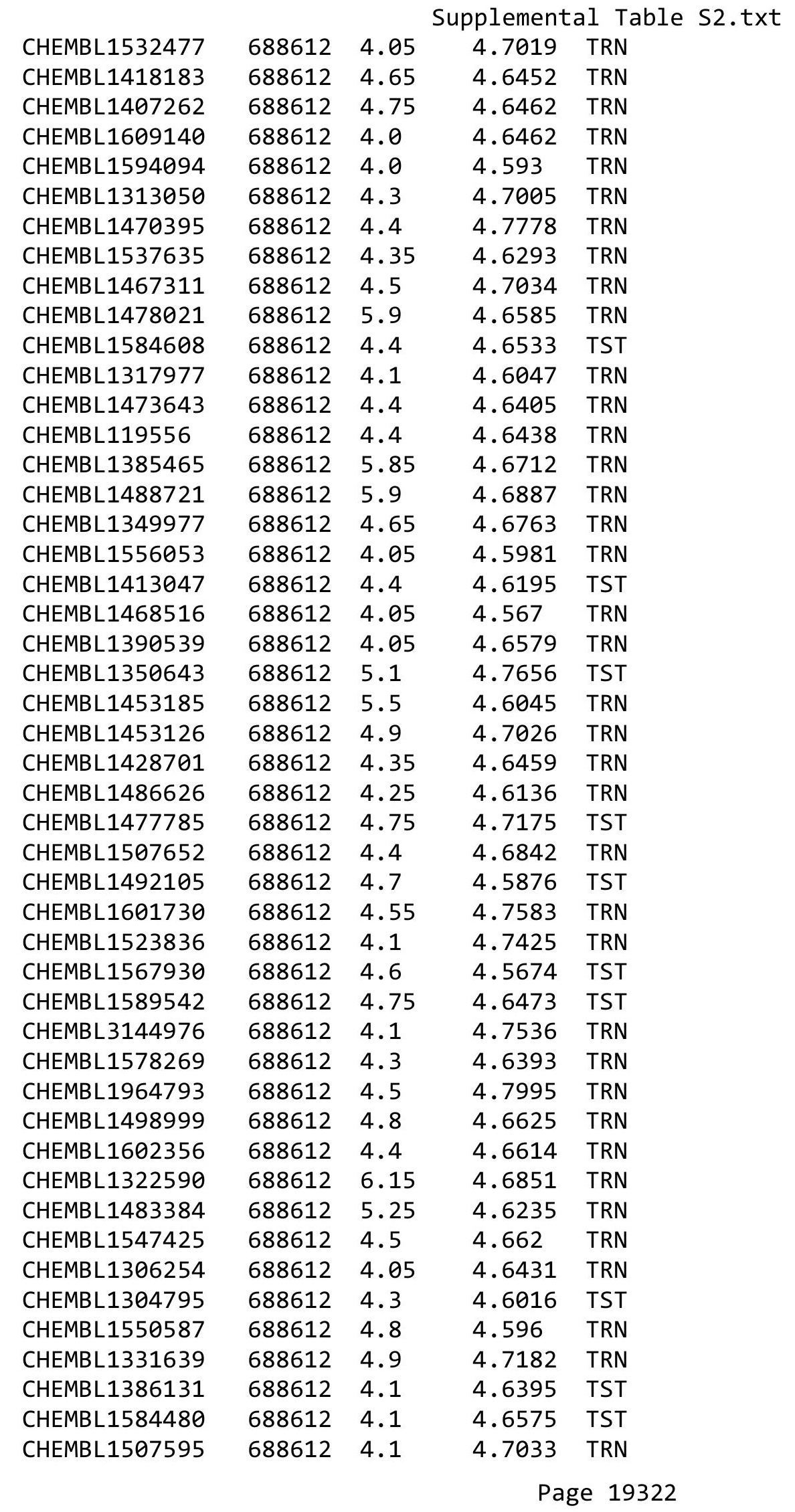




\begin{tabular}{|c|c|c|c|c|}
\hline \multicolumn{5}{|c|}{ Supplemental Table S2.txt } \\
\hline CHEMBL1372605 & 688612 & 4.65 & 4.6316 & TRN \\
\hline CHEMBL1320223 & 688612 & 7.0 & 4.6742 & TRN \\
\hline CHEMBL1299269 & 688612 & 6.8 & 4.7039 & TST \\
\hline CHEMBL1420020 & 688612 & 4.0 & 4.6724 & TST \\
\hline CHEMBL3199290 & 688612 & 4.4 & 4.7456 & TST \\
\hline CHEMBL1326619 & 688612 & 4.05 & 4.6849 & TST \\
\hline CHEMBL1485730 & 688612 & 4.05 & 4.6282 & TST \\
\hline CHEMBL1497198 & 688612 & 4.05 & 4.6478 & TRN \\
\hline CHEMBL3197798 & 688612 & 4.7 & 4.7092 & TRN \\
\hline CHEMBL1521415 & 688612 & 6.3 & 4.6105 & TRN \\
\hline CHEMBL1448837 & 688612 & 4.1 & 4.7059 & TRN \\
\hline CHEMBL1597961 & 688612 & 4.0 & 4.6172 & TRN \\
\hline CHEMBL1400764 & 688612 & 4.7 & 4.6851 & TRN \\
\hline CHEMBL1526609 & 688612 & 4.1 & 4.6463 & TST \\
\hline CHEMBL1570172 & 688612 & 5.25 & 4.6699 & TRN \\
\hline CHEMBL1566601 & 688612 & 4.4 & 4.7005 & TRN \\
\hline CHEMBL1331352 & 688612 & 4.05 & 4.6257 & TRN \\
\hline CHEMBL1580198 & 688612 & 4.6 & 4.6861 & TRN \\
\hline CHEMBL577938 & 688612 & 4.4 & 4.8035 & TRN \\
\hline CHEMBL1336446 & 688612 & 4.0 & 4.7376 & TRN \\
\hline CHEMBL1463470 & 688612 & 4.6 & 4.7066 & TST \\
\hline CHEMBL1550429 & 688612 & 5.0 & 4.6378 & TRN \\
\hline CHEMBL1424663 & 688612 & 4.4 & 4.7204 & TST \\
\hline CHEMBL1965254 & 688612 & 5.5 & 4.6694 & TST \\
\hline CHEMBL1604357 & 688612 & 5.5 & 4.6973 & TRN \\
\hline CHEMBL1331597 & 688612 & 4.4 & 4.6713 & TST \\
\hline CHEMBL1389985 & 688612 & 4.05 & 4.6727 & TRN \\
\hline CHEMBL3213714 & 688612 & 4.1 & 4.6199 & TST \\
\hline CHEMBL1303477 & 688612 & 4.35 & 4.7281 & TRN \\
\hline CHEMBL1357797 & 688612 & 4.8 & 4.6019 & TRN \\
\hline CHEMBL1576137 & 688612 & 4.05 & 4.6601 & TRN \\
\hline CHEMBL1380719 & 688612 & 4.4 & 4.5985 & TRN \\
\hline CHEMBL1504655 & 688612 & 5.4 & 4.7077 & TST \\
\hline CHEMBL1541933 & 688612 & 5.0 & 4.7781 & TRN \\
\hline CHEMBL1332744 & 688612 & 5.05 & 4.6225 & TST \\
\hline CHEMBL1431081 & 688612 & 4.4 & 4.69 & TRN \\
\hline CHEMBL 1483416 & 688612 & 6.15 & 4.6513 & TST \\
\hline CHEMBL1527691 & 688612 & 4.4 & 4.7655 & TRN \\
\hline CHEMBL1508433 & 688612 & 6.0 & 4.7618 & TRN \\
\hline CHEMBL1331839 & 688612 & 4.1 & 4.6767 & TST \\
\hline CHEMBL1433965 & 688612 & 4.0 & 4.6569 & TRN \\
\hline CHEMBL1498053 & 688612 & 4.1 & 4.6749 & TRN \\
\hline CHEMBL1357585 & 688612 & 6.8499 & 4.7054 & TRN \\
\hline CHEMBL1340118 & 688612 & 4.05 & 4.5366 & TRN \\
\hline CHEMBL1559732 & 688612 & 4.1 & 4.6734 & TST \\
\hline CHEMBL1367845 & 688612 & 6.35 & 4.6249 & TRN \\
\hline CHEMBL1540212 & 688612 & 4.05 & 4.6468 & TRN \\
\hline CHEMBL1338887 & 688612 & 4.1 & 4.5824 & TRN \\
\hline
\end{tabular}




\begin{tabular}{|c|c|c|c|c|c|}
\hline \multicolumn{6}{|c|}{ Supplemental Table S2.txt } \\
\hline CHEMBL1543513 & 688612 & 4.8 & 4.7775 & TRN & \\
\hline CHEMBL1456177 & 688612 & 4.05 & 4.69300 & 00000000005 & TRN \\
\hline CHEMBL1508996 & 688612 & 4.05 & 4.7053 & TRN & \\
\hline CHEMBL1374841 & 688612 & 4.7 & 4.7062 & TRN & \\
\hline CHEMBL1357748 & 688612 & 4.0 & 4.6654 & TST & \\
\hline CHEMBL398282 & 688612 & 4.0 & 4.752 & TRN & \\
\hline CHEMBL1478446 & 688612 & 4.05 & 4.6358 & TRN & \\
\hline CHEMBL1545530 & 688612 & 5.05 & 4.7321 & TRN & \\
\hline CHEMBL1497920 & 688612 & 4.1 & 4.6221 & TRN & \\
\hline CHEMBL1488386 & 688612 & 4.45 & 4.7002 & TRN & \\
\hline CHEMBL1408356 & 688612 & 4.0 & 4.6152 & TRN & \\
\hline CHEMBL1505130 & 688612 & 6.3 & 4.6869 & TRN & \\
\hline CHEMBL1355286 & 688612 & 4.2 & 4.6178 & TST & \\
\hline CHEMBL1612556 & 688612 & 4.8 & 4.6538 & TRN & \\
\hline CHEMBL1502648 & 688612 & 4.1 & 4.6998 & TRN & \\
\hline CHEMBL1324894 & 688612 & 4.3 & 4.7324 & TRN & \\
\hline CHEMBL1341091 & 688612 & 4.05 & 4.6155 & TST & \\
\hline CHEMBL1478722 & 688612 & 4.2 & 4.7088 & TRN & \\
\hline CHEMBL604311 & 688612 & 4.4 & 4.6823 & TRN & \\
\hline CHEMBL1579292 & 688612 & 4.05 & 4.7258 & TRN & \\
\hline CHEMBL1533296 & 688612 & 6.05 & 4.6747 & TRN & \\
\hline CHEMBL1568835 & 688612 & 4.5 & 4.6803 & TRN & \\
\hline CHEMBL1485559 & 688612 & 6.8499 & 4.6539 & TRN & \\
\hline CHEMBL1606874 & 688612 & 4.1 & 4.75899 & 99999999995 & TRN \\
\hline CHEMBL1353406 & 688612 & 4.2 & 4.737 & TST & \\
\hline CHEMBL1572789 & 688612 & 4.35 & 4.6881 & TRN & \\
\hline CHEMBL1598617 & 688612 & 4.05 & 4.7146 & TST & \\
\hline CHEMBL1533153 & 688612 & 4.7 & 4.7674 & TRN & \\
\hline CHEMBL 3194804 & 688612 & 4.05 & 4.6018 & TRN & \\
\hline CHEMBL1563367 & 688612 & 6.5501 & 4.6797 & TRN & \\
\hline CHEMBL1447403 & 688612 & 4.05 & 4.8077 & TST & \\
\hline CHEMBL1547667 & 688612 & 4.75 & 4.6076 & TRN & \\
\hline CHEMBL1380781 & 688612 & 4.0 & 4.6384 & TST & \\
\hline CHEMBL1308975 & 688612 & 4.15 & 4.6473 & TST & \\
\hline CHEMBL1469521 & 688612 & 6.0 & 4.7261 & TST & \\
\hline CHEMBL1497408 & 688612 & 4.0 & 4.6405 & TRN & \\
\hline CHEMBL1351375 & 688612 & 6.25 & 4.789 & TRN & \\
\hline CHEMBL1544973 & 688612 & 4.05 & 4.6851 & TST & \\
\hline CHEMBL 2000877 & 688612 & 5.1 & 4.6969 & TRN & \\
\hline CHEMBL1313672 & 688612 & 4.1 & 4.6414 & TST & \\
\hline CHEMBL3189394 & 688612 & 4.6 & 4.7175 & TRN & \\
\hline CHEMBL334378 & 688612 & 4.55 & 4.7112 & TST & \\
\hline CHEMBL1407224 & 688612 & 4.4 & 4.63399 & 99999999995 & TRN \\
\hline CHEMBL1336276 & 688612 & 4.6 & 4.6056 & TRN & \\
\hline CHEMBL1465404 & 688612 & 5.75 & 4.6808 & TRN & \\
\hline CHEMBL1423181 & 688612 & 4.05 & 4.6718 & TRN & \\
\hline CHEMBL1400557 & 688612 & 4.8 & 4.6524 & TRN & \\
\hline CHEMBL1978817 & 688612 & 4.3 & 4.6434 & TRN & \\
\hline
\end{tabular}




\begin{tabular}{|c|c|c|c|c|c|}
\hline \multirow{3}{*}{$\begin{array}{l}\text { CHEMBL1403741 } \\
\text { CHEMBL1979849 }\end{array}$} & \multirow{3}{*}{$\begin{array}{l}688612 \\
688612\end{array}$} & \multicolumn{4}{|c|}{ Supplemental Table S2.txt } \\
\hline & & 4.65 & 4.73606 & 0000000001 & TRN \\
\hline & & 6.5501 & 4.7443 & TRN & \\
\hline CHEMBL1581468 & 688612 & 4.05 & 4.8023 & TST & \\
\hline CHEMBL1423386 & 688612 & 4.15 & 4.6713 & TRN & \\
\hline CHEMBL1302871 & 688612 & 5.7 & 4.6549 & TRN & \\
\hline CHEMBL 3145161 & 688612 & 4.6 & 4.7225 & TRN & \\
\hline CHEMBL1384624 & 688612 & 4.6 & 4.7181 & TRN & \\
\hline CHEMBL1423320 & 688612 & 4.8 & 4.6908 & TST & \\
\hline CHEMBL1360353 & 688612 & 4.6 & 4.6074 & TRN & \\
\hline CHEMBL1506757 & 688612 & 4.05 & 4.7146 & TST & \\
\hline CHEMBL1328108 & 688612 & 5.35 & 4.6539 & TRN & \\
\hline CHEMBL1328624 & 688612 & 4.05 & 4.7076 & TST & \\
\hline CHEMBL1408090 & 688612 & 4.25 & 4.7434 & TRN & \\
\hline CHEMBL1583390 & 688612 & 4.6 & 4.691 & TRN & \\
\hline CHEMBL1305239 & 688612 & 4.35 & 4.6909 & TST & \\
\hline CHEMBL1564363 & 688612 & 4.75 & 4.6882 & TST & \\
\hline CHEMBL1501290 & 688612 & 5.25 & 4.6221 & TRN & \\
\hline CHEMBL1447205 & 688612 & 5.0 & 4.7249 & TST & \\
\hline CHEMBL1453433 & 688612 & 4.1 & 4.6872 & TRN & \\
\hline CHEMBL1330740 & 688612 & 4.4 & 4.709 & TST & \\
\hline CHEMBL1333804 & 688612 & 4.0 & 4.6931 & TRN & \\
\hline CHEMBL3198816 & 688612 & 4.6 & 4.7894 & TRN & \\
\hline CHEMBL1545245 & 688612 & 6.8 & 4.6249 & TRN & \\
\hline CHEMBL1504403 & 688612 & 4.1 & 4.6404 & TRN & \\
\hline CHEMBL1317663 & 688612 & 4.05 & 4.6346 & TRN & \\
\hline CHEMBL1372727 & 688612 & 6.1 & 4.6056 & TRN & \\
\hline CHEMBL1535384 & 688612 & 4.1 & 4.6243 & TST & \\
\hline CHEMBL1574830 & 688612 & 4.35 & 4.7423 & TRN & \\
\hline CHEMBL1588786 & 688612 & 4.45 & 4.7294 & TRN & \\
\hline CHEMBL1437962 & 688612 & 4.45 & 4.7117 & TST & \\
\hline CHEMBL1447278 & 688612 & 4.05 & 4.7443 & TRN & \\
\hline CHEMBL1349887 & 688612 & 4.05 & 4.6685 & TRN & \\
\hline CHEMBL1604580 & 688612 & 4.1 & 4.7288 & TRN & \\
\hline CHEMBL1383003 & 688612 & 4.15 & 4.7463 & TST & \\
\hline CHEMBL1586235 & 688612 & 4.3 & 4.7293 & TRN & \\
\hline CHEMBL1486207 & 688612 & 4.4 & 4.6439 & TRN & \\
\hline CHEMBL3195219 & 688612 & 4.1 & 4.6423 & TRN & \\
\hline CHEMBL1482513 & 688612 & 4.6 & 4.7336 & TRN & \\
\hline CHEMBL3196534 & 688612 & 4.1 & 4.7196 & TRN & \\
\hline CHEMBL1594936 & 688612 & 5.0 & 4.7184 & TST & \\
\hline CHEMBL1978358 & 688612 & 4.5 & 4.6955 & TRN & \\
\hline CHEMBL1547825 & 688612 & 4.9 & 4.6313 & TRN & \\
\hline CHEMBL3193609 & 688612 & 4.1 & 4.6339 & TRN & \\
\hline CHEMBL1351417 & 688612 & 6.8499 & 4.6801 & TRN & \\
\hline CHEMBL1409877 & 688612 & 4.4 & 4.6191 & TST & \\
\hline CHEMBL1342492 & 688612 & 4.45 & 4.7061 & TRN & \\
\hline CHEMBL1459864 & 688612 & 4.35 & 4.7035 & TRN & \\
\hline CHEMBL1413939 & 688612 & 4.05 & 4.7226 & TST & \\
\hline
\end{tabular}




\begin{tabular}{|c|c|c|c|c|c|}
\hline & & \multicolumn{4}{|c|}{ Supplemental Table S2.txt } \\
\hline CHEMBL1437275 & 688612 & 5.05 & 4.6617 & TRN & \\
\hline CHEMBL1584691 & 688612 & 4.5 & 4.6803 & TRN & \\
\hline CHEMBL1590798 & 688612 & 5.3 & 4.6148 & TST & \\
\hline CHEMBL1319676 & 688612 & 5.05 & 4.6688 & TRN & \\
\hline CHEMBL1492599 & 688612 & 6.15 & 4.6402 & TRN & \\
\hline CHEMBL1612406 & 688612 & 4.75 & 4.6886 & TST & \\
\hline CHEMBL1305218 & 688612 & 4.05 & 4.668 & TST & \\
\hline CHEMBL1315254 & 688612 & 4.2 & 4.7192 & TRN & \\
\hline CHEMBL1576239 & 688612 & 4.9 & 4.7144 & TRN & \\
\hline CHEMBL 2369275 & 688612 & 4.55 & 4.7376 & TRN & \\
\hline CHEMBL1308999 & 688612 & 4.45 & 4.6941 & TRN & \\
\hline CHEMBL3196980 & 688612 & 4.5 & 4.6503 & TRN & \\
\hline CHEMBL521762 & 688612 & 4.95 & 4.7123 & TRN & \\
\hline CHEMBL 1454365 & 688612 & 5.5 & 4.6835 & TRN & \\
\hline CHEMBL1396725 & 688612 & 5.85 & 4.6757 & TRN & \\
\hline CHEMBL1610461 & 688612 & 4.05 & 4.7569 & TRN & \\
\hline CHEMBL1329177 & 688612 & 4.0 & 4.606 & TRN & \\
\hline CHEMBL1528574 & 688612 & 4.1 & 4.7811 & TST & \\
\hline CHEMBL1391459 & 688612 & 6.0 & 4.6561 & TRN & \\
\hline CHEMBL119171 & 688612 & 6.8 & 4.7431 & TRN & \\
\hline CHEMBL1473165 & 688612 & 4.4 & 4.6943 & TST & \\
\hline CHEMBL1434365 & 688612 & 4.85 & 4.7078 & TRN & \\
\hline CHEMBL1497419 & 688612 & 4.0 & 4.7305 & TRN & \\
\hline CHEMBL1509986 & 688612 & 4.05 & 4.5895 & TRN & \\
\hline CHEMBL1525946 & 688612 & 4.05 & 4.6993 & TST & \\
\hline CHEMBL1485243 & 688612 & 4.6 & 4.6746 & TRN & \\
\hline CHEMBL1343827 & 688612 & 4.05 & 4.6547 & TRN & \\
\hline CHEMBL1384911 & 688612 & 4.4 & 4.6309 & TRN & \\
\hline CHEMBL1402658 & 688612 & 4.05 & 4.6713 & TRN & \\
\hline CHEMBL1458368 & 688612 & 4.4 & 4.65300 & 00000000005 & TRN \\
\hline CHEMBL3210300 & 688612 & 4.4 & 4.6501 & TRN & \\
\hline CHEMBL1407294 & 688612 & 5.45 & 4.6309 & TRN & \\
\hline CHEMBL1553807 & 688612 & 6.0 & 4.65 & TRN & \\
\hline CHEMBL1979367 & 688612 & 4.1 & 4.7465 & TRN & \\
\hline CHEMBL1600825 & 688612 & 4.4 & 4.7003 & TST & \\
\hline CHEMBL1312050 & 688612 & 4.3 & 4.6335 & TST & \\
\hline CHEMBL1538399 & 688612 & 4.25 & 4.6587 & TRN & \\
\hline CHEMBL1455226 & 688612 & 6.5 & 4.7694 & TRN & \\
\hline CHEMBL1451211 & 688612 & 4.1 & 4.6345 & TST & \\
\hline CHEMBL1581055 & 688612 & 5.4 & 4.6848 & TRN & \\
\hline CHEMBL1410534 & 688612 & 4.55 & 4.7369 & TRN & \\
\hline CHEMBL1353817 & 688612 & 4.45 & 4.7253 & TST & \\
\hline CHEMBL1531783 & 688612 & 4.4 & 4.6993 & TRN & \\
\hline CHEMBL1505412 & 688612 & 5.45 & 4.6957 & TST & \\
\hline CHEMBL1399109 & 688612 & 6.35 & 4.7519 & TRN & \\
\hline CHEMBL1451307 & 688612 & 4.35 & 4.76 & TRN & \\
\hline CHEMBL1412819 & 688612 & 4.25 & 4.7829 & TRN & \\
\hline CHEMBL 3214256 & 688612 & 5.1 & 4.7112 & TST & \\
\hline
\end{tabular}




\begin{tabular}{|c|c|c|c|c|}
\hline \multicolumn{5}{|c|}{ Supplemental Table S2.txt } \\
\hline CHEMBL1337181 & 688612 & 4.1 & 4.6738 & TRN \\
\hline CHEMBL1579209 & 688612 & 4.4 & 4.6965 & TRN \\
\hline CHEMBL1497931 & 688612 & 4.0 & 4.6303 & TST \\
\hline CHEMBL1389601 & 688612 & 5.0 & 4.6123 & TRN \\
\hline CHEMBL1543088 & 688612 & 4.1 & 4.6768 & TRN \\
\hline CHEMBL1418330 & 688612 & 4.05 & 4.6419 & TST \\
\hline CHEMBL1352121 & 688612 & 4.5 & 4.6504 & TRN \\
\hline CHEMBL1573928 & 688612 & 5.3 & 4.6329 & TRN \\
\hline CHEMBL1470259 & 688612 & 5.4 & 4.5941 & TRN \\
\hline CHEMBL1397396 & 688612 & 5.6 & 4.6695 & TRN \\
\hline CHEMBL1566812 & 688612 & 4.2 & 4.664 & TRN \\
\hline CHEMBL1369852 & 688612 & 4.1 & 4.6013 & TRN \\
\hline CHEMBL1364547 & 688612 & 4.35 & 4.6511 & TRN \\
\hline CHEMBL 3193581 & 688612 & 4.35 & 4.7588 & TRN \\
\hline CHEMBL1358338 & 688612 & 5.35 & 4.6474 & TRN \\
\hline CHEMBL1485164 & 688612 & 4.1 & 4.5935 & TRN \\
\hline CHEMBL1348610 & 688612 & 4.45 & 4.7253 & TST \\
\hline CHEMBL1545956 & 688612 & 5.4 & 4.6835 & TRN \\
\hline CHEMBL1497766 & 688612 & 6.25 & 4.664 & TRN \\
\hline CHEMBL1480763 & 688612 & 4.0 & 4.6239 & TRN \\
\hline CHEMBL1510100 & 688612 & 4.05 & 4.6088 & TRN \\
\hline CHEMBL1302335 & 688612 & 4.3 & 4.6604 & TRN \\
\hline CHEMBL1390497 & 688612 & 5.55 & 4.7275 & TRN \\
\hline CHEMBL1536649 & 688612 & 4.6 & 4.6856 & TRN \\
\hline CHEMBL1523972 & 688612 & 4.55 & 4.6926 & TST \\
\hline CHEMBL1575481 & 688612 & 4.05 & 4.6648 & TRN \\
\hline CHEMBL1322116 & 688612 & 4.05 & 4.7101 & TST \\
\hline CHEMBL1492642 & 688612 & 4.4 & 4.6797 & TRN \\
\hline CHEMBL1498575 & 688612 & 4.3 & 4.7547 & TRN \\
\hline CHEMBL1573380 & 688612 & 6.5 & 4.6093 & TRN \\
\hline CHEMBL1406237 & 688612 & 4.05 & 4.6572 & TST \\
\hline CHEMBL1332890 & 688612 & 4.45 & 4.7172 & TRN \\
\hline CHEMBL1556350 & 688612 & 4.75 & 4.675 & TRN \\
\hline CHEMBL1308363 & 688612 & 4.05 & 4.7494 & TRN \\
\hline CHEMBL1563317 & 688612 & 5.05 & 4.765 & TRN \\
\hline CHEMBL1593697 & 688612 & 4.95 & 4.8144 & TRN \\
\hline CHEMBL1393008 & 688612 & 4.7 & 4.7219 & TRN \\
\hline CHEMBL1335461 & 688612 & 4.4 & 4.7006 & TST \\
\hline CHEMBL1312340 & 688612 & 4.05 & 4.6083 & TRN \\
\hline CHEMBL1484717 & 688612 & 4.1 & 4.6884 & TRN \\
\hline CHEMBL1569568 & 688612 & 4.05 & 4.6293 & TRN \\
\hline CHEMBL1320181 & 688612 & 5.0 & 4.6679 & TRN \\
\hline CHEMBL1603086 & 688612 & 5.35 & 4.6866 & TRN \\
\hline CHEMBL1523051 & 688612 & 4.3 & 4.5981 & TRN \\
\hline CHEMBL1566980 & 688612 & 5.35 & 4.7296 & TST \\
\hline CHEMBL1402211 & 688612 & 4.1 & 4.7435 & TST \\
\hline CHEMBL1445192 & 688612 & 4.45 & 4.7331 & TRN \\
\hline CHEMBL1457533 & 688612 & 4.55 & 4.6326 & TRN \\
\hline
\end{tabular}




\begin{tabular}{|c|c|c|c|c|}
\hline \multicolumn{5}{|c|}{ Supplemental Table S2.txt } \\
\hline CHEMBL1452837 & 688612 & 4.4 & 4.6486 & TRN \\
\hline CHEMBL1492085 & 688612 & 4.05 & 4.6604 & TST \\
\hline CHEMBL1608446 & 688612 & 4.8 & 4.6252 & TRN \\
\hline CHEMBL1501104 & 688612 & 4.1 & 4.6102 & TRN \\
\hline CHEMBL1313227 & 688612 & 4.4 & 4.5818 & TRN \\
\hline CHEMBL1384208 & 688612 & 4.05 & 4.6874 & TRN \\
\hline CHEMBL1428274 & 688612 & 4.65 & 4.6224 & TRN \\
\hline CHEMBL275938 & 688612 & 7.6498 & 4.806 & TST \\
\hline CHEMBL1417056 & 688612 & 4.05 & 4.7054 & TRN \\
\hline CHEMBL1443422 & 688612 & 4.7 & 4.7208 & TRN \\
\hline CHEMBL1508782 & 688612 & 4.0 & 4.6149 & TRN \\
\hline CHEMBL1307485 & 688612 & 4.55 & 4.6717 & TST \\
\hline CHEMBL1363416 & 688612 & 4.3 & 4.6456 & TRN \\
\hline CHEMBL1502889 & 688612 & 4.05 & 4.6149 & TST \\
\hline CHEMBL1566935 & 688612 & 4.1 & 4.691 & TRN \\
\hline CHEMBL1990355 & 688612 & 4.45 & 4.7545 & TRN \\
\hline CHEMBL1601854 & 688612 & 4.7 & 4.6691 & TST \\
\hline CHEMBL1492590 & 688612 & 5.0 & 4.66 & TRN \\
\hline CHEMBL1403497 & 688612 & 5.05 & 4.7788 & TRN \\
\hline CHEMBL1389020 & 688612 & 5.0 & 4.6813 & TRN \\
\hline CHEMBL1572534 & 688612 & 5.25 & 4.7309 & TRN \\
\hline CHEMBL1485382 & 688612 & 5.95 & 4.6293 & TRN \\
\hline CHEMBL1387766 & 688612 & 4.2 & 4.6902 & TRN \\
\hline CHEMBL1483447 & 688612 & 4.5 & 4.6337 & TRN \\
\hline CHEMBL1358439 & 688612 & 5.95 & 4.684 & TRN \\
\hline CHEMBL1494607 & 688612 & 5.65 & 4.6293 & TRN \\
\hline CHEMBL1460092 & 688612 & 4.3 & 4.7771 & TRN \\
\hline CHEMBL1493570 & 688612 & 4.75 & 4.5819 & TRN \\
\hline CHEMBL1532470 & 688612 & 6.45 & 4.5926 & TST \\
\hline CHEMBL1340074 & 688612 & 4.05 & 4.5964 & TRN \\
\hline CHEMBL1500413 & 688612 & 4.05 & 4.6407 & TRN \\
\hline CHEMBL1318541 & 688612 & 4.9 & 4.6752 & TRN \\
\hline CHEMBL1359537 & 688612 & 4.75 & 4.7089 & TRN \\
\hline CHEMBL1340172 & 688612 & 4.6 & 4.7174 & TRN \\
\hline CHEMBL1481326 & 688612 & 5.3 & 4.6041 & TRN \\
\hline CHEMBL1433108 & 688612 & 4.8 & 4.6649 & TRN \\
\hline CHEMBL 3210593 & 688612 & 4.05 & 4.6954 & TST \\
\hline CHEMBL1996139 & 688612 & 5.05 & 4.7051 & TRN \\
\hline CHEMBL1363343 & 688612 & 4.0 & 4.6934 & TRN \\
\hline CHEMBL1599032 & 688612 & 4.05 & 4.6314 & TRN \\
\hline CHEMBL1427124 & 688612 & 4.05 & 4.6393 & TST \\
\hline CHEMBL1340391 & 688612 & 4.05 & 4.6825 & TRN \\
\hline CHEMBL1522351 & 688612 & 5.2 & 4.7236 & TRN \\
\hline CHEMBL3192169 & 688612 & 4.3 & 4.7442 & TST \\
\hline CHEMBL1355927 & 688612 & 5.5 & 4.6735 & TRN \\
\hline CHEMBL1548302 & 688612 & 5.1 & 4.6845 & TRN \\
\hline CHEMBL1427946 & 688612 & 4.05 & 4.6377 & TST \\
\hline CHEMBL1573731 & 688612 & 5.45 & 4.8502 & TRN \\
\hline
\end{tabular}




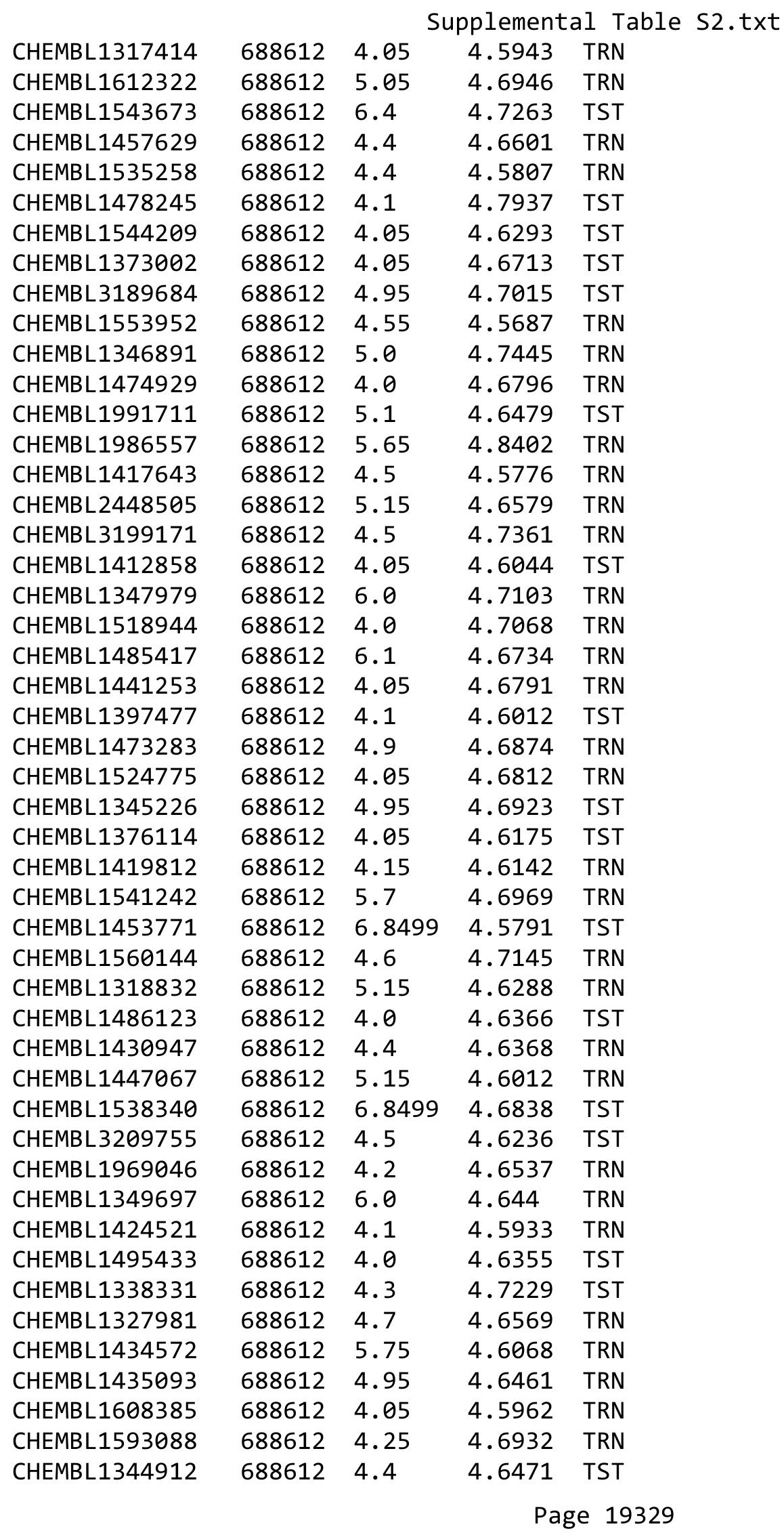




\begin{tabular}{|c|c|c|c|c|}
\hline \multicolumn{5}{|c|}{ Supplemental Table s2.txt } \\
\hline CHEMBL1331775 & 688612 & 6.0 & 4.7451 & TRN \\
\hline CHEMBL1322894 & 688612 & 4.6 & 4.7145 & TRN \\
\hline CHEMBL1492926 & 688612 & 4.8 & 4.7464 & TRN \\
\hline CHEMBL1533072 & 688612 & 6.8499 & 4.6443 & TST \\
\hline CHEMBL1579120 & 688612 & 4.8 & 4.6949 & TRN \\
\hline CHEMBL1340435 & 688612 & 4.0 & 4.6468 & TRN \\
\hline CHEMBL1582729 & 688612 & 4.0 & 4.6188 & TRN \\
\hline CHEMBL1430363 & 688612 & 4.0 & 4.6573 & TRN \\
\hline CHEMBL1393636 & 688612 & 5.95 & 4.6607 & TRN \\
\hline CHEMBL1313670 & 688612 & 6.8499 & 4.713 & TRN \\
\hline CHEMBL1611574 & 688612 & 4.4 & 4.6678 & TRN \\
\hline CHEMBL1531256 & 688612 & 4.35 & 4.7164 & TRN \\
\hline CHEMBL1559230 & 688612 & 5.35 & 4.6361 & TST \\
\hline CHEMBL1535962 & 688612 & 4.55 & 4.6252 & TRN \\
\hline CHEMBL1584249 & 688612 & 4.55 & 4.6514 & TRN \\
\hline CHEMBL1604460 & 688612 & 4.7 & 4.6065 & TRN \\
\hline CHEMBL1328627 & 688612 & 4.05 & 4.6078 & TRN \\
\hline CHEMBL1299315 & 688612 & 6.0 & 4.6496 & TST \\
\hline CHEMBL1599408 & 688612 & 4.5 & 4.7245 & TRN \\
\hline CHEMBL1611979 & 688612 & 5.7 & 4.626 & TRN \\
\hline CHEMBL1530993 & 688612 & 5.6 & 4.6372 & TRN \\
\hline CHEMBL1519409 & 688612 & 4.75 & 4.6612 & TRN \\
\hline CHEMBL1302260 & 688612 & 6.2 & 4.6483 & TST \\
\hline CHEMBL3198368 & 688612 & 4.6 & 4.6427 & TRN \\
\hline CHEMBL1499339 & 688612 & 6.95 & 4.65 & TST \\
\hline CHEMBL1458472 & 688612 & 4.1 & 4.7657 & TST \\
\hline CHEMBL1556542 & 688612 & 4.45 & 4.6174 & TRN \\
\hline CHEMBL1602335 & 688612 & 4.45 & 4.6595 & TST \\
\hline CHEMBL1564096 & 688612 & 4.1 & 4.5638 & TRN \\
\hline CHEMBL 3189373 & 688612 & 4.05 & 4.667 & TRN \\
\hline CHEMBL1321066 & 688612 & 6.6 & 4.7178 & TRN \\
\hline CHEMBL1539951 & 688612 & 5.3 & 4.6864 & TST \\
\hline CHEMBL1330055 & 688612 & 4.05 & 4.6049 & TST \\
\hline CHEMBL1331415 & 688612 & 4.5 & 4.772 & TRN \\
\hline CHEMBL1396999 & 688612 & 4.0 & 4.5426 & TRN \\
\hline CHEMBL1492607 & 688612 & 4.65 & 4.7374 & TRN \\
\hline CHEMBL1301784 & 688612 & 4.05 & 4.7279 & TST \\
\hline CHEMBL3211610 & 688612 & 6.35 & 4.6722 & TST \\
\hline CHEMBL1366152 & 688612 & 4.0 & 4.6955 & TRN \\
\hline CHEMBL1528031 & 688612 & 4.4 & 4.5497 & TRN \\
\hline CHEMBL1547205 & 688612 & 5.0 & 4.7196 & TST \\
\hline CHEMBL1332674 & 688612 & 6.3 & 4.6879 & TRN \\
\hline CHEMBL1606240 & 688612 & 5.5 & $4.6610 e$ & 00000000005 \\
\hline CHEMBL1437759 & 688612 & 4.45 & 4.6327 & TST \\
\hline CHEMBL3210223 & 688612 & 5.6 & 4.6675 & TRN \\
\hline CHEMBL1445585 & 688612 & 4.05 & 4.6099 & TST \\
\hline CHEMBL1422112 & 688612 & 4.3 & 4.6682 & TST \\
\hline CHEMBL1423773 & 688612 & 4.5 & 4.6754 & TST \\
\hline
\end{tabular}




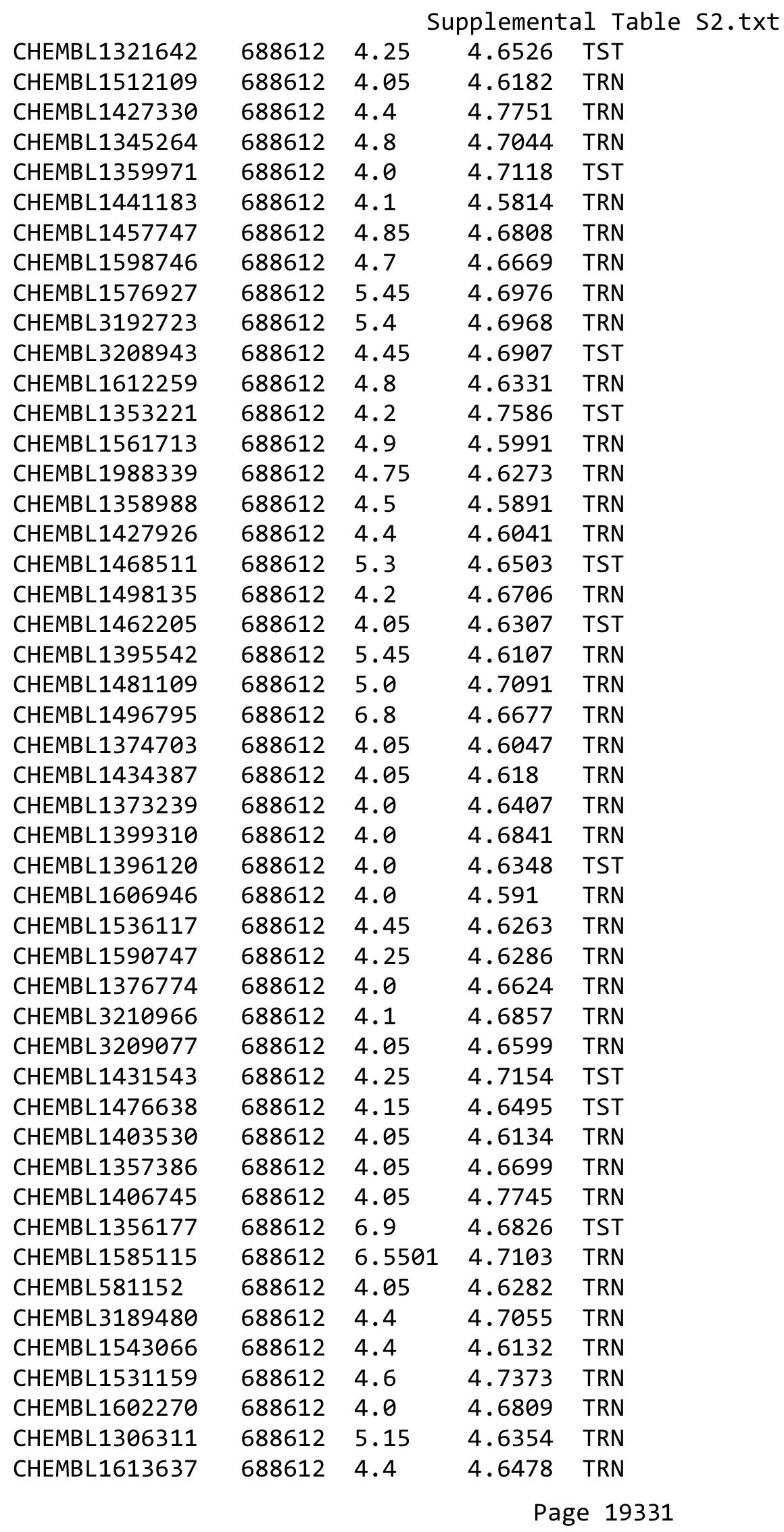




\begin{tabular}{|c|c|c|c|c|c|}
\hline \multicolumn{6}{|c|}{ Supplemental Table S2.txt } \\
\hline CHEMBL1472394 & 688612 & 4.8 & 4.6463 & TRN & \\
\hline CHEMBL1571122 & 688612 & 4.0 & 4.6544 & TRN & \\
\hline CHEMBL1530112 & 688612 & 4.65 & \multicolumn{2}{|c|}{ 4.718999999999999 } & TRN \\
\hline CHEMBL1336344 & 688612 & 4.2 & 4.6961 & TST & \\
\hline CHEMBL1331715 & 688612 & 4.1 & 4.6415 & TST & \\
\hline CHEMBL1453811 & 688612 & 4.8 & 4.7503 & TST & \\
\hline CHEMBL1489909 & 688612 & 4.35 & 4.6379 & TRN & \\
\hline CHEMBL3197755 & 688612 & 5.0 & 4.7157 & TRN & \\
\hline CHEMBL1408269 & 688612 & 4.25 & 4.6329 & TRN & \\
\hline CHEMBL1586621 & 688612 & 4.4 & 4.6696 & TST & \\
\hline CHEMBL1607260 & 688612 & 5.85 & 4.6061 & TRN & \\
\hline CHEMBL1508234 & 688612 & 6.5501 & 4.5767 & TRN & \\
\hline CHEMBL1486001 & 688612 & 4.65 & 4.6727 & TRN & \\
\hline CHEMBL1465946 & 688612 & 5.7 & 4.646 & TRN & \\
\hline CHEMBL1421833 & 688612 & 4.35 & 4.6432 & TRN & \\
\hline CHEMBL1588604 & 688612 & 4.05 & 4.7401 & TST & \\
\hline CHEMBL1338773 & 688612 & 4.65 & 4.6342 & TRN & \\
\hline CHEMBL1311680 & 688612 & 4.15 & 4.6098 & TST & \\
\hline CHEMBL1345044 & 688612 & 4.05 & 4.6916 & TST & \\
\hline CHEMBL1563165 & 688612 & 4.05 & 4.5632 & TRN & \\
\hline CHEMBL1608450 & 688612 & 6.0 & 4.6769 & TRN & \\
\hline CHEMBL1563996 & 688612 & 5.15 & 4.6664 & TRN & \\
\hline CHEMBL1330709 & 688612 & 4.45 & 4.6889 & TST & \\
\hline CHEMBL1510061 & 688612 & 4.0 & 4.6102 & TRN & \\
\hline CHEMBL 2002223 & 688612 & 5.5 & 4.6982 & TST & \\
\hline CHEMBL1439287 & 688612 & 4.2 & 4.5543 & TRN & \\
\hline CHEMBL1378397 & 688612 & 4.15 & 4.6679 & TRN & \\
\hline CHEMBL1535094 & 688612 & 4.2 & 4.6632 & TST & \\
\hline CHEMBL1311639 & 688612 & 4.4 & 4.6797 & TRN & \\
\hline CHEMBL1445484 & 688612 & 4.3 & 4.7052 & TST & \\
\hline CHEMBL1411221 & 688612 & 4.15 & 4.6138 & TRN & \\
\hline CHEMBL1519309 & 688612 & 4.15 & 4.6321 & TRN & \\
\hline CHEMBL1387426 & 688612 & 5.05 & 4.6612 & TRN & \\
\hline CHEMBL1368751 & 688612 & 4.05 & 4.6725 & TRN & \\
\hline CHEMBL1386339 & 688612 & 4.05 & 4.6698 & TRN & \\
\hline CHEMBL1453462 & 688612 & 4.05 & 4.6999 & TST & \\
\hline CHEMBL1489113 & 688612 & 4.0 & 4.6447 & TRN & \\
\hline CHEMBL1538223 & 688612 & 4.6 & 4.74100 & 00000000005 & TRN \\
\hline CHEMBL1492368 & 688612 & 4.9 & 4.7205 & TRN & \\
\hline CHEMBL1573186 & 688612 & 5.4 & 4.7954 & TRN & \\
\hline CHEMBL1550941 & 688612 & 4.0 & 4.7106 & TRN & \\
\hline CHEMBL1342406 & 688612 & 4.45 & 4.6799 & TRN & \\
\hline CHEMBL1594180 & 688612 & 6.1 & 4.6231 & TRN & \\
\hline CHEMBL1488685 & 688612 & 4.0 & 4.6925 & TRN & \\
\hline CHEMBL1523911 & 688612 & 4.4 & 4.7282 & TRN & \\
\hline CHEMBL3195512 & 688612 & 4.75 & 4.7669 & TRN & \\
\hline CHEMBL1454358 & 688612 & 4.6 & 4.6561 & TRN & \\
\hline \multirow[t]{2}{*}{ CHEMBL1519448 } & 688612 & 4.1 & 4.61100 & 000000 & TRN \\
\hline & & \multicolumn{4}{|c|}{ Page 19332} \\
\hline
\end{tabular}




\begin{tabular}{|c|c|c|c|c|c|}
\hline \multicolumn{6}{|c|}{ Supplemental Table s2.txt } \\
\hline CHEMBL1593338 & 688612 & 4.0 & 4.715 & TST & \\
\hline CHEMBL1432645 & 688612 & 5.3 & 4.6096 & TRN & \\
\hline CHEMBL1303681 & 688612 & 4.4 & 4.7784 & TST & \\
\hline CHEMBL1477262 & 688612 & 4.05 & 4.6883 & TST & \\
\hline CHEMBL1463041 & 688612 & 5.35 & 4.5997 & TRN & \\
\hline CHEMBL179024 & 688612 & 4.05 & 4.7144 & TRN & \\
\hline CHEMBL3192690 & 688612 & 5.45 & 4.7531 & TRN & \\
\hline CHEMBL1358182 & 688612 & 5.25 & 4.5834 & TRN & \\
\hline CHEMBL1431959 & 688612 & 4.1 & 4.7486 & TST & \\
\hline CHEMBL1604492 & 688612 & 4.1 & 4.7021 & TRN & \\
\hline CHEMBL1359931 & 688612 & 4.65 & 4.7165 & TRN & \\
\hline CHEMBL1508137 & 688612 & 4.0 & 4.6357 & TRN & \\
\hline CHEMBL1520205 & 688612 & 4.1 & 4.6104 & TST & \\
\hline CHEMBL1481633 & 688612 & 4.2 & 4.5646 & TRN & \\
\hline CHEMBL3193624 & 688612 & 4.4 & 4.7139 & TRN & \\
\hline CHEMBL 2006340 & 688612 & 4.85 & 4.6984 & TRN & \\
\hline CHEMBL1457865 & 688612 & 6.8499 & 4.7078 & TRN & \\
\hline CHEMBL1338878 & 688612 & 4.6 & 4.7171 & TST & \\
\hline CHEMBL1611967 & 688612 & 4.4 & 4.6668 & TRN & \\
\hline CHEMBL1321572 & 688612 & 5.5 & 4.7826 & TST & \\
\hline CHEMBL1398139 & 688612 & 4.4 & 4.668 & TST & \\
\hline CHEMBL1492001 & 688612 & 4.25 & 4.6678 & TRN & \\
\hline CHEMBL1515156 & 688612 & 4.2 & 4.628 & TST & \\
\hline CHEMBL1500831 & 688612 & 4.0 & 4.6478 & TRN & \\
\hline CHEMBL3197012 & 688612 & 4.1 & 4.73300 & 00000000005 & TRN \\
\hline CHEMBL1513475 & 688612 & 5.55 & 4.7162 & TRN & \\
\hline CHEMBL1408144 & 688612 & 4.05 & 4.6607 & TRN & \\
\hline CHEMBL1354517 & 688612 & 4.3 & 4.7553 & TRN & \\
\hline CHEMBL1522821 & 688612 & 4.95 & 4.7689 & TRN & \\
\hline CHEMBL1368506 & 688612 & 4.05 & 4.6659 & TRN & \\
\hline CHEMBL1345613 & 688612 & 5.3 & 4.691 & TRN & \\
\hline CHEMBL3193192 & 688612 & 5.1 & 4.6804 & TRN & \\
\hline CHEMBL1391882 & 688612 & 4.05 & 4.6267 & TRN & \\
\hline CHEMBL1450039 & 688612 & 4.05 & 4.6751 & TRN & \\
\hline CHEMBL1590392 & 688612 & 4.75 & 4.6592 & TRN & \\
\hline CHEMBL1377789 & 688612 & 4.1 & 4.6968 & TST & \\
\hline CHEMBL1500633 & 688612 & 4.05 & 4.7122 & TRN & \\
\hline CHEMBL3194330 & 688612 & 5.35 & 4.8621 & TRN & \\
\hline CHEMBL1329282 & 688612 & 4.4 & 4.6318 & TRN & \\
\hline CHEMBL1383575 & 688612 & 4.7 & 4.6688 & TRN & \\
\hline CHEMBL1344037 & 688612 & 4.05 & 4.6408 & TRN & \\
\hline CHEMBL 244965 & 688612 & 4.0 & 4.6336 & TST & \\
\hline CHEMBL1521230 & 688612 & 4.05 & 4.6262 & TRN & \\
\hline CHEMBL1481100 & 688612 & 4.05 & 4.6817 & TST & \\
\hline CHEMBL1598243 & 688612 & 4.5 & 4.6505 & TRN & \\
\hline CHEMBL1483610 & 688612 & 5.45 & 4.631 & TRN & \\
\hline CHEMBL1606647 & 688612 & 5.15 & 4.671 & TRN & \\
\hline CHEMBL1590014 & 688612 & 6.35 & 4.6424 & TRN & \\
\hline
\end{tabular}




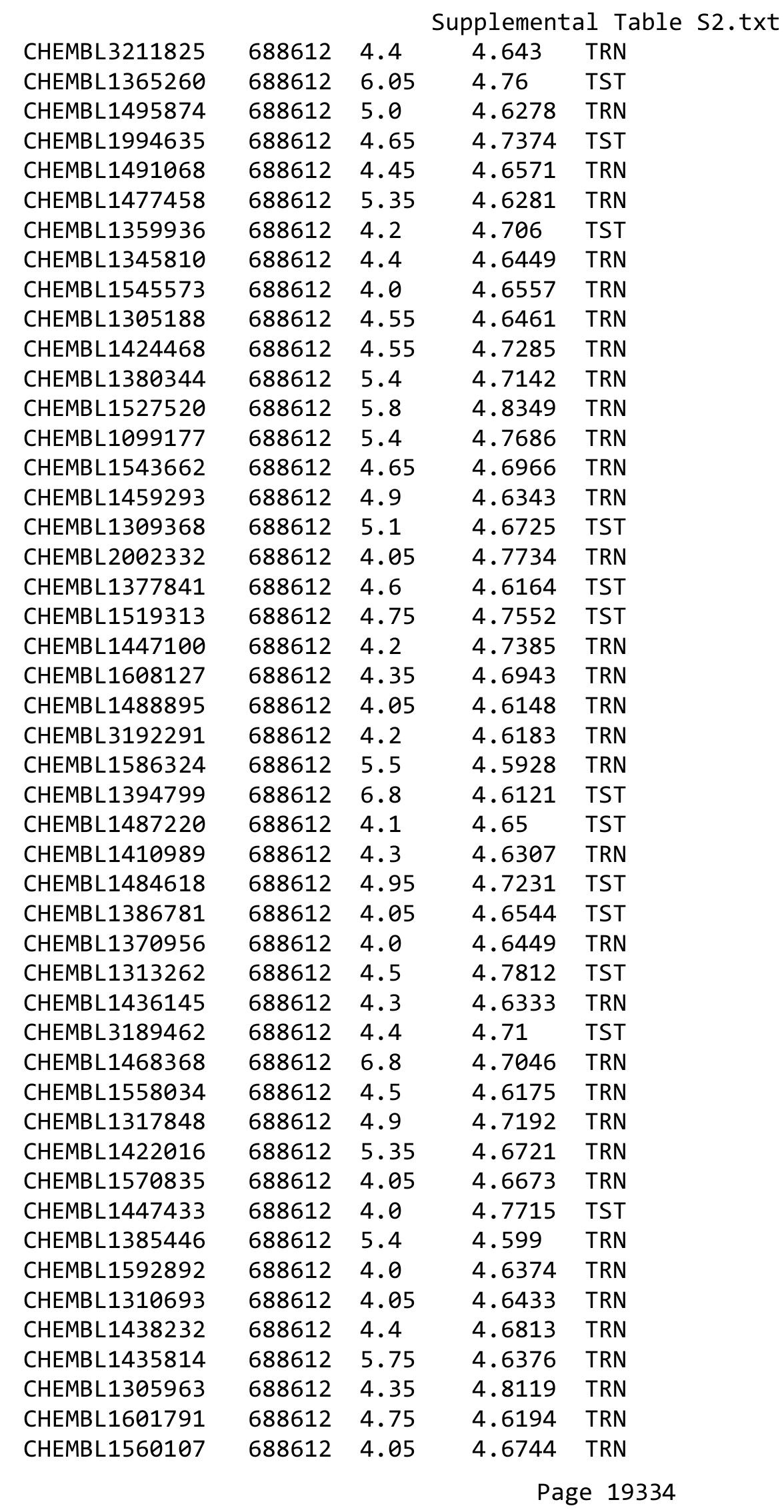




\begin{tabular}{|c|c|c|c|c|c|}
\hline \multicolumn{6}{|c|}{ Supplemental Table S2.txt } \\
\hline CHEMBL1486375 & 688612 & 4.4 & 4.5617 & TRN & \\
\hline CHEMBL1540666 & 688612 & 4.9 & 4.6483 & TRN & \\
\hline CHEMBL1480578 & 688612 & 4.1 & 4.6862 & TST & \\
\hline CHEMBL1566554 & 688612 & 4.25 & 4.6685 & TRN & \\
\hline CHEMBL1481766 & 688612 & 5.5 & 4.7067 & TRN & \\
\hline CHEMBL1399884 & 688612 & 4.7 & 4.658 & TRN & \\
\hline CHEMBL1384753 & 688612 & 4.1 & 4.564 & TST & \\
\hline CHEMBL1309881 & 688612 & 4.4 & 4.598 & TST & \\
\hline CHEMBL1599159 & 688612 & 5.0 & 4.6342 & TRN & \\
\hline CHEMBL3198501 & 688612 & 4.3 & 4.7665 & TRN & \\
\hline CHEMBL1498770 & 688612 & 4.1 & 4.6319 & TST & \\
\hline CHEMBL1600010 & 688612 & 4.1 & 4.6583 & TRN & \\
\hline CHEMBL1607347 & 688612 & 6.9 & 4.6461 & TRN & \\
\hline CHEMBL1407135 & 688612 & 4.1 & 4.7183 & TRN & \\
\hline CHEMBL1308702 & 688612 & 4.05 & 4.6199 & TRN & \\
\hline CHEMBL1338805 & 688612 & 4.75 & 4.6644 & TRN & \\
\hline CHEMBL1427879 & 688612 & 4.55 & 4.6666 & TRN & \\
\hline CHEMBL1366450 & 688612 & 4.05 & 4.6919 & TST & \\
\hline CHEMBL1480353 & 688612 & 4.05 & 4.6071 & TRN & \\
\hline CHEMBL1572112 & 688612 & 5.0 & 4.7989 & TRN & \\
\hline CHEMBL1336855 & 688612 & 5.8 & 4.6502 & TRN & \\
\hline CHEMBL1530848 & 688612 & 4.4 & 4.6115 & TRN & \\
\hline CHEMBL1463879 & 688612 & 4.6 & 4.7138 & TRN & \\
\hline CHEMBL1457439 & 688612 & 4.05 & 4.6836 & TST & \\
\hline CHEMBL1326582 & 688612 & 4.0 & 4.6405 & TST & \\
\hline CHEMBL1349813 & 688612 & 5.1 & 4.7606 & TRN & \\
\hline CHEMBL1507142 & 688612 & 6.7001 & 4.5914 & TRN & \\
\hline CHEMBL1605526 & 688612 & 4.8 & 4.7337 & TRN & \\
\hline CHEMBL1537727 & 688612 & 4.85 & 4.6508 & TST & \\
\hline CHEMBL1609285 & 688612 & 5.55 & 4.6882 & TST & \\
\hline CHEMBL1445503 & 688612 & 4.3 & 4.6644 & TRN & \\
\hline CHEMBL1456130 & 688612 & 4.65 & 4.6718 & TRN & \\
\hline CHEMBL592099 & 688612 & 4.1 & 4.5922 & TST & \\
\hline CHEMBL1529285 & 688612 & 4.45 & 4.65600 & 2000000001 & TRN \\
\hline CHEMBL1412590 & 688612 & 4.4 & 4.7184 & TRN & \\
\hline CHEMBL1435239 & 688612 & 4.6 & 4.7047 & TRN & \\
\hline CHEMBL1542453 & 688612 & 5.05 & 4.7462 & TRN & \\
\hline CHEMBL1608149 & 688612 & 4.65 & 4.6336 & TRN & \\
\hline CHEMBL1519554 & 688612 & 4.8 & 4.79 & TRN & \\
\hline CHEMBL1550661 & 688612 & 4.1 & 4.6519 & TST & \\
\hline CHEMBL2002162 & 688612 & 4.05 & 4.7471 & TST & \\
\hline CHEMBL116569 & 688612 & 4.7 & 4.7902 & TRN & \\
\hline CHEMBL1350915 & 688612 & 4.55 & 4.7351 & TRN & \\
\hline CHEMBL1584372 & 688612 & 4.0 & 4.6197 & TRN & \\
\hline CHEMBL1523846 & 688612 & 4.05 & 4.7431 & TRN & \\
\hline CHEMBL1356944 & 688612 & 5.9 & 4.627 & TRN & \\
\hline CHEMBL1438883 & 688612 & 5.4 & 4.6299 & TRN & \\
\hline CHEMBL1423322 & 688612 & 4.2 & 4.6724 & TRN & \\
\hline
\end{tabular}




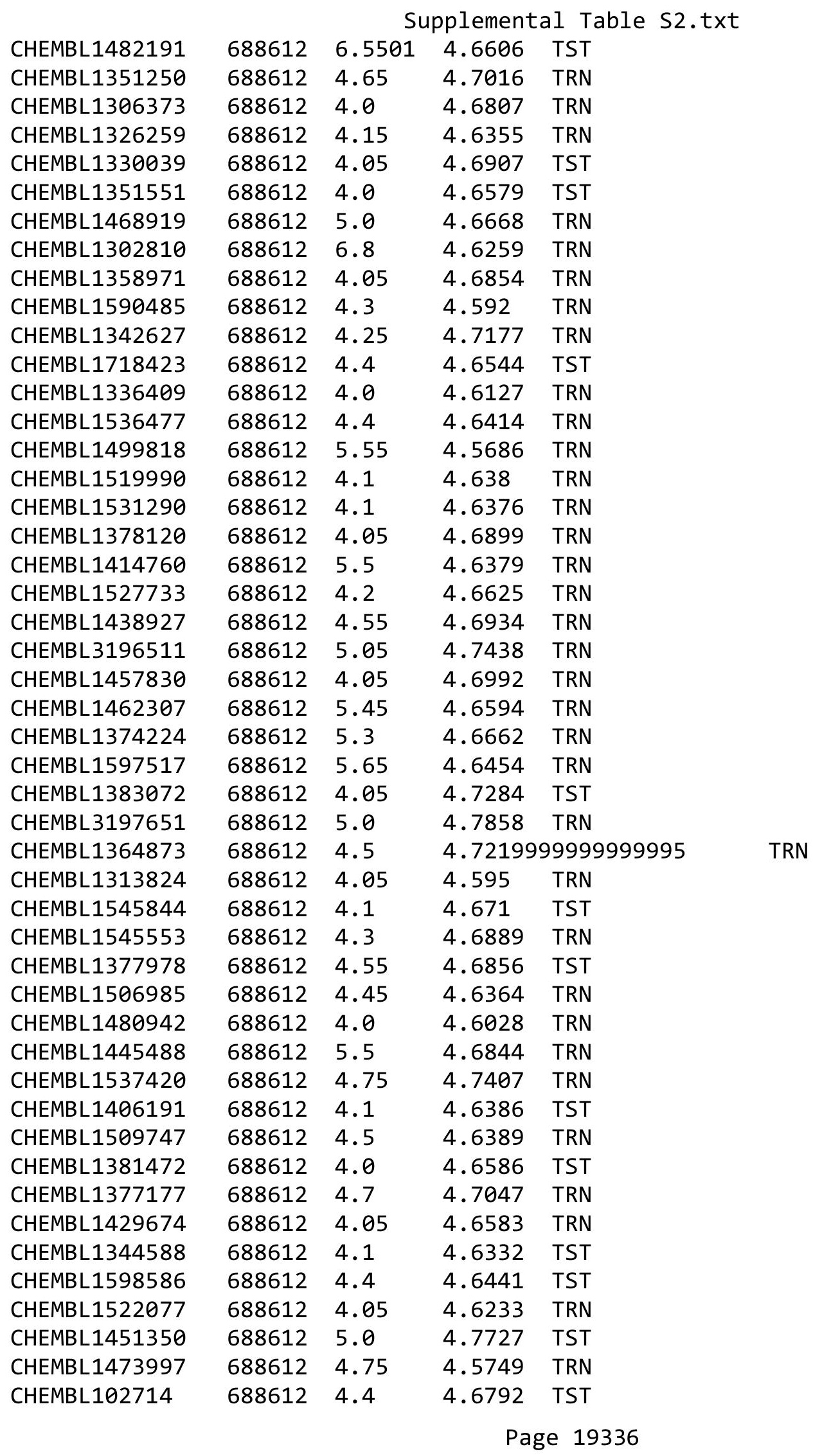




\begin{tabular}{|c|c|c|c|c|c|}
\hline & & \multicolumn{4}{|c|}{ Supplemental Table S2.txt } \\
\hline CHEMBL1406667 & 688612 & 4.75 & 4.6973 & TRN & \\
\hline CHEMBL1327091 & 688612 & 5.0 & 4.6871 & TST & \\
\hline CHEMBL1488387 & 688612 & 4.35 & 4.6588 & TRN & \\
\hline CHEMBL1506234 & 688612 & 4.15 & 4.7846 & TRN & \\
\hline CHEMBL1322598 & 688612 & 4.55 & 4.6295 & TRN & \\
\hline CHEMBL1334062 & 688612 & 4.5 & 4.7125 & TRN & \\
\hline CHEMBL3190093 & 688612 & 4.0 & 4.7007 & TST & \\
\hline CHEMBL1343585 & 688612 & 4.5 & 4.5733 & TRN & \\
\hline CHEMBL1350407 & 688612 & 4.05 & 4.6396 & TRN & \\
\hline CHEMBL1581365 & 688612 & 6.8499 & 4.6717 & TRN & \\
\hline CHEMBL1500600 & 688612 & 5.55 & 4.7916 & TRN & \\
\hline CHEMBL1581136 & 688612 & 4.05 & 4.6474 & TST & \\
\hline CHEMBL3193140 & 688612 & 4.1 & 4.6833 & TST & \\
\hline CHEMBL1562059 & 688612 & 4.0 & 4.6247 & TRN & \\
\hline CHEMBL1473417 & 688612 & 4.4 & 4.6466 & TST & \\
\hline CHEMBL1397424 & 688612 & 4.05 & 4.6697 & TST & \\
\hline CHEMBL1455546 & 688612 & 4.1 & 4.6506 & TST & \\
\hline CHEMBL1337986 & 688612 & 4.75 & 4.6902 & TRN & \\
\hline CHEMBL1528133 & 688612 & 4.55 & 4.6166 & TRN & \\
\hline CHEMBL1352827 & 688612 & 4.95 & 4.6621 & TRN & \\
\hline CHEMBL1302138 & 688612 & 6.6 & 4.6578 & TRN & \\
\hline CHEMBL3192701 & 688612 & 4.25 & 4.6576 & TST & \\
\hline CHEMBL1315620 & 688612 & 4.15 & 4.649 & TRN & \\
\hline CHEMBL1462388 & 688612 & 4.8 & 4.6706 & TRN & \\
\hline CHEMBL1597819 & 688612 & 4.05 & 4.6584 & TST & \\
\hline CHEMBL1379578 & 688612 & 4.0 & 4.6243 & TRN & \\
\hline CHEMBL1358748 & 688612 & 5.2 & 4.6367 & TRN & \\
\hline CHEMBL1577382 & 688612 & 4.0 & 4.6059 & TRN & \\
\hline CHEMBL1466457 & 688612 & 4.1 & 4.67399 & 99999999995 & TRN \\
\hline CHEMBL1528926 & 688612 & 4.45 & 4.6791 & TRN & \\
\hline CHEMBL3145086 & 688612 & 4.45 & 4.7225 & TST & \\
\hline CHEMBL1407434 & 688612 & 5.6 & $4.6080 e$ & 00000000005 & TRN \\
\hline CHEMBL1410406 & 688612 & 4.1 & 4.6121 & TRN & \\
\hline CHEMBL1304906 & 688612 & 4.0 & 4.644 & TRN & \\
\hline CHEMBL1522510 & 688612 & 4.1 & 4.6405 & TST & \\
\hline CHEMBL3196665 & 688612 & 6.8 & 4.6657 & TST & \\
\hline CHEMBL1507988 & 688612 & 4.6 & 4.6599 & TRN & \\
\hline CHEMBL1412782 & 688612 & 4.65 & 4.5897 & TRN & \\
\hline CHEMBL1430496 & 688612 & 4.05 & 4.7146 & TRN & \\
\hline CHEMBL1318691 & 688612 & 4.1 & 4.6351 & TST & \\
\hline CHEMBL1456906 & 688612 & 4.05 & 4.7459 & TST & \\
\hline CHEMBL1379712 & 688612 & 4.05 & 4.7296 & TRN & \\
\hline CHEMBL3211016 & 688612 & 4.0 & 4.703 & TST & \\
\hline CHEMBL3197870 & 688612 & 4.25 & 4.7327 & TRN & \\
\hline CHEMBL1410931 & 688612 & 4.8 & 4.6757 & TRN & \\
\hline CHEMBL3210625 & 688612 & 4.05 & 4.684 & TRN & \\
\hline CHEMBL1494308 & 688612 & 4.5 & 4.6455 & TRN & \\
\hline CHEMBL1543337 & 688612 & 5.4 & 4.7404 & TRN & \\
\hline
\end{tabular}




\begin{tabular}{|c|c|c|c|c|}
\hline \multicolumn{5}{|c|}{ Supplemental Table S2.txt } \\
\hline CHEMBL1459264 & 688612 & 4.4 & 4.7112 & TRN \\
\hline CHEMBL1372875 & 688612 & 4.35 & 4.7472 & TRN \\
\hline CHEMBL3211273 & 688612 & 4.05 & 4.7155 & TST \\
\hline CHEMBL1532812 & 688612 & 5.45 & 4.5788 & TRN \\
\hline CHEMBL1408448 & 688612 & 4.1 & 4.6846 & TST \\
\hline CHEMBL1571769 & 688612 & 4.15 & 4.6177 & TST \\
\hline CHEMBL1425888 & 688612 & 4.05 & 4.5733 & TRN \\
\hline CHEMBL1537871 & 688612 & 5.0 & 4.7065 & TRN \\
\hline CHEMBL1372249 & 688612 & 4.15 & 4.6828 & TST \\
\hline CHEMBL1502793 & 688612 & 4.0 & 4.6079 & TST \\
\hline CHEMBL1381046 & 688612 & 4.75 & 4.6214 & TRN \\
\hline CHEMBL1351608 & 688612 & 4.0 & 4.5441 & TRN \\
\hline CHEMBL1325852 & 688612 & 6.5501 & 4.6311 & TRN \\
\hline CHEMBL1577300 & 688612 & 5.5 & 4.721 & TRN \\
\hline CHEMBL3197282 & 688612 & 4.8 & 4.6587 & TRN \\
\hline CHEMBL1400490 & 688612 & 4.05 & 4.6975 & TRN \\
\hline CHEMBL1382050 & 688612 & 4.45 & 4.5921 & TST \\
\hline CHEMBL3212304 & 688612 & 4.9 & 4.8116 & TRN \\
\hline CHEMBL1602376 & 688612 & 4.5 & 4.7044 & TST \\
\hline CHEMBL1554767 & 688612 & 4.05 & 4.6652 & TST \\
\hline CHEMBL1469944 & 688612 & 4.0 & 4.595 & TRN \\
\hline CHEMBL1399821 & 688612 & 4.05 & 4.6236 & TRN \\
\hline CHEMBL1504850 & 688612 & 5.0 & 4.6513 & TRN \\
\hline CHEMBL1483591 & 688612 & 4.0 & 4.581 & TST \\
\hline CHEMBL1505815 & 688612 & 6.2 & 4.6083 & TRN \\
\hline CHEMBL1396432 & 688612 & 4.05 & 4.6462 & TRN \\
\hline CHEMBL3392069 & 688612 & 4.4 & 4.7251 & TST \\
\hline CHEMBL1486150 & 688612 & 4.05 & 4.6907 & TRN \\
\hline CHEMBL1415108 & 688612 & 4.3 & 4.7082 & TRN \\
\hline CHEMBL1334260 & 688612 & 5.35 & 4.6853 & TRN \\
\hline CHEMBL1409414 & 688612 & 4.5 & 4.7491 & TRN \\
\hline CHEMBL1423297 & 688612 & 4.55 & 4.6087 & TRN \\
\hline CHEMBL1566594 & 688612 & 5.5 & 4.6119 & TRN \\
\hline CHEMBL1331061 & 688612 & 6.5501 & 4.6434 & TRN \\
\hline CHEMBL3192270 & 688612 & 5.0 & 4.6761 & TRN \\
\hline CHEMBL1434513 & 688612 & 4.45 & 4.7989 & TRN \\
\hline CHEMBL1541456 & 688612 & 4.1 & 4.5888 & TRN \\
\hline CHEMBL1594642 & 688612 & 4.05 & 4.6536 & TRN \\
\hline CHEMBL1582311 & 688612 & 6.0 & 4.5963 & TRN \\
\hline CHEMBL1513412 & 688612 & 4.35 & 4.6825 & TRN \\
\hline CHEMBL1315493 & 688612 & 4.0 & 4.6316 & TRN \\
\hline CHEMBL1501995 & 688612 & 4.25 & 4.6276 & TRN \\
\hline CHEMBL1367567 & 688612 & 4.4 & 4.6335 & TRN \\
\hline CHEMBL1541205 & 688612 & 4.05 & 4.6452 & TRN \\
\hline CHEMBL1363689 & 688612 & 4.65 & 4.6701 & TRN \\
\hline CHEMBL1454435 & 688612 & 4.05 & 4.6513 & TRN \\
\hline CHEMBL1343030 & 688612 & 4.05 & 4.658 & TST \\
\hline CHEMBL1502583 & 688612 & 6.05 & 4.609 & TRN \\
\hline
\end{tabular}




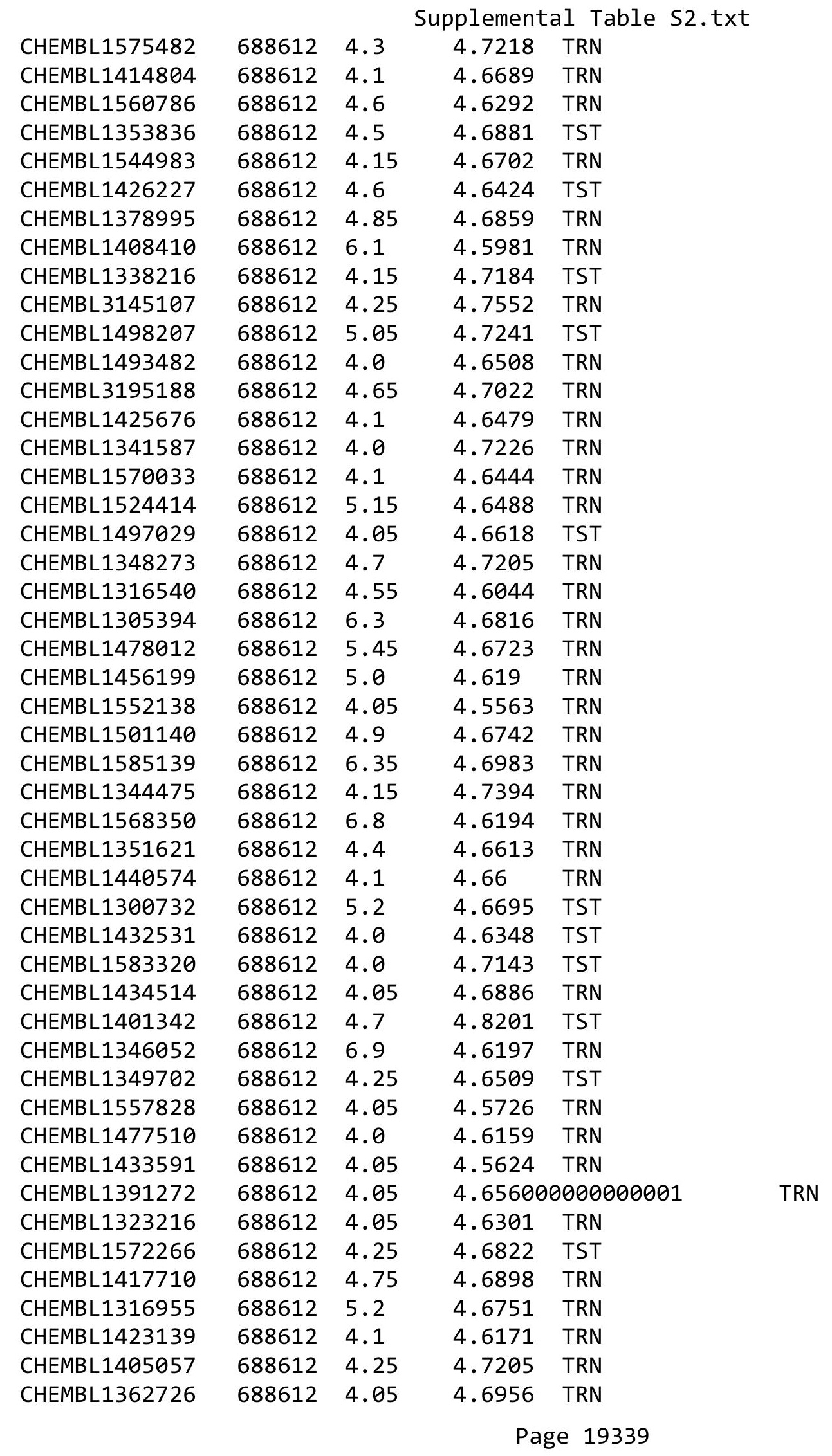




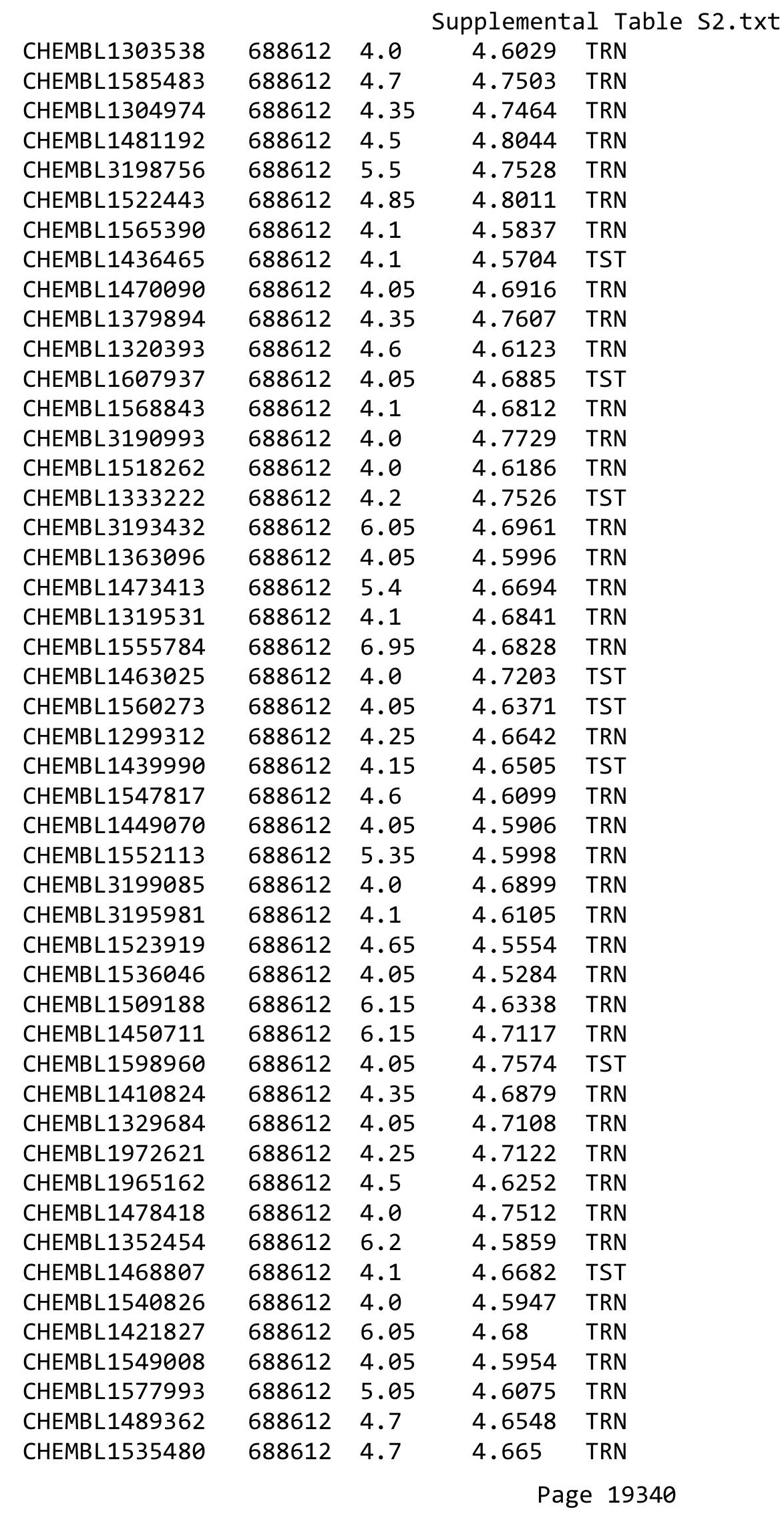




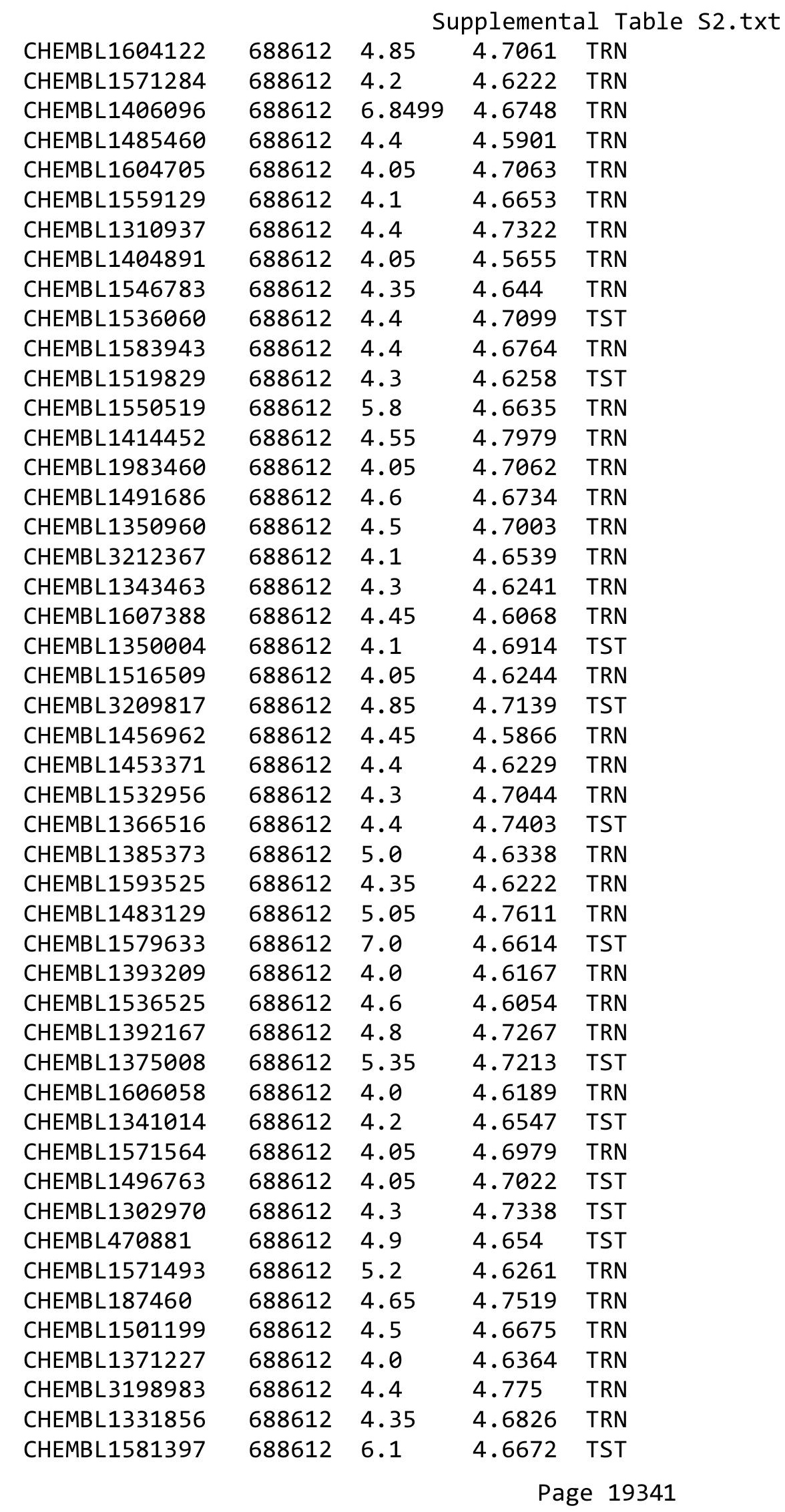




\begin{tabular}{|c|c|c|c|c|}
\hline \multicolumn{5}{|c|}{ Supplemental Table s2.txt } \\
\hline CHEMBL1423796 & 688612 & 4.35 & 4.73 & TRN \\
\hline CHEMBL1368263 & 688612 & 4.1 & 4.614 & TRN \\
\hline CHEMBL1462945 & 688612 & 4.55 & 4.6605 & TRN \\
\hline CHEMBL1549732 & 688612 & 4.65 & 4.6269 & TRN \\
\hline CHEMBL1593728 & 688612 & 4.35 & 4.6832 & TRN \\
\hline CHEMBL1984272 & 688612 & 5.0 & 4.8106 & TRN \\
\hline CHEMBL1304316 & 688612 & 4.1 & 4.6769 & TRN \\
\hline CHEMBL3197450 & 688612 & 4.5 & 4.6968 & TRN \\
\hline CHEMBL3214394 & 688612 & 4.05 & 4.6748 & TRN \\
\hline CHEMBL1385195 & 688612 & 4.05 & 4.7174 & TRN \\
\hline CHEMBL1494012 & 688612 & 4.3 & 4.6182 & TRN \\
\hline CHEMBL1426058 & 688612 & 4.4 & 4.6367 & TST \\
\hline CHEMBL1305979 & 688612 & 4.7 & 4.7353 & TRN \\
\hline CHEMBL1463774 & 688612 & 4.0 & 4.6959 & TST \\
\hline CHEMBL1386412 & 688612 & 5.0 & 4.6262 & TRN \\
\hline CHEMBL1443231 & 688612 & 4.75 & 4.6651 & TST \\
\hline CHEMBL1426525 & 688612 & 4.0 & 4.6075 & TRN \\
\hline CHEMBL1456895 & 688612 & 4.05 & 4.6515 & TST \\
\hline CHEMBL1299771 & 688612 & 4.05 & 4.5981 & TRN \\
\hline CHEMBL1430935 & 688612 & 4.4 & 4.7227 & TRN \\
\hline CHEMBL1449112 & 688612 & 5.05 & 4.7344 & TRN \\
\hline CHEMBL1533790 & 688612 & 4.05 & 4.6291 & TRN \\
\hline CHEMBL1457710 & 688612 & 4.05 & 4.6254 & TRN \\
\hline CHEMBL1302345 & 688612 & 4.1 & 4.6703 & TST \\
\hline CHEMBL1322271 & 688612 & 4.05 & 4.7036 & TST \\
\hline CHEMBL1482658 & 688612 & 6.8 & 4.6697 & TRN \\
\hline CHEMBL400585 & 688612 & 4.45 & 4.6986 & TRN \\
\hline CHEMBL1535285 & 688612 & 4.9 & 4.7619 & TRN \\
\hline CHEMBL1307516 & 688612 & 4.05 & 4.6299 & TRN \\
\hline CHEMBL 1378647 & 688612 & 4.3 & 4.7055 & TRN \\
\hline CHEMBL1337277 & 688612 & 4.65 & 4.7187 & TRN \\
\hline CHEMBL1389673 & 688612 & 4.5 & 4.645 & TRN \\
\hline CHEMBL1607816 & 688612 & 4.1 & 4.6953 & TST \\
\hline CHEMBL1485596 & 688612 & 4.05 & 4.6881 & TRN \\
\hline CHEMBL446827 & 688612 & 4.1 & 4.7822 & TRN \\
\hline CHEMBL1417203 & 688612 & 4.95 & 4.7352 & TRN \\
\hline CHEMBL1972915 & 688612 & 4.35 & 4.6078 & TRN \\
\hline CHEMBL1435386 & 688612 & 4.05 & 4.5765 & TRN \\
\hline CHEMBL1459270 & 688612 & 6.5501 & 4.6725 & TRN \\
\hline CHEMBL1350240 & 688612 & 4.75 & 4.7927 & TRN \\
\hline CHEMBL1578279 & 688612 & 4.65 & 4.7158 & TRN \\
\hline CHEMBL1394625 & 688612 & 4.3 & 4.643 & TRN \\
\hline CHEMBL1529584 & 688612 & 4.3 & 4.6548 & TRN \\
\hline CHEMBL1384224 & 688612 & 6.45 & 4.6311 & TRN \\
\hline CHEMBL1399523 & 688612 & 4.5 & 4.6489 & TST \\
\hline CHEMBL1397672 & 688612 & 4.75 & 4.6039 & TRN \\
\hline CHEMBL1388590 & 688612 & 4.7 & 4.6958 & TRN \\
\hline CHEMBL1392105 & 688612 & 4.15 & 4.6262 & TRN \\
\hline
\end{tabular}




\begin{tabular}{|c|c|c|c|c|}
\hline \multicolumn{5}{|c|}{ Supplemental Table } \\
\hline CHEMBL1535691 & 688612 & 4.05 & 4.7095 & TRN \\
\hline CHEMBL1308132 & 688612 & 6.1 & 4.7261 & TRN \\
\hline CHEMBL1442460 & 688612 & 4.3 & 4.7531 & TST \\
\hline CHEMBL1591823 & 688612 & 4.7 & 4.7025 & TRN \\
\hline CHEMBL 1583850 & 688612 & 4.6 & 4.6751 & TRN \\
\hline CHEMBL1310522 & 688612 & 5.1 & 4.5807 & TRN \\
\hline CHEMBL1319860 & 688612 & 4.6 & 4.6277 & TRN \\
\hline CHEMBL1371712 & 688612 & 4.45 & 4.6739 & TRN \\
\hline CHEMBL1404728 & 688612 & 4.05 & 4.5924 & TRN \\
\hline CHEMBL3214002 & 688612 & 6.3 & 4.7871 & TST \\
\hline CHEMBL1325175 & 688612 & 6.0 & 4.6364 & TRN \\
\hline CHEMBL1488484 & 688612 & 4.1 & 4.6249 & TST \\
\hline CHEMBL1563132 & 688612 & 4.1 & 4.7169 & TRN \\
\hline CHEMBL1477871 & 688612 & 4.5 & 4.6303 & TRN \\
\hline CHEMBL3193134 & 688612 & 5.55 & 4.7206 & TRN \\
\hline CHEMBL1391297 & 688612 & 4.55 & 4.654 & TRN \\
\hline CHEMBL1570702 & 688612 & 4.05 & 4.7048 & TRN \\
\hline CHEMBL1500616 & 688612 & 4.05 & 4.6744 & TST \\
\hline CHEMBL1423705 & 688612 & 5.45 & 4.7324 & TST \\
\hline CHEMBL1481494 & 688612 & 4.1 & 4.6007 & TRN \\
\hline CHEMBL1600298 & 688612 & 4.05 & 4.6253 & TRN \\
\hline CHEMBL1347536 & 688612 & 5.8 & 4.6667 & TST \\
\hline CHEMBL1585532 & 688612 & 5.0 & 4.6318 & TRN \\
\hline CHEMBL1349714 & 688612 & 6.4 & 4.7062 & TST \\
\hline CHEMBL1444763 & 688612 & 4.1 & 4.6868 & TRN \\
\hline CHEMBL1568497 & 688612 & 5.4 & 4.7052 & TRN \\
\hline CHEMBL1345344 & 688612 & 4.1 & 4.6676 & TRN \\
\hline CHEMBL3195145 & 688612 & 4.75 & 4.6966 & TRN \\
\hline CHEMBL1455221 & 688612 & 4.0 & 4.7047 & TRN \\
\hline CHEMBL73441 & 688612 & 6.5 & 4.7048 & TRN \\
\hline CHEMBL1333370 & 688612 & 4.05 & 4.5927 & TRN \\
\hline CHEMBL1446569 & 688612 & 4.55 & 4.6516 & TRN \\
\hline CHEMBL1461958 & 688612 & 4.6 & 4.6292 & TRN \\
\hline CHEMBL1509249 & 688612 & 6.6 & 4.6334 & TRN \\
\hline CHEMBL1436064 & 688612 & 5.1 & 4.6499 & TRN \\
\hline CHEMBL57171 & 688612 & 4.4 & 4.7887 & TRN \\
\hline CHEMBL3194556 & 688612 & 4.25 & 4.6828 & TRN \\
\hline CHEMBL1321709 & 688612 & 4.35 & 4.6911 & TRN \\
\hline CHEMBL1300936 & 688612 & 4.8 & 4.6589 & TST \\
\hline CHEMBL1547770 & 688612 & 4.0 & 4.7177 & TRN \\
\hline CHEMBL1543386 & 688612 & 4.05 & 4.6577 & TRN \\
\hline CHEMBL1395115 & 688612 & 4.1 & 4.5836 & TRN \\
\hline CHEMBL1577807 & 688612 & 4.05 & 4.7408 & TST \\
\hline CHEMBL1457549 & 688612 & 4.1 & 4.7037 & TRN \\
\hline CHEMBL1401360 & 688612 & 4.15 & 4.6735 & TRN \\
\hline CHEMBL1483611 & 688612 & 4.7 & 4.659 & TRN \\
\hline CHEMBL1448619 & 688612 & 4.1 & 4.6386 & TRN \\
\hline CHEMBL1555386 & 688612 & 4.95 & 4.6069 & TRN \\
\hline
\end{tabular}




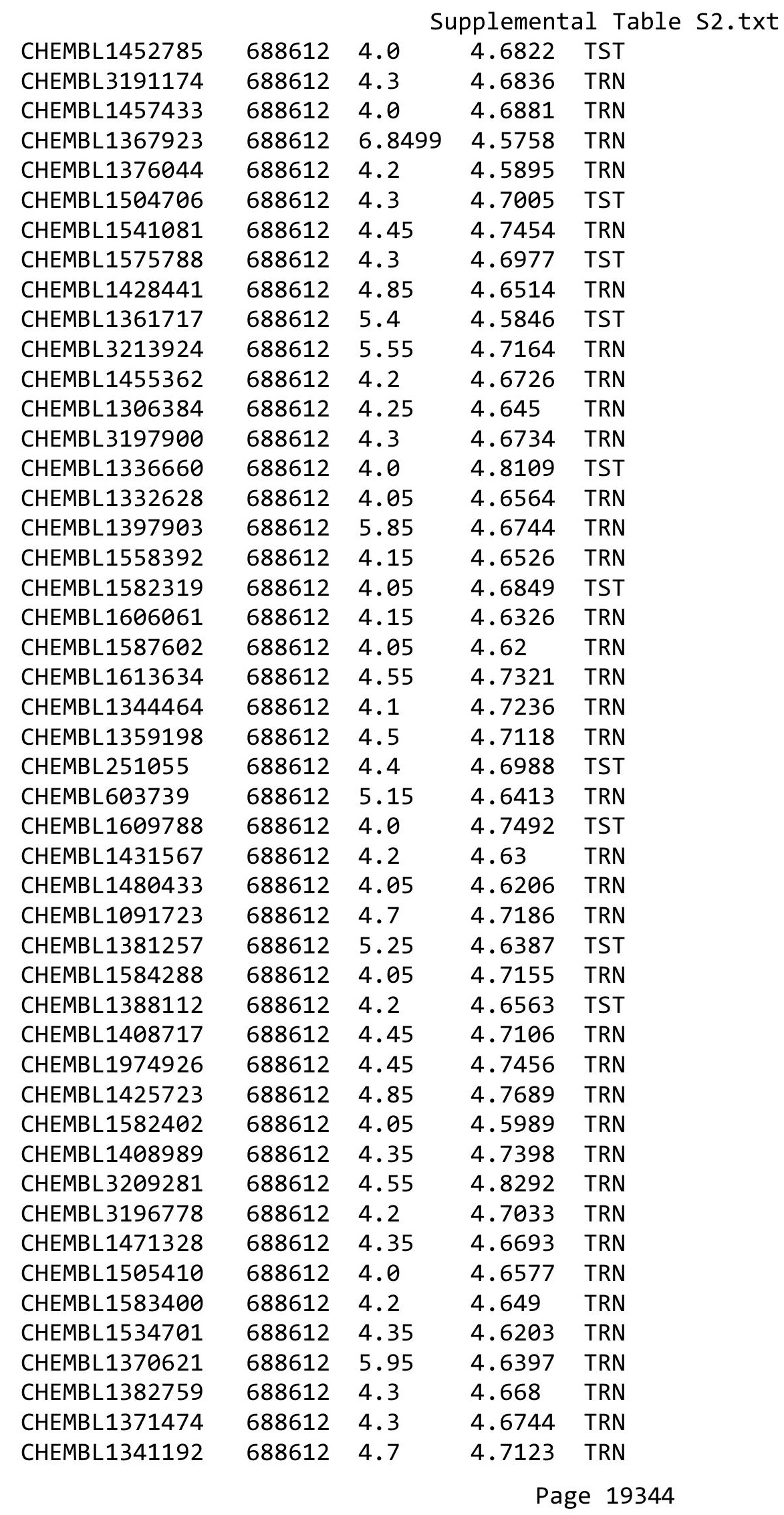




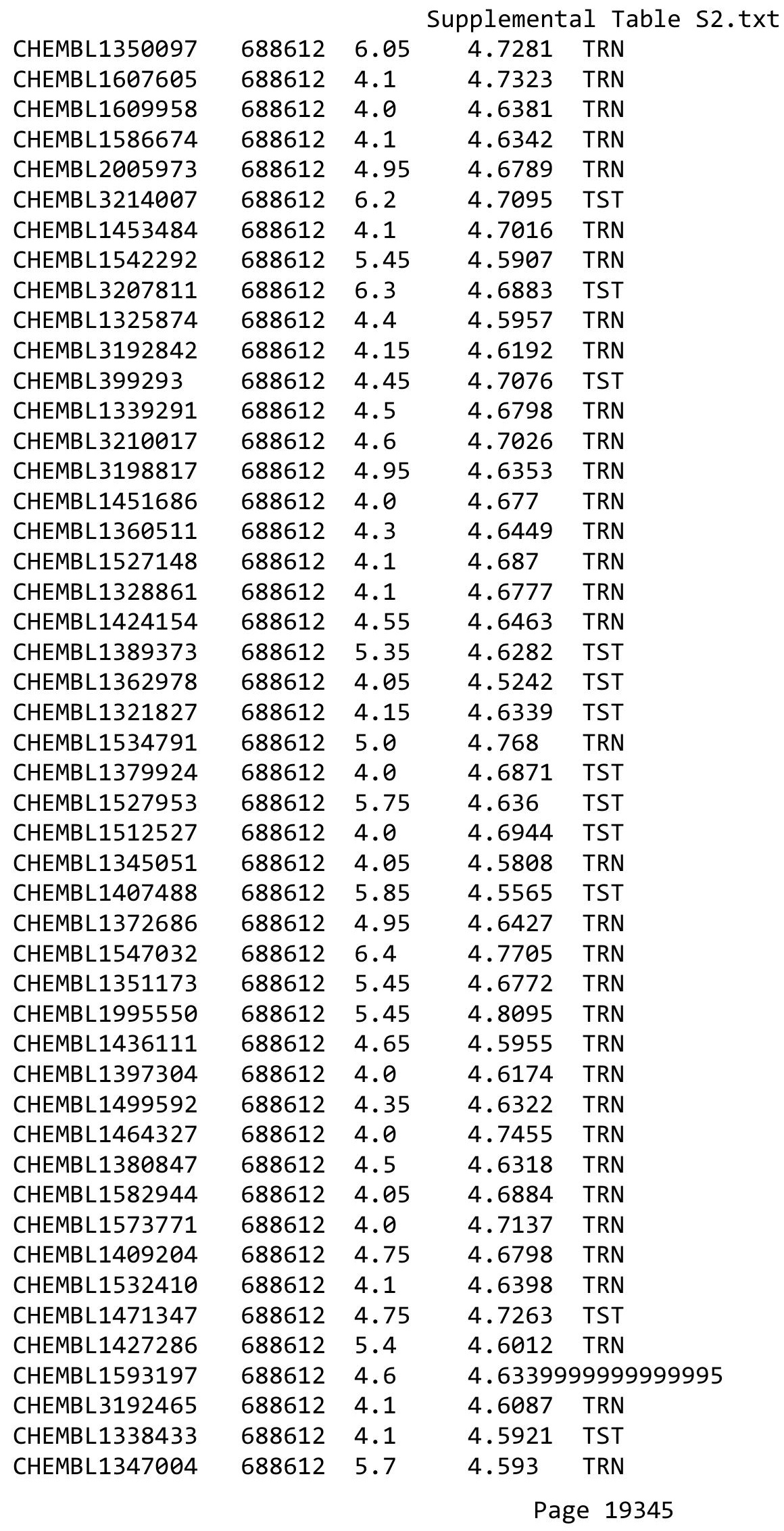

TRN 


\begin{tabular}{|c|c|c|c|c|}
\hline \multicolumn{5}{|c|}{ Supplemental Table S2.txt } \\
\hline CHEMBL1374020 & 688612 & 4.1 & 4.6609 & TRN \\
\hline CHEMBL1598163 & 688612 & 4.2 & 4.6766 & TST \\
\hline CHEMBL1316566 & 688612 & 4.2 & 4.7263 & TRN \\
\hline CHEMBL1369945 & 688612 & 4.15 & 4.6718 & TRN \\
\hline CHEMBL1336395 & 688612 & 5.05 & 4.7138 & TST \\
\hline CHEMBL584452 & 688612 & 4.6 & 4.6724 & TRN \\
\hline CHEMBL1432130 & 688612 & 4.55 & 4.6982 & TST \\
\hline CHEMBL1533935 & 688612 & 4.0 & 4.6949 & TST \\
\hline CHEMBL425764 & 688612 & 4.6 & 4.6824 & TRN \\
\hline CHEMBL1334378 & 688612 & 4.05 & 4.6258 & TST \\
\hline CHEMBL 2001867 & 688612 & 4.2 & 4.7535 & TRN \\
\hline CHEMBL1417804 & 688612 & 5.7 & 4.6081 & TRN \\
\hline CHEMBL1312996 & 688612 & 4.4 & 4.7069 & TRN \\
\hline CHEMBL1311115 & 688612 & 6.0 & 4.6573 & TRN \\
\hline CHEMBL1440727 & 688612 & 4.05 & 4.7489 & TRN \\
\hline CHEMBL1521711 & 688612 & 4.4 & 4.7115 & TRN \\
\hline CHEMBL1374060 & 688612 & 4.45 & 4.6217 & TRN \\
\hline CHEMBL1362638 & 688612 & 4.2 & 4.6157 & TRN \\
\hline CHEMBL1503095 & 688612 & 4.5 & 4.7794 & TRN \\
\hline CHEMBL1485727 & 688612 & 4.1 & 4.7231 & TST \\
\hline CHEMBL193627 & 688612 & 4.55 & 4.7088 & TRN \\
\hline CHEMBL1092508 & 688612 & 4.85 & 4.6595 & TRN \\
\hline CHEMBL1416954 & 688612 & 5.4 & 4.565 & TRN \\
\hline CHEMBL601351 & 688612 & 4.0 & 4.7028 & TST \\
\hline CHEMBL1370076 & 688612 & 4.05 & 4.651 & TST \\
\hline CHEMBL1391350 & 688612 & 5.45 & 4.5867 & TRN \\
\hline CHEMBL1356090 & 688612 & 4.1 & 4.6008 & TRN \\
\hline CHEMBL1486470 & 688612 & 4.2 & 4.7459 & TRN \\
\hline CHEMBL1494155 & 688612 & 4.4 & 4.7268 & TRN \\
\hline CHEMBL1378401 & 688612 & 4.2 & 4.7027 & TRN \\
\hline CHEMBL1326281 & 688612 & 4.4 & 4.6478 & TST \\
\hline CHEMBL1306243 & 688612 & 3.95 & 4.6576 & TST \\
\hline CHEMBL1329465 & 688612 & 4.9 & 4.7141 & TRN \\
\hline CHEMBL1371568 & 688612 & 4.05 & 4.6813 & TRN \\
\hline CHEMBL1598958 & 688612 & 6.35 & 4.6473 & TRN \\
\hline CHEMBL1581681 & 688612 & 4.0 & 4.6799 & TRN \\
\hline CHEMBL239009 & 688612 & 6.5 & 4.7288 & TRN \\
\hline CHEMBL1325507 & 688612 & 4.0 & 4.5939 & TRN \\
\hline CHEMBL1524243 & 688612 & 4.1 & 4.6013 & TST \\
\hline CHEMBL1353644 & 688612 & 4.6 & 4.6909 & TRN \\
\hline CHEMBL1542797 & 688612 & 4.95 & 4.6507 & TRN \\
\hline CHEMBL195455 & 688612 & 4.6 & 4.7004 & TRN \\
\hline CHEMBL1478585 & 688612 & 4.0 & 4.6978 & TRN \\
\hline CHEMBL1498113 & 688612 & 4.5 & 4.7602 & TRN \\
\hline CHEMBL1560921 & 688612 & 4.4 & 4.6439 & TST \\
\hline CHEMBL1312717 & 688612 & 5.15 & 4.7037 & TRN \\
\hline CHEMBL1548012 & 688612 & 4.4 & 4.6943 & TRN \\
\hline CHEMBL1366338 & 688612 & 4.75 & 4.6856 & TRN \\
\hline
\end{tabular}




\begin{tabular}{|c|c|c|c|c|c|}
\hline \multicolumn{6}{|c|}{ Supplemental Table S2.txt } \\
\hline CHEMBL1309506 & 688612 & 4.9 & 4.689 & TRN & \\
\hline CHEMBL1471943 & 688612 & 4.1 & 4.7802 & TST & \\
\hline CHEMBL1553917 & 688612 & 5.4 & 4.6597 & TRN & \\
\hline CHEMBL1357729 & 688612 & 4.0 & 4.5807 & TST & \\
\hline CHEMBL1976111 & 688612 & 4.05 & 4.5953 & TRN & \\
\hline CHEMBL1518271 & 688612 & 4.55 & 4.6748 & TRN & \\
\hline CHEMBL1499348 & 688612 & 4.05 & 4.6908 & TST & \\
\hline CHEMBL1997052 & 688612 & 4.3 & 4.7208 & TRN & \\
\hline CHEMBL1330924 & 688612 & 4.1 & 4.6656 & TRN & \\
\hline CHEMBL1446626 & 688612 & 4.7 & 4.7822 & TRN & \\
\hline CHEMBL1306897 & 688612 & 4.35 & $4.7010 e$ & 00000000005 & TRN \\
\hline CHEMBL1364493 & 688612 & 6.95 & 4.662 & TRN & \\
\hline CHEMBL1424729 & 688612 & 4.15 & 4.643 & TST & \\
\hline CHEMBL1309624 & 688612 & 5.25 & 4.6693 & TRN & \\
\hline CHEMBL1316446 & 688612 & 4.5 & 4.5833 & TRN & \\
\hline CHEMBL 238188 & 688612 & 4.8 & 4.8319 & TST & \\
\hline CHEMBL1561244 & 688612 & 4.7 & 4.6786 & TRN & \\
\hline CHEMBL1600466 & 688612 & 4.05 & 4.6183 & TRN & \\
\hline CHEMBL1426698 & 688612 & 4.2 & 4.6015 & TRN & \\
\hline CHEMBL1504702 & 688612 & 4.0 & 4.6745 & TST & \\
\hline CHEMBL1352356 & 688612 & 4.05 & 4.6788 & TST & \\
\hline CHEMBL1401108 & 688612 & 4.5 & 4.6187 & TRN & \\
\hline CHEMBL1409526 & 688612 & 4.65 & 4.8271 & TRN & \\
\hline CHEMBL1432831 & 688612 & 4.65 & 4.7356 & TST & \\
\hline CHEMBL1525517 & 688612 & 4.05 & 4.6707 & TRN & \\
\hline CHEMBL1494173 & 688612 & 4.2 & 4.6167 & TRN & \\
\hline CHEMBL1494895 & 688612 & 4.3 & 4.7143 & TRN & \\
\hline CHEMBL1549319 & 688612 & 4.9 & 4.5943 & TRN & \\
\hline CHEMBL1494595 & 688612 & 5.35 & 4.7025 & TST & \\
\hline CHEMBL3196623 & 688612 & 4.3 & 4.7556 & TRN & \\
\hline CHEMBL1571847 & 688612 & 4.05 & 4.5996 & TRN & \\
\hline CHEMBL3213960 & 688612 & 4.6 & 4.7241 & TST & \\
\hline CHEMBL3199093 & 688612 & 4.45 & 4.7882 & TRN & \\
\hline CHEMBL1383914 & 688612 & 6.8499 & 4.6126 & TRN & \\
\hline CHEMBL3196535 & 688612 & 4.1 & 4.7717 & TRN & \\
\hline CHEMBL1412899 & 688612 & 4.1 & 4.5274 & TRN & \\
\hline CHEMBL 1445410 & 688612 & 4.4 & 4.8046 & TRN & \\
\hline CHEMBL3193796 & 688612 & 4.65 & 4.7815 & TRN & \\
\hline CHEMBL1305771 & 688612 & 5.2 & 4.6969 & TRN & \\
\hline CHEMBL1492015 & 688612 & 4.1 & 4.6828 & TST & \\
\hline CHEMBL1455433 & 688612 & 4.05 & 4.5745 & TRN & \\
\hline CHEMBL1461189 & 688612 & 4.05 & 4.5791 & TRN & \\
\hline CHEMBL1396573 & 688612 & 4.55 & 4.668 & TRN & \\
\hline CHEMBL1380113 & 688612 & 4.65 & 4.7437 & TRN & \\
\hline CHEMBL 2002767 & 688612 & 4.45 & 4.7224 & TRN & \\
\hline CHEMBL1419723 & 688612 & 4.05 & 4.6407 & TRN & \\
\hline CHEMBL1423809 & 688612 & 5.6 & 4.6037 & TRN & \\
\hline CHEMBL1374340 & 688612 & 4.45 & 4.7089 & TRN & \\
\hline
\end{tabular}




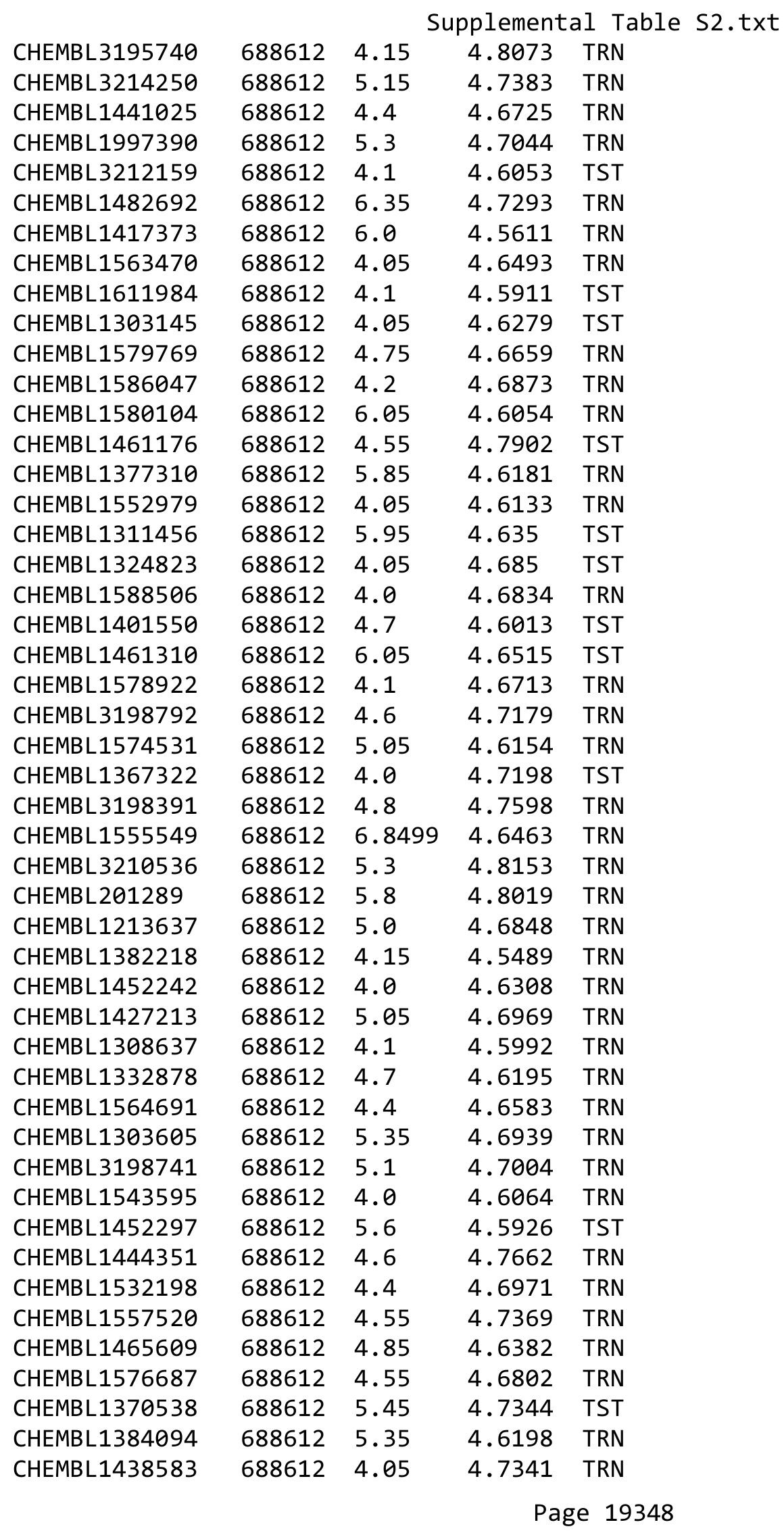




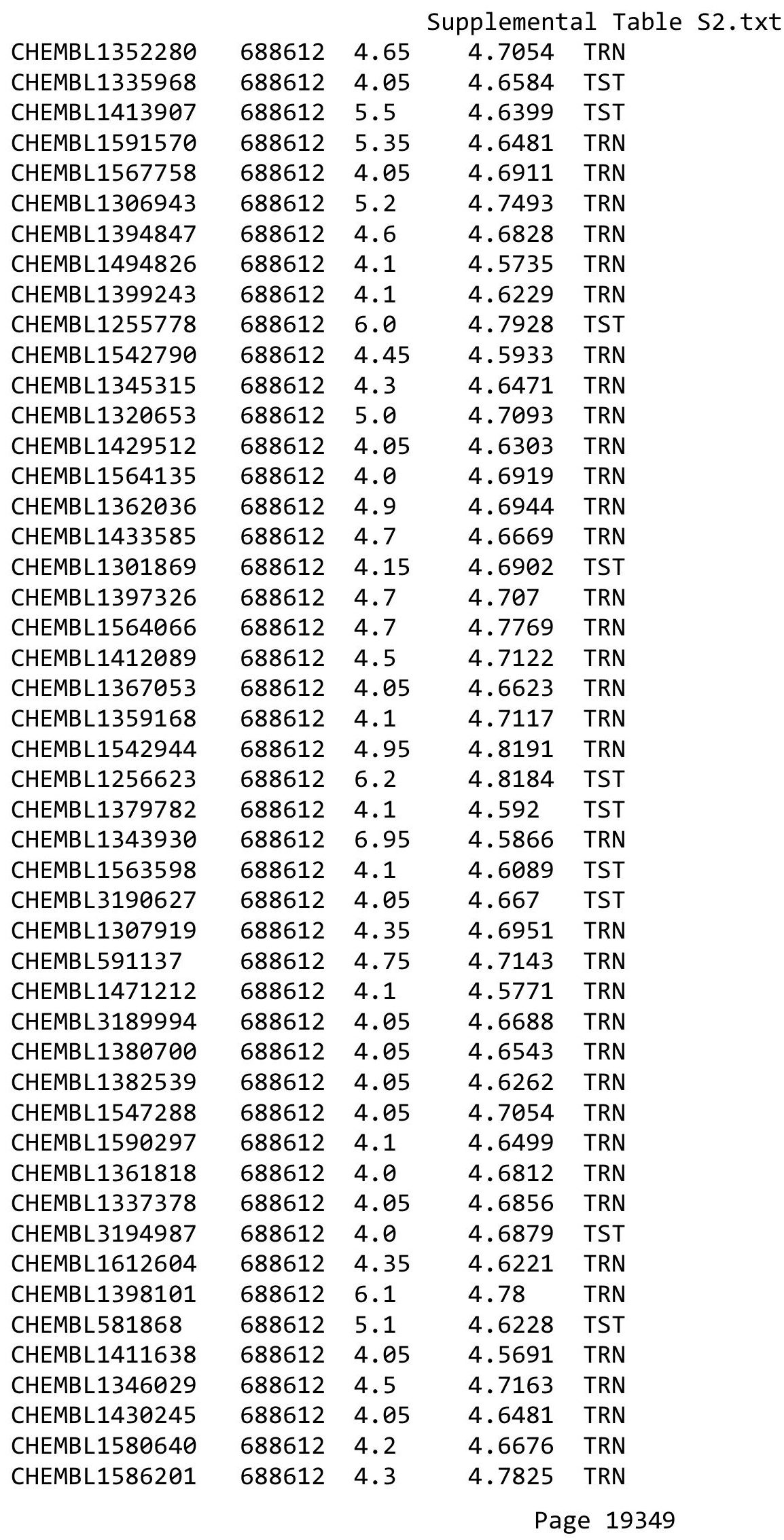




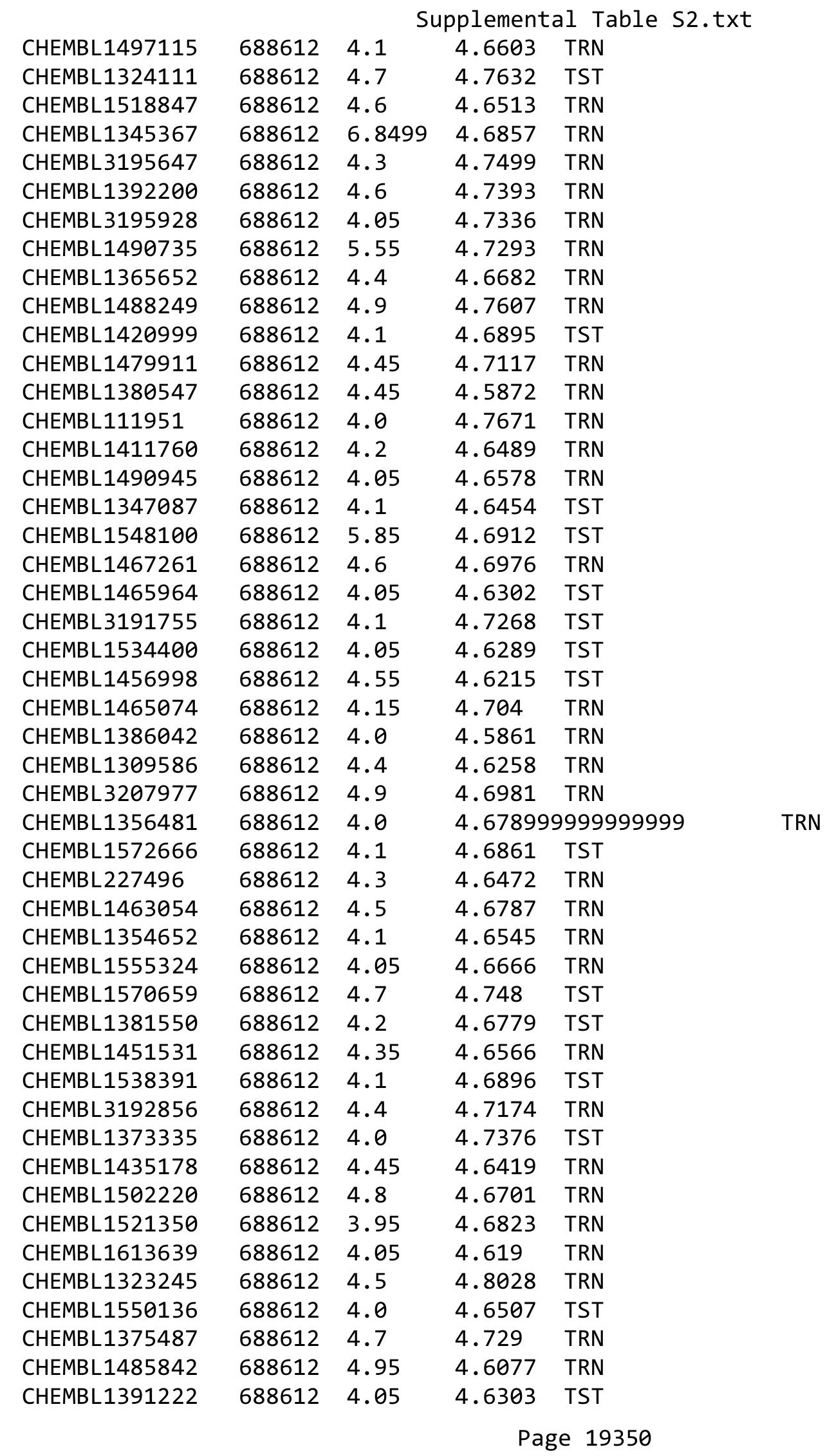




\begin{tabular}{|c|c|c|c|c|c|}
\hline \multicolumn{6}{|c|}{ Supplemental Table S2.txt } \\
\hline CHEMBL1448406 & 688612 & 4.95 & 4.6778 & TRN & \\
\hline CHEMBL1362671 & 688612 & 4.0 & 4.6108 & TRN & \\
\hline CHEMBL1447668 & 688612 & 6.0 & 4.7026 & TRN & \\
\hline CHEMBL1371294 & 688612 & 5.3 & 4.7393 & TRN & \\
\hline CHEMBL1443090 & 688612 & 4.1 & 4.6927 & TST & \\
\hline CHEMBL1613460 & 688612 & 5.05 & 4.6107 & TRN & \\
\hline CHEMBL1398435 & 688612 & 4.1 & 4.6028 & TRN & \\
\hline CHEMBL 3211445 & 688612 & 4.25 & 4.6969 & TRN & \\
\hline CHEMBL1378869 & 688612 & 4.4 & 4.5962 & TRN & \\
\hline CHEMBL1372461 & 688612 & 5.2 & 4.7307 & TST & \\
\hline CHEMBL3207897 & 688612 & 4.0 & 4.6178 & TRN & \\
\hline CHEMBL1441718 & 688612 & 4.25 & 4.5083 & TRN & \\
\hline CHEMBL1327471 & 688612 & 4.15 & 4.6766 & TRN & \\
\hline CHEMBL3197533 & 688612 & 4.25 & 4.6817 & TRN & \\
\hline CHEMBL1332852 & 688612 & 4.05 & 4.6134 & TRN & \\
\hline CHEMBL1441738 & 688612 & 5.2 & 4.8036 & TST & \\
\hline CHEMBL1348090 & 688612 & 5.05 & 4.7805 & TRN & \\
\hline CHEMBL1366088 & 688612 & 4.65 & 4.6758 & TST & \\
\hline CHEMBL1609502 & 688612 & 4.05 & 4.575 & TST & \\
\hline CHEMBL1609006 & 688612 & 5.1 & 4.7777 & TRN & \\
\hline CHEMBL1387325 & 688612 & 4.4 & 4.6365 & TRN & \\
\hline CHEMBL1517384 & 688612 & 4.2 & 4.6193 & TRN & \\
\hline CHEMBL1429744 & 688612 & 4.05 & 4.6798 & TRN & \\
\hline CHEMBL1300420 & 688612 & 4.05 & 4.7063 & TST & \\
\hline CHEMBL1560575 & 688612 & 5.2 & 4.6181 & TRN & \\
\hline CHEMBL3191854 & 688612 & 4.5 & 4.6945 & TRN & \\
\hline CHEMBL1400801 & 688612 & 4.0 & 4.6579 & TRN & \\
\hline CHEMBL1561342 & 688612 & 4.55 & 4.59699 & 99999999995 & TRN \\
\hline CHEMBL1420825 & 688612 & 4.65 & 4.7208 & TST & \\
\hline CHEMBL1380142 & 688612 & 4.0 & 4.6958 & TRN & \\
\hline CHEMBL1363156 & 688612 & 4.3 & 4.746 & TST & \\
\hline CHEMBL1310527 & 688612 & 4.25 & 4.6433 & TRN & \\
\hline CHEMBL1392424 & 688612 & 4.75 & 4.7494 & TRN & \\
\hline CHEMBL1379025 & 688612 & 6.9 & 4.7363 & TRN & \\
\hline CHEMBL1536466 & 688612 & 4.4 & 4.68 & TST & \\
\hline CHEMBL1508109 & 688612 & 5.0 & 4.7587 & TRN & \\
\hline CHEMBL1603796 & 688612 & 4.05 & 4.7257 & TST & \\
\hline CHEMBL 2005484 & 688612 & 4.05 & 4.6119 & TRN & \\
\hline CHEMBL1559818 & 688612 & 5.65 & 4.6315 & TRN & \\
\hline CHEMBL1529139 & 688612 & 5.0 & 4.6379 & TRN & \\
\hline CHEMBL1613081 & 688612 & 4.1 & 4.7591 & TST & \\
\hline CHEMBL1373095 & 688612 & 5.45 & 4.6946 & TRN & \\
\hline CHEMBL1471587 & 688612 & 4.05 & 4.6845 & TRN & \\
\hline CHEMBL1462303 & 688612 & 6.25 & 4.6487 & TRN & \\
\hline CHEMBL1342588 & 688612 & 5.0 & 4.7119 & TRN & \\
\hline CHEMBL1515202 & 688612 & 4.1 & 4.709 & TST & \\
\hline CHEMBL1382668 & 688612 & 4.1 & 4.6766 & TRN & \\
\hline CHEMBL1493816 & 688612 & 4.05 & 4.6678 & TRN & \\
\hline
\end{tabular}




\begin{tabular}{|c|c|c|c|c|c|}
\hline & & \multicolumn{4}{|c|}{ Supplemental Table S2.txt } \\
\hline CHEMBL1386365 & 688612 & 4.7 & 4.6728 & TRN & \\
\hline CHEMBL1343548 & 688612 & 5.4 & 4.6134 & TRN & \\
\hline CHEMBL140796 & 688612 & 4.75 & 4.7518 & TST & \\
\hline CHEMBL1577360 & 688612 & 4.7 & 4.7601 & TST & \\
\hline CHEMBL1561314 & 688612 & 4.25 & 4.7503 & TRN & \\
\hline CHEMBL1546668 & 688612 & 4.05 & 4.6148 & TST & \\
\hline CHEMBL1590402 & 688612 & 4.1 & 4.6833 & TRN & \\
\hline CHEMBL1329597 & 688612 & 6.35 & 4.7107 & TST & \\
\hline CHEMBL1436700 & 688612 & 7.1002 & 4.6518 & TST & \\
\hline CHEMBL1440399 & 688612 & 4.0 & 4.7281 & TST & \\
\hline CHEMBL1374203 & 688612 & 5.2 & 4.6839 & TRN & \\
\hline CHEMBL 3210083 & 688612 & 4.05 & 4.7194 & TST & \\
\hline CHEMBL1517548 & 688612 & 4.05 & 4.55399 & 9999999999 & TRN \\
\hline CHEMBL1587434 & 688612 & 4.0 & 4.7548 & TST & \\
\hline CHEMBL1544132 & 688612 & 5.1 & 4.6859 & TST & \\
\hline CHEMBL1554657 & 688612 & 4.35 & 4.5971 & TRN & \\
\hline CHEMBL1492206 & 688612 & 4.05 & 4.6292 & TRN & \\
\hline CHEMBL1334725 & 688612 & 4.0 & 4.6364 & TST & \\
\hline CHEMBL3190474 & 688612 & 6.2 & 4.683 & TRN & \\
\hline CHEMBL1523835 & 688612 & 4.4 & 4.7349 & TST & \\
\hline CHEMBL1512071 & 688612 & 4.95 & 4.6546 & TRN & \\
\hline CHEMBL1600388 & 688612 & 4.4 & 4.7379 & TRN & \\
\hline CHEMBL1328392 & 688612 & 5.95 & 4.6488 & TRN & \\
\hline CHEMBL1312654 & 688612 & 4.05 & 4.6715 & TRN & \\
\hline CHEMBL1477052 & 688612 & 4.05 & 4.7441 & TST & \\
\hline CHEMBL1524830 & 688612 & 5.0 & 4.607 & TRN & \\
\hline CHEMBL1537738 & 688612 & 4.1 & 4.6682 & TRN & \\
\hline CHEMBL1547379 & 688612 & 4.7 & 4.7161 & TRN & \\
\hline CHEMBL1372427 & 688612 & 4.85 & 4.6331 & TST & \\
\hline CHEMBL3186541 & 688612 & 4.05 & 4.6265 & TRN & \\
\hline CHEMBL1605798 & 688612 & 4.05 & 4.6819 & TRN & \\
\hline CHEMBL1500001 & 688612 & 4.05 & 4.6605 & TRN & \\
\hline CHEMBL1547905 & 688612 & 4.3 & 4.6505 & TRN & \\
\hline CHEMBL1374731 & 688612 & 4.05 & 4.6075 & TRN & \\
\hline CHEMBL1557478 & 688612 & 5.5 & 4.6626 & TRN & \\
\hline CHEMBL1533015 & 688612 & 4.4 & 4.6215 & TRN & \\
\hline CHEMBL1568715 & 688612 & 4.0 & 4.6311 & TST & \\
\hline CHEMBL1564286 & 688612 & 4.1 & 4.6323 & TRN & \\
\hline CHEMBL1309132 & 688612 & 4.0 & 4.6699 & TRN & \\
\hline CHEMBL1508494 & 688612 & 4.05 & 4.7322 & TRN & \\
\hline CHEMBL1579824 & 688612 & 4.75 & 4.6753 & TRN & \\
\hline CHEMBL1373490 & 688612 & 4.05 & 4.6879 & TRN & \\
\hline CHEMBL1529423 & 688612 & 4.0 & 4.6416 & TRN & \\
\hline CHEMBL1313816 & 688612 & 4.05 & 4.6969 & TRN & \\
\hline CHEMBL1985987 & 688612 & 5.8 & 4.7018 & TRN & \\
\hline CHEMBL1411219 & 688612 & 6.8499 & 4.5891 & TRN & \\
\hline CHEMBL1536550 & 688612 & 4.0 & 4.6853 & TRN & \\
\hline CHEMBL1517889 & 688612 & 6.1 & 4.7341 & TRN & \\
\hline
\end{tabular}




\begin{tabular}{|c|c|c|c|c|c|}
\hline \multicolumn{6}{|c|}{ Supplemental Table S2.txt } \\
\hline CHEMBL1490608 & 688612 & 6.05 & 4.66 & TRN & \\
\hline CHEMBL1595190 & 688612 & 4.6 & 4.6241 & TRN & \\
\hline CHEMBL1604893 & 688612 & 4.05 & 4.6576 & TRN & \\
\hline CHEMBL3194499 & 688612 & 5.75 & 4.6398 & TRN & \\
\hline CHEMBL1449798 & 688612 & 4.4 & 4.67899 & 9999999999 & TRN \\
\hline CHEMBL3194633 & 688612 & 4.85 & 4.7607 & TRN & \\
\hline CHEMBL1425680 & 688612 & 4.4 & 4.6921 & TRN & \\
\hline CHEMBL1327249 & 688612 & 4.45 & 4.6129 & TRN & \\
\hline CHEMBL1304807 & 688612 & 4.4 & 4.7682 & TRN & \\
\hline CHEMBL1382616 & 688612 & 4.25 & 4.7346 & TRN & \\
\hline CHEMBL3199938 & 688612 & 4.55 & 4.7168 & TRN & \\
\hline CHEMBL1496753 & 688612 & 4.45 & 4.729 & TRN & \\
\hline CHEMBL234338 & 688612 & 5.65 & 4.8382 & TRN & \\
\hline CHEMBL1526714 & 688612 & 4.4 & 4.6697 & TST & \\
\hline CHEMBL1453927 & 688612 & 4.05 & 4.6638 & TRN & \\
\hline CHEMBL1095804 & 688612 & 6.8499 & 4.6297 & TST & \\
\hline CHEMBL1410133 & 688612 & 4.55 & 4.6913 & TRN & \\
\hline CHEMBL1585187 & 688612 & 4.4 & 4.7187 & TRN & \\
\hline CHEMBL1584716 & 688612 & 4.0 & 4.6151 & TRN & \\
\hline CHEMBL1428557 & 688612 & 4.05 & 4.6784 & TST & \\
\hline CHEMBL1421580 & 688612 & 4.6 & 4.6627 & TST & \\
\hline CHEMBL1541106 & 688612 & 4.0 & 4.7254 & TST & \\
\hline CHEMBL1330666 & 688612 & 5.0 & 4.6027 & TRN & \\
\hline CHEMBL1468711 & 688612 & 4.65 & 4.6579 & TRN & \\
\hline CHEMBL1310911 & 688612 & 4.1 & 4.6762 & TRN & \\
\hline CHEMBL3198540 & 688612 & 4.05 & 4.78100 & 0000000001 & TRN \\
\hline CHEMBL1347921 & 688612 & 5.0 & 4.7411 & TST & \\
\hline CHEMBL1591142 & 688612 & 4.05 & 4.6446 & TRN & \\
\hline CHEMBL1491237 & 688612 & 4.05 & 4.6295 & TRN & \\
\hline CHEMBL1794232 & 688612 & 4.85 & 4.7241 & TRN & \\
\hline CHEMBL1311643 & 688612 & 4.25 & 4.6959 & TRN & \\
\hline CHEMBL1341023 & 688612 & 4.4 & 4.7696 & TST & \\
\hline CHEMBL1591510 & 688612 & 4.55 & 4.6147 & TRN & \\
\hline CHEMBL1482852 & 688612 & 4.65 & 4.7575 & TRN & \\
\hline CHEMBL3193643 & 688612 & 4.8 & 4.6936 & TRN & \\
\hline CHEMBL1485114 & 688612 & 4.55 & 4.6534 & TRN & \\
\hline CHEMBL1469841 & 688612 & 4.1 & 4.6455 & TST & \\
\hline CHEMBL1341588 & 688612 & 5.1 & 4.5603 & TRN & \\
\hline CHEMBL1572925 & 688612 & 5.6 & 4.671 & TRN & \\
\hline CHEMBL1595411 & 688612 & 4.1 & 4.5632 & TRN & \\
\hline CHEMBL1583275 & 688612 & 4.0 & 4.6445 & TST & \\
\hline CHEMBL1506593 & 688612 & 4.05 & 4.7112 & TST & \\
\hline CHEMBL1331035 & 688612 & 4.3 & 4.6972 & TRN & \\
\hline CHEMBL1440648 & 688612 & 4.1 & 4.7039 & TRN & \\
\hline CHEMBL1422576 & 688612 & 5.2 & 4.6803 & TRN & \\
\hline CHEMBL1558271 & 688612 & 4.05 & 4.6874 & TST & \\
\hline CHEMBL 1473010 & 688612 & 4.05 & 4.6799 & TRN & \\
\hline CHEMBL1447676 & 688612 & 4.65 & 4.6582 & TRN & \\
\hline
\end{tabular}




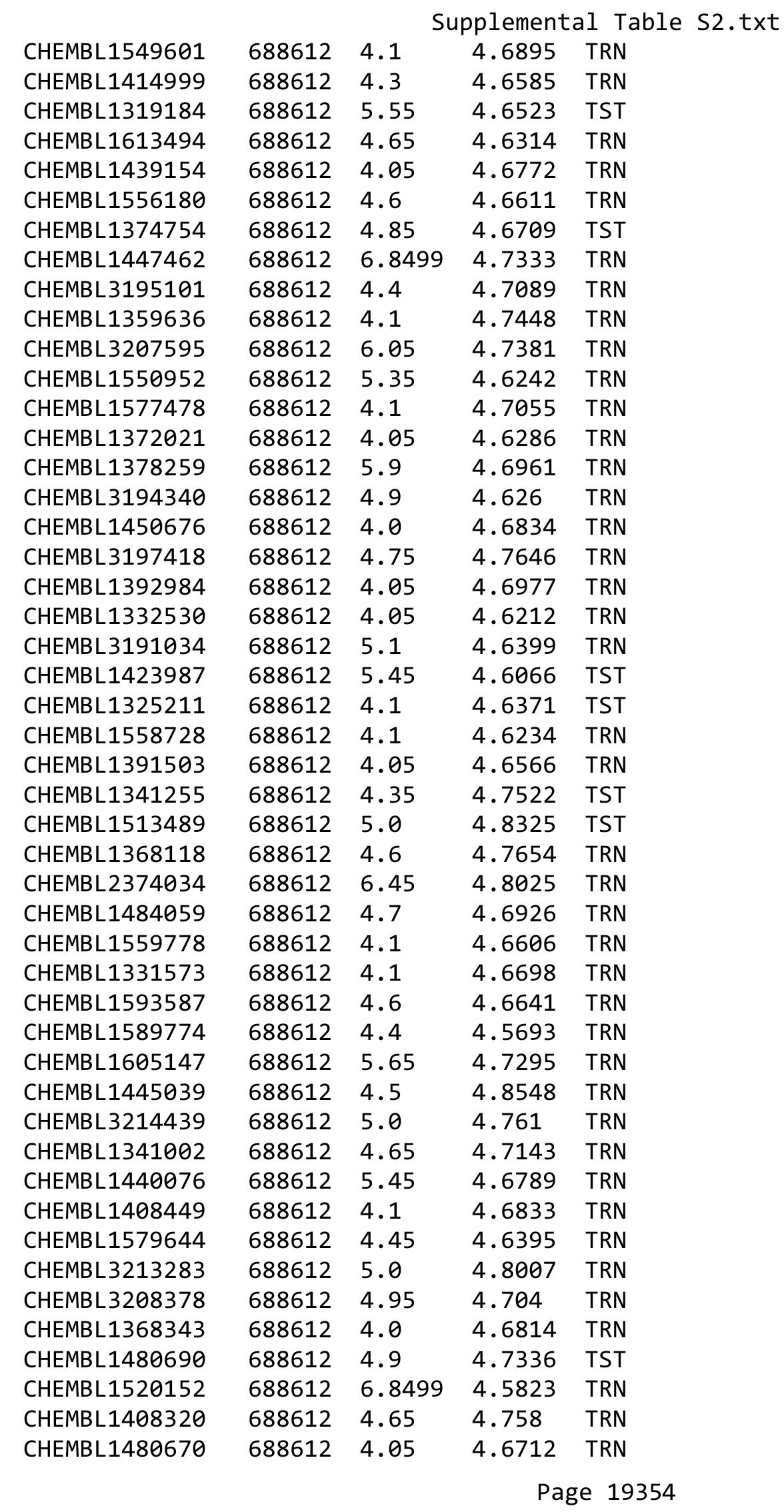




\begin{tabular}{|c|c|c|c|c|c|}
\hline \multirow[b]{2}{*}{ CHEMBL1505049 } & \multicolumn{5}{|c|}{ able S2. } \\
\hline & 688612 & 4.7 & 4.7357 & TST & \\
\hline CHEMBL1416859 & 688612 & 4.0 & 4.7257 & TST & \\
\hline CHEMBL1583525 & 688612 & 4.7 & 4.6719 & TRN & \\
\hline CHEMBL1306087 & 688612 & 4.4 & 4.64199 & 99999999995 & TST \\
\hline CHEMBL1312994 & 688612 & 4.05 & 4.63 & TRN & \\
\hline CHEMBL3195835 & 688612 & 4.9 & 4.7266 & TRN & \\
\hline CHEMBL1433232 & 688612 & 4.45 & 4.5982 & TRN & \\
\hline CHEMBL1459901 & 688612 & 6.5501 & 4.7663 & TRN & \\
\hline CHEMBL1390796 & 688612 & 4.0 & 4.6815 & TRN & \\
\hline CHEMBL1408802 & 688612 & 4.4 & 4.776 & TRN & \\
\hline CHEMBL1573583 & 688612 & 4.25 & 4.6612 & TST & \\
\hline CHEMBL1478082 & 688612 & 4.4 & 4.7139 & TST & \\
\hline CHEMBL3208536 & 688612 & 4.5 & 4.64199 & 99999999995 & TRN \\
\hline CHEMBL1492138 & 688612 & 4.0 & 4.7088 & TRN & \\
\hline CHEMBL1518631 & 688612 & 5.15 & 4.6548 & TRN & \\
\hline CHEMBL1332848 & 688612 & 5.3 & 4.7338 & TRN & \\
\hline CHEMBL1545890 & 688612 & 4.35 & 4.7428 & TRN & \\
\hline CHEMBL3199886 & 688612 & 4.55 & 4.6685 & TRN & \\
\hline CHEMBL1520135 & 688612 & 4.05 & 4.582 & TRN & \\
\hline CHEMBL1540300 & 688612 & 4.4 & 4.7002 & TRN & \\
\hline CHEMBL1345415 & 688612 & 4.3 & 4.7112 & TST & \\
\hline CHEMBL1566165 & 688612 & 5.65 & 4.7495 & TRN & \\
\hline CHEMBL3191560 & 688612 & 4.4 & 4.6977 & TST & \\
\hline CHEMBL1591937 & 688612 & 4.05 & 4.6342 & TRN & \\
\hline CHEMBL1439210 & 688612 & 4.0 & 4.7464 & TRN & \\
\hline CHEMBL1506536 & 688612 & 5.4 & 4.6859 & TRN & \\
\hline CHEMBL1299992 & 688612 & 4.4 & 4.6125 & TRN & \\
\hline CHEMBL1470625 & 688612 & 4.6 & 4.6922 & TRN & \\
\hline CHEMBL1392184 & 688612 & 4.4 & 4.6443 & TRN & \\
\hline CHEMBL1305295 & 688612 & 4.95 & 4.711 & TRN & \\
\hline CHEMBL1499849 & 688612 & 4.05 & 4.6722 & TRN & \\
\hline CHEMBL1492600 & 688612 & 4.25 & 4.5143 & TRN & \\
\hline CHEMBL1331405 & 688612 & 6.5 & 4.5921 & TRN & \\
\hline CHEMBL1388860 & 688612 & 5.85 & 4.6483 & TRN & \\
\hline CHEMBL1553454 & 688612 & 5.3 & 4.7387 & TST & \\
\hline CHEMBL1362357 & 688612 & 4.05 & 4.693006 & 00000000005 & TRN \\
\hline CHEMBL1486131 & 688612 & 5.45 & 4.7582 & TRN & \\
\hline CHEMBL1485870 & 688612 & 4.0 & 4.6577 & TRN & \\
\hline CHEMBL1465455 & 688612 & 4.8 & 4.665 & TRN & \\
\hline CHEMBL1612204 & 688612 & 4.05 & 4.6307 & TRN & \\
\hline CHEMBL3198755 & 688612 & 4.0 & 4.6965 & TRN & \\
\hline CHEMBL1439664 & 688612 & 4.55 & 4.7088 & TRN & \\
\hline CHEMBL1468647 & 688612 & 4.2 & 4.7073 & TST & \\
\hline CHEMBL1363068 & 688612 & 4.55 & 4.6543 & TRN & \\
\hline CHEMBL1379102 & 688612 & 4.45 & 4.6651 & TST & \\
\hline CHEMBL1301381 & 688612 & 4.0 & 4.657 & TRN & \\
\hline CHEMBL1440963 & 688612 & 4.0 & 4.6159 & TRN & \\
\hline CHEMBL1559100 & 688612 & 4.0 & 4.5652 & TRN & \\
\hline & & & & 19355 & \\
\hline
\end{tabular}




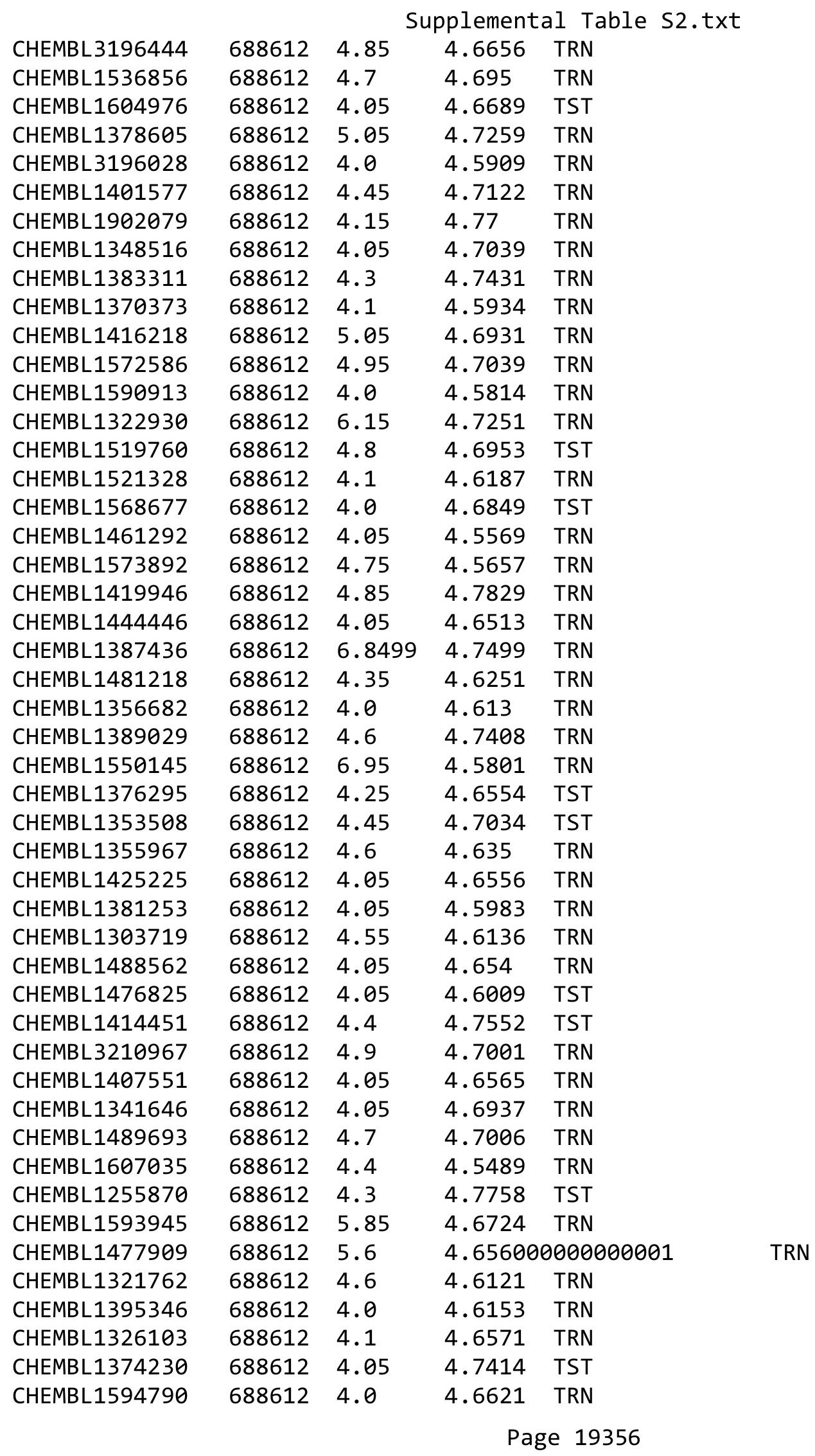




\begin{tabular}{|c|c|c|c|c|c|}
\hline \multicolumn{6}{|c|}{ Supplemental Table S2.txt } \\
\hline CHEMBL1474580 & 688612 & 6.0 & 4.7174 & TRN & \\
\hline CHEMBL1466480 & 688612 & 4.1 & 4.6581 & TRN & \\
\hline CHEMBL1558486 & 688612 & 4.05 & 4.6772 & TRN & \\
\hline CHEMBL1530346 & 688612 & 4.3 & 4.6495 & TRN & \\
\hline CHEMBL1417884 & 688612 & 4.65 & 4.6452 & TRN & \\
\hline CHEMBL1333480 & 688612 & 4.0 & 4.6526 & TRN & \\
\hline CHEMBL1507688 & 688612 & 4.2 & 4.6198 & TST & \\
\hline CHEMBL1555763 & 688612 & 4.8 & 4.6808 & TRN & \\
\hline CHEMBL1366367 & 688612 & 4.1 & 4.6683 & TRN & \\
\hline CHEMBL1400919 & 688612 & 5.45 & $4.6530 e$ & 00000000005 & TRN \\
\hline CHEMBL1612233 & 688612 & 5.4 & 4.6736 & TRN & \\
\hline CHEMBL1312741 & 688612 & 6.9 & 4.6493 & TST & \\
\hline CHEMBL1387357 & 688612 & 4.75 & 4.5275 & TRN & \\
\hline CHEMBL1994973 & 688612 & 4.5 & 4.7188 & TRN & \\
\hline CHEMBL1404139 & 688612 & 4.1 & 4.6453 & TRN & \\
\hline CHEMBL1507555 & 688612 & 5.45 & 4.7257 & TST & \\
\hline CHEMBL1510605 & 688612 & 5.5 & 4.7247 & TST & \\
\hline CHEMBL1477534 & 688612 & 4.4 & 4.6243 & TRN & \\
\hline CHEMBL 2000219 & 688612 & 5.3 & 4.6644 & TRN & \\
\hline CHEMBL1482309 & 688612 & 4.55 & 4.8031 & TRN & \\
\hline CHEMBL1333641 & 688612 & 4.05 & 4.591 & TRN & \\
\hline CHEMBL3213311 & 688612 & 4.4 & 4.7235 & TRN & \\
\hline CHEMBL1507307 & 688612 & 4.5 & 4.7409 & TST & \\
\hline CHEMBL1564428 & 688612 & 4.55 & 4.765 & TRN & \\
\hline CHEMBL3194598 & 688612 & 5.4 & 4.6712 & TST & \\
\hline CHEMBL3190974 & 688612 & 5.5 & 4.7429 & TST & \\
\hline CHEMBL1532688 & 688612 & 6.45 & 4.6507 & TRN & \\
\hline CHEMBL1468344 & 688612 & 4.15 & 4.6154 & TST & \\
\hline CHEMBL1303456 & 688612 & 4.05 & 4.7779 & TRN & \\
\hline CHEMBL1389034 & 688612 & 4.55 & 4.7147 & TRN & \\
\hline CHEMBL1509776 & 688612 & 4.05 & 4.5897 & TRN & \\
\hline CHEMBL1322437 & 688612 & 5.4 & 4.7101 & TRN & \\
\hline CHEMBL1609077 & 688612 & 4.7 & 4.6297 & TRN & \\
\hline CHEMBL581910 & 688612 & 4.45 & 4.7295 & TRN & \\
\hline CHEMBL1523984 & 688612 & 5.05 & 4.7176 & TRN & \\
\hline CHEMBL172439 & 688612 & 5.65 & 4.7999 & TST & \\
\hline CHEMBL1374036 & 688612 & 4.95 & 4.7345 & TRN & \\
\hline CHEMBL1539235 & 688612 & 5.2 & 4.7667 & TRN & \\
\hline CHEMBL1397856 & 688612 & 4.0 & 4.67 & TRN & \\
\hline CHEMBL1399047 & 688612 & 4.35 & 4.6967 & TST & \\
\hline CHEMBL1548053 & 688612 & 4.35 & 4.6602 & TRN & \\
\hline CHEMBL1531374 & 688612 & 4.35 & 4.706 & TST & \\
\hline CHEMBL1504460 & 688612 & 6.8499 & 4.7511 & TST & \\
\hline CHEMBL1529010 & 688612 & 7.0 & 4.7396 & TRN & \\
\hline CHEMBL1529700 & 688612 & 5.25 & 4.6849 & TRN & \\
\hline CHEMBL1508773 & 688612 & 4.0 & 4.6976 & TRN & \\
\hline CHEMBL1394510 & 688612 & 4.05 & 4.5901 & TRN & \\
\hline CHEMBL1400004 & 688612 & 4.85 & 4.5943 & TRN & \\
\hline
\end{tabular}




\begin{tabular}{|c|c|c|c|c|c|}
\hline \multicolumn{6}{|c|}{ Supplemental Table S2.txt } \\
\hline CHEMBL1408293 & 688612 & 4.7 & 4.7464 & TRN & \\
\hline CHEMBL1310730 & 688612 & 4.75 & 4.6183 & TRN & \\
\hline CHEMBL1447460 & 688612 & 4.1 & 4.6237 & TRN & \\
\hline CHEMBL1586326 & 688612 & 4.4 & 4.7626 & TST & \\
\hline CHEMBL1504795 & 688612 & 5.4 & 4.6443 & TRN & \\
\hline CHEMBL1458704 & 688612 & 4.4 & 4.609 & TRN & \\
\hline CHEMBL1572976 & 688612 & 4.45 & 4.6878 & TRN & \\
\hline CHEMBL1511889 & 688612 & 4.05 & 4.6333 & TRN & \\
\hline CHEMBL 1377857 & 688612 & 4.0 & 4.5178 & TRN & \\
\hline CHEMBL1542099 & 688612 & 5.4 & 4.7037 & TRN & \\
\hline CHEMBL1548062 & 688612 & 4.4 & 4.6531 & TRN & \\
\hline CHEMBL1421993 & 688612 & 4.55 & 4.7003 & TST & \\
\hline CHEMBL1564638 & 688612 & 4.65 & 4.7827 & TRN & \\
\hline CHEMBL1428680 & 688612 & 4.0 & 4.6592 & TST & \\
\hline CHEMBL1475327 & 688612 & 4.55 & 4.6331 & TST & \\
\hline CHEMBL1406363 & 688612 & 4.7 & 4.7262 & TST & \\
\hline CHEMBL1506864 & 688612 & 6.1 & 4.7103 & TRN & \\
\hline CHEMBL1419366 & 688612 & 4.6 & 4.6546 & TST & \\
\hline CHEMBL1587273 & 688612 & 4.2 & 4.6297 & TST & \\
\hline CHEMBL1442608 & 688612 & 4.0 & 4.6923 & TRN & \\
\hline CHEMBL1484240 & 688612 & 4.0 & 4.6853 & TST & \\
\hline CHEMBL1482662 & 688612 & 4.0 & 4.5969 & TST & \\
\hline CHEMBL1454034 & 688612 & 4.9 & 4.6232 & TRN & \\
\hline CHEMBL1510455 & 688612 & 4.25 & 4.7249 & TRN & \\
\hline CHEMBL1402639 & 688612 & 5.15 & 4.5776 & TRN & \\
\hline CHEMBL1549471 & 688612 & 4.4 & 4.7525 & TRN & \\
\hline CHEMBL1604621 & 688612 & 4.2 & 4.6486 & TST & \\
\hline CHEMBL1566530 & 688612 & 4.5 & 4.6868 & TRN & \\
\hline CHEMBL3211467 & 688612 & 4.05 & 4.7119 & TRN & \\
\hline CHEMBL1303254 & 688612 & 6.95 & 4.6019 & TRN & \\
\hline CHEMBL1516904 & 688612 & 4.05 & 4.7025 & TRN & \\
\hline CHEMBL1368385 & 688612 & 4.65 & 4.6678 & TST & \\
\hline CHEMBL1987514 & 688612 & 4.85 & 4.7438 & TRN & \\
\hline CHEMBL1995947 & 688612 & 5.0 & 4.71399 & 99999999995 & TRN \\
\hline CHEMBL1403482 & 688612 & 4.4 & 4.588 & TRN & \\
\hline CHEMBL1986690 & 688612 & 4.05 & 4.7561 & TST & \\
\hline CHEMBL1562250 & 688612 & 4.0 & 4.5144 & TRN & \\
\hline CHEMBL1405932 & 688612 & 4.55 & 4.698 & TRN & \\
\hline CHEMBL1594037 & 688612 & 4.5 & 4.6232 & TRN & \\
\hline CHEMBL1575834 & 688612 & 4.05 & 4.6654 & TRN & \\
\hline CHEMBL1580422 & 688612 & 5.15 & 4.6956 & TST & \\
\hline CHEMBL1585067 & 688612 & 5.6 & 4.6628 & TRN & \\
\hline CHEMBL1538898 & 688612 & 4.0 & 4.6653 & TRN & \\
\hline CHEMBL1538089 & 688612 & 4.55 & 4.6067 & TRN & \\
\hline CHEMBL1380684 & 688612 & 5.3 & 4.7917 & TRN & \\
\hline CHEMBL1440888 & 688612 & 4.05 & 4.5839 & TRN & \\
\hline CHEMBL3196132 & 688612 & 4.1 & 4.6263 & TST & \\
\hline CHEMBL1453361 & 688612 & 4.2 & 4.5883 & TRN & \\
\hline
\end{tabular}




\begin{tabular}{|c|c|c|c|c|c|}
\hline & & \multicolumn{4}{|c|}{ Supplemental Table S2.txt } \\
\hline CHEMBL1381925 & 688612 & 4.05 & 4.6385 & TST & \\
\hline CHEMBL1581251 & 688612 & 5.5 & 4.7207 & TRN & \\
\hline CHEMBL1367154 & 688612 & 4.1 & 4.7035 & TRN & \\
\hline CHEMBL596674 & 688612 & 4.35 & 4.6455 & TST & \\
\hline CHEMBL1455479 & 688612 & 4.4 & 4.6516 & TST & \\
\hline CHEMBL3195388 & 688612 & 4.3 & 4.7371 & TST & \\
\hline CHEMBL1571724 & 688612 & 4.3 & 4.6118 & TRN & \\
\hline CHEMBL1512428 & 688612 & 4.0 & 4.619 & TRN & \\
\hline CHEMBL1561155 & 688612 & 4.95 & 4.676 & TRN & \\
\hline CHEMBL1430542 & 688612 & 4.4 & 4.7027 & TRN & \\
\hline CHEMBL 3208358 & 688612 & 4.35 & 4.783 & TST & \\
\hline CHEMBL1353207 & 688612 & 4.0 & 4.5998 & TRN & \\
\hline CHEMBL1486879 & 688612 & 5.85 & 4.5977 & TST & \\
\hline CHEMBL1428406 & 688612 & 4.75 & 4.6337 & TRN & \\
\hline CHEMBL1581915 & 688612 & 4.6 & 4.788 & TRN & \\
\hline CHEMBL3209040 & 688612 & 5.2 & 4.6842 & TRN & \\
\hline CHEMBL375966 & 688612 & 4.55 & 4.747 & TRN & \\
\hline CHEMBL1463968 & 688612 & 4.65 & 4.7373 & TRN & \\
\hline CHEMBL1310179 & 688612 & 4.0 & 4.6976 & TRN & \\
\hline CHEMBL1550064 & 688612 & 4.7 & 4.6115 & TRN & \\
\hline CHEMBL1502137 & 688612 & 4.55 & 4.80399 & 9999999999 & TRN \\
\hline CHEMBL1367996 & 688612 & 4.7 & 4.6578 & TRN & \\
\hline CHEMBL1369950 & 688612 & 5.1 & 4.5877 & TRN & \\
\hline CHEMBL3192900 & 688612 & 5.75 & 4.7649 & TRN & \\
\hline CHEMBL1535661 & 688612 & 4.7 & 4.6164 & TRN & \\
\hline CHEMBL1339319 & 688612 & 4.05 & 4.6473 & TRN & \\
\hline CHEMBL1426583 & 688612 & 4.05 & 4.6753 & TRN & \\
\hline CHEMBL1512196 & 688612 & 4.25 & 4.5867 & TRN & \\
\hline CHEMBL1363357 & 688612 & 4.65 & 4.6638 & TRN & \\
\hline CHEMBL1299445 & 688612 & 4.3 & 4.6499 & TST & \\
\hline CHEMBL1422657 & 688612 & 4.6 & 4.6119 & TRN & \\
\hline CHEMBL1328608 & 688612 & 4.2 & 4.7894 & TST & \\
\hline CHEMBL1409493 & 688612 & 5.4 & 4.6272 & TRN & \\
\hline CHEMBL1454617 & 688612 & 6.5 & 4.6133 & TRN & \\
\hline CHEMBL3193783 & 688612 & 4.8 & 4.6147 & TST & \\
\hline CHEMBL1455917 & 688612 & 4.55 & 4.6474 & TRN & \\
\hline CHEMBL1569616 & 688612 & 5.6 & 4.6486 & TRN & \\
\hline CHEMBL1374307 & 688612 & 4.0 & 4.6278 & TRN & \\
\hline CHEMBL1421081 & 688612 & 4.6 & 4.75 & TRN & \\
\hline CHEMBL1392584 & 688612 & 4.85 & 4.664 & TRN & \\
\hline CHEMBL3198331 & 688612 & 5.85 & 4.7238 & TRN & \\
\hline CHEMBL1301922 & 688612 & 4.25 & 4.646 & TRN & \\
\hline CHEMBL1545867 & 688612 & 4.1 & 4.63 & TRN & \\
\hline CHEMBL1560328 & 688612 & 4.0 & 4.6515 & TRN & \\
\hline CHEMBL1596398 & 688612 & 5.85 & 4.6769 & TRN & \\
\hline CHEMBL1499691 & 688612 & 4.2 & 4.6213 & TST & \\
\hline CHEMBL1418133 & 688612 & 4.5 & 4.6403 & TRN & \\
\hline CHEMBL3189477 & 688612 & 4.65 & 4.7408 & TRN & \\
\hline
\end{tabular}




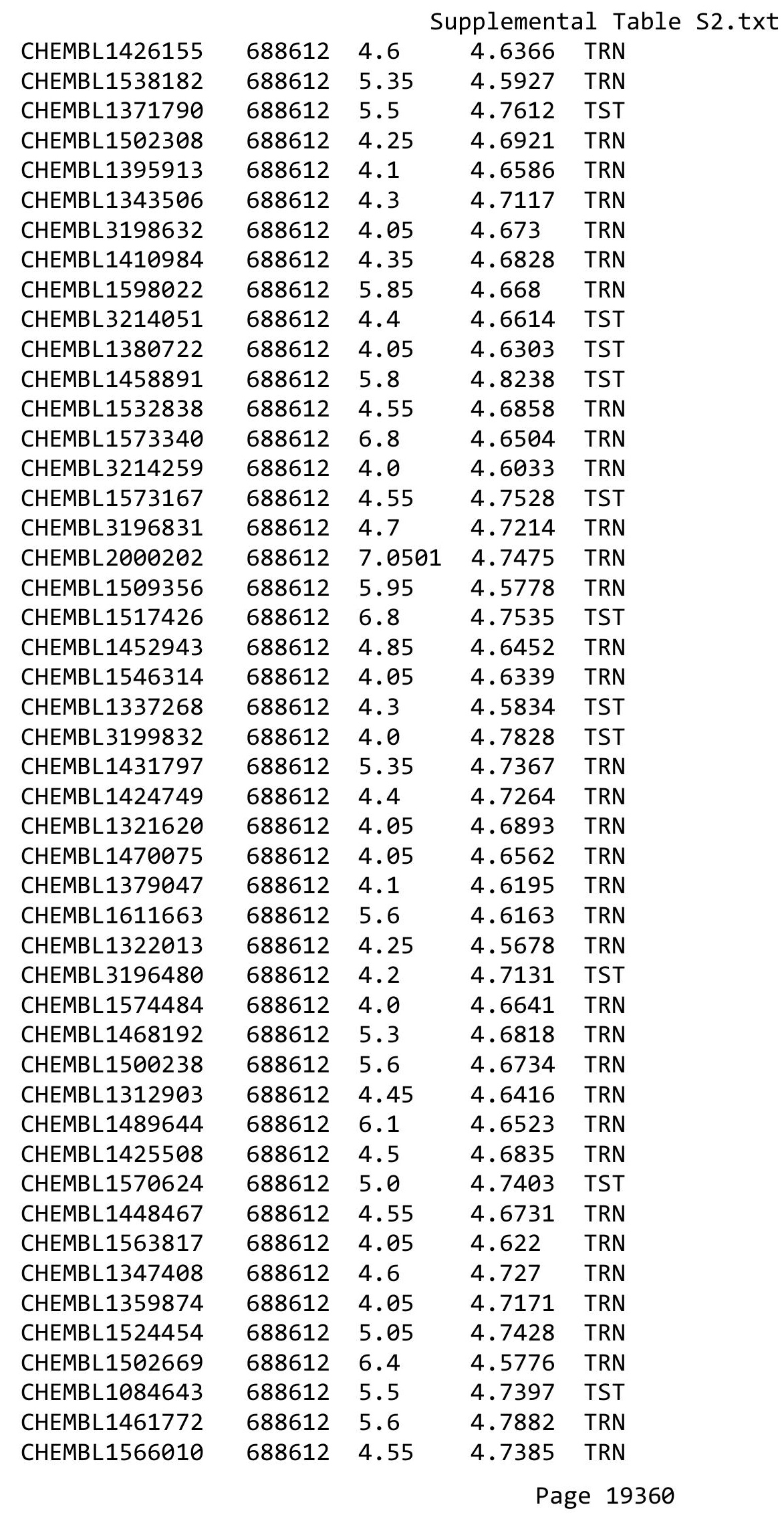




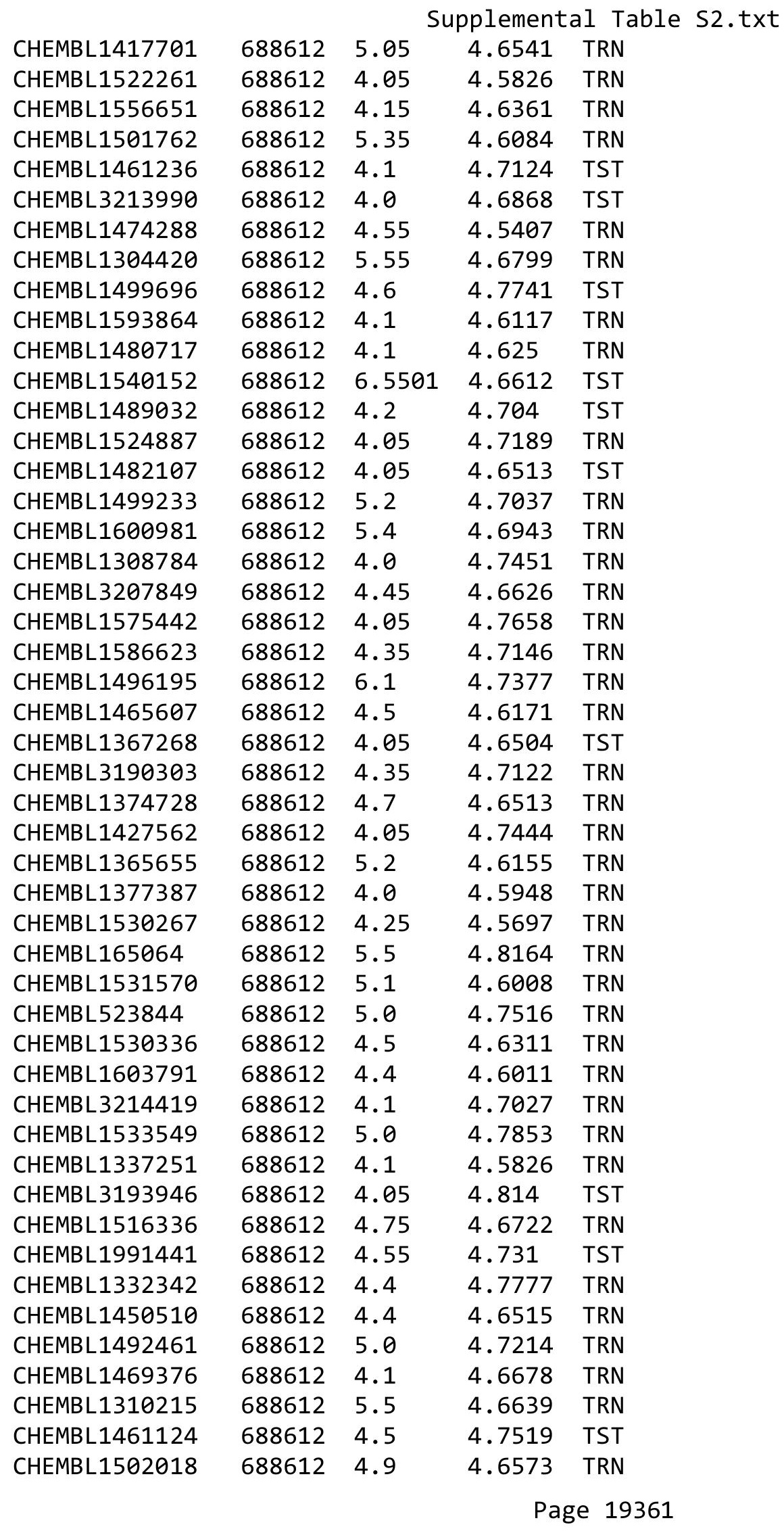




\begin{tabular}{|c|c|c|c|c|c|}
\hline \multicolumn{6}{|c|}{ Supplemental Table s2.txt } \\
\hline CHEMBL1500719 & 688612 & 5.6 & 4.6277 & TRN & \\
\hline CHEMBL1522618 & 688612 & 4.3 & 4.7021 & TRN & \\
\hline CHEMBL1555676 & 688612 & 4.05 & 4.7242 & TRN & \\
\hline CHEMBL1506991 & 688612 & 4.05 & 4.6949 & TRN & \\
\hline CHEMBL1542502 & 688612 & 4.05 & 4.6426 & TRN & \\
\hline CHEMBL1595290 & 688612 & 4.1 & 4.6124 & TST & \\
\hline CHEMBL1459330 & 688612 & 4.25 & 4.5735 & TST & \\
\hline CHEMBL536480 & 688612 & 4.1 & 4.6149 & TST & \\
\hline CHEMBL1610902 & 688612 & 4.9 & 4.6644 & TST & \\
\hline CHEMBL1462636 & 688612 & 4.65 & 4.7375 & TRN & \\
\hline CHEMBL1600474 & 688612 & 5.4 & 4.5662 & TRN & \\
\hline CHEMBL1386415 & 688612 & 5.15 & 4.614 & TRN & \\
\hline CHEMBL1414390 & 688612 & 6.8 & 4.7135 & TRN & \\
\hline CHEMBL1340713 & 688612 & 4.3 & 4.7403 & TRN & \\
\hline CHEMBL1407196 & 688612 & 4.05 & 4.63899 & 9999999999 & TRN \\
\hline CHEMBL1392794 & 688612 & 6.15 & 4.7168 & TRN & \\
\hline CHEMBL1587973 & 688612 & 4.1 & 4.6276 & TRN & \\
\hline CHEMBL1467240 & 688612 & 4.6 & 4.6584 & TRN & \\
\hline CHEMBL1507312 & 688612 & 5.8 & 4.6696 & TRN & \\
\hline CHEMBL1430309 & 688612 & 4.7 & 4.7304 & TST & \\
\hline CHEMBL1606814 & 688612 & 4.05 & 4.6069 & TRN & \\
\hline CHEMBL1460679 & 688612 & 4.05 & 4.7631 & TRN & \\
\hline CHEMBL3199908 & 688612 & 4.65 & 4.7678 & TRN & \\
\hline CHEMBL1450384 & 688612 & 4.45 & 4.7329 & TRN & \\
\hline CHEMBL1451059 & 688612 & 5.45 & 4.7646 & TRN & \\
\hline CHEMBL1367954 & 688612 & 4.65 & 4.7821 & TRN & \\
\hline CHEMBL1420569 & 688612 & 4.6 & 4.6219 & TRN & \\
\hline CHEMBL1413131 & 688612 & 4.15 & 4.6258 & TST & \\
\hline CHEMBL1505334 & 688612 & 5.25 & 4.72199 & 99999999995 & TRN \\
\hline CHEMBL1548876 & 688612 & 4.05 & 4.5978 & TRN & \\
\hline CHEMBL1611445 & 688612 & 4.6 & 4.6594 & TRN & \\
\hline CHEMBL1329761 & 688612 & 4.2 & 4.6805 & TRN & \\
\hline CHEMBL1501353 & 688612 & 4.0 & 4.5891 & TST & \\
\hline CHEMBL1540106 & 688612 & 4.15 & 4.5881 & TRN & \\
\hline CHEMBL1586477 & 688612 & 4.1 & 4.7103 & TRN & \\
\hline CHEMBL1553829 & 688612 & 4.5 & 4.7305 & TRN & \\
\hline CHEMBL3189604 & 688612 & 5.35 & 4.6415 & TRN & \\
\hline CHEMBL447111 & 688612 & 4.75 & 4.655 & TST & \\
\hline CHEMBL1524400 & 688612 & 4.75 & 4.7805 & TRN & \\
\hline CHEMBL3190381 & 688612 & 4.75 & 4.6978 & TRN & \\
\hline CHEMBL1480575 & 688612 & 4.05 & 4.6769 & TST & \\
\hline CHEMBL1602846 & 688612 & 4.25 & 4.7022 & TST & \\
\hline CHEMBL1485960 & 688612 & 5.1 & 4.7228 & TRN & \\
\hline CHEMBL2369285 & 688612 & 4.05 & 4.6783 & TST & \\
\hline CHEMBL1578974 & 688612 & 4.1 & 4.6092 & TRN & \\
\hline CHEMBL3144970 & 688612 & 4.5 & 4.6671 & TRN & \\
\hline CHEMBL3189545 & 688612 & 4.7 & 4.724 & TRN & \\
\hline CHEMBL1488170 & 688612 & 6.0 & 4.7158 & TRN & \\
\hline
\end{tabular}




\begin{tabular}{|c|c|c|c|c|c|}
\hline \multicolumn{6}{|c|}{ Supplemental Table s2.txt } \\
\hline CHEMBL3198598 & 688612 & 4.1 & 4.7482 & TRN & \\
\hline CHEMBL1530601 & 688612 & 4.85 & 4.6771 & TRN & \\
\hline CHEMBL1484203 & 688612 & 5.0 & 4.6375 & TST & \\
\hline CHEMBL1313386 & 688612 & 4.25 & 4.6747 & TRN & \\
\hline CHEMBL1477068 & 688612 & 5.75 & 4.6509 & TRN & \\
\hline CHEMBL1549707 & 688612 & 4.4 & 4.6651 & TRN & \\
\hline CHEMBL3199632 & 688612 & 4.05 & 4.6384 & TRN & \\
\hline CHEMBL1579881 & 688612 & 4.05 & 4.647 & TST & \\
\hline CHEMBL1381634 & 688612 & 4.45 & 4.6621 & TRN & \\
\hline CHEMBL1411962 & 688612 & 5.75 & 4.7242 & TST & \\
\hline CHEMBL3196561 & 688612 & 4.0 & 4.7278 & TRN & \\
\hline CHEMBL1308848 & 688612 & 5.25 & 4.7661 & TST & \\
\hline CHEMBL1300952 & 688612 & 4.75 & 4.74100 & 00000000005 & TRN \\
\hline CHEMBL1355144 & 688612 & 4.45 & 4.6538 & TRN & \\
\hline CHEMBL1363323 & 688612 & 4.5 & 4.7288 & TRN & \\
\hline CHEMBL1589196 & 688612 & 4.0 & 4.6328 & TRN & \\
\hline CHEMBL1446729 & 688612 & 4.5 & 4.6525 & TRN & \\
\hline CHEMBL1525551 & 688612 & 4.4 & 4.651 & TST & \\
\hline CHEMBL1301408 & 688612 & 4.15 & 4.6376 & TRN & \\
\hline CHEMBL1358465 & 688612 & 4.45 & 4.7279 & TRN & \\
\hline CHEMBL1385740 & 688612 & 4.05 & 4.7444 & TRN & \\
\hline CHEMBL1358953 & 688612 & 6.25 & 4.7062 & TST & \\
\hline CHEMBL1500816 & 688612 & 4.05 & 4.7009 & TRN & \\
\hline CHEMBL1342894 & 688612 & 4.5 & 4.7152 & TRN & \\
\hline CHEMBL1599967 & 688612 & 5.4 & 4.6725 & TRN & \\
\hline CHEMBL1523306 & 688612 & 4.1 & 4.6956 & TST & \\
\hline CHEMBL1593519 & 688612 & 4.15 & 4.6307 & TRN & \\
\hline CHEMBL1372529 & 688612 & 4.7 & 4.66 & TRN & \\
\hline CHEMBL1564502 & 688612 & 6.0 & 4.5957 & TST & \\
\hline CHEMBL1456071 & 688612 & 4.0 & 4.7423 & TRN & \\
\hline CHEMBL1552923 & 688612 & 4.3 & 4.5937 & TRN & \\
\hline CHEMBL1329431 & 688612 & 5.55 & 4.5812 & TRN & \\
\hline CHEMBL1561298 & 688612 & 4.4 & 4.6581 & TRN & \\
\hline CHEMBL1394763 & 688612 & 4.6 & 4.63899 & 7999999999 & TRN \\
\hline CHEMBL 2001337 & 688612 & 4.95 & 4.7236 & TRN & \\
\hline CHEMBL1342299 & 688612 & 5.05 & 4.7887 & TST & \\
\hline CHEMBL1595621 & 688612 & 5.0 & 4.7261 & TST & \\
\hline CHEMBL1563364 & 688612 & 6.5 & 4.6498 & TRN & \\
\hline CHEMBL1389595 & 688612 & 6.8499 & 4.6016 & TRN & \\
\hline CHEMBL1987928 & 688612 & 6.5 & 4.8457 & TRN & \\
\hline CHEMBL6665 & 688612 & 4.5 & 4.8423 & TRN & \\
\hline CHEMBL1307891 & 688612 & 4.1 & 4.6039 & TRN & \\
\hline CHEMBL1349705 & 688612 & 4.45 & 4.7274 & TRN & \\
\hline CHEMBL1361856 & 688612 & 4.4 & 4.729 & TST & \\
\hline CHEMBL1299713 & 688612 & 7.0 & 4.5987 & TRN & \\
\hline CHEMBL1559072 & 688612 & 5.85 & 4.6399 & TRN & \\
\hline CHEMBL1416182 & 688612 & 4.1 & 4.5997 & TRN & \\
\hline CHEMBL1387073 & 688612 & 7.0 & 4.6875 & TRN & \\
\hline
\end{tabular}




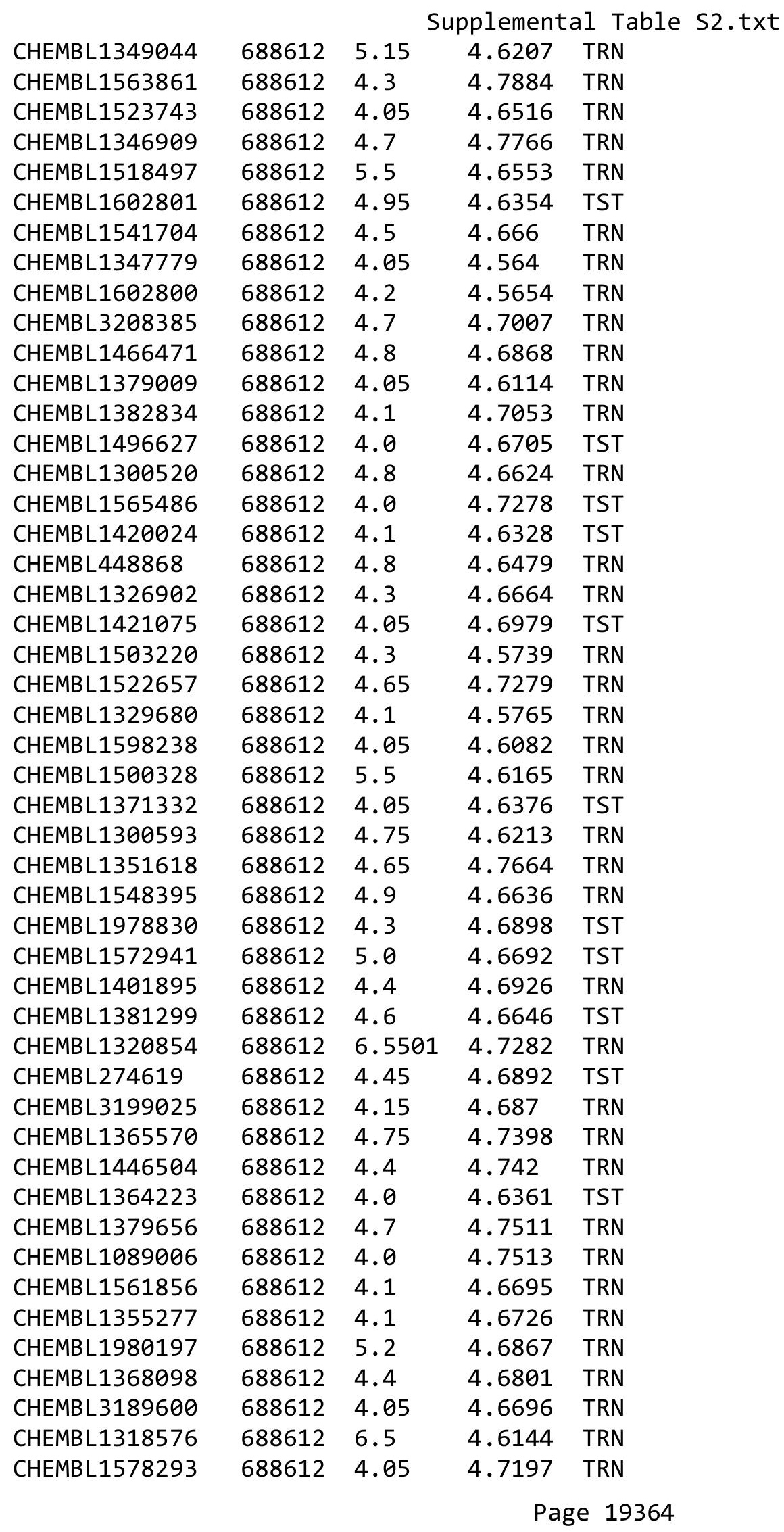




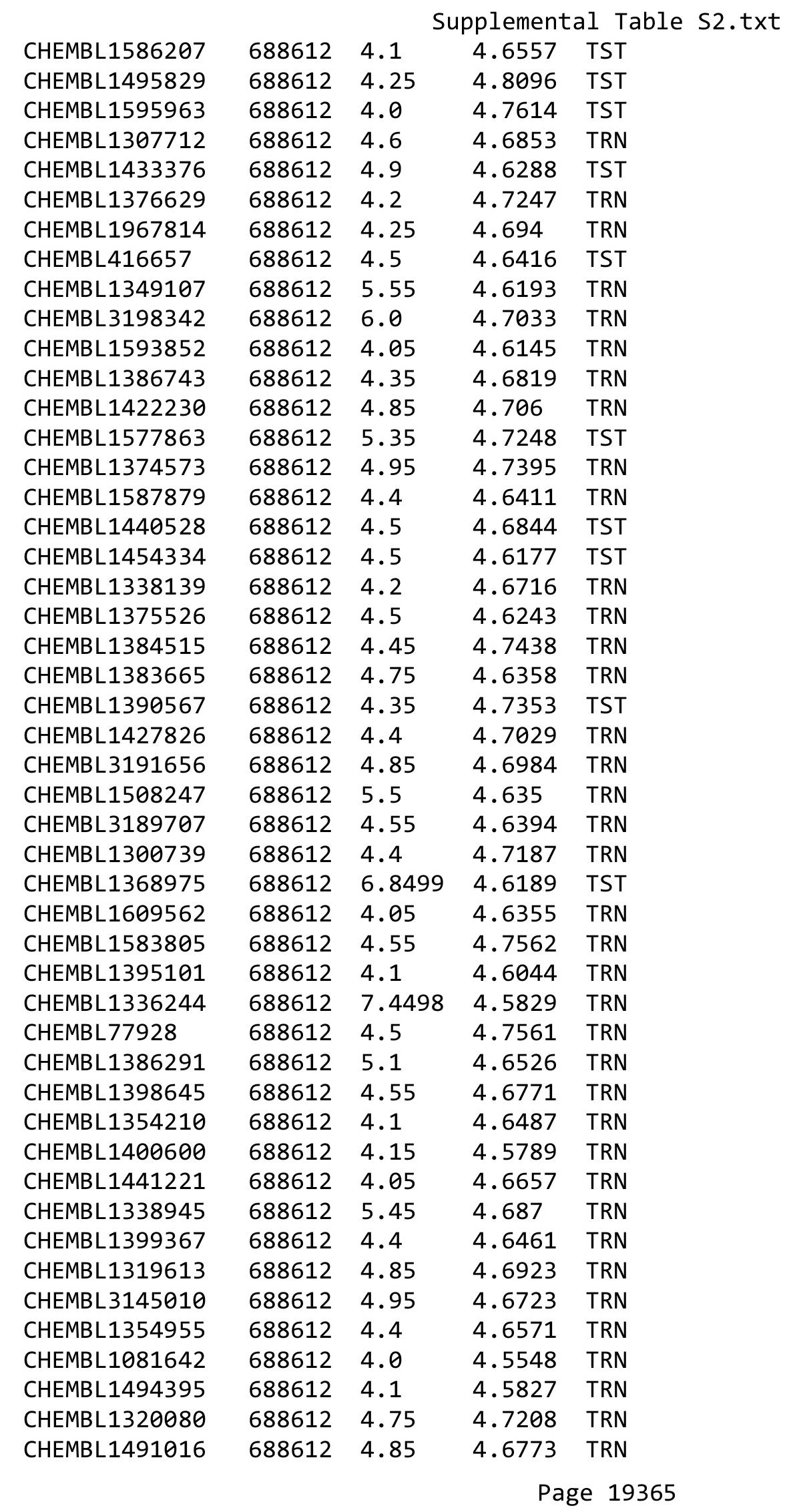




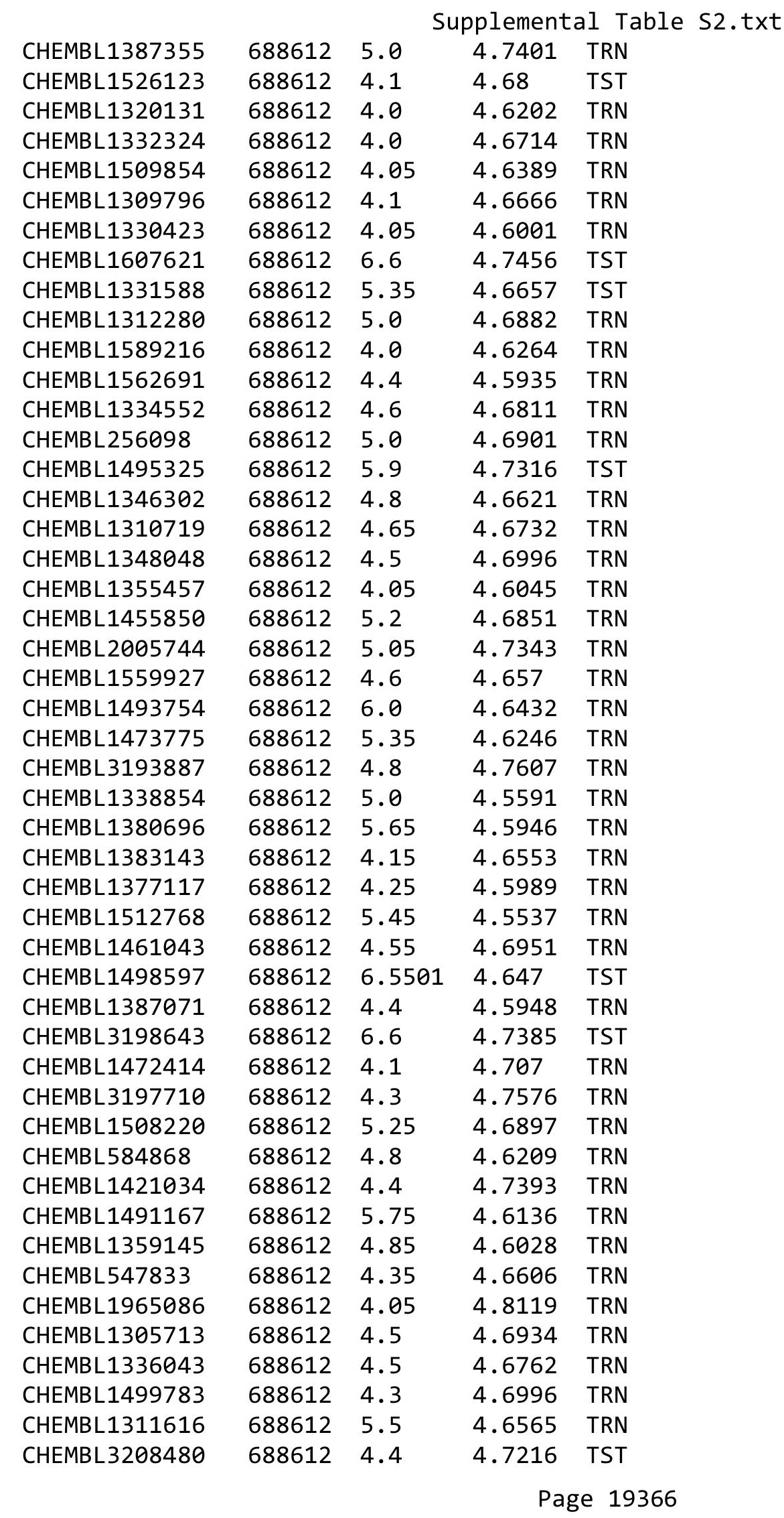




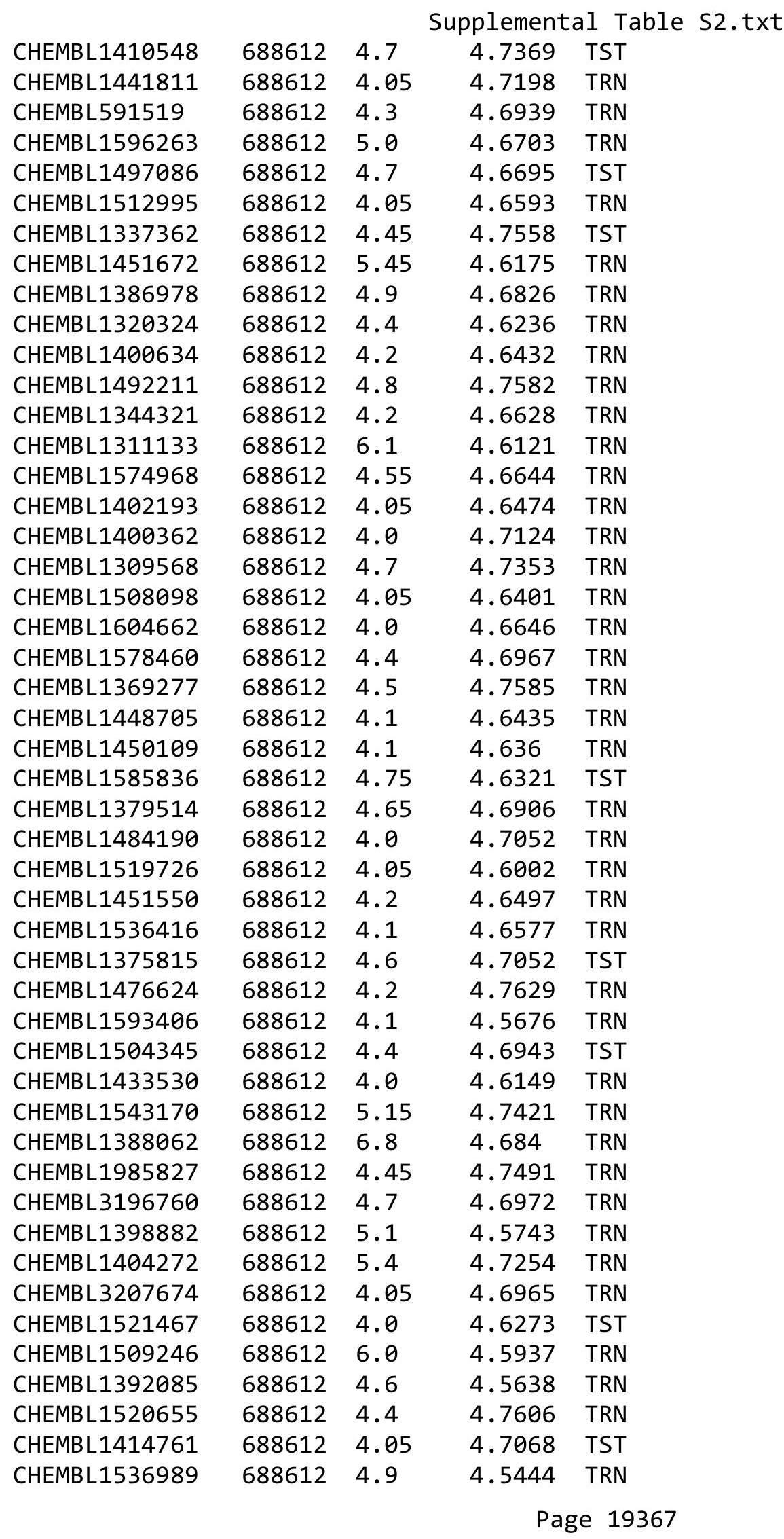




\begin{tabular}{|c|c|c|c|c|c|}
\hline \multicolumn{6}{|c|}{ Supplemental Table s2.txt } \\
\hline CHEMBL1526292 & 688612 & 4.2 & 4.6152 & TRN & \\
\hline CHEMBL1475274 & 688612 & 4.45 & 4.6131 & TRN & \\
\hline CHEMBL3195739 & 688612 & 4.1 & 4.6354 & TRN & \\
\hline CHEMBL1306030 & 688612 & 4.05 & 4.7284 & TST & \\
\hline CHEMBL1392976 & 688612 & 5.65 & 4.7127 & TST & \\
\hline CHEMBL1451882 & 688612 & 4.05 & 4.6776 & TRN & \\
\hline CHEMBL1499762 & 688612 & 4.3 & 4.6763 & TRN & \\
\hline CHEMBL1301322 & 688612 & 4.15 & 4.6552 & TRN & \\
\hline CHEMBL1499072 & 688612 & 4.3 & 4.6876 & TRN & \\
\hline CHEMBL1340650 & 688612 & 5.45 & 4.6862 & TRN & \\
\hline CHEMBL1329269 & 688612 & 4.0 & 4.6221 & TRN & \\
\hline CHEMBL1501701 & 688612 & 6.7501 & 4.658 & TRN & \\
\hline CHEMBL1346433 & 688612 & 4.05 & 4.6841 & TRN & \\
\hline CHEMBL1332108 & 688612 & 4.05 & 4.7177 & TST & \\
\hline CHEMBL1425858 & 688612 & 4.05 & 4.7353 & TST & \\
\hline CHEMBL1446952 & 688612 & 6.05 & 4.6309 & TRN & \\
\hline CHEMBL1372780 & 688612 & 4.65 & 4.71399 & 99999999995 & TRN \\
\hline CHEMBL1429903 & 688612 & 4.05 & 4.676 & TRN & \\
\hline CHEMBL1513209 & 688612 & 4.1 & 4.6386 & TRN & \\
\hline CHEMBL1599122 & 688612 & 6.9 & 4.6419 & TRN & \\
\hline CHEMBL1350172 & 688612 & 5.2 & 4.6595 & TST & \\
\hline CHEMBL1597784 & 688612 & 4.05 & 4.636 & TRN & \\
\hline CHEMBL1523004 & 688612 & 4.05 & 4.6724 & TRN & \\
\hline CHEMBL1570558 & 688612 & 4.3 & 4.5543 & TRN & \\
\hline CHEMBL1323674 & 688612 & 5.55 & 4.7177 & TRN & \\
\hline CHEMBL3192654 & 688612 & 4.05 & 4.6984 & TRN & \\
\hline CHEMBL1602895 & 688612 & 4.7 & 4.6561 & TRN & \\
\hline CHEMBL1541487 & 688612 & 4.7 & 4.6524 & TRN & \\
\hline CHEMBL1468864 & 688612 & 4.4 & 4.6615 & TRN & \\
\hline CHEMBL3209478 & 688612 & 5.35 & 4.6956 & TRN & \\
\hline CHEMBL1361699 & 688612 & 5.15 & 4.7422 & TRN & \\
\hline CHEMBL1426557 & 688612 & 4.1 & 4.5952 & TRN & \\
\hline CHEMBL1380020 & 688612 & 5.15 & 4.734 & TRN & \\
\hline CHEMBL1358917 & 688612 & 4.95 & 4.649 & TRN & \\
\hline CHEMBL1520540 & 688612 & 4.75 & 4.6318 & TRN & \\
\hline CHEMBL1572823 & 688612 & 4.4 & 4.5758 & TRN & \\
\hline CHEMBL1457702 & 688612 & 4.55 & 4.6838 & TRN & \\
\hline CHEMBL1505809 & 688612 & 4.9 & 4.7931 & TRN & \\
\hline CHEMBL1581440 & 688612 & 5.1 & 4.7526 & TRN & \\
\hline CHEMBL1456745 & 688612 & 4.65 & 4.6902 & TST & \\
\hline CHEMBL1495920 & 688612 & 4.35 & 4.6934 & TRN & \\
\hline CHEMBL1531738 & 688612 & 4.05 & 4.66 & TST & \\
\hline CHEMBL1585927 & 688612 & 4.05 & 4.5762 & TRN & \\
\hline CHEMBL1405580 & 688612 & 4.7 & 4.7033 & TRN & \\
\hline CHEMBL1601269 & 688612 & 6.15 & 4.6092 & TRN & \\
\hline CHEMBL1524947 & 688612 & 4.35 & 4.6625 & TRN & \\
\hline CHEMBL1461611 & 688612 & 4.05 & 4.6147 & TST & \\
\hline CHEMBL1399451 & 688612 & 4.05 & 4.6661 & TRN & \\
\hline
\end{tabular}




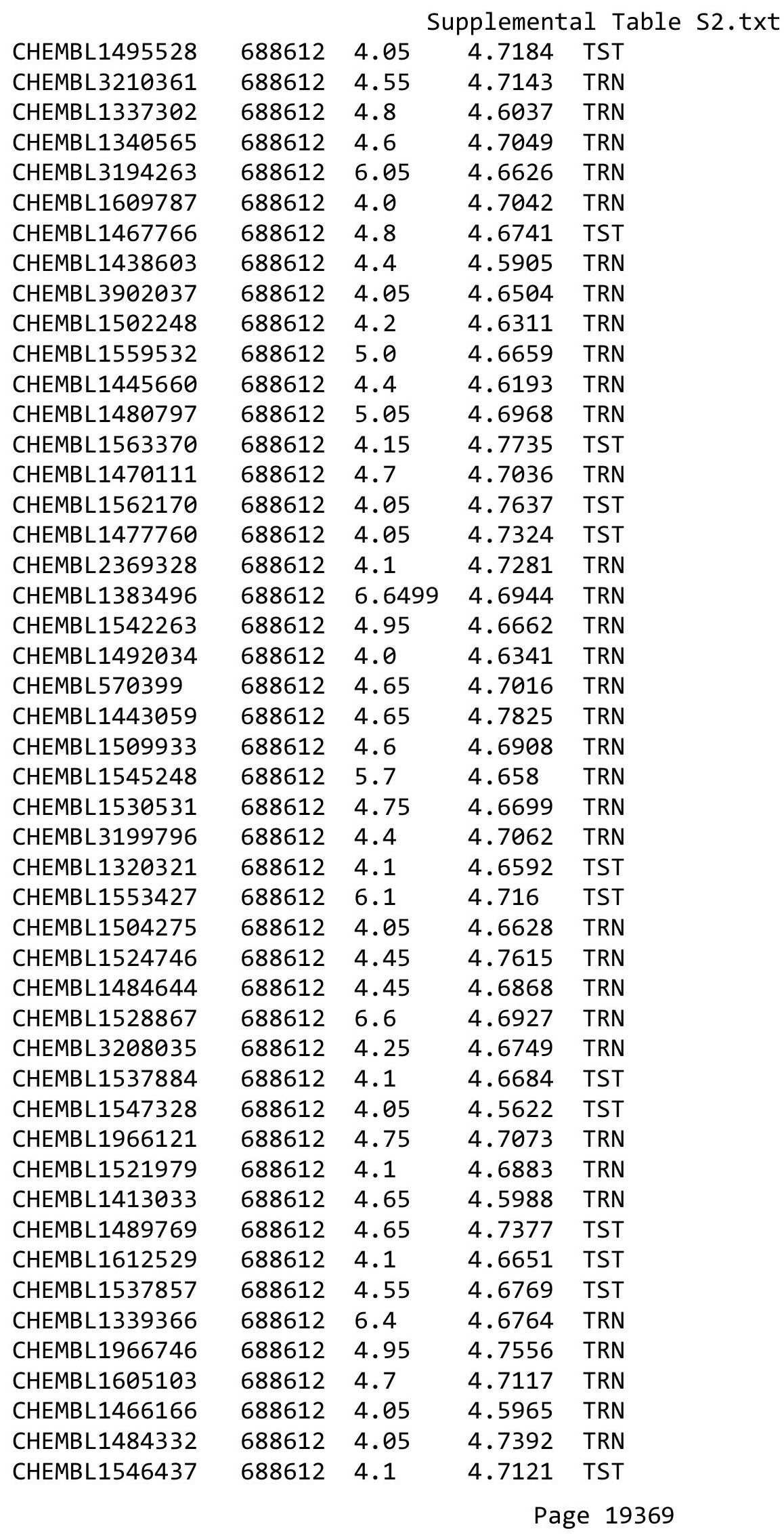




\begin{tabular}{|c|c|c|c|c|}
\hline \multicolumn{5}{|c|}{ Supplemental Table S2.txt } \\
\hline CHEMBL1414998 & 688612 & 4.4 & 4.6528 & TST \\
\hline CHEMBL3193968 & 688612 & 4.3 & 4.7151 & TRN \\
\hline CHEMBL1508902 & 688612 & 4.1 & 4.6496 & TRN \\
\hline CHEMBL1490976 & 688612 & 4.55 & 4.6988 & TRN \\
\hline CHEMBL1360793 & 688612 & 4.85 & 4.7465 & TRN \\
\hline CHEMBL1465331 & 688612 & 6.5501 & 4.6257 & TRN \\
\hline CHEMBL1604520 & 688612 & 4.45 & 4.7278 & TRN \\
\hline CHEMBL1339786 & 688612 & 4.75 & 4.7648 & TRN \\
\hline CHEMBL1504122 & 688612 & 4.05 & 4.5658 & TST \\
\hline CHEMBL1516957 & 688612 & 4.1 & 4.7487 & TST \\
\hline CHEMBL 3207645 & 688612 & 4.0 & 4.6917 & TRN \\
\hline CHEMBL1421540 & 688612 & 4.05 & 4.6248 & TRN \\
\hline CHEMBL1455426 & 688612 & 4.05 & 4.5937 & TRN \\
\hline CHEMBL 3197412 & 688612 & 5.5 & 4.737 & TRN \\
\hline CHEMBL1525995 & 688612 & 4.0 & 4.6924 & TST \\
\hline CHEMBL1384330 & 688612 & 5.35 & 4.7136 & TRN \\
\hline CHEMBL1608571 & 688612 & 4.05 & 4.6099 & TRN \\
\hline CHEMBL1405855 & 688612 & 4.9 & 4.7457 & TST \\
\hline CHEMBL1514498 & 688612 & 6.1 & 4.6141 & TRN \\
\hline CHEMBL1420675 & 688612 & 5.65 & 4.6791 & TRN \\
\hline CHEMBL1601838 & 688612 & 4.35 & 4.6865 & TST \\
\hline CHEMBL1562488 & 688612 & 4.7 & 4.6528 & TST \\
\hline CHEMBL1471804 & 688612 & 5.5 & 4.5324 & TRN \\
\hline CHEMBL1418178 & 688612 & 4.45 & 4.6665 & TRN \\
\hline CHEMBL1366757 & 688612 & 4.05 & 4.6668 & TRN \\
\hline CHEMBL1600440 & 688612 & 4.95 & 4.7596 & TRN \\
\hline CHEMBL1545158 & 688612 & 4.3 & 4.6487 & TRN \\
\hline CHEMBL1613610 & 688612 & 4.75 & 4.6052 & TRN \\
\hline CHEMBL 3194940 & 688612 & 4.05 & 4.631 & TRN \\
\hline CHEMBL1300584 & 688612 & 4.1 & 4.6798 & TRN \\
\hline CHEMBL1471844 & 688612 & 5.45 & 4.7434 & TRN \\
\hline CHEMBL1476408 & 688612 & 4.4 & 4.6341 & TRN \\
\hline CHEMBL3195734 & 688612 & 4.6 & 4.7085 & TST \\
\hline CHEMBL1515092 & 688612 & 4.05 & 4.544 & TRN \\
\hline CHEMBL1437446 & 688612 & 4.85 & 4.6205 & TRN \\
\hline CHEMBL280998 & 688612 & 4.4 & 4.7813 & TST \\
\hline CHEMBL1582389 & 688612 & 4.8 & 4.6502 & TST \\
\hline CHEMBL1352938 & 688612 & 4.05 & 4.6992 & TRN \\
\hline CHEMBL1516737 & 688612 & 5.5 & 4.6714 & TRN \\
\hline CHEMBL1575821 & 688612 & 4.8 & 4.5616 & TRN \\
\hline CHEMBL1386397 & 688612 & 5.05 & 4.6253 & TRN \\
\hline CHEMBL1334176 & 688612 & 4.15 & 4.6015 & TRN \\
\hline CHEMBL1463160 & 688612 & 4.4 & 4.6878 & TRN \\
\hline CHEMBL171637 & 688612 & 4.35 & 4.7433 & TST \\
\hline CHEMBL33715 & 688612 & 4.0 & 4.5687 & TRN \\
\hline CHEMBL601137 & 688612 & 4.5 & 4.7531 & TRN \\
\hline CHEMBL1523416 & 688612 & 4.45 & 4.6157 & TRN \\
\hline CHEMBL1419679 & 688612 & 4.55 & 4.6739 & TRN \\
\hline
\end{tabular}




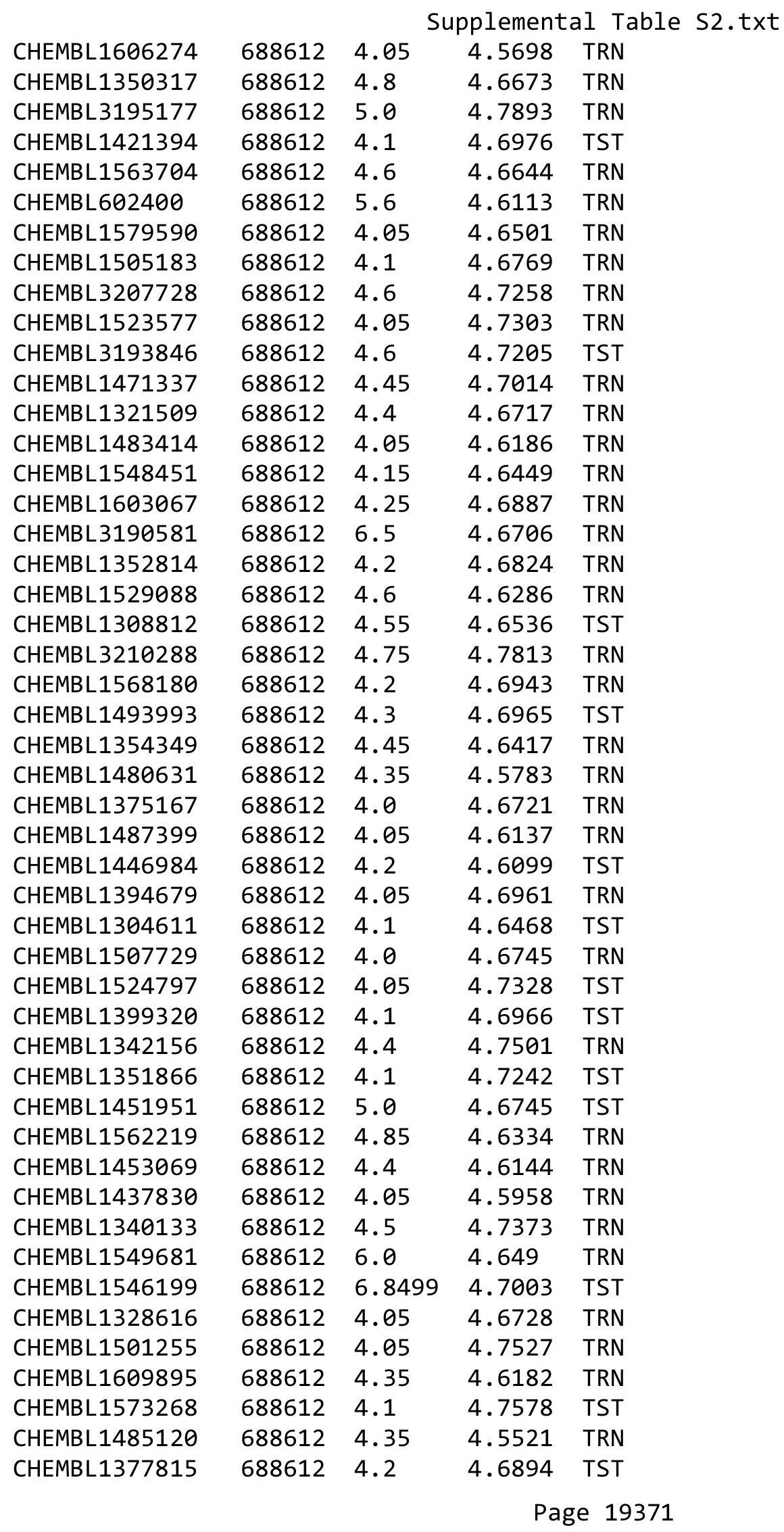




\begin{tabular}{|c|c|c|c|c|}
\hline \multicolumn{5}{|c|}{ Supplemental Table S2.txt } \\
\hline CHEMBL1545560 & 688612 & 6.25 & 4.5991 & TRN \\
\hline CHEMBL3210097 & 688612 & 7.0 & 4.6417 & TRN \\
\hline CHEMBL1376671 & 688612 & 4.05 & 4.6337 & TRN \\
\hline CHEMBL1394372 & 688612 & 4.0 & 4.5841 & TRN \\
\hline CHEMBL1459856 & 688612 & 4.05 & 4.677 & TST \\
\hline CHEMBL3196129 & 688612 & 4.1 & 4.7763 & TRN \\
\hline CHEMBL1539195 & 688612 & 4.05 & 4.7361 & TRN \\
\hline CHEMBL1524427 & 688612 & 4.05 & 4.6273 & TST \\
\hline CHEMBL1432677 & 688612 & 4.05 & 4.6112 & TRN \\
\hline CHEMBL1402603 & 688612 & 4.4 & 4.6688 & TRN \\
\hline CHEMBL1300861 & 688612 & 7.0 & 4.7481 & TRN \\
\hline CHEMBL1517068 & 688612 & 4.4 & 4.6862 & TRN \\
\hline CHEMBL3195431 & 688612 & 5.5 & 4.7106 & TRN \\
\hline CHEMBL1357226 & 688612 & 4.0 & 4.6889 & TST \\
\hline CHEMBL1529471 & 688612 & 4.95 & 4.7891 & TRN \\
\hline CHEMBL 2000510 & 688612 & 4.05 & 4.6608 & TST \\
\hline CHEMBL1465900 & 688612 & 4.45 & 4.6526 & TRN \\
\hline CHEMBL1409247 & 688612 & 4.4 & 4.7002 & TRN \\
\hline CHEMBL 3197644 & 688612 & 5.95 & 4.6504 & TRN \\
\hline CHEMBL1547092 & 688612 & 4.6 & 4.755 & TRN \\
\hline CHEMBL1370836 & 688612 & 5.0 & 4.7617 & TRN \\
\hline CHEMBL1564963 & 688612 & 4.05 & 4.6078 & TST \\
\hline CHEMBL 3194373 & 688612 & 4.7 & 4.683 & TRN \\
\hline CHEMBL1996136 & 688612 & 5.35 & 4.71 & TST \\
\hline CHEMBL1373606 & 688612 & 4.05 & 4.7129 & TRN \\
\hline CHEMBL1510352 & 688612 & 5.2 & 4.7373 & TRN \\
\hline CHEMBL1431460 & 688612 & 5.5 & 4.5388 & TRN \\
\hline CHEMBL1359671 & 688612 & 6.6 & 4.6617 & TRN \\
\hline CHEMBL1593215 & 688612 & 5.25 & 4.6036 & TRN \\
\hline CHEMBL1480488 & 688612 & 4.0 & 4.743 & TST \\
\hline CHEMBL1559049 & 688612 & 6.2 & 4.6143 & TRN \\
\hline CHEMBL1532633 & 688612 & 4.65 & 4.7634 & TRN \\
\hline CHEMBL 1437787 & 688612 & 4.1 & 4.753 & TRN \\
\hline CHEMBL1370849 & 688612 & 4.05 & 4.6505 & TRN \\
\hline CHEMBL1422573 & 688612 & 4.85 & 4.6907 & TRN \\
\hline CHEMBL1420312 & 688612 & 4.65 & 4.5772 & TRN \\
\hline CHEMBL1374502 & 688612 & 6.8499 & 4.6426 & TRN \\
\hline CHEMBL 3209620 & 688612 & 4.05 & 4.6631 & TRN \\
\hline CHEMBL1459677 & 688612 & 5.4 & 4.6536 & TRN \\
\hline CHEMBL1418692 & 688612 & 4.1 & 4.6253 & TRN \\
\hline CHEMBL1364697 & 688612 & 4.4 & 4.5964 & TRN \\
\hline CHEMBL1368500 & 688612 & 4.8 & 4.6899 & TST \\
\hline CHEMBL1547238 & 688612 & 6.05 & 4.7419 & TRN \\
\hline CHEMBL1965373 & 688612 & 5.3 & 4.6698 & TRN \\
\hline CHEMBL1377315 & 688612 & 4.8 & 4.6047 & TST \\
\hline CHEMBL1307695 & 688612 & 4.2 & 4.7231 & TST \\
\hline CHEMBL1316710 & 688612 & 4.15 & 4.6735 & TRN \\
\hline CHEMBL 1606359 & 688612 & 6.6499 & 4.6997 & TRN \\
\hline
\end{tabular}

Page 19372 


\begin{tabular}{|c|c|c|c|c|}
\hline \multicolumn{5}{|c|}{ Supplemental Table S2.txt } \\
\hline CHEMBL408129 & 688612 & 4.3 & 4.7386 & TST \\
\hline CHEMBL1454739 & 688612 & 4.75 & 4.7049 & TRN \\
\hline CHEMBL1453871 & 688612 & 4.1 & 4.7371 & TRN \\
\hline CHEMBL1399670 & 688612 & 6.25 & 4.612 & TRN \\
\hline CHEMBL1583137 & 688612 & 4.85 & 4.662 & TRN \\
\hline CHEMBL1486500 & 688612 & 4.05 & 4.609 & TRN \\
\hline CHEMBL3198806 & 688612 & 4.65 & 4.7772 & TRN \\
\hline CHEMBL1350311 & 688612 & 4.2 & 4.5835 & TRN \\
\hline CHEMBL1549213 & 688612 & 4.85 & 4.6949 & TRN \\
\hline CHEMBL1414242 & 688612 & 4.0 & 4.6194 & TRN \\
\hline CHEMBL1343882 & 688612 & 4.05 & 4.6336 & TRN \\
\hline CHEMBL1392599 & 688612 & 4.3 & 4.6024 & TST \\
\hline CHEMBL1571965 & 688612 & 4.05 & 4.6708 & TRN \\
\hline CHEMBL1514454 & 688612 & 4.05 & 4.6804 & TRN \\
\hline CHEMBL1579250 & 688612 & 6.8 & 4.7047 & TST \\
\hline CHEMBL1414294 & 688612 & 5.2 & 4.7643 & TRN \\
\hline CHEMBL1518995 & 688612 & 4.95 & 4.6304 & TRN \\
\hline CHEMBL1999885 & 688612 & 5.1 & 4.6828 & TST \\
\hline CHEMBL1438989 & 688612 & 5.7 & 4.6583 & TRN \\
\hline CHEMBL1529358 & 688612 & 4.0 & 4.6137 & TRN \\
\hline CHEMBL1577002 & 688612 & 4.7 & 4.6524 & TRN \\
\hline CHEMBL1550719 & 688612 & 5.5 & 4.6921 & TRN \\
\hline CHEMBL1565931 & 688612 & 6.8 & 4.6422 & TRN \\
\hline CHEMBL1567935 & 688612 & 6.15 & 4.5958 & TRN \\
\hline CHEMBL1395116 & 688612 & 4.1 & 4.6239 & TRN \\
\hline CHEMBL1529704 & 688612 & 5.7 & 4.6712 & TRN \\
\hline CHEMBL1461843 & 688612 & 5.1 & 4.6498 & TRN \\
\hline CHEMBL1404792 & 688612 & 4.3 & 4.7054 & TRN \\
\hline CHEMBL1424673 & 688612 & 4.55 & 4.7307 & TRN \\
\hline CHEMBL1437680 & 688612 & 4.7 & 4.6874 & TRN \\
\hline CHEMBL1387555 & 688612 & 4.05 & 4.5684 & TRN \\
\hline CHEMBL1465398 & 688612 & 4.7 & 4.6114 & TST \\
\hline CHEMBL1539089 & 688612 & 6.2 & 4.5819 & TST \\
\hline CHEMBL1405369 & 688612 & 5.35 & 4.7519 & TST \\
\hline CHEMBL1540927 & 688612 & 5.05 & 4.5796 & TRN \\
\hline CHEMBL1429818 & 688612 & 4.05 & 4.7177 & TST \\
\hline CHEMBL3191340 & 688612 & 4.05 & 4.6805 & TST \\
\hline CHEMBL1490082 & 688612 & 4.3 & 4.7407 & TST \\
\hline CHEMBL3196792 & 688612 & 4.25 & 4.748 & TRN \\
\hline CHEMBL1324673 & 688612 & 4.4 & 4.6268 & TRN \\
\hline CHEMBL1303064 & 688612 & 4.05 & 4.6538 & TST \\
\hline CHEMBL3190917 & 688612 & 4.1 & 4.745 & TRN \\
\hline CHEMBL1452673 & 688612 & 4.05 & 4.6439 & TST \\
\hline CHEMBL1441992 & 688612 & 4.0 & 4.5883 & TRN \\
\hline CHEMBL1560628 & 688612 & 5.75 & 4.7901 & TST \\
\hline CHEMBL3196841 & 688612 & 4.1 & 4.7652 & TST \\
\hline CHEMBL1587265 & 688612 & 4.05 & 4.7441 & TRN \\
\hline CHEMBL1413293 & 688612 & 4.1 & 4.6165 & TRN \\
\hline
\end{tabular}




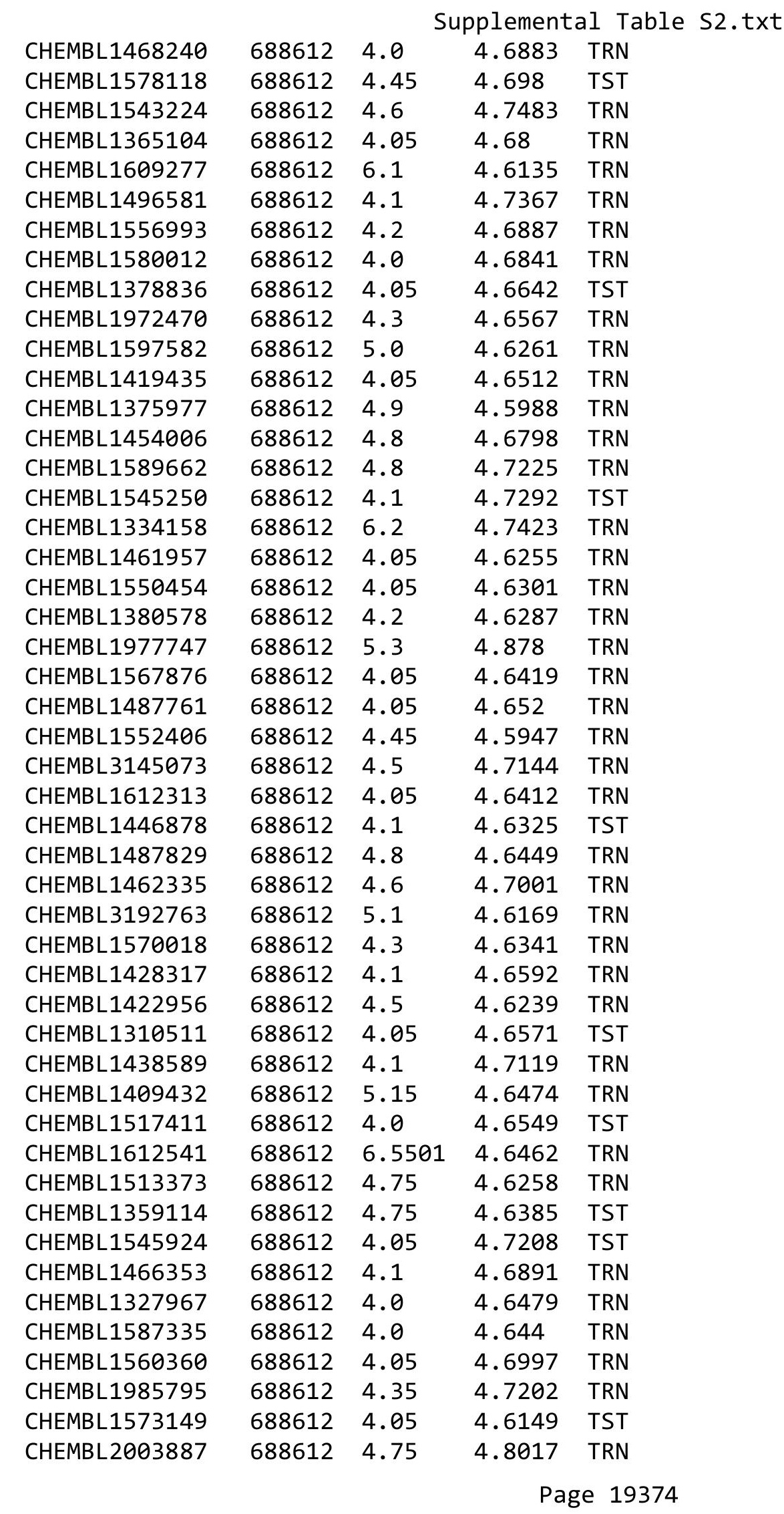




\begin{tabular}{|c|c|c|c|c|c|}
\hline \multicolumn{6}{|c|}{ Supplemental Table S2.txt } \\
\hline CHEMBL1426297 & 688612 & 4.3 & 4.7464 & TRN & \\
\hline CHEMBL1416221 & 688612 & 4.05 & 4.6668 & TRN & \\
\hline CHEMBL1342396 & 688612 & 4.55 & 4.6946 & TRN & \\
\hline CHEMBL1371254 & 688612 & 4.25 & 4.6674 & TST & \\
\hline CHEMBL1474677 & 688612 & 4.4 & 4.6047 & TST & \\
\hline CHEMBL522983 & 688612 & 6.0 & 4.8517 & TRN & \\
\hline CHEMBL1989527 & 688612 & 4.05 & 4.6113 & TRN & \\
\hline CHEMBL1470728 & 688612 & 5.9 & 4.688 & TST & \\
\hline CHEMBL1528584 & 688612 & 4.3 & 4.63899 & 9999999999 & TRN \\
\hline CHEMBL1578367 & 688612 & 4.6 & 4.7383 & TRN & \\
\hline CHEMBL1457137 & 688612 & 4.85 & 4.7234 & TST & \\
\hline CHEMBL1359310 & 688612 & 4.05 & 4.6457 & TRN & \\
\hline CHEMBL1437320 & 688612 & 4.05 & 4.65300 & 00000000005 & TRN \\
\hline CHEMBL1346488 & 688612 & 4.3 & 4.6539 & TRN & \\
\hline CHEMBL1491530 & 688612 & 4.65 & 4.7144 & TRN & \\
\hline CHEMBL1411251 & 688612 & 4.1 & 4.65 & TRN & \\
\hline CHEMBL1323514 & 688612 & 4.5 & 4.6696 & TST & \\
\hline CHEMBL1448060 & 688612 & 4.05 & 4.6416 & TRN & \\
\hline CHEMBL1475198 & 688612 & 4.45 & 4.7392 & TRN & \\
\hline CHEMBL1337055 & 688612 & 4.4 & 4.6156 & TRN & \\
\hline CHEMBL1322349 & 688612 & 4.65 & 4.6176 & TST & \\
\hline CHEMBL1519474 & 688612 & 6.9 & 4.6443 & TRN & \\
\hline CHEMBL1711538 & 688612 & 4.7 & 4.6289 & TRN & \\
\hline CHEMBL1520820 & 688612 & 5.1 & 4.646 & TST & \\
\hline CHEMBL1588195 & 688612 & 4.05 & 4.6593 & TRN & \\
\hline CHEMBL1523970 & 688612 & 4.3 & 4.6322 & TRN & \\
\hline CHEMBL1345603 & 688612 & 6.95 & 4.6998 & TST & \\
\hline CHEMBL1588356 & 688612 & 5.55 & 4.6842 & TST & \\
\hline CHEMBL1595562 & 688612 & 6.15 & 4.6923 & TRN & \\
\hline CHEMBL1521576 & 688612 & 4.35 & 4.6328 & TRN & \\
\hline CHEMBL1421732 & 688612 & 4.05 & 4.6265 & TRN & \\
\hline CHEMBL1580084 & 688612 & 5.45 & 4.6348 & TRN & \\
\hline CHEMBL1509146 & 688612 & 4.0 & 4.6542 & TST & \\
\hline CHEMBL1532407 & 688612 & 4.55 & 4.7871 & TRN & \\
\hline CHEMBL1488215 & 688612 & 4.1 & 4.6889 & TST & \\
\hline CHEMBL1378562 & 688612 & 4.4 & 4.5938 & TST & \\
\hline CHEMBL1447291 & 688612 & 7.0 & 4.6321 & TRN & \\
\hline CHEMBL3196177 & 688612 & 4.05 & 4.6326 & TST & \\
\hline CHEMBL1580412 & 688612 & 4.85 & 4.6745 & TRN & \\
\hline CHEMBL1309377 & 688612 & 4.75 & 4.7157 & TRN & \\
\hline CHEMBL1352209 & 688612 & 4.4 & 4.6735 & TRN & \\
\hline CHEMBL1411534 & 688612 & 4.25 & 4.6105 & TRN & \\
\hline CHEMBL1381087 & 688612 & 4.05 & 4.6774 & TRN & \\
\hline CHEMBL1367934 & 688612 & 4.4 & 4.6375 & TST & \\
\hline CHEMBL1458561 & 688612 & 4.25 & 4.6012 & TRN & \\
\hline CHEMBL1556014 & 688612 & 6.5 & 4.6791 & TRN & \\
\hline CHEMBL163316 & 688612 & 5.35 & 4.84 & TRN & \\
\hline CHEMBL1402282 & 688612 & 5.05 & 4.6972 & TST & \\
\hline
\end{tabular}




\begin{tabular}{|c|c|c|c|c|c|}
\hline \multirow[b]{2}{*}{ CHEMBL1418989 } & \multicolumn{5}{|c|}{ Supplemental Table S2.txt } \\
\hline & 688612 & 4.05 & 4.6895 & TST & \\
\hline CHEMBL1308788 & 688612 & 4.6 & $4.7410 €$ & 00000000005 & TRN \\
\hline CHEMBL1481864 & 688612 & 4.4 & 4.6932 & TRN & \\
\hline CHEMBL1365010 & 688612 & 4.1 & 4.6479 & TRN & \\
\hline CHEMBL 1417650 & 688612 & 4.3 & 4.7327 & TRN & \\
\hline CHEMBL1411069 & 688612 & 4.05 & 4.6416 & TST & \\
\hline CHEMBL1330515 & 688612 & 6.0 & 4.5742 & TRN & \\
\hline CHEMBL1466563 & 688612 & 4.05 & 4.6813 & TRN & \\
\hline CHEMBL1602802 & 688612 & 6.9 & 4.6285 & TRN & \\
\hline CHEMBL1564371 & 688612 & 7.0 & 4.7054 & TST & \\
\hline CHEMBL3208399 & 688612 & 5.7 & 4.6804 & TST & \\
\hline CHEMBL1359927 & 688612 & 7.0 & 4.6605 & TRN & \\
\hline CHEMBL1447178 & 688612 & 4.1 & 4.665 & TRN & \\
\hline CHEMBL1536732 & 688612 & 4.05 & 4.7452 & TST & \\
\hline CHEMBL1387307 & 688612 & 6.5 & 4.7469 & TST & \\
\hline CHEMBL3193533 & 688612 & 4.4 & 4.7148 & TRN & \\
\hline CHEMBL1548834 & 688612 & 4.7 & 4.6666 & TRN & \\
\hline CHEMBL1589853 & 688612 & 4.2 & 4.7237 & TST & \\
\hline CHEMBL1463289 & 688612 & 4.3 & 4.7354 & TRN & \\
\hline CHEMBL1340549 & 688612 & 4.7 & 4.6025 & TRN & \\
\hline CHEMBL1546283 & 688612 & 4.1 & 4.6762 & TRN & \\
\hline CHEMBL1463132 & 688612 & 4.05 & 4.6996 & TRN & \\
\hline CHEMBL1554934 & 688612 & 5.5 & 4.6267 & TRN & \\
\hline CHEMBL1577029 & 688612 & 4.6 & 4.7154 & TRN & \\
\hline CHEMBL1337247 & 688612 & 4.8 & 4.7626 & TRN & \\
\hline CHEMBL1365252 & 688612 & 4.05 & 4.5981 & TST & \\
\hline CHEMBL1448865 & 688612 & 4.15 & 4.6556 & TST & \\
\hline CHEMBL1493061 & 688612 & 4.05 & 4.6859 & TRN & \\
\hline CHEMBL1446896 & 688612 & 4.0 & 4.6629 & TRN & \\
\hline CHEMBL1327155 & 688612 & 5.8 & 4.6569 & TRN & \\
\hline CHEMBL1525774 & 688612 & 4.05 & 4.6517 & TST & \\
\hline CHEMBL1347806 & 688612 & 6.8499 & 4.7029 & TRN & \\
\hline CHEMBL1602872 & 688612 & 4.05 & 4.6914 & TRN & \\
\hline CHEMBL1453688 & 688612 & 4.7 & 4.6645 & TST & \\
\hline CHEMBL1469851 & 688612 & 4.8 & 4.6812 & TRN & \\
\hline CHEMBL1350264 & 688612 & 4.0 & 4.7005 & TRN & \\
\hline CHEMBL1600683 & 688612 & 4.45 & 4.7694 & TST & \\
\hline CHEMBL3189175 & 688612 & 4.3 & 4.6373 & TRN & \\
\hline CHEMBL1460052 & 688612 & 5.25 & 4.7367 & TST & \\
\hline CHEMBL1404923 & 688612 & 4.0 & 4.6043 & TRN & \\
\hline CHEMBL1564224 & 688612 & 4.55 & 4.7223 & TRN & \\
\hline CHEMBL1555116 & 688612 & 6.8499 & 4.6531 & TRN & \\
\hline CHEMBL1391501 & 688612 & 4.25 & 4.6488 & TST & \\
\hline CHEMBL1407944 & 688612 & 4.3 & 4.6957 & TRN & \\
\hline CHEMBL1494783 & 688612 & 4.05 & 4.6414 & TST & \\
\hline CHEMBL1572822 & 688612 & 7.0 & 4.7109 & TRN & \\
\hline CHEMBL 1306856 & 688612 & 5.2 & 4.7031 & TRN & \\
\hline CHEMBL1502667 & 688612 & 5.05 & 4.6867 & TRN & \\
\hline
\end{tabular}




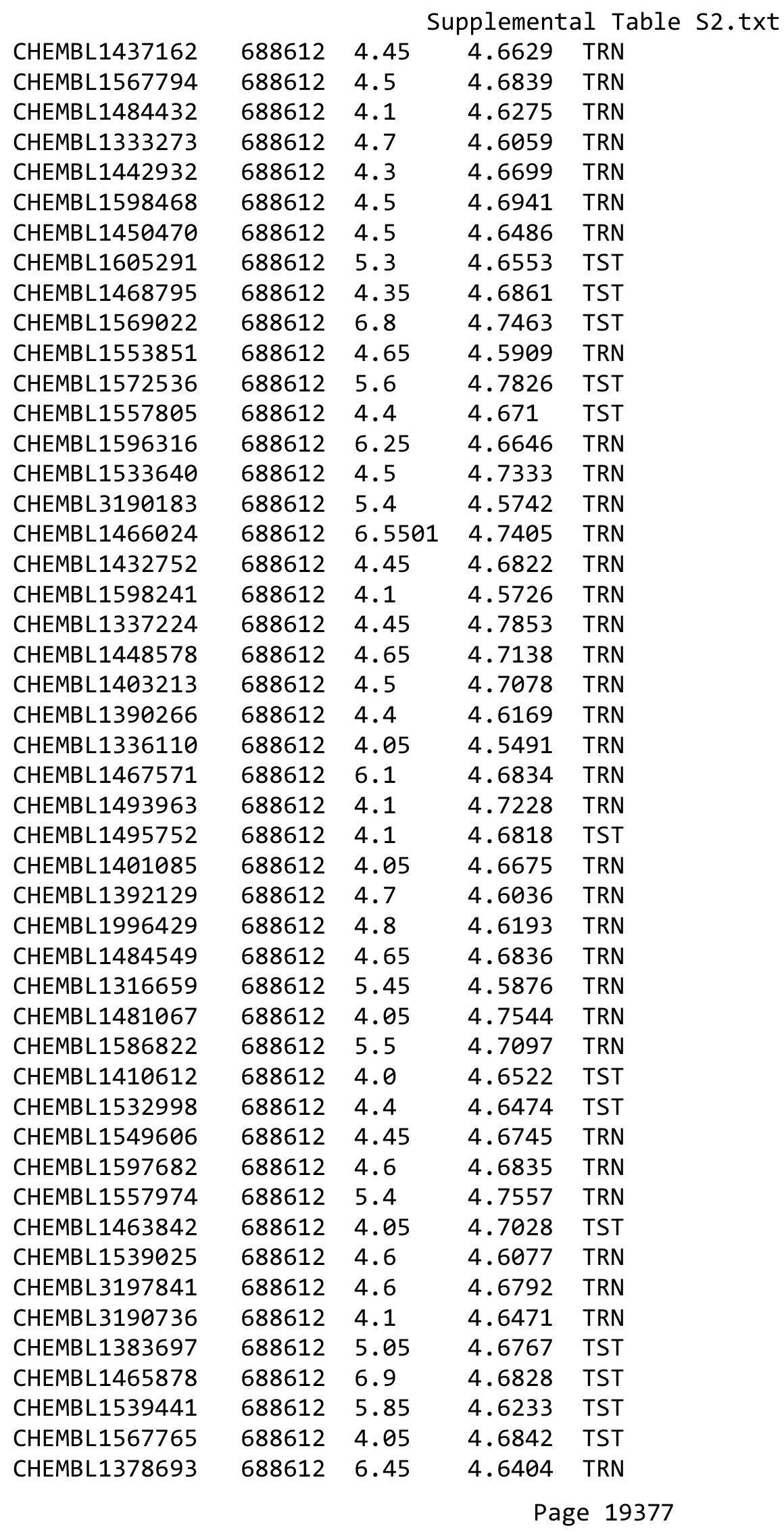




\begin{tabular}{|c|c|c|c|c|}
\hline \multicolumn{5}{|c|}{ Supplemental Table S2.txt } \\
\hline CHEMBL1317075 & 688612 & 6.8 & 4.6221 & TRN \\
\hline CHEMBL1557164 & 688612 & 4.05 & 4.5778 & TRN \\
\hline CHEMBL1388513 & 688612 & 6.2 & 4.6025 & TRN \\
\hline CHEMBL 3194634 & 688612 & 4.4 & 4.7414 & TRN \\
\hline CHEMBL1382527 & 688612 & 4.05 & 4.6574 & TRN \\
\hline CHEMBL1450321 & 688612 & 5.1 & 4.5663 & TRN \\
\hline CHEMBL1582807 & 688612 & 6.0 & 4.6944 & TST \\
\hline CHEMBL1560850 & 688612 & 4.65 & 4.6653 & TRN \\
\hline CHEMBL1478117 & 688612 & 4.95 & 4.6222 & TRN \\
\hline CHEMBL1554113 & 688612 & 4.7 & 4.6621 & TRN \\
\hline CHEMBL1299230 & 688612 & 5.65 & 4.6464 & TRN \\
\hline CHEMBL1550841 & 688612 & 5.55 & 4.6442 & TRN \\
\hline CHEMBL1333304 & 688612 & 4.4 & 4.6141 & TRN \\
\hline CHEMBL1544647 & 688612 & 4.8 & 4.6733 & TRN \\
\hline CHEMBL1565193 & 688612 & 4.75 & 4.6843 & TRN \\
\hline CHEMBL1326410 & 688612 & 4.5 & 4.6878 & TRN \\
\hline CHEMBL1498167 & 688612 & 5.1 & 4.6533 & TRN \\
\hline CHEMBL1355730 & 688612 & 4.15 & 4.6191 & TRN \\
\hline CHEMBL1382621 & 688612 & 5.5 & 4.6875 & TRN \\
\hline CHEMBL1503852 & 688612 & 5.0 & 4.7994 & TRN \\
\hline CHEMBL1423492 & 688612 & 6.0 & 4.6475 & TRN \\
\hline CHEMBL1589571 & 688612 & 4.25 & 4.8013 & TRN \\
\hline CHEMBL1399638 & 688612 & 4.8 & 4.7348 & TRN \\
\hline CHEMBL1309088 & 688612 & 4.05 & 4.7228 & TRN \\
\hline CHEMBL1543997 & 688612 & 4.8 & 4.7337 & TST \\
\hline CHEMBL1330441 & 688612 & 4.1 & 4.7266 & TRN \\
\hline CHEMBL1438877 & 688612 & 4.4 & 4.6666 & TST \\
\hline CHEMBL1473459 & 688612 & 4.1 & 4.6632 & TST \\
\hline CHEMBL1304421 & 688612 & 6.5501 & 4.6611 & TST \\
\hline CHEMBL1380162 & 688612 & 4.05 & 4.695 & TRN \\
\hline CHEMBL1309334 & 688612 & 4.9 & 4.7248 & TRN \\
\hline CHEMBL1314269 & 688612 & 4.95 & 4.6014 & TRN \\
\hline CHEMBL1474726 & 688612 & 6.9 & 4.7018 & TST \\
\hline CHEMBL1456415 & 688612 & 5.45 & 4.5981 & TST \\
\hline CHEMBL1325996 & 688612 & 4.15 & 4.6134 & TRN \\
\hline CHEMBL1345588 & 688612 & 5.35 & 4.7239 & TRN \\
\hline CHEMBL1438617 & 688612 & 4.3 & 4.6273 & TST \\
\hline CHEMBL1327418 & 688612 & 5.1 & 4.6865 & TRN \\
\hline CHEMBL1302063 & 688612 & 4.5 & 4.6886 & TRN \\
\hline CHEMBL1300939 & 688612 & 4.7 & 4.6247 & TST \\
\hline CHEMBL1475023 & 688612 & 4.45 & 4.6869 & TRN \\
\hline CHEMBL3210559 & 688612 & 4.4 & 4.7696 & TST \\
\hline CHEMBL1458959 & 688612 & 4.05 & 4.6585 & TST \\
\hline CHEMBL1519442 & 688612 & 5.45 & 4.7077 & TST \\
\hline CHEMBL1417191 & 688612 & 4.8 & 4.6935 & TRN \\
\hline CHEMBL1516615 & 688612 & 4.0 & 4.6381 & TRN \\
\hline CHEMBL1356848 & 688612 & 4.0 & 4.6281 & TRN \\
\hline CHEMBL1532969 & 688612 & 4.05 & 4.6345 & TRN \\
\hline
\end{tabular}




\begin{tabular}{|c|c|c|c|c|c|}
\hline \multicolumn{6}{|c|}{ Supplemental Table S2.txt } \\
\hline CHEMBL1423129 & 688612 & 4.7 & 4.6292 & TRN & \\
\hline CHEMBL1307000 & 688612 & 4.65 & 4.6902 & TRN & \\
\hline CHEMBL1987136 & 688612 & 4.6 & 4.7188 & TRN & \\
\hline CHEMBL1369930 & 688612 & 4.95 & 4.7497 & TRN & \\
\hline CHEMBL1351543 & 688612 & 4.4 & 4.68199 & 99999999995 & TST \\
\hline CHEMBL1532501 & 688612 & 4.4 & 4.6482 & TRN & \\
\hline CHEMBL1403079 & 688612 & 4.5 & 4.5898 & TRN & \\
\hline CHEMBL1385339 & 688612 & 5.1 & 4.7212 & TST & \\
\hline CHEMBL1601859 & 688612 & 4.1 & 4.6477 & TRN & \\
\hline CHEMBL3198884 & 688612 & 4.4 & 4.801 & TST & \\
\hline CHEMBL1428578 & 688612 & 4.4 & 4.7507 & TRN & \\
\hline CHEMBL1325413 & 688612 & 4.15 & 4.6751 & TST & \\
\hline CHEMBL1569663 & 688612 & 4.05 & 4.6545 & TRN & \\
\hline CHEMBL1496473 & 688612 & 4.6 & 4.7247 & TST & \\
\hline CHEMBL1339313 & 688612 & 4.15 & 4.6749 & TST & \\
\hline CHEMBL1316572 & 688612 & 4.1 & 4.5773 & TRN & \\
\hline CHEMBL1349486 & 688612 & 4.1 & 4.6472 & TRN & \\
\hline CHEMBL1173127 & 688612 & 4.5 & 4.6131 & TRN & \\
\hline CHEMBL1527340 & 688612 & 4.1 & 4.7187 & TRN & \\
\hline CHEMBL1381585 & 688612 & 4.4 & 4.7095 & TST & \\
\hline CHEMBL1465729 & 688612 & 4.55 & 4.655 & TRN & \\
\hline CHEMBL1601874 & 688612 & 4.95 & 4.6117 & TRN & \\
\hline CHEMBL1560262 & 688612 & 4.0 & 4.5942 & TRN & \\
\hline CHEMBL1373197 & 688612 & 4.35 & 4.7037 & TRN & \\
\hline CHEMBL1607306 & 688612 & 4.7 & 4.7633 & TRN & \\
\hline CHEMBL1518845 & 688612 & 6.0 & 4.6865 & TRN & \\
\hline CHEMBL1443498 & 688612 & 4.6 & 4.6948 & TST & \\
\hline CHEMBL1301061 & 688612 & 6.95 & 4.6526 & TRN & \\
\hline CHEMBL1346632 & 688612 & 4.2 & 4.5753 & TRN & \\
\hline CHEMBL233119 & 688612 & 4.8 & 4.7331 & TRN & \\
\hline CHEMBL1330687 & 688612 & 4.25 & 4.6474 & TST & \\
\hline CHEMBL1351799 & 688612 & 4.45 & 4.7435 & TRN & \\
\hline CHEMBL1476360 & 688612 & 4.4 & 4.6271 & TRN & \\
\hline CHEMBL1555052 & 688612 & 4.05 & 4.6022 & TRN & \\
\hline CHEMBL1405872 & 688612 & 4.0 & 4.6066 & TRN & \\
\hline CHEMBL1432921 & 688612 & 6.8 & 4.6599 & TST & \\
\hline CHEMBL3196453 & 688612 & 4.3 & 4.7293 & TST & \\
\hline CHEMBL1378431 & 688612 & 4.05 & 4.7016 & TRN & \\
\hline CHEMBL1460097 & 688612 & 4.9 & 4.605 & TST & \\
\hline CHEMBL1496724 & 688612 & 4.6 & 4.60800 & 00000000005 & TRN \\
\hline CHEMBL1387433 & 688612 & 5.25 & 4.6752 & TRN & \\
\hline CHEMBL1376459 & 688612 & 4.15 & 4.6809 & TST & \\
\hline CHEMBL1312541 & 688612 & 4.0 & 4.6365 & TRN & \\
\hline CHEMBL1603227 & 688612 & 4.35 & 4.7402 & TST & \\
\hline CHEMBL1471366 & 688612 & 4.3 & 4.5655 & TRN & \\
\hline CHEMBL1357087 & 688612 & 5.5 & 4.5947 & TRN & \\
\hline CHEMBL491716 & 688612 & 4.6 & 4.7297 & TRN & \\
\hline CHEMBL1566005 & 688612 & 4.7 & 4.702 & TRN & \\
\hline
\end{tabular}




\begin{tabular}{|c|c|c|c|c|c|}
\hline \multicolumn{6}{|c|}{ Supplemental Table S2.txt } \\
\hline CHEMBL1520640 & 688612 & 4.0 & 4.7577 & TST & \\
\hline CHEMBL1343487 & 688612 & 4.1 & 4.6245 & TRN & \\
\hline CHEMBL1359991 & 688612 & 4.75 & 4.6139 & TRN & \\
\hline CHEMBL1497881 & 688612 & 4.2 & 4.6465 & TST & \\
\hline CHEMBL1346830 & 688612 & 4.2 & 4.6304 & TRN & \\
\hline CHEMBL1345770 & 688612 & 4.05 & 4.7566 & TST & \\
\hline CHEMBL1609457 & 688612 & 6.8 & 4.6723 & TRN & \\
\hline CHEMBL3209346 & 688612 & 4.4 & 4.7022 & TRN & \\
\hline CHEMBL1308127 & 688612 & 4.05 & 4.6293 & TST & \\
\hline CHEMBL1345906 & 688612 & 4.6 & 4.6904 & TST & \\
\hline CHEMBL1306424 & 688612 & 4.05 & 4.6176 & TST & \\
\hline CHEMBL1411384 & 688612 & 4.5 & 4.6208 & TRN & \\
\hline CHEMBL1389574 & 688612 & 4.4 & 4.6436 & TRN & \\
\hline CHEMBL1470361 & 688612 & 4.25 & 4.6951 & TRN & \\
\hline CHEMBL1609079 & 688612 & 4.05 & 4.6229 & TST & \\
\hline CHEMBL1572847 & 688612 & 4.85 & 4.6557 & TRN & \\
\hline CHEMBL1375691 & 688612 & 4.4 & 4.6399 & TRN & \\
\hline CHEMBL1423724 & 688612 & 4.1 & 4.6414 & TRN & \\
\hline CHEMBL1308044 & 688612 & 4.05 & 4.5959 & TRN & \\
\hline CHEMBL1525083 & 688612 & 4.65 & 4.6238 & TRN & \\
\hline CHEMBL3194069 & 688612 & 4.8 & 4.6236 & TST & \\
\hline CHEMBL1392297 & 688612 & 4.0 & 4.6424 & TRN & \\
\hline CHEMBL1479843 & 688612 & 4.1 & 4.7066 & TST & \\
\hline CHEMBL1557462 & 688612 & 4.55 & 4.6573 & TST & \\
\hline CHEMBL1381340 & 688612 & 4.75 & 4.6789 & TRN & \\
\hline CHEMBL3197538 & 688612 & 4.6 & 4.7316 & TRN & \\
\hline CHEMBL1443421 & 688612 & 4.85 & 4.711 & TRN & \\
\hline CHEMBL1426630 & 688612 & 4.1 & 4.6873 & TRN & \\
\hline CHEMBL1548670 & 688612 & 6.5 & 4.7416 & TRN & \\
\hline CHEMBL1559616 & 688612 & 4.25 & 4.791 & TRN & \\
\hline CHEMBL1545129 & 688612 & 4.55 & 4.7085 & TRN & \\
\hline CHEMBL1470643 & 688612 & 5.4 & 4.6631 & TRN & \\
\hline CHEMBL1578470 & 688612 & 4.05 & 4.6082 & TRN & \\
\hline CHEMBL 3145028 & 688612 & 4.35 & 4.6764 & TRN & \\
\hline CHEMBL1336435 & 688612 & 4.05 & 4.6922 & TRN & \\
\hline CHEMBL1560940 & 688612 & 4.4 & 4.65600 & 0000000001 & TRN \\
\hline CHEMBL1310476 & 688612 & 6.2 & 4.7549 & TRN & \\
\hline CHEMBL3199367 & 688612 & 4.3 & 4.6379 & TRN & \\
\hline CHEMBL1449253 & 688612 & 5.05 & 4.668 & TRN & \\
\hline CHEMBL1371946 & 688612 & 4.4 & 4.7073 & TST & \\
\hline CHEMBL1392597 & 688612 & 4.8 & 4.5807 & TRN & \\
\hline CHEMBL1469199 & 688612 & 4.25 & 4.7044 & TRN & \\
\hline CHEMBL1505965 & 688612 & 4.2 & 4.7505 & TRN & \\
\hline CHEMBL1514810 & 688612 & 6.9 & 4.72199 & 99999999995 & TRN \\
\hline CHEMBL3199441 & 688612 & 4.5 & 4.6959 & TRN & \\
\hline CHEMBL1563659 & 688612 & 6.8 & 4.6294 & TRN & \\
\hline CHEMBL1523650 & 688612 & 4.35 & 4.6882 & TST & \\
\hline CHEMBL1467533 & 688612 & 4.4 & 4.5863 & TRN & \\
\hline
\end{tabular}




\begin{tabular}{|c|c|c|c|c|c|}
\hline \multicolumn{6}{|c|}{ Supplemental Table S2.txt } \\
\hline CHEMBL1547705 & 688612 & 5.3 & 4.6061 & TRN & \\
\hline CHEMBL1544691 & 688612 & 4.35 & 4.7195 & TRN & \\
\hline CHEMBL3197501 & 688612 & 4.65 & 4.7148 & TRN & \\
\hline CHEMBL3189877 & 688612 & 4.55 & 4.7929 & TRN & \\
\hline CHEMBL1350332 & 688612 & 4.45 & 4.6836 & TRN & \\
\hline CHEMBL3191939 & 688612 & 6.8499 & 4.6642 & TST & \\
\hline CHEMBL1583782 & 688612 & 4.55 & 4.7099 & TST & \\
\hline CHEMBL1366238 & 688612 & 4.45 & 4.7675 & TST & \\
\hline CHEMBL1426788 & 688612 & 4.0 & 4.6226 & TST & \\
\hline CHEMBL1515045 & 688612 & 4.4 & 4.6396 & TRN & \\
\hline CHEMBL1443559 & 688612 & 4.4 & 4.7342 & TST & \\
\hline CHEMBL3191022 & 688612 & 5.8 & 4.7395 & TRN & \\
\hline CHEMBL1392314 & 688612 & 4.1 & 4.6829 & TST & \\
\hline CHEMBL1432987 & 688612 & 4.05 & 4.6324 & TRN & \\
\hline CHEMBL1336814 & 688612 & 4.3 & 4.6498 & TST & \\
\hline CHEMBL1460751 & 688612 & 4.25 & 4.5792 & TRN & \\
\hline CHEMBL 1456876 & 688612 & 4.3 & 4.7405 & TRN & \\
\hline CHEMBL1410860 & 688612 & 4.5 & 4.5969 & TRN & \\
\hline CHEMBL1486546 & 688612 & 4.55 & 4.6992 & TRN & \\
\hline CHEMBL1577781 & 688612 & 6.5501 & 4.6365 & TRN & \\
\hline CHEMBL1610849 & 688612 & 4.1 & 4.6124 & TRN & \\
\hline CHEMBL1343750 & 688612 & 4.45 & 4.6535 & TST & \\
\hline CHEMBL 367741 & 688612 & 4.1 & 4.6521 & TRN & \\
\hline CHEMBL1504948 & 688612 & 4.3 & 4.6725 & TRN & \\
\hline CHEMBL1383444 & 688612 & 4.6 & 4.6441 & TST & \\
\hline CHEMBL1515312 & 688612 & 4.2 & 4.6348 & TRN & \\
\hline CHEMBL 1540400 & 688612 & 4.55 & 4.68199 & 99999999995 & TST \\
\hline CHEMBL1482274 & 688612 & 6.15 & 4.6259 & TST & \\
\hline CHEMBL1430356 & 688612 & 4.1 & 4.7197 & TST & \\
\hline CHEMBL1394559 & 688612 & 5.85 & 4.6458 & TRN & \\
\hline CHEMBL1578392 & 688612 & 4.05 & 4.676 & TRN & \\
\hline CHEMBL1608031 & 688612 & 4.7 & 4.6836 & TRN & \\
\hline CHEMBL1305630 & 688612 & 4.4 & 4.6465 & TRN & \\
\hline CHEMBL1503011 & 688612 & 4.25 & 4.7499 & TRN & \\
\hline CHEMBL1409207 & 688612 & 4.35 & 4.7492 & TRN & \\
\hline CHEMBL1463028 & 688612 & 4.0 & 4.6215 & TRN & \\
\hline CHEMBL1391481 & 688612 & 4.4 & 4.7497 & TRN & \\
\hline CHEMBL1523857 & 688612 & 4.05 & 4.6009 & TRN & \\
\hline CHEMBL1522218 & 688612 & 4.5 & 4.7331 & TRN & \\
\hline CHEMBL1462133 & 688612 & 4.7 & 4.6651 & TST & \\
\hline CHEMBL3213070 & 688612 & 4.05 & 4.6975 & TRN & \\
\hline CHEMBL1360717 & 688612 & 4.05 & 4.6165 & TRN & \\
\hline CHEMBL1604077 & 688612 & 4.1 & 4.7275 & TST & \\
\hline CHEMBL1378478 & 688612 & 4.45 & 4.7166 & TRN & \\
\hline CHEMBL1305959 & 688612 & 4.55 & 4.6202 & TRN & \\
\hline CHEMBL1487349 & 688612 & 4.0 & 4.7626 & TRN & \\
\hline CHEMBL322970 & 688612 & 6.0 & 4.7571 & TST & \\
\hline CHEMBL1543670 & 688612 & 4.25 & 4.6533 & TRN & \\
\hline
\end{tabular}




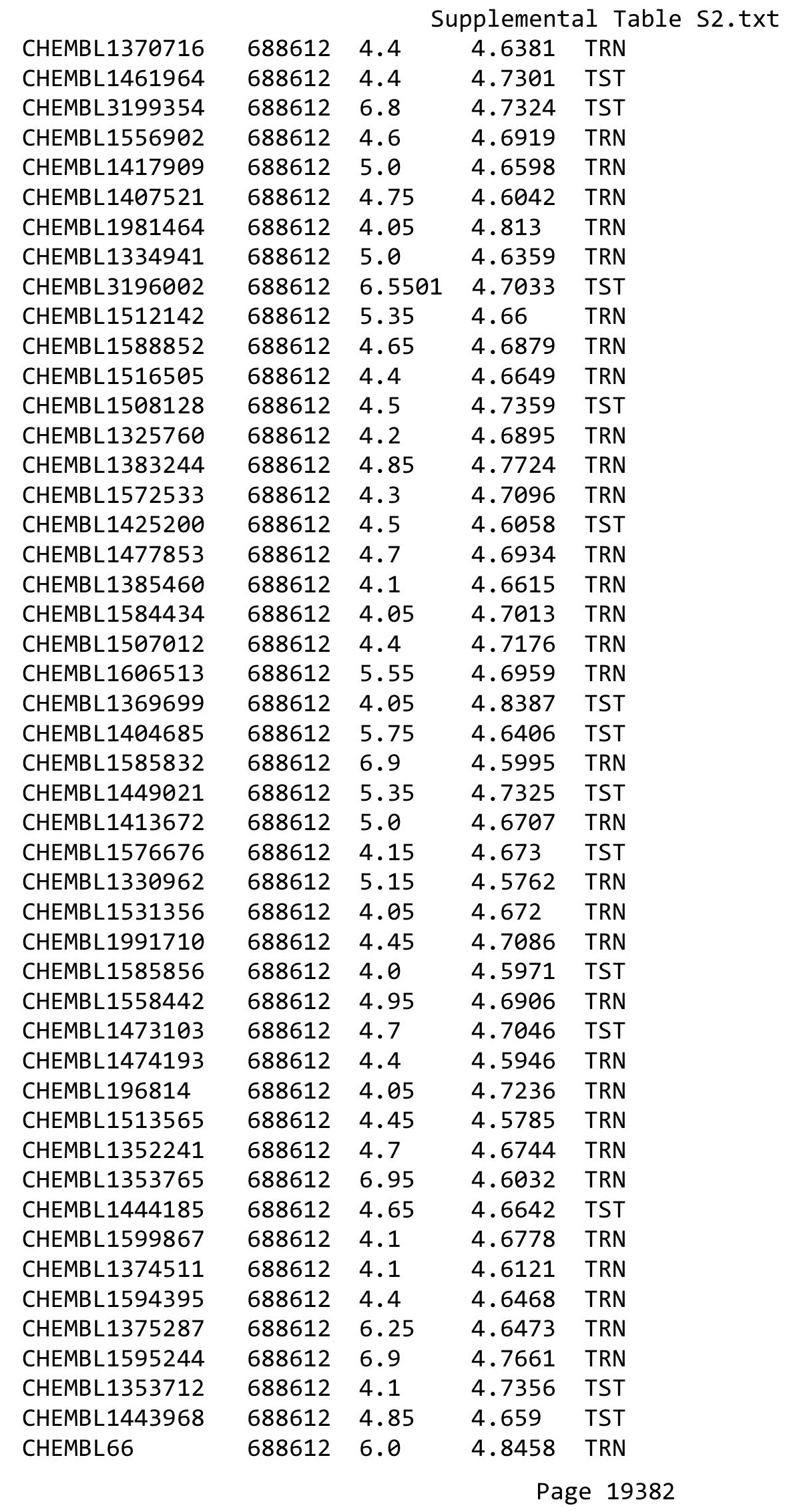




\begin{tabular}{|c|c|c|c|c|c|}
\hline & & \multicolumn{4}{|c|}{ Supplemental Table S2.txt } \\
\hline CHEMBL1591704 & 688612 & 4.9 & 4.5869 & TRN & \\
\hline CHEMBL1534309 & 688612 & 6.2 & 4.6409 & TST & \\
\hline CHEMBL3191632 & 688612 & 4.8 & 4.671 & TRN & \\
\hline CHEMBL1520566 & 688612 & 4.1 & 4.7014 & TST & \\
\hline CHEMBL1574686 & 688612 & 4.4 & 4.6478 & TST & \\
\hline CHEMBL1483954 & 688612 & 4.1 & 4.7219 & TST & \\
\hline CHEMBL1490715 & 688612 & 5.05 & 4.6375 & TRN & \\
\hline CHEMBL1480999 & 688612 & 6.0 & 4.6238 & TRN & \\
\hline CHEMBL1425765 & 688612 & 4.95 & 4.6423 & TRN & \\
\hline CHEMBL1559239 & 688612 & 4.85 & 4.751 & TRN & \\
\hline CHEMBL1320282 & 688612 & 4.1 & 4.6423 & TRN & \\
\hline CHEMBL1566528 & 688612 & 4.7 & 4.7471 & TRN & \\
\hline CHEMBL579105 & 688612 & 4.1 & 4.6131 & TRN & \\
\hline CHEMBL3198477 & 688612 & 6.6 & 4.7061 & TRN & \\
\hline CHEMBL1417046 & 688612 & 4.05 & 4.6314 & TST & \\
\hline CHEMBL1351419 & 688612 & 4.4 & 4.5806 & TRN & \\
\hline CHEMBL1535943 & 688612 & 5.6 & 4.6757 & TST & \\
\hline CHEMBL1302158 & 688612 & 4.05 & 4.5775 & TRN & \\
\hline CHEMBL1330156 & 688612 & 4.0 & 4.6811 & TRN & \\
\hline CHEMBL1336023 & 688612 & 5.55 & 4.6933 & TRN & \\
\hline CHEMBL1545632 & 688612 & 4.65 & 4.7444 & TRN & \\
\hline CHEMBL1314514 & 688612 & 4.45 & 4.583 & TRN & \\
\hline CHEMBL1987587 & 688612 & 6.8499 & 4.6229 & TST & \\
\hline CHEMBL1382910 & 688612 & 4.9 & 4.6806 & TRN & \\
\hline CHEMBL1581900 & 688612 & 4.65 & 4.5806 & TRN & \\
\hline CHEMBL3190039 & 688612 & 6.2 & 4.6802 & TRN & \\
\hline CHEMBL1312244 & 688612 & 4.35 & 4.7728 & TST & \\
\hline CHEMBL1316347 & 688612 & 5.0 & 4.6526 & TRN & \\
\hline CHEMBL1528925 & 688612 & 4.7 & 4.7565 & TST & \\
\hline CHEMBL1562724 & 688612 & 4.65 & 4.735 & TRN & \\
\hline CHEMBL1307336 & 688612 & 4.4 & 4.694 & TRN & \\
\hline CHEMBL1304875 & 688612 & 5.25 & 4.6903 & TRN & \\
\hline CHEMBL1324957 & 688612 & 4.65 & 4.66100 & 00000000005 & TRN \\
\hline CHEMBL1302946 & 688612 & 4.4 & 4.7444 & TRN & \\
\hline CHEMBL1303045 & 688612 & 4.5 & 4.6973 & TRN & \\
\hline CHEMBL1450337 & 688612 & 4.05 & 4.658 & TRN & \\
\hline CHEMBL1443674 & 688612 & 4.65 & 4.7155 & TRN & \\
\hline CHEMBL1492513 & 688612 & 4.45 & 4.6308 & TRN & \\
\hline CHEMBL1565819 & 688612 & 4.3 & 4.748 & TRN & \\
\hline CHEMBL1544974 & 688612 & 4.1 & 4.5889 & TRN & \\
\hline CHEMBL1441044 & 688612 & 5.15 & 4.6777 & TRN & \\
\hline CHEMBL1551900 & 688612 & 4.0 & 4.5435 & TST & \\
\hline CHEMBL1582403 & 688612 & 4.9 & 4.7665 & TRN & \\
\hline CHEMBL1457411 & 688612 & 5.25 & 4.6242 & TRN & \\
\hline CHEMBL1380515 & 688612 & 4.05 & 4.7149 & TST & \\
\hline CHEMBL1417461 & 688612 & 4.05 & 4.6901 & TST & \\
\hline CHEMBL1304495 & 688612 & 4.3 & 4.7874 & TRN & \\
\hline CHEMBL1302096 & 688612 & 4.55 & 4.6665 & TRN & \\
\hline
\end{tabular}




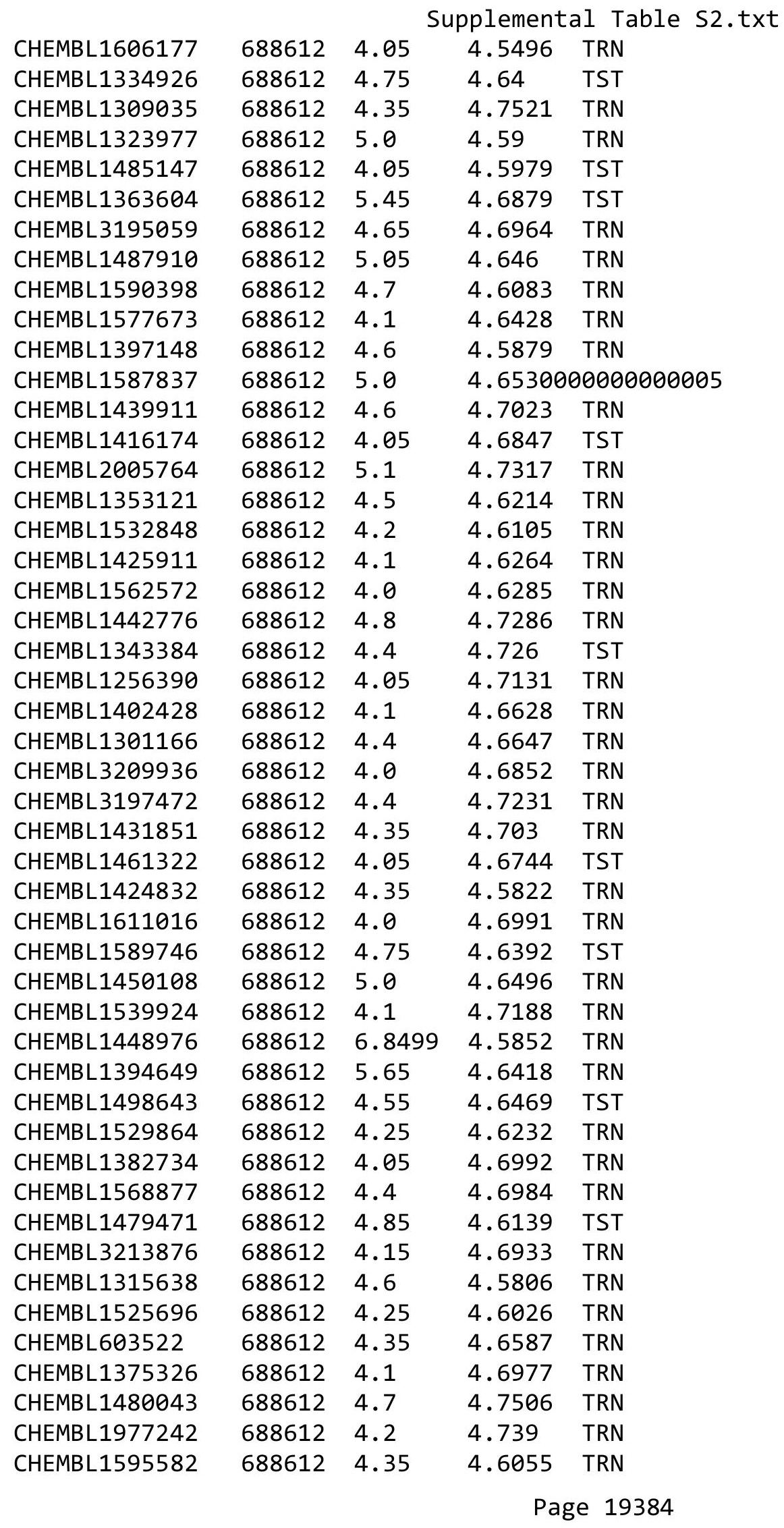




\begin{tabular}{|c|c|c|c|c|c|}
\hline \multirow[b]{2}{*}{ CHEMBL1368061 } & & \multicolumn{4}{|c|}{ Supplemental Table S2.txt } \\
\hline & 688612 & 4.65 & 4.54899 & 99999999995 & TRN \\
\hline CHEMBL1312238 & 688612 & 4.0 & 4.6489 & TRN & \\
\hline CHEMBL1374609 & 688612 & 4.05 & 4.6113 & TRN & \\
\hline CHEMBL1460847 & 688612 & 4.05 & 4.6743 & TRN & \\
\hline CHEMBL1342256 & 688612 & 4.1 & 4.7172 & TRN & \\
\hline CHEMBL1311896 & 688612 & 4.05 & 4.6562 & TRN & \\
\hline CHEMBL1441890 & 688612 & 4.4 & 4.7328 & TRN & \\
\hline CHEMBL1325812 & 688612 & 4.05 & 4.5979 & TRN & \\
\hline CHEMBL1310173 & 688612 & 6.6 & 4.6498 & TRN & \\
\hline CHEMBL1316208 & 688612 & 4.55 & 4.6199 & TRN & \\
\hline CHEMBL1471516 & 688612 & 4.05 & 4.6946 & TST & \\
\hline CHEMBL1407634 & 688612 & 6.8499 & 4.6432 & TST & \\
\hline CHEMBL1462701 & 688612 & 4.05 & 4.6328 & TRN & \\
\hline CHEMBL1602585 & 688612 & 4.9 & 4.6081 & TRN & \\
\hline CHEMBL1602238 & 688612 & 4.4 & 4.6218 & TRN & \\
\hline CHEMBL1304644 & 688612 & 4.7 & 4.6553 & TRN & \\
\hline CHEMBL1538734 & 688612 & 4.05 & 4.6777 & TST & \\
\hline CHEMBL3216873 & 688612 & 4.85 & 4.6913 & TST & \\
\hline CHEMBL1391234 & 688612 & 5.3 & 4.6992 & TST & \\
\hline CHEMBL1550788 & 688612 & 4.65 & 4.66100 & 00000000005 & TRN \\
\hline CHEMBL1446973 & 688612 & 4.6 & 4.72199 & 99999999995 & TRN \\
\hline CHEMBL1453059 & 688612 & 4.0 & 4.6291 & TST & \\
\hline CHEMBL1359256 & 688612 & 4.05 & 4.6802 & TRN & \\
\hline CHEMBL1532659 & 688612 & 4.35 & 4.7122 & TRN & \\
\hline CHEMBL1500203 & 688612 & 4.55 & 4.7209 & TRN & \\
\hline CHEMBL1353468 & 688612 & 4.0 & 4.6136 & TRN & \\
\hline CHEMBL1487407 & 688612 & 4.0 & 4.6729 & TRN & \\
\hline CHEMBL1324675 & 688612 & 4.4 & 4.7365 & TRN & \\
\hline CHEMBL3196149 & 688612 & 4.45 & 4.7091 & TRN & \\
\hline CHEMBL1342118 & 688612 & 4.05 & 4.6158 & TRN & \\
\hline CHEMBL1459786 & 688612 & 5.6 & 4.7649 & TRN & \\
\hline CHEMBL1347122 & 688612 & 4.7 & 4.7386 & TRN & \\
\hline CHEMBL3191452 & 688612 & 4.05 & 4.7577 & TRN & \\
\hline CHEMBL3192949 & 688612 & 4.55 & 4.6656 & TRN & \\
\hline CHEMBL1332557 & 688612 & 4.05 & 4.6697 & TRN & \\
\hline CHEMBL1328164 & 688612 & 4.55 & 4.6881 & TRN & \\
\hline CHEMBL1479917 & 688612 & 5.05 & 4.6427 & TST & \\
\hline CHEMBL1531188 & 688612 & 4.0 & 4.6201 & TRN & \\
\hline CHEMBL1357652 & 688612 & 4.3 & 4.6381 & TRN & \\
\hline CHEMBL1420258 & 688612 & 4.4 & 4.621 & TRN & \\
\hline CHEMBL1603729 & 688612 & 4.4 & 4.685 & TRN & \\
\hline CHEMBL1400277 & 688612 & 4.0 & 4.6026 & TRN & \\
\hline CHEMBL1402012 & 688612 & 4.65 & 4.7032 & TRN & \\
\hline CHEMBL1452182 & 688612 & 6.7501 & 4.6972 & TRN & \\
\hline CHEMBL1581966 & 688612 & 5.4 & 4.6983 & TST & \\
\hline CHEMBL1607786 & 688612 & 4.75 & 4.6704 & TST & \\
\hline CHEMBL1588759 & 688612 & 4.0 & 4.6988 & TST & \\
\hline CHEMBL1985415 & 688612 & 4.1 & 4.7245 & TST & \\
\hline
\end{tabular}




\begin{tabular}{|c|c|c|c|c|}
\hline \multicolumn{5}{|c|}{ Supplemental Table S2.txt } \\
\hline CHEMBL1609717 & 688612 & 4.05 & 4.6356 & TRN \\
\hline CHEMBL1516389 & 688612 & 4.95 & 4.6243 & TRN \\
\hline CHEMBL1611241 & 688612 & 4.1 & 4.6625 & TRN \\
\hline CHEMBL1589338 & 688612 & 6.15 & 4.7167 & TST \\
\hline CHEMBL1523292 & 688612 & 4.05 & 4.6568 & TST \\
\hline CHEMBL1513454 & 688612 & 5.0 & 4.6457 & TRN \\
\hline CHEMBL1556760 & 688612 & 4.1 & 4.6878 & TRN \\
\hline CHEMBL1599249 & 688612 & 4.05 & 4.7252 & TRN \\
\hline CHEMBL3199847 & 688612 & 4.15 & 4.6684 & TRN \\
\hline CHEMBL1401774 & 688612 & 5.5 & 4.7022 & TRN \\
\hline CHEMBL1367035 & 688612 & 4.5 & 4.6033 & TRN \\
\hline CHEMBL1470091 & 688612 & 4.8 & 4.5794 & TRN \\
\hline CHEMBL1578975 & 688612 & 4.7 & 4.6303 & TRN \\
\hline CHEMBL136344 & 688612 & 4.5 & 4.8445 & TRN \\
\hline CHEMBL1390729 & 688612 & 4.35 & 4.7334 & TRN \\
\hline CHEMBL1414775 & 688612 & 4.4 & 4.5961 & TRN \\
\hline CHEMBL1364280 & 688612 & 6.8499 & 4.6783 & TST \\
\hline CHEMBL1425000 & 688612 & 4.05 & 4.7029 & TST \\
\hline CHEMBL1596516 & 688612 & 4.6 & 4.7063 & TRN \\
\hline CHEMBL1308657 & 688612 & 4.05 & 4.6575 & TST \\
\hline CHEMBL1566050 & 688612 & 5.2 & 4.609 & TRN \\
\hline CHEMBL1567963 & 688612 & 4.3 & 4.73 & TRN \\
\hline CHEMBL1597497 & 688612 & 4.35 & 4.6574 & TRN \\
\hline CHEMBL1486505 & 688612 & 5.0 & 4.6275 & TRN \\
\hline CHEMBL1316685 & 688612 & 4.45 & 4.6116 & TRN \\
\hline CHEMBL1582127 & 688612 & 6.8499 & 4.6537 & TST \\
\hline CHEMBL1512438 & 688612 & 4.65 & 4.6453 & TRN \\
\hline CHEMBL1315334 & 688612 & 4.05 & 4.6751 & TRN \\
\hline CHEMBL1369936 & 688612 & 4.4 & 4.7132 & TRN \\
\hline CHEMBL1541895 & 688612 & 4.05 & 4.6613 & TRN \\
\hline CHEMBL1567464 & 688612 & 4.4 & 4.6892 & TRN \\
\hline CHEMBL1506435 & 688612 & 4.65 & 4.6991 & TRN \\
\hline CHEMBL1438567 & 688612 & 4.3 & 4.6945 & TRN \\
\hline CHEMBL1451802 & 688612 & 4.6 & 4.7091 & TRN \\
\hline CHEMBL1598383 & 688612 & 5.45 & 4.7452 & TRN \\
\hline CHEMBL1482135 & 688612 & 4.4 & 4.7107 & TRN \\
\hline CHEMBL1313581 & 688612 & 4.0 & 4.6533 & TRN \\
\hline CHEMBL 2004428 & 688612 & 5.5 & 4.6736 & TST \\
\hline CHEMBL1347348 & 688612 & 4.2 & 4.6824 & TRN \\
\hline CHEMBL1444829 & 688612 & 4.6 & 4.5556 & TRN \\
\hline CHEMBL1581767 & 688612 & 4.2 & 4.6429 & TRN \\
\hline CHEMBL1388271 & 688612 & 4.65 & 4.7115 & TRN \\
\hline CHEMBL1329417 & 688612 & 4.4 & 4.7398 & TST \\
\hline CHEMBL1467560 & 688612 & 5.0 & 4.6212 & TRN \\
\hline CHEMBL1407064 & 688612 & 4.05 & 4.6242 & TST \\
\hline CHEMBL1416848 & 688612 & 4.1 & 4.7162 & TRN \\
\hline CHEMBL1545392 & 688612 & 5.05 & 4.6933 & TST \\
\hline CHEMBL1522047 & 688612 & 4.3 & 4.5753 & TRN \\
\hline
\end{tabular}




\begin{tabular}{|c|c|c|c|c|}
\hline \multicolumn{5}{|c|}{ Supplemental Table S2.txt } \\
\hline CHEMBL1375737 & 688612 & 4.65 & 4.6726 & TRN \\
\hline CHEMBL3196863 & 688612 & 5.3 & 4.7017 & TRN \\
\hline CHEMBL1419456 & 688612 & 4.05 & 4.6504 & TST \\
\hline CHEMBL1456726 & 688612 & 4.0 & 4.6543 & TRN \\
\hline CHEMBL1379240 & 688612 & 4.0 & 4.6779 & TRN \\
\hline CHEMBL1312512 & 688612 & 4.1 & 4.6988 & TRN \\
\hline CHEMBL1501342 & 688612 & 4.65 & 4.6205 & TST \\
\hline CHEMBL1492814 & 688612 & 4.2 & 4.6849 & TRN \\
\hline CHEMBL1565888 & 688612 & 4.5 & 4.6776 & TRN \\
\hline CHEMBL1472193 & 688612 & 5.05 & 4.6753 & TRN \\
\hline CHEMBL1331411 & 688612 & 4.1 & 4.7325 & TRN \\
\hline CHEMBL1583513 & 688612 & 4.1 & 4.614 & TRN \\
\hline CHEMBL1413235 & 688612 & 4.75 & 4.6899 & TRN \\
\hline CHEMBL3210503 & 688612 & 4.1 & 4.6669 & TRN \\
\hline CHEMBL3196556 & 688612 & 7.0501 & 4.6003 & TST \\
\hline CHEMBL1441381 & 688612 & 4.0 & 4.615 & TRN \\
\hline CHEMBL1507981 & 688612 & 4.4 & 4.6888 & TRN \\
\hline CHEMBL1412994 & 688612 & 5.05 & 4.6742 & TRN \\
\hline CHEMBL3196338 & 688612 & 4.2 & 4.7775 & TST \\
\hline CHEMBL1472067 & 688612 & 4.7 & 4.6776 & TST \\
\hline CHEMBL1364869 & 688612 & 4.6 & 4.6247 & TST \\
\hline CHEMBL1382979 & 688612 & 4.7 & 4.7475 & TRN \\
\hline CHEMBL1362164 & 688612 & 4.0 & 4.598 & TRN \\
\hline CHEMBL1510155 & 688612 & 6.8499 & 4.6647 & TRN \\
\hline CHEMBL3192978 & 688612 & 4.05 & 4.7039 & TRN \\
\hline CHEMBL1325355 & 688612 & 4.1 & 4.7404 & TRN \\
\hline CHEMBL1547740 & 688612 & 5.1 & 4.6938 & TRN \\
\hline CHEMBL1575747 & 688612 & 4.9 & 4.7413 & TRN \\
\hline CHEMBL1516763 & 688612 & 4.95 & 4.666 & TRN \\
\hline CHEMBL1985295 & 688612 & 4.3 & 4.6202 & TRN \\
\hline CHEMBL1420318 & 688612 & 4.7 & 4.6931 & TRN \\
\hline CHEMBL1377207 & 688612 & 4.1 & 4.7641 & TST \\
\hline CHEMBL1582179 & 688612 & 4.75 & 4.6683 & TST \\
\hline CHEMBL1314790 & 688612 & 4.1 & 4.65 & TRN \\
\hline CHEMBL1562363 & 688612 & 6.4 & 4.7141 & TRN \\
\hline CHEMBL1440026 & 688612 & 4.05 & 4.7556 & TST \\
\hline CHEMBL1481645 & 688612 & 4.3 & 4.64 & TST \\
\hline CHEMBL1561501 & 688612 & 5.0 & 4.7066 & TST \\
\hline CHEMBL1494590 & 688612 & 4.85 & 4.6764 & TRN \\
\hline CHEMBL1562805 & 688612 & 6.4 & 4.6432 & TRN \\
\hline CHEMBL1336403 & 688612 & 4.25 & 4.6933 & TRN \\
\hline CHEMBL1565577 & 688612 & 6.5501 & 4.6795 & TRN \\
\hline CHEMBL1439083 & 688612 & 4.85 & 4.6445 & TRN \\
\hline CHEMBL1577646 & 688612 & 4.05 & 4.657 & TST \\
\hline CHEMBL3212376 & 688612 & 4.0 & 4.73300 & 00000000005 \\
\hline CHEMBL1404974 & 688612 & 4.15 & 4.6814 & TRN \\
\hline CHEMBL1375418 & 688612 & 4.25 & 4.6387 & TRN \\
\hline CHEMBL1538098 & 688612 & 4.05 & 4.6536 & TRN \\
\hline
\end{tabular}

TRN 


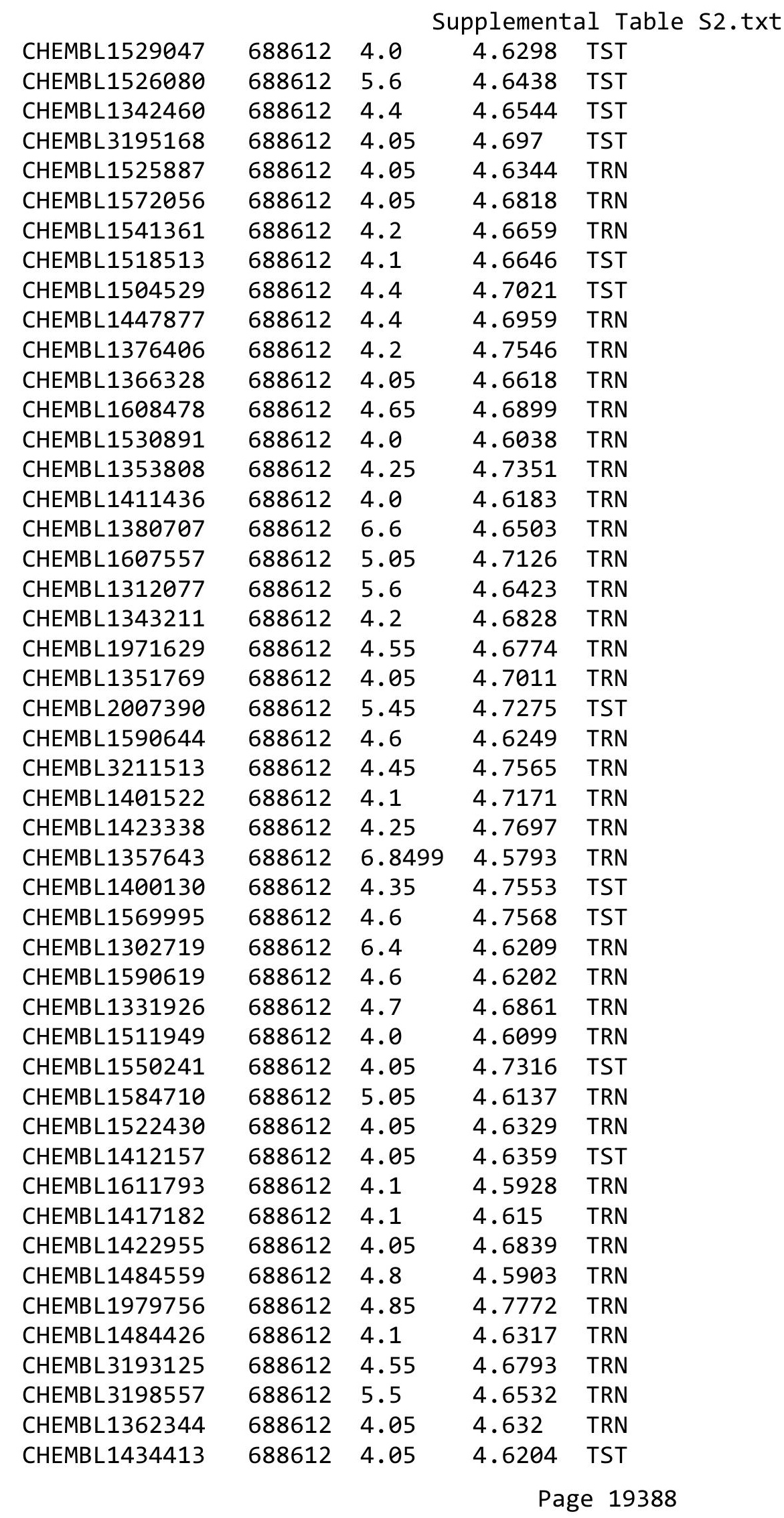




\begin{tabular}{|c|c|c|c|c|}
\hline \multicolumn{5}{|c|}{ Supplemental Table S2.txt } \\
\hline CHEMBL1487501 & 688612 & 5.4 & 4.6476 & TRN \\
\hline CHEMBL1404010 & 688612 & 4.1 & 4.6611 & TRN \\
\hline CHEMBL1423442 & 688612 & 4.5 & 4.6828 & TST \\
\hline CHEMBL1472528 & 688612 & 4.4 & 4.62 & TRN \\
\hline CHEMBL 1426026 & 688612 & 4.0 & 4.5997 & TRN \\
\hline CHEMBL1499495 & 688612 & 4.35 & 4.685 & TST \\
\hline CHEMBL1576947 & 688612 & 4.6 & 4.6475 & TST \\
\hline CHEMBL1357138 & 688612 & 4.55 & 4.6744 & TRN \\
\hline CHEMBL1498229 & 688612 & 5.95 & 4.6067 & TST \\
\hline CHEMBL3210842 & 688612 & 4.6 & 4.6659 & TRN \\
\hline CHEMBL1309841 & 688612 & 6.0 & 4.7007 & TRN \\
\hline CHEMBL1405763 & 688612 & 5.95 & 4.7393 & TRN \\
\hline CHEMBL1573735 & 688612 & 4.0 & 4.7693 & TST \\
\hline CHEMBL1610314 & 688612 & 4.05 & 4.5794 & TRN \\
\hline CHEMBL1606839 & 688612 & 4.1 & 4.703 & TRN \\
\hline CHEMBL1495658 & 688612 & 6.3 & 4.5704 & TRN \\
\hline CHEMBL1594669 & 688612 & 4.0 & 4.6586 & TRN \\
\hline CHEMBL3196666 & 688612 & 4.4 & 4.7095 & TRN \\
\hline CHEMBL1340403 & 688612 & 4.05 & 4.6801 & TRN \\
\hline CHEMBL1533166 & 688612 & 4.95 & 4.7034 & TRN \\
\hline CHEMBL1407037 & 688612 & 4.9 & 4.6995 & TRN \\
\hline CHEMBL1318443 & 688612 & 4.55 & 4.7044 & TST \\
\hline CHEMBL1479954 & 688612 & 6.5 & 4.5823 & TRN \\
\hline CHEMBL1585956 & 688612 & 4.05 & 4.5912 & TRN \\
\hline CHEMBL1450750 & 688612 & 5.25 & 4.6938 & TST \\
\hline CHEMBL1560128 & 688612 & 4.9 & 4.6462 & TRN \\
\hline CHEMBL3214141 & 688612 & 6.1 & 4.7082 & TRN \\
\hline CHEMBL1600597 & 688612 & 4.05 & 4.6854 & TRN \\
\hline CHEMBL1562924 & 688612 & 4.65 & 4.6911 & TST \\
\hline CHEMBL1967540 & 688612 & 4.4 & 4.7205 & TRN \\
\hline CHEMBL1426124 & 688612 & 4.4 & 4.6701 & TRN \\
\hline CHEMBL1505345 & 688612 & 4.95 & 4.6946 & TRN \\
\hline CHEMBL1397321 & 688612 & 6.5 & 4.5912 & TRN \\
\hline CHEMBL1453169 & 688612 & 4.05 & 4.6064 & TRN \\
\hline CHEMBL1576297 & 688612 & 4.4 & 4.7162 & TST \\
\hline CHEMBL1559558 & 688612 & 4.3 & 4.6368 & TRN \\
\hline CHEMBL1479365 & 688612 & 4.05 & 4.6415 & TRN \\
\hline CHEMBL3190895 & 688612 & 5.0 & 4.7535 & TRN \\
\hline CHEMBL1325819 & 688612 & 4.5 & 4.7262 & TRN \\
\hline CHEMBL1541184 & 688612 & 4.1 & 4.6301 & TRN \\
\hline CHEMBL1431810 & 688612 & 4.3 & 4.7738 & TRN \\
\hline CHEMBL1554963 & 688612 & 4.05 & 4.5214 & TRN \\
\hline CHEMBL1493625 & 688612 & 4.2 & 4.6879 & TRN \\
\hline CHEMBL1394082 & 688612 & 4.5 & 4.5873 & TRN \\
\hline CHEMBL1514785 & 688612 & 5.15 & 4.6801 & TRN \\
\hline CHEMBL1466147 & 688612 & 4.05 & 4.6928 & TRN \\
\hline CHEMBL1462311 & 688612 & 4.2 & 4.6538 & TST \\
\hline CHEMBL1528707 & 688612 & 4.3 & 4.6495 & TST \\
\hline
\end{tabular}




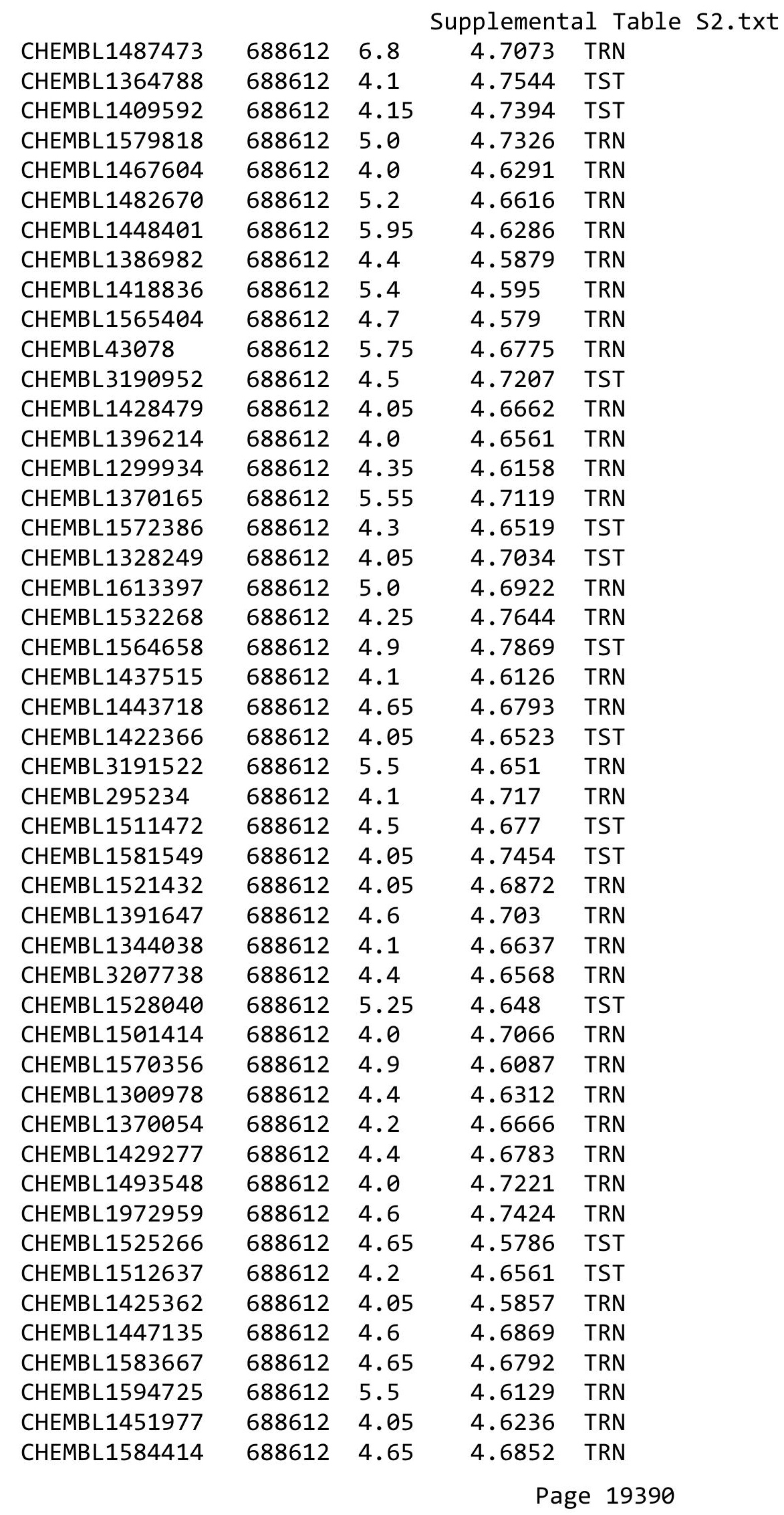




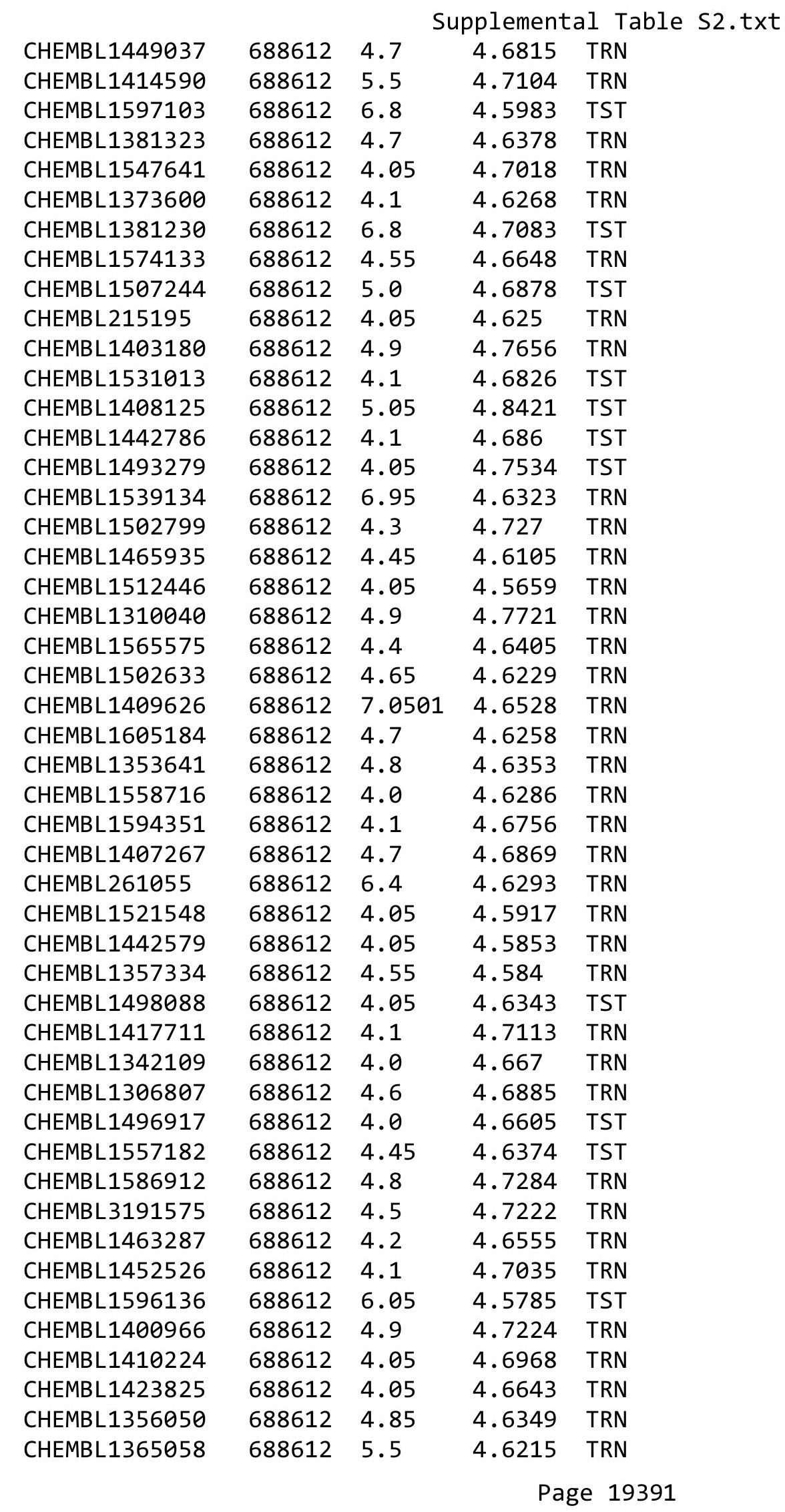




\begin{tabular}{|c|c|c|c|c|c|}
\hline \multicolumn{6}{|c|}{ Supplemental Table S2.txt } \\
\hline CHEMBL1299989 & 688612 & 4.4 & 4.7378 & TST & \\
\hline CHEMBL1409833 & 688612 & 4.0 & 4.5181 & TRN & \\
\hline CHEMBL1480260 & 688612 & 4.9 & 4.6553 & TRN & \\
\hline CHEMBL1401820 & 688612 & 4.4 & 4.6716 & TRN & \\
\hline CHEMBL1322708 & 688612 & 4.35 & 4.7077 & TST & \\
\hline CHEMBL1466805 & 688612 & 4.4 & 4.6965 & TST & \\
\hline CHEMBL1353006 & 688612 & 5.4 & 4.5887 & TRN & \\
\hline CHEMBL1360575 & 688612 & 4.05 & 4.6636 & TST & \\
\hline CHEMBL1513541 & 688612 & 5.25 & 4.61600 & 00000000005 & TRN \\
\hline CHEMBL1378318 & 688612 & 4.05 & 4.6831 & TRN & \\
\hline CHEMBL1552807 & 688612 & 4.1 & 4.7063 & TRN & \\
\hline CHEMBL1452149 & 688612 & 4.55 & 4.6469 & TRN & \\
\hline CHEMBL1480700 & 688612 & 6.7001 & 4.73300 & 00000000005 & TRN \\
\hline CHEMBL1322665 & 688612 & 5.75 & 4.6884 & TST & \\
\hline CHEMBL1309939 & 688612 & 4.15 & 4.5774 & TRN & \\
\hline CHEMBL1530943 & 688612 & 4.05 & 4.6814 & TRN & \\
\hline CHEMBL1399924 & 688612 & 4.55 & 4.6573 & TRN & \\
\hline CHEMBL1510524 & 688612 & 4.3 & 4.6947 & TRN & \\
\hline CHEMBL1369253 & 688612 & 6.8 & 4.7014 & TST & \\
\hline CHEMBL1390753 & 688612 & 4.05 & 4.6483 & TST & \\
\hline CHEMBL3192633 & 688612 & 4.0 & 4.6791 & TST & \\
\hline CHEMBL1500589 & 688612 & 4.05 & 4.6339 & TRN & \\
\hline CHEMBL1519023 & 688612 & 4.75 & 4.643 & TRN & \\
\hline CHEMBL1421871 & 688612 & 4.0 & 4.712 & TST & \\
\hline CHEMBL1358442 & 688612 & 4.25 & 4.621 & TRN & \\
\hline CHEMBL1459778 & 688612 & 4.85 & 4.7247 & TRN & \\
\hline CHEMBL1313320 & 688612 & 4.0 & 4.6281 & TRN & \\
\hline CHEMBL1321452 & 688612 & 4.1 & 4.7229 & TST & \\
\hline CHEMBL1322857 & 688612 & 5.1 & 4.7953 & TRN & \\
\hline CHEMBL1535644 & 688612 & 4.0 & 4.5986 & TRN & \\
\hline CHEMBL1316309 & 688612 & 4.0 & 4.6123 & TRN & \\
\hline CHEMBL1362679 & 688612 & 4.9 & 4.6489 & TRN & \\
\hline CHEMBL1311871 & 688612 & 7.0 & 4.7074 & TRN & \\
\hline CHEMBL1584321 & 688612 & 4.05 & 4.5977 & TRN & \\
\hline CHEMBL1466182 & 688612 & 5.0 & 4.7176 & TST & \\
\hline CHEMBL1559853 & 688612 & 4.4 & 4.7016 & TST & \\
\hline CHEMBL1976049 & 688612 & 4.75 & 4.829 & TRN & \\
\hline CHEMBL1523375 & 688612 & 5.4 & 4.7339 & TRN & \\
\hline CHEMBL1540723 & 688612 & 4.1 & 4.6563 & TRN & \\
\hline CHEMBL1530837 & 688612 & 4.95 & 4.6873 & TRN & \\
\hline CHEMBL1401245 & 688612 & 5.2 & 4.6111 & TST & \\
\hline CHEMBL1456011 & 688612 & 4.0 & 4.5646 & TRN & \\
\hline CHEMBL1600901 & 688612 & 5.45 & 4.7487 & TRN & \\
\hline CHEMBL1408473 & 688612 & 4.35 & 4.6872 & TRN & \\
\hline CHEMBL1470798 & 688612 & 4.45 & 4.6368 & TRN & \\
\hline CHEMBL1524570 & 688612 & 4.05 & 4.5866 & TRN & \\
\hline CHEMBL1598234 & 688612 & 4.3 & 4.6451 & TST & \\
\hline CHEMBL1318206 & 688612 & 4.05 & 4.7401 & TST & \\
\hline
\end{tabular}




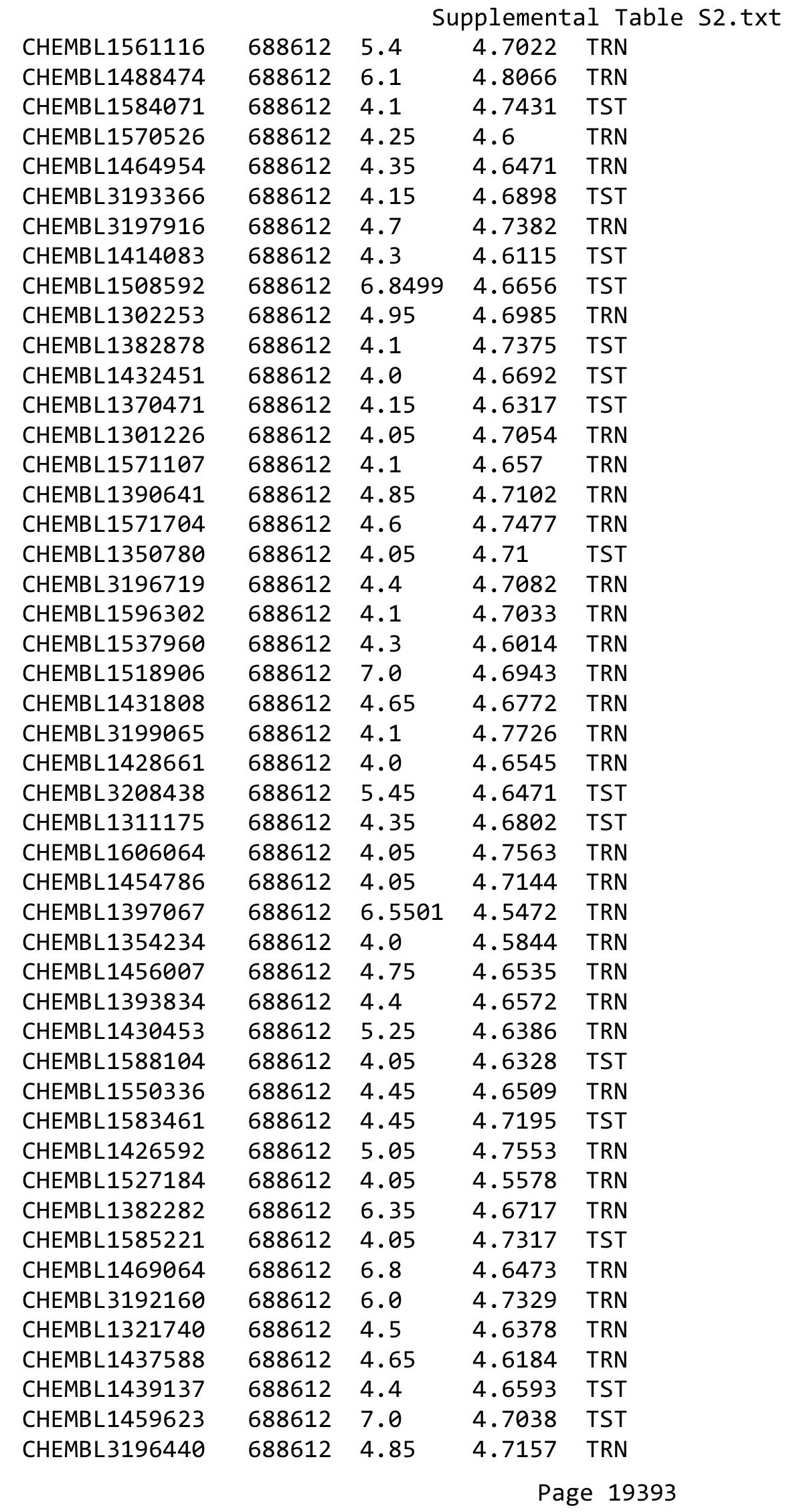




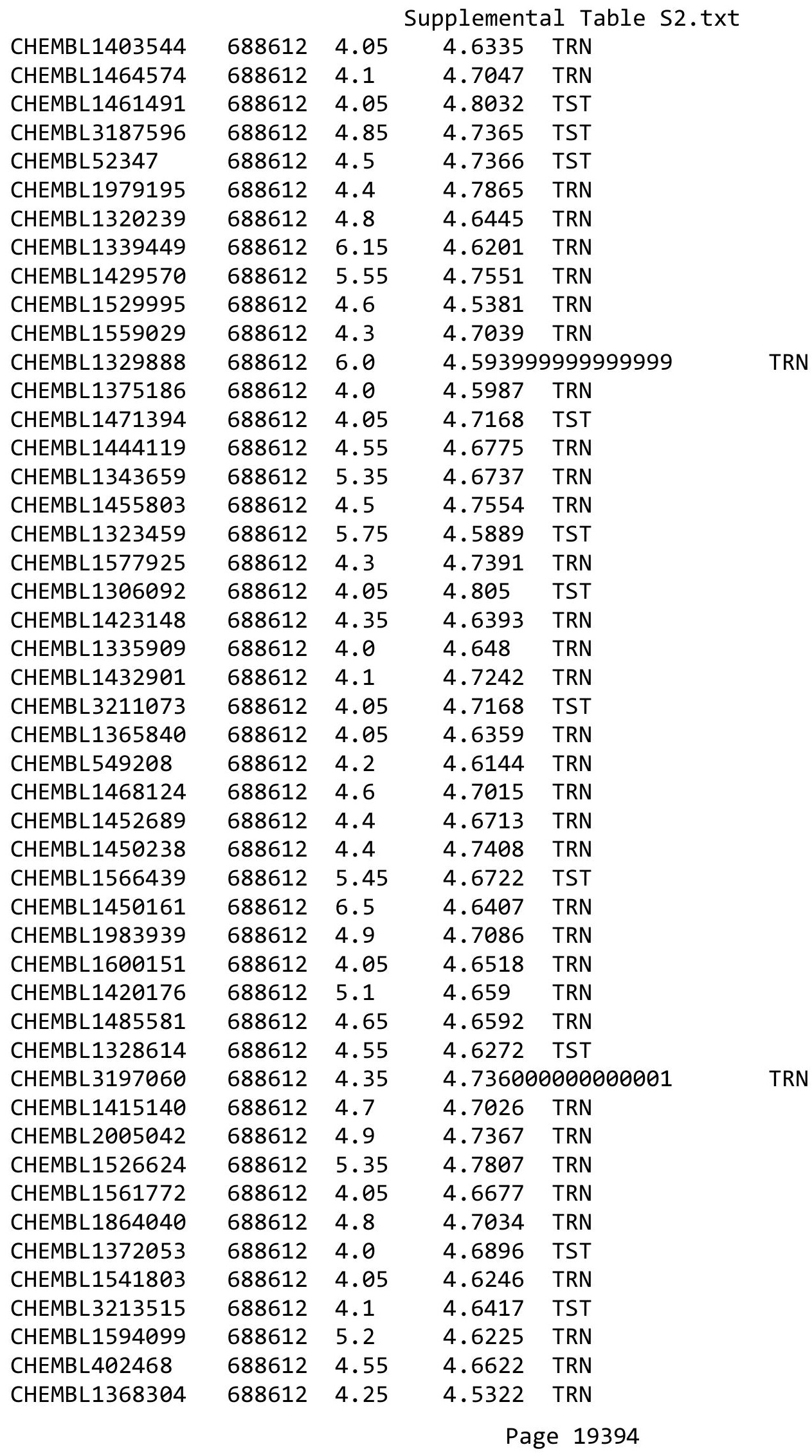




\begin{tabular}{|c|c|c|c|c|c|}
\hline \multirow[b]{2}{*}{ CHEMBL 3189361} & \multicolumn{5}{|c|}{ Supplemental Table S2.txt } \\
\hline & 688612 & 4.35 & 4.7164 & TRN & \\
\hline CHEMBL1398231 & 688612 & 6.0 & $4.6560 e$ & 2000000001 & TRN \\
\hline CHEMBL1572760 & 688612 & 4.2 & 4.6349 & TRN & \\
\hline CHEMBL1415241 & 688612 & 4.45 & 4.7015 & TRN & \\
\hline CHEMBL1497539 & 688612 & 5.0 & 4.6752 & TRN & \\
\hline CHEMBL1593492 & 688612 & 4.4 & 4.5888 & TRN & \\
\hline CHEMBL3207776 & 688612 & 4.1 & 4.7545 & TST & \\
\hline CHEMBL1365733 & 688612 & 4.05 & 4.526 & TRN & \\
\hline CHEMBL1416034 & 688612 & 4.05 & 4.6399 & TRN & \\
\hline CHEMBL1550713 & 688612 & 4.6 & 4.7192 & TST & \\
\hline CHEMBL1535291 & 688612 & 4.75 & 4.6058 & TRN & \\
\hline CHEMBL1374280 & 688612 & 4.05 & 4.606 & TRN & \\
\hline CHEMBL1422559 & 688612 & 4.4 & 4.6137 & TRN & \\
\hline CHEMBL1552702 & 688612 & 5.1 & 4.6453 & TRN & \\
\hline CHEMBL1581311 & 688612 & 4.6 & 4.7467 & TRN & \\
\hline CHEMBL599013 & 688612 & 5.05 & 4.7557 & TRN & \\
\hline CHEMBL1487112 & 688612 & 6.8499 & 4.672 & TRN & \\
\hline CHEMBL1489878 & 688612 & 4.4 & 4.5878 & TRN & \\
\hline CHEMBL1335311 & 688612 & 5.95 & 4.6378 & TRN & \\
\hline CHEMBL1496745 & 688612 & 5.5 & 4.6633 & TRN & \\
\hline CHEMBL1536849 & 688612 & 5.05 & 4.6209 & TRN & \\
\hline CHEMBL1349145 & 688612 & 5.35 & 4.6587 & TRN & \\
\hline CHEMBL1416572 & 688612 & 4.0 & 4.63 & TRN & \\
\hline CHEMBL1326636 & 688612 & 4.05 & 4.6912 & TRN & \\
\hline CHEMBL1603630 & 688612 & 4.05 & 4.6243 & TRN & \\
\hline CHEMBL3196572 & 688612 & 4.5 & 4.7109 & TRN & \\
\hline CHEMBL1371025 & 688612 & 4.15 & 4.5721 & TRN & \\
\hline CHEMBL1416224 & 688612 & 6.45 & 4.6562 & TST & \\
\hline CHEMBL1529118 & 688612 & 4.4 & 4.5864 & TRN & \\
\hline CHEMBL1514396 & 688612 & 4.6 & 4.6207 & TRN & \\
\hline CHEMBL1401060 & 688612 & 4.1 & 4.6018 & TRN & \\
\hline CHEMBL1541385 & 688612 & 4.05 & 4.633 & TRN & \\
\hline CHEMBL1376622 & 688612 & 4.4 & 4.6458 & TRN & \\
\hline CHEMBL1420446 & 688612 & 4.05 & 4.699 & TRN & \\
\hline CHEMBL1546267 & 688612 & 4.05 & 4.7054 & TST & \\
\hline CHEMBL1307976 & 688612 & 4.65 & 4.6765 & TRN & \\
\hline CHEMBL1409196 & 688612 & 5.35 & 4.64 & TRN & \\
\hline CHEMBL1483843 & 688612 & 4.85 & 4.6409 & TRN & \\
\hline CHEMBL1391841 & 688612 & 5.4 & 4.6706 & TRN & \\
\hline CHEMBL1523695 & 688612 & 4.05 & 4.6298 & TRN & \\
\hline CHEMBL1506933 & 688612 & 4.2 & 4.6958 & TRN & \\
\hline CHEMBL3213711 & 688612 & 5.3 & 4.7648 & TRN & \\
\hline CHEMBL1580937 & 688612 & 4.05 & 4.637 & TRN & \\
\hline CHEMBL1568871 & 688612 & 4.05 & 4.6449 & TRN & \\
\hline CHEMBL1540710 & 688612 & 6.8 & 4.7123 & TRN & \\
\hline CHEMBL1479652 & 688612 & 4.0 & 4.5717 & TST & \\
\hline CHEMBL1432957 & 688612 & 4.45 & 4.7211 & TST & \\
\hline CHEMBL1468608 & 688612 & 4.1 & 4.6161 & TRN & \\
\hline
\end{tabular}




\begin{tabular}{|c|c|c|c|c|c|}
\hline \multicolumn{6}{|c|}{ Supplemental Table S2.txt } \\
\hline CHEMBL1611889 & 688612 & 4.1 & 4.6683 & TRN & \\
\hline CHEMBL1432607 & 688612 & 5.8 & 4.5908 & TRN & \\
\hline CHEMBL1487448 & 688612 & 4.65 & 4.7292 & TST & \\
\hline CHEMBL1471903 & 688612 & 5.6 & 4.6841 & TST & \\
\hline CHEMBL1442176 & 688612 & 4.9 & 4.6481 & TRN & \\
\hline CHEMBL1445103 & 688612 & 4.0 & 4.6499 & TRN & \\
\hline CHEMBL1427295 & 688612 & 5.4 & 4.6374 & TST & \\
\hline CHEMBL1304911 & 688612 & 5.35 & 4.6932 & TST & \\
\hline CHEMBL1508584 & 688612 & 4.45 & 4.7211 & TRN & \\
\hline CHEMBL1419688 & 688612 & 6.6499 & 4.7105 & TST & \\
\hline CHEMBL1458696 & 688612 & 4.0 & 4.6253 & TRN & \\
\hline CHEMBL1311782 & 688612 & 6.1 & $4.6610 e$ & 00000000005 & TST \\
\hline CHEMBL1349564 & 688612 & 4.0 & 4.664 & TRN & \\
\hline CHEMBL1330950 & 688612 & 4.2 & 4.6761 & TRN & \\
\hline CHEMBL1531346 & 688612 & 5.15 & 4.6294 & TRN & \\
\hline CHEMBL1355983 & 688612 & 5.0 & 4.71399 & 99999999995 & TST \\
\hline CHEMBL1496772 & 688612 & 6.3 & 4.6221 & TRN & \\
\hline CHEMBL1387158 & 688612 & 6.8 & 4.7561 & TST & \\
\hline CHEMBL363241 & 688612 & 4.0 & 4.6809 & TRN & \\
\hline CHEMBL1440179 & 688612 & 4.6 & 4.6764 & TRN & \\
\hline CHEMBL1343866 & 688612 & 4.05 & 4.6191 & TRN & \\
\hline CHEMBL1369224 & 688612 & 5.25 & 4.5927 & TRN & \\
\hline CHEMBL1456032 & 688612 & 4.0 & 4.6454 & TRN & \\
\hline CHEMBL1318065 & 688612 & 4.35 & 4.6018 & TRN & \\
\hline CHEMBL1464727 & 688612 & 4.4 & 4.7435 & TRN & \\
\hline CHEMBL1522496 & 688612 & 4.05 & 4.6472 & TRN & \\
\hline CHEMBL1568275 & 688612 & 4.95 & 4.6351 & TRN & \\
\hline CHEMBL1393470 & 688612 & 4.0 & 4.6682 & TST & \\
\hline CHEMBL1525088 & 688612 & 4.0 & 4.6095 & TRN & \\
\hline CHEMBL1304490 & 688612 & 4.75 & 4.6986 & TRN & \\
\hline CHEMBL17468 & 688612 & 4.45 & 4.6561 & TST & \\
\hline CHEMBL3212901 & 688612 & 4.0 & 4.6586 & TRN & \\
\hline CHEMBL3199351 & 688612 & 6.05 & 4.6629 & TRN & \\
\hline CHEMBL1521883 & 688612 & 4.0 & 4.6194 & TRN & \\
\hline CHEMBL1580524 & 688612 & 5.4 & 4.6108 & TRN & \\
\hline CHEMBL1968732 & 688612 & 4.4 & 4.6812 & TRN & \\
\hline CHEMBL 1438587 & 688612 & 5.65 & 4.7028 & TST & \\
\hline CHEMBL1309608 & 688612 & 4.1 & 4.6632 & TRN & \\
\hline CHEMBL3197567 & 688612 & 4.7 & 4.5991 & TRN & \\
\hline CHEMBL1428958 & 688612 & 4.05 & 4.6312 & TRN & \\
\hline CHEMBL1303641 & 688612 & 4.6 & 4.6453 & TRN & \\
\hline CHEMBL1471792 & 688612 & 6.8499 & 4.6699 & TST & \\
\hline CHEMBL1600820 & 688612 & 4.1 & 4.6307 & TST & \\
\hline CHEMBL1462647 & 688612 & 4.5 & 4.703 & TRN & \\
\hline CHEMBL1598055 & 688612 & 4.1 & 4.5619 & TRN & \\
\hline CHEMBL1482656 & 688612 & 4.05 & 4.5746 & TRN & \\
\hline CHEMBL1988133 & 688612 & 5.7 & 4.7333 & TRN & \\
\hline CHEMBL1521165 & 688612 & 4.65 & 4.7001 & TRN & \\
\hline
\end{tabular}




\begin{tabular}{|c|c|c|c|c|c|}
\hline \multicolumn{6}{|c|}{ Supplemental Table S2.txt } \\
\hline CHEMBL571296 & 688612 & 4.85 & 4.6876 & TRN & \\
\hline CHEMBL1371795 & 688612 & 4.05 & 4.7158 & TRN & \\
\hline CHEMBL1398415 & 688612 & 4.05 & 4.5199 & TST & \\
\hline CHEMBL1566918 & 688612 & 4.55 & 4.6393 & TRN & \\
\hline CHEMBL1423507 & 688612 & 4.4 & 4.6771 & TRN & \\
\hline CHEMBL1482707 & 688612 & 4.05 & 4.6557 & TRN & \\
\hline CHEMBL1487321 & 688612 & 4.4 & 4.6251 & TRN & \\
\hline CHEMBL1569732 & 688612 & 4.9 & 4.6213 & TST & \\
\hline CHEMBL1544685 & 688612 & 4.4 & 4.6792 & TRN & \\
\hline CHEMBL1362088 & 688612 & 6.1 & 4.6837 & TST & \\
\hline CHEMBL1601446 & 688612 & 4.4 & 4.6626 & TRN & \\
\hline CHEMBL1579986 & 688612 & 4.05 & 4.673 & TRN & \\
\hline CHEMBL1314491 & 688612 & 4.0 & 4.6553 & TRN & \\
\hline CHEMBL1568626 & 688612 & 4.9 & 4.71899 & 9999999999 & TRN \\
\hline CHEMBL1461701 & 688612 & 6.9 & 4.5835 & TST & \\
\hline CHEMBL1305014 & 688612 & 4.7 & 4.7806 & TRN & \\
\hline CHEMBL1501050 & 688612 & 4.05 & 4.7371 & TRN & \\
\hline CHEMBL1311062 & 688612 & 4.45 & 4.6063 & TRN & \\
\hline CHEMBL1313192 & 688612 & 6.05 & 4.6402 & TRN & \\
\hline CHEMBL3195383 & 688612 & 4.3 & 4.6822 & TRN & \\
\hline CHEMBL1457473 & 688612 & 4.4 & 4.5874 & TRN & \\
\hline CHEMBL1339858 & 688612 & 4.2 & 4.5914 & TRN & \\
\hline CHEMBL1393056 & 688612 & 4.05 & 4.6979 & TST & \\
\hline CHEMBL1308965 & 688612 & 4.4 & 4.6277 & TST & \\
\hline CHEMBL1485475 & 688612 & 4.65 & 4.6682 & TRN & \\
\hline CHEMBL1590786 & 688612 & 4.95 & 4.5788 & TRN & \\
\hline CHEMBL1526573 & 688612 & 4.65 & 4.711 & TRN & \\
\hline CHEMBL1604012 & 688612 & 4.7 & 4.7967 & TRN & \\
\hline CHEMBL1456621 & 688612 & 4.6 & 4.6578 & TRN & \\
\hline CHEMBL1310429 & 688612 & 4.05 & 4.692 & TRN & \\
\hline CHEMBL1453987 & 688612 & 4.45 & 4.6216 & TRN & \\
\hline CHEMBL1533958 & 688612 & 6.5 & 4.7398 & TRN & \\
\hline CHEMBL1301726 & 688612 & 4.6 & 4.7413 & TRN & \\
\hline CHEMBL1422570 & 688612 & 6.25 & 4.6494 & TRN & \\
\hline CHEMBL1532516 & 688612 & 4.65 & 4.5818 & TRN & \\
\hline CHEMBL1561518 & 688612 & 5.3 & 4.6279 & TST & \\
\hline CHEMBL1375681 & 688612 & 4.0 & 4.609 & TRN & \\
\hline CHEMBL1357576 & 688612 & 4.3 & 4.574 & TRN & \\
\hline CHEMBL1476626 & 688612 & 4.35 & 4.6273 & TRN & \\
\hline CHEMBL1369180 & 688612 & 5.35 & 4.6696 & TRN & \\
\hline CHEMBL3192976 & 688612 & 4.8 & 4.7661 & TRN & \\
\hline CHEMBL1562987 & 688612 & 4.25 & 4.6557 & TRN & \\
\hline CHEMBL1512323 & 688612 & 4.45 & 4.645 & TRN & \\
\hline CHEMBL1447391 & 688612 & 4.4 & 4.7358 & TST & \\
\hline CHEMBL1605937 & 688612 & 4.7 & 4.6901 & TRN & \\
\hline CHEMBL1450891 & 688612 & 4.95 & 4.6257 & TRN & \\
\hline CHEMBL1379707 & 688612 & 6.2 & 4.6612 & TRN & \\
\hline CHEMBL3191948 & 688612 & 4.55 & 4.732 & TRN & \\
\hline
\end{tabular}




\begin{tabular}{|c|c|c|c|c|c|}
\hline \multicolumn{6}{|c|}{ Supplemental Table S2.txt } \\
\hline CHEMBL1468128 & 688612 & 4.5 & 4.6928 & TRN & \\
\hline CHEMBL1425127 & 688612 & 4.0 & 4.7425 & TRN & \\
\hline CHEMBL1516396 & 688612 & 4.75 & 4.6797 & TRN & \\
\hline CHEMBL1501850 & 688612 & 4.1 & 4.5891 & TRN & \\
\hline CHEMBL1467698 & 688612 & 4.1 & 4.6559 & TRN & \\
\hline CHEMBL3208582 & 688612 & 4.05 & 4.6553 & TRN & \\
\hline CHEMBL1439291 & 688612 & 5.0 & 4.7189 & TRN & \\
\hline CHEMBL1574512 & 688612 & 4.4 & 4.6961 & TST & \\
\hline CHEMBL1388853 & 688612 & 4.1 & 4.6515 & TRN & \\
\hline CHEMBL 2004475 & 688612 & 4.65 & 4.7665 & TST & \\
\hline CHEMBL3210146 & 688612 & 5.45 & 4.6669 & TRN & \\
\hline CHEMBL1611022 & 688612 & 4.4 & 4.812 & TST & \\
\hline CHEMBL1299858 & 688612 & 4.05 & 4.7034 & TST & \\
\hline CHEMBL1361858 & 688612 & 4.5 & 4.7112 & TRN & \\
\hline CHEMBL1500530 & 688612 & 4.5 & 4.7246 & TRN & \\
\hline CHEMBL1490699 & 688612 & 5.5 & 4.6683 & TRN & \\
\hline CHEMBL3210144 & 688612 & 4.05 & 4.784 & TST & \\
\hline CHEMBL1563244 & 688612 & 4.05 & 4.6612 & TRN & \\
\hline CHEMBL 1370328 & 688612 & 5.5 & 4.7199 & TRN & \\
\hline CHEMBL1379096 & 688612 & 4.15 & 4.6551 & TRN & \\
\hline CHEMBL1378924 & 688612 & 4.25 & 4.654 & TST & \\
\hline CHEMBL1442232 & 688612 & 4.8 & 4.6045 & TRN & \\
\hline CHEMBL1385987 & 688612 & 4.85 & 4.6653 & TRN & \\
\hline CHEMBL1554686 & 688612 & 6.7001 & 4.6089 & TRN & \\
\hline CHEMBL1490595 & 688612 & 4.8 & 4.7023 & TRN & \\
\hline CHEMBL1538061 & 688612 & 4.1 & 4.7019 & TRN & \\
\hline CHEMBL1544183 & 688612 & 4.05 & 4.6434 & TST & \\
\hline CHEMBL1361682 & 688612 & 4.05 & 4.6444 & TRN & \\
\hline CHEMBL1435978 & 688612 & 4.0 & 4.6011 & TRN & \\
\hline CHEMBL1341771 & 688612 & 4.55 & 4.6839 & TST & \\
\hline CHEMBL1525912 & 688612 & 4.1 & 4.6025 & TST & \\
\hline CHEMBL1551607 & 688612 & 4.0 & 4.5654 & TRN & \\
\hline CHEMBL1340447 & 688612 & 4.4 & 4.7113 & TST & \\
\hline CHEMBL1300236 & 688612 & 4.65 & 4.7676 & TST & \\
\hline CHEMBL1442882 & 688612 & 4.4 & 4.7039 & TRN & \\
\hline CHEMBL1500142 & 688612 & 5.0 & 4.75899 & 99999999995 & TRN \\
\hline CHEMBL1515224 & 688612 & 5.35 & 4.6704 & TRN & \\
\hline CHEMBL1544859 & 688612 & 5.2 & 4.6533 & TRN & \\
\hline CHEMBL1602222 & 688612 & 4.05 & 4.6804 & TST & \\
\hline CHEMBL1528968 & 688612 & 4.35 & 4.6274 & TRN & \\
\hline CHEMBL1435101 & 688612 & 4.05 & 4.5808 & TRN & \\
\hline CHEMBL1381760 & 688612 & 5.4 & 4.6201 & TST & \\
\hline CHEMBL1300695 & 688612 & 4.05 & 4.6944 & TST & \\
\hline CHEMBL1454511 & 688612 & 4.4 & 4.6694 & TST & \\
\hline CHEMBL1468042 & 688612 & 4.4 & 4.6384 & TRN & \\
\hline CHEMBL1412784 & 688612 & 4.1 & 4.7581 & TRN & \\
\hline CHEMBL1603477 & 688612 & 4.1 & 4.6859 & TST & \\
\hline CHEMBL1393670 & 688612 & 4.1 & 4.6764 & TRN & \\
\hline
\end{tabular}




\begin{tabular}{|c|c|c|c|c|}
\hline \multicolumn{5}{|c|}{ Supplemental Table S2.txt } \\
\hline CHEMBL1508672 & 688612 & 4.6 & 4.6698 & TRN \\
\hline CHEMBL1371777 & 688612 & 5.35 & 4.7376 & TRN \\
\hline CHEMBL3191913 & 688612 & 4.5 & 4.6991 & TRN \\
\hline CHEMBL1417746 & 688612 & 4.45 & 4.6377 & TRN \\
\hline CHEMBL1335073 & 688612 & 4.1 & 4.7122 & TST \\
\hline CHEMBL3145305 & 688612 & 4.65 & 4.6192 & TRN \\
\hline CHEMBL1391146 & 688612 & 4.2 & 4.5525 & TRN \\
\hline CHEMBL1335694 & 688612 & 4.05 & 4.6239 & TST \\
\hline CHEMBL1462993 & 688612 & 4.65 & 4.6622 & TRN \\
\hline CHEMBL1418517 & 688612 & 4.05 & 4.5998 & TRN \\
\hline CHEMBL1578913 & 688612 & 4.0 & 4.6978 & TRN \\
\hline CHEMBL1594070 & 688612 & 4.05 & 4.5923 & TRN \\
\hline CHEMBL1997747 & 688612 & 4.5 & 4.6689 & TRN \\
\hline CHEMBL3190772 & 688612 & 4.05 & 4.7273 & TRN \\
\hline CHEMBL1428682 & 688612 & 4.0 & 4.703 & TRN \\
\hline CHEMBL1609439 & 688612 & 6.0 & 4.7483 & TRN \\
\hline CHEMBL1344943 & 688612 & 4.0 & 4.6069 & TRN \\
\hline CHEMBL1397131 & 688612 & 4.7 & 4.6186 & TRN \\
\hline CHEMBL1575009 & 688612 & 4.0 & 4.6109 & TRN \\
\hline CHEMBL591631 & 688612 & 4.4 & 4.6983 & TST \\
\hline CHEMBL1371147 & 688612 & 4.55 & 4.7372 & TST \\
\hline CHEMBL1472464 & 688612 & 4.1 & 4.583 & TRN \\
\hline CHEMBL1348181 & 688612 & 4.35 & 4.7342 & TRN \\
\hline CHEMBL1300435 & 688612 & 4.05 & 4.6253 & TST \\
\hline CHEMBL1301969 & 688612 & 4.2 & 4.6817 & TRN \\
\hline CHEMBL1461915 & 688612 & 4.1 & 4.6928 & TRN \\
\hline CHEMBL1375217 & 688612 & 5.25 & 4.6966 & TST \\
\hline CHEMBL1418275 & 688612 & 5.95 & 4.6401 & TRN \\
\hline CHEMBL1562454 & 688612 & 4.1 & 4.7512 & TRN \\
\hline CHEMBL1523854 & 688612 & 4.0 & 4.6303 & TRN \\
\hline CHEMBL1464669 & 688612 & 4.05 & 4.7299 & TRN \\
\hline CHEMBL1417225 & 688612 & 4.05 & 4.6237 & TRN \\
\hline CHEMBL1319637 & 688612 & 4.0 & 4.6299 & TRN \\
\hline CHEMBL1575119 & 688612 & 4.0 & 4.6661 & TST \\
\hline CHEMBL1454505 & 688612 & 4.55 & 4.6521 & TRN \\
\hline CHEMBL1376711 & 688612 & 6.25 & 4.8155 & TRN \\
\hline CHEMBL1568927 & 688612 & 4.05 & 4.6573 & TRN \\
\hline CHEMBL1389888 & 688612 & 5.55 & 4.6107 & TRN \\
\hline CHEMBL1449374 & 688612 & 6.2 & 4.7597 & TRN \\
\hline CHEMBL1403879 & 688612 & 4.3 & 4.724 & TRN \\
\hline CHEMBL1461308 & 688612 & 6.5501 & 4.6908 & TST \\
\hline CHEMBL1578194 & 688612 & 4.0 & 4.6408 & TRN \\
\hline CHEMBL1461165 & 688612 & 4.55 & 4.6892 & TST \\
\hline CHEMBL1604733 & 688612 & 4.6 & 4.6244 & TRN \\
\hline CHEMBL3196679 & 688612 & 4.8 & 4.6664 & TRN \\
\hline CHEMBL1547645 & 688612 & 4.05 & 4.6396 & TST \\
\hline CHEMBL1389990 & 688612 & 4.7 & 4.7895 & TRN \\
\hline CHEMBL3197492 & 688612 & 4.35 & 4.7017 & TRN \\
\hline
\end{tabular}




\begin{tabular}{|c|c|c|c|c|}
\hline \multicolumn{5}{|c|}{ Supplemental Table } \\
\hline CHEMBL1378148 & 688612 & 4.25 & 4.6031 & TST \\
\hline CHEMBL1369219 & 688612 & 4.1 & 4.6591 & TST \\
\hline CHEMBL3195547 & 688612 & 4.1 & 4.6862 & TRN \\
\hline CHEMBL1577649 & 688612 & 4.0 & 4.69 & TRN \\
\hline CHEMBL1490617 & 688612 & 4.7 & 4.7274 & TRN \\
\hline CHEMBL1580443 & 688612 & 6.8 & 4.6259 & TRN \\
\hline CHEMBL1579817 & 688612 & 4.95 & 4.6199 & TST \\
\hline CHEMBL1468143 & 688612 & 4.65 & 4.6963 & TRN \\
\hline CHEMBL1543054 & 688612 & 6.6499 & 4.6011 & TRN \\
\hline CHEMBL1567492 & 688612 & 6.1 & 4.6631 & TST \\
\hline CHEMBL3197968 & 688612 & 4.45 & 4.7702 & TRN \\
\hline CHEMBL1496385 & 688612 & 4.35 & 4.6336 & TRN \\
\hline CHEMBL1549629 & 688612 & 4.7 & 4.5996 & TRN \\
\hline CHEMBL1347746 & 688612 & 4.1 & 4.6913 & TRN \\
\hline CHEMBL1596561 & 688612 & 6.05 & 4.7207 & TRN \\
\hline CHEMBL1313275 & 688612 & 4.1 & 4.5954 & TRN \\
\hline CHEMBL1540468 & 688612 & 4.1 & 4.5802 & TRN \\
\hline CHEMBL1313077 & 688612 & 4.05 & 4.6546 & TRN \\
\hline CHEMBL1571889 & 688612 & 4.3 & 4.7521 & TST \\
\hline CHEMBL1606895 & 688612 & 4.55 & 4.6478 & TST \\
\hline CHEMBL1340514 & 688612 & 4.7 & 4.744 & TRN \\
\hline CHEMBL1598476 & 688612 & 4.6 & 4.5414 & TRN \\
\hline CHEMBL1405810 & 688612 & 4.4 & 4.6746 & TST \\
\hline CHEMBL1506159 & 688612 & 4.6 & 4.703 & TRN \\
\hline CHEMBL1388318 & 688612 & 4.05 & 4.6267 & TRN \\
\hline CHEMBL1325320 & 688612 & 6.35 & 4.6124 & TRN \\
\hline CHEMBL1433049 & 688612 & 4.45 & 4.7126 & TRN \\
\hline CHEMBL1523480 & 688612 & 5.8 & 4.6465 & TRN \\
\hline CHEMBL1401570 & 688612 & 4.35 & 4.5979 & TRN \\
\hline CHEMBL1479594 & 688612 & 4.0 & 4.6125 & TRN \\
\hline CHEMBL1450894 & 688612 & 5.7 & 4.6941 & TRN \\
\hline CHEMBL1309443 & 688612 & 6.5 & 4.5837 & TRN \\
\hline CHEMBL3213716 & 688612 & 4.05 & 4.6665 & TRN \\
\hline CHEMBL1986893 & 688612 & 4.65 & 4.7432 & TRN \\
\hline CHEMBL1430248 & 688612 & 4.1 & 4.6055 & TST \\
\hline CHEMBL1495915 & 688612 & 5.3 & 4.6807 & TST \\
\hline CHEMBL1352285 & 688612 & 4.05 & 4.6365 & TST \\
\hline CHEMBL1506693 & 688612 & 4.65 & 4.6856 & TST \\
\hline CHEMBL1489251 & 688612 & 4.35 & 4.63 & TRN \\
\hline CHEMBL3212614 & 688612 & 4.55 & 4.6933 & TST \\
\hline CHEMBL3197719 & 688612 & 4.2 & 4.6701 & TRN \\
\hline CHEMBL1343619 & 688612 & 4.3 & 4.6735 & TST \\
\hline CHEMBL1478410 & 688612 & 4.05 & 4.6429 & TRN \\
\hline CHEMBL1361249 & 688612 & 4.1 & 4.6001 & TRN \\
\hline CHEMBL1447988 & 688612 & 4.05 & 4.7158 & TRN \\
\hline CHEMBL1349781 & 688612 & 4.65 & 4.6136 & TRN \\
\hline CHEMBL1444551 & 688612 & 4.6 & 4.6445 & TRN \\
\hline CHEMBL1486484 & 688612 & 7.0 & 4.6543 & TRN \\
\hline
\end{tabular}




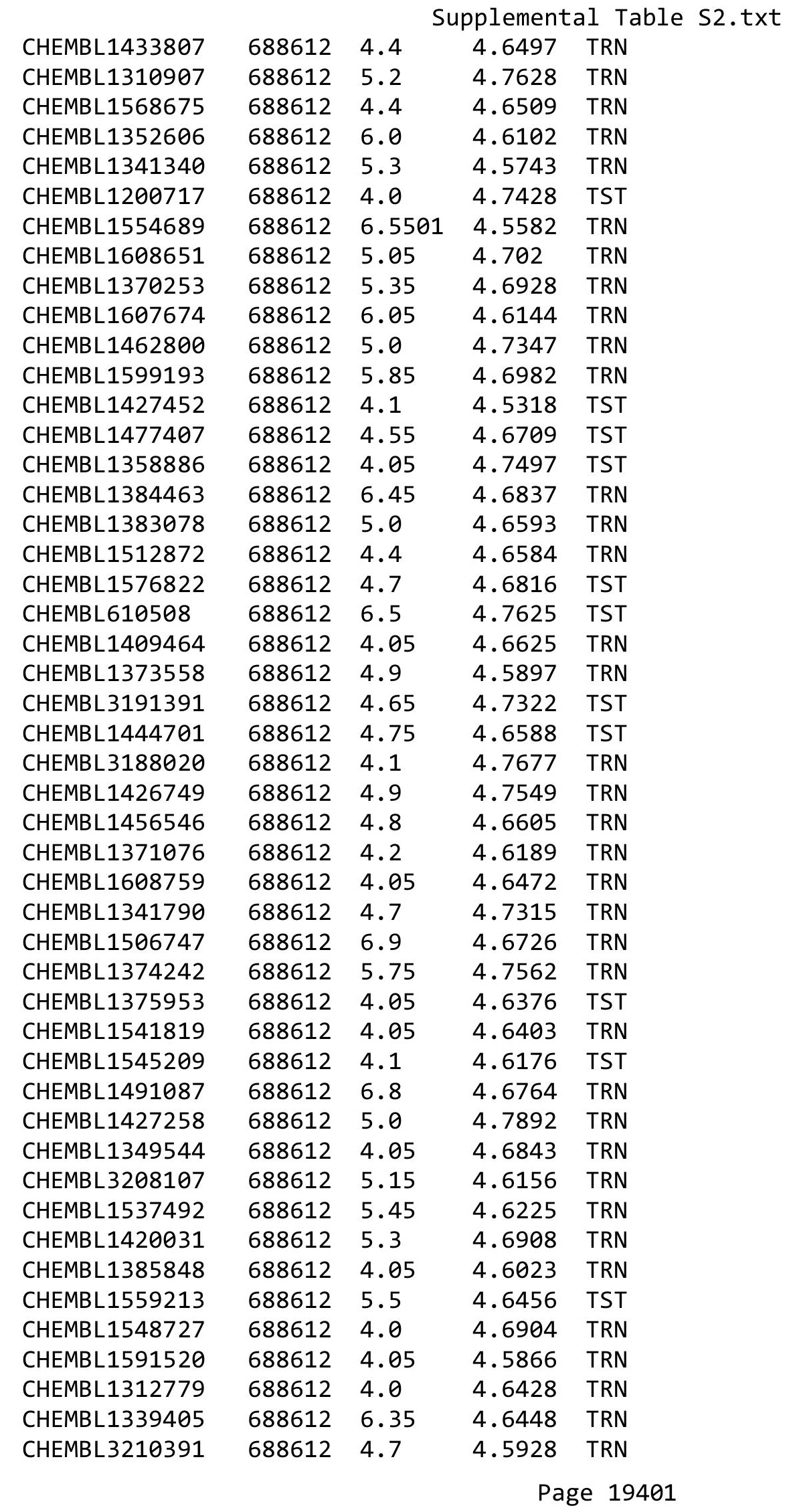




\begin{tabular}{|c|c|c|c|c|}
\hline \multicolumn{5}{|c|}{ Supplemental Table } \\
\hline CHEMBL1544268 & 688612 & 6.8499 & 4.558 & TST \\
\hline CHEMBL1395006 & 688612 & 4.0 & 4.6048 & TRN \\
\hline CHEMBL1612880 & 688612 & 4.95 & 4.6319 & TRN \\
\hline CHEMBL1447908 & 688612 & 4.2 & 4.5484 & TRN \\
\hline CHEMBL1426988 & 688612 & 4.6 & 4.5989 & TRN \\
\hline CHEMBL1386298 & 688612 & 4.35 & 4.6285 & TRN \\
\hline CHEMBL1440196 & 688612 & 4.75 & 4.6757 & TRN \\
\hline CHEMBL1335085 & 688612 & 4.2 & 4.7437 & TRN \\
\hline CHEMBL1455996 & 688612 & 4.05 & 4.6918 & TST \\
\hline CHEMBL1991573 & 688612 & 5.4 & 4.8104 & TRN \\
\hline CHEMBL1458778 & 688612 & 5.55 & 4.7445 & TRN \\
\hline CHEMBL1591054 & 688612 & 4.0 & 4.5903 & TRN \\
\hline CHEMBL1573213 & 688612 & 4.1 & 4.6691 & TRN \\
\hline CHEMBL1574739 & 688612 & 4.1 & 4.6868 & TRN \\
\hline CHEMBL1333050 & 688612 & 4.05 & 4.5853 & TRN \\
\hline CHEMBL1526550 & 688612 & 4.7 & 4.6401 & TRN \\
\hline CHEMBL1444334 & 688612 & 4.45 & 4.7126 & TST \\
\hline CHEMBL1315947 & 688612 & 4.6 & 4.588 & TST \\
\hline CHEMBL1557270 & 688612 & 4.1 & 4.6285 & TST \\
\hline CHEMBL1607221 & 688612 & 4.1 & 4.5755 & TRN \\
\hline CHEMBL1573023 & 688612 & 4.6 & 4.7088 & TRN \\
\hline CHEMBL1460857 & 688612 & 5.0 & 4.5725 & TRN \\
\hline CHEMBL1557114 & 688612 & 5.3 & 4.5397 & TRN \\
\hline CHEMBL1339981 & 688612 & 5.45 & 4.7154 & TST \\
\hline CHEMBL1374948 & 688612 & 4.25 & 4.7392 & TST \\
\hline CHEMBL1466100 & 688612 & 4.75 & 4.6941 & TST \\
\hline CHEMBL1408682 & 688612 & 4.7 & 4.6201 & TRN \\
\hline CHEMBL1419123 & 688612 & 4.1 & 4.7122 & TRN \\
\hline CHEMBL1499002 & 688612 & 4.5 & 4.6284 & TRN \\
\hline CHEMBL1325481 & 688612 & 4.45 & 4.6223 & TST \\
\hline CHEMBL1603434 & 688612 & 4.05 & 4.6081 & TST \\
\hline CHEMBL1474984 & 688612 & 4.3 & 4.614 & TRN \\
\hline CHEMBL1326655 & 688612 & 6.5 & 4.7433 & TRN \\
\hline CHEMBL1409344 & 688612 & 5.25 & 4.8041 & TST \\
\hline CHEMBL1521194 & 688612 & 4.6 & 4.7008 & TRN \\
\hline CHEMBL1586974 & 688612 & 4.4 & 4.7672 & TRN \\
\hline CHEMBL1401568 & 688612 & 4.7 & 4.6647 & TRN \\
\hline CHEMBL1556642 & 688612 & 4.9 & 4.6182 & TRN \\
\hline CHEMBL1561179 & 688612 & 4.0 & 4.6488 & TRN \\
\hline CHEMBL1496056 & 688612 & 6.15 & 4.6363 & TRN \\
\hline CHEMBL1576037 & 688612 & 6.0 & 4.6717 & TRN \\
\hline CHEMBL1338638 & 688612 & 4.55 & 4.5838 & TRN \\
\hline CHEMBL1481165 & 688612 & 4.95 & 4.6853 & TRN \\
\hline CHEMBL1480968 & 688612 & 4.8 & 4.6909 & TRN \\
\hline CHEMBL1299507 & 688612 & 6.05 & 4.6462 & TRN \\
\hline CHEMBL1484433 & 688612 & 4.0 & 4.6825 & TRN \\
\hline CHEMBL1401494 & 688612 & 5.4 & 4.7925 & TST \\
\hline CHEMBL1364525 & 688612 & 4.05 & 4.6172 & TST \\
\hline
\end{tabular}




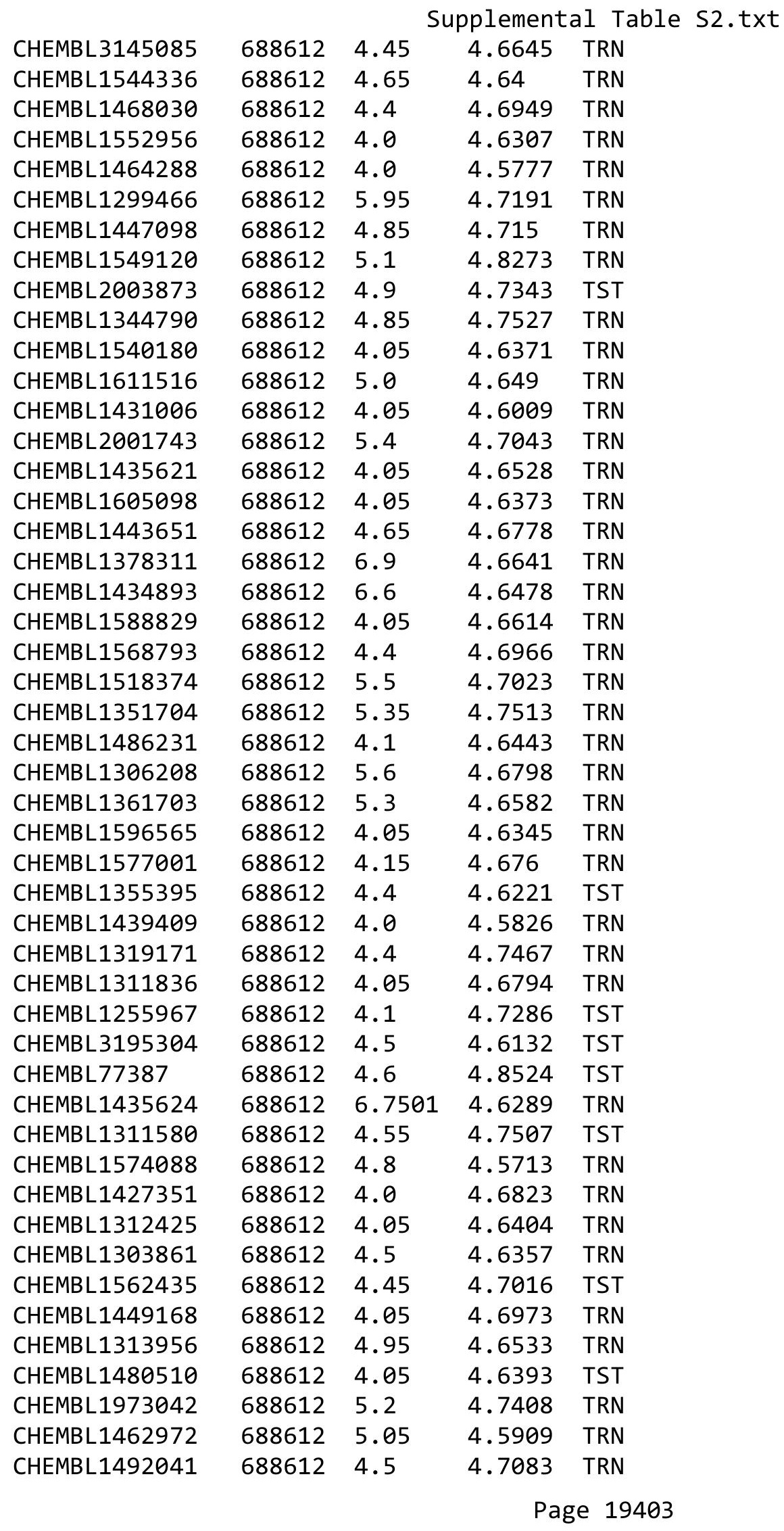




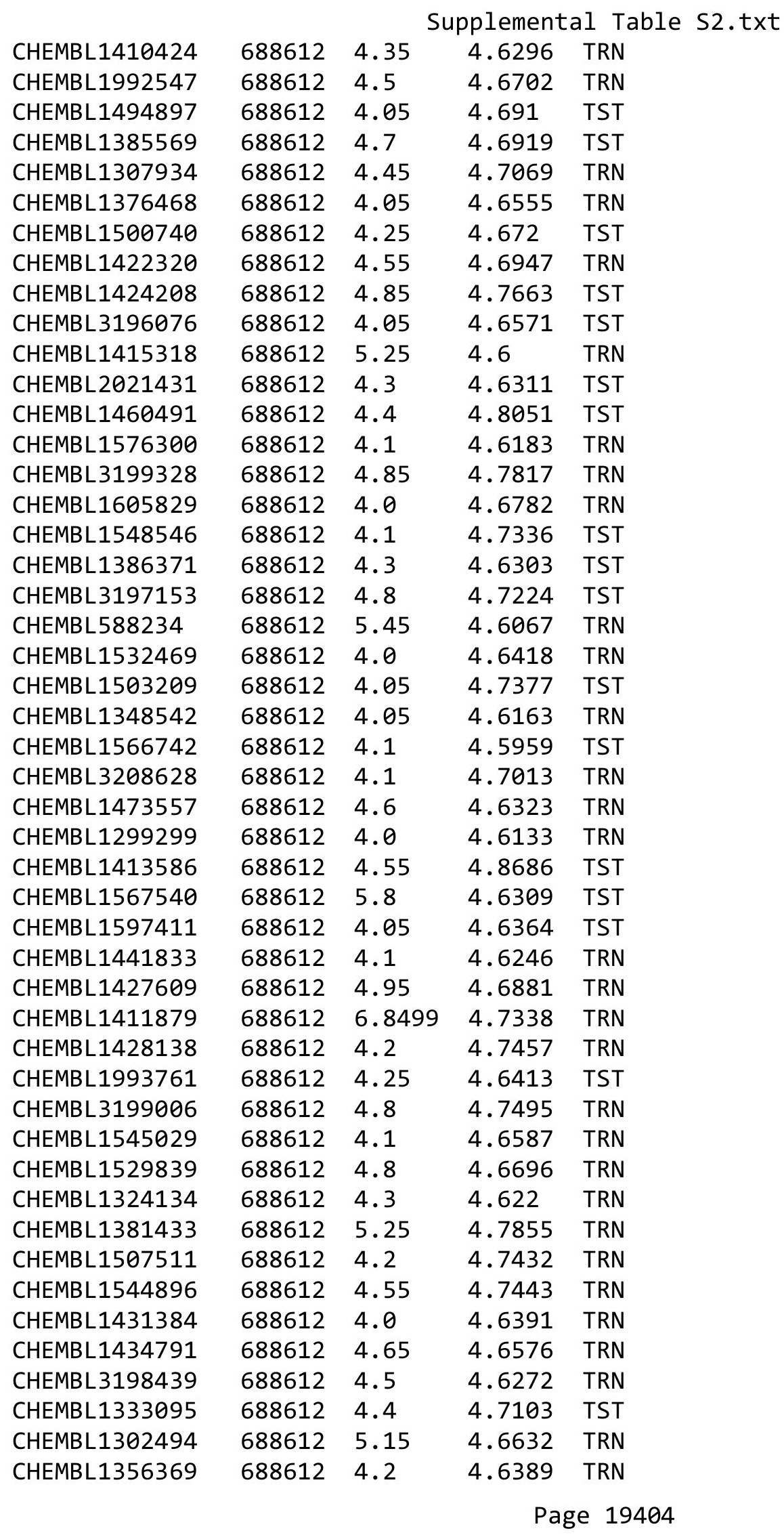




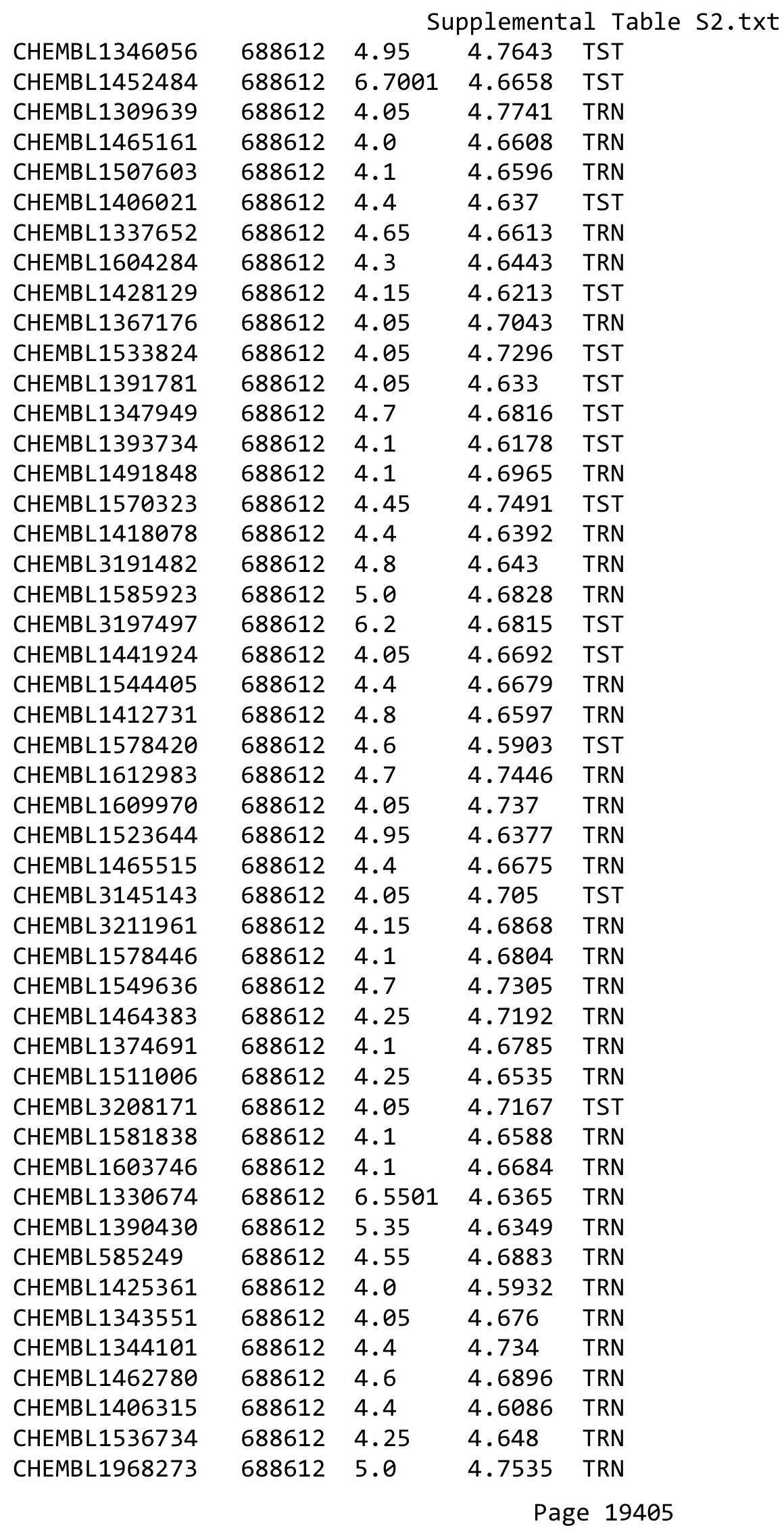




\begin{tabular}{|c|c|c|c|c|c|}
\hline \multicolumn{6}{|c|}{ Supplemental Table S2.txt } \\
\hline CHEMBL1448494 & 688612 & 4.1 & 4.7166 & TST & \\
\hline CHEMBL1500072 & 688612 & 5.55 & 4.7517 & TRN & \\
\hline CHEMBL1408804 & 688612 & 5.3 & 4.588 & TST & \\
\hline CHEMBL1256674 & 688612 & 5.0 & 4.7298 & TST & \\
\hline CHEMBL1351131 & 688612 & 4.4 & 4.6322 & TRN & \\
\hline CHEMBL1607360 & 688612 & 6.8499 & 4.7025 & TRN & \\
\hline CHEMBL1611072 & 688612 & 4.05 & 4.649 & TRN & \\
\hline CHEMBL1436430 & 688612 & 4.0 & 4.6721 & TRN & \\
\hline CHEMBL1528784 & 688612 & 5.4 & 4.6267 & TRN & \\
\hline CHEMBL1475933 & 688612 & 4.8 & 4.6571 & TRN & \\
\hline CHEMBL1483435 & 688612 & 4.6 & 4.6434 & TRN & \\
\hline CHEMBL1305930 & 688612 & 5.8 & 4.6781 & TRN & \\
\hline CHEMBL1560245 & 688612 & 5.0 & 4.6664 & TRN & \\
\hline CHEMBL1465160 & 688612 & 5.8 & 4.6575 & TST & \\
\hline CHEMBL1336322 & 688612 & 5.1 & 4.5637 & TST & \\
\hline CHEMBL1477375 & 688612 & 4.0 & 4.6055 & TRN & \\
\hline CHEMBL1526935 & 688612 & 5.75 & 4.7236 & TST & \\
\hline CHEMBL1381678 & 688612 & 5.1 & 4.6258 & TRN & \\
\hline CHEMBL1584735 & 688612 & 4.85 & 4.6619 & TRN & \\
\hline CHEMBL1375182 & 688612 & 4.9 & 4.702 & TST & \\
\hline CHEMBL1565572 & 688612 & 5.6 & 4.7112 & TST & \\
\hline CHEMBL3192134 & 688612 & 4.15 & 4.6307 & TRN & \\
\hline CHEMBL1395961 & 688612 & 4.05 & 4.6081 & TRN & \\
\hline CHEMBL1398148 & 688612 & 4.6 & 4.6454 & TRN & \\
\hline CHEMBL1563898 & 688612 & 6.5 & 4.82100 & 0000000001 & TRN \\
\hline CHEMBL1519122 & 688612 & 4.25 & 4.5537 & TRN & \\
\hline CHEMBL1546182 & 688612 & 5.5 & 4.6186 & TRN & \\
\hline CHEMBL1543965 & 688612 & 5.4 & 4.8733 & TST & \\
\hline CHEMBL1494877 & 688612 & 6.35 & 4.6096 & TRN & \\
\hline CHEMBL1522556 & 688612 & 4.5 & 4.6093 & TRN & \\
\hline CHEMBL1975746 & 688612 & 4.75 & 4.7168 & TRN & \\
\hline CHEMBL1323592 & 688612 & 5.55 & 4.6745 & TRN & \\
\hline CHEMBL1561063 & 688612 & 4.4 & 4.6717 & TRN & \\
\hline CHEMBL1576094 & 688612 & 4.4 & 4.78600 & 00000000005 & TRN \\
\hline CHEMBL1543216 & 688612 & 4.25 & 4.6363 & TRN & \\
\hline CHEMBL1480138 & 688612 & 6.2 & 4.6512 & TRN & \\
\hline CHEMBL1388107 & 688612 & 4.7 & 4.5881 & TRN & \\
\hline CHEMBL1459531 & 688612 & 4.9 & 4.7264 & TRN & \\
\hline CHEMBL1538555 & 688612 & 4.05 & 4.6641 & TRN & \\
\hline CHEMBL1509375 & 688612 & 4.1 & 4.6748 & TST & \\
\hline CHEMBL1510723 & 688612 & 4.1 & 4.6743 & TRN & \\
\hline CHEMBL1442956 & 688612 & 4.75 & 4.7447 & TRN & \\
\hline CHEMBL1548441 & 688612 & 4.1 & 4.6061 & TRN & \\
\hline CHEMBL1469211 & 688612 & 4.05 & 4.6583 & TST & \\
\hline CHEMBL3211928 & 688612 & 4.0 & 4.6951 & TST & \\
\hline CHEMBL52101 & 688612 & 4.8 & 4.6232 & TRN & \\
\hline CHEMBL1389823 & 688612 & 6.8 & 4.7078 & TST & \\
\hline CHEMBL1491556 & 688612 & 4.55 & 4.6939 & TRN & \\
\hline
\end{tabular}




\begin{tabular}{|c|c|c|c|c|c|}
\hline \multicolumn{6}{|c|}{ Supplemental Table S2.txt } \\
\hline CHEMBL1543508 & 688612 & 4.65 & 4.6751 & TRN & \\
\hline CHEMBL1308138 & 688612 & 4.5 & 4.6061 & TST & \\
\hline CHEMBL1346226 & 688612 & 5.1 & 4.7759 & TRN & \\
\hline CHEMBL1568638 & 688612 & 4.55 & 4.6451 & TRN & \\
\hline CHEMBL1412532 & 688612 & 4.0 & 4.6453 & TRN & \\
\hline CHEMBL1588777 & 688612 & 4.15 & 4.6771 & TRN & \\
\hline CHEMBL1558503 & 688612 & 4.4 & 4.627 & TRN & \\
\hline CHEMBL1474632 & 688612 & 4.05 & 4.6453 & TST & \\
\hline CHEMBL1367292 & 688612 & 4.4 & 4.5656 & TRN & \\
\hline CHEMBL1344985 & 688612 & 4.95 & 4.7835 & TST & \\
\hline CHEMBL1473672 & 688612 & 6.6 & 4.63899 & 9999999999 & TRN \\
\hline CHEMBL1488826 & 688612 & 4.05 & 4.5989 & TRN & \\
\hline CHEMBL1433180 & 688612 & 4.8 & 4.7356 & TRN & \\
\hline CHEMBL1399039 & 688612 & 4.05 & 4.7423 & TRN & \\
\hline CHEMBL1519761 & 688612 & 4.8 & 4.6456 & TRN & \\
\hline CHEMBL1475384 & 688612 & 4.2 & 4.6731 & TST & \\
\hline CHEMBL 2005967 & 688612 & 4.35 & 4.6063 & TRN & \\
\hline CHEMBL1361206 & 688612 & 5.45 & 4.586 & TRN & \\
\hline CHEMBL1484657 & 688612 & 4.35 & 4.7429 & TRN & \\
\hline CHEMBL1395906 & 688612 & 4.05 & 4.7132 & TRN & \\
\hline CHEMBL1351973 & 688612 & 4.55 & 4.6613 & TST & \\
\hline CHEMBL1326483 & 688612 & 4.35 & 4.6906 & TST & \\
\hline CHEMBL1309494 & 688612 & 4.2 & 4.6123 & TST & \\
\hline CHEMBL1503962 & 688612 & 4.4 & 4.7186 & TRN & \\
\hline CHEMBL1313507 & 688612 & 4.6 & 4.7215 & TST & \\
\hline CHEMBL1507602 & 688612 & 4.65 & 4.6993 & TRN & \\
\hline CHEMBL1346172 & 688612 & 5.5 & 4.734 & TRN & \\
\hline CHEMBL1511545 & 688612 & 4.05 & 4.622 & TST & \\
\hline CHEMBL1545772 & 688612 & 4.0 & 4.6957 & TRN & \\
\hline CHEMBL1401562 & 688612 & 4.8 & 4.6066 & TRN & \\
\hline CHEMBL1513212 & 688612 & 4.0 & 4.6673 & TRN & \\
\hline CHEMBL 1558170 & 688612 & 4.05 & 4.6395 & TRN & \\
\hline CHEMBL1404752 & 688612 & 4.05 & 4.6164 & TRN & \\
\hline CHEMBL1987816 & 688612 & 5.0 & 4.7484 & TRN & \\
\hline CHEMBL1517566 & 688612 & 4.55 & 4.6387 & TST & \\
\hline CHEMBL1611935 & 688612 & 5.0 & 4.6636 & TRN & \\
\hline CHEMBL 1460126 & 688612 & 4.3 & 4.7231 & TRN & \\
\hline CHEMBL1396003 & 688612 & 5.5 & 4.6115 & TRN & \\
\hline CHEMBL1451983 & 688612 & 4.3 & 4.6575 & TRN & \\
\hline CHEMBL1365694 & 688612 & 4.1 & 4.7272 & TRN & \\
\hline CHEMBL1500319 & 688612 & 6.05 & 4.6053 & TST & \\
\hline CHEMBL 1357150 & 688612 & 4.15 & 4.6511 & TRN & \\
\hline CHEMBL1334651 & 688612 & 5.35 & 4.6661 & TST & \\
\hline CHEMBL1434015 & 688612 & 4.05 & 4.6532 & TST & \\
\hline CHEMBL3190347 & 688612 & 4.05 & 4.7097 & TRN & \\
\hline CHEMBL1557391 & 688612 & 4.4 & 4.6263 & TRN & \\
\hline CHEMBL1326867 & 688612 & 4.0 & 4.6829 & TST & \\
\hline CHEMBL1514878 & 688612 & 4.65 & 4.6594 & TRN & \\
\hline
\end{tabular}




\begin{tabular}{|c|c|c|c|c|}
\hline \multicolumn{5}{|c|}{ Supplemental Table s2.txt } \\
\hline CHEMBL1368333 & 688612 & 4.1 & 4.6561 & TRN \\
\hline CHEMBL1421978 & 688612 & 4.0 & 4.6016 & TRN \\
\hline CHEMBL1307608 & 688612 & 4.6 & 4.6578 & TRN \\
\hline CHEMBL1375735 & 688612 & 6.5 & 4.6291 & TST \\
\hline CHEMBL 2006431 & 688612 & 5.3 & 4.6596 & TST \\
\hline CHEMBL1514519 & 688612 & 4.15 & 4.6 & TRN \\
\hline CHEMBL1580730 & 688612 & 4.05 & 4.5756 & TRN \\
\hline CHEMBL1576673 & 688612 & 4.0 & 4.71899 & 9999999999 \\
\hline CHEMBL1542301 & 688612 & 5.0 & 4.8004 & TRN \\
\hline CHEMBL1527671 & 688612 & 4.05 & 4.6523 & TST \\
\hline CHEMBL1517835 & 688612 & 4.05 & 4.6119 & TST \\
\hline CHEMBL1550089 & 688612 & 4.8 & 4.6907 & TRN \\
\hline CHEMBL1386470 & 688612 & 4.6 & 4.6596 & TST \\
\hline CHEMBL1496905 & 688612 & 4.8 & 4.63 & TST \\
\hline CHEMBL1444698 & 688612 & 5.0 & 4.7094 & TRN \\
\hline CHEMBL 2003806 & 688612 & 4.1 & 4.6643 & TRN \\
\hline CHEMBL1358701 & 688612 & 4.65 & 4.6534 & TRN \\
\hline CHEMBL3198836 & 688612 & 4.05 & 4.8051 & TRN \\
\hline CHEMBL1413575 & 688612 & 4.4 & 4.5943 & TRN \\
\hline CHEMBL1416474 & 688612 & 4.1 & 4.6631 & TRN \\
\hline CHEMBL 1504278 & 688612 & 4.05 & 4.6897 & TST \\
\hline CHEMBL1375960 & 688612 & 4.05 & 4.6704 & TRN \\
\hline CHEMBL1373374 & 688612 & 5.0 & 4.6483 & TRN \\
\hline CHEMBL1566196 & 688612 & 4.05 & 4.6681 & TRN \\
\hline CHEMBL1542652 & 688612 & 4.05 & 4.6864 & TST \\
\hline CHEMBL1302737 & 688612 & 4.2 & 4.6763 & TRN \\
\hline CHEMBL1575311 & 688612 & 4.4 & 4.6534 & TRN \\
\hline CHEMBL1328537 & 688612 & 6.0 & 4.6264 & TST \\
\hline CHEMBL1415367 & 688612 & 4.0 & 4.6234 & TST \\
\hline CHEMBL1456208 & 688612 & 4.25 & 4.5954 & TRN \\
\hline CHEMBL1560574 & 688612 & 4.3 & 4.6716 & TRN \\
\hline CHEMBL1440543 & 688612 & 4.0 & 4.628 & TRN \\
\hline CHEMBL1452473 & 688612 & 6.5501 & 4.7296 & TRN \\
\hline CHEMBL1432198 & 688612 & 4.4 & 4.7077 & TST \\
\hline CHEMBL1451610 & 688612 & 5.35 & 4.7244 & TST \\
\hline CHEMBL3191942 & 688612 & 6.0 & 4.7226 & TRN \\
\hline CHEMBL3199005 & 688612 & 4.0 & 4.7246 & TRN \\
\hline CHEMBL1515414 & 688612 & 4.4 & 4.6264 & TRN \\
\hline CHEMBL 3198750 & 688612 & 4.55 & 4.6586 & TRN \\
\hline CHEMBL1371327 & 688612 & 6.8499 & 4.6101 & TRN \\
\hline CHEMBL1546979 & 688612 & 4.45 & 4.7439 & TRN \\
\hline CHEMBL1421794 & 688612 & 4.9 & 4.6526 & TRN \\
\hline CHEMBL1410741 & 688612 & 4.7 & 4.6449 & TST \\
\hline CHEMBL1562537 & 688612 & 4.9 & 4.7264 & TRN \\
\hline CHEMBL1399765 & 688612 & 6.4 & 4.6641 & TRN \\
\hline CHEMBL 271620 & 688612 & 6.15 & 4.6284 & TST \\
\hline CHEMBL1613428 & 688612 & 4.4 & 4.5547 & TRN \\
\hline CHEMBL3190924 & 688612 & 4.05 & 4.7406 & TRN \\
\hline
\end{tabular}




\begin{tabular}{|c|c|c|c|c|c|}
\hline & & \multicolumn{4}{|c|}{ Supplemental Table S2.txt } \\
\hline CHEMBL3196867 & 688612 & 4.25 & 4.7167 & TST & \\
\hline CHEMBL1460015 & 688612 & 4.3 & 4.6519 & TRN & \\
\hline CHEMBL1380146 & 688612 & 4.6 & 4.60800 & 00000000005 & TRN \\
\hline CHEMBL1578803 & 688612 & 5.35 & 4.5972 & TRN & \\
\hline CHEMBL1568115 & 688612 & 6.05 & 4.7184 & TST & \\
\hline CHEMBL80941 & 688612 & 4.55 & 4.8423 & TRN & \\
\hline CHEMBL1432010 & 688612 & 4.05 & 4.6674 & TRN & \\
\hline CHEMBL3197835 & 688612 & 4.05 & 4.6694 & TRN & \\
\hline CHEMBL1470106 & 688612 & 4.05 & 4.6565 & TST & \\
\hline CHEMBL1998566 & 688612 & 4.55 & 4.6957 & TST & \\
\hline CHEMBL1518235 & 688612 & 4.3 & 4.6522 & TRN & \\
\hline CHEMBL1438182 & 688612 & 5.55 & 4.7665 & TRN & \\
\hline CHEMBL1999959 & 688612 & 4.65 & 4.7607 & TRN & \\
\hline CHEMBL1334327 & 688612 & 4.05 & 4.692 & TST & \\
\hline CHEMBL1432814 & 688612 & 4.35 & 4.7547 & TRN & \\
\hline CHEMBL1424390 & 688612 & 4.6 & 4.583 & TRN & \\
\hline CHEMBL1564366 & 688612 & 5.1 & 4.753 & TRN & \\
\hline CHEMBL1486049 & 688612 & 5.95 & 4.6146 & TRN & \\
\hline CHEMBL1337830 & 688612 & 4.1 & 4.7567 & TST & \\
\hline CHEMBL1442506 & 688612 & 4.6 & 4.6149 & TRN & \\
\hline CHEMBL1447570 & 688612 & 6.15 & 4.6531 & TRN & \\
\hline CHEMBL1448700 & 688612 & 4.3 & 4.6622 & TRN & \\
\hline CHEMBL3199299 & 688612 & 6.5 & 4.8049 & TRN & \\
\hline CHEMBL1301796 & 688612 & 4.45 & 4.703 & TRN & \\
\hline CHEMBL1602685 & 688612 & 4.4 & 4.6695 & TST & \\
\hline CHEMBL1553063 & 688612 & 5.75 & 4.6274 & TRN & \\
\hline CHEMBL1509705 & 688612 & 4.2 & 4.628 & TRN & \\
\hline CHEMBL1588531 & 688612 & 5.5 & 4.6465 & TRN & \\
\hline CHEMBL1313654 & 688612 & 4.2 & 4.5733 & TRN & \\
\hline CHEMBL1305326 & 688612 & 4.15 & 4.6393 & TST & \\
\hline CHEMBL1514697 & 688612 & 4.7 & 4.7242 & TRN & \\
\hline CHEMBL1478395 & 688612 & 4.65 & 4.7632 & TST & \\
\hline CHEMBL1458300 & 688612 & 4.1 & 4.6859 & TRN & \\
\hline CHEMBL1530995 & 688612 & 5.4 & 4.675 & TST & \\
\hline CHEMBL1537545 & 688612 & 4.05 & 4.635 & TRN & \\
\hline CHEMBL1560760 & 688612 & 4.8 & 4.7646 & TRN & \\
\hline CHEMBL1524439 & 688612 & 4.7 & 4.7019 & TRN & \\
\hline CHEMBL1606471 & 688612 & 4.1 & 4.6813 & TRN & \\
\hline CHEMBL1474099 & 688612 & 4.5 & 4.7017 & TST & \\
\hline CHEMBL1575255 & 688612 & 4.25 & 4.7041 & TRN & \\
\hline CHEMBL1465229 & 688612 & 5.05 & 4.7144 & TRN & \\
\hline CHEMBL1394280 & 688612 & 4.05 & 4.6 & TRN & \\
\hline CHEMBL1484257 & 688612 & 4.4 & 4.7061 & TRN & \\
\hline CHEMBL1612012 & 688612 & 4.05 & 4.6889 & TST & \\
\hline CHEMBL1465639 & 688612 & 4.05 & 4.67399 & 99999999995 & TST \\
\hline CHEMBL1412729 & 688612 & 4.0 & 4.58899 & 99999999995 & TRN \\
\hline CHEMBL1419394 & 688612 & 4.0 & 4.6458 & TRN & \\
\hline CHEMBL1410294 & 688612 & 5.35 & 4.6735 & TRN & \\
\hline
\end{tabular}




\begin{tabular}{|c|c|c|c|c|c|}
\hline \multicolumn{6}{|c|}{ Supplemental Table S2.txt } \\
\hline CHEMBL1561769 & 688612 & 4.4 & 4.6881 & TRN & \\
\hline CHEMBL1503521 & 688612 & 4.05 & 4.5635 & TRN & \\
\hline CHEMBL1309404 & 688612 & 4.65 & 4.7085 & TRN & \\
\hline CHEMBL1388911 & 688612 & 4.1 & 4.67 & TRN & \\
\hline CHEMBL1470833 & 688612 & 4.4 & 4.7137 & TST & \\
\hline CHEMBL1363505 & 688612 & 5.2 & 4.6324 & TRN & \\
\hline CHEMBL1520408 & 688612 & 4.05 & 4.7206 & TST & \\
\hline CHEMBL1606967 & 688612 & 4.45 & 4.7123 & TST & \\
\hline CHEMBL1462706 & 688612 & 4.65 & 4.7237 & TST & \\
\hline CHEMBL1588534 & 688612 & 4.05 & 4.5818 & TRN & \\
\hline CHEMBL1996030 & 688612 & 4.1 & 4.7312 & TST & \\
\hline CHEMBL1423290 & 688612 & 5.75 & 4.6893 & TRN & \\
\hline CHEMBL1377965 & 688612 & 6.8499 & 4.7179 & TST & \\
\hline CHEMBL1429988 & 688612 & 4.75 & 4.6869 & TRN & \\
\hline CHEMBL1585685 & 688612 & 4.4 & 4.7014 & TRN & \\
\hline CHEMBL1490031 & 688612 & 4.0 & 4.7408 & TRN & \\
\hline CHEMBL1558857 & 688612 & 6.6499 & 4.5879 & TRN & \\
\hline CHEMBL1573528 & 688612 & 4.0 & 4.6906 & TRN & \\
\hline CHEMBL1403444 & 688612 & 4.25 & 4.6415 & TST & \\
\hline CHEMBL1505110 & 688612 & 4.3 & 4.6373 & TRN & \\
\hline CHEMBL1336846 & 688612 & 4.05 & 4.7395 & TST & \\
\hline CHEMBL547269 & 688612 & 6.0 & 4.5787 & TRN & \\
\hline CHEMBL3193588 & 688612 & 4.45 & 4.6781 & TRN & \\
\hline CHEMBL1349196 & 688612 & 4.15 & 4.6419 & TRN & \\
\hline CHEMBL1482115 & 688612 & 4.05 & 4.6406 & TST & \\
\hline CHEMBL1429513 & 688612 & 4.4 & 4.6706 & TRN & \\
\hline CHEMBL1581854 & 688612 & 5.45 & 4.7144 & TST & \\
\hline CHEMBL1369130 & 688612 & 4.8 & 4.7018 & TRN & \\
\hline CHEMBL1346703 & 688612 & 5.4 & 4.7313 & TST & \\
\hline CHEMBL1415814 & 688612 & 4.45 & 4.612 & TST & \\
\hline CHEMBL1551804 & 688612 & 4.05 & 4.6341 & TRN & \\
\hline CHEMBL1534229 & 688612 & 4.05 & 4.6544 & TST & \\
\hline CHEMBL1386041 & 688612 & 4.6 & 4.6851 & TST & \\
\hline CHEMBL1542792 & 688612 & 4.9 & 4.6313 & TRN & \\
\hline CHEMBL1545938 & 688612 & 4.0 & 4.7336 & TST & \\
\hline CHEMBL3191752 & 688612 & 4.35 & 4.6277 & TRN & \\
\hline CHEMBL1599666 & 688612 & 5.0 & 4.753 & TST & \\
\hline CHEMBL1548333 & 688612 & 4.55 & 4.7286 & TRN & \\
\hline CHEMBL1518552 & 688612 & 4.3 & 4.63899 & 9999999999 & TRN \\
\hline CHEMBL1496732 & 688612 & 4.8 & 4.6854 & TRN & \\
\hline CHEMBL1576139 & 688612 & 4.05 & 4.6108 & TRN & \\
\hline CHEMBL1469332 & 688612 & 4.55 & 4.7579 & TRN & \\
\hline CHEMBL1443188 & 688612 & 6.0 & 4.6113 & TST & \\
\hline CHEMBL1459315 & 688612 & 4.55 & 4.7401 & TRN & \\
\hline CHEMBL1549850 & 688612 & 4.65 & 4.6082 & TRN & \\
\hline CHEMBL1512519 & 688612 & 4.55 & 4.6216 & TRN & \\
\hline CHEMBL1471861 & 688612 & 4.05 & 4.6525 & TST & \\
\hline CHEMBL1312642 & 688612 & 4.3 & 4.73 & TRN & \\
\hline
\end{tabular}




\begin{tabular}{|c|c|c|c|c|c|}
\hline & & \multicolumn{4}{|c|}{ Supplemental Table S2.txt } \\
\hline CHEMBL1331399 & 688612 & 4.15 & 4.7066 & TRN & \\
\hline CHEMBL1560627 & 688612 & 5.3 & 4.7065 & TST & \\
\hline CHEMBL1416302 & 688612 & 5.0 & 4.6379 & TRN & \\
\hline CHEMBL1428997 & 688612 & 4.5 & 4.7389 & TRN & \\
\hline CHEMBL1607910 & 688612 & 4.6 & 4.63899 & 9999999999 & TRN \\
\hline CHEMBL1535261 & 688612 & 5.0 & 4.629 & TST & \\
\hline CHEMBL1334484 & 688612 & 5.2 & 4.8279 & TST & \\
\hline CHEMBL1405901 & 688612 & 7.0 & 4.6593 & TRN & \\
\hline CHEMBL1500226 & 688612 & 4.4 & 4.7471 & TRN & \\
\hline CHEMBL1609323 & 688612 & 4.05 & 4.6147 & TST & \\
\hline CHEMBL1606187 & 688612 & 4.9 & 4.5737 & TRN & \\
\hline CHEMBL 1490770 & 688612 & 6.05 & 4.6652 & TRN & \\
\hline CHEMBL1488862 & 688612 & 5.0 & 4.6246 & TRN & \\
\hline CHEMBL1534461 & 688612 & 4.4 & 4.6444 & TRN & \\
\hline CHEMBL1394046 & 688612 & 5.35 & 4.7474 & TRN & \\
\hline CHEMBL1531270 & 688612 & 4.1 & 4.6277 & TRN & \\
\hline CHEMBL1485303 & 688612 & 4.7 & 4.6405 & TRN & \\
\hline CHEMBL1473863 & 688612 & 4.6 & 4.578 & TRN & \\
\hline CHEMBL1493712 & 688612 & 4.0 & 4.6176 & TST & \\
\hline CHEMBL1481493 & 688612 & 4.5 & 4.7068 & TRN & \\
\hline CHEMBL1501635 & 688612 & 5.1 & 4.7245 & TST & \\
\hline CHEMBL1322551 & 688612 & 4.4 & 4.6326 & TRN & \\
\hline CHEMBL1584100 & 688612 & 6.45 & 4.5838 & TRN & \\
\hline CHEMBL1559999 & 688612 & 4.05 & 4.715 & TRN & \\
\hline CHEMBL1465370 & 688612 & 4.8 & 4.6862 & TRN & \\
\hline CHEMBL1503164 & 688612 & 5.4 & 4.6709 & TRN & \\
\hline CHEMBL1359167 & 688612 & 4.05 & 4.6835 & TRN & \\
\hline CHEMBL1448995 & 688612 & 4.35 & 4.6019 & TRN & \\
\hline CHEMBL1582213 & 688612 & 5.6 & 4.5856 & TRN & \\
\hline CHEMBL1487236 & 688612 & 4.85 & 4.7089 & TRN & \\
\hline CHEMBL1565772 & 688612 & 4.2 & 4.5791 & TRN & \\
\hline CHEMBL1337907 & 688612 & 4.45 & 4.63899 & 9999999999 & TRN \\
\hline CHEMBL1329496 & 688612 & 4.4 & 4.74 & TRN & \\
\hline CHEMBL1328841 & 688612 & 4.2 & 4.6359 & TRN & \\
\hline CHEMBL1547445 & 688612 & 4.9 & 4.6844 & TRN & \\
\hline CHEMBL1573987 & 688612 & 6.9 & 4.684 & TRN & \\
\hline CHEMBL1461585 & 688612 & 5.0 & 4.6534 & TST & \\
\hline CHEMBL1319619 & 688612 & 4.5 & 4.7825 & TRN & \\
\hline CHEMBL1501561 & 688612 & 4.85 & 4.6069 & TRN & \\
\hline CHEMBL1315076 & 688612 & 4.6 & 4.6394 & TRN & \\
\hline CHEMBL1561204 & 688612 & 4.35 & 4.6946 & TRN & \\
\hline CHEMBL1521348 & 688612 & 4.15 & 4.6205 & TRN & \\
\hline CHEMBL1552711 & 688612 & 4.0 & 4.6368 & TRN & \\
\hline CHEMBL1601255 & 688612 & 4.05 & 4.6474 & TRN & \\
\hline CHEMBL1978388 & 688612 & 4.15 & 4.712 & TRN & \\
\hline CHEMBL1444504 & 688612 & 4.35 & 4.6798 & TST & \\
\hline CHEMBL1331636 & 688612 & 5.25 & 4.6452 & TRN & \\
\hline CHEMBL1577757 & 688612 & 4.85 & 4.6637 & TRN & \\
\hline
\end{tabular}




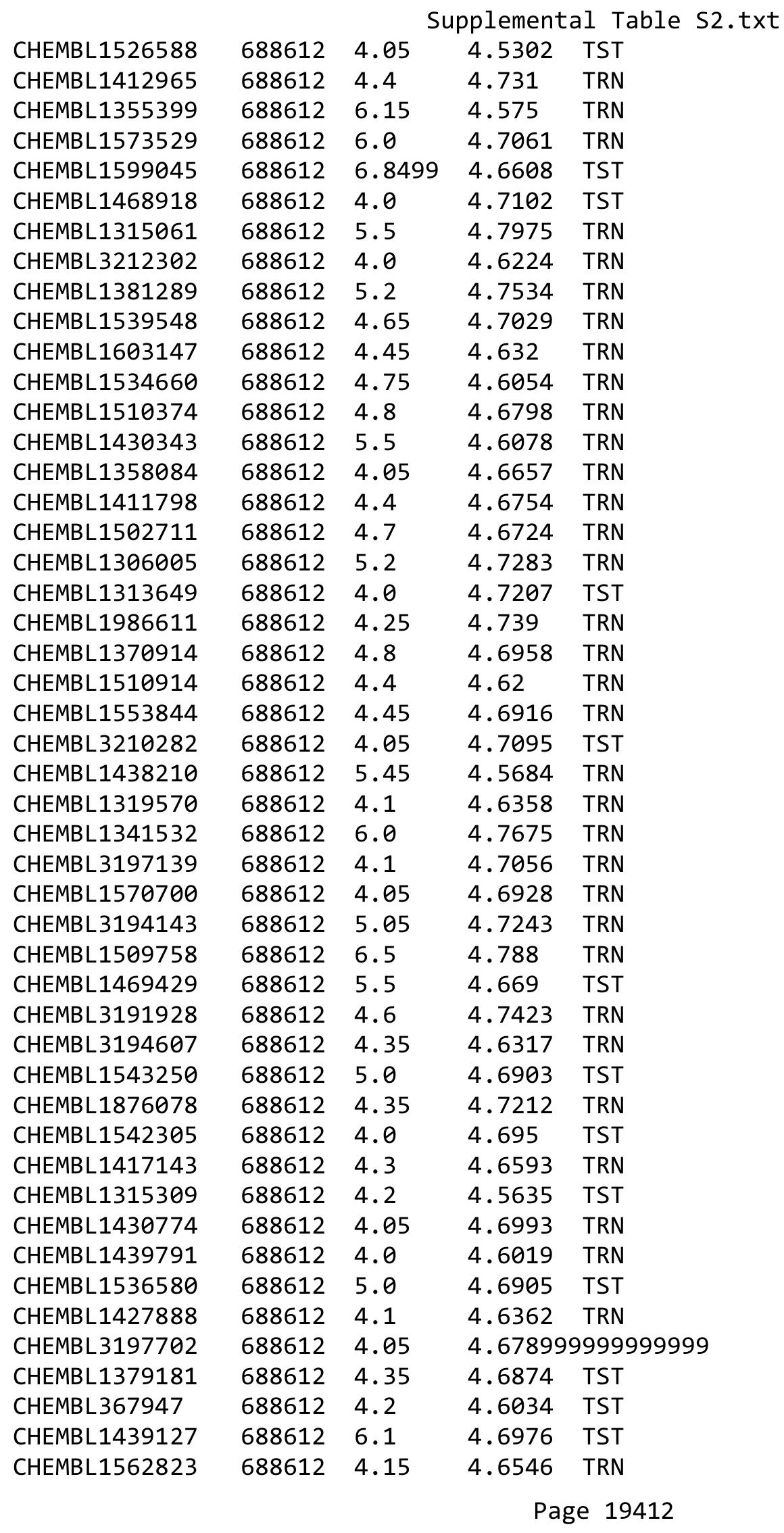




\begin{tabular}{|c|c|c|c|c|c|}
\hline \multicolumn{6}{|c|}{ Supplemental Table S2.txt } \\
\hline CHEMBL1505300 & 688612 & 5.0 & 4.6753 & TRN & \\
\hline CHEMBL1606193 & 688612 & 4.4 & 4.6391 & TST & \\
\hline CHEMBL1612392 & 688612 & 5.4 & 4.7444 & TRN & \\
\hline CHEMBL1336831 & 688612 & 4.0 & 4.6657 & TRN & \\
\hline CHEMBL1341960 & 688612 & 4.1 & 4.6641 & TRN & \\
\hline CHEMBL1401733 & 688612 & 5.4 & 4.6809 & TRN & \\
\hline CHEMBL1414926 & 688612 & 4.55 & 4.6765 & TRN & \\
\hline CHEMBL1389318 & 688612 & 4.45 & 4.6749 & TRN & \\
\hline CHEMBL1609454 & 688612 & 4.65 & 4.7572 & TRN & \\
\hline CHEMBL1310209 & 688612 & 4.0 & 4.6825 & TRN & \\
\hline CHEMBL1525867 & 688612 & 4.05 & 4.6293 & TRN & \\
\hline CHEMBL1470227 & 688612 & 4.0 & 4.6892 & TRN & \\
\hline CHEMBL1358832 & 688612 & 4.1 & 4.6935 & TST & \\
\hline CHEMBL1548833 & 688612 & 6.2 & 4.675 & TRN & \\
\hline CHEMBL1323930 & 688612 & 4.0 & 4.6529 & TST & \\
\hline CHEMBL1459470 & 688612 & 4.65 & 4.6089 & TRN & \\
\hline CHEMBL1455103 & 688612 & 4.25 & 4.6722 & TRN & \\
\hline CHEMBL1345966 & 688612 & 4.3 & 4.7094 & TRN & \\
\hline CHEMBL1391433 & 688612 & 5.25 & 4.7624 & TST & \\
\hline CHEMBL1310972 & 688612 & 4.5 & 4.7413 & TRN & \\
\hline CHEMBL1582731 & 688612 & 4.6 & $4.6160 e$ & 00000000005 & TRN \\
\hline CHEMBL1482883 & 688612 & 5.1 & 4.845 & TRN & \\
\hline CHEMBL585686 & 817940 & 3.4948 & 3.6342 & TRN & \\
\hline CHEMBL2028046 & 817940 & 3.4948 & 4.5642 & TRN & \\
\hline CHEMBL529603 & 817940 & 3.4948 & 3.7112 & TRN & \\
\hline CHEMBL525826 & 817940 & 4.8762 & 5.3177 & TRN & \\
\hline CHEMBL 2028068 & 817940 & 4.8922 & 4.2381 & TST & \\
\hline CHEMBL592786 & 817940 & 3.4948 & 4.3782 & TRN & \\
\hline CHEMBL602366 & 817940 & 3.4948 & 3.6057 & TRN & \\
\hline CHEMBL606531 & 817940 & 3.4948 & 4.7106 & TRN & \\
\hline CHEMBL586026 & 817940 & 6.0295 & 4.8346 & TST & \\
\hline CHEMBL527234 & 817940 & 3.4948 & 4.1113 & TRN & \\
\hline CHEMBL611070 & 817940 & 3.4948 & 3.9303 & TRN & \\
\hline CHEMBL529773 & 817940 & 5.5137 & 4.2705 & TRN & \\
\hline CHEMBL527541 & 817940 & 5.727 & 3.6056 & TRN & \\
\hline CHEMBL587410 & 817940 & 5.9506 & 4.7795 & TST & \\
\hline CHEMBL1485159 & 817940 & 4.7959 & 4.4281 & TRN & \\
\hline CHEMBL 2028047 & 817940 & 5.8651 & 4.8494 & TRN & \\
\hline CHEMBL1623897 & 817940 & 3.4948 & 4.2708 & TRN & \\
\hline CHEMBL532879 & 817940 & 3.4948 & 3.8822 & TRN & \\
\hline CHEMBL531222 & 817940 & 3.4948 & 3.98199 & 99999999998 & TRN \\
\hline CHEMBL589920 & 817940 & 6.7827 & 4.6347 & TRN & \\
\hline CHEMBL578508 & 817940 & 3.4948 & 3.685 & TRN & \\
\hline CHEMBL547488 & 817940 & 3.4948 & 4.0927 & TRN & \\
\hline CHEMBL607975 & 817940 & 3.4948 & 3.4846 & TRN & \\
\hline CHEMBL581349 & 817940 & 3.4948 & 3.7336 & TRN & \\
\hline CHEMBL549210 & 817940 & 4.9356 & 4.9087 & TRN & \\
\hline CHEMBL579331 & 817940 & 3.4948 & 4.369 & TRN & \\
\hline
\end{tabular}




\begin{tabular}{|c|c|c|c|c|}
\hline & & & oplement & al $\mathrm{Tc}$ \\
\hline CHEMBL125044 & 817940 & 3.4948 & 3.3897 & TRN \\
\hline CHEMBL589060 & 817940 & 3.4948 & 3.6053 & TRN \\
\hline CHEMBL525486 & 817940 & 5.0969 & 5.7494 & TRN \\
\hline CHEMBL581874 & 817940 & 3.4948 & 3.8014 & TRN \\
\hline CHEMBL579294 & 817940 & 5.5088 & 4.1422 & TRN \\
\hline CHEMBL582495 & 817940 & 4.7443 & 5.2433 & TRN \\
\hline CHEMBL 2028056 & 817940 & 4.5111 & 4.5869 & TRN \\
\hline CHEMBL 2028051 & 817940 & 4.6478 & 4.5728 & TRN \\
\hline CHEMBL532560 & 817940 & 3.4948 & 4.3236 & TRN \\
\hline CHEMBL587485 & 817940 & 3.4948 & 3.5622 & TRN \\
\hline CHEMBL547614 & 817940 & 3.4948 & 3.5829 & TST \\
\hline CHEMBL534283 & 817940 & 5.0367 & 4.9863 & TST \\
\hline CHEMBL600305 & 817940 & 3.4948 & 3.4914 & TRN \\
\hline CHEMBL579459 & 817940 & 4.7926 & 4.5249 & TST \\
\hline CHEMBL602234 & 817940 & 5.3755 & 5.8049 & TRN \\
\hline CHEMBL590159 & 817940 & 4.6077 & 3.7538 & TRN \\
\hline CHEMBL605751 & 817940 & 6.8662 & 6.1131 & TRN \\
\hline CHEMBL592550 & 817940 & 4.7529 & 4.2812 & TRN \\
\hline CHEMBL546162 & 817940 & 3.4948 & 5.2838 & TRN \\
\hline CHEMBL601567 & 817940 & 3.4948 & 4.3778 & TRN \\
\hline CHEMBL530438 & 817940 & 4.7189 & 4.1595 & TST \\
\hline CHEMBL 2028048 & 817940 & 4.8751 & 4.5134 & TRN \\
\hline CHEMBL583844 & 817940 & 3.4948 & 3.6374 & TST \\
\hline CHEMBL588501 & 817940 & 6.0708 & 6.404 & TRN \\
\hline CHEMBL547266 & 817940 & 5.978 & 6.1409 & TRN \\
\hline CHEMBL585622 & 817940 & 5.7226 & 6.0758 & TRN \\
\hline CHEMBL584237 & 817940 & 3.4948 & 4.3158 & TRN \\
\hline CHEMBL124006 & 817940 & 6.0 & 7.0972 & TRN \\
\hline CHEMBL548338 & 817940 & 4.824 & 4.4104 & TRN \\
\hline CHEMBL537778 & 817940 & 5.4537 & 5.3133 & TRN \\
\hline CHEMBL534288 & 817940 & 5.3873 & 4.504 & TRN \\
\hline CHEMBL532597 & 817940 & 3.4948 & 3.4981 & TRN \\
\hline CHEMBL602552 & 817940 & 5.2596 & 4.1777 & TRN \\
\hline CHEMBL585983 & 817940 & 3.4948 & 4.5591 & TRN \\
\hline CHEMBL579760 & 817940 & 4.7959 & 4.873 & TST \\
\hline CHEMBL 2028050 & 817940 & 5.9954 & 5.8825 & TRN \\
\hline CHEMBL601528 & 817940 & 3.4948 & 4.1705 & TRN \\
\hline CHEMBL529385 & 817940 & 4.8007 & 4.5946 & TRN \\
\hline CHEMBL547193 & 817940 & 4.8159 & 4.2027 & TRN \\
\hline CHEMBL582072 & 817940 & 5.4077 & 5.2477 & TRN \\
\hline CHEMBL607308 & 817940 & 4.7401 & 4.7631 & TRN \\
\hline CHEMBL535079 & 817940 & 3.4948 & 3.8756 & TRN \\
\hline CHEMBL597262 & 817940 & 3.4948 & 3.5591 & TRN \\
\hline CHEMBL591623 & 817940 & 4.8798 & 4.6255 & TRN \\
\hline CHEMBL578933 & 817940 & 4.9536 & 5.0334 & TRN \\
\hline CHEMBL 2028066 & 817940 & 4.8689 & 4.5094 & TST \\
\hline CHEMBL589733 & 817940 & 6.4652 & 5.7689 & TRN \\
\hline CHEMBL529984 & 817940 & 4.8247 & 4.7915 & TRN \\
\hline
\end{tabular}


Supplemental Table S2.txt

\begin{tabular}{|c|c|c|c|c|}
\hline CHEMBL 577014 & 17940 & 5.3573 & 5.0081 & (10 \\
\hline HEMBL537505 & 17940 & 4.7279 & 4.1923 & \\
\hline HEMBL 5 & 7940 & 4948 & 3385 & \\
\hline HEMBL582478 & 17940 & 3843 & 3424 & \\
\hline HEMBL 584655 & 17940 & .8079 & 8534 & \\
\hline HEMBL531060 & 17940 & 3.4948 & 4.0667 & \\
\hline HEMBL5 & 17940 & 4.8802 & 4.8051 & \\
\hline HEMBL 578294 & 7940 & .9809 & 5.6385 & PN \\
\hline HEMBL 2028061 & 17940 & 3.4948 & 3.7815 & 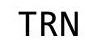 \\
\hline HEMBL602580 & 17940 & .9655 & 6.5736 & TST \\
\hline HEMBL5 & 17940 & 9163 & 4.8015 & \\
\hline HEMBL 5 & 7940 & 658 & 4.4874 & RN \\
\hline HEMBL6 & 7940 & 203 & 4.7205 & RN \\
\hline HEMBL12 & 17940 & 4.7311 & 4.5139 & TRN \\
\hline HEMBL17 & 7940 & 3.4948 & 2449 & TRN \\
\hline HEMBL 6 & 7940 & 3.4948 & 4.3243 & II \\
\hline HEMBL2 & 7940 & 948 & 498 & RN \\
\hline HEMBL 5 & 7940 & 948 & 5923 & TRN \\
\hline HEMBL6 & 7940 & & 6122 & TST \\
\hline HEMBL 532141 & & & & I RN \\
\hline HEMBL5 & 940 & 2 & 316 & RiN \\
\hline HEMBL: & 940 & & & RN \\
\hline HEMBL $€$ & 940 & 48 & 636 & TST \\
\hline HEMBL5 & 940 & & 278 & IRN \\
\hline HEMBL5 & 940 & & & 15 \\
\hline HEMBL5 & 7940 & 13 & 04 & TST \\
\hline HEMBL & 940 & 48 & 56 & ST \\
\hline HEMBL5 & 940 & 83 & 5077 & TRN \\
\hline HEMBL6 & 940 & & 3498 & $|S|$ \\
\hline HEMBL 2 & 7940 & 948 & 9042 & TST \\
\hline HEMBL5 & 940 & & 964 & TRN \\
\hline HFM & 40 & & 08 & TRN \\
\hline HEMBL 5 & & & 5.7599 & TRN \\
\hline HEMBL5 & 7940 & & 3513 & TRN \\
\hline HEMBL5C & 7940 & 11 & 5562 & TRN \\
\hline HEMBL 2 & 940 & 48 & 831 & 「RN \\
\hline HEMP I & 940 & 3. & 14 & TRN \\
\hline HEMBL5 & 7940 & & 3.693 & TRN \\
\hline HEMBL $5 \subseteq$ & 7940 & 4 & 7831 & TRN \\
\hline HEMBL1 & 940 & & 223 & TST \\
\hline HEMBL5 & 7940 & 948 & 1856 & TRN \\
\hline CHEMBL 5 & 7940 & 4.853 & 5015 & TRN \\
\hline HEMBL 6 & 7940 & 5.3645 & 5.7489 & TRN \\
\hline CHEMBL 5 & 7940 & 41 & 932 & $\mathrm{TR}$ \\
\hline SHEME & +6 & & & IRN \\
\hline CHEMBL 5 & 17940 & 3.4948 & 3.8172 & \\
\hline CHEMBL5 & 17940 & 3.4948 & 3.9541 & RN \\
\hline CHEMBL582486 & 817940 & 3.4948 & 3.6952 & 3 \\
\hline
\end{tabular}

Page 19415 


\begin{tabular}{|c|c|c|c|c|c|}
\hline & & & & & \\
\hline CHEMBL600174 & 817940 & 3.4948 & 4.333 & TRN & \\
\hline CHEMBL530223 & 817940 & 5.0355 & 4.7729 & TRN & \\
\hline CHEMBL601786 & 817940 & 4.7138 & 3.8699 & TRN & \\
\hline CHEMBL591395 & 817940 & 4.899 & 4.1195 & TRN & \\
\hline CHEMBL590888 & 817940 & 6.3644 & $4.61600 t$ & 00000000005 & TST \\
\hline CHEMBL590212 & 817940 & 4.8543 & 5.49799 & 9999999999 & TRN \\
\hline CHEMBL581489 & 817940 & 3.4948 & 3.6164 & TRN & \\
\hline CHEMBL590435 & 817940 & 3.4948 & 3.3455 & TRN & \\
\hline CHEMBL601566 & 817940 & 3.4948 & 4.2219 & TST & \\
\hline CHEMBL590683 & 817940 & 5.4241 & 4.6864 & TRN & \\
\hline CHEMBL586178 & 817940 & 3.4948 & 3.6206 & TRN & \\
\hline CHEMBL590680 & 817940 & 3.4948 & 3.6524 & TRN & \\
\hline CHEMBL528245 & 817940 & 4.5875 & 4.063 & TRN & \\
\hline CHEMBL597444 & 817940 & 3.4948 & 3.8086 & TRN & \\
\hline CHEMBL590919 & 817940 & 4.8036 & 5.5449 & TRN & \\
\hline CHEMBL606252 & 817940 & 3.4948 & 4.0545 & TRN & \\
\hline CHEMBL598369 & 817940 & 3.4948 & 3.383 & TRN & \\
\hline CHEMBL533999 & 817940 & 3.4948 & 3.5492 & TRN & \\
\hline CHEMBL1615697 & 817940 & 4.8136 & 4.3381 & TST & \\
\hline CHEMBL604982 & 817940 & 3.4948 & 4.2462 & TRN & \\
\hline CHEMBL530978 & 817940 & 5.3798 & 4.8748 & TRN & \\
\hline CHEMBL587022 & 817940 & 3.4948 & 4.457 & TST & \\
\hline CHEMBL604323 & 817940 & 3.4948 & 3.5842 & TRN & \\
\hline CHEMBL591362 & 817940 & 6.585 & 6.0793 & TRN & \\
\hline CHEMBL609036 & 817940 & 4.9543 & 4.9902 & TRN & \\
\hline CHEMBL535514 & 817940 & 3.4948 & 3.9074 & TRN & \\
\hline CHEMBL549208 & 817940 & 4.7887 & 4.4739 & TRN & \\
\hline CHEMBL587104 & 817940 & 4.548 & 4.5557 & TRN & \\
\hline CHEMBL529874 & 817940 & 3.4948 & 3.8436 & TST & \\
\hline CHEMBL601378 & 817940 & 5.4409 & 5.2297 & TRN & \\
\hline CHEMBL532155 & 817940 & 3.4948 & 4.2504 & TRN & \\
\hline CHEMBL589224 & 817940 & 4.789 & 4.2309 & TST & \\
\hline CHEMBL602179 & 817940 & 3.4948 & 3.5516 & TRN & \\
\hline CHEMBL1616787 & 817940 & 5.3484 & 5.3436 & TRN & \\
\hline CHEMBL524784 & 817940 & 4.6129 & 3.9165 & TRN & \\
\hline CHEMBL586704 & 817940 & 4.82 & 4.0779 & TRN & \\
\hline CHEMBL338094 & 817940 & 3.4948 & 3.4904 & TRN & \\
\hline CHEMBL533017 & 817940 & 3.4948 & 3.6952 & TRN & \\
\hline CHEMBL589916 & 817940 & 3.4948 & 3.4697 & TRN & \\
\hline CHEMBL597855 & 817940 & 5.8155 & 4.3499 & TRN & \\
\hline CHEMBL533855 & 817940 & 5.5958 & 5.3284 & TRN & \\
\hline CHEMBL 2028044 & 817940 & 3.4948 & 4.0407 & TRN & \\
\hline CHEMBL587371 & 817940 & 3.4948 & 4.2167 & TRN & \\
\hline CHEMBL599886 & 817940 & 3.4948 & 4.2692 & TST & \\
\hline CHEMBL534589 & 817940 & 3.4948 & 3.4229 & TRN & \\
\hline CHEMBL590674 & 817940 & 5.4294 & 5.0156 & TRN & \\
\hline CHEMBL 317364 & 817940 & 5.1973 & 4.5654 & TRN & \\
\hline CHEMBL582180 & 817940 & 5.0635 & 4.5841 & TRN & \\
\hline
\end{tabular}




\begin{tabular}{|c|c|c|c|c|c|}
\hline & & \multicolumn{4}{|c|}{ Supplemental Table S2.txt } \\
\hline CHEMBL577012 & 817940 & 3.4948 & 3.9538 & TRN & \\
\hline CHEMBL1198307 & 817940 & 5.9025 & 5.7957 & TRN & \\
\hline CHEMBL601814 & 817940 & 3.4948 & 3.8276 & TRN & \\
\hline CHEMBL589723 & 817940 & 5.225 & 5.0725 & TRN & \\
\hline CHEMBL588481 & 817940 & 6.0446 & 5.6897 & TRN & \\
\hline CHEMBL527620 & 817940 & 4.8351 & 4.9955 & TRN & \\
\hline CHEMBL536421 & 817940 & 3.4948 & 3.6261 & TRN & \\
\hline CHEMBL588855 & 817940 & 5.657 & 6.1 & TRN & \\
\hline CHEMBL 2028043 & 817940 & 6.0916 & 5.6078 & TRN & \\
\hline CHEMBL10835 & 817940 & 5.4185 & 4.8498 & TRN & \\
\hline CHEMBL475813 & 817940 & 3.4948 & 3.696 & TRN & \\
\hline CHEMBL590675 & 817940 & 4.7051 & 4.0016 & TRN & \\
\hline CHEMBL533921 & 817940 & 3.4948 & 4.0775 & TRN & \\
\hline CHEMBL592344 & 817940 & 4.8268 & 3.9849 & TRN & \\
\hline CHEMBL587892 & 817940 & 5.4191 & 5.2199 & TRN & \\
\hline CHEMBL601492 & 817940 & 5.6345 & 4.3335 & TRN & \\
\hline CHEMBL536393 & 817940 & 3.4948 & 3.4648 & TRN & \\
\hline CHEMBL591641 & 817940 & 3.4948 & 4.34399 & 9999999999 & TRN \\
\hline CHEMBL597857 & 817940 & 4.6719 & 4.2256 & TRN & \\
\hline CHEMBL531611 & 817940 & 4.7196 & 4.954 & TRN & \\
\hline CHEMBL587825 & 817940 & 3.4948 & 4.1584 & TRN & \\
\hline CHEMBL590201 & 817940 & 3.4948 & 4.4092 & TRN & \\
\hline CHEMBL603945 & 817940 & 4.8851 & 4.5617 & TRN & \\
\hline CHEMBL2028049 & 817940 & 3.4948 & 3.8759 & TRN & \\
\hline CHEMBL587989 & 817940 & 3.4948 & 3.8828 & TRN & \\
\hline CHEMBL584841 & 817940 & 4.8444 & 4.8326 & TRN & \\
\hline CHEMBL1545915 & 817940 & 3.4948 & 3.6811 & TRN & \\
\hline CHEMBL526800 & 817940 & 4.8502 & 4.8575 & TRN & \\
\hline CHEMBL591147 & 817940 & 3.4948 & 4.1755 & TRN & \\
\hline CHEMBL604389 & 817940 & 3.4948 & 3.8489 & TRN & \\
\hline CHEMBL532079 & 817940 & 4.6744 & 4.7522 & TRN & \\
\hline CHEMBL 2028062 & 817940 & 4.8617 & 4.1603 & TRN & \\
\hline CHEMBL601957 & 817940 & 6.3821 & 4.6547 & TRN & \\
\hline CHEMBL 2028064 & 817940 & 6.6314 & 5.7256 & TST & \\
\hline CHEMBL579443 & 817940 & 4.9364 & 4.6248 & TRN & \\
\hline CHEMBL591183 & 817940 & 6.6314 & 6.5084 & TRN & \\
\hline CHEMBL528533 & 817940 & 5.4365 & 4.9264 & TRN & \\
\hline CHEMBL605281 & 817940 & 3.4948 & 4.1242 & TRN & \\
\hline CHEMBL548374 & 817940 & 5.4351 & 5.4929 & TRN & \\
\hline CHEMBL582552 & 817940 & 4.7607 & 4.1279 & TRN & \\
\hline CHEMBL549216 & 817940 & 4.9185 & 5.0662 & TRN & \\
\hline CHEMBL591128 & 817940 & 4.7483 & 3.8501 & TRN & \\
\hline CHEMBL261693 & 817940 & 3.4948 & 3.5569 & TRN & \\
\hline CHEMBL49055 & 817940 & 5.1389 & 5.5616 & TRN & \\
\hline CHEMBL601348 & 817940 & 3.4948 & 4.0321 & TST & \\
\hline CHEMBL600549 & 817940 & 3.4948 & 3.6436 & TRN & \\
\hline CHEMBL 2028042 & 817940 & 3.4948 & 3.3764 & TRN & \\
\hline CHEMBL530973 & 817940 & 3.4948 & 3.4867 & TRN & \\
\hline
\end{tabular}




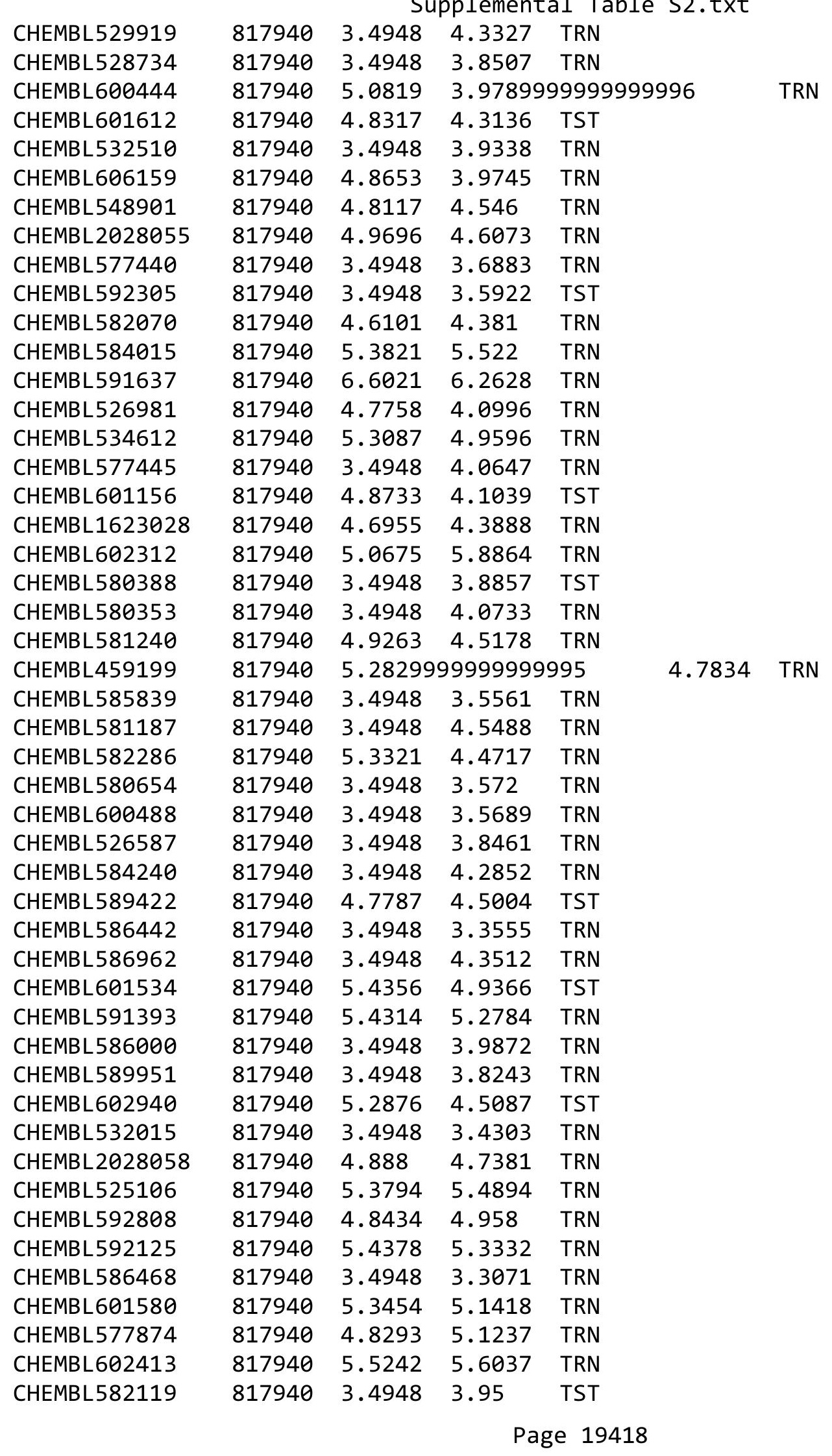




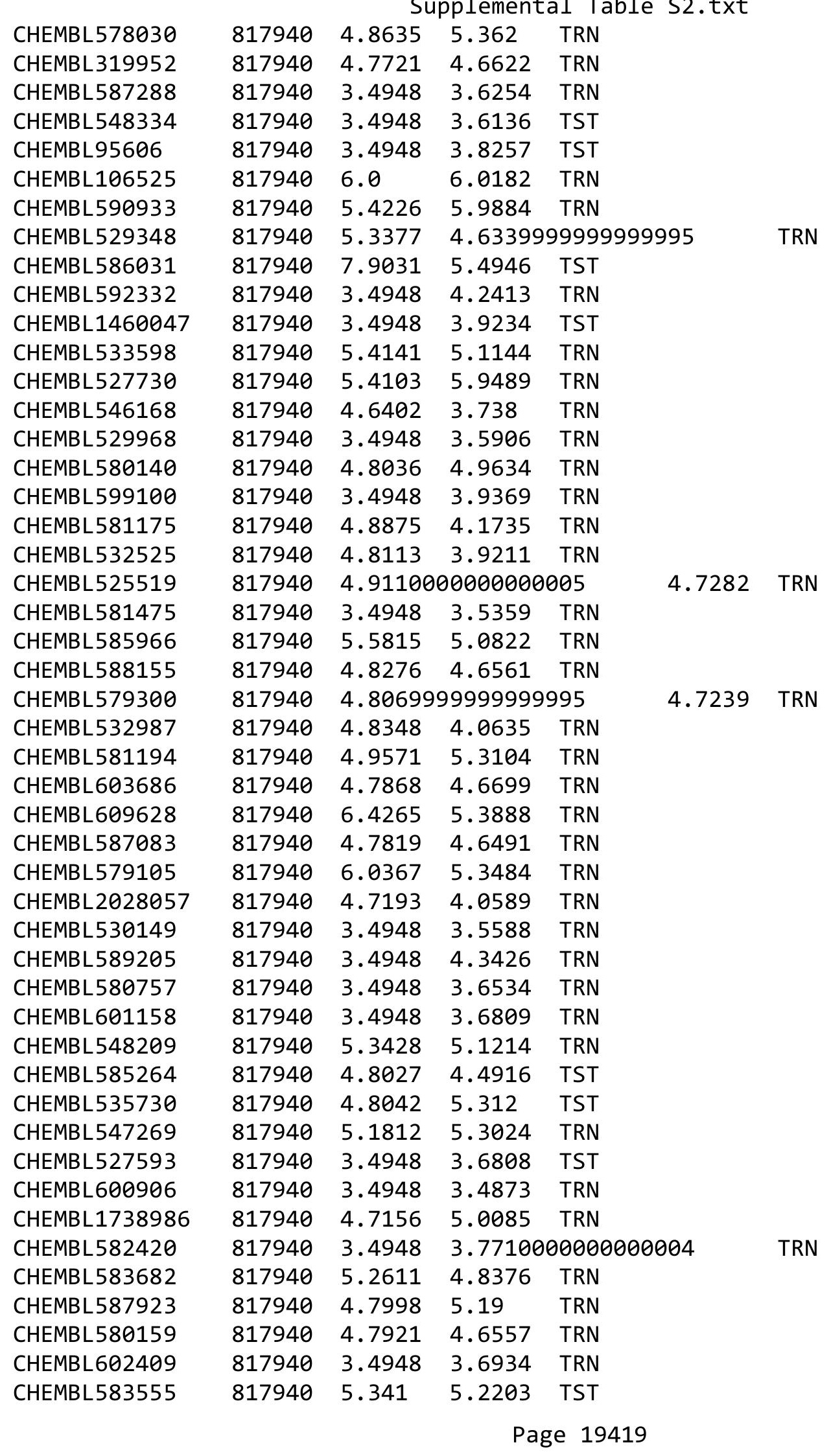




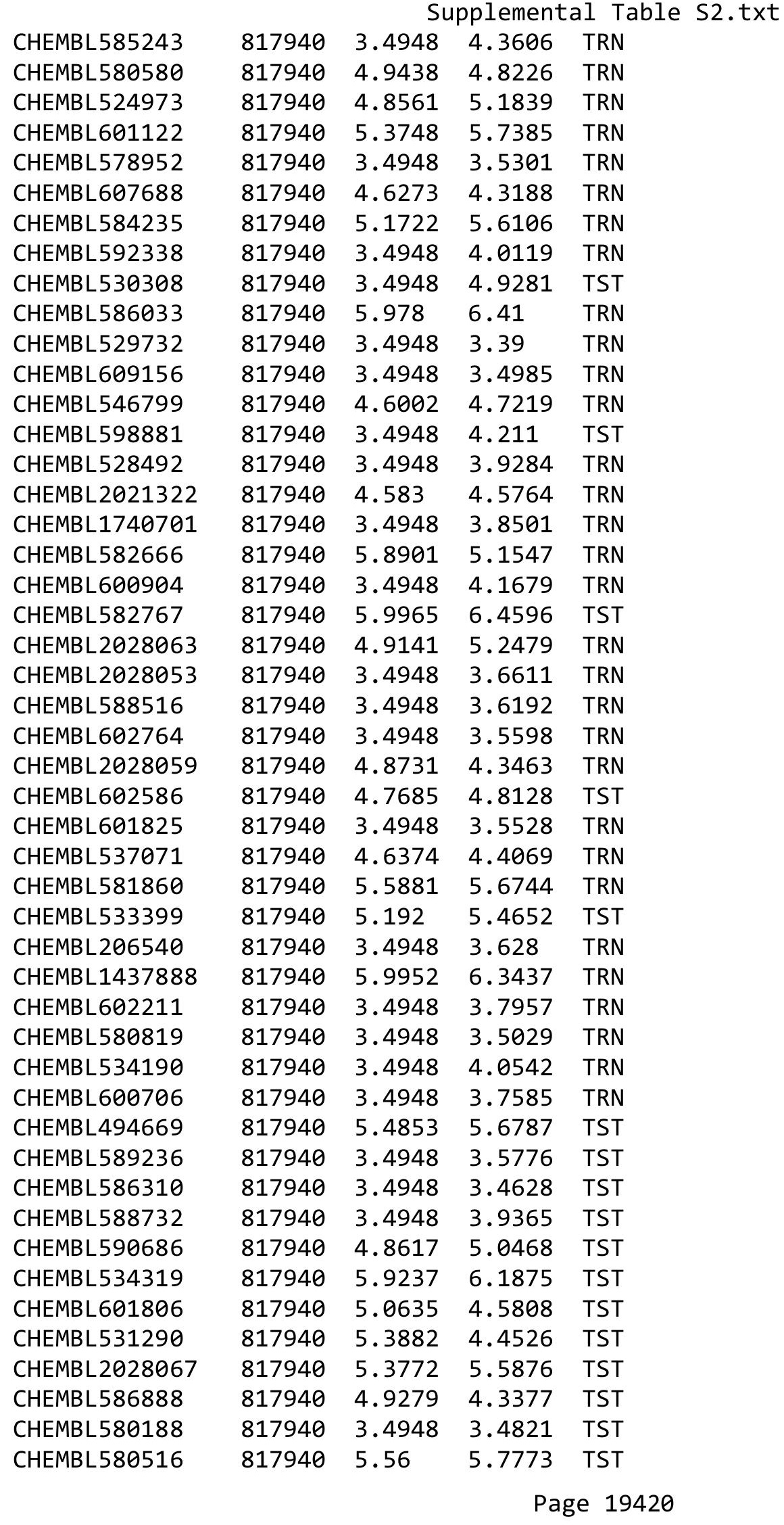


Supplemental Table S2.txt

\begin{tabular}{|c|c|c|c|c|}
\hline HEMBL 589946 & 17940 & 4.9765 & 5.4054 & TST \\
\hline HEMBL592123 & 17940 & 6.0206 & 6.3363 & \\
\hline HFMRI 5 & 7940 & & & \\
\hline JEMBL586933 & 940 & 948 & 2313 & \\
\hline HEMBL591890 & 17940 & .8676 & 8275 & \\
\hline HEMBL 596652 & 17940 & 3.4948 & .6705 & \\
\hline HEMBL4 & 7940 & 507 & 8293 & \\
\hline HEMBL1594640 & 7940 & & .7267 & \\
\hline HEMBL530531 & 17940 & 5.4147 & 6.1644 & \\
\hline HEMBL584829 & 17940 & 04 & .8025 & \\
\hline HEMBL 580381 & 17940 & & 4.1866 & \\
\hline AEMBL5 & 7940 & & 5078 & \\
\hline HEMBL6 & 940 & & 5511 & \\
\hline HEMBL1619026 & .7940 & 952 & 4.3336 & \\
\hline HEMBL 547476 & 7940 & & 3.6815 & \\
\hline HEMBL5 & 940 & 2 & 4.8289 & \\
\hline HEMBL6 & 940 & & 665 & \\
\hline HEMBL 5 & 940 & & 349 & \\
\hline HEMBL589922 & 7940 & & 4.8755 & \\
\hline HEMBL 546531 & & & & \\
\hline HEMBL5 & 940 & & 139 & SI \\
\hline HEMBL & 940 & & 93 & \\
\hline HEMBLS & 940 & & 237 & \\
\hline HEMBL590914 & 940 & & & \\
\hline HEMBL600030 & 40 & & & TST \\
\hline HEMBL6 & 1940 & & 46 & SI \\
\hline HEMBL & 40 & & 962 & \\
\hline HFMR I & 40 & 5 & 4.2253 & \\
\hline HEMBL596852 & & & & IST \\
\hline HEMBL 2028041 & 940 & & 4.7802 & TST \\
\hline HEMBL 2 & 940 & & 35 & 31 \\
\hline HFM & 40 & & 59 & \\
\hline ? & & & 557 & \\
\hline HEMBL 545880 & 7940 & & 4.7572 & is \\
\hline HEMBL 580876 & 7940 & & 3.5069 & ГST \\
\hline HEMBL590182 & 940 & & 3036 & ST \\
\hline HEM & 44 & & 337 & $\mathrm{RN}$ \\
\hline HEMBL1209922 & 244 & & 4.7023 & RN \\
\hline HEMBL1210929 & 4244 & & 4913 & $\Gamma \mathrm{RN}$ \\
\hline HEMBL1 & & & 199 & RN \\
\hline HEMBL1209923 & 244 & & 574 & \\
\hline CHEMBL1209987 & 244 & 5 . & 4.6442 & ST \\
\hline HEMBL1210586 & 4244 & 3.3 & 1184 & $\Gamma R$ \\
\hline CHEMBL12107 & 244 & & 5009 & TR \\
\hline CHEMBL2 & & & 5095 & \\
\hline HEMBL1210530 & 4244 & 4. & 4.5155 & \\
\hline CHEMBL121065 & 544244 & 3.301 & 3.3304 & \\
\hline CHEMBL1209985 & 644244 & 4.6778 & 4.6052 & \\
\hline
\end{tabular}

Page 19421 


\begin{tabular}{|c|c|c|c|c|c|c|}
\hline & & \multicolumn{5}{|c|}{ Supplemental Table S2.txt } \\
\hline CHEMBL397685 & 644244 & 3.301 & 4.3595 & TRN & & \\
\hline CHEMBL1210793 & 644244 & 5.699 & 4.8377 & TRN & & \\
\hline CHEMBL1209920 & 644244 & 5.284 & 4.7592 & TRN & & \\
\hline CHEMBL1210930 & 644244 & 5.3279 & 4.8537 & TRN & & \\
\hline CHEMBL 1210650 & 644244 & 5.0 & 4.3843 & TRN & & \\
\hline CHEMBL1208810 & 644244 & 3.301 & 4.2092 & TRN & & \\
\hline CHEMBL1210796 & 644244 & 3.301 & 4.1724 & TRN & & \\
\hline CHEMBL1210924 & 644244 & 4.3251 & 4.4423 & TRN & & \\
\hline CHEMBL1210925 & 644244 & 3.301 & 3.4639 & TRN & & \\
\hline CHEMBL1210927 & 644244 & 3.301 & 3.3569 & TRN & & \\
\hline CHEMBL1210857 & 644244 & 4.3307 & 3.6734 & TRN & & \\
\hline CHEMBL 243813 & 644244 & 3.301 & 3.3527 & TRN & & \\
\hline CHEMBL1210652 & 644244 & 4.757 & 3.9701 & TRN & & \\
\hline CHEMBL1210649 & 644244 & 3.301 & 3.1993 & TRN & & \\
\hline CHEMBL1209924 & 644244 & 4.3206 & 4.564 & TRN & & \\
\hline CHEMBL1210715 & 644244 & 3.301 & 3.4086 & TRN & & \\
\hline CHEMBL1209919 & 644244 & 5.0555 & 4.1194 & TRN & & \\
\hline CHEMBL1210856 & 644244 & 4.5901 & 4.6539 & TRN & & \\
\hline CHEMBL146089 & 644244 & 3.301 & 4.5755 & TST & & \\
\hline CHEMBL243814 & 644244 & 3.301 & 3.3952 & TRN & & \\
\hline CHEMBL388886 & 644244 & 3.301 & 3.3559 & TST & & \\
\hline CHEMBL1210926 & 644244 & 3.301 & 4.3492 & TRN & & \\
\hline CHEMBL1210855 & 644244 & 3.301 & 4.6251 & TST & & \\
\hline CHEMBL1210859 & 644244 & 4.3585 & 3.5407 & TRN & & \\
\hline CHEMBL1210799 & 644244 & 4.5638 & 4.4735 & TRN & & \\
\hline CHEMBL1209989 & 644244 & 4.9066 & 4.3642 & TRN & & \\
\hline CHEMBL1210713 & 644244 & 3.301 & 3.4327 & TRN & & \\
\hline CHEMBL1209988 & 644244 & 4.6676 & 4.2062 & TRN & & \\
\hline CHEMBL1210928 & 644244 & 4.5544 & 4.4997 & TRN & & \\
\hline CHEMBL242942 & 644244 & 4.3344 & 4.1586 & TRN & & \\
\hline CHEMBL242515 & 644244 & 3.301 & 4.2026 & TRN & & \\
\hline CHEMBL1210712 & 644244 & 5.3468 & 4.646 & TRN & & \\
\hline CHEMBL1210858 & 644244 & 4.58 & 4.5706 & TRN & & \\
\hline CHEMBL1209921 & 644244 & 4.9666 & 4.1198 & TST & & \\
\hline CHEMBL1210797 & 644244 & 3.301 & 3.4522 & TST & & \\
\hline CHEMBL1209986 & 644244 & 4.76699 & 99999999 & 995 & 4.5549 & TST \\
\hline CHEMBL422129 & 644244 & 6.0969 & 4.6513 & TST & & \\
\hline CHEMBL1210716 & 644244 & 5.0757 & 4.6438 & TST & & \\
\hline CHEMBL1210585 & 644244 & 3.301 & 3.4647 & TST & & \\
\hline CHEMBL1210714 & 644244 & 4.3116 & 4.6329 & TST & & \\
\hline CHEMBL147974 & 644244 & 4.4647 & 3.9963 & TST & & \\
\hline CHEMBL440350 & 644244 & 4.6716 & 4.1457 & TST & & \\
\hline CHEMBL1210587 & 644244 & 3.301 & 3.3709 & TST & & \\
\hline CHEMBL192139 & 303366 & 6.9747 & 6.8238 & TRN & & \\
\hline CHEMBL192589 & 303366 & 7.5143 & 7.5607 & TRN & & \\
\hline CHEMBL190496 & 303366 & 3.0 & 3.057 & TRN & & \\
\hline CHEMBL364729 & 303366 & 6.058 & 5.5979 & TST & & \\
\hline CHEMBL364588 & 303366 & 3.0 & 3.0717 & TRN & & \\
\hline
\end{tabular}




\begin{tabular}{|c|c|c|c|c|c|c|}
\hline \multicolumn{7}{|c|}{ P } \\
\hline CHEMBL193228 & 303366 & 3.0 & 3.5988 & TRN & & \\
\hline CHEMBL364734 & 303366 & 3.0 & 2.9698 & TRN & & \\
\hline CHEMBL190613 & 303366 & 3.0 & 2.1017 & TST & & \\
\hline CHEMBL192712 & 303366 & 3.0 & 2.9106 & TST & & \\
\hline CHEMBL365161 & 303366 & 5.8697 & 5.1116 & TST & & \\
\hline CHEMBL189886 & 303366 & 7.8327 & 7.4426 & TRN & & \\
\hline CHEMBL191688 & 303366 & 3.0 & 2.3052 & TST & & \\
\hline CHEMBL372856 & 303366 & 3.0 & 2.9922 & TRN & & \\
\hline CHEMBL435109 & 303366 & 6.857 & 6.8894 & TRN & & \\
\hline CHEMBL370299 & 303366 & 3.0 & 3.498 & TRN & & \\
\hline CHEMBL362996 & 303366 & 8.2518 & 8.0045 & TRN & & \\
\hline CHEMBL191513 & 303366 & 7.1537 & 6.5182 & TRN & & \\
\hline CHEMBL191800 & 303366 & 3.0 & 2.727 & TST & & \\
\hline CHEMBL191847 & 303366 & 8.1024 & 7.7467 & TRN & & \\
\hline CHEMBL284028 & 303366 & 3.0 & 4.7339 & TST & & \\
\hline CHEMBL192039 & 303366 & 5.76200 & $\partial 0000000$ & 205 & 5.8870000000000005 & TRN \\
\hline CHEMBL192657 & 303366 & 3.0 & 3.3525 & TRN & & \\
\hline CHEMBL191625 & 303366 & 3.0 & 2.7354 & TRN & & \\
\hline CHEMBL191822 & 303366 & 8.0506 & 7.8531 & TRN & & \\
\hline CHEMBL371858 & 303366 & 7.4776 & 7.8694 & TRN & & \\
\hline CHEMBL192180 & 303366 & 7.7399 & 8.1403 & TRN & & \\
\hline CHEMBL192258 & 303366 & 5.7352 & 6.1026 & TRN & & \\
\hline CHEMBL192474 & 303366 & 7.9872 & 8.3451 & TRN & & \\
\hline CHEMBL371371 & 303366 & 3.0 & 2.5942 & TST & & \\
\hline CHEMBL370059 & 303366 & 7.1457 & 7.1991 & TRN & & \\
\hline CHEMBL425192 & 303366 & 5.9208 & 5.8387 & TRN & & \\
\hline CHEMBL371523 & 303366 & 3.0 & 3.27 & TRN & & \\
\hline CHEMBL192648 & 303366 & 3.0 & 2.8176 & TRN & & \\
\hline CHEMBL365392 & 303366 & 6.4522 & 6.8242 & TRN & & \\
\hline CHEMBL 8320 & 303366 & 3.0 & 3.0024 & TST & & \\
\hline CHEMBL191676 & 303366 & 3.0 & 3.8382 & TRN & & \\
\hline CHEMBL192595 & 303366 & 3.0 & 2.5401 & TRN & & \\
\hline CHEMBL90039 & 303366 & 3.0 & 2.6332 & TRN & & \\
\hline CHEMBL363855 & 303366 & 3.0 & 2.455 & TRN & & \\
\hline CHEMBL189988 & 303366 & 3.0 & 3.1985 & TRN & & \\
\hline CHEMBL189727 & 303366 & 3.0 & 2.3039 & TST & & \\
\hline CHEMBL193140 & 303366 & 8.3872 & 8.7918 & TRN & & \\
\hline CHEMBL191796 & 303366 & 6.4012 & 6.0065 & TRN & & \\
\hline CHEMBL192625 & 303366 & 7.21899 & 99999999 & 99 & 6.7617 TRN & \\
\hline CHEMBL192627 & 303366 & 7.2411 & 6.1386 & TST & & \\
\hline CHEMBL365129 & 303366 & 3.0 & 3.2148 & TRN & & \\
\hline CHEMBL366205 & 303366 & 7.1385 & 6.6288 & TRN & & \\
\hline CHEMBL193229 & 303366 & 7.6308 & 7.5592 & TRN & & \\
\hline CHEMBL193180 & 303366 & 6.5867 & 6.7321 & TRN & & \\
\hline CHEMBL365517 & 303366 & 6.6799 & 6.7586 & TRN & & \\
\hline CHEMBL192252 & 303366 & 7.6421 & 7.7364 & TRN & & \\
\hline CHEMBL363919 & 303366 & 3.0 & 2.427 & TST & & \\
\hline CHEMBL365809 & 303366 & 3.0 & 3.2009 & TRN & & \\
\hline
\end{tabular}




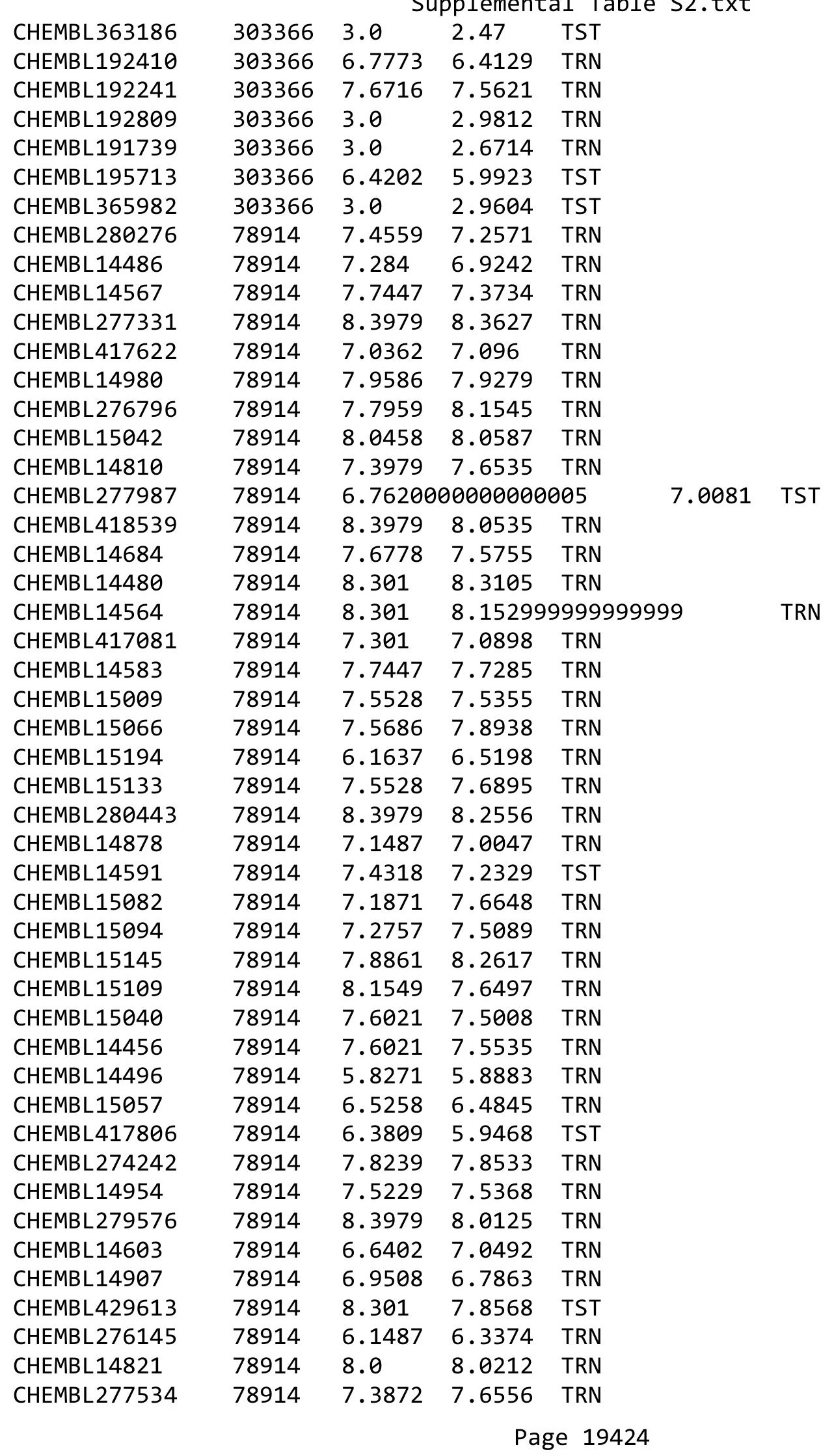




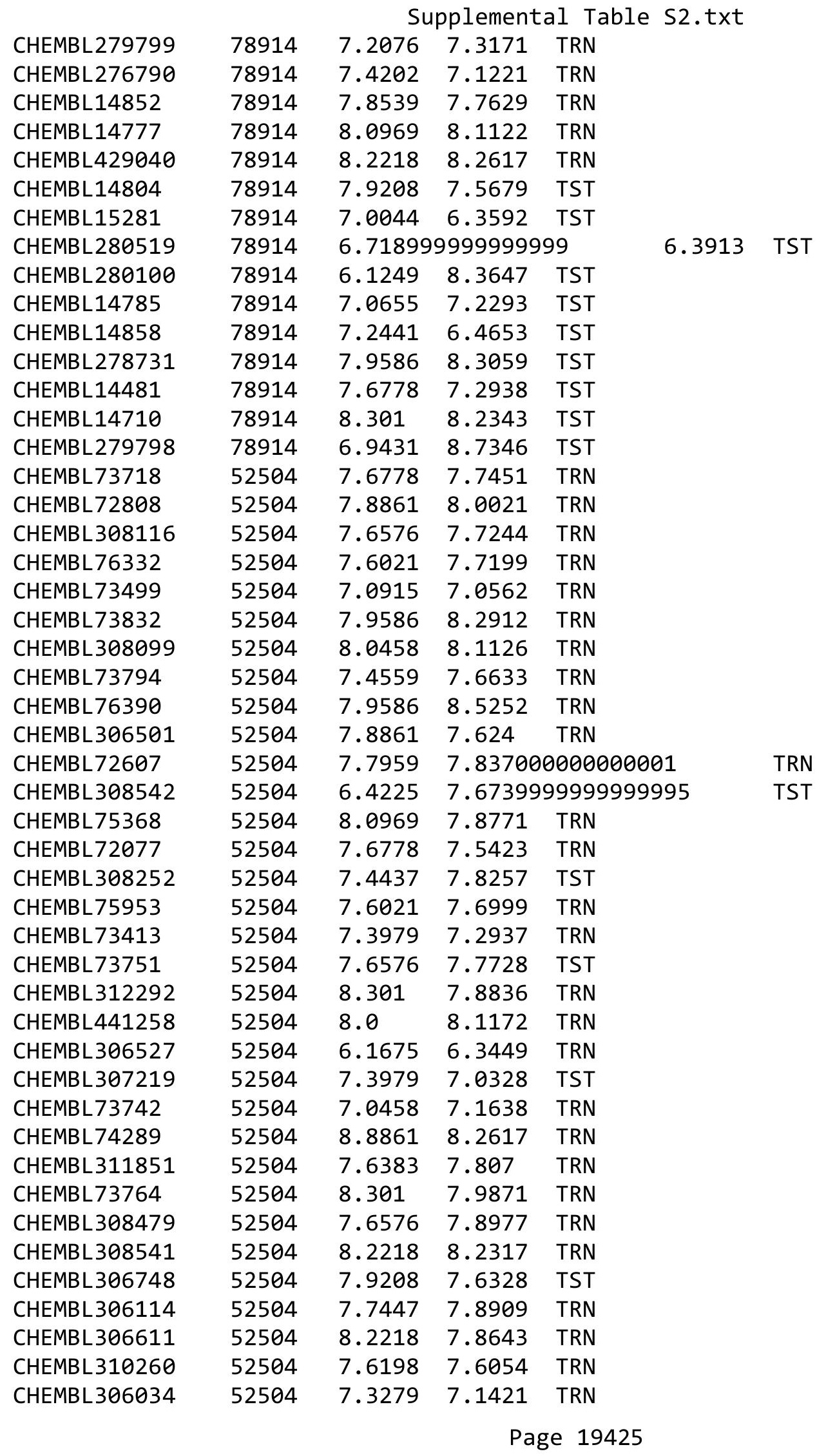




\begin{tabular}{|c|c|c|c|c|}
\hline \multicolumn{5}{|c|}{ Supplemental Table S2.txt } \\
\hline CHEMBL 76326 & 52504 & 8.0 & 7.8483 & TRN \\
\hline CHEMBL 73080 & 52504 & 6.8665 & 7.0981 & TRN \\
\hline CHEMBL 74883 & 52504 & 7.7447 & 7.8454 & TRN \\
\hline CHEMBL308994 & 52504 & 7.4089 & 7.1729 & TRN \\
\hline CHEMBL307007 & 52504 & 7.7212 & 7.6274 & TRN \\
\hline CHEMBL 75952 & 52504 & 7.6383 & 7.6021 & TST \\
\hline CHEMBL 73781 & 52504 & 7.5528 & 7.6324 & TST \\
\hline CHEMBL 72661 & 52504 & 6.3487 & 6.9101 & TST \\
\hline CHEMBL308594 & 52504 & 7.1249 & 7.4938 & TRN \\
\hline CHEMBL268368 & 52504 & 6.7878 & 7.2538 & TST \\
\hline CHEMBL307150 & 52504 & 8.699 & 8.0899 & TRN \\
\hline CHEMBL 75610 & 52504 & 7.4815 & 7.3884 & TST \\
\hline CHEMBL 76337 & 52504 & 7.7212 & 7.8538 & TRN \\
\hline CHEMBL308979 & 52504 & 7.6383 & 7.9793 & TRN \\
\hline CHEMBL306856 & 52504 & 8.3979 & 7.7981 & TST \\
\hline CHEMBL 73772 & 52504 & 7.3665 & 7.7129 & TRN \\
\hline CHEMBL431181 & 52504 & 6.6655 & 6.7243 & TRN \\
\hline CHEMBL306367 & 52504 & 7.3468 & 7.4448 & TST \\
\hline CHEMBL307152 & 52504 & 7.7212 & 8.0068 & TRN \\
\hline CHEMBL 72076 & 52504 & 7.6198 & 7.7487 & TRN \\
\hline CHEMBL 75984 & 52504 & 6.3904 & 6.4022 & TRN \\
\hline CHEMBL 74637 & 52504 & 7.7696 & 8.0633 & TST \\
\hline CHEMBL 76464 & 52504 & 7.8539 & 7.4248 & TST \\
\hline CHEMBL430606 & 52504 & 7.8239 & 7.8559 & TRN \\
\hline CHEMBL 72754 & 52504 & 7.3768 & 7.2138 & TST \\
\hline CHEMBL 73343 & 52504 & 7.9208 & 7.5191 & TST \\
\hline CHEMBL307630 & 52504 & 7.9586 & 7.8247 & TRN \\
\hline CHEMBL 73485 & 52504 & 8.1549 & 8.0277 & TRN \\
\hline CHEMBL 306047 & 52504 & 7.8239 & 7.7394 & TRN \\
\hline CHEMBL 76499 & 52504 & 8.0458 & 7.6388 & TRN \\
\hline CHEMBL310491 & 52504 & 7.6198 & 7.4371 & TRN \\
\hline CHEMBL1700772 & 737194 & 6.1805 & 4.3006 & TRN \\
\hline CHEMBL1729980 & 737194 & 3.4948 & 4.2622 & TRN \\
\hline CHEMBL1728799 & 737194 & 3.4948 & 3.7558 & TRN \\
\hline CHEMBL1707232 & 737194 & 3.4948 & 3.3301 & TRN \\
\hline CHEMBL1726077 & 737194 & 5.4921 & 4.2764 & TRN \\
\hline CHEMBL1711271 & 737194 & 3.4948 & 3.9029 & TRN \\
\hline CHEMBL1717840 & 737194 & 3.4948 & 3.5412 & TRN \\
\hline CHEMBL1702166 & 737194 & 5.4112 & 2.9681 & TST \\
\hline CHEMBL1716094 & 737194 & 3.4948 & 3.9427 & TRN \\
\hline CHEMBL1715436 & 737194 & 3.4948 & 4.3211 & TRN \\
\hline CHEMBL1720680 & 737194 & 3.4948 & 2.9364 & TST \\
\hline CHEMBL1701674 & 737194 & 3.4948 & 4.2542 & TRN \\
\hline CHEMBL1714715 & 737194 & 5.1986 & 4.1554 & TST \\
\hline CHEMBL1711389 & 737194 & 3.4948 & 3.7841 & TRN \\
\hline CHEMBL1734997 & 737194 & 3.4948 & 3.4185 & TRN \\
\hline CHEMBL1725189 & 737194 & 3.4948 & 3.4046 & TRN \\
\hline CHEMBL1725847 & 737194 & 4.9666 & 5.3634 & TRN \\
\hline
\end{tabular}




\begin{tabular}{|c|c|c|c|c|c|c|}
\hline & & \multicolumn{5}{|c|}{ Supplemental Table S2.txt } \\
\hline CHEMBL1455766 & 737194 & 4.8539 & 4.1825 & TRN & & \\
\hline CHEMBL1729120 & 737194 & 3.4948 & 4.2274 & TRN & & \\
\hline CHEMBL1714010 & 737194 & 3.4948 & 3.097 & TST & & \\
\hline CHEMBL1726781 & 737194 & 3.4948 & 3.7437 & TST & & \\
\hline CHEMBL1706901 & 737194 & 3.4948 & 3.5289 & TRN & & \\
\hline CHEMBL1725095 & 737194 & 3.4948 & 3.8794 & TRN & & \\
\hline CHEMBL1725537 & 737194 & 5.4802 & 4.3848 & TRN & & \\
\hline CHEMBL1735732 & 737194 & 3.4948 & 3.0946 & TST & & \\
\hline CHEMBL1736447 & 737194 & 3.4948 & 3.6336 & TRN & & \\
\hline CHEMBL1719211 & 737194 & 3.4948 & 4.0124 & TRN & & \\
\hline CHEMBL1719053 & 737194 & 5.0726 & 4.3018 & TRN & & \\
\hline CHEMBL1714925 & 737194 & 3.4948 & 3.927 & TRN & & \\
\hline CHEMBL1717720 & 737194 & 5.6073 & 4.5745 & TRN & & \\
\hline CHEMBL1719256 & 737194 & 3.4948 & 4.1462 & TRN & & \\
\hline CHEMBL1701756 & 737194 & 3.4948 & 3.9936 & TRN & & \\
\hline CHEMBL1726155 & 737194 & 4.7258 & 3.8777 & TRN & & \\
\hline CHEMBL1724868 & 737194 & 3.4948 & 4.398 & TRN & & \\
\hline CHEMBL1711929 & 737194 & 4.9872 & 4.1702 & TRN & & \\
\hline CHEMBL1733940 & 737194 & 3.4948 & 2.3741 & TST & & \\
\hline CHEMBL1699195 & 737194 & 5.4001 & 4.5424 & TST & & \\
\hline CHEMBL1707989 & 737194 & 3.4948 & 3.7303 & TRN & & \\
\hline CHEMBL1702620 & 737194 & 4.51 & 4.8589 & TRN & & \\
\hline CHEMBL1698780 & 737194 & 5.6925 & 4.587 & TRN & & \\
\hline CHEMBL1721558 & 737194 & 5.0975 & 4.4593 & TRN & & \\
\hline CHEMBL1729417 & 737194 & 3.4948 & 3.5192 & TRN & & \\
\hline CHEMBL1702752 & 737194 & 4.9914 & 5.6111 & TRN & & \\
\hline CHEMBL1733754 & 737194 & 3.4948 & 3.5979 & TRN & & \\
\hline CHEMBL1698790 & 737194 & 4.8239 & 2.7711 & TST & & \\
\hline CHEMBL1710148 & 737194 & 3.4948 & 3.3534 & TST & & \\
\hline CHEMBL1719120 & 737194 & 3.4948 & 3.8661 & TRN & & \\
\hline CHEMBL1699177 & 737194 & 3.4948 & 4.0471 & TRN & & \\
\hline CHEMBL1707988 & 737194 & 5.2741 & 4.5874 & TRN & & \\
\hline CHEMBL1712885 & 737194 & 6.3288 & 4.4336 & TST & & \\
\hline CHEMBL1723702 & 737194 & 3.4948 & 4.1522 & TRN & & \\
\hline CHEMBL1721727 & 737194 & 4.71 & 4.2442 & TRN & & \\
\hline CHEMBL1706771 & 737194 & 3.4948 & 2.9136 & TST & & \\
\hline CHEMBL1736339 & 737194 & 4.9872 & 4.2403 & TRN & & \\
\hline CHEMBL1455045 & 737194 & 3.4948 & 3.935 & TRN & & \\
\hline CHEMBL1710945 & 737194 & 3.4948 & 4.4455 & TRN & & \\
\hline CHEMBL1717312 & 737194 & 4.6478 & 3.7767 & TRN & & \\
\hline CHEMBL1725577 & 737194 & 3.4948 & 3.9391 & TRN & & \\
\hline CHEMBL1730619 & 737194 & 3.4948 & 3.5978 & TRN & & \\
\hline CHEMBL1702857 & 737194 & 3.4948 & 4.2115 & TST & & \\
\hline CHEMBL1724354 & 737194 & 3.4948 & 4.0126 & TRN & & \\
\hline CHEMBL1720462 & 737194 & 5.1707 & 4.0014 & TST & & \\
\hline CHEMBL1701286 & 737194 & 3.4948 & 4.288 & TRN & & \\
\hline CHEMBL1729698 & 737194 & 4.82100 & 00000000 & 01 & 4.2463 & TST \\
\hline CHEMBL1718365 & 737194 & 3.4948 & 4.1514 & TRN & & \\
\hline
\end{tabular}




\begin{tabular}{|c|c|c|c|c|c|}
\hline \multicolumn{6}{|c|}{ Supplemental Table S2.txt } \\
\hline CHEMBL1714242 & 737194 & 3.4948 & 3.4596 & TRN & \\
\hline CHEMBL1730588 & 737194 & 3.4948 & 4.2924 & TRN & \\
\hline CHEMBL1704988 & 737194 & 4.7645 & 4.1655 & TRN & \\
\hline CHEMBL1732727 & 737194 & 3.4948 & 3.6535 & TRN & \\
\hline CHEMBL1713967 & 737194 & 5.857 & 4.0763 & TRN & \\
\hline CHEMBL1714757 & 737194 & 3.4948 & 4.1527 & TST & \\
\hline CHEMBL1731563 & 737194 & 3.4948 & 3.7741 & TRN & \\
\hline CHEMBL1713943 & 737194 & 4.8447 & 4.3653 & TRN & \\
\hline CHEMBL1727825 & 737194 & 3.4948 & 4.5615 & TRN & \\
\hline CHEMBL1699035 & 737194 & 4.8996 & 4.2573 & TRN & \\
\hline CHEMBL1718184 & 737194 & 5.5391 & 4.4989 & TST & \\
\hline CHEMBL1728022 & 737194 & 5.7721 & 2.7319 & TST & \\
\hline CHEMBL1713635 & 737194 & 5.0177 & 3.9489 & TRN & \\
\hline CHEMBL1704494 & 737194 & 3.4948 & 3.6619 & TRN & \\
\hline CHEMBL1730909 & 737194 & 3.4948 & 3.6243 & TST & \\
\hline CHEMBL1727011 & 737194 & 3.4948 & 2.7675 & TST & \\
\hline CHEMBL1715251 & 737194 & 3.4948 & 3.2531 & TST & \\
\hline CHEMBL 3728264 & 1537108 & 5.0 & 5.1293 & TST & \\
\hline CHEMBL3729561 & 1537108 & 6.301 & 6.1079 & TRN & \\
\hline CHEMBL3732745 & 1537108 & 6.301 & 5.836 & TRN & \\
\hline CHEMBL3731890 & 1537108 & 6.301 & 5.4705 & TRN & \\
\hline CHEMBL 3730600 & 1537108 & 5.0 & 5.7532 & TST & \\
\hline CHEMBL3727468 & 1537108 & 6.301 & 6.0484 & TRN & \\
\hline CHEMBL 3729266 & 1537108 & 5.0 & 5.7772 & TRN & \\
\hline CHEMBL3729628 & 1537108 & 5.0 & 5.4543 & TRN & \\
\hline CHEMBL 3729623 & 1537108 & 6.0 & 6.2006 & TRN & \\
\hline CHEMBL3729850 & 1537108 & 6.301 & 6.21700 & 00000000005 & TRN \\
\hline CHEMBL 3729410 & 1537108 & 5.0 & 5.3937 & TRN & \\
\hline CHEMBL 3732249 & 1537108 & 6.301 & 5.9038 & TRN & \\
\hline CHEMBL3728904 & 1537108 & 6.0 & 6.1882 & TRN & \\
\hline CHEMBL 3728141 & 1537108 & 5.0 & 5.7706 & TST & \\
\hline CHEMBL 3730561 & 1537108 & 5.0 & 5.0303 & TRN & \\
\hline CHEMBL3732812 & 1537108 & 5.0 & 5.3832 & TRN & \\
\hline CHEMBL3731265 & 1537108 & 5.0 & 5.3036 & TRN & \\
\hline CHEMBL3732122 & 1537108 & 6.301 & 6.0746 & TRN & \\
\hline CHEMBL3729334 & 1537108 & 6.301 & 6.0115 & TRN & \\
\hline CHEMBL3731501 & 1537108 & 6.301 & 5.5007 & TST & \\
\hline CHEMBL 3733078 & 1537108 & 5.0 & 5.7915 & TRN & \\
\hline CHEMBL3729592 & 1537108 & 6.301 & 5.8051 & TRN & \\
\hline CHEMBL3730840 & 1537108 & 5.0 & 5.2395 & TRN & \\
\hline CHEMBL3731046 & 1537108 & 6.0 & 6.3256 & TRN & \\
\hline CHEMBL 3730238 & 1537108 & 6.0 & 5.9634 & TRN & \\
\hline CHEMBL3729662 & 1537108 & 5.0 & 5.7041 & TRN & \\
\hline CHEMBL3727524 & 1537108 & 6.301 & 5.8686 & TRN & \\
\hline CHEMBL3727808 & 1537108 & 6.301 & 5.9523 & TST & \\
\hline CHEMBL3730693 & 1537108 & 6.301 & 5.7691 & TRN & \\
\hline CHEMBL3731947 & 1537108 & 5.0 & 5.7522 & TRN & \\
\hline CHEMBL3732835 & 1537108 & 6.301 & 5.8327 & TRN & \\
\hline
\end{tabular}




\begin{tabular}{|c|c|c|c|c|}
\hline \multicolumn{5}{|c|}{ Supplemental Table S2.txt } \\
\hline CHEMBL3731099 & 1537108 & 5.0 & 5.5071 & TST \\
\hline CHEMBL3729692 & 1537108 & 6.301 & 4.7001 & TST \\
\hline CHEMBL3729624 & 1537108 & 5.0 & 5.7323 & TRN \\
\hline CHEMBL 3727851 & 1537108 & 6.301 & 5.9525 & TRN \\
\hline CHEMBL3732635 & 1537108 & 6.301 & 5.735 & TRN \\
\hline CHEMBL3729673 & 1537108 & 5.0 & 5.2524 & TST \\
\hline CHEMBL 3727575 & 1537108 & 6.301 & 5.4345 & TRN \\
\hline CHEMBL 3730880 & 1537108 & 6.301 & 5.9043 & TRN \\
\hline CHEMBL 3727948 & 1537108 & 5.0 & 5.4895 & TRN \\
\hline CHEMBL3729858 & 1537108 & 5.0 & 5.8832 & TRN \\
\hline CHEMBL 3727823 & 1537108 & 5.0 & 5.138 & TST \\
\hline CHEMBL3729799 & 1537108 & 6.301 & 5.6798 & TRN \\
\hline CHEMBL3732261 & 1537108 & 6.301 & 5.9433 & TRN \\
\hline CHEMBL3729619 & 1537108 & 5.0 & 5.7474 & TRN \\
\hline CHEMBL 3727489 & 1537108 & 6.301 & 5.7015 & TST \\
\hline CHEMBL3729286 & 1537108 & 6.301 & 5.7343 & TRN \\
\hline CHEMBL3727988 & 1537108 & 6.301 & 5.5928 & TRN \\
\hline CHEMBL3731409 & 1537108 & 6.0 & 6.3012 & TRN \\
\hline CHEMBL 3727475 & 1537108 & 5.0 & 5.6809 & TST \\
\hline CHEMBL3729636 & 1537108 & 5.0 & 5.1301 & TST \\
\hline CHEMBL 3730485 & 1537108 & 6.301 & 5.5192 & TRN \\
\hline CHEMBL3730875 & 1537108 & 5.0 & 5.7001 & TRN \\
\hline CHEMBL 3728070 & 1537108 & 6.301 & 5.0134 & TST \\
\hline CHEMBL 3728655 & 1537108 & 5.0 & 5.1445 & TRN \\
\hline CHEMBL3728161 & 1537108 & 6.301 & 6.0731 & TRN \\
\hline CHEMBL3728193 & 1537108 & 5.0 & 5.4025 & TST \\
\hline CHEMBL3728549 & 1537108 & 5.0 & 5.3169 & TRN \\
\hline CHEMBL3731662 & 1537108 & 6.301 & 6.0005 & TRN \\
\hline CHEMBL 3729020 & 1537108 & 6.301 & 5.099 & TST \\
\hline CHEMBL 3727504 & 1537108 & 5.0 & 5.1466 & TRN \\
\hline CHEMBL3729803 & 1537108 & 5.0 & 5.1956 & TRN \\
\hline CHEMBL3730833 & 1537108 & 6.301 & 5.1529 & TST \\
\hline CHEMBL3732932 & 1537108 & 5.0 & 5.7472 & TRN \\
\hline CHEMBL 3730460 & 1537108 & 6.301 & 6.0075 & TRN \\
\hline CHEMBL3730336 & 1537108 & 5.0 & 5.2908 & TRN \\
\hline CHEMBL3731313 & 1537108 & 5.0 & 5.0727 & TRN \\
\hline CHEMBL3733211 & 1537108 & 6.301 & 5.8327 & TRN \\
\hline CHEMBL3733001 & 1537108 & 6.301 & 5.9339 & TRN \\
\hline CHEMBL 3731714 & 1537108 & 5.0 & 5.1399 & TRN \\
\hline CHEMBL3729708 & 1537108 & 6.301 & 5.6044 & TRN \\
\hline CHEMBL 3730788 & 1537108 & 6.301 & 6.7182 & TRN \\
\hline CHEMBL3731938 & 1537108 & 5.0 & 5.7164 & TRN \\
\hline CHEMBL3729694 & 1537108 & 5.0 & 5.2596 & TRN \\
\hline CHEMBL3729187 & 1537108 & 5.0 & 5.8545 & TRN \\
\hline CHEMBL3727673 & 1537108 & 6.301 & 6.0299 & TRN \\
\hline CHEMBL3730106 & 1537108 & 6.301 & 5.1016 & TST \\
\hline CHEMBL 3727871 & 1537108 & 6.301 & 5.9015 & TRN \\
\hline CHEMBL 3729287 & 1537108 & 5.0 & 5.2422 & TRN \\
\hline
\end{tabular}


Supplemental Table S2.txt

\begin{tabular}{|c|c|c|c|c|c|}
\hline CHEMBL3732581 & 1537108 & 6.301 & 5.8608 & TRN & \\
\hline CHEMBL3731523 & 1537108 & 5.0 & 5.847 & TST & \\
\hline CHEMBL3732914 & 1537108 & 5.0 & 5.6622 & TRN & \\
\hline CHEMBL3733235 & 1537108 & 5.0 & 5.1273 & TRN & \\
\hline CHEMBL3728785 & 1537108 & 6.301 & 5.0262 & TST & \\
\hline CHEMBL3731414 & 1537108 & 6.301 & 5.8197 & TRN & \\
\hline CHEMBL3729861 & 1537108 & 5.0 & 4.9784 & TST & \\
\hline CHEMBL3732942 & 1537108 & 6.0 & 6.437 & TRN & \\
\hline CHEMBL3727817 & 1537108 & 5.0 & 5.8262 & TRN & \\
\hline CHEMBL3733257 & 1537108 & 6.301 & 5.5305 & TRN & \\
\hline CHEMBL3732692 & 1537108 & 6.0 & 6.3062 & TRN & \\
\hline CHEMBL3730870 & 1537108 & 6.301 & 5.8122 & TRN & \\
\hline CHEMBL3731868 & 1537108 & 6.301 & 6.0357 & TRN & \\
\hline CHEMBL3729815 & 1537108 & 6.301 & 5.2276 & TST & \\
\hline CHEMBL3732926 & 1537108 & 6.301 & 5.8768 & TRN & \\
\hline CHEMBL3731642 & 1537108 & 5.0 & 5.1572 & TST & \\
\hline CHEMBL3732337 & 1537108 & 6.301 & 6.0009 & TRN & \\
\hline CHEMBL3731349 & 1537108 & 6.301 & 5.9091 & TRN & \\
\hline CHEMBL3730757 & 1537108 & 5.0 & \multicolumn{2}{|c|}{5.367000000000001} & TRN \\
\hline CHEMBL3728890 & 1537108 & 5.0 & 4.7006 & TST & \\
\hline CHEMBL3728811 & 1537108 & 5.0 & 6.2761 & TRN & \\
\hline CHEMBL3728305 & 1537108 & 5.0 & 5.3582 & TST & \\
\hline CHEMBL3728510 & 1537108 & 5.0 & 4.6654 & TRN & \\
\hline CHEMBL3729674 & 1537108 & 5.0 & 5.3058 & TST & \\
\hline CHEMBL3732751 & 1537108 & 5.0 & 5.7044 & TST & \\
\hline CHEMBL3728960 & 1537108 & 5.0 & 5.6661 & TRN & \\
\hline CHEMBL3729971 & 1537108 & 6.0 & \multicolumn{2}{|c|}{6.037000000000001} & TRN \\
\hline CHEMBL3731278 & 1537108 & 5.0 & 5.0414 & TRN & \\
\hline CHEMBL3729134 & 1537108 & 6.301 & \multicolumn{2}{|c|}{5.8260000000000005} & TRN \\
\hline CHEMBL3731779 & 1537108 & 5.0 & 5.5197 & TRN & \\
\hline CHEMBL3728085 & 1537108 & 6.301 & 5.8447 & TRN & \\
\hline CHEMBL3732162 & 1537108 & 6.301 & 6.0256 & TRN & \\
\hline CHEMBL3731575 & 1537108 & 5.0 & 5.1663 & TRN & \\
\hline CHEMBL3730726 & 1537108 & 6.301 & 5.894 & TRN & \\
\hline CHEMBL3732570 & 1537108 & 6.301 & 5.4849 & TRN & \\
\hline CHEMBL3731580 & 1537108 & 6.0 & 6.0234 & TRN & \\
\hline CHEMBL3731807 & 1537108 & 5.0 & 5.7093 & TST & \\
\hline CHEMBL3732874 & 1537108 & 6.301 & 5.859 & TRN & \\
\hline CHEMBL3730687 & 1537108 & 5.0 & 5.7645 & TRN & \\
\hline CHEMBL3733304 & 1537108 & 5.0 & 5.7371 & TRN & \\
\hline CHEMBL 3731286 & 1537108 & 5.0 & 5.5361 & TST & \\
\hline CHEMBL3729335 & 1537108 & 6.301 & 5.3467 & TST & \\
\hline CHEMBL3730510 & 1537108 & 6.301 & 5.8532 & TRN & \\
\hline CHEMBL3731480 & 1537108 & 5.0 & 5.9422 & TRN & \\
\hline CHEMBL3730750 & 1537108 & 5.0 & 5.6924 & TST & \\
\hline CHEMBL 3731571 & 1537108 & 6.301 & 5.9062 & TRN & \\
\hline CHEMBL3732875 & 1537108 & 5.0 & 5.6811 & TRN & \\
\hline CHEMBL3730072 & 1537108 & 6.301 & 5.6031 & TRN & \\
\hline
\end{tabular}




$$
\text { Supplemental Table S2.txt }
$$

\begin{tabular}{|c|c|c|c|c|c|}
\hline CHEMBL3729026 & 1537108 & 6.301 & 5.8248 & TRN & \\
\hline CHEMBL3732484 & 1537108 & 6.301 & 5.8873 & TRN & \\
\hline CHEMBL3728692 & 1537108 & 6.301 & 5.801 & TRN & \\
\hline CHEMBL3730835 & 1537108 & 5.0 & 5.5989 & TRN & \\
\hline CHEMBL3728598 & 1537108 & 6.301 & 6.5443 & TRN & \\
\hline CHEMBL3729648 & 1537108 & 6.301 & 5.6793 & TRN & \\
\hline CHEMBL3729426 & 1537108 & 6.301 & 5.8224 & TST & \\
\hline CHEMBL3727683 & 1537108 & 6.301 & 5.3288 & TST & \\
\hline CHEMBL3730710 & 1537108 & 5.0 & 5.8682 & TST & \\
\hline CHEMBL3731679 & 1537108 & 5.0 & 5.7736 & TRN & \\
\hline CHEMBL3729388 & 1537108 & 5.0 & 5.6235 & TST & \\
\hline CHEMBL3729431 & 1537108 & 5.0 & 5.0505 & TRN & \\
\hline CHEMBL3731588 & 1537108 & 6.301 & 5.6322 & TRN & \\
\hline CHEMBL3733080 & 1537108 & 5.0 & 5.4613 & TRN & \\
\hline CHEMBL3732406 & 1537108 & 5.0 & 5.5873 & TST & \\
\hline CHEMBL3730493 & 1537108 & 5.0 & 5.3416 & TST & \\
\hline CHEMBL3731069 & 1537108 & 6.301 & 5.5833 & TRN & \\
\hline CHEMBL1802282 & 1640932 & 8.0 & 7.2685 & TRN & \\
\hline CHEMBL 237440 & 1640932 & 8.0 & 6.5973 & TRN & \\
\hline CHEMBL3965823 & 1640932 & 6.0 & 5.8145 & TST & \\
\hline CHEMBL391658 & 1640932 & 5.0 & 7.3324 & TRN & \\
\hline CHEMBL1802330 & 1640932 & 9.0 & 7.8124 & TRN & \\
\hline CHEMBL 235311 & 1640932 & 6.0 & 6.5781 & TRN & \\
\hline CHEMBL3926884 & 1640932 & 5.0 & 4.323 & TRN & \\
\hline CHEMBL393882 & 1640932 & 10.0 & 5.2088 & TST & \\
\hline CHEMBL 237630 & 1640932 & 5.0 & 6.5265 & TRN & \\
\hline CHEMBL3969566 & 1640932 & 5.0 & 4.935 & TRN & \\
\hline CHEMBL3977155 & 1640932 & 5.0 & 4.6772 & TRN & \\
\hline CHEMBL3974314 & 1640932 & 6.0 & 7.5503 & TRN & \\
\hline CHEMBL393855 & 1640932 & 5.0 & 3.661 & TST & \\
\hline CHEMBL3934251 & 1640932 & 6.0 & 6.8101 & TRN & \\
\hline CHEMBL 237629 & 1640932 & 9.0 & 7.8893 & TRN & \\
\hline CHEMBL398014 & 1640932 & 9.0 & 7.8369 & TRN & \\
\hline CHEMBL 235309 & 1640932 & 6.0 & 6.5175 & TRN & \\
\hline CHEMBL396667 & 1640932 & 8.0 & 5.8224 & TST & \\
\hline CHEMBL3909689 & 1640932 & 8.0 & 7.9675 & TRN & \\
\hline CHEMBL1802283 & 1640932 & 8.0 & 8.3661 & TRN & \\
\hline CHEMBL1802323 & 1640932 & 9.0 & 9.1295 & TRN & \\
\hline CHEMBL3964805 & 1640932 & 9.0 & 5.5191 & TST & \\
\hline CHEMBL237631 & 1640932 & 9.0 & 7.9171 & TRN & \\
\hline CHEMBL3986129 & 1640932 & 9.0 & 5.9306 & TST & \\
\hline CHEMBL1802286 & 1640932 & 9.0 & \multicolumn{2}{|c|}{8.232000000000001} & TRN \\
\hline CHEMBL1802285 & 1640932 & 8.0 & 8.5989 & TRN & \\
\hline CHEMBL3939396 & 1640932 & 5.0 & 6.1834 & TRN & \\
\hline CHEMBL3979002 & 1640932 & 7.0 & 5.1416 & TST & \\
\hline CHEMBL 237415 & 1640932 & 6.0 & 5.3187 & TRN & \\
\hline CHEMBL3912875 & 1640932 & 9.0 & 7.0584 & TRN & \\
\hline CHEMBL3896101 & 1640932 & 9.0 & 5.064 & TST & \\
\hline
\end{tabular}




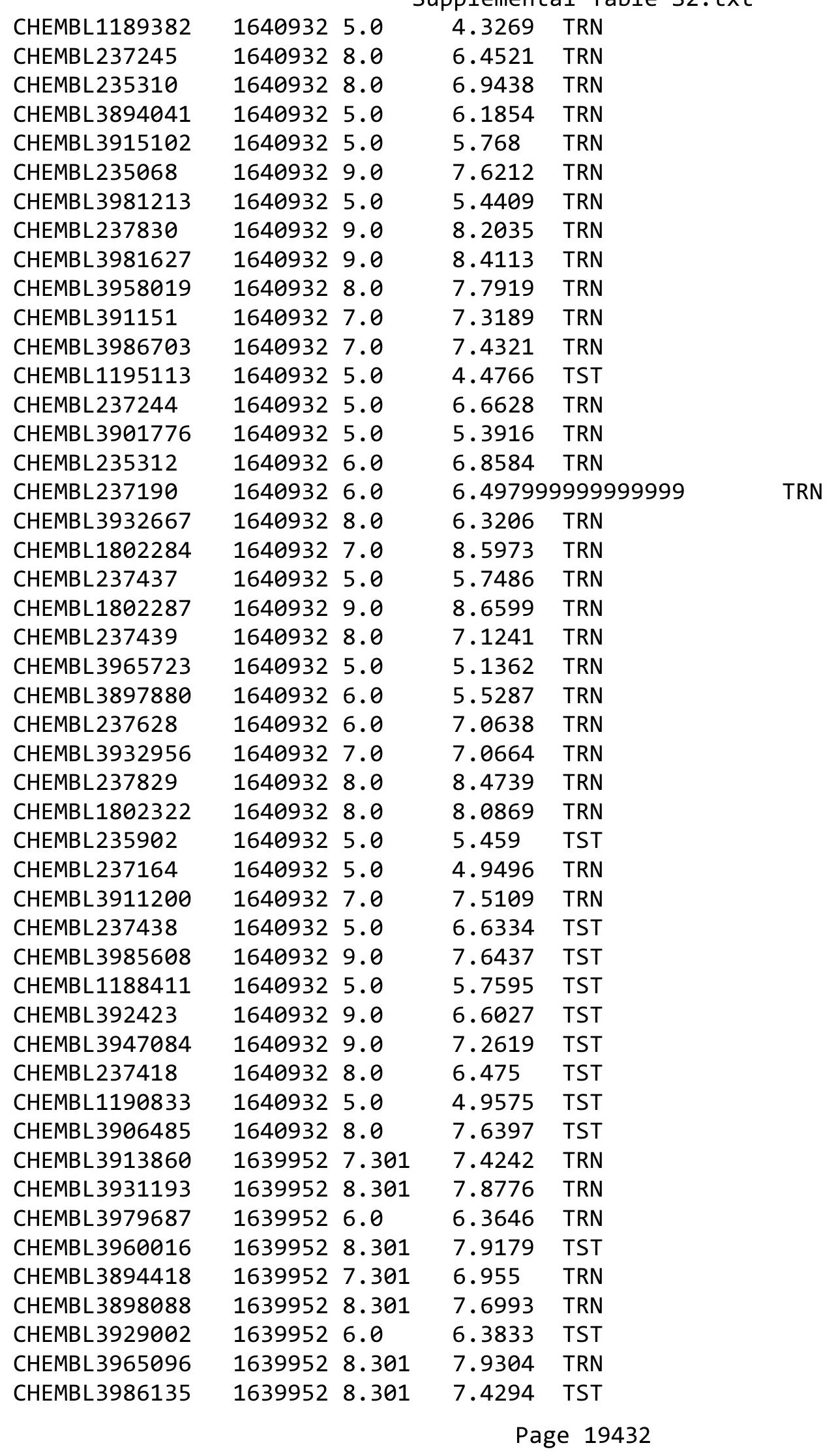


Supplemental Table S2.txt

\begin{tabular}{|c|c|c|c|c|}
\hline CHEMBL 3925803 & 1639952 & 7.301 & 7.6672 & TRN \\
\hline CHEMBL 3935851 & 1639952 & 7.301 & 7.3974 & TST \\
\hline CHEMBL 3893845 & 1639952 & 7.301 & 7.2961 & TRN \\
\hline CHEMBL 3921689 & 1639952 & 6.0 & 6.1578 & TRN \\
\hline CHEMBL3906715 & 1639952 & 7.301 & 7.5481 & TRN \\
\hline CHEMBL 3972712 & 1639952 & 8.301 & 8.1809 & TRN \\
\hline CHEMBL 3979317 & 1639952 & 6.0 & 7.0856 & TRN \\
\hline CHEMBL3959857 & 1639952 & 8.301 & 7.5821 & TST \\
\hline CHEMBL 3930406 & 1639952 & 7.301 & 7.6254 & TRN \\
\hline CHEMBL3968322 & 1639952 & 7.301 & 6.9158 & TST \\
\hline CHEMBL 3986301 & 1639952 & 7.301 & 7.7799 & TRN \\
\hline CHEMBL 3959638 & 1639952 & 8.301 & 8.6956 & TRN \\
\hline CHEMBL 3955359 & 1639952 & 6.0 & 5.5432 & TRN \\
\hline CHEMBL 3924442 & 1639952 & 6.0 & 5.6016 & TST \\
\hline CHEMBL3959195 & 1639952 & 7.301 & 7.3623 & TST \\
\hline CHEMBL 3931724 & 1639952 & 7.301 & 7.2276 & TRN \\
\hline CHEMBL3916567 & 1639952 & 7.301 & 7.6356 & TRN \\
\hline CHEMBL 3952693 & 1639952 & 8.301 & 7.4589 & TST \\
\hline CHEMBL 3959038 & 1639952 & 7.301 & 7.2331 & TRN \\
\hline CHEMBL3907764 & 1639952 & 7.301 & 6.9802 & TRN \\
\hline CHEMBL 3955083 & 1639952 & 8.301 & 7.6947 & TRN \\
\hline CHEMBL3933398 & 1639952 & 7.301 & 6.879 & TRN \\
\hline CHEMBL 3898808 & 1639952 & 8.301 & 8.1938 & TRN \\
\hline CHEMBL 3893575 & 1639952 & 7.301 & 7.9456 & TRN \\
\hline CHEMBL 3983179 & 1639952 & 6.0 & 6.96399 & 99999999995 \\
\hline CHEMBL3979195 & 1639952 & 7.301 & 7.4858 & TRN \\
\hline CHEMBL 3951403 & 1639952 & 7.301 & 7.5641 & TRN \\
\hline CHEMBL 3907215 & 1639952 & 7.301 & 7.5085 & TRN \\
\hline CHEMBL 3895848 & 1639952 & 6.0 & 6.28700 & 0000000001 \\
\hline CHEMBL 3944502 & 1639952 & 6.0 & 6.3366 & TST \\
\hline CHEMBL 3944780 & 1639952 & 7.301 & 7.4984 & TRN \\
\hline CHEMBL 3926038 & 1639952 & 7.301 & 7.8453 & TRN \\
\hline CHEMBL 3978177 & 1639952 & 8.301 & 7.7476 & TRN \\
\hline CHEMBL 3959160 & 1639952 & 3.699 & 4.9468 & TRN \\
\hline CHEMBL 3961472 & 1639952 & 7.301 & 7.6862 & TRN \\
\hline CHEMBL 3900295 & 1639952 & 7.301 & 7.3217 & TRN \\
\hline CHEMBL 3956820 & 1639952 & 6.0 & 7.2417 & TRN \\
\hline CHEMBL 3939874 & 1639952 & 8.301 & 7.2729 & TST \\
\hline CHEMBL 3933359 & 1639952 & 6.0 & 5.7083 & TRN \\
\hline CHEMBL 3895424 & 1639952 & 6.0 & 6.0056 & TRN \\
\hline CHEMBL 3949155 & 1639952 & 7.301 & 7.2921 & TRN \\
\hline CHEMBL 3945353 & 1639952 & 7.301 & 7.347 & TST \\
\hline CHEMBL 3934134 & 1639952 & 7.301 & 6.6904 & TRN \\
\hline CHEMBL 3964605 & 1639952 & 6.0 & 6.4801 & TST \\
\hline CHEMBL 3943632 & 1639952 & 6.0 & 6.2573 & TST \\
\hline CHEMBL 3921482 & 1639952 & 8.301 & 8.129 & TRN \\
\hline CHEMBL 3937048 & 1639952 & 6.0 & 5.5766 & TRN \\
\hline CHEMBL3968192 & 1639952 & 7.301 & 7.4973 & TRN \\
\hline
\end{tabular}




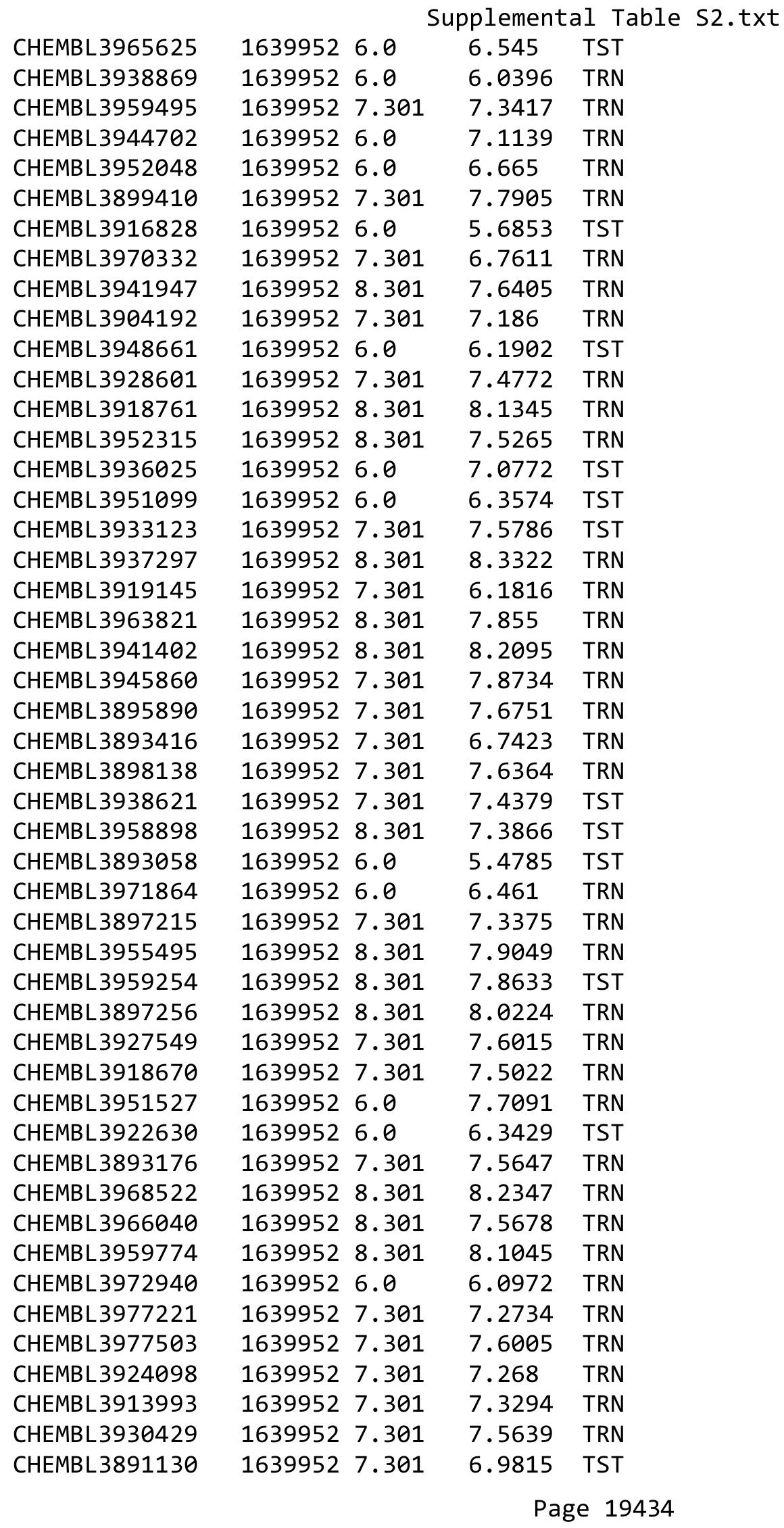


Supplemental Table S2.txt

\begin{tabular}{|c|c|c|c|c|c|}
\hline CHEMBL3897525 & 1639952 & 8.301 & 8.1302 & TRN & \\
\hline CHEMBL3925935 & 1639952 & 8.301 & 8.0344 & TRN & \\
\hline CHEMBL3914264 & 1639952 & 6.0 & 6.4625 & TST & \\
\hline CHEMBL3976826 & 1639952 & 6.0 & 6.5164 & TST & \\
\hline CHEMBL3909596 & 1639952 & 7.301 & 7.7689 & TST & \\
\hline CHEMBL3920114 & 1639952 & 7.301 & 7.5425 & TRN & \\
\hline CHEMBL3983201 & 1639952 & 6.0 & 6.4571 & TRN & \\
\hline CHEMBL3921228 & 1639952 & 7.301 & 7.4312 & TRN & \\
\hline CHEMBL3905114 & 1639952 & 7.301 & 6.7368 & TRN & \\
\hline CHEMBL3933130 & 1639952 & 7.301 & 7.2697 & TST & \\
\hline CHEMBL3907230 & 1639952 & 6.0 & 6.1642 & TRN & \\
\hline CHEMBL3914671 & 1639952 & 7.301 & 7.1059 & TRN & \\
\hline CHEMBL3977030 & 1639952 & 8.301 & 8.03 & TRN & \\
\hline CHEMBL3910102 & 1639952 & 7.301 & 7.6168 & TRN & \\
\hline CHEMBL3893128 & 1639952 & 6.0 & 6.3543 & TST & \\
\hline CHEMBL3968030 & 1639952 & 6.0 & 6.9178 & TRN & \\
\hline CHEMBL3968843 & 1639952 & 7.301 & 7.03799 & 9999999999 & TRN \\
\hline CHEMBL 3955447 & 1639952 & 7.301 & 7.6481 & TRN & \\
\hline CHEMBL3945062 & 1639952 & 7.301 & 7.0045 & TRN & \\
\hline CHEMBL3942082 & 1639952 & 7.301 & 7.6379 & TRN & \\
\hline CHEMBL3946018 & 1639952 & 6.0 & 6.3339 & TST & \\
\hline CHEMBL 3933848 & 1639952 & 6.0 & 6.5592 & TST & \\
\hline CHEMBL3910031 & 1639952 & 6.0 & 5.9054 & TRN & \\
\hline CHEMBL 3947700 & 1639952 & 7.301 & 7.3656 & TRN & \\
\hline CHEMBL3917294 & 1639952 & 7.301 & 7.7153 & TRN & \\
\hline CHEMBL3962203 & 1639952 & 7.301 & 7.3497 & TRN & \\
\hline CHEMBL3912646 & 1639952 & 8.301 & 7.6925 & TRN & \\
\hline CHEMBL3892030 & 1639952 & 7.301 & 7.7707 & TRN & \\
\hline CHEMBL3934095 & 1639952 & 7.301 & 7.5898 & TRN & \\
\hline CHEMBL3937092 & 1639952 & 6.0 & 6.9694 & TRN & \\
\hline CHEMBL3911207 & 1639952 & 7.301 & 7.3245 & TRN & \\
\hline CHEMBL3949434 & 1639952 & 7.301 & 6.9956 & TST & \\
\hline CHEMBL3967776 & 1639952 & 8.301 & 7.502006 & 0000000001 & TRN \\
\hline CHEMBL3919051 & 1639952 & 8.301 & 7.5826 & TRN & \\
\hline CHEMBL3986404 & 1639952 & 6.0 & 6.22 & TRN & \\
\hline CHEMBL3955486 & 1639952 & 6.0 & 5.9758 & TRN & \\
\hline CHEMBL 3895458 & 1639952 & 3.699 & 5.0638 & TRN & \\
\hline CHEMBL3958481 & 1639952 & 6.0 & 5.7906 & TRN & \\
\hline CHEMBL3965160 & 1639952 & 7.301 & 6.819 & TST & \\
\hline CHEMBL3962487 & 1639952 & 8.301 & 8.2106 & TRN & \\
\hline CHEMBL3955824 & 1639952 & 7.301 & 7.82 & TRN & \\
\hline CHEMBL3929966 & 1639952 & 7.301 & 7.3752 & TRN & \\
\hline CHEMBL3916953 & 1639952 & 6.0 & 6.2455 & TRN & \\
\hline CHEMBL3914599 & 1639952 & 8.301 & 7.8843 & TRN & \\
\hline CHEMBL3974328 & 1639952 & 6.0 & 6.0608 & TRN & \\
\hline CHEMBL 3890263 & 1639952 & 6.0 & 6.6502 & TRN & \\
\hline CHEMBL3916225 & 1639952 & 8.301 & 7.6792 & TRN & \\
\hline CHEMBL3986123 & 1639952 & 7.301 & 7.2211 & TRN & \\
\hline
\end{tabular}




\begin{tabular}{|c|c|c|c|c|c|}
\hline \multicolumn{6}{|c|}{ plement } \\
\hline CHEMBL3916485 & 1639952 & 6.0 & 6.7214 & TST & \\
\hline CHEMBL3932115 & 1639952 & 6.0 & 6.075 & TRN & \\
\hline CHEMBL3986082 & 1639952 & 6.0 & 5.6967 & TRN & \\
\hline CHEMBL3914180 & 1639952 & 8.301 & 7.8588 & TRN & \\
\hline CHEMBL3979728 & 1639952 & 7.301 & 7.7843 & TRN & \\
\hline CHEMBL3961982 & 1639952 & 6.0 & 6.4373 & TST & \\
\hline CHEMBL3961005 & 1639952 & 7.301 & 6.218 & TRN & \\
\hline CHEMBL3914394 & 1639952 & 7.301 & 7.5668 & TRN & \\
\hline CHEMBL3953937 & 1639952 & 7.301 & 7.2924 & TRN & \\
\hline CHEMBL3932698 & 1639952 & 7.301 & 7.0856 & TRN & \\
\hline CHEMBL3900858 & 1639952 & 6.0 & 6.3741 & TST & \\
\hline CHEMBL3976896 & 1639952 & 7.301 & 7.0856 & TRN & \\
\hline CHEMBL3923449 & 1639952 & 8.301 & 8.0879 & TRN & \\
\hline CHEMBL3933897 & 1639952 & 7.301 & 7.6073 & TRN & \\
\hline CHEMBL3905501 & 1639952 & 7.301 & 7.4083 & TRN & \\
\hline CHEMBL3976226 & 1639952 & 7.301 & 7.4008 & TRN & \\
\hline CHEMBL3904481 & 1639952 & 8.301 & 7.6863 & TST & \\
\hline CHEMBL3916297 & 1639952 & 7.301 & 7.0697 & TRN & \\
\hline CHEMBL3947769 & 1639952 & 7.301 & 7.7114 & TRN & \\
\hline CHEMBL3942161 & 1639952 & 7.301 & 7.76399 & 9999999999 & TRN \\
\hline CHEMBL3952465 & 1639952 & 8.301 & 7.5826 & TRN & \\
\hline CHEMBL3951755 & 1639952 & 8.301 & 7.3808 & TRN & \\
\hline CHEMBL3896699 & 1639952 & 8.301 & 7.5624 & TRN & \\
\hline CHEMBL3892117 & 1639952 & 7.301 & 7.2785 & TRN & \\
\hline CHEMBL3917442 & 1639952 & 8.301 & 8.5996 & TRN & \\
\hline CHEMBL 3966429 & 1639952 & 7.301 & 7.4317 & TRN & \\
\hline CHEMBL3912287 & 1639952 & 7.301 & 6.9092 & TRN & \\
\hline CHEMBL3896122 & 1639952 & 8.301 & 8.1249 & TRN & \\
\hline CHEMBL3960730 & 1639952 & 6.0 & 6.8369 & TST & \\
\hline CHEMBL3965938 & 1639952 & 7.301 & 7.2429 & TRN & \\
\hline CHEMBL3986102 & 1639952 & 7.301 & 7.8586 & TRN & \\
\hline CHEMBL3952493 & 1639952 & 6.0 & 6.6946 & TST & \\
\hline CHEMBL3905012 & 1639952 & 7.301 & 6.9974 & TRN & \\
\hline CHEMBL3961417 & 1639952 & 6.0 & 5.7547 & TRN & \\
\hline CHEMBL3923692 & 1639952 & 7.301 & 7.51 & TRN & \\
\hline CHEMBL3924998 & 1639952 & 8.301 & 7.9441 & TRN & \\
\hline CHEMBL3896067 & 1639952 & 6.0 & 6.0248 & TRN & \\
\hline CHEMBL3968519 & 1639952 & 8.301 & 7.3061 & TST & \\
\hline CHEMBL3942671 & 1639952 & 7.301 & 7.2629 & TST & \\
\hline CHEMBL3964536 & 1639952 & 8.301 & 8.184 & TRN & \\
\hline CHEMBL3965901 & 1639952 & 7.301 & 6.8566 & TST & \\
\hline CHEMBL3983466 & 1639952 & 7.301 & 7.2666 & TST & \\
\hline CHEMBL3939828 & 1639952 & 7.301 & 6.43 & TST & \\
\hline CHEMBL3909572 & 1639952 & 7.301 & 6.04799 & 9999999999 & TRN \\
\hline CHEMBL3928439 & 1639952 & 7.301 & 7.5167 & TRN & \\
\hline CHEMBL3906789 & 1639952 & 7.301 & 7.5212 & TST & \\
\hline CHEMBL3922278 & 1639952 & 7.301 & 8.0147 & TRN & \\
\hline CHEMBL3895129 & 1639952 & 7.301 & 8.0168 & TRN & \\
\hline
\end{tabular}


Supplemental Table S2.txt

\begin{tabular}{|c|c|c|c|c|}
\hline HEMBL 3895645 & 639952 & 7.301 & 7.2959 & TRN \\
\hline HEMBL3931393 & 639952 & 7.301 & 7.496 & T \\
\hline HEMBL3929188 & 539952 & 7.301 & 9907 & [RN \\
\hline HEMBL3983245 & 639952 & 8.301 & 7692 & $\mathrm{BN}$ \\
\hline HEMBL3956056 & 639952 & 7.301 & 6061 & ST \\
\hline HEMBL3927849 & 639952 & 6.0 & .9675 & \\
\hline HEMBL3901787 & 639952 & 7.301 & 2332 & RN \\
\hline HEMBL3945028 & 639952 & & .8469 & $\mathrm{RN}$ \\
\hline HEMBL3982666 & 639952 & 7.301 & .2719 & RN \\
\hline HEMBL3918306 & 639952 & 7.301 & .0718 & N \\
\hline HEMBL3944791 & 639952 & 8.301 & .6062 & \\
\hline HEMBL3893032 & 639952 & 7.301 & 5885 & \\
\hline HEMBL3921861 & 639952 & 6. & 047 & RN \\
\hline HEMBL3981613 & 639952 & 7.301 & .6649 & $\mathrm{RN}$ \\
\hline HEMBL3947643 & 639952 & 6.0 & $\partial 862$ & \\
\hline HEMBL3946590 & 1639952 & 6.0 & 0983 & RN \\
\hline HEMBL3906936 & .639952 & 01 & 9916 & RIN \\
\hline HEMBL3891059 & 639952 & 01 & 119 & \\
\hline HEMBL3953606 & 639952 & 7.301 & .1319 & RN \\
\hline HEMBL3958466 & 639 & 7.301 & 4106 & TRN \\
\hline HEMBL3928180 & 639 & 7.301 & 8418 & RIV \\
\hline HEMBL3929942 & 0394 & 7.301 & 2741 & RN \\
\hline HEMBL3985116 & 639952 & 6 . & 5059 & \\
\hline HEMBL3923645 & 639952 & 6.0 & 9798 & TRN \\
\hline HEMBL3939717 & 639 & 301 & 59 & TST \\
\hline HEMBL3937598 & 639 & 7. & 2952 & RN \\
\hline HEMBL3983938 & 9952 & 01 & 3755 & RN \\
\hline HEMBL3932218 & 639952 & 301 & 1316 & 「RN \\
\hline HEMBL3899440 & 639952 & 7.301 & 3873 & TRN \\
\hline HEMBL3907879 & 639952 & 7.301 & 186 & TRN \\
\hline HEMBL3976788 & 16399 & & 9471 & ГRN \\
\hline HEMBL 39 & 2 & 01 & 349 & ГST \\
\hline HEMBL3981432 & 52 & 01 & 935 & TRN \\
\hline HEMBL3949400 & 1639952 & 7.301 & 8211 & TST \\
\hline HEMBL3910064 & 639952 & 7.301 & 3324 & TST \\
\hline HEMBL3949560 & 6399 & 301 & 5656 & TRN \\
\hline HEMBL 39 & 52 & 01 & 224 & TRN \\
\hline CHEMBL3893846 & 1639952 & 7.301 & 5996 & TRN \\
\hline HEMBL3909603 & 639952 & 7.301 & 8642 & TST \\
\hline HEMBL3966752 & 639952 & 301 & 1046 & TRN \\
\hline CHEMBL3973632 & 1639952 & 301 & 9497 & $\Gamma \mathrm{RN}$ \\
\hline CHEMBL3985896 & 1639952 & 7.301 & 7.347 & TRN \\
\hline CHEMBL 3939671 & 1639952 & 8.301 & .2647 & TRN \\
\hline CHEMBL3971050 & 1639952 & 7.301 & .0214 & TRN \\
\hline CHEMBL3913496 & 1639952 & 301 & 7.6834 & TST \\
\hline CHEMBL3943734 & 1639952 & & .9636 & \\
\hline CHEMBL3931427 & 1639952 & .301 & .879 & \\
\hline CHEMBL3909626 & 1639952 & 7.301 & 6.801 & TST \\
\hline
\end{tabular}

Page 19437 
Supplemental Table S2.txt

\begin{tabular}{|c|c|c|c|c|c|}
\hline CHEMBL3977320 & 1639952 & 8.301 & 7.6128 & TST & \\
\hline CHEMBL3940839 & 1639952 & 7.301 & 7.8757 & TRN & \\
\hline CHEMBL3984213 & 1639952 & 7.301 & 6.6993 & TST & \\
\hline CHEMBL3904460 & 1639952 & 7.301 & 7.7441 & TRN & \\
\hline CHEMBL3899485 & 1639952 & 7.301 & 7.1865 & TRN & \\
\hline CHEMBL3924380 & 1639952 & 6.0 & 6.0208 & TRN & \\
\hline CHEMBL3919501 & 1639952 & 6.0 & 6.8389 & TRN & \\
\hline CHEMBL3935265 & 1639952 & 8.301 & 8.1552 & TRN & \\
\hline CHEMBL3968956 & 1639952 & 8.301 & 7.4756 & TRN & \\
\hline CHEMBL3963620 & 1639952 & 6.0 & 6.5733 & TST & \\
\hline CHEMBL3952188 & 1639952 & 8.301 & 7.8303 & TST & \\
\hline CHEMBL3949535 & 1639952 & 7.301 & 7.1389 & TRN & \\
\hline CHEMBL3920036 & 1639952 & 7.301 & 6.7352 & TRN & \\
\hline CHEMBL3914189 & 1639952 & 8.301 & 7.5998 & TRN & \\
\hline CHEMBL3957171 & 1639952 & 8.301 & 7.8337 & TST & \\
\hline CHEMBL3923153 & 1639952 & 8.301 & 7.9107 & TRN & \\
\hline CHEMBL3919493 & 1639952 & 7.301 & 7.5599 & TRN & \\
\hline CHEMBL3916759 & 1639952 & 8.301 & 7.6979 & TRN & \\
\hline CHEMBL3946469 & 1639952 & 7.301 & 7.6161 & TRN & \\
\hline CHEMBL3923013 & 1639952 & 7.301 & 7.6857 & TRN & \\
\hline CHEMBL3903022 & 1639952 & 7.301 & 7.0934 & TST & \\
\hline CHEMBL 3947408 & 1639952 & 7.301 & 7.5788 & TRN & \\
\hline CHEMBL3896044 & 1639952 & 6.0 & 6.6476 & TST & \\
\hline CHEMBL3932578 & 1639952 & 8.301 & 7.8811 & TRN & \\
\hline CHEMBL3900567 & 1639952 & 6.0 & 6.1897 & TST & \\
\hline CHEMBL3969472 & 1639952 & 7.301 & 7.3724 & TRN & \\
\hline CHEMBL3936151 & 1639952 & 8.301 & 7.6153 & TRN & \\
\hline CHEMBL3952023 & 1639952 & 7.301 & 7.8817 & TST & \\
\hline CHEMBL3944857 & 1639952 & 8.301 & 7.9436 & TRN & \\
\hline CHEMBL3958778 & 1639952 & 7.301 & 7.2394 & TRN & \\
\hline CHEMBL 3898627 & 1639952 & 7.301 & 7.53799 & 9999999999 & TST \\
\hline CHEMBL3958507 & 1639952 & 7.301 & 6.966 & TST & \\
\hline CHEMBL3895123 & 1639952 & 8.301 & 7.1949 & TST & \\
\hline CHEMBL3958678 & 1639952 & 7.301 & 7.2936 & TST & \\
\hline CHEMBL3890300 & 1639952 & 6.0 & 5.6588 & TST & \\
\hline CHEMBL3941200 & 1639952 & 7.301 & 6.966 & TRN & \\
\hline CHEMBL 3909744 & 1639952 & 8.301 & 7.8868 & TRN & \\
\hline CHEMBL3951258 & 1639952 & 8.301 & 8.0231 & TRN & \\
\hline CHEMBL3968233 & 1639952 & 7.301 & 7.6533 & TRN & \\
\hline CHEMBL3939133 & 1639952 & 7.301 & 7.1002 & TRN & \\
\hline CHEMBL3955873 & 1639952 & 6.0 & 6.4178 & TST & \\
\hline CHEMBL3964556 & 1639952 & 6.0 & 5.9805 & TRN & \\
\hline CHEMBL3896927 & 1639952 & 7.301 & 7.0098 & TRN & \\
\hline CHEMBL3962355 & 1639952 & 7.301 & 7.2019 & TRN & \\
\hline CHEMBL3937857 & 1639952 & 6.0 & 6.7714 & TST & \\
\hline CHEMBL3942387 & 1639952 & 7.301 & 7.3767 & TRN & \\
\hline CHEMBL3983450 & 1639952 & 6.0 & 6.4872 & TRN & \\
\hline CHEMBL3943570 & 1639952 & 8.301 & 7.6765 & TRN & \\
\hline
\end{tabular}




\begin{tabular}{|c|c|c|c|c|c|}
\hline & & & & & \\
\hline CHEMBL3985840 & 1639952 & 6.0 & 6.4329 & TST & \\
\hline CHEMBL3945177 & 1639952 & 8.301 & 7.923999 & 99999999995 & TRN \\
\hline CHEMBL3958721 & 1639952 & 6.0 & 5.7858 & TRN & \\
\hline CHEMBL3913719 & 1639952 & 7.301 & 7.8094 & TRN & \\
\hline CHEMBL3954731 & 1639952 & 6.0 & 6.732 & TRN & \\
\hline CHEMBL3928696 & 1639952 & 7.301 & 7.1377 & TRN & \\
\hline CHEMBL3900296 & 1639952 & 6.0 & 6.5649 & TST & \\
\hline CHEMBL3904510 & 1639952 & 6.0 & 6.6526 & TST & \\
\hline CHEMBL3952805 & 1639952 & 8.301 & 7.2737 & TST & \\
\hline CHEMBL3985254 & 1639952 & 7.301 & 7.3476 & TRN & \\
\hline CHEMBL 3650038 & 1534973 & 8.6198 & 8.6426 & TRN & \\
\hline CHEMBL3650036 & 1534973 & 8.699 & 8.7074 & TRN & \\
\hline CHEMBL3647272 & 1534973 & 7.3768 & 7.4104 & TRN & \\
\hline CHEMBL3650029 & 1534973 & 9.3372 & 7.5572 & TST & \\
\hline CHEMBL3650026 & 1534973 & 7.3565 & 7.3569 & TRN & \\
\hline CHEMBL 3647288 & 1534973 & 7.7696 & 7.8105 & TRN & \\
\hline CHEMBL3647289 & 1534973 & 7.301 & 7.3091 & TRN & \\
\hline CHEMBL3650043 & 1534973 & 8.0862 & 8.0075 & TRN & \\
\hline CHEMBL3650027 & 1534973 & 7.4202 & 7.3804 & TRN & \\
\hline CHEMBL3647262 & 1534973 & 8.7447 & 8.7956 & TRN & \\
\hline CHEMBL3647265 & 1534973 & 8.0458 & 8.0741 & TRN & \\
\hline CHEMBL 3650025 & 1534973 & 6.5528 & 6.5497 & TRN & \\
\hline CHEMBL3647268 & 1534973 & 9.0506 & 9.0459 & TRN & \\
\hline CHEMBL3650039 & 1534973 & 8.8539 & 8.798 & TRN & \\
\hline CHEMBL3647286 & 1534973 & 9.0 & 8.9684 & TRN & \\
\hline CHEMBL3647264 & 1534973 & 7.0862 & 7.0922 & TRN & \\
\hline CHEMBL3650035 & 1534973 & 8.1549 & 8.0331 & TST & \\
\hline CHEMBL3647267 & 1534973 & 8.7447 & 8.7761 & TRN & \\
\hline CHEMBL3650046 & 1534973 & 7.9586 & 7.9499 & TRN & \\
\hline CHEMBL3647282 & 1534973 & 9.2518 & 9.287 & TRN & \\
\hline CHEMBL 3647284 & 1534973 & 8.6383 & 8.6609 & TRN & \\
\hline CHEMBL3647276 & 1534973 & 9.1549 & 9.1077 & TRN & \\
\hline CHEMBL3650030 & 1534973 & 8.4559 & 8.4026 & TRN & \\
\hline CHEMBL3647275 & 1534973 & 8.4815 & 8.515 & TRN & \\
\hline CHEMBL 3647261 & 1534973 & 9.28399 & 999999999 & 9.3033 & TRN \\
\hline CHEMBL3650032 & 1534973 & 7.1805 & 7.112999 & 99999999995 & TRN \\
\hline CHEMBL3647285 & 1534973 & 7.4559 & 7.419 & TRN & \\
\hline CHEMBL3647260 & 1534973 & 8.9586 & 8.7846 & TST & \\
\hline CHEMBL3647273 & 1534973 & 7.7959 & 7.7883 & TRN & \\
\hline CHEMBL3650031 & 1534973 & 8.7959 & 8.9433 & TST & \\
\hline CHEMBL3647266 & 1534973 & 9.5528 & 9.5717 & TRN & \\
\hline CHEMBL 3647283 & 1534973 & 7.5086 & 7.5559 & TRN & \\
\hline CHEMBL3647280 & 1534973 & 8.041 & 8.007 & TRN & \\
\hline CHEMBL3647270 & 1534973 & 9.0555 & 9.0999 & TRN & \\
\hline CHEMBL3647263 & 1534973 & 7.4318 & 7.3609 & TRN & \\
\hline CHEMBL3647279 & 1534973 & 7.2007 & 7.2173 & TRN & \\
\hline CHEMBL3647278 & 1534973 & 8.1192 & 8.1539 & TRN & \\
\hline CHEMBL3647271 & 1534973 & 8.1871 & 8.2203 & TRN & \\
\hline
\end{tabular}

Page 19439 
Supplemental Table S2.txt

\begin{tabular}{|c|c|c|c|c|}
\hline CHEMBL3650045 & 1534973 & 6.8539 & 6.9793 & TRN \\
\hline CHEMBL3647274 & 1534973 & 8.3565 & 8.2019 & TRN \\
\hline CHEMBL3647277 & 1534973 & 8.0 & 8.0146 & TRN \\
\hline CHEMBL 3650040 & 1534973 & 7.7212 & 7.78700 & 3000000001 \\
\hline CHEMBL 3647281 & 1534973 & 8.8539 & 8.8061 & TRN \\
\hline CHEMBL 3650034 & 1534973 & 7.1367 & 6.7981 & TST \\
\hline CHEMBL3647287 & 1534973 & 7.7212 & 8.0644 & TST \\
\hline CHEMBL3650037 & 1534973 & 7.699 & 7.9134 & TST \\
\hline CHEMBL3647269 & 1534973 & 8.6778 & 8.2561 & TST \\
\hline CHEMBL3650033 & 1534973 & 8.8861 & 7.9109 & TST \\
\hline CHEMBL 3650044 & 1534973 & 8.301 & 8.5116 & TST \\
\hline CHEMBL3647259 & 1534973 & 7.7212 & 8.3624 & TST \\
\hline CHEMBL3650041 & 1534973 & 8.1135 & 8.5796 & TST \\
\hline CHEMBL3650042 & 1534973 & 7.8539 & 8.4778 & TST \\
\hline CHEMBL3650028 & 1534973 & 7.4685 & 7.8073 & TST \\
\hline CHEMBL3933739 & 1642436 & 8.2218 & 8.1146 & TRN \\
\hline CHEMBL3909349 & 1642436 & 8.1024 & 8.5704 & TST \\
\hline CHEMBL3963605 & 1642436 & 9.0757 & 8.613 & TST \\
\hline CHEMBL3892099 & 1642436 & 9.5229 & 9.1736 & TRN \\
\hline CHEMBL3901073 & 1642436 & 8.6778 & 8.4775 & TRN \\
\hline CHEMBL3919379 & 1642436 & 8.4202 & 8.9826 & TRN \\
\hline CHEMBL3908251 & 1642436 & 8.6778 & 8.7588 & TRN \\
\hline CHEMBL3918138 & 1642436 & 8.4089 & 8.2719 & TRN \\
\hline CHEMBL3942617 & 1642436 & 7.5686 & 8.0527 & TRN \\
\hline CHEMBL3949162 & 1642436 & 6.2291 & 7.3156 & TST \\
\hline CHEMBL3946659 & 1642436 & 6.0 & 7.2993 & TRN \\
\hline CHEMBL3919287 & 1642436 & 8.7447 & 8.2946 & TRN \\
\hline CHEMBL3903385 & 1642436 & 7.585 & 7.5441 & TRN \\
\hline CHEMBL3904204 & 1642436 & 8.5376 & 8.6213 & TST \\
\hline CHEMBL3966643 & 1642436 & 9.4437 & 9.1209 & TRN \\
\hline CHEMBL3943813 & 1642436 & 9.6021 & 8.8977 & TST \\
\hline CHEMBL3914252 & 1642436 & 7.7959 & 8.1782 & TRN \\
\hline CHEMBL3966595 & 1642436 & 9.699 & 9.1145 & TRN \\
\hline CHEMBL3969856 & 1642436 & 9.4437 & 8.9715 & TST \\
\hline CHEMBL3933423 & 1642436 & 8.3979 & 8.4572 & TRN \\
\hline CHEMBL3891200 & 1642436 & 7.0 & 7.0971 & TRN \\
\hline CHEMBL3959314 & 1642436 & 8.7447 & 8.5309 & TRN \\
\hline CHEMBL3968875 & 1642436 & 8.5376 & 9.0008 & TRN \\
\hline CHEMBL3935341 & 1642436 & 9.0655 & 8.2964 & TRN \\
\hline CHEMBL3970381 & 1642436 & 8.9208 & 8.8411 & TRN \\
\hline CHEMBL3905625 & 1642436 & 7.1805 & 7.7574 & TRN \\
\hline CHEMBL3950697 & 1642436 & 8.8239 & 8.8064 & TRN \\
\hline CHEMBL3915489 & 1642436 & 8.8861 & 8.3816 & TRN \\
\hline CHEMBL3980746 & 1642436 & 9.0555 & \multicolumn{2}{|c|}{9.306000000000001} \\
\hline CHEMBL3957149 & 1642436 & 8.8861 & 9.001 & TRN \\
\hline CHEMBL3942619 & 1642436 & 8.8239 & 8.7572 & TST \\
\hline CHEMBL3937993 & 1642436 & 9.5686 & 9.008 & TRN \\
\hline CHEMBL3900688 & 1642436 & 7.5229 & 6.9173 & TRN \\
\hline
\end{tabular}


Supplemental Table S2.txt

\begin{tabular}{|c|c|c|c|c|c|}
\hline CHEMBL3939304 & 1642436 & 8.699 & \multicolumn{2}{|c|}{8.386000000000001} & TRN \\
\hline CHEMBL 3892068 & 1642436 & 6.0 & 8.6738 & TST & \\
\hline CHEMBL3987185 & 1642436 & 9.5376 & 9.1622 & TRN & \\
\hline CHEMBL3893533 & 1642436 & 9.7959 & 9.4773 & TRN & \\
\hline CHEMBL 3945647 & 1642436 & 9.1675 & 9.2501 & TRN & \\
\hline CHEMBL 3977527 & 1642436 & 7.2924 & 7.7798 & TRN & \\
\hline CHEMBL3919244 & 1642436 & 8.9208 & 8.791 & TRN & \\
\hline CHEMBL 3889877 & 1642436 & 9.2007 & 8.9129 & TRN & \\
\hline CHEMBL 3925357 & 1642436 & 8.0655 & 8.2325 & TRN & \\
\hline CHEMBL3893839 & 1642436 & 8.5086 & 9.28 & TRN & \\
\hline CHEMBL 3907088 & 1642436 & 9.6198 & 9.3575 & TRN & \\
\hline CHEMBL3967547 & 1642436 & 8.7959 & 8.5313 & TST & \\
\hline CHEMBL 3927615 & 1642436 & 7.7959 & 8.2418 & TRN & \\
\hline CHEMBL 3976541 & 1642436 & 8.8239 & 8.891 & TRN & \\
\hline CHEMBL 3984070 & 1642436 & 9.5686 & 9.2744 & TRN & \\
\hline CHEMBL3932525 & 1642436 & 7.9208 & 8.3289 & TRN & \\
\hline CHEMBL3943147 & 1642436 & 9.0605 & 9.0792 & TRN & \\
\hline CHEMBL 3909775 & 1642436 & 8.5686 & 9.0885 & TRN & \\
\hline CHEMBL 3964163 & 1642436 & 7.5376 & 8.2333 & TRN & \\
\hline CHEMBL 3891166 & 1642436 & 8.9208 & 8.8078 & TRN & \\
\hline CHEMBL 3928145 & 1642436 & 8.4437 & 8.2943 & TRN & \\
\hline CHEMBL3899197 & 1642436 & 9.3468 & 9.1795 & TRN & \\
\hline CHEMBL 3965722 & 1642436 & 7.7212 & 7.5743 & TRN & \\
\hline CHEMBL 3892736 & 1642436 & 9.0458 & 9.2003 & TRN & \\
\hline CHEMBL 3889579 & 1642436 & 7.5528 & 8.2239 & TRN & \\
\hline CHEMBL 3921551 & 1642436 & 9.8861 & 9.6878 & TRN & \\
\hline CHEMBL3982497 & 1642436 & 9.6383 & 8.8458 & TST & \\
\hline CHEMBL 3933598 & 1642436 & 8.3279 & 7.3474 & TRN & \\
\hline CHEMBL 3952413 & 1642436 & 7.6778 & 7.7868 & TRN & \\
\hline CHEMBL3983009 & 1642436 & 9.1675 & 8.8053 & TST & \\
\hline CHEMBL 3951893 & 1642436 & 9.0044 & 9.2864 & TST & \\
\hline CHEMBL3890986 & 1642436 & 8.5528 & 8.6981 & TRN & \\
\hline CHEMBL 3896642 & 1642436 & 8.4437 & 8.6818 & TRN & \\
\hline CHEMBL 3895998 & 1642436 & 9.4815 & 8.6369 & TST & \\
\hline CHEMBL 3916984 & 1642436 & 8.5376 & 8.4549 & TRN & \\
\hline CHEMBL3984009 & 1642436 & 8.7696 & 9.0782 & TRN & \\
\hline CHEMBL3958917 & 1642436 & 9.3665 & 8.9414 & TST & \\
\hline CHEMBL3981979 & 1642436 & 7.8239 & 8.0853 & TRN & \\
\hline CHEMBL 3905583 & 1642436 & 8.6778 & 8.7155 & TRN & \\
\hline CHEMBL 3970893 & 1642436 & 8.5686 & 9.3797 & TRN & \\
\hline CHEMBL3954062 & 1642436 & 8.5528 & 8.4278 & TRN & \\
\hline CHEMBL3896683 & 1642436 & 7.8539 & 6.9939 & TRN & \\
\hline CHEMBL 3928682 & 1642436 & 8.4437 & 8.4176 & TRN & \\
\hline CHEMBL 3920740 & 1642436 & 8.9586 & 8.92 & TRN & \\
\hline CHEMBL 3933646 & 1642436 & 7.5376 & 7.8571 & TRN & \\
\hline CHEMBL 3942560 & 1642436 & 8.9208 & 8.6718 & TRN & \\
\hline CHEMBL3912781 & 1642436 & 8.2757 & 8.8957 & TRN & \\
\hline CHEMBL3935905 & 1642436 & 8.8861 & 8.407 & TRN & \\
\hline
\end{tabular}


Supplemental Table S2.txt

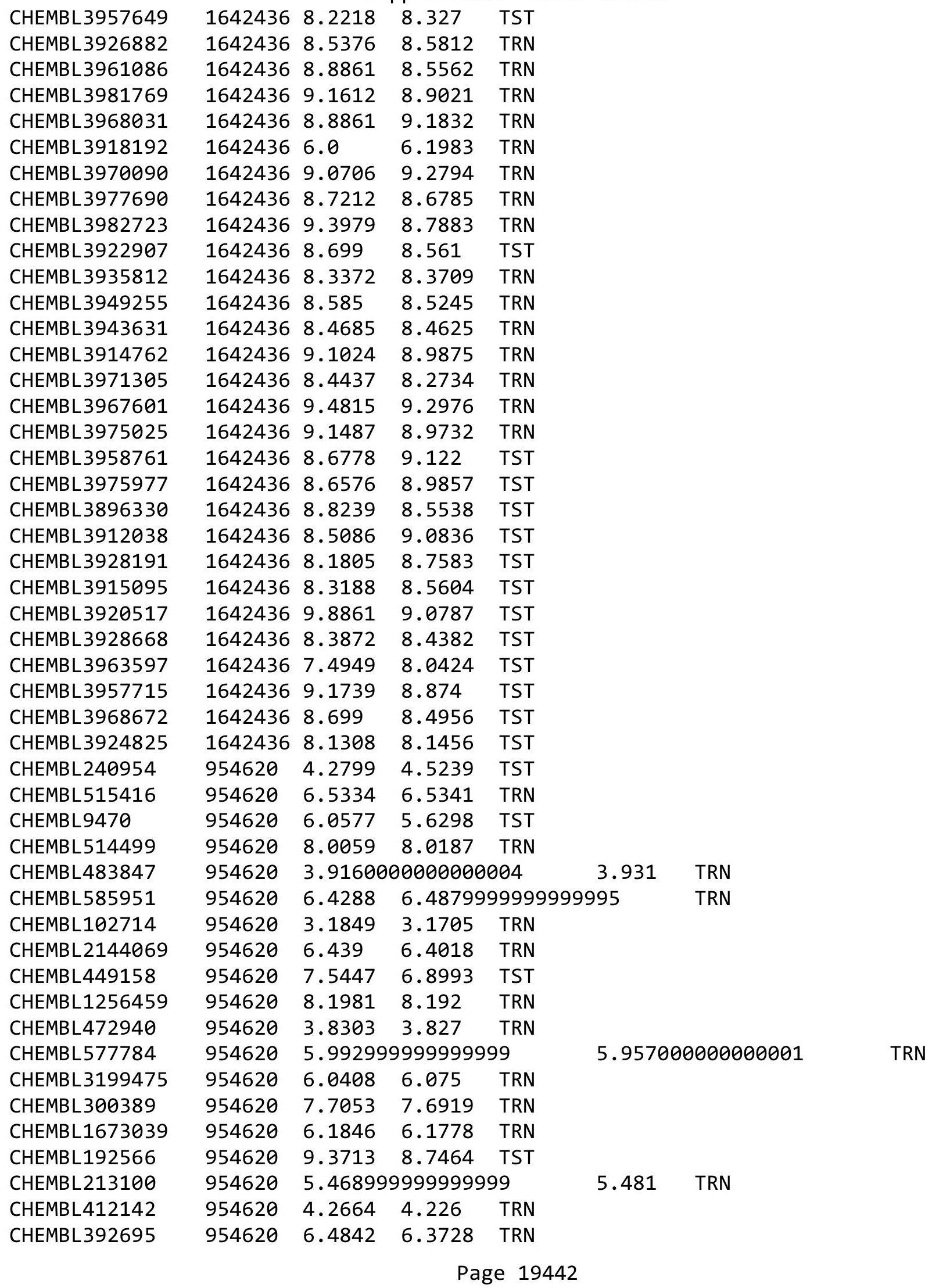




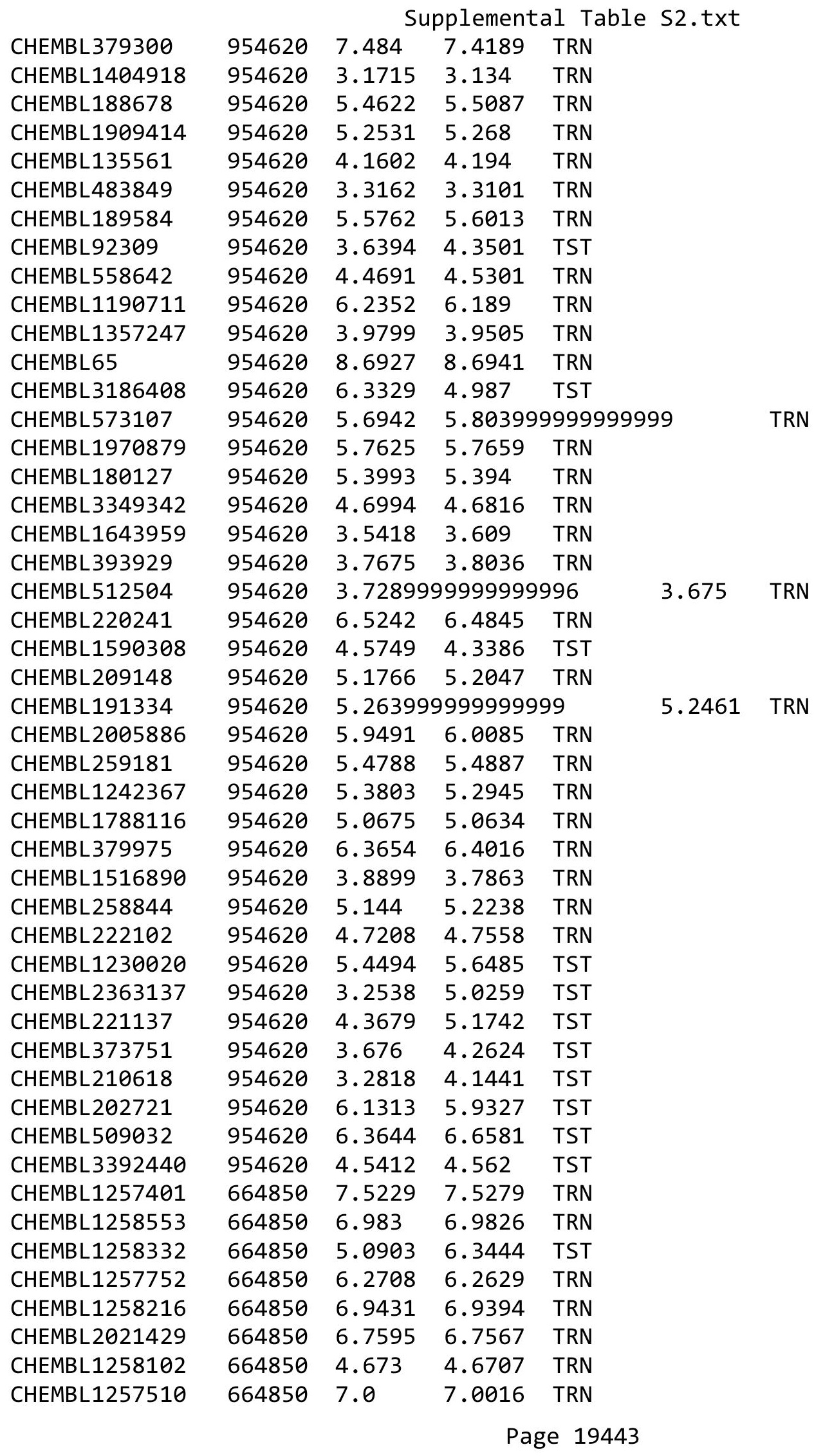


Supplemental Table S2.txt

\begin{tabular}{|c|c|c|c|c|c|c|}
\hline CHEMBL1258442 & 664850 & 6.9281 & 6.9265 & TRN & & \\
\hline CHEMBL1258898 & 664850 & 7.2924 & 7.2958 & TRN & & \\
\hline CHEMBL1257985 & 664850 & 6.0921 & 6.102 & TRN & & \\
\hline CHEMBL1257751 & 664850 & 7.0088 & 7.0116 & TRN & & \\
\hline CHEMBL1257873 & 664850 & 6.0615 & 6.059 & TRN & & \\
\hline CHEMBL1257511 & 664850 & 7.2676 & 7.2666 & TRN & & \\
\hline CHEMBL1258899 & 664850 & 7.0915 & 7.0904 & TRN & & \\
\hline CHEMBL1257281 & 664850 & 6.0768 & 6.0827 & TRN & & \\
\hline CHEMBL1257513 & 664850 & \multicolumn{3}{|c|}{6.218999999999999} & 6.2221 & TRN \\
\hline CHEMBL1257282 & 664850 & 8.5229 & 8.5186 & TRN & & \\
\hline CHEMBL1258330 & 664850 & 7.699 & 7.6888 & TRN & & \\
\hline CHEMBL1258778 & 664850 & 6.2255 & 6.2212 & TRN & & \\
\hline CHEMBL1258329 & 664850 & 6.0535 & 6.0523 & TRN & & \\
\hline CHEMBL1258215 & 664850 & 5.4787 & 7.2299 & TST & & \\
\hline CHEMBL1257512 & 664850 & 8.699 & 8.2006 & TST & & \\
\hline CHEMBL1258551 & 664850 & 7.1308 & 7.1378 & TRN & & \\
\hline CHEMBL1258550 & 664850 & 6.8239 & 6.817 & TRN & & \\
\hline CHEMBL1257165 & 664850 & 7.7447 & 7.7422 & TRN & & \\
\hline CHEMBL1255592 & 664850 & 5.4944 & 5.4945 & TRN & & \\
\hline CHEMBL1258101 & 664850 & 7.3372 & 7.3392 & TRN & & \\
\hline CHEMBL1257402 & 664850 & 8.699 & 8.6941 & TRN & & \\
\hline CHEMBL1257166 & 664850 & 7.0555 & 7.0527 & TRN & & \\
\hline CHEMBL1257280 & 664850 & 6.1612 & 6.1558 & TRN & & \\
\hline CHEMBL1258665 & 664850 & 8.699 & 8.6956 & TRN & & \\
\hline CHEMBL1258444 & 664850 & 5.6887 & 5.6948 & TRN & & \\
\hline CHEMBL1258443 & 664850 & 4.6398 & 6.4431 & TST & & \\
\hline CHEMBL1258664 & 664850 & 9.0 & 9.0079 & TRN & & \\
\hline CHEMBL1258663 & 664850 & 5.6297 & 5.6321 & TRN & & \\
\hline CHEMBL1258331 & 664850 & 8.0969 & 8.0857 & TRN & & \\
\hline CHEMBL1258781 & 664850 & 9.0 & 8.9953 & TRN & & \\
\hline CHEMBL1258662 & 664850 & 7.5229 & 7.5272 & TRN & & \\
\hline CHEMBL1258552 & 664850 & 8.301 & 8.3244 & TRN & & \\
\hline CHEMBL1258441 & 664850 & 6.5467 & 6.5466 & TRN & & \\
\hline CHEMBL1258900 & 664850 & 8.699 & 8.7291 & TST & & \\
\hline CHEMBL1257163 & 664850 & 7.0223 & 6.44 & TST & & \\
\hline CHEMBL1257283 & 664850 & 7.5229 & 7.2217 & TST & & \\
\hline CHEMBL1257629 & 664850 & 7.3665 & 7.16700 & 0000000001 & & TST \\
\hline CHEMBL1257164 & 664850 & 5.5402 & 5.9126 & TST & & \\
\hline CHEMBL1257628 & 664850 & 7.0969 & 6.3854 & TST & & \\
\hline CHEMBL1258780 & 664850 & 8.699 & 8.5873 & TST & & \\
\hline CHEMBL1258779 & 664850 & 6.8477 & 6.5183 & TST & & \\
\hline CHEMBL1257986 & 664850 & 5.8356 & 6.5564 & TST & & \\
\hline CHEMBL 3138151 & 47498 & 6.3979 & 6.3292 & TRN & & \\
\hline CHEMBL3138179 & 47498 & 7.1805 & 7.0768 & TRN & & \\
\hline CHEMBL 3138153 & 47498 & 5.4225 & 5.3549 & TRN & & \\
\hline CHEMBL 3137807 & 47498 & 7.1135 & 7.1147 & TRN & & \\
\hline CHEMBL 3137757 & 47498 & 6.5452 & 6.5454 & TRN & & \\
\hline CHEMBL 3138180 & 47498 & 5.0915 & 5.0887 & TRN & & \\
\hline
\end{tabular}

Page 19444 


\begin{tabular}{|c|c|c|c|c|c|}
\hline & & \multicolumn{4}{|c|}{ Supplemental Table S2.txt } \\
\hline CHEMBL3137796 & 47498 & 6.699 & 6.7826 & TST & \\
\hline CHEMBL 3138143 & 47498 & 4.4935 & 4.7735 & TRN & \\
\hline CHEMBL3137777 & 47498 & 6.699 & 7.6308 & TST & \\
\hline CHEMBL 3137814 & 47498 & 7.4437 & 7.4227 & TRN & \\
\hline CHEMBL3137762 & 47498 & 7.6576 & 8.2309 & TST & \\
\hline CHEMBL 3137791 & 47498 & 6.9208 & 6.7371 & TRN & \\
\hline CHEMBL 3138384 & 47498 & 5.9208 & 6.0012 & TRN & \\
\hline CHEMBL 2113375 & 47498 & 6.0 & 6.2883 & TST & \\
\hline CHEMBL 3138367 & 47498 & 6.1871 & 6.2908 & TRN & \\
\hline CHEMBL2113370 & 47498 & 6.6198 & 7.0939 & TST & \\
\hline CHEMBL 3138141 & 47498 & 5.1284 & 5.1444 & TRN & \\
\hline CHEMBL 3138434 & 47498 & 6.041 & 6.0733 & TRN & \\
\hline CHEMBL3137789 & 47498 & 6.699 & 7.4215 & TST & \\
\hline CHEMBL3137795 & 47498 & 7.4089 & 7.4103 & TRN & \\
\hline CHEMBL3138150 & 47498 & 6.699 & 6.5604 & TRN & \\
\hline CHEMBL3137759 & 47498 & 6.0 & 5.7133 & TRN & \\
\hline CHEMBL3137792 & 47498 & 6.4377 & 6.5183 & TRN & \\
\hline CHEMBL3137765 & 47498 & 6.0 & 6.0527 & TRN & \\
\hline CHEMBL3138166 & 47498 & 7.4559 & 7.1536 & TRN & \\
\hline CHEMBL3137752 & 47498 & 6.6478 & 6.4644 & TRN & \\
\hline CHEMBL 3138163 & 47498 & 6.0969 & 6.0184 & TRN & \\
\hline CHEMBL3138138 & 47498 & 5.767 & 5.6035 & TRN & \\
\hline CHEMBL3137764 & 47498 & 7.2518 & 7.4323 & TRN & \\
\hline CHEMBL3137771 & 47498 & 6.6778 & 7.34399 & 9999999999 & TST \\
\hline CHEMBL3138162 & 47498 & 6.9208 & 6.7642 & TRN & \\
\hline CHEMBL 3138146 & 47498 & 7.4089 & 7.5368 & TRN & \\
\hline CHEMBL3137753 & 47498 & 6.0531 & 5.8952 & TRN & \\
\hline CHEMBL3137779 & 47498 & 5.9393 & 5.8895 & TRN & \\
\hline CHEMBL 3137775 & 47498 & 6.4437 & 6.5004 & TRN & \\
\hline CHEMBL 2113374 & 47498 & 6.6882 & 7.2441 & TST & \\
\hline CHEMBL3138159 & 47498 & 4.6716 & 4.614 & TRN & \\
\hline CHEMBL3137755 & 47498 & 6.2218 & 6.2547 & TRN & \\
\hline CHEMBL 3138427 & 47498 & 6.0 & 5.78600 & 00000000005 & TRN \\
\hline CHEMBL3137767 & 47498 & 6.0 & 6.1327 & TRN & \\
\hline CHEMBL3137768 & 47498 & 6.0 & 6.1983 & TRN & \\
\hline CHEMBL3138410 & 47498 & 6.0506 & 6.0466 & TRN & \\
\hline CHEMBL 2113371 & 47498 & 7.5376 & 7.9905 & TST & \\
\hline CHEMBL3137761 & 47498 & 6.3768 & 6.2941 & TST & \\
\hline CHEMBL3138165 & 47498 & 6.0132 & 5.8674 & TRN & \\
\hline CHEMBL3138167 & 47498 & 6.0 & 5.9079 & TRN & \\
\hline CHEMBL3137806 & 47498 & 4.8239 & 5.0342 & TRN & \\
\hline CHEMBL 3137802 & 47498 & 6.6021 & 7.0436 & TST & \\
\hline CHEMBL3138139 & 47498 & 5.4318 & 5.3436 & TRN & \\
\hline CHEMBL3138169 & 47498 & 6.38200 & 30000000 & 6.1419 & TST \\
\hline CHEMBL3137799 & 47498 & 6.2218 & 6.26399 & 9999999999 & TRN \\
\hline CHEMBL 3138158 & 47498 & 6.8861 & 6.7155 & TRN & \\
\hline CHEMBL 3137808 & 47498 & 7.3468 & 7.32700 & $\partial 000000001$ & TRN \\
\hline CHEMBL3137772 & 47498 & 6.0 & 5.4174 & TST & \\
\hline
\end{tabular}




\begin{tabular}{|c|c|c|c|c|c|c|}
\hline & & \multicolumn{5}{|c|}{ Supplemental Table s2.txt } \\
\hline CHEMBL3137797 & 47498 & 5.2007 & 5.356 & TRN & & \\
\hline CHEMBL 3138424 & 47498 & 7.4089 & 7.7531 & TST & & \\
\hline CHEMBL3138160 & 47498 & 7.3188 & 7.3916 & TRN & & \\
\hline CHEMBL 3138147 & 47498 & 6.0 & 6.1914 & TST & & \\
\hline CHEMBL3137811 & 47498 & 6.0 & 5.8648 & TRN & & \\
\hline CHEMBL 3137798 & 47498 & 4.5935 & 4.5107 & TST & & \\
\hline CHEMBL 3137780 & 47498 & 7.4815 & 7.9133 & TST & & \\
\hline CHEMBL 3137787 & 47498 & 5.8239 & 5.7349 & TRN & & \\
\hline CHEMBL 3138172 & 47498 & 6.1079 & 6.0787 & TRN & & \\
\hline CHEMBL3138373 & 47498 & 5.4685 & 5.5463 & TRN & & \\
\hline CHEMBL 3138149 & 47498 & 6.0 & 6.0952 & TST & & \\
\hline CHEMBL 3138178 & 47498 & 6.0 & 6.2056 & TRN & & \\
\hline CHEMBL3138154 & 47498 & 6.699 & 6.8838 & TRN & & \\
\hline CHEMBL3137766 & 47498 & 4.6383 & 4.7763 & TRN & & \\
\hline CHEMBL3137770 & 47498 & 4.9208 & 4.8929 & TRN & & \\
\hline CHEMBL3138176 & 47498 & 4.6778 & 4.8114 & TRN & & \\
\hline CHEMBL 3138487 & 47498 & 5.0223 & 5.1239 & TRN & & \\
\hline CHEMBL3137785 & 47498 & 6.0 & 5.8347 & TRN & & \\
\hline CHEMBL 3137754 & 47498 & 4.8962 & 4.8246 & TRN & & \\
\hline CHEMBL3138168 & 47498 & 6.1427 & 6.4877 & TRN & & \\
\hline CHEMBL3138155 & 47498 & 6.2041 & 6.1438 & TRN & & \\
\hline CHEMBL 3138183 & 47498 & 6.0 & 6.2481 & TRN & & \\
\hline CHEMBL3138182 & 47498 & 6.1549 & 6.4923 & TST & & \\
\hline CHEMBL 3138145 & 47498 & 5.8928 & 5.8429 & TRN & & \\
\hline CHEMBL3138419 & 47498 & 7.4949 & 7.381 & TRN & & \\
\hline CHEMBL 3137784 & 47498 & 6.0 & 6.1726 & TRN & & \\
\hline CHEMBL3137805 & 47498 & 6.0 & 6.1435 & TRN & & \\
\hline CHEMBL3137793 & 47498 & 7.3872 & 8.2615 & TST & & \\
\hline CHEMBL 3137782 & 47498 & 6.3468 & 5.9585 & TST & & \\
\hline CHEMBL3137786 & 47498 & 6.5452 & 6.6345 & TRN & & \\
\hline CHEMBL3138142 & 47498 & 6.6778 & 6.7205 & TRN & & \\
\hline CHEMBL 3137788 & 47498 & 6.3979 & 6.1736 & TST & & \\
\hline CHEMBL 3138171 & 47498 & 7.3979 & 7.3013 & TRN & & \\
\hline CHEMBL3138174 & 47498 & 7.5229 & 7.8651 & TST & & \\
\hline CHEMBL3138148 & 47498 & 6.38200 & 30000000 & $\partial 1$ & 6.4156 & TRN \\
\hline CHEMBL3138161 & 47498 & 4.8945 & 4.8545 & TRN & & \\
\hline CHEMBL 3137751 & 47498 & 6.2924 & 6.2371 & TRN & & \\
\hline CHEMBL3138157 & 47498 & 7.4318 & 7.6984 & TRN & & \\
\hline CHEMBL3137756 & 47498 & 5.0362 & 4.7985 & TST & & \\
\hline CHEMBL3137781 & 47498 & 6.0 & 5.8475 & TRN & & \\
\hline CHEMBL3138364 & 47498 & 4.6968 & 4.5463 & TST & & \\
\hline CHEMBL3138498 & 47498 & 6.0 & 6.0086 & TRN & & \\
\hline CHEMBL3138164 & 47498 & 7.2147 & 7.2072 & TRN & & \\
\hline CHEMBL3137750 & 47498 & 6.0 & 5.8019 & TRN & & \\
\hline CHEMBL505395 & 501795 & 8.28399 & 99999999 & 99 & 8.2302 & TRN \\
\hline CHEMBL484159 & 501795 & 8.1308 & 7.7859 & TRN & & \\
\hline CHEMBL511313 & 501795 & 7.9208 & 7.6192 & TRN & & \\
\hline CHEMBL446227 & 501795 & 8.7959 & 8.0342 & TRN & & \\
\hline
\end{tabular}




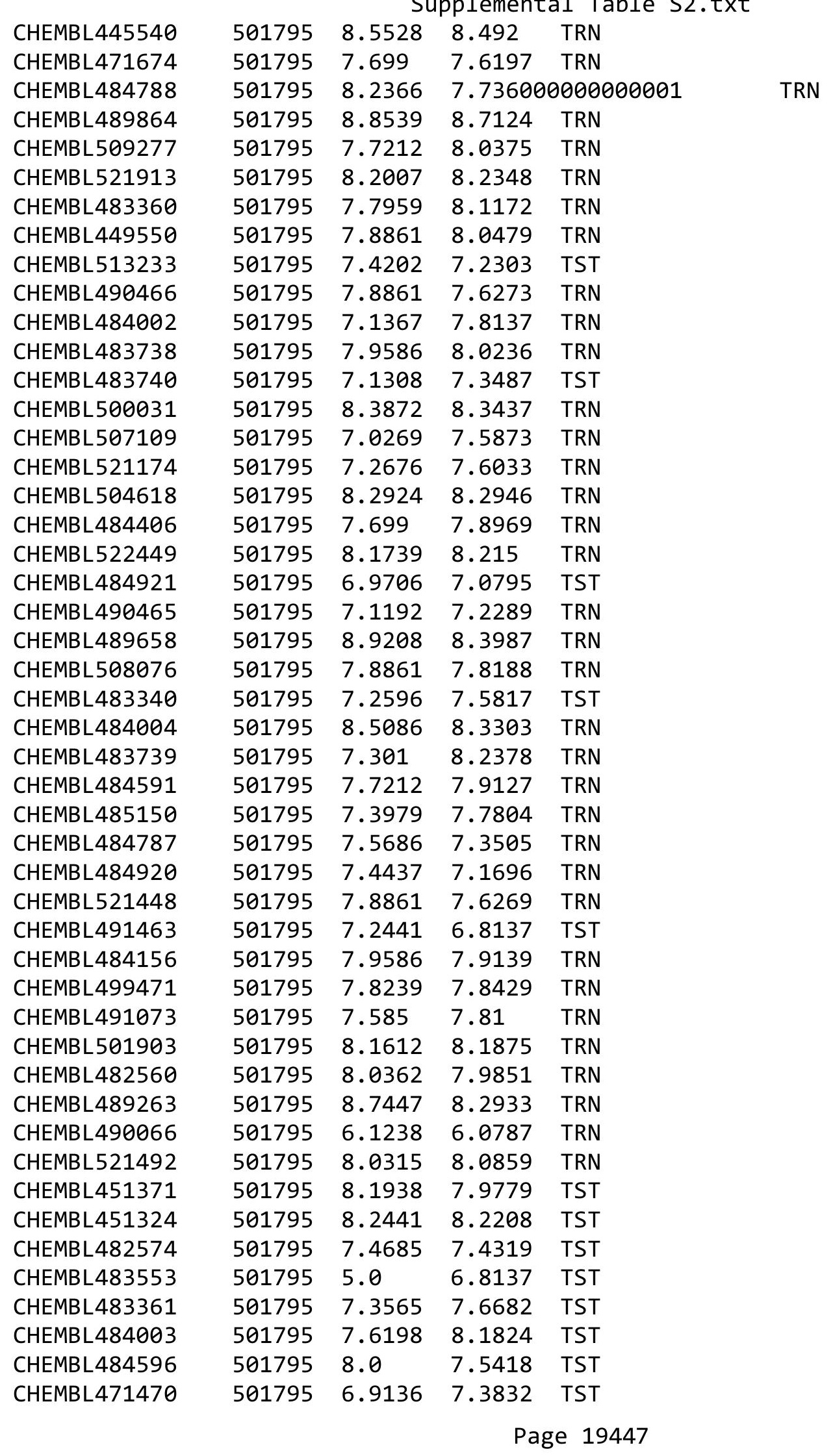




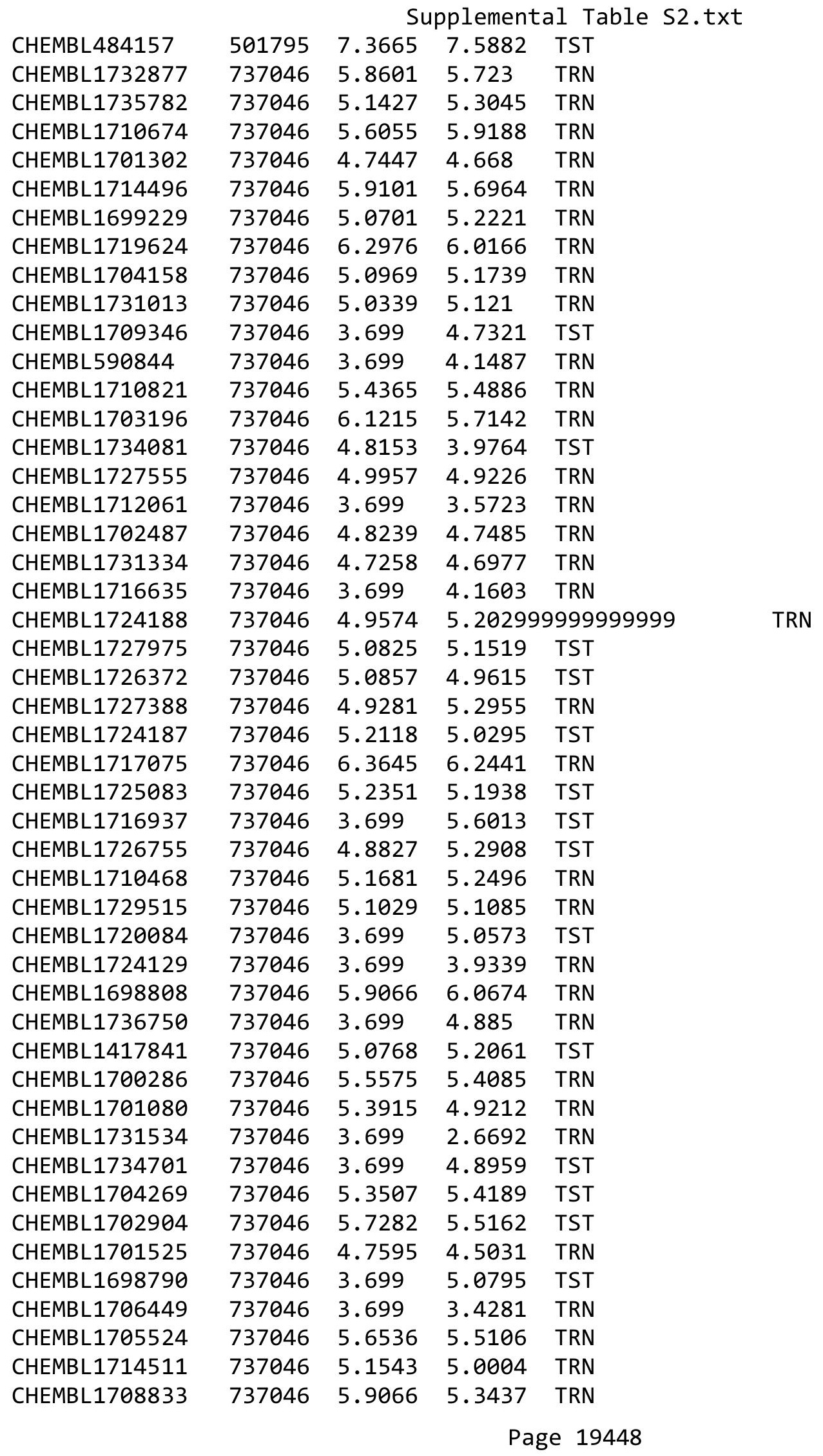




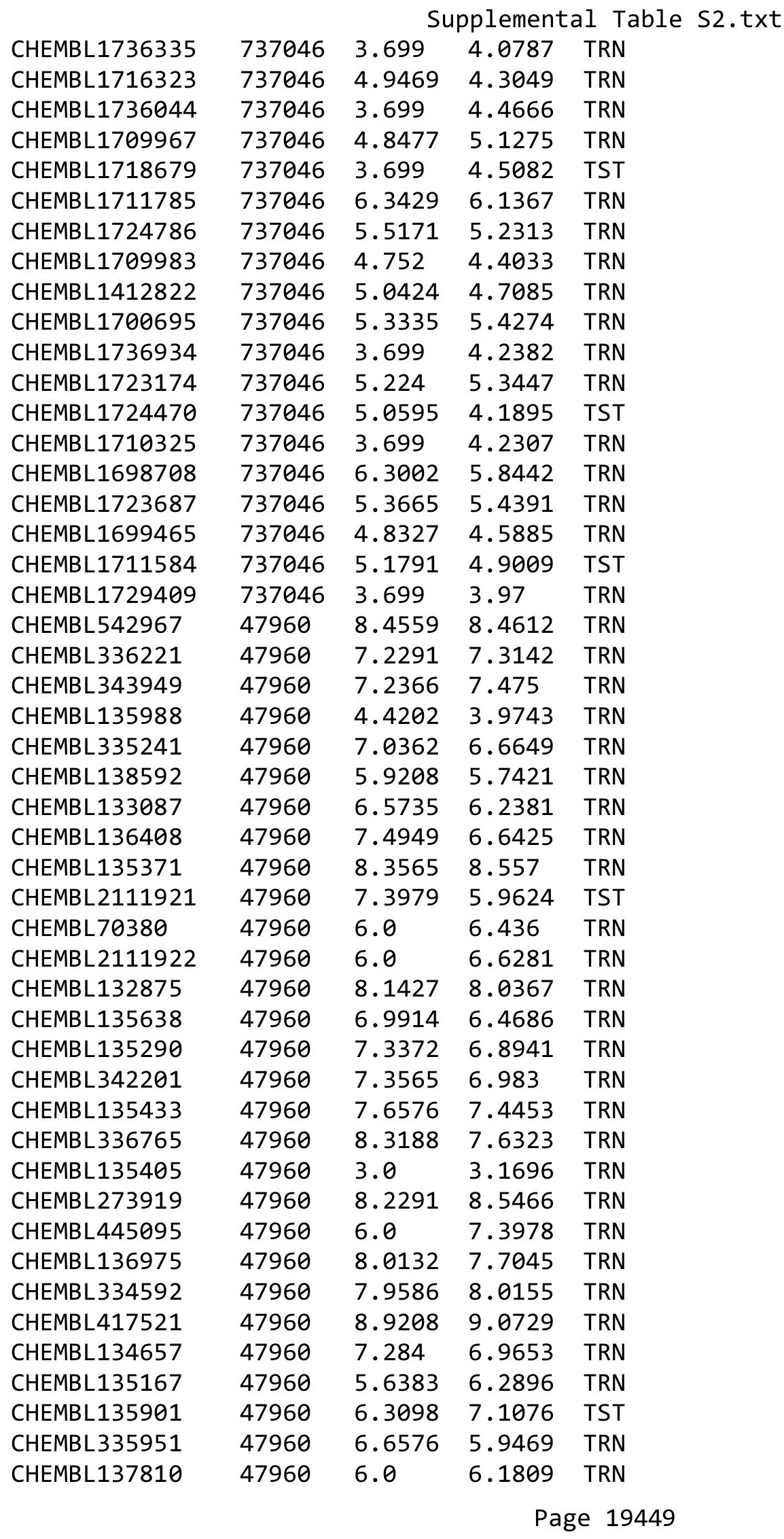




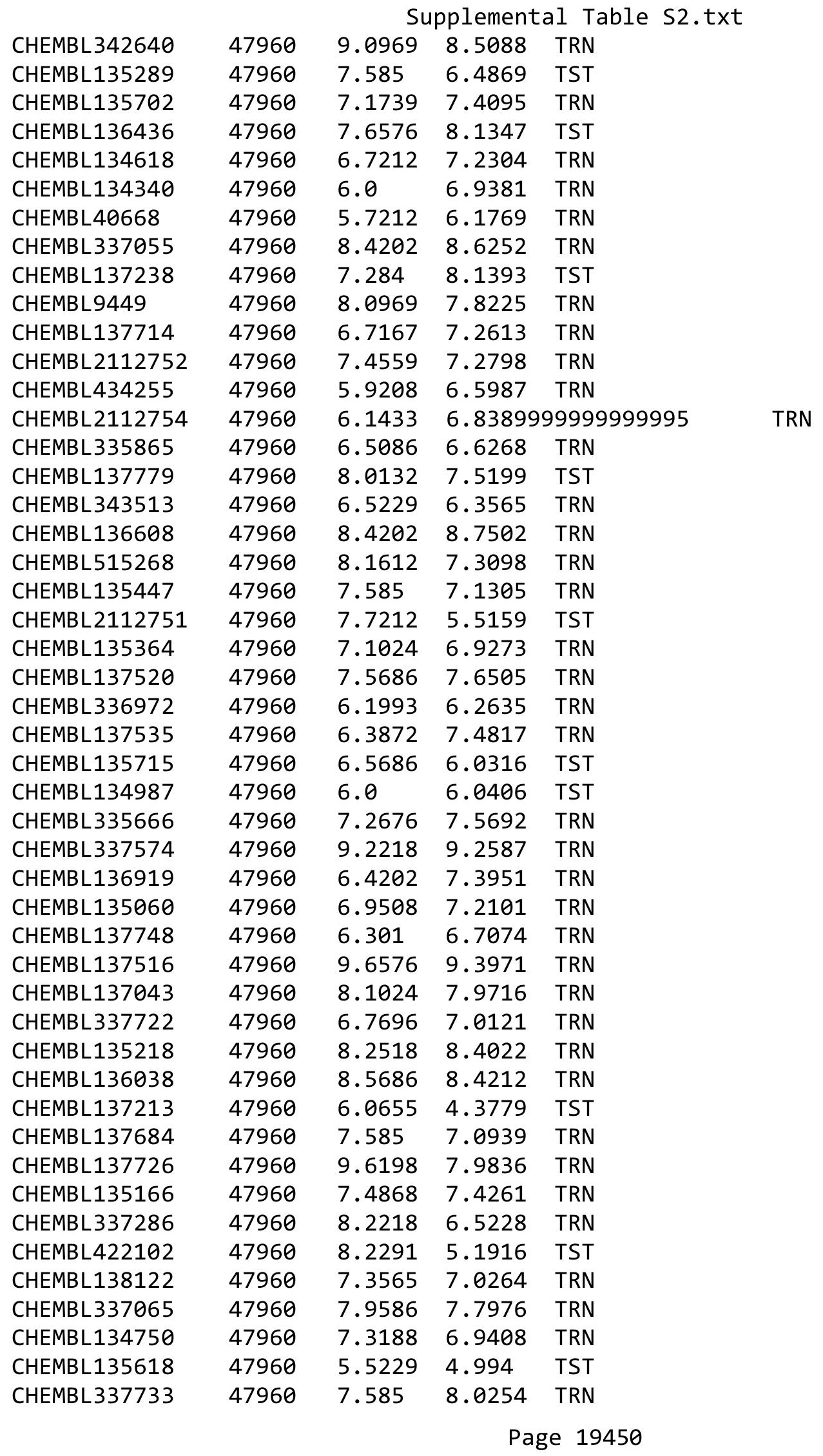




\begin{tabular}{|c|c|c|c|c|c|c|}
\hline & & \multicolumn{5}{|c|}{ Supplemental Table S2.txt } \\
\hline CHEMBL335239 & 47960 & 7.3188 & 7.2721 & TRN & & \\
\hline CHEMBL340975 & 47960 & 5.9586 & 6.6867 & TRN & & \\
\hline CHEMBL136990 & 47960 & 6.8861 & 7.365 & TST & & \\
\hline CHEMBL137066 & 47960 & 6.0 & 6.274 & TRN & & \\
\hline CHEMBL424076 & 47960 & 7.6576 & 7.5632 & TRN & & \\
\hline CHEMBL342614 & 47960 & 7.1427 & 7.0982 & TRN & & \\
\hline CHEMBL137240 & 47960 & 7.3372 & 7.7745 & TRN & & \\
\hline CHEMBL82685 & 47960 & 7.1805 & 7.3651 & TRN & & \\
\hline CHEMBL137567 & 47960 & 8.3098 & 7.6894 & TRN & & \\
\hline CHEMBL135538 & 47960 & 8.2441 & 8.2192 & TRN & & \\
\hline CHEMBL33554 & 47960 & 6.0 & 6.2778 & TRN & & \\
\hline CHEMBL 2112753 & 47960 & 7.8327 & 7.7311 & TRN & & \\
\hline CHEMBL136966 & 47960 & 9.0 & 8.5623 & TRN & & \\
\hline CHEMBL336749 & 47960 & 7.1805 & 7.2133 & TRN & & \\
\hline CHEMBL136412 & 47960 & 8.0132 & 7.4959 & TST & & \\
\hline CHEMBL334735 & 47960 & 6.983 & 6.3552 & TST & & \\
\hline CHEMBL355092 & 47960 & 6.0 & 6.4154 & TST & & \\
\hline CHEMBL313813 & 47960 & 9.2518 & 9.7781 & TST & & \\
\hline CHEMBL 2112750 & 47960 & 6.301 & 7.2139 & TST & & \\
\hline CHEMBL 72546 & 47960 & 5.4949 & 6.4616 & TST & & \\
\hline CHEMBL132699 & 47960 & 5.9706 & 6.3792 & TST & & \\
\hline CHEMBL 2112749 & 47960 & 7.4815 & 7.1395 & TST & & \\
\hline CHEMBL342142 & 47960 & 6.3372 & 6.6897 & TST & & \\
\hline CHEMBL337285 & 47960 & 6.4724 & 5.8941 & TST & & \\
\hline CHEMBL38404 & 47960 & 9.0 & 8.1923 & TST & & \\
\hline CHEMBL137208 & 47960 & 4.9586 & 4.5853 & TST & & \\
\hline CHEMBL132603 & 47960 & 6.6021 & 7.8765 & TST & & \\
\hline CHEMBL346401 & 67518 & 6.3820 & 00000006 & $\partial 1$ & 6.1369 & TRN \\
\hline CHEMBL153100 & 67518 & 4.0 & 4.0238 & TRN & & \\
\hline CHEMBL150554 & 67518 & 4.0 & 4.9232 & TST & & \\
\hline CHEMBL152972 & 67518 & 5.8861 & 5.9537 & TRN & & \\
\hline CHEMBL358009 & 67518 & 4.0 & 4.0878 & TST & & \\
\hline CHEMBL150279 & 67518 & 6.4202 & 6.3871 & TRN & & \\
\hline CHEMBL153407 & 67518 & 6.3188 & 6.3517 & TRN & & \\
\hline CHEMBL347063 & 67518 & 5.9469 & 6.0122 & TRN & & \\
\hline CHEMBL149806 & 67518 & 6.4437 & 6.4224 & TRN & & \\
\hline CHEMBL150290 & 67518 & 5.9788 & 6.0547 & TRN & & \\
\hline CHEMBL152916 & 67518 & 6.0 & 6.0282 & TRN & & \\
\hline CHEMBL153471 & 67518 & 6.3233 & 6.3205 & TRN & & \\
\hline CHEMBL434502 & 67518 & 6.1871 & 6.2184 & TRN & & \\
\hline CHEMBL347560 & 67518 & 6.4034 & 6.4626 & TRN & & \\
\hline CHEMBL 356852 & 67518 & 5.4895 & 5.7551 & TRN & & \\
\hline CHEMBL149803 & 67518 & 5.9431 & 5.9897 & TRN & & \\
\hline CHEMBL152970 & 67518 & 5.6271 & 5.6418 & TRN & & \\
\hline CHEMBL153303 & 67518 & 6.0 & 5.1619 & TST & & \\
\hline CHEMBL155044 & 67518 & 6.0915 & 6.0997 & TRN & & \\
\hline CHEMBL153289 & 67518 & 5.9893 & 5.9222 & TRN & & \\
\hline CHEMBL150594 & 67518 & 7.2218 & 7.2134 & TRN & & \\
\hline
\end{tabular}




\begin{tabular}{|c|c|c|c|c|c|c|}
\hline & & \multicolumn{5}{|c|}{ Supplemental Table S2.txt } \\
\hline CHEMBL150466 & 67518 & 6.2441 & 6.3214 & TRN & & \\
\hline CHEMBL155510 & 67518 & 6.2518 & 6.2044 & TRN & & \\
\hline CHEMBL355980 & 67518 & 5.8386 & 5.8288 & TRN & & \\
\hline CHEMBL154988 & 67518 & 6.8386 & 6.8428 & TRN & & \\
\hline CHEMBL153245 & 67518 & 6.068 & 6.0701 & TRN & & \\
\hline CHEMBL153765 & 67518 & 5.8477 & 5.8743 & TRN & & \\
\hline CHEMBL346215 & 67518 & 6.1675 & 6.0999 & TRN & & \\
\hline CHEMBL153211 & 67518 & 5.2899 & 5.2737 & TRN & & \\
\hline CHEMBL356893 & 67518 & 6.1707 & 6.1977 & TRN & & \\
\hline CHEMBL358938 & 67518 & 5.6904 & 5.7073 & TRN & & \\
\hline CHEMBL150356 & 67518 & 5.6253 & 5.6192 & TRN & & \\
\hline CHEMBL150704 & 67518 & 5.8601 & 5.8775 & TRN & & \\
\hline CHEMBL153709 & 67518 & 6.699 & 6.6672 & TRN & & \\
\hline CHEMBL150879 & 67518 & 5.5229 & 5.5517 & TRN & & \\
\hline CHEMBL348343 & 67518 & 6.2441 & 6.2314 & TRN & & \\
\hline CHEMBL153706 & 67518 & 6.7447 & 6.7419 & TRN & & \\
\hline CHEMBL356635 & 67518 & 4.0 & 3.8939 & TRN & & \\
\hline CHEMBL152993 & 67518 & 6.5686 & 6.5178 & TRN & & \\
\hline CHEMBL150721 & 67518 & 6.6021 & 6.5482 & TRN & & \\
\hline CHEMBL153653 & 67518 & 4.0 & 5.1116 & TST & & \\
\hline CHEMBL356874 & 67518 & 6.9031 & 6.8842 & TRN & & \\
\hline CHEMBL358468 & 67518 & 4.0 & 4.463 & TST & & \\
\hline CHEMBL 2112892 & 67518 & 5.643 & 6.6987 & TST & & \\
\hline CHEMBL 356668 & 67518 & 6.9208 & 6.8593 & TRN & & \\
\hline CHEMBL153113 & 67518 & 5.1993 & 5.1431 & TRN & & \\
\hline CHEMBL153359 & 67518 & 6.2441 & 5.6852 & TST & & \\
\hline CHEMBL152913 & 67518 & 6.0809 & 5.9582 & TST & & \\
\hline CHEMBL358890 & 67518 & 5.6198 & 5.8729 & TST & & \\
\hline CHEMBL150503 & 67518 & 5.16299 & 99999999 & 99 & 5.5811 & TST \\
\hline CHEMBL346455 & 67518 & 6.7959 & 7.0638 & TST & & \\
\hline CHEMBL150593 & 67518 & 4.0 & 4.9933 & TST & & \\
\hline CHEMBL153115 & 67518 & 6.699 & 6.4165 & TST & & \\
\hline CHEMBL153405 & 67518 & 6.5229 & 6.7364 & TST & & \\
\hline CHEMBL1553173 & 688293 & 4.6 & 4.8274 & TRN & & \\
\hline CHEMBL421215 & 688293 & 4.9 & 4.9213 & TST & & \\
\hline CHEMBL1349159 & 688293 & 5.7 & 5.011 & TRN & & \\
\hline CHEMBL1561533 & 688293 & 4.9 & 4.8456 & TRN & & \\
\hline CHEMBL1561913 & 688293 & 4.5 & 5.1445 & TRN & & \\
\hline CHEMBL1475695 & 688293 & 4.9 & 4.8532 & TRN & & \\
\hline CHEMBL 397209 & 688293 & 6.0 & 5.1054 & TST & & \\
\hline CHEMBL1324832 & 688293 & 4.7 & 4.9688 & TRN & & \\
\hline CHEMBL1372505 & 688293 & 4.4 & 4.9258 & TST & & \\
\hline CHEMBL1601200 & 688293 & 5.0 & 5.1952 & TRN & & \\
\hline CHEMBL1537937 & 688293 & 4.5 & 4.9268 & TRN & & \\
\hline CHEMBL1549993 & 688293 & 4.9 & 5.1919 & TRN & & \\
\hline CHEMBL1527008 & 688293 & 4.5 & 4.9278 & TRN & & \\
\hline CHEMBL580819 & 688293 & 5.3 & 4.8144 & TRN & & \\
\hline CHEMBL1329433 & 688293 & 4.7 & 5.0139 & TRN & & \\
\hline
\end{tabular}




\begin{tabular}{|c|c|c|c|c|}
\hline \multicolumn{5}{|c|}{ Supplemental Table S2.txt } \\
\hline CHEMBL1521233 & 688293 & 4.4 & 5.0398 & TRN \\
\hline CHEMBL1467517 & 688293 & 8.2007 & 5.1375 & TRN \\
\hline CHEMBL1415608 & 688293 & 5.6 & 4.995 & TRN \\
\hline CHEMBL1384527 & 688293 & 4.6 & 5.0723 & TRN \\
\hline CHEMBL1431188 & 688293 & 5.3 & 5.0041 & TRN \\
\hline CHEMBL1511260 & 688293 & 4.8 & 5.0121 & TRN \\
\hline CHEMBL1539023 & 688293 & 4.5 & 5.032 & TRN \\
\hline CHEMBL1494710 & 688293 & 6.1 & 5.2553 & TRN \\
\hline CHEMBL1301860 & 688293 & 4.4 & 5.1446 & TRN \\
\hline CHEMBL1488728 & 688293 & 4.9 & 4.8257 & TRN \\
\hline CHEMBL1531860 & 688293 & 4.9 & 5.0516 & TRN \\
\hline CHEMBL1361706 & 688293 & 4.6 & 4.9693 & TRN \\
\hline CHEMBL1428184 & 688293 & 4.5 & 4.9547 & TRN \\
\hline CHEMBL1590261 & 688293 & 4.9 & 4.7371 & TRN \\
\hline CHEMBL1545416 & 688293 & 4.6 & 4.9722 & TST \\
\hline CHEMBL1389972 & 688293 & 5.4 & 5.0481 & TRN \\
\hline CHEMBL1471358 & 688293 & 4.5 & 5.0153 & TRN \\
\hline CHEMBL1421557 & 688293 & 4.8 & 4.8724 & TRN \\
\hline CHEMBL1587570 & 688293 & 4.5 & 5.0158 & TRN \\
\hline CHEMBL1464442 & 688293 & 4.4 & 5.0038 & TRN \\
\hline CHEMBL1482816 & 688293 & 4.5 & 5.0141 & TRN \\
\hline CHEMBL1379297 & 688293 & 5.7 & 5.1656 & TRN \\
\hline CHEMBL1559493 & 688293 & 4.9 & 4.949 & TRN \\
\hline CHEMBL1324121 & 688293 & 4.8 & 4.9021 & TRN \\
\hline CHEMBL1319748 & 688293 & 8.0 & 5.0972 & TRN \\
\hline CHEMBL1537214 & 688293 & 5.0 & 5.0573 & TRN \\
\hline CHEMBL1387022 & 688293 & 4.7 & 4.99 & TRN \\
\hline CHEMBL1361692 & 688293 & 4.5 & 4.8126 & TRN \\
\hline CHEMBL1541257 & 688293 & 4.8 & 4.9218 & TST \\
\hline CHEMBL1378255 & 688293 & 4.6 & 5.0849 & TRN \\
\hline CHEMBL1544031 & 688293 & 5.6 & 4.936 & TRN \\
\hline CHEMBL1489215 & 688293 & 5.1 & 5.0401 & TRN \\
\hline CHEMBL1424900 & 688293 & 4.6 & 5.1981 & TRN \\
\hline CHEMBL1601324 & 688293 & 4.5 & 5.1901 & TRN \\
\hline CHEMBL1562203 & 688293 & 4.5 & 5.1024 & TRN \\
\hline CHEMBL1555369 & 688293 & 4.9 & 5.0296 & TST \\
\hline CHEMBL1571560 & 688293 & 4.6 & 4.8691 & TST \\
\hline CHEMBL1601294 & 688293 & 4.9 & 5.0782 & TRN \\
\hline CHEMBL1355139 & 688293 & 4.5 & 4.8364 & TRN \\
\hline CHEMBL1606330 & 688293 & 4.6 & 4.9893 & TST \\
\hline CHEMBL1564891 & 688293 & 4.8 & 4.7362 & TRN \\
\hline CHEMBL1372201 & 688293 & 4.6 & 4.825 & TRN \\
\hline CHEMBL1434411 & 688293 & 4.4 & 4.815 & TRN \\
\hline CHEMBL1507227 & 688293 & 5.1 & 5.0073 & TRN \\
\hline CHEMBL1391062 & 688293 & 5.1 & 4.9681 & TRN \\
\hline CHEMBL1524299 & 688293 & 4.8 & 5.1296 & TRN \\
\hline CHEMBL1467677 & 688293 & 4.5 & 5.1823 & TRN \\
\hline CHEMBL1612611 & 688293 & 4.9 & 4.8391 & TRN \\
\hline
\end{tabular}




\begin{tabular}{|c|c|c|c|c|}
\hline \multicolumn{5}{|c|}{ Supplemental Table s2.txt } \\
\hline CHEMBL577635 & 688293 & 5.7 & 5.0793 & TST \\
\hline CHEMBL1351418 & 688293 & 5.2 & 5.0187 & TRN \\
\hline CHEMBL1374801 & 688293 & 5.0 & 5.1376 & TRN \\
\hline CHEMBL1530519 & 688293 & 7.4001 & 4.9308 & TRN \\
\hline CHEMBL1499130 & 688293 & 4.8 & 5.0232 & TRN \\
\hline CHEMBL1611186 & 688293 & 4.7 & 4.8496 & TRN \\
\hline CHEMBL1584031 & 688293 & 4.8 & 5.1945 & TRN \\
\hline CHEMBL1345903 & 688293 & 6.0 & 5.0579 & TRN \\
\hline CHEMBL1587226 & 688293 & 4.6 & 4.9722 & TRN \\
\hline CHEMBL1379900 & 688293 & 4.6 & 4.9004 & TRN \\
\hline CHEMBL1448030 & 688293 & 5.1 & 5.1391 & TRN \\
\hline CHEMBL1412697 & 688293 & 4.8 & 5.0359 & TRN \\
\hline CHEMBL1341087 & 688293 & 4.9 & 4.9247 & TRN \\
\hline CHEMBL1385434 & 688293 & 5.1 & 5.2102 & TRN \\
\hline CHEMBL1535317 & 688293 & 4.8 & 5.1431 & TRN \\
\hline CHEMBL1326618 & 688293 & 5.0 & 4.9969 & TRN \\
\hline CHEMBL1256719 & 688293 & 5.0 & 5.0976 & TST \\
\hline CHEMBL1485219 & 688293 & 4.7 & 4.9992 & TRN \\
\hline CHEMBL1321438 & 688293 & 6.0 & 4.9089 & TRN \\
\hline CHEMBL1393919 & 688293 & 4.6 & 4.9412 & TRN \\
\hline CHEMBL1312565 & 688293 & 6.0 & 5.1999 & TRN \\
\hline CHEMBL495068 & 688293 & 4.8 & 4.819 & TRN \\
\hline CHEMBL1522306 & 688293 & 7.8996 & 5.0964 & TRN \\
\hline CHEMBL1366537 & 688293 & 4.9 & 4.9145 & TRN \\
\hline CHEMBL23327 & 688293 & 4.5 & 4.8112 & TST \\
\hline CHEMBL1308536 & 688293 & 4.4 & 4.836 & TST \\
\hline CHEMBL1452403 & 688293 & 5.8 & 5.0148 & TRN \\
\hline CHEMBL1550252 & 688293 & 4.7 & 5.0374 & TRN \\
\hline CHEMBL1453475 & 688293 & 6.0 & 5.1163 & TRN \\
\hline CHEMBL1385471 & 688293 & 4.6 & 5.0824 & TST \\
\hline CHEMBL1384258 & 688293 & 6.6 & 5.0383 & TRN \\
\hline CHEMBL1521545 & 688293 & 4.5 & 4.8144 & TRN \\
\hline CHEMBL1485968 & 688293 & 8.4949 & 5.0984 & TST \\
\hline CHEMBL574181 & 688293 & 4.8 & 4.9767 & TST \\
\hline CHEMBL1401673 & 688293 & 4.8 & 5.1776 & TRN \\
\hline CHEMBL1369497 & 688293 & 4.4 & 4.9221 & TST \\
\hline CHEMBL1371239 & 688293 & 4.8 & 5.1185 & TRN \\
\hline CHEMBL1332207 & 688293 & 4.6 & 5.03 & TRN \\
\hline CHEMBL1583589 & 688293 & 4.4 & 5.0583 & TRN \\
\hline CHEMBL1362027 & 688293 & 7.1002 & 5.2531 & TRN \\
\hline CHEMBL1978564 & 688293 & 4.5 & 4.8872 & TRN \\
\hline CHEMBL1507894 & 688293 & 4.4 & 4.9837 & TRN \\
\hline CHEMBL1379036 & 688293 & 4.7 & 4.9816 & TRN \\
\hline CHEMBL 86676 & 688293 & 4.4 & 4.9483 & TST \\
\hline CHEMBL3197924 & 688293 & 4.8 & 4.7544 & TRN \\
\hline CHEMBL1536158 & 688293 & 4.7 & 4.9812 & TRN \\
\hline CHEMBL502936 & 688293 & 4.7 & 5.0925 & TRN \\
\hline CHEMBL1528083 & 688293 & 4.7 & 4.8325 & TST \\
\hline
\end{tabular}




\begin{tabular}{|c|c|c|c|c|c|}
\hline \multicolumn{6}{|c|}{ Supplemental Table s2.txt } \\
\hline CHEMBL1417991 & 688293 & 6.0 & 4.8808 & TRN & \\
\hline CHEMBL1426679 & 688293 & 4.6 & 4.9544 & TRN & \\
\hline CHEMBL412059 & 688293 & 5.7 & 5.1861 & TRN & \\
\hline CHEMBL1328299 & 688293 & 4.8 & 4.8599 & TRN & \\
\hline CHEMBL1365692 & 688293 & 4.9 & 4.9286 & TRN & \\
\hline CHEMBL3191783 & 688293 & 4.9 & 4.9784 & TST & \\
\hline CHEMBL 3197322 & 688293 & 4.8 & 5.0514 & TRN & \\
\hline CHEMBL1433117 & 688293 & 4.8 & 5.025 & TRN & \\
\hline CHEMBL1488030 & 688293 & 5.8 & 5.0982 & TRN & \\
\hline CHEMBL1482905 & 688293 & 6.7001 & 5.1113 & TST & \\
\hline CHEMBL1310609 & 688293 & 4.6 & 4.9753 & TRN & \\
\hline CHEMBL1596698 & 688293 & 5.4 & 5.0393 & TRN & \\
\hline CHEMBL1496083 & 688293 & 5.0 & 4.92 & TRN & \\
\hline CHEMBL1521722 & 688293 & 4.5 & 5.0915 & TRN & \\
\hline CHEMBL1568735 & 688293 & 4.4 & 4.7498 & TRN & \\
\hline CHEMBL1369990 & 688293 & 5.2 & 5.1251 & TST & \\
\hline CHEMBL1497920 & 688293 & 4.4 & 5.0504 & TRN & \\
\hline CHEMBL1498363 & 688293 & 4.8 & 4.805 & TRN & \\
\hline CHEMBL1362196 & 688293 & 5.0 & 5.0832 & TRN & \\
\hline CHEMBL1549692 & 688293 & 4.8 & 4.8544 & TRN & \\
\hline CHEMBL1429119 & 688293 & 6.4 & 4.9403 & TRN & \\
\hline CHEMBL1430859 & 688293 & 6.7001 & 4.9069 & TRN & \\
\hline CHEMBL1462950 & 688293 & 4.6 & 4.9498 & TRN & \\
\hline CHEMBL1488097 & 688293 & 4.4 & 4.8889 & TRN & \\
\hline CHEMBL1518903 & 688293 & 4.4 & 4.9218 & TRN & \\
\hline CHEMBL1529538 & 688293 & 4.9 & 4.9587 & TST & \\
\hline CHEMBL1597230 & 688293 & 5.5 & 5.1202 & TRN & \\
\hline CHEMBL1538485 & 688293 & 4.5 & 5.0901 & TRN & \\
\hline CHEMBL1469341 & 688293 & 4.5 & 5.03100 & 0000000001 & TST \\
\hline CHEMBL1369588 & 688293 & 8.6021 & 4.8295 & TST & \\
\hline CHEMBL1603585 & 688293 & 4.8 & 4.8942 & TRN & \\
\hline CHEMBL1397636 & 688293 & 6.0 & 4.8562 & TRN & \\
\hline CHEMBL1611235 & 688293 & 4.7 & 4.7907 & TRN & \\
\hline CHEMBL1390986 & 688293 & 5.5 & 5.1587 & TRN & \\
\hline CHEMBL1382629 & 688293 & 4.5 & 5.1802 & TST & \\
\hline CHEMBL1569027 & 688293 & 4.6 & 5.1153 & TRN & \\
\hline CHEMBL17331 & 688293 & 4.7 & 4.846 & TST & \\
\hline CHEMBL1503818 & 688293 & 4.8 & 5.1302 & TRN & \\
\hline CHEMBL1324727 & 688293 & 4.5 & 4.8554 & TRN & \\
\hline CHEMBL1612285 & 688293 & 4.4 & 4.9859 & TRN & \\
\hline CHEMBL1523890 & 688293 & 4.4 & 4.8317 & TRN & \\
\hline CHEMBL1345001 & 688293 & 4.9 & 4.9962 & TRN & \\
\hline CHEMBL1394044 & 688293 & 7.4001 & 5.3222 & TRN & \\
\hline CHEMBL1586660 & 688293 & 4.4 & 5.0466 & TRN & \\
\hline CHEMBL1470058 & 688293 & 4.8 & 5.0328 & TRN & \\
\hline CHEMBL1574375 & 688293 & 4.8 & 5.0333 & TRN & \\
\hline CHEMBL1539600 & 688293 & 5.2 & 5.0256 & TRN & \\
\hline CHEMBL1355256 & 688293 & 4.9 & 4.8048 & TRN & \\
\hline
\end{tabular}




\begin{tabular}{|c|c|c|c|c|}
\hline \multicolumn{5}{|c|}{ Supplemental Table S2.txt } \\
\hline CHEMBL1437226 & 688293 & 4.4 & 4.8765 & TRN \\
\hline CHEMBL1502228 & 688293 & 4.6 & 4.7534 & TRN \\
\hline CHEMBL1432019 & 688293 & 4.5 & 5.001 & TRN \\
\hline CHEMBL1584074 & 688293 & 4.4 & 5.1077 & TRN \\
\hline CHEMBL1596335 & 688293 & 5.1 & 5.0673 & TST \\
\hline CHEMBL1524034 & 688293 & 4.5 & 5.0096 & TRN \\
\hline CHEMBL1568850 & 688293 & 4.7 & 4.9553 & TRN \\
\hline CHEMBL1384729 & 688293 & 5.1 & 4.8625 & TRN \\
\hline CHEMBL1346978 & 688293 & 5.8 & 5.1902 & TST \\
\hline CHEMBL1565033 & 688293 & 5.3 & 5.065 & TRN \\
\hline CHEMBL1568714 & 688293 & 4.5 & 4.9861 & TRN \\
\hline CHEMBL1332176 & 688293 & 5.1 & 5.0713 & TRN \\
\hline CHEMBL1256686 & 688293 & 5.3 & 5.0878 & TST \\
\hline CHEMBL1324563 & 688293 & 5.6 & 4.9709 & TRN \\
\hline CHEMBL1505151 & 688293 & 10.0 & 4.9115 & TRN \\
\hline CHEMBL1500597 & 688293 & 4.9 & 5.0538 & TRN \\
\hline CHEMBL1383031 & 688293 & 5.7 & 5.1333 & TRN \\
\hline CHEMBL1494654 & 688293 & 8.0 & 5.0282 & TRN \\
\hline CHEMBL1581420 & 688293 & 4.6 & 4.945 & TRN \\
\hline CHEMBL1424916 & 688293 & 4.9 & 5.125 & TRN \\
\hline CHEMBL1430208 & 688293 & 4.4 & 4.8793 & TRN \\
\hline CHEMBL1457907 & 688293 & 4.6 & 4.8135 & TRN \\
\hline CHEMBL1468507 & 688293 & 5.0 & 4.9884 & TST \\
\hline CHEMBL1388376 & 688293 & 4.9 & 4.8705 & TST \\
\hline CHEMBL1968355 & 688293 & 6.0 & 4.8137 & TST \\
\hline CHEMBL1712082 & 688293 & 4.5 & 5.1334 & TST \\
\hline CHEMBL1364184 & 688293 & 4.5 & 4.9547 & TRN \\
\hline CHEMBL1495909 & 688293 & 4.8 & 5.088 & TRN \\
\hline CHEMBL491953 & 688293 & 4.8 & 4.7809 & TRN \\
\hline CHEMBL541229 & 688293 & 9.0 & 4.9522 & TST \\
\hline CHEMBL1525668 & 688293 & 4.8 & 5.0466 & TRN \\
\hline CHEMBL1446013 & 688293 & 4.6 & 5.0355 & TRN \\
\hline CHEMBL1320220 & 688293 & 4.5 & 4.9703 & TRN \\
\hline CHEMBL1335059 & 688293 & 4.6 & 4.7856 & TRN \\
\hline CHEMBL1408765 & 688293 & 5.4 & 5.0056 & TST \\
\hline CHEMBL1596703 & 688293 & 4.5 & 5.1389 & TST \\
\hline CHEMBL1305471 & 688293 & 4.8 & 4.8966 & TRN \\
\hline CHEMBL1408273 & 688293 & 4.4 & 5.2014 & TRN \\
\hline CHEMBL1348949 & 688293 & 4.8 & 4.8789 & TRN \\
\hline CHEMBL1307923 & 688293 & 4.6 & 4.976 & TST \\
\hline CHEMBL1414263 & 688293 & 4.9 & 4.9048 & TST \\
\hline CHEMBL1317916 & 688293 & 9.0 & 4.9918 & TST \\
\hline CHEMBL75967 & 688293 & 7.6003 & 4.9582 & TST \\
\hline CHEMBL1377135 & 688293 & 4.7 & 4.9157 & TRN \\
\hline CHEMBL1417976 & 688293 & 4.8 & 5.0644 & TRN \\
\hline CHEMBL1571785 & 688293 & 4.6 & 4.9949 & TRN \\
\hline CHEMBL1376444 & 688293 & 6.5 & 4.8781 & TRN \\
\hline CHEMBL1608535 & 688293 & 4.6 & 5.0325 & TRN \\
\hline
\end{tabular}




\begin{tabular}{|c|c|c|c|c|c|}
\hline \multicolumn{6}{|c|}{ Supplemental Table S2.txt } \\
\hline CHEMBL1440311 & 688293 & 4.5 & 4.9773 & TRN & \\
\hline CHEMBL1355408 & 688293 & 4.7 & 4.8631 & TRN & \\
\hline CHEMBL1544161 & 688293 & 4.4 & 5.0073 & TRN & \\
\hline CHEMBL551842 & 688293 & 4.6 & 4.989 & TST & \\
\hline CHEMBL1563438 & 688293 & 4.4 & 4.9466 & TRN & \\
\hline CHEMBL1581337 & 688293 & 4.4 & 4.888 & TRN & \\
\hline CHEMBL1601920 & 688293 & 5.1 & 4.9561 & TRN & \\
\hline CHEMBL1522364 & 688293 & 5.0 & 5.0293 & TRN & \\
\hline CHEMBL1423096 & 688293 & 4.4 & 4.7476 & TST & \\
\hline CHEMBL1609686 & 688293 & 4.4 & 5.1267 & TRN & \\
\hline CHEMBL1474302 & 688293 & 4.7 & 4.923 & TRN & \\
\hline CHEMBL1587932 & 688293 & 5.3 & 4.9712 & TRN & \\
\hline CHEMBL1491977 & 688293 & 4.8 & 4.8689 & TRN & \\
\hline CHEMBL1586416 & 688293 & 5.0 & 4.8785 & TST & \\
\hline CHEMBL1703229 & 688293 & 5.4 & 4.9422 & TRN & \\
\hline CHEMBL1546102 & 688293 & 4.6 & 4.7863 & TRN & \\
\hline CHEMBL1485132 & 688293 & 5.1 & 4.8212 & TRN & \\
\hline CHEMBL1299529 & 688293 & 5.1 & 5.0558 & TRN & \\
\hline CHEMBL1461791 & 688293 & 4.9 & $5.0310 e$ & 0000000001 & TRN \\
\hline CHEMBL1450380 & 688293 & 7.8013 & 4.825 & TRN & \\
\hline CHEMBL1345867 & 688293 & 5.7 & 4.9858 & TRN & \\
\hline CHEMBL1608647 & 688293 & 4.5 & 5.0652 & TRN & \\
\hline CHEMBL1451483 & 688293 & 4.7 & 5.0208 & TRN & \\
\hline CHEMBL1302965 & 688293 & 4.4 & 5.0958 & TRN & \\
\hline CHEMBL492122 & 688293 & 4.6 & 4.8921 & TRN & \\
\hline CHEMBL1446361 & 688293 & 4.6 & 5.0661 & TRN & \\
\hline CHEMBL1562034 & 688293 & 4.4 & 5.17299 & 9999999999 & TRN \\
\hline CHEMBL1588977 & 688293 & 4.8 & 4.8645 & TRN & \\
\hline CHEMBL1443713 & 688293 & 4.7 & 4.9083 & TRN & \\
\hline CHEMBL1304204 & 688293 & 4.9 & 5.1593 & TRN & \\
\hline CHEMBL1523550 & 688293 & 4.7 & 4.8805 & TRN & \\
\hline CHEMBL1582353 & 688293 & 4.5 & 4.9191 & TRN & \\
\hline CHEMBL1527737 & 688293 & 4.4 & 4.90306 & 00000000005 & TRN \\
\hline CHEMBL1302479 & 688293 & 4.7 & 5.0459 & TRN & \\
\hline CHEMBL479014 & 688293 & 4.6 & 4.90306 & 30000000005 & TST \\
\hline CHEMBL1569096 & 688293 & 5.5 & 5.0957 & TRN & \\
\hline CHEMBL1981675 & 688293 & 4.9 & 5.0921 & TST & \\
\hline CHEMBL1517765 & 688293 & 4.6 & 5.1445 & TST & \\
\hline CHEMBL1485575 & 688293 & 4.6 & 4.9518 & TRN & \\
\hline CHEMBL1484189 & 688293 & 4.7 & 5.0057 & TST & \\
\hline CHEMBL1522131 & 688293 & 4.4 & 4.9765 & TRN & \\
\hline CHEMBL1417771 & 688293 & 4.8 & 4.773 & TRN & \\
\hline CHEMBL1559230 & 688293 & 4.5 & 4.9901 & TRN & \\
\hline CHEMBL1485781 & 688293 & 4.4 & 4.8562 & TRN & \\
\hline CHEMBL1603834 & 688293 & 4.6 & 5.0678 & TRN & \\
\hline CHEMBL1487887 & 688293 & 4.5 & 4.855 & TRN & \\
\hline CHEMBL1441425 & 688293 & 4.7 & 4.9422 & TRN & \\
\hline CHEMBL1479757 & 688293 & 4.5 & 5.1979 & TRN & \\
\hline
\end{tabular}




\begin{tabular}{|c|c|c|c|c|}
\hline \multirow[b]{2}{*}{ CHEMBL1586500 } & \multicolumn{4}{|c|}{ Supplemental Table S2.txt } \\
\hline & 688293 & 4.7 & 5.045 & TRN \\
\hline CHEMBL1532928 & 688293 & 4.5 & 4.7148 & TRN \\
\hline CHEMBL1588325 & 688293 & 4.9 & 4.9864 & TRN \\
\hline CHEMBL1606811 & 688293 & 5.9 & 5.0749 & TRN \\
\hline CHEMBL1511011 & 688293 & 5.5 & 5.0576 & TRN \\
\hline CHEMBL1498028 & 688293 & 4.8 & 5.1361 & TRN \\
\hline CHEMBL1309538 & 688293 & 4.7 & 5.0783 & TRN \\
\hline CHEMBL1484081 & 688293 & 5.5 & 4.8203 & TRN \\
\hline CHEMBL1342529 & 688293 & 7.5003 & 5.0688 & TRN \\
\hline CHEMBL1383554 & 688293 & 4.6 & 5.079 & TRN \\
\hline CHEMBL1482105 & 688293 & 4.6 & 4.7456 & TRN \\
\hline CHEMBL1336039 & 688293 & 4.6 & 4.961 & TRN \\
\hline CHEMBL1612575 & 688293 & 4.4 & 5.1421 & TRN \\
\hline CHEMBL1602975 & 688293 & 4.9 & 4.8433 & TRN \\
\hline CHEMBL3214340 & 688293 & 4.6 & 5.0156 & TST \\
\hline CHEMBL1405602 & 688293 & 4.6 & 4.8243 & TRN \\
\hline CHEMBL1355203 & 688293 & 4.4 & 4.7912 & TRN \\
\hline CHEMBL1336950 & 688293 & 5.3 & 5.0675 & TRN \\
\hline CHEMBL 3213656 & 688293 & 4.7 & 4.827 & TST \\
\hline CHEMBL1403333 & 688293 & 5.0 & 4.8233 & TRN \\
\hline CHEMBL1542609 & 688293 & 7.699 & 5.3035 & TRN \\
\hline CHEMBL1308140 & 688293 & 4.8 & 5.0077 & TRN \\
\hline CHEMBL1533853 & 688293 & 4.9 & 4.8448 & TRN \\
\hline CHEMBL1407308 & 688293 & 4.4 & 4.8496 & TRN \\
\hline CHEMBL 1604588 & 688293 & 5.0 & 4.9691 & TRN \\
\hline CHEMBL1313927 & 688293 & 4.5 & 5.0446 & TRN \\
\hline CHEMBL1343768 & 688293 & 5.7 & 5.2779 & TRN \\
\hline CHEMBL1485331 & 688293 & 5.0 & 4.9444 & TRN \\
\hline CHEMBL1424250 & 688293 & 5.0 & 5.1756 & TRN \\
\hline CHEMBL8747 & 688293 & 4.8 & 4.8036 & TRN \\
\hline CHEMBL1591635 & 688293 & 4.7 & 5.0309 & TRN \\
\hline CHEMBL1507882 & 688293 & 4.8 & 5.0038 & TRN \\
\hline CHEMBL1546090 & 688293 & 5.4 & 5.1635 & TRN \\
\hline CHEMBL1520940 & 688293 & 4.9 & 4.9364 & TRN \\
\hline CHEMBL1438454 & 688293 & 4.7 & 4.9167 & TST \\
\hline CHEMBL1584211 & 688293 & 4.8 & 4.9282 & TRN \\
\hline CHEMBL1437718 & 688293 & 4.8 & 4.8467 & TRN \\
\hline CHEMBL1375546 & 688293 & 4.6 & 4.9025 & TRN \\
\hline CHEMBL1431278 & 688293 & 4.6 & 5.0799 & TRN \\
\hline CHEMBL1550515 & 688293 & 5.0 & 5.1395 & TRN \\
\hline CHEMBL1372513 & 688293 & 4.6 & 4.8316 & TRN \\
\hline CHEMBL1302713 & 688293 & 4.5 & 5.1194 & TRN \\
\hline CHEMBL1337039 & 688293 & 4.5 & 4.8782 & TRN \\
\hline CHEMBL 3192682 & 688293 & 7.8013 & 5.087 & TRN \\
\hline CHEMBL1560810 & 688293 & 7.8013 & 5.2168 & TRN \\
\hline CHEMBL1347816 & 688293 & 4.9 & 5.0158 & TRN \\
\hline CHEMBL1394764 & 688293 & 4.7 & 5.1221 & TST \\
\hline CHEMBL1550241 & 688293 & 4.8 & 4.9726 & TRN \\
\hline
\end{tabular}




\begin{tabular}{|c|c|c|c|c|}
\hline \multicolumn{5}{|c|}{ Supplemental Table S2.txt } \\
\hline CHEMBL1330993 & 688293 & 6.1 & 5.1176 & TRN \\
\hline CHEMBL1313504 & 688293 & 4.4 & 5.0931 & TRN \\
\hline CHEMBL1436715 & 688293 & 4.6 & 4.8236 & TRN \\
\hline CHEMBL1580903 & 688293 & 4.4 & 5.0095 & TRN \\
\hline CHEMBL1350028 & 688293 & 4.4 & 5.063 & TRN \\
\hline CHEMBL1429929 & 688293 & 5.7 & 4.9387 & TRN \\
\hline CHEMBL1612696 & 688293 & 4.8 & 5.1098 & TRN \\
\hline CHEMBL1535402 & 688293 & 5.4 & 4.9937 & TST \\
\hline CHEMBL1451023 & 688293 & 4.5 & 5.0321 & TRN \\
\hline CHEMBL1600475 & 688293 & 4.6 & 4.987 & TRN \\
\hline CHEMBL1541030 & 688293 & 4.6 & 4.9693 & TRN \\
\hline CHEMBL1388275 & 688293 & 4.7 & 5.0348 & TRN \\
\hline CHEMBL1576558 & 688293 & 4.9 & 4.9011 & TRN \\
\hline CHEMBL44 & 688293 & 6.0 & 4.9169 & TRN \\
\hline CHEMBL1380507 & 688293 & 4.7 & 4.9193 & TRN \\
\hline CHEMBL1605749 & 688293 & 5.0 & 5.0779 & TRN \\
\hline CHEMBL1340620 & 688293 & 5.0 & 4.9719 & TRN \\
\hline CHEMBL1540060 & 688293 & 5.6 & 5.0201 & TRN \\
\hline CHEMBL1330698 & 688293 & 5.4 & 4.9481 & TRN \\
\hline CHEMBL1541994 & 688293 & 4.5 & 5.024 & TST \\
\hline CHEMBL343732 & 688293 & 4.9 & 5.0279 & TRN \\
\hline CHEMBL1341221 & 688293 & 5.3 & 4.7611 & TRN \\
\hline CHEMBL1430352 & 688293 & 4.4 & 4.934 & TRN \\
\hline CHEMBL1256019 & 688293 & 8.2007 & 5.1875 & TST \\
\hline CHEMBL1567743 & 688293 & 4.4 & 4.9549 & TRN \\
\hline CHEMBL1533142 & 688293 & 8.301 & 5.0264 & TRN \\
\hline CHEMBL1448207 & 688293 & 5.5 & 4.9564 & TRN \\
\hline CHEMBL1479781 & 688293 & 4.6 & 5.1763 & TRN \\
\hline CHEMBL1369040 & 688293 & 4.9 & 5.0158 & TRN \\
\hline CHEMBL1323800 & 688293 & 4.5 & 5.0611 & TRN \\
\hline CHEMBL1327225 & 688293 & 4.7 & 4.9923 & TST \\
\hline CHEMBL1412662 & 688293 & 4.8 & 5.1107 & TRN \\
\hline CHEMBL1451101 & 688293 & 4.8 & 4.744 & TRN \\
\hline CHEMBL1612483 & 688293 & 4.7 & 4.7961 & TRN \\
\hline CHEMBL1505210 & 688293 & 4.9 & 4.6787 & TRN \\
\hline CHEMBL1445388 & 688293 & 5.1 & 5.1306 & TRN \\
\hline CHEMBL 388676 & 688293 & 4.8 & 5.0683 & TST \\
\hline CHEMBL1605497 & 688293 & 5.8 & 5.1856 & TRN \\
\hline CHEMBL1468928 & 688293 & 5.5 & 4.9103 & TRN \\
\hline CHEMBL1386210 & 688293 & 4.7 & 5.0598 & TST \\
\hline CHEMBL1423750 & 688293 & 4.4 & 5.1074 & TRN \\
\hline CHEMBL1450621 & 688293 & 4.6 & 5.1694 & TRN \\
\hline CHEMBL1544307 & 688293 & 4.7 & 4.9442 & TRN \\
\hline CHEMBL1348847 & 688293 & 4.5 & 4.7307 & TRN \\
\hline CHEMBL1534302 & 688293 & 4.6 & 4.9692 & TRN \\
\hline CHEMBL1477697 & 688293 & 4.6 & 4.8722 & TRN \\
\hline CHEMBL1561850 & 688293 & 5.5 & 4.8358 & TRN \\
\hline CHEMBL1583122 & 688293 & 7.8996 & 5.0369 & TRN \\
\hline
\end{tabular}




\begin{tabular}{|c|c|c|c|c|c|}
\hline \\
\hline CHEMBL1314890 & 688293 & 4.6 & 5.0254 & TST & \\
\hline CHEMBL1599779 & 688293 & 4.4 & 5.0731 & TRN & \\
\hline CHEMBL1353834 & 688293 & 4.5 & 5.0627 & TRN & \\
\hline CHEMBL1575603 & 688293 & 4.6 & 4.7907 & TRN & \\
\hline CHEMBL1401831 & 688293 & 4.8 & 5.107 & TRN & \\
\hline CHEMBL1305533 & 688293 & 6.0 & 5.2144 & TRN & \\
\hline CHEMBL1595002 & 688293 & 4.6 & 4.7624 & TRN & \\
\hline CHEMBL1603688 & 688293 & 4.8 & 5.0005 & TST & \\
\hline CHEMBL1424699 & 688293 & 4.4 & 4.9773 & TRN & \\
\hline CHEMBL1305316 & 688293 & 4.4 & 5.0258 & TRN & \\
\hline CHEMBL1430766 & 688293 & 5.2 & 5.1584 & TRN & \\
\hline CHEMBL1443205 & 688293 & 4.9 & 4.8511 & TRN & \\
\hline CHEMBL1334083 & 688293 & 4.5 & 5.2014 & TRN & \\
\hline CHEMBL1270169 & 688293 & 5.4 & 4.9955 & TRN & \\
\hline CHEMBL1353176 & 688293 & 4.8 & 5.0922 & TRN & \\
\hline CHEMBL1545114 & 688293 & 5.0 & 4.836 & TRN & \\
\hline CHEMBL57376 & 688293 & 8.8861 & 4.9363 & TRN & \\
\hline CHEMBL1443795 & 688293 & 4.8 & 5.0429 & TRN & \\
\hline CHEMBL1429819 & 688293 & 4.5 & 5.0274 & TRN & \\
\hline CHEMBL1545361 & 688293 & 4.8 & 4.7634 & TRN & \\
\hline CHEMBL1415808 & 688293 & 8.2007 & 5.0791 & TRN & \\
\hline CHEMBL1550109 & 688293 & 4.6 & 4.9475 & TRN & \\
\hline CHEMBL1506804 & 688293 & 4.6 & 5.2 & TRN & \\
\hline CHEMBL1411108 & 688293 & 4.8 & 5.1061 & TRN & \\
\hline CHEMBL60718 & 688293 & 4.7 & 5.0397 & TRN & \\
\hline CHEMBL1379398 & 688293 & 4.4 & 4.80399 & 9999999999 & TRN \\
\hline CHEMBL1479771 & 688293 & 5.2 & 5.0641 & TST & \\
\hline CHEMBL1414563 & 688293 & 4.6 & 4.9055 & TST & \\
\hline CHEMBL1405669 & 688293 & 4.8 & 4.9803 & TRN & \\
\hline CHEMBL1334586 & 688293 & 4.6 & 5.0139 & TST & \\
\hline CHEMBL1366393 & 688293 & 5.3 & 4.6937 & TRN & \\
\hline CHEMBL1549179 & 688293 & 4.9 & 5.0169 & TRN & \\
\hline CHEMBL1605917 & 688293 & 4.5 & 4.9028 & TRN & \\
\hline CHEMBL1442131 & 688293 & 6.2 & 5.1925 & TRN & \\
\hline CHEMBL1515355 & 688293 & 4.7 & 4.8044 & TRN & \\
\hline CHEMBL1415251 & 688293 & 4.5 & 5.1123 & TRN & \\
\hline CHEMBL1530795 & 688293 & 4.5 & 4.8738 & TST & \\
\hline CHEMBL1338000 & 688293 & 4.6 & 5.0555 & TRN & \\
\hline CHEMBL1477982 & 688293 & 5.3 & 4.8746 & TRN & \\
\hline CHEMBL1592352 & 688293 & 5.3 & 5.1145 & TST & \\
\hline CHEMBL1360934 & 688293 & 4.9 & 4.9081 & TRN & \\
\hline CHEMBL1303411 & 688293 & 4.6 & 5.1044 & TRN & \\
\hline CHEMBL1388937 & 688293 & 4.4 & 5.1034 & TRN & \\
\hline CHEMBL1396384 & 688293 & 4.8 & 4.7937 & TRN & \\
\hline CHEMBL1410099 & 688293 & 4.7 & 5.0466 & TRN & \\
\hline CHEMBL375270 & 688293 & 4.6 & 4.9441 & TRN & \\
\hline CHEMBL1355307 & 688293 & 4.4 & 4.7736 & TRN & \\
\hline CHEMBL1410491 & 688293 & 4.9 & 5.0214 & TST & \\
\hline & & & & 460 & \\
\hline
\end{tabular}




\begin{tabular}{|c|c|c|c|c|}
\hline & & & pplement & al $\mathrm{Ta}$ \\
\hline CHEMBL1450686 & 688293 & 4.6 & 5.0191 & TRN \\
\hline CHEMBL578741 & 688293 & 4.9 & 4.7841 & TRN \\
\hline CHEMBL1531070 & 688293 & 4.9 & 5.0466 & TST \\
\hline CHEMBL1367330 & 688293 & 4.7 & 5.1286 & TRN \\
\hline CHEMBL1520991 & 688293 & 4.4 & 5.0652 & TRN \\
\hline CHEMBL75978 & 688293 & 5.1 & 4.9698 & TRN \\
\hline CHEMBL1450564 & 688293 & 4.4 & 4.9627 & TST \\
\hline CHEMBL611494 & 688293 & 9.0 & 5.1239 & TST \\
\hline CHEMBL1527530 & 688293 & 5.6 & 4.8966 & TRN \\
\hline CHEMBL3189531 & 688293 & 4.4 & 5.0548 & TRN \\
\hline CHEMBL602158 & 688293 & 5.1 & 5.0338 & TRN \\
\hline CHEMBL1592464 & 688293 & 4.6 & 4.7111 & TRN \\
\hline CHEMBL1540005 & 688293 & 4.7 & 5.0056 & TRN \\
\hline CHEMBL1476670 & 688293 & 5.0 & 4.7885 & TRN \\
\hline CHEMBL1589752 & 688293 & 5.5 & 5.2137 & TRN \\
\hline CHEMBL1388966 & 688293 & 4.9 & 4.915 & TRN \\
\hline CHEMBL242385 & 688293 & 4.4 & 4.9325 & TRN \\
\hline CHEMBL1367149 & 688293 & 8.2007 & 5.1616 & TRN \\
\hline CHEMBL1341438 & 688293 & 5.0 & 5.0549 & TRN \\
\hline CHEMBL1383267 & 688293 & 4.4 & 5.1363 & TRN \\
\hline CHEMBL1332556 & 688293 & 8.2007 & 4.9458 & TRN \\
\hline CHEMBL1465617 & 688293 & 4.4 & 4.9515 & TRN \\
\hline CHEMBL1497284 & 688293 & 4.5 & 4.9116 & TRN \\
\hline CHEMBL1404474 & 688293 & 5.3 & 5.1603 & TRN \\
\hline CHEMBL1417970 & 688293 & 5.5 & 4.9515 & TRN \\
\hline CHEMBL454893 & 688293 & 4.9 & 5.0052 & TST \\
\hline CHEMBL1523137 & 688293 & 4.5 & 5.0366 & TRN \\
\hline CHEMBL1351392 & 688293 & 6.4 & 4.9973 & TRN \\
\hline CHEMBL1437054 & 688293 & 8.6021 & 4.9687 & TST \\
\hline CHEMBL1308847 & 688293 & 4.5 & 4.9728 & TRN \\
\hline CHEMBL1449871 & 688293 & 4.6 & 4.9965 & TRN \\
\hline CHEMBL1419438 & 688293 & 4.4 & 5.1008 & TRN \\
\hline CHEMBL1365881 & 688293 & 4.4 & 5.0943 & TRN \\
\hline CHEMBL1414101 & 688293 & 5.5 & 5.1742 & TRN \\
\hline CHEMBL1507091 & 688293 & 6.4 & 5.0321 & TRN \\
\hline CHEMBL1386337 & 688293 & 5.0 & 5.0319 & TRN \\
\hline CHEMBL1580296 & 688293 & 4.4 & 4.8875 & TRN \\
\hline CHEMBL1328941 & 688293 & 7.6003 & 5.1033 & TRN \\
\hline CHEMBL1449023 & 688293 & 4.5 & 4.9849 & TRN \\
\hline CHEMBL1580759 & 688293 & 4.7 & 4.8261 & TST \\
\hline CHEMBL1384715 & 688293 & 5.1 & 4.8118 & TRN \\
\hline CHEMBL1417287 & 688293 & 4.4 & 5.0303 & TRN \\
\hline CHEMBL1422539 & 688293 & 4.5 & 5.0609 & TRN \\
\hline CHEMBL1403711 & 688293 & 4.7 & 5.0766 & TRN \\
\hline CHEMBL1476155 & 688293 & 5.6 & 5.0035 & TST \\
\hline CHEMBL1493127 & 688293 & 4.8 & 5.1444 & TRN \\
\hline CHEMBL1374482 & 688293 & 4.4 & 4.9911 & TRN \\
\hline CHEMBL1492643 & 688293 & 4.7 & 5.0406 & TRN \\
\hline
\end{tabular}




\begin{tabular}{|c|c|c|c|c|}
\hline \multicolumn{5}{|c|}{ Supplemental Table S2.txt } \\
\hline CHEMBL1494313 & 688293 & 4.7 & 4.9076 & TRN \\
\hline CHEMBL1355718 & 688293 & 4.5 & 4.9048 & TRN \\
\hline CHEMBL105739 & 688293 & 5.0 & 4.8835 & TST \\
\hline CHEMBL1437809 & 688293 & 4.8 & 5.1184 & TRN \\
\hline CHEMBL1427075 & 688293 & 7.8013 & 5.1921 & TST \\
\hline CHEMBL1378859 & 688293 & 4.7 & 4.9703 & TRN \\
\hline CHEMBL1498933 & 688293 & 4.4 & 4.8498 & TST \\
\hline CHEMBL1384680 & 688293 & 6.8 & 5.0169 & TRN \\
\hline CHEMBL1391039 & 688293 & 5.3 & 5.0515 & TRN \\
\hline CHEMBL1475924 & 688293 & 4.4 & 4.9624 & TRN \\
\hline CHEMBL1595111 & 688293 & 4.5 & 4.8994 & TRN \\
\hline CHEMBL1509065 & 688293 & 7.8996 & 4.9364 & TRN \\
\hline CHEMBL1461734 & 688293 & 4.6 & 4.9654 & TRN \\
\hline CHEMBL1566841 & 688293 & 4.7 & 5.0056 & TRN \\
\hline CHEMBL1482582 & 688293 & 4.8 & 4.7388 & TRN \\
\hline CHEMBL1509699 & 688293 & 4.8 & 4.9676 & TRN \\
\hline CHEMBL126077 & 688293 & 5.0 & 4.9404 & TST \\
\hline CHEMBL1335446 & 688293 & 4.7 & 5.1139 & TRN \\
\hline CHEMBL1517431 & 688293 & 5.8 & 5.2322 & TRN \\
\hline CHEMBL1565084 & 688293 & 4.7 & 5.0215 & TRN \\
\hline CHEMBL192627 & 688293 & 5.0 & 4.9664 & TST \\
\hline CHEMBL1360310 & 688293 & 4.8 & 4.808 & TRN \\
\hline CHEMBL1555882 & 688293 & 7.5003 & 5.0194 & TST \\
\hline CHEMBL1445772 & 688293 & 4.6 & 5.1349 & TST \\
\hline CHEMBL1426501 & 688293 & 4.8 & 4.8099 & TRN \\
\hline CHEMBL1533285 & 688293 & 4.5 & 5.0212 & TST \\
\hline CHEMBL1600780 & 688293 & 7.2 & 4.8131 & TRN \\
\hline CHEMBL1587880 & 688293 & 4.4 & 5.087 & TRN \\
\hline CHEMBL1427864 & 688293 & 5.1 & 4.9937 & TST \\
\hline CHEMBL1305663 & 688293 & 4.7 & 4.8169 & TRN \\
\hline CHEMBL1371117 & 688293 & 4.5 & 5.0616 & TRN \\
\hline CHEMBL1610796 & 688293 & 4.5 & 4.9671 & TRN \\
\hline CHEMBL1339025 & 688293 & 7.1002 & 5.1095 & TRN \\
\hline CHEMBL1492364 & 688293 & 4.6 & 4.9567 & TRN \\
\hline CHEMBL1461347 & 688293 & 4.9 & 5.0928 & TRN \\
\hline CHEMBL1471942 & 688293 & 5.1 & 4.8295 & TRN \\
\hline CHEMBL1516005 & 688293 & 4.9 & 4.9163 & TRN \\
\hline CHEMBL1360842 & 688293 & 4.7 & 5.0889 & TRN \\
\hline CHEMBL1534168 & 688293 & 4.4 & 4.9341 & TRN \\
\hline CHEMBL60518 & 688293 & 4.9 & 4.9112 & TRN \\
\hline CHEMBL363207 & 688293 & 4.8 & 4.8661 & TRN \\
\hline CHEMBL1512208 & 688293 & 5.9 & 5.0114 & TRN \\
\hline CHEMBL1402563 & 688293 & 5.0 & 4.9061 & TRN \\
\hline CHEMBL1338150 & 688293 & 5.6 & 5.1191 & TRN \\
\hline CHEMBL1340758 & 688293 & 4.5 & 4.9792 & TRN \\
\hline CHEMBL1390871 & 688293 & 4.5 & 5.0316 & TRN \\
\hline CHEMBL3212561 & 688293 & 6.6 & 4.9999 & TST \\
\hline CHEMBL1517986 & 688293 & 4.7 & 5.0088 & TST \\
\hline
\end{tabular}




\begin{tabular}{|c|c|c|c|c|c|}
\hline \\
\hline CHEMBL1363924 & 688293 & 4.5 & 5.0726 & TRN & \\
\hline CHEMBL1334354 & 688293 & 5.4 & 5.0215 & TST & \\
\hline CHEMBL1438628 & 688293 & 6.1 & 4.9192 & TRN & \\
\hline CHEMBL1611800 & 688293 & 5.5 & 5.0494 & TST & \\
\hline CHEMBL1470371 & 688293 & 4.4 & 5.0757 & TST & \\
\hline CHEMBL1358033 & 688293 & 4.8 & 4.7778 & TRN & \\
\hline CHEMBL1555461 & 688293 & 4.8 & 5.063 & TRN & \\
\hline CHEMBL1364699 & 688293 & 4.4 & 5.0134 & TRN & \\
\hline CHEMBL1567944 & 688293 & 6.0 & 5.0326 & TRN & \\
\hline CHEMBL1581224 & 688293 & 4.7 & 4.941 & TRN & \\
\hline CHEMBL1414915 & 688293 & 4.8 & 5.0491 & TRN & \\
\hline CHEMBL1328193 & 688293 & 4.5 & 4.9261 & TST & \\
\hline CHEMBL1330188 & 688293 & 5.2 & 4.9447 & TST & \\
\hline CHEMBL1548127 & 688293 & 4.4 & 4.9776 & TRN & \\
\hline CHEMBL1308058 & 688293 & 4.5 & 4.9613 & TRN & \\
\hline CHEMBL1499329 & 688293 & 7.5003 & 5.1869 & TRN & \\
\hline CHEMBL3199902 & 688293 & 4.4 & 4.9447 & TST & \\
\hline CHEMBL1454945 & 688293 & 4.8 & 5.1334 & TRN & \\
\hline CHEMBL1363603 & 688293 & 5.2 & 5.1831 & TRN & \\
\hline CHEMBL1388457 & 688293 & 4.8 & 5.2109 & TST & \\
\hline CHEMBL1543053 & 688293 & 8.301 & 5.0427 & TRN & \\
\hline CHEMBL1597033 & 688293 & 4.6 & 4.8974 & TRN & \\
\hline CHEMBL1467317 & 688293 & 4.6 & 4.9849 & TRN & \\
\hline CHEMBL1542892 & 688293 & 6.0 & 5.1663 & TRN & \\
\hline CHEMBL1534969 & 688293 & 4.4 & 5.20200 & 3000000001 & TRN \\
\hline CHEMBL1348384 & 688293 & 4.8 & 4.856 & TRN & \\
\hline CHEMBL1583259 & 688293 & 4.9 & 4.7638 & TRN & \\
\hline CHEMBL1532225 & 688293 & 5.1 & 5.1595 & TRN & \\
\hline CHEMBL1526115 & 688293 & 4.9 & 5.0419 & TRN & \\
\hline CHEMBL1326134 & 688293 & 4.4 & 4.8103 & TRN & \\
\hline CHEMBL1526030 & 688293 & 4.6 & 4.8913 & TRN & \\
\hline CHEMBL1550339 & 688293 & 4.9 & 4.9855 & TRN & \\
\hline CHEMBL1464123 & 688293 & 4.4 & 5.039 & TRN & \\
\hline CHEMBL1471326 & 688293 & 4.6 & 4.8215 & TRN & \\
\hline CHEMBL1482369 & 688293 & 4.6 & 4.9883 & TRN & \\
\hline CHEMBL1586852 & 688293 & 4.7 & 5.0313 & TST & \\
\hline CHEMBL1434882 & 688293 & 4.6 & 4.7688 & TRN & \\
\hline CHEMBL1364282 & 688293 & 5.5 & 4.9628 & TRN & \\
\hline CHEMBL1345280 & 688293 & 4.4 & 4.9583 & TST & \\
\hline CHEMBL1464412 & 688293 & 5.2 & 5.0257 & TRN & \\
\hline CHEMBL1545160 & 688293 & 4.6 & 4.8817 & TRN & \\
\hline CHEMBL1358722 & 688293 & 7.4001 & 5.1392 & TST & \\
\hline CHEMBL1372029 & 688293 & 4.6 & 4.9591 & TRN & \\
\hline CHEMBL1533639 & 688293 & 4.4 & 4.9777 & TRN & \\
\hline CHEMBL1560856 & 688293 & 4.4 & 5.0305 & TRN & \\
\hline CHEMBL1344384 & 688293 & 5.4 & 4.9762 & TST & \\
\hline CHEMBL1545634 & 688293 & 6.0 & 4.9236 & TRN & \\
\hline CHEMBL1506005 & 688293 & 7.699 & 5.131 & TRN & \\
\hline
\end{tabular}




\begin{tabular}{|c|c|c|c|c|}
\hline \multicolumn{5}{|c|}{ Supplemental Table S2.txt } \\
\hline CHEMBL 3190358 & 688293 & 4.4 & 4.7973 & TRN \\
\hline CHEMBL1352852 & 688293 & 4.4 & 5.1062 & TRN \\
\hline CHEMBL1369633 & 688293 & 4.6 & 4.9643 & TST \\
\hline CHEMBL1575167 & 688293 & 5.5 & 4.9923 & TRN \\
\hline CHEMBL1541819 & 688293 & 4.6 & 5.0317 & TRN \\
\hline CHEMBL1438469 & 688293 & 4.7 & 4.9497 & TRN \\
\hline CHEMBL1398581 & 688293 & 7.8996 & 5.046 & TRN \\
\hline CHEMBL1568562 & 688293 & 4.6 & 5.0549 & TST \\
\hline CHEMBL 2374055 & 688293 & 4.4 & 5.0862 & TST \\
\hline CHEMBL1595235 & 688293 & 4.5 & 4.9382 & TST \\
\hline CHEMBL1532568 & 688293 & 4.4 & 4.9078 & TRN \\
\hline CHEMBL1361422 & 688293 & 4.6 & 5.2005 & TST \\
\hline CHEMBL1429947 & 688293 & 4.6 & 4.6726 & TRN \\
\hline CHEMBL1432038 & 688293 & 4.4 & 5.0323 & TRN \\
\hline CHEMBL1561263 & 688293 & 4.6 & 4.9581 & TRN \\
\hline CHEMBL1374656 & 688293 & 4.4 & 5.0607 & TRN \\
\hline CHEMBL3194220 & 688293 & 4.9 & 4.8651 & TST \\
\hline CHEMBL1572280 & 688293 & 4.5 & 4.8191 & TST \\
\hline CHEMBL1346011 & 688293 & 5.3 & 4.9734 & TRN \\
\hline CHEMBL1993627 & 688293 & 4.6 & 4.9049 & TST \\
\hline CHEMBL1493328 & 688293 & 5.3 & 4.8818 & TRN \\
\hline CHEMBL1401610 & 688293 & 4.7 & 4.9733 & TRN \\
\hline CHEMBL482687 & 688293 & 4.8 & 4.8897 & TRN \\
\hline CHEMBL1325891 & 688293 & 4.8 & 4.9965 & TRN \\
\hline CHEMBL1423064 & 688293 & 5.4 & 5.0041 & TRN \\
\hline CHEMBL1537658 & 688293 & 4.8 & 4.9716 & TRN \\
\hline CHEMBL1447673 & 688293 & 4.5 & 4.8716 & TST \\
\hline CHEMBL1598873 & 688293 & 5.1 & 5.2208 & TRN \\
\hline CHEMBL1468355 & 688293 & 4.7 & 4.9596 & TRN \\
\hline CHEMBL1400292 & 688293 & 4.8 & 5.1169 & TRN \\
\hline CHEMBL1540207 & 688293 & 5.8 & 4.9499 & TRN \\
\hline CHEMBL1425023 & 688293 & 4.4 & 5.0407 & TRN \\
\hline CHEMBL1450221 & 688293 & 6.5 & 5.1165 & TRN \\
\hline CHEMBL1554888 & 688293 & 4.9 & 4.7286 & TRN \\
\hline CHEMBL14377 & 688293 & 4.7 & 4.876 & TST \\
\hline CHEMBL509531 & 688293 & 4.5 & 5.0613 & TST \\
\hline CHEMBL1318789 & 688293 & 7.699 & 5.1728 & TST \\
\hline CHEMBL1566496 & 688293 & 4.8 & 4.8509 & TRN \\
\hline CHEMBL1546372 & 688293 & 5.3 & 4.8429 & TRN \\
\hline CHEMBL1583863 & 688293 & 5.7 & 5.2144 & TRN \\
\hline CHEMBL1484660 & 688293 & 4.7 & 4.7762 & TRN \\
\hline CHEMBL1602394 & 688293 & 4.8 & 4.8511 & TRN \\
\hline CHEMBL1414038 & 688293 & 6.3 & 4.8959 & TRN \\
\hline CHEMBL1352443 & 688293 & 4.5 & 4.97 & TRN \\
\hline CHEMBL1335001 & 688293 & 6.8 & 5.1853 & TRN \\
\hline CHEMBL1457682 & 688293 & 4.4 & 4.8281 & TRN \\
\hline CHEMBL1400874 & 688293 & 4.6 & 5.0845 & TRN \\
\hline CHEMBL1332328 & 688293 & 4.4 & 5.0877 & TRN \\
\hline
\end{tabular}




\begin{tabular}{|c|c|c|c|c|c|}
\hline \\
\hline CHEMBL1256024 & 688293 & 5.1 & 5.1069 & TST & \\
\hline CHEMBL1491064 & 688293 & 4.8 & 4.9353 & TST & \\
\hline CHEMBL1516903 & 688293 & 4.4 & 5.0145 & TRN & \\
\hline CHEMBL1383746 & 688293 & 5.7 & 4.9837 & TRN & \\
\hline CHEMBL1575830 & 688293 & 4.5 & 4.9898 & TRN & \\
\hline CHEMBL1590270 & 688293 & 5.7 & 4.9589 & TRN & \\
\hline CHEMBL1330095 & 688293 & 4.7 & 4.9531 & TRN & \\
\hline CHEMBL1393735 & 688293 & 4.7 & 4.8973 & TRN & \\
\hline CHEMBL1393452 & 688293 & 5.0 & 5.0405 & TRN & \\
\hline CHEMBL1601161 & 688293 & 4.4 & 5.2933 & TRN & \\
\hline CHEMBL1564449 & 688293 & 4.4 & 5.0826 & TRN & \\
\hline CHEMBL1372085 & 688293 & 4.8 & 4.937 & TST & \\
\hline CHEMBL3190705 & 688293 & 4.5 & 5.09399 & 9999999999 & TRN \\
\hline CHEMBL1596683 & 688293 & 4.6 & 5.1823 & TRN & \\
\hline CHEMBL1307459 & 688293 & 4.8 & 5.1129 & TRN & \\
\hline CHEMBL1358266 & 688293 & 4.4 & 5.0854 & TST & \\
\hline CHEMBL1524851 & 688293 & 4.6 & 4.8724 & TRN & \\
\hline CHEMBL1592982 & 688293 & 4.7 & 4.7128 & TRN & \\
\hline CHEMBL1487649 & 688293 & 6.9 & 5.1345 & TST & \\
\hline CHEMBL1347853 & 688293 & 4.8 & 5.0682 & TRN & \\
\hline CHEMBL1421272 & 688293 & 5.9 & 5.1344 & TRN & \\
\hline CHEMBL1527520 & 688293 & 4.4 & 5.0589 & TST & \\
\hline CHEMBL1544388 & 688293 & 4.5 & 4.9529 & TRN & \\
\hline CHEMBL1351088 & 688293 & 4.4 & 4.9138 & TRN & \\
\hline CHEMBL1501540 & 688293 & 4.5 & 4.9842 & TRN & \\
\hline CHEMBL1384913 & 688293 & 6.0 & 5.0123 & TRN & \\
\hline CHEMBL1383705 & 688293 & 4.7 & 5.2605 & TRN & \\
\hline CHEMBL1479987 & 688293 & 4.4 & 5.1286 & TST & \\
\hline CHEMBL1508646 & 688293 & 4.6 & 4.9596 & TRN & \\
\hline CHEMBL1487083 & 688293 & 5.2 & 4.9371 & TRN & \\
\hline CHEMBL1335873 & 688293 & 4.7 & 5.0084 & TRN & \\
\hline CHEMBL1438323 & 688293 & 5.7 & 4.6695 & TRN & \\
\hline CHEMBL1348062 & 688293 & 4.6 & 4.8313 & TRN & \\
\hline CHEMBL1432163 & 688293 & 4.9 & 5.0437 & TST & \\
\hline CHEMBL1312502 & 688293 & 5.1 & 4.9046 & TRN & \\
\hline CHEMBL1461491 & 688293 & 6.0 & 5.0232 & TST & \\
\hline CHEMBL 2001481 & 688293 & 4.9 & 4.8275 & TRN & \\
\hline CHEMBL1482818 & 688293 & 5.0 & 5.1086 & TST & \\
\hline CHEMBL1320191 & 688293 & 4.9 & 5.0205 & TRN & \\
\hline CHEMBL1407724 & 688293 & 4.6 & 4.9046 & TRN & \\
\hline CHEMBL1369799 & 688293 & 4.7 & 4.8011 & TRN & \\
\hline CHEMBL1548349 & 688293 & 6.0 & 4.9952 & TRN & \\
\hline CHEMBL1235226 & 688293 & 5.5 & 5.0933 & TST & \\
\hline CHEMBL1603008 & 688293 & 4.4 & 5.05 & TRN & \\
\hline CHEMBL1315374 & 688293 & 8.4949 & 5.2312 & TST & \\
\hline CHEMBL129795 & 688293 & 6.6 & 4.9827 & TRN & \\
\hline CHEMBL1343926 & 688293 & 4.4 & 4.9082 & TST & \\
\hline CHEMBL1539444 & 688293 & 4.4 & 4.9599 & TRN & \\
\hline
\end{tabular}




\begin{tabular}{|c|c|c|c|c|}
\hline \multicolumn{5}{|c|}{ Supplemental Table S2.txt } \\
\hline CHEMBL1410746 & 688293 & 4.7 & 5.1085 & TRN \\
\hline CHEMBL1500691 & 688293 & 4.6 & 4.9368 & TST \\
\hline CHEMBL1403712 & 688293 & 6.2 & 5.1183 & TRN \\
\hline CHEMBL1472023 & 688293 & 4.5 & 4.8946 & TRN \\
\hline CHEMBL19032 & 688293 & 6.0 & 4.882 & TRN \\
\hline CHEMBL1437056 & 688293 & 4.7 & 4.8359 & TRN \\
\hline CHEMBL1522834 & 688293 & 4.7 & 5.1191 & TRN \\
\hline CHEMBL1349023 & 688293 & 4.8 & 4.9102 & TRN \\
\hline CHEMBL1351266 & 688293 & 4.4 & 4.9994 & TRN \\
\hline CHEMBL1305299 & 688293 & 5.5 & 5.0344 & TRN \\
\hline CHEMBL1478585 & 688293 & 6.0 & 5.0549 & TRN \\
\hline CHEMBL1495163 & 688293 & 4.5 & 4.8017 & TRN \\
\hline CHEMBL1580342 & 688293 & 4.8 & 4.8488 & TRN \\
\hline CHEMBL1568433 & 688293 & 5.0 & 5.0244 & TRN \\
\hline CHEMBL1300999 & 688293 & 4.6 & 5.0912 & TRN \\
\hline CHEMBL6390 & 688293 & 6.0 & 5.033 & TST \\
\hline CHEMBL1458853 & 688293 & 5.0 & 5.2691 & TRN \\
\hline CHEMBL1311370 & 688293 & 4.6 & 5.2036 & TRN \\
\hline CHEMBL1378391 & 688293 & 6.3 & 4.9988 & TRN \\
\hline CHEMBL1418567 & 688293 & 4.5 & 4.9955 & TRN \\
\hline CHEMBL1586695 & 688293 & 4.7 & 5.2225 & TRN \\
\hline CHEMBL1368728 & 688293 & 4.5 & 4.9554 & TRN \\
\hline CHEMBL338479 & 688293 & 5.0 & 5.1199 & TRN \\
\hline CHEMBL565856 & 688293 & 5.0 & 4.7639 & TRN \\
\hline CHEMBL1398728 & 688293 & 4.8 & 5.0951 & TST \\
\hline CHEMBL1555396 & 688293 & 4.9 & 4.7675 & TRN \\
\hline CHEMBL1363631 & 688293 & 5.0 & 4.9941 & TRN \\
\hline CHEMBL1564246 & 688293 & 4.4 & 4.9495 & TRN \\
\hline CHEMBL1392398 & 688293 & 4.6 & 5.0049 & TRN \\
\hline CHEMBL1343508 & 688293 & 4.4 & 5.1486 & TRN \\
\hline CHEMBL533954 & 688293 & 4.6 & 5.038 & TRN \\
\hline CHEMBL1345016 & 688293 & 5.0 & 4.9986 & TRN \\
\hline CHEMBL1401945 & 688293 & 4.4 & 4.8656 & TRN \\
\hline CHEMBL1582065 & 688293 & 5.1 & 5.1035 & TRN \\
\hline CHEMBL1580616 & 688293 & 5.0 & 4.928 & TRN \\
\hline CHEMBL1596602 & 688293 & 5.6 & 4.8125 & TRN \\
\hline CHEMBL1586738 & 688293 & 4.7 & 5.0473 & TRN \\
\hline CHEMBL1561382 & 688293 & 4.6 & 4.988 & TRN \\
\hline CHEMBL1990300 & 688293 & 4.4 & 5.1288 & TST \\
\hline CHEMBL1464468 & 688293 & 4.7 & 4.8434 & TRN \\
\hline CHEMBL1301377 & 688293 & 4.4 & 5.0989 & TRN \\
\hline CHEMBL1556970 & 688293 & 7.4001 & 4.9757 & TRN \\
\hline CHEMBL1409586 & 688293 & 4.8 & 4.954 & TST \\
\hline CHEMBL1609660 & 688293 & 4.5 & 4.8987 & TRN \\
\hline CHEMBL1544623 & 688293 & 4.9 & 5.0317 & TRN \\
\hline CHEMBL31970 & 688293 & 5.1 & 4.9803 & TST \\
\hline CHEMBL1613098 & 688293 & 4.5 & 5.1657 & TRN \\
\hline CHEMBL1341821 & 688293 & 4.5 & 5.0184 & TRN \\
\hline
\end{tabular}




\begin{tabular}{|c|c|c|c|c|c|}
\hline \\
\hline CHEMBL1370486 & 688293 & 4.5 & 5.0464 & TST & \\
\hline CHEMBL1423013 & 688293 & 4.6 & 4.9416 & TRN & \\
\hline CHEMBL1435450 & 688293 & 4.8 & 4.6977 & TRN & \\
\hline CHEMBL1324649 & 688293 & 4.5 & 5.0971 & TRN & \\
\hline CHEMBL1519327 & 688293 & 4.5 & 5.095 & TST & \\
\hline CHEMBL1345440 & 688293 & 4.5 & 5.1888 & TRN & \\
\hline CHEMBL1333358 & 688293 & 6.2 & 5.0209 & TST & \\
\hline CHEMBL1549966 & 688293 & 4.5 & 5.0597 & TRN & \\
\hline CHEMBL1352121 & 688293 & 4.4 & 5.0871 & TRN & \\
\hline CHEMBL1338747 & 688293 & 4.6 & 4.9524 & TST & \\
\hline CHEMBL1599118 & 688293 & 4.7 & 4.8088 & TRN & \\
\hline CHEMBL1438865 & 688293 & 4.4 & 5.1819 & TRN & \\
\hline CHEMBL294264 & 688293 & 6.0 & 4.93 & TST & \\
\hline CHEMBL1465681 & 688293 & 4.4 & 4.8571 & TRN & \\
\hline CHEMBL1438442 & 688293 & 4.5 & 5.0989 & TRN & \\
\hline CHEMBL1580253 & 688293 & 7.5003 & 5.2062 & TRN & \\
\hline CHEMBL1439721 & 688293 & 8.1024 & 5.0278 & TRN & \\
\hline CHEMBL1465340 & 688293 & 4.6 & 5.0738 & TRN & \\
\hline CHEMBL322970 & 688293 & 5.2 & 4.8497 & TST & \\
\hline CHEMBL1459182 & 688293 & 5.6 & 5.0834 & TRN & \\
\hline CHEMBL1545628 & 688293 & 4.4 & 5.0027 & TRN & \\
\hline CHEMBL1585289 & 688293 & 6.6 & 5.1458 & TST & \\
\hline CHEMBL1510082 & 688293 & 4.8 & 4.8132 & TRN & \\
\hline CHEMBL1352752 & 688293 & 4.7 & 5.0876 & TRN & \\
\hline CHEMBL1581244 & 688293 & 4.5 & 4.8507 & TRN & \\
\hline CHEMBL1574355 & 688293 & 4.5 & 5.11600 & 00000000005 & TRN \\
\hline CHEMBL1503027 & 688293 & 4.7 & 5.1139 & TRN & \\
\hline CHEMBL1568767 & 688293 & 5.4 & 4.6712 & TRN & \\
\hline CHEMBL1527238 & 688293 & 5.0 & 4.9108 & TRN & \\
\hline CHEMBL1542284 & 688293 & 5.6 & 4.9464 & TRN & \\
\hline CHEMBL1321713 & 688293 & 4.8 & 4.913 & TRN & \\
\hline CHEMBL1429838 & 688293 & 4.6 & 4.7822 & TRN & \\
\hline CHEMBL3209429 & 688293 & 6.7001 & 5.065 & TST & \\
\hline CHEMBL1335967 & 688293 & 4.7 & 4.8908 & TRN & \\
\hline CHEMBL1403866 & 688293 & 4.9 & 5.0348 & TRN & \\
\hline CHEMBL1526543 & 688293 & 4.6 & 5.0372 & TST & \\
\hline CHEMBL1380884 & 688293 & 4.8 & 4.7664 & TRN & \\
\hline CHEMBL1386396 & 688293 & 5.0 & 4.8257 & TRN & \\
\hline CHEMBL1570149 & 688293 & 4.5 & 5.1432 & TRN & \\
\hline CHEMBL310396 & 688293 & 4.4 & 4.9688 & TST & \\
\hline CHEMBL1382307 & 688293 & 5.1 & 5.1095 & TRN & \\
\hline CHEMBL1588101 & 688293 & 4.6 & 5.02800 & 00000000005 & TRN \\
\hline CHEMBL1533452 & 688293 & 5.5 & 4.9708 & TRN & \\
\hline CHEMBL1516965 & 688293 & 6.1 & 5.1355 & TRN & \\
\hline CHEMBL1338163 & 688293 & 4.8 & 5.0516 & TST & \\
\hline CHEMBL1567327 & 688293 & 4.6 & 5.1404 & TRN & \\
\hline CHEMBL 281622 & 688293 & 4.4 & 4.9194 & TST & \\
\hline CHEMBL1336216 & 688293 & 5.0 & 4.8792 & TRN & \\
\hline
\end{tabular}




\begin{tabular}{|c|c|c|c|c|}
\hline & & & & \\
\hline CHEMBL1521453 & 688293 & 4.9 & 5.0683 & TST \\
\hline CHEMBL1560612 & 688293 & 4.5 & 4.7398 & TRN \\
\hline CHEMBL1524520 & 688293 & 4.8 & 4.854 & TRN \\
\hline CHEMBL1566762 & 688293 & 4.5 & 4.6762 & TST \\
\hline CHEMBL1470281 & 688293 & 4.4 & 5.0945 & TST \\
\hline CHEMBL1335278 & 688293 & 4.6 & 5.0898 & TRN \\
\hline CHEMBL1570633 & 688293 & 4.8 & 4.7491 & TRN \\
\hline CHEMBL1316219 & 688293 & 4.9 & 4.8652 & TST \\
\hline CHEMBL1401376 & 688293 & 4.8 & 5.1186 & TRN \\
\hline CHEMBL1528876 & 688293 & 4.6 & 5.1133 & TST \\
\hline CHEMBL1325976 & 688293 & 4.4 & 4.9294 & TRN \\
\hline CHEMBL607536 & 688293 & 5.6 & 4.9925 & TRN \\
\hline CHEMBL1541834 & 688293 & 4.8 & 4.85 & TRN \\
\hline CHEMBL1526981 & 688293 & 4.7 & 5.1359 & TRN \\
\hline CHEMBL1360128 & 688293 & 4.7 & 4.8297 & TRN \\
\hline CHEMBL1393494 & 688293 & 4.4 & 5.08 & TST \\
\hline CHEMBL3209617 & 688293 & 4.7 & 4.9621 & TST \\
\hline CHEMBL1385388 & 688293 & 4.9 & 4.9944 & TRN \\
\hline CHEMBL1310308 & 688293 & 4.6 & 4.9545 & TRN \\
\hline CHEMBL1595023 & 688293 & 4.5 & 5.0989 & TRN \\
\hline CHEMBL1541707 & 688293 & 4.5 & 4.9656 & TRN \\
\hline CHEMBL1423017 & 688293 & 4.6 & 5.0325 & TRN \\
\hline CHEMBL1440199 & 688293 & 5.6 & 5.1053 & TRN \\
\hline CHEMBL1484854 & 688293 & 4.4 & 5.0693 & TRN \\
\hline CHEMBL1548014 & 688293 & 4.6 & 5.0363 & TRN \\
\hline CHEMBL1321179 & 688293 & 4.4 & 4.862 & TRN \\
\hline CHEMBL1554348 & 688293 & 5.3 & 4.8016 & TRN \\
\hline CHEMBL1507431 & 688293 & 4.8 & 4.7905 & TRN \\
\hline CHEMBL1333986 & 688293 & 4.9 & 5.2013 & TRN \\
\hline CHEMBL1565705 & 688293 & 5.6 & 4.8572 & TST \\
\hline CHEMBL1332819 & 688293 & 6.1 & 5.2628 & TRN \\
\hline CHEMBL52 & 688293 & 6.0 & 5.0093 & TRN \\
\hline CHEMBL1307155 & 688293 & 4.7 & 5.1102 & TRN \\
\hline CHEMBL1581440 & 688293 & 4.6 & 5.0503 & TRN \\
\hline CHEMBL1516857 & 688293 & 4.4 & 5.0148 & TRN \\
\hline CHEMBL1344014 & 688293 & 4.9 & 5.0848 & TRN \\
\hline CHEMBL1364985 & 688293 & 4.5 & 5.0158 & TRN \\
\hline CHEMBL1370089 & 688293 & 4.5 & 4.97 & TRN \\
\hline CHEMBL1570696 & 688293 & 4.6 & 5.0745 & TRN \\
\hline CHEMBL1493037 & 688293 & 4.6 & 5.0917 & TST \\
\hline CHEMBL1415385 & 688293 & 4.6 & 5.0119 & TRN \\
\hline CHEMBL1489389 & 688293 & 4.4 & 5.1283 & TRN \\
\hline CHEMBL1300055 & 688293 & 4.6 & 4.9403 & TRN \\
\hline CHEMBL1385245 & 688293 & 4.8 & 5.0507 & TST \\
\hline CHEMBL1597691 & 688293 & 5.1 & 4.9301 & TRN \\
\hline CHEMBL1341227 & 688293 & 4.5 & 5.1138 & TRN \\
\hline CHEMBL1339701 & 688293 & 6.7001 & 4.6961 & TRN \\
\hline CHEMBL1461578 & 688293 & 4.6 & 4.6457 & TRN \\
\hline
\end{tabular}




\begin{tabular}{|c|c|c|c|c|c|}
\hline \multicolumn{6}{|c|}{ Supplemental Table S2.txt } \\
\hline CHEMBL1304743 & 688293 & 4.4 & 4.9298 & TRN & \\
\hline CHEMBL1374260 & 688293 & 4.9 & 4.8833 & TRN & \\
\hline CHEMBL1429415 & 688293 & 4.6 & 5.0538 & TRN & \\
\hline CHEMBL597035 & 688293 & 4.6 & 4.8387 & TRN & \\
\hline CHEMBL1523031 & 688293 & 4.5 & 5.0044 & TRN & \\
\hline CHEMBL1362059 & 688293 & 4.4 & 5.0047 & TRN & \\
\hline CHEMBL1329630 & 688293 & 7.6003 & 5.0155 & TRN & \\
\hline CHEMBL1450001 & 688293 & 4.4 & 5.0793 & TRN & \\
\hline CHEMBL1387072 & 688293 & 4.9 & 4.9302 & TRN & \\
\hline CHEMBL1425595 & 688293 & 4.4 & 4.7838 & TRN & \\
\hline CHEMBL1586062 & 688293 & 4.6 & 4.8765 & TRN & \\
\hline CHEMBL1493279 & 688293 & 4.7 & 5.0868 & TRN & \\
\hline CHEMBL1400807 & 688293 & 4.4 & 4.9046 & TRN & \\
\hline CHEMBL1555508 & 688293 & 4.7 & 5.0527 & TRN & \\
\hline CHEMBL1538218 & 688293 & 4.6 & 4.9353 & TRN & \\
\hline CHEMBL1382363 & 688293 & 5.3 & 4.9799 & TRN & \\
\hline CHEMBL1577584 & 688293 & 4.6 & 5.0777 & TRN & \\
\hline CHEMBL1370553 & 688293 & 4.4 & 4.9103 & TRN & \\
\hline CHEMBL1566336 & 688293 & 5.3 & 5.0715 & TRN & \\
\hline CHEMBL1348538 & 688293 & 4.4 & 4.9323 & TRN & \\
\hline CHEMBL1418655 & 688293 & 5.2 & 5.1595 & TST & \\
\hline CHEMBL1604435 & 688293 & 4.5 & 5.008 & TRN & \\
\hline CHEMBL 275084 & 688293 & 6.0 & 5.1077 & TST & \\
\hline CHEMBL1555037 & 688293 & 4.6 & 4.7516 & TRN & \\
\hline CHEMBL1449309 & 688293 & 6.0 & 5.2018 & TRN & \\
\hline CHEMBL1496162 & 688293 & 4.9 & 4.9448 & TRN & \\
\hline CHEMBL1599728 & 688293 & 4.6 & 5.0706 & TRN & \\
\hline CHEMBL1328827 & 688293 & 5.8 & 4.8456 & TRN & \\
\hline CHEMBL1352315 & 688293 & 4.4 & 5.1370 & 00000000005 & TRN \\
\hline CHEMBL1521658 & 688293 & 4.6 & 4.9658 & TRN & \\
\hline CHEMBL1527083 & 688293 & 5.6 & 5.225 & TST & \\
\hline CHEMBL1488009 & 688293 & 4.5 & 5.0883 & TRN & \\
\hline CHEMBL1505916 & 688293 & 7.4001 & 5.0782 & TRN & \\
\hline CHEMBL1580119 & 688293 & 4.5 & 5.0256 & TRN & \\
\hline CHEMBL1306807 & 688293 & 4.4 & 4.9689 & TRN & \\
\hline CHEMBL1445711 & 688293 & 4.5 & 5.0443 & TRN & \\
\hline CHEMBL1447412 & 688293 & 4.7 & 5.0197 & TRN & \\
\hline CHEMBL1441883 & 688293 & 4.8 & 4.9341 & TRN & \\
\hline CHEMBL1578133 & 688293 & 4.6 & 5.0085 & TRN & \\
\hline CHEMBL1399249 & 688293 & 4.5 & 5.1228 & TST & \\
\hline CHEMBL1340268 & 688293 & 4.4 & 5.0619 & TRN & \\
\hline CHEMBL1452049 & 688293 & 4.9 & 4.9232 & TRN & \\
\hline CHEMBL1587516 & 688293 & 4.7 & 4.97 & TRN & \\
\hline CHEMBL1407387 & 688293 & 4.9 & 4.82 & TRN & \\
\hline CHEMBL1471323 & 688293 & 4.6 & 5.0431 & TRN & \\
\hline CHEMBL1438123 & 688293 & 6.1 & 5.2229 & TRN & \\
\hline CHEMBL1300779 & 688293 & 4.6 & 4.8087 & TRN & \\
\hline CHEMBL1527744 & 688293 & 4.6 & 5.0382 & TRN & \\
\hline
\end{tabular}




\begin{tabular}{|c|c|c|c|c|c|}
\hline & & & & & \\
\hline CHEMBL1610944 & 688293 & 4.8 & 5.0606 & TRN & \\
\hline CHEMBL1596737 & 688293 & 5.4 & 4.9519 & TRN & \\
\hline CHEMBL1404565 & 688293 & 4.5 & 4.9188 & TRN & \\
\hline CHEMBL1487028 & 688293 & 4.6 & 4.9473 & TRN & \\
\hline CHEMBL1599589 & 688293 & 5.4 & 4.9943 & TRN & \\
\hline CHEMBL1472104 & 688293 & 5.0 & $5.0760 e$ & 00000000005 & TRN \\
\hline CHEMBL1303252 & 688293 & 7.0 & 5.0808 & TRN & \\
\hline CHEMBL1578420 & 688293 & 4.9 & 5.1567 & TRN & \\
\hline CHEMBL1488332 & 688293 & 4.7 & 4.9529 & TRN & \\
\hline CHEMBL1331237 & 688293 & 4.9 & 5.0013 & TRN & \\
\hline CHEMBL1578739 & 688293 & 4.7 & 5.1352 & TRN & \\
\hline CHEMBL1458694 & 688293 & 4.5 & 5.3287 & TRN & \\
\hline CHEMBL1590360 & 688293 & 5.1 & 4.809 & TRN & \\
\hline CHEMBL1313554 & 688293 & 4.4 & 5.1817 & TRN & \\
\hline CHEMBL1424364 & 688293 & 4.9 & 5.0827 & TRN & \\
\hline CHEMBL1577877 & 688293 & 4.5 & 5.1552 & TRN & \\
\hline CHEMBL1593663 & 688293 & 4.5 & 4.8665 & TRN & \\
\hline CHEMBL1566459 & 688293 & 4.4 & 5.1351 & TRN & \\
\hline CHEMBL1500716 & 688293 & 4.6 & 5.0046 & TRN & \\
\hline CHEMBL1426506 & 688293 & 5.2 & 5.003 & TRN & \\
\hline CHEMBL 243652 & 688293 & 4.5 & 5.092 & TST & \\
\hline CHEMBL3199569 & 688293 & 5.1 & 5.1263 & TRN & \\
\hline CHEMBL1320147 & 688293 & 4.7 & 5.0214 & TST & \\
\hline CHEMBL 2006154 & 688293 & 4.4 & 4.7603 & TRN & \\
\hline CHEMBL182653 & 688293 & 4.4 & 4.8695 & TRN & \\
\hline CHEMBL1420286 & 688293 & 4.4 & 4.7898 & TRN & \\
\hline CHEMBL475198 & 688293 & 4.6 & 4.7711 & TRN & \\
\hline CHEMBL1578607 & 688293 & 5.3 & 4.7954 & TRN & \\
\hline CHEMBL1375423 & 688293 & 4.6 & 5.0968 & TST & \\
\hline CHEMBL1426183 & 688293 & 4.9 & 4.9732 & TRN & \\
\hline CHEMBL1442745 & 688293 & 4.6 & 4.9818 & TRN & \\
\hline CHEMBL531709 & 688293 & 4.4 & 5.0992 & TRN & \\
\hline CHEMBL1395882 & 688293 & 4.4 & 4.9495 & TRN & \\
\hline CHEMBL1398721 & 688293 & 4.9 & 5.0591 & TRN & \\
\hline CHEMBL1413235 & 688293 & 5.0 & 5.0337 & TRN & \\
\hline CHEMBL1344273 & 688293 & 4.4 & 5.1007 & TRN & \\
\hline CHEMBL1728023 & 688293 & 4.9 & 4.887 & TRN & \\
\hline CHEMBL1429038 & 688293 & 4.4 & 4.7666 & TRN & \\
\hline CHEMBL1378015 & 688293 & 4.7 & 5.0642 & TRN & \\
\hline CHEMBL1519049 & 688293 & 5.1 & 4.9005 & TST & \\
\hline CHEMBL1329554 & 688293 & 4.6 & 4.8256 & TRN & \\
\hline CHEMBL1425704 & 688293 & 5.3 & 4.936 & TRN & \\
\hline CHEMBL1407739 & 688293 & 4.5 & 4.9177 & TRN & \\
\hline CHEMBL1572391 & 688293 & 4.7 & 4.8582 & TRN & \\
\hline CHEMBL1464595 & 688293 & 4.9 & 4.8191 & TRN & \\
\hline CHEMBL1533998 & 688293 & 6.0 & 4.9954 & TRN & \\
\hline CHEMBL371523 & 688293 & 5.2 & 5.0963 & TRN & \\
\hline CHEMBL1377511 & 688293 & 4.4 & 4.89199 & 99999999995 & TRN \\
\hline & & & & 19470 & \\
\hline
\end{tabular}




\begin{tabular}{|c|c|c|c|c|c|}
\hline \multicolumn{6}{|c|}{ Supplemental Table S2.txt } \\
\hline CHEMBL1476851 & 688293 & 4.7 & 4.8565 & TRN & \\
\hline CHEMBL1299399 & 688293 & 4.4 & 5.0451 & TRN & \\
\hline CHEMBL1543636 & 688293 & 4.9 & 4.7542 & TRN & \\
\hline CHEMBL1382618 & 688293 & 4.6 & 4.8513 & TRN & \\
\hline CHEMBL1448538 & 688293 & 4.7 & 5.1015 & TRN & \\
\hline CHEMBL3198370 & 688293 & 4.9 & 4.8627 & TRN & \\
\hline CHEMBL1581737 & 688293 & 7.3002 & 5.2022 & TRN & \\
\hline CHEMBL1336779 & 688293 & 4.9 & 4.9547 & TRN & \\
\hline CHEMBL1570135 & 688293 & 4.7 & 4.8336 & TRN & \\
\hline CHEMBL1488305 & 688293 & 5.4 & 5.0833 & TST & \\
\hline CHEMBL140 & 688293 & 6.0 & 5.0763 & TRN & \\
\hline CHEMBL1399847 & 688293 & 4.4 & 4.9667 & TRN & \\
\hline CHEMBL1311710 & 688293 & 4.4 & 5.0644 & TRN & \\
\hline CHEMBL1302808 & 688293 & 4.9 & 5.0977 & TST & \\
\hline CHEMBL1572637 & 688293 & 5.0 & 4.86600 & 00000000005 & TRN \\
\hline CHEMBL1333797 & 688293 & 5.6 & 5.1405 & TST & \\
\hline CHEMBL1570967 & 688293 & 5.3 & 4.9782 & TRN & \\
\hline CHEMBL1464517 & 688293 & 4.9 & 4.9179 & TRN & \\
\hline CHEMBL1527563 & 688293 & 4.6 & 4.9791 & TRN & \\
\hline CHEMBL1370891 & 688293 & 7.2 & 5.0851 & TST & \\
\hline CHEMBL1310986 & 688293 & 5.0 & 5.0546 & TST & \\
\hline CHEMBL 2004794 & 688293 & 4.5 & 4.7851 & TRN & \\
\hline CHEMBL1332022 & 688293 & 4.9 & 5.0245 & TRN & \\
\hline CHEMBL1304579 & 688293 & 4.6 & 5.211 & TRN & \\
\hline CHEMBL1411002 & 688293 & 5.2 & 4.96399 & 99999999995 & TRN \\
\hline CHEMBL1461744 & 688293 & 5.1 & 5.0552 & TRN & \\
\hline CHEMBL1306407 & 688293 & 4.9 & 5.101 & TRN & \\
\hline CHEMBL1431088 & 688293 & 5.2 & 5.1346 & TRN & \\
\hline CHEMBL1584610 & 688293 & 4.7 & 4.7148 & TRN & \\
\hline CHEMBL1480377 & 688293 & 4.4 & 4.9226 & TRN & \\
\hline CHEMBL1299403 & 688293 & 4.5 & 4.988 & TRN & \\
\hline CHEMBL1501462 & 688293 & 4.6 & 4.9487 & TRN & \\
\hline CHEMBL1536883 & 688293 & 4.7 & 5.1608 & TRN & \\
\hline CHEMBL1527559 & 688293 & 4.5 & 5.045 & TRN & \\
\hline CHEMBL1385272 & 688293 & 8.2007 & 5.0069 & TRN & \\
\hline CHEMBL1329577 & 688293 & 4.5 & 4.9462 & TRN & \\
\hline CHEMBL1561370 & 688293 & 4.5 & 4.9825 & TST & \\
\hline CHEMBL271023 & 688293 & 4.6 & 4.9299 & TST & \\
\hline CHEMBL1487447 & 688293 & 5.0 & 5.0564 & TRN & \\
\hline CHEMBL1571358 & 688293 & 7.1002 & 5.1904 & TST & \\
\hline CHEMBL3214392 & 688293 & 4.5 & 5.0123 & TST & \\
\hline CHEMBL1534514 & 688293 & 4.4 & 4.8298 & TRN & \\
\hline CHEMBL1411120 & 688293 & 4.6 & 4.9829 & TRN & \\
\hline CHEMBL1390005 & 688293 & 4.6 & 5.0891 & TRN & \\
\hline CHEMBL577455 & 688293 & 8.6021 & 5.0632 & TST & \\
\hline CHEMBL1540332 & 688293 & 4.7 & 5.1594 & TRN & \\
\hline CHEMBL1498329 & 688293 & 4.8 & 4.8594 & TRN & \\
\hline CHEMBL159096 & 688293 & 4.6 & 4.8435 & TST & \\
\hline
\end{tabular}




\begin{tabular}{|c|c|c|c|c|c|}
\hline \multicolumn{6}{|c|}{ Supplemental Table S2.txt } \\
\hline CHEMBL37708 & 688293 & 4.4 & 4.9424 & TRN & \\
\hline CHEMBL1382071 & 688293 & 6.8 & 5.0175 & TRN & \\
\hline CHEMBL1581335 & 688293 & 5.6 & 5.0756 & TRN & \\
\hline CHEMBL1472561 & 688293 & 8.2007 & 5.1582 & TST & \\
\hline CHEMBL1334638 & 688293 & 4.7 & 4.9173 & TRN & \\
\hline CHEMBL1256851 & 688293 & 4.8 & 4.9134 & TRN & \\
\hline CHEMBL1428856 & 688293 & 4.8 & 5.11 & TRN & \\
\hline CHEMBL1307391 & 688293 & 4.4 & 4.8532 & TST & \\
\hline CHEMBL1539403 & 688293 & 4.6 & 5.1075 & TRN & \\
\hline CHEMBL1450277 & 688293 & 4.7 & 5.0521 & TRN & \\
\hline CHEMBL1538118 & 688293 & 4.5 & 5.0513 & TRN & \\
\hline CHEMBL1548931 & 688293 & 6.2 & 5.0712 & TRN & \\
\hline CHEMBL1449836 & 688293 & 4.9 & 4.8522 & TRN & \\
\hline CHEMBL346516 & 688293 & 4.4 & 4.9223 & TRN & \\
\hline CHEMBL1415169 & 688293 & 4.5 & 5.0583 & TRN & \\
\hline CHEMBL1320258 & 688293 & 4.4 & 5.2399 & TRN & \\
\hline CHEMBL1402874 & 688293 & 4.4 & 5.0222 & TRN & \\
\hline CHEMBL1336469 & 688293 & 5.9 & 5.0285 & TRN & \\
\hline CHEMBL1527979 & 688293 & 4.4 & 5.1837 & TRN & \\
\hline CHEMBL1412825 & 688293 & 4.9 & 4.8208 & TRN & \\
\hline CHEMBL1538140 & 688293 & 4.8 & 5.0757 & TRN & \\
\hline CHEMBL1581818 & 688293 & 4.5 & 4.9789 & TST & \\
\hline CHEMBL1520880 & 688293 & 4.6 & $4.9110 e$ & 00000000005 & TRN \\
\hline CHEMBL1547470 & 688293 & 4.4 & 4.9998 & TRN & \\
\hline CHEMBL1384119 & 688293 & 4.9 & 5.1426 & TRN & \\
\hline CHEMBL1486886 & 688293 & 4.8 & 4.8644 & TRN & \\
\hline CHEMBL1310198 & 688293 & 4.5 & 5.0007 & TRN & \\
\hline CHEMBL1384763 & 688293 & 5.7 & 4.8645 & TRN & \\
\hline CHEMBL1442709 & 688293 & 4.4 & 4.8794 & TRN & \\
\hline CHEMBL1556956 & 688293 & 4.6 & 4.9937 & TRN & \\
\hline CHEMBL1445404 & 688293 & 4.7 & 5.0463 & TRN & \\
\hline CHEMBL1424294 & 688293 & 4.5 & 4.9168 & TRN & \\
\hline CHEMBL1478249 & 688293 & 6.2 & 4.8237 & TRN & \\
\hline CHEMBL1507271 & 688293 & 4.4 & 5.0483 & TRN & \\
\hline CHEMBL1356775 & 688293 & 4.5 & 4.8768 & TRN & \\
\hline CHEMBL1578243 & 688293 & 4.4 & 5.0137 & TRN & \\
\hline CHEMBL1505683 & 688293 & 6.3 & 5.1594 & TRN & \\
\hline CHEMBL1385355 & 688293 & 5.2 & 4.9726 & TRN & \\
\hline CHEMBL1340543 & 688293 & 6.7001 & 5.0245 & TRN & \\
\hline CHEMBL1566068 & 688293 & 4.9 & 4.9092 & TRN & \\
\hline CHEMBL1551841 & 688293 & 4.6 & 4.7817 & TRN & \\
\hline CHEMBL1300635 & 688293 & 4.4 & 5.1075 & TRN & \\
\hline CHEMBL1583062 & 688293 & 6.4 & 4.9975 & TRN & \\
\hline CHEMBL1372744 & 688293 & 4.4 & 4.9502 & TST & \\
\hline CHEMBL1457262 & 688293 & 4.4 & 4.9541 & TRN & \\
\hline CHEMBL1567080 & 688293 & 4.9 & 4.8767 & TRN & \\
\hline CHEMBL1457526 & 688293 & 4.4 & 5.3359 & TRN & \\
\hline CHEMBL1368850 & 688293 & 4.8 & 5.0665 & TRN & \\
\hline
\end{tabular}




\begin{tabular}{|c|c|c|c|c|}
\hline & & & pplement & \\
\hline CHEMBL1545708 & 688293 & 4.9 & 4.9275 & TRN \\
\hline CHEMBL1401480 & 688293 & 9.0 & 5.222 & TST \\
\hline CHEMBL1488668 & 688293 & 7.699 & 5.0389 & TRN \\
\hline CHEMBL1506303 & 688293 & 4.5 & 5.0744 & TRN \\
\hline CHEMBL1528511 & 688293 & 8.0 & 5.1206 & TRN \\
\hline CHEMBL1316492 & 688293 & 4.4 & 4.7285 & TRN \\
\hline CHEMBL3213585 & 688293 & 4.7 & 4.8968 & TRN \\
\hline CHEMBL1410321 & 688293 & 4.6 & 5.0919 & TRN \\
\hline CHEMBL1370652 & 688293 & 4.5 & 4.8713 & TRN \\
\hline CHEMBL1349575 & 688293 & 5.1 & 5.1332 & TRN \\
\hline CHEMBL1484400 & 688293 & 5.1 & 5.0027 & TRN \\
\hline CHEMBL1548010 & 688293 & 4.5 & 5.0842 & TRN \\
\hline CHEMBL1599191 & 688293 & 4.4 & 5.1729 & TRN \\
\hline CHEMBL1325702 & 688293 & 4.9 & 4.8649 & TRN \\
\hline CHEMBL1577814 & 688293 & 4.6 & 4.7959 & TRN \\
\hline CHEMBL1556323 & 688293 & 4.5 & 4.7968 & TRN \\
\hline CHEMBL1347243 & 688293 & 5.4 & 5.1479 & TRN \\
\hline CHEMBL1446926 & 688293 & 4.6 & 5.0072 & TRN \\
\hline CHEMBL1478718 & 688293 & 4.6 & 5.1232 & TRN \\
\hline CHEMBL1582912 & 688293 & 5.3 & 5.1695 & TRN \\
\hline CHEMBL1490887 & 688293 & 4.4 & 5.2153 & TST \\
\hline CHEMBL1410566 & 688293 & 7.3002 & 4.8898 & TST \\
\hline CHEMBL1408854 & 688293 & 5.9 & 4.9094 & TRN \\
\hline CHEMBL1408861 & 688293 & 5.0 & 4.9932 & TRN \\
\hline CHEMBL1401360 & 688293 & 4.4 & 4.9594 & TRN \\
\hline CHEMBL1561281 & 688293 & 6.9 & 4.8414 & TRN \\
\hline CHEMBL1491878 & 688293 & 4.4 & 5.0432 & TRN \\
\hline CHEMBL3194605 & 688293 & 8.0 & 4.8869 & TRN \\
\hline CHEMBL1568641 & 688293 & 4.7 & 4.8267 & TRN \\
\hline CHEMBL1594964 & 688293 & 8.0 & 4.9497 & TRN \\
\hline CHEMBL1509700 & 688293 & 4.5 & 4.8721 & TRN \\
\hline CHEMBL1507728 & 688293 & 7.6003 & 5.1918 & TRN \\
\hline CHEMBL1426800 & 688293 & 5.1 & 5.0784 & TST \\
\hline CHEMBL1530588 & 688293 & 4.4 & 5.2083 & TST \\
\hline CHEMBL494081 & 688293 & 4.9 & 5.2401 & TRN \\
\hline CHEMBL1408479 & 688293 & 8.0 & 5.035 & TRN \\
\hline CHEMBL1428373 & 688293 & 4.9 & 5.0696 & TRN \\
\hline CHEMBL288096 & 688293 & 5.4 & 5.0432 & TRN \\
\hline CHEMBL1466304 & 688293 & 4.5 & 4.9255 & TRN \\
\hline CHEMBL1499165 & 688293 & 4.9 & 4.8704 & TRN \\
\hline CHEMBL1529586 & 688293 & 4.6 & 4.9743 & TRN \\
\hline CHEMBL1374761 & 688293 & 4.6 & 5.0567 & TRN \\
\hline CHEMBL1492896 & 688293 & 4.8 & 4.8624 & TST \\
\hline CHEMBL1335744 & 688293 & 4.5 & 5.0886 & TRN \\
\hline CHEMBL1560900 & 688293 & 4.5 & 4.8068 & TRN \\
\hline CHEMBL1407677 & 688293 & 4.5 & 5.0728 & TRN \\
\hline CHEMBL1586886 & 688293 & 4.4 & 4.9672 & TRN \\
\hline CHEMBL1457362 & 688293 & 4.4 & 4.9875 & TRN \\
\hline
\end{tabular}




\begin{tabular}{|c|c|c|c|c|}
\hline \multicolumn{5}{|c|}{ Supplemental Table S2.txt } \\
\hline CHEMBL1399624 & 688293 & 4.5 & 4.9315 & TRN \\
\hline CHEMBL1360145 & 688293 & 4.8 & 5.1353 & TRN \\
\hline CHEMBL1447777 & 688293 & 4.6 & 4.7629 & TRN \\
\hline CHEMBL195789 & 688293 & 4.9 & 5.0145 & TRN \\
\hline CHEMBL1349633 & 688293 & 4.6 & 5.1123 & TRN \\
\hline CHEMBL1573271 & 688293 & 7.6003 & 5.2736 & TRN \\
\hline CHEMBL1604555 & 688293 & 7.0 & 5.0968 & TRN \\
\hline CHEMBL1569508 & 688293 & 4.8 & 5.1208 & TRN \\
\hline CHEMBL1504634 & 688293 & 4.5 & 5.1948 & TRN \\
\hline CHEMBL 1607420 & 688293 & 4.6 & 5.0809 & TRN \\
\hline CHEMBL1448032 & 688293 & 4.5 & 5.1451 & TRN \\
\hline CHEMBL1378282 & 688293 & 4.8 & 5.007 & TRN \\
\hline CHEMBL1548546 & 688293 & 5.8 & 4.9418 & TST \\
\hline CHEMBL1362267 & 688293 & 5.4 & 5.0323 & TRN \\
\hline CHEMBL1464985 & 688293 & 5.5 & 5.0552 & TRN \\
\hline CHEMBL1482580 & 688293 & 8.0 & 5.1001 & TRN \\
\hline CHEMBL1500491 & 688293 & 4.4 & 5.0888 & TRN \\
\hline CHEMBL1523695 & 688293 & 7.1002 & 5.2154 & TRN \\
\hline CHEMBL1368905 & 688293 & 4.7 & 4.9107 & TRN \\
\hline CHEMBL1578362 & 688293 & 4.6 & 5.1692 & TRN \\
\hline CHEMBL1455260 & 688293 & 4.9 & 5.075 & TRN \\
\hline CHEMBL1554937 & 688293 & 4.6 & 4.9648 & TRN \\
\hline CHEMBL1397009 & 688293 & 4.4 & 5.0092 & TRN \\
\hline CHEMBL1394045 & 688293 & 4.4 & 4.9858 & TRN \\
\hline CHEMBL1611449 & 688293 & 4.7 & 4.9084 & TRN \\
\hline CHEMBL1384195 & 688293 & 4.6 & 4.9772 & TRN \\
\hline CHEMBL1573264 & 688293 & 4.6 & 4.9912 & TRN \\
\hline CHEMBL1407853 & 688293 & 4.7 & 5.0717 & TRN \\
\hline CHEMBL1366750 & 688293 & 4.3 & 4.8085 & TRN \\
\hline CHEMBL1531703 & 688293 & 5.7 & 5.0165 & TRN \\
\hline CHEMBL1417897 & 688293 & 7.2 & 5.1498 & TRN \\
\hline CHEMBL1342657 & 688293 & 4.4 & 4.9686 & TRN \\
\hline CHEMBL1541318 & 688293 & 4.6 & 4.9305 & TRN \\
\hline CHEMBL228511 & 688293 & 4.5 & 4.8669 & TST \\
\hline CHEMBL1576324 & 688293 & 4.7 & 4.9624 & TRN \\
\hline CHEMBL1568081 & 688293 & 5.8 & 4.873 & TRN \\
\hline CHEMBL1592533 & 688293 & 4.5 & 4.9206 & TRN \\
\hline CHEMBL1438053 & 688293 & 4.7 & 5.0362 & TRN \\
\hline CHEMBL3207615 & 688293 & 6.2 & 5.0442 & TRN \\
\hline CHEMBL1411575 & 688293 & 6.1 & 5.2885 & TRN \\
\hline CHEMBL1585641 & 688293 & 4.8 & 4.9796 & TRN \\
\hline CHEMBL1601643 & 688293 & 4.5 & 4.9919 & TRN \\
\hline CHEMBL1362029 & 688293 & 4.8 & 4.7592 & TRN \\
\hline CHEMBL1389963 & 688293 & 7.0 & 5.1242 & TRN \\
\hline CHEMBL3212042 & 688293 & 5.5 & 4.9586 & TST \\
\hline CHEMBL1484516 & 688293 & 4.6 & 5.0403 & TRN \\
\hline CHEMBL1329936 & 688293 & 4.5 & 5.0843 & TRN \\
\hline CHEMBL1596927 & 688293 & 4.6 & 5.0838 & TRN \\
\hline
\end{tabular}




\begin{tabular}{|c|c|c|c|c|}
\hline \multicolumn{5}{|c|}{ Supplemental Table S2.txt } \\
\hline CHEMBL1460392 & 688293 & 4.4 & 5.2392 & TRN \\
\hline CHEMBL1479324 & 688293 & 4.7 & 5.0389 & TRN \\
\hline CHEMBL1446323 & 688293 & 5.0 & 4.7516 & TRN \\
\hline CHEMBL1440005 & 688293 & 4.4 & 5.0408 & TST \\
\hline CHEMBL1530191 & 688293 & 4.8 & 5.0882 & TRN \\
\hline CHEMBL1343105 & 688293 & 4.7 & 4.8412 & TRN \\
\hline CHEMBL1333251 & 688293 & 4.6 & 4.9947 & TRN \\
\hline CHEMBL1461086 & 688293 & 4.7 & 4.9198 & TRN \\
\hline CHEMBL1372854 & 688293 & 5.1 & 5.1865 & TRN \\
\hline CHEMBL1444434 & 688293 & 5.8 & 5.0219 & TRN \\
\hline CHEMBL1482706 & 688293 & 5.0 & 5.0048 & TRN \\
\hline CHEMBL1597107 & 688293 & 6.1 & 4.9576 & TRN \\
\hline CHEMBL1588430 & 688293 & 4.5 & 5.0339 & TRN \\
\hline CHEMBL1570523 & 688293 & 4.7 & 5.0936 & TRN \\
\hline CHEMBL3214281 & 688293 & 4.4 & 4.9656 & TRN \\
\hline CHEMBL1471387 & 688293 & 6.0 & 5.0247 & TRN \\
\hline CHEMBL1322600 & 688293 & 4.6 & 4.9289 & TRN \\
\hline CHEMBL1256687 & 688293 & 4.8 & 4.9494 & TST \\
\hline CHEMBL1606892 & 688293 & 4.5 & 4.9434 & TST \\
\hline CHEMBL1309150 & 688293 & 4.5 & 5.0263 & TRN \\
\hline CHEMBL1563807 & 688293 & 4.8 & 5.1747 & TRN \\
\hline CHEMBL1582759 & 688293 & 4.7 & 5.0483 & TRN \\
\hline CHEMBL1411129 & 688293 & 5.5 & 4.9571 & TRN \\
\hline CHEMBL1230276 & 688293 & 5.4 & 4.9195 & TRN \\
\hline CHEMBL1478881 & 688293 & 5.3 & 4.8129 & TST \\
\hline CHEMBL1594557 & 688293 & 4.6 & 5.1277 & TRN \\
\hline CHEMBL1495228 & 688293 & 5.1 & 5.154 & TRN \\
\hline CHEMBL1450778 & 688293 & 4.5 & 5.0737 & TRN \\
\hline CHEMBL1606519 & 688293 & 4.5 & 5.0093 & TRN \\
\hline CHEMBL1363989 & 688293 & 5.2 & 5.0265 & TRN \\
\hline CHEMBL3186408 & 688293 & 6.0 & 5.075 & TST \\
\hline CHEMBL1416105 & 688293 & 5.2 & 5.2756 & TRN \\
\hline CHEMBL1571352 & 688293 & 5.1 & 5.0237 & TRN \\
\hline CHEMBL1459223 & 688293 & 5.1 & 5.0833 & TRN \\
\hline CHEMBL1522777 & 688293 & 4.8 & 4.8807 & TRN \\
\hline CHEMBL1353885 & 688293 & 4.6 & 5.0049 & TRN \\
\hline CHEMBL1405581 & 688293 & 5.7 & 5.1269 & TRN \\
\hline CHEMBL405358 & 688293 & 5.1 & 4.8479 & TST \\
\hline CHEMBL1537053 & 688293 & 5.4 & 5.1404 & TRN \\
\hline CHEMBL1396310 & 688293 & 5.5 & 4.8188 & TRN \\
\hline CHEMBL1384825 & 688293 & 5.6 & 5.0783 & TRN \\
\hline CHEMBL1376970 & 688293 & 4.9 & 4.9815 & TRN \\
\hline CHEMBL1507610 & 688293 & 5.0 & 4.9965 & TRN \\
\hline CHEMBL1377249 & 688293 & 4.4 & 4.8533 & TRN \\
\hline CHEMBL1434441 & 688293 & 7.1002 & 5.1613 & TST \\
\hline CHEMBL1489081 & 688293 & 4.6 & 5.0544 & TRN \\
\hline CHEMBL1474890 & 688293 & 4.8 & 4.8799 & TRN \\
\hline CHEMBL1380799 & 688293 & 5.4 & 5.2029 & TRN \\
\hline
\end{tabular}




\begin{tabular}{|c|c|c|c|c|c|}
\hline \multirow{3}{*}{$\begin{array}{l}\text { CHEMBL1434833 } \\
\text { CHEMBL1440650 }\end{array}$} & \multirow{3}{*}{$\begin{array}{l}688293 \\
688293\end{array}$} & \multicolumn{4}{|c|}{ Supplemental Table S2.txt } \\
\hline & & 5.9 & \multicolumn{2}{|c|}{4.9239999999999995} & TRN \\
\hline & & 4.9 & 4.7621 & TRN & \\
\hline CHEMBL1472216 & 688293 & 4.9 & 5.1171 & TRN & \\
\hline CHEMBL1373443 & 688293 & 4.7 & 5.067 & TRN & \\
\hline CHEMBL1311841 & 688293 & 4.5 & 5.0404 & TRN & \\
\hline CHEMBL99203 & 688293 & 5.5 & 4.984 & TST & \\
\hline CHEMBL1349724 & 688293 & 6.7001 & 5.1429 & TRN & \\
\hline CHEMBL1602544 & 688293 & 5.7 & 5.1189 & TRN & \\
\hline CHEMBL1489152 & 688293 & 4.6 & 4.9284 & TRN & \\
\hline CHEMBL1471305 & 688293 & 4.8 & 5.1231 & TRN & \\
\hline CHEMBL1314989 & 688293 & 4.4 & 5.1783 & TST & \\
\hline CHEMBL1346885 & 688293 & 4.6 & 4.8033 & TRN & \\
\hline CHEMBL1349651 & 688293 & 4.7 & 4.7637 & TRN & \\
\hline CHEMBL1594363 & 688293 & 4.8 & 5.1258 & TRN & \\
\hline CHEMBL1566244 & 688293 & 5.4 & 5.0966 & TRN & \\
\hline CHEMBL1491507 & 688293 & 4.9 & 5.1906 & TRN & \\
\hline CHEMBL1384652 & 688293 & 5.2 & 5.2105 & TRN & \\
\hline CHEMBL116438 & 688293 & 5.0 & 5.0281 & TRN & \\
\hline CHEMBL1522577 & 688293 & 4.4 & 4.9111 & TRN & \\
\hline CHEMBL1453824 & 688293 & 4.8 & 5.0968 & TRN & \\
\hline CHEMBL1449759 & 688293 & 4.8 & 4.7773 & TRN & \\
\hline CHEMBL1521489 & 688293 & 5.6 & 4.9908 & TRN & \\
\hline CHEMBL3197627 & 688293 & 8.4949 & 5.228 & TST & \\
\hline CHEMBL562192 & 688293 & 4.5 & 4.9488 & TRN & \\
\hline CHEMBL1483036 & 688293 & 4.4 & 4.9215 & TRN & \\
\hline CHEMBL1376802 & 688293 & 4.9 & 5.0888 & TRN & \\
\hline CHEMBL399761 & 688293 & 5.0 & 4.7796 & TRN & \\
\hline CHEMBL1408999 & 688293 & 4.5 & 5.06 & TRN & \\
\hline CHEMBL1511191 & 688293 & 4.4 & 5.2283 & TRN & \\
\hline CHEMBL1493968 & 688293 & 4.7 & 4.9127 & TRN & \\
\hline CHEMBL402063 & 688293 & 4.5 & 5.1047 & TST & \\
\hline CHEMBL1496560 & 688293 & 4.4 & 4.7966 & TRN & \\
\hline CHEMBL1523983 & 688293 & 4.8 & 5.0029 & TRN & \\
\hline CHEMBL1377686 & 688293 & 6.5 & 4.9442 & TST & \\
\hline CHEMBL1310741 & 688293 & 4.9 & 4.9947 & TRN & \\
\hline CHEMBL1572056 & 688293 & 4.9 & 5.0341 & TRN & \\
\hline CHEMBL1392831 & 688293 & 4.7 & 5.0644 & TRN & \\
\hline CHEMBL1341140 & 688293 & 5.5 & 5.0256 & TRN & \\
\hline CHEMBL47529 & 688293 & 4.5 & 4.8506 & TST & \\
\hline CHEMBL1587416 & 688293 & 4.9 & 5.1508 & TRN & \\
\hline CHEMBL1447004 & 688293 & 4.6 & 5.1877 & TRN & \\
\hline CHEMBL1346656 & 688293 & 4.8 & 4.9813 & TRN & \\
\hline CHEMBL1343885 & 688293 & 4.4 & 5.1578 & TRN & \\
\hline CHEMBL1592571 & 688293 & 4.5 & 4.8329 & TRN & \\
\hline CHEMBL1521269 & 688293 & 5.1 & 4.9636 & TRN & \\
\hline CHEMBL1575149 & 688293 & 4.4 & 5.0026 & TRN & \\
\hline CHEMBL1414002 & 688293 & 5.1 & 5.1404 & TRN & \\
\hline CHEMBL1489492 & 688293 & 4.8 & 4.9861 & TRN & \\
\hline
\end{tabular}




\begin{tabular}{|c|c|c|c|c|}
\hline \multicolumn{5}{|c|}{ Supplemental Table S2.txt } \\
\hline CHEMBL1396374 & 688293 & 4.7 & 4.7808 & TRN \\
\hline CHEMBL1386171 & 688293 & 4.8 & 4.994 & TRN \\
\hline CHEMBL1363982 & 688293 & 5.2 & 4.9001 & TRN \\
\hline CHEMBL1456679 & 688293 & 5.0 & 5.0653 & TST \\
\hline CHEMBL1611496 & 688293 & 4.8 & 4.7016 & TRN \\
\hline CHEMBL1595560 & 688293 & 5.1 & 5.0042 & TRN \\
\hline CHEMBL1330094 & 688293 & 4.5 & 5.1077 & TRN \\
\hline CHEMBL45176 & 688293 & 5.7 & 4.9051 & TST \\
\hline CHEMBL1470367 & 688293 & 4.5 & 4.9771 & TST \\
\hline CHEMBL1555348 & 688293 & 4.4 & 4.8512 & TRN \\
\hline CHEMBL1385448 & 688293 & 4.5 & 4.9969 & TRN \\
\hline CHEMBL1382476 & 688293 & 4.7 & 5.0004 & TST \\
\hline CHEMBL 273386 & 688293 & 4.5 & 4.9701 & TRN \\
\hline CHEMBL1402127 & 688293 & 4.6 & 5.1048 & TRN \\
\hline CHEMBL1508235 & 688293 & 7.4001 & 5.0179 & TRN \\
\hline CHEMBL1601002 & 688293 & 4.4 & 4.9387 & TRN \\
\hline CHEMBL1516103 & 688293 & 5.3 & 4.8614 & TRN \\
\hline CHEMBL1377499 & 688293 & 5.1 & 5.0962 & TRN \\
\hline CHEMBL1362051 & 688293 & 5.5 & 5.0392 & TRN \\
\hline CHEMBL1549072 & 688293 & 4.4 & 4.8841 & TRN \\
\hline CHEMBL1600031 & 688293 & 4.5 & 4.7719 & TRN \\
\hline CHEMBL1555190 & 688293 & 8.301 & 5.0736 & TRN \\
\hline CHEMBL1332293 & 688293 & 7.0 & 5.1148 & TRN \\
\hline CHEMBL1499758 & 688293 & 4.6 & 4.9382 & TRN \\
\hline CHEMBL1491239 & 688293 & 4.4 & 5.0726 & TRN \\
\hline CHEMBL1381721 & 688293 & 5.9 & 5.1234 & TRN \\
\hline CHEMBL1539702 & 688293 & 4.8 & 4.8838 & TRN \\
\hline CHEMBL 229760 & 688293 & 4.4 & 4.9236 & TST \\
\hline CHEMBL1322532 & 688293 & 5.8 & 4.9526 & TRN \\
\hline CHEMBL 258767 & 688293 & 6.0 & 4.9973 & TRN \\
\hline CHEMBL1437713 & 688293 & 4.8 & 4.9266 & TRN \\
\hline CHEMBL1374812 & 688293 & 4.4 & 5.0233 & TRN \\
\hline CHEMBL1481608 & 688293 & 6.4 & 4.8235 & TRN \\
\hline CHEMBL1402143 & 688293 & 4.8 & 5.1356 & TRN \\
\hline CHEMBL1382005 & 688293 & 5.5 & 5.0804 & TRN \\
\hline CHEMBL1444488 & 688293 & 4.6 & 5.2384 & TRN \\
\hline CHEMBL1567616 & 688293 & 4.5 & 5.1216 & TRN \\
\hline CHEMBL1477399 & 688293 & 4.6 & 4.9436 & TRN \\
\hline CHEMBL1489358 & 688293 & 4.5 & 4.9485 & TRN \\
\hline CHEMBL1387162 & 688293 & 4.5 & 4.8783 & TRN \\
\hline CHEMBL1356069 & 688293 & 6.7001 & 5.0089 & TRN \\
\hline CHEMBL1483944 & 688293 & 4.9 & 5.1367 & TRN \\
\hline CHEMBL1504882 & 688293 & 5.1 & 5.0334 & TRN \\
\hline CHEMBL1588928 & 688293 & 4.6 & 4.8884 & TRN \\
\hline CHEMBL1472703 & 688293 & 6.6 & 5.0674 & TRN \\
\hline CHEMBL1332354 & 688293 & 7.3002 & 5.1994 & TRN \\
\hline CHEMBL1419214 & 688293 & 4.4 & 4.9313 & TRN \\
\hline CHEMBL1606996 & 688293 & 4.4 & 5.1082 & TRN \\
\hline
\end{tabular}




\begin{tabular}{|c|c|c|c|c|}
\hline & & & pplement & al $\mathrm{Ta}$ \\
\hline CHEMBL1481995 & 688293 & 5.8 & 5.0575 & TRN \\
\hline CHEMBL1453678 & 688293 & 4.8 & 5.2156 & TRN \\
\hline CHEMBL251785 & 688293 & 5.3 & 4.8164 & TRN \\
\hline CHEMBL1548415 & 688293 & 5.4 & 5.0634 & TRN \\
\hline CHEMBL1486140 & 688293 & 4.4 & 5.1348 & TRN \\
\hline CHEMBL1468870 & 688293 & 4.5 & 4.9489 & TRN \\
\hline CHEMBL1466376 & 688293 & 7.0 & 4.9719 & TST \\
\hline CHEMBL1341211 & 688293 & 6.0 & 4.8928 & TRN \\
\hline CHEMBL1333153 & 688293 & 4.4 & 4.8385 & TRN \\
\hline CHEMBL1390539 & 688293 & 4.8 & 4.9236 & TRN \\
\hline CHEMBL1408398 & 688293 & 4.8 & 4.9623 & TRN \\
\hline CHEMBL1310614 & 688293 & 4.4 & 5.059 & TRN \\
\hline CHEMBL1423407 & 688293 & 4.6 & 5.0058 & TRN \\
\hline CHEMBL 233302 & 688293 & 4.9 & 4.7119 & TRN \\
\hline CHEMBL1581991 & 688293 & 4.4 & 4.9969 & TRN \\
\hline CHEMBL1305293 & 688293 & 5.0 & 4.8786 & TST \\
\hline CHEMBL1338771 & 688293 & 4.5 & 4.9646 & TRN \\
\hline CHEMBL2094573 & 688293 & 4.9 & 4.7698 & TRN \\
\hline CHEMBL319244 & 688293 & 4.6 & 4.9656 & TRN \\
\hline CHEMBL1588672 & 688293 & 4.5 & 4.8426 & TRN \\
\hline CHEMBL1606364 & 688293 & 6.2 & 5.1782 & TRN \\
\hline CHEMBL252526 & 688293 & 4.4 & 5.0605 & TRN \\
\hline CHEMBL1481474 & 688293 & 6.4 & 4.9517 & TRN \\
\hline CHEMBL1417537 & 688293 & 4.8 & 4.9134 & TRN \\
\hline CHEMBL1504416 & 688293 & 4.7 & 5.0061 & TRN \\
\hline CHEMBL1460603 & 688293 & 4.5 & 5.0569 & TRN \\
\hline CHEMBL1602838 & 688293 & 4.6 & 4.9873 & TRN \\
\hline CHEMBL1521895 & 688293 & 4.8 & 4.94 & TRN \\
\hline CHEMBL1581436 & 688293 & 5.6 & 4.9806 & TRN \\
\hline CHEMBL1597777 & 688293 & 4.5 & 4.9806 & TRN \\
\hline CHEMBL1587962 & 688293 & 5.1 & 5.0346 & TRN \\
\hline CHEMBL1452079 & 688293 & 4.5 & 5.0188 & TRN \\
\hline CHEMBL1540513 & 688293 & 5.5 & 4.9548 & TRN \\
\hline CHEMBL1440541 & 688293 & 4.7 & 5.0257 & TRN \\
\hline CHEMBL1399142 & 688293 & 4.6 & 5.1645 & TRN \\
\hline CHEMBL1324769 & 688293 & 4.6 & 4.8963 & TRN \\
\hline CHEMBL1596499 & 688293 & 4.5 & 4.8091 & TRN \\
\hline CHEMBL1334519 & 688293 & 8.301 & 4.9925 & TRN \\
\hline CHEMBL1438492 & 688293 & 4.9 & 5.1779 & TRN \\
\hline CHEMBL1592343 & 688293 & 4.4 & 4.9534 & TRN \\
\hline CHEMBL1438226 & 688293 & 4.5 & 4.9515 & TRN \\
\hline CHEMBL1411663 & 688293 & 4.4 & 4.7896 & TRN \\
\hline CHEMBL1341783 & 688293 & 8.0 & 4.9755 & TRN \\
\hline CHEMBL1454544 & 688293 & 4.8 & 4.6827 & TRN \\
\hline CHEMBL1364432 & 688293 & 4.6 & 4.774 & TRN \\
\hline CHEMBL1324691 & 688293 & 4.9 & 5.1116 & TRN \\
\hline CHEMBL1374544 & 688293 & 4.5 & 4.815 & TRN \\
\hline CHEMBL1402142 & 688293 & 4.4 & 5.0237 & TRN \\
\hline
\end{tabular}




\begin{tabular}{|c|c|c|c|c|c|}
\hline \multirow[b]{2}{*}{ CHEMBL1577603 } & \multicolumn{5}{|c|}{ Supplemental Table S2.txt } \\
\hline & 688293 & 8.4949 & 5.1472 & TRN & \\
\hline CHEMBL32827 & 688293 & 5.2 & 5.2181 & TRN & \\
\hline CHEMBL1482771 & 688293 & 4.4 & 4.9678 & TST & \\
\hline CHEMBL 3198962 & 688293 & 4.6 & 4.9031 & TRN & \\
\hline CHEMBL1585575 & 688293 & 4.4 & 5.0674 & TRN & \\
\hline CHEMBL1362829 & 688293 & 4.7 & 4.8089 & TST & \\
\hline CHEMBL1491811 & 688293 & 4.5 & 5.1674 & TRN & \\
\hline CHEMBL1521625 & 688293 & 4.9 & 5.065 & TRN & \\
\hline CHEMBL1421232 & 688293 & 4.4 & 4.9556 & TRN & \\
\hline CHEMBL1334104 & 688293 & 6.9 & 5.1382 & TRN & \\
\hline CHEMBL1322500 & 688293 & 4.4 & 4.9818 & TRN & \\
\hline CHEMBL1406459 & 688293 & 4.9 & 5.0348 & TRN & \\
\hline CHEMBL1335008 & 688293 & 4.8 & 4.9649 & TRN & \\
\hline CHEMBL1598344 & 688293 & 4.6 & 5.0365 & TRN & \\
\hline CHEMBL1360383 & 688293 & 4.5 & 4.8472 & TRN & \\
\hline CHEMBL554041 & 688293 & 4.9 & 5.1309 & TRN & \\
\hline CHEMBL1385404 & 688293 & 4.6 & 4.9883 & TRN & \\
\hline CHEMBL464859 & 688293 & 6.5 & 5.1339 & TST & \\
\hline CHEMBL1467058 & 688293 & 5.0 & 4.9457 & TST & \\
\hline CHEMBL 267548 & 688293 & 4.9 & 5.0357 & TST & \\
\hline CHEMBL1608266 & 688293 & 4.9 & 4.8924 & TRN & \\
\hline CHEMBL1383728 & 688293 & 7.2 & 5.1253 & TRN & \\
\hline CHEMBL1534126 & 688293 & 4.6 & 4.8955 & TRN & \\
\hline CHEMBL236685 & 688293 & 4.9 & 5.16200 & 0000000001 & TRN \\
\hline CHEMBL1598065 & 688293 & 4.4 & 4.9805 & TRN & \\
\hline CHEMBL1460731 & 688293 & 4.7 & 4.9242 & TRN & \\
\hline CHEMBL1343526 & 688293 & 5.1 & 4.8586 & TRN & \\
\hline CHEMBL1580614 & 688293 & 4.9 & 5.0443 & TRN & \\
\hline CHEMBL1506084 & 688293 & 4.4 & 5.1777 & TRN & \\
\hline CHEMBL1602443 & 688293 & 5.1 & 4.9469 & TRN & \\
\hline CHEMBL1383533 & 688293 & 5.0 & 4.7803 & TRN & \\
\hline CHEMBL1325576 & 688293 & 4.7 & 4.8507 & TRN & \\
\hline CHEMBL1371891 & 688293 & 4.5 & 5.1469 & TRN & \\
\hline CHEMBL1455591 & 688293 & 4.4 & 5.0796 & TRN & \\
\hline CHEMBL1394840 & 688293 & 5.0 & 5.0499 & TRN & \\
\hline CHEMBL1573146 & 688293 & 4.6 & 5.0996 & TRN & \\
\hline CHEMBL1599428 & 688293 & 4.8 & 5.0363 & TRN & \\
\hline CHEMBL1480286 & 688293 & 4.7 & 5.1013 & TRN & \\
\hline CHEMBL1423851 & 688293 & 4.6 & 5.0428 & TRN & \\
\hline CHEMBL589458 & 688293 & 4.4 & 5.0833 & TST & \\
\hline CHEMBL1490891 & 688293 & 4.4 & 5.1709 & TRN & \\
\hline CHEMBL 2374266 & 688293 & 4.4 & 4.9875 & TRN & \\
\hline CHEMBL1473073 & 688293 & 4.4 & 4.9758 & TRN & \\
\hline CHEMBL1334465 & 688293 & 4.8 & 4.9903 & TST & \\
\hline CHEMBL1542747 & 688293 & 4.8 & 5.2107 & TRN & \\
\hline CHEMBL1579346 & 688293 & 5.7 & 5.0265 & TRN & \\
\hline CHEMBL1506733 & 688293 & 4.8 & 4.8969 & TRN & \\
\hline CHEMBL547833 & 688293 & 4.5 & 4.9229 & TRN & \\
\hline
\end{tabular}




\begin{tabular}{|c|c|c|c|c|c|}
\hline & & & & & \\
\hline CHEMBL1444938 & 688293 & 4.8 & 4.927 & TRN & \\
\hline CHEMBL1544757 & 688293 & 5.3 & 5.0155 & TRN & \\
\hline CHEMBL1437423 & 688293 & 4.8 & 4.9458 & TRN & \\
\hline CHEMBL1386981 & 688293 & 4.6 & 4.9374 & TST & \\
\hline CHEMBL1363762 & 688293 & 4.4 & 4.9685 & TRN & \\
\hline CHEMBL1539570 & 688293 & 4.6 & 4.9771 & TRN & \\
\hline CHEMBL1523968 & 688293 & 4.4 & 5.0036 & TRN & \\
\hline CHEMBL1423004 & 688293 & 5.5 & 5.1728 & TRN & \\
\hline CHEMBL 240963 & 688293 & 7.5003 & 5.0059 & TST & \\
\hline CHEMBL1347962 & 688293 & 4.4 & 4.8603 & TRN & \\
\hline CHEMBL1333791 & 688293 & 5.6 & 4.8729 & TRN & \\
\hline CHEMBL1524788 & 688293 & 4.9 & 5.1001 & TRN & \\
\hline CHEMBL1454211 & 688293 & 4.7 & 5.1123 & TRN & \\
\hline CHEMBL1513686 & 688293 & 4.6 & 4.9638 & TST & \\
\hline CHEMBL1564566 & 688293 & 4.4 & 5.0749 & TST & \\
\hline CHEMBL1307208 & 688293 & 5.5 & 4.956 & TRN & \\
\hline CHEMBL1606400 & 688293 & 5.3 & 4.8763 & TRN & \\
\hline CHEMBL1613534 & 688293 & 4.8 & 4.9297 & TST & \\
\hline CHEMBL1335212 & 688293 & 4.6 & 4.9684 & TRN & \\
\hline CHEMBL3196620 & 688293 & 4.5 & 4.859 & TRN & \\
\hline CHEMBL1465221 & 688293 & 4.5 & 4.928 & TRN & \\
\hline CHEMBL1307319 & 688293 & 5.2 & 5.05 & TRN & \\
\hline CHEMBL1323619 & 688293 & 4.5 & 5.107 & TST & \\
\hline CHEMBL1428162 & 688293 & 4.5 & 4.99100 & 00000000005 & TRN \\
\hline CHEMBL1439353 & 688293 & 7.6003 & 4.9629 & TST & \\
\hline CHEMBL1488141 & 688293 & 4.6 & 5.0028 & TRN & \\
\hline CHEMBL1446729 & 688293 & 4.5 & 5.0489 & TRN & \\
\hline CHEMBL1574787 & 688293 & 5.3 & 5.0258 & TST & \\
\hline CHEMBL1300891 & 688293 & 5.4 & 5.0048 & TRN & \\
\hline CHEMBL1389530 & 688293 & 4.5 & 4.9691 & TRN & \\
\hline CHEMBL1312482 & 688293 & 4.5 & 5.0566 & TRN & \\
\hline CHEMBL1415458 & 688293 & 4.9 & 5.0849 & TRN & \\
\hline CHEMBL1093246 & 688293 & 4.7 & 4.8936 & TRN & \\
\hline CHEMBL1431657 & 688293 & 4.7 & 5.0686 & TRN & \\
\hline CHEMBL1523687 & 688293 & 4.5 & 5.087 & TRN & \\
\hline CHEMBL1441531 & 688293 & 6.1 & 5.2167 & TRN & \\
\hline CHEMBL491771 & 688293 & 4.6 & 4.751 & TRN & \\
\hline CHEMBL 1408532 & 688293 & 6.0 & 4.8635 & TRN & \\
\hline CHEMBL1513614 & 688293 & 6.0 & 4.9443 & TST & \\
\hline CHEMBL1523003 & 688293 & 6.8 & 5.0915 & TRN & \\
\hline CHEMBL1304242 & 688293 & 5.1 & 5.1105 & TRN & \\
\hline CHEMBL1562716 & 688293 & 5.4 & 5.0961 & TST & \\
\hline CHEMBL1534916 & 688293 & 4.8 & 5.1491 & TRN & \\
\hline CHEMBL294009 & 688293 & 4.4 & 4.9086 & TRN & \\
\hline CHEMBL1360025 & 688293 & 4.6 & 4.99100 & 00000000005 & TRN \\
\hline CHEMBL1540853 & 688293 & 4.6 & 5.2133 & TRN & \\
\hline CHEMBL1310889 & 688293 & 4.4 & 5.1324 & TRN & \\
\hline CHEMBL1379945 & 688293 & 4.7 & 5.0026 & TRN & \\
\hline
\end{tabular}




\begin{tabular}{|c|c|c|c|c|c|}
\hline & & & & & \\
\hline CHEMBL1395408 & 688293 & 4.9 & 5.1299 & TST & \\
\hline CHEMBL1329661 & 688293 & 4.6 & 4.9441 & TRN & \\
\hline CHEMBL1608377 & 688293 & 4.6 & 4.9094 & TRN & \\
\hline CHEMBL1366020 & 688293 & 4.8 & 4.7661 & TRN & \\
\hline CHEMBL1561641 & 688293 & 4.6 & 4.9132 & TRN & \\
\hline CHEMBL1537440 & 688293 & 4.4 & 5.0144 & TRN & \\
\hline CHEMBL1363327 & 688293 & 5.9 & 5.0927 & TRN & \\
\hline CHEMBL1363077 & 688293 & 4.7 & 4.8974 & TRN & \\
\hline CHEMBL1313122 & 688293 & 4.6 & 5.0921 & TRN & \\
\hline CHEMBL1561782 & 688293 & 4.6 & 4.9067 & TRN & \\
\hline CHEMBL1596301 & 688293 & 4.6 & 5.083 & TRN & \\
\hline CHEMBL1383457 & 688293 & 4.8 & 5.0454 & TRN & \\
\hline CHEMBL285480 & 688293 & 4.4 & 5.008 & TST & \\
\hline CHEMBL1340593 & 688293 & 4.7 & 5.0354 & TRN & \\
\hline CHEMBL1416556 & 688293 & 5.0 & 4.8178 & TRN & \\
\hline CHEMBL1357558 & 688293 & 5.1 & 5.0138 & TST & \\
\hline CHEMBL1256876 & 688293 & 4.6 & 4.9889 & TST & \\
\hline CHEMBL1351631 & 688293 & 5.2 & 5.0661 & TRN & \\
\hline CHEMBL1414426 & 688293 & 5.4 & 5.0019 & TRN & \\
\hline CHEMBL1360376 & 688293 & 4.7 & 4.8383 & TRN & \\
\hline CHEMBL1576552 & 688293 & 4.7 & 5.0219 & TRN & \\
\hline CHEMBL1452142 & 688293 & 4.9 & 5.0654 & TRN & \\
\hline CHEMBL1353950 & 688293 & 4.4 & 5.1081 & TRN & \\
\hline CHEMBL1453411 & 688293 & 4.5 & 4.8528 & TRN & \\
\hline CHEMBL1321097 & 688293 & 4.4 & 4.9448 & TRN & \\
\hline CHEMBL1374633 & 688293 & 5.8 & 4.9329 & TRN & \\
\hline CHEMBL1519490 & 688293 & 5.2 & 5.084 & TST & \\
\hline CHEMBL1538200 & 688293 & 4.8 & 4.8546 & TRN & \\
\hline CHEMBL 3187748 & 688293 & 5.9 & 4.9947 & TRN & \\
\hline CHEMBL1397221 & 688293 & 4.6 & 5.1131 & TRN & \\
\hline CHEMBL1508370 & 688293 & 5.0 & 4.8587 & TRN & \\
\hline CHEMBL1354388 & 688293 & 4.6 & 4.9118 & TRN & \\
\hline CHEMBL1328930 & 688293 & 4.6 & 4.8274 & TRN & \\
\hline CHEMBL1429775 & 688293 & 5.2 & 5.1093 & TRN & \\
\hline CHEMBL1452910 & 688293 & 4.6 & 4.9533 & TST & \\
\hline CHEMBL1403474 & 688293 & 5.1 & 5.0101 & TRN & \\
\hline CHEMBL1462934 & 688293 & 5.1 & 4.9713 & TRN & \\
\hline CHEMBL1367356 & 688293 & 4.8 & 4.9236 & TRN & \\
\hline CHEMBL1317124 & 688293 & 4.8 & 4.9815 & TST & \\
\hline CHEMBL1524331 & 688293 & 5.1 & 4.9843 & TST & \\
\hline CHEMBL1412695 & 688293 & 4.6 & 4.8336 & TRN & \\
\hline CHEMBL1341362 & 688293 & 5.1 & 4.8895 & TRN & \\
\hline CHEMBL1338700 & 688293 & 4.8 & $5.0680 e$ & 20000000005 & TRN \\
\hline CHEMBL416657 & 688293 & 4.7 & 4.9603 & TST & \\
\hline CHEMBL1605585 & 688293 & 4.6 & 4.927 & TRN & \\
\hline CHEMBL1471171 & 688293 & 5.2 & 4.9355 & TRN & \\
\hline CHEMBL 261123 & 688293 & 4.8 & 4.663 & TRN & \\
\hline CHEMBL1427693 & 688293 & 4.6 & 5.1157 & TRN & \\
\hline & & & & 19481 & \\
\hline
\end{tabular}




\begin{tabular}{|c|c|c|c|c|}
\hline \multicolumn{5}{|c|}{ Supplemental Table S2.txt } \\
\hline CHEMBL56543 & 688293 & 4.5 & 5.0157 & TRN \\
\hline CHEMBL1367008 & 688293 & 4.9 & 5.1906 & TRN \\
\hline CHEMBL1373746 & 688293 & 4.6 & 5.1393 & TRN \\
\hline CHEMBL1566202 & 688293 & 6.5 & 5.1152 & TRN \\
\hline CHEMBL1613087 & 688293 & 4.4 & 4.7949 & TRN \\
\hline CHEMBL1499272 & 688293 & 4.5 & 5.0351 & TRN \\
\hline CHEMBL1594650 & 688293 & 5.1 & 4.8991 & TRN \\
\hline CHEMBL1357444 & 688293 & 4.6 & 4.82 & TRN \\
\hline CHEMBL1341925 & 688293 & 4.5 & 5.1248 & TRN \\
\hline CHEMBL598263 & 688293 & 7.3002 & 4.9795 & TST \\
\hline CHEMBL1605558 & 688293 & 4.6 & 5.2475 & TRN \\
\hline CHEMBL1604672 & 688293 & 5.8 & 5.0512 & TST \\
\hline CHEMBL566899 & 688293 & 4.5 & 4.6839 & TRN \\
\hline CHEMBL1412509 & 688293 & 5.0 & 5.2481 & TRN \\
\hline CHEMBL1565371 & 688293 & 4.9 & 5.0082 & TST \\
\hline CHEMBL1307669 & 688293 & 4.8 & 5.0639 & TRN \\
\hline CHEMBL1351008 & 688293 & 5.2 & 5.1504 & TRN \\
\hline CHEMBL 272005 & 688293 & 4.4 & 4.8006 & TRN \\
\hline CHEMBL1547186 & 688293 & 6.0 & 4.9269 & TRN \\
\hline CHEMBL1567756 & 688293 & 5.0 & 5.0697 & TST \\
\hline CHEMBL1456266 & 688293 & 4.4 & 5.0974 & TRN \\
\hline CHEMBL1338342 & 688293 & 4.6 & 5.0121 & TRN \\
\hline CHEMBL1325303 & 688293 & 4.4 & 4.9227 & TRN \\
\hline CHEMBL1557058 & 688293 & 5.5 & 5.0956 & TRN \\
\hline CHEMBL1463960 & 688293 & 5.7 & 4.845 & TRN \\
\hline CHEMBL1603586 & 688293 & 8.301 & 5.062 & TRN \\
\hline CHEMBL1162485 & 688293 & 7.0 & 5.1681 & TST \\
\hline CHEMBL1312156 & 688293 & 5.5 & 5.1297 & TST \\
\hline CHEMBL1351557 & 688293 & 4.4 & 5.1708 & TRN \\
\hline CHEMBL1370480 & 688293 & 4.9 & 4.9695 & TRN \\
\hline CHEMBL1581519 & 688293 & 4.7 & 5.0691 & TRN \\
\hline CHEMBL1492910 & 688293 & 5.0 & 4.9398 & TRN \\
\hline CHEMBL1613422 & 688293 & 4.4 & 5.1227 & TRN \\
\hline CHEMBL1256360 & 688293 & 5.2 & 5.0646 & TRN \\
\hline CHEMBL1337490 & 688293 & 4.5 & 4.941 & TRN \\
\hline CHEMBL1312338 & 688293 & 5.0 & 4.8365 & TRN \\
\hline CHEMBL1494026 & 688293 & 5.3 & 5.0774 & TRN \\
\hline CHEMBL3209733 & 688293 & 4.7 & 4.8564 & TRN \\
\hline CHEMBL16687 & 688293 & 5.4 & 4.6998 & TRN \\
\hline CHEMBL1583717 & 688293 & 5.0 & 5.2199 & TRN \\
\hline CHEMBL1360601 & 688293 & 4.4 & 5.121 & TRN \\
\hline CHEMBL1313583 & 688293 & 4.4 & 4.9762 & TST \\
\hline CHEMBL1563648 & 688293 & 6.1 & 5.0077 & TRN \\
\hline CHEMBL1436644 & 688293 & 5.7 & 4.789 & TRN \\
\hline CHEMBL1316828 & 688293 & 5.0 & 5.0184 & TST \\
\hline CHEMBL1520976 & 688293 & 6.0 & 5.1046 & TST \\
\hline CHEMBL1611023 & 688293 & 4.4 & 4.8785 & TRN \\
\hline CHEMBL1569493 & 688293 & 5.3 & 4.9873 & TRN \\
\hline
\end{tabular}




\begin{tabular}{|c|c|c|c|c|}
\hline \multicolumn{5}{|c|}{ plemental T } \\
\hline CHEMBL1526964 & 688293 & 5.5 & 4.8273 & TST \\
\hline CHEMBL1549452 & 688293 & 5.2 & 5.0797 & TRN \\
\hline CHEMBL1491195 & 688293 & 4.7 & 5.0974 & TRN \\
\hline CHEMBL1455438 & 688293 & 5.9 & 4.7751 & TRN \\
\hline CHEMBL1419290 & 688293 & 4.4 & 5.0423 & TRN \\
\hline CHEMBL1598592 & 688293 & 5.3 & 5.0746 & TST \\
\hline CHEMBL1358402 & 688293 & 6.0 & 5.1304 & TST \\
\hline CHEMBL1518718 & 688293 & 5.1 & 4.7909 & TRN \\
\hline CHEMBL1483442 & 688293 & 4.4 & 4.8794 & TRN \\
\hline CHEMBL1567100 & 688293 & 5.5 & 5.0042 & TRN \\
\hline CHEMBL1507997 & 688293 & 5.1 & 5.0127 & TRN \\
\hline CHEMBL1601590 & 688293 & 4.8 & 4.8868 & TRN \\
\hline CHEMBL1488501 & 688293 & 4.6 & 5.1144 & TRN \\
\hline CHEMBL526034 & 688293 & 4.4 & 4.9272 & TST \\
\hline CHEMBL1532745 & 688293 & 5.5 & 5.0638 & TRN \\
\hline CHEMBL 1352846 & 688293 & 4.4 & 4.8989 & TRN \\
\hline CHEMBL1172020 & 688293 & 4.6 & 4.9903 & TRN \\
\hline CHEMBL1383856 & 688293 & 4.4 & 4.9376 & TRN \\
\hline CHEMBL1407366 & 688293 & 4.4 & 5.0984 & TRN \\
\hline CHEMBL1538825 & 688293 & 4.5 & 4.9551 & TRN \\
\hline CHEMBL1606164 & 688293 & 4.8 & 4.9594 & TRN \\
\hline CHEMBL1372613 & 688293 & 4.5 & 4.9996 & TRN \\
\hline CHEMBL1345910 & 688293 & 4.4 & 4.9497 & TRN \\
\hline CHEMBL1428989 & 688293 & 4.4 & 5.051 & TRN \\
\hline CHEMBL1319007 & 688293 & 4.5 & 5.0372 & TRN \\
\hline CHEMBL1333655 & 688293 & 5.3 & 4.9926 & TRN \\
\hline CHEMBL1315820 & 688293 & 4.5 & 4.9532 & TRN \\
\hline CHEMBL1418954 & 688293 & 5.6 & 4.9615 & TRN \\
\hline CHEMBL1439821 & 688293 & 4.7 & 4.7646 & TRN \\
\hline CHEMBL1403793 & 688293 & 4.6 & 4.855 & TRN \\
\hline CHEMBL1578193 & 688293 & 6.0 & 5.0455 & TRN \\
\hline CHEMBL1378793 & 688293 & 4.7 & 4.8347 & TRN \\
\hline CHEMBL582507 & 688293 & 4.4 & 4.9259 & TRN \\
\hline CHEMBL1523204 & 688293 & 4.5 & 5.062 & TST \\
\hline CHEMBL1344414 & 688293 & 4.8 & 4.9357 & TRN \\
\hline CHEMBL1544856 & 688293 & 4.5 & 5.1644 & TRN \\
\hline CHEMBL68534 & 688293 & 4.4 & 4.9708 & TRN \\
\hline CHEMBL1387672 & 688293 & 5.5 & 5.1879 & TRN \\
\hline CHEMBL30432 & 688293 & 4.8 & 4.8215 & TRN \\
\hline CHEMBL1522728 & 688293 & 8.0 & 4.9984 & TRN \\
\hline CHEMBL1554844 & 688293 & 5.5 & 5.1635 & TST \\
\hline CHEMBL1416324 & 688293 & 5.2 & 5.1075 & TRN \\
\hline CHEMBL1611646 & 688293 & 5.3 & 4.9643 & TRN \\
\hline CHEMBL1997370 & 688293 & 4.7 & 5.0638 & TST \\
\hline CHEMBL1483462 & 688293 & 4.7 & 5.1482 & TRN \\
\hline CHEMBL1459902 & 688293 & 5.0 & 4.9037 & TST \\
\hline CHEMBL1543055 & 688293 & 4.9 & 5.1988 & TRN \\
\hline CHEMBL1519055 & 688293 & 4.5 & 4.9067 & TST \\
\hline
\end{tabular}




\begin{tabular}{|c|c|c|c|c|c|}
\hline \multicolumn{6}{|c|}{ Supplemental Table S2.txt } \\
\hline CHEMBL1554745 & 688293 & 4.5 & 4.7337 & TRN & \\
\hline CHEMBL1485893 & 688293 & 4.7 & 4.863 & TRN & \\
\hline CHEMBL1378544 & 688293 & 5.5 & 5.1665 & TRN & \\
\hline CHEMBL1562777 & 688293 & 5.6 & 5.0271 & TRN & \\
\hline CHEMBL1372751 & 688293 & 4.5 & 4.9114 & TRN & \\
\hline CHEMBL1214270 & 688293 & 4.5 & 5.0592 & TRN & \\
\hline CHEMBL1370036 & 688293 & 5.0 & 5.2464 & TRN & \\
\hline CHEMBL1442736 & 688293 & 6.1 & 5.0821 & TRN & \\
\hline CHEMBL1489479 & 688293 & 5.7 & 5.2884 & TRN & \\
\hline CHEMBL1503816 & 688293 & 4.6 & 4.9354 & TRN & \\
\hline CHEMBL1436228 & 688293 & 4.6 & 4.99 & TRN & \\
\hline CHEMBL1510817 & 688293 & 5.0 & 4.8648 & TRN & \\
\hline CHEMBL1512562 & 688293 & 5.2 & 4.7001 & TRN & \\
\hline CHEMBL1364314 & 688293 & 6.2 & 4.9646 & TRN & \\
\hline CHEMBL1532135 & 688293 & 7.8996 & 5.1148 & TST & \\
\hline CHEMBL1482950 & 688293 & 4.6 & 4.8821 & TRN & \\
\hline CHEMBL1313249 & 688293 & 5.9 & 4.9254 & TRN & \\
\hline CHEMBL1392463 & 688293 & 5.4 & 5.0767 & TRN & \\
\hline CHEMBL 3192608 & 688293 & 6.0 & 4.8629 & TRN & \\
\hline CHEMBL1481585 & 688293 & 5.9 & 5.0182 & TRN & \\
\hline CHEMBL1575954 & 688293 & 4.4 & 5.1082 & TRN & \\
\hline CHEMBL1477636 & 688293 & 4.8 & 5.0944 & TRN & \\
\hline CHEMBL1583115 & 688293 & 4.6 & 5.2084 & TRN & \\
\hline CHEMBL1555832 & 688293 & 8.0 & 4.9464 & TRN & \\
\hline CHEMBL1322656 & 688293 & 4.9 & 4.8345 & TRN & \\
\hline CHEMBL1345920 & 688293 & 4.8 & 5.02800 & 00000000005 & TRN \\
\hline CHEMBL1407057 & 688293 & 4.4 & 5.1197 & TRN & \\
\hline CHEMBL1397596 & 688293 & 4.4 & 5.032 & TRN & \\
\hline CHEMBL1557564 & 688293 & 5.1 & 5.0484 & TRN & \\
\hline CHEMBL1342298 & 688293 & 4.4 & 5.0258 & TRN & \\
\hline CHEMBL1495094 & 688293 & 4.4 & 5.0511 & TRN & \\
\hline CHEMBL1483698 & 688293 & 4.4 & 5.1221 & TRN & \\
\hline CHEMBL1517718 & 688293 & 5.1 & 4.8562 & TRN & \\
\hline CHEMBL1464447 & 688293 & 4.6 & 4.9998 & TRN & \\
\hline CHEMBL1305455 & 688293 & 4.5 & 4.9325 & TRN & \\
\hline CHEMBL1489206 & 688293 & 4.7 & 4.9337 & TRN & \\
\hline CHEMBL1398846 & 688293 & 4.4 & 4.8861 & TRN & \\
\hline CHEMBL1571874 & 688293 & 5.4 & 4.8657 & TST & \\
\hline CHEMBL1533214 & 688293 & 6.4 & 4.9698 & TRN & \\
\hline CHEMBL1440672 & 688293 & 5.5 & 5.073 & TRN & \\
\hline CHEMBL1488247 & 688293 & 6.1 & 5.0321 & TST & \\
\hline CHEMBL1491398 & 688293 & 4.5 & 5.063 & TRN & \\
\hline CHEMBL1533236 & 688293 & 4.9 & 4.9101 & TRN & \\
\hline CHEMBL1401253 & 688293 & 4.4 & 4.9856 & TRN & \\
\hline CHEMBL1351353 & 688293 & 4.4 & 4.8532 & TRN & \\
\hline CHEMBL3194422 & 688293 & 4.7 & 4.8515 & TRN & \\
\hline CHEMBL1511584 & 688293 & 6.6 & 5.1351 & TRN & \\
\hline CHEMBL1506309 & 688293 & 4.8 & 4.8688 & TRN & \\
\hline
\end{tabular}




\begin{tabular}{|c|c|c|c|c|}
\hline & & & pplement & al $\mathrm{T}$ \\
\hline CHEMBL1587057 & 688293 & 6.0 & 5.1387 & TRN \\
\hline CHEMBL1471218 & 688293 & 4.7 & 4.9501 & TRN \\
\hline CHEMBL1592589 & 688293 & 4.4 & 5.0227 & TST \\
\hline CHEMBL1386745 & 688293 & 4.5 & 5.0642 & TRN \\
\hline CHEMBL1333530 & 688293 & 4.4 & 4.9515 & TRN \\
\hline CHEMBL1561168 & 688293 & 5.8 & 4.9541 & TRN \\
\hline CHEMBL1351420 & 688293 & 6.9 & 5.1753 & TRN \\
\hline CHEMBL1599234 & 688293 & 4.8 & 4.9834 & TRN \\
\hline CHEMBL1494756 & 688293 & 4.9 & 4.9639 & TRN \\
\hline CHEMBL52030 & 688293 & 4.6 & 5.0778 & TRN \\
\hline CHEMBL1570526 & 688293 & 4.8 & 4.8454 & TRN \\
\hline CHEMBL1550809 & 688293 & 4.4 & 4.7781 & TRN \\
\hline CHEMBL1430258 & 688293 & 6.9 & 4.9239 & TRN \\
\hline CHEMBL1323359 & 688293 & 6.3 & 5.0979 & TST \\
\hline CHEMBL1373261 & 688293 & 8.0 & 5.0319 & TRN \\
\hline CHEMBL1356824 & 688293 & 4.5 & 4.9976 & TRN \\
\hline CHEMBL3213142 & 688293 & 4.8 & 4.9721 & TRN \\
\hline CHEMBL1377572 & 688293 & 4.6 & 5.0471 & TST \\
\hline CHEMBL1314172 & 688293 & 4.8 & 4.9288 & TRN \\
\hline CHEMBL1534832 & 688293 & 4.9 & 5.1444 & TRN \\
\hline CHEMBL1311660 & 688293 & 4.8 & 5.067 & TRN \\
\hline CHEMBL 2369308 & 688293 & 5.3 & 4.9004 & TST \\
\hline CHEMBL1411473 & 688293 & 4.7 & 4.9876 & TRN \\
\hline CHEMBL1487590 & 688293 & 4.5 & 4.9579 & TRN \\
\hline CHEMBL1343279 & 688293 & 4.4 & 4.8546 & TRN \\
\hline CHEMBL1302158 & 688293 & 5.5 & 5.0347 & TRN \\
\hline CHEMBL1584441 & 688293 & 4.5 & 5.1712 & TST \\
\hline CHEMBL1520615 & 688293 & 4.6 & 5.0857 & TST \\
\hline CHEMBL237833 & 688293 & 4.8 & 4.8011 & TRN \\
\hline CHEMBL1568483 & 688293 & 5.1 & 4.901 & TST \\
\hline CHEMBL1544978 & 688293 & 4.7 & 4.9364 & TRN \\
\hline CHEMBL1524766 & 688293 & 4.9 & 4.7949 & TRN \\
\hline CHEMBL1472046 & 688293 & 4.6 & 4.8319 & TRN \\
\hline CHEMBL1552708 & 688293 & 5.4 & 5.0054 & TST \\
\hline CHEMBL1414483 & 688293 & 4.4 & 4.8934 & TRN \\
\hline CHEMBL1497531 & 688293 & 5.9 & 5.2757 & TST \\
\hline CHEMBL1401847 & 688293 & 4.5 & 5.1002 & TST \\
\hline CHEMBL1601176 & 688293 & 5.0 & 4.9208 & TRN \\
\hline CHEMBL 3208787 & 688293 & 5.8 & 5.0487 & TRN \\
\hline CHEMBL1596194 & 688293 & 4.4 & 5.0145 & TRN \\
\hline CHEMBL1380354 & 688293 & 7.6003 & 5.1602 & TRN \\
\hline CHEMBL1355970 & 688293 & 6.5 & 4.8591 & TRN \\
\hline CHEMBL1576495 & 688293 & 5.2 & 4.8071 & TRN \\
\hline CHEMBL3196904 & 688293 & 4.8 & 4.8139 & TST \\
\hline CHEMBL1451420 & 688293 & 5.4 & 5.2395 & TRN \\
\hline CHEMBL1372588 & 688293 & 4.7 & 4.7983 & TST \\
\hline CHEMBL406557 & 688293 & 4.6 & 4.75 & TRN \\
\hline CHEMBL1376234 & 688293 & 7.5003 & 5.0494 & TRN \\
\hline
\end{tabular}




\begin{tabular}{|c|c|c|c|c|c|}
\hline \multicolumn{6}{|c|}{ Supplemental Table S2.txt } \\
\hline CHEMBL598952 & 688293 & 4.8 & 4.8668 & TST & \\
\hline CHEMBL1318419 & 688293 & 4.6 & 4.8851 & TRN & \\
\hline CHEMBL1379405 & 688293 & 4.8 & 4.8199 & TRN & \\
\hline CHEMBL1396108 & 688293 & 5.5 & 4.8087 & TRN & \\
\hline CHEMBL1567345 & 688293 & 4.5 & 4.994 & TST & \\
\hline CHEMBL1469915 & 688293 & 4.5 & 4.9159 & TRN & \\
\hline CHEMBL1364572 & 688293 & 5.4 & 4.9336 & TRN & \\
\hline CHEMBL1585865 & 688293 & 4.4 & 4.9315 & TRN & \\
\hline CHEMBL1330678 & 688293 & 4.4 & 5.1377 & TRN & \\
\hline CHEMBL1390886 & 688293 & 4.6 & 4.8743 & TST & \\
\hline CHEMBL1430355 & 688293 & 7.8996 & 5.0444 & TRN & \\
\hline CHEMBL1435638 & 688293 & 4.7 & 4.6648 & TRN & \\
\hline CHEMBL1429616 & 688293 & 4.5 & 5.0939 & TRN & \\
\hline CHEMBL567331 & 688293 & 5.5 & 4.8086 & TRN & \\
\hline CHEMBL1473543 & 688293 & 5.4 & 4.6995 & TST & \\
\hline CHEMBL1456075 & 688293 & 5.6 & 4.9316 & TRN & \\
\hline CHEMBL532641 & 688293 & 4.8 & 4.9062 & TRN & \\
\hline CHEMBL1556174 & 688293 & 4.6 & 5.0889 & TRN & \\
\hline CHEMBL1371627 & 688293 & 4.4 & 4.9749 & TRN & \\
\hline CHEMBL1611824 & 688293 & 4.4 & 5.061 & TST & \\
\hline CHEMBL 3208804 & 688293 & 4.4 & 4.9675 & TST & \\
\hline CHEMBL1370015 & 688293 & 5.5 & 5.06800 & 00000000005 & TRN \\
\hline CHEMBL1594412 & 688293 & 7.8996 & 4.9968 & TRN & \\
\hline CHEMBL1586711 & 688293 & 5.4 & 4.8586 & TRN & \\
\hline CHEMBL1456850 & 688293 & 4.4 & 4.9163 & TST & \\
\hline CHEMBL1370122 & 688293 & 8.2007 & 4.8504 & TRN & \\
\hline CHEMBL1335363 & 688293 & 4.6 & 4.8655 & TRN & \\
\hline CHEMBL1487655 & 688293 & 4.6 & 5.148 & TRN & \\
\hline CHEMBL1606022 & 688293 & 4.8 & 4.9531 & TRN & \\
\hline CHEMBL1502148 & 688293 & 5.5 & 4.9533 & TRN & \\
\hline CHEMBL1557927 & 688293 & 4.6 & 5.0259 & TRN & \\
\hline CHEMBL1556576 & 688293 & 4.6 & 5.0294 & TRN & \\
\hline CHEMBL1596318 & 688293 & 4.5 & 4.8629 & TRN & \\
\hline CHEMBL1442091 & 688293 & 5.0 & 5.2567 & TRN & \\
\hline CHEMBL1256698 & 688293 & 4.9 & 5.04899 & 99999999995 & TST \\
\hline CHEMBL1469138 & 688293 & 5.1 & 5.0196 & TRN & \\
\hline CHEMBL1381382 & 688293 & 5.5 & 5.0264 & TRN & \\
\hline CHEMBL1353717 & 688293 & 4.5 & 5.1638 & TRN & \\
\hline CHEMBL1523579 & 688293 & 4.8 & 4.9367 & TRN & \\
\hline CHEMBL 3214556 & 688293 & 4.9 & 5.0608 & TRN & \\
\hline CHEMBL1401672 & 688293 & 5.3 & 4.8546 & TRN & \\
\hline CHEMBL1418770 & 688293 & 4.4 & 4.9929 & TRN & \\
\hline CHEMBL1428325 & 688293 & 4.5 & 4.9268 & TRN & \\
\hline CHEMBL1475377 & 688293 & 4.4 & 5.0176 & TRN & \\
\hline CHEMBL1301126 & 688293 & 7.6003 & 4.7545 & TST & \\
\hline CHEMBL1500646 & 688293 & 4.4 & 4.9543 & TRN & \\
\hline CHEMBL1580954 & 688293 & 4.9 & 4.9334 & TRN & \\
\hline CHEMBL1413788 & 688293 & 5.4 & 4.948 & TRN & \\
\hline
\end{tabular}




\begin{tabular}{|c|c|c|c|c|c|}
\hline \multicolumn{6}{|c|}{ Supplemental Table S2.txt } \\
\hline CHEMBL1403616 & 688293 & 4.8 & 4.9969 & TRN & \\
\hline CHEMBL1556962 & 688293 & 4.4 & 5.1259 & TRN & \\
\hline CHEMBL1462290 & 688293 & 4.6 & 4.9572 & TRN & \\
\hline CHEMBL1384489 & 688293 & 4.6 & 4.9591 & TRN & \\
\hline CHEMBL1408176 & 688293 & 5.1 & 4.8062 & TRN & \\
\hline CHEMBL1475902 & 688293 & 5.3 & 4.7104 & TRN & \\
\hline CHEMBL1421003 & 688293 & 8.0 & 5.1549 & TRN & \\
\hline CHEMBL1349449 & 688293 & 7.8996 & 4.952 & TRN & \\
\hline CHEMBL1256869 & 688293 & 6.0 & 4.9795 & TRN & \\
\hline CHEMBL1588463 & 688293 & 4.4 & 4.8609 & TRN & \\
\hline CHEMBL1457261 & 688293 & 4.7 & 4.9464 & TRN & \\
\hline CHEMBL1607464 & 688293 & 4.6 & 4.9832 & TST & \\
\hline CHEMBL1389592 & 688293 & 5.0 & 4.8901 & TRN & \\
\hline CHEMBL1455689 & 688293 & 5.5 & 5.0138 & TRN & \\
\hline CHEMBL1538893 & 688293 & 5.5 & 5.0713 & TRN & \\
\hline CHEMBL 3212575 & 688293 & 5.9 & 5.0709 & TST & \\
\hline CHEMBL3199519 & 688293 & 4.4 & 5.1077 & TST & \\
\hline CHEMBL1506649 & 688293 & 4.6 & 5.2638 & TRN & \\
\hline CHEMBL1568198 & 688293 & 4.5 & 4.9705 & TRN & \\
\hline CHEMBL1467552 & 688293 & 4.4 & 4.967 & TRN & \\
\hline CHEMBL1521349 & 688293 & 4.6 & 5.0659 & TRN & \\
\hline CHEMBL1479951 & 688293 & 4.5 & 5.0974 & TRN & \\
\hline CHEMBL 76589 & 688293 & 4.9 & 4.9458 & TRN & \\
\hline CHEMBL1577745 & 688293 & 4.6 & 5.078 & TRN & \\
\hline CHEMBL1439079 & 688293 & 4.8 & 4.9733 & TRN & \\
\hline CHEMBL1491258 & 688293 & 6.7001 & 4.9772 & TST & \\
\hline CHEMBL1327547 & 688293 & 5.3 & 5.0353 & TRN & \\
\hline CHEMBL1385074 & 688293 & 4.7 & 5.0026 & TRN & \\
\hline CHEMBL1418387 & 688293 & 4.7 & 4.8086 & TRN & \\
\hline CHEMBL1434098 & 688293 & 4.6 & 4.8439 & TRN & \\
\hline CHEMBL1526913 & 688293 & 4.5 & $4.9060 e$ & 0000000001 & TRN \\
\hline CHEMBL1402797 & 688293 & 4.9 & 5.1358 & TRN & \\
\hline CHEMBL1430895 & 688293 & 4.4 & 4.9117 & TRN & \\
\hline CHEMBL1313193 & 688293 & 5.4 & 5.0698 & TRN & \\
\hline CHEMBL1419334 & 688293 & 4.5 & 4.7658 & TRN & \\
\hline CHEMBL1436540 & 688293 & 4.4 & 4.6868 & TRN & \\
\hline CHEMBL1536129 & 688293 & 4.5 & 5.0007 & TRN & \\
\hline CHEMBL1486333 & 688293 & 8.0 & 4.9677 & TRN & \\
\hline CHEMBL1429941 & 688293 & 5.9 & 5.1437 & TRN & \\
\hline CHEMBL1323605 & 688293 & 5.1 & 5.0198 & TRN & \\
\hline CHEMBL530115 & 688293 & 4.5 & 5.0386 & TRN & \\
\hline CHEMBL1371445 & 688293 & 4.8 & 5.0507 & TRN & \\
\hline CHEMBL1384684 & 688293 & 4.7 & 5.0534 & TRN & \\
\hline CHEMBL1441833 & 688293 & 4.9 & 4.9906 & TRN & \\
\hline CHEMBL1493135 & 688293 & 4.4 & $5.0710 e$ & 2000000001 & TRN \\
\hline CHEMBL1583874 & 688293 & 4.9 & 5.0538 & TST & \\
\hline CHEMBL1436024 & 688293 & 5.3 & 4.6915 & TRN & \\
\hline CHEMBL1535517 & 688293 & 5.2 & 5.0011 & TRN & \\
\hline
\end{tabular}




\begin{tabular}{|c|c|c|c|c|c|}
\hline \multicolumn{6}{|c|}{ Supplemental Table S2.txt } \\
\hline CHEMBL1457544 & 688293 & 5.0 & 4.755 & TRN & \\
\hline CHEMBL1446200 & 688293 & 4.8 & 5.2038 & TRN & \\
\hline CHEMBL154580 & 688293 & 5.0 & 4.9415 & TST & \\
\hline CHEMBL1302523 & 688293 & 4.4 & 4.8131 & TRN & \\
\hline CHEMBL1452126 & 688293 & 5.1 & 5.0487 & TRN & \\
\hline CHEMBL1585425 & 688293 & 4.6 & 5.0201 & TRN & \\
\hline CHEMBL1369930 & 688293 & 4.6 & 5.1004 & TRN & \\
\hline CHEMBL1456047 & 688293 & 4.7 & 4.9987 & TRN & \\
\hline CHEMBL1374043 & 688293 & 6.0 & 5.0181 & TRN & \\
\hline CHEMBL1431517 & 688293 & 7.5003 & 5.1379 & TST & \\
\hline CHEMBL1537401 & 688293 & 6.5 & 5.1949 & TRN & \\
\hline CHEMBL1346338 & 688293 & 4.4 & 4.7798 & TRN & \\
\hline CHEMBL1369408 & 688293 & 4.4 & 5.0056 & TRN & \\
\hline CHEMBL1328241 & 688293 & 4.4 & 4.9243 & TRN & \\
\hline CHEMBL1361939 & 688293 & 4.6 & 5.082 & TRN & \\
\hline CHEMBL1428248 & 688293 & 4.8 & 5.0732 & TRN & \\
\hline CHEMBL1596996 & 688293 & 4.4 & 4.9305 & TRN & \\
\hline CHEMBL1493896 & 688293 & 4.8 & 4.9829 & TRN & \\
\hline CHEMBL1546680 & 688293 & 5.3 & 4.9065 & TRN & \\
\hline CHEMBL1529094 & 688293 & 5.1 & 4.8628 & TRN & \\
\hline CHEMBL1562193 & 688293 & 4.5 & 4.7117 & TRN & \\
\hline CHEMBL592712 & 688293 & 4.9 & 4.9466 & TRN & \\
\hline CHEMBL1479675 & 688293 & 4.4 & 4.8528 & TRN & \\
\hline CHEMBL1504352 & 688293 & 4.7 & 5.2052 & TRN & \\
\hline CHEMBL1515666 & 688293 & 4.6 & 5.061 & TRN & \\
\hline CHEMBL1345866 & 688293 & 4.6 & 4.9733 & TST & \\
\hline CHEMBL1162293 & 688293 & 7.699 & 4.8703 & TRN & \\
\hline CHEMBL 3184468 & 688293 & 5.4 & 5.1381 & TST & \\
\hline CHEMBL1494356 & 688293 & 4.6 & 5.0124 & TRN & \\
\hline CHEMBL1521091 & 688293 & 7.6003 & $5.0310 e$ & 0000000001 & TRN \\
\hline CHEMBL1365779 & 688293 & 4.5 & 5.1931 & TRN & \\
\hline CHEMBL1468590 & 688293 & 7.6003 & 4.9999 & TRN & \\
\hline CHEMBL1404884 & 688293 & 4.9 & 4.7744 & TRN & \\
\hline CHEMBL1462922 & 688293 & 4.6 & 4.9996 & TRN & \\
\hline CHEMBL1381731 & 688293 & 4.5 & 5.0878 & TST & \\
\hline CHEMBL1406537 & 688293 & 5.0 & 4.8475 & TST & \\
\hline CHEMBL1331593 & 688293 & 4.6 & 5.0519 & TRN & \\
\hline CHEMBL1505737 & 688293 & 5.6 & 4.8963 & TRN & \\
\hline CHEMBL1387442 & 688293 & 4.6 & 4.9849 & TRN & \\
\hline CHEMBL1351321 & 688293 & 4.4 & 4.9786 & TRN & \\
\hline CHEMBL1459538 & 688293 & 4.9 & 5.0015 & TRN & \\
\hline CHEMBL1418225 & 688293 & 5.2 & 4.8009 & TRN & \\
\hline CHEMBL1612274 & 688293 & 4.8 & 4.9308 & TRN & \\
\hline CHEMBL1454903 & 688293 & 4.6 & 4.7825 & TST & \\
\hline CHEMBL1475487 & 688293 & 4.7 & 4.7733 & TRN & \\
\hline CHEMBL1507963 & 688293 & 5.3 & 4.8888 & TRN & \\
\hline CHEMBL1455128 & 688293 & 4.9 & 5.1228 & TRN & \\
\hline CHEMBL1397079 & 688293 & 5.5 & 4.6987 & TRN & \\
\hline
\end{tabular}




\begin{tabular}{|c|c|c|c|c|}
\hline \multicolumn{5}{|c|}{ Supplemental Table s2.txt } \\
\hline CHEMBL294878 & 688293 & 5.0 & 4.9192 & TRN \\
\hline CHEMBL524222 & 688293 & 4.4 & 5.1422 & TRN \\
\hline CHEMBL1540890 & 688293 & 4.8 & 4.93 & TRN \\
\hline CHEMBL1406590 & 688293 & 5.6 & 5.1321 & TRN \\
\hline CHEMBL1555567 & 688293 & 4.8 & 4.9147 & TRN \\
\hline CHEMBL1437997 & 688293 & 5.0 & 4.7904 & TST \\
\hline CHEMBL1378991 & 688293 & 5.0 & 5.0164 & TRN \\
\hline CHEMBL1446363 & 688293 & 4.7 & 5.0153 & TRN \\
\hline CHEMBL1490257 & 688293 & 4.8 & 5.1202 & TRN \\
\hline CHEMBL1609334 & 688293 & 4.6 & 5.1249 & TRN \\
\hline CHEMBL1384525 & 688293 & 4.4 & 4.8921 & TRN \\
\hline CHEMBL1526851 & 688293 & 4.8 & 4.7694 & TRN \\
\hline CHEMBL1401598 & 688293 & 4.5 & 5.0934 & TRN \\
\hline CHEMBL1457774 & 688293 & 5.0 & 4.8605 & TRN \\
\hline CHEMBL268809 & 688293 & 6.5 & 4.8727 & TRN \\
\hline CHEMBL1454997 & 688293 & 4.9 & 4.9852 & TRN \\
\hline CHEMBL1449638 & 688293 & 4.6 & 5.0432 & TRN \\
\hline CHEMBL1364681 & 688293 & 5.6 & 5.1219 & TRN \\
\hline CHEMBL1545339 & 688293 & 5.0 & 5.1705 & TRN \\
\hline CHEMBL1597352 & 688293 & 4.4 & 5.0946 & TRN \\
\hline CHEMBL1442668 & 688293 & 4.6 & 4.9221 & TST \\
\hline CHEMBL1346304 & 688293 & 4.5 & 5.0503 & TRN \\
\hline CHEMBL1366323 & 688293 & 7.3002 & 5.1593 & TRN \\
\hline CHEMBL3212723 & 688293 & 5.5 & 4.8742 & TST \\
\hline CHEMBL444236 & 688293 & 4.4 & 5.0488 & TST \\
\hline CHEMBL2373281 & 688293 & 6.2 & 5.0366 & TST \\
\hline CHEMBL1574388 & 688293 & 4.7 & 5.2073 & TRN \\
\hline CHEMBL1510261 & 688293 & 4.9 & 4.8972 & TRN \\
\hline CHEMBL1730100 & 688293 & 6.0 & 5.0141 & TST \\
\hline CHEMBL1566165 & 688293 & 5.1 & 5.0359 & TRN \\
\hline CHEMBL1371738 & 688293 & 8.0 & 5.1555 & TRN \\
\hline CHEMBL1422470 & 688293 & 4.6 & 5.0631 & TRN \\
\hline CHEMBL1331172 & 688293 & 4.6 & 5.0678 & TRN \\
\hline CHEMBL285819 & 688293 & 6.0 & 4.9362 & TST \\
\hline CHEMBL3195747 & 688293 & 5.5 & 4.8859 & TST \\
\hline CHEMBL1427957 & 688293 & 8.301 & 5.2159 & TRN \\
\hline CHEMBL1586111 & 688293 & 5.0 & 4.877 & TRN \\
\hline CHEMBL1484885 & 688293 & 4.4 & 4.8638 & TST \\
\hline CHEMBL1344911 & 688293 & 5.7 & 4.8955 & TRN \\
\hline CHEMBL1360816 & 688293 & 4.9 & 4.8999 & TRN \\
\hline CHEMBL1373492 & 688293 & 4.4 & 4.8934 & TRN \\
\hline CHEMBL315348 & 688293 & 4.6 & 4.9819 & TRN \\
\hline CHEMBL1443854 & 688293 & 5.3 & 5.0291 & TRN \\
\hline CHEMBL1543399 & 688293 & 4.4 & 5.0934 & TRN \\
\hline CHEMBL1457918 & 688293 & 4.6 & 4.9775 & TRN \\
\hline CHEMBL1445474 & 688293 & 4.5 & 4.9832 & TRN \\
\hline CHEMBL1556879 & 688293 & 5.6 & 5.20299 & 9999999999 \\
\hline CHEMBL1498282 & 688293 & 4.8 & 5.0916 & TST \\
\hline
\end{tabular}

TRN 


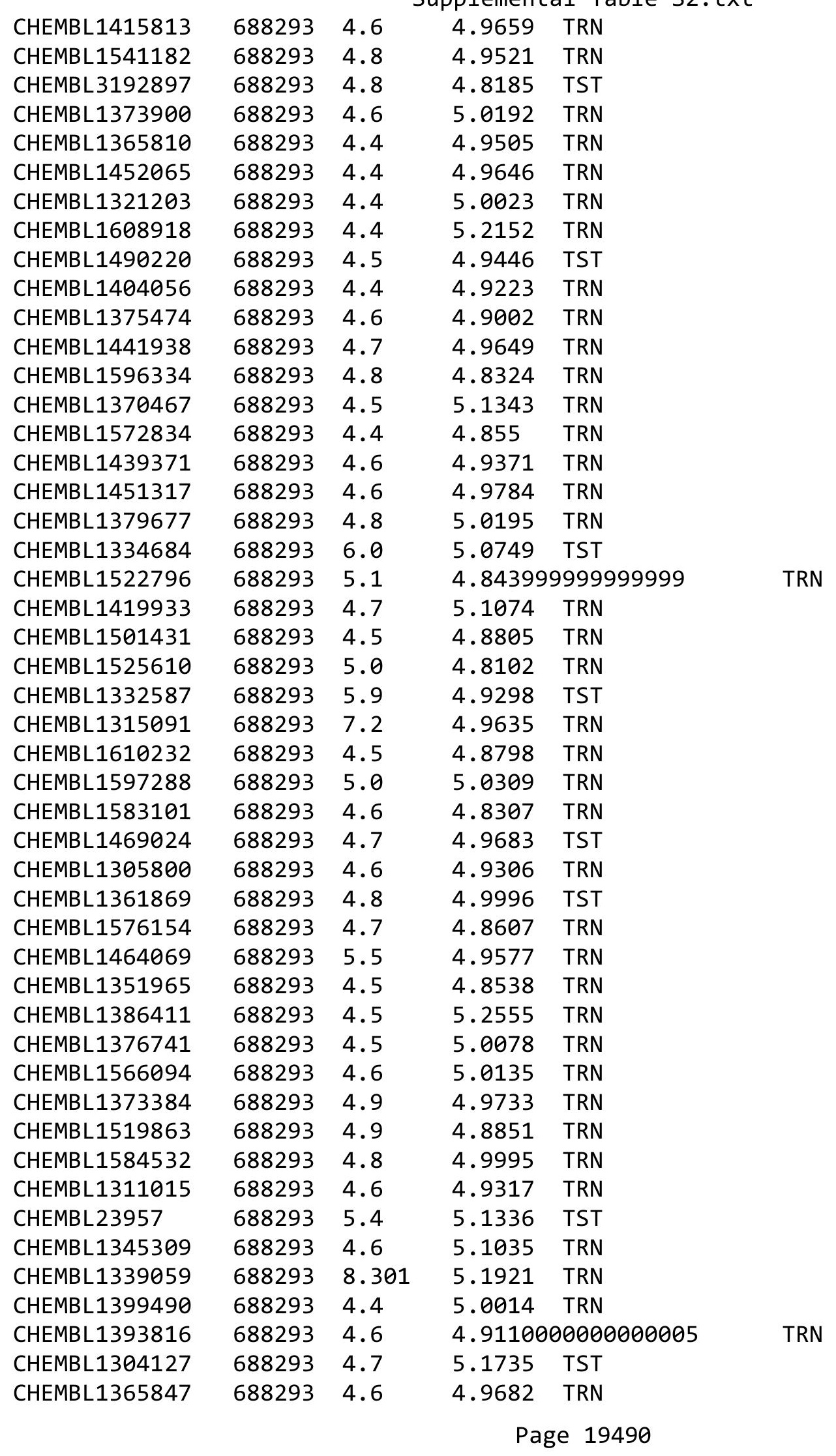




\begin{tabular}{|c|c|c|c|c|c|}
\hline \multicolumn{6}{|c|}{ Supplemental Table S2.txt } \\
\hline CHEMBL280822 & 688293 & 4.4 & 4.8897 & TST & \\
\hline CHEMBL1361135 & 688293 & 4.8 & 5.0112 & TRN & \\
\hline CHEMBL1455830 & 688293 & 4.4 & 5.0072 & TRN & \\
\hline CHEMBL1349178 & 688293 & 4.8 & 4.825 & TRN & \\
\hline CHEMBL1488433 & 688293 & 4.9 & 4.8237 & TRN & \\
\hline CHEMBL375015 & 688293 & 4.8 & 5.0703 & TRN & \\
\hline CHEMBL1562633 & 688293 & 4.5 & 4.8332 & TRN & \\
\hline CHEMBL484662 & 688293 & 5.4 & 4.8811 & TRN & \\
\hline CHEMBL1583248 & 688293 & 4.5 & 4.9972 & TRN & \\
\hline CHEMBL1405585 & 688293 & 5.3 & 5.0701 & TRN & \\
\hline CHEMBL1256914 & 688293 & 7.4001 & 4.8355 & TST & \\
\hline CHEMBL1478430 & 688293 & 4.4 & 4.7497 & TRN & \\
\hline CHEMBL1337771 & 688293 & 4.5 & 4.8964 & TST & \\
\hline CHEMBL1603817 & 688293 & 4.9 & 5.0202 & TRN & \\
\hline CHEMBL1565286 & 688293 & 4.5 & 4.8814 & TRN & \\
\hline CHEMBL1494778 & 688293 & 5.1 & 4.962 & TST & \\
\hline CHEMBL1447259 & 688293 & 4.4 & 4.8883 & TRN & \\
\hline CHEMBL1339240 & 688293 & 4.6 & 4.8679 & TRN & \\
\hline CHEMBL1528058 & 688293 & 4.8 & 5.0392 & TRN & \\
\hline CHEMBL1330599 & 688293 & 5.8 & 5.2124 & TST & \\
\hline CHEMBL1488689 & 688293 & 4.8 & 4.9443 & TRN & \\
\hline CHEMBL1594665 & 688293 & 4.9 & 5.056 & TRN & \\
\hline CHEMBL1547695 & 688293 & 5.1 & 5.0072 & TRN & \\
\hline CHEMBL1573699 & 688293 & 4.6 & 5.045 & TRN & \\
\hline CHEMBL1383591 & 688293 & 7.0 & 5.0364 & TST & \\
\hline CHEMBL1538503 & 688293 & 5.2 & 4.8708 & TRN & \\
\hline CHEMBL1359848 & 688293 & 5.2 & 5.1069 & TRN & \\
\hline CHEMBL1357186 & 688293 & 4.8 & 4.80399 & & TRN \\
\hline CHEMBL1582263 & 688293 & 5.7 & 5.0468 & TRN & \\
\hline CHEMBL1546734 & 688293 & 6.7001 & 5.0355 & TRN & \\
\hline CHEMBL1357293 & 688293 & 4.9 & 4.8029 & TRN & \\
\hline CHEMBL1506339 & 688293 & 4.6 & 4.9259 & TRN & \\
\hline CHEMBL1339659 & 688293 & 4.5 & 4.9886 & TRN & \\
\hline CHEMBL1449616 & 688293 & 5.0 & 5.103 & TRN & \\
\hline CHEMBL1568238 & 688293 & 4.7 & 4.9778 & TRN & \\
\hline CHEMBL1599163 & 688293 & 4.5 & 4.7841 & TRN & \\
\hline CHEMBL1412940 & 688293 & 4.5 & 5.0585 & TRN & \\
\hline CHEMBL1427121 & 688293 & 4.9 & 5.1189 & TST & \\
\hline CHEMBL1432651 & 688293 & 5.0 & 5.1029 & TRN & \\
\hline CHEMBL1348066 & 688293 & 4.5 & 4.8332 & TRN & \\
\hline CHEMBL1543611 & 688293 & 5.6 & 4.8398 & TRN & \\
\hline CHEMBL1606830 & 688293 & 4.4 & 4.9421 & TST & \\
\hline CHEMBL1422976 & 688293 & 4.5 & 4.8446 & TRN & \\
\hline CHEMBL1488447 & 688293 & 6.3 & 5.1656 & TST & \\
\hline CHEMBL1329717 & 688293 & 4.6 & 4.994 & TRN & \\
\hline CHEMBL1389029 & 688293 & 4.5 & 5.0672 & TRN & \\
\hline CHEMBL1487098 & 688293 & 4.9 & 4.8506 & TRN & \\
\hline CHEMBL64239 & 688293 & 8.1024 & 5.0331 & TST & \\
\hline
\end{tabular}




\begin{tabular}{|c|c|c|c|c|c|}
\hline \multirow{2}{*}{ CHEMBL1379264 } & \multirow{2}{*}{688293} & \multirow[b]{2}{*}{5.0} & \\
\hline & & & 4.8841 & TRN & \\
\hline CHEMBL328710 & 688293 & 4.8 & 4.9144 & TST & \\
\hline CHEMBL481577 & 688293 & 5.0 & 4.9808 & TRN & \\
\hline CHEMBL1528323 & 688293 & 4.8 & 4.8953 & TRN & \\
\hline CHEMBL1404982 & 688293 & 4.7 & 4.9711 & TRN & \\
\hline CHEMBL1379571 & 688293 & 4.8 & 5.0374 & TST & \\
\hline CHEMBL1528565 & 688293 & 4.7 & 5.0447 & TST & \\
\hline CHEMBL1558846 & 688293 & 4.9 & 5.0187 & TRN & \\
\hline CHEMBL1583898 & 688293 & 4.8 & 4.8043 & TRN & \\
\hline CHEMBL1349215 & 688293 & 4.8 & 4.9803 & TRN & \\
\hline CHEMBL1313754 & 688293 & 4.4 & 4.9553 & TRN & \\
\hline CHEMBL1503484 & 688293 & 4.9 & 4.7867 & TRN & \\
\hline CHEMBL261693 & 688293 & 4.7 & 4.8463 & TST & \\
\hline CHEMBL1349721 & 688293 & 6.0 & \multicolumn{2}{|c|}{4.8839999999999995} & TST \\
\hline CHEMBL1489252 & 688293 & 4.7 & 4.7752 & TRN & \\
\hline CHEMBL1438688 & 688293 & 4.9 & 4.753 & TRN & \\
\hline CHEMBL1498063 & 688293 & 4.6 & 5.0808 & TRN & \\
\hline CHEMBL1540094 & 688293 & 4.8 & 4.9731 & TST & \\
\hline CHEMBL1568751 & 688293 & 4.6 & 4.8034 & TST & \\
\hline CHEMBL1452733 & 688293 & 4.7 & 5.056 & TRN & \\
\hline CHEMBL1532817 & 688293 & 4.4 & 4.9078 & TST & \\
\hline CHEMBL1413229 & 688293 & 4.6 & 4.8984 & TRN & \\
\hline CHEMBL1564077 & 688293 & 5.1 & 5.0565 & TRN & \\
\hline CHEMBL1500265 & 688293 & 4.9 & 4.8665 & TST & \\
\hline CHEMBL1378629 & 688293 & 4.5 & 5.1375 & TRN & \\
\hline CHEMBL355496 & 688293 & 5.0 & 4.8839 & TST & \\
\hline CHEMBL1302596 & 688293 & 4.4 & 4.9564 & TRN & \\
\hline CHEMBL1348395 & 688293 & 4.4 & \multicolumn{2}{|c|}{5.0089999999999995} & TRN \\
\hline CHEMBL1395850 & 688293 & 5.5 & 4.8594 & TRN & \\
\hline CHEMBL1602613 & 688293 & 4.6 & 5.0956 & TRN & \\
\hline CHEMBL542493 & 688293 & 4.8 & 5.0004 & TRN & \\
\hline CHEMBL1568028 & 688293 & 4.5 & 4.9873 & TRN & \\
\hline CHEMBL1362232 & 688293 & 4.9 & 4.9839 & TRN & \\
\hline CHEMBL1577395 & 688293 & 4.4 & 4.9405 & TRN & \\
\hline CHEMBL1504333 & 688293 & 4.4 & 4.9688 & TST & \\
\hline CHEMBL1608187 & 688293 & 4.6 & 4.9046 & TRN & \\
\hline CHEMBL1603890 & 688293 & 4.4 & 5.0243 & TST & \\
\hline CHEMBL 1440540 & 688293 & 4.6 & 5.0809 & TRN & \\
\hline CHEMBL1583513 & 688293 & 4.8 & 5.0507 & TRN & \\
\hline CHEMBL1337702 & 688293 & 4.6 & 4.9393 & TRN & \\
\hline CHEMBL1410676 & 688293 & 4.4 & 4.8325 & TRN & \\
\hline CHEMBL1326944 & 688293 & 5.2 & 4.7621 & TRN & \\
\hline CHEMBL1506450 & 688293 & 4.7 & 4.9399 & TRN & \\
\hline CHEMBL1546747 & 688293 & 4.9 & 5.0217 & TRN & \\
\hline CHEMBL1363554 & 688293 & 4.7 & 4.863 & TRN & \\
\hline CHEMBL1448387 & 688293 & 4.8 & 4.9883 & TST & \\
\hline CHEMBL1365553 & 688293 & 4.6 & 4.8432 & TST & \\
\hline CHEMBL1313264 & 688293 & 4.6 & 5.2768 & TRN & \\
\hline & & & & 19492 & \\
\hline
\end{tabular}




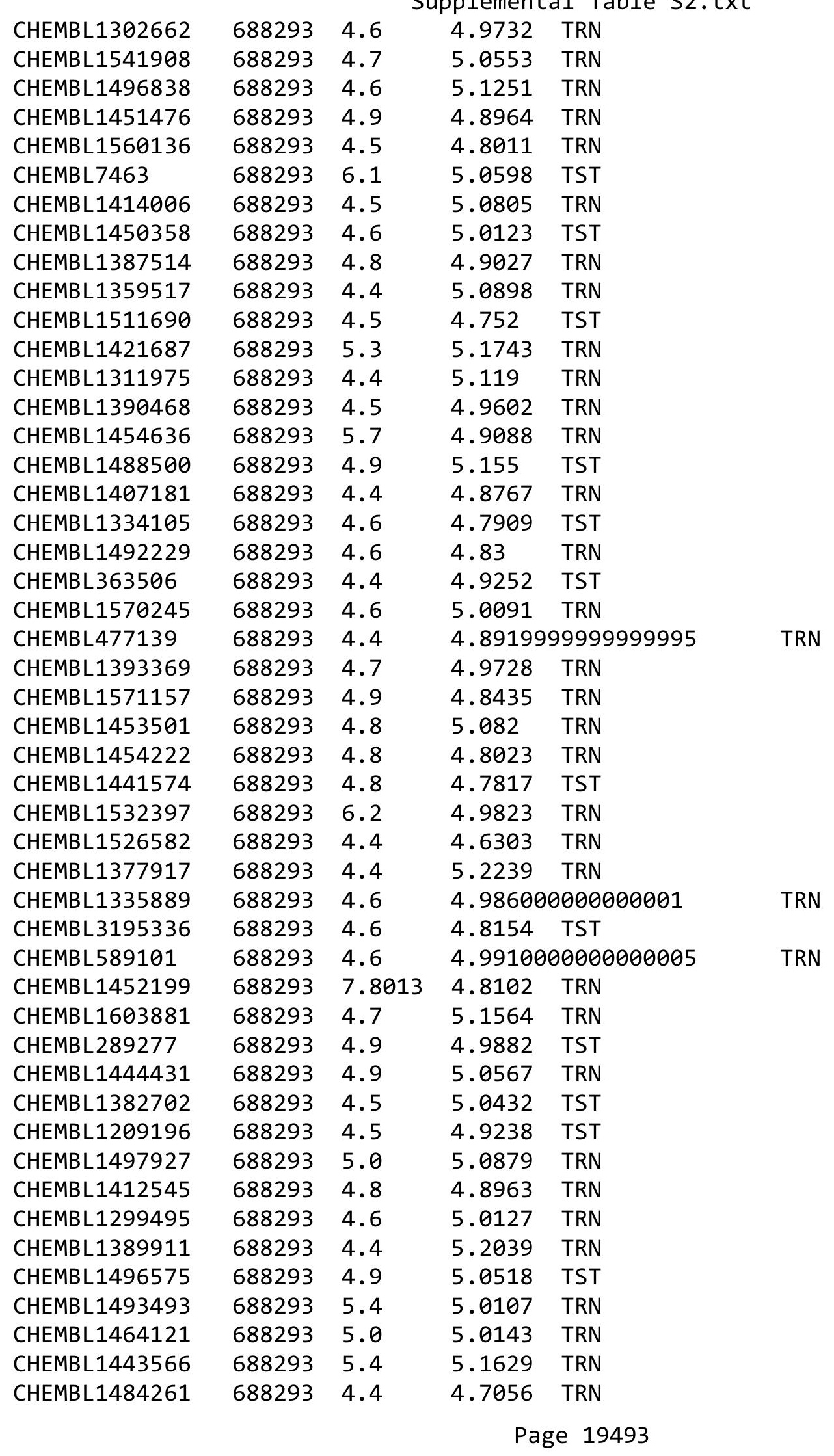




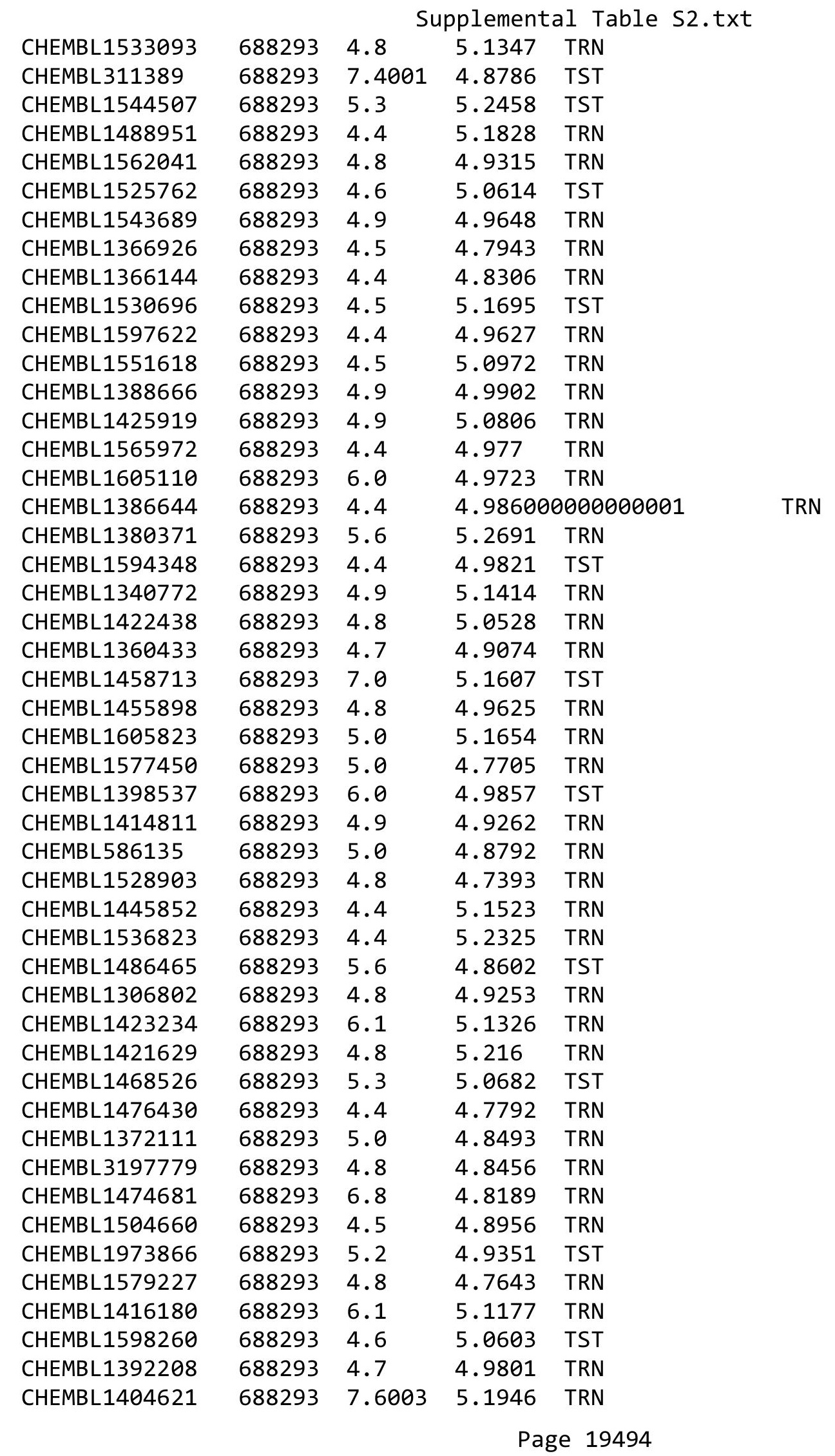




\begin{tabular}{|c|c|c|c|c|c|}
\hline & & \multicolumn{4}{|c|}{ Supplemental Table S2.txt } \\
\hline CHEMBL1482398 & 688293 & 4.6 & 4.7444 & TRN & \\
\hline CHEMBL1403858 & 688293 & 6.7001 & 5.0319 & TRN & \\
\hline CHEMBL1302088 & 688293 & 4.5 & 5.0536 & TRN & \\
\hline CHEMBL1339089 & 688293 & 4.8 & 4.9684 & TST & \\
\hline CHEMBL1418219 & 688293 & 4.8 & 5.1289 & TRN & \\
\hline CHEMBL1450545 & 688293 & 4.4 & 4.9789 & TRN & \\
\hline CHEMBL1488743 & 688293 & 4.5 & 5.0484 & TRN & \\
\hline CHEMBL1387615 & 688293 & 4.4 & 4.904 & TRN & \\
\hline CHEMBL1303635 & 688293 & 4.5 & 4.9608 & TRN & \\
\hline CHEMBL1427061 & 688293 & 5.0 & 4.9886 & TRN & \\
\hline CHEMBL1572043 & 688293 & 4.5 & 5.0535 & TRN & \\
\hline CHEMBL1358724 & 688293 & 4.5 & 4.9999 & TST & \\
\hline CHEMBL1416669 & 688293 & 5.0 & 5.1187 & TRN & \\
\hline CHEMBL1582435 & 688293 & 4.5 & 5.0975 & TRN & \\
\hline CHEMBL1586851 & 688293 & 4.6 & 4.9436 & TRN & \\
\hline CHEMBL1569048 & 688293 & 4.4 & 4.9539 & TRN & \\
\hline CHEMBL1404688 & 688293 & 4.7 & 4.931 & TRN & \\
\hline CHEMBL1999418 & 688293 & 4.6 & 4.8604 & TRN & \\
\hline CHEMBL1576580 & 688293 & 4.8 & 5.3029 & TRN & \\
\hline CHEMBL1519413 & 688293 & 4.6 & 5.0114 & TRN & \\
\hline CHEMBL1492037 & 688293 & 4.5 & 4.7177 & TRN & \\
\hline CHEMBL1309311 & 688293 & 5.0 & 4.9011 & TRN & \\
\hline CHEMBL1390824 & 688293 & 6.1 & 5.0954 & TRN & \\
\hline CHEMBL1328258 & 688293 & 6.0 & 5.188 & TRN & \\
\hline CHEMBL1256709 & 688293 & 7.8996 & 5.1907 & TRN & \\
\hline CHEMBL1352138 & 688293 & 4.7 & 4.8503 & TRN & \\
\hline CHEMBL1521069 & 688293 & 4.6 & 5.0588 & TRN & \\
\hline CHEMBL1510257 & 688293 & 4.8 & 4.9636 & TST & \\
\hline CHEMBL1486458 & 688293 & 7.1002 & 5.0783 & TRN & \\
\hline CHEMBL1468756 & 688293 & 4.6 & 4.93199 & 99999999995 & TRN \\
\hline CHEMBL1365739 & 688293 & 4.5 & 5.1115 & TRN & \\
\hline CHEMBL1309506 & 688293 & 5.1 & 5.0779 & TRN & \\
\hline CHEMBL1594281 & 688293 & 4.8 & 5.1188 & TRN & \\
\hline CHEMBL1559102 & 688293 & 4.4 & 4.8708 & TRN & \\
\hline CHEMBL1492194 & 688293 & 4.9 & 4.9571 & TRN & \\
\hline CHEMBL1462157 & 688293 & 4.5 & 4.9622 & TRN & \\
\hline CHEMBL1311642 & 688293 & 7.6003 & 5.2124 & TRN & \\
\hline CHEMBL1519870 & 688293 & 4.7 & 5.0475 & TRN & \\
\hline CHEMBL3210911 & 688293 & 4.5 & 4.8615 & TRN & \\
\hline CHEMBL1342589 & 688293 & 7.8996 & 5.2362 & TRN & \\
\hline CHEMBL507756 & 688293 & 4.8 & 5.0628 & TRN & \\
\hline CHEMBL1501296 & 688293 & 4.6 & 5.2295 & TRN & \\
\hline CHEMBL1515691 & 688293 & 4.7 & 4.9976 & TST & \\
\hline CHEMBL1500966 & 688293 & 4.9 & 5.0323 & TRN & \\
\hline CHEMBL3212391 & 688293 & 4.4 & 5.0864 & TST & \\
\hline CHEMBL1540505 & 688293 & 4.9 & 4.9803 & TRN & \\
\hline CHEMBL1325877 & 688293 & 4.6 & 4.9032 & TRN & \\
\hline CHEMBL1461449 & 688293 & 4.5 & 4.9097 & TRN & \\
\hline
\end{tabular}




\begin{tabular}{|c|c|c|c|c|}
\hline \multicolumn{5}{|c|}{ Supplemental Table S2.txt } \\
\hline CHEMBL1308223 & 688293 & 5.0 & 5.1565 & TRN \\
\hline CHEMBL1336641 & 688293 & 6.0 & 5.0648 & TRN \\
\hline CHEMBL1423551 & 688293 & 4.7 & 4.9561 & TRN \\
\hline CHEMBL530280 & 688293 & 4.9 & 4.9543 & TRN \\
\hline CHEMBL1416670 & 688293 & 4.5 & 4.9786 & TRN \\
\hline CHEMBL1349444 & 688293 & 5.0 & 4.9795 & TRN \\
\hline CHEMBL1594881 & 688293 & 5.5 & 4.9069 & TST \\
\hline CHEMBL1311188 & 688293 & 4.9 & 4.9299 & TRN \\
\hline CHEMBL1330907 & 688293 & 4.5 & 4.9712 & TRN \\
\hline CHEMBL1540900 & 688293 & 4.7 & 5.146 & TRN \\
\hline CHEMBL1345645 & 688293 & 4.8 & 4.9599 & TRN \\
\hline CHEMBL1566108 & 688293 & 4.8 & 5.1372 & TRN \\
\hline CHEMBL1420313 & 688293 & 4.8 & 4.9925 & TRN \\
\hline CHEMBL1299274 & 688293 & 4.4 & 4.9403 & TST \\
\hline CHEMBL1406316 & 688293 & 4.8 & 5.07 & TST \\
\hline CHEMBL1360735 & 688293 & 4.5 & 4.9838 & TRN \\
\hline CHEMBL3144868 & 688293 & 7.0 & 4.9868 & TRN \\
\hline CHEMBL1370846 & 688293 & 4.4 & 5.0307 & TRN \\
\hline CHEMBL1367007 & 688293 & 5.2 & 5.1768 & TRN \\
\hline CHEMBL1596886 & 688293 & 4.6 & 5.1 & TRN \\
\hline CHEMBL1447959 & 688293 & 4.9 & 4.6775 & TRN \\
\hline CHEMBL1341324 & 688293 & 4.6 & 5.0074 & TRN \\
\hline CHEMBL1358244 & 688293 & 5.8 & 5.0859 & TRN \\
\hline CHEMBL1402982 & 688293 & 4.6 & 5.0655 & TRN \\
\hline CHEMBL1200471 & 688293 & 4.9 & 4.9734 & TST \\
\hline CHEMBL1256654 & 688293 & 4.8 & 5.0658 & TST \\
\hline CHEMBL1557371 & 688293 & 4.4 & 5.1409 & TRN \\
\hline CHEMBL1428148 & 688293 & 4.7 & 4.9057 & TRN \\
\hline CHEMBL1528296 & 688293 & 4.6 & 4.9326 & TRN \\
\hline CHEMBL1529550 & 688293 & 5.4 & 5.1428 & TST \\
\hline CHEMBL1328444 & 688293 & 4.6 & 5.0511 & TRN \\
\hline CHEMBL1453801 & 688293 & 4.5 & 4.925 & TRN \\
\hline CHEMBL1568514 & 688293 & 8.2007 & 5.0681 & TRN \\
\hline CHEMBL1991908 & 688293 & 5.5 & 4.937 & TRN \\
\hline CHEMBL 34704 & 688293 & 6.0 & 4.9662 & TST \\
\hline CHEMBL1585074 & 688293 & 4.6 & 5.0887 & TRN \\
\hline CHEMBL1566101 & 688293 & 4.6 & 4.8829 & TRN \\
\hline CHEMBL68423 & 688293 & 4.9 & 4.7942 & TST \\
\hline CHEMBL1599594 & 688293 & 4.7 & 5.0131 & TRN \\
\hline CHEMBL1371199 & 688293 & 4.6 & 4.8683 & TRN \\
\hline CHEMBL3192376 & 688293 & 5.0 & 4.9322 & TST \\
\hline CHEMBL1531670 & 688293 & 4.6 & 4.7082 & TRN \\
\hline CHEMBL1369442 & 688293 & 5.9 & 5.2534 & TRN \\
\hline CHEMBL1447719 & 688293 & 4.5 & 4.9873 & TRN \\
\hline CHEMBL1323007 & 688293 & 4.4 & 4.9577 & TST \\
\hline CHEMBL1305311 & 688293 & 5.6 & 5.1049 & TRN \\
\hline CHEMBL1419549 & 688293 & 4.6 & 5.1278 & TRN \\
\hline CHEMBL1415791 & 688293 & 5.4 & 5.183 & TRN \\
\hline
\end{tabular}




\begin{tabular}{|c|c|c|c|c|c|}
\hline \multirow{3}{*}{$\begin{array}{l}\text { CHEMBL1448605 } \\
\text { CHEMBL1443315 }\end{array}$} & \multirow{3}{*}{$\begin{array}{l}688293 \\
688293\end{array}$} & \multicolumn{4}{|c|}{ Supplemental Table S2.txt } \\
\hline & & 5.5 & \multicolumn{2}{|c|}{ 4.97199999999999995 } & TST \\
\hline & & 4.5 & 5.0642 & TRN & \\
\hline CHEMBL1406964 & 688293 & 4.4 & 4.8464 & TRN & \\
\hline CHEMBL1517449 & 688293 & 9.699 & 5.1423 & TST & \\
\hline CHEMBL1355783 & 688293 & 5.4 & 4.8942 & TST & \\
\hline CHEMBL1386652 & 688293 & 4.6 & 5.0871 & TRN & \\
\hline CHEMBL1547250 & 688293 & 4.5 & 4.9718 & TRN & \\
\hline CHEMBL1514375 & 688293 & 6.7001 & 4.966 & TST & \\
\hline CHEMBL1519843 & 688293 & 4.8 & 5.0176 & TRN & \\
\hline CHEMBL17468 & 688293 & 5.1 & 5.0414 & TRN & \\
\hline CHEMBL1389776 & 688293 & 5.0 & 5.0076 & TRN & \\
\hline CHEMBL1598161 & 688293 & 4.6 & 5.0 & TST & \\
\hline CHEMBL1531911 & 688293 & 4.8 & 4.9534 & TRN & \\
\hline CHEMBL1438567 & 688293 & 4.5 & 4.9148 & TRN & \\
\hline CHEMBL1551271 & 688293 & 6.0 & 5.0632 & TST & \\
\hline CHEMBL1466190 & 688293 & 4.5 & 5.0873 & TRN & \\
\hline CHEMBL1588895 & 688293 & 4.4 & 4.6878 & TRN & \\
\hline CHEMBL1447891 & 688293 & 4.8 & 5.1432 & TRN & \\
\hline CHEMBL1468708 & 688293 & 4.5 & 5.0896 & TRN & \\
\hline CHEMBL1519575 & 688293 & 4.7 & 5.0154 & TRN & \\
\hline CHEMBL1439271 & 688293 & 4.5 & 5.0141 & TRN & \\
\hline CHEMBL1554935 & 688293 & 5.6 & 4.8758 & TRN & \\
\hline CHEMBL1558400 & 688293 & 5.3 & 4.9061 & TST & \\
\hline CHEMBL1345880 & 688293 & 7.0 & 5.0883 & TRN & \\
\hline CHEMBL1311222 & 688293 & 7.1002 & 5.0102 & TRN & \\
\hline CHEMBL 257856 & 688293 & 4.6 & 5.1581 & TRN & \\
\hline CHEMBL1462784 & 688293 & 4.7 & 4.6678 & TRN & \\
\hline CHEMBL1567086 & 688293 & 4.8 & 4.9262 & TST & \\
\hline CHEMBL1490454 & 688293 & 4.9 & 4.9891 & TRN & \\
\hline CHEMBL1449326 & 688293 & 4.6 & 5.0109 & TRN & \\
\hline CHEMBL1405054 & 688293 & 5.3 & 4.947 & TRN & \\
\hline CHEMBL1570538 & 688293 & 4.4 & 5.0178 & TRN & \\
\hline CHEMBL1333716 & 688293 & 6.0 & 5.1322 & TRN & \\
\hline CHEMBL1522160 & 688293 & 5.2 & 4.8172 & TRN & \\
\hline CHEMBL1372964 & 688293 & 4.3 & 5.0528 & TST & \\
\hline CHEMBL1418284 & 688293 & 4.6 & 5.2502 & TRN & \\
\hline CHEMBL1466064 & 688293 & 7.0 & 5.2059 & TRN & \\
\hline CHEMBL1438188 & 688293 & 4.8 & 4.8884 & TRN & \\
\hline CHEMBL1406211 & 688293 & 4.7 & 4.8484 & TRN & \\
\hline CHEMBL 305195 & 688293 & 4.9 & 5.1176 & TRN & \\
\hline CHEMBL1446259 & 688293 & 4.7 & 4.7369 & TRN & \\
\hline CHEMBL1411444 & 688293 & 4.7 & 5.0552 & TRN & \\
\hline CHEMBL1377459 & 688293 & 4.7 & 5.1315 & TRN & \\
\hline CHEMBL1608480 & 688293 & 4.5 & 4.8131 & TRN & \\
\hline CHEMBL1606495 & 688293 & 4.9 & 5.0654 & TRN & \\
\hline CHEMBL1459497 & 688293 & 4.4 & 5.0451 & TRN & \\
\hline CHEMBL1513485 & 688293 & 5.4 & 4.7218 & TRN & \\
\hline CHEMBL1517649 & 688293 & 4.9 & 4.9607 & TRN & \\
\hline
\end{tabular}




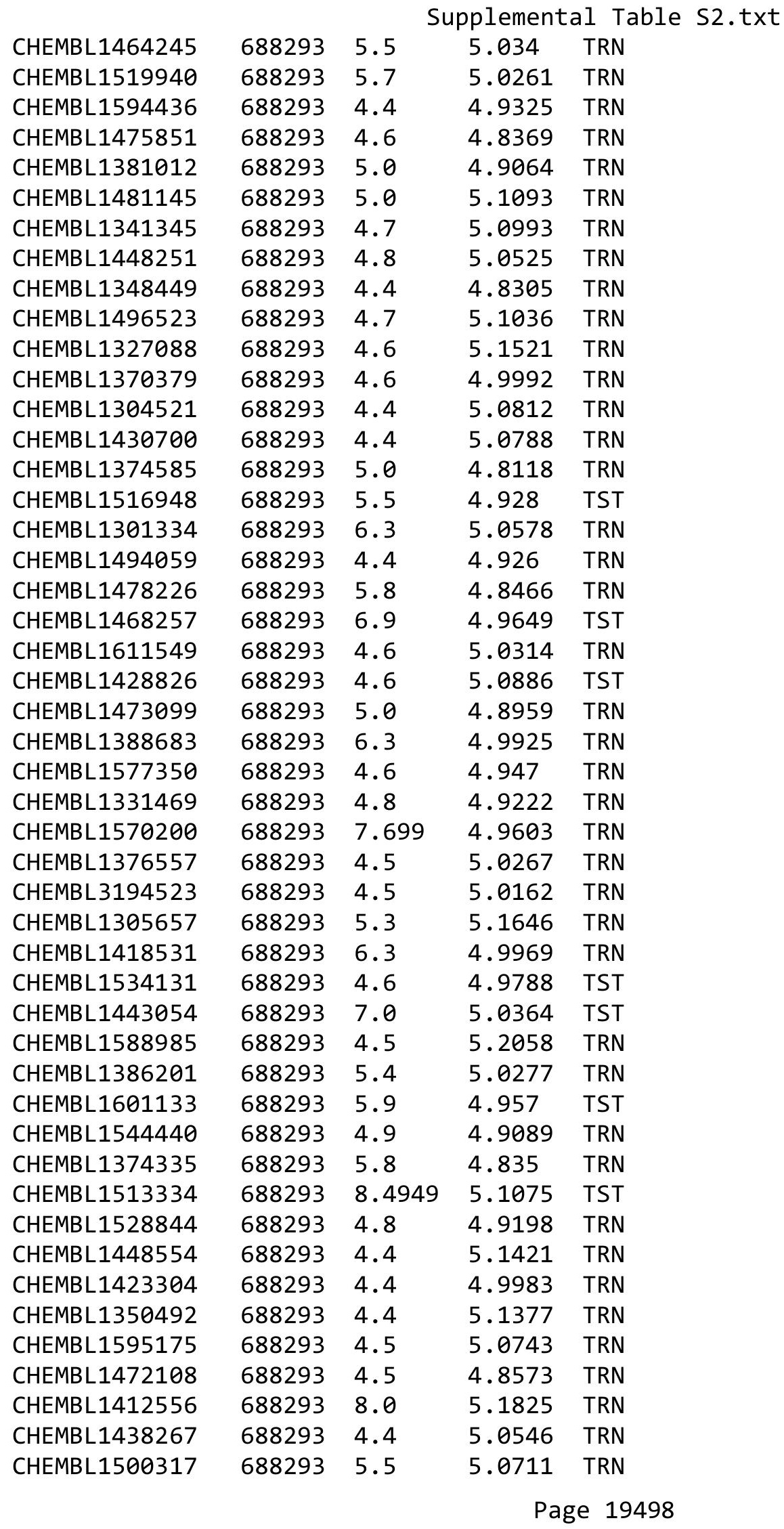




\begin{tabular}{|c|c|c|c|c|c|}
\hline \multicolumn{6}{|c|}{ Supplemental Table S2.txt } \\
\hline CHEMBL1478989 & 688293 & 4.4 & 5.0723 & TRN & \\
\hline CHEMBL1560603 & 688293 & 4.9 & 5.0122 & TRN & \\
\hline CHEMBL1608247 & 688293 & 4.4 & 5.1819 & TRN & \\
\hline CHEMBL1497218 & 688293 & 5.5 & 5.11100 & 2000000001 & TRN \\
\hline CHEMBL1386080 & 688293 & 5.7 & 5.0359 & TRN & \\
\hline CHEMBL119841 & 688293 & 6.1 & 4.8341 & TRN & \\
\hline CHEMBL1424889 & 688293 & 4.5 & 4.9168 & TRN & \\
\hline CHEMBL1494268 & 688293 & 6.9 & 5.0348 & TRN & \\
\hline CHEMBL1300098 & 688293 & 4.6 & 4.9559 & TRN & \\
\hline CHEMBL1373511 & 688293 & 4.4 & 5.2492 & TRN & \\
\hline CHEMBL1311916 & 688293 & 5.4 & 5.1349 & TRN & \\
\hline CHEMBL137498 & 688293 & 4.5 & 4.8289 & TRN & \\
\hline CHEMBL1465680 & 688293 & 8.2007 & 5.1118 & TRN & \\
\hline CHEMBL1372519 & 688293 & 5.0 & 5.0224 & TRN & \\
\hline CHEMBL1363615 & 688293 & 5.1 & 4.7729 & TRN & \\
\hline CHEMBL1433464 & 688293 & 7.1002 & 4.7601 & TRN & \\
\hline CHEMBL1372644 & 688293 & 5.5 & 5.27 & TRN & \\
\hline CHEMBL1415605 & 688293 & 4.4 & 5.1493 & TRN & \\
\hline CHEMBL1546497 & 688293 & 4.7 & 5.2062 & TRN & \\
\hline CHEMBL1566504 & 688293 & 4.7 & 5.0032 & TST & \\
\hline CHEMBL1530463 & 688293 & 4.4 & 5.2389 & TRN & \\
\hline CHEMBL1331288 & 688293 & 5.5 & 4.9508 & TST & \\
\hline CHEMBL1608401 & 688293 & 4.8 & 5.0491 & TRN & \\
\hline CHEMBL1528006 & 688293 & 4.4 & 5.0526 & TRN & \\
\hline CHEMBL67932 & 688293 & 4.5 & 4.9803 & TRN & \\
\hline CHEMBL1496947 & 688293 & 5.8 & 4.9698 & TRN & \\
\hline CHEMBL1594720 & 688293 & 4.4 & 4.7533 & TRN & \\
\hline CHEMBL1341600 & 688293 & 4.9 & 5.058 & TRN & \\
\hline CHEMBL1528235 & 688293 & 5.8 & 5.0036 & TST & \\
\hline CHEMBL519344 & 688293 & 4.9 & 5.1315 & TRN & \\
\hline CHEMBL3197036 & 688293 & 4.7 & 4.8972 & TST & \\
\hline CHEMBL1608942 & 688293 & 7.2 & 5.2257 & TRN & \\
\hline CHEMBL1390086 & 688293 & 4.5 & 5.0077 & TRN & \\
\hline CHEMBL1405618 & 688293 & 5.5 & 4.8447 & TRN & \\
\hline CHEMBL113180 & 688293 & 6.1 & 5.1249 & TST & \\
\hline CHEMBL240331 & 688293 & 4.8 & 4.9379 & TRN & \\
\hline CHEMBL3213599 & 688293 & 4.6 & 4.904 & TRN & \\
\hline CHEMBL1326100 & 688293 & 5.1 & 5.0515 & TRN & \\
\hline CHEMBL1417636 & 688293 & 5.0 & 4.784 & TRN & \\
\hline CHEMBL1400868 & 688293 & 4.6 & 4.8967 & TRN & \\
\hline CHEMBL1371386 & 688293 & 4.4 & 4.8739 & TRN & \\
\hline CHEMBL1380365 & 688293 & 4.4 & 4.9044 & TRN & \\
\hline CHEMBL1552150 & 688293 & 4.6 & 4.8223 & TRN & \\
\hline CHEMBL1548739 & 688293 & 4.4 & 4.9906 & TST & \\
\hline CHEMBL1599915 & 688293 & 5.0 & 4.9769 & TRN & \\
\hline CHEMBL1544839 & 688293 & 4.8 & 4.86100 & 2000000001 & TRN \\
\hline CHEMBL1421429 & 688293 & 4.6 & 5.0168 & TRN & \\
\hline CHEMBL1533107 & 688293 & 4.6 & 4.7663 & TRN & \\
\hline
\end{tabular}




\begin{tabular}{|c|c|c|c|c|}
\hline \multicolumn{5}{|c|}{ Supplemental Table S2.txt } \\
\hline CHEMBL563047 & 688293 & 4.6 & 5.0665 & TRN \\
\hline CHEMBL1396595 & 688293 & 4.4 & 4.8126 & TRN \\
\hline CHEMBL1478935 & 688293 & 4.9 & 5.0353 & TRN \\
\hline CHEMBL1378869 & 688293 & 4.7 & 5.1286 & TRN \\
\hline CHEMBL1399018 & 688293 & 6.4 & 5.1571 & TRN \\
\hline CHEMBL1371501 & 688293 & 6.0 & 5.1758 & TRN \\
\hline CHEMBL1521142 & 688293 & 7.4001 & 5.2212 & TRN \\
\hline CHEMBL1321118 & 688293 & 6.6 & 4.8558 & TRN \\
\hline CHEMBL1372673 & 688293 & 4.8 & 5.0555 & TRN \\
\hline CHEMBL1589893 & 688293 & 4.5 & 4.8596 & TRN \\
\hline CHEMBL1300775 & 688293 & 4.4 & 5.1226 & TST \\
\hline CHEMBL1608065 & 688293 & 4.6 & 4.877 & TRN \\
\hline CHEMBL1521352 & 688293 & 4.8 & 4.9797 & TRN \\
\hline CHEMBL1481541 & 688293 & 4.6 & 5.081 & TRN \\
\hline CHEMBL1436661 & 688293 & 4.9 & 5.0543 & TRN \\
\hline CHEMBL1478482 & 688293 & 6.0 & 5.0392 & TRN \\
\hline CHEMBL1300171 & 688293 & 4.6 & 4.9958 & TRN \\
\hline CHEMBL1454876 & 688293 & 4.6 & 5.0052 & TRN \\
\hline CHEMBL1475758 & 688293 & 6.1 & 5.1874 & TST \\
\hline CHEMBL1421338 & 688293 & 4.4 & 4.9211 & TRN \\
\hline CHEMBL1548451 & 688293 & 4.9 & 4.8727 & TRN \\
\hline CHEMBL1465527 & 688293 & 4.5 & 5.0417 & TST \\
\hline CHEMBL1608407 & 688293 & 4.6 & 5.0699 & TRN \\
\hline CHEMBL1526403 & 688293 & 4.6 & 5.1149 & TRN \\
\hline CHEMBL1560914 & 688293 & 8.1024 & 4.9755 & TRN \\
\hline CHEMBL1571308 & 688293 & 4.8 & 5.0623 & TRN \\
\hline CHEMBL 291536 & 688293 & 4.4 & 4.9198 & TRN \\
\hline CHEMBL1301191 & 688293 & 7.8996 & 4.9385 & TRN \\
\hline CHEMBL1313851 & 688293 & 4.7 & 4.9874 & TRN \\
\hline CHEMBL1372820 & 688293 & 4.4 & 5.1457 & TRN \\
\hline CHEMBL1469423 & 688293 & 6.1 & 5.0821 & TST \\
\hline CHEMBL1499114 & 688293 & 4.4 & 5.0043 & TST \\
\hline CHEMBL1471888 & 688293 & 4.4 & 4.9019 & TRN \\
\hline CHEMBL1583131 & 688293 & 4.9 & 5.0655 & TRN \\
\hline CHEMBL47814 & 688293 & 6.2 & 4.9671 & TRN \\
\hline CHEMBL1312087 & 688293 & 4.8 & 4.7722 & TRN \\
\hline CHEMBL 293749 & 688293 & 4.6 & 5.0483 & TRN \\
\hline CHEMBL272682 & 688293 & 5.8 & 4.8971 & TRN \\
\hline CHEMBL1395915 & 688293 & 4.9 & 4.8671 & TRN \\
\hline CHEMBL1358562 & 688293 & 5.9 & 4.8932 & TRN \\
\hline CHEMBL1517147 & 688293 & 4.8 & 5.1305 & TRN \\
\hline CHEMBL1534019 & 688293 & 5.0 & 4.9451 & TRN \\
\hline CHEMBL1469056 & 688293 & 4.4 & 5.0417 & TRN \\
\hline CHEMBL1517599 & 688293 & 4.9 & 4.9718 & TRN \\
\hline CHEMBL1370757 & 688293 & 4.6 & 5.0073 & TRN \\
\hline CHEMBL1443681 & 688293 & 4.8 & 4.8254 & TRN \\
\hline CHEMBL1457118 & 688293 & 7.4001 & 4.9143 & TRN \\
\hline CHEMBL 310578 & 688293 & 4.7 & 5.2769 & TST \\
\hline
\end{tabular}




\begin{tabular}{|c|c|c|c|c|c|}
\hline \multirow[b]{2}{*}{ CHEMBL1398022 } & \multirow[b]{2}{*}{688293} & \\
\hline & & 5.1 & 4.9638 & TST & \\
\hline CHEMBL1414251 & 688293 & 5.3 & 4.8497 & TRN & \\
\hline CHEMBL1339290 & 688293 & 5.3 & 5.0744 & TST & \\
\hline CHEMBL1370720 & 688293 & 4.5 & 5.0868 & TRN & \\
\hline CHEMBL1402196 & 688293 & 5.9 & 4.976 & TRN & \\
\hline CHEMBL1351580 & 688293 & 4.6 & 4.7472 & TRN & \\
\hline CHEMBL1594781 & 688293 & 4.5 & 4.904 & TRN & \\
\hline CHEMBL1560726 & 688293 & 6.8 & 5.0466 & TRN & \\
\hline CHEMBL1568288 & 688293 & 5.0 & 4.8879 & TRN & \\
\hline CHEMBL1451780 & 688293 & 6.0 & 4.9535 & TST & \\
\hline CHEMBL1579125 & 688293 & 4.6 & 5.0557 & TRN & \\
\hline CHEMBL1443091 & 688293 & 4.4 & 5.0645 & TRN & \\
\hline CHEMBL1255936 & 688293 & 4.4 & 5.0513 & TRN & \\
\hline CHEMBL3213120 & 688293 & 4.4 & 4.9654 & TRN & \\
\hline CHEMBL1383666 & 688293 & 5.0 & 4.8157 & TRN & \\
\hline CHEMBL1327563 & 688293 & 6.1 & 5.006 & TRN & \\
\hline CHEMBL1539308 & 688293 & 6.9 & 5.148 & TRN & \\
\hline CHEMBL1602150 & 688293 & 4.4 & 4.8023 & TRN & \\
\hline CHEMBL1502457 & 688293 & 7.1002 & 5.0783 & TST & \\
\hline CHEMBL1572658 & 688293 & 4.6 & 5.003 & TST & \\
\hline CHEMBL1583106 & 688293 & 4.9 & 5.04899 & 99999999995 & TRN \\
\hline CHEMBL1327087 & 688293 & 5.3 & 5.1475 & TRN & \\
\hline CHEMBL1444151 & 688293 & 6.0 & 4.9313 & TST & \\
\hline CHEMBL1302290 & 688293 & 5.8 & 4.9599 & TRN & \\
\hline CHEMBL1481007 & 688293 & 4.5 & 5.0428 & TRN & \\
\hline CHEMBL1504491 & 688293 & 4.8 & 4.982 & TRN & \\
\hline CHEMBL1399952 & 688293 & 5.9 & 4.9969 & TRN & \\
\hline CHEMBL1517187 & 688293 & 6.0 & 5.224 & TST & \\
\hline CHEMBL1479246 & 688293 & 4.4 & 5.2718 & TRN & \\
\hline CHEMBL1397914 & 688293 & 4.5 & 4.7994 & TRN & \\
\hline CHEMBL429023 & 688293 & 6.1 & 5.0265 & TST & \\
\hline CHEMBL1374185 & 688293 & 7.2 & 4.9753 & TST & \\
\hline CHEMBL1440892 & 688293 & 4.7 & 4.88899 & 9999999999 & TRN \\
\hline CHEMBL1391334 & 688293 & 4.7 & 4.7973 & TRN & \\
\hline CHEMBL1319142 & 688293 & 4.9 & 4.8373 & TST & \\
\hline CHEMBL1323915 & 688293 & 4.6 & 5.1572 & TRN & \\
\hline CHEMBL1505048 & 688293 & 4.6 & 5.0553 & TRN & \\
\hline CHEMBL1557199 & 688293 & 5.9 & 5.2368 & TRN & \\
\hline CHEMBL1470095 & 688293 & 4.5 & 4.9885 & TRN & \\
\hline CHEMBL1491818 & 688293 & 5.0 & 4.8638 & TRN & \\
\hline CHEMBL1612117 & 688293 & 4.7 & 4.9221 & TRN & \\
\hline CHEMBL1426641 & 688293 & 4.6 & 4.9759 & TRN & \\
\hline CHEMBL1331734 & 688293 & 4.7 & 4.9273 & TST & \\
\hline CHEMBL1326295 & 688293 & 5.6 & 5.1261 & TRN & \\
\hline CHEMBL1444856 & 688293 & 4.8 & 4.8467 & TRN & \\
\hline CHEMBL49247 & 688293 & 4.4 & 5.0335 & TST & \\
\hline CHEMBL571087 & 688293 & 4.7 & 4.9627 & TRN & \\
\hline CHEMBL1409587 & 688293 & 4.7 & 5.0888 & TRN & \\
\hline & & & & 19501 & \\
\hline
\end{tabular}




\begin{tabular}{|c|c|c|c|c|c|}
\hline \\
\hline CHEMBL1304075 & 688293 & 4.0 & 5.0892 & TRN & \\
\hline CHEMBL1463769 & 688293 & 4.5 & 4.9258 & TRN & \\
\hline CHEMBL1335945 & 688293 & 4.6 & 4.8897 & TST & \\
\hline CHEMBL1443093 & 688293 & 4.6 & 5.0444 & TRN & \\
\hline CHEMBL1366238 & 688293 & 4.7 & 4.84399 & 9999999999 & TRN \\
\hline CHEMBL1331137 & 688293 & 5.6 & 5.1273 & TRN & \\
\hline CHEMBL1440699 & 688293 & 4.5 & 5.062 & TRN & \\
\hline CHEMBL1448718 & 688293 & 4.4 & 5.1093 & TRN & \\
\hline CHEMBL1551915 & 688293 & 4.9 & 5.1157 & TST & \\
\hline CHEMBL1335426 & 688293 & 8.2007 & 5.28799 & 9999999999 & TRN \\
\hline CHEMBL1492686 & 688293 & 5.4 & 4.8336 & TRN & \\
\hline CHEMBL1604283 & 688293 & 4.9 & 5.0434 & TST & \\
\hline CHEMBL567337 & 688293 & 4.5 & 5.0967 & TRN & \\
\hline CHEMBL 28 & 688293 & 4.7 & 4.9337 & TRN & \\
\hline CHEMBL1416815 & 688293 & 4.4 & 4.8275 & TRN & \\
\hline CHEMBL1432702 & 688293 & 5.4 & 4.8512 & TRN & \\
\hline CHEMBL1522997 & 688293 & 4.8 & 4.9808 & TRN & \\
\hline CHEMBL1351020 & 688293 & 4.7 & 4.8387 & TRN & \\
\hline CHEMBL1346626 & 688293 & 4.9 & 4.9489 & TRN & \\
\hline CHEMBL1386496 & 688293 & 4.4 & 4.8343 & TRN & \\
\hline CHEMBL1551557 & 688293 & 5.1 & 4.8834 & TRN & \\
\hline CHEMBL1422695 & 688293 & 4.5 & 4.9044 & TRN & \\
\hline CHEMBL1566245 & 688293 & 4.9 & 4.9477 & TST & \\
\hline CHEMBL1403174 & 688293 & 5.0 & 4.9566 & TRN & \\
\hline CHEMBL1532436 & 688293 & 4.4 & 5.1531 & TRN & \\
\hline CHEMBL1375049 & 688293 & 8.4949 & 5.114 & TST & \\
\hline CHEMBL1337502 & 688293 & 4.7 & 4.8302 & TST & \\
\hline CHEMBL1256693 & 688293 & 4.8 & 4.8916 & TRN & \\
\hline CHEMBL1372268 & 688293 & 4.4 & 5.0063 & TRN & \\
\hline CHEMBL1333822 & 688293 & 4.8 & 4.9823 & TRN & \\
\hline CHEMBL1485970 & 688293 & 4.5 & 4.94600 & 0000000001 & TST \\
\hline CHEMBL1610972 & 688293 & 4.4 & 5.0446 & TST & \\
\hline CHEMBL1431996 & 688293 & 4.4 & 5.0474 & TRN & \\
\hline CHEMBL1605926 & 688293 & 4.5 & 5.0649 & TRN & \\
\hline CHEMBL1374399 & 688293 & 4.6 & 5.0188 & TRN & \\
\hline CHEMBL1607616 & 688293 & 5.2 & 4.9776 & TRN & \\
\hline CHEMBL1512797 & 688293 & 5.5 & 5.1966 & TST & \\
\hline CHEMBL1323061 & 688293 & 4.5 & 4.9488 & TRN & \\
\hline CHEMBL 235453 & 688293 & 5.1 & 4.9769 & TRN & \\
\hline CHEMBL1581806 & 688293 & 4.5 & 5.0834 & TRN & \\
\hline CHEMBL1474989 & 688293 & 4.7 & 4.8086 & TRN & \\
\hline CHEMBL1471589 & 688293 & 5.5 & 5.0702 & TRN & \\
\hline CHEMBL1333952 & 688293 & 4.5 & 5.05 & TRN & \\
\hline CHEMBL1357114 & 688293 & 4.5 & 5.17299 & 9999999999 & TST \\
\hline CHEMBL1486517 & 688293 & 4.9 & 5.12799 & 9999999999 & TRN \\
\hline CHEMBL1469464 & 688293 & 4.5 & 4.8599 & TRN & \\
\hline CHEMBL1604354 & 688293 & 4.9 & 4.9686 & TRN & \\
\hline CHEMBL1582821 & 688293 & 5.3 & 4.9737 & TRN & \\
\hline
\end{tabular}




\begin{tabular}{|c|c|c|c|c|c|}
\hline \multicolumn{6}{|c|}{ Supplemental Table S2.txt } \\
\hline CHEMBL1453521 & 688293 & 4.6 & 4.8543 & TRN & \\
\hline CHEMBL1413178 & 688293 & 4.5 & 4.9283 & TST & \\
\hline CHEMBL1312239 & 688293 & 4.6 & 4.9615 & TRN & \\
\hline CHEMBL1497998 & 688293 & 4.8 & 5.0492 & TRN & \\
\hline CHEMBL427449 & 688293 & 5.0 & 4.9873 & TRN & \\
\hline CHEMBL1419581 & 688293 & 4.6 & 4.9831 & TST & \\
\hline CHEMBL1360940 & 688293 & 4.7 & 4.9181 & TRN & \\
\hline CHEMBL1304099 & 688293 & 4.4 & 5.2097 & TRN & \\
\hline CHEMBL1256484 & 688293 & 4.4 & 4.9817 & TRN & \\
\hline CHEMBL454173 & 688293 & 6.0 & 5.0984 & TST & \\
\hline CHEMBL1532856 & 688293 & 5.7 & 5.1129 & TRN & \\
\hline CHEMBL75267 & 688293 & 5.6 & 4.8768 & TRN & \\
\hline CHEMBL1442455 & 688293 & 5.2 & 5.0029 & TST & \\
\hline CHEMBL1533988 & 688293 & 4.6 & 4.9839 & TRN & \\
\hline CHEMBL1524223 & 688293 & 5.8 & 5.1021 & TRN & \\
\hline CHEMBL1546161 & 688293 & 5.0 & 4.6786 & TRN & \\
\hline CHEMBL1362587 & 688293 & 5.8 & 5.0871 & TST & \\
\hline CHEMBL1334330 & 688293 & 4.5 & 4.8524 & TRN & \\
\hline CHEMBL1443810 & 688293 & 4.9 & 5.1361 & TRN & \\
\hline CHEMBL1416773 & 688293 & 5.0 & 4.8698 & TRN & \\
\hline CHEMBL1544367 & 688293 & 4.3 & 4.9962 & TRN & \\
\hline CHEMBL1303203 & 688293 & 4.5 & 4.8364 & TRN & \\
\hline CHEMBL598773 & 688293 & 4.5 & 5.0489 & TST & \\
\hline CHEMBL1325774 & 688293 & 4.5 & 5.1359 & TST & \\
\hline CHEMBL1303063 & 688293 & 4.5 & 4.9827 & TRN & \\
\hline CHEMBL1548391 & 688293 & 7.1002 & 5.0808 & TRN & \\
\hline CHEMBL1507838 & 688293 & 5.3 & 4.9203 & TST & \\
\hline CHEMBL1399493 & 688293 & 4.9 & 4.88899 & 9999999999 & TRN \\
\hline CHEMBL1500536 & 688293 & 5.0 & 4.9737 & TRN & \\
\hline CHEMBL1448845 & 688293 & 4.8 & 4.9401 & TRN & \\
\hline CHEMBL1426137 & 688293 & 4.7 & 4.9506 & TST & \\
\hline CHEMBL1325898 & 688293 & 4.9 & 5.142 & TRN & \\
\hline CHEMBL1558709 & 688293 & 4.6 & 4.9846 & TRN & \\
\hline CHEMBL1574924 & 688293 & 4.7 & 5.0637 & TRN & \\
\hline CHEMBL1438116 & 688293 & 4.8 & 5.2111 & TRN & \\
\hline CHEMBL1526546 & 688293 & 4.6 & 4.9409 & TRN & \\
\hline CHEMBL249190 & 688293 & 4.4 & 5.101 & TRN & \\
\hline CHEMBL1405431 & 688293 & 6.5 & 5.0835 & TRN & \\
\hline CHEMBL1557831 & 688293 & 6.1 & 5.0601 & TRN & \\
\hline CHEMBL1547450 & 688293 & 4.6 & 4.717 & TRN & \\
\hline CHEMBL1469282 & 688293 & 4.6 & 5.006 & TRN & \\
\hline CHEMBL606166 & 688293 & 4.4 & 4.8985 & TST & \\
\hline CHEMBL1354013 & 688293 & 8.2007 & 5.0284 & TRN & \\
\hline CHEMBL323197 & 688293 & 4.7 & 5.0123 & TRN & \\
\hline CHEMBL1301492 & 688293 & 5.3 & 5.2747 & TRN & \\
\hline CHEMBL1410284 & 688293 & 4.4 & 5.2707 & TRN & \\
\hline CHEMBL3209071 & 688293 & 4.8 & 5.0023 & TRN & \\
\hline CHEMBL1464293 & 688293 & 4.5 & 5.0457 & TRN & \\
\hline
\end{tabular}




\begin{tabular}{|c|c|c|c|c|}
\hline \multicolumn{5}{|c|}{ Supplemental Table S2.txt } \\
\hline CHEMBL1512719 & 688293 & 4.4 & 5.1218 & TST \\
\hline CHEMBL1304071 & 688293 & 6.7001 & 4.7989 & TRN \\
\hline CHEMBL1448138 & 688293 & 7.5003 & 4.8648 & TRN \\
\hline CHEMBL1459111 & 688293 & 4.5 & 4.9775 & TRN \\
\hline CHEMBL1482007 & 688293 & 4.5 & 4.7238 & TRN \\
\hline CHEMBL1503167 & 688293 & 4.9 & 5.1857 & TRN \\
\hline CHEMBL1304812 & 688293 & 4.9 & 4.9314 & TRN \\
\hline CHEMBL1577029 & 688293 & 4.8 & 4.9194 & TRN \\
\hline CHEMBL1599790 & 688293 & 4.5 & 4.967 & TST \\
\hline CHEMBL1569072 & 688293 & 4.5 & 5.1188 & TRN \\
\hline CHEMBL1429400 & 688293 & 5.6 & 4.9926 & TRN \\
\hline CHEMBL1468171 & 688293 & 4.5 & 5.0901 & TRN \\
\hline CHEMBL1477649 & 688293 & 4.7 & 5.0465 & TRN \\
\hline CHEMBL1509933 & 688293 & 4.6 & 5.0629 & TRN \\
\hline CHEMBL1481785 & 688293 & 5.3 & 4.9775 & TRN \\
\hline CHEMBL1357381 & 688293 & 4.9 & 4.7328 & TRN \\
\hline CHEMBL1440703 & 688293 & 4.4 & 5.1013 & TST \\
\hline CHEMBL1581280 & 688293 & 4.8 & 4.9057 & TRN \\
\hline CHEMBL1575033 & 688293 & 4.5 & 4.7866 & TRN \\
\hline CHEMBL1561598 & 688293 & 4.7 & 4.8667 & TRN \\
\hline CHEMBL18701 & 688293 & 7.6003 & 5.0391 & TST \\
\hline CHEMBL1435200 & 688293 & 5.0 & 5.142 & TST \\
\hline CHEMBL 294018 & 688293 & 4.5 & 5.1184 & TST \\
\hline CHEMBL1401244 & 688293 & 4.4 & 4.9692 & TRN \\
\hline CHEMBL1357941 & 688293 & 4.4 & 4.9447 & TST \\
\hline CHEMBL1538713 & 688293 & 4.4 & 4.9476 & TRN \\
\hline CHEMBL1461811 & 688293 & 5.0 & 5.0476 & TRN \\
\hline CHEMBL1464255 & 688293 & 7.8013 & 5.1957 & TRN \\
\hline CHEMBL1582724 & 688293 & 5.1 & 5.0546 & TRN \\
\hline CHEMBL1599856 & 688293 & 4.5 & 4.8642 & TRN \\
\hline CHEMBL1448839 & 688293 & 5.6 & 4.9989 & TRN \\
\hline CHEMBL1491586 & 688293 & 4.4 & 4.9756 & TRN \\
\hline CHEMBL3211027 & 688293 & 5.0 & 4.9784 & TRN \\
\hline CHEMBL1548716 & 688293 & 5.0 & 4.9778 & TRN \\
\hline CHEMBL1548983 & 688293 & 4.4 & 4.9981 & TRN \\
\hline CHEMBL1401083 & 688293 & 5.3 & 5.0606 & TRN \\
\hline CHEMBL1314982 & 688293 & 5.2 & 5.03 & TST \\
\hline CHEMBL1607311 & 688293 & 4.4 & 5.2199 & TST \\
\hline CHEMBL1420689 & 688293 & 5.6 & 5.021 & TRN \\
\hline CHEMBL1363313 & 688293 & 4.9 & 4.92399 & 99999999995 \\
\hline CHEMBL1596008 & 688293 & 4.6 & 5.0582 & TRN \\
\hline CHEMBL1577940 & 688293 & 4.4 & 5.1098 & TRN \\
\hline CHEMBL1492801 & 688293 & 4.8 & 4.832 & TRN \\
\hline CHEMBL1532795 & 688293 & 4.8 & 4.7438 & TRN \\
\hline CHEMBL1482218 & 688293 & 8.0 & 5.0917 & TRN \\
\hline CHEMBL1383282 & 688293 & 5.1 & 5.0072 & TST \\
\hline CHEMBL1514670 & 688293 & 7.1002 & 4.9871 & TST \\
\hline CHEMBL1505711 & 688293 & 7.0 & 4.9182 & TRN \\
\hline
\end{tabular}




\begin{tabular}{|c|c|c|c|c|}
\hline \multicolumn{5}{|c|}{ Supplemental Table S2.txt } \\
\hline CHEMBL1386323 & 688293 & 5.5 & 5.0326 & TRN \\
\hline CHEMBL1590266 & 688293 & 4.4 & 5.002 & TRN \\
\hline CHEMBL1595606 & 688293 & 4.8 & 5.0429 & TRN \\
\hline CHEMBL393136 & 688293 & 4.9 & 4.8991 & TRN \\
\hline CHEMBL1403419 & 688293 & 5.4 & 5.105 & TRN \\
\hline CHEMBL1586980 & 688293 & 4.4 & 4.9896 & TRN \\
\hline CHEMBL1423002 & 688293 & 4.5 & 4.8121 & TRN \\
\hline CHEMBL1484413 & 688293 & 5.4 & 5.1003 & TRN \\
\hline CHEMBL1320151 & 688293 & 4.4 & 4.7414 & TRN \\
\hline CHEMBL1508507 & 688293 & 4.8 & 4.9679 & TRN \\
\hline CHEMBL1353522 & 688293 & 4.4 & 5.1501 & TRN \\
\hline CHEMBL1348792 & 688293 & 4.5 & 4.9887 & TRN \\
\hline CHEMBL1368672 & 688293 & 4.5 & 5.0786 & TRN \\
\hline CHEMBL489947 & 688293 & 4.6 & 4.9423 & TRN \\
\hline CHEMBL1552623 & 688293 & 4.7 & 4.7441 & TRN \\
\hline CHEMBL1420862 & 688293 & 4.5 & 5.0997 & TRN \\
\hline CHEMBL1565793 & 688293 & 5.6 & 4.9552 & TRN \\
\hline CHEMBL1520491 & 688293 & 4.6 & 5.0361 & TRN \\
\hline CHEMBL1549407 & 688293 & 4.6 & 4.8984 & TRN \\
\hline CHEMBL1449641 & 688293 & 4.8 & 4.9304 & TRN \\
\hline CHEMBL1369732 & 688293 & 4.9 & 5.0864 & TRN \\
\hline CHEMBL1319871 & 688293 & 6.0 & 4.9325 & TRN \\
\hline CHEMBL1522425 & 688293 & 5.0 & 5.0922 & TRN \\
\hline CHEMBL1513511 & 688293 & 4.7 & 4.8174 & TRN \\
\hline CHEMBL1493715 & 688293 & 4.7 & 5.1969 & TRN \\
\hline CHEMBL279218 & 688293 & 4.6 & 4.9118 & TST \\
\hline CHEMBL1488158 & 688293 & 4.4 & 5.0991 & TRN \\
\hline CHEMBL1360064 & 688293 & 4.4 & 4.9185 & TRN \\
\hline CHEMBL1366061 & 688293 & 4.8 & 4.7974 & TRN \\
\hline CHEMBL1367112 & 688293 & 6.4 & 5.2391 & TRN \\
\hline CHEMBL1364611 & 688293 & 4.8 & 4.8243 & TRN \\
\hline CHEMBL1393543 & 688293 & 4.8 & 4.9947 & TRN \\
\hline CHEMBL1594831 & 688293 & 4.5 & 4.9276 & TRN \\
\hline CHEMBL126804 & 688293 & 5.4 & 4.9575 & TRN \\
\hline CHEMBL1443320 & 688293 & 4.5 & 5.181 & TRN \\
\hline CHEMBL1523123 & 688293 & 7.6003 & 5.1276 & TRN \\
\hline CHEMBL1480903 & 688293 & 5.0 & 4.9871 & TST \\
\hline CHEMBL1312236 & 688293 & 4.7 & 4.8699 & TRN \\
\hline CHEMBL1524890 & 688293 & 4.4 & 5.0964 & TRN \\
\hline CHEMBL1470359 & 688293 & 4.5 & 4.8719 & TRN \\
\hline CHEMBL399491 & 688293 & 5.0 & 5.1666 & TST \\
\hline CHEMBL1365057 & 688293 & 4.5 & 4.949 & TRN \\
\hline CHEMBL1330296 & 688293 & 4.4 & 4.8438 & TRN \\
\hline CHEMBL1367089 & 688293 & 4.5 & 4.9745 & TRN \\
\hline CHEMBL1337007 & 688293 & 4.4 & 5.0086 & TRN \\
\hline CHEMBL1392044 & 688293 & 5.7 & 5.0248 & TRN \\
\hline CHEMBL1602926 & 688293 & 5.1 & 4.9587 & TRN \\
\hline CHEMBL1377119 & 688293 & 6.0 & 4.9901 & TRN \\
\hline
\end{tabular}




\begin{tabular}{|c|c|c|c|c|c|}
\hline \multicolumn{6}{|c|}{ Supplemental Table S2.txt } \\
\hline CHEMBL1585433 & 688293 & 5.5 & 5.1558 & TRN & \\
\hline CHEMBL1508333 & 688293 & 4.7 & 4.9199 & TRN & \\
\hline CHEMBL1486701 & 688293 & 5.4 & 5.1496 & TRN & \\
\hline CHEMBL1529847 & 688293 & 4.5 & 5.026 & TRN & \\
\hline CHEMBL1352425 & 688293 & 4.6 & 5.1311 & TRN & \\
\hline CHEMBL1492526 & 688293 & 5.8 & 5.1006 & TRN & \\
\hline CHEMBL1486929 & 688293 & 4.6 & 4.9038 & TRN & \\
\hline CHEMBL1555238 & 688293 & 4.4 & 5.0168 & TRN & \\
\hline CHEMBL1394302 & 688293 & 4.6 & 4.9165 & TRN & \\
\hline CHEMBL1424619 & 688293 & 6.6 & 5.1565 & TRN & \\
\hline CHEMBL1439445 & 688293 & 4.7 & 5.0472 & TRN & \\
\hline CHEMBL1981840 & 688293 & 5.1 & 4.8289 & TST & \\
\hline CHEMBL1540673 & 688293 & 4.6 & 4.935 & TRN & \\
\hline CHEMBL1467836 & 688293 & 4.9 & 4.7947 & TRN & \\
\hline CHEMBL1372420 & 688293 & 6.1 & 5.211 & TST & \\
\hline CHEMBL1314582 & 688293 & 4.8 & 5.1633 & TST & \\
\hline CHEMBL1612246 & 688293 & 4.8 & 5.0424 & TRN & \\
\hline CHEMBL1347919 & 688293 & 6.5 & 5.0987 & TRN & \\
\hline CHEMBL1482270 & 688293 & 4.4 & 5.003 & TST & \\
\hline CHEMBL1325732 & 688293 & 6.4 & 4.9979 & TST & \\
\hline CHEMBL458765 & 688293 & 5.5 & 5.05399 & 9999999999 & TRN \\
\hline CHEMBL1418268 & 688293 & 4.8 & 5.0707 & TST & \\
\hline CHEMBL1450426 & 688293 & 5.1 & 5.0525 & TST & \\
\hline CHEMBL1562745 & 688293 & 4.6 & 4.9349 & TRN & \\
\hline CHEMBL1495281 & 688293 & 4.4 & 4.9145 & TRN & \\
\hline CHEMBL1411876 & 688293 & 4.5 & 4.9382 & TRN & \\
\hline CHEMBL1180 & 688293 & 4.4 & 4.9292 & TST & \\
\hline CHEMBL1592556 & 688293 & 5.1 & 4.9769 & TRN & \\
\hline CHEMBL1386370 & 688293 & 4.9 & 5.1579 & TRN & \\
\hline CHEMBL1481914 & 688293 & 4.6 & 5.0512 & TRN & \\
\hline CHEMBL1503366 & 688293 & 4.4 & 4.9342 & TRN & \\
\hline CHEMBL1600003 & 688293 & 5.1 & 4.7266 & TRN & \\
\hline CHEMBL1567411 & 688293 & 5.4 & 5.1354 & TST & \\
\hline CHEMBL1368961 & 688293 & 5.0 & 5.0862 & TRN & \\
\hline CHEMBL1465175 & 688293 & 4.8 & 5.0702 & TRN & \\
\hline CHEMBL1412131 & 688293 & 4.7 & 4.9705 & TRN & \\
\hline CHEMBL 262083 & 688293 & 4.7 & 4.9411 & TST & \\
\hline CHEMBL1484258 & 688293 & 4.6 & 5.0256 & TRN & \\
\hline CHEMBL1341031 & 688293 & 7.8996 & 5.1194 & TRN & \\
\hline CHEMBL1563204 & 688293 & 4.5 & 4.9743 & TRN & \\
\hline CHEMBL1438568 & 688293 & 4.4 & 5.1314 & TRN & \\
\hline CHEMBL1572239 & 688293 & 5.1 & 5.0455 & TST & \\
\hline CHEMBL1578064 & 688293 & 4.7 & 4.9546 & TRN & \\
\hline CHEMBL1431654 & 688293 & 4.4 & 5.0156 & TRN & \\
\hline CHEMBL1530521 & 688293 & 4.4 & 5.0812 & TRN & \\
\hline CHEMBL1603639 & 688293 & 4.5 & 5.1036 & TRN & \\
\hline CHEMBL1462394 & 688293 & 4.5 & 5.2212 & TRN & \\
\hline CHEMBL1343134 & 688293 & 4.8 & 4.8574 & TRN & \\
\hline
\end{tabular}




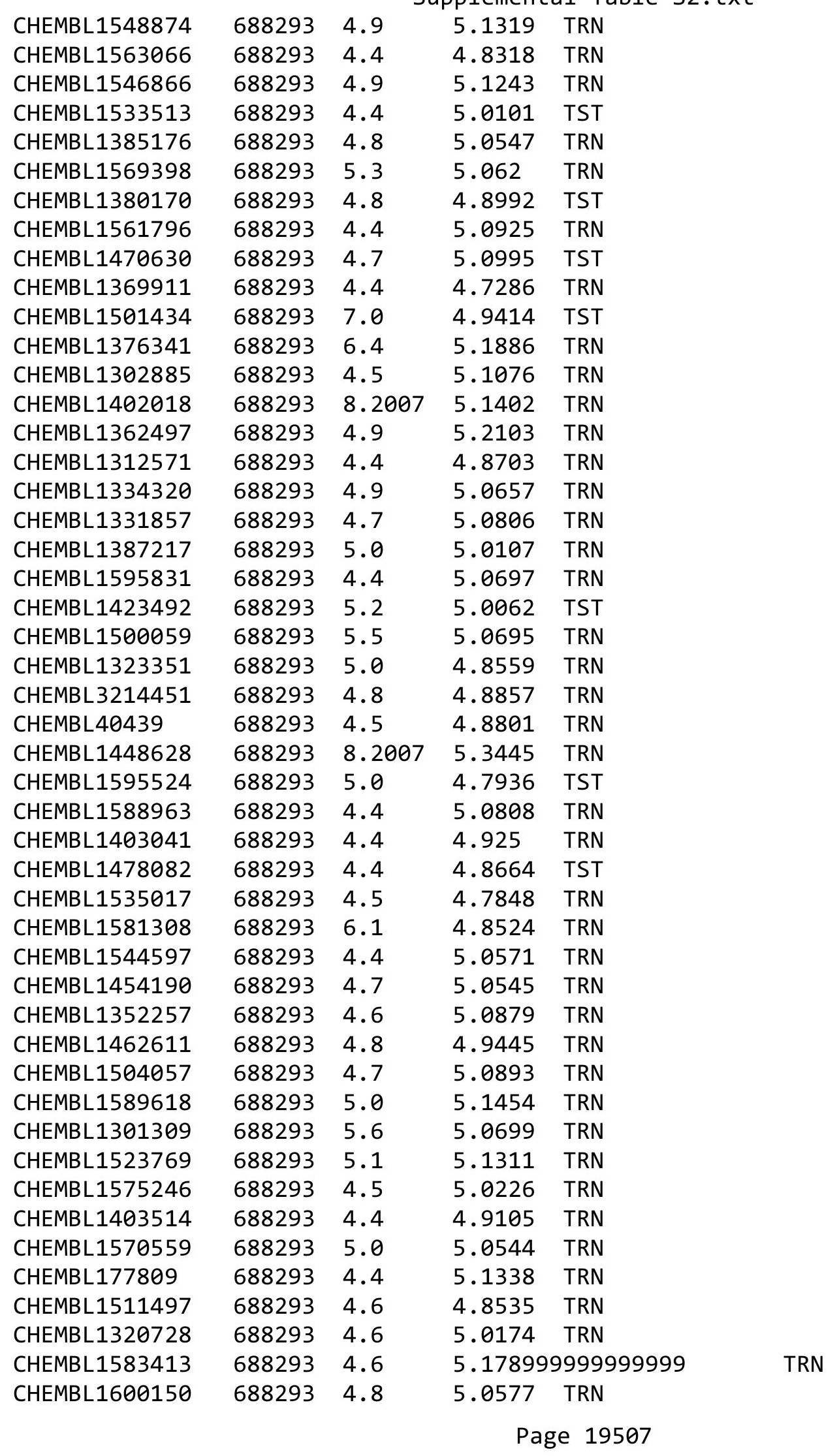




\begin{tabular}{|c|c|c|c|c|}
\hline \multicolumn{5}{|c|}{ Supplemental Table S2.txt } \\
\hline CHEMBL1608783 & 688293 & 4.5 & 4.8861 & TRN \\
\hline CHEMBL1572997 & 688293 & 4.5 & 5.075 & TRN \\
\hline CHEMBL1359463 & 688293 & 5.9 & 5.0158 & TRN \\
\hline CHEMBL1520850 & 688293 & 4.5 & 5.1054 & TST \\
\hline CHEMBL1462847 & 688293 & 4.6 & 4.9955 & TRN \\
\hline CHEMBL1364124 & 688293 & 4.5 & 5.0451 & TRN \\
\hline CHEMBL1532200 & 688293 & 4.4 & 5.0482 & TRN \\
\hline CHEMBL1316979 & 688293 & 5.2 & 4.8649 & TRN \\
\hline CHEMBL1610761 & 688293 & 7.2 & 5.0059 & TRN \\
\hline CHEMBL1569309 & 688293 & 4.9 & 4.9741 & TRN \\
\hline CHEMBL1379916 & 688293 & 4.8 & 4.9031 & TRN \\
\hline CHEMBL1610916 & 688293 & 4.8 & 4.8938 & TRN \\
\hline CHEMBL1436110 & 688293 & 5.4 & 5.0114 & TRN \\
\hline CHEMBL1469736 & 688293 & 4.6 & 4.9493 & TRN \\
\hline CHEMBL1521239 & 688293 & 5.9 & 5.112 & TRN \\
\hline CHEMBL1465045 & 688293 & 4.5 & 4.8441 & TRN \\
\hline CHEMBL1608983 & 688293 & 6.0 & 5.0024 & TRN \\
\hline CHEMBL1550802 & 688293 & 4.8 & 4.9957 & TRN \\
\hline CHEMBL1402756 & 688293 & 4.6 & 5.0876 & TRN \\
\hline CHEMBL1498744 & 688293 & 4.4 & 5.0321 & TRN \\
\hline CHEMBL1604391 & 688293 & 6.2 & 5.0086 & TRN \\
\hline CHEMBL1421509 & 688293 & 4.9 & 5.0433 & TRN \\
\hline CHEMBL1319730 & 688293 & 4.9 & 5.0008 & TRN \\
\hline CHEMBL1438039 & 688293 & 5.0 & 5.0275 & TRN \\
\hline CHEMBL1533197 & 688293 & 5.2 & 4.8843 & TRN \\
\hline CHEMBL1331493 & 688293 & 4.9 & 5.0489 & TRN \\
\hline CHEMBL1395277 & 688293 & 4.5 & 4.9442 & TRN \\
\hline CHEMBL1597687 & 688293 & 8.2007 & 5.0869 & TRN \\
\hline CHEMBL1522082 & 688293 & 4.7 & 5.1605 & TRN \\
\hline CHEMBL1370456 & 688293 & 4.7 & 4.9825 & TST \\
\hline CHEMBL1570890 & 688293 & 5.0 & 5.1269 & TRN \\
\hline CHEMBL1593707 & 688293 & 4.9 & 4.9857 & TRN \\
\hline CHEMBL1447108 & 688293 & 4.6 & 4.9663 & TRN \\
\hline CHEMBL1450349 & 688293 & 4.5 & 4.9814 & TRN \\
\hline CHEMBL1600898 & 688293 & 5.0 & 5.0445 & TRN \\
\hline CHEMBL1331486 & 688293 & 4.5 & 4.9568 & TRN \\
\hline CHEMBL1487133 & 688293 & 4.4 & 5.1301 & TRN \\
\hline CHEMBL1558864 & 688293 & 5.3 & 5.3089 & TRN \\
\hline CHEMBL1372925 & 688293 & 5.3 & 4.7696 & TRN \\
\hline CHEMBL1560515 & 688293 & 7.6003 & 4.9594 & TRN \\
\hline CHEMBL261118 & 688293 & 5.3 & 4.8315 & TRN \\
\hline CHEMBL1556783 & 688293 & 4.8 & 5.1584 & TRN \\
\hline CHEMBL1447026 & 688293 & 4.5 & 5.0527 & TRN \\
\hline CHEMBL1455378 & 688293 & 4.4 & 4.9207 & TRN \\
\hline CHEMBL1337117 & 688293 & 5.8 & 5.0392 & TRN \\
\hline CHEMBL1488216 & 688293 & 4.9 & 5.192 & TRN \\
\hline CHEMBL1419137 & 688293 & 4.4 & 5.0765 & TRN \\
\hline CHEMBL1529294 & 688293 & 4.4 & 4.9412 & TRN \\
\hline
\end{tabular}




\begin{tabular}{|c|c|c|c|c|c|}
\hline \multicolumn{6}{|c|}{ Supplemental Table S2.txt } \\
\hline CHEMBL1591956 & 688293 & 4.5 & 4.8044 & TRN & \\
\hline CHEMBL1572237 & 688293 & 4.6 & 5.0613 & TRN & \\
\hline CHEMBL303579 & 688293 & 4.6 & 5.019 & TRN & \\
\hline CHEMBL1375274 & 688293 & 4.9 & 5.0783 & TRN & \\
\hline CHEMBL1606782 & 688293 & 4.6 & 5.2023 & TRN & \\
\hline CHEMBL1426491 & 688293 & 4.4 & 5.0298 & TRN & \\
\hline CHEMBL521970 & 688293 & 5.1 & 4.7903 & TRN & \\
\hline CHEMBL1565054 & 688293 & 5.6 & 5.2056 & TRN & \\
\hline CHEMBL1343727 & 688293 & 5.3 & 5.0894 & TRN & \\
\hline CHEMBL1508575 & 688293 & 5.6 & 5.0428 & TRN & \\
\hline CHEMBL1342549 & 688293 & 4.5 & 5.1819 & TRN & \\
\hline CHEMBL1526697 & 688293 & 4.4 & 4.7404 & TRN & \\
\hline CHEMBL1470784 & 688293 & 4.8 & 4.8851 & TST & \\
\hline CHEMBL1337500 & 688293 & 5.1 & 4.9718 & TST & \\
\hline CHEMBL1319229 & 688293 & 4.4 & 5.0833 & TRN & \\
\hline CHEMBL1485559 & 688293 & 4.5 & 5.0417 & TRN & \\
\hline CHEMBL1584502 & 688293 & 5.3 & 5.095 & TRN & \\
\hline CHEMBL1408033 & 688293 & 4.5 & 5.0844 & TRN & \\
\hline CHEMBL1599850 & 688293 & 4.6 & 4.8772 & TRN & \\
\hline CHEMBL545050 & 688293 & 6.8 & 5.1228 & TST & \\
\hline CHEMBL1481740 & 688293 & 4.6 & 4.8617 & TRN & \\
\hline CHEMBL1470084 & 688293 & 6.5 & 5.1223 & TRN & \\
\hline CHEMBL1560057 & 688293 & 4.7 & 5.0674 & TRN & \\
\hline CHEMBL1410677 & 688293 & 5.1 & 4.9994 & TRN & \\
\hline CHEMBL3198875 & 688293 & 4.8 & 5.1347 & TRN & \\
\hline CHEMBL1524490 & 688293 & 4.7 & 5.2063 & TRN & \\
\hline CHEMBL1308779 & 688293 & 4.6 & 4.9237 & TRN & \\
\hline CHEMBL1328771 & 688293 & 5.4 & 5.11600 & 00000000005 & TRN \\
\hline CHEMBL1316056 & 688293 & 4.5 & 4.705 & TRN & \\
\hline CHEMBL1531713 & 688293 & 4.4 & 5.0941 & TRN & \\
\hline CHEMBL1595194 & 688293 & 4.5 & 4.7757 & TRN & \\
\hline CHEMBL1453820 & 688293 & 5.0 & 4.9895 & TRN & \\
\hline CHEMBL1536423 & 688293 & 4.6 & 5.1353 & TST & \\
\hline CHEMBL1453655 & 688293 & 4.5 & 4.7086 & TRN & \\
\hline CHEMBL1416386 & 688293 & 4.9 & 5.1533 & TRN & \\
\hline CHEMBL1345810 & 688293 & 4.6 & 5.0467 & TRN & \\
\hline CHEMBL1611005 & 688293 & 7.699 & 5.0079 & TRN & \\
\hline CHEMBL1603965 & 688293 & 7.6003 & 5.1118 & TRN & \\
\hline CHEMBL1539969 & 688293 & 4.4 & 4.9007 & TRN & \\
\hline CHEMBL1565737 & 688293 & 5.0 & 4.7532 & TRN & \\
\hline CHEMBL1606020 & 688293 & 5.4 & 4.9204 & TRN & \\
\hline CHEMBL1401224 & 688293 & 4.9 & 5.15600 & 0000000001 & TRN \\
\hline CHEMBL1559880 & 688293 & 4.7 & 5.0324 & TRN & \\
\hline CHEMBL576349 & 688293 & 4.9 & 4.8768 & TST & \\
\hline CHEMBL1543363 & 688293 & 4.9 & 4.9193 & TST & \\
\hline CHEMBL1340657 & 688293 & 4.4 & 4.9394 & TRN & \\
\hline CHEMBL1481715 & 688293 & 6.8 & 5.1135 & TRN & \\
\hline CHEMBL1413890 & 688293 & 4.7 & 4.953 & TRN & \\
\hline
\end{tabular}




\begin{tabular}{|c|c|c|c|c|c|}
\hline \multicolumn{6}{|c|}{ Supplemental Table S2.txt } \\
\hline CHEMBL1411311 & 688293 & 6.1 & 4.8973 & TRN & \\
\hline CHEMBL1498314 & 688293 & 4.9 & 5.1063 & TRN & \\
\hline CHEMBL1390280 & 688293 & 4.7 & 5.0743 & TRN & \\
\hline CHEMBL1442663 & 688293 & 5.6 & 4.9464 & TRN & \\
\hline CHEMBL1547853 & 688293 & 4.9 & 4.9063 & TRN & \\
\hline CHEMBL1407141 & 688293 & 4.8 & 5.0281 & TRN & \\
\hline CHEMBL1401987 & 688293 & 4.5 & 5.0426 & TRN & \\
\hline CHEMBL1581434 & 688293 & 5.1 & 4.9969 & TST & \\
\hline CHEMBL1459193 & 688293 & 5.6 & 5.2084 & TRN & \\
\hline CHEMBL1420155 & 688293 & 4.7 & 4.9752 & TRN & \\
\hline CHEMBL1448441 & 688293 & 7.8996 & 5.2767 & TRN & \\
\hline CHEMBL1348621 & 688293 & 5.5 & 5.0678 & TRN & \\
\hline CHEMBL1454427 & 688293 & 4.5 & 4.9027 & TRN & \\
\hline CHEMBL1358007 & 688293 & 6.7001 & 4.9489 & TST & \\
\hline CHEMBL1580438 & 688293 & 5.0 & 5.1636 & TRN & \\
\hline CHEMBL1510959 & 688293 & 4.4 & 5.1136 & TST & \\
\hline CHEMBL527271 & 688293 & 4.5 & 4.842 & TRN & \\
\hline CHEMBL1490845 & 688293 & 4.4 & 4.917 & TRN & \\
\hline CHEMBL1586817 & 688293 & 4.4 & 4.8973 & TRN & \\
\hline CHEMBL382628 & 688293 & 4.7 & 5.0581 & TST & \\
\hline CHEMBL1534466 & 688293 & 4.6 & 5.0459 & TRN & \\
\hline CHEMBL1256910 & 688293 & 6.0 & 5.0226 & TRN & \\
\hline CHEMBL1349706 & 688293 & 4.5 & 4.9632 & TRN & \\
\hline CHEMBL1445578 & 688293 & 4.9 & 4.7216 & TRN & \\
\hline CHEMBL1551331 & 688293 & 5.0 & 5.0312 & TRN & \\
\hline CHEMBL1426773 & 688293 & 5.1 & 5.032 & TRN & \\
\hline CHEMBL1506825 & 688293 & 4.4 & 4.9161 & TRN & \\
\hline CHEMBL1498407 & 688293 & 4.5 & 5.1939 & TRN & \\
\hline CHEMBL1517432 & 688293 & 5.1 & 5.069 & TRN & \\
\hline CHEMBL1576107 & 688293 & 4.8 & 4.7641 & TRN & \\
\hline CHEMBL1574303 & 688293 & 4.6 & 5.0021 & TRN & \\
\hline CHEMBL1373854 & 688293 & 4.4 & 5.0398 & TRN & \\
\hline CHEMBL530361 & 688293 & 4.8 & 4.8673 & TRN & \\
\hline CHEMBL258877 & 688293 & 8.2007 & 5.0886 & TST & \\
\hline CHEMBL1542576 & 688293 & 4.4 & 5.0352 & TRN & \\
\hline CHEMBL1444124 & 688293 & 4.5 & 4.7989 & TRN & \\
\hline CHEMBL1506015 & 688293 & 5.7 & 4.9617 & TRN & \\
\hline CHEMBL1485770 & 688293 & 5.5 & 4.9172 & TRN & \\
\hline CHEMBL1300185 & 688293 & 4.6 & $5.0360 e$ & 00000000005 & TRN \\
\hline CHEMBL1329329 & 688293 & 4.6 & 5.1905 & TRN & \\
\hline CHEMBL1359715 & 688293 & 5.4 & 5.0149 & TRN & \\
\hline CHEMBL1380156 & 688293 & 5.0 & 5.0114 & TRN & \\
\hline CHEMBL26320 & 688293 & 6.0 & 5.0012 & TRN & \\
\hline CHEMBL1608722 & 688293 & 4.4 & 4.955 & TST & \\
\hline CHEMBL1527714 & 688293 & 5.0 & 5.1217 & TRN & \\
\hline CHEMBL1580789 & 688293 & 4.8 & 4.9641 & TST & \\
\hline CHEMBL1494490 & 688293 & 4.4 & 5.0584 & TRN & \\
\hline CHEMBL1579020 & 688293 & 4.6 & 4.9924 & TST & \\
\hline
\end{tabular}




\begin{tabular}{|c|c|c|c|c|}
\hline \multicolumn{5}{|c|}{ Supplemental Table S2.txt } \\
\hline CHEMBL1501974 & 688293 & 5.7 & 4.9644 & TRN \\
\hline CHEMBL1515221 & 688293 & 5.0 & 4.87 & TRN \\
\hline CHEMBL1558254 & 688293 & 4.5 & 5.2163 & TST \\
\hline CHEMBL1518067 & 688293 & 4.7 & 4.8297 & TRN \\
\hline CHEMBL1391613 & 688293 & 4.6 & 5.1067 & TRN \\
\hline CHEMBL1307610 & 688293 & 4.7 & 5.0919 & TRN \\
\hline CHEMBL1318989 & 688293 & 4.6 & 4.8179 & TRN \\
\hline CHEMBL1429402 & 688293 & 4.9 & 5.2885 & TST \\
\hline CHEMBL6291 & 688293 & 5.7 & 5.0844 & TST \\
\hline CHEMBL1548693 & 688293 & 5.2 & 4.9808 & TRN \\
\hline CHEMBL1406070 & 688293 & 4.9 & 5.0311 & TRN \\
\hline CHEMBL1342128 & 688293 & 4.4 & 4.9613 & TRN \\
\hline CHEMBL1376797 & 688293 & 5.2 & 5.1699 & TRN \\
\hline CHEMBL1470045 & 688293 & 7.0 & 5.0472 & TRN \\
\hline CHEMBL1477714 & 688293 & 5.0 & 4.8704 & TRN \\
\hline CHEMBL1419668 & 688293 & 4.9 & 5.1494 & TST \\
\hline CHEMBL1439866 & 688293 & 4.9 & 5.1288 & TST \\
\hline CHEMBL1339977 & 688293 & 5.1 & 5.1205 & TRN \\
\hline CHEMBL1482184 & 688293 & 4.4 & 5.0711 & TST \\
\hline CHEMBL1560802 & 688293 & 4.4 & 5.0089 & TRN \\
\hline CHEMBL1497794 & 688293 & 5.9 & 5.2163 & TRN \\
\hline CHEMBL1483537 & 688293 & 5.5 & 4.8905 & TRN \\
\hline CHEMBL1601545 & 688293 & 4.8 & 5.0302 & TRN \\
\hline CHEMBL1546938 & 688293 & 5.1 & 4.9581 & TST \\
\hline CHEMBL167997 & 688293 & 4.3 & 5.0702 & TRN \\
\hline CHEMBL1595142 & 688293 & 5.5 & 4.8899 & TRN \\
\hline CHEMBL1558616 & 688293 & 5.5 & 5.1369 & TRN \\
\hline CHEMBL1379708 & 688293 & 4.8 & 4.987 & TRN \\
\hline CHEMBL1411246 & 688293 & 8.8861 & 5.1526 & TST \\
\hline CHEMBL1371143 & 688293 & 4.4 & 5.0236 & TRN \\
\hline CHEMBL1550158 & 688293 & 5.5 & 5.0294 & TST \\
\hline CHEMBL1390047 & 688293 & 4.8 & 4.975 & TRN \\
\hline CHEMBL1503206 & 688293 & 4.7 & 4.9814 & TRN \\
\hline CHEMBL1428466 & 688293 & 4.8 & 4.8708 & TRN \\
\hline CHEMBL1390050 & 688293 & 4.6 & 5.0393 & TRN \\
\hline CHEMBL1458562 & 688293 & 4.6 & 5.1132 & TRN \\
\hline CHEMBL1557386 & 688293 & 4.8 & 4.9295 & TRN \\
\hline CHEMBL1576787 & 688293 & 4.4 & 4.7722 & TRN \\
\hline CHEMBL11348 & 688293 & 6.8 & 4.9254 & TRN \\
\hline CHEMBL1571520 & 688293 & 4.4 & 5.1197 & TST \\
\hline CHEMBL1373893 & 688293 & 5.7 & 4.9556 & TST \\
\hline CHEMBL1318480 & 688293 & 4.6 & 4.9013 & TRN \\
\hline CHEMBL1434715 & 688293 & 4.6 & 4.7745 & TRN \\
\hline CHEMBL1379272 & 688293 & 4.6 & 5.2356 & TRN \\
\hline CHEMBL1408956 & 688293 & 5.1 & 4.9502 & TRN \\
\hline CHEMBL1572750 & 688293 & 4.4 & 4.9751 & TRN \\
\hline CHEMBL1375958 & 688293 & 4.8 & 4.834 & TRN \\
\hline CHEMBL1380744 & 688293 & 5.9 & 4.8306 & TST \\
\hline
\end{tabular}




\begin{tabular}{|c|c|c|c|c|c|}
\hline \multirow[b]{2}{*}{ CHEMBL1454922 } & \multirow[b]{2}{*}{688293} & \\
\hline & & 4.9 & 4.8185 & TRN & \\
\hline CHEMBL1593765 & 688293 & 4.6 & 4.9672 & TRN & \\
\hline CHEMBL582355 & 688293 & 4.5 & 4.7924 & TST & \\
\hline CHEMBL1449350 & 688293 & 4.5 & 4.796 & TRN & \\
\hline CHEMBL1529858 & 688293 & 5.2 & 5.1897 & TST & \\
\hline CHEMBL1502414 & 688293 & 6.1 & 5.1848 & TRN & \\
\hline CHEMBL1413201 & 688293 & 5.5 & 5.1322 & TRN & \\
\hline CHEMBL1579893 & 688293 & 4.6 & 5.0026 & TST & \\
\hline CHEMBL596271 & 688293 & 4.6 & 4.7925 & TRN & \\
\hline CHEMBL1411146 & 688293 & 4.4 & 4.7506 & TRN & \\
\hline CHEMBL1626274 & 688293 & 4.6 & 5.0886 & TST & \\
\hline CHEMBL1539788 & 688293 & 4.4 & 4.8764 & TRN & \\
\hline CHEMBL1560928 & 688293 & 6.3 & 5.1088 & TRN & \\
\hline CHEMBL1574475 & 688293 & 6.0 & 5.3197 & TRN & \\
\hline CHEMBL1340945 & 688293 & 4.5 & 5.0926 & TRN & \\
\hline CHEMBL54909 & 688293 & 6.0 & 4.9681 & TRN & \\
\hline CHEMBL1410898 & 688293 & 4.5 & 5.0209 & TRN & \\
\hline CHEMBL1602194 & 688293 & 5.1 & 5.0169 & TRN & \\
\hline CHEMBL1331522 & 688293 & 4.6 & 5.0384 & TRN & \\
\hline CHEMBL1415409 & 688293 & 4.6 & 4.9787 & TRN & \\
\hline CHEMBL1354915 & 688293 & 4.6 & 5.0181 & TRN & \\
\hline CHEMBL1376980 & 688293 & 6.3 & 5.0447 & TST & \\
\hline CHEMBL1537729 & 688293 & 4.8 & 5.2017 & TRN & \\
\hline CHEMBL1373287 & 688293 & 5.7 & 4.8857 & TRN & \\
\hline CHEMBL1515246 & 688293 & 4.6 & 4.8161 & TRN & \\
\hline CHEMBL1367217 & 688293 & 4.9 & 4.9192 & TRN & \\
\hline CHEMBL1417648 & 688293 & 6.1 & 4.977 & TRN & \\
\hline CHEMBL1459923 & 688293 & 6.6 & 4.941 & TRN & \\
\hline CHEMBL1508148 & 688293 & 5.0 & $5.0680 e$ & 00000000005 & TRN \\
\hline CHEMBL1564694 & 688293 & 4.4 & 4.9532 & TRN & \\
\hline CHEMBL1321322 & 688293 & 4.4 & 5.0185 & TST & \\
\hline CHEMBL1406203 & 688293 & 4.8 & 4.9879 & TRN & \\
\hline CHEMBL1359771 & 688293 & 5.9 & 4.9909 & TRN & \\
\hline CHEMBL1549529 & 688293 & 4.6 & 4.8874 & TRN & \\
\hline CHEMBL1418558 & 688293 & 4.9 & 5.0896 & TST & \\
\hline CHEMBL1601910 & 688293 & 4.5 & 5.0151 & TRN & \\
\hline CHEMBL1509090 & 688293 & 5.1 & 5.0719 & TRN & \\
\hline CHEMBL1407907 & 688293 & 4.4 & 4.8815 & TRN & \\
\hline CHEMBL1328426 & 688293 & 6.4 & 5.0219 & TRN & \\
\hline CHEMBL1533766 & 688293 & 4.8 & 4.9974 & TRN & \\
\hline CHEMBL1518739 & 688293 & 5.8 & 5.0764 & TRN & \\
\hline CHEMBL1466443 & 688293 & 5.1 & 4.8909 & TRN & \\
\hline CHEMBL1601007 & 688293 & 5.1 & 4.9136 & TRN & \\
\hline CHEMBL1596965 & 688293 & 4.5 & 4.6664 & TRN & \\
\hline CHEMBL1497693 & 688293 & 4.6 & 4.852 & TRN & \\
\hline CHEMBL1309056 & 688293 & 4.6 & 5.047 & TRN & \\
\hline CHEMBL1455732 & 688293 & 4.5 & 4.9319 & TST & \\
\hline CHEMBL1495290 & 688293 & 5.0 & 4.9231 & TST & \\
\hline & & & & 19512 & \\
\hline
\end{tabular}




\begin{tabular}{|c|c|c|c|c|}
\hline \multicolumn{5}{|c|}{ Supplemental Table S2.txt } \\
\hline CHEMBL1374111 & 688293 & 4.6 & 4.9463 & TRN \\
\hline CHEMBL327035 & 688293 & 5.5 & 4.9893 & TRN \\
\hline CHEMBL8320 & 688293 & 4.6 & 5.051 & TST \\
\hline CHEMBL1522275 & 688293 & 5.3 & 5.0191 & TRN \\
\hline CHEMBL1490371 & 688293 & 8.301 & 5.2174 & TRN \\
\hline CHEMBL1477858 & 688293 & 4.4 & 5.0525 & TRN \\
\hline CHEMBL1453130 & 688293 & 8.0 & 5.1755 & TRN \\
\hline CHEMBL601764 & 688293 & 4.7 & 4.9683 & TRN \\
\hline CHEMBL1330662 & 688293 & 4.8 & 5.0744 & TRN \\
\hline CHEMBL3192808 & 688293 & 4.4 & 4.9769 & TRN \\
\hline CHEMBL1364576 & 688293 & 4.7 & 5.0614 & TRN \\
\hline CHEMBL1478519 & 688293 & 4.4 & 5.0493 & TRN \\
\hline CHEMBL274619 & 688293 & 4.6 & 5.016 & TST \\
\hline CHEMBL1376723 & 688293 & 4.6 & 4.9421 & TST \\
\hline CHEMBL1381306 & 688293 & 4.6 & 5.0273 & TRN \\
\hline CHEMBL380071 & 688293 & 4.6 & 4.8571 & TRN \\
\hline CHEMBL1417180 & 688293 & 4.6 & 4.8667 & TRN \\
\hline CHEMBL111545 & 688293 & 4.7 & 4.9576 & TST \\
\hline CHEMBL1563855 & 688293 & 5.5 & 4.9455 & TRN \\
\hline CHEMBL1366408 & 688293 & 5.4 & 5.0757 & TST \\
\hline CHEMBL1464386 & 688293 & 5.0 & 4.8113 & TRN \\
\hline CHEMBL1589137 & 688293 & 4.4 & 4.9343 & TRN \\
\hline CHEMBL1300327 & 688293 & 4.9 & 4.9622 & TRN \\
\hline CHEMBL1412354 & 688293 & 4.8 & 4.857 & TST \\
\hline CHEMBL1348815 & 688293 & 5.3 & 5.2753 & TRN \\
\hline CHEMBL1539125 & 688293 & 4.4 & 4.9106 & TST \\
\hline CHEMBL1256390 & 688293 & 8.4949 & 5.0552 & TST \\
\hline CHEMBL1485221 & 688293 & 4.7 & 5.0344 & TRN \\
\hline CHEMBL375107 & 688293 & 4.7 & 5.1122 & TST \\
\hline CHEMBL1407908 & 688293 & 4.5 & 5.1043 & TRN \\
\hline CHEMBL1566006 & 688293 & 4.8 & 5.0509 & TRN \\
\hline CHEMBL258893 & 688293 & 4.5 & 4.9607 & TST \\
\hline CHEMBL76904 & 688293 & 4.4 & 4.9103 & TRN \\
\hline CHEMBL1415559 & 688293 & 4.6 & 5.1832 & TRN \\
\hline CHEMBL1256814 & 688293 & 4.5 & 4.8839 & TRN \\
\hline CHEMBL1313986 & 688293 & 4.4 & 4.9583 & TRN \\
\hline CHEMBL1408418 & 688293 & 4.8 & 5.0613 & TRN \\
\hline CHEMBL1599066 & 688293 & 4.9 & 5.0947 & TRN \\
\hline CHEMBL1333692 & 688293 & 4.5 & 4.9957 & TRN \\
\hline CHEMBL1333227 & 688293 & 5.1 & 5.1379 & TRN \\
\hline CHEMBL1444829 & 688293 & 4.8 & 4.8179 & TRN \\
\hline CHEMBL1413023 & 688293 & 4.4 & 4.9536 & TRN \\
\hline CHEMBL1343554 & 688293 & 4.5 & 5.1247 & TRN \\
\hline CHEMBL1411783 & 688293 & 4.4 & 4.9148 & TST \\
\hline CHEMBL1468342 & 688293 & 5.9 & 4.9841 & TRN \\
\hline CHEMBL1588208 & 688293 & 4.7 & 5.1707 & TRN \\
\hline CHEMBL1367116 & 688293 & 6.7001 & 5.2157 & TRN \\
\hline CHEMBL1552051 & 688293 & 4.4 & 4.8321 & TRN \\
\hline
\end{tabular}




\begin{tabular}{|c|c|c|c|c|c|}
\hline \multicolumn{6}{|c|}{ Supplemental Table S2.txt } \\
\hline CHEMBL1377654 & 688293 & 4.5 & 5.0403 & TST & \\
\hline CHEMBL2369279 & 688293 & 4.9 & 5.0708 & TRN & \\
\hline CHEMBL1428843 & 688293 & 4.9 & 4.843 & TRN & \\
\hline CHEMBL508779 & 688293 & 4.4 & 5.0054 & TST & \\
\hline CHEMBL1336572 & 688293 & 4.8 & 4.82100 & $\partial 000000001$ & TRN \\
\hline CHEMBL1418959 & 688293 & 4.4 & 5.101 & TRN & \\
\hline CHEMBL1309697 & 688293 & 4.6 & 4.9642 & TST & \\
\hline CHEMBL1503577 & 688293 & 4.6 & 5.1886 & TRN & \\
\hline CHEMBL1321563 & 688293 & 4.7 & 4.8555 & TRN & \\
\hline CHEMBL1582184 & 688293 & 4.5 & 5.023 & TRN & \\
\hline CHEMBL1562420 & 688293 & 4.7 & 4.978 & TST & \\
\hline CHEMBL1707911 & 688293 & 8.1024 & 5.087 & TST & \\
\hline CHEMBL1388468 & 688293 & 4.6 & 5.0962 & TRN & \\
\hline CHEMBL1437133 & 688293 & 4.9 & 5.0497 & TRN & \\
\hline CHEMBL1519914 & 688293 & 7.5003 & 4.9559 & TRN & \\
\hline CHEMBL1409062 & 688293 & 4.6 & 5.1414 & TRN & \\
\hline CHEMBL1583427 & 688293 & 4.8 & 4.9555 & TRN & \\
\hline CHEMBL1454947 & 688293 & 4.8 & 5.0593 & TRN & \\
\hline CHEMBL1330692 & 688293 & 4.7 & 4.9046 & TRN & \\
\hline CHEMBL1420523 & 688293 & 4.7 & 5.007 & TRN & \\
\hline CHEMBL1518892 & 688293 & 4.5 & 4.8669 & TRN & \\
\hline CHEMBL1590909 & 688293 & 5.3 & 4.705 & TRN & \\
\hline CHEMBL1339652 & 688293 & 4.4 & 5.0416 & TRN & \\
\hline CHEMBL1492301 & 688293 & 5.4 & 5.072 & TRN & \\
\hline CHEMBL1495893 & 688293 & 9.0 & 4.9862 & TST & \\
\hline CHEMBL3196267 & 688293 & 4.8 & 4.9281 & TST & \\
\hline CHEMBL1396407 & 688293 & 4.9 & 4.7231 & TRN & \\
\hline CHEMBL1337829 & 688293 & 4.8 & 5.0456 & TRN & \\
\hline CHEMBL1490807 & 688293 & 4.6 & 4.9141 & TRN & \\
\hline CHEMBL1330820 & 688293 & 4.7 & 5.1003 & TRN & \\
\hline CHEMBL1526492 & 688293 & 4.6 & 5.1611 & TRN & \\
\hline CHEMBL1605875 & 688293 & 4.6 & 4.9435 & TRN & \\
\hline CHEMBL1459795 & 688293 & 6.0 & 4.9304 & TRN & \\
\hline CHEMBL1544070 & 688293 & 8.301 & 5.0317 & TRN & \\
\hline CHEMBL1579564 & 688293 & 4.7 & 4.9934 & TST & \\
\hline CHEMBL1520424 & 688293 & 4.8 & 4.9021 & TRN & \\
\hline CHEMBL1485898 & 688293 & 6.0 & 5.0229 & TRN & \\
\hline CHEMBL1553322 & 688293 & 5.5 & 4.8597 & TRN & \\
\hline CHEMBL1562740 & 688293 & 4.4 & 5.1037 & TRN & \\
\hline CHEMBL122701 & 688293 & 4.6 & 4.8774 & TRN & \\
\hline CHEMBL1463305 & 688293 & 4.7 & 5.01 & TST & \\
\hline CHEMBL1441145 & 688293 & 4.8 & 5.09 & TRN & \\
\hline CHEMBL1309339 & 688293 & 4.9 & 4.9381 & TRN & \\
\hline CHEMBL1393450 & 688293 & 4.8 & 5.0621 & TRN & \\
\hline CHEMBL1400183 & 688293 & 4.4 & 5.1987 & TRN & \\
\hline CHEMBL1482825 & 688293 & 4.7 & 5.1923 & TST & \\
\hline CHEMBL1306845 & 688293 & 5.0 & 5.1119 & TRN & \\
\hline CHEMBL1413787 & 688293 & 4.8 & 4.9439 & TST & \\
\hline
\end{tabular}




\begin{tabular}{|c|c|c|c|c|}
\hline \multicolumn{5}{|c|}{ Supplemental Table S2.txt } \\
\hline CHEMBL1570056 & 688293 & 4.6 & 5.2535 & TRN \\
\hline CHEMBL1402956 & 688293 & 4.4 & 5.0386 & TST \\
\hline CHEMBL510009 & 688293 & 5.5 & 4.7076 & TRN \\
\hline CHEMBL1440645 & 688293 & 4.4 & 5.21899 & 9999999999 \\
\hline CHEMBL1602357 & 688293 & 4.5 & 4.9443 & TRN \\
\hline CHEMBL1340596 & 688293 & 7.4001 & 5.0904 & TRN \\
\hline CHEMBL1462584 & 688293 & 4.4 & 4.8321 & TRN \\
\hline CHEMBL1444092 & 688293 & 4.8 & 5.0946 & TRN \\
\hline CHEMBL1492974 & 688293 & 4.5 & 5.3009 & TRN \\
\hline CHEMBL1256759 & 688293 & 5.3 & 5.0582 & TRN \\
\hline CHEMBL1394135 & 688293 & 4.4 & 4.8852 & TRN \\
\hline CHEMBL1531295 & 688293 & 4.9 & 5.0639 & TRN \\
\hline CHEMBL1491545 & 688293 & 5.2 & 4.842 & TRN \\
\hline CHEMBL1470303 & 688293 & 4.6 & 4.8561 & TRN \\
\hline CHEMBL1591815 & 688293 & 5.1 & 4.82 & TRN \\
\hline CHEMBL10284 & 688293 & 6.6 & 4.9749 & TST \\
\hline CHEMBL1591731 & 688293 & 6.0 & 5.1617 & TST \\
\hline CHEMBL1460712 & 688293 & 4.4 & 5.0295 & TRN \\
\hline CHEMBL1442312 & 688293 & 4.7 & 5.1532 & TRN \\
\hline CHEMBL1520591 & 688293 & 4.4 & 5.0976 & TRN \\
\hline CHEMBL1606581 & 688293 & 4.4 & 5.1336 & TRN \\
\hline CHEMBL409024 & 688293 & 4.5 & 4.9172 & TST \\
\hline CHEMBL1511483 & 688293 & 5.7 & 5.146 & TRN \\
\hline CHEMBL3190186 & 688293 & 4.8 & 5.0211 & TST \\
\hline CHEMBL1360154 & 688293 & 5.7 & 5.0316 & TRN \\
\hline CHEMBL1458025 & 688293 & 4.7 & 5.0368 & TRN \\
\hline CHEMBL1328934 & 688293 & 4.4 & 5.0198 & TRN \\
\hline CHEMBL1495849 & 688293 & 6.3 & 4.996 & TRN \\
\hline CHEMBL1369413 & 688293 & 4.6 & 5.1581 & TRN \\
\hline CHEMBL1385622 & 688293 & 7.2 & 4.8827 & TRN \\
\hline CHEMBL1334784 & 688293 & 4.4 & 4.9197 & TST \\
\hline CHEMBL1342852 & 688293 & 4.7 & 4.8593 & TST \\
\hline CHEMBL3210299 & 688293 & 4.7 & 4.9931 & TRN \\
\hline CHEMBL1349437 & 688293 & 4.6 & 5.006 & TRN \\
\hline CHEMBL1579035 & 688293 & 4.4 & 5.114 & TRN \\
\hline CHEMBL36296 & 688293 & 4.4 & 4.9717 & TRN \\
\hline CHEMBL1603476 & 688293 & 5.2 & 4.8101 & TRN \\
\hline CHEMBL1493884 & 688293 & 4.4 & 5.1345 & TRN \\
\hline CHEMBL1594890 & 688293 & 4.4 & 5.0081 & TRN \\
\hline CHEMBL1320485 & 688293 & 6.9 & 5.0445 & TRN \\
\hline CHEMBL1452646 & 688293 & 4.7 & 4.8894 & TRN \\
\hline CHEMBL1323076 & 688293 & 4.7 & 4.8478 & TRN \\
\hline CHEMBL1495244 & 688293 & 4.6 & 5.0805 & TRN \\
\hline CHEMBL465843 & 688293 & 4.6 & 5.1376 & TST \\
\hline CHEMBL1319648 & 688293 & 4.7 & 5.0528 & TST \\
\hline CHEMBL1489704 & 688293 & 6.0 & 5.1208 & TRN \\
\hline CHEMBL1550596 & 688293 & 4.4 & 4.9895 & TRN \\
\hline CHEMBL1386118 & 688293 & 4.8 & 4.9727 & TRN \\
\hline
\end{tabular}




\begin{tabular}{|c|c|c|c|c|}
\hline \multicolumn{5}{|c|}{ Supplemental Table S2.txt } \\
\hline CHEMBL1493477 & 688293 & 8.2007 & 5.0653 & TRN \\
\hline CHEMBL1372193 & 688293 & 5.1 & 5.0862 & TRN \\
\hline CHEMBL275626 & 688293 & 5.3 & 5.0974 & TST \\
\hline CHEMBL1483908 & 688293 & 4.8 & 4.978 & TRN \\
\hline CHEMBL1572747 & 688293 & 4.6 & 4.8868 & TRN \\
\hline CHEMBL1299509 & 688293 & 4.8 & 5.0447 & TRN \\
\hline CHEMBL1595576 & 688293 & 5.0 & 4.7402 & TRN \\
\hline CHEMBL1302980 & 688293 & 4.6 & 5.0897 & TRN \\
\hline CHEMBL1419791 & 688293 & 4.5 & 4.9423 & TRN \\
\hline CHEMBL1605382 & 688293 & 6.7001 & 5.022 & TRN \\
\hline CHEMBL1543606 & 688293 & 4.5 & 5.0995 & TRN \\
\hline CHEMBL1302847 & 688293 & 4.4 & 5.0772 & TST \\
\hline CHEMBL1382628 & 688293 & 4.4 & 4.9741 & TRN \\
\hline CHEMBL1455644 & 688293 & 4.8 & 4.8575 & TRN \\
\hline CHEMBL1399081 & 688293 & 6.5 & 5.1136 & TRN \\
\hline CHEMBL 1466690 & 688293 & 4.6 & 5.1719 & TRN \\
\hline CHEMBL1486481 & 688293 & 4.5 & 5.1443 & TRN \\
\hline CHEMBL516075 & 688293 & 4.6 & 4.6289 & TRN \\
\hline CHEMBL1378098 & 688293 & 4.4 & 4.923 & TRN \\
\hline CHEMBL1460378 & 688293 & 4.5 & 5.0081 & TRN \\
\hline CHEMBL 1459256 & 688293 & 4.7 & 5.2104 & TRN \\
\hline CHEMBL1346587 & 688293 & 5.3 & 4.9705 & TRN \\
\hline CHEMBL 3191344 & 688293 & 4.6 & 5.0405 & TRN \\
\hline CHEMBL1462456 & 688293 & 4.6 & 4.9646 & TRN \\
\hline CHEMBL1368661 & 688293 & 5.3 & 5.0148 & TRN \\
\hline CHEMBL1570699 & 688293 & 4.4 & 5.0214 & TRN \\
\hline CHEMBL1532840 & 688293 & 5.6 & 4.9689 & TRN \\
\hline CHEMBL268868 & 688293 & 4.5 & 4.9258 & TRN \\
\hline CHEMBL1450205 & 688293 & 4.6 & 4.8331 & TRN \\
\hline CHEMBL1302023 & 688293 & 5.6 & 4.7766 & TRN \\
\hline CHEMBL 1455628 & 688293 & 4.4 & 4.8788 & TRN \\
\hline CHEMBL512908 & 688293 & 5.1 & 4.9576 & TST \\
\hline CHEMBL1402202 & 688293 & 4.6 & 5.0479 & TRN \\
\hline CHEMBL1430160 & 688293 & 6.0 & 4.9429 & TRN \\
\hline CHEMBL1442228 & 688293 & 4.6 & 4.9363 & TRN \\
\hline CHEMBL1985765 & 688293 & 4.8 & 5.0534 & TST \\
\hline CHEMBL1495725 & 688293 & 5.0 & 5.0732 & TRN \\
\hline CHEMBL166050 & 688293 & 4.6 & 4.8163 & TST \\
\hline CHEMBL1603542 & 688293 & 4.4 & 5.0052 & TRN \\
\hline CHEMBL1604504 & 688293 & 4.5 & 4.9047 & TRN \\
\hline CHEMBL1557048 & 688293 & 5.2 & 4.8654 & TRN \\
\hline CHEMBL1537158 & 688293 & 4.6 & 5.1809 & TRN \\
\hline CHEMBL3197885 & 688293 & 4.7 & 4.9311 & TST \\
\hline CHEMBL1302376 & 688293 & 4.7 & 5.0294 & TRN \\
\hline CHEMBL1481000 & 688293 & 4.4 & 4.9286 & TRN \\
\hline CHEMBL1337235 & 688293 & 5.6 & 5.0224 & TRN \\
\hline CHEMBL1485469 & 688293 & 4.9 & 5.1302 & TRN \\
\hline CHEMBL1340038 & 688293 & 4.7 & 5.0286 & TRN \\
\hline
\end{tabular}




\begin{tabular}{|c|c|c|c|c|}
\hline & & & 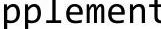 & al Ta \\
\hline CHEMBL1572127 & 688293 & 4.9 & 5.0135 & TRN \\
\hline CHEMBL1584488 & 688293 & 4.5 & 5.061 & TRN \\
\hline CHEMBL1322757 & 688293 & 4.8 & 4.7155 & TRN \\
\hline CHEMBL1381854 & 688293 & 4.8 & 4.9275 & TST \\
\hline CHEMBL1439981 & 688293 & 4.8 & 4.8731 & TRN \\
\hline CHEMBL1421442 & 688293 & 6.0 & 4.962 & TRN \\
\hline CHEMBL1337579 & 688293 & 4.5 & 5.0945 & TRN \\
\hline CHEMBL1543644 & 688293 & 4.7 & 4.8256 & TRN \\
\hline CHEMBL1310211 & 688293 & 5.0 & 4.845 & TRN \\
\hline CHEMBL2373651 & 688293 & 4.8 & 5.0877 & TST \\
\hline CHEMBL1560337 & 688293 & 4.7 & 4.9242 & TRN \\
\hline CHEMBL1405769 & 688293 & 5.0 & 4.8166 & TRN \\
\hline CHEMBL1487087 & 688293 & 4.6 & 4.9888 & TRN \\
\hline CHEMBL1338985 & 688293 & 4.4 & 4.7911 & TRN \\
\hline CHEMBL1494857 & 688293 & 6.0 & 4.9485 & TRN \\
\hline CHEMBL1530934 & 688293 & 4.6 & 5.077 & TRN \\
\hline CHEMBL1528312 & 688293 & 4.5 & 5.3821 & TRN \\
\hline CHEMBL1582006 & 688293 & 4.5 & 4.8506 & TRN \\
\hline CHEMBL1411218 & 688293 & 4.5 & 5.1556 & TRN \\
\hline CHEMBL1209369 & 688293 & 4.7 & 4.8404 & TRN \\
\hline CHEMBL1324393 & 688293 & 5.3 & 4.8835 & TRN \\
\hline CHEMBL1552720 & 688293 & 4.5 & 4.7481 & TRN \\
\hline CHEMBL1527065 & 688293 & 4.6 & 5.0972 & TRN \\
\hline CHEMBL1391331 & 688293 & 4.9 & 4.9342 & TRN \\
\hline CHEMBL1541708 & 688293 & 5.9 & 5.0321 & TRN \\
\hline CHEMBL1316893 & 688293 & 5.0 & 4.7922 & TRN \\
\hline CHEMBL1573454 & 688293 & 5.4 & 4.8253 & TRN \\
\hline CHEMBL510698 & 688293 & 4.4 & 4.9871 & TRN \\
\hline CHEMBL1370398 & 688293 & 4.9 & 4.9522 & TRN \\
\hline CHEMBL1565302 & 688293 & 5.5 & 5.1817 & TST \\
\hline CHEMBL1344977 & 688293 & 4.7 & 5.0646 & TST \\
\hline CHEMBL1595724 & 688293 & 4.5 & 5.0033 & TRN \\
\hline CHEMBL1368453 & 688293 & 5.8 & 5.015 & TRN \\
\hline CHEMBL1381347 & 688293 & 6.0 & 4.9619 & TST \\
\hline CHEMBL1442026 & 688293 & 4.6 & 5.1056 & TRN \\
\hline CHEMBL1415937 & 688293 & 5.0 & 5.0085 & TRN \\
\hline CHEMBL1591714 & 688293 & 4.5 & 4.9964 & TRN \\
\hline CHEMBL1575910 & 688293 & 6.1 & 4.9669 & TRN \\
\hline CHEMBL1305974 & 688293 & 4.7 & 4.9564 & TRN \\
\hline CHEMBL1388271 & 688293 & 4.6 & 5.0821 & TRN \\
\hline CHEMBL91153 & 688293 & 4.9 & 4.8992 & TRN \\
\hline CHEMBL1359573 & 688293 & 4.9 & 4.8252 & TRN \\
\hline CHEMBL1554637 & 688293 & 5.7 & 4.9745 & TRN \\
\hline CHEMBL1573668 & 688293 & 4.5 & 5.0366 & TRN \\
\hline CHEMBL1349660 & 688293 & 4.9 & 4.9363 & TRN \\
\hline CHEMBL1489383 & 688293 & 4.7 & 4.9782 & TRN \\
\hline CHEMBL1586973 & 688293 & 4.7 & 5.0422 & TRN \\
\hline CHEMBL1483990 & 688293 & 5.0 & 5.0342 & TRN \\
\hline
\end{tabular}




\begin{tabular}{|c|c|c|c|c|c|}
\hline \multirow[b]{2}{*}{ CHEMBL1471289 } & \multirow[b]{2}{*}{688293} & \\
\hline & & 4.8 & 4.8957 & TST & \\
\hline CHEMBL1487551 & 688293 & 6.4 & 5.0538 & TRN & \\
\hline CHEMBL1324546 & 688293 & 6.0 & 5.1539 & TRN & \\
\hline CHEMBL1374710 & 688293 & 4.7 & 4.8408 & TRN & \\
\hline CHEMBL1540621 & 688293 & 4.7 & 4.9346 & TRN & \\
\hline CHEMBL1467034 & 688293 & 4.7 & 5.05699 & 99999999995 & TRN \\
\hline CHEMBL1339432 & 688293 & 4.4 & 5.1349 & TRN & \\
\hline CHEMBL1395387 & 688293 & 4.7 & 5.0704 & TST & \\
\hline CHEMBL313938 & 688293 & 4.6 & 5.0746 & TRN & \\
\hline CHEMBL1344342 & 688293 & 4.9 & 5.0864 & TRN & \\
\hline CHEMBL1566987 & 688293 & 5.7 & 4.8022 & TRN & \\
\hline CHEMBL1430034 & 688293 & 8.301 & 5.059 & TRN & \\
\hline CHEMBL1480161 & 688293 & 5.3 & 5.0013 & TRN & \\
\hline CHEMBL1565777 & 688293 & 7.2 & 4.9962 & TRN & \\
\hline CHEMBL1586184 & 688293 & 4.4 & 5.1057 & TRN & \\
\hline CHEMBL1613619 & 688293 & 4.8 & 5.1304 & TRN & \\
\hline CHEMBL1605977 & 688293 & 7.8996 & 4.9512 & TRN & \\
\hline CHEMBL1603477 & 688293 & 4.4 & 5.1691 & TRN & \\
\hline CHEMBL1605106 & 688293 & 4.8 & 5.144 & TST & \\
\hline CHEMBL1547290 & 688293 & 5.1 & 5.0682 & TRN & \\
\hline CHEMBL1350257 & 688293 & 4.6 & 4.9495 & TRN & \\
\hline CHEMBL260148 & 688293 & 4.7 & 5.0278 & TRN & \\
\hline CHEMBL1438559 & 688293 & 4.6 & 4.9998 & TRN & \\
\hline CHEMBL1412390 & 688293 & 4.6 & 4.6553 & TRN & \\
\hline CHEMBL1606472 & 688293 & 7.6003 & 5.0654 & TRN & \\
\hline CHEMBL1383968 & 688293 & 4.6 & 5.0037 & TST & \\
\hline CHEMBL1388273 & 688293 & 4.8 & 4.8669 & TRN & \\
\hline CHEMBL1543686 & 688293 & 4.7 & 4.9342 & TRN & \\
\hline CHEMBL1305260 & 688293 & 6.8 & 5.3071 & TRN & \\
\hline CHEMBL1521456 & 688293 & 4.8 & 5.0401 & TRN & \\
\hline CHEMBL1374179 & 688293 & 4.4 & 5.0829 & TRN & \\
\hline CHEMBL1557944 & 688293 & 4.7 & 4.8438 & TRN & \\
\hline CHEMBL1496423 & 688293 & 5.0 & 5.13399 & 99999999995 & TRN \\
\hline CHEMBL1428499 & 688293 & 4.7 & 4.8607 & TRN & \\
\hline CHEMBL1332614 & 688293 & 4.9 & 5.1366 & TST & \\
\hline CHEMBL1423121 & 688293 & 4.8 & 5.0641 & TRN & \\
\hline CHEMBL1530816 & 688293 & 5.1 & 4.9602 & TRN & \\
\hline CHEMBL1487114 & 688293 & 4.4 & 5.0672 & TRN & \\
\hline CHEMBL1588297 & 688293 & 5.1 & 5.0149 & TRN & \\
\hline CHEMBL1483427 & 688293 & 4.5 & 4.9391 & TRN & \\
\hline CHEMBL3190113 & 688293 & 6.0 & 5.0929 & TST & \\
\hline CHEMBL1313395 & 688293 & 4.7 & 4.8933 & TRN & \\
\hline CHEMBL1346683 & 688293 & 4.6 & 4.9357 & TRN & \\
\hline CHEMBL1533516 & 688293 & 4.9 & 4.72199 & 99999999995 & TRN \\
\hline CHEMBL1372821 & 688293 & 4.6 & 5.0012 & TRN & \\
\hline CHEMBL1321943 & 688293 & 4.5 & 5.0968 & TRN & \\
\hline CHEMBL1396463 & 688293 & 4.4 & 5.0633 & TST & \\
\hline CHEMBL1561829 & 688293 & 7.5003 & 5.0498 & TST & \\
\hline & & & & 19518 & \\
\hline
\end{tabular}




\begin{tabular}{|c|c|c|c|c|c|}
\hline \multicolumn{6}{|c|}{ Supplemental Table S2.txt } \\
\hline CHEMBL1428568 & 688293 & 4.7 & 5.0592 & TRN & \\
\hline CHEMBL1371161 & 688293 & 4.5 & 4.9318 & TRN & \\
\hline CHEMBL1489506 & 688293 & 4.8 & 4.9462 & TRN & \\
\hline CHEMBL1427972 & 688293 & 4.8 & 4.9642 & TST & \\
\hline CHEMBL1582546 & 688293 & 5.6 & 5.0231 & TRN & \\
\hline CHEMBL1364945 & 688293 & 4.4 & 5.0037 & TST & \\
\hline CHEMBL1510927 & 688293 & 5.5 & 5.1202 & TRN & \\
\hline CHEMBL1480952 & 688293 & 4.5 & 4.9949 & TRN & \\
\hline CHEMBL 3193145 & 688293 & 4.6 & 4.8305 & TRN & \\
\hline CHEMBL1430185 & 688293 & 4.5 & 4.9459 & TRN & \\
\hline CHEMBL1365850 & 688293 & 4.5 & 4.9352 & TRN & \\
\hline CHEMBL1483375 & 688293 & 5.8 & 5.1892 & TRN & \\
\hline CHEMBL1325231 & 688293 & 5.0 & 4.8599 & TRN & \\
\hline CHEMBL1419120 & 688293 & 8.1024 & 5.0711 & TRN & \\
\hline CHEMBL1527443 & 688293 & 5.9 & 5.0178 & TST & \\
\hline CHEMBL1383720 & 688293 & 5.4 & 5.0416 & TRN & \\
\hline CHEMBL1483348 & 688293 & 4.7 & 4.9804 & TRN & \\
\hline CHEMBL3192942 & 688293 & 5.6 & 5.0648 & TST & \\
\hline CHEMBL1441891 & 688293 & 4.6 & 4.7119 & TRN & \\
\hline CHEMBL1554448 & 688293 & 4.4 & 5.0506 & TST & \\
\hline CHEMBL1585158 & 688293 & 4.8 & 5.0912 & TRN & \\
\hline CHEMBL1541721 & 688293 & 4.8 & 4.9885 & TRN & \\
\hline CHEMBL1518723 & 688293 & 4.7 & 5.0615 & TRN & \\
\hline CHEMBL290914 & 688293 & 4.5 & 5.0372 & TST & \\
\hline CHEMBL1339805 & 688293 & 5.5 & 5.225 & TRN & \\
\hline CHEMBL1344212 & 688293 & 4.4 & 4.9126 & TRN & \\
\hline CHEMBL1607320 & 688293 & 5.6 & 4.9254 & TRN & \\
\hline CHEMBL1303091 & 688293 & 4.5 & 4.8097 & TRN & \\
\hline CHEMBL1311847 & 688293 & 5.5 & 4.8156 & TRN & \\
\hline CHEMBL1421806 & 688293 & 4.4 & 4.9508 & TRN & \\
\hline CHEMBL1583270 & 688293 & 4.5 & 4.9372 & TRN & \\
\hline CHEMBL1312369 & 688293 & 4.5 & 5.0258 & TRN & \\
\hline CHEMBL1589363 & 688293 & 4.6 & 5.0761 & TRN & \\
\hline CHEMBL1586877 & 688293 & 4.8 & 5.2062 & TRN & \\
\hline CHEMBL1353014 & 688293 & 5.3 & 5.01699 & 99999999995 & TRN \\
\hline CHEMBL1609665 & 688293 & 4.5 & 5.1105 & TRN & \\
\hline CHEMBL1351990 & 688293 & 4.7 & 4.9017 & TST & \\
\hline CHEMBL1364932 & 688293 & 5.5 & 5.129 & TRN & \\
\hline CHEMBL1453214 & 688293 & 4.7 & 5.0779 & TRN & \\
\hline CHEMBL1375377 & 688293 & 4.6 & 5.0342 & TRN & \\
\hline CHEMBL1349741 & 688293 & 6.3 & 5.1217 & TRN & \\
\hline CHEMBL1539307 & 688293 & 4.7 & 4.9447 & TRN & \\
\hline CHEMBL1369796 & 688293 & 4.4 & 4.8023 & TRN & \\
\hline CHEMBL1513439 & 688293 & 4.7 & 5.1196 & TRN & \\
\hline CHEMBL1448001 & 688293 & 4.8 & 4.9433 & TRN & \\
\hline CHEMBL1391411 & 688293 & 6.6 & 5.0725 & TRN & \\
\hline CHEMBL1318718 & 688293 & 4.6 & 4.9661 & TRN & \\
\hline CHEMBL1545511 & 688293 & 4.8 & 4.8495 & TRN & \\
\hline
\end{tabular}




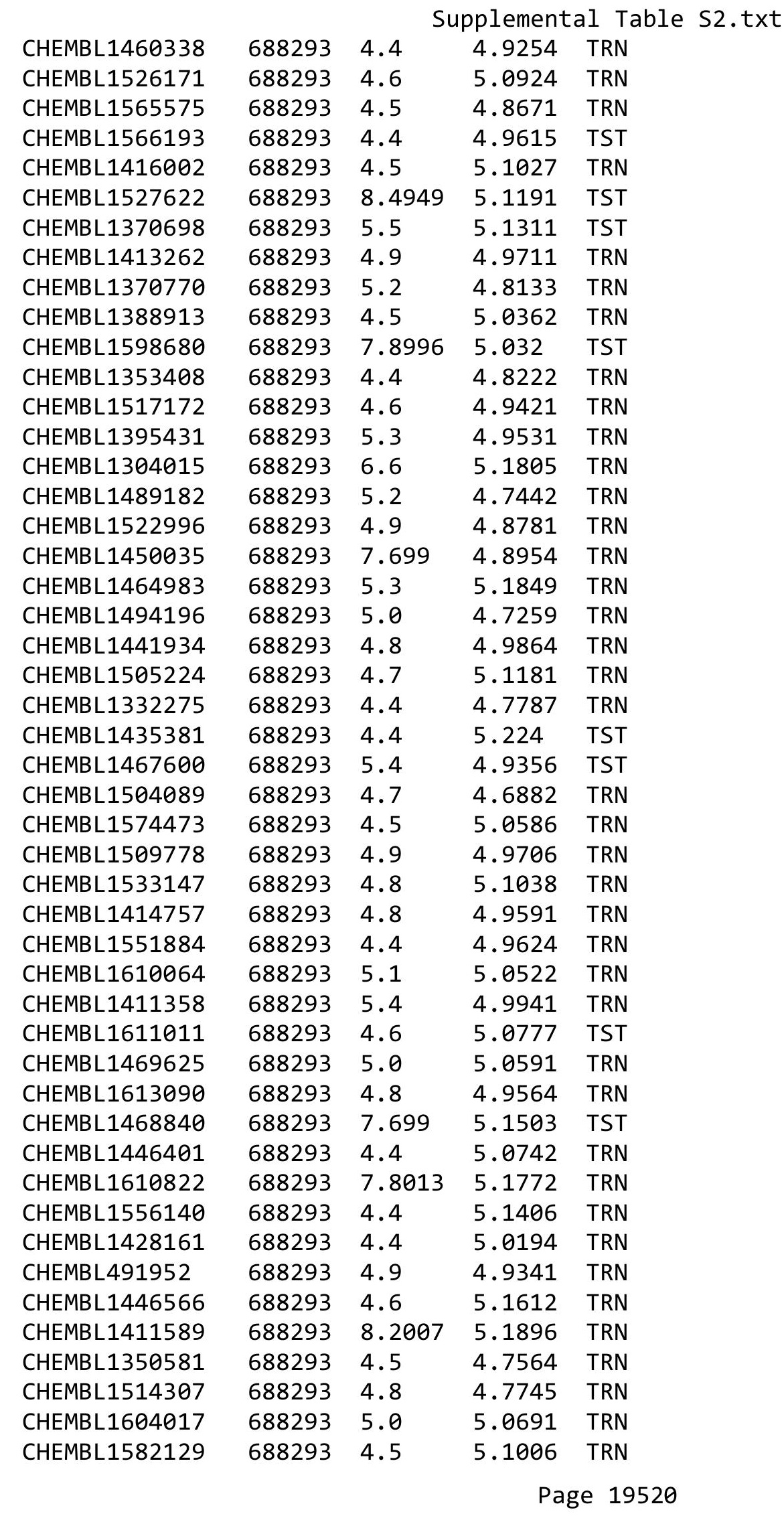




\begin{tabular}{|c|c|c|c|c|c|}
\hline CHEMBL1299527 & 688293 & 4.6 & 4.8871 & TRN & \\
\hline CHEMBL251389 & 688293 & 4.5 & \multicolumn{2}{|c|}{4.8260000000000005} & TST \\
\hline CHEMBL1419089 & 688293 & 5.0 & 4.9656 & TRN & \\
\hline CHEMBL1610545 & 688293 & 4.8 & 5.2219 & TRN & \\
\hline CHEMBL1547605 & 688293 & 4.6 & 4.7972 & TRN & \\
\hline CHEMBL1302760 & 688293 & 5.0 & 4.8747 & TRN & \\
\hline CHEMBL573781 & 688293 & 4.4 & 5.0868 & TRN & \\
\hline CHEMBL1487575 & 688293 & 5.0 & 5.1986 & TRN & \\
\hline CHEMBL1337505 & 688293 & 4.6 & 4.9714 & TST & \\
\hline CHEMBL313737 & 688293 & 4.8 & 4.9915 & TST & \\
\hline CHEMBL1552839 & 688293 & 5.5 & 4.9171 & TRN & \\
\hline CHEMBL1371798 & 688293 & 4.8 & 5.0593 & TRN & \\
\hline CHEMBL283196 & 688293 & 4.5 & 4.8503 & TRN & \\
\hline CHEMBL1559341 & 688293 & 4.6 & 4.8693 & TST & \\
\hline CHEMBL1396109 & 688293 & 4.8 & 4.7297 & TRN & \\
\hline CHEMBL1407527 & 688293 & 4.8 & 4.9022 & TRN & \\
\hline CHEMBL1507243 & 688293 & 5.5 & 4.9631 & TRN & \\
\hline CHEMBL1595148 & 688293 & 4.9 & 5.0083 & TRN & \\
\hline CHEMBL1559673 & 688293 & 4.8 & 4.8606 & TRN & \\
\hline CHEMBL1517051 & 688293 & 5.3 & 4.9423 & TRN & \\
\hline CHEMBL1466860 & 688293 & 4.4 & 4.9877 & TRN & \\
\hline CHEMBL1318114 & 688293 & 4.5 & 4.6625 & TRN & \\
\hline CHEMBL1506312 & 688293 & 5.5 & 5.2038 & TRN & \\
\hline CHEMBL1459342 & 688293 & 5.0 & \multicolumn{2}{|c|}{ 4.928999999999999 } & TRN \\
\hline CHEMBL1376874 & 688293 & 6.5 & 5.0232 & TRN & \\
\hline CHEMBL1595687 & 688293 & 4.5 & 4.8824 & TRN & \\
\hline CHEMBL1542808 & 688293 & 4.8 & 5.2582 & TRN & \\
\hline CHEMBL1449356 & 688293 & 4.4 & 4.9706 & TRN & \\
\hline CHEMBL1531020 & 688293 & 4.8 & 5.0622 & TRN & \\
\hline CHEMBL1379045 & 688293 & 5.3 & 4.9318 & TRN & \\
\hline CHEMBL1538146 & 688293 & 4.9 & 5.1093 & TRN & \\
\hline CHEMBL1367159 & 688293 & 6.8 & 4.9984 & TRN & \\
\hline CHEMBL1365427 & 688293 & 4.8 & 5.1032 & TRN & \\
\hline CHEMBL1426299 & 688293 & 4.6 & 4.9702 & TRN & \\
\hline CHEMBL1571510 & 688293 & 4.7 & 5.1661 & TRN & \\
\hline CHEMBL1381534 & 688293 & 5.5 & 5.1097 & TRN & \\
\hline CHEMBL1419737 & 688293 & 7.699 & 5.0976 & TRN & \\
\hline CHEMBL1451874 & 688293 & 4.4 & 4.993 & TST & \\
\hline CHEMBL1502715 & 688293 & 4.9 & 4.9832 & TRN & \\
\hline CHEMBL1531037 & 688293 & 4.7 & 4.7605 & TRN & \\
\hline CHEMBL1361294 & 688293 & 5.1 & 4.9612 & TRN & \\
\hline CHEMBL1490919 & 688293 & 4.9 & 4.9804 & TST & \\
\hline CHEMBL1344103 & 688293 & 4.5 & 4.7884 & TRN & \\
\hline CHEMBL1334914 & 688293 & 4.5 & 4.7924 & TST & \\
\hline CHEMBL1415889 & 688293 & 5.2 & 5.1794 & TRN & \\
\hline CHEMBL1588403 & 688293 & 5.0 & 4.9752 & TRN & \\
\hline CHEMBL1326010 & 688293 & 4.6 & 4.8967 & TST & \\
\hline CHEMBL1376804 & 688293 & 6.7001 & 4.9142 & TRN & \\
\hline
\end{tabular}




\begin{tabular}{|c|c|c|c|c|c|}
\hline \\
\hline CHEMBL1421907 & 688293 & 4.8 & 5.189 & TRN & \\
\hline CHEMBL1534503 & 688293 & 5.5 & 5.1454 & TRN & \\
\hline CHEMBL1362741 & 688293 & 4.6 & 5.1302 & TRN & \\
\hline CHEMBL1332660 & 688293 & 4.9 & 5.0533 & TRN & \\
\hline CHEMBL1332706 & 688293 & 4.4 & 5.1018 & TRN & \\
\hline CHEMBL1529694 & 688293 & 4.4 & 5.171 & TRN & \\
\hline CHEMBL1565677 & 688293 & 4.6 & 4.828 & TRN & \\
\hline CHEMBL1331657 & 688293 & 4.4 & 4.934 & TRN & \\
\hline CHEMBL1438328 & 688293 & 4.5 & 5.0518 & TRN & \\
\hline CHEMBL1569640 & 688293 & 4.9 & 5.0644 & TRN & \\
\hline CHEMBL1477974 & 688293 & 4.4 & 5.1556 & TRN & \\
\hline CHEMBL1449821 & 688293 & 4.8 & 4.9011 & TST & \\
\hline CHEMBL1484360 & 688293 & 5.0 & 5.0204 & TRN & \\
\hline CHEMBL1307517 & 688293 & 4.6 & 5.1872 & TRN & \\
\hline CHEMBL1362253 & 688293 & 4.5 & 5.1304 & TRN & \\
\hline CHEMBL1391644 & 688293 & 4.6 & 4.9875 & TRN & \\
\hline CHEMBL1478628 & 688293 & 4.4 & 4.7798 & TRN & \\
\hline CHEMBL1256916 & 688293 & 4.4 & 4.97 & TST & \\
\hline CHEMBL1485544 & 688293 & 5.3 & 5.1499 & TRN & \\
\hline CHEMBL1463921 & 688293 & 6.9 & 5.0464 & TRN & \\
\hline CHEMBL1393757 & 688293 & 4.6 & 4.989 & TST & \\
\hline CHEMBL1343147 & 688293 & 4.4 & 5.0527 & TST & \\
\hline CHEMBL1332633 & 688293 & 5.3 & 4.9503 & TRN & \\
\hline CHEMBL1323290 & 688293 & 5.2 & 5.0616 & TST & \\
\hline CHEMBL1442918 & 688293 & 4.4 & 4.9129 & TRN & \\
\hline CHEMBL1599281 & 688293 & 8.2007 & 5.0868 & TRN & \\
\hline CHEMBL1308234 & 688293 & 4.8 & 4.864 & TRN & \\
\hline CHEMBL3209093 & 688293 & 4.8 & 4.7958 & TRN & \\
\hline CHEMBL1482341 & 688293 & 7.699 & 5.1148 & TRN & \\
\hline CHEMBL1409445 & 688293 & 4.7 & 5.0897 & TRN & \\
\hline CHEMBL1517563 & 688293 & 4.8 & 5.1263 & TRN & \\
\hline CHEMBL1580276 & 688293 & 5.2 & 4.9666 & TRN & \\
\hline CHEMBL1596248 & 688293 & 4.4 & 4.7507 & TRN & \\
\hline CHEMBL1520621 & 688293 & 4.8 & 4.8557 & TST & \\
\hline CHEMBL1525627 & 688293 & 5.0 & 5.0804 & TRN & \\
\hline CHEMBL1351716 & 688293 & 4.6 & 4.9956 & TRN & \\
\hline CHEMBL1301699 & 688293 & 4.9 & 4.8622 & TRN & \\
\hline CHEMBL1403227 & 688293 & 4.4 & 5.0483 & TST & \\
\hline CHEMBL1426223 & 688293 & 4.6 & 4.8955 & TST & \\
\hline CHEMBL465339 & 688293 & 5.5 & 5.0428 & TRN & \\
\hline CHEMBL1521690 & 688293 & 4.8 & 5.19799 & 99999999995 & TRN \\
\hline CHEMBL1429186 & 688293 & 4.5 & 4.8653 & TRN & \\
\hline CHEMBL462314 & 688293 & 5.4 & 5.0763 & TST & \\
\hline CHEMBL87285 & 688293 & 4.5 & 5.1339 & TST & \\
\hline CHEMBL1589103 & 688293 & 4.9 & 5.0037 & TRN & \\
\hline CHEMBL1438100 & 688293 & 4.4 & 4.9745 & TRN & \\
\hline CHEMBL1306250 & 688293 & 5.1 & 5.0343 & TRN & \\
\hline CHEMBL1584015 & 688293 & 4.9 & 4.9294 & TRN & \\
\hline & & & & 2 & \\
\hline
\end{tabular}




\begin{tabular}{|c|c|c|c|c|}
\hline & & & pplement & $\mathrm{a} \perp \mathrm{Ta}$ \\
\hline CHEMBL1350100 & 688293 & 2.3 & 5.3354 & TRN \\
\hline CHEMBL1518353 & 688293 & 4.7 & 5.1828 & TRN \\
\hline CHEMBL1489611 & 688293 & 4.7 & 4.9943 & TRN \\
\hline CHEMBL1319523 & 688293 & 4.5 & 5.0962 & TRN \\
\hline CHEMBL1599130 & 688293 & 4.4 & 5.0013 & TRN \\
\hline CHEMBL1382277 & 688293 & 4.4 & 4.811 & TRN \\
\hline CHEMBL570345 & 688293 & 5.3 & 4.989 & TRN \\
\hline CHEMBL1352800 & 688293 & 4.5 & 5.0144 & TRN \\
\hline CHEMBL1441773 & 688293 & 4.7 & 4.7724 & TRN \\
\hline CHEMBL3199093 & 688293 & 4.7 & 4.9389 & TST \\
\hline CHEMBL1359750 & 688293 & 4.5 & 5.0132 & TRN \\
\hline CHEMBL1480444 & 688293 & 4.9 & 5.0875 & TRN \\
\hline CHEMBL510539 & 688293 & 4.5 & 4.9896 & TST \\
\hline CHEMBL1594618 & 688293 & 4.8 & 4.8237 & TST \\
\hline CHEMBL1390779 & 688293 & 4.4 & 4.9499 & TRN \\
\hline CHEMBL1444568 & 688293 & 4.8 & 4.8875 & TRN \\
\hline CHEMBL1389807 & 688293 & 5.0 & 5.0455 & TRN \\
\hline CHEMBL1386667 & 688293 & 4.5 & 4.9867 & TRN \\
\hline CHEMBL1463057 & 688293 & 5.0 & 4.8064 & TRN \\
\hline CHEMBL1457355 & 688293 & 4.8 & 5.1128 & TRN \\
\hline CHEMBL1518866 & 688293 & 4.9 & 4.8173 & TRN \\
\hline CHEMBL1486958 & 688293 & 5.3 & 4.9526 & TRN \\
\hline CHEMBL1338891 & 688293 & 4.4 & 4.9811 & TRN \\
\hline CHEMBL1518017 & 688293 & 4.8 & 5.1193 & TST \\
\hline CHEMBL1581985 & 688293 & 4.7 & 5.0101 & TST \\
\hline CHEMBL1414084 & 688293 & 4.7 & 5.0623 & TRN \\
\hline CHEMBL1330307 & 688293 & 5.1 & 4.8661 & TST \\
\hline CHEMBL1344361 & 688293 & 4.9 & 4.9995 & TRN \\
\hline CHEMBL1499261 & 688293 & 5.9 & 4.7597 & TRN \\
\hline CHEMBL1329064 & 688293 & 4.8 & 5.2097 & TST \\
\hline CHEMBL1439767 & 688293 & 4.9 & 4.9602 & TST \\
\hline CHEMBL473107 & 688293 & 4.6 & 4.8653 & TRN \\
\hline CHEMBL1471435 & 688293 & 4.4 & 4.7591 & TRN \\
\hline CHEMBL1548335 & 688293 & 4.6 & 5.2613 & TRN \\
\hline CHEMBL1449204 & 688293 & 4.6 & 4.9202 & TRN \\
\hline CHEMBL492611 & 688293 & 4.9 & 4.8707 & TRN \\
\hline CHEMBL1305312 & 688293 & 4.4 & 5.0348 & TRN \\
\hline CHEMBL1607407 & 688293 & 5.0 & 5.1781 & TRN \\
\hline CHEMBL1503851 & 688293 & 4.7 & 5.166 & TRN \\
\hline CHEMBL1327038 & 688293 & 4.8 & 4.7327 & TRN \\
\hline CHEMBL1436179 & 688293 & 4.8 & 4.9384 & TRN \\
\hline CHEMBL1318943 & 688293 & 4.6 & 4.905 & TST \\
\hline CHEMBL1480329 & 688293 & 4.7 & 4.8477 & TRN \\
\hline CHEMBL1351054 & 688293 & 4.8 & 4.9099 & TRN \\
\hline CHEMBL492719 & 688293 & 4.5 & 4.8915 & TRN \\
\hline CHEMBL1412222 & 688293 & 8.0 & 5.1385 & TRN \\
\hline CHEMBL198759 & 688293 & 4.9 & 5.1126 & TST \\
\hline CHEMBL1300858 & 688293 & 4.4 & 4.9593 & TRN \\
\hline
\end{tabular}




\begin{tabular}{|c|c|c|c|c|}
\hline \multicolumn{5}{|c|}{ Supplemental Table S2.txt } \\
\hline CHEMBL1355135 & 688293 & 4.8 & 4.665 & TRN \\
\hline CHEMBL1410885 & 688293 & 4.6 & 5.1218 & TRN \\
\hline CHEMBL1371113 & 688293 & 4.7 & 4.9408 & TRN \\
\hline CHEMBL1609288 & 688293 & 4.4 & 5.0409 & TRN \\
\hline CHEMBL1495481 & 688293 & 4.7 & 4.8364 & TRN \\
\hline CHEMBL1388004 & 688293 & 4.5 & 5.0314 & TRN \\
\hline CHEMBL1594757 & 688293 & 4.6 & 5.0466 & TRN \\
\hline CHEMBL1463381 & 688293 & 5.3 & 4.9637 & TST \\
\hline CHEMBL1418737 & 688293 & 8.0 & 5.0146 & TRN \\
\hline CHEMBL1543317 & 688293 & 4.5 & 4.9481 & TRN \\
\hline CHEMBL1339209 & 688293 & 4.5 & 4.7286 & TRN \\
\hline CHEMBL1442492 & 688293 & 4.6 & 5.1103 & TST \\
\hline CHEMBL1416552 & 688293 & 7.4001 & 5.2013 & TRN \\
\hline CHEMBL1360852 & 688293 & 4.4 & 4.9493 & TST \\
\hline CHEMBL1466068 & 688293 & 4.5 & 5.0107 & TRN \\
\hline CHEMBL1481663 & 688293 & 4.9 & 4.9701 & TRN \\
\hline CHEMBL1325093 & 688293 & 5.6 & 4.8579 & TST \\
\hline CHEMBL1606863 & 688293 & 4.9 & 4.8606 & TRN \\
\hline CHEMBL1301166 & 688293 & 4.5 & 4.9727 & TRN \\
\hline CHEMBL1592651 & 688293 & 4.6 & 4.845 & TRN \\
\hline CHEMBL1400252 & 688293 & 4.7 & 5.0508 & TRN \\
\hline CHEMBL1597022 & 688293 & 5.2 & 5.1177 & TRN \\
\hline CHEMBL1542714 & 688293 & 4.4 & 5.1206 & TRN \\
\hline CHEMBL1606407 & 688293 & 4.4 & 4.9908 & TST \\
\hline CHEMBL1327747 & 688293 & 5.5 & 4.9872 & TRN \\
\hline CHEMBL1349513 & 688293 & 5.0 & 5.0859 & TRN \\
\hline CHEMBL1466233 & 688293 & 4.7 & 5.0953 & TRN \\
\hline CHEMBL 2007329 & 688293 & 5.0 & 5.0108 & TRN \\
\hline CHEMBL1478008 & 688293 & 4.6 & 5.0981 & TRN \\
\hline CHEMBL1595229 & 688293 & 4.4 & 5.0286 & TRN \\
\hline CHEMBL1335331 & 688293 & 5.0 & 5.0493 & TRN \\
\hline CHEMBL1577801 & 688293 & 4.6 & 5.227 & TRN \\
\hline CHEMBL1465244 & 688293 & 4.4 & 5.2215 & TST \\
\hline CHEMBL1478 & 688293 & 6.0 & 5.2147 & TST \\
\hline CHEMBL1417726 & 688293 & 4.6 & 4.9971 & TRN \\
\hline CHEMBL1569751 & 688293 & 4.4 & 4.9901 & TRN \\
\hline CHEMBL1520012 & 688293 & 5.2 & 4.9567 & TRN \\
\hline CHEMBL1516232 & 688293 & 4.6 & 4.8376 & TRN \\
\hline CHEMBL 389516 & 688293 & 4.4 & 4.9533 & TRN \\
\hline CHEMBL1439106 & 688293 & 5.0 & 4.8852 & TRN \\
\hline CHEMBL1464168 & 688293 & 4.6 & 4.841 & TRN \\
\hline CHEMBL1542605 & 688293 & 4.5 & 4.9295 & TRN \\
\hline CHEMBL1467815 & 688293 & 4.4 & 4.7236 & TRN \\
\hline CHEMBL1568666 & 688293 & 4.9 & 5.0561 & TRN \\
\hline CHEMBL1592754 & 688293 & 4.4 & 4.9427 & TRN \\
\hline CHEMBL1380287 & 688293 & 4.5 & 4.7448 & TRN \\
\hline CHEMBL1546336 & 688293 & 6.7001 & 5.0577 & TRN \\
\hline CHEMBL1584754 & 688293 & 4.6 & 4.783 & TST \\
\hline
\end{tabular}




\begin{tabular}{|c|c|c|c|c|c|}
\hline & & & & & \\
\hline CHEMBL1536048 & 688293 & 5.0 & 4.9407 & TRN & \\
\hline CHEMBL1454716 & 688293 & 4.5 & 4.9816 & TRN & \\
\hline CHEMBL1580822 & 688293 & 4.8 & 5.1208 & TRN & \\
\hline CHEMBL517444 & 688293 & 4.5 & 4.8392 & TRN & \\
\hline CHEMBL1390926 & 688293 & 4.8 & 5.0056 & TRN & \\
\hline CHEMBL1388993 & 688293 & 4.4 & 5.2223 & TRN & \\
\hline CHEMBL1396010 & 688293 & 4.4 & 5.0186 & TRN & \\
\hline CHEMBL1313757 & 688293 & 5.8 & 4.9427 & TRN & \\
\hline CHEMBL1392258 & 688293 & 4.6 & 4.9084 & TRN & \\
\hline CHEMBL1506451 & 688293 & 4.8 & 5.0241 & TRN & \\
\hline CHEMBL1336941 & 688293 & 5.5 & 4.997 & TRN & \\
\hline CHEMBL1555938 & 688293 & 4.4 & 5.0047 & TRN & \\
\hline CHEMBL1585117 & 688293 & 8.2007 & 5.1343 & TRN & \\
\hline CHEMBL1579264 & 688293 & 4.9 & 5.11600 & 00000000005 & TRN \\
\hline CHEMBL1478067 & 688293 & 4.9 & 4.9212 & TRN & \\
\hline CHEMBL1447264 & 688293 & 5.8 & 5.2037 & TRN & \\
\hline CHEMBL1492580 & 688293 & 5.6 & 5.2533 & TRN & \\
\hline CHEMBL1446896 & 688293 & 4.9 & 5.0092 & TRN & \\
\hline CHEMBL1453548 & 688293 & 4.5 & 5.0607 & TRN & \\
\hline CHEMBL1581348 & 688293 & 6.3 & 5.0922 & TRN & \\
\hline CHEMBL1565621 & 688293 & 4.9 & 5.0164 & TRN & \\
\hline CHEMBL1561002 & 688293 & 4.9 & 5.0098 & TRN & \\
\hline CHEMBL1466477 & 688293 & 5.4 & 5.1077 & TRN & \\
\hline CHEMBL1465806 & 688293 & 4.5 & 4.9395 & TRN & \\
\hline CHEMBL1344681 & 688293 & 5.7 & 4.9962 & TRN & \\
\hline CHEMBL1556063 & 688293 & 6.0 & 4.9252 & TRN & \\
\hline CHEMBL1606667 & 688293 & 8.0 & 4.9835 & TRN & \\
\hline CHEMBL1482542 & 688293 & 5.7 & 5.1763 & TRN & \\
\hline CHEMBL1603852 & 688293 & 4.7 & 4.8146 & TRN & \\
\hline CHEMBL1307173 & 688293 & 5.6 & 5.1156 & TRN & \\
\hline CHEMBL 270299 & 688293 & 4.5 & 4.9928 & TST & \\
\hline CHEMBL1594521 & 688293 & 4.6 & 5.0315 & TRN & \\
\hline CHEMBL1360609 & 688293 & 4.9 & 5.0738 & TRN & \\
\hline CHEMBL1476107 & 688293 & 5.3 & 4.976 & TST & \\
\hline CHEMBL1402324 & 688293 & 4.6 & 4.8525 & TRN & \\
\hline CHEMBL1604045 & 688293 & 6.0 & 5.0844 & TRN & \\
\hline CHEMBL3190797 & 688293 & 4.4 & 5.0229 & TRN & \\
\hline CHEMBL1373002 & 688293 & 4.5 & 5.0077 & TRN & \\
\hline CHEMBL1486074 & 688293 & 7.4001 & 5.1282 & TRN & \\
\hline CHEMBL1587649 & 688293 & 4.4 & 4.8754 & TRN & \\
\hline CHEMBL1440599 & 688293 & 5.8 & 4.8031 & TRN & \\
\hline CHEMBL1324347 & 688293 & 4.7 & 5.0728 & TRN & \\
\hline CHEMBL1419576 & 688293 & 7.6003 & 5.1893 & TRN & \\
\hline CHEMBL104264 & 688293 & 4.7 & 4.9283 & TST & \\
\hline CHEMBL1377975 & 688293 & 5.0 & 5.0577 & TRN & \\
\hline CHEMBL1576068 & 688293 & 4.4 & 4.9118 & TRN & \\
\hline CHEMBL1538732 & 688293 & 4.8 & 4.9219 & TRN & \\
\hline CHEMBL1613268 & 688293 & 4.6 & 5.0589 & TRN & \\
\hline & & & & 19525 & \\
\hline
\end{tabular}




\begin{tabular}{|c|c|c|c|c|c|}
\hline \multicolumn{6}{|c|}{ Supplemental Table S2.txt } \\
\hline CHEMBL1349253 & 688293 & 6.9 & 4.8624 & TST & \\
\hline CHEMBL1500640 & 688293 & 4.4 & 5.0162 & TRN & \\
\hline CHEMBL1540576 & 688293 & 4.4 & 5.0464 & TRN & \\
\hline CHEMBL1546004 & 688293 & 7.0 & 4.9638 & TRN & \\
\hline CHEMBL1488186 & 688293 & 4.4 & 5.1036 & TST & \\
\hline CHEMBL1431034 & 688293 & 4.6 & 4.9761 & TRN & \\
\hline CHEMBL1489973 & 688293 & 4.4 & 4.999 & TRN & \\
\hline CHEMBL1449579 & 688293 & 4.8 & 4.9574 & TRN & \\
\hline CHEMBL1457503 & 688293 & 4.8 & 5.0079 & TRN & \\
\hline CHEMBL1575538 & 688293 & 6.0 & 4.9286 & TRN & \\
\hline CHEMBL3191752 & 688293 & 4.8 & 4.8616 & TRN & \\
\hline CHEMBL 3213424 & 688293 & 5.2 & 5.0996 & TRN & \\
\hline CHEMBL1409629 & 688293 & 4.4 & 4.9355 & TST & \\
\hline CHEMBL1356280 & 688293 & 4.9 & 5.1394 & TST & \\
\hline CHEMBL1612736 & 688293 & 4.5 & 5.1115 & TRN & \\
\hline CHEMBL1600726 & 688293 & 4.8 & 5.0754 & TRN & \\
\hline CHEMBL1446905 & 688293 & 5.1 & 4.9184 & TRN & \\
\hline CHEMBL1543601 & 688293 & 4.4 & 4.8279 & TRN & \\
\hline CHEMBL1360890 & 688293 & 6.0 & 5.0155 & TRN & \\
\hline CHEMBL1368316 & 688293 & 4.4 & 4.8126 & TRN & \\
\hline CHEMBL1326534 & 688293 & 4.4 & 4.9073 & TRN & \\
\hline CHEMBL1444884 & 688293 & 5.0 & 4.8234 & TRN & \\
\hline CHEMBL1572928 & 688293 & 4.9 & 4.8092 & TRN & \\
\hline CHEMBL1428011 & 688293 & 6.6 & 5.1488 & TRN & \\
\hline CHEMBL1548596 & 688293 & 4.6 & 5.0043 & TRN & \\
\hline CHEMBL1395417 & 688293 & 4.8 & 4.69 & TRN & \\
\hline CHEMBL1609896 & 688293 & 5.3 & $4.9110 e$ & 00000000005 & TRN \\
\hline CHEMBL1416760 & 688293 & 5.0 & 5.1476 & TRN & \\
\hline CHEMBL1504756 & 688293 & 4.5 & 4.996 & TRN & \\
\hline CHEMBL1527667 & 688293 & 4.4 & 5.0964 & TRN & \\
\hline CHEMBL1598001 & 688293 & 5.1 & 5.0831 & TRN & \\
\hline CHEMBL1361853 & 688293 & 4.5 & 5.1151 & TRN & \\
\hline CHEMBL1522696 & 688293 & 5.0 & 5.0682 & TRN & \\
\hline CHEMBL1549583 & 688293 & 6.5 & 5.2034 & TRN & \\
\hline CHEMBL56731 & 688293 & 4.6 & 4.9509 & TRN & \\
\hline CHEMBL1527566 & 688293 & 4.4 & 5.1231 & TRN & \\
\hline CHEMBL50112 & 688293 & 4.9 & 5.1963 & TRN & \\
\hline CHEMBL1577104 & 688293 & 4.4 & 4.9666 & TST & \\
\hline CHEMBL1522803 & 688293 & 4.8 & 4.9147 & TRN & \\
\hline CHEMBL1548720 & 688293 & 4.6 & 5.1509 & TRN & \\
\hline CHEMBL1317761 & 688293 & 4.6 & 4.7181 & TRN & \\
\hline CHEMBL1555638 & 688293 & 4.9 & 4.9534 & TRN & \\
\hline CHEMBL1408760 & 688293 & 4.5 & 5.0161 & TRN & \\
\hline CHEMBL1565612 & 688293 & 8.2007 & 5.1406 & TRN & \\
\hline CHEMBL1528848 & 688293 & 6.6 & 5.1256 & TST & \\
\hline CHEMBL1311854 & 688293 & 4.7 & 4.9815 & TST & \\
\hline CHEMBL1452804 & 688293 & 5.3 & 5.113 & TRN & \\
\hline CHEMBL1504626 & 688293 & 8.301 & 5.0338 & TRN & \\
\hline
\end{tabular}




\begin{tabular}{|c|c|c|c|c|c|}
\hline & & & & & \\
\hline CHEMBL1320539 & 688293 & 4.8 & 5.1041 & TRN & \\
\hline CHEMBL 208484 & 688293 & 4.4 & 4.836 & TRN & \\
\hline CHEMBL1310871 & 688293 & 4.5 & 5.0807 & TRN & \\
\hline CHEMBL1382690 & 688293 & 6.6 & 5.0537 & TRN & \\
\hline CHEMBL1475657 & 688293 & 5.0 & 4.7276 & TRN & \\
\hline CHEMBL1331669 & 688293 & 4.6 & 5.2286 & TRN & \\
\hline CHEMBL1569930 & 688293 & 4.7 & 5.16 & TRN & \\
\hline CHEMBL1446384 & 688293 & 4.5 & 5.0074 & TST & \\
\hline CHEMBL504598 & 688293 & 5.0 & 4.9894 & TRN & \\
\hline CHEMBL1460452 & 688293 & 4.8 & $4.9860 e$ & 3000000001 & TRN \\
\hline CHEMBL1338958 & 688293 & 5.1 & 5.0785 & TRN & \\
\hline CHEMBL1589415 & 688293 & 4.4 & 4.8292 & TRN & \\
\hline CHEMBL1367224 & 688293 & 4.5 & 5.0386 & TRN & \\
\hline CHEMBL1594586 & 688293 & 4.5 & 4.9644 & TRN & \\
\hline CHEMBL1450838 & 688293 & 4.7 & 4.7832 & TRN & \\
\hline CHEMBL1360895 & 688293 & 5.2 & 5.1588 & TRN & \\
\hline CHEMBL1725279 & 688293 & 5.0 & 4.9099 & TST & \\
\hline CHEMBL28449 & 688293 & 5.3 & 5.1598 & TST & \\
\hline CHEMBL1558908 & 688293 & 4.6 & 5.0806 & TRN & \\
\hline CHEMBL1300645 & 688293 & 4.6 & 4.8639 & TRN & \\
\hline CHEMBL1369961 & 688293 & 4.6 & 5.0816 & TRN & \\
\hline CHEMBL1493396 & 688293 & 4.6 & 4.9272 & TST & \\
\hline CHEMBL1455836 & 688293 & 6.5 & 5.1698 & TRN & \\
\hline CHEMBL1360306 & 688293 & 4.7 & 4.8012 & TRN & \\
\hline CHEMBL1408538 & 688293 & 5.2 & 5.0374 & TRN & \\
\hline CHEMBL1344072 & 688293 & 4.5 & 5.1209 & TRN & \\
\hline CHEMBL1347671 & 688293 & 4.6 & 5.1211 & TRN & \\
\hline CHEMBL1531090 & 688293 & 5.8 & 4.9307 & TRN & \\
\hline CHEMBL1340776 & 688293 & 5.5 & 4.6998 & TRN & \\
\hline CHEMBL1330966 & 688293 & 4.6 & 5.119 & TRN & \\
\hline CHEMBL1328025 & 688293 & 5.0 & 4.9402 & TRN & \\
\hline CHEMBL1565801 & 688293 & 4.4 & 4.8334 & TRN & \\
\hline CHEMBL1345370 & 688293 & 5.0 & 5.1333 & TRN & \\
\hline CHEMBL77030 & 688293 & 4.8 & 4.9175 & TRN & \\
\hline CHEMBL3210823 & 688293 & 5.0 & 5.001 & TRN & \\
\hline CHEMBL3209962 & 688293 & 5.6 & 4.8939 & TST & \\
\hline CHEMBL429095 & 688293 & 4.8 & 5.0701 & TST & \\
\hline CHEMBL1414258 & 688293 & 4.4 & 4.9337 & TRN & \\
\hline CHEMBL1489356 & 688293 & 4.7 & 4.9299 & TRN & \\
\hline CHEMBL1552270 & 688293 & 4.5 & 4.7527 & TRN & \\
\hline CHEMBL1406674 & 688293 & 4.8 & 4.9335 & TRN & \\
\hline CHEMBL1302752 & 688293 & 4.8 & 5.0994 & TRN & \\
\hline CHEMBL1507132 & 688293 & 4.4 & 4.9992 & TRN & \\
\hline CHEMBL1588989 & 688293 & 4.4 & 4.9151 & TRN & \\
\hline CHEMBL1458225 & 688293 & 4.9 & 4.9978 & TST & \\
\hline CHEMBL1494609 & 688293 & 5.8 & 4.915 & TRN & \\
\hline CHEMBL1325533 & 688293 & 4.7 & 5.0533 & TRN & \\
\hline CHEMBL1404660 & 688293 & 4.4 & 4.9346 & TRN & \\
\hline & & & & 19527 & \\
\hline
\end{tabular}




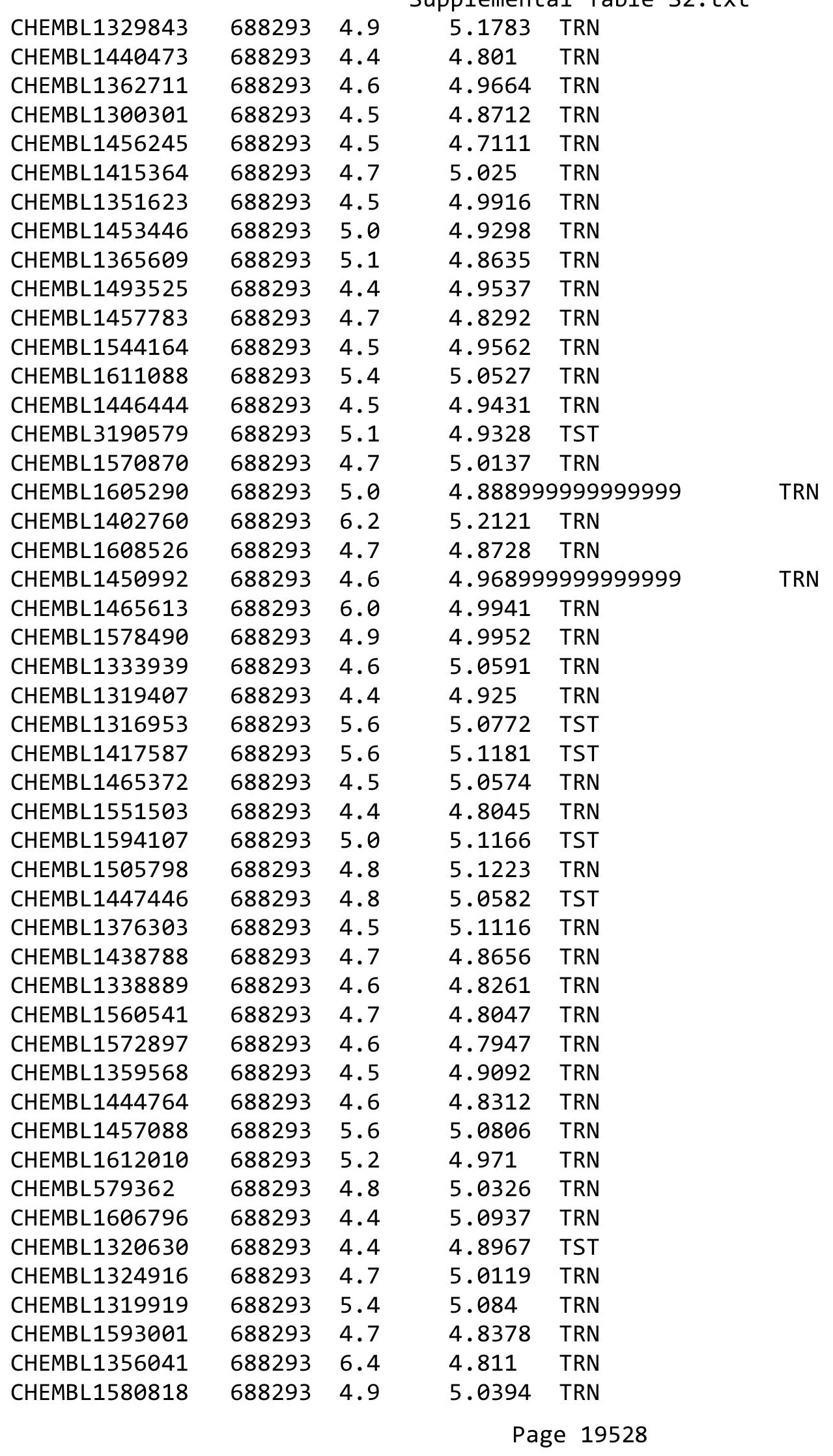




\begin{tabular}{|c|c|c|c|c|}
\hline \multicolumn{5}{|c|}{ oplemental Iable s2.txt } \\
\hline CHEMBL1270217 & 688293 & 4.4 & 4.9132 & TRN \\
\hline CHEMBL1336195 & 688293 & 6.2 & 4.8826 & TRN \\
\hline CHEMBL518252 & 688293 & 4.6 & 5.1112 & TST \\
\hline CHEMBL1412264 & 688293 & 4.4 & 5.0381 & TRN \\
\hline CHEMBL1415442 & 688293 & 4.8 & 4.8908 & TRN \\
\hline CHEMBL1449937 & 688293 & 4.5 & 4.8652 & TRN \\
\hline CHEMBL1382622 & 688293 & 5.6 & 5.0321 & TRN \\
\hline CHEMBL1334313 & 688293 & 4.9 & 5.0568 & TRN \\
\hline CHEMBL1235157 & 688293 & 4.4 & 5.0255 & TST \\
\hline CHEMBL1322000 & 688293 & 5.9 & 5.0728 & TRN \\
\hline CHEMBL1456054 & 688293 & 5.3 & 5.0133 & TRN \\
\hline CHEMBL1371069 & 688293 & 4.4 & 5.2305 & TRN \\
\hline CHEMBL1449800 & 688293 & 6.1 & 5.0398 & TRN \\
\hline CHEMBL1460550 & 688293 & 4.9 & 5.0239 & TRN \\
\hline CHEMBL1411684 & 688293 & 4.4 & 5.022 & TST \\
\hline CHEMBL1372368 & 688293 & 4.8 & 5.0712 & TRN \\
\hline CHEMBL1569965 & 688293 & 4.7 & 5.0288 & TRN \\
\hline CHEMBL1422715 & 688293 & 4.4 & 5.0258 & TRN \\
\hline CHEMBL1530113 & 688293 & 4.7 & 4.7909 & TRN \\
\hline CHEMBL442956 & 688293 & 6.1 & 5.0457 & TRN \\
\hline CHEMBL1543314 & 688293 & 5.4 & 5.1795 & TRN \\
\hline CHEMBL1352100 & 688293 & 6.8 & 5.2443 & TRN \\
\hline CHEMBL1529543 & 688293 & 4.6 & 4.8775 & TRN \\
\hline CHEMBL1560835 & 688293 & 4.9 & 5.0918 & TRN \\
\hline CHEMBL1452558 & 688293 & 4.8 & 4.9913 & TRN \\
\hline CHEMBL 269550 & 688293 & 4.9 & 5.0387 & TRN \\
\hline CHEMBL1365541 & 688293 & 4.5 & 4.8966 & TRN \\
\hline CHEMBL1346293 & 688293 & 4.4 & 5.096 & TST \\
\hline CHEMBL1535332 & 688293 & 4.4 & 5.2011 & TRN \\
\hline CHEMBL1482650 & 688293 & 4.8 & 5.1221 & TRN \\
\hline CHEMBL 242383 & 688293 & 4.6 & 4.9089 & TRN \\
\hline CHEMBL1398540 & 688293 & 4.9 & 4.7805 & TRN \\
\hline CHEMBL1606871 & 688293 & 4.7 & 4.7967 & TRN \\
\hline CHEMBL1516433 & 688293 & 4.6 & 4.9922 & TRN \\
\hline CHEMBL608699 & 688293 & 4.4 & 4.9368 & TST \\
\hline CHEMBL1511551 & 688293 & 4.4 & 4.9068 & TRN \\
\hline CHEMBL1386823 & 688293 & 4.9 & 5.0356 & TRN \\
\hline CHEMBL1387918 & 688293 & 6.4 & 5.1964 & TRN \\
\hline CHEMBL1335838 & 688293 & 6.4 & 5.1943 & TRN \\
\hline CHEMBL1328707 & 688293 & 4.6 & 4.9282 & TRN \\
\hline CHEMBL1607984 & 688293 & 4.4 & 5.149 & TRN \\
\hline CHEMBL 1555665 & 688293 & 4.6 & 4.8157 & TRN \\
\hline CHEMBL1410971 & 688293 & 5.7 & 5.0459 & TRN \\
\hline CHEMBL1505008 & 688293 & 4.9 & 5.05699 & 99999999995 \\
\hline CHEMBL1479366 & 688293 & 4.4 & 5.0286 & TST \\
\hline CHEMBL1423554 & 688293 & 4.5 & 5.1504 & TRN \\
\hline CHEMBL1609692 & 688293 & 4.7 & 5.0709 & TRN \\
\hline CHEMBL1527346 & 688293 & 4.5 & 5.013 & TRN \\
\hline
\end{tabular}




\begin{tabular}{|c|c|c|c|c|c|}
\hline \multicolumn{6}{|c|}{ Supplemental Table S2.txt } \\
\hline CHEMBL1525939 & 688293 & 4.6 & 4.8639 & TRN & \\
\hline CHEMBL391997 & 688293 & 4.5 & 4.9878 & TST & \\
\hline CHEMBL1415816 & 688293 & 4.5 & 4.9849 & TRN & \\
\hline CHEMBL1517897 & 688293 & 8.0 & 5.1069 & TRN & \\
\hline CHEMBL1528949 & 688293 & 4.6 & 4.7883 & TRN & \\
\hline CHEMBL1334493 & 688293 & 4.4 & 4.9571 & TRN & \\
\hline CHEMBL1482713 & 688293 & 4.6 & 4.9806 & TRN & \\
\hline CHEMBL1609849 & 688293 & 5.1 & 5.0149 & TRN & \\
\hline CHEMBL1413795 & 688293 & 4.4 & 5.0551 & TST & \\
\hline CHEMBL1553056 & 688293 & 4.8 & 5.0665 & TRN & \\
\hline CHEMBL1588086 & 688293 & 5.4 & 4.9812 & TRN & \\
\hline CHEMBL1368420 & 688293 & 4.6 & 4.9001 & TRN & \\
\hline CHEMBL1597019 & 688293 & 4.8 & 4.8969 & TST & \\
\hline CHEMBL1414274 & 688293 & 4.4 & 5.2304 & TST & \\
\hline CHEMBL1388584 & 688293 & 5.7 & 4.9312 & TST & \\
\hline CHEMBL1453432 & 688293 & 7.699 & 5.1008 & TRN & \\
\hline CHEMBL513116 & 688293 & 4.4 & 4.9613 & TST & \\
\hline CHEMBL1449612 & 688293 & 5.3 & 4.8282 & TRN & \\
\hline CHEMBL1427578 & 688293 & 4.6 & 4.7284 & TRN & \\
\hline CHEMBL1306266 & 688293 & 5.0 & 4.7043 & TST & \\
\hline CHEMBL1402656 & 688293 & 4.6 & 4.9627 & TST & \\
\hline CHEMBL1510449 & 688293 & 4.7 & 4.9835 & TST & \\
\hline CHEMBL1524617 & 688293 & 4.8 & 5.0017 & TST & \\
\hline CHEMBL106265 & 688293 & 5.8 & 5.1213 & TRN & \\
\hline CHEMBL1589064 & 688293 & 5.7 & 5.2049 & TRN & \\
\hline CHEMBL1344260 & 688293 & 4.5 & 4.8609 & TRN & \\
\hline CHEMBL1352212 & 688293 & 4.7 & 5.1726 & TRN & \\
\hline CHEMBL1519365 & 688293 & 4.6 & 4.9824 & TRN & \\
\hline CHEMBL1384309 & 688293 & 7.8996 & 5.1017 & TST & \\
\hline CHEMBL1414061 & 688293 & 4.6 & 5.0292 & TRN & \\
\hline CHEMBL1549860 & 688293 & 4.5 & 4.9762 & TRN & \\
\hline CHEMBL1396146 & 688293 & 4.7 & 4.8959 & TRN & \\
\hline CHEMBL1484038 & 688293 & 4.8 & 4.9461 & TRN & \\
\hline CHEMBL1410798 & 688293 & 4.8 & 4.9731 & TRN & \\
\hline CHEMBL1569894 & 688293 & 4.6 & 5.0424 & TRN & \\
\hline CHEMBL1439575 & 688293 & 4.6 & 5.2078 & TRN & \\
\hline CHEMBL 88272 & 688293 & 4.4 & 4.9146 & TST & \\
\hline CHEMBL1365489 & 688293 & 7.8996 & 4.9286 & TST & \\
\hline CHEMBL1441618 & 688293 & 4.6 & 4.9088 & TRN & \\
\hline CHEMBL1352186 & 688293 & 4.4 & 5.0155 & TRN & \\
\hline CHEMBL1338459 & 688293 & 5.8 & 5.0097 & TST & \\
\hline CHEMBL491748 & 688293 & 4.8 & 4.74100 & 00000000005 & TRN \\
\hline CHEMBL1381498 & 688293 & 5.2 & 5.0229 & TRN & \\
\hline CHEMBL1500426 & 688293 & 4.5 & 4.9833 & TRN & \\
\hline CHEMBL1383736 & 688293 & 4.7 & 4.9772 & TRN & \\
\hline CHEMBL1426729 & 688293 & 4.5 & 4.977 & TRN & \\
\hline CHEMBL1451429 & 688293 & 4.8 & 5.0527 & TRN & \\
\hline CHEMBL1589768 & 688293 & 4.4 & 4.7683 & TRN & \\
\hline
\end{tabular}




\begin{tabular}{|c|c|c|c|c|c|}
\hline & & & & & \\
\hline CHEMBL1390967 & 688293 & 4.6 & 5.1169 & TRN & \\
\hline CHEMBL1351746 & 688293 & 4.6 & 5.0218 & TRN & \\
\hline CHEMBL1526559 & 688293 & 4.6 & 4.7581 & TRN & \\
\hline CHEMBL1316092 & 688293 & 4.6 & 5.1454 & TST & \\
\hline CHEMBL1516905 & 688293 & 5.5 & 5.0583 & TRN & \\
\hline CHEMBL1564477 & 688293 & 4.5 & 4.8604 & TRN & \\
\hline CHEMBL1439226 & 688293 & 4.5 & 5.169 & TRN & \\
\hline CHEMBL1413339 & 688293 & 4.5 & 5.0549 & TRN & \\
\hline CHEMBL1552194 & 688293 & 5.0 & 4.7853 & TRN & \\
\hline CHEMBL1421449 & 688293 & 4.4 & 5.1032 & TRN & \\
\hline CHEMBL1464538 & 688293 & 4.7 & 5.1764 & TRN & \\
\hline CHEMBL1539156 & 688293 & 4.6 & 5.0765 & TRN & \\
\hline CHEMBL1387914 & 688293 & 6.5 & 5.1285 & TRN & \\
\hline CHEMBL1561023 & 688293 & 4.5 & 4.76399 & 9999999999 & TRN \\
\hline CHEMBL1359872 & 688293 & 4.7 & 5.0236 & TRN & \\
\hline CHEMBL1555814 & 688293 & 4.4 & 4.8017 & TRN & \\
\hline CHEMBL1541927 & 688293 & 4.9 & 4.9728 & TRN & \\
\hline CHEMBL1410827 & 688293 & 7.3002 & 5.0576 & TRN & \\
\hline CHEMBL1482134 & 688293 & 6.2 & 5.0249 & TST & \\
\hline CHEMBL 301100 & 688293 & 4.4 & 4.9689 & TRN & \\
\hline CHEMBL1344196 & 688293 & 5.0 & 5.0187 & TRN & \\
\hline CHEMBL1560052 & 688293 & 4.4 & 5.1234 & TRN & \\
\hline CHEMBL1517687 & 688293 & 8.0 & 4.9423 & TST & \\
\hline CHEMBL1304797 & 688293 & 4.4 & 4.9747 & TRN & \\
\hline CHEMBL1466910 & 688293 & 6.8 & 5.0155 & TRN & \\
\hline CHEMBL1580209 & 688293 & 4.8 & 5.1635 & TRN & \\
\hline CHEMBL1504119 & 688293 & 5.0 & 5.0869 & TRN & \\
\hline CHEMBL1580245 & 688293 & 4.9 & 4.8672 & TRN & \\
\hline CHEMBL1516483 & 688293 & 4.6 & 5.0212 & TRN & \\
\hline CHEMBL1541741 & 688293 & 4.4 & 4.9847 & TRN & \\
\hline CHEMBL1472495 & 688293 & 4.7 & 5.1052 & TRN & \\
\hline CHEMBL1322563 & 688293 & 4.7 & 5.0107 & TRN & \\
\hline CHEMBL1593754 & 688293 & 6.0 & 5.1601 & TST & \\
\hline CHEMBL1344630 & 688293 & 4.8 & 4.8934 & TRN & \\
\hline CHEMBL1450018 & 688293 & 4.8 & 4.9462 & TRN & \\
\hline CHEMBL1535521 & 688293 & 4.7 & 5.1704 & TST & \\
\hline CHEMBL1377905 & 688293 & 4.8 & 5.2539 & TRN & \\
\hline CHEMBL1464128 & 688293 & 5.0 & 4.9832 & TST & \\
\hline CHEMBL1411739 & 688293 & 4.8 & 5.0121 & TRN & \\
\hline CHEMBL1498956 & 688293 & 4.4 & 5.237 & TRN & \\
\hline CHEMBL1367949 & 688293 & 4.4 & 4.9983 & TRN & \\
\hline CHEMBL1429872 & 688293 & 4.8 & 4.9672 & TRN & \\
\hline CHEMBL1481530 & 688293 & 4.4 & 4.9942 & TRN & \\
\hline CHEMBL1592803 & 688293 & 4.6 & 4.7701 & TRN & \\
\hline CHEMBL1503135 & 688293 & 4.6 & 4.7492 & TRN & \\
\hline CHEMBL1479236 & 688293 & 4.6 & 4.9353 & TRN & \\
\hline CHEMBL1431830 & 688293 & 4.5 & 5.1204 & TRN & \\
\hline CHEMBL1597841 & 688293 & 4.9 & 5.2268 & TST & \\
\hline & & & & 19531 & \\
\hline
\end{tabular}




\begin{tabular}{|c|c|c|c|c|c|}
\hline & \\
\hline CHEMBL373137 & 688293 & 4.4 & 4.9324 & TRN & \\
\hline CHEMBL1594397 & 688293 & 6.2 & 5.1138 & TRN & \\
\hline CHEMBL1302494 & 688293 & 4.5 & 4.7837 & TRN & \\
\hline CHEMBL1437831 & 688293 & 8.1024 & 5.0717 & TST & \\
\hline CHEMBL1492217 & 688293 & 4.5 & 4.7953 & TRN & \\
\hline CHEMBL1329481 & 688293 & 4.4 & 5.1757 & TST & \\
\hline CHEMBL1541041 & 688293 & 5.1 & 5.1904 & TRN & \\
\hline CHEMBL1338297 & 688293 & 4.9 & 5.1353 & TRN & \\
\hline CHEMBL1570853 & 688293 & 4.6 & 4.9466 & TRN & \\
\hline CHEMBL1417721 & 688293 & 4.7 & 5.1608 & TRN & \\
\hline CHEMBL38576 & 688293 & 4.4 & 5.0521 & TST & \\
\hline CHEMBL1508787 & 688293 & 4.7 & 5.1888 & TRN & \\
\hline CHEMBL1467528 & 688293 & 4.4 & 5.129 & TRN & \\
\hline CHEMBL1403626 & 688293 & 4.4 & 5.0938 & TRN & \\
\hline CHEMBL1340393 & 688293 & 5.1 & 4.8666 & TRN & \\
\hline CHEMBL3189530 & 688293 & 4.9 & 4.8223 & TST & \\
\hline CHEMBL395808 & 688293 & 4.5 & 4.9084 & TRN & \\
\hline CHEMBL1544460 & 688293 & 4.4 & 4.9077 & TRN & \\
\hline CHEMBL1387047 & 688293 & 4.6 & 4.9231 & TRN & \\
\hline CHEMBL1452250 & 688293 & 4.8 & 4.8716 & TRN & \\
\hline CHEMBL1459153 & 688293 & 4.9 & 4.8916 & TRN & \\
\hline CHEMBL1577213 & 688293 & 4.4 & 4.9607 & TRN & \\
\hline CHEMBL1399968 & 688293 & 4.7 & 4.7971 & TRN & \\
\hline CHEMBL1472765 & 688293 & 4.4 & 4.8741 & TRN & \\
\hline CHEMBL1389165 & 688293 & 4.5 & 4.9913 & TRN & \\
\hline CHEMBL1578948 & 688293 & 4.6 & 5.0844 & TRN & \\
\hline CHEMBL1311755 & 688293 & 4.5 & 4.84399 & 9999999999 & TRN \\
\hline CHEMBL1489716 & 688293 & 4.4 & 4.8808 & TRN & \\
\hline CHEMBL1335023 & 688293 & 4.4 & 4.9863 & TRN & \\
\hline CHEMBL1368300 & 688293 & 4.5 & 4.9432 & TRN & \\
\hline CHEMBL1306412 & 688293 & 4.4 & 4.9834 & TRN & \\
\hline CHEMBL1459655 & 688293 & 4.5 & 5.0349 & TRN & \\
\hline CHEMBL1344285 & 688293 & 5.1 & 4.8745 & TRN & \\
\hline CHEMBL1395337 & 688293 & 4.4 & 4.9851 & TRN & \\
\hline CHEMBL1327355 & 688293 & 5.5 & 4.744 & TRN & \\
\hline CHEMBL3211328 & 688293 & 4.8 & 4.9196 & TST & \\
\hline CHEMBL1595195 & 688293 & 4.5 & 4.9146 & TRN & \\
\hline CHEMBL1368693 & 688293 & 6.9 & 5.1963 & TST & \\
\hline CHEMBL1518317 & 688293 & 4.4 & 5.1341 & TRN & \\
\hline CHEMBL1587632 & 688293 & 4.5 & 4.9842 & TRN & \\
\hline CHEMBL1586975 & 688293 & 4.8 & 5.0158 & TRN & \\
\hline CHEMBL1418088 & 688293 & 5.5 & 5.2044 & TST & \\
\hline CHEMBL1343836 & 688293 & 5.1 & 5.1102 & TRN & \\
\hline CHEMBL1330613 & 688293 & 7.2 & 5.215 & TST & \\
\hline CHEMBL1341852 & 688293 & 4.4 & 4.9641 & TRN & \\
\hline CHEMBL3208584 & 688293 & 4.7 & 4.8982 & TST & \\
\hline CHEMBL1489171 & 688293 & 4.6 & 5.0902 & TRN & \\
\hline CHEMBL1461249 & 688293 & 4.6 & 4.8423 & TRN & \\
\hline & & & & 19532 & \\
\hline
\end{tabular}




\begin{tabular}{|c|c|c|c|c|c|}
\hline \multirow[b]{2}{*}{ CHEMBL1438663 } & \multirow[b]{2}{*}{688293} & \\
\hline & & 4.6 & 5.0341 & TRN & \\
\hline CHEMBL1304205 & 688293 & 4.6 & 4.8816 & TRN & \\
\hline CHEMBL428789 & 688293 & 4.5 & 4.8956 & TRN & \\
\hline CHEMBL497781 & 688293 & 4.4 & 4.8075 & TRN & \\
\hline CHEMBL3191413 & 688293 & 4.5 & 4.7756 & TST & \\
\hline CHEMBL1488258 & 688293 & 4.6 & 4.9292 & TRN & \\
\hline CHEMBL1374352 & 688293 & 4.6 & 5.0491 & TRN & \\
\hline CHEMBL1386092 & 688293 & 4.4 & 4.8956 & TRN & \\
\hline CHEMBL1386883 & 688293 & 4.4 & 4.8655 & TRN & \\
\hline CHEMBL1460562 & 688293 & 5.0 & 5.1171 & TRN & \\
\hline CHEMBL1462694 & 688293 & 4.6 & 4.995 & TRN & \\
\hline CHEMBL1564640 & 688293 & 4.8 & 4.8438 & TRN & \\
\hline CHEMBL1359368 & 688293 & 5.1 & 5.0551 & TRN & \\
\hline CHEMBL3190679 & 688293 & 4.8 & 4.9713 & TRN & \\
\hline CHEMBL1418407 & 688293 & 5.4 & 4.8101 & TST & \\
\hline CHEMBL1336048 & 688293 & 6.8 & 5.0973 & TRN & \\
\hline CHEMBL1347208 & 688293 & 4.5 & 5.01699 & 99999999995 & TRN \\
\hline CHEMBL1603948 & 688293 & 4.5 & 5.1018 & TRN & \\
\hline CHEMBL117 & 688293 & 4.5 & 4.8896 & TRN & \\
\hline CHEMBL1347975 & 688293 & 4.5 & 4.9925 & TST & \\
\hline CHEMBL1574849 & 688293 & 4.8 & 5.0274 & TRN & \\
\hline CHEMBL1577449 & 688293 & 4.5 & 5.0169 & TRN & \\
\hline CHEMBL1301956 & 688293 & 5.7 & 4.9537 & TRN & \\
\hline CHEMBL1588513 & 688293 & 4.6 & 4.7939 & TST & \\
\hline CHEMBL1509092 & 688293 & 4.4 & 5.0474 & TRN & \\
\hline CHEMBL1460061 & 688293 & 4.4 & 5.027 & TRN & \\
\hline CHEMBL1371175 & 688293 & 4.5 & 4.8798 & TRN & \\
\hline CHEMBL1524133 & 688293 & 5.5 & 4.9919 & TRN & \\
\hline CHEMBL1516534 & 688293 & 5.8 & 4.8071 & TRN & \\
\hline CHEMBL1549281 & 688293 & 4.4 & 4.9567 & TST & \\
\hline CHEMBL1382147 & 688293 & 4.8 & 5.2063 & TRN & \\
\hline CHEMBL1588601 & 688293 & 5.1 & 5.0047 & TRN & \\
\hline CHEMBL1372584 & 688293 & 4.4 & 5.0887 & TRN & \\
\hline CHEMBL1314388 & 688293 & 5.1 & 4.8238 & TRN & \\
\hline CHEMBL1448974 & 688293 & 5.4 & 5.0065 & TRN & \\
\hline CHEMBL1399613 & 688293 & 4.7 & 5.1559 & TRN & \\
\hline CHEMBL1393347 & 688293 & 4.6 & 5.033 & TRN & \\
\hline CHEMBL1507310 & 688293 & 4.4 & 5.0658 & TRN & \\
\hline CHEMBL1594134 & 688293 & 5.6 & 4.7517 & TRN & \\
\hline CHEMBL1477411 & 688293 & 5.1 & 4.9196 & TST & \\
\hline CHEMBL1446009 & 688293 & 4.4 & 4.8526 & TRN & \\
\hline CHEMBL1577159 & 688293 & 7.1002 & 4.9863 & TRN & \\
\hline CHEMBL1574043 & 688293 & 4.5 & 5.0198 & TRN & \\
\hline CHEMBL1544909 & 688293 & 5.5 & 5.0617 & TST & \\
\hline CHEMBL1489223 & 688293 & 4.5 & 4.9741 & TRN & \\
\hline CHEMBL1308887 & 688293 & 4.4 & 5.0023 & TRN & \\
\hline CHEMBL1315891 & 688293 & 5.4 & 5.1301 & TST & \\
\hline CHEMBL76447 & 688293 & 4.5 & 4.9322 & TRN & \\
\hline & & & & 19533 & \\
\hline
\end{tabular}




\begin{tabular}{|c|c|c|c|c|}
\hline \multicolumn{5}{|c|}{ Supplemental Table S2.txt } \\
\hline CHEMBL1427237 & 688293 & 4.5 & 5.0154 & TRN \\
\hline CHEMBL1498876 & 688293 & 4.7 & 5.0001 & TRN \\
\hline CHEMBL1432209 & 688293 & 6.9 & 5.0357 & TRN \\
\hline CHEMBL1319971 & 688293 & 4.9 & 5.1606 & TST \\
\hline CHEMBL1600210 & 688293 & 4.9 & 4.8255 & TRN \\
\hline CHEMBL1342330 & 688293 & 4.4 & 5.0348 & TRN \\
\hline CHEMBL1467812 & 688293 & 4.7 & 5.1375 & TRN \\
\hline CHEMBL1578233 & 688293 & 4.4 & 4.7737 & TRN \\
\hline CHEMBL1454183 & 688293 & 5.6 & 4.978 & TST \\
\hline CHEMBL20963 & 688293 & 4.5 & 4.9815 & TRN \\
\hline CHEMBL1322651 & 688293 & 8.0 & 4.9513 & TRN \\
\hline CHEMBL3190774 & 688293 & 4.9 & 4.8491 & TRN \\
\hline CHEMBL1598870 & 688293 & 4.5 & 4.895 & TRN \\
\hline CHEMBL1451867 & 688293 & 4.4 & 5.1297 & TRN \\
\hline CHEMBL1433489 & 688293 & 4.7 & 4.9112 & TST \\
\hline CHEMBL1441885 & 688293 & 4.6 & 4.8915 & TRN \\
\hline CHEMBL1256625 & 688293 & 6.8 & 4.9808 & TST \\
\hline CHEMBL1370738 & 688293 & 4.4 & 4.9382 & TRN \\
\hline CHEMBL1490602 & 688293 & 5.0 & 4.8147 & TRN \\
\hline CHEMBL1414830 & 688293 & 4.5 & 5.0417 & TST \\
\hline CHEMBL1522139 & 688293 & 7.5003 & 4.8732 & TST \\
\hline CHEMBL1477081 & 688293 & 4.6 & 5.06 & TST \\
\hline CHEMBL1560323 & 688293 & 4.4 & 4.9864 & TRN \\
\hline CHEMBL1530492 & 688293 & 4.4 & 4.9556 & TRN \\
\hline CHEMBL1425319 & 688293 & 4.8 & 5.1551 & TRN \\
\hline CHEMBL1410792 & 688293 & 4.4 & 5.114 & TRN \\
\hline CHEMBL1606945 & 688293 & 5.2 & 5.149 & TRN \\
\hline CHEMBL1371137 & 688293 & 4.6 & 4.9822 & TRN \\
\hline CHEMBL1556351 & 688293 & 5.3 & 4.8995 & TST \\
\hline CHEMBL1337908 & 688293 & 4.4 & 5.0939 & TRN \\
\hline CHEMBL1393762 & 688293 & 4.7 & 5.1551 & TRN \\
\hline CHEMBL1412622 & 688293 & 6.8 & 4.9634 & TRN \\
\hline CHEMBL1570215 & 688293 & 4.8 & 5.2606 & TRN \\
\hline CHEMBL1598104 & 688293 & 4.7 & 4.93 & TRN \\
\hline CHEMBL1424572 & 688293 & 4.6 & 5.1057 & TRN \\
\hline CHEMBL1488678 & 688293 & 4.7 & 4.9744 & TRN \\
\hline CHEMBL1428593 & 688293 & 5.4 & 5.1823 & TRN \\
\hline CHEMBL1580578 & 688293 & 8.2007 & 5.0916 & TRN \\
\hline CHEMBL1344031 & 688293 & 4.5 & 5.065 & TRN \\
\hline CHEMBL489738 & 688293 & 4.6 & 4.8873 & TRN \\
\hline CHEMBL1516868 & 688293 & 9.0 & 4.9982 & TRN \\
\hline CHEMBL1407257 & 688293 & 4.6 & 4.8463 & TRN \\
\hline CHEMBL1385254 & 688293 & 4.6 & 4.8545 & TRN \\
\hline CHEMBL1368572 & 688293 & 5.1 & 5.0017 & TRN \\
\hline CHEMBL1344610 & 688293 & 4.6 & 5.3188 & TRN \\
\hline CHEMBL1471674 & 688293 & 4.8 & 4.9254 & TRN \\
\hline CHEMBL1586970 & 688293 & 4.5 & 4.9595 & TST \\
\hline CHEMBL1537232 & 688293 & 4.4 & 4.9685 & TRN \\
\hline
\end{tabular}




\begin{tabular}{|c|c|c|c|c|}
\hline & & & pplement & al $\mathrm{Ta}$ \\
\hline CHEMBL1598997 & 688293 & 4.8 & 5.0228 & TRN \\
\hline CHEMBL1415054 & 688293 & 5.5 & 5.0285 & TST \\
\hline CHEMBL299155 & 688293 & 4.5 & 5.006 & TRN \\
\hline CHEMBL1380503 & 688293 & 4.6 & 5.0596 & TRN \\
\hline CHEMBL1418716 & 688293 & 4.8 & 5.2387 & TRN \\
\hline CHEMBL529939 & 688293 & 5.1 & 5.0159 & TRN \\
\hline CHEMBL1463982 & 688293 & 5.0 & 5.0249 & TRN \\
\hline CHEMBL88961 & 688293 & 4.5 & 4.9841 & TRN \\
\hline CHEMBL1603718 & 688293 & 5.0 & 4.8404 & TRN \\
\hline CHEMBL1561366 & 688293 & 5.5 & 4.8183 & TRN \\
\hline CHEMBL1371693 & 688293 & 4.6 & 5.0614 & TRN \\
\hline CHEMBL1558124 & 688293 & 4.6 & 5.1504 & TRN \\
\hline CHEMBL 89445 & 688293 & 4.4 & 4.7648 & TRN \\
\hline CHEMBL1369064 & 688293 & 5.5 & 5.1738 & TRN \\
\hline CHEMBL1481298 & 688293 & 8.0 & 5.0081 & TRN \\
\hline CHEMBL1573165 & 688293 & 4.6 & 5.0333 & TST \\
\hline CHEMBL1543808 & 688293 & 4.4 & 5.0526 & TRN \\
\hline CHEMBL1592507 & 688293 & 5.2 & 5.039 & TST \\
\hline CHEMBL1336289 & 688293 & 4.7 & 4.9234 & TRN \\
\hline CHEMBL1503340 & 688293 & 5.0 & 5.0479 & TST \\
\hline CHEMBL1527671 & 688293 & 5.2 & 4.955 & TST \\
\hline CHEMBL546257 & 688293 & 4.9 & 4.7755 & TST \\
\hline CHEMBL1374062 & 688293 & 4.6 & 4.9662 & TRN \\
\hline CHEMBL1402304 & 688293 & 4.8 & 4.9532 & TRN \\
\hline CHEMBL1532407 & 688293 & 5.0 & 4.8729 & TRN \\
\hline CHEMBL1433156 & 688293 & 4.7 & 4.9489 & TRN \\
\hline CHEMBL1372214 & 688293 & 4.8 & 5.0673 & TRN \\
\hline CHEMBL1525066 & 688293 & 4.8 & 5.0542 & TRN \\
\hline CHEMBL1314416 & 688293 & 5.3 & 4.7661 & TRN \\
\hline CHEMBL1468442 & 688293 & 4.6 & 4.9225 & TRN \\
\hline CHEMBL1341830 & 688293 & 4.4 & 4.9073 & TST \\
\hline CHEMBL1512988 & 688293 & 4.5 & 4.9075 & TRN \\
\hline CHEMBL1448182 & 688293 & 4.4 & 5.0627 & TRN \\
\hline CHEMBL1496686 & 688293 & 4.4 & 5.1006 & TRN \\
\hline CHEMBL1532732 & 688293 & 6.0 & 4.9571 & TRN \\
\hline CHEMBL1387911 & 688293 & 5.9 & 5.1093 & TRN \\
\hline CHEMBL1565469 & 688293 & 4.8 & 4.9566 & TRN \\
\hline CHEMBL1407035 & 688293 & 6.4 & 4.8225 & TRN \\
\hline CHEMBL1348929 & 688293 & 5.2 & 4.9016 & TRN \\
\hline CHEMBL1301760 & 688293 & 4.7 & 5.0152 & TRN \\
\hline CHEMBL1461412 & 688293 & 6.2 & 4.9006 & TRN \\
\hline CHEMBL1362198 & 688293 & 4.9 & 5.02 & TRN \\
\hline CHEMBL1420853 & 688293 & 6.0 & 4.891 & TRN \\
\hline CHEMBL1535831 & 688293 & 4.6 & 5.1559 & TST \\
\hline CHEMBL1464358 & 688293 & 8.0 & 5.1516 & TRN \\
\hline CHEMBL1392174 & 688293 & 4.8 & 5.3103 & TRN \\
\hline CHEMBL1503267 & 688293 & 4.6 & 5.2149 & TRN \\
\hline CHEMBL1466790 & 688293 & 4.7 & 5.0807 & TST \\
\hline
\end{tabular}




\begin{tabular}{|c|c|c|c|c|}
\hline \multicolumn{5}{|c|}{ Supplemental Table s2.txt } \\
\hline CHEMBL489534 & 688293 & 5.7 & 4.7839 & TRN \\
\hline CHEMBL1525979 & 688293 & 4.4 & 4.8322 & TRN \\
\hline CHEMBL1348876 & 688293 & 5.0 & 4.9576 & TRN \\
\hline CHEMBL1541293 & 688293 & 4.7 & 5.2688 & TRN \\
\hline CHEMBL1460472 & 688293 & 5.3 & 5.0412 & TRN \\
\hline CHEMBL1326955 & 688293 & 7.4001 & 5.1369 & TRN \\
\hline CHEMBL1490455 & 688293 & 4.9 & 5.0792 & TRN \\
\hline CHEMBL1310499 & 688293 & 5.0 & 4.9561 & TRN \\
\hline CHEMBL1256996 & 688293 & 4.4 & 5.0705 & TST \\
\hline CHEMBL1471497 & 688293 & 4.5 & 4.9903 & TRN \\
\hline CHEMBL1556792 & 688293 & 4.8 & 4.8495 & TRN \\
\hline CHEMBL1504969 & 688293 & 5.0 & 5.1074 & TRN \\
\hline CHEMBL1558287 & 688293 & 4.5 & 4.9091 & TRN \\
\hline CHEMBL1549175 & 688293 & 4.8 & 5.0092 & TRN \\
\hline CHEMBL1343219 & 688293 & 4.4 & 4.9674 & TRN \\
\hline CHEMBL1511432 & 688293 & 6.6 & 5.1999 & TRN \\
\hline CHEMBL1491326 & 688293 & 4.4 & 4.8629 & TRN \\
\hline CHEMBL1208858 & 688293 & 4.7 & 4.8026 & TST \\
\hline CHEMBL1579821 & 688293 & 4.7 & 5.0798 & TST \\
\hline CHEMBL1460497 & 688293 & 4.4 & 4.9972 & TRN \\
\hline CHEMBL1463575 & 688293 & 4.8 & 4.9821 & TRN \\
\hline CHEMBL1546263 & 688293 & 5.3 & 4.7974 & TST \\
\hline CHEMBL1387029 & 688293 & 4.4 & 5.0443 & TRN \\
\hline CHEMBL1565379 & 688293 & 4.5 & 4.9069 & TRN \\
\hline CHEMBL1417097 & 688293 & 7.8013 & 4.8686 & TRN \\
\hline CHEMBL1544045 & 688293 & 8.0 & 5.1211 & TRN \\
\hline CHEMBL1568217 & 688293 & 4.6 & 4.9319 & TRN \\
\hline CHEMBL1256984 & 688293 & 4.8 & 4.9131 & TST \\
\hline CHEMBL1479620 & 688293 & 4.4 & 4.8167 & TRN \\
\hline CHEMBL1326308 & 688293 & 5.5 & 4.9817 & TRN \\
\hline CHEMBL405912 & 688293 & 4.5 & 4.7192 & TRN \\
\hline CHEMBL1588030 & 688293 & 6.7001 & 5.1877 & TRN \\
\hline CHEMBL1485196 & 688293 & 4.4 & 4.919 & TRN \\
\hline CHEMBL1568540 & 688293 & 8.2007 & 5.1883 & TRN \\
\hline CHEMBL1318042 & 688293 & 4.5 & 4.8425 & TRN \\
\hline CHEMBL1304169 & 688293 & 4.8 & 5.01 & TRN \\
\hline CHEMBL1568572 & 688293 & 4.9 & 5.1548 & TRN \\
\hline CHEMBL1302582 & 688293 & 4.8 & 5.0951 & TST \\
\hline CHEMBL1344060 & 688293 & 4.4 & 5.1153 & TRN \\
\hline CHEMBL1547349 & 688293 & 4.9 & 4.8713 & TRN \\
\hline CHEMBL1308001 & 688293 & 5.0 & 4.8633 & TRN \\
\hline CHEMBL1388876 & 688293 & 5.1 & 5.0786 & TRN \\
\hline CHEMBL1538317 & 688293 & 6.0 & 5.0429 & TRN \\
\hline CHEMBL1405464 & 688293 & 4.6 & 4.8048 & TRN \\
\hline CHEMBL1362308 & 688293 & 4.8 & 4.9185 & TRN \\
\hline CHEMBL1330317 & 688293 & 4.6 & 4.7077 & TRN \\
\hline CHEMBL1433805 & 688293 & 5.3 & 4.7321 & TRN \\
\hline CHEMBL1355090 & 688293 & 8.3979 & 5.0692 & TRN \\
\hline
\end{tabular}




\begin{tabular}{|c|c|c|c|c|c|}
\hline \multirow{3}{*}{$\begin{array}{l}\text { CHEMBL1480516 } \\
\text { CHEMBL1371286 }\end{array}$} & \multirow{3}{*}{$\begin{array}{l}688293 \\
688293\end{array}$} & \multicolumn{4}{|c|}{ Supplemental Table S2.txt } \\
\hline & & 8.4949 & \multicolumn{2}{|c|}{5.1770000000000005} & TST \\
\hline & & 5.4 & 5.129 & TRN & \\
\hline CHEMBL1519579 & 688293 & 6.9 & 5.1547 & TRN & \\
\hline CHEMBL1524222 & 688293 & 4.8 & 5.0109 & TRN & \\
\hline CHEMBL1362419 & 688293 & 4.6 & 4.8708 & TRN & \\
\hline CHEMBL1528870 & 688293 & 4.5 & 5.0391 & TRN & \\
\hline CHEMBL1308632 & 688293 & 5.0 & 5.0147 & TRN & \\
\hline CHEMBL1526455 & 688293 & 4.7 & 4.9717 & TST & \\
\hline CHEMBL1971815 & 688293 & 5.6 & 4.9634 & TRN & \\
\hline CHEMBL1430319 & 688293 & 4.6 & 4.7019 & TRN & \\
\hline CHEMBL1399549 & 688293 & 5.3 & 5.0671 & TRN & \\
\hline CHEMBL1351765 & 688293 & 4.6 & \multicolumn{2}{|c|}{5.132000000000001} & TRN \\
\hline CHEMBL1386757 & 688293 & 4.7 & 4.8671 & TRN & \\
\hline CHEMBL1417243 & 688293 & 5.4 & 4.8484 & TRN & \\
\hline CHEMBL1408337 & 688293 & 4.4 & 4.9552 & TRN & \\
\hline CHEMBL3209274 & 688293 & 4.6 & 4.9035 & TST & \\
\hline CHEMBL1315508 & 688293 & 6.1 & 4.8265 & TRN & \\
\hline CHEMBL1303634 & 688293 & 4.5 & 5.1005 & TRN & \\
\hline CHEMBL1352886 & 688293 & 4.7 & 5.0611 & TRN & \\
\hline CHEMBL1578557 & 688293 & 5.1 & 4.9173 & TRN & \\
\hline CHEMBL1236872 & 688293 & 6.0 & 4.9953 & TST & \\
\hline CHEMBL1529093 & 688293 & 6.1 & 4.9758 & TST & \\
\hline CHEMBL1308898 & 688293 & 5.0 & 4.8978 & TRN & \\
\hline CHEMBL1422099 & 688293 & 5.6 & 5.0715 & TRN & \\
\hline CHEMBL1493859 & 688293 & 4.8 & 5.0859 & TRN & \\
\hline CHEMBL1314486 & 688293 & 4.5 & 4.8605 & TRN & \\
\hline CHEMBL1609672 & 688293 & 4.4 & 4.9389 & TRN & \\
\hline CHEMBL1403448 & 688293 & 4.6 & 4.8252 & TRN & \\
\hline CHEMBL1541174 & 688293 & 4.6 & 4.9497 & TRN & \\
\hline CHEMBL1338330 & 688293 & 4.7 & 5.0134 & TRN & \\
\hline CHEMBL1519762 & 688293 & 4.7 & 5.0586 & TRN & \\
\hline CHEMBL1441589 & 688293 & 5.7 & 4.8914 & TRN & \\
\hline CHEMBL 252744 & 688293 & 4.7 & 4.9225 & TST & \\
\hline CHEMBL1304784 & 688293 & 5.1 & 5.0234 & TST & \\
\hline CHEMBL1328358 & 688293 & 5.9 & 5.0166 & TRN & \\
\hline CHEMBL1584208 & 688293 & 4.9 & 4.9945 & TRN & \\
\hline CHEMBL1561474 & 688293 & 4.7 & 5.1435 & TST & \\
\hline CHEMBL540848 & 688293 & 4.1 & 5.0266 & TST & \\
\hline CHEMBL1608125 & 688293 & 4.4 & 4.8012 & TRN & \\
\hline CHEMBL1504816 & 688293 & 4.4 & 4.9457 & TRN & \\
\hline CHEMBL1547516 & 688293 & 4.7 & 5.0105 & TRN & \\
\hline CHEMBL1327883 & 688293 & 4.5 & 4.9395 & TRN & \\
\hline CHEMBL1354961 & 688293 & 7.2 & 4.909 & TST & \\
\hline CHEMBL1441415 & 688293 & 4.8 & 4.8052 & TRN & \\
\hline CHEMBL1499096 & 688293 & 4.8 & 5.0953 & TRN & \\
\hline CHEMBL1607354 & 688293 & 4.6 & 5.0758 & TRN & \\
\hline CHEMBL1299416 & 688293 & 7.0 & 5.0162 & TRN & \\
\hline CHEMBL1524731 & 688293 & 4.4 & 4.9082 & TRN & \\
\hline
\end{tabular}




\begin{tabular}{|c|c|c|c|c|c|}
\hline \\
\hline CHEMBL1411217 & 688293 & 4.8 & 5.1825 & TRN & \\
\hline CHEMBL1339597 & 688293 & 5.5 & 5.2182 & TRN & \\
\hline CHEMBL105310 & 688293 & 4.5 & 4.9221 & TRN & \\
\hline CHEMBL1455600 & 688293 & 5.4 & 4.8102 & TRN & \\
\hline CHEMBL1452574 & 688293 & 4.7 & 5.0499 & TRN & \\
\hline CHEMBL1480678 & 688293 & 4.7 & 4.8677 & TST & \\
\hline CHEMBL1612517 & 688293 & 5.4 & 5.0497 & TRN & \\
\hline CHEMBL1600468 & 688293 & 5.6 & 4.9177 & TRN & \\
\hline CHEMBL1546294 & 688293 & 5.8 & 5.2111 & TRN & \\
\hline CHEMBL1344668 & 688293 & 4.8 & 5.0144 & TST & \\
\hline CHEMBL 1404538 & 688293 & 5.4 & 4.9428 & TST & \\
\hline CHEMBL1373679 & 688293 & 4.7 & $5.1160 e$ & 00000000005 & TRN \\
\hline CHEMBL1396898 & 688293 & 4.9 & 4.8564 & TRN & \\
\hline CHEMBL1305080 & 688293 & 8.0 & 4.9906 & TST & \\
\hline CHEMBL1570372 & 688293 & 4.5 & 5.0195 & TRN & \\
\hline CHEMBL1531879 & 688293 & 4.5 & 4.8049 & TST & \\
\hline CHEMBL1566696 & 688293 & 4.4 & 4.9934 & TRN & \\
\hline CHEMBL12014 & 688293 & 4.0 & 4.8355 & TST & \\
\hline CHEMBL523167 & 688293 & 6.6 & 4.9012 & TST & \\
\hline CHEMBL1589719 & 688293 & 5.1 & 5.1317 & TRN & \\
\hline CHEMBL1462618 & 688293 & 4.9 & 5.033 & TRN & \\
\hline CHEMBL1517593 & 688293 & 4.9 & 4.9003 & TST & \\
\hline CHEMBL1567878 & 688293 & 5.0 & 4.9156 & TRN & \\
\hline CHEMBL1425896 & 688293 & 5.1 & 4.9822 & TRN & \\
\hline CHEMBL 1486462 & 688293 & 4.4 & 4.9325 & TRN & \\
\hline CHEMBL1347549 & 688293 & 4.7 & 5.1311 & TST & \\
\hline CHEMBL356703 & 688293 & 4.6 & 5.118 & TST & \\
\hline CHEMBL1306620 & 688293 & 5.8 & 5.222 & TRN & \\
\hline CHEMBL1349053 & 688293 & 5.4 & 4.9783 & TST & \\
\hline CHEMBL 3194664 & 688293 & 4.4 & 4.7487 & TRN & \\
\hline CHEMBL1317647 & 688293 & 5.2 & 5.1102 & TST & \\
\hline CHEMBL1301351 & 688293 & 4.4 & 5.276 & TRN & \\
\hline CHEMBL1611210 & 688293 & 4.4 & 4.8855 & TRN & \\
\hline CHEMBL1425417 & 688293 & 6.0 & 4.9241 & TRN & \\
\hline CHEMBL 1489349 & 688293 & 4.5 & 5.1224 & TRN & \\
\hline CHEMBL1431385 & 688293 & 4.8 & 5.2069 & TRN & \\
\hline CHEMBL1307836 & 688293 & 4.4 & 5.066 & TRN & \\
\hline CHEMBL1412582 & 688293 & 4.4 & 5.0453 & TRN & \\
\hline CHEMBL1458653 & 688293 & 5.0 & 4.8014 & TRN & \\
\hline CHEMBL1305284 & 688293 & 4.5 & 4.8813 & TRN & \\
\hline CHEMBL72365 & 688293 & 4.9 & 4.9126 & TST & \\
\hline CHEMBL1388770 & 688293 & 4.7 & 4.7618 & TRN & \\
\hline CHEMBL1517848 & 688293 & 4.9 & 5.008 & TRN & \\
\hline CHEMBL1384754 & 688293 & 4.4 & 4.9138 & TRN & \\
\hline CHEMBL1407250 & 688293 & 5.0 & 5.0471 & TRN & \\
\hline CHEMBL1522395 & 688293 & 5.6 & 5.1518 & TST & \\
\hline CHEMBL1462482 & 688293 & 5.5 & 4.8912 & TRN & \\
\hline CHEMBL1336025 & 688293 & 4.8 & 5.0736 & TRN & \\
\hline
\end{tabular}




\begin{tabular}{|c|c|c|c|c|c|}
\hline & & \multicolumn{4}{|c|}{ Supplemental Table S2.txt } \\
\hline CHEMBL1350197 & 688293 & 7.5003 & 5.101 & TST & \\
\hline CHEMBL1485401 & 688293 & 4.5 & 5.1567 & TRN & \\
\hline CHEMBL1510400 & 688293 & 4.4 & 4.8774 & TST & \\
\hline CHEMBL1538313 & 688293 & 4.7 & 4.7898 & TRN & \\
\hline CHEMBL1378090 & 688293 & 4.5 & 4.9609 & TST & \\
\hline CHEMBL1323407 & 688293 & 6.0 & 4.9864 & TST & \\
\hline CHEMBL1318837 & 688293 & 5.8 & 5.26399 & 9999999999 & TRN \\
\hline CHEMBL1407548 & 688293 & 4.6 & 4.963 & TRN & \\
\hline CHEMBL1611622 & 688293 & 5.0 & 4.9557 & TRN & \\
\hline CHEMBL1458077 & 688293 & 5.6 & 4.9793 & TST & \\
\hline CHEMBL1435053 & 688293 & 4.8 & 4.7687 & TST & \\
\hline CHEMBL1438876 & 688293 & 4.4 & 4.9177 & TRN & \\
\hline CHEMBL1329715 & 688293 & 4.4 & 5.1429 & TRN & \\
\hline CHEMBL1356943 & 688293 & 4.4 & 4.9511 & TRN & \\
\hline CHEMBL1338369 & 688293 & 4.5 & 4.9009 & TRN & \\
\hline CHEMBL1421962 & 688293 & 8.2007 & 4.9658 & TST & \\
\hline CHEMBL227925 & 688293 & 4.7 & 4.9788 & TRN & \\
\hline CHEMBL1386871 & 688293 & 5.4 & 5.0159 & TRN & \\
\hline CHEMBL1456053 & 688293 & 5.5 & 5.0399 & TRN & \\
\hline CHEMBL1340532 & 688293 & 5.8 & 5.1246 & TRN & \\
\hline CHEMBL1511009 & 688293 & 4.4 & 4.9924 & TRN & \\
\hline CHEMBL1579699 & 688293 & 4.8 & 5.0731 & TRN & \\
\hline CHEMBL1305486 & 688293 & 8.0 & 5.0577 & TRN & \\
\hline CHEMBL1442840 & 688293 & 5.4 & 4.9251 & TRN & \\
\hline CHEMBL1381073 & 688293 & 8.301 & 4.9719 & TRN & \\
\hline CHEMBL1451590 & 688293 & 4.0 & 5.1533 & TRN & \\
\hline CHEMBL1597696 & 688293 & 5.9 & 5.0506 & TRN & \\
\hline CHEMBL1372127 & 688293 & 5.1 & 5.046 & TRN & \\
\hline CHEMBL1420530 & 688293 & 4.9 & 4.9031 & TRN & \\
\hline CHEMBL1588151 & 688293 & 4.5 & 4.9448 & TRN & \\
\hline CHEMBL1391126 & 688293 & 4.6 & 5.1099 & TRN & \\
\hline CHEMBL1428587 & 688293 & 6.6 & 5.1227 & TRN & \\
\hline CHEMBL1572915 & 688293 & 4.4 & 4.89 & TRN & \\
\hline CHEMBL1301130 & 688293 & 5.3 & 5.1709 & TRN & \\
\hline CHEMBL1501994 & 688293 & 4.5 & 5.0059 & TRN & \\
\hline CHEMBL1401742 & 688293 & 6.1 & 5.1527 & TRN & \\
\hline CHEMBL1592110 & 688293 & 4.9 & 4.8624 & TRN & \\
\hline CHEMBL1591600 & 688293 & 5.6 & 4.9076 & TRN & \\
\hline CHEMBL1361078 & 688293 & 4.5 & 5.1338 & TRN & \\
\hline CHEMBL1596598 & 688293 & 4.7 & 5.053 & TRN & \\
\hline CHEMBL35482 & 688293 & 5.4 & 4.9072 & TRN & \\
\hline CHEMBL43612 & 688293 & 5.2 & 4.9729 & TST & \\
\hline CHEMBL1358796 & 688293 & 5.1 & 4.7796 & TRN & \\
\hline CHEMBL1392076 & 688293 & 4.7 & 4.7816 & TRN & \\
\hline CHEMBL1388233 & 688293 & 4.6 & 4.8758 & TST & \\
\hline CHEMBL259615 & 688293 & 4.5 & 4.8778 & TRN & \\
\hline CHEMBL468018 & 688293 & 4.8 & 4.8229 & TRN & \\
\hline CHEMBL1567983 & 688293 & 4.7 & 4.9111 & TRN & \\
\hline
\end{tabular}




\begin{tabular}{|c|c|c|c|c|c|}
\hline \\
\hline CHEMBL1581459 & 688293 & 4.9 & 5.084 & TRN & \\
\hline CHEMBL1506105 & 688293 & 4.4 & 4.9952 & TRN & \\
\hline CHEMBL1586993 & 688293 & 4.5 & 5.0581 & TST & \\
\hline CHEMBL1355387 & 688293 & 5.0 & 4.6737 & TRN & \\
\hline CHEMBL1493349 & 688293 & 4.6 & 4.9452 & TRN & \\
\hline CHEMBL1379838 & 688293 & 6.0 & 5.0191 & TRN & \\
\hline CHEMBL1566622 & 688293 & 4.7 & 4.9532 & TRN & \\
\hline CHEMBL1330808 & 688293 & 4.7 & 5.104 & TRN & \\
\hline CHEMBL1587578 & 688293 & 4.7 & 5.3309 & TRN & \\
\hline CHEMBL1173823 & 688293 & 4.6 & 4.879 & TRN & \\
\hline CHEMBL1596743 & 688293 & 4.8 & 4.9415 & TRN & \\
\hline CHEMBL1531073 & 688293 & 5.0 & 4.6978 & TRN & \\
\hline CHEMBL1310104 & 688293 & 4.4 & 4.9555 & TRN & \\
\hline CHEMBL250711 & 688293 & 5.5 & 5.1156 & TRN & \\
\hline CHEMBL1333260 & 688293 & 4.4 & 5.1092 & TRN & \\
\hline CHEMBL1438791 & 688293 & 5.8 & 5.129 & TRN & \\
\hline CHEMBL1548834 & 688293 & 4.4 & 5.0296 & TRN & \\
\hline CHEMBL1380958 & 688293 & 4.6 & 4.9447 & TRN & \\
\hline CHEMBL1496962 & 688293 & 4.6 & 5.1439 & TRN & \\
\hline CHEMBL1461878 & 688293 & 5.0 & 5.1014 & TRN & \\
\hline CHEMBL1424036 & 688293 & 4.6 & 4.8303 & TRN & \\
\hline CHEMBL1235001 & 688293 & 4.7 & 5.0546 & TRN & \\
\hline CHEMBL1380047 & 688293 & 6.0 & 5.0283 & TRN & \\
\hline CHEMBL1370387 & 688293 & 4.4 & 4.6925 & TRN & \\
\hline CHEMBL1330106 & 688293 & 4.8 & 4.9415 & TRN & \\
\hline CHEMBL1488465 & 688293 & 4.6 & 5.1335 & TRN & \\
\hline CHEMBL1304420 & 688293 & 4.4 & 4.9657 & TRN & \\
\hline CHEMBL1302466 & 688293 & 5.0 & 5.0229 & TRN & \\
\hline CHEMBL1509822 & 688293 & 4.7 & 5.0202 & TRN & \\
\hline CHEMBL1326021 & 688293 & 4.7 & 4.8837 & TRN & \\
\hline CHEMBL1466072 & 688293 & 4.8 & $5.2010 e$ & 20000000005 & TRN \\
\hline CHEMBL1333186 & 688293 & 4.7 & 5.1441 & TRN & \\
\hline CHEMBL1427078 & 688293 & 4.6 & 4.9509 & TRN & \\
\hline CHEMBL1394187 & 688293 & 4.5 & 5.1804 & TRN & \\
\hline CHEMBL1457201 & 688293 & 4.6 & 4.9487 & TRN & \\
\hline CHEMBL1606344 & 688293 & 4.7 & 5.025 & TRN & \\
\hline CHEMBL1498596 & 688293 & 4.7 & 4.9272 & TRN & \\
\hline CHEMBL1611371 & 688293 & 4.6 & 4.9122 & TRN & \\
\hline CHEMBL1330081 & 688293 & 7.0 & 5.2007 & TRN & \\
\hline CHEMBL1506052 & 688293 & 7.5003 & 5.0343 & TRN & \\
\hline CHEMBL1332350 & 688293 & 4.6 & 5.0354 & TRN & \\
\hline CHEMBL1570093 & 688293 & 4.4 & 4.9696 & TRN & \\
\hline CHEMBL1461399 & 688293 & 4.9 & 5.1893 & TRN & \\
\hline CHEMBL1322090 & 688293 & 5.4 & 5.0837 & TRN & \\
\hline CHEMBL1373659 & 688293 & 4.4 & 4.9464 & TRN & \\
\hline CHEMBL 1486510 & 688293 & 4.9 & 5.0257 & TRN & \\
\hline CHEMBL1584826 & 688293 & 7.699 & 5.0903 & TRN & \\
\hline CHEMBL1375857 & 688293 & 4.4 & 5.1824 & TRN & \\
\hline
\end{tabular}




\begin{tabular}{|c|c|c|c|c|c|}
\hline CHEMBL1402888 & 688293 & 4.5 & 5.0154 & TRN & \\
\hline CHEMBL1380684 & 688293 & 4.4 & \multicolumn{2}{|c|}{5.0489999999999995} & TRN \\
\hline CHEMBL3191329 & 688293 & 4.9 & 4.9023 & TRN & \\
\hline CHEMBL1471681 & 688293 & 4.7 & 4.9274 & TST & \\
\hline CHEMBL1583061 & 688293 & 4.4 & 5.0321 & TRN & \\
\hline CHEMBL1388153 & 688293 & 4.6 & 5.1374 & TRN & \\
\hline CHEMBL1315145 & 688293 & 5.1 & 4.842 & TRN & \\
\hline CHEMBL1595775 & 688293 & 4.6 & 5.078 & TRN & \\
\hline CHEMBL1406630 & 688293 & 4.9 & 5.0254 & TRN & \\
\hline CHEMBL1408664 & 688293 & 5.0 & \multicolumn{2}{|c|}{5.162000000000001} & TRN \\
\hline CHEMBL1574004 & 688293 & 4.8 & 5.0857 & TRN & \\
\hline CHEMBL1576652 & 688293 & 7.5003 & 5.0938 & TRN & \\
\hline CHEMBL1545979 & 688293 & 4.4 & 4.8924 & TRN & \\
\hline CHEMBL1399216 & 688293 & 4.6 & \multicolumn{2}{|c|}{4.9430000000000005} & TRN \\
\hline CHEMBL1431620 & 688293 & 4.6 & 4.9077 & TRN & \\
\hline CHEMBL1330523 & 688293 & 6.5 & 5.1452 & TRN & \\
\hline CHEMBL1416583 & 688293 & 4.4 & 5.2506 & TRN & \\
\hline CHEMBL1718398 & 688293 & 4.4 & 5.002 & TST & \\
\hline CHEMBL1420994 & 688293 & 4.4 & 5.1912 & TRN & \\
\hline CHEMBL1338425 & 688293 & 4.7 & 4.895 & TRN & \\
\hline CHEMBL1575591 & 688293 & 4.4 & 5.0727 & TRN & \\
\hline CHEMBL1372862 & 688293 & 4.9 & 5.1589 & TRN & \\
\hline CHEMBL1375637 & 688293 & 4.7 & 5.0992 & TRN & \\
\hline CHEMBL1347716 & 688293 & 4.9 & 4.8255 & TRN & \\
\hline CHEMBL1605631 & 688293 & 4.5 & 5.0798 & TRN & \\
\hline CHEMBL1337685 & 688293 & 4.6 & 5.0342 & TST & \\
\hline CHEMBL1337997 & 688293 & 4.5 & 4.8349 & TRN & \\
\hline CHEMBL1497783 & 688293 & 4.9 & 4.967 & TRN & \\
\hline CHEMBL1548408 & 688293 & 4.9 & 4.8687 & TRN & \\
\hline CHEMBL1411045 & 688293 & 6.2 & 5.0658 & TST & \\
\hline CHEMBL1447828 & 688293 & 4.8 & 4.8415 & TRN & \\
\hline CHEMBL1362068 & 688293 & 6.5 & 4.76 & TRN & \\
\hline CHEMBL1307167 & 688293 & 4.9 & 4.9431 & TRN & \\
\hline CHEMBL1538911 & 688293 & 4.9 & 5.0168 & TRN & \\
\hline CHEMBL1607067 & 688293 & 4.6 & 5.0697 & TRN & \\
\hline CHEMBL1414261 & 688293 & 4.4 & 4.9528 & TRN & \\
\hline CHEMBL1547832 & 688293 & 5.5 & 5.0323 & TRN & \\
\hline CHEMBL1464257 & 688293 & 4.6 & 4.9533 & TRN & \\
\hline CHEMBL191015 & 688293 & 4.4 & 4.7583 & TRN & \\
\hline CHEMBL1567532 & 688293 & 4.6 & 4.8734 & TRN & \\
\hline CHEMBL1596039 & 688293 & 4.9 & 5.0285 & TRN & \\
\hline CHEMBL1439137 & 688293 & 5.4 & 4.8561 & TST & \\
\hline CHEMBL1608888 & 688293 & 4.4 & 4.963 & TRN & \\
\hline CHEMBL1496732 & 688293 & 5.2 & 4.975 & TRN & \\
\hline CHEMBL1597811 & 688293 & 4.6 & 4.9529 & TRN & \\
\hline CHEMBL1428272 & 688293 & 4.8 & 4.852 & TST & \\
\hline CHEMBL1521862 & 688293 & 5.7 & 5.0538 & TRN & \\
\hline CHEMBL1431901 & 688293 & 5.1 & 4.8304 & TST & \\
\hline
\end{tabular}




\begin{tabular}{|c|c|c|c|c|}
\hline & & & oplement & al $\mathrm{Ta}$ \\
\hline CHEMBL1576877 & 688293 & 4.9 & 5.1087 & TRN \\
\hline CHEMBL1589797 & 688293 & 4.8 & 4.8352 & TST \\
\hline CHEMBL1569863 & 688293 & 4.9 & 4.9237 & TST \\
\hline CHEMBL1459296 & 688293 & 4.9 & 4.8242 & TRN \\
\hline CHEMBL1488976 & 688293 & 5.0 & 5.0301 & TRN \\
\hline CHEMBL1578365 & 688293 & 4.6 & 4.8799 & TRN \\
\hline CHEMBL1551610 & 688293 & 8.2007 & 5.0087 & TST \\
\hline CHEMBL1525925 & 688293 & 4.8 & 4.9011 & TRN \\
\hline CHEMBL1363854 & 688293 & 4.6 & 4.8195 & TRN \\
\hline CHEMBL1388947 & 688293 & 6.1 & 4.9337 & TRN \\
\hline CHEMBL1539454 & 688293 & 4.8 & 4.9908 & TRN \\
\hline CHEMBL1573155 & 688293 & 5.0 & 5.1802 & TRN \\
\hline CHEMBL1418548 & 688293 & 4.9 & 4.7717 & TRN \\
\hline CHEMBL1488944 & 688293 & 4.5 & 5.1148 & TST \\
\hline CHEMBL 3212424 & 688293 & 4.7 & 4.9219 & TST \\
\hline CHEMBL1421675 & 688293 & 4.4 & 4.8522 & TRN \\
\hline CHEMBL1366759 & 688293 & 4.4 & 5.0177 & TRN \\
\hline CHEMBL1476762 & 688293 & 4.4 & 5.1233 & TST \\
\hline CHEMBL1491146 & 688293 & 4.9 & 4.9439 & TST \\
\hline CHEMBL549321 & 688293 & 4.8 & 4.9161 & TRN \\
\hline CHEMBL1417448 & 688293 & 4.4 & 4.8474 & TRN \\
\hline CHEMBL1499767 & 688293 & 4.8 & 4.9449 & TRN \\
\hline CHEMBL1483373 & 688293 & 4.8 & 5.1071 & TRN \\
\hline CHEMBL1412637 & 688293 & 5.3 & 4.8724 & TRN \\
\hline CHEMBL1527817 & 688293 & 6.2 & 4.7834 & TRN \\
\hline CHEMBL1426630 & 688293 & 4.4 & 5.1597 & TRN \\
\hline CHEMBL1304196 & 688293 & 4.5 & 4.7721 & TRN \\
\hline CHEMBL1341844 & 688293 & 4.7 & 4.9176 & TST \\
\hline CHEMBL1369033 & 688293 & 8.301 & 5.0442 & TRN \\
\hline CHEMBL1536947 & 688293 & 4.5 & 5.1084 & TRN \\
\hline CHEMBL1469425 & 688293 & 5.6 & 4.9814 & TRN \\
\hline CHEMBL282489 & 688293 & 4.6 & 4.9856 & TST \\
\hline CHEMBL1441690 & 688293 & 5.8 & 4.8106 & TRN \\
\hline CHEMBL1329375 & 688293 & 5.9 & 5.0569 & TRN \\
\hline CHEMBL3210009 & 688293 & 4.9 & 4.8125 & TRN \\
\hline CHEMBL3213043 & 688293 & 5.0 & 5.1198 & TST \\
\hline CHEMBL1326670 & 688293 & 7.699 & 4.8942 & TRN \\
\hline CHEMBL1457532 & 688293 & 4.7 & 4.9578 & TRN \\
\hline CHEMBL1464808 & 688293 & 4.4 & 5.1764 & TRN \\
\hline CHEMBL1401348 & 688293 & 8.6021 & 5.2768 & TST \\
\hline CHEMBL1256364 & 688293 & 4.9 & 4.9176 & TRN \\
\hline CHEMBL1410589 & 688293 & 4.9 & 5.1429 & TRN \\
\hline CHEMBL1320525 & 688293 & 6.8 & 5.1075 & TST \\
\hline CHEMBL1482207 & 688293 & 4.4 & 4.9503 & TRN \\
\hline CHEMBL1334229 & 688293 & 5.1 & 5.1301 & TRN \\
\hline CHEMBL1610143 & 688293 & 4.4 & 4.9236 & TST \\
\hline CHEMBL1342825 & 688293 & 5.7 & 5.1975 & TRN \\
\hline CHEMBL1326553 & 688293 & 4.5 & 5.1184 & TRN \\
\hline
\end{tabular}




\begin{tabular}{|c|c|c|c|c|}
\hline \multicolumn{5}{|c|}{ Supplemental Table S2.txt } \\
\hline CHEMBL1405719 & 688293 & 4.6 & 5.0724 & TRN \\
\hline CHEMBL1530033 & 688293 & 4.6 & 5.0667 & TRN \\
\hline CHEMBL1553114 & 688293 & 4.9 & 4.7613 & TRN \\
\hline CHEMBL1359478 & 688293 & 4.5 & 4.8951 & TRN \\
\hline CHEMBL1450334 & 688293 & 4.8 & 5.0333 & TST \\
\hline CHEMBL1554664 & 688293 & 4.7 & 4.8241 & TRN \\
\hline CHEMBL1326812 & 688293 & 4.7 & 4.8159 & TRN \\
\hline CHEMBL1555719 & 688293 & 4.9 & 4.9793 & TRN \\
\hline CHEMBL1459176 & 688293 & 8.0 & 5.2947 & TRN \\
\hline CHEMBL3212816 & 688293 & 5.0 & 4.9443 & TRN \\
\hline CHEMBL1576943 & 688293 & 5.0 & 5.0545 & TRN \\
\hline CHEMBL1337218 & 688293 & 4.4 & 4.8383 & TRN \\
\hline CHEMBL196590 & 688293 & 4.6 & 4.8333 & TST \\
\hline CHEMBL1345126 & 688293 & 4.9 & 4.8617 & TRN \\
\hline CHEMBL1611187 & 688293 & 4.6 & 4.9113 & TRN \\
\hline CHEMBL1173475 & 688293 & 4.4 & 4.9054 & TRN \\
\hline CHEMBL1367570 & 688293 & 6.8 & 5.3248 & TRN \\
\hline CHEMBL1470858 & 688293 & 4.7 & 4.9855 & TRN \\
\hline CHEMBL1349813 & 688293 & 4.8 & 4.8674 & TRN \\
\hline CHEMBL1483739 & 688293 & 4.4 & 4.9195 & TRN \\
\hline CHEMBL1349977 & 688293 & 4.4 & 4.9006 & TRN \\
\hline CHEMBL1414688 & 688293 & 7.8996 & 5.0104 & TST \\
\hline CHEMBL 3211174 & 688293 & 4.4 & 4.8594 & TRN \\
\hline CHEMBL1393096 & 688293 & 4.5 & 4.8269 & TRN \\
\hline CHEMBL1441714 & 688293 & 4.6 & 5.0046 & TST \\
\hline CHEMBL1348181 & 688293 & 5.0 & 4.9244 & TRN \\
\hline CHEMBL1547766 & 688293 & 7.699 & 5.2835 & TRN \\
\hline CHEMBL1376054 & 688293 & 4.9 & 5.034 & TRN \\
\hline CHEMBL1516625 & 688293 & 4.4 & 5.0616 & TRN \\
\hline CHEMBL1310014 & 688293 & 4.8 & 5.1523 & TRN \\
\hline CHEMBL3207292 & 688293 & 4.4 & 5.1371 & TRN \\
\hline CHEMBL1511212 & 688293 & 5.1 & 4.7318 & TRN \\
\hline CHEMBL1526319 & 688293 & 7.2 & 4.9638 & TST \\
\hline CHEMBL1520347 & 688293 & 4.9 & 4.984 & TRN \\
\hline CHEMBL1580250 & 688293 & 6.0 & 5.1701 & TRN \\
\hline CHEMBL1587522 & 688293 & 6.9 & 5.0202 & TRN \\
\hline CHEMBL1363831 & 688293 & 5.4 & 4.9369 & TRN \\
\hline CHEMBL1532720 & 688293 & 5.2 & 4.8065 & TRN \\
\hline CHEMBL271138 & 688293 & 4.9 & 4.9683 & TRN \\
\hline CHEMBL157351 & 688293 & 4.7 & 4.8693 & TST \\
\hline CHEMBL1606699 & 688293 & 4.4 & 5.0221 & TRN \\
\hline CHEMBL1478675 & 688293 & 5.0 & 5.0171 & TRN \\
\hline CHEMBL1583795 & 688293 & 7.8996 & 5.0477 & TRN \\
\hline CHEMBL1394738 & 688293 & 4.4 & 5.0852 & TST \\
\hline CHEMBL1468996 & 688293 & 4.6 & 5.1111 & TRN \\
\hline CHEMBL491547 & 688293 & 5.4 & 4.7451 & TRN \\
\hline CHEMBL1432734 & 688293 & 4.6 & 4.9285 & TST \\
\hline CHEMBL1380257 & 688293 & 4.6 & 4.9275 & TRN \\
\hline
\end{tabular}




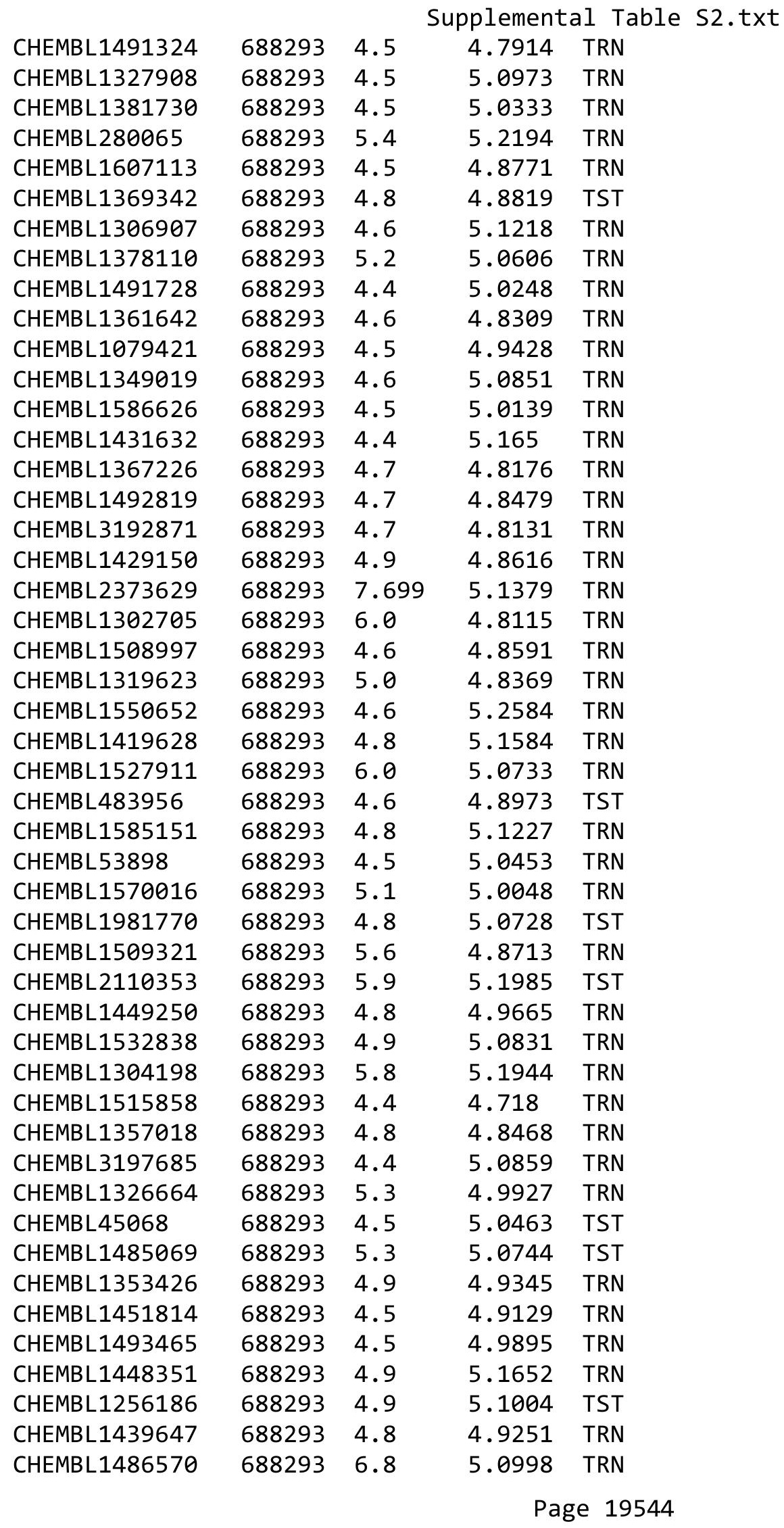




\begin{tabular}{|c|c|c|c|c|c|}
\hline \multirow{2}{*}{ CHEMBL1387077 } & \multirow{2}{*}{688293} & & & & \\
\hline & & 4.9 & 4.9906 & TRN & \\
\hline CHEMBL1470714 & 688293 & 4.8 & 4.8049 & TRN & \\
\hline CHEMBL1568585 & 688293 & 7.6003 & 5.09699 & 99999999995 & TRN \\
\hline CHEMBL1527963 & 688293 & 4.9 & 4.9124 & TRN & \\
\hline CHEMBL1341044 & 688293 & 4.4 & 5.0627 & TRN & \\
\hline CHEMBL1542674 & 688293 & 5.1 & 4.8319 & TRN & \\
\hline CHEMBL1515004 & 688293 & 5.3 & 4.9469 & TRN & \\
\hline CHEMBL1556010 & 688293 & 4.4 & 4.9758 & TRN & \\
\hline CHEMBL1350339 & 688293 & 7.0 & 5.066 & TRN & \\
\hline CHEMBL1604905 & 688293 & 4.9 & 5.0215 & TRN & \\
\hline CHEMBL1401091 & 688293 & 7.2 & 5.0049 & TST & \\
\hline CHEMBL1323989 & 688293 & 4.9 & 4.8948 & TRN & \\
\hline CHEMBL1544093 & 688293 & 5.1 & 5.0137 & TRN & \\
\hline CHEMBL 1456042 & 688293 & 4.4 & 5.09399 & 9999999999 & TRN \\
\hline CHEMBL1712181 & 688293 & 4.6 & 4.8908 & TST & \\
\hline CHEMBL 1539576 & 688293 & 5.0 & 4.8549 & TRN & \\
\hline CHEMBL1409216 & 688293 & 4.4 & 5.0162 & TRN & \\
\hline CHEMBL1373244 & 688293 & 4.9 & 5.1441 & TRN & \\
\hline CHEMBL 278980 & 688293 & 7.4001 & 5.0073 & TST & \\
\hline CHEMBL1441471 & 688293 & 4.4 & 5.1133 & TRN & \\
\hline CHEMBL1486429 & 688293 & 8.0 & 5.2036 & TRN & \\
\hline CHEMBL1351330 & 688293 & 5.0 & 5.0034 & TRN & \\
\hline CHEMBL1383713 & 688293 & 4.6 & 4.8479 & TRN & \\
\hline CHEMBL1603305 & 688293 & 4.8 & 5.2103 & TRN & \\
\hline CHEMBL664 & 688293 & 8.301 & 5.142 & TST & \\
\hline CHEMBL168279 & 688293 & 4.9 & 5.1612 & TST & \\
\hline CHEMBL1569346 & 688293 & 4.5 & 5.0658 & TRN & \\
\hline CHEMBL1563413 & 688293 & 5.3 & 5.0505 & TRN & \\
\hline CHEMBL1591158 & 688293 & 7.5003 & 5.1192 & TST & \\
\hline CHEMBL1609459 & 688293 & 4.9 & 4.9779 & TST & \\
\hline CHEMBL1417628 & 688293 & 4.5 & 5.0663 & TST & \\
\hline CHEMBL 1381070 & 688293 & 4.7 & 5.1035 & TRN & \\
\hline CHEMBL1538755 & 688293 & 4.6 & 5.0779 & TRN & \\
\hline CHEMBL1592549 & 688293 & 4.4 & 4.9118 & TRN & \\
\hline CHEMBL1462702 & 688293 & 5.3 & 5.1732 & TRN & \\
\hline CHEMBL1477811 & 688293 & 4.5 & 5.2299 & TRN & \\
\hline CHEMBL1510982 & 688293 & 5.9 & 5.0113 & TRN & \\
\hline CHEMBL1575051 & 688293 & 5.0 & 5.0312 & TRN & \\
\hline CHEMBL1329102 & 688293 & 5.1 & 4.9524 & TST & \\
\hline CHEMBL1439869 & 688293 & 5.3 & 5.1624 & TRN & \\
\hline CHEMBL1461304 & 688293 & 4.8 & 5.2211 & TRN & \\
\hline CHEMBL1520242 & 688293 & 7.5003 & 5.0545 & TST & \\
\hline CHEMBL1370834 & 688293 & 4.6 & 5.0373 & TRN & \\
\hline CHEMBL1445927 & 688293 & 4.9 & 5.1385 & TRN & \\
\hline CHEMBL1328565 & 688293 & 4.4 & 4.752 & TRN & \\
\hline CHEMBL1399289 & 688293 & 4.5 & 4.7431 & TRN & \\
\hline CHEMBL1386729 & 688293 & 5.0 & 5.1581 & TRN & \\
\hline CHEMBL1359028 & 688293 & 7.8013 & 5.1526 & TRN & \\
\hline
\end{tabular}




\begin{tabular}{|c|c|c|c|c|c|}
\hline \multicolumn{6}{|c|}{ Supplemental Table S2.txt } \\
\hline CHEMBL1459796 & 688293 & 4.6 & 5.1435 & TRN & \\
\hline CHEMBL1548323 & 688293 & 4.5 & 5.1353 & TRN & \\
\hline CHEMBL1357167 & 688293 & 5.3 & 4.5981 & TRN & \\
\hline CHEMBL1605619 & 688293 & 4.5 & 5.1528 & TST & \\
\hline CHEMBL1400681 & 688293 & 4.4 & 4.9562 & TRN & \\
\hline CHEMBL3197797 & 688293 & 8.0 & 5.0368 & TST & \\
\hline CHEMBL1402855 & 688293 & 4.5 & 5.065 & TRN & \\
\hline CHEMBL1473834 & 688293 & 4.8 & 4.8786 & TRN & \\
\hline CHEMBL545523 & 688293 & 4.6 & 4.8371 & TRN & \\
\hline CHEMBL1376719 & 688293 & 4.6 & 4.9969 & TRN & \\
\hline CHEMBL1446951 & 688293 & 4.7 & 4.9829 & TRN & \\
\hline CHEMBL1584149 & 688293 & 4.4 & 5.0705 & TRN & \\
\hline CHEMBL489935 & 688293 & 4.9 & 4.7516 & TRN & \\
\hline CHEMBL1469745 & 688293 & 4.4 & 4.88899 & 7999999999 & TRN \\
\hline CHEMBL1471864 & 688293 & 8.1024 & 5.2615 & TRN & \\
\hline CHEMBL1477509 & 688293 & 4.6 & 4.928 & TRN & \\
\hline CHEMBL1569585 & 688293 & 5.0 & 5.0817 & TST & \\
\hline CHEMBL1491247 & 688293 & 5.3 & 4.9402 & TRN & \\
\hline CHEMBL428496 & 688293 & 5.1 & 5.1262 & TST & \\
\hline CHEMBL1403505 & 688293 & 4.5 & 4.896 & TRN & \\
\hline CHEMBL1456828 & 688293 & 4.4 & 4.9902 & TRN & \\
\hline CHEMBL1576374 & 688293 & 4.6 & 4.9093 & TRN & \\
\hline CHEMBL1508399 & 688293 & 4.4 & 5.0677 & TRN & \\
\hline CHEMBL1425231 & 688293 & 4.8 & 5.0265 & TRN & \\
\hline CHEMBL1482624 & 688293 & 4.6 & 4.8901 & TRN & \\
\hline CHEMBL1462097 & 688293 & 4.9 & 4.7208 & TRN & \\
\hline CHEMBL1315072 & 688293 & 4.8 & 4.8589 & TRN & \\
\hline CHEMBL1531919 & 688293 & 4.6 & 5.0802 & TRN & \\
\hline CHEMBL1319555 & 688293 & 4.4 & 4.8973 & TRN & \\
\hline CHEMBL1593375 & 688293 & 5.5 & 4.8907 & TRN & \\
\hline CHEMBL259140 & 688293 & 4.9 & 4.7662 & TRN & \\
\hline CHEMBL1609952 & 688293 & 5.3 & 4.9661 & TRN & \\
\hline CHEMBL1418360 & 688293 & 4.4 & 5.0631 & TRN & \\
\hline CHEMBL1495375 & 688293 & 4.8 & 5.0897 & TRN & \\
\hline CHEMBL604116 & 688293 & 4.4 & 4.87 & TRN & \\
\hline CHEMBL1569408 & 688293 & 4.6 & 4.9878 & TRN & \\
\hline CHEMBL1306024 & 688293 & 4.6 & 5.0048 & TRN & \\
\hline CHEMBL1306004 & 688293 & 4.5 & 4.8135 & TRN & \\
\hline CHEMBL1592227 & 688293 & 4.7 & 4.8004 & TRN & \\
\hline CHEMBL1486960 & 688293 & 4.9 & 4.8992 & TRN & \\
\hline CHEMBL1461504 & 688293 & 4.8 & 5.0552 & TRN & \\
\hline CHEMBL1355712 & 688293 & 4.4 & 4.8619 & TRN & \\
\hline CHEMBL1488646 & 688293 & 6.2 & 4.8738 & TRN & \\
\hline CHEMBL1482426 & 688293 & 4.9 & 4.7925 & TRN & \\
\hline CHEMBL492127 & 688293 & 4.9 & 4.831 & TRN & \\
\hline CHEMBL1383536 & 688293 & 4.9 & 5.0643 & TRN & \\
\hline CHEMBL1310611 & 688293 & 5.9 & 5.0874 & TRN & \\
\hline CHEMBL1521261 & 688293 & 4.6 & 4.9088 & TST & \\
\hline
\end{tabular}




\begin{tabular}{|c|c|c|c|c|c|}
\hline \multirow[b]{2}{*}{ CHEMBL1410058 } & \multirow[b]{2}{*}{688293} & \\
\hline & & 4.6 & 5.1137 & TRN & \\
\hline CHEMBL1310408 & 688293 & 4.4 & 5.1375 & TST & \\
\hline CHEMBL1478329 & 688293 & 4.9 & 4.9282 & TRN & \\
\hline CHEMBL1330013 & 688293 & 4.9 & 5.0033 & TRN & \\
\hline CHEMBL1410947 & 688293 & 4.6 & 5.003 & TRN & \\
\hline CHEMBL3190000 & 688293 & 6.8 & 5.0364 & TRN & \\
\hline CHEMBL1467705 & 688293 & 4.6 & 4.8777 & TRN & \\
\hline CHEMBL1604404 & 688293 & 4.6 & 5.0874 & TRN & \\
\hline CHEMBL1540512 & 688293 & 4.5 & 5.0118 & TRN & \\
\hline CHEMBL471225 & 688293 & 5.1 & 4.9416 & TST & \\
\hline CHEMBL1382086 & 688293 & 4.8 & 4.9632 & TRN & \\
\hline CHEMBL1419459 & 688293 & 5.4 & 5.1067 & TRN & \\
\hline CHEMBL1412664 & 688293 & 4.9 & 5.0557 & TST & \\
\hline CHEMBL1489475 & 688293 & 7.2 & 5.1646 & TRN & \\
\hline CHEMBL1490409 & 688293 & 4.7 & 4.9358 & TRN & \\
\hline CHEMBL1412625 & 688293 & 4.9 & 5.0143 & TRN & \\
\hline CHEMBL1377088 & 688293 & 7.8996 & 5.1713 & TRN & \\
\hline CHEMBL1340876 & 688293 & 5.1 & 5.0312 & TRN & \\
\hline CHEMBL1551294 & 688293 & 4.7 & 5.0251 & TRN & \\
\hline CHEMBL1551139 & 688293 & 5.1 & 4.7878 & TRN & \\
\hline CHEMBL1530663 & 688293 & 4.6 & 4.9169 & TRN & \\
\hline CHEMBL1488337 & 688293 & 4.8 & 4.8574 & TRN & \\
\hline CHEMBL1505696 & 688293 & 7.699 & 5.2043 & TRN & \\
\hline CHEMBL226512 & 688293 & 5.0 & 4.8348 & TRN & \\
\hline CHEMBL1307406 & 688293 & 4.6 & 5.1869 & TRN & \\
\hline CHEMBL1495801 & 688293 & 4.7 & 5.1817 & TRN & \\
\hline CHEMBL1503112 & 688293 & 4.4 & 5.16200 & 0000000001 & TRN \\
\hline CHEMBL1508508 & 688293 & 4.5 & 4.9234 & TRN & \\
\hline CHEMBL1561544 & 688293 & 5.3 & 5.09699 & 99999999995 & TST \\
\hline CHEMBL1434460 & 688293 & 5.3 & 4.8633 & TRN & \\
\hline CHEMBL1574110 & 688293 & 4.7 & 4.7595 & TST & \\
\hline CHEMBL1343571 & 688293 & 4.5 & 4.9689 & TRN & \\
\hline CHEMBL1256667 & 688293 & 4.7 & 5.0537 & TST & \\
\hline CHEMBL1490209 & 688293 & 4.6 & 5.0373 & TST & \\
\hline CHEMBL295652 & 688293 & 8.2007 & 4.852 & TRN & \\
\hline CHEMBL1454033 & 688293 & 5.1 & 4.8824 & TST & \\
\hline CHEMBL1420724 & 688293 & 4.7 & 4.9171 & TST & \\
\hline CHEMBL1550038 & 688293 & 4.4 & 4.9254 & TRN & \\
\hline CHEMBL1455565 & 688293 & 4.8 & 5.0776 & TRN & \\
\hline CHEMBL1526331 & 688293 & 4.5 & 5.1011 & TRN & \\
\hline CHEMBL1363446 & 688293 & 4.6 & 4.9607 & TRN & \\
\hline CHEMBL1302113 & 688293 & 6.7001 & 4.99100 & 00000000005 & TRN \\
\hline CHEMBL1554577 & 688293 & 4.5 & 4.7504 & TRN & \\
\hline CHEMBL1360235 & 688293 & 4.4 & 4.8673 & TST & \\
\hline CHEMBL1560551 & 688293 & 4.5 & 4.7937 & TST & \\
\hline CHEMBL1492657 & 688293 & 4.8 & 4.9272 & TRN & \\
\hline CHEMBL1489737 & 688293 & 5.2 & 4.789 & TRN & \\
\hline CHEMBL1503426 & 688293 & 4.4 & 4.8193 & TRN & \\
\hline & & & & 195 & \\
\hline
\end{tabular}




\begin{tabular}{|c|c|c|c|c|}
\hline \multicolumn{5}{|c|}{ Supplemental Table S2.txt } \\
\hline CHEMBL1535042 & 688293 & 4.8 & 5.0882 & TRN \\
\hline CHEMBL1358614 & 688293 & 5.0 & 4.68199 & 99999999995 \\
\hline CHEMBL3199318 & 688293 & 4.5 & 4.9527 & TST \\
\hline CHEMBL1546310 & 688293 & 4.6 & 5.0141 & TRN \\
\hline CHEMBL1476952 & 688293 & 5.4 & 4.9388 & TST \\
\hline CHEMBL1505118 & 688293 & 4.9 & 5.1113 & TRN \\
\hline CHEMBL1466042 & 688293 & 8.2007 & 5.2466 & TRN \\
\hline CHEMBL1588808 & 688293 & 4.5 & 5.2927 & TRN \\
\hline CHEMBL3213131 & 688293 & 4.9 & 4.9104 & TST \\
\hline CHEMBL1345634 & 688293 & 5.0 & 4.8279 & TRN \\
\hline CHEMBL1526230 & 688293 & 4.8 & 5.002 & TRN \\
\hline CHEMBL1500595 & 688293 & 6.2 & 5.1803 & TRN \\
\hline CHEMBL1299486 & 688293 & 5.5 & 4.8672 & TRN \\
\hline CHEMBL1390244 & 688293 & 5.8 & 4.9405 & TRN \\
\hline CHEMBL1456775 & 688293 & 4.5 & 5.0863 & TRN \\
\hline CHEMBL1413213 & 688293 & 4.9 & 4.9919 & TRN \\
\hline CHEMBL1573134 & 688293 & 4.5 & 4.9179 & TST \\
\hline CHEMBL1394137 & 688293 & 5.2 & 4.9451 & TRN \\
\hline CHEMBL1431969 & 688293 & 4.8 & 5.2624 & TRN \\
\hline CHEMBL1373976 & 688293 & 4.4 & 4.9768 & TRN \\
\hline CHEMBL1473996 & 688293 & 4.5 & 4.837 & TRN \\
\hline CHEMBL1396816 & 688293 & 4.4 & 5.1695 & TST \\
\hline CHEMBL1214407 & 688293 & 4.4 & 4.9254 & TRN \\
\hline CHEMBL1528726 & 688293 & 4.8 & 4.953 & TRN \\
\hline CHEMBL1383189 & 688293 & 6.5 & 4.993 & TRN \\
\hline CHEMBL1373718 & 688293 & 4.6 & 5.2181 & TRN \\
\hline CHEMBL1442142 & 688293 & 4.4 & 4.8392 & TRN \\
\hline CHEMBL1382416 & 688293 & 4.4 & 4.8535 & TRN \\
\hline CHEMBL1499118 & 688293 & 4.6 & 5.0045 & TRN \\
\hline CHEMBL1374573 & 688293 & 4.6 & 5.0943 & TRN \\
\hline CHEMBL1603346 & 688293 & 4.6 & 4.9014 & TRN \\
\hline CHEMBL1543721 & 688293 & 5.4 & 5.1275 & TRN \\
\hline CHEMBL1367075 & 688293 & 4.6 & 4.7512 & TRN \\
\hline CHEMBL1343906 & 688293 & 4.6 & 4.7687 & TRN \\
\hline CHEMBL1557566 & 688293 & 4.7 & 4.9964 & TRN \\
\hline CHEMBL1362180 & 688293 & 4.9 & 4.909 & TRN \\
\hline CHEMBL1465162 & 688293 & 6.7001 & 5.0894 & TRN \\
\hline CHEMBL1442011 & 688293 & 5.4 & 4.8944 & TRN \\
\hline CHEMBL1607991 & 688293 & 4.4 & 4.9271 & TST \\
\hline CHEMBL 259507 & 688293 & 5.7 & 5.1716 & TRN \\
\hline CHEMBL1534413 & 688293 & 4.6 & 4.6154 & TRN \\
\hline CHEMBL3199576 & 688293 & 7.8013 & 5.1321 & TST \\
\hline CHEMBL1999166 & 688293 & 4.6 & 4.9925 & TST \\
\hline CHEMBL1340626 & 688293 & 6.7001 & 4.875 & TRN \\
\hline CHEMBL1472989 & 688293 & 8.301 & 4.9662 & TST \\
\hline CHEMBL1512786 & 688293 & 4.5 & 4.874 & TRN \\
\hline CHEMBL10009 & 688293 & 4.9 & 5.0479 & TST \\
\hline CHEMBL460366 & 688293 & 4.8 & 4.9922 & TST \\
\hline
\end{tabular}

TRN 


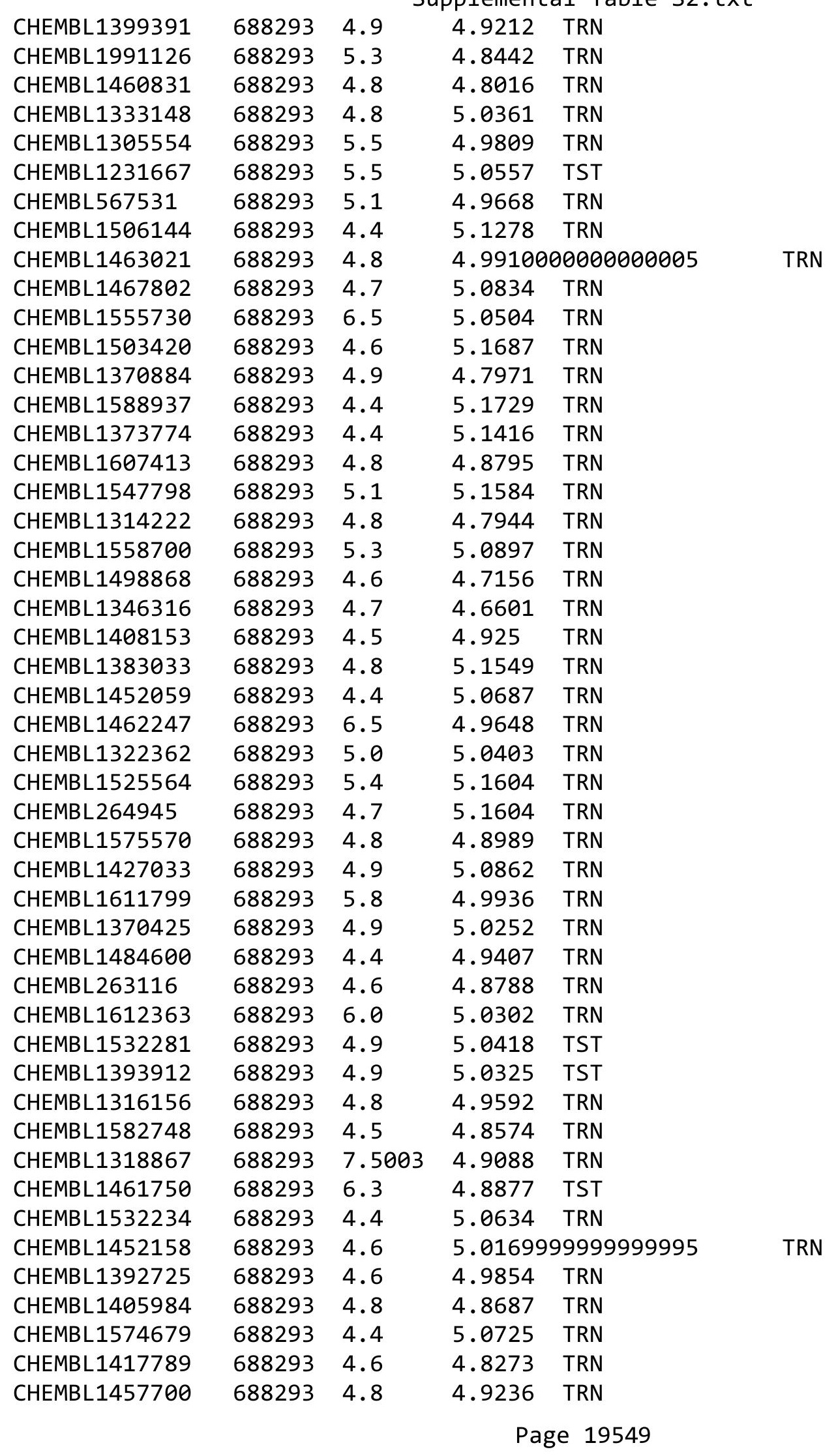




\begin{tabular}{|c|c|c|c|c|c|}
\hline \multicolumn{6}{|c|}{ pplemental Table } \\
\hline CHEMBL1392880 & 688293 & 4.9 & 5.2092 & TRN & \\
\hline CHEMBL1367702 & 688293 & 4.5 & 5.1068 & TRN & \\
\hline CHEMBL1491942 & 688293 & 4.4 & 5.0691 & TRN & \\
\hline CHEMBL1302390 & 688293 & 4.8 & 5.1761 & TRN & \\
\hline CHEMBL1344409 & 688293 & 4.9 & 4.8954 & TRN & \\
\hline CHEMBL1471211 & 688293 & 4.6 & 4.8438 & TRN & \\
\hline CHEMBL1500158 & 688293 & 6.0 & 4.7476 & TRN & \\
\hline CHEMBL1584314 & 688293 & 5.0 & 5.1094 & TRN & \\
\hline CHEMBL1478187 & 688293 & 7.4001 & 4.9913 & TRN & \\
\hline CHEMBL1486020 & 688293 & 4.6 & 5.0731 & TRN & \\
\hline CHEMBL1544907 & 688293 & 5.9 & 4.7236 & TRN & \\
\hline CHEMBL1540335 & 688293 & 4.5 & 5.0179 & TRN & \\
\hline CHEMBL356169 & 688293 & 4.6 & 4.7463 & TST & \\
\hline CHEMBL1362206 & 688293 & 8.1024 & 4.9879 & TRN & \\
\hline CHEMBL1970272 & 688293 & 4.4 & 4.9418 & TST & \\
\hline CHEMBL1477191 & 688293 & 4.8 & 4.9903 & TRN & \\
\hline CHEMBL1575391 & 688293 & 5.7 & 4.7987 & TRN & \\
\hline CHEMBL1322742 & 688293 & 4.8 & 5.0173 & TRN & \\
\hline CHEMBL1588244 & 688293 & 5.1 & 5.1528 & TRN & \\
\hline CHEMBL1451698 & 688293 & 5.4 & 4.8889 & TRN & \\
\hline CHEMBL1333180 & 688293 & 5.9 & 5.0951 & TRN & \\
\hline CHEMBL1464381 & 688293 & 4.9 & 4.9412 & TST & \\
\hline CHEMBL1450165 & 688293 & 5.0 & 4.8977 & TST & \\
\hline CHEMBL3190178 & 688293 & 4.4 & 4.9435 & TRN & \\
\hline CHEMBL1435086 & 688293 & 5.0 & 4.8931 & TRN & \\
\hline CHEMBL1353216 & 688293 & 4.9 & 4.9563 & TRN & \\
\hline CHEMBL1427666 & 688293 & 4.7 & 5.0507 & TRN & \\
\hline CHEMBL1304290 & 688293 & 4.8 & 4.9015 & TRN & \\
\hline CHEMBL1437918 & 688293 & 5.0 & 4.8746 & TRN & \\
\hline CHEMBL1329505 & 688293 & 4.7 & 5.0532 & TRN & \\
\hline CHEMBL1541279 & 688293 & 5.0 & 5.0168 & TRN & \\
\hline CHEMBL1431152 & 688293 & 4.4 & 5.1559 & TRN & \\
\hline CHEMBL1611004 & 688293 & 4.5 & 5.0021 & TRN & \\
\hline CHEMBL1608550 & 688293 & 4.7 & 5.21299 & 9999999999 & TRN \\
\hline CHEMBL1497224 & 688293 & 6.6 & 5.067 & TRN & \\
\hline CHEMBL1341124 & 688293 & 4.6 & 4.7865 & TRN & \\
\hline CHEMBL1567897 & 688293 & 4.4 & 4.8857 & TRN & \\
\hline CHEMBL1572611 & 688293 & 4.6 & 4.7737 & TRN & \\
\hline CHEMBL1532517 & 688293 & 5.7 & 5.0008 & TRN & \\
\hline CHEMBL1532508 & 688293 & 4.6 & 5.1923 & TRN & \\
\hline CHEMBL1334474 & 688293 & 4.9 & 4.9107 & TRN & \\
\hline CHEMBL1486305 & 688293 & 4.8 & 4.9892 & TST & \\
\hline CHEMBL1508373 & 688293 & 4.7 & 4.8657 & TRN & \\
\hline CHEMBL1350141 & 688293 & 4.5 & 5.1313 & TRN & \\
\hline CHEMBL1364250 & 688293 & 4.6 & 5.1296 & TRN & \\
\hline CHEMBL1221925 & 688293 & 4.4 & 5.0115 & TST & \\
\hline CHEMBL1496993 & 688293 & 4.4 & 5.0236 & TRN & \\
\hline CHEMBL1550829 & 688293 & 4.8 & 4.8416 & TRN & \\
\hline
\end{tabular}




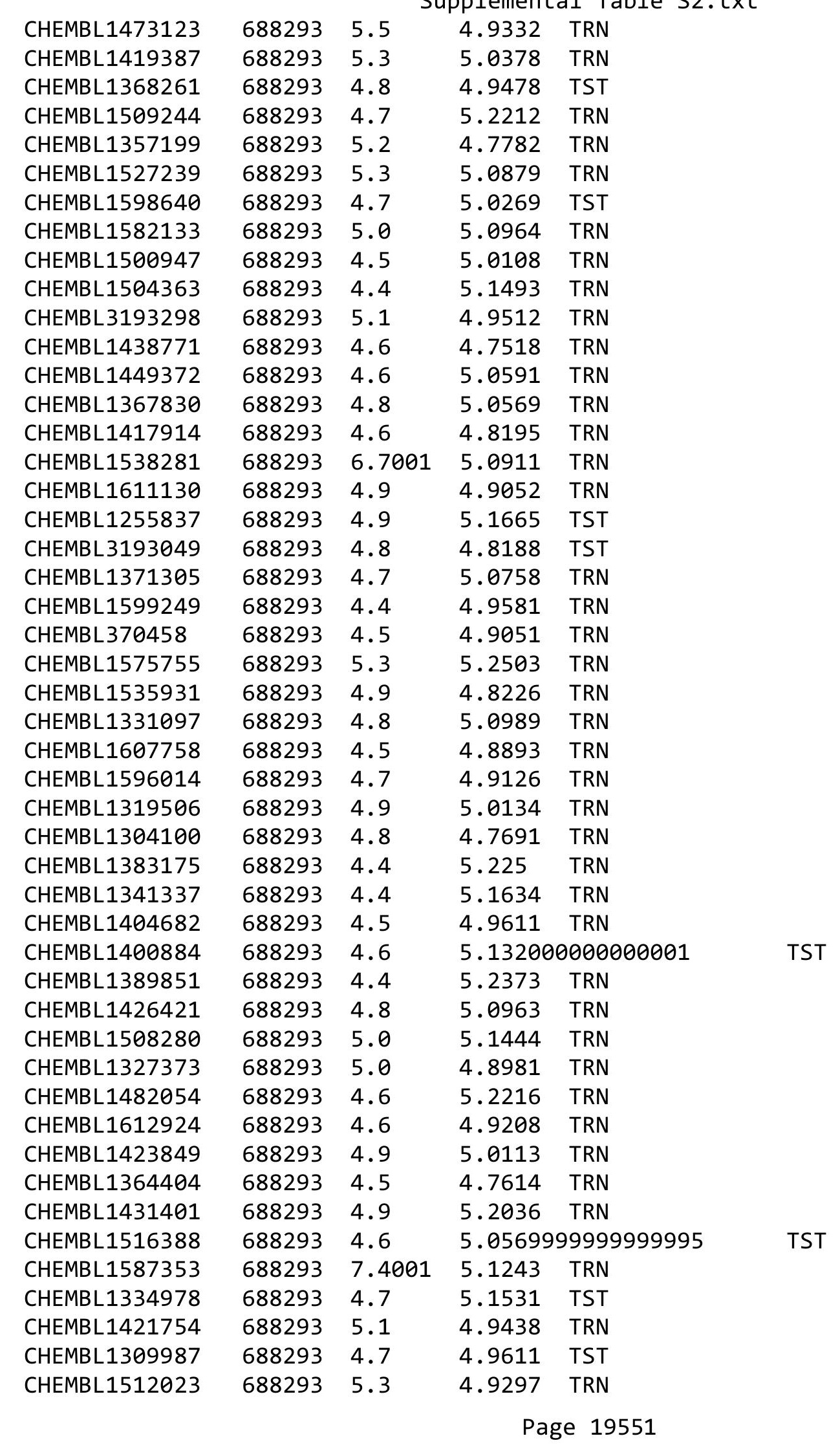




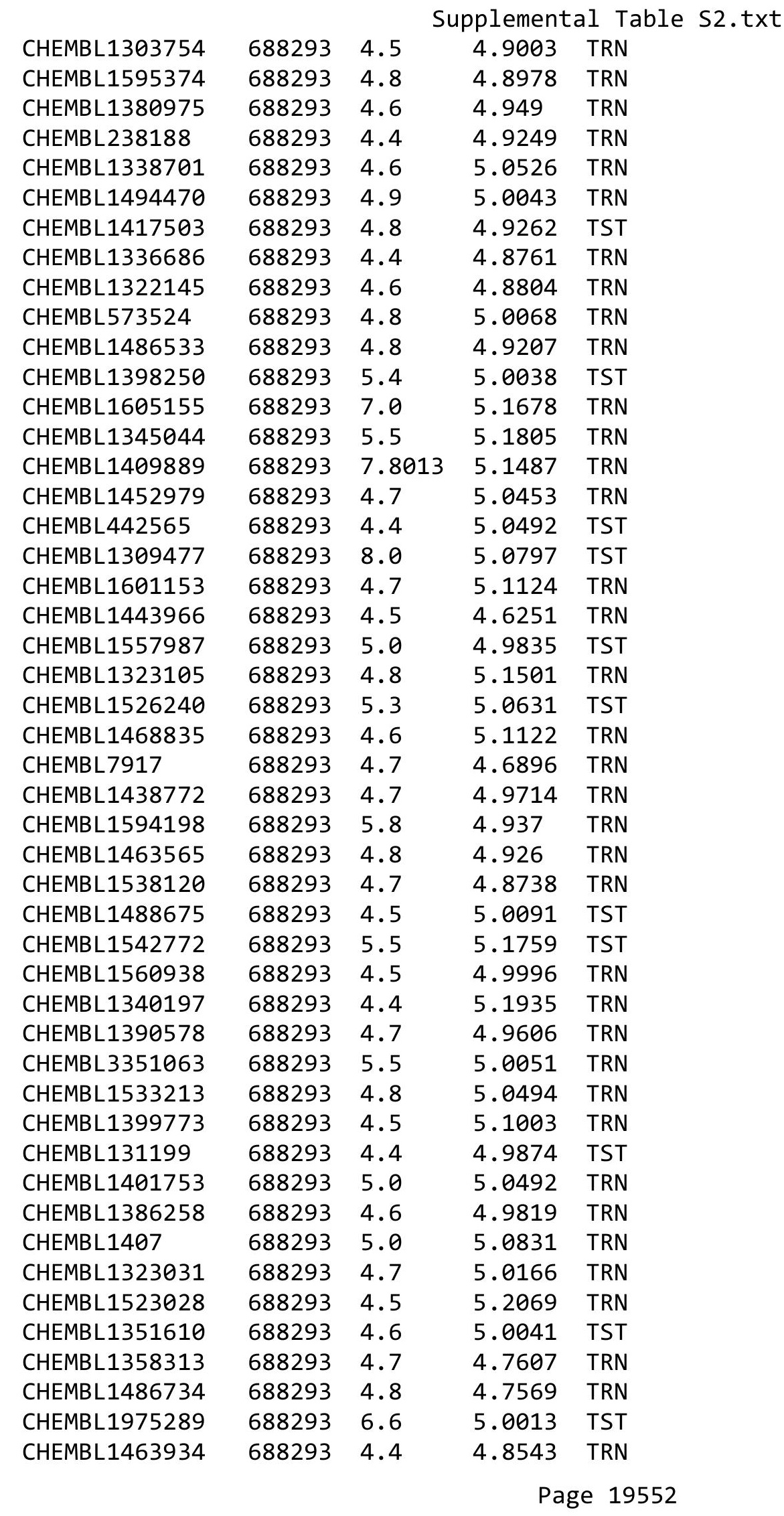




\begin{tabular}{|c|c|c|c|c|}
\hline \multicolumn{5}{|c|}{ Supplemental Table S2.txt } \\
\hline CHEMBL1470485 & 688293 & 4.7 & 4.9633 & TST \\
\hline CHEMBL1468216 & 688293 & 7.8996 & 5.0304 & TRN \\
\hline CHEMBL1452688 & 688293 & 4.9 & 4.9466 & TRN \\
\hline CHEMBL1542963 & 688293 & 4.7 & 4.9442 & TRN \\
\hline CHEMBL1550363 & 688293 & 5.5 & 4.9868 & TRN \\
\hline CHEMBL1559473 & 688293 & 4.7 & 4.9789 & TRN \\
\hline CHEMBL1593774 & 688293 & 5.0 & 4.8273 & TRN \\
\hline CHEMBL1439401 & 688293 & 4.9 & 4.7309 & TRN \\
\hline CHEMBL1552332 & 688293 & 5.1 & 4.9785 & TRN \\
\hline CHEMBL1378610 & 688293 & 4.4 & 5.1067 & TRN \\
\hline CHEMBL1558796 & 688293 & 4.5 & 4.973 & TRN \\
\hline CHEMBL1608628 & 688293 & 4.5 & 5.1363 & TRN \\
\hline CHEMBL1486740 & 688293 & 4.8 & 5.0347 & TRN \\
\hline CHEMBL1607572 & 688293 & 4.5 & 4.8856 & TST \\
\hline CHEMBL1368238 & 688293 & 4.5 & 5.1631 & TRN \\
\hline CHEMBL1606542 & 688293 & 5.3 & 4.9939 & TRN \\
\hline CHEMBL1310887 & 688293 & 4.6 & 5.2396 & TST \\
\hline CHEMBL1384158 & 688293 & 4.6 & 4.9172 & TST \\
\hline CHEMBL1534488 & 688293 & 4.6 & 4.8632 & TRN \\
\hline CHEMBL1604690 & 688293 & 5.0 & 4.8836 & TRN \\
\hline CHEMBL1444128 & 688293 & 4.7 & 4.95 & TRN \\
\hline CHEMBL1378470 & 688293 & 4.5 & 4.9096 & TRN \\
\hline CHEMBL1384533 & 688293 & 4.7 & 4.9122 & TRN \\
\hline CHEMBL1445500 & 688293 & 4.6 & 4.9955 & TRN \\
\hline CHEMBL492610 & 688293 & 4.9 & 4.7388 & TRN \\
\hline CHEMBL1529881 & 688293 & 4.7 & 4.8538 & TRN \\
\hline CHEMBL585265 & 688293 & 4.8 & 4.9987 & TRN \\
\hline CHEMBL1486729 & 688293 & 4.4 & 5.0496 & TST \\
\hline CHEMBL1445582 & 688293 & 5.1 & 5.0356 & TST \\
\hline CHEMBL1334591 & 688293 & 4.6 & 5.039 & TRN \\
\hline CHEMBL1558283 & 688293 & 4.6 & 5.0406 & TRN \\
\hline CHEMBL1509860 & 688293 & 5.6 & 4.8031 & TRN \\
\hline CHEMBL1468900 & 688293 & 4.5 & 5.0488 & TRN \\
\hline CHEMBL1607514 & 688293 & 4.6 & 4.7387 & TRN \\
\hline CHEMBL 3196375 & 688293 & 4.5 & 4.86 & TST \\
\hline CHEMBL474933 & 688293 & 4.5 & 5.0401 & TST \\
\hline CHEMBL1321059 & 688293 & 6.1 & 5.1754 & TRN \\
\hline CHEMBL1393926 & 688293 & 7.0 & 5.0913 & TST \\
\hline CHEMBL1582162 & 688293 & 6.0 & 5.0204 & TRN \\
\hline CHEMBL1457205 & 688293 & 4.9 & 5.2789 & TRN \\
\hline CHEMBL1572173 & 688293 & 4.9 & 4.9503 & TRN \\
\hline CHEMBL1334962 & 688293 & 6.6 & 5.0107 & TST \\
\hline CHEMBL1386232 & 688293 & 8.0 & 4.827 & TRN \\
\hline CHEMBL1561537 & 688293 & 4.4 & 5.0873 & TRN \\
\hline CHEMBL1422850 & 688293 & 4.6 & 5.0636 & TRN \\
\hline CHEMBL275516 & 688293 & 5.1 & 5.2077 & TST \\
\hline CHEMBL1367076 & 688293 & 4.4 & 4.8187 & TRN \\
\hline CHEMBL 225513 & 688293 & 4.7 & 4.8895 & TRN \\
\hline
\end{tabular}




\begin{tabular}{|c|c|c|c|c|c|}
\hline \multicolumn{6}{|c|}{ Supplemental Table S2.txt } \\
\hline CHEMBL1414751 & 688293 & 4.7 & 4.9107 & TST & \\
\hline CHEMBL1401763 & 688293 & 4.4 & 4.7739 & TRN & \\
\hline CHEMBL1506761 & 688293 & 8.0 & 5.0734 & TST & \\
\hline CHEMBL1568250 & 688293 & 4.7 & 4.7556 & TRN & \\
\hline CHEMBL1564277 & 688293 & 4.7 & 5.1173 & TRN & \\
\hline CHEMBL1485774 & 688293 & 4.5 & 5.157 & TRN & \\
\hline CHEMBL1341760 & 688293 & 5.6 & 4.9817 & TST & \\
\hline CHEMBL1339920 & 688293 & 4.9 & 5.1137 & TRN & \\
\hline CHEMBL1363641 & 688293 & 8.2007 & 5.1767 & TRN & \\
\hline CHEMBL1596752 & 688293 & 5.7 & 4.9766 & TRN & \\
\hline CHEMBL1450413 & 688293 & 8.2007 & 5.0979 & TRN & \\
\hline CHEMBL1312791 & 688293 & 4.8 & 4.963 & TRN & \\
\hline CHEMBL1527401 & 688293 & 4.4 & 5.1005 & TRN & \\
\hline CHEMBL1314255 & 688293 & 4.6 & 4.8766 & TRN & \\
\hline CHEMBL1606808 & 688293 & 5.9 & 5.1163 & TRN & \\
\hline CHEMBL1346737 & 688293 & 4.5 & 5.1577 & TRN & \\
\hline CHEMBL1443317 & 688293 & 5.3 & 4.8997 & TRN & \\
\hline CHEMBL1313560 & 688293 & 4.6 & 5.0286 & TST & \\
\hline CHEMBL1588727 & 688293 & 4.7 & 5.0597 & TST & \\
\hline CHEMBL1338416 & 688293 & 5.0 & 4.9319 & TRN & \\
\hline CHEMBL1200765 & 688293 & 4.5 & 4.92899 & 9999999999 & TST \\
\hline CHEMBL1362496 & 688293 & 5.2 & 4.9206 & TRN & \\
\hline CHEMBL1494876 & 688293 & 4.8 & 5.3014 & TRN & \\
\hline CHEMBL1371792 & 688293 & 4.6 & 5.0379 & TRN & \\
\hline CHEMBL1372732 & 688293 & 4.9 & 4.7961 & TST & \\
\hline CHEMBL1359547 & 688293 & 4.4 & 5.0257 & TRN & \\
\hline CHEMBL3208361 & 688293 & 4.4 & 4.8158 & TST & \\
\hline CHEMBL1469710 & 688293 & 5.1 & 5.0705 & TRN & \\
\hline CHEMBL539027 & 688293 & 4.9 & 4.9332 & TRN & \\
\hline CHEMBL1412835 & 688293 & 7.8996 & 4.9297 & TRN & \\
\hline CHEMBL1588024 & 688293 & 4.5 & 4.98300 & 00000000005 & TRN \\
\hline CHEMBL1550163 & 688293 & 4.5 & 5.1736 & TRN & \\
\hline CHEMBL1393129 & 688293 & 4.8 & 4.9364 & TRN & \\
\hline CHEMBL1381267 & 688293 & 4.4 & 5.0754 & TST & \\
\hline CHEMBL1495827 & 688293 & 5.0 & 5.0848 & TRN & \\
\hline CHEMBL1350980 & 688293 & 4.6 & 5.0035 & TRN & \\
\hline CHEMBL1447587 & 688293 & 4.9 & 4.9657 & TRN & \\
\hline CHEMBL460516 & 688293 & 4.9 & 5.1393 & TRN & \\
\hline CHEMBL1534591 & 688293 & 5.8 & 4.8716 & TRN & \\
\hline CHEMBL1312952 & 688293 & 5.4 & 4.9956 & TRN & \\
\hline CHEMBL1578194 & 688293 & 4.5 & 4.77 & TRN & \\
\hline CHEMBL559612 & 688293 & 4.5 & 5.0296 & TST & \\
\hline CHEMBL1534566 & 688293 & 4.6 & 5.1585 & TRN & \\
\hline CHEMBL1321018 & 688293 & 4.6 & 5.2445 & TRN & \\
\hline CHEMBL1546420 & 688293 & 5.2 & 4.8434 & TRN & \\
\hline CHEMBL1561977 & 688293 & 4.8 & 4.801 & TRN & \\
\hline CHEMBL1490562 & 688293 & 4.6 & 5.1029 & TRN & \\
\hline CHEMBL1561815 & 688293 & 4.8 & 5.1046 & TRN & \\
\hline
\end{tabular}




\begin{tabular}{|c|c|c|c|c|c|}
\hline & & & & & \\
\hline CHEMBL1581898 & 688293 & 4.8 & 5.0764 & TRN & \\
\hline CHEMBL1368979 & 688293 & 5.1 & 5.0823 & TRN & \\
\hline CHEMBL2000175 & 688293 & 5.6 & 4.8922 & TST & \\
\hline CHEMBL1486934 & 688293 & 5.2 & 4.9357 & TRN & \\
\hline CHEMBL1334016 & 688293 & 4.9 & 5.0758 & TST & \\
\hline CHEMBL1364819 & 688293 & 5.7 & 4.9135 & TRN & \\
\hline CHEMBL1398543 & 688293 & 4.6 & 4.8809 & TRN & \\
\hline CHEMBL1373997 & 688293 & 4.4 & 4.9485 & TRN & \\
\hline CHEMBL3193107 & 688293 & 4.7 & 4.7744 & TRN & \\
\hline CHEMBL1559515 & 688293 & 4.4 & 4.9993 & TRN & \\
\hline CHEMBL1325045 & 688293 & 5.3 & 5.1742 & TRN & \\
\hline CHEMBL1999648 & 688293 & 4.9 & 4.7963 & TST & \\
\hline CHEMBL3925157 & 688293 & 4.5 & 4.9639 & TRN & \\
\hline CHEMBL1445163 & 688293 & 4.8 & 4.85800 & 00000000005 & TRN \\
\hline CHEMBL1611099 & 688293 & 7.1002 & 5.1597 & TRN & \\
\hline CHEMBL1308291 & 688293 & 4.4 & 5.0205 & TRN & \\
\hline CHEMBL1526780 & 688293 & 6.7001 & 5.0855 & TST & \\
\hline CHEMBL1557550 & 688293 & 4.4 & 4.9608 & TRN & \\
\hline CHEMBL1468781 & 688293 & 4.9 & 5.0926 & TRN & \\
\hline CHEMBL1335961 & 688293 & 5.0 & 5.0582 & TST & \\
\hline CHEMBL1406095 & 688293 & 4.6 & 5.0224 & TRN & \\
\hline CHEMBL1568261 & 688293 & 6.7001 & 4.9198 & TRN & \\
\hline CHEMBL1323038 & 688293 & 4.6 & 4.8444 & TRN & \\
\hline CHEMBL1465579 & 688293 & 4.5 & 4.9575 & TRN & \\
\hline CHEMBL1495359 & 688293 & 4.9 & 5.0414 & TRN & \\
\hline CHEMBL1429534 & 688293 & 4.5 & 5.0802 & TRN & \\
\hline CHEMBL1407417 & 688293 & 4.7 & 5.0644 & TST & \\
\hline CHEMBL1556910 & 688293 & 4.5 & 5.0942 & TRN & \\
\hline CHEMBL1516772 & 688293 & 4.4 & 4.8342 & TRN & \\
\hline CHEMBL1378735 & 688293 & 6.8 & 5.0566 & TRN & \\
\hline CHEMBL410484 & 688293 & 4.6 & 4.8546 & TRN & \\
\hline CHEMBL1368126 & 688293 & 4.6 & 4.9959 & TRN & \\
\hline CHEMBL1506932 & 688293 & 5.5 & 5.1061 & TST & \\
\hline CHEMBL251647 & 688293 & 4.6 & 4.9644 & TST & \\
\hline CHEMBL1304821 & 688293 & 8.0 & 5.24 & TRN & \\
\hline CHEMBL1455767 & 688293 & 6.3 & 4.9702 & TRN & \\
\hline CHEMBL1453712 & 688293 & 4.7 & 4.90300 & 20000000005 & TRN \\
\hline CHEMBL1586251 & 688293 & 6.7001 & 5.1031 & TST & \\
\hline CHEMBL1493117 & 688293 & 4.4 & 4.9771 & TST & \\
\hline CHEMBL1507925 & 688293 & 5.4 & 5.1565 & TRN & \\
\hline CHEMBL105457 & 688293 & 5.5 & 5.1008 & TST & \\
\hline CHEMBL1418494 & 688293 & 4.6 & 4.7988 & TRN & \\
\hline CHEMBL1567336 & 688293 & 4.5 & 4.8423 & TRN & \\
\hline CHEMBL1386936 & 688293 & 4.7 & 5.205 & TST & \\
\hline CHEMBL1564425 & 688293 & 4.8 & 4.9852 & TRN & \\
\hline CHEMBL1403758 & 688293 & 4.5 & 5.0102 & TRN & \\
\hline CHEMBL1402289 & 688293 & 4.6 & 5.0214 & TRN & \\
\hline CHEMBL1314749 & 688293 & 6.9 & 5.0705 & TST & \\
\hline & & & & 19555 & \\
\hline
\end{tabular}




\begin{tabular}{|c|c|c|c|c|c|}
\hline \multicolumn{6}{|c|}{ Supplemental Table S2.txt } \\
\hline CHEMBL1573664 & 688293 & 4.5 & 5.1519 & TRN & \\
\hline CHEMBL1345482 & 688293 & 4.6 & 5.1234 & TRN & \\
\hline CHEMBL1426502 & 688293 & 4.7 & 5.1068 & TRN & \\
\hline CHEMBL1300788 & 688293 & 4.8 & 5.0331 & TRN & \\
\hline CHEMBL1496594 & 688293 & 4.4 & 4.9818 & TST & \\
\hline CHEMBL1511225 & 688293 & 4.6 & 5.0657 & TRN & \\
\hline CHEMBL1565435 & 688293 & 4.5 & 5.0342 & TRN & \\
\hline CHEMBL1584069 & 688293 & 4.6 & 5.0566 & TRN & \\
\hline CHEMBL1330065 & 688293 & 4.7 & 5.1198 & TRN & \\
\hline CHEMBL1387894 & 688293 & 4.4 & 5.0696 & TRN & \\
\hline CHEMBL1451172 & 688293 & 5.1 & 4.9525 & TRN & \\
\hline CHEMBL1519177 & 688293 & 4.5 & 5.1176 & TRN & \\
\hline CHEMBL1530686 & 688293 & 4.5 & 4.8709 & TRN & \\
\hline CHEMBL1444435 & 688293 & 4.6 & 5.2848 & TRN & \\
\hline CHEMBL 307341 & 688293 & 4.4 & 4.915 & TRN & \\
\hline CHEMBL1345223 & 688293 & 4.4 & 4.9871 & TRN & \\
\hline CHEMBL1456417 & 688293 & 7.8996 & 5.0954 & TST & \\
\hline CHEMBL1612488 & 688293 & 4.8 & 4.9955 & TRN & \\
\hline CHEMBL1432842 & 688293 & 4.5 & 4.79899 & 99999999995 & TRN \\
\hline CHEMBL1607198 & 688293 & 5.1 & 4.9611 & TRN & \\
\hline CHEMBL1316389 & 688293 & 7.5003 & 5.0681 & TRN & \\
\hline CHEMBL1606199 & 688293 & 4.8 & 4.8729 & TRN & \\
\hline CHEMBL1415188 & 688293 & 4.6 & 5.0802 & TRN & \\
\hline CHEMBL1382202 & 688293 & 4.8 & 5.0419 & TRN & \\
\hline CHEMBL1497417 & 688293 & 4.8 & 4.8414 & TRN & \\
\hline CHEMBL1506442 & 688293 & 4.4 & 5.0321 & TRN & \\
\hline CHEMBL1324051 & 688293 & 4.6 & 4.9305 & TST & \\
\hline CHEMBL1613260 & 688293 & 4.9 & 4.9763 & TRN & \\
\hline CHEMBL1602759 & 688293 & 4.4 & 4.8305 & TRN & \\
\hline CHEMBL1378711 & 688293 & 4.7 & 5.0039 & TRN & \\
\hline CHEMBL1580641 & 688293 & 5.0 & 5.0419 & TRN & \\
\hline CHEMBL1592327 & 688293 & 6.6 & 4.7304 & TRN & \\
\hline CHEMBL1388370 & 688293 & 4.9 & 4.9118 & TST & \\
\hline CHEMBL1503798 & 688293 & 4.9 & 5.0899 & TRN & \\
\hline CHEMBL1309176 & 688293 & 4.7 & 5.0128 & TRN & \\
\hline CHEMBL1543293 & 688293 & 4.9 & 5.1349 & TRN & \\
\hline CHEMBL1604551 & 688293 & 4.5 & 4.8955 & TRN & \\
\hline CHEMBL1374588 & 688293 & 4.5 & 4.8926 & TST & \\
\hline CHEMBL1438667 & 688293 & 5.0 & 4.706 & TRN & \\
\hline CHEMBL83552 & 688293 & 4.8 & 4.8839 & TST & \\
\hline CHEMBL1544723 & 688293 & 4.4 & 5.0602 & TRN & \\
\hline CHEMBL1540519 & 688293 & 5.8 & 5.1217 & TRN & \\
\hline CHEMBL1331018 & 688293 & 4.5 & 5.0683 & TRN & \\
\hline CHEMBL1450910 & 688293 & 4.7 & 5.0815 & TST & \\
\hline CHEMBL1472358 & 688293 & 7.1002 & 4.9245 & TRN & \\
\hline CHEMBL1367693 & 688293 & 8.0 & 5.1254 & TST & \\
\hline CHEMBL1401075 & 688293 & 5.0 & 5.0079 & TRN & \\
\hline CHEMBL1605353 & 688293 & 4.6 & 4.8963 & TRN & \\
\hline
\end{tabular}




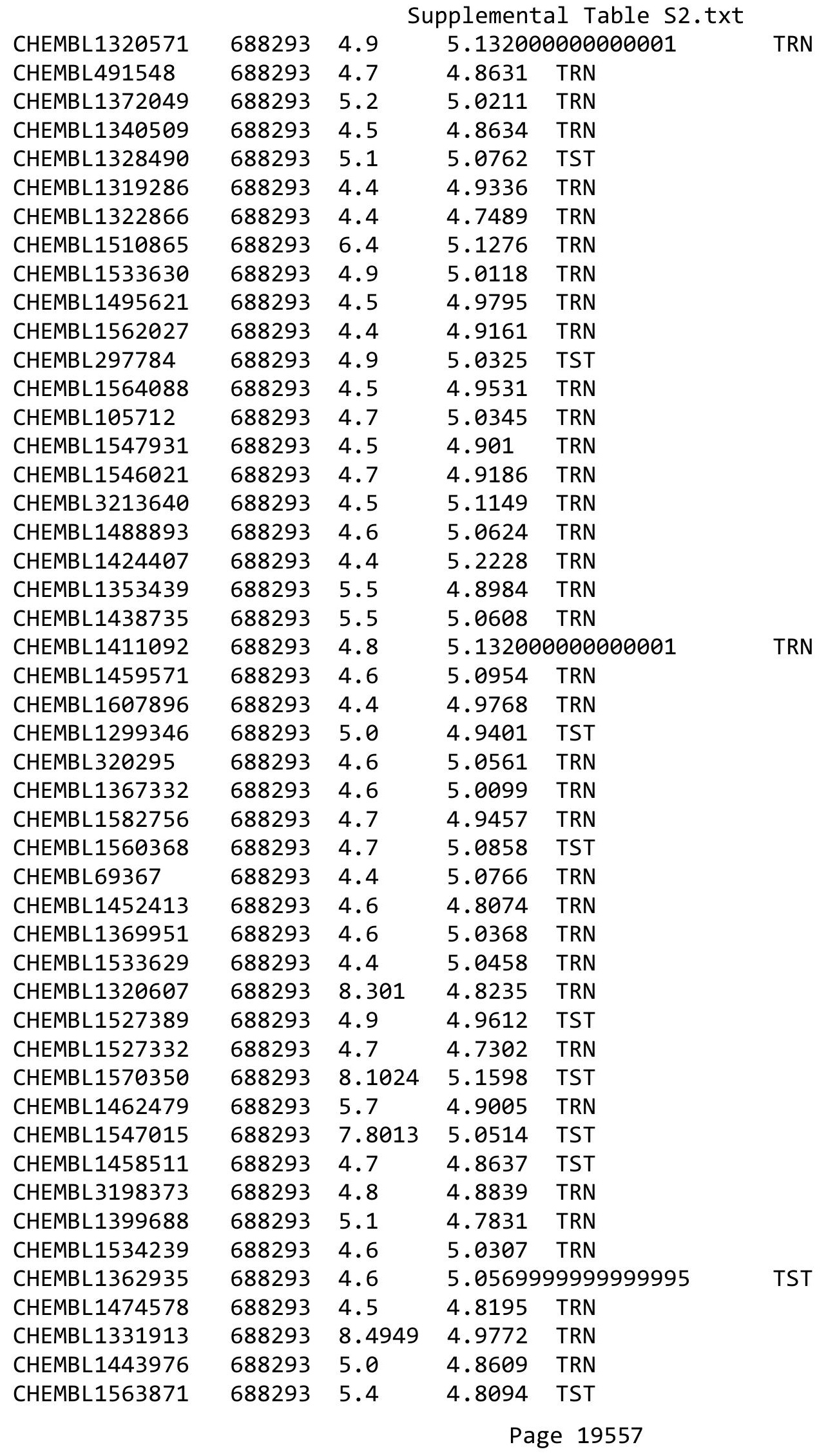




\begin{tabular}{|c|c|c|c|c|}
\hline \multicolumn{5}{|c|}{ Supplemental Table S2.txt } \\
\hline CHEMBL1603373 & 688293 & 4.8 & 5.1073 & TRN \\
\hline CHEMBL1376935 & 688293 & 4.8 & 4.9059 & TRN \\
\hline CHEMBL605003 & 688293 & 4.9 & 5.0079 & TST \\
\hline CHEMBL1509059 & 688293 & 4.4 & 5.0672 & TRN \\
\hline CHEMBL1490144 & 688293 & 4.7 & 4.9609 & TRN \\
\hline CHEMBL 2068217 & 688293 & 8.699 & 4.9868 & TST \\
\hline CHEMBL1518206 & 688293 & 4.9 & 5.0209 & TST \\
\hline CHEMBL1559578 & 688293 & 4.4 & 4.9359 & TST \\
\hline CHEMBL1454820 & 688293 & 4.6 & 5.0991 & TST \\
\hline CHEMBL1344317 & 688293 & 4.4 & 4.9645 & TRN \\
\hline CHEMBL1467824 & 688293 & 4.4 & 4.8032 & TRN \\
\hline CHEMBL1348025 & 688293 & 4.9 & 5.0731 & TRN \\
\hline CHEMBL1389934 & 688293 & 4.5 & 5.1476 & TRN \\
\hline CHEMBL1456081 & 688293 & 4.9 & 4.9768 & TRN \\
\hline CHEMBL10 & 688293 & 6.0 & 4.8611 & TST \\
\hline CHEMBL1544223 & 688293 & 4.4 & 4.8704 & TRN \\
\hline CHEMBL1315582 & 688293 & 5.2 & 4.9503 & TRN \\
\hline CHEMBL1403452 & 688293 & 6.4 & 5.0463 & TRN \\
\hline CHEMBL1605511 & 688293 & 4.6 & 4.8513 & TRN \\
\hline CHEMBL1350152 & 688293 & 4.9 & 5.0075 & TRN \\
\hline CHEMBL3191913 & 688293 & 4.4 & 4.9572 & TST \\
\hline CHEMBL1605965 & 688293 & 4.8 & 5.015 & TRN \\
\hline CHEMBL1507822 & 688293 & 4.6 & 4.9992 & TST \\
\hline CHEMBL1308869 & 688293 & 7.4001 & 5.2415 & TRN \\
\hline CHEMBL1301720 & 688293 & 4.4 & 4.9395 & TRN \\
\hline CHEMBL1421517 & 688293 & 4.4 & 4.7129 & TRN \\
\hline CHEMBL1541633 & 688293 & 4.7 & 5.185 & TRN \\
\hline CHEMBL 203606 & 688293 & 4.6 & 5.1059 & TST \\
\hline CHEMBL1545129 & 688293 & 4.8 & 4.9126 & TRN \\
\hline CHEMBL1434513 & 688293 & 4.4 & 4.9748 & TRN \\
\hline CHEMBL1575188 & 688293 & 5.1 & 5.0816 & TST \\
\hline CHEMBL1454689 & 688293 & 4.4 & 5.0774 & TST \\
\hline CHEMBL1401317 & 688293 & 4.7 & 5.218 & TRN \\
\hline CHEMBL1402957 & 688293 & 4.5 & 5.1442 & TST \\
\hline CHEMBL1325053 & 688293 & 4.4 & 4.9845 & TST \\
\hline CHEMBL1558065 & 688293 & 4.5 & 4.8796 & TRN \\
\hline CHEMBL1565537 & 688293 & 4.5 & 4.9334 & TRN \\
\hline CHEMBL1324815 & 688293 & 5.5 & 4.9952 & TRN \\
\hline CHEMBL1423165 & 688293 & 4.7 & 4.8769 & TRN \\
\hline CHEMBL1480218 & 688293 & 5.1 & 5.1339 & TRN \\
\hline CHEMBL1399261 & 688293 & 8.301 & 5.0082 & TRN \\
\hline CHEMBL1302338 & 688293 & 5.5 & 5.1007 & TRN \\
\hline CHEMBL1504324 & 688293 & 5.1 & 4.7757 & TRN \\
\hline CHEMBL1393118 & 688293 & 5.4 & 5.0088 & TRN \\
\hline CHEMBL1413519 & 688293 & 4.6 & 4.8009 & TRN \\
\hline CHEMBL 323542 & 688293 & 7.0 & 5.015 & TST \\
\hline CHEMBL1420487 & 688293 & 4.8 & 5.1344 & TRN \\
\hline CHEMBL1366732 & 688293 & 5.0 & 4.7433 & TRN \\
\hline
\end{tabular}




\begin{tabular}{|c|c|c|c|c|c|}
\hline \\
\hline CHEMBL1408909 & 688293 & 4.4 & 4.9516 & TRN & \\
\hline CHEMBL1466310 & 688293 & 4.6 & 4.8272 & TRN & \\
\hline CHEMBL3211567 & 688293 & 4.9 & 4.9425 & TST & \\
\hline CHEMBL1534598 & 688293 & 4.6 & 4.9223 & TRN & \\
\hline CHEMBL1505809 & 688293 & 4.5 & 4.98300 & 00000000005 & TRN \\
\hline CHEMBL1572708 & 688293 & 4.8 & 4.7777 & TRN & \\
\hline CHEMBL1578087 & 688293 & 4.6 & 4.7116 & TRN & \\
\hline CHEMBL1373582 & 688293 & 4.9 & 4.9102 & TRN & \\
\hline CHEMBL1411954 & 688293 & 4.9 & 5.1206 & TRN & \\
\hline CHEMBL286721 & 688293 & 4.5 & 4.9111 & TST & \\
\hline CHEMBL1381089 & 688293 & 4.7 & 5.1381 & TRN & \\
\hline CHEMBL1551919 & 688293 & 4.6 & 4.7534 & TRN & \\
\hline CHEMBL1446626 & 688293 & 4.7 & 4.9107 & TRN & \\
\hline CHEMBL1483338 & 688293 & 4.7 & 4.7734 & TRN & \\
\hline CHEMBL1603264 & 688293 & 4.8 & 4.9722 & TST & \\
\hline CHEMBL1575772 & 688293 & 5.1 & 5.0285 & TRN & \\
\hline CHEMBL1374653 & 688293 & 5.0 & 4.9514 & TRN & \\
\hline CHEMBL1503998 & 688293 & 4.4 & 4.882 & TRN & \\
\hline CHEMBL1599032 & 688293 & 4.6 & 5.04 & TRN & \\
\hline CHEMBL1492463 & 688293 & 5.4 & 5.2565 & TRN & \\
\hline CHEMBL47940 & 688293 & 5.1 & 4.8196 & TST & \\
\hline CHEMBL1450680 & 688293 & 6.7001 & 4.8634 & TRN & \\
\hline CHEMBL1434801 & 688293 & 5.4 & 4.9749 & TRN & \\
\hline CHEMBL1334484 & 688293 & 4.5 & 4.8101 & TRN & \\
\hline CHEMBL 274189 & 688293 & 8.1024 & 4.9745 & TST & \\
\hline CHEMBL1303198 & 688293 & 4.6 & 4.7959 & TRN & \\
\hline CHEMBL1497207 & 688293 & 4.6 & 5.1176 & TRN & \\
\hline CHEMBL1552227 & 688293 & 4.8 & 4.9816 & TRN & \\
\hline CHEMBL1525024 & 688293 & 6.0 & 5.0497 & TRN & \\
\hline CHEMBL1597957 & 688293 & 4.8 & 4.959 & TRN & \\
\hline CHEMBL1383567 & 688293 & 4.8 & 5.0526 & TRN & \\
\hline CHEMBL1412538 & 688293 & 4.5 & 4.9473 & TRN & \\
\hline CHEMBL1588000 & 688293 & 4.8 & 4.9155 & TRN & \\
\hline CHEMBL1429581 & 688293 & 4.8 & 4.9588 & TRN & \\
\hline CHEMBL1424508 & 688293 & 4.4 & 4.9546 & TRN & \\
\hline CHEMBL1507334 & 688293 & 5.1 & 4.8376 & TRN & \\
\hline CHEMBL1386853 & 688293 & 4.8 & 4.8227 & TST & \\
\hline CHEMBL1359780 & 688293 & 7.2 & 5.006 & TST & \\
\hline CHEMBL1539467 & 688293 & 5.0 & 5.0282 & TST & \\
\hline CHEMBL1480497 & 688293 & 4.6 & 4.6641 & TRN & \\
\hline CHEMBL1581838 & 688293 & 4.7 & 4.9694 & TRN & \\
\hline CHEMBL1381437 & 688293 & 4.4 & 5.0151 & TRN & \\
\hline CHEMBL1352108 & 688293 & 4.6 & 5.1035 & TRN & \\
\hline CHEMBL1399328 & 688293 & 5.3 & 5.1642 & TRN & \\
\hline CHEMBL1586957 & 688293 & 4.5 & 5.0233 & TRN & \\
\hline CHEMBL1329528 & 688293 & 4.4 & 5.0268 & TRN & \\
\hline CHEMBL1404701 & 688293 & 5.2 & 5.0254 & TRN & \\
\hline CHEMBL1562581 & 688293 & 5.0 & 5.0585 & TRN & \\
\hline
\end{tabular}




\begin{tabular}{|c|c|c|c|c|c|}
\hline \multicolumn{6}{|c|}{ Supplemental Table S2.txt } \\
\hline CHEMBL21260 & 688293 & 6.0 & 5.1093 & TRN & \\
\hline CHEMBL1531260 & 688293 & 4.8 & 4.9722 & TRN & \\
\hline CHEMBL1483464 & 688293 & 4.5 & 4.8435 & TRN & \\
\hline CHEMBL1540820 & 688293 & 8.0 & 5.058 & TRN & \\
\hline CHEMBL1499433 & 688293 & 5.6 & 4.8994 & TRN & \\
\hline CHEMBL1385095 & 688293 & 6.8 & 4.8343 & TRN & \\
\hline CHEMBL1451654 & 688293 & 7.0 & 5.1401 & TRN & \\
\hline CHEMBL1533424 & 688293 & 4.8 & 4.8751 & TST & \\
\hline CHEMBL1416890 & 688293 & 4.9 & 5.0495 & TRN & \\
\hline CHEMBL1321000 & 688293 & 6.9 & 5.1517 & TRN & \\
\hline CHEMBL1502445 & 688293 & 7.5003 & 5.0977 & TRN & \\
\hline CHEMBL1601286 & 688293 & 4.9 & 5.0515 & TRN & \\
\hline CHEMBL1564753 & 688293 & 4.4 & 5.0263 & TRN & \\
\hline CHEMBL491742 & 688293 & 4.6 & 4.8542 & TRN & \\
\hline CHEMBL1419608 & 688293 & 4.4 & 5.0834 & TRN & \\
\hline CHEMBL365739 & 688293 & 4.7 & 4.9165 & TST & \\
\hline CHEMBL1390063 & 688293 & 4.9 & 5.0334 & TRN & \\
\hline CHEMBL1573621 & 688293 & 4.5 & 5.2804 & TRN & \\
\hline CHEMBL1515956 & 688293 & 5.4 & 5.2456 & TST & \\
\hline CHEMBL1403374 & 688293 & 5.0 & 5.0357 & TRN & \\
\hline CHEMBL1525504 & 688293 & 4.7 & 5.2772 & TRN & \\
\hline CHEMBL1480546 & 688293 & 4.8 & 4.8067 & TRN & \\
\hline CHEMBL491940 & 688293 & 5.5 & 4.6965 & TRN & \\
\hline CHEMBL1479817 & 688293 & 5.5 & 4.7563 & TRN & \\
\hline CHEMBL1480886 & 688293 & 4.8 & 5.0968 & TST & \\
\hline CHEMBL1570238 & 688293 & 4.6 & 4.8656 & TRN & \\
\hline CHEMBL1361750 & 688293 & 5.6 & 4.7771 & TRN & \\
\hline CHEMBL1412656 & 688293 & 4.6 & 4.9556 & TRN & \\
\hline CHEMBL546576 & 688293 & 4.5 & 5.0073 & TRN & \\
\hline CHEMBL1399091 & 688293 & 4.8 & 5.12700 & 0000000001 & TRN \\
\hline CHEMBL1539964 & 688293 & 7.0 & 5.0803 & TRN & \\
\hline CHEMBL1421178 & 688293 & 4.9 & 4.7996 & TRN & \\
\hline CHEMBL1321421 & 688293 & 5.1 & 4.8156 & TRN & \\
\hline CHEMBL1322220 & 688293 & 5.7 & 4.9569 & TRN & \\
\hline CHEMBL1564619 & 688293 & 8.1024 & 4.8022 & TRN & \\
\hline CHEMBL1607125 & 688293 & 4.4 & 5.1061 & TST & \\
\hline CHEMBL1551913 & 688293 & 5.6 & 4.9501 & TRN & \\
\hline CHEMBL1430111 & 688293 & 8.0 & 5.3055 & TST & \\
\hline CHEMBL1474475 & 688293 & 4.5 & 4.7469 & TRN & \\
\hline CHEMBL1413280 & 688293 & 4.8 & 4.7263 & TRN & \\
\hline CHEMBL1546601 & 688293 & 4.5 & 4.9501 & TRN & \\
\hline CHEMBL1305880 & 688293 & 4.6 & 5.0261 & TRN & \\
\hline CHEMBL369142 & 688293 & 4.9 & 5.1041 & TRN & \\
\hline CHEMBL1369506 & 688293 & 4.9 & 4.7821 & TRN & \\
\hline CHEMBL1487947 & 688293 & 4.9 & 5.0114 & TRN & \\
\hline CHEMBL1302845 & 688293 & 4.7 & 5.0592 & TRN & \\
\hline CHEMBL1554098 & 688293 & 6.0 & 5.129 & TST & \\
\hline CHEMBL1301917 & 688293 & 6.0 & 5.1023 & TRN & \\
\hline
\end{tabular}




\begin{tabular}{|c|c|c|c|c|c|}
\hline \multicolumn{6}{|c|}{ Supplemental Table S2.txt } \\
\hline CHEMBL1327766 & 688293 & 4.7 & 4.8328 & TRN & \\
\hline CHEMBL1323791 & 688293 & 4.7 & 5.1301 & TRN & \\
\hline CHEMBL1477253 & 688293 & 4.4 & 4.9554 & TRN & \\
\hline CHEMBL1407464 & 688293 & 6.0 & 5.1222 & TRN & \\
\hline CHEMBL1504256 & 688293 & 7.6003 & 5.041 & TRN & \\
\hline CHEMBL1483977 & 688293 & 5.0 & 4.9733 & TST & \\
\hline CHEMBL1549248 & 688293 & 4.6 & 5.2507 & TRN & \\
\hline CHEMBL1485746 & 688293 & 4.5 & 4.8083 & TRN & \\
\hline CHEMBL1307204 & 688293 & 4.6 & 4.9871 & TRN & \\
\hline CHEMBL1342690 & 688293 & 4.9 & 4.7774 & TRN & \\
\hline CHEMBL1494237 & 688293 & 4.9 & 5.0738 & TST & \\
\hline CHEMBL1362994 & 688293 & 4.6 & 4.95 & TRN & \\
\hline CHEMBL1352447 & 688293 & 5.8 & 5.1047 & TRN & \\
\hline CHEMBL1453703 & 688293 & 4.7 & 5.157 & TRN & \\
\hline CHEMBL1440612 & 688293 & 4.9 & 5.1225 & TRN & \\
\hline CHEMBL1492963 & 688293 & 4.9 & 5.0059 & TRN & \\
\hline CHEMBL1565421 & 688293 & 5.2 & 4.9852 & TRN & \\
\hline CHEMBL1529557 & 688293 & 5.1 & 4.9165 & TRN & \\
\hline CHEMBL1332162 & 688293 & 5.3 & 5.0439 & TRN & \\
\hline CHEMBL1437929 & 688293 & 5.0 & 4.9556 & TRN & \\
\hline CHEMBL1421118 & 688293 & 4.4 & 5.1103 & TRN & \\
\hline CHEMBL1393737 & 688293 & 8.2007 & 5.2582 & TRN & \\
\hline CHEMBL1462735 & 688293 & 4.8 & 5.043 & TRN & \\
\hline CHEMBL1467999 & 688293 & 5.5 & 4.976 & TRN & \\
\hline CHEMBL1312996 & 688293 & 4.8 & 5.075 & TRN & \\
\hline CHEMBL1497853 & 688293 & 4.5 & 4.9602 & TRN & \\
\hline CHEMBL3207875 & 688293 & 4.4 & 5.1138 & TRN & \\
\hline CHEMBL110739 & 688293 & 5.5 & 5.1995 & TST & \\
\hline CHEMBL1328481 & 688293 & 5.5 & 4.9906 & TRN & \\
\hline CHEMBL1224512 & 688293 & 4.8 & 4.9173 & TRN & \\
\hline CHEMBL1429319 & 688293 & 4.6 & 5.0843 & TRN & \\
\hline CHEMBL1439673 & 688293 & 4.4 & 4.7828 & TRN & \\
\hline CHEMBL1333249 & 688293 & 5.0 & 4.9302 & TRN & \\
\hline CHEMBL1471520 & 688293 & 4.8 & 5.0296 & TST & \\
\hline CHEMBL1419855 & 688293 & 4.7 & 5.0839 & TRN & \\
\hline CHEMBL1540677 & 688293 & 4.7 & $5.0760 e$ & 00000000005 & TRN \\
\hline CHEMBL1444632 & 688293 & 5.0 & 5.1154 & TRN & \\
\hline CHEMBL1440062 & 688293 & 4.4 & 5.0037 & TRN & \\
\hline CHEMBL1423454 & 688293 & 4.4 & 5.0667 & TRN & \\
\hline CHEMBL1410437 & 688293 & 4.5 & 4.6867 & TRN & \\
\hline CHEMBL1470619 & 688293 & 4.5 & 5.2897 & TRN & \\
\hline CHEMBL1421029 & 688293 & 5.5 & 4.893 & TRN & \\
\hline CHEMBL1364368 & 688293 & 6.0 & 4.8992 & TST & \\
\hline CHEMBL1379136 & 688293 & 4.4 & 4.8916 & TRN & \\
\hline CHEMBL1592500 & 688293 & 5.8 & 5.0816 & TST & \\
\hline CHEMBL1469865 & 688293 & 5.9 & 5.1155 & TRN & \\
\hline CHEMBL1359181 & 688293 & 4.5 & 4.8138 & TRN & \\
\hline CHEMBL1391320 & 688293 & 4.7 & 5.1099 & TST & \\
\hline
\end{tabular}




\begin{tabular}{|c|c|c|c|c|c|}
\hline \multicolumn{6}{|c|}{ Supplemental Table S2.txt } \\
\hline CHEMBL1446243 & 688293 & 4.9 & 5.0656 & TRN & \\
\hline CHEMBL1450889 & 688293 & 4.7 & 4.8878 & TRN & \\
\hline CHEMBL1443946 & 688293 & 4.8 & 4.9811 & TRN & \\
\hline CHEMBL1440011 & 688293 & 4.6 & 4.7932 & TRN & \\
\hline CHEMBL1429681 & 688293 & 4.4 & 5.0825 & TRN & \\
\hline CHEMBL1586623 & 688293 & 6.9 & 4.9472 & TRN & \\
\hline CHEMBL1405744 & 688293 & 6.1 & 4.8364 & TRN & \\
\hline CHEMBL1369929 & 688293 & 4.6 & 4.7369 & TRN & \\
\hline CHEMBL84685 & 688293 & 5.2 & 4.944 & TST & \\
\hline CHEMBL1583117 & 688293 & 4.5 & 5.1189 & TRN & \\
\hline CHEMBL1368730 & 688293 & 5.6 & 5.1878 & TRN & \\
\hline CHEMBL169233 & 688293 & 4.8 & 4.9106 & TST & \\
\hline CHEMBL1374152 & 688293 & 5.6 & 5.2312 & TRN & \\
\hline CHEMBL1354445 & 688293 & 5.9 & 5.0518 & TRN & \\
\hline CHEMBL1335634 & 688293 & 4.7 & 5.1978 & TST & \\
\hline CHEMBL1468159 & 688293 & 4.5 & 4.9692 & TRN & \\
\hline CHEMBL1358161 & 688293 & 4.7 & 5.1153 & TST & \\
\hline CHEMBL1549356 & 688293 & 4.6 & 4.9462 & TRN & \\
\hline CHEMBL1401953 & 688293 & 4.6 & 5.0166 & TRN & \\
\hline CHEMBL1541213 & 688293 & 4.9 & 4.8425 & TRN & \\
\hline CHEMBL1425658 & 688293 & 4.5 & 4.8772 & TRN & \\
\hline CHEMBL1366821 & 688293 & 4.8 & 5.0644 & TRN & \\
\hline CHEMBL1433776 & 688293 & 4.6 & 4.8216 & TRN & \\
\hline CHEMBL1608249 & 688293 & 5.0 & 4.9388 & TRN & \\
\hline CHEMBL1416218 & 688293 & 5.0 & 4.947 & TST & \\
\hline CHEMBL1302268 & 688293 & 4.6 & 5.1352 & TRN & \\
\hline CHEMBL1546809 & 688293 & 5.0 & 5.02800 & 00000000005 & TRN \\
\hline CHEMBL1439205 & 688293 & 7.1002 & 4.8642 & TRN & \\
\hline CHEMBL3209422 & 688293 & 5.2 & 5.1247 & TST & \\
\hline CHEMBL1402230 & 688293 & 4.4 & 4.9589 & TRN & \\
\hline CHEMBL407501 & 688293 & 4.6 & 5.0291 & TRN & \\
\hline CHEMBL1599369 & 688293 & 5.7 & 5.0481 & TRN & \\
\hline CHEMBL1318708 & 688293 & 4.7 & 4.9715 & TST & \\
\hline CHEMBL1329230 & 688293 & 4.7 & 4.9383 & TRN & \\
\hline CHEMBL1488598 & 688293 & 4.4 & 5.0176 & TRN & \\
\hline CHEMBL1337055 & 688293 & 4.7 & 5.0986 & TRN & \\
\hline CHEMBL1512540 & 688293 & 4.6 & 4.7143 & TRN & \\
\hline CHEMBL1448615 & 688293 & 4.6 & 4.9435 & TRN & \\
\hline CHEMBL565654 & 688293 & 4.8 & 4.6612 & TRN & \\
\hline CHEMBL1556570 & 688293 & 4.4 & 5.0102 & TRN & \\
\hline CHEMBL1562928 & 688293 & 4.5 & 4.8446 & TST & \\
\hline CHEMBL1453299 & 688293 & 4.8 & 4.9147 & TRN & \\
\hline CHEMBL1388031 & 688293 & 4.4 & 5.0691 & TRN & \\
\hline CHEMBL1320385 & 688293 & 4.4 & 4.6377 & TRN & \\
\hline CHEMBL 261919 & 688293 & 8.699 & 4.9783 & TRN & \\
\hline CHEMBL1505296 & 688293 & 4.9 & 4.9828 & TRN & \\
\hline CHEMBL1411716 & 688293 & 5.7 & 5.1219 & TRN & \\
\hline CHEMBL1561833 & 688293 & 5.0 & 5.0645 & TST & \\
\hline
\end{tabular}




\begin{tabular}{|c|c|c|c|c|}
\hline \multicolumn{5}{|c|}{ Supplemental Table S2.txt } \\
\hline CHEMBL1334817 & 688293 & 7.0 & 4.9992 & TST \\
\hline CHEMBL1328850 & 688293 & 4.6 & 4.9545 & TRN \\
\hline CHEMBL1257003 & 688293 & 4.8 & 5.015 & TRN \\
\hline CHEMBL1408968 & 688293 & 4.9 & 4.995 & TRN \\
\hline CHEMBL1403768 & 688293 & 6.8 & 4.9042 & TRN \\
\hline CHEMBL1589582 & 688293 & 4.4 & 4.9449 & TRN \\
\hline CHEMBL1564662 & 688293 & 4.7 & 5.1273 & TRN \\
\hline CHEMBL1348203 & 688293 & 6.2 & 5.0282 & TRN \\
\hline CHEMBL1304398 & 688293 & 7.3002 & 5.0122 & TRN \\
\hline CHEMBL475376 & 688293 & 4.7 & 4.8203 & TRN \\
\hline CHEMBL1488206 & 688293 & 4.7 & 4.8567 & TRN \\
\hline CHEMBL1456695 & 688293 & 4.4 & 5.0821 & TST \\
\hline CHEMBL1357850 & 688293 & 4.7 & 4.8148 & TRN \\
\hline CHEMBL1529042 & 688293 & 4.5 & 5.0102 & TRN \\
\hline CHEMBL1300081 & 688293 & 4.5 & 5.0211 & TRN \\
\hline CHEMBL1564749 & 688293 & 4.6 & 5.1064 & TRN \\
\hline CHEMBL1592160 & 688293 & 4.5 & 4.791 & TRN \\
\hline CHEMBL1579769 & 688293 & 4.6 & 4.9653 & TRN \\
\hline CHEMBL1486113 & 688293 & 8.2007 & 5.2007 & TRN \\
\hline CHEMBL1495954 & 688293 & 4.5 & 5.1315 & TRN \\
\hline CHEMBL327588 & 688293 & 4.7 & 5.1061 & TRN \\
\hline CHEMBL1325890 & 688293 & 4.5 & 4.8755 & TRN \\
\hline CHEMBL1478244 & 688293 & 4.8 & 5.0932 & TRN \\
\hline CHEMBL222409 & 688293 & 4.4 & 4.8836 & TRN \\
\hline CHEMBL1364557 & 688293 & 4.4 & 5.1685 & TRN \\
\hline CHEMBL3190009 & 688293 & 4.4 & 4.8388 & TRN \\
\hline CHEMBL1384466 & 688293 & 4.7 & 5.0318 & TST \\
\hline CHEMBL1506490 & 688293 & 4.5 & 5.1974 & TRN \\
\hline CHEMBL1340822 & 688293 & 4.7 & 4.8778 & TRN \\
\hline CHEMBL1334745 & 688293 & 6.7001 & 4.9465 & TRN \\
\hline CHEMBL1544488 & 688293 & 4.4 & 5.0988 & TRN \\
\hline CHEMBL1494205 & 688293 & 4.6 & 5.1767 & TRN \\
\hline CHEMBL1423359 & 688293 & 4.8 & 4.8713 & TRN \\
\hline CHEMBL1561768 & 688293 & 4.7 & 4.8581 & TRN \\
\hline CHEMBL1379523 & 688293 & 4.8 & 5.1453 & TRN \\
\hline CHEMBL1502530 & 688293 & 4.8 & 5.0993 & TRN \\
\hline CHEMBL 1576578 & 688293 & 4.6 & 5.1065 & TRN \\
\hline CHEMBL1305254 & 688293 & 4.9 & 4.8302 & TST \\
\hline CHEMBL1309830 & 688293 & 4.6 & 4.9068 & TRN \\
\hline CHEMBL1590663 & 688293 & 4.7 & 4.8329 & TRN \\
\hline CHEMBL1541610 & 688293 & 4.7 & 5.0544 & TRN \\
\hline CHEMBL1329000 & 688293 & 4.7 & 4.8243 & TRN \\
\hline CHEMBL1321371 & 688293 & 4.5 & 5.185 & TRN \\
\hline CHEMBL1440154 & 688293 & 4.4 & 5.0835 & TRN \\
\hline CHEMBL1423373 & 688293 & 4.5 & 5.0416 & TST \\
\hline CHEMBL1572017 & 688293 & 5.1 & 4.8667 & TRN \\
\hline CHEMBL1360889 & 688293 & 4.4 & 4.8909 & TST \\
\hline CHEMBL1327681 & 688293 & 4.7 & 4.7401 & TRN \\
\hline
\end{tabular}




\begin{tabular}{|c|c|c|c|c|c|}
\hline \\
\hline CHEMBL1395219 & 688293 & 4.4 & 4.7618 & TRN & \\
\hline CHEMBL1580837 & 688293 & 4.6 & 5.0346 & TRN & \\
\hline CHEMBL1408404 & 688293 & 4.9 & 4.9555 & TST & \\
\hline CHEMBL1319698 & 688293 & 4.4 & 5.0764 & TRN & \\
\hline CHEMBL1596922 & 688293 & 4.4 & 4.9854 & TRN & \\
\hline CHEMBL1608984 & 688293 & 4.6 & 5.0329 & TRN & \\
\hline CHEMBL1487332 & 688293 & 5.0 & 4.9154 & TRN & \\
\hline CHEMBL1416727 & 688293 & 5.4 & 5.0913 & TRN & \\
\hline CHEMBL1401324 & 688293 & 4.5 & 4.8574 & TRN & \\
\hline CHEMBL1590639 & 688293 & 5.0 & 4.9352 & TRN & \\
\hline CHEMBL320361 & 688293 & 4.4 & 4.899 & TST & \\
\hline CHEMBL 3213783 & 688293 & 4.7 & 4.8663 & TRN & \\
\hline CHEMBL1519535 & 688293 & 4.4 & 4.9863 & TST & \\
\hline CHEMBL1564253 & 688293 & 4.6 & 5.0124 & TST & \\
\hline CHEMBL1499381 & 688293 & 4.6 & 4.9979 & TRN & \\
\hline CHEMBL1371350 & 688293 & 9.0 & 5.1751 & TST & \\
\hline CHEMBL1578860 & 688293 & 4.8 & 5.1729 & TST & \\
\hline CHEMBL1309562 & 688293 & 4.8 & 4.7891 & TRN & \\
\hline CHEMBL1489891 & 688293 & 4.4 & 4.855 & TRN & \\
\hline CHEMBL1446807 & 688293 & 4.4 & 4.901 & TRN & \\
\hline CHEMBL1449481 & 688293 & 4.4 & 4.9416 & TRN & \\
\hline CHEMBL1333512 & 688293 & 5.1 & $4.9110 e$ & 00000000005 & TRN \\
\hline CHEMBL 70902 & 688293 & 4.4 & 4.9483 & TST & \\
\hline CHEMBL1493551 & 688293 & 5.0 & 4.8793 & TRN & \\
\hline CHEMBL1611366 & 688293 & 6.2 & 4.9755 & TRN & \\
\hline CHEMBL1455249 & 688293 & 4.8 & 4.9958 & TST & \\
\hline CHEMBL3193629 & 688293 & 4.6 & 4.9912 & TST & \\
\hline CHEMBL1325876 & 688293 & 4.4 & 4.9047 & TST & \\
\hline CHEMBL1478074 & 688293 & 7.0 & 4.8496 & TRN & \\
\hline CHEMBL1484754 & 688293 & 4.5 & 4.9794 & TRN & \\
\hline CHEMBL509256 & 688293 & 5.1 & 4.9129 & TRN & \\
\hline CHEMBL1578302 & 688293 & 4.0 & 4.9553 & TRN & \\
\hline CHEMBL1423761 & 688293 & 4.5 & 4.9387 & TRN & \\
\hline CHEMBL1443000 & 688293 & 4.7 & $4.9910 e$ & 00000000005 & TRN \\
\hline CHEMBL1525442 & 688293 & 4.7 & 5.048 & TST & \\
\hline CHEMBL1469270 & 688293 & 4.6 & 5.1841 & TST & \\
\hline CHEMBL1476184 & 688293 & 4.8 & 4.9624 & TRN & \\
\hline CHEMBL1506121 & 688293 & 5.5 & 4.8932 & TRN & \\
\hline CHEMBL1489281 & 688293 & 4.6 & 4.9928 & TRN & \\
\hline CHEMBL1544478 & 688293 & 4.5 & 5.09399 & 9999999999 & TRN \\
\hline CHEMBL1364003 & 688293 & 4.5 & 5.0953 & TRN & \\
\hline CHEMBL1316317 & 688293 & 5.0 & 4.8024 & TRN & \\
\hline CHEMBL1412163 & 688293 & 4.6 & 4.9673 & TST & \\
\hline CHEMBL1522165 & 688293 & 4.6 & 4.9881 & TRN & \\
\hline CHEMBL1300790 & 688293 & 5.0 & 5.0762 & TST & \\
\hline CHEMBL1428502 & 688293 & 4.6 & 5.0082 & TRN & \\
\hline CHEMBL1501053 & 688293 & 4.8 & 4.942 & TRN & \\
\hline CHEMBL3210001 & 688293 & 5.4 & 5.035 & TRN & \\
\hline
\end{tabular}




\begin{tabular}{|c|c|c|c|c|c|}
\hline \multicolumn{6}{|c|}{ Supplemental Table S2.txt } \\
\hline CHEMBL1478464 & 688293 & 4.7 & 4.8354 & TRN & \\
\hline CHEMBL594957 & 688293 & 5.4 & 4.9346 & TRN & \\
\hline CHEMBL1498994 & 688293 & 5.5 & 4.993 & TST & \\
\hline CHEMBL581194 & 688293 & 4.5 & 5.0286 & TRN & \\
\hline CHEMBL 1436648 & 688293 & 6.5 & 5.0864 & TST & \\
\hline CHEMBL206483 & 688293 & 4.6 & 4.8652 & TRN & \\
\hline CHEMBL1543402 & 688293 & 6.3 & 4.8843 & TRN & \\
\hline CHEMBL1598033 & 688293 & 4.7 & 4.9071 & TRN & \\
\hline CHEMBL1356794 & 688293 & 4.7 & 4.8847 & TRN & \\
\hline CHEMBL1563799 & 688293 & 4.4 & 5.0141 & TRN & \\
\hline CHEMBL1323355 & 688293 & 5.2 & 4.8933 & TST & \\
\hline CHEMBL566933 & 688293 & 5.3 & 5.0774 & TRN & \\
\hline CHEMBL1322513 & 688293 & 4.4 & 5.2757 & TRN & \\
\hline CHEMBL1344261 & 688293 & 4.4 & 5.1591 & TRN & \\
\hline CHEMBL1315609 & 688293 & 5.4 & 4.7953 & TRN & \\
\hline CHEMBL 3212022 & 688293 & 5.4 & 5.0499 & TST & \\
\hline CHEMBL2374259 & 688293 & 6.0 & 5.0017 & TST & \\
\hline CHEMBL1574743 & 688293 & 4.4 & 5.0915 & TRN & \\
\hline CHEMBL1431981 & 688293 & 4.4 & 5.1944 & TRN & \\
\hline CHEMBL1399767 & 688293 & 4.5 & 5.0779 & TRN & \\
\hline CHEMBL131091 & 688293 & 4.4 & 4.97 & TST & \\
\hline CHEMBL1316808 & 688293 & 4.7 & 4.9357 & TRN & \\
\hline CHEMBL1573112 & 688293 & 4.9 & 5.0722 & TRN & \\
\hline CHEMBL1461877 & 688293 & 4.4 & 5.0539 & TRN & \\
\hline CHEMBL1563607 & 688293 & 4.4 & 4.9357 & TRN & \\
\hline CHEMBL1477366 & 688293 & 4.9 & 4.9963 & TRN & \\
\hline CHEMBL1522396 & 688293 & 4.5 & 5.0106 & TST & \\
\hline CHEMBL1498615 & 688293 & 4.4 & 5.1085 & TRN & \\
\hline CHEMBL1381308 & 688293 & 4.7 & 5.1462 & TRN & \\
\hline CHEMBL1369639 & 688293 & 4.5 & 4.7639 & TRN & \\
\hline CHEMBL1458525 & 688293 & 4.4 & 4.8064 & TRN & \\
\hline CHEMBL1414026 & 688293 & 6.2 & 5.1434 & TRN & \\
\hline CHEMBL 290943 & 688293 & 4.8 & 5.2057 & TST & \\
\hline CHEMBL1479341 & 688293 & 8.301 & 4.9553 & TRN & \\
\hline CHEMBL1518566 & 688293 & 4.7 & 4.9096 & TRN & \\
\hline CHEMBL1569226 & 688293 & 4.8 & 4.9478 & TRN & \\
\hline CHEMBL1577149 & 688293 & 4.9 & 5.0714 & TRN & \\
\hline CHEMBL1405804 & 688293 & 4.8 & 4.9844 & TST & \\
\hline CHEMBL1398137 & 688293 & 4.4 & 4.9378 & TRN & \\
\hline CHEMBL1362247 & 688293 & 4.7 & $4.9910 e$ & 00000000005 & TRN \\
\hline CHEMBL1364735 & 688293 & 7.5003 & 4.976 & TRN & \\
\hline CHEMBL1526388 & 688293 & 4.8 & 5.1939 & TRN & \\
\hline CHEMBL1347594 & 688293 & 4.7 & 5.0509 & TRN & \\
\hline CHEMBL1303653 & 688293 & 5.0 & 5.0584 & TRN & \\
\hline CHEMBL1304632 & 688293 & 4.6 & 5.1042 & TRN & \\
\hline CHEMBL1378254 & 688293 & 5.9 & 4.9666 & TRN & \\
\hline CHEMBL1432964 & 688293 & 4.5 & 5.114 & TRN & \\
\hline CHEMBL1331084 & 688293 & 5.5 & 5.026 & TRN & \\
\hline
\end{tabular}




\begin{tabular}{|c|c|c|c|c|c|}
\hline \multicolumn{6}{|c|}{ Supplemental Table S2.txt } \\
\hline CHEMBL1359648 & 688293 & 4.9 & 4.9564 & TRN & \\
\hline CHEMBL1391643 & 688293 & 5.5 & 4.9901 & TRN & \\
\hline CHEMBL1319400 & 688293 & 4.4 & 5.0314 & TRN & \\
\hline CHEMBL1544495 & 688293 & 4.5 & 4.9818 & TRN & \\
\hline CHEMBL1433051 & 688293 & 4.4 & 5.0679 & TRN & \\
\hline CHEMBL1424998 & 688293 & 6.7001 & 5.1198 & TRN & \\
\hline CHEMBL1382822 & 688293 & 4.9 & 5.0295 & TRN & \\
\hline CHEMBL1536038 & 688293 & 4.4 & 5.0701 & TRN & \\
\hline CHEMBL1436037 & 688293 & 5.1 & 4.7693 & TRN & \\
\hline CHEMBL1509409 & 688293 & 4.5 & 5.0396 & TRN & \\
\hline CHEMBL1079460 & 688293 & 4.8 & 5.0178 & TST & \\
\hline CHEMBL1563638 & 688293 & 7.3002 & 5.1709 & TRN & \\
\hline CHEMBL1394089 & 688293 & 4.7 & 5.1568 & TST & \\
\hline CHEMBL584520 & 688293 & 4.5 & 4.885 & TST & \\
\hline CHEMBL1456994 & 688293 & 7.2 & 4.9708 & TRN & \\
\hline CHEMBL1438073 & 688293 & 4.8 & 4.8599 & TRN & \\
\hline CHEMBL3189329 & 688293 & 4.4 & 5.0391 & TRN & \\
\hline CHEMBL1420683 & 688293 & 4.6 & 4.916 & TRN & \\
\hline CHEMBL1612714 & 688293 & 4.6 & 5.114 & TRN & \\
\hline CHEMBL1413391 & 688293 & 4.5 & 4.9351 & TRN & \\
\hline CHEMBL1607497 & 688293 & 4.4 & 4.9209 & TRN & \\
\hline CHEMBL1455750 & 688293 & 4.7 & 4.8625 & TRN & \\
\hline CHEMBL405072 & 688293 & 8.1024 & 5.0443 & TRN & \\
\hline CHEMBL1399664 & 688293 & 4.5 & 5.0113 & TRN & \\
\hline CHEMBL1502203 & 688293 & 4.5 & 4.8247 & TRN & \\
\hline CHEMBL1303320 & 688293 & 4.7 & 4.9314 & TRN & \\
\hline CHEMBL3351064 & 688293 & 5.2 & 5.0111 & TST & \\
\hline CHEMBL1256940 & 688293 & 8.8861 & 5.0091 & TST & \\
\hline CHEMBL1517892 & 688293 & 4.5 & 5.0515 & TRN & \\
\hline CHEMBL1495282 & 688293 & 5.0 & 4.9971 & TRN & \\
\hline CHEMBL1535257 & 688293 & 4.4 & 5.0183 & TRN & \\
\hline CHEMBL66 & 688293 & 7.5003 & 5.0123 & TRN & \\
\hline CHEMBL1410299 & 688293 & 4.6 & 4.9416 & TRN & \\
\hline CHEMBL1604546 & 688293 & 5.0 & 5.0244 & TST & \\
\hline CHEMBL1537574 & 688293 & 4.4 & 5.0318 & TRN & \\
\hline CHEMBL3196041 & 688293 & 4.6 & 4.96399 & 99999999995 & TRN \\
\hline CHEMBL1522115 & 688293 & 4.6 & 4.8375 & TRN & \\
\hline CHEMBL1311033 & 688293 & 4.4 & 4.9373 & TRN & \\
\hline CHEMBL1486808 & 688293 & 4.4 & 4.9133 & TRN & \\
\hline CHEMBL1470059 & 688293 & 4.5 & 4.8328 & TST & \\
\hline CHEMBL1312153 & 688293 & 4.5 & 4.9565 & TRN & \\
\hline CHEMBL1406275 & 688293 & 7.4001 & 5.0845 & TRN & \\
\hline CHEMBL1350579 & 688293 & 4.5 & 4.7576 & TRN & \\
\hline CHEMBL1432443 & 688293 & 4.6 & 4.8872 & TRN & \\
\hline CHEMBL1374357 & 688293 & 4.6 & 4.8554 & TRN & \\
\hline CHEMBL1342792 & 688293 & 7.2 & 5.1918 & TRN & \\
\hline CHEMBL1573215 & 688293 & 4.8 & 5.0014 & TRN & \\
\hline CHEMBL1443347 & 688293 & 4.9 & 4.8966 & TRN & \\
\hline
\end{tabular}




\begin{tabular}{|c|c|c|c|c|}
\hline & & & ent & \\
\hline CHEMBL1413158 & 688293 & 5.5 & 4.9645 & TRN \\
\hline CHEMBL1516006 & 688293 & 6.3 & 4.8145 & TRN \\
\hline CHEMBL1390073 & 688293 & 4.6 & 5.14 & TRN \\
\hline CHEMBL1588879 & 688293 & 4.8 & 5.0171 & TST \\
\hline CHEMBL1441523 & 688293 & 5.1 & 4.7703 & TRN \\
\hline CHEMBL1507557 & 688293 & 4.5 & 4.7559 & TRN \\
\hline CHEMBL1500636 & 688293 & 4.8 & 4.9018 & TRN \\
\hline CHEMBL1604278 & 688293 & 4.9 & 4.9033 & TRN \\
\hline CHEMBL1524085 & 688293 & 4.4 & 4.8641 & TST \\
\hline CHEMBL1318067 & 688293 & 5.1 & 4.8757 & TRN \\
\hline CHEMBL1325724 & 688293 & 5.2 & 4.9376 & TST \\
\hline CHEMBL18132 & 688293 & 4.5 & 4.852 & TRN \\
\hline CHEMBL1315504 & 688293 & 5.1 & 4.8161 & TRN \\
\hline CHEMBL1407411 & 688293 & 4.9 & 5.1338 & TRN \\
\hline CHEMBL1409307 & 688293 & 5.2 & 5.0604 & TRN \\
\hline CHEMBL1504120 & 688293 & 4.6 & 5.2891 & TRN \\
\hline CHEMBL326958 & 688293 & 4.4 & 5.0006 & TST \\
\hline CHEMBL1584396 & 688293 & 4.5 & 4.9256 & TRN \\
\hline CHEMBL1539865 & 688293 & 4.7 & 4.6518 & TRN \\
\hline CHEMBL1526600 & 688293 & 5.1 & 5.086 & TRN \\
\hline CHEMBL1348280 & 688293 & 4.9 & 5.0356 & TRN \\
\hline CHEMBL1604314 & 688293 & 4.4 & 5.075 & TRN \\
\hline CHEMBL1422629 & 688293 & 6.1 & 4.8193 & TRN \\
\hline CHEMBL1362978 & 688293 & 4.5 & 5.1395 & TRN \\
\hline CHEMBL1301960 & 688293 & 4.8 & 5.1551 & TRN \\
\hline CHEMBL1360011 & 688293 & 5.9 & 4.7048 & TRN \\
\hline CHEMBL1458119 & 688293 & 4.7 & 5.0552 & TRN \\
\hline CHEMBL1411379 & 688293 & 6.4 & 5.0624 & TRN \\
\hline CHEMBL1544250 & 688293 & 4.4 & 4.8363 & TRN \\
\hline CHEMBL1447133 & 688293 & 4.4 & 4.7508 & TST \\
\hline CHEMBL1401044 & 688293 & 5.8 & 4.9656 & TRN \\
\hline CHEMBL1605483 & 688293 & 8.2007 & 5.2921 & TRN \\
\hline CHEMBL1555718 & 688293 & 4.4 & 5.1233 & TRN \\
\hline CHEMBL1448287 & 688293 & 4.5 & 5.2068 & TRN \\
\hline CHEMBL1506607 & 688293 & 4.7 & 4.8746 & TRN \\
\hline CHEMBL1213137 & 688293 & 4.8 & 4.8833 & TST \\
\hline CHEMBL1461844 & 688293 & 4.4 & 5.0809 & TRN \\
\hline CHEMBL1402714 & 688293 & 4.5 & 5.0276 & TRN \\
\hline CHEMBL1598188 & 688293 & 4.4 & 5.1286 & TRN \\
\hline CHEMBL1600390 & 688293 & 5.6 & 4.9953 & TRN \\
\hline CHEMBL1417569 & 688293 & 4.9 & 5.0758 & TRN \\
\hline CHEMBL1595886 & 688293 & 5.6 & 5.1439 & TRN \\
\hline CHEMBL1529465 & 688293 & 4.5 & 4.9121 & TRN \\
\hline CHEMBL1372129 & 688293 & 4.4 & 4.9151 & TRN \\
\hline CHEMBL1577496 & 688293 & 6.2 & 4.9736 & TST \\
\hline CHEMBL1447625 & 688293 & 4.4 & 4.9754 & TRN \\
\hline CHEMBL1306761 & 688293 & 8.2007 & 5.1478 & TST \\
\hline CHEMBL1503929 & 688293 & 4.4 & 4.8655 & TRN \\
\hline
\end{tabular}




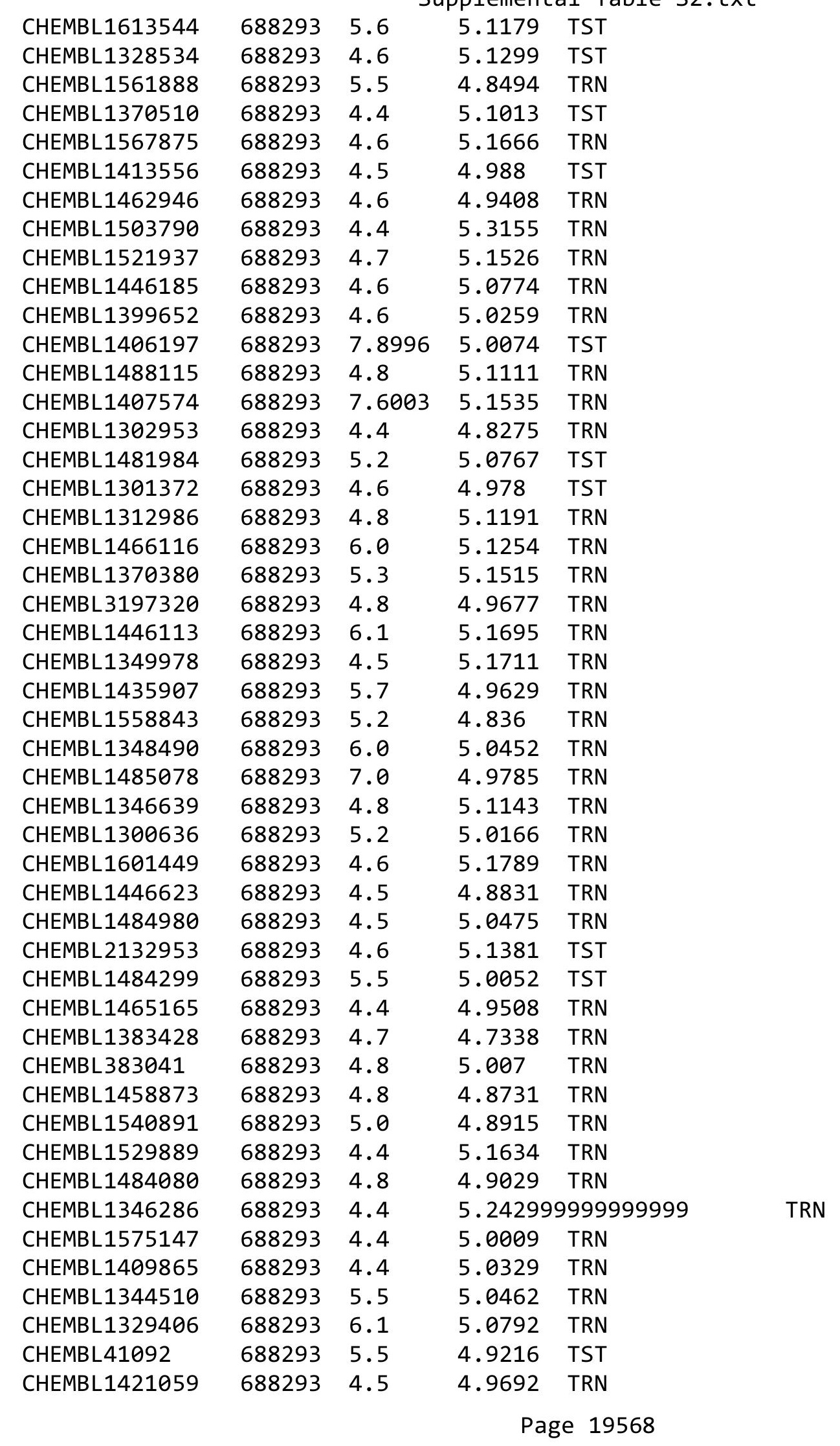




\begin{tabular}{|c|c|c|c|c|c|}
\hline \multicolumn{6}{|c|}{ Supplemental Table S2.txt } \\
\hline CHEMBL1456705 & 688293 & 4.4 & 5.0679 & TRN & \\
\hline CHEMBL507900 & 688293 & 6.7001 & 5.1892 & TST & \\
\hline CHEMBL1498174 & 688293 & 5.7 & 5.0322 & TRN & \\
\hline CHEMBL1608304 & 688293 & 4.7 & 4.838 & TRN & \\
\hline CHEMBL1529009 & 688293 & 5.1 & 4.8064 & TST & \\
\hline CHEMBL1580859 & 688293 & 4.7 & 5.1277 & TRN & \\
\hline CHEMBL601578 & 688293 & 4.6 & 4.9154 & TST & \\
\hline CHEMBL1574392 & 688293 & 4.5 & 4.9511 & TRN & \\
\hline CHEMBL1567569 & 688293 & 5.2 & 4.7986 & TRN & \\
\hline CHEMBL1388070 & 688293 & 4.4 & 5.17399 & 99999999995 & TRN \\
\hline CHEMBL1515918 & 688293 & 6.3 & 4.8523 & TRN & \\
\hline CHEMBL1573081 & 688293 & 8.4949 & 5.1467 & TST & \\
\hline CHEMBL1442969 & 688293 & 5.1 & 4.9125 & TST & \\
\hline CHEMBL1488329 & 688293 & 4.6 & 4.9711 & TRN & \\
\hline CHEMBL1532645 & 688293 & 4.7 & 4.9401 & TRN & \\
\hline CHEMBL1555014 & 688293 & 4.8 & 4.7948 & TRN & \\
\hline CHEMBL1308072 & 688293 & 4.4 & 4.9291 & TRN & \\
\hline CHEMBL1342900 & 688293 & 4.7 & 5.1452 & TRN & \\
\hline CHEMBL1332089 & 688293 & 6.5 & 5.0035 & TRN & \\
\hline CHEMBL1559127 & 688293 & 4.5 & 4.8448 & TRN & \\
\hline CHEMBL1335233 & 688293 & 4.9 & 5.08899 & 99999999995 & TRN \\
\hline CHEMBL1542023 & 688293 & 5.0 & 5.1356 & TRN & \\
\hline CHEMBL1981833 & 688293 & 5.0 & 5.0929 & TRN & \\
\hline CHEMBL1600282 & 688293 & 4.5 & 4.9063 & TST & \\
\hline CHEMBL1598091 & 688293 & 4.6 & 4.859 & TRN & \\
\hline CHEMBL1369097 & 688293 & 5.3 & 4.8321 & TRN & \\
\hline CHEMBL1528588 & 688293 & 5.7 & 5.271 & TRN & \\
\hline CHEMBL1580419 & 688293 & 5.9 & 5.0637 & TRN & \\
\hline CHEMBL3207567 & 688293 & 6.0 & 5.0459 & TST & \\
\hline CHEMBL1437486 & 688293 & 5.4 & 4.9964 & TST & \\
\hline CHEMBL1572687 & 688293 & 4.8 & 4.9635 & TRN & \\
\hline CHEMBL1412745 & 688293 & 5.4 & 5.1722 & TRN & \\
\hline CHEMBL1379362 & 688293 & 4.6 & 4.7876 & TRN & \\
\hline CHEMBL1597951 & 688293 & 4.8 & 4.9785 & TST & \\
\hline CHEMBL1600295 & 688293 & 4.6 & 4.9916 & TRN & \\
\hline CHEMBL1533940 & 688293 & 4.8 & 4.9052 & TRN & \\
\hline CHEMBL1539432 & 688293 & 4.9 & 5.0466 & TRN & \\
\hline CHEMBL1520703 & 688293 & 4.4 & 5.1831 & TRN & \\
\hline CHEMBL1568873 & 688293 & 5.5 & 4.8082 & TST & \\
\hline CHEMBL1603489 & 688293 & 4.6 & 5.1923 & TRN & \\
\hline CHEMBL489934 & 688293 & 4.7 & 4.7127 & TRN & \\
\hline CHEMBL1501948 & 688293 & 4.7 & 4.8487 & TRN & \\
\hline CHEMBL1325085 & 688293 & 4.9 & 5.0898 & TRN & \\
\hline CHEMBL1488423 & 688293 & 4.5 & 5.0187 & TRN & \\
\hline CHEMBL1463327 & 688293 & 5.7 & 5.0392 & TRN & \\
\hline CHEMBL1607905 & 688293 & 4.6 & 4.9372 & TST & \\
\hline CHEMBL1391214 & 688293 & 4.4 & 4.8842 & TRN & \\
\hline CHEMBL1602519 & 688293 & 4.6 & 5.148 & TRN & \\
\hline
\end{tabular}




\begin{tabular}{|c|c|c|c|c|}
\hline & & & ient & al Ta \\
\hline CHEMBL1488320 & 688293 & 4.5 & 4.9428 & TRN \\
\hline CHEMBL1384101 & 688293 & 4.6 & 4.9855 & TRN \\
\hline CHEMBL1554131 & 688293 & 6.1 & 5.0396 & TST \\
\hline CHEMBL1371340 & 688293 & 6.5 & 5.1071 & TRN \\
\hline CHEMBL1386431 & 688293 & 5.1 & 4.9038 & TRN \\
\hline CHEMBL 1442750 & 688293 & 4.7 & 4.9929 & TRN \\
\hline CHEMBL1559160 & 688293 & 4.9 & 5.0189 & TRN \\
\hline CHEMBL1356628 & 688293 & 4.6 & 4.9935 & TST \\
\hline CHEMBL1347292 & 688293 & 4.7 & 5.1678 & TRN \\
\hline CHEMBL1474471 & 688293 & 5.5 & 4.918 & TRN \\
\hline CHEMBL1499393 & 688293 & 4.6 & 4.9968 & TRN \\
\hline CHEMBL1389728 & 688293 & 4.4 & 5.0206 & TRN \\
\hline CHEMBL1488838 & 688293 & 4.8 & 4.9167 & TRN \\
\hline CHEMBL1518112 & 688293 & 5.8 & 5.1658 & TRN \\
\hline CHEMBL1484095 & 688293 & 4.6 & 4.8666 & TRN \\
\hline CHEMBL1388103 & 688293 & 4.5 & 4.9001 & TRN \\
\hline CHEMBL1385148 & 688293 & 4.8 & 4.9052 & TRN \\
\hline CHEMBL1460938 & 688293 & 4.5 & 4.7592 & TRN \\
\hline CHEMBL1420841 & 688293 & 5.3 & 5.0318 & TRN \\
\hline CHEMBL1530444 & 688293 & 4.4 & 5.1515 & TRN \\
\hline CHEMBL15192 & 688293 & 4.5 & 4.9844 & TST \\
\hline CHEMBL1429289 & 688293 & 4.6 & 5.0742 & TRN \\
\hline CHEMBL1470176 & 688293 & 4.4 & 5.0887 & TRN \\
\hline CHEMBL561936 & 688293 & 4.4 & 4.9244 & TRN \\
\hline CHEMBL1592211 & 688293 & 4.6 & 4.7122 & TRN \\
\hline CHEMBL1462825 & 688293 & 4.9 & 4.9399 & TRN \\
\hline CHEMBL1306076 & 688293 & 4.7 & 5.0333 & TST \\
\hline CHEMBL1344207 & 688293 & 5.1 & 5.1074 & TRN \\
\hline CHEMBL1460485 & 688293 & 4.6 & 5.1038 & TRN \\
\hline CHEMBL1552172 & 688293 & 5.0 & 5.0108 & TRN \\
\hline CHEMBL1598823 & 688293 & 4.6 & 4.9756 & TRN \\
\hline CHEMBL1446054 & 688293 & 4.7 & 5.0765 & TRN \\
\hline CHEMBL1304097 & 688293 & 4.8 & 4.9816 & TRN \\
\hline CHEMBL1611804 & 688293 & 4.6 & 5.2471 & TRN \\
\hline CHEMBL1444266 & 688293 & 4.4 & 5.0998 & TRN \\
\hline CHEMBL1325297 & 688293 & 4.5 & 5.0361 & TRN \\
\hline CHEMBL1349037 & 688293 & 4.4 & 5.0804 & TRN \\
\hline CHEMBL1502701 & 688293 & 4.8 & 4.9941 & TRN \\
\hline CHEMBL1310750 & 688293 & 4.4 & 4.7861 & TRN \\
\hline CHEMBL1504007 & 688293 & 5.5 & 4.8879 & TRN \\
\hline CHEMBL1535832 & 688293 & 4.8 & 5.2085 & TRN \\
\hline CHEMBL1506967 & 688293 & 4.4 & 4.9941 & TST \\
\hline CHEMBL1411259 & 688293 & 5.0 & 5.1618 & TST \\
\hline CHEMBL1312623 & 688293 & 4.4 & 5.0138 & TRN \\
\hline CHEMBL1320547 & 688293 & 4.5 & 4.9546 & TRN \\
\hline CHEMBL602219 & 688293 & 6.4 & 4.9554 & TRN \\
\hline CHEMBL1534684 & 688293 & 4.4 & 5.1036 & TRN \\
\hline CHEMBL1565522 & 688293 & 5.6 & 5.0858 & TRN \\
\hline
\end{tabular}




\begin{tabular}{|c|c|c|c|c|c|}
\hline \multicolumn{6}{|c|}{ Supplemental Table s2.txt } \\
\hline CHEMBL157026 & 688293 & 7.2 & 4.9875 & TST & \\
\hline CHEMBL1422415 & 688293 & 5.0 & 4.8711 & TRN & \\
\hline CHEMBL1438105 & 688293 & 5.0 & 5.0681 & TRN & \\
\hline CHEMBL1392975 & 688293 & 4.5 & 5.0852 & TRN & \\
\hline CHEMBL1401606 & 688293 & 5.4 & 4.9899 & TRN & \\
\hline CHEMBL1398954 & 688293 & 7.4001 & 5.3638 & TRN & \\
\hline CHEMBL1598114 & 688293 & 4.7 & 4.9874 & TRN & \\
\hline CHEMBL1488055 & 688293 & 4.6 & 4.9787 & TRN & \\
\hline CHEMBL1494256 & 688293 & 4.8 & 4.7786 & TRN & \\
\hline CHEMBL1328621 & 688293 & 4.4 & 5.15 & TRN & \\
\hline CHEMBL1367611 & 688293 & 4.6 & 5.0509 & TRN & \\
\hline CHEMBL1325738 & 688293 & 7.1002 & 5.1399 & TRN & \\
\hline CHEMBL1384108 & 688293 & 4.8 & 4.9344 & TRN & \\
\hline CHEMBL1483315 & 688293 & 5.1 & 4.9665 & TRN & \\
\hline CHEMBL1585697 & 688293 & 4.6 & 5.0233 & TRN & \\
\hline CHEMBL1348591 & 688293 & 5.4 & 5.0087 & TRN & \\
\hline CHEMBL1411449 & 688293 & 5.3 & 4.9046 & TST & \\
\hline CHEMBL1388354 & 688293 & 4.9 & 5.0883 & TRN & \\
\hline CHEMBL1299323 & 688293 & 4.7 & 5.0259 & TRN & \\
\hline CHEMBL1413240 & 688293 & 4.5 & 5.0122 & TRN & \\
\hline CHEMBL1508615 & 688293 & 4.4 & 4.9723 & TRN & \\
\hline CHEMBL1444923 & 688293 & 7.8013 & 5.0127 & TRN & \\
\hline CHEMBL1324053 & 688293 & 4.4 & 5.1565 & TST & \\
\hline CHEMBL18879 & 688293 & 4.5 & 4.9959 & TST & \\
\hline CHEMBL1531362 & 688293 & 4.8 & 4.9508 & TRN & \\
\hline CHEMBL1548137 & 688293 & 4.5 & 4.8414 & TRN & \\
\hline CHEMBL1346880 & 688293 & 4.6 & 5.0773 & TRN & \\
\hline CHEMBL1503244 & 688293 & 4.7 & 4.9294 & TRN & \\
\hline CHEMBL1431368 & 688293 & 4.6 & 4.9574 & TRN & \\
\hline CHEMBL1609453 & 688293 & 7.6003 & 4.98 & TRN & \\
\hline CHEMBL412010 & 688293 & 4.6 & 4.9611 & TRN & \\
\hline CHEMBL1593547 & 688293 & 4.4 & 4.8876 & TRN & \\
\hline CHEMBL1333515 & 688293 & 4.9 & 5.0159 & TRN & \\
\hline CHEMBL1345826 & 688293 & 4.4 & 5.0654 & TRN & \\
\hline CHEMBL1603225 & 688293 & 4.7 & 4.9296 & TST & \\
\hline CHEMBL1384723 & 688293 & 4.4 & 4.9063 & TST & \\
\hline CHEMBL48449 & 688293 & 6.0 & 5.1076 & TST & \\
\hline CHEMBL1607122 & 688293 & 4.4 & 5.1625 & TST & \\
\hline CHEMBL1422216 & 688293 & 4.5 & 4.9388 & TRN & \\
\hline CHEMBL1580076 & 688293 & 4.6 & 5.109 & TRN & \\
\hline CHEMBL1607188 & 688293 & 5.5 & 5.1348 & TRN & \\
\hline CHEMBL1486586 & 688293 & 8.0 & 5.1622 & TRN & \\
\hline CHEMBL1408226 & 688293 & 4.8 & 4.9981 & TST & \\
\hline CHEMBL1587997 & 688293 & 8.301 & 5.01399 & 9999999999 & TRN \\
\hline CHEMBL1313247 & 688293 & 4.7 & 5.0215 & TRN & \\
\hline CHEMBL1423060 & 688293 & 4.6 & 4.9762 & TRN & \\
\hline CHEMBL1393541 & 688293 & 4.4 & 4.9966 & TRN & \\
\hline CHEMBL1362475 & 688293 & 5.2 & 5.1693 & TRN & \\
\hline
\end{tabular}




\begin{tabular}{|c|c|c|c|c|c|}
\hline \multicolumn{6}{|c|}{ Supplemental Table S2.txt } \\
\hline CHEMBL1311605 & 688293 & 4.7 & 5.1175 & TRN & \\
\hline CHEMBL1606558 & 688293 & 4.8 & 4.725 & TRN & \\
\hline CHEMBL1256749 & 688293 & 4.4 & 4.921 & TST & \\
\hline CHEMBL1531320 & 688293 & 4.5 & 5.0248 & TRN & \\
\hline CHEMBL1556539 & 688293 & 4.8 & 4.9676 & TRN & \\
\hline CHEMBL1326624 & 688293 & 4.8 & 4.8802 & TRN & \\
\hline CHEMBL1401859 & 688293 & 5.4 & 4.6457 & TRN & \\
\hline CHEMBL3192707 & 688293 & 5.0 & 4.9543 & TST & \\
\hline CHEMBL1464140 & 688293 & 4.6 & 4.7672 & TRN & \\
\hline CHEMBL1397308 & 688293 & 4.5 & 5.0746 & TRN & \\
\hline CHEMBL1472955 & 688293 & 5.4 & 4.824 & TRN & \\
\hline CHEMBL51697 & 688293 & 9.0 & 5.0184 & TST & \\
\hline CHEMBL1548641 & 688293 & 4.8 & 5.0262 & TRN & \\
\hline CHEMBL1344112 & 688293 & 4.4 & 5.0159 & TRN & \\
\hline CHEMBL580183 & 688293 & 4.5 & 4.9444 & TST & \\
\hline CHEMBL1598791 & 688293 & 4.8 & 4.9262 & TST & \\
\hline CHEMBL1396949 & 688293 & 4.4 & 5.0799 & TST & \\
\hline CHEMBL1323139 & 688293 & 4.6 & 4.8449 & TRN & \\
\hline CHEMBL1327864 & 688293 & 4.5 & 5.0149 & TRN & \\
\hline CHEMBL1443737 & 688293 & 5.1 & 5.1537 & TRN & \\
\hline CHEMBL1306408 & 688293 & 5.5 & 5.118 & TRN & \\
\hline CHEMBL1398994 & 688293 & 4.6 & 4.9411 & TRN & \\
\hline CHEMBL1471717 & 688293 & 4.9 & 4.9348 & TRN & \\
\hline CHEMBL1424650 & 688293 & 5.9 & 5.2476 & TST & \\
\hline CHEMBL1405142 & 688293 & 5.9 & 5.1915 & TRN & \\
\hline CHEMBL1454855 & 688293 & 4.9 & 4.9391 & TRN & \\
\hline CHEMBL1377655 & 688293 & 5.2 & 5.0131 & TRN & \\
\hline CHEMBL1324522 & 688293 & 4.6 & 4.9842 & TRN & \\
\hline CHEMBL1452913 & 688293 & 4.9 & 5.0525 & TRN & \\
\hline CHEMBL454746 & 688293 & 4.8 & 4.9525 & TRN & \\
\hline CHEMBL1510382 & 688293 & 4.5 & 5.0136 & TRN & \\
\hline CHEMBL1604606 & 688293 & 5.9 & 4.901 & TRN & \\
\hline CHEMBL1409974 & 688293 & 4.8 & 4.9186 & TRN & \\
\hline CHEMBL1446519 & 688293 & 4.6 & 5.0056 & TST & \\
\hline CHEMBL1513936 & 688293 & 4.9 & 4.7787 & TRN & \\
\hline CHEMBL1327952 & 688293 & 5.1 & 5.146 & TRN & \\
\hline CHEMBL1402071 & 688293 & 5.0 & 5.0743 & TRN & \\
\hline CHEMBL1484731 & 688293 & 4.4 & 5.1889 & TRN & \\
\hline CHEMBL1313598 & 688293 & 7.8013 & 5.0688 & TRN & \\
\hline CHEMBL1342384 & 688293 & 4.7 & 5.2137 & TRN & \\
\hline CHEMBL1356262 & 688293 & 4.9 & 4.75899 & 99999999995 & TRN \\
\hline CHEMBL1300068 & 688293 & 4.4 & 5.0152 & TST & \\
\hline CHEMBL1446523 & 688293 & 6.0 & 4.8126 & TRN & \\
\hline CHEMBL1540418 & 688293 & 4.9 & 5.1506 & TRN & \\
\hline CHEMBL1302787 & 688293 & 5.0 & 4.879 & TRN & \\
\hline CHEMBL1496811 & 688293 & 5.2 & 5.0963 & TRN & \\
\hline CHEMBL1594540 & 688293 & 5.2 & 4.8621 & TRN & \\
\hline CHEMBL1458840 & 688293 & 4.4 & 4.958 & TST & \\
\hline
\end{tabular}




\begin{tabular}{|c|c|c|c|c|}
\hline \multicolumn{5}{|c|}{ Supplemental Table S2.txt } \\
\hline CHEMBL1473317 & 688293 & 4.6 & 4.8345 & TRN \\
\hline CHEMBL1348018 & 688293 & 4.4 & 4.8357 & TRN \\
\hline CHEMBL1391377 & 688293 & 4.4 & 5.2246 & TRN \\
\hline CHEMBL1332117 & 688293 & 4.6 & 4.9169 & TRN \\
\hline CHEMBL1548605 & 688293 & 4.6 & 4.938 & TRN \\
\hline CHEMBL1611300 & 688293 & 4.4 & 4.9643 & TRN \\
\hline CHEMBL491978 & 688293 & 5.0 & 4.945 & TRN \\
\hline CHEMBL1388003 & 688293 & 4.6 & 5.0235 & TRN \\
\hline CHEMBL 222556 & 688293 & 5.1 & 4.881 & TRN \\
\hline CHEMBL1600987 & 688293 & 4.5 & 5.0635 & TRN \\
\hline CHEMBL1607283 & 688293 & 8.1024 & 5.0859 & TRN \\
\hline CHEMBL1383688 & 688293 & 4.5 & 4.9753 & TRN \\
\hline CHEMBL1564374 & 688293 & 4.5 & 4.8465 & TRN \\
\hline CHEMBL1416646 & 688293 & 4.5 & 4.9173 & TRN \\
\hline CHEMBL410873 & 688293 & 5.1 & 5.0897 & TST \\
\hline CHEMBL1433247 & 688293 & 4.8 & 4.8698 & TRN \\
\hline CHEMBL1384748 & 688293 & 5.3 & 4.9515 & TRN \\
\hline CHEMBL1440679 & 688293 & 5.2 & 4.8896 & TRN \\
\hline CHEMBL1548013 & 688293 & 4.6 & 5.1161 & TRN \\
\hline CHEMBL1454969 & 688293 & 5.1 & 5.0916 & TRN \\
\hline CHEMBL1255659 & 688293 & 4.6 & 4.9048 & TST \\
\hline CHEMBL1393143 & 688293 & 5.0 & 4.9542 & TRN \\
\hline CHEMBL1534844 & 688293 & 4.7 & 5.0419 & TRN \\
\hline CHEMBL1598352 & 688293 & 5.0 & 5.1252 & TRN \\
\hline CHEMBL1608457 & 688293 & 5.0 & 5.2437 & TRN \\
\hline CHEMBL1423006 & 688293 & 4.7 & 4.9479 & TRN \\
\hline CHEMBL1346091 & 688293 & 4.4 & 5.0914 & TRN \\
\hline CHEMBL1550793 & 688293 & 4.5 & 5.0365 & TST \\
\hline CHEMBL1487801 & 688293 & 5.5 & 5.0031 & TRN \\
\hline CHEMBL1580667 & 688293 & 5.8 & 4.8006 & TRN \\
\hline CHEMBL1589556 & 688293 & 4.4 & 4.9919 & TRN \\
\hline CHEMBL1434072 & 688293 & 4.6 & 4.925 & TRN \\
\hline CHEMBL1407860 & 688293 & 4.4 & 5.2133 & TRN \\
\hline CHEMBL1350000 & 688293 & 4.9 & 4.9559 & TRN \\
\hline CHEMBL1608798 & 688293 & 5.0 & 4.9246 & TRN \\
\hline CHEMBL1610601 & 688293 & 4.7 & 5.0358 & TRN \\
\hline CHEMBL1598437 & 688293 & 4.4 & 4.9678 & TRN \\
\hline CHEMBL1558951 & 688293 & 4.4 & 4.9602 & TRN \\
\hline CHEMBL1584016 & 688293 & 4.6 & 5.0559 & TRN \\
\hline CHEMBL1560160 & 688293 & 4.6 & 4.885 & TRN \\
\hline CHEMBL1469125 & 688293 & 4.8 & 4.9155 & TRN \\
\hline CHEMBL1322335 & 688293 & 4.6 & 4.938 & TRN \\
\hline CHEMBL1533840 & 688293 & 4.7 & 5.2504 & TRN \\
\hline CHEMBL1322743 & 688293 & 5.0 & 4.8695 & TRN \\
\hline CHEMBL 3195980 & 688293 & 5.1 & 5.0417 & TRN \\
\hline CHEMBL1501332 & 688293 & 4.4 & 4.9323 & TRN \\
\hline CHEMBL1486478 & 688293 & 8.4949 & 4.9813 & TRN \\
\hline CHEMBL1350359 & 688293 & 5.5 & 5.016 & TRN \\
\hline
\end{tabular}




\begin{tabular}{|c|c|c|c|c|}
\hline & & & 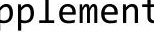 & \\
\hline CHEMBL1607477 & 688293 & 4.5 & 4.9829 & TRN \\
\hline CHEMBL3197622 & 688293 & 5.1 & 4.8608 & TRN \\
\hline CHEMBL1526239 & 688293 & 5.1 & 4.9975 & TRN \\
\hline CHEMBL1303827 & 688293 & 4.5 & 5.0508 & TRN \\
\hline CHEMBL1390197 & 688293 & 4.5 & 5.2175 & TRN \\
\hline CHEMBL1603994 & 688293 & 5.3 & 4.8956 & TRN \\
\hline CHEMBL1405583 & 688293 & 4.4 & 4.9902 & TRN \\
\hline CHEMBL1310799 & 688293 & 4.4 & 5.0283 & TRN \\
\hline CHEMBL1483801 & 688293 & 5.5 & 5.0182 & TST \\
\hline CHEMBL1431867 & 688293 & 4.4 & 4.9989 & TRN \\
\hline CHEMBL1378691 & 688293 & 4.9 & 5.0575 & TRN \\
\hline CHEMBL1421070 & 688293 & 4.8 & 5.0315 & TRN \\
\hline CHEMBL1598520 & 688293 & 4.4 & 4.9686 & TRN \\
\hline CHEMBL1503700 & 688293 & 4.7 & 4.8604 & TRN \\
\hline CHEMBL1536421 & 688293 & 4.5 & 5.1508 & TST \\
\hline CHEMBL1299942 & 688293 & 4.6 & 4.9046 & TRN \\
\hline CHEMBL1469129 & 688293 & 4.5 & 5.1128 & TRN \\
\hline CHEMBL1329863 & 688293 & 4.4 & 5.0104 & TRN \\
\hline CHEMBL608555 & 688293 & 7.6003 & 5.1189 & TST \\
\hline CHEMBL578136 & 688293 & 4.4 & 4.9385 & TRN \\
\hline CHEMBL1433730 & 688293 & 4.7 & 4.7444 & TRN \\
\hline CHEMBL1574824 & 688293 & 4.5 & 5.0465 & TRN \\
\hline CHEMBL1511490 & 688293 & 4.6 & 5.0541 & TRN \\
\hline CHEMBL1486342 & 688293 & 4.4 & 4.8597 & TST \\
\hline CHEMBL1419934 & 688293 & 8.0 & 5.1852 & TST \\
\hline CHEMBL1601121 & 688293 & 4.5 & 4.7937 & TRN \\
\hline CHEMBL1494575 & 688293 & 4.6 & 5.1011 & TRN \\
\hline CHEMBL1567185 & 688293 & 4.8 & 4.8874 & TRN \\
\hline CHEMBL1485726 & 688293 & 4.8 & 5.1603 & TRN \\
\hline CHEMBL1483679 & 688293 & 4.8 & 4.8764 & TRN \\
\hline CHEMBL1076555 & 688293 & 4.5 & 4.7166 & TRN \\
\hline CHEMBL1482301 & 688293 & 6.4 & 5.1937 & TRN \\
\hline CHEMBL1448077 & 688293 & 5.7 & 5.0695 & TRN \\
\hline CHEMBL307893 & 688293 & 8.1024 & 5.0548 & TRN \\
\hline CHEMBL1531873 & 688293 & 7.3002 & 5.0551 & TRN \\
\hline CHEMBL1515132 & 688293 & 4.8 & 5.0856 & TST \\
\hline CHEMBL34730 & 688293 & 4.4 & 5.1105 & TRN \\
\hline CHEMBL1341981 & 688293 & 5.5 & 5.104 & TRN \\
\hline CHEMBL1319221 & 688293 & 7.2 & 4.9518 & TRN \\
\hline CHEMBL1304960 & 688293 & 4.7 & 4.9609 & TRN \\
\hline CHEMBL1597281 & 688293 & 4.9 & 5.2183 & TST \\
\hline CHEMBL1310926 & 688293 & 4.9 & 5.1399 & TST \\
\hline CHEMBL1477186 & 688293 & 4.6 & 4.8816 & TRN \\
\hline CHEMBL1335108 & 688293 & 4.6 & 5.0496 & TRN \\
\hline CHEMBL1441969 & 688293 & 4.6 & 5.0029 & TRN \\
\hline CHEMBL1410488 & 688293 & 4.5 & 4.9401 & TRN \\
\hline CHEMBL1325006 & 688293 & 4.5 & 4.8985 & TRN \\
\hline CHEMBL 274438 & 688293 & 4.8 & 5.0665 & TST \\
\hline
\end{tabular}




\begin{tabular}{|c|c|c|c|c|c|}
\hline \multicolumn{6}{|c|}{ Supplemental Table S2.txt } \\
\hline CHEMBL1340538 & 688293 & 4.5 & 5.2209 & TRN & \\
\hline CHEMBL1426566 & 688293 & 6.1 & 5.0222 & TRN & \\
\hline CHEMBL1302121 & 688293 & 4.6 & 5.1334 & TRN & \\
\hline CHEMBL1436272 & 688293 & 5.0 & 4.6698 & TRN & \\
\hline CHEMBL245265 & 688293 & 5.0 & 5.0373 & TST & \\
\hline CHEMBL1388976 & 688293 & 4.5 & 5.0631 & TRN & \\
\hline CHEMBL1418570 & 688293 & 5.6 & 4.9274 & TRN & \\
\hline CHEMBL1588791 & 688293 & 4.4 & 4.92899 & 9999999999 & TRN \\
\hline CHEMBL1460775 & 688293 & 5.3 & 5.1535 & TRN & \\
\hline CHEMBL566064 & 688293 & 6.6 & 5.0561 & TRN & \\
\hline CHEMBL1331809 & 688293 & 4.4 & 4.9822 & TST & \\
\hline CHEMBL243677 & 688293 & 4.7 & 4.879 & TRN & \\
\hline CHEMBL1384903 & 688293 & 4.6 & 4.8775 & TRN & \\
\hline CHEMBL3211626 & 688293 & 4.4 & 4.9219 & TRN & \\
\hline CHEMBL1308625 & 688293 & 4.4 & 5.0486 & TRN & \\
\hline CHEMBL1479039 & 688293 & 4.5 & 4.9975 & TRN & \\
\hline CHEMBL1533139 & 688293 & 4.8 & 4.7381 & TRN & \\
\hline CHEMBL1088173 & 688293 & 6.8 & 5.0568 & TRN & \\
\hline CHEMBL1408228 & 688293 & 4.4 & 5.1429 & TRN & \\
\hline CHEMBL1324203 & 688293 & 4.8 & 4.8552 & TST & \\
\hline CHEMBL1491399 & 688293 & 5.4 & 5.129 & TRN & \\
\hline CHEMBL1454601 & 688293 & 4.6 & 5.0036 & TRN & \\
\hline CHEMBL1457400 & 688293 & 4.7 & 5.1549 & TRN & \\
\hline CHEMBL1500377 & 688293 & 4.8 & 5.1227 & TST & \\
\hline CHEMBL1552066 & 688293 & 4.6 & 5.0243 & TRN & \\
\hline CHEMBL1402898 & 688293 & 5.8 & 4.9656 & TRN & \\
\hline CHEMBL1604679 & 688293 & 4.7 & 4.8866 & TRN & \\
\hline CHEMBL1500401 & 688293 & 4.4 & 4.9036 & TRN & \\
\hline CHEMBL1559654 & 688293 & 5.1 & 4.7704 & TRN & \\
\hline CHEMBL1571778 & 688293 & 4.4 & 4.9293 & TRN & \\
\hline CHEMBL1565345 & 688293 & 4.6 & 5.0606 & TRN & \\
\hline CHEMBL1407493 & 688293 & 4.9 & 5.1764 & TRN & \\
\hline CHEMBL1428934 & 688293 & 4.4 & 5.0146 & TRN & \\
\hline CHEMBL1472444 & 688293 & 4.7 & 4.9328 & TRN & \\
\hline CHEMBL1457336 & 688293 & 4.7 & 5.0795 & TRN & \\
\hline CHEMBL1364693 & 688293 & 4.5 & 5.0361 & TRN & \\
\hline CHEMBL1458566 & 688293 & 4.8 & 5.0894 & TRN & \\
\hline CHEMBL1585428 & 688293 & 4.7 & 5.0434 & TRN & \\
\hline CHEMBL1590876 & 688293 & 5.2 & 4.955 & TST & \\
\hline CHEMBL1346846 & 688293 & 4.8 & 4.987 & TRN & \\
\hline CHEMBL1349743 & 688293 & 4.8 & 5.0959 & TRN & \\
\hline CHEMBL1523035 & 688293 & 4.7 & 4.9191 & TRN & \\
\hline CHEMBL1387932 & 688293 & 7.6003 & 5.1985 & TRN & \\
\hline CHEMBL1478807 & 688293 & 5.4 & 5.0351 & TRN & \\
\hline CHEMBL1339829 & 688293 & 4.5 & 5.1097 & TRN & \\
\hline CHEMBL1344566 & 688293 & 4.9 & 4.9395 & TRN & \\
\hline CHEMBL1325377 & 688293 & 5.4 & 4.9277 & TRN & \\
\hline CHEMBL1377446 & 688293 & 6.1 & 4.9157 & TRN & \\
\hline
\end{tabular}




\begin{tabular}{|c|c|c|c|c|c|}
\hline \multicolumn{6}{|c|}{ Supplemental Table S2.txt } \\
\hline CHEMBL1594511 & 688293 & 4.8 & 5.0315 & TRN & \\
\hline CHEMBL1407816 & 688293 & 6.0 & 5.0865 & TST & \\
\hline CHEMBL1561855 & 688293 & 4.7 & 5.1684 & TST & \\
\hline CHEMBL1509585 & 688293 & 4.4 & 4.9607 & TST & \\
\hline CHEMBL1306449 & 688293 & 4.6 & 4.7874 & TRN & \\
\hline CHEMBL1593827 & 688293 & 4.7 & 4.7318 & TRN & \\
\hline CHEMBL1404734 & 688293 & 5.0 & 5.0163 & TRN & \\
\hline CHEMBL1522373 & 688293 & 6.4 & 5.0197 & TRN & \\
\hline CHEMBL1418081 & 688293 & 4.4 & 4.8925 & TRN & \\
\hline CHEMBL1368924 & 688293 & 7.0 & 5.0417 & TRN & \\
\hline CHEMBL1472926 & 688293 & 4.5 & 4.7391 & TRN & \\
\hline CHEMBL1602731 & 688293 & 5.5 & 4.9468 & TST & \\
\hline CHEMBL1408982 & 688293 & 4.4 & 4.9443 & TRN & \\
\hline CHEMBL1504983 & 688293 & 5.0 & 4.8701 & TRN & \\
\hline CHEMBL1455056 & 688293 & 4.9 & 5.0507 & TRN & \\
\hline CHEMBL1300290 & 688293 & 6.6 & 5.1384 & TRN & \\
\hline CHEMBL1365163 & 688293 & 6.0 & 5.1282 & TRN & \\
\hline CHEMBL1370676 & 688293 & 4.6 & 5.0342 & TRN & \\
\hline CHEMBL1334751 & 688293 & 5.3 & 4.9535 & TST & \\
\hline CHEMBL1333962 & 688293 & 5.6 & 4.8472 & TRN & \\
\hline CHEMBL1582368 & 688293 & 4.7 & 4.8519 & TRN & \\
\hline CHEMBL1402623 & 688293 & 4.4 & 4.9459 & TST & \\
\hline CHEMBL1329033 & 688293 & 4.5 & 5.0443 & TRN & \\
\hline CHEMBL1539220 & 688293 & 4.5 & 5.0729 & TRN & \\
\hline CHEMBL1492648 & 688293 & 5.6 & 4.862 & TRN & \\
\hline CHEMBL1301330 & 688293 & 4.4 & 5.0828 & TRN & \\
\hline CHEMBL1450327 & 688293 & 4.8 & 5.0298 & TRN & \\
\hline CHEMBL1410773 & 688293 & 4.9 & 4.9525 & TRN & \\
\hline CHEMBL1404557 & 688293 & 7.8996 & 4.9563 & TRN & \\
\hline CHEMBL1342446 & 688293 & 4.4 & 4.9377 & TRN & \\
\hline CHEMBL1404501 & 688293 & 4.6 & 4.9941 & TRN & \\
\hline CHEMBL1310582 & 688293 & 4.7 & 4.9494 & TRN & \\
\hline CHEMBL1309097 & 688293 & 4.5 & 5.1227 & TRN & \\
\hline CHEMBL1489500 & 688293 & 4.7 & 5.0883 & TRN & \\
\hline CHEMBL1401386 & 688293 & 4.9 & 4.9588 & TRN & \\
\hline CHEMBL1358628 & 688293 & 4.5 & 5.0732 & TST & \\
\hline CHEMBL1339346 & 688293 & 4.9 & 5.0724 & TRN & \\
\hline CHEMBL1420552 & 688293 & 4.6 & 5.04899 & 99999999995 & TRN \\
\hline CHEMBL1324202 & 688293 & 4.5 & 4.8641 & TRN & \\
\hline CHEMBL333985 & 688293 & 8.301 & 4.9364 & TST & \\
\hline CHEMBL1586481 & 688293 & 4.9 & 4.8285 & TRN & \\
\hline CHEMBL1521893 & 688293 & 4.6 & 4.9649 & TRN & \\
\hline CHEMBL556001 & 688293 & 8.0 & 5.0394 & TRN & \\
\hline CHEMBL1385837 & 688293 & 4.7 & 5.2267 & TRN & \\
\hline CHEMBL1323315 & 688293 & 4.6 & 4.9812 & TRN & \\
\hline CHEMBL1407440 & 688293 & 4.5 & 4.8841 & TRN & \\
\hline CHEMBL1606419 & 688293 & 4.6 & 5.0209 & TRN & \\
\hline CHEMBL1407267 & 688293 & 4.6 & 4.8664 & TRN & \\
\hline
\end{tabular}




\begin{tabular}{|c|c|c|c|c|c|}
\hline \multirow{3}{*}{$\begin{array}{l}\text { CHEMBL1399140 } \\
\text { CHEMBL1441079 }\end{array}$} & \multirow{3}{*}{$\begin{array}{l}688293 \\
688293\end{array}$} & \multicolumn{4}{|c|}{ Supplemental Table S2.txt } \\
\hline & & 4.4 & 5.1789 & 9999999999 & TRN \\
\hline & & 4.8 & 5.0237 & TRN & \\
\hline CHEMBL1565462 & 688293 & 4.4 & 5.0718 & TRN & \\
\hline CHEMBL1408592 & 688293 & 4.8 & 5.0454 & TRN & \\
\hline CHEMBL1488131 & 688293 & 4.4 & 4.9195 & TST & \\
\hline CHEMBL1329263 & 688293 & 6.0 & 4.9709 & TRN & \\
\hline CHEMBL1388432 & 688293 & 4.8 & 4.8989 & TRN & \\
\hline CHEMBL1299880 & 688293 & 4.6 & 5.0952 & TRN & \\
\hline CHEMBL1445335 & 688293 & 4.4 & 4.9131 & TRN & \\
\hline CHEMBL1505824 & 688293 & 5.5 & 5.1876 & TRN & \\
\hline CHEMBL1427931 & 688293 & 6.2 & 4.9303 & TRN & \\
\hline CHEMBL1472355 & 688293 & 4.9 & 4.8856 & TST & \\
\hline CHEMBL1605488 & 688293 & 4.5 & 5.0164 & TRN & \\
\hline CHEMBL1599639 & 688293 & 4.6 & 5.0033 & TRN & \\
\hline CHEMBL1343161 & 688293 & 4.7 & 4.8613 & TRN & \\
\hline CHEMBL1495063 & 688293 & 4.5 & 5.0561 & TST & \\
\hline CHEMBL1585005 & 688293 & 5.2 & 5.0602 & TRN & \\
\hline CHEMBL1482566 & 688293 & 4.9 & 4.9173 & TRN & \\
\hline CHEMBL1429988 & 688293 & 4.8 & 5.0916 & TRN & \\
\hline CHEMBL3207432 & 688293 & 6.4 & 4.8713 & TRN & \\
\hline CHEMBL1355537 & 688293 & 4.8 & 4.8446 & TST & \\
\hline CHEMBL1527209 & 688293 & 6.8 & 5.1199 & TST & \\
\hline CHEMBL196228 & 688293 & 4.5 & 5.1309 & TST & \\
\hline CHEMBL1499247 & 688293 & 4.5 & 4.8618 & TRN & \\
\hline CHEMBL1395415 & 688293 & 5.6 & 4.7602 & TRN & \\
\hline CHEMBL1391664 & 688293 & 4.7 & 5.1369 & TRN & \\
\hline CHEMBL1570159 & 688293 & 5.6 & 5.0316 & TST & \\
\hline CHEMBL184074 & 688293 & 4.9 & 5.0657 & TST & \\
\hline CHEMBL1407442 & 688293 & 4.7 & 4.8847 & TST & \\
\hline CHEMBL1306258 & 688293 & 4.5 & 4.8527 & TRN & \\
\hline CHEMBL1571048 & 688293 & 6.5 & 4.9148 & TRN & \\
\hline CHEMBL1330946 & 688293 & 6.4 & 5.0498 & TRN & \\
\hline CHEMBL1383255 & 688293 & 4.8 & 4.7793 & TRN & \\
\hline CHEMBL1451621 & 688293 & 4.7 & 5.0607 & TRN & \\
\hline CHEMBL1521607 & 688293 & 5.8 & 4.954 & TRN & \\
\hline CHEMBL1299666 & 688293 & 5.1 & 4.7913 & TRN & \\
\hline CHEMBL1449548 & 688293 & 4.8 & 5.0069 & TRN & \\
\hline CHEMBL1361461 & 688293 & 4.6 & 4.827 & TRN & \\
\hline CHEMBL3193983 & 688293 & 4.5 & 5.0165 & TST & \\
\hline CHEMBL1594058 & 688293 & 5.3 & 4.8909 & TRN & \\
\hline CHEMBL1568248 & 688293 & 4.8 & 4.9193 & TRN & \\
\hline CHEMBL1307403 & 688293 & 4.4 & 4.9464 & TST & \\
\hline CHEMBL1338879 & 688293 & 4.5 & 4.9225 & TRN & \\
\hline CHEMBL1608243 & 688293 & 5.2 & 4.9548 & TRN & \\
\hline CHEMBL490577 & 688293 & 4.4 & 5.0287 & TRN & \\
\hline CHEMBL1587288 & 688293 & 5.4 & 5.0885 & TRN & \\
\hline CHEMBL1465836 & 688293 & 4.6 & 5.0674 & TRN & \\
\hline CHEMBL1546824 & 688293 & 5.5 & 4.8482 & TRN & \\
\hline
\end{tabular}




\begin{tabular}{|c|c|c|c|c|c|}
\hline \multicolumn{6}{|c|}{ plemental } \\
\hline CHEMBL1506097 & 688293 & 4.6 & 5.1976 & TRN & \\
\hline CHEMBL1472229 & 688293 & 4.6 & 5.1933 & TRN & \\
\hline CHEMBL1518450 & 688293 & 6.2 & 5.0327 & TRN & \\
\hline CHEMBL1588765 & 688293 & 4.4 & 5.12299 & 9999999999 & TST \\
\hline CHEMBL1086445 & 688293 & 4.8 & 5.058 & TST & \\
\hline CHEMBL551883 & 688293 & 4.5 & 4.9602 & TST & \\
\hline CHEMBL1512614 & 688293 & 5.3 & 5.0022 & TRN & \\
\hline CHEMBL1528842 & 688293 & 4.5 & 4.8494 & TRN & \\
\hline CHEMBL 3214555 & 688293 & 4.4 & 5.0199 & TST & \\
\hline CHEMBL1327501 & 688293 & 4.7 & 4.9974 & TRN & \\
\hline CHEMBL1345733 & 688293 & 4.9 & 4.9054 & TRN & \\
\hline CHEMBL1509922 & 688293 & 7.0 & 5.0978 & TRN & \\
\hline CHEMBL1577187 & 688293 & 4.7 & 4.9296 & TRN & \\
\hline CHEMBL1559098 & 688293 & 5.3 & 4.9506 & TRN & \\
\hline CHEMBL1493196 & 688293 & 7.1002 & 5.0943 & TST & \\
\hline CHEMBL1451614 & 688293 & 4.4 & 4.9632 & TRN & \\
\hline CHEMBL1504505 & 688293 & 4.4 & 4.7787 & TRN & \\
\hline CHEMBL1347431 & 688293 & 4.4 & 5.088 & TRN & \\
\hline CHEMBL 235260 & 688293 & 5.0 & 5.0039 & TRN & \\
\hline CHEMBL 227725 & 688293 & 5.3 & 5.0661 & TST & \\
\hline CHEMBL1544930 & 688293 & 5.8 & 5.29799 & 9999999999 & TRN \\
\hline CHEMBL1333384 & 688293 & 8.0 & 4.9338 & TST & \\
\hline CHEMBL1331573 & 688293 & 4.6 & 4.9733 & TRN & \\
\hline CHEMBL1605507 & 688293 & 5.6 & 4.8037 & TRN & \\
\hline CHEMBL1560320 & 688293 & 4.6 & 5.07 & TRN & \\
\hline CHEMBL1600947 & 688293 & 6.7001 & 4.8669 & TRN & \\
\hline CHEMBL1514804 & 688293 & 4.4 & 5.0008 & TRN & \\
\hline CHEMBL1438690 & 688293 & 4.8 & 4.695 & TRN & \\
\hline CHEMBL1526443 & 688293 & 4.8 & 4.9046 & TRN & \\
\hline CHEMBL3211367 & 688293 & 4.4 & 4.9227 & TST & \\
\hline CHEMBL1496443 & 688293 & 4.4 & 5.0932 & TRN & \\
\hline CHEMBL1364682 & 688293 & 4.6 & 4.8341 & TRN & \\
\hline CHEMBL1496621 & 688293 & 7.8996 & 4.9904 & TRN & \\
\hline CHEMBL1256697 & 688293 & 4.5 & 4.9636 & TST & \\
\hline CHEMBL1574529 & 688293 & 5.5 & 5.1655 & TRN & \\
\hline CHEMBL3199055 & 688293 & 4.9 & 4.9009 & TST & \\
\hline CHEMBL1485735 & 688293 & 5.6 & 5.244 & TRN & \\
\hline CHEMBL1570008 & 688293 & 4.5 & 5.0037 & TRN & \\
\hline CHEMBL1456367 & 688293 & 4.4 & 5.1637 & TRN & \\
\hline CHEMBL1598424 & 688293 & 4.4 & 4.8767 & TST & \\
\hline CHEMBL1383035 & 688293 & 4.6 & 5.0278 & TRN & \\
\hline CHEMBL1578426 & 688293 & 4.5 & 5.1365 & TST & \\
\hline CHEMBL1565338 & 688293 & 5.5 & 5.1891 & TRN & \\
\hline CHEMBL1485375 & 688293 & 4.7 & 4.937 & TRN & \\
\hline CHEMBL1605113 & 688293 & 4.4 & 5.1286 & TRN & \\
\hline CHEMBL1431303 & 688293 & 4.6 & 5.0654 & TRN & \\
\hline CHEMBL1544220 & 688293 & 4.9 & 4.944 & TRN & \\
\hline CHEMBL1486857 & 688293 & 5.2 & 4.9932 & TRN & \\
\hline
\end{tabular}




\begin{tabular}{|c|c|c|c|c|}
\hline \multicolumn{5}{|c|}{ Supplemental Table S2.txt } \\
\hline CHEMBL1439280 & 688293 & 4.7 & 5.0436 & TRN \\
\hline CHEMBL1386096 & 688293 & 4.5 & 4.9977 & TST \\
\hline CHEMBL1384878 & 688293 & 4.6 & 5.1024 & TRN \\
\hline CHEMBL566135 & 688293 & 6.1 & 4.9859 & TRN \\
\hline CHEMBL1363544 & 688293 & 5.4 & 4.925 & TRN \\
\hline CHEMBL1377111 & 688293 & 4.9 & 5.0387 & TST \\
\hline CHEMBL2369309 & 688293 & 4.7 & 4.8975 & TRN \\
\hline CHEMBL1334989 & 688293 & 4.6 & 4.7826 & TRN \\
\hline CHEMBL1418483 & 688293 & 4.5 & 4.8268 & TST \\
\hline CHEMBL1302139 & 688293 & 4.6 & 5.117 & TRN \\
\hline CHEMBL1310076 & 688293 & 5.0 & 5.1099 & TRN \\
\hline CHEMBL1355693 & 688293 & 5.4 & 4.8364 & TRN \\
\hline CHEMBL1334527 & 688293 & 4.7 & 5.0907 & TRN \\
\hline CHEMBL1607791 & 688293 & 4.5 & 5.1075 & TRN \\
\hline CHEMBL1478946 & 688293 & 7.5003 & 5.058 & TRN \\
\hline CHEMBL1489424 & 688293 & 5.1 & 4.9667 & TRN \\
\hline CHEMBL1488940 & 688293 & 5.5 & 5.0253 & TRN \\
\hline CHEMBL1507555 & 688293 & 4.7 & 5.0707 & TST \\
\hline CHEMBL1425718 & 688293 & 4.5 & 5.0682 & TRN \\
\hline CHEMBL1425853 & 688293 & 4.6 & 4.7842 & TRN \\
\hline CHEMBL1317016 & 688293 & 4.5 & 5.1384 & TST \\
\hline CHEMBL1420022 & 688293 & 4.4 & 4.9723 & TRN \\
\hline CHEMBL1441404 & 688293 & 5.1 & 5.0218 & TRN \\
\hline CHEMBL1445873 & 688293 & 4.7 & 5.0159 & TRN \\
\hline CHEMBL1564660 & 688293 & 5.6 & 4.7741 & TST \\
\hline CHEMBL1579643 & 688293 & 5.0 & 4.9311 & TRN \\
\hline CHEMBL1429330 & 688293 & 6.0 & 4.9283 & TRN \\
\hline CHEMBL1341593 & 688293 & 4.5 & 4.853 & TRN \\
\hline CHEMBL1471549 & 688293 & 6.8 & 5.1003 & TRN \\
\hline CHEMBL1554088 & 688293 & 4.5 & 4.9648 & TRN \\
\hline CHEMBL1517241 & 688293 & 4.4 & 4.8985 & TRN \\
\hline CHEMBL1529671 & 688293 & 4.8 & 4.7862 & TRN \\
\hline CHEMBL1394596 & 688293 & 4.5 & 5.0533 & TRN \\
\hline CHEMBL1513282 & 688293 & 4.7 & 4.8905 & TRN \\
\hline CHEMBL1428889 & 688293 & 5.0 & 4.8166 & TRN \\
\hline CHEMBL1489518 & 688293 & 5.6 & 5.2137 & TRN \\
\hline CHEMBL1446115 & 688293 & 4.6 & 5.1181 & TRN \\
\hline CHEMBL1521490 & 688293 & 4.8 & 4.7685 & TRN \\
\hline CHEMBL492116 & 688293 & 4.9 & 5.1205 & TRN \\
\hline CHEMBL1371789 & 688293 & 4.4 & 4.8272 & TRN \\
\hline CHEMBL1417930 & 688293 & 6.0 & 4.8665 & TRN \\
\hline CHEMBL1587635 & 688293 & 5.3 & 5.1807 & TRN \\
\hline CHEMBL1416812 & 688293 & 4.4 & 5.0439 & TST \\
\hline CHEMBL1405209 & 688293 & 4.6 & 5.1202 & TRN \\
\hline CHEMBL1575331 & 688293 & 4.7 & 4.9968 & TRN \\
\hline CHEMBL1467289 & 688293 & 5.1 & 4.8929 & TRN \\
\hline CHEMBL1516882 & 688293 & 5.3 & 4.9732 & TRN \\
\hline CHEMBL1370563 & 688293 & 4.8 & 4.9371 & TRN \\
\hline
\end{tabular}




\begin{tabular}{|c|c|c|c|c|c|}
\hline \multicolumn{6}{|c|}{ Supplemental Table S2.txt } \\
\hline CHEMBL1380292 & 688293 & 5.5 & 4.9134 & TRN & \\
\hline CHEMBL1383121 & 688293 & 4.4 & 5.1184 & TRN & \\
\hline CHEMBL1490798 & 688293 & 4.6 & 4.8828 & TRN & \\
\hline CHEMBL1421453 & 688293 & 6.9 & 5.0273 & TRN & \\
\hline CHEMBL1535514 & 688293 & 5.1 & 5.1152 & TRN & \\
\hline CHEMBL473313 & 688293 & 5.0 & 5.0729 & TST & \\
\hline CHEMBL1558384 & 688293 & 5.0 & 4.81800 & 00000000005 & TRN \\
\hline CHEMBL1480806 & 688293 & 5.1 & 4.7024 & TRN & \\
\hline CHEMBL1338498 & 688293 & 4.8 & 4.9663 & TRN & \\
\hline CHEMBL1563201 & 688293 & 4.8 & 4.9504 & TRN & \\
\hline CHEMBL1606570 & 688293 & 5.0 & 4.9357 & TRN & \\
\hline CHEMBL1429566 & 688293 & 4.6 & 5.0486 & TRN & \\
\hline CHEMBL1528298 & 688293 & 5.1 & 5.1011 & TRN & \\
\hline CHEMBL243664 & 688293 & 4.4 & 4.8218 & TRN & \\
\hline CHEMBL1531520 & 688293 & 4.5 & 4.7802 & TRN & \\
\hline CHEMBL1480338 & 688293 & 4.4 & 5.084 & TRN & \\
\hline CHEMBL1605369 & 688293 & 4.8 & 4.912 & TRN & \\
\hline CHEMBL1348453 & 688293 & 4.0 & 5.0406 & TST & \\
\hline CHEMBL1536089 & 688293 & 4.7 & 4.8314 & TRN & \\
\hline CHEMBL1578516 & 688293 & 4.6 & 5.0522 & TRN & \\
\hline CHEMBL1568343 & 688293 & 4.7 & 5.0201 & TRN & \\
\hline CHEMBL277525 & 688293 & 6.3 & 4.9128 & TRN & \\
\hline CHEMBL438909 & 688293 & 5.3 & 5.0637 & TST & \\
\hline CHEMBL1596118 & 688293 & 4.8 & 5.0103 & TRN & \\
\hline CHEMBL1368802 & 688293 & 4.6 & 5.0776 & TRN & \\
\hline CHEMBL1300548 & 688293 & 4.8 & 5.1265 & TRN & \\
\hline CHEMBL1376626 & 688293 & 4.9 & 5.029 & TRN & \\
\hline CHEMBL1565756 & 688293 & 4.6 & 5.058 & TRN & \\
\hline CHEMBL1556701 & 688293 & 4.8 & 4.8308 & TRN & \\
\hline CHEMBL1340207 & 688293 & 8.4949 & 5.1697 & TRN & \\
\hline CHEMBL1342633 & 688293 & 5.3 & 5.0188 & TRN & \\
\hline CHEMBL1495172 & 688293 & 4.4 & 5.0214 & TRN & \\
\hline CHEMBL1312558 & 688293 & 4.8 & 5.0011 & TRN & \\
\hline CHEMBL1562602 & 688293 & 5.4 & 4.9186 & TRN & \\
\hline CHEMBL1428465 & 688293 & 4.9 & 4.9932 & TRN & \\
\hline CHEMBL1560374 & 688293 & 5.3 & 5.1273 & TRN & \\
\hline CHEMBL1361262 & 688293 & 5.4 & 5.0561 & TRN & \\
\hline CHEMBL1392671 & 688293 & 4.9 & 4.8825 & TRN & \\
\hline CHEMBL577938 & 688293 & 4.4 & 4.7643 & TRN & \\
\hline CHEMBL1324794 & 688293 & 4.4 & 4.9417 & TRN & \\
\hline CHEMBL1403744 & 688293 & 4.4 & 4.9977 & TST & \\
\hline CHEMBL1352614 & 688293 & 4.7 & 5.218 & TRN & \\
\hline CHEMBL1331584 & 688293 & 4.7 & 5.1135 & TRN & \\
\hline CHEMBL1462011 & 688293 & 4.8 & 4.8898 & TRN & \\
\hline CHEMBL1365833 & 688293 & 4.7 & 4.9643 & TRN & \\
\hline CHEMBL1411133 & 688293 & 4.7 & 5.1053 & TRN & \\
\hline CHEMBL1358122 & 688293 & 4.7 & 4.73600 & 0000000001 & TRN \\
\hline CHEMBL1506076 & 688293 & 4.4 & 4.9994 & TRN & \\
\hline
\end{tabular}




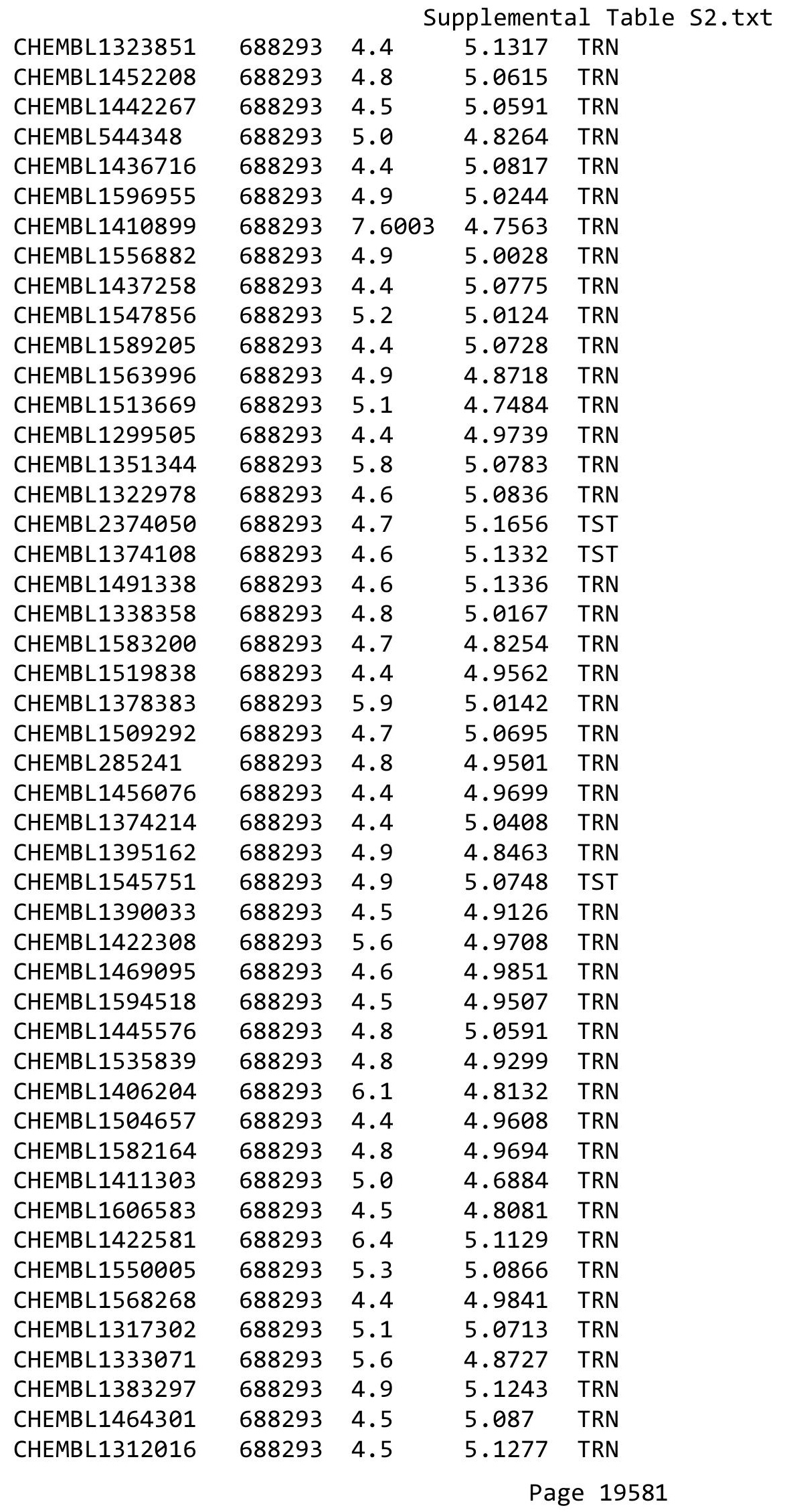




\begin{tabular}{|c|c|c|c|c|}
\hline & & & pplement & al Table \\
\hline CHEMBL1578546 & 688293 & 6.8 & 5.1078 & TRN \\
\hline CHEMBL1473379 & 688293 & 4.6 & 4.7894 & TRN \\
\hline CHEMBL1441481 & 688293 & 4.8 & 4.952 & TRN \\
\hline CHEMBL567332 & 688293 & 4.6 & 4.7472 & TRN \\
\hline CHEMBL3199337 & 688293 & 5.9 & 4.8922 & TRN \\
\hline CHEMBL1479267 & 688293 & 4.5 & 5.1164 & TRN \\
\hline CHEMBL1611316 & 688293 & 4.8 & 4.9992 & TRN \\
\hline CHEMBL1573114 & 688293 & 4.4 & 5.0843 & TRN \\
\hline CHEMBL1332341 & 688293 & 4.9 & 5.0153 & TRN \\
\hline CHEMBL1592493 & 688293 & 4.6 & 4.8767 & TRN \\
\hline CHEMBL1404530 & 688293 & 4.5 & 4.9123 & TRN \\
\hline CHEMBL1569696 & 688293 & 4.8 & 5.0575 & TRN \\
\hline CHEMBL1424253 & 688293 & 4.8 & 5.0917 & TRN \\
\hline CHEMBL1399977 & 688293 & 5.0 & 5.0221 & TRN \\
\hline CHEMBL1606181 & 688293 & 4.5 & 4.8633 & TST \\
\hline CHEMBL1306968 & 688293 & 4.8 & 5.1016 & TRN \\
\hline CHEMBL1324862 & 688293 & 5.7 & 5.0976 & TRN \\
\hline CHEMBL1375068 & 688293 & 5.1 & 5.0054 & TRN \\
\hline CHEMBL1333618 & 688293 & 4.5 & 4.9965 & TRN \\
\hline CHEMBL1455492 & 688293 & 4.9 & 5.2261 & TRN \\
\hline CHEMBL1547314 & 688293 & 4.6 & 5.0932 & TRN \\
\hline CHEMBL1326192 & 688293 & 4.6 & 5.0327 & TRN \\
\hline CHEMBL1503621 & 688293 & 4.8 & 4.9886 & TRN \\
\hline CHEMBL1425932 & 688293 & 4.4 & 4.8878 & TRN \\
\hline CHEMBL1600302 & 688293 & 4.7 & 4.9802 & TRN \\
\hline CHEMBL3195995 & 688293 & 4.6 & 4.9376 & TRN \\
\hline CHEMBL1414133 & 688293 & 4.4 & 4.9112 & TRN \\
\hline CHEMBL1423564 & 688293 & 4.5 & 5.0751 & TRN \\
\hline CHEMBL1444530 & 688293 & 6.1 & 5.1778 & TRN \\
\hline CHEMBL1433055 & 688293 & 4.7 & 4.8555 & TRN \\
\hline CHEMBL1483298 & 688293 & 5.0 & 5.0568 & TST \\
\hline CHEMBL1603589 & 688293 & 5.0 & 4.9085 & TRN \\
\hline CHEMBL1440725 & 688293 & 4.6 & 4.8896 & TRN \\
\hline CHEMBL1399950 & 688293 & 7.4001 & 5.0296 & TRN \\
\hline CHEMBL1363237 & 688293 & 6.4 & 5.0315 & TRN \\
\hline CHEMBL1601364 & 688293 & 4.7 & 5.1378 & TRN \\
\hline CHEMBL1494350 & 688293 & 4.4 & 4.8632 & TRN \\
\hline CHEMBL1326188 & 688293 & 5.2 & 4.9106 & TRN \\
\hline CHEMBL1359729 & 688293 & 4.4 & 4.9272 & TRN \\
\hline CHEMBL1439720 & 688293 & 4.5 & 5.0617 & TRN \\
\hline CHEMBL1330717 & 688293 & 4.6 & 4.7465 & TRN \\
\hline CHEMBL1412261 & 688293 & 5.7 & 5.035 & TST \\
\hline CHEMBL1591140 & 688293 & 4.6 & 4.8554 & TRN \\
\hline CHEMBL1390346 & 688293 & 4.6 & 5.1104 & TRN \\
\hline CHEMBL1415917 & 688293 & 4.8 & 5.2457 & TRN \\
\hline CHEMBL1565860 & 688293 & 4.9 & 5.0065 & TRN \\
\hline CHEMBL1370622 & 688293 & 4.4 & 4.6577 & TRN \\
\hline CHEMBL1524482 & 688293 & 4.7 & 4.8882 & TRN \\
\hline
\end{tabular}




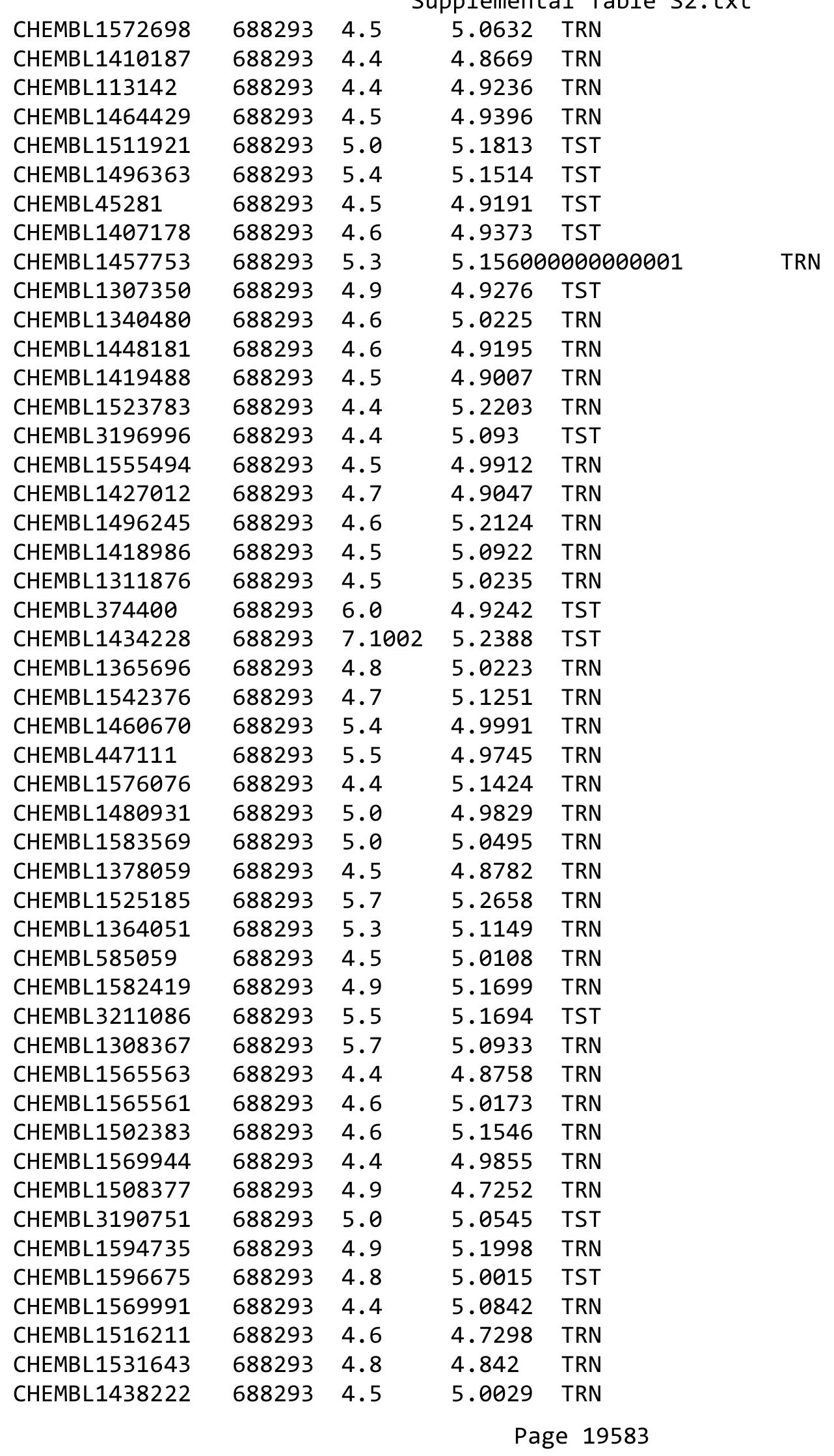




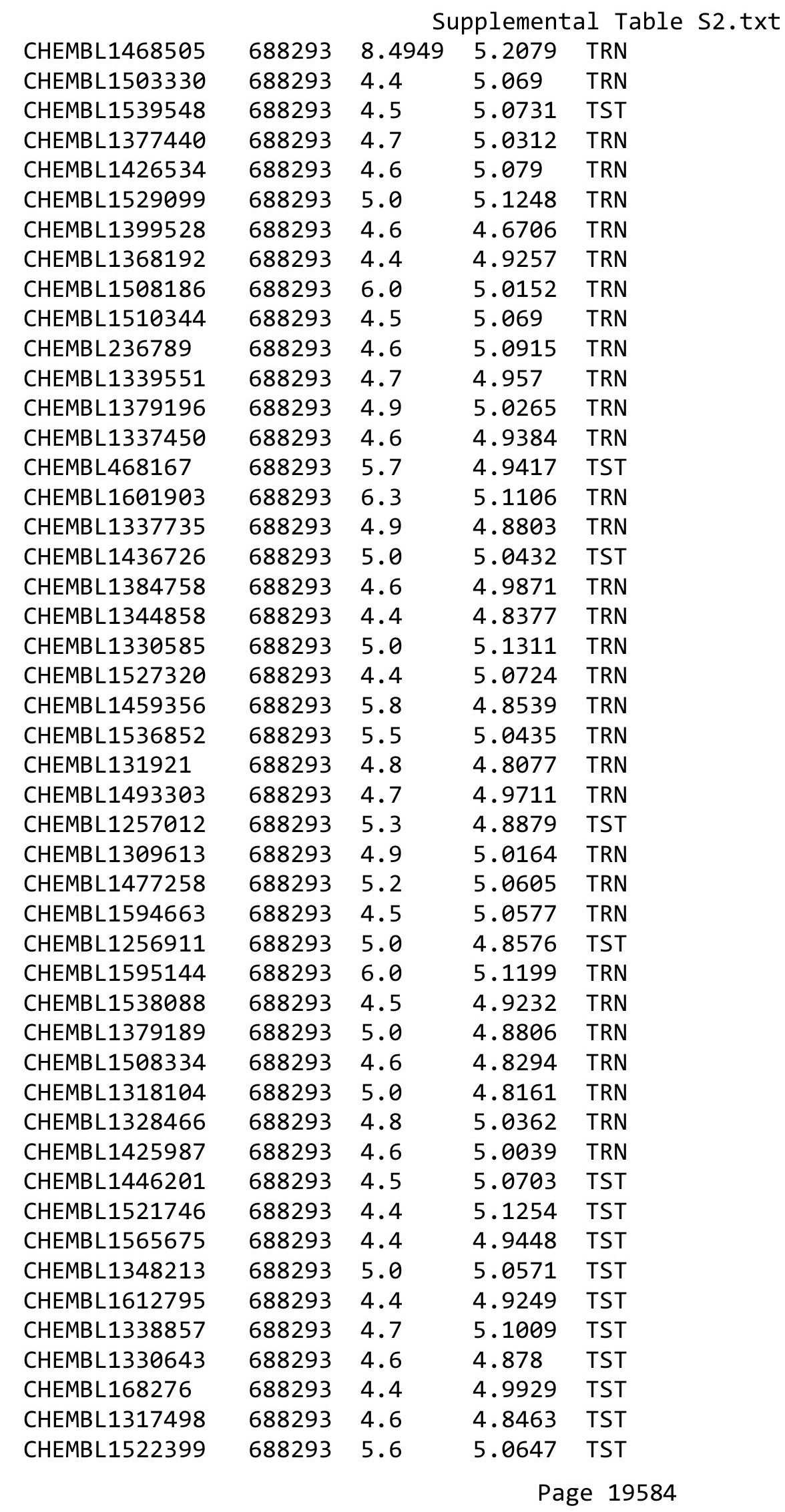




\begin{tabular}{|c|c|c|c|c|}
\hline \\
\hline CHEMBL1583046 & 688293 & 5.8 & 5.0959 & TST \\
\hline CHEMBL1469299 & 688293 & 4.4 & 4.8943 & TST \\
\hline CHEMBL1456751 & 688293 & 5.3 & 4.8884 & TST \\
\hline CHEMBL1472507 & 688293 & 4.4 & 4.9387 & TST \\
\hline CHEMBL1590197 & 688293 & 4.4 & 4.9714 & TST \\
\hline CHEMBL1438646 & 688293 & 6.2 & 5.1042 & TST \\
\hline CHEMBL1547207 & 688293 & 4.7 & 4.9585 & TST \\
\hline CHEMBL1559588 & 688293 & 5.0 & 4.9799 & TST \\
\hline CHEMBL1525511 & 688293 & 5.5 & 4.8418 & TST \\
\hline CHEMBL1388948 & 688293 & 4.4 & 5.0206 & TST \\
\hline CHEMBL1316759 & 688293 & 4.4 & 4.9652 & TST \\
\hline CHEMBL1596170 & 688293 & 5.3 & 4.8269 & TST \\
\hline CHEMBL1610515 & 688293 & 4.4 & 5.1146 & TST \\
\hline CHEMBL1522086 & 688293 & 5.6 & 5.0142 & TST \\
\hline CHEMBL1595054 & 688293 & 4.4 & 5.0913 & TST \\
\hline CHEMBL1374082 & 688293 & 5.1 & 5.1752 & TST \\
\hline CHEMBL1601710 & 688293 & 4.8 & 5.1249 & TST \\
\hline CHEMBL1573989 & 688293 & 5.1 & 5.1103 & TST \\
\hline CHEMBL1499345 & 688293 & 4.5 & 5.0322 & TST \\
\hline CHEMBL1389942 & 688293 & 4.9 & 5.211 & TST \\
\hline CHEMBL1594517 & 688293 & 4.9 & 5.0313 & TST \\
\hline CHEMBL1562688 & 688293 & 4.8 & 5.0049 & TST \\
\hline CHEMBL1568086 & 688293 & 4.5 & 4.6681 & TST \\
\hline CHEMBL1372961 & 688293 & 4.7 & 5.1829 & TST \\
\hline CHEMBL1345977 & 688293 & 4.6 & 5.0616 & TST \\
\hline CHEMBL1363931 & 688293 & 4.6 & 4.8789 & TST \\
\hline CHEMBL1472302 & 688293 & 4.7 & 4.9652 & TST \\
\hline CHEMBL107131 & 688293 & 4.5 & 4.9567 & TST \\
\hline CHEMBL1594715 & 688293 & 4.4 & 5.0009 & TST \\
\hline CHEMBL1350593 & 688293 & 5.5 & 4.8297 & TST \\
\hline CHEMBL1531210 & 688293 & 4.4 & 4.8931 & TST \\
\hline CHEMBL1488203 & 688293 & 4.8 & 5.0237 & TST \\
\hline CHEMBL1367886 & 688293 & 4.8 & 4.9733 & TST \\
\hline CHEMBL1311215 & 688293 & 4.5 & 4.9832 & TST \\
\hline CHEMBL150809 & 688293 & 4.5 & 4.86 & TST \\
\hline CHEMBL1415148 & 688293 & 4.5 & 5.0773 & TST \\
\hline CHEMBL1376163 & 688293 & 4.6 & 4.8346 & TST \\
\hline CHEMBL1325791 & 688293 & 5.8 & 5.1301 & TST \\
\hline CHEMBL 221300 & 688293 & 5.7 & 4.846 & TST \\
\hline CHEMBL1442802 & 688293 & 4.9 & 4.9226 & TST \\
\hline CHEMBL1411975 & 688293 & 4.9 & 4.88399 & 99999999995 \\
\hline CHEMBL1311651 & 688293 & 6.9 & 5.0007 & TST \\
\hline CHEMBL1530323 & 688293 & 5.5 & 4.9848 & TST \\
\hline CHEMBL1344053 & 688293 & 4.4 & 4.8311 & TST \\
\hline CHEMBL1532659 & 688293 & 5.4 & 4.8743 & TST \\
\hline CHEMBL1606431 & 688293 & 4.5 & 5.0132 & TST \\
\hline CHEMBL1324508 & 688293 & 4.5 & 4.8878 & TST \\
\hline CHEMBL1417302 & 688293 & 4.6 & 5.0306 & TST \\
\hline
\end{tabular}




\begin{tabular}{|c|c|c|c|c|c|}
\hline \multicolumn{6}{|c|}{ oplemental Iabıe s. } \\
\hline CHEMBL1388744 & 688293 & 4.7 & 4.8784 & TST & \\
\hline CHEMBL1342666 & 688293 & 4.5 & 4.9004 & TST & \\
\hline CHEMBL1613088 & 688293 & 4.9 & 4.978 & TST & \\
\hline CHEMBL1418690 & 688293 & 4.6 & 5.149 & TST & \\
\hline CHEMBL1399183 & 688293 & 4.4 & 4.9921 & TST & \\
\hline CHEMBL1584942 & 688293 & 4.6 & 4.9698 & TST & \\
\hline CHEMBL1353251 & 688293 & 8.2007 & 5.1358 & TST & \\
\hline CHEMBL1395747 & 688293 & 7.6003 & 5.0496 & TST & \\
\hline CHEMBL1313870 & 688293 & 4.6 & 4.8639 & TST & \\
\hline CHEMBL1470572 & 688293 & 4.4 & 5.042 & TST & \\
\hline CHEMBL1201091 & 688293 & 6.0 & 5.1352 & TST & \\
\hline CHEMBL1588098 & 688293 & 4.4 & 5.216 & TST & \\
\hline CHEMBL1467225 & 688293 & 4.4 & 5.0552 & TST & \\
\hline CHEMBL1500220 & 688293 & 4.6 & 4.7777 & TST & \\
\hline CHEMBL1384931 & 688293 & 4.6 & 4.9794 & TST & \\
\hline CHEMBL1608228 & 688293 & 4.6 & 4.94 & TST & \\
\hline CHEMBL239276 & 688293 & 4.4 & 4.8793 & TST & \\
\hline CHEMBL1568663 & 688293 & 4.7 & 5.0553 & TST & \\
\hline CHEMBL1587512 & 688293 & 5.7 & 5.09399 & 9999999999 & TST \\
\hline CHEMBL1498409 & 688293 & 6.0 & 4.9168 & TST & \\
\hline CHEMBL1306966 & 688293 & 6.1 & 5.1204 & TST & \\
\hline CHEMBL1575123 & 688293 & 4.6 & 4.8342 & TST & \\
\hline CHEMBL1335188 & 688293 & 4.4 & 4.8823 & TST & \\
\hline CHEMBL1173522 & 688293 & 4.7 & 4.8915 & TST & \\
\hline CHEMBL1402435 & 688293 & 4.4 & 5.2218 & TST & \\
\hline CHEMBL1363915 & 688293 & 5.3 & 5.0331 & TST & \\
\hline CHEMBL1487660 & 688293 & 4.4 & 4.9442 & TST & \\
\hline CHEMBL306764 & 688293 & 4.7 & 5.0708 & TST & \\
\hline CHEMBL1539115 & 688293 & 4.8 & 5.1845 & TST & \\
\hline CHEMBL1594144 & 688293 & 6.2 & 5.0073 & TST & \\
\hline CHEMBL1597936 & 688293 & 5.3 & 5.0733 & TST & \\
\hline CHEMBL1482554 & 688293 & 4.6 & 4.9978 & TST & \\
\hline CHEMBL1389239 & 688293 & 4.5 & 5.1044 & TST & \\
\hline CHEMBL1608006 & 688293 & 5.4 & 5.0393 & TST & \\
\hline CHEMBL1488889 & 688293 & 8.2007 & 4.9727 & TST & \\
\hline CHEMBL1503324 & 688293 & 4.7 & 5.0664 & TST & \\
\hline CHEMBL1568588 & 688293 & 5.0 & 5.1281 & TST & \\
\hline CHEMBL1529669 & 688293 & 4.4 & 5.0186 & TST & \\
\hline CHEMBL1586107 & 688293 & 4.5 & 4.949 & TST & \\
\hline CHEMBL1322517 & 688293 & 4.4 & 4.9981 & TST & \\
\hline CHEMBL1509650 & 688293 & 4.7 & 5.0026 & TST & \\
\hline CHEMBL1510394 & 688293 & 4.8 & 5.0829 & TST & \\
\hline CHEMBL1532987 & 688293 & 4.4 & 5.0049 & TST & \\
\hline CHEMBL1371638 & 688293 & 4.6 & 5.1234 & TST & \\
\hline CHEMBL1438838 & 688293 & 4.4 & 5.0169 & TST & \\
\hline CHEMBL1499110 & 688293 & 4.7 & 5.0197 & TST & \\
\hline CHEMBL1368219 & 688293 & 5.7 & 5.0549 & TST & \\
\hline CHEMBL3191258 & 688293 & 4.4 & 4.9273 & TST & \\
\hline
\end{tabular}




\begin{tabular}{|c|c|c|c|c|c|}
\hline CHEMBL1605081 & 688293 & 4.4 & \multicolumn{2}{|c|}{4.7330000000000005} & TST \\
\hline CHEMBL1502322 & 688293 & 6.2 & 5.0582 & TST & \\
\hline CHEMBL230056 & 688293 & 4.4 & 4.9767 & TST & \\
\hline CHEMBL1560508 & 688293 & 5.1 & 5.0958 & TST & \\
\hline CHEMBL1452561 & 688293 & 4.4 & 5.0374 & TST & \\
\hline CHEMBL1483966 & 688293 & 4.5 & 5.1304 & TST & \\
\hline CHEMBL1310699 & 688293 & 5.3 & 5.0865 & TST & \\
\hline CHEMBL1401575 & 688293 & 4.8 & 5.0595 & TST & \\
\hline CHEMBL1563483 & 688293 & 5.5 & 5.0777 & TST & \\
\hline CHEMBL1596952 & 688293 & 4.7 & 4.8365 & TST & \\
\hline CHEMBL1555028 & 688293 & 4.5 & 4.9447 & TST & \\
\hline CHEMBL1483759 & 688293 & 4.4 & 4.9051 & TST & \\
\hline CHEMBL1417381 & 688293 & 4.9 & 4.8811 & TST & \\
\hline CHEMBL1494870 & 688293 & 4.8 & 4.9798 & TST & \\
\hline CHEMBL1576363 & 688293 & 5.0 & 4.8854 & TST & \\
\hline CHEMBL1475574 & 688293 & 4.4 & 5.034 & TST & \\
\hline CHEMBL1493179 & 688293 & 5.3 & 4.9334 & TST & \\
\hline CHEMBL1372232 & 688293 & 4.9 & 4.9262 & TST & \\
\hline CHEMBL1416549 & 688293 & 4.8 & 4.9703 & TST & \\
\hline CHEMBL1332463 & 688293 & 5.7 & 4.7261 & TST & \\
\hline CHEMBL1542995 & 688293 & 4.5 & 4.9685 & TST & \\
\hline CHEMBL1374355 & 688293 & 5.5 & 4.7924 & TST & \\
\hline CHEMBL1385762 & 688293 & 5.5 & 5.1793 & TST & \\
\hline CHEMBL1558146 & 688293 & 5.1 & 5.0044 & TST & \\
\hline CHEMBL1484237 & 688293 & 4.7 & 5.0034 & TST & \\
\hline CHEMBL1452101 & 688293 & 4.7 & 5.0374 & TST & \\
\hline CHEMBL297453 & 688293 & 4.4 & 5.0346 & TST & \\
\hline CHEMBL1353697 & 688293 & 4.5 & 4.7935 & TST & \\
\hline CHEMBL1482912 & 688293 & 6.0 & 4.9945 & TST & \\
\hline CHEMBL1544342 & 688293 & 4.8 & 4.8282 & TST & \\
\hline CHEMBL1326787 & 688293 & 4.5 & 4.9042 & TST & \\
\hline CHEMBL1520028 & 688293 & 4.5 & 4.9796 & TST & \\
\hline CHEMBL1454225 & 688293 & 5.8 & 5.0885 & TST & \\
\hline CHEMBL1377161 & 688293 & 4.6 & 5.0301 & TST & \\
\hline CHEMBL55814 & 688293 & 6.0 & 4.9627 & TST & \\
\hline CHEMBL1510572 & 688293 & 6.2 & 4.9248 & TST & \\
\hline CHEMBL1376206 & 688293 & 4.5 & 5.0441 & TST & \\
\hline CHEMBL1570746 & 688293 & 4.6 & 5.0821 & TST & \\
\hline CHEMBL1301505 & 688293 & 4.4 & 5.0314 & TST & \\
\hline CHEMBL1342119 & 688293 & 5.0 & 4.7906 & TST & \\
\hline CHEMBL1601997 & 688293 & 4.4 & 4.9993 & TST & \\
\hline CHEMBL1320518 & 688293 & 5.6 & 4.962 & TST & \\
\hline CHEMBL1528209 & 688293 & 4.7 & 5.0259 & TST & \\
\hline CHEMBL1456740 & 688293 & 8.4949 & 4.9341 & TST & \\
\hline CHEMBL1390386 & 688293 & 5.0 & 4.7761 & TST & \\
\hline CHEMBL1521629 & 688293 & 4.7 & 5.0223 & TST & \\
\hline CHEMBL1431928 & 688293 & 4.6 & 4.9709 & TST & \\
\hline CHEMBL1320914 & 688293 & 4.8 & 5.183 & TST & \\
\hline
\end{tabular}




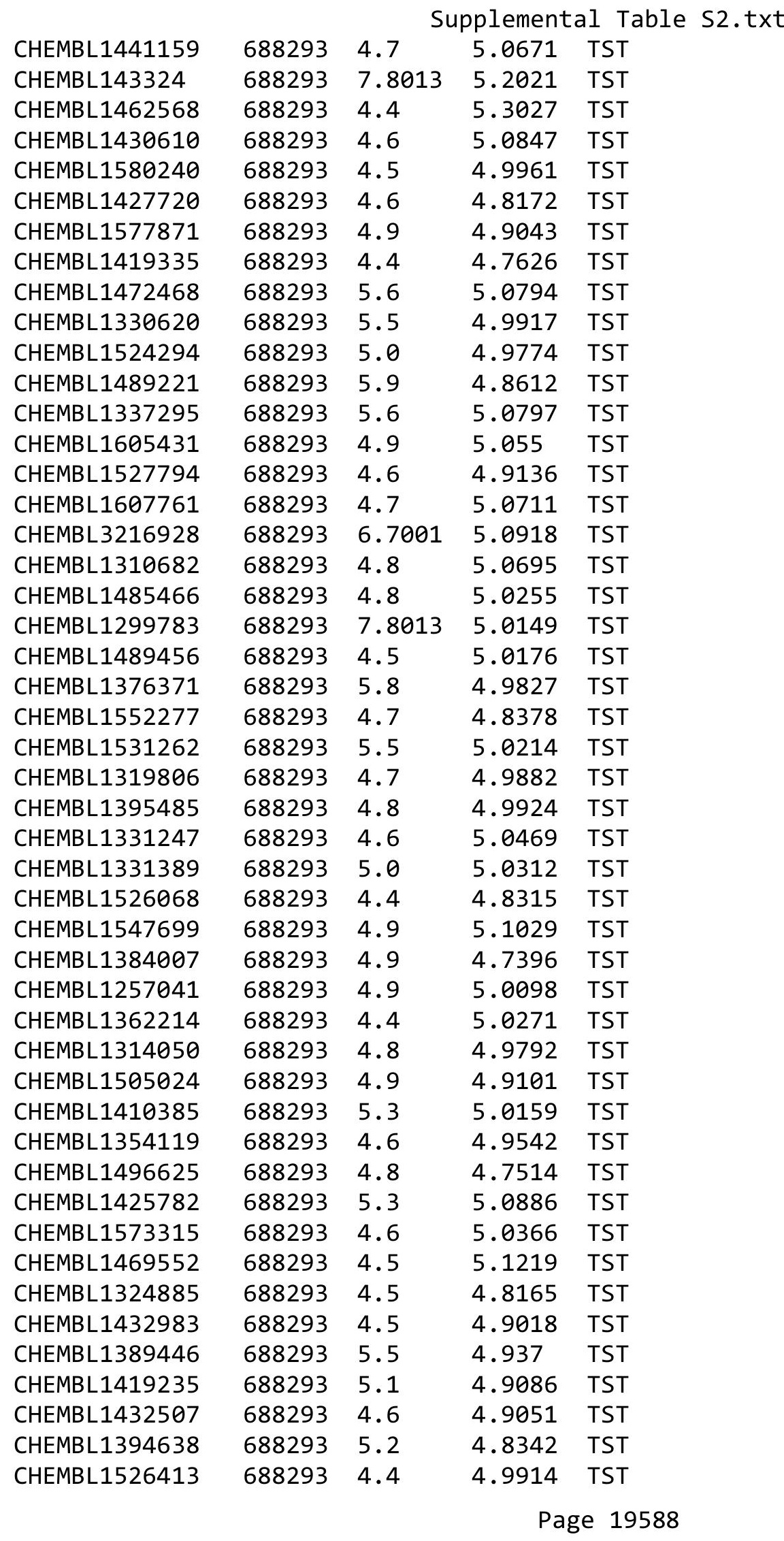




\begin{tabular}{|c|c|c|c|c|c|}
\hline \\
\hline CHEMBL1315268 & 688293 & 5.0 & 4.9297 & TST & \\
\hline CHEMBL1469705 & 688293 & 4.8 & 4.9476 & TST & \\
\hline CHEMBL1331815 & 688293 & 4.8 & 5.1907 & TST & \\
\hline CHEMBL1301577 & 688293 & 8.2007 & 5.2158 & TST & \\
\hline CHEMBL440084 & 688293 & 4.4 & 4.8514 & TST & \\
\hline CHEMBL1318332 & 688293 & 5.4 & 5.0815 & TST & \\
\hline CHEMBL1496934 & 688293 & 4.8 & 4.7843 & TST & \\
\hline CHEMBL1348663 & 688293 & 5.0 & 5.0567 & TST & \\
\hline CHEMBL1332664 & 688293 & 5.3 & 5.2637 & TST & \\
\hline CHEMBL1331045 & 688293 & 4.4 & 5.1312 & TST & \\
\hline CHEMBL1305334 & 688293 & 5.5 & 5.1741 & TST & \\
\hline CHEMBL1413799 & 688293 & 4.4 & 5.1715 & TST & \\
\hline CHEMBL1416274 & 688293 & 4.8 & 5.0438 & TST & \\
\hline CHEMBL1483022 & 688293 & 4.6 & 5.0345 & TST & \\
\hline CHEMBL1580192 & 688293 & 4.7 & 5.038 & TST & \\
\hline CHEMBL1588491 & 688293 & 4.8 & 5.0134 & TST & \\
\hline CHEMBL3195099 & 688293 & 4.6 & 4.8986 & TST & \\
\hline CHEMBL1530831 & 688293 & 5.0 & 5.0239 & TST & \\
\hline CHEMBL1381732 & 688293 & 4.7 & 5.008 & TST & \\
\hline CHEMBL 3214458 & 688293 & 4.6 & 4.9251 & TST & \\
\hline CHEMBL1504458 & 688293 & 4.4 & 5.231 & TST & \\
\hline CHEMBL1583283 & 688293 & 4.4 & 5.0229 & TST & \\
\hline CHEMBL1368302 & 688293 & 4.7 & 5.1686 & TST & \\
\hline CHEMBL1489478 & 688293 & 5.9 & 5.0378 & TST & \\
\hline CHEMBL56393 & 688293 & 4.7 & 5.0026 & TST & \\
\hline CHEMBL1581825 & 688293 & 4.9 & 4.8852 & TST & \\
\hline CHEMBL1468103 & 688293 & 4.4 & 4.9954 & TST & \\
\hline CHEMBL1487039 & 688293 & 6.5 & 5.0884 & TST & \\
\hline CHEMBL1389769 & 688293 & 5.1 & 4.9523 & TST & \\
\hline CHEMBL1345961 & 688293 & 5.1 & 5.0307 & TST & \\
\hline CHEMBL1526514 & 688293 & 4.4 & 5.0559 & TST & \\
\hline CHEMBL1512312 & 688293 & 4.5 & 4.7977 & TST & \\
\hline CHEMBL1477856 & 688293 & 4.5 & 4.8586 & TST & \\
\hline CHEMBL1416112 & 688293 & 4.9 & 5.0205 & TST & \\
\hline CHEMBL1352525 & 688293 & 4.6 & 5.0902 & TST & \\
\hline CHEMBL1565927 & 688293 & 4.4 & 4.80699 & 99999999995 & TST \\
\hline CHEMBL278041 & 688293 & 5.1 & 4.8432 & TST & \\
\hline CHEMBL1509995 & 688293 & 4.7 & 4.8203 & TST & \\
\hline CHEMBL1460155 & 688293 & 4.6 & 4.9348 & TST & \\
\hline CHEMBL1473420 & 688293 & 4.9 & 4.7728 & TST & \\
\hline CHEMBL1482961 & 688293 & 4.4 & 4.9506 & TST & \\
\hline CHEMBL1362579 & 688293 & 4.5 & 4.9393 & TST & \\
\hline CHEMBL1577082 & 688293 & 4.8 & 5.0374 & TST & \\
\hline CHEMBL1516883 & 688293 & 4.8 & 4.9291 & TST & \\
\hline CHEMBL1310005 & 688293 & 5.5 & 4.9609 & TST & \\
\hline CHEMBL1488380 & 688293 & 4.8 & 4.9847 & TST & \\
\hline CHEMBL168461 & 688293 & 5.4 & 5.1427 & TST & \\
\hline CHEMBL1330718 & 688293 & 4.5 & 4.9747 & TST & \\
\hline
\end{tabular}




\begin{tabular}{|c|c|c|c|c|}
\hline \multicolumn{5}{|c|}{ Supplemental Table S2.txt } \\
\hline CHEMBL371811 & 688293 & 8.4949 & 4.8691 & TST \\
\hline CHEMBL1487760 & 688293 & 4.5 & 5.0422 & TST \\
\hline CHEMBL1339794 & 688293 & 5.0 & 4.8306 & TST \\
\hline CHEMBL1325833 & 688293 & 5.5 & 4.8524 & TST \\
\hline CHEMBL1373222 & 688293 & 5.0 & 5.1431 & TST \\
\hline CHEMBL1446644 & 688293 & 4.4 & 5.0464 & TST \\
\hline CHEMBL1311470 & 688293 & 5.3 & 5.1218 & TST \\
\hline CHEMBL1612923 & 688293 & 4.7 & 4.7886 & TST \\
\hline CHEMBL1525481 & 688293 & 4.9 & 4.927 & TST \\
\hline CHEMBL3212239 & 688293 & 4.4 & 4.9101 & TST \\
\hline CHEMBL1437075 & 688293 & 4.5 & 4.9149 & TST \\
\hline CHEMBL1094843 & 688293 & 4.9 & 5.0453 & TST \\
\hline CHEMBL1991885 & 688293 & 6.0 & 4.8834 & TST \\
\hline CHEMBL1506109 & 688293 & 4.9 & 4.8583 & TST \\
\hline CHEMBL1350157 & 688293 & 4.6 & 5.0487 & TST \\
\hline CHEMBL1581772 & 688293 & 4.6 & 4.9796 & TST \\
\hline CHEMBL1331733 & 688293 & 4.7 & 5.0456 & TST \\
\hline CHEMBL1588878 & 688293 & 5.0 & 5.0975 & TST \\
\hline CHEMBL1545280 & 688293 & 6.2 & 4.994 & TST \\
\hline CHEMBL1304585 & 688293 & 4.9 & 4.936 & TST \\
\hline CHEMBL323356 & 688293 & 4.5 & 5.0286 & TST \\
\hline CHEMBL1457994 & 688293 & 4.4 & 4.9174 & TST \\
\hline CHEMBL1424254 & 688293 & 6.3 & 5.1058 & TST \\
\hline CHEMBL1424968 & 688293 & 5.1 & 4.9662 & TST \\
\hline CHEMBL1479419 & 688293 & 4.9 & 4.9958 & TST \\
\hline CHEMBL1490024 & 688293 & 5.3 & 4.7599 & TST \\
\hline CHEMBL1606763 & 688293 & 4.8 & 4.8958 & TST \\
\hline CHEMBL1433027 & 688293 & 7.1002 & 5.0503 & TST \\
\hline CHEMBL1550753 & 688293 & 4.4 & 4.926 & TST \\
\hline CHEMBL3193472 & 688293 & 4.5 & 4.9242 & TST \\
\hline CHEMBL1575003 & 688293 & 7.4001 & 5.1962 & TST \\
\hline CHEMBL1556060 & 688293 & 7.3002 & 5.2186 & TST \\
\hline CHEMBL1518551 & 688293 & 4.4 & 4.9925 & TST \\
\hline CHEMBL1471373 & 688293 & 4.4 & 5.0067 & TST \\
\hline CHEMBL1586106 & 688293 & 4.8 & 5.1961 & TST \\
\hline CHEMBL1414873 & 688293 & 4.4 & 4.7878 & TST \\
\hline CHEMBL1566938 & 688293 & 4.6 & 5.0843 & TST \\
\hline CHEMBL1337012 & 688293 & 4.4 & 5.1209 & TST \\
\hline CHEMBL1610581 & 688293 & 5.3 & 5.1245 & TST \\
\hline CHEMBL1419327 & 688293 & 5.1 & 4.9305 & TST \\
\hline CHEMBL1490390 & 688293 & 4.6 & 5.0069 & TST \\
\hline CHEMBL1359223 & 688293 & 6.5 & 5.1145 & TST \\
\hline CHEMBL1303639 & 688293 & 5.5 & 4.9293 & TST \\
\hline CHEMBL1341571 & 688293 & 4.6 & 5.1107 & TST \\
\hline CHEMBL1412263 & 688293 & 4.4 & 5.0045 & TST \\
\hline CHEMBL1304455 & 688293 & 4.6 & 4.8634 & TST \\
\hline CHEMBL1342540 & 688293 & 4.7 & 5.1374 & TST \\
\hline CHEMBL1334368 & 688293 & 4.6 & 5.075 & TST \\
\hline
\end{tabular}




\begin{tabular}{|c|c|c|c|c|}
\hline & & & & \\
\hline CHEMBL1510097 & 688293 & 4.8 & 5.0934 & TST \\
\hline CHEMBL1440391 & 688293 & 4.6 & 4.9853 & TST \\
\hline CHEMBL1564824 & 688293 & 4.4 & 4.9849 & TST \\
\hline CHEMBL1486645 & 688293 & 4.5 & 5.1053 & TST \\
\hline CHEMBL1573977 & 688293 & 4.9 & 4.977 & TST \\
\hline CHEMBL 1448326 & 688293 & 4.4 & 5.0011 & TST \\
\hline CHEMBL1304601 & 688293 & 5.5 & 4.9177 & TST \\
\hline CHEMBL1600077 & 688293 & 5.6 & 5.1098 & TST \\
\hline CHEMBL1580966 & 688293 & 4.6 & 5.0386 & TST \\
\hline CHEMBL1412260 & 688293 & 4.6 & 4.939 & TST \\
\hline CHEMBL1549473 & 688293 & 4.6 & 5.115 & TST \\
\hline CHEMBL1383872 & 688293 & 5.2 & 4.8782 & TST \\
\hline CHEMBL1442458 & 688293 & 4.8 & 4.9139 & TST \\
\hline CHEMBL1574985 & 688293 & 4.7 & 4.9249 & TST \\
\hline CHEMBL137648 & 688293 & 4.4 & 5.0184 & TST \\
\hline CHEMBL1558476 & 688293 & 4.7 & 5.1958 & TST \\
\hline CHEMBL1305098 & 688293 & 4.6 & 5.135 & TST \\
\hline CHEMBL1308964 & 688293 & 4.6 & 5.1296 & TST \\
\hline CHEMBL1331823 & 688293 & 4.6 & 5.0653 & TST \\
\hline CHEMBL1604673 & 688293 & 4.9 & 4.9649 & TST \\
\hline CHEMBL1325753 & 688293 & 4.5 & 4.9924 & TST \\
\hline CHEMBL1493772 & 688293 & 4.5 & 4.7681 & TST \\
\hline CHEMBL1324889 & 688293 & 7.1002 & 4.7919 & TST \\
\hline CHEMBL1414221 & 688293 & 5.0 & 4.9583 & TST \\
\hline CHEMBL1447733 & 688293 & 4.8 & 4.8191 & TST \\
\hline CHEMBL550826 & 688293 & 4.6 & 4.8909 & TST \\
\hline CHEMBL1492350 & 688293 & 4.6 & 5.1138 & TST \\
\hline CHEMBL1488628 & 688293 & 4.4 & 4.9681 & TST \\
\hline CHEMBL1483555 & 688293 & 4.4 & 4.6522 & TST \\
\hline CHEMBL1479730 & 688293 & 4.6 & 5.0403 & TST \\
\hline CHEMBL1552551 & 688293 & 4.8 & 4.9522 & TST \\
\hline CHEMBL1313565 & 688293 & 5.5 & 4.8893 & TST \\
\hline CHEMBL1537857 & 688293 & 4.4 & 4.8993 & TST \\
\hline CHEMBL1450384 & 688293 & 4.8 & 5.0444 & TST \\
\hline CHEMBL1408389 & 688293 & 4.7 & 5.0645 & TST \\
\hline CHEMBL1307769 & 688293 & 4.9 & 4.8897 & TST \\
\hline CHEMBL1589923 & 688293 & 4.4 & 4.9862 & TST \\
\hline CHEMBL1385764 & 688293 & 4.8 & 5.0681 & TST \\
\hline CHEMBL1439593 & 688293 & 4.5 & 4.9678 & TST \\
\hline CHEMBL1256995 & 688293 & 7.8996 & 4.9185 & TST \\
\hline CHEMBL1508110 & 688293 & 4.6 & 4.9244 & TST \\
\hline CHEMBL1330386 & 688293 & 4.5 & 5.0354 & TST \\
\hline CHEMBL1502678 & 688293 & 4.9 & 5.0568 & TST \\
\hline CHEMBL1582814 & 688293 & 4.6 & 5.275 & TST \\
\hline CHEMBL1300104 & 688293 & 5.8 & 4.9864 & TST \\
\hline CHEMBL1603989 & 688293 & 5.0 & 4.9574 & TST \\
\hline CHEMBL1533893 & 688293 & 4.5 & 4.8887 & TST \\
\hline CHEMBL1429124 & 688293 & 4.4 & 4.9728 & TST \\
\hline
\end{tabular}


Supplemental Table S2.txt

\begin{tabular}{|c|c|c|c|c|}
\hline CHEMBL1401138 & 688293 & 7.1002 & 4.9757 & TST \\
\hline CHEMBL1414636 & 688293 & 7.2 & 5.1491 & TST \\
\hline CHEMBL1386762 & 688293 & 4.4 & 4.9187 & TST \\
\hline CHEMBL1431003 & 688293 & 4.6 & 5.1132 & TST \\
\hline CHEMBL1370284 & 688293 & 6.8 & 5.0775 & TST \\
\hline CHEMBL1495847 & 688293 & 6.5 & 5.1328 & TST \\
\hline CHEMBL1456116 & 688293 & 5.1 & \multicolumn{2}{|c|}{ 4.928999999999999 } \\
\hline CHEMBL1301914 & 688293 & 5.6 & 4.8199 & TST \\
\hline CHEMBL1387412 & 688293 & 4.6 & 4.9223 & TST \\
\hline CHEMBL1322625 & 688293 & 4.5 & 4.8979 & TST \\
\hline CHEMBL1432632 & 688293 & 5.8 & 4.9674 & TST \\
\hline CHEMBL1613690 & 688293 & 4.9 & 5.0928 & TST \\
\hline CHEMBL1498052 & 688293 & 4.5 & 4.8647 & TST \\
\hline CHEMBL1533335 & 688293 & 4.4 & 4.7865 & TST \\
\hline CHEMBL1432711 & 688293 & 4.5 & 4.734 & TST \\
\hline CHEMBL1473055 & 688293 & 4.4 & 4.9483 & TST \\
\hline CHEMBL1447750 & 688293 & 6.2 & 4.7358 & TST \\
\hline CHEMBL261237 & 688293 & 6.5 & 4.9167 & TST \\
\hline CHEMBL1326129 & 688293 & 4.4 & 4.7629 & TST \\
\hline CHEMBL1528391 & 688293 & 4.9 & 4.8547 & TST \\
\hline CHEMBL1506857 & 688293 & 4.8 & 5.2281 & TST \\
\hline CHEMBL1505751 & 688293 & 4.9 & 4.9559 & TST \\
\hline CHEMBL1331615 & 688293 & 4.7 & 4.9611 & TST \\
\hline CHEMBL1367722 & 688293 & 4.9 & 5.0744 & TST \\
\hline CHEMBL516952 & 688293 & 4.4 & 5.1319 & TST \\
\hline CHEMBL1446025 & 688293 & 4.5 & 4.9714 & TST \\
\hline CHEMBL1437979 & 688293 & 4.9 & 4.8099 & TST \\
\hline CHEMBL1474286 & 688293 & 8.2007 & 5.0678 & TST \\
\hline CHEMBL1442087 & 688293 & 5.1 & 5.1062 & TST \\
\hline CHEMBL1469822 & 688293 & 5.0 & 5.0254 & TST \\
\hline CHEMBL1540363 & 688293 & 4.5 & 5.015 & TST \\
\hline CHEMBL2369215 & 688293 & 4.9 & 4.8697 & TST \\
\hline CHEMBL1576957 & 688293 & 4.7 & 5.0446 & TST \\
\hline CHEMBL1460443 & 688293 & 4.9 & 5.0198 & TST \\
\hline CHEMBL1459368 & 688293 & 4.8 & 4.7704 & TST \\
\hline CHEMBL1374175 & 688293 & 4.4 & 5.1587 & TST \\
\hline CHEMBL29898 & 688293 & 5.5 & 4.9976 & TST \\
\hline CHEMBL1400016 & 688293 & 5.4 & 5.2129 & TST \\
\hline CHEMBL1612219 & 688293 & 4.6 & 5.0274 & TST \\
\hline CHEMBL1425108 & 688293 & 5.1 & 4.9021 & TST \\
\hline CHEMBL1566137 & 688293 & 4.4 & 5.103 & TST \\
\hline CHEMBL1523978 & 688293 & 6.8 & 5.2059 & TST \\
\hline CHEMBL1437981 & 688293 & 5.0 & 4.982 & TST \\
\hline CHEMBL1399463 & 688293 & 4.5 & 4.9284 & TST \\
\hline CHEMBL592842 & 688293 & 4.6 & 4.7738 & TST \\
\hline CHEMBL77971 & 688293 & 4.9 & 4.8873 & TST \\
\hline CHEMBL1554659 & 688293 & 4.7 & 4.8011 & TST \\
\hline CHEMBL1490452 & 688293 & 4.5 & 5.2963 & TST \\
\hline
\end{tabular}




\begin{tabular}{|c|c|c|c|c|}
\hline \multicolumn{5}{|c|}{ Supplemental Table S2.txt } \\
\hline CHEMBL1401243 & 688293 & 4.7 & 4.8193 & TST \\
\hline CHEMBL1339329 & 688293 & 4.5 & 5.0796 & TST \\
\hline CHEMBL1464027 & 688293 & 4.4 & 5.091 & TST \\
\hline CHEMBL1325740 & 688293 & 4.5 & 5.1236 & TST \\
\hline CHEMBL1380131 & 688293 & 4.9 & 4.9468 & TST \\
\hline CHEMBL1305740 & 688293 & 5.8 & 5.056 & TST \\
\hline CHEMBL1519016 & 688293 & 7.5003 & 5.0141 & TST \\
\hline CHEMBL1529039 & 688293 & 4.7 & 4.9729 & TST \\
\hline CHEMBL1608868 & 688293 & 5.6 & 4.9264 & TST \\
\hline CHEMBL1448568 & 688293 & 4.7 & 4.9846 & TST \\
\hline CHEMBL1256656 & 688293 & 4.9 & 4.9906 & TST \\
\hline CHEMBL1470577 & 688293 & 4.7 & 5.0508 & TST \\
\hline CHEMBL1515706 & 688293 & 8.0 & 5.0959 & TST \\
\hline CHEMBL1309507 & 688293 & 4.5 & 5.058 & TST \\
\hline CHEMBL1389999 & 688293 & 4.9 & 5.1734 & TST \\
\hline CHEMBL1421142 & 688293 & 4.7 & 4.909 & TST \\
\hline CHEMBL1314107 & 688293 & 6.3 & 5.0214 & TST \\
\hline CHEMBL1533245 & 688293 & 8.0 & 4.8625 & TST \\
\hline CHEMBL1549476 & 688293 & 5.7 & 5.0701 & TST \\
\hline CHEMBL1322232 & 688293 & 4.5 & 4.9501 & TST \\
\hline CHEMBL1371555 & 688293 & 5.3 & 4.9991 & TST \\
\hline CHEMBL1426762 & 688293 & 5.0 & 5.0872 & TST \\
\hline CHEMBL1445118 & 688293 & 4.9 & 5.0321 & TST \\
\hline CHEMBL1608078 & 688293 & 4.4 & 5.1579 & TST \\
\hline CHEMBL1600561 & 688293 & 4.8 & 4.976 & TST \\
\hline CHEMBL1483350 & 688293 & 4.9 & 4.9934 & TST \\
\hline CHEMBL1305149 & 688293 & 4.7 & 5.1826 & TST \\
\hline CHEMBL1582970 & 688293 & 4.4 & 5.1899 & TST \\
\hline CHEMBL1380053 & 688293 & 4.6 & 4.9537 & TST \\
\hline CHEMBL1450470 & 688293 & 4.7 & 5.0307 & TST \\
\hline CHEMBL1374131 & 688293 & 4.5 & 4.8587 & TST \\
\hline CHEMBL1501213 & 688293 & 4.7 & 5.0196 & TST \\
\hline CHEMBL1335360 & 688293 & 6.1 & 5.2078 & TST \\
\hline CHEMBL1589095 & 688293 & 5.6 & 4.9989 & TST \\
\hline CHEMBL1353804 & 688293 & 4.5 & 4.7682 & TST \\
\hline CHEMBL1995948 & 688293 & 5.6 & 4.9813 & TST \\
\hline CHEMBL1561930 & 688293 & 4.5 & 5.0521 & TST \\
\hline CHEMBL1302381 & 688293 & 5.1 & 5.0989 & TST \\
\hline CHEMBL1362853 & 688293 & 5.0 & 4.9346 & TST \\
\hline CHEMBL1523375 & 688293 & 4.7 & 4.8339 & TST \\
\hline CHEMBL1500854 & 688293 & 5.1 & 4.9456 & TST \\
\hline CHEMBL1404317 & 688293 & 4.6 & 4.7458 & TST \\
\hline CHEMBL600060 & 688293 & 4.5 & 4.8506 & TST \\
\hline CHEMBL1567402 & 688293 & 4.6 & 4.9649 & TST \\
\hline CHEMBL1399701 & 688293 & 4.4 & 5.1319 & TST \\
\hline CHEMBL258465 & 688293 & 4.5 & 4.9819 & TST \\
\hline CHEMBL 389390 & 688293 & 6.0 & 5.0275 & TST \\
\hline CHEMBL1307824 & 688293 & 4.5 & 5.0856 & TST \\
\hline
\end{tabular}




\begin{tabular}{|c|c|c|c|c|}
\hline & & & pplement & $d+1$ \\
\hline CHEMBL1560952 & 688293 & 4.8 & 5.0779 & TST \\
\hline CHEMBL1534536 & 688293 & 4.8 & 4.9549 & TST \\
\hline CHEMBL1329237 & 688293 & 4.5 & 4.9506 & TST \\
\hline CHEMBL1411401 & 688293 & 4.6 & 4.9255 & TST \\
\hline CHEMBL1303367 & 688293 & 4.6 & 5.1451 & TST \\
\hline CHEMBL1507389 & 688293 & 4.4 & 4.9223 & TST \\
\hline CHEMBL1487527 & 688293 & 8.0 & 4.9354 & TST \\
\hline CHEMBL1256191 & 688293 & 4.4 & 5.0027 & TST \\
\hline CHEMBL1595322 & 688293 & 4.4 & 4.9351 & TST \\
\hline CHEMBL1550444 & 688293 & 4.6 & 5.0556 & TST \\
\hline CHEMBL1596295 & 688293 & 4.5 & 4.9638 & TST \\
\hline CHEMBL1492025 & 688293 & 4.4 & 4.9805 & TST \\
\hline CHEMBL3198180 & 688293 & 5.9 & 5.1385 & TST \\
\hline CHEMBL1612880 & 688293 & 5.7 & 4.9833 & TST \\
\hline CHEMBL18785 & 688293 & 4.8 & 4.8511 & TST \\
\hline CHEMBL1569975 & 688293 & 5.0 & 4.9626 & TST \\
\hline CHEMBL1572857 & 688293 & 4.5 & 5.0956 & TST \\
\hline CHEMBL1605579 & 688293 & 4.8 & 4.7992 & TST \\
\hline CHEMBL66953 & 688293 & 4.4 & 4.9129 & TST \\
\hline CHEMBL1560229 & 688293 & 4.8 & 4.9024 & TST \\
\hline CHEMBL1305473 & 688293 & 4.8 & 5.062 & TST \\
\hline CHEMBL1457348 & 688293 & 6.0 & 4.8918 & TST \\
\hline CHEMBL1600740 & 688293 & 4.5 & 4.9341 & TST \\
\hline CHEMBL1486831 & 688293 & 4.4 & 4.7862 & TST \\
\hline CHEMBL1382110 & 688293 & 4.7 & 4.8821 & TST \\
\hline CHEMBL1395128 & 688293 & 5.4 & 5.0235 & TST \\
\hline CHEMBL1450289 & 688293 & 4.6 & 5.2228 & TST \\
\hline CHEMBL1347376 & 688293 & 4.8 & 5.0703 & TST \\
\hline CHEMBL1531620 & 688293 & 4.5 & 4.9662 & TST \\
\hline CHEMBL1483446 & 688293 & 4.9 & 5.0158 & TST \\
\hline CHEMBL36148 & 688293 & 4.8 & 4.9903 & TST \\
\hline CHEMBL1552100 & 688293 & 4.4 & 4.9076 & TST \\
\hline CHEMBL1588755 & 688293 & 5.3 & 5.06 & TST \\
\hline CHEMBL3193785 & 688293 & 4.8 & 4.9726 & TST \\
\hline CHEMBL1483004 & 688293 & 4.4 & 5.0619 & TST \\
\hline CHEMBL1466451 & 688293 & 4.4 & 4.9557 & TST \\
\hline CHEMBL1485625 & 688293 & 4.7 & 5.0985 & TST \\
\hline CHEMBL1329643 & 688293 & 5.5 & 4.8876 & TST \\
\hline CHEMBL1369723 & 688293 & 6.9 & 5.1349 & TST \\
\hline CHEMBL1456361 & 688293 & 4.4 & 4.9391 & TST \\
\hline CHEMBL1537357 & 688293 & 5.0 & 4.8824 & TST \\
\hline CHEMBL1543339 & 688293 & 4.9 & 5.0619 & TST \\
\hline CHEMBL1433762 & 688293 & 8.699 & 4.9345 & TST \\
\hline CHEMBL153036 & 688293 & 4.6 & 4.9093 & TST \\
\hline CHEMBL1543010 & 688293 & 5.4 & 5.0349 & TST \\
\hline CHEMBL1686 & 688293 & 5.4 & 5.2066 & TST \\
\hline CHEMBL1561532 & 688293 & 4.4 & 4.8593 & TST \\
\hline CHEMBL1492359 & 688293 & 4.6 & 4.984 & TST \\
\hline
\end{tabular}




\begin{tabular}{|c|c|c|c|c|c|}
\hline \multicolumn{6}{|c|}{ ptomer } \\
\hline CHEMBL452409 & 688293 & 4.6 & 4.7643 & TST & \\
\hline CHEMBL1511537 & 688293 & 4.6 & 5.018 & TST & \\
\hline CHEMBL1345386 & 688293 & 4.6 & 5.0296 & TST & \\
\hline CHEMBL1591459 & 688293 & 5.6 & 4.8039 & TST & \\
\hline CHEMBL1550718 & 688293 & 5.0 & 5.09699 & 99999999995 & TST \\
\hline CHEMBL1474125 & 688293 & 6.3 & 5.1195 & TST & \\
\hline CHEMBL1562805 & 688293 & 4.7 & 5.0815 & TST & \\
\hline CHEMBL3194052 & 688293 & 4.9 & 4.9351 & TST & \\
\hline CHEMBL1333951 & 688293 & 7.8013 & 5.2203 & TST & \\
\hline CHEMBL1427065 & 688293 & 4.6 & 4.8628 & TST & \\
\hline CHEMBL1546987 & 688293 & 5.1 & 5.0128 & TST & \\
\hline CHEMBL1421370 & 688293 & 5.0 & 5.0256 & TST & \\
\hline CHEMBL567175 & 688293 & 4.6 & 4.9924 & TST & \\
\hline CHEMBL1427637 & 688293 & 4.8 & 4.859 & TST & \\
\hline CHEMBL1450728 & 688293 & 4.4 & 4.8312 & TST & \\
\hline CHEMBL1489733 & 688293 & 5.3 & 5.0222 & TST & \\
\hline CHEMBL1530449 & 688293 & 4.6 & 5.0402 & TST & \\
\hline CHEMBL348856 & 688293 & 4.4 & 4.9694 & TST & \\
\hline CHEMBL1379147 & 688293 & 4.4 & 5.0968 & TST & \\
\hline CHEMBL1579034 & 688293 & 5.3 & 5.0058 & TST & \\
\hline CHEMBL1555898 & 688293 & 4.7 & 4.8542 & TST & \\
\hline CHEMBL1385345 & 688293 & 5.2 & 5.1292 & TST & \\
\hline CHEMBL1478263 & 688293 & 4.6 & 4.9892 & TST & \\
\hline CHEMBL1518598 & 688293 & 4.4 & 4.9866 & TST & \\
\hline CHEMBL1489926 & 688293 & 4.8 & 4.9621 & TST & \\
\hline CHEMBL1361177 & 688293 & 4.5 & 5.0155 & TST & \\
\hline CHEMBL1430200 & 688293 & 4.6 & 5.1938 & TST & \\
\hline CHEMBL1473133 & 688293 & 4.5 & 4.8065 & TST & \\
\hline CHEMBL1482982 & 688293 & 4.6 & 5.0447 & TST & \\
\hline CHEMBL1554826 & 688293 & 5.5 & 4.7831 & TST & \\
\hline CHEMBL1375563 & 688293 & 5.5 & 5.0449 & TST & \\
\hline CHEMBL1302093 & 688293 & 4.5 & 5.1341 & TST & \\
\hline CHEMBL1256623 & 688293 & 8.3979 & 5.0204 & TST & \\
\hline CHEMBL1587280 & 688293 & 5.5 & 4.9904 & TST & \\
\hline CHEMBL1377491 & 688293 & 6.4 & 4.9934 & TST & \\
\hline CHEMBL1483112 & 688293 & 4.4 & 4.9681 & TST & \\
\hline CHEMBL1340066 & 688293 & 4.4 & 5.0029 & TST & \\
\hline CHEMBL1310396 & 688293 & 5.1 & 5.013 & TST & \\
\hline CHEMBL 260028 & 688293 & 5.2 & 4.6353 & TST & \\
\hline CHEMBL1462957 & 688293 & 4.4 & 5.0395 & TST & \\
\hline CHEMBL1518801 & 688293 & 4.9 & 4.9867 & TST & \\
\hline CHEMBL1542091 & 688293 & 4.5 & 4.9679 & TST & \\
\hline CHEMBL1505668 & 688293 & 6.1 & 4.9607 & TST & \\
\hline CHEMBL1424065 & 688293 & 4.5 & 4.9724 & TST & \\
\hline CHEMBL1497964 & 688293 & 4.9 & 4.9582 & TST & \\
\hline CHEMBL1417140 & 688293 & 4.6 & 4.8154 & TST & \\
\hline CHEMBL1441693 & 688293 & 4.7 & 4.9185 & TST & \\
\hline CHEMBL1328380 & 688293 & 4.9 & 5.1797 & TST & \\
\hline
\end{tabular}




\begin{tabular}{|c|c|c|c|c|}
\hline & & & & \\
\hline CHEMBL1421461 & 688293 & 5.5 & 5.1555 & TST \\
\hline CHEMBL1373682 & 688293 & 4.4 & 5.0103 & TST \\
\hline CHEMBL1535215 & 688293 & 4.4 & 5.0324 & TST \\
\hline CHEMBL1445110 & 688293 & 4.4 & 5.20100 & 00000000005 \\
\hline CHEMBL1332280 & 688293 & 4.8 & 4.9961 & TST \\
\hline CHEMBL1609385 & 688293 & 4.9 & 4.9567 & TST \\
\hline CHEMBL1433333 & 688293 & 5.0 & 5.0254 & TST \\
\hline CHEMBL355014 & 688293 & 4.4 & 4.8432 & TST \\
\hline CHEMBL1611372 & 688293 & 4.8 & 5.04899 & 99999999995 \\
\hline CHEMBL1428915 & 688293 & 5.8 & 5.1876 & TST \\
\hline CHEMBL1522852 & 688293 & 4.4 & 5.0971 & TST \\
\hline CHEMBL1545369 & 688293 & 4.5 & 5.0599 & TST \\
\hline CHEMBL1602694 & 688293 & 4.7 & 5.106 & TST \\
\hline CHEMBL1511184 & 688293 & 4.6 & 4.9936 & TST \\
\hline CHEMBL1602699 & 688293 & 4.8 & 5.1298 & TST \\
\hline CHEMBL1452914 & 688293 & 4.8 & 5.1917 & TST \\
\hline CHEMBL1343539 & 688293 & 5.6 & 5.1746 & TST \\
\hline CHEMBL73933 & 688293 & 5.0 & 5.0524 & TST \\
\hline CHEMBL1475620 & 688293 & 4.4 & 5.0614 & TST \\
\hline CHEMBL1330055 & 688293 & 4.5 & 5.091 & TST \\
\hline CHEMBL1609851 & 688293 & 5.9 & 4.7311 & TST \\
\hline CHEMBL1411001 & 688293 & 4.6 & 5.0395 & TST \\
\hline CHEMBL1525474 & 688293 & 4.9 & 4.9618 & TST \\
\hline CHEMBL1305963 & 688293 & 4.8 & 4.8508 & TST \\
\hline CHEMBL1333874 & 688293 & 4.6 & 4.9384 & TST \\
\hline CHEMBL1372768 & 688293 & 8.1024 & 5.1193 & TST \\
\hline CHEMBL329673 & 688293 & 4.4 & 4.9234 & TST \\
\hline CHEMBL1551200 & 688293 & 4.5 & 4.7977 & TST \\
\hline CHEMBL1418209 & 688293 & 4.6 & 5.0459 & TST \\
\hline CHEMBL1574151 & 688293 & 8.301 & 5.104 & TST \\
\hline CHEMBL1430680 & 688293 & 4.7 & 5.02 & TST \\
\hline CHEMBL1323563 & 688293 & 4.4 & 4.9803 & TST \\
\hline CHEMBL1509253 & 688293 & 4.5 & 4.9516 & TST \\
\hline CHEMBL1503922 & 688293 & 4.8 & 4.9569 & TST \\
\hline CHEMBL1335688 & 688293 & 4.8 & 4.7647 & TST \\
\hline CHEMBL1490664 & 688293 & 4.4 & 5.1418 & TST \\
\hline CHEMBL1366970 & 688293 & 5.0 & 5.1033 & TST \\
\hline CHEMBL1528303 & 688293 & 4.5 & 4.8875 & TST \\
\hline CHEMBL1509003 & 688293 & 7.3002 & 4.9736 & TST \\
\hline CHEMBL1315318 & 688293 & 5.0 & 4.8882 & TST \\
\hline CHEMBL1599179 & 688293 & 4.4 & 5.0198 & TST \\
\hline CHEMBL1535024 & 688293 & 4.8 & 5.0245 & TST \\
\hline CHEMBL1518338 & 688293 & 5.8 & 4.854 & TST \\
\hline CHEMBL1507753 & 688293 & 4.4 & 5.0929 & TST \\
\hline CHEMBL1320489 & 688293 & 4.4 & 5.0576 & TST \\
\hline CHEMBL1423390 & 688293 & 4.6 & 4.9441 & TST \\
\hline CHEMBL1427520 & 688293 & 4.8 & 5.062 & TST \\
\hline CHEMBL1409327 & 688293 & 4.4 & 4.994 & TST \\
\hline
\end{tabular}




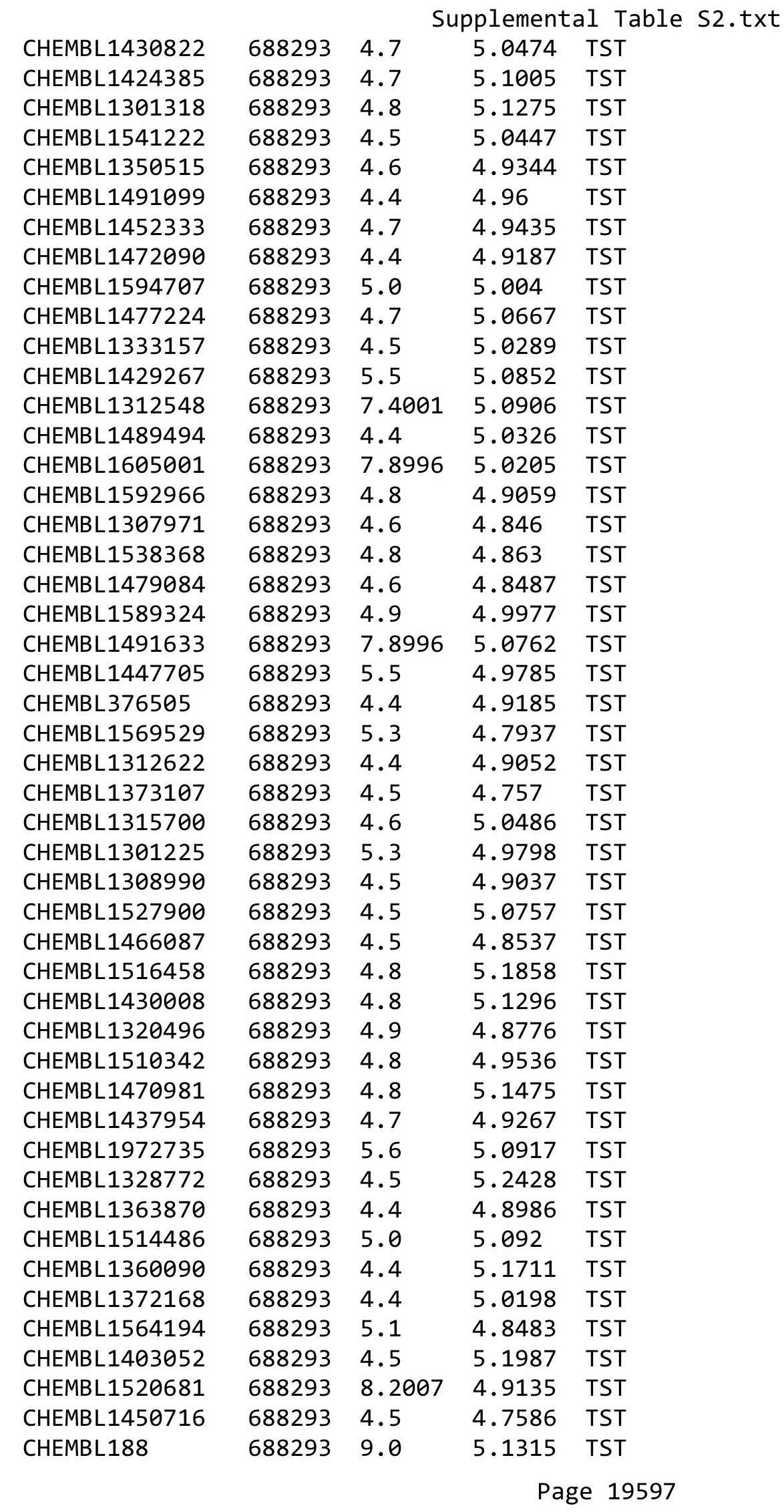




\begin{tabular}{|c|c|c|c|c|c|c|}
\hline \\
\hline CHEMBL1526325 & 688293 & 4.5 & 5.0171 & TST & & \\
\hline CHEMBL1497932 & 688293 & 4.7 & 4.9809 & TST & & \\
\hline CHEMBL1321156 & 688293 & 4.6 & 4.8454 & TST & & \\
\hline CHEMBL1405909 & 688293 & 4.5 & 4.9266 & TST & & \\
\hline CHEMBL1548955 & 688293 & 4.6 & 5.1304 & TST & & \\
\hline CHEMBL1383057 & 688293 & 4.4 & 5.0067 & TST & & \\
\hline CHEMBL1606108 & 688293 & 4.8 & 5.0504 & TST & & \\
\hline CHEMBL1312126 & 688293 & 4.9 & 5.0469 & TST & & \\
\hline CHEMBL1330103 & 688293 & 5.3 & 4.7803 & TST & & \\
\hline CHEMBL1543932 & 688293 & 4.5 & 4.9448 & TST & & \\
\hline CHEMBL1414671 & 688293 & 4.4 & 4.893 & TST & & \\
\hline CHEMBL1585752 & 688293 & 5.1 & 4.7193 & TST & & \\
\hline CHEMBL1577637 & 688293 & 4.8 & 4.8467 & TST & & \\
\hline CHEMBL1526223 & 688293 & 4.4 & 5.0336 & TST & & \\
\hline CHEMBL1584686 & 688293 & 4.8 & 4.9016 & TST & & \\
\hline CHEMBL1573240 & 688293 & 4.4 & 5.1138 & TST & & \\
\hline CHEMBL1553700 & 688293 & 4.5 & 5.0662 & TST & & \\
\hline CHEMBL1257075 & 688293 & 7.3002 & 5.001 & TST & & \\
\hline CHEMBL1502164 & 688293 & 6.4 & 4.8896 & TST & & \\
\hline CHEMBL1535204 & 688293 & 4.5 & 4.9495 & TST & & \\
\hline CHEMBL1391857 & 688293 & 4.6 & 4.9406 & TST & & \\
\hline CHEMBL1370309 & 688293 & 5.0 & 4.9679 & TST & & \\
\hline CHEMBL578112 & 688293 & 4.8 & 5.224 & TST & & \\
\hline CHEMBL1446282 & 688293 & 4.5 & 5.1933 & TST & & \\
\hline CHEMBL1444824 & 688293 & 4.7 & 4.9558 & TST & & \\
\hline CHEMBL3197060 & 688293 & 4.9 & 5.0178 & TST & & \\
\hline CHEMBL362919 & 688293 & 5.9 & 4.8112 & TST & & \\
\hline CHEMBL1547936 & 688293 & 4.4 & 4.8469 & TST & & \\
\hline CHEMBL1608403 & 688293 & 5.7 & 5.0953 & TST & & \\
\hline CHEMBL1541186 & 688293 & 4.6 & 5.0807 & TST & & \\
\hline CHEMBL1499872 & 688293 & 8.0 & 5.1889 & TST & & \\
\hline CHEMBL1455126 & 688293 & 8.2007 & 5.2805 & TST & & \\
\hline CHEMBL1512708 & 688293 & 4.7 & 4.7769 & TST & & \\
\hline CHEMBL1460970 & 688293 & 4.4 & 4.9892 & TST & & \\
\hline CHEMBL1577952 & 688293 & 4.6 & 4.9343 & TST & & \\
\hline CHEMBL385295 & 393314 & 5.8038 & 6.6175 & TRN & & \\
\hline CHEMBL379593 & 393314 & 6.0009 & 5.6791 & TRN & & \\
\hline CHEMBL212950 & 393314 & 4.5229 & 5.1065 & TRN & & \\
\hline CHEMBL379560 & 393314 & 5.9485 & 6.1491 & TRN & & \\
\hline CHEMBL212807 & 393314 & 7.0132 & 7.17 & TRN & & \\
\hline CHEMBL379875 & 393314 & 5.2548 & 5.2628 & TRN & & \\
\hline CHEMBL213668 & 393314 & 6.08200 & 30000000 & & 5.7061 & TRN \\
\hline CHEMBL215997 & 393314 & 4.8959 & 4.4893 & TRN & & \\
\hline CHEMBL213336 & 393314 & 6.5421 & 6.3095 & TRN & & \\
\hline CHEMBL212912 & 393314 & 6.7423 & 6.3408 & TRN & & \\
\hline CHEMBL211910 & 393314 & 6.6946 & 6.129 & TRN & & \\
\hline CHEMBL377877 & 393314 & 6.1013 & 6.3036 & TRN & & \\
\hline CHEMBL384634 & 393314 & 8.0969 & 4.9056 & TST & & \\
\hline
\end{tabular}




\begin{tabular}{|c|c|c|c|c|c|c|}
\hline & & \multicolumn{5}{|c|}{ Supplemental Table s2.txt } \\
\hline CHEMBL211915 & 393314 & 7.0969 & 5.1328 & TST & & \\
\hline CHEMBL215669 & 393314 & 8.4685 & 4.5929 & TST & & \\
\hline CHEMBL212905 & 393314 & 5.4379 & 5.6038 & TRN & & \\
\hline CHEMBL212936 & 393314 & 7.4437 & 7.1761 & TRN & & \\
\hline CHEMBL378543 & 393314 & 5.3074 & 6.0907 & TST & & \\
\hline CHEMBL386336 & 393314 & 4.5229 & 4.8016 & TRN & & \\
\hline CHEMBL377452 & 393314 & 7.2007 & 6.2454 & TST & & \\
\hline CHEMBL213239 & 393314 & 5.8604 & 5.9779 & TRN & & \\
\hline CHEMBL216047 & 393314 & 4.5229 & 4.7078 & TRN & & \\
\hline CHEMBL212402 & 393314 & \multicolumn{3}{|c|}{6.757000000000001} & 6.5904 & TRN \\
\hline CHEMBL380236 & 393314 & 5.8658 & 5.5004 & TRN & & \\
\hline CHEMBL213193 & 393314 & 6.3757 & 6.2426 & TRN & & \\
\hline CHEMBL379862 & 393314 & 4.5229 & 4.5327 & TRN & & \\
\hline CHEMBL384269 & 393314 & 6.2733 & 6.1957 & TRN & & \\
\hline CHEMBL384069 & 393314 & 6.857 & 6.651 & TRN & & \\
\hline CHEMBL437917 & 393314 & 5.7916 & 5.8183 & TRN & & \\
\hline CHEMBL215414 & 393314 & 6.7055 & 6.5686 & TRN & & \\
\hline CHEMBL378301 & 393314 & 7.1871 & 5.1756 & TST & & \\
\hline CHEMBL215641 & 393314 & 4.699 & 4.6723 & TRN & & \\
\hline CHEMBL385590 & 393314 & 4.5229 & 4.9952 & TRN & & \\
\hline CHEMBL213466 & 393314 & 6.5686 & 7.1263 & TRN & & \\
\hline CHEMBL212334 & 393314 & 4.699 & 5.36700 & 0000000001 & & TRN \\
\hline CHEMBL378893 & 393314 & 4.5229 & 4.2883 & TRN & & \\
\hline CHEMBL213472 & 393314 & 5.8993 & 6.0042 & TRN & & \\
\hline CHEMBL213238 & 393314 & 5.9259 & 5.9099 & TRN & & \\
\hline CHEMBL213110 & 393314 & 6.5735 & 6.4152 & TRN & & \\
\hline CHEMBL213200 & 393314 & \multicolumn{3}{|c|}{6.752000000000001} & 4.9059 & TST \\
\hline CHEMBL213577 & 393314 & 7.5376 & 4.9433 & TST & & \\
\hline CHEMBL215842 & 393314 & 6.1494 & 5.4695 & TRN & & \\
\hline CHEMBL378648 & 393314 & 6.7122 & 6.5779 & TRN & & \\
\hline CHEMBL212700 & 393314 & 6.5436 & 6.6565 & TRN & & \\
\hline CHEMBL377420 & 393314 & 5.4908 & 5.5977 & TRN & & \\
\hline CHEMBL213145 & 393314 & 6.1198 & 6.2423 & TRN & & \\
\hline CHEMBL214503 & 393314 & 6.6364 & 6.8491 & TRN & & \\
\hline CHEMBL212608 & 393314 & 5.9393 & 5.59 & TRN & & \\
\hline CHEMBL379942 & 393314 & \multicolumn{3}{|c|}{6.757000000000001} & 7.0401 & TRN \\
\hline CHEMBL384248 & 393314 & 4.5463 & 4.8272 & TRN & & \\
\hline CHEMBL425069 & 393314 & 6.4685 & 6.2788 & TRN & & \\
\hline CHEMBL377564 & 393314 & 4.5229 & 4.5908 & TRN & & \\
\hline CHEMBL212384 & 393314 & 5.4094 & 6.1331 & TST & & \\
\hline CHEMBL378341 & 393314 & 7.1612 & 6.8915 & TRN & & \\
\hline CHEMBL213201 & 393314 & 5.7058 & 5.6829 & TRN & & \\
\hline CHEMBL209805 & 393314 & 6.4711 & 6.3617 & TST & & \\
\hline CHEMBL377043 & 393314 & 4.699 & 4.8194 & TST & & \\
\hline CHEMBL215885 & 393314 & 4.5229 & 5.7249 & TST & & \\
\hline CHEMBL212438 & 393314 & 5.8928 & 5.9896 & TST & & \\
\hline CHEMBL213335 & 393314 & 6.3883 & 5.5668 & TST & & \\
\hline CHEMBL379286 & 393314 & 4.699 & 4.8105 & TST & & \\
\hline
\end{tabular}




\begin{tabular}{|c|c|c|c|c|c|}
\hline & & \multicolumn{4}{|c|}{ Supplemental Table S2.txt } \\
\hline CHEMBL212966 & 393314 & 4.5229 & 5.1275 & TST & \\
\hline CHEMBL1090901 & 623653 & 3.0655 & 3.1371 & TRN & \\
\hline CHEMBL1090902 & 623653 & 3.5686 & 4.0665 & TRN & \\
\hline CHEMBL1092936 & 623653 & 3.0 & 3.0019 & TST & \\
\hline CHEMBL1092095 & 623653 & 3.0 & 3.3689 & TRN & \\
\hline CHEMBL1090678 & 623653 & 3.0 & 2.9098 & TRN & \\
\hline CHEMBL1093263 & 623653 & 3.0 & 3.0322 & TRN & \\
\hline CHEMBL1091037 & 623653 & 3.0 & 3.0727 & TRN & \\
\hline CHEMBL418899 & 623653 & 5.7447 & 4.0542 & TST & \\
\hline CHEMBL1093520 & 623653 & 3.2924 & 3.238 & TRN & \\
\hline CHEMBL1091953 & 623653 & 3.0 & 2.9209 & TRN & \\
\hline CHEMBL1092947 & 623653 & 3.7447 & 3.8107 & TRN & \\
\hline CHEMBL1089234 & 623653 & 3.0706 & 3.135 & TRN & \\
\hline CHEMBL159895 & 623653 & 3.0 & 3.5779 & TST & \\
\hline CHEMBL1095562 & 623653 & 5.1549 & 4.5218 & TRN & \\
\hline CHEMBL1092703 & 623653 & 3.7959 & 3.3253 & TRN & \\
\hline CHEMBL98778 & 623653 & 3.0 & 3.58699 & 99999999997 & TST \\
\hline CHEMBL1092746 & 623653 & 3.5376 & 3.8026 & TRN & \\
\hline CHEMBL1093907 & 623653 & 3.3872 & 3.9056 & TRN & \\
\hline CHEMBL1091258 & 623653 & 3.7447 & 3.7269 & TRN & \\
\hline CHEMBL1093920 & 623653 & 3.0458 & 2.9252 & TRN & \\
\hline CHEMBL1093507 & 623653 & 3.0 & 2.5929 & TRN & \\
\hline CHEMBL1089907 & 623653 & 3.0 & 3.2462 & TRN & \\
\hline CHEMBL1093875 & 623653 & 3.0 & 3.2959 & TRN & \\
\hline CHEMBL1092984 & 623653 & 3.0 & 3.2445 & TST & \\
\hline CHEMBL1088991 & 623653 & 3.0 & 3.5537 & TST & \\
\hline CHEMBL1092966 & 623653 & 3.0 & 3.1411 & TRN & \\
\hline CHEMBL1091653 & 623653 & 3.4948 & 3.2697 & TRN & \\
\hline CHEMBL341112 & 623653 & 3.0 & 2.6838 & TRN & \\
\hline CHEMBL1093511 & 623653 & 3.0 & 2.9614 & TRN & \\
\hline CHEMBL1092674 & 623653 & 3.0969 & 2.9082 & TRN & \\
\hline CHEMBL1092985 & 623653 & 3.0 & 3.17100 & 00000000003 & TST \\
\hline CHEMBL111951 & 623653 & 3.0 & 2.9525 & TST & \\
\hline CHEMBL1092673 & 623653 & 3.7447 & 2.9266 & TRN & \\
\hline CHEMBL1092935 & 623653 & 3.0 & 2.8609 & TRN & \\
\hline CHEMBL1093919 & 623653 & 3.0 & 3.5683 & TRN & \\
\hline CHEMBL1092614 & 623653 & 3.5086 & 3.641 & TRN & \\
\hline CHEMBL1092701 & 623653 & 3.8239 & 3.2007 & TRN & \\
\hline CHEMBL1094255 & 623653 & 3.0 & 3.4037 & TRN & \\
\hline CHEMBL1093826 & 623653 & 3.0 & 3.4865 & TRN & \\
\hline CHEMBL1093873 & 623653 & 4.3372 & 3.9672 & TRN & \\
\hline CHEMBL1093827 & 623653 & 3.6576 & 3.5784 & TRN & \\
\hline CHEMBL1094254 & 623653 & 3.0 & 3.20899 & 99999999996 & TRN \\
\hline CHEMBL1095561 & 623653 & 3.0 & 3.2114 & TRN & \\
\hline CHEMBL1093553 & 623653 & 3.5229 & 2.9795 & TRN & \\
\hline CHEMBL1093492 & 623653 & 5.1549 & 4.4078 & TRN & \\
\hline CHEMBL1091652 & 623653 & 3.0 & 3.1941 & TRN & \\
\hline CHEMBL1093988 & 623653 & 3.0 & 3.5687 & TRN & \\
\hline
\end{tabular}




\begin{tabular}{|c|c|c|c|c|c|}
\hline \multirow{3}{*}{$\begin{array}{l}\text { CHEMBL1092967 } \\
\text { CHEMBL1092979 }\end{array}$} & & \multicolumn{4}{|c|}{ Supplemental Table S2.txt } \\
\hline & 623653 & 3.0 & \multicolumn{2}{|c|}{3.4219999999999997} & \multirow[t]{2}{*}{ TST } \\
\hline & 623653 & 3.6021 & 3.5956 & TRN & \\
\hline CHEMBL1089235 & 623653 & 3.0 & 3.1792 & TRN & \\
\hline CHEMBL1093512 & 623653 & 3.1938 & 3.8755 & TRN & \\
\hline CHEMBL1090903 & 623653 & 3.0 & 3.9694 & TRN & \\
\hline CHEMBL1093233 & 623653 & 5.1549 & 4.8551 & TRN & \\
\hline CHEMBL1090692 & 623653 & 3.7696 & 3.6412 & TRN & \\
\hline CHEMBL1093853 & 623653 & 3.0 & 2.9109 & TRN & \\
\hline CHEMBL1093508 & 623653 & 3.2757 & 3.6499 & TRN & \\
\hline CHEMBL1092937 & 623653 & 3.0 & 2.5777 & TST & \\
\hline CHEMBL1089893 & 623653 & 3.0 & 3.4549 & TRN & \\
\hline CHEMBL1092938 & 623653 & 3.0 & 3.1096 & TRN & \\
\hline CHEMBL1093874 & 623653 & 5.1549 & 4.1778 & TRN & \\
\hline CHEMBL 209918 & 623653 & 3.0 & 2.9321 & TRN & \\
\hline CHEMBL1091736 & 623653 & 4.9208 & 4.3712 & TRN & \\
\hline CHEMBL1091651 & 623653 & 3.0 & 3.2727 & TRN & \\
\hline CHEMBL1093493 & 623653 & 3.9208 & \multicolumn{2}{|c|}{ 4. 388999999999999} & TRN \\
\hline CHEMBL1090567 & 623653 & 3.0 & 3.17 & TRN & \\
\hline CHEMBL1092613 & 623653 & 4.7212 & 3.7076 & TRN & \\
\hline CHEMBL1091257 & 623653 & 4.699 & \multicolumn{2}{|c|}{3.4619999999999997} & TST \\
\hline CHEMBL1090936 & 623653 & 3.5086 & 3.2957 & TST & \\
\hline CHEMBL1093513 & 623653 & 3.4089 & 3.7699 & TST & \\
\hline CHEMBL1093220 & 623653 & 3.0 & 2.9518 & TST & \\
\hline CHEMBL1090566 & 623653 & 3.0 & 4.0187 & TST & \\
\hline CHEMBL1093876 & 623653 & 3.0 & 3.1807 & TST & \\
\hline CHEMBL1092702 & 623653 & 3.8239 & 3.4837 & TST & \\
\hline CHEMBL564201 & 623653 & 4.585 & 3.5166 & TST & \\
\hline CHEMBL1092978 & 623653 & 4.0969 & 3.7759 & TST & \\
\hline CHEMBL2003651 & 688231 & 3.1736 & 4.0978 & TRN & \\
\hline CHEMBL1346300 & 688231 & 5.0147 & 4.6853 & TST & \\
\hline CHEMBL1463829 & 688231 & 4.9872 & 4.5971 & TRN & \\
\hline CHEMBL1456440 & 688231 & 5.0564 & 4.8223 & TRN & \\
\hline CHEMBL1405287 & 688231 & 5.0004 & 4.9117 & TRN & \\
\hline CHEMBL1495013 & 688231 & 4.3519 & 3.6653 & TRN & \\
\hline CHEMBL1362561 & 688231 & 4.7686 & 4.5626 & TST & \\
\hline CHEMBL1563939 & 688231 & 5.0032 & 4.4254 & TST & \\
\hline CHEMBL 2006503 & 688231 & 5.6038 & 5.9958 & TRN & \\
\hline CHEMBL3193011 & 688231 & 5.3963 & 5.3753 & TRN & \\
\hline CHEMBL1361173 & 688231 & 4.6788 & 4.7563 & TRN & \\
\hline CHEMBL1585740 & 688231 & 3.6507 & 4.3312 & TRN & \\
\hline CHEMBL1458321 & 688231 & 4.605 & 4.6942 & TRN & \\
\hline CHEMBL1299200 & 688231 & 4.605 & 4.615 & TST & \\
\hline CHEMBL1392911 & 688231 & 4.605 & 4.8726 & TRN & \\
\hline CHEMBL3189714 & 688231 & 5.7371 & \multicolumn{2}{|c|}{5.792999999999999} & TRN \\
\hline CHEMBL1376540 & 688231 & 5.0821 & 5.1321 & TRN & \\
\hline CHEMBL1379448 & 688231 & 3.1736 & 3.6066 & TRN & \\
\hline CHEMBL175434 & 688231 & 3.1736 & 3.6529 & TRN & \\
\hline CHEMBL1898479 & 688231 & 5.2343 & 5.1689 & TRN & \\
\hline
\end{tabular}


Supplemental Table S2.txt

\begin{tabular}{|c|c|c|c|c|}
\hline CHEMBL1397706 & 688231 & 4.1278 & 4.7363 & TST \\
\hline CHEMBL1410383 & 688231 & 5.0479 & 4.9159 & TST \\
\hline CHEMBL3144999 & 688231 & 5.019 & 4.1858 & TST \\
\hline CHEMBL1446100 & 688231 & 3.1736 & 4.5391 & TST \\
\hline CHEMBL1426692 & 688231 & 4.1278 & 4.0147 & TST \\
\hline CHEMBL578905 & 688231 & 3.1736 & 3.7918 & TRN \\
\hline CHEMBL1536273 & 688231 & 4.8725 & 4.3294 & TRN \\
\hline CHEMBL3187596 & 688231 & 4.5791 & 4.5663 & TRN \\
\hline CHEMBL1562466 & 688231 & 4.605 & 4.537 & TRN \\
\hline CHEMBL1402456 & 688231 & 4.5009 & 3.9661 & TRN \\
\hline CHEMBL1450505 & 688231 & 4.9284 & 4.502 & TST \\
\hline CHEMBL1902079 & 688231 & 5.2428 & 5.2975 & TRN \\
\hline CHEMBL 205040 & 688231 & 4.7078 & 4.8761 & TRN \\
\hline CHEMBL1864348 & 688231 & 4.9637 & 4.9684 & TRN \\
\hline CHEMBL1432553 & 688231 & 4.8187 & 4.6873 & TST \\
\hline CHEMBL1996724 & 688231 & 4.9099 & 5.188 & TRN \\
\hline CHEMBL1577193 & 688231 & 3.1736 & 4.2637 & TRN \\
\hline CHEMBL1541408 & 688231 & 4.7154 & 4.2314 & TRN \\
\hline CHEMBL1381436 & 688231 & 4.605 & 4.6829 & TRN \\
\hline CHEMBL3190880 & 688231 & 5.1645 & 4.5167 & TRN \\
\hline CHEMBL1303854 & 688231 & 4.8873 & 4.3063 & TST \\
\hline CHEMBL1477061 & 688231 & 5.3868 & 4.8992 & TRN \\
\hline CHEMBL567967 & 688231 & 4.9889 & 4.5839 & TRN \\
\hline CHEMBL1387843 & 688231 & 4.605 & 4.4018 & TRN \\
\hline CHEMBL1432243 & 688231 & 4.7466 & 4.4023 & TRN \\
\hline CHEMBL3196591 & 688231 & 5.3711 & 5.029 & TRN \\
\hline CHEMBL1530147 & 688231 & 4.1278 & 4.3723 & TRN \\
\hline CHEMBL1334040 & 688231 & 4.5306 & 4.0268 & TRN \\
\hline CHEMBL1453503 & 688231 & 3.1736 & 3.7989 & TRN \\
\hline CHEMBL1516738 & 688231 & 4.9584 & 4.6079 & TST \\
\hline CHEMBL1378634 & 688231 & 5.0821 & 4.8843 & TRN \\
\hline CHEMBL1501990 & 688231 & 5.0821 & 4.6057 & TRN \\
\hline CHEMBL3194941 & 688231 & 5.1273 & 5.4795 & TRN \\
\hline CHEMBL1598762 & 688231 & 5.2274 & 4.8448 & TRN \\
\hline CHEMBL1412774 & 688231 & 4.426 & 4.8659 & TST \\
\hline CHEMBL2003806 & 688231 & 5.3776 & 5.5926 & TRN \\
\hline CHEMBL1502394 & 688231 & 5.0821 & 4.58 & TRN \\
\hline CHEMBL1516601 & 688231 & 4.3325 & 4.4044 & TRN \\
\hline CHEMBL1969046 & 688231 & 4.9111 & 5.2824 & TRN \\
\hline CHEMBL1888528 & 688231 & 5.215 & 5.066 & TST \\
\hline CHEMBL1536803 & 688738 & 4.6 & 4.9955 & TRN \\
\hline CHEMBL1348607 & 688738 & 4.45 & 4.2437 & TRN \\
\hline CHEMBL1993522 & 688738 & 4.4 & 4.6538 & TRN \\
\hline CHEMBL1449083 & 688738 & 4.4 & 4.5961 & TRN \\
\hline CHEMBL 2004417 & 688738 & 4.65 & 4.9086 & TRN \\
\hline CHEMBL1305276 & 688738 & 6.1 & 4.8675 & TRN \\
\hline CHEMBL1510125 & 688738 & 4.45 & 4.4146 & TRN \\
\hline CHEMBL586031 & 688738 & 4.9 & 4.6821 & TRN \\
\hline
\end{tabular}




\begin{tabular}{|c|c|c|c|c|}
\hline \multicolumn{5}{|c|}{ Supplemental Table s2.txt } \\
\hline CHEMBL1456425 & 688738 & 5.5 & 4.8086 & TRN \\
\hline CHEMBL1502487 & 688738 & 4.5 & 4.5307 & TRN \\
\hline CHEMBL592124 & 688738 & 4.85 & 5.0605 & TRN \\
\hline CHEMBL 3190181 & 688738 & 5.5 & 5.0416 & TRN \\
\hline CHEMBL1503764 & 688738 & 4.4 & 4.7976 & TRN \\
\hline CHEMBL1363984 & 688738 & 7.4498 & 5.21899 & 9999999999 \\
\hline CHEMBL1485721 & 688738 & 4.5 & 4.7503 & TRN \\
\hline CHEMBL1332015 & 688738 & 4.45 & 4.1824 & TRN \\
\hline CHEMBL1304647 & 688738 & 4.4 & 4.5336 & TRN \\
\hline CHEMBL1596871 & 688738 & 4.7 & 4.6927 & TRN \\
\hline CHEMBL1586200 & 688738 & 4.4 & 4.9125 & TRN \\
\hline CHEMBL1556968 & 688738 & 4.4 & 5.2989 & TRN \\
\hline CHEMBL1407693 & 688738 & 4.5 & 4.8617 & TRN \\
\hline CHEMBL1975583 & 688738 & 4.4 & 4.4632 & TRN \\
\hline CHEMBL1383038 & 688738 & 4.4 & 5.0682 & TRN \\
\hline CHEMBL3199467 & 688738 & 5.7 & 4.83 & TST \\
\hline CHEMBL1540232 & 688738 & 4.45 & 4.8771 & TST \\
\hline CHEMBL3189405 & 688738 & 4.4 & 4.7579 & TRN \\
\hline CHEMBL455284 & 688738 & 6.05 & 5.0413 & TRN \\
\hline CHEMBL3198581 & 688738 & 4.95 & 5.6975 & TRN \\
\hline CHEMBL 2095095 & 688738 & 5.55 & 5.1286 & TRN \\
\hline CHEMBL1352747 & 688738 & 4.4 & 4.6261 & TRN \\
\hline CHEMBL1466050 & 688738 & 5.65 & 5.4327 & TST \\
\hline CHEMBL1433302 & 688738 & 4.4 & 4.5781 & TRN \\
\hline CHEMBL1599784 & 688738 & 4.4 & 5.2083 & TRN \\
\hline CHEMBL1486095 & 688738 & 6.25 & 5.0138 & TRN \\
\hline CHEMBL578502 & 688738 & 5.2 & 4.797 & TRN \\
\hline CHEMBL1439171 & 688738 & 6.35 & 5.7097 & TRN \\
\hline CHEMBL1598647 & 688738 & 4.4 & 5.4027 & TRN \\
\hline CHEMBL1363585 & 688738 & 4.45 & 4.8415 & TRN \\
\hline CHEMBL 3195746 & 688738 & 4.4 & 4.7925 & TRN \\
\hline CHEMBL146525 & 688738 & 5.2 & 4.6241 & TRN \\
\hline CHEMBL1353865 & 688738 & 4.45 & 4.6661 & TRN \\
\hline CHEMBL1501444 & 688738 & 4.85 & 4.9821 & TRN \\
\hline CHEMBL1320641 & 688738 & 4.45 & 4.6015 & TRN \\
\hline CHEMBL1330929 & 688738 & 4.55 & 5.1237 & TRN \\
\hline CHEMBL1588066 & 688738 & 4.85 & 4.4656 & TRN \\
\hline CHEMBL1501003 & 688738 & 5.05 & 4.8991 & TRN \\
\hline CHEMBL1386874 & 688738 & 4.45 & 5.1607 & TRN \\
\hline CHEMBL3193835 & 688738 & 5.05 & 4.9746 & TRN \\
\hline CHEMBL1303819 & 688738 & 4.4 & 4.3845 & TRN \\
\hline CHEMBL3198912 & 688738 & 5.4 & 5.1901 & TRN \\
\hline CHEMBL1545760 & 688738 & 4.55 & 4.5304 & TRN \\
\hline CHEMBL1428112 & 688738 & 4.4 & 4.3148 & TRN \\
\hline CHEMBL1347831 & 688738 & 6.0 & 5.3226 & TRN \\
\hline CHEMBL1610733 & 688738 & 4.8 & 4.7528 & TST \\
\hline CHEMBL1319488 & 688738 & 4.5 & 4.9651 & TRN \\
\hline CHEMBL1979455 & 688738 & 4.4 & 4.815 & TRN \\
\hline
\end{tabular}




\begin{tabular}{|c|c|c|c|c|}
\hline \multicolumn{5}{|c|}{ Supplemental Table S2.txt } \\
\hline CHEMBL 2003806 & 688738 & 4.9 & 4.7648 & TRN \\
\hline CHEMBL1520067 & 688738 & 4.45 & 5.1396 & TRN \\
\hline CHEMBL1594943 & 688738 & 6.95 & 5.1401 & TRN \\
\hline CHEMBL1312676 & 688738 & 4.45 & 5.0934 & TRN \\
\hline CHEMBL1453489 & 688738 & 5.6 & 4.7668 & TST \\
\hline CHEMBL1979574 & 688738 & 5.2 & 4.772 & TRN \\
\hline CHEMBL1721986 & 688738 & 5.05 & 4.9048 & TRN \\
\hline CHEMBL1498509 & 688738 & 5.35 & 4.8118 & TRN \\
\hline CHEMBL1524398 & 688738 & 4.65 & 4.5962 & TST \\
\hline CHEMBL1368466 & 688738 & 4.4 & 4.925 & TRN \\
\hline CHEMBL1457791 & 688738 & 4.4 & 4.3576 & TRN \\
\hline CHEMBL1483754 & 688738 & 4.45 & 4.6936 & TRN \\
\hline CHEMBL1570129 & 688738 & 4.95 & 4.9784 & TST \\
\hline CHEMBL1535710 & 688738 & 4.5 & 4.7747 & TRN \\
\hline CHEMBL3195343 & 688738 & 4.4 & 4.8949 & TRN \\
\hline CHEMBL1440794 & 688738 & 4.5 & 4.7709 & TRN \\
\hline CHEMBL1442022 & 688738 & 6.2 & 4.684 & TST \\
\hline CHEMBL3197259 & 688738 & 4.8 & 4.7311 & TRN \\
\hline CHEMBL1562876 & 688738 & 5.75 & 4.7878 & TST \\
\hline CHEMBL1489856 & 688738 & 4.5 & 5.2354 & TRN \\
\hline CHEMBL1506271 & 688738 & 4.4 & 4.6744 & TRN \\
\hline CHEMBL1452461 & 688738 & 6.7501 & 5.6585 & TRN \\
\hline CHEMBL3194487 & 688738 & 4.4 & 4.7485 & TRN \\
\hline CHEMBL1544917 & 688738 & 4.4 & 4.8736 & TRN \\
\hline CHEMBL1426243 & 688738 & 4.4 & 4.5085 & TRN \\
\hline CHEMBL 3194167 & 688738 & 5.5 & 4.5281 & TRN \\
\hline CHEMBL1575897 & 688738 & 4.35 & 4.8667 & TST \\
\hline CHEMBL1412578 & 688738 & 4.7 & 4.5787 & TST \\
\hline CHEMBL1341407 & 688738 & 4.45 & 5.1439 & TST \\
\hline CHEMBL3209157 & 688738 & 4.45 & 4.6921 & TST \\
\hline CHEMBL3196451 & 688738 & 5.45 & 4.9065 & TST \\
\hline CHEMBL1413518 & 688738 & 6.5501 & 5.1158 & TST \\
\hline CHEMBL1521656 & 688738 & 4.4 & 4.7363 & TST \\
\hline CHEMBL1312553 & 688738 & 4.45 & 4.7639 & TST \\
\hline CHEMBL3191023 & 688738 & 4.45 & 4.9534 & TST \\
\hline CHEMBL1494527 & 688738 & 4.55 & 5.3370 & 0000000001 \\
\hline CHEMBL582491 & 688738 & 5.5 & 4.7997 & TST \\
\hline CHEMBL417727 & 688738 & 4.9 & 4.7334 & TST \\
\hline CHEMBL1451774 & 688738 & 4.6 & 4.8506 & TST \\
\hline CHEMBL1988042 & 688738 & 4.6 & 4.788 & TST \\
\hline CHEMBL3391713 & 688738 & 6.5501 & 4.9546 & TST \\
\hline CHEMBL1539905 & 688738 & 4.45 & 4.6872 & TST \\
\hline CHEMBL2206725 & 886791 & 7.3098 & 7.3098 & TRN \\
\hline CHEMBL 2206154 & 886791 & 7.3768 & 7.3751 & TRN \\
\hline CHEMBL 2206722 & 886791 & 7.2596 & 7.2746 & TRN \\
\hline CHEMBL2206716 & 886791 & 6.8356 & 6.8248 & TRN \\
\hline CHEMBL 2206715 & 886791 & 6.6421 & 6.6605 & TRN \\
\hline CHEMBL2206166 & 886791 & 5.0888 & 5.0962 & TRN \\
\hline
\end{tabular}




\begin{tabular}{|c|c|c|c|c|c|}
\hline \multirow[b]{2}{*}{ CHEMBL2206165 } & \multicolumn{5}{|c|}{ Supplemental Table S2.txt } \\
\hline & 886791 & 6.644 & 6.6491 & TRN & \\
\hline CHEMBL2206151 & 886791 & 6.3516 & 6.34399 & 9999999999 & TRN \\
\hline CHEMBL2206142 & 886791 & 6.7747 & 6.7634 & TRN & \\
\hline CHEMBL2206139 & 886791 & 6.8996 & 6.943 & TRN & \\
\hline CHEMBL 2206712 & 886791 & 7.8239 & 7.8181 & TRN & \\
\hline CHEMBL2206159 & 886791 & 7.1024 & 7.1127 & TRN & \\
\hline CHEMBL2206160 & 886791 & 7.2291 & 7.2271 & TRN & \\
\hline CHEMBL 2206702 & 886791 & 7.3098 & 7.3303 & TRN & \\
\hline CHEMBL 2206156 & 886791 & 7.5086 & 7.7857 & TST & \\
\hline CHEMBL2206173 & 886791 & 6.7399 & 6.74100 & 00000000005 & TRN \\
\hline CHEMBL2206709 & 886791 & 7.699 & 7.7123 & TRN & \\
\hline CHEMBL2206157 & 886791 & 7.7447 & 7.7079 & TRN & \\
\hline CHEMBL2206175 & 886791 & 6.6003 & 6.5871 & TRN & \\
\hline CHEMBL 2206724 & 886791 & 7.0706 & 7.0019 & TRN & \\
\hline CHEMBL 2206723 & 886791 & 6.5436 & 7.2906 & TST & \\
\hline CHEMBL 2206161 & 886791 & 7.284 & 7.2819 & TRN & \\
\hline CHEMBL2206701 & 886791 & 6.064 & 6.8351 & TST & \\
\hline CHEMBL2206155 & 886791 & 7.585 & 7.6296 & TRN & \\
\hline CHEMBL 2206713 & 886791 & 6.4191 & 6.4123 & TRN & \\
\hline CHEMBL2206177 & 886791 & 7.1308 & 7.1259 & TRN & \\
\hline CHEMBL 2206720 & 886791 & 7.2147 & 7.1888 & TRN & \\
\hline CHEMBL2206719 & 886791 & 7.7696 & 7.7815 & TRN & \\
\hline CHEMBL2206176 & 886791 & 7.1938 & 7.189 & TRN & \\
\hline CHEMBL2206721 & 886791 & 6.8386 & 7.3049 & TST & \\
\hline CHEMBL 2206174 & 886791 & 7.2007 & 7.21 & TRN & \\
\hline CHEMBL 2206158 & 886791 & 6.9393 & 7.05200 & 00000000005 & TST \\
\hline CHEMBL2206708 & 886791 & 7.6198 & 7.6121 & TRN & \\
\hline CHEMBL 2206171 & 886791 & 6.82100 & 00000000 & 6.8272 & TRN \\
\hline CHEMBL 2206714 & 886791 & 6.7825 & 6.8485 & TST & \\
\hline CHEMBL 2206153 & 886791 & 5.2187 & 5.7212 & TST & \\
\hline CHEMBL2206144 & 886791 & 6.3363 & 6.4488 & TST & \\
\hline CHEMBL 2206726 & 886791 & 7.284 & 7.2656 & TRN & \\
\hline CHEMBL2206164 & 886791 & 7.041 & 7.0479 & TRN & \\
\hline CHEMBL2206143 & 886791 & 5.5105 & 6.318 & TST & \\
\hline CHEMBL2206181 & 886791 & 6.3161 & 6.2347 & TST & \\
\hline CHEMBL 2206140 & 886791 & 6.3458 & 6.5709 & TST & \\
\hline CHEMBL 2206168 & 886791 & 5.8821 & 5.8984 & TRN & \\
\hline CHEMBL 2206706 & 886791 & 6.7496 & 6.7474 & TRN & \\
\hline CHEMBL2206167 & 886791 & 5.0647 & 5.0595 & TRN & \\
\hline CHEMBL2206141 & 886791 & 7.3098 & 7.3098 & TRN & \\
\hline CHEMBL2206183 & 886791 & 6.0752 & 5.9175 & TST & \\
\hline CHEMBL 2206710 & 886791 & 7.6198 & 7.6234 & TRN & \\
\hline CHEMBL2206705 & 886791 & 6.6696 & 6.6676 & TRN & \\
\hline CHEMBL 2206703 & 886791 & 7.3665 & 7.3672 & TRN & \\
\hline CHEMBL 2206718 & 886791 & 6.1002 & 6.32 & TST & \\
\hline CHEMBL2206162 & 886791 & 6.6498 & 6.7592 & TST & \\
\hline CHEMBL 2206180 & 886791 & 6.4895 & 6.49299 & 9999999999 & TRN \\
\hline CHEMBL597593 & 612849 & 5.7077 & 4.7814 & TST & \\
\hline
\end{tabular}




\begin{tabular}{|c|c|c|c|c|c|}
\hline \multicolumn{6}{|c|}{ pıemental } \\
\hline CHEMBL603674 & 612849 & 3.0 & 3.4792 & TRN & \\
\hline CHEMBL598019 & 612849 & 3.0 & 3.0986 & TST & \\
\hline CHEMBL599041 & 612849 & 3.0 & 3.7134 & TRN & \\
\hline CHEMBL598626 & 612849 & 5.9626 & 4.0932 & TST & \\
\hline CHEMBL603161 & 612849 & 4.5287 & 3.56100 & 00000000004 & TRN \\
\hline CHEMBL589802 & 612849 & 3.0 & 4.2737 & TRN & \\
\hline CHEMBL598624 & 612849 & 4.2441 & 4.1764 & TRN & \\
\hline CHEMBL603252 & 612849 & 4.0269 & 3.9877 & TRN & \\
\hline CHEMBL591264 & 612849 & 4.2993 & 4.181 & TRN & \\
\hline CHEMBL591265 & 612849 & 4.4089 & 4.2187 & TRN & \\
\hline CHEMBL596998 & 612849 & 5.2441 & 5.0446 & TRN & \\
\hline CHEMBL599437 & 612849 & 5.0969 & 5.0446 & TRN & \\
\hline CHEMBL604919 & 612849 & 3.0 & 3.3482 & TRN & \\
\hline CHEMBL596788 & 612849 & 3.0 & 3.8656 & TRN & \\
\hline CHEMBL599438 & 612849 & 4.8861 & 4.9529 & TRN & \\
\hline CHEMBL603328 & 612849 & 4.8356 & 5.1166 & TRN & \\
\hline CHEMBL598008 & 612849 & 5.1215 & 5.1166 & TRN & \\
\hline CHEMBL596778 & 612849 & 4.9706 & 4.8979 & TRN & \\
\hline CHEMBL599672 & 612849 & 4.9872 & 4.6317 & TRN & \\
\hline CHEMBL597605 & 612849 & 5.1739 & 4.5825 & TRN & \\
\hline CHEMBL603185 & 612849 & 4.0 & 4.2084 & TRN & \\
\hline CHEMBL599851 & 612849 & 5.3188 & 4.6528 & TST & \\
\hline CHEMBL598429 & 612849 & 4.5575 & 4.8297 & TRN & \\
\hline CHEMBL599048 & 612849 & 3.0 & 4.3798 & TRN & \\
\hline CHEMBL596793 & 612849 & 4.8239 & 4.8222 & TRN & \\
\hline CHEMBL596984 & 612849 & 3.0 & 4.3724 & TRN & \\
\hline CHEMBL598651 & 612849 & 4.4112 & 3.6616 & TST & \\
\hline CHEMBL606404 & 612849 & 4.5376 & 4.0593 & TRN & \\
\hline CHEMBL591257 & 612849 & 3.0 & 3.7748 & TRN & \\
\hline CHEMBL599049 & 612849 & 4.8125 & 4.381 & TRN & \\
\hline CHEMBL603265 & 612849 & 4.6904 & 4.3112 & TRN & \\
\hline CHEMBL592685 & 612849 & 4.6757 & 4.4168 & TST & \\
\hline CHEMBL599441 & 612849 & 4.1871 & 4.4089 & TRN & \\
\hline CHEMBL602123 & 612849 & 5.3925 & 4.621 & TRN & \\
\hline CHEMBL603693 & 612849 & 4.9136 & 5.082 & TRN & \\
\hline CHEMBL591492 & 612849 & 3.0 & 4.0555 & TRN & \\
\hline CHEMBL599236 & 612849 & 4.4559 & 4.359 & TRN & \\
\hline CHEMBL597389 & 612849 & 4.8633 & 4.4487 & TST & \\
\hline CHEMBL606192 & 612849 & 6.0809 & 4.541 & TST & \\
\hline CHEMBL599661 & 612849 & 3.0 & 3.2958 & TRN & \\
\hline CHEMBL599235 & 612849 & 5.0862 & 4.6909 & TRN & \\
\hline CHEMBL589803 & 612849 & 4.7799 & 4.4845 & TRN & \\
\hline CHEMBL601728 & 612849 & 4.7959 & 4.8599 & TRN & \\
\hline CHEMBL596981 & 612849 & 4.1805 & 3.5842 & TRN & \\
\hline CHEMBL604705 & 612849 & 4.7496 & 4.0071 & TRN & \\
\hline CHEMBL596997 & 612849 & 4.8356 & 4.7235 & TRN & \\
\hline CHEMBL597618 & 612849 & 4.1805 & 3.9913 & TST & \\
\hline CHEMBL597617 & 612849 & 3.0 & 3.1566 & TST & \\
\hline
\end{tabular}




\begin{tabular}{|c|c|c|c|c|}
\hline \multicolumn{5}{|c|}{ Supplemental Table S2.txt } \\
\hline CHEMBL599861 & 612849 & 3.0 & 3.5736 & TRN \\
\hline CHEMBL598834 & 612849 & 3.0 & 3.2858 & TRN \\
\hline CHEMBL598835 & 612849 & 3.0 & 3.3517 & TRN \\
\hline CHEMBL599852 & 612849 & 4.6716 & 3.5285 & TRN \\
\hline CHEMBL597592 & 612849 & 5.8761 & 4.5519 & TST \\
\hline CHEMBL598836 & 612849 & 4.3768 & 3.0635 & TRN \\
\hline CHEMBL592616 & 612849 & 3.0 & 3.0974 & TRN \\
\hline CHEMBL598428 & 612849 & 4.4461 & 4.3302 & TRN \\
\hline CHEMBL603679 & 612849 & 4.8928 & 3.5188 & TRN \\
\hline CHEMBL603696 & 612849 & 4.3768 & 4.8902 & TRN \\
\hline CHEMBL590543 & 612849 & 5.1612 & 4.6524 & TRN \\
\hline CHEMBL603253 & 612849 & 3.0 & 3.6138 & TST \\
\hline CHEMBL597589 & 612849 & 4.8633 & 3.8834 & TST \\
\hline CHEMBL605328 & 612849 & 5.1884 & 5.1166 & TRN \\
\hline CHEMBL599660 & 612849 & 5.5086 & 4.8828 & TRN \\
\hline CHEMBL599440 & 612849 & 4.6216 & 4.3126 & TST \\
\hline CHEMBL598652 & 612849 & 4.1024 & 3.2579 & TST \\
\hline CHEMBL598856 & 612849 & 4.0362 & 3.2401 & TST \\
\hline CHEMBL598004 & 612849 & 5.6882 & 4.0447 & TST \\
\hline CHEMBL606415 & 612849 & 4.5528 & 4.6484 & TRN \\
\hline CHEMBL597619 & 612849 & 3.0 & 3.1752 & TRN \\
\hline CHEMBL597388 & 612849 & 4.4202 & 3.8294 & TST \\
\hline CHEMBL599659 & 612849 & 5.4559 & 4.8908 & TRN \\
\hline CHEMBL591493 & 612849 & 4.9469 & 4.6333 & TRN \\
\hline CHEMBL606189 & 612849 & 3.0 & 4.058 & TRN \\
\hline CHEMBL598005 & 612849 & 4.8297 & 4.2235 & TST \\
\hline CHEMBL 3696290 & 1528662 & 6.1561 & 6.933 & TST \\
\hline CHEMBL3696239 & 1528662 & 7.1487 & 7.0407 & TRN \\
\hline CHEMBL3696273 & 1528662 & 7.1487 & 6.9971 & TRN \\
\hline CHEMBL3696310 & 1528662 & 7.2518 & 6.7419 & TRN \\
\hline CHEMBL3696293 & 1528662 & 7.7696 & 7.0691 & TRN \\
\hline CHEMBL 2151930 & 1528662 & 6.4685 & 6.7712 & TST \\
\hline CHEMBL3699779 & 1528662 & 7.585 & 7.0856 & TRN \\
\hline CHEMBL3699792 & 1528662 & 7.1549 & 7.0216 & TRN \\
\hline CHEMBL3696275 & 1528662 & 6.5376 & 6.9403 & TRN \\
\hline CHEMBL3696309 & 1528662 & 7.6198 & 7.1724 & TRN \\
\hline CHEMBL3699801 & 1528662 & 6.3251 & 7.0709 & TST \\
\hline CHEMBL3696284 & 1528662 & 6.9208 & 6.994 & TRN \\
\hline CHEMBL3696280 & 1528662 & 6.8827 & 7.3939 & TRN \\
\hline CHEMBL3696269 & 1528662 & 7.1805 & 6.9729 & TRN \\
\hline CHEMBL3699794 & 1528662 & 6.2733 & 7.6714 & TRN \\
\hline CHEMBL 3699784 & 1528662 & 7.3565 & 7.4847 & TRN \\
\hline CHEMBL3696298 & 1528662 & 7.2441 & 7.7622 & TRN \\
\hline CHEMBL3699782 & 1528662 & 6.7122 & 7.1768 & TRN \\
\hline CHEMBL3696258 & 1528662 & 7.2218 & 6.9223 & TRN \\
\hline CHEMBL 2151935 & 1528662 & 7.1024 & 7.1365 & TST \\
\hline CHEMBL3696296 & 1528662 & 7.8539 & 7.1817 & TRN \\
\hline CHEMBL 3112862 & 1528662 & 6.0 & 7.4007 & TST \\
\hline
\end{tabular}


Supplemental Table S2.txt

\begin{tabular}{|c|c|c|c|c|}
\hline CHEMBL 3696237 & 1528662 & 7.6383 & 6.968 & TRN \\
\hline CHEMBL 3699807 & 1528662 & 6.7235 & 6.818 & TRN \\
\hline CHEMBL3699799 & 1528662 & 6.52 & 6.8724 & TRN \\
\hline CHEMBL 3696303 & 1528662 & 6.6596 & 7.0841 & TST \\
\hline CHEMBL 3112861 & 1528662 & 7.699 & 7.1385 & TRN \\
\hline CHEMBL 3699806 & 1528662 & 7.3665 & 7.8149 & TRN \\
\hline CHEMBL 3696248 & 1528662 & 5.9872 & 6.7674 & TRN \\
\hline CHEMBL 3696270 & 1528662 & 7.1739 & 6.8296 & TRN \\
\hline CHEMBL3699802 & 1528662 & 6.3645 & \multicolumn{2}{|c|}{6.9079999999999995} \\
\hline CHEMBL3699791 & 1528662 & 6.0 & 7.317 & TST \\
\hline CHEMBL 3112592 & 1528662 & 6.9066 & 7.6465 & TRN \\
\hline CHEMBL 3696308 & 1528662 & 7.5686 & 7.4515 & TST \\
\hline CHEMBL3699795 & 1528662 & 6.7595 & 7.058 & TRN \\
\hline CHEMBL3696313 & 1528662 & 6.5214 & 7.3836 & TST \\
\hline CHEMBL3696285 & 1528662 & 7.0506 & 7.1214 & TST \\
\hline CHEMBL 3696295 & 1528662 & 7.1249 & 7.1988 & TRN \\
\hline CHEMBL3696235 & 1528662 & 6.8386 & 6.8069 & TRN \\
\hline CHEMBL 3696305 & 1528662 & 7.3665 & 7.3756 & TRN \\
\hline CHEMBL 3696245 & 1528662 & 6.6073 & \multicolumn{2}{|c|}{6.827000000000001} \\
\hline CHEMBL3699781 & 1528662 & 7.2924 & 7.6638 & TRN \\
\hline CHEMBL 3696278 & 1528662 & 5.0 & 6.7929 & TRN \\
\hline CHEMBL3699785 & 1528662 & 6.2984 & \multicolumn{2}{|c|}{7.412999999999999} \\
\hline CHEMBL 3696304 & 1528662 & 6.1765 & 6.9207 & TRN \\
\hline CHEMBL 3696287 & 1528662 & 8.0 & 6.8071 & TRN \\
\hline CHEMBL3696299 & 1528662 & 7.2007 & 6.8861 & TST \\
\hline CHEMBL3112849 & 1528662 & 8.5229 & 7.8392 & TRN \\
\hline CHEMBL 3696314 & 1528662 & 7.6383 & 7.1767 & TRN \\
\hline CHEMBL 3112852 & 1528662 & 7.2218 & 7.4603 & TRN \\
\hline CHEMBL3699789 & 1528662 & 7.2147 & 7.5661 & TRN \\
\hline CHEMBL 3696276 & 1528662 & 7.1135 & 7.2067 & TRN \\
\hline CHEMBL2151934 & 1528662 & 6.9393 & 7.0083 & TST \\
\hline CHEMBL 3699783 & 1528662 & 7.9586 & 7.3265 & TST \\
\hline CHEMBL 3699787 & 1528662 & 6.9066 & 7.4225 & TRN \\
\hline CHEMBL3699786 & 1528662 & 7.1135 & 7.1217 & TST \\
\hline CHEMBL3696266 & 1528662 & 6.8356 & 6.9324 & TRN \\
\hline CHEMBL3112848 & 1528662 & 8.301 & 7.7504 & TRN \\
\hline CHEMBL3696236 & 1528662 & 7.2924 & 7.0523 & TRN \\
\hline CHEMBL3699797 & 1528662 & 7.4559 & 6.8635 & TRN \\
\hline CHEMBL3696306 & 1528662 & 7.3768 & 7.5279 & TRN \\
\hline CHEMBL 3699804 & 1528662 & 8.3979 & 7.8429 & TRN \\
\hline CHEMBL2151933 & 1528662 & 7.0269 & 7.0907 & TST \\
\hline CHEMBL3696294 & 1528662 & 7.585 & \multicolumn{2}{|c|}{6.962999999999999} \\
\hline CHEMBL 2151932 & 1528662 & 6.8894 & 6.9096 & TST \\
\hline CHEMBL3112851 & 1528662 & 8.5229 & 7.4955 & TRN \\
\hline CHEMBL2151820 & 1528662 & 7.1308 & 6.9089 & TRN \\
\hline CHEMBL3696315 & 1528662 & 6.1778 & 6.7069 & TRN \\
\hline CHEMBL3696241 & 1528662 & 7.3768 & 6.7649 & TRN \\
\hline CHEMBL3696311 & 1528662 & 7.3665 & 7.1594 & TRN \\
\hline
\end{tabular}


Supplemental Table S2.txt

\begin{tabular}{|c|c|c|c|c|}
\hline HEN & 528662 & 6.8761 & & \\
\hline UГMDI & 528662 & 7.2366 & 6.9802 & \\
\hline & 662 & & & \\
\hline IEMBL & 8662 & & & \\
\hline AEMBL3699809 & 528662 & 278 & & \\
\hline HEMBL3696302 & 528662 & 6.585 & 896 & \\
\hline 599805 & 28662 & & $\partial 082$ & \\
\hline IEMBL 3696288 & 662 & & & \\
\hline AEMBL3696300 & 528662 & 9586 & 5919 & \\
\hline HEMBL3696301 & 528662 & & 7.721 & \\
\hline HEMBL3699790 & 528662 & 7.1 & 7.2506 & \\
\hline IEMBL 3699793 & 62 & & 592 & \\
\hline AEMBL3699803 & & & & \\
\hline HEMBL3639986 & 528662 & 02 & 649 & \\
\hline AEMBL3696291 & 62 & 22 & 7995 & \\
\hline AEMBL3112850 & 528662 & 9. & 0944 & \\
\hline AEMBL36 & $0<$ & & 168 & \\
\hline HEMBL36 & & & & \\
\hline HEMBL3699800 & 62 & & 7.2556 & \\
\hline AEMBL3696274 & 62 & & & \\
\hline HEMBLS & 528662 & & 41 & \\
\hline AEMBL & 52 & & & +2 \\
\hline HEMBL3. & 62 & & 86 & \\
\hline HEMBL3699808 & & & & \\
\hline AEMBL3696307 & & & & \\
\hline HEMBL3696283 & 62 & & 51 & $\cdot$ \\
\hline HEMBL; & & & & $2 \mathrm{~N}$ \\
\hline$H F M B I=$ & 62 & & 75 & \\
\hline AEMBL3260085 & & & 268 & N \\
\hline AEMBL3260075 & & & & 151 \\
\hline HEMBL596282 & & & 224 & RN \\
\hline HEMBL & & & 78 & RN \\
\hline AEMBL3 & & & 363 & RN \\
\hline HEMBL3260087 & & & 846 & IRN \\
\hline HEMBL3260096 & 42 & & 5028 & TRN \\
\hline HEMBL3260092 & 42 & & & RN \\
\hline HFMRI 3 & & 1 & 69 & RN \\
\hline HEMBL326e & & & 128 & RN \\
\hline HEMBL3260093 & $349 / 42$ & & 5627 & $\Gamma \mathrm{RN}$ \\
\hline AEMBL 32601 & 3497 & & 561 & RN \\
\hline HEMBL3260e & 31 & 1 & 778 & \\
\hline HEMBL3260083 & & & 3.8466 & RN \\
\hline HEMBL3260111 & 42 & 5 . & & RN \\
\hline AEMBL32601 & 349742 & 5 . & 0954 & TRN \\
\hline$M B L 3$ & & & 4.7958 & $\mathrm{~N}$ \\
\hline HEMBL3260051 & & & & \\
\hline CHEMBL 32600 & & 3.6021 & 3.6696 & \\
\hline THEMBL3260069 & 1349742 & 3.6021 & 4.1327 & RN \\
\hline
\end{tabular}

Page 19609 
Supplemental Table S2.txt

\begin{tabular}{|c|c|c|c|c|c|}
\hline CHEMBL3260059 & 1349742 & 3.6021 & 4.198 & TRN & \\
\hline CHEMBL3260103 & 1349742 & 4.8356 & 4.4965 & TRN & \\
\hline CHEMBL3260071 & 1349742 & 3.6021 & 4.13 & TRN & \\
\hline CHEMBL3260049 & 1349742 & 3.6021 & 3.3526 & TRN & \\
\hline CHEMBL3260079 & 1349742 & 4.9208 & 4.9093 & TST & \\
\hline CHEMBL3260086 & 1349742 & 4.9586 & 4.9685 & TRN & \\
\hline CHEMBL3260044 & 1349742 & 6.2218 & 6.092006 & 00000000005 & TRN \\
\hline CHEMBL3260080 & 1349742 & 3.6021 & 3.4537 & TRN & \\
\hline CHEMBL1632300 & 1349742 & 5.3979 & 5.53299 & & TRN \\
\hline CHEMBL3260061 & 1349742 & 3.6021 & 3.7897 & TRN & \\
\hline CHEMBL3260045 & 1349742 & 5.7696 & 6.1393 & TST & \\
\hline CHEMBL3260082 & 1349742 & 3.6021 & 3.8045 & TRN & \\
\hline CHEMBL3260060 & 1349742 & 3.6021 & 3.3836 & TRN & \\
\hline CHEMBL3260109 & 1349742 & 4.8239 & 4.9276 & TRN & \\
\hline CHEMBL 3260055 & 1349742 & 3.6021 & 3.1974 & TRN & \\
\hline CHEMBL3260076 & 1349742 & 5.5376 & 5.01399 & э999999999 & TST \\
\hline CHEMBL3260078 & 1349742 & 3.6021 & 4.5891 & TST & \\
\hline CHEMBL3260089 & 1349742 & 3.6021 & 5.1068 & TST & \\
\hline CHEMBL3260095 & 1349742 & 3.6021 & 3.5914 & TRN & \\
\hline CHEMBL 3260077 & 1349742 & 3.6021 & 4.324 & TST & \\
\hline CHEMBL3260100 & 1349742 & 4.6021 & 4.7212 & TRN & \\
\hline CHEMBL3260104 & 1349742 & 3.6021 & 5.0805 & TST & \\
\hline CHEMBL3260102 & 1349742 & 3.6021 & 5.3503 & TST & \\
\hline CHEMBL3260091 & 1349742 & 3.6021 & 3.6599 & TRN & \\
\hline CHEMBL3260068 & 1349742 & 3.6021 & 3.9523 & TRN & \\
\hline CHEMBL3260112 & 1349742 & 5.8861 & 5.3502 & TRN & \\
\hline CHEMBL3260056 & 1349742 & 3.6021 & 3.5712 & TRN & \\
\hline CHEMBL3260074 & 1349742 & 3.6021 & 4.1234 & TRN & \\
\hline CHEMBL3260105 & 1349742 & 5.2676 & 4.8443 & TST & \\
\hline CHEMBL3260081 & 1349742 & 5.1805 & 5.2593 & TST & \\
\hline CHEMBL3260116 & 1349742 & 3.6021 & 5.2854 & TST & \\
\hline CHEMBL3260098 & 1349742 & 4.9586 & 6.1286 & TST & \\
\hline CHEMBL3260073 & 1349742 & 4.9586 & 4.6986 & TRN & \\
\hline CHEMBL3260094 & 1349742 & 3.6021 & 3.6568 & TRN & \\
\hline CHEMBL140193 & 1349742 & 4.6021 & 4.3225 & TST & \\
\hline CHEMBL3260107 & 1349742 & 4.7696 & 5.0601 & TST & \\
\hline CHEMBL 3260043 & 1349742 & 5.3279 & 5.2502 & TST & \\
\hline CHEMBL3260113 & 1349742 & 5.5376 & 5.1175 & TRN & \\
\hline CHEMBL3260067 & 1349742 & 5.4815 & 4.5505 & TRN & \\
\hline CHEMBL596283 & 1349742 & 3.6021 & 5.7105 & TST & \\
\hline CHEMBL3260106 & 1349742 & 3.6021 & 4.9378 & TST & \\
\hline CHEMBL 3260048 & 1349742 & 5.8861 & 4.9256 & TRN & \\
\hline CHEMBL3260063 & 1349742 & 4.8539 & 4.8922 & TRN & \\
\hline CHEMBL3260047 & 1349742 & 3.6021 & 3.5826 & TRN & \\
\hline CHEMBL3260066 & 1349742 & 5.0 & 5.5338 & TRN & \\
\hline CHEMBL3260064 & 1349742 & 5.3098 & 5.3115 & TRN & \\
\hline CHEMBL3260108 & 1349742 & 3.6021 & 3.6689 & TRN & \\
\hline CHEMBL3260099 & 1349742 & 3.6021 & 3.7442 & TRN & \\
\hline
\end{tabular}


Supplemental Table S2.txt

\begin{tabular}{|c|c|c|c|c|}
\hline CHEMBL 3260090 & 1349742 & 3.6021 & 4.9394 & TST \\
\hline CHEMBL3260046 & 1349742 & 3.6021 & 4.1429 & TRN \\
\hline CHEMBL3260053 & 1349742 & 3.6021 & 3.4557 & TRN \\
\hline HEMBL3260072 & 349742 & 3.6021 & .0075 & $I^{2}$ \\
\hline HEMBL3260052 & 1349742 & 3.6021 & 4.1591 & TRN \\
\hline CHEMBL3260065 & 1349742 & 5.0 & 4.8056 & RN \\
\hline HEMBL3260097 & 1349742 & 5.4949 & 4.8296 & IRN \\
\hline CHEMBL3260101 & 1349742 & 5.301 & 5.0113 & RN \\
\hline HEMBL199265 & 326472 & 3.0 & 2.0624 & 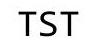 \\
\hline CHEMBL197374 & 26472 & 5.301 & 4.7753 & TRN \\
\hline CHEMBL424841 & 326472 & 3.0 & 3.0081 & ГRN \\
\hline HEMBL200929 & 326472 & 3.0 & 2.7867 & RN \\
\hline LHEMBL198683 & 326472 & 3.0 & 2.8809 & RN \\
\hline HEMBL198885 & 326472 & 3.0 & 2.8352 & TRN \\
\hline LHEMBL197486 & 26472 & 3.0 & 3.1773 & TRN \\
\hline CHEMBL425390 & 326472 & 3.0 & 3.0008 & RN \\
\hline HEMBL197057 & 326 & 3.0 & 4.4408 & RN \\
\hline HEMBL 200345 & 326 & 3.0 & 2.9757 & TRN \\
\hline HEMBL425212 & 326472 & 3.0 & 2.9633 & TRN \\
\hline CHEMBL197534 & 26 & 3.0 & 2.9358 & TRN \\
\hline CHEMBL427373 & 326 & 3. & 2.9736 & TRN \\
\hline HEMBL370812 & 72 & 3.0 & 2.9618 & TRN \\
\hline CHEMBL198793 & 326 & 3.0 & 3.1754 & TRN \\
\hline CHEMBL198466 & 326 & 5.7696 & 5.5794 & TRN \\
\hline CHEMBL198484 & 326472 & 3.0 & 2.5191 & TST \\
\hline CHEMBL197009 & 326472 & 3. & 3.661 & TST \\
\hline CHEMBL381671 & 326 & 3.0 & 3.5193 & TST \\
\hline CHEMBL144589 & 326 & 5.4949 & 5.2676 & TRN \\
\hline CHEMBL197490 & 326472 & 3.0 & 2.7821 & TRN \\
\hline CHEMBL380566 & 326472 & 3.0 & 3.1571 & TRN \\
\hline HEMBL371768 & 326472 & 3 . & 3.0939 & TRN \\
\hline CHEMBL 371714 & 326 & 3.0 & 2.8506 & TRN \\
\hline CHEMBL197387 & 72 & 3.0 & 3.2294 & TRN \\
\hline CHEMBL197238 & 326472 & 3.0 & 2.9394 & TRN \\
\hline CHEMBL196904 & 326472 & 3. & 4.0716 & TRN \\
\hline CHEMBL372628 & 326 & 3 . & 2.6928 & TRN \\
\hline CHEMBL199213 & $32 \epsilon$ & 3.0 & 2.8662 & TRN \\
\hline CHEMBL371657 & 326472 & 3.0 & 2.8662 & TRN \\
\hline CHEMBL199185 & 326472 & 3.0 & 2.2291 & TST \\
\hline CHEMBL372539 & 326 & 3. & 3.3741 & TST \\
\hline CHEMBL144842 & 326472 & 5.301 & 4.4408 & TRN \\
\hline CHEMBL198626 & 326472 & 3.0 & 3.0637 & TRN \\
\hline CHEMBL197008 & 326472 & 3.0 & 3.114 & TRN \\
\hline CHEMBL196922 & 326472 & 3.0 & 3.5578 & TST \\
\hline CHEMBL373193 & 326472 & 3.0 & 4.5546 & TRN \\
\hline CHEMBL196865 & 326472 & 3.0 & 3.0193 & IRIV \\
\hline CHEMBL197531 & 326472 & 3.0 & 2.9381 & TRN \\
\hline CHEMBL383809 & 326472 & 3.0 & 2.9627 & TRN \\
\hline
\end{tabular}

Page 19611 


\begin{tabular}{|c|c|c|c|c|c|}
\hline \multicolumn{6}{|c|}{ Supplemental Table S2.txt } \\
\hline CHEMBL198911 & 326472 & 3.0 & 2.748 & TRN & \\
\hline CHEMBL197530 & 326472 & 3.0 & 2.9822 & TRN & \\
\hline CHEMBL381414 & 326472 & 3.0 & 2.9771 & TRN & \\
\hline CHEMBL197425 & 326472 & 3.0 & 3.1747 & TST & \\
\hline CHEMBL371943 & 326472 & 3.0 & 2.779 & TRN & \\
\hline CHEMBL371250 & 326472 & 3.0 & 3.1295 & TRN & \\
\hline CHEMBL198512 & 326472 & 3.0 & 3.1824 & TRN & \\
\hline CHEMBL196859 & 326472 & 3.0 & 3.1433 & TRN & \\
\hline CHEMBL198901 & 326472 & 3.0 & 3.0591 & TRN & \\
\hline CHEMBL198593 & 326472 & 3.0 & 3.2118 & TRN & \\
\hline CHEMBL197068 & 326472 & 5.2218 & 4.5546 & TRN & \\
\hline CHEMBL144908 & 326472 & 5.2924 & 5.2313 & TRN & \\
\hline CHEMBL370851 & 326472 & 3.0 & 2.8149 & TRN & \\
\hline CHEMBL67535 & 326472 & 5.7696 & 5.794 & TRN & \\
\hline CHEMBL427553 & 326472 & 3.0 & 3.0889 & TRN & \\
\hline CHEMBL197180 & 326472 & 3.0 & 2.2315 & TST & \\
\hline CHEMBL381439 & 326472 & 3.0 & 2.8556 & TRN & \\
\hline CHEMBL198649 & 326472 & 3.0 & 3.2323 & TST & \\
\hline CHEMBL77030 & 326472 & 4.1549 & 4.0677 & TST & \\
\hline CHEMBL197383 & 326472 & 3.0 & 2.7677 & TRN & \\
\hline CHEMBL198783 & 326472 & 3.0 & 2.9771 & TRN & \\
\hline CHEMBL371021 & 326472 & 3.0 & 2.3882 & TST & \\
\hline CHEMBL425028 & 326472 & 3.0 & 2.9977 & TRN & \\
\hline CHEMBL198671 & 326472 & 3.0 & 3.1858 & TRN & \\
\hline CHEMBL358494 & 326472 & 3.0 & 3.7442 & TST & \\
\hline CHEMBL198967 & 326472 & 3.0 & 2.748 & TRN & \\
\hline CHEMBL199010 & 326472 & 3.0 & 2.8803 & TRN & \\
\hline CHEMBL358746 & 326472 & 5.6778 & 5.2334 & TRN & \\
\hline CHEMBL197291 & 326472 & 3.0 & 3.1484 & TRN & \\
\hline CHEMBL198915 & 326472 & 5.0458 & 4.8839 & TRN & \\
\hline CHEMBL200918 & 326472 & 3.0 & 3.0652 & TRN & \\
\hline CHEMBL198528 & 326472 & 3.0 & 2.9058 & TRN & \\
\hline CHEMBL371303 & 326472 & 4.0223 & 3.5694 & TST & \\
\hline CHEMBL197231 & 326472 & 3.0 & 3.1151 & TRN & \\
\hline CHEMBL198585 & 326472 & 3.0 & 2.9481 & TRN & \\
\hline CHEMBL445859 & 326472 & 4.3768 & 3.1203 & TST & \\
\hline CHEMBL198787 & 326472 & 3.0 & 2.9936 & TRN & \\
\hline CHEMBL198699 & 326472 & 3.0 & 3.1451 & TRN & \\
\hline CHEMBL382271 & 326472 & 3.0 & 2.9121 & TRN & \\
\hline CHEMBL199112 & 326472 & 3.0 & 2.2291 & TST & \\
\hline CHEMBL199009 & 326472 & 3.0 & 3.0158 & TRN & \\
\hline CHEMBL197484 & 326472 & 3.0 & 2.9785 & TRN & \\
\hline CHEMBL198513 & 326472 & 3.0 & 2.0081 & TST & \\
\hline CHEMBL198751 & 326472 & 3.0 & 2.8268 & TRN & \\
\hline CHEMBL198857 & 326472 & 3.0 & 3.1117 & TRN & \\
\hline CHEMBL382758 & 326472 & 3.0 & 3.27699 & 99999999997 & TRN \\
\hline CHEMBL198839 & 326472 & 3.0 & 2.9381 & TRN & \\
\hline CHEMBL199005 & 326472 & 3.0 & 3.0049 & TRN & \\
\hline
\end{tabular}




\begin{tabular}{|c|c|c|c|c|c|}
\hline \multirow[b]{2}{*}{ CHEMBL198705 } & \multicolumn{5}{|c|}{ Supplemental Table s2.txt } \\
\hline & 326472 & 5.2924 & 4.1722 & TST & \\
\hline CHEMBL200843 & 326472 & 3.0 & 3.3668 & TST & \\
\hline CHEMBL144760 & 326472 & 4.585 & 4.4408 & TRN & \\
\hline CHEMBL199469 & 326472 & 5.7696 & 5.4983 & TRN & \\
\hline CHEMBL198838 & 326472 & 3.0 & 3.1879 & TRN & \\
\hline CHEMBL198573 & 326472 & 5.0969 & 4.6714 & TRN & \\
\hline CHEMBL382303 & 326472 & 3.0 & 2.8193 & TRN & \\
\hline CHEMBL425207 & 326472 & 3.0 & 2.6404 & TST & \\
\hline CHEMBL198621 & 326472 & 3.0 & 3.0084 & TRN & \\
\hline CHEMBL381002 & 326472 & 3.0 & 2.9627 & TRN & \\
\hline CHEMBL372329 & 326472 & 3.0 & 3.0476 & TRN & \\
\hline CHEMBL198627 & 326472 & 3.0 & 3.0796 & TRN & \\
\hline CHEMBL296407 & 326472 & 2.5229 & 4.4458 & TST & \\
\hline CHEMBL370661 & 326472 & 3.0 & 3.326 & TRN & \\
\hline CHEMBL198841 & 326472 & 3.0 & 2.8506 & TRN & \\
\hline CHEMBL198459 & 326472 & 3.0 & 3.1303 & TST & \\
\hline CHEMBL200380 & 326472 & 3.0 & 3.3794 & TST & \\
\hline CHEMBL198889 & 326472 & 3.0 & 2.9686 & TRN & \\
\hline CHEMBL196757 & 326472 & 3.0 & 3.0416 & TRN & \\
\hline CHEMBL199105 & 326472 & 3.0 & 3.0841 & TRN & \\
\hline CHEMBL371102 & 326472 & 4.0969 & 4.0716 & TST & \\
\hline CHEMBL144159 & 326472 & 4.0757 & 4.1919 & TST & \\
\hline CHEMBL371526 & 326472 & 4.2147 & 3.2924 & TST & \\
\hline CHEMBL198541 & 326472 & 3.0 & 3.0591 & TRN & \\
\hline CHEMBL369901 & 326472 & 3.0 & 2.9358 & TRN & \\
\hline CHEMBL198947 & 326472 & 3.0 & 3.1087 & TRN & \\
\hline CHEMBL199184 & 326472 & 3.0 & 2.9312 & TRN & \\
\hline CHEMBL371093 & 326472 & 3.0 & 3.116 & TRN & \\
\hline CHEMBL372752 & 326472 & 3.0 & 2.3118 & TST & \\
\hline CHEMBL200917 & 326472 & 3.0 & 2.4663 & TST & \\
\hline CHEMBL197061 & 326472 & 3.0 & 3.1137 & TRN & \\
\hline CHEMBL371711 & 326472 & 3.0 & 3.21100 & 00000000003 & TRN \\
\hline CHEMBL197388 & 326472 & 4.4202 & 3.3175 & TST & \\
\hline CHEMBL198672 & 326472 & 3.0 & 2.99600 & 00000000004 & TRN \\
\hline CHEMBL197017 & 326472 & 5.0969 & 4.0716 & TST & \\
\hline CHEMBL197441 & 326472 & 3.0 & 3.18399 & 99999999997 & TRN \\
\hline CHEMBL436325 & 326472 & 3.0 & 2.4073 & TST & \\
\hline CHEMBL198971 & 326472 & 3.0 & 2.779 & TRN & \\
\hline CHEMBL198520 & 326472 & 3.0 & 2.9121 & TRN & \\
\hline CHEMBL196854 & 326472 & 5.7696 & 4.5546 & TST & \\
\hline CHEMBL3944233 & 1640872 & 9.0 & 8.4931 & TRN & \\
\hline CHEMBL 3899294 & 1640872 & 8.5376 & 8.4877 & TRN & \\
\hline CHEMBL 3956240 & 1640872 & 6.0 & 6.1501 & TRN & \\
\hline CHEMBL 3944501 & 1640872 & 8.8239 & 8.9765 & TST & \\
\hline CHEMBL3976899 & 1640872 & 6.0 & 6.0924 & TRN & \\
\hline CHEMBL3938831 & 1640872 & 8.3768 & 7.5014 & TRN & \\
\hline CHEMBL3919483 & 1640872 & 7.8239 & 8.2856 & TST & \\
\hline CHEMBL 3975142 & 1640872 & 8.301 & 8.8177 & TST & \\
\hline
\end{tabular}


Supplemental Table S2.txt

\begin{tabular}{|c|c|c|c|c|c|}
\hline CHEMBL3923797 & 1640872 & 7.585 & 7.1485 & TRN & \\
\hline CHEMBL3955181 & 1640872 & 6.0 & 8.4993 & TST & \\
\hline CHEMBL 3954080 & 1640872 & 8.2518 & 8.3403 & TRN & \\
\hline CHEMBL 3982745 & 1640872 & 6.8041 & 7.6674 & TRN & \\
\hline CHEMBL3903396 & 1640872 & 7.8239 & 8.1215 & TRN & \\
\hline CHEMBL 3895015 & 1640872 & 8.4437 & 8.5236 & TRN & \\
\hline CHEMBL3954924 & 1640872 & 8.28399 & 79999999 & 8.476 & TRN \\
\hline CHEMBL 3970902 & 1640872 & 6.0 & \multicolumn{2}{|c|}{6.1579999999999995} & TRN \\
\hline CHEMBL3971997 & 1640872 & 8.3979 & 6.9992 & TST & \\
\hline CHEMBL3981953 & 1640872 & 7.2284 & 7.1724 & TRN & \\
\hline CHEMBL 3920813 & 1640872 & 6.0 & 5.8394 & TRN & \\
\hline CHEMBL3970751 & 1640872 & 6.0 & 6.124 & TRN & \\
\hline CHEMBL 3899752 & 1640872 & 6.0 & 5.8296 & TRN & \\
\hline CHEMBL3907361 & 1640872 & 8.6778 & 8.4537 & TRN & \\
\hline CHEMBL3927960 & 1640872 & 8.5086 & 8.067 & TRN & \\
\hline CHEMBL3983706 & 1640872 & 8.6576 & 7.85 & TRN & \\
\hline CHEMBL3960473 & 1640872 & 8.699 & 8.6443 & TRN & \\
\hline CHEMBL 3964771 & 1640872 & 8.8539 & 7.5411 & TRN & \\
\hline CHEMBL 3898796 & 1640872 & 8.6021 & 8.6081 & TST & \\
\hline CHEMBL 3968650 & 1640872 & 8.0706 & 9.0267 & TST & \\
\hline CHEMBL 3982835 & 1640872 & 8.7696 & 8.9794 & TRN & \\
\hline CHEMBL3960006 & 1640872 & 6.0 & 5.847 & TRN & \\
\hline CHEMBL 3963891 & 1640872 & 6.0 & 5.4734 & TRN & \\
\hline CHEMBL 3936962 & 1640872 & 6.0177 & \multicolumn{2}{|c|}{5.952000000000001} & TRN \\
\hline CHEMBL 3969925 & 1640872 & 7.9666 & 7.9123 & TST & \\
\hline CHEMBL 3947367 & 1640872 & 7.068 & 7.0327 & TRN & \\
\hline CHEMBL3976284 & 1640872 & 9.2218 & 8.6322 & TRN & \\
\hline CHEMBL 3976794 & 1640872 & 8.1549 & 7.7617 & TRN & \\
\hline CHEMBL 3968462 & 1640872 & 7.8861 & 8.0528 & TRN & \\
\hline CHEMBL3954439 & 1640872 & 6.0 & 6.3529 & TRN & \\
\hline CHEMBL 3981301 & 1640872 & 8.1612 & 7.9921 & TST & \\
\hline CHEMBL3986554 & 1640872 & 6.0 & 7.3439 & TRN & \\
\hline CHEMBL 3955822 & 1640872 & 7.857 & 7.7775 & TST & \\
\hline CHEMBL 3892334 & 1640872 & 7.699 & 7.8461 & TST & \\
\hline CHEMBL 3952319 & 1640872 & 9.2218 & 9.6188 & TRN & \\
\hline CHEMBL3976343 & 1640872 & 8.699 & 8.8098 & TRN & \\
\hline CHEMBL3951275 & 1640872 & 7.6198 & 7.6142 & TRN & \\
\hline CHEMBL 3931367 & 1640872 & 6.0 & 6.3523 & TRN & \\
\hline CHEMBL3918339 & 1640872 & 7.4609 & 8.8649 & TST & \\
\hline CHEMBL 3958447 & 1640872 & 8.6198 & 8.6277 & TRN & \\
\hline CHEMBL 3984339 & 1640872 & 8.301 & 8.4906 & TRN & \\
\hline CHEMBL3975792 & 1640872 & 8.3188 & 7.3325 & TST & \\
\hline CHEMBL3942385 & 1640872 & 8.6383 & 8.7101 & TRN & \\
\hline CHEMBL 3925301 & 1640872 & 6.0 & 8.5092 & TST & \\
\hline CHEMBL 3962200 & 1640872 & 8.0862 & 8.3119 & TRN & \\
\hline CHEMBL 3940403 & 1640872 & 6.0 & 5.8917 & TRN & \\
\hline CHEMBL 3892024 & 1640872 & 6.0 & 6.0467 & TRN & \\
\hline CHEMBL 3903954 & 1640872 & 8.1675 & 6.5455 & TST & \\
\hline
\end{tabular}




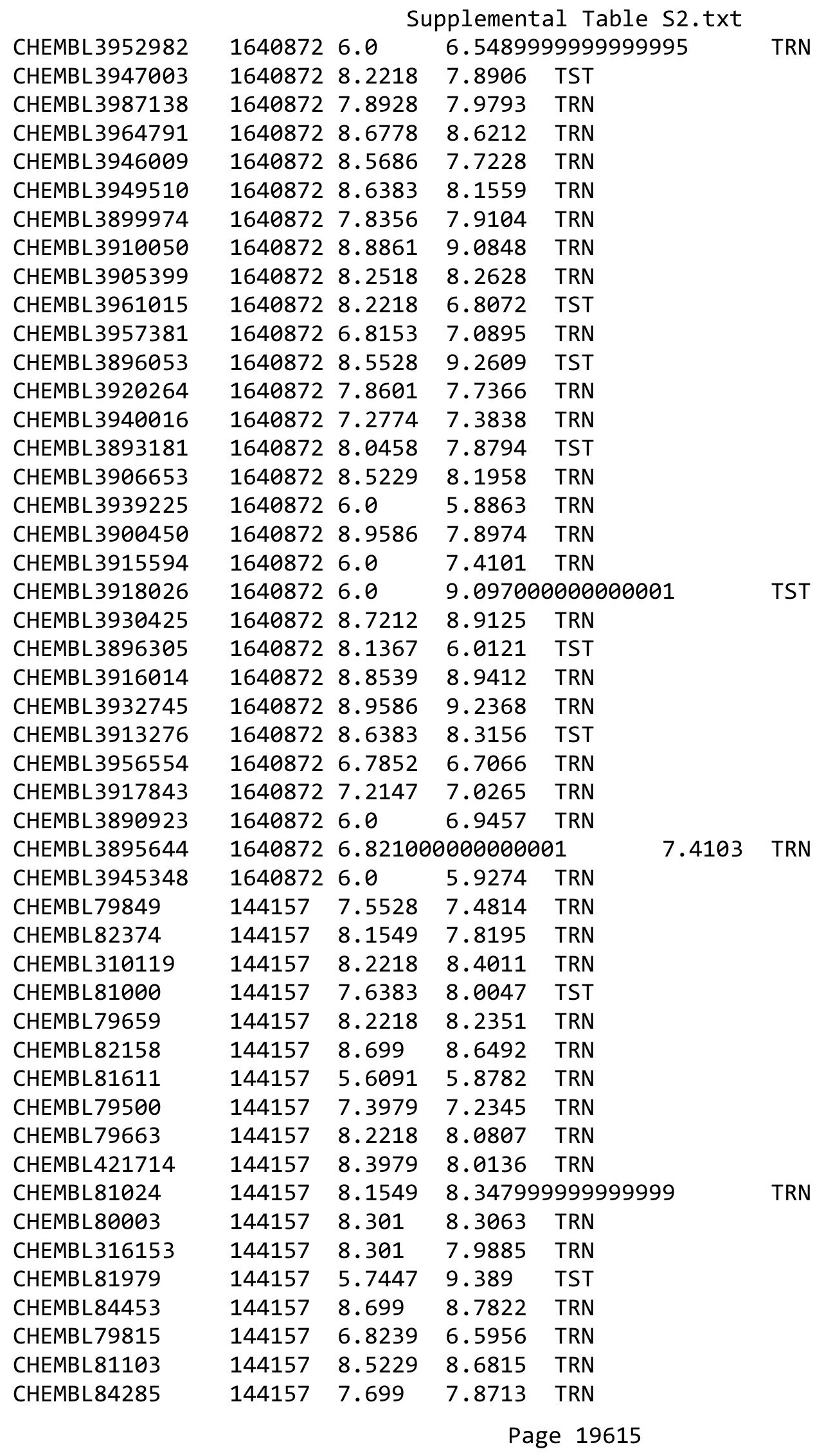


Supplemental Table S2.txt

\begin{tabular}{|c|c|c|c|c|c|}
\hline CHEMBL313454 & 144157 & 8.699 & 8.4367 & TRN & \\
\hline CHEMBL 309550 & 144157 & 8.3979 & \multicolumn{2}{|c|}{8.488999999999999} & TRN \\
\hline CHEMBL420399 & 144157 & 6.5376 & 6.7683 & TRN & \\
\hline CHEMBL81337 & 144157 & 7.0044 & 7.234 & TRN & \\
\hline CHEMBL 82408 & 144157 & 7.0915 & 7.5787 & TRN & \\
\hline CHEMBL81994 & 144157 & 9.0 & 8.8298 & TRN & \\
\hline CHEMBL421521 & 144157 & 8.1549 & 8.4596 & TRN & \\
\hline CHEMBL 83748 & 144157 & 7.8239 & 7.9633 & TRN & \\
\hline CHEMBL 273597 & 144157 & 8.5229 & \multicolumn{2}{|c|}{8.783999999999999} & TST \\
\hline CHEMBL79308 & 144157 & 8.2218 & 7.8938 & TRN & \\
\hline CHEMBL82196 & 144157 & 7.7696 & 7.6488 & TRN & \\
\hline CHEMBL81621 & 144157 & 7.8239 & 7.7837 & TRN & \\
\hline CHEMBL81104 & 144157 & 8.2218 & 8.4265 & TRN & \\
\hline CHEMBL309449 & 144157 & 7.6021 & 7.4352 & TRN & \\
\hline CHEMBL 81636 & 144157 & 7.8239 & 7.9782 & TRN & \\
\hline CHEMBL419104 & 144157 & 7.8239 & 8.2429 & TST & \\
\hline CHEMBL313087 & 144157 & 8.699 & 8.4833 & TRN & \\
\hline CHEMBL80006 & 144157 & 7.4202 & 7.7133 & TRN & \\
\hline CHEMBL80041 & 144157 & 7.699 & 7.5837 & TRN & \\
\hline CHEMBL312711 & 144157 & 5.7959 & 8.1634 & TST & \\
\hline CHEMBL441059 & 144157 & 7.8861 & 7.4452 & TRN & \\
\hline CHEMBL 83255 & 144157 & 7.1612 & 7.6856 & TRN & \\
\hline CHEMBL78901 & 144157 & 7.1079 & 6.9226 & TRN & \\
\hline CHEMBL84269 & 144157 & 7.7447 & 8.0957 & TRN & \\
\hline CHEMBL432931 & 144157 & 6.6778 & 6.8095 & TRN & \\
\hline CHEMBL82080 & 144157 & 8.3979 & 8.192 & TRN & \\
\hline CHEMBL312361 & 144157 & 7.5376 & 7.4374 & TRN & \\
\hline CHEMBL83830 & 144157 & 8.5229 & 7.935 & TST & \\
\hline CHEMBL310292 & 144157 & 7.6021 & 7.3218 & TRN & \\
\hline CHEMBL310674 & 144157 & 8.2218 & 8.324 & TRN & \\
\hline CHEMBL81484 & 144157 & 8.699 & 7.9732 & TST & \\
\hline CHEMBL309967 & 144157 & 8.699 & 7.8478 & TST & \\
\hline CHEMBL 82710 & 144157 & 7.6778 & 7.8513 & TST & \\
\hline CHEMBL81982 & 144157 & 8.2218 & 8.4225 & TST & \\
\hline CHEMBL 81586 & 144157 & 8.699 & 8.1653 & TST & \\
\hline CHEMBL 83860 & 144157 & 8.3979 & 8.2152 & TST & \\
\hline CHEMBL 79714 & 144157 & 7.6198 & 7.7016 & TST & \\
\hline CHEMBL310670 & 144157 & 8.5229 & \multicolumn{2}{|c|}{8.091000000000001} & TST \\
\hline CHEMBL57655 & 70416 & 8.3872 & 8.4056 & TRN & \\
\hline CHEMBL134175 & 70416 & 7.0706 & 7.1738 & TRN & \\
\hline CHEMBL368179 & 70416 & 6.3979 & 6.7329 & TRN & \\
\hline CHEMBL131977 & 70416 & 6.7721 & 6.9384 & TRN & \\
\hline CHEMBL335888 & 70416 & 7.0132 & 6.7777 & TRN & \\
\hline CHEMBL339172 & 70416 & 6.7352 & 6.9089 & TRN & \\
\hline CHEMBL 368919 & 70416 & 8.9208 & 8.8938 & TRN & \\
\hline CHEMBL45346 & 70416 & 5.5229 & 5.5947 & TRN & \\
\hline CHEMBL173938 & 70416 & 7.5157 & 7.9359 & TST & \\
\hline CHEMBL415293 & 70416 & 7.5361 & 7.598 & TRN & \\
\hline
\end{tabular}




\begin{tabular}{|c|c|c|c|c|c|c|}
\hline & & \multicolumn{5}{|c|}{ Supplemental Table S2.txt } \\
\hline CHEMBL43724 & 70416 & 5.5622 & 5.6285 & TRN & & \\
\hline CHEMBL10534 & 70416 & 8.3143 & 8.5306 & TRN & & \\
\hline CHEMBL130416 & 70416 & 7.3188 & 7.0691 & TRN & & \\
\hline CHEMBL 367051 & 70416 & 5.5229 & 5.7792 & TRN & & \\
\hline CHEMBL52030 & 70416 & 7.6108 & 7.6671 & TRN & & \\
\hline CHEMBL368171 & 70416 & 6.567 & 6.8577 & TRN & & \\
\hline CHEMBL69719 & 70416 & 7.6778 & 7.6019 & TRN & & \\
\hline CHEMBL 3144753 & 70416 & 9.699 & 10.1037 & TST & & \\
\hline CHEMBL173082 & 70416 & 8.1487 & 8.11399 & 9999999999 & & TRN \\
\hline CHEMBL141039 & 70416 & 7.9586 & 7.8464 & TRN & & \\
\hline CHEMBL420044 & 70416 & 6.7852 & 6.3734 & TRN & & \\
\hline CHEMBL85861 & 70416 & 8.3979 & 8.0358 & TRN & & \\
\hline CHEMBL84921 & 70416 & 6.1549 & 6.8615 & TST & & \\
\hline CHEMBL58385 & 70416 & 7.5834 & 7.9269 & TRN & & \\
\hline CHEMBL87331 & 70416 & 4.5229 & 4.7836 & TRN & & \\
\hline CHEMBL73096 & 70416 & 6.4976 & 6.8585 & TRN & & \\
\hline CHEMBL368768 & 70416 & 7.5086 & 7.6241 & TRN & & \\
\hline CHEMBL84668 & 70416 & 4.5229 & 4.6736 & TST & & \\
\hline CHEMBL83581 & 70416 & 6.568 & 7.0295 & TST & & \\
\hline CHEMBL3144795 & 70416 & 8.3279 & 9.2738 & TST & & \\
\hline CHEMBL301605 & 70416 & 8.9586 & 8.6166 & TST & & \\
\hline CHEMBL6597 & 70416 & 8.6021 & 8.6045 & TRN & & \\
\hline CHEMBL85539 & 70416 & 5.5229 & 5.4473 & TRN & & \\
\hline CHEMBL171302 & 70416 & 5.3354 & 6.439 & TST & & \\
\hline CHEMBL58570 & 70416 & 7.5969 & 7.6239 & TRN & & \\
\hline CHEMBL314804 & 70416 & 5.5229 & 5.57100 & 0000000001 & & TRN \\
\hline CHEMBL295981 & 70416 & 5.5229 & 5.5435 & TRN & & \\
\hline CHEMBL337166 & 70416 & 7.041 & 7.2217 & TRN & & \\
\hline CHEMBL 299250 & 70416 & 7.5498 & 7.1414 & TRN & & \\
\hline CHEMBL3144617 & 70416 & 8.8996 & 9.4379 & TST & & \\
\hline CHEMBL3144697 & 70416 & 10.3009 & 99999999 & 998 & 10.6572 & TST \\
\hline CHEMBL 275115 & 70416 & 6.4559 & 6.651 & TRN & & \\
\hline CHEMBL47853 & 70416 & 4.8125 & 4.7947 & TRN & & \\
\hline CHEMBL133049 & 70416 & 8.1296 & 8.0177 & TRN & & \\
\hline CHEMBL3144696 & 70416 & 10.6990 & 00000000 & $\partial 02$ & 10.8062 & TST \\
\hline CHEMBL58757 & 70416 & 7.7282 & 7.6295 & TRN & & \\
\hline CHEMBL67421 & 70416 & 4.5229 & 4.7143 & TRN & & \\
\hline CHEMBL339165 & 70416 & 7.4191 & 7.4252 & TRN & & \\
\hline CHEMBL 3144610 & 70416 & 9.1024 & 9.418 & TST & & \\
\hline CHEMBL366789 & 70416 & 4.5229 & 4.7075 & TST & & \\
\hline CHEMBL84842 & 70416 & 4.5229 & 3.9665 & TST & & \\
\hline CHEMBL 267665 & 70416 & 8.9586 & 8.9988 & TRN & & \\
\hline CHEMBL176457 & 70416 & 6.5331 & 6.7344 & TRN & & \\
\hline CHEMBL 273464 & 70416 & 7.2314 & 6.8235 & TRN & & \\
\hline CHEMBL335960 & 70416 & 6.4724 & 6.0375 & TRN & & \\
\hline CHEMBL133705 & 70416 & 6.9136 & 6.688 & TRN & & \\
\hline CHEMBL435550 & 70416 & 6.5229 & 6.1798 & TRN & & \\
\hline CHEMBL3144615 & 70416 & 9.9208 & 10.3139 & TST & & \\
\hline
\end{tabular}




\begin{tabular}{|c|c|c|c|c|c|}
\hline & & \multicolumn{4}{|c|}{ Supplemental Table S2.txt } \\
\hline CHEMBL408797 & 70416 & 7.284 & 8.0287 & TST & \\
\hline CHEMBL133219 & 70416 & 7.8861 & 8.0359 & TRN & \\
\hline CHEMBL173087 & 70416 & 6.2441 & 6.2326 & TRN & \\
\hline CHEMBL13662 & 70416 & 5.9355 & 5.8194 & TST & \\
\hline CHEMBL6659 & 70416 & 7.9626 & 7.9354 & TRN & \\
\hline CHEMBL43718 & 70416 & 5.9469 & 5.9125 & TRN & \\
\hline CHEMBL 307783 & 70416 & 7.7235 & 7.6841 & TRN & \\
\hline CHEMBL172866 & 70416 & 6.8069 & 7.4795 & TST & \\
\hline CHEMBL44784 & 70416 & 5.5229 & 5.6207 & TRN & \\
\hline CHEMBL415290 & 70416 & 8.0362 & 8.0616 & TRN & \\
\hline CHEMBL 7290 & 70416 & 7.52 & 8.0361 & TRN & \\
\hline CHEMBL46957 & 70416 & 5.2027 & 4.8854 & TRN & \\
\hline CHEMBL 314788 & 70416 & 4.4559 & 4.4813 & TST & \\
\hline CHEMBL 268262 & 70416 & 7.3107 & 7.4355 & TRN & \\
\hline CHEMBL431973 & 70416 & 5.5229 & 5.4993 & TRN & \\
\hline CHEMBL43725 & 70416 & 4.6556 & 4.8764 & TRN & \\
\hline CHEMBL 78766 & 70416 & 6.2741 & 7.2888 & TST & \\
\hline CHEMBL53651 & 70416 & 6.8508 & 6.4037 & TRN & \\
\hline CHEMBL133272 & 70416 & 8.1612 & 8.2541 & TRN & \\
\hline CHEMBL87641 & 70416 & 4.5229 & 4.8916 & TRN & \\
\hline CHEMBL170808 & 70416 & 9.1192 & 9.1717 & TRN & \\
\hline CHEMBL369358 & 70416 & 6.6882 & 6.6089 & TRN & \\
\hline CHEMBL340546 & 70416 & 6.8297 & 6.9454 & TRN & \\
\hline CHEMBL 298561 & 70416 & 6.8996 & 6.8095 & TRN & \\
\hline CHEMBL66902 & 70416 & 6.6108 & 6.742000 & 0000000001 & TRN \\
\hline CHEMBL1269093 & 70416 & 6.857 & 6.8702 & TST & \\
\hline CHEMBL11709 & 70416 & 8.2441 & 8.1921 & TRN & \\
\hline CHEMBL173339 & 70416 & 7.8729 & 7.7459 & TRN & \\
\hline CHEMBL176307 & 70416 & 5.5229 & 5.3084 & TRN & \\
\hline CHEMBL174535 & 70416 & 7.3242 & 7.1481 & TRN & \\
\hline CHEMBL49141 & 70416 & 8.6576 & 8.243 & TST & \\
\hline CHEMBL52750 & 70416 & 7.1624 & 7.1862 & TRN & \\
\hline CHEMBL 368130 & 70416 & 6.3925 & 6.1739 & TRN & \\
\hline CHEMBL 132529 & 70416 & 7.7212 & 7.8625 & TRN & \\
\hline CHEMBL416450 & 70416 & 7.7721 & 7.8749 & TRN & \\
\hline CHEMBL59180 & 70416 & 7.7825 & 7.6871 & TRN & \\
\hline CHEMBL13458 & 70416 & 6.4559 & 6.3371 & TST & \\
\hline CHEMBL173329 & 70416 & 8.5528 & 8.5589 & TRN & \\
\hline CHEMBL 286594 & 70416 & 7.5884 & 7.9002 & TRN & \\
\hline CHEMBL 3144698 & 70416 & 9.6021 & 10.1504 & TST & \\
\hline CHEMBL341398 & 70416 & 8.1739 & 7.89 & TRN & \\
\hline CHEMBL130609 & 70416 & 9.2757 & 8.3732 & TRN & \\
\hline CHEMBL6655 & 70416 & 8.0362 & 8.0025 & TRN & \\
\hline CHEMBL6421 & 70416 & 8.007 & 7.9958 & TRN & \\
\hline CHEMBL3144841 & 70416 & 10.0458 & 10.4086 & TST & \\
\hline CHEMBL 295277 & 70416 & 5.5229 & 5.1877 & TRN & \\
\hline CHEMBL314844 & 70416 & 5.0 & 5.2379 & TST & \\
\hline CHEMBL 300840 & 70416 & 6.5935 & 6.7574 & TRN & \\
\hline
\end{tabular}




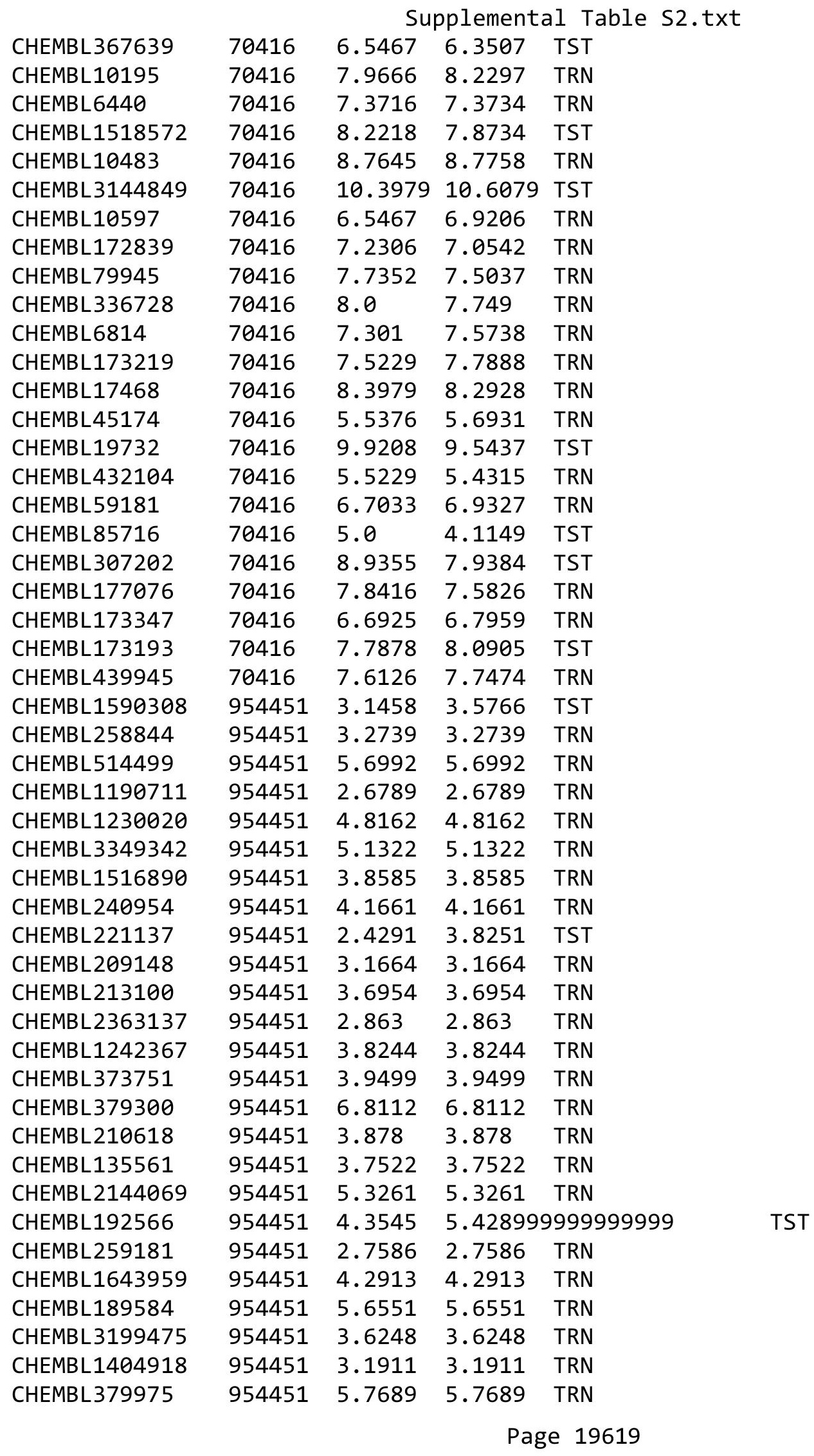




\begin{tabular}{|c|c|c|c|c|c|}
\hline \multicolumn{6}{|c|}{ Supplemental Table S2.txt } \\
\hline CHEMBL472940 & 954451 & 3.0667 & 3.0667 & TRN & \\
\hline CHEMBL3392440 & 954451 & 4.7265 & 4.7265 & TRN & \\
\hline CHEMBL220241 & 954451 & 5.6105 & 5.6105 & TRN & \\
\hline CHEMBL 3186408 & 954451 & 4.9554 & 3.4245 & TST & \\
\hline CHEMBL2005886 & 954451 & 3.536 & 3.536 & TRN & \\
\hline CHEMBL449158 & 954451 & 6.1958 & 5.9044 & TST & \\
\hline CHEMBL1909414 & 954451 & 4.7816 & 4.7816 & TRN & \\
\hline CHEMBL558642 & 954451 & 2.5955 & 2.5955 & TRN & \\
\hline CHEMBL512504 & 954451 & 3.7766 & 3.7766 & TRN & \\
\hline CHEMBL1788116 & 954451 & 3.06100 & 20000000 & 004 & 3.0610000000000004 \\
\hline CHEMBL1673039 & 954451 & 2.7716 & 2.7716 & TRN & \\
\hline CHEMBL180127 & 954451 & 5.1208 & 5.1208 & TRN & \\
\hline CHEMBL412142 & 954451 & 3.4561 & 3.4561 & TRN & \\
\hline CHEMBL1357247 & 954451 & 2.4407 & 2.4407 & TRN & \\
\hline CHEMBL585951 & 954451 & 3.054 & 3.054 & TRN & \\
\hline CHEMBL1970879 & 954451 & 4.2198 & 4.2198 & TRN & \\
\hline CHEMBL392695 & 954451 & 3.2623 & 3.2623 & TRN & \\
\hline CHEMBL300389 & 954451 & 5.6759 & 5.6759 & TRN & \\
\hline CHEMBL65 & 954451 & 7.3498 & 7.3498 & TRN & \\
\hline CHEMBL393929 & 954451 & 4.2836 & 4.2836 & TRN & \\
\hline CHEMBL 202721 & 954451 & 5.9186 & 4.867 & TST & \\
\hline CHEMBL191334 & 954451 & 4.7959 & 4.2428 & TST & \\
\hline CHEMBL515416 & 954451 & 3.7649 & 4.2929 & TST & \\
\hline CHEMBL1256459 & 954451 & 6.2599 & 5.1921 & TST & \\
\hline CHEMBL9470 & 954451 & 2.9443 & 3.8241 & TST & \\
\hline CHEMBL483847 & 954451 & 4.9636 & 4.2272 & TST & \\
\hline CHEMBL92309 & 954451 & 1.6402 & 2.298 & TST & \\
\hline CHEMBL509032 & 954451 & 5.8653 & 3.5718 & TST & \\
\hline CHEMBL573107 & 954451 & 6.7646 & 4.8862 & TST & \\
\hline CHEMBL 3105672 & 1285944 & 8.0 & 8.2533 & TRN & \\
\hline CHEMBL3105671 & 1285944 & 7.9 & 8.1 & TRN & \\
\hline CHEMBL 3105670 & 1285944 & 8.2 & 8.0465 & TRN & \\
\hline CHEMBL3105669 & 1285944 & 8.1 & 8.0204 & TRN & \\
\hline CHEMBL3105692 & 1285944 & 8.0 & 8.1032 & TRN & \\
\hline CHEMBL3105691 & 1285944 & 7.8 & 7.9235 & TRN & \\
\hline CHEMBL3105690 & 1285944 & 7.9 & 7.8809 & TRN & \\
\hline CHEMBL3105686 & 1285944 & 8.0 & 7.5494 & TRN & \\
\hline CHEMBL 3105685 & 1285944 & 7.6 & 7.8374 & TRN & \\
\hline CHEMBL 3105684 & 1285944 & 7.7 & 7.6633 & TRN & \\
\hline CHEMBL 3105683 & 1285944 & 7.9 & 8.2437 & TRN & \\
\hline CHEMBL 3105682 & 1285944 & 8.0 & 7.7793 & TRN & \\
\hline CHEMBL3105681 & 1285944 & 7.8 & 7.7194 & TRN & \\
\hline CHEMBL 3105680 & 1285944 & 5.1 & 4.9421 & TRN & \\
\hline CHEMBL3105679 & 1285944 & 6.1 & 6.1443 & TRN & \\
\hline CHEMBL 3105678 & 1285944 & 7.5 & 7.3717 & TRN & \\
\hline CHEMBL3105677 & 1285944 & 7.4 & 7.5352 & TRN & \\
\hline CHEMBL3105676 & 1285944 & 7.9 & 7.6226 & TRN & \\
\hline CHEMBL 3105675 & 1285944 & 7.4 & 7.4316 & TRN & \\
\hline
\end{tabular}




\begin{tabular}{|c|c|c|c|c|c|}
\hline CHEMBL3105674 & 1285944 & 7.5 & \multicolumn{2}{|c|}{6.9479999999999995} & TRN \\
\hline CHEMBL3105673 & 1285944 & 7.6 & 7.4808 & TRN & \\
\hline CHEMBL3105807 & 1285944 & 5.6 & 5.9738 & TRN & \\
\hline CHEMBL3105806 & 1285944 & 5.2 & 5.2582 & TRN & \\
\hline CHEMBL3105805 & 1285944 & 5.0 & 5.0632 & TRN & \\
\hline CHEMBL 3102888 & 1285944 & 6.4 & 6.4869 & TRN & \\
\hline CHEMBL3105804 & 1285944 & 6.2 & 6.3052 & TRN & \\
\hline CHEMBL3105803 & 1285944 & 5.7 & 5.7728 & TRN & \\
\hline CHEMBL 3105802 & 1285944 & 5.3 & 5.4201 & TRN & \\
\hline CHEMBL3105801 & 1285944 & 5.0 & 5.1538 & TRN & \\
\hline CHEMBL 3105800 & 1285944 & 5.2 & 5.2922 & TRN & \\
\hline CHEMBL3105799 & 1285944 & 5.9 & 5.8564 & TRN & \\
\hline CHEMBL3105798 & 1285944 & 6.1 & 6.0308 & TRN & \\
\hline CHEMBL 3105797 & 1285944 & 5.4 & 5.6354 & TRN & \\
\hline CHEMBL3105796 & 1285944 & 5.4 & 5.4783 & TRN & \\
\hline CHEMBL3105795 & 1285944 & 5.7 & 5.7646 & TRN & \\
\hline CHEMBL3105794 & 1285944 & 5.1 & 4.9953 & TRN & \\
\hline CHEMBL3105695 & 1285944 & 5.8 & 4.9851 & TST & \\
\hline CHEMBL3105694 & 1285944 & 3.6 & 4.9088 & TST & \\
\hline CHEMBL3105693 & 1285944 & 3.6 & 4.8286 & TST & \\
\hline CHEMBL3105820 & 1285944 & 4.9 & 4.4879 & TRN & \\
\hline CHEMBL3105819 & 1285944 & 5.9 & 5.705 & TRN & \\
\hline CHEMBL3105818 & 1285944 & 3.6 & 3.7234 & TRN & \\
\hline CHEMBL3105817 & 1285944 & 5.3 & 5.1162 & TST & \\
\hline CHEMBL3105816 & 1285944 & 5.8 & 5.2276 & TST & \\
\hline CHEMBL3105815 & 1285944 & 6.0 & 5.2173 & TST & \\
\hline CHEMBL3105814 & 1285944 & 5.4 & 4.6626 & TST & \\
\hline CHEMBL3105813 & 1285944 & 5.3 & 5.0691 & TST & \\
\hline CHEMBL3105812 & 1285944 & 5.1 & 4.3558 & TST & \\
\hline CHEMBL3105811 & 1285944 & 5.0 & 4.3142 & TST & \\
\hline CHEMBL3105810 & 1285944 & 3.6 & 4.4505 & TST & \\
\hline CHEMBL3105809 & 1285944 & 3.6 & 4.8374 & TST & \\
\hline CHEMBL3105808 & 1285944 & 3.6 & 4.5214 & TST & \\
\hline CHEMBL1341756 & 688482 & 5.3776 & 5.4316 & TRN & \\
\hline CHEMBL203543 & 688482 & 5.004 & 5.3902 & TRN & \\
\hline CHEMBL1532443 & 688482 & 4.9777 & 4.7767 & TRN & \\
\hline CHEMBL1487869 & 688482 & 4.9441 & 4.9727 & TRN & \\
\hline CHEMBL1301700 & 688482 & 5.5535 & 5.6392 & TRN & \\
\hline CHEMBL1496905 & 688482 & 5.0116 & 4.9991 & TRN & \\
\hline CHEMBL1439783 & 688482 & 4.981 & 4.9991 & TRN & \\
\hline CHEMBL1593666 & 688482 & 5.0289 & 4.7352 & TRN & \\
\hline CHEMBL1351399 & 688482 & 4.6171 & 4.607 & TRN & \\
\hline CHEMBL3199236 & 688482 & 4.5903 & 4.38899 & 9999999999 & TRN \\
\hline CHEMBL1322436 & 688482 & 5.1104 & 5.1346 & TRN & \\
\hline CHEMBL1378166 & 688482 & 4.9544 & 4.6542 & TRN & \\
\hline CHEMBL1548894 & 688482 & 5.1418 & 5.347 & TRN & \\
\hline CHEMBL1488035 & 688482 & 3.2245 & 3.1008 & TRN & \\
\hline CHEMBL1579174 & 688482 & 4.3925 & 4.3925 & TRN & \\
\hline
\end{tabular}


Supplemental Table S2.txt

\begin{tabular}{|c|c|c|c|c|c|}
\hline CHEMBL1344648 & 688482 & 5.1202 & 5.1163 & TRN & \\
\hline CHEMBL1465537 & 688482 & 5.0238 & 4.456 & TST & \\
\hline CHEMBL1345387 & 688482 & 4.3437 & 4.5207 & TRN & \\
\hline CHEMBL1575183 & 688482 & 3.2245 & 3.5533 & TRN & \\
\hline CHEMBL1579917 & 688482 & 4.9156 & 4.934 & TST & \\
\hline CHEMBL1520448 & 688482 & 5.3118 & 5.2264 & TRN & \\
\hline CHEMBL1328547 & 688482 & 4.7323 & 4.6973 & TRN & \\
\hline CHEMBL1564543 & 688482 & 5.3386 & 5.3661 & TRN & \\
\hline CHEMBL1399615 & 688482 & 5.3341 & 5.2189 & TRN & \\
\hline CHEMBL1553293 & 688482 & 3.2245 & 3.4651 & TRN & \\
\hline CHEMBL1467709 & 688482 & 4.5557 & 4.6641 & TRN & \\
\hline CHEMBL1594527 & 688482 & 3.2245 & 4.7761 & TST & \\
\hline CHEMBL1385156 & 688482 & 4.8739 & 4.9102 & TRN & \\
\hline CHEMBL1562713 & 688482 & 5.2824 & 4.8115 & TST & \\
\hline CHEMBL1346278 & 688482 & 5.3157 & 5.1791 & TRN & \\
\hline CHEMBL1537296 & 688482 & 5.0024 & 4.9526 & TRN & \\
\hline CHEMBL1344788 & 688482 & 3.2245 & 3.7181 & TRN & \\
\hline CHEMBL1419772 & 688482 & 3.2245 & 5.0646 & TST & \\
\hline CHEMBL1607173 & 688482 & 4.5506 & 4.3539 & TRN & \\
\hline CHEMBL1491319 & 688482 & 4.5509 & 4.6777 & TRN & \\
\hline CHEMBL1405735 & 688482 & 5.6523 & 5.6516 & TRN & \\
\hline CHEMBL1338157 & 688482 & 4.4345 & 4.7994 & TRN & \\
\hline CHEMBL1310488 & 688482 & 4.667 & 4.4792 & TRN & \\
\hline CHEMBL1542071 & 688482 & \multicolumn{3}{|c|}{5.537000000000001} & 5.5499 \\
\hline CHEMBL1583409 & 688482 & 5.2272 & 5.3336 & TRN & \\
\hline CHEMBL1388469 & 688482 & 5.6385 & 5.6627 & TRN & \\
\hline CHEMBL1522210 & 688482 & 3.2245 & 3.37 & TRN & \\
\hline CHEMBL3193419 & 688482 & 4.841 & 4.9803 & TRN & \\
\hline CHEMBL1556438 & 688482 & 5.2 & 4.3459 & TRN & \\
\hline CHEMBL1491717 & 688482 & 4.9657 & 4.7883 & TRN & \\
\hline CHEMBL1588059 & 688482 & 5.9646 & 6.1684 & TRN & \\
\hline CHEMBL1473747 & 688482 & 4.6962 & 4.7564 & TRN & \\
\hline CHEMBL1453099 & 688482 & 4.9512 & 5.0303 & TRN & \\
\hline CHEMBL1498450 & 688482 & 5.5284 & 5.4164 & TRN & \\
\hline CHEMBL1334062 & 688482 & 3.7016 & 3.5322 & TRN & \\
\hline CHEMBL1430538 & 688482 & 4.9511 & 4.9765 & TRN & \\
\hline CHEMBL1382175 & 688482 & 4.507 & 4.4767 & TRN & \\
\hline CHEMBL1467618 & 688482 & 5.1031 & 5.1765 & TRN & \\
\hline CHEMBL1450675 & 688482 & 5.3965 & 5.1364 & TRN & \\
\hline CHEMBL1318749 & 688482 & 5.1475 & 5.2236 & TRN & \\
\hline CHEMBL1486207 & 688482 & 3.2245 & 3.1833 & TRN & \\
\hline CHEMBL1611922 & 688482 & 5.2844 & 5.2024 & TRN & \\
\hline CHEMBL1366838 & 688482 & 5.4458 & 5.4992 & TRN & \\
\hline CHEMBL3207442 & 688482 & 5.2858 & 5.2391 & TRN & \\
\hline CHEMBL1327635 & 688482 & 5.4761 & 5.2939 & TRN & \\
\hline CHEMBL1409007 & 688482 & 3.2245 & 3.3293 & TRN & \\
\hline CHEMBL1378567 & 688482 & 4.465 & 5.06 & TST & \\
\hline CHEMBL1498141 & 688482 & 4.5961 & 4.8635 & TST & \\
\hline
\end{tabular}




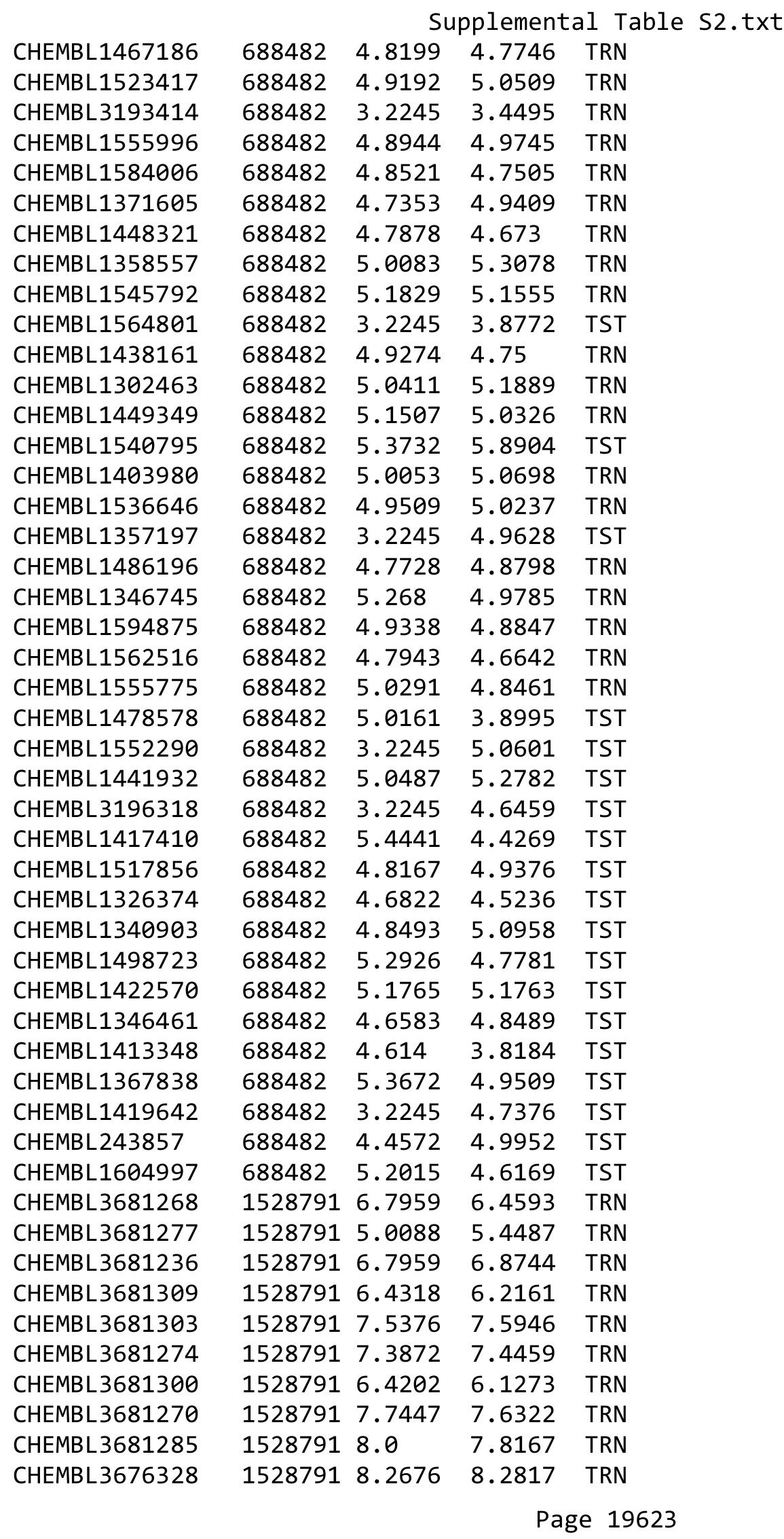


Supplemental Table S2.txt

\begin{tabular}{|c|c|c|c|c|c|}
\hline CHEMBL 3676323 & 1528791 & 7.1135 & 7.2039 & TRN & \\
\hline CHEMBL 3676330 & 1528791 & 6.8239 & 6.7842 & TRN & \\
\hline CHEMBL 3681253 & 1528791 & 5.1024 & 4.783 & TST & \\
\hline CHEMBL 3681267 & 1528791 & 7.1871 & 7.3937 & TRN & \\
\hline CHEMBL3676317 & 1528791 & 6.301 & 6.8912 & TRN & \\
\hline CHEMBL 3681282 & 1528791 & 8.2518 & 7.5112 & TRN & \\
\hline CHEMBL 3676316 & 1528791 & 8.1739 & 8.036 & TRN & \\
\hline CHEMBL 3681294 & 1528791 & 7.7212 & 7.4612 & TST & \\
\hline CHEMBL 3676336 & 1528791 & 6.4949 & 6.6377 & TRN & \\
\hline CHEMBL3681248 & 1528791 & 6.4318 & 7.0968 & TRN & \\
\hline CHEMBL 3681249 & 1528791 & 6.1739 & \multicolumn{2}{|c|}{6.8660000000000005} & TRN \\
\hline CHEMBL 3681254 & 1528791 & 6.4815 & 6.0541 & TRN & \\
\hline CHEMBL 3681237 & 1528791 & 7.3665 & 7.1489 & TRN & \\
\hline CHEMBL 3681316 & 1528791 & 6.9208 & 7.1944 & TRN & \\
\hline CHEMBL3681238 & 1528791 & 7.0862 & 7.3789 & TRN & \\
\hline CHEMBL 3681290 & 1528791 & 8.9208 & 8.3588 & TRN & \\
\hline CHEMBL3681311 & 1528791 & 6.4949 & 6.0901 & TST & \\
\hline CHEMBL 3681263 & 1528791 & 7.1135 & 6.7535 & TRN & \\
\hline CHEMBL3676319 & 1528791 & 4.301 & 5.5099 & TRN & \\
\hline CHEMBL3681257 & 1528791 & 6.585 & 6.6525 & TRN & \\
\hline CHEMBL3681269 & 1528791 & 6.8539 & 6.7735 & TRN & \\
\hline CHEMBL3681299 & 1528791 & 6.0223 & 6.3809 & TRN & \\
\hline CHEMBL3681279 & 1528791 & 6.7212 & \multicolumn{2}{|c|}{7.627000000000001} & TRN \\
\hline CHEMBL 3681284 & 1528791 & 8.7959 & 8.2807 & TRN & \\
\hline CHEMBL 3676335 & 1528791 & 6.2366 & 5.8068 & TST & \\
\hline CHEMBL 3681244 & 1528791 & 6.6383 & 6.6553 & TRN & \\
\hline CHEMBL 3681259 & 1528791 & 6.585 & 6.3423 & TST & \\
\hline CHEMBL 3676334 & 1528791 & 6.7447 & 6.6408 & TRN & \\
\hline CHEMBL 3681306 & 1528791 & 7.0 & 7.2633 & TRN & \\
\hline CHEMBL 3681298 & 1528791 & 6.8539 & 7.0819 & TRN & \\
\hline CHEMBL 3681266 & 1528791 & 7.1675 & 6.5452 & TST & \\
\hline CHEMBL 3676333 & 1528791 & 6.7212 & 6.4008 & TRN & \\
\hline CHEMBL 3676327 & 1528791 & 7.1549 & 7.2039 & TRN & \\
\hline CHEMBL 3681295 & 1528791 & 8.0757 & 7.6644 & TRN & \\
\hline CHEMBL 3681242 & 1528791 & 7.0862 & 7.0089 & TRN & \\
\hline CHEMBL3681245 & 1528791 & 7.0655 & 7.0309 & TRN & \\
\hline CHEMBL3681255 & 1528791 & 6.8239 & 6.7056 & TRN & \\
\hline CHEMBL 3681251 & 1528791 & 7.0458 & 6.9013 & TRN & \\
\hline CHEMBL 3676326 & 1528791 & 7.4685 & 7.1523 & TST & \\
\hline CHEMBL 3676313 & 1528791 & 7.8861 & 8.0587 & TRN & \\
\hline CHEMBL 3681288 & 1528791 & 6.0362 & 6.1912 & TRN & \\
\hline CHEMBL3681301 & 1528791 & 7.1135 & 6.8664 & TRN & \\
\hline CHEMBL 3681247 & 1528791 & 7.3468 & 7.2051 & TRN & \\
\hline CHEMBL3681243 & 1528791 & 6.0969 & 6.5752 & TRN & \\
\hline CHEMBL3681305 & 1528791 & 5.8861 & 6.3622 & TRN & \\
\hline CHEMBL 3639801 & 1528791 & 6.8861 & 7.0751 & TRN & \\
\hline CHEMBL 3681241 & 1528791 & 6.8861 & 6.7388 & TRN & \\
\hline CHEMBL 3681302 & 1528791 & 6.7447 & 6.5239 & TRN & \\
\hline
\end{tabular}

Page 19624 
Supplemental Table S2.txt

\begin{tabular}{|c|c|c|c|c|}
\hline CHEMBL 3681250 & 1528791 & 7.0269 & 7.1016 & TRN \\
\hline CHEMBL 3681307 & 1528791 & 7.0269 & 7.108 & TRN \\
\hline CHEMBL3681286 & 1528791 & 6.5528 & 6.3032 & TRN \\
\hline CHEMBL 3676315 & 1528791 & 8.2676 & 8.0687 & TRN \\
\hline CHEMBL3676318 & 1528791 & 6.4437 & 6.7282 & TRN \\
\hline CHEMBL 3681273 & 1528791 & 6.8861 & 6.5225 & TRN \\
\hline CHEMBL 3681278 & 1528791 & 8.4559 & 8.4822 & TRN \\
\hline CHEMBL 3676320 & 1528791 & 8.5086 & 7.2286 & TRN \\
\hline CHEMBL 3681312 & 1528791 & 6.6383 & 6.2138 & TST \\
\hline CHEMBL3681293 & 1528791 & 6.7212 & 6.4318 & TRN \\
\hline CHEMBL 3681265 & 1528791 & 7.8239 & 6.6819 & TST \\
\hline CHEMBL 3676314 & 1528791 & 7.4202 & 7.4734 & TRN \\
\hline CHEMBL 3681260 & 1528791 & 6.0555 & 6.08799 & 9999999999 \\
\hline CHEMBL 3681246 & 1528791 & 7.5686 & 7.2542 & TRN \\
\hline CHEMBL3681292 & 1528791 & 8.0 & 8.3396 & TRN \\
\hline CHEMBL 3681281 & 1528791 & 7.585 & 7.4899 & TRN \\
\hline CHEMBL3681319 & 1528791 & 5.7447 & 5.2062 & TRN \\
\hline CHEMBL 3681271 & 1528791 & 7.9208 & 8.3118 & TRN \\
\hline CHEMBL 3676312 & 1528791 & 7.7447 & 7.1987 & TST \\
\hline CHEMBL3681317 & 1528791 & 7.1675 & 6.9843 & TRN \\
\hline CHEMBL 3681313 & 1528791 & 5.4976 & 5.3453 & TRN \\
\hline CHEMBL 3681262 & 1528791 & 6.4202 & 6.3293 & TST \\
\hline CHEMBL 3681275 & 1528791 & 5.6778 & 5.57100 & 000000001 \\
\hline CHEMBL 3681240 & 1528791 & 7.2218 & 7.1696 & TRN \\
\hline CHEMBL 3681280 & 1528791 & 7.4559 & 7.7466 & TRN \\
\hline CHEMBL 3681310 & 1528791 & 7.0862 & 6.621 & TST \\
\hline CHEMBL 3681272 & 1528791 & 7.5229 & 8.1808 & TRN \\
\hline CHEMBL3681296 & 1528791 & 7.0969 & 7.0186 & TRN \\
\hline CHEMBL 3681239 & 1528791 & 6.3979 & 6.0901 & TRN \\
\hline CHEMBL 3681287 & 1528791 & 7.1024 & 6.9916 & TRN \\
\hline CHEMBL 3676324 & 1528791 & 7.3372 & 7.5363 & TRN \\
\hline CHEMBL 3681315 & 1528791 & 7.0458 & 7.3529 & TRN \\
\hline CHEMBL 3681261 & 1528791 & 5.3979 & 5.3422 & TRN \\
\hline CHEMBL 3676337 & 1528791 & 6.4437 & 6.7871 & TST \\
\hline CHEMBL 3676325 & 1528791 & 8.4318 & 7.933 & TRN \\
\hline CHEMBL3681252 & 1528791 & 6.4318 & 6.5884 & TRN \\
\hline CHEMBL 3681283 & 1528791 & 7.7447 & 7.2302 & TST \\
\hline CHEMBL 3676322 & 1528791 & 6.4559 & 6.3549 & TST \\
\hline CHEMBL 3681276 & 1528791 & 5.2596 & 5.3411 & TST \\
\hline CHEMBL 3681318 & 1528791 & 5.8539 & 5.9632 & TST \\
\hline CHEMBL 3681304 & 1528791 & 6.6021 & 6.8046 & TST \\
\hline CHEMBL 3681258 & 1528791 & 6.4559 & 6.9938 & TST \\
\hline CHEMBL3676331 & 1528791 & 6.6778 & 7.4226 & TST \\
\hline CHEMBL 3681264 & 1528791 & 7.4949 & 7.4192 & TST \\
\hline CHEMBL 3681291 & 1528791 & 7.9208 & 8.3066 & TST \\
\hline CHEMBL3681256 & 1528791 & 6.6778 & 6.9031 & TST \\
\hline CHEMBL 3676321 & 1528791 & 6.6778 & 6.5745 & TST \\
\hline CHEMBL3681314 & 1528791 & 6.8861 & 7.9473 & TST \\
\hline
\end{tabular}

Page 19625 
Supplemental Table S2.txt

\begin{tabular}{|c|c|c|c|c|c|}
\hline CHEMBL3676332 & 1528791 & 6.8239 & 6.7056 & TST & \\
\hline CHEMBL3681297 & 1528791 & 7.1024 & 6.9326 & TST & \\
\hline CHEMBL3681308 & 1528791 & 6.9586 & 6.9774 & TST & \\
\hline CHEMBL3352839 & 1451733 & 4.0 & 5.3294 & TRN & \\
\hline CHEMBL3354586 & 1451733 & 4.0 & 4.4277 & TRN & \\
\hline CHEMBL3353955 & 1451733 & 6.4559 & 5.8795 & TRN & \\
\hline CHEMBL3353931 & 1451733 & 4.0 & 4.4666 & TRN & \\
\hline CHEMBL3354578 & 1451733 & 5.6021 & 5.6348 & TRN & \\
\hline CHEMBL3353954 & 1451733 & 6.1367 & 5.9493 & TRN & \\
\hline CHEMBL3354577 & 1451733 & 4.0 & 5.5324 & TRN & \\
\hline CHEMBL3353951 & 1451733 & 5.8861 & 5.5824 & TRN & \\
\hline CHEMBL3354581 & 1451733 & 4.0 & 4.5003 & TRN & \\
\hline CHEMBL3354571 & 1451733 & 6.5528 & 5.8798 & TRN & \\
\hline CHEMBL 3353932 & 1451733 & 4.0 & 4.3694 & TRN & \\
\hline CHEMBL3354598 & 1451733 & 6.1938 & 5.92200 & 0000000001 & TRN \\
\hline CHEMBL3353941 & 1451733 & 5.699 & 5.0199 & TRN & \\
\hline CHEMBL3353935 & 1451733 & 7.7696 & 4.7705 & TST & \\
\hline CHEMBL3353952 & 1451733 & 5.4949 & 5.6389 & TRN & \\
\hline CHEMBL3354574 & 1451733 & 4.0 & 5.4613 & TST & \\
\hline CHEMBL3353938 & 1451733 & 4.0 & 3.2018 & TRN & \\
\hline CHEMBL3353950 & 1451733 & 5.6576 & 5.8408 & TRN & \\
\hline CHEMBL3354579 & 1451733 & 5.8539 & 5.0063 & TRN & \\
\hline CHEMBL 3354583 & 1451733 & 6.5229 & 4.823 & TRN & \\
\hline CHEMBL3354597 & 1451733 & 6.3098 & 5.7991 & TRN & \\
\hline CHEMBL3353953 & 1451733 & 6.5686 & 5.8409 & TRN & \\
\hline CHEMBL3354580 & 1451733 & 5.7447 & 5.1732 & TRN & \\
\hline CHEMBL3353943 & 1451733 & 5.4685 & 5.0437 & TRN & \\
\hline CHEMBL 3354585 & 1451733 & 4.0 & 3.6211 & TRN & \\
\hline CHEMBL3354588 & 1451733 & 5.8539 & 5.532 & TRN & \\
\hline CHEMBL3353956 & 1451733 & 5.9208 & 5.7988 & TRN & \\
\hline CHEMBL3354576 & 1451733 & 6.0044 & 5.4536 & TRN & \\
\hline CHEMBL3353937 & 1451733 & 5.8539 & 5.0507 & TST & \\
\hline CHEMBL3353945 & 1451733 & 5.7212 & 5.4857 & TRN & \\
\hline CHEMBL3354591 & 1451733 & 4.0 & 4.9895 & TRN & \\
\hline CHEMBL3353949 & 1451733 & 6.0132 & 5.403 & TRN & \\
\hline CHEMBL3353942 & 1451733 & 5.7447 & 5.3758 & TRN & \\
\hline CHEMBL3354570 & 1451733 & 6.4089 & 5.6403 & TRN & \\
\hline CHEMBL3353936 & 1451733 & 7.2596 & 4.5864 & TST & \\
\hline CHEMBL3354572 & 1451733 & 5.8239 & 5.3334 & TST & \\
\hline CHEMBL439044 & 1451733 & 4.0 & 4.3515 & TST & \\
\hline CHEMBL3354590 & 1451733 & 5.7959 & 5.6406 & TRN & \\
\hline CHEMBL3353947 & 1451733 & 5.8539 & 5.1697 & TRN & \\
\hline CHEMBL3354592 & 1451733 & 4.0 & 4.3844 & TRN & \\
\hline CHEMBL3354575 & 1451733 & 4.0 & 5.3313 & TRN & \\
\hline CHEMBL3354601 & 1451733 & 6.4202 & 5.8396 & TRN & \\
\hline CHEMBL3353944 & 1451733 & 4.0 & 5.5686 & TRN & \\
\hline CHEMBL3354587 & 1451733 & 4.0 & 4.6962 & TRN & \\
\hline CHEMBL3354600 & 1451733 & 5.6778 & 5.7492 & TRN & \\
\hline
\end{tabular}

Page 19626 
Supplemental Table S2.txt

\begin{tabular}{|c|c|c|c|c|}
\hline AEMBL3353934 & 1451733 & 6.1739 & 421 & \\
\hline & 451733 & 4.0 & 4.9761 & \\
\hline EMPI & 1733 & 6.4815 & & \\
\hline IEMBL 3353933 & 451733 & 5.8861 & & \\
\hline AEMBL 3354582 & 451733 & 4.0 & 607 & \\
\hline 353946 & 733 & 4.0 & 683 & \\
\hline 96 & 733 & 5.8861 & & \\
\hline AEMBL & & 4.0 & & \\
\hline AEMBL3353939 & 733 & 4.0 & & \\
\hline AEMBL3354595 & 733 & 4.0 & & \\
\hline 54594 & & & & \\
\hline 54602 & & $5 . c$ & & \\
\hline 53930 & & 4.0 & & \\
\hline AEMBL3354573 & & 5.8861 & 969 & \\
\hline 54584 & & & & \\
\hline 53948 & & $6.6-x)+1$ & & \\
\hline 54593 & & 6. & & \\
\hline 54589 & & 4.0 & & \\
\hline IEMBL1271738 & 2 & 4.0 & & \\
\hline 71525 & & & & \\
\hline 3 & 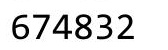 & 4. & & \\
\hline 79 & & 4. & & \\
\hline 72080 & & 4.0 & & \\
\hline 71741 & & 4. & & \\
\hline 71580 & & & & \\
\hline 69043 & & 5 . & & \\
\hline 5 & & 4. & & \\
\hline 969 & & & & \\
\hline 271856 & & 4. & & \\
\hline 272293 & & 4. & & \\
\hline & & & & \\
\hline 8 & & 7. & & \\
\hline 34 & & 4. & & \\
\hline & & & & $\mathrm{TR}$ \\
\hline CHEMBL1271800 & & & & \\
\hline & & & & \\
\hline $\mathrm{CH}$ & & 4. & & \\
\hline 72292 & & 4. & & \\
\hline CHEMBL1272023 & & 7.82 & & $\mathrm{R}$ \\
\hline 739 & & 4. & & \\
\hline $\mathrm{CH}$ & & 4. & & \\
\hline CHEMBL: & & 5. & 5 . & \\
\hline CHEMBL & & 7.0044 & & \\
\hline CHEMBL1269064 & & 4. & & R \\
\hline ס & & 4. & 71 & \\
\hline $\mathrm{CH}$ & & & & \\
\hline CHEMBL1271799 & 674832 & 4.0 & 3.7151 & \\
\hline CHEMBL1271911 & 674832 & 4.0 & 3.7259 & \\
\hline
\end{tabular}

Page 19627 


\begin{tabular}{|c|c|c|c|c|c|}
\hline & & \multicolumn{4}{|c|}{ Supplemental Table S2.txt } \\
\hline CHEMBL1272082 & 674832 & 7.2366 & 7.2939 & TRN & \\
\hline CHEMBL1269063 & 674832 & 4.0 & 4.2165 & TRN & \\
\hline CHEMBL1272026 & 674832 & 5.4799 & 5.9911 & TST & \\
\hline CHEMBL1271798 & 674832 & 4.0 & 4.1122 & TRN & \\
\hline CHEMBL1272129 & 674832 & 7.4437 & 7.5377 & TRN & \\
\hline CHEMBL1272130 & 674832 & 7.1871 & 7.1421 & TRN & \\
\hline CHEMBL1271579 & 674832 & 4.0 & 4.6813 & TRN & \\
\hline CHEMBL1272024 & 674832 & 7.1079 & 5.8127 & TRN & \\
\hline CHEMBL1272184 & 674832 & 7.1427 & 7.12299 & 9999999999 & TRN \\
\hline CHEMBL1271970 & 674832 & 6.8416 & 6.0179 & TST & \\
\hline CHEMBL1271737 & 674832 & 6.699 & 6.8607 & TRN & \\
\hline CHEMBL1272131 & 674832 & 5.0 & 5.3928 & TRN & \\
\hline CHEMBL1269807 & 674832 & 6.0706 & 5.7991 & TRN & \\
\hline CHEMBL1271913 & 674832 & 7.1938 & 7.4717 & TST & \\
\hline CHEMBL1271740 & 674832 & 6.0726 & 6.2427 & TST & \\
\hline CHEMBL1272081 & 674832 & 4.0 & 3.9996 & TST & \\
\hline CHEMBL1272027 & 674832 & 4.0 & 3.6045 & TST & \\
\hline CHEMBL1269065 & 674832 & 4.0 & 3.7606 & TST & \\
\hline CHEMBL1271854 & 674832 & 4.0 & 3.8945 & TST & \\
\hline CHEMBL1271685 & 674832 & 4.0 & 4.1948 & TST & \\
\hline CHEMBL1271912 & 674832 & 6.8794 & 6.7402 & TRN & \\
\hline CHEMBL1272239 & 674832 & 6.7747 & 6.5392 & TRN & \\
\hline CHEMBL1271857 & 674832 & 4.0 & 4.7591 & TST & \\
\hline CHEMBL1386731 & 688497 & 4.95 & 5.4945 & TRN & \\
\hline CHEMBL1374684 & 688497 & 5.25 & 4.9142 & TRN & \\
\hline CHEMBL 3210024 & 688497 & 4.85 & 5.1834 & TST & \\
\hline CHEMBL1381243 & 688497 & 4.45 & 4.6873 & TRN & \\
\hline CHEMBL1540861 & 688497 & 4.45 & 4.936 & TRN & \\
\hline CHEMBL1534666 & 688497 & 5.5 & 4.966 & TRN & \\
\hline CHEMBL1416408 & 688497 & 6.05 & 4.9715 & TRN & \\
\hline CHEMBL601119 & 688497 & 4.8 & 5.1577 & TRN & \\
\hline CHEMBL 3198075 & 688497 & 4.45 & 4.8924 & TRN & \\
\hline CHEMBL1409680 & 688497 & 4.45 & 4.7428 & TRN & \\
\hline CHEMBL1577745 & 688497 & 4.7 & 5.0323 & TRN & \\
\hline CHEMBL1457796 & 688497 & 5.6 & 4.8564 & TST & \\
\hline CHEMBL44664 & 688497 & 4.45 & 4.8702 & TRN & \\
\hline CHEMBL1600361 & 688497 & 5.6 & 5.4686 & TST & \\
\hline CHEMBL1565292 & 688497 & 5.55 & 5.2491 & TRN & \\
\hline CHEMBL1351746 & 688497 & 4.7 & 4.9526 & TRN & \\
\hline CHEMBL1550383 & 688497 & 5.4 & 5.1869 & TRN & \\
\hline CHEMBL1300319 & 688497 & 5.05 & 5.0305 & TRN & \\
\hline CHEMBL1305450 & 688497 & 4.45 & 5.1333 & TRN & \\
\hline CHEMBL1431172 & 688497 & 4.6 & 4.9118 & TST & \\
\hline CHEMBL1380986 & 688497 & 5.25 & 5.1696 & TST & \\
\hline CHEMBL1500138 & 688497 & 4.55 & 4.9542 & TRN & \\
\hline CHEMBL1458314 & 688497 & 5.55 & 5.2028 & TRN & \\
\hline CHEMBL1545719 & 688497 & 4.6 & 4.9476 & TRN & \\
\hline CHEMBL1588352 & 688497 & 4.5 & 4.7276 & TRN & \\
\hline
\end{tabular}




\begin{tabular}{|c|c|c|c|c|}
\hline \multicolumn{5}{|c|}{ Supplemental Table S2.txt } \\
\hline CHEMBL1461196 & 688497 & 7.6003 & 5.2648 & TRN \\
\hline CHEMBL1491238 & 688497 & 4.45 & 4.7162 & TRN \\
\hline CHEMBL1389514 & 688497 & 4.95 & 4.7548 & TRN \\
\hline CHEMBL1612518 & 688497 & 4.8 & 4.9169 & TST \\
\hline CHEMBL1307516 & 688497 & 4.95 & 5.0591 & TRN \\
\hline CHEMBL1557357 & 688497 & 4.7 & 5.0797 & TST \\
\hline CHEMBL1319623 & 688497 & 4.45 & 4.7952 & TRN \\
\hline CHEMBL1567335 & 688497 & 4.85 & 5.02 & TRN \\
\hline CHEMBL1524678 & 688497 & 4.45 & 4.7459 & TST \\
\hline CHEMBL526034 & 688497 & 5.35 & 4.9336 & TST \\
\hline CHEMBL 3145070 & 688497 & 4.45 & 5.0727 & TST \\
\hline CHEMBL1354019 & 688497 & 4.75 & 4.6235 & TRN \\
\hline CHEMBL1332366 & 688497 & 4.8 & 4.9888 & TRN \\
\hline CHEMBL1576308 & 688497 & 5.4 & 4.8473 & TRN \\
\hline CHEMBL1383587 & 688497 & 5.45 & 5.0849 & TST \\
\hline CHEMBL1485078 & 688497 & 4.5 & 5.2919 & TRN \\
\hline CHEMBL1386211 & 688497 & 4.45 & 5.1035 & TST \\
\hline CHEMBL1409316 & 688497 & 4.45 & 5.1634 & TRN \\
\hline CHEMBL1360235 & 688497 & 5.1 & 5.2694 & TRN \\
\hline CHEMBL1564492 & 688497 & 4.85 & 5.4926 & TRN \\
\hline CHEMBL1430400 & 688497 & 4.9 & 4.9748 & TRN \\
\hline CHEMBL1400896 & 688497 & 4.8 & 4.9773 & TST \\
\hline CHEMBL1306902 & 688497 & 5.25 & 5.5439 & TRN \\
\hline CHEMBL1415311 & 688497 & 5.25 & 4.9911 & TST \\
\hline CHEMBL493506 & 688497 & 4.75 & 4.8537 & TRN \\
\hline CHEMBL3192837 & 688497 & 5.0 & 4.7229 & TRN \\
\hline CHEMBL1558699 & 688497 & 4.75 & 5.1969 & TRN \\
\hline CHEMBL1415308 & 688497 & 4.8 & 4.8119 & TRN \\
\hline CHEMBL1460452 & 688497 & 5.9 & 5.2277 & TRN \\
\hline CHEMBL3197433 & 688497 & 5.95 & 5.0945 & TRN \\
\hline CHEMBL1424676 & 688497 & 7.0501 & 5.3388 & TRN \\
\hline CHEMBL1491246 & 688497 & 4.75 & 5.075 & TRN \\
\hline CHEMBL1471155 & 688497 & 5.75 & 5.1348 & TRN \\
\hline CHEMBL1332559 & 688497 & 4.95 & 5.0257 & TRN \\
\hline CHEMBL1299402 & 688497 & 6.05 & 5.2982 & TRN \\
\hline CHEMBL1489835 & 688497 & 4.45 & 4.6887 & TRN \\
\hline CHEMBL1441677 & 688497 & 4.45 & 4.8062 & TRN \\
\hline CHEMBL1508612 & 688497 & 5.2 & 5.278 & TRN \\
\hline CHEMBL1525780 & 688497 & 4.55 & 4.8884 & TRN \\
\hline CHEMBL1540513 & 688497 & 4.45 & 4.8333 & TRN \\
\hline CHEMBL1326188 & 688497 & 4.7 & 5.0976 & TRN \\
\hline CHEMBL1393034 & 688497 & 4.45 & 5.2087 & TRN \\
\hline CHEMBL1538674 & 688497 & 4.7 & 5.0181 & TRN \\
\hline CHEMBL1510664 & 688497 & 4.45 & 4.8084 & TRN \\
\hline CHEMBL1413367 & 688497 & 5.2 & 4.9756 & TRN \\
\hline CHEMBL1547834 & 688497 & 4.5 & 5.4086 & TRN \\
\hline CHEMBL1360574 & 688497 & 5.9 & 5.23799 & 99999999995 \\
\hline CHEMBL1598231 & 688497 & 4.55 & 5.3584 & TRN \\
\hline
\end{tabular}




\begin{tabular}{|c|c|c|c|c|c|}
\hline \multicolumn{6}{|c|}{ Supplemental Table S2.txt } \\
\hline CHEMBL1303998 & 688497 & 5.5 & 5.5031 & TRN & \\
\hline CHEMBL1503208 & 688497 & 4.75 & 4.9972 & TRN & \\
\hline CHEMBL1362256 & 688497 & 4.55 & 4.8609 & TRN & \\
\hline CHEMBL1326231 & 688497 & 5.55 & 5.0379 & TST & \\
\hline CHEMBL1209369 & 688497 & 5.15 & 5.0882 & TRN & \\
\hline CHEMBL3190346 & 688497 & 5.25 & 4.8781 & TRN & \\
\hline CHEMBL1600937 & 688497 & 4.45 & 4.7788 & TRN & \\
\hline CHEMBL3192292 & 688497 & 5.75 & 5.1356 & TRN & \\
\hline CHEMBL1430772 & 688497 & 4.45 & 4.9959 & TST & \\
\hline CHEMBL1577367 & 688497 & 4.95 & 5.0299 & TRN & \\
\hline CHEMBL1309711 & 688497 & 4.45 & 5.2593 & TRN & \\
\hline CHEMBL1432331 & 688497 & 5.25 & 5.3682 & TRN & \\
\hline CHEMBL1587301 & 688497 & 4.5 & 4.8991 & TRN & \\
\hline CHEMBL1385157 & 688497 & 5.5 & 5.0415 & TST & \\
\hline CHEMBL1605435 & 688497 & 4.9 & 4.9428 & TST & \\
\hline CHEMBL1240787 & 688497 & 4.9 & 5.1322 & TST & \\
\hline CHEMBL1494505 & 688497 & 4.6 & 4.9401 & TRN & \\
\hline CHEMBL1304363 & 688497 & 6.05 & 5.1413 & TRN & \\
\hline CHEMBL1390389 & 688497 & 4.45 & 4.9156 & TST & \\
\hline CHEMBL1535191 & 688497 & 7.5003 & 5.10800 & 00000000005 & TST \\
\hline CHEMBL1519428 & 688497 & 5.4 & 5.0817 & TRN & \\
\hline CHEMBL1449858 & 688497 & 5.5 & 5.4516 & TRN & \\
\hline CHEMBL1440005 & 688497 & 5.0 & 5.0943 & TRN & \\
\hline CHEMBL1600767 & 688497 & 4.45 & 4.9049 & TST & \\
\hline CHEMBL 3039774 & 688497 & 5.5 & 5.6014 & TRN & \\
\hline CHEMBL1564201 & 688497 & 4.45 & 5.0852 & TRN & \\
\hline CHEMBL1438438 & 688497 & 4.45 & 5.0876 & TRN & \\
\hline CHEMBL1444764 & 688497 & 5.35 & 5.1646 & TRN & \\
\hline CHEMBL1381668 & 688497 & 4.6 & 4.7698 & TRN & \\
\hline CHEMBL3198496 & 688497 & 5.05 & 5.0979 & TRN & \\
\hline CHEMBL1559375 & 688497 & 4.75 & 4.9574 & TRN & \\
\hline CHEMBL1500190 & 688497 & 5.1 & 5.07 & TRN & \\
\hline CHEMBL1365533 & 688497 & 4.7 & 4.5781 & TRN & \\
\hline CHEMBL1384298 & 688497 & 4.8 & 4.6703 & TST & \\
\hline CHEMBL1519220 & 688497 & 4.9 & 4.5955 & TRN & \\
\hline CHEMBL1393727 & 688497 & 5.25 & 5.1957 & TRN & \\
\hline CHEMBL1542543 & 688497 & 4.6 & 5.182 & TRN & \\
\hline CHEMBL1401101 & 688497 & 4.8 & 4.8331 & TRN & \\
\hline CHEMBL1527817 & 688497 & 5.0 & 4.7741 & TRN & \\
\hline CHEMBL1523537 & 688497 & 4.95 & 4.9983 & TRN & \\
\hline CHEMBL1424479 & 688497 & 4.95 & 4.7667 & TRN & \\
\hline CHEMBL1353790 & 688497 & 4.9 & 5.4495 & TRN & \\
\hline CHEMBL1465290 & 688497 & 5.0 & 4.6256 & TRN & \\
\hline CHEMBL1560695 & 688497 & 4.45 & 5.1128 & TRN & \\
\hline CHEMBL1369724 & 688497 & 4.45 & 4.7516 & TRN & \\
\hline CHEMBL1493464 & 688497 & 4.45 & 5.1626 & TRN & \\
\hline CHEMBL1501913 & 688497 & 5.4 & 5.1086 & TRN & \\
\hline CHEMBL1487823 & 688497 & 4.45 & 4.8859 & TST & \\
\hline
\end{tabular}




\begin{tabular}{|c|c|c|c|c|c|}
\hline \multicolumn{6}{|c|}{ Supplemental Table S2.txt } \\
\hline CHEMBL1562795 & 688497 & 4.65 & 5.1787 & TST & \\
\hline CHEMBL1485494 & 688497 & 4.45 & 5.0688 & TST & \\
\hline CHEMBL3191224 & 688497 & 5.75 & 4.8828 & TST & \\
\hline CHEMBL1602802 & 688497 & 4.45 & 4.6815 & TRN & \\
\hline CHEMBL3199844 & 688497 & 4.45 & 5.1262 & TST & \\
\hline CHEMBL1503387 & 688497 & 4.45 & 4.4478 & TRN & \\
\hline CHEMBL585221 & 688497 & 4.6 & 4.9518 & TST & \\
\hline CHEMBL1441181 & 688497 & 4.55 & 4.8656 & TRN & \\
\hline CHEMBL1303288 & 688497 & 5.2 & 5.3021 & TST & \\
\hline CHEMBL1310438 & 688497 & 5.05 & 4.8492 & TRN & \\
\hline CHEMBL1486921 & 688497 & 4.6 & 5.0642 & TRN & \\
\hline CHEMBL3192969 & 688497 & 4.9 & 5.1128 & TRN & \\
\hline CHEMBL1566737 & 688497 & 5.0 & 4.9518 & TRN & \\
\hline CHEMBL1568114 & 688497 & 5.25 & 5.0846 & TRN & \\
\hline CHEMBL1412716 & 688497 & 7.0501 & 5.0972 & TRN & \\
\hline CHEMBL1309868 & 688497 & 4.8 & 4.9946 & TRN & \\
\hline CHEMBL1443827 & 688497 & 4.45 & 5.058 & TRN & \\
\hline CHEMBL1310536 & 688497 & 4.45 & 5.0911 & TRN & \\
\hline CHEMBL1967081 & 688497 & 5.85 & 5.09399 & 9999999999 & TRN \\
\hline CHEMBL1610903 & 688497 & 4.85 & 5.0108 & TRN & \\
\hline CHEMBL3194675 & 688497 & 4.45 & 5.0652 & TRN & \\
\hline CHEMBL1483976 & 688497 & 5.55 & 5.1661 & TST & \\
\hline CHEMBL3210295 & 688497 & 4.45 & 5.0267 & TRN & \\
\hline CHEMBL1398840 & 688497 & 5.6 & 5.1038 & TRN & \\
\hline CHEMBL1561991 & 688497 & 5.0 & 4.9218 & TRN & \\
\hline CHEMBL1321278 & 688497 & 5.45 & 4.7403 & TRN & \\
\hline CHEMBL1539180 & 688497 & 4.45 & 4.7921 & TRN & \\
\hline CHEMBL1522635 & 688497 & 4.65 & 5.3036 & TRN & \\
\hline CHEMBL568092 & 688497 & 5.65 & 5.4323 & TRN & \\
\hline CHEMBL1491257 & 688497 & 5.1 & 5.0033 & TRN & \\
\hline CHEMBL1400875 & 688497 & 4.7 & 5.3843 & TST & \\
\hline CHEMBL1312716 & 688497 & 4.45 & 5.1039 & TRN & \\
\hline CHEMBL1572923 & 688497 & 4.6 & 4.9148 & TRN & \\
\hline CHEMBL1413642 & 688497 & 4.85 & 4.879 & TRN & \\
\hline CHEMBL1338774 & 688497 & 4.45 & 4.9143 & TRN & \\
\hline CHEMBL1503110 & 688497 & 4.6 & 4.7438 & TRN & \\
\hline CHEMBL1384465 & 688497 & 4.6 & 4.7828 & TST & \\
\hline CHEMBL1582999 & 688497 & 4.65 & 4.9896 & TRN & \\
\hline CHEMBL1380046 & 688497 & 4.5 & 4.8018 & TRN & \\
\hline CHEMBL3193700 & 688497 & 4.45 & 4.8242 & TRN & \\
\hline CHEMBL1572134 & 688497 & 4.9 & 4.6877 & TRN & \\
\hline CHEMBL1566645 & 688497 & 4.6 & 4.7777 & TST & \\
\hline CHEMBL1463373 & 688497 & 5.5 & 4.7886 & TST & \\
\hline CHEMBL1373171 & 688497 & 5.45 & 4.9877 & TST & \\
\hline CHEMBL1492907 & 688497 & 6.4 & 5.1508 & TRN & \\
\hline CHEMBL3145281 & 688497 & 5.05 & 4.9348 & TST & \\
\hline CHEMBL1429330 & 688497 & 4.9 & 4.9019 & TRN & \\
\hline CHEMBL1560235 & 688497 & 4.45 & 5.0835 & TRN & \\
\hline
\end{tabular}




\begin{tabular}{|c|c|c|c|c|c|}
\hline \\
\hline CHEMBL1563724 & 688497 & 5.2 & 4.8017 & TRN & \\
\hline CHEMBL1310672 & 688497 & 4.45 & 4.9862 & TST & \\
\hline CHEMBL598680 & 688497 & 4.5 & 5.1914 & TRN & \\
\hline CHEMBL3198114 & 688497 & 4.9 & 4.7269 & TRN & \\
\hline CHEMBL1402500 & 688497 & 7.5003 & 5.3077 & TST & \\
\hline CHEMBL1469529 & 688497 & 5.05 & 4.8105 & TST & \\
\hline CHEMBL1439063 & 688497 & 4.45 & 5.2214 & TRN & \\
\hline CHEMBL1964464 & 688497 & 5.5 & 5.1889 & TRN & \\
\hline CHEMBL1481611 & 688497 & 5.2 & 5.2028 & TST & \\
\hline CHEMBL1904459 & 688497 & 5.55 & 5.1401 & TRN & \\
\hline CHEMBL1567857 & 688497 & 5.05 & 5.1329 & TRN & \\
\hline CHEMBL1574544 & 688497 & 4.45 & 4.8382 & TST & \\
\hline CHEMBL1537418 & 688497 & 6.25 & 5.0022 & TRN & \\
\hline CHEMBL1443590 & 688497 & 5.0 & 5.1846 & TRN & \\
\hline CHEMBL1422308 & 688497 & 5.1 & 4.7781 & TST & \\
\hline CHEMBL1430790 & 688497 & 4.45 & 4.8204 & TST & \\
\hline CHEMBL1519602 & 688497 & 4.45 & 4.8433 & TST & \\
\hline CHEMBL1968580 & 688497 & 5.25 & 5.1163 & TRN & \\
\hline CHEMBL1540280 & 688497 & 4.45 & 5.1426 & TRN & \\
\hline CHEMBL1544342 & 688497 & 4.45 & 4.9154 & TRN & \\
\hline CHEMBL1567111 & 688497 & 5.9 & 5.1407 & TRN & \\
\hline CHEMBL1405855 & 688497 & 5.75 & 5.0203 & TRN & \\
\hline CHEMBL1467082 & 688497 & 4.45 & 4.7571 & TRN & \\
\hline CHEMBL1411547 & 688497 & 5.15 & 5.1298 & TRN & \\
\hline CHEMBL1424069 & 688497 & 4.45 & 4.72199 & 99999999995 & TRN \\
\hline CHEMBL1332887 & 688497 & 4.9 & 5.0771 & TRN & \\
\hline CHEMBL1312208 & 688497 & 4.45 & 4.7659 & TST & \\
\hline CHEMBL1537791 & 688497 & 6.95 & 4.8988 & TST & \\
\hline CHEMBL1608453 & 688497 & 4.6 & 5.1521 & TRN & \\
\hline CHEMBL1390089 & 688497 & 5.9 & 5.0977 & TST & \\
\hline CHEMBL1470304 & 688497 & 4.45 & 4.9816 & TST & \\
\hline CHEMBL1360361 & 688497 & 6.0 & 5.4491 & TST & \\
\hline CHEMBL1454194 & 688497 & 4.45 & 4.9905 & TRN & \\
\hline CHEMBL1538196 & 688497 & 5.25 & 5.1785 & TRN & \\
\hline CHEMBL1562534 & 688497 & 4.9 & 5.3207 & TST & \\
\hline CHEMBL1378045 & 688497 & 4.45 & 4.8476 & TRN & \\
\hline CHEMBL1432787 & 688497 & 4.55 & 4.5381 & TRN & \\
\hline CHEMBL1567331 & 688497 & 6.15 & 5.0884 & TRN & \\
\hline CHEMBL1365201 & 688497 & 4.75 & 4.8772 & TRN & \\
\hline CHEMBL1581221 & 688497 & 4.95 & 5.0996 & TRN & \\
\hline CHEMBL1419585 & 688497 & 4.45 & 4.6948 & TST & \\
\hline CHEMBL1373533 & 688497 & 4.9 & 5.1562 & TRN & \\
\hline CHEMBL1511274 & 688497 & 5.25 & 4.7729 & TRN & \\
\hline CHEMBL1452140 & 688497 & 4.45 & 5.1698 & TRN & \\
\hline CHEMBL1349832 & 688497 & 4.9 & 5.1451 & TRN & \\
\hline CHEMBL1608090 & 688497 & 4.7 & 4.7754 & TRN & \\
\hline CHEMBL1420047 & 688497 & 4.45 & 5.2219 & TRN & \\
\hline CHEMBL1467512 & 688497 & 6.05 & 5.2222 & TRN & \\
\hline
\end{tabular}




\begin{tabular}{|c|c|c|c|c|c|}
\hline \\
\hline CHEMBL1585062 & 688497 & 4.8 & 4.8165 & TRN & \\
\hline CHEMBL1444031 & 688497 & 5.1 & 5.3274 & TRN & \\
\hline CHEMBL1481739 & 688497 & 4.9 & 5.0648 & TRN & \\
\hline CHEMBL1597807 & 688497 & 6.25 & 5.0069 & TST & \\
\hline CHEMBL1558218 & 688497 & 4.65 & 4.8546 & TRN & \\
\hline CHEMBL1539883 & 688497 & 5.9 & 5.2866 & TRN & \\
\hline CHEMBL1586023 & 688497 & 4.45 & 5.114 & TST & \\
\hline CHEMBL1594802 & 688497 & 4.95 & 4.8541 & TRN & \\
\hline CHEMBL1346995 & 688497 & 4.8 & 4.8209 & TRN & \\
\hline CHEMBL1476181 & 688497 & 4.45 & 4.8633 & TRN & \\
\hline CHEMBL90181 & 688497 & 4.95 & 5.188 & TST & \\
\hline CHEMBL1336537 & 688497 & 5.25 & 5.2056 & TRN & \\
\hline CHEMBL1431941 & 688497 & 5.1 & 5.0966 & TRN & \\
\hline CHEMBL224869 & 688497 & 5.1 & 4.8416 & TRN & \\
\hline CHEMBL1379545 & 688497 & 4.45 & 4.8536 & TST & \\
\hline CHEMBL1578375 & 688497 & 5.5 & 5.195 & TRN & \\
\hline CHEMBL1325176 & 688497 & 5.55 & 5.3077 & TRN & \\
\hline CHEMBL1392116 & 688497 & 4.55 & 4.69600 & $\partial 000000001$ & TRN \\
\hline CHEMBL1529772 & 688497 & 4.95 & 4.8163 & TRN & \\
\hline CHEMBL1313294 & 688497 & 4.9 & 5.1538 & TRN & \\
\hline CHEMBL1304478 & 688497 & 4.6 & 4.7495 & TRN & \\
\hline CHEMBL1304162 & 688497 & 4.45 & 4.872 & TRN & \\
\hline CHEMBL1382146 & 688497 & 4.45 & 5.03 & TST & \\
\hline CHEMBL1341544 & 688497 & 4.45 & 4.9034 & TRN & \\
\hline CHEMBL1540009 & 688497 & 4.45 & 4.9191 & TRN & \\
\hline CHEMBL1463041 & 688497 & 4.45 & 4.9493 & TST & \\
\hline CHEMBL1421544 & 688497 & 4.6 & 4.8586 & TRN & \\
\hline CHEMBL1589768 & 688497 & 4.45 & 4.8538 & TRN & \\
\hline CHEMBL1346720 & 688497 & 6.3 & 4.8767 & TRN & \\
\hline CHEMBL1424441 & 688497 & 4.45 & 4.8441 & TRN & \\
\hline CHEMBL1584533 & 688497 & 4.45 & 5.5068 & TRN & \\
\hline CHEMBL1560925 & 688497 & 4.9 & 4.8874 & TST & \\
\hline CHEMBL1338889 & 688497 & 5.1 & 4.9181 & TRN & \\
\hline CHEMBL1557790 & 688497 & 4.8 & 4.7131 & TRN & \\
\hline CHEMBL1471701 & 688497 & 5.55 & 4.9791 & TRN & \\
\hline CHEMBL1544050 & 688497 & 4.45 & 4.9124 & TRN & \\
\hline CHEMBL1575590 & 688497 & 4.45 & 4.7858 & TRN & \\
\hline CHEMBL1413208 & 688497 & 4.5 & 4.9905 & TST & \\
\hline CHEMBL1467557 & 688497 & 5.45 & 5.1131 & TRN & \\
\hline CHEMBL3192181 & 688497 & 5.45 & 5.3951 & TRN & \\
\hline CHEMBL1482275 & 688497 & 5.5 & 5.1166 & TRN & \\
\hline CHEMBL1343219 & 688497 & 4.45 & 5.0497 & TST & \\
\hline CHEMBL1385952 & 688497 & 6.05 & 4.8127 & TST & \\
\hline CHEMBL1481132 & 688497 & 4.45 & 5.0847 & TRN & \\
\hline CHEMBL1598910 & 688497 & 4.45 & 4.99100 & 00000000005 & TST \\
\hline CHEMBL1583535 & 688497 & 4.95 & 5.0289 & TST & \\
\hline CHEMBL1311206 & 688497 & 6.0 & 5.0466 & TRN & \\
\hline CHEMBL1540541 & 688497 & 4.9 & 4.9313 & TRN & \\
\hline
\end{tabular}




\begin{tabular}{|c|c|c|c|c|c|}
\hline & & & & & \\
\hline CHEMBL1550449 & 688497 & 5.5 & 4.9488 & TST & \\
\hline CHEMBL3199555 & 688497 & 4.45 & 4.9216 & TRN & \\
\hline CHEMBL1608132 & 688497 & 5.1 & 5.2595 & TRN & \\
\hline CHEMBL1341672 & 688497 & 4.85 & 5.3176 & TST & \\
\hline CHEMBL1568002 & 688497 & 5.5 & 5.1644 & TST & \\
\hline CHEMBL1463564 & 688497 & 4.5 & 4.6518 & TRN & \\
\hline CHEMBL1429813 & 688497 & 5.4 & 5.2652 & TST & \\
\hline CHEMBL1322295 & 688497 & 5.85 & 5.10800 & 00000000005 & TRN \\
\hline CHEMBL1366446 & 688497 & 4.45 & 4.9185 & TRN & \\
\hline CHEMBL1566136 & 688497 & 4.75 & 4.5754 & TST & \\
\hline CHEMBL1523832 & 688497 & 7.5003 & 5.4311 & TST & \\
\hline CHEMBL1342917 & 688497 & 5.5 & 5.2617 & TST & \\
\hline CHEMBL1547278 & 688497 & 4.65 & 4.6125 & TST & \\
\hline CHEMBL1585457 & 688497 & 4.45 & 5.0321 & TRN & \\
\hline CHEMBL1580303 & 688497 & 4.45 & 5.0957 & TRN & \\
\hline CHEMBL1407258 & 688497 & 5.1 & 4.9558 & TRN & \\
\hline CHEMBL3194091 & 688497 & 5.0 & 4.8734 & TRN & \\
\hline CHEMBL3189995 & 688497 & 4.45 & 4.9261 & TRN & \\
\hline CHEMBL1442271 & 688497 & 4.45 & 5.3273 & TST & \\
\hline CHEMBL1986889 & 688497 & 5.4 & 4.9919 & TRN & \\
\hline CHEMBL1530583 & 688497 & 4.95 & 5.1198 & TRN & \\
\hline CHEMBL1516388 & 688497 & 4.9 & 5.3944 & TST & \\
\hline CHEMBL1583645 & 688497 & 6.2 & 4.9613 & TRN & \\
\hline CHEMBL1463920 & 688497 & 4.5 & 4.8913 & TST & \\
\hline CHEMBL1413713 & 688497 & 4.65 & 5.0457 & TRN & \\
\hline CHEMBL1581809 & 688497 & 5.2 & 5.1108 & TRN & \\
\hline CHEMBL1575542 & 688497 & 4.45 & 5.3369 & TRN & \\
\hline CHEMBL1313231 & 688497 & 4.95 & 5.3655 & TST & \\
\hline CHEMBL1326527 & 688497 & 4.9 & 4.7039 & TRN & \\
\hline CHEMBL1340792 & 688497 & 4.45 & 4.6426 & TST & \\
\hline CHEMBL1609327 & 688497 & 4.7 & 5.1696 & TST & \\
\hline CHEMBL1348188 & 688497 & 4.95 & 5.0892 & TRN & \\
\hline CHEMBL1486359 & 688497 & 4.6 & 5.1668 & TST & \\
\hline CHEMBL1469855 & 688497 & 6.2 & 4.7197 & TST & \\
\hline CHEMBL1547645 & 688497 & 4.9 & 4.9472 & TRN & \\
\hline CHEMBL1351948 & 688497 & 5.45 & 5.2758 & TRN & \\
\hline CHEMBL1460352 & 688497 & 5.55 & 5.1279 & TRN & \\
\hline CHEMBL1885024 & 688497 & 5.25 & 4.7622 & TRN & \\
\hline CHEMBL1534349 & 688497 & 6.25 & 4.9741 & TST & \\
\hline CHEMBL1401330 & 688497 & 4.65 & 4.8003 & TST & \\
\hline CHEMBL1605179 & 688497 & 5.45 & 5.0443 & TRN & \\
\hline CHEMBL1533597 & 688497 & 4.45 & 5.0755 & TRN & \\
\hline CHEMBL1353130 & 688497 & 4.9 & 4.7612 & TRN & \\
\hline CHEMBL1986773 & 688497 & 6.15 & 5.2705 & TRN & \\
\hline CHEMBL468341 & 688497 & 4.45 & 5.1057 & TST & \\
\hline CHEMBL3210469 & 688497 & 6.2 & 4.8989 & TRN & \\
\hline CHEMBL3191071 & 688497 & 5.1 & 5.1861 & TRN & \\
\hline CHEMBL1491855 & 688497 & 4.45 & 5.1322 & TST & \\
\hline
\end{tabular}




\begin{tabular}{|c|c|c|c|c|c|}
\hline \multicolumn{6}{|c|}{ Supplemental Table s2.txt } \\
\hline CHEMBL1573504 & 688497 & 5.0 & 4.8865 & TRN & \\
\hline CHEMBL1416235 & 688497 & 4.95 & 4.8758 & TRN & \\
\hline CHEMBL1378744 & 688497 & 5.0 & 4.7869 & TRN & \\
\hline CHEMBL1426812 & 688497 & 5.1 & 5.1358 & TRN & \\
\hline CHEMBL1390928 & 688497 & 4.9 & 4.9327 & TST & \\
\hline CHEMBL1406070 & 688497 & 4.45 & 4.9174 & TRN & \\
\hline CHEMBL1309611 & 688497 & 6.25 & 5.1433 & TRN & \\
\hline CHEMBL1582382 & 688497 & 4.8 & 4.9286 & TRN & \\
\hline CHEMBL1348199 & 688497 & 4.95 & 5.1031 & TST & \\
\hline CHEMBL1489504 & 688497 & 5.25 & 5.0813 & TRN & \\
\hline CHEMBL1349329 & 688497 & 4.95 & 5.0278 & TRN & \\
\hline CHEMBL1428258 & 688497 & 4.65 & 5.3084 & TST & \\
\hline CHEMBL1321931 & 688497 & 4.45 & 5.3434 & TRN & \\
\hline CHEMBL1997716 & 688497 & 4.45 & 5.3052 & TRN & \\
\hline CHEMBL1502397 & 688497 & 4.75 & 4.7295 & TRN & \\
\hline CHEMBL1600216 & 688497 & 5.95 & 5.2741 & TRN & \\
\hline CHEMBL1560955 & 688497 & 4.75 & 4.945 & TRN & \\
\hline CHEMBL1306574 & 688497 & 4.95 & 4.8499 & TRN & \\
\hline CHEMBL1550545 & 688497 & 4.8 & 5.0571 & TRN & \\
\hline CHEMBL1415330 & 688497 & 6.05 & 5.13200 & 0000000001 & TST \\
\hline CHEMBL1598004 & 688497 & 5.05 & 5.6301 & TST & \\
\hline CHEMBL1341236 & 688497 & 5.4 & 5.0365 & TST & \\
\hline CHEMBL1300136 & 688497 & 4.45 & 4.8918 & TRN & \\
\hline CHEMBL1300219 & 688497 & 5.35 & 5.3415 & TRN & \\
\hline CHEMBL1580276 & 688497 & 4.6 & 4.97199 & 99999999995 & TRN \\
\hline CHEMBL1521086 & 688497 & 4.95 & 5.199 & TRN & \\
\hline CHEMBL1305712 & 688497 & 4.75 & 5.00899 & 99999999995 & TRN \\
\hline CHEMBL1388380 & 688497 & 4.45 & 4.9373 & TRN & \\
\hline CHEMBL1522020 & 688497 & 4.95 & 4.8823 & TRN & \\
\hline CHEMBL1518635 & 688497 & 5.0 & 4.9089 & TRN & \\
\hline CHEMBL1308446 & 688497 & 6.25 & 5.0802 & TRN & \\
\hline CHEMBL1559390 & 688497 & 5.2 & 5.4197 & TRN & \\
\hline CHEMBL1358822 & 688497 & 4.55 & 4.5193 & TRN & \\
\hline CHEMBL1898074 & 688497 & 4.9 & 5.4423 & TRN & \\
\hline CHEMBL297304 & 688497 & 4.45 & 5.3685 & TST & \\
\hline CHEMBL1491446 & 688497 & 4.45 & 4.8237 & TST & \\
\hline CHEMBL1439227 & 688497 & 6.15 & 5.199 & TRN & \\
\hline CHEMBL1422453 & 688497 & 5.55 & 5.1822 & TRN & \\
\hline CHEMBL1422646 & 688497 & 5.2 & 5.0089 & TRN & \\
\hline CHEMBL1320418 & 688497 & 4.45 & 4.9158 & TRN & \\
\hline CHEMBL1606161 & 688497 & 4.55 & 5.0347 & TRN & \\
\hline CHEMBL1419443 & 688497 & 4.45 & 4.5416 & TRN & \\
\hline CHEMBL1424535 & 688497 & 4.45 & 5.0723 & TST & \\
\hline CHEMBL1403243 & 688497 & 4.45 & 4.8957 & TRN & \\
\hline CHEMBL1470038 & 688497 & 4.45 & 4.8651 & TRN & \\
\hline CHEMBL1516897 & 688497 & 4.95 & 4.6922 & TRN & \\
\hline CHEMBL1538924 & 688497 & 4.45 & 4.6813 & TST & \\
\hline CHEMBL1596589 & 688497 & 4.75 & 5.1062 & TRN & \\
\hline
\end{tabular}




\begin{tabular}{|c|c|c|c|c|c|}
\hline \multicolumn{6}{|c|}{ Supplemental Table S2.txt } \\
\hline CHEMBL1366577 & 688497 & 4.6 & 4.5791 & TRN & \\
\hline CHEMBL1574469 & 688497 & 4.45 & 5.1879 & TRN & \\
\hline CHEMBL1309785 & 688497 & 4.9 & 5.0424 & TRN & \\
\hline CHEMBL1307026 & 688497 & 4.45 & 5.1389 & TRN & \\
\hline CHEMBL1305241 & 688497 & 4.45 & 4.8606 & TRN & \\
\hline CHEMBL1430074 & 688497 & 4.95 & 4.9108 & TST & \\
\hline CHEMBL1414090 & 688497 & 4.8 & 4.9689 & TRN & \\
\hline CHEMBL1421654 & 688497 & 4.45 & 4.9094 & TST & \\
\hline CHEMBL1407147 & 688497 & 5.05 & 4.8784 & TRN & \\
\hline CHEMBL1578030 & 688497 & 4.45 & 5.2214 & TRN & \\
\hline CHEMBL586031 & 688497 & 4.9 & 5.12299 & 9999999999 & TRN \\
\hline CHEMBL3197509 & 688497 & 4.95 & 5.0466 & TRN & \\
\hline CHEMBL1411663 & 688497 & 4.45 & 4.6834 & TRN & \\
\hline CHEMBL1589062 & 688497 & 4.45 & 4.8175 & TRN & \\
\hline CHEMBL1455534 & 688497 & 6.1 & 5.3044 & TRN & \\
\hline CHEMBL1571885 & 688497 & 4.8 & 5.1362 & TRN & \\
\hline CHEMBL1302642 & 688497 & 4.45 & 4.8262 & TRN & \\
\hline CHEMBL1349444 & 688497 & 4.45 & 4.9004 & TRN & \\
\hline CHEMBL1344814 & 688497 & 4.45 & 4.5479 & TRN & \\
\hline CHEMBL1465114 & 688497 & 4.45 & 4.7769 & TRN & \\
\hline CHEMBL1575714 & 688497 & 4.45 & 4.9118 & TRN & \\
\hline CHEMBL1559772 & 688497 & 5.0 & 5.0355 & TRN & \\
\hline CHEMBL1300353 & 688497 & 4.95 & 4.9984 & TST & \\
\hline CHEMBL1538399 & 688497 & 4.45 & 4.8583 & TST & \\
\hline CHEMBL1391893 & 688497 & 6.05 & 5.0435 & TRN & \\
\hline CHEMBL1366992 & 688497 & 5.75 & 5.1834 & TRN & \\
\hline CHEMBL1565569 & 688497 & 4.5 & 5.4403 & TST & \\
\hline CHEMBL1414166 & 688497 & 6.05 & 5.4621 & TRN & \\
\hline CHEMBL1413157 & 688497 & 4.95 & 5.0386 & TRN & \\
\hline CHEMBL1386558 & 688497 & 4.9 & 4.7706 & TRN & \\
\hline CHEMBL1305380 & 688497 & 5.15 & 5.2375 & TRN & \\
\hline CHEMBL1599458 & 688497 & 5.0 & 4.9968 & TRN & \\
\hline CHEMBL1458153 & 688497 & 5.5 & 4.9918 & TRN & \\
\hline CHEMBL1561420 & 688497 & 4.6 & 4.6984 & TRN & \\
\hline CHEMBL1443849 & 688497 & 6.15 & 4.9247 & TST & \\
\hline CHEMBL1608339 & 688497 & 5.9 & 5.2053 & TST & \\
\hline CHEMBL1350296 & 688497 & 4.45 & 5.2448 & TST & \\
\hline CHEMBL1599847 & 688497 & 4.95 & 4.6432 & TRN & \\
\hline CHEMBL1420623 & 688497 & 5.25 & 5.1909 & TRN & \\
\hline CHEMBL1582324 & 688497 & 4.45 & 4.7077 & TRN & \\
\hline CHEMBL1596779 & 688497 & 4.45 & 5.1797 & TST & \\
\hline CHEMBL1488010 & 688497 & 5.55 & 5.2368 & TST & \\
\hline CHEMBL1385323 & 688497 & 5.0 & 5.1488 & TRN & \\
\hline CHEMBL1477495 & 688497 & 4.9 & 5.0176 & TST & \\
\hline CHEMBL1599088 & 688497 & 4.9 & 4.9801 & TRN & \\
\hline CHEMBL1312522 & 688497 & 6.1 & 4.9137 & TRN & \\
\hline CHEMBL1575751 & 688497 & 4.45 & 4.9567 & TRN & \\
\hline CHEMBL3207700 & 688497 & 4.45 & 5.1849 & TRN & \\
\hline
\end{tabular}




\begin{tabular}{|c|c|c|c|c|c|}
\hline \multicolumn{6}{|c|}{ Supplemental Table S2.txt } \\
\hline CHEMBL1318758 & 688497 & 5.45 & 5.2023 & TST & \\
\hline CHEMBL1534490 & 688497 & 4.95 & 5.1868 & TST & \\
\hline CHEMBL1383759 & 688497 & 4.45 & 5.0555 & TRN & \\
\hline CHEMBL1348148 & 688497 & 5.45 & 4.9382 & TRN & \\
\hline CHEMBL3198130 & 688497 & 4.45 & 4.7935 & TRN & \\
\hline CHEMBL1400858 & 688497 & 6.3 & 5.3127 & TST & \\
\hline CHEMBL1342031 & 688497 & 4.95 & 5.2415 & TST & \\
\hline CHEMBL1516767 & 688497 & 5.45 & 5.0594 & TST & \\
\hline CHEMBL1570871 & 688497 & 4.45 & 4.4775 & TRN & \\
\hline CHEMBL1483673 & 688497 & 4.45 & 5.2257 & TST & \\
\hline CHEMBL1343376 & 688497 & 6.6 & 5.0217 & TRN & \\
\hline CHEMBL1343793 & 688497 & 4.9 & 5.0372 & TRN & \\
\hline CHEMBL1470382 & 688497 & 5.5 & 5.1243 & TRN & \\
\hline CHEMBL1509530 & 688497 & 4.45 & 4.9692 & TST & \\
\hline CHEMBL1479341 & 688497 & 5.25 & 5.0404 & TST & \\
\hline CHEMBL1438084 & 688497 & 5.0 & 4.9762 & TRN & \\
\hline CHEMBL1411664 & 688497 & 5.0 & 4.9865 & TRN & \\
\hline CHEMBL1510609 & 688497 & 6.5 & 4.9213 & TST & \\
\hline CHEMBL1374962 & 688497 & 4.8 & 4.8561 & TRN & \\
\hline CHEMBL3189880 & 688497 & 4.9 & 5.1833 & TRN & \\
\hline CHEMBL1520818 & 688497 & 4.7 & 4.8813 & TRN & \\
\hline CHEMBL1493307 & 688497 & 5.0 & 5.1349 & TRN & \\
\hline CHEMBL1543216 & 688497 & 5.25 & 5.0096 & TRN & \\
\hline CHEMBL1451034 & 688497 & 4.45 & 5.0671 & TST & \\
\hline CHEMBL1327470 & 688497 & 4.45 & 4.9771 & TRN & \\
\hline CHEMBL1364235 & 688497 & 5.9 & 5.20799 & 9999999999 & TST \\
\hline CHEMBL1494497 & 688497 & 4.45 & 5.0848 & TST & \\
\hline CHEMBL1525616 & 688497 & 5.5 & 5.1344 & TRN & \\
\hline CHEMBL1518224 & 688497 & 5.9 & 5.0841 & TRN & \\
\hline CHEMBL1527671 & 688497 & 4.45 & 5.0512 & TRN & \\
\hline CHEMBL3192756 & 688497 & 4.95 & 4.9321 & TRN & \\
\hline CHEMBL1307862 & 688497 & 4.55 & 5.0447 & TRN & \\
\hline CHEMBL1450710 & 688497 & 4.85 & 4.6198 & TRN & \\
\hline CHEMBL1342182 & 688497 & 5.75 & 4.9103 & TRN & \\
\hline CHEMBL1549553 & 688497 & 4.75 & 5.0505 & TST & \\
\hline CHEMBL1351212 & 688497 & 4.6 & 5.0288 & TRN & \\
\hline CHEMBL1420348 & 688497 & 6.0 & 5.2074 & TRN & \\
\hline CHEMBL3210191 & 688497 & 4.95 & 5.0124 & TRN & \\
\hline CHEMBL1608079 & 688497 & 5.45 & 4.9966 & TST & \\
\hline CHEMBL1459273 & 688497 & 4.85 & 4.8468 & TRN & \\
\hline CHEMBL1574982 & 688497 & 4.6 & 5.2436 & TRN & \\
\hline CHEMBL1540605 & 688497 & 5.0 & 4.8319 & TRN & \\
\hline CHEMBL1540030 & 688497 & 6.25 & 5.2373 & TST & \\
\hline CHEMBL1517756 & 688497 & 5.9 & 5.1165 & TST & \\
\hline CHEMBL3198440 & 688497 & 4.45 & 4.8141 & TRN & \\
\hline CHEMBL1403392 & 688497 & 5.55 & 5.4188 & TRN & \\
\hline CHEMBL3199756 & 688497 & 6.5 & 5.2424 & TRN & \\
\hline CHEMBL1348607 & 688497 & 4.45 & 4.9928 & TRN & \\
\hline
\end{tabular}




\begin{tabular}{|c|c|c|c|c|}
\hline \multicolumn{5}{|c|}{ Supplemental Table S2.txt } \\
\hline CHEMBL1371219 & 688497 & 5.55 & 5.1032 & TRN \\
\hline CHEMBL1451939 & 688497 & 5.2 & 5.1578 & TRN \\
\hline CHEMBL1430651 & 688497 & 4.45 & 5.1992 & TRN \\
\hline CHEMBL1574035 & 688497 & 5.25 & 5.1093 & TST \\
\hline CHEMBL 1486238 & 688497 & 4.75 & 5.2727 & TRN \\
\hline CHEMBL1970872 & 688497 & 4.8 & 4.9467 & TRN \\
\hline CHEMBL3197270 & 688497 & 6.25 & 5.21 & TRN \\
\hline CHEMBL1318718 & 688497 & 4.45 & 4.9148 & TRN \\
\hline CHEMBL1429542 & 688497 & 5.45 & 4.9807 & TST \\
\hline CHEMBL1386744 & 688497 & 4.95 & 5.0462 & TRN \\
\hline CHEMBL1511350 & 688497 & 5.0 & 5.1182 & TRN \\
\hline CHEMBL1521520 & 688497 & 4.45 & 5.1227 & TRN \\
\hline CHEMBL1583248 & 688497 & 4.45 & 4.9118 & TRN \\
\hline CHEMBL1242180 & 688497 & 5.6 & 5.7023 & TRN \\
\hline CHEMBL1509413 & 688497 & 5.55 & 5.3799 & TRN \\
\hline CHEMBL1404541 & 688497 & 4.45 & 4.9714 & TRN \\
\hline CHEMBL1521618 & 688497 & 4.5 & 4.9589 & TST \\
\hline CHEMBL1477212 & 688497 & 5.3 & 5.1385 & TRN \\
\hline CHEMBL3190638 & 688497 & 4.65 & 4.7307 & TRN \\
\hline CHEMBL1593765 & 688497 & 5.0 & 5.0264 & TRN \\
\hline CHEMBL1341432 & 688497 & 5.0 & 4.7707 & TRN \\
\hline CHEMBL1540808 & 688497 & 5.1 & 4.7634 & TRN \\
\hline CHEMBL1374933 & 688497 & 5.25 & 5.0726 & TRN \\
\hline CHEMBL1412301 & 688497 & 6.25 & 4.9552 & TRN \\
\hline CHEMBL1467787 & 688497 & 5.55 & 5.1871 & TRN \\
\hline CHEMBL1427501 & 688497 & 7.8013 & 5.2405 & TRN \\
\hline CHEMBL1610342 & 688497 & 5.6 & 5.3671 & TRN \\
\hline CHEMBL1594875 & 688497 & 4.45 & 4.761 & TRN \\
\hline CHEMBL1495939 & 688497 & 4.95 & 4.606 & TRN \\
\hline CHEMBL1468225 & 688497 & 4.45 & 4.9195 & TRN \\
\hline CHEMBL1323456 & 688497 & 5.05 & 5.2666 & TRN \\
\hline CHEMBL 1453857 & 688497 & 5.7 & 5.0444 & TRN \\
\hline CHEMBL1444896 & 688497 & 4.45 & 4.8539 & TRN \\
\hline CHEMBL3189343 & 688497 & 5.4 & 5.3702 & TRN \\
\hline CHEMBL1372218 & 688497 & 4.95 & 4.7483 & TRN \\
\hline CHEMBL1346813 & 688497 & 5.25 & 5.0009 & TST \\
\hline CHEMBL1330390 & 688497 & 4.55 & 4.5348 & TRN \\
\hline CHEMBL1428623 & 688497 & 4.5 & 5.2463 & TST \\
\hline CHEMBL1372939 & 688497 & 4.45 & 5.0767 & TST \\
\hline CHEMBL1377309 & 688497 & 4.45 & 5.3399 & TRN \\
\hline CHEMBL1439666 & 688497 & 5.7 & 4.8119 & TRN \\
\hline CHEMBL1310284 & 688497 & 4.5 & 4.8573 & TRN \\
\hline CHEMBL1583808 & 688497 & 6.25 & 5.4431 & TST \\
\hline CHEMBL1603731 & 688497 & 4.5 & 4.6382 & TRN \\
\hline CHEMBL1563546 & 688497 & 4.45 & 4.9508 & TRN \\
\hline CHEMBL1428261 & 688497 & 4.65 & 4.8513 & TRN \\
\hline CHEMBL1385219 & 688497 & 4.45 & 4.8212 & TST \\
\hline CHEMBL1341301 & 688497 & 4.65 & 4.8858 & TRN \\
\hline
\end{tabular}




\begin{tabular}{|c|c|c|c|c|c|}
\hline \multicolumn{6}{|c|}{ Supplemental Table S2.txt } \\
\hline CHEMBL1511784 & 688497 & 4.45 & 4.8065 & TST & \\
\hline CHEMBL1501302 & 688497 & 4.8 & 4.7673 & TRN & \\
\hline CHEMBL1603150 & 688497 & 4.65 & 4.6199 & TRN & \\
\hline CHEMBL1523567 & 688497 & 4.45 & 4.7655 & TRN & \\
\hline CHEMBL1532562 & 688497 & 6.15 & 4.9632 & TRN & \\
\hline CHEMBL1532208 & 688497 & 5.5 & 5.1497 & TST & \\
\hline CHEMBL1486062 & 688497 & 5.0 & 4.8366 & TRN & \\
\hline CHEMBL1453819 & 688497 & 5.25 & 4.9231 & TRN & \\
\hline CHEMBL1313749 & 688497 & 5.75 & 5.0568 & TRN & \\
\hline CHEMBL1406590 & 688497 & 4.75 & 5.24100 & 00000000005 & TRN \\
\hline CHEMBL1449578 & 688497 & 4.95 & 5.0275 & TST & \\
\hline CHEMBL1302767 & 688497 & 5.9 & 5.2351 & TRN & \\
\hline CHEMBL1452762 & 688497 & 5.45 & 5.0429 & TRN & \\
\hline CHEMBL1323568 & 688497 & 4.45 & 4.8355 & TRN & \\
\hline CHEMBL1507840 & 688497 & 4.45 & 4.8103 & TRN & \\
\hline CHEMBL1558776 & 688497 & 5.95 & 5.1305 & TST & \\
\hline CHEMBL1411576 & 688497 & 5.45 & 5.0722 & TST & \\
\hline CHEMBL3191866 & 688497 & 5.0 & 5.2362 & TRN & \\
\hline CHEMBL448741 & 688497 & 4.6 & 5.0818 & TST & \\
\hline CHEMBL1299389 & 688497 & 4.9 & 4.8234 & TRN & \\
\hline CHEMBL1998741 & 688497 & 4.85 & 5.2944 & TRN & \\
\hline CHEMBL1540036 & 688497 & 4.95 & 5.092 & TST & \\
\hline CHEMBL1545498 & 688497 & 4.95 & 5.3057 & TST & \\
\hline CHEMBL1540957 & 688497 & 5.25 & 5.1769 & TRN & \\
\hline CHEMBL1392736 & 688497 & 4.45 & 4.9279 & TRN & \\
\hline CHEMBL1480930 & 688497 & 6.45 & 5.0504 & TRN & \\
\hline CHEMBL1372755 & 688497 & 5.2 & 4.9245 & TRN & \\
\hline CHEMBL1309705 & 688497 & 5.2 & 5.5774 & TRN & \\
\hline CHEMBL1466926 & 688497 & 4.45 & 4.7921 & TST & \\
\hline CHEMBL1351977 & 688497 & 6.05 & 5.1264 & TRN & \\
\hline CHEMBL1508246 & 688497 & 4.9 & 5.0684 & TRN & \\
\hline CHEMBL1505294 & 688497 & 4.4 & 5.474 & TRN & \\
\hline CHEMBL3194251 & 688497 & 4.6 & 5.1839 & TRN & \\
\hline CHEMBL1537481 & 688497 & 4.7 & 4.8266 & TST & \\
\hline CHEMBL1367220 & 688497 & 4.95 & 5.0448 & TRN & \\
\hline CHEMBL1607505 & 688497 & 5.25 & 5.3215 & TST & \\
\hline CHEMBL1324038 & 688497 & 5.25 & 5.1101 & TST & \\
\hline CHEMBL105457 & 688497 & 5.3 & 5.39 & TST & \\
\hline CHEMBL1585962 & 688497 & 5.5 & 5.1707 & TST & \\
\hline CHEMBL1390765 & 688497 & 4.45 & 4.9898 & TRN & \\
\hline CHEMBL1307349 & 688497 & 5.4 & 4.9619 & TRN & \\
\hline CHEMBL1369565 & 688497 & 5.8 & 5.02800 & 00000000005 & TRN \\
\hline CHEMBL1350143 & 688497 & 5.5 & 4.9984 & TST & \\
\hline CHEMBL1352279 & 688497 & 5.25 & 4.9141 & TRN & \\
\hline CHEMBL1520233 & 688497 & 5.4 & 5.0078 & TST & \\
\hline CHEMBL1535056 & 688497 & 5.2 & 5.0565 & TST & \\
\hline CHEMBL3194664 & 688497 & 5.3 & 5.0651 & TRN & \\
\hline CHEMBL1349361 & 688497 & 6.25 & 5.2163 & TRN & \\
\hline
\end{tabular}




\begin{tabular}{|c|c|c|c|c|c|}
\hline \multicolumn{6}{|c|}{ Supplemental Table S2.txt } \\
\hline CHEMBL1458849 & 688497 & 4.45 & 4.8154 & TRN & \\
\hline CHEMBL1516976 & 688497 & 4.45 & 4.7725 & TRN & \\
\hline CHEMBL1481697 & 688497 & 4.45 & 4.8424 & TRN & \\
\hline CHEMBL1999513 & 688497 & 5.15 & 4.9257 & TRN & \\
\hline CHEMBL19980 & 688497 & 6.0 & 5.7324 & TST & \\
\hline CHEMBL1468532 & 688497 & 4.9 & 4.9022 & TST & \\
\hline CHEMBL1325782 & 688497 & 4.55 & 5.0409 & TST & \\
\hline CHEMBL1450527 & 688497 & 5.1 & 5.638 & TRN & \\
\hline CHEMBL1564583 & 688497 & 5.45 & 5.0767 & TST & \\
\hline CHEMBL1544703 & 688497 & 4.45 & 4.8909 & TRN & \\
\hline CHEMBL1343187 & 688497 & 4.45 & 4.7585 & TST & \\
\hline CHEMBL1311318 & 688497 & 4.95 & 4.9878 & TRN & \\
\hline CHEMBL610198 & 688497 & 5.05 & 4.989 & TRN & \\
\hline CHEMBL1309002 & 688497 & 4.9 & 5.3099 & TRN & \\
\hline CHEMBL1507990 & 688497 & 4.85 & 4.7585 & TRN & \\
\hline CHEMBL1605351 & 688497 & 4.85 & 5.1794 & TST & \\
\hline CHEMBL1485427 & 688497 & 5.25 & 5.4587 & TRN & \\
\hline CHEMBL1572922 & 688497 & 5.5 & 5.5284 & TRN & \\
\hline CHEMBL1364602 & 688497 & 4.85 & 5.17700 & 00000000005 & TRN \\
\hline CHEMBL1544473 & 688497 & 6.95 & 5.1812 & TRN & \\
\hline CHEMBL1335288 & 688497 & 5.25 & 4.9865 & TRN & \\
\hline CHEMBL1594637 & 688497 & 4.6 & 4.7997 & TST & \\
\hline CHEMBL1443422 & 688497 & 4.8 & 5.0716 & TRN & \\
\hline CHEMBL1360018 & 688497 & 4.45 & 4.678 & TRN & \\
\hline CHEMBL1609765 & 688497 & 6.05 & 5.0755 & TRN & \\
\hline CHEMBL1443775 & 688497 & 4.45 & 5.1286 & TRN & \\
\hline CHEMBL1505555 & 688497 & 4.45 & 4.9258 & TRN & \\
\hline CHEMBL1550470 & 688497 & 4.45 & 5.077 & TST & \\
\hline CHEMBL457228 & 688497 & 5.5 & 5.54899 & 99999999995 & TRN \\
\hline CHEMBL 3208154 & 688497 & 4.45 & 4.9217 & TRN & \\
\hline CHEMBL1313835 & 688497 & 5.9 & 5.2631 & TRN & \\
\hline CHEMBL1417331 & 688497 & 5.9 & 5.0897 & TRN & \\
\hline CHEMBL1469835 & 688497 & 4.6 & 4.7043 & TRN & \\
\hline CHEMBL 3214048 & 688497 & 4.85 & 5.18 & TRN & \\
\hline CHEMBL3211220 & 688497 & 5.05 & 5.4738 & TRN & \\
\hline CHEMBL1347788 & 688497 & 4.9 & 4.8129 & TRN & \\
\hline CHEMBL1467533 & 688497 & 4.9 & 5.1243 & TRN & \\
\hline CHEMBL1539815 & 688497 & 4.95 & 5.0688 & TRN & \\
\hline CHEMBL3214563 & 688497 & 4.45 & 4.8586 & TST & \\
\hline CHEMBL1388722 & 688497 & 4.8 & 4.9627 & TRN & \\
\hline CHEMBL1311043 & 688497 & 4.9 & 5.1561 & TST & \\
\hline CHEMBL1491878 & 688497 & 6.35 & 5.2831 & TRN & \\
\hline CHEMBL1376429 & 688497 & 5.4 & 5.1238 & TST & \\
\hline CHEMBL1332844 & 688497 & 5.2 & 5.0696 & TRN & \\
\hline CHEMBL1582827 & 688497 & 5.05 & 4.7633 & TST & \\
\hline CHEMBL1455874 & 688497 & 5.45 & 5.2359 & TRN & \\
\hline CHEMBL1443169 & 688497 & 5.35 & 5.0609 & TRN & \\
\hline CHEMBL1326842 & 688497 & 4.45 & 5.1338 & TRN & \\
\hline
\end{tabular}




\begin{tabular}{|c|c|c|c|c|c|}
\hline \multicolumn{6}{|c|}{ Supplemental Table S2.txt } \\
\hline CHEMBL1308841 & 688497 & 4.45 & 5.0351 & TRN & \\
\hline CHEMBL3189342 & 688497 & 5.1 & 5.4668 & TRN & \\
\hline CHEMBL1416633 & 688497 & 4.9 & 5.3583 & TRN & \\
\hline CHEMBL1484588 & 688497 & 5.25 & 5.5625 & TST & \\
\hline CHEMBL1380735 & 688497 & 6.25 & 5.6001 & TST & \\
\hline CHEMBL1516510 & 688497 & 6.4 & 5.4981 & TRN & \\
\hline CHEMBL1559410 & 688497 & 4.45 & 5.148 & TRN & \\
\hline CHEMBL1446095 & 688497 & 4.8 & 4.7342 & TRN & \\
\hline CHEMBL1368861 & 688497 & 4.95 & 4.9346 & TRN & \\
\hline CHEMBL1538269 & 688497 & 5.25 & 5.3512 & TRN & \\
\hline CHEMBL1508916 & 688497 & 4.85 & 4.6662 & TRN & \\
\hline CHEMBL 3207747 & 688497 & 6.2 & 5.4461 & TST & \\
\hline CHEMBL1331459 & 688497 & 5.4 & 5.3589 & TRN & \\
\hline CHEMBL602718 & 688497 & 5.5 & 5.3382 & TRN & \\
\hline CHEMBL3194989 & 688497 & 4.85 & 4.77 & TRN & \\
\hline CHEMBL1470485 & 688497 & 4.5 & 5.0929 & TRN & \\
\hline CHEMBL1369750 & 688497 & 5.0 & 4.671 & TST & \\
\hline CHEMBL1568751 & 688497 & 5.1 & 4.7795 & TRN & \\
\hline CHEMBL1499380 & 688497 & 5.45 & 4.9367 & TST & \\
\hline CHEMBL1302503 & 688497 & 4.65 & 5.2697 & TST & \\
\hline CHEMBL1544568 & 688497 & 5.25 & 5.2199 & TST & \\
\hline CHEMBL1427205 & 688497 & 6.0 & 5.5232 & TRN & \\
\hline CHEMBL3196561 & 688497 & 4.45 & 5.2214 & TRN & \\
\hline CHEMBL1300338 & 688497 & 5.1 & 4.9431 & TRN & \\
\hline CHEMBL1549493 & 688497 & 4.8 & 5.0135 & TRN & \\
\hline CHEMBL1545696 & 688497 & 4.65 & 5.0383 & TRN & \\
\hline CHEMBL1384524 & 688497 & 4.95 & 5.2113 & TRN & \\
\hline CHEMBL1313301 & 688497 & 5.4 & 5.3682 & TST & \\
\hline CHEMBL1384366 & 688497 & 4.85 & 5.0259 & TRN & \\
\hline CHEMBL1308707 & 688497 & 6.25 & 5.0487 & TRN & \\
\hline CHEMBL1516454 & 688497 & 4.55 & 5.1433 & TRN & \\
\hline CHEMBL1505384 & 688497 & 5.0 & 4.8 & TRN & \\
\hline CHEMBL1534903 & 688497 & 4.9 & 4.92899 & 9999999999 & TRN \\
\hline CHEMBL1348278 & 688497 & 4.6 & 4.9441 & TRN & \\
\hline CHEMBL 3209878 & 688497 & 4.9 & 5.0868 & TST & \\
\hline CHEMBL1444191 & 688497 & 4.45 & 4.8008 & TRN & \\
\hline CHEMBL1573896 & 688497 & 4.8 & 4.9311 & TST & \\
\hline CHEMBL1351458 & 688497 & 4.65 & 4.8084 & TRN & \\
\hline CHEMBL1367302 & 688497 & 4.8 & 5.2122 & TRN & \\
\hline CHEMBL1557777 & 688497 & 4.45 & 5.1219 & TST & \\
\hline CHEMBL1370681 & 688497 & 4.45 & 4.8398 & TRN & \\
\hline CHEMBL1577901 & 688497 & 5.4 & 5.1172 & TRN & \\
\hline CHEMBL1344426 & 688497 & 4.75 & 4.8212 & TRN & \\
\hline CHEMBL1540268 & 688497 & 4.95 & 4.9773 & TRN & \\
\hline CHEMBL175451 & 688497 & 4.95 & 4.7787 & TRN & \\
\hline CHEMBL1462038 & 688497 & 4.45 & 4.793 & TRN & \\
\hline CHEMBL1488998 & 688497 & 4.45 & 5.2227 & TRN & \\
\hline CHEMBL1383576 & 688497 & 5.25 & 5.0869 & TST & \\
\hline
\end{tabular}




\begin{tabular}{|c|c|c|c|c|c|}
\hline \multicolumn{6}{|c|}{ Supplemental Table S2.txt } \\
\hline CHEMBL3211628 & 688497 & 4.45 & 5.3475 & TST & \\
\hline CHEMBL1384512 & 688497 & 4.45 & 4.8602 & TRN & \\
\hline CHEMBL1533823 & 688497 & 5.3 & 5.0757 & TRN & \\
\hline CHEMBL1366836 & 688497 & 4.8 & 4.7559 & TST & \\
\hline CHEMBL1479951 & 688497 & 4.75 & 4.9979 & TRN & \\
\hline CHEMBL3199600 & 688497 & 4.65 & 4.8611 & TRN & \\
\hline CHEMBL1381860 & 688497 & 6.25 & 5.3057 & TST & \\
\hline CHEMBL1588018 & 688497 & 4.9 & 5.1857 & TRN & \\
\hline CHEMBL1311052 & 688497 & 4.6 & 4.5251 & TRN & \\
\hline CHEMBL1575946 & 688497 & 4.45 & 4.9028 & TRN & \\
\hline CHEMBL1388149 & 688497 & 5.1 & 4.8888 & TRN & \\
\hline CHEMBL1438594 & 688497 & 4.65 & 4.9422 & TRN & \\
\hline CHEMBL1532650 & 688497 & 5.45 & 4.965 & TRN & \\
\hline CHEMBL1312871 & 688497 & 4.45 & 4.8439 & TST & \\
\hline CHEMBL 3211610 & 688497 & 4.45 & 4.6323 & TST & \\
\hline CHEMBL1605295 & 688497 & 4.8 & 4.9235 & TRN & \\
\hline CHEMBL1349707 & 688497 & 4.6 & 5.232 & TRN & \\
\hline CHEMBL1409056 & 688497 & 4.45 & 4.9789 & TST & \\
\hline CHEMBL1491454 & 688497 & 4.45 & 5.0521 & TST & \\
\hline CHEMBL1325703 & 688497 & 5.45 & 5.5073 & TST & \\
\hline CHEMBL3190031 & 688497 & 4.6 & 4.8741 & TRN & \\
\hline CHEMBL1303592 & 688497 & 4.6 & 5.1818 & TRN & \\
\hline CHEMBL1341533 & 688497 & 4.45 & 5.2596 & TRN & \\
\hline CHEMBL1405741 & 688497 & 6.3 & 4.7656 & TRN & \\
\hline CHEMBL1544982 & 688497 & 5.95 & 5.2752 & TRN & \\
\hline CHEMBL1527926 & 688497 & 5.45 & 5.2053 & TRN & \\
\hline CHEMBL1605466 & 688497 & 5.6 & 5.138 & TRN & \\
\hline CHEMBL454893 & 688497 & 4.9 & 4.9591 & TST & \\
\hline CHEMBL1573968 & 688497 & 5.95 & 5.2645 & TRN & \\
\hline CHEMBL1525530 & 688497 & 5.1 & 4.8424 & TRN & \\
\hline CHEMBL3208361 & 688497 & 4.45 & 4.8749 & TST & \\
\hline CHEMBL1578386 & 688497 & 4.45 & 4.9074 & TRN & \\
\hline CHEMBL1379252 & 688497 & 4.45 & 4.6684 & TST & \\
\hline CHEMBL1349590 & 688497 & 4.45 & 5.10800 & 00000000005 & TRN \\
\hline CHEMBL1331772 & 688497 & 6.25 & 5.1172 & TST & \\
\hline CHEMBL1451268 & 688497 & 4.45 & 4.9325 & TRN & \\
\hline CHEMBL1445286 & 688497 & 5.0 & 5.0768 & TRN & \\
\hline CHEMBL 3189326 & 688497 & 4.8 & 5.0308 & TRN & \\
\hline CHEMBL1352748 & 688497 & 5.1 & 4.9571 & TRN & \\
\hline CHEMBL1360433 & 688497 & 4.45 & 5.2767 & TST & \\
\hline CHEMBL1517337 & 688497 & 6.45 & 5.2739 & TRN & \\
\hline CHEMBL1505184 & 688497 & 5.4 & 5.6279 & TRN & \\
\hline CHEMBL1368100 & 688497 & 5.45 & 5.3041 & TRN & \\
\hline CHEMBL1447396 & 688497 & 5.9 & 4.8985 & TRN & \\
\hline CHEMBL 3199539 & 688497 & 4.9 & 5.1023 & TRN & \\
\hline CHEMBL1507944 & 688497 & 5.9 & 5.1519 & TRN & \\
\hline CHEMBL1300171 & 688497 & 5.85 & 5.0634 & TRN & \\
\hline CHEMBL1426195 & 688497 & 4.75 & 5.0827 & TRN & \\
\hline
\end{tabular}




\begin{tabular}{|c|c|c|c|c|c|}
\hline \multirow[b]{2}{*}{ CHEMBL1336283 } & \multirow[b]{2}{*}{688497} & \multicolumn{4}{|c|}{ Supplemental Table S2.txt } \\
\hline & & 4.45 & 4.954 & TRN & \\
\hline CHEMBL1337558 & 688497 & 5.85 & 5.08899 & 99999999995 & TRN \\
\hline CHEMBL1442380 & 688497 & 5.4 & 5.0585 & TRN & \\
\hline CHEMBL3213887 & 688497 & 4.95 & 4.9933 & TRN & \\
\hline CHEMBL1463984 & 688497 & 4.65 & 4.9007 & TRN & \\
\hline CHEMBL1421882 & 688497 & 4.65 & 5.5944 & TRN & \\
\hline CHEMBL1312648 & 688497 & 4.5 & 4.9395 & TST & \\
\hline CHEMBL1496188 & 688497 & 5.55 & 5.0967 & TRN & \\
\hline CHEMBL1519925 & 688497 & 4.6 & 4.8485 & TST & \\
\hline CHEMBL1599255 & 688497 & 4.6 & 4.9144 & TRN & \\
\hline CHEMBL1603464 & 688497 & 6.05 & 5.1508 & TST & \\
\hline CHEMBL1388606 & 688497 & 4.65 & 5.1421 & TRN & \\
\hline CHEMBL1569892 & 688497 & 4.9 & 4.8039 & TRN & \\
\hline CHEMBL1373090 & 688497 & 4.45 & 5.0147 & TRN & \\
\hline CHEMBL1588981 & 688497 & 4.45 & 5.3302 & TRN & \\
\hline CHEMBL1610610 & 688497 & 5.25 & 4.9018 & TST & \\
\hline CHEMBL1312943 & 688497 & 5.2 & 4.728 & TRN & \\
\hline CHEMBL1336690 & 688497 & 6.95 & 5.0283 & TRN & \\
\hline CHEMBL1347227 & 688497 & 4.85 & 4.9819 & TRN & \\
\hline CHEMBL1544423 & 688497 & 4.45 & 4.7679 & TRN & \\
\hline CHEMBL1380282 & 688497 & 5.9 & 4.9701 & TRN & \\
\hline CHEMBL1490088 & 688497 & 6.25 & 5.0651 & TST & \\
\hline CHEMBL1334877 & 688497 & 4.95 & 4.7709 & TST & \\
\hline CHEMBL1334797 & 688497 & 4.95 & 4.7515 & TST & \\
\hline CHEMBL1573419 & 688497 & 5.25 & 5.2599 & TRN & \\
\hline CHEMBL1533155 & 688497 & 2.85 & 4.9757 & TRN & \\
\hline CHEMBL1440784 & 688497 & 5.0 & 5.2932 & TST & \\
\hline CHEMBL1582973 & 688497 & 4.7 & 4.8048 & TRN & \\
\hline CHEMBL1589197 & 688497 & 4.8 & 4.6179 & TST & \\
\hline CHEMBL3197548 & 688497 & 5.5 & 5.2794 & TST & \\
\hline CHEMBL1459717 & 688497 & 4.9 & 5.1505 & TRN & \\
\hline CHEMBL 1448578 & 688497 & 4.5 & 5.1547 & TST & \\
\hline CHEMBL1383762 & 688497 & 4.5 & 4.8219 & TRN & \\
\hline CHEMBL1389982 & 688497 & 4.6 & 4.8739 & TST & \\
\hline CHEMBL1350445 & 688497 & 6.25 & 5.21299 & 9999999999 & TRN \\
\hline CHEMBL1479052 & 688497 & 5.5 & 4.8262 & TRN & \\
\hline CHEMBL1371178 & 688497 & 5.9 & 5.0251 & TRN & \\
\hline CHEMBL1583947 & 688497 & 4.75 & 5.2643 & TRN & \\
\hline CHEMBL1344732 & 688497 & 5.25 & 4.9299 & TRN & \\
\hline CHEMBL1462911 & 688497 & 4.45 & 5.1464 & TRN & \\
\hline CHEMBL1402883 & 688497 & 4.9 & 4.9792 & TRN & \\
\hline CHEMBL1338081 & 688497 & 5.2 & 5.1147 & TRN & \\
\hline CHEMBL1606106 & 688497 & 4.85 & 4.8675 & TRN & \\
\hline CHEMBL1452943 & 688497 & 4.45 & 5.1248 & TST & \\
\hline CHEMBL1335491 & 688497 & 4.9 & 4.9176 & TRN & \\
\hline CHEMBL1568408 & 688497 & 5.3 & 4.9272 & TRN & \\
\hline CHEMBL1407282 & 688497 & 4.95 & 4.8343 & TRN & \\
\hline CHEMBL1390930 & 688497 & 4.45 & 5.1348 & TRN & \\
\hline
\end{tabular}




\begin{tabular}{|c|c|c|c|c|c|}
\hline \\
\hline CHEMBL1385570 & 688497 & 4.6 & 5.0079 & TRN & \\
\hline CHEMBL1499296 & 688497 & 4.7 & 4.9267 & TRN & \\
\hline CHEMBL1454247 & 688497 & 5.9 & 5.1936 & TRN & \\
\hline CHEMBL1348716 & 688497 & 5.1 & 5.2182 & TST & \\
\hline CHEMBL1603192 & 688497 & 4.75 & 4.6477 & TRN & \\
\hline CHEMBL1350047 & 688497 & 4.45 & 4.8339 & TRN & \\
\hline CHEMBL1502201 & 688497 & 4.8 & 4.8438 & TRN & \\
\hline CHEMBL1532453 & 688497 & 5.35 & 5.101 & TRN & \\
\hline CHEMBL1536140 & 688497 & 4.65 & 5.2942 & TST & \\
\hline CHEMBL1405657 & 688497 & 5.25 & 5.1937 & TRN & \\
\hline CHEMBL1548890 & 688497 & 5.25 & 4.7213 & TRN & \\
\hline CHEMBL1588073 & 688497 & 6.25 & 5.0573 & TRN & \\
\hline CHEMBL1312038 & 688497 & 7.0501 & 5.0118 & TRN & \\
\hline CHEMBL1587351 & 688497 & 4.9 & 4.9097 & TST & \\
\hline CHEMBL1446899 & 688497 & 4.6 & 4.9957 & TRN & \\
\hline CHEMBL1306751 & 688497 & 5.9 & 5.3413 & TRN & \\
\hline CHEMBL1432526 & 688497 & 4.95 & 4.7733 & TRN & \\
\hline CHEMBL1352916 & 688497 & 4.9 & 4.9289 & TRN & \\
\hline CHEMBL1573854 & 688497 & 4.5 & 5.1577 & TRN & \\
\hline CHEMBL1511000 & 688497 & 4.75 & 4.9959 & TRN & \\
\hline CHEMBL1312961 & 688497 & 4.45 & 4.8789 & TRN & \\
\hline CHEMBL1365764 & 688497 & 4.6 & 5.291 & TST & \\
\hline CHEMBL1538127 & 688497 & 4.45 & 4.8773 & TRN & \\
\hline CHEMBL1330307 & 688497 & 5.55 & 5.3815 & TRN & \\
\hline CHEMBL1453924 & 688497 & 4.45 & 5.1695 & TRN & \\
\hline CHEMBL1511396 & 688497 & 5.8 & 5.40600 & 2000000001 & TRN \\
\hline CHEMBL1360997 & 688497 & 5.55 & 5.183 & TRN & \\
\hline CHEMBL1345625 & 688497 & 4.45 & 5.0506 & TST & \\
\hline CHEMBL1410587 & 688497 & 4.8 & 5.0218 & TRN & \\
\hline CHEMBL1710 & 688497 & 4.65 & 5.2087 & TST & \\
\hline CHEMBL1340188 & 688497 & 4.45 & 5.1871 & TRN & \\
\hline CHEMBL1392852 & 688497 & 5.4 & 5.3273 & TRN & \\
\hline CHEMBL3195551 & 688497 & 5.6 & 5.1492 & TRN & \\
\hline CHEMBL3212340 & 688497 & 5.45 & 4.9253 & TRN & \\
\hline CHEMBL1490748 & 688497 & 5.45 & 5.2636 & TST & \\
\hline CHEMBL1311871 & 688497 & 4.65 & 4.933 & TST & \\
\hline CHEMBL1414823 & 688497 & 4.95 & 5.1524 & TST & \\
\hline CHEMBL1420734 & 688497 & 5.35 & 5.45 & TST & \\
\hline CHEMBL1391743 & 688497 & 4.45 & 5.0608 & TRN & \\
\hline CHEMBL1470558 & 688497 & 5.15 & 4.7903 & TRN & \\
\hline CHEMBL1421112 & 688497 & 4.45 & 4.9737 & TRN & \\
\hline CHEMBL1588657 & 688497 & 4.8 & 5.0548 & TRN & \\
\hline CHEMBL1604220 & 688497 & 4.75 & 4.7965 & TRN & \\
\hline CHEMBL1465490 & 688497 & 4.65 & 4.7514 & TRN & \\
\hline CHEMBL1603489 & 688497 & 5.5 & 5.1683 & TST & \\
\hline CHEMBL2005149 & 688497 & 5.95 & 5.2359 & TRN & \\
\hline CHEMBL1536459 & 688497 & 4.8 & 5.0734 & TRN & \\
\hline CHEMBL1372126 & 688497 & 5.75 & 4.9149 & TRN & \\
\hline & & & & 96 & \\
\hline
\end{tabular}




\begin{tabular}{|c|c|c|c|c|c|}
\hline & & \multicolumn{4}{|c|}{ Supplemental Table S2.txt } \\
\hline CHEMBL3199467 & 688497 & 5.8 & 5.3155 & TST & \\
\hline CHEMBL1531334 & 688497 & 4.9 & 4.6566 & TRN & \\
\hline CHEMBL1527563 & 688497 & 4.45 & 4.8734 & TST & \\
\hline CHEMBL1392507 & 688497 & 5.25 & 5.1408 & TRN & \\
\hline CHEMBL1367086 & 688497 & 5.1 & 5.0387 & TRN & \\
\hline CHEMBL1508452 & 688497 & 4.95 & 4.9603 & TRN & \\
\hline CHEMBL3210981 & 688497 & 4.45 & 5.1959 & TRN & \\
\hline CHEMBL1342165 & 688497 & 4.45 & 5.3582 & TST & \\
\hline CHEMBL1484233 & 688497 & 6.05 & 4.8616 & TST & \\
\hline CHEMBL3191970 & 688497 & 4.45 & 4.805 & TST & \\
\hline CHEMBL1486397 & 688497 & 6.15 & 4.9402 & TRN & \\
\hline CHEMBL1413484 & 688497 & 4.9 & 4.9659 & TRN & \\
\hline CHEMBL1365700 & 688497 & 4.7 & 4.9946 & TST & \\
\hline CHEMBL1379426 & 688497 & 5.65 & 4.9071 & TRN & \\
\hline CHEMBL1402055 & 688497 & 4.45 & 5.2597 & TST & \\
\hline CHEMBL1378104 & 688497 & 4.65 & 5.1837 & TRN & \\
\hline CHEMBL1604223 & 688497 & 4.65 & 4.9053 & TRN & \\
\hline CHEMBL1608985 & 688497 & 4.65 & 5.1101 & TRN & \\
\hline CHEMBL1320804 & 688497 & 5.0 & 4.9452 & TST & \\
\hline CHEMBL1443439 & 688497 & 5.2 & 5.0938 & TST & \\
\hline CHEMBL1378913 & 688497 & 4.45 & 4.8146 & TRN & \\
\hline CHEMBL1431783 & 688497 & 4.45 & 4.7531 & TRN & \\
\hline CHEMBL3194039 & 688497 & 5.7 & 5.2683 & TRN & \\
\hline CHEMBL1385349 & 688497 & 4.7 & 4.8362 & TRN & \\
\hline CHEMBL1508680 & 688497 & 5.0 & 4.8553 & TRN & \\
\hline CHEMBL1345654 & 688497 & 4.9 & 5.0827 & TST & \\
\hline CHEMBL1533506 & 688497 & 5.25 & 5.2231 & TRN & \\
\hline CHEMBL1438389 & 688497 & 4.95 & 5.0228 & TRN & \\
\hline CHEMBL1303612 & 688497 & 5.5 & 5.159 & TST & \\
\hline CHEMBL1546139 & 688497 & 4.6 & 4.6466 & TRN & \\
\hline CHEMBL1365720 & 688497 & 5.25 & 4.9603 & TRN & \\
\hline CHEMBL3212331 & 688497 & 3.5 & $4.8260 e$ & 00000000005 & TRN \\
\hline CHEMBL1585156 & 688497 & 6.8 & 5.1402 & TST & \\
\hline CHEMBL1501764 & 688497 & 4.45 & 4.7773 & TRN & \\
\hline CHEMBL1331598 & 688497 & 5.45 & 5.0613 & TRN & \\
\hline CHEMBL1582760 & 688497 & 4.45 & 5.1099 & TRN & \\
\hline CHEMBL1498155 & 688497 & 6.25 & 5.0738 & TST & \\
\hline CHEMBL1324457 & 688497 & 4.95 & 4.885 & TRN & \\
\hline CHEMBL1427713 & 688497 & 5.45 & 4.948 & TST & \\
\hline CHEMBL1370846 & 688497 & 5.65 & 5.064 & TRN & \\
\hline CHEMBL120568 & 688497 & 5.4 & 5.3683 & TRN & \\
\hline CHEMBL1330619 & 688497 & 4.9 & 4.891 & TRN & \\
\hline CHEMBL1342574 & 688497 & 4.45 & 4.981 & TST & \\
\hline CHEMBL1422088 & 688497 & 6.9 & 5.5058 & TRN & \\
\hline CHEMBL1604074 & 688497 & 4.95 & 5.376 & TST & \\
\hline CHEMBL1334522 & 688497 & 6.25 & 5.4275 & TRN & \\
\hline CHEMBL1586443 & 688497 & 4.45 & 4.9576 & TST & \\
\hline CHEMBL1491555 & 688497 & 6.25 & 4.9674 & TST & \\
\hline
\end{tabular}




\begin{tabular}{|c|c|c|c|c|c|}
\hline \multicolumn{6}{|c|}{ Supplemental Table S2.txt } \\
\hline CHEMBL1542974 & 688497 & 4.9 & 5.1481 & TRN & \\
\hline CHEMBL3189222 & 688497 & 4.6 & 5.1854 & TRN & \\
\hline CHEMBL1539000 & 688497 & 4.45 & 5.083 & TRN & \\
\hline CHEMBL1478232 & 688497 & 5.25 & 4.9735 & TRN & \\
\hline CHEMBL1987344 & 688497 & 4.65 & 4.9757 & TRN & \\
\hline CHEMBL1426831 & 688497 & 5.15 & 5.4018 & TRN & \\
\hline CHEMBL1306160 & 688497 & 4.95 & 5.1307 & TST & \\
\hline CHEMBL1606682 & 688497 & 5.9 & 5.2157 & TRN & \\
\hline CHEMBL1383635 & 688497 & 4.65 & 4.6074 & TRN & \\
\hline CHEMBL1449660 & 688497 & 6.25 & 4.5308 & TST & \\
\hline CHEMBL1308939 & 688497 & 5.0 & 4.7693 & TRN & \\
\hline CHEMBL1599520 & 688497 & 4.95 & 5.3877 & TRN & \\
\hline CHEMBL 3213263 & 688497 & 5.4 & 4.8487 & TRN & \\
\hline CHEMBL1360723 & 688497 & 4.75 & 4.9273 & TRN & \\
\hline CHEMBL1571820 & 688497 & 5.6 & 5.0419 & TST & \\
\hline CHEMBL209101 & 688497 & 6.25 & 5.043 & TRN & \\
\hline CHEMBL1333081 & 688497 & 6.25 & 5.1249 & TRN & \\
\hline CHEMBL1564543 & 688497 & 4.8 & 4.543 & TRN & \\
\hline CHEMBL 3212844 & 688497 & 4.45 & 5.0579 & TRN & \\
\hline CHEMBL1408732 & 688497 & 5.6 & 5.21899 & 9999999999 & TRN \\
\hline CHEMBL1366557 & 688497 & 6.05 & 5.3324 & TRN & \\
\hline CHEMBL1600871 & 688497 & 5.25 & 5.0893 & TRN & \\
\hline CHEMBL1331925 & 688497 & 4.45 & 5.0842 & TRN & \\
\hline CHEMBL1560765 & 688497 & 4.5 & 5.1898 & TRN & \\
\hline CHEMBL1579464 & 688497 & 4.65 & 4.9056 & TRN & \\
\hline CHEMBL1361390 & 688497 & 4.45 & 4.7866 & TRN & \\
\hline CHEMBL1485263 & 688497 & 5.4 & 5.2269 & TRN & \\
\hline CHEMBL1492622 & 688497 & 5.5 & 4.9195 & TRN & \\
\hline CHEMBL1421256 & 688497 & 5.55 & 5.2176 & TST & \\
\hline CHEMBL 3194788 & 688497 & 5.6 & 4.9726 & TRN & \\
\hline CHEMBL1379547 & 688497 & 5.95 & 5.0316 & TRN & \\
\hline CHEMBL1579749 & 688497 & 5.5 & 5.101 & TRN & \\
\hline CHEMBL1329573 & 688497 & 4.45 & 4.9082 & TRN & \\
\hline CHEMBL3199017 & 688497 & 5.2 & 5.0315 & TRN & \\
\hline CHEMBL1508158 & 688497 & 4.95 & 4.8256 & TRN & \\
\hline CHEMBL1521360 & 688497 & 4.8 & 4.7341 & TRN & \\
\hline CHEMBL3193095 & 688497 & 4.9 & 4.6697 & TRN & \\
\hline CHEMBL1449558 & 688497 & 5.05 & 5.0425 & TRN & \\
\hline CHEMBL492116 & 688497 & 5.0 & 4.937 & TRN & \\
\hline CHEMBL1481616 & 688497 & 6.25 & 5.3765 & TST & \\
\hline CHEMBL1597435 & 688497 & 5.0 & 4.9982 & TRN & \\
\hline CHEMBL1333095 & 688497 & 4.45 & 4.9381 & TRN & \\
\hline CHEMBL1460199 & 688497 & 5.45 & 5.1653 & TST & \\
\hline CHEMBL1499146 & 688497 & 6.3 & 5.0468 & TST & \\
\hline CHEMBL 3192134 & 688497 & 4.45 & 5.0502 & TRN & \\
\hline CHEMBL1545411 & 688497 & 5.1 & 5.2645 & TST & \\
\hline CHEMBL1585705 & 688497 & 5.0 & 5.1358 & TST & \\
\hline CHEMBL 3210010 & 688497 & 4.45 & 5.0356 & TST & \\
\hline
\end{tabular}




\begin{tabular}{|c|c|c|c|c|}
\hline \multicolumn{5}{|c|}{ Supplemental Table S2.txt } \\
\hline CHEMBL1362898 & 688497 & 5.8 & 4.8992 & TST \\
\hline CHEMBL1301435 & 688497 & 4.45 & 4.7484 & TRN \\
\hline CHEMBL1427453 & 688497 & 4.45 & 5.1007 & TST \\
\hline CHEMBL 3189257 & 688497 & 5.25 & 5.2967 & TST \\
\hline CHEMBL 1425822 & 688497 & 6.1 & 4.6512 & TRN \\
\hline CHEMBL1497853 & 688497 & 4.75 & 4.7271 & TRN \\
\hline CHEMBL1377193 & 688497 & 4.45 & 4.7612 & TRN \\
\hline CHEMBL1388620 & 688497 & 4.45 & 4.8513 & TRN \\
\hline CHEMBL1310049 & 688497 & 5.05 & 5.2012 & TST \\
\hline CHEMBL1451603 & 688497 & 5.2 & 5.2897 & TRN \\
\hline CHEMBL1569970 & 688497 & 4.45 & 4.9849 & TST \\
\hline CHEMBL1428162 & 688497 & 4.95 & 5.1221 & TRN \\
\hline CHEMBL1440469 & 688497 & 5.4 & 5.0263 & TRN \\
\hline CHEMBL1608758 & 688497 & 4.95 & 4.9394 & TST \\
\hline CHEMBL1613088 & 688497 & 5.95 & 4.868 & TRN \\
\hline CHEMBL1378838 & 688497 & 5.1 & 4.9563 & TST \\
\hline CHEMBL1335850 & 688497 & 4.7 & 4.9062 & TRN \\
\hline CHEMBL1507020 & 688497 & 4.9 & 4.6888 & TRN \\
\hline CHEMBL1538244 & 688497 & 6.0 & 5.1188 & TST \\
\hline CHEMBL1347003 & 688497 & 4.95 & 5.8841 & TRN \\
\hline CHEMBL1441401 & 688497 & 5.65 & 5.1305 & TST \\
\hline CHEMBL1438452 & 688497 & 4.95 & 4.8229 & TRN \\
\hline CHEMBL1491665 & 688497 & 5.25 & 5.3237 & TRN \\
\hline CHEMBL1538328 & 688497 & 5.2 & 5.0083 & TST \\
\hline CHEMBL1469557 & 688497 & 4.7 & 4.7674 & TRN \\
\hline CHEMBL1557680 & 688497 & 6.45 & 5.2419 & TRN \\
\hline CHEMBL1495181 & 688497 & 4.5 & 5.0935 & TRN \\
\hline CHEMBL1424885 & 688497 & 6.25 & 5.1011 & TRN \\
\hline CHEMBL3190599 & 688497 & 4.95 & 5.0155 & TRN \\
\hline CHEMBL1359037 & 688497 & 4.45 & 4.8789 & TRN \\
\hline CHEMBL1432486 & 688497 & 4.7 & 5.002 & TRN \\
\hline CHEMBL1570673 & 688497 & 4.55 & 4.7493 & TRN \\
\hline CHEMBL1446753 & 688497 & 4.55 & 5.0501 & TRN \\
\hline CHEMBL1547350 & 688497 & 5.1 & 4.9029 & TRN \\
\hline CHEMBL1367073 & 688497 & 4.75 & 5.2223 & TST \\
\hline CHEMBL1606342 & 688497 & 4.65 & 5.1213 & TRN \\
\hline CHEMBL1335986 & 688497 & 6.5 & 5.4189 & TRN \\
\hline CHEMBL1532028 & 688497 & 4.65 & 5.0272 & TRN \\
\hline CHEMBL1438265 & 688497 & 5.45 & 4.8937 & TRN \\
\hline CHEMBL1487375 & 688497 & 5.25 & 4.9301 & TRN \\
\hline CHEMBL1415385 & 688497 & 5.0 & 4.7164 & TRN \\
\hline CHEMBL1448067 & 688497 & 4.5 & 5.0966 & TST \\
\hline CHEMBL1347444 & 688497 & 4.85 & 4.7935 & TRN \\
\hline CHEMBL1509433 & 688497 & 4.95 & 5.0022 & TRN \\
\hline CHEMBL1539560 & 688497 & 4.45 & 5.1229 & TRN \\
\hline CHEMBL1472240 & 688497 & 4.65 & 4.8398 & TRN \\
\hline CHEMBL1410601 & 688497 & 5.25 & 5.0513 & TRN \\
\hline CHEMBL1345666 & 688497 & 4.6 & 4.7377 & TRN \\
\hline
\end{tabular}




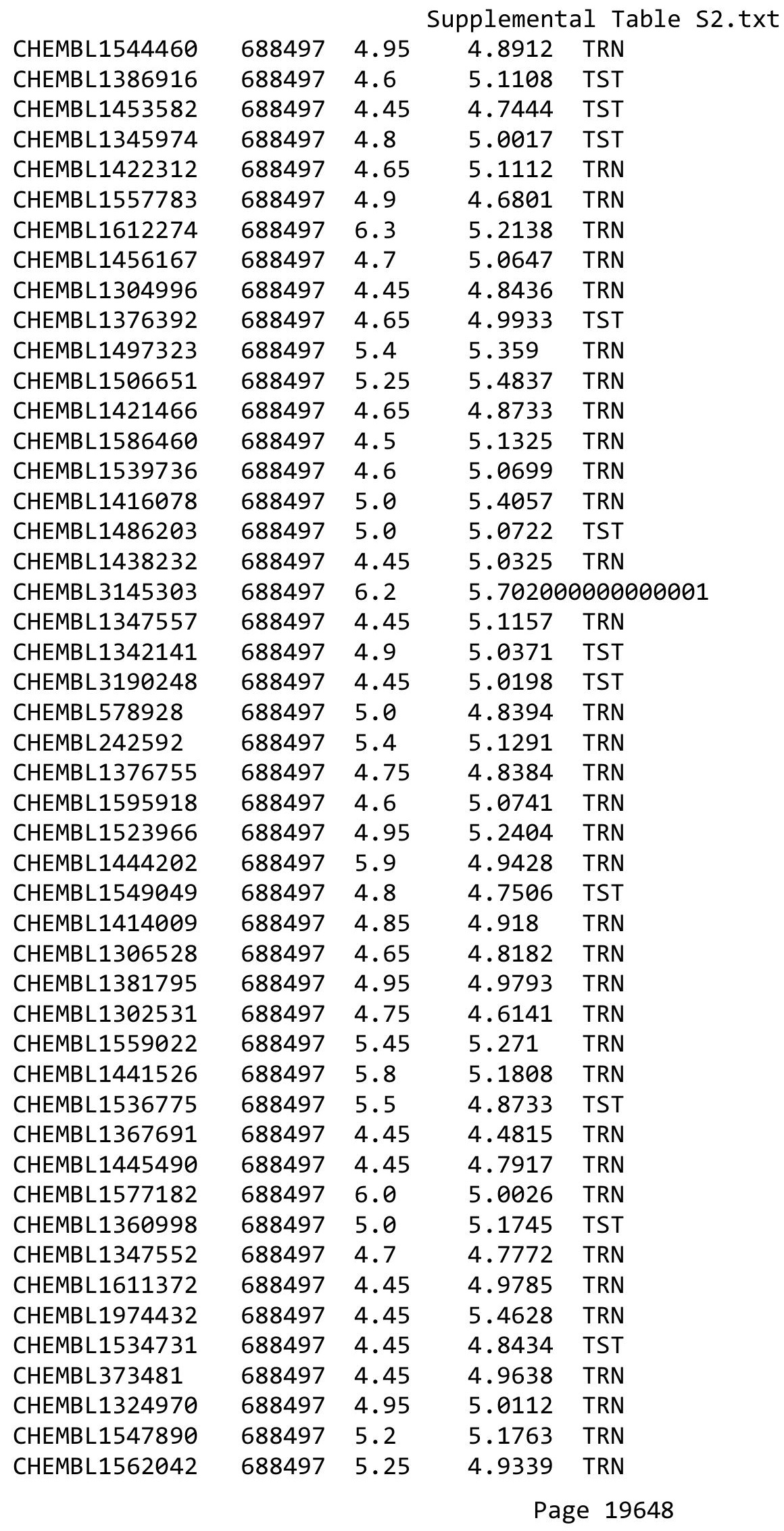

TRN 


\begin{tabular}{|c|c|c|c|c|c|}
\hline \multicolumn{6}{|c|}{ Supplemental Table s2.txt } \\
\hline CHEMBL1467671 & 688497 & 5.45 & 5.3075 & TST & \\
\hline CHEMBL1326540 & 688497 & 5.25 & 5.4493 & TST & \\
\hline CHEMBL1402442 & 688497 & 4.75 & 4.8598 & TRN & \\
\hline CHEMBL1496854 & 688497 & 5.0 & 5.3037 & TRN & \\
\hline CHEMBL1490954 & 688497 & 6.25 & 4.9927 & TRN & \\
\hline CHEMBL1606291 & 688497 & 5.4 & 5.4342 & TRN & \\
\hline CHEMBL1467232 & 688497 & 4.45 & 4.878 & TRN & \\
\hline CHEMBL3189301 & 688497 & 5.0 & 5.205 & TRN & \\
\hline CHEMBL1335161 & 688497 & 5.9 & 4.995 & TST & \\
\hline CHEMBL3209687 & 688497 & 4.45 & 4.9942 & TRN & \\
\hline CHEMBL1446348 & 688497 & 4.85 & 5.3695 & TST & \\
\hline CHEMBL1503563 & 688497 & 4.45 & 4.9218 & TRN & \\
\hline CHEMBL3197506 & 688497 & 4.8 & 4.8258 & TRN & \\
\hline CHEMBL1519298 & 688497 & 4.65 & 5.2275 & TRN & \\
\hline CHEMBL1520694 & 688497 & 4.8 & 4.8797 & TRN & \\
\hline CHEMBL1611695 & 688497 & 4.45 & 4.7639 & TST & \\
\hline CHEMBL1408503 & 688497 & 5.05 & 5.0582 & TRN & \\
\hline CHEMBL1313152 & 688497 & 5.5 & 5.0355 & TST & \\
\hline CHEMBL1423501 & 688497 & 4.45 & 4.67399 & 99999999995 & TST \\
\hline CHEMBL1508613 & 688497 & 4.9 & 4.9541 & TRN & \\
\hline CHEMBL1432160 & 688497 & 4.95 & 5.0087 & TST & \\
\hline CHEMBL1583310 & 688497 & 5.9 & 5.0741 & TRN & \\
\hline CHEMBL1523318 & 688497 & 5.2 & 5.347 & TRN & \\
\hline CHEMBL1419998 & 688497 & 5.75 & 5.0893 & TST & \\
\hline CHEMBL1528493 & 688497 & 4.8 & 5.3535 & TRN & \\
\hline CHEMBL1353530 & 688497 & 5.05 & 4.7384 & TST & \\
\hline CHEMBL1386058 & 688497 & 5.45 & 5.4689 & TRN & \\
\hline CHEMBL1559596 & 688497 & 4.45 & 5.1969 & TST & \\
\hline CHEMBL1413915 & 688497 & 4.45 & 5.1192 & TRN & \\
\hline CHEMBL388025 & 688497 & 4.45 & 5.0166 & TST & \\
\hline CHEMBL1380991 & 688497 & 6.05 & 5.4545 & TST & \\
\hline CHEMBL1425630 & 688497 & 4.45 & 4.8899 & TRN & \\
\hline CHEMBL1448929 & 688497 & 4.85 & 5.0168 & TRN & \\
\hline CHEMBL1445723 & 688497 & 5.4 & 5.4242 & TRN & \\
\hline CHEMBL1993746 & 688497 & 5.5 & 4.8797 & TRN & \\
\hline CHEMBL3196020 & 688497 & 4.9 & 5.2544 & TRN & \\
\hline CHEMBL1441566 & 688497 & 4.8 & 4.7303 & TRN & \\
\hline CHEMBL1535599 & 688497 & 4.6 & 4.9587 & TST & \\
\hline CHEMBL1596876 & 688497 & 6.1 & 5.0046 & TRN & \\
\hline CHEMBL1447076 & 688497 & 4.45 & 4.7202 & TRN & \\
\hline CHEMBL3210873 & 688497 & 4.95 & 4.9594 & TRN & \\
\hline CHEMBL1424099 & 688497 & 4.85 & 5.16200 & 0000000001 & TST \\
\hline CHEMBL1411658 & 688497 & 4.45 & 4.8177 & TRN & \\
\hline CHEMBL1449514 & 688497 & 4.45 & 4.9442 & TRN & \\
\hline CHEMBL3212894 & 688497 & 4.5 & 4.9113 & TRN & \\
\hline CHEMBL1380353 & 688497 & 4.65 & 4.8002 & TRN & \\
\hline CHEMBL1523019 & 688497 & 4.45 & 5.2705 & TRN & \\
\hline CHEMBL1426200 & 688497 & 4.45 & 5.2295 & TRN & \\
\hline
\end{tabular}




\begin{tabular}{|c|c|c|c|c|c|}
\hline & & \multicolumn{4}{|c|}{ Supplemental Table s2.txt } \\
\hline CHEMBL1452108 & 688497 & 6.25 & 5.272 & TRN & \\
\hline CHEMBL1599169 & 688497 & 6.1 & 4.7365 & TST & \\
\hline CHEMBL1585544 & 688497 & 4.85 & 4.9656 & TST & \\
\hline CHEMBL1503294 & 688497 & 4.45 & 4.9333 & TRN & \\
\hline CHEMBL1416324 & 688497 & 5.15 & 5.1315 & TRN & \\
\hline CHEMBL 3183210 & 688497 & 5.3 & 4.9352 & TRN & \\
\hline CHEMBL1484774 & 688497 & 5.0 & 4.7285 & TRN & \\
\hline CHEMBL1500601 & 688497 & 5.25 & 5.1842 & TST & \\
\hline CHEMBL1586573 & 688497 & 5.4 & 5.1539 & TRN & \\
\hline CHEMBL1415135 & 688497 & 4.45 & 4.9769 & TRN & \\
\hline CHEMBL1547042 & 688497 & 5.0 & 5.2774 & TRN & \\
\hline CHEMBL1384843 & 688497 & 4.95 & 4.7999 & TRN & \\
\hline CHEMBL1338746 & 688497 & 4.45 & 4.99 & TRN & \\
\hline CHEMBL1504494 & 688497 & 4.45 & 4.7766 & TRN & \\
\hline CHEMBL1581158 & 688497 & 5.25 & 4.9461 & TST & \\
\hline CHEMBL1336939 & 688497 & 5.0 & 4.9829 & TRN & \\
\hline CHEMBL1307017 & 688497 & 4.45 & 5.6811 & TST & \\
\hline CHEMBL1308052 & 688497 & 5.05 & 4.9584 & TRN & \\
\hline CHEMBL1603720 & 688497 & 4.95 & 5.0405 & TRN & \\
\hline CHEMBL1604779 & 688497 & 4.45 & 4.6375 & TRN & \\
\hline CHEMBL1308657 & 688497 & 5.0 & 5.1506 & TRN & \\
\hline CHEMBL3193400 & 688497 & 4.45 & 5.0217 & TST & \\
\hline CHEMBL1529183 & 688497 & 4.45 & 5.1775 & TRN & \\
\hline CHEMBL1417167 & 688497 & 4.65 & 5.001 & TRN & \\
\hline CHEMBL1303203 & 688497 & 4.75 & 4.9669 & TRN & \\
\hline CHEMBL1361680 & 688497 & 4.85 & 4.7339 & TST & \\
\hline CHEMBL1545682 & 688497 & 6.3 & 5.499 & TST & \\
\hline CHEMBL1426340 & 688497 & 5.25 & 5.3937 & TRN & \\
\hline CHEMBL1454957 & 688497 & 5.7 & 5.0173 & TRN & \\
\hline CHEMBL1420007 & 688497 & 5.65 & 4.7872 & TRN & \\
\hline CHEMBL1545937 & 688497 & 6.35 & 5.3727 & TST & \\
\hline CHEMBL1981538 & 688497 & 5.6 & 5.1561 & TRN & \\
\hline CHEMBL1418151 & 688497 & 5.85 & 5.4966 & TRN & \\
\hline CHEMBL1372732 & 688497 & 5.5 & 4.8976 & TST & \\
\hline CHEMBL535331 & 688497 & 4.9 & 5.0975 & TRN & \\
\hline CHEMBL1529434 & 688497 & 4.75 & 5.2722 & TRN & \\
\hline CHEMBL1456496 & 688497 & 4.85 & 5.0592 & TRN & \\
\hline CHEMBL1319635 & 688497 & 6.25 & 5.0917 & TST & \\
\hline CHEMBL51931 & 688497 & 5.55 & 5.2792 & TRN & \\
\hline CHEMBL1500410 & 688497 & 5.2 & 5.0048 & TRN & \\
\hline CHEMBL1467499 & 688497 & 4.95 & 4.8148 & TRN & \\
\hline CHEMBL3195461 & 688497 & 4.8 & 4.9549 & TRN & \\
\hline CHEMBL1465031 & 688497 & 5.45 & 5.3623 & TRN & \\
\hline CHEMBL1343036 & 688497 & 4.45 & 5.0259 & TST & \\
\hline CHEMBL2006503 & 688497 & 5.8 & 5.2941 & TRN & \\
\hline CHEMBL1543761 & 688497 & 4.65 & 5.1702 & TRN & \\
\hline CHEMBL1427646 & 688497 & 4.45 & 5.2572 & TST & \\
\hline CHEMBL1343330 & 688497 & 5.25 & $5.2020 e$ & 0000000001 & TRN \\
\hline & & & & 19650 & \\
\hline
\end{tabular}




\begin{tabular}{|c|c|c|c|c|c|}
\hline \\
\hline CHEMBL1548600 & 688497 & 5.3 & 4.9981 & TRN & \\
\hline CHEMBL3190949 & 688497 & 4.6 & 5.5235 & TRN & \\
\hline CHEMBL1312320 & 688497 & 5.15 & 4.6066 & TRN & \\
\hline CHEMBL1350252 & 688497 & 5.1 & 4.6992 & TRN & \\
\hline CHEMBL1578846 & 688497 & 6.0 & 5.4703 & TRN & \\
\hline CHEMBL1559972 & 688497 & 5.25 & 5.1063 & TST & \\
\hline CHEMBL1352519 & 688497 & 4.95 & 4.9084 & TST & \\
\hline CHEMBL1539483 & 688497 & 4.85 & 4.7015 & TRN & \\
\hline CHEMBL1500854 & 688497 & 4.45 & 5.0311 & TST & \\
\hline CHEMBL1535122 & 688497 & 5.9 & 5.3083 & TST & \\
\hline CHEMBL1338018 & 688497 & 4.5 & 5.032 & TST & \\
\hline CHEMBL1557861 & 688497 & 4.65 & 4.7272 & TRN & \\
\hline CHEMBL1390427 & 688497 & 4.6 & 4.7439 & TST & \\
\hline CHEMBL1461958 & 688497 & 5.4 & 5.2784 & TRN & \\
\hline CHEMBL1452116 & 688497 & 6.1 & 5.091 & TST & \\
\hline CHEMBL1380000 & 688497 & 4.45 & 4.9997 & TRN & \\
\hline CHEMBL1312040 & 688497 & 5.25 & 4.9746 & TRN & \\
\hline CHEMBL1966872 & 688497 & 4.45 & 5.2329 & TRN & \\
\hline CHEMBL1536472 & 688497 & 4.45 & 5.0148 & TST & \\
\hline CHEMBL1540231 & 688497 & 5.0 & 4.9211 & TST & \\
\hline CHEMBL1555801 & 688497 & 4.9 & 5.2651 & TRN & \\
\hline CHEMBL1415494 & 688497 & 4.75 & 5.0788 & TRN & \\
\hline CHEMBL1539864 & 688497 & 5.0 & 5.0486 & TST & \\
\hline CHEMBL1419694 & 688497 & 5.2 & 5.01 & TST & \\
\hline CHEMBL1561809 & 688497 & 4.75 & 4.7594 & TRN & \\
\hline CHEMBL1424393 & 688497 & 4.85 & 5.1761 & TRN & \\
\hline CHEMBL1361935 & 688497 & 4.55 & 5.1235 & TRN & \\
\hline CHEMBL3197928 & 688497 & 5.25 & 5.171 & TRN & \\
\hline CHEMBL1416584 & 688497 & 5.65 & 5.0254 & TRN & \\
\hline CHEMBL1550403 & 688497 & 7.0501 & 5.0381 & TRN & \\
\hline CHEMBL1564997 & 688497 & 4.45 & 5.10800 & 00000000005 & TRN \\
\hline CHEMBL1613578 & 688497 & 5.55 & 5.0551 & TST & \\
\hline CHEMBL3190983 & 688497 & 5.5 & 5.371 & TRN & \\
\hline CHEMBL1561199 & 688497 & 4.45 & 5.0931 & TRN & \\
\hline CHEMBL1327989 & 688497 & 4.9 & 4.9383 & TRN & \\
\hline CHEMBL1331699 & 688497 & 5.25 & 5.3665 & TST & \\
\hline CHEMBL1306496 & 688497 & 5.1 & 4.9898 & TRN & \\
\hline CHEMBL1582780 & 688497 & 6.35 & 5.2361 & TST & \\
\hline CHEMBL1470903 & 688497 & 5.0 & 4.7504 & TRN & \\
\hline CHEMBL1577705 & 688497 & 5.25 & 5.2207 & TRN & \\
\hline CHEMBL1391519 & 688497 & 4.6 & 4.9188 & TRN & \\
\hline CHEMBL1587874 & 688497 & 5.0 & 5.3785 & TRN & \\
\hline CHEMBL1576791 & 688497 & 4.6 & 5.2066 & TRN & \\
\hline CHEMBL1568899 & 688497 & 4.55 & 5.0302 & TRN & \\
\hline CHEMBL1321790 & 688497 & 4.45 & 4.8914 & TRN & \\
\hline CHEMBL1350574 & 688497 & 4.55 & 4.9273 & TRN & \\
\hline CHEMBL1496089 & 688497 & 5.25 & 5.1854 & TRN & \\
\hline CHEMBL1522134 & 688497 & 6.25 & 4.928 & TRN & \\
\hline
\end{tabular}




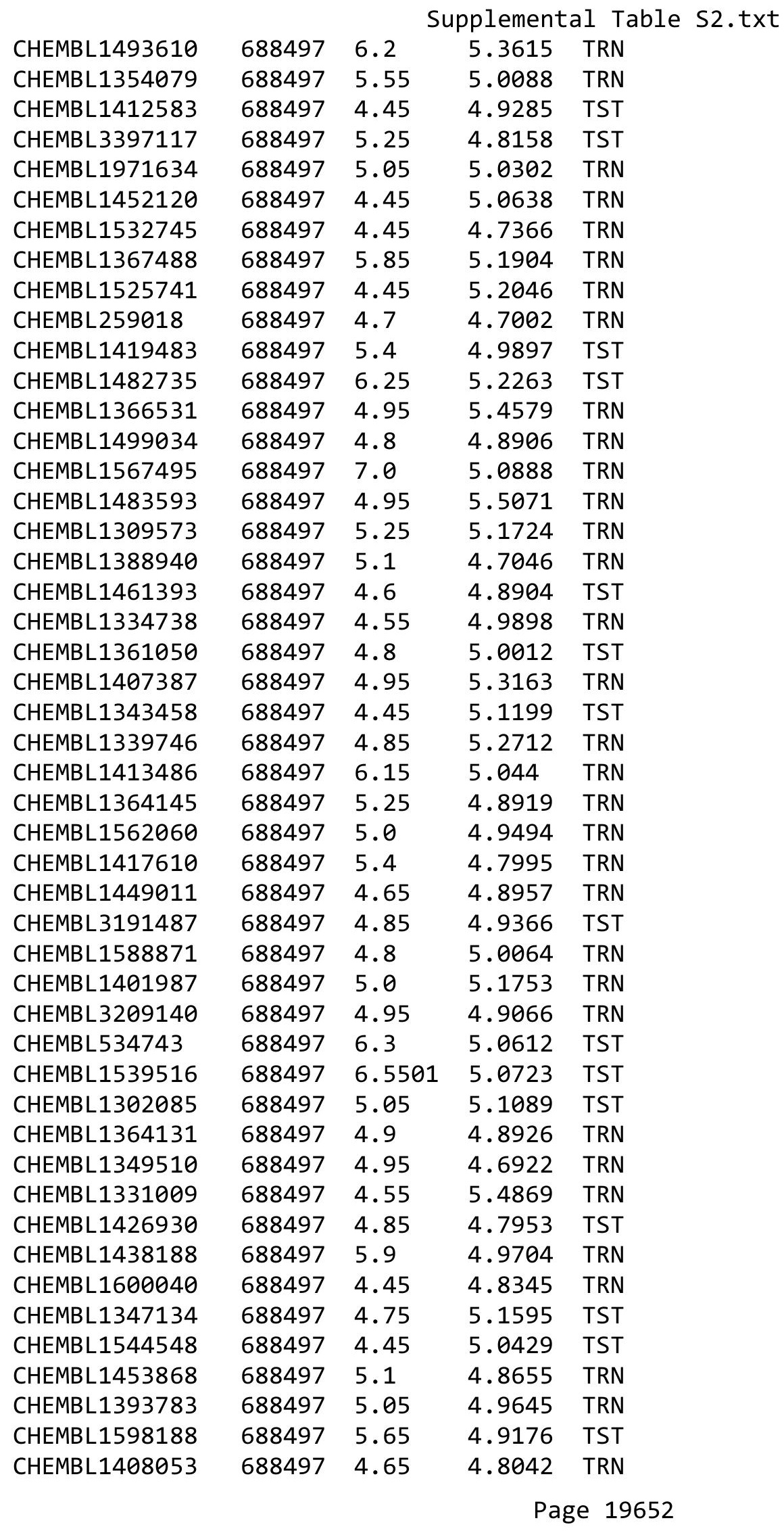




\begin{tabular}{|c|c|c|c|c|}
\hline \multicolumn{5}{|c|}{ Supplemental Table S2.txt } \\
\hline CHEMBL1333441 & 688497 & 4.45 & 5.0851 & TST \\
\hline CHEMBL1457828 & 688497 & 4.6 & 4.9313 & TRN \\
\hline CHEMBL1584485 & 688497 & 4.95 & 5.0816 & TRN \\
\hline CHEMBL1333088 & 688497 & 4.45 & 5.1162 & TST \\
\hline CHEMBL1423783 & 688497 & 4.45 & 5.1851 & TRN \\
\hline CHEMBL607299 & 688497 & 4.9 & 4.8944 & TST \\
\hline CHEMBL1367980 & 688497 & 5.4 & 5.2672 & TRN \\
\hline CHEMBL1391324 & 688497 & 4.45 & 4.7676 & TRN \\
\hline CHEMBL1456486 & 688497 & 4.5 & 5.0946 & TRN \\
\hline CHEMBL2002980 & 688497 & 5.45 & 5.2816 & TRN \\
\hline CHEMBL1588229 & 688497 & 7.0501 & 5.0334 & TRN \\
\hline CHEMBL1361024 & 688497 & 4.65 & 5.1567 & TRN \\
\hline CHEMBL1579475 & 688497 & 5.55 & 4.9654 & TRN \\
\hline CHEMBL1452115 & 688497 & 4.45 & 4.8381 & TRN \\
\hline CHEMBL3195803 & 688497 & 6.3 & 4.9731 & TRN \\
\hline CHEMBL1588966 & 688497 & 4.45 & 4.915 & TRN \\
\hline CHEMBL1343711 & 688497 & 5.55 & 5.0928 & TRN \\
\hline CHEMBL1381570 & 688497 & 5.05 & 5.0515 & TRN \\
\hline CHEMBL1406994 & 688497 & 4.95 & 5.1957 & TST \\
\hline CHEMBL1564386 & 688497 & 4.45 & 4.7876 & TRN \\
\hline CHEMBL1340704 & 688497 & 4.85 & 4.9061 & TRN \\
\hline CHEMBL1326561 & 688497 & 4.65 & 5.003 & TRN \\
\hline CHEMBL3209476 & 688497 & 4.65 & 5.265 & TRN \\
\hline CHEMBL1563727 & 688497 & 4.45 & 4.9606 & TRN \\
\hline CHEMBL1336709 & 688497 & 5.25 & 4.7184 & TRN \\
\hline CHEMBL3199050 & 688497 & 4.45 & 5.204 & TRN \\
\hline CHEMBL237615 & 688497 & 5.45 & 4.9734 & TST \\
\hline CHEMBL1528198 & 688497 & 4.75 & 5.1139 & TRN \\
\hline CHEMBL1325477 & 688497 & 4.9 & 5.0311 & TRN \\
\hline CHEMBL1609096 & 688497 & 4.5 & 4.995 & TRN \\
\hline CHEMBL1522790 & 688497 & 5.55 & 5.1258 & TRN \\
\hline CHEMBL1416139 & 688497 & 6.1 & 4.9747 & TRN \\
\hline CHEMBL1421471 & 688497 & 5.25 & 5.2056 & TRN \\
\hline CHEMBL1499559 & 688497 & 6.15 & 4.9767 & TRN \\
\hline CHEMBL1505952 & 688497 & 5.0 & 4.9952 & TRN \\
\hline CHEMBL1488320 & 688497 & 4.45 & 4.7953 & TRN \\
\hline CHEMBL1348161 & 688497 & 4.45 & 5.0257 & TRN \\
\hline CHEMBL1419969 & 688497 & 5.2 & 5.2448 & TRN \\
\hline CHEMBL1499939 & 688497 & 4.85 & 4.9039 & TRN \\
\hline CHEMBL1520416 & 688497 & 5.7 & 5.3749 & TST \\
\hline CHEMBL1365155 & 688497 & 5.4 & 5.1944 & TRN \\
\hline CHEMBL1309733 & 688497 & 4.5 & 4.8244 & TST \\
\hline CHEMBL1339229 & 688497 & 4.45 & 4.9675 & TST \\
\hline CHEMBL1468306 & 688497 & 4.95 & 5.3836 & TRN \\
\hline CHEMBL1409160 & 688497 & 5.25 & 4.9743 & TRN \\
\hline CHEMBL1564494 & 688497 & 5.25 & 5.1786 & TRN \\
\hline CHEMBL3213027 & 688497 & 5.0 & 5.1824 & TRN \\
\hline CHEMBL3199060 & 688497 & 4.45 & 4.7727 & TST \\
\hline
\end{tabular}




\begin{tabular}{|c|c|c|c|c|c|}
\hline & & \multicolumn{4}{|c|}{ Supplemental Table s2.txt } \\
\hline CHEMBL1526369 & 688497 & 5.35 & 5.1673 & TST & \\
\hline CHEMBL1538582 & 688497 & 4.45 & 4.9332 & TST & \\
\hline CHEMBL249032 & 688497 & 5.55 & 5.2357 & TRN & \\
\hline CHEMBL1603005 & 688497 & 6.15 & 5.2233 & TRN & \\
\hline CHEMBL1531896 & 688497 & 5.0 & 5.2263 & TST & \\
\hline CHEMBL1345355 & 688497 & 4.65 & 5.3787 & TRN & \\
\hline CHEMBL586000 & 688497 & 4.45 & 4.9224 & TST & \\
\hline CHEMBL1427051 & 688497 & 4.7 & 4.9769 & TST & \\
\hline CHEMBL1559291 & 688497 & 5.45 & 4.8384 & TST & \\
\hline CHEMBL1541518 & 688497 & 4.85 & 4.8583 & TST & \\
\hline CHEMBL1527601 & 688497 & 4.85 & 4.8374 & TRN & \\
\hline CHEMBL582259 & 688497 & 5.15 & 5.3192 & TRN & \\
\hline CHEMBL1456547 & 688497 & 4.95 & 4.875 & TRN & \\
\hline CHEMBL1421710 & 688497 & 4.75 & 5.0839 & TST & \\
\hline CHEMBL1587218 & 688497 & 5.0 & 4.9968 & TRN & \\
\hline CHEMBL1486569 & 688497 & 5.15 & 4.6695 & TRN & \\
\hline CHEMBL1467832 & 688497 & 4.85 & 5.0332 & TRN & \\
\hline CHEMBL1379338 & 688497 & 4.45 & 5.0035 & TRN & \\
\hline CHEMBL1545211 & 688497 & 4.45 & 5.126 & TRN & \\
\hline CHEMBL1431475 & 688497 & 4.5 & 4.9829 & TST & \\
\hline CHEMBL1547941 & 688497 & 5.65 & 5.0276 & TST & \\
\hline CHEMBL1349451 & 688497 & 4.9 & 5.0398 & TRN & \\
\hline CHEMBL3209971 & 688497 & 4.9 & 5.2503 & TST & \\
\hline CHEMBL1572777 & 688497 & 5.0 & 5.2138 & TRN & \\
\hline CHEMBL1605170 & 688497 & 5.45 & 5.4025 & TRN & \\
\hline CHEMBL1371848 & 688497 & 4.45 & 4.9007 & TRN & \\
\hline CHEMBL1542457 & 688497 & 4.65 & 5.1304 & TRN & \\
\hline CHEMBL1564866 & 688497 & 5.25 & 4.9234 & TST & \\
\hline CHEMBL1585333 & 688497 & 4.45 & 4.7899 & TRN & \\
\hline CHEMBL1501720 & 688497 & 5.5 & 4.9114 & TRN & \\
\hline CHEMBL1478307 & 688497 & 6.45 & 5.0549 & TRN & \\
\hline CHEMBL1337347 & 688497 & 4.95 & 5.2978 & TRN & \\
\hline CHEMBL1467492 & 688497 & 4.85 & 4.7427 & TRN & \\
\hline CHEMBL1328303 & 688497 & 4.9 & 5.1893 & TRN & \\
\hline CHEMBL1325801 & 688497 & 4.6 & 4.82600 & 00000000005 & TRN \\
\hline CHEMBL1462433 & 688497 & 4.6 & 5.28600 & 00000000005 & TST \\
\hline CHEMBL1598011 & 688497 & 4.45 & 4.8283 & TRN & \\
\hline CHEMBL1428877 & 688497 & 5.45 & 5.0247 & TRN & \\
\hline CHEMBL1471993 & 688497 & 4.9 & 4.8713 & TRN & \\
\hline CHEMBL1423241 & 688497 & 4.45 & 4.8812 & TRN & \\
\hline CHEMBL1443757 & 688497 & 4.65 & 5.0386 & TRN & \\
\hline CHEMBL1308396 & 688497 & 5.5 & 5.0163 & TRN & \\
\hline CHEMBL1586436 & 688497 & 4.9 & 5.2555 & TST & \\
\hline CHEMBL1438856 & 688497 & 5.55 & 5.275 & TRN & \\
\hline CHEMBL3193093 & 688497 & 4.45 & 5.1139 & TST & \\
\hline CHEMBL1411550 & 688497 & 4.45 & 4.9689 & TRN & \\
\hline CHEMBL1456762 & 688497 & 6.95 & 5.3927 & TRN & \\
\hline CHEMBL3189931 & 688497 & 4.6 & 5.0606 & TST & \\
\hline
\end{tabular}




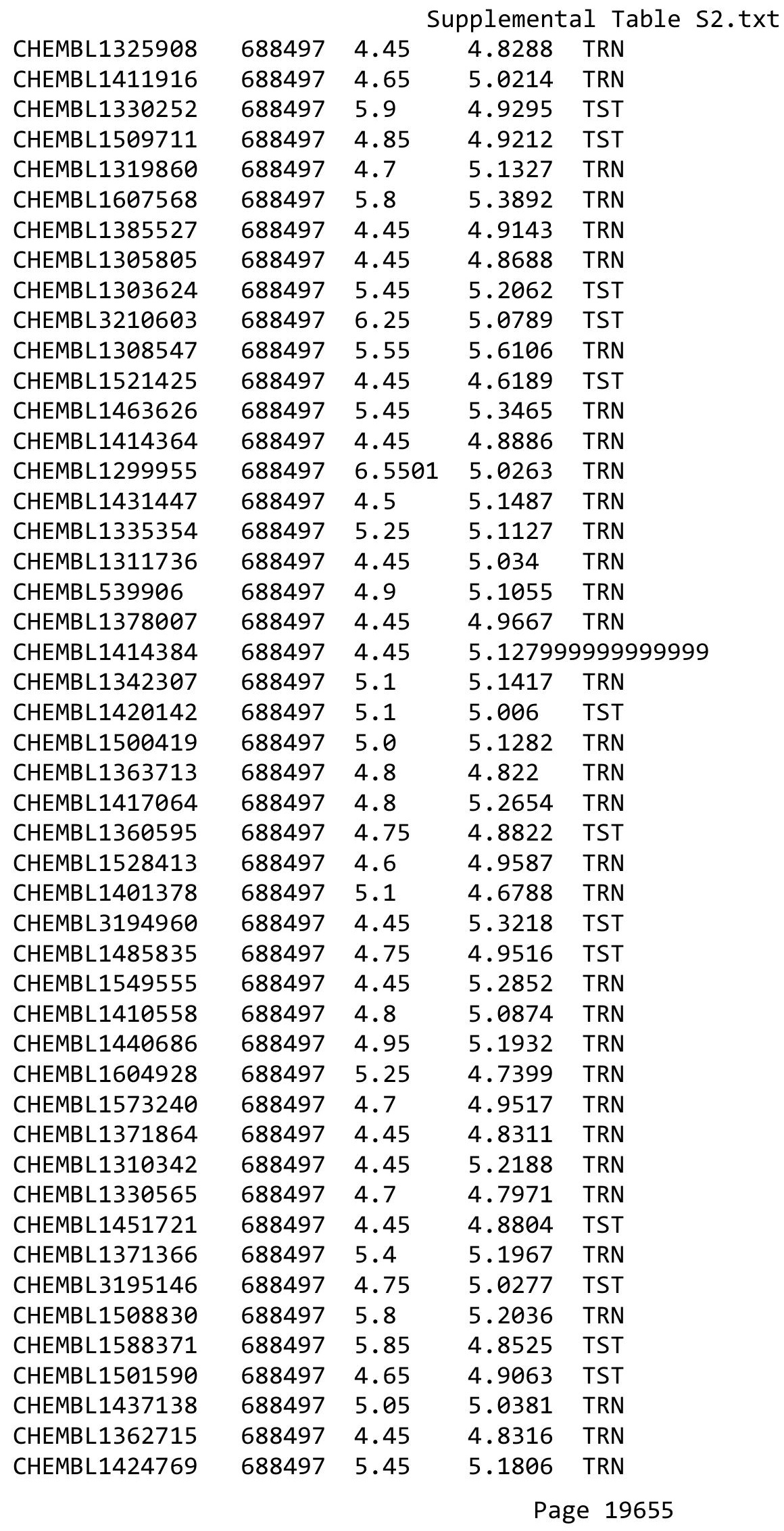




\begin{tabular}{|c|c|c|c|c|}
\hline \multicolumn{5}{|c|}{ Supplemental Table S2.txt } \\
\hline CHEMBL1432566 & 688497 & 4.75 & 5.0982 & TRN \\
\hline CHEMBL1464254 & 688497 & 6.25 & 5.4247 & TRN \\
\hline CHEMBL1464159 & 688497 & 4.6 & 4.8551 & TRN \\
\hline CHEMBL1311174 & 688497 & 4.75 & 4.8726 & TST \\
\hline CHEMBL 1410348 & 688497 & 5.2 & 5.1865 & TRN \\
\hline CHEMBL1536596 & 688497 & 6.1 & 5.115 & TST \\
\hline CHEMBL3191263 & 688497 & 5.0 & 4.7793 & TRN \\
\hline CHEMBL1489294 & 688497 & 6.05 & 5.0093 & TRN \\
\hline CHEMBL1612349 & 688497 & 5.0 & 5.2072 & TST \\
\hline CHEMBL1371202 & 688497 & 4.8 & 4.7492 & TRN \\
\hline CHEMBL1392770 & 688497 & 5.45 & 4.8681 & TRN \\
\hline CHEMBL1609230 & 688497 & 4.5 & 5.1332 & TRN \\
\hline CHEMBL1452903 & 688497 & 5.5 & 5.2276 & TST \\
\hline CHEMBL1528822 & 688497 & 5.05 & 4.7667 & TRN \\
\hline CHEMBL1505913 & 688497 & 5.65 & 4.8249 & TST \\
\hline CHEMBL1548893 & 688497 & 4.5 & 4.8409 & TRN \\
\hline CHEMBL1336245 & 688497 & 4.55 & 4.885 & TRN \\
\hline CHEMBL1402665 & 688497 & 5.45 & 4.9069 & TRN \\
\hline CHEMBL576932 & 688497 & 5.5 & 5.0193 & TST \\
\hline CHEMBL1412096 & 688497 & 4.95 & 5.0569 & TRN \\
\hline CHEMBL1320170 & 688497 & 4.45 & 4.9382 & TRN \\
\hline CHEMBL1596133 & 688497 & 5.0 & 5.3038 & TRN \\
\hline CHEMBL1542124 & 688497 & 4.85 & 5.1347 & TRN \\
\hline CHEMBL1410809 & 688497 & 4.7 & 4.9516 & TRN \\
\hline CHEMBL1341217 & 688497 & 4.45 & 5.1936 & TST \\
\hline CHEMBL1437815 & 688497 & 4.45 & 5.3257 & TRN \\
\hline CHEMBL1543931 & 688497 & 4.95 & 4.754 & TRN \\
\hline CHEMBL1981464 & 688497 & 4.8 & 5.1281 & TRN \\
\hline CHEMBL1416692 & 688497 & 6.3 & 4.8422 & TST \\
\hline CHEMBL1572788 & 688497 & 4.45 & 5.228 & TRN \\
\hline CHEMBL1612745 & 688497 & 4.45 & 5.0122 & TRN \\
\hline CHEMBL1409606 & 688497 & 4.6 & 4.971 & TST \\
\hline CHEMBL1564857 & 688497 & 4.45 & 5.2264 & TRN \\
\hline CHEMBL1583455 & 688497 & 6.05 & 5.5739 & TST \\
\hline CHEMBL1510991 & 688497 & 4.8 & 4.8704 & TST \\
\hline CHEMBL1578252 & 688497 & 5.9 & 5.3006 & TRN \\
\hline CHEMBL3198557 & 688497 & 4.8 & 5.0998 & TRN \\
\hline CHEMBL1566044 & 688497 & 4.45 & 5.3601 & TST \\
\hline CHEMBL1558524 & 688497 & 6.25 & 5.0511 & TST \\
\hline CHEMBL1563210 & 688497 & 4.45 & 5.0693 & TRN \\
\hline CHEMBL1596936 & 688497 & 4.85 & 5.2865 & TRN \\
\hline CHEMBL1306576 & 688497 & 5.25 & 5.0273 & TRN \\
\hline CHEMBL1419329 & 688497 & 4.45 & 5.1942 & TRN \\
\hline CHEMBL1346278 & 688497 & 4.95 & 5.2574 & TRN \\
\hline CHEMBL1556784 & 688497 & 4.55 & 4.7824 & TST \\
\hline CHEMBL1556248 & 688497 & 5.95 & 4.9601 & TST \\
\hline CHEMBL1403568 & 688497 & 4.45 & 4.7384 & TRN \\
\hline CHEMBL1588411 & 688497 & 4.45 & 4.8793 & TRN \\
\hline
\end{tabular}




\begin{tabular}{|c|c|c|c|c|}
\hline & & & upplement & at \\
\hline CHEMBL1369649 & 688497 & 4.9 & 4.8244 & TST \\
\hline CHEMBL3194528 & 688497 & 4.9 & 5.0817 & TRN \\
\hline CHEMBL1304150 & 688497 & 4.45 & 4.902 & TRN \\
\hline CHEMBL128427 & 688497 & 5.45 & 5.2002 & TRN \\
\hline CHEMBL1563134 & 688497 & 4.45 & 4.7436 & TRN \\
\hline CHEMBL1572896 & 688497 & 4.45 & 4.8365 & TRN \\
\hline CHEMBL1452706 & 688497 & 5.7 & 4.9941 & TRN \\
\hline CHEMBL1420529 & 688497 & 4.95 & 4.9087 & TRN \\
\hline CHEMBL1969161 & 688497 & 4.85 & 5.295 & TRN \\
\hline CHEMBL1503960 & 688497 & 4.9 & 5.0544 & TRN \\
\hline CHEMBL1612720 & 688497 & 5.0 & 4.8931 & TRN \\
\hline CHEMBL1408080 & 688497 & 4.65 & 5.1749 & TRN \\
\hline CHEMBL1351091 & 688497 & 5.7 & 5.0413 & TRN \\
\hline CHEMBL1565372 & 688497 & 4.45 & 5.0576 & TST \\
\hline CHEMBL1572789 & 688497 & 5.25 & 4.908 & TST \\
\hline CHEMBL1336106 & 688497 & 5.35 & 5.0716 & TST \\
\hline CHEMBL1379136 & 688497 & 4.45 & 4.8069 & TRN \\
\hline CHEMBL1721986 & 688497 & 5.45 & 5.0471 & TRN \\
\hline CHEMBL3192707 & 688497 & 4.95 & 4.9215 & TRN \\
\hline CHEMBL1521307 & 688497 & 5.35 & 5.2647 & TST \\
\hline CHEMBL3189991 & 688497 & 5.05 & 5.3516 & TRN \\
\hline CHEMBL1587518 & 688497 & 4.45 & 4.8066 & TRN \\
\hline CHEMBL1486649 & 688497 & 5.8 & 5.0297 & TST \\
\hline CHEMBL1545657 & 688497 & 4.9 & 5.0737 & TRN \\
\hline CHEMBL1536569 & 688497 & 4.45 & 4.7408 & TST \\
\hline CHEMBL1352525 & 688497 & 5.15 & 4.9703 & TST \\
\hline CHEMBL1600388 & 688497 & 4.45 & 5.0237 & TRN \\
\hline CHEMBL1323160 & 688497 & 4.45 & 5.2046 & TST \\
\hline CHEMBL1320243 & 688497 & 4.45 & 4.8863 & TRN \\
\hline CHEMBL1373052 & 688497 & 6.3 & 5.1489 & TRN \\
\hline CHEMBL1508068 & 688497 & 5.05 & 5.0811 & TRN \\
\hline CHEMBL1342237 & 688497 & 4.45 & 4.8454 & TRN \\
\hline CHEMBL1451690 & 688497 & 5.45 & 5.2405 & TRN \\
\hline CHEMBL1389161 & 688497 & 4.9 & 5.0607 & TRN \\
\hline CHEMBL1375553 & 688497 & 4.45 & 4.9601 & TRN \\
\hline CHEMBL1556623 & 688497 & 4.95 & 4.9041 & TRN \\
\hline CHEMBL1588226 & 688497 & 4.95 & 4.8373 & TST \\
\hline CHEMBL1448054 & 688497 & 5.55 & 5.3118 & TRN \\
\hline CHEMBL1509367 & 688497 & 4.45 & 4.8911 & TRN \\
\hline CHEMBL1354043 & 688497 & 4.55 & 4.9952 & TRN \\
\hline CHEMBL1604510 & 688497 & 6.0 & 4.8205 & TRN \\
\hline CHEMBL1580283 & 688497 & 5.95 & 5.2565 & TRN \\
\hline CHEMBL1611689 & 688497 & 4.45 & 4.985 & TRN \\
\hline CHEMBL1585088 & 688497 & 5.25 & 4.8032 & TRN \\
\hline CHEMBL1546068 & 688497 & 4.45 & 4.5843 & TRN \\
\hline CHEMBL1510941 & 688497 & 4.45 & 5.1278 & TST \\
\hline CHEMBL1509050 & 688497 & 6.05 & 4.9474 & TST \\
\hline CHEMBL1414440 & 688497 & 4.75 & 4.9689 & TRN \\
\hline
\end{tabular}




\begin{tabular}{|c|c|c|c|c|c|}
\hline \\
\hline CHEMBL1565647 & 688497 & 5.0 & 5.1137 & TRN & \\
\hline CHEMBL3193200 & 688497 & 4.7 & 5.0125 & TST & \\
\hline CHEMBL1487635 & 688497 & 4.9 & 5.1148 & TRN & \\
\hline CHEMBL1308266 & 688497 & 4.45 & 4.9577 & TRN & \\
\hline CHEMBL590706 & 688497 & 5.95 & 5.4323 & TRN & \\
\hline CHEMBL1569245 & 688497 & 5.95 & 5.1101 & TRN & \\
\hline CHEMBL1568593 & 688497 & 5.55 & 4.9646 & TRN & \\
\hline CHEMBL1372085 & 688497 & 5.0 & 5.232 & TST & \\
\hline CHEMBL1408491 & 688497 & 4.45 & 5.3683 & TRN & \\
\hline CHEMBL1555739 & 688497 & 4.45 & 5.0762 & TST & \\
\hline CHEMBL1335620 & 688497 & 5.45 & 4.9459 & TRN & \\
\hline CHEMBL1601133 & 688497 & 5.4 & 5.3532 & TRN & \\
\hline CHEMBL1376376 & 688497 & 5.35 & 5.0705 & TST & \\
\hline CHEMBL1312568 & 688497 & 4.45 & 5.192 & TRN & \\
\hline CHEMBL3199005 & 688497 & 5.8 & 5.0726 & TST & \\
\hline CHEMBL1378467 & 688497 & 5.25 & 5.3915 & TST & \\
\hline CHEMBL1581350 & 688497 & 4.95 & 4.8885 & TST & \\
\hline CHEMBL1476264 & 688497 & 7.0 & 5.7078 & TRN & \\
\hline CHEMBL1536433 & 688497 & 5.4 & 4.8719 & TRN & \\
\hline CHEMBL1326768 & 688497 & 5.45 & 5.3833 & TRN & \\
\hline CHEMBL1351027 & 688497 & 5.25 & 5.1307 & TRN & \\
\hline CHEMBL1569503 & 688497 & 4.85 & 4.6615 & TRN & \\
\hline CHEMBL1526077 & 688497 & 5.35 & 5.4821 & TST & \\
\hline CHEMBL1348824 & 688497 & 4.6 & 5.0915 & TRN & \\
\hline CHEMBL1444902 & 688497 & 5.2 & 5.2991 & TRN & \\
\hline CHEMBL1334559 & 688497 & 5.45 & 5.1318 & TRN & \\
\hline CHEMBL3199509 & 688497 & 4.45 & 5.4077 & TRN & \\
\hline CHEMBL1336660 & 688497 & 4.7 & 5.1294 & TST & \\
\hline CHEMBL1345746 & 688497 & 5.55 & 5.2949 & TST & \\
\hline CHEMBL1467556 & 688497 & 5.25 & 5.1369 & TRN & \\
\hline CHEMBL1362160 & 688497 & 4.6 & 5.1104 & TRN & \\
\hline CHEMBL1407753 & 688497 & 5.05 & 4.9264 & TRN & \\
\hline CHEMBL1403744 & 688497 & 5.6 & 5.0419 & TST & \\
\hline CHEMBL589101 & 688497 & 4.9 & 5.0171 & TRN & \\
\hline CHEMBL1399652 & 688497 & 4.85 & 5.0739 & TRN & \\
\hline CHEMBL1344374 & 688497 & 4.9 & 4.8368 & TRN & \\
\hline CHEMBL1323770 & 688497 & 4.65 & 5.2279 & TST & \\
\hline CHEMBL1502122 & 688497 & 4.45 & 5.2167 & TRN & \\
\hline CHEMBL1540673 & 688497 & 5.5 & 5.1624 & TRN & \\
\hline CHEMBL1467086 & 688497 & 4.95 & 4.8892 & TST & \\
\hline CHEMBL1309898 & 688497 & 5.25 & 5.0152 & TST & \\
\hline CHEMBL1422733 & 688497 & 4.65 & 4.9049 & TRN & \\
\hline CHEMBL1425767 & 688497 & 4.95 & 4.8637 & TRN & \\
\hline CHEMBL1359804 & 688497 & 5.45 & 5.2194 & TRN & \\
\hline CHEMBL1391471 & 688497 & 4.45 & $5.1320 e$ & 0000000001 & TST \\
\hline CHEMBL1574879 & 688497 & 5.3 & $5.1270 e$ & $\partial 000000001$ & TRN \\
\hline CHEMBL1498430 & 688497 & 4.45 & 5.0144 & TRN & \\
\hline CHEMBL1420015 & 688497 & 4.45 & 5.0465 & TST & \\
\hline
\end{tabular}




\begin{tabular}{|c|c|c|c|c|c|}
\hline & & & pplement & Table S2. & \\
\hline CHEMBL1335833 & 688497 & 4.45 & 5.0582 & TRN & \\
\hline CHEMBL1577775 & 688497 & 6.05 & 5.11100 & 0000000001 & TRN \\
\hline CHEMBL3191762 & 688497 & 4.9 & 4.7845 & TRN & \\
\hline CHEMBL1389922 & 688497 & 6.3 & 5.1423 & TRN & \\
\hline CHEMBL1542522 & 688497 & 6.2 & 5.3344 & TRN & \\
\hline CHEMBL1543138 & 688497 & 6.0 & 5.0773 & TRN & \\
\hline CHEMBL1550518 & 688497 & 5.3 & 5.2603 & TRN & \\
\hline CHEMBL1556254 & 688497 & 4.65 & 4.9686 & TRN & \\
\hline CHEMBL1469748 & 688497 & 5.6 & 4.8503 & TST & \\
\hline CHEMBL1603637 & 688497 & 4.65 & 4.4053 & TRN & \\
\hline CHEMBL1533534 & 688497 & 5.05 & 4.8209 & TST & \\
\hline CHEMBL528694 & 688497 & 6.05 & 5.51200 & 00000000005 & TRN \\
\hline CHEMBL3190602 & 688497 & 4.45 & 4.7022 & TRN & \\
\hline CHEMBL1507948 & 688497 & 4.95 & 4.9876 & TRN & \\
\hline CHEMBL1607253 & 688497 & 4.45 & 4.7556 & TST & \\
\hline CHEMBL1308088 & 688497 & 4.45 & 5.261 & TST & \\
\hline CHEMBL1393861 & 688497 & 4.85 & 4.8198 & TRN & \\
\hline CHEMBL1337414 & 688497 & 5.35 & 4.7795 & TST & \\
\hline CHEMBL1310999 & 688497 & 4.5 & 5.2753 & TST & \\
\hline CHEMBL1602145 & 688497 & 4.8 & 4.939 & TST & \\
\hline CHEMBL603410 & 688497 & 5.55 & 5.0645 & TST & \\
\hline CHEMBL1574744 & 688497 & 4.45 & 5.2222 & TRN & \\
\hline CHEMBL1597425 & 688497 & 4.95 & 4.8925 & TRN & \\
\hline CHEMBL1499871 & 688497 & 4.45 & 4.7745 & TRN & \\
\hline CHEMBL1505991 & 688497 & 4.9 & 5.001 & TRN & \\
\hline CHEMBL3199116 & 688497 & 7.5498 & 4.9047 & TRN & \\
\hline CHEMBL1380396 & 688497 & 4.9 & 4.83899 & 99999999995 & TRN \\
\hline CHEMBL1303703 & 688497 & 4.45 & 4.6428 & TRN & \\
\hline CHEMBL1530438 & 688497 & 5.8 & 5.0041 & TRN & \\
\hline CHEMBL1471418 & 688497 & 4.6 & 4.7686 & TRN & \\
\hline CHEMBL1376879 & 688497 & 5.2 & 5.0501 & TRN & \\
\hline CHEMBL1450869 & 688497 & 4.8 & 4.8174 & TRN & \\
\hline CHEMBL1550218 & 688497 & 4.5 & 4.7877 & TST & \\
\hline CHEMBL1464477 & 688497 & 4.45 & 4.8293 & TRN & \\
\hline CHEMBL1602333 & 688497 & 4.45 & 4.8883 & TRN & \\
\hline CHEMBL1342242 & 688497 & 6.95 & 4.9769 & TRN & \\
\hline CHEMBL262627 & 688497 & 5.2 & 4.7752 & TRN & \\
\hline CHEMBL1369891 & 688497 & 4.45 & 4.9117 & TST & \\
\hline CHEMBL1586806 & 688497 & 4.8 & 4.6611 & TST & \\
\hline CHEMBL1494593 & 688497 & 4.75 & 5.0057 & TRN & \\
\hline CHEMBL1323778 & 688497 & 4.45 & 4.9743 & TRN & \\
\hline CHEMBL1431687 & 688497 & 5.75 & 5.0544 & TST & \\
\hline CHEMBL1359830 & 688497 & 4.45 & 5.0543 & TST & \\
\hline CHEMBL1584033 & 688497 & 5.2 & 5.0219 & TST & \\
\hline CHEMBL1999480 & 688497 & 5.55 & 4.9585 & TRN & \\
\hline CHEMBL1331505 & 688497 & 7.0501 & 5.1325 & TRN & \\
\hline CHEMBL 3208564 & 688497 & 5.0 & 5.0431 & TST & \\
\hline CHEMBL1519446 & 688497 & 4.6 & 4.8921 & TRN & \\
\hline
\end{tabular}




\begin{tabular}{|c|c|c|c|c|c|}
\hline \multicolumn{6}{|c|}{ Supplemental Table S } \\
\hline CHEMBL1606849 & 688497 & 4.85 & 5.003 & TRN & \\
\hline CHEMBL1359157 & 688497 & 4.45 & 4.9043 & TST & \\
\hline CHEMBL1995112 & 688497 & 4.9 & 4.6754 & TRN & \\
\hline CHEMBL1585220 & 688497 & 4.65 & 4.7738 & TRN & \\
\hline CHEMBL1477697 & 688497 & 4.45 & 4.8325 & TRN & \\
\hline CHEMBL1350118 & 688497 & 4.9 & 5.1655 & TRN & \\
\hline CHEMBL1381384 & 688497 & 5.45 & 4.9829 & TRN & \\
\hline CHEMBL1301232 & 688497 & 4.95 & 4.9853 & TRN & \\
\hline CHEMBL1414609 & 688497 & 4.45 & 5.0124 & TST & \\
\hline CHEMBL1485793 & 688497 & 5.5 & 5.197 & TRN & \\
\hline CHEMBL1350889 & 688497 & 4.65 & 5.08 & TRN & \\
\hline CHEMBL1479708 & 688497 & 4.95 & 5.2231 & TRN & \\
\hline CHEMBL1343652 & 688497 & 5.35 & 5.2773 & TRN & \\
\hline CHEMBL1519422 & 688497 & 4.45 & 4.7607 & TST & \\
\hline CHEMBL1611659 & 688497 & 4.95 & 5.1057 & TRN & \\
\hline CHEMBL 1543856 & 688497 & 5.25 & 4.9769 & TRN & \\
\hline CHEMBL1363127 & 688497 & 5.1 & 5.0115 & TRN & \\
\hline CHEMBL1490864 & 688497 & 4.45 & 4.9296 & TRN & \\
\hline CHEMBL1426121 & 688497 & 4.95 & 4.9328 & TRN & \\
\hline CHEMBL1983418 & 688497 & 5.45 & 5.4434 & TRN & \\
\hline CHEMBL 1577077 & 688497 & 4.9 & 4.8462 & TRN & \\
\hline CHEMBL1380511 & 688497 & 4.45 & 4.5137 & TRN & \\
\hline CHEMBL1346069 & 688497 & 4.95 & 4.7376 & TRN & \\
\hline CHEMBL1383876 & 688497 & 4.45 & 5.0355 & TST & \\
\hline CHEMBL 3208367 & 688497 & 4.45 & 5.1365 & TRN & \\
\hline CHEMBL1427149 & 688497 & 5.55 & 5.3325 & TST & \\
\hline CHEMBL1469969 & 688497 & 5.55 & 5.0353 & TRN & \\
\hline CHEMBL1558598 & 688497 & 5.5 & 5.3429 & TST & \\
\hline CHEMBL1605523 & 688497 & 6.95 & 5.521 & TRN & \\
\hline CHEMBL1581149 & 688497 & 4.75 & 4.7839 & TRN & \\
\hline CHEMBL1582906 & 688497 & 5.25 & 5.0395 & TRN & \\
\hline CHEMBL1574616 & 688497 & 4.8 & 4.4983 & TRN & \\
\hline CHEMBL 3214100 & 688497 & 4.8 & 5.1014 & TRN & \\
\hline CHEMBL1478172 & 688497 & 4.85 & 5.0851 & TRN & \\
\hline CHEMBL3199744 & 688497 & 4.95 & 5.1502 & TRN & \\
\hline CHEMBL1336407 & 688497 & 5.25 & 4.8061 & TST & \\
\hline CHEMBL1526738 & 688497 & 5.5 & 5.2803 & TRN & \\
\hline CHEMBL1320274 & 688497 & 4.9 & 4.3687 & TRN & \\
\hline CHEMBL1503523 & 688497 & 4.95 & 4.64199 & 99999999995 & TRN \\
\hline CHEMBL1479888 & 688497 & 4.95 & 4.8073 & TRN & \\
\hline CHEMBL1431779 & 688497 & 5.05 & 5.144 & TST & \\
\hline CHEMBL1332710 & 688497 & 5.9 & 4.8842 & TRN & \\
\hline CHEMBL598679 & 688497 & 4.45 & 4.7635 & TRN & \\
\hline CHEMBL1306248 & 688497 & 4.45 & 5.0344 & TST & \\
\hline CHEMBL1498407 & 688497 & 4.85 & 4.8918 & TRN & \\
\hline CHEMBL1468966 & 688497 & 4.45 & 4.9548 & TST & \\
\hline CHEMBL1311796 & 688497 & 5.0 & 4.9155 & TRN & \\
\hline CHEMBL1496160 & 688497 & 4.45 & 5.1992 & TST & \\
\hline
\end{tabular}




\begin{tabular}{|c|c|c|c|c|c|}
\hline \multicolumn{6}{|c|}{ Supplemental Table S2.txt } \\
\hline CHEMBL1574971 & 688497 & 6.0 & 4.8271 & TRN & \\
\hline CHEMBL1498710 & 688497 & 5.9 & 4.9448 & TST & \\
\hline CHEMBL1535313 & 688497 & 5.05 & 5.0794 & TST & \\
\hline CHEMBL1429071 & 688497 & 5.25 & 5.12700 & 0000000001 & TRN \\
\hline CHEMBL1340962 & 688497 & 4.5 & 4.9167 & TRN & \\
\hline CHEMBL1589454 & 688497 & 4.85 & 4.9722 & TRN & \\
\hline CHEMBL1392545 & 688497 & 5.85 & 5.3079 & TRN & \\
\hline CHEMBL1496126 & 688497 & 4.9 & 4.8772 & TST & \\
\hline CHEMBL1423935 & 688497 & 5.1 & 5.0564 & TRN & \\
\hline CHEMBL1567428 & 688497 & 4.75 & 5.0974 & TRN & \\
\hline CHEMBL1492723 & 688497 & 5.25 & 5.1854 & TRN & \\
\hline CHEMBL1467481 & 688497 & 5.5 & 4.8984 & TST & \\
\hline CHEMBL1547872 & 688497 & 6.0 & 5.454 & TRN & \\
\hline CHEMBL1501996 & 688497 & 4.45 & 5.0987 & TST & \\
\hline CHEMBL1548500 & 688497 & 4.45 & 5.115 & TRN & \\
\hline CHEMBL1305152 & 688497 & 4.75 & 4.9337 & TST & \\
\hline CHEMBL1532633 & 688497 & 4.6 & 4.9285 & TST & \\
\hline CHEMBL1407464 & 688497 & 4.7 & 5.1723 & TST & \\
\hline CHEMBL1301885 & 688497 & 5.45 & 4.8131 & TRN & \\
\hline CHEMBL1486993 & 688497 & 4.55 & 4.8646 & TRN & \\
\hline CHEMBL1482307 & 688497 & 4.6 & 4.8072 & TRN & \\
\hline CHEMBL1581618 & 688497 & 4.65 & 4.9988 & TRN & \\
\hline CHEMBL1538833 & 688497 & 4.45 & 4.8894 & TRN & \\
\hline CHEMBL1376683 & 688497 & 4.65 & 4.7197 & TRN & \\
\hline CHEMBL1478469 & 688497 & 5.5 & 4.8431 & TST & \\
\hline CHEMBL1490592 & 688497 & 5.25 & 5.1099 & TRN & \\
\hline CHEMBL1332165 & 688497 & 4.5 & 4.9352 & TRN & \\
\hline CHEMBL1535921 & 688497 & 4.8 & 5.2698 & TRN & \\
\hline CHEMBL1562033 & 688497 & 5.05 & 5.1994 & TRN & \\
\hline CHEMBL1441206 & 688497 & 4.85 & 4.7857 & TRN & \\
\hline CHEMBL1608762 & 688497 & 5.3 & 5.2529 & TRN & \\
\hline CHEMBL473735 & 688497 & 7.5003 & 5.4642 & TRN & \\
\hline CHEMBL1572520 & 688497 & 5.0 & 4.9292 & TRN & \\
\hline CHEMBL1408195 & 688497 & 4.6 & 5.0155 & TST & \\
\hline CHEMBL1469703 & 688497 & 4.95 & 5.1714 & TRN & \\
\hline CHEMBL1524881 & 688497 & 4.45 & 4.6696 & TRN & \\
\hline CHEMBL1339338 & 688497 & 4.7 & 4.7647 & TRN & \\
\hline CHEMBL1454686 & 688497 & 4.65 & 5.0542 & TRN & \\
\hline CHEMBL1522566 & 688497 & 4.85 & 4.6706 & TRN & \\
\hline CHEMBL3209967 & 688497 & 4.45 & 5.0409 & TRN & \\
\hline CHEMBL3397122 & 688497 & 4.5 & 4.6602 & TST & \\
\hline CHEMBL1432209 & 688497 & 5.0 & 5.08 & TST & \\
\hline CHEMBL1391613 & 688497 & 5.05 & 5.1325 & TST & \\
\hline CHEMBL1472344 & 688497 & 5.4 & 4.9843 & TRN & \\
\hline CHEMBL1502859 & 688497 & 4.45 & 5.0182 & TRN & \\
\hline CHEMBL1299526 & 688497 & 4.45 & 4.9924 & TRN & \\
\hline CHEMBL1534678 & 688497 & 5.3 & 5.0697 & TRN & \\
\hline CHEMBL1460337 & 688497 & 6.1 & 5.1462 & TRN & \\
\hline
\end{tabular}




\begin{tabular}{|c|c|c|c|c|}
\hline \multicolumn{5}{|c|}{ Supplemental Table S2.txt } \\
\hline CHEMBL1320411 & 688497 & 5.25 & 5.2462 & TRN \\
\hline CHEMBL1457503 & 688497 & 4.6 & 4.8754 & TRN \\
\hline CHEMBL1550095 & 688497 & 5.55 & 5.0166 & TRN \\
\hline CHEMBL 305469 & 688497 & 5.4 & 4.9098 & TRN \\
\hline CHEMBL1478987 & 688497 & 4.45 & 5.0617 & TRN \\
\hline CHEMBL478501 & 688497 & 4.65 & 5.0126 & TST \\
\hline CHEMBL1561547 & 688497 & 5.25 & 5.0906 & TRN \\
\hline CHEMBL1586958 & 688497 & 5.45 & 5.1796 & TST \\
\hline CHEMBL1466500 & 688497 & 5.95 & 4.979 & TRN \\
\hline CHEMBL1457791 & 688497 & 4.95 & 4.9213 & TRN \\
\hline CHEMBL1310609 & 688497 & 4.65 & 4.8335 & TRN \\
\hline CHEMBL1387175 & 688497 & 4.85 & 4.9391 & TRN \\
\hline CHEMBL1577493 & 688497 & 4.9 & 5.3775 & TRN \\
\hline CHEMBL3189736 & 688497 & 4.85 & 4.6821 & TRN \\
\hline CHEMBL1506765 & 688497 & 4.8 & 4.5304 & TST \\
\hline CHEMBL1382967 & 688497 & 4.45 & 4.8668 & TRN \\
\hline CHEMBL1301529 & 688497 & 5.25 & 4.8406 & TST \\
\hline CHEMBL1527549 & 688497 & 4.45 & 5.1679 & TST \\
\hline CHEMBL1322078 & 688497 & 5.7 & 4.9157 & TRN \\
\hline CHEMBL1425921 & 688497 & 5.1 & 4.8774 & TRN \\
\hline CHEMBL1347695 & 688497 & 4.9 & 5.0074 & TRN \\
\hline CHEMBL1567944 & 688497 & 6.45 & 5.9384 & TST \\
\hline CHEMBL1584333 & 688497 & 4.95 & 5.0107 & TRN \\
\hline CHEMBL1404705 & 688497 & 6.45 & 5.0959 & TST \\
\hline CHEMBL1570647 & 688497 & 4.85 & 5.1005 & TRN \\
\hline CHEMBL1501427 & 688497 & 4.95 & 5.063 & TST \\
\hline CHEMBL1561092 & 688497 & 4.45 & 4.8342 & TRN \\
\hline CHEMBL1540483 & 688497 & 4.45 & 5.1977 & TST \\
\hline CHEMBL1338761 & 688497 & 4.7 & 5.251 & TRN \\
\hline CHEMBL1327816 & 688497 & 4.45 & 4.8912 & TRN \\
\hline CHEMBL1576143 & 688497 & 4.45 & 5.184 & TST \\
\hline CHEMBL1511029 & 688497 & 5.55 & 5.4016 & TRN \\
\hline CHEMBL1558076 & 688497 & 4.95 & 4.8551 & TST \\
\hline CHEMBL1565485 & 688497 & 5.0 & 4.8213 & TST \\
\hline CHEMBL1550238 & 688497 & 4.7 & 4.6642 & TRN \\
\hline CHEMBL1471716 & 688497 & 4.45 & 4.8887 & TRN \\
\hline CHEMBL1507774 & 688497 & 4.45 & 4.9702 & TRN \\
\hline CHEMBL1502730 & 688497 & 6.0 & 5.1594 & TRN \\
\hline CHEMBL1543912 & 688497 & 5.25 & 4.7788 & TST \\
\hline CHEMBL1451226 & 688497 & 6.1 & 5.0502 & TST \\
\hline CHEMBL1394002 & 688497 & 4.45 & 4.7608 & TRN \\
\hline CHEMBL1332390 & 688497 & 4.45 & 4.8182 & TST \\
\hline CHEMBL1542448 & 688497 & 4.85 & 4.7872 & TRN \\
\hline CHEMBL1349282 & 688497 & 5.15 & 4.9805 & TRN \\
\hline CHEMBL1527476 & 688497 & 4.45 & 4.7917 & TRN \\
\hline CHEMBL1479799 & 688497 & 5.2 & 5.2924 & TRN \\
\hline CHEMBL3199217 & 688497 & 4.45 & 4.7053 & TST \\
\hline CHEMBL1567521 & 688497 & 5.6 & 5.0841 & TRN \\
\hline
\end{tabular}




\begin{tabular}{|c|c|c|c|c|c|}
\hline \\
\hline CHEMBL1524655 & 688497 & 4.7 & 5.1348 & TST & \\
\hline CHEMBL1478942 & 688497 & 5.85 & 5.1828 & TST & \\
\hline CHEMBL1405263 & 688497 & 4.45 & 5.1204 & TRN & \\
\hline CHEMBL1509861 & 688497 & 5.45 & 4.8741 & TRN & \\
\hline CHEMBL1402384 & 688497 & 4.7 & 5.1218 & TRN & \\
\hline CHEMBL3191537 & 688497 & 4.45 & 4.8861 & TST & \\
\hline CHEMBL1448697 & 688497 & 5.2 & 4.9263 & TRN & \\
\hline CHEMBL1495107 & 688497 & 5.4 & 5.2391 & TRN & \\
\hline CHEMBL1503814 & 688497 & 4.7 & 5.0871 & TRN & \\
\hline CHEMBL1346986 & 688497 & 5.0 & 4.9165 & TRN & \\
\hline CHEMBL1466669 & 688497 & 4.9 & 5.0875 & TRN & \\
\hline CHEMBL1383822 & 688497 & 5.25 & 4.9967 & TRN & \\
\hline CHEMBL1567927 & 688497 & 4.95 & 4.9765 & TRN & \\
\hline CHEMBL1605875 & 688497 & 5.1 & 4.84399 & 9999999999 & TRN \\
\hline CHEMBL1470905 & 688497 & 4.8 & 4.9647 & TRN & \\
\hline CHEMBL1598691 & 688497 & 5.55 & 5.0342 & TRN & \\
\hline CHEMBL407864 & 688497 & 5.5 & 5.0744 & TST & \\
\hline CHEMBL3195136 & 688497 & 5.65 & 4.974 & TRN & \\
\hline CHEMBL1464561 & 688497 & 4.65 & 4.8595 & TRN & \\
\hline CHEMBL1504348 & 688497 & 6.25 & 4.9323 & TRN & \\
\hline CHEMBL1500091 & 688497 & 4.45 & 4.8204 & TRN & \\
\hline CHEMBL1544592 & 688497 & 5.65 & 4.9595 & TST & \\
\hline CHEMBL3190965 & 688497 & 5.15 & 5.1819 & TRN & \\
\hline CHEMBL1609884 & 688497 & 5.9 & 5.1251 & TRN & \\
\hline CHEMBL1588873 & 688497 & 4.45 & 5.0026 & TRN & \\
\hline CHEMBL1604403 & 688497 & 4.8 & 5.0879 & TRN & \\
\hline CHEMBL1598373 & 688497 & 4.5 & 4.817 & TRN & \\
\hline CHEMBL1601632 & 688497 & 4.65 & 5.1886 & TRN & \\
\hline CHEMBL1568380 & 688497 & 6.25 & 5.4415 & TRN & \\
\hline CHEMBL1428264 & 688497 & 4.95 & 5.1195 & TRN & \\
\hline CHEMBL1579460 & 688497 & 4.45 & 4.9613 & TRN & \\
\hline CHEMBL1531761 & 688497 & 5.95 & 5.0094 & TRN & \\
\hline CHEMBL1569513 & 688497 & 5.2 & 5.0292 & TRN & \\
\hline CHEMBL1603676 & 688497 & 4.9 & 4.79 & TRN & \\
\hline CHEMBL1549450 & 688497 & 5.15 & 5.3134 & TRN & \\
\hline CHEMBL1402041 & 688497 & 6.25 & 4.9337 & TRN & \\
\hline CHEMBL1491342 & 688497 & 4.65 & 4.7713 & TRN & \\
\hline CHEMBL1324846 & 688497 & 5.0 & 5.1661 & TRN & \\
\hline CHEMBL1495454 & 688497 & 4.6 & 4.933 & TRN & \\
\hline CHEMBL1534400 & 688497 & 4.75 & 5.1518 & TRN & \\
\hline CHEMBL1550676 & 688497 & 4.65 & 5.1313 & TST & \\
\hline CHEMBL1456725 & 688497 & 5.15 & 5.4042 & TST & \\
\hline CHEMBL1548215 & 688497 & 5.15 & 4.9937 & TST & \\
\hline CHEMBL1570920 & 688497 & 4.6 & 4.5663 & TST & \\
\hline CHEMBL1539150 & 688497 & 5.1 & 5.0683 & TST & \\
\hline CHEMBL1541620 & 688497 & 4.45 & 5.0878 & TST & \\
\hline CHEMBL1526766 & 688497 & 4.9 & 4.8769 & TST & \\
\hline CHEMBL1560223 & 688497 & 4.45 & 5.2364 & TRN & \\
\hline
\end{tabular}




\begin{tabular}{|c|c|c|c|c|c|}
\hline & & & oplement & al lable S2 & \\
\hline CHEMBL1506662 & 688497 & 4.5 & 5.0628 & TST & \\
\hline CHEMBL1471295 & 688497 & 6.8499 & 5.17700 & 20000000005 & TRN \\
\hline CHEMBL1595175 & 688497 & 4.95 & 5.0184 & TRN & \\
\hline CHEMBL1489407 & 688497 & 4.45 & 4.9848 & TRN & \\
\hline CHEMBL1496452 & 688497 & 4.45 & 4.899 & TRN & \\
\hline CHEMBL3211754 & 688497 & 5.0 & 4.8792 & TRN & \\
\hline CHEMBL1479979 & 688497 & 5.25 & 5.2312 & TST & \\
\hline CHEMBL1424588 & 688497 & 4.85 & 5.1332 & TRN & \\
\hline CHEMBL1427859 & 688497 & 4.45 & 4.9055 & TRN & \\
\hline CHEMBL1415972 & 688497 & 4.95 & 5.0919 & TST & \\
\hline CHEMBL1349236 & 688497 & 4.9 & 4.9716 & TST & \\
\hline CHEMBL1305780 & 688497 & 5.45 & 4.98600 & 0000000001 & TST \\
\hline CHEMBL1527741 & 688497 & 5.9 & 4.9408 & TRN & \\
\hline CHEMBL1563223 & 688497 & 5.25 & 5.1252 & TST & \\
\hline CHEMBL1390645 & 688497 & 5.45 & 4.7253 & TRN & \\
\hline CHEMBL1507748 & 688497 & 4.95 & 5.1213 & TST & \\
\hline CHEMBL1332746 & 688497 & 4.9 & 5.1971 & TRN & \\
\hline CHEMBL1583676 & 688497 & 4.95 & 5.4193 & TRN & \\
\hline CHEMBL1419254 & 688497 & 5.9 & 4.9575 & TST & \\
\hline CHEMBL1420385 & 688497 & 5.5 & 4.9617 & TST & \\
\hline CHEMBL1346781 & 688497 & 4.45 & 4.868 & TST & \\
\hline CHEMBL1329255 & 688497 & 5.65 & 4.9164 & TRN & \\
\hline CHEMBL1531799 & 688497 & 5.9 & 5.1455 & TST & \\
\hline CHEMBL3197955 & 688497 & 4.45 & 4.9365 & TRN & \\
\hline CHEMBL1325250 & 688497 & 4.45 & 4.5969 & TRN & \\
\hline CHEMBL1993555 & 688497 & 5.15 & 5.2012 & TST & \\
\hline CHEMBL1550290 & 688497 & 4.45 & 4.8528 & TRN & \\
\hline CHEMBL1507672 & 688497 & 4.95 & 4.9512 & TRN & \\
\hline CHEMBL1431676 & 688497 & 5.0 & 5.0471 & TRN & \\
\hline CHEMBL1312157 & 688497 & 4.45 & 5.0587 & TRN & \\
\hline CHEMBL1556882 & 688497 & 4.5 & 5.0584 & TRN & \\
\hline CHEMBL1520777 & 688497 & 4.95 & 5.145 & TRN & \\
\hline CHEMBL1549911 & 688497 & 4.45 & 4.5657 & TST & \\
\hline CHEMBL1578791 & 688497 & 4.45 & 4.8081 & TRN & \\
\hline CHEMBL1367036 & 688497 & 5.45 & 5.2833 & TRN & \\
\hline CHEMBL1380024 & 688497 & 4.6 & 5.1121 & TST & \\
\hline CHEMBL1390198 & 688497 & 4.45 & 5.1378 & TRN & \\
\hline CHEMBL1413071 & 688497 & 4.95 & 5.0188 & TRN & \\
\hline CHEMBL1300196 & 688497 & 5.2 & 5.3222 & TRN & \\
\hline CHEMBL1495409 & 688497 & 5.0 & 5.0274 & TRN & \\
\hline CHEMBL1558385 & 688497 & 6.45 & 4.9381 & TST & \\
\hline CHEMBL1600794 & 688497 & 5.05 & 5.0879 & TRN & \\
\hline CHEMBL3190560 & 688497 & 4.65 & 5.0115 & TST & \\
\hline CHEMBL1546044 & 688497 & 5.25 & 5.2119 & TRN & \\
\hline CHEMBL1394045 & 688497 & 4.75 & 4.9152 & TRN & \\
\hline CHEMBL1472004 & 688497 & 4.95 & 4.7369 & TRN & \\
\hline CHEMBL1518468 & 688497 & 4.45 & 4.9297 & TRN & \\
\hline CHEMBL1506604 & 688497 & 4.45 & 4.9753 & TRN & \\
\hline
\end{tabular}




\begin{tabular}{|c|c|c|c|c|c|}
\hline \multicolumn{6}{|c|}{ Supplemental Table S2.txt } \\
\hline CHEMBL1346981 & 688497 & 4.6 & 4.8803 & TST & \\
\hline CHEMBL1469013 & 688497 & 5.95 & 5.0208 & TRN & \\
\hline CHEMBL1486943 & 688497 & 4.9 & 4.862 & TRN & \\
\hline CHEMBL 273103 & 688497 & 4.95 & 4.8374 & TRN & \\
\hline CHEMBL1481985 & 688497 & 4.9 & 5.1758 & TST & \\
\hline CHEMBL1582151 & 688497 & 4.45 & 4.8943 & TRN & \\
\hline CHEMBL1508357 & 688497 & 4.45 & 5.0424 & TST & \\
\hline CHEMBL1457776 & 688497 & 4.45 & 4.9866 & TRN & \\
\hline CHEMBL1337469 & 688497 & 4.45 & 5.14 & TRN & \\
\hline CHEMBL264666 & 688497 & 5.0 & 5.3325 & TRN & \\
\hline CHEMBL1345694 & 688497 & 4.85 & 5.0302 & TST & \\
\hline CHEMBL1387564 & 688497 & 4.8 & 5.1393 & TRN & \\
\hline CHEMBL3192760 & 688497 & 5.6 & 5.1318 & TRN & \\
\hline CHEMBL1510778 & 688497 & 4.45 & 4.8761 & TRN & \\
\hline CHEMBL1587530 & 688497 & 4.45 & 5.0922 & TRN & \\
\hline CHEMBL1467902 & 688497 & 5.0 & 5.3738 & TRN & \\
\hline CHEMBL1425736 & 688497 & 4.75 & 4.8879 & TRN & \\
\hline CHEMBL1417144 & 688497 & 4.95 & 4.9051 & TRN & \\
\hline CHEMBL1375084 & 688497 & 5.35 & 4.9998 & TST & \\
\hline CHEMBL1549229 & 688497 & 6.1 & 5.3575 & TRN & \\
\hline CHEMBL1417654 & 688497 & 5.0 & 4.9163 & TRN & \\
\hline CHEMBL1564334 & 688497 & 6.5501 & 5.24700 & 3000000001 & TST \\
\hline CHEMBL1334866 & 688497 & 4.45 & 5.0633 & TRN & \\
\hline CHEMBL1462110 & 688497 & 5.45 & 5.0523 & TRN & \\
\hline CHEMBL1565005 & 688497 & 5.95 & 5.3919 & TRN & \\
\hline CHEMBL1335687 & 688497 & 4.45 & 4.6905 & TRN & \\
\hline CHEMBL1299740 & 688497 & 6.25 & 5.1569 & TRN & \\
\hline CHEMBL1380008 & 688497 & 4.7 & 5.0257 & TRN & \\
\hline CHEMBL1405621 & 688497 & 5.25 & 4.8283 & TST & \\
\hline CHEMBL1340454 & 688497 & 4.65 & 4.761 & TRN & \\
\hline CHEMBL1341696 & 688497 & 5.1 & 4.79 & TRN & \\
\hline CHEMBL1494737 & 688497 & 5.25 & 4.8102 & TRN & \\
\hline CHEMBL1482074 & 688497 & 6.15 & 4.8919 & TRN & \\
\hline CHEMBL1549688 & 688497 & 5.55 & 5.0242 & TST & \\
\hline CHEMBL1502724 & 688497 & 4.9 & 4.8204 & TRN & \\
\hline CHEMBL1380672 & 688497 & 5.9 & 5.205 & TRN & \\
\hline CHEMBL1341424 & 688497 & 4.45 & 4.9125 & TRN & \\
\hline CHEMBL1577517 & 688497 & 6.3 & 4.9603 & TST & \\
\hline CHEMBL1330302 & 688497 & 4.45 & 5.102 & TRN & \\
\hline CHEMBL1612810 & 688497 & 4.45 & 5.1983 & TST & \\
\hline CHEMBL1303455 & 688497 & 5.45 & 5.0601 & TRN & \\
\hline CHEMBL1386983 & 688497 & 4.8 & 4.6424 & TRN & \\
\hline CHEMBL1431954 & 688497 & 6.1 & 4.9869 & TRN & \\
\hline CHEMBL1299751 & 688497 & 4.8 & 4.7227 & TRN & \\
\hline CHEMBL1231193 & 688497 & 4.9 & 5.4068 & TST & \\
\hline CHEMBL1539698 & 688497 & 5.1 & 5.0213 & TRN & \\
\hline CHEMBL153101 & 688497 & 4.85 & 5.085 & TRN & \\
\hline CHEMBL1527929 & 688497 & 5.2 & 5.0132 & TRN & \\
\hline
\end{tabular}




\begin{tabular}{|c|c|c|c|c|c|}
\hline \multicolumn{6}{|c|}{ Supplemental Table S2.txt } \\
\hline CHEMBL1425058 & 688497 & 4.45 & 4.9842 & TRN & \\
\hline CHEMBL1301475 & 688497 & 4.65 & 4.8498 & TST & \\
\hline CHEMBL3197404 & 688497 & 5.55 & 4.9111 & TRN & \\
\hline CHEMBL1421040 & 688497 & 4.45 & 5.0745 & TRN & \\
\hline CHEMBL1483024 & 688497 & 5.4 & 5.4686 & TRN & \\
\hline CHEMBL1336728 & 688497 & 4.45 & 4.4447 & TRN & \\
\hline CHEMBL1427167 & 688497 & 5.55 & 4.9665 & TRN & \\
\hline CHEMBL1338593 & 688497 & 4.85 & 5.0306 & TST & \\
\hline CHEMBL1430197 & 688497 & 4.45 & 5.0154 & TST & \\
\hline CHEMBL1338475 & 688497 & 5.45 & 5.109 & TRN & \\
\hline CHEMBL1598397 & 688497 & 5.9 & 5.4881 & TRN & \\
\hline CHEMBL1370623 & 688497 & 5.05 & 5.1483 & TRN & \\
\hline CHEMBL1412600 & 688497 & 6.05 & 5.1875 & TRN & \\
\hline CHEMBL935 & 688497 & 6.0 & 5.3217 & TST & \\
\hline CHEMBL1482289 & 688497 & 4.65 & 5.0475 & TRN & \\
\hline CHEMBL1407925 & 688497 & 4.65 & 4.9184 & TRN & \\
\hline CHEMBL1526148 & 688497 & 4.6 & 4.8332 & TRN & \\
\hline CHEMBL1453335 & 688497 & 4.65 & 4.8526 & TRN & \\
\hline CHEMBL1989673 & 688497 & 5.0 & 4.7366 & TRN & \\
\hline CHEMBL1271881 & 688497 & 4.45 & 5.0111 & TST & \\
\hline CHEMBL1477718 & 688497 & 4.65 & 4.9873 & TRN & \\
\hline CHEMBL1610923 & 688497 & 4.45 & 4.8518 & TRN & \\
\hline CHEMBL1350960 & 688497 & 5.45 & 5.3294 & TRN & \\
\hline CHEMBL1309228 & 688497 & 4.5 & 4.8335 & TRN & \\
\hline CHEMBL1380884 & 688497 & 4.45 & 4.8855 & TRN & \\
\hline CHEMBL1341895 & 688497 & 4.9 & 4.9076 & TRN & \\
\hline CHEMBL1577532 & 688497 & 4.65 & 5.1549 & TST & \\
\hline CHEMBL1578506 & 688497 & 4.45 & 4.8654 & TRN & \\
\hline CHEMBL3194951 & 688497 & 5.25 & 4.9723 & TRN & \\
\hline CHEMBL1383568 & 688497 & 4.85 & 4.8553 & TST & \\
\hline CHEMBL3190530 & 688497 & 5.45 & 5.2804 & TST & \\
\hline CHEMBL1386050 & 688497 & 4.95 & 5.0342 & TRN & \\
\hline CHEMBL1340383 & 688497 & 4.45 & 4.9271 & TST & \\
\hline CHEMBL373784 & 688497 & 5.5 & 5.1624 & TRN & \\
\hline CHEMBL1303535 & 688497 & 5.45 & 5.1596 & TRN & \\
\hline CHEMBL1498537 & 688497 & 4.65 & 4.75899 & 99999999995 & TRN \\
\hline CHEMBL1455567 & 688497 & 4.95 & 5.2295 & TRN & \\
\hline CHEMBL1550596 & 688497 & 5.65 & 5.2797 & TST & \\
\hline CHEMBL1368337 & 688497 & 4.45 & 4.9511 & TRN & \\
\hline CHEMBL1606087 & 688497 & 4.45 & 4.7639 & TRN & \\
\hline CHEMBL1472126 & 688497 & 5.65 & 4.5537 & TRN & \\
\hline CHEMBL1425516 & 688497 & 4.45 & 4.8444 & TRN & \\
\hline CHEMBL1431810 & 688497 & 4.45 & 4.8338 & TRN & \\
\hline CHEMBL1599151 & 688497 & 4.45 & 4.7111 & TRN & \\
\hline CHEMBL1408033 & 688497 & 6.0 & 5.0614 & TRN & \\
\hline CHEMBL 2006039 & 688497 & 6.6499 & 5.1655 & TRN & \\
\hline CHEMBL1360860 & 688497 & 5.5 & 5.0758 & TST & \\
\hline CHEMBL 3192638 & 688497 & 4.45 & 4.8566 & TRN & \\
\hline
\end{tabular}




\begin{tabular}{|c|c|c|c|c|c|}
\hline \multicolumn{6}{|c|}{ Supplemental Table S2.txt } \\
\hline CHEMBL3191963 & 688497 & 4.45 & 4.9626 & TRN & \\
\hline CHEMBL1530649 & 688497 & 4.45 & 4.9914 & TST & \\
\hline CHEMBL1400052 & 688497 & 6.25 & 5.2889 & TRN & \\
\hline CHEMBL1447789 & 688497 & 5.0 & 4.9857 & TRN & \\
\hline CHEMBL1569760 & 688497 & 6.3 & 5.0552 & TST & \\
\hline CHEMBL1511205 & 688497 & 6.3 & 5.4737 & TST & \\
\hline CHEMBL1506413 & 688497 & 5.25 & 5.06800 & 00000000005 & TRN \\
\hline CHEMBL1385037 & 688497 & 4.95 & 5.0474 & TST & \\
\hline CHEMBL1499009 & 688497 & 5.25 & 5.45700 & 0000000001 & TRN \\
\hline CHEMBL1454464 & 688497 & 5.45 & 4.8434 & TRN & \\
\hline CHEMBL1565148 & 688497 & 5.25 & 5.301 & TRN & \\
\hline CHEMBL1529309 & 688497 & 4.85 & 5.1219 & TRN & \\
\hline CHEMBL1483847 & 688497 & 4.75 & 5.1971 & TRN & \\
\hline CHEMBL1511280 & 688497 & 5.25 & 5.0607 & TST & \\
\hline CHEMBL99408 & 688497 & 4.45 & 5.4713 & TRN & \\
\hline CHEMBL1332105 & 688497 & 4.95 & 5.3124 & TRN & \\
\hline CHEMBL1403095 & 688497 & 4.95 & 5.1417 & TRN & \\
\hline CHEMBL1461880 & 688497 & 4.5 & 5.2432 & TRN & \\
\hline CHEMBL3189193 & 688497 & 5.0 & 5.2488 & TRN & \\
\hline CHEMBL1503155 & 688497 & 4.9 & 4.9051 & TRN & \\
\hline CHEMBL1364633 & 688497 & 4.45 & 4.9656 & TST & \\
\hline CHEMBL1570273 & 688497 & 4.45 & 5.0288 & TRN & \\
\hline CHEMBL1509989 & 688497 & 5.55 & 5.1738 & TRN & \\
\hline CHEMBL3191023 & 688497 & 4.65 & 5.0781 & TST & \\
\hline CHEMBL1508260 & 688497 & 4.85 & 5.1916 & TRN & \\
\hline CHEMBL1446742 & 688497 & 4.85 & 4.7972 & TRN & \\
\hline CHEMBL1586139 & 688497 & 4.95 & 4.9483 & TRN & \\
\hline CHEMBL1340806 & 688497 & 5.95 & 5.1636 & TST & \\
\hline CHEMBL3213726 & 688497 & 5.4 & 4.7945 & TST & \\
\hline CHEMBL1566994 & 688497 & 5.4 & 4.6979 & TRN & \\
\hline CHEMBL3196371 & 688497 & 4.5 & 5.0135 & TST & \\
\hline CHEMBL3191689 & 688497 & 4.85 & 5.0825 & TRN & \\
\hline CHEMBL1414795 & 688497 & 4.95 & 5.0998 & TRN & \\
\hline CHEMBL1588509 & 688497 & 4.95 & 4.9536 & TST & \\
\hline CHEMBL1428697 & 688497 & 6.3 & 5.32 & TRN & \\
\hline CHEMBL1493331 & 688497 & 4.45 & 4.9837 & TST & \\
\hline CHEMBL1302527 & 688497 & 4.7 & 5.0701 & TRN & \\
\hline CHEMBL1442219 & 688497 & 4.65 & 5.0143 & TRN & \\
\hline CHEMBL1510910 & 688497 & 5.25 & 5.0191 & TST & \\
\hline CHEMBL1499477 & 688497 & 7.5003 & 4.9888 & TRN & \\
\hline CHEMBL1491784 & 688497 & 4.45 & 5.3125 & TRN & \\
\hline CHEMBL1506141 & 688497 & 5.25 & 5.1382 & TRN & \\
\hline CHEMBL3190869 & 688497 & 5.05 & 4.9087 & TRN & \\
\hline CHEMBL1431888 & 688497 & 4.95 & 4.8422 & TRN & \\
\hline CHEMBL1599394 & 688497 & 6.5 & 5.4746 & TRN & \\
\hline CHEMBL1510543 & 688497 & 5.9 & 5.1516 & TST & \\
\hline CHEMBL 2369315 & 688497 & 4.9 & 4.8259 & TST & \\
\hline CHEMBL1327545 & 688497 & 4.6 & 4.7743 & TRN & \\
\hline
\end{tabular}




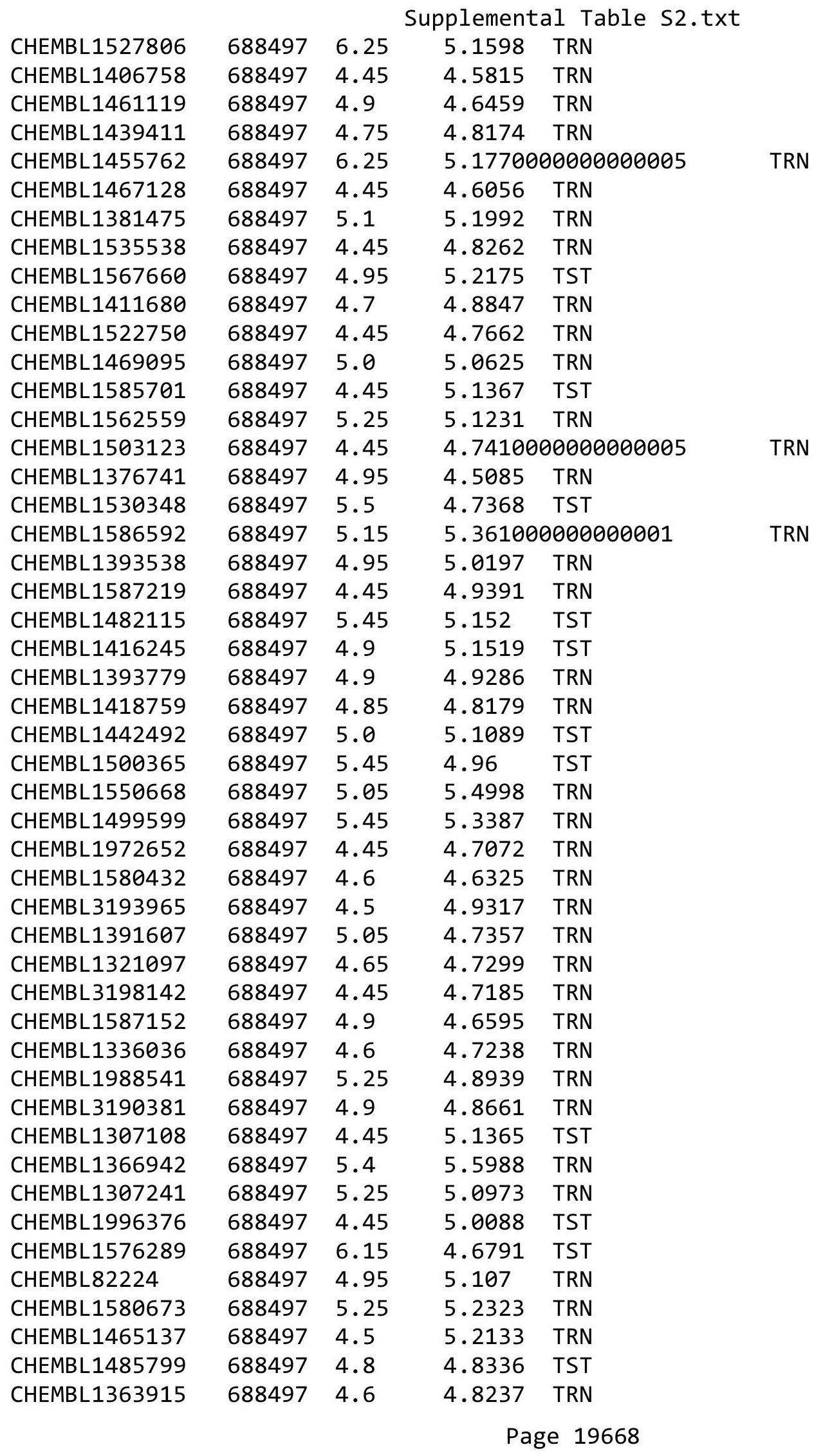




\begin{tabular}{|c|c|c|c|c|}
\hline & & & pplement & \\
\hline CHEMBL271139 & 688497 & 5.0 & 5.6337 & TRN \\
\hline CHEMBL1544927 & 688497 & 4.85 & 5.0013 & TRN \\
\hline CHEMBL1390238 & 688497 & 4.8 & 5.0813 & TRN \\
\hline CHEMBL1420937 & 688497 & 4.45 & 5.3328 & TRN \\
\hline CHEMBL1416130 & 688497 & 4.45 & 5.0171 & TRN \\
\hline CHEMBL1384345 & 688497 & 4.5 & 5.0479 & TRN \\
\hline CHEMBL1454230 & 688497 & 5.4 & 5.099 & TRN \\
\hline CHEMBL1387110 & 688497 & 4.45 & 5.1028 & TRN \\
\hline CHEMBL1492972 & 688497 & 5.0 & 4.7326 & TRN \\
\hline CHEMBL1431658 & 688497 & 4.95 & 4.8662 & TRN \\
\hline CHEMBL1490247 & 688497 & 4.9 & 4.794 & TRN \\
\hline CHEMBL1598538 & 688497 & 4.6 & 4.8998 & TST \\
\hline CHEMBL1487153 & 688497 & 4.6 & 4.8252 & TST \\
\hline CHEMBL1524277 & 688497 & 6.2 & 5.0458 & TST \\
\hline CHEMBL1477419 & 688497 & 4.9 & 4.9937 & TRN \\
\hline CHEMBL1420072 & 688497 & 4.45 & 5.1203 & TRN \\
\hline CHEMBL1503798 & 688497 & 5.25 & 5.2661 & TST \\
\hline CHEMBL1459949 & 688497 & 4.45 & 4.9258 & TRN \\
\hline CHEMBL1606280 & 688497 & 4.95 & 5.2891 & TRN \\
\hline CHEMBL1603598 & 688497 & 6.3 & 5.2435 & TRN \\
\hline CHEMBL1594395 & 688497 & 4.9 & 5.059 & TRN \\
\hline CHEMBL3191889 & 688497 & 4.95 & 4.8818 & TRN \\
\hline CHEMBL1382865 & 688497 & 4.45 & 5.2765 & TRN \\
\hline CHEMBL1492691 & 688497 & 4.9 & 5.3251 & TST \\
\hline CHEMBL1611443 & 688497 & 6.05 & 5.3664 & TRN \\
\hline CHEMBL1493942 & 688497 & 4.45 & 5.0175 & TRN \\
\hline CHEMBL1336816 & 688497 & 4.45 & 5.1872 & TST \\
\hline CHEMBL1419714 & 688497 & 4.65 & 4.743 & TRN \\
\hline CHEMBL1540632 & 688497 & 2.8 & 4.9661 & TRN \\
\hline CHEMBL1510945 & 688497 & 5.5 & 5.1728 & TRN \\
\hline CHEMBL1500324 & 688497 & 4.45 & 5.1775 & TST \\
\hline CHEMBL1517608 & 688497 & 5.0 & 5.0189 & TRN \\
\hline CHEMBL1580704 & 688497 & 4.6 & 5.2373 & TRN \\
\hline CHEMBL1373869 & 688497 & 5.05 & 4.6371 & TRN \\
\hline CHEMBL1537379 & 688497 & 5.85 & 5.0998 & TRN \\
\hline CHEMBL1543881 & 688497 & 4.8 & 5.1981 & TRN \\
\hline CHEMBL1558851 & 688497 & 4.45 & 4.9004 & TRN \\
\hline CHEMBL1362793 & 688497 & 4.45 & 4.9451 & TRN \\
\hline CHEMBL1485472 & 688497 & 4.85 & 4.9926 & TRN \\
\hline CHEMBL1589493 & 688497 & 4.95 & 5.0032 & TRN \\
\hline CHEMBL1307895 & 688497 & 4.6 & 4.6807 & TRN \\
\hline CHEMBL1456371 & 688497 & 5.4 & 4.7047 & TRN \\
\hline CHEMBL1489190 & 688497 & 4.45 & 4.6897 & TRN \\
\hline CHEMBL1350529 & 688497 & 6.25 & 5.0933 & TRN \\
\hline CHEMBL1586230 & 688497 & 4.95 & 4.6487 & TRN \\
\hline CHEMBL1532709 & 688497 & 6.1 & 5.2773 & TST \\
\hline CHEMBL1507331 & 688497 & 4.7 & 4.9511 & TRN \\
\hline CHEMBL3196086 & 688497 & 4.45 & 4.8219 & TST \\
\hline
\end{tabular}




\begin{tabular}{|c|c|c|c|c|}
\hline & & & pplement & al $\mathrm{Ta}$ \\
\hline CHEMBL1558768 & 688497 & 4.6 & 4.9919 & TST \\
\hline CHEMBL1308296 & 688497 & 4.85 & 5.1368 & TRN \\
\hline CHEMBL1567325 & 688497 & 4.45 & 5.088 & TRN \\
\hline CHEMBL 3214253 & 688497 & 4.85 & 4.9179 & TST \\
\hline CHEMBL1535092 & 688497 & 4.85 & 5.3993 & TRN \\
\hline CHEMBL1536876 & 688497 & 4.45 & 4.9211 & TRN \\
\hline CHEMBL1580823 & 688497 & 4.8 & 4.6862 & TRN \\
\hline CHEMBL1584941 & 688497 & 6.25 & 5.358 & TRN \\
\hline CHEMBL1564491 & 688497 & 6.25 & 5.0466 & TRN \\
\hline CHEMBL3191805 & 688497 & 4.45 & 4.9365 & TRN \\
\hline CHEMBL1607104 & 688497 & 4.45 & 4.7947 & TRN \\
\hline CHEMBL1477994 & 688497 & 5.45 & 5.1299 & TRN \\
\hline CHEMBL1330885 & 688497 & 4.45 & 4.9281 & TRN \\
\hline CHEMBL1411764 & 688497 & 4.9 & 5.0943 & TRN \\
\hline CHEMBL1548781 & 688497 & 4.8 & 5.1412 & TST \\
\hline CHEMBL1338778 & 688497 & 6.25 & 4.954 & TRN \\
\hline CHEMBL1458302 & 688497 & 5.0 & 4.9978 & TRN \\
\hline CHEMBL1423656 & 688497 & 4.85 & 4.7886 & TRN \\
\hline CHEMBL1501171 & 688497 & 5.25 & 4.9548 & TRN \\
\hline CHEMBL1454327 & 688497 & 4.45 & 5.0355 & TRN \\
\hline CHEMBL3190774 & 688497 & 4.9 & 5.0496 & TRN \\
\hline CHEMBL3198581 & 688497 & 4.45 & 4.8461 & TRN \\
\hline CHEMBL1544989 & 688497 & 4.7 & 4.8508 & TRN \\
\hline CHEMBL1389769 & 688497 & 4.95 & 4.8035 & TRN \\
\hline CHEMBL1441135 & 688497 & 4.45 & 4.8528 & TRN \\
\hline CHEMBL1537338 & 688497 & 4.45 & 4.9559 & TRN \\
\hline CHEMBL1575272 & 688497 & 5.0 & 4.8121 & TRN \\
\hline CHEMBL1445007 & 688497 & 6.25 & 5.3647 & TRN \\
\hline CHEMBL1522987 & 688497 & 4.45 & 4.4799 & TRN \\
\hline CHEMBL3213069 & 688497 & 4.75 & 5.0838 & TRN \\
\hline CHEMBL1313843 & 688497 & 4.9 & 5.0847 & TST \\
\hline CHEMBL1361264 & 688497 & 5.4 & 5.3247 & TST \\
\hline CHEMBL1359999 & 688497 & 6.4 & 4.9155 & TRN \\
\hline CHEMBL1599976 & 688497 & 5.5 & 5.0833 & TST \\
\hline CHEMBL1500626 & 688497 & 4.45 & 4.9959 & TST \\
\hline CHEMBL1457476 & 688497 & 4.6 & 4.9026 & TST \\
\hline CHEMBL1524738 & 688497 & 4.45 & 5.2611 & TST \\
\hline CHEMBL1581265 & 688497 & 6.1 & 5.0514 & TRN \\
\hline CHEMBL1499414 & 688497 & 5.45 & 5.2612 & TST \\
\hline CHEMBL3190592 & 688497 & 5.9 & 5.1915 & TRN \\
\hline CHEMBL1305409 & 688497 & 5.0 & 4.9917 & TRN \\
\hline CHEMBL1323587 & 688497 & 5.0 & 4.8938 & TRN \\
\hline CHEMBL1498285 & 688497 & 4.45 & 4.7599 & TRN \\
\hline CHEMBL46703 & 688497 & 4.85 & 5.3402 & TRN \\
\hline CHEMBL 223453 & 688497 & 4.95 & 5.007 & TRN \\
\hline CHEMBL1352899 & 688497 & 5.5 & 5.2252 & TRN \\
\hline CHEMBL3193064 & 688497 & 4.45 & 4.7553 & TST \\
\hline CHEMBL1304736 & 688497 & 4.45 & 5.0378 & TST \\
\hline
\end{tabular}




\begin{tabular}{|c|c|c|c|c|c|}
\hline \multicolumn{6}{|c|}{ Supplemental Table S2.txt } \\
\hline CHEMBL 3212833 & 688497 & 4.45 & 5.0176 & TRN & \\
\hline CHEMBL1505250 & 688497 & 4.65 & 4.9566 & TRN & \\
\hline CHEMBL1493746 & 688497 & 5.55 & 4.6821 & TST & \\
\hline CHEMBL1299250 & 688497 & 4.45 & 5.3403 & TRN & \\
\hline CHEMBL1449992 & 688497 & 5.0 & 4.6795 & TRN & \\
\hline CHEMBL1550760 & 688497 & 4.9 & 4.8359 & TRN & \\
\hline CHEMBL 3190588 & 688497 & 4.45 & 4.868 & TRN & \\
\hline CHEMBL1351750 & 688497 & 4.7 & 4.7711 & TRN & \\
\hline CHEMBL1369655 & 688497 & 5.5 & 5.0391 & TRN & \\
\hline CHEMBL1401080 & 688497 & 4.8 & 4.9719 & TRN & \\
\hline CHEMBL351042 & 688497 & 4.5 & 5.2991 & TST & \\
\hline CHEMBL587801 & 688497 & 4.45 & 5.0097 & TRN & \\
\hline CHEMBL1417970 & 688497 & 4.45 & 4.6691 & TRN & \\
\hline CHEMBL1464106 & 688497 & 5.05 & 5.2361 & TST & \\
\hline CHEMBL591137 & 688497 & 5.05 & 5.0653 & TRN & \\
\hline CHEMBL1606763 & 688497 & 4.45 & 5.1256 & TST & \\
\hline CHEMBL1528130 & 688497 & 4.9 & 5.0987 & TRN & \\
\hline CHEMBL1478086 & 688497 & 4.85 & 5.0109 & TRN & \\
\hline CHEMBL 3196537 & 688497 & 5.45 & 5.148 & TST & \\
\hline CHEMBL1304603 & 688497 & 4.45 & 5.0254 & TST & \\
\hline CHEMBL1993301 & 688497 & 4.8 & 4.8363 & TRN & \\
\hline CHEMBL1547407 & 688497 & 5.4 & 5.263 & TST & \\
\hline CHEMBL1547468 & 688497 & 4.7 & 4.6667 & TST & \\
\hline CHEMBL1401043 & 688497 & 5.45 & 5.1595 & TST & \\
\hline CHEMBL1491695 & 688497 & 5.8 & 5.2281 & TRN & \\
\hline CHEMBL1466809 & 688497 & 4.45 & 4.883 & TST & \\
\hline CHEMBL1549650 & 688497 & 5.4 & 5.2546 & TRN & \\
\hline CHEMBL1546374 & 688497 & 5.75 & 5.2413 & TRN & \\
\hline CHEMBL1308972 & 688497 & 4.65 & 5.2279 & TRN & \\
\hline CHEMBL1562304 & 688497 & 4.45 & 4.735 & TRN & \\
\hline CHEMBL1450031 & 688497 & 4.6 & 5.0438 & TST & \\
\hline CHEMBL1301422 & 688497 & 4.6 & 5.3608 & TRN & \\
\hline CHEMBL1543473 & 688497 & 4.7 & 5.187 & TST & \\
\hline CHEMBL1483018 & 688497 & 5.1 & 4.9015 & TST & \\
\hline CHEMBL1343966 & 688497 & 4.45 & 5.131 & TRN & \\
\hline CHEMBL3210840 & 688497 & 5.6 & 5.1632 & TST & \\
\hline CHEMBL1321892 & 688497 & 4.45 & 4.8538 & TRN & \\
\hline CHEMBL1483707 & 688497 & 4.9 & 5.0259 & TRN & \\
\hline CHEMBL1985486 & 688497 & 4.45 & 4.8238 & TST & \\
\hline CHEMBL1326643 & 688497 & 4.45 & 4.9557 & TRN & \\
\hline CHEMBL1386472 & 688497 & 4.6 & 5.1659 & TST & \\
\hline CHEMBL1529863 & 688497 & 4.45 & 5.1067 & TRN & \\
\hline CHEMBL1381554 & 688497 & 6.25 & 4.9883 & TRN & \\
\hline CHEMBL1419279 & 688497 & 4.45 & 5.3137 & TRN & \\
\hline CHEMBL1522486 & 688497 & 6.0 & 5.49799 & 9999999999 & TRN \\
\hline CHEMBL1605599 & 688497 & 4.65 & 4.88399 & 99999999995 & TRN \\
\hline CHEMBL1583698 & 688497 & 4.85 & 4.9141 & TST & \\
\hline CHEMBL1566541 & 688497 & 5.75 & 5.3389 & TRN & \\
\hline
\end{tabular}




\begin{tabular}{|c|c|c|c|c|}
\hline \multicolumn{5}{|c|}{ Supplemental Table S2.txt } \\
\hline CHEMBL1480943 & 688497 & 4.65 & 4.8593 & TRN \\
\hline CHEMBL 3189855 & 688497 & 4.55 & 4.8568 & TRN \\
\hline CHEMBL1388662 & 688497 & 5.0 & 4.9298 & TRN \\
\hline CHEMBL1320455 & 688497 & 5.9 & 5.0238 & TRN \\
\hline CHEMBL1507759 & 688497 & 5.05 & 5.0314 & TST \\
\hline CHEMBL1563323 & 688497 & 6.0 & 5.3108 & TRN \\
\hline CHEMBL1424231 & 688497 & 6.0 & 5.0281 & TRN \\
\hline CHEMBL1313778 & 688497 & 8.5528 & 5.3493 & TRN \\
\hline CHEMBL1562280 & 688497 & 4.95 & 5.0708 & TST \\
\hline CHEMBL1518408 & 688497 & 6.1 & 5.3536 & TRN \\
\hline CHEMBL 3213871 & 688497 & 5.2 & 5.1225 & TST \\
\hline CHEMBL1414291 & 688497 & 4.45 & 4.9812 & TRN \\
\hline CHEMBL1403122 & 688497 & 4.75 & 4.9669 & TRN \\
\hline CHEMBL1369125 & 688497 & 4.6 & 4.6118 & TRN \\
\hline CHEMBL1440685 & 688497 & 5.55 & 5.2255 & TRN \\
\hline CHEMBL1500336 & 688497 & 4.9 & 5.1526 & TST \\
\hline CHEMBL1454611 & 688497 & 5.25 & 5.1257 & TRN \\
\hline CHEMBL1505219 & 688497 & 4.45 & 4.908 & TRN \\
\hline CHEMBL517444 & 688497 & 4.45 & 4.7379 & TRN \\
\hline CHEMBL1423274 & 688497 & 6.3 & 5.2894 & TRN \\
\hline CHEMBL1406195 & 688497 & 5.0 & 4.7768 & TRN \\
\hline CHEMBL1480696 & 688497 & 4.45 & 5.1679 & TRN \\
\hline CHEMBL1535055 & 688497 & 4.45 & 4.9952 & TRN \\
\hline CHEMBL1461960 & 688497 & 5.65 & 4.8818 & TRN \\
\hline CHEMBL1521983 & 688497 & 4.95 & 5.0597 & TRN \\
\hline CHEMBL1389329 & 688497 & 5.55 & 5.3099 & TRN \\
\hline CHEMBL1304864 & 688497 & 5.55 & 5.0921 & TRN \\
\hline CHEMBL1496304 & 688497 & 4.45 & 5.0233 & TRN \\
\hline CHEMBL1580359 & 688497 & 8.2007 & 4.9146 & TRN \\
\hline CHEMBL1577861 & 688497 & 5.6 & 5.1105 & TST \\
\hline CHEMBL1347481 & 688497 & 4.65 & 5.0905 & TRN \\
\hline CHEMBL1486796 & 688497 & 6.0 & 5.2942 & TRN \\
\hline CHEMBL1575814 & 688497 & 4.45 & 5.0972 & TRN \\
\hline CHEMBL1437873 & 688497 & 4.5 & 4.9942 & TRN \\
\hline CHEMBL1454300 & 688497 & 4.45 & 5.3901 & TRN \\
\hline CHEMBL1613133 & 688497 & 4.45 & 4.9488 & TRN \\
\hline CHEMBL1320912 & 688497 & 4.8 & 5.1268 & TST \\
\hline CHEMBL1362687 & 688497 & 4.65 & 4.7752 & TST \\
\hline CHEMBL1402289 & 688497 & 4.95 & 4.8188 & TRN \\
\hline CHEMBL1367580 & 688497 & 4.45 & 4.9512 & TRN \\
\hline CHEMBL1393172 & 688497 & 5.2 & 4.8361 & TRN \\
\hline CHEMBL3192225 & 688497 & 5.05 & 4.9862 & TST \\
\hline CHEMBL1334299 & 688497 & 4.45 & 5.1926 & TRN \\
\hline CHEMBL1481967 & 688497 & 4.45 & 4.8904 & TRN \\
\hline CHEMBL1441370 & 688497 & 4.55 & 5.0527 & TRN \\
\hline CHEMBL3214442 & 688497 & 5.95 & 5.1278 & TST \\
\hline CHEMBL1345771 & 688497 & 6.25 & 5.1526 & TRN \\
\hline CHEMBL1348868 & 688497 & 4.45 & 5.0606 & TRN \\
\hline
\end{tabular}




\begin{tabular}{|c|c|c|c|c|}
\hline \multicolumn{5}{|c|}{ Supplemental Table S2.txt } \\
\hline CHEMBL1549827 & 688497 & 4.75 & 4.8027 & TRN \\
\hline CHEMBL1308571 & 688497 & 4.9 & 5.2744 & TST \\
\hline CHEMBL255068 & 688497 & 5.85 & 5.0241 & TRN \\
\hline CHEMBL1509690 & 688497 & 4.55 & 5.0331 & TRN \\
\hline CHEMBL1492514 & 688497 & 5.1 & 4.9981 & TRN \\
\hline CHEMBL1499310 & 688497 & 4.45 & 4.9408 & TRN \\
\hline CHEMBL1307416 & 688497 & 4.9 & 5.0069 & TRN \\
\hline CHEMBL1401057 & 688497 & 4.85 & 5.4934 & TRN \\
\hline CHEMBL1501884 & 688497 & 4.6 & 4.878 & TRN \\
\hline CHEMBL1442421 & 688497 & 4.6 & 4.8462 & TRN \\
\hline CHEMBL1350975 & 688497 & 4.5 & 4.803 & TST \\
\hline CHEMBL1387717 & 688497 & 4.45 & 4.9075 & TRN \\
\hline CHEMBL1539639 & 688497 & 6.25 & 5.0836 & TST \\
\hline CHEMBL1369671 & 688497 & 4.65 & 4.6647 & TRN \\
\hline CHEMBL1384809 & 688497 & 6.25 & 5.3769 & TRN \\
\hline CHEMBL1455904 & 688497 & 5.0 & 5.3917 & TRN \\
\hline CHEMBL1542349 & 688497 & 4.45 & 4.7504 & TRN \\
\hline CHEMBL1516886 & 688497 & 5.7 & 5.5057 & TST \\
\hline CHEMBL1491812 & 688497 & 4.65 & 4.631 & TRN \\
\hline CHEMBL1585236 & 688497 & 4.95 & 5.2415 & TST \\
\hline CHEMBL1452543 & 688497 & 5.45 & 5.1593 & TRN \\
\hline CHEMBL1508157 & 688497 & 4.45 & 4.8983 & TRN \\
\hline CHEMBL1545354 & 688497 & 5.45 & 5.3426 & TRN \\
\hline CHEMBL3194725 & 688497 & 6.1 & 4.7924 & TRN \\
\hline CHEMBL1479264 & 688497 & 6.0 & 5.2679 & TRN \\
\hline CHEMBL1415409 & 688497 & 4.6 & 4.9874 & TRN \\
\hline CHEMBL1455324 & 688497 & 5.25 & 5.2431 & TST \\
\hline CHEMBL1366454 & 688497 & 6.25 & 5.0997 & TRN \\
\hline CHEMBL1429838 & 688497 & 4.45 & 5.1276 & TRN \\
\hline CHEMBL1413448 & 688497 & 7.5498 & 5.2739 & TRN \\
\hline CHEMBL1589426 & 688497 & 5.45 & 5.0612 & TST \\
\hline CHEMBL1602800 & 688497 & 5.5 & 5.0056 & TRN \\
\hline CHEMBL1455655 & 688497 & 7.5003 & 4.9875 & TST \\
\hline CHEMBL1335773 & 688497 & 5.15 & 5.2216 & TRN \\
\hline CHEMBL1338328 & 688497 & 5.5 & 5.1941 & TRN \\
\hline CHEMBL1346665 & 688497 & 4.65 & 5.1532 & TRN \\
\hline CHEMBL1608868 & 688497 & 4.45 & 4.9773 & TRN \\
\hline CHEMBL3208618 & 688497 & 4.8 & 5.1623 & TST \\
\hline CHEMBL1502712 & 688497 & 6.05 & 4.6757 & TST \\
\hline CHEMBL1375641 & 688497 & 4.95 & 5.4006 & TRN \\
\hline CHEMBL1343791 & 688497 & 5.0 & 5.2077 & TRN \\
\hline CHEMBL1462172 & 688497 & 5.15 & 4.9567 & TRN \\
\hline CHEMBL1518225 & 688497 & 5.55 & 5.2857 & TRN \\
\hline CHEMBL342995 & 688497 & 4.45 & 5.0057 & TRN \\
\hline CHEMBL1455697 & 688497 & 4.45 & 4.9082 & TRN \\
\hline CHEMBL1365652 & 688497 & 4.95 & 4.8671 & TRN \\
\hline CHEMBL1340259 & 688497 & 4.75 & 4.9705 & TRN \\
\hline CHEMBL1585464 & 688497 & 5.85 & 5.119 & TST \\
\hline
\end{tabular}




\begin{tabular}{|c|c|c|c|c|}
\hline & & & pplement & al $\mathrm{Ta}$ \\
\hline CHEMBL1411208 & 688497 & 4.9 & 4.8741 & TRN \\
\hline CHEMBL1500562 & 688497 & 4.6 & 5.0534 & TRN \\
\hline CHEMBL1998863 & 688497 & 5.9 & 5.2872 & TRN \\
\hline CHEMBL1334310 & 688497 & 4.9 & 4.7196 & TRN \\
\hline CHEMBL3197010 & 688497 & 4.6 & 4.8776 & TRN \\
\hline CHEMBL1376514 & 688497 & 4.45 & 5.0213 & TST \\
\hline CHEMBL1300046 & 688497 & 4.75 & 5.0314 & TRN \\
\hline CHEMBL3192758 & 688497 & 4.55 & 5.0368 & TST \\
\hline CHEMBL1332015 & 688497 & 4.8 & 4.6203 & TRN \\
\hline CHEMBL1570958 & 688497 & 5.15 & 5.1431 & TRN \\
\hline CHEMBL1548888 & 688497 & 3.0 & 4.7164 & TRN \\
\hline CHEMBL1520874 & 688497 & 4.6 & 5.1716 & TRN \\
\hline CHEMBL1412509 & 688497 & 6.25 & 5.2109 & TRN \\
\hline CHEMBL1383191 & 688497 & 5.5 & 4.7693 & TST \\
\hline CHEMBL1495589 & 688497 & 4.95 & 4.8271 & TRN \\
\hline CHEMBL1525586 & 688497 & 4.65 & 5.2248 & TST \\
\hline CHEMBL1471308 & 688497 & 5.5 & 5.0768 & TRN \\
\hline CHEMBL1312478 & 688497 & 6.05 & 4.8865 & TRN \\
\hline CHEMBL1487526 & 688497 & 5.0 & 5.0585 & TRN \\
\hline CHEMBL1608460 & 688497 & 6.95 & 5.5395 & TRN \\
\hline CHEMBL1399595 & 688497 & 4.45 & 5.03 & TRN \\
\hline CHEMBL1348395 & 688497 & 4.8 & 5.0714 & TRN \\
\hline CHEMBL1578226 & 688497 & 4.55 & 5.4479 & TRN \\
\hline CHEMBL1505229 & 688497 & 4.7 & 5.0321 & TRN \\
\hline CHEMBL1525916 & 688497 & 4.45 & 4.7242 & TRN \\
\hline CHEMBL1539905 & 688497 & 5.05 & 5.0125 & TRN \\
\hline CHEMBL1446466 & 688497 & 5.65 & 5.0173 & TRN \\
\hline CHEMBL1451617 & 688497 & 5.2 & 4.8619 & TRN \\
\hline CHEMBL1506369 & 688497 & 4.6 & 4.885 & TST \\
\hline CHEMBL1462692 & 688497 & 4.85 & 4.7311 & TST \\
\hline CHEMBL3194473 & 688497 & 5.0 & 5.0366 & TRN \\
\hline CHEMBL1480059 & 688497 & 4.75 & 4.7151 & TST \\
\hline CHEMBL1566487 & 688497 & 5.15 & 5.1438 & TRN \\
\hline CHEMBL1495475 & 688497 & 4.45 & 5.4031 & TRN \\
\hline CHEMBL1540982 & 688497 & 4.75 & 4.9156 & TRN \\
\hline CHEMBL1427609 & 688497 & 4.45 & 5.0434 & TRN \\
\hline CHEMBL1400751 & 688497 & 4.9 & 4.8491 & TRN \\
\hline CHEMBL1567221 & 688497 & 5.7 & 5.0456 & TRN \\
\hline CHEMBL1507468 & 688497 & 4.95 & 4.6812 & TRN \\
\hline CHEMBL1310099 & 688497 & 5.9 & 5.3822 & TRN \\
\hline CHEMBL1347056 & 688497 & 5.0 & 4.9761 & TRN \\
\hline CHEMBL1427756 & 688497 & 6.0 & 5.2761 & TRN \\
\hline CHEMBL3198576 & 688497 & 5.2 & 5.2789 & TRN \\
\hline CHEMBL1557649 & 688497 & 4.65 & 5.1436 & TST \\
\hline CHEMBL1299793 & 688497 & 4.85 & 5.2759 & TRN \\
\hline CHEMBL1455957 & 688497 & 4.95 & 4.8264 & TST \\
\hline CHEMBL1420742 & 688497 & 4.7 & 4.9224 & TST \\
\hline CHEMBL1499216 & 688497 & 4.45 & 4.771 & TRN \\
\hline
\end{tabular}




\begin{tabular}{|c|c|c|c|c|}
\hline \multicolumn{5}{|c|}{ Supplemental Table S2.txt } \\
\hline CHEMBL1426587 & 688497 & 4.65 & 5.2229 & TRN \\
\hline CHEMBL1302882 & 688497 & 5.5 & 4.9758 & TRN \\
\hline CHEMBL1305571 & 688497 & 5.25 & 4.7599 & TRN \\
\hline CHEMBL1343401 & 688497 & 5.25 & 5.1073 & TRN \\
\hline CHEMBL3194897 & 688497 & 5.25 & 5.0796 & TST \\
\hline CHEMBL1299470 & 688497 & 4.75 & 4.9718 & TRN \\
\hline CHEMBL1541206 & 688497 & 4.7 & 5.0061 & TST \\
\hline CHEMBL1589036 & 688497 & 4.45 & 4.9084 & TRN \\
\hline CHEMBL1332925 & 688497 & 4.45 & 5.0203 & TRN \\
\hline CHEMBL1372094 & 688497 & 4.45 & 5.1084 & TRN \\
\hline CHEMBL1609334 & 688497 & 5.25 & 5.1771 & TST \\
\hline CHEMBL1988416 & 688497 & 5.3 & 4.7005 & TST \\
\hline CHEMBL1992346 & 688497 & 4.45 & 5.3253 & TST \\
\hline CHEMBL1422484 & 688497 & 4.45 & 5.5777 & TRN \\
\hline CHEMBL1609117 & 688497 & 4.45 & 4.7011 & TRN \\
\hline CHEMBL 2369177 & 688497 & 4.95 & 5.1828 & TST \\
\hline CHEMBL1342746 & 688497 & 5.15 & 5.3454 & TRN \\
\hline CHEMBL1488473 & 688497 & 6.25 & 4.9745 & TRN \\
\hline CHEMBL1392107 & 688497 & 4.6 & 5.2757 & TRN \\
\hline CHEMBL1461191 & 688497 & 4.9 & 5.0837 & TRN \\
\hline CHEMBL 2094652 & 688497 & 6.25 & 5.3137 & TRN \\
\hline CHEMBL1414157 & 688497 & 5.55 & 5.1796 & TRN \\
\hline CHEMBL1568155 & 688497 & 6.25 & 5.2301 & TRN \\
\hline CHEMBL3189942 & 688497 & 5.4 & 5.0359 & TST \\
\hline CHEMBL1455204 & 688497 & 6.35 & 5.0862 & TST \\
\hline CHEMBL1413056 & 688497 & 5.2 & 5.0965 & TRN \\
\hline CHEMBL1523563 & 688497 & 4.6 & 4.8448 & TST \\
\hline CHEMBL3212286 & 688497 & 5.5 & 4.9196 & TRN \\
\hline CHEMBL1371576 & 688497 & 5.25 & 4.9236 & TRN \\
\hline CHEMBL1465135 & 688497 & 4.85 & 4.9195 & TRN \\
\hline CHEMBL1359380 & 688497 & 4.45 & 5.046 & TRN \\
\hline CHEMBL1560423 & 688497 & 4.55 & 5.0487 & TST \\
\hline CHEMBL1466959 & 688497 & 4.9 & 4.91 & TRN \\
\hline CHEMBL1501863 & 688497 & 5.2 & 5.1463 & TRN \\
\hline CHEMBL1406688 & 688497 & 5.5 & 4.9714 & TRN \\
\hline CHEMBL1557066 & 688497 & 4.45 & 4.7574 & TRN \\
\hline CHEMBL1338713 & 688497 & 4.95 & 5.3503 & TRN \\
\hline CHEMBL1349532 & 688497 & 4.9 & 5.0665 & TST \\
\hline CHEMBL1371282 & 688497 & 4.7 & 5.2595 & TST \\
\hline CHEMBL1420800 & 688497 & 5.2 & 4.798 & TRN \\
\hline CHEMBL1493551 & 688497 & 4.85 & 5.0666 & TRN \\
\hline CHEMBL1970761 & 688497 & 5.25 & 4.9557 & TRN \\
\hline CHEMBL1417419 & 688497 & 5.3 & 4.9914 & TST \\
\hline CHEMBL1326611 & 688497 & 5.8 & 4.8585 & TRN \\
\hline CHEMBL1490452 & 688497 & 5.05 & 4.9295 & TRN \\
\hline CHEMBL1417809 & 688497 & 4.95 & 5.3826 & TRN \\
\hline CHEMBL1371842 & 688497 & 4.45 & 4.6756 & TRN \\
\hline CHEMBL1337420 & 688497 & 4.45 & 4.7239 & TRN \\
\hline
\end{tabular}




\begin{tabular}{|c|c|c|c|c|}
\hline \multicolumn{5}{|c|}{ Supplemental Table S2.txt } \\
\hline CHEMBL1353474 & 688497 & 5.2 & 5.4186 & TRN \\
\hline CHEMBL3189611 & 688497 & 4.45 & 4.8173 & TRN \\
\hline CHEMBL1331927 & 688497 & 4.45 & 4.9922 & TRN \\
\hline CHEMBL1520743 & 688497 & 4.8 & 4.9479 & TRN \\
\hline CHEMBL1382304 & 688497 & 4.95 & 4.9142 & TRN \\
\hline CHEMBL1464435 & 688497 & 5.0 & 4.9541 & TRN \\
\hline CHEMBL1524381 & 688497 & 4.45 & 4.9088 & TRN \\
\hline CHEMBL1486554 & 688497 & 4.95 & 5.1252 & TRN \\
\hline CHEMBL1448265 & 688497 & 4.6 & 4.7519 & TRN \\
\hline CHEMBL1467935 & 688497 & 5.5 & 5.3417 & TST \\
\hline CHEMBL1309062 & 688497 & 4.45 & 5.4355 & TST \\
\hline CHEMBL1529295 & 688497 & 4.45 & 4.6418 & TST \\
\hline CHEMBL1300625 & 688497 & 5.5 & 4.9286 & TRN \\
\hline CHEMBL1458643 & 688497 & 4.65 & 4.8289 & TRN \\
\hline CHEMBL1603771 & 688497 & 6.1 & 5.2107 & TRN \\
\hline CHEMBL1333372 & 688497 & 5.9 & 5.4481 & TRN \\
\hline CHEMBL1313391 & 688497 & 4.95 & 5.1394 & TRN \\
\hline CHEMBL1506978 & 688497 & 5.25 & 4.9938 & TRN \\
\hline CHEMBL1543945 & 688497 & 5.45 & 5.1731 & TRN \\
\hline CHEMBL1326749 & 688497 & 5.45 & 4.9978 & TST \\
\hline CHEMBL1984190 & 688497 & 5.25 & 5.2745 & TRN \\
\hline CHEMBL3192692 & 688497 & 6.1 & 5.1483 & TST \\
\hline CHEMBL1482408 & 688497 & 4.45 & 4.6856 & TRN \\
\hline CHEMBL1302240 & 688497 & 5.25 & 5.037 & TRN \\
\hline CHEMBL1549831 & 688497 & 4.6 & 4.9155 & TST \\
\hline CHEMBL1440932 & 688497 & 5.0 & 5.295 & TRN \\
\hline CHEMBL1489337 & 688497 & 4.7 & 5.1571 & TRN \\
\hline CHEMBL1606179 & 688497 & 4.65 & 4.9774 & TRN \\
\hline CHEMBL3189832 & 688497 & 4.45 & 4.8751 & TRN \\
\hline CHEMBL1462064 & 688497 & 5.4 & 5.4324 & TRN \\
\hline CHEMBL1375468 & 688497 & 4.85 & 4.9908 & TST \\
\hline CHEMBL1451362 & 688497 & 4.45 & 4.9582 & TRN \\
\hline CHEMBL3197977 & 688497 & 4.85 & 5.3498 & TRN \\
\hline CHEMBL1301498 & 688497 & 6.5 & 5.1265 & TRN \\
\hline CHEMBL3190426 & 688497 & 4.45 & 5.2187 & TST \\
\hline CHEMBL1454102 & 688497 & 4.45 & 4.5943 & TRN \\
\hline CHEMBL1518396 & 688497 & 4.75 & 4.9795 & TRN \\
\hline CHEMBL1504424 & 688497 & 4.65 & 4.9239 & TRN \\
\hline CHEMBL1594604 & 688497 & 4.6 & 4.9854 & TST \\
\hline CHEMBL1310617 & 688497 & 6.1 & 5.2554 & TST \\
\hline CHEMBL1446415 & 688497 & 4.9 & 4.8602 & TRN \\
\hline CHEMBL1495714 & 688497 & 4.75 & 4.9724 & TRN \\
\hline CHEMBL1545971 & 688497 & 4.95 & 4.8018 & TRN \\
\hline CHEMBL1374095 & 688497 & 4.45 & 5.2251 & TST \\
\hline CHEMBL1529012 & 688497 & 5.45 & 5.152 & TST \\
\hline CHEMBL1490455 & 688497 & 5.75 & 5.3932 & TRN \\
\hline CHEMBL1525945 & 688497 & 6.0 & 4.9486 & TST \\
\hline CHEMBL1463229 & 688497 & 4.95 & 5.0463 & TRN \\
\hline
\end{tabular}




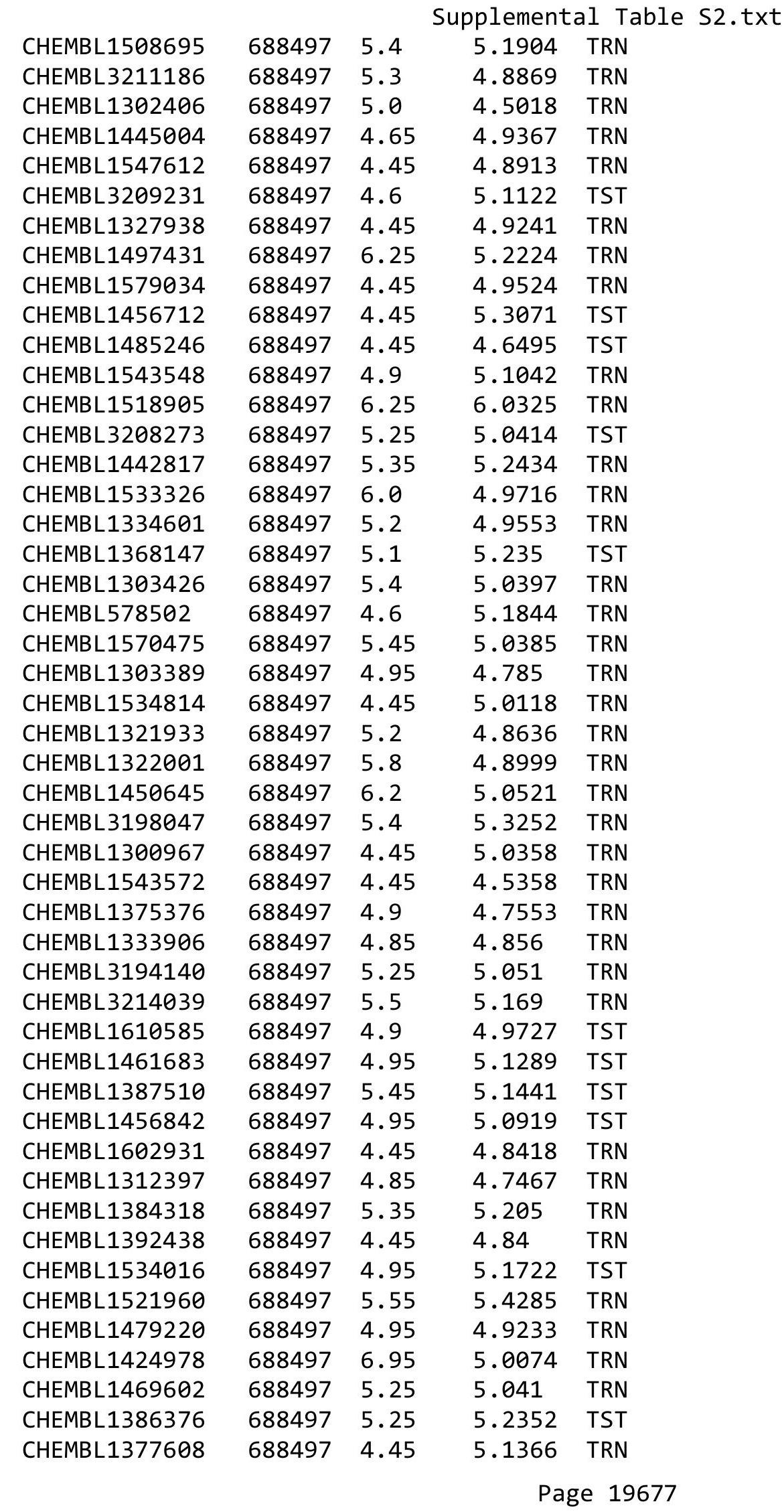




\begin{tabular}{|c|c|c|c|c|}
\hline & & & pplement & al $\mathrm{Ta}$ \\
\hline CHEMBL1381378 & 688497 & 4.9 & 4.9803 & TRN \\
\hline CHEMBL1344611 & 688497 & 5.45 & 4.7982 & TRN \\
\hline CHEMBL1580990 & 688497 & 4.75 & 4.8091 & TRN \\
\hline CHEMBL1604664 & 688497 & 5.55 & 4.7453 & TRN \\
\hline CHEMBL1496622 & 688497 & 6.05 & 5.0033 & TRN \\
\hline CHEMBL1442546 & 688497 & 4.6 & 4.685 & TRN \\
\hline CHEMBL 3214354 & 688497 & 4.9 & 5.2979 & TST \\
\hline CHEMBL1383868 & 688497 & 6.3 & 5.4498 & TRN \\
\hline CHEMBL1571093 & 688497 & 6.05 & 5.0283 & TRN \\
\hline CHEMBL1313653 & 688497 & 4.45 & 4.6983 & TRN \\
\hline CHEMBL1454999 & 688497 & 4.45 & 4.8914 & TRN \\
\hline CHEMBL3197259 & 688497 & 5.65 & 5.2679 & TRN \\
\hline CHEMBL1535318 & 688497 & 4.45 & 4.8789 & TRN \\
\hline CHEMBL1319682 & 688497 & 4.45 & 5.0641 & TRN \\
\hline CHEMBL1323736 & 688497 & 4.95 & 4.8701 & TRN \\
\hline CHEMBL1377893 & 688497 & 6.1 & 5.077 & TST \\
\hline CHEMBL1429359 & 688497 & 5.0 & 5.1 & TRN \\
\hline CHEMBL1487159 & 688497 & 4.75 & 5.0957 & TRN \\
\hline CHEMBL1493694 & 688497 & 4.5 & 4.814 & TRN \\
\hline CHEMBL1565084 & 688497 & 4.45 & 5.2198 & TRN \\
\hline CHEMBL1595525 & 688497 & 4.6 & 4.795 & TST \\
\hline CHEMBL1453222 & 688497 & 4.45 & 4.7399 & TRN \\
\hline CHEMBL1425381 & 688497 & 4.85 & 4.8849 & TRN \\
\hline CHEMBL1575615 & 688497 & 6.0 & 5.1835 & TRN \\
\hline CHEMBL1384630 & 688497 & 4.45 & 4.9828 & TST \\
\hline CHEMBL1577763 & 688497 & 5.7 & 5.0099 & TST \\
\hline CHEMBL1613375 & 688497 & 4.45 & 4.9142 & TRN \\
\hline CHEMBL3198905 & 688497 & 4.45 & 4.6952 & TRN \\
\hline CHEMBL1545631 & 688497 & 4.95 & 4.9381 & TRN \\
\hline CHEMBL1464356 & 688497 & 4.7 & 5.018 & TRN \\
\hline CHEMBL1585232 & 688497 & 5.9 & 5.5718 & TRN \\
\hline CHEMBL1601723 & 688497 & 4.45 & 4.9765 & TRN \\
\hline CHEMBL1304471 & 688497 & 4.45 & 4.8782 & TRN \\
\hline CHEMBL1378878 & 688497 & 5.9 & 5.1614 & TRN \\
\hline CHEMBL1600390 & 688497 & 4.45 & 4.9953 & TRN \\
\hline CHEMBL1351359 & 688497 & 5.95 & 4.9321 & TST \\
\hline CHEMBL1453469 & 688497 & 5.1 & 4.8928 & TRN \\
\hline CHEMBL1341408 & 688497 & 4.45 & 4.9589 & TRN \\
\hline CHEMBL1970371 & 688497 & 5.05 & 5.2246 & TST \\
\hline CHEMBL1380585 & 688497 & 4.95 & 4.9682 & TRN \\
\hline CHEMBL577419 & 688497 & 4.9 & 4.744 & TRN \\
\hline CHEMBL1414448 & 688497 & 5.9 & 5.0809 & TST \\
\hline CHEMBL1407914 & 688497 & 4.45 & 5.0472 & TRN \\
\hline CHEMBL3199495 & 688497 & 5.75 & 5.0541 & TST \\
\hline CHEMBL1406221 & 688497 & 5.25 & 5.1431 & TST \\
\hline CHEMBL1350666 & 688497 & 5.0 & 5.144 & TRN \\
\hline CHEMBL1385782 & 688497 & 5.25 & 5.2771 & TST \\
\hline CHEMBL1425936 & 688497 & 5.25 & 5.3511 & TST \\
\hline
\end{tabular}




\begin{tabular}{|c|c|c|c|c|c|}
\hline \multicolumn{6}{|c|}{ Supplemental Table S2.txt } \\
\hline CHEMBL1463446 & 688497 & 4.85 & 5.0033 & TRN & \\
\hline CHEMBL1424063 & 688497 & 4.95 & 4.9658 & TRN & \\
\hline CHEMBL1306290 & 688497 & 4.55 & 4.8291 & TRN & \\
\hline CHEMBL532160 & 688497 & 4.55 & 4.7351 & TRN & \\
\hline CHEMBL1568961 & 688497 & 5.0 & 4.9737 & TRN & \\
\hline CHEMBL528181 & 688497 & 4.45 & 4.6875 & TRN & \\
\hline CHEMBL1489269 & 688497 & 4.45 & 4.7941 & TST & \\
\hline CHEMBL3189365 & 688497 & 4.75 & 5.1696 & TRN & \\
\hline CHEMBL140425 & 688497 & 5.1 & 5.1869 & TRN & \\
\hline CHEMBL1469567 & 688497 & 5.25 & 5.0918 & TRN & \\
\hline CHEMBL3194435 & 688497 & 4.65 & 4.9774 & TRN & \\
\hline CHEMBL3193024 & 688497 & 6.25 & 5.1833 & TRN & \\
\hline CHEMBL1345294 & 688497 & 4.45 & 4.879 & TRN & \\
\hline CHEMBL1464666 & 688497 & 5.15 & 5.1358 & TRN & \\
\hline CHEMBL1406570 & 688497 & 4.65 & 5.2949 & TRN & \\
\hline CHEMBL1580031 & 688497 & 6.0 & 5.2428 & TRN & \\
\hline CHEMBL1369460 & 688497 & 4.5 & 5.2018 & TST & \\
\hline CHEMBL1481790 & 688497 & 5.25 & 4.6842 & TST & \\
\hline CHEMBL1518073 & 688497 & 6.0 & 4.8535 & TRN & \\
\hline CHEMBL1367689 & 688497 & 4.95 & 5.0591 & TRN & \\
\hline CHEMBL1588585 & 688497 & 7.5003 & 5.42899 & 9999999999 & TST \\
\hline CHEMBL1348218 & 688497 & 7.0 & 5.1793 & TRN & \\
\hline CHEMBL1504691 & 688497 & 4.45 & 5.1828 & TRN & \\
\hline CHEMBL1360873 & 688497 & 4.45 & 4.7515 & TRN & \\
\hline CHEMBL1299595 & 688497 & 6.2 & 5.1503 & TST & \\
\hline CHEMBL1471907 & 688497 & 4.45 & 4.5087 & TRN & \\
\hline CHEMBL1520429 & 688497 & 4.8 & 5.12299 & 9999999999 & TST \\
\hline CHEMBL1607953 & 688497 & 4.55 & 4.7993 & TRN & \\
\hline CHEMBL3198485 & 688497 & 5.1 & 5.5028 & TRN & \\
\hline CHEMBL1453888 & 688497 & 5.55 & 5.0493 & TST & \\
\hline CHEMBL1490988 & 688497 & 5.6 & 5.0927 & TRN & \\
\hline CHEMBL1338857 & 688497 & 4.6 & 4.9764 & TST & \\
\hline CHEMBL1391155 & 688497 & 5.5 & 5.3508 & TRN & \\
\hline CHEMBL1457134 & 688497 & 5.55 & 4.9089 & TRN & \\
\hline CHEMBL1544559 & 688497 & 4.8 & 4.6683 & TRN & \\
\hline CHEMBL1303799 & 688497 & 4.9 & 4.8747 & TRN & \\
\hline CHEMBL1563287 & 688497 & 4.65 & 4.8106 & TRN & \\
\hline CHEMBL1328302 & 688497 & 5.2 & 5.2765 & TRN & \\
\hline CHEMBL1372513 & 688497 & 4.6 & 4.8446 & TRN & \\
\hline CHEMBL1545441 & 688497 & 4.55 & 4.898 & TRN & \\
\hline CHEMBL1548043 & 688497 & 5.55 & 4.8732 & TST & \\
\hline CHEMBL1344786 & 688497 & 5.05 & 5.0893 & TST & \\
\hline CHEMBL1583011 & 688497 & 4.75 & 4.7215 & TRN & \\
\hline CHEMBL1447432 & 688497 & 5.55 & 4.9415 & TRN & \\
\hline CHEMBL1471750 & 688497 & 4.45 & 4.8838 & TRN & \\
\hline CHEMBL1526027 & 688497 & 5.25 & 4.8912 & TST & \\
\hline CHEMBL1509077 & 688497 & 5.3 & 4.9298 & TRN & \\
\hline CHEMBL1386221 & 688497 & 4.7 & 5.1688 & TST & \\
\hline
\end{tabular}




\begin{tabular}{|c|c|c|c|c|}
\hline \multicolumn{5}{|c|}{ Supplemental Table S2.txt } \\
\hline CHEMBL1372293 & 688497 & 4.95 & 4.8491 & TRN \\
\hline CHEMBL1371806 & 688497 & 5.25 & 5.2493 & TRN \\
\hline CHEMBL1736377 & 688497 & 5.25 & 5.0148 & TRN \\
\hline CHEMBL1353983 & 688497 & 5.15 & 5.1806 & TRN \\
\hline CHEMBL409695 & 688497 & 4.75 & 5.0176 & TRN \\
\hline CHEMBL1481585 & 688497 & 4.9 & 4.9467 & TRN \\
\hline CHEMBL1341771 & 688497 & 4.85 & 4.6854 & TRN \\
\hline CHEMBL1562359 & 688497 & 4.45 & 5.1039 & TRN \\
\hline CHEMBL1455042 & 688497 & 4.7 & 4.8364 & TRN \\
\hline CHEMBL1304336 & 688497 & 5.1 & 4.8599 & TRN \\
\hline CHEMBL3214526 & 688497 & 7.0 & 5.1711 & TST \\
\hline CHEMBL1499975 & 688497 & 5.0 & 5.4002 & TRN \\
\hline CHEMBL1547847 & 688497 & 4.65 & 4.9176 & TRN \\
\hline CHEMBL1486168 & 688497 & 4.45 & 4.9448 & TRN \\
\hline CHEMBL1339864 & 688497 & 5.55 & 5.2757 & TST \\
\hline CHEMBL1374291 & 688497 & 4.95 & 4.8914 & TST \\
\hline CHEMBL1337654 & 688497 & 4.95 & 5.144 & TRN \\
\hline CHEMBL1300843 & 688497 & 5.05 & 4.9248 & TRN \\
\hline CHEMBL1494695 & 688497 & 5.9 & 5.1914 & TRN \\
\hline CHEMBL1457798 & 688497 & 5.5 & 5.4041 & TRN \\
\hline CHEMBL1337614 & 688497 & 5.1 & 5.4666 & TRN \\
\hline CHEMBL1349027 & 688497 & 5.6 & 5.2582 & TRN \\
\hline CHEMBL1305743 & 688497 & 5.5 & 5.1862 & TRN \\
\hline CHEMBL1596598 & 688497 & 5.25 & 5.1451 & TRN \\
\hline CHEMBL1425952 & 688497 & 4.75 & 4.9794 & TST \\
\hline CHEMBL1609306 & 688497 & 5.55 & 5.0655 & TRN \\
\hline CHEMBL1503675 & 688497 & 5.0 & 5.341 & TST \\
\hline CHEMBL1606215 & 688497 & 5.2 & 5.0057 & TRN \\
\hline CHEMBL1409733 & 688497 & 5.55 & 5.0717 & TST \\
\hline CHEMBL1333825 & 688497 & 4.45 & 5.1099 & TST \\
\hline CHEMBL3192890 & 688497 & 4.95 & 5.0857 & TRN \\
\hline CHEMBL 1535572 & 688497 & 4.8 & 5.1079 & TST \\
\hline CHEMBL3145289 & 688497 & 5.0 & 4.8317 & TST \\
\hline CHEMBL1422850 & 688497 & 6.0 & 5.0136 & TRN \\
\hline CHEMBL1408872 & 688497 & 4.65 & 5.0004 & TRN \\
\hline CHEMBL1312654 & 688497 & 4.45 & 4.7318 & TRN \\
\hline CHEMBL1432333 & 688497 & 5.55 & 4.9577 & TST \\
\hline CHEMBL1363372 & 688497 & 4.65 & 5.0155 & TRN \\
\hline CHEMBL1324885 & 688497 & 4.8 & 5.0175 & TRN \\
\hline CHEMBL1312122 & 688497 & 4.7 & 5.0569 & TRN \\
\hline CHEMBL1364417 & 688497 & 4.75 & 5.0471 & TST \\
\hline CHEMBL1466204 & 688497 & 6.2 & 5.2602 & TRN \\
\hline CHEMBL1575831 & 688497 & 4.6 & 5.0065 & TST \\
\hline CHEMBL1306609 & 688497 & 4.45 & 4.8128 & TRN \\
\hline CHEMBL1469542 & 688497 & 4.45 & 4.7755 & TRN \\
\hline CHEMBL1500482 & 688497 & 6.3 & 5.2659 & TST \\
\hline CHEMBL3192270 & 688497 & 5.7 & 5.1946 & TRN \\
\hline CHEMBL1560531 & 688497 & 5.45 & 5.1202 & TRN \\
\hline
\end{tabular}




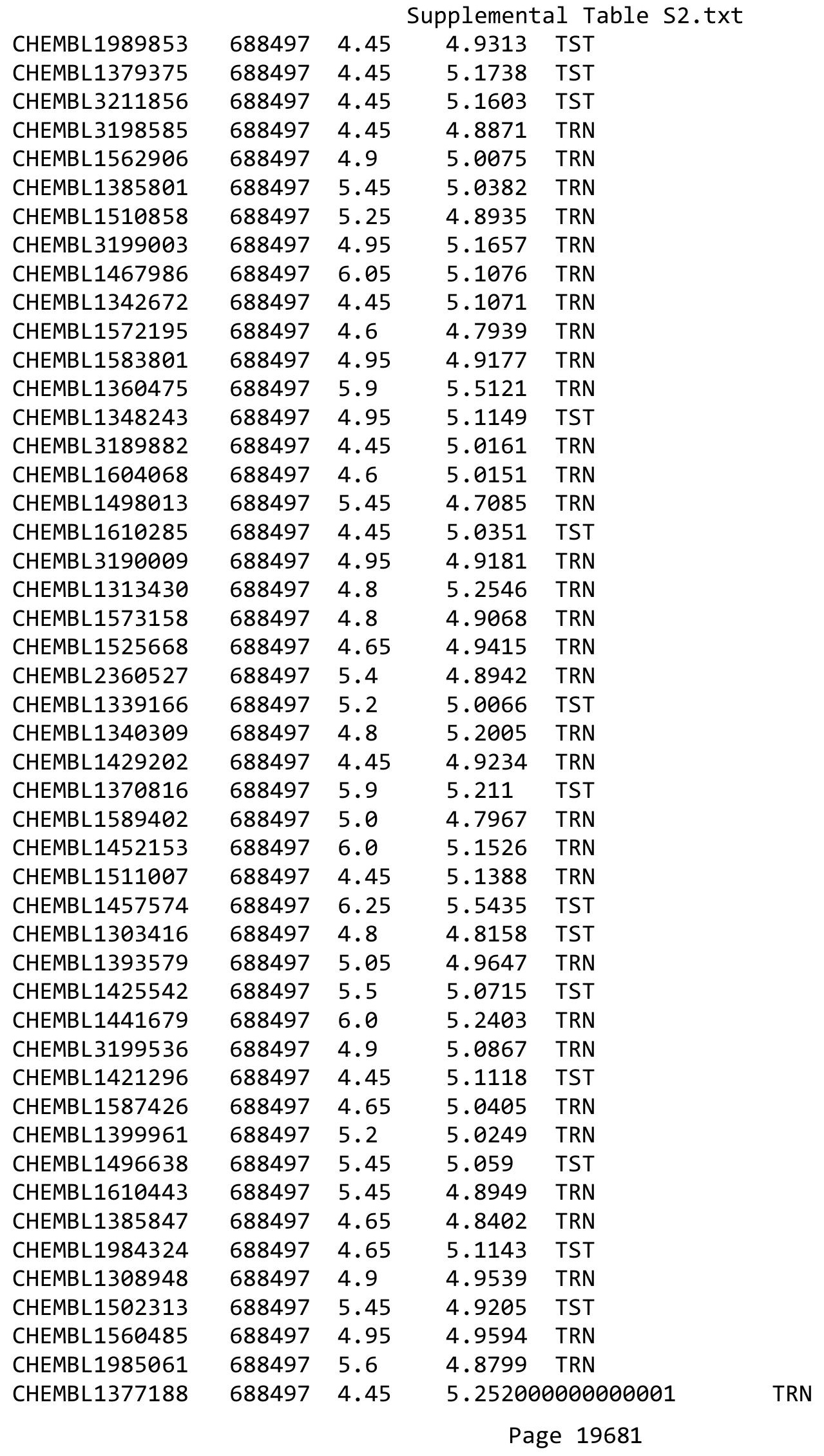




\begin{tabular}{|c|c|c|c|c|c|}
\hline \multicolumn{6}{|c|}{ Supplemental Table S2.txt } \\
\hline CHEMBL1598230 & 688497 & 5.5 & 4.9946 & TRN & \\
\hline CHEMBL1429539 & 688497 & 4.45 & 4.7753 & TRN & \\
\hline CHEMBL3211099 & 688497 & 4.5 & 4.9251 & TST & \\
\hline CHEMBL1550432 & 688497 & 6.25 & 4.9495 & TRN & \\
\hline CHEMBL1374487 & 688497 & 4.9 & 5.0185 & TRN & \\
\hline CHEMBL1472271 & 688497 & 4.9 & 4.9499 & TST & \\
\hline CHEMBL3193481 & 688497 & 5.45 & 5.3255 & TRN & \\
\hline CHEMBL1589415 & 688497 & 4.95 & 5.1359 & TST & \\
\hline CHEMBL1572963 & 688497 & 4.65 & 4.9002 & TRN & \\
\hline CHEMBL1340338 & 688497 & 4.45 & 5.0404 & TST & \\
\hline CHEMBL1583010 & 688497 & 4.85 & 4.9282 & TRN & \\
\hline CHEMBL1384414 & 688497 & 4.95 & 4.6628 & TRN & \\
\hline CHEMBL1424475 & 688497 & 4.65 & 4.9823 & TRN & \\
\hline CHEMBL1703256 & 688497 & 5.4 & 4.6384 & TRN & \\
\hline CHEMBL1390555 & 688497 & 4.45 & 4.7961 & TRN & \\
\hline CHEMBL1538477 & 688497 & 4.45 & 5.0977 & TRN & \\
\hline CHEMBL3213832 & 688497 & 4.6 & 4.8329 & TRN & \\
\hline CHEMBL1418463 & 688497 & 4.45 & 4.94600 & 0000000001 & TRN \\
\hline CHEMBL1462818 & 688497 & 5.15 & 4.9349 & TST & \\
\hline CHEMBL1613195 & 688497 & 4.8 & 4.8943 & TRN & \\
\hline CHEMBL1320486 & 688497 & 4.75 & 4.688 & TRN & \\
\hline CHEMBL1536852 & 688497 & 4.6 & 4.9859 & TRN & \\
\hline CHEMBL1508058 & 688497 & 5.75 & 4.9205 & TST & \\
\hline CHEMBL1538430 & 688497 & 5.25 & 5.08 & TRN & \\
\hline CHEMBL1613708 & 688497 & 4.45 & 5.1002 & TRN & \\
\hline CHEMBL1305577 & 688497 & 6.05 & 5.2519 & TRN & \\
\hline CHEMBL3196135 & 688497 & 4.55 & 4.8258 & TST & \\
\hline CHEMBL1548067 & 688497 & 4.45 & 4.8854 & TRN & \\
\hline CHEMBL1550670 & 688497 & 5.25 & 4.7695 & TRN & \\
\hline CHEMBL1365456 & 688497 & 4.6 & 5.2923 & TRN & \\
\hline CHEMBL1544502 & 688497 & 4.9 & 4.7741 & TRN & \\
\hline CHEMBL1999756 & 688497 & 4.95 & 5.0623 & TRN & \\
\hline CHEMBL1491681 & 688497 & 4.5 & 5.1964 & TRN & \\
\hline CHEMBL1363550 & 688497 & 5.55 & 5.0754 & TRN & \\
\hline CHEMBL1410760 & 688497 & 5.45 & 5.1677 & TRN & \\
\hline CHEMBL1526349 & 688497 & 4.95 & 4.7595 & TST & \\
\hline CHEMBL1461400 & 688497 & 5.75 & 5.0303 & TRN & \\
\hline CHEMBL1520808 & 688497 & 5.25 & 4.8205 & TRN & \\
\hline CHEMBL3196232 & 688497 & 6.3 & 4.8908 & TRN & \\
\hline CHEMBL1994815 & 688497 & 4.45 & 4.7185 & TRN & \\
\hline CHEMBL1345620 & 688497 & 4.95 & 5.0097 & TRN & \\
\hline CHEMBL1493047 & 688497 & 4.45 & 5.0166 & TRN & \\
\hline CHEMBL1348819 & 688497 & 4.95 & 4.8124 & TRN & \\
\hline CHEMBL1494858 & 688497 & 4.95 & 5.0389 & TRN & \\
\hline CHEMBL1447912 & 688497 & 5.25 & 5.0477 & TST & \\
\hline CHEMBL1459432 & 688497 & 6.1 & 5.0541 & TRN & \\
\hline CHEMBL1499551 & 688497 & 5.95 & 5.0912 & TRN & \\
\hline CHEMBL1313155 & 688497 & 5.0 & 5.1146 & TST & \\
\hline
\end{tabular}




\begin{tabular}{|c|c|c|c|c|c|}
\hline \multicolumn{6}{|c|}{ splemental } \\
\hline CHEMBL1507763 & 688497 & 6.2 & 5.4833 & TRN & \\
\hline CHEMBL1404701 & 688497 & 6.25 & 4.8263 & TRN & \\
\hline CHEMBL1603719 & 688497 & 4.85 & 5.1716 & TRN & \\
\hline CHEMBL1534425 & 688497 & 4.95 & 4.8634 & TRN & \\
\hline CHEMBL1422664 & 688497 & 5.05 & 4.9755 & TST & \\
\hline CHEMBL1442742 & 688497 & 4.45 & 4.4799 & TRN & \\
\hline CHEMBL3196351 & 688497 & 5.9 & 5.0188 & TRN & \\
\hline CHEMBL1547250 & 688497 & 4.45 & 4.7818 & TRN & \\
\hline CHEMBL1349466 & 688497 & 5.25 & 5.0503 & TRN & \\
\hline CHEMBL1521619 & 688497 & 4.45 & 4.8475 & TRN & \\
\hline CHEMBL1506459 & 688497 & 4.6 & 4.7153 & TRN & \\
\hline CHEMBL1308898 & 688497 & 4.9 & 4.8591 & TRN & \\
\hline CHEMBL1466340 & 688497 & 5.4 & 4.5472 & TST & \\
\hline CHEMBL1612474 & 688497 & 4.45 & 5.3453 & TRN & \\
\hline CHEMBL1303200 & 688497 & 4.7 & 4.9442 & TRN & \\
\hline CHEMBL1526855 & 688497 & 5.25 & 4.8182 & TST & \\
\hline CHEMBL1348050 & 688497 & 5.25 & 5.0046 & TST & \\
\hline CHEMBL3190721 & 688497 & 4.9 & 4.9767 & TRN & \\
\hline CHEMBL3190805 & 688497 & 5.5 & 5.36799 & 9999999999 & TRN \\
\hline CHEMBL1370276 & 688497 & 4.9 & 5.0363 & TRN & \\
\hline CHEMBL1600974 & 688497 & 4.9 & 5.1629 & TRN & \\
\hline CHEMBL1511447 & 688497 & 5.55 & 5.1241 & TRN & \\
\hline CHEMBL1320224 & 688497 & 4.65 & 4.8644 & TRN & \\
\hline CHEMBL1323285 & 688497 & 5.0 & 5.148 & TRN & \\
\hline CHEMBL1348406 & 688497 & 4.6 & 4.8731 & TRN & \\
\hline CHEMBL1578918 & 688497 & 4.45 & 5.0838 & TST & \\
\hline CHEMBL1505389 & 688497 & 4.45 & 4.9232 & TRN & \\
\hline CHEMBL1391448 & 688497 & 4.85 & 4.9391 & TRN & \\
\hline CHEMBL3192213 & 688497 & 5.65 & 5.1104 & TST & \\
\hline CHEMBL1504437 & 688497 & 6.3 & 5.4015 & TRN & \\
\hline CHEMBL 3207672 & 688497 & 4.45 & 4.955 & TRN & \\
\hline CHEMBL1369693 & 688497 & 4.9 & 4.874 & TRN & \\
\hline CHEMBL1559481 & 688497 & 4.55 & 4.9868 & TRN & \\
\hline CHEMBL1535949 & 688497 & 5.25 & 5.2336 & TRN & \\
\hline CHEMBL1423271 & 688497 & 4.7 & 4.9186 & TRN & \\
\hline CHEMBL1363689 & 688497 & 5.35 & 5.4053 & TRN & \\
\hline CHEMBL1415449 & 688497 & 4.45 & 4.8317 & TST & \\
\hline CHEMBL1308756 & 688497 & 4.45 & 4.9051 & TST & \\
\hline CHEMBL1362096 & 688497 & 4.45 & 5.0458 & TST & \\
\hline CHEMBL1489113 & 688497 & 4.65 & 5.0386 & TRN & \\
\hline CHEMBL1311176 & 688497 & 4.8 & 5.041 & TRN & \\
\hline CHEMBL3194766 & 688497 & 5.0 & 5.2013 & TRN & \\
\hline CHEMBL1441442 & 688497 & 4.75 & 5.0833 & TRN & \\
\hline CHEMBL1428066 & 688497 & 4.75 & 5.4235 & TST & \\
\hline CHEMBL3190063 & 688497 & 5.0 & 4.9779 & TRN & \\
\hline CHEMBL1459626 & 688497 & 4.45 & 4.8678 & TRN & \\
\hline CHEMBL1372105 & 688497 & 6.1 & 4.9473 & TST & \\
\hline CHEMBL3195475 & 688497 & 4.75 & 4.9757 & TRN & \\
\hline
\end{tabular}




\begin{tabular}{|c|c|c|c|c|}
\hline \multicolumn{5}{|c|}{ Supplemental Table S2.txt } \\
\hline CHEMBL1990685 & 688497 & 5.2 & 4.8023 & TRN \\
\hline CHEMBL1550034 & 688497 & 4.45 & 4.8898 & TRN \\
\hline CHEMBL1587403 & 688497 & 5.85 & 5.0583 & TST \\
\hline CHEMBL1563212 & 688497 & 6.15 & 5.2324 & TRN \\
\hline CHEMBL1490330 & 688497 & 4.6 & 4.963 & TST \\
\hline CHEMBL1459899 & 688497 & 4.7 & 4.9184 & TRN \\
\hline CHEMBL1308037 & 688497 & 4.85 & 4.5603 & TRN \\
\hline CHEMBL1300243 & 688497 & 5.6 & 5.3434 & TST \\
\hline CHEMBL1520741 & 688497 & 4.45 & 4.9742 & TRN \\
\hline CHEMBL1309790 & 688497 & 4.45 & 5.025 & TST \\
\hline CHEMBL1345687 & 688497 & 4.45 & 5.1022 & TRN \\
\hline CHEMBL1568758 & 688497 & 4.9 & 4.7159 & TRN \\
\hline CHEMBL1353969 & 688497 & 5.05 & 5.062 & TRN \\
\hline CHEMBL1359429 & 688497 & 5.25 & 5.3999 & TST \\
\hline CHEMBL1442037 & 688497 & 5.35 & 4.8686 & TST \\
\hline CHEMBL1466558 & 688497 & 5.4 & 4.705 & TRN \\
\hline CHEMBL1543770 & 688497 & 5.5 & 4.9024 & TST \\
\hline CHEMBL1603910 & 688497 & 4.9 & 4.6812 & TRN \\
\hline CHEMBL1432451 & 688497 & 4.9 & 5.0049 & TRN \\
\hline CHEMBL1559961 & 688497 & 4.95 & 4.9736 & TRN \\
\hline CHEMBL3207534 & 688497 & 4.8 & 5.2289 & TRN \\
\hline CHEMBL1611832 & 688497 & 5.45 & 4.8441 & TST \\
\hline CHEMBL 3856088 & 688497 & 4.85 & 5.0478 & TRN \\
\hline CHEMBL1499790 & 688497 & 4.65 & 4.9185 & TRN \\
\hline CHEMBL1606373 & 688497 & 5.5 & 5.1162 & TST \\
\hline CHEMBL1484371 & 688497 & 4.9 & 5.4157 & TST \\
\hline CHEMBL1492122 & 688497 & 4.45 & 4.8238 & TRN \\
\hline CHEMBL1340058 & 688497 & 5.85 & 5.12 & TRN \\
\hline CHEMBL1359788 & 688497 & 4.65 & 5.0383 & TRN \\
\hline CHEMBL1368924 & 688497 & 4.8 & 4.9551 & TRN \\
\hline CHEMBL1456311 & 688497 & 4.95 & 4.6136 & TRN \\
\hline CHEMBL3195295 & 688497 & 4.45 & 5.2707 & TRN \\
\hline CHEMBL1470158 & 688497 & 4.8 & 4.9916 & TRN \\
\hline CHEMBL1555839 & 688497 & 5.25 & 5.0041 & TST \\
\hline CHEMBL1448382 & 688497 & 5.0 & 4.7215 & TRN \\
\hline CHEMBL1597179 & 688497 & 4.65 & 4.8356 & TRN \\
\hline CHEMBL1325852 & 688497 & 4.45 & 4.8344 & TRN \\
\hline CHEMBL1430437 & 688497 & 4.85 & 4.8704 & TRN \\
\hline CHEMBL1335944 & 688497 & 4.45 & 5.0482 & TRN \\
\hline CHEMBL1363333 & 688497 & 5.9 & 5.2064 & TST \\
\hline CHEMBL1509159 & 688497 & 4.7 & 5.0258 & TRN \\
\hline CHEMBL1311305 & 688497 & 4.45 & 4.9976 & TRN \\
\hline CHEMBL1612438 & 688497 & 7.0 & 5.431 & TRN \\
\hline CHEMBL1463982 & 688497 & 4.95 & 5.0859 & TRN \\
\hline CHEMBL1523867 & 688497 & 4.95 & 5.1065 & TRN \\
\hline CHEMBL1440967 & 688497 & 4.95 & 5.1492 & TST \\
\hline CHEMBL1992040 & 688497 & 4.8 & 4.8197 & TRN \\
\hline CHEMBL3189408 & 688497 & 4.7 & 4.9532 & TST \\
\hline
\end{tabular}




\begin{tabular}{|c|c|c|c|c|}
\hline & & & \multicolumn{2}{|c|}{ Supplemental Table S2.txt } \\
\hline CHEMBL1599234 & 688497 & 4.75 & 4.7956 & TRN \\
\hline CHEMBL1471916 & 688497 & 5.4 & 5.087 & TRN \\
\hline CHEMBL2003195 & 688497 & 4.45 & 5.0212 & TRN \\
\hline CHEMBL 3198242 & 688497 & 4.45 & 4.99 & TRN \\
\hline CHEMBL1607495 & 688497 & 4.95 & 4.8859 & TRN \\
\hline CHEMBL1467782 & 688497 & 4.65 & 4.8249 & TST \\
\hline CHEMBL1339994 & 688497 & 4.5 & 4.7885 & TRN \\
\hline CHEMBL1408398 & 688497 & 5.45 & 4.974 & TRN \\
\hline CHEMBL1310876 & 688497 & 5.6 & 5.1657 & TST \\
\hline CHEMBL1417672 & 688497 & 4.85 & 5.15 & TRN \\
\hline CHEMBL1493660 & 688497 & 4.45 & 4.7702 & TRN \\
\hline CHEMBL1612444 & 688497 & 4.45 & 4.7738 & TRN \\
\hline CHEMBL3195436 & 688497 & 5.1 & 5.3268 & TRN \\
\hline CHEMBL1528004 & 688497 & 5.85 & 5.2123 & TRN \\
\hline CHEMBL1548714 & 688497 & 6.25 & 5.0229 & TRN \\
\hline CHEMBL1533767 & 688497 & 4.8 & 5.024 & TRN \\
\hline CHEMBL1333636 & 688497 & 4.45 & 5.0906 & TRN \\
\hline CHEMBL1368544 & 688497 & 4.45 & 4.7497 & TRN \\
\hline CHEMBL1378366 & 688497 & 4.65 & 5.1564 & TRN \\
\hline CHEMBL89445 & 688497 & 5.75 & 5.7056 & TST \\
\hline CHEMBL1611476 & 688497 & 5.25 & 4.9686 & TRN \\
\hline CHEMBL1610413 & 688497 & 4.45 & 5.2733 & TST \\
\hline CHEMBL1378513 & 688497 & 4.8 & 4.8884 & TRN \\
\hline CHEMBL1589485 & 688497 & 4.75 & 5.1005 & TRN \\
\hline CHEMBL1540032 & 688497 & 4.65 & 5.1204 & TST \\
\hline CHEMBL1410423 & 688497 & 4.45 & 4.7366 & TRN \\
\hline CHEMBL1539137 & 688497 & 6.0 & 5.3643 & TRN \\
\hline CHEMBL1302792 & 688497 & 4.45 & 5.478 & TRN \\
\hline CHEMBL1322588 & 688497 & 5.0 & 5.4411 & TRN \\
\hline CHEMBL3190468 & 688497 & 4.8 & 5.0133 & TRN \\
\hline CHEMBL1580211 & 688497 & 5.25 & 5.309 & TST \\
\hline CHEMBL1340698 & 688497 & 5.0 & 5.0252 & TRN \\
\hline CHEMBL1460271 & 688497 & 5.0 & 5.2336 & TRN \\
\hline CHEMBL1496284 & 688497 & 4.95 & 5.0728 & TRN \\
\hline CHEMBL1485259 & 688497 & 4.95 & 4.7271 & TRN \\
\hline CHEMBL285157 & 688497 & 4.85 & 4.9978 & TRN \\
\hline CHEMBL1549222 & 688497 & 4.75 & 4.8606 & TRN \\
\hline CHEMBL1343359 & 688497 & 5.2 & 5.0521 & TST \\
\hline CHEMBL1587055 & 688497 & 6.25 & 5.1167 & TRN \\
\hline CHEMBL3192433 & 688497 & 5.5 & 5.113 & TRN \\
\hline CHEMBL1432548 & 688497 & 4.75 & 4.9614 & TRN \\
\hline CHEMBL1595927 & 688497 & 4.9 & 4.9346 & TRN \\
\hline CHEMBL1318971 & 688497 & 4.45 & 4.8599 & TST \\
\hline CHEMBL1609971 & 688497 & 4.95 & 5.046 & TRN \\
\hline CHEMBL1579675 & 688497 & 5.7 & 5.1349 & TRN \\
\hline CHEMBL3193507 & 688497 & 4.95 & 4.6175 & TRN \\
\hline CHEMBL 3198554 & 688497 & 5.05 & 5.1243 & TRN \\
\hline CHEMBL1478755 & 688497 & 5.6 & 5.3399 & TRN \\
\hline
\end{tabular}




\begin{tabular}{|c|c|c|c|c|c|}
\hline \multicolumn{6}{|c|}{ Supplemental Table S2.txt } \\
\hline CHEMBL1580183 & 688497 & 5.2 & 5.1544 & TRN & \\
\hline CHEMBL1385529 & 688497 & 5.75 & 5.2468 & TRN & \\
\hline CHEMBL1608383 & 688497 & 4.95 & 5.3754 & TST & \\
\hline CHEMBL1305747 & 688497 & 4.65 & 5.04 & TRN & \\
\hline CHEMBL1546431 & 688497 & 4.95 & 5.0812 & TRN & \\
\hline CHEMBL1495112 & 688497 & 4.5 & 4.7375 & TRN & \\
\hline CHEMBL1446181 & 688497 & 4.7 & 4.7825 & TRN & \\
\hline CHEMBL1256364 & 688497 & 5.3 & 5.3252 & TST & \\
\hline CHEMBL 3199748 & 688497 & 4.95 & 5.084 & TRN & \\
\hline CHEMBL1385690 & 688497 & 4.95 & 5.1083 & TRN & \\
\hline CHEMBL1977877 & 688497 & 5.75 & 5.4597 & TRN & \\
\hline CHEMBL1411613 & 688497 & 6.3 & 5.0793 & TRN & \\
\hline CHEMBL1400298 & 688497 & 5.5 & 5.26200 & 00000000005 & TST \\
\hline CHEMBL1365395 & 688497 & 4.8 & 4.5913 & TRN & \\
\hline CHEMBL1568720 & 688497 & 5.2 & 5.3232 & TRN & \\
\hline CHEMBL1450690 & 688497 & 5.1 & 4.692 & TRN & \\
\hline CHEMBL1532459 & 688497 & 4.8 & 4.9315 & TST & \\
\hline CHEMBL1986380 & 688497 & 4.85 & 4.6854 & TST & \\
\hline CHEMBL1424022 & 688497 & 5.0 & 4.8386 & TRN & \\
\hline CHEMBL1510926 & 688497 & 6.0 & 5.0482 & TST & \\
\hline CHEMBL1613383 & 688497 & 4.7 & 5.2013 & TST & \\
\hline CHEMBL3191350 & 688497 & 4.55 & 5.1514 & TST & \\
\hline CHEMBL1466932 & 688497 & 4.45 & 4.7153 & TRN & \\
\hline CHEMBL1306934 & 688497 & 5.0 & 4.8099 & TRN & \\
\hline CHEMBL3211122 & 688497 & 4.9 & 5.3406 & TRN & \\
\hline CHEMBL1383267 & 688497 & 4.95 & 5.1238 & TRN & \\
\hline CHEMBL1312502 & 688497 & 4.45 & 4.7502 & TRN & \\
\hline CHEMBL1544711 & 688497 & 4.45 & 4.67899 & 9999999999 & TRN \\
\hline CHEMBL3198134 & 688497 & 5.35 & 5.4121 & TRN & \\
\hline CHEMBL1584536 & 688497 & 4.85 & 4.9567 & TRN & \\
\hline CHEMBL1383584 & 688497 & 5.3 & 5.0894 & TST & \\
\hline CHEMBL1423066 & 688497 & 6.1 & 5.1006 & TST & \\
\hline CHEMBL1489583 & 688497 & 4.85 & 5.0633 & TST & \\
\hline CHEMBL3197902 & 688497 & 5.65 & 4.9557 & TRN & \\
\hline CHEMBL 2094789 & 688497 & 5.15 & 5.289 & TST & \\
\hline CHEMBL1525725 & 688497 & 4.45 & 4.6924 & TRN & \\
\hline CHEMBL3191658 & 688497 & 5.25 & 5.2938 & TST & \\
\hline CHEMBL1609794 & 688497 & 4.8 & 5.0768 & TRN & \\
\hline CHEMBL1608732 & 688497 & 5.5 & 5.1648 & TST & \\
\hline CHEMBL1389418 & 688497 & 4.7 & 5.0255 & TRN & \\
\hline CHEMBL1503262 & 688497 & 5.55 & 5.073 & TRN & \\
\hline CHEMBL1415002 & 688497 & 5.4 & 5.0949 & TRN & \\
\hline CHEMBL1480031 & 688497 & 5.15 & 4.7355 & TRN & \\
\hline CHEMBL3196362 & 688497 & 4.45 & 5.0392 & TRN & \\
\hline CHEMBL1377698 & 688497 & 4.45 & 5.023 & TST & \\
\hline CHEMBL1546299 & 688497 & 4.45 & 4.9767 & TRN & \\
\hline CHEMBL3195599 & 688497 & 4.45 & 5.0786 & TRN & \\
\hline CHEMBL1580116 & 688497 & 4.45 & 4.574 & TRN & \\
\hline
\end{tabular}




\begin{tabular}{|c|c|c|c|c|c|}
\hline & & & & & \\
\hline CHEMBL1403940 & 688497 & 5.9 & 4.9737 & TRN & \\
\hline CHEMBL1337085 & 688497 & 4.9 & 5.2477 & TRN & \\
\hline CHEMBL1610119 & 688497 & 4.45 & 5.0871 & TRN & \\
\hline CHEMBL1541967 & 688497 & 4.5 & 4.9277 & TRN & \\
\hline CHEMBL1510885 & 688497 & 5.9 & 5.3394 & TRN & \\
\hline CHEMBL1599630 & 688497 & 4.95 & 4.7809 & TRN & \\
\hline CHEMBL1452496 & 688497 & 5.35 & 5.2775 & TRN & \\
\hline CHEMBL1566545 & 688497 & 4.45 & 4.836 & TRN & \\
\hline CHEMBL1360586 & 688497 & 6.2 & 5.1109 & TST & \\
\hline CHEMBL1534301 & 688497 & 5.2 & 5.0624 & TRN & \\
\hline CHEMBL1581326 & 688497 & 6.0 & 5.3411 & TST & \\
\hline CHEMBL1384724 & 688497 & 4.85 & 5.3084 & TRN & \\
\hline CHEMBL1343643 & 688497 & 5.25 & 5.1457 & TST & \\
\hline CHEMBL1500912 & 688497 & 4.45 & 4.835 & TST & \\
\hline CHEMBL3197858 & 688497 & 5.25 & 5.1531 & TST & \\
\hline CHEMBL1594828 & 688497 & 4.45 & 4.9564 & TRN & \\
\hline CHEMBL1540596 & 688497 & 5.05 & 4.9573 & TRN & \\
\hline CHEMBL1451735 & 688497 & 5.15 & 5.1702 & TRN & \\
\hline CHEMBL1384365 & 688497 & 4.45 & 4.8613 & TRN & \\
\hline CHEMBL1390716 & 688497 & 5.15 & 5.1345 & TST & \\
\hline CHEMBL1973050 & 688497 & 5.0 & 4.8295 & TST & \\
\hline CHEMBL1423795 & 688497 & 4.95 & 4.8966 & TRN & \\
\hline CHEMBL1459214 & 688497 & 4.65 & 4.728 & TRN & \\
\hline CHEMBL1517373 & 688497 & 6.5 & 4.9262 & TST & \\
\hline CHEMBL1523280 & 688497 & 4.9 & 5.0999 & TRN & \\
\hline CHEMBL1534359 & 688497 & 4.85 & 4.7854 & TRN & \\
\hline CHEMBL3193073 & 688497 & 4.45 & 5.0224 & TRN & \\
\hline CHEMBL1576513 & 688497 & 4.9 & 5.0425 & TRN & \\
\hline CHEMBL1577291 & 688497 & 5.25 & 5.1614 & TRN & \\
\hline CHEMBL1360539 & 688497 & 5.3 & 4.876 & TRN & \\
\hline CHEMBL1583378 & 688497 & 4.45 & 4.7902 & TRN & \\
\hline CHEMBL1364323 & 688497 & 6.25 & 5.3028 & TST & \\
\hline CHEMBL1563936 & 688497 & 4.45 & 5.0008 & TRN & \\
\hline CHEMBL1499839 & 688497 & 5.25 & 4.9038 & TST & \\
\hline CHEMBL1458475 & 688497 & 4.9 & 5.1591 & TRN & \\
\hline CHEMBL1466833 & 688497 & 6.3 & 5.0921 & TRN & \\
\hline CHEMBL1527545 & 688497 & 4.45 & 5.1108 & TST & \\
\hline CHEMBL1522988 & 688497 & 4.65 & 4.7996 & TRN & \\
\hline CHEMBL1595926 & 688497 & 4.75 & 5.0518 & TRN & \\
\hline CHEMBL1311492 & 688497 & 5.15 & 4.8744 & TRN & \\
\hline CHEMBL1537926 & 688497 & 4.45 & 4.6416 & TRN & \\
\hline CHEMBL601952 & 688497 & 4.8 & 5.1885 & TRN & \\
\hline CHEMBL1346672 & 688497 & 4.45 & 4.6306 & TRN & \\
\hline CHEMBL1403438 & 688497 & 4.45 & 5.1084 & TRN & \\
\hline CHEMBL1370746 & 688497 & 4.45 & 4.80399 & 9999999999 & TRN \\
\hline CHEMBL1965579 & 688497 & 6.15 & 4.9538 & TRN & \\
\hline CHEMBL1558488 & 688497 & 4.45 & 5.0205 & TRN & \\
\hline CHEMBL1413986 & 688497 & 5.0 & 5.1102 & TRN & \\
\hline & & & & 19687 & \\
\hline
\end{tabular}




\begin{tabular}{|c|c|c|c|c|c|}
\hline \multicolumn{6}{|c|}{ Supplemental Table S2.txt } \\
\hline CHEMBL1365909 & 688497 & 5.2 & 5.1871 & TRN & \\
\hline CHEMBL1388256 & 688497 & 4.75 & 5.0931 & TST & \\
\hline CHEMBL549216 & 688497 & 4.75 & 4.9313 & TRN & \\
\hline CHEMBL1588257 & 688497 & 4.45 & 5.1372 & TRN & \\
\hline CHEMBL1367772 & 688497 & 4.45 & 5.26200 & 00000000005 & TRN \\
\hline CHEMBL1424269 & 688497 & 5.1 & 5.265 & TRN & \\
\hline CHEMBL1407515 & 688497 & 4.45 & 5.1818 & TRN & \\
\hline CHEMBL1351201 & 688497 & 4.45 & 5.0073 & TRN & \\
\hline CHEMBL235891 & 688497 & 4.65 & 5.1497 & TRN & \\
\hline CHEMBL1381360 & 688497 & 4.45 & 4.7561 & TRN & \\
\hline CHEMBL1518794 & 688497 & 4.9 & 4.7082 & TRN & \\
\hline CHEMBL1530216 & 688497 & 4.95 & 4.6637 & TRN & \\
\hline CHEMBL1499125 & 688497 & 4.45 & 4.8489 & TRN & \\
\hline CHEMBL 2006740 & 688497 & 4.45 & 5.2979 & TRN & \\
\hline CHEMBL1333426 & 688497 & 6.25 & 5.3488 & TST & \\
\hline CHEMBL1442136 & 688497 & 4.45 & 4.6123 & TRN & \\
\hline CHEMBL1487899 & 688497 & 5.7 & 5.2328 & TRN & \\
\hline CHEMBL1406702 & 688497 & 5.0 & 5.2494 & TRN & \\
\hline CHEMBL3198409 & 688497 & 6.2 & 4.9885 & TST & \\
\hline CHEMBL1585209 & 688497 & 5.6 & 5.0381 & TST & \\
\hline CHEMBL1462579 & 688497 & 4.9 & 5.6066 & TRN & \\
\hline CHEMBL1426634 & 688497 & 4.45 & 4.5752 & TRN & \\
\hline CHEMBL1576980 & 688497 & 4.45 & 5.0326 & TST & \\
\hline CHEMBL1605959 & 688497 & 4.45 & 4.8344 & TRN & \\
\hline CHEMBL1455868 & 688497 & 4.45 & 4.7952 & TRN & \\
\hline CHEMBL1325969 & 688497 & 4.7 & 4.9884 & TRN & \\
\hline CHEMBL1388353 & 688497 & 5.0 & 4.8697 & TST & \\
\hline CHEMBL1584414 & 688497 & 4.45 & 4.5528 & TRN & \\
\hline CHEMBL3195232 & 688497 & 4.9 & 4.7671 & TRN & \\
\hline CHEMBL3194213 & 688497 & 4.9 & 5.1681 & TRN & \\
\hline CHEMBL3191831 & 688497 & 5.55 & 5.3582 & TRN & \\
\hline CHEMBL1602709 & 688497 & 4.85 & 4.6921 & TRN & \\
\hline CHEMBL1326302 & 688497 & 4.9 & 4.8032 & TRN & \\
\hline CHEMBL1970621 & 688497 & 4.7 & 4.6653 & TRN & \\
\hline CHEMBL1441296 & 688497 & 5.5 & 5.2426 & TRN & \\
\hline CHEMBL1518142 & 688497 & 5.3 & 5.0993 & TRN & \\
\hline CHEMBL 1451938 & 688497 & 5.9 & 4.9135 & TST & \\
\hline CHEMBL1319737 & 688497 & 5.75 & 4.8608 & TST & \\
\hline CHEMBL1587986 & 688497 & 5.5 & 5.0906 & TRN & \\
\hline CHEMBL1385217 & 688497 & 4.45 & 5.1608 & TRN & \\
\hline CHEMBL1423811 & 688497 & 4.45 & 5.0141 & TST & \\
\hline CHEMBL1505944 & 688497 & 4.65 & 5.1805 & TRN & \\
\hline CHEMBL1441604 & 688497 & 5.6 & 5.1394 & TRN & \\
\hline CHEMBL1489461 & 688497 & 5.1 & 5.0112 & TRN & \\
\hline CHEMBL579045 & 688497 & 5.25 & 5.2166 & TRN & \\
\hline CHEMBL1568399 & 688497 & 4.45 & 5.1873 & TST & \\
\hline CHEMBL1361559 & 688497 & 4.5 & 5.209 & TRN & \\
\hline CHEMBL3195343 & 688497 & 5.8 & 5.2373 & TST & \\
\hline
\end{tabular}




\begin{tabular}{|c|c|c|c|c|}
\hline \multicolumn{5}{|c|}{ Supplemental Table } \\
\hline CHEMBL1324137 & 688497 & 4.55 & 4.765 & TRN \\
\hline CHEMBL1469863 & 688497 & 6.25 & 5.2443 & TST \\
\hline CHEMBL1480895 & 688497 & 4.85 & 5.2263 & TST \\
\hline CHEMBL1379776 & 688497 & 5.7 & 4.8771 & TRN \\
\hline CHEMBL1328896 & 688497 & 5.0 & 4.8762 & TST \\
\hline CHEMBL1523938 & 688497 & 4.45 & 5.1134 & TST \\
\hline CHEMBL1506256 & 688497 & 5.4 & 4.9208 & TRN \\
\hline CHEMBL1453826 & 688497 & 4.45 & 4.8471 & TRN \\
\hline CHEMBL3214425 & 688497 & 5.3 & 5.3553 & TST \\
\hline CHEMBL1496449 & 688497 & 4.85 & 5.0077 & TRN \\
\hline CHEMBL1311576 & 688497 & 4.45 & 5.0411 & TST \\
\hline CHEMBL1541647 & 688497 & 4.45 & 5.0475 & TST \\
\hline CHEMBL3196068 & 688497 & 5.0 & 5.3204 & TRN \\
\hline CHEMBL1347408 & 688497 & 4.9 & 5.118 & TRN \\
\hline CHEMBL1388530 & 688497 & 5.0 & 4.798 & TRN \\
\hline CHEMBL3195713 & 688497 & 4.65 & 4.9395 & TRN \\
\hline CHEMBL1338370 & 688497 & 4.45 & 5.2004 & TRN \\
\hline CHEMBL1337604 & 688497 & 4.95 & 5.1636 & TRN \\
\hline CHEMBL1458376 & 688497 & 5.15 & 5.088 & TRN \\
\hline CHEMBL1311612 & 688497 & 5.4 & 4.9427 & TST \\
\hline CHEMBL3191933 & 688497 & 4.65 & 5.1515 & TRN \\
\hline CHEMBL1431033 & 688497 & 4.6 & 5.0149 & TRN \\
\hline CHEMBL1429243 & 688497 & 5.2 & 4.8092 & TST \\
\hline CHEMBL1391933 & 688497 & 5.75 & 4.9699 & TRN \\
\hline CHEMBL1326650 & 688497 & 6.05 & 5.0697 & TRN \\
\hline CHEMBL1530033 & 688497 & 5.7 & 5.1031 & TRN \\
\hline CHEMBL1312391 & 688497 & 4.75 & 5.005 & TST \\
\hline CHEMBL1573115 & 688497 & 4.95 & 5.1886 & TST \\
\hline CHEMBL1505922 & 688497 & 5.45 & 5.1332 & TRN \\
\hline CHEMBL1326664 & 688497 & 4.65 & 5.1361 & TRN \\
\hline CHEMBL1402628 & 688497 & 5.2 & 4.9131 & TRN \\
\hline CHEMBL607253 & 688497 & 5.25 & 4.9441 & TST \\
\hline CHEMBL578878 & 688497 & 4.95 & 5.0302 & TRN \\
\hline CHEMBL1301332 & 688497 & 5.15 & 4.936 & TRN \\
\hline CHEMBL1547039 & 688497 & 4.45 & 5.1354 & TRN \\
\hline CHEMBL1310309 & 688497 & 5.0 & 4.8084 & TRN \\
\hline CHEMBL1329000 & 688497 & 4.95 & 4.9264 & TRN \\
\hline CHEMBL1587009 & 688497 & 4.45 & 4.9092 & TRN \\
\hline CHEMBL1387617 & 688497 & 5.2 & 4.8345 & TRN \\
\hline CHEMBL1523465 & 688497 & 5.15 & 5.1402 & TRN \\
\hline CHEMBL1602408 & 688497 & 4.45 & 5.1256 & TRN \\
\hline CHEMBL1465876 & 688497 & 5.2 & 5.3253 & TST \\
\hline CHEMBL1368811 & 688497 & 5.9 & 5.3248 & TST \\
\hline CHEMBL3211833 & 688497 & 4.45 & 5.0825 & TRN \\
\hline CHEMBL1404709 & 688497 & 4.65 & 4.7473 & TRN \\
\hline CHEMBL1400413 & 688497 & 5.25 & 4.9647 & TRN \\
\hline CHEMBL1413264 & 688497 & 6.25 & 4.9026 & TST \\
\hline CHEMBL1482071 & 688497 & 4.65 & 5.0338 & TRN \\
\hline
\end{tabular}




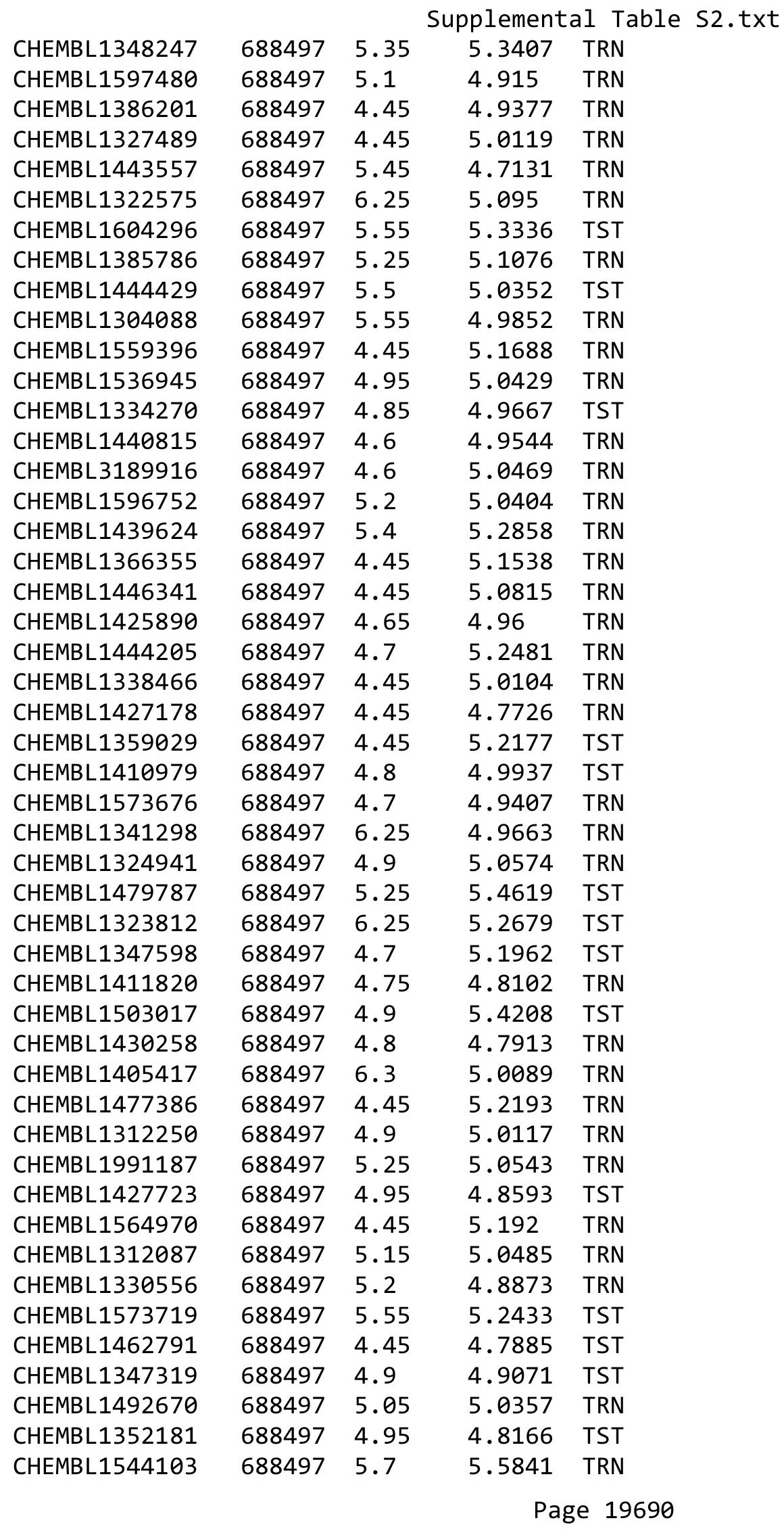




\begin{tabular}{|c|c|c|c|c|c|}
\hline \multicolumn{6}{|c|}{ Supplemental Table S2.txt } \\
\hline CHEMBL1464916 & 688497 & 4.45 & 4.9987 & TRN & \\
\hline CHEMBL1419829 & 688497 & 4.95 & 4.8789 & TST & \\
\hline CHEMBL3189688 & 688497 & 5.3 & 5.12200 & 0000000001 & TRN \\
\hline CHEMBL1529027 & 688497 & 6.05 & 5.0525 & TRN & \\
\hline CHEMBL1224310 & 688497 & 5.4 & 4.8547 & TRN & \\
\hline CHEMBL1377118 & 688497 & 4.9 & 5.0649 & TST & \\
\hline CHEMBL1363112 & 688497 & 4.75 & 4.8242 & TRN & \\
\hline CHEMBL 2000091 & 688497 & 4.45 & 5.0903 & TRN & \\
\hline CHEMBL3194752 & 688497 & 5.25 & 4.979 & TRN & \\
\hline CHEMBL1427906 & 688497 & 4.95 & 4.7252 & TRN & \\
\hline CHEMBL1455998 & 688497 & 4.45 & 4.9529 & TRN & \\
\hline CHEMBL1718568 & 688497 & 5.4 & 4.9928 & TRN & \\
\hline CHEMBL1444691 & 688497 & 4.85 & 4.9465 & TRN & \\
\hline CHEMBL1387537 & 688497 & 4.75 & 5.0907 & TRN & \\
\hline CHEMBL1431310 & 688497 & 4.85 & 4.8791 & TRN & \\
\hline CHEMBL1385058 & 688497 & 4.45 & 4.5758 & TRN & \\
\hline CHEMBL3189914 & 688497 & 5.0 & 4.9086 & TST & \\
\hline CHEMBL1529268 & 688497 & 6.15 & 5.44799 & 99999999995 & TRN \\
\hline CHEMBL1302966 & 688497 & 4.45 & 4.9786 & TRN & \\
\hline CHEMBL1392810 & 688497 & 4.85 & 5.0132 & TRN & \\
\hline CHEMBL1585332 & 688497 & 4.45 & 4.6155 & TRN & \\
\hline CHEMBL1545677 & 688497 & 5.65 & 5.0106 & TRN & \\
\hline CHEMBL1457201 & 688497 & 4.45 & 4.9395 & TST & \\
\hline CHEMBL1546713 & 688497 & 4.7 & 5.2978 & TST & \\
\hline CHEMBL1606110 & 688497 & 4.45 & 4.7917 & TRN & \\
\hline CHEMBL1978067 & 688497 & 5.05 & 4.9052 & TST & \\
\hline CHEMBL1456009 & 688497 & 4.9 & 4.7753 & TST & \\
\hline CHEMBL1326819 & 688497 & 5.2 & 4.7639 & TRN & \\
\hline CHEMBL1318773 & 688497 & 4.95 & 4.9994 & TST & \\
\hline CHEMBL1349566 & 688497 & 4.8 & 5.0465 & TST & \\
\hline CHEMBL1584952 & 688497 & 6.95 & 4.7759 & TRN & \\
\hline CHEMBL1585938 & 688497 & 4.45 & 4.8719 & TRN & \\
\hline CHEMBL1312802 & 688497 & 5.2 & 5.1581 & TST & \\
\hline CHEMBL1573661 & 688497 & 4.45 & 4.8435 & TRN & \\
\hline CHEMBL1432388 & 688497 & 4.65 & 4.988 & TRN & \\
\hline CHEMBL1441178 & 688497 & 4.9 & 4.8531 & TST & \\
\hline CHEMBL1388157 & 688497 & 4.9 & 5.0195 & TRN & \\
\hline CHEMBL1439874 & 688497 & 4.8 & 4.8753 & TST & \\
\hline CHEMBL1588263 & 688497 & 4.45 & 5.186 & TST & \\
\hline CHEMBL3196394 & 688497 & 4.85 & 5.2609 & TST & \\
\hline CHEMBL1380189 & 688497 & 5.05 & 5.0266 & TST & \\
\hline CHEMBL1510240 & 688497 & 4.75 & 5.2187 & TST & \\
\hline CHEMBL1561893 & 688497 & 4.7 & 4.7927 & TRN & \\
\hline CHEMBL1352224 & 688497 & 7.0501 & 5.1249 & TRN & \\
\hline CHEMBL1446957 & 688497 & 5.4 & 4.8103 & TRN & \\
\hline CHEMBL1452795 & 688497 & 5.9 & 5.5714 & TST & \\
\hline CHEMBL1423043 & 688497 & 4.95 & 5.6247 & TRN & \\
\hline CHEMBL1430214 & 688497 & 4.6 & 5.1472 & TST & \\
\hline
\end{tabular}




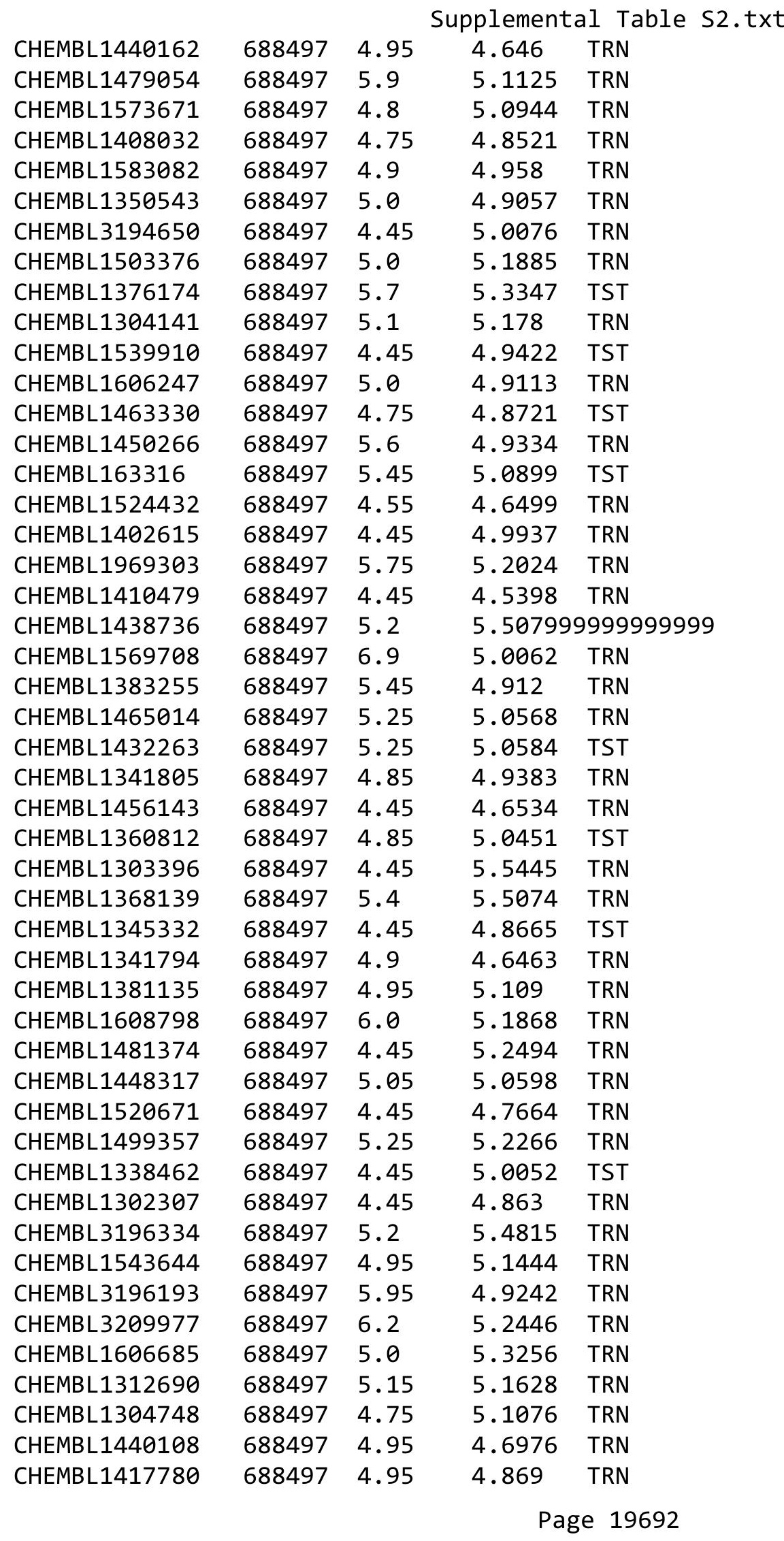




\begin{tabular}{|c|c|c|c|c|}
\hline & & & & al Table \\
\hline CHEMBL1527800 & 688497 & 4.9 & 4.8189 & TRN \\
\hline CHEMBL1983243 & 688497 & 5.5 & 5.4437 & TRN \\
\hline CHEMBL1598218 & 688497 & 4.9 & 5.1229 & TRN \\
\hline CHEMBL1307051 & 688497 & 4.45 & 5.1223 & TRN \\
\hline CHEMBL1484715 & 688497 & 5.25 & 5.4558 & TRN \\
\hline CHEMBL1558175 & 688497 & 4.8 & 4.724 & TRN \\
\hline CHEMBL1324073 & 688497 & 4.95 & 5.0903 & TST \\
\hline CHEMBL1529762 & 688497 & 6.0 & 5.2819 & TST \\
\hline CHEMBL1470470 & 688497 & 5.0 & 4.8987 & TRN \\
\hline CHEMBL1603204 & 688497 & 5.15 & 5.2988 & TRN \\
\hline CHEMBL1425544 & 688497 & 5.15 & 4.8636 & TRN \\
\hline CHEMBL 2002465 & 688497 & 5.1 & 5.0745 & TRN \\
\hline CHEMBL1601587 & 688497 & 4.65 & 4.8264 & TRN \\
\hline CHEMBL1456826 & 688497 & 4.75 & 4.7746 & TRN \\
\hline CHEMBL1339208 & 688497 & 4.7 & 4.7303 & TRN \\
\hline CHEMBL1569470 & 688497 & 5.25 & 5.2789 & TRN \\
\hline CHEMBL1506265 & 688497 & 5.9 & 5.3073 & TRN \\
\hline CHEMBL1336389 & 688497 & 5.5 & 5.5246 & TRN \\
\hline CHEMBL1459755 & 688497 & 4.95 & 4.7042 & TRN \\
\hline CHEMBL1319060 & 688497 & 4.95 & 5.5127 & TRN \\
\hline CHEMBL1393070 & 688497 & 4.45 & 5.0349 & TRN \\
\hline CHEMBL1569304 & 688497 & 6.25 & 5.2956 & TRN \\
\hline CHEMBL1358184 & 688497 & 4.95 & 4.8587 & TST \\
\hline CHEMBL3190125 & 688497 & 5.2 & 5.0271 & TRN \\
\hline CHEMBL1578649 & 688497 & 4.45 & 5.16200 & 0000000001 \\
\hline CHEMBL1530938 & 688497 & 4.45 & 5.1175 & TRN \\
\hline CHEMBL1376643 & 688497 & 4.7 & 5.044 & TRN \\
\hline CHEMBL602409 & 688497 & 4.95 & 5.023 & TST \\
\hline CHEMBL1601712 & 688497 & 4.85 & 4.7201 & TRN \\
\hline CHEMBL1458987 & 688497 & 5.25 & 5.5445 & TRN \\
\hline CHEMBL1462949 & 688497 & 6.25 & 5.2648 & TST \\
\hline CHEMBL1544731 & 688497 & 4.95 & 5.1004 & TRN \\
\hline CHEMBL1389634 & 688497 & 4.45 & 5.1759 & TST \\
\hline CHEMBL3210687 & 688497 & 4.45 & 4.9039 & TRN \\
\hline CHEMBL1510371 & 688497 & 5.05 & 4.8949 & TRN \\
\hline CHEMBL1564542 & 688497 & 4.45 & 4.3257 & TRN \\
\hline CHEMBL1574401 & 688497 & 5.7 & 5.1591 & TRN \\
\hline CHEMBL1535155 & 688497 & 4.95 & 4.9163 & TRN \\
\hline CHEMBL1545916 & 688497 & 4.45 & 5.1828 & TST \\
\hline CHEMBL1535361 & 688497 & 5.6 & 5.228 & TRN \\
\hline CHEMBL1449181 & 688497 & 5.5 & 5.3045 & TST \\
\hline CHEMBL1525641 & 688497 & 4.9 & 5.0662 & TRN \\
\hline CHEMBL1376277 & 688497 & 5.9 & 4.9258 & TST \\
\hline CHEMBL1608789 & 688497 & 6.3 & 4.8949 & TRN \\
\hline CHEMBL1429370 & 688497 & 4.85 & 5.0788 & TRN \\
\hline CHEMBL1582317 & 688497 & 5.35 & 5.0053 & TRN \\
\hline CHEMBL1375659 & 688497 & 4.9 & 4.9972 & TRN \\
\hline CHEMBL1308630 & 688497 & 5.0 & 5.186 & TRN \\
\hline
\end{tabular}

TRN 


\begin{tabular}{|c|c|c|c|c|}
\hline \multicolumn{5}{|c|}{ Supplemental Table S2.txt } \\
\hline CHEMBL1500773 & 688497 & 7.0501 & 5.1603 & TRN \\
\hline CHEMBL1393745 & 688497 & 5.05 & 5.0096 & TST \\
\hline CHEMBL532239 & 688497 & 4.6 & 4.808 & TRN \\
\hline CHEMBL1531713 & 688497 & 4.45 & 5.1181 & TRN \\
\hline CHEMBL1410224 & 688497 & 5.1 & 4.7404 & TRN \\
\hline CHEMBL1523753 & 688497 & 4.45 & 4.8425 & TRN \\
\hline CHEMBL3145304 & 688497 & 5.2 & 5.0196 & TRN \\
\hline CHEMBL1351105 & 688497 & 4.45 & 4.9454 & TST \\
\hline CHEMBL1524817 & 688497 & 4.9 & 5.0274 & TRN \\
\hline CHEMBL1340926 & 688497 & 6.95 & 5.1371 & TST \\
\hline CHEMBL1585670 & 688497 & 5.8 & 5.2785 & TRN \\
\hline CHEMBL 3211028 & 688497 & 5.0 & 5.2951 & TST \\
\hline CHEMBL1311173 & 688497 & 4.45 & 4.6424 & TRN \\
\hline CHEMBL1304316 & 688497 & 5.45 & 5.0965 & TRN \\
\hline CHEMBL1529460 & 688497 & 5.3 & 5.1932 & TST \\
\hline CHEMBL1385332 & 688497 & 5.5 & 5.0778 & TRN \\
\hline CHEMBL1391309 & 688497 & 5.2 & 5.0652 & TRN \\
\hline CHEMBL1337310 & 688497 & 5.0 & 4.9831 & TRN \\
\hline CHEMBL1538234 & 688497 & 4.75 & 4.7604 & TRN \\
\hline CHEMBL1446570 & 688497 & 4.45 & 4.613 & TRN \\
\hline CHEMBL1612654 & 688497 & 6.25 & 5.5098 & TST \\
\hline CHEMBL1491806 & 688497 & 4.65 & 4.9617 & TRN \\
\hline CHEMBL1492591 & 688497 & 6.45 & 5.0729 & TST \\
\hline CHEMBL1575634 & 688497 & 5.1 & 4.7416 & TRN \\
\hline CHEMBL1604546 & 688497 & 4.45 & 5.1118 & TST \\
\hline CHEMBL3189492 & 688497 & 4.85 & 5.1005 & TST \\
\hline CHEMBL1408076 & 688497 & 4.45 & 5.2235 & TRN \\
\hline CHEMBL1381565 & 688497 & 5.55 & 5.2147 & TRN \\
\hline CHEMBL1344838 & 688497 & 4.75 & 4.8836 & TRN \\
\hline CHEMBL1503249 & 688497 & 6.15 & 4.9959 & TRN \\
\hline CHEMBL1515671 & 688497 & 4.85 & 4.7985 & TRN \\
\hline CHEMBL1412667 & 688497 & 4.5 & 4.9975 & TST \\
\hline CHEMBL1466071 & 688497 & 5.6 & 5.1964 & TRN \\
\hline CHEMBL1344130 & 688497 & 4.9 & 5.0198 & TRN \\
\hline CHEMBL1529294 & 688497 & 4.8 & 4.7049 & TRN \\
\hline CHEMBL1432564 & 688497 & 4.55 & 4.9043 & TST \\
\hline CHEMBL1402502 & 688497 & 4.5 & 5.1968 & TRN \\
\hline CHEMBL1349481 & 688497 & 6.25 & 4.9921 & TRN \\
\hline CHEMBL3199091 & 688497 & 4.45 & 4.9738 & TRN \\
\hline CHEMBL1312643 & 688497 & 4.45 & 5.0694 & TRN \\
\hline CHEMBL1323983 & 688497 & 4.5 & 5.1277 & TRN \\
\hline CHEMBL 3144926 & 688497 & 4.85 & 5.1486 & TST \\
\hline CHEMBL1463885 & 688497 & 4.85 & 4.5041 & TRN \\
\hline CHEMBL1342662 & 688497 & 4.45 & 4.8189 & TST \\
\hline CHEMBL1518326 & 688497 & 5.5 & 4.8359 & TST \\
\hline CHEMBL1425732 & 688497 & 4.95 & 4.6184 & TRN \\
\hline CHEMBL1596334 & 688497 & 5.0 & 4.7108 & TRN \\
\hline CHEMBL 3667549 & 688497 & 5.25 & 5.0517 & TRN \\
\hline
\end{tabular}




\begin{tabular}{|c|c|c|c|c|}
\hline \multicolumn{5}{|c|}{ Supplemental Table S2.txt } \\
\hline CHEMBL1390500 & 688497 & 4.45 & 5.0258 & TRN \\
\hline CHEMBL1480129 & 688497 & 5.05 & 5.1978 & TRN \\
\hline CHEMBL1310341 & 688497 & 4.45 & 4.833 & TRN \\
\hline CHEMBL1541159 & 688497 & 5.15 & 5.058 & TRN \\
\hline CHEMBL1321756 & 688497 & 5.15 & 4.7613 & TRN \\
\hline CHEMBL1382888 & 688497 & 4.45 & 4.9152 & TRN \\
\hline CHEMBL1310930 & 688497 & 4.95 & 4.8738 & TRN \\
\hline CHEMBL1351001 & 688497 & 4.65 & 5.0446 & TRN \\
\hline CHEMBL1525450 & 688497 & 6.35 & 5.2397 & TRN \\
\hline CHEMBL1423304 & 688497 & 4.45 & 4.8881 & TRN \\
\hline CHEMBL1519044 & 688497 & 5.2 & 5.0344 & TRN \\
\hline CHEMBL1424630 & 688497 & 4.45 & 4.6241 & TRN \\
\hline CHEMBL1359550 & 688497 & 6.2 & 5.1537 & TRN \\
\hline CHEMBL1422002 & 688497 & 5.45 & 4.8159 & TRN \\
\hline CHEMBL1499603 & 688497 & 5.25 & 5.2423 & TRN \\
\hline CHEMBL1556661 & 688497 & 4.85 & 4.9194 & TST \\
\hline CHEMBL1440507 & 688497 & 4.45 & 5.0112 & TST \\
\hline CHEMBL566068 & 688497 & 4.7 & 4.8775 & TRN \\
\hline CHEMBL1398673 & 688497 & 4.75 & 5.1473 & TRN \\
\hline CHEMBL1568105 & 688497 & 4.8 & 4.7426 & TRN \\
\hline CHEMBL1331364 & 688497 & 4.45 & 4.9418 & TRN \\
\hline CHEMBL1369061 & 688497 & 4.45 & 4.9057 & TRN \\
\hline CHEMBL1449836 & 688497 & 4.5 & 4.8448 & TRN \\
\hline CHEMBL1451112 & 688497 & 5.1 & 4.9774 & TRN \\
\hline CHEMBL1974389 & 688497 & 4.45 & 4.9005 & TRN \\
\hline CHEMBL1571615 & 688497 & 4.9 & 5.2234 & TRN \\
\hline CHEMBL1563714 & 688497 & 5.35 & 5.0657 & TRN \\
\hline CHEMBL1381720 & 688497 & 4.95 & 5.1723 & TST \\
\hline CHEMBL1392617 & 688497 & 4.45 & 4.445 & TRN \\
\hline CHEMBL1563117 & 688497 & 4.45 & 4.7925 & TST \\
\hline CHEMBL1310227 & 688497 & 4.45 & 4.9519 & TRN \\
\hline CHEMBL1407503 & 688497 & 5.2 & 5.2139 & TST \\
\hline CHEMBL1970242 & 688497 & 5.45 & 5.3236 & TRN \\
\hline CHEMBL1576007 & 688497 & 5.75 & 5.0379 & TRN \\
\hline CHEMBL1549204 & 688497 & 6.95 & 5.5063 & TST \\
\hline CHEMBL1378646 & 688497 & 4.6 & 4.9588 & TRN \\
\hline CHEMBL1460547 & 688497 & 4.45 & 4.7188 & TRN \\
\hline CHEMBL1431655 & 688497 & 5.15 & 5.4318 & TRN \\
\hline CHEMBL1300364 & 688497 & 4.95 & 4.5713 & TRN \\
\hline CHEMBL1466743 & 688497 & 4.95 & 5.224 & TRN \\
\hline CHEMBL1347710 & 688497 & 4.65 & 4.776 & TRN \\
\hline CHEMBL1546865 & 688497 & 6.25 & 4.9976 & TRN \\
\hline CHEMBL1457530 & 688497 & 4.8 & 4.913 & TRN \\
\hline CHEMBL1465893 & 688497 & 5.25 & 5.1176 & TRN \\
\hline CHEMBL1461508 & 688497 & 4.9 & 4.9196 & TST \\
\hline CHEMBL1327254 & 688497 & 6.0 & 5.0571 & TRN \\
\hline CHEMBL1483740 & 688497 & 5.1 & 5.1131 & TRN \\
\hline CHEMBL1302217 & 688497 & 4.45 & 4.7958 & TST \\
\hline
\end{tabular}




\begin{tabular}{|c|c|c|c|c|}
\hline \multicolumn{5}{|c|}{ Supplemental Table S2.txt } \\
\hline CHEMBL 3191360 & 688497 & 4.45 & 4.994 & TRN \\
\hline CHEMBL1485587 & 688497 & 4.45 & 4.8851 & TST \\
\hline CHEMBL1451875 & 688497 & 4.6 & 4.9231 & TRN \\
\hline CHEMBL1363757 & 688497 & 5.0 & 5.1062 & TRN \\
\hline CHEMBL1310582 & 688497 & 4.9 & 5.0965 & TST \\
\hline CHEMBL1334121 & 688497 & 4.45 & 5.1654 & TST \\
\hline CHEMBL1579248 & 688497 & 4.5 & 4.7845 & TRN \\
\hline CHEMBL560919 & 688497 & 4.45 & 4.9314 & TRN \\
\hline CHEMBL1564312 & 688497 & 4.65 & 5.1754 & TRN \\
\hline CHEMBL1399938 & 688497 & 4.45 & 4.71 & TRN \\
\hline CHEMBL1562831 & 688497 & 4.95 & 5.0016 & TST \\
\hline CHEMBL1577664 & 688497 & 4.9 & 5.0202 & TRN \\
\hline CHEMBL1432467 & 688497 & 5.45 & 5.1482 & TST \\
\hline CHEMBL1510582 & 688497 & 5.0 & 5.0221 & TRN \\
\hline CHEMBL1335594 & 688497 & 5.35 & 5.1121 & TRN \\
\hline CHEMBL1372314 & 688497 & 4.95 & 4.7938 & TRN \\
\hline CHEMBL1491068 & 688497 & 4.95 & 4.7504 & TRN \\
\hline CHEMBL1499406 & 688497 & 5.9 & 5.0554 & TST \\
\hline CHEMBL 3192625 & 688497 & 4.95 & 4.9532 & TRN \\
\hline CHEMBL1498599 & 688497 & 4.45 & 4.769 & TRN \\
\hline CHEMBL 272465 & 688497 & 6.15 & 5.1113 & TRN \\
\hline CHEMBL1994803 & 688497 & 4.9 & 5.052 & TRN \\
\hline CHEMBL1368490 & 688497 & 5.1 & 4.9527 & TRN \\
\hline CHEMBL1324975 & 688497 & 6.25 & 5.1885 & TRN \\
\hline CHEMBL1441024 & 688497 & 4.45 & 4.8757 & TRN \\
\hline CHEMBL1454032 & 688497 & 4.8 & 5.1018 & TRN \\
\hline CHEMBL1439833 & 688497 & 5.55 & 5.5244 & TRN \\
\hline CHEMBL1319914 & 688497 & 7.0501 & 5.1385 & TRN \\
\hline CHEMBL1351595 & 688497 & 4.9 & 4.6358 & TRN \\
\hline CHEMBL1444873 & 688497 & 4.95 & 4.9531 & TRN \\
\hline CHEMBL1596090 & 688497 & 4.95 & 4.994 & TRN \\
\hline CHEMBL 240546 & 688497 & 5.25 & 4.9724 & TRN \\
\hline CHEMBL1375769 & 688497 & 4.45 & 4.7157 & TRN \\
\hline CHEMBL1342314 & 688497 & 4.6 & 5.291 & TRN \\
\hline CHEMBL1532645 & 688497 & 5.05 & 5.0849 & TST \\
\hline CHEMBL1506230 & 688497 & 4.45 & 4.9058 & TRN \\
\hline CHEMBL1328854 & 688497 & 5.75 & 5.3894 & TST \\
\hline CHEMBL1603403 & 688497 & 4.8 & 5.0253 & TRN \\
\hline CHEMBL1532452 & 688497 & 4.85 & 4.8857 & TST \\
\hline CHEMBL1544205 & 688497 & 4.45 & 5.096 & TRN \\
\hline CHEMBL3211050 & 688497 & 5.4 & 5.2229 & TRN \\
\hline CHEMBL 1589540 & 688497 & 7.0501 & 4.8321 & TRN \\
\hline CHEMBL1381567 & 688497 & 4.45 & 4.8483 & TRN \\
\hline CHEMBL1477794 & 688497 & 4.9 & 5.1378 & TRN \\
\hline CHEMBL1325226 & 688497 & 5.1 & 4.9695 & TRN \\
\hline CHEMBL1494441 & 688497 & 4.8 & 5.147 & TRN \\
\hline CHEMBL 1535578 & 688497 & 4.45 & 4.7795 & TRN \\
\hline CHEMBL1504612 & 688497 & 5.0 & 5.0651 & TRN \\
\hline
\end{tabular}




\begin{tabular}{|c|c|c|c|c|c|}
\hline \multicolumn{6}{|c|}{ Supplemental Table S2.txt } \\
\hline CHEMBL1982901 & 688497 & 5.0 & 5.2384 & TRN & \\
\hline CHEMBL1381808 & 688497 & 5.25 & 4.7406 & TRN & \\
\hline CHEMBL1384647 & 688497 & 4.7 & 5.0575 & TRN & \\
\hline CHEMBL1478815 & 688497 & 4.95 & 4.8997 & TRN & \\
\hline CHEMBL1520604 & 688497 & 5.7 & 5.2292 & TST & \\
\hline CHEMBL1558635 & 688497 & 5.4 & 4.8461 & TRN & \\
\hline CHEMBL1461360 & 688497 & 6.25 & 5.2926 & TST & \\
\hline CHEMBL1386178 & 688497 & 5.65 & 5.3146 & TRN & \\
\hline CHEMBL1397833 & 688497 & 4.65 & 5.1893 & TRN & \\
\hline CHEMBL1363275 & 688497 & 4.95 & 4.45100 & 00000000005 & TRN \\
\hline CHEMBL1602949 & 688497 & 5.8 & 5.2136 & TST & \\
\hline CHEMBL1487166 & 688497 & 4.8 & 4.9562 & TST & \\
\hline CHEMBL1602975 & 688497 & 5.25 & 5.0554 & TRN & \\
\hline CHEMBL1414869 & 688497 & 5.6 & 4.9104 & TRN & \\
\hline CHEMBL1352170 & 688497 & 4.45 & 5.0478 & TRN & \\
\hline CHEMBL1329060 & 688497 & 5.05 & 5.032 & TRN & \\
\hline CHEMBL1418273 & 688497 & 4.85 & 5.0495 & TRN & \\
\hline CHEMBL1578956 & 688497 & 4.5 & 4.9432 & TST & \\
\hline CHEMBL1455446 & 688497 & 4.8 & 4.8794 & TRN & \\
\hline CHEMBL1504970 & 688497 & 5.5 & 4.742 & TRN & \\
\hline CHEMBL1444103 & 688497 & 5.15 & 4.9886 & TRN & \\
\hline CHEMBL1567165 & 688497 & 4.45 & 4.9232 & TRN & \\
\hline CHEMBL3190293 & 688497 & 5.05 & 5.1865 & TRN & \\
\hline CHEMBL1351724 & 688497 & 4.45 & 4.8388 & TRN & \\
\hline CHEMBL1575440 & 688497 & 4.9 & 4.8707 & TRN & \\
\hline CHEMBL1353999 & 688497 & 6.3 & 4.9851 & TRN & \\
\hline CHEMBL1417679 & 688497 & 5.95 & 5.0186 & TST & \\
\hline CHEMBL1400268 & 688497 & 4.8 & 5.1198 & TRN & \\
\hline CHEMBL1531951 & 688497 & 5.3 & 4.9809 & TST & \\
\hline CHEMBL1522965 & 688497 & 5.35 & 5.1315 & TRN & \\
\hline CHEMBL1486562 & 688497 & 4.6 & 4.9098 & TRN & \\
\hline CHEMBL1610671 & 688497 & 4.95 & 5.1947 & TRN & \\
\hline CHEMBL1498922 & 688497 & 5.05 & 5.0397 & TST & \\
\hline CHEMBL1468795 & 688497 & 5.45 & 4.6378 & TRN & \\
\hline CHEMBL1494649 & 688497 & 5.4 & 4.9478 & TRN & \\
\hline CHEMBL1459256 & 688497 & 4.95 & 4.8821 & TRN & \\
\hline CHEMBL1439384 & 688497 & 5.35 & 4.8201 & TRN & \\
\hline CHEMBL394242 & 688497 & 5.4 & 5.2889 & TRN & \\
\hline CHEMBL1558234 & 688497 & 5.25 & 5.0619 & TST & \\
\hline CHEMBL1413130 & 688497 & 6.2 & 5.1093 & TRN & \\
\hline CHEMBL1530995 & 688497 & 5.4 & 5.1546 & TST & \\
\hline CHEMBL1450465 & 688497 & 4.8 & 5.0316 & TRN & \\
\hline CHEMBL3144884 & 688497 & 4.9 & 4.7932 & TRN & \\
\hline CHEMBL1331634 & 688497 & 4.45 & 4.9398 & TRN & \\
\hline CHEMBL3190659 & 688497 & 4.95 & 5.0206 & TST & \\
\hline CHEMBL1555461 & 688497 & 5.25 & 5.0192 & TRN & \\
\hline CHEMBL1555980 & 688497 & 5.9 & 5.0818 & TRN & \\
\hline CHEMBL468018 & 688497 & 5.25 & 4.9013 & TRN & \\
\hline
\end{tabular}




\begin{tabular}{|c|c|c|c|c|c|}
\hline \multirow{3}{*}{$\begin{array}{l}\text { CHEMBL1407234 } \\
\text { CHEMBL1543875 }\end{array}$} & \multirow{3}{*}{$\begin{array}{l}688497 \\
688497\end{array}$} & \multicolumn{4}{|c|}{ Supplemental Table S2.txt } \\
\hline & & 4.85 & \multicolumn{2}{|c|}{4.906000000000001} & TST \\
\hline & & 5.45 & 4.774 & TRN & \\
\hline CHEMBL1347101 & 688497 & 4.6 & 5.0421 & TRN & \\
\hline CHEMBL1306329 & 688497 & 4.45 & 5.0891 & TRN & \\
\hline CHEMBL1304436 & 688497 & 6.05 & 4.96 & TRN & \\
\hline CHEMBL1568198 & 688497 & 4.45 & 4.9617 & TRN & \\
\hline CHEMBL1388928 & 688497 & 5.05 & 5.0646 & TRN & \\
\hline CHEMBL1581224 & 688497 & 5.0 & 5.2435 & TRN & \\
\hline CHEMBL1494329 & 688497 & 6.4 & 5.0413 & TRN & \\
\hline CHEMBL3212987 & 688497 & 4.95 & 4.8724 & TST & \\
\hline CHEMBL1303727 & 688497 & 5.35 & 5.3522 & TST & \\
\hline CHEMBL1546693 & 688497 & 5.05 & 5.1562 & TRN & \\
\hline CHEMBL1497805 & 688497 & 6.0 & 4.9067 & TRN & \\
\hline CHEMBL1440300 & 688497 & 5.25 & 5.1289 & TST & \\
\hline CHEMBL1424564 & 688497 & 4.65 & 4.766 & TRN & \\
\hline CHEMBL1989090 & 688497 & 5.15 & 5.3751 & TRN & \\
\hline CHEMBL1353127 & 688497 & 4.8 & 5.0914 & TRN & \\
\hline CHEMBL1598359 & 688497 & 5.25 & 5.2822 & TST & \\
\hline CHEMBL1495847 & 688497 & 5.45 & 5.2071 & TRN & \\
\hline CHEMBL1380683 & 688497 & 4.9 & 5.1482 & TRN & \\
\hline CHEMBL1534330 & 688497 & 4.5 & 4.8981 & TRN & \\
\hline CHEMBL1460142 & 688497 & 6.3 & 4.9582 & TST & \\
\hline CHEMBL1560834 & 688497 & 5.9 & 5.3242 & TST & \\
\hline CHEMBL1310281 & 688497 & 6.05 & 4.9045 & TRN & \\
\hline CHEMBL1478725 & 688497 & 4.45 & 4.8714 & TST & \\
\hline CHEMBL1611902 & 688497 & 5.0 & 4.6503 & TRN & \\
\hline CHEMBL3213441 & 688497 & 6.25 & 4.8996 & TRN & \\
\hline CHEMBL1581879 & 688497 & 5.35 & 4.5928 & TRN & \\
\hline CHEMBL1334026 & 688497 & 5.0 & 5.0599 & TRN & \\
\hline CHEMBL1990383 & 688497 & 4.65 & 4.6801 & TRN & \\
\hline CHEMBL1408244 & 688497 & 6.5501 & 5.4268 & TRN & \\
\hline CHEMBL1391217 & 688497 & 4.9 & 5.2433 & TST & \\
\hline CHEMBL1611990 & 688497 & 5.6 & \multicolumn{2}{|c|}{5.1160000000000005} & TRN \\
\hline CHEMBL1500386 & 688497 & 5.5 & 4.8758 & TRN & \\
\hline CHEMBL1504762 & 688497 & 4.45 & 5.1073 & TRN & \\
\hline CHEMBL1409090 & 688497 & 6.2 & 5.1021 & TRN & \\
\hline CHEMBL1511131 & 688497 & 4.65 & 4.9842 & TRN & \\
\hline CHEMBL1463433 & 688497 & 4.65 & 5.027 & TRN & \\
\hline CHEMBL1549193 & 688497 & 4.75 & 5.0195 & TRN & \\
\hline CHEMBL 3198419 & 688497 & 5.25 & 5.0852 & TRN & \\
\hline CHEMBL1502211 & 688497 & 4.75 & 4.9929 & TRN & \\
\hline CHEMBL1308168 & 688497 & 4.75 & 4.7286 & TRN & \\
\hline CHEMBL1533362 & 688497 & 4.9 & 4.8768 & TRN & \\
\hline CHEMBL1579114 & 688497 & 4.75 & 5.2024 & TRN & \\
\hline CHEMBL1393899 & 688497 & 6.25 & 5.2192 & TRN & \\
\hline CHEMBL1391420 & 688497 & 4.45 & 5.0345 & TRN & \\
\hline CHEMBL1323631 & 688497 & 4.9 & 4.599 & TRN & \\
\hline CHEMBL1965069 & 688497 & 5.0 & 5.2718 & TRN & \\
\hline
\end{tabular}




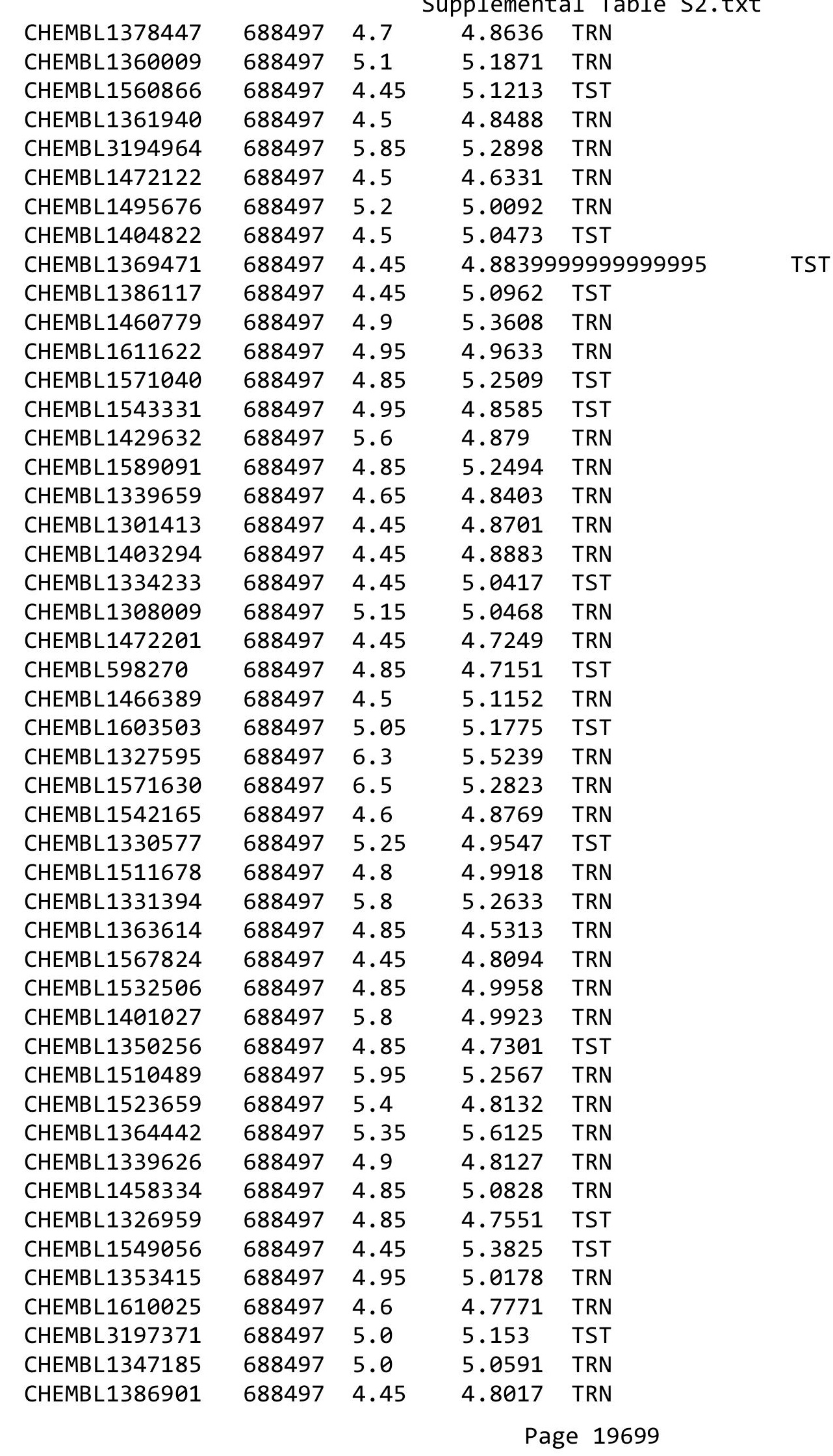




\begin{tabular}{|c|c|c|c|c|c|}
\hline & & \multicolumn{4}{|c|}{ Supplemental Table s2.txt } \\
\hline CHEMBL1417302 & 688497 & 4.65 & 4.8272 & TRN & \\
\hline CHEMBL1381537 & 688497 & 4.45 & 4.8074 & TRN & \\
\hline CHEMBL1319477 & 688497 & 5.05 & 5.0239 & TRN & \\
\hline CHEMBL1353753 & 688497 & 4.9 & 5.1359 & TRN & \\
\hline CHEMBL585591 & 688497 & 6.45 & 5.5705 & TST & \\
\hline CHEMBL1358935 & 688497 & 4.6 & 5.3193 & TRN & \\
\hline CHEMBL1379817 & 688497 & 4.55 & 4.6655 & TRN & \\
\hline CHEMBL1311215 & 688497 & 4.45 & 4.9137 & TRN & \\
\hline CHEMBL1302343 & 688497 & 4.45 & 4.7866 & TRN & \\
\hline CHEMBL1506271 & 688497 & 4.45 & 4.9115 & TST & \\
\hline CHEMBL1305428 & 688497 & 6.25 & 5.2316 & TRN & \\
\hline CHEMBL1336542 & 688497 & 4.7 & 5.28299 & 99999999995 & TST \\
\hline CHEMBL1599024 & 688497 & 4.85 & 4.8938 & TRN & \\
\hline CHEMBL1412835 & 688497 & 4.95 & 4.9755 & TRN & \\
\hline CHEMBL1586269 & 688497 & 4.65 & 4.7553 & TRN & \\
\hline CHEMBL1333902 & 688497 & 5.4 & 5.4819 & TRN & \\
\hline CHEMBL1449625 & 688497 & 4.7 & 5.2599 & TRN & \\
\hline CHEMBL1380862 & 688497 & 5.55 & 5.1485 & TRN & \\
\hline CHEMBL1577322 & 688497 & 5.1 & 5.1935 & TST & \\
\hline CHEMBL3210321 & 688497 & 4.45 & 5.0183 & TRN & \\
\hline CHEMBL1422032 & 688497 & 4.95 & 5.1241 & TRN & \\
\hline CHEMBL1537627 & 688497 & 5.05 & 5.3109 & TRN & \\
\hline CHEMBL1304685 & 688497 & 6.15 & 4.9211 & TST & \\
\hline CHEMBL1461878 & 688497 & 5.0 & 4.8747 & TRN & \\
\hline CHEMBL1581025 & 688497 & 4.5 & 4.8941 & TST & \\
\hline CHEMBL1313588 & 688497 & 4.65 & 4.8781 & TST & \\
\hline CHEMBL1459310 & 688497 & 4.45 & 4.7022 & TRN & \\
\hline CHEMBL1484449 & 688497 & 4.45 & 4.8947 & TRN & \\
\hline CHEMBL1419820 & 688497 & 4.85 & 4.9929 & TRN & \\
\hline CHEMBL1452610 & 688497 & 4.75 & 4.7798 & TRN & \\
\hline CHEMBL1586522 & 688497 & 4.6 & 4.9363 & TRN & \\
\hline CHEMBL1312215 & 688497 & 4.45 & 4.9472 & TST & \\
\hline CHEMBL1393556 & 688497 & 4.45 & 5.1158 & TST & \\
\hline CHEMBL1409126 & 688497 & 4.75 & 5.1198 & TST & \\
\hline CHEMBL1367120 & 688497 & 4.45 & 5.1608 & TRN & \\
\hline CHEMBL1335844 & 688497 & 5.35 & 5.0559 & TRN & \\
\hline CHEMBL1320788 & 688497 & 5.4 & 5.1153 & TRN & \\
\hline CHEMBL1346640 & 688497 & 4.45 & 4.5176 & TRN & \\
\hline CHEMBL1565338 & 688497 & 6.1 & 5.1216 & TRN & \\
\hline CHEMBL1342957 & 688497 & 5.4 & 4.8966 & TRN & \\
\hline CHEMBL1370217 & 688497 & 4.9 & 4.8622 & TRN & \\
\hline CHEMBL1432812 & 688497 & 4.9 & 5.1354 & TRN & \\
\hline CHEMBL1604781 & 688497 & 4.45 & 4.8353 & TRN & \\
\hline CHEMBL1549599 & 688497 & 4.8 & 5.1798 & TST & \\
\hline CHEMBL1455021 & 688497 & 5.9 & 5.1562 & TST & \\
\hline CHEMBL1542284 & 688497 & 4.95 & 5.0247 & TRN & \\
\hline CHEMBL1586862 & 688497 & 4.45 & 5.0066 & TRN & \\
\hline CHEMBL1510358 & 688497 & 6.15 & 5.3319 & TRN & \\
\hline
\end{tabular}




\begin{tabular}{|c|c|c|c|c|}
\hline \multicolumn{5}{|c|}{ Supplemental Table S2.txt } \\
\hline CHEMBL1498063 & 688497 & 4.45 & 5.0495 & TRN \\
\hline CHEMBL1337890 & 688497 & 6.1 & 5.1212 & TST \\
\hline CHEMBL1331593 & 688497 & 4.65 & 4.6623 & TRN \\
\hline CHEMBL1379726 & 688497 & 5.2 & 5.0193 & TRN \\
\hline CHEMBL1348018 & 688497 & 4.55 & 4.9249 & TRN \\
\hline CHEMBL1577046 & 688497 & 5.25 & 5.1047 & TRN \\
\hline CHEMBL1375452 & 688497 & 4.65 & 4.7982 & TRN \\
\hline CHEMBL1564503 & 688497 & 6.25 & 5.4103 & TST \\
\hline CHEMBL1520140 & 688497 & 4.45 & 4.9677 & TRN \\
\hline CHEMBL1307526 & 688497 & 4.5 & 4.9902 & TRN \\
\hline CHEMBL1519949 & 688497 & 5.05 & 5.273 & TST \\
\hline CHEMBL1576146 & 688497 & 4.6 & 5.265 & TST \\
\hline CHEMBL1561791 & 688497 & 4.7 & 5.0642 & TRN \\
\hline CHEMBL1305716 & 688497 & 5.0 & 4.9701 & TST \\
\hline CHEMBL1537471 & 688497 & 5.25 & 5.038 & TRN \\
\hline CHEMBL1465899 & 688497 & 4.45 & 4.8452 & TRN \\
\hline CHEMBL1547298 & 688497 & 5.0 & 4.9003 & TRN \\
\hline CHEMBL1543640 & 688497 & 5.0 & 4.6829 & TRN \\
\hline CHEMBL1537834 & 688497 & 5.0 & 4.9401 & TST \\
\hline CHEMBL1528675 & 688497 & 5.55 & 5.2438 & TRN \\
\hline CHEMBL1576132 & 688497 & 4.8 & 5.4555 & TRN \\
\hline CHEMBL1513736 & 688497 & 5.3 & 5.5271 & TST \\
\hline CHEMBL1405822 & 688497 & 4.8 & 4.9652 & TRN \\
\hline CHEMBL1578152 & 688497 & 4.55 & 5.2425 & TST \\
\hline CHEMBL1575705 & 688497 & 4.5 & 5.0628 & TRN \\
\hline CHEMBL1526551 & 688497 & 5.25 & 5.1519 & TST \\
\hline CHEMBL1610565 & 688497 & 5.0 & 4.6054 & TRN \\
\hline CHEMBL1465761 & 688497 & 4.45 & 4.7141 & TST \\
\hline CHEMBL1353324 & 688497 & 4.6 & 4.744 & TST \\
\hline CHEMBL1308313 & 688497 & 6.0 & 5.2652 & TRN \\
\hline CHEMBL1480310 & 688497 & 6.25 & 5.2588 & TRN \\
\hline CHEMBL1483624 & 688497 & 4.65 & 4.8785 & TRN \\
\hline CHEMBL526952 & 688497 & 4.65 & 5.1586 & TRN \\
\hline CHEMBL1569989 & 688497 & 5.8 & 5.7133 & TRN \\
\hline CHEMBL1583513 & 688497 & 4.55 & 4.8304 & TRN \\
\hline CHEMBL1443946 & 688497 & 4.45 & 4.8631 & TRN \\
\hline CHEMBL1535384 & 688497 & 4.65 & 4.9194 & TRN \\
\hline CHEMBL3198030 & 688497 & 4.45 & 4.8497 & TRN \\
\hline CHEMBL1542674 & 688497 & 4.6 & 4.7947 & TRN \\
\hline CHEMBL1455296 & 688497 & 5.0 & 5.3816 & TRN \\
\hline CHEMBL1384658 & 688497 & 4.45 & 4.9374 & TRN \\
\hline CHEMBL1370453 & 688497 & 4.65 & 4.8062 & TRN \\
\hline CHEMBL1511551 & 688497 & 4.45 & 4.9163 & TRN \\
\hline CHEMBL1457864 & 688497 & 4.65 & 5.3068 & TRN \\
\hline CHEMBL1583898 & 688497 & 4.95 & 5.0109 & TRN \\
\hline CHEMBL3191117 & 688497 & 5.5 & 4.9461 & TRN \\
\hline CHEMBL1536598 & 688497 & 4.95 & 4.8007 & TRN \\
\hline CHEMBL1566345 & 688497 & 4.45 & 5.0025 & TRN \\
\hline
\end{tabular}




\begin{tabular}{|c|c|c|c|c|c|}
\hline & & \multicolumn{4}{|c|}{ Supplemental Table s2.txt } \\
\hline CHEMBL590660 & 688497 & 4.45 & 4.955 & TRN & \\
\hline CHEMBL1401825 & 688497 & 5.0 & 5.48600 & 0000000001 & TST \\
\hline CHEMBL1506022 & 688497 & 4.75 & 4.9548 & TST & \\
\hline CHEMBL1451537 & 688497 & 6.0 & 5.1452 & TRN & \\
\hline CHEMBL1389553 & 688497 & 6.1 & 5.0281 & TRN & \\
\hline CHEMBL3209468 & 688497 & 4.6 & 4.895 & TRN & \\
\hline CHEMBL1349117 & 688497 & 4.4 & 4.8385 & TST & \\
\hline CHEMBL3199425 & 688497 & 4.95 & 4.7822 & TRN & \\
\hline CHEMBL1492984 & 688497 & 4.9 & 5.2823 & TRN & \\
\hline CHEMBL1303754 & 688497 & 4.45 & 4.8794 & TRN & \\
\hline CHEMBL1431541 & 688497 & 5.2 & 5.2066 & TST & \\
\hline CHEMBL1448681 & 688497 & 4.65 & 5.02 & TRN & \\
\hline CHEMBL1313912 & 688497 & 4.5 & 5.015 & TST & \\
\hline CHEMBL1300798 & 688497 & 4.5 & 4.8847 & TRN & \\
\hline CHEMBL3193510 & 688497 & 5.9 & 5.2316 & TRN & \\
\hline CHEMBL3198723 & 688497 & 4.7 & 4.8715 & TRN & \\
\hline CHEMBL1559204 & 688497 & 4.6 & 4.7896 & TRN & \\
\hline CHEMBL1387013 & 688497 & 6.25 & 5.1096 & TRN & \\
\hline CHEMBL1521908 & 688497 & 5.5 & 5.1378 & TRN & \\
\hline CHEMBL1564028 & 688497 & 4.45 & 4.90300 & 00000000005 & TST \\
\hline CHEMBL1530895 & 688497 & 6.25 & 5.1866 & TRN & \\
\hline CHEMBL1341556 & 688497 & 5.9 & 4.8968 & TST & \\
\hline CHEMBL1310172 & 688497 & 4.65 & 4.9996 & TRN & \\
\hline CHEMBL3213019 & 688497 & 5.7 & 5.0456 & TRN & \\
\hline CHEMBL1348122 & 688497 & 6.7001 & 5.0682 & TRN & \\
\hline CHEMBL1542068 & 688497 & 5.25 & 5.1332 & TST & \\
\hline CHEMBL1197556 & 688497 & 5.5 & 5.6668 & TRN & \\
\hline CHEMBL1485865 & 688497 & 4.95 & 5.4907 & TST & \\
\hline CHEMBL1430469 & 688497 & 4.7 & 4.8224 & TRN & \\
\hline CHEMBL1416992 & 688497 & 4.9 & 4.9333 & TST & \\
\hline CHEMBL1383146 & 688497 & 4.75 & 5.0938 & TRN & \\
\hline CHEMBL1579509 & 688497 & 4.45 & 4.957 & TRN & \\
\hline CHEMBL3195083 & 688497 & 5.9 & 5.1511 & TRN & \\
\hline CHEMBL1580409 & 688497 & 4.45 & 4.9141 & TRN & \\
\hline CHEMBL1373649 & 688497 & 4.95 & 5.0065 & TRN & \\
\hline CHEMBL1586591 & 688497 & 5.0 & 4.8422 & TRN & \\
\hline CHEMBL1588732 & 688497 & 4.95 & 5.063 & TRN & \\
\hline CHEMBL1499828 & 688497 & 4.9 & 4.7422 & TRN & \\
\hline CHEMBL1576080 & 688497 & 7.0501 & 4.9223 & TRN & \\
\hline CHEMBL1312037 & 688497 & 4.8 & 4.8205 & TST & \\
\hline CHEMBL1544093 & 688497 & 4.65 & 5.099 & TRN & \\
\hline CHEMBL1351158 & 688497 & 4.85 & 4.8915 & TST & \\
\hline CHEMBL1406920 & 688497 & 5.0 & 4.8511 & TRN & \\
\hline CHEMBL1459891 & 688497 & 4.7 & 4.92 & TRN & \\
\hline CHEMBL1587116 & 688497 & 6.4 & 4.8841 & TST & \\
\hline CHEMBL1598520 & 688497 & 4.45 & 4.5827 & TRN & \\
\hline CHEMBL1340037 & 688497 & 4.85 & 5.1165 & TRN & \\
\hline CHEMBL1429636 & 688497 & 4.55 & 4.5466 & TRN & \\
\hline
\end{tabular}




\begin{tabular}{|c|c|c|c|c|c|}
\hline \multicolumn{6}{|c|}{ Supplemental Table S2.txt } \\
\hline CHEMBL1371774 & 688497 & 5.0 & 4.922 & TRN & \\
\hline CHEMBL1429273 & 688497 & 4.6 & 4.9131 & TRN & \\
\hline CHEMBL1572827 & 688497 & 4.65 & 4.888 & TRN & \\
\hline CHEMBL1456572 & 688497 & 4.9 & 4.9684 & TRN & \\
\hline CHEMBL1576826 & 688497 & 4.55 & 5.1253 & TST & \\
\hline CHEMBL1524288 & 688497 & 4.45 & 4.7588 & TRN & \\
\hline CHEMBL1484951 & 688497 & 5.55 & 5.215 & TRN & \\
\hline CHEMBL1483138 & 688497 & 4.45 & 4.6375 & TRN & \\
\hline CHEMBL1504141 & 688497 & 4.55 & 4.8092 & TRN & \\
\hline CHEMBL1389633 & 688497 & 4.45 & 4.915 & TRN & \\
\hline CHEMBL1600349 & 688497 & 7.5003 & 5.0769 & TST & \\
\hline CHEMBL1369807 & 688497 & 5.55 & 5.519 & TST & \\
\hline CHEMBL1374044 & 688497 & 4.45 & 5.2849 & TRN & \\
\hline CHEMBL1508684 & 688497 & 6.25 & 5.0715 & TRN & \\
\hline CHEMBL1586337 & 688497 & 4.9 & 5.195 & TRN & \\
\hline CHEMBL1380165 & 688497 & 5.25 & 5.1116 & TST & \\
\hline CHEMBL1353526 & 688497 & 4.6 & 4.8861 & TST & \\
\hline CHEMBL1571883 & 688497 & 5.9 & 4.7552 & TRN & \\
\hline CHEMBL1501578 & 688497 & 6.05 & 5.0949 & TST & \\
\hline CHEMBL1606138 & 688497 & 4.9 & 4.8074 & TRN & \\
\hline CHEMBL1334680 & 688497 & 4.95 & 4.7875 & TRN & \\
\hline CHEMBL3193652 & 688497 & 5.2 & 5.3191 & TST & \\
\hline CHEMBL1904396 & 688497 & 5.1 & 5.2457 & TST & \\
\hline CHEMBL1403158 & 688497 & 5.5 & 5.3266 & TRN & \\
\hline CHEMBL1336173 & 688497 & 4.65 & 5.2219 & TRN & \\
\hline CHEMBL1348979 & 688497 & 4.45 & 4.9883 & TRN & \\
\hline CHEMBL1504310 & 688497 & 4.45 & 4.8897 & TST & \\
\hline CHEMBL1470312 & 688497 & 5.45 & 4.9182 & TRN & \\
\hline CHEMBL1416104 & 688497 & 4.45 & 4.6433 & TRN & \\
\hline CHEMBL1442502 & 688497 & 6.95 & 5.166 & TRN & \\
\hline CHEMBL1584578 & 688497 & 4.45 & 4.8926 & TRN & \\
\hline CHEMBL1497797 & 688497 & 5.05 & 4.8531 & TST & \\
\hline CHEMBL3197662 & 688497 & 4.75 & 4.6264 & TRN & \\
\hline CHEMBL1544552 & 688497 & 5.55 & 5.066 & TST & \\
\hline CHEMBL1613117 & 688497 & 4.7 & 4.9655 & TRN & \\
\hline CHEMBL1496826 & 688497 & 4.9 & 5.16799 & 9999999999 & TRN \\
\hline CHEMBL1602236 & 688497 & 4.65 & 5.3638 & TST & \\
\hline CHEMBL1381257 & 688497 & 4.95 & 5.3547 & TRN & \\
\hline CHEMBL1544202 & 688497 & 5.1 & 5.1278 & TST & \\
\hline CHEMBL1404805 & 688497 & 4.45 & 4.9351 & TRN & \\
\hline CHEMBL1477793 & 688497 & 4.45 & 4.6094 & TRN & \\
\hline CHEMBL1584869 & 688497 & 4.45 & 4.9019 & TRN & \\
\hline CHEMBL1448849 & 688497 & 4.45 & 4.7867 & TRN & \\
\hline CHEMBL1391737 & 688497 & 4.45 & 5.1693 & TRN & \\
\hline CHEMBL1445602 & 688497 & 4.45 & 4.8469 & TRN & \\
\hline CHEMBL1402822 & 688497 & 5.15 & 5.0558 & TRN & \\
\hline CHEMBL1572214 & 688497 & 4.45 & 5.1234 & TRN & \\
\hline CHEMBL1340694 & 688497 & 4.45 & 4.7167 & TRN & \\
\hline
\end{tabular}




\begin{tabular}{|c|c|c|c|c|c|}
\hline \multicolumn{6}{|c|}{ Supplemental Table S2.txt } \\
\hline CHEMBL1302895 & 688497 & 4.45 & 5.1778 & TST & \\
\hline CHEMBL1594517 & 688497 & 4.45 & 4.7588 & TRN & \\
\hline CHEMBL1325039 & 688497 & 4.45 & 4.8328 & TRN & \\
\hline CHEMBL1483426 & 688497 & 5.9 & 4.9871 & TRN & \\
\hline CHEMBL1557388 & 688497 & 5.5 & 5.0015 & TST & \\
\hline CHEMBL1363313 & 688497 & 4.8 & 4.7545 & TRN & \\
\hline CHEMBL 3191230 & 688497 & 4.5 & 5.0152 & TRN & \\
\hline CHEMBL1582729 & 688497 & 5.5 & 5.1605 & TRN & \\
\hline CHEMBL1388436 & 688497 & 5.05 & 5.0159 & TRN & \\
\hline CHEMBL1428496 & 688497 & 4.45 & 5.07600 & 00000000005 & TRN \\
\hline CHEMBL1324032 & 688497 & 5.25 & 5.1678 & TST & \\
\hline CHEMBL1407677 & 688497 & 4.8 & 4.7359 & TRN & \\
\hline CHEMBL1606461 & 688497 & 4.95 & 5.0752 & TRN & \\
\hline CHEMBL1417663 & 688497 & 5.1 & 5.1999 & TRN & \\
\hline CHEMBL1454867 & 688497 & 5.4 & 4.9906 & TRN & \\
\hline CHEMBL1330934 & 688497 & 4.8 & 4.6542 & TRN & \\
\hline CHEMBL1428589 & 688497 & 5.25 & 4.9785 & TRN & \\
\hline CHEMBL1377170 & 688497 & 4.45 & 4.9629 & TST & \\
\hline CHEMBL1600011 & 688497 & 4.95 & 4.9576 & TRN & \\
\hline CHEMBL1388935 & 688497 & 4.6 & 5.0989 & TRN & \\
\hline CHEMBL1368206 & 688497 & 4.65 & 5.1912 & TST & \\
\hline CHEMBL1401171 & 688497 & 4.45 & 4.7366 & TST & \\
\hline CHEMBL1601046 & 688497 & 5.5 & 5.0157 & TRN & \\
\hline CHEMBL1429139 & 688497 & 6.2 & 5.064 & TRN & \\
\hline CHEMBL1503091 & 688497 & 4.95 & 4.9221 & TRN & \\
\hline CHEMBL1376201 & 688497 & 4.65 & 5.121 & TRN & \\
\hline CHEMBL1491438 & 688497 & 4.45 & 4.7112 & TRN & \\
\hline CHEMBL1596208 & 688497 & 6.95 & 5.1809 & TRN & \\
\hline CHEMBL1463372 & 688497 & 5.3 & 5.1392 & TRN & \\
\hline CHEMBL1482362 & 688497 & 5.6 & 5.0768 & TRN & \\
\hline CHEMBL1325063 & 688497 & 4.65 & 4.843 & TST & \\
\hline CHEMBL1404154 & 688497 & 5.05 & 5.1221 & TRN & \\
\hline CHEMBL1391022 & 688497 & 4.45 & 4.9862 & TRN & \\
\hline CHEMBL1446218 & 688497 & 4.45 & 5.1789 & TRN & \\
\hline CHEMBL1458178 & 688497 & 5.15 & 5.0549 & TRN & \\
\hline CHEMBL1338171 & 688497 & 4.7 & 4.555 & TRN & \\
\hline CHEMBL1366374 & 688497 & 5.5 & 5.0409 & TST & \\
\hline CHEMBL 3145107 & 688497 & 4.5 & 4.872 & TST & \\
\hline CHEMBL1372028 & 688497 & 5.6 & 5.1583 & TST & \\
\hline CHEMBL1478881 & 688497 & 4.45 & 4.8706 & TRN & \\
\hline CHEMBL1488035 & 688497 & 5.05 & 5.0983 & TRN & \\
\hline CHEMBL1997915 & 688497 & 5.2 & 5.3554 & TRN & \\
\hline CHEMBL1439846 & 688497 & 4.95 & 5.0172 & TRN & \\
\hline CHEMBL1377730 & 688497 & 4.45 & 4.9891 & TRN & \\
\hline CHEMBL1484149 & 688497 & 6.1 & 5.0653 & TRN & \\
\hline CHEMBL 3198143 & 688497 & 5.4 & 5.0347 & TST & \\
\hline CHEMBL 3193288 & 688497 & 5.45 & 5.1496 & TST & \\
\hline CHEMBL1498623 & 688497 & 4.95 & 5.1178 & TRN & \\
\hline
\end{tabular}




\begin{tabular}{|c|c|c|c|c|c|}
\hline \multicolumn{6}{|c|}{ Supplemental Table S2.txt } \\
\hline CHEMBL170993 & 688497 & 4.8 & 5.1879 & TRN & \\
\hline CHEMBL1401888 & 688497 & 4.45 & 4.9361 & TRN & \\
\hline CHEMBL1390259 & 688497 & 4.7 & 5.0141 & TRN & \\
\hline CHEMBL1586968 & 688497 & 4.75 & 5.0951 & TRN & \\
\hline CHEMBL1382905 & 688497 & 4.9 & 4.783 & TRN & \\
\hline CHEMBL1419371 & 688497 & 4.45 & 5.1628 & TRN & \\
\hline CHEMBL1429606 & 688497 & 4.9 & 5.0354 & TST & \\
\hline CHEMBL1583236 & 688497 & 4.45 & 5.0163 & TRN & \\
\hline CHEMBL1469453 & 688497 & 6.05 & 4.9022 & TRN & \\
\hline CHEMBL1541666 & 688497 & 4.45 & 5.2109 & TRN & \\
\hline CHEMBL606167 & 688497 & 4.95 & 4.8287 & TST & \\
\hline CHEMBL1486366 & 688497 & 4.45 & 4.7453 & TRN & \\
\hline CHEMBL1428380 & 688497 & 4.45 & 5.3092 & TRN & \\
\hline CHEMBL1486174 & 688497 & 4.45 & 4.9774 & TRN & \\
\hline CHEMBL1547023 & 688497 & 4.45 & 5.0907 & TRN & \\
\hline CHEMBL1529341 & 688497 & 4.45 & $5.3670 e$ & 0000000001 & TRN \\
\hline CHEMBL1330963 & 688497 & 5.25 & 4.8361 & TRN & \\
\hline CHEMBL 321747 & 688497 & 6.0 & 5.5071 & TRN & \\
\hline CHEMBL1607879 & 688497 & 4.55 & 5.1669 & TRN & \\
\hline CHEMBL1567983 & 688497 & 4.6 & 4.7429 & TST & \\
\hline CHEMBL1966751 & 688497 & 4.9 & 4.9875 & TRN & \\
\hline CHEMBL1453454 & 688497 & 4.45 & 5.17399 & 99999999995 & TST \\
\hline CHEMBL1601540 & 688497 & 4.9 & 5.0581 & TRN & \\
\hline CHEMBL1415040 & 688497 & 4.75 & 5.1233 & TRN & \\
\hline CHEMBL1319522 & 688497 & 4.95 & 5.2842 & TRN & \\
\hline CHEMBL1303094 & 688497 & 4.95 & 4.9537 & TRN & \\
\hline CHEMBL494326 & 688497 & 5.65 & 4.9067 & TRN & \\
\hline CHEMBL1536618 & 688497 & 4.45 & 5.0603 & TRN & \\
\hline CHEMBL1366128 & 688497 & 5.0 & 5.2292 & TRN & \\
\hline CHEMBL1523270 & 688497 & 4.45 & 5.2666 & TRN & \\
\hline CHEMBL1362378 & 688497 & 5.9 & 4.8349 & TRN & \\
\hline CHEMBL1417688 & 688497 & 4.9 & 5.1515 & TST & \\
\hline CHEMBL1422458 & 688497 & 5.25 & $5.3210 e$ & 3000000001 & TRN \\
\hline CHEMBL1376136 & 688497 & 5.85 & 5.374 & TST & \\
\hline CHEMBL1348840 & 688497 & 4.8 & 4.8575 & TRN & \\
\hline CHEMBL1492120 & 688497 & 5.45 & 4.8749 & TRN & \\
\hline CHEMBL1588827 & 688497 & 4.9 & 4.7935 & TRN & \\
\hline CHEMBL1480989 & 688497 & 5.05 & 5.525 & TRN & \\
\hline CHEMBL1565712 & 688497 & 4.65 & 4.6042 & TRN & \\
\hline CHEMBL1604735 & 688497 & 4.9 & 4.7216 & TRN & \\
\hline CHEMBL1572336 & 688497 & 4.45 & 5.1742 & TST & \\
\hline CHEMBL1373433 & 688497 & 4.75 & 5.052 & TRN & \\
\hline CHEMBL1333358 & 688497 & 4.55 & 5.1834 & TRN & \\
\hline CHEMBL1495114 & 688497 & 5.25 & 5.2168 & TST & \\
\hline CHEMBL1408808 & 688497 & 5.85 & 5.197 & TST & \\
\hline CHEMBL3197791 & 688497 & 4.45 & 4.88399 & 99999999995 & TRN \\
\hline CHEMBL3208905 & 688497 & 4.45 & 5.1457 & TRN & \\
\hline CHEMBL1580472 & 688497 & 4.95 & 5.0321 & TRN & \\
\hline
\end{tabular}




\begin{tabular}{|c|c|c|c|c|}
\hline \multicolumn{5}{|c|}{ Supplemental Table S2.txt } \\
\hline CHEMBL1485362 & 688497 & 4.45 & 4.965 & TRN \\
\hline CHEMBL 2000067 & 688497 & 5.4 & 4.8981 & TST \\
\hline CHEMBL1538762 & 688497 & 5.55 & 5.2156 & TST \\
\hline CHEMBL1465601 & 688497 & 5.9 & 5.059 & TST \\
\hline CHEMBL 1376386 & 688497 & 5.0 & 4.9633 & TST \\
\hline CHEMBL1424856 & 688497 & 4.45 & 4.5914 & TRN \\
\hline CHEMBL1579458 & 688497 & 5.6 & 5.2433 & TST \\
\hline CHEMBL444810 & 688497 & 5.3 & 5.2834 & TRN \\
\hline CHEMBL1511153 & 688497 & 4.8 & 5.0696 & TRN \\
\hline CHEMBL1605458 & 688497 & 5.25 & 5.0679 & TST \\
\hline CHEMBL2311906 & 688497 & 5.55 & 5.0092 & TST \\
\hline CHEMBL1601009 & 688497 & 5.6 & 5.1376 & TRN \\
\hline CHEMBL1477293 & 688497 & 5.8 & 5.0543 & TST \\
\hline CHEMBL1578574 & 688497 & 6.25 & 5.2492 & TRN \\
\hline CHEMBL1589457 & 688497 & 5.2 & 4.6367 & TST \\
\hline CHEMBL 2000175 & 688497 & 5.0 & 5.0872 & TRN \\
\hline CHEMBL1565158 & 688497 & 4.45 & 4.7577 & TRN \\
\hline CHEMBL1420031 & 688497 & 4.85 & 4.9529 & TRN \\
\hline CHEMBL1420808 & 688497 & 4.5 & 4.7052 & TRN \\
\hline CHEMBL1596707 & 688497 & 5.6 & 5.0147 & TRN \\
\hline CHEMBL1413543 & 688497 & 4.5 & 4.7962 & TST \\
\hline CHEMBL1420093 & 688497 & 5.45 & 5.1432 & TST \\
\hline CHEMBL1428974 & 688497 & 4.95 & 5.5072 & TRN \\
\hline CHEMBL 3198624 & 688497 & 5.95 & 5.0412 & TRN \\
\hline CHEMBL1506275 & 688497 & 5.35 & 5.2504 & TRN \\
\hline CHEMBL1337416 & 688497 & 5.15 & 5.5023 & TRN \\
\hline CHEMBL1466965 & 688497 & 5.0 & 5.1391 & TRN \\
\hline CHEMBL1532679 & 688497 & 4.45 & 4.6431 & TRN \\
\hline CHEMBL1511358 & 688497 & 4.95 & 5.0556 & TRN \\
\hline CHEMBL1583472 & 688497 & 4.45 & 4.9352 & TRN \\
\hline CHEMBL1499456 & 688497 & 5.0 & 5.0589 & TRN \\
\hline CHEMBL1308505 & 688497 & 5.25 & 4.9258 & TST \\
\hline CHEMBL1430366 & 688497 & 5.9 & 5.4989 & TST \\
\hline CHEMBL2001739 & 688497 & 5.5 & 5.2759 & TST \\
\hline CHEMBL1464854 & 688497 & 5.1 & 5.3809 & TRN \\
\hline CHEMBL3195499 & 688497 & 6.1 & 5.2234 & TRN \\
\hline CHEMBL1404929 & 688497 & 5.0 & 5.119 & TST \\
\hline CHEMBL1455551 & 688497 & 5.2 & 4.9293 & TST \\
\hline CHEMBL1347385 & 688497 & 4.45 & 4.4736 & TST \\
\hline CHEMBL1573958 & 688497 & 4.95 & 5.0261 & TST \\
\hline CHEMBL1541996 & 688497 & 4.45 & 4.9901 & TRN \\
\hline CHEMBL1479629 & 688497 & 4.75 & 4.7307 & TRN \\
\hline CHEMBL1411204 & 688497 & 5.7 & 4.9223 & TRN \\
\hline CHEMBL3193220 & 688497 & 4.45 & 5.1092 & TRN \\
\hline CHEMBL1455150 & 688497 & 4.65 & 5.2062 & TRN \\
\hline CHEMBL1542745 & 688497 & 5.25 & 4.9993 & TRN \\
\hline CHEMBL 1447457 & 688497 & 4.7 & 4.846 & TST \\
\hline CHEMBL3196041 & 688497 & 7.0 & 5.0744 & TRN \\
\hline
\end{tabular}




\begin{tabular}{|c|c|c|c|c|c|}
\hline \multicolumn{6}{|c|}{ Supplemental Table S2.txt } \\
\hline CHEMBL 3208220 & 688497 & 5.45 & 4.9495 & TRN & \\
\hline CHEMBL1426695 & 688497 & 4.8 & 4.8488 & TRN & \\
\hline CHEMBL1472108 & 688497 & 4.45 & 4.7135 & TRN & \\
\hline CHEMBL1391071 & 688497 & 4.7 & 4.8626 & TRN & \\
\hline CHEMBL1320403 & 688497 & 5.25 & 5.8861 & TRN & \\
\hline CHEMBL1343808 & 688497 & 4.55 & 4.9283 & TRN & \\
\hline CHEMBL1432015 & 688497 & 4.45 & 4.907 & TRN & \\
\hline CHEMBL1478213 & 688497 & 4.75 & 4.8181 & TST & \\
\hline CHEMBL1428516 & 688497 & 4.45 & 5.0577 & TRN & \\
\hline CHEMBL1607435 & 688497 & 5.45 & 5.0255 & TRN & \\
\hline CHEMBL1300939 & 688497 & 4.45 & 4.9244 & TST & \\
\hline CHEMBL1525551 & 688497 & 6.3 & 5.4448 & TST & \\
\hline CHEMBL1446542 & 688497 & 5.05 & 4.998 & TRN & \\
\hline CHEMBL1528850 & 688497 & 5.5 & 4.9632 & TRN & \\
\hline CHEMBL1352113 & 688497 & 5.4 & 5.2205 & TST & \\
\hline CHEMBL1414508 & 688497 & 4.8 & 4.5989 & TRN & \\
\hline CHEMBL1325698 & 688497 & 5.25 & 5.2992 & TRN & \\
\hline CHEMBL1409650 & 688497 & 5.25 & 5.3914 & TST & \\
\hline CHEMBL1414601 & 688497 & 6.2 & 5.2956 & TRN & \\
\hline CHEMBL1509566 & 688497 & 4.6 & 4.9117 & TRN & \\
\hline CHEMBL3197107 & 688497 & 4.45 & 5.0345 & TRN & \\
\hline CHEMBL1528661 & 688497 & 5.9 & 5.2501 & TRN & \\
\hline CHEMBL1401721 & 688497 & 5.0 & 5.1413 & TST & \\
\hline CHEMBL1329022 & 688497 & 5.65 & 5.317 & TRN & \\
\hline CHEMBL1485945 & 688497 & 5.25 & 4.855 & TRN & \\
\hline CHEMBL1549525 & 688497 & 4.45 & 5.0481 & TRN & \\
\hline CHEMBL1447658 & 688497 & 5.3 & 4.8535 & TRN & \\
\hline CHEMBL1522067 & 688497 & 4.6 & 4.9994 & TRN & \\
\hline CHEMBL1587029 & 688497 & 5.5 & 5.0518 & TST & \\
\hline CHEMBL 3193593 & 688497 & 4.45 & 4.9456 & TRN & \\
\hline CHEMBL1488081 & 688497 & 4.65 & 4.9784 & TRN & \\
\hline CHEMBL1507750 & 688497 & 4.45 & 5.29799 & 9999999999 & TRN \\
\hline CHEMBL1570008 & 688497 & 4.65 & 4.8857 & TRN & \\
\hline CHEMBL1440045 & 688497 & 6.8499 & 5.026 & TRN & \\
\hline CHEMBL1428563 & 688497 & 4.45 & 5.0509 & TST & \\
\hline CHEMBL1313927 & 688497 & 4.45 & 5.1696 & TST & \\
\hline CHEMBL1379675 & 688497 & 4.45 & 4.8442 & TRN & \\
\hline CHEMBL1306283 & 688497 & 5.75 & 5.4074 & TRN & \\
\hline CHEMBL1549798 & 688497 & 4.9 & 4.6807 & TRN & \\
\hline CHEMBL1502216 & 688497 & 4.5 & 5.1403 & TRN & \\
\hline CHEMBL1558455 & 688497 & 5.45 & 5.1945 & TST & \\
\hline CHEMBL1415437 & 688497 & 5.45 & 5.1175 & TST & \\
\hline CHEMBL1332434 & 688497 & 4.85 & 5.1767 & TRN & \\
\hline CHEMBL1578962 & 688497 & 4.45 & 4.7157 & TRN & \\
\hline CHEMBL1544544 & 688497 & 5.4 & 5.2826 & TRN & \\
\hline CHEMBL1493225 & 688497 & 4.55 & 4.728 & TRN & \\
\hline CHEMBL1423963 & 688497 & 5.15 & 5.0067 & TRN & \\
\hline CHEMBL3212972 & 688497 & 5.3 & 4.8883 & TRN & \\
\hline
\end{tabular}




\begin{tabular}{|c|c|c|c|c|c|}
\hline \multirow[b]{2}{*}{ CHEMBL164271 } & & \multicolumn{4}{|c|}{ Supplemental Table S2.txt } \\
\hline & 688497 & 5.4 & \multicolumn{2}{|c|}{5.242999999999999} & TST \\
\hline CHEMBL1487386 & 688497 & 4.45 & 5.0214 & TST & \\
\hline CHEMBL1604919 & 688497 & 4.65 & 4.8173 & TRN & \\
\hline CHEMBL1572325 & 688497 & 4.95 & 5.1915 & TST & \\
\hline CHEMBL1965911 & 688497 & 5.55 & 4.7921 & TRN & \\
\hline CHEMBL1531003 & 688497 & 4.85 & 5.0569 & TST & \\
\hline CHEMBL1383279 & 688497 & 4.45 & 5.0119 & TRN & \\
\hline CHEMBL598903 & 688497 & 5.0 & 4.769 & TST & \\
\hline CHEMBL1366573 & 688497 & 4.45 & 5.0988 & TRN & \\
\hline CHEMBL1436438 & 688497 & 5.55 & 5.5158 & TRN & \\
\hline CHEMBL1308319 & 688497 & 4.95 & 5.0205 & TRN & \\
\hline CHEMBL3213563 & 688497 & 5.15 & 5.0282 & TRN & \\
\hline CHEMBL1497996 & 688497 & 4.45 & 5.2275 & TRN & \\
\hline CHEMBL3191544 & 688497 & 5.0 & 5.3227 & TST & \\
\hline CHEMBL1574799 & 688497 & 4.65 & 5.0898 & TRN & \\
\hline CHEMBL1358873 & 688497 & 4.55 & 4.6918 & TRN & \\
\hline CHEMBL1301125 & 688497 & 5.25 & 5.2518 & TRN & \\
\hline CHEMBL1339184 & 688497 & 4.8 & \multicolumn{2}{|c|}{4.8260000000000005} & TRN \\
\hline CHEMBL1303045 & 688497 & 4.45 & 5.0523 & TRN & \\
\hline CHEMBL1588717 & 688497 & 5.4 & 5.1601 & TST & \\
\hline CHEMBL1380721 & 688497 & 5.4 & 5.1932 & TST & \\
\hline CHEMBL1613528 & 688497 & 4.7 & 5.0574 & TRN & \\
\hline CHEMBL3196358 & 688497 & 4.95 & 4.9558 & TRN & \\
\hline CHEMBL1583656 & 688497 & 4.45 & 4.9851 & TRN & \\
\hline CHEMBL1464038 & 688497 & 6.15 & 5.0789 & TST & \\
\hline CHEMBL1424596 & 688497 & 4.8 & 4.7798 & TRN & \\
\hline CHEMBL1561281 & 688497 & 4.45 & 4.8302 & TRN & \\
\hline CHEMBL1426576 & 688497 & 5.5 & 5.0865 & TRN & \\
\hline CHEMBL 388087 & 688497 & 5.15 & 5.1069 & TRN & \\
\hline CHEMBL1413697 & 688497 & 4.75 & 4.8388 & TRN & \\
\hline CHEMBL1500821 & 688497 & 4.45 & 4.7784 & TST & \\
\hline CHEMBL3196035 & 688497 & 4.45 & 4.975 & TRN & \\
\hline CHEMBL1499752 & 688497 & 4.45 & 4.8241 & TRN & \\
\hline CHEMBL1588716 & 688497 & 4.45 & 4.7953 & TRN & \\
\hline CHEMBL3191010 & 688497 & 6.45 & 5.1587 & TRN & \\
\hline CHEMBL1460670 & 688497 & 5.3 & 5.0256 & TRN & \\
\hline CHEMBL1441487 & 688497 & 4.45 & 5.3359 & TRN & \\
\hline CHEMBL1527502 & 688497 & 4.45 & 4.8725 & TRN & \\
\hline CHEMBL1400787 & 688497 & 5.5 & 5.1916 & TRN & \\
\hline CHEMBL1349721 & 688497 & 4.45 & 4.9094 & TRN & \\
\hline CHEMBL3191322 & 688497 & 5.15 & 5.1869 & TRN & \\
\hline CHEMBL1449260 & 688497 & 5.05 & 4.8596 & TRN & \\
\hline CHEMBL1597905 & 688497 & 5.0 & 5.3108 & TST & \\
\hline CHEMBL1482207 & 688497 & 4.5 & 4.7968 & TRN & \\
\hline CHEMBL1404533 & 688497 & 4.45 & 4.9403 & TRN & \\
\hline CHEMBL1497356 & 688497 & 6.25 & 5.0645 & TRN & \\
\hline CHEMBL1341188 & 688497 & 5.65 & 5.1796 & TRN & \\
\hline CHEMBL1606490 & 688497 & 4.45 & 4.9878 & TST & \\
\hline
\end{tabular}




\begin{tabular}{|c|c|c|c|c|}
\hline \multicolumn{5}{|c|}{ Supplemental Table S2.txt } \\
\hline CHEMBL1299463 & 688497 & 4.85 & 4.7302 & TRN \\
\hline CHEMBL1517880 & 688497 & 5.0 & 5.0619 & TRN \\
\hline CHEMBL1464832 & 688497 & 4.45 & 4.7892 & TRN \\
\hline CHEMBL1391533 & 688497 & 5.4 & 4.9026 & TRN \\
\hline CHEMBL1401094 & 688497 & 5.8 & 5.0242 & TST \\
\hline CHEMBL3192613 & 688497 & 4.8 & 5.058 & TST \\
\hline CHEMBL1426798 & 688497 & 5.25 & 5.4282 & TRN \\
\hline CHEMBL 2007318 & 688497 & 4.95 & 4.9155 & TRN \\
\hline CHEMBL142630 & 688497 & 4.5 & 5.0866 & TRN \\
\hline CHEMBL1414754 & 688497 & 4.85 & 4.729 & TRN \\
\hline CHEMBL1347310 & 688497 & 4.5 & 4.9355 & TST \\
\hline CHEMBL558569 & 688497 & 4.85 & 5.1531 & TRN \\
\hline CHEMBL1304290 & 688497 & 4.9 & 5.0781 & TRN \\
\hline CHEMBL1542436 & 688497 & 4.45 & 4.8435 & TRN \\
\hline CHEMBL1359532 & 688497 & 4.45 & 5.0481 & TRN \\
\hline CHEMBL1573665 & 688497 & 4.45 & 5.0724 & TRN \\
\hline CHEMBL1365941 & 688497 & 4.85 & 4.9799 & TRN \\
\hline CHEMBL1420823 & 688497 & 5.25 & 5.0785 & TRN \\
\hline CHEMBL1341396 & 688497 & 5.65 & 4.9914 & TRN \\
\hline CHEMBL1594536 & 688497 & 4.45 & 4.6728 & TRN \\
\hline CHEMBL1374851 & 688497 & 5.75 & 5.2695 & TRN \\
\hline CHEMBL1428354 & 688497 & 3.85 & 5.0456 & TRN \\
\hline CHEMBL1300980 & 688497 & 4.45 & 5.0971 & TST \\
\hline CHEMBL1464687 & 688497 & 4.9 & 4.7377 & TRN \\
\hline CHEMBL3198038 & 688497 & 5.0 & 4.9219 & TST \\
\hline CHEMBL3208369 & 688497 & 5.2 & 5.2105 & TST \\
\hline CHEMBL1360064 & 688497 & 5.0 & 4.9983 & TRN \\
\hline CHEMBL1377971 & 688497 & 4.85 & 4.9184 & TRN \\
\hline CHEMBL1341979 & 688497 & 4.45 & 4.8354 & TRN \\
\hline CHEMBL225012 & 688497 & 4.45 & 5.2915 & TRN \\
\hline CHEMBL1313191 & 688497 & 6.95 & 4.9936 & TST \\
\hline CHEMBL1504364 & 688497 & 5.05 & 4.9254 & TST \\
\hline CHEMBL1306318 & 688497 & 4.45 & 5.0376 & TST \\
\hline CHEMBL1373974 & 688497 & 4.65 & 4.6413 & TRN \\
\hline CHEMBL1489824 & 688497 & 6.5501 & 5.2311 & TRN \\
\hline CHEMBL1496497 & 688497 & 6.0 & 4.9954 & TRN \\
\hline CHEMBL3193960 & 688497 & 5.2 & 4.9026 & TRN \\
\hline CHEMBL1422567 & 688497 & 5.4 & 4.7509 & TRN \\
\hline CHEMBL1425943 & 688497 & 4.6 & 4.8462 & TRN \\
\hline CHEMBL 3214307 & 688497 & 4.45 & 4.7599 & TRN \\
\hline CHEMBL1498332 & 688497 & 5.25 & 5.3529 & TRN \\
\hline CHEMBL1610796 & 688497 & 4.6 & 5.2325 & TRN \\
\hline CHEMBL1343485 & 688497 & 4.45 & 4.8343 & TST \\
\hline CHEMBL1342703 & 688497 & 5.0 & 4.8997 & TRN \\
\hline CHEMBL1488717 & 688497 & 5.25 & 5.6838 & TRN \\
\hline CHEMBL1443660 & 688497 & 5.1 & 4.8992 & TRN \\
\hline CHEMBL1995314 & 688497 & 4.45 & 5.0762 & TRN \\
\hline CHEMBL1601898 & 688497 & 4.45 & 4.6428 & TRN \\
\hline
\end{tabular}




\begin{tabular}{|c|c|c|c|c|c|}
\hline \multicolumn{6}{|c|}{ Supplemental Table S2.txt } \\
\hline CHEMBL1423852 & 688497 & 4.8 & 4.9445 & TRN & \\
\hline CHEMBL1595354 & 688497 & 5.95 & 5.3096 & TRN & \\
\hline CHEMBL1518985 & 688497 & 5.2 & 4.9547 & TRN & \\
\hline CHEMBL3193149 & 688497 & 4.45 & \multicolumn{2}{|c|}{5.2589999999999995} & TRN \\
\hline CHEMBL1464249 & 688497 & 4.95 & 4.7492 & TRN & \\
\hline CHEMBL1524007 & 688497 & 4.65 & 4.891 & TRN & \\
\hline CHEMBL1371232 & 688497 & 5.0 & 5.0271 & TRN & \\
\hline CHEMBL577894 & 688497 & 4.65 & 5.2021 & TRN & \\
\hline CHEMBL1498133 & 688497 & 4.85 & 5.1053 & TST & \\
\hline CHEMBL1371791 & 688497 & 4.6 & 4.9241 & TRN & \\
\hline CHEMBL1413782 & 688497 & 4.7 & 5.0287 & TST & \\
\hline CHEMBL1376622 & 688497 & 4.8 & 4.8756 & TRN & \\
\hline CHEMBL1382339 & 688497 & 4.45 & 4.7769 & TST & \\
\hline CHEMBL1518705 & 688497 & 4.45 & 4.8305 & TST & \\
\hline CHEMBL3210263 & 688497 & 5.25 & 5.0342 & TRN & \\
\hline CHEMBL1330054 & 688497 & 4.8 & 4.9 & TRN & \\
\hline CHEMBL3193021 & 688497 & 4.6 & 5.0787 & TRN & \\
\hline CHEMBL1568641 & 688497 & 5.15 & 5.0492 & TST & \\
\hline CHEMBL3195241 & 688497 & 5.75 & 5.0123 & TRN & \\
\hline CHEMBL1484713 & 688497 & 4.45 & 4.7438 & TRN & \\
\hline CHEMBL1508516 & 688497 & 6.95 & 5.3477 & TRN & \\
\hline CHEMBL1497953 & 688497 & 4.45 & 4.8554 & TRN & \\
\hline CHEMBL3194249 & 688497 & 4.95 & 5.0986 & TRN & \\
\hline CHEMBL1477013 & 688497 & 5.1 & 5.1531 & TRN & \\
\hline CHEMBL1383439 & 688497 & 4.45 & 4.7284 & TRN & \\
\hline CHEMBL599890 & 688497 & 4.45 & 4.9177 & TRN & \\
\hline CHEMBL1313258 & 688497 & 4.9 & 4.9046 & TRN & \\
\hline CHEMBL1320755 & 688497 & 5.1 & 5.0787 & TRN & \\
\hline CHEMBL1336378 & 688497 & 4.95 & 5.0201 & TRN & \\
\hline CHEMBL1343603 & 688497 & 5.0 & 4.9074 & TRN & \\
\hline CHEMBL1452697 & 688497 & 4.7 & 4.9753 & TRN & \\
\hline CHEMBL1402428 & 688497 & 4.55 & 4.6591 & TRN & \\
\hline CHEMBL1492620 & 688497 & 5.5 & 4.9855 & TRN & \\
\hline CHEMBL1534134 & 688497 & 4.85 & 4.7767 & TST & \\
\hline CHEMBL1537465 & 688497 & 4.95 & 4.9177 & TRN & \\
\hline CHEMBL3212372 & 688497 & 4.45 & 5.4447 & TRN & \\
\hline CHEMBL1500924 & 688497 & 4.45 & 4.8182 & TRN & \\
\hline CHEMBL1329074 & 688497 & 4.7 & 4.795 & TRN & \\
\hline CHEMBL1430703 & 688497 & 4.45 & 4.7754 & TRN & \\
\hline CHEMBL1372606 & 688497 & 5.3 & 5.0738 & TRN & \\
\hline CHEMBL1312953 & 688497 & 4.9 & 5.3218 & TRN & \\
\hline CHEMBL1344667 & 688497 & 4.85 & 4.8454 & TRN & \\
\hline CHEMBL1390086 & 688497 & 4.45 & 4.9377 & TST & \\
\hline CHEMBL1470744 & 688497 & 4.6 & 4.7126 & TRN & \\
\hline CHEMBL1477133 & 688497 & 4.85 & 5.3234 & TST & \\
\hline CHEMBL1312325 & 688497 & 5.45 & 5.058 & TRN & \\
\hline CHEMBL3214589 & 688497 & 6.9 & 5.24799 & 9999999999 & TST \\
\hline CHEMBL3190712 & 688497 & 5.55 & 5.2717 & TRN & \\
\hline
\end{tabular}




\begin{tabular}{|c|c|c|c|c|c|}
\hline \multicolumn{6}{|c|}{ Supplemental Table S2.txt } \\
\hline CHEMBL1560238 & 688497 & 4.45 & 4.9056 & TST & \\
\hline CHEMBL1365654 & 688497 & 4.65 & 4.8224 & TST & \\
\hline CHEMBL3191627 & 688497 & 4.45 & 5.0555 & TRN & \\
\hline CHEMBL1309644 & 688497 & 4.95 & 5.2695 & TRN & \\
\hline CHEMBL1388431 & 688497 & 6.1 & 4.9887 & TRN & \\
\hline CHEMBL1378056 & 688497 & 4.95 & 5.1629 & TST & \\
\hline CHEMBL1414931 & 688497 & 4.8 & 5.2149 & TST & \\
\hline CHEMBL1489030 & 688497 & 5.2 & 5.237 & TRN & \\
\hline CHEMBL3192772 & 688497 & 4.95 & 5.2439 & TRN & \\
\hline CHEMBL1613323 & 688497 & 4.85 & 4.8503 & TRN & \\
\hline CHEMBL1346861 & 688497 & 4.45 & 4.8104 & TST & \\
\hline CHEMBL1416442 & 688497 & 4.8 & 5.0294 & TRN & \\
\hline CHEMBL1352430 & 688497 & 4.45 & 4.9437 & TRN & \\
\hline CHEMBL1613300 & 688497 & 4.95 & 5.0961 & TRN & \\
\hline CHEMBL1432823 & 688497 & 5.4 & 4.9713 & TST & \\
\hline CHEMBL1572872 & 688497 & 5.25 & 5.21299 & 9999999999 & TST \\
\hline CHEMBL1491019 & 688497 & 5.25 & 4.9136 & TRN & \\
\hline CHEMBL1321127 & 688497 & 6.25 & 5.184 & TRN & \\
\hline CHEMBL1574934 & 688497 & 4.45 & 5.0518 & TRN & \\
\hline CHEMBL1486558 & 688497 & 5.2 & 4.9907 & TST & \\
\hline CHEMBL1613690 & 688497 & 5.35 & 5.0883 & TRN & \\
\hline CHEMBL1452854 & 688497 & 4.45 & 5.0628 & TRN & \\
\hline CHEMBL1453086 & 688497 & 4.6 & 4.8169 & TRN & \\
\hline CHEMBL1399495 & 688497 & 5.05 & 5.0226 & TRN & \\
\hline CHEMBL1566419 & 688497 & 4.45 & 4.7525 & TRN & \\
\hline CHEMBL1611868 & 688497 & 4.45 & 4.7811 & TRN & \\
\hline CHEMBL1366461 & 688497 & 4.45 & 5.0682 & TRN & \\
\hline CHEMBL1359366 & 688497 & 4.7 & 4.7004 & TRN & \\
\hline CHEMBL1483963 & 688497 & 5.45 & 5.2061 & TST & \\
\hline CHEMBL3191874 & 688497 & 4.5 & 5.4651 & TRN & \\
\hline CHEMBL1490887 & 688497 & 4.45 & 4.7572 & TST & \\
\hline CHEMBL3191940 & 688497 & 4.45 & 4.923 & TRN & \\
\hline CHEMBL1352348 & 688497 & 5.0 & 5.2377 & TRN & \\
\hline CHEMBL1441999 & 688497 & 6.05 & 5.4184 & TRN & \\
\hline CHEMBL1301770 & 688497 & 4.45 & 5.0176 & TRN & \\
\hline CHEMBL1318022 & 688497 & 5.95 & 5.3605 & TST & \\
\hline CHEMBL1345853 & 688497 & 4.9 & 5.2251 & TRN & \\
\hline CHEMBL1313134 & 688497 & 4.8 & 5.0424 & TST & \\
\hline CHEMBL1494604 & 688497 & 4.85 & 5.0915 & TRN & \\
\hline CHEMBL1589234 & 688497 & 4.45 & 4.7901 & TST & \\
\hline CHEMBL1448182 & 688497 & 4.45 & 4.7123 & TRN & \\
\hline CHEMBL1574911 & 688497 & 4.45 & 4.8098 & TRN & \\
\hline CHEMBL1600752 & 688497 & 4.45 & 4.9401 & TRN & \\
\hline CHEMBL3193181 & 688497 & 5.15 & 5.1856 & TST & \\
\hline CHEMBL1533277 & 688497 & 4.45 & 4.83899 & 99999999995 & TRN \\
\hline CHEMBL1543701 & 688497 & 4.75 & 4.5905 & TRN & \\
\hline CHEMBL1547266 & 688497 & 4.7 & 4.8746 & TRN & \\
\hline CHEMBL1518540 & 688497 & 5.25 & 4.9476 & TRN & \\
\hline
\end{tabular}




\begin{tabular}{|c|c|c|c|c|}
\hline \multicolumn{5}{|c|}{ Supplemental Table S2.txt } \\
\hline CHEMBL1407237 & 688497 & 4.75 & 4.812 & TRN \\
\hline CHEMBL1471236 & 688497 & 6.2 & 4.9398 & TRN \\
\hline CHEMBL1438023 & 688497 & 4.45 & 5.2298 & TRN \\
\hline CHEMBL1459155 & 688497 & 5.55 & 5.0673 & TRN \\
\hline CHEMBL1471779 & 688497 & 4.55 & 4.8251 & TRN \\
\hline CHEMBL3198711 & 688497 & 4.95 & 5.0635 & TRN \\
\hline CHEMBL 1457240 & 688497 & 4.45 & 4.7531 & TRN \\
\hline CHEMBL1349340 & 688497 & 4.95 & 5.1363 & TRN \\
\hline CHEMBL1485168 & 688497 & 4.45 & 5.2635 & TRN \\
\hline CHEMBL1350293 & 688497 & 4.45 & 4.7893 & TRN \\
\hline CHEMBL1532700 & 688497 & 5.25 & 5.0199 & TST \\
\hline CHEMBL1345433 & 688497 & 4.7 & 4.8542 & TST \\
\hline CHEMBL1507605 & 688497 & 4.45 & 5.0996 & TST \\
\hline CHEMBL1563992 & 688497 & 5.05 & 4.7776 & TRN \\
\hline CHEMBL1599623 & 688497 & 4.65 & 5.1726 & TST \\
\hline CHEMBL1299525 & 688497 & 4.75 & 4.7603 & TRN \\
\hline CHEMBL1441375 & 688497 & 5.6 & 5.0178 & TRN \\
\hline CHEMBL1532634 & 688497 & 5.05 & 5.3348 & TST \\
\hline CHEMBL1340774 & 688497 & 4.7 & 4.8195 & TRN \\
\hline CHEMBL1431080 & 688497 & 5.25 & 5.348 & TST \\
\hline CHEMBL3192474 & 688497 & 4.6 & 4.9882 & TRN \\
\hline CHEMBL 2005998 & 688497 & 5.5 & 5.0632 & TST \\
\hline CHEMBL1343939 & 688497 & 4.45 & 4.8575 & TRN \\
\hline CHEMBL1444941 & 688497 & 4.45 & 4.9558 & TRN \\
\hline CHEMBL1582796 & 688497 & 5.2 & 5.2257 & TST \\
\hline CHEMBL1563483 & 688497 & 5.25 & 5.0716 & TST \\
\hline CHEMBL3197572 & 688497 & 5.35 & 5.0605 & TST \\
\hline CHEMBL1613109 & 688497 & 4.45 & 5.2448 & TRN \\
\hline CHEMBL1374594 & 688497 & 4.6 & 4.9484 & TRN \\
\hline CHEMBL1462649 & 688497 & 4.8 & 4.9411 & TRN \\
\hline CHEMBL1581276 & 688497 & 5.45 & 5.1871 & TRN \\
\hline CHEMBL1420772 & 688497 & 4.5 & 5.3414 & TRN \\
\hline CHEMBL1542801 & 688497 & 4.85 & 5.6241 & TRN \\
\hline CHEMBL1323274 & 688497 & 4.9 & 4.9615 & TST \\
\hline CHEMBL1404507 & 688497 & 4.6 & 4.7736 & TRN \\
\hline CHEMBL590408 & 688497 & 4.85 & 4.9735 & TRN \\
\hline CHEMBL3198105 & 688497 & 4.8 & 5.0312 & TRN \\
\hline CHEMBL1494630 & 688497 & 4.45 & 5.1493 & TST \\
\hline CHEMBL1562551 & 688497 & 4.45 & 4.9001 & TRN \\
\hline CHEMBL1363455 & 688497 & 4.45 & 4.7747 & TRN \\
\hline CHEMBL1522968 & 688497 & 4.8 & 5.0366 & TST \\
\hline CHEMBL1359436 & 688497 & 5.2 & 4.9826 & TST \\
\hline CHEMBL1580082 & 688497 & 4.45 & 5.0234 & TRN \\
\hline CHEMBL1559707 & 688497 & 4.85 & 4.7379 & TST \\
\hline CHEMBL1411285 & 688497 & 4.9 & 5.1846 & TST \\
\hline CHEMBL1557520 & 688497 & 4.5 & 4.7499 & TRN \\
\hline CHEMBL3211480 & 688497 & 5.3 & 5.0657 & TST \\
\hline CHEMBL1535422 & 688497 & 5.1 & 5.1581 & TST \\
\hline
\end{tabular}




\begin{tabular}{|c|c|c|c|c|c|}
\hline \multicolumn{6}{|c|}{ Supplemental Table S2.txt } \\
\hline CHEMBL1455229 & 688497 & 5.85 & 5.3109 & TRN & \\
\hline CHEMBL1365373 & 688497 & 5.0 & 5.2574 & TST & \\
\hline CHEMBL1334053 & 688497 & 4.85 & 4.6688 & TRN & \\
\hline CHEMBL1431705 & 688497 & 4.8 & 4.7995 & TRN & \\
\hline CHEMBL1579368 & 688497 & 4.45 & 5.204 & TST & \\
\hline CHEMBL1544126 & 688497 & 6.15 & 4.9261 & TRN & \\
\hline CHEMBL1549940 & 688497 & 6.0 & 5.0565 & TRN & \\
\hline CHEMBL1408037 & 688497 & 6.05 & 5.0465 & TRN & \\
\hline CHEMBL1320011 & 688497 & 7.0501 & 5.0871 & TRN & \\
\hline CHEMBL1299701 & 688497 & 4.45 & 4.8699 & TRN & \\
\hline CHEMBL1411484 & 688497 & 5.2 & 5.0332 & TRN & \\
\hline CHEMBL1370744 & 688497 & 4.45 & 5.3322 & TRN & \\
\hline CHEMBL498373 & 688497 & 5.35 & 5.0544 & TRN & \\
\hline CHEMBL1335899 & 688497 & 4.75 & 4.9347 & TRN & \\
\hline CHEMBL1572700 & 688497 & 4.6 & 5.1464 & TST & \\
\hline CHEMBL1519320 & 688497 & 6.25 & 4.9697 & TRN & \\
\hline CHEMBL1495762 & 688497 & 4.85 & 5.1124 & TRN & \\
\hline CHEMBL1412265 & 688497 & 5.45 & 5.3806 & TST & \\
\hline CHEMBL1540436 & 688497 & 4.65 & 4.9558 & TRN & \\
\hline CHEMBL1560502 & 688497 & 4.5 & 4.7079 & TRN & \\
\hline CHEMBL1463540 & 688497 & 4.65 & 4.8379 & TRN & \\
\hline CHEMBL3194415 & 688497 & 4.45 & 4.8675 & TRN & \\
\hline CHEMBL1527735 & 688497 & 4.95 & 5.192 & TST & \\
\hline CHEMBL1405934 & 688497 & 4.45 & 4.9305 & TRN & \\
\hline CHEMBL1605780 & 688497 & 5.05 & 4.84 & TRN & \\
\hline CHEMBL1460938 & 688497 & 5.4 & 4.9671 & TRN & \\
\hline CHEMBL1389269 & 688497 & 4.8 & 5.0032 & TST & \\
\hline CHEMBL1414345 & 688497 & 4.75 & 4.9357 & TRN & \\
\hline CHEMBL547101 & 688497 & 6.25 & 5.2798 & TST & \\
\hline CHEMBL1327123 & 688497 & 5.5 & 5.1545 & TRN & \\
\hline CHEMBL1364018 & 688497 & 4.65 & 4.8633 & TRN & \\
\hline CHEMBL1369174 & 688497 & 4.45 & 5.0287 & TST & \\
\hline CHEMBL1389542 & 688497 & 4.95 & 5.1663 & TRN & \\
\hline CHEMBL1585652 & 688497 & 4.95 & 4.9641 & TRN & \\
\hline CHEMBL1609770 & 688497 & 5.0 & 5.3112 & TRN & \\
\hline CHEMBL1415953 & 688497 & 4.45 & 5.0296 & TST & \\
\hline CHEMBL1351653 & 688497 & 4.45 & 4.762 & TRN & \\
\hline CHEMBL1573697 & 688497 & 5.3 & 5.1207 & TRN & \\
\hline CHEMBL1588945 & 688497 & 5.7 & 4.82600 & 90000000005 & TRN \\
\hline CHEMBL3191623 & 688497 & 5.7 & 5.1571 & TRN & \\
\hline CHEMBL1304960 & 688497 & 4.45 & 4.9582 & TST & \\
\hline CHEMBL1423737 & 688497 & 5.25 & 4.9539 & TRN & \\
\hline CHEMBL3190124 & 688497 & 4.95 & 5.3151 & TST & \\
\hline CHEMBL1333734 & 688497 & 4.8 & 4.9491 & TRN & \\
\hline CHEMBL 2005486 & 688497 & 4.45 & 5.0248 & TRN & \\
\hline CHEMBL1456576 & 688497 & 6.0 & 5.01 & TRN & \\
\hline CHEMBL1510393 & 688497 & 4.8 & 5.0492 & TST & \\
\hline CHEMBL1320386 & 688497 & 4.45 & 5.1828 & TST & \\
\hline
\end{tabular}




\begin{tabular}{|c|c|c|c|c|c|}
\hline & & & oplement & al Table S & \\
\hline CHEMBL3196530 & 688497 & 4.9 & 5.2088 & TRN & \\
\hline CHEMBL591135 & 688497 & 4.95 & 4.9994 & TRN & \\
\hline CHEMBL1525533 & 688497 & 4.95 & 4.94300 & 00000000005 & TRN \\
\hline CHEMBL1459189 & 688497 & 5.2 & 5.0086 & TRN & \\
\hline CHEMBL1522152 & 688497 & 4.8 & 4.9342 & TRN & \\
\hline CHEMBL1467336 & 688497 & 6.3 & 5.0273 & TST & \\
\hline CHEMBL1438348 & 688497 & 5.0 & 4.9048 & TRN & \\
\hline CHEMBL1430566 & 688497 & 4.75 & 4.9509 & TST & \\
\hline CHEMBL1442725 & 688497 & 4.45 & 5.0219 & TRN & \\
\hline CHEMBL1467768 & 688497 & 6.25 & 5.1102 & TRN & \\
\hline CHEMBL1480464 & 688497 & 4.45 & 4.8528 & TRN & \\
\hline CHEMBL1609476 & 688497 & 4.95 & 4.7572 & TRN & \\
\hline CHEMBL1550274 & 688497 & 4.95 & 4.9274 & TRN & \\
\hline CHEMBL1541581 & 688497 & 7.0501 & 5.308 & TST & \\
\hline CHEMBL1596678 & 688497 & 4.6 & 5.0028 & TRN & \\
\hline CHEMBL1542374 & 688497 & 5.0 & 5.1729 & TRN & \\
\hline CHEMBL1538361 & 688497 & 4.45 & 5.2812 & TST & \\
\hline CHEMBL1965821 & 688497 & 4.45 & 4.9353 & TRN & \\
\hline CHEMBL1604454 & 688497 & 4.85 & 4.7641 & TRN & \\
\hline CHEMBL3198595 & 688497 & 4.95 & 5.0633 & TRN & \\
\hline CHEMBL 2006168 & 688497 & 5.45 & 5.331 & TRN & \\
\hline CHEMBL1440797 & 688497 & 5.7 & 5.4725 & TST & \\
\hline CHEMBL1407034 & 688497 & 6.0 & 5.1447 & TST & \\
\hline CHEMBL1368750 & 688497 & 4.7 & 4.9866 & TST & \\
\hline CHEMBL1389379 & 688497 & 4.45 & 5.2291 & TST & \\
\hline CHEMBL3194762 & 688497 & 4.45 & 4.6561 & TRN & \\
\hline CHEMBL1384998 & 688497 & 4.6 & 4.6576 & TRN & \\
\hline CHEMBL3212625 & 688497 & 4.8 & 4.9103 & TST & \\
\hline CHEMBL1421601 & 688497 & 5.25 & 5.1989 & TRN & \\
\hline CHEMBL1409486 & 688497 & 4.45 & 4.5971 & TRN & \\
\hline CHEMBL1525358 & 688497 & 5.2 & 5.1525 & TRN & \\
\hline CHEMBL1330487 & 688497 & 4.45 & 4.9767 & TST & \\
\hline CHEMBL1507898 & 688497 & 4.65 & 4.9816 & TRN & \\
\hline CHEMBL1485579 & 688497 & 4.7 & 4.8935 & TRN & \\
\hline CHEMBL1369898 & 688497 & 5.9 & 5.1075 & TRN & \\
\hline CHEMBL1340893 & 688497 & 4.9 & 4.8572 & TRN & \\
\hline CHEMBL3194833 & 688497 & 5.0 & 5.2688 & TRN & \\
\hline CHEMBL1367165 & 688497 & 5.0 & 5.3271 & TRN & \\
\hline CHEMBL1506258 & 688497 & 4.85 & 5.1995 & TRN & \\
\hline CHEMBL1611742 & 688497 & 4.7 & 5.2274 & TST & \\
\hline CHEMBL1390393 & 688497 & 5.9 & 5.3246 & TST & \\
\hline CHEMBL1440833 & 688497 & 4.45 & 4.8064 & TRN & \\
\hline CHEMBL1532099 & 688497 & 5.25 & 5.0533 & TRN & \\
\hline CHEMBL1391181 & 688497 & 5.0 & 5.3365 & TST & \\
\hline CHEMBL1481444 & 688497 & 4.8 & 4.6051 & TRN & \\
\hline CHEMBL1091556 & 688497 & 5.4 & 5.1272 & TRN & \\
\hline CHEMBL1418831 & 688497 & 5.0 & 5.2515 & TST & \\
\hline CHEMBL3192274 & 688497 & 5.25 & 5.1269 & TRN & \\
\hline
\end{tabular}




\begin{tabular}{|c|c|c|c|c|}
\hline & & & upplement & al $\mathrm{T}$ \\
\hline CHEMBL1518608 & 688497 & 4.8 & 4.5688 & TRN \\
\hline CHEMBL1591005 & 688497 & 4.9 & 4.9449 & TST \\
\hline CHEMBL1494423 & 688497 & 5.05 & 5.1042 & TRN \\
\hline CHEMBL1447386 & 688497 & 4.85 & 5.2549 & TRN \\
\hline CHEMBL1525095 & 688497 & 4.75 & 4.9221 & TRN \\
\hline CHEMBL1412039 & 688497 & 5.35 & 4.8143 & TRN \\
\hline CHEMBL1494467 & 688497 & 5.25 & 5.2002 & TRN \\
\hline CHEMBL1384103 & 688497 & 4.45 & 4.8564 & TRN \\
\hline CHEMBL1569629 & 688497 & 4.95 & 4.9886 & TRN \\
\hline CHEMBL1579548 & 688497 & 4.45 & 4.6924 & TRN \\
\hline CHEMBL1442682 & 688497 & 5.45 & 4.8214 & TRN \\
\hline CHEMBL1532819 & 688497 & 4.75 & 4.8269 & TRN \\
\hline CHEMBL1415310 & 688497 & 4.6 & 4.8695 & TRN \\
\hline CHEMBL1324575 & 688497 & 5.3 & 5.3021 & TRN \\
\hline CHEMBL1303737 & 688497 & 4.45 & 5.0039 & TRN \\
\hline CHEMBL1535720 & 688497 & 4.45 & 4.9546 & TST \\
\hline CHEMBL1384508 & 688497 & 4.75 & 5.1941 & TRN \\
\hline CHEMBL1612432 & 688497 & 4.45 & 4.9338 & TRN \\
\hline CHEMBL1351309 & 688497 & 5.0 & 5.1577 & TRN \\
\hline CHEMBL 3199278 & 688497 & 5.15 & 4.9946 & TRN \\
\hline CHEMBL1443499 & 688497 & 4.95 & 4.9875 & TRN \\
\hline CHEMBL1361735 & 688497 & 6.25 & 5.1337 & TST \\
\hline CHEMBL1495149 & 688497 & 5.2 & 4.9399 & TST \\
\hline CHEMBL1496285 & 688497 & 5.95 & 5.1553 & TST \\
\hline CHEMBL1503865 & 688497 & 5.25 & 5.182 & TRN \\
\hline CHEMBL1522184 & 688497 & 5.55 & 5.1891 & TST \\
\hline CHEMBL1301917 & 688497 & 4.45 & 4.8255 & TRN \\
\hline CHEMBL1457068 & 688497 & 4.65 & 4.8862 & TRN \\
\hline CHEMBL1597855 & 688497 & 4.6 & 5.175 & TST \\
\hline CHEMBL1452622 & 688497 & 4.45 & 5.0976 & TST \\
\hline CHEMBL1335089 & 688497 & 6.05 & 5.0102 & TRN \\
\hline CHEMBL1423478 & 688497 & 5.55 & 4.9272 & TRN \\
\hline CHEMBL 3189428 & 688497 & 5.45 & 5.16 & TST \\
\hline CHEMBL1528132 & 688497 & 6.0 & 5.2979 & TST \\
\hline CHEMBL1348030 & 688497 & 4.75 & 4.9835 & TRN \\
\hline CHEMBL1550557 & 688497 & 5.0 & 4.8457 & TRN \\
\hline CHEMBL1568188 & 688497 & 5.95 & 5.2279 & TRN \\
\hline CHEMBL1522998 & 688497 & 4.5 & 5.1369 & TST \\
\hline CHEMBL1373080 & 688497 & 4.45 & 4.9942 & TST \\
\hline CHEMBL 3198394 & 688497 & 4.8 & 5.1772 & TRN \\
\hline CHEMBL1389510 & 688497 & 4.45 & 4.9436 & TRN \\
\hline CHEMBL1448757 & 688497 & 4.65 & 5.1024 & TST \\
\hline CHEMBL1524279 & 688497 & 4.8 & 5.0551 & TST \\
\hline CHEMBL3209176 & 688497 & 5.0 & 5.1044 & TST \\
\hline CHEMBL1558372 & 688497 & 5.15 & 4.9729 & TST \\
\hline CHEMBL1611338 & 688497 & 4.7 & 4.6238 & TRN \\
\hline CHEMBL1365154 & 688497 & 4.45 & 5.0879 & TRN \\
\hline CHEMBL1561091 & 688497 & 4.65 & 5.0113 & TRN \\
\hline
\end{tabular}




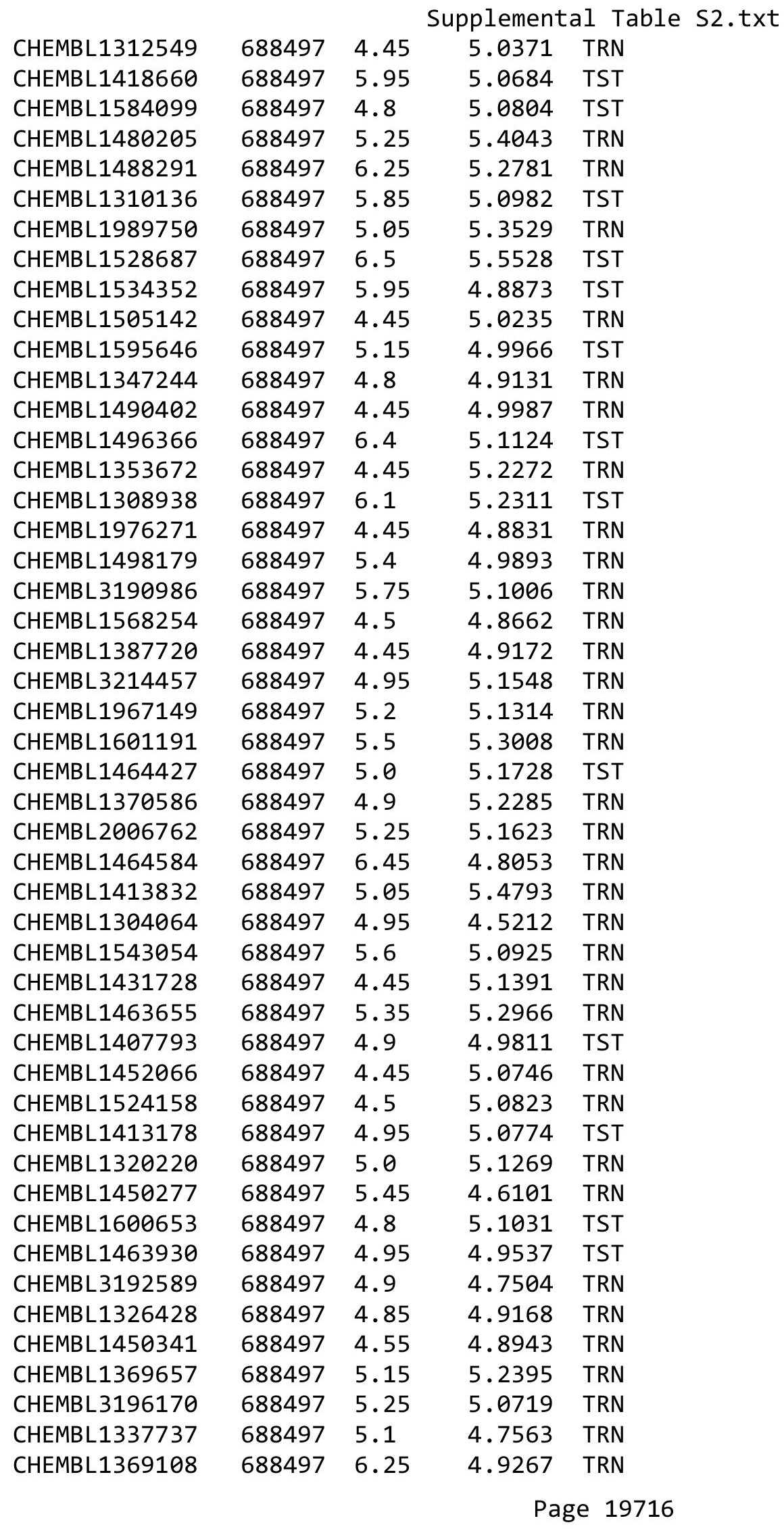




\begin{tabular}{|c|c|c|c|c|c|}
\hline & & \multicolumn{4}{|c|}{ Supplemental Table s2.txt } \\
\hline CHEMBL1399998 & 688497 & 4.95 & 5.0392 & TRN & \\
\hline CHEMBL1411646 & 688497 & 5.25 & 5.1208 & TRN & \\
\hline CHEMBL1307175 & 688497 & 4.45 & 5.1866 & TST & \\
\hline CHEMBL1523095 & 688497 & 6.2 & 5.2361 & TRN & \\
\hline CHEMBL1424264 & 688497 & 5.15 & 4.9656 & TST & \\
\hline CHEMBL3196933 & 688497 & 4.45 & 4.9322 & TRN & \\
\hline CHEMBL1539688 & 688497 & 5.4 & 5.2346 & TRN & \\
\hline CHEMBL1326184 & 688497 & 4.5 & 5.1907 & TRN & \\
\hline CHEMBL1573266 & 688497 & 5.2 & 5.0209 & TST & \\
\hline CHEMBL1502010 & 688497 & 4.85 & 5.0927 & TST & \\
\hline CHEMBL1466193 & 688497 & 4.45 & 4.7656 & TRN & \\
\hline CHEMBL1417662 & 688497 & 6.0 & 5.3124 & TST & \\
\hline CHEMBL1447885 & 688497 & 4.45 & 4.7663 & TRN & \\
\hline CHEMBL1372039 & 688497 & 4.65 & 5.1644 & TRN & \\
\hline CHEMBL1302762 & 688497 & 5.5 & 5.1341 & TRN & \\
\hline CHEMBL3194891 & 688497 & 4.45 & 4.9946 & TRN & \\
\hline CHEMBL1571018 & 688497 & 4.9 & 4.9835 & TST & \\
\hline CHEMBL1558702 & 688497 & 4.7 & 5.38200 & 0000000001 & TST \\
\hline CHEMBL1344822 & 688497 & 4.45 & 5.0681 & TRN & \\
\hline CHEMBL1344571 & 688497 & 4.65 & 4.7752 & TRN & \\
\hline CHEMBL1442172 & 688497 & 4.6 & 4.9773 & TRN & \\
\hline CHEMBL1613615 & 688497 & 4.45 & 4.9019 & TRN & \\
\hline CHEMBL601135 & 688497 & 5.1 & 4.9009 & TRN & \\
\hline CHEMBL1520173 & 688497 & 4.85 & 4.8005 & TST & \\
\hline CHEMBL1360591 & 688497 & 4.5 & 4.4977 & TST & \\
\hline CHEMBL1712384 & 688497 & 4.85 & 4.8098 & TRN & \\
\hline CHEMBL1482757 & 688497 & 4.95 & 4.8986 & TRN & \\
\hline CHEMBL1366948 & 688497 & 4.95 & 4.9451 & TST & \\
\hline CHEMBL 3212263 & 688497 & 4.9 & 5.1009 & TRN & \\
\hline CHEMBL1577801 & 688497 & 4.45 & 4.9547 & TRN & \\
\hline CHEMBL1506420 & 688497 & 5.1 & 5.0209 & TRN & \\
\hline CHEMBL1559993 & 688497 & 4.45 & 4.9511 & TRN & \\
\hline CHEMBL3207932 & 688497 & 4.9 & 5.2657 & TRN & \\
\hline CHEMBL3213943 & 688497 & 4.95 & 4.8734 & TRN & \\
\hline CHEMBL1380969 & 688497 & 4.75 & 4.6541 & TRN & \\
\hline CHEMBL1544420 & 688497 & 4.85 & 4.8644 & TRN & \\
\hline CHEMBL1541848 & 688497 & 5.0 & 5.2924 & TST & \\
\hline CHEMBL1428282 & 688497 & 4.65 & 4.9472 & TRN & \\
\hline CHEMBL1612699 & 688497 & 6.2 & 5.2039 & TST & \\
\hline CHEMBL1457861 & 688497 & 4.75 & 5.2573 & TRN & \\
\hline CHEMBL1987015 & 688497 & 4.95 & 4.8883 & TRN & \\
\hline CHEMBL1352974 & 688497 & 5.9 & 4.7847 & TRN & \\
\hline CHEMBL1312203 & 688497 & 5.2 & 4.9321 & TRN & \\
\hline CHEMBL1450152 & 688497 & 5.0 & 4.9396 & TRN & \\
\hline CHEMBL1307370 & 688497 & 4.9 & 5.1575 & TRN & \\
\hline CHEMBL1411492 & 688497 & 5.0 & 5.1103 & TRN & \\
\hline CHEMBL1978755 & 688497 & 4.6 & 4.8113 & TRN & \\
\hline CHEMBL1447975 & 688497 & 4.65 & 5.0059 & TRN & \\
\hline
\end{tabular}




\begin{tabular}{|c|c|c|c|c|c|}
\hline \multicolumn{6}{|c|}{ Supplemental Table S2.txt } \\
\hline CHEMBL1421959 & 688497 & 4.45 & 4.7287 & TRN & \\
\hline CHEMBL1403023 & 688497 & 5.95 & 5.6884 & TRN & \\
\hline CHEMBL1605353 & 688497 & 4.6 & 5.0461 & TRN & \\
\hline CHEMBL1421392 & 688497 & 4.5 & 5.1658 & TRN & \\
\hline CHEMBL1490040 & 688497 & 5.9 & 4.8848 & TRN & \\
\hline CHEMBL1385342 & 688497 & 4.65 & 4.871 & TRN & \\
\hline CHEMBL1570845 & 688497 & 4.45 & 5.0322 & TST & \\
\hline CHEMBL1477177 & 688497 & 4.95 & 4.9625 & TRN & \\
\hline CHEMBL1991234 & 688497 & 5.55 & 5.06 & TRN & \\
\hline CHEMBL1322701 & 688497 & 5.45 & 4.9478 & TRN & \\
\hline CHEMBL1422001 & 688497 & 5.05 & 5.129 & TRN & \\
\hline CHEMBL1471973 & 688497 & 5.05 & 5.1335 & TRN & \\
\hline CHEMBL1499411 & 688497 & 6.25 & 5.048 & TST & \\
\hline CHEMBL3194397 & 688497 & 5.1 & 4.743 & TRN & \\
\hline CHEMBL1352048 & 688497 & 4.75 & 4.7905 & TST & \\
\hline CHEMBL1439995 & 688497 & 6.4 & 5.21399 & 99999999995 & TST \\
\hline CHEMBL1575372 & 688497 & 5.0 & 4.8891 & TRN & \\
\hline CHEMBL1487660 & 688497 & 4.45 & 5.1448 & TRN & \\
\hline CHEMBL1404240 & 688497 & 5.4 & 5.1101 & TRN & \\
\hline CHEMBL3197275 & 688497 & 4.6 & 5.1098 & TRN & \\
\hline CHEMBL1526390 & 688497 & 6.05 & 4.9293 & TRN & \\
\hline CHEMBL1369623 & 688497 & 5.25 & 5.0039 & TRN & \\
\hline CHEMBL1508370 & 688497 & 4.95 & 4.9459 & TRN & \\
\hline CHEMBL1375555 & 688497 & 4.45 & 4.827 & TRN & \\
\hline CHEMBL1400965 & 688497 & 5.5 & 5.5023 & TRN & \\
\hline CHEMBL578109 & 688497 & 5.2 & 4.9594 & TRN & \\
\hline CHEMBL1969593 & 688497 & 4.85 & 5.0858 & TST & \\
\hline CHEMBL 2005825 & 688497 & 5.1 & 5.0006 & TRN & \\
\hline CHEMBL3196551 & 688497 & 4.45 & 5.0192 & TRN & \\
\hline CHEMBL 3214233 & 688497 & 5.6 & 4.8923 & TST & \\
\hline CHEMBL1345757 & 688497 & 4.85 & 5.4691 & TRN & \\
\hline CHEMBL3209065 & 688497 & 4.45 & 4.6452 & TRN & \\
\hline CHEMBL1530249 & 688497 & 5.95 & 4.9402 & TST & \\
\hline CHEMBL1415923 & 688497 & 5.25 & 5.3057 & TST & \\
\hline CHEMBL1556068 & 688497 & 4.45 & 4.9083 & TRN & \\
\hline CHEMBL1393582 & 688497 & 4.45 & 4.7734 & TRN & \\
\hline CHEMBL1347628 & 688497 & 4.6 & 5.4875 & TRN & \\
\hline CHEMBL1496539 & 688497 & 5.25 & 4.9691 & TRN & \\
\hline CHEMBL1425291 & 688497 & 5.05 & 4.9427 & TRN & \\
\hline CHEMBL1382496 & 688497 & 5.9 & 5.1833 & TRN & \\
\hline CHEMBL1386757 & 688497 & 4.9 & 4.8949 & TRN & \\
\hline CHEMBL1301495 & 688497 & 4.45 & 5.1304 & TST & \\
\hline CHEMBL1369199 & 688497 & 4.95 & 4.8778 & TRN & \\
\hline CHEMBL1330352 & 688497 & 4.45 & 5.1087 & TRN & \\
\hline CHEMBL3191398 & 688497 & 4.45 & 5.2091 & TRN & \\
\hline CHEMBL 3209451 & 688497 & 5.3 & 5.1616 & TRN & \\
\hline CHEMBL1581769 & 688497 & 5.2 & 5.0153 & TST & \\
\hline CHEMBL1224755 & 688497 & 4.45 & 5.1631 & TRN & \\
\hline
\end{tabular}




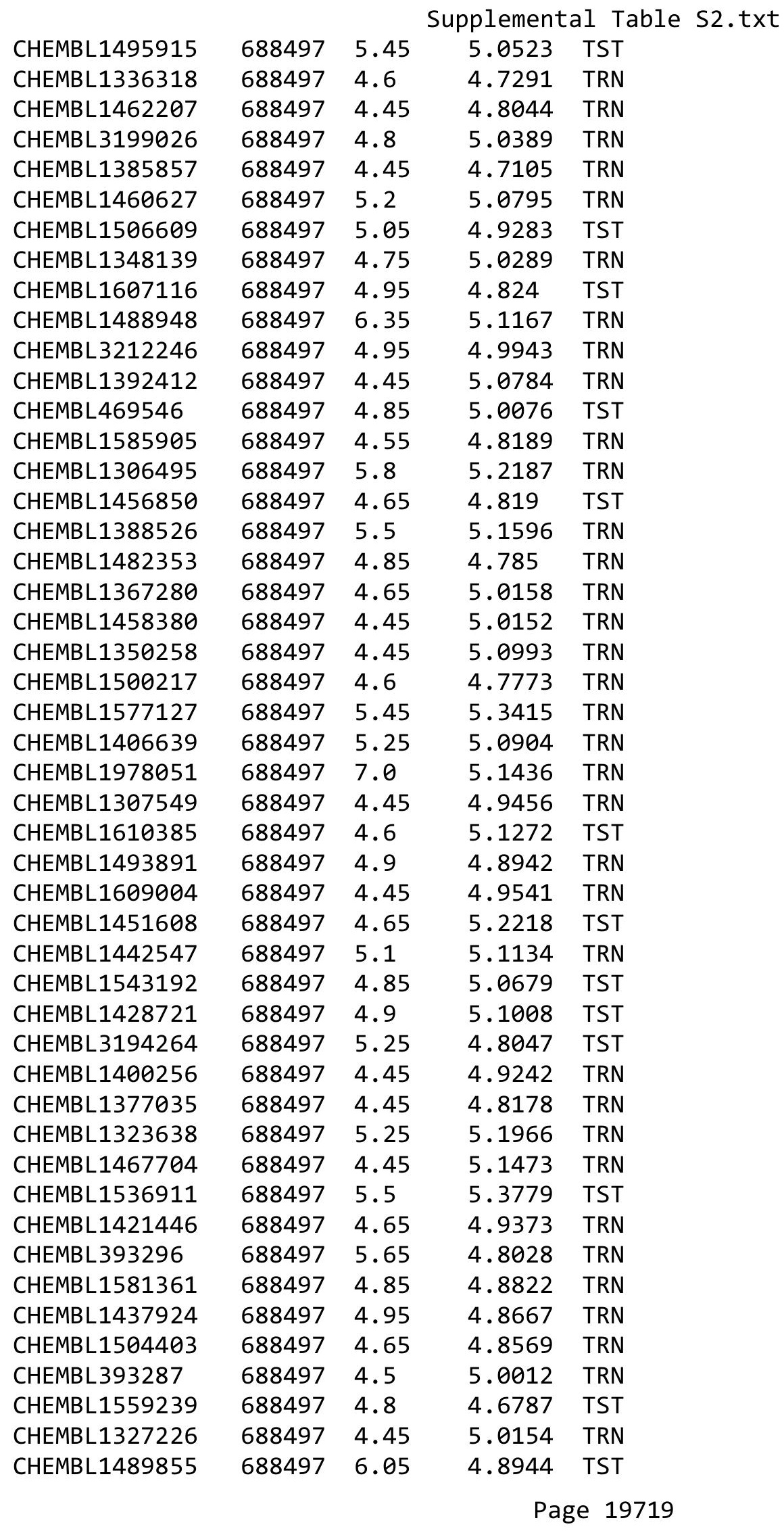




\begin{tabular}{|c|c|c|c|c|c|}
\hline & & \multicolumn{4}{|c|}{ Supplemental Table S2.txt } \\
\hline CHEMBL1323732 & 688497 & 4.45 & 4.8892 & TST & \\
\hline CHEMBL1526767 & 688497 & 4.85 & 5.1019 & TRN & \\
\hline CHEMBL1484484 & 688497 & 4.5 & 5.2164 & TRN & \\
\hline CHEMBL1602160 & 688497 & 4.45 & 5.0508 & TRN & \\
\hline CHEMBL1415476 & 688497 & 5.5 & 5.1351 & TST & \\
\hline CHEMBL563503 & 688497 & 4.95 & 5.0622 & TST & \\
\hline CHEMBL1368609 & 688497 & 4.65 & 4.7536 & TRN & \\
\hline CHEMBL1577373 & 688497 & 4.8 & 5.0522 & TRN & \\
\hline CHEMBL1596293 & 688497 & 4.45 & 5.0985 & TRN & \\
\hline CHEMBL1359031 & 688497 & 4.6 & 5.0399 & TRN & \\
\hline CHEMBL1322179 & 688497 & 7.5498 & 5.0756 & TST & \\
\hline CHEMBL1364924 & 688497 & 5.5 & 4.9976 & TRN & \\
\hline CHEMBL1557618 & 688497 & 5.2 & 5.2954 & TRN & \\
\hline CHEMBL1399774 & 688497 & 4.45 & 4.7263 & TRN & \\
\hline CHEMBL1607681 & 688497 & 4.45 & 4.88399 & 99999999995 & TST \\
\hline CHEMBL1531133 & 688497 & 4.95 & 4.9724 & TST & \\
\hline CHEMBL1462001 & 688497 & 4.6 & 4.9713 & TST & \\
\hline CHEMBL1485605 & 688497 & 4.45 & 4.7364 & TRN & \\
\hline CHEMBL1427578 & 688497 & 4.9 & 4.8856 & TRN & \\
\hline CHEMBL3208307 & 688497 & 4.45 & 5.02800 & 00000000005 & TST \\
\hline CHEMBL1311983 & 688497 & 3.0 & 5.3065 & TST & \\
\hline CHEMBL3209833 & 688497 & 5.25 & 4.7776 & TST & \\
\hline CHEMBL1578903 & 688497 & 5.65 & 4.9735 & TRN & \\
\hline CHEMBL1419791 & 688497 & 4.7 & 4.8966 & TST & \\
\hline CHEMBL1527131 & 688497 & 4.95 & 4.9014 & TRN & \\
\hline CHEMBL1606063 & 688497 & 6.25 & 4.9827 & TST & \\
\hline CHEMBL1432491 & 688497 & 5.1 & 5.12 & TRN & \\
\hline CHEMBL1341869 & 688497 & 4.9 & 4.9337 & TRN & \\
\hline CHEMBL1440612 & 688497 & 4.45 & 5.1634 & TRN & \\
\hline CHEMBL1349414 & 688497 & 5.35 & 4.9778 & TRN & \\
\hline CHEMBL1300317 & 688497 & 4.45 & 4.7546 & TRN & \\
\hline CHEMBL1312665 & 688497 & 5.0 & 4.5847 & TRN & \\
\hline CHEMBL1599496 & 688497 & 4.6 & 4.9818 & TRN & \\
\hline CHEMBL1572778 & 688497 & 5.25 & 5.5238 & TST & \\
\hline CHEMBL1496299 & 688497 & 4.45 & 4.9669 & TST & \\
\hline CHEMBL1463803 & 688497 & 4.45 & 5.1753 & TST & \\
\hline CHEMBL1409944 & 688497 & 4.65 & 4.7663 & TRN & \\
\hline CHEMBL3208427 & 688497 & 5.2 & 5.2184 & TRN & \\
\hline CHEMBL3196682 & 688497 & 4.6 & 4.9912 & TRN & \\
\hline CHEMBL1537100 & 688497 & 4.8 & 4.9293 & TRN & \\
\hline CHEMBL1425846 & 688497 & 6.45 & 4.8252 & TRN & \\
\hline CHEMBL1344522 & 688497 & 5.25 & 5.0629 & TST & \\
\hline CHEMBL1362081 & 688497 & 4.45 & 5.1112 & TRN & \\
\hline CHEMBL1493907 & 688497 & 4.5 & 5.0849 & TST & \\
\hline CHEMBL1418980 & 688497 & 5.05 & 4.9138 & TRN & \\
\hline CHEMBL1438357 & 688497 & 4.45 & 5.5059 & TST & \\
\hline CHEMBL1327074 & 688497 & 5.45 & 4.8255 & TRN & \\
\hline CHEMBL1498603 & 688497 & 4.45 & 4.7222 & TRN & \\
\hline
\end{tabular}




\begin{tabular}{|c|c|c|c|c|c|}
\hline \multicolumn{6}{|c|}{ Supplemental Table s2.txt } \\
\hline CHEMBL1330558 & 688497 & 5.35 & 5.1918 & TRN & \\
\hline CHEMBL1302886 & 688497 & 5.15 & 5.2303 & TRN & \\
\hline CHEMBL1301881 & 688497 & 4.45 & 4.6814 & TST & \\
\hline CHEMBL1401720 & 688497 & 4.5 & 4.8388 & TRN & \\
\hline CHEMBL1410805 & 688497 & 5.5 & 4.8594 & TRN & \\
\hline CHEMBL1586716 & 688497 & 4.8 & 4.9576 & TRN & \\
\hline CHEMBL1406399 & 688497 & 5.35 & 5.3408 & TRN & \\
\hline CHEMBL1312385 & 688497 & 5.0 & 5.1249 & TST & \\
\hline CHEMBL1580571 & 688497 & 4.95 & 4.848 & TRN & \\
\hline CHEMBL1470256 & 688497 & 5.1 & 5.5285 & TRN & \\
\hline CHEMBL1609746 & 688497 & 4.95 & 5.1724 & TRN & \\
\hline CHEMBL1376328 & 688497 & 5.25 & 4.746 & TRN & \\
\hline CHEMBL1432657 & 688497 & 4.95 & 5.3915 & TRN & \\
\hline CHEMBL1347441 & 688497 & 4.45 & 5.3498 & TST & \\
\hline CHEMBL1491290 & 688497 & 4.45 & 5.2894 & TRN & \\
\hline CHEMBL1462878 & 688497 & 4.85 & 4.9339 & TRN & \\
\hline CHEMBL1412273 & 688497 & 5.5 & 4.772 & TRN & \\
\hline CHEMBL1499962 & 688497 & 5.5 & 4.915 & TST & \\
\hline CHEMBL1412723 & 688497 & 4.6 & 5.09399 & 9999999999 & TRN \\
\hline CHEMBL1390783 & 688497 & 6.5 & 5.1176 & TRN & \\
\hline CHEMBL1365170 & 688497 & 4.75 & 4.8622 & TRN & \\
\hline CHEMBL1546223 & 688497 & 4.65 & 4.9869 & TRN & \\
\hline CHEMBL1391796 & 688497 & 6.4 & 5.1661 & TST & \\
\hline CHEMBL1577278 & 688497 & 5.35 & 5.4562 & TRN & \\
\hline CHEMBL1333467 & 688497 & 5.25 & 4.8989 & TST & \\
\hline CHEMBL3191675 & 688497 & 4.45 & 5.0181 & TST & \\
\hline CHEMBL1429719 & 688497 & 5.5 & 5.2577 & TST & \\
\hline CHEMBL1464684 & 688497 & 4.7 & 4.9522 & TRN & \\
\hline CHEMBL1499209 & 688497 & 5.0 & 4.9911 & TRN & \\
\hline CHEMBL1365369 & 688497 & 6.7501 & 5.0702 & TRN & \\
\hline CHEMBL1392251 & 688497 & 5.0 & 4.9918 & TRN & \\
\hline CHEMBL1562186 & 688497 & 4.95 & 5.3422 & TST & \\
\hline CHEMBL3211236 & 688497 & 5.5 & 4.9161 & TRN & \\
\hline CHEMBL1419587 & 688497 & 4.9 & 5.1173 & TST & \\
\hline CHEMBL1431091 & 688497 & 4.8 & 4.9162 & TRN & \\
\hline CHEMBL1477778 & 688497 & 5.5 & 4.5995 & TRN & \\
\hline CHEMBL1431833 & 688497 & 5.55 & 5.3076 & TRN & \\
\hline CHEMBL1606119 & 688497 & 4.45 & 5.0168 & TRN & \\
\hline CHEMBL1563229 & 688497 & 5.55 & 4.8616 & TRN & \\
\hline CHEMBL1606861 & 688497 & 5.2 & 5.2473 & TST & \\
\hline CHEMBL1583773 & 688497 & 6.0 & 5.1454 & TRN & \\
\hline CHEMBL1402676 & 688497 & 5.25 & 4.9469 & TST & \\
\hline CHEMBL1570002 & 688497 & 4.9 & 4.7825 & TRN & \\
\hline CHEMBL1560379 & 688497 & 4.55 & 4.7278 & TRN & \\
\hline CHEMBL1987454 & 688497 & 6.25 & 5.2042 & TRN & \\
\hline CHEMBL1511471 & 688497 & 4.45 & 4.7114 & TRN & \\
\hline CHEMBL1989897 & 688497 & 5.65 & 5.0425 & TRN & \\
\hline CHEMBL1344292 & 688497 & 5.3 & 5.0348 & TRN & \\
\hline
\end{tabular}




\begin{tabular}{|c|c|c|c|c|c|}
\hline \\
\hline CHEMBL1560598 & 688497 & 5.9 & 5.1589 & TST & \\
\hline CHEMBL578504 & 688497 & 5.55 & 5.4496 & TRN & \\
\hline CHEMBL1609980 & 688497 & 5.55 & 5.1052 & TST & \\
\hline CHEMBL 3198503 & 688497 & 5.7 & 5.2141 & TRN & \\
\hline CHEMBL1510930 & 688497 & 4.45 & 4.9181 & TRN & \\
\hline CHEMBL1445415 & 688497 & 4.45 & 4.816 & TST & \\
\hline CHEMBL1594279 & 688497 & 4.95 & 4.5052 & TRN & \\
\hline CHEMBL1444222 & 688497 & 5.5 & 5.3438 & TRN & \\
\hline CHEMBL1465475 & 688497 & 5.05 & 4.6942 & TRN & \\
\hline CHEMBL1418839 & 688497 & 4.95 & 5.0963 & TRN & \\
\hline CHEMBL1531123 & 688497 & 4.9 & 5.1507 & TRN & \\
\hline CHEMBL1300358 & 688497 & 4.95 & 4.9773 & TRN & \\
\hline CHEMBL1469464 & 688497 & 4.45 & 4.5823 & TRN & \\
\hline CHEMBL1352867 & 688497 & 5.5 & 5.1882 & TRN & \\
\hline CHEMBL1306438 & 688497 & 5.0 & 4.7177 & TRN & \\
\hline CHEMBL1432841 & 688497 & 5.45 & 4.8754 & TRN & \\
\hline CHEMBL 2003909 & 688497 & 4.45 & 5.0281 & TRN & \\
\hline CHEMBL1427001 & 688497 & 4.45 & 5.018 & TRN & \\
\hline CHEMBL1522032 & 688497 & 4.45 & 5.0218 & TRN & \\
\hline CHEMBL1307304 & 688497 & 4.65 & 4.8522 & TRN & \\
\hline CHEMBL1383241 & 688497 & 4.6 & 5.1137 & TST & \\
\hline CHEMBL1371554 & 688497 & 4.65 & 4.6846 & TRN & \\
\hline CHEMBL1481417 & 688497 & 4.45 & 5.2266 & TST & \\
\hline CHEMBL1345824 & 688497 & 4.6 & 4.8967 & TRN & \\
\hline CHEMBL1455542 & 688497 & 5.1 & 4.885 & TRN & \\
\hline CHEMBL1520120 & 688497 & 5.0 & 5.01399 & & TRN \\
\hline CHEMBL1558799 & 688497 & 4.85 & 5.0148 & TRN & \\
\hline CHEMBL1310906 & 688497 & 5.05 & 4.7379 & TRN & \\
\hline CHEMBL3212651 & 688497 & 6.5 & 5.3831 & TST & \\
\hline CHEMBL1499792 & 688497 & 5.05 & 5.2469 & TRN & \\
\hline CHEMBL1334792 & 688497 & 5.0 & 5.1203 & TRN & \\
\hline CHEMBL1299985 & 688497 & 4.65 & 4.8206 & TRN & \\
\hline CHEMBL1432255 & 688497 & 6.15 & 5.1776 & TRN & \\
\hline CHEMBL1454922 & 688497 & 6.2 & 5.1615 & TRN & \\
\hline CHEMBL3208292 & 688497 & 4.45 & 4.8581 & TRN & \\
\hline CHEMBL1588189 & 688497 & 5.2 & 5.1515 & TST & \\
\hline CHEMBL1542809 & 688497 & 5.0 & 5.0324 & TRN & \\
\hline CHEMBL1545404 & 688497 & 5.7 & 5.1537 & TST & \\
\hline CHEMBL1349394 & 688497 & 4.45 & 4.9301 & TRN & \\
\hline CHEMBL1571211 & 688497 & 4.45 & 5.0716 & TRN & \\
\hline CHEMBL1361472 & 688497 & 4.7 & 5.1586 & TRN & \\
\hline CHEMBL1507568 & 688497 & 5.3 & 4.8319 & TRN & \\
\hline CHEMBL1586082 & 688497 & 4.45 & 5.3839 & TST & \\
\hline CHEMBL1388753 & 688497 & 4.85 & 4.8309 & TRN & \\
\hline CHEMBL1597490 & 688497 & 4.5 & 5.0153 & TRN & \\
\hline CHEMBL1472388 & 688497 & 5.2 & 5.2089 & TRN & \\
\hline CHEMBL1311098 & 688497 & 6.25 & 5.0709 & TRN & \\
\hline CHEMBL1540428 & 688497 & 5.9 & 5.2652 & TRN & \\
\hline
\end{tabular}




\begin{tabular}{|c|c|c|c|c|c|}
\hline \multicolumn{6}{|c|}{ Supplemental Table s2.txt } \\
\hline CHEMBL1535514 & 688497 & 4.45 & 5.2714 & TRN & \\
\hline CHEMBL1482951 & 688497 & 5.65 & 5.0969 & TRN & \\
\hline CHEMBL1300923 & 688497 & 4.45 & 5.0499 & TRN & \\
\hline CHEMBL1407154 & 688497 & 5.8 & 5.1647 & TRN & \\
\hline CHEMBL1401211 & 688497 & 4.45 & 4.8282 & TRN & \\
\hline CHEMBL1489256 & 688497 & 4.9 & 4.793 & TRN & \\
\hline CHEMBL1337197 & 688497 & 6.0 & 5.0574 & TRN & \\
\hline CHEMBL1452119 & 688497 & 4.8 & 4.78 & TRN & \\
\hline CHEMBL1501990 & 688497 & 5.2 & 5.1582 & TST & \\
\hline CHEMBL1430662 & 688497 & 5.2 & 5.10800 & 00000000005 & TST \\
\hline CHEMBL1575333 & 688497 & 5.05 & 5.1053 & TRN & \\
\hline CHEMBL1479749 & 688497 & 6.05 & 5.0949 & TST & \\
\hline CHEMBL1378736 & 688497 & 5.2 & 4.9215 & TRN & \\
\hline CHEMBL1609757 & 688497 & 4.45 & 5.0817 & TRN & \\
\hline CHEMBL1555931 & 688497 & 5.55 & 4.8834 & TRN & \\
\hline CHEMBL1324938 & 688497 & 4.55 & 4.6969 & TRN & \\
\hline CHEMBL1608133 & 688497 & 4.45 & 4.7903 & TRN & \\
\hline CHEMBL1477979 & 688497 & 4.45 & 5.1532 & TRN & \\
\hline CHEMBL1587425 & 688497 & 4.9 & 4.8091 & TRN & \\
\hline CHEMBL1595774 & 688497 & 4.45 & 4.9545 & TRN & \\
\hline CHEMBL1545558 & 688497 & 6.25 & 4.9686 & TRN & \\
\hline CHEMBL1580646 & 688497 & 6.1 & 5.1505 & TRN & \\
\hline CHEMBL3208686 & 688497 & 4.45 & 4.9352 & TRN & \\
\hline CHEMBL585071 & 688497 & 4.45 & 5.2902 & TRN & \\
\hline CHEMBL1505546 & 688497 & 5.9 & 5.0732 & TRN & \\
\hline CHEMBL1377637 & 688497 & 4.5 & 5.0202 & TRN & \\
\hline CHEMBL1300709 & 688497 & 5.45 & 5.2072 & TRN & \\
\hline CHEMBL1490656 & 688497 & 4.45 & 4.8537 & TRN & \\
\hline CHEMBL1304887 & 688497 & 6.15 & 4.9825 & TRN & \\
\hline CHEMBL1449569 & 688497 & 4.45 & 4.6386 & TST & \\
\hline CHEMBL1586534 & 688497 & 5.45 & 5.2521 & TRN & \\
\hline CHEMBL1332130 & 688497 & 5.2 & 5.2073 & TRN & \\
\hline CHEMBL1599989 & 688497 & 5.45 & 5.0343 & TRN & \\
\hline CHEMBL1532067 & 688497 & 4.6 & 5.0792 & TRN & \\
\hline CHEMBL1459523 & 688497 & 5.15 & 5.2027 & TRN & \\
\hline CHEMBL1428950 & 688497 & 4.45 & 4.9197 & TRN & \\
\hline CHEMBL1423577 & 688497 & 5.25 & 5.0788 & TST & \\
\hline CHEMBL1312941 & 688497 & 5.65 & 5.3474 & TRN & \\
\hline CHEMBL1339650 & 688497 & 6.35 & 4.9942 & TRN & \\
\hline CHEMBL1422932 & 688497 & 4.95 & 4.8916 & TRN & \\
\hline CHEMBL1464558 & 688497 & 4.6 & 5.2139 & TRN & \\
\hline CHEMBL1309499 & 688497 & 5.25 & 5.1601 & TRN & \\
\hline CHEMBL1458003 & 688497 & 4.45 & 5.2989 & TRN & \\
\hline CHEMBL1393914 & 688497 & 5.65 & 4.8962 & TRN & \\
\hline CHEMBL1451752 & 688497 & 4.45 & 5.1674 & TRN & \\
\hline CHEMBL1325082 & 688497 & 5.05 & 5.19799 & 99999999995 & 151 \\
\hline CHEMBL464157 & 688497 & 6.3 & 5.2311 & TRN & \\
\hline CHEMBL1517577 & 688497 & 5.75 & 5.1059 & TRN & \\
\hline
\end{tabular}




\begin{tabular}{|c|c|c|c|c|}
\hline \multicolumn{5}{|c|}{ Supplemental Table S2.txt } \\
\hline CHEMBL1463840 & 688497 & 4.55 & 4.8803 & TRN \\
\hline CHEMBL1595884 & 688497 & 5.0 & 4.9274 & TRN \\
\hline CHEMBL1461082 & 688497 & 4.9 & 5.0711 & TRN \\
\hline CHEMBL1516456 & 688497 & 4.6 & 4.7283 & TST \\
\hline CHEMBL580183 & 688497 & 5.0 & 5.1056 & TST \\
\hline CHEMBL1579153 & 688497 & 4.65 & 5.2097 & TRN \\
\hline CHEMBL1374715 & 688497 & 4.8 & 5.4244 & TRN \\
\hline CHEMBL1417590 & 688497 & 4.5 & 4.7486 & TRN \\
\hline CHEMBL1503786 & 688497 & 4.45 & 4.6298 & TRN \\
\hline CHEMBL1428580 & 688497 & 4.8 & 4.8566 & TRN \\
\hline CHEMBL1444643 & 688497 & 4.95 & 4.9083 & TRN \\
\hline CHEMBL1509803 & 688497 & 4.45 & 5.1708 & TST \\
\hline CHEMBL1369101 & 688497 & 5.5 & 4.8389 & TRN \\
\hline CHEMBL1388168 & 688497 & 6.1 & 5.1388 & TST \\
\hline CHEMBL1373569 & 688497 & 4.45 & 4.9195 & TRN \\
\hline CHEMBL1373439 & 688497 & 4.9 & 5.0704 & TRN \\
\hline CHEMBL1478073 & 688497 & 4.45 & 4.8876 & TRN \\
\hline CHEMBL1460405 & 688497 & 4.45 & 4.67 & TRN \\
\hline CHEMBL1393113 & 688497 & 5.5 & 5.2613 & TRN \\
\hline CHEMBL1324051 & 688497 & 4.45 & 4.6821 & TRN \\
\hline CHEMBL1255837 & 688497 & 4.45 & 5.0799 & TST \\
\hline CHEMBL1524042 & 688497 & 5.25 & 5.1079 & TST \\
\hline CHEMBL244645 & 688497 & 4.6 & 5.1623 & TRN \\
\hline CHEMBL1594642 & 688497 & 6.95 & 5.1492 & TRN \\
\hline CHEMBL1504600 & 688497 & 5.9 & 4.6502 & TST \\
\hline CHEMBL1375532 & 688497 & 4.5 & 4.7789 & TRN \\
\hline CHEMBL1333538 & 688497 & 4.45 & 5.1007 & TRN \\
\hline CHEMBL1456225 & 688497 & 4.45 & 4.8717 & TRN \\
\hline CHEMBL3193882 & 688497 & 5.45 & 4.9257 & TRN \\
\hline CHEMBL547483 & 688497 & 4.45 & 5.0172 & TRN \\
\hline CHEMBL1486574 & 688497 & 4.45 & 4.9898 & TRN \\
\hline CHEMBL1990866 & 688497 & 4.45 & 4.9099 & TST \\
\hline CHEMBL1581280 & 688497 & 5.4 & 4.9349 & TRN \\
\hline CHEMBL1503392 & 688497 & 4.8 & 4.9709 & TRN \\
\hline CHEMBL1414443 & 688497 & 4.65 & 5.2125 & TRN \\
\hline CHEMBL1537558 & 688497 & 4.45 & 5.1247 & TRN \\
\hline CHEMBL1518432 & 688497 & 4.45 & 4.8846 & TRN \\
\hline CHEMBL1479010 & 688497 & 4.45 & 5.3231 & TST \\
\hline CHEMBL1385383 & 688497 & 4.9 & 4.7719 & TRN \\
\hline CHEMBL1389301 & 688497 & 5.5 & 4.8554 & TRN \\
\hline CHEMBL1495055 & 688497 & 4.8 & 5.0108 & TRN \\
\hline CHEMBL 1458775 & 688497 & 5.55 & 5.1839 & TRN \\
\hline CHEMBL1452003 & 688497 & 4.45 & 5.0057 & TRN \\
\hline CHEMBL578512 & 688497 & 5.3 & 5.3767 & TRN \\
\hline CHEMBL1378488 & 688497 & 5.3 & 4.8917 & TRN \\
\hline CHEMBL1366891 & 688497 & 4.9 & 5.0114 & TST \\
\hline CHEMBL1566600 & 688497 & 4.45 & 5.03 & TRN \\
\hline CHEMBL1333773 & 688497 & 4.95 & 4.9356 & TRN \\
\hline
\end{tabular}




\begin{tabular}{|c|c|c|c|c|c|}
\hline \multicolumn{6}{|c|}{ Supplemental Table S2.txt } \\
\hline CHEMBL1580514 & 688497 & 5.3 & 5.1541 & TRN & \\
\hline CHEMBL1604295 & 688497 & 4.45 & 5.2652 & TRN & \\
\hline CHEMBL1387592 & 688497 & 5.2 & 5.0048 & TRN & \\
\hline CHEMBL1480652 & 688497 & 5.7 & 5.1722 & TRN & \\
\hline CHEMBL1385207 & 688497 & 5.6 & 4.9537 & TRN & \\
\hline CHEMBL3193859 & 688497 & 6.0 & 5.1665 & TRN & \\
\hline CHEMBL1448074 & 688497 & 4.85 & 5.0533 & TRN & \\
\hline CHEMBL1399513 & 688497 & 4.45 & 5.2933 & TST & \\
\hline CHEMBL1304273 & 688497 & 4.95 & 5.3173 & TST & \\
\hline CHEMBL1305649 & 688497 & 4.45 & 4.9602 & TRN & \\
\hline CHEMBL3199705 & 688497 & 5.05 & 5.1465 & TRN & \\
\hline CHEMBL1543887 & 688497 & 4.8 & 5.069 & TRN & \\
\hline CHEMBL1558588 & 688497 & 4.7 & 4.9731 & TRN & \\
\hline CHEMBL1392426 & 688497 & 4.45 & 5.1164 & TST & \\
\hline CHEMBL1510439 & 688497 & 5.3 & 5.0345 & TRN & \\
\hline CHEMBL1569916 & 688497 & 5.25 & 5.3509 & TST & \\
\hline CHEMBL1346857 & 688497 & 4.9 & 5.1107 & TRN & \\
\hline CHEMBL1488699 & 688497 & 5.1 & 4.9443 & TST & \\
\hline CHEMBL1338476 & 688497 & 5.4 & 4.8149 & TRN & \\
\hline CHEMBL3209315 & 688497 & 5.25 & 4.9902 & TST & \\
\hline CHEMBL572203 & 688497 & 5.4 & 5.1353 & TRN & \\
\hline CHEMBL1419481 & 688497 & 6.25 & 4.9829 & TST & \\
\hline CHEMBL1406827 & 688497 & 4.45 & 5.5023 & TST & \\
\hline CHEMBL1302492 & 688497 & 4.75 & 4.6391 & TRN & \\
\hline CHEMBL1311319 & 688497 & 5.2 & 4.7938 & TRN & \\
\hline CHEMBL1544947 & 688497 & 5.45 & 4.9878 & TRN & \\
\hline CHEMBL1612223 & 688497 & 4.8 & 5.0784 & TST & \\
\hline CHEMBL1525518 & 688497 & 4.45 & 5.114 & TRN & \\
\hline CHEMBL1605224 & 688497 & 4.65 & 4.8445 & TRN & \\
\hline CHEMBL1509178 & 688497 & 5.45 & 5.5779 & TRN & \\
\hline CHEMBL1307998 & 688497 & 4.8 & 5.0387 & TRN & \\
\hline CHEMBL1490260 & 688497 & 4.45 & 5.1029 & TST & \\
\hline CHEMBL1347663 & 688497 & 4.5 & 4.7456 & TRN & \\
\hline CHEMBL3190786 & 688497 & 7.1002 & 5.3414 & TRN & \\
\hline CHEMBL1484425 & 688497 & 4.75 & 4.9696 & TST & \\
\hline CHEMBL1556864 & 688497 & 4.65 & 4.9107 & TST & \\
\hline CHEMBL1373467 & 688497 & 4.85 & 4.976 & TST & \\
\hline CHEMBL1535757 & 688497 & 4.6 & 5.0819 & TRN & \\
\hline CHEMBL1538161 & 688497 & 5.0 & 4.8308 & TRN & \\
\hline CHEMBL1556602 & 688497 & 5.05 & $5.2020 e$ & 0000000001 & TRN \\
\hline CHEMBL1506728 & 688497 & 4.45 & 5.0144 & TRN & \\
\hline CHEMBL1500879 & 688497 & 5.9 & 4.9988 & TRN & \\
\hline CHEMBL1392844 & 688497 & 5.5 & 5.3029 & TRN & \\
\hline CHEMBL1324386 & 688497 & 4.9 & 4.9222 & TRN & \\
\hline CHEMBL1309632 & 688497 & 6.3 & 4.9398 & TRN & \\
\hline CHEMBL1354210 & 688497 & 4.45 & 4.6684 & TRN & \\
\hline CHEMBL1430895 & 688497 & 5.15 & 4.7665 & TRN & \\
\hline CHEMBL1511887 & 688497 & 5.45 & 4.8897 & TRN & \\
\hline
\end{tabular}




\begin{tabular}{|c|c|c|c|c|c|}
\hline \multicolumn{6}{|c|}{ Supplemental Table S2.txt } \\
\hline CHEMBL1322916 & 688497 & 5.0 & 5.2544 & TST & \\
\hline CHEMBL581225 & 688497 & 5.3 & 5.2807 & TST & \\
\hline CHEMBL1539797 & 688497 & 4.45 & 5.151 & TST & \\
\hline CHEMBL1510635 & 688497 & 5.0 & 4.9879 & TRN & \\
\hline CHEMBL1370299 & 688497 & 6.3 & 5.1963 & TST & \\
\hline CHEMBL1575657 & 688497 & 5.9 & 5.2146 & TRN & \\
\hline CHEMBL1534035 & 688497 & 4.95 & 5.1402 & TST & \\
\hline CHEMBL1595820 & 688497 & 4.8 & 5.0735 & TRN & \\
\hline CHEMBL1546343 & 688497 & 5.0 & 4.872 & TRN & \\
\hline CHEMBL3191835 & 688497 & 4.9 & 5.0951 & TRN & \\
\hline CHEMBL1596457 & 688497 & 4.95 & 4.8692 & TRN & \\
\hline CHEMBL1477643 & 688497 & 5.45 & 5.0498 & TRN & \\
\hline CHEMBL1996757 & 688497 & 4.55 & 4.61600 & 00000000005 & TST \\
\hline CHEMBL1453708 & 688497 & 4.45 & 4.7598 & TRN & \\
\hline CHEMBL3197773 & 688497 & 4.45 & 5.1253 & TRN & \\
\hline CHEMBL1377133 & 688497 & 4.95 & 4.9643 & TRN & \\
\hline CHEMBL1486258 & 688497 & 4.45 & 5.2641 & TRN & \\
\hline CHEMBL1483757 & 688497 & 4.85 & 4.8664 & TST & \\
\hline CHEMBL1425667 & 688497 & 4.45 & 5.2633 & TST & \\
\hline CHEMBL1419909 & 688497 & 4.75 & 5.0521 & TRN & \\
\hline CHEMBL1338374 & 688497 & 4.95 & 5.2826 & TST & \\
\hline CHEMBL1428889 & 688497 & 4.9 & 4.9988 & TRN & \\
\hline CHEMBL1576427 & 688497 & 5.25 & 4.9111 & TRN & \\
\hline CHEMBL1307513 & 688497 & 4.7 & 5.1401 & TST & \\
\hline CHEMBL1424818 & 688497 & 4.9 & 4.6925 & TRN & \\
\hline CHEMBL1310543 & 688497 & 4.45 & 5.0928 & TRN & \\
\hline CHEMBL1588083 & 688497 & 4.9 & 5.0623 & TST & \\
\hline CHEMBL1368283 & 688497 & 4.65 & 5.0465 & TRN & \\
\hline CHEMBL1508912 & 688497 & 5.45 & 5.0274 & TRN & \\
\hline CHEMBL1581152 & 688497 & 5.0 & 5.1926 & TST & \\
\hline CHEMBL1384141 & 688497 & 5.55 & 5.0737 & TRN & \\
\hline CHEMBL1490512 & 688497 & 5.25 & 5.3326 & TST & \\
\hline CHEMBL1448116 & 688497 & 7.0 & 5.2258 & TRN & \\
\hline CHEMBL1371387 & 688497 & 9.0458 & 5.2538 & TRN & \\
\hline CHEMBL1539295 & 688497 & 4.95 & 4.9389 & TST & \\
\hline CHEMBL1517139 & 688497 & 5.6 & 5.0561 & TST & \\
\hline CHEMBL1498360 & 688497 & 4.95 & 4.984 & TST & \\
\hline CHEMBL1334794 & 688497 & 5.15 & 4.6576 & TRN & \\
\hline CHEMBL1588739 & 688497 & 6.1 & 5.2069 & TST & \\
\hline CHEMBL1376504 & 688497 & 4.45 & 4.6541 & TRN & \\
\hline CHEMBL1405332 & 688497 & 6.25 & 5.3664 & TST & \\
\hline CHEMBL1500199 & 688497 & 4.65 & 4.7793 & TRN & \\
\hline CHEMBL1362889 & 688497 & 4.45 & 4.947 & TRN & \\
\hline CHEMBL1402360 & 688497 & 5.5 & 4.7732 & TRN & \\
\hline CHEMBL65374 & 688497 & 5.25 & 5.0143 & TRN & \\
\hline CHEMBL1424021 & 688497 & 4.5 & 4.8792 & TST & \\
\hline CHEMBL1511215 & 688497 & 5.1 & 5.1392 & TST & \\
\hline CHEMBL1392332 & 688497 & 5.25 & 5.0431 & TST & \\
\hline
\end{tabular}




\begin{tabular}{|c|c|c|c|c|}
\hline \multirow[b]{2}{*}{ CHEMBL2002849 } & \multicolumn{4}{|c|}{ Supplemental Table S2.txt } \\
\hline & 688497 & 5.5 & 5.0391 & TST \\
\hline CHEMBL1423541 & 688497 & 5.5 & 5.1295 & TRN \\
\hline CHEMBL1459355 & 688497 & 4.45 & 4.992 & TRN \\
\hline CHEMBL1578033 & 688497 & 6.25 & 5.2887 & TRN \\
\hline CHEMBL1609564 & 688497 & 5.4 & 5.0265 & TST \\
\hline CHEMBL1550371 & 688497 & 4.45 & 5.0485 & TRN \\
\hline CHEMBL 1468000 & 688497 & 5.45 & 5.0793 & TST \\
\hline CHEMBL1412412 & 688497 & 4.5 & 4.9081 & TRN \\
\hline CHEMBL1497821 & 688497 & 4.45 & 5.1247 & TRN \\
\hline CHEMBL1610851 & 688497 & 5.55 & 5.0703 & TRN \\
\hline CHEMBL 3193808 & 688497 & 4.45 & 5.2017 & TST \\
\hline CHEMBL1566873 & 688497 & 4.45 & 5.0948 & TRN \\
\hline CHEMBL 3198544 & 688497 & 5.5 & 5.4853 & TRN \\
\hline CHEMBL1333510 & 688497 & 4.45 & 4.8764 & TRN \\
\hline CHEMBL1583377 & 688497 & 4.5 & 5.1851 & TST \\
\hline CHEMBL1610271 & 688497 & 5.05 & 5.1445 & TRN \\
\hline CHEMBL1400385 & 688497 & 4.95 & 5.0606 & TRN \\
\hline CHEMBL1563060 & 688497 & 5.3 & 5.0588 & TRN \\
\hline CHEMBL1334347 & 688497 & 4.9 & 5.2615 & TST \\
\hline CHEMBL1547895 & 688497 & 4.45 & 4.8907 & TRN \\
\hline CHEMBL1321614 & 688497 & 4.45 & 4.6338 & TRN \\
\hline CHEMBL1412098 & 688497 & 5.55 & 4.816 & TST \\
\hline CHEMBL1622981 & 688497 & 4.45 & 4.9393 & TST \\
\hline CHEMBL1505313 & 688497 & 4.45 & 4.9267 & TST \\
\hline CHEMBL 2001071 & 688497 & 5.0 & 5.0041 & TRN \\
\hline CHEMBL1501344 & 688497 & 5.5 & 5.4249 & TST \\
\hline CHEMBL1605642 & 688497 & 4.95 & 4.8476 & TRN \\
\hline CHEMBL1467216 & 688497 & 5.7 & 4.9937 & TRN \\
\hline CHEMBL1448990 & 688497 & 4.45 & 5.3008 & TRN \\
\hline CHEMBL1969992 & 688497 & 5.95 & 5.2788 & TRN \\
\hline CHEMBL1612884 & 688497 & 7.5003 & 5.5137 & TRN \\
\hline CHEMBL1565059 & 688497 & 4.95 & 5.0462 & TRN \\
\hline CHEMBL1567312 & 688497 & 6.3 & 5.2001 & TST \\
\hline CHEMBL1419182 & 688497 & 5.55 & 5.1594 & TST \\
\hline CHEMBL1407203 & 688497 & 4.65 & 5.1706 & TRN \\
\hline CHEMBL1377581 & 688497 & 5.95 & 5.0692 & TRN \\
\hline CHEMBL1472133 & 688497 & 4.65 & 4.9261 & TRN \\
\hline CHEMBL1481713 & 688497 & 4.9 & 4.8283 & TRN \\
\hline CHEMBL1325108 & 688497 & 5.3 & 5.3713 & TRN \\
\hline CHEMBL1461901 & 688497 & 4.45 & 5.1201 & TRN \\
\hline CHEMBL1464866 & 688497 & 4.6 & 4.9159 & TRN \\
\hline CHEMBL1424664 & 688497 & 4.6 & 5.1812 & TRN \\
\hline CHEMBL 2004351 & 688497 & 5.2 & 5.1585 & TST \\
\hline CHEMBL1337889 & 688497 & 5.9 & 4.9975 & TRN \\
\hline CHEMBL1519667 & 688497 & 4.95 & 4.9173 & TST \\
\hline CHEMBL1485010 & 688497 & 5.4 & 4.9615 & TRN \\
\hline CHEMBL1596758 & 688497 & 4.5 & 4.9813 & TRN \\
\hline CHEMBL1605100 & 688497 & 4.85 & 4.9266 & TRN \\
\hline
\end{tabular}




\begin{tabular}{|c|c|c|c|c|}
\hline \multicolumn{5}{|c|}{ Supplemental Table S2.txt } \\
\hline CHEMBL419815 & 688497 & 4.45 & 4.9423 & TST \\
\hline CHEMBL1607806 & 688497 & 5.45 & 5.3008 & TRN \\
\hline CHEMBL10276 & 688497 & 4.45 & 5.1198 & TST \\
\hline CHEMBL1312783 & 688497 & 4.7 & 5.0302 & TST \\
\hline CHEMBL1598279 & 688497 & 4.45 & 5.2496 & TRN \\
\hline CHEMBL1579942 & 688497 & 5.4 & 5.0583 & TRN \\
\hline CHEMBL1417711 & 688497 & 6.25 & 4.9979 & TST \\
\hline CHEMBL1428758 & 688497 & 5.5 & 4.7431 & TRN \\
\hline CHEMBL1371873 & 688497 & 4.75 & 4.7384 & TRN \\
\hline CHEMBL1576787 & 688497 & 5.0 & 4.7231 & TRN \\
\hline CHEMBL1342385 & 688497 & 4.9 & 4.7672 & TST \\
\hline CHEMBL1508723 & 688497 & 4.85 & 4.9519 & TRN \\
\hline CHEMBL1507490 & 688497 & 4.95 & 5.0898 & TRN \\
\hline CHEMBL1491702 & 688497 & 4.45 & 4.9221 & TRN \\
\hline CHEMBL1575090 & 688497 & 5.5 & 5.4714 & TST \\
\hline CHEMBL1532044 & 688497 & 5.95 & 5.2922 & TRN \\
\hline CHEMBL1472513 & 688497 & 4.6 & 5.3021 & TRN \\
\hline CHEMBL1447393 & 688497 & 4.45 & 5.4812 & TRN \\
\hline CHEMBL1411331 & 688497 & 4.45 & 5.0715 & TRN \\
\hline CHEMBL1390126 & 688497 & 4.75 & 5.1104 & TRN \\
\hline CHEMBL1389300 & 688497 & 4.45 & 5.1059 & TRN \\
\hline CHEMBL3211326 & 688497 & 5.0 & 5.1211 & TRN \\
\hline CHEMBL1457679 & 688497 & 4.45 & 5.0085 & TRN \\
\hline CHEMBL1507680 & 688497 & 4.45 & 5.1725 & TRN \\
\hline CHEMBL3197516 & 688497 & 5.6 & 4.9556 & TRN \\
\hline CHEMBL1328442 & 688497 & 7.5003 & 5.0363 & TRN \\
\hline CHEMBL3199710 & 688497 & 4.45 & 4.8827 & TRN \\
\hline CHEMBL1560564 & 688497 & 5.05 & 4.8022 & TST \\
\hline CHEMBL1497999 & 688497 & 5.1 & 5.0953 & TRN \\
\hline CHEMBL1462989 & 688497 & 4.85 & 5.2023 & TRN \\
\hline CHEMBL1863606 & 688497 & 4.9 & 5.0005 & TRN \\
\hline CHEMBL1502254 & 688497 & 5.5 & 4.5862 & TRN \\
\hline CHEMBL1464644 & 688497 & 4.8 & 5.0129 & TRN \\
\hline CHEMBL1444635 & 688497 & 5.45 & 5.2634 & TRN \\
\hline CHEMBL154358 & 688497 & 6.25 & 5.4443 & TST \\
\hline CHEMBL1333983 & 688497 & 4.45 & 5.1368 & TST \\
\hline CHEMBL1341676 & 688497 & 4.6 & 4.6353 & TRN \\
\hline CHEMBL1319393 & 688497 & 5.25 & 5.316 & TRN \\
\hline CHEMBL3208960 & 688497 & 5.55 & 5.1404 & TRN \\
\hline CHEMBL3189959 & 688497 & 4.75 & 4.8686 & TST \\
\hline CHEMBL1608045 & 688497 & 6.3 & 5.2134 & TRN \\
\hline CHEMBL1589130 & 688497 & 4.45 & 4.8935 & TRN \\
\hline CHEMBL1372076 & 688497 & 4.5 & 4.8863 & TRN \\
\hline CHEMBL1491828 & 688497 & 5.0 & 5.2124 & TRN \\
\hline CHEMBL1988851 & 688497 & 5.25 & 4.8522 & TRN \\
\hline CHEMBL1579585 & 688497 & 4.8 & 4.7824 & TRN \\
\hline CHEMBL 1407290 & 688497 & 5.25 & 4.9386 & TST \\
\hline CHEMBL1489149 & 688497 & 5.4 & 5.409 & TRN \\
\hline
\end{tabular}




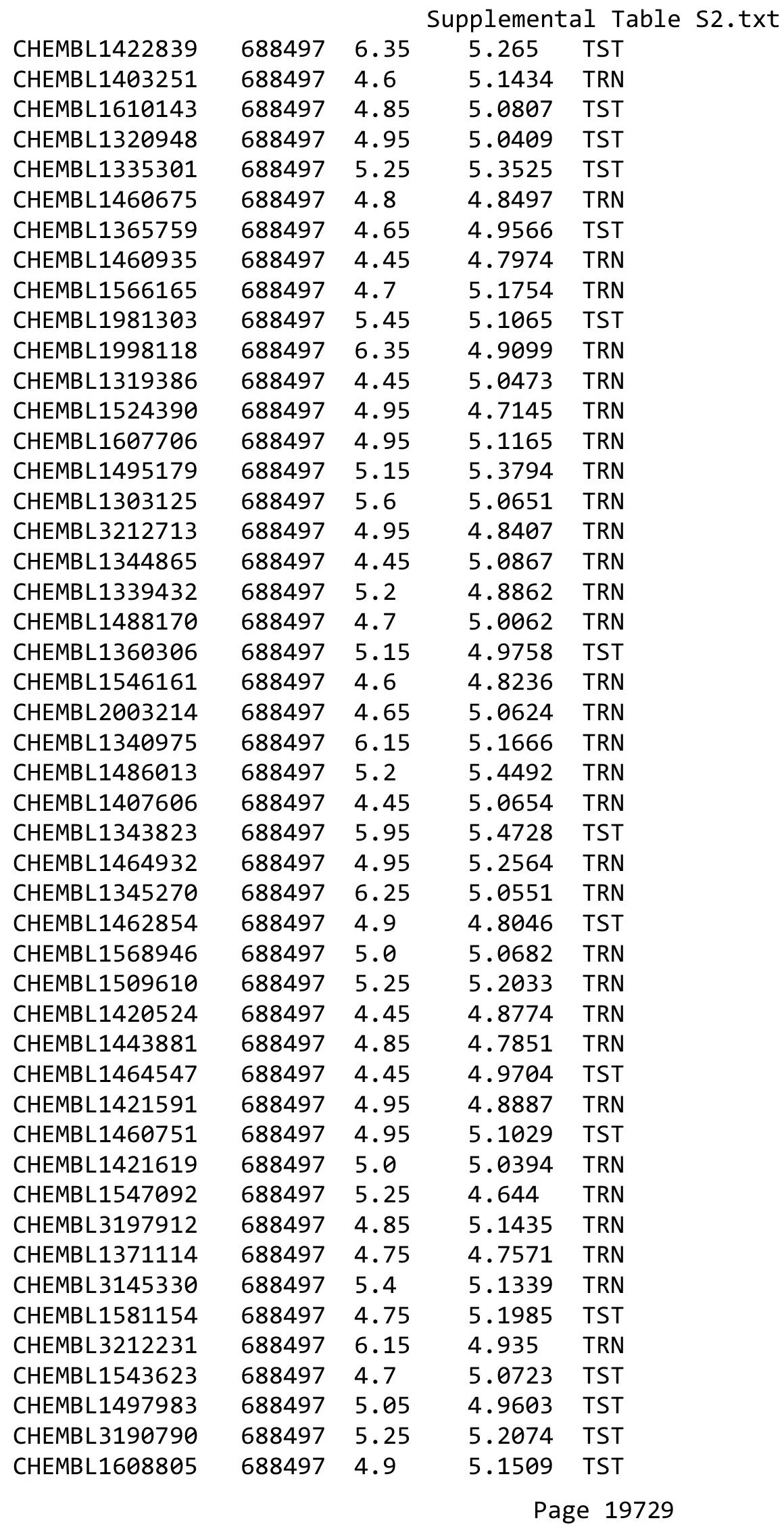




\begin{tabular}{|c|c|c|c|c|c|}
\hline \multicolumn{6}{|c|}{ Supplemental Table S2.txt } \\
\hline CHEMBL1458308 & 688497 & 5.5 & 5.318 & TRN & \\
\hline CHEMBL1451470 & 688497 & 5.5 & 4.8395 & TRN & \\
\hline CHEMBL1350280 & 688497 & 5.2 & 5.4224 & TRN & \\
\hline CHEMBL1546497 & 688497 & 5.05 & 4.9309 & TRN & \\
\hline CHEMBL1374866 & 688497 & 4.45 & 4.977 & TRN & \\
\hline CHEMBL1381531 & 688497 & 4.9 & 5.2233 & TRN & \\
\hline CHEMBL1479201 & 688497 & 5.0 & 4.8306 & TRN & \\
\hline CHEMBL1383244 & 688497 & 4.8 & 4.8952 & TRN & \\
\hline CHEMBL1447995 & 688497 & 6.1 & 4.965 & TRN & \\
\hline CHEMBL1544847 & 688497 & 5.2 & 5.0811 & TRN & \\
\hline CHEMBL1380324 & 688497 & 4.45 & 5.2787 & TST & \\
\hline CHEMBL1517551 & 688497 & 4.5 & 4.8071 & TRN & \\
\hline CHEMBL1449135 & 688497 & 4.8 & 4.8678 & TRN & \\
\hline CHEMBL1323072 & 688497 & 4.6 & 4.7456 & TRN & \\
\hline CHEMBL1402174 & 688497 & 4.8 & 5.0589 & TRN & \\
\hline CHEMBL1326935 & 688497 & 5.2 & 5.3495 & TRN & \\
\hline CHEMBL1561936 & 688497 & 4.45 & 5.1323 & TRN & \\
\hline CHEMBL1600092 & 688497 & 4.85 & 5.2036 & TST & \\
\hline CHEMBL1556460 & 688497 & 5.05 & 5.0965 & TRN & \\
\hline CHEMBL1346004 & 688497 & 4.6 & 4.7487 & TRN & \\
\hline CHEMBL1390633 & 688497 & 4.95 & 5.1514 & TST & \\
\hline CHEMBL1427857 & 688497 & 5.25 & 4.9134 & TST & \\
\hline CHEMBL1350673 & 688497 & 6.2 & 5.2388 & TRN & \\
\hline CHEMBL1488101 & 688497 & 4.45 & 5.0695 & TST & \\
\hline CHEMBL1491786 & 688497 & 5.55 & 4.8795 & TST & \\
\hline CHEMBL1416064 & 688497 & 5.9 & 5.12299 & 9999999999 & TRN \\
\hline CHEMBL1376266 & 688497 & 4.85 & 4.8354 & TRN & \\
\hline CHEMBL1493204 & 688497 & 4.45 & 4.8796 & TST & \\
\hline CHEMBL1531357 & 688497 & 4.95 & 4.7244 & TRN & \\
\hline CHEMBL1586594 & 688497 & 4.45 & 5.0859 & TRN & \\
\hline CHEMBL1385771 & 688497 & 4.45 & 4.6856 & TRN & \\
\hline CHEMBL1581975 & 688497 & 4.95 & 5.2801 & TRN & \\
\hline CHEMBL1509377 & 688497 & 5.85 & 5.3608 & TRN & \\
\hline CHEMBL1431524 & 688497 & 4.65 & 4.8247 & TRN & \\
\hline CHEMBL1481094 & 688497 & 4.8 & 4.7702 & TRN & \\
\hline CHEMBL1362352 & 688497 & 4.45 & 5.0198 & TRN & \\
\hline CHEMBL1495076 & 688497 & 5.8 & 5.0224 & TST & \\
\hline CHEMBL1607687 & 688497 & 4.45 & 5.2006 & TST & \\
\hline CHEMBL1446949 & 688497 & 4.95 & 5.17899 & 9999999999 & TST \\
\hline CHEMBL1430723 & 688497 & 6.1 & 5.1799 & TRN & \\
\hline CHEMBL3196267 & 688497 & 5.25 & 5.1676 & TRN & \\
\hline CHEMBL1529511 & 688497 & 6.25 & 4.9734 & TRN & \\
\hline CHEMBL1337481 & 688497 & 5.75 & 5.2426 & TST & \\
\hline CHEMBL1302460 & 688497 & 5.45 & 4.9499 & TRN & \\
\hline CHEMBL1360861 & 688497 & 5.25 & 5.1266 & TRN & \\
\hline CHEMBL1347697 & 688497 & 5.7 & 5.1344 & TRN & \\
\hline CHEMBL1335678 & 688497 & 4.95 & 4.7758 & TRN & \\
\hline CHEMBL1983342 & 688497 & 6.2 & 5.0038 & TST & \\
\hline
\end{tabular}




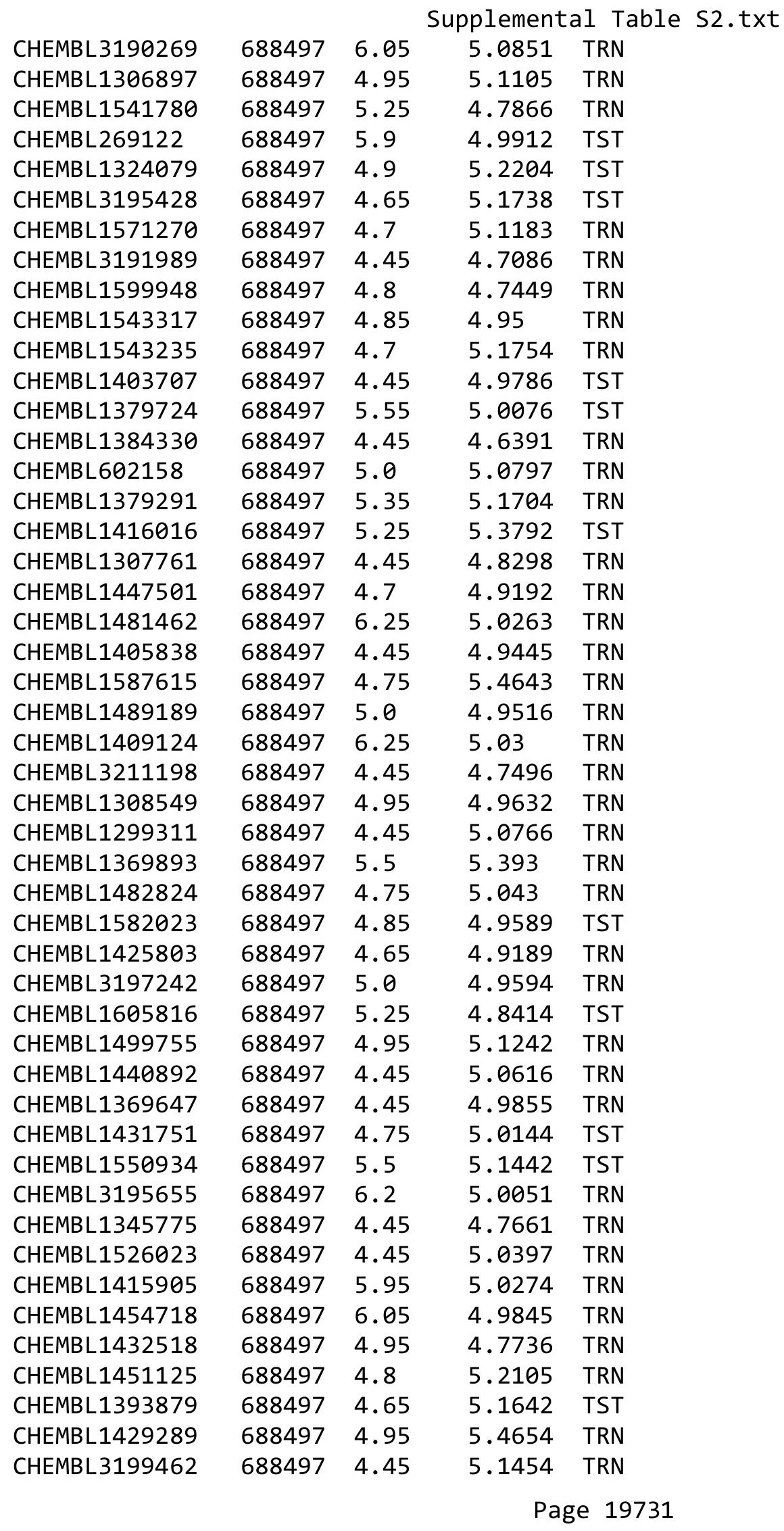




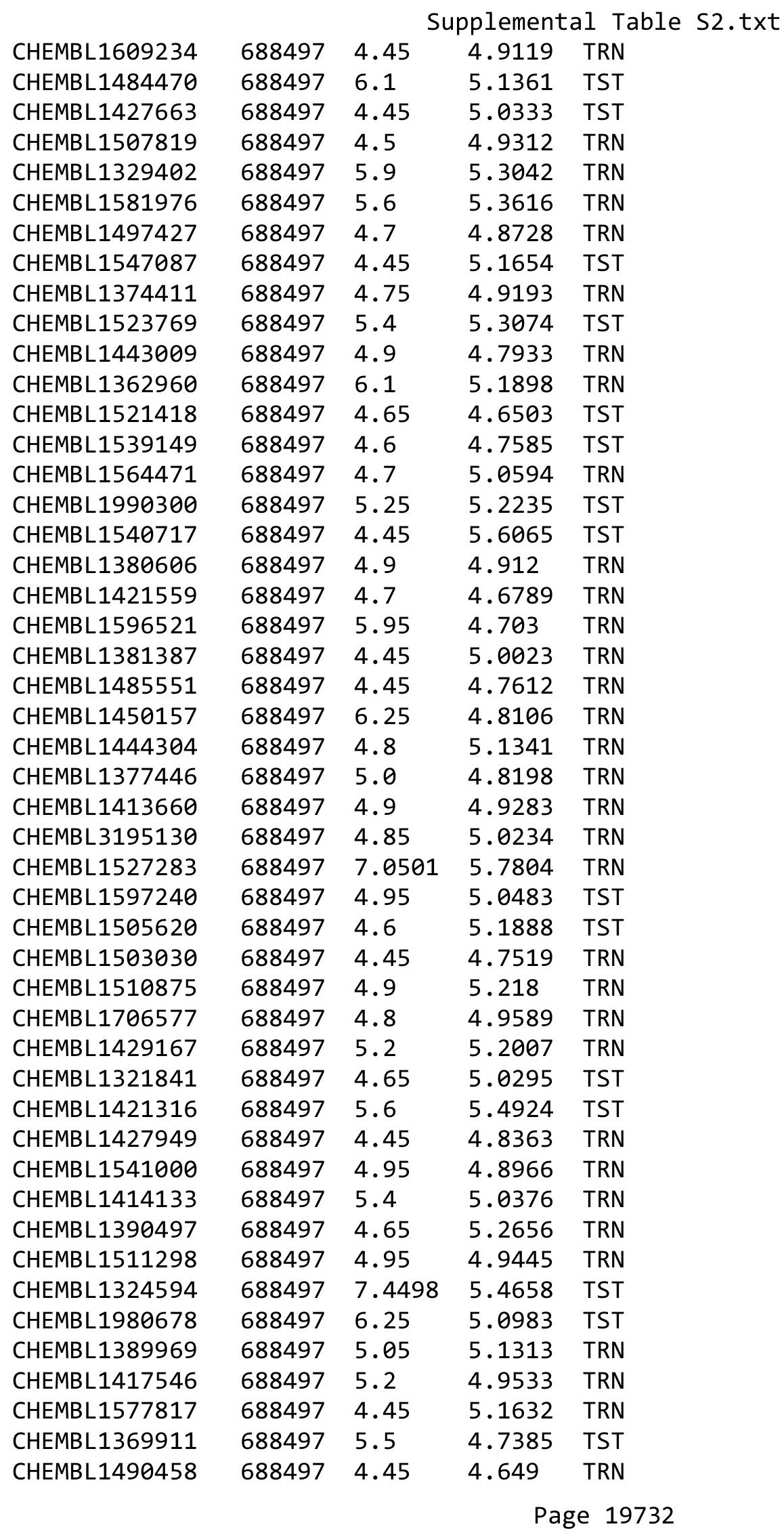




\begin{tabular}{|c|c|c|c|c|}
\hline & & & & al Table \\
\hline CHEMBL1410575 & 688497 & 4.6 & 5.0111 & TRN \\
\hline CHEMBL1349076 & 688497 & 6.25 & 5.1933 & TST \\
\hline CHEMBL3196139 & 688497 & 5.35 & 5.5958 & TRN \\
\hline CHEMBL1387850 & 688497 & 4.45 & 4.9959 & TST \\
\hline CHEMBL1470636 & 688497 & 4.75 & 4.8226 & TRN \\
\hline CHEMBL1457542 & 688497 & 4.45 & 4.9741 & TRN \\
\hline CHEMBL1588714 & 688497 & 4.65 & 5.0151 & TRN \\
\hline CHEMBL1430910 & 688497 & 4.95 & 5.0671 & TST \\
\hline CHEMBL1604011 & 688497 & 4.6 & 4.755 & TRN \\
\hline CHEMBL1365380 & 688497 & 5.0 & 4.9582 & TST \\
\hline CHEMBL1540269 & 688497 & 5.25 & 5.2102 & TST \\
\hline CHEMBL1340201 & 688497 & 4.8 & 4.9456 & TRN \\
\hline CHEMBL1458225 & 688497 & 4.55 & 4.9093 & TRN \\
\hline CHEMBL1408705 & 688497 & 4.45 & 4.5294 & TRN \\
\hline CHEMBL1454133 & 688497 & 5.8 & 5.1897 & TRN \\
\hline CHEMBL 1457910 & 688497 & 4.45 & 5.1187 & TRN \\
\hline CHEMBL1467422 & 688497 & 4.45 & 4.9258 & TRN \\
\hline CHEMBL1487352 & 688497 & 6.25 & 5.33700 & 0000000001 \\
\hline CHEMBL1303508 & 688497 & 5.5 & 4.7465 & TRN \\
\hline CHEMBL1457427 & 688497 & 4.8 & 4.7567 & TRN \\
\hline CHEMBL1390139 & 688497 & 4.45 & 4.6052 & TRN \\
\hline CHEMBL1384609 & 688497 & 4.65 & 5.3227 & TRN \\
\hline CHEMBL1441782 & 688497 & 5.05 & 4.9244 & TRN \\
\hline CHEMBL1335712 & 688497 & 4.45 & 4.8142 & TRN \\
\hline CHEMBL1587722 & 688497 & 4.9 & 5.0463 & TRN \\
\hline CHEMBL1531910 & 688497 & 4.95 & 5.0348 & TRN \\
\hline CHEMBL1369825 & 688497 & 4.95 & 5.193 & TST \\
\hline CHEMBL1412709 & 688497 & 4.8 & 4.9799 & TRN \\
\hline CHEMBL1601427 & 688497 & 5.0 & 4.9296 & TRN \\
\hline CHEMBL1332391 & 688497 & 4.65 & 4.9823 & TST \\
\hline CHEMBL1607984 & 688497 & 5.25 & 5.1525 & TRN \\
\hline CHEMBL1506460 & 688497 & 5.05 & 4.8708 & TRN \\
\hline CHEMBL3196335 & 688497 & 4.45 & 5.2154 & TRN \\
\hline CHEMBL1450770 & 688497 & 4.65 & 5.0973 & TST \\
\hline CHEMBL1535811 & 688497 & 4.5 & 5.2126 & TST \\
\hline CHEMBL1449642 & 688497 & 5.25 & 4.9649 & TRN \\
\hline CHEMBL1494420 & 688497 & 5.2 & 5.1119 & TRN \\
\hline CHEMBL1418634 & 688497 & 4.6 & 5.0028 & TRN \\
\hline CHEMBL1370083 & 688497 & 5.45 & 4.7168 & TRN \\
\hline CHEMBL1492188 & 688497 & 4.75 & 4.8186 & TRN \\
\hline CHEMBL1334714 & 688497 & 4.85 & 4.8419 & TST \\
\hline CHEMBL1380684 & 688497 & 6.0 & 5.402 & TST \\
\hline CHEMBL1342609 & 688497 & 4.45 & 4.9761 & TRN \\
\hline CHEMBL1443931 & 688497 & 5.6 & 5.3599 & TST \\
\hline CHEMBL1359249 & 688497 & 4.45 & 5.0741 & TRN \\
\hline CHEMBL1335610 & 688497 & 4.45 & 4.8451 & TRN \\
\hline CHEMBL1545064 & 688497 & 4.8 & 4.8595 & TRN \\
\hline CHEMBL1333877 & 688497 & 5.0 & 4.9966 & TST \\
\hline
\end{tabular}




\begin{tabular}{|c|c|c|c|c|c|}
\hline & & \multicolumn{4}{|c|}{ Supplemental Table s2.txt } \\
\hline CHEMBL1310654 & 688497 & 3.7 & 5.5788 & TST & \\
\hline CHEMBL1299698 & 688497 & 4.65 & 4.9285 & TRN & \\
\hline CHEMBL1401449 & 688497 & 5.95 & 5.1308 & TRN & \\
\hline CHEMBL1560982 & 688497 & 4.75 & 5.1315 & TRN & \\
\hline CHEMBL1367899 & 688497 & 4.5 & 4.6382 & TRN & \\
\hline CHEMBL3207593 & 688497 & 5.9 & 5.0004 & TST & \\
\hline CHEMBL1575776 & 688497 & 4.8 & 5.0724 & TST & \\
\hline CHEMBL1497710 & 688497 & 6.3 & 5.0756 & TST & \\
\hline CHEMBL1385618 & 688497 & 5.45 & 5.1462 & TRN & \\
\hline CHEMBL1413846 & 688497 & 4.45 & 4.9658 & TRN & \\
\hline CHEMBL1584692 & 688497 & 4.6 & 5.1505 & TRN & \\
\hline CHEMBL1611137 & 688497 & 4.6 & 4.745 & TRN & \\
\hline CHEMBL1322563 & 688497 & 5.45 & 4.7762 & TRN & \\
\hline CHEMBL1352840 & 688497 & 4.6 & 5.1665 & TRN & \\
\hline CHEMBL1585764 & 688497 & 4.55 & 4.8165 & TRN & \\
\hline CHEMBL1374907 & 688497 & 5.5 & 5.0157 & TRN & \\
\hline CHEMBL1558079 & 688497 & 4.45 & 4.8507 & TRN & \\
\hline CHEMBL1539536 & 688497 & 5.0 & 4.6834 & TRN & \\
\hline CHEMBL1352614 & 688497 & 5.4 & 5.0781 & TRN & \\
\hline CHEMBL1462032 & 688497 & 4.45 & 5.0305 & TST & \\
\hline CHEMBL1387421 & 688497 & 4.45 & 4.3968 & TST & \\
\hline CHEMBL1507676 & 688497 & 4.6 & 5.3 & TST & \\
\hline CHEMBL 2000259 & 688497 & 4.45 & 5.1709 & TST & \\
\hline CHEMBL1331226 & 688497 & 4.65 & 4.999 & TRN & \\
\hline CHEMBL1416916 & 688497 & 5.25 & 5.4153 & TST & \\
\hline CHEMBL1312078 & 688497 & 5.35 & 5.2874 & TRN & \\
\hline CHEMBL1466712 & 688497 & 4.75 & 5.1227 & TRN & \\
\hline CHEMBL 3192785 & 688497 & 4.95 & 5.2379 & TRN & \\
\hline CHEMBL1307587 & 688497 & 4.6 & 4.8254 & TST & \\
\hline CHEMBL1477597 & 688497 & 4.45 & 4.7471 & TRN & \\
\hline CHEMBL1523624 & 688497 & 4.45 & 5.225 & TST & \\
\hline CHEMBL1450583 & 688497 & 4.75 & 5.1708 & TRN & \\
\hline CHEMBL1965132 & 688497 & 5.2 & 5.3297 & TRN & \\
\hline CHEMBL1537140 & 688497 & 4.6 & 4.8734 & TRN & \\
\hline CHEMBL1462270 & 688497 & 5.0 & 4.9039 & TRN & \\
\hline CHEMBL 3197594 & 688497 & 4.9 & 5.2203 & TRN & \\
\hline CHEMBL1596718 & 688497 & 4.9 & 4.9444 & TRN & \\
\hline CHEMBL1301887 & 688497 & 5.55 & 4.8293 & TRN & \\
\hline CHEMBL1530816 & 688497 & 5.7 & 5.229 & TST & \\
\hline CHEMBL 3189531 & 688497 & 5.5 & 5.1771 & TRN & \\
\hline CHEMBL1323620 & 688497 & 5.25 & 5.3744 & TRN & \\
\hline CHEMBL1566205 & 688497 & 5.15 & 5.3135 & TST & \\
\hline CHEMBL1348059 & 688497 & 5.2 & 4.9006 & TST & \\
\hline CHEMBL1401787 & 688497 & 5.9 & 5.4853 & TRN & \\
\hline CHEMBL1353163 & 688497 & 4.55 & 4.9261 & TRN & \\
\hline CHEMBL1382263 & 688497 & 5.4 & 5.0927 & TST & \\
\hline CHEMBL1308842 & 688497 & 5.25 & 5.16299 & 9999999999 & TRN \\
\hline CHEMBL1582319 & 688497 & 4.65 & 5.0105 & TRN & \\
\hline
\end{tabular}




\begin{tabular}{|c|c|c|c|c|c|}
\hline \multicolumn{6}{|c|}{ Supplemental Table s2.txt } \\
\hline CHEMBL1528139 & 688497 & 4.95 & 5.0684 & TST & \\
\hline CHEMBL391533 & 688497 & 4.9 & 4.9827 & TST & \\
\hline CHEMBL3192872 & 688497 & 5.55 & 5.2539 & TRN & \\
\hline CHEMBL1365585 & 688497 & 5.1 & 4.8892 & TRN & \\
\hline CHEMBL1455866 & 688497 & 6.35 & 5.0577 & TRN & \\
\hline CHEMBL1405111 & 688497 & 4.5 & 4.5385 & TRN & \\
\hline CHEMBL1306752 & 688497 & 4.45 & 5.0839 & TRN & \\
\hline CHEMBL1377924 & 688497 & 4.55 & 4.9891 & TRN & \\
\hline CHEMBL1386368 & 688497 & 4.95 & 5.2095 & TST & \\
\hline CHEMBL1464080 & 688497 & 4.85 & 4.9845 & TRN & \\
\hline CHEMBL1499195 & 688497 & 5.05 & 4.9028 & TRN & \\
\hline CHEMBL1486468 & 688497 & 6.5 & 5.3434 & TRN & \\
\hline CHEMBL1584810 & 688497 & 4.7 & \multicolumn{2}{|c|}{5.0569999999999995} & TST \\
\hline CHEMBL1489644 & 688497 & 4.45 & 5.0576 & TRN & \\
\hline CHEMBL1528150 & 688497 & 6.3 & 5.2436 & TRN & \\
\hline CHEMBL469036 & 688497 & 5.4 & 5.2392 & TST & \\
\hline CHEMBL1557031 & 688497 & 5.15 & 5.2904 & TRN & \\
\hline CHEMBL1367388 & 688497 & 5.9 & 5.0282 & TRN & \\
\hline CHEMBL1546240 & 688497 & 4.45 & 5.1414 & TRN & \\
\hline CHEMBL1594182 & 688497 & 4.45 & 4.8662 & TRN & \\
\hline CHEMBL1485988 & 688497 & 5.55 & 5.0052 & TRN & \\
\hline CHEMBL1485727 & 688497 & 5.2 & 5.2348 & TRN & \\
\hline CHEMBL1566725 & 688497 & 5.25 & 5.0061 & TRN & \\
\hline CHEMBL1575148 & 688497 & 4.45 & 5.1088 & TRN & \\
\hline CHEMBL1490461 & 688497 & 5.25 & 5.2848 & TST & \\
\hline CHEMBL3210205 & 688497 & 5.4 & 5.3102 & TST & \\
\hline CHEMBL1465271 & 688497 & 4.95 & 5.2285 & TRN & \\
\hline CHEMBL1429312 & 688497 & 5.4 & 4.9369 & TRN & \\
\hline CHEMBL1425562 & 688497 & 4.9 & 5.0971 & TST & \\
\hline CHEMBL1461090 & 688497 & 4.45 & 4.7497 & TRN & \\
\hline CHEMBL1539122 & 688497 & 4.6 & 5.3647 & TST & \\
\hline CHEMBL1485898 & 688497 & 4.45 & 5.0527 & TRN & \\
\hline CHEMBL1410609 & 688497 & 4.9 & 4.7033 & TRN & \\
\hline CHEMBL1415932 & 688497 & 4.6 & 4.5726 & TRN & \\
\hline CHEMBL1985429 & 688497 & 5.25 & 4.8353 & TST & \\
\hline CHEMBL1561395 & 688497 & 4.45 & 4.8202 & TST & \\
\hline CHEMBL1444859 & 688497 & 4.45 & 5.003 & TRN & \\
\hline CHEMBL1479793 & 688497 & 5.05 & 5.1586 & TRN & \\
\hline CHEMBL1574116 & 688497 & 4.6 & 4.8053 & TRN & \\
\hline CHEMBL1328297 & 688497 & 5.45 & 5.0292 & TRN & \\
\hline CHEMBL1323362 & 688497 & 4.45 & 5.1281 & TST & \\
\hline CHEMBL1306311 & 688497 & 4.85 & 5.0669 & TRN & \\
\hline CHEMBL1542884 & 688497 & 5.6 & 4.9883 & TST & \\
\hline CHEMBL1536690 & 688497 & 5.55 & 5.3544 & TST & \\
\hline CHEMBL1539459 & 688497 & 5.55 & 4.9493 & TRN & \\
\hline CHEMBL1432344 & 688497 & 5.9 & 5.2313 & TST & \\
\hline CHEMBL3210272 & 688497 & 4.65 & 5.2249 & TRN & \\
\hline \multirow[t]{2}{*}{ CHEMBL1539432 } & 688497 & 5.8 & 5.16799 & 9999999999 & TRN \\
\hline & & \multicolumn{4}{|c|}{ Page 19735} \\
\hline
\end{tabular}




\begin{tabular}{|c|c|c|c|c|c|}
\hline \multicolumn{6}{|c|}{ Supplemental Table S2.txt } \\
\hline CHEMBL1586425 & 688497 & 5.5 & 5.3554 & TRN & \\
\hline CHEMBL1353958 & 688497 & 5.9 & 4.9568 & TST & \\
\hline CHEMBL1448912 & 688497 & 4.45 & 5.3187 & TRN & \\
\hline CHEMBL1452169 & 688497 & 5.9 & 4.9496 & TRN & \\
\hline CHEMBL1545612 & 688497 & 5.35 & 5.2206 & TST & \\
\hline CHEMBL1312337 & 688497 & 4.45 & 4.8016 & TRN & \\
\hline CHEMBL1327617 & 688497 & 5.0 & 4.7782 & TST & \\
\hline CHEMBL1416651 & 688497 & 4.45 & 5.0446 & TRN & \\
\hline CHEMBL1457932 & 688497 & 6.0 & 5.4857 & TST & \\
\hline CHEMBL1337685 & 688497 & 4.9 & 5.254 & TST & \\
\hline CHEMBL1416591 & 688497 & 4.45 & 4.9952 & TRN & \\
\hline CHEMBL1414867 & 688497 & 4.85 & 5.0509 & TRN & \\
\hline CHEMBL3192865 & 688497 & 4.45 & 4.7219 & TRN & \\
\hline CHEMBL1419685 & 688497 & 4.45 & 4.6555 & TST & \\
\hline CHEMBL1352566 & 688497 & 5.95 & 5.3368 & TRN & \\
\hline CHEMBL1608610 & 688497 & 4.45 & 4.8451 & TRN & \\
\hline CHEMBL1350667 & 688497 & 6.25 & 5.1284 & TST & \\
\hline CHEMBL1430886 & 688497 & 4.95 & 4.7449 & TRN & \\
\hline CHEMBL1534711 & 688497 & 5.9 & 5.0641 & TRN & \\
\hline CHEMBL1347295 & 688497 & 4.8 & 4.7253 & TST & \\
\hline CHEMBL1385938 & 688497 & 5.95 & 5.3159 & TRN & \\
\hline CHEMBL1305849 & 688497 & 4.45 & 4.6093 & TRN & \\
\hline CHEMBL1363519 & 688497 & 6.95 & 5.1119 & TRN & \\
\hline CHEMBL1409202 & 688497 & 4.45 & 5.0314 & TRN & \\
\hline CHEMBL1455873 & 688497 & 4.45 & 4.7994 & TRN & \\
\hline CHEMBL1489944 & 688497 & 5.0 & 5.0145 & TRN & \\
\hline CHEMBL1422102 & 688497 & 5.55 & 5.0405 & TST & \\
\hline CHEMBL1384217 & 688497 & 7.0501 & 4.9918 & TRN & \\
\hline CHEMBL1309087 & 688497 & 5.5 & 5.05699 & 99999999995 & TRN \\
\hline CHEMBL1362418 & 688497 & 4.9 & 5.2974 & TRN & \\
\hline CHEMBL1320542 & 688497 & 4.85 & 5.0106 & TRN & \\
\hline CHEMBL 3210881 & 688497 & 5.9 & 5.0985 & TRN & \\
\hline CHEMBL1997827 & 688497 & 5.55 & 5.232 & TRN & \\
\hline CHEMBL1345104 & 688497 & 5.65 & 4.6772 & TRN & \\
\hline CHEMBL1369795 & 688497 & 6.25 & 5.2009 & TRN & \\
\hline CHEMBL1387914 & 688497 & 5.55 & 5.0749 & TRN & \\
\hline CHEMBL1312935 & 688497 & 7.0 & 5.3068 & TRN & \\
\hline CHEMBL1508914 & 688497 & 4.8 & 4.7084 & TRN & \\
\hline CHEMBL1324999 & 688497 & 5.25 & 4.8475 & TST & \\
\hline CHEMBL 2007184 & 688497 & 6.25 & 5.2771 & TST & \\
\hline CHEMBL1567815 & 688497 & 5.05 & 4.8703 & TRN & \\
\hline CHEMBL1505410 & 688497 & 4.45 & 5.0433 & TRN & \\
\hline CHEMBL1400175 & 688497 & 5.45 & 5.3799 & TRN & \\
\hline CHEMBL1453167 & 688497 & 5.25 & 5.0672 & TRN & \\
\hline CHEMBL1525164 & 688497 & 4.45 & 4.9799 & TRN & \\
\hline CHEMBL1508694 & 688497 & 5.9 & 5.2656 & TRN & \\
\hline CHEMBL1417430 & 688497 & 4.45 & 5.0461 & TST & \\
\hline CHEMBL1325582 & 688497 & 6.25 & 5.2362 & TRN & \\
\hline
\end{tabular}




\begin{tabular}{|c|c|c|c|c|c|}
\hline & & \multicolumn{4}{|c|}{ Supplemental Table S2.txt } \\
\hline CHEMBL3209502 & 688497 & 6.25 & 5.3693 & TRN & \\
\hline CHEMBL1323327 & 688497 & 4.8 & 5.0666 & TRN & \\
\hline CHEMBL1373313 & 688497 & 4.45 & 4.9485 & TST & \\
\hline CHEMBL1532412 & 688497 & 5.5 & 5.1388 & TRN & \\
\hline CHEMBL1560875 & 688497 & 6.0 & 5.11600 & 00000000005 & TRN \\
\hline CHEMBL3198057 & 688497 & 5.15 & 5.1775 & TST & \\
\hline CHEMBL1484105 & 688497 & 4.45 & 4.96899 & 9999999999 & TST \\
\hline CHEMBL1439293 & 688497 & 5.2 & 5.0517 & TST & \\
\hline CHEMBL1370128 & 688497 & 4.45 & 5.0477 & TRN & \\
\hline CHEMBL1307723 & 688497 & 4.85 & 5.3445 & TRN & \\
\hline CHEMBL1549644 & 688497 & 4.45 & 5.1705 & TRN & \\
\hline CHEMBL1342795 & 688497 & 4.9 & 4.9586 & TRN & \\
\hline CHEMBL1369304 & 688497 & 4.45 & 4.9413 & TRN & \\
\hline CHEMBL1384476 & 688497 & 4.7 & 4.9614 & TRN & \\
\hline CHEMBL1412203 & 688497 & 4.75 & 5.0032 & TRN & \\
\hline CHEMBL1340170 & 688497 & 4.95 & 5.0441 & TRN & \\
\hline CHEMBL1503609 & 688497 & 4.95 & 4.6169 & TRN & \\
\hline CHEMBL1449196 & 688497 & 4.45 & 4.9337 & TRN & \\
\hline CHEMBL1310454 & 688497 & 4.6 & 4.8811 & TRN & \\
\hline CHEMBL1478123 & 688497 & 4.75 & 4.9171 & TRN & \\
\hline CHEMBL1392776 & 688497 & 6.0 & 5.0329 & TRN & \\
\hline CHEMBL1499748 & 688497 & 4.45 & 4.9088 & TST & \\
\hline CHEMBL1322482 & 688497 & 5.05 & 4.9762 & TST & \\
\hline CHEMBL3192113 & 688497 & 4.65 & 4.9592 & TST & \\
\hline CHEMBL1430718 & 688497 & 4.65 & 4.9945 & TRN & \\
\hline CHEMBL1993662 & 688497 & 5.05 & 5.1406 & TRN & \\
\hline CHEMBL1560067 & 688497 & 5.5 & 5.3192 & TST & \\
\hline CHEMBL3194297 & 688497 & 4.45 & 5.1954 & TRN & \\
\hline CHEMBL1368952 & 688497 & 5.0 & 4.9426 & TST & \\
\hline CHEMBL1324755 & 688497 & 5.45 & 5.4193 & TRN & \\
\hline CHEMBL1536551 & 688497 & 6.25 & 5.4277 & TRN & \\
\hline CHEMBL327574 & 688497 & 4.6 & 5.2288 & TRN & \\
\hline CHEMBL1421039 & 688497 & 4.95 & 4.9223 & TRN & \\
\hline CHEMBL601146 & 688497 & 4.95 & 5.4977 & TRN & \\
\hline CHEMBL3144970 & 688497 & 4.7 & 4.8867 & TST & \\
\hline CHEMBL1572979 & 688497 & 5.0 & 4.9196 & TRN & \\
\hline CHEMBL1401489 & 688497 & 5.0 & 5.3648 & TST & \\
\hline CHEMBL1596357 & 688497 & 4.65 & 4.547 & TRN & \\
\hline CHEMBL1443237 & 688497 & 4.95 & 4.8135 & TRN & \\
\hline CHEMBL1407153 & 688497 & 5.4 & 4.9217 & TRN & \\
\hline CHEMBL3194477 & 688497 & 4.45 & 5.018 & TRN & \\
\hline CHEMBL1439675 & 688497 & 4.45 & 4.7429 & TRN & \\
\hline CHEMBL1410160 & 688497 & 4.45 & 4.9269 & TRN & \\
\hline CHEMBL1463795 & 688497 & 6.5 & 5.4694 & TRN & \\
\hline CHEMBL1543919 & 688497 & 4.55 & 4.985 & TST & \\
\hline CHEMBL1581244 & 688497 & 4.95 & 4.7993 & TST & \\
\hline CHEMBL1442118 & 688497 & 4.65 & 4.941 & TRN & \\
\hline CHEMBL1545417 & 688497 & 4.95 & 5.0957 & TRN & \\
\hline
\end{tabular}




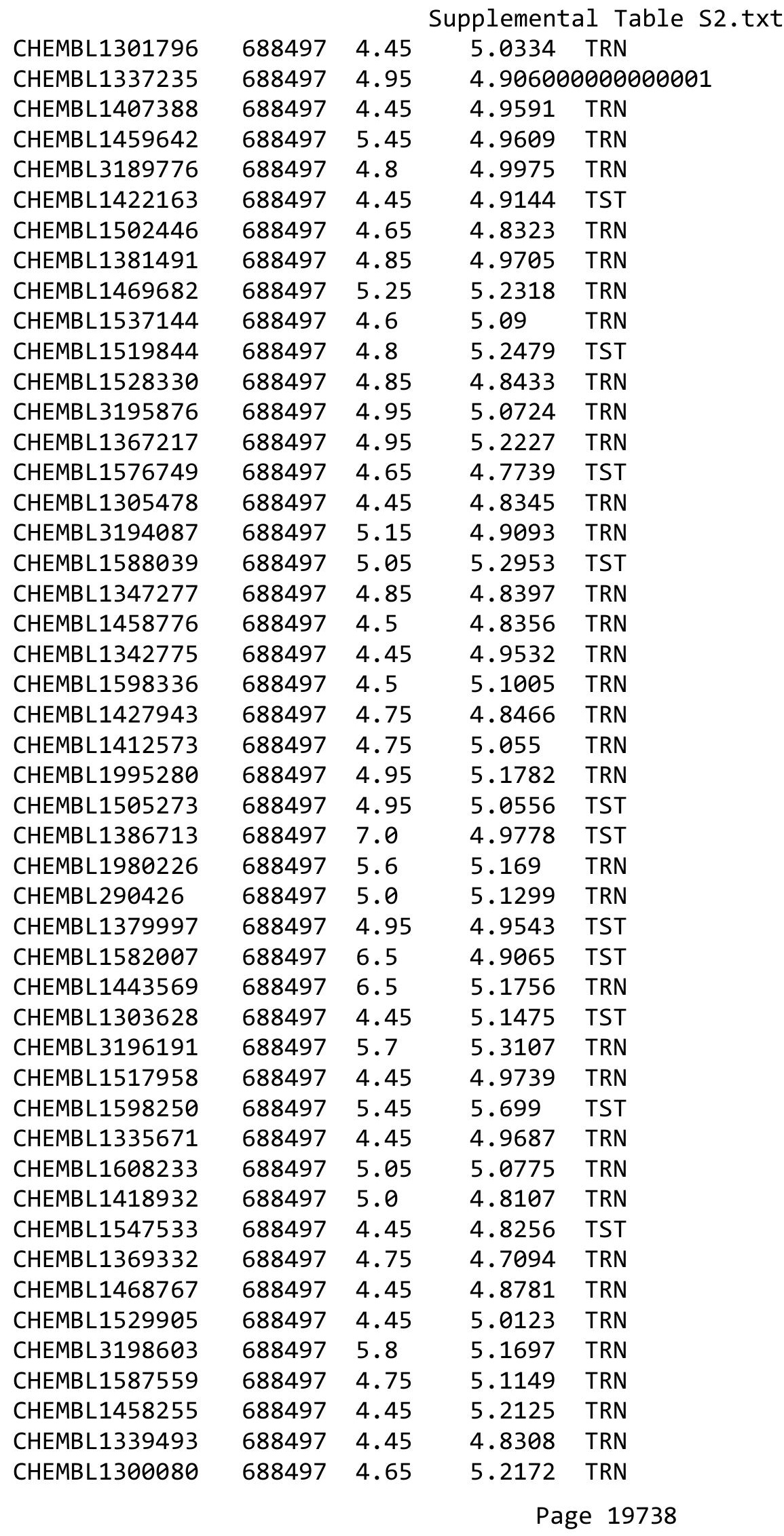

TRN 


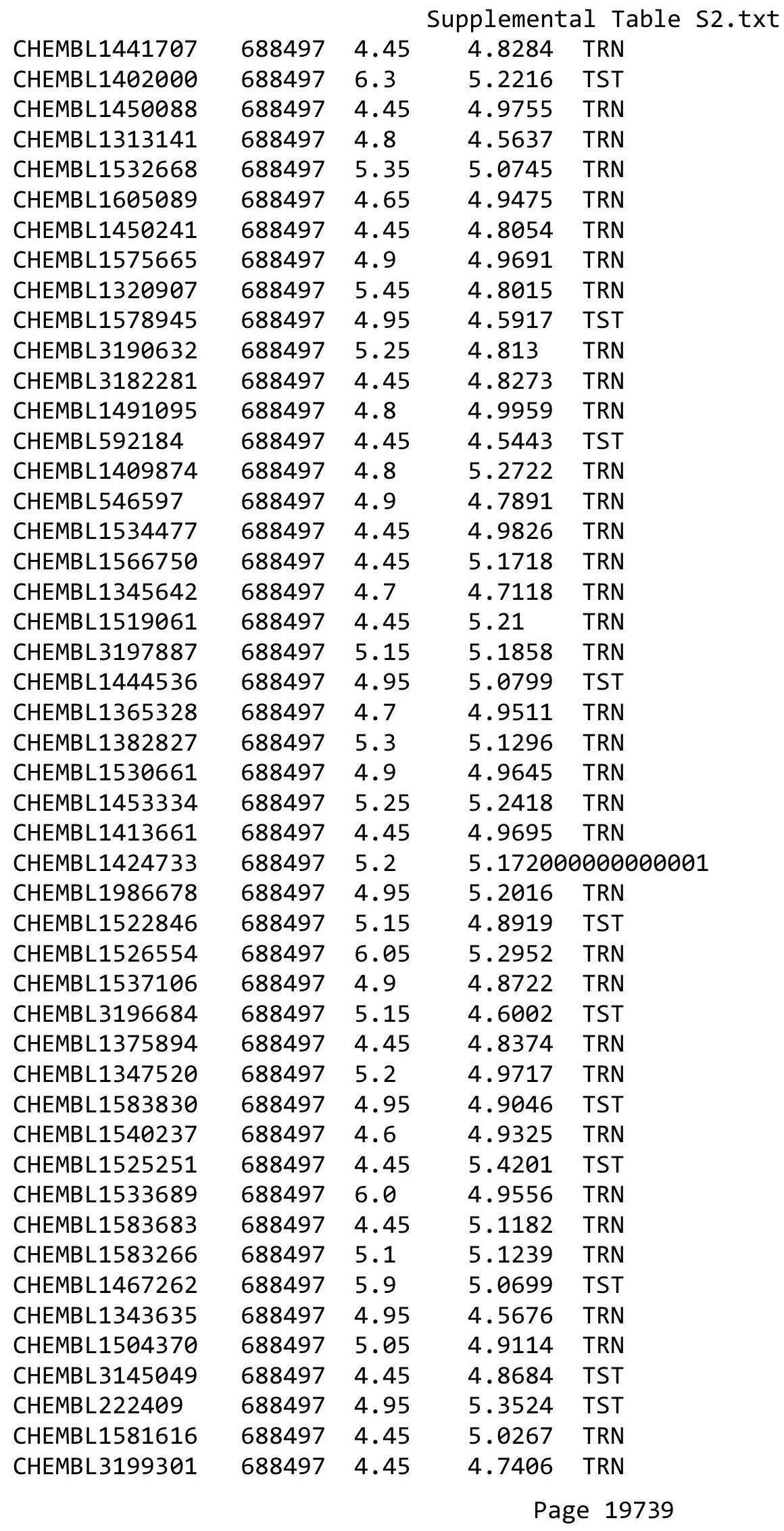




\begin{tabular}{|c|c|c|c|c|c|}
\hline \multicolumn{6}{|c|}{ Supplemental Table s2.txt } \\
\hline CHEMBL1459981 & 688497 & 5.15 & 5.1041 & TRN & \\
\hline CHEMBL1509369 & 688497 & 4.45 & 5.0838 & TST & \\
\hline CHEMBL1541076 & 688497 & 6.5 & 5.4091 & TST & \\
\hline CHEMBL1420271 & 688497 & 5.0 & 5.0785 & TRN & \\
\hline CHEMBL1495128 & 688497 & 6.2 & 5.1517 & TRN & \\
\hline CHEMBL1424480 & 688497 & 4.45 & 4.9307 & TRN & \\
\hline CHEMBL3192482 & 688497 & 4.5 & 5.0473 & TRN & \\
\hline CHEMBL1496401 & 688497 & 6.5501 & 5.2502 & TRN & \\
\hline CHEMBL3211289 & 688497 & 5.45 & 5.0915 & TRN & \\
\hline CHEMBL404406 & 688497 & 4.55 & $5.0710 e$ & 0000000001 & TST \\
\hline CHEMBL1566246 & 688497 & 4.9 & 5.3167 & TRN & \\
\hline CHEMBL589235 & 688497 & 4.65 & 4.9217 & TRN & \\
\hline CHEMBL1494575 & 688497 & 5.0 & 5.4124 & TRN & \\
\hline CHEMBL1443780 & 688497 & 5.4 & 4.9391 & TRN & \\
\hline CHEMBL1526496 & 688497 & 4.45 & 4.9101 & TRN & \\
\hline CHEMBL3197786 & 688497 & 4.45 & 4.7505 & TRN & \\
\hline CHEMBL1423524 & 688497 & 4.7 & 5.0132 & TRN & \\
\hline CHEMBL3208530 & 688497 & 4.9 & 4.7889 & TRN & \\
\hline CHEMBL1310778 & 688497 & 4.75 & 5.1277 & TRN & \\
\hline CHEMBL1576310 & 688497 & 4.5 & 5.1081 & TST & \\
\hline CHEMBL1376644 & 688497 & 6.25 & 5.2523 & TRN & \\
\hline CHEMBL1442979 & 688497 & 4.45 & 4.9709 & TST & \\
\hline CHEMBL1459612 & 688497 & 4.55 & 5.1136 & TST & \\
\hline CHEMBL1537605 & 688497 & 4.45 & 4.9666 & TST & \\
\hline CHEMBL1417819 & 688497 & 5.05 & 5.2168 & TRN & \\
\hline CHEMBL1576046 & 688497 & 4.7 & $4.8610 e$ & 0000000001 & TST \\
\hline CHEMBL1406530 & 688497 & 4.45 & 5.2595 & TRN & \\
\hline CHEMBL 2095095 & 688497 & 5.2 & 5.2892 & TRN & \\
\hline CHEMBL 2006545 & 688497 & 5.6 & 5.027 & TRN & \\
\hline CHEMBL1531536 & 688497 & 5.0 & 4.9136 & TRN & \\
\hline CHEMBL1996954 & 688497 & 5.25 & 4.8234 & TST & \\
\hline CHEMBL1380893 & 688497 & 5.25 & 5.2283 & TST & \\
\hline CHEMBL1310526 & 688497 & 6.05 & 5.2671 & TST & \\
\hline CHEMBL1536361 & 688497 & 4.65 & 5.1153 & TRN & \\
\hline CHEMBL1416556 & 688497 & 5.8 & 4.9519 & TST & \\
\hline CHEMBL1402492 & 688497 & 5.5 & 5.3712 & TRN & \\
\hline CHEMBL1465736 & 688497 & 5.5 & 5.2592 & TRN & \\
\hline CHEMBL1605511 & 688497 & 5.6 & 4.9777 & TRN & \\
\hline CHEMBL1464951 & 688497 & 4.65 & 4.6817 & TRN & \\
\hline CHEMBL1305455 & 688497 & 5.15 & 5.1588 & TRN & \\
\hline CHEMBL1419849 & 688497 & 4.8 & 5.0023 & TST & \\
\hline CHEMBL1319606 & 688497 & 4.45 & 5.1763 & TST & \\
\hline CHEMBL1544664 & 688497 & 4.65 & 4.5322 & TRN & \\
\hline CHEMBL1546891 & 688497 & 4.45 & 4.7934 & TRN & \\
\hline CHEMBL3197487 & 688497 & 5.55 & 4.9301 & TST & \\
\hline CHEMBL1566836 & 688497 & 5.9 & 5.2476 & TST & \\
\hline CHEMBL1361319 & 688497 & 4.65 & 4.7497 & TRN & \\
\hline CHEMBL1462616 & 688497 & 5.25 & 4.9384 & TST & \\
\hline
\end{tabular}




\begin{tabular}{|c|c|c|c|c|c|}
\hline \multicolumn{6}{|c|}{ Supplemental Table s2.txt } \\
\hline CHEMBL1607034 & 688497 & 5.5 & 5.2743 & TRN & \\
\hline CHEMBL1488616 & 688497 & 6.3 & 4.8583 & TRN & \\
\hline CHEMBL1352070 & 688497 & 4.45 & 4.8573 & TRN & \\
\hline CHEMBL1579557 & 688497 & 5.0 & 4.9765 & TST & \\
\hline CHEMBL1542849 & 688497 & 4.45 & 5.061 & TRN & \\
\hline CHEMBL1508139 & 688497 & 6.1 & 5.3378 & TST & \\
\hline CHEMBL1864040 & 688497 & 5.2 & 5.1544 & TRN & \\
\hline CHEMBL1371783 & 688497 & 4.5 & 5.2893 & TRN & \\
\hline CHEMBL1548486 & 688497 & 4.65 & 5.2329 & TRN & \\
\hline CHEMBL1386061 & 688497 & 4.95 & 4.982 & TRN & \\
\hline CHEMBL1331625 & 688497 & 5.3 & 4.9446 & TRN & \\
\hline CHEMBL1465342 & 688497 & 4.85 & 4.8507 & TRN & \\
\hline CHEMBL1542594 & 688497 & 5.3 & 5.1104 & TRN & \\
\hline CHEMBL1367425 & 688497 & 5.45 & 4.9235 & TRN & \\
\hline CHEMBL1325863 & 688497 & 4.65 & 5.3009 & TRN & \\
\hline CHEMBL1420114 & 688497 & 5.4 & 4.8851 & TRN & \\
\hline CHEMBL1483479 & 688497 & 4.95 & 4.7257 & TRN & \\
\hline CHEMBL1464467 & 688497 & 4.95 & 5.1311 & TRN & \\
\hline CHEMBL1319618 & 688497 & 4.65 & 4.6255 & TRN & \\
\hline CHEMBL1411839 & 688497 & 4.7 & 4.8484 & TST & \\
\hline CHEMBL1454820 & 688497 & 5.05 & 5.0927 & TST & \\
\hline CHEMBL588038 & 688497 & 5.25 & 5.1446 & TRN & \\
\hline CHEMBL1529263 & 688497 & 5.25 & 4.9098 & TST & \\
\hline CHEMBL1340965 & 688497 & 4.45 & 4.8251 & TST & \\
\hline CHEMBL1415642 & 688497 & 4.95 & 4.6673 & TRN & \\
\hline CHEMBL1413888 & 688497 & 5.45 & 5.1088 & TST & \\
\hline CHEMBL1427516 & 688497 & 4.75 & 4.9685 & TST & \\
\hline CHEMBL1572139 & 688497 & 5.45 & 5.5495 & TRN & \\
\hline CHEMBL1358777 & 688497 & 5.0 & 5.1969 & TRN & \\
\hline CHEMBL1566266 & 688497 & 4.45 & 5.0716 & TRN & \\
\hline CHEMBL 325245 & 688497 & 4.95 & 4.9812 & TRN & \\
\hline CHEMBL1424665 & 688497 & 5.4 & 5.4432 & TRN & \\
\hline CHEMBL1546767 & 688497 & 4.95 & 5.4138 & TRN & \\
\hline CHEMBL1535000 & 688497 & 4.45 & 4.9389 & TRN & \\
\hline CHEMBL1445840 & 688497 & 4.45 & 4.7522 & TRN & \\
\hline CHEMBL1301791 & 688497 & 5.1 & 4.934 & TST & \\
\hline CHEMBL119769 & 688497 & 5.6 & 4.9598 & TRN & \\
\hline CHEMBL1500801 & 688497 & 4.9 & 5.1063 & TRN & \\
\hline CHEMBL1605251 & 688497 & 5.5 & 5.0977 & TRN & \\
\hline CHEMBL1304179 & 688497 & 4.5 & 5.0194 & TRN & \\
\hline CHEMBL3190095 & 688497 & 4.65 & 5.07600 & 00000000005 & \\
\hline CHEMBL3195235 & 688497 & 5.5 & 5.0318 & TRN & \\
\hline CHEMBL1389704 & 688497 & 4.75 & 5.0047 & TRN & \\
\hline CHEMBL1411129 & 688497 & 4.9 & 5.1769 & TRN & \\
\hline CHEMBL1325974 & 688497 & 4.7 & 5.3407 & TRN & \\
\hline CHEMBL1511162 & 688497 & 4.6 & 4.8661 & TRN & \\
\hline CHEMBL1448066 & 688497 & 4.8 & 4.8881 & TRN & \\
\hline CHEMBL1388175 & 688497 & 5.05 & 4.904 & TRN & \\
\hline
\end{tabular}




\begin{tabular}{|c|c|c|c|c|}
\hline \multicolumn{5}{|c|}{ Supplemental Table } \\
\hline CHEMBL1503962 & 688497 & 5.45 & 5.4255 & TST \\
\hline CHEMBL1351993 & 688497 & 6.25 & 5.1783 & TRN \\
\hline CHEMBL1582076 & 688497 & 4.8 & 4.9656 & TRN \\
\hline CHEMBL1550972 & 688497 & 4.45 & 4.9706 & TRN \\
\hline CHEMBL1388790 & 688497 & 6.5 & 4.8563 & TRN \\
\hline CHEMBL1588246 & 688497 & 4.45 & 4.8242 & TRN \\
\hline CHEMBL3193737 & 688497 & 5.45 & 5.0852 & TRN \\
\hline CHEMBL1545379 & 688497 & 5.25 & 4.9715 & TRN \\
\hline CHEMBL1567571 & 688497 & 5.3 & 4.9911 & TRN \\
\hline CHEMBL1431716 & 688497 & 5.8 & 5.2248 & TRN \\
\hline CHEMBL1413556 & 688497 & 6.3 & 5.407 & TST \\
\hline CHEMBL1321166 & 688497 & 4.55 & 5.0505 & TST \\
\hline CHEMBL1492145 & 688497 & 4.45 & 4.8168 & TRN \\
\hline CHEMBL1501814 & 688497 & 4.5 & 5.2351 & TST \\
\hline CHEMBL1350192 & 688497 & 4.45 & 5.311 & TRN \\
\hline CHEMBL1536797 & 688497 & 6.3 & 5.2402 & TRN \\
\hline CHEMBL1525209 & 688497 & 5.55 & 5.2439 & TRN \\
\hline CHEMBL1572271 & 688497 & 6.2 & 4.7574 & TRN \\
\hline CHEMBL1559982 & 688497 & 5.15 & 5.3138 & TST \\
\hline CHEMBL1400852 & 688497 & 4.45 & 4.7264 & TRN \\
\hline CHEMBL1611106 & 688497 & 4.95 & 4.8657 & TRN \\
\hline CHEMBL1359889 & 688497 & 4.75 & 5.3752 & TRN \\
\hline CHEMBL1346165 & 688497 & 5.9 & 5.067 & TRN \\
\hline CHEMBL577662 & 688497 & 5.65 & 5.2299 & TRN \\
\hline CHEMBL1601244 & 688497 & 4.9 & 5.1133 & TRN \\
\hline CHEMBL1566094 & 688497 & 4.65 & 4.7603 & TRN \\
\hline CHEMBL1329801 & 688497 & 5.35 & 5.0827 & TRN \\
\hline CHEMBL1477273 & 688497 & 4.45 & 5.0329 & TRN \\
\hline CHEMBL1321526 & 688497 & 4.75 & 4.89 & TRN \\
\hline CHEMBL1173522 & 688497 & 4.45 & 4.9311 & TRN \\
\hline CHEMBL1524324 & 688497 & 4.75 & 4.6717 & TRN \\
\hline CHEMBL1595600 & 688497 & 6.2 & 4.9795 & TRN \\
\hline CHEMBL3196467 & 688497 & 4.85 & 4.832 & TRN \\
\hline CHEMBL1429628 & 688497 & 4.45 & 4.9301 & TRN \\
\hline CHEMBL1546101 & 688497 & 6.3 & 5.3937 & TST \\
\hline CHEMBL1577742 & 688497 & 4.65 & 4.9214 & TRN \\
\hline CHEMBL1580553 & 688497 & 4.8 & 4.6935 & TRN \\
\hline CHEMBL1326788 & 688497 & 4.85 & 4.8355 & TRN \\
\hline CHEMBL1501105 & 688497 & 4.45 & 4.8274 & TRN \\
\hline CHEMBL3199347 & 688497 & 4.85 & 4.8985 & TST \\
\hline CHEMBL1305554 & 688497 & 4.65 & 5.1365 & TRN \\
\hline CHEMBL166209 & 688497 & 5.05 & 5.0919 & TST \\
\hline CHEMBL1609651 & 688497 & 5.5 & 4.9936 & TRN \\
\hline CHEMBL92824 & 688497 & 4.9 & 5.0201 & TRN \\
\hline CHEMBL3192764 & 688497 & 6.25 & 5.1392 & TRN \\
\hline CHEMBL1335401 & 688497 & 4.45 & 4.9185 & TRN \\
\hline CHEMBL1716494 & 688497 & 4.45 & 4.7109 & TRN \\
\hline CHEMBL1302852 & 688497 & 4.85 & 5.0063 & TRN \\
\hline
\end{tabular}




\begin{tabular}{|c|c|c|c|c|c|}
\hline \multicolumn{6}{|c|}{ Supplemental Table S2.txt } \\
\hline CHEMBL1465615 & 688497 & 5.4 & 5.1549 & TRN & \\
\hline CHEMBL1529606 & 688497 & 6.0 & 5.0365 & TRN & \\
\hline CHEMBL1311633 & 688497 & 4.45 & 4.9003 & TRN & \\
\hline CHEMBL 3198513 & 688497 & 5.75 & 5.0851 & TRN & \\
\hline CHEMBL1305353 & 688497 & 5.05 & 5.1313 & TRN & \\
\hline CHEMBL1339710 & 688497 & 5.4 & 5.181 & TST & \\
\hline CHEMBL590927 & 688497 & 6.2 & 5.6127 & TRN & \\
\hline CHEMBL1447057 & 688497 & 4.8 & 5.5414 & TST & \\
\hline CHEMBL1578673 & 688497 & 5.95 & 5.2383 & TRN & \\
\hline CHEMBL1346048 & 688497 & 4.45 & 5.09699 & 99999999995 & TST \\
\hline CHEMBL1538700 & 688497 & 4.6 & 5.1139 & TRN & \\
\hline CHEMBL1374531 & 688497 & 4.9 & 5.0446 & TST & \\
\hline CHEMBL1384700 & 688497 & 4.45 & 5.0608 & TRN & \\
\hline CHEMBL1313540 & 688497 & 5.95 & 5.32799 & 9999999999 & TRN \\
\hline CHEMBL1530638 & 688497 & 5.65 & 4.9788 & TRN & \\
\hline CHEMBL1505230 & 688497 & 4.75 & 4.9518 & TST & \\
\hline CHEMBL1440643 & 688497 & 4.55 & 4.896 & TRN & \\
\hline CHEMBL1333268 & 688497 & 4.45 & 4.9421 & TRN & \\
\hline CHEMBL1402745 & 688497 & 4.95 & 5.0685 & TRN & \\
\hline CHEMBL1537679 & 688497 & 5.1 & 4.9072 & TRN & \\
\hline CHEMBL1492693 & 688497 & 6.45 & 5.239 & TRN & \\
\hline CHEMBL1445710 & 688497 & 4.95 & 4.7789 & TRN & \\
\hline CHEMBL1598130 & 688497 & 4.95 & 5.1842 & TRN & \\
\hline CHEMBL1420768 & 688497 & 4.45 & 4.8612 & TRN & \\
\hline CHEMBL1386774 & 688497 & 4.95 & 5.0053 & TRN & \\
\hline CHEMBL1347133 & 688497 & 5.65 & 4.9978 & TST & \\
\hline CHEMBL3208959 & 688497 & 4.45 & 4.9581 & TST & \\
\hline CHEMBL1470446 & 688497 & 4.45 & 4.6791 & TST & \\
\hline CHEMBL1575345 & 688497 & 4.95 & 4.7505 & TRN & \\
\hline CHEMBL1468104 & 688497 & 4.7 & 4.7761 & TST & \\
\hline CHEMBL1478844 & 688497 & 4.9 & 4.8529 & TRN & \\
\hline CHEMBL1527380 & 688497 & 5.85 & 5.3391 & TRN & \\
\hline CHEMBL1387762 & 688497 & 6.15 & 4.7914 & TRN & \\
\hline CHEMBL 3214287 & 688497 & 4.7 & 4.7698 & TRN & \\
\hline CHEMBL1427260 & 688497 & 5.8 & 5.2435 & TST & \\
\hline CHEMBL1403538 & 688497 & 4.75 & 5.0319 & TRN & \\
\hline CHEMBL1419203 & 688497 & 5.45 & 5.2532 & TST & \\
\hline CHEMBL1486661 & 688497 & 4.9 & 4.9505 & TRN & \\
\hline CHEMBL1544192 & 688497 & 4.6 & 4.9212 & TRN & \\
\hline CHEMBL1486319 & 688497 & 4.75 & 5.0312 & TRN & \\
\hline CHEMBL1557669 & 688497 & 5.0 & 4.8758 & TRN & \\
\hline CHEMBL1455933 & 688497 & 4.7 & 5.2266 & TRN & \\
\hline CHEMBL1365517 & 688497 & 4.9 & 5.0317 & TRN & \\
\hline CHEMBL1585594 & 688497 & 5.05 & 5.0765 & TRN & \\
\hline CHEMBL 3191884 & 688497 & 4.75 & 4.9898 & TRN & \\
\hline CHEMBL1994034 & 688497 & 5.5 & 5.244 & TRN & \\
\hline CHEMBL1441016 & 688497 & 4.45 & 4.9347 & TRN & \\
\hline CHEMBL1460485 & 688497 & 4.45 & 5.5089 & TST & \\
\hline
\end{tabular}




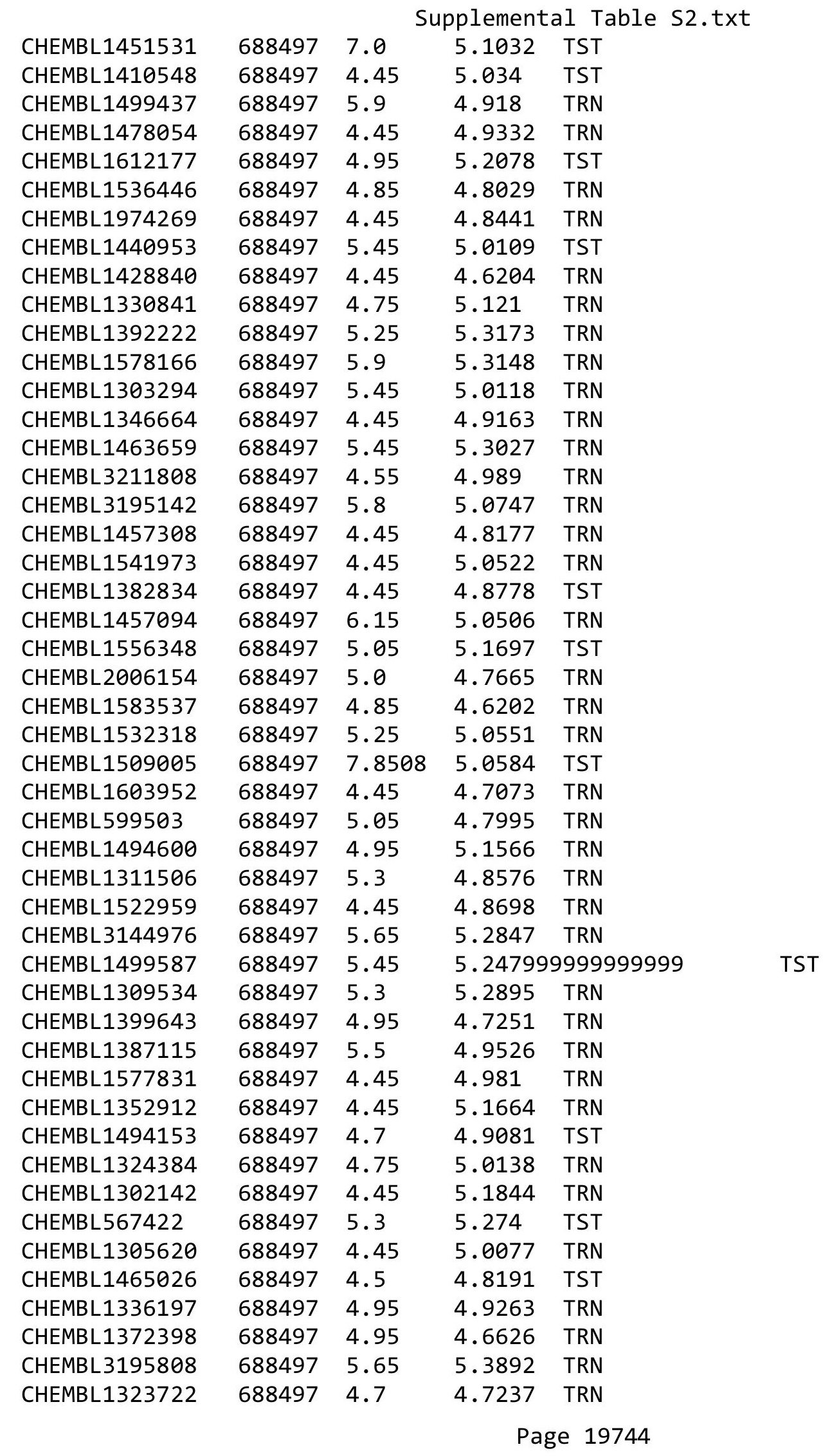




\begin{tabular}{|c|c|c|c|c|c|}
\hline \multicolumn{6}{|c|}{ Supplemental Table S2.txt } \\
\hline CHEMBL1380381 & 688497 & 6.25 & 5.3872 & TRN & \\
\hline CHEMBL1454770 & 688497 & 4.45 & 4.9047 & TRN & \\
\hline CHEMBL1509744 & 688497 & 5.2 & 4.7335 & TRN & \\
\hline CHEMBL1327431 & 688497 & 5.9 & 4.9719 & TST & \\
\hline CHEMBL1587394 & 688497 & 5.95 & 5.2589 & TST & \\
\hline CHEMBL1338355 & 688497 & 4.95 & 5.0831 & TST & \\
\hline CHEMBL1487663 & 688497 & 5.4 & 5.2326 & TST & \\
\hline CHEMBL1544926 & 688497 & 4.45 & 5.2482 & TRN & \\
\hline CHEMBL524376 & 688497 & 4.55 & 4.9206 & TRN & \\
\hline CHEMBL1467305 & 688497 & 4.45 & 5.0583 & TST & \\
\hline CHEMBL1490629 & 688497 & 4.75 & 4.9915 & TRN & \\
\hline CHEMBL1418003 & 688497 & 4.85 & 5.0071 & TRN & \\
\hline CHEMBL1378788 & 688497 & 4.9 & 4.7632 & TRN & \\
\hline CHEMBL1430445 & 688497 & 5.65 & 5.1092 & TRN & \\
\hline CHEMBL1565403 & 688497 & 5.35 & 5.3736 & TRN & \\
\hline CHEMBL1391979 & 688497 & 5.25 & 5.1077 & TST & \\
\hline CHEMBL1382372 & 688497 & 4.6 & 5.052 & TST & \\
\hline CHEMBL1462338 & 688497 & 5.8 & 5.0807 & TRN & \\
\hline CHEMBL1340482 & 688497 & 4.45 & 5.0934 & TRN & \\
\hline CHEMBL1493477 & 688497 & 5.5 & 5.1457 & TRN & \\
\hline CHEMBL1328462 & 688497 & 4.65 & 4.959 & TRN & \\
\hline CHEMBL1517889 & 688497 & 4.45 & 4.9103 & TST & \\
\hline CHEMBL1354100 & 688497 & 4.9 & 5.0331 & TRN & \\
\hline CHEMBL1511040 & 688497 & 4.95 & 5.3286 & TRN & \\
\hline CHEMBL1529339 & 688497 & 5.2 & 5.0957 & TRN & \\
\hline CHEMBL1529687 & 688497 & 5.4 & 5.2445 & TRN & \\
\hline CHEMBL1532566 & 688497 & 5.3 & 4.8265 & TRN & \\
\hline CHEMBL1545184 & 688497 & 5.0 & 5.0651 & TST & \\
\hline CHEMBL1586297 & 688497 & 5.35 & 5.1503 & TST & \\
\hline CHEMBL1537658 & 688497 & 4.65 & 4.8827 & TST & \\
\hline CHEMBL1516967 & 688497 & 5.0 & 5.0869 & TRN & \\
\hline CHEMBL1387220 & 688497 & 4.45 & 4.8911 & TRN & \\
\hline CHEMBL555689 & 688497 & 4.75 & 5.1477 & TRN & \\
\hline CHEMBL1519539 & 688497 & 4.9 & 4.711 & TRN & \\
\hline CHEMBL1320640 & 688497 & 5.45 & 4.8795 & TRN & \\
\hline CHEMBL1388535 & 688497 & 5.5 & 5.0246 & TRN & \\
\hline CHEMBL1467194 & 688497 & 4.9 & 4.8371 & TST & \\
\hline CHEMBL1391815 & 688497 & 3.05 & 5.1407 & TRN & \\
\hline CHEMBL1589079 & 688497 & 4.8 & 4.9087 & TST & \\
\hline CHEMBL1481162 & 688497 & 4.95 & 5.2012 & TRN & \\
\hline CHEMBL1371101 & 688497 & 4.85 & 4.7001 & TRN & \\
\hline CHEMBL1370022 & 688497 & 4.95 & 4.6530 & 00000000005 & TRN \\
\hline CHEMBL1455033 & 688497 & 4.55 & 5.3439 & 9999999999 & TRN \\
\hline CHEMBL1420065 & 688497 & 5.55 & 5.2255 & TRN & \\
\hline CHEMBL1533909 & 688497 & 4.45 & 4.9636 & TRN & \\
\hline CHEMBL1575075 & 688497 & 4.65 & 5.0512 & TRN & \\
\hline CHEMBL1998940 & 688497 & 4.8 & 4.6241 & TRN & \\
\hline CHEMBL1386036 & 688497 & 4.95 & 5.0871 & TRN & \\
\hline
\end{tabular}




\begin{tabular}{|c|c|c|c|c|c|}
\hline \multicolumn{6}{|c|}{ Supplemental Table S2.txt } \\
\hline CHEMBL1393442 & 688497 & 4.75 & 4.9033 & TRN & \\
\hline CHEMBL1569585 & 688497 & 5.3 & 5.4577 & TRN & \\
\hline CHEMBL1346803 & 688497 & 6.3 & 5.3064 & TRN & \\
\hline CHEMBL1506219 & 688497 & 6.2 & 5.3576 & TRN & \\
\hline CHEMBL1563518 & 688497 & 5.9 & 5.7397 & TST & \\
\hline CHEMBL1312831 & 688497 & 6.4 & 4.908 & TST & \\
\hline CHEMBL1500830 & 688497 & 4.45 & 4.6828 & TRN & \\
\hline CHEMBL410533 & 688497 & 4.45 & 4.8116 & TRN & \\
\hline CHEMBL 2006258 & 688497 & 4.7 & 5.00899 & 99999999995 & TRN \\
\hline CHEMBL1602775 & 688497 & 5.35 & 5.1472 & TST & \\
\hline CHEMBL1306686 & 688497 & 4.45 & 5.2479 & TRN & \\
\hline CHEMBL1503313 & 688497 & 4.45 & 5.2281 & TRN & \\
\hline CHEMBL1507657 & 688497 & 4.55 & 4.478 & TRN & \\
\hline CHEMBL1359682 & 688497 & 4.9 & 5.2612 & TRN & \\
\hline CHEMBL1480572 & 688497 & 4.45 & 5.2021 & TST & \\
\hline CHEMBL1327614 & 688497 & 4.85 & 5.059 & TRN & \\
\hline CHEMBL1529848 & 688497 & 4.75 & 4.8986 & TRN & \\
\hline CHEMBL1379493 & 688497 & 4.85 & 5.0766 & TRN & \\
\hline CHEMBL1308455 & 688497 & 4.45 & 4.7679 & TRN & \\
\hline CHEMBL3210795 & 688497 & 5.0 & 4.9266 & TRN & \\
\hline CHEMBL1300839 & 688497 & 4.4 & 5.0751 & TRN & \\
\hline CHEMBL1377771 & 688497 & 5.9 & 4.9211 & TST & \\
\hline CHEMBL1458742 & 688497 & 4.95 & 4.4725 & TRN & \\
\hline CHEMBL1588859 & 688497 & 4.8 & 4.8442 & TRN & \\
\hline CHEMBL1550784 & 688497 & 4.5 & 4.9707 & TRN & \\
\hline CHEMBL1341784 & 688497 & 5.9 & 4.982 & TST & \\
\hline CHEMBL1389097 & 688497 & 6.5 & 5.0902 & TRN & \\
\hline CHEMBL1404006 & 688497 & 4.45 & 5.1921 & TRN & \\
\hline CHEMBL1465909 & 688497 & 5.45 & 4.8589 & TRN & \\
\hline CHEMBL3212224 & 688497 & 5.5 & 4.9088 & TST & \\
\hline CHEMBL1408489 & 688497 & 5.25 & 5.0707 & TST & \\
\hline CHEMBL1384263 & 688497 & 4.9 & 4.7896 & TRN & \\
\hline CHEMBL1488965 & 688497 & 6.25 & 5.0913 & TRN & \\
\hline CHEMBL1555825 & 688497 & 5.45 & 5.3007 & TST & \\
\hline CHEMBL1464361 & 688497 & 6.3 & 5.2956 & TRN & \\
\hline CHEMBL1485372 & 688497 & 5.0 & 4.954 & TRN & \\
\hline CHEMBL1464827 & 688497 & 4.45 & 4.8579 & TST & \\
\hline CHEMBL1550490 & 688497 & 4.9 & 5.0906 & TST & \\
\hline CHEMBL1606392 & 688497 & 6.35 & 5.0904 & TRN & \\
\hline CHEMBL1463429 & 688497 & 5.25 & 5.106 & TRN & \\
\hline CHEMBL1385534 & 688497 & 4.85 & 4.7942 & TRN & \\
\hline CHEMBL1508714 & 688497 & 5.5 & 5.2718 & TST & \\
\hline CHEMBL1377931 & 688497 & 4.95 & 5.0728 & TST & \\
\hline CHEMBL3209787 & 688497 & 4.65 & 5.0935 & TST & \\
\hline CHEMBL1505192 & 688497 & 4.95 & 5.2135 & TRN & \\
\hline CHEMBL1608757 & 688497 & 4.85 & 4.789 & TST & \\
\hline CHEMBL1494200 & 688497 & 5.0 & 5.1427 & TRN & \\
\hline CHEMBL1467421 & 688497 & 4.9 & 5.0402 & TRN & \\
\hline
\end{tabular}




\begin{tabular}{|c|c|c|c|c|c|}
\hline & & \multicolumn{4}{|c|}{ Supplemental Table S2.txt } \\
\hline CHEMBL1538069 & 688497 & 6.15 & 4.5966 & TST & \\
\hline CHEMBL1543868 & 688497 & 4.45 & 5.1627 & TRN & \\
\hline CHEMBL1500249 & 688497 & 4.5 & 5.3291 & TST & \\
\hline CHEMBL1581142 & 688497 & 4.95 & 5.141 & TST & \\
\hline CHEMBL1488611 & 688497 & 5.25 & 4.9655 & TRN & \\
\hline CHEMBL1521190 & 688497 & 4.9 & 5.03100 & 0000000001 & TRN \\
\hline CHEMBL507264 & 688497 & 4.95 & 4.9231 & TRN & \\
\hline CHEMBL1599063 & 688497 & 5.65 & 4.9312 & TRN & \\
\hline CHEMBL1573112 & 688497 & 5.55 & 5.2164 & TRN & \\
\hline CHEMBL1431952 & 688497 & 4.65 & 5.1947 & TST & \\
\hline CHEMBL1371536 & 688497 & 4.8 & 4.9686 & TRN & \\
\hline CHEMBL1384101 & 688497 & 5.95 & 4.848 & TRN & \\
\hline CHEMBL1550992 & 688497 & 4.6 & 5.0418 & TRN & \\
\hline CHEMBL1528718 & 688497 & 5.0 & 5.4034 & TRN & \\
\hline CHEMBL1496882 & 688497 & 5.55 & 5.1425 & TRN & \\
\hline CHEMBL1588028 & 688497 & 5.0 & 4.8861 & TRN & \\
\hline CHEMBL1989225 & 688497 & 4.9 & 5.5177 & TRN & \\
\hline CHEMBL1305860 & 688497 & 4.8 & 4.7698 & TRN & \\
\hline CHEMBL1492756 & 688497 & 5.4 & 5.1438 & TST & \\
\hline CHEMBL1501083 & 688497 & 5.0 & 5.101 & TRN & \\
\hline CHEMBL1390701 & 688497 & 5.15 & 5.1507 & TRN & \\
\hline CHEMBL1308911 & 688497 & 6.25 & 4.8662 & TRN & \\
\hline CHEMBL1465396 & 688497 & 4.85 & 5.0469 & TRN & \\
\hline CHEMBL1378421 & 688497 & 4.9 & 5.0063 & TRN & \\
\hline CHEMBL1350653 & 688497 & 4.45 & 4.6848 & TRN & \\
\hline CHEMBL1422682 & 688497 & 4.6 & 4.7965 & TRN & \\
\hline CHEMBL1424204 & 688497 & 4.65 & 4.7404 & TRN & \\
\hline CHEMBL1351859 & 688497 & 5.5 & 5.0873 & TRN & \\
\hline CHEMBL1538383 & 688497 & 4.5 & 4.9499 & TRN & \\
\hline CHEMBL1549324 & 688497 & 4.45 & 4.8232 & TRN & \\
\hline CHEMBL1548871 & 688497 & 4.45 & 4.6806 & TRN & \\
\hline CHEMBL1343422 & 688497 & 5.7 & 5.0553 & TRN & \\
\hline CHEMBL1570765 & 688497 & 5.05 & 5.2361 & TRN & \\
\hline CHEMBL1529216 & 688497 & 4.5 & 5.1437 & TRN & \\
\hline CHEMBL1534589 & 688497 & 5.4 & 5.0893 & TST & \\
\hline CHEMBL1404253 & 688497 & 5.25 & 5.244 & TRN & \\
\hline CHEMBL1378665 & 688497 & 4.6 & 4.7432 & TRN & \\
\hline CHEMBL1541994 & 688497 & 5.1 & 4.98 & TRN & \\
\hline CHEMBL1308010 & 688497 & 4.45 & 4.8263 & TRN & \\
\hline CHEMBL1566706 & 688497 & 5.45 & 4.7057 & TRN & \\
\hline CHEMBL1558312 & 688497 & 5.25 & 4.8619 & TRN & \\
\hline CHEMBL3193919 & 688497 & 6.3 & 4.8173 & TRN & \\
\hline CHEMBL1447277 & 688497 & 4.45 & 4.8078 & TRN & \\
\hline CHEMBL1342376 & 688497 & 5.5 & 5.0623 & TST & \\
\hline CHEMBL1408756 & 688497 & 4.5 & 4.9096 & TRN & \\
\hline CHEMBL1507621 & 688497 & 6.05 & 5.2332 & TRN & \\
\hline CHEMBL1341919 & 688497 & 5.45 & 4.8452 & TST & \\
\hline CHEMBL3210338 & 688497 & 4.9 & 5.1418 & TRN & \\
\hline
\end{tabular}




\begin{tabular}{|c|c|c|c|c|c|}
\hline \multicolumn{6}{|c|}{ Supplemental Table s2.txt } \\
\hline CHEMBL1340822 & 688497 & 5.25 & 4.9176 & TRN & \\
\hline CHEMBL1492341 & 688497 & 4.9 & 4.9515 & TRN & \\
\hline CHEMBL1421364 & 688497 & 6.1 & 5.1918 & TST & \\
\hline CHEMBL1585024 & 688497 & 6.05 & 4.6603 & TRN & \\
\hline CHEMBL3190014 & 688497 & 5.05 & 4.8224 & TRN & \\
\hline CHEMBL1321025 & 688497 & 4.75 & 4.8396 & TRN & \\
\hline CHEMBL1339463 & 688497 & 4.45 & 4.7953 & TRN & \\
\hline CHEMBL1375429 & 688497 & 5.9 & 5.3886 & TRN & \\
\hline CHEMBL1363492 & 688497 & 6.25 & 4.9975 & TRN & \\
\hline CHEMBL1465095 & 688497 & 4.45 & 5.0757 & TRN & \\
\hline CHEMBL1412448 & 688497 & 5.1 & 4.8975 & TRN & \\
\hline CHEMBL1563110 & 688497 & 4.45 & 4.9167 & TRN & \\
\hline CHEMBL1605635 & 688497 & 4.45 & 4.833 & TRN & \\
\hline CHEMBL1401650 & 688497 & 4.6 & 4.9095 & TRN & \\
\hline CHEMBL1483047 & 688497 & 4.95 & 4.6598 & TRN & \\
\hline CHEMBL1326952 & 688497 & 5.25 & 5.0395 & TRN & \\
\hline CHEMBL1429342 & 688497 & 7.0501 & 4.9558 & TRN & \\
\hline CHEMBL1467368 & 688497 & 4.65 & 5.1315 & TRN & \\
\hline CHEMBL1517833 & 688497 & 4.45 & 4.9773 & TRN & \\
\hline CHEMBL1517893 & 688497 & 5.55 & 5.1668 & TRN & \\
\hline CHEMBL1345229 & 688497 & 4.85 & 5.1135 & TRN & \\
\hline CHEMBL1422442 & 688497 & 4.65 & 5.0737 & TRN & \\
\hline CHEMBL1599411 & 688497 & 4.7 & 5.2835 & TRN & \\
\hline CHEMBL1309874 & 688497 & 4.6 & 4.6304 & TRN & \\
\hline CHEMBL1402158 & 688497 & 4.65 & 5.0145 & TST & \\
\hline CHEMBL3190261 & 688497 & 4.9 & 5.0445 & TRN & \\
\hline CHEMBL1424729 & 688497 & 5.25 & 4.8651 & TRN & \\
\hline CHEMBL1457196 & 688497 & 5.25 & 5.0672 & TRN & \\
\hline CHEMBL1428965 & 688497 & 4.45 & 4.6584 & TRN & \\
\hline CHEMBL1517325 & 688497 & 5.4 & 5.38299 & 9999999999 & TS \\
\hline CHEMBL 2001794 & 688497 & 4.85 & 4.7699 & TRN & \\
\hline CHEMBL1326644 & 688497 & 4.45 & 5.1308 & TRN & \\
\hline CHEMBL3214119 & 688497 & 5.05 & 4.9171 & TST & \\
\hline CHEMBL3193814 & 688497 & 4.85 & 4.9801 & TRN & \\
\hline CHEMBL1577035 & 688497 & 5.9 & 4.883 & TRN & \\
\hline CHEMBL1529610 & 688497 & 4.5 & 5.0388 & TRN & \\
\hline CHEMBL1431434 & 688497 & 5.9 & 5.3541 & TST & \\
\hline CHEMBL1322635 & 688497 & 4.85 & 5.1428 & TRN & \\
\hline CHEMBL1498500 & 688497 & 4.6 & 4.7449 & TRN & \\
\hline CHEMBL1497622 & 688497 & 5.45 & 5.3648 & TRN & \\
\hline CHEMBL1562581 & 688497 & 4.65 & 4.905 & TRN & \\
\hline CHEMBL1484030 & 688497 & 4.95 & 5.2781 & TRN & \\
\hline CHEMBL1405901 & 688497 & 5.05 & 5.3109 & TRN & \\
\hline CHEMBL1496177 & 688497 & 4.45 & 5.3251 & TST & \\
\hline CHEMBL1509727 & 688497 & 5.1 & 4.9218 & TRN & \\
\hline CHEMBL1426896 & 688497 & 4.45 & 4.7041 & TRN & \\
\hline CHEMBL1548453 & 688497 & 5.05 & 4.9389 & TRN & \\
\hline CHEMBL1423933 & 688497 & 4.45 & 5.0791 & TST & \\
\hline
\end{tabular}




\begin{tabular}{|c|c|c|c|c|c|}
\hline \multicolumn{6}{|c|}{ Supplemental Table S2.txt } \\
\hline CHEMBL3196672 & 688497 & 4.9 & 4.8966 & TST & \\
\hline CHEMBL1318801 & 688497 & 5.2 & 5.0443 & TRN & \\
\hline CHEMBL1538482 & 688497 & 4.45 & 5.0511 & TRN & \\
\hline CHEMBL1337622 & 688497 & 5.95 & 4.8192 & TRN & \\
\hline CHEMBL1982869 & 688497 & 4.45 & 5.1916 & TRN & \\
\hline CHEMBL1508606 & 688497 & 5.25 & 5.0677 & TRN & \\
\hline CHEMBL395978 & 688497 & 4.9 & 5.0889 & TRN & \\
\hline CHEMBL3196326 & 688497 & 5.45 & 5.2193 & TRN & \\
\hline CHEMBL1535472 & 688497 & 4.45 & 5.4047 & TRN & \\
\hline CHEMBL1408418 & 688497 & 4.7 & 5.1139 & TRN & \\
\hline CHEMBL1460705 & 688497 & 5.25 & 5.1275 & TRN & \\
\hline CHEMBL1566610 & 688497 & 6.2 & 5.8361 & TRN & \\
\hline CHEMBL1489291 & 688497 & 4.9 & 4.9659 & TRN & \\
\hline CHEMBL578689 & 688497 & 4.65 & 5.1097 & TRN & \\
\hline CHEMBL1996724 & 688497 & 5.25 & 5.3311 & TRN & \\
\hline CHEMBL1611020 & 688497 & 4.8 & 5.107 & TST & \\
\hline CHEMBL1337275 & 688497 & 5.55 & 5.0209 & TRN & \\
\hline CHEMBL1340619 & 688497 & 4.6 & 4.6433 & TRN & \\
\hline CHEMBL3193599 & 688497 & 4.6 & 4.8465 & TRN & \\
\hline CHEMBL1483676 & 688497 & 4.5 & 5.188 & TRN & \\
\hline CHEMBL1321839 & 688497 & 5.25 & 5.1666 & TST & \\
\hline CHEMBL1503152 & 688497 & 4.45 & 4.8991 & TRN & \\
\hline CHEMBL1500185 & 688497 & 4.65 & 4.8342 & TST & \\
\hline CHEMBL1556967 & 688497 & 4.45 & 5.4013 & TRN & \\
\hline CHEMBL1412114 & 688497 & 4.45 & 4.8746 & TRN & \\
\hline CHEMBL3210451 & 688497 & 5.2 & 5.2155 & TRN & \\
\hline CHEMBL1585629 & 688497 & 6.05 & 5.3147 & TST & \\
\hline CHEMBL1471839 & 688497 & 4.45 & 5.20706 & 0000000001 & TST \\
\hline CHEMBL2006131 & 688497 & 4.6 & $5.2520 e$ & 0000000001 & TRN \\
\hline CHEMBL1386805 & 688497 & 4.45 & 4.9266 & TRN & \\
\hline CHEMBL1371949 & 688497 & 5.2 & 4.9141 & TRN & \\
\hline CHEMBL1577342 & 688497 & 4.85 & 5.3001 & TRN & \\
\hline CHEMBL1546959 & 688497 & 4.45 & 4.9102 & TRN & \\
\hline CHEMBL1454487 & 688497 & 6.0 & 5.4956 & TST & \\
\hline CHEMBL1493155 & 688497 & 6.2 & 5.2828 & TST & \\
\hline CHEMBL556398 & 688497 & 4.65 & 4.8619 & TRN & \\
\hline CHEMBL1528889 & 688497 & 5.9 & 5.1736 & TRN & \\
\hline CHEMBL2007163 & 688497 & 4.6 & 4.7 & TRN & \\
\hline CHEMBL1439859 & 688497 & 4.5 & 5.0889 & TRN & \\
\hline CHEMBL1477397 & 688497 & 5.55 & 5.1995 & TRN & \\
\hline CHEMBL1374633 & 688497 & 4.8 & 4.7899 & TRN & \\
\hline CHEMBL1439738 & 688497 & 4.45 & 4.8963 & TRN & \\
\hline CHEMBL1423390 & 688497 & 4.6 & 5.0498 & TRN & \\
\hline CHEMBL1334698 & 688497 & 4.45 & 5.0175 & TST & \\
\hline CHEMBL3197105 & 688497 & 5.45 & 5.1343 & TST & \\
\hline CHEMBL1545361 & 688497 & 4.65 & 4.7335 & TRN & \\
\hline CHEMBL1431542 & 688497 & 4.4 & 5.2427 & TRN & \\
\hline CHEMBL3193761 & 688497 & 4.95 & 4.7845 & TRN & \\
\hline
\end{tabular}




\begin{tabular}{|c|c|c|c|c|c|}
\hline \\
\hline CHEMBL1311514 & 688497 & 5.5 & 4.9474 & TRN & \\
\hline CHEMBL1606494 & 688497 & 6.2 & 5.2044 & TRN & \\
\hline CHEMBL1320824 & 688497 & 5.3 & 5.3195 & TRN & \\
\hline CHEMBL 3191151 & 688497 & 5.8 & 5.3919 & TST & \\
\hline CHEMBL1588832 & 688497 & 5.25 & 5.3258 & TRN & \\
\hline CHEMBL1559259 & 688497 & 4.75 & 5.0976 & TRN & \\
\hline CHEMBL1446863 & 688497 & 4.6 & 4.7046 & TRN & \\
\hline CHEMBL1471465 & 688497 & 4.8 & 4.7847 & TRN & \\
\hline CHEMBL1336028 & 688497 & 4.95 & 4.9995 & TRN & \\
\hline CHEMBL1536634 & 688497 & 4.8 & 5.0448 & TST & \\
\hline CHEMBL1411897 & 688497 & 4.45 & 5.0848 & TST & \\
\hline CHEMBL1430266 & 688497 & 4.45 & 4.7472 & TRN & \\
\hline CHEMBL 2005424 & 688497 & 5.2 & 5.1191 & TRN & \\
\hline CHEMBL1495568 & 688497 & 4.95 & 5.0223 & TST & \\
\hline CHEMBL1341157 & 688497 & 4.45 & 4.9372 & TRN & \\
\hline CHEMBL1549732 & 688497 & 5.4 & 5.246 & TRN & \\
\hline CHEMBL1384591 & 688497 & 4.45 & 5.1482 & TRN & \\
\hline CHEMBL1523566 & 688497 & 5.15 & 4.8559 & TRN & \\
\hline CHEMBL3193130 & 688497 & 4.45 & 4.8889 & 9999999999 & TRN \\
\hline CHEMBL1581745 & 688497 & 4.45 & 4.6758 & TRN & \\
\hline CHEMBL1470800 & 688497 & 4.9 & 4.8384 & TST & \\
\hline CHEMBL 3211962 & 688497 & 5.45 & 5.2267 & TRN & \\
\hline CHEMBL1399307 & 688497 & 4.45 & 5.2177 & TST & \\
\hline CHEMBL1506397 & 688497 & 5.5 & 5.0111 & TST & \\
\hline CHEMBL1495998 & 688497 & 5.0 & 5.1532 & TRN & \\
\hline CHEMBL1602323 & 688497 & 4.6 & 5.0877 & TRN & \\
\hline CHEMBL1481025 & 688497 & 4.95 & 5.0023 & TRN & \\
\hline CHEMBL1547536 & 688497 & 5.2 & 5.3317 & TRN & \\
\hline CHEMBL1406045 & 688497 & 5.0 & 4.8923 & TRN & \\
\hline CHEMBL1487887 & 688497 & 4.45 & 4.8204 & TRN & \\
\hline CHEMBL1367149 & 688497 & 4.85 & 5.0478 & TRN & \\
\hline CHEMBL1532091 & 688497 & 4.95 & 5.0754 & TST & \\
\hline CHEMBL1532161 & 688497 & 5.05 & 4.7733 & TRN & \\
\hline CHEMBL1409171 & 688497 & 5.5 & 5.1197 & TRN & \\
\hline CHEMBL3197031 & 688497 & 4.85 & 5.3261 & TRN & \\
\hline CHEMBL1370437 & 688497 & 5.95 & 4.9715 & TRN & \\
\hline CHEMBL1311422 & 688497 & 5.0 & 5.0497 & TRN & \\
\hline CHEMBL1519282 & 688497 & 4.85 & 4.8349 & TST & \\
\hline CHEMBL1488280 & 688497 & 4.45 & 4.8487 & TRN & \\
\hline CHEMBL504791 & 688497 & 4.45 & 5.1758 & TST & \\
\hline CHEMBL1526005 & 688497 & 4.9 & 5.309 & TST & \\
\hline CHEMBL1339310 & 688497 & 5.25 & 4.7958 & TRN & \\
\hline CHEMBL1425743 & 688497 & 4.45 & 4.9037 & TRN & \\
\hline CHEMBL1596744 & 688497 & 5.25 & 5.091 & TRN & \\
\hline CHEMBL1522747 & 688497 & 5.5 & 5.2832 & TRN & \\
\hline CHEMBL1496573 & 688497 & 4.9 & 5.0846 & TRN & \\
\hline CHEMBL1360735 & 688497 & 4.95 & 4.8241 & TST & \\
\hline CHEMBL582073 & 688497 & 6.0 & 5.6471 & TRN & \\
\hline & & & & 97 & \\
\hline
\end{tabular}




\begin{tabular}{|c|c|c|c|c|}
\hline \multicolumn{5}{|c|}{ Supplemental Table S2.txt } \\
\hline CHEMBL1486354 & 688497 & 4.9 & 4.9907 & TST \\
\hline CHEMBL1404497 & 688497 & 4.75 & 5.2085 & TRN \\
\hline CHEMBL3197209 & 688497 & 5.25 & 5.2306 & TRN \\
\hline CHEMBL1441519 & 688497 & 4.95 & 4.5846 & TRN \\
\hline CHEMBL1416184 & 688497 & 4.75 & 4.6279 & TRN \\
\hline CHEMBL1307728 & 688497 & 4.45 & 5.2779 & TRN \\
\hline CHEMBL1582067 & 688497 & 4.8 & 5.0272 & TRN \\
\hline CHEMBL1456557 & 688497 & 5.25 & 5.2789 & TRN \\
\hline CHEMBL1524783 & 688497 & 4.8 & 4.9148 & TRN \\
\hline CHEMBL1327647 & 688497 & 4.45 & 4.9623 & TST \\
\hline CHEMBL1383165 & 688497 & 5.5 & 5.0869 & TRN \\
\hline CHEMBL1594144 & 688497 & 4.95 & 4.9608 & TRN \\
\hline CHEMBL1564774 & 688497 & 6.25 & 5.2658 & TRN \\
\hline CHEMBL1402549 & 688497 & 5.9 & 5.0845 & TST \\
\hline CHEMBL1320499 & 688497 & 4.45 & 5.3167 & TRN \\
\hline CHEMBL1430208 & 688497 & 5.05 & 5.191 & TST \\
\hline CHEMBL1578704 & 688497 & 4.9 & 4.912 & TRN \\
\hline CHEMBL483956 & 688497 & 4.95 & 5.2937 & TST \\
\hline CHEMBL1414963 & 688497 & 5.15 & 5.1762 & TRN \\
\hline CHEMBL1339979 & 688497 & 4.45 & 5.1099 & TRN \\
\hline CHEMBL1421836 & 688497 & 4.45 & 5.0917 & TRN \\
\hline CHEMBL3196186 & 688497 & 5.4 & 5.2786 & TRN \\
\hline CHEMBL1595381 & 688497 & 4.45 & 4.8692 & TRN \\
\hline CHEMBL1401844 & 688497 & 4.85 & 5.0411 & TRN \\
\hline CHEMBL1378508 & 688497 & 5.45 & 5.364 & TST \\
\hline CHEMBL1451002 & 688497 & 5.1 & 5.1819 & TRN \\
\hline CHEMBL1443875 & 688497 & 4.75 & 4.9529 & TRN \\
\hline CHEMBL1453443 & 688497 & 4.95 & 4.9036 & TRN \\
\hline CHEMBL1416076 & 688497 & 5.0 & 5.2425 & TRN \\
\hline CHEMBL1310044 & 688497 & 4.6 & 5.2785 & TRN \\
\hline CHEMBL3194822 & 688497 & 5.2 & 5.3939 & TRN \\
\hline CHEMBL1580902 & 688497 & 5.25 & 5.2016 & TRN \\
\hline CHEMBL1347145 & 688497 & 5.25 & 4.7839 & TST \\
\hline CHEMBL1464925 & 688497 & 5.35 & 5.0497 & TST \\
\hline CHEMBL1306985 & 688497 & 5.8 & 5.0477 & TRN \\
\hline CHEMBL1584980 & 688497 & 6.25 & 5.2399 & TRN \\
\hline CHEMBL1500987 & 688497 & 4.95 & 4.7464 & TST \\
\hline CHEMBL1607290 & 688497 & 4.45 & 4.8533 & TRN \\
\hline CHEMBL1564195 & 688497 & 4.8 & 4.8791 & TRN \\
\hline CHEMBL1339536 & 688497 & 5.1 & 4.9393 & TRN \\
\hline CHEMBL1588995 & 688497 & 5.45 & 5.2472 & TRN \\
\hline CHEMBL1461680 & 688497 & 4.65 & 4.6926 & TRN \\
\hline CHEMBL1360343 & 688497 & 4.65 & 4.7044 & TST \\
\hline CHEMBL1431611 & 688497 & 4.7 & 5.0826 & TRN \\
\hline CHEMBL1606976 & 688497 & 4.45 & 5.0719 & TRN \\
\hline CHEMBL1485881 & 688497 & 4.95 & 5.1011 & TRN \\
\hline CHEMBL1577843 & 688497 & 5.0 & 5.2092 & TST \\
\hline CHEMBL1405804 & 688497 & 5.1 & 5.19 & TRN \\
\hline
\end{tabular}




\begin{tabular}{|c|c|c|c|c|c|}
\hline \multicolumn{6}{|c|}{ Supplemental Table S2.txt } \\
\hline CHEMBL2369168 & 688497 & 4.5 & 4.8037 & TST & \\
\hline CHEMBL1587288 & 688497 & 5.4 & 4.8782 & TRN & \\
\hline CHEMBL1410187 & 688497 & 4.45 & 4.9268 & TRN & \\
\hline CHEMBL1328184 & 688497 & 5.2 & 5.0587 & TRN & \\
\hline CHEMBL1303707 & 688497 & 4.45 & 4.9557 & TRN & \\
\hline CHEMBL1497994 & 688497 & 5.3 & 5.1658 & TRN & \\
\hline CHEMBL1404799 & 688497 & 5.3 & 4.7879 & TRN & \\
\hline CHEMBL1372464 & 688497 & 4.55 & 5.1177 & TRN & \\
\hline CHEMBL1349440 & 688497 & 4.75 & 4.9124 & TRN & \\
\hline CHEMBL1300001 & 688497 & 4.95 & 5.082 & TRN & \\
\hline CHEMBL1451774 & 688497 & 4.5 & 4.5992 & TRN & \\
\hline CHEMBL1486652 & 688497 & 4.85 & 4.9239 & TRN & \\
\hline CHEMBL1365781 & 688497 & 4.95 & 5.2372 & TRN & \\
\hline CHEMBL1462881 & 688497 & 5.05 & 5.0936 & TRN & \\
\hline CHEMBL1568851 & 688497 & 4.5 & 4.8883 & TRN & \\
\hline CHEMBL1525748 & 688497 & 5.45 & 5.261 & TST & \\
\hline CHEMBL1404060 & 688497 & 4.45 & 4.7086 & TRN & \\
\hline CHEMBL1341697 & 688497 & 5.0 & 4.9615 & TST & \\
\hline CHEMBL3199639 & 688497 & 6.0 & 5.4205 & TRN & \\
\hline CHEMBL1517243 & 688497 & 4.45 & 4.9197 & TRN & \\
\hline CHEMBL1348186 & 688497 & 4.45 & 5.2288 & TRN & \\
\hline CHEMBL1426523 & 688497 & 4.9 & 4.8852 & TRN & \\
\hline CHEMBL1543164 & 688497 & 5.2 & 5.3188 & TRN & \\
\hline CHEMBL1608041 & 688497 & 4.45 & 5.0523 & TST & \\
\hline CHEMBL1611583 & 688497 & 4.45 & 4.6737 & TRN & \\
\hline CHEMBL1447766 & 688497 & 4.45 & 5.1437 & TST & \\
\hline CHEMBL1335200 & 688497 & 4.8 & 5.0696 & TRN & \\
\hline CHEMBL1380629 & 688497 & 4.45 & 4.8356 & TST & \\
\hline CHEMBL1570238 & 688497 & 4.95 & 4.8762 & TRN & \\
\hline CHEMBL1582976 & 688497 & 4.5 & 4.7139 & TST & \\
\hline CHEMBL1529697 & 688497 & 4.9 & 5.2922 & TRN & \\
\hline CHEMBL1344249 & 688497 & 4.45 & 4.8511 & TRN & \\
\hline CHEMBL1339737 & 688497 & 5.6 & 5.4323 & TRN & \\
\hline CHEMBL1418430 & 688497 & 4.85 & 4.5103 & TRN & \\
\hline CHEMBL1353710 & 688497 & 5.2 & 4.9094 & TRN & \\
\hline CHEMBL1491550 & 688497 & 4.75 & 5.1021 & TST & \\
\hline CHEMBL1459087 & 688497 & 4.95 & 4.9262 & TRN & \\
\hline CHEMBL1097687 & 688497 & 4.45 & 5.2774 & TST & \\
\hline CHEMBL1485349 & 688497 & 4.45 & 4.8735 & TRN & \\
\hline CHEMBL1612983 & 688497 & 4.95 & 4.7997 & TRN & \\
\hline CHEMBL1461188 & 688497 & 4.45 & 4.76699 & 99999999995 & TRN \\
\hline CHEMBL1586985 & 688497 & 5.25 & 4.9894 & TRN & \\
\hline CHEMBL1995825 & 688497 & 4.45 & 4.8585 & TST & \\
\hline CHEMBL1549407 & 688497 & 4.45 & 4.4266 & TRN & \\
\hline CHEMBL1536829 & 688497 & 4.45 & 5.1159 & TST & \\
\hline CHEMBL1300434 & 688497 & 6.0 & 5.5315 & TST & \\
\hline CHEMBL1597484 & 688497 & 4.8 & 4.7959 & TRN & \\
\hline CHEMBL1438751 & 688497 & 4.65 & 5.1905 & TST & \\
\hline
\end{tabular}




\begin{tabular}{|c|c|c|c|c|c|}
\hline \multicolumn{6}{|c|}{ Supplemental Table S2.txt } \\
\hline CHEMBL1341778 & 688497 & 4.75 & 5.1142 & TST & \\
\hline CHEMBL1353847 & 688497 & 5.9 & 5.2419 & TRN & \\
\hline CHEMBL1381312 & 688497 & 5.45 & 4.8393 & TRN & \\
\hline CHEMBL1432732 & 688497 & 5.5 & 5.2809 & TST & \\
\hline CHEMBL1524449 & 688497 & 4.95 & 4.9775 & TRN & \\
\hline CHEMBL1594821 & 688497 & 5.1 & 5.1722 & TRN & \\
\hline CHEMBL1446909 & 688497 & 4.6 & 5.0613 & TST & \\
\hline CHEMBL1458022 & 688497 & 5.35 & 5.3624 & TST & \\
\hline CHEMBL1418853 & 688497 & 7.0501 & 5.2765 & TRN & \\
\hline CHEMBL1523979 & 688497 & 4.6 & 4.7664 & TRN & \\
\hline CHEMBL1305285 & 688497 & 5.75 & 5.1422 & TRN & \\
\hline CHEMBL1582997 & 688497 & 4.65 & 4.9677 & TRN & \\
\hline CHEMBL1560948 & 688497 & 5.25 & 5.3232 & TST & \\
\hline CHEMBL1549883 & 688497 & 4.9 & 4.82600 & 00000000005 & TRN \\
\hline CHEMBL3213516 & 688497 & 4.7 & 5.1832 & TST & \\
\hline CHEMBL1360482 & 688497 & 4.6 & 5.0965 & TRN & \\
\hline CHEMBL1601865 & 688497 & 4.6 & 4.8046 & TRN & \\
\hline CHEMBL1530423 & 688497 & 4.45 & 4.7308 & TRN & \\
\hline CHEMBL3210432 & 688497 & 4.95 & 5.0941 & TRN & \\
\hline CHEMBL1582875 & 688497 & 4.95 & 4.9191 & TST & \\
\hline CHEMBL1580641 & 688497 & 5.2 & 5.0293 & TRN & \\
\hline CHEMBL1332346 & 688497 & 4.65 & 4.7359 & TRN & \\
\hline CHEMBL1499053 & 688497 & 4.45 & 5.2691 & TRN & \\
\hline CHEMBL1498740 & 688497 & 5.05 & 4.9933 & TRN & \\
\hline CHEMBL3196538 & 688497 & 5.5 & 4.9791 & TST & \\
\hline CHEMBL579621 & 688497 & 5.0 & 4.8178 & TRN & \\
\hline CHEMBL1353570 & 688497 & 5.0 & 5.2228 & TST & \\
\hline CHEMBL1524122 & 688497 & 4.6 & 5.2055 & TST & \\
\hline CHEMBL1599152 & 688497 & 5.0 & 5.0649 & TRN & \\
\hline CHEMBL1459724 & 688497 & 5.25 & 5.3623 & TRN & \\
\hline CHEMBL1325494 & 688497 & 4.45 & 4.8042 & TRN & \\
\hline CHEMBL1507579 & 688497 & 5.45 & 5.7109 & TST & \\
\hline CHEMBL1501194 & 688497 & 6.25 & 5.07600 & 00000000005 & TRN \\
\hline CHEMBL1542440 & 688497 & 4.9 & 5.0876 & TRN & \\
\hline CHEMBL1503620 & 688497 & 6.2 & 4.9943 & TST & \\
\hline CHEMBL1330109 & 688497 & 4.45 & 4.691 & TRN & \\
\hline CHEMBL1332802 & 688497 & 5.95 & 5.0794 & TRN & \\
\hline CHEMBL1564153 & 688497 & 4.5 & 4.9317 & TRN & \\
\hline CHEMBL 2004884 & 688497 & 4.7 & 5.0932 & TST & \\
\hline CHEMBL1401240 & 688497 & 4.45 & 5.1437 & TST & \\
\hline CHEMBL3198499 & 688497 & 5.05 & 4.9764 & TRN & \\
\hline CHEMBL1549175 & 688497 & 4.45 & 4.6228 & TRN & \\
\hline CHEMBL1520414 & 688497 & 4.45 & 4.8685 & TRN & \\
\hline CHEMBL1568248 & 688497 & 4.7 & 4.958 & TST & \\
\hline CHEMBL3198751 & 688497 & 4.55 & 5.0829 & TST & \\
\hline CHEMBL1490352 & 688497 & 4.95 & 5.3008 & TRN & \\
\hline CHEMBL1581638 & 688497 & 4.45 & 4.9656 & TST & \\
\hline CHEMBL1503625 & 688497 & 4.45 & 5.1694 & TRN & \\
\hline
\end{tabular}




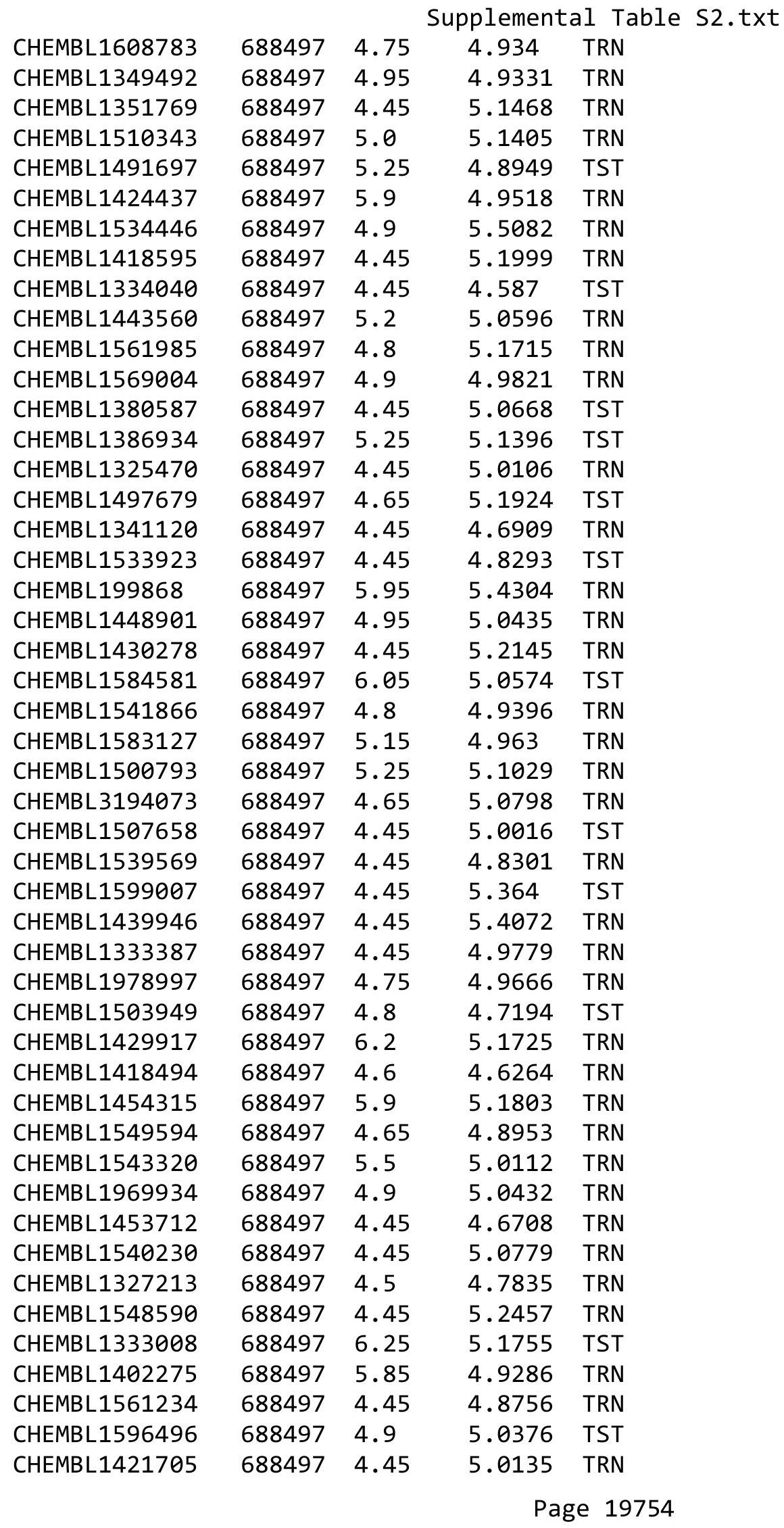




\begin{tabular}{|c|c|c|c|c|c|}
\hline \\
\hline CHEMBL1413447 & 688497 & 5.5 & 5.0404 & TST & \\
\hline CHEMBL1414019 & 688497 & 5.5 & 5.1393 & TST & \\
\hline CHEMBL1340268 & 688497 & 4.65 & 5.3228 & TRN & \\
\hline CHEMBL1503312 & 688497 & 5.0 & 4.8638 & TRN & \\
\hline CHEMBL1365519 & 688497 & 4.45 & $4.9460 e$ & 0000000001 & TRN \\
\hline CHEMBL1375153 & 688497 & 4.45 & 4.8799 & TRN & \\
\hline CHEMBL1487217 & 688497 & 4.95 & 5.1898 & TRN & \\
\hline CHEMBL3196784 & 688497 & 4.6 & 5.1774 & TRN & \\
\hline CHEMBL1362463 & 688497 & 4.6 & 5.0739 & TST & \\
\hline CHEMBL1567814 & 688497 & 4.65 & 4.8337 & TRN & \\
\hline CHEMBL1358821 & 688497 & 5.25 & 4.8887 & TRN & \\
\hline CHEMBL1523293 & 688497 & 5.0 & 4.8728 & TRN & \\
\hline CHEMBL1311953 & 688497 & 5.25 & 4.8117 & TRN & \\
\hline CHEMBL1565371 & 688497 & 4.65 & 5.0146 & TRN & \\
\hline CHEMBL1564638 & 688497 & 4.45 & 4.8675 & TRN & \\
\hline CHEMBL1560069 & 688497 & 4.65 & 4.8113 & TRN & \\
\hline CHEMBL1568084 & 688497 & 4.6 & 4.9285 & TRN & \\
\hline CHEMBL1307805 & 688497 & 4.45 & 5.0813 & TRN & \\
\hline CHEMBL1308262 & 688497 & 5.5 & 5.0854 & TST & \\
\hline CHEMBL1500035 & 688497 & 4.85 & 4.8492 & TRN & \\
\hline CHEMBL1347109 & 688497 & 4.7 & 4.7105 & TRN & \\
\hline CHEMBL1369193 & 688497 & 5.4 & 4.9327 & TRN & \\
\hline CHEMBL1578738 & 688497 & 6.25 & 5.1281 & TRN & \\
\hline CHEMBL1303343 & 688497 & 4.7 & 5.1273 & TST & \\
\hline CHEMBL1537051 & 688497 & 5.25 & 5.0075 & TRN & \\
\hline CHEMBL1455098 & 688497 & 5.9 & 5.3375 & TRN & \\
\hline CHEMBL1471088 & 688497 & 5.35 & 4.7271 & TRN & \\
\hline CHEMBL1458873 & 688497 & 4.9 & 4.9916 & TRN & \\
\hline CHEMBL3193255 & 688497 & 5.5 & 4.9858 & TRN & \\
\hline CHEMBL1327873 & 688497 & 5.85 & 5.7338 & TRN & \\
\hline CHEMBL1541826 & 688497 & 4.45 & 4.9606 & TRN & \\
\hline CHEMBL1572436 & 688497 & 4.75 & 5.0979 & TRN & \\
\hline CHEMBL1545224 & 688497 & 6.25 & 5.3684 & TRN & \\
\hline CHEMBL1469370 & 688497 & 5.9 & 5.0595 & TRN & \\
\hline CHEMBL1446926 & 688497 & 4.8 & 4.7218 & TRN & \\
\hline CHEMBL1385009 & 688497 & 6.5 & 5.1267 & TRN & \\
\hline CHEMBL1338839 & 688497 & 5.4 & 4.8339 & TRN & \\
\hline CHEMBL1452268 & 688497 & 5.1 & 4.99 & TRN & \\
\hline CHEMBL1410245 & 688497 & 4.05 & 5.3454 & TRN & \\
\hline CHEMBL1300209 & 688497 & 5.9 & 5.2487 & TST & \\
\hline CHEMBL1447522 & 688497 & 5.05 & 5.2613 & TRN & \\
\hline CHEMBL1390521 & 688497 & 4.65 & 5.4774 & TST & \\
\hline CHEMBL1604962 & 688497 & 5.9 & 5.3772 & TRN & \\
\hline CHEMBL1402010 & 688497 & 5.0 & 4.9507 & TRN & \\
\hline CHEMBL1492526 & 688497 & 4.5 & 5.0365 & TRN & \\
\hline CHEMBL1307354 & 688497 & 5.5 & 4.8979 & TRN & \\
\hline CHEMBL1603092 & 688497 & 5.05 & 5.0983 & TRN & \\
\hline CHEMBL1971674 & 688497 & 4.65 & 4.8278 & TST & \\
\hline
\end{tabular}




\begin{tabular}{|c|c|c|c|c|c|}
\hline \multicolumn{6}{|c|}{ Supplemental Table s2.txt } \\
\hline CHEMBL3191655 & 688497 & 4.45 & 5.0258 & TST & \\
\hline CHEMBL1380441 & 688497 & 4.95 & 5.1122 & TST & \\
\hline CHEMBL1332589 & 688497 & 4.95 & 4.8436 & TRN & \\
\hline CHEMBL1328120 & 688497 & 5.25 & 5.0334 & TRN & \\
\hline CHEMBL1505435 & 688497 & 4.65 & 4.9626 & TRN & \\
\hline CHEMBL1544447 & 688497 & 4.9 & 4.8859 & TRN & \\
\hline CHEMBL1364623 & 688497 & 5.75 & 5.2014 & TST & \\
\hline CHEMBL1386367 & 688497 & 6.05 & 5.1527 & TRN & \\
\hline CHEMBL1360879 & 688497 & 4.85 & 4.8439 & TRN & \\
\hline CHEMBL1468267 & 688497 & 4.65 & 4.9124 & TRN & \\
\hline CHEMBL1484081 & 688497 & 4.45 & 4.9867 & TRN & \\
\hline CHEMBL3199457 & 688497 & 5.55 & 5.5212 & TST & \\
\hline CHEMBL3197921 & 688497 & 4.45 & 4.8267 & TRN & \\
\hline CHEMBL1518037 & 688497 & 4.45 & 5.3838 & TST & \\
\hline CHEMBL1430195 & 688497 & 5.15 & 4.7648 & TRN & \\
\hline CHEMBL1599671 & 688497 & 5.2 & 4.9083 & TRN & \\
\hline CHEMBL494255 & 688497 & 5.25 & 5.4235 & TRN & \\
\hline CHEMBL 3199751 & 688497 & 4.85 & 4.8697 & TRN & \\
\hline CHEMBL1976412 & 688497 & 4.45 & 5.0201 & TRN & \\
\hline CHEMBL1605104 & 688497 & 5.15 & 5.1138 & TRN & \\
\hline CHEMBL1501937 & 688497 & 4.95 & 4.8406 & TRN & \\
\hline CHEMBL1307682 & 688497 & 4.45 & 4.9423 & TRN & \\
\hline CHEMBL1549900 & 688497 & 4.85 & 4.9674 & TST & \\
\hline CHEMBL1459296 & 688497 & 5.05 & 5.0665 & TRN & \\
\hline CHEMBL1572928 & 688497 & 4.45 & 4.7026 & TRN & \\
\hline CHEMBL1386649 & 688497 & 5.0 & 5.0467 & TST & \\
\hline CHEMBL1582079 & 688497 & 4.6 & 4.9806 & TRN & \\
\hline CHEMBL1543188 & 688497 & 4.45 & 4.9798 & TRN & \\
\hline CHEMBL1490203 & 688497 & 5.0 & 5.0965 & TRN & \\
\hline CHEMBL1469312 & 688497 & 6.25 & 5.6939 & TST & \\
\hline CHEMBL1518825 & 688497 & 6.25 & 4.8513 & TRN & \\
\hline CHEMBL1373384 & 688497 & 4.45 & 4.9125 & TST & \\
\hline CHEMBL1428454 & 688497 & 4.6 & 5.1059 & TST & \\
\hline CHEMBL1421093 & 688497 & 4.45 & 5.1678 & TRN & \\
\hline CHEMBL1535164 & 688497 & 4.6 & 5.0261 & TRN & \\
\hline CHEMBL1373042 & 688497 & 5.55 & 4.877 & TRN & \\
\hline CHEMBL1478675 & 688497 & 4.45 & 4.5938 & TRN & \\
\hline CHEMBL3196661 & 688497 & 4.45 & 4.6768 & TRN & \\
\hline CHEMBL1364242 & 688497 & 4.6 & 4.8565 & TST & \\
\hline CHEMBL1519210 & 688497 & 5.1 & 4.8649 & TRN & \\
\hline CHEMBL1342915 & 688497 & 5.0 & 4.9458 & TRN & \\
\hline CHEMBL1418247 & 688497 & 5.25 & 5.1628 & TRN & \\
\hline CHEMBL1304552 & 688497 & 5.45 & 4.9488 & TST & \\
\hline CHEMBL1368553 & 688497 & 4.5 & 4.7571 & TRN & \\
\hline CHEMBL1578522 & 688497 & 5.5 & 5.3409 & TRN & \\
\hline CHEMBL590168 & 688497 & 4.45 & 4.8676 & TRN & \\
\hline CHEMBL1311622 & 688497 & 5.0 & 5.20299 & 9999999999 & TRN \\
\hline CHEMBL1529775 & 688497 & 4.45 & 5.3506 & TRN & \\
\hline
\end{tabular}




\begin{tabular}{|c|c|c|c|c|c|}
\hline \multicolumn{6}{|c|}{ Supplemental Table S2.txt } \\
\hline CHEMBL1579617 & 688497 & 4.85 & 4.9299 & TRN & \\
\hline CHEMBL1491322 & 688497 & 4.45 & 4.7192 & TRN & \\
\hline CHEMBL1459168 & 688497 & 5.05 & 5.1496 & TRN & \\
\hline CHEMBL1393366 & 688497 & 5.0 & 4.878 & TRN & \\
\hline CHEMBL1881714 & 688497 & 5.15 & 4.7121 & TRN & \\
\hline CHEMBL1311220 & 688497 & 4.6 & 4.7547 & TRN & \\
\hline CHEMBL1430068 & 688497 & 4.45 & 4.4518 & TRN & \\
\hline CHEMBL1369612 & 688497 & 5.55 & 4.9698 & TRN & \\
\hline CHEMBL1337204 & 688497 & 4.6 & 5.077 & TRN & \\
\hline CHEMBL 2004511 & 688497 & 4.45 & 4.8582 & TRN & \\
\hline CHEMBL1581780 & 688497 & 4.45 & 5.0969 & TST & \\
\hline CHEMBL1302740 & 688497 & 5.4 & 5.2329 & TST & \\
\hline CHEMBL1426646 & 688497 & 4.6 & 5.0315 & TRN & \\
\hline CHEMBL1535999 & 688497 & 5.45 & 4.8798 & TRN & \\
\hline CHEMBL1460531 & 688497 & 4.6 & 5.0136 & TRN & \\
\hline CHEMBL1519076 & 688497 & 4.8 & 4.7538 & TRN & \\
\hline CHEMBL1374947 & 688497 & 5.3 & 4.9597 & TRN & \\
\hline CHEMBL1330925 & 688497 & 6.25 & 5.2776 & TST & \\
\hline CHEMBL1478801 & 688497 & 4.95 & 5.0094 & TRN & \\
\hline CHEMBL1570465 & 688497 & 4.45 & 4.6007 & TRN & \\
\hline CHEMBL1508620 & 688497 & 4.75 & 4.7264 & TRN & \\
\hline CHEMBL1567229 & 688497 & 4.8 & 5.2272 & TST & \\
\hline CHEMBL3196502 & 688497 & 4.75 & 5.1673 & TRN & \\
\hline CHEMBL1560552 & 688497 & 4.45 & 4.7886 & TRN & \\
\hline CHEMBL1520155 & 688497 & 4.9 & 5.0627 & TRN & \\
\hline CHEMBL1416483 & 688497 & 4.45 & 4.8863 & TRN & \\
\hline CHEMBL1361625 & 688497 & 4.45 & 5.2427 & TRN & \\
\hline CHEMBL1507344 & 688497 & 4.65 & 5.0441 & TST & \\
\hline CHEMBL1341031 & 688497 & 5.4 & 5.3014 & TRN & \\
\hline CHEMBL581865 & 688497 & 4.45 & 4.9114 & TRN & \\
\hline CHEMBL1494000 & 688497 & 4.45 & 5.0116 & TST & \\
\hline CHEMBL1409132 & 688497 & 4.45 & 5.13399 & 99999999995 & TRN \\
\hline CHEMBL1464140 & 688497 & 4.9 & 4.9575 & TRN & \\
\hline CHEMBL1448732 & 688497 & 5.0 & 4.7898 & TST & \\
\hline CHEMBL1577395 & 688497 & 4.95 & 4.9662 & TRN & \\
\hline CHEMBL1353554 & 688497 & 5.0 & 5.1711 & TST & \\
\hline CHEMBL1440188 & 688497 & 5.0 & 5.2596 & TRN & \\
\hline CHEMBL1464588 & 688497 & 9.2218 & 4.9328 & TRN & \\
\hline CHEMBL1349206 & 688497 & 5.25 & 4.9769 & TRN & \\
\hline CHEMBL1445605 & 688497 & 5.0 & 5.1209 & TST & \\
\hline CHEMBL1584016 & 688497 & 4.65 & 4.7729 & TRN & \\
\hline CHEMBL1574996 & 688497 & 6.25 & 5.4024 & TRN & \\
\hline CHEMBL1498511 & 688497 & 4.45 & 5.20700 & 0000000001 & TRN \\
\hline CHEMBL1392463 & 688497 & 5.25 & 5.1265 & TST & \\
\hline CHEMBL1433269 & 688497 & 4.45 & 5.4061 & TST & \\
\hline CHEMBL1595161 & 688497 & 4.45 & 4.5855 & TST & \\
\hline CHEMBL1568547 & 688497 & 4.45 & 4.8977 & TST & \\
\hline CHEMBL1372304 & 688497 & 4.5 & 4.7641 & TST & \\
\hline
\end{tabular}




\begin{tabular}{|c|c|c|c|c|}
\hline \multicolumn{5}{|c|}{ Supplemental Table } \\
\hline CHEMBL1327987 & 688497 & 4.95 & 4.9152 & TRN \\
\hline CHEMBL1576186 & 688497 & 5.25 & 5.1317 & TRN \\
\hline CHEMBL1312730 & 688497 & 6.95 & 5.3501 & TST \\
\hline CHEMBL1480466 & 688497 & 5.45 & 5.1103 & TRN \\
\hline CHEMBL1466117 & 688497 & 4.8 & 5.1598 & TST \\
\hline CHEMBL1301948 & 688497 & 4.45 & 4.8103 & TRN \\
\hline CHEMBL1487272 & 688497 & 5.2 & 4.8754 & TST \\
\hline CHEMBL1508588 & 688497 & 5.25 & 5.1277 & TST \\
\hline CHEMBL1453953 & 688497 & 5.0 & 4.9626 & TRN \\
\hline CHEMBL1324698 & 688497 & 6.1 & 4.7471 & TRN \\
\hline CHEMBL1311773 & 688497 & 5.9 & 4.9864 & TST \\
\hline CHEMBL1349666 & 688497 & 5.2 & 5.1087 & TRN \\
\hline CHEMBL1460719 & 688497 & 5.35 & 5.0941 & TRN \\
\hline CHEMBL1538035 & 688497 & 5.0 & 4.7211 & TRN \\
\hline CHEMBL1562800 & 688497 & 4.45 & 4.9183 & TRN \\
\hline CHEMBL1470464 & 688497 & 5.6 & 4.9286 & TST \\
\hline CHEMBL1364693 & 688497 & 4.45 & 4.9016 & TRN \\
\hline CHEMBL1332522 & 688497 & 6.5 & 5.3179 & TRN \\
\hline CHEMBL 3197431 & 688497 & 4.45 & 4.935 & TRN \\
\hline CHEMBL1604777 & 688497 & 6.5 & 5.3184 & TST \\
\hline CHEMBL1403920 & 688497 & 4.6 & 5.0482 & TRN \\
\hline CHEMBL1391079 & 688497 & 6.3 & 5.2601 & TRN \\
\hline CHEMBL1407563 & 688497 & 4.45 & 4.8399 & TRN \\
\hline CHEMBL1557922 & 688497 & 4.55 & 4.8305 & TRN \\
\hline CHEMBL1333390 & 688497 & 4.5 & 4.8651 & TRN \\
\hline CHEMBL1602321 & 688497 & 8.0 & 5.2127 & TST \\
\hline CHEMBL1410374 & 688497 & 4.8 & 4.6643 & TRN \\
\hline CHEMBL1600604 & 688497 & 4.65 & 5.0265 & TRN \\
\hline CHEMBL1511108 & 688497 & 4.65 & 5.1453 & TRN \\
\hline CHEMBL1545288 & 688497 & 6.0 & 5.0987 & TRN \\
\hline CHEMBL1444621 & 688497 & 5.0 & 5.187 & TRN \\
\hline CHEMBL1427160 & 688497 & 4.65 & 5.1507 & TRN \\
\hline CHEMBL3189674 & 688497 & 4.9 & 5.0072 & TRN \\
\hline CHEMBL1346158 & 688497 & 5.9 & 5.1699 & TST \\
\hline CHEMBL1487951 & 688497 & 4.6 & 4.8446 & TRN \\
\hline CHEMBL 3192294 & 688497 & 4.45 & 4.8629 & TRN \\
\hline CHEMBL1532867 & 688497 & 4.45 & 4.8015 & TRN \\
\hline CHEMBL1311396 & 688497 & 6.25 & 5.2892 & TRN \\
\hline CHEMBL1369327 & 688497 & 4.9 & 4.8743 & TRN \\
\hline CHEMBL1405957 & 688497 & 5.45 & 4.9172 & TRN \\
\hline CHEMBL3209157 & 688497 & 5.35 & 5.1693 & TRN \\
\hline CHEMBL1506600 & 688497 & 4.45 & 5.0189 & TRN \\
\hline CHEMBL1547696 & 688497 & 4.6 & 4.9568 & TRN \\
\hline CHEMBL1409585 & 688497 & 4.45 & 5.0337 & TRN \\
\hline CHEMBL1414986 & 688497 & 5.35 & 5.289 & TST \\
\hline CHEMBL1432243 & 688497 & 4.45 & 4.6471 & TRN \\
\hline CHEMBL1329100 & 688497 & 4.9 & 5.0513 & TRN \\
\hline CHEMBL3190135 & 688497 & 5.55 & 4.9063 & TRN \\
\hline
\end{tabular}




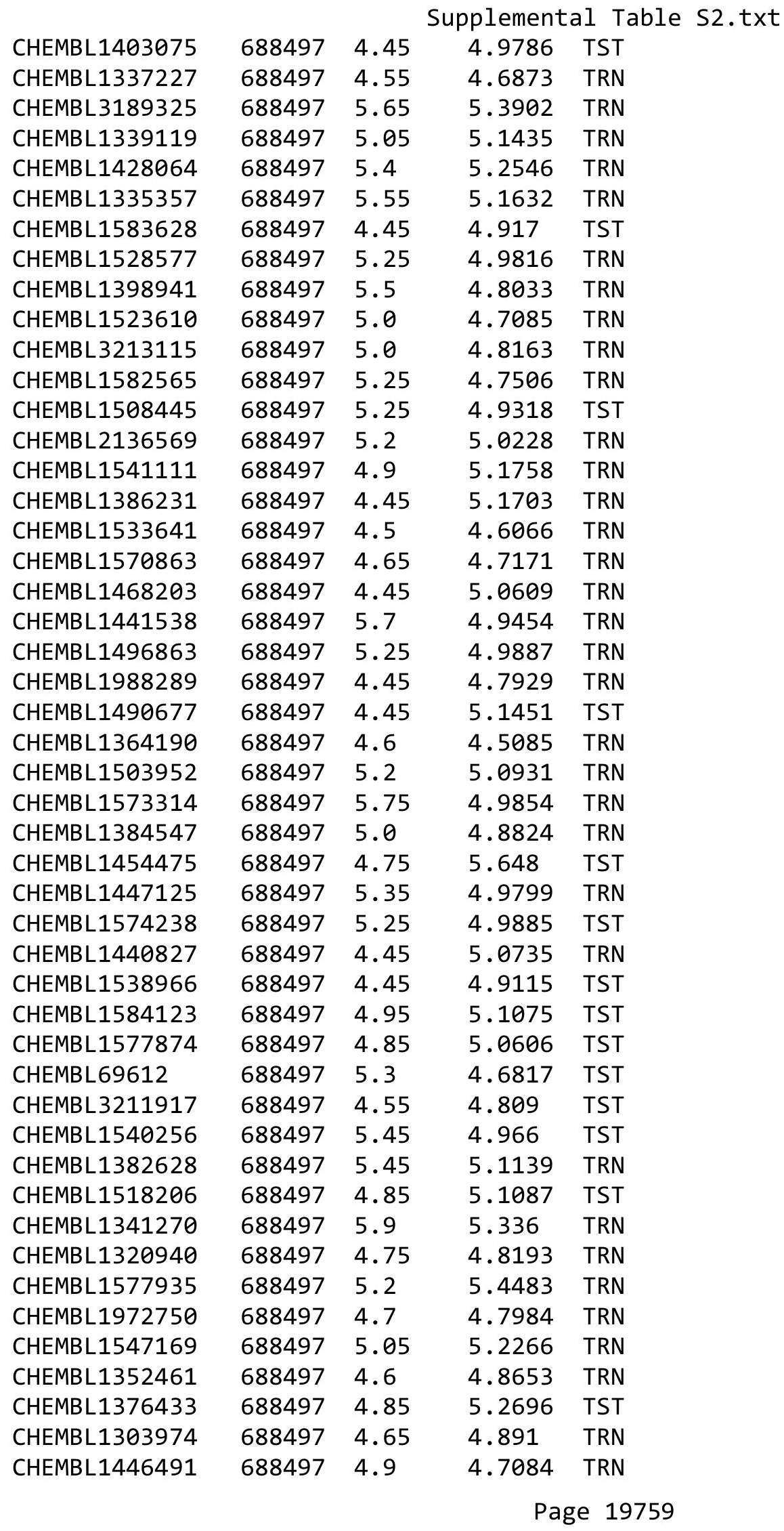




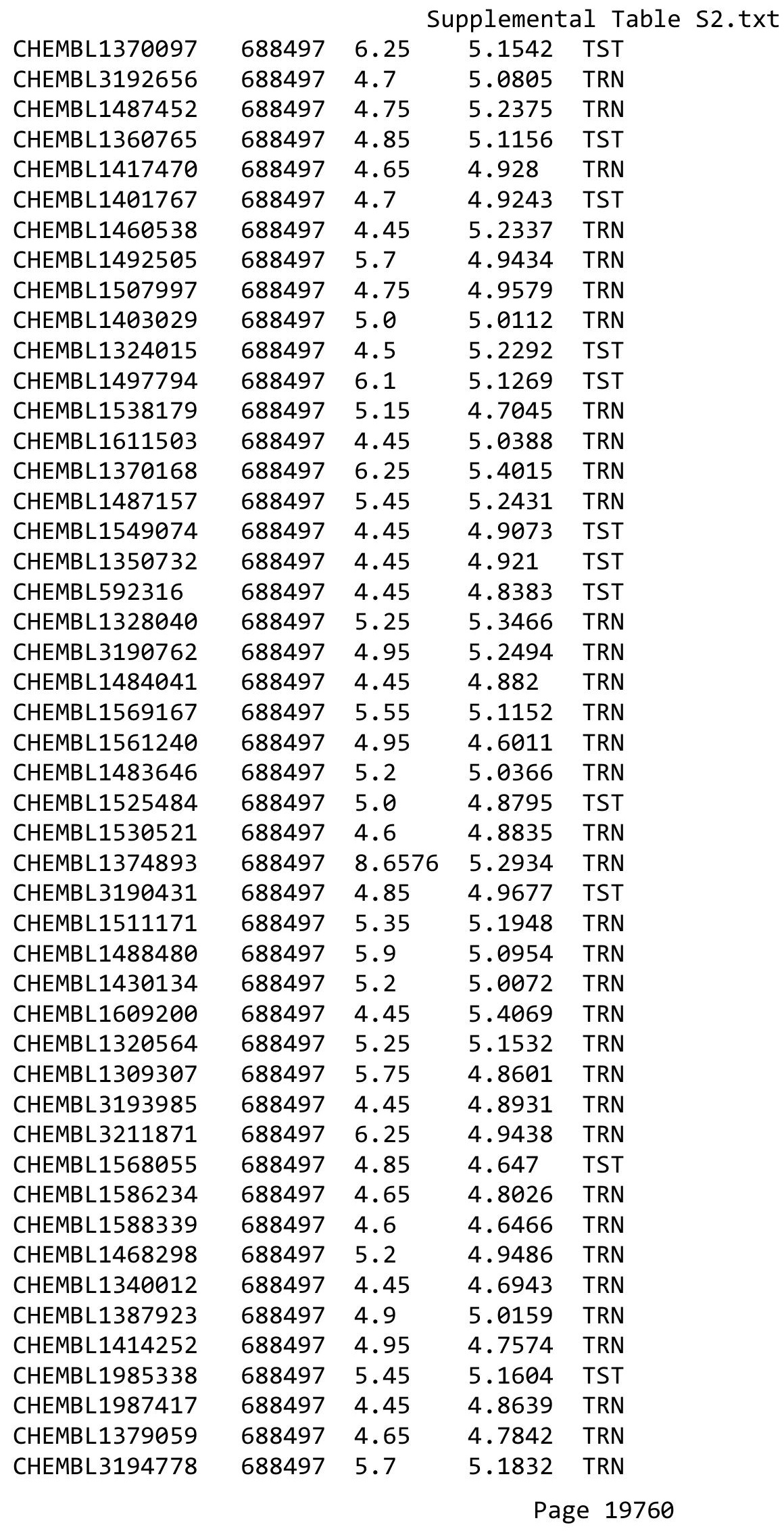




\begin{tabular}{|c|c|c|c|c|c|}
\hline \multicolumn{6}{|c|}{ Supplemental Table S2.txt } \\
\hline CHEMBL1536625 & 688497 & 4.45 & 4.793 & TRN & \\
\hline CHEMBL1528094 & 688497 & 4.45 & 5.0171 & TRN & \\
\hline CHEMBL1306129 & 688497 & 4.45 & 5.1644 & TRN & \\
\hline CHEMBL1584120 & 688497 & 4.45 & 5.3213 & TST & \\
\hline CHEMBL1449887 & 688497 & 4.95 & 4.9997 & TST & \\
\hline CHEMBL1584402 & 688497 & 4.45 & 5.1981 & TST & \\
\hline CHEMBL1406772 & 688497 & 5.35 & 5.1987 & TRN & \\
\hline CHEMBL1452612 & 688497 & 4.5 & 4.873 & TRN & \\
\hline CHEMBL1391965 & 688497 & 4.85 & 4.89 & TRN & \\
\hline CHEMBL1306923 & 688497 & 4.65 & 4.7942 & TRN & \\
\hline CHEMBL1510126 & 688497 & 6.25 & 5.2333 & TRN & \\
\hline CHEMBL1575953 & 688497 & 5.6 & 5.4383 & TRN & \\
\hline CHEMBL1487851 & 688497 & 6.35 & 4.9755 & TST & \\
\hline CHEMBL1431759 & 688497 & 5.9 & 5.3408 & TST & \\
\hline CHEMBL1347380 & 688497 & 4.45 & 5.2362 & TRN & \\
\hline CHEMBL1584914 & 688497 & 5.0 & 5.011 & TRN & \\
\hline CHEMBL1430845 & 688497 & 4.45 & 5.1501 & TST & \\
\hline CHEMBL1585708 & 688497 & 4.9 & 5.2212 & TST & \\
\hline CHEMBL1425248 & 688497 & 4.95 & 5.0204 & TRN & \\
\hline CHEMBL 3198228 & 688497 & 4.9 & 5.1165 & TST & \\
\hline CHEMBL1524369 & 688497 & 5.7 & 4.9547 & TST & \\
\hline CHEMBL1379956 & 688497 & 4.6 & 5.0959 & TST & \\
\hline CHEMBL1518615 & 688497 & 5.4 & 4.926 & TST & \\
\hline CHEMBL1548497 & 688497 & 4.8 & 5.0406 & TST & \\
\hline CHEMBL1969760 & 688497 & 4.95 & 5.0493 & TRN & \\
\hline CHEMBL3208041 & 688497 & 5.55 & 5.2628 & TST & \\
\hline CHEMBL1338747 & 688497 & 5.25 & 5.1503 & TST & \\
\hline CHEMBL1472290 & 688497 & 5.5 & 5.01399 & 9999999999 & TRN \\
\hline CHEMBL1478187 & 688497 & 4.45 & 5.0423 & TRN & \\
\hline CHEMBL1525187 & 688497 & 4.65 & 5.2657 & TST & \\
\hline CHEMBL1336630 & 688497 & 4.45 & 4.6512 & TRN & \\
\hline CHEMBL1532718 & 688497 & 4.75 & 5.1898 & TRN & \\
\hline CHEMBL1457669 & 688497 & 4.45 & 4.7984 & TRN & \\
\hline CHEMBL1497134 & 688497 & 5.2 & 5.2655 & TST & \\
\hline CHEMBL1528023 & 688497 & 5.9 & 5.0293 & TRN & \\
\hline CHEMBL1976308 & 688497 & 6.45 & 5.2097 & TRN & \\
\hline CHEMBL1567496 & 688497 & 5.05 & 5.0262 & TST & \\
\hline CHEMBL1994506 & 688497 & 5.25 & 4.9407 & TST & \\
\hline CHEMBL1322423 & 688497 & 6.25 & 5.4451 & TRN & \\
\hline CHEMBL1575619 & 688497 & 5.7 & 5.0969 & TRN & \\
\hline CHEMBL1509529 & 688497 & 4.45 & 5.1152 & TRN & \\
\hline CHEMBL1336558 & 688497 & 4.45 & 5.0631 & TRN & \\
\hline CHEMBL3209810 & 688497 & 5.5 & 5.0609 & TRN & \\
\hline CHEMBL1569267 & 688497 & 4.85 & 4.6698 & TRN & \\
\hline CHEMBL1489005 & 688497 & 5.5 & 4.9141 & TRN & \\
\hline CHEMBL 3190583 & 688497 & 5.95 & 4.7905 & TST & \\
\hline CHEMBL3191466 & 688497 & 4.45 & 5.1905 & TRN & \\
\hline CHEMBL1456944 & 688497 & 4.6 & 5.1415 & TRN & \\
\hline
\end{tabular}




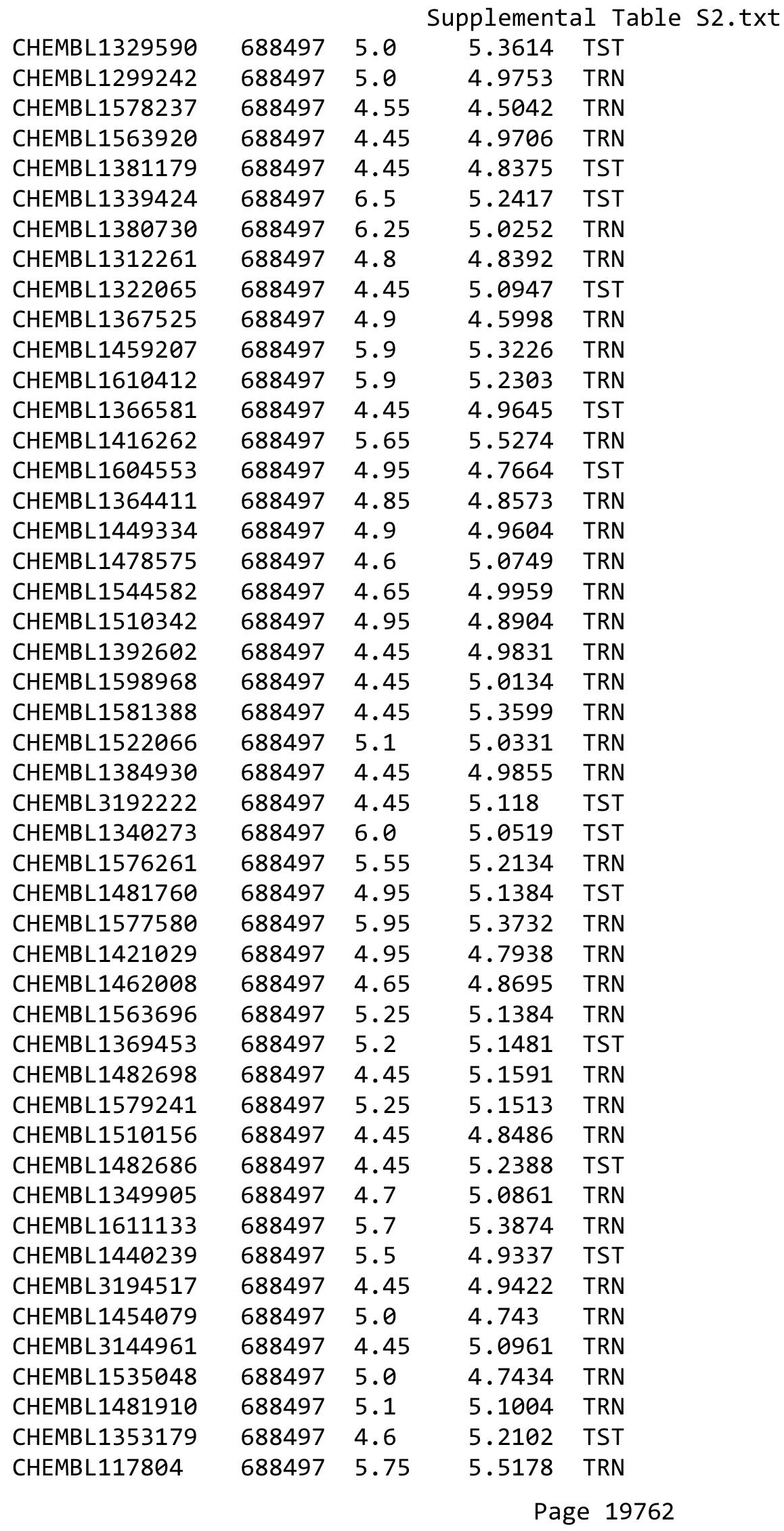




\begin{tabular}{|c|c|c|c|c|c|}
\hline \multicolumn{6}{|c|}{ Supplemental Table S2.txt } \\
\hline CHEMBL1344935 & 688497 & 5.8 & 5.2839 & TST & \\
\hline CHEMBL3213728 & 688497 & 4.45 & 4.8405 & TST & \\
\hline CHEMBL1364586 & 688497 & 5.9 & 5.1498 & TST & \\
\hline CHEMBL1537060 & 688497 & 4.55 & 5.0873 & TRN & \\
\hline CHEMBL1441954 & 688497 & 6.1 & 5.1399 & TRN & \\
\hline CHEMBL1556555 & 688497 & 4.45 & 4.7399 & TST & \\
\hline CHEMBL1529470 & 688497 & 6.25 & 5.16700 & 0000000001 & TRN \\
\hline CHEMBL 3212130 & 688497 & 5.5 & 5.2973 & TRN & \\
\hline CHEMBL1320358 & 688497 & 6.2 & 5.4309 & TRN & \\
\hline CHEMBL1580773 & 688497 & 4.75 & 4.9758 & TRN & \\
\hline CHEMBL1470674 & 688497 & 4.6 & 5.0437 & TRN & \\
\hline CHEMBL1485014 & 688497 & 4.75 & 4.8425 & TST & \\
\hline CHEMBL1608403 & 688497 & 5.4 & 5.0157 & TRN & \\
\hline CHEMBL1584898 & 688497 & 4.9 & 4.8627 & TST & \\
\hline CHEMBL1520323 & 688497 & 5.05 & 4.791 & TRN & \\
\hline CHEMBL1422809 & 688497 & 5.55 & 4.9101 & TRN & \\
\hline CHEMBL1327086 & 688497 & 5.5 & 5.1623 & TRN & \\
\hline CHEMBL1302291 & 688497 & 5.25 & 5.246 & TRN & \\
\hline CHEMBL1587890 & 688497 & 5.25 & 5.2015 & TRN & \\
\hline CHEMBL1539141 & 688497 & 4.75 & 4.7857 & TRN & \\
\hline CHEMBL1451172 & 688497 & 4.7 & 5.0369 & TRN & \\
\hline CHEMBL1499273 & 688497 & 7.1002 & 5.1092 & TST & \\
\hline CHEMBL1577394 & 688497 & 5.25 & 5.039 & TRN & \\
\hline CHEMBL1423443 & 688497 & 5.25 & 5.2344 & TRN & \\
\hline CHEMBL1572921 & 688497 & 4.65 & 5.1902 & TRN & \\
\hline CHEMBL1443647 & 688497 & 6.25 & 5.3134 & TRN & \\
\hline CHEMBL1416200 & 688497 & 4.9 & 4.7838 & TST & \\
\hline CHEMBL1470367 & 688497 & 4.95 & 5.1092 & TST & \\
\hline CHEMBL1544239 & 688497 & 4.45 & 5.019 & TST & \\
\hline CHEMBL1380365 & 688497 & 4.9 & 4.7826 & TRN & \\
\hline CHEMBL1570293 & 688497 & 4.65 & 5.4437 & TST & \\
\hline CHEMBL1329856 & 688497 & 5.2 & 5.0772 & TRN & \\
\hline CHEMBL1384290 & 688497 & 4.45 & 4.9179 & TRN & \\
\hline CHEMBL1363237 & 688497 & 4.6 & 5.0763 & TRN & \\
\hline CHEMBL1332396 & 688497 & 4.65 & 5.5813 & TRN & \\
\hline CHEMBL1586059 & 688497 & 4.95 & 5.2344 & TST & \\
\hline CHEMBL 1463260 & 688497 & 4.5 & 5.1126 & TRN & \\
\hline CHEMBL1549233 & 688497 & 5.6 & 5.1795 & TRN & \\
\hline CHEMBL1556805 & 688497 & 5.45 & 5.6366 & TRN & \\
\hline CHEMBL1331851 & 688497 & 4.7 & 4.9825 & TRN & \\
\hline CHEMBL1597702 & 688497 & 5.2 & 5.0544 & TST & \\
\hline CHEMBL 1424440 & 688497 & 4.85 & 5.1099 & TST & \\
\hline CHEMBL1541505 & 688497 & 4.45 & 5.0414 & TST & \\
\hline CHEMBL1384527 & 688497 & 5.0 & 5.2406 & TRN & \\
\hline CHEMBL1322138 & 688497 & 4.45 & 5.1082 & TRN & \\
\hline CHEMBL1311879 & 688497 & 5.5 & 5.5159 & TST & \\
\hline CHEMBL1601093 & 688497 & 4.45 & 5.239 & TRN & \\
\hline CHEMBL1488466 & 688497 & 4.85 & 5.0056 & TRN & \\
\hline
\end{tabular}




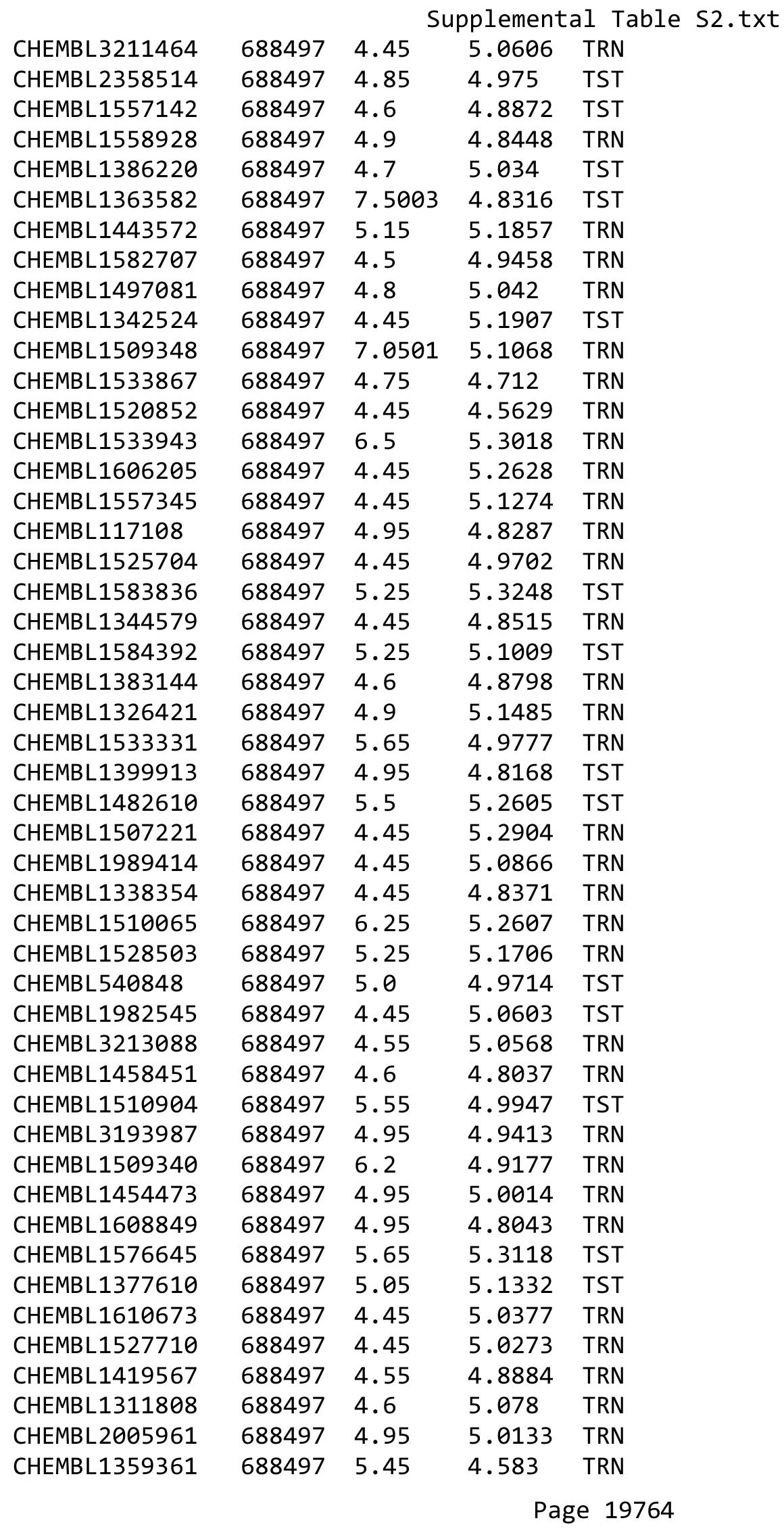




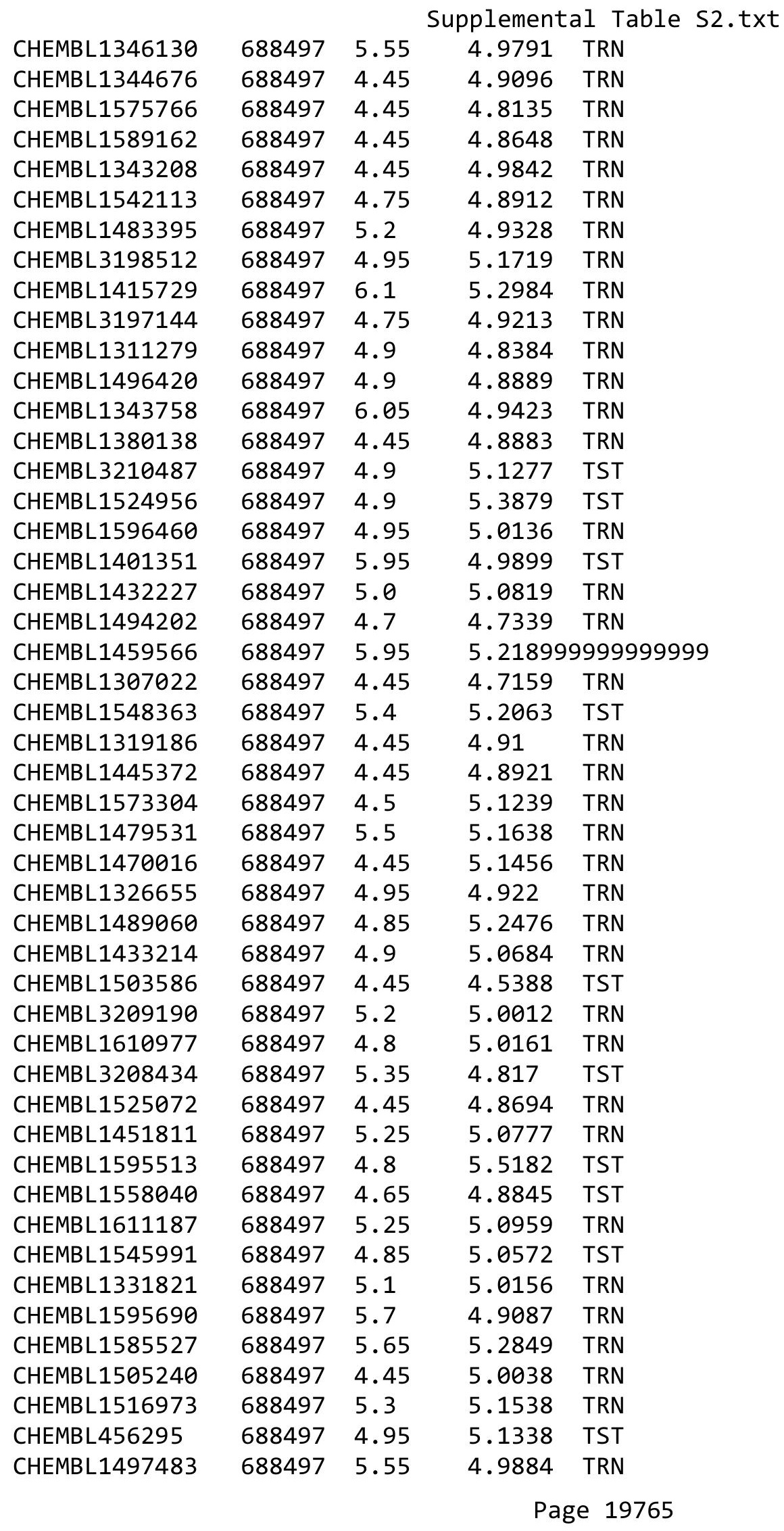




\begin{tabular}{|c|c|c|c|c|}
\hline \multicolumn{5}{|c|}{ Supplemental Table S2.txt } \\
\hline CHEMBL1468882 & 688497 & 5.15 & 4.9837 & TRN \\
\hline CHEMBL1326304 & 688497 & 5.4 & 5.2524 & TRN \\
\hline CHEMBL1359466 & 688497 & 5.9 & 4.8835 & TRN \\
\hline CHEMBL1506706 & 688497 & 4.6 & 5.0369 & TST \\
\hline CHEMBL1486533 & 688497 & 4.45 & 4.8018 & TRN \\
\hline CHEMBL1403575 & 688497 & 5.5 & 4.8056 & TRN \\
\hline CHEMBL1322960 & 688497 & 6.5 & 4.8291 & TRN \\
\hline CHEMBL1335256 & 688497 & 4.45 & 5.0293 & TST \\
\hline CHEMBL1345264 & 688497 & 5.1 & 5.3102 & TRN \\
\hline CHEMBL1368708 & 688497 & 4.9 & 5.3205 & TRN \\
\hline CHEMBL1446541 & 688497 & 4.75 & 4.9702 & TRN \\
\hline CHEMBL1458288 & 688497 & 5.2 & 5.0008 & TST \\
\hline CHEMBL1544132 & 688497 & 4.8 & 4.8472 & TST \\
\hline CHEMBL1506016 & 688497 & 4.45 & 4.8817 & TRN \\
\hline CHEMBL1973122 & 688497 & 4.8 & 4.6778 & TRN \\
\hline CHEMBL1329484 & 688497 & 5.05 & 4.9276 & TRN \\
\hline CHEMBL1421231 & 688497 & 4.75 & 4.9153 & TRN \\
\hline CHEMBL1582018 & 688497 & 5.5 & 5.2479 & TRN \\
\hline CHEMBL1439184 & 688497 & 4.65 & 4.8173 & TRN \\
\hline CHEMBL1988536 & 688497 & 5.6 & 4.7854 & TRN \\
\hline CHEMBL1478740 & 688497 & 4.95 & 5.1812 & TST \\
\hline CHEMBL1581277 & 688497 & 5.95 & 4.8883 & TRN \\
\hline CHEMBL1337246 & 688497 & 4.45 & 5.0068 & TRN \\
\hline CHEMBL1994599 & 688497 & 5.4 & 4.9969 & TST \\
\hline CHEMBL1519944 & 688497 & 5.4 & 5.0567 & TST \\
\hline CHEMBL1383320 & 688497 & 5.35 & 4.6826 & TRN \\
\hline CHEMBL1373862 & 688497 & 6.15 & 5.3147 & TRN \\
\hline CHEMBL1483225 & 688497 & 4.85 & 5.0383 & TRN \\
\hline CHEMBL405110 & 688497 & 4.9 & 5.1956 & TST \\
\hline CHEMBL1555721 & 688497 & 4.45 & 4.9969 & TST \\
\hline CHEMBL1599693 & 688497 & 6.25 & 5.4379 & TST \\
\hline CHEMBL1537872 & 688497 & 4.9 & 5.1528 & TRN \\
\hline CHEMBL1405131 & 688497 & 6.05 & 5.1676 & TRN \\
\hline CHEMBL1430991 & 688497 & 4.65 & 4.8882 & TRN \\
\hline CHEMBL1422482 & 688497 & 5.45 & 5.0117 & TRN \\
\hline CHEMBL1386668 & 688497 & 4.75 & 4.905 & TST \\
\hline CHEMBL 1444020 & 688497 & 4.45 & 4.4077 & TRN \\
\hline CHEMBL3208179 & 688497 & 4.8 & 4.8749 & TST \\
\hline CHEMBL1455766 & 688497 & 4.95 & 5.11 & TRN \\
\hline CHEMBL1605553 & 688497 & 4.9 & 4.999 & TRN \\
\hline CHEMBL1550335 & 688497 & 4.9 & 5.0778 & TST \\
\hline CHEMBL1458881 & 688497 & 4.45 & 4.9939 & TRN \\
\hline CHEMBL1350286 & 688497 & 4.45 & 4.8363 & TRN \\
\hline CHEMBL1337611 & 688497 & 4.95 & 5.1521 & TRN \\
\hline CHEMBL1588217 & 688497 & 5.6 & 4.94 & TRN \\
\hline CHEMBL1486729 & 688497 & 4.45 & 5.0428 & TRN \\
\hline CHEMBL3209959 & 688497 & 4.55 & 5.1943 & TRN \\
\hline CHEMBL3193964 & 688497 & 4.45 & 4.9425 & TST \\
\hline
\end{tabular}




\begin{tabular}{|c|c|c|c|c|c|}
\hline \multicolumn{6}{|c|}{ Supplemental Table S2.txt } \\
\hline CHEMBL1421937 & 688497 & 4.95 & 5.0748 & TRN & \\
\hline CHEMBL1441780 & 688497 & 5.9 & 5.0053 & TRN & \\
\hline CHEMBL1457902 & 688497 & 5.1 & 5.0634 & TRN & \\
\hline CHEMBL1369945 & 688497 & 5.1 & 4.8578 & TRN & \\
\hline CHEMBL1402497 & 688497 & 4.85 & 5.0519 & TRN & \\
\hline CHEMBL1424953 & 688497 & 4.65 & 4.9162 & TRN & \\
\hline CHEMBL1608011 & 688497 & 4.7 & 4.8918 & TRN & \\
\hline CHEMBL1608247 & 688497 & 5.25 & 5.3412 & TRN & \\
\hline CHEMBL1540208 & 688497 & 5.0 & 4.766 & TRN & \\
\hline CHEMBL1988708 & 688497 & 4.9 & 5.3149 & TRN & \\
\hline CHEMBL1518885 & 688497 & 4.95 & 5.1077 & TRN & \\
\hline CHEMBL428909 & 688497 & 5.85 & 5.1329 & TRN & \\
\hline CHEMBL1542651 & 688497 & 4.5 & 4.93199 & 99999999995 & TRN \\
\hline CHEMBL1381439 & 688497 & 4.45 & 5.0905 & TRN & \\
\hline CHEMBL1324883 & 688497 & 5.95 & 5.0893 & TST & \\
\hline CHEMBL1344844 & 688497 & 4.8 & 5.0874 & TST & \\
\hline CHEMBL1565526 & 688497 & 5.25 & 5.0767 & TRN & \\
\hline CHEMBL1601045 & 688497 & 5.55 & 5.1682 & TRN & \\
\hline CHEMBL1967772 & 688497 & 4.8 & 4.9285 & TRN & \\
\hline CHEMBL1341882 & 688497 & 5.5 & 4.9822 & TRN & \\
\hline CHEMBL1518663 & 688497 & 4.65 & 5.0843 & TST & \\
\hline CHEMBL1484577 & 688497 & 4.95 & 5.1241 & TRN & \\
\hline CHEMBL1544304 & 688497 & 4.75 & 5.07 & TRN & \\
\hline CHEMBL3193102 & 688497 & 5.25 & 4.9059 & TST & \\
\hline CHEMBL1441739 & 688497 & 6.5 & 5.0829 & TST & \\
\hline CHEMBL1510676 & 688497 & 4.9 & 4.8282 & TST & \\
\hline CHEMBL1519692 & 688497 & 4.45 & 4.9355 & TRN & \\
\hline CHEMBL3199654 & 688497 & 6.25 & 4.8561 & TST & \\
\hline CHEMBL1426836 & 688497 & 5.0 & 5.1201 & TRN & \\
\hline CHEMBL1381253 & 688497 & 6.0 & 5.3293 & TRN & \\
\hline CHEMBL1597739 & 688497 & 6.9 & 5.4143 & TRN & \\
\hline CHEMBL1326397 & 688497 & 5.05 & 5.0688 & TRN & \\
\hline CHEMBL1527651 & 688497 & 6.25 & 5.2632 & TST & \\
\hline CHEMBL1415958 & 688497 & 5.5 & 5.0528 & TRN & \\
\hline CHEMBL1416445 & 688497 & 4.75 & 4.9058 & TRN & \\
\hline CHEMBL1419919 & 688497 & 4.45 & 4.8062 & TRN & \\
\hline CHEMBL1420646 & 688497 & 5.25 & 5.1374 & TRN & \\
\hline CHEMBL1419001 & 688497 & 6.2 & 5.225 & TST & \\
\hline CHEMBL1527530 & 688497 & 4.8 & 4.7557 & TRN & \\
\hline CHEMBL1516772 & 688497 & 4.95 & 4.6465 & TRN & \\
\hline CHEMBL1489362 & 688497 & 4.45 & 4.8328 & TRN & \\
\hline CHEMBL1446696 & 688497 & 4.65 & 4.8223 & TRN & \\
\hline CHEMBL1550237 & 688497 & 4.45 & 4.8237 & TRN & \\
\hline CHEMBL1599776 & 688497 & 5.35 & 5.3021 & TRN & \\
\hline CHEMBL1596145 & 688497 & 4.45 & 5.1462 & TRN & \\
\hline CHEMBL1445964 & 688497 & 4.95 & 4.8348 & TRN & \\
\hline CHEMBL1550106 & 688497 & 4.8 & 5.2513 & TRN & \\
\hline CHEMBL1325017 & 688497 & 4.45 & 4.9316 & TRN & \\
\hline
\end{tabular}




\begin{tabular}{|c|c|c|c|c|c|}
\hline \multicolumn{6}{|c|}{ Supplemental Table S2.txt } \\
\hline CHEMBL1336026 & 688497 & 4.45 & 5.0659 & TRN & \\
\hline CHEMBL1495008 & 688497 & 5.25 & 5.4235 & TST & \\
\hline CHEMBL1327993 & 688497 & 5.35 & 5.08899 & 99999999995 & TRN \\
\hline CHEMBL1410076 & 688497 & 5.25 & 5.0274 & TRN & \\
\hline CHEMBL1523699 & 688497 & 4.6 & 4.6877 & TRN & \\
\hline CHEMBL1456937 & 688497 & 5.0 & 4.9031 & TRN & \\
\hline CHEMBL1427426 & 688497 & 4.45 & 5.1723 & TST & \\
\hline CHEMBL1563700 & 688497 & 4.65 & 5.0748 & TRN & \\
\hline CHEMBL1351274 & 688497 & 5.25 & 5.3241 & TRN & \\
\hline CHEMBL1567534 & 688497 & 5.05 & 5.0831 & TRN & \\
\hline CHEMBL1408181 & 688497 & 5.9 & 5.1062 & TRN & \\
\hline CHEMBL1367311 & 688497 & 5.1 & 5.2028 & TRN & \\
\hline CHEMBL1550957 & 688497 & 4.45 & 5.2296 & TST & \\
\hline CHEMBL1348742 & 688497 & 4.45 & 4.9536 & TRN & \\
\hline CHEMBL1508611 & 688497 & 4.45 & 5.1769 & TRN & \\
\hline CHEMBL1549943 & 688497 & 5.4 & 5.3966 & TRN & \\
\hline CHEMBL1586625 & 688497 & 5.2 & 4.7687 & TRN & \\
\hline CHEMBL1349063 & 688497 & 5.75 & 5.3489 & TRN & \\
\hline CHEMBL1487431 & 688497 & 5.5 & 5.0449 & TRN & \\
\hline CHEMBL1507537 & 688497 & 5.4 & 5.1626 & TRN & \\
\hline CHEMBL1595766 & 688497 & 4.7 & 4.9128 & TRN & \\
\hline CHEMBL339561 & 688497 & 4.6 & 5.1758 & TST & \\
\hline CHEMBL1472135 & 688497 & 4.95 & 4.9439 & TRN & \\
\hline CHEMBL1479408 & 688497 & 4.45 & 4.8696 & TRN & \\
\hline CHEMBL1612016 & 688497 & 5.25 & 5.2202 & TST & \\
\hline CHEMBL3189345 & 688497 & 4.95 & 4.9551 & TRN & \\
\hline CHEMBL1570004 & 688497 & 4.8 & 4.5534 & TRN & \\
\hline CHEMBL1559211 & 688497 & 4.5 & 5.1873 & TST & \\
\hline CHEMBL1545722 & 688497 & 6.5 & 5.2024 & TST & \\
\hline CHEMBL1416348 & 688497 & 4.65 & 4.9741 & TRN & \\
\hline CHEMBL1303649 & 688497 & 4.95 & 4.8971 & TRN & \\
\hline CHEMBL1430585 & 688497 & 5.05 & 5.1924 & TRN & \\
\hline CHEMBL1370874 & 688497 & 4.45 & 4.7733 & TRN & \\
\hline CHEMBL1429739 & 688497 & 4.45 & 4.996 & TRN & \\
\hline CHEMBL1532859 & 688497 & 6.3 & 5.3266 & TRN & \\
\hline CHEMBL1545753 & 688497 & 4.65 & 5.4476 & TRN & \\
\hline CHEMBL1432884 & 688497 & 5.0 & 4.802 & TRN & \\
\hline CHEMBL1333664 & 688497 & 4.55 & 4.8531 & TRN & \\
\hline CHEMBL1518842 & 688497 & 5.05 & 4.7619 & TRN & \\
\hline CHEMBL1467815 & 688497 & 4.6 & 4.9264 & TRN & \\
\hline CHEMBL1464429 & 688497 & 4.9 & 4.9359 & TRN & \\
\hline CHEMBL1360791 & 688497 & 5.05 & 5.2556 & TRN & \\
\hline CHEMBL1600919 & 688497 & 4.75 & 5.2426 & TRN & \\
\hline CHEMBL1462026 & 688497 & 5.45 & 5.0393 & TRN & \\
\hline CHEMBL1343650 & 688497 & 5.45 & 5.4698 & TST & \\
\hline CHEMBL1421321 & 688497 & 4.95 & 5.1953 & TRN & \\
\hline CHEMBL1463563 & 688497 & 4.7 & 4.9867 & TST & \\
\hline CHEMBL1574871 & 688497 & 4.45 & 5.1139 & TST & \\
\hline
\end{tabular}




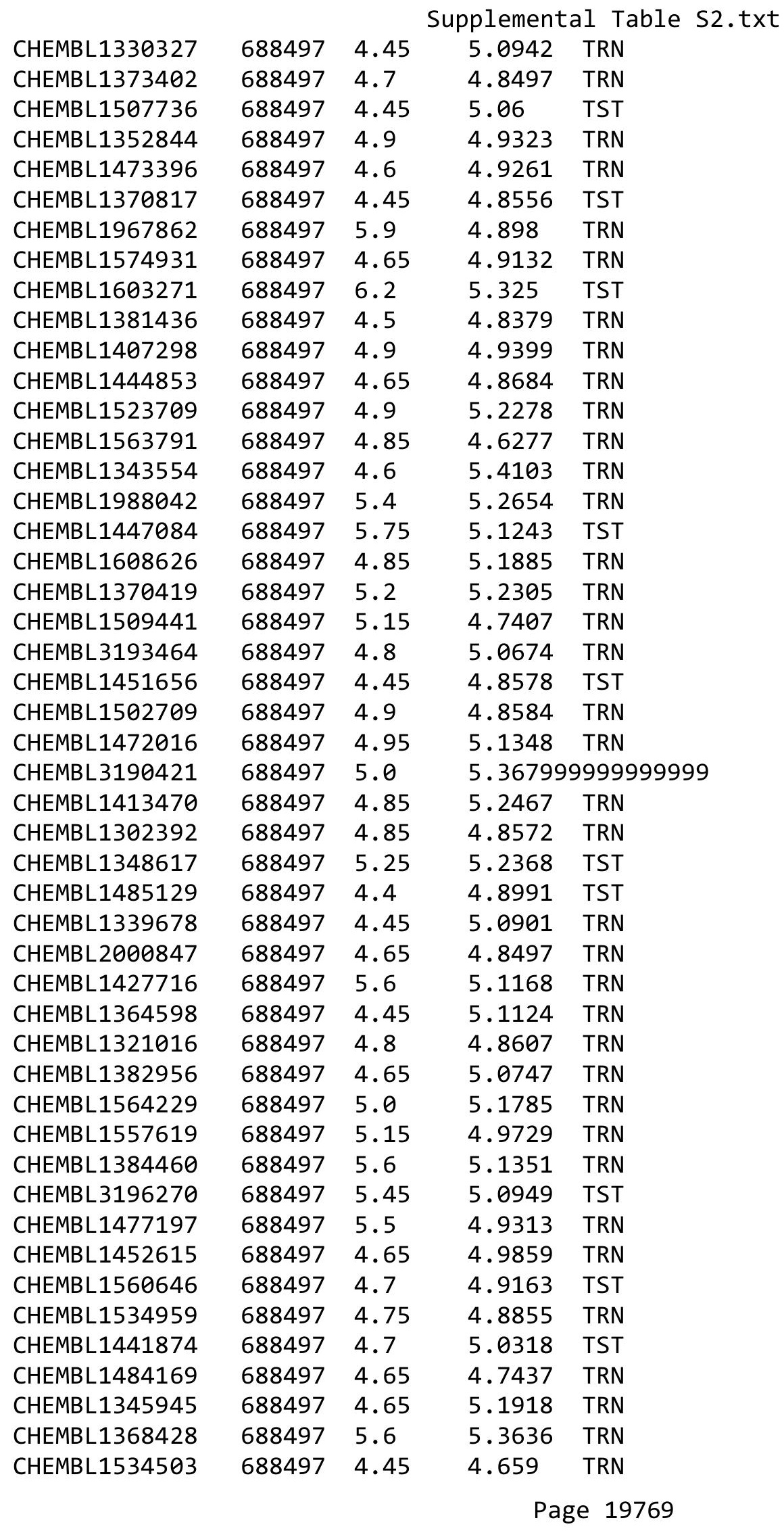

TRN 


\begin{tabular}{|c|c|c|c|c|c|}
\hline \multicolumn{6}{|c|}{ Supplemental Table S2.txt } \\
\hline CHEMBL1307904 & 688497 & 4.45 & 4.8423 & TRN & \\
\hline CHEMBL1331439 & 688497 & 4.65 & 5.1654 & TST & \\
\hline CHEMBL3195795 & 688497 & 5.4 & 5.1696 & TRN & \\
\hline CHEMBL395209 & 688497 & 4.65 & 4.899 & TRN & \\
\hline CHEMBL1525742 & 688497 & 4.9 & 4.8419 & TST & \\
\hline CHEMBL1527275 & 688497 & 5.05 & 4.8661 & TST & \\
\hline CHEMBL1585588 & 688497 & 5.0 & 4.9524 & TRN & \\
\hline CHEMBL1584173 & 688497 & 5.5 & 5.0562 & TRN & \\
\hline CHEMBL1346753 & 688497 & 4.5 & 5.3769 & TST & \\
\hline CHEMBL1494949 & 688497 & 4.45 & 5.1774 & TRN & \\
\hline CHEMBL1438099 & 688497 & 5.15 & 5.1234 & TRN & \\
\hline CHEMBL1418499 & 688497 & 4.9 & 5.0522 & TST & \\
\hline CHEMBL 3214613 & 688497 & 4.5 & 4.754 & TRN & \\
\hline CHEMBL1309580 & 688497 & 5.0 & 5.0306 & TST & \\
\hline CHEMBL1377754 & 688497 & 5.75 & 5.1276 & TRN & \\
\hline CHEMBL1980308 & 688497 & 4.45 & 4.7591 & TRN & \\
\hline CHEMBL1324528 & 688497 & 4.45 & 5.0088 & TRN & \\
\hline CHEMBL1393742 & 688497 & 6.0 & 4.8585 & TST & \\
\hline CHEMBL1503436 & 688497 & 5.0 & 5.0929 & TST & \\
\hline CHEMBL1530087 & 688497 & 5.45 & 4.8185 & TRN & \\
\hline CHEMBL1537226 & 688497 & 4.45 & 4.9884 & TRN & \\
\hline CHEMBL1346179 & 688497 & 4.6 & 4.9314 & TRN & \\
\hline CHEMBL1598460 & 688497 & 5.2 & 4.7246 & TRN & \\
\hline CHEMBL1405964 & 688497 & 4.45 & 4.6565 & TRN & \\
\hline CHEMBL273101 & 688497 & 4.6 & 5.228 & TRN & \\
\hline CHEMBL1550564 & 688497 & 4.45 & 4.9726 & TST & \\
\hline CHEMBL1504634 & 688497 & 4.65 & 5.2783 & TRN & \\
\hline CHEMBL1379600 & 688497 & 4.45 & 4.6264 & TST & \\
\hline CHEMBL42529 & 688497 & 5.35 & 5.42200 & 0000000001 & TRN \\
\hline CHEMBL1501801 & 688497 & 4.95 & 5.1704 & TRN & \\
\hline CHEMBL1422132 & 688497 & 5.25 & 5.2551 & TRN & \\
\hline CHEMBL1302870 & 688497 & 5.55 & 5.2536 & TRN & \\
\hline CHEMBL1442861 & 688497 & 6.0 & 4.8242 & TRN & \\
\hline CHEMBL1364867 & 688497 & 4.55 & 5.0416 & TRN & \\
\hline CHEMBL1525601 & 688497 & 4.65 & 5.2382 & TST & \\
\hline CHEMBL1499560 & 688497 & 6.3 & 5.1456 & TST & \\
\hline CHEMBL 3193056 & 688497 & 5.3 & 4.9984 & TST & \\
\hline CHEMBL1516543 & 688497 & 5.0 & 4.94600 & 2000000001 & TST \\
\hline CHEMBL1546996 & 688497 & 5.75 & 4.7305 & TRN & \\
\hline CHEMBL1453817 & 688497 & 4.95 & 5.0784 & TRN & \\
\hline CHEMBL1433254 & 688497 & 7.8508 & 4.9597 & TRN & \\
\hline CHEMBL1543163 & 688497 & 5.1 & 5.2539 & TST & \\
\hline CHEMBL1423758 & 688497 & 5.35 & 4.9047 & TST & \\
\hline CHEMBL1488669 & 688497 & 4.45 & 5.2067 & TRN & \\
\hline CHEMBL1382773 & 688497 & 5.05 & 4.8991 & TRN & \\
\hline CHEMBL1536190 & 688497 & 5.25 & 5.0697 & TST & \\
\hline CHEMBL1500885 & 688497 & 4.45 & 5.0625 & TRN & \\
\hline CHEMBL1510382 & 688497 & 4.95 & 5.0401 & TRN & \\
\hline
\end{tabular}




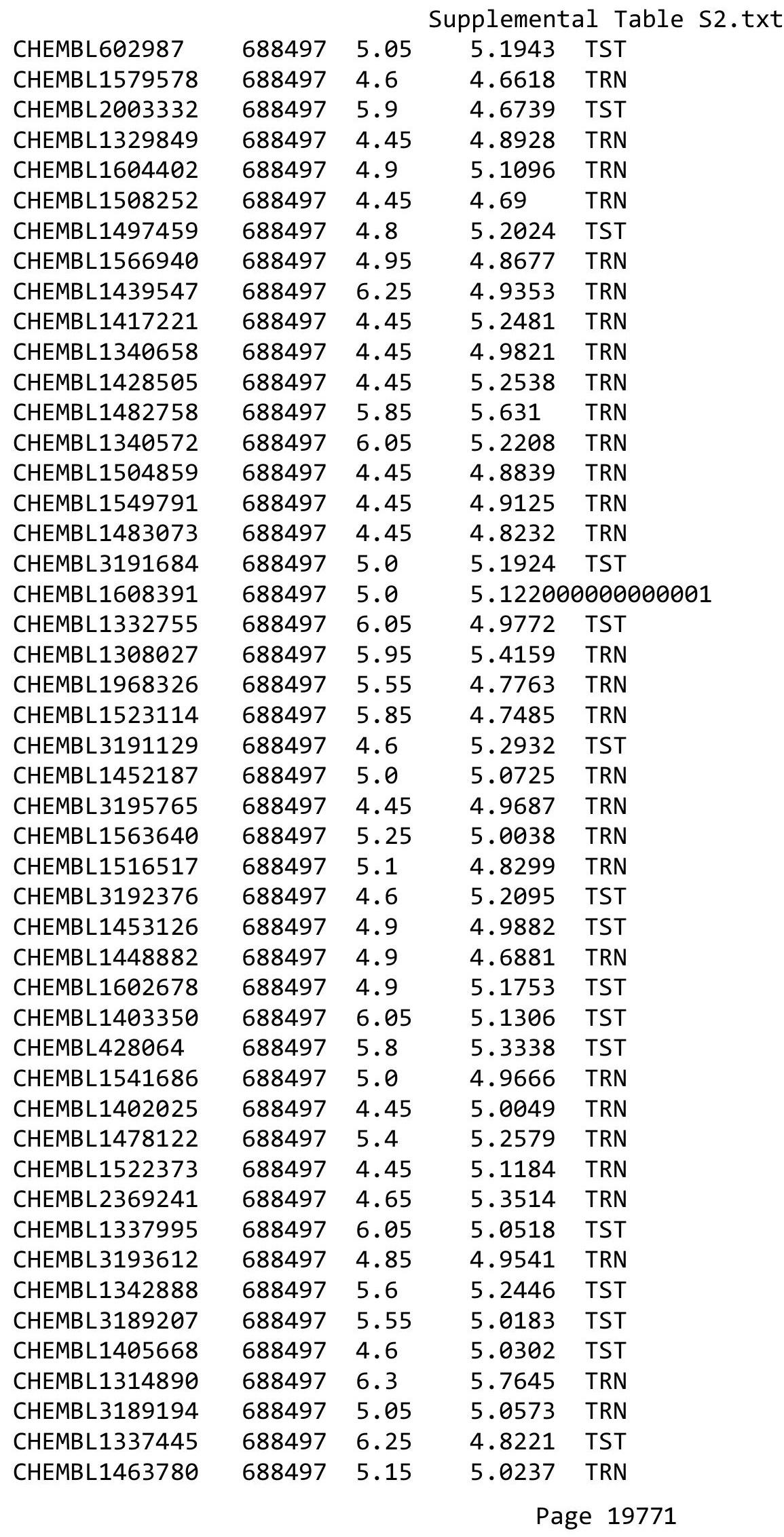




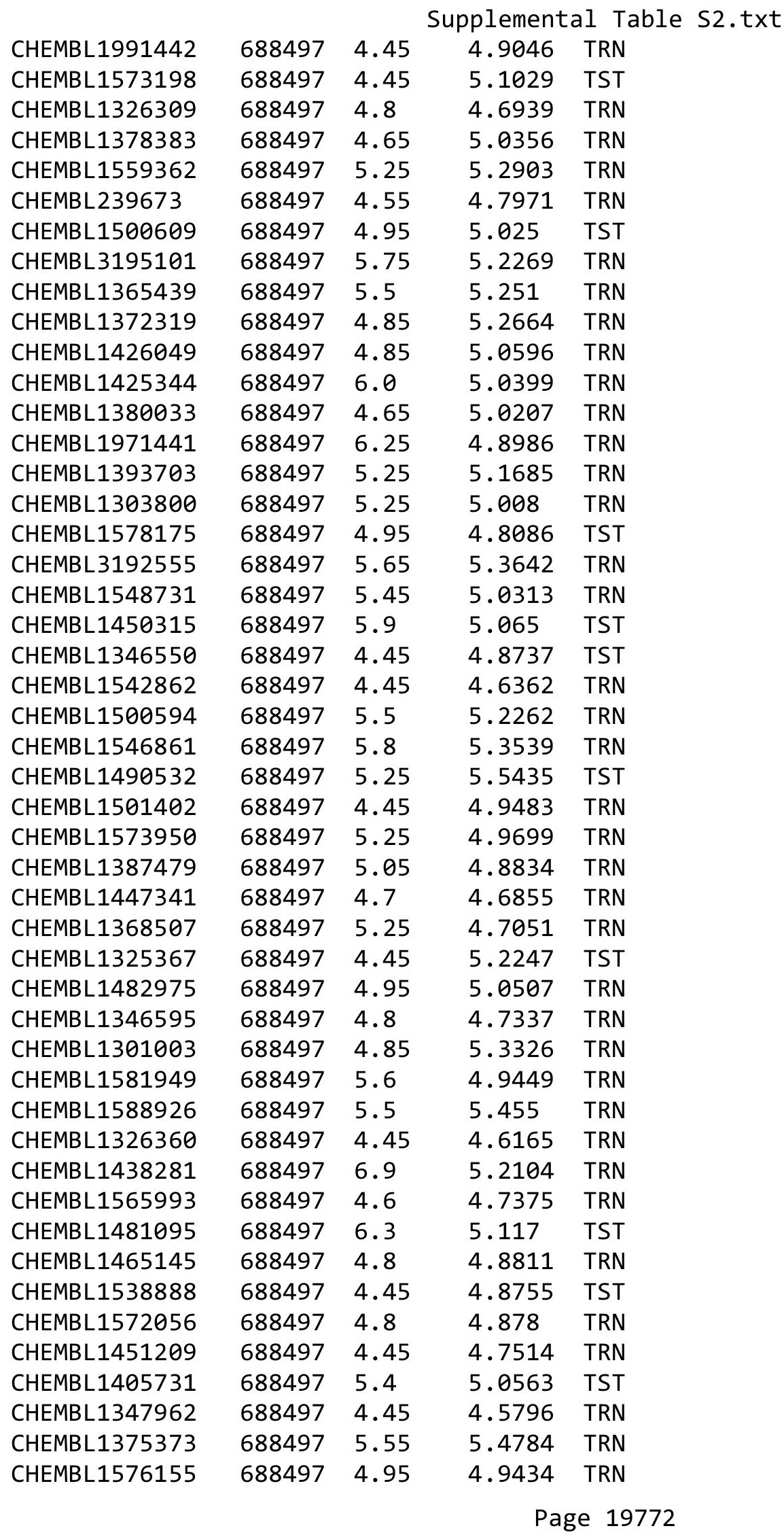




\begin{tabular}{|c|c|c|c|c|}
\hline \multicolumn{5}{|c|}{ Supplemental Table S2.txt } \\
\hline CHEMBL1321132 & 688497 & 4.8 & 4.8691 & TRN \\
\hline CHEMBL1299974 & 688497 & 5.65 & 5.2532 & TST \\
\hline CHEMBL1480781 & 688497 & 5.5 & 5.2175 & TRN \\
\hline CHEMBL1450755 & 688497 & 4.9 & 5.256 & TST \\
\hline CHEMBL1304998 & 688497 & 4.95 & 5.066 & TRN \\
\hline CHEMBL1497309 & 688497 & 4.85 & 4.9098 & TRN \\
\hline CHEMBL1549079 & 688497 & 4.6 & 4.8443 & TRN \\
\hline CHEMBL3212614 & 688497 & 4.5 & 4.8945 & TRN \\
\hline CHEMBL1555584 & 688497 & 4.45 & 5.16 & TST \\
\hline CHEMBL1506087 & 688497 & 4.45 & 4.6129 & TRN \\
\hline CHEMBL1548974 & 688497 & 4.5 & 4.8087 & TRN \\
\hline CHEMBL1976542 & 688497 & 4.75 & 5.059 & TRN \\
\hline CHEMBL1301880 & 688497 & 6.1 & 5.1355 & TRN \\
\hline CHEMBL1504933 & 688497 & 5.6 & 5.1246 & TRN \\
\hline CHEMBL1407080 & 688497 & 4.45 & 5.1247 & TRN \\
\hline CHEMBL1311618 & 688497 & 4.75 & 4.898 & TST \\
\hline CHEMBL1488395 & 688497 & 4.45 & 4.9645 & TRN \\
\hline CHEMBL1576855 & 688497 & 4.9 & 5.0111 & TRN \\
\hline CHEMBL1382229 & 688497 & 4.45 & 4.77 & TRN \\
\hline CHEMBL1340592 & 688497 & 4.6 & 4.9414 & TRN \\
\hline CHEMBL3196289 & 688497 & 5.0 & 5.003 & TRN \\
\hline CHEMBL1352490 & 688497 & 4.45 & 5.0967 & TST \\
\hline CHEMBL8197 & 688497 & 4.5 & 5.465 & TRN \\
\hline CHEMBL1320854 & 688497 & 4.45 & 5.441 & TRN \\
\hline CHEMBL1503729 & 688497 & 4.6 & 5.3122 & TRN \\
\hline CHEMBL1517755 & 688497 & 4.45 & 4.8111 & TRN \\
\hline CHEMBL1305552 & 688497 & 5.55 & 5.435 & TRN \\
\hline CHEMBL1389582 & 688497 & 4.45 & 5.629 & TRN \\
\hline CHEMBL1450138 & 688497 & 5.9 & 5.2132 & TRN \\
\hline CHEMBL3207397 & 688497 & 4.5 & 4.5646 & TRN \\
\hline CHEMBL1334327 & 688497 & 5.0 & 5.2813 & TRN \\
\hline CHEMBL1562664 & 688497 & 5.6 & 5.4323 & TRN \\
\hline CHEMBL1458807 & 688497 & 5.9 & 5.3726 & TRN \\
\hline CHEMBL1300081 & 688497 & 4.45 & 5.0563 & TRN \\
\hline CHEMBL1374274 & 688497 & 6.05 & 4.9478 & TRN \\
\hline CHEMBL1571606 & 688497 & 4.45 & 5.267 & TRN \\
\hline CHEMBL1432327 & 688497 & 5.45 & 4.6982 & TRN \\
\hline CHEMBL1974713 & 688497 & 4.9 & 4.7721 & TRN \\
\hline CHEMBL3196504 & 688497 & 4.9 & 5.1497 & TST \\
\hline CHEMBL 1488376 & 688497 & 5.6 & 5.0195 & TRN \\
\hline CHEMBL1338804 & 688497 & 4.85 & 4.8968 & TRN \\
\hline CHEMBL576407 & 688497 & 5.85 & 5.085 & TRN \\
\hline CHEMBL1429863 & 688497 & 4.65 & 5.102 & TRN \\
\hline CHEMBL1563950 & 688497 & 6.3 & 4.9841 & TRN \\
\hline CHEMBL1503700 & 688497 & 5.05 & 4.879 & TRN \\
\hline CHEMBL1526325 & 688497 & 4.55 & $4.6530 e$ & 00000000005 \\
\hline CHEMBL1399239 & 688497 & 4.95 & 4.9896 & TRN \\
\hline CHEMBL1414661 & 688497 & 4.95 & 5.0387 & TST \\
\hline
\end{tabular}

TRN 


\begin{tabular}{|c|c|c|c|c|}
\hline \multicolumn{5}{|c|}{ Supplemental Table S2.txt } \\
\hline CHEMBL1526966 & 688497 & 4.45 & 4.6074 & TRN \\
\hline CHEMBL1423307 & 688497 & 6.3 & 5.0886 & TRN \\
\hline CHEMBL1384608 & 688497 & 6.25 & 5.3773 & TST \\
\hline CHEMBL1385413 & 688497 & 4.6 & 4.8702 & TRN \\
\hline CHEMBL1409653 & 688497 & 4.45 & 4.9932 & TST \\
\hline CHEMBL1540581 & 688497 & 5.15 & 4.8889 & TRN \\
\hline CHEMBL3210913 & 688497 & 4.9 & 5.0994 & TRN \\
\hline CHEMBL1409445 & 688497 & 6.1 & 5.1775 & TRN \\
\hline CHEMBL1501158 & 688497 & 4.9 & 5.0227 & TRN \\
\hline CHEMBL1318829 & 688497 & 4.6 & 4.8609 & TRN \\
\hline CHEMBL1334820 & 688497 & 4.6 & 5.1263 & TST \\
\hline CHEMBL1567698 & 688497 & 4.65 & 4.7141 & TRN \\
\hline CHEMBL1572381 & 688497 & 4.7 & 5.0516 & TRN \\
\hline CHEMBL1530200 & 688497 & 4.6 & 5.1066 & TST \\
\hline CHEMBL1583459 & 688497 & 4.45 & 4.9947 & TRN \\
\hline CHEMBL1340197 & 688497 & 4.45 & 4.7269 & TRN \\
\hline CHEMBL1545864 & 688497 & 4.6 & 4.8226 & TRN \\
\hline CHEMBL1447602 & 688497 & 5.2 & 4.771 & TRN \\
\hline CHEMBL1566950 & 688497 & 4.45 & 4.8222 & TRN \\
\hline CHEMBL1373240 & 688497 & 5.55 & 5.1589 & TRN \\
\hline CHEMBL3210008 & 688497 & 5.95 & 4.9484 & TRN \\
\hline CHEMBL1345969 & 688497 & 4.45 & 4.8015 & TRN \\
\hline CHEMBL1516900 & 688497 & 4.8 & 4.9017 & TRN \\
\hline CHEMBL1535755 & 688497 & 4.45 & 4.8037 & TST \\
\hline CHEMBL3208812 & 688497 & 4.7 & 5.3666 & TRN \\
\hline CHEMBL1369200 & 688497 & 5.75 & 4.8379 & TRN \\
\hline CHEMBL1374788 & 688497 & 4.65 & 5.0044 & TST \\
\hline CHEMBL1313447 & 688497 & 4.75 & 4.67 & TRN \\
\hline CHEMBL1462474 & 688497 & 4.45 & 5.0574 & TST \\
\hline CHEMBL1490799 & 688497 & 4.45 & 5.0313 & TRN \\
\hline CHEMBL1556972 & 688497 & 4.5 & 5.0303 & TRN \\
\hline CHEMBL1540926 & 688497 & 4.45 & 4.7068 & TRN \\
\hline CHEMBL1526836 & 688497 & 4.45 & 4.7588 & TRN \\
\hline CHEMBL1310614 & 688497 & 5.4 & 5.0033 & TRN \\
\hline CHEMBL1430198 & 688497 & 5.5 & 5.081 & TRN \\
\hline CHEMBL3197418 & 688497 & 5.5 & 5.0239 & TST \\
\hline CHEMBL1469841 & 688497 & 4.8 & 4.8404 & TRN \\
\hline CHEMBL1568607 & 688497 & 4.9 & 4.8094 & TRN \\
\hline CHEMBL1573013 & 688497 & 4.45 & 4.8308 & TRN \\
\hline CHEMBL1530659 & 688497 & 4.95 & 5.3782 & TRN \\
\hline CHEMBL1466214 & 688497 & 5.05 & 4.9376 & TST \\
\hline CHEMBL1527298 & 688497 & 4.45 & 5.0896 & TST \\
\hline CHEMBL1370885 & 688497 & 4.65 & 5.2636 & TRN \\
\hline CHEMBL1428077 & 688497 & 6.25 & 4.8281 & TRN \\
\hline CHEMBL1578905 & 688497 & 4.55 & 5.0204 & TRN \\
\hline CHEMBL1521875 & 688497 & 6.05 & 5.2086 & TRN \\
\hline CHEMBL1350764 & 688497 & 4.45 & 4.9196 & TRN \\
\hline CHEMBL1391228 & 688497 & 5.9 & 5.09 & TRN \\
\hline
\end{tabular}




\begin{tabular}{|c|c|c|c|c|c|}
\hline \multicolumn{6}{|c|}{ Supplemental Table S2.txt } \\
\hline CHEMBL1370603 & 688497 & 4.95 & 5.0209 & TRN & \\
\hline CHEMBL1377607 & 688497 & 5.1 & 5.2148 & TST & \\
\hline CHEMBL1325877 & 688497 & 4.5 & 4.6508 & TRN & \\
\hline CHEMBL1488258 & 688497 & 4.9 & 4.8903 & TRN & \\
\hline CHEMBL1325388 & 688497 & 4.95 & 5.0505 & TRN & \\
\hline CHEMBL1384798 & 688497 & 5.35 & 5.0954 & TST & \\
\hline CHEMBL1320822 & 688497 & 5.55 & 4.8794 & TST & \\
\hline CHEMBL1469941 & 688497 & 4.8 & 4.9931 & TRN & \\
\hline CHEMBL1599438 & 688497 & 4.45 & 4.8775 & TST & \\
\hline CHEMBL1447267 & 688497 & 5.1 & 5.1743 & TRN & \\
\hline CHEMBL1463919 & 688497 & 4.9 & 4.8762 & TRN & \\
\hline CHEMBL1307850 & 688497 & 4.95 & 5.0454 & TRN & \\
\hline CHEMBL1376553 & 688497 & 5.5 & 5.1119 & TRN & \\
\hline CHEMBL1528454 & 688497 & 6.25 & 5.1642 & TST & \\
\hline CHEMBL1458052 & 688497 & 6.25 & 5.55399 & 9999999999 & TRN \\
\hline CHEMBL1414159 & 688497 & 4.8 & 5.2122 & TRN & \\
\hline CHEMBL258316 & 688497 & 5.45 & 5.2505 & TRN & \\
\hline CHEMBL1399221 & 688497 & 4.65 & 5.0528 & TRN & \\
\hline CHEMBL1497265 & 688497 & 4.5 & 5.2268 & TRN & \\
\hline CHEMBL1378497 & 688497 & 6.2 & 5.16200 & $\partial 000000001$ & TRN \\
\hline CHEMBL1382486 & 688497 & 4.95 & 5.28100 & 2000000001 & TST \\
\hline CHEMBL1490316 & 688497 & 6.45 & 5.2322 & TRN & \\
\hline CHEMBL1328899 & 688497 & 5.25 & 5.0051 & TST & \\
\hline CHEMBL1418235 & 688497 & 4.5 & 4.9321 & TRN & \\
\hline CHEMBL1462417 & 688497 & 5.8 & 5.0945 & TRN & \\
\hline CHEMBL1612042 & 688497 & 5.0 & 4.9893 & TRN & \\
\hline CHEMBL1427637 & 688497 & 4.45 & 4.9875 & TST & \\
\hline CHEMBL1560341 & 688497 & 4.55 & 4.6971 & TRN & \\
\hline CHEMBL1491981 & 688497 & 4.95 & 5.1197 & TRN & \\
\hline CHEMBL1366816 & 688497 & 4.85 & 4.9639 & TRN & \\
\hline CHEMBL1419784 & 688497 & 5.25 & 5.0353 & TRN & \\
\hline CHEMBL1321129 & 688497 & 4.65 & 4.9663 & TRN & \\
\hline CHEMBL1421069 & 688497 & 5.65 & 5.2873 & TST & \\
\hline CHEMBL1303039 & 688497 & 5.45 & 5.419 & TRN & \\
\hline CHEMBL1328112 & 688497 & 4.45 & 4.8316 & TRN & \\
\hline CHEMBL1548115 & 688497 & 4.5 & 4.8989 & TST & \\
\hline CHEMBL1483349 & 688497 & 4.45 & 5.0933 & TST & \\
\hline CHEMBL1412568 & 688497 & 4.8 & 4.8673 & TRN & \\
\hline CHEMBL1334638 & 688497 & 4.95 & 4.9014 & TRN & \\
\hline CHEMBL1595744 & 688497 & 4.7 & 4.83899 & 99999999995 & TRN \\
\hline CHEMBL1362905 & 688497 & 5.05 & 4.9111 & TRN & \\
\hline CHEMBL1334510 & 688497 & 5.0 & 5.0137 & TRN & \\
\hline CHEMBL1582741 & 688497 & 4.95 & 5.3388 & TRN & \\
\hline CHEMBL1438768 & 688497 & 4.9 & 5.115 & TRN & \\
\hline CHEMBL1484205 & 688497 & 4.7 & 5.2026 & TRN & \\
\hline CHEMBL1543424 & 688497 & 4.75 & 5.185 & TST & \\
\hline CHEMBL1444044 & 688497 & 4.45 & 4.8807 & TRN & \\
\hline CHEMBL1363912 & 688497 & 5.95 & 4.9372 & TRN & \\
\hline
\end{tabular}




\begin{tabular}{|c|c|c|c|c|c|}
\hline \multicolumn{6}{|c|}{ Supplemental Table s2.txt } \\
\hline CHEMBL1383297 & 688497 & 5.0 & 5.0325 & TRN & \\
\hline CHEMBL1301722 & 688497 & 4.9 & 5.5621 & TST & \\
\hline CHEMBL1441545 & 688497 & 4.5 & 4.7315 & TRN & \\
\hline CHEMBL1400505 & 688497 & 7.8013 & 5.0591 & TST & \\
\hline CHEMBL1384702 & 688497 & 5.5 & 4.7133 & TRN & \\
\hline CHEMBL1563048 & 688497 & 4.7 & 5.066 & TRN & \\
\hline CHEMBL1535943 & 688497 & 5.6 & 4.864 & TST & \\
\hline CHEMBL1345913 & 688497 & 4.45 & 5.2635 & TST & \\
\hline CHEMBL1359188 & 688497 & 5.25 & 5.2569 & TRN & \\
\hline CHEMBL1506494 & 688497 & 5.5 & 5.3747 & TRN & \\
\hline CHEMBL1327713 & 688497 & 4.55 & 5.2599 & TRN & \\
\hline CHEMBL1490691 & 688497 & 4.45 & 5.0155 & TST & \\
\hline CHEMBL1443587 & 688497 & 5.2 & 5.4195 & TRN & \\
\hline CHEMBL1519378 & 688497 & 5.9 & 5.1506 & TRN & \\
\hline CHEMBL1385391 & 688497 & 5.45 & 5.2164 & TST & \\
\hline CHEMBL1464503 & 688497 & 4.95 & 5.0716 & TST & \\
\hline CHEMBL1391709 & 688497 & 4.9 & 4.9445 & TRN & \\
\hline CHEMBL1335518 & 688497 & 4.45 & 4.6669 & TRN & \\
\hline CHEMBL1336286 & 688497 & 4.45 & 4.963 & TRN & \\
\hline CHEMBL1425922 & 688497 & 5.35 & 5.4254 & TST & \\
\hline CHEMBL1493968 & 688497 & 4.45 & 4.8358 & TRN & \\
\hline CHEMBL1412724 & 688497 & 5.0 & 4.9646 & TRN & \\
\hline CHEMBL1403383 & 688497 & 5.55 & 5.1731 & TST & \\
\hline CHEMBL1444145 & 688497 & 4.8 & 5.0464 & TST & \\
\hline CHEMBL1550831 & 688497 & 4.75 & 5.2157 & TST & \\
\hline CHEMBL1451869 & 688497 & 4.6 & 4.8764 & TST & \\
\hline CHEMBL1548496 & 688497 & 6.05 & 4.8964 & TRN & \\
\hline CHEMBL1509029 & 688497 & 5.25 & 5.0694 & TRN & \\
\hline CHEMBL1333643 & 688497 & 4.9 & 5.2565 & TRN & \\
\hline CHEMBL1299490 & 688497 & 5.0 & 5.1262 & TRN & \\
\hline CHEMBL3189714 & 688497 & 5.85 & 5.4431 & TRN & \\
\hline CHEMBL1460740 & 688497 & 4.45 & 5.0806 & TST & \\
\hline CHEMBL1390351 & 688497 & 4.45 & 4.9425 & TRN & \\
\hline CHEMBL563294 & 688497 & 4.9 & 4.9059 & TRN & \\
\hline CHEMBL1511091 & 688497 & 4.45 & 4.7922 & TRN & \\
\hline CHEMBL3198487 & 688497 & 4.8 & 5.4737 & TST & \\
\hline CHEMBL1583639 & 688497 & 4.8 & 4.96399 & 99999999995 & \\
\hline CHEMBL1347449 & 688497 & 4.45 & 4.5597 & TST & \\
\hline CHEMBL1451273 & 688497 & 5.25 & 5.0017 & TRN & \\
\hline CHEMBL1350980 & 688497 & 4.9 & 5.2106 & TRN & \\
\hline CHEMBL1527686 & 688497 & 6.1 & 5.3666 & TRN & \\
\hline CHEMBL1381600 & 688497 & 5.5 & 4.9854 & TRN & \\
\hline CHEMBL1570707 & 688497 & 4.45 & 5.284 & TRN & \\
\hline CHEMBL1466795 & 688497 & 4.45 & 4.6862 & TST & \\
\hline CHEMBL1550687 & 688497 & 4.85 & 4.9614 & TRN & \\
\hline CHEMBL1996536 & 688497 & 4.45 & 4.922 & TRN & \\
\hline CHEMBL1575081 & 688497 & 5.2 & 5.3307 & TST & \\
\hline CHEMBL3193350 & 688497 & 5.0 & 4.9449 & TRN & \\
\hline
\end{tabular}




\begin{tabular}{|c|c|c|c|c|c|}
\hline & & \multicolumn{4}{|c|}{ Supplemental Table S2.txt } \\
\hline CHEMBL1427457 & 688497 & 8.5528 & 5.334 & TRN & \\
\hline CHEMBL1450420 & 688497 & 5.95 & 4.9445 & TST & \\
\hline CHEMBL1406155 & 688497 & 4.85 & 4.8854 & TRN & \\
\hline CHEMBL51085 & 688497 & 4.45 & 5.7498 & TST & \\
\hline CHEMBL1402715 & 688497 & 5.1 & 4.6633 & TRN & \\
\hline CHEMBL 3198863 & 688497 & 4.8 & 5.0163 & TRN & \\
\hline CHEMBL1406208 & 688497 & 4.75 & 5.2656 & TRN & \\
\hline CHEMBL1425270 & 688497 & 4.65 & 4.9351 & TST & \\
\hline CHEMBL1529669 & 688497 & 4.85 & 4.6657 & TRN & \\
\hline CHEMBL1415277 & 688497 & 4.45 & 4.9066 & TRN & \\
\hline CHEMBL1583978 & 688497 & 5.2 & 5.0137 & TRN & \\
\hline CHEMBL1596203 & 688497 & 4.45 & 4.8832 & TRN & \\
\hline CHEMBL1509975 & 688497 & 4.5 & \multicolumn{2}{|c|}{4.6819999999999995} & TRN \\
\hline CHEMBL1373646 & 688497 & 5.1 & 4.9231 & TRN & \\
\hline CHEMBL1498227 & 688497 & 4.5 & 4.8434 & TRN & \\
\hline CHEMBL3212930 & 688497 & 4.45 & 4.8777 & TRN & \\
\hline CHEMBL1495310 & 688497 & 5.0 & 5.0481 & TRN & \\
\hline CHEMBL1302290 & 688497 & 5.0 & 4.962 & TRN & \\
\hline CHEMBL1350432 & 688497 & 4.6 & 4.7516 & TST & \\
\hline CHEMBL1582517 & 688497 & 4.9 & 4.7663 & TST & \\
\hline CHEMBL1352921 & 688497 & 5.25 & 5.0567 & TRN & \\
\hline CHEMBL1883149 & 688497 & 4.6 & 4.7389 & TRN & \\
\hline CHEMBL1570111 & 688497 & 4.45 & 4.9647 & TRN & \\
\hline CHEMBL1507267 & 688497 & 5.2 & 4.9889 & TRN & \\
\hline CHEMBL1305050 & 688497 & 4.75 & 5.0035 & TRN & \\
\hline CHEMBL1367016 & 688497 & 5.25 & 5.0446 & TRN & \\
\hline CHEMBL1446972 & 688497 & 6.0 & 5.1462 & TST & \\
\hline CHEMBL3197021 & 688497 & 5.5 & 5.084 & TRN & \\
\hline CHEMBL1548173 & 688497 & 5.6 & 5.1563 & TRN & \\
\hline CHEMBL1589350 & 688497 & 4.5 & 4.7883 & TRN & \\
\hline CHEMBL1319802 & 688497 & 5.25 & 5.1395 & TST & \\
\hline CHEMBL1539936 & 688497 & 4.6 & 5.2089 & TRN & \\
\hline CHEMBL1300389 & 688497 & 5.05 & 4.902 & TRN & \\
\hline CHEMBL1509244 & 688497 & 5.15 & 5.1325 & TRN & \\
\hline CHEMBL1354189 & 688497 & 6.0 & 5.2642 & TST & \\
\hline CHEMBL1480992 & 688497 & 5.05 & 5.2099 & TST & \\
\hline CHEMBL1400196 & 688497 & 5.0 & 4.8609 & TRN & \\
\hline CHEMBL1500899 & 688497 & 6.3 & 5.148 & TRN & \\
\hline CHEMBL1336282 & 688497 & 5.25 & 5.0138 & TRN & \\
\hline CHEMBL1505687 & 688497 & 4.85 & 4.9619 & TRN & \\
\hline CHEMBL1333962 & 688497 & 4.45 & 4.8292 & TRN & \\
\hline CHEMBL1310137 & 688497 & 5.45 & 5.1543 & TRN & \\
\hline CHEMBL1541303 & 688497 & 4.65 & 4.9898 & TRN & \\
\hline CHEMBL1509395 & 688497 & 4.6 & 5.2909 & TRN & \\
\hline CHEMBL1523432 & 688497 & 4.45 & 4.7708 & TRN & \\
\hline CHEMBL1524828 & 688497 & 5.05 & 5.2002 & TRN & \\
\hline CHEMBL3199877 & 688497 & 5.9 & 5.0803 & TRN & \\
\hline \multirow[t]{2}{*}{ CHEMBL1561494 } & 688497 & 5.4 & \multicolumn{2}{|c|}{5.132000000000001} & RN \\
\hline & & & & 19777 & \\
\hline
\end{tabular}




\begin{tabular}{|c|c|c|c|c|c|}
\hline \multicolumn{6}{|c|}{ Supplemental Table S2.txt } \\
\hline CHEMBL1594827 & 688497 & 4.45 & 4.9229 & TST & \\
\hline CHEMBL533293 & 688497 & 6.05 & 5.4015 & TST & \\
\hline CHEMBL1973435 & 688497 & 4.45 & 5.0402 & TST & \\
\hline CHEMBL1412700 & 688497 & 4.8 & 4.9803 & TRN & \\
\hline CHEMBL1307333 & 688497 & 4.45 & 5.1887 & TRN & \\
\hline CHEMBL572994 & 688497 & 4.45 & 5.1142 & TST & \\
\hline CHEMBL1478135 & 688497 & 5.05 & 4.98 & TRN & \\
\hline CHEMBL1464354 & 688497 & 4.6 & 5.1115 & TST & \\
\hline CHEMBL1416333 & 688497 & 4.45 & 5.1212 & TST & \\
\hline CHEMBL1444324 & 688497 & 4.8 & 5.0274 & TRN & \\
\hline CHEMBL1566169 & 688497 & 4.75 & 5.3249 & TST & \\
\hline CHEMBL1563520 & 688497 & 4.95 & 5.2671 & TRN & \\
\hline CHEMBL1522508 & 688497 & 4.95 & 5.0877 & TRN & \\
\hline CHEMBL1376835 & 688497 & 5.05 & 4.8888 & TRN & \\
\hline CHEMBL1506637 & 688497 & 4.45 & 4.8778 & TRN & \\
\hline CHEMBL1502654 & 688497 & 4.45 & 4.8375 & TRN & \\
\hline CHEMBL1451059 & 688497 & 4.95 & 4.9289 & TST & \\
\hline CHEMBL 2007120 & 688497 & 4.8 & 5.07600 & 00000000005 & TRN \\
\hline CHEMBL1524466 & 688497 & 4.85 & 5.1697 & TST & \\
\hline CHEMBL1308656 & 688497 & 4.45 & 5.1501 & TST & \\
\hline CHEMBL1449886 & 688497 & 6.5 & 5.1436 & TRN & \\
\hline CHEMBL1724937 & 688497 & 5.0 & 4.9219 & TRN & \\
\hline CHEMBL1455060 & 688497 & 5.15 & 5.151 & TRN & \\
\hline CHEMBL1525033 & 688497 & 5.0 & 4.685 & TRN & \\
\hline CHEMBL1423173 & 688497 & 4.7 & 5.1096 & TST & \\
\hline CHEMBL3213460 & 688497 & 5.35 & 4.9915 & TST & \\
\hline CHEMBL1419224 & 688497 & 5.5 & 4.9973 & TRN & \\
\hline CHEMBL1498372 & 688497 & 4.45 & 5.0576 & TRN & \\
\hline CHEMBL1552808 & 688497 & 5.1 & 5.532 & TRN & \\
\hline CHEMBL592363 & 688497 & 5.15 & 4.9675 & TRN & \\
\hline CHEMBL1391272 & 688497 & 5.3 & 4.802 & TST & \\
\hline CHEMBL1329706 & 688497 & 5.5 & 5.1507 & TST & \\
\hline CHEMBL1369075 & 688497 & 5.85 & 5.3372 & TRN & \\
\hline CHEMBL1488628 & 688497 & 4.45 & 5.245 & TRN & \\
\hline CHEMBL1501994 & 688497 & 4.45 & 4.8719 & TRN & \\
\hline CHEMBL1385108 & 688497 & 4.45 & 5.1614 & TST & \\
\hline CHEMBL1500819 & 688497 & 4.9 & 5.2267 & TRN & \\
\hline CHEMBL1444849 & 688497 & 4.85 & 4.9776 & TRN & \\
\hline CHEMBL1406970 & 688497 & 5.25 & 5.1983 & TRN & \\
\hline CHEMBL3194135 & 688497 & 6.2 & 5.1957 & TRN & \\
\hline CHEMBL1464712 & 688497 & 6.25 & 5.4 & TRN & \\
\hline CHEMBL1508477 & 688497 & 6.05 & 4.8094 & TRN & \\
\hline CHEMBL3190324 & 688497 & 5.4 & 4.8092 & TRN & \\
\hline CHEMBL1335769 & 688497 & 4.45 & 4.9286 & TRN & \\
\hline CHEMBL1483038 & 688497 & 5.2 & 5.1527 & TRN & \\
\hline CHEMBL1437613 & 688497 & 4.9 & 5.0899 & TRN & \\
\hline CHEMBL1584394 & 688497 & 5.5 & 5.0575 & TST & \\
\hline CHEMBL1523777 & 688497 & 5.4 & 4.877 & TST & \\
\hline
\end{tabular}




\begin{tabular}{|c|c|c|c|c|c|}
\hline CHEMBL1352079 & 688497 & 4.9 & 5.11100 & al lable s & TRN \\
\hline CHEMBL1965376 & 688497 & 5.0 & 5.178 & TRN & \\
\hline CHEMBL1299253 & 688497 & 4.65 & 4.7501 & TRN & \\
\hline CHEMBL3194235 & 688497 & 4.65 & 5.17899 & 9999999999 & TRN \\
\hline CHEMBL1563905 & 688497 & 4.9 & 4.8646 & TRN & \\
\hline CHEMBL1534412 & 688497 & 4.45 & 5.3084 & TRN & \\
\hline CHEMBL1371999 & 688497 & 4.45 & 4.9317 & TRN & \\
\hline CHEMBL1340865 & 688497 & 4.65 & 5.1244 & TRN & \\
\hline CHEMBL1494973 & 688497 & 4.45 & 4.7796 & TRN & \\
\hline CHEMBL1536786 & 688497 & 4.9 & 5.2696 & TRN & \\
\hline CHEMBL1556845 & 688497 & 4.45 & 5.2714 & TST & \\
\hline CHEMBL1465870 & 688497 & 4.8 & 4.9697 & TST & \\
\hline CHEMBL182786 & 688497 & 4.85 & 4.7909 & TST & \\
\hline CHEMBL1471818 & 688497 & 9.2218 & 4.9453 & TST & \\
\hline CHEMBL1504013 & 688497 & 5.0 & 5.0289 & TRN & \\
\hline CHEMBL1531914 & 688497 & 6.6 & 4.9382 & TRN & \\
\hline CHEMBL1371143 & 688497 & 6.95 & 5.0268 & TST & \\
\hline CHEMBL1609711 & 688497 & 5.75 & 4.9345 & TRN & \\
\hline CHEMBL1390471 & 688497 & 4.8 & 4.9853 & TRN & \\
\hline CHEMBL1523905 & 688497 & 5.3 & 4.9762 & TRN & \\
\hline CHEMBL1613127 & 688497 & 5.9 & 4.9238 & TST & \\
\hline CHEMBL3199590 & 688497 & 4.5 & 4.9405 & TRN & \\
\hline CHEMBL1331027 & 688497 & 6.45 & 5.4797 & TRN & \\
\hline CHEMBL1453521 & 688497 & 4.45 & 4.684 & TRN & \\
\hline CHEMBL1533067 & 688497 & 4.45 & 5.0133 & TST & \\
\hline CHEMBL1517434 & 688497 & 5.4 & 5.3263 & TST & \\
\hline CHEMBL1505221 & 688497 & 6.05 & 4.7933 & TRN & \\
\hline CHEMBL1518580 & 688497 & 4.45 & 5.0155 & TRN & \\
\hline CHEMBL1547400 & 688497 & 5.35 & 5.0285 & TRN & \\
\hline CHEMBL3209779 & 688497 & 4.45 & 4.7077 & TRN & \\
\hline CHEMBL1440048 & 688497 & 6.0 & 5.3488 & TRN & \\
\hline CHEMBL3194649 & 688497 & 4.95 & 5.1672 & TRN & \\
\hline CHEMBL1524796 & 688497 & 4.45 & 5.2161 & TST & \\
\hline CHEMBL1419057 & 688497 & 4.7 & 4.9144 & TRN & \\
\hline CHEMBL1350641 & 688497 & 4.85 & 4.9163 & TRN & \\
\hline CHEMBL1447194 & 688497 & 5.05 & 4.9892 & TST & \\
\hline CHEMBL1424912 & 688497 & 5.25 & 5.1025 & TRN & \\
\hline CHEMBL1328429 & 688497 & 4.45 & 4.9785 & TRN & \\
\hline CHEMBL1548147 & 688497 & 4.8 & 5.3274 & TRN & \\
\hline CHEMBL1518220 & 688497 & 6.2 & 5.4406 & TRN & \\
\hline CHEMBL1349496 & 688497 & 4.45 & 4.8761 & TRN & \\
\hline CHEMBL1327880 & 688497 & 4.8 & 5.0868 & TST & \\
\hline CHEMBL1530492 & 688497 & 4.45 & 4.9747 & TST & \\
\hline CHEMBL1573754 & 688497 & 5.0 & 5.3277 & TRN & \\
\hline CHEMBL1530977 & 688497 & 5.35 & 5.0045 & TST & \\
\hline CHEMBL1594995 & 688497 & 5.0 & 4.9923 & TRN & \\
\hline CHEMBL1567503 & 688497 & 4.45 & 5.0429 & TST & \\
\hline CHEMBL1543453 & 688497 & 4.9 & 4.9461 & TRN & \\
\hline
\end{tabular}




\begin{tabular}{|c|c|c|c|c|c|}
\hline & & \multicolumn{4}{|c|}{ Supplemental Table s2.txt } \\
\hline CHEMBL3198502 & 688497 & 5.65 & 4.9847 & TST & \\
\hline CHEMBL1329507 & 688497 & 5.15 & 5.0285 & TRN & \\
\hline CHEMBL1319610 & 688497 & 5.9 & 4.9796 & TST & \\
\hline CHEMBL1541371 & 688497 & 5.5 & 4.7406 & TST & \\
\hline CHEMBL1311887 & 688497 & 4.7 & 5.0219 & TRN & \\
\hline CHEMBL1491750 & 688497 & 4.85 & 4.8286 & TST & \\
\hline CHEMBL1445507 & 688497 & 4.85 & 5.0013 & TRN & \\
\hline CHEMBL1340519 & 688497 & 4.85 & 4.9608 & TRN & \\
\hline CHEMBL1353882 & 688497 & 4.45 & 5.1649 & TRN & \\
\hline CHEMBL3198741 & 688497 & 4.45 & 5.1192 & TRN & \\
\hline CHEMBL1965976 & 688497 & 4.5 & 4.9618 & TRN & \\
\hline CHEMBL1337500 & 688497 & 4.45 & 5.1664 & TST & \\
\hline CHEMBL1422039 & 688497 & 4.45 & 5.024 & TRN & \\
\hline CHEMBL1506312 & 688497 & 4.65 & 4.9588 & TRN & \\
\hline CHEMBL3192010 & 688497 & 4.45 & 5.1798 & TRN & \\
\hline CHEMBL1528133 & 688497 & 4.8 & 5.0036 & TRN & \\
\hline CHEMBL1319301 & 688497 & 5.9 & 4.9487 & TST & \\
\hline CHEMBL1450612 & 688497 & 4.7 & 5.106 & TRN & \\
\hline CHEMBL1596003 & 688497 & 4.8 & 4.958 & TRN & \\
\hline CHEMBL1342093 & 688497 & 4.6 & 4.6886 & TRN & \\
\hline CHEMBL1369764 & 688497 & 4.45 & 4.9145 & TRN & \\
\hline CHEMBL1393129 & 688497 & 5.4 & 5.2825 & TRN & \\
\hline CHEMBL1330937 & 688497 & 5.6 & 5.2485 & TRN & \\
\hline CHEMBL1426542 & 688497 & 5.7 & 5.1492 & TRN & \\
\hline CHEMBL1979558 & 688497 & 5.25 & 4.857 & TRN & \\
\hline CHEMBL1564410 & 688497 & 5.25 & 5.4018 & TRN & \\
\hline CHEMBL1994963 & 688497 & 4.8 & 4.9416 & TRN & \\
\hline CHEMBL1557494 & 688497 & 4.5 & 5.1189 & TRN & \\
\hline CHEMBL1313096 & 688497 & 4.45 & 4.7129 & TRN & \\
\hline CHEMBL1409333 & 688497 & 5.5 & 4.7576 & TRN & \\
\hline CHEMBL327035 & 688497 & 4.45 & 5.081 & TRN & \\
\hline CHEMBL1431131 & 688497 & 4.7 & 5.0937 & TRN & \\
\hline CHEMBL1340177 & 688497 & 5.3 & 5.1516 & TRN & \\
\hline CHEMBL1407723 & 688497 & 4.95 & 4.8907 & TRN & \\
\hline CHEMBL3196028 & 688497 & 4.45 & 5.0579 & TRN & \\
\hline CHEMBL1598986 & 688497 & 5.75 & 5.2561 & TRN & \\
\hline CHEMBL1329766 & 688497 & 5.9 & 5.251 & TRN & \\
\hline CHEMBL1458615 & 688497 & 4.5 & 5.0125 & TST & \\
\hline CHEMBL1343814 & 688497 & 4.55 & 5.0186 & TRN & \\
\hline CHEMBL1998254 & 688497 & 4.45 & 4.992 & TST & \\
\hline CHEMBL1409280 & 688497 & 4.8 & 4.9385 & TRN & \\
\hline CHEMBL1558607 & 688497 & 4.5 & 5.026 & TRN & \\
\hline CHEMBL1483325 & 688497 & 4.85 & 5.2049 & TRN & \\
\hline CHEMBL1529127 & 688497 & 4.45 & 4.55699 & 99999999995 & TRN \\
\hline CHEMBL1507002 & 688497 & 4.85 & 4.9469 & TRN & \\
\hline CHEMBL1445168 & 688497 & 6.05 & 4.7228 & TST & \\
\hline CHEMBL1329891 & 688497 & 5.65 & 5.2604 & TRN & \\
\hline CHEMBL1543256 & 688497 & 4.5 & 4.9257 & TST & \\
\hline
\end{tabular}




\begin{tabular}{|c|c|c|c|c|c|}
\hline \\
\hline CHEMBL1382949 & 688497 & 4.9 & 4.8477 & TRN & \\
\hline CHEMBL1605616 & 688497 & 4.45 & 4.8636 & TRN & \\
\hline CHEMBL1354056 & 688497 & 4.45 & 4.6241 & TRN & \\
\hline CHEMBL1301108 & 688497 & 5.0 & 4.8953 & TST & \\
\hline CHEMBL1322826 & 688497 & 4.95 & 5.032 & TRN & \\
\hline CHEMBL1313024 & 688497 & 4.65 & 5.0186 & TRN & \\
\hline CHEMBL1426736 & 688497 & 4.8 & 4.92399 & 99999999995 & TRN \\
\hline CHEMBL1332486 & 688497 & 5.05 & 5.1687 & TRN & \\
\hline CHEMBL1609986 & 688497 & 5.05 & 5.0857 & TRN & \\
\hline CHEMBL1416890 & 688497 & 4.45 & 4.9702 & TRN & \\
\hline CHEMBL1463487 & 688497 & 4.45 & 5.025 & TRN & \\
\hline CHEMBL1471326 & 688497 & 5.95 & 5.1855 & TRN & \\
\hline CHEMBL1602297 & 688497 & 5.5 & 5.1224 & TRN & \\
\hline CHEMBL1468479 & 688497 & 4.45 & 5.0278 & TRN & \\
\hline CHEMBL3208699 & 688497 & 4.45 & 5.1152 & TRN & \\
\hline CHEMBL1438166 & 688497 & 4.45 & 4.9814 & TRN & \\
\hline CHEMBL1462276 & 688497 & 5.0 & 5.0191 & TRN & \\
\hline CHEMBL1464539 & 688497 & 4.45 & 5.1415 & TRN & \\
\hline CHEMBL1568277 & 688497 & 4.95 & 4.7308 & TRN & \\
\hline CHEMBL1380443 & 688497 & 4.75 & 4.9296 & TRN & \\
\hline CHEMBL1600768 & 688497 & 4.45 & 4.703 & TRN & \\
\hline CHEMBL1380978 & 688497 & 4.45 & 5.2127 & TRN & \\
\hline CHEMBL1336692 & 688497 & 4.65 & 4.7307 & TRN & \\
\hline CHEMBL1462268 & 688497 & 5.95 & 5.1339 & TST & \\
\hline CHEMBL1341100 & 688497 & 4.45 & 5.1883 & TST & \\
\hline CHEMBL1491163 & 688497 & 6.05 & 4.8156 & TST & \\
\hline CHEMBL1327783 & 688497 & 4.95 & 5.3603 & TRN & \\
\hline CHEMBL1549469 & 688497 & 4.45 & 4.7801 & TRN & \\
\hline CHEMBL1402379 & 688497 & 5.95 & 5.2501 & TRN & \\
\hline CHEMBL1601310 & 688497 & 4.85 & 5.117 & TST & \\
\hline CHEMBL1342736 & 688497 & 4.45 & 4.84699 & 99999999995 & TRN \\
\hline CHEMBL609110 & 688497 & 5.45 & 4.995 & TRN & \\
\hline CHEMBL1310507 & 688497 & 5.45 & 4.8485 & TRN & \\
\hline CHEMBL1502002 & 688497 & 4.45 & 5.1732 & TST & \\
\hline CHEMBL1536491 & 688497 & 4.6 & 4.7088 & TRN & \\
\hline CHEMBL1401951 & 688497 & 4.45 & 4.923 & TST & \\
\hline CHEMBL1544371 & 688497 & 5.15 & 5.438 & TRN & \\
\hline CHEMBL1502095 & 688497 & 4.45 & 5.1814 & TRN & \\
\hline CHEMBL1333897 & 688497 & 6.25 & 5.2283 & TRN & \\
\hline CHEMBL1399840 & 688497 & 5.55 & 5.331 & TRN & \\
\hline CHEMBL1588771 & 688497 & 4.45 & 4.9407 & TRN & \\
\hline CHEMBL1385583 & 688497 & 4.8 & 5.0462 & TRN & \\
\hline CHEMBL1429224 & 688497 & 6.05 & 5.2869 & TRN & \\
\hline CHEMBL1459324 & 688497 & 4.9 & 4.8711 & TRN & \\
\hline CHEMBL1585826 & 688497 & 4.45 & 4.8168 & TRN & \\
\hline CHEMBL1527270 & 688497 & 6.1 & 5.4472 & TST & \\
\hline CHEMBL1545132 & 688497 & 4.6 & 4.8847 & TST & \\
\hline CHEMBL1372326 & 688497 & 4.8 & 4.8569 & TRN & \\
\hline
\end{tabular}




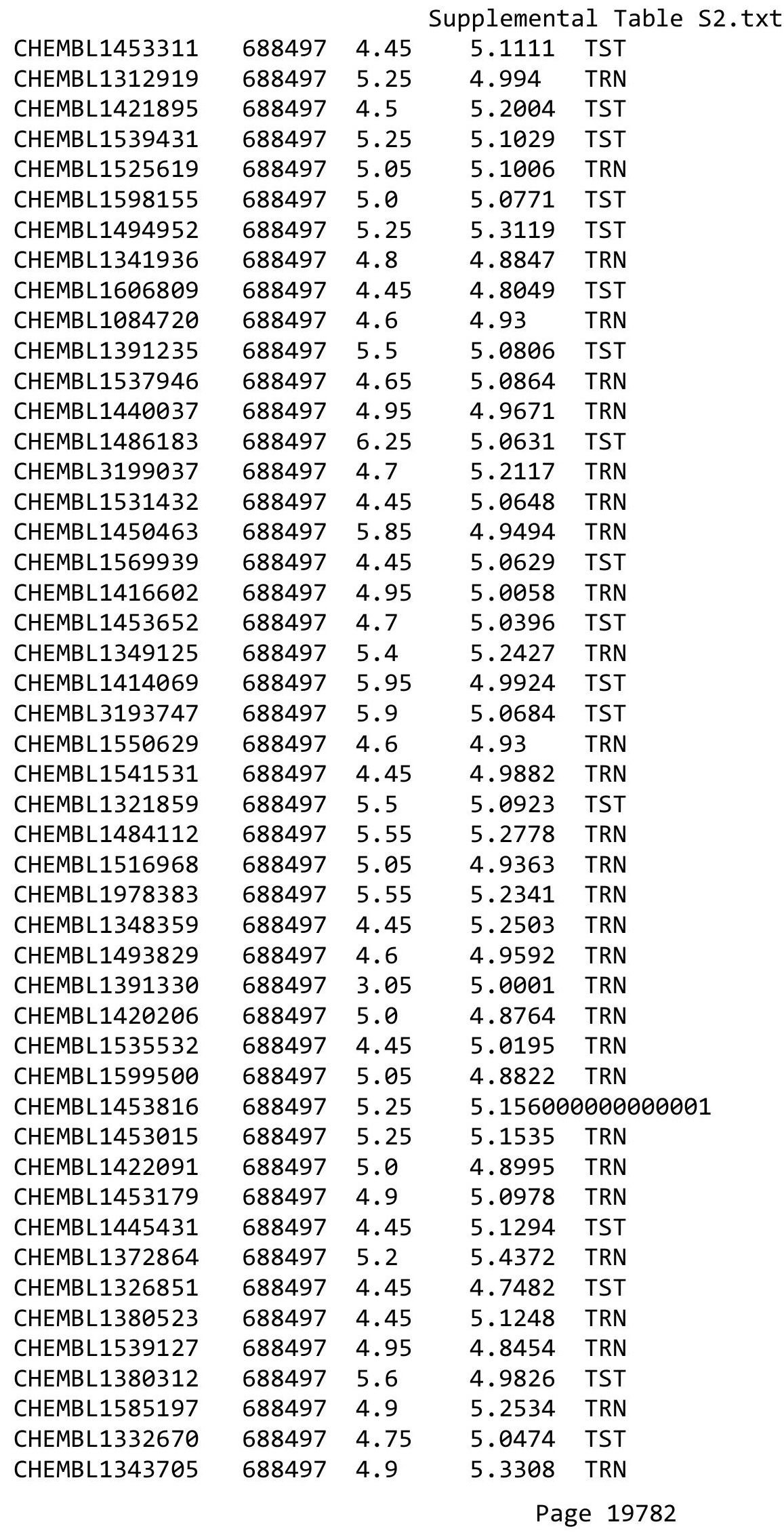




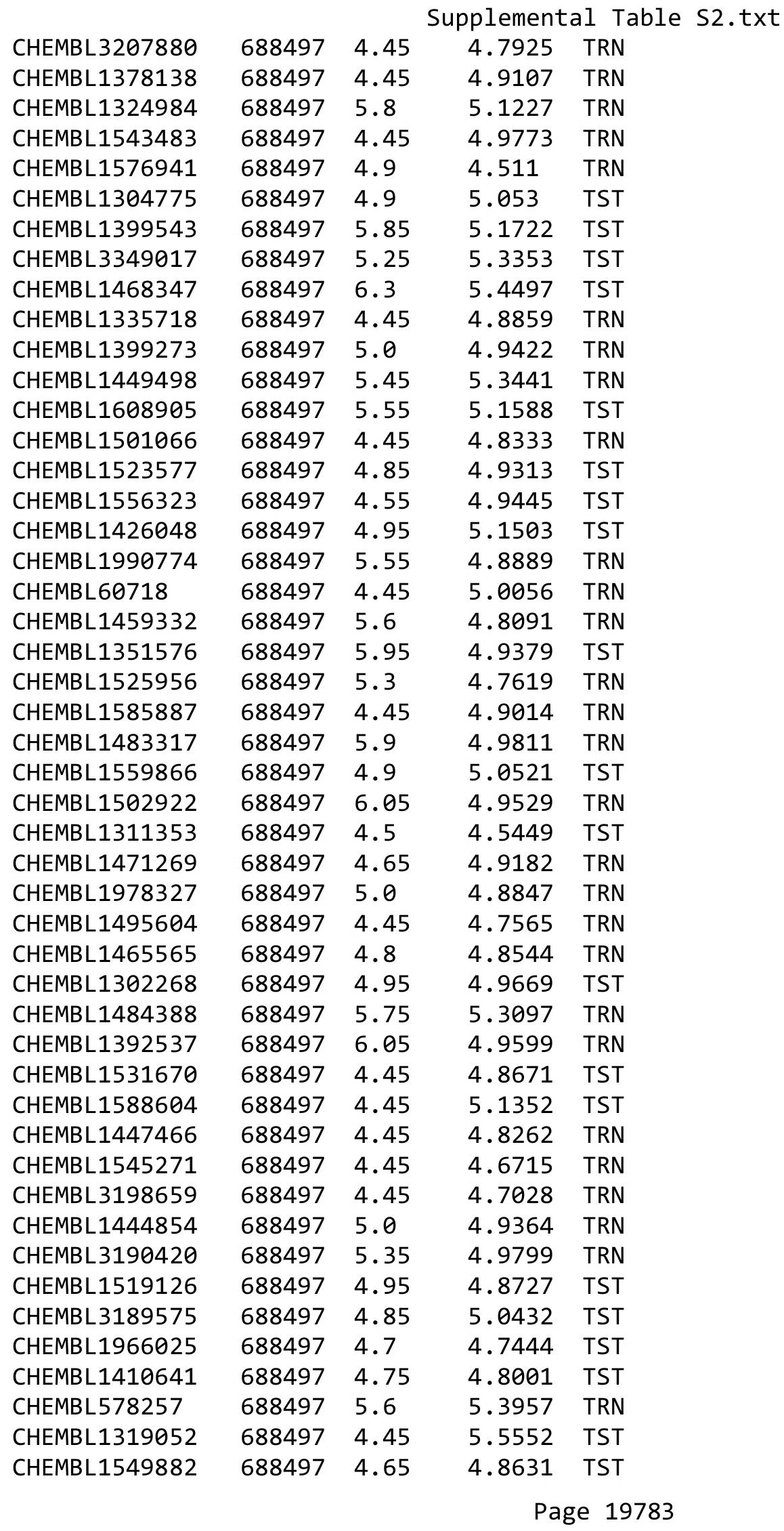




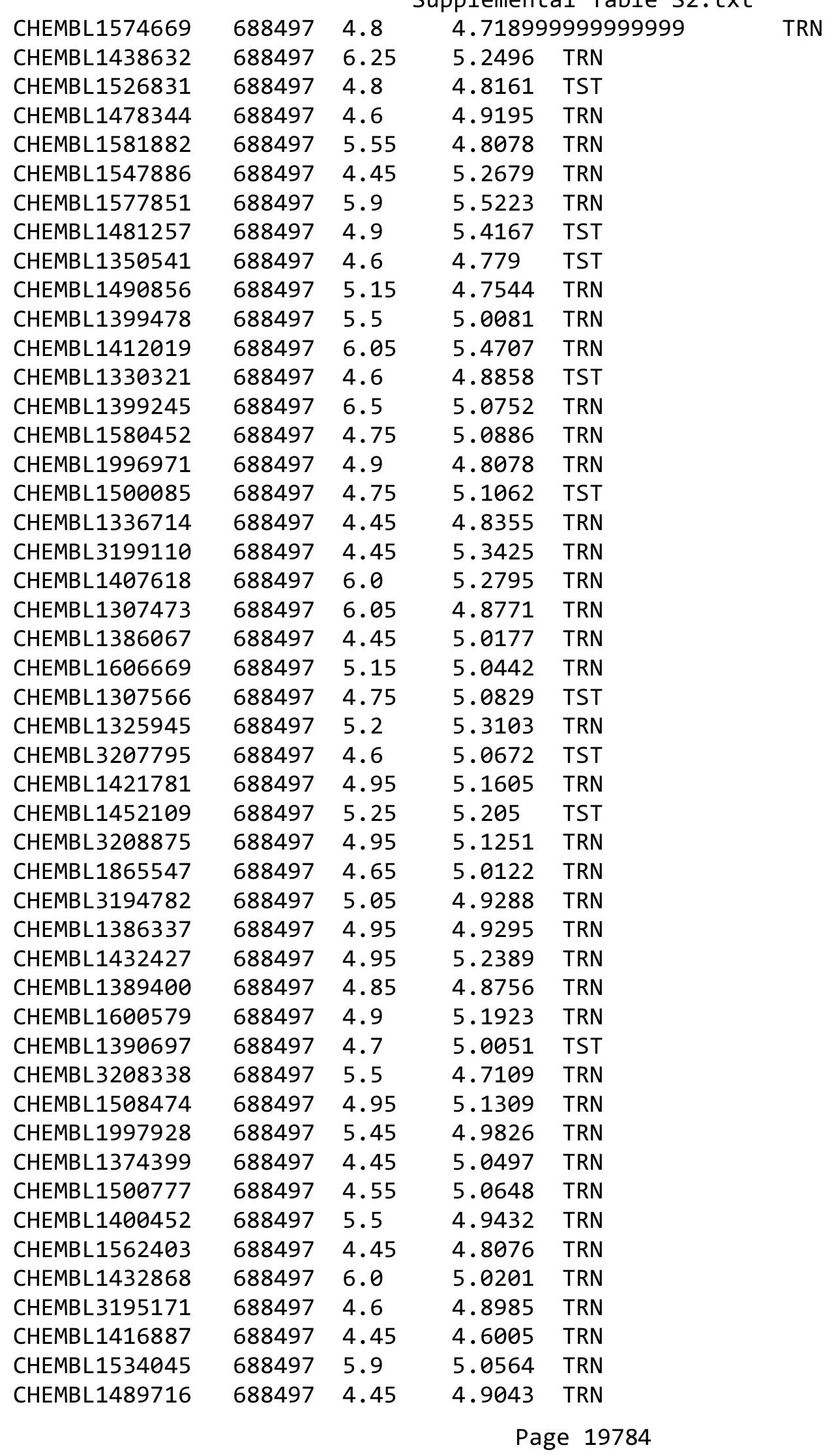




\begin{tabular}{|c|c|c|c|c|c|}
\hline & & \multicolumn{4}{|c|}{ Supplemental Table s2.txt } \\
\hline CHEMBL1605924 & 688497 & 4.45 & 4.9974 & TST & \\
\hline CHEMBL1602962 & 688497 & 6.6 & 5.1709 & TRN & \\
\hline CHEMBL1403774 & 688497 & 5.1 & 4.9658 & TRN & \\
\hline CHEMBL1335866 & 688497 & 4.45 & 4.9395 & TRN & \\
\hline CHEMBL1520621 & 688497 & 4.85 & 4.8221 & TRN & \\
\hline CHEMBL1309765 & 688497 & 4.45 & 4.8331 & TRN & \\
\hline CHEMBL1458891 & 688497 & 4.45 & 4.8461 & TRN & \\
\hline CHEMBL1380658 & 688497 & 5.55 & 5.3135 & TRN & \\
\hline CHEMBL1311809 & 688497 & 5.6 & 5.0076 & TST & \\
\hline CHEMBL1520266 & 688497 & 4.7 & 4.8435 & TST & \\
\hline CHEMBL1415502 & 688497 & 6.3 & 5.0403 & TST & \\
\hline CHEMBL1319919 & 688497 & 5.0 & 5.1098 & TRN & \\
\hline CHEMBL3209534 & 688497 & 4.85 & 5.1348 & TRN & \\
\hline CHEMBL1472490 & 688497 & 4.45 & 5.2857 & TRN & \\
\hline CHEMBL1307951 & 688497 & 5.0 & 5.0872 & TRN & \\
\hline CHEMBL1463106 & 688497 & 5.0 & 5.1455 & TRN & \\
\hline CHEMBL1306525 & 688497 & 4.9 & 5.21200 & 0000000001 & TRN \\
\hline CHEMBL318990 & 688497 & 4.45 & 5.115 & TRN & \\
\hline CHEMBL1347533 & 688497 & 4.6 & 5.3481 & TRN & \\
\hline CHEMBL1472175 & 688497 & 4.75 & 5.0662 & TRN & \\
\hline CHEMBL1329450 & 688497 & 4.65 & 4.654 & TRN & \\
\hline CHEMBL1339178 & 688497 & 4.45 & 5.2023 & TST & \\
\hline CHEMBL3198639 & 688497 & 4.9 & 4.6918 & TST & \\
\hline CHEMBL1389509 & 688497 & 4.45 & 4.8569 & TRN & \\
\hline CHEMBL1409718 & 688497 & 4.65 & 4.7005 & TRN & \\
\hline CHEMBL3189989 & 688497 & 6.25 & 4.9083 & TST & \\
\hline CHEMBL1378483 & 688497 & 4.85 & 5.0637 & TST & \\
\hline CHEMBL 1445800 & 688497 & 5.0 & 4.5335 & TST & \\
\hline CHEMBL1328778 & 688497 & 4.75 & 4.941 & TRN & \\
\hline CHEMBL1322092 & 688497 & 5.1 & 5.2564 & TST & \\
\hline CHEMBL1508128 & 688497 & 4.5 & 4.6402 & TRN & \\
\hline CHEMBL1340336 & 688497 & 5.25 & 5.1173 & TRN & \\
\hline CHEMBL1581735 & 688497 & 5.8 & 5.4671 & TST & \\
\hline CHEMBL1483326 & 688497 & 5.15 & 5.1716 & TRN & \\
\hline CHEMBL1373979 & 688497 & 5.2 & 5.1177 & TRN & \\
\hline CHEMBL1558771 & 688497 & 4.45 & 4.802 & TRN & \\
\hline CHEMBL1549526 & 688497 & 5.4 & 5.3267 & TRN & \\
\hline CHEMBL1450543 & 688497 & 4.7 & 5.0536 & TST & \\
\hline CHEMBL3208266 & 688497 & 4.45 & 5.0643 & TRN & \\
\hline CHEMBL1546853 & 688497 & 4.6 & 4.6627 & TRN & \\
\hline CHEMBL1566069 & 688497 & 5.25 & 5.1749 & TRN & \\
\hline CHEMBL1308361 & 688497 & 4.45 & 5.2902 & TST & \\
\hline CHEMBL1528265 & 688497 & 4.95 & 4.8629 & TRN & \\
\hline CHEMBL1430859 & 688497 & 4.45 & 5.0591 & TRN & \\
\hline CHEMBL1501288 & 688497 & 4.65 & 4.9114 & TST & \\
\hline CHEMBL1499595 & 688497 & 4.85 & 5.0487 & TRN & \\
\hline CHEMBL1555793 & 688497 & 4.45 & 4.7954 & TRN & \\
\hline CHEMBL1414465 & 688497 & 5.35 & 4.9376 & TST & \\
\hline
\end{tabular}




\begin{tabular}{|c|c|c|c|c|c|}
\hline \\
\hline CHEMBL1461426 & 688497 & 5.8 & 5.0288 & TRN & \\
\hline CHEMBL1375199 & 688497 & 4.6 & 4.5619 & TRN & \\
\hline CHEMBL1346502 & 688497 & 4.8 & 5.2994 & TRN & \\
\hline CHEMBL1306382 & 688497 & 4.75 & 4.8744 & TRN & \\
\hline CHEMBL1347213 & 688497 & 6.0 & 5.1174 & TRN & \\
\hline CHEMBL1597229 & 688497 & 6.05 & 5.1117 & TRN & \\
\hline CHEMBL1414322 & 688497 & 6.0 & 5.3883 & TST & \\
\hline CHEMBL1545499 & 688497 & 5.4 & 5.0249 & TRN & \\
\hline CHEMBL1588460 & 688497 & 4.9 & 5.0212 & TRN & \\
\hline CHEMBL1449103 & 688497 & 4.45 & 4.6603 & TST & \\
\hline CHEMBL1527952 & 688497 & 5.9 & 5.1291 & TRN & \\
\hline CHEMBL1582630 & 688497 & 4.8 & 5.00899 & 99999999995 & TST \\
\hline CHEMBL1612243 & 688497 & 4.85 & 4.8439 & TRN & \\
\hline CHEMBL1320936 & 688497 & 4.45 & 5.19799 & 99999999995 & TRN \\
\hline CHEMBL1540178 & 688497 & 4.9 & 4.8627 & TRN & \\
\hline CHEMBL1427972 & 688497 & 5.45 & 5.50200 & 0000000001 & TRN \\
\hline CHEMBL1408948 & 688497 & 5.85 & 5.1309 & TRN & \\
\hline CHEMBL1406027 & 688497 & 4.85 & 5.1748 & TRN & \\
\hline CHEMBL1605568 & 688497 & 4.45 & 4.9946 & TRN & \\
\hline CHEMBL1301417 & 688497 & 4.9 & 5.0989 & TRN & \\
\hline CHEMBL1536296 & 688497 & 4.5 & 5.0946 & TST & \\
\hline CHEMBL1325363 & 688497 & 4.45 & 4.7811 & TST & \\
\hline CHEMBL1490845 & 688497 & 4.45 & 4.7991 & TRN & \\
\hline CHEMBL1460114 & 688497 & 4.45 & 4.982 & TRN & \\
\hline CHEMBL1470481 & 688497 & 4.6 & 5.027 & TST & \\
\hline CHEMBL1470359 & 688497 & 4.75 & 4.8455 & TST & \\
\hline CHEMBL1534106 & 688497 & 5.5 & 5.1578 & TRN & \\
\hline CHEMBL1609264 & 688497 & 5.45 & 5.1911 & TRN & \\
\hline CHEMBL1604476 & 688497 & 6.2 & 5.4857 & TRN & \\
\hline CHEMBL1986545 & 688497 & 5.0 & 5.1779 & TRN & \\
\hline CHEMBL1520769 & 688497 & 6.25 & 5.0378 & TRN & \\
\hline CHEMBL1481295 & 688497 & 4.45 & 4.8595 & TRN & \\
\hline CHEMBL1443804 & 688497 & 4.65 & 4.8275 & TRN & \\
\hline CHEMBL1565101 & 688497 & 4.45 & 4.8044 & TRN & \\
\hline CHEMBL1563201 & 688497 & 5.95 & 5.24100 & 00000000005 & TST \\
\hline CHEMBL1364561 & 688497 & 5.45 & 5.2194 & TRN & \\
\hline CHEMBL1406631 & 688497 & 5.25 & 5.4053 & TRN & \\
\hline CHEMBL1581410 & 688497 & 4.95 & 5.1221 & TRN & \\
\hline CHEMBL1609498 & 688497 & 5.9 & 5.0186 & TST & \\
\hline CHEMBL1439210 & 688497 & 5.0 & 5.0938 & TRN & \\
\hline CHEMBL1610961 & 688497 & 4.6 & 4.7959 & TST & \\
\hline CHEMBL1378446 & 688497 & 4.9 & 5.0927 & TRN & \\
\hline CHEMBL1577122 & 688497 & 4.85 & 4.8889 & TRN & \\
\hline CHEMBL1599870 & 688497 & 5.2 & 5.441 & TRN & \\
\hline CHEMBL1393098 & 688497 & 4.6 & 4.9425 & TRN & \\
\hline CHEMBL3195981 & 688497 & 4.8 & 4.6975 & TRN & \\
\hline CHEMBL1311697 & 688497 & 5.4 & 5.1479 & TRN & \\
\hline CHEMBL1596755 & 688497 & 5.1 & 4.9506 & TRN & \\
\hline
\end{tabular}




\begin{tabular}{|c|c|c|c|c|}
\hline \multicolumn{5}{|c|}{ Supplemental Table S2.txt } \\
\hline CHEMBL1579223 & 688497 & 4.45 & 4.7155 & TRN \\
\hline CHEMBL1480370 & 688497 & 5.9 & 5.0376 & TST \\
\hline CHEMBL455284 & 688497 & 5.45 & 5.8464 & TRN \\
\hline CHEMBL1414641 & 688497 & 4.45 & 5.1478 & TRN \\
\hline CHEMBL 1424036 & 688497 & 4.7 & 4.9644 & TRN \\
\hline CHEMBL1309839 & 688497 & 5.9 & 5.4354 & TST \\
\hline CHEMBL1583625 & 688497 & 5.0 & 4.994 & TRN \\
\hline CHEMBL1468759 & 688497 & 4.85 & 4.9682 & TRN \\
\hline CHEMBL3145291 & 688497 & 5.65 & 5.2507 & TRN \\
\hline CHEMBL1549245 & 688497 & 4.95 & 4.9959 & TRN \\
\hline CHEMBL1581860 & 688497 & 5.9 & 5.2432 & TRN \\
\hline CHEMBL1390258 & 688497 & 4.75 & 4.867 & TRN \\
\hline CHEMBL3194797 & 688497 & 4.9 & 5.0605 & TST \\
\hline CHEMBL1567974 & 688497 & 4.9 & 4.9674 & TRN \\
\hline CHEMBL1431314 & 688497 & 4.7 & 4.9496 & TST \\
\hline CHEMBL1607917 & 688497 & 5.5 & 5.2992 & TRN \\
\hline CHEMBL1545099 & 688497 & 5.3 & 5.1688 & TRN \\
\hline CHEMBL1399698 & 688497 & 5.15 & 5.1452 & TRN \\
\hline CHEMBL3192736 & 688497 & 6.15 & 4.9899 & TRN \\
\hline CHEMBL1544579 & 688497 & 4.6 & 5.1796 & TRN \\
\hline CHEMBL1505597 & 688497 & 4.45 & 4.9701 & TRN \\
\hline CHEMBL1538952 & 688497 & 4.95 & 4.9578 & TRN \\
\hline CHEMBL1423761 & 688497 & 4.6 & 4.7442 & TST \\
\hline CHEMBL1613478 & 688497 & 4.45 & 4.8013 & TST \\
\hline CHEMBL1504264 & 688497 & 6.25 & 5.4022 & TRN \\
\hline CHEMBL1310703 & 688497 & 4.45 & 5.0072 & TRN \\
\hline CHEMBL1339008 & 688497 & 5.25 & 5.0656 & TST \\
\hline CHEMBL1527980 & 688497 & 4.45 & 5.0515 & TRN \\
\hline CHEMBL 3214630 & 688497 & 4.95 & 5.0665 & TRN \\
\hline CHEMBL1306449 & 688497 & 5.0 & 5.032 & TRN \\
\hline CHEMBL1519696 & 688497 & 5.05 & 5.0028 & TRN \\
\hline CHEMBL1578469 & 688497 & 4.45 & 4.9684 & TRN \\
\hline CHEMBL1999947 & 688497 & 5.75 & 4.948 & TRN \\
\hline CHEMBL3210891 & 688497 & 4.9 & 5.0822 & TRN \\
\hline CHEMBL1563496 & 688497 & 4.95 & 5.1248 & TRN \\
\hline CHEMBL1457787 & 688497 & 4.75 & 5.0198 & TST \\
\hline CHEMBL1608797 & 688497 & 4.95 & 5.2755 & TRN \\
\hline CHEMBL1309756 & 688497 & 5.25 & 4.7491 & TRN \\
\hline CHEMBL1419673 & 688497 & 5.05 & 4.9776 & TRN \\
\hline CHEMBL1386065 & 688497 & 5.25 & 5.2042 & TRN \\
\hline CHEMBL1444690 & 688497 & 5.25 & 4.7081 & TST \\
\hline CHEMBL1427056 & 688497 & 5.4 & 5.2609 & TST \\
\hline CHEMBL1596929 & 688497 & 4.85 & 4.8192 & TRN \\
\hline CHEMBL1575872 & 688497 & 4.7 & 5.1854 & TRN \\
\hline CHEMBL 2000814 & 688497 & 4.95 & 5.0961 & TST \\
\hline CHEMBL1410942 & 688497 & 5.9 & 5.2305 & TRN \\
\hline CHEMBL1500979 & 688497 & 4.9 & 4.6767 & TST \\
\hline CHEMBL3192766 & 688497 & 5.25 & 4.9655 & TRN \\
\hline
\end{tabular}




\begin{tabular}{|c|c|c|c|c|c|}
\hline & & & & & \\
\hline CHEMBL1371881 & 688497 & 6.3 & 4.9856 & TST & \\
\hline CHEMBL1572393 & 688497 & 5.9 & 5.0442 & TRN & \\
\hline CHEMBL1539613 & 688497 & 4.85 & 5.3801 & TRN & \\
\hline CHEMBL1414470 & 688497 & 5.9 & 5.1577 & TRN & \\
\hline CHEMBL1382544 & 688497 & 5.25 & 5.0736 & TST & \\
\hline CHEMBL1428645 & 688497 & 5.5 & 4.9272 & TRN & \\
\hline CHEMBL28324 & 688497 & 5.8 & 4.792 & TST & \\
\hline CHEMBL1550441 & 688497 & 4.8 & 4.9709 & TRN & \\
\hline CHEMBL1568171 & 688497 & 4.75 & 5.0054 & TST & \\
\hline CHEMBL1559545 & 688497 & 4.55 & 4.7839 & TST & \\
\hline CHEMBL1312509 & 688497 & 4.6 & 5.0137 & TRN & \\
\hline CHEMBL3193575 & 688497 & 4.95 & 4.8742 & TST & \\
\hline CHEMBL1304889 & 688497 & 4.55 & 5.1729 & TST & \\
\hline CHEMBL1499354 & 688497 & 4.95 & 5.0909 & TST & \\
\hline CHEMBL1496753 & 688497 & 4.85 & 4.9079 & TRN & \\
\hline CHEMBL3190781 & 688497 & 4.45 & 5.0387 & TRN & \\
\hline CHEMBL1386786 & 688497 & 4.95 & 4.6519 & TRN & \\
\hline CHEMBL1518578 & 688497 & 4.9 & 4.6277 & TRN & \\
\hline CHEMBL1373376 & 688497 & 5.0 & 5.058 & TST & \\
\hline CHEMBL1443340 & 688497 & 4.45 & 4.7947 & TRN & \\
\hline CHEMBL1424562 & 688497 & 4.5 & 4.9752 & TRN & \\
\hline CHEMBL1454021 & 688497 & 4.45 & 4.8796 & TST & \\
\hline CHEMBL3208482 & 688497 & 5.25 & 5.0609 & TRN & \\
\hline CHEMBL1423063 & 688497 & 5.75 & 4.8664 & TRN & \\
\hline CHEMBL1584128 & 688497 & 5.35 & 4.8761 & TRN & \\
\hline CHEMBL1310564 & 688497 & 5.5 & 5.4164 & TRN & \\
\hline CHEMBL1408410 & 688497 & 4.8 & 4.9516 & TRN & \\
\hline CHEMBL1388265 & 688497 & 4.9 & 5.0226 & TRN & \\
\hline CHEMBL1451253 & 688497 & 5.0 & 5.0112 & TST & \\
\hline CHEMBL1350417 & 688497 & 4.45 & 4.9841 & TRN & \\
\hline CHEMBL1410353 & 688497 & 4.45 & 5.15 & TST & \\
\hline CHEMBL1595769 & 688497 & 4.45 & 4.9064 & TRN & \\
\hline CHEMBL1329504 & 688497 & 4.75 & 4.8967 & TRN & \\
\hline CHEMBL1469402 & 688497 & 4.45 & 4.9242 & TRN & \\
\hline CHEMBL1327079 & 688497 & 4.7 & 4.8658 & TST & \\
\hline CHEMBL1457677 & 688497 & 4.5 & 5.1587 & TST & \\
\hline CHEMBL1426377 & 688497 & 4.45 & 5.1096 & TRN & \\
\hline CHEMBL1588174 & 688497 & 4.9 & 5.2279 & TRN & \\
\hline CHEMBL1428752 & 688497 & 4.45 & 4.9163 & TRN & \\
\hline CHEMBL1385815 & 688497 & 4.45 & 5.0883 & TRN & \\
\hline CHEMBL1508844 & 688497 & 4.45 & 4.8716 & TRN & \\
\hline CHEMBL1597195 & 688497 & 4.65 & 4.9877 & TST & \\
\hline CHEMBL1432173 & 688497 & 4.8 & 5.2082 & TRN & \\
\hline CHEMBL1536588 & 688497 & 4.45 & 4.8578 & TRN & \\
\hline CHEMBL1376701 & 688497 & 4.75 & 4.8396 & TRN & \\
\hline CHEMBL1323000 & 688497 & 4.45 & 4.4576 & TRN & \\
\hline CHEMBL1587814 & 688497 & 5.25 & 5.0248 & TRN & \\
\hline CHEMBL1452090 & 688497 & 5.1 & 5.37799 & 9999999999 & TRN \\
\hline & & & & 19788 & \\
\hline
\end{tabular}




\begin{tabular}{|c|c|c|c|c|}
\hline \multicolumn{5}{|c|}{ Supplemental Table S2.txt } \\
\hline CHEMBL1412300 & 688497 & 4.6 & 4.9554 & TRN \\
\hline CHEMBL1345048 & 688497 & 5.25 & 4.9179 & TRN \\
\hline CHEMBL1582173 & 688497 & 5.2 & 5.1203 & TST \\
\hline CHEMBL1546100 & 688497 & 5.9 & 5.3568 & TST \\
\hline CHEMBL1483004 & 688497 & 4.45 & 4.9995 & TRN \\
\hline CHEMBL1300998 & 688497 & 4.45 & 5.5425 & TST \\
\hline CHEMBL1984894 & 688497 & 4.45 & 4.9246 & TRN \\
\hline CHEMBL1350167 & 688497 & 4.55 & 4.6546 & TRN \\
\hline CHEMBL1423440 & 688497 & 5.25 & 4.9308 & TRN \\
\hline CHEMBL1469460 & 688497 & 4.45 & 4.7677 & TRN \\
\hline CHEMBL1582357 & 688497 & 4.8 & 5.0269 & TRN \\
\hline CHEMBL1327686 & 688497 & 5.25 & 5.1977 & TST \\
\hline CHEMBL1376738 & 688497 & 5.5 & 5.3293 & TST \\
\hline CHEMBL1584157 & 688497 & 4.6 & 5.0673 & TRN \\
\hline CHEMBL1334984 & 688497 & 5.55 & 4.8294 & TRN \\
\hline CHEMBL261617 & 688497 & 5.2 & 4.9484 & TRN \\
\hline CHEMBL1340703 & 688497 & 5.05 & 4.8456 & TRN \\
\hline CHEMBL1471369 & 688497 & 5.0 & 4.9184 & TRN \\
\hline CHEMBL1504303 & 688497 & 4.85 & 5.0578 & TRN \\
\hline CHEMBL1329258 & 688497 & 4.45 & 4.7996 & TRN \\
\hline CHEMBL1463185 & 688497 & 4.9 & 4.9349 & TRN \\
\hline CHEMBL1467484 & 688497 & 5.4 & 5.2121 & TRN \\
\hline CHEMBL1307163 & 688497 & 6.45 & 5.3197 & TRN \\
\hline CHEMBL1408745 & 688497 & 4.6 & 4.9426 & TST \\
\hline CHEMBL1384987 & 688497 & 5.5 & 4.8692 & TRN \\
\hline CHEMBL1343895 & 688497 & 4.45 & 4.6689 & TRN \\
\hline CHEMBL1365507 & 688497 & 4.45 & 4.9644 & TRN \\
\hline CHEMBL1339873 & 688497 & 4.45 & 4.958 & TRN \\
\hline CHEMBL1571801 & 688497 & 4.65 & 5.1199 & TRN \\
\hline CHEMBL1467678 & 688497 & 5.0 & 5.1043 & TRN \\
\hline CHEMBL1319488 & 688497 & 4.65 & 5.0675 & TRN \\
\hline CHEMBL1299502 & 688497 & 5.0 & 4.6683 & TRN \\
\hline CHEMBL1456780 & 688497 & 4.45 & 4.588 & TRN \\
\hline CHEMBL1409060 & 688497 & 4.75 & 5.1083 & TST \\
\hline CHEMBL1447828 & 688497 & 4.45 & 4.789 & TRN \\
\hline CHEMBL1604386 & 688497 & 4.45 & 5.1086 & TST \\
\hline CHEMBL1594340 & 688497 & 5.6 & 4.999 & TST \\
\hline CHEMBL1573293 & 688497 & 4.95 & 5.0765 & TRN \\
\hline CHEMBL1423586 & 688497 & 4.6 & 4.769 & TRN \\
\hline CHEMBL1566828 & 688497 & 5.25 & 5.2257 & TST \\
\hline CHEMBL1532422 & 688497 & 5.8 & 5.2237 & TRN \\
\hline CHEMBL3207867 & 688497 & 4.45 & 4.8436 & TRN \\
\hline CHEMBL1452301 & 688497 & 5.25 & 5.2209 & TRN \\
\hline CHEMBL1398919 & 688497 & 4.45 & 4.9205 & TRN \\
\hline CHEMBL1541693 & 688497 & 4.95 & 4.8439 & TRN \\
\hline CHEMBL1569959 & 688497 & 5.45 & 4.9205 & TST \\
\hline CHEMBL1529845 & 688497 & 4.9 & 4.9128 & TRN \\
\hline CHEMBL1544647 & 688497 & 4.9 & 4.5925 & TRN \\
\hline
\end{tabular}




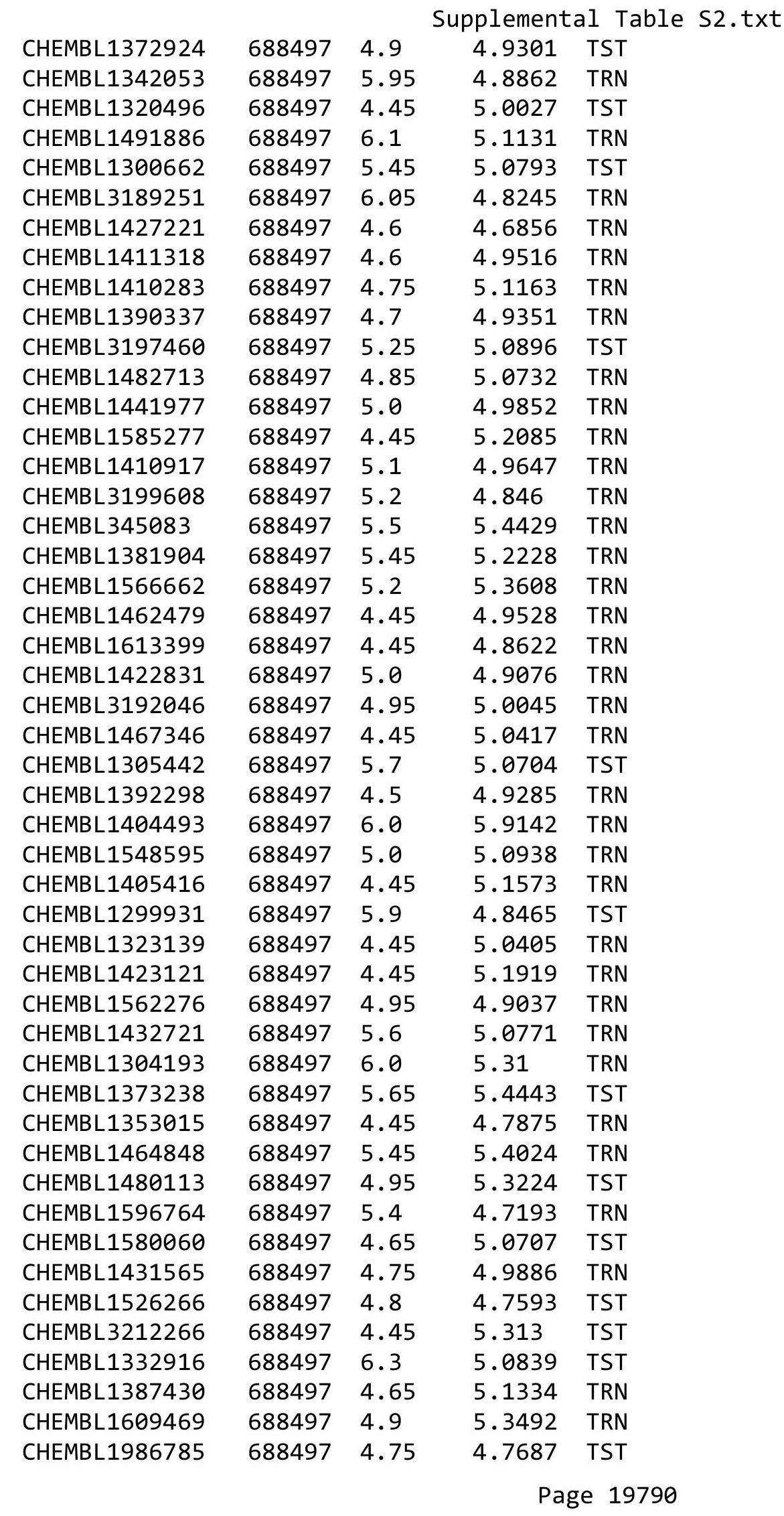




\begin{tabular}{|c|c|c|c|c|c|}
\hline \multicolumn{6}{|c|}{ Supplemental Table S2.txt } \\
\hline CHEMBL1495452 & 688497 & 4.45 & 5.0923 & TST & \\
\hline CHEMBL1584434 & 688497 & 5.45 & 5.2991 & TRN & \\
\hline CHEMBL1366856 & 688497 & 4.45 & 4.9957 & TRN & \\
\hline CHEMBL1598557 & 688497 & 6.25 & 5.12700 & 0000000001 & TST \\
\hline CHEMBL1451480 & 688497 & 4.45 & 4.8387 & TRN & \\
\hline CHEMBL1968954 & 688497 & 4.75 & 4.87 & TST & \\
\hline CHEMBL1504492 & 688497 & 5.6 & 5.0016 & TRN & \\
\hline CHEMBL1571326 & 688497 & 4.8 & 5.2575 & TRN & \\
\hline CHEMBL1303332 & 688497 & 4.7 & 4.6314 & TRN & \\
\hline CHEMBL1310127 & 688497 & 4.45 & 5.1344 & TST & \\
\hline CHEMBL1527144 & 688497 & 5.0 & 5.0745 & TST & \\
\hline CHEMBL1453020 & 688497 & 6.25 & 4.8471 & TST & \\
\hline CHEMBL1498241 & 688497 & 4.65 & 4.782 & TRN & \\
\hline CHEMBL1334894 & 688497 & 5.35 & 5.0136 & TRN & \\
\hline CHEMBL1303341 & 688497 & 4.9 & 4.7606 & TRN & \\
\hline CHEMBL1493031 & 688497 & 4.95 & 4.8752 & TRN & \\
\hline CHEMBL1412527 & 688497 & 5.5 & 5.0884 & TST & \\
\hline CHEMBL241657 & 688497 & 4.6 & 4.8015 & TRN & \\
\hline CHEMBL1310690 & 688497 & 5.35 & 5.0706 & TRN & \\
\hline CHEMBL1504223 & 688497 & 4.85 & 4.9936 & TRN & \\
\hline CHEMBL1987516 & 688497 & 5.55 & 5.1839 & TST & \\
\hline CHEMBL1409997 & 688497 & 4.45 & 4.8082 & TRN & \\
\hline CHEMBL1322388 & 688497 & 4.75 & 5.3365 & TST & \\
\hline CHEMBL 3190843 & 688497 & 4.65 & 4.7658 & TRN & \\
\hline CHEMBL1543839 & 688497 & 4.5 & 4.8248 & TRN & \\
\hline CHEMBL1452840 & 688497 & 5.4 & 5.0429 & TST & \\
\hline CHEMBL1536795 & 688497 & 5.25 & 5.0134 & TRN & \\
\hline CHEMBL1383761 & 688497 & 4.7 & 4.86100 & 0000000001 & TRN \\
\hline CHEMBL1375510 & 688497 & 4.45 & 4.7052 & TRN & \\
\hline CHEMBL1503166 & 688497 & 5.4 & 4.9115 & TST & \\
\hline CHEMBL1325429 & 688497 & 5.25 & 5.285 & TST & \\
\hline CHEMBL1569411 & 688497 & 7.0501 & 5.1468 & TRN & \\
\hline CHEMBL1566368 & 688497 & 4.4 & 5.2407 & TRN & \\
\hline CHEMBL1581425 & 688497 & 6.4 & 4.6429 & TRN & \\
\hline CHEMBL1545560 & 688497 & 4.45 & 4.8084 & TRN & \\
\hline CHEMBL1524271 & 688497 & 4.45 & 5.2615 & TST & \\
\hline CHEMBL3195983 & 688497 & 5.25 & 4.9568 & TRN & \\
\hline CHEMBL3192823 & 688497 & 6.05 & 4.9817 & TRN & \\
\hline CHEMBL227447 & 688497 & 4.85 & 4.9575 & TST & \\
\hline CHEMBL1458249 & 688497 & 5.0 & 4.9628 & TRN & \\
\hline CHEMBL1517563 & 688497 & 4.95 & 5.0788 & TRN & \\
\hline CHEMBL1428521 & 688497 & 4.9 & 4.8533 & TRN & \\
\hline CHEMBL1360282 & 688497 & 4.45 & 4.9152 & TRN & \\
\hline CHEMBL1450063 & 688497 & 4.45 & 5.4522 & TST & \\
\hline CHEMBL1986541 & 688497 & 5.05 & 5.064 & TRN & \\
\hline CHEMBL1477421 & 688497 & 4.45 & 4.973 & TRN & \\
\hline CHEMBL1538711 & 688497 & 5.1 & 5.3874 & TST & \\
\hline CHEMBL2003886 & 688497 & 5.7 & 5.0886 & TST & \\
\hline
\end{tabular}




\begin{tabular}{|c|c|c|c|c|}
\hline \multicolumn{5}{|c|}{ Supplemental Table S2.txt } \\
\hline CHEMBL3189712 & 688497 & 5.6 & 5.3646 & TRN \\
\hline CHEMBL1599854 & 688497 & 5.95 & 5.0662 & TRN \\
\hline CHEMBL1496707 & 688497 & 4.45 & 5.0046 & TST \\
\hline CHEMBL1329626 & 688497 & 4.5 & 4.7123 & TRN \\
\hline CHEMBL1464266 & 688497 & 4.45 & 5.0196 & TRN \\
\hline CHEMBL1498004 & 688497 & 4.45 & 5.0949 & TRN \\
\hline CHEMBL3196731 & 688497 & 4.6 & 4.7104 & TST \\
\hline CHEMBL1341978 & 688497 & 5.05 & 4.8695 & TRN \\
\hline CHEMBL1341036 & 688497 & 4.45 & 5.1756 & TRN \\
\hline CHEMBL1589443 & 688497 & 4.5 & 4.8296 & TRN \\
\hline CHEMBL1487723 & 688497 & 4.5 & 4.7219 & TRN \\
\hline CHEMBL1545436 & 688497 & 5.2 & 5.4838 & TRN \\
\hline CHEMBL1418959 & 688497 & 4.75 & 5.2359 & TRN \\
\hline CHEMBL1362466 & 688497 & 4.5 & 5.3 & TRN \\
\hline CHEMBL1347975 & 688497 & 4.7 & 4.876 & TRN \\
\hline CHEMBL1301727 & 688497 & 4.65 & 5.1765 & TRN \\
\hline CHEMBL1333361 & 688497 & 6.1 & 4.977 & TRN \\
\hline CHEMBL1373478 & 688497 & 4.65 & 5.1359 & TRN \\
\hline CHEMBL1497448 & 688497 & 6.4 & 5.0948 & TRN \\
\hline CHEMBL1407945 & 688497 & 4.95 & 4.9118 & TRN \\
\hline CHEMBL1438183 & 688497 & 5.45 & 4.7279 & TRN \\
\hline CHEMBL597035 & 688497 & 4.45 & 5.1071 & TRN \\
\hline CHEMBL1394040 & 688497 & 4.45 & 4.995 & TRN \\
\hline CHEMBL1433058 & 688497 & 4.8 & 5.1305 & TST \\
\hline CHEMBL1450358 & 688497 & 6.05 & 5.018 & TRN \\
\hline CHEMBL1599370 & 688497 & 5.05 & 5.1182 & TRN \\
\hline CHEMBL1987685 & 688497 & 6.25 & 4.8438 & TRN \\
\hline CHEMBL1573654 & 688497 & 5.25 & 5.3363 & TRN \\
\hline CHEMBL1498953 & 688497 & 4.45 & 4.8214 & TRN \\
\hline CHEMBL1403905 & 688497 & 4.45 & 4.6319 & TRN \\
\hline CHEMBL1451524 & 688497 & 5.25 & 5.0652 & TST \\
\hline CHEMBL1570373 & 688497 & 6.2 & 5.2048 & TST \\
\hline CHEMBL1460187 & 688497 & 4.95 & 5.2599 & TRN \\
\hline CHEMBL1369980 & 688497 & 5.55 & 5.0507 & TRN \\
\hline CHEMBL1544533 & 688497 & 4.5 & 5.3087 & TRN \\
\hline CHEMBL1461320 & 688497 & 5.45 & 5.0514 & TRN \\
\hline CHEMBL1347084 & 688497 & 5.3 & 4.747 & TRN \\
\hline CHEMBL1470406 & 688497 & 4.45 & 4.8369 & TRN \\
\hline CHEMBL1587756 & 688497 & 6.4 & 5.0497 & TST \\
\hline CHEMBL1510257 & 688497 & 4.45 & 5.1265 & TRN \\
\hline CHEMBL1556505 & 688497 & 4.95 & 4.6779 & TRN \\
\hline CHEMBL1324387 & 688497 & 5.1 & 5.1155 & TRN \\
\hline CHEMBL1556653 & 688497 & 5.65 & 5.3146 & TST \\
\hline CHEMBL1404457 & 688497 & 4.45 & 5.0025 & TRN \\
\hline CHEMBL1569162 & 688497 & 5.35 & 5.2137 & TST \\
\hline CHEMBL1523206 & 688497 & 4.55 & 4.7815 & TST \\
\hline CHEMBL1483308 & 688497 & 4.6 & 4.86 & TRN \\
\hline CHEMBL1366910 & 688497 & 5.4 & 5.1349 & TST \\
\hline
\end{tabular}




\begin{tabular}{|c|c|c|c|c|c|}
\hline \multicolumn{6}{|c|}{ Supplemental Table S2.txt } \\
\hline CHEMBL1971810 & 688497 & 5.25 & 5.1204 & TRN & \\
\hline CHEMBL1332109 & 688497 & 5.4 & 4.8932 & TRN & \\
\hline CHEMBL1359253 & 688497 & 6.2 & 5.3446 & TRN & \\
\hline CHEMBL1469038 & 688497 & 4.45 & 4.8928 & TRN & \\
\hline CHEMBL3192485 & 688497 & 4.45 & 4.9171 & TST & \\
\hline CHEMBL3199776 & 688497 & 4.65 & 5.2517 & TRN & \\
\hline CHEMBL1334326 & 688497 & 4.65 & 4.9804 & TRN & \\
\hline CHEMBL 2002776 & 688497 & 4.95 & 5.2606 & TRN & \\
\hline CHEMBL1568279 & 688497 & 5.15 & 4.7545 & TRN & \\
\hline CHEMBL1555417 & 688497 & 4.45 & 4.8966 & TRN & \\
\hline CHEMBL1418021 & 688497 & 4.8 & 5.12799 & 9999999999 & TRN \\
\hline CHEMBL1535167 & 688497 & 4.7 & 4.7339 & TRN & \\
\hline CHEMBL1401798 & 688497 & 4.45 & 4.973 & TRN & \\
\hline CHEMBL1307996 & 688497 & 4.45 & 5.1903 & TRN & \\
\hline CHEMBL1525546 & 688497 & 5.75 & 5.1374 & TRN & \\
\hline CHEMBL1556272 & 688497 & 4.45 & 4.9167 & TRN & \\
\hline CHEMBL1605651 & 688497 & 5.95 & 5.2228 & TST & \\
\hline CHEMBL1541257 & 688497 & 4.6 & 4.9635 & TRN & \\
\hline CHEMBL1391538 & 688497 & 5.55 & 5.3733 & TRN & \\
\hline CHEMBL597047 & 688497 & 4.95 & 5.1458 & TST & \\
\hline CHEMBL1425424 & 688497 & 4.45 & 5.4169 & TRN & \\
\hline CHEMBL1404103 & 688497 & 4.5 & 5.1927 & TRN & \\
\hline CHEMBL1398980 & 688497 & 4.8 & 4.6772 & TST & \\
\hline CHEMBL1608385 & 688497 & 4.95 & 5.0561 & TRN & \\
\hline CHEMBL1568429 & 688497 & 6.0 & 5.1048 & TRN & \\
\hline CHEMBL1569650 & 688497 & 4.8 & 4.8111 & TRN & \\
\hline CHEMBL1522288 & 688497 & 5.4 & 4.8791 & TST & \\
\hline CHEMBL1461011 & 688497 & 4.9 & 5.033 & TST & \\
\hline CHEMBL1535571 & 688497 & 4.95 & 4.8193 & TST & \\
\hline CHEMBL1448274 & 688497 & 4.65 & 4.8401 & TRN & \\
\hline CHEMBL1432373 & 688497 & 6.25 & 5.1112 & TST & \\
\hline CHEMBL1343735 & 688497 & 4.65 & 4.9656 & TRN & \\
\hline CHEMBL1576057 & 688497 & 4.75 & 4.9773 & TRN & \\
\hline CHEMBL1540772 & 688497 & 4.9 & 5.2466 & TRN & \\
\hline CHEMBL1410792 & 688497 & 6.1 & 5.1736 & TRN & \\
\hline CHEMBL1439766 & 688497 & 5.45 & 5.0514 & TST & \\
\hline CHEMBL1530045 & 688497 & 4.85 & 5.0334 & TST & \\
\hline CHEMBL1521658 & 688497 & 4.6 & 4.5761 & TRN & \\
\hline CHEMBL1580706 & 688497 & 6.05 & 5.1619 & TRN & \\
\hline CHEMBL1376682 & 688497 & 4.75 & 5.1754 & TRN & \\
\hline CHEMBL 2005721 & 688497 & 5.1 & 5.0424 & TRN & \\
\hline CHEMBL1379902 & 688497 & 4.45 & 5.2272 & TRN & \\
\hline CHEMBL1451261 & 688497 & 6.05 & 5.2462 & TRN & \\
\hline CHEMBL1300584 & 688497 & 4.55 & 4.7233 & TST & \\
\hline CHEMBL1362828 & 688497 & 5.45 & 5.4035 & TST & \\
\hline CHEMBL1505729 & 688497 & 6.05 & 5.1014 & TRN & \\
\hline CHEMBL1502828 & 688497 & 5.45 & 5.1941 & TST & \\
\hline CHEMBL1546534 & 688497 & 4.9 & 4.8778 & TRN & \\
\hline
\end{tabular}




\begin{tabular}{|c|c|c|c|c|c|}
\hline \multicolumn{6}{|c|}{ Supplemental Table S2.txt } \\
\hline CHEMBL1499318 & 688497 & 5.55 & 5.0375 & TST & \\
\hline CHEMBL1577156 & 688497 & 5.1 & 5.144 & TRN & \\
\hline CHEMBL1393480 & 688497 & 5.9 & 5.3478 & TRN & \\
\hline CHEMBL1389275 & 688497 & 4.45 & 5.0995 & TST & \\
\hline CHEMBL1385794 & 688497 & 4.7 & 5.1175 & TRN & \\
\hline CHEMBL1508579 & 688497 & 4.8 & 4.8639 & TST & \\
\hline CHEMBL1326567 & 688497 & 4.45 & 5.0191 & TRN & \\
\hline CHEMBL1550554 & 688497 & 4.6 & 4.75 & TRN & \\
\hline CHEMBL1422429 & 688497 & 5.95 & 5.7689 & TRN & \\
\hline CHEMBL1404067 & 688497 & 4.45 & 4.6264 & TRN & \\
\hline CHEMBL1433006 & 688497 & 4.45 & 5.0116 & TST & \\
\hline CHEMBL1385142 & 688497 & 4.8 & 4.8026 & TRN & \\
\hline CHEMBL1330740 & 688497 & 4.45 & 5.1261 & TST & \\
\hline CHEMBL1393349 & 688497 & 5.25 & 5.0939 & TRN & \\
\hline CHEMBL1574339 & 688497 & 5.25 & 5.44 & TST & \\
\hline CHEMBL1364354 & 688497 & 4.45 & 4.7427 & TST & \\
\hline CHEMBL1506778 & 688497 & 4.85 & 4.8624 & TST & \\
\hline CHEMBL1608909 & 688497 & 4.45 & 5.1038 & TST & \\
\hline CHEMBL1460225 & 688497 & 4.9 & 5.0517 & TST & \\
\hline CHEMBL1698037 & 688497 & 4.75 & 4.9081 & TRN & \\
\hline CHEMBL1452645 & 688497 & 5.55 & 5.0511 & TST & \\
\hline CHEMBL1452168 & 688497 & 5.05 & 5.0316 & TRN & \\
\hline CHEMBL1543990 & 688497 & 4.45 & 5.1993 & TRN & \\
\hline CHEMBL1383033 & 688497 & 4.8 & 4.7586 & TRN & \\
\hline CHEMBL1610173 & 688497 & 5.65 & 4.8074 & TRN & \\
\hline CHEMBL3210160 & 688497 & 4.45 & $4.9860 e$ & 0000000001 & TRN \\
\hline CHEMBL1399605 & 688497 & 4.45 & 4.9746 & TST & \\
\hline CHEMBL1481579 & 688497 & 6.0 & 5.5029 & TRN & \\
\hline CHEMBL1506617 & 688497 & 4.9 & 5.3178 & TST & \\
\hline CHEMBL1582100 & 688497 & 5.45 & 5.2275 & TRN & \\
\hline CHEMBL3145119 & 688497 & 4.45 & 4.9263 & TST & \\
\hline CHEMBL1556776 & 688497 & 5.5 & 5.0754 & TRN & \\
\hline CHEMBL1377031 & 688497 & 5.35 & 4.9473 & TRN & \\
\hline CHEMBL1575981 & 688497 & 4.65 & 4.9789 & TRN & \\
\hline CHEMBL1471043 & 688497 & 4.5 & 4.918 & TRN & \\
\hline CHEMBL1414584 & 688497 & 4.9 & 4.9605 & TRN & \\
\hline CHEMBL1420135 & 688497 & 4.95 & 5.1497 & TST & \\
\hline CHEMBL1558461 & 688497 & 4.65 & 4.8337 & TRN & \\
\hline CHEMBL1418674 & 688497 & 5.15 & 5.2403 & TRN & \\
\hline CHEMBL1370552 & 688497 & 5.1 & 5.2212 & TRN & \\
\hline CHEMBL1413010 & 688497 & 5.6 & 5.1164 & TRN & \\
\hline CHEMBL1543255 & 688497 & 4.5 & 5.1754 & TRN & \\
\hline CHEMBL1420053 & 688497 & 4.45 & 4.8273 & TST & \\
\hline CHEMBL1479340 & 688497 & 4.45 & 4.9237 & TST & \\
\hline CHEMBL1605094 & 688497 & 6.0 & 4.7098 & TRN & \\
\hline CHEMBL1323872 & 688497 & 6.05 & 5.5925 & TRN & \\
\hline CHEMBL1352117 & 688497 & 4.6 & 4.7567 & TRN & \\
\hline CHEMBL1501751 & 688497 & 4.45 & 4.8241 & TRN & \\
\hline
\end{tabular}




\begin{tabular}{|c|c|c|c|c|c|}
\hline & & \multicolumn{4}{|c|}{ Supplemental Table S2.txt } \\
\hline CHEMBL1429434 & 688497 & 6.5501 & 5.415 & TRN & \\
\hline CHEMBL1506350 & 688497 & 6.45 & 5.2417 & TRN & \\
\hline CHEMBL1348393 & 688497 & 4.7 & 4.6884 & TRN & \\
\hline CHEMBL1535441 & 688497 & 4.9 & 5.0211 & TRN & \\
\hline CHEMBL1337991 & 688497 & 4.45 & 4.7803 & TST & \\
\hline CHEMBL1426594 & 688497 & 4.5 & 4.8612 & TRN & \\
\hline CHEMBL1487065 & 688497 & 4.45 & 4.8874 & TST & \\
\hline CHEMBL1328378 & 688497 & 6.25 & 5.2445 & TRN & \\
\hline CHEMBL1299757 & 688497 & 4.7 & 4.9299 & TRN & \\
\hline CHEMBL1529428 & 688497 & 4.75 & 4.743 & TST & \\
\hline CHEMBL1382320 & 688497 & 5.25 & 5.1158 & TRN & \\
\hline CHEMBL1463970 & 688497 & 4.45 & 4.8766 & TRN & \\
\hline CHEMBL1564801 & 688497 & 5.3 & 4.9006 & TRN & \\
\hline CHEMBL1584680 & 688497 & 5.25 & \multicolumn{2}{|c|}{5.1770000000000005} & TRN \\
\hline CHEMBL1584259 & 688497 & 6.45 & 5.2458 & TRN & \\
\hline CHEMBL1608077 & 688497 & 4.9 & 4.769 & TRN & \\
\hline CHEMBL1603351 & 688497 & 4.45 & 5.0088 & TRN & \\
\hline CHEMBL1450042 & 688497 & 5.4 & 5.1187 & TRN & \\
\hline CHEMBL1500404 & 688497 & 5.55 & 5.2373 & TRN & \\
\hline CHEMBL1492862 & 688497 & 4.7 & 5.1147 & TRN & \\
\hline CHEMBL1205690 & 688497 & 6.25 & 5.2214 & TRN & \\
\hline CHEMBL1350055 & 688497 & 4.5 & 5.2145 & TST & \\
\hline CHEMBL1411418 & 688497 & 4.45 & 5.0927 & TRN & \\
\hline CHEMBL1560961 & 688497 & 5.0 & 5.1703 & TRN & \\
\hline CHEMBL1329650 & 688497 & 5.05 & 5.2085 & TRN & \\
\hline CHEMBL1470585 & 688497 & 4.6 & 5.1173 & TRN & \\
\hline CHEMBL1542533 & 688497 & 4.5 & 5.0337 & TST & \\
\hline CHEMBL1481348 & 688497 & 4.65 & 4.9802 & TST & \\
\hline CHEMBL1453214 & 688497 & 4.55 & 5.0793 & TRN & \\
\hline CHEMBL3191503 & 688497 & 4.95 & 5.2293 & TRN & \\
\hline CHEMBL1522211 & 688497 & 4.9 & 4.9794 & TRN & \\
\hline CHEMBL1549532 & 688497 & 9.699 & 5.3268 & TRN & \\
\hline CHEMBL1532162 & 688497 & 4.45 & 5.1639 & TRN & \\
\hline CHEMBL1413124 & 688497 & 4.95 & 5.1066 & TRN & \\
\hline CHEMBL1307254 & 688497 & 4.45 & 5.0477 & TST & \\
\hline CHEMBL1448984 & 688497 & 5.15 & 5.2859 & TRN & \\
\hline CHEMBL1582330 & 688497 & 5.85 & 5.4314 & TST & \\
\hline CHEMBL1389272 & 688497 & 4.45 & 5.3022 & TRN & \\
\hline CHEMBL1330437 & 688497 & 4.95 & 4.7225 & TRN & \\
\hline CHEMBL1462450 & 688497 & 4.9 & 5.0144 & TRN & \\
\hline CHEMBL1585145 & 688497 & 5.15 & 4.6702 & TST & \\
\hline CHEMBL1337612 & 688497 & 5.25 & 4.8038 & TRN & \\
\hline CHEMBL1301738 & 688497 & 6.3 & 5.1565 & TRN & \\
\hline CHEMBL1445554 & 688497 & 4.95 & 5.2997 & TST & \\
\hline CHEMBL1543244 & 688497 & 8.3468 & 5.1157 & TRN & \\
\hline CHEMBL1319414 & 688497 & 4.8 & 4.9261 & TRN & \\
\hline CHEMBL1459284 & 688497 & 4.5 & \multicolumn{2}{|c|}{ 5. 327999999999999} & TRN \\
\hline CHEMBL1586249 & 688497 & 4.95 & 4.9875 & TRN & \\
\hline
\end{tabular}




\begin{tabular}{|c|c|c|c|c|c|}
\hline \multicolumn{6}{|c|}{ Supplemental Table S2.txt } \\
\hline CHEMBL1372988 & 688497 & 4.45 & 5.3202 & TRN & \\
\hline CHEMBL1534091 & 688497 & 6.05 & 5.2563 & TRN & \\
\hline CHEMBL1368778 & 688497 & 4.65 & 4.9077 & TST & \\
\hline CHEMBL1530548 & 688497 & 4.95 & 4.9857 & TRN & \\
\hline CHEMBL 3196782 & 688497 & 5.0 & 4.8512 & TST & \\
\hline CHEMBL3195725 & 688497 & 6.25 & 4.9121 & TST & \\
\hline CHEMBL1505020 & 688497 & 4.65 & 4.8257 & TRN & \\
\hline CHEMBL 373137 & 688497 & 6.7501 & 5.4773 & TRN & \\
\hline CHEMBL1425234 & 688497 & 4.65 & 5.1801 & TST & \\
\hline CHEMBL1610885 & 688497 & 6.25 & 5.3007 & TRN & \\
\hline CHEMBL1584985 & 688497 & 5.3 & 5.3286 & TRN & \\
\hline CHEMBL1416622 & 688497 & 5.15 & 4.9339 & TST & \\
\hline CHEMBL578112 & 688497 & 4.85 & 4.9936 & TRN & \\
\hline CHEMBL3199665 & 688497 & 4.9 & 5.385 & TST & \\
\hline CHEMBL58527 & 688497 & 6.5 & 5.388 & TRN & \\
\hline CHEMBL1349088 & 688497 & 5.25 & 4.8886 & TST & \\
\hline CHEMBL1384085 & 688497 & 4.55 & 4.9399 & TST & \\
\hline CHEMBL1424801 & 688497 & 4.95 & 4.9891 & TRN & \\
\hline CHEMBL1601612 & 688497 & 4.65 & 5.3862 & TRN & \\
\hline CHEMBL1542885 & 688497 & 4.7 & 5.0616 & TRN & \\
\hline CHEMBL410063 & 688497 & 4.5 & 4.9853 & TST & \\
\hline CHEMBL1526693 & 688497 & 5.5 & 5.1851 & TRN & \\
\hline CHEMBL1472496 & 688497 & 4.95 & 4.9495 & TRN & \\
\hline CHEMBL1505503 & 688497 & 4.55 & 4.8473 & TST & \\
\hline CHEMBL1375251 & 688497 & 4.6 & 4.7518 & TRN & \\
\hline CHEMBL1538737 & 688497 & 4.75 & 5.0088 & TRN & \\
\hline CHEMBL1490225 & 688497 & 4.45 & 5.0772 & TRN & \\
\hline CHEMBL1586681 & 688497 & 6.0 & 5.1597 & TRN & \\
\hline CHEMBL1575206 & 688497 & 5.2 & 5.3697 & TRN & \\
\hline CHEMBL1608294 & 688497 & 4.45 & 4.7095 & TRN & \\
\hline CHEMBL1530733 & 688497 & 4.45 & 4.8813 & TRN & \\
\hline CHEMBL1339644 & 688497 & 4.65 & 4.8343 & TRN & \\
\hline CHEMBL3210791 & 688497 & 5.5 & 5.2042 & TST & \\
\hline CHEMBL1307942 & 688497 & 4.75 & 4.8212 & TRN & \\
\hline CHEMBL1579676 & 688497 & 4.95 & 5.2215 & TRN & \\
\hline CHEMBL1360308 & 688497 & 4.95 & 4.6233 & TRN & \\
\hline CHEMBL1977555 & 688497 & 4.8 & 4.89199 & 99999999995 & TRN \\
\hline CHEMBL1432432 & 688497 & 4.75 & 4.7876 & TRN & \\
\hline CHEMBL1993204 & 688497 & 5.55 & 5.0773 & TRN & \\
\hline CHEMBL1565209 & 688497 & 6.15 & 5.1606 & TST & \\
\hline CHEMBL1326180 & 688497 & 5.55 & 4.8762 & TST & \\
\hline CHEMBL1452045 & 688497 & 4.45 & 4.7206 & TRN & \\
\hline CHEMBL1423040 & 688497 & 5.25 & 5.0999 & TST & \\
\hline CHEMBL1429297 & 688497 & 5.05 & 4.8168 & TRN & \\
\hline CHEMBL609606 & 688497 & 5.05 & 5.5232 & TRN & \\
\hline CHEMBL1488375 & 688497 & 6.95 & 5.2558 & TST & \\
\hline CHEMBL1380841 & 688497 & 5.25 & 5.1568 & TRN & \\
\hline CHEMBL1548266 & 688497 & 5.1 & 5.0096 & TRN & \\
\hline
\end{tabular}




\begin{tabular}{|c|c|c|c|c|}
\hline \multicolumn{5}{|c|}{ Supplemental Table S2.txt } \\
\hline CHEMBL1398797 & 688497 & 5.55 & 4.9906 & TST \\
\hline CHEMBL1527239 & 688497 & 5.0 & 5.1537 & TST \\
\hline CHEMBL1379552 & 688497 & 5.8 & 5.0248 & TST \\
\hline CHEMBL 2002522 & 688497 & 4.9 & 4.96 & TST \\
\hline CHEMBL1326845 & 688497 & 5.55 & 5.0581 & TST \\
\hline CHEMBL1418330 & 688497 & 4.45 & 4.7502 & TRN \\
\hline CHEMBL1340901 & 688497 & 4.4 & 5.3051 & TST \\
\hline CHEMBL1605288 & 688497 & 4.5 & 5.1936 & TRN \\
\hline CHEMBL1346771 & 688497 & 5.1 & 5.2784 & TRN \\
\hline CHEMBL1585100 & 688497 & 4.95 & 4.7952 & TST \\
\hline CHEMBL1531592 & 688497 & 6.95 & 5.391 & TRN \\
\hline CHEMBL 3190482 & 688497 & 4.9 & 4.8803 & TST \\
\hline CHEMBL1492648 & 688497 & 5.35 & 4.9334 & TRN \\
\hline CHEMBL1427146 & 688497 & 4.65 & 5.1569 & TRN \\
\hline CHEMBL1424992 & 688497 & 5.3 & 5.0696 & TRN \\
\hline CHEMBL1320946 & 688497 & 5.1 & 4.8505 & TST \\
\hline CHEMBL1499667 & 688497 & 5.55 & 5.0321 & TST \\
\hline CHEMBL1538232 & 688497 & 4.45 & 5.0307 & TRN \\
\hline CHEMBL1339782 & 688497 & 4.45 & 4.9948 & TRN \\
\hline CHEMBL1604971 & 688497 & 4.45 & 4.9545 & TST \\
\hline CHEMBL1587420 & 688497 & 4.5 & 5.1774 & TRN \\
\hline CHEMBL1362729 & 688497 & 5.5 & 5.0042 & TST \\
\hline CHEMBL1376959 & 688497 & 4.95 & 5.2294 & TRN \\
\hline CHEMBL1340113 & 688497 & 4.45 & 5.0265 & TRN \\
\hline CHEMBL1999960 & 688497 & 4.8 & 4.8427 & TRN \\
\hline CHEMBL1497759 & 688497 & 4.6 & 5.1276 & TST \\
\hline CHEMBL1557550 & 688497 & 5.3 & 4.9588 & TRN \\
\hline CHEMBL1533024 & 688497 & 4.45 & 4.9106 & TRN \\
\hline CHEMBL1391045 & 688497 & 4.85 & 5.0786 & TST \\
\hline CHEMBL1506951 & 688497 & 4.95 & 4.6265 & TRN \\
\hline CHEMBL1411104 & 688497 & 5.0 & 5.015 & TRN \\
\hline CHEMBL1378644 & 688497 & 4.45 & 4.3877 & TRN \\
\hline CHEMBL1990036 & 688497 & 5.35 & 4.8697 & TRN \\
\hline CHEMBL1522140 & 688497 & 4.7 & 4.9667 & TRN \\
\hline CHEMBL3191846 & 688497 & 4.95 & 5.2618 & TRN \\
\hline CHEMBL1406323 & 688497 & 4.45 & 4.9643 & TST \\
\hline CHEMBL1379540 & 688497 & 5.5 & 5.2762 & TRN \\
\hline CHEMBL1391091 & 688497 & 4.9 & 4.9414 & TRN \\
\hline CHEMBL1312586 & 688497 & 4.45 & 4.7794 & TRN \\
\hline CHEMBL1575397 & 688497 & 5.05 & 5.5841 & TRN \\
\hline CHEMBL1342087 & 688497 & 5.3 & 5.1397 & TST \\
\hline CHEMBL1312084 & 688497 & 6.25 & 5.2302 & TRN \\
\hline CHEMBL1516774 & 688497 & 4.45 & 4.8377 & TST \\
\hline CHEMBL600908 & 688497 & 4.45 & 4.8168 & TRN \\
\hline CHEMBL1446203 & 688497 & 4.65 & 4.748 & TST \\
\hline CHEMBL1441801 & 688497 & 5.25 & 5.0352 & TST \\
\hline CHEMBL1586658 & 688497 & 4.65 & 5.0633 & TRN \\
\hline CHEMBL1329925 & 688497 & 5.6 & 4.9059 & TRN \\
\hline
\end{tabular}




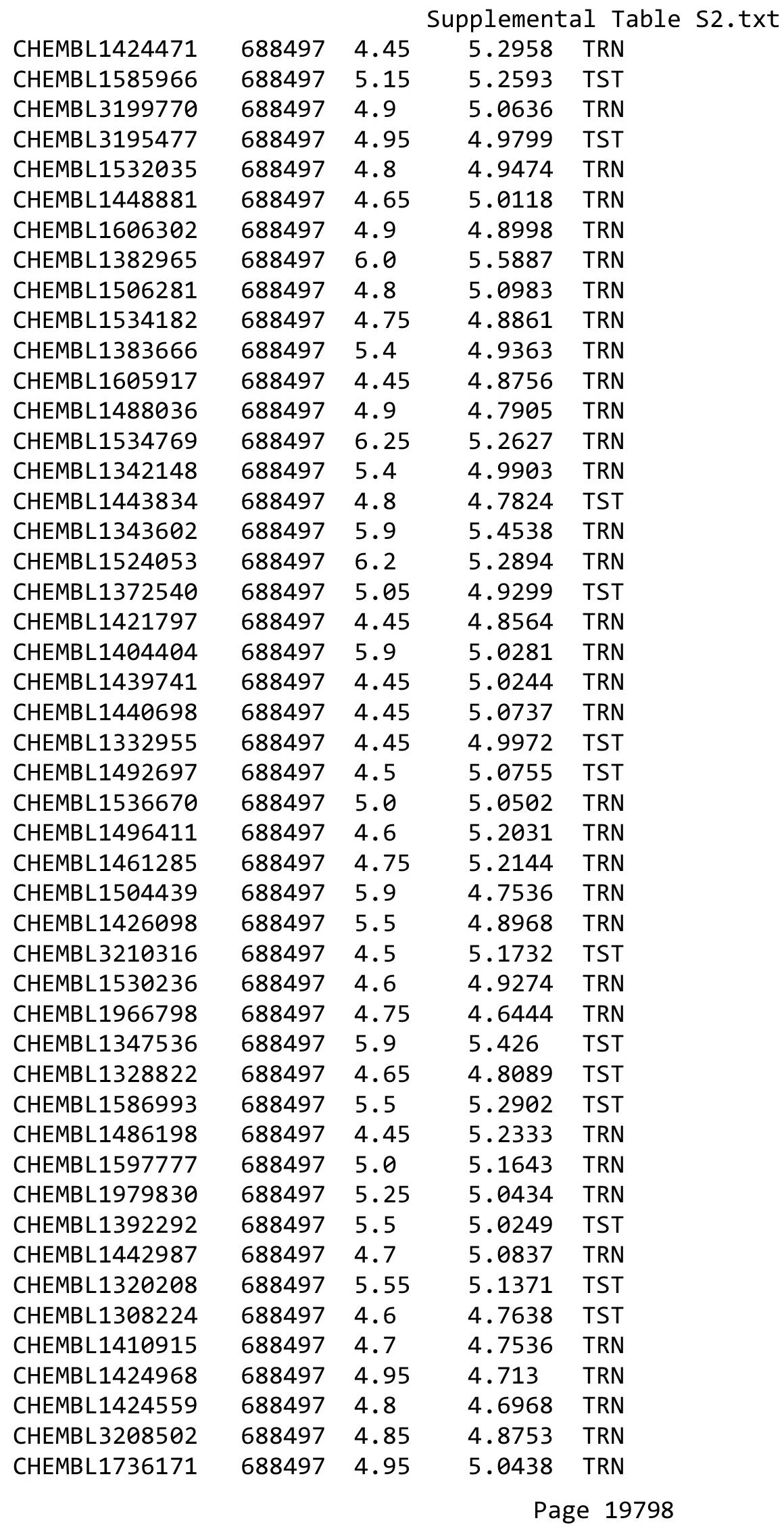




\begin{tabular}{|c|c|c|c|c|}
\hline \multicolumn{5}{|c|}{ Supplemental Table S2.txt } \\
\hline CHEMBL1463934 & 688497 & 4.45 & 4.9993 & TRN \\
\hline CHEMBL1587012 & 688497 & 4.8 & 5.4021 & TRN \\
\hline CHEMBL1493700 & 688497 & 4.45 & 4.7525 & TRN \\
\hline CHEMBL1497024 & 688497 & 5.15 & 4.9562 & TRN \\
\hline CHEMBL1455796 & 688497 & 4.5 & 5.0024 & TST \\
\hline CHEMBL1517298 & 688497 & 5.0 & 5.1871 & TRN \\
\hline CHEMBL1370334 & 688497 & 5.3 & 5.1313 & TRN \\
\hline CHEMBL1352894 & 688497 & 4.85 & 5.0184 & TST \\
\hline CHEMBL1612194 & 688497 & 5.5 & 5.0589 & TRN \\
\hline CHEMBL1386872 & 688497 & 4.5 & 5.0788 & TRN \\
\hline CHEMBL1571360 & 688497 & 5.0 & 5.0266 & TRN \\
\hline CHEMBL1611508 & 688497 & 5.45 & 4.9711 & TRN \\
\hline CHEMBL1539511 & 688497 & 4.6 & 4.9974 & TRN \\
\hline CHEMBL1581727 & 688497 & 4.8 & 4.8801 & TRN \\
\hline CHEMBL1382214 & 688497 & 4.6 & 4.9231 & TRN \\
\hline CHEMBL1347094 & 688497 & 4.8 & 5.4488 & TRN \\
\hline CHEMBL1427969 & 688497 & 5.0 & 4.7231 & TRN \\
\hline CHEMBL1575547 & 688497 & 4.65 & 5.1812 & TRN \\
\hline CHEMBL1545066 & 688497 & 4.45 & 5.6227 & TST \\
\hline CHEMBL1480332 & 688497 & 4.5 & 4.6467 & TRN \\
\hline CHEMBL1447434 & 688497 & 4.8 & 5.0993 & TST \\
\hline CHEMBL1597234 & 688497 & 4.9 & 4.9294 & TRN \\
\hline CHEMBL1499324 & 688497 & 5.45 & 5.3326 & TRN \\
\hline CHEMBL 3208669 & 688497 & 5.0 & 5.3845 & TRN \\
\hline CHEMBL1320326 & 688497 & 5.6 & 4.9775 & TRN \\
\hline CHEMBL1402623 & 688497 & 4.45 & 4.9692 & TRN \\
\hline CHEMBL1418885 & 688497 & 4.45 & 4.4164 & TRN \\
\hline CHEMBL1424647 & 688497 & 5.5 & 5.1003 & TST \\
\hline CHEMBL1369444 & 688497 & 4.95 & 5.153 & TRN \\
\hline CHEMBL1555853 & 688497 & 4.9 & 4.5645 & TRN \\
\hline CHEMBL1362928 & 688497 & 4.9 & 5.0357 & TST \\
\hline CHEMBL1412697 & 688497 & 4.95 & 5.1873 & TRN \\
\hline CHEMBL1510206 & 688497 & 4.45 & 5.0793 & TRN \\
\hline CHEMBL1567267 & 688497 & 4.45 & 4.9569 & TST \\
\hline CHEMBL1406312 & 688497 & 4.9 & 4.9015 & TRN \\
\hline CHEMBL1363753 & 688497 & 4.45 & 4.7131 & TRN \\
\hline CHEMBL1381297 & 688497 & 4.45 & 4.8718 & TST \\
\hline CHEMBL1457877 & 688497 & 4.45 & 5.1337 & TRN \\
\hline CHEMBL 3197489 & 688497 & 4.45 & 4.7505 & TST \\
\hline CHEMBL1600993 & 688497 & 6.05 & 4.8405 & TRN \\
\hline CHEMBL1560947 & 688497 & 5.45 & 5.1004 & TRN \\
\hline CHEMBL3193098 & 688497 & 5.95 & 5.4442 & TRN \\
\hline CHEMBL1348873 & 688497 & 4.65 & 5.0783 & TRN \\
\hline CHEMBL1332417 & 688497 & 4.65 & 5.2051 & TRN \\
\hline CHEMBL3191629 & 688497 & 4.45 & 5.1815 & TRN \\
\hline CHEMBL1451132 & 688497 & 4.6 & 4.9818 & TRN \\
\hline CHEMBL1538206 & 688497 & 4.8 & 5.2034 & TST \\
\hline CHEMBL1392244 & 688497 & 4.5 & 5.1235 & TST \\
\hline
\end{tabular}




\begin{tabular}{|c|c|c|c|c|}
\hline \multicolumn{5}{|c|}{ Supplemental Table S2.txt } \\
\hline CHEMBL3190630 & 688497 & 5.15 & 5.4144 & TRN \\
\hline CHEMBL1336234 & 688497 & 6.3 & 5.2576 & TRN \\
\hline CHEMBL1610051 & 688497 & 4.45 & 4.6767 & TRN \\
\hline CHEMBL1447370 & 688497 & 4.8 & 5.0673 & TST \\
\hline CHEMBL1378329 & 688497 & 4.45 & 5.0942 & TRN \\
\hline CHEMBL1400498 & 688497 & 4.75 & 4.8555 & TST \\
\hline CHEMBL1439245 & 688497 & 5.0 & 5.0436 & TRN \\
\hline CHEMBL1608168 & 688497 & 4.75 & 4.888 & TRN \\
\hline CHEMBL1376120 & 688497 & 4.8 & 4.6562 & TRN \\
\hline CHEMBL1370608 & 688497 & 4.45 & 4.8988 & TST \\
\hline CHEMBL1414301 & 688497 & 5.0 & 4.9446 & TRN \\
\hline CHEMBL1524597 & 688497 & 4.45 & 5.0154 & TRN \\
\hline CHEMBL1363780 & 688497 & 5.5 & 5.3537 & TRN \\
\hline CHEMBL 3196775 & 688497 & 4.85 & 4.8876 & TRN \\
\hline CHEMBL3196786 & 688497 & 5.0 & 5.0791 & TRN \\
\hline CHEMBL1343392 & 688497 & 5.5 & 4.8466 & TRN \\
\hline CHEMBL1536437 & 688497 & 4.45 & 4.7743 & TRN \\
\hline CHEMBL3190625 & 688497 & 4.65 & 5.0693 & TST \\
\hline CHEMBL1445754 & 688497 & 6.3 & 5.2906 & TRN \\
\hline CHEMBL1347397 & 688497 & 4.45 & 5.2767 & TST \\
\hline CHEMBL1404349 & 688497 & 4.45 & 4.9842 & TRN \\
\hline CHEMBL1312636 & 688497 & 4.9 & 5.0236 & TRN \\
\hline CHEMBL1608833 & 688497 & 4.45 & 5.0053 & TRN \\
\hline CHEMBL1468600 & 688497 & 4.75 & 4.9324 & TRN \\
\hline CHEMBL1408494 & 688497 & 6.3 & 5.2562 & TST \\
\hline CHEMBL3197607 & 688497 & 4.9 & 4.8178 & TRN \\
\hline CHEMBL1420422 & 688497 & 6.2 & 5.0654 & TST \\
\hline CHEMBL3207634 & 688497 & 4.6 & 4.9602 & TRN \\
\hline CHEMBL1471200 & 688497 & 5.0 & 5.2458 & TRN \\
\hline CHEMBL1353619 & 688497 & 4.9 & 4.944 & TRN \\
\hline CHEMBL1600873 & 688497 & 4.9 & 5.0936 & TRN \\
\hline CHEMBL1324727 & 688497 & 4.55 & 4.8906 & TRN \\
\hline CHEMBL1407033 & 688497 & 5.25 & 5.0785 & TRN \\
\hline CHEMBL3211458 & 688497 & 4.5 & 4.6956 & TRN \\
\hline CHEMBL3209209 & 688497 & 4.95 & 4.8998 & TRN \\
\hline CHEMBL1359017 & 688497 & 4.45 & 5.0803 & TST \\
\hline CHEMBL1407659 & 688497 & 5.15 & 4.863 & TRN \\
\hline CHEMBL1501022 & 688497 & 4.45 & 4.7527 & TRN \\
\hline CHEMBL1467769 & 688497 & 5.0 & 5.2479 & TRN \\
\hline CHEMBL1538891 & 688497 & 4.9 & 4.9823 & TST \\
\hline CHEMBL1432742 & 688497 & 4.45 & 5.1383 & TRN \\
\hline CHEMBL1322318 & 688497 & 4.45 & 5.2938 & TRN \\
\hline CHEMBL1425374 & 688497 & 4.45 & 5.3124 & TST \\
\hline CHEMBL1507725 & 688497 & 4.65 & 4.9738 & TRN \\
\hline CHEMBL1968355 & 688497 & 4.65 & 4.7804 & TRN \\
\hline CHEMBL1342448 & 688497 & 5.5 & 5.0355 & TRN \\
\hline CHEMBL1388617 & 688497 & 5.65 & 5.1521 & TRN \\
\hline CHEMBL1391016 & 688497 & 4.45 & 4.9758 & TST \\
\hline
\end{tabular}




\begin{tabular}{|c|c|c|c|c|}
\hline \multicolumn{5}{|c|}{ Supplemental Table S2.txt } \\
\hline CHEMBL1577562 & 688497 & 5.0 & 5.2911 & TRN \\
\hline CHEMBL1479737 & 688497 & 4.7 & 5.2306 & TRN \\
\hline CHEMBL1521737 & 688497 & 5.35 & 5.1208 & TRN \\
\hline CHEMBL1438667 & 688497 & 5.9 & 5.1243 & TRN \\
\hline CHEMBL1310096 & 688497 & 5.15 & 5.0325 & TRN \\
\hline CHEMBL1469003 & 688497 & 5.0 & 5.0666 & TRN \\
\hline CHEMBL1447768 & 688497 & 5.7 & 4.7955 & TRN \\
\hline CHEMBL1540272 & 688497 & 4.65 & 5.1079 & TRN \\
\hline CHEMBL1310318 & 688497 & 4.45 & 5.0371 & TST \\
\hline CHEMBL1596327 & 688497 & 5.0 & 5.2895 & TRN \\
\hline CHEMBL1337802 & 688497 & 4.8 & 4.9692 & TRN \\
\hline CHEMBL1583967 & 688497 & 4.45 & 5.1087 & TRN \\
\hline CHEMBL1505057 & 688497 & 4.55 & 5.0546 & TRN \\
\hline CHEMBL1486378 & 688497 & 5.2 & 5.4373 & TRN \\
\hline CHEMBL1306561 & 688497 & 5.25 & 5.2058 & TRN \\
\hline CHEMBL1378705 & 688497 & 5.25 & 4.9596 & TRN \\
\hline CHEMBL1441114 & 688497 & 4.45 & 4.8121 & TST \\
\hline CHEMBL1546830 & 688497 & 4.65 & 5.0481 & TRN \\
\hline CHEMBL1571295 & 688497 & 5.3 & 5.0799 & TST \\
\hline CHEMBL1367239 & 688497 & 5.1 & 4.8912 & TRN \\
\hline CHEMBL1312571 & 688497 & 4.45 & 4.9743 & TRN \\
\hline CHEMBL1573421 & 688497 & 4.85 & 4.988 & TRN \\
\hline CHEMBL1376822 & 688497 & 6.3 & 5.1303 & TRN \\
\hline CHEMBL1438894 & 688497 & 4.45 & 4.9002 & TRN \\
\hline CHEMBL3212293 & 688497 & 4.45 & 4.9296 & TRN \\
\hline CHEMBL1424199 & 688497 & 5.05 & 4.9773 & TRN \\
\hline CHEMBL1330463 & 688497 & 4.45 & 5.3732 & TRN \\
\hline CHEMBL1545105 & 688497 & 5.25 & 5.0051 & TRN \\
\hline CHEMBL1405753 & 688497 & 4.45 & 5.0545 & TRN \\
\hline CHEMBL1359238 & 688497 & 4.85 & 4.7978 & TRN \\
\hline CHEMBL1471667 & 688497 & 5.5 & 5.1837 & TRN \\
\hline CHEMBL1548538 & 688497 & 4.45 & 5.1438 & TRN \\
\hline CHEMBL1596319 & 688497 & 5.8 & 5.1945 & TRN \\
\hline CHEMBL1569058 & 688497 & 5.6 & 4.9261 & TRN \\
\hline CHEMBL1363579 & 688497 & 4.95 & 5.2244 & TST \\
\hline CHEMBL1556041 & 688497 & 4.85 & 4.8579 & TRN \\
\hline CHEMBL1568288 & 688497 & 4.95 & 4.8506 & TRN \\
\hline CHEMBL1588103 & 688497 & 4.45 & 5.1378 & TRN \\
\hline CHEMBL1503966 & 688497 & 5.25 & 4.9524 & TRN \\
\hline CHEMBL1318891 & 688497 & 5.5 & 5.1979 & TRN \\
\hline CHEMBL1400951 & 688497 & 6.25 & 5.2222 & TRN \\
\hline CHEMBL1385886 & 688497 & 4.6 & 4.8432 & TRN \\
\hline CHEMBL1453291 & 688497 & 4.45 & 5.4966 & TRN \\
\hline CHEMBL1430815 & 688497 & 5.2 & 5.0209 & TRN \\
\hline CHEMBL3194613 & 688497 & 4.95 & 4.9416 & TRN \\
\hline CHEMBL1494499 & 688497 & 4.9 & 4.9298 & TST \\
\hline CHEMBL1518939 & 688497 & 5.3 & 5.0518 & TRN \\
\hline CHEMBL1377813 & 688497 & 4.45 & 4.9082 & TRN \\
\hline
\end{tabular}




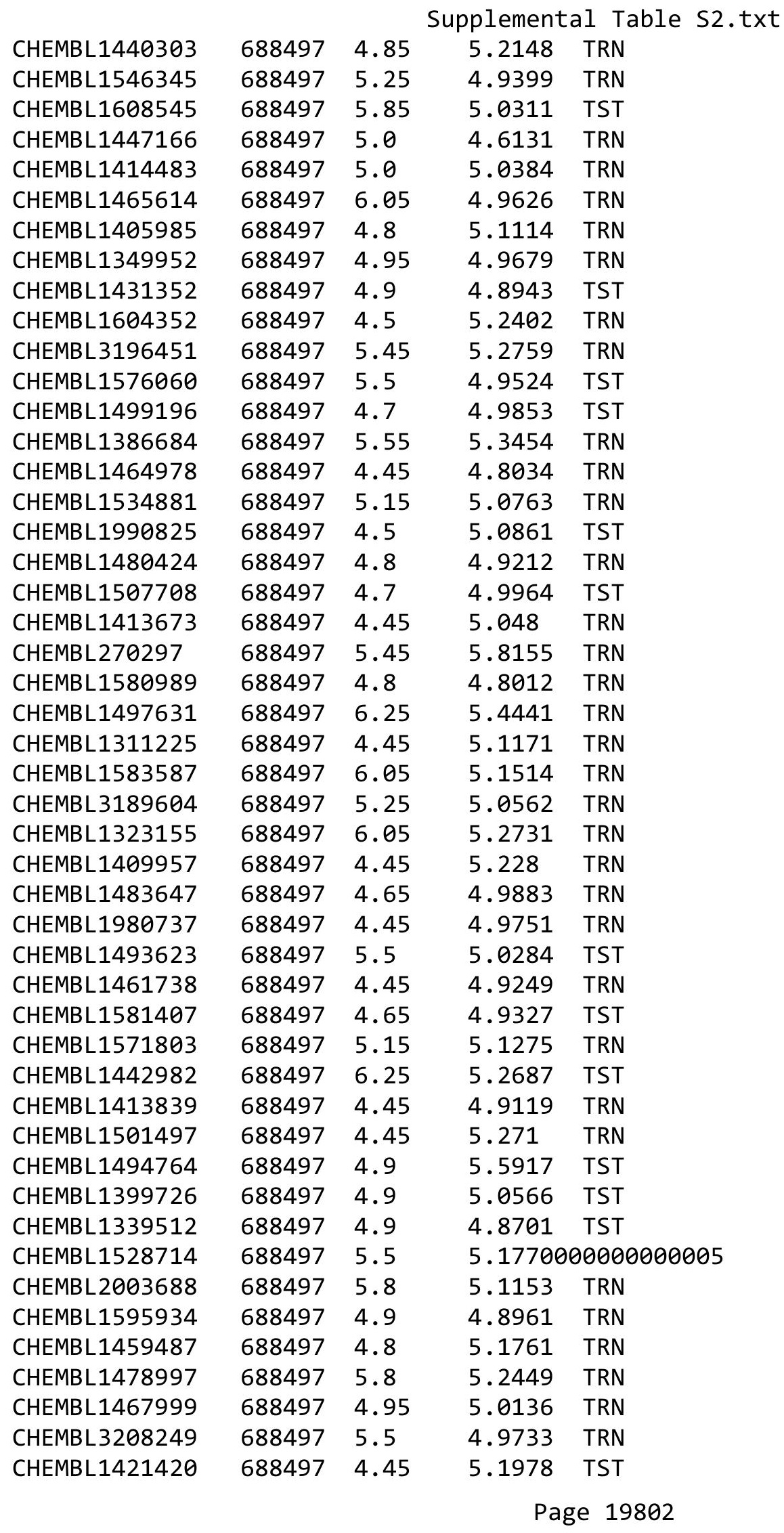




\begin{tabular}{|c|c|c|c|c|c|}
\hline \multicolumn{6}{|c|}{ Supplemental Table S2.txt } \\
\hline CHEMBL1601624 & 688497 & 4.45 & 5.0021 & TRN & \\
\hline CHEMBL1549975 & 688497 & 6.5 & 5.3034 & TRN & \\
\hline CHEMBL1380680 & 688497 & 5.45 & 4.7396 & TRN & \\
\hline CHEMBL1518661 & 688497 & 4.45 & 4.8145 & TST & \\
\hline CHEMBL1374484 & 688497 & 7.5003 & 5.7608 & TRN & \\
\hline CHEMBL1440490 & 688497 & 5.7 & 4.7286 & TST & \\
\hline CHEMBL1391391 & 688497 & 5.25 & 5.36100 & 0000000001 & TRN \\
\hline CHEMBL1345939 & 688497 & 5.0 & 5.0575 & TRN & \\
\hline CHEMBL1538175 & 688497 & 4.45 & 5.0932 & TRN & \\
\hline CHEMBL1495283 & 688497 & 4.5 & 5.1326 & TRN & \\
\hline CHEMBL1411502 & 688497 & 4.75 & 4.84 & TRN & \\
\hline CHEMBL1564871 & 688497 & 7.0501 & 4.994 & TRN & \\
\hline CHEMBL1350593 & 688497 & 4.45 & 4.9355 & TRN & \\
\hline CHEMBL1410464 & 688497 & 6.25 & 5.6777 & TRN & \\
\hline CHEMBL1468216 & 688497 & 4.9 & 5.2131 & TST & \\
\hline CHEMBL1403657 & 688497 & 4.95 & 4.9997 & TRN & \\
\hline CHEMBL1423663 & 688497 & 4.45 & 4.9598 & TRN & \\
\hline CHEMBL1411070 & 688497 & 4.45 & 4.9216 & TRN & \\
\hline CHEMBL1502991 & 688497 & 6.25 & 5.0714 & TST & \\
\hline CHEMBL1458183 & 688497 & 5.25 & 5.1242 & TST & \\
\hline CHEMBL1486016 & 688497 & 5.5 & 4.7408 & TRN & \\
\hline CHEMBL 2005246 & 688497 & 5.0 & 4.9993 & TRN & \\
\hline CHEMBL1589298 & 688497 & 4.45 & 5.2184 & TST & \\
\hline CHEMBL1343111 & 688497 & 4.85 & 5.0757 & TRN & \\
\hline CHEMBL1464639 & 688497 & 5.5 & 5.1859 & TRN & \\
\hline CHEMBL1596152 & 688497 & 4.45 & 4.9152 & TST & \\
\hline CHEMBL3193338 & 688497 & 5.1 & 5.0989 & TRN & \\
\hline CHEMBL1379398 & 688497 & 4.85 & 4.9271 & TRN & \\
\hline CHEMBL1414061 & 688497 & 4.45 & 5.1158 & TST & \\
\hline CHEMBL1405585 & 688497 & 4.45 & 5.1756 & TRN & \\
\hline CHEMBL 3214103 & 688497 & 5.0 & 5.2232 & TST & \\
\hline CHEMBL1536074 & 688497 & 5.1 & 4.9216 & TRN & \\
\hline CHEMBL1412013 & 688497 & 4.45 & 4.8119 & TRN & \\
\hline CHEMBL1489442 & 688497 & 4.75 & 5.0312 & TST & \\
\hline CHEMBL1606174 & 688497 & 4.7 & 5.0095 & TRN & \\
\hline CHEMBL1499346 & 688497 & 4.45 & 4.4682 & TRN & \\
\hline CHEMBL1322646 & 688497 & 6.25 & 4.7288 & TRN & \\
\hline CHEMBL1569515 & 688497 & 5.5 & 5.1505 & TRN & \\
\hline CHEMBL3194654 & 688497 & 4.95 & 4.9012 & TRN & \\
\hline CHEMBL1599549 & 688497 & 4.45 & 5.0764 & TRN & \\
\hline CHEMBL3189318 & 688497 & 4.45 & 4.9458 & TRN & \\
\hline CHEMBL1461452 & 688497 & 4.95 & 5.1245 & TST & \\
\hline CHEMBL1332013 & 688497 & 5.2 & 5.1011 & TRN & \\
\hline CHEMBL1390396 & 688497 & 5.65 & 4.9575 & TRN & \\
\hline CHEMBL1335106 & 688497 & 4.7 & 4.8159 & TST & \\
\hline CHEMBL1449328 & 688497 & 4.85 & 4.8803 & TRN & \\
\hline CHEMBL1577210 & 688497 & 4.95 & 4.7516 & TRN & \\
\hline CHEMBL1506511 & 688497 & 6.3 & 5.0047 & TRN & \\
\hline
\end{tabular}




\begin{tabular}{|c|c|c|c|c|c|}
\hline \multicolumn{6}{|c|}{ Supplemental Table S2.txt } \\
\hline CHEMBL1482083 & 688497 & 5.25 & 4.876 & TST & \\
\hline CHEMBL3213271 & 688497 & 5.15 & 5.1203 & TST & \\
\hline CHEMBL1464470 & 688497 & 4.5 & 5.1444 & TRN & \\
\hline CHEMBL1509666 & 688497 & 5.0 & 4.7956 & TST & \\
\hline CHEMBL1321860 & 688497 & 4.45 & 5.0235 & TRN & \\
\hline CHEMBL1600698 & 688497 & 5.9 & 4.8794 & TRN & \\
\hline CHEMBL1587681 & 688497 & 4.45 & 5.0213 & TRN & \\
\hline CHEMBL1326578 & 688497 & 4.7 & 4.909 & TRN & \\
\hline CHEMBL1375191 & 688497 & 4.95 & 5.0166 & TST & \\
\hline CHEMBL1985295 & 688497 & 4.45 & 4.9962 & TRN & \\
\hline CHEMBL1585390 & 688497 & 5.2 & 5.1112 & TRN & \\
\hline CHEMBL1469864 & 688497 & 4.45 & 4.7864 & TRN & \\
\hline CHEMBL1482529 & 688497 & 4.45 & 4.8136 & TRN & \\
\hline CHEMBL1531705 & 688497 & 5.1 & 5.17700 & 00000000005 & TRN \\
\hline CHEMBL1557418 & 688497 & 4.45 & 4.9789 & TST & \\
\hline CHEMBL1401960 & 688497 & 4.45 & 4.8006 & TRN & \\
\hline CHEMBL3197461 & 688497 & 5.25 & 4.73 & TRN & \\
\hline CHEMBL1487004 & 688497 & 5.3 & 4.7075 & TST & \\
\hline CHEMBL1494650 & 688497 & 4.6 & 5.244 & TRN & \\
\hline CHEMBL1387134 & 688497 & 5.45 & 5.1842 & TST & \\
\hline CHEMBL1343483 & 688497 & 5.0 & 5.1142 & TRN & \\
\hline CHEMBL1333498 & 688497 & 4.6 & 4.8381 & TRN & \\
\hline CHEMBL1565980 & 688497 & 5.2 & 4.8603 & TST & \\
\hline CHEMBL1443767 & 688497 & 4.45 & 4.9947 & TRN & \\
\hline CHEMBL1964928 & 688497 & 5.5 & 5.0243 & TRN & \\
\hline CHEMBL1431627 & 688497 & 5.2 & 5.1947 & TST & \\
\hline CHEMBL1427607 & 688497 & 4.45 & 4.9958 & TRN & \\
\hline CHEMBL1439672 & 688497 & 4.45 & 4.7204 & TRN & \\
\hline CHEMBL1408191 & 688497 & 4.75 & 4.7819 & TRN & \\
\hline CHEMBL1572685 & 688497 & 4.95 & 5.2138 & TRN & \\
\hline CHEMBL1334634 & 688497 & 5.6 & 5.2689 & TRN & \\
\hline CHEMBL1566060 & 688497 & 5.25 & 5.2899 & TRN & \\
\hline CHEMBL1387605 & 688497 & 4.5 & 5.1779 & TST & \\
\hline CHEMBL1377975 & 688497 & 6.0 & 5.312 & TRN & \\
\hline CHEMBL1449387 & 688497 & 4.65 & 5.2315 & TRN & \\
\hline CHEMBL1517818 & 688497 & 5.2 & 5.0106 & TRN & \\
\hline CHEMBL1571874 & 688497 & 4.5 & 4.8401 & TST & \\
\hline CHEMBL1417886 & 688497 & 4.7 & 4.9815 & TRN & \\
\hline CHEMBL 3212646 & 688497 & 5.65 & 5.0069 & TST & \\
\hline CHEMBL1299973 & 688497 & 4.45 & 4.9837 & TRN & \\
\hline CHEMBL1528935 & 688497 & 4.8 & 5.5931 & TRN & \\
\hline CHEMBL1577080 & 688497 & 5.45 & 5.30200 & 00000000005 & TST \\
\hline CHEMBL1384238 & 688497 & 4.95 & 4.7563 & TRN & \\
\hline CHEMBL1602731 & 688497 & 5.05 & 5.0385 & TST & \\
\hline CHEMBL1362476 & 688497 & 4.45 & 4.9452 & TRN & \\
\hline CHEMBL1324005 & 688497 & 4.65 & 4.9771 & TST & \\
\hline CHEMBL1607959 & 688497 & 4.45 & 4.6601 & TRN & \\
\hline CHEMBL1417730 & 688497 & 4.65 & 4.6141 & TRN & \\
\hline
\end{tabular}




\begin{tabular}{|c|c|c|c|c|c|}
\hline & & \multicolumn{4}{|c|}{ Supplemental Table s2.txt } \\
\hline CHEMBL1505224 & 688497 & 4.95 & 5.0865 & TRN & \\
\hline CHEMBL1383532 & 688497 & 4.65 & 5.1365 & TST & \\
\hline CHEMBL1521717 & 688497 & 5.25 & 5.1084 & TRN & \\
\hline CHEMBL1477164 & 688497 & 5.95 & 4.831 & TST & \\
\hline CHEMBL1319074 & 688497 & 6.45 & 5.0583 & TRN & \\
\hline CHEMBL1339798 & 688497 & 5.55 & 5.0263 & TRN & \\
\hline CHEMBL1427860 & 688497 & 4.45 & 4.6615 & TRN & \\
\hline CHEMBL1581337 & 688497 & 6.2 & 4.7664 & TRN & \\
\hline CHEMBL 3192148 & 688497 & 4.6 & 5.0298 & TRN & \\
\hline CHEMBL1483738 & 688497 & 4.95 & 5.1808 & TRN & \\
\hline CHEMBL1520215 & 688497 & 4.5 & 5.0109 & TST & \\
\hline CHEMBL1589173 & 688497 & 4.45 & 5.3138 & TRN & \\
\hline CHEMBL 2000517 & 688497 & 5.6 & 5.2134 & TRN & \\
\hline CHEMBL 3195874 & 688497 & 6.15 & 4.8871 & TST & \\
\hline CHEMBL1505172 & 688497 & 5.25 & 5.3062 & TST & \\
\hline CHEMBL1344294 & 688497 & 4.45 & 4.9266 & TRN & \\
\hline CHEMBL1470102 & 688497 & 4.5 & 4.7004 & TRN & \\
\hline CHEMBL3192019 & 688497 & 5.25 & 5.0088 & TRN & \\
\hline CHEMBL1975756 & 688497 & 5.2 & 4.9039 & TRN & \\
\hline CHEMBL1456729 & 688497 & 4.65 & 5.2157 & TRN & \\
\hline CHEMBL1541861 & 688497 & 5.05 & 5.2436 & TRN & \\
\hline CHEMBL1598295 & 688497 & 5.2 & 5.3605 & TST & \\
\hline CHEMBL1581891 & 688497 & 4.45 & 4.9643 & TRN & \\
\hline CHEMBL1369241 & 688497 & 5.25 & 5.0144 & TRN & \\
\hline CHEMBL1423660 & 688497 & 6.0 & 5.8196 & TRN & \\
\hline CHEMBL1509958 & 688497 & 5.0 & 5.1643 & TRN & \\
\hline CHEMBL1547257 & 688497 & 4.5 & 4.7572 & TST & \\
\hline CHEMBL 348588 & 688497 & 4.65 & 4.8935 & TRN & \\
\hline CHEMBL1423138 & 688497 & 5.0 & 4.587 & TST & \\
\hline CHEMBL1501223 & 688497 & 4.6 & 5.2858 & TST & \\
\hline CHEMBL1441191 & 688497 & 4.45 & 4.7342 & TRN & \\
\hline CHEMBL 3196449 & 688497 & 4.5 & 5.1505 & TRN & \\
\hline CHEMBL1450985 & 688497 & 5.45 & 5.3535 & TST & \\
\hline CHEMBL1469115 & 688497 & 4.95 & 5.2329 & TST & \\
\hline CHEMBL1351371 & 688497 & 5.05 & 4.9646 & TRN & \\
\hline CHEMBL1585037 & 688497 & 4.95 & 4.8499 & TRN & \\
\hline CHEMBL1604336 & 688497 & 5.5 & 5.24200 & 0000000001 & TRN \\
\hline CHEMBL1389114 & 688497 & 5.45 & 5.2446 & TRN & \\
\hline CHEMBL1328788 & 688497 & 5.85 & 4.9362 & TST & \\
\hline CHEMBL1587105 & 688497 & 4.9 & 5.2809 & TRN & \\
\hline CHEMBL1547347 & 688497 & 4.5 & 5.1674 & TST & \\
\hline CHEMBL1428562 & 688497 & 4.45 & 4.8298 & TST & \\
\hline CHEMBL1364569 & 688497 & 5.0 & 4.9206 & TRN & \\
\hline CHEMBL1330886 & 688497 & 6.25 & 4.8585 & TST & \\
\hline CHEMBL1459963 & 688497 & 4.45 & 4.9259 & TRN & \\
\hline CHEMBL1579659 & 688497 & 5.6 & 5.2357 & TST & \\
\hline CHEMBL1391810 & 688497 & 4.95 & 4.7018 & TRN & \\
\hline CHEMBL1494908 & 688497 & 4.45 & 5.1193 & TRN & \\
\hline
\end{tabular}




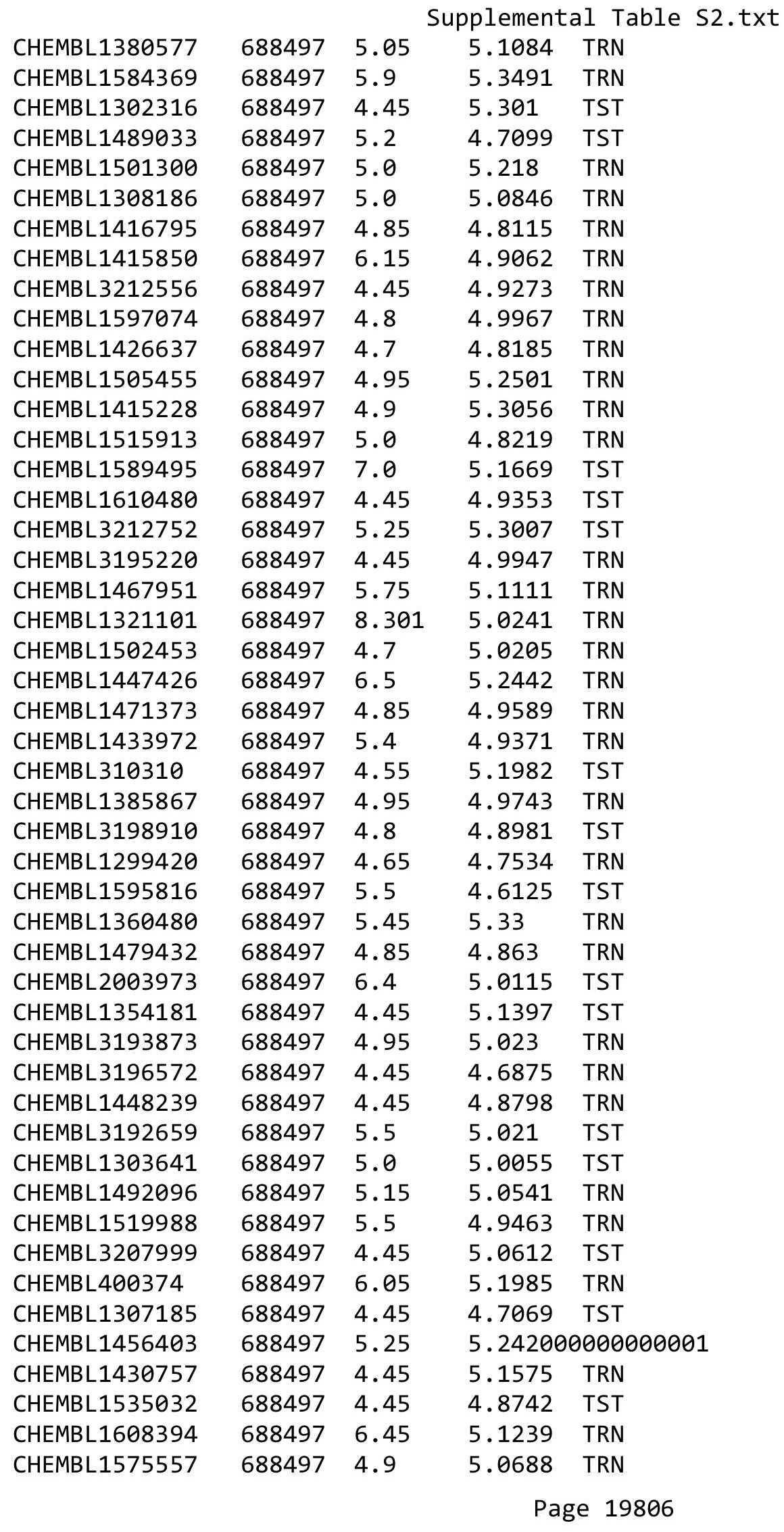




\begin{tabular}{|c|c|c|c|c|}
\hline & & & pplement & al $\mathrm{T}$ \\
\hline CHEMBL1611625 & 688497 & 5.5 & 4.8047 & TRN \\
\hline CHEMBL3194085 & 688497 & 4.9 & 4.7746 & TRN \\
\hline CHEMBL1404447 & 688497 & 4.45 & 4.7574 & TRN \\
\hline CHEMBL1350986 & 688497 & 4.9 & 4.8238 & TRN \\
\hline CHEMBL1430227 & 688497 & 5.6 & 4.8807 & TRN \\
\hline CHEMBL1523735 & 688497 & 4.45 & 4.7528 & TRN \\
\hline CHEMBL1485239 & 688497 & 4.45 & 5.0769 & TRN \\
\hline CHEMBL1466362 & 688497 & 4.45 & 5.0706 & TRN \\
\hline CHEMBL1548665 & 688497 & 4.45 & 5.3336 & TRN \\
\hline CHEMBL1371100 & 688497 & 5.25 & 4.9391 & TRN \\
\hline CHEMBL1330062 & 688497 & 4.85 & 4.9893 & TRN \\
\hline CHEMBL1379991 & 688497 & 4.65 & 4.6347 & TST \\
\hline CHEMBL1577399 & 688497 & 4.45 & 4.9772 & TRN \\
\hline CHEMBL 3191624 & 688497 & 5.65 & 5.1348 & TRN \\
\hline CHEMBL1319030 & 688497 & 5.55 & 5.1331 & TST \\
\hline CHEMBL1465709 & 688497 & 4.95 & 4.7739 & TRN \\
\hline CHEMBL1302816 & 688497 & 4.45 & 4.8068 & TST \\
\hline CHEMBL1566742 & 688497 & 4.8 & 4.7428 & TRN \\
\hline CHEMBL1392785 & 688497 & 5.05 & 4.8386 & TRN \\
\hline CHEMBL1714915 & 688497 & 4.95 & 5.1262 & TST \\
\hline CHEMBL1403329 & 688497 & 4.65 & 5.0644 & TRN \\
\hline CHEMBL1451782 & 688497 & 6.3 & 5.085 & TRN \\
\hline CHEMBL 3207835 & 688497 & 4.65 & 4.9873 & TST \\
\hline CHEMBL1577213 & 688497 & 4.95 & 4.9618 & TRN \\
\hline CHEMBL1305663 & 688497 & 4.45 & 4.8505 & TST \\
\hline CHEMBL1560638 & 688497 & 5.25 & 5.148 & TRN \\
\hline CHEMBL1308415 & 688497 & 4.45 & 4.7695 & TRN \\
\hline CHEMBL1400593 & 688497 & 4.65 & 5.1027 & TST \\
\hline CHEMBL3189369 & 688497 & 5.1 & 5.1786 & TRN \\
\hline CHEMBL1427458 & 688497 & 4.95 & 5.1679 & TRN \\
\hline CHEMBL1503735 & 688497 & 4.95 & 5.1369 & TRN \\
\hline CHEMBL1528306 & 688497 & 4.85 & 4.8551 & TRN \\
\hline CHEMBL1527471 & 688497 & 4.95 & 5.2338 & TST \\
\hline CHEMBL1452342 & 688497 & 4.65 & 4.9988 & TRN \\
\hline CHEMBL1499692 & 688497 & 5.9 & 5.2329 & TST \\
\hline CHEMBL1377247 & 688497 & 4.95 & 5.1572 & TRN \\
\hline CHEMBL1337512 & 688497 & 6.25 & 5.4033 & TRN \\
\hline CHEMBL3198692 & 688497 & 4.95 & 4.9645 & TRN \\
\hline CHEMBL570345 & 688497 & 5.25 & 5.1335 & TRN \\
\hline CHEMBL1461558 & 688497 & 5.1 & 5.1053 & TRN \\
\hline CHEMBL3189147 & 688497 & 4.85 & 5.2411 & TRN \\
\hline CHEMBL1606751 & 688497 & 6.7501 & 5.0891 & TST \\
\hline CHEMBL1578774 & 688497 & 4.65 & 5.0949 & TRN \\
\hline CHEMBL1338723 & 688497 & 5.4 & 4.9537 & TRN \\
\hline CHEMBL1308000 & 688497 & 5.2 & 4.9839 & TRN \\
\hline CHEMBL1303602 & 688497 & 4.95 & 4.9805 & TRN \\
\hline CHEMBL1453691 & 688497 & 8.5528 & 5.2711 & TRN \\
\hline CHEMBL1306964 & 688497 & 4.65 & 5.0772 & TRN \\
\hline
\end{tabular}




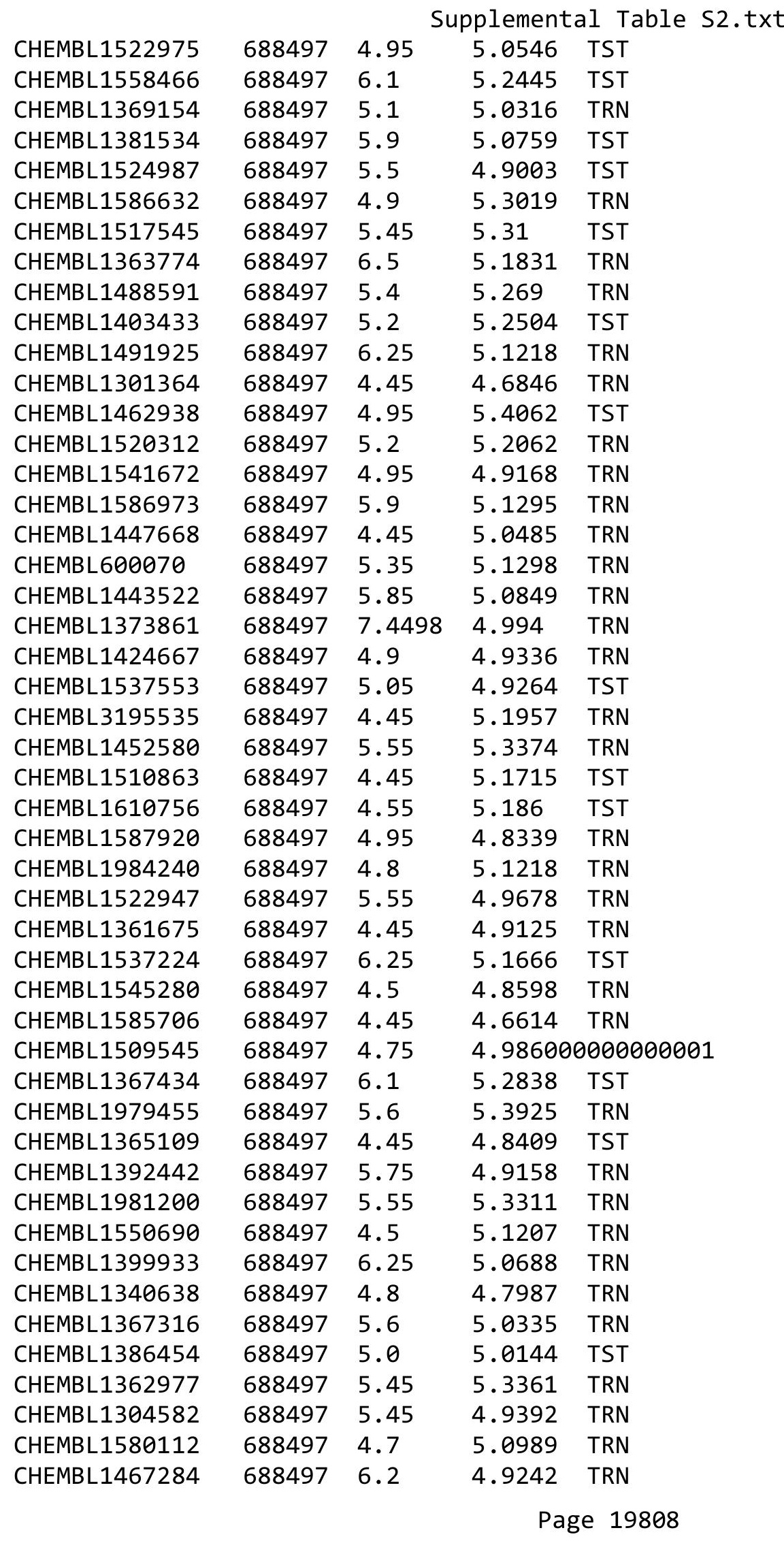




\begin{tabular}{|c|c|c|c|c|c|}
\hline \multicolumn{6}{|c|}{ Supplemental Table S2.txt } \\
\hline CHEMBL1342999 & 688497 & 4.7 & 4.9019 & TRN & \\
\hline CHEMBL1360086 & 688497 & 4.45 & 5.0236 & TRN & \\
\hline CHEMBL1500144 & 688497 & 4.45 & 4.9389 & TRN & \\
\hline CHEMBL493764 & 688497 & 6.25 & 5.2598 & TRN & \\
\hline CHEMBL1321885 & 688497 & 6.5501 & 5.0412 & TRN & \\
\hline CHEMBL1305122 & 688497 & 5.1 & 4.9885 & TRN & \\
\hline CHEMBL1510946 & 688497 & 5.1 & 4.721 & TRN & \\
\hline CHEMBL1487131 & 688497 & 4.5 & 4.7975 & TRN & \\
\hline CHEMBL1352235 & 688497 & 4.45 & 4.7847 & TRN & \\
\hline CHEMBL1608675 & 688497 & 4.9 & 5.331 & TST & \\
\hline CHEMBL1421178 & 688497 & 4.45 & 4.996 & TRN & \\
\hline CHEMBL1448275 & 688497 & 6.5 & 5.2399 & TRN & \\
\hline CHEMBL1407739 & 688497 & 4.45 & 4.9076 & TRN & \\
\hline CHEMBL1431448 & 688497 & 5.25 & 4.8163 & TST & \\
\hline CHEMBL1498314 & 688497 & 4.45 & 5.211 & TRN & \\
\hline CHEMBL1464631 & 688497 & 4.8 & 4.8173 & TRN & \\
\hline CHEMBL1328974 & 688497 & 5.0 & 5.1548 & TRN & \\
\hline CHEMBL1415219 & 688497 & 5.25 & 5.1692 & TRN & \\
\hline CHEMBL1462876 & 688497 & 5.85 & 4.9447 & TRN & \\
\hline CHEMBL1328875 & 688497 & 4.5 & 4.8291 & TRN & \\
\hline CHEMBL1537025 & 688497 & 4.45 & $5.1110 e$ & 0000000001 & TST \\
\hline CHEMBL1338284 & 688497 & 4.75 & 5.0908 & TRN & \\
\hline CHEMBL1409883 & 688497 & 4.95 & 5.2538 & TRN & \\
\hline CHEMBL1349114 & 688497 & 5.4 & 5.1026 & TRN & \\
\hline CHEMBL1510937 & 688497 & 4.95 & 5.0162 & TST & \\
\hline CHEMBL1445219 & 688497 & 4.95 & 5.0268 & TRN & \\
\hline CHEMBL1575804 & 688497 & 5.55 & 5.3147 & TRN & \\
\hline CHEMBL1576110 & 688497 & 4.45 & 4.7469 & TRN & \\
\hline CHEMBL1311826 & 688497 & 5.25 & 5.4273 & TRN & \\
\hline CHEMBL 2137766 & 688497 & 5.4 & 5.2892 & TST & \\
\hline CHEMBL2373598 & 688497 & 6.05 & 5.25899 & 99999999995 & TST \\
\hline CHEMBL3212312 & 688497 & 5.0 & 5.1539 & TRN & \\
\hline CHEMBL1350313 & 688497 & 5.25 & 4.9865 & TRN & \\
\hline CHEMBL1576290 & 688497 & 4.6 & 5.012 & TST & \\
\hline CHEMBL1489318 & 688497 & 4.45 & 5.1702 & TST & \\
\hline CHEMBL507237 & 688497 & 4.65 & 5.2458 & TST & \\
\hline CHEMBL1561563 & 688497 & 5.45 & 5.0312 & TRN & \\
\hline CHEMBL1538268 & 688497 & 4.6 & 5.0244 & TST & \\
\hline CHEMBL1560847 & 688497 & 4.45 & 5.0257 & TRN & \\
\hline CHEMBL1596628 & 688497 & 4.45 & 5.053 & TRN & \\
\hline CHEMBL1480674 & 688497 & 5.25 & 5.3845 & TRN & \\
\hline CHEMBL1307923 & 688497 & 5.25 & 5.1051 & TRN & \\
\hline CHEMBL1299662 & 688497 & 5.25 & 5.034 & TRN & \\
\hline CHEMBL1416417 & 688497 & 4.75 & 4.9984 & TST & \\
\hline CHEMBL3197129 & 688497 & 4.45 & 5.2372 & TST & \\
\hline CHEMBL1419188 & 688497 & 4.6 & 4.9229 & TRN & \\
\hline CHEMBL1313410 & 688497 & 5.05 & 5.1215 & TRN & \\
\hline CHEMBL3191770 & 688497 & 5.85 & 5.2091 & TRN & \\
\hline
\end{tabular}




\begin{tabular}{|c|c|c|c|c|c|}
\hline \multicolumn{6}{|c|}{ Supplemental Table S2.txt } \\
\hline CHEMBL1524089 & 688497 & 4.45 & 4.6194 & TRN & \\
\hline CHEMBL1486430 & 688497 & 4.6 & 4.9552 & TST & \\
\hline CHEMBL3197920 & 688497 & 4.9 & 5.2486 & TRN & \\
\hline CHEMBL1370884 & 688497 & 5.35 & 4.9855 & TRN & \\
\hline CHEMBL1539380 & 688497 & 5.9 & 5.8338 & TRN & \\
\hline CHEMBL1349280 & 688497 & 4.45 & 5.2589 & TST & \\
\hline CHEMBL1305974 & 688497 & 4.95 & 4.843 & TRN & \\
\hline CHEMBL1509788 & 688497 & 5.05 & 4.8372 & TRN & \\
\hline CHEMBL1575133 & 688497 & 4.45 & 5.2149 & TST & \\
\hline CHEMBL1494937 & 688497 & 6.5 & 5.2313 & TST & \\
\hline CHEMBL1538221 & 688497 & 5.35 & 5.19600 & 0000000001 & TRN \\
\hline CHEMBL1307769 & 688497 & 4.45 & 5.2593 & TRN & \\
\hline CHEMBL1558819 & 688497 & 4.8 & 4.6994 & TRN & \\
\hline CHEMBL1389268 & 688497 & 4.95 & 5.007 & TRN & \\
\hline CHEMBL1424650 & 688497 & 5.9 & 5.2882 & TST & \\
\hline CHEMBL1438066 & 688497 & 6.25 & 5.1753 & TRN & \\
\hline CHEMBL1498938 & 688497 & 6.5501 & 4.6535 & TRN & \\
\hline CHEMBL3198111 & 688497 & 4.9 & 5.2041 & TRN & \\
\hline CHEMBL1586739 & 688497 & 4.55 & 4.7303 & TRN & \\
\hline CHEMBL1336392 & 688497 & 4.65 & 5.0749 & TST & \\
\hline CHEMBL1405797 & 688497 & 5.1 & 5.0778 & TRN & \\
\hline CHEMBL1546473 & 688497 & 4.8 & 5.1077 & TRN & \\
\hline CHEMBL1986765 & 688497 & 4.6 & 5.1691 & TRN & \\
\hline CHEMBL1545894 & 688497 & 4.7 & 4.8679 & TST & \\
\hline CHEMBL1329615 & 688497 & 4.8 & 4.9795 & TRN & \\
\hline CHEMBL1568183 & 688497 & 4.45 & 5.0749 & TRN & \\
\hline CHEMBL1603890 & 688497 & 5.05 & 4.8263 & TST & \\
\hline CHEMBL1410867 & 688497 & 4.45 & 4.9374 & TRN & \\
\hline CHEMBL1490993 & 688497 & 5.05 & 4.8859 & TRN & \\
\hline CHEMBL1555491 & 688497 & 4.45 & 4.7763 & TST & \\
\hline CHEMBL1398824 & 688497 & 4.95 & 4.7738 & TST & \\
\hline CHEMBL1341114 & 688497 & 4.8 & 4.7571 & TRN & \\
\hline CHEMBL1431002 & 688497 & 4.85 & 4.7258 & TST & \\
\hline CHEMBL1406457 & 688497 & 4.5 & 4.7462 & TRN & \\
\hline CHEMBL1420676 & 688497 & 4.45 & 5.2095 & TST & \\
\hline CHEMBL1458940 & 688497 & 4.45 & 5.0232 & TRN & \\
\hline CHEMBL1541906 & 688497 & 5.1 & 4.9659 & TRN & \\
\hline CHEMBL1325302 & 688497 & 4.8 & 5.3489 & TRN & \\
\hline CHEMBL1586623 & 688497 & 5.0 & 5.1442 & TRN & \\
\hline CHEMBL1333929 & 688497 & 6.0 & 4.7938 & TRN & \\
\hline CHEMBL1329604 & 688497 & 5.5 & 5.1387 & TST & \\
\hline CHEMBL1598807 & 688497 & 4.55 & 4.9262 & TRN & \\
\hline CHEMBL1342745 & 688497 & 4.7 & 4.6826 & TRN & \\
\hline CHEMBL1511276 & 688497 & 4.45 & 4.78100 & 2000000001 & TRN \\
\hline CHEMBL3209366 & 688497 & 6.95 & 5.11 & TRN & \\
\hline CHEMBL1485151 & 688497 & 4.45 & 5.2436 & TRN & \\
\hline CHEMBL1451356 & 688497 & 5.0 & 5.2446 & TST & \\
\hline CHEMBL1371210 & 688497 & 4.85 & 5.0565 & TST & \\
\hline
\end{tabular}




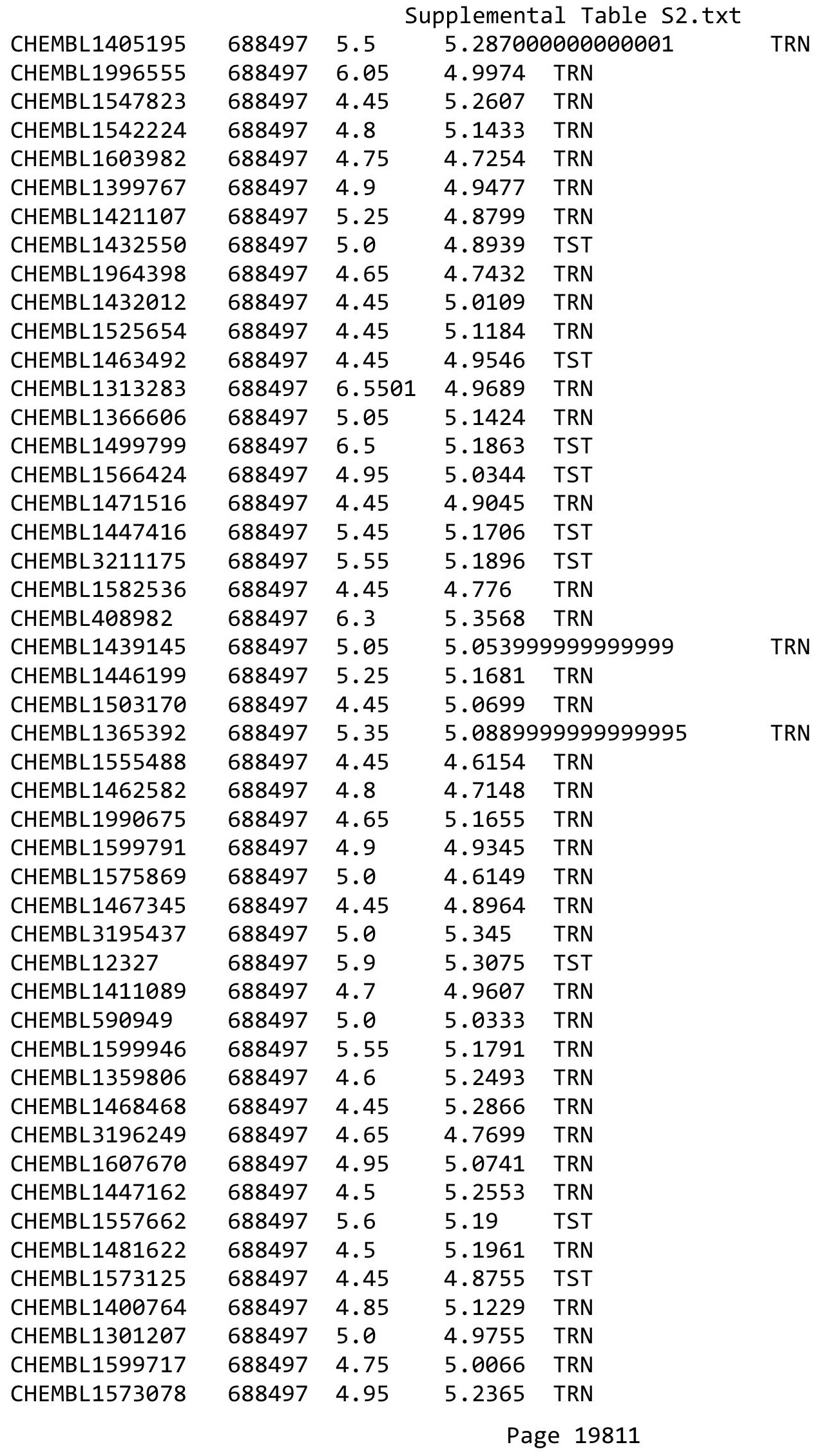




\begin{tabular}{|c|c|c|c|c|}
\hline \multicolumn{5}{|c|}{ Supplemental Table S2.txt } \\
\hline CHEMBL1414744 & 688497 & 5.25 & 5.2701 & TRN \\
\hline CHEMBL1574715 & 688497 & 6.35 & 5.0453 & TRN \\
\hline CHEMBL1454585 & 688497 & 4.5 & 4.9481 & TRN \\
\hline CHEMBL1483275 & 688497 & 5.25 & 5.166 & TST \\
\hline CHEMBL1490849 & 688497 & 5.3 & 5.0035 & TRN \\
\hline CHEMBL1224483 & 688497 & 4.75 & 4.8785 & TRN \\
\hline CHEMBL1500265 & 688497 & 5.25 & 5.1129 & TRN \\
\hline CHEMBL1507600 & 688497 & 4.7 & 4.9382 & TRN \\
\hline CHEMBL1516533 & 688497 & 5.0 & 4.8255 & TRN \\
\hline CHEMBL1339485 & 688497 & 4.5 & 5.0367 & TRN \\
\hline CHEMBL1312531 & 688497 & 5.0 & 4.8592 & TRN \\
\hline CHEMBL1393047 & 688497 & 4.7 & 5.0038 & TRN \\
\hline CHEMBL554041 & 688497 & 4.8 & 5.1334 & TST \\
\hline CHEMBL1311126 & 688497 & 6.25 & 5.1256 & TST \\
\hline CHEMBL1549604 & 688497 & 5.55 & 5.2013 & TRN \\
\hline CHEMBL1429559 & 688497 & 4.75 & 5.1917 & TRN \\
\hline CHEMBL1576094 & 688497 & 4.45 & 4.5897 & TRN \\
\hline CHEMBL1366176 & 688497 & 6.25 & 5.1811 & TST \\
\hline CHEMBL1460723 & 688497 & 4.95 & 4.7174 & TRN \\
\hline CHEMBL1308151 & 688497 & 5.45 & 5.189 & TRN \\
\hline CHEMBL3211728 & 688497 & 5.95 & 5.0836 & TRN \\
\hline CHEMBL1589205 & 688497 & 4.7 & 4.8991 & TST \\
\hline CHEMBL1532756 & 688497 & 4.9 & 4.7299 & TRN \\
\hline CHEMBL1352138 & 688497 & 4.45 & 4.8076 & TRN \\
\hline CHEMBL1604736 & 688497 & 5.1 & 4.7785 & TST \\
\hline CHEMBL1431342 & 688497 & 6.1 & 5.8042 & TST \\
\hline CHEMBL1518886 & 688497 & 6.15 & 5.3527 & TRN \\
\hline CHEMBL1386858 & 688497 & 4.45 & 5.0784 & TST \\
\hline CHEMBL1446954 & 688497 & 4.45 & 4.9072 & TRN \\
\hline CHEMBL1492339 & 688497 & 4.45 & 4.5827 & TRN \\
\hline CHEMBL1309662 & 688497 & 5.5 & 5.1978 & TRN \\
\hline CHEMBL1539115 & 688497 & 4.45 & 5.1418 & TRN \\
\hline CHEMBL1494338 & 688497 & 4.45 & 4.9784 & TRN \\
\hline CHEMBL1442086 & 688497 & 7.0501 & 5.3079 & TST \\
\hline CHEMBL1428472 & 688497 & 4.85 & 4.7388 & TRN \\
\hline CHEMBL1583706 & 688497 & 4.7 & 4.9422 & TST \\
\hline CHEMBL1560539 & 688497 & 5.2 & 4.6507 & TRN \\
\hline CHEMBL1541299 & 688497 & 5.15 & 5.3732 & TRN \\
\hline CHEMBL1308382 & 688497 & 4.7 & 4.9784 & TST \\
\hline CHEMBL1529943 & 688497 & 4.6 & 4.8521 & TRN \\
\hline CHEMBL1312004 & 688497 & 4.7 & 4.8092 & TST \\
\hline CHEMBL1432026 & 688497 & 4.45 & 4.9454 & TST \\
\hline CHEMBL1378479 & 688497 & 5.45 & 5.1479 & TRN \\
\hline CHEMBL1606657 & 688497 & 4.8 & 5.0966 & TRN \\
\hline CHEMBL1325721 & 688497 & 4.55 & 4.8957 & TRN \\
\hline CHEMBL1563656 & 688497 & 5.5 & 5.0378 & TRN \\
\hline CHEMBL1511655 & 688497 & 6.25 & 5.1729 & TRN \\
\hline CHEMBL1539384 & 688497 & 4.5 & 5.1526 & TRN \\
\hline
\end{tabular}




\begin{tabular}{|c|c|c|c|c|c|}
\hline \multicolumn{6}{|c|}{ Supplemental Table S2.txt } \\
\hline CHEMBL1608373 & 688497 & 4.45 & 4.7327 & TRN & \\
\hline CHEMBL1410063 & 688497 & 4.95 & 4.8685 & TRN & \\
\hline CHEMBL1485383 & 688497 & 5.25 & 5.0952 & TRN & \\
\hline CHEMBL1409968 & 688497 & 6.25 & 5.2029 & TRN & \\
\hline CHEMBL1495093 & 688497 & 5.25 & 5.3741 & TRN & \\
\hline CHEMBL1548008 & 688497 & 4.45 & 5.0781 & TRN & \\
\hline CHEMBL1527393 & 688497 & 4.45 & 4.8478 & TRN & \\
\hline CHEMBL1364846 & 688497 & 5.25 & 5.2712 & TST & \\
\hline CHEMBL1445465 & 688497 & 4.85 & 5.2503 & TRN & \\
\hline CHEMBL1344604 & 688497 & 4.65 & 4.6304 & TRN & \\
\hline CHEMBL1364447 & 688497 & 4.65 & 5.0083 & TST & \\
\hline CHEMBL1537615 & 688497 & 5.45 & 4.9462 & TRN & \\
\hline CHEMBL1493987 & 688497 & 4.5 & 4.6697 & TRN & \\
\hline CHEMBL1606843 & 688497 & 4.85 & 5.052 & TRN & \\
\hline CHEMBL1330524 & 688497 & 5.9 & 4.9952 & TRN & \\
\hline CHEMBL1299531 & 688497 & 4.45 & 4.9501 & TRN & \\
\hline CHEMBL1379577 & 688497 & 5.9 & 5.4436 & TRN & \\
\hline CHEMBL1442213 & 688497 & 4.95 & 4.9425 & TRN & \\
\hline CHEMBL1358842 & 688497 & 4.45 & 4.802 & TRN & \\
\hline CHEMBL1345798 & 688497 & 4.45 & 4.8968 & TRN & \\
\hline CHEMBL1500106 & 688497 & 6.3 & 5.2074 & TRN & \\
\hline CHEMBL1421517 & 688497 & 4.45 & 4.9902 & TST & \\
\hline CHEMBL310080 & 688497 & 5.05 & 4.9726 & TRN & \\
\hline CHEMBL1557015 & 688497 & 4.45 & 5.0309 & TRN & \\
\hline CHEMBL1578645 & 688497 & 4.85 & 4.8192 & TRN & \\
\hline CHEMBL1366622 & 688497 & 5.2 & 5.25299 & 9999999999 & TRN \\
\hline CHEMBL1493637 & 688497 & 7.0 & 4.9868 & TST & \\
\hline CHEMBL1346596 & 688497 & 4.85 & 4.8601 & TST & \\
\hline CHEMBL1518393 & 688497 & 4.45 & 4.829 & TRN & \\
\hline CHEMBL1433125 & 688497 & 5.3 & 5.2482 & TST & \\
\hline CHEMBL1489130 & 688497 & 5.95 & 5.0243 & TRN & \\
\hline CHEMBL1320633 & 688497 & 4.6 & 4.9481 & TRN & \\
\hline CHEMBL1304799 & 688497 & 4.45 & 4.7614 & TST & \\
\hline CHEMBL1527223 & 688497 & 4.6 & 5.2362 & TRN & \\
\hline CHEMBL1460748 & 688497 & 4.6 & 4.761 & TRN & \\
\hline CHEMBL1425059 & 688497 & 4.45 & 4.9983 & TRN & \\
\hline CHEMBL1984703 & 688497 & 6.0 & 5.1008 & TRN & \\
\hline CHEMBL1410313 & 688497 & 7.0 & 5.1418 & TST & \\
\hline CHEMBL1983389 & 688497 & 4.45 & 5.0456 & TST & \\
\hline CHEMBL1322982 & 688497 & 4.85 & 4.9857 & TRN & \\
\hline CHEMBL1579775 & 688497 & 4.95 & 4.9419 & TRN & \\
\hline CHEMBL1509738 & 688497 & 5.45 & 5.0093 & TRN & \\
\hline CHEMBL1536476 & 688497 & 4.95 & 5.1139 & TRN & \\
\hline CHEMBL1603830 & 688497 & 4.45 & 5.0155 & TRN & \\
\hline CHEMBL1305221 & 688497 & 5.0 & 4.9353 & TRN & \\
\hline CHEMBL1353237 & 688497 & 5.9 & 5.2814 & TRN & \\
\hline CHEMBL1609836 & 688497 & 4.8 & 4.7366 & TST & \\
\hline CHEMBL1532681 & 688497 & 4.45 & 5.0797 & TRN & \\
\hline
\end{tabular}




\begin{tabular}{|c|c|c|c|c|}
\hline & & & pplement & al Ta \\
\hline CHEMBL1511718 & 688497 & 4.65 & 4.7668 & TST \\
\hline CHEMBL1979756 & 688497 & 4.65 & 4.9516 & TRN \\
\hline CHEMBL1462265 & 688497 & 5.55 & 4.832 & TRN \\
\hline CHEMBL 3210052 & 688497 & 5.6 & 5.2288 & TRN \\
\hline CHEMBL1386883 & 688497 & 4.7 & 4.9246 & TRN \\
\hline CHEMBL3198223 & 688497 & 4.45 & 5.0801 & TRN \\
\hline CHEMBL1504100 & 688497 & 4.75 & 4.9955 & TST \\
\hline CHEMBL1462076 & 688497 & 5.5 & 5.2833 & TRN \\
\hline CHEMBL3193399 & 688497 & 5.3 & 4.8554 & TRN \\
\hline CHEMBL1445590 & 688497 & 5.1 & 5.0216 & TRN \\
\hline CHEMBL1380914 & 688497 & 4.45 & 4.6981 & TRN \\
\hline CHEMBL1422792 & 688497 & 5.45 & 5.3078 & TRN \\
\hline CHEMBL3207418 & 688497 & 6.6499 & 5.121 & TRN \\
\hline CHEMBL1416999 & 688497 & 5.25 & 5.2358 & TRN \\
\hline CHEMBL1418428 & 688497 & 4.5 & 4.6089 & TST \\
\hline CHEMBL1369747 & 688497 & 4.9 & 5.1657 & TRN \\
\hline CHEMBL1347586 & 688497 & 4.85 & 5.0431 & TST \\
\hline CHEMBL1580710 & 688497 & 4.45 & 4.792 & TST \\
\hline CHEMBL1450314 & 688497 & 4.45 & 4.7729 & TRN \\
\hline CHEMBL2369166 & 688497 & 5.1 & 4.6991 & TRN \\
\hline CHEMBL1389285 & 688497 & 4.6 & 4.832 & TRN \\
\hline CHEMBL1400145 & 688497 & 5.4 & 4.9628 & TRN \\
\hline CHEMBL1465275 & 688497 & 5.55 & 5.3529 & TRN \\
\hline CHEMBL1331442 & 688497 & 4.65 & 4.8961 & TRN \\
\hline CHEMBL1487309 & 688497 & 4.6 & 4.6196 & TST \\
\hline CHEMBL1550219 & 688497 & 4.95 & 4.9935 & TRN \\
\hline CHEMBL1320530 & 688497 & 4.5 & 5.0673 & TRN \\
\hline CHEMBL1415108 & 688497 & 5.2 & 4.9604 & TST \\
\hline CHEMBL1385710 & 688497 & 5.55 & 5.1201 & TRN \\
\hline CHEMBL1548485 & 688497 & 5.9 & 4.7763 & TRN \\
\hline CHEMBL1600357 & 688497 & 5.25 & 5.28 & TST \\
\hline CHEMBL1393118 & 688497 & 5.2 & 5.033 & TST \\
\hline CHEMBL1306051 & 688497 & 6.05 & 5.0492 & TRN \\
\hline CHEMBL 3189405 & 688497 & 5.95 & 5.1289 & TRN \\
\hline CHEMBL1504609 & 688497 & 5.0 & 4.9687 & TRN \\
\hline CHEMBL1398620 & 688497 & 5.05 & 4.6988 & TST \\
\hline CHEMBL1594751 & 688497 & 4.9 & 5.0191 & TRN \\
\hline CHEMBL1422394 & 688497 & 6.2 & 5.0874 & TRN \\
\hline CHEMBL1527310 & 688497 & 5.25 & 4.9396 & TST \\
\hline CHEMBL1535520 & 688497 & 4.95 & 5.0763 & TRN \\
\hline CHEMBL1427851 & 688497 & 4.45 & 5.0912 & TRN \\
\hline CHEMBL1463007 & 688497 & 4.45 & 4.8128 & TRN \\
\hline CHEMBL1469620 & 688497 & 4.7 & 4.8835 & TRN \\
\hline CHEMBL1574262 & 688497 & 5.15 & 4.9734 & TRN \\
\hline CHEMBL1375365 & 688497 & 4.7 & 4.8091 & TRN \\
\hline CHEMBL376426 & 688497 & 5.45 & 4.9914 & TST \\
\hline CHEMBL1520296 & 688497 & 5.45 & 5.0816 & TRN \\
\hline CHEMBL1585235 & 688497 & 5.25 & 5.5243 & TRN \\
\hline
\end{tabular}




\begin{tabular}{|c|c|c|c|c|}
\hline \multicolumn{5}{|c|}{ Supplemental Table } \\
\hline CHEMBL1408115 & 688497 & 5.55 & 5.2603 & TRN \\
\hline CHEMBL1543021 & 688497 & 5.4 & 5.1742 & TST \\
\hline CHEMBL3198914 & 688497 & 4.85 & 5.2302 & TRN \\
\hline CHEMBL1345388 & 688497 & 5.2 & 5.0066 & TRN \\
\hline CHEMBL3144932 & 688497 & 4.65 & 4.8115 & TRN \\
\hline CHEMBL1335399 & 688497 & 6.3 & 5.1048 & TRN \\
\hline CHEMBL1326691 & 688497 & 4.85 & 5.1633 & TRN \\
\hline CHEMBL3195953 & 688497 & 5.4 & 5.1276 & TRN \\
\hline CHEMBL1517911 & 688497 & 4.7 & 4.9357 & TRN \\
\hline CHEMBL1419303 & 688497 & 4.65 & 4.7765 & TRN \\
\hline CHEMBL1343287 & 688497 & 5.7 & 5.0354 & TRN \\
\hline CHEMBL1372578 & 688497 & 6.0 & 5.1337 & TST \\
\hline CHEMBL1538684 & 688497 & 6.0 & 5.4372 & TRN \\
\hline CHEMBL3194605 & 688497 & 4.95 & 4.9779 & TRN \\
\hline CHEMBL1351932 & 688497 & 5.5 & 5.0729 & TRN \\
\hline CHEMBL1380376 & 688497 & 4.45 & 4.9547 & TRN \\
\hline CHEMBL1536784 & 688497 & 4.5 & 5.307 & TRN \\
\hline CHEMBL1493194 & 688497 & 5.1 & 5.0384 & TRN \\
\hline CHEMBL1364999 & 688497 & 5.45 & 5.3792 & TST \\
\hline CHEMBL1499808 & 688497 & 5.25 & 5.197 & TST \\
\hline CHEMBL1581663 & 688497 & 5.0 & 4.8882 & TRN \\
\hline CHEMBL1594385 & 688497 & 4.95 & 4.7683 & TST \\
\hline CHEMBL1611482 & 688497 & 4.95 & 4.8499 & TRN \\
\hline CHEMBL1479198 & 688497 & 5.1 & 5.1224 & TST \\
\hline CHEMBL1363336 & 688497 & 6.05 & 5.0498 & TRN \\
\hline CHEMBL1382105 & 688497 & 5.1 & 5.2318 & TRN \\
\hline CHEMBL1454628 & 688497 & 5.4 & 5.1979 & TRN \\
\hline CHEMBL1575852 & 688497 & 4.45 & 5.0938 & TRN \\
\hline CHEMBL3208138 & 688497 & 4.95 & 5.1984 & TST \\
\hline CHEMBL541388 & 688497 & 4.9 & 5.1823 & TST \\
\hline CHEMBL1563993 & 688497 & 6.25 & 5.3036 & TST \\
\hline CHEMBL1393152 & 688497 & 4.9 & 4.9843 & TRN \\
\hline CHEMBL1586196 & 688497 & 4.95 & 5.1978 & TST \\
\hline CHEMBL1535919 & 688497 & 4.7 & 4.9119 & TRN \\
\hline CHEMBL1309656 & 688497 & 5.5 & 5.0267 & TRN \\
\hline CHEMBL1541834 & 688497 & 5.45 & 5.4537 & TRN \\
\hline CHEMBL1372207 & 688497 & 4.45 & 5.1665 & TRN \\
\hline CHEMBL1546703 & 688497 & 4.9 & 4.6761 & TRN \\
\hline CHEMBL1495216 & 688497 & 5.0 & 4.8472 & TRN \\
\hline CHEMBL1495438 & 688497 & 4.45 & 4.8124 & TRN \\
\hline CHEMBL1392651 & 688497 & 4.9 & 4.7671 & TST \\
\hline CHEMBL1571328 & 688497 & 5.55 & 5.0763 & TST \\
\hline CHEMBL1472583 & 688497 & 4.4 & 4.9688 & TST \\
\hline CHEMBL1311023 & 688497 & 4.8 & 5.2074 & TRN \\
\hline CHEMBL1603896 & 688497 & 4.65 & 4.9328 & TRN \\
\hline CHEMBL1506496 & 688497 & 4.65 & 4.8773 & TRN \\
\hline CHEMBL1411056 & 688497 & 4.6 & 4.8887 & TRN \\
\hline CHEMBL1419590 & 688497 & 4.45 & 5.1942 & TRN \\
\hline
\end{tabular}




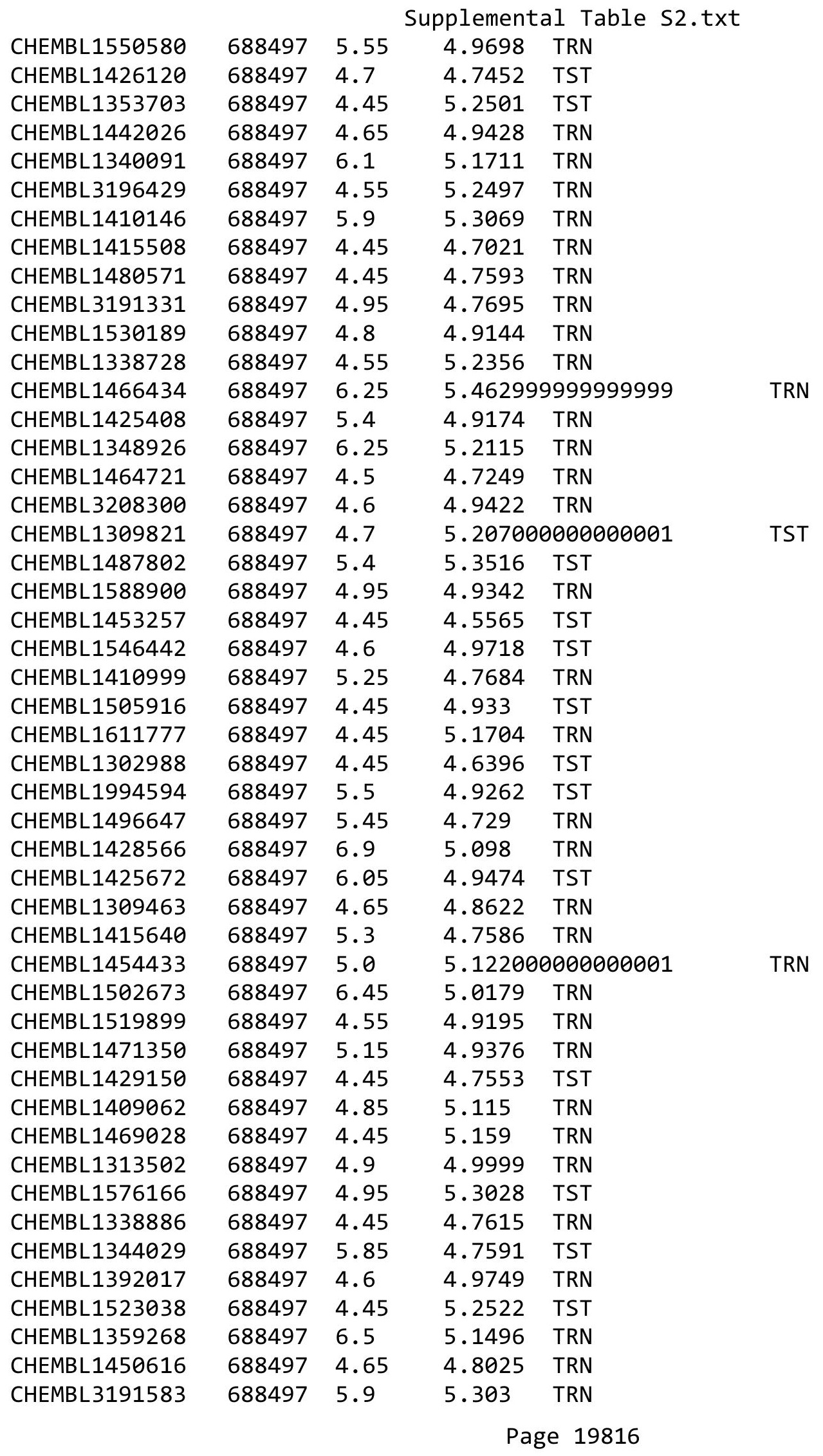




\begin{tabular}{|c|c|c|c|c|c|}
\hline \multicolumn{6}{|c|}{ Supplemental Table s2.txt } \\
\hline CHEMBL1342852 & 688497 & 4.45 & 4.9861 & TRN & \\
\hline CHEMBL1336346 & 688497 & 5.0 & 4.8189 & TRN & \\
\hline CHEMBL1433333 & 688497 & 5.6 & 5.0679 & TRN & \\
\hline CHEMBL1455241 & 688497 & 6.15 & 5.2954 & TST & \\
\hline CHEMBL1393564 & 688497 & 4.95 & 4.8604 & TST & \\
\hline CHEMBL1446369 & 688497 & 5.4 & 5.0526 & TRN & \\
\hline CHEMBL1319704 & 688497 & 4.85 & 4.9575 & TRN & \\
\hline CHEMBL1458441 & 688497 & 4.7 & 4.5231 & TRN & \\
\hline CHEMBL1445427 & 688497 & 4.7 & 5.2797 & TST & \\
\hline CHEMBL1506878 & 688497 & 4.65 & 4.7345 & TRN & \\
\hline CHEMBL1584179 & 688497 & 4.65 & 4.8051 & TRN & \\
\hline CHEMBL1556968 & 688497 & 4.55 & 4.6663 & TRN & \\
\hline CHEMBL1347204 & 688497 & 4.45 & 4.6988 & TRN & \\
\hline CHEMBL1578156 & 688497 & 5.7 & 4.8999 & TRN & \\
\hline CHEMBL1584194 & 688497 & 4.55 & 4.9534 & TST & \\
\hline CHEMBL1497872 & 688497 & 4.6 & 5.0807 & TRN & \\
\hline CHEMBL1359350 & 688497 & 4.7 & 4.8701 & TST & \\
\hline CHEMBL1432712 & 688497 & 4.95 & 4.8981 & TRN & \\
\hline CHEMBL 3210137 & 688497 & 4.45 & 4.8994 & TRN & \\
\hline CHEMBL1569003 & 688497 & 4.7 & 5.0296 & TRN & \\
\hline CHEMBL1605583 & 688497 & 4.85 & 4.8538 & TRN & \\
\hline CHEMBL1528190 & 688497 & 6.25 & 5.25200 & 0000000001 & TRN \\
\hline CHEMBL1507613 & 688497 & 4.95 & 4.9455 & TRN & \\
\hline CHEMBL1594926 & 688497 & 4.45 & 4.9595 & TRN & \\
\hline CHEMBL1539576 & 688497 & 5.25 & 5.2293 & TRN & \\
\hline CHEMBL1610504 & 688497 & 5.5 & 4.9474 & TST & \\
\hline CHEMBL1325376 & 688497 & 4.95 & 4.6016 & TRN & \\
\hline CHEMBL1595755 & 688497 & 4.45 & 4.9548 & TST & \\
\hline CHEMBL1525909 & 688497 & 4.95 & 5.2502 & TRN & \\
\hline CHEMBL1584420 & 688497 & 4.45 & 4.9041 & TRN & \\
\hline CHEMBL 2359467 & 688497 & 5.75 & 5.2162 & TRN & \\
\hline CHEMBL1481807 & 688497 & 4.45 & 5.0016 & TST & \\
\hline CHEMBL1326933 & 688497 & 5.0 & 5.1975 & TRN & \\
\hline CHEMBL1547542 & 688497 & 4.5 & 5.1465 & TST & \\
\hline CHEMBL1311293 & 688497 & 4.65 & 5.007 & TRN & \\
\hline CHEMBL1573026 & 688497 & 7.6003 & 5.1529 & TRN & \\
\hline CHEMBL1440409 & 688497 & 5.85 & 5.1122 & TRN & \\
\hline CHEMBL1569257 & 688497 & 4.45 & 4.8589 & TRN & \\
\hline CHEMBL1587557 & 688497 & 5.45 & 4.9362 & TRN & \\
\hline CHEMBL1426022 & 688497 & 4.55 & 5.0735 & TST & \\
\hline CHEMBL1480876 & 688497 & 6.1 & 5.0866 & TST & \\
\hline CHEMBL1562195 & 688497 & 5.0 & 4.9307 & TRN & \\
\hline CHEMBL1483253 & 688497 & 6.4 & 5.26200 & 00000000005 & TRN \\
\hline CHEMBL1583408 & 688497 & 5.25 & 5.1071 & TRN & \\
\hline CHEMBL1334275 & 688497 & 4.85 & 4.7917 & TRN & \\
\hline CHEMBL1406829 & 688497 & 4.5 & 5.0882 & TRN & \\
\hline CHEMBL1454419 & 688497 & 4.9 & 4.7906 & TRN & \\
\hline CHEMBL1241420 & 688497 & 4.5 & 4.8826 & TST & \\
\hline
\end{tabular}




\begin{tabular}{|c|c|c|c|c|c|}
\hline \multicolumn{6}{|c|}{ Supplemental Table S2.txt } \\
\hline CHEMBL1564600 & 688497 & 4.45 & 5.1425 & TST & \\
\hline CHEMBL1532722 & 688497 & 4.8 & 5.0673 & TRN & \\
\hline CHEMBL1310332 & 688497 & 4.65 & 4.6507 & TRN & \\
\hline CHEMBL1451242 & 688497 & 5.15 & 5.4691 & TST & \\
\hline CHEMBL3197024 & 688497 & 5.45 & 5.0634 & TRN & \\
\hline CHEMBL1368029 & 688497 & 5.9 & 5.0252 & TRN & \\
\hline CHEMBL1392025 & 688497 & 4.45 & 4.9844 & TRN & \\
\hline CHEMBL1439498 & 688497 & 4.65 & 4.8153 & TST & \\
\hline CHEMBL1546942 & 688497 & 4.6 & 4.7402 & TST & \\
\hline CHEMBL1576930 & 688497 & 5.5 & 4.958 & TST & \\
\hline CHEMBL1302093 & 688497 & 5.55 & 4.95100 & 00000000005 & TRN \\
\hline CHEMBL1483187 & 688497 & 4.95 & 4.8259 & TRN & \\
\hline CHEMBL1610522 & 688497 & 4.45 & 5.0415 & TST & \\
\hline CHEMBL1461934 & 688497 & 5.3 & 5.1652 & TRN & \\
\hline CHEMBL1372571 & 688497 & 4.8 & 4.871 & TRN & \\
\hline CHEMBL1538848 & 688497 & 5.25 & 4.9222 & TST & \\
\hline CHEMBL1171204 & 688497 & 5.4 & 5.1163 & TRN & \\
\hline CHEMBL1445962 & 688497 & 4.45 & 4.7434 & TRN & \\
\hline CHEMBL 240862 & 688497 & 4.95 & 5.0154 & TST & \\
\hline CHEMBL1319473 & 688497 & 4.65 & 5.0136 & TRN & \\
\hline CHEMBL1558527 & 688497 & 5.2 & 5.0395 & TST & \\
\hline CHEMBL1558556 & 688497 & 5.6 & 5.2547 & TRN & \\
\hline CHEMBL1322656 & 688497 & 4.45 & 4.7719 & TRN & \\
\hline CHEMBL1381551 & 688497 & 4.95 & 4.9397 & TST & \\
\hline CHEMBL1372801 & 688497 & 4.6 & 4.8255 & TRN & \\
\hline CHEMBL1302146 & 688497 & 5.0 & 5.3777 & TRN & \\
\hline CHEMBL1510032 & 688497 & 4.45 & 4.9635 & TRN & \\
\hline CHEMBL3197599 & 688497 & 4.8 & 4.8456 & TRN & \\
\hline CHEMBL306380 & 688497 & 5.0 & 4.9169 & TRN & \\
\hline CHEMBL1567547 & 688497 & 5.65 & 5.1201 & TRN & \\
\hline CHEMBL1386876 & 688497 & 5.9 & 4.9341 & TST & \\
\hline CHEMBL1430356 & 688497 & 4.45 & 4.8648 & TRN & \\
\hline CHEMBL1466310 & 688497 & 4.5 & 4.8669 & TRN & \\
\hline CHEMBL1504973 & 688497 & 5.15 & 4.7912 & TRN & \\
\hline CHEMBL1574248 & 688497 & 6.15 & 4.9252 & TRN & \\
\hline CHEMBL3208278 & 688497 & 4.45 & 4.8451 & TRN & \\
\hline CHEMBL1363939 & 688497 & 4.45 & 5.1426 & TST & \\
\hline CHEMBL1415670 & 688497 & 4.45 & 4.8851 & TST & \\
\hline CHEMBL1484231 & 688497 & 4.95 & 5.0666 & TRN & \\
\hline CHEMBL1390022 & 688497 & 5.4 & 5.2588 & TST & \\
\hline CHEMBL1425396 & 688497 & 5.45 & 5.2256 & TST & \\
\hline CHEMBL1336570 & 688497 & 4.95 & 4.9084 & TRN & \\
\hline CHEMBL1481000 & 688497 & 4.75 & 4.8528 & TST & \\
\hline CHEMBL1349690 & 688497 & 5.05 & 5.1932 & TRN & \\
\hline CHEMBL 3210434 & 688497 & 5.4 & 5.0618 & TST & \\
\hline CHEMBL1438434 & 688497 & 4.45 & 5.0174 & TST & \\
\hline CHEMBL1311952 & 688497 & 4.65 & 4.9074 & TRN & \\
\hline CHEMBL1464261 & 688497 & 5.5 & 4.6923 & TRN & \\
\hline
\end{tabular}




\begin{tabular}{|c|c|c|c|c|}
\hline \multicolumn{5}{|c|}{ Supplemental Table S2.txt } \\
\hline CHEMBL1570696 & 688497 & 5.0 & 4.881 & TRN \\
\hline CHEMBL1334616 & 688497 & 5.5 & 5.2634 & TRN \\
\hline CHEMBL1432663 & 688497 & 5.25 & 5.0872 & TST \\
\hline CHEMBL1401410 & 688497 & 4.9 & 4.7689 & TRN \\
\hline CHEMBL1465856 & 688497 & 4.5 & 4.9462 & TRN \\
\hline CHEMBL1607961 & 688497 & 4.45 & 5.0812 & TST \\
\hline CHEMBL1321357 & 688497 & 4.9 & 5.1161 & TST \\
\hline CHEMBL1359664 & 688497 & 5.6 & 5.1244 & TRN \\
\hline CHEMBL1444260 & 688497 & 6.1 & \multicolumn{2}{|c|}{5.162000000000001} \\
\hline CHEMBL1488920 & 688497 & 4.45 & 5.3011 & TRN \\
\hline CHEMBL1532122 & 688497 & 4.6 & 5.0085 & TST \\
\hline CHEMBL1299692 & 688497 & 4.65 & 4.8739 & TRN \\
\hline CHEMBL1503034 & 688497 & 5.55 & 4.8545 & TRN \\
\hline CHEMBL1414513 & 688497 & 4.45 & 4.9601 & TRN \\
\hline CHEMBL1450897 & 688497 & 4.45 & 4.7543 & TRN \\
\hline CHEMBL1569819 & 688497 & 4.45 & 4.9831 & TRN \\
\hline CHEMBL1381724 & 688497 & 4.45 & 5.13 & TST \\
\hline CHEMBL3197742 & 688497 & 5.45 & 5.1926 & TRN \\
\hline CHEMBL1353925 & 688497 & 4.75 & 5.2884 & TRN \\
\hline CHEMBL1414134 & 688497 & 6.25 & 5.1529 & TRN \\
\hline CHEMBL1309594 & 688497 & 4.65 & 4.8919 & TRN \\
\hline CHEMBL1565815 & 688497 & 4.45 & 4.9845 & TRN \\
\hline CHEMBL1525423 & 688497 & 5.85 & 5.6598 & TRN \\
\hline CHEMBL 3210086 & 688497 & 5.25 & 4.9216 & TRN \\
\hline CHEMBL1529368 & 688497 & 5.55 & 4.8425 & TRN \\
\hline CHEMBL1480313 & 688497 & 4.45 & 4.9911 & TRN \\
\hline CHEMBL1407590 & 688497 & 4.45 & 4.945 & TST \\
\hline CHEMBL1425679 & 688497 & 4.45 & 5.0395 & TRN \\
\hline CHEMBL 3212077 & 688497 & 4.75 & 5.0468 & TRN \\
\hline CHEMBL1424472 & 688497 & 5.0 & 4.927 & TRN \\
\hline CHEMBL1303540 & 688497 & 6.25 & 5.2519 & TST \\
\hline CHEMBL1534749 & 688497 & 4.85 & 4.5418 & TRN \\
\hline CHEMBL1411395 & 688497 & 4.45 & 4.8121 & TRN \\
\hline CHEMBL1450943 & 688497 & 5.25 & 5.3642 & TRN \\
\hline CHEMBL1497481 & 688497 & 4.45 & 4.7501 & TRN \\
\hline CHEMBL1419246 & 688497 & 6.05 & 5.1252 & TST \\
\hline CHEMBL1509267 & 688497 & 4.8 & 4.8661 & TRN \\
\hline CHEMBL1580917 & 688497 & 4.45 & 4.7105 & TRN \\
\hline CHEMBL1587755 & 688497 & 4.85 & 4.9672 & TRN \\
\hline CHEMBL1377549 & 688497 & 4.45 & 4.8367 & TST \\
\hline CHEMBL1541551 & 688497 & 4.8 & 5.2153 & TRN \\
\hline CHEMBL1606035 & 688497 & 3.95 & 4.9193 & TRN \\
\hline CHEMBL1343656 & 688497 & 4.95 & 5.2298 & TRN \\
\hline CHEMBL1337446 & 688497 & 5.85 & 5.3325 & TRN \\
\hline CHEMBL1425551 & 688497 & 4.65 & 4.9731 & TST \\
\hline CHEMBL1307172 & 688497 & 4.45 & 5.0036 & TRN \\
\hline CHEMBL1585821 & 688497 & 4.5 & 4.9523 & TRN \\
\hline CHEMBL1464167 & 688497 & 5.35 & 5.1658 & TRN \\
\hline
\end{tabular}




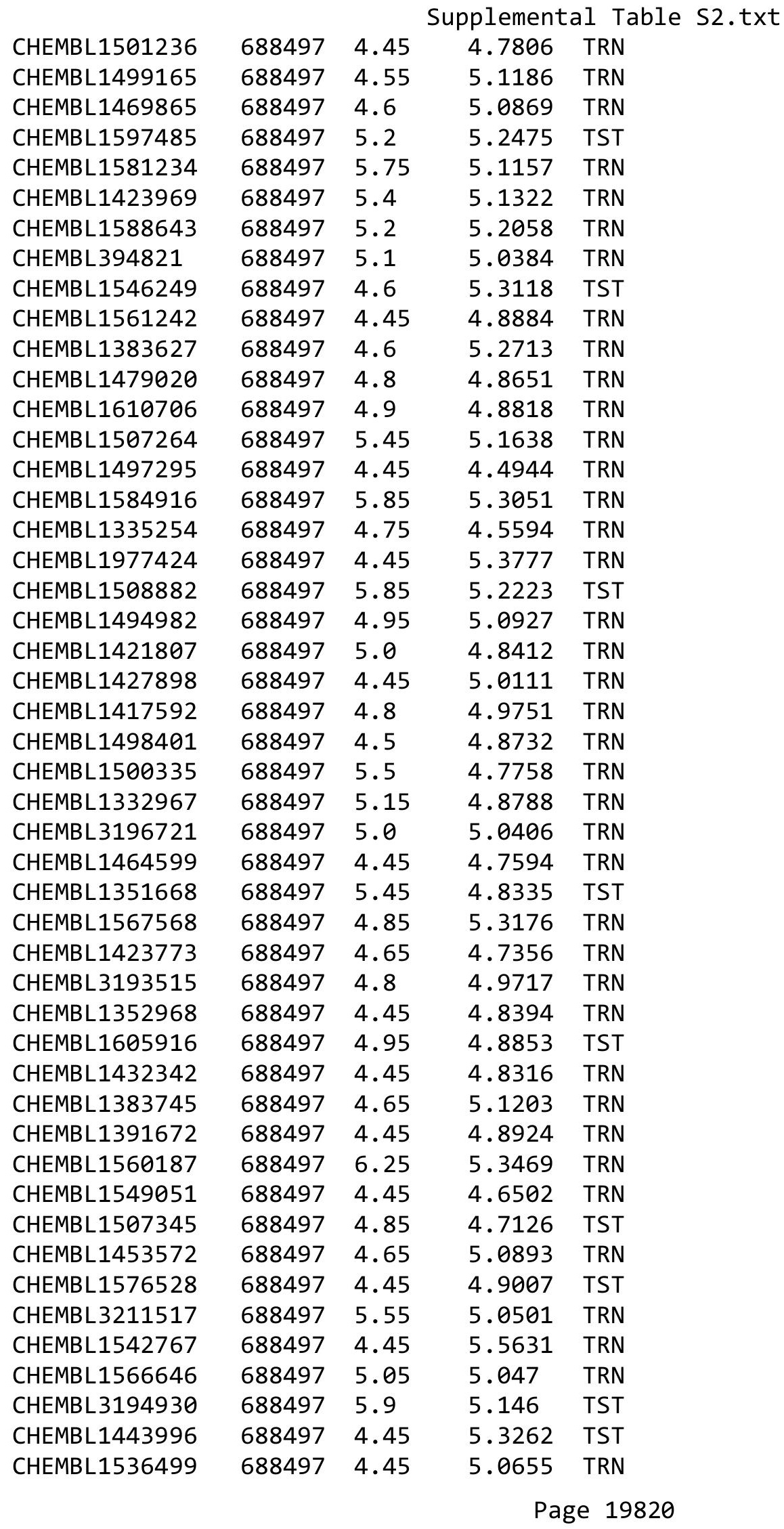




\begin{tabular}{|c|c|c|c|c|}
\hline & & & upplement & al Table S2 \\
\hline CHEMBL1518447 & 688497 & 4.45 & 5.0299 & TST \\
\hline CHEMBL1398830 & 688497 & 5.2 & 5.1205 & TRN \\
\hline CHEMBL1536734 & 688497 & 5.0 & 4.6545 & TST \\
\hline CHEMBL1531909 & 688497 & 5.65 & 5.4113 & TRN \\
\hline CHEMBL3198046 & 688497 & 4.45 & 5.085 & TST \\
\hline CHEMBL 3208860 & 688497 & 4.5 & 4.918 & TRN \\
\hline CHEMBL1607400 & 688497 & 6.1 & 5.083 & TRN \\
\hline CHEMBL1390756 & 688497 & 4.8 & 5.1752 & TRN \\
\hline CHEMBL1385369 & 688497 & 5.55 & 4.968 & TRN \\
\hline CHEMBL1351293 & 688497 & 4.95 & 4.6269 & TST \\
\hline CHEMBL1587286 & 688497 & 4.45 & 4.8062 & TRN \\
\hline CHEMBL1301717 & 688497 & 4.45 & 4.9968 & TRN \\
\hline CHEMBL1561933 & 688497 & 4.45 & 4.7703 & TST \\
\hline CHEMBL1519393 & 688497 & 6.25 & 5.0404 & TRN \\
\hline CHEMBL1387626 & 688497 & 5.5 & 4.9783 & TRN \\
\hline CHEMBL3193483 & 688497 & 4.45 & 5.0819 & TRN \\
\hline CHEMBL1968316 & 688497 & 4.85 & 4.7663 & TST \\
\hline CHEMBL1584720 & 688497 & 4.45 & 4.7125 & TRN \\
\hline CHEMBL1382438 & 688497 & 5.25 & 5.0029 & TRN \\
\hline CHEMBL1404731 & 688497 & 4.6 & 5.11 & TST \\
\hline CHEMBL1405922 & 688497 & 4.45 & 5.1779 & TRN \\
\hline CHEMBL1558070 & 688497 & 5.25 & 5.347 & TRN \\
\hline CHEMBL1366253 & 688497 & 6.25 & 5.4174 & TST \\
\hline CHEMBL1545157 & 688497 & 4.95 & 4.829 & TRN \\
\hline CHEMBL1565085 & 688497 & 4.95 & 4.88399 & 99999999995 \\
\hline CHEMBL1384734 & 688497 & 4.95 & 4.949 & TRN \\
\hline CHEMBL1528112 & 688497 & 4.45 & 5.0209 & TRN \\
\hline CHEMBL1608375 & 688497 & 4.55 & 4.9055 & TST \\
\hline CHEMBL1422277 & 688497 & 4.45 & 4.9639 & TRN \\
\hline CHEMBL1494102 & 688497 & 4.8 & 4.8409 & TRN \\
\hline CHEMBL1406086 & 688497 & 4.95 & 4.9525 & TRN \\
\hline CHEMBL1505604 & 688497 & 5.25 & 5.1988 & TRN \\
\hline CHEMBL1341254 & 688497 & 4.45 & 4.6784 & TRN \\
\hline CHEMBL1485429 & 688497 & 5.0 & 4.8792 & TRN \\
\hline CHEMBL1427212 & 688497 & 4.9 & 5.0185 & TST \\
\hline CHEMBL1367908 & 688497 & 4.55 & 4.9925 & TST \\
\hline CHEMBL1546001 & 688497 & 5.7 & 5.2441 & TST \\
\hline CHEMBL1329020 & 688497 & 4.65 & 4.9242 & TRN \\
\hline CHEMBL1600169 & 688497 & 4.95 & 4.9231 & TRN \\
\hline CHEMBL1544057 & 688497 & 4.45 & 4.9309 & TRN \\
\hline CHEMBL1300548 & 688497 & 4.45 & 4.9039 & TST \\
\hline CHEMBL1422741 & 688497 & 4.7 & 4.8335 & TRN \\
\hline CHEMBL1452842 & 688497 & 4.45 & 4.8164 & TRN \\
\hline CHEMBL1415068 & 688497 & 4.45 & 5.1638 & TST \\
\hline CHEMBL1423474 & 688497 & 4.95 & 4.6759 & TRN \\
\hline CHEMBL1535157 & 688497 & 4.5 & 4.8594 & TRN \\
\hline CHEMBL1440964 & 688497 & 6.3 & 5.2215 & TRN \\
\hline CHEMBL1589405 & 688497 & 4.65 & 4.9108 & TRN \\
\hline
\end{tabular}




\begin{tabular}{|c|c|c|c|c|c|}
\hline \multicolumn{6}{|c|}{ Supplemental Table S2.txt } \\
\hline CHEMBL417727 & 688497 & 6.1 & 5.2026 & TRN & \\
\hline CHEMBL1427040 & 688497 & 4.45 & 5.1375 & TRN & \\
\hline CHEMBL1313479 & 688497 & 4.45 & 4.8505 & TRN & \\
\hline CHEMBL1377690 & 688497 & 4.95 & 4.9128 & TRN & \\
\hline CHEMBL1422207 & 688497 & 6.5 & 5.3911 & TRN & \\
\hline CHEMBL1342069 & 688497 & 4.45 & 4.9001 & TST & \\
\hline CHEMBL1332942 & 688497 & 4.45 & 5.1856 & TST & \\
\hline CHEMBL1574121 & 688497 & 5.0 & 5.1862 & TST & \\
\hline CHEMBL1328707 & 688497 & 5.25 & 5.0233 & TRN & \\
\hline CHEMBL1413497 & 688497 & 4.9 & 5.0943 & TRN & \\
\hline CHEMBL1545093 & 688497 & 5.95 & 5.0995 & TST & \\
\hline CHEMBL1501689 & 688497 & 5.45 & 5.0305 & TRN & \\
\hline CHEMBL1613574 & 688497 & 4.7 & 4.726 & TRN & \\
\hline CHEMBL3191908 & 688497 & 5.2 & 5.3572 & TRN & \\
\hline CHEMBL1539092 & 688497 & 5.2 & 5.0674 & TST & \\
\hline CHEMBL1343101 & 688497 & 4.45 & 4.9542 & TST & \\
\hline CHEMBL1545407 & 688497 & 4.85 & 4.8437 & TRN & \\
\hline CHEMBL1313483 & 688497 & 4.95 & 5.0856 & TRN & \\
\hline CHEMBL1463624 & 688497 & 4.6 & 5.0452 & TRN & \\
\hline CHEMBL1324018 & 688497 & 4.95 & 5.1109 & TST & \\
\hline CHEMBL1979954 & 688497 & 6.0 & 5.1787 & TST & \\
\hline CHEMBL1303834 & 688497 & 4.45 & 4.9803 & TRN & \\
\hline CHEMBL1415794 & 688497 & 4.45 & 4.9628 & TRN & \\
\hline CHEMBL1335501 & 688497 & 6.45 & 5.1573 & TRN & \\
\hline CHEMBL1998061 & 688497 & 4.45 & 5.0987 & TST & \\
\hline CHEMBL1378666 & 688497 & 5.0 & 5.17299 & 9999999999 & TST \\
\hline CHEMBL1427968 & 688497 & 4.45 & 5.0305 & TRN & \\
\hline CHEMBL1377849 & 688497 & 5.05 & 4.7025 & TRN & \\
\hline CHEMBL1523126 & 688497 & 4.45 & 4.9165 & TRN & \\
\hline CHEMBL1333893 & 688497 & 5.45 & 5.04 & TRN & \\
\hline CHEMBL1542899 & 688497 & 5.25 & 5.2148 & TST & \\
\hline CHEMBL1612007 & 688497 & 4.45 & 5.114 & TST & \\
\hline CHEMBL1416041 & 688497 & 4.45 & 4.9803 & TRN & \\
\hline CHEMBL1530415 & 688497 & 5.95 & 5.2752 & TRN & \\
\hline CHEMBL1364403 & 688497 & 5.55 & 5.2045 & TRN & \\
\hline CHEMBL1574596 & 688497 & 6.25 & 5.2216 & TRN & \\
\hline CHEMBL1601692 & 688497 & 4.65 & 5.1647 & TRN & \\
\hline CHEMBL1407442 & 688497 & 4.95 & 4.7829 & TST & \\
\hline CHEMBL1539841 & 688497 & 5.15 & 5.1932 & TRN & \\
\hline CHEMBL1333410 & 688497 & 4.45 & 5.3624 & TRN & \\
\hline CHEMBL535315 & 688497 & 5.25 & 5.0889 & TST & \\
\hline CHEMBL1535276 & 688497 & 4.9 & 4.4337 & TRN & \\
\hline CHEMBL1518472 & 688497 & 4.85 & 5.08 & TST & \\
\hline CHEMBL1339591 & 688497 & 4.7 & 4.9105 & TST & \\
\hline CHEMBL1531450 & 688497 & 5.4 & 5.2035 & TRN & \\
\hline CHEMBL1420667 & 688497 & 4.65 & 4.9983 & TRN & \\
\hline CHEMBL1535643 & 688497 & 5.25 & 5.3189 & TST & \\
\hline CHEMBL1313356 & 688497 & 4.45 & 4.7764 & TRN & \\
\hline
\end{tabular}




\begin{tabular}{|c|c|c|c|c|c|}
\hline & & \multicolumn{4}{|c|}{ Supplemental Table S2.txt } \\
\hline CHEMBL1481532 & 688497 & 5.25 & 5.138 & TRN & \\
\hline CHEMBL1495830 & 688497 & 4.85 & 5.1438 & TRN & \\
\hline CHEMBL1331190 & 688497 & 4.5 & 5.0789 & TRN & \\
\hline CHEMBL603129 & 688497 & 5.4 & 4.9383 & TRN & \\
\hline CHEMBL1535788 & 688497 & 4.6 & 5.0703 & TRN & \\
\hline CHEMBL1606158 & 688497 & 4.65 & 4.8356 & TRN & \\
\hline CHEMBL1337947 & 688497 & 4.45 & 5.0934 & TST & \\
\hline CHEMBL3193950 & 688497 & 5.9 & 4.9303 & TRN & \\
\hline CHEMBL1303825 & 688497 & 4.95 & 5.05699 & 99999999995 & TRN \\
\hline CHEMBL1410106 & 688497 & 5.5 & 5.5439 & TRN & \\
\hline CHEMBL1608730 & 688497 & 5.6 & 5.1837 & TST & \\
\hline CHEMBL1413195 & 688497 & 5.55 & 5.0205 & TRN & \\
\hline CHEMBL3210417 & 688497 & 4.45 & 4.9544 & TST & \\
\hline CHEMBL1604007 & 688497 & 5.3 & 4.8019 & TRN & \\
\hline CHEMBL1597230 & 688497 & 5.0 & 4.9634 & TST & \\
\hline CHEMBL579837 & 688497 & 4.8 & 4.8391 & TRN & \\
\hline CHEMBL1430309 & 688497 & 4.55 & 4.5079 & TST & \\
\hline CHEMBL1447890 & 688497 & 5.25 & 5.3136 & TRN & \\
\hline CHEMBL1548758 & 688497 & 5.25 & 5.6296 & TRN & \\
\hline CHEMBL1542772 & 688497 & 4.45 & 5.0215 & TST & \\
\hline CHEMBL1974348 & 688497 & 4.9 & 4.9104 & TRN & \\
\hline CHEMBL1341849 & 688497 & 4.85 & 4.8116 & TRN & \\
\hline CHEMBL1407754 & 688497 & 4.95 & 4.7621 & TRN & \\
\hline CHEMBL3199613 & 688497 & 4.55 & 5.2214 & TST & \\
\hline CHEMBL1534716 & 688497 & 4.95 & 4.9654 & TRN & \\
\hline CHEMBL1426669 & 688497 & 4.95 & 4.649 & TST & \\
\hline CHEMBL1565363 & 688497 & 4.95 & 4.9521 & TRN & \\
\hline CHEMBL1501797 & 688497 & 6.25 & 5.1033 & TRN & \\
\hline CHEMBL1399626 & 688497 & 5.25 & 5.0038 & TRN & \\
\hline CHEMBL1390754 & 688497 & 4.45 & 5.0141 & TRN & \\
\hline CHEMBL1506684 & 688497 & 4.95 & 4.8005 & TRN & \\
\hline CHEMBL1412298 & 688497 & 5.25 & 5.2116 & TST & \\
\hline CHEMBL1550591 & 688497 & 4.65 & 4.894 & TST & \\
\hline CHEMBL1604847 & 688497 & 5.0 & 4.9783 & TRN & \\
\hline CHEMBL1385235 & 688497 & 4.8 & 4.8766 & TRN & \\
\hline CHEMBL1521065 & 688497 & 4.7 & 5.4284 & TRN & \\
\hline CHEMBL1579354 & 688497 & 5.2 & 4.9594 & TST & \\
\hline CHEMBL1524766 & 688497 & 5.3 & 4.8821 & TRN & \\
\hline CHEMBL1538117 & 688497 & 5.3 & 5.1501 & TRN & \\
\hline CHEMBL1325640 & 688497 & 4.6 & 4.849 & TST & \\
\hline CHEMBL1587496 & 688497 & 4.9 & 4.8748 & TRN & \\
\hline CHEMBL1374215 & 688497 & 5.65 & 5.5013 & TST & \\
\hline CHEMBL1467688 & 688497 & 5.25 & 5.5525 & TST & \\
\hline CHEMBL3144931 & 688497 & 4.95 & 5.1781 & TRN & \\
\hline CHEMBL 2004745 & 688497 & 4.45 & 4.9553 & TST & \\
\hline CHEMBL1300984 & 688497 & 4.65 & 5.0579 & TRN & \\
\hline CHEMBL1545459 & 688497 & 6.5 & 5.0537 & TRN & \\
\hline CHEMBL1477384 & 688497 & 4.45 & 4.8624 & TRN & \\
\hline
\end{tabular}




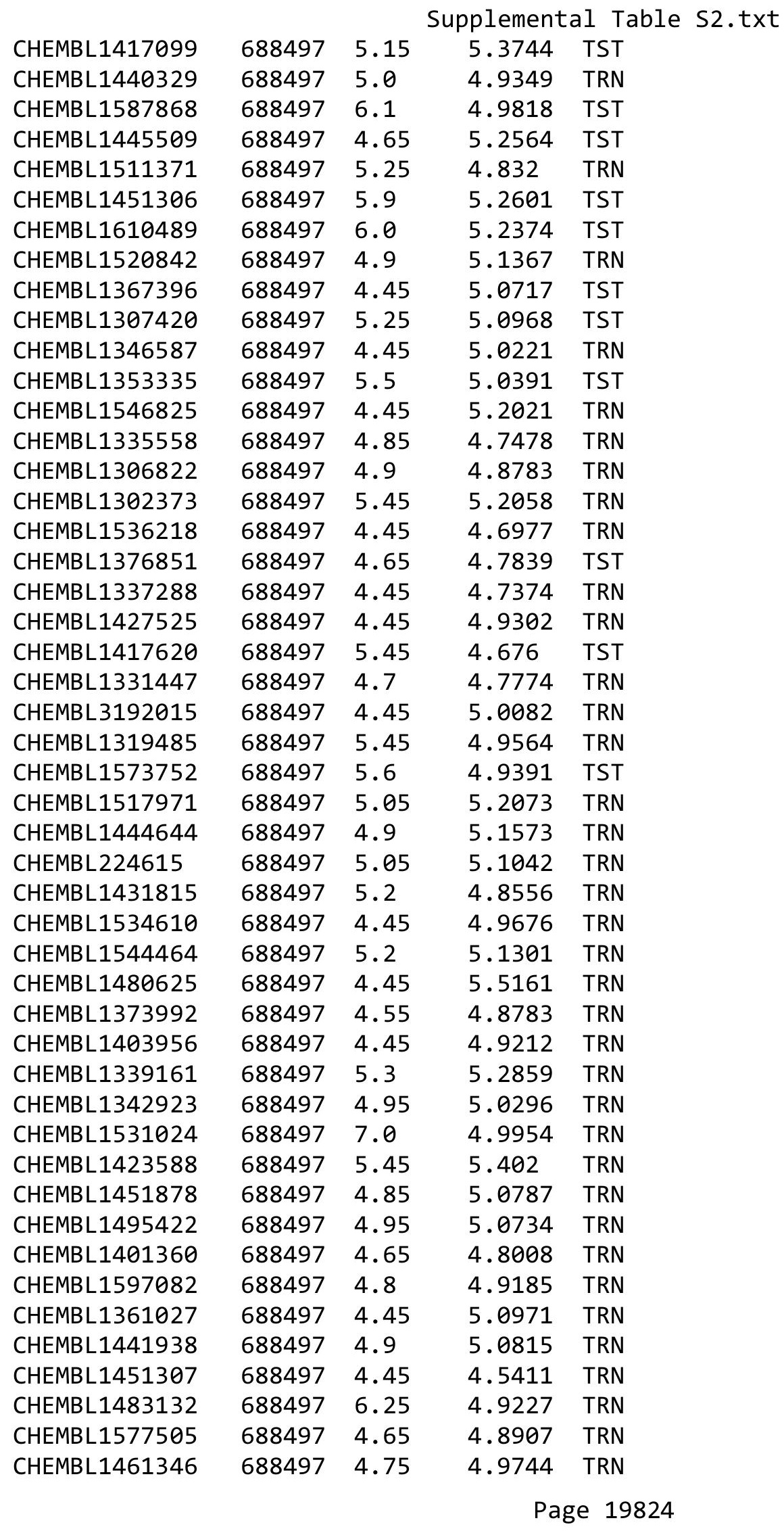




\begin{tabular}{|c|c|c|c|c|}
\hline & & & pplement & al $\mathrm{Ta}$ \\
\hline CHEMBL1443748 & 688497 & 5.9 & 4.9294 & TST \\
\hline CHEMBL1360601 & 688497 & 4.45 & 4.9939 & TRN \\
\hline CHEMBL1522422 & 688497 & 4.95 & 4.95 & TST \\
\hline CHEMBL1342790 & 688497 & 5.25 & 5.5841 & TRN \\
\hline CHEMBL1361294 & 688497 & 4.9 & 4.8685 & TRN \\
\hline CHEMBL1465913 & 688497 & 4.45 & 4.853 & TRN \\
\hline CHEMBL1978651 & 688497 & 4.45 & 5.3974 & TST \\
\hline CHEMBL1543707 & 688497 & 5.9 & 5.3937 & TRN \\
\hline CHEMBL1462451 & 688497 & 4.95 & 5.0505 & TRN \\
\hline CHEMBL1377316 & 688497 & 5.7 & 5.1387 & TRN \\
\hline CHEMBL1303052 & 688497 & 4.95 & 4.9614 & TRN \\
\hline CHEMBL1362054 & 688497 & 4.85 & 4.9692 & TRN \\
\hline CHEMBL1392171 & 688497 & 4.9 & 4.7823 & TRN \\
\hline CHEMBL1568472 & 688497 & 5.25 & 5.3146 & TRN \\
\hline CHEMBL1585572 & 688497 & 5.9 & 5.2298 & TRN \\
\hline CHEMBL1374970 & 688497 & 4.45 & 4.8077 & TST \\
\hline CHEMBL1521462 & 688497 & 4.95 & 5.0522 & TRN \\
\hline CHEMBL1353408 & 688497 & 5.3 & 5.047 & TRN \\
\hline CHEMBL1343393 & 688497 & 4.45 & 5.0321 & TST \\
\hline CHEMBL1381974 & 688497 & 4.45 & 5.084 & TRN \\
\hline CHEMBL1528917 & 688497 & 4.45 & 5.0849 & TRN \\
\hline CHEMBL1494870 & 688497 & 4.6 & 5.1142 & TRN \\
\hline CHEMBL1438872 & 688497 & 4.65 & 4.8086 & TRN \\
\hline CHEMBL1505565 & 688497 & 4.8 & 5.2591 & TRN \\
\hline CHEMBL1577064 & 688497 & 4.45 & 5.0488 & TST \\
\hline CHEMBL3209400 & 688497 & 4.45 & 4.9801 & TST \\
\hline CHEMBL1376243 & 688497 & 5.45 & 4.9611 & TRN \\
\hline CHEMBL1410381 & 688497 & 4.45 & 5.3342 & TRN \\
\hline CHEMBL1467014 & 688497 & 5.9 & 5.2057 & TRN \\
\hline CHEMBL1304837 & 688497 & 4.95 & 4.8529 & TRN \\
\hline CHEMBL1991710 & 688497 & 4.45 & 4.8673 & TRN \\
\hline CHEMBL1511315 & 688497 & 4.45 & 4.8388 & TST \\
\hline CHEMBL1531463 & 688497 & 4.45 & 5.2689 & TST \\
\hline CHEMBL1439783 & 688497 & 4.45 & 4.842 & TRN \\
\hline CHEMBL1431634 & 688497 & 4.45 & 4.6828 & TRN \\
\hline CHEMBL1304655 & 688497 & 4.85 & 4.8127 & TST \\
\hline CHEMBL1511224 & 688497 & 4.45 & 4.9732 & TRN \\
\hline CHEMBL1546832 & 688497 & 4.45 & 4.7444 & TST \\
\hline CHEMBL3191134 & 688497 & 5.2 & 4.975 & TRN \\
\hline CHEMBL1520586 & 688497 & 6.25 & 4.9591 & TRN \\
\hline CHEMBL1335360 & 688497 & 4.45 & 4.8704 & TST \\
\hline CHEMBL1483331 & 688497 & 4.85 & 4.9355 & TRN \\
\hline CHEMBL1488197 & 688497 & 5.05 & 5.1713 & TRN \\
\hline CHEMBL1391857 & 688497 & 5.9 & 5.4643 & TST \\
\hline CHEMBL1393250 & 688497 & 4.75 & 5.1179 & TRN \\
\hline CHEMBL1504234 & 688497 & 5.4 & 4.967 & TRN \\
\hline CHEMBL3211567 & 688497 & 4.45 & 5.154 & TRN \\
\hline CHEMBL1581725 & 688497 & 4.45 & 5.1397 & TST \\
\hline
\end{tabular}




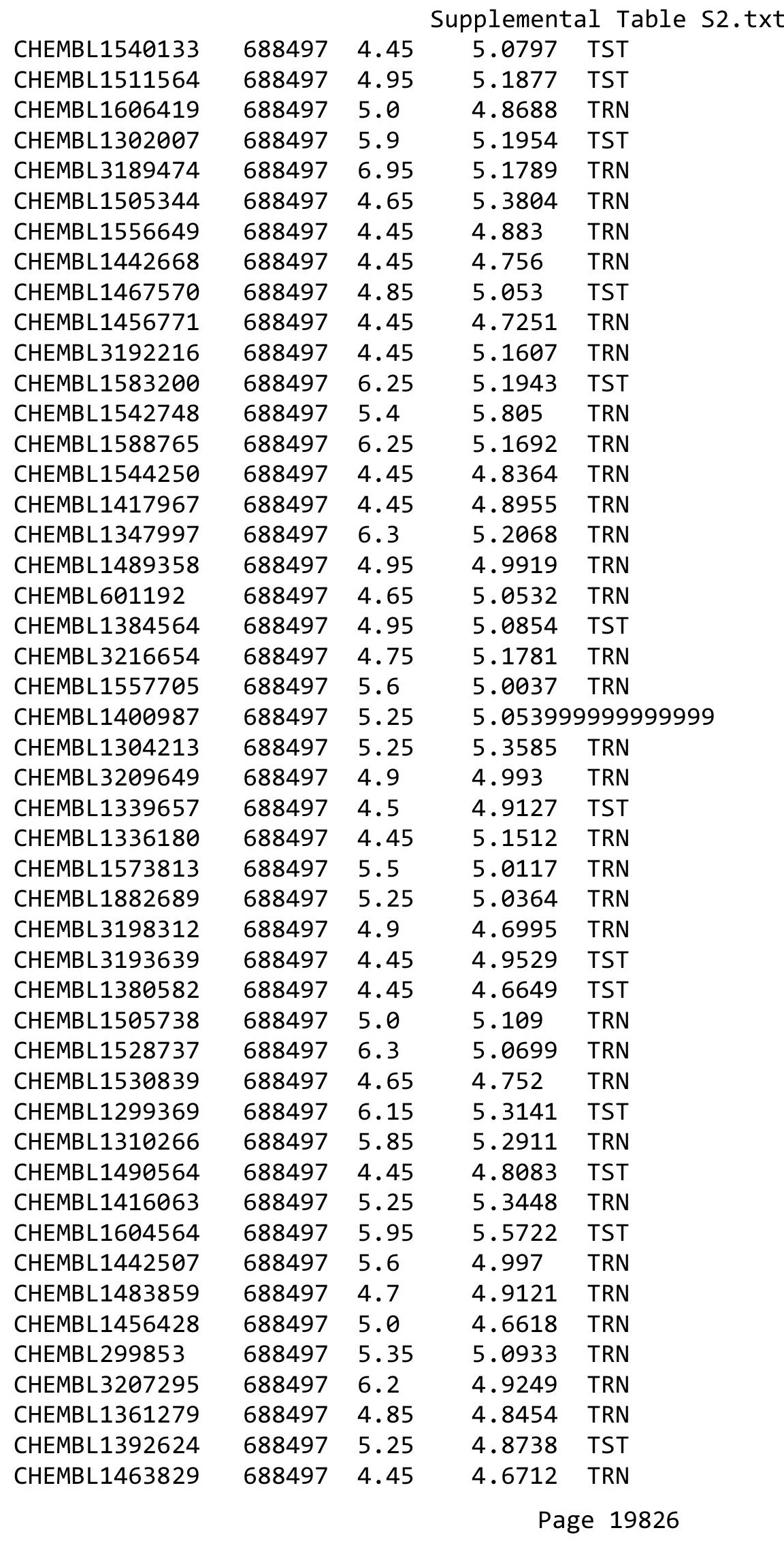




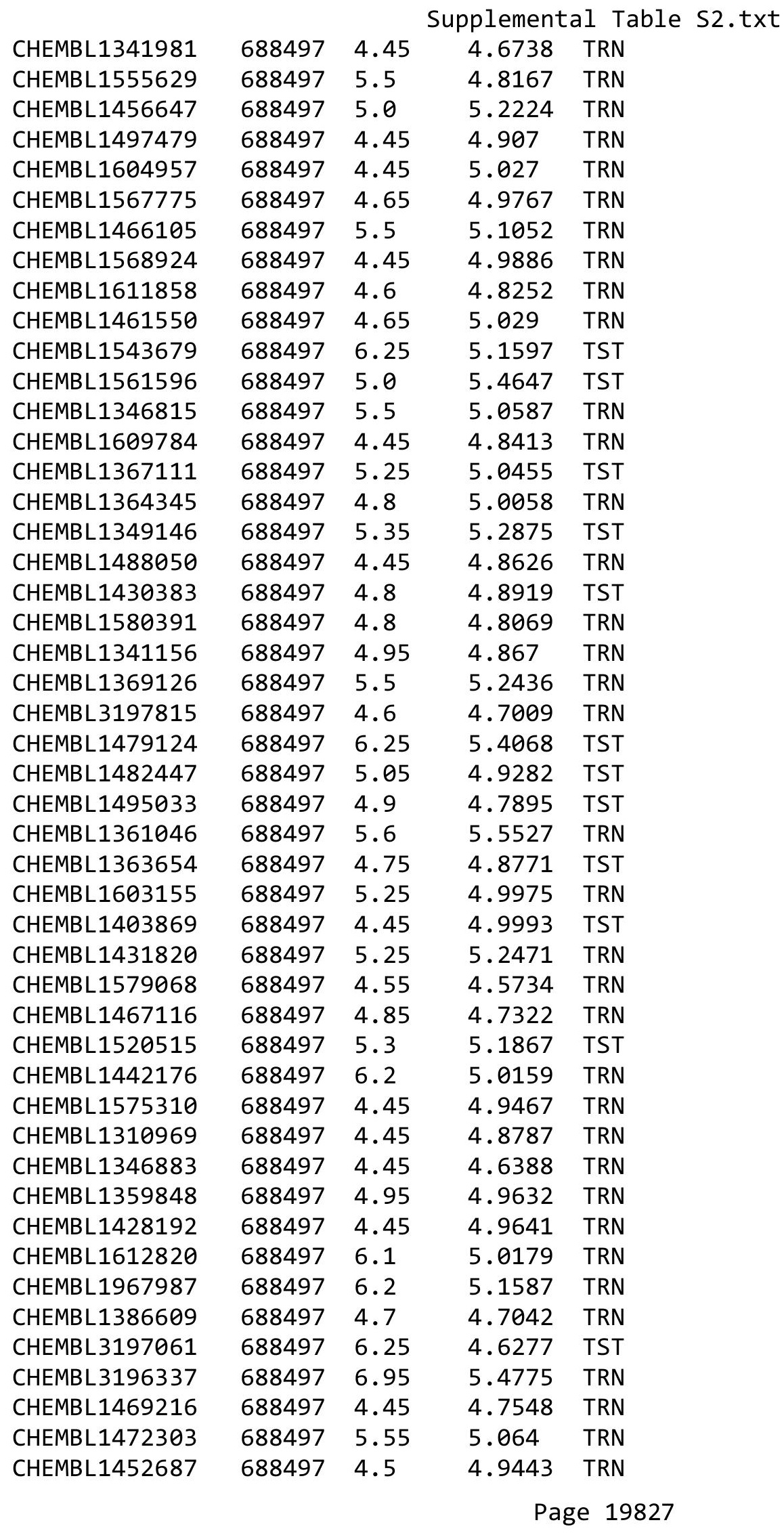




\begin{tabular}{|c|c|c|c|c|c|}
\hline & & \multicolumn{4}{|c|}{ Supplemental Table s2.txt } \\
\hline CHEMBL1302071 & 688497 & 4.45 & 4.9549 & TRN & \\
\hline CHEMBL1392855 & 688497 & 5.25 & 5.3553 & TST & \\
\hline CHEMBL1299464 & 688497 & 5.45 & 4.7983 & TST & \\
\hline CHEMBL1564043 & 688497 & 5.2 & 4.9731 & TRN & \\
\hline CHEMBL 3144828 & 688497 & 4.45 & 4.8627 & TRN & \\
\hline CHEMBL1321159 & 688497 & 4.45 & 4.6131 & TRN & \\
\hline CHEMBL1348954 & 688497 & 4.65 & 4.9828 & TRN & \\
\hline CHEMBL1376248 & 688497 & 4.9 & 4.6835 & TRN & \\
\hline CHEMBL1345891 & 688497 & 4.45 & 4.9692 & TRN & \\
\hline CHEMBL1446747 & 688497 & 4.95 & 4.896 & TST & \\
\hline CHEMBL1351344 & 688497 & 4.45 & 4.9999 & TRN & \\
\hline CHEMBL1365961 & 688497 & 4.45 & 4.9565 & TST & \\
\hline CHEMBL1322657 & 688497 & 4.45 & 4.8081 & TRN & \\
\hline CHEMBL3199092 & 688497 & 4.85 & 5.0136 & TRN & \\
\hline CHEMBL1371885 & 688497 & 4.9 & 4.8769 & TST & \\
\hline CHEMBL1581810 & 688497 & 4.8 & 5.0014 & TRN & \\
\hline CHEMBL1342679 & 688497 & 4.65 & 4.9304 & TRN & \\
\hline CHEMBL1309433 & 688497 & 5.5 & 5.1744 & TST & \\
\hline CHEMBL1484883 & 688497 & 4.7 & 4.7355 & TRN & \\
\hline CHEMBL1457621 & 688497 & 4.95 & 5.1483 & TST & \\
\hline CHEMBL3208211 & 688497 & 4.45 & 5.0761 & TRN & \\
\hline CHEMBL1307475 & 688497 & 9.0 & 5.4042 & TRN & \\
\hline CHEMBL1349770 & 688497 & 5.45 & 4.6859 & TRN & \\
\hline CHEMBL1418656 & 688497 & 4.45 & 4.8836 & TRN & \\
\hline CHEMBL1500638 & 688497 & 4.65 & 5.4023 & TST & \\
\hline CHEMBL3195289 & 688497 & 6.2 & 4.8073 & TRN & \\
\hline CHEMBL1491654 & 688497 & 5.0 & 5.0727 & TRN & \\
\hline CHEMBL1407507 & 688497 & 5.4 & 5.235 & TRN & \\
\hline CHEMBL1584143 & 688497 & 4.75 & 4.8339 & TST & \\
\hline CHEMBL1427265 & 688497 & 4.9 & 5.0481 & TRN & \\
\hline CHEMBL1349292 & 688497 & 5.5 & 4.959 & TRN & \\
\hline CHEMBL1352655 & 688497 & 4.8 & 4.6053 & TST & \\
\hline CHEMBL1419529 & 688497 & 4.9 & 4.82100 & 0000000001 & TRN \\
\hline CHEMBL1351537 & 688497 & 5.2 & 5.1504 & TRN & \\
\hline CHEMBL1390624 & 688497 & 5.15 & 5.2212 & TRN & \\
\hline CHEMBL1400375 & 688497 & 4.6 & 5.4617 & TST & \\
\hline CHEMBL1417211 & 688497 & 5.25 & 4.9633 & TST & \\
\hline CHEMBL1534533 & 688497 & 4.75 & 5.1472 & TRN & \\
\hline CHEMBL3144903 & 688497 & 6.2 & 5.2654 & TRN & \\
\hline CHEMBL1510620 & 688497 & 4.9 & 4.9602 & TRN & \\
\hline CHEMBL1449268 & 688497 & 4.7 & 4.8523 & TRN & \\
\hline CHEMBL1576075 & 688497 & 4.95 & 4.9067 & TRN & \\
\hline CHEMBL1515929 & 688497 & 4.45 & 5.0111 & TRN & \\
\hline CHEMBL1350350 & 688497 & 4.45 & 4.904 & TRN & \\
\hline CHEMBL1481167 & 688497 & 4.45 & 5.3185 & TRN & \\
\hline CHEMBL1304105 & 688497 & 5.0 & 4.8885 & TRN & \\
\hline CHEMBL1537323 & 688497 & 5.45 & 5.0942 & TST & \\
\hline CHEMBL1401270 & 688497 & 4.8 & 4.9893 & TRN & \\
\hline
\end{tabular}




\begin{tabular}{|c|c|c|c|c|}
\hline \multicolumn{5}{|c|}{ Supplemental Table S2.txt } \\
\hline CHEMBL1538218 & 688497 & 5.35 & 5.1007 & TRN \\
\hline CHEMBL1388482 & 688497 & 5.55 & 5.2597 & TST \\
\hline CHEMBL3195091 & 688497 & 5.9 & 5.3043 & TST \\
\hline CHEMBL1542077 & 688497 & 5.05 & 5.1625 & TRN \\
\hline CHEMBL1440513 & 688497 & 5.25 & 5.0968 & TRN \\
\hline CHEMBL1421270 & 688497 & 5.9 & 4.6641 & TST \\
\hline CHEMBL1487907 & 688497 & 5.15 & 4.7687 & TRN \\
\hline CHEMBL1564604 & 688497 & 4.8 & 4.9938 & TRN \\
\hline CHEMBL1556669 & 688497 & 4.85 & 4.9319 & TRN \\
\hline CHEMBL1344025 & 688497 & 5.15 & 4.8116 & TRN \\
\hline CHEMBL 365423 & 688497 & 4.65 & 5.0517 & TRN \\
\hline CHEMBL1578505 & 688497 & 4.45 & 4.6546 & TRN \\
\hline CHEMBL1575686 & 688497 & 5.5 & 4.982 & TRN \\
\hline CHEMBL1452628 & 688497 & 5.5 & 4.9133 & TRN \\
\hline CHEMBL1366268 & 688497 & 4.45 & 4.8787 & TST \\
\hline CHEMBL3192197 & 688497 & 5.0 & 4.8845 & TRN \\
\hline CHEMBL1413104 & 688497 & 5.9 & 4.9597 & TRN \\
\hline CHEMBL1409430 & 688497 & 4.45 & 4.9446 & TRN \\
\hline CHEMBL1517259 & 688497 & 4.45 & 4.7286 & TRN \\
\hline CHEMBL1579925 & 688497 & 4.45 & 4.8397 & TRN \\
\hline CHEMBL1573337 & 688497 & 4.9 & 5.2213 & TRN \\
\hline CHEMBL1307689 & 688497 & 5.0 & 5.0937 & TRN \\
\hline CHEMBL1414190 & 688497 & 5.9 & 5.16 & TST \\
\hline CHEMBL3195849 & 688497 & 4.95 & 4.7547 & TRN \\
\hline CHEMBL1571875 & 688497 & 4.45 & 4.7511 & TRN \\
\hline CHEMBL1611356 & 688497 & 4.45 & 4.8739 & TST \\
\hline CHEMBL1500422 & 688497 & 4.85 & 4.6259 & TST \\
\hline CHEMBL1597288 & 688497 & 4.5 & 4.9846 & TRN \\
\hline CHEMBL1378539 & 688497 & 5.45 & 5.1907 & TRN \\
\hline CHEMBL1565296 & 688497 & 4.65 & 5.2366 & TST \\
\hline CHEMBL1574813 & 688497 & 4.95 & 4.8698 & TRN \\
\hline CHEMBL1569039 & 688497 & 5.0 & 5.2963 & TRN \\
\hline CHEMBL1581101 & 688497 & 6.0 & 5.1083 & TRN \\
\hline CHEMBL1359572 & 688497 & 4.7 & 4.9392 & TRN \\
\hline CHEMBL2311878 & 688497 & 4.95 & 5.1915 & TRN \\
\hline CHEMBL1441918 & 688497 & 4.45 & 5.0195 & TRN \\
\hline CHEMBL1498055 & 688497 & 6.5501 & 5.3944 & TRN \\
\hline CHEMBL1583788 & 688497 & 4.6 & 5.0324 & TRN \\
\hline CHEMBL1971613 & 688497 & 5.05 & 4.8508 & TST \\
\hline CHEMBL1896972 & 688497 & 4.85 & 4.8216 & TRN \\
\hline CHEMBL1518170 & 688497 & 5.2 & 4.7972 & TRN \\
\hline CHEMBL1597968 & 688497 & 5.15 & 4.819 & TRN \\
\hline CHEMBL1565765 & 688497 & 4.95 & 4.8803 & TRN \\
\hline CHEMBL1319307 & 688497 & 6.05 & 4.9297 & TRN \\
\hline CHEMBL 240333 & 688497 & 4.45 & 5.0755 & TST \\
\hline CHEMBL1384684 & 688497 & 5.0 & 4.9379 & TRN \\
\hline CHEMBL1559898 & 688497 & 4.45 & 4.834 & TRN \\
\hline CHEMBL1319612 & 688497 & 4.85 & 5.0267 & TRN \\
\hline
\end{tabular}




\begin{tabular}{|c|c|c|c|c|c|}
\hline \multicolumn{6}{|c|}{ Supplemental Table S2.txt } \\
\hline CHEMBL1414033 & 688497 & 5.05 & 5.046 & TRN & \\
\hline CHEMBL3189694 & 688497 & 4.95 & 4.7784 & TRN & \\
\hline CHEMBL 2002008 & 688497 & 5.5 & 5.2136 & TRN & \\
\hline CHEMBL1425292 & 688497 & 5.85 & 5.0358 & TRN & \\
\hline CHEMBL1421357 & 688497 & 5.25 & 5.4636 & TRN & \\
\hline CHEMBL1611725 & 688497 & 4.5 & 5.0124 & TRN & \\
\hline CHEMBL1382334 & 688497 & 4.45 & 5.1344 & TRN & \\
\hline CHEMBL1529922 & 688497 & 4.8 & 4.8904 & TRN & \\
\hline CHEMBL1405173 & 688497 & 5.25 & 5.3556 & TRN & \\
\hline CHEMBL1362998 & 688497 & 4.95 & 4.8307 & TRN & \\
\hline CHEMBL1403178 & 688497 & 5.6 & 4.8803 & TRN & \\
\hline CHEMBL1505071 & 688497 & 5.15 & 4.9165 & TRN & \\
\hline CHEMBL1439902 & 688497 & 5.25 & 5.2612 & TST & \\
\hline CHEMBL1418383 & 688497 & 5.5 & 4.9135 & TRN & \\
\hline CHEMBL1311324 & 688497 & 4.75 & 4.7152 & TRN & \\
\hline CHEMBL1395128 & 688497 & 5.55 & 5.2496 & TST & \\
\hline CHEMBL1339681 & 688497 & 6.0 & 5.2547 & TST & \\
\hline CHEMBL525826 & 688497 & 5.05 & 4.98600 & 0000000001 & TRN \\
\hline CHEMBL1569277 & 688497 & 5.85 & 5.061 & TRN & \\
\hline CHEMBL1582670 & 688497 & 5.5 & 5.0491 & TRN & \\
\hline CHEMBL1582152 & 688497 & 5.9 & 5.075 & TRN & \\
\hline CHEMBL1457532 & 688497 & 4.9 & 4.9711 & TRN & \\
\hline CHEMBL1337567 & 688497 & 4.45 & 4.8507 & TRN & \\
\hline CHEMBL1441508 & 688497 & 4.45 & 4.8906 & TRN & \\
\hline CHEMBL1585127 & 688497 & 4.8 & 5.2104 & TST & \\
\hline CHEMBL1341491 & 688497 & 5.35 & 4.9037 & TRN & \\
\hline CHEMBL1561740 & 688497 & 5.35 & 4.9774 & TRN & \\
\hline CHEMBL1989234 & 688497 & 4.45 & 4.6997 & TRN & \\
\hline CHEMBL1971120 & 688497 & 5.8 & 5.041 & TRN & \\
\hline CHEMBL1537900 & 688497 & 4.95 & 5.1424 & TRN & \\
\hline CHEMBL1362918 & 688497 & 4.95 & 4.9428 & TST & \\
\hline CHEMBL1367947 & 688497 & 5.9 & 5.1052 & TRN & \\
\hline CHEMBL1409617 & 688497 & 4.95 & 5.1494 & TRN & \\
\hline CHEMBL1416886 & 688497 & 4.85 & 5.3039 & TST & \\
\hline CHEMBL1542954 & 688497 & 4.7 & 5.3731 & TST & \\
\hline CHEMBL3191886 & 688497 & 4.45 & 4.7064 & TRN & \\
\hline CHEMBL1498553 & 688497 & 4.45 & 4.7043 & TRN & \\
\hline CHEMBL1494527 & 688497 & 4.45 & 4.9042 & TRN & \\
\hline CHEMBL1372781 & 688497 & 4.45 & 4.8297 & TRN & \\
\hline CHEMBL1502224 & 688497 & 6.5 & 5.2142 & TRN & \\
\hline CHEMBL1497317 & 688497 & 4.45 & 4.8653 & TRN & \\
\hline CHEMBL1300037 & 688497 & 4.95 & 5.1034 & TST & \\
\hline CHEMBL3211643 & 688497 & 4.95 & 5.1055 & TST & \\
\hline CHEMBL3210714 & 688497 & 4.45 & 4.7778 & TRN & \\
\hline CHEMBL1542613 & 688497 & 4.75 & 4.8351 & TRN & \\
\hline CHEMBL1558735 & 688497 & 5.4 & 5.32799 & 9999999999 & TRN \\
\hline CHEMBL1462302 & 688497 & 4.6 & 5.0011 & TRN & \\
\hline CHEMBL1482624 & 688497 & 4.75 & 5.1195 & TRN & \\
\hline
\end{tabular}




\begin{tabular}{|c|c|c|c|c|}
\hline & & & upplement & $\mathrm{T}$ \\
\hline CHEMBL1503847 & 688497 & 4.45 & 4.8364 & TRN \\
\hline CHEMBL1333931 & 688497 & 4.45 & 4.9907 & TST \\
\hline CHEMBL1447566 & 688497 & 4.95 & 5.0294 & TRN \\
\hline CHEMBL1986025 & 688497 & 4.6 & 5.3141 & TRN \\
\hline CHEMBL1311615 & 688497 & 4.95 & 4.9063 & TRN \\
\hline CHEMBL1557387 & 688497 & 4.45 & 5.0638 & TST \\
\hline CHEMBL1305465 & 688497 & 4.45 & 5.0911 & TRN \\
\hline CHEMBL1510634 & 688497 & 4.55 & 4.9031 & TST \\
\hline CHEMBL1603203 & 688497 & 4.45 & 5.1988 & TST \\
\hline CHEMBL1425063 & 688497 & 4.45 & 5.2506 & TST \\
\hline CHEMBL1454195 & 688497 & 4.7 & 4.7195 & TRN \\
\hline CHEMBL1534694 & 688497 & 5.35 & 5.1133 & TRN \\
\hline CHEMBL 3214317 & 688497 & 6.1 & 5.1805 & TRN \\
\hline CHEMBL1608784 & 688497 & 4.45 & 5.2611 & TRN \\
\hline CHEMBL1582695 & 688497 & 4.9 & 4.7735 & TRN \\
\hline CHEMBL1522396 & 688497 & 5.55 & 4.9304 & TRN \\
\hline CHEMBL1319461 & 688497 & 4.9 & 4.8369 & TST \\
\hline CHEMBL1340514 & 688497 & 4.45 & 4.5483 & TRN \\
\hline CHEMBL1499213 & 688497 & 4.8 & 4.8181 & TRN \\
\hline CHEMBL1441505 & 688497 & 4.9 & 4.8551 & TRN \\
\hline CHEMBL1983843 & 688497 & 4.45 & 4.9696 & TST \\
\hline CHEMBL1562055 & 688497 & 5.25 & 5.1622 & TST \\
\hline CHEMBL1607665 & 688497 & 5.45 & 5.0414 & TST \\
\hline CHEMBL1477470 & 688497 & 4.8 & 5.3628 & TRN \\
\hline CHEMBL1441265 & 688497 & 4.6 & 4.9333 & TRN \\
\hline CHEMBL1464156 & 688497 & 4.45 & 5.2338 & TRN \\
\hline CHEMBL1441756 & 688497 & 5.9 & 4.8428 & TST \\
\hline CHEMBL1364221 & 688497 & 4.55 & 4.9085 & TRN \\
\hline CHEMBL 394930 & 688497 & 6.05 & 5.062 & TRN \\
\hline CHEMBL1446306 & 688497 & 4.45 & 5.2438 & TRN \\
\hline CHEMBL1312620 & 688497 & 4.55 & 4.8068 & TRN \\
\hline CHEMBL1300654 & 688497 & 4.95 & 5.0363 & TRN \\
\hline CHEMBL1520641 & 688497 & 4.65 & 5.2254 & TST \\
\hline CHEMBL1441235 & 688497 & 4.45 & 5.0112 & TRN \\
\hline CHEMBL1426636 & 688497 & 5.3 & 5.1841 & TRN \\
\hline CHEMBL1353114 & 688497 & 6.1 & 5.2138 & TRN \\
\hline CHEMBL1351731 & 688497 & 4.95 & 4.8088 & TRN \\
\hline CHEMBL1458383 & 688497 & 4.45 & 5.1288 & TST \\
\hline CHEMBL1533068 & 688497 & 4.7 & 4.9471 & TRN \\
\hline CHEMBL1540491 & 688497 & 5.1 & 4.9979 & TRN \\
\hline CHEMBL1329237 & 688497 & 4.9 & 5.3625 & TST \\
\hline CHEMBL1531852 & 688497 & 4.55 & 5.1816 & TRN \\
\hline CHEMBL1331252 & 688497 & 4.6 & 5.1149 & TRN \\
\hline CHEMBL 3208617 & 688497 & 4.45 & 4.9479 & TRN \\
\hline CHEMBL1340701 & 688497 & 6.2 & 5.1143 & TRN \\
\hline CHEMBL1548244 & 688497 & 4.75 & 4.8865 & TRN \\
\hline CHEMBL3196726 & 688497 & 5.65 & 5.2754 & TRN \\
\hline CHEMBL1452813 & 688497 & 4.45 & 5.1657 & TRN \\
\hline
\end{tabular}




\begin{tabular}{|c|c|c|c|c|}
\hline \multicolumn{5}{|c|}{ Supplemental Table s2.txt } \\
\hline CHEMBL1608996 & 688497 & 6.3 & 5.2757 & TST \\
\hline CHEMBL 3192506 & 688497 & 4.45 & 4.9871 & TST \\
\hline CHEMBL1349606 & 688497 & 4.45 & 5.1167 & TRN \\
\hline CHEMBL1340313 & 688497 & 5.0 & 5.0811 & TST \\
\hline CHEMBL1341231 & 688497 & 4.85 & 4.9326 & TRN \\
\hline CHEMBL1546361 & 688497 & 5.35 & 5.0115 & TRN \\
\hline CHEMBL1518430 & 688497 & 5.25 & 5.2612 & TST \\
\hline CHEMBL1429735 & 688497 & 4.65 & 5.2077 & TST \\
\hline CHEMBL1502530 & 688497 & 5.45 & 5.1022 & TRN \\
\hline CHEMBL1419241 & 688497 & 4.45 & 5.0563 & TST \\
\hline CHEMBL1987579 & 688497 & 5.05 & 5.0181 & TRN \\
\hline CHEMBL1557479 & 688497 & 4.65 & 5.0694 & TRN \\
\hline CHEMBL1596409 & 688497 & 6.45 & 5.3455 & TRN \\
\hline CHEMBL1346930 & 688497 & 4.85 & 5.1622 & TST \\
\hline CHEMBL1307720 & 688497 & 4.45 & 5.0746 & TRN \\
\hline CHEMBL1447013 & 688497 & 4.8 & 5.0794 & TST \\
\hline CHEMBL1609391 & 688497 & 5.1 & 4.9186 & TST \\
\hline CHEMBL1543133 & 688497 & 4.45 & 5.0513 & TRN \\
\hline CHEMBL1469915 & 688497 & 5.0 & 4.9798 & TRN \\
\hline CHEMBL1543136 & 688497 & 4.45 & 4.941 & TRN \\
\hline CHEMBL1535260 & 688497 & 4.65 & 4.8009 & TRN \\
\hline CHEMBL1458662 & 688497 & 4.7 & 4.7585 & TRN \\
\hline CHEMBL1502788 & 688497 & 4.5 & 4.8046 & TRN \\
\hline CHEMBL1458565 & 688497 & 5.15 & 5.0659 & TRN \\
\hline CHEMBL1506899 & 688497 & 4.5 & 4.9467 & TRN \\
\hline CHEMBL1566218 & 688497 & 4.95 & 5.1048 & TRN \\
\hline CHEMBL1970542 & 688497 & 4.7 & 5.066 & TST \\
\hline CHEMBL1300956 & 688497 & 4.9 & 5.1412 & TRN \\
\hline CHEMBL1569370 & 688497 & 4.85 & 4.7185 & TRN \\
\hline CHEMBL1377956 & 688497 & 4.9 & 5.2813 & TRN \\
\hline CHEMBL1479040 & 688497 & 6.25 & 5.2089 & TST \\
\hline CHEMBL1523026 & 688497 & 4.65 & 5.0228 & TST \\
\hline CHEMBL1330201 & 688497 & 4.45 & 4.6939 & TRN \\
\hline CHEMBL1572672 & 688497 & 5.0 & 5.1371 & TST \\
\hline CHEMBL1321021 & 688497 & 6.25 & 5.0977 & TST \\
\hline CHEMBL1973802 & 688497 & 4.45 & 4.646 & TST \\
\hline CHEMBL1392626 & 688497 & 4.6 & 4.8488 & TST \\
\hline CHEMBL1976099 & 688497 & 5.5 & 5.1447 & TRN \\
\hline CHEMBL1327616 & 688497 & 5.4 & 5.1251 & TRN \\
\hline CHEMBL1519411 & 688497 & 4.6 & 4.8255 & TRN \\
\hline CHEMBL1568449 & 688497 & 4.5 & 4.9802 & TRN \\
\hline CHEMBL1428071 & 688497 & 4.95 & 4.7259 & TRN \\
\hline CHEMBL1575735 & 688497 & 5.1 & 4.9504 & TRN \\
\hline CHEMBL1409480 & 688497 & 6.05 & 5.2234 & TRN \\
\hline CHEMBL3193221 & 688497 & 4.45 & 4.8898 & TRN \\
\hline CHEMBL155563 & 688497 & 4.9 & 4.7961 & TRN \\
\hline CHEMBL1429655 & 688497 & 6.0 & 5.2915 & TST \\
\hline CHEMBL548615 & 688497 & 5.9 & 5.0159 & TRN \\
\hline
\end{tabular}




\begin{tabular}{|c|c|c|c|c|}
\hline \multicolumn{5}{|c|}{ Supplemental Table S2.txt } \\
\hline CHEMBL1369575 & 688497 & 4.45 & 4.7859 & TRN \\
\hline CHEMBL1402845 & 688497 & 4.85 & 4.96899 & 9999999999 \\
\hline CHEMBL1347419 & 688497 & 4.85 & 4.9508 & TST \\
\hline CHEMBL1518668 & 688497 & 5.25 & 4.996 & TRN \\
\hline CHEMBL 1460378 & 688497 & 4.45 & 5.0602 & TRN \\
\hline CHEMBL1455465 & 688497 & 6.0 & 5.1683 & TRN \\
\hline CHEMBL1353986 & 688497 & 5.8 & 4.9502 & TRN \\
\hline CHEMBL1587608 & 688497 & 4.45 & 4.8688 & TRN \\
\hline CHEMBL1390180 & 688497 & 6.05 & 5.0376 & TRN \\
\hline CHEMBL1486687 & 688497 & 5.2 & 4.6874 & TST \\
\hline CHEMBL1546975 & 688497 & 4.95 & 4.9285 & TST \\
\hline CHEMBL1431162 & 688497 & 5.1 & 5.2009 & TRN \\
\hline CHEMBL1310056 & 688497 & 5.25 & 5.3154 & TRN \\
\hline CHEMBL1497648 & 688497 & 6.25 & 5.5314 & TRN \\
\hline CHEMBL1328388 & 688497 & 4.95 & 5.1394 & TRN \\
\hline CHEMBL1503147 & 688497 & 4.45 & 5.0617 & TRN \\
\hline CHEMBL1320690 & 688497 & 4.85 & 5.3665 & TST \\
\hline CHEMBL1389029 & 688497 & 5.45 & 5.3755 & TRN \\
\hline CHEMBL1380642 & 688497 & 5.75 & 4.9029 & TST \\
\hline CHEMBL1561187 & 688497 & 4.45 & 4.8088 & TRN \\
\hline CHEMBL1548773 & 688497 & 4.45 & 4.869 & TRN \\
\hline CHEMBL1300143 & 688497 & 5.25 & 4.9252 & TST \\
\hline CHEMBL1407952 & 688497 & 5.35 & 5.5822 & TRN \\
\hline CHEMBL1539051 & 688497 & 5.9 & 5.5804 & TST \\
\hline CHEMBL1373983 & 688497 & 8.4949 & 5.1041 & TST \\
\hline CHEMBL1497611 & 688497 & 6.25 & 5.1927 & TRN \\
\hline CHEMBL1544121 & 688497 & 4.6 & 4.77 & TRN \\
\hline CHEMBL1458869 & 688497 & 4.45 & 5.0083 & TRN \\
\hline CHEMBL1320080 & 688497 & 4.9 & 4.7904 & TRN \\
\hline CHEMBL1379751 & 688497 & 4.45 & 4.9046 & TRN \\
\hline CHEMBL1550642 & 688497 & 4.45 & 5.046 & TST \\
\hline CHEMBL1462979 & 688497 & 4.85 & 5.4783 & TRN \\
\hline CHEMBL1485781 & 688497 & 4.95 & 4.8268 & TRN \\
\hline CHEMBL 2007173 & 688497 & 4.75 & 4.7292 & TRN \\
\hline CHEMBL1499127 & 688497 & 4.9 & 5.4532 & TRN \\
\hline CHEMBL1336419 & 688497 & 5.45 & 4.7383 & TST \\
\hline CHEMBL1409853 & 688497 & 6.3 & 5.0159 & TRN \\
\hline CHEMBL 3198868 & 688497 & 5.0 & 5.2632 & TRN \\
\hline CHEMBL1562662 & 688497 & 5.8 & 5.1135 & TRN \\
\hline CHEMBL1444200 & 688497 & 5.2 & 5.3076 & TST \\
\hline CHEMBL1976498 & 688497 & 5.45 & 5.1032 & TST \\
\hline CHEMBL1412377 & 688497 & 5.45 & 5.0177 & TRN \\
\hline CHEMBL1533555 & 688497 & 5.95 & 5.0828 & TRN \\
\hline CHEMBL1334840 & 688497 & 4.8 & 5.2265 & TRN \\
\hline CHEMBL1565007 & 688497 & 4.45 & 4.9834 & TRN \\
\hline CHEMBL601351 & 688497 & 4.9 & 4.7609 & TST \\
\hline CHEMBL1526667 & 688497 & 6.3 & 5.2662 & TRN \\
\hline CHEMBL1526683 & 688497 & 6.25 & 5.0585 & TST \\
\hline
\end{tabular}

TRN 


\begin{tabular}{|c|c|c|c|c|c|}
\hline \multicolumn{6}{|c|}{ Supplemental Table S2.txt } \\
\hline CHEMBL1509451 & 688497 & 4.5 & 4.9864 & TRN & \\
\hline CHEMBL1605296 & 688497 & 4.65 & 5.0472 & TRN & \\
\hline CHEMBL1308646 & 688497 & 4.95 & 5.1356 & TST & \\
\hline CHEMBL1561232 & 688497 & 4.45 & 5.0916 & TRN & \\
\hline CHEMBL578883 & 688497 & 4.5 & 5.0851 & TRN & \\
\hline CHEMBL1595103 & 688497 & 4.45 & 4.9325 & TRN & \\
\hline CHEMBL1401398 & 688497 & 5.25 & 5.1623 & TST & \\
\hline CHEMBL1449850 & 688497 & 4.65 & 5.1661 & TRN & \\
\hline CHEMBL1561748 & 688497 & 6.15 & 5.0472 & TST & \\
\hline CHEMBL1330459 & 688497 & 4.9 & 5.3849 & TST & \\
\hline CHEMBL1530797 & 688497 & 4.5 & 4.8389 & TST & \\
\hline CHEMBL3196591 & 688497 & 4.45 & 5.0371 & TRN & \\
\hline CHEMBL1406961 & 688497 & 4.95 & 4.6336 & TRN & \\
\hline CHEMBL1324077 & 688497 & 4.8 & 4.9479 & TST & \\
\hline CHEMBL1511653 & 688497 & 4.75 & 4.9143 & TRN & \\
\hline CHEMBL1360490 & 688497 & 4.5 & 4.9863 & TRN & \\
\hline CHEMBL1428134 & 688497 & 4.45 & 5.1073 & TST & \\
\hline CHEMBL1609640 & 688497 & 4.65 & 5.1405 & TRN & \\
\hline CHEMBL1309157 & 688497 & 4.55 & 4.7532 & TST & \\
\hline CHEMBL1331444 & 688497 & 4.9 & 5.0458 & TRN & \\
\hline CHEMBL1495566 & 688497 & 7.0 & 5.1112 & TRN & \\
\hline CHEMBL1610725 & 688497 & 5.0 & 5.1233 & TRN & \\
\hline CHEMBL1596245 & 688497 & 4.45 & 4.8389 & TRN & \\
\hline CHEMBL527271 & 688497 & 4.45 & 5.1608 & TRN & \\
\hline CHEMBL1416398 & 688497 & 4.45 & 4.75899 & 99999999995 & TRN \\
\hline CHEMBL1993522 & 688497 & 5.55 & 5.1976 & TRN & \\
\hline CHEMBL1400853 & 688497 & 5.5 & 5.2171 & TRN & \\
\hline CHEMBL1557018 & 688497 & 4.95 & 4.8431 & TRN & \\
\hline CHEMBL1517426 & 688497 & 4.9 & 5.0988 & TRN & \\
\hline CHEMBL1425804 & 688497 & 5.0 & 5.025 & TRN & \\
\hline CHEMBL1332308 & 688497 & 4.65 & 4.7448 & TRN & \\
\hline CHEMBL1497370 & 688497 & 4.6 & 4.8156 & TST & \\
\hline CHEMBL1304397 & 688497 & 4.95 & 5.016 & TRN & \\
\hline CHEMBL1524124 & 688497 & 6.9 & 5.4786 & TRN & \\
\hline CHEMBL1376574 & 688497 & 4.45 & 4.9672 & TRN & \\
\hline CHEMBL1572749 & 688497 & 4.85 & 5.0619 & TRN & \\
\hline CHEMBL1441868 & 688497 & 5.55 & 4.8023 & TRN & \\
\hline CHEMBL1489194 & 688497 & 4.95 & 4.7649 & TRN & \\
\hline CHEMBL1431899 & 688497 & 6.05 & 5.2553 & TRN & \\
\hline CHEMBL1559566 & 688497 & 5.0 & 4.8909 & TST & \\
\hline CHEMBL1170485 & 688497 & 5.0 & 5.1792 & TST & \\
\hline CHEMBL1308217 & 688497 & 5.85 & 5.0595 & TST & \\
\hline CHEMBL1415594 & 688497 & 4.95 & 4.8723 & TRN & \\
\hline CHEMBL1569507 & 688497 & 4.9 & 5.1168 & TRN & \\
\hline CHEMBL1308147 & 688497 & 4.75 & 4.8352 & TRN & \\
\hline CHEMBL3208968 & 688497 & 4.45 & 4.6687 & TST & \\
\hline CHEMBL1425129 & 688497 & 4.45 & 5.0037 & TST & \\
\hline CHEMBL1564375 & 688497 & 4.45 & $4.9060 e$ & $\partial 000000001$ & TRN \\
\hline & & & & 19834 & \\
\hline
\end{tabular}




\begin{tabular}{|c|c|c|c|c|}
\hline \multicolumn{5}{|c|}{ Supplemental Table S2.txt } \\
\hline CHEMBL1499527 & 688497 & 5.35 & 4.9573 & TRN \\
\hline CHEMBL3192140 & 688497 & 6.4 & 5.2467 & TST \\
\hline CHEMBL1311842 & 688497 & 5.9 & 5.4885 & TRN \\
\hline CHEMBL3195569 & 688497 & 4.55 & 4.9963 & TRN \\
\hline CHEMBL3196813 & 688497 & 5.6 & 5.3062 & TRN \\
\hline CHEMBL3196439 & 688497 & 5.7 & 5.1306 & TST \\
\hline CHEMBL1387068 & 688497 & 4.75 & 5.1699 & TRN \\
\hline CHEMBL1527346 & 688497 & 4.45 & 5.0919 & TST \\
\hline CHEMBL1390556 & 688497 & 4.45 & 4.7782 & TRN \\
\hline CHEMBL1367439 & 688497 & 5.0 & 5.1101 & TRN \\
\hline CHEMBL1391342 & 688497 & 5.85 & 5.1136 & TST \\
\hline CHEMBL1464984 & 688497 & 5.0 & 5.1492 & TRN \\
\hline CHEMBL1500316 & 688497 & 4.45 & 5.1576 & TST \\
\hline CHEMBL1307624 & 688497 & 5.55 & 5.0093 & TRN \\
\hline CHEMBL1449393 & 688497 & 4.75 & 4.8488 & TRN \\
\hline CHEMBL1568310 & 688497 & 4.75 & 5.0373 & TRN \\
\hline CHEMBL1586518 & 688497 & 4.45 & 5.0226 & TRN \\
\hline CHEMBL1352924 & 688497 & 4.6 & 5.0223 & TRN \\
\hline CHEMBL1990959 & 688497 & 5.5 & 5.225 & TRN \\
\hline CHEMBL1568018 & 688497 & 4.95 & 5.01 & TRN \\
\hline CHEMBL1458548 & 688497 & 5.1 & 5.274 & TRN \\
\hline CHEMBL1360146 & 688497 & 4.65 & 5.0618 & TRN \\
\hline CHEMBL1482299 & 688497 & 5.6 & 4.9826 & TRN \\
\hline CHEMBL1410970 & 688497 & 4.6 & 5.153 & TST \\
\hline CHEMBL1546699 & 688497 & 4.45 & 5.319 & TRN \\
\hline CHEMBL1393270 & 688497 & 4.9 & 5.1693 & TST \\
\hline CHEMBL1404032 & 688497 & 6.05 & 4.9357 & TST \\
\hline CHEMBL1510254 & 688497 & 5.25 & 5.2567 & TRN \\
\hline CHEMBL1444201 & 688497 & 6.25 & 5.4261 & TRN \\
\hline CHEMBL1430439 & 688497 & 4.45 & 4.7847 & TRN \\
\hline CHEMBL 2000807 & 688497 & 4.45 & 4.9587 & TRN \\
\hline CHEMBL1370449 & 688497 & 4.65 & 5.1627 & TRN \\
\hline CHEMBL1533399 & 688497 & 5.2 & 5.0865 & TRN \\
\hline CHEMBL1470450 & 688497 & 5.1 & 4.7916 & TRN \\
\hline CHEMBL1377546 & 688497 & 6.05 & 4.9767 & TRN \\
\hline CHEMBL1419822 & 688497 & 5.5 & 5.0384 & TRN \\
\hline CHEMBL1489133 & 688497 & 4.95 & 4.8919 & TRN \\
\hline CHEMBL1521482 & 688497 & 5.15 & 4.8728 & TRN \\
\hline CHEMBL1604533 & 688497 & 4.45 & 4.9972 & TRN \\
\hline CHEMBL1493321 & 688497 & 6.25 & 5.6507 & TRN \\
\hline CHEMBL1519302 & 688497 & 5.25 & 5.087 & TRN \\
\hline CHEMBL 261687 & 688497 & 4.45 & 5.0468 & TRN \\
\hline CHEMBL1384931 & 688497 & 4.65 & 4.9263 & TRN \\
\hline CHEMBL1349158 & 688497 & 5.05 & 5.2441 & TST \\
\hline CHEMBL1489457 & 688497 & 4.9 & 4.9847 & TST \\
\hline CHEMBL1510111 & 688497 & 5.25 & 5.3568 & TST \\
\hline CHEMBL1500088 & 688497 & 4.45 & 5.0586 & TRN \\
\hline CHEMBL1466304 & 688497 & 4.9 & 4.9502 & TRN \\
\hline
\end{tabular}




\begin{tabular}{|c|c|c|c|c|}
\hline & & & pplement & al $\mathrm{Ta}$ \\
\hline CHEMBL1459746 & 688497 & 4.6 & 5.4494 & TRN \\
\hline CHEMBL 3192404 & 688497 & 4.7 & 5.1375 & TRN \\
\hline CHEMBL1341428 & 688497 & 4.6 & 5.2183 & TST \\
\hline CHEMBL1462280 & 688497 & 5.3 & 4.6849 & TRN \\
\hline CHEMBL1383321 & 688497 & 4.45 & 4.9689 & TST \\
\hline CHEMBL1407812 & 688497 & 4.6 & 5.0515 & TRN \\
\hline CHEMBL579503 & 688497 & 4.85 & 4.9049 & TRN \\
\hline CHEMBL1325377 & 688497 & 5.4 & 5.0853 & TRN \\
\hline CHEMBL3195937 & 688497 & 4.95 & 4.9214 & TRN \\
\hline CHEMBL1519748 & 688497 & 5.9 & 5.2033 & TST \\
\hline CHEMBL 1457754 & 688497 & 4.45 & 5.1773 & TST \\
\hline CHEMBL1596380 & 688497 & 4.85 & 5.0124 & TRN \\
\hline CHEMBL1576943 & 688497 & 6.3 & 4.9888 & TST \\
\hline CHEMBL1360808 & 688497 & 4.45 & 4.5939 & TRN \\
\hline CHEMBL1466085 & 688497 & 5.9 & 5.271 & TRN \\
\hline CHEMBL591834 & 688497 & 5.05 & 5.13 & TST \\
\hline CHEMBL1599092 & 688497 & 6.35 & 5.2605 & TRN \\
\hline CHEMBL1550442 & 688497 & 5.05 & 5.0029 & TRN \\
\hline CHEMBL1531097 & 688497 & 5.35 & 5.5279 & TRN \\
\hline CHEMBL1432867 & 688497 & 5.25 & 5.1959 & TRN \\
\hline CHEMBL1429693 & 688497 & 4.5 & 4.7978 & TRN \\
\hline CHEMBL 3145030 & 688497 & 4.95 & 5.2641 & TRN \\
\hline CHEMBL1532101 & 688497 & 4.45 & 4.7419 & TRN \\
\hline CHEMBL1598834 & 688497 & 5.5 & 4.9989 & TRN \\
\hline CHEMBL1305954 & 688497 & 5.45 & 4.8633 & TRN \\
\hline CHEMBL1345001 & 688497 & 5.15 & 5.0117 & TRN \\
\hline CHEMBL1403067 & 688497 & 4.65 & 4.8797 & TRN \\
\hline CHEMBL1409108 & 688497 & 5.05 & 4.99 & TRN \\
\hline CHEMBL1560671 & 688497 & 4.45 & 5.5217 & TRN \\
\hline CHEMBL1485684 & 688497 & 5.2 & 5.3128 & TRN \\
\hline CHEMBL3190209 & 688497 & 5.55 & 5.2835 & TRN \\
\hline CHEMBL1498530 & 688497 & 4.6 & 5.0268 & TRN \\
\hline CHEMBL1415136 & 688497 & 4.75 & 4.9232 & TST \\
\hline CHEMBL1563926 & 688497 & 5.9 & 5.3438 & TRN \\
\hline CHEMBL 3198941 & 688497 & 4.45 & 4.9147 & TST \\
\hline CHEMBL1442084 & 688497 & 6.25 & 5.1949 & TRN \\
\hline CHEMBL1600209 & 688497 & 4.85 & 4.7285 & TRN \\
\hline CHEMBL1353704 & 688497 & 4.95 & 5.2243 & TRN \\
\hline CHEMBL1533594 & 688497 & 5.5 & 4.9579 & TRN \\
\hline CHEMBL1367715 & 688497 & 5.6 & 5.2023 & TST \\
\hline CHEMBL3207378 & 688497 & 4.45 & 5.0612 & TST \\
\hline CHEMBL1584449 & 688497 & 4.9 & 4.9823 & TRN \\
\hline CHEMBL1462208 & 688497 & 4.65 & 4.8514 & TRN \\
\hline CHEMBL1373982 & 688497 & 5.6 & 4.9938 & TST \\
\hline CHEMBL 1470502 & 688497 & 4.45 & 5.1203 & TST \\
\hline CHEMBL1399758 & 688497 & 4.45 & 4.9474 & TRN \\
\hline CHEMBL1587981 & 688497 & 4.45 & 4.9527 & TRN \\
\hline CHEMBL1613522 & 688497 & 4.85 & 4.9016 & TST \\
\hline
\end{tabular}




\begin{tabular}{|c|c|c|c|c|}
\hline \multicolumn{5}{|c|}{ Supplemental Table S2.txt } \\
\hline CHEMBL1550573 & 688497 & 4.45 & 4.9076 & TRN \\
\hline CHEMBL1303548 & 688497 & 5.2 & 5.1202 & TRN \\
\hline CHEMBL3144917 & 688497 & 4.45 & 4.9371 & TRN \\
\hline CHEMBL1441833 & 688497 & 4.5 & 5.1113 & TRN \\
\hline CHEMBL3195761 & 688497 & 4.45 & 5.5221 & TST \\
\hline CHEMBL1425264 & 688497 & 6.5501 & 5.1431 & TST \\
\hline CHEMBL1313666 & 688497 & 4.45 & 4.8824 & TRN \\
\hline CHEMBL1470108 & 688497 & 4.45 & 5.1818 & TST \\
\hline CHEMBL1300611 & 688497 & 5.25 & 5.2092 & TRN \\
\hline CHEMBL1579450 & 688497 & 5.2 & 5.3326 & TRN \\
\hline CHEMBL1344950 & 688497 & 5.9 & 5.3484 & TRN \\
\hline CHEMBL1411116 & 688497 & 4.9 & 5.0502 & TST \\
\hline CHEMBL1347211 & 688497 & 5.4 & 5.0437 & TRN \\
\hline CHEMBL1383004 & 688497 & 7.0501 & 5.0919 & TST \\
\hline CHEMBL1387815 & 688497 & 5.9 & 4.9227 & TST \\
\hline CHEMBL1557516 & 688497 & 5.2 & 5.3682 & TRN \\
\hline CHEMBL398969 & 688497 & 5.1 & 5.0701 & TRN \\
\hline CHEMBL1310857 & 688497 & 4.45 & 4.5842 & TRN \\
\hline CHEMBL1371445 & 688497 & 4.65 & 5.0524 & TST \\
\hline CHEMBL1348807 & 688497 & 4.85 & 4.5944 & TST \\
\hline CHEMBL1472083 & 688497 & 4.65 & 5.056 & TRN \\
\hline CHEMBL3195506 & 688497 & 4.9 & 4.7898 & TST \\
\hline CHEMBL1576604 & 688497 & 6.25 & 5.2741 & TST \\
\hline CHEMBL1559423 & 688497 & 4.8 & 5.1404 & TRN \\
\hline CHEMBL1400089 & 688497 & 4.85 & 5.1048 & TRN \\
\hline CHEMBL1587285 & 688497 & 4.5 & 5.1496 & TST \\
\hline CHEMBL1336788 & 688497 & 4.8 & 4.6614 & TRN \\
\hline CHEMBL1384485 & 688497 & 6.3 & 5.0978 & TRN \\
\hline CHEMBL1429804 & 688497 & 4.45 & 5.0552 & TRN \\
\hline CHEMBL1566350 & 688497 & 4.5 & 4.9565 & TST \\
\hline CHEMBL3190516 & 688497 & 4.95 & 5.4562 & TRN \\
\hline CHEMBL1535839 & 688497 & 4.45 & 5.2102 & TRN \\
\hline CHEMBL3192280 & 688497 & 4.95 & 5.0394 & TRN \\
\hline CHEMBL1450107 & 688497 & 5.45 & 5.1696 & TRN \\
\hline CHEMBL1352368 & 688497 & 5.0 & 4.8612 & TRN \\
\hline CHEMBL1589343 & 688497 & 4.45 & 4.7991 & TRN \\
\hline CHEMBL1540010 & 688497 & 4.75 & 5.0805 & TRN \\
\hline CHEMBL1423288 & 688497 & 4.45 & 4.8416 & TRN \\
\hline CHEMBL3210311 & 688497 & 5.35 & 5.0377 & TRN \\
\hline CHEMBL1503292 & 688497 & 4.45 & 4.9749 & TRN \\
\hline CHEMBL1594826 & 688497 & 4.45 & 5.0474 & TST \\
\hline CHEMBL1359371 & 688497 & 6.0 & 5.2436 & TRN \\
\hline CHEMBL1535772 & 688497 & 4.45 & 4.8472 & TRN \\
\hline CHEMBL1374413 & 688497 & 4.65 & 5.1301 & TRN \\
\hline CHEMBL1548546 & 688497 & 4.7 & 5.0884 & TST \\
\hline CHEMBL1373189 & 688497 & 4.45 & 5.0066 & TRN \\
\hline CHEMBL3196747 & 688497 & 5.1 & 5.0961 & TRN \\
\hline CHEMBL1453773 & 688497 & 4.9 & 4.8344 & TRN \\
\hline
\end{tabular}




\begin{tabular}{|c|c|c|c|c|}
\hline \multicolumn{5}{|c|}{ Supplemental Table S2.txt } \\
\hline CHEMBL1392200 & 688497 & 4.95 & 5.1184 & TRN \\
\hline CHEMBL1502443 & 688497 & 4.95 & 5.0523 & TST \\
\hline CHEMBL3197790 & 688497 & 4.8 & 5.1788 & TRN \\
\hline CHEMBL1536467 & 688497 & 6.2 & 5.0312 & TRN \\
\hline CHEMBL1418191 & 688497 & 5.35 & 5.0378 & TRN \\
\hline CHEMBL1455194 & 688497 & 5.55 & 4.992 & TRN \\
\hline CHEMBL1562041 & 688497 & 4.85 & 4.7946 & TRN \\
\hline CHEMBL3191284 & 688497 & 6.2 & 4.8875 & TRN \\
\hline CHEMBL1320163 & 688497 & 9.0969 & 5.4187 & TRN \\
\hline CHEMBL1479649 & 688497 & 5.0 & 5.216 & TRN \\
\hline CHEMBL1502330 & 688497 & 5.0 & 4.9723 & TRN \\
\hline CHEMBL1502112 & 688497 & 6.25 & 5.0977 & TST \\
\hline CHEMBL1374919 & 688497 & 4.65 & 4.9716 & TRN \\
\hline CHEMBL1449746 & 688497 & 4.45 & 5.2257 & TST \\
\hline CHEMBL1541840 & 688497 & 4.45 & 4.8102 & TRN \\
\hline CHEMBL1366473 & 688497 & 5.0 & 5.0453 & TRN \\
\hline CHEMBL1566213 & 688497 & 5.35 & 5.4611 & TRN \\
\hline CHEMBL1581829 & 688497 & 4.6 & 5.2827 & TST \\
\hline CHEMBL1580736 & 688497 & 5.0 & 5.1145 & TRN \\
\hline CHEMBL1428468 & 688497 & 4.9 & 5.045 & TST \\
\hline CHEMBL1319858 & 688497 & 5.1 & 5.1402 & TST \\
\hline CHEMBL1469885 & 688497 & 5.0 & 5.0298 & TRN \\
\hline CHEMBL1583471 & 688497 & 4.45 & 5.0587 & TRN \\
\hline CHEMBL1536326 & 688497 & 5.0 & 4.8508 & TRN \\
\hline CHEMBL1302225 & 688497 & 4.9 & 4.9817 & TRN \\
\hline CHEMBL1498643 & 688497 & 4.45 & 4.7625 & TRN \\
\hline CHEMBL3196241 & 688497 & 6.25 & 5.3702 & TRN \\
\hline CHEMBL3196431 & 688497 & 4.45 & 4.9667 & TRN \\
\hline CHEMBL1382279 & 688497 & 4.7 & 4.5213 & TRN \\
\hline CHEMBL1399332 & 688497 & 4.45 & 4.7308 & TRN \\
\hline CHEMBL1302096 & 688497 & 5.2 & 5.14 & TRN \\
\hline CHEMBL1606671 & 688497 & 4.9 & 4.9278 & TRN \\
\hline CHEMBL1383122 & 688497 & 4.5 & 4.8537 & TRN \\
\hline CHEMBL436589 & 688497 & 4.45 & 5.1729 & TST \\
\hline CHEMBL1392953 & 688497 & 4.95 & 4.9429 & TRN \\
\hline CHEMBL1605299 & 688497 & 5.1 & 4.9927 & TRN \\
\hline CHEMBL1510636 & 688497 & 4.5 & 5.0115 & TRN \\
\hline CHEMBL582030 & 688497 & 5.2 & 4.8697 & TRN \\
\hline CHEMBL1310815 & 688497 & 4.45 & 5.018 & TRN \\
\hline CHEMBL576208 & 688497 & 5.15 & 4.8257 & TRN \\
\hline CHEMBL1528903 & 688497 & 4.75 & 4.8713 & TRN \\
\hline CHEMBL3207561 & 688497 & 4.95 & 4.8204 & TRN \\
\hline CHEMBL1564641 & 688497 & 5.45 & 5.0451 & TRN \\
\hline CHEMBL1500847 & 688497 & 4.9 & 5.1277 & TRN \\
\hline CHEMBL1610970 & 688497 & 5.35 & 5.164 & TST \\
\hline CHEMBL1560582 & 688497 & 4.95 & 4.8098 & TRN \\
\hline CHEMBL1509049 & 688497 & 5.5 & 5.3214 & TST \\
\hline CHEMBL1431563 & 688497 & 4.65 & 4.7853 & TST \\
\hline
\end{tabular}




\begin{tabular}{|c|c|c|c|c|}
\hline \multicolumn{5}{|c|}{ Supplemental Table S2.txt } \\
\hline CHEMBL1502297 & 688497 & 4.45 & 4.8645 & TRN \\
\hline CHEMBL1324985 & 688497 & 4.6 & 5.121 & TRN \\
\hline CHEMBL521298 & 688497 & 6.15 & 5.2309 & TRN \\
\hline CHEMBL1464786 & 688497 & 4.95 & 4.7987 & TRN \\
\hline CHEMBL1452157 & 688497 & 5.35 & 5.2109 & TRN \\
\hline CHEMBL1540742 & 688497 & 5.25 & 4.9131 & TST \\
\hline CHEMBL1601767 & 688497 & 5.0 & 5.0518 & TST \\
\hline CHEMBL1502020 & 688497 & 5.2 & 5.1499 & TRN \\
\hline CHEMBL3210831 & 688497 & 4.45 & 5.1399 & TRN \\
\hline CHEMBL3192573 & 688497 & 4.45 & 5.1963 & TST \\
\hline CHEMBL1450917 & 688497 & 4.75 & 5.0518 & TRN \\
\hline CHEMBL1488623 & 688497 & 4.8 & 4.8571 & TST \\
\hline CHEMBL1566754 & 688497 & 5.4 & 4.9863 & TRN \\
\hline CHEMBL1303353 & 688497 & 5.2 & 4.8176 & TRN \\
\hline CHEMBL1455162 & 688497 & 7.4498 & 5.1969 & TST \\
\hline CHEMBL3193389 & 688497 & 4.85 & 4.7572 & TRN \\
\hline CHEMBL1310941 & 688497 & 6.0 & 5.1096 & TRN \\
\hline CHEMBL1423219 & 688497 & 5.55 & 5.0002 & TRN \\
\hline CHEMBL1997062 & 688497 & 4.95 & 5.0357 & TRN \\
\hline CHEMBL1527913 & 688497 & 5.4 & 5.3721 & TRN \\
\hline CHEMBL1557435 & 688497 & 5.1 & 5.0018 & TST \\
\hline CHEMBL1516581 & 688497 & 4.85 & 4.8611 & TRN \\
\hline CHEMBL1311642 & 688497 & 4.9 & 5.1922 & TRN \\
\hline CHEMBL1458067 & 688497 & 4.45 & 4.9983 & TRN \\
\hline CHEMBL1462834 & 688497 & 4.45 & 5.1314 & TRN \\
\hline CHEMBL1308291 & 688497 & 4.95 & 4.8242 & TRN \\
\hline CHEMBL573444 & 688497 & 4.95 & 5.3214 & TST \\
\hline CHEMBL1606830 & 688497 & 5.25 & 5.0811 & TST \\
\hline CHEMBL1606408 & 688497 & 5.0 & 4.9864 & TRN \\
\hline CHEMBL1350951 & 688497 & 5.45 & 5.1094 & TST \\
\hline CHEMBL3198447 & 688497 & 5.15 & 5.5785 & TST \\
\hline CHEMBL1338487 & 688497 & 5.3 & 4.974 & TRN \\
\hline CHEMBL1439856 & 688497 & 5.9 & 5.2121 & TRN \\
\hline CHEMBL1431610 & 688497 & 5.45 & 4.9125 & TST \\
\hline CHEMBL1367665 & 688497 & 5.0 & 5.1462 & TST \\
\hline CHEMBL3208264 & 688497 & 4.7 & 5.2394 & TRN \\
\hline CHEMBL 1445829 & 688497 & 4.45 & 4.9243 & TRN \\
\hline CHEMBL1333855 & 688497 & 5.65 & 5.7238 & TRN \\
\hline CHEMBL1311453 & 688497 & 4.45 & 4.5103 & TST \\
\hline CHEMBL1338064 & 688497 & 4.45 & 4.9537 & TRN \\
\hline CHEMBL1301082 & 688497 & 5.25 & 4.9306 & TRN \\
\hline CHEMBL1312031 & 688497 & 5.25 & 5.0841 & TST \\
\hline CHEMBL1442419 & 688497 & 6.0 & 5.1403 & TRN \\
\hline CHEMBL1528123 & 688497 & 5.25 & 4.9242 & TRN \\
\hline CHEMBL 3190594 & 688497 & 6.05 & 5.4538 & TRN \\
\hline CHEMBL1507171 & 688497 & 5.1 & 4.8899 & TST \\
\hline CHEMBL1527572 & 688497 & 4.9 & 5.2681 & TST \\
\hline CHEMBL1448690 & 688497 & 4.9 & 5.0929 & TRN \\
\hline
\end{tabular}




\begin{tabular}{|c|c|c|c|c|}
\hline \multicolumn{5}{|c|}{ Supplemental Table S2.txt } \\
\hline CHEMBL1379298 & 688497 & 5.25 & 5.449 & TRN \\
\hline CHEMBL1430147 & 688497 & 4.45 & 4.7808 & TRN \\
\hline CHEMBL1478468 & 688497 & 4.65 & 4.9427 & TRN \\
\hline CHEMBL 2005296 & 688497 & 5.25 & 4.993 & TRN \\
\hline CHEMBL1601713 & 688497 & 8.0506 & 5.3067 & TRN \\
\hline CHEMBL1498496 & 688497 & 4.5 & 4.9966 & TRN \\
\hline CHEMBL1500780 & 688497 & 5.45 & 5.2192 & TST \\
\hline CHEMBL1583505 & 688497 & 5.05 & 4.9318 & TST \\
\hline CHEMBL1331809 & 688497 & 4.6 & 4.8448 & TRN \\
\hline CHEMBL1566611 & 688497 & 4.85 & 5.0929 & TST \\
\hline CHEMBL1449276 & 688497 & 5.2 & 5.2579 & TRN \\
\hline CHEMBL1336167 & 688497 & 5.9 & 5.0971 & TRN \\
\hline CHEMBL1314115 & 688497 & 5.9 & 5.2522 & TST \\
\hline CHEMBL1305054 & 688497 & 5.7 & 5.0874 & TRN \\
\hline CHEMBL1333980 & 688497 & 4.95 & 4.8676 & TRN \\
\hline CHEMBL1399768 & 688497 & 4.75 & 4.88 & TRN \\
\hline CHEMBL1568793 & 688497 & 4.45 & 5.1039 & TRN \\
\hline CHEMBL1497753 & 688497 & 5.0 & 4.9372 & TRN \\
\hline CHEMBL1610180 & 688497 & 5.45 & 5.0262 & TRN \\
\hline CHEMBL1328128 & 688497 & 5.0 & 5.058 & TRN \\
\hline CHEMBL1496338 & 688497 & 4.5 & 4.7902 & TRN \\
\hline CHEMBL1504312 & 688497 & 4.45 & 5.0073 & TRN \\
\hline CHEMBL1347216 & 688497 & 4.45 & 5.0891 & TST \\
\hline CHEMBL1326210 & 688497 & 5.65 & 4.931 & TST \\
\hline CHEMBL1322679 & 688497 & 4.95 & 4.9397 & TRN \\
\hline CHEMBL1491916 & 688497 & 4.95 & 4.9489 & TRN \\
\hline CHEMBL1559106 & 688497 & 5.0 & 4.9325 & TST \\
\hline CHEMBL1494120 & 688497 & 5.35 & 5.0642 & TRN \\
\hline CHEMBL 3194195 & 688497 & 5.8 & 4.8812 & TRN \\
\hline CHEMBL1327147 & 688497 & 4.45 & 5.1963 & TRN \\
\hline CHEMBL1477689 & 688497 & 4.8 & 5.0687 & TRN \\
\hline CHEMBL1545139 & 688497 & 4.4 & 5.3037 & TRN \\
\hline CHEMBL1453630 & 688497 & 6.25 & 5.0235 & TRN \\
\hline CHEMBL1500142 & 688497 & 5.0 & 5.1104 & TRN \\
\hline CHEMBL1496993 & 688497 & 4.95 & 5.0365 & TRN \\
\hline CHEMBL 3191440 & 688497 & 4.45 & 5.1454 & TST \\
\hline CHEMBL1369249 & 688497 & 4.95 & 4.9261 & TRN \\
\hline CHEMBL1470330 & 688497 & 4.85 & 5.2533 & TST \\
\hline CHEMBL484901 & 688497 & 4.5 & 5.3058 & TRN \\
\hline CHEMBL1341881 & 688497 & 4.65 & 5.2574 & TRN \\
\hline CHEMBL1447632 & 688497 & 4.45 & 4.563 & TRN \\
\hline CHEMBL1329054 & 688497 & 4.45 & 4.9669 & TRN \\
\hline CHEMBL1456373 & 688497 & 4.45 & 4.7421 & TRN \\
\hline CHEMBL1381511 & 688497 & 6.25 & 5.0866 & TRN \\
\hline CHEMBL1328499 & 688497 & 5.25 & 5.092 & TST \\
\hline CHEMBL1443773 & 688497 & 5.0 & 4.9924 & TRN \\
\hline CHEMBL3198849 & 688497 & 4.45 & 4.9643 & TRN \\
\hline CHEMBL1444381 & 688497 & 4.45 & 4.723 & TRN \\
\hline
\end{tabular}




\begin{tabular}{|c|c|c|c|c|c|}
\hline \multicolumn{6}{|c|}{ Supplemental Table S2.txt } \\
\hline CHEMBL1300479 & 688497 & 4.95 & 5.273 & TRN & \\
\hline CHEMBL1426965 & 688497 & 6.05 & 5.0823 & TRN & \\
\hline CHEMBL1613580 & 688497 & 4.85 & 4.7893 & TRN & \\
\hline CHEMBL297548 & 688497 & 4.65 & 4.8837 & TRN & \\
\hline CHEMBL1421665 & 688497 & 7.0 & 5.0332 & TRN & \\
\hline CHEMBL1603973 & 688497 & 5.4 & 4.8607 & TRN & \\
\hline CHEMBL1388358 & 688497 & 5.45 & 4.7181 & TRN & \\
\hline CHEMBL1377938 & 688497 & 4.45 & 5.2625 & TRN & \\
\hline CHEMBL1600203 & 688497 & 4.45 & 4.9625 & TRN & \\
\hline CHEMBL1416769 & 688497 & 4.7 & 4.5052 & TRN & \\
\hline CHEMBL1451332 & 688497 & 5.2 & 5.0969 & TST & \\
\hline CHEMBL1520975 & 688497 & 4.65 & 5.1617 & TST & \\
\hline CHEMBL1469937 & 688497 & 5.0 & 4.8904 & TRN & \\
\hline CHEMBL1499999 & 688497 & 4.95 & 5.0157 & TRN & \\
\hline CHEMBL1489906 & 688497 & 4.8 & 5.4343 & TST & \\
\hline CHEMBL1399858 & 688497 & 4.85 & 5.0278 & TST & \\
\hline CHEMBL1390971 & 688497 & 4.85 & 5.0522 & TRN & \\
\hline CHEMBL1569275 & 688497 & 4.45 & 4.8913 & TRN & \\
\hline CHEMBL1367183 & 688497 & 4.6 & 4.5763 & TRN & \\
\hline CHEMBL1483228 & 688497 & 5.25 & 5.0636 & TRN & \\
\hline CHEMBL1558159 & 688497 & 4.45 & 4.9076 & TRN & \\
\hline CHEMBL1412091 & 688497 & 5.45 & 4.7039 & TRN & \\
\hline CHEMBL1456947 & 688497 & 4.9 & 5.2577 & TRN & \\
\hline CHEMBL3197766 & 688497 & 4.45 & 5.1461 & TRN & \\
\hline CHEMBL1410333 & 688497 & 4.45 & 5.3386 & TRN & \\
\hline CHEMBL1360779 & 688497 & 4.45 & 5.0699 & TRN & \\
\hline CHEMBL1560520 & 688497 & 5.5 & 5.1116 & TRN & \\
\hline CHEMBL1460497 & 688497 & 4.75 & 4.8173 & TRN & \\
\hline CHEMBL1555882 & 688497 & 5.25 & 5.1051 & TST & \\
\hline CHEMBL1405002 & 688497 & 4.95 & 5.1085 & TRN & \\
\hline CHEMBL1451897 & 688497 & 4.45 & 4.8835 & TRN & \\
\hline CHEMBL1342728 & 688497 & 4.45 & 4.6443 & TRN & \\
\hline CHEMBL1484356 & 688497 & 5.25 & 5.4661 & TRN & \\
\hline CHEMBL1309548 & 688497 & 5.15 & 4.9477 & TRN & \\
\hline CHEMBL1340766 & 688497 & 4.9 & 4.7360 & 2000000001 & TRN \\
\hline CHEMBL1549993 & 688497 & 4.65 & 4.9948 & TRN & \\
\hline CHEMBL1388140 & 688497 & 4.6 & 4.9869 & TST & \\
\hline CHEMBL1520645 & 688497 & 5.0 & 5.0657 & TRN & \\
\hline CHEMBL1349269 & 688497 & 4.75 & 5.0771 & TRN & \\
\hline CHEMBL1537959 & 688497 & 6.0 & 4.9964 & TST & \\
\hline CHEMBL1491980 & 688497 & 5.9 & 5.2475 & TRN & \\
\hline CHEMBL1349894 & 688497 & 4.9 & 5.0496 & TRN & \\
\hline CHEMBL3213776 & 688497 & 5.25 & 5.0710 & 0000000001 & TRN \\
\hline CHEMBL1607187 & 688497 & 5.55 & 5.3088 & TRN & \\
\hline CHEMBL1495358 & 688497 & 4.45 & 4.9095 & TRN & \\
\hline CHEMBL1537642 & 688497 & 4.85 & 4.9172 & TRN & \\
\hline CHEMBL1568953 & 688497 & 5.9 & 5.1354 & TRN & \\
\hline CHEMBL1330320 & 688497 & 5.55 & 5.2861 & TRN & \\
\hline
\end{tabular}




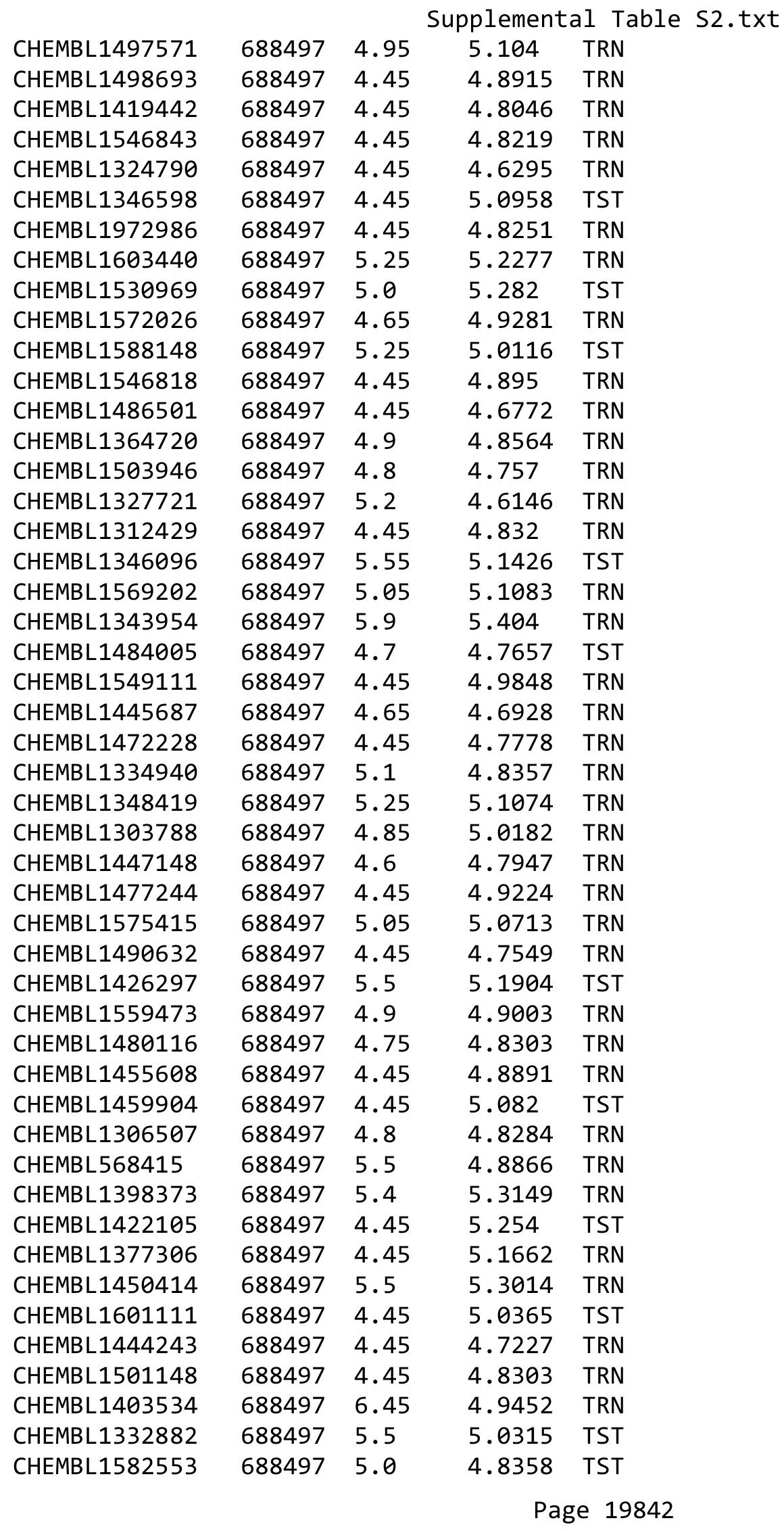




\begin{tabular}{|c|c|c|c|c|c|}
\hline \\
\hline CHEMBL1300348 & 688497 & 4.7 & 5.0077 & TST & \\
\hline CHEMBL1381673 & 688497 & 4.5 & 4.8695 & TRN & \\
\hline CHEMBL1428640 & 688497 & 6.3 & 5.2354 & TST & \\
\hline CHEMBL1501538 & 688497 & 5.2 & 5.215 & TST & \\
\hline CHEMBL1343309 & 688497 & 4.65 & 4.82100 & 0000000001 & TRN \\
\hline CHEMBL1350693 & 688497 & 4.45 & 4.9794 & TRN & \\
\hline CHEMBL1568038 & 688497 & 4.45 & 5.1758 & TRN & \\
\hline CHEMBL3190103 & 688497 & 4.45 & 5.2419 & TST & \\
\hline CHEMBL1526525 & 688497 & 4.45 & 5.3763 & TRN & \\
\hline CHEMBL1984804 & 688497 & 4.65 & 4.9103 & TRN & \\
\hline CHEMBL1462019 & 688497 & 4.95 & 4.8445 & TST & \\
\hline CHEMBL1540048 & 688497 & 4.45 & 4.8348 & TRN & \\
\hline CHEMBL1576597 & 688497 & 5.2 & 5.2795 & TST & \\
\hline CHEMBL1375747 & 688497 & 4.5 & 4.7152 & TRN & \\
\hline CHEMBL1579056 & 688497 & 4.7 & 5.0207 & TRN & \\
\hline CHEMBL1306180 & 688497 & 5.3 & 5.1996 & TRN & \\
\hline CHEMBL1582561 & 688497 & 5.85 & 4.849 & TRN & \\
\hline CHEMBL1305462 & 688497 & 5.6 & 4.9421 & TRN & \\
\hline CHEMBL1415545 & 688497 & 5.0 & 5.0755 & TRN & \\
\hline CHEMBL1401744 & 688497 & 4.45 & 4.9678 & TRN & \\
\hline CHEMBL1302010 & 688497 & 4.9 & 5.2919 & TST & \\
\hline CHEMBL1368766 & 688497 & 5.35 & 5.1475 & TRN & \\
\hline CHEMBL1530141 & 688497 & 6.05 & 5.1547 & TRN & \\
\hline CHEMBL3212279 & 688497 & 4.7 & 4.9413 & TST & \\
\hline CHEMBL 3197484 & 688497 & 5.55 & 5.1959 & TST & \\
\hline CHEMBL1310837 & 688497 & 4.45 & 4.7631 & TRN & \\
\hline CHEMBL1610755 & 688497 & 5.4 & 5.0824 & TST & \\
\hline CHEMBL1562249 & 688497 & 5.4 & 5.26 & TRN & \\
\hline CHEMBL1535019 & 688497 & 5.0 & 4.9234 & TRN & \\
\hline CHEMBL1508162 & 688497 & 6.25 & 5.0622 & TRN & \\
\hline CHEMBL1575958 & 688497 & 6.0 & 4.9189 & TRN & \\
\hline CHEMBL1528103 & 688497 & 4.45 & 5.41 & TRN & \\
\hline CHEMBL1307119 & 688497 & 4.9 & 5.2016 & TST & \\
\hline CHEMBL1984098 & 688497 & 5.45 & 5.0336 & TST & \\
\hline CHEMBL1389616 & 688497 & 4.65 & 5.0346 & TST & \\
\hline CHEMBL1548309 & 688497 & 6.05 & 4.9739 & TST & \\
\hline CHEMBL1382577 & 688497 & 5.45 & 5.5052 & TRN & \\
\hline CHEMBL1546378 & 688497 & 4.45 & 5.0716 & TST & \\
\hline CHEMBL1490818 & 688497 & 4.45 & 5.0128 & TRN & \\
\hline CHEMBL1392138 & 688497 & 5.5 & 4.8346 & TST & \\
\hline CHEMBL1305142 & 688497 & 4.6 & 5.0248 & TST & \\
\hline CHEMBL1336199 & 688497 & 5.35 & 5.2342 & TRN & \\
\hline CHEMBL1501307 & 688497 & 4.55 & 4.9119 & TST & \\
\hline CHEMBL1439919 & 688497 & 6.2 & 5.2635 & TRN & \\
\hline CHEMBL3210390 & 688497 & 5.0 & 4.9967 & TRN & \\
\hline CHEMBL1582639 & 688497 & 5.4 & 5.1523 & TRN & \\
\hline CHEMBL1992293 & 688497 & 5.05 & 5.1014 & TST & \\
\hline CHEMBL1445497 & 688497 & 4.85 & 5.1615 & TRN & \\
\hline
\end{tabular}




\begin{tabular}{|c|c|c|c|c|c|}
\hline \multicolumn{6}{|c|}{ Supplemental Table S2.txt } \\
\hline CHEMBL1470009 & 688497 & 4.55 & 5.0979 & TST & \\
\hline CHEMBL1566829 & 688497 & 4.9 & 4.8605 & TRN & \\
\hline CHEMBL1377902 & 688497 & 6.45 & 5.0685 & TRN & \\
\hline CHEMBL 3194037 & 688497 & 4.95 & 4.6082 & TRN & \\
\hline CHEMBL1303348 & 688497 & 4.6 & 4.7945 & TRN & \\
\hline CHEMBL1521937 & 688497 & 4.9 & 4.7103 & TST & \\
\hline CHEMBL1598493 & 688497 & 5.0 & 5.0126 & TRN & \\
\hline CHEMBL1500523 & 688497 & 5.55 & 5.3079 & TRN & \\
\hline CHEMBL500601 & 688497 & 5.4 & 5.1699 & TRN & \\
\hline CHEMBL1402884 & 688497 & 5.9 & 5.091 & TRN & \\
\hline CHEMBL1336602 & 688497 & 4.6 & 4.7935 & TRN & \\
\hline CHEMBL 3208232 & 688497 & 4.75 & 5.1462 & TRN & \\
\hline CHEMBL1454798 & 688497 & 4.8 & 4.9683 & TRN & \\
\hline CHEMBL1390071 & 688497 & 5.25 & 5.3488 & TRN & \\
\hline CHEMBL1441773 & 688497 & 5.5 & 5.1697 & TST & \\
\hline CHEMBL1393180 & 688497 & 4.95 & 5.1672 & TST & \\
\hline CHEMBL1343828 & 688497 & 5.75 & 4.9652 & TRN & \\
\hline CHEMBL606532 & 688497 & 5.55 & 5.3921 & TRN & \\
\hline CHEMBL1532219 & 688497 & 4.45 & 5.1741 & TRN & \\
\hline CHEMBL1563930 & 688497 & 4.45 & 4.8811 & TRN & \\
\hline CHEMBL1505091 & 688497 & 5.05 & 5.0704 & TRN & \\
\hline CHEMBL1422254 & 688497 & 5.05 & 4.948 & TRN & \\
\hline CHEMBL1607077 & 688497 & 4.95 & 5.2008 & TRN & \\
\hline CHEMBL1378295 & 688497 & 4.6 & 4.8813 & TRN & \\
\hline CHEMBL1498845 & 688497 & 4.85 & 5.4054 & TST & \\
\hline CHEMBL1412433 & 688497 & 4.6 & 4.8758 & TRN & \\
\hline CHEMBL1526457 & 688497 & 4.45 & 4.8813 & TRN & \\
\hline CHEMBL1442947 & 688497 & 6.05 & 4.8843 & TRN & \\
\hline CHEMBL1483904 & 688497 & 4.65 & 5.0849 & TRN & \\
\hline CHEMBL1492044 & 688497 & 6.5 & 5.3754 & TST & \\
\hline CHEMBL1481265 & 688497 & 6.6499 & 5.1052 & TRN & \\
\hline CHEMBL1595157 & 688497 & 5.9 & 5.4578 & TST & \\
\hline CHEMBL1440223 & 688497 & 4.95 & 4.9471 & TRN & \\
\hline CHEMBL1501971 & 688497 & 6.0 & 4.9109 & TRN & \\
\hline CHEMBL1998816 & 688497 & 5.25 & 4.79899 & 99999999995 & TRN \\
\hline CHEMBL1557385 & 688497 & 4.45 & 4.8949 & TRN & \\
\hline CHEMBL1565384 & 688497 & 3.65 & 5.266 & TRN & \\
\hline CHEMBL1353719 & 688497 & 4.6 & 5.087 & TST & \\
\hline CHEMBL 3198564 & 688497 & 4.85 & 5.1963 & TRN & \\
\hline CHEMBL1387162 & 688497 & 5.15 & 5.0538 & TRN & \\
\hline CHEMBL1559999 & 688497 & 4.45 & 4.845 & TRN & \\
\hline CHEMBL1311645 & 688497 & 4.45 & 5.2725 & TST & \\
\hline CHEMBL 2007593 & 688497 & 4.45 & 4.8121 & TST & \\
\hline CHEMBL1967814 & 688497 & 4.95 & 5.1009 & TRN & \\
\hline CHEMBL1335100 & 688497 & 4.45 & 5.1904 & TRN & \\
\hline CHEMBL1406079 & 688497 & 4.65 & 5.3064 & TRN & \\
\hline CHEMBL1350387 & 688497 & 4.9 & 4.7708 & TRN & \\
\hline CHEMBL1323821 & 688497 & 4.45 & 5.0502 & TST & \\
\hline
\end{tabular}




\begin{tabular}{|c|c|c|c|c|}
\hline \multicolumn{5}{|c|}{ Supplemental Table s2.txt } \\
\hline CHEMBL1425784 & 688497 & 7.0 & 5.3417 & TRN \\
\hline CHEMBL1583046 & 688497 & 4.6 & 5.0769 & TRN \\
\hline CHEMBL1404931 & 688497 & 4.8 & 5.2245 & TRN \\
\hline CHEMBL1471617 & 688497 & 4.6 & 4.9712 & TRN \\
\hline CHEMBL1508294 & 688497 & 5.05 & 4.9334 & TST \\
\hline CHEMBL1368252 & 688497 & 5.5 & 5.041 & TRN \\
\hline CHEMBL1572883 & 688497 & 5.0 & 4.8346 & TRN \\
\hline CHEMBL3194640 & 688497 & 5.0 & 5.0879 & TRN \\
\hline CHEMBL1469462 & 688497 & 4.65 & 5.1264 & TRN \\
\hline CHEMBL1384273 & 688497 & 4.9 & 5.2556 & TRN \\
\hline CHEMBL1381778 & 688497 & 4.45 & 5.0752 & TRN \\
\hline CHEMBL3211904 & 688497 & 4.9 & 4.8756 & TRN \\
\hline CHEMBL1445047 & 688497 & 4.85 & 5.1306 & TRN \\
\hline CHEMBL1392046 & 688497 & 4.95 & 4.6088 & TST \\
\hline CHEMBL1401369 & 688497 & 4.5 & 4.6333 & TRN \\
\hline CHEMBL1352345 & 688497 & 4.95 & 5.0683 & TRN \\
\hline CHEMBL1418015 & 688497 & 6.25 & 4.9471 & TRN \\
\hline CHEMBL1430692 & 688497 & 4.95 & 5.0378 & TST \\
\hline CHEMBL1432276 & 688497 & 5.4 & 5.0573 & TRN \\
\hline CHEMBL1429415 & 688497 & 4.6 & 4.9791 & TRN \\
\hline CHEMBL1425916 & 688497 & 5.0 & 4.9104 & TRN \\
\hline CHEMBL3194032 & 688497 & 5.45 & $5.1220 e$ & 0000000001 \\
\hline CHEMBL1564401 & 688497 & 4.9 & 5.17 & TRN \\
\hline CHEMBL1559953 & 688497 & 4.45 & 5.1341 & TST \\
\hline CHEMBL171699 & 688497 & 5.55 & 5.6237 & TRN \\
\hline CHEMBL1486338 & 688497 & 4.45 & 5.2374 & TST \\
\hline CHEMBL3208471 & 688497 & 4.65 & 5.126 & TRN \\
\hline CHEMBL1567420 & 688497 & 5.95 & 5.041 & TRN \\
\hline CHEMBL1360098 & 688497 & 5.15 & 5.2859 & TRN \\
\hline CHEMBL1327964 & 688497 & 4.8 & 4.723 & TRN \\
\hline CHEMBL1556453 & 688497 & 6.6499 & 4.7961 & TST \\
\hline CHEMBL1304408 & 688497 & 4.65 & 4.657 & TRN \\
\hline CHEMBL1300834 & 688497 & 5.2 & 4.9971 & TRN \\
\hline CHEMBL1532078 & 688497 & 4.95 & 4.8688 & TRN \\
\hline CHEMBL3191465 & 688497 & 5.8 & 4.9821 & TRN \\
\hline CHEMBL1578113 & 688497 & 4.85 & 4.9099 & TRN \\
\hline CHEMBL1469709 & 688497 & 4.45 & 4.6141 & TRN \\
\hline CHEMBL1313746 & 688497 & 6.2 & 5.2854 & TRN \\
\hline CHEMBL1529054 & 688497 & 4.45 & 5.3332 & TRN \\
\hline CHEMBL1393586 & 688497 & 5.15 & 5.3198 & TST \\
\hline CHEMBL1408013 & 688497 & 4.6 & 4.85 & TRN \\
\hline CHEMBL1437993 & 688497 & 5.8 & 4.9702 & TRN \\
\hline CHEMBL1576386 & 688497 & 4.95 & 4.9529 & TST \\
\hline CHEMBL1490855 & 688497 & 6.05 & 5.0042 & TRN \\
\hline CHEMBL1447917 & 688497 & 4.95 & 4.9746 & TRN \\
\hline CHEMBL1406624 & 688497 & 4.45 & 5.1223 & TST \\
\hline CHEMBL1379516 & 688497 & 4.7 & 5.3944 & TST \\
\hline CHEMBL1400519 & 688497 & 4.65 & 4.8218 & TST \\
\hline
\end{tabular}




\begin{tabular}{|c|c|c|c|c|c|}
\hline \multirow{3}{*}{$\begin{array}{l}\text { CHEMBL1547671 } \\
\text { CHEMBL } 140\end{array}$} & \multirow{3}{*}{$\begin{array}{l}688497 \\
688497\end{array}$} & \multicolumn{4}{|c|}{ Supplemental Table s2.txt } \\
\hline & & 5.35 & 5.1620 & 0000000001 & TRN \\
\hline & & 5.45 & 5.2391 & TRN & \\
\hline CHEMBL1588933 & 688497 & 5.25 & 5.1246 & TRN & \\
\hline CHEMBL1350390 & 688497 & 4.75 & 5.3467 & TST & \\
\hline CHEMBL 1406676 & 688497 & 4.65 & 5.2805 & TRN & \\
\hline CHEMBL1368535 & 688497 & 4.5 & 5.5717 & TRN & \\
\hline CHEMBL3193162 & 688497 & 5.0 & 5.1082 & TRN & \\
\hline CHEMBL1440565 & 688497 & 5.25 & 4.8491 & TRN & \\
\hline CHEMBL1381644 & 688497 & 5.15 & 5.3778 & TRN & \\
\hline CHEMBL1537933 & 688497 & 5.15 & 5.3237 & TRN & \\
\hline CHEMBL1520374 & 688497 & 5.0 & 5.0602 & TRN & \\
\hline CHEMBL1966224 & 688497 & 4.45 & 4.9365 & TST & \\
\hline CHEMBL1502711 & 688497 & 4.75 & 5.1098 & TRN & \\
\hline CHEMBL1599132 & 688497 & 4.95 & 4.689 & TRN & \\
\hline CHEMBL 2369240 & 688497 & 6.0 & 5.3786 & TRN & \\
\hline CHEMBL1307063 & 688497 & 5.5 & 4.8735 & TST & \\
\hline CHEMBL484385 & 688497 & 5.0 & 5.3383 & TRN & \\
\hline CHEMBL1456623 & 688497 & 5.4 & 4.9778 & TRN & \\
\hline CHEMBL1495282 & 688497 & 5.95 & 5.0441 & TRN & \\
\hline CHEMBL1484662 & 688497 & 5.95 & 5.1039 & TST & \\
\hline CHEMBL1550612 & 688497 & 4.45 & 4.9792 & TRN & \\
\hline CHEMBL1313273 & 688497 & 5.55 & 5.2769 & TRN & \\
\hline CHEMBL1307708 & 688497 & 4.55 & 4.9038 & TRN & \\
\hline CHEMBL1566835 & 688497 & 4.65 & 5.0638 & TST & \\
\hline CHEMBL1319304 & 688497 & 5.05 & 5.1732 & TRN & \\
\hline CHEMBL3207948 & 688497 & 5.15 & 4.9612 & TST & \\
\hline CHEMBL1336032 & 688497 & 4.45 & 5.2327 & TRN & \\
\hline CHEMBL1347518 & 688497 & 5.25 & 4.8911 & TST & \\
\hline CHEMBL1364298 & 688497 & 4.9 & 4.8159 & TRN & \\
\hline CHEMBL1472406 & 688497 & 4.65 & 4.9828 & TRN & \\
\hline CHEMBL1386408 & 688497 & 5.2 & 5.0484 & TRN & \\
\hline CHEMBL1375364 & 688497 & 4.75 & 5.0518 & TRN & \\
\hline CHEMBL1425322 & 688497 & 6.3 & 5.1118 & TRN & \\
\hline CHEMBL1612574 & 688497 & 5.6 & 5.0775 & TRN & \\
\hline CHEMBL1611658 & 688497 & 4.45 & 4.7447 & TRN & \\
\hline CHEMBL1423849 & 688497 & 4.8 & 4.6007 & TRN & \\
\hline CHEMBL1407890 & 688497 & 4.45 & 5.0405 & TRN & \\
\hline CHEMBL1585661 & 688497 & 4.75 & 4.7985 & TRN & \\
\hline CHEMBL1339786 & 688497 & 5.0 & 5.0564 & TRN & \\
\hline CHEMBL1576973 & 688497 & 4.45 & 5.1368 & TRN & \\
\hline CHEMBL1392922 & 688497 & 4.7 & 4.9245 & TRN & \\
\hline CHEMBL1466488 & 688497 & 4.45 & 4.9394 & TRN & \\
\hline CHEMBL1416155 & 688497 & 4.45 & 4.9133 & TRN & \\
\hline CHEMBL1455689 & 688497 & 5.0 & 5.0854 & TRN & \\
\hline CHEMBL1501061 & 688497 & 5.05 & 4.8334 & TRN & \\
\hline CHEMBL1541291 & 688497 & 5.2 & 5.0232 & TRN & \\
\hline CHEMBL1608942 & 688497 & 4.9 & 5.0323 & TRN & \\
\hline CHEMBL1446779 & 688497 & 4.8 & 4.8103 & TRN & \\
\hline
\end{tabular}




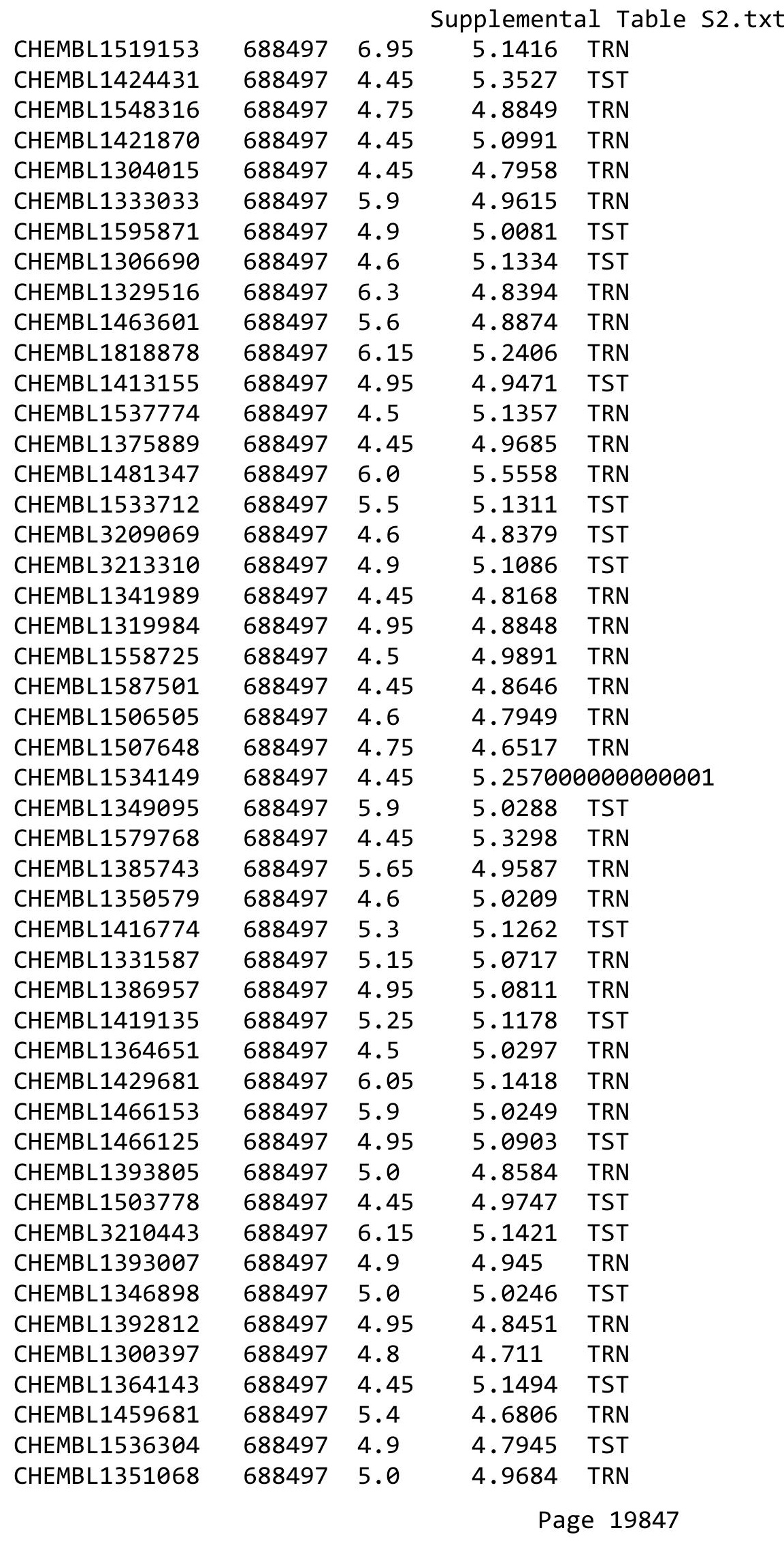




\begin{tabular}{|c|c|c|c|c|}
\hline \multicolumn{5}{|c|}{ Supplemental Table S2.txt } \\
\hline CHEMBL1555516 & 688497 & 5.05 & 4.7069 & TRN \\
\hline CHEMBL1606906 & 688497 & 4.45 & 4.9626 & TST \\
\hline CHEMBL1401424 & 688497 & 4.65 & 5.2275 & TRN \\
\hline CHEMBL1370953 & 688497 & 4.45 & 4.8883 & TST \\
\hline CHEMBL1312754 & 688497 & 5.35 & 5.1632 & TRN \\
\hline CHEMBL600715 & 688497 & 5.7 & 5.3391 & TRN \\
\hline CHEMBL1324618 & 688497 & 4.45 & 4.8772 & TST \\
\hline CHEMBL1488173 & 688497 & 4.85 & 4.8166 & TRN \\
\hline CHEMBL1601794 & 688497 & 5.65 & 5.0781 & TRN \\
\hline CHEMBL1977709 & 688497 & 4.45 & 4.8637 & TRN \\
\hline CHEMBL1441426 & 688497 & 4.8 & 4.9408 & TRN \\
\hline CHEMBL3208127 & 688497 & 4.65 & 4.7055 & TRN \\
\hline CHEMBL1988072 & 688497 & 4.9 & 5.1624 & TRN \\
\hline CHEMBL1338551 & 688497 & 4.8 & 5.1532 & TST \\
\hline CHEMBL1334989 & 688497 & 4.75 & 5.0498 & TST \\
\hline CHEMBL1402073 & 688497 & 5.25 & 5.5406 & TST \\
\hline CHEMBL1580805 & 688497 & 4.45 & 4.965 & TRN \\
\hline CHEMBL1424691 & 688497 & 4.45 & 4.9308 & TST \\
\hline CHEMBL1562190 & 688497 & 6.3 & 4.9411 & TRN \\
\hline CHEMBL1340399 & 688497 & 5.15 & 4.8249 & TRN \\
\hline CHEMBL1464072 & 688497 & 4.85 & 4.7773 & TRN \\
\hline CHEMBL1346368 & 688497 & 5.45 & 5.0081 & TST \\
\hline CHEMBL1382124 & 688497 & 4.45 & 4.6882 & TRN \\
\hline CHEMBL1378418 & 688497 & 5.2 & 5.0312 & TRN \\
\hline CHEMBL1405705 & 688497 & 4.95 & 5.063 & TRN \\
\hline CHEMBL1542264 & 688497 & 6.5501 & 5.3235 & TST \\
\hline CHEMBL1367915 & 688497 & 4.75 & 4.6495 & TRN \\
\hline CHEMBL1507536 & 688497 & 4.45 & 5.0336 & TRN \\
\hline CHEMBL1581716 & 688497 & 4.75 & 4.8947 & TRN \\
\hline CHEMBL1408097 & 688497 & 5.5 & 4.9923 & TRN \\
\hline CHEMBL1501091 & 688497 & 5.5 & 5.073 & TRN \\
\hline CHEMBL1480185 & 688497 & 5.25 & 5.0126 & TRN \\
\hline CHEMBL1470505 & 688497 & 4.6 & 5.2792 & TRN \\
\hline CHEMBL1698464 & 688497 & 4.45 & 4.8843 & TST \\
\hline CHEMBL1390194 & 688497 & 5.05 & 5.3633 & TRN \\
\hline CHEMBL1466123 & 688497 & 5.65 & 4.9345 & TRN \\
\hline CHEMBL1612026 & 688497 & 4.95 & 4.6065 & TST \\
\hline CHEMBL1392055 & 688497 & 4.9 & 5.1137 & TRN \\
\hline CHEMBL604321 & 688497 & 4.95 & 4.9936 & TRN \\
\hline CHEMBL1525286 & 688497 & 4.95 & 4.9288 & TRN \\
\hline CHEMBL510773 & 688497 & 6.2 & 5.1945 & TRN \\
\hline CHEMBL1442412 & 688497 & 4.6 & 4.7828 & TRN \\
\hline CHEMBL1441224 & 688497 & 4.45 & 5.0151 & TRN \\
\hline CHEMBL1459350 & 688497 & 5.0 & 5.152 & TRN \\
\hline CHEMBL585840 & 688497 & 4.95 & 5.0433 & TRN \\
\hline CHEMBL1505209 & 688497 & 4.55 & 5.2578 & TRN \\
\hline CHEMBL1403781 & 688497 & 4.45 & 5.2239 & TRN \\
\hline CHEMBL1365262 & 688497 & 4.45 & 4.8223 & TRN \\
\hline
\end{tabular}




\begin{tabular}{|c|c|c|c|c|}
\hline \multicolumn{5}{|c|}{ Supplemental Table S2.txt } \\
\hline CHEMBL3190967 & 688497 & 5.15 & 5.2198 & TRN \\
\hline CHEMBL1534621 & 688497 & 4.45 & 5.4905 & TRN \\
\hline CHEMBL1379045 & 688497 & 4.95 & 4.937 & TRN \\
\hline CHEMBL1376861 & 688497 & 4.45 & 4.7774 & TRN \\
\hline CHEMBL1462779 & 688497 & 4.45 & 4.9896 & TRN \\
\hline CHEMBL1464416 & 688497 & 5.45 & 5.3679 & TST \\
\hline CHEMBL1481805 & 688497 & 4.45 & 4.8951 & TRN \\
\hline CHEMBL1466835 & 688497 & 6.0 & 5.3833 & TRN \\
\hline CHEMBL1420841 & 688497 & 4.8 & 4.9785 & TRN \\
\hline CHEMBL1596468 & 688497 & 4.45 & 4.9141 & TRN \\
\hline CHEMBL1563158 & 688497 & 4.8 & 5.1531 & TST \\
\hline CHEMBL48310 & 688497 & 5.05 & 5.2613 & TST \\
\hline CHEMBL1391401 & 688497 & 6.25 & 5.1712 & TRN \\
\hline CHEMBL1362560 & 688497 & 4.45 & 4.9478 & TRN \\
\hline CHEMBL602828 & 688497 & 5.35 & 5.2532 & TRN \\
\hline CHEMBL 2004241 & 688497 & 6.05 & 5.1811 & TST \\
\hline CHEMBL1467225 & 688497 & 5.6 & 4.9035 & TRN \\
\hline CHEMBL1529988 & 688497 & 4.45 & 5.12 & TRN \\
\hline CHEMBL1352088 & 688497 & 5.5 & 5.0227 & TST \\
\hline CHEMBL1487918 & 688497 & 6.95 & 5.0917 & TRN \\
\hline CHEMBL1364681 & 688497 & 6.15 & 5.3149 & TRN \\
\hline CHEMBL1611779 & 688497 & 4.6 & 4.7067 & TRN \\
\hline CHEMBL1363249 & 688497 & 5.4 & 5.2296 & TRN \\
\hline CHEMBL1410239 & 688497 & 5.5 & 5.3698 & TRN \\
\hline CHEMBL3194250 & 688497 & 4.45 & 4.8139 & TST \\
\hline CHEMBL1559618 & 688497 & 4.6 & 5.0677 & TRN \\
\hline CHEMBL1597309 & 688497 & 6.25 & 5.0158 & TRN \\
\hline CHEMBL1352698 & 688497 & 5.6 & 5.0493 & TRN \\
\hline CHEMBL1606638 & 688497 & 5.25 & 4.8362 & TRN \\
\hline CHEMBL1391346 & 688497 & 4.45 & 4.7974 & TRN \\
\hline CHEMBL1378771 & 688497 & 4.5 & 4.9823 & TRN \\
\hline CHEMBL1495497 & 688497 & 4.65 & 5.0926 & TRN \\
\hline CHEMBL1383035 & 688497 & 4.65 & 4.8928 & TST \\
\hline CHEMBL1372163 & 688497 & 5.95 & 5.4093 & TRN \\
\hline CHEMBL1526621 & 688497 & 4.9 & 4.8603 & TRN \\
\hline CHEMBL1463695 & 688497 & 4.45 & 5.0836 & TST \\
\hline CHEMBL3186408 & 688497 & 4.85 & 5.3731 & TST \\
\hline CHEMBL1372554 & 688497 & 5.25 & 5.093 & TRN \\
\hline CHEMBL1457745 & 688497 & 4.9 & 4.8906 & TRN \\
\hline CHEMBL1415402 & 688497 & 4.55 & 5.0077 & TRN \\
\hline CHEMBL1561030 & 688497 & 4.75 & 4.9463 & TRN \\
\hline CHEMBL1521444 & 688497 & 4.45 & 5.1116 & TRN \\
\hline CHEMBL1522085 & 688497 & 5.6 & 5.1847 & TST \\
\hline CHEMBL1322685 & 688497 & 4.45 & 4.9468 & TST \\
\hline CHEMBL3195040 & 688497 & 4.6 & 4.7069 & TRN \\
\hline CHEMBL1408320 & 688497 & 4.6 & 4.7929 & TRN \\
\hline CHEMBL1458299 & 688497 & 6.0 & 4.9519 & TST \\
\hline CHEMBL1372884 & 688497 & 4.6 & 5.1506 & TST \\
\hline
\end{tabular}




\begin{tabular}{|c|c|c|c|c|c|}
\hline \multicolumn{6}{|c|}{ Supplemental Table S2.txt } \\
\hline CHEMBL1996451 & 688497 & 5.0 & 4.9967 & TRN & \\
\hline CHEMBL1594228 & 688497 & 4.45 & 5.1065 & TST & \\
\hline CHEMBL1461972 & 688497 & 4.95 & 5.1148 & TRN & \\
\hline CHEMBL1610440 & 688497 & 5.15 & 4.6195 & TST & \\
\hline CHEMBL1502873 & 688497 & 4.45 & 5.2627 & TRN & \\
\hline CHEMBL1607562 & 688497 & 4.5 & 5.4962 & TRN & \\
\hline CHEMBL1461074 & 688497 & 4.9 & 5.2662 & TRN & \\
\hline CHEMBL1526864 & 688497 & 5.05 & 4.8609 & TRN & \\
\hline CHEMBL1351387 & 688497 & 4.5 & 5.2601 & TRN & \\
\hline CHEMBL1577055 & 688497 & 4.45 & 4.8642 & TRN & \\
\hline CHEMBL1558862 & 688497 & 4.7 & 5.1788 & TRN & \\
\hline CHEMBL1548620 & 688497 & 7.0501 & 5.1583 & TST & \\
\hline CHEMBL1511526 & 688497 & 4.45 & 4.5761 & TRN & \\
\hline CHEMBL1358722 & 688497 & 6.45 & 5.7875 & TST & \\
\hline CHEMBL1450148 & 688497 & 4.85 & $5.0680 e$ & 00000000005 & TRN \\
\hline CHEMBL1364573 & 688497 & 4.85 & 5.1304 & TST & \\
\hline CHEMBL1319848 & 688497 & 5.45 & 4.9224 & TST & \\
\hline CHEMBL1542058 & 688497 & 5.15 & 5.0396 & TST & \\
\hline CHEMBL1300342 & 688497 & 5.5 & 5.6055 & TRN & \\
\hline CHEMBL473106 & 688497 & 4.45 & 5.0876 & TST & \\
\hline CHEMBL1365426 & 688497 & 5.45 & 5.0569 & TRN & \\
\hline CHEMBL1468035 & 688497 & 5.9 & 5.0658 & TST & \\
\hline CHEMBL1440746 & 688497 & 5.55 & 5.1461 & TRN & \\
\hline CHEMBL1478762 & 688497 & 4.55 & 5.0053 & TRN & \\
\hline CHEMBL1484565 & 688497 & 4.85 & 5.0033 & TRN & \\
\hline CHEMBL309016 & 688497 & 4.6 & 4.7993 & TRN & \\
\hline CHEMBL1300959 & 688497 & 5.05 & 4.8533 & TRN & \\
\hline CHEMBL171620 & 688497 & 4.7 & 4.9778 & TST & \\
\hline CHEMBL1351864 & 688497 & 6.2 & 5.1519 & TRN & \\
\hline CHEMBL1373552 & 688497 & 4.45 & 5.1171 & TRN & \\
\hline CHEMBL1563347 & 688497 & 5.5 & 5.0049 & TRN & \\
\hline CHEMBL1559795 & 688497 & 5.35 & 5.42 & TST & \\
\hline CHEMBL1464425 & 688497 & 5.75 & 5.1437 & TRN & \\
\hline CHEMBL1377955 & 688497 & 4.65 & 5.3427 & TRN & \\
\hline CHEMBL1968732 & 688497 & 5.5 & 5.0427 & TRN & \\
\hline CHEMBL1429998 & 688497 & 4.45 & 5.0211 & TST & \\
\hline CHEMBL 1458566 & 688497 & 4.95 & 5.1494 & TRN & \\
\hline CHEMBL1371188 & 688497 & 4.85 & 4.7154 & TRN & \\
\hline CHEMBL1608535 & 688497 & 4.5 & 5.1402 & TRN & \\
\hline CHEMBL1379146 & 688497 & 5.45 & 5.2961 & TRN & \\
\hline CHEMBL1383374 & 688497 & 4.95 & 5.2609 & TRN & \\
\hline CHEMBL1597789 & 688497 & 4.8 & 5.2562 & TRN & \\
\hline CHEMBL1578607 & 688497 & 4.65 & 5.0466 & TRN & \\
\hline CHEMBL1480001 & 688497 & 4.45 & 5.0141 & TST & \\
\hline CHEMBL1307495 & 688497 & 4.45 & 4.6216 & TRN & \\
\hline CHEMBL1326167 & 688497 & 4.45 & 4.7091 & TRN & \\
\hline CHEMBL1421576 & 688497 & 4.8 & 4.7793 & TRN & \\
\hline CHEMBL1460085 & 688497 & 5.05 & 5.1028 & TRN & \\
\hline
\end{tabular}




\begin{tabular}{|c|c|c|c|c|c|}
\hline \multicolumn{6}{|c|}{ pıemental } \\
\hline CHEMBL150809 & 688497 & 4.95 & 5.1471 & TST & \\
\hline CHEMBL1501755 & 688497 & 4.45 & 4.7579 & TRN & \\
\hline CHEMBL1981103 & 688497 & 5.25 & 5.2253 & TST & \\
\hline CHEMBL1993788 & 688497 & 4.8 & 4.631 & TRN & \\
\hline CHEMBL1587742 & 688497 & 4.5 & 5.0631 & TRN & \\
\hline CHEMBL1418230 & 688497 & 4.45 & 5.0579 & TRN & \\
\hline CHEMBL1511914 & 688497 & 5.5 & 5.0679 & TST & \\
\hline CHEMBL1605546 & 688497 & 4.95 & 4.82600 & 00000000005 & TRN \\
\hline CHEMBL1331195 & 688497 & 5.6 & 5.0897 & TST & \\
\hline CHEMBL1334561 & 688497 & 4.65 & 4.9967 & TRN & \\
\hline CHEMBL1982203 & 688497 & 5.5 & 4.7552 & TRN & \\
\hline CHEMBL1380455 & 688497 & 5.9 & 5.0151 & TST & \\
\hline CHEMBL1428837 & 688497 & 4.45 & 5.1422 & TST & \\
\hline CHEMBL1392181 & 688497 & 4.9 & 5.2896 & TST & \\
\hline CHEMBL1383603 & 688497 & 5.45 & 4.7458 & TRN & \\
\hline CHEMBL1458403 & 688497 & 4.65 & 5.077 & TST & \\
\hline CHEMBL1577346 & 688497 & 4.75 & 4.9717 & TRN & \\
\hline CHEMBL1364085 & 688497 & 4.55 & 4.92399 & 99999999995 & TST \\
\hline CHEMBL1490048 & 688497 & 5.45 & 4.9451 & TRN & \\
\hline CHEMBL1557636 & 688497 & 5.65 & 5.1305 & TRN & \\
\hline CHEMBL1423464 & 688497 & 4.85 & 5.2175 & TST & \\
\hline CHEMBL1311755 & 688497 & 4.8 & 4.516 & TRN & \\
\hline CHEMBL1430426 & 688497 & 5.7 & 5.3284 & TRN & \\
\hline CHEMBL1569612 & 688497 & 5.5 & 5.3258 & TRN & \\
\hline CHEMBL1982381 & 688497 & 5.15 & 4.9903 & TST & \\
\hline CHEMBL1600841 & 688497 & 4.95 & 5.0232 & TST & \\
\hline CHEMBL1409563 & 688497 & 5.85 & 5.2367 & TST & \\
\hline CHEMBL1548403 & 688497 & 5.2 & 5.0599 & TRN & \\
\hline CHEMBL1544451 & 688497 & 4.45 & 5.221 & TRN & \\
\hline CHEMBL1402115 & 688497 & 4.95 & 5.3096 & TRN & \\
\hline CHEMBL1986111 & 688497 & 5.25 & 4.999 & TRN & \\
\hline CHEMBL1352429 & 688497 & 4.9 & 4.99100 & 00000000005 & TRN \\
\hline CHEMBL1340054 & 688497 & 4.65 & 4.9179 & TST & \\
\hline CHEMBL1466636 & 688497 & 5.1 & 4.9506 & TRN & \\
\hline CHEMBL1478289 & 688497 & 5.0 & 5.0189 & TRN & \\
\hline CHEMBL1544164 & 688497 & 4.45 & 4.6929 & TRN & \\
\hline CHEMBL1528919 & 688497 & 5.55 & 5.1792 & TRN & \\
\hline CHEMBL1582746 & 688497 & 4.95 & 5.1452 & TRN & \\
\hline CHEMBL1416536 & 688497 & 5.05 & 4.7371 & TRN & \\
\hline CHEMBL1528991 & 688497 & 4.4 & 4.8839 & TST & \\
\hline CHEMBL425808 & 688497 & 4.4 & 5.1974 & TST & \\
\hline CHEMBL1300631 & 688497 & 4.6 & 4.89 & TRN & \\
\hline CHEMBL3197771 & 688497 & 4.95 & 4.7519 & TRN & \\
\hline CHEMBL1610127 & 688497 & 5.25 & 5.2478 & TRN & \\
\hline CHEMBL1361574 & 688497 & 5.0 & 5.1403 & TRN & \\
\hline CHEMBL1340302 & 688497 & 4.8 & 4.8153 & TRN & \\
\hline CHEMBL1583500 & 688497 & 4.45 & 5.0855 & TST & \\
\hline CHEMBL1547893 & 688497 & 5.0 & 4.8382 & TST & \\
\hline
\end{tabular}




\begin{tabular}{|c|c|c|c|c|c|}
\hline \multicolumn{6}{|c|}{ Supplemental Table S2.txt } \\
\hline CHEMBL3214525 & 688497 & 4.45 & 5.0633 & TRN & \\
\hline CHEMBL1607369 & 688497 & 5.0 & 5.1099 & TRN & \\
\hline CHEMBL1327733 & 688497 & 5.6 & 5.2138 & TRN & \\
\hline CHEMBL3197761 & 688497 & 5.65 & 5.2158 & TRN & \\
\hline CHEMBL1424921 & 688497 & 6.0 & 5.1567 & TST & \\
\hline CHEMBL1452585 & 688497 & 4.95 & 4.7361 & TST & \\
\hline CHEMBL1585609 & 688497 & 5.6 & 5.0793 & TST & \\
\hline CHEMBL1353317 & 688497 & 4.9 & 4.7847 & TST & \\
\hline CHEMBL1324181 & 688497 & 4.45 & 4.9314 & TRN & \\
\hline CHEMBL1309620 & 688497 & 4.7 & 4.6987 & TRN & \\
\hline CHEMBL1348582 & 688497 & 5.5 & 5.2607 & TRN & \\
\hline CHEMBL1375245 & 688497 & 4.7 & 5.2806 & TRN & \\
\hline CHEMBL1986418 & 688497 & 6.1 & 5.5254 & TRN & \\
\hline CHEMBL1325115 & 688497 & 5.9 & 4.9847 & TRN & \\
\hline CHEMBL1385473 & 688497 & 5.4 & 5.1537 & TRN & \\
\hline CHEMBL1491910 & 688497 & 5.3 & 5.0162 & TRN & \\
\hline CHEMBL1418425 & 688497 & 4.95 & 5.1262 & TRN & \\
\hline CHEMBL1511556 & 688497 & 5.0 & 4.5915 & TRN & \\
\hline CHEMBL1461817 & 688497 & 4.9 & 5.2901 & TRN & \\
\hline CHEMBL1604790 & 688497 & 5.9 & 5.2907 & TST & \\
\hline CHEMBL1505502 & 688497 & 4.9 & 5.0576 & TST & \\
\hline CHEMBL394034 & 688497 & 5.1 & 5.1278 & TST & \\
\hline CHEMBL1415555 & 688497 & 4.95 & 4.8659 & TRN & \\
\hline CHEMBL1308931 & 688497 & 5.45 & 5.1603 & TRN & \\
\hline CHEMBL1402807 & 688497 & 4.65 & 4.9492 & TRN & \\
\hline CHEMBL1448642 & 688497 & 4.95 & 5.1707 & TRN & \\
\hline CHEMBL1609817 & 688497 & 4.45 & 5.2376 & TRN & \\
\hline CHEMBL1341103 & 688497 & 4.45 & 4.9803 & TRN & \\
\hline CHEMBL1612222 & 688497 & 5.1 & 4.9855 & TRN & \\
\hline CHEMBL1413946 & 688497 & 6.0 & 4.90600 & 0000000001 & TRN \\
\hline CHEMBL1388423 & 688497 & 6.15 & 4.8762 & TRN & \\
\hline CHEMBL1304755 & 688497 & 5.1 & 4.9545 & TRN & \\
\hline CHEMBL1305066 & 688497 & 4.45 & 4.7811 & TST & \\
\hline CHEMBL1571532 & 688497 & 5.3 & 5.0703 & TRN & \\
\hline CHEMBL1559514 & 688497 & 5.05 & 5.1996 & TRN & \\
\hline CHEMBL1359418 & 688497 & 4.95 & 5.4087 & TRN & \\
\hline CHEMBL1457385 & 688497 & 4.45 & 4.6314 & TST & \\
\hline CHEMBL1393005 & 688497 & 5.25 & 4.8559 & TST & \\
\hline CHEMBL1448492 & 688497 & 4.45 & 5.3086 & TST & \\
\hline CHEMBL1371624 & 688497 & 4.75 & 4.7611 & TRN & \\
\hline CHEMBL1456650 & 688497 & 4.45 & 4.8622 & TRN & \\
\hline CHEMBL1367761 & 688497 & 5.0 & 5.1738 & TRN & \\
\hline CHEMBL1345941 & 688497 & 4.9 & 4.9287 & TRN & \\
\hline CHEMBL1306240 & 688497 & 4.45 & 5.1697 & TST & \\
\hline CHEMBL1610431 & 688497 & 5.45 & 5.0767 & TRN & \\
\hline CHEMBL1453319 & 688497 & 4.45 & 5.5273 & TST & \\
\hline CHEMBL1582831 & 688497 & 5.85 & 5.2676 & TRN & \\
\hline CHEMBL1309450 & 688497 & 6.1 & 5.1473 & TST & \\
\hline
\end{tabular}




\begin{tabular}{|c|c|c|c|c|c|}
\hline \multirow[b]{2}{*}{ CHEMBL1493465 } & \multicolumn{5}{|c|}{ olemental Table S2. } \\
\hline & 688497 & 4.95 & 4.8661 & TRN & \\
\hline CHEMBL1598845 & 688497 & 6.45 & $5.2020 e$ & 0000000001 & TST \\
\hline CHEMBL1403484 & 688497 & 5.75 & 5.3735 & TST & \\
\hline CHEMBL1322742 & 688497 & 4.85 & 4.8746 & TRN & \\
\hline CHEMBL1495779 & 688497 & 5.1 & 5.0591 & TRN & \\
\hline CHEMBL1342278 & 688497 & 4.7 & 4.8371 & TRN & \\
\hline CHEMBL1345489 & 688497 & 4.95 & 4.9607 & TRN & \\
\hline CHEMBL1471305 & 688497 & 4.95 & 4.9223 & TRN & \\
\hline CHEMBL1447463 & 688497 & 4.45 & 4.9386 & TST & \\
\hline CHEMBL1605073 & 688497 & 4.45 & 4.7926 & TRN & \\
\hline CHEMBL1326683 & 688497 & 5.85 & 5.3772 & TST & \\
\hline CHEMBL1598391 & 688497 & 4.4 & 4.9043 & TRN & \\
\hline CHEMBL 3210845 & 688497 & 5.5 & 5.0275 & TST & \\
\hline CHEMBL1510974 & 688497 & 4.75 & 4.8304 & TRN & \\
\hline CHEMBL1424213 & 688497 & 4.6 & 5.112 & TST & \\
\hline CHEMBL1463326 & 688497 & 4.45 & 4.6201 & TRN & \\
\hline CHEMBL1612174 & 688497 & 5.65 & 5.001 & TRN & \\
\hline CHEMBL1304902 & 688497 & 4.65 & 4.6646 & TRN & \\
\hline CHEMBL1371663 & 688497 & 4.45 & 5.4367 & TST & \\
\hline CHEMBL1405179 & 688497 & 5.45 & 5.2364 & TRN & \\
\hline CHEMBL1307645 & 688497 & 5.8 & 5.1898 & TRN & \\
\hline CHEMBL1340942 & 688497 & 4.95 & 5.2155 & TST & \\
\hline CHEMBL1584534 & 688497 & 4.45 & 5.1943 & TST & \\
\hline CHEMBL1607896 & 688497 & 4.55 & 4.9202 & TRN & \\
\hline CHEMBL1468338 & 688497 & 4.65 & 5.06 & TRN & \\
\hline CHEMBL1597627 & 688497 & 5.45 & 5.1886 & TRN & \\
\hline CHEMBL1365226 & 688497 & 4.5 & 4.9311 & TRN & \\
\hline CHEMBL1487300 & 688497 & 4.45 & 4.5401 & TRN & \\
\hline CHEMBL1223397 & 688497 & 6.25 & 5.3827 & TRN & \\
\hline CHEMBL1519258 & 688497 & 5.25 & 5.1078 & TRN & \\
\hline CHEMBL1510528 & 688497 & 5.1 & 5.1828 & TST & \\
\hline CHEMBL1381821 & 688497 & 5.0 & 4.93199 & 99999999995 & TRN \\
\hline CHEMBL1299218 & 688497 & 5.0 & 5.3201 & TRN & \\
\hline CHEMBL1351058 & 688497 & 4.65 & 4.8366 & TRN & \\
\hline CHEMBL1964415 & 688497 & 5.4 & 4.8096 & TST & \\
\hline CHEMBL1497812 & 688497 & 4.95 & 5.2902 & TRN & \\
\hline CHEMBL1359316 & 688497 & 5.2 & 5.1925 & TRN & \\
\hline CHEMBL1568022 & 688497 & 5.0 & 4.9559 & TRN & \\
\hline CHEMBL1485612 & 688497 & 6.25 & 4.9398 & TRN & \\
\hline CHEMBL1349505 & 688497 & 4.5 & 5.2119 & TST & \\
\hline CHEMBL1497549 & 688497 & 6.5 & 5.6423 & TRN & \\
\hline CHEMBL1391554 & 688497 & 6.2 & 5.1048 & TRN & \\
\hline CHEMBL1510585 & 688497 & 4.95 & 4.9331 & TRN & \\
\hline CHEMBL1302706 & 688497 & 5.4 & 4.7876 & TST & \\
\hline CHEMBL1601188 & 688497 & 5.25 & $5.1560 e$ & 0000000001 & TRN \\
\hline CHEMBL1334524 & 688497 & 4.7 & 4.8473 & TST & \\
\hline CHEMBL1493797 & 688497 & 4.45 & 4.9749 & TRN & \\
\hline CHEMBL1384825 & 688497 & 4.9 & 4.8722 & TRN & \\
\hline
\end{tabular}




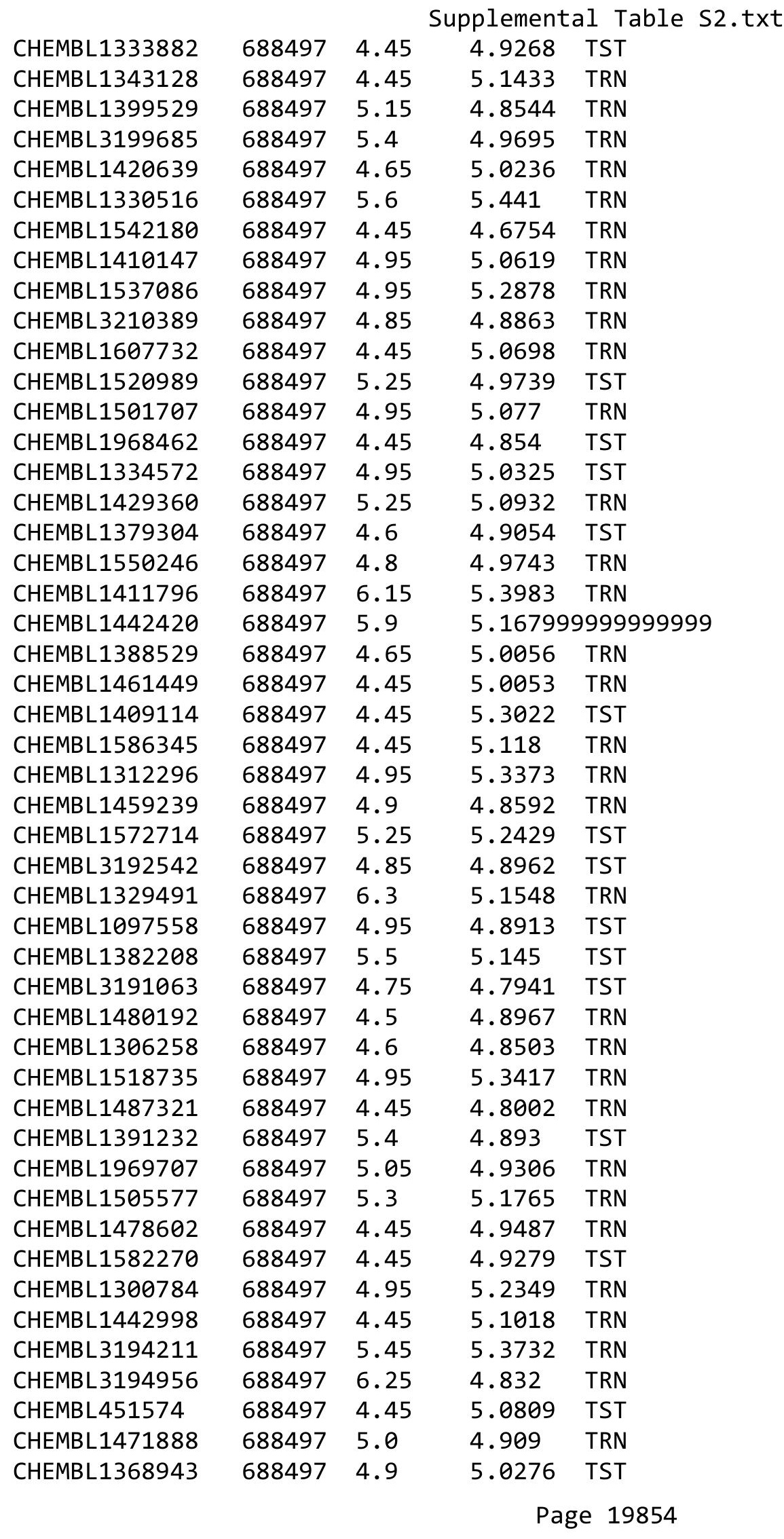




\begin{tabular}{|c|c|c|c|c|c|}
\hline \multicolumn{6}{|c|}{ Supplemental Table S2.txt } \\
\hline CHEMBL1370572 & 688497 & 4.45 & 5.0601 & TRN & \\
\hline CHEMBL1453168 & 688497 & 4.45 & 5.1981 & TST & \\
\hline CHEMBL1301184 & 688497 & 4.45 & 4.8784 & TRN & \\
\hline CHEMBL1400927 & 688497 & 4.45 & 4.958 & TRN & \\
\hline CHEMBL1335622 & 688497 & 6.25 & 4.8924 & TST & \\
\hline CHEMBL1313622 & 688497 & 4.7 & 5.0174 & TRN & \\
\hline CHEMBL1339283 & 688497 & 5.1 & 5.0185 & TRN & \\
\hline CHEMBL1459989 & 688497 & 5.55 & 5.1922 & TRN & \\
\hline CHEMBL1544409 & 688497 & 5.0 & 4.7268 & TRN & \\
\hline CHEMBL1380196 & 688497 & 5.2 & 4.9944 & TST & \\
\hline CHEMBL1327335 & 688497 & 4.9 & 4.9135 & TRN & \\
\hline CHEMBL1322334 & 688497 & 5.25 & 5.2341 & TRN & \\
\hline CHEMBL1565848 & 688497 & 4.7 & 5.0845 & TRN & \\
\hline CHEMBL1363716 & 688497 & 6.0 & 4.9713 & TST & \\
\hline CHEMBL1566677 & 688497 & 4.45 & 4.9038 & TRN & \\
\hline CHEMBL1528489 & 688497 & 4.75 & 5.4248 & TRN & \\
\hline CHEMBL1543416 & 688497 & 4.45 & 4.8783 & TRN & \\
\hline CHEMBL1605622 & 688497 & 4.45 & 5.0302 & TST & \\
\hline CHEMBL1580372 & 688497 & 5.0 & 5.0021 & TRN & \\
\hline CHEMBL1494212 & 688497 & 5.25 & 5.0455 & TST & \\
\hline CHEMBL1499709 & 688497 & 5.1 & 4.9502 & TRN & \\
\hline CHEMBL1520801 & 688497 & 5.05 & 5.0865 & TRN & \\
\hline CHEMBL1457341 & 688497 & 5.5 & 5.0653 & TRN & \\
\hline CHEMBL1447350 & 688497 & 4.8 & 4.9771 & TST & \\
\hline CHEMBL3199895 & 688497 & 4.6 & 5.2159 & TST & \\
\hline CHEMBL3196936 & 688497 & 5.35 & 5.3747 & TRN & \\
\hline CHEMBL1602299 & 688497 & 4.45 & 4.9033 & TRN & \\
\hline CHEMBL1421675 & 688497 & 4.45 & 4.7358 & TRN & \\
\hline CHEMBL1484690 & 688497 & 4.9 & 4.9155 & TST & \\
\hline CHEMBL 3208887 & 688497 & 6.95 & 5.0281 & TST & \\
\hline CHEMBL1559427 & 688497 & 4.9 & 5.13299 & 9999999999 & TST \\
\hline CHEMBL1343092 & 688497 & 4.6 & 5.032 & TRN & \\
\hline CHEMBL1329637 & 688497 & 4.45 & 4.8943 & TRN & \\
\hline CHEMBL1349631 & 688497 & 5.6 & 5.2674 & TRN & \\
\hline CHEMBL1418469 & 688497 & 4.45 & 4.6483 & TRN & \\
\hline CHEMBL1431161 & 688497 & 5.9 & 5.2511 & TST & \\
\hline CHEMBL1439596 & 688497 & 4.75 & 5.0183 & TRN & \\
\hline CHEMBL1400272 & 688497 & 4.7 & 4.9309 & TRN & \\
\hline CHEMBL1491893 & 688497 & 5.45 & 5.0666 & TRN & \\
\hline CHEMBL1576518 & 688497 & 4.45 & 4.9436 & TRN & \\
\hline CHEMBL1307139 & 688497 & 4.45 & 5.0339 & TST & \\
\hline CHEMBL1433282 & 688497 & 5.9 & 5.2004 & TRN & \\
\hline CHEMBL1372730 & 688497 & 4.45 & 4.6947 & TRN & \\
\hline CHEMBL1350778 & 688497 & 5.55 & 4.8888 & TRN & \\
\hline CHEMBL1996730 & 688497 & 6.0 & 5.4759 & TRN & \\
\hline CHEMBL1451301 & 688497 & 6.0 & 5.1544 & TST & \\
\hline CHEMBL1347253 & 688497 & 4.95 & 5.2315 & TRN & \\
\hline CHEMBL3193600 & 688497 & 5.5 & 4.9574 & TRN & \\
\hline
\end{tabular}




\begin{tabular}{|c|c|c|c|c|c|}
\hline \multicolumn{6}{|c|}{ Supplemental Table S2.txt } \\
\hline CHEMBL1448587 & 688497 & 4.45 & 5.0392 & TRN & \\
\hline CHEMBL1541483 & 688497 & 4.45 & 5.165 & TRN & \\
\hline CHEMBL1390546 & 688497 & 4.45 & 4.6332 & TRN & \\
\hline CHEMBL1428933 & 688497 & 4.45 & 5.5175 & TRN & \\
\hline CHEMBL3211905 & 688497 & 4.9 & 5.0057 & TRN & \\
\hline CHEMBL1613616 & 688497 & 4.95 & 4.7566 & TST & \\
\hline CHEMBL1351608 & 688497 & 4.95 & 4.9693 & TRN & \\
\hline CHEMBL1466192 & 688497 & 4.45 & 5.2966 & TST & \\
\hline CHEMBL1595410 & 688497 & 5.9 & 4.8736 & TRN & \\
\hline CHEMBL1319368 & 688497 & 4.45 & 4.9562 & TRN & \\
\hline CHEMBL1518893 & 688497 & 5.05 & 5.0642 & TRN & \\
\hline CHEMBL1498043 & 688497 & 4.45 & 4.7409 & TRN & \\
\hline CHEMBL1334256 & 688497 & 5.4 & 5.3208 & TRN & \\
\hline CHEMBL3191025 & 688497 & 6.05 & 5.25200 & 3000000001 & TRN \\
\hline CHEMBL1306021 & 688497 & 4.95 & 4.9406 & TRN & \\
\hline CHEMBL1581843 & 688497 & 4.8 & 5.1102 & TRN & \\
\hline CHEMBL1502977 & 688497 & 4.45 & 5.1174 & TRN & \\
\hline CHEMBL1531172 & 688497 & 4.95 & 4.9582 & TRN & \\
\hline CHEMBL1319011 & 688497 & 4.7 & 5.0858 & TRN & \\
\hline CHEMBL1498258 & 688497 & 4.7 & 4.8456 & TRN & \\
\hline CHEMBL1539023 & 688497 & 4.65 & 5.0021 & TST & \\
\hline CHEMBL1313872 & 688497 & 6.05 & 5.0623 & TRN & \\
\hline CHEMBL1501674 & 688497 & 5.15 & 5.2386 & TRN & \\
\hline CHEMBL1576958 & 688497 & 4.8 & 5.0353 & TRN & \\
\hline CHEMBL1334189 & 688497 & 4.95 & 4.9449 & TRN & \\
\hline CHEMBL1410014 & 688497 & 4.45 & 5.2405 & TRN & \\
\hline CHEMBL1430981 & 688497 & 4.45 & 5.0989 & TST & \\
\hline CHEMBL1360170 & 688497 & 4.45 & 4.8485 & TRN & \\
\hline CHEMBL1432870 & 688497 & 4.45 & 4.72 & TRN & \\
\hline CHEMBL1387598 & 688497 & 5.95 & 5.0389 & TRN & \\
\hline CHEMBL1402750 & 688497 & 4.65 & 5.0219 & TST & \\
\hline CHEMBL1583872 & 688497 & 5.0 & 5.3527 & TRN & \\
\hline CHEMBL1404337 & 688497 & 5.45 & 5.1624 & TRN & \\
\hline CHEMBL1401711 & 688497 & 4.5 & 4.8804 & TRN & \\
\hline CHEMBL1331961 & 688497 & 4.65 & 5.0474 & TRN & \\
\hline CHEMBL1381695 & 688497 & 6.1 & 5.1438 & TRN & \\
\hline CHEMBL1466677 & 688497 & 4.45 & 4.7539 & TRN & \\
\hline CHEMBL1607137 & 688497 & 4.45 & 5.0848 & TRN & \\
\hline CHEMBL1521026 & 688497 & 4.45 & 4.9009 & TST & \\
\hline CHEMBL 242080 & 688497 & 4.6 & 5.2073 & TST & \\
\hline CHEMBL1990716 & 688497 & 4.45 & 4.8586 & TST & \\
\hline CHEMBL1569289 & 688497 & 5.45 & 4.9726 & TRN & \\
\hline CHEMBL1409554 & 688497 & 5.7 & 5.1539 & TRN & \\
\hline CHEMBL1361658 & 688497 & 5.9 & 5.2329 & TST & \\
\hline CHEMBL1379178 & 688497 & 5.45 & 4.8986 & TRN & \\
\hline CHEMBL1490036 & 688497 & 6.25 & 5.2478 & TRN & \\
\hline CHEMBL1563976 & 688497 & 5.25 & 5.0938 & TST & \\
\hline CHEMBL1420058 & 688497 & 5.25 & 5.2542 & TRN & \\
\hline
\end{tabular}




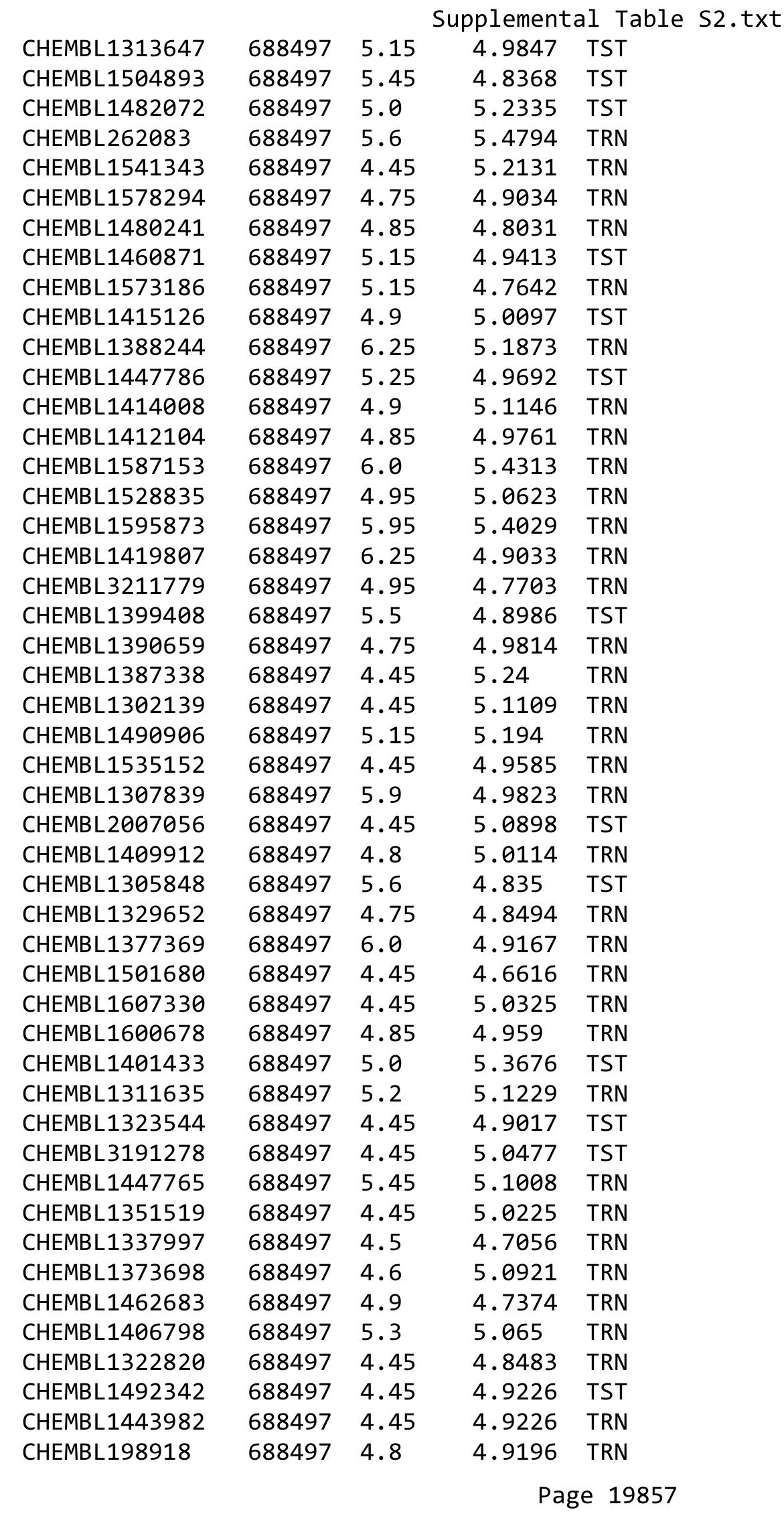




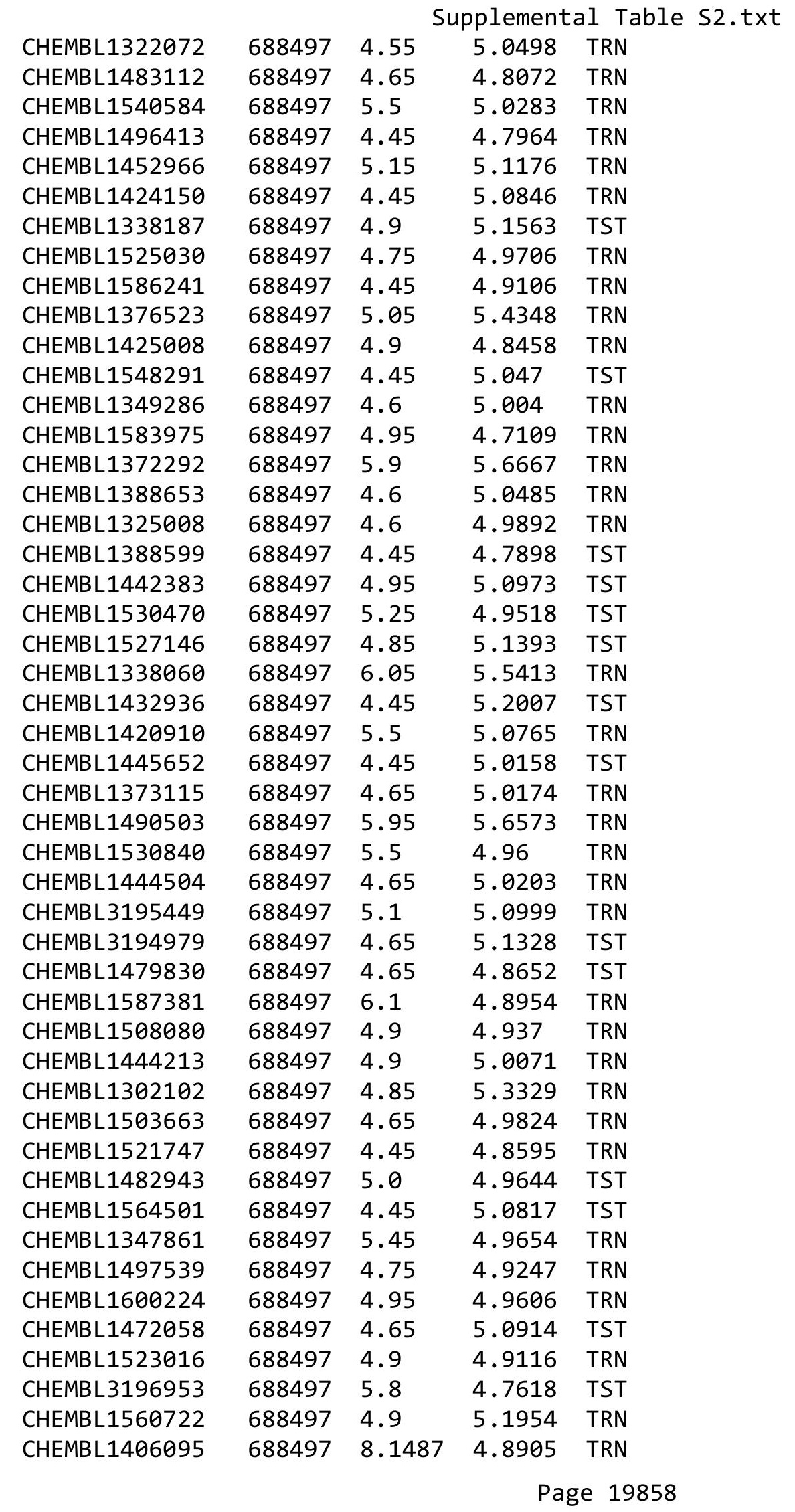




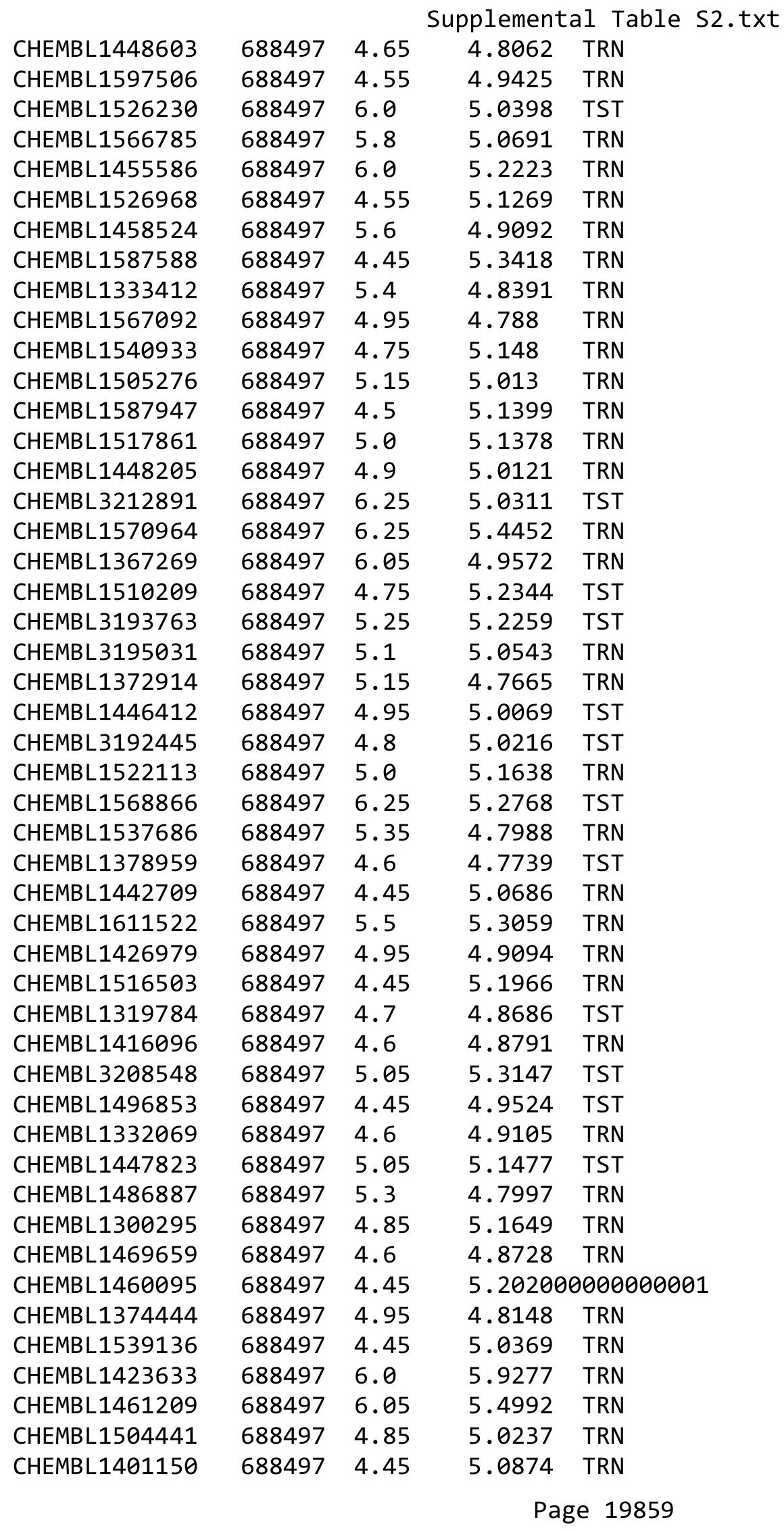

TRN 


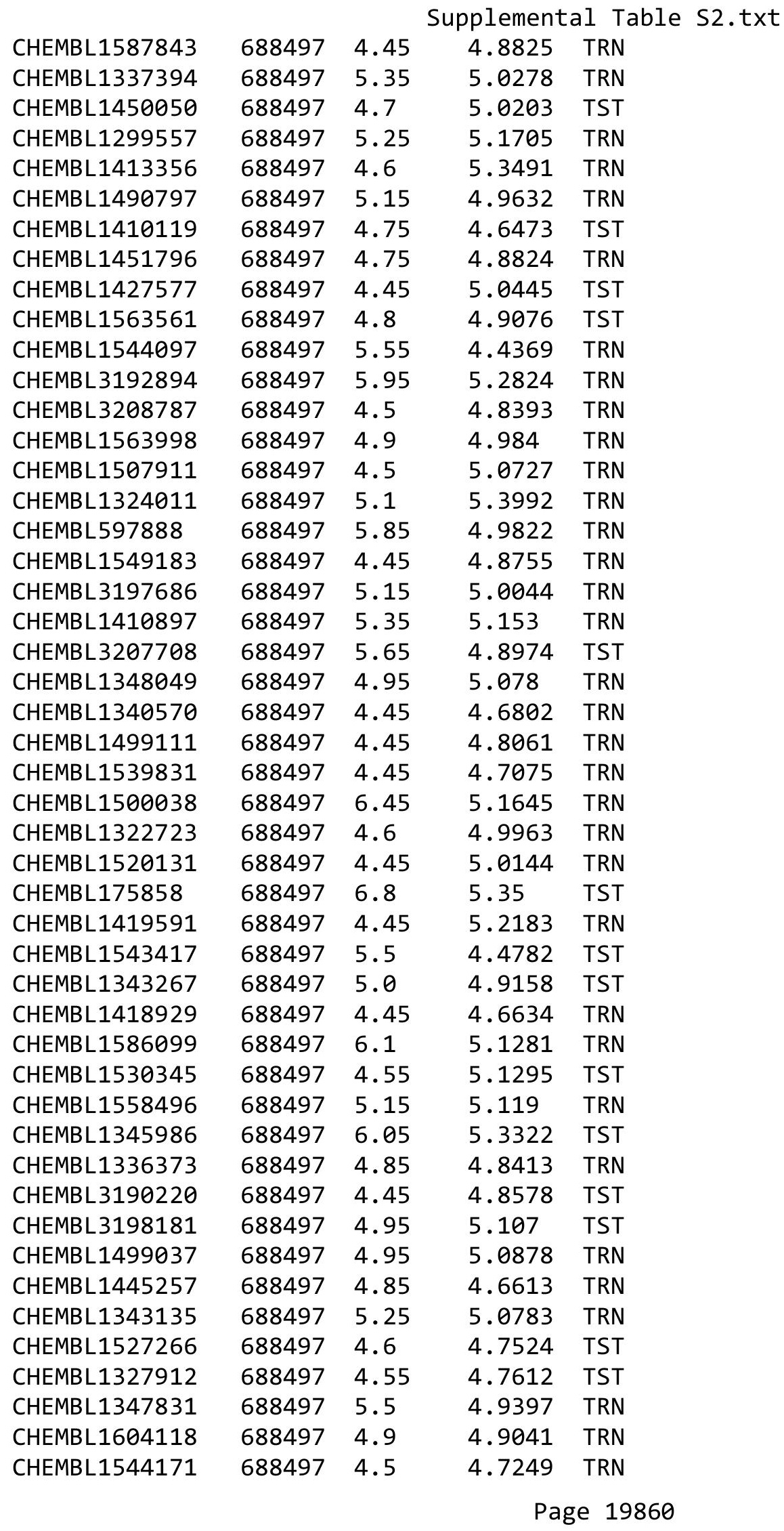




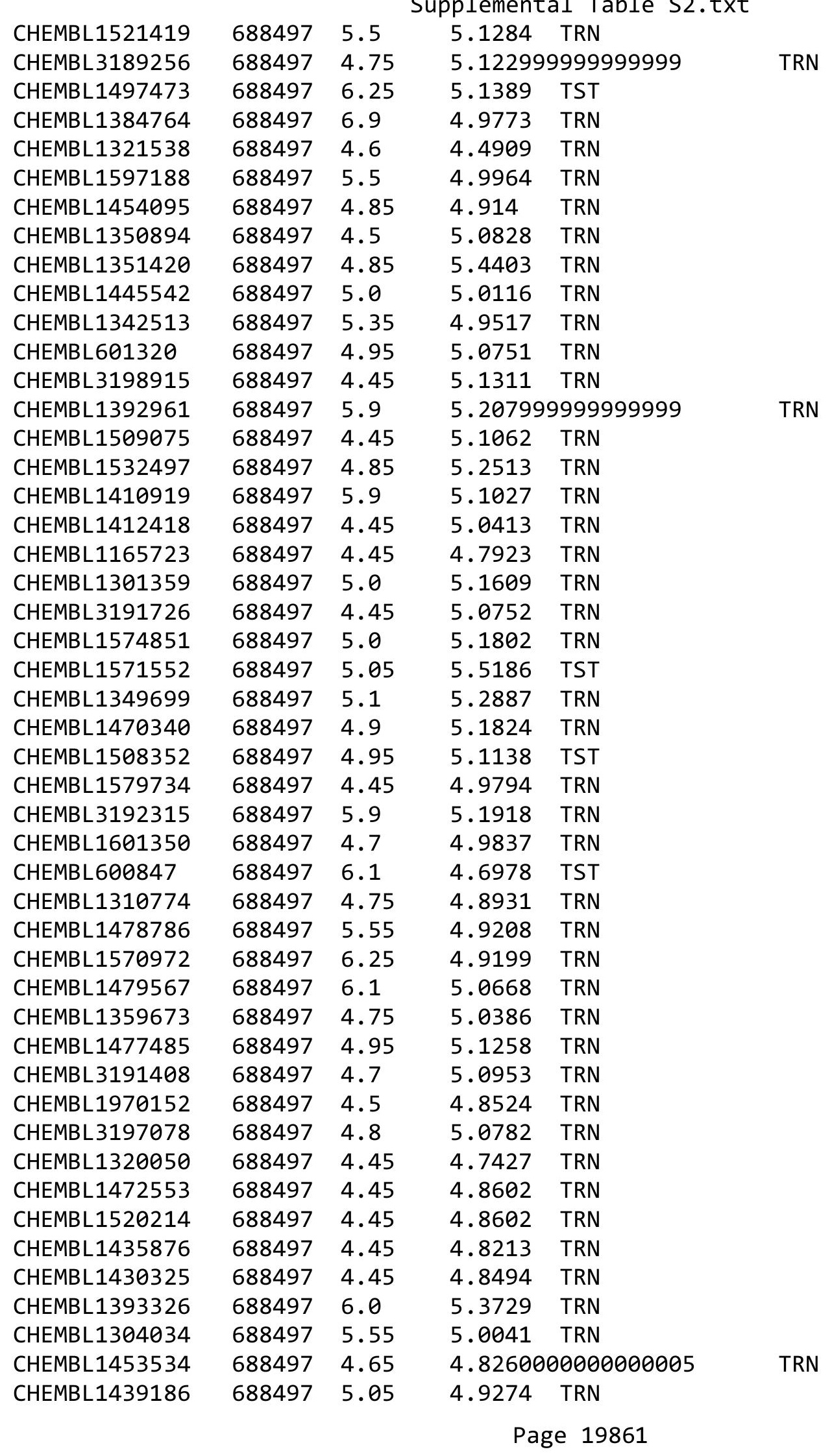




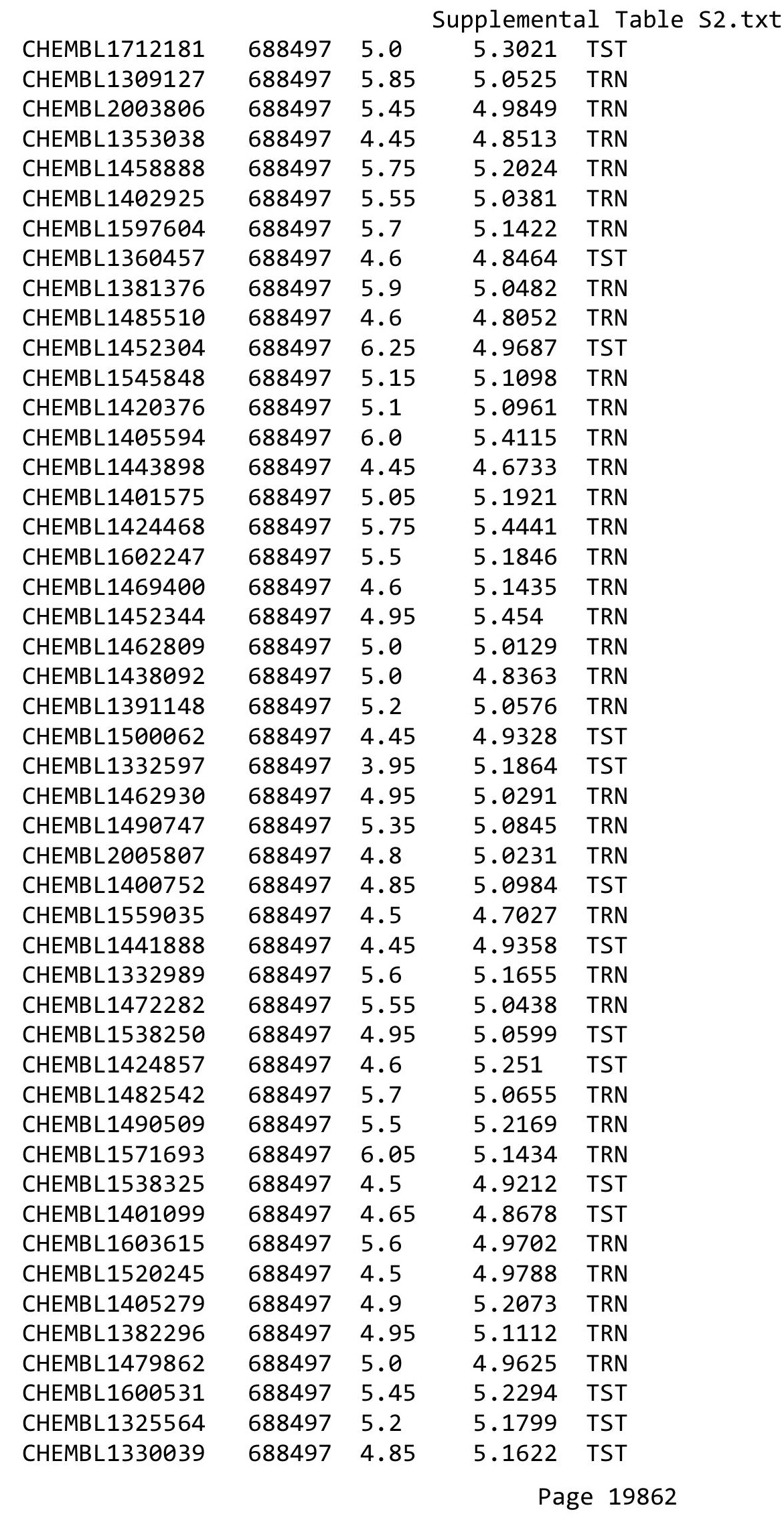




\begin{tabular}{|c|c|c|c|c|}
\hline & & & pplement & $d \perp$ \\
\hline CHEMBL1596176 & 688497 & 6.4 & 5.3157 & TST \\
\hline CHEMBL1401358 & 688497 & 5.9 & 5.0282 & TST \\
\hline CHEMBL1565290 & 688497 & 4.45 & 4.7728 & TRN \\
\hline CHEMBL1351738 & 688497 & 4.8 & 4.8612 & TST \\
\hline CHEMBL3198719 & 688497 & 6.25 & 5.0379 & TRN \\
\hline CHEMBL3199360 & 688497 & 4.65 & 5.0699 & TST \\
\hline CHEMBL1505630 & 688497 & 4.9 & 5.4341 & TRN \\
\hline CHEMBL1322066 & 688497 & 5.1 & 5.2522 & TRN \\
\hline CHEMBL1511313 & 688497 & 4.7 & 5.2588 & TST \\
\hline CHEMBL1563262 & 688497 & 4.6 & 5.0007 & TRN \\
\hline CHEMBL1529203 & 688497 & 5.05 & 5.0831 & TRN \\
\hline CHEMBL1421574 & 688497 & 4.7 & 4.7723 & TRN \\
\hline CHEMBL1525025 & 688497 & 4.6 & 5.0874 & TRN \\
\hline CHEMBL1498308 & 688497 & 4.45 & 4.7831 & TRN \\
\hline CHEMBL1543371 & 688497 & 4.85 & 4.9247 & TRN \\
\hline CHEMBL3193107 & 688497 & 5.15 & 4.9452 & TRN \\
\hline CHEMBL1359792 & 688497 & 4.85 & 5.0274 & TRN \\
\hline CHEMBL1587673 & 688497 & 4.45 & 5.0967 & TRN \\
\hline CHEMBL1431276 & 688497 & 6.95 & 4.9593 & TRN \\
\hline CHEMBL1414633 & 688497 & 4.45 & 4.7203 & TRN \\
\hline CHEMBL1468908 & 688497 & 5.5 & 5.1438 & TST \\
\hline CHEMBL1579809 & 688497 & 4.65 & 5.1423 & TST \\
\hline CHEMBL1611954 & 688497 & 5.0 & 4.7542 & TRN \\
\hline CHEMBL1484038 & 688497 & 4.7 & 4.9644 & TRN \\
\hline CHEMBL1582419 & 688497 & 4.45 & 5.142 & TRN \\
\hline CHEMBL1404185 & 688497 & 5.65 & 5.3281 & TST \\
\hline CHEMBL1329787 & 688497 & 4.45 & 5.0696 & TRN \\
\hline CHEMBL1380102 & 688497 & 5.25 & 5.0462 & TRN \\
\hline CHEMBL1521319 & 688497 & 4.85 & 5.0745 & TRN \\
\hline CHEMBL1500686 & 688497 & 4.55 & 4.7046 & TRN \\
\hline CHEMBL3207369 & 688497 & 5.5 & 4.9959 & TST \\
\hline CHEMBL1445336 & 688497 & 4.9 & 5.0167 & TRN \\
\hline CHEMBL1511397 & 688497 & 4.45 & 4.9056 & TRN \\
\hline CHEMBL1478280 & 688497 & 4.45 & 5.0339 & TRN \\
\hline CHEMBL1440703 & 688497 & 5.15 & 5.2431 & TST \\
\hline CHEMBL1439925 & 688497 & 5.9 & 4.7591 & TRN \\
\hline CHEMBL1415012 & 688497 & 4.85 & 4.9791 & TST \\
\hline CHEMBL1487705 & 688497 & 4.65 & 4.9974 & TRN \\
\hline CHEMBL1537842 & 688497 & 5.4 & 5.1889 & TST \\
\hline CHEMBL1363965 & 688497 & 5.55 & 4.7964 & TST \\
\hline CHEMBL1555696 & 688497 & 5.55 & 5.0873 & TRN \\
\hline CHEMBL1484163 & 688497 & 4.65 & 4.9346 & TRN \\
\hline CHEMBL1577768 & 688497 & 4.45 & 5.1936 & TRN \\
\hline CHEMBL1608585 & 688497 & 4.75 & 4.8767 & TST \\
\hline CHEMBL1426461 & 688497 & 5.5 & 4.8988 & TRN \\
\hline CHEMBL1462003 & 688497 & 5.1 & 4.9621 & TST \\
\hline CHEMBL1462335 & 688497 & 4.85 & 4.8693 & TRN \\
\hline CHEMBL1431962 & 688497 & 5.0 & 4.8005 & TST \\
\hline
\end{tabular}




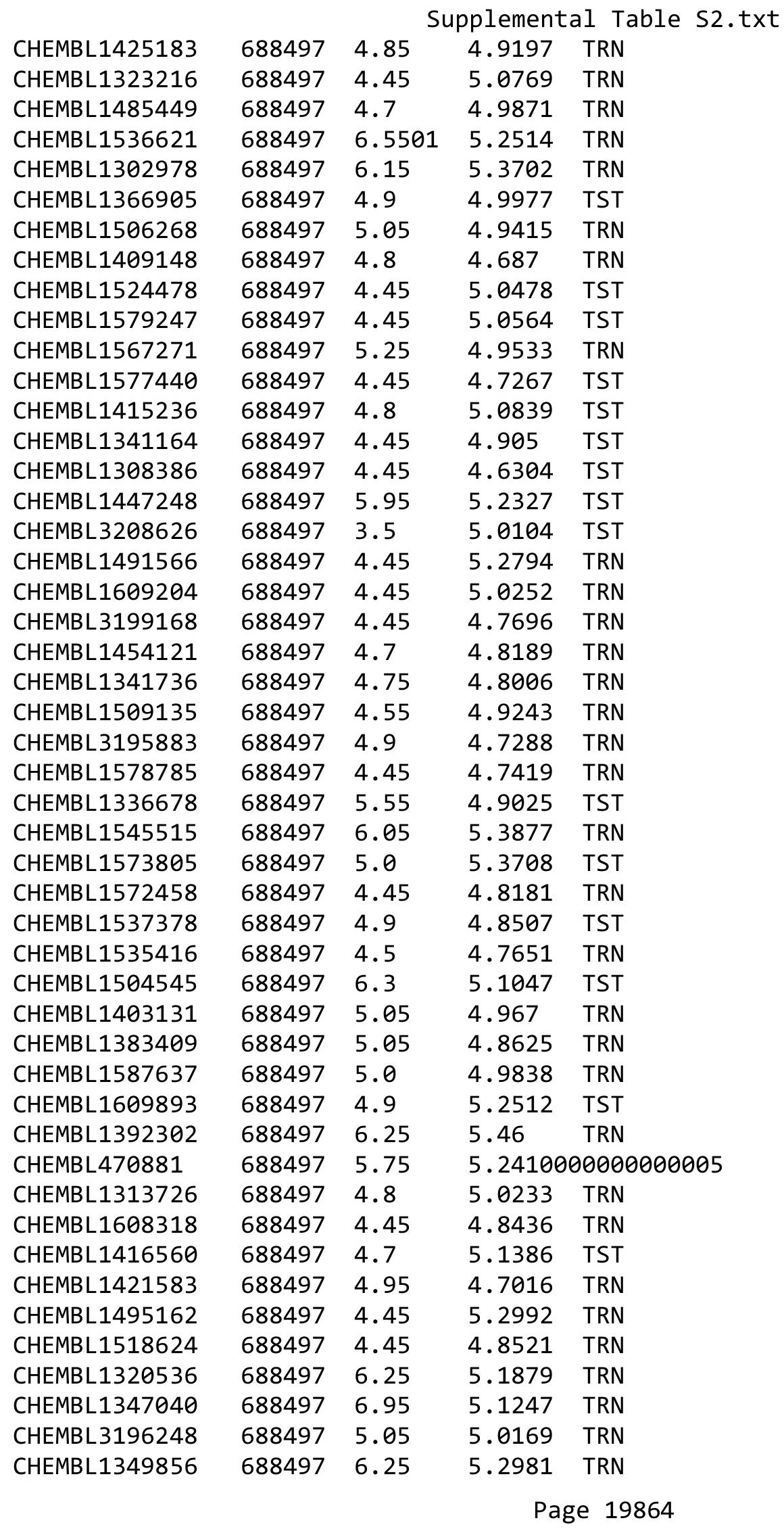




\begin{tabular}{|c|c|c|c|c|c|}
\hline \multicolumn{6}{|c|}{ Supplemental Table s2.txt } \\
\hline CHEMBL1577983 & 688497 & 5.45 & 4.8586 & TRN & \\
\hline CHEMBL1550877 & 688497 & 4.9 & 5.006 & TST & \\
\hline CHEMBL1526666 & 688497 & 5.9 & 5.3075 & TRN & \\
\hline CHEMBL1998606 & 688497 & 6.05 & 5.2983 & TRN & \\
\hline CHEMBL1876078 & 688497 & 4.85 & 5.0247 & TRN & \\
\hline CHEMBL1411106 & 688497 & 4.6 & 4.9415 & TRN & \\
\hline CHEMBL1578821 & 688497 & 5.1 & 5.0891 & TST & \\
\hline CHEMBL1563213 & 688497 & 4.9 & 4.7138 & TRN & \\
\hline CHEMBL1459294 & 688497 & 5.7 & 5.1693 & TST & \\
\hline CHEMBL1391422 & 688497 & 4.45 & 4.9365 & TRN & \\
\hline CHEMBL1494965 & 688497 & 5.0 & 5.3078 & TRN & \\
\hline CHEMBL1378331 & 688497 & 4.45 & 4.5579 & TRN & \\
\hline CHEMBL1409845 & 688497 & 5.45 & 5.1128 & TST & \\
\hline CHEMBL1429822 & 688497 & 4.9 & 4.6967 & TRN & \\
\hline CHEMBL1344409 & 688497 & 5.45 & 4.9327 & TRN & \\
\hline CHEMBL1507497 & 688497 & 4.7 & 4.9803 & TRN & \\
\hline CHEMBL1379708 & 688497 & 4.9 & 4.8941 & TRN & \\
\hline CHEMBL1329658 & 688497 & 4.95 & 5.0012 & TRN & \\
\hline CHEMBL1430499 & 688497 & 6.0 & 5.2484 & TRN & \\
\hline CHEMBL3194876 & 688497 & 5.45 & 5.0399 & TRN & \\
\hline CHEMBL1610483 & 688497 & 6.3 & 5.1006 & TRN & \\
\hline CHEMBL1559624 & 688497 & 5.55 & 4.5763 & TRN & \\
\hline CHEMBL1546596 & 688497 & 4.45 & 5.0287 & TRN & \\
\hline CHEMBL1559099 & 688497 & 6.25 & 5.0014 & TRN & \\
\hline CHEMBL1307669 & 688497 & 4.45 & 4.9028 & TRN & \\
\hline CHEMBL3208443 & 688497 & 5.0 & 5.3682 & TRN & \\
\hline CHEMBL1362611 & 688497 & 5.9 & 5.3219 & TST & \\
\hline CHEMBL1307021 & 688497 & 4.7 & 4.7412 & TRN & \\
\hline CHEMBL1546759 & 688497 & 5.25 & 5.3311 & TST & \\
\hline CHEMBL1410577 & 688497 & 4.9 & 4.8553 & TRN & \\
\hline CHEMBL1360238 & 688497 & 5.0 & 4.9977 & TRN & \\
\hline CHEMBL1583846 & 688497 & 5.2 & 5.1269 & TST & \\
\hline CHEMBL1420404 & 688497 & 4.45 & 4.7937 & TRN & \\
\hline CHEMBL1403397 & 688497 & 4.45 & 5.1257 & TST & \\
\hline CHEMBL1452484 & 688497 & 4.8 & 4.716 & TRN & \\
\hline CHEMBL3198769 & 688497 & 5.0 & 4.8709 & TRN & \\
\hline CHEMBL1484401 & 688497 & 4.55 & 4.9014 & TRN & \\
\hline CHEMBL1563215 & 688497 & 4.6 & 5.53100 & 2000000001 & TST \\
\hline CHEMBL1543510 & 688497 & 4.7 & 5.0736 & TRN & \\
\hline CHEMBL1449661 & 688497 & 6.25 & 5.1721 & TRN & \\
\hline CHEMBL1485404 & 688497 & 5.65 & 5.37700 & 0000000001 & TST \\
\hline CHEMBL1602290 & 688497 & 4.8 & 4.9122 & TRN & \\
\hline CHEMBL494838 & 688497 & 5.15 & 5.0571 & TRN & \\
\hline CHEMBL3190703 & 688497 & 4.45 & 4.8999 & TRN & \\
\hline CHEMBL1363585 & 688497 & 5.45 & 4.9148 & TRN & \\
\hline CHEMBL1341853 & 688497 & 5.0 & 5.018 & TST & \\
\hline CHEMBL1452264 & 688497 & 4.65 & 5.301 & TRN & \\
\hline CHEMBL1336823 & 688497 & 4.95 & 5.1445 & TST & \\
\hline
\end{tabular}




\begin{tabular}{|c|c|c|c|c|c|}
\hline \multicolumn{6}{|c|}{ Supplemental Table s2.txt } \\
\hline CHEMBL1416756 & 688497 & 4.95 & 4.8893 & TRN & \\
\hline CHEMBL1340617 & 688497 & 4.45 & 4.9695 & TRN & \\
\hline CHEMBL1418061 & 688497 & 5.45 & 4.9926 & TRN & \\
\hline CHEMBL1601100 & 688497 & 4.6 & 5.0182 & TST & \\
\hline CHEMBL1438918 & 688497 & 4.75 & 5.0324 & TRN & \\
\hline CHEMBL1585873 & 688497 & 4.45 & 4.7952 & TST & \\
\hline CHEMBL1598092 & 688497 & 4.45 & 5.1382 & TRN & \\
\hline CHEMBL1359004 & 688497 & 5.25 & 5.0045 & TST & \\
\hline CHEMBL1413035 & 688497 & 5.45 & 5.0565 & TRN & \\
\hline CHEMBL1612236 & 688497 & 5.0 & 5.0053 & TST & \\
\hline CHEMBL1546134 & 688497 & 4.8 & 4.6829 & TRN & \\
\hline CHEMBL1349450 & 688497 & 5.3 & 4.9512 & TRN & \\
\hline CHEMBL1376777 & 688497 & 4.8 & 4.7199 & TRN & \\
\hline CHEMBL1506172 & 688497 & 5.45 & 5.5279 & TRN & \\
\hline CHEMBL1439473 & 688497 & 5.25 & 5.1801 & TST & \\
\hline CHEMBL 3193878 & 688497 & 4.85 & 5.0124 & TRN & \\
\hline CHEMBL1371168 & 688497 & 4.9 & 5.2539 & TST & \\
\hline CHEMBL1546902 & 688497 & 5.3 & 5.143 & TRN & \\
\hline CHEMBL1480465 & 688497 & 4.6 & 4.7903 & TST & \\
\hline CHEMBL1385982 & 688497 & 6.5501 & 5.0785 & TST & \\
\hline CHEMBL1393059 & 688497 & 4.45 & 4.9633 & TRN & \\
\hline CHEMBL1549192 & 688497 & 5.65 & 5.0784 & TRN & \\
\hline CHEMBL1557474 & 688497 & 5.45 & 4.8239 & TRN & \\
\hline CHEMBL1361866 & 688497 & 4.95 & 4.9779 & TRN & \\
\hline CHEMBL1331376 & 688497 & 4.45 & 4.8865 & TST & \\
\hline CHEMBL1347249 & 688497 & 4.95 & 5.1772 & TRN & \\
\hline CHEMBL1399076 & 688497 & 6.25 & 5.1397 & TRN & \\
\hline CHEMBL1468664 & 688497 & 4.45 & 4.9271 & TRN & \\
\hline CHEMBL1570816 & 688497 & 6.2 & 5.46299 & 9999999999 & TRN \\
\hline CHEMBL1438259 & 688497 & 5.45 & 4.7947 & TRN & \\
\hline CHEMBL1606613 & 688497 & 4.45 & 4.8148 & TRN & \\
\hline CHEMBL1559333 & 688497 & 5.45 & 5.1097 & TST & \\
\hline CHEMBL1353938 & 688497 & 5.1 & 5.2685 & TRN & \\
\hline CHEMBL1382261 & 688497 & 4.45 & 5.0322 & TST & \\
\hline CHEMBL1300008 & 688497 & 4.95 & 5.0087 & TRN & \\
\hline CHEMBL1573311 & 688497 & 4.5 & 4.9314 & TRN & \\
\hline CHEMBL494325 & 688497 & 5.95 & 4.914 & TRN & \\
\hline CHEMBL3192672 & 688497 & 5.0 & 5.2559 & TRN & \\
\hline CHEMBL1430605 & 688497 & 4.9 & 5.0001 & TRN & \\
\hline CHEMBL1421218 & 688497 & 4.45 & 5.0808 & TRN & \\
\hline CHEMBL1358527 & 688497 & 5.7 & 5.0488 & TRN & \\
\hline CHEMBL1549188 & 688497 & 4.8 & 5.2361 & TRN & \\
\hline CHEMBL1609998 & 688497 & 5.95 & 5.3214 & TRN & \\
\hline CHEMBL1595564 & 688497 & 4.45 & 4.9771 & TST & \\
\hline CHEMBL1361038 & 688497 & 5.0 & 5.2007 & TRN & \\
\hline CHEMBL 2136498 & 688497 & 4.65 & 4.9333 & TRN & \\
\hline CHEMBL3213879 & 688497 & 4.8 & 4.9021 & TRN & \\
\hline CHEMBL592068 & 688497 & 4.95 & 4.9357 & TRN & \\
\hline
\end{tabular}




\begin{tabular}{|c|c|c|c|c|}
\hline \multicolumn{5}{|c|}{ Supplemental Table S2.txt } \\
\hline CHEMBL1423649 & 688497 & 4.45 & 4.8218 & TRN \\
\hline CHEMBL1576979 & 688497 & 7.0501 & 4.9386 & TRN \\
\hline CHEMBL1389828 & 688497 & 6.5 & 5.16799 & 9999999999 \\
\hline CHEMBL1393625 & 688497 & 4.9 & 4.6281 & TRN \\
\hline CHEMBL1442958 & 688497 & 4.45 & 5.4293 & TST \\
\hline CHEMBL1320705 & 688497 & 4.7 & 5.3071 & TST \\
\hline CHEMBL1387468 & 688497 & 4.65 & 5.0131 & TRN \\
\hline CHEMBL1347850 & 688497 & 4.6 & 4.945 & TRN \\
\hline CHEMBL 3195443 & 688497 & 4.45 & 4.797 & TRN \\
\hline CHEMBL1369590 & 688497 & 4.45 & 4.8002 & TRN \\
\hline CHEMBL1324944 & 688497 & 5.6 & 4.9251 & TRN \\
\hline CHEMBL1353112 & 688497 & 5.5 & 4.8173 & TRN \\
\hline CHEMBL1301760 & 688497 & 4.45 & 4.8337 & TRN \\
\hline CHEMBL1338752 & 688497 & 7.0501 & 5.294 & TRN \\
\hline CHEMBL1333282 & 688497 & 5.05 & 5.0056 & TRN \\
\hline CHEMBL1350440 & 688497 & 4.9 & 5.0994 & TRN \\
\hline CHEMBL1405122 & 688497 & 4.9 & 5.6629 & TST \\
\hline CHEMBL1529824 & 688497 & 4.45 & 5.0789 & TST \\
\hline CHEMBL1470619 & 688497 & 4.45 & 5.03 & TRN \\
\hline CHEMBL1336561 & 688497 & 4.75 & 5.0232 & TST \\
\hline CHEMBL1572371 & 688497 & 4.5 & 4.8657 & TRN \\
\hline CHEMBL1440400 & 688497 & 4.85 & 5.1165 & TRN \\
\hline CHEMBL1515681 & 688497 & 6.25 & 5.2298 & TST \\
\hline CHEMBL1430381 & 688497 & 5.2 & 4.9575 & TRN \\
\hline CHEMBL1982539 & 688497 & 4.8 & 5.1018 & TRN \\
\hline CHEMBL3190694 & 688497 & 4.65 & 4.7381 & TRN \\
\hline CHEMBL1365163 & 688497 & 5.0 & 4.8631 & TRN \\
\hline CHEMBL1527074 & 688497 & 6.3 & 5.044 & TRN \\
\hline CHEMBL1303927 & 688497 & 4.65 & 4.8681 & TRN \\
\hline CHEMBL1452537 & 688497 & 4.55 & 5.0293 & TRN \\
\hline CHEMBL 3189623 & 688497 & 5.55 & 5.0705 & TST \\
\hline CHEMBL 3195763 & 688497 & 4.45 & 5.1393 & TRN \\
\hline CHEMBL1497200 & 688497 & 4.45 & 4.8586 & TRN \\
\hline CHEMBL1412371 & 688497 & 4.5 & 5.1613 & TRN \\
\hline CHEMBL1509778 & 688497 & 4.65 & 4.9568 & TRN \\
\hline CHEMBL1546660 & 688497 & 4.9 & 5.0848 & TRN \\
\hline CHEMBL1549548 & 688497 & 5.4 & 4.7676 & TST \\
\hline CHEMBL1338243 & 688497 & 4.65 & 4.8325 & TST \\
\hline CHEMBL1442211 & 688497 & 5.45 & 5.1516 & TRN \\
\hline CHEMBL1305292 & 688497 & 5.15 & 5.0545 & TST \\
\hline CHEMBL1558216 & 688497 & 5.25 & 4.9464 & TST \\
\hline CHEMBL1549452 & 688497 & 5.7 & 5.1714 & TRN \\
\hline CHEMBL1538071 & 688497 & 4.45 & 5.2612 & TST \\
\hline CHEMBL1569265 & 688497 & 5.25 & 4.8198 & TRN \\
\hline CHEMBL1392235 & 688497 & 5.2 & 4.9367 & TRN \\
\hline CHEMBL1303750 & 688497 & 5.15 & 5.16 & TRN \\
\hline CHEMBL1419190 & 688497 & 5.1 & 5.1621 & TST \\
\hline CHEMBL1326572 & 688497 & 6.5501 & 5.0313 & TST \\
\hline
\end{tabular}

TRN 


\begin{tabular}{|c|c|c|c|c|c|}
\hline \multicolumn{6}{|c|}{ Supplemental Table s2.txt } \\
\hline CHEMBL1310331 & 688497 & 5.5 & 5.1361 & TRN & \\
\hline CHEMBL1570501 & 688497 & 4.45 & 5.0148 & TST & \\
\hline CHEMBL1423504 & 688497 & 4.65 & 5.21200 & 2000000001 & TST \\
\hline CHEMBL1531875 & 688497 & 4.8 & 5.1433 & TST & \\
\hline CHEMBL1384489 & 688497 & 4.6 & 4.88899 & 9999999999 & TRN \\
\hline CHEMBL3190717 & 688497 & 4.85 & 5.2798 & TRN & \\
\hline CHEMBL1335597 & 688497 & 4.95 & 5.0698 & TRN & \\
\hline CHEMBL1526446 & 688497 & 5.35 & 5.2791 & TRN & \\
\hline CHEMBL1324956 & 688497 & 5.45 & 5.1262 & TRN & \\
\hline CHEMBL1607739 & 688497 & 5.9 & 5.1544 & TST & \\
\hline CHEMBL1408779 & 688497 & 5.15 & 4.6764 & TRN & \\
\hline CHEMBL1344810 & 688497 & 5.05 & 4.8942 & TRN & \\
\hline CHEMBL1608283 & 688497 & 4.55 & 4.9799 & TRN & \\
\hline CHEMBL1573997 & 688497 & 5.25 & 5.3093 & TRN & \\
\hline CHEMBL1503351 & 688497 & 4.8 & 5.1356 & TRN & \\
\hline CHEMBL1322082 & 688497 & 5.25 & 5.0289 & TST & \\
\hline CHEMBL1308936 & 688497 & 5.25 & 4.9219 & TRN & \\
\hline CHEMBL1391184 & 688497 & 4.45 & 4.7577 & TRN & \\
\hline CHEMBL1460108 & 688497 & 4.65 & 4.9218 & TRN & \\
\hline CHEMBL1580887 & 688497 & 4.45 & 4.9979 & TRN & \\
\hline CHEMBL1387948 & 688497 & 4.9 & 4.6911 & TRN & \\
\hline CHEMBL1349308 & 688497 & 5.35 & 5.1052 & TRN & \\
\hline CHEMBL 3210738 & 688497 & 4.9 & 5.0323 & TRN & \\
\hline CHEMBL1320372 & 688497 & 4.8 & 4.7949 & TRN & \\
\hline CHEMBL300389 & 688497 & 6.15 & 5.3312 & TST & \\
\hline CHEMBL1519229 & 688497 & 4.7 & 4.81 & TRN & \\
\hline CHEMBL1306688 & 688497 & 4.65 & 4.9084 & TRN & \\
\hline CHEMBL1429239 & 688497 & 4.45 & 5.0671 & TRN & \\
\hline CHEMBL3191488 & 688497 & 4.45 & 5.2749 & TRN & \\
\hline CHEMBL1461249 & 688497 & 5.0 & 4.9674 & TRN & \\
\hline CHEMBL1334460 & 688497 & 4.45 & 4.7372 & TST & \\
\hline CHEMBL1348874 & 688497 & 5.05 & 4.7393 & TRN & \\
\hline CHEMBL1343766 & 688497 & 7.0 & 5.1343 & TRN & \\
\hline CHEMBL1370902 & 688497 & 5.05 & 4.8506 & TRN & \\
\hline CHEMBL1597805 & 688497 & 4.45 & 4.8796 & TST & \\
\hline CHEMBL1564952 & 688497 & 5.55 & 5.4297 & TRN & \\
\hline CHEMBL3196240 & 688497 & 4.8 & 5.2219 & TRN & \\
\hline CHEMBL1431735 & 688497 & 4.45 & 4.9434 & TRN & \\
\hline CHEMBL1966666 & 688497 & 5.0 & 4.9155 & TRN & \\
\hline CHEMBL1492583 & 688497 & 6.1 & 5.1129 & TST & \\
\hline CHEMBL1392793 & 688497 & 4.75 & 4.9262 & TRN & \\
\hline CHEMBL1608076 & 688497 & 6.5 & 5.3814 & TRN & \\
\hline CHEMBL1493355 & 688497 & 4.45 & 4.9838 & TRN & \\
\hline CHEMBL1431123 & 688497 & 4.45 & 4.5596 & TRN & \\
\hline CHEMBL1458016 & 688497 & 5.1 & 5.2046 & TRN & \\
\hline CHEMBL1430937 & 688497 & 4.45 & 4.9077 & TRN & \\
\hline CHEMBL1330032 & 688497 & 4.6 & 5.0841 & TRN & \\
\hline CHEMBL1402312 & 688497 & 4.95 & 5.1439 & TST & \\
\hline
\end{tabular}




\begin{tabular}{|c|c|c|c|c|c|}
\hline \\
\hline CHEMBL1509065 & 688497 & 4.9 & 5.1404 & TRN & \\
\hline CHEMBL3196980 & 688497 & 4.45 & 5.1977 & TRN & \\
\hline CHEMBL1606775 & 688497 & 6.0 & 5.2916 & TRN & \\
\hline CHEMBL1465410 & 688497 & 4.45 & 4.8695 & TRN & \\
\hline CHEMBL1579787 & 688497 & 5.5 & 5.2742 & TRN & \\
\hline CHEMBL1574703 & 688497 & 4.7 & 5.3907 & TRN & \\
\hline CHEMBL1379881 & 688497 & 4.6 & 4.9976 & TRN & \\
\hline CHEMBL1302639 & 688497 & 5.2 & 4.6903 & TRN & \\
\hline CHEMBL1578326 & 688497 & 5.55 & 5.3345 & TRN & \\
\hline CHEMBL1414092 & 688497 & 4.7 & 5.5333 & TRN & \\
\hline CHEMBL1411028 & 688497 & 5.15 & 5.005 & TRN & \\
\hline CHEMBL1609569 & 688497 & 4.45 & 4.6779 & TRN & \\
\hline CHEMBL1352637 & 688497 & 6.25 & 4.9978 & TRN & \\
\hline CHEMBL1307796 & 688497 & 4.45 & 4.9448 & TRN & \\
\hline CHEMBL1438881 & 688497 & 5.1 & 5.322 & TRN & \\
\hline CHEMBL1504277 & 688497 & 6.25 & 4.9149 & TST & \\
\hline CHEMBL1451535 & 688497 & 4.75 & 5.03600 & 20000000005 & TRN \\
\hline CHEMBL1565189 & 688497 & 5.4 & 5.0299 & TST & \\
\hline CHEMBL1530705 & 688497 & 6.3 & 5.1866 & TRN & \\
\hline CHEMBL1479080 & 688497 & 5.5 & 5.2986 & TST & \\
\hline CHEMBL1311399 & 688497 & 4.8 & 4.9508 & TRN & \\
\hline CHEMBL1500274 & 688497 & 5.15 & 4.868 & TRN & \\
\hline CHEMBL1510331 & 688497 & 4.45 & 4.9232 & TRN & \\
\hline CHEMBL1401775 & 688497 & 4.7 & 5.2013 & TRN & \\
\hline CHEMBL1564133 & 688497 & 4.55 & 5.0987 & TRN & \\
\hline CHEMBL1581520 & 688497 & 5.95 & 5.4707 & TRN & \\
\hline CHEMBL3193180 & 688497 & 4.95 & 4.798 & TRN & \\
\hline CHEMBL3192735 & 688497 & 5.25 & 4.9423 & TRN & \\
\hline CHEMBL1463263 & 688497 & 4.45 & 4.7112 & TRN & \\
\hline CHEMBL1337039 & 688497 & 5.0 & 4.904 & TRN & \\
\hline CHEMBL1583309 & 688497 & 4.95 & 5.15799 & 99999999995 & TRN \\
\hline CHEMBL3195813 & 688497 & 4.45 & 4.8113 & TST & \\
\hline CHEMBL1363514 & 688497 & 4.45 & 4.7544 & TRN & \\
\hline CHEMBL1429520 & 688497 & 5.15 & 5.2201 & TRN & \\
\hline CHEMBL1480824 & 688497 & 5.25 & 5.2164 & TRN & \\
\hline CHEMBL1326624 & 688497 & 4.95 & 4.6292 & TRN & \\
\hline CHEMBL1306168 & 688497 & 5.2 & 5.1544 & TRN & \\
\hline CHEMBL1561783 & 688497 & 4.8 & 4.9761 & TRN & \\
\hline CHEMBL1507713 & 688497 & 5.1 & 4.7426 & TRN & \\
\hline CHEMBL1468205 & 688497 & 5.8 & 5.1247 & TRN & \\
\hline CHEMBL3198004 & 688497 & 5.0 & 5.1232 & TRN & \\
\hline CHEMBL1306659 & 688497 & 4.95 & 5.0001 & TRN & \\
\hline CHEMBL1329708 & 688497 & 4.95 & 4.8448 & TRN & \\
\hline CHEMBL1545268 & 688497 & 6.45 & 5.1185 & TRN & \\
\hline CHEMBL1566928 & 688497 & 4.45 & 4.9525 & TRN & \\
\hline CHEMBL1519770 & 688497 & 4.45 & 5.1269 & TRN & \\
\hline CHEMBL1545634 & 688497 & 5.2 & 5.5359 & TST & \\
\hline CHEMBL581677 & 688497 & 5.45 & 4.7475 & TRN & \\
\hline
\end{tabular}




\begin{tabular}{|c|c|c|c|c|}
\hline \multicolumn{5}{|c|}{ Supplemental Table S2.txt } \\
\hline CHEMBL1579561 & 688497 & 4.65 & 4.8114 & TRN \\
\hline CHEMBL1452523 & 688497 & 4.45 & 5.103 & TRN \\
\hline CHEMBL1572967 & 688497 & 4.85 & 4.7993 & TRN \\
\hline CHEMBL1336094 & 688497 & 4.45 & 5.1052 & TRN \\
\hline CHEMBL1610150 & 688497 & 5.05 & 4.8603 & TRN \\
\hline CHEMBL3195474 & 688497 & 4.45 & 4.9362 & TRN \\
\hline CHEMBL1545160 & 688497 & 4.65 & 4.7945 & TRN \\
\hline CHEMBL1543991 & 688497 & 4.85 & 5.2091 & TST \\
\hline CHEMBL1610718 & 688497 & 6.45 & 5.2319 & TST \\
\hline CHEMBL3191708 & 688497 & 5.0 & 4.9586 & TRN \\
\hline CHEMBL1384900 & 688497 & 6.15 & 5.0218 & TRN \\
\hline CHEMBL1496419 & 688497 & 4.45 & 5.2715 & TRN \\
\hline CHEMBL1988121 & 688497 & 5.4 & 5.08 & TRN \\
\hline CHEMBL1329878 & 688497 & 4.45 & 4.7812 & TST \\
\hline CHEMBL1612948 & 688497 & 5.25 & 4.9216 & TRN \\
\hline CHEMBL1599782 & 688497 & 4.6 & 5.0014 & TRN \\
\hline CHEMBL1345803 & 688497 & 4.95 & 4.9512 & TRN \\
\hline CHEMBL1579680 & 688497 & 6.25 & 5.0925 & TST \\
\hline CHEMBL1426054 & 688497 & 4.45 & 4.9701 & TRN \\
\hline CHEMBL1609946 & 688497 & 5.2 & 5.3976 & TRN \\
\hline CHEMBL1304647 & 688497 & 5.25 & 5.0258 & TST \\
\hline CHEMBL1504670 & 688497 & 4.85 & 4.8856 & TST \\
\hline CHEMBL1378294 & 688497 & 5.45 & 5.035 & TST \\
\hline CHEMBL1420943 & 688497 & 4.45 & 4.981 & TRN \\
\hline CHEMBL1547262 & 688497 & 4.45 & 5.3992 & TST \\
\hline CHEMBL1505531 & 688497 & 5.9 & 5.3801 & TRN \\
\hline CHEMBL1501400 & 688497 & 4.95 & 4.9005 & TRN \\
\hline CHEMBL1353598 & 688497 & 4.6 & 5.0407 & TRN \\
\hline CHEMBL1563043 & 688497 & 4.65 & 5.0393 & TRN \\
\hline CHEMBL1480673 & 688497 & 4.65 & 4.9272 & TRN \\
\hline CHEMBL1338140 & 688497 & 5.05 & 4.8946 & TRN \\
\hline CHEMBL1558220 & 688497 & 4.45 & 4.7804 & TRN \\
\hline CHEMBL1326449 & 688497 & 4.45 & 4.6277 & TRN \\
\hline CHEMBL1323610 & 688497 & 5.0 & 4.8251 & TRN \\
\hline CHEMBL581880 & 688497 & 4.75 & 5.24 & TRN \\
\hline CHEMBL1497978 & 688497 & 5.05 & 4.9854 & TRN \\
\hline CHEMBL1346972 & 688497 & 4.65 & 4.8447 & TRN \\
\hline CHEMBL1997585 & 688497 & 4.7 & 4.8444 & TRN \\
\hline CHEMBL1393765 & 688497 & 4.45 & 5.0432 & TST \\
\hline CHEMBL1548987 & 688497 & 4.65 & 5.232 & TST \\
\hline CHEMBL1349318 & 688497 & 4.65 & 5.0766 & TST \\
\hline CHEMBL1224757 & 688497 & 4.6 & 5.1888 & TRN \\
\hline CHEMBL1438312 & 688497 & 5.2 & 4.996 & TRN \\
\hline CHEMBL1348651 & 688497 & 4.95 & 5.0106 & TST \\
\hline CHEMBL1312576 & 688497 & 4.95 & 5.2243 & TST \\
\hline CHEMBL1362735 & 688497 & 5.25 & 5.1509 & TST \\
\hline CHEMBL 2006325 & 688497 & 4.95 & 5.1293 & TRN \\
\hline CHEMBL1607304 & 688497 & 5.3 & 5.0832 & TRN \\
\hline
\end{tabular}




\begin{tabular}{|c|c|c|c|c|}
\hline & & & pplement & al $\mathrm{Ta}$ \\
\hline CHEMBL1986151 & 688497 & 4.6 & 5.0603 & TRN \\
\hline CHEMBL1511004 & 688497 & 4.65 & 4.9667 & TRN \\
\hline CHEMBL1438328 & 688497 & 6.25 & 5.3401 & TRN \\
\hline CHEMBL1547784 & 688497 & 4.5 & 4.7829 & TRN \\
\hline CHEMBL3192696 & 688497 & 5.5 & 5.2849 & TRN \\
\hline CHEMBL3196295 & 688497 & 5.0 & 5.1311 & TRN \\
\hline CHEMBL1462852 & 688497 & 4.55 & 4.9601 & TRN \\
\hline CHEMBL1559248 & 688497 & 4.8 & 4.9361 & TRN \\
\hline CHEMBL1486913 & 688497 & 4.9 & 4.8771 & TST \\
\hline CHEMBL1359797 & 688497 & 4.65 & 4.82 & TRN \\
\hline CHEMBL1410385 & 688497 & 4.45 & 4.9488 & TRN \\
\hline CHEMBL1407940 & 688497 & 6.25 & 5.0254 & TST \\
\hline CHEMBL586135 & 688497 & 5.85 & 5.3245 & TRN \\
\hline CHEMBL1597665 & 688497 & 5.45 & 5.131 & TRN \\
\hline CHEMBL1409113 & 688497 & 5.7 & 4.7792 & TRN \\
\hline CHEMBL1985582 & 688497 & 5.5 & 5.1801 & TRN \\
\hline CHEMBL1577923 & 688497 & 4.95 & 4.803 & TRN \\
\hline CHEMBL1361550 & 688497 & 4.45 & 4.8938 & TRN \\
\hline CHEMBL3194333 & 688497 & 5.65 & 4.9578 & TRN \\
\hline CHEMBL1595160 & 688497 & 5.25 & 4.9026 & TST \\
\hline CHEMBL1563489 & 688497 & 4.95 & 5.5904 & TST \\
\hline CHEMBL1319713 & 688497 & 5.85 & 5.1631 & TRN \\
\hline CHEMBL1537117 & 688497 & 5.4 & 4.8044 & TST \\
\hline CHEMBL1366112 & 688497 & 4.45 & 5.1386 & TRN \\
\hline CHEMBL1516729 & 688497 & 4.9 & 4.8782 & TRN \\
\hline CHEMBL1422860 & 688497 & 4.45 & 5.2245 & TRN \\
\hline CHEMBL1501828 & 688497 & 4.45 & 4.6978 & TRN \\
\hline CHEMBL1564805 & 688497 & 5.5 & 4.8419 & TRN \\
\hline CHEMBL1387342 & 688497 & 5.0 & 5.2774 & TRN \\
\hline CHEMBL1530932 & 688497 & 4.45 & 4.9001 & TRN \\
\hline CHEMBL1372796 & 688497 & 5.35 & 4.9597 & TRN \\
\hline CHEMBL578905 & 688497 & 5.15 & 5.1419 & TRN \\
\hline CHEMBL1585845 & 688497 & 4.45 & 4.6684 & TRN \\
\hline CHEMBL1570980 & 688497 & 5.6 & 4.9551 & TST \\
\hline CHEMBL1465234 & 688497 & 5.2 & 5.0815 & TRN \\
\hline CHEMBL1508872 & 688497 & 4.9 & 4.9872 & TRN \\
\hline CHEMBL3191942 & 688497 & 6.0 & 4.9609 & TRN \\
\hline CHEMBL1525941 & 688497 & 6.2 & 5.0697 & TRN \\
\hline CHEMBL1303115 & 688497 & 4.9 & 4.6872 & TRN \\
\hline CHEMBL1432989 & 688497 & 5.5 & 5.0835 & TRN \\
\hline CHEMBL1546392 & 688497 & 5.15 & 4.745 & TRN \\
\hline CHEMBL 3212348 & 688497 & 4.95 & 4.834 & TST \\
\hline CHEMBL1458718 & 688497 & 5.6 & 5.0196 & TRN \\
\hline CHEMBL1453508 & 688497 & 5.3 & 4.7325 & TRN \\
\hline CHEMBL3191720 & 688497 & 4.45 & 4.8584 & TRN \\
\hline CHEMBL1401555 & 688497 & 5.0 & 5.0449 & TRN \\
\hline CHEMBL1584441 & 688497 & 5.45 & 5.1747 & TST \\
\hline CHEMBL1349072 & 688497 & 4.75 & 4.8223 & TST \\
\hline
\end{tabular}




\begin{tabular}{|c|c|c|c|c|}
\hline \multicolumn{5}{|c|}{ Supplemental Table S2.txt } \\
\hline CHEMBL1384315 & 688497 & 4.45 & 5.1316 & TRN \\
\hline CHEMBL1442698 & 688497 & 4.85 & 4.8014 & TRN \\
\hline CHEMBL1613087 & 688497 & 6.0 & 5.1403 & TRN \\
\hline CHEMBL1447066 & 688497 & 4.8 & 5.2609 & TRN \\
\hline CHEMBL1560072 & 688497 & 4.6 & 5.1954 & TRN \\
\hline CHEMBL3195459 & 688497 & 4.45 & 5.065 & TRN \\
\hline CHEMBL1575649 & 688497 & 4.6 & 4.7323 & TRN \\
\hline CHEMBL1343885 & 688497 & 4.95 & 4.8502 & TRN \\
\hline CHEMBL1504183 & 688497 & 4.45 & 5.2334 & TST \\
\hline CHEMBL1493906 & 688497 & 5.0 & 5.1601 & TST \\
\hline CHEMBL1411344 & 688497 & 4.5 & 4.6737 & TRN \\
\hline CHEMBL1527798 & 688497 & 4.45 & 4.8137 & TRN \\
\hline CHEMBL1370381 & 688497 & 5.15 & 4.8035 & TRN \\
\hline CHEMBL3210133 & 688497 & 5.4 & 5.1814 & TST \\
\hline CHEMBL1503342 & 688497 & 4.95 & 4.9265 & TRN \\
\hline CHEMBL1977078 & 688497 & 4.45 & 5.0435 & TST \\
\hline CHEMBL1993194 & 688497 & 5.85 & 5.2995 & TRN \\
\hline CHEMBL1327962 & 688497 & 4.45 & 4.8098 & TST \\
\hline CHEMBL356169 & 688497 & 5.0 & 5.1275 & TRN \\
\hline CHEMBL1413626 & 688497 & 4.6 & 5.0562 & TRN \\
\hline CHEMBL1465029 & 688497 & 4.45 & 5.2225 & TST \\
\hline CHEMBL1331842 & 688497 & 4.8 & 4.797 & TRN \\
\hline CHEMBL1411967 & 688497 & 5.5 & 5.3458 & TRN \\
\hline CHEMBL1531042 & 688497 & 5.1 & 4.7433 & TRN \\
\hline CHEMBL1586957 & 688497 & 5.5 & 4.8235 & TST \\
\hline CHEMBL1361530 & 688497 & 4.9 & 5.2072 & TRN \\
\hline CHEMBL1502505 & 688497 & 4.45 & 4.8833 & TRN \\
\hline CHEMBL1465372 & 688497 & 4.95 & 5.0343 & TRN \\
\hline CHEMBL1497489 & 688497 & 6.1 & 5.2545 & TST \\
\hline CHEMBL1345515 & 688497 & 5.2 & 5.0447 & TRN \\
\hline CHEMBL1350084 & 688497 & 5.1 & 4.9007 & TRN \\
\hline CHEMBL1428364 & 688497 & 6.25 & 5.3079 & TST \\
\hline CHEMBL1497171 & 688497 & 4.95 & 5.2773 & TST \\
\hline CHEMBL1432670 & 688497 & 4.6 & 4.6877 & TRN \\
\hline CHEMBL1328930 & 688497 & 5.55 & 4.909 & TRN \\
\hline CHEMBL1349032 & 688497 & 4.75 & 5.1639 & TRN \\
\hline CHEMBL 1327140 & 688497 & 4.45 & 5.1849 & TST \\
\hline CHEMBL1527869 & 688497 & 5.5 & 5.278 & TRN \\
\hline CHEMBL1424601 & 688497 & 4.45 & 4.76 & TRN \\
\hline CHEMBL3199594 & 688497 & 4.75 & 4.8275 & TRN \\
\hline CHEMBL3209623 & 688497 & 4.85 & 4.901 & TRN \\
\hline CHEMBL1487973 & 688497 & 4.65 & 4.7336 & TRN \\
\hline CHEMBL1981883 & 688497 & 5.95 & 5.004 & TRN \\
\hline CHEMBL1456425 & 688497 & 5.2 & 5.0749 & TRN \\
\hline CHEMBL1426980 & 688497 & 5.5 & 4.9236 & TRN \\
\hline CHEMBL1528505 & 688497 & 4.75 & 4.9335 & TRN \\
\hline CHEMBL3189304 & 688497 & 4.9 & 5.019 & TRN \\
\hline CHEMBL1333276 & 688497 & 4.45 & 4.9119 & TRN \\
\hline
\end{tabular}




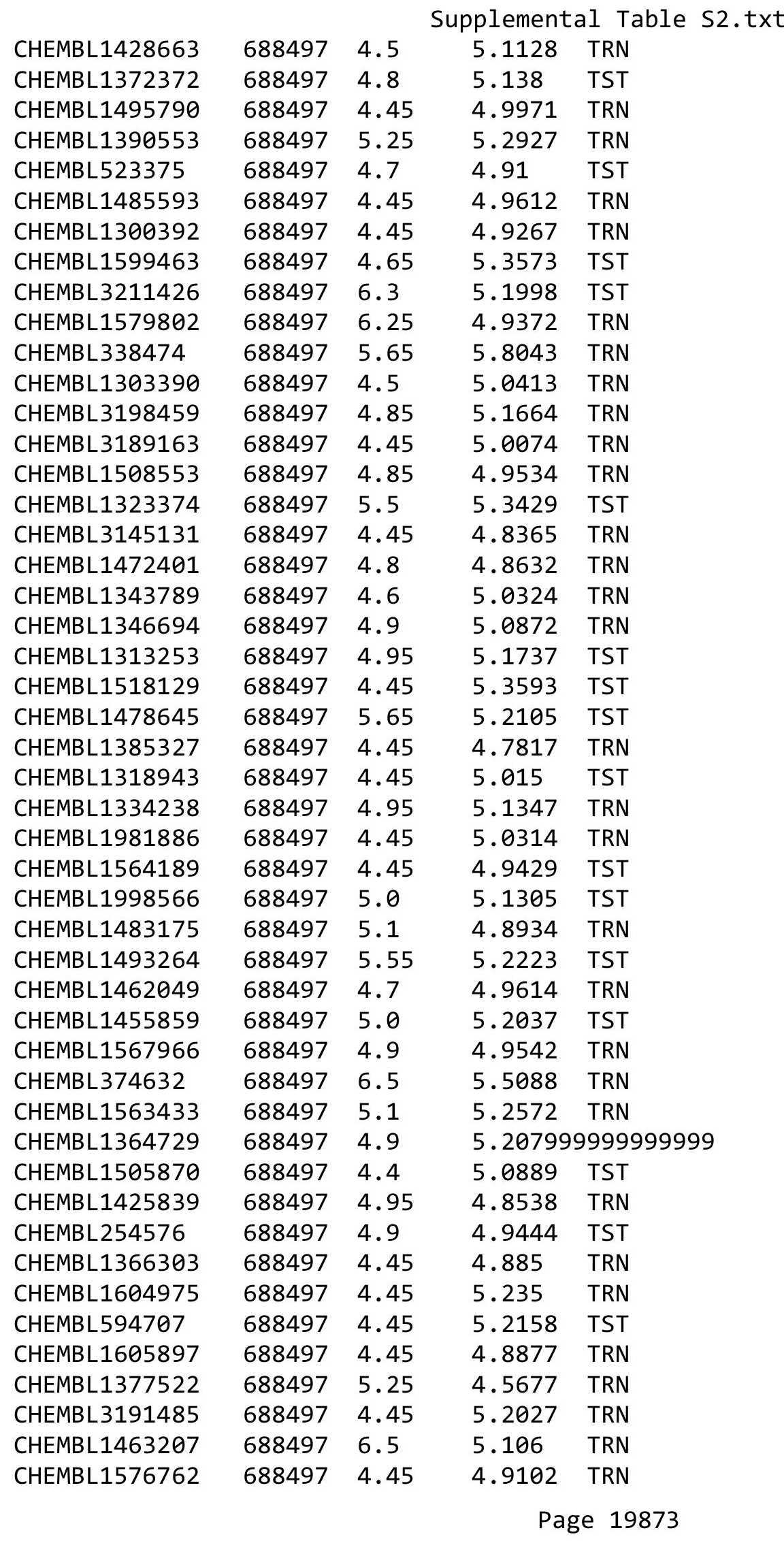




\begin{tabular}{|c|c|c|c|c|c|}
\hline \multicolumn{6}{|c|}{ Supplemental Table S2.txt } \\
\hline CHEMBL1301453 & 688497 & 5.45 & 5.0928 & TST & \\
\hline CHEMBL1536120 & 688497 & 5.25 & 5.5486 & TRN & \\
\hline CHEMBL1391809 & 688497 & 4.45 & 4.7367 & TRN & \\
\hline CHEMBL1469584 & 688497 & 4.45 & 4.9448 & TST & \\
\hline CHEMBL1329291 & 688497 & 4.85 & 4.8578 & TST & \\
\hline CHEMBL1416108 & 688497 & 6.0 & 5.1877 & TRN & \\
\hline CHEMBL1305247 & 688497 & 4.45 & 4.68199 & 99999999995 & TST \\
\hline CHEMBL 3211578 & 688497 & 6.25 & 4.8946 & TST & \\
\hline CHEMBL1346839 & 688497 & 5.25 & 5.0013 & TRN & \\
\hline CHEMBL1369905 & 688497 & 4.95 & 4.9367 & TRN & \\
\hline CHEMBL1372624 & 688497 & 5.25 & 5.0666 & TRN & \\
\hline CHEMBL1540038 & 688497 & 5.45 & 4.7808 & TST & \\
\hline CHEMBL1431827 & 688497 & 4.55 & 5.045 & TRN & \\
\hline CHEMBL1348732 & 688497 & 4.45 & 4.965 & TRN & \\
\hline CHEMBL1299705 & 688497 & 4.75 & 4.8844 & TRN & \\
\hline CHEMBL1545400 & 688497 & 4.95 & 4.7447 & TRN & \\
\hline CHEMBL1547818 & 688497 & 4.45 & 4.993 & TRN & \\
\hline CHEMBL1372707 & 688497 & 4.9 & 4.8561 & TRN & \\
\hline CHEMBL1498124 & 688497 & 4.45 & 5.1695 & TST & \\
\hline CHEMBL1331095 & 688497 & 3.9 & 5.1217 & TST & \\
\hline CHEMBL1595937 & 688497 & 4.85 & 5.064 & TRN & \\
\hline CHEMBL1597693 & 688497 & 4.8 & 4.9988 & TRN & \\
\hline CHEMBL1606778 & 688497 & 5.15 & 5.3395 & TRN & \\
\hline CHEMBL1422155 & 688497 & 6.25 & 5.0668 & TRN & \\
\hline CHEMBL1484063 & 688497 & 5.35 & 5.0516 & TRN & \\
\hline CHEMBL1421249 & 688497 & 5.0 & 5.1076 & TRN & \\
\hline CHEMBL1509033 & 688497 & 4.7 & 5.0868 & TRN & \\
\hline CHEMBL1601532 & 688497 & 4.45 & 4.9501 & TRN & \\
\hline CHEMBL1428317 & 688497 & 4.95 & 4.9482 & TRN & \\
\hline CHEMBL1518604 & 688497 & 9.2218 & 5.2386 & TRN & \\
\hline CHEMBL1569388 & 688497 & 4.45 & 4.9712 & TRN & \\
\hline CHEMBL1585075 & 688497 & 4.65 & 4.8272 & TRN & \\
\hline CHEMBL1501388 & 688497 & 5.9 & 4.971 & TST & \\
\hline CHEMBL1557704 & 688497 & 5.45 & 4.7588 & TRN & \\
\hline CHEMBL1401569 & 688497 & 4.85 & 4.795 & TRN & \\
\hline CHEMBL1343689 & 688497 & 5.4 & 5.2328 & TRN & \\
\hline CHEMBL3144956 & 688497 & 5.25 & 5.0348 & TST & \\
\hline CHEMBL1487679 & 688497 & 5.25 & 5.0223 & TST & \\
\hline CHEMBL1464720 & 688497 & 5.25 & 5.0941 & TST & \\
\hline CHEMBL1365249 & 688497 & 5.55 & 4.9286 & TST & \\
\hline CHEMBL1544917 & 688497 & 4.45 & 4.9104 & TST & \\
\hline CHEMBL1313436 & 688497 & 4.6 & 5.1237 & TRN & \\
\hline CHEMBL1463217 & 688497 & 4.9 & 5.2499 & TST & \\
\hline CHEMBL1390174 & 688497 & 4.45 & 4.9881 & TRN & \\
\hline CHEMBL1349962 & 688497 & 4.7 & 5.3595 & TRN & \\
\hline CHEMBL1412501 & 688497 & 5.9 & 5.0827 & TRN & \\
\hline CHEMBL3190260 & 688497 & 5.85 & 5.3928 & TRN & \\
\hline CHEMBL1325873 & 688497 & 4.45 & 4.9834 & TRN & \\
\hline
\end{tabular}




\begin{tabular}{|c|c|c|c|c|}
\hline \multicolumn{5}{|c|}{ Supplemental Table S2.txt } \\
\hline CHEMBL1529859 & 688497 & 4.45 & 4.9168 & TRN \\
\hline CHEMBL1974180 & 688497 & 5.6 & 5.2502 & TST \\
\hline CHEMBL1440719 & 688497 & 4.8 & 5.2455 & TST \\
\hline CHEMBL1538751 & 688497 & 6.0 & 5.0628 & TST \\
\hline CHEMBL1578174 & 688497 & 4.45 & 5.1114 & TRN \\
\hline CHEMBL1502686 & 688497 & 4.65 & 4.7466 & TRN \\
\hline CHEMBL1599467 & 688497 & 4.85 & 4.8454 & TRN \\
\hline CHEMBL1413495 & 688497 & 4.45 & 4.8849 & TRN \\
\hline CHEMBL1608862 & 688497 & 5.4 & 5.004 & TST \\
\hline CHEMBL1371706 & 688497 & 5.6 & 5.1818 & TRN \\
\hline CHEMBL3196641 & 688497 & 5.15 & 4.8778 & TRN \\
\hline CHEMBL1496640 & 688497 & 4.45 & 5.1066 & TRN \\
\hline CHEMBL1430669 & 688497 & 5.4 & 4.7837 & TRN \\
\hline CHEMBL3192732 & 688497 & 4.65 & 4.9789 & TST \\
\hline CHEMBL1561002 & 688497 & 5.0 & 5.0981 & TRN \\
\hline CHEMBL1426863 & 688497 & 5.45 & 5.1572 & TRN \\
\hline CHEMBL1546725 & 688497 & 5.15 & 5.0141 & TRN \\
\hline CHEMBL1582039 & 688497 & 4.45 & 4.8985 & TRN \\
\hline CHEMBL1522465 & 688497 & 5.5 & 5.2732 & TRN \\
\hline CHEMBL1312526 & 688497 & 4.95 & 5.1149 & TRN \\
\hline CHEMBL1420161 & 688497 & 5.15 & 5.0285 & TRN \\
\hline CHEMBL1353776 & 688497 & 4.7 & 4.9902 & TST \\
\hline CHEMBL1425410 & 688497 & 5.05 & 4.8555 & TRN \\
\hline CHEMBL1558306 & 688497 & 5.4 & 4.9848 & TRN \\
\hline CHEMBL1566334 & 688497 & 4.9 & 4.7583 & TRN \\
\hline CHEMBL1386791 & 688497 & 4.95 & 4.9555 & TST \\
\hline CHEMBL1328937 & 688497 & 5.2 & 5.5141 & TST \\
\hline CHEMBL1433100 & 688497 & 5.45 & 4.8871 & TRN \\
\hline CHEMBL1457034 & 688497 & 5.4 & 4.9485 & TRN \\
\hline CHEMBL1322968 & 688497 & 5.25 & 5.0705 & TRN \\
\hline CHEMBL3212554 & 688497 & 5.95 & 5.3836 & TST \\
\hline CHEMBL1390386 & 688497 & 4.65 & 4.9983 & TRN \\
\hline CHEMBL1368514 & 688497 & 4.7 & 5.0813 & TRN \\
\hline CHEMBL1299772 & 688497 & 6.2 & 5.2135 & TST \\
\hline CHEMBL1612834 & 688497 & 4.45 & 5.0194 & TST \\
\hline CHEMBL1487529 & 688497 & 4.45 & 5.18 & TST \\
\hline CHEMBL1530147 & 688497 & 4.8 & 4.6647 & TRN \\
\hline CHEMBL1575715 & 688497 & 4.8 & 4.8961 & TST \\
\hline CHEMBL1493848 & 688497 & 6.25 & 5.397 & TRN \\
\hline CHEMBL1576548 & 688497 & 4.6 & 5.0984 & TRN \\
\hline CHEMBL1487525 & 688497 & 6.3 & 5.1298 & TRN \\
\hline CHEMBL1312515 & 688497 & 5.5 & 5.0086 & TST \\
\hline CHEMBL1576409 & 688497 & 5.2 & 5.1715 & TRN \\
\hline CHEMBL1325685 & 688497 & 5.55 & 5.2524 & TRN \\
\hline CHEMBL1560687 & 688497 & 6.3 & 5.3257 & TRN \\
\hline CHEMBL1484321 & 688497 & 4.85 & 5.0341 & TRN \\
\hline CHEMBL1604435 & 688497 & 5.0 & 5.0242 & TRN \\
\hline CHEMBL1419164 & 688497 & 5.0 & 4.9246 & TRN \\
\hline
\end{tabular}




\begin{tabular}{|c|c|c|c|c|}
\hline \multicolumn{5}{|c|}{ Supplemental Table } \\
\hline CHEMBL1414034 & 688497 & 5.55 & 4.8729 & TRN \\
\hline CHEMBL1382181 & 688497 & 5.4 & 4.9699 & TST \\
\hline CHEMBL1327420 & 688497 & 5.5 & 5.1093 & TRN \\
\hline CHEMBL 3198048 & 688497 & 5.9 & 4.9338 & TST \\
\hline CHEMBL1472193 & 688497 & 5.45 & 4.8839 & TST \\
\hline CHEMBL1322754 & 688497 & 4.9 & 4.8122 & TRN \\
\hline CHEMBL1525599 & 688497 & 6.0 & 5.2386 & TRN \\
\hline CHEMBL1587998 & 688497 & 6.25 & 5.142 & TRN \\
\hline CHEMBL1412290 & 688497 & 5.85 & 4.8892 & TST \\
\hline CHEMBL1520247 & 688497 & 5.3 & 4.9147 & TRN \\
\hline CHEMBL1418747 & 688497 & 4.45 & 5.104 & TST \\
\hline CHEMBL1589538 & 688497 & 4.7 & 5.0501 & TRN \\
\hline CHEMBL1438761 & 688497 & 4.6 & 4.7839 & TRN \\
\hline CHEMBL1327090 & 688497 & 4.45 & 5.2376 & TST \\
\hline CHEMBL3212969 & 688497 & 4.45 & 5.1365 & TRN \\
\hline CHEMBL1569200 & 688497 & 5.2 & 5.2142 & TRN \\
\hline CHEMBL1439544 & 688497 & 6.5 & 5.0935 & TRN \\
\hline CHEMBL1540227 & 688497 & 4.75 & 4.9147 & TST \\
\hline CHEMBL1432493 & 688497 & 4.75 & 5.0237 & TRN \\
\hline CHEMBL1372477 & 688497 & 5.45 & 5.4153 & TRN \\
\hline CHEMBL3196901 & 688497 & 4.45 & 4.8569 & TRN \\
\hline CHEMBL1534392 & 688497 & 4.45 & 5.0911 & TRN \\
\hline CHEMBL1390575 & 688497 & 5.55 & 5.2974 & TRN \\
\hline CHEMBL1993627 & 688497 & 4.45 & 5.0115 & TST \\
\hline CHEMBL1300297 & 688497 & 5.45 & 4.7003 & TRN \\
\hline CHEMBL1467655 & 688497 & 4.6 & 4.6342 & TRN \\
\hline CHEMBL1471994 & 688497 & 4.8 & 5.3208 & TRN \\
\hline CHEMBL1424303 & 688497 & 4.7 & 5.0791 & TRN \\
\hline CHEMBL3209128 & 688497 & 5.0 & 5.0351 & TST \\
\hline CHEMBL3196181 & 688497 & 5.85 & 5.2005 & TRN \\
\hline CHEMBL1495977 & 688497 & 4.95 & 5.545 & TRN \\
\hline CHEMBL1325149 & 688497 & 5.35 & 5.0102 & TRN \\
\hline CHEMBL1566675 & 688497 & 4.95 & 5.0452 & TST \\
\hline CHEMBL1346822 & 688497 & 4.85 & 4.8046 & TRN \\
\hline CHEMBL1426554 & 688497 & 4.45 & 5.397 & TRN \\
\hline CHEMBL1425143 & 688497 & 4.45 & 4.8015 & TRN \\
\hline CHEMBL1485236 & 688497 & 4.45 & 5.3789 & TRN \\
\hline CHEMBL1462977 & 688497 & 5.2 & 5.317 & TRN \\
\hline CHEMBL1428880 & 688497 & 4.9 & 5.234 & TRN \\
\hline CHEMBL1415885 & 688497 & 4.8 & 4.6813 & TRN \\
\hline CHEMBL1497165 & 688497 & 5.1 & 4.9396 & TRN \\
\hline CHEMBL1309398 & 688497 & 4.55 & 5.1175 & TRN \\
\hline CHEMBL1601289 & 688497 & 4.95 & 4.7667 & TST \\
\hline CHEMBL1459711 & 688497 & 4.45 & 4.7423 & TRN \\
\hline CHEMBL1494713 & 688497 & 4.5 & 4.5353 & TST \\
\hline CHEMBL1337451 & 688497 & 4.45 & 4.8643 & TRN \\
\hline CHEMBL1340715 & 688497 & 5.9 & 5.6523 & TRN \\
\hline CHEMBL1376281 & 688497 & 5.0 & 5.0682 & TST \\
\hline
\end{tabular}




\begin{tabular}{|c|c|c|c|c|c|}
\hline \multicolumn{6}{|c|}{ Supplemental Table S2.txt } \\
\hline CHEMBL1988782 & 688497 & 4.45 & 4.8416 & TST & \\
\hline CHEMBL546257 & 688497 & 4.45 & 5.2482 & TST & \\
\hline CHEMBL3211559 & 688497 & 6.25 & 5.3042 & TRN & \\
\hline CHEMBL1401522 & 688497 & 5.95 & 5.0799 & TRN & \\
\hline CHEMBL1588024 & 688497 & 4.9 & 4.8706 & TRN & \\
\hline CHEMBL1575354 & 688497 & 4.45 & 5.1116 & TST & \\
\hline CHEMBL1491307 & 688497 & 4.95 & 5.0471 & TRN & \\
\hline CHEMBL1444556 & 688497 & 4.9 & 4.9678 & TST & \\
\hline CHEMBL1501422 & 688497 & 5.4 & 5.2202 & TRN & \\
\hline CHEMBL1359467 & 688497 & 4.65 & 4.882 & TRN & \\
\hline CHEMBL 1457780 & 688497 & 4.9 & 5.0787 & TRN & \\
\hline CHEMBL1600107 & 688497 & 5.25 & 5.1962 & TRN & \\
\hline CHEMBL1982896 & 688497 & 4.8 & 5.1027 & TRN & \\
\hline CHEMBL1299421 & 688497 & 4.45 & 4.9133 & TRN & \\
\hline CHEMBL1599861 & 688497 & 5.8 & 4.9679 & TST & \\
\hline CHEMBL1520938 & 688497 & 5.25 & 4.9233 & TRN & \\
\hline CHEMBL1382686 & 688497 & 4.45 & 4.9613 & TST & \\
\hline CHEMBL1611753 & 688497 & 4.8 & 4.9365 & TRN & \\
\hline CHEMBL1560016 & 688497 & 4.85 & 4.7735 & TRN & \\
\hline CHEMBL1413033 & 688497 & 4.45 & 5.0564 & TRN & \\
\hline CHEMBL584883 & 688497 & 6.0 & 5.1949 & TRN & \\
\hline CHEMBL1456092 & 688497 & 4.5 & 4.7283 & TRN & \\
\hline CHEMBL1716038 & 688497 & 4.9 & 4.9174 & TRN & \\
\hline CHEMBL3193531 & 688497 & 4.85 & 4.9596 & TRN & \\
\hline CHEMBL1525666 & 688497 & 4.45 & 5.4425 & TST & \\
\hline CHEMBL1510033 & 688497 & 4.6 & 4.8416 & TRN & \\
\hline CHEMBL1608567 & 688497 & 4.9 & 4.8431 & TRN & \\
\hline CHEMBL1546896 & 688497 & 4.7 & 5.15799 & 99999999995 & TRN \\
\hline CHEMBL1369746 & 688497 & 4.95 & 5.0029 & TRN & \\
\hline CHEMBL1471209 & 688497 & 4.6 & 4.7409 & TRN & \\
\hline CHEMBL1466983 & 688497 & 4.45 & 4.9454 & TST & \\
\hline CHEMBL1428765 & 688497 & 4.85 & 4.7763 & TRN & \\
\hline CHEMBL1543680 & 688497 & 4.75 & 4.8445 & TRN & \\
\hline CHEMBL3213359 & 688497 & 5.15 & 4.7575 & TST & \\
\hline CHEMBL1573221 & 688497 & 6.0 & 5.0263 & TRN & \\
\hline CHEMBL1414410 & 688497 & 5.8 & 5.0087 & TRN & \\
\hline CHEMBL1362680 & 688497 & 5.25 & 5.0404 & TST & \\
\hline CHEMBL1528817 & 688497 & 4.85 & 4.8306 & TRN & \\
\hline CHEMBL1487345 & 688497 & 5.3 & 4.6837 & TRN & \\
\hline CHEMBL1372654 & 688497 & 4.95 & 4.9024 & TRN & \\
\hline CHEMBL3195621 & 688497 & 4.45 & 5.0577 & TRN & \\
\hline CHEMBL1402564 & 688497 & 4.45 & 5.2332 & TST & \\
\hline CHEMBL1362507 & 688497 & 6.45 & 5.3538 & TRN & \\
\hline CHEMBL1494996 & 688497 & 4.7 & 4.6796 & TRN & \\
\hline CHEMBL1304946 & 688497 & 4.7 & 4.7289 & TRN & \\
\hline CHEMBL1348747 & 688497 & 4.45 & 4.9567 & TRN & \\
\hline CHEMBL1469840 & 688497 & 4.95 & 5.2307 & TST & \\
\hline CHEMBL1323952 & 688497 & 4.95 & 5.1342 & TST & \\
\hline
\end{tabular}




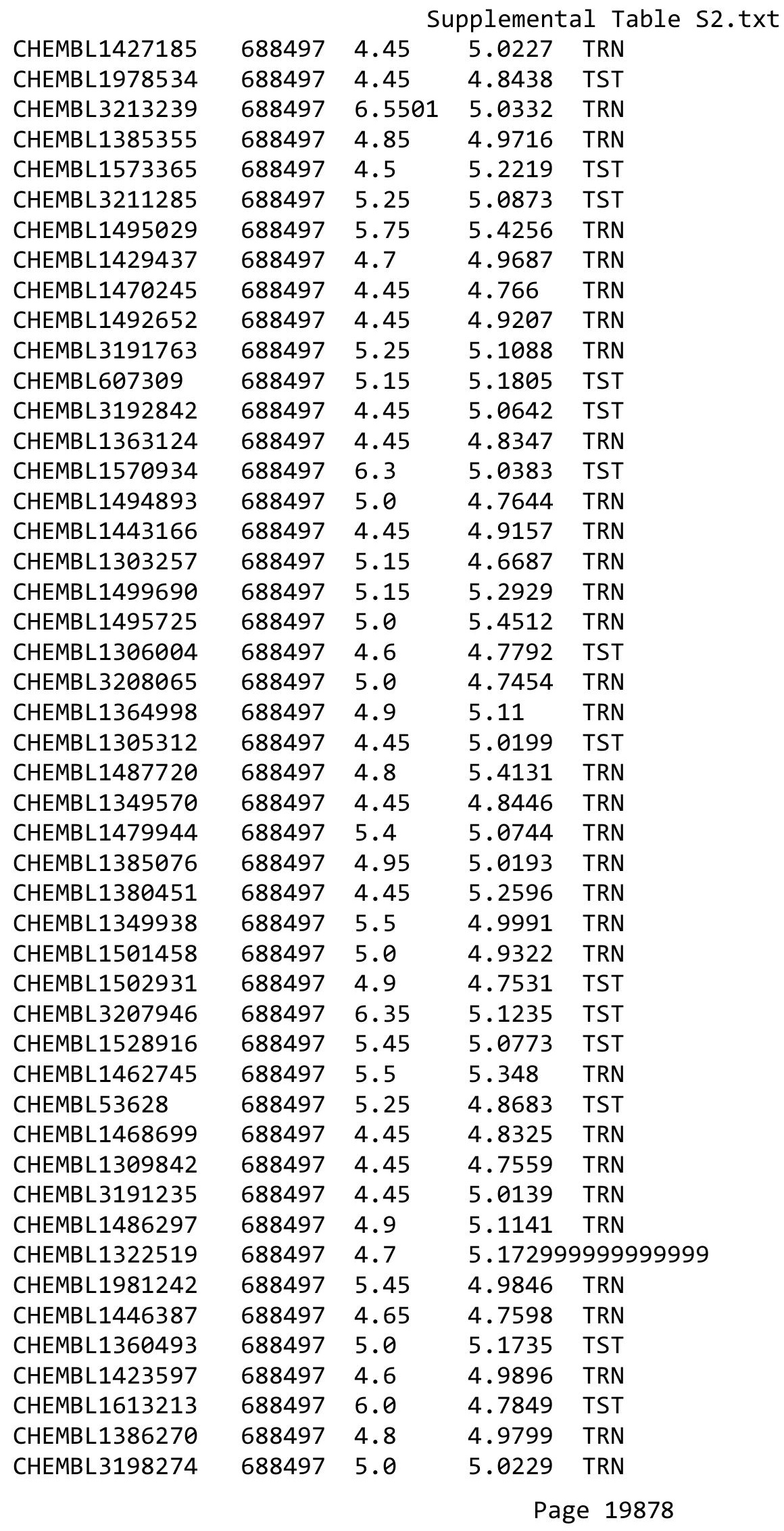




\begin{tabular}{|c|c|c|c|c|c|}
\hline \multicolumn{6}{|c|}{ Supplemental Table S2.txt } \\
\hline CHEMBL1579412 & 688497 & 5.65 & 5.3975 & TST & \\
\hline CHEMBL1365959 & 688497 & 4.45 & 5.0236 & TST & \\
\hline CHEMBL1981570 & 688497 & 5.25 & 5.3286 & TRN & \\
\hline CHEMBL 3199876 & 688497 & 5.05 & 4.9232 & TST & \\
\hline CHEMBL1309887 & 688497 & 4.9 & 5.1815 & TRN & \\
\hline CHEMBL1571290 & 688497 & 4.8 & 5.0703 & TRN & \\
\hline CHEMBL1518175 & 688497 & 5.25 & 4.8299 & TRN & \\
\hline CHEMBL1400095 & 688497 & 4.9 & 5.0397 & TRN & \\
\hline CHEMBL1327038 & 688497 & 4.95 & 5.1379 & TRN & \\
\hline CHEMBL1388695 & 688497 & 5.1 & 4.7674 & TRN & \\
\hline CHEMBL1457884 & 688497 & 4.45 & 5.0308 & TRN & \\
\hline CHEMBL1520595 & 688497 & 4.45 & 4.7513 & TST & \\
\hline CHEMBL1509710 & 688497 & 4.65 & 5.1424 & TRN & \\
\hline CHEMBL1609442 & 688497 & 4.65 & 4.8836 & TRN & \\
\hline CHEMBL1564394 & 688497 & 5.4 & 5.2779 & TRN & \\
\hline CHEMBL1510394 & 688497 & 4.6 & 5.1679 & TRN & \\
\hline CHEMBL1384548 & 688497 & 5.0 & 4.76399 & 9999999999 & TRN \\
\hline CHEMBL1319326 & 688497 & 4.8 & 5.2613 & TRN & \\
\hline CHEMBL1478310 & 688497 & 5.5 & 5.3638 & TST & \\
\hline CHEMBL1467579 & 688497 & 4.65 & 4.6783 & TST & \\
\hline CHEMBL1389805 & 688497 & 6.15 & 5.0173 & TRN & \\
\hline CHEMBL1547229 & 688497 & 5.25 & 4.748 & TRN & \\
\hline CHEMBL3209391 & 688497 & 4.45 & 5.0772 & TRN & \\
\hline CHEMBL1391453 & 688497 & 4.45 & 4.8738 & TRN & \\
\hline CHEMBL1533623 & 688497 & 5.65 & 5.1342 & TST & \\
\hline CHEMBL1359525 & 688497 & 4.45 & 4.7993 & TST & \\
\hline CHEMBL3211623 & 688497 & 4.95 & 4.9684 & TST & \\
\hline CHEMBL1352295 & 688497 & 4.95 & 5.1727 & TRN & \\
\hline CHEMBL1588816 & 688497 & 6.2 & 5.1032 & TRN & \\
\hline CHEMBL1502351 & 688497 & 5.0 & 4.9809 & TRN & \\
\hline CHEMBL1530229 & 688497 & 4.45 & 5.0093 & TRN & \\
\hline CHEMBL1312139 & 688497 & 4.65 & 4.9355 & TRN & \\
\hline CHEMBL515998 & 688497 & 4.45 & 5.3373 & TST & \\
\hline CHEMBL1420518 & 688497 & 4.8 & 5.2324 & TRN & \\
\hline CHEMBL1549261 & 688497 & 6.95 & 5.05699 & э9999999995 & TRN \\
\hline CHEMBL1311136 & 688497 & 5.85 & 5.1767 & TRN & \\
\hline CHEMBL1349062 & 688497 & 4.9 & 5.0597 & TRN & \\
\hline CHEMBL1351748 & 688497 & 4.45 & 5.193 & TST & \\
\hline CHEMBL1972977 & 688497 & 5.45 & 4.8861 & TRN & \\
\hline CHEMBL1374615 & 688497 & 4.45 & 5.0522 & TRN & \\
\hline CHEMBL3195151 & 688497 & 5.45 & 5.0203 & TRN & \\
\hline CHEMBL1550065 & 688497 & 6.6499 & 5.1738 & TST & \\
\hline CHEMBL3212680 & 688497 & 4.95 & 5.2015 & TST & \\
\hline CHEMBL1968859 & 688497 & 5.5 & 5.4137 & TRN & \\
\hline CHEMBL1558210 & 688497 & 4.45 & 4.9522 & TST & \\
\hline CHEMBL1425432 & 688497 & 4.55 & 4.7535 & TRN & \\
\hline CHEMBL1542282 & 688497 & 4.45 & 4.6873 & TRN & \\
\hline CHEMBL1987419 & 688497 & 6.0 & 5.2965 & TRN & \\
\hline
\end{tabular}




\begin{tabular}{|c|c|c|c|c|}
\hline \multicolumn{5}{|c|}{ Supplemental Table S2.txt } \\
\hline CHEMBL1478263 & 688497 & 4.45 & 4.6845 & TRN \\
\hline CHEMBL1518934 & 688497 & 6.25 & 4.9847 & TRN \\
\hline CHEMBL3145111 & 688497 & 4.45 & 4.8729 & TRN \\
\hline CHEMBL1604939 & 688497 & 6.95 & 5.016 & TRN \\
\hline CHEMBL1460468 & 688497 & 4.45 & 4.5751 & TRN \\
\hline CHEMBL1453255 & 688497 & 4.85 & 4.8557 & TRN \\
\hline CHEMBL1574046 & 688497 & 5.95 & 5.1997 & TST \\
\hline CHEMBL578915 & 688497 & 4.45 & 4.9628 & TRN \\
\hline CHEMBL441083 & 688497 & 4.9 & 5.0054 & TRN \\
\hline CHEMBL1613264 & 688497 & 4.65 & 5.1222 & TST \\
\hline CHEMBL3191441 & 688497 & 6.5501 & 4.8383 & TRN \\
\hline CHEMBL1417579 & 688497 & 4.45 & 4.9607 & TRN \\
\hline CHEMBL1384704 & 688497 & 4.45 & 5.2083 & TRN \\
\hline CHEMBL1575613 & 688497 & 4.5 & 4.9448 & TRN \\
\hline CHEMBL1548488 & 688497 & 4.7 & 4.8744 & TRN \\
\hline CHEMBL3191361 & 688497 & 4.65 & 5.2953 & TST \\
\hline CHEMBL1503882 & 688497 & 5.05 & 4.5889 & TRN \\
\hline CHEMBL3195159 & 688497 & 4.45 & 4.9959 & TRN \\
\hline CHEMBL1600941 & 688497 & 4.5 & 4.916 & TRN \\
\hline CHEMBL1472131 & 688497 & 5.3 & 5.0108 & TRN \\
\hline CHEMBL1532425 & 688497 & 4.85 & 4.8519 & TRN \\
\hline CHEMBL3213623 & 688497 & 6.25 & 5.1536 & TRN \\
\hline CHEMBL 3196457 & 688497 & 5.75 & 5.1648 & TRN \\
\hline CHEMBL1415950 & 688497 & 4.95 & 5.1038 & TRN \\
\hline CHEMBL1439658 & 688497 & 4.45 & 5.1672 & TRN \\
\hline CHEMBL1343568 & 688497 & 4.45 & 4.9863 & TRN \\
\hline CHEMBL1490976 & 688497 & 4.45 & 5.0911 & TRN \\
\hline CHEMBL582722 & 688497 & 4.45 & 4.7539 & TRN \\
\hline CHEMBL1338695 & 688497 & 5.45 & 5.0323 & TRN \\
\hline CHEMBL1351610 & 688497 & 4.45 & 4.7713 & TST \\
\hline CHEMBL1498566 & 688497 & 4.45 & 5.3341 & TRN \\
\hline CHEMBL1504221 & 688497 & 4.45 & 4.7643 & TRN \\
\hline CHEMBL1439540 & 688497 & 4.45 & 4.9296 & TRN \\
\hline CHEMBL1350255 & 688497 & 4.85 & 5.0012 & TRN \\
\hline CHEMBL1329048 & 688497 & 5.15 & 4.8334 & TRN \\
\hline CHEMBL1550685 & 688497 & 4.95 & 5.0247 & TRN \\
\hline CHEMBL1485443 & 688497 & 4.45 & 4.8491 & TRN \\
\hline CHEMBL1571157 & 688497 & 5.0 & 5.1115 & TRN \\
\hline CHEMBL1518456 & 688497 & 4.45 & 5.0942 & TST \\
\hline CHEMBL1502171 & 688497 & 5.5 & 5.1078 & TRN \\
\hline CHEMBL1454726 & 688497 & 4.8 & 4.8181 & TRN \\
\hline CHEMBL3191385 & 688497 & 4.45 & 5.2351 & TRN \\
\hline CHEMBL1438062 & 688497 & 4.45 & 5.2751 & TST \\
\hline CHEMBL1462838 & 688497 & 5.4 & 4.9751 & TRN \\
\hline CHEMBL 2007601 & 688497 & 5.05 & 5.131 & TST \\
\hline CHEMBL251785 & 688497 & 5.2 & 5.3994 & TRN \\
\hline CHEMBL1402141 & 688497 & 5.1 & 5.3575 & TRN \\
\hline CHEMBL1403846 & 688497 & 5.9 & 5.2298 & TRN \\
\hline
\end{tabular}




\begin{tabular}{|c|c|c|c|c|c|}
\hline \multicolumn{6}{|c|}{ Supplemental Table S2.txt } \\
\hline CHEMBL3212065 & 688497 & 4.45 & 4.8497 & TST & \\
\hline CHEMBL1499501 & 688497 & 5.65 & 5.164 & TRN & \\
\hline CHEMBL1537895 & 688497 & 4.9 & 5.1186 & TRN & \\
\hline CHEMBL1509045 & 688497 & 5.6 & 5.0214 & TST & \\
\hline CHEMBL1360473 & 688497 & 5.5 & 4.9097 & TRN & \\
\hline CHEMBL1364581 & 688497 & 4.85 & 4.8978 & TST & \\
\hline CHEMBL1523890 & 688497 & 4.45 & 4.8278 & TRN & \\
\hline CHEMBL1595765 & 688497 & 4.95 & 4.8167 & TRN & \\
\hline CHEMBL1483147 & 688497 & 4.9 & 4.9989 & TRN & \\
\hline CHEMBL1362805 & 688497 & 5.45 & 5.2947 & TRN & \\
\hline CHEMBL1446393 & 688497 & 6.25 & 5.1867 & TRN & \\
\hline CHEMBL1588303 & 688497 & 6.25 & 5.1914 & TRN & \\
\hline CHEMBL1347940 & 688497 & 6.25 & 4.9807 & TST & \\
\hline CHEMBL1518523 & 688497 & 5.25 & 4.8434 & TST & \\
\hline CHEMBL1588679 & 688497 & 4.9 & 4.9101 & TRN & \\
\hline CHEMBL1451447 & 688497 & 6.95 & 5.1263 & TRN & \\
\hline CHEMBL1568298 & 688497 & 4.5 & 4.7996 & TRN & \\
\hline CHEMBL1486332 & 688497 & 5.2 & 4.65300 & 00000000005 & TRN \\
\hline CHEMBL1328601 & 688497 & 5.9 & 5.1623 & TRN & \\
\hline CHEMBL1343799 & 688497 & 4.45 & 5.0707 & TST & \\
\hline CHEMBL1555719 & 688497 & 4.45 & 4.9232 & TRN & \\
\hline CHEMBL3192393 & 688497 & 5.0 & 4.7997 & TRN & \\
\hline CHEMBL1495094 & 688497 & 5.0 & 4.8666 & TRN & \\
\hline CHEMBL1454430 & 688497 & 4.8 & 4.7238 & TRN & \\
\hline CHEMBL1485445 & 688497 & 4.55 & 4.5853 & TRN & \\
\hline CHEMBL 3210527 & 688497 & 6.25 & 5.0306 & TRN & \\
\hline CHEMBL1458591 & 688497 & 4.45 & 4.5054 & TST & \\
\hline CHEMBL1508502 & 688497 & 4.8 & 4.9291 & TRN & \\
\hline CHEMBL1423940 & 688497 & 5.4 & 5.0548 & TRN & \\
\hline CHEMBL1544733 & 688497 & 6.25 & 5.1469 & TRN & \\
\hline CHEMBL1423277 & 688497 & 4.45 & 4.7932 & TRN & \\
\hline CHEMBL1363865 & 688497 & 6.0 & 4.827 & TST & \\
\hline CHEMBL1458479 & 688497 & 4.45 & 4.9943 & TRN & \\
\hline CHEMBL3191958 & 688497 & 4.8 & 5.1336 & TRN & \\
\hline CHEMBL1979800 & 688497 & 5.2 & 4.9959 & TRN & \\
\hline CHEMBL3192857 & 688497 & 4.45 & 4.9261 & TST & \\
\hline CHEMBL1381998 & 688497 & 5.65 & 4.9711 & TRN & \\
\hline CHEMBL3212403 & 688497 & 4.7 & 4.7788 & TST & \\
\hline CHEMBL1412417 & 688497 & 4.95 & 5.1487 & TST & \\
\hline CHEMBL1351423 & 688497 & 4.45 & 5.0667 & TST & \\
\hline CHEMBL1605795 & 688497 & 5.85 & 5.0491 & TRN & \\
\hline CHEMBL1388035 & 688497 & 5.25 & 5.2431 & TST & \\
\hline CHEMBL1323992 & 688497 & 5.6 & 5.5196 & TRN & \\
\hline CHEMBL1501505 & 688497 & 4.8 & 4.9585 & TRN & \\
\hline CHEMBL486078 & 688497 & 5.05 & 5.0354 & TRN & \\
\hline CHEMBL1469275 & 688497 & 5.4 & 4.7868 & TRN & \\
\hline CHEMBL1576875 & 688497 & 5.0 & 5.1318 & TRN & \\
\hline CHEMBL1545489 & 688497 & 5.55 & 5.0511 & TRN & \\
\hline
\end{tabular}




\begin{tabular}{|c|c|c|c|c|}
\hline \multicolumn{5}{|c|}{ Supplemental Table S2.txt } \\
\hline CHEMBL1578547 & 688497 & 4.45 & 4.9644 & TRN \\
\hline CHEMBL1439981 & 688497 & 5.55 & 5.0825 & TRN \\
\hline CHEMBL1460333 & 688497 & 5.0 & 4.9259 & TRN \\
\hline CHEMBL1538799 & 688497 & 5.45 & 4.8385 & TRN \\
\hline CHEMBL1335443 & 688497 & 5.0 & 5.1471 & TRN \\
\hline CHEMBL1490953 & 688497 & 4.45 & 5.0253 & TRN \\
\hline CHEMBL1469424 & 688497 & 5.0 & 4.9922 & TRN \\
\hline CHEMBL1341995 & 688497 & 5.9 & 5.3861 & TRN \\
\hline CHEMBL1540711 & 688497 & 5.5 & 4.9363 & TST \\
\hline CHEMBL1443976 & 688497 & 4.9 & 4.8746 & TRN \\
\hline CHEMBL1529994 & 688497 & 4.95 & 5.3112 & TRN \\
\hline CHEMBL1334903 & 688497 & 5.4 & 4.7692 & TRN \\
\hline CHEMBL1451525 & 688497 & 4.45 & 4.8377 & TRN \\
\hline CHEMBL1580126 & 688497 & 4.95 & 4.768 & TRN \\
\hline CHEMBL1529852 & 688497 & 6.05 & 4.9399 & TRN \\
\hline CHEMBL1343059 & 688497 & 5.2 & 5.3992 & TST \\
\hline CHEMBL3195118 & 688497 & 5.05 & 4.832 & TRN \\
\hline CHEMBL1460367 & 688497 & 4.45 & 4.9882 & TRN \\
\hline CHEMBL1550041 & 688497 & 4.65 & 5.0907 & TRN \\
\hline CHEMBL1493187 & 688497 & 4.45 & 5.3142 & TST \\
\hline CHEMBL1361719 & 688497 & 4.95 & 5.2014 & TRN \\
\hline CHEMBL1604572 & 688497 & 5.25 & 5.0158 & TRN \\
\hline CHEMBL1346089 & 688497 & 6.05 & 5.2346 & TRN \\
\hline CHEMBL1501444 & 688497 & 5.0 & 5.0194 & TRN \\
\hline CHEMBL505670 & 688497 & 5.95 & 5.0341 & TST \\
\hline CHEMBL1343006 & 688497 & 4.8 & 4.8772 & TRN \\
\hline CHEMBL1540302 & 688497 & 6.2 & 5.5177 & TRN \\
\hline CHEMBL1469727 & 688497 & 4.5 & 4.9949 & TRN \\
\hline CHEMBL1441397 & 688497 & 4.7 & 4.8626 & TRN \\
\hline CHEMBL1555652 & 688497 & 4.45 & 4.7407 & TRN \\
\hline CHEMBL1586762 & 688497 & 5.5 & 5.0755 & TST \\
\hline CHEMBL1444553 & 688497 & 4.9 & 5.0436 & TRN \\
\hline CHEMBL1418389 & 688497 & 5.0 & 4.7142 & TST \\
\hline CHEMBL1454532 & 688497 & 4.45 & 5.0558 & TRN \\
\hline CHEMBL1381070 & 688497 & 4.85 & 4.7872 & TRN \\
\hline CHEMBL1391513 & 688497 & 5.05 & 4.976 & TRN \\
\hline CHEMBL1304922 & 688497 & 4.6 & 4.9461 & TRN \\
\hline CHEMBL1481512 & 688497 & 6.3 & 5.5573 & TRN \\
\hline CHEMBL1864436 & 688497 & 4.65 & 5.0185 & TST \\
\hline CHEMBL1511312 & 688497 & 4.55 & 4.8477 & TRN \\
\hline CHEMBL1373922 & 688497 & 5.6 & 5.1271 & TST \\
\hline CHEMBL1393695 & 688497 & 4.45 & 4.9891 & TRN \\
\hline CHEMBL1565033 & 688497 & 4.45 & 5.0309 & TRN \\
\hline CHEMBL1365843 & 688497 & 4.95 & 4.9772 & TRN \\
\hline CHEMBL1371580 & 688497 & 4.9 & 4.9723 & TRN \\
\hline CHEMBL1567154 & 688497 & 5.35 & 4.9719 & TRN \\
\hline CHEMBL 1366350 & 688497 & 4.45 & 5.2916 & TRN \\
\hline CHEMBL1367713 & 688497 & 5.4 & 5.1815 & TRN \\
\hline
\end{tabular}




\begin{tabular}{|c|c|c|c|c|c|}
\hline CHEMBL1493101 & 688497 & 4.8 & \multicolumn{2}{|c|}{5.031000000000001} & TRN \\
\hline CHEMBL1498325 & 688497 & 5.95 & 5.38 & TRN & \\
\hline CHEMBL1308772 & 688497 & 4.45 & 4.9008 & TRN & \\
\hline CHEMBL1585848 & 688497 & 4.45 & 4.7359 & TRN & \\
\hline CHEMBL1441242 & 688497 & 4.45 & 4.8656 & TRN & \\
\hline CHEMBL1580174 & 688497 & 5.45 & 5.1276 & TRN & \\
\hline CHEMBL3199382 & 688497 & 5.05 & 4.9869 & TRN & \\
\hline CHEMBL1579170 & 688497 & 4.45 & 4.8605 & TST & \\
\hline CHEMBL1605247 & 688497 & 4.45 & 4.8406 & TRN & \\
\hline CHEMBL1539706 & 688497 & 4.65 & 5.1313 & TST & \\
\hline CHEMBL1537818 & 688497 & 6.3 & 5.3282 & TRN & \\
\hline CHEMBL1982484 & 688497 & 5.25 & 5.1574 & TRN & \\
\hline CHEMBL1412772 & 688497 & 6.15 & 5.1599 & TRN & \\
\hline CHEMBL1525186 & 688497 & 4.45 & 4.9451 & TRN & \\
\hline CHEMBL1532617 & 688497 & 5.6 & 5.1017 & TRN & \\
\hline CHEMBL1587568 & 688497 & 6.25 & 5.1209 & TRN & \\
\hline CHEMBL1452189 & 688497 & 4.6 & 4.8175 & TRN & \\
\hline CHEMBL1304919 & 688497 & 4.45 & 4.7123 & TRN & \\
\hline CHEMBL1333256 & 688497 & 4.45 & 4.9748 & TRN & \\
\hline CHEMBL1406092 & 688497 & 5.5 & 5.2861 & TRN & \\
\hline CHEMBL1341308 & 688497 & 4.45 & 4.6641 & TRN & \\
\hline CHEMBL1342837 & 688497 & 5.7 & 5.0638 & TRN & \\
\hline CHEMBL1601077 & 688497 & 4.45 & 4.8454 & TRN & \\
\hline CHEMBL3192617 & 688497 & 4.45 & 4.8736 & TRN & \\
\hline CHEMBL1401288 & 688497 & 4.45 & 5.2536 & TST & \\
\hline CHEMBL1459542 & 688497 & 3.5 & 5.2018 & TRN & \\
\hline CHEMBL1428284 & 688497 & 4.8 & 5.2205 & TRN & \\
\hline CHEMBL1425741 & 688497 & 5.25 & 4.8323 & TST & \\
\hline CHEMBL1506452 & 688497 & 4.8 & 4.8311 & TRN & \\
\hline CHEMBL1427117 & 688497 & 6.25 & 5.2984 & TRN & \\
\hline CHEMBL1488613 & 688497 & 4.45 & 5.0494 & TRN & \\
\hline CHEMBL1339433 & 688497 & 5.55 & 4.9443 & TRN & \\
\hline CHEMBL1583742 & 688497 & 5.05 & \multicolumn{2}{|c|}{5.422999999999999} & TRN \\
\hline CHEMBL1399082 & 688497 & 4.75 & 5.0773 & TRN & \\
\hline CHEMBL1572934 & 688497 & 6.25 & 5.1227 & TRN & \\
\hline CHEMBL1430943 & 688497 & 5.1 & 5.0641 & TRN & \\
\hline CHEMBL1400110 & 688497 & 4.45 & 5.0289 & TRN & \\
\hline CHEMBL1971875 & 688497 & 5.45 & 4.8115 & TRN & \\
\hline CHEMBL1558961 & 688497 & 4.45 & 4.8483 & TRN & \\
\hline CHEMBL1406073 & 688497 & 4.65 & 5.2892 & TRN & \\
\hline CHEMBL1496771 & 688497 & 5.35 & 4.933 & TRN & \\
\hline CHEMBL1309312 & 688497 & 4.95 & 4.8424 & TRN & \\
\hline CHEMBL1500880 & 688497 & 5.25 & 5.3628 & TST & \\
\hline CHEMBL1588628 & 688497 & 5.25 & 5.05 & TRN & \\
\hline CHEMBL1466793 & 688497 & 6.1 & 5.2947 & TRN & \\
\hline CHEMBL1416237 & 688497 & 4.8 & 4.5994 & TRN & \\
\hline CHEMBL1392366 & 688497 & 4.45 & 4.561 & TRN & \\
\hline CHEMBL1375405 & 688497 & 6.3 & 5.2566 & TRN & \\
\hline
\end{tabular}




\begin{tabular}{|c|c|c|c|c|}
\hline \multicolumn{5}{|c|}{ Supplemental Table S2.txt } \\
\hline CHEMBL1303657 & 688497 & 4.8 & 4.7847 & TRN \\
\hline CHEMBL1383769 & 688497 & 4.7 & 5.2411 & TST \\
\hline CHEMBL1463289 & 688497 & 4.85 & 4.8299 & TST \\
\hline CHEMBL1306287 & 688497 & 4.65 & 4.9312 & TRN \\
\hline CHEMBL 1470515 & 688497 & 5.5 & 5.072 & TRN \\
\hline CHEMBL1449890 & 688497 & 5.55 & 5.0519 & TRN \\
\hline CHEMBL1547207 & 688497 & 4.75 & 4.8911 & TST \\
\hline CHEMBL1575447 & 688497 & 4.6 & 4.8367 & TRN \\
\hline CHEMBL1491626 & 688497 & 5.25 & 4.8708 & TRN \\
\hline CHEMBL1324526 & 688497 & 4.95 & 5.1888 & TRN \\
\hline CHEMBL1300974 & 688497 & 6.25 & 5.1107 & TST \\
\hline CHEMBL1478769 & 688497 & 5.1 & 4.9822 & TRN \\
\hline CHEMBL1523410 & 688497 & 4.65 & 4.6387 & TRN \\
\hline CHEMBL1571202 & 688497 & 5.55 & 4.8579 & TRN \\
\hline CHEMBL1413948 & 688497 & 4.45 & 4.9267 & TRN \\
\hline CHEMBL1320353 & 688497 & 5.05 & 5.107 & TRN \\
\hline CHEMBL1327932 & 688497 & 5.25 & 5.0554 & TRN \\
\hline CHEMBL1346254 & 688497 & 4.85 & 5.074 & TRN \\
\hline CHEMBL1462352 & 688497 & 5.25 & 5.0827 & TRN \\
\hline CHEMBL1443706 & 688497 & 5.05 & 5.072 & TRN \\
\hline CHEMBL1418251 & 688497 & 4.45 & 5.1685 & TRN \\
\hline CHEMBL1385209 & 688497 & 6.25 & 5.1 & TRN \\
\hline CHEMBL1418720 & 688497 & 4.95 & 4.9882 & TRN \\
\hline CHEMBL1333550 & 688497 & 6.35 & 5.193 & TRN \\
\hline CHEMBL1404711 & 688497 & 4.45 & 5.1346 & TRN \\
\hline CHEMBL597251 & 688497 & 4.45 & 4.7068 & TRN \\
\hline CHEMBL1452926 & 688497 & 4.45 & 4.8232 & TRN \\
\hline CHEMBL1389497 & 688497 & 4.95 & 4.8149 & TST \\
\hline CHEMBL3198116 & 688497 & 4.45 & 4.9235 & TRN \\
\hline CHEMBL1383599 & 688497 & 4.45 & 4.8972 & TST \\
\hline CHEMBL1522550 & 688497 & 4.45 & 4.8148 & TRN \\
\hline CHEMBL1372751 & 688497 & 4.8 & 4.8937 & TRN \\
\hline CHEMBL1480813 & 688497 & 4.45 & 5.0224 & TRN \\
\hline CHEMBL1335738 & 688497 & 4.45 & 4.64 & TRN \\
\hline CHEMBL1346115 & 688497 & 5.5 & 4.9935 & TST \\
\hline CHEMBL3199702 & 688497 & 5.45 & 4.9893 & TST \\
\hline CHEMBL1338027 & 688497 & 5.05 & 4.6344 & TRN \\
\hline CHEMBL1524270 & 688497 & 4.45 & 5.1009 & TST \\
\hline CHEMBL1345758 & 688497 & 5.4 & 5.1915 & TST \\
\hline CHEMBL1489380 & 688497 & 5.25 & 4.7744 & TRN \\
\hline CHEMBL1605393 & 688497 & 4.8 & 5.1389 & TRN \\
\hline CHEMBL1403650 & 688497 & 4.9 & 4.8933 & TRN \\
\hline CHEMBL1408327 & 688497 & 5.55 & 5.2666 & TRN \\
\hline CHEMBL1599628 & 688497 & 4.6 & 5.0107 & TRN \\
\hline CHEMBL1570319 & 688497 & 6.25 & 4.8639 & TRN \\
\hline CHEMBL3213078 & 688497 & 4.45 & 5.0276 & TST \\
\hline CHEMBL1438034 & 688497 & 9.2218 & 5.5128 & TRN \\
\hline CHEMBL1543323 & 688497 & 5.15 & 5.3033 & TST \\
\hline
\end{tabular}




\begin{tabular}{|c|c|c|c|c|c|}
\hline \multicolumn{6}{|c|}{ Supplemental Table s2.txt } \\
\hline CHEMBL2005437 & 688497 & 5.05 & 5.1946 & TRN & \\
\hline CHEMBL1706619 & 688497 & 4.45 & 4.6925 & TST & \\
\hline CHEMBL1490974 & 688497 & 4.45 & \multicolumn{2}{|c|}{5.031000000000001} & TRN \\
\hline CHEMBL 246957 & 688497 & 4.85 & 5.2015 & TST & \\
\hline CHEMBL1387433 & 688497 & 4.45 & 5.305 & TRN & \\
\hline CHEMBL1344755 & 688497 & 4.75 & \multicolumn{2}{|c|}{4.986000000000001} & TRN \\
\hline CHEMBL1573915 & 688497 & 6.25 & 5.4726 & TRN & \\
\hline CHEMBL1420897 & 688497 & 4.45 & 5.0635 & TRN & \\
\hline CHEMBL1505879 & 688497 & 4.45 & 5.2039 & TRN & \\
\hline CHEMBL1351532 & 688497 & 4.5 & 5.166 & TST & \\
\hline CHEMBL3195009 & 688497 & 4.75 & 4.7782 & TRN & \\
\hline CHEMBL1427175 & 688497 & 4.95 & 5.1138 & TRN & \\
\hline CHEMBL1542070 & 688497 & 4.45 & 4.9423 & TRN & \\
\hline CHEMBL1482585 & 688497 & 5.05 & 5.0709 & TRN & \\
\hline CHEMBL1392058 & 688497 & 6.9 & 5.5329 & TRN & \\
\hline CHEMBL1366729 & 688497 & 4.65 & 4.7264 & TRN & \\
\hline CHEMBL1502348 & 688497 & 4.75 & \multicolumn{2}{|c|}{4.696000000000001} & TRN \\
\hline CHEMBL1480767 & 688497 & 4.8 & 4.8688 & TRN & \\
\hline CHEMBL1517642 & 688497 & 6.25 & 5.3431 & TRN & \\
\hline CHEMBL1477317 & 688497 & 4.45 & 5.2264 & TST & \\
\hline CHEMBL1600103 & 688497 & 5.25 & 5.2416 & TST & \\
\hline CHEMBL2354668 & 688497 & 4.45 & 4.9828 & TRN & \\
\hline CHEMBL1462218 & 688497 & 4.5 & 5.1867 & TRN & \\
\hline CHEMBL1366118 & 688497 & 4.45 & 4.8456 & TRN & \\
\hline CHEMBL1351321 & 688497 & 6.25 & 5.0099 & TRN & \\
\hline CHEMBL1336751 & 688497 & 4.45 & \multicolumn{2}{|c|}{5.2410000000000005} & TRN \\
\hline CHEMBL1526063 & 688497 & 4.75 & 5.3899 & TRN & \\
\hline CHEMBL1597746 & 688497 & 4.45 & 4.9906 & TRN & \\
\hline CHEMBL1558021 & 688497 & 4.6 & 4.8396 & TRN & \\
\hline CHEMBL1518732 & 688497 & 4.45 & 5.3038 & TST & \\
\hline CHEMBL1383544 & 688497 & 4.95 & 5.2021 & TRN & \\
\hline CHEMBL1355982 & 688497 & 5.6 & 5.0714 & TST & \\
\hline CHEMBL1587680 & 688497 & 5.2 & 4.8832 & TRN & \\
\hline CHEMBL1306343 & 688497 & 6.25 & 5.4188 & TRN & \\
\hline CHEMBL1438874 & 688497 & 6.25 & 5.2031 & TRN & \\
\hline CHEMBL1582365 & 688497 & 5.4 & 5.1374 & TRN & \\
\hline CHEMBL1569426 & 688497 & 5.5 & 5.1783 & TST & \\
\hline CHEMBL1429321 & 688497 & 6.5 & 5.1272 & TST & \\
\hline CHEMBL1501279 & 688497 & 5.5 & 4.765 & TRN & \\
\hline CHEMBL1499711 & 688497 & 4.7 & 4.959 & TRN & \\
\hline CHEMBL1342647 & 688497 & 4.45 & 5.0924 & TST & \\
\hline CHEMBL1448448 & 688497 & 4.45 & 5.0803 & TST & \\
\hline CHEMBL1433308 & 688497 & 4.95 & 5.0519 & TRN & \\
\hline CHEMBL1331721 & 688497 & 5.6 & 5.0499 & TRN & \\
\hline CHEMBL1417524 & 688497 & 4.45 & 4.8737 & TST & \\
\hline CHEMBL1576939 & 688497 & 5.5 & 4.8117 & TRN & \\
\hline CHEMBL3193609 & 688497 & 5.45 & 5.2163 & TST & \\
\hline \multirow[t]{2}{*}{ CHEMBL1490009 } & 688497 & 5.05 & \multicolumn{2}{|c|}{4.9430000000000005} & TRN \\
\hline & & & & 19885 & \\
\hline
\end{tabular}




\begin{tabular}{|c|c|c|c|c|}
\hline & & & upplement & al Table S \\
\hline CHEMBL1566597 & 688497 & 6.15 & 5.0574 & TRN \\
\hline CHEMBL1299744 & 688497 & 4.9 & 5.066 & TRN \\
\hline CHEMBL518430 & 688497 & 4.45 & 5.0 & TRN \\
\hline CHEMBL1347210 & 688497 & 5.9 & 5.0955 & TRN \\
\hline CHEMBL1362194 & 688497 & 4.75 & 4.8701 & TRN \\
\hline CHEMBL1602142 & 688497 & 4.6 & 4.9313 & TRN \\
\hline CHEMBL1465085 & 688497 & 5.25 & 5.2571 & TRN \\
\hline CHEMBL1300515 & 688497 & 5.25 & 4.8809 & TRN \\
\hline CHEMBL1412024 & 688497 & 5.35 & 5.331 & TRN \\
\hline CHEMBL1446480 & 688497 & 4.5 & 4.9695 & TRN \\
\hline CHEMBL1600772 & 688497 & 4.6 & 4.9673 & TRN \\
\hline CHEMBL1566233 & 688497 & 4.45 & 5.062 & TRN \\
\hline CHEMBL1412921 & 688497 & 5.45 & 4.9242 & TRN \\
\hline CHEMBL1310132 & 688497 & 5.25 & 5.0947 & TRN \\
\hline CHEMBL1528425 & 688497 & 5.45 & 5.3233 & TRN \\
\hline CHEMBL3189568 & 688497 & 4.45 & 4.8566 & TRN \\
\hline CHEMBL1550366 & 688497 & 5.4 & 4.9668 & TST \\
\hline CHEMBL1600284 & 688497 & 5.45 & 4.9323 & TRN \\
\hline CHEMBL1462724 & 688497 & 5.6 & 5.2283 & TRN \\
\hline CHEMBL1320151 & 688497 & 4.85 & 5.1519 & TRN \\
\hline CHEMBL1495776 & 688497 & 4.65 & 5.0692 & TST \\
\hline CHEMBL1610679 & 688497 & 6.0 & 5.1304 & TRN \\
\hline CHEMBL1501600 & 688497 & 5.45 & 5.0961 & TRN \\
\hline CHEMBL1426192 & 688497 & 4.9 & 4.7999 & TRN \\
\hline CHEMBL1463570 & 688497 & 6.25 & 5.5349 & TRN \\
\hline CHEMBL1477352 & 688497 & 4.45 & 4.9173 & TRN \\
\hline CHEMBL1608647 & 688497 & 4.9 & 5.2785 & TRN \\
\hline CHEMBL1586315 & 688497 & 4.45 & 4.8992 & TST \\
\hline CHEMBL226876 & 688497 & 4.5 & 4.8934 & TRN \\
\hline CHEMBL 239883 & 688497 & 4.45 & 5.0365 & TRN \\
\hline CHEMBL1523429 & 688497 & 4.8 & 5.1639 & TRN \\
\hline CHEMBL 3213680 & 688497 & 5.25 & 5.5721 & TST \\
\hline CHEMBL1524254 & 688497 & 4.45 & 4.7613 & TRN \\
\hline CHEMBL567622 & 688497 & 5.25 & 4.9158 & TRN \\
\hline CHEMBL1531270 & 688497 & 4.45 & 4.8968 & TRN \\
\hline CHEMBL1504246 & 688497 & 5.6 & 5.1698 & TRN \\
\hline CHEMBL475754 & 688497 & 5.1 & 4.9492 & TRN \\
\hline CHEMBL1333378 & 688497 & 5.0 & 5.5116 & TRN \\
\hline CHEMBL1531169 & 688497 & 4.85 & 4.9015 & TST \\
\hline CHEMBL3195298 & 688497 & 5.15 & 5.0908 & TST \\
\hline CHEMBL1574403 & 688497 & 4.9 & 4.9423 & TRN \\
\hline CHEMBL1594473 & 688497 & 4.45 & 4.803 & TRN \\
\hline CHEMBL1504342 & 688497 & 4.95 & 5.1497 & TST \\
\hline CHEMBL1510273 & 688497 & 6.3 & 5.09399 & 9999999999 \\
\hline CHEMBL1424929 & 688497 & 5.55 & 5.1754 & TRN \\
\hline CHEMBL1306198 & 688497 & 5.2 & 4.8721 & TST \\
\hline CHEMBL3198437 & 688497 & 5.4 & 5.2641 & TRN \\
\hline CHEMBL1461214 & 688497 & 5.5 & 5.1903 & TST \\
\hline
\end{tabular}




\begin{tabular}{|c|c|c|c|c|}
\hline \multicolumn{5}{|c|}{ Supplemental Table S2.txt } \\
\hline CHEMBL1569698 & 688497 & 5.4 & 5.0447 & TRN \\
\hline CHEMBL1342842 & 688497 & 4.45 & 4.5198 & TRN \\
\hline CHEMBL1383310 & 688497 & 5.2 & 5.2783 & TRN \\
\hline CHEMBL 3199125 & 688497 & 5.05 & 5.1644 & TRN \\
\hline CHEMBL 1460206 & 688497 & 5.05 & 4.8563 & TRN \\
\hline CHEMBL1563911 & 688497 & 4.6 & 5.1004 & TST \\
\hline CHEMBL1555494 & 688497 & 4.5 & 5.026 & TRN \\
\hline CHEMBL1400427 & 688497 & 5.25 & 4.8218 & TRN \\
\hline CHEMBL1461698 & 688497 & 4.8 & 4.8528 & TRN \\
\hline CHEMBL1372475 & 688497 & 4.5 & 5.0518 & TST \\
\hline CHEMBL1530611 & 688497 & 5.3 & 4.7859 & TST \\
\hline CHEMBL1509648 & 688497 & 4.85 & 4.7876 & TRN \\
\hline CHEMBL1449076 & 688497 & 5.15 & 5.0355 & TST \\
\hline CHEMBL1603769 & 688497 & 6.35 & 5.1762 & TRN \\
\hline CHEMBL1594685 & 688497 & 4.45 & 4.8192 & TRN \\
\hline CHEMBL1311908 & 688497 & 5.25 & 5.0015 & TRN \\
\hline CHEMBL1583427 & 688497 & 6.0 & 4.958 & TST \\
\hline CHEMBL1338599 & 688497 & 4.65 & 5.0005 & TST \\
\hline CHEMBL1486911 & 688497 & 4.5 & 4.7973 & TRN \\
\hline CHEMBL1522541 & 688497 & 4.45 & 5.1367 & TRN \\
\hline CHEMBL1568598 & 688497 & 4.45 & 5.0763 & TRN \\
\hline CHEMBL1430215 & 688497 & 4.45 & 4.95 & TRN \\
\hline CHEMBL 3145178 & 688497 & 4.85 & 5.1659 & TRN \\
\hline CHEMBL1498353 & 688497 & 5.55 & 4.859 & TST \\
\hline CHEMBL1577112 & 688497 & 5.65 & 5.1501 & TST \\
\hline CHEMBL1487849 & 688497 & 5.2 & 5.4679 & TRN \\
\hline CHEMBL1360933 & 688497 & 4.45 & 5.3423 & TRN \\
\hline CHEMBL1303793 & 688497 & 4.9 & 4.8528 & TST \\
\hline CHEMBL1447615 & 688497 & 4.9 & 5.0344 & TRN \\
\hline CHEMBL1483731 & 688497 & 4.45 & 5.0089 & TRN \\
\hline CHEMBL1608295 & 688497 & 6.3 & 5.3277 & TST \\
\hline CHEMBL1527478 & 688497 & 5.25 & 4.7667 & TRN \\
\hline CHEMBL1443990 & 688497 & 5.25 & 5.3032 & TST \\
\hline CHEMBL1604880 & 688497 & 6.25 & 5.063 & TRN \\
\hline CHEMBL1540043 & 688497 & 4.8 & 4.8004 & TRN \\
\hline CHEMBL1359940 & 688497 & 4.9 & 4.9265 & TRN \\
\hline CHEMBL1347782 & 688497 & 4.95 & 4.8924 & TRN \\
\hline CHEMBL1532635 & 688497 & 4.65 & 5.0187 & TRN \\
\hline CHEMBL1566648 & 688497 & 5.5 & 4.9921 & TRN \\
\hline CHEMBL1545234 & 688497 & 4.55 & 4.9939 & TRN \\
\hline CHEMBL1370417 & 688497 & 5.55 & 5.0749 & TRN \\
\hline CHEMBL1572503 & 688497 & 4.45 & 5.061 & TRN \\
\hline CHEMBL1491929 & 688497 & 6.25 & 5.0309 & TRN \\
\hline CHEMBL1399663 & 688497 & 5.5 & 4.724 & TRN \\
\hline CHEMBL1454913 & 688497 & 4.45 & 5.0169 & TST \\
\hline CHEMBL1538363 & 688497 & 5.1 & 5.06 & TRN \\
\hline CHEMBL3196268 & 688497 & 4.5 & 5.1436 & TST \\
\hline CHEMBL1492542 & 688497 & 5.45 & 5.4844 & TRN \\
\hline
\end{tabular}




\begin{tabular}{|c|c|c|c|c|c|}
\hline \multicolumn{6}{|c|}{ Supplemental Table S2.txt } \\
\hline CHEMBL1380514 & 688497 & 4.75 & 4.988 & TRN & \\
\hline CHEMBL1521090 & 688497 & 4.95 & 4.8372 & TRN & \\
\hline CHEMBL1974063 & 688497 & 5.1 & 5.0998 & TST & \\
\hline CHEMBL1459917 & 688497 & 4.8 & 4.9331 & TRN & \\
\hline CHEMBL1307812 & 688497 & 5.9 & 5.3322 & TRN & \\
\hline CHEMBL1426792 & 688497 & 5.2 & 4.944 & TRN & \\
\hline CHEMBL1463533 & 688497 & 4.45 & 4.9649 & TRN & \\
\hline CHEMBL1981951 & 688497 & 5.25 & 5.1768 & TST & \\
\hline CHEMBL1372210 & 688497 & 5.15 & 4.6429 & TRN & \\
\hline CHEMBL1713905 & 688497 & 5.0 & 4.8419 & TRN & \\
\hline CHEMBL1449127 & 688497 & 4.45 & 4.9106 & TST & \\
\hline CHEMBL1303453 & 688497 & 4.45 & 5.4628 & TST & \\
\hline CHEMBL1562110 & 688497 & 5.15 & 5.0335 & TRN & \\
\hline CHEMBL1607089 & 688497 & 5.35 & 4.9983 & TRN & \\
\hline CHEMBL1559098 & 688497 & 4.7 & 4.8795 & TRN & \\
\hline CHEMBL1449161 & 688497 & 4.65 & 5.0587 & TST & \\
\hline CHEMBL1986086 & 688497 & 4.45 & 4.7574 & TRN & \\
\hline CHEMBL1339078 & 688497 & 5.15 & 5.0612 & TST & \\
\hline CHEMBL1503900 & 688497 & 5.45 & 4.9741 & TRN & \\
\hline CHEMBL1393983 & 688497 & 5.75 & 5.4577 & TRN & \\
\hline CHEMBL1604282 & 688497 & 4.9 & 4.7608 & TRN & \\
\hline CHEMBL587433 & 688497 & 4.75 & 4.71399 & 99999999995 & TRN \\
\hline CHEMBL1465679 & 688497 & 5.2 & 5.124 & TRN & \\
\hline CHEMBL1333600 & 688497 & 6.0 & 5.7128 & TST & \\
\hline CHEMBL1451522 & 688497 & 5.55 & 4.8018 & TST & \\
\hline CHEMBL1332066 & 688497 & 5.2 & 5.1152 & TRN & \\
\hline CHEMBL1580715 & 688497 & 4.65 & 4.8425 & TST & \\
\hline CHEMBL1541016 & 688497 & 5.95 & 4.8918 & TRN & \\
\hline CHEMBL1320316 & 688497 & 5.9 & 5.2808 & TRN & \\
\hline CHEMBL1577748 & 688497 & 6.0 & 5.0173 & TST & \\
\hline CHEMBL1331248 & 688497 & 6.45 & 4.9775 & TRN & \\
\hline CHEMBL1368233 & 688497 & 4.5 & 4.9953 & TRN & \\
\hline CHEMBL1367043 & 688497 & 4.55 & 4.5546 & TRN & \\
\hline CHEMBL1587837 & 688497 & 4.45 & 4.9228 & TST & \\
\hline CHEMBL1456701 & 688497 & 4.95 & 5.2103 & TRN & \\
\hline CHEMBL1361461 & 688497 & 4.95 & 5.1756 & TRN & \\
\hline CHEMBL1394030 & 688497 & 4.8 & 4.9566 & TST & \\
\hline CHEMBL1352951 & 688497 & 4.95 & 5.1195 & TST & \\
\hline CHEMBL1481988 & 688497 & 6.2 & 4.7149 & TRN & \\
\hline CHEMBL1351764 & 688497 & 4.45 & 5.1561 & TRN & \\
\hline CHEMBL1351197 & 688497 & 5.1 & 5.032 & TST & \\
\hline CHEMBL1399935 & 688497 & 4.95 & 5.3576 & TRN & \\
\hline CHEMBL1414923 & 688497 & 5.2 & 4.6591 & TRN & \\
\hline CHEMBL1310527 & 688497 & 4.45 & 4.8142 & TST & \\
\hline CHEMBL1587493 & 688497 & 5.25 & 5.1235 & TRN & \\
\hline CHEMBL1391676 & 688497 & 5.55 & 5.2831 & TRN & \\
\hline CHEMBL1331180 & 688497 & 5.35 & 5.0896 & TRN & \\
\hline CHEMBL1446626 & 688497 & 4.45 & 5.0704 & TRN & \\
\hline
\end{tabular}




\begin{tabular}{|c|c|c|c|c|}
\hline & & & $p p+e m e$ & \\
\hline CHEMBL1516870 & 688497 & 4.8 & 4.829 & TRN \\
\hline CHEMBL3210642 & 688497 & 4.9 & 5.1051 & TST \\
\hline CHEMBL1331319 & 688497 & 5.55 & 5.2109 & TST \\
\hline CHEMBL1360375 & 688497 & 4.9 & 4.7573 & TRN \\
\hline CHEMBL1595098 & 688497 & 4.95 & 4.9527 & TRN \\
\hline CHEMBL1386670 & 688497 & 4.45 & 4.9721 & TST \\
\hline CHEMBL1541586 & 688497 & 6.5 & 5.0723 & TST \\
\hline CHEMBL1331578 & 688497 & 4.45 & 5.2117 & TRN \\
\hline CHEMBL1596288 & 688497 & 5.9 & 5.1588 & TRN \\
\hline CHEMBL1582982 & 688497 & 5.9 & 5.2003 & TRN \\
\hline CHEMBL3192939 & 688497 & 5.45 & 4.7693 & TST \\
\hline CHEMBL3189165 & 688497 & 4.45 & 4.8605 & TST \\
\hline CHEMBL1422059 & 688497 & 9.3979 & 5.0443 & TST \\
\hline CHEMBL1549389 & 688497 & 6.3 & 5.1937 & TRN \\
\hline CHEMBL1574319 & 688497 & 5.35 & 5.1481 & TRN \\
\hline CHEMBL1999959 & 688497 & 5.65 & 5.0695 & TRN \\
\hline CHEMBL1518379 & 688497 & 5.5 & 5.2294 & TRN \\
\hline CHEMBL1415501 & 688497 & 4.95 & 5.0482 & TRN \\
\hline CHEMBL1352062 & 688497 & 4.5 & 4.8213 & TRN \\
\hline CHEMBL1347469 & 688497 & 5.45 & 5.0547 & TRN \\
\hline CHEMBL3214167 & 688497 & 4.45 & 5.05 & TST \\
\hline CHEMBL1520873 & 688497 & 5.75 & 5.2054 & TST \\
\hline CHEMBL1350237 & 688497 & 5.45 & 5.1214 & TRN \\
\hline CHEMBL1376888 & 688497 & 4.6 & 4.6686 & TRN \\
\hline CHEMBL1344790 & 688497 & 4.8 & 4.8386 & TST \\
\hline CHEMBL1422038 & 688497 & 4.75 & 4.762 & TST \\
\hline CHEMBL1363960 & 688497 & 4.45 & 5.1541 & TRN \\
\hline CHEMBL1496407 & 688497 & 6.25 & 4.9795 & TRN \\
\hline CHEMBL1588704 & 688497 & 6.95 & 5.1109 & TST \\
\hline CHEMBL1330337 & 688497 & 5.25 & 5.0658 & TST \\
\hline CHEMBL1493186 & 688497 & 5.95 & 5.1944 & TRN \\
\hline CHEMBL3189412 & 688497 & 4.45 & 4.666 & TRN \\
\hline CHEMBL1569013 & 688497 & 4.9 & 4.9682 & TRN \\
\hline CHEMBL1299263 & 688497 & 4.5 & 4.9024 & TRN \\
\hline CHEMBL1583585 & 688497 & 5.65 & 5.5747 & TRN \\
\hline CHEMBL1450453 & 688497 & 5.25 & 5.0746 & TRN \\
\hline CHEMBL1522239 & 688497 & 4.45 & 4.9286 & TRN \\
\hline CHEMBL1586531 & 688497 & 4.45 & 4.8745 & TST \\
\hline CHEMBL1325375 & 688497 & 4.75 & 4.8444 & TRN \\
\hline CHEMBL 3145314 & 688497 & 4.45 & 5.2318 & TST \\
\hline CHEMBL1560628 & 688497 & 5.1 & 4.8272 & TST \\
\hline CHEMBL1407891 & 688497 & 4.95 & 4.8106 & TRN \\
\hline CHEMBL1539146 & 688497 & 4.9 & 5.2383 & TRN \\
\hline CHEMBL1429164 & 688497 & 4.45 & 4.7991 & TRN \\
\hline CHEMBL1448655 & 688497 & 4.95 & 5.1434 & TST \\
\hline CHEMBL399761 & 688497 & 6.7001 & 5.4257 & TRN \\
\hline CHEMBL1344753 & 688497 & 5.8 & 4.9605 & TST \\
\hline CHEMBL 259073 & 688497 & 4.5 & 5.1735 & TRN \\
\hline
\end{tabular}




\begin{tabular}{|c|c|c|c|c|c|}
\hline & & \multicolumn{4}{|c|}{ Supplemental Table S2.txt } \\
\hline CHEMBL1309692 & 688497 & 4.45 & 4.9195 & TRN & \\
\hline CHEMBL1381979 & 688497 & 5.5 & 4.8611 & TST & \\
\hline CHEMBL1430531 & 688497 & 5.45 & 5.0706 & TRN & \\
\hline CHEMBL1398976 & 688497 & 4.65 & 5.042 & TRN & \\
\hline CHEMBL1572110 & 688497 & 5.2 & 5.2242 & TRN & \\
\hline CHEMBL1382347 & 688497 & 4.95 & 4.9013 & TRN & \\
\hline CHEMBL1408148 & 688497 & 5.45 & 5.1123 & TST & \\
\hline CHEMBL1442046 & 688497 & 6.25 & 5.1112 & TRN & \\
\hline CHEMBL1432952 & 688497 & 4.65 & 5.0721 & TST & \\
\hline CHEMBL1446123 & 688497 & 5.25 & 5.55200 & 00000000005 & TRN \\
\hline CHEMBL1321713 & 688497 & 4.85 & 4.7646 & TRN & \\
\hline CHEMBL1378972 & 688497 & 4.45 & 4.8425 & TST & \\
\hline CHEMBL1564020 & 688497 & 5.25 & 5.1983 & TRN & \\
\hline CHEMBL472437 & 688497 & 5.55 & 5.1244 & TRN & \\
\hline CHEMBL1343282 & 688497 & 5.15 & 4.9826 & TRN & \\
\hline CHEMBL1441337 & 688497 & 4.85 & 4.8438 & TRN & \\
\hline CHEMBL1353792 & 688497 & 4.85 & 5.3376 & TST & \\
\hline CHEMBL193872 & 688497 & 5.95 & 5.6788 & TRN & \\
\hline CHEMBL1304762 & 688497 & 4.8 & 4.8672 & TST & \\
\hline CHEMBL1541604 & 688497 & 4.95 & 5.1356 & TRN & \\
\hline CHEMBL1545701 & 688497 & 4.45 & 4.86100 & 0000000001 & TST \\
\hline CHEMBL433680 & 688497 & 7.0 & 6.24100 & 00000000005 & TST \\
\hline CHEMBL1458812 & 688497 & 4.45 & 4.8728 & TRN & \\
\hline CHEMBL1454400 & 688497 & 4.45 & 5.5072 & TRN & \\
\hline CHEMBL1584091 & 688497 & 4.85 & 5.1499 & TRN & \\
\hline CHEMBL1526878 & 688497 & 4.85 & 4.9205 & TRN & \\
\hline CHEMBL1374583 & 688497 & 4.45 & 4.6405 & TRN & \\
\hline CHEMBL1495809 & 688497 & 6.25 & 4.9172 & TRN & \\
\hline CHEMBL1522937 & 688497 & 4.85 & 4.8853 & TRN & \\
\hline CHEMBL1344370 & 688497 & 5.2 & 4.834 & TRN & \\
\hline CHEMBL1539012 & 688497 & 4.6 & 4.9422 & TRN & \\
\hline CHEMBL1969761 & 688497 & 5.0 & 5.0475 & TRN & \\
\hline CHEMBL1564569 & 688497 & 4.6 & 4.9595 & TST & \\
\hline CHEMBL1332753 & 688497 & 4.8 & 4.9783 & TST & \\
\hline CHEMBL1600229 & 688497 & 4.45 & 5.0151 & TRN & \\
\hline CHEMBL1529889 & 688497 & 4.65 & 5.0572 & TRN & \\
\hline CHEMBL1561598 & 688497 & 5.2 & 5.2015 & TST & \\
\hline CHEMBL1508182 & 688497 & 4.45 & 4.7084 & TRN & \\
\hline CHEMBL1523944 & 688497 & 4.85 & 5.147 & TST & \\
\hline CHEMBL1335843 & 688497 & 4.8 & 5.3032 & TRN & \\
\hline CHEMBL1431042 & 688497 & 4.7 & 4.6732 & TRN & \\
\hline CHEMBL1365724 & 688497 & 4.95 & 5.1504 & TRN & \\
\hline CHEMBL1603420 & 688497 & 5.4 & 4.7632 & TRN & \\
\hline CHEMBL1483675 & 688497 & 4.95 & 4.8897 & TRN & \\
\hline CHEMBL3214051 & 688497 & 4.65 & 4.8965 & TST & \\
\hline CHEMBL1533351 & 688497 & 4.45 & 4.4958 & TRN & \\
\hline CHEMBL3209353 & 688497 & 4.5 & 5.098 & TRN & \\
\hline CHEMBL1578888 & 688497 & 6.35 & 4.9551 & TRN & \\
\hline
\end{tabular}




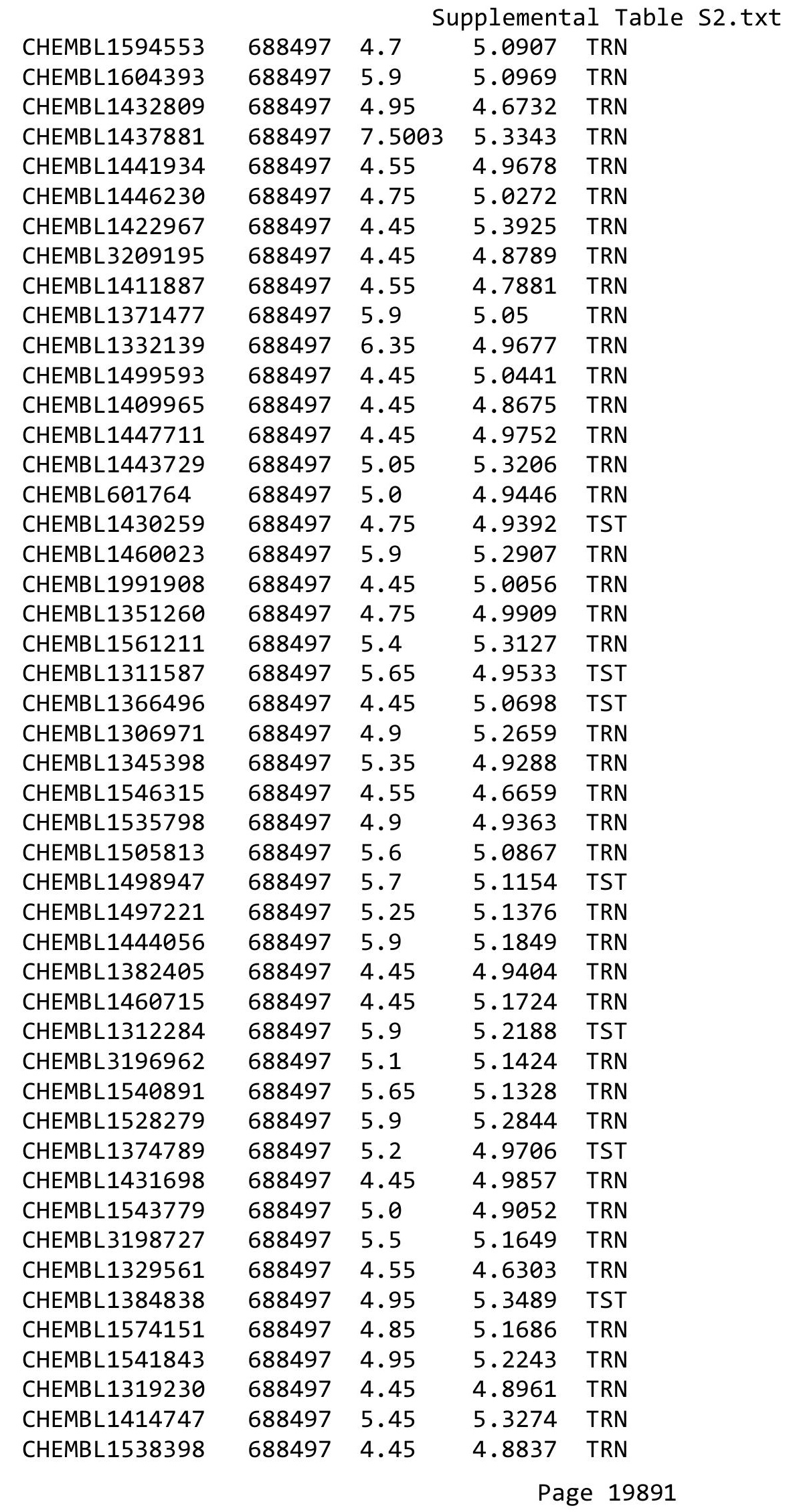




\begin{tabular}{|c|c|c|c|c|c|}
\hline \\
\hline CHEMBL1606450 & 688497 & 4.4 & 4.809 & TST & \\
\hline CHEMBL1310852 & 688497 & 5.0 & 4.8842 & TRN & \\
\hline CHEMBL221190 & 688497 & 5.65 & 4.9383 & TST & \\
\hline CHEMBL1506384 & 688497 & 4.95 & 4.9512 & TRN & \\
\hline CHEMBL1409365 & 688497 & 4.8 & 5.3859 & TST & \\
\hline CHEMBL1503463 & 688497 & 4.95 & 4.9995 & TST & \\
\hline CHEMBL1546605 & 688497 & 4.5 & 5.0368 & TRN & \\
\hline CHEMBL3208978 & 688497 & 4.65 & 5.0455 & TRN & \\
\hline CHEMBL1335107 & 688497 & 5.7 & 5.2345 & TRN & \\
\hline CHEMBL1432976 & 688497 & 5.3 & 5.1487 & TRN & \\
\hline CHEMBL1457755 & 688497 & 4.45 & 5.0057 & TRN & \\
\hline CHEMBL1547345 & 688497 & 6.25 & 5.1642 & TRN & \\
\hline CHEMBL1526961 & 688497 & 4.6 & 4.9436 & TST & \\
\hline CHEMBL1570067 & 688497 & 6.05 & 5.28299 & 99999999995 & TRN \\
\hline CHEMBL1586036 & 688497 & 6.25 & 5.1704 & TRN & \\
\hline CHEMBL1432372 & 688497 & 4.85 & 5.2264 & TRN & \\
\hline CHEMBL1329103 & 688497 & 4.45 & 5.0883 & TRN & \\
\hline CHEMBL1470466 & 688497 & 5.25 & 5.1734 & TRN & \\
\hline CHEMBL3199843 & 688497 & 4.45 & 4.9575 & TRN & \\
\hline CHEMBL1438939 & 688497 & 4.45 & 5.2227 & TRN & \\
\hline CHEMBL1542288 & 688497 & 6.25 & 5.4168 & TST & \\
\hline CHEMBL1313105 & 688497 & 5.25 & 5.0866 & TST & \\
\hline CHEMBL1406754 & 688497 & 4.75 & 5.1896 & TRN & \\
\hline CHEMBL1401091 & 688497 & 4.45 & 4.7178 & TST & \\
\hline CHEMBL1378907 & 688497 & 5.1 & 5.2778 & TST & \\
\hline CHEMBL1392386 & 688497 & 6.25 & 5.1658 & TRN & \\
\hline CHEMBL3210213 & 688497 & 4.9 & 4.98 & TRN & \\
\hline CHEMBL1504815 & 688497 & 4.95 & 4.8162 & TRN & \\
\hline CHEMBL1452368 & 688497 & 6.0 & 5.0923 & TST & \\
\hline CHEMBL1505202 & 688497 & 5.9 & 5.1883 & TST & \\
\hline CHEMBL1607115 & 688497 & 5.65 & 5.3265 & TRN & \\
\hline CHEMBL1353967 & 688497 & 4.9 & 5.0537 & TST & \\
\hline CHEMBL1508602 & 688497 & 5.05 & 5.4289 & TST & \\
\hline CHEMBL1402365 & 688497 & 6.15 & 4.8729 & TRN & \\
\hline CHEMBL1400715 & 688497 & 4.45 & 5.2015 & TRN & \\
\hline CHEMBL1451622 & 688497 & 4.9 & 4.8383 & TRN & \\
\hline CHEMBL3197272 & 688497 & 5.0 & 5.3277 & TRN & \\
\hline CHEMBL1587800 & 688497 & 5.5 & 5.2182 & TRN & \\
\hline CHEMBL1489401 & 688497 & 4.9 & 5.1134 & TRN & \\
\hline CHEMBL1542218 & 688497 & 5.25 & 5.072 & TRN & \\
\hline CHEMBL1332007 & 688497 & 5.6 & 5.3193 & TRN & \\
\hline CHEMBL1412429 & 688497 & 4.45 & 4.8599 & TST & \\
\hline CHEMBL1421478 & 688497 & 4.8 & 5.1439 & TRN & \\
\hline CHEMBL3209314 & 688497 & 5.5 & 5.1319 & TRN & \\
\hline CHEMBL1556615 & 688497 & 5.1 & 5.0348 & TRN & \\
\hline CHEMBL317364 & 688497 & 5.25 & 5.17299 & 9999999999 & TST \\
\hline CHEMBL1609988 & 688497 & 4.8 & 4.5699 & TRN & \\
\hline CHEMBL1457467 & 688497 & 4.8 & 4.8743 & TRN & \\
\hline
\end{tabular}




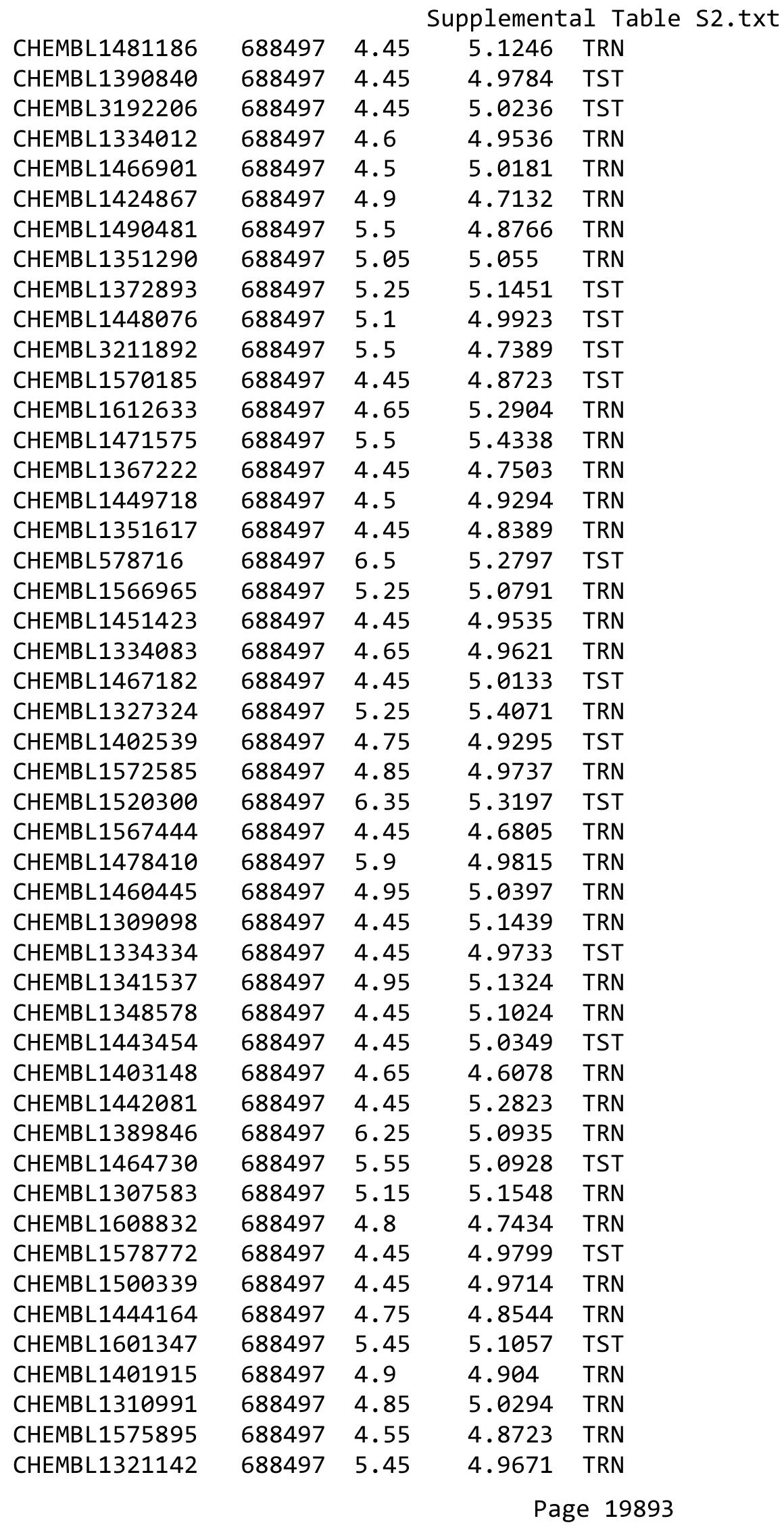




\begin{tabular}{|c|c|c|c|c|}
\hline & & & pplement & al $\mathrm{Ta}$ \\
\hline CHEMBL1300874 & 688497 & 4.85 & 4.9004 & TST \\
\hline CHEMBL1598249 & 688497 & 5.55 & 4.9733 & TRN \\
\hline CHEMBL1577657 & 688497 & 5.65 & 5.042 & TRN \\
\hline CHEMBL1495091 & 688497 & 4.6 & 4.8854 & TRN \\
\hline CHEMBL1467226 & 688497 & 4.8 & 4.8725 & TST \\
\hline CHEMBL523663 & 688497 & 6.25 & 4.817 & TRN \\
\hline CHEMBL1344860 & 688497 & 5.35 & 4.9981 & TST \\
\hline CHEMBL1302894 & 688497 & 4.45 & 4.6153 & TRN \\
\hline CHEMBL1314020 & 688497 & 4.95 & 4.8788 & TRN \\
\hline CHEMBL1469340 & 688497 & 5.05 & 5.1673 & TRN \\
\hline CHEMBL1546519 & 688497 & 5.5 & 4.9789 & TST \\
\hline CHEMBL1334430 & 688497 & 4.8 & 5.0668 & TRN \\
\hline CHEMBL1572396 & 688497 & 4.45 & 4.705 & TRN \\
\hline CHEMBL3198729 & 688497 & 4.45 & 4.9151 & TRN \\
\hline CHEMBL1541186 & 688497 & 4.95 & 4.8907 & TRN \\
\hline CHEMBL567132 & 688497 & 4.45 & 4.8159 & TRN \\
\hline CHEMBL3193604 & 688497 & 4.95 & 5.0918 & TRN \\
\hline CHEMBL1564233 & 688497 & 4.85 & 4.8789 & TRN \\
\hline CHEMBL1543858 & 688497 & 5.2 & 5.2092 & TRN \\
\hline CHEMBL1319031 & 688497 & 4.8 & 4.9889 & TST \\
\hline CHEMBL1456111 & 688497 & 4.95 & 4.6813 & TRN \\
\hline CHEMBL1548803 & 688497 & 4.95 & 5.1314 & TRN \\
\hline CHEMBL1307621 & 688497 & 5.95 & 4.96 & TST \\
\hline CHEMBL1389995 & 688497 & 4.9 & 4.9446 & TRN \\
\hline CHEMBL1575588 & 688497 & 5.2 & 4.8631 & TRN \\
\hline CHEMBL3196443 & 688497 & 4.95 & 4.9655 & TRN \\
\hline CHEMBL1504204 & 688497 & 6.0 & 4.9242 & TRN \\
\hline CHEMBL1419903 & 688497 & 5.25 & 4.9898 & TST \\
\hline CHEMBL1370162 & 688497 & 4.8 & 4.9074 & TRN \\
\hline CHEMBL1320568 & 688497 & 6.25 & 5.2656 & TST \\
\hline CHEMBL1506210 & 688497 & 4.85 & 4.7393 & TRN \\
\hline CHEMBL1986725 & 688497 & 6.3 & 5.3162 & TRN \\
\hline CHEMBL1520054 & 688497 & 5.0 & 5.5047 & TRN \\
\hline CHEMBL 1458360 & 688497 & 4.6 & 4.8665 & TRN \\
\hline CHEMBL1321271 & 688497 & 5.15 & 4.8473 & TST \\
\hline CHEMBL3209882 & 688497 & 4.9 & 4.9426 & TRN \\
\hline CHEMBL1413213 & 688497 & 4.9 & 4.8676 & TRN \\
\hline CHEMBL1531383 & 688497 & 4.45 & 4.7972 & TRN \\
\hline CHEMBL1583184 & 688497 & 4.45 & 4.6847 & TST \\
\hline CHEMBL1480237 & 688497 & 6.1 & 5.1934 & TRN \\
\hline CHEMBL1507187 & 688497 & 4.45 & 4.7948 & TRN \\
\hline CHEMBL1586057 & 688497 & 4.95 & 4.9806 & TRN \\
\hline CHEMBL3199057 & 688497 & 5.9 & 4.8562 & TST \\
\hline CHEMBL1504505 & 688497 & 4.45 & 4.8187 & TRN \\
\hline CHEMBL1581193 & 688497 & 4.75 & 4.8827 & TRN \\
\hline CHEMBL1344800 & 688497 & 4.45 & 4.7371 & TRN \\
\hline CHEMBL1578372 & 688497 & 4.45 & 5.0689 & TRN \\
\hline CHEMBL1353152 & 688497 & 4.45 & 4.8182 & TRN \\
\hline
\end{tabular}




\begin{tabular}{|c|c|c|c|c|c|}
\hline & & \multicolumn{4}{|c|}{ Supplemental Table s2.txt } \\
\hline CHEMBL1302318 & 688497 & 4.95 & 4.643 & TRN & \\
\hline CHEMBL1589671 & 688497 & 4.7 & 5.0737 & TRN & \\
\hline CHEMBL1566082 & 688497 & 4.45 & 5.2451 & TRN & \\
\hline CHEMBL1390768 & 688497 & 4.45 & 4.888 & TST & \\
\hline CHEMBL1353528 & 688497 & 4.95 & 4.6599 & TRN & \\
\hline CHEMBL1543121 & 688497 & 4.45 & 5.2864 & TST & \\
\hline CHEMBL1369950 & 688497 & 5.15 & 4.9376 & TRN & \\
\hline CHEMBL1529223 & 688497 & 5.25 & 5.0451 & TST & \\
\hline CHEMBL 3197588 & 688497 & 4.5 & 5.0068 & TRN & \\
\hline CHEMBL1329417 & 688497 & 4.85 & 5.042 & TRN & \\
\hline CHEMBL1498210 & 688497 & 5.55 & 5.4157 & TRN & \\
\hline CHEMBL1557927 & 688497 & 6.95 & 5.1284 & TRN & \\
\hline CHEMBL1443311 & 688497 & 4.45 & 4.8166 & TST & \\
\hline CHEMBL1496110 & 688497 & 4.95 & 5.034 & TST & \\
\hline CHEMBL1581141 & 688497 & 5.35 & 4.935 & TRN & \\
\hline CHEMBL1379149 & 688497 & 4.75 & 4.7499 & TRN & \\
\hline CHEMBL1411209 & 688497 & 4.85 & 4.8508 & TRN & \\
\hline CHEMBL1329458 & 688497 & 4.45 & 5.4128 & TST & \\
\hline CHEMBL1309222 & 688497 & 5.2 & 5.0026 & TRN & \\
\hline CHEMBL1412218 & 688497 & 4.45 & 4.9694 & TST & \\
\hline CHEMBL1304584 & 688497 & 5.25 & 4.7636 & TRN & \\
\hline CHEMBL1577986 & 688497 & 4.7 & 4.7829 & TRN & \\
\hline CHEMBL1301650 & 688497 & 4.95 & 5.0563 & TRN & \\
\hline CHEMBL1970734 & 688497 & 4.45 & 4.8485 & TRN & \\
\hline CHEMBL1569186 & 688497 & 4.9 & 4.85800 & 00000000005 & TRN \\
\hline CHEMBL1505187 & 688497 & 4.9 & 5.1862 & TRN & \\
\hline CHEMBL1339562 & 688497 & 5.25 & 4.6352 & TRN & \\
\hline CHEMBL1369269 & 688497 & 4.9 & 5.0259 & TRN & \\
\hline CHEMBL1489704 & 688497 & 4.45 & 4.9695 & TRN & \\
\hline CHEMBL578177 & 688497 & 5.6 & 5.0574 & TRN & \\
\hline CHEMBL1338960 & 688497 & 5.35 & 4.5934 & TRN & \\
\hline CHEMBL1307629 & 688497 & 4.85 & 5.0282 & TST & \\
\hline CHEMBL1557307 & 688497 & 4.45 & 5.0742 & TST & \\
\hline CHEMBL1309148 & 688497 & 4.85 & 4.9266 & TRN & \\
\hline CHEMBL1413444 & 688497 & 5.45 & 4.9734 & TST & \\
\hline CHEMBL1340102 & 688497 & 5.0 & 5.2312 & TRN & \\
\hline CHEMBL1330941 & 688497 & 4.45 & 5.0216 & TRN & \\
\hline CHEMBL1550400 & 688497 & 5.45 & 5.0521 & TRN & \\
\hline CHEMBL1416762 & 688497 & 4.5 & 4.6606 & TRN & \\
\hline CHEMBL1510486 & 688497 & 5.25 & 5.006 & TRN & \\
\hline CHEMBL1343210 & 688497 & 4.45 & 4.9418 & TST & \\
\hline CHEMBL3190566 & 688497 & 4.9 & 5.0412 & TRN & \\
\hline CHEMBL1580741 & 688497 & 4.6 & 5.1537 & TST & \\
\hline CHEMBL1460841 & 688497 & 4.95 & 5.1574 & TST & \\
\hline CHEMBL1565286 & 688497 & 4.65 & 4.8762 & TRN & \\
\hline CHEMBL1530541 & 688497 & 5.3 & 5.1853 & TRN & \\
\hline CHEMBL1520384 & 688497 & 5.35 & 5.32299 & 99999999995 & TRN \\
\hline CHEMBL1545902 & 688497 & 5.45 & 4.8885 & TRN & \\
\hline
\end{tabular}




\begin{tabular}{|c|c|c|c|c|}
\hline \multicolumn{5}{|c|}{ Supplemental Table S2.txt } \\
\hline CHEMBL1462213 & 688497 & 4.45 & 4.9505 & TRN \\
\hline CHEMBL1467490 & 688497 & 4.45 & 4.6994 & TRN \\
\hline CHEMBL1609513 & 688497 & 4.95 & 4.9834 & TRN \\
\hline CHEMBL1538504 & 688497 & 6.05 & 5.1281 & TRN \\
\hline CHEMBL1533447 & 688497 & 4.45 & 4.9096 & TRN \\
\hline CHEMBL1997899 & 688497 & 5.25 & 5.2545 & TST \\
\hline CHEMBL1505040 & 688497 & 4.45 & 4.9086 & TRN \\
\hline CHEMBL1423171 & 688497 & 4.7 & 5.1108 & TRN \\
\hline CHEMBL1378097 & 688497 & 4.7 & 4.8339 & TRN \\
\hline CHEMBL1573502 & 688497 & 5.2 & 5.2366 & TRN \\
\hline CHEMBL1480327 & 688497 & 6.05 & 5.0539 & TRN \\
\hline CHEMBL1339114 & 688497 & 4.45 & 5.0984 & TRN \\
\hline CHEMBL1433109 & 688497 & 4.7 & 5.0049 & TST \\
\hline CHEMBL1429930 & 688497 & 4.8 & 4.7654 & TST \\
\hline CHEMBL1582940 & 688497 & 4.45 & 4.6322 & TRN \\
\hline CHEMBL1364803 & 688497 & 4.75 & 4.6729 & TRN \\
\hline CHEMBL1429108 & 688497 & 4.6 & 4.8781 & TRN \\
\hline CHEMBL1494746 & 688497 & 4.45 & 4.7006 & TRN \\
\hline CHEMBL1342743 & 688497 & 6.05 & 5.0084 & TRN \\
\hline CHEMBL1468756 & 688497 & 4.95 & 5.114 & TRN \\
\hline CHEMBL1480238 & 688497 & 5.2 & 5.6358 & TRN \\
\hline CHEMBL1350516 & 688497 & 4.7 & 5.263 & TRN \\
\hline CHEMBL1427934 & 688497 & 5.3 & 5.4045 & TRN \\
\hline CHEMBL1387403 & 688497 & 5.4 & 5.3331 & TRN \\
\hline CHEMBL1518703 & 688497 & 6.9 & 5.082 & TST \\
\hline CHEMBL1589435 & 688497 & 5.9 & 4.8919 & TRN \\
\hline CHEMBL3196976 & 688497 & 4.45 & 5.1015 & TRN \\
\hline CHEMBL1414808 & 688497 & 4.7 & 4.9823 & TRN \\
\hline CHEMBL1373084 & 688497 & 4.65 & 4.6562 & TRN \\
\hline CHEMBL 3193844 & 688497 & 5.5 & 5.3143 & TRN \\
\hline CHEMBL1549366 & 688497 & 5.15 & 5.1332 & TST \\
\hline CHEMBL1421115 & 688497 & 7.0501 & 5.0986 & TRN \\
\hline CHEMBL1340513 & 688497 & 4.45 & 4.7121 & TRN \\
\hline CHEMBL1445414 & 688497 & 4.95 & 5.0142 & TRN \\
\hline CHEMBL3193298 & 688497 & 5.15 & 5.2153 & TRN \\
\hline CHEMBL1381340 & 688497 & 4.8 & 4.9632 & TRN \\
\hline CHEMBL 1580578 & 688497 & 4.85 & 5.1518 & TRN \\
\hline CHEMBL1302250 & 688497 & 4.85 & 4.958 & TST \\
\hline CHEMBL1525919 & 688497 & 4.45 & 5.0766 & TRN \\
\hline CHEMBL1360458 & 688497 & 5.2 & 4.9874 & TRN \\
\hline CHEMBL1511583 & 688497 & 4.8 & 5.1249 & TST \\
\hline CHEMBL 257856 & 688497 & 4.95 & 4.95 & TRN \\
\hline CHEMBL1505449 & 688497 & 4.9 & 5.0879 & TRN \\
\hline CHEMBL1495262 & 688497 & 6.95 & 5.0671 & TRN \\
\hline CHEMBL1519438 & 688497 & 5.15 & 5.0171 & TST \\
\hline CHEMBL1375551 & 688497 & 4.45 & 4.8668 & TRN \\
\hline CHEMBL 1334570 & 688497 & 4.9 & 5.4041 & TST \\
\hline CHEMBL1456296 & 688497 & 4.7 & 4.7451 & TRN \\
\hline
\end{tabular}




\begin{tabular}{|c|c|c|c|c|c|}
\hline \multicolumn{6}{|c|}{ Supplemental Table S2.txt } \\
\hline CHEMBL1602896 & 688497 & 5.25 & 5.1689 & TRN & \\
\hline CHEMBL1392359 & 688497 & 4.45 & 4.6503 & TRN & \\
\hline CHEMBL1407037 & 688497 & 4.45 & 5.0683 & TRN & \\
\hline CHEMBL1555449 & 688497 & 4.45 & 4.832 & TRN & \\
\hline CHEMBL 1570272 & 688497 & 4.45 & 4.7061 & TRN & \\
\hline CHEMBL1583242 & 688497 & 4.9 & 4.8849 & TRN & \\
\hline CHEMBL1486934 & 688497 & 5.45 & 5.005 & TRN & \\
\hline CHEMBL 2002444 & 688497 & 4.9 & 5.1319 & TRN & \\
\hline CHEMBL1421768 & 688497 & 4.8 & 5.1628 & TRN & \\
\hline CHEMBL1489371 & 688497 & 4.8 & 4.9361 & TST & \\
\hline CHEMBL1584637 & 688497 & 4.45 & 5.1932 & TRN & \\
\hline CHEMBL3195783 & 688497 & 5.35 & 5.1227 & TRN & \\
\hline CHEMBL1470712 & 688497 & 5.0 & 5.3054 & TRN & \\
\hline CHEMBL3191067 & 688497 & 4.95 & 5.1349 & TRN & \\
\hline CHEMBL1489061 & 688497 & 5.25 & 5.4297 & TRN & \\
\hline CHEMBL1344875 & 688497 & 4.45 & 4.8599 & TRN & \\
\hline CHEMBL1532663 & 688497 & 4.65 & 5.0417 & TRN & \\
\hline CHEMBL3193782 & 688497 & 4.45 & 5.24700 & 0000000001 & TRN \\
\hline CHEMBL1482431 & 688497 & 5.1 & 4.8484 & TST & \\
\hline CHEMBL1431645 & 688497 & 4.6 & 4.9383 & TRN & \\
\hline CHEMBL1419967 & 688497 & 5.0 & 4.8806 & TRN & \\
\hline CHEMBL1302232 & 688497 & 4.45 & 5.0924 & TRN & \\
\hline CHEMBL3190913 & 688497 & 5.6 & 4.9815 & TRN & \\
\hline CHEMBL1342907 & 688497 & 4.95 & 4.8491 & TRN & \\
\hline CHEMBL1460750 & 688497 & 4.45 & 5.0115 & TRN & \\
\hline CHEMBL1446442 & 688497 & 4.65 & 5.0797 & TRN & \\
\hline CHEMBL1540304 & 688497 & 4.9 & 5.0552 & TRN & \\
\hline CHEMBL1544332 & 688497 & 4.6 & 4.9981 & TST & \\
\hline CHEMBL1482369 & 688497 & 4.9 & 5.0159 & TRN & \\
\hline CHEMBL1486799 & 688497 & 5.2 & 5.17700 & 00000000005 & TRN \\
\hline CHEMBL468471 & 688497 & 6.25 & 4.9586 & TST & \\
\hline CHEMBL1456001 & 688497 & 4.75 & 4.6273 & TRN & \\
\hline CHEMBL1488371 & 688497 & 5.7 & 5.0488 & TRN & \\
\hline CHEMBL1444402 & 688497 & 4.95 & 5.0076 & TRN & \\
\hline CHEMBL1452449 & 688497 & 4.95 & 5.2396 & TRN & \\
\hline CHEMBL1422220 & 688497 & 5.3 & 5.0469 & TST & \\
\hline CHEMBL1339106 & 688497 & 4.85 & 4.9421 & TRN & \\
\hline CHEMBL1454500 & 688497 & 4.95 & 5.0096 & TRN & \\
\hline CHEMBL1399374 & 688497 & 5.2 & 5.1182 & TRN & \\
\hline CHEMBL1498749 & 688497 & 5.4 & 5.0166 & TST & \\
\hline CHEMBL1332797 & 688497 & 5.45 & 4.8577 & TST & \\
\hline CHEMBL3211679 & 688497 & 5.1 & 4.9941 & TST & \\
\hline CHEMBL1581740 & 688497 & 5.45 & 5.1392 & TST & \\
\hline CHEMBL1373476 & 688497 & 4.45 & 5.0223 & TRN & \\
\hline CHEMBL3190389 & 688497 & 4.95 & 4.6886 & TRN & \\
\hline CHEMBL1403616 & 688497 & 4.95 & 4.7891 & TRN & \\
\hline CHEMBL 1336770 & 688497 & 4.45 & 5.2045 & TST & \\
\hline CHEMBL1559182 & 688497 & 6.2 & 5.0779 & TRN & \\
\hline
\end{tabular}




\begin{tabular}{|c|c|c|c|c|c|}
\hline \multicolumn{6}{|c|}{ Supplemental Table S2.txt } \\
\hline CHEMBL1361858 & 688497 & 4.6 & 5.1877 & TRN & \\
\hline CHEMBL1608869 & 688497 & 4.55 & 5.234 & TRN & \\
\hline CHEMBL1384668 & 688497 & 6.25 & 5.0541 & TRN & \\
\hline CHEMBL 3195074 & 688497 & 5.15 & 4.7334 & TRN & \\
\hline CHEMBL1459263 & 688497 & 4.95 & 4.8431 & TRN & \\
\hline CHEMBL1509918 & 688497 & 5.5 & 5.0752 & TRN & \\
\hline CHEMBL1307579 & 688497 & 4.95 & 5.3297 & TST & \\
\hline CHEMBL414890 & 688497 & 4.45 & 4.9343 & TST & \\
\hline CHEMBL 2000815 & 688497 & 4.45 & 4.8053 & TRN & \\
\hline CHEMBL1467117 & 688497 & 4.95 & 4.7169 & TST & \\
\hline CHEMBL1414714 & 688497 & 5.95 & 4.9538 & TRN & \\
\hline CHEMBL1409297 & 688497 & 4.6 & 5.1711 & TRN & \\
\hline CHEMBL1492286 & 688497 & 4.45 & 4.6063 & TRN & \\
\hline CHEMBL3192317 & 688497 & 5.85 & 5.2409 & TST & \\
\hline CHEMBL1463954 & 688497 & 4.45 & 4.7925 & TRN & \\
\hline CHEMBL1307264 & 688497 & 5.0 & 5.1822 & TRN & \\
\hline CHEMBL1374456 & 688497 & 5.3 & 5.0374 & TRN & \\
\hline CHEMBL1321864 & 688497 & 5.0 & 4.9838 & TST & \\
\hline CHEMBL3196163 & 688497 & 5.5 & 5.1732 & TRN & \\
\hline CHEMBL1359683 & 688497 & 4.85 & 4.9992 & TRN & \\
\hline CHEMBL1323512 & 688497 & 4.5 & 5.0462 & TRN & \\
\hline CHEMBL1323013 & 688497 & 5.1 & 5.1149 & TRN & \\
\hline CHEMBL1451652 & 688497 & 5.95 & 5.1574 & TRN & \\
\hline CHEMBL1599559 & 688497 & 4.9 & 4.92399 & 99999999995 & TRN \\
\hline CHEMBL1439435 & 688497 & 5.25 & 4.9051 & TRN & \\
\hline CHEMBL1471146 & 688497 & 4.95 & 5.2735 & TRN & \\
\hline CHEMBL1547276 & 688497 & 4.45 & 4.9906 & TRN & \\
\hline CHEMBL3192073 & 688497 & 6.0 & 5.2558 & TRN & \\
\hline CHEMBL1478356 & 688497 & 4.6 & 5.2076 & TST & \\
\hline CHEMBL1578496 & 688497 & 4.8 & 5.358 & TST & \\
\hline CHEMBL1466305 & 688497 & 5.15 & 5.4258 & TRN & \\
\hline CHEMBL1412924 & 688497 & 5.35 & 5.1387 & TRN & \\
\hline CHEMBL591412 & 688497 & 5.85 & 5.5041 & TRN & \\
\hline CHEMBL1588078 & 688497 & 4.45 & 5.14 & TRN & \\
\hline CHEMBL1353646 & 688497 & 4.7 & 4.6697 & TRN & \\
\hline CHEMBL1586026 & 688497 & 5.85 & 4.9529 & TRN & \\
\hline CHEMBL1549839 & 688497 & 5.55 & 5.0046 & TST & \\
\hline CHEMBL1457994 & 688497 & 4.95 & 4.9014 & TRN & \\
\hline CHEMBL1426144 & 688497 & 4.8 & 4.6976 & TRN & \\
\hline CHEMBL1505185 & 688497 & 4.7 & 4.7477 & TRN & \\
\hline CHEMBL1597839 & 688497 & 4.45 & 5.0416 & TRN & \\
\hline CHEMBL3197290 & 688497 & 4.95 & 4.8024 & TRN & \\
\hline CHEMBL1439294 & 688497 & 5.0 & 4.9116 & TRN & \\
\hline CHEMBL1361956 & 688497 & 4.65 & 5.0203 & TRN & \\
\hline CHEMBL1588749 & 688497 & 4.45 & 5.1339 & TST & \\
\hline CHEMBL1519955 & 688497 & 6.6 & 5.5021 & TRN & \\
\hline CHEMBL1310685 & 688497 & 4.95 & 5.1111 & TRN & \\
\hline CHEMBL1459370 & 688497 & 5.0 & 5.025 & TST & \\
\hline
\end{tabular}




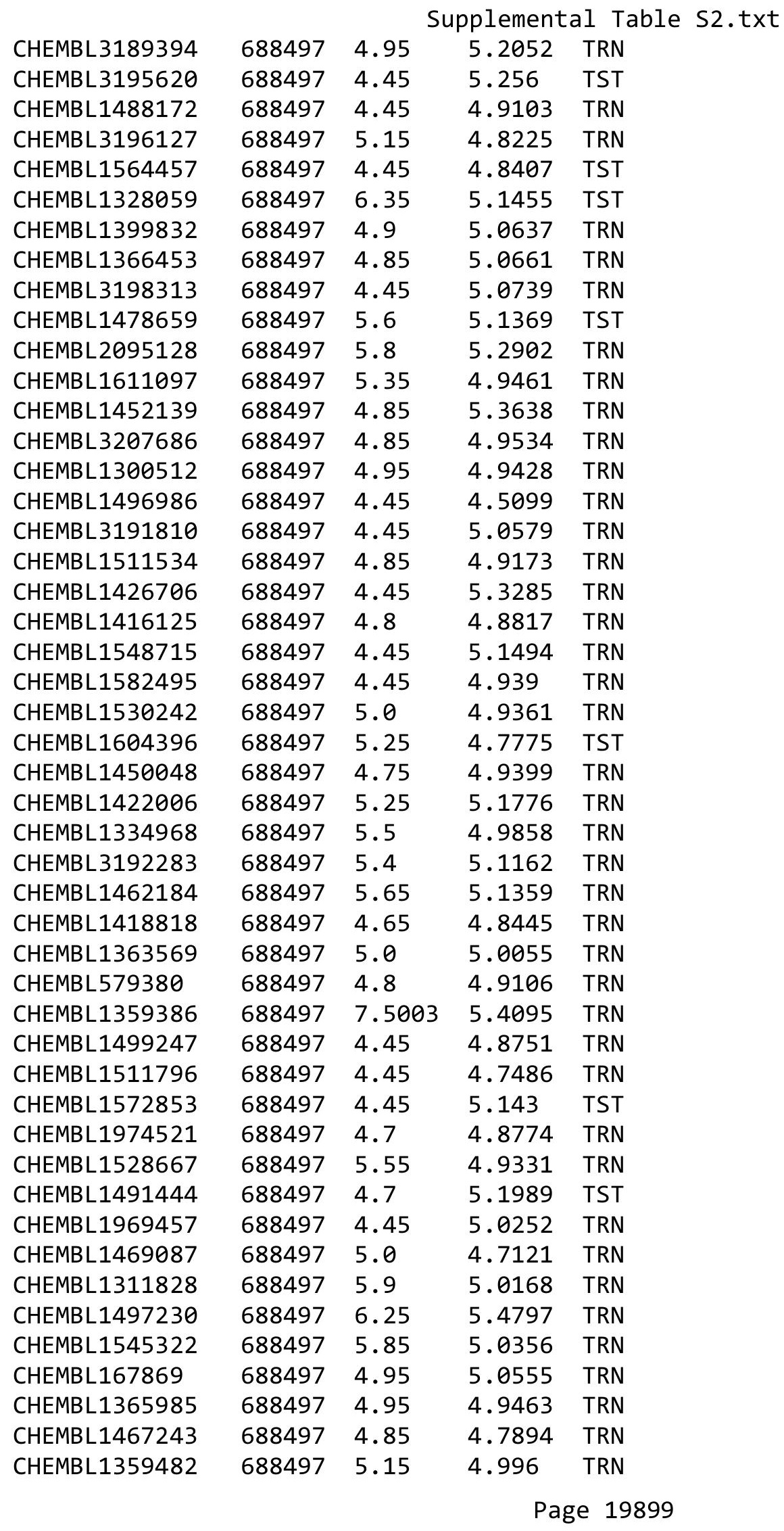




\begin{tabular}{|c|c|c|c|c|c|}
\hline \multicolumn{6}{|c|}{ Supplemental Table S2.txt } \\
\hline CHEMBL1584641 & 688497 & 4.45 & 4.9004 & TRN & \\
\hline CHEMBL1459715 & 688497 & 5.05 & 5.0277 & TRN & \\
\hline CHEMBL1329027 & 688497 & 5.0 & 5.0069 & TRN & \\
\hline CHEMBL 2359911 & 688497 & 5.9 & 5.336 & TRN & \\
\hline CHEMBL1352396 & 688497 & 4.7 & 5.1006 & TRN & \\
\hline CHEMBL1322403 & 688497 & 4.45 & 5.1866 & TRN & \\
\hline CHEMBL1418079 & 688497 & 4.45 & 4.9791 & TST & \\
\hline CHEMBL1453581 & 688497 & 4.45 & 4.8457 & TRN & \\
\hline CHEMBL1417914 & 688497 & 6.25 & 4.7567 & TRN & \\
\hline CHEMBL1448286 & 688497 & 4.45 & 5.0039 & TRN & \\
\hline CHEMBL1412157 & 688497 & 5.0 & 5.0583 & TST & \\
\hline CHEMBL1518249 & 688497 & 4.5 & 4.8682 & TRN & \\
\hline CHEMBL1439301 & 688497 & 5.0 & 4.9301 & TRN & \\
\hline CHEMBL1305254 & 688497 & 4.8 & 5.1334 & TST & \\
\hline CHEMBL1327850 & 688497 & 4.85 & 4.9668 & TST & \\
\hline CHEMBL1301723 & 688497 & 5.5 & 4.9829 & TRN & \\
\hline CHEMBL1999390 & 688497 & 5.1 & 5.0224 & TRN & \\
\hline CHEMBL1446553 & 688497 & 5.0 & 5.2657 & TST & \\
\hline CHEMBL1369391 & 688497 & 5.25 & 4.995 & TRN & \\
\hline CHEMBL1575502 & 688497 & 6.45 & 6.2439 & TRN & \\
\hline CHEMBL3209432 & 688497 & 5.45 & 5.0763 & TRN & \\
\hline CHEMBL1328498 & 688497 & 4.85 & 4.8523 & TST & \\
\hline CHEMBL1556576 & 688497 & 5.05 & 4.9107 & TRN & \\
\hline CHEMBL1333083 & 688497 & 5.25 & 5.1198 & TST & \\
\hline CHEMBL1567438 & 688497 & 4.9 & 4.5537 & TRN & \\
\hline CHEMBL1367897 & 688497 & 5.0 & 4.6616 & TRN & \\
\hline CHEMBL3210051 & 688497 & 4.45 & 4.5952 & TST & \\
\hline CHEMBL1443249 & 688497 & 4.45 & 4.8851 & TST & \\
\hline CHEMBL1546714 & 688497 & 6.1 & 5.42200 & 0000000001 & TRN \\
\hline CHEMBL1426351 & 688497 & 5.4 & 5.1944 & TST & \\
\hline CHEMBL1580655 & 688497 & 4.55 & 5.0224 & TRN & \\
\hline CHEMBL1458840 & 688497 & 5.5 & 4.7606 & TST & \\
\hline CHEMBL1467977 & 688497 & 4.65 & 4.8517 & TRN & \\
\hline CHEMBL1360744 & 688497 & 5.2 & 4.941 & TRN & \\
\hline CHEMBL1399776 & 688497 & 5.0 & 4.8614 & TRN & \\
\hline CHEMBL1566162 & 688497 & 5.6 & 5.2362 & TST & \\
\hline CHEMBL1543224 & 688497 & 4.5 & 4.9658 & TRN & \\
\hline CHEMBL1602465 & 688497 & 4.5 & 5.0071 & TRN & \\
\hline CHEMBL1421906 & 688497 & 5.7 & 5.1258 & TRN & \\
\hline CHEMBL1311717 & 688497 & 5.9 & 5.2811 & TRN & \\
\hline CHEMBL1342062 & 688497 & 5.1 & 4.9803 & TRN & \\
\hline CHEMBL1571324 & 688497 & 4.6 & 4.7403 & TRN & \\
\hline CHEMBL1550467 & 688497 & 4.9 & 5.0947 & TRN & \\
\hline CHEMBL1306095 & 688497 & 6.5 & 4.9493 & TRN & \\
\hline CHEMBL1401582 & 688497 & 4.45 & 4.9034 & TRN & \\
\hline CHEMBL1307445 & 688497 & 4.5 & 5.1162 & TRN & \\
\hline CHEMBL1340719 & 688497 & 5.6 & 5.2658 & TST & \\
\hline CHEMBL1351479 & 688497 & 4.95 & 5.1018 & TRN & \\
\hline
\end{tabular}




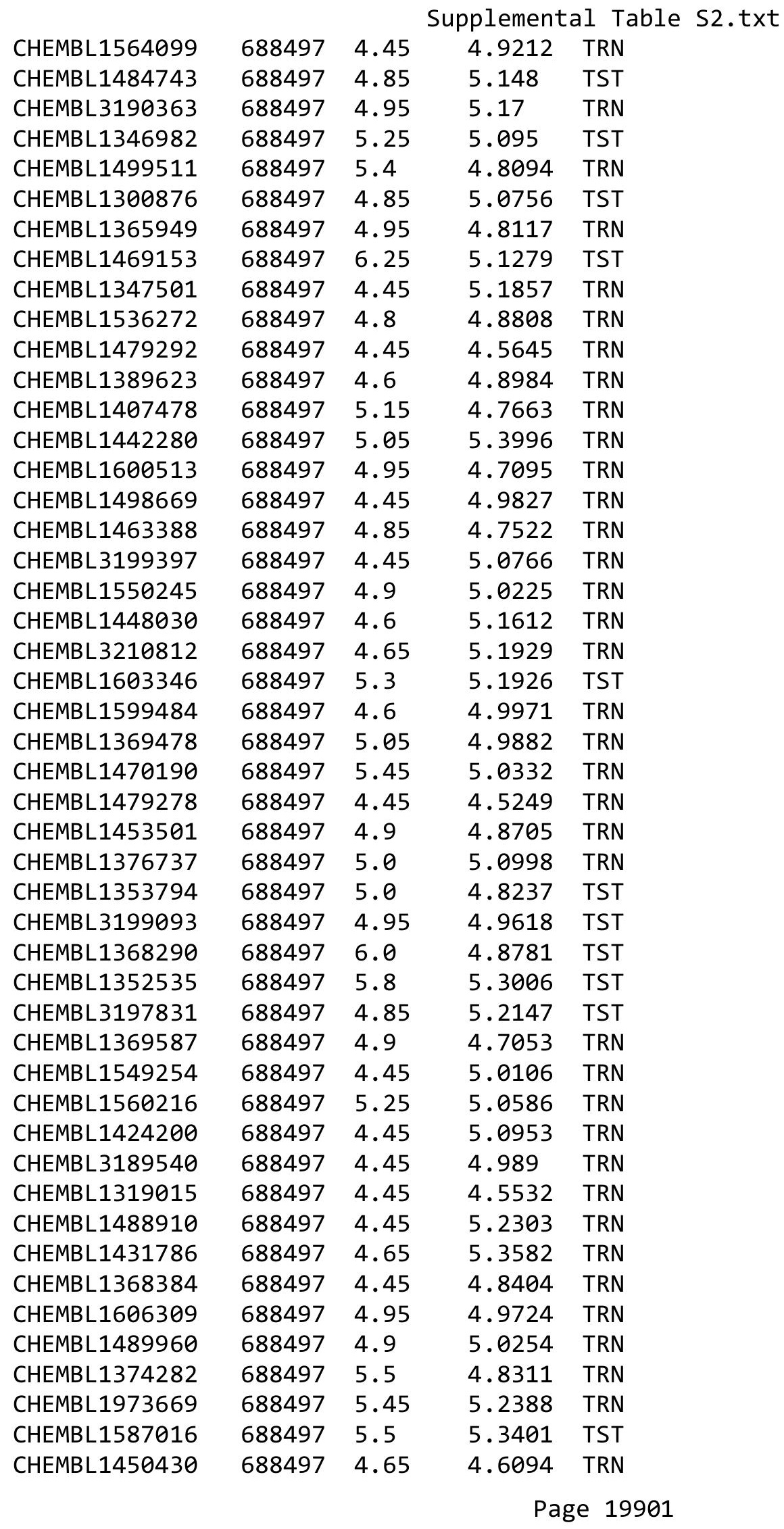




\begin{tabular}{|c|c|c|c|c|c|}
\hline \multicolumn{6}{|c|}{ Supplemental Table S2.txt } \\
\hline CHEMBL1304568 & 688497 & 5.2 & 5.3475 & TRN & \\
\hline CHEMBL1406568 & 688497 & 6.25 & 5.2987 & TRN & \\
\hline CHEMBL1326052 & 688497 & 4.45 & 4.8472 & TRN & \\
\hline CHEMBL1539526 & 688497 & 4.45 & 4.7246 & TRN & \\
\hline CHEMBL 3198689 & 688497 & 5.0 & 5.1502 & TRN & \\
\hline CHEMBL1334593 & 688497 & 5.5 & 4.8976 & TRN & \\
\hline CHEMBL1306010 & 688497 & 5.15 & 5.4067 & TRN & \\
\hline CHEMBL1987108 & 688497 & 4.45 & 4.7221 & TRN & \\
\hline CHEMBL1431894 & 688497 & 5.75 & 5.1011 & TRN & \\
\hline CHEMBL1581016 & 688497 & 5.85 & 5.2003 & TRN & \\
\hline CHEMBL1556846 & 688497 & 6.25 & 5.4155 & TRN & \\
\hline CHEMBL1408486 & 688497 & 5.5 & 5.4502 & TST & \\
\hline CHEMBL1361563 & 688497 & 4.85 & 5.2689 & TRN & \\
\hline CHEMBL1451696 & 688497 & 4.45 & 4.9402 & TRN & \\
\hline CHEMBL1372519 & 688497 & 4.85 & 5.1664 & TRN & \\
\hline CHEMBL3192627 & 688497 & 4.45 & 4.9848 & TRN & \\
\hline CHEMBL1463336 & 688497 & 4.9 & 4.9853 & TRN & \\
\hline CHEMBL1965687 & 688497 & 4.9 & 4.7471 & TRN & \\
\hline CHEMBL1449024 & 688497 & 5.9 & 5.3455 & TRN & \\
\hline CHEMBL1465297 & 688497 & 4.5 & 4.5881 & TRN & \\
\hline CHEMBL1571378 & 688497 & 5.9 & 5.1 & TRN & \\
\hline CHEMBL1457690 & 688497 & 4.9 & 5.0104 & TRN & \\
\hline CHEMBL589479 & 688497 & 4.45 & 5.3772 & TRN & \\
\hline CHEMBL1424110 & 688497 & 5.95 & 4.9409 & TRN & \\
\hline CHEMBL1366367 & 688497 & 4.85 & 4.6742 & TRN & \\
\hline CHEMBL1490392 & 688497 & 4.9 & 5.57700 & 0000000001 & TRN \\
\hline CHEMBL1361334 & 688497 & 4.45 & 5.0622 & TRN & \\
\hline CHEMBL1522758 & 688497 & 4.9 & 4.9505 & TST & \\
\hline CHEMBL1585538 & 688497 & 2.5 & 5.1127 & TRN & \\
\hline CHEMBL1577269 & 688497 & 5.05 & 5.2256 & TRN & \\
\hline CHEMBL1329240 & 688497 & 6.0 & 5.2048 & TRN & \\
\hline CHEMBL1520896 & 688497 & 5.0 & 5.138 & TRN & \\
\hline CHEMBL1445628 & 688497 & 5.45 & 5.1523 & TRN & \\
\hline CHEMBL1319154 & 688497 & 4.45 & 4.6784 & TRN & \\
\hline CHEMBL 3210668 & 688497 & 4.45 & 5.0544 & TRN & \\
\hline CHEMBL1502448 & 688497 & 4.45 & 4.6871 & TRN & \\
\hline CHEMBL1990184 & 688497 & 4.95 & 5.0378 & TRN & \\
\hline CHEMBL1372199 & 688497 & 4.45 & 5.3381 & TRN & \\
\hline CHEMBL1428523 & 688497 & 5.5 & 4.9878 & TST & \\
\hline CHEMBL1306058 & 688497 & 4.95 & 4.9426 & TRN & \\
\hline CHEMBL1477131 & 688497 & 4.95 & 5.0235 & TRN & \\
\hline CHEMBL1576578 & 688497 & 5.0 & 4.8854 & TST & \\
\hline CHEMBL1333007 & 688497 & 5.0 & 5.0516 & TST & \\
\hline CHEMBL1344112 & 688497 & 4.65 & 4.905 & TRN & \\
\hline CHEMBL1609332 & 688497 & 5.25 & 4.9177 & TRN & \\
\hline CHEMBL1544186 & 688497 & 5.45 & 4.9534 & TRN & \\
\hline CHEMBL1401331 & 688497 & 5.05 & 4.9999 & TRN & \\
\hline CHEMBL1329989 & 688497 & 5.75 & 5.1994 & TRN & \\
\hline
\end{tabular}




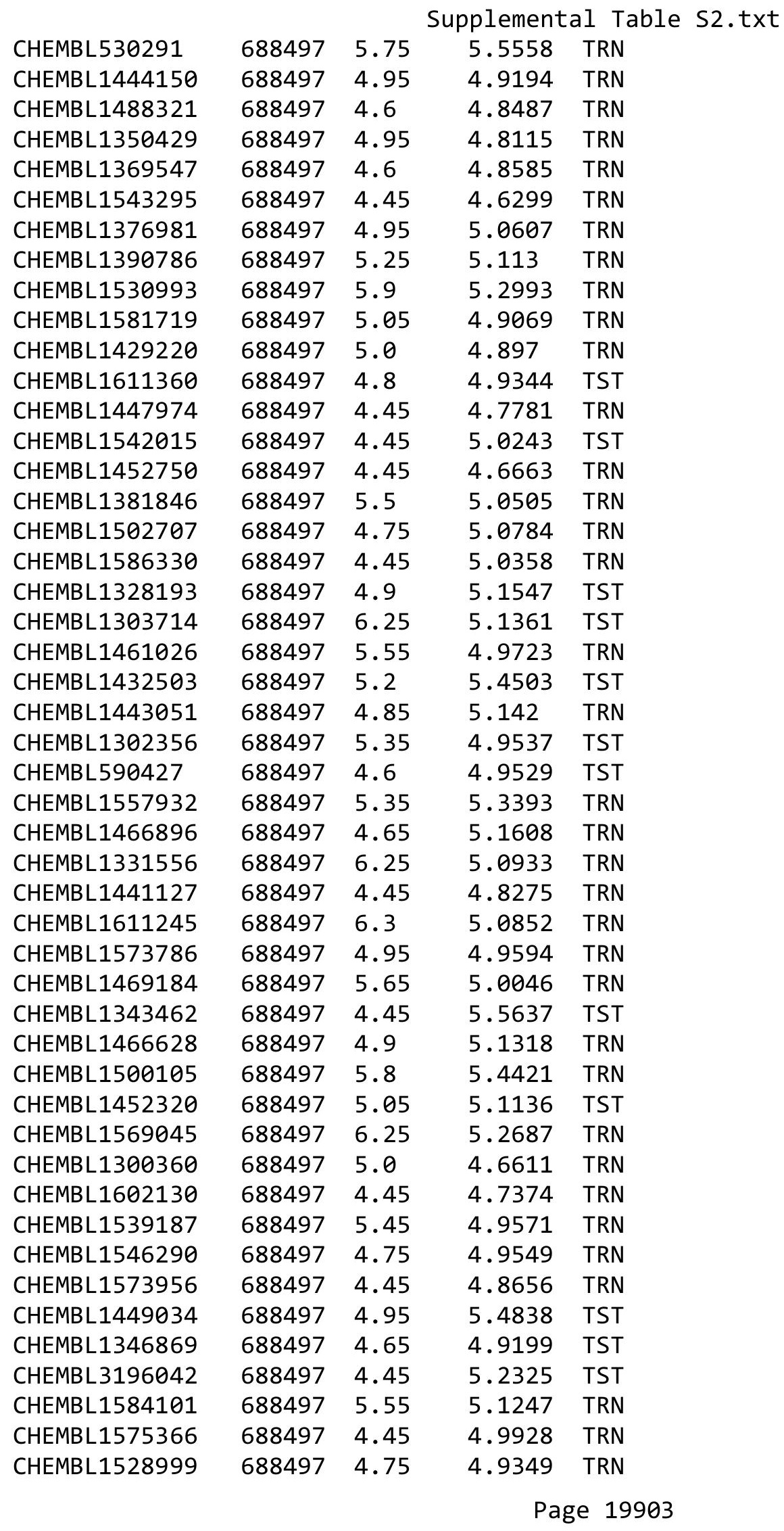




\begin{tabular}{|c|c|c|c|c|c|}
\hline & & \multicolumn{4}{|c|}{ Supplemental Table S2.txt } \\
\hline CHEMBL1301480 & 688497 & 4.95 & 4.7866 & TRN & \\
\hline CHEMBL1609218 & 688497 & 4.45 & 4.727 & TRN & \\
\hline CHEMBL590422 & 688497 & 4.9 & 4.8846 & TRN & \\
\hline CHEMBL1546347 & 688497 & 6.6 & 5.4667 & TRN & \\
\hline CHEMBL1431538 & 688497 & 4.45 & 4.7875 & TRN & \\
\hline CHEMBL1549396 & 688497 & 5.45 & 4.9187 & TST & \\
\hline CHEMBL237424 & 688497 & 5.25 & 4.9001 & TRN & \\
\hline CHEMBL1351392 & 688497 & 4.45 & 5.0536 & TRN & \\
\hline CHEMBL1558334 & 688497 & 5.25 & 4.9445 & TST & \\
\hline CHEMBL1539681 & 688497 & 5.65 & 5.1588 & TRN & \\
\hline CHEMBL1580272 & 688497 & 5.55 & 5.254 & TRN & \\
\hline CHEMBL1388809 & 688497 & 4.55 & 4.8411 & TRN & \\
\hline CHEMBL1468055 & 688497 & 4.65 & 4.7166 & TRN & \\
\hline CHEMBL1329857 & 688497 & 5.1 & 5.2028 & TST & \\
\hline CHEMBL1300311 & 688497 & 4.45 & 4.8818 & TRN & \\
\hline CHEMBL1609098 & 688497 & 6.15 & 5.5096 & TRN & \\
\hline CHEMBL1350295 & 688497 & 4.75 & 5.0114 & TRN & \\
\hline CHEMBL1471095 & 688497 & 5.4 & 5.0568 & TRN & \\
\hline CHEMBL1372102 & 688497 & 5.0 & 4.8267 & TST & \\
\hline CHEMBL1371752 & 688497 & 5.05 & 4.8979 & TST & \\
\hline CHEMBL1565695 & 688497 & 4.95 & 5.07600 & 00000000005 & TRN \\
\hline CHEMBL1410261 & 688497 & 5.25 & 5.232 & TST & \\
\hline CHEMBL1443788 & 688497 & 4.45 & 5.1845 & TRN & \\
\hline CHEMBL1337165 & 688497 & 5.0 & 4.8845 & TRN & \\
\hline CHEMBL1544435 & 688497 & 4.95 & 4.9542 & TRN & \\
\hline CHEMBL3195308 & 688497 & 4.85 & 4.6747 & TRN & \\
\hline CHEMBL1531805 & 688497 & 4.45 & 4.7589 & TRN & \\
\hline CHEMBL1348100 & 688497 & 6.45 & 4.9679 & TST & \\
\hline CHEMBL1595083 & 688497 & 4.6 & 5.3136 & TST & \\
\hline CHEMBL1331513 & 688497 & 4.95 & 4.8959 & TRN & \\
\hline CHEMBL1332226 & 688497 & 4.95 & 5.0825 & TRN & \\
\hline CHEMBL1549272 & 688497 & 4.85 & 4.8703 & TRN & \\
\hline CHEMBL1386723 & 688497 & 4.9 & 4.967 & TRN & \\
\hline CHEMBL1488150 & 688497 & 4.6 & 4.6466 & TRN & \\
\hline CHEMBL576412 & 688497 & 5.4 & 4.8499 & TRN & \\
\hline CHEMBL1324563 & 688497 & 4.8 & 4.9808 & TRN & \\
\hline CHEMBL1522248 & 688497 & 4.65 & 5.2131 & TST & \\
\hline CHEMBL1460059 & 688497 & 4.45 & 4.896 & TST & \\
\hline CHEMBL585828 & 688497 & 4.9 & 5.2153 & TST & \\
\hline CHEMBL1390281 & 688497 & 4.75 & 5.078 & TRN & \\
\hline CHEMBL1348703 & 688497 & 4.95 & 4.9808 & TRN & \\
\hline CHEMBL1416753 & 688497 & 4.65 & 5.2961 & TST & \\
\hline CHEMBL3209839 & 688497 & 4.45 & 4.8619 & TRN & \\
\hline CHEMBL1424651 & 688497 & 4.9 & 5.0413 & TRN & \\
\hline CHEMBL1545550 & 688497 & 5.35 & 5.2118 & TST & \\
\hline CHEMBL1547232 & 688497 & 4.9 & 4.9228 & TRN & \\
\hline CHEMBL1578679 & 688497 & 4.9 & 4.8737 & TRN & \\
\hline CHEMBL478 & 688497 & 4.45 & 5.0485 & TRN & \\
\hline
\end{tabular}




\begin{tabular}{|c|c|c|c|c|}
\hline \multicolumn{5}{|c|}{ Supplemental Table S2.txt } \\
\hline CHEMBL1557934 & 688497 & 6.0 & 5.0908 & TRN \\
\hline CHEMBL1303443 & 688497 & 4.65 & 4.973 & TRN \\
\hline CHEMBL3199083 & 688497 & 4.85 & 4.9766 & TST \\
\hline CHEMBL1467442 & 688497 & 4.45 & 4.6886 & TRN \\
\hline CHEMBL1982774 & 688497 & 5.9 & 5.349 & TRN \\
\hline CHEMBL1364294 & 688497 & 4.55 & 4.6122 & TRN \\
\hline CHEMBL1351533 & 688497 & 4.45 & 4.754 & TRN \\
\hline CHEMBL1373448 & 688497 & 5.2 & 4.7873 & TRN \\
\hline CHEMBL 3211094 & 688497 & 4.95 & 5.2188 & TST \\
\hline CHEMBL1329907 & 688497 & 5.75 & 4.7892 & TRN \\
\hline CHEMBL1428244 & 688497 & 4.95 & 4.9 & TRN \\
\hline CHEMBL1359126 & 688497 & 4.95 & 4.9664 & TRN \\
\hline CHEMBL1543217 & 688497 & 4.45 & 5.0463 & TRN \\
\hline CHEMBL1529607 & 688497 & 4.9 & 4.9503 & TRN \\
\hline CHEMBL1450393 & 688497 & 5.25 & 5.3259 & TST \\
\hline CHEMBL1495591 & 688497 & 4.6 & 4.7384 & TST \\
\hline CHEMBL1499225 & 688497 & 4.8 & 5.3851 & TST \\
\hline CHEMBL1490982 & 688497 & 5.45 & 5.2916 & TRN \\
\hline CHEMBL1309254 & 688497 & 4.8 & 5.5767 & TRN \\
\hline CHEMBL1589544 & 688497 & 4.7 & 4.8039 & TST \\
\hline CHEMBL1565799 & 688497 & 4.45 & 5.4199 & TST \\
\hline CHEMBL1529029 & 688497 & 4.8 & 4.7111 & TRN \\
\hline CHEMBL1341067 & 688497 & 4.45 & 4.8418 & TRN \\
\hline CHEMBL1400162 & 688497 & 4.45 & 5.0686 & TRN \\
\hline CHEMBL1374480 & 688497 & 4.45 & 5.0369 & TRN \\
\hline CHEMBL1375195 & 688497 & 7.5003 & 5.0464 & TST \\
\hline CHEMBL1420708 & 688497 & 5.25 & 5.119 & TST \\
\hline CHEMBL1510389 & 688497 & 4.45 & 5.3173 & TRN \\
\hline CHEMBL 3191974 & 688497 & 4.5 & 5.2588 & TST \\
\hline CHEMBL1456592 & 688497 & 6.8499 & 5.3497 & TST \\
\hline CHEMBL1380300 & 688497 & 4.45 & 4.8668 & TRN \\
\hline CHEMBL1340282 & 688497 & 5.9 & 5.0995 & TRN \\
\hline CHEMBL3192822 & 688497 & 4.95 & 5.0285 & TRN \\
\hline CHEMBL584442 & 688497 & 5.4 & 5.5256 & TRN \\
\hline CHEMBL1406317 & 688497 & 4.55 & 5.1093 & TST \\
\hline CHEMBL1490332 & 688497 & 6.2 & 5.1061 & TRN \\
\hline CHEMBL2001211 & 688497 & 4.5 & 5.4248 & TST \\
\hline CHEMBL1381892 & 688497 & 4.95 & 4.994 & TRN \\
\hline CHEMBL1517034 & 688497 & 5.25 & 5.0878 & TRN \\
\hline CHEMBL1482188 & 688497 & 5.3 & 5.1139 & TRN \\
\hline CHEMBL1571845 & 688497 & 5.25 & 5.1024 & TRN \\
\hline CHEMBL1390384 & 688497 & 5.0 & 4.6966 & TRN \\
\hline CHEMBL1460664 & 688497 & 4.95 & 4.9293 & TRN \\
\hline CHEMBL1485251 & 688497 & 4.45 & 4.8072 & TRN \\
\hline CHEMBL1576175 & 688497 & 5.25 & 4.9501 & TRN \\
\hline CHEMBL1599567 & 688497 & 6.0 & 5.1017 & TRN \\
\hline CHEMBL1448773 & 688497 & 5.15 & 4.8995 & TRN \\
\hline CHEMBL1502863 & 688497 & 5.0 & 4.9049 & TRN \\
\hline
\end{tabular}




\begin{tabular}{|c|c|c|c|c|}
\hline & & & upplement & al Ta \\
\hline CHEMBL1201088 & 688497 & 5.05 & 5.3277 & TST \\
\hline CHEMBL1518929 & 688497 & 4.85 & 4.8161 & TRN \\
\hline CHEMBL1440636 & 688497 & 5.0 & 4.5786 & TRN \\
\hline CHEMBL1456946 & 688497 & 5.25 & 4.9077 & TRN \\
\hline CHEMBL1535257 & 688497 & 4.65 & 5.1551 & TRN \\
\hline CHEMBL1468714 & 688497 & 4.45 & 4.827 & TRN \\
\hline CHEMBL1457238 & 688497 & 5.5 & 5.4863 & TST \\
\hline CHEMBL1368493 & 688497 & 4.8 & 4.8913 & TRN \\
\hline CHEMBL1549880 & 688497 & 4.45 & 4.7346 & TRN \\
\hline CHEMBL1308081 & 688497 & 4.85 & 4.8394 & TRN \\
\hline CHEMBL1597200 & 688497 & 4.45 & 5.0086 & TST \\
\hline CHEMBL1309979 & 688497 & 4.45 & 4.9544 & TRN \\
\hline CHEMBL1410964 & 688497 & 5.55 & 5.1998 & TST \\
\hline CHEMBL1563415 & 688497 & 5.55 & 4.9343 & TRN \\
\hline CHEMBL1489356 & 688497 & 4.45 & 4.9971 & TRN \\
\hline CHEMBL1576426 & 688497 & 6.25 & 5.4794 & TRN \\
\hline CHEMBL1568747 & 688497 & 6.0 & 4.9463 & TRN \\
\hline CHEMBL1494161 & 688497 & 4.45 & 5.0985 & TRN \\
\hline CHEMBL1594196 & 688497 & 4.95 & 4.833 & TRN \\
\hline CHEMBL1982308 & 688497 & 4.45 & 4.5576 & TRN \\
\hline CHEMBL1607599 & 688497 & 4.45 & 5.0825 & TST \\
\hline CHEMBL1415914 & 688497 & 6.15 & 5.2379 & TRN \\
\hline CHEMBL3196140 & 688497 & 4.45 & 5.1192 & TRN \\
\hline CHEMBL1411535 & 688497 & 6.25 & 5.2718 & TRN \\
\hline CHEMBL1527386 & 688497 & 4.85 & 4.8119 & TRN \\
\hline CHEMBL1538098 & 688497 & 4.75 & 4.8895 & TRN \\
\hline CHEMBL1359239 & 688497 & 5.05 & 5.1378 & TRN \\
\hline CHEMBL1549659 & 688497 & 4.65 & 5.2032 & TRN \\
\hline CHEMBL3191730 & 688497 & 4.95 & 5.4115 & TRN \\
\hline CHEMBL1470465 & 688497 & 4.45 & 5.1708 & TST \\
\hline CHEMBL1328895 & 688497 & 4.9 & 5.0085 & TRN \\
\hline CHEMBL1331676 & 688497 & 5.25 & 5.1189 & TST \\
\hline CHEMBL3212159 & 688497 & 4.7 & 4.9365 & TST \\
\hline CHEMBL1360300 & 688497 & 4.45 & 4.7874 & TRN \\
\hline CHEMBL1566161 & 688497 & 4.55 & 4.6874 & TRN \\
\hline CHEMBL1563839 & 688497 & 4.85 & 4.9571 & TRN \\
\hline CHEMBL1458398 & 688497 & 4.6 & 4.8802 & TRN \\
\hline CHEMBL1417290 & 688497 & 4.45 & 5.0783 & TRN \\
\hline CHEMBL1359233 & 688497 & 4.95 & 4.9212 & TRN \\
\hline CHEMBL1306773 & 688497 & 4.9 & 5.1926 & TST \\
\hline CHEMBL1578087 & 688497 & 4.45 & 5.0437 & TRN \\
\hline CHEMBL1479129 & 688497 & 5.5 & 5.209 & TRN \\
\hline CHEMBL1343070 & 688497 & 4.45 & 4.8481 & TRN \\
\hline CHEMBL3212088 & 688497 & 4.9 & 5.2947 & TRN \\
\hline CHEMBL1567302 & 688497 & 5.05 & 5.228 & TRN \\
\hline CHEMBL 3193887 & 688497 & 4.45 & 4.9972 & TRN \\
\hline CHEMBL 3189448 & 688497 & 5.5 & 5.3409 & TRN \\
\hline CHEMBL1334320 & 688497 & 4.5 & 4.9687 & TRN \\
\hline
\end{tabular}




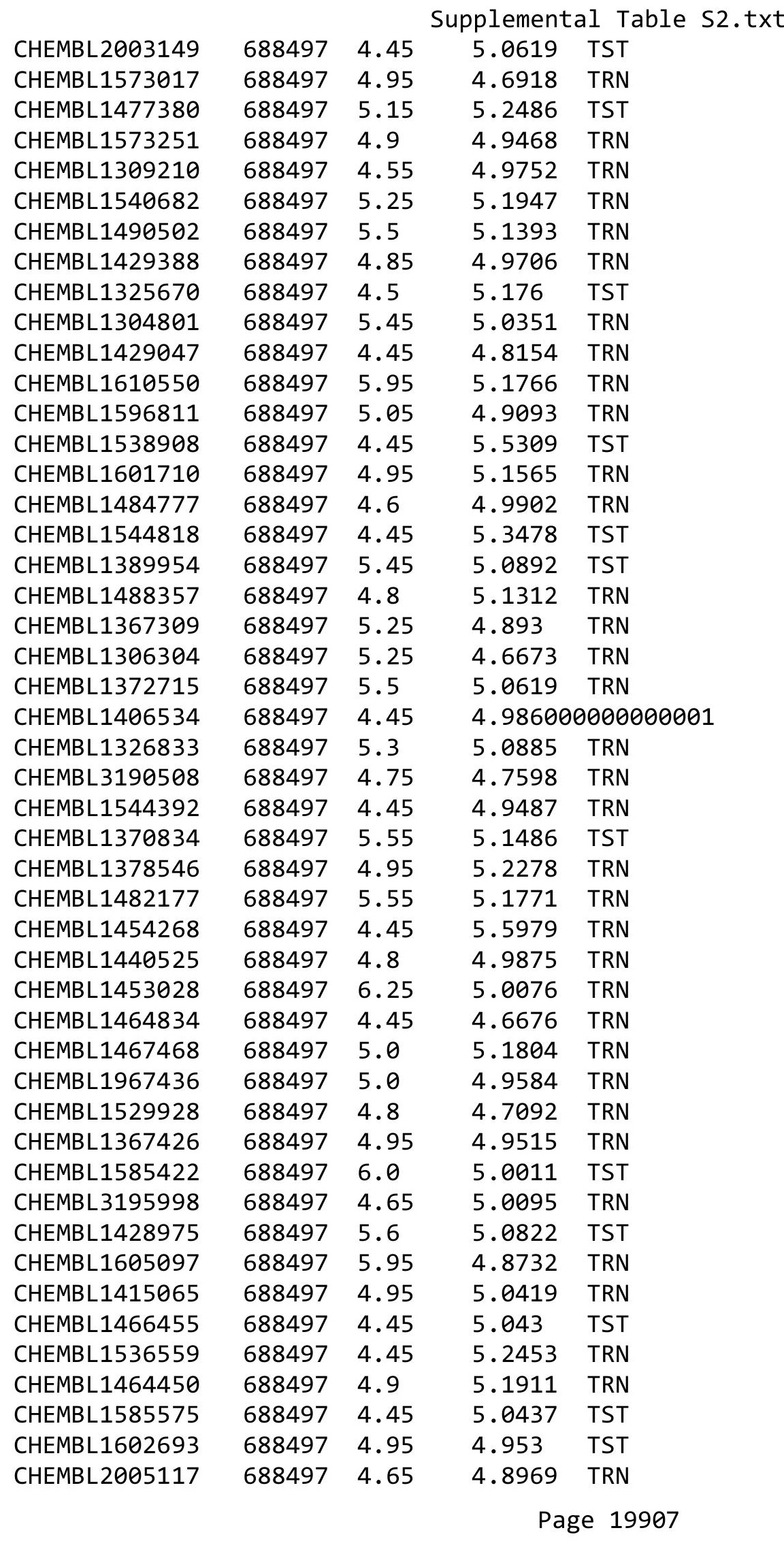




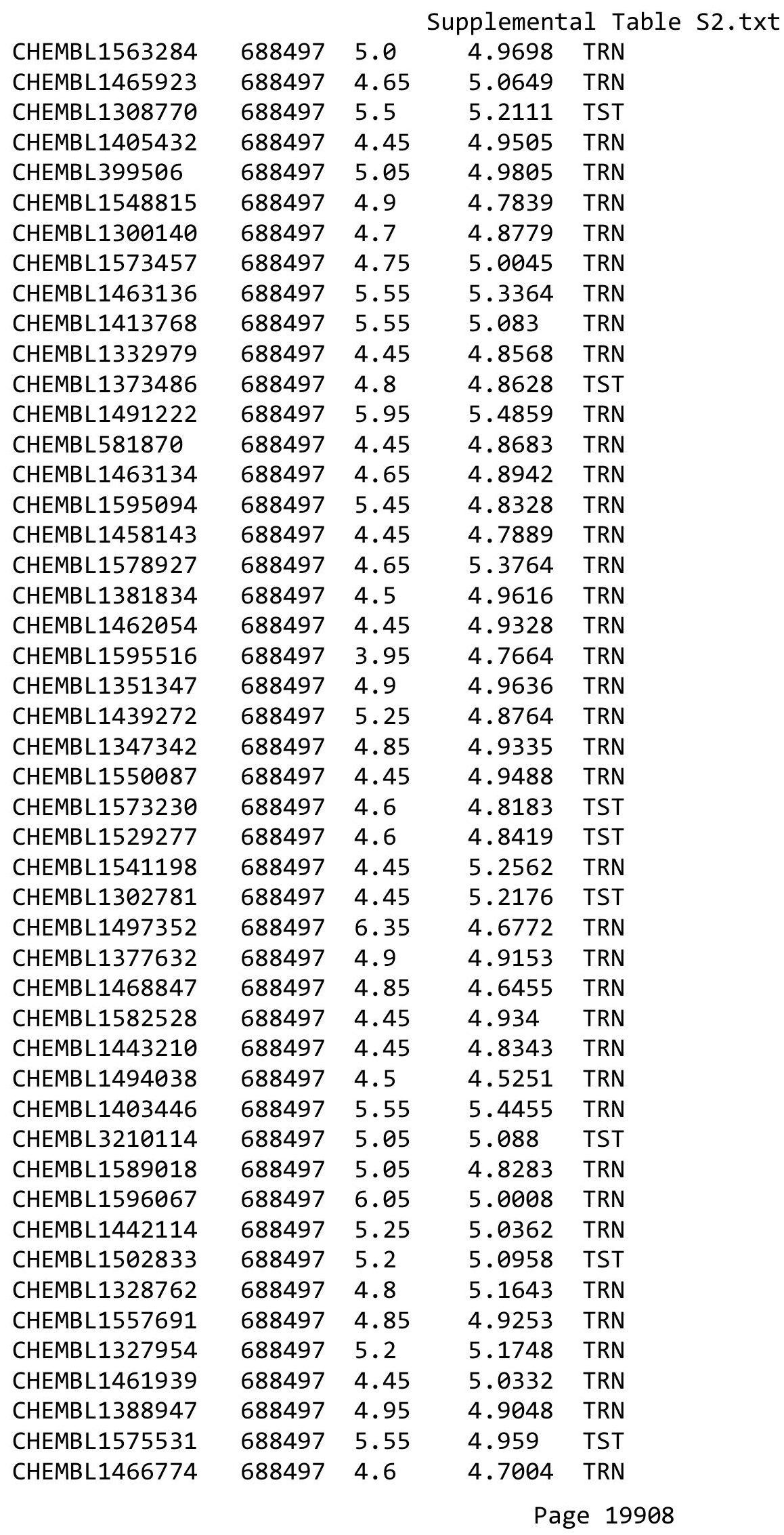




\begin{tabular}{|c|c|c|c|c|c|}
\hline \multicolumn{6}{|c|}{ Supplemental Table S2.txt } \\
\hline CHEMBL1324564 & 688497 & 4.45 & 4.9506 & TRN & \\
\hline CHEMBL1479699 & 688497 & 4.45 & 4.5558 & TRN & \\
\hline CHEMBL1423004 & 688497 & 4.45 & 5.9459 & TRN & \\
\hline CHEMBL1468159 & 688497 & 4.6 & 5.064 & TRN & \\
\hline CHEMBL1507292 & 688497 & 4.5 & 5.2505 & TRN & \\
\hline CHEMBL1470373 & 688497 & 4.95 & 4.8212 & TST & \\
\hline CHEMBL1530241 & 688497 & 5.55 & 4.9518 & TRN & \\
\hline CHEMBL1429003 & 688497 & 4.95 & 4.8713 & TST & \\
\hline CHEMBL1345869 & 688497 & 4.6 & 4.9999 & TRN & \\
\hline CHEMBL1580860 & 688497 & 5.6 & 5.3424 & TRN & \\
\hline CHEMBL1558814 & 688497 & 4.45 & 4.7935 & TRN & \\
\hline CHEMBL1521545 & 688497 & 4.45 & 4.9096 & TRN & \\
\hline CHEMBL1404058 & 688497 & 4.85 & 5.34399 & 9999999999 & TRN \\
\hline CHEMBL3192082 & 688497 & 4.45 & 5.0786 & TRN & \\
\hline CHEMBL1588525 & 688497 & 5.5 & 5.2668 & TRN & \\
\hline CHEMBL1313274 & 688497 & 5.95 & 5.3084 & TRN & \\
\hline CHEMBL3196037 & 688497 & 5.9 & 5.4104 & TRN & \\
\hline CHEMBL1525636 & 688497 & 4.85 & 5.2227 & TRN & \\
\hline CHEMBL1584444 & 688497 & 5.2 & 5.2128 & TST & \\
\hline CHEMBL1324590 & 688497 & 4.45 & 4.9093 & TRN & \\
\hline CHEMBL1565349 & 688497 & 5.6 & 4.9629 & TRN & \\
\hline CHEMBL1387047 & 688497 & 4.65 & 4.7786 & TRN & \\
\hline CHEMBL1496077 & 688497 & 4.45 & 5.092 & TST & \\
\hline CHEMBL1481342 & 688497 & 5.5 & 5.1909 & TRN & \\
\hline CHEMBL1321937 & 688497 & 4.85 & 5.171 & TRN & \\
\hline CHEMBL1975151 & 688497 & 4.45 & 5.1126 & TRN & \\
\hline CHEMBL1414084 & 688497 & 5.25 & 4.9603 & TST & \\
\hline CHEMBL1586438 & 688497 & 4.55 & 4.8183 & TRN & \\
\hline CHEMBL1463198 & 688497 & 5.0 & 4.7628 & TRN & \\
\hline CHEMBL1508455 & 688497 & 4.45 & 4.5551 & TRN & \\
\hline CHEMBL1588295 & 688497 & 4.65 & 4.8835 & TST & \\
\hline CHEMBL1529441 & 688497 & 4.85 & 5.0389 & TST & \\
\hline CHEMBL1458910 & 688497 & 4.85 & 4.9168 & TST & \\
\hline CHEMBL1449336 & 688497 & 4.65 & 5.1807 & TST & \\
\hline CHEMBL1413360 & 688497 & 5.25 & 5.6237 & TST & \\
\hline CHEMBL1365696 & 688497 & 4.45 & 4.7311 & TRN & \\
\hline CHEMBL1361757 & 688497 & 4.45 & 4.6685 & TRN & \\
\hline CHEMBL1372596 & 688497 & 4.7 & 5.4399 & TRN & \\
\hline CHEMBL1518891 & 688497 & 4.95 & 4.9443 & TRN & \\
\hline CHEMBL1610110 & 688497 & 5.25 & 5.0995 & TRN & \\
\hline CHEMBL1412291 & 688497 & 4.8 & 5.0315 & TRN & \\
\hline CHEMBL3208924 & 688497 & 5.4 & 5.2906 & TST & \\
\hline CHEMBL1562307 & 688497 & 5.1 & 5.023 & TST & \\
\hline CHEMBL1420367 & 688497 & 6.15 & 5.1408 & TRN & \\
\hline CHEMBL3190376 & 688497 & 5.5 & 4.835 & TST & \\
\hline CHEMBL1411759 & 688497 & 4.9 & 5.1014 & TRN & \\
\hline CHEMBL1309183 & 688497 & 4.55 & 4.5151 & TRN & \\
\hline CHEMBL3212774 & 688497 & 4.9 & 5.0426 & TRN & \\
\hline
\end{tabular}




\begin{tabular}{|c|c|c|c|c|}
\hline \multicolumn{5}{|c|}{ Supplemental Table S2.txt } \\
\hline CHEMBL1384758 & 688497 & 6.15 & 4.9547 & TRN \\
\hline CHEMBL1557622 & 688497 & 4.45 & 4.8537 & TRN \\
\hline CHEMBL1520355 & 688497 & 5.7 & 4.9785 & TST \\
\hline CHEMBL1603037 & 688497 & 4.6 & 4.7949 & TRN \\
\hline CHEMBL3197170 & 688497 & 5.35 & 5.0492 & TRN \\
\hline CHEMBL1520533 & 688497 & 6.05 & 4.8376 & TRN \\
\hline CHEMBL1453707 & 688497 & 5.25 & 5.0205 & TRN \\
\hline CHEMBL1443958 & 688497 & 5.5 & 5.2147 & TRN \\
\hline CHEMBL1417378 & 688497 & 4.6 & 5.175 & TRN \\
\hline CHEMBL1468094 & 688497 & 4.45 & 4.9041 & TST \\
\hline CHEMBL1303489 & 688497 & 4.75 & 4.8621 & TRN \\
\hline CHEMBL1450743 & 688497 & 6.1 & 5.0158 & TST \\
\hline CHEMBL1462981 & 688497 & 5.65 & 4.8707 & TST \\
\hline CHEMBL3196868 & 688497 & 5.5 & 5.2467 & TST \\
\hline CHEMBL1466481 & 688497 & 4.45 & 5.003 & TRN \\
\hline CHEMBL1428442 & 688497 & 5.9 & 5.0391 & TRN \\
\hline CHEMBL1492585 & 688497 & 4.65 & 5.7479 & TRN \\
\hline CHEMBL1348904 & 688497 & 4.65 & 5.1845 & TRN \\
\hline CHEMBL1375563 & 688497 & 4.7 & 4.9093 & TRN \\
\hline CHEMBL1462615 & 688497 & 4.45 & 4.7483 & TRN \\
\hline CHEMBL1321924 & 688497 & 5.7 & 4.9984 & TRN \\
\hline CHEMBL1494526 & 688497 & 4.45 & 4.8178 & TST \\
\hline CHEMBL1585799 & 688497 & 4.8 & 5.0392 & TRN \\
\hline CHEMBL1589110 & 688497 & 4.4 & 4.864 & TRN \\
\hline CHEMBL1409903 & 688497 & 4.9 & 4.9788 & TRN \\
\hline CHEMBL1343552 & 688497 & 4.45 & 5.0739 & TRN \\
\hline CHEMBL1575698 & 688497 & 5.25 & 5.1547 & TST \\
\hline CHEMBL1571054 & 688497 & 6.95 & 4.9094 & TRN \\
\hline CHEMBL1500223 & 688497 & 4.45 & 4.9017 & TRN \\
\hline CHEMBL1392261 & 688497 & 6.15 & 5.1501 & TST \\
\hline CHEMBL1571245 & 688497 & 4.9 & 4.8844 & TST \\
\hline CHEMBL1339846 & 688497 & 5.45 & 5.2922 & TRN \\
\hline CHEMBL1346283 & 688497 & 4.45 & 5.1219 & TRN \\
\hline CHEMBL1490229 & 688497 & 4.75 & 5.0043 & TRN \\
\hline CHEMBL1310794 & 688497 & 4.65 & 5.1347 & TRN \\
\hline CHEMBL1369698 & 688497 & 5.0 & 5.0715 & TRN \\
\hline CHEMBL1964690 & 688497 & 4.65 & 4.922 & TRN \\
\hline CHEMBL1471170 & 688497 & 4.55 & 4.7287 & TRN \\
\hline CHEMBL 2094833 & 688497 & 5.6 & 5.2265 & TRN \\
\hline CHEMBL1586983 & 688497 & 4.5 & 4.88 & TRN \\
\hline CHEMBL3190837 & 688497 & 4.45 & 5.0852 & TST \\
\hline CHEMBL1505287 & 688497 & 5.6 & 5.2821 & TRN \\
\hline CHEMBL1527559 & 688497 & 5.35 & 5.3813 & TRN \\
\hline CHEMBL1340630 & 688497 & 4.85 & 5.1641 & TST \\
\hline CHEMBL1429823 & 688497 & 5.0 & 4.9696 & TRN \\
\hline CHEMBL1595597 & 688497 & 5.1 & 5.0672 & TRN \\
\hline CHEMBL3210236 & 688497 & 4.65 & 4.6921 & TRN \\
\hline CHEMBL1376001 & 688497 & 4.95 & 4.9319 & TRN \\
\hline
\end{tabular}




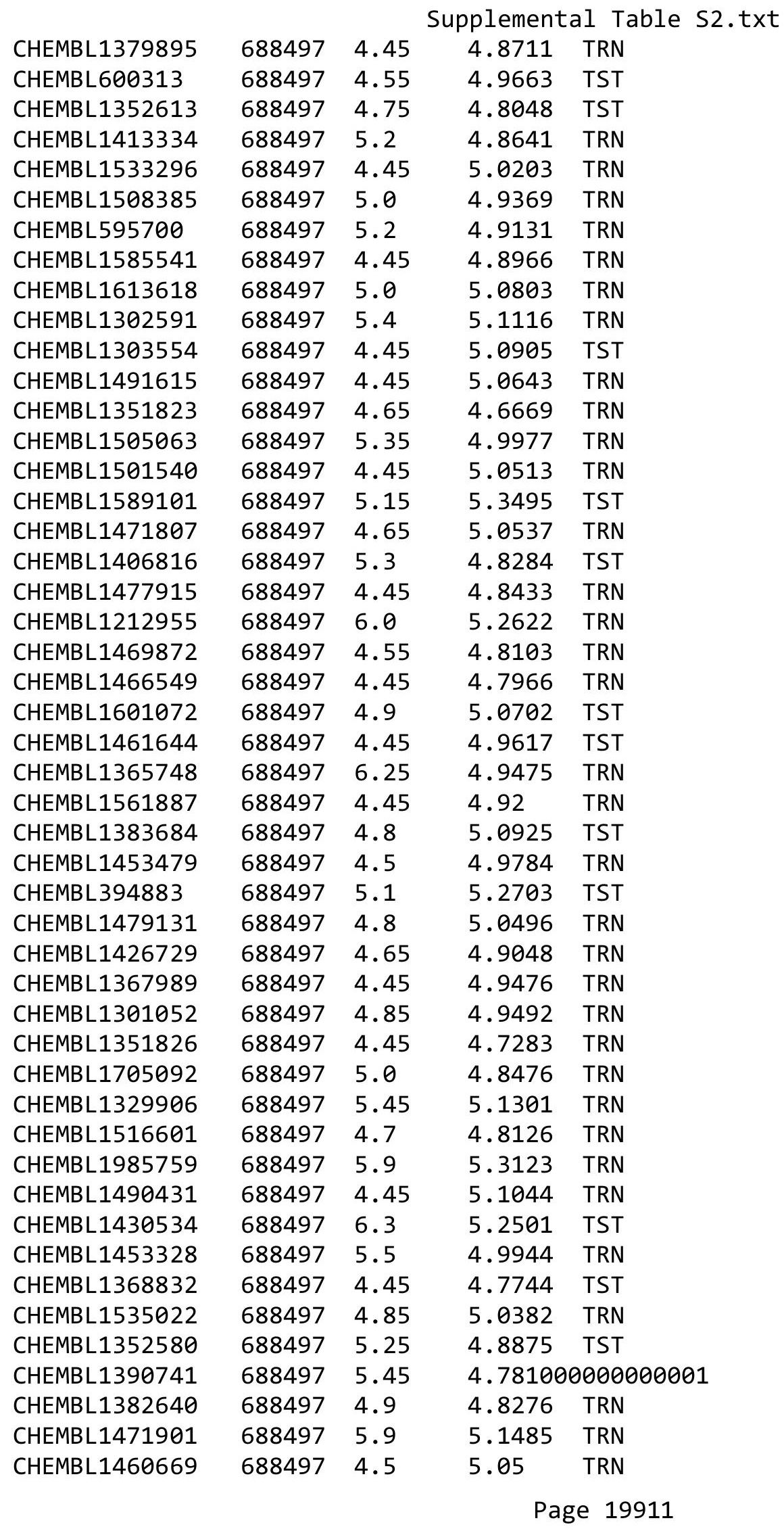

TRN 


\begin{tabular}{|c|c|c|c|c|c|}
\hline \\
\hline CHEMBL1415746 & 688497 & 5.9 & 4.8912 & TST & \\
\hline CHEMBL1361712 & 688497 & 5.25 & 5.1953 & TRN & \\
\hline CHEMBL1450727 & 688497 & 4.5 & 5.2052 & TST & \\
\hline CHEMBL1465239 & 688497 & 5.2 & 5.0055 & TRN & \\
\hline CHEMBL1399662 & 688497 & 4.55 & 5.1855 & TRN & \\
\hline CHEMBL1409149 & 688497 & 4.45 & 4.8989 & TRN & \\
\hline CHEMBL1378967 & 688497 & 4.85 & 5.1823 & TST & \\
\hline CHEMBL1477573 & 688497 & 4.75 & 4.6378 & TRN & \\
\hline CHEMBL3197313 & 688497 & 4.9 & 5.1457 & TRN & \\
\hline CHEMBL1402287 & 688497 & 3.4 & 5.0777 & TST & \\
\hline CHEMBL1524861 & 688497 & 5.5 & 5.0379 & TRN & \\
\hline CHEMBL1510985 & 688497 & 4.45 & 5.0726 & TRN & \\
\hline CHEMBL1535876 & 688497 & 4.45 & 5.1326 & TRN & \\
\hline CHEMBL1335785 & 688497 & 5.95 & 5.0367 & TRN & \\
\hline CHEMBL1541405 & 688497 & 4.7 & 4.6125 & TRN & \\
\hline CHEMBL1529534 & 688497 & 4.95 & 4.9594 & TRN & \\
\hline CHEMBL1496587 & 688497 & 5.0 & 5.1796 & TRN & \\
\hline CHEMBL1589095 & 688497 & 4.55 & 4.917 & TRN & \\
\hline CHEMBL1311969 & 688497 & 4.95 & 5.2368 & TRN & \\
\hline CHEMBL1426897 & 688497 & 4.45 & 4.96899 & 9999999999 & TRN \\
\hline CHEMBL1968569 & 688497 & 4.45 & 5.2141 & TRN & \\
\hline CHEMBL1303048 & 688497 & 4.75 & 5.3476 & TST & \\
\hline CHEMBL590947 & 688497 & 5.5 & 4.7716 & TRN & \\
\hline CHEMBL1374388 & 688497 & 5.05 & 5.0057 & TRN & \\
\hline CHEMBL1429304 & 688497 & 4.9 & 5.1072 & TST & \\
\hline CHEMBL451748 & 688497 & 4.45 & 5.0643 & TRN & \\
\hline CHEMBL3208768 & 688497 & 4.55 & 5.3205 & TRN & \\
\hline CHEMBL1460190 & 688497 & 4.45 & 5.0845 & TRN & \\
\hline CHEMBL1278035 & 688497 & 4.45 & 4.7383 & TST & \\
\hline CHEMBL1338589 & 688497 & 5.25 & 5.204 & TRN & \\
\hline CHEMBL1718423 & 688497 & 4.45 & 4.8714 & TST & \\
\hline CHEMBL1998302 & 688497 & 4.8 & 5.0473 & TRN & \\
\hline CHEMBL1576907 & 688497 & 4.5 & 5.1168 & TRN & \\
\hline CHEMBL3198468 & 688497 & 4.95 & 5.1171 & TRN & \\
\hline CHEMBL1575594 & 688497 & 5.25 & 5.4075 & TRN & \\
\hline CHEMBL1326464 & 688497 & 6.3 & 5.5514 & TST & \\
\hline CHEMBL1417381 & 688497 & 6.0 & 5.1459 & TRN & \\
\hline CHEMBL1345330 & 688497 & 4.45 & 4.7602 & TRN & \\
\hline CHEMBL587728 & 688497 & 4.95 & 5.0015 & TRN & \\
\hline CHEMBL1451974 & 688497 & 4.55 & 4.8616 & TST & \\
\hline CHEMBL1442815 & 688497 & 6.25 & 5.4346 & TST & \\
\hline CHEMBL1540356 & 688497 & 5.45 & 5.0471 & TRN & \\
\hline CHEMBL259784 & 688497 & 4.45 & 5.6819 & TST & \\
\hline CHEMBL1548456 & 688497 & 4.55 & 4.9231 & TRN & \\
\hline CHEMBL1328367 & 688497 & 4.95 & 4.9328 & TRN & \\
\hline CHEMBL 3197550 & 688497 & 5.25 & 4.8931 & TRN & \\
\hline CHEMBL 3207549 & 688497 & 5.25 & 4.8887 & TST & \\
\hline CHEMBL1384890 & 688497 & 4.95 & 5.1648 & TRN & \\
\hline
\end{tabular}




\begin{tabular}{|c|c|c|c|c|c|}
\hline \\
\hline CHEMBL1444565 & 688497 & 4.7 & 5.1259 & TRN & \\
\hline CHEMBL1545156 & 688497 & 6.05 & 5.03600 & 00000000005 & TRN \\
\hline CHEMBL1533827 & 688497 & 5.05 & 5.2171 & TRN & \\
\hline CHEMBL1530776 & 688497 & 4.7 & 5.1595 & TRN & \\
\hline CHEMBL1608727 & 688497 & 5.25 & 5.3641 & TST & \\
\hline CHEMBL1548896 & 688497 & 4.95 & 5.0566 & TST & \\
\hline CHEMBL601547 & 688497 & 5.0 & 4.9578 & TRN & \\
\hline CHEMBL1589879 & 688497 & 4.7 & 4.769 & TST & \\
\hline CHEMBL1524848 & 688497 & 4.9 & 5.0311 & TRN & \\
\hline CHEMBL1441495 & 688497 & 4.7 & 5.16299 & 9999999999 & TRN \\
\hline CHEMBL1334887 & 688497 & 4.45 & 4.8075 & TRN & \\
\hline CHEMBL1425613 & 688497 & 4.8 & 4.3957 & TRN & \\
\hline CHEMBL1563189 & 688497 & 4.5 & 4.8123 & TRN & \\
\hline CHEMBL1393847 & 688497 & 5.35 & 5.31 & TRN & \\
\hline CHEMBL1351116 & 688497 & 4.5 & 4.7153 & TRN & \\
\hline CHEMBL1371667 & 688497 & 6.35 & 4.9761 & TRN & \\
\hline CHEMBL3197688 & 688497 & 4.8 & 4.8681 & TRN & \\
\hline CHEMBL1424533 & 688497 & 4.8 & 5.149 & TRN & \\
\hline CHEMBL1402649 & 688497 & 5.15 & 4.9652 & TRN & \\
\hline CHEMBL3208465 & 688497 & 4.8 & 4.9158 & TRN & \\
\hline CHEMBL1424931 & 688497 & 4.7 & 5.2546 & TRN & \\
\hline CHEMBL1313852 & 688497 & 6.7001 & 4.8386 & TRN & \\
\hline CHEMBL1501896 & 688497 & 4.95 & 5.091 & TRN & \\
\hline CHEMBL1613715 & 688497 & 4.55 & 4.806 & TRN & \\
\hline CHEMBL1587910 & 688497 & 4.45 & 5.0007 & TRN & \\
\hline CHEMBL1468577 & 688497 & 4.85 & 4.9922 & TRN & \\
\hline CHEMBL1365345 & 688497 & 4.45 & 4.9031 & TRN & \\
\hline CHEMBL1446802 & 688497 & 4.45 & 4.6505 & TRN & \\
\hline CHEMBL1450010 & 688497 & 4.45 & 5.045 & TRN & \\
\hline CHEMBL1517141 & 688497 & 4.45 & 5.2833 & TRN & \\
\hline CHEMBL1422230 & 688497 & 4.55 & 4.8538 & TST & \\
\hline CHEMBL1609918 & 688497 & 4.45 & 5.1681 & TST & \\
\hline CHEMBL1569726 & 688497 & 5.0 & 4.8217 & TRN & \\
\hline CHEMBL1451628 & 688497 & 4.7 & 4.8274 & TST & \\
\hline CHEMBL1345669 & 688497 & 4.95 & 5.2786 & TRN & \\
\hline CHEMBL3190813 & 688497 & 5.55 & 5.06 & TST & \\
\hline CHEMBL1488834 & 688497 & 4.45 & 5.0704 & TRN & \\
\hline CHEMBL1566108 & 688497 & 4.55 & 5.1039 & TRN & \\
\hline CHEMBL1305004 & 688497 & 5.15 & 4.9918 & TRN & \\
\hline CHEMBL1449476 & 688497 & 6.3 & 5.2321 & TRN & \\
\hline CHEMBL1558756 & 688497 & 4.95 & 5.0148 & TRN & \\
\hline CHEMBL1535109 & 688497 & 5.1 & 5.0449 & TRN & \\
\hline CHEMBL1419328 & 688497 & 4.85 & 5.0694 & TRN & \\
\hline CHEMBL1605706 & 688497 & 4.45 & 5.0737 & TRN & \\
\hline CHEMBL1610722 & 688497 & 5.55 & 4.9538 & TST & \\
\hline CHEMBL1599620 & 688497 & 5.7 & 5.1256 & TRN & \\
\hline CHEMBL1549075 & 688497 & 7.0 & 5.1938 & TRN & \\
\hline CHEMBL1352775 & 688497 & 4.75 & 4.9076 & TRN & \\
\hline
\end{tabular}




\begin{tabular}{|c|c|c|c|c|c|}
\hline \multicolumn{6}{|c|}{ Supplemental Table S2.txt } \\
\hline CHEMBL1313263 & 688497 & 5.0 & 5.4264 & TST & \\
\hline CHEMBL1338436 & 688497 & 5.35 & 4.9961 & TRN & \\
\hline CHEMBL1582393 & 688497 & 6.25 & 5.1124 & TST & \\
\hline CHEMBL530049 & 688497 & 5.45 & 5.0837 & TST & \\
\hline CHEMBL1548624 & 688497 & 4.95 & 4.7801 & TRN & \\
\hline CHEMBL1306633 & 688497 & 5.1 & 5.0954 & TRN & \\
\hline CHEMBL1570310 & 688497 & 4.45 & 5.155 & TRN & \\
\hline CHEMBL1392319 & 688497 & 6.25 & 5.2485 & TST & \\
\hline CHEMBL 3198757 & 688497 & 5.15 & 4.9783 & TRN & \\
\hline CHEMBL1307319 & 688497 & 5.2 & 5.2075 & TST & \\
\hline CHEMBL1349840 & 688497 & 4.65 & 4.9511 & TRN & \\
\hline CHEMBL1428636 & 688497 & 4.8 & 4.8242 & TRN & \\
\hline CHEMBL1482067 & 688497 & 4.75 & 4.9997 & TRN & \\
\hline CHEMBL1574903 & 688497 & 5.45 & 5.0573 & TRN & \\
\hline CHEMBL3192567 & 688497 & 5.1 & 5.0556 & TRN & \\
\hline CHEMBL1581263 & 688497 & 5.9 & 4.8046 & TRN & \\
\hline CHEMBL1443561 & 688497 & 4.6 & 4.9065 & TRN & \\
\hline CHEMBL1327789 & 688497 & 5.15 & 5.1059 & TRN & \\
\hline CHEMBL1581870 & 688497 & 5.9 & 5.1606 & TST & \\
\hline CHEMBL1569696 & 688497 & 5.25 & 5.2092 & TST & \\
\hline CHEMBL1610367 & 688497 & 4.65 & 4.7897 & TRN & \\
\hline CHEMBL1599641 & 688497 & 5.5 & 5.5078 & TRN & \\
\hline CHEMBL1550293 & 688497 & 4.9 & 4.9852 & TRN & \\
\hline CHEMBL600572 & 688497 & 4.7 & 5.0722 & TRN & \\
\hline CHEMBL1497402 & 688497 & 5.9 & 5.1102 & TRN & \\
\hline CHEMBL1542439 & 688497 & 4.45 & 5.1821 & TRN & \\
\hline CHEMBL1339243 & 688497 & 4.65 & 4.90600 & 3000000001 & TRN \\
\hline CHEMBL1420618 & 688497 & 4.95 & 4.6452 & TRN & \\
\hline CHEMBL1377564 & 688497 & 5.9 & 4.9406 & TST & \\
\hline CHEMBL1336113 & 688497 & 5.9 & 4.9452 & TST & \\
\hline CHEMBL1562216 & 688497 & 4.45 & 4.9425 & TST & \\
\hline CHEMBL1561537 & 688497 & 4.45 & 4.8699 & TRN & \\
\hline CHEMBL1340706 & 688497 & 4.95 & 5.0864 & TRN & \\
\hline CHEMBL1344702 & 688497 & 4.65 & 4.841 & TRN & \\
\hline CHEMBL1453778 & 688497 & 4.75 & 5.1707 & TST & \\
\hline CHEMBL1481785 & 688497 & 5.15 & 4.9051 & TRN & \\
\hline CHEMBL 1384840 & 688497 & 4.45 & 5.3609 & TRN & \\
\hline CHEMBL1350410 & 688497 & 5.0 & 5.0561 & TST & \\
\hline CHEMBL1331498 & 688497 & 5.65 & 4.798 & TRN & \\
\hline CHEMBL1531569 & 688497 & 8.6021 & 5.1504 & TRN & \\
\hline CHEMBL1334943 & 688497 & 6.3 & 5.0457 & TST & \\
\hline CHEMBL1526609 & 688497 & 5.55 & 5.1458 & TST & \\
\hline CHEMBL1563810 & 688497 & 5.25 & 4.9586 & TST & \\
\hline CHEMBL1559979 & 688497 & 4.5 & 4.8629 & TRN & \\
\hline CHEMBL1390602 & 688497 & 4.45 & 5.0692 & TRN & \\
\hline CHEMBL1482663 & 688497 & 5.4 & 5.1126 & TST & \\
\hline CHEMBL1465128 & 688497 & 5.0 & 4.7446 & TST & \\
\hline CHEMBL1432625 & 688497 & 4.95 & 5.1632 & TRN & \\
\hline
\end{tabular}




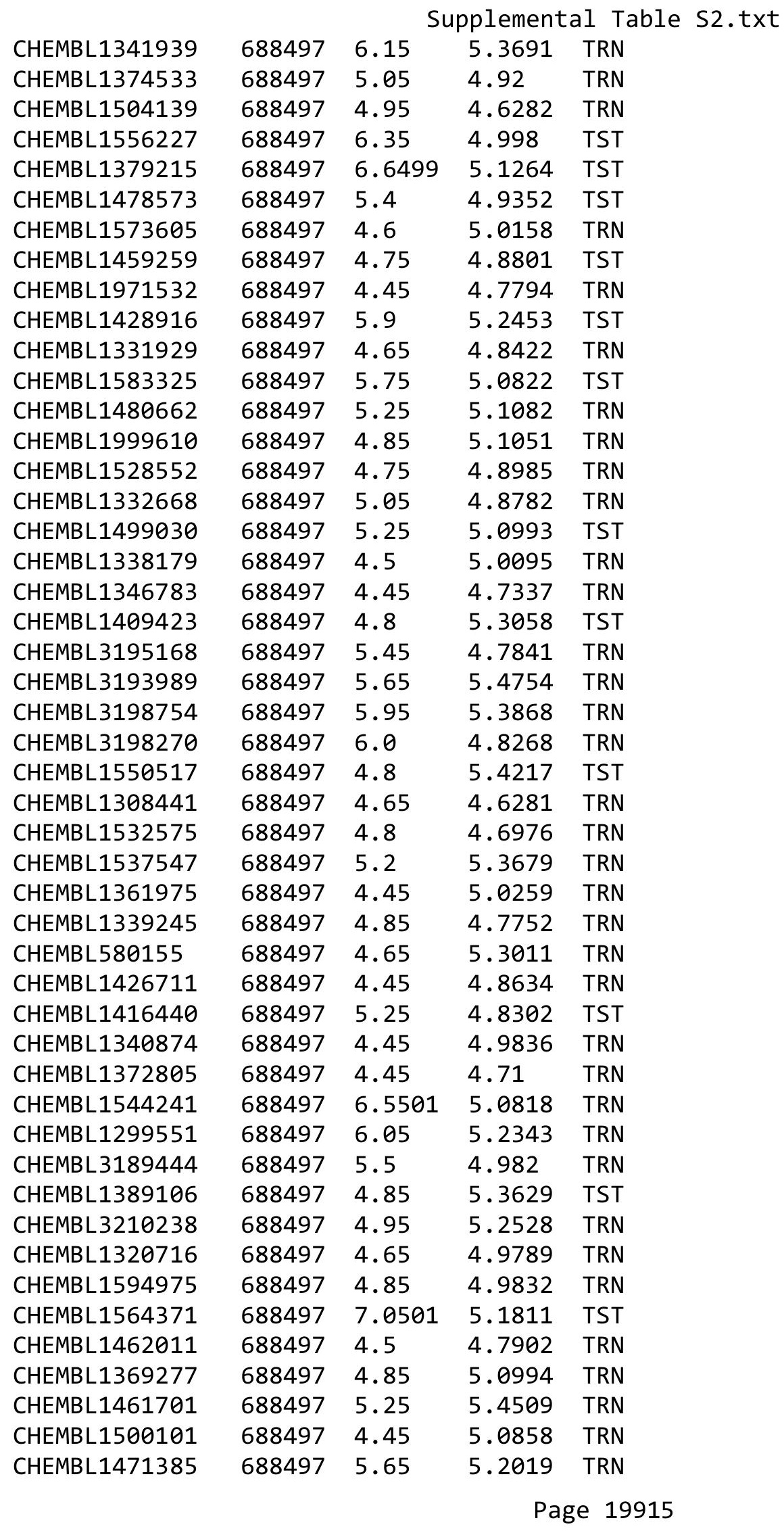




\begin{tabular}{|c|c|c|c|c|}
\hline \multicolumn{5}{|c|}{ Supplemental Table S2.tx } \\
\hline CHEMBL1468973 & 688497 & 4.5 & 4.8963 & TST \\
\hline CHEMBL1529485 & 688497 & 5.4 & 5.0929 & TST \\
\hline CHEMBL1531336 & 688497 & 4.85 & 5.2476 & TST \\
\hline CHEMBL1439934 & 688497 & 5.25 & 5.409 & TST \\
\hline CHEMBL1416931 & 688497 & 5.25 & 4.999 & TRN \\
\hline CHEMBL1386133 & 688497 & 6.3 & 5.2376 & TRN \\
\hline CHEMBL1406279 & 688497 & 5.25 & 5.3971 & TRN \\
\hline CHEMBL1505128 & 688497 & 5.25 & 5.32299 & 99999999995 \\
\hline CHEMBL1508932 & 688497 & 4.45 & 4.9646 & TRN \\
\hline CHEMBL1309348 & 688497 & 4.45 & 5.1283 & TRN \\
\hline CHEMBL1369658 & 688497 & 5.0 & 4.9446 & TRN \\
\hline CHEMBL1373692 & 688497 & 4.6 & 4.9897 & TRN \\
\hline CHEMBL1425166 & 688497 & 4.45 & 4.7576 & TRN \\
\hline CHEMBL1600364 & 688497 & 6.25 & 5.0407 & TRN \\
\hline CHEMBL1482459 & 688497 & 4.75 & 5.109 & TRN \\
\hline CHEMBL1500137 & 688497 & 5.25 & 5.051 & TRN \\
\hline CHEMBL1454562 & 688497 & 5.75 & 4.9133 & TRN \\
\hline CHEMBL1451054 & 688497 & 4.9 & 4.7196 & TRN \\
\hline CHEMBL1391059 & 688497 & 4.8 & 5.0649 & TST \\
\hline CHEMBL1572785 & 688497 & 5.0 & 5.365 & TRN \\
\hline CHEMBL1468601 & 688497 & 6.25 & 4.899 & TST \\
\hline CHEMBL1575881 & 688497 & 4.85 & 4.747 & TRN \\
\hline CHEMBL1387346 & 688497 & 4.5 & 4.9443 & TRN \\
\hline CHEMBL1341691 & 688497 & 4.8 & 4.9427 & TRN \\
\hline CHEMBL1373474 & 688497 & 4.45 & 4.8773 & TRN \\
\hline CHEMBL1603878 & 688497 & 6.25 & 5.3035 & TRN \\
\hline CHEMBL1353944 & 688497 & 4.55 & 4.8989 & TRN \\
\hline CHEMBL3211511 & 688497 & 5.3 & 5.0288 & TRN \\
\hline CHEMBL1994902 & 688497 & 4.95 & 5.044 & TRN \\
\hline CHEMBL1890899 & 688497 & 4.45 & 5.0887 & TRN \\
\hline CHEMBL1347762 & 688497 & 5.0 & 5.1598 & TRN \\
\hline CHEMBL1573371 & 688497 & 4.45 & 4.8842 & TRN \\
\hline CHEMBL1342858 & 688497 & 4.45 & 4.6455 & TRN \\
\hline CHEMBL1542342 & 688497 & 4.5 & 5.184 & TRN \\
\hline CHEMBL1461585 & 688497 & 4.85 & 4.6788 & TRN \\
\hline CHEMBL3194167 & 688497 & 5.45 & 5.0622 & TRN \\
\hline CHEMBL1399600 & 688497 & 4.45 & 4.8679 & TRN \\
\hline CHEMBL1485525 & 688497 & 4.9 & 5.0167 & TRN \\
\hline CHEMBL1488338 & 688497 & 4.65 & 4.8835 & TRN \\
\hline CHEMBL1487717 & 688497 & 4.85 & 4.9221 & TRN \\
\hline CHEMBL1393933 & 688497 & 4.85 & 5.2544 & TRN \\
\hline CHEMBL1440126 & 688497 & 5.0 & 5.415 & TRN \\
\hline CHEMBL1501325 & 688497 & 5.35 & 5.1082 & TRN \\
\hline CHEMBL1604606 & 688497 & 5.0 & 4.7999 & TRN \\
\hline CHEMBL1559029 & 688497 & 4.45 & 4.8028 & TRN \\
\hline CHEMBL3145137 & 688497 & 5.2 & 5.3062 & TST \\
\hline CHEMBL528506 & 688497 & 4.45 & 5.0246 & TRN \\
\hline CHEMBL1544334 & 688497 & 5.9 & 5.0507 & TRN \\
\hline
\end{tabular}




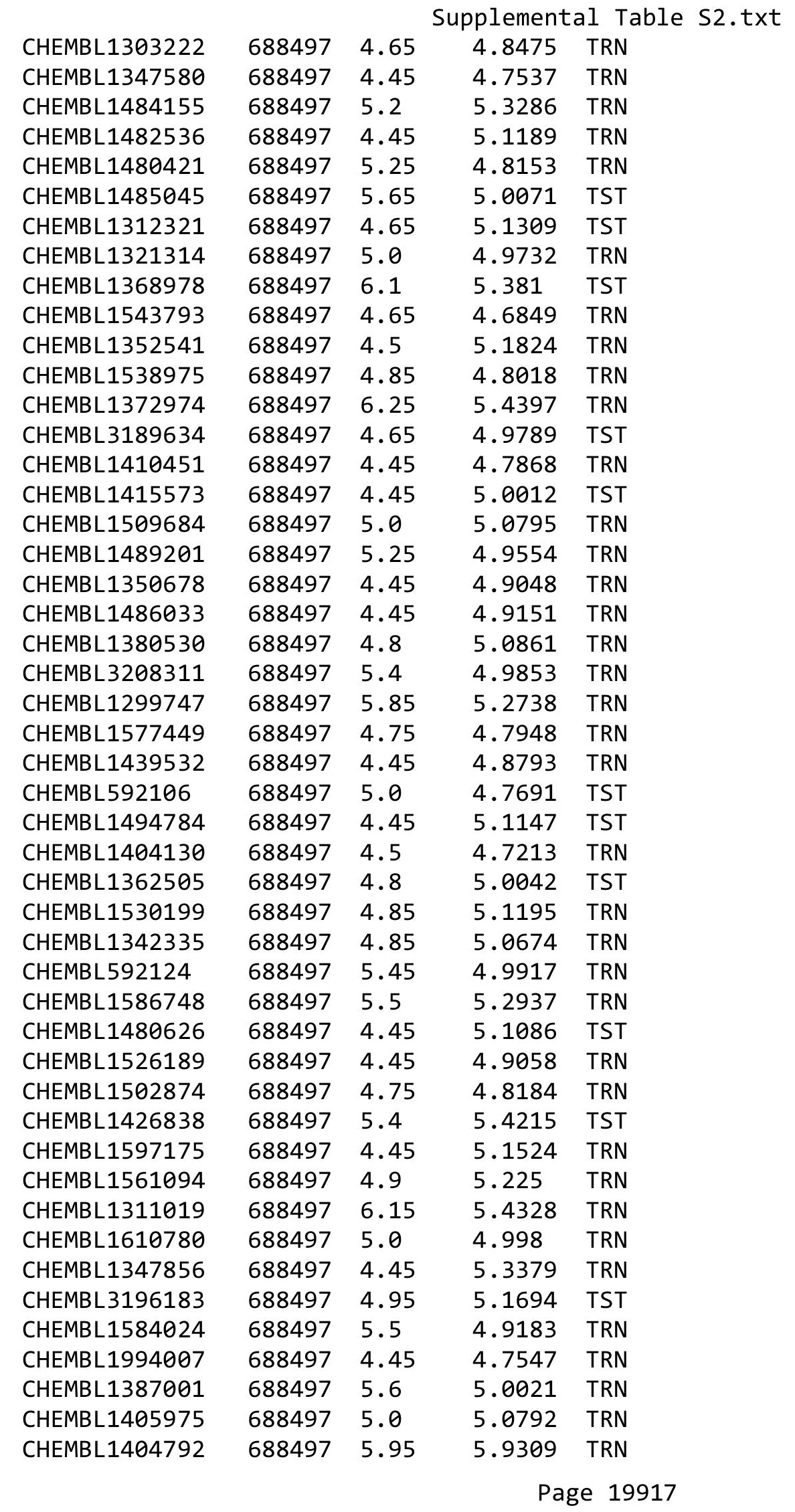




\begin{tabular}{|c|c|c|c|c|}
\hline & & & upplement & al $\mathrm{Ta}$ \\
\hline CHEMBL1526451 & 688497 & 6.1 & 5.136 & TRN \\
\hline CHEMBL1489008 & 688497 & 4.95 & 5.2227 & TRN \\
\hline CHEMBL1332770 & 688497 & 5.25 & 5.2191 & TRN \\
\hline CHEMBL 3196282 & 688497 & 5.25 & 5.1275 & TRN \\
\hline CHEMBL1383424 & 688497 & 4.45 & 5.0647 & TRN \\
\hline CHEMBL1364682 & 688497 & 4.45 & 4.7574 & TRN \\
\hline CHEMBL1340495 & 688497 & 4.85 & 5.2833 & TRN \\
\hline CHEMBL1520738 & 688497 & 4.45 & 5.4951 & TST \\
\hline CHEMBL1509423 & 688497 & 5.25 & 5.0557 & TST \\
\hline CHEMBL518292 & 688497 & 5.05 & 5.1393 & TST \\
\hline CHEMBL1430042 & 688497 & 5.05 & 4.9227 & TST \\
\hline CHEMBL1559563 & 688497 & 5.25 & 5.4328 & TRN \\
\hline CHEMBL1502227 & 688497 & 4.6 & 5.0383 & TST \\
\hline CHEMBL1612117 & 688497 & 4.55 & 4.7203 & TRN \\
\hline CHEMBL1409440 & 688497 & 6.0 & 4.953 & TRN \\
\hline CHEMBL1423194 & 688497 & 4.65 & 5.0221 & TRN \\
\hline CHEMBL1570129 & 688497 & 5.25 & 4.7232 & TRN \\
\hline CHEMBL1308528 & 688497 & 5.25 & 4.9058 & TRN \\
\hline CHEMBL1401251 & 688497 & 4.45 & 4.9693 & TST \\
\hline CHEMBL1505299 & 688497 & 4.45 & 4.6691 & TST \\
\hline CHEMBL1485447 & 688497 & 4.6 & 4.8724 & TRN \\
\hline CHEMBL2001831 & 688497 & 4.65 & 4.8445 & TST \\
\hline CHEMBL1575959 & 688497 & 5.45 & 5.2819 & TRN \\
\hline CHEMBL1346187 & 688497 & 4.45 & 4.8006 & TRN \\
\hline CHEMBL1516801 & 688497 & 5.45 & 5.3034 & TRN \\
\hline CHEMBL1503995 & 688497 & 4.45 & 4.7775 & TRN \\
\hline CHEMBL1572097 & 688497 & 6.1 & 5.3973 & TRN \\
\hline CHEMBL1546866 & 688497 & 5.0 & 4.9049 & TRN \\
\hline CHEMBL1550430 & 688497 & 4.95 & 5.0841 & TRN \\
\hline CHEMBL1558901 & 688497 & 4.9 & 5.3197 & TST \\
\hline CHEMBL1524403 & 688497 & 4.45 & 4.7095 & TRN \\
\hline CHEMBL1349075 & 688497 & 5.75 & 5.2176 & TRN \\
\hline CHEMBL 3189413 & 688497 & 4.45 & 4.7317 & TRN \\
\hline CHEMBL1412264 & 688497 & 5.25 & 5.0109 & TRN \\
\hline CHEMBL1509825 & 688497 & 5.9 & 4.8629 & TRN \\
\hline CHEMBL1364097 & 688497 & 4.45 & 5.037 & TST \\
\hline CHEMBL1420993 & 688497 & 4.85 & 4.9266 & TRN \\
\hline CHEMBL1560642 & 688497 & 4.45 & 5.0668 & TST \\
\hline CHEMBL1500842 & 688497 & 4.95 & 4.9492 & TRN \\
\hline CHEMBL1353064 & 688497 & 5.5 & 5.2022 & TRN \\
\hline CHEMBL1304653 & 688497 & 6.05 & 5.1689 & TRN \\
\hline CHEMBL1534623 & 688497 & 5.45 & 5.0911 & TST \\
\hline CHEMBL1350166 & 688497 & 6.5 & 4.9714 & TST \\
\hline CHEMBL1561472 & 688497 & 4.95 & 5.0016 & TRN \\
\hline CHEMBL1429309 & 688497 & 4.45 & 5.0345 & TRN \\
\hline CHEMBL1549030 & 688497 & 4.45 & 4.879 & TRN \\
\hline CHEMBL1450098 & 688497 & 5.65 & 5.2304 & TRN \\
\hline CHEMBL1387002 & 688497 & 5.5 & 5.046 & TRN \\
\hline
\end{tabular}




\begin{tabular}{|c|c|c|c|c|c|}
\hline & & \multicolumn{4}{|c|}{ Supplemental Table s2.txt } \\
\hline CHEMBL1326194 & 688497 & 5.25 & 4.6754 & TRN & \\
\hline CHEMBL1458393 & 688497 & 4.85 & 5.0309 & TRN & \\
\hline CHEMBL1361420 & 688497 & 4.95 & 4.76699 & 99999999995 & TST \\
\hline CHEMBL1563358 & 688497 & 4.55 & 5.0494 & TST & \\
\hline CHEMBL1449129 & 688497 & 6.25 & 5.175 & TRN & \\
\hline CHEMBL1444241 & 688497 & 4.45 & 5.0997 & TST & \\
\hline CHEMBL1355323 & 688497 & 6.05 & 5.3146 & TST & \\
\hline CHEMBL1415432 & 688497 & 5.7 & 4.8532 & TST & \\
\hline CHEMBL1448573 & 688497 & 4.6 & 4.8129 & TRN & \\
\hline CHEMBL1606443 & 688497 & 4.45 & 5.0352 & TRN & \\
\hline CHEMBL1480517 & 688497 & 5.9 & 5.1068 & TRN & \\
\hline CHEMBL594152 & 688497 & 4.6 & 5.5291 & TST & \\
\hline CHEMBL1461714 & 688497 & 4.95 & 4.9729 & TRN & \\
\hline CHEMBL1487236 & 688497 & 4.45 & 4.9241 & TRN & \\
\hline CHEMBL1573692 & 688497 & 4.6 & 4.8833 & TRN & \\
\hline CHEMBL1310405 & 688497 & 4.65 & 5.0512 & TRN & \\
\hline CHEMBL1463900 & 688497 & 4.95 & 5.0468 & TRN & \\
\hline CHEMBL1536070 & 688497 & 4.45 & 5.0352 & TST & \\
\hline CHEMBL1594362 & 688497 & 4.95 & 5.2037 & TRN & \\
\hline CHEMBL1468417 & 688497 & 4.45 & 5.1353 & TST & \\
\hline CHEMBL1431189 & 688497 & 5.3 & 5.0545 & TRN & \\
\hline CHEMBL1410737 & 688497 & 5.9 & 5.0993 & TRN & \\
\hline CHEMBL1454734 & 688497 & 4.95 & 4.9908 & TRN & \\
\hline CHEMBL1526662 & 688497 & 5.1 & 4.8337 & TST & \\
\hline CHEMBL1414562 & 688497 & 4.45 & 5.0195 & TST & \\
\hline CHEMBL1501782 & 688497 & 6.25 & 4.8653 & TRN & \\
\hline CHEMBL1594535 & 688497 & 5.25 & 4.7406 & TRN & \\
\hline CHEMBL3190579 & 688497 & 6.3 & 4.7431 & TST & \\
\hline CHEMBL1385287 & 688497 & 5.25 & 4.8263 & TST & \\
\hline CHEMBL1530767 & 688497 & 5.45 & 5.0178 & TRN & \\
\hline CHEMBL1604217 & 688497 & 5.75 & 4.9708 & TRN & \\
\hline CHEMBL1466361 & 688497 & 5.2 & 5.2681 & TRN & \\
\hline CHEMBL1605369 & 688497 & 4.8 & 5.1381 & TRN & \\
\hline CHEMBL1483697 & 688497 & 5.25 & 5.1799 & TRN & \\
\hline CHEMBL1987514 & 688497 & 4.45 & 4.89 & TRN & \\
\hline CHEMBL1328003 & 688497 & 5.0 & 4.9989 & TST & \\
\hline CHEMBL1408563 & 688497 & 3.6 & 4.9258 & TRN & \\
\hline CHEMBL1573946 & 688497 & 4.8 & 5.0408 & TRN & \\
\hline CHEMBL1426832 & 688497 & 5.25 & 4.9681 & TRN & \\
\hline CHEMBL1489015 & 688497 & 4.45 & 5.4336 & TRN & \\
\hline CHEMBL1589677 & 688497 & 4.95 & 5.0716 & TRN & \\
\hline CHEMBL1383782 & 688497 & 5.05 & 4.9996 & TRN & \\
\hline CHEMBL1438907 & 688497 & 4.8 & 4.8704 & TST & \\
\hline CHEMBL1438559 & 688497 & 5.0 & 4.9675 & TRN & \\
\hline CHEMBL1302750 & 688497 & 4.95 & 5.0449 & TST & \\
\hline CHEMBL1421604 & 688497 & 4.45 & 5.0409 & TST & \\
\hline CHEMBL1575559 & 688497 & 4.85 & 4.9228 & TRN & \\
\hline CHEMBL1484268 & 688497 & 4.45 & 5.1977 & TST & \\
\hline
\end{tabular}




\begin{tabular}{|c|c|c|c|c|c|}
\hline \multicolumn{6}{|c|}{ Supplemental Table S2.txt } \\
\hline CHEMBL1352064 & 688497 & 5.15 & 5.0765 & TRN & \\
\hline CHEMBL1504808 & 688497 & 5.4 & 5.1139 & TRN & \\
\hline CHEMBL1432507 & 688497 & 4.85 & 5.0756 & TRN & \\
\hline CHEMBL1418676 & 688497 & 4.45 & 5.2816 & TRN & \\
\hline CHEMBL1414282 & 688497 & 4.65 & 5.1797 & TST & \\
\hline CHEMBL1587968 & 688497 & 4.9 & 4.978 & TRN & \\
\hline CHEMBL1371600 & 688497 & 5.4 & 5.3921 & TRN & \\
\hline CHEMBL1373002 & 688497 & 5.2 & 5.07100 & 0000000001 & TRN \\
\hline CHEMBL1501005 & 688497 & 4.65 & 4.8393 & TRN & \\
\hline CHEMBL1342693 & 688497 & 5.0 & 5.41200 & 0000000001 & TRN \\
\hline CHEMBL1384427 & 688497 & 6.25 & 5.3288 & TRN & \\
\hline CHEMBL1403026 & 688497 & 5.45 & 4.5468 & TRN & \\
\hline CHEMBL1288156 & 688497 & 4.4 & 5.1444 & TRN & \\
\hline CHEMBL1371111 & 688497 & 4.45 & 4.8062 & TRN & \\
\hline CHEMBL1446659 & 688497 & 6.0 & 5.013 & TRN & \\
\hline CHEMBL1393357 & 688497 & 4.8 & 4.9026 & TRN & \\
\hline CHEMBL1390261 & 688497 & 4.95 & 4.7279 & TRN & \\
\hline CHEMBL1400912 & 688497 & 4.45 & 4.8632 & TRN & \\
\hline CHEMBL3212652 & 688497 & 4.45 & 4.5134 & TRN & \\
\hline CHEMBL1384145 & 688497 & 4.8 & 5.0346 & TRN & \\
\hline CHEMBL1546229 & 688497 & 5.2 & 5.20799 & 9999999999 & TRN \\
\hline CHEMBL1312376 & 688497 & 5.4 & 5.16799 & 9999999999 & TRN \\
\hline CHEMBL1497749 & 688497 & 5.9 & 5.29899 & 99999999995 & TRN \\
\hline CHEMBL1370099 & 688497 & 5.05 & 4.6894 & TRN & \\
\hline CHEMBL3189906 & 688497 & 5.2 & 4.8594 & TRN & \\
\hline CHEMBL1420531 & 688497 & 5.35 & 4.9483 & TST & \\
\hline CHEMBL1410086 & 688497 & 5.55 & 5.1153 & TST & \\
\hline CHEMBL1299290 & 688497 & 4.8 & 5.1507 & TRN & \\
\hline CHEMBL1443167 & 688497 & 5.7 & 5.3281 & TST & \\
\hline CHEMBL1385443 & 688497 & 4.45 & 4.9097 & TRN & \\
\hline CHEMBL3212522 & 688497 & 4.9 & 4.9562 & TRN & \\
\hline CHEMBL1391827 & 688497 & 4.65 & 5.1041 & TST & \\
\hline CHEMBL1300919 & 688497 & 5.6 & 5.1368 & TRN & \\
\hline CHEMBL3194824 & 688497 & 4.95 & 4.9761 & TRN & \\
\hline CHEMBL1560813 & 688497 & 4.45 & 4.9128 & TRN & \\
\hline CHEMBL1606145 & 688497 & 6.05 & 5.051 & TRN & \\
\hline CHEMBL1594563 & 688497 & 5.45 & 5.3432 & TST & \\
\hline CHEMBL1567345 & 688497 & 4.95 & 4.9631 & TRN & \\
\hline CHEMBL1305463 & 688497 & 4.45 & 4.896 & TRN & \\
\hline CHEMBL1574150 & 688497 & 4.45 & 4.9427 & TRN & \\
\hline CHEMBL1613238 & 688497 & 6.15 & 5.5139 & TRN & \\
\hline CHEMBL1337961 & 688497 & 4.6 & 5.0024 & TRN & \\
\hline CHEMBL1365552 & 688497 & 4.8 & 4.9618 & TRN & \\
\hline CHEMBL1333772 & 688497 & 4.45 & 4.9258 & TRN & \\
\hline CHEMBL1580908 & 688497 & 4.45 & 5.012 & TST & \\
\hline CHEMBL1464525 & 688497 & 4.45 & 4.7522 & TST & \\
\hline CHEMBL1481525 & 688497 & 4.45 & 4.4718 & TST & \\
\hline CHEMBL1346034 & 688497 & 4.45 & 5.0839 & TRN & \\
\hline
\end{tabular}




\begin{tabular}{|c|c|c|c|c|c|}
\hline \multicolumn{6}{|c|}{ Supplemental Table S2.txt } \\
\hline CHEMBL1376345 & 688497 & 4.9 & 4.9463 & TRN & \\
\hline CHEMBL1388663 & 688497 & 4.55 & 5.0655 & TST & \\
\hline CHEMBL1563552 & 688497 & 4.45 & 4.6942 & TRN & \\
\hline CHEMBL1574404 & 688497 & 4.45 & 5.0158 & TST & \\
\hline CHEMBL1531058 & 688497 & 4.7 & 5.1247 & TRN & \\
\hline CHEMBL1382884 & 688497 & 5.25 & 5.1073 & TST & \\
\hline CHEMBL1490169 & 688497 & 5.0 & 4.9188 & TRN & \\
\hline CHEMBL1406663 & 688497 & 4.95 & 4.9702 & TRN & \\
\hline CHEMBL1401606 & 688497 & 5.5 & 5.1215 & TRN & \\
\hline CHEMBL1582125 & 688497 & 4.45 & 4.6577 & TRN & \\
\hline CHEMBL1416454 & 688497 & 4.7 & 5.0679 & TRN & \\
\hline CHEMBL1492655 & 688497 & 4.6 & 4.9834 & TST & \\
\hline CHEMBL1578269 & 688497 & 5.45 & 4.8034 & TRN & \\
\hline CHEMBL1301557 & 688497 & 5.6 & $4.7330 e$ & 00000000005 & TRN \\
\hline CHEMBL1539704 & 688497 & 5.9 & 5.4403 & TRN & \\
\hline CHEMBL1452948 & 688497 & 4.45 & 4.8178 & TST & \\
\hline CHEMBL1531352 & 688497 & 5.45 & 5.4821 & TRN & \\
\hline CHEMBL3192422 & 688497 & 4.75 & 5.0492 & TST & \\
\hline CHEMBL1377276 & 688497 & 4.45 & 4.8505 & TRN & \\
\hline CHEMBL1368578 & 688497 & 5.45 & 4.8315 & TRN & \\
\hline CHEMBL1351497 & 688497 & 4.6 & 5.2912 & TRN & \\
\hline CHEMBL1580978 & 688497 & 4.65 & 4.7174 & TRN & \\
\hline CHEMBL1582500 & 688497 & 5.9 & 5.3271 & TRN & \\
\hline CHEMBL1597103 & 688497 & 4.95 & 5.0899 & TRN & \\
\hline CHEMBL1418522 & 688497 & 5.0 & 5.0564 & TRN & \\
\hline CHEMBL1337472 & 688497 & 5.1 & 5.1168 & TRN & \\
\hline CHEMBL1526814 & 688497 & 4.95 & 4.8797 & TRN & \\
\hline CHEMBL1329235 & 688497 & 6.45 & 5.7477 & TRN & \\
\hline CHEMBL1605725 & 688497 & 4.6 & 4.8269 & TRN & \\
\hline CHEMBL1327046 & 688497 & 5.35 & 4.5708 & TRN & \\
\hline CHEMBL1428951 & 688497 & 4.95 & 5.1793 & TST & \\
\hline CHEMBL1569847 & 688497 & 5.85 & 4.7206 & TRN & \\
\hline CHEMBL1350075 & 688497 & 4.6 & 4.8106 & TRN & \\
\hline CHEMBL1508375 & 688497 & 4.45 & 5.3285 & TRN & \\
\hline CHEMBL1334179 & 688497 & 5.45 & 4.6341 & TST & \\
\hline CHEMBL1559062 & 688497 & 4.6 & 4.7056 & TRN & \\
\hline CHEMBL1309802 & 688497 & 4.5 & 4.7152 & TRN & \\
\hline CHEMBL1559237 & 688497 & 4.45 & 5.1925 & TRN & \\
\hline CHEMBL1999049 & 688497 & 5.85 & 4.9527 & TST & \\
\hline CHEMBL1469397 & 688497 & 6.4 & 5.0465 & TST & \\
\hline CHEMBL1563381 & 688497 & 4.95 & 4.9902 & TRN & \\
\hline CHEMBL1416810 & 688497 & 4.95 & 5.1471 & TRN & \\
\hline CHEMBL1573140 & 688497 & 5.4 & 5.2653 & TRN & \\
\hline CHEMBL1445171 & 688497 & 4.75 & 5.0712 & TRN & \\
\hline CHEMBL1363949 & 688497 & 4.45 & 4.7059 & TRN & \\
\hline CHEMBL1377172 & 688497 & 5.45 & 5.0782 & TRN & \\
\hline CHEMBL3189581 & 688497 & 4.9 & 5.3073 & TRN & \\
\hline CHEMBL1541362 & 688497 & 5.9 & 5.1143 & TRN & \\
\hline
\end{tabular}




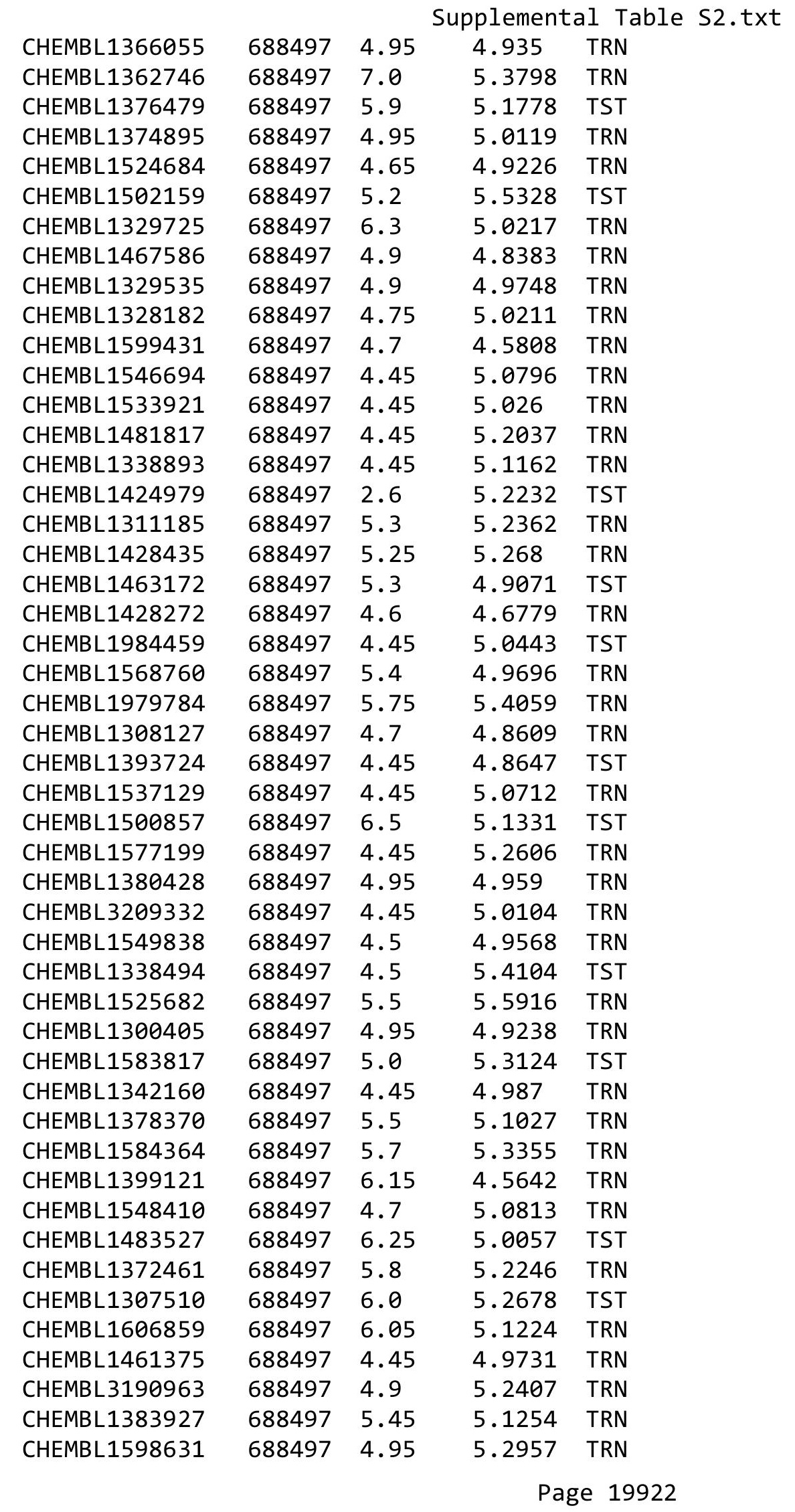




\begin{tabular}{|c|c|c|c|c|c|}
\hline \multicolumn{6}{|c|}{ Supplemental Table S2.txt } \\
\hline CHEMBL1399736 & 688497 & 4.9 & 5.1503 & TRN & \\
\hline CHEMBL1499851 & 688497 & 4.9 & 4.9176 & TST & \\
\hline CHEMBL1558810 & 688497 & 4.45 & 4.4547 & TRN & \\
\hline CHEMBL1511826 & 688497 & 5.05 & 4.98 & TRN & \\
\hline CHEMBL1487401 & 688497 & 4.95 & 5.0855 & TRN & \\
\hline CHEMBL3195393 & 688497 & 4.45 & 5.0742 & TRN & \\
\hline CHEMBL1581267 & 688497 & 5.9 & 5.1106 & TRN & \\
\hline CHEMBL1965710 & 688497 & 4.8 & 5.0906 & TRN & \\
\hline CHEMBL1385397 & 688497 & 4.55 & 4.8404 & TRN & \\
\hline CHEMBL1480976 & 688497 & 4.55 & 5.0407 & TRN & \\
\hline CHEMBL1381221 & 688497 & 4.65 & 5.1819 & TST & \\
\hline CHEMBL1607452 & 688497 & 4.45 & 4.7197 & TRN & \\
\hline CHEMBL1536220 & 688497 & 5.95 & 4.9612 & TRN & \\
\hline CHEMBL1501953 & 688497 & 4.45 & 4.9819 & TST & \\
\hline CHEMBL1608539 & 688497 & 4.8 & 5.3053 & TST & \\
\hline CHEMBL 260342 & 688497 & 4.45 & 5.1739 & TRN & \\
\hline CHEMBL1416383 & 688497 & 6.7501 & 5.2063 & TRN & \\
\hline CHEMBL1310251 & 688497 & 6.2 & 5.0647 & TRN & \\
\hline CHEMBL1523096 & 688497 & 4.6 & 4.9104 & TRN & \\
\hline CHEMBL1456825 & 688497 & 4.45 & 5.0574 & TRN & \\
\hline CHEMBL1468428 & 688497 & 4.95 & 4.8786 & TRN & \\
\hline CHEMBL1610155 & 688497 & 4.45 & 5.30399 & 9999999999 & TRN \\
\hline CHEMBL1329285 & 688497 & 5.5 & 5.184 & TRN & \\
\hline CHEMBL1549166 & 688497 & 4.5 & 4.8829 & TRN & \\
\hline CHEMBL3192127 & 688497 & 4.95 & 5.289 & TST & \\
\hline CHEMBL52018 & 688497 & 4.45 & 4.9984 & TRN & \\
\hline CHEMBL1564598 & 688497 & 4.85 & 5.0564 & TRN & \\
\hline CHEMBL1374649 & 688497 & 6.3 & 4.9944 & TST & \\
\hline CHEMBL1467728 & 688497 & 5.5 & 5.2525 & TST & \\
\hline CHEMBL1421261 & 688497 & 4.6 & 4.5596 & TRN & \\
\hline CHEMBL3195994 & 688497 & 5.25 & 4.8159 & TRN & \\
\hline CHEMBL1487081 & 688497 & 5.25 & 5.42700 & 00000000005 & TRN \\
\hline CHEMBL1577776 & 688497 & 4.9 & 4.7447 & TST & \\
\hline CHEMBL131037 & 688497 & 5.45 & 5.0587 & TST & \\
\hline CHEMBL162347 & 688497 & 4.45 & 5.1766 & TRN & \\
\hline CHEMBL1460158 & 688497 & 4.45 & 5.0197 & TRN & \\
\hline CHEMBL3195918 & 688497 & 4.65 & 4.9557 & TST & \\
\hline CHEMBL1402436 & 688497 & 4.85 & 4.914 & TRN & \\
\hline CHEMBL1346453 & 688497 & 4.7 & 5.2521 & TRN & \\
\hline CHEMBL1444074 & 688497 & 4.95 & 5.0586 & TRN & \\
\hline CHEMBL1541883 & 688497 & 4.65 & 4.8871 & TRN & \\
\hline CHEMBL1975051 & 688497 & 4.45 & 5.2119 & TRN & \\
\hline CHEMBL1587494 & 688497 & 6.25 & 5.3797 & TST & \\
\hline CHEMBL1568848 & 688497 & 5.2 & 4.9771 & TRN & \\
\hline CHEMBL1402725 & 688497 & 4.85 & 4.9912 & TRN & \\
\hline CHEMBL1537525 & 688497 & 4.45 & 5.2348 & TRN & \\
\hline CHEMBL1341296 & 688497 & 5.0 & 5.0221 & TRN & \\
\hline CHEMBL1415588 & 688497 & 5.0 & 4.8923 & TRN & \\
\hline
\end{tabular}




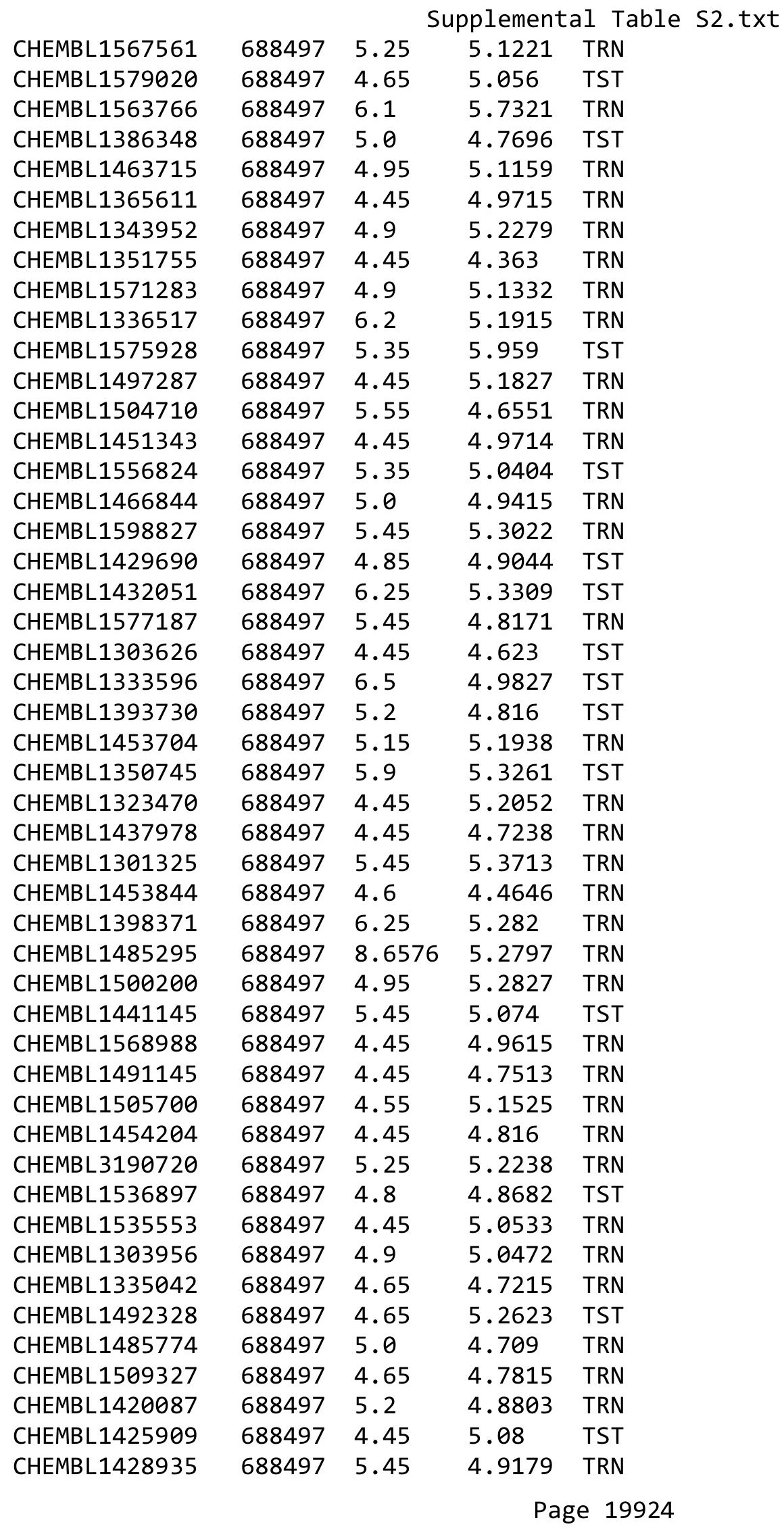




\begin{tabular}{|c|c|c|c|c|c|}
\hline \multicolumn{6}{|c|}{ Supplemental Table S2.txt } \\
\hline CHEMBL1445647 & 688497 & 4.45 & 5.0388 & TRN & \\
\hline CHEMBL1569126 & 688497 & 4.45 & 4.8807 & TRN & \\
\hline CHEMBL1308517 & 688497 & 5.0 & 5.3005 & TST & \\
\hline CHEMBL1343255 & 688497 & 5.6 & 5.13899 & 9999999999 & TRN \\
\hline CHEMBL1500431 & 688497 & 4.45 & 5.0234 & TRN & \\
\hline CHEMBL1556718 & 688497 & 4.95 & 5.0613 & TRN & \\
\hline CHEMBL1373547 & 688497 & 4.85 & 4.7634 & TRN & \\
\hline CHEMBL1452898 & 688497 & 4.65 & 4.8305 & TRN & \\
\hline CHEMBL1486369 & 688497 & 4.95 & 4.8069 & TRN & \\
\hline CHEMBL1417532 & 688497 & 5.5 & 4.9745 & TRN & \\
\hline CHEMBL1341208 & 688497 & 4.8 & 4.9432 & TST & \\
\hline CHEMBL1991157 & 688497 & 6.05 & 5.0769 & TRN & \\
\hline CHEMBL1311237 & 688497 & 6.0 & 5.483 & TST & \\
\hline CHEMBL1486506 & 688497 & 5.9 & 5.1629 & TRN & \\
\hline CHEMBL1350245 & 688497 & 6.0 & 5.2045 & TRN & \\
\hline CHEMBL1567849 & 688497 & 5.05 & 5.1031 & TRN & \\
\hline CHEMBL1341140 & 688497 & 5.05 & 5.1792 & TST & \\
\hline CHEMBL3196499 & 688497 & 5.55 & $5.2620 e$ & 00000000005 & TRN \\
\hline CHEMBL2000656 & 688497 & 5.0 & 5.0428 & TRN & \\
\hline CHEMBL1370753 & 688497 & 5.45 & 5.0622 & TRN & \\
\hline CHEMBL1441856 & 688497 & 5.0 & 4.8285 & TST & \\
\hline CHEMBL1505204 & 688497 & 4.95 & 5.1822 & TRN & \\
\hline CHEMBL1339431 & 688497 & 5.55 & 5.2435 & TRN & \\
\hline CHEMBL1330400 & 688497 & 4.45 & 5.2096 & TRN & \\
\hline CHEMBL1313174 & 688497 & 4.9 & 4.7726 & TRN & \\
\hline CHEMBL1446651 & 688497 & 4.5 & 5.0341 & TRN & \\
\hline CHEMBL1550812 & 688497 & 5.05 & 4.8546 & TRN & \\
\hline CHEMBL1459701 & 688497 & 4.7 & 5.004 & TRN & \\
\hline CHEMBL1602084 & 688497 & 4.45 & 4.5071 & TRN & \\
\hline CHEMBL1527752 & 688497 & 4.45 & 4.7091 & TRN & \\
\hline CHEMBL3199411 & 688497 & 5.15 & 5.29799 & 9999999999 & TRN \\
\hline CHEMBL1402026 & 688497 & 4.45 & $4.8580 e$ & 00000000005 & TST \\
\hline CHEMBL1438627 & 688497 & 4.9 & 5.0208 & TRN & \\
\hline CHEMBL3193486 & 688497 & 4.45 & 5.029 & TRN & \\
\hline CHEMBL603020 & 688497 & 4.85 & 4.8598 & TRN & \\
\hline CHEMBL1547641 & 688497 & 4.95 & 4.6805 & TRN & \\
\hline CHEMBL1496005 & 688497 & 4.95 & 4.9778 & TRN & \\
\hline CHEMBL1998184 & 688497 & 5.75 & 4.9268 & TRN & \\
\hline CHEMBL1386049 & 688497 & 5.3 & 5.2331 & TRN & \\
\hline CHEMBL1409287 & 688497 & 4.45 & 5.314 & TST & \\
\hline CHEMBL3213713 & 688497 & 4.95 & 4.9608 & TRN & \\
\hline CHEMBL1362724 & 688497 & 4.45 & 4.7945 & TRN & \\
\hline CHEMBL1508642 & 688497 & 6.2 & 5.1798 & TRN & \\
\hline CHEMBL1530139 & 688497 & 5.05 & 4.9272 & TRN & \\
\hline CHEMBL1381604 & 688497 & 5.75 & 4.8468 & TST & \\
\hline CHEMBL1564295 & 688497 & 6.2 & 4.9421 & TRN & \\
\hline CHEMBL1562718 & 688497 & 4.8 & 4.8971 & TRN & \\
\hline CHEMBL1583216 & 688497 & 5.2 & 5.2806 & TRN & \\
\hline
\end{tabular}




\begin{tabular}{|c|c|c|c|c|c|}
\hline CHEMBL1344661 & 688497 & 6.0 & \multicolumn{2}{|c|}{5.2010000000000005} & \multirow[t]{2}{*}{ TRN } \\
\hline CHEMBL1419634 & 688497 & 4.7 & 4.9676 & TRN & \\
\hline CHEMBL1428528 & 688497 & 5.55 & 5.0861 & TRN & \\
\hline CHEMBL584015 & 688497 & 4.75 & 4.9486 & TST & \\
\hline CHEMBL1382215 & 688497 & 5.25 & 4.9819 & TRN & \\
\hline CHEMBL1501601 & 688497 & 4.8 & 5.2713 & TST & \\
\hline CHEMBL1606572 & 688497 & 4.45 & 4.6826 & TRN & \\
\hline CHEMBL1487028 & 688497 & 4.95 & 5.3989 & TST & \\
\hline CHEMBL1442155 & 688497 & 6.05 & 5.2179 & TRN & \\
\hline CHEMBL1598726 & 688497 & 4.95 & 5.0408 & TRN & \\
\hline CHEMBL1421602 & 688497 & 4.9 & 5.0167 & TRN & \\
\hline CHEMBL1377200 & 688497 & 4.7 & 5.0811 & TRN & \\
\hline CHEMBL1380354 & 688497 & 5.8 & 5.0367 & TRN & \\
\hline CHEMBL 1351040 & 688497 & 7.0501 & 5.2593 & TRN & \\
\hline CHEMBL1433183 & 688497 & 4.85 & 4.9579 & TRN & \\
\hline CHEMBL1365333 & 688497 & 4.6 & 5.2136 & TRN & \\
\hline CHEMBL1505207 & 688497 & 4.95 & 4.8053 & TRN & \\
\hline CHEMBL1333018 & 688497 & 4.95 & 5.0459 & TRN & \\
\hline CHEMBL1547422 & 688497 & 4.45 & 5.2081 & TST & \\
\hline CHEMBL1303983 & 688497 & 4.45 & 4.7485 & TST & \\
\hline CHEMBL1349539 & 688497 & 4.45 & 4.8576 & TST & \\
\hline CHEMBL1442202 & 688497 & 4.95 & 4.9773 & TRN & \\
\hline CHEMBL1363474 & 688497 & 5.5 & 5.0922 & TRN & \\
\hline CHEMBL1584755 & 688497 & 4.5 & 4.9829 & TST & \\
\hline CHEMBL1322695 & 688497 & 4.8 & 4.7977 & TRN & \\
\hline CHEMBL1581179 & 688497 & 6.05 & 5.0587 & TST & \\
\hline CHEMBL1312476 & 688497 & 4.6 & 4.9658 & TRN & \\
\hline CHEMBL1540622 & 688497 & 4.8 & 4.9058 & TRN & \\
\hline CHEMBL1537049 & 688497 & 5.25 & 5.025 & TRN & \\
\hline CHEMBL1612090 & 688497 & 5.45 & 5.3523 & TRN & \\
\hline CHEMBL1545999 & 688497 & 4.95 & 4.6076 & TRN & \\
\hline CHEMBL1530057 & 688497 & 4.95 & 5.0811 & TRN & \\
\hline CHEMBL1995645 & 688497 & 4.85 & 5.2037 & TRN & \\
\hline CHEMBL1549793 & 688497 & 4.55 & 5.1108 & TRN & \\
\hline CHEMBL233896 & 688497 & 4.65 & 4.8736 & TST & \\
\hline CHEMBL1345220 & 688497 & 4.5 & 5.1206 & TST & \\
\hline CHEMBL1423463 & 688497 & 4.65 & 5.2289 & TRN & \\
\hline CHEMBL1602326 & 688497 & 4.95 & 5.13 & TRN & \\
\hline CHEMBL 3195546 & 688497 & 4.95 & 5.1576 & TRN & \\
\hline CHEMBL1999182 & 688497 & 4.7 & 5.1249 & TST & \\
\hline CHEMBL1602869 & 688497 & 6.25 & 5.5706 & TST & \\
\hline CHEMBL1544119 & 688497 & 5.25 & 4.95100 & 00000000005 & TRN \\
\hline CHEMBL1299810 & 688497 & 4.45 & 5.0282 & TRN & \\
\hline CHEMBL1301423 & 688497 & 5.25 & 5.2525 & TRN & \\
\hline CHEMBL1304181 & 688497 & 4.6 & 4.7946 & TRN & \\
\hline CHEMBL1370775 & 688497 & 5.3 & 4.9329 & TRN & \\
\hline CHEMBL1381989 & 688497 & 5.1 & 5.21899 & 9999999999 & TST \\
\hline CHEMBL1464060 & 688497 & 6.25 & 4.9247 & TST & \\
\hline & & & & 19926 & \\
\hline
\end{tabular}




\begin{tabular}{|c|c|c|c|c|}
\hline & & \multicolumn{3}{|c|}{ Supplemental Table S2.txt } \\
\hline CHEMBL1581250 & 688497 & 4.55 & 4.8178 & TRN \\
\hline CHEMBL1341879 & 688497 & 4.6 & 5.1482 & TRN \\
\hline CHEMBL1314100 & 688497 & 4.45 & 5.0246 & TRN \\
\hline CHEMBL1549128 & 688497 & 4.95 & 5.1938 & TST \\
\hline CHEMBL1492208 & 688497 & 5.05 & 5.0299 & TRN \\
\hline CHEMBL1575885 & 688497 & 4.95 & 5.3289 & TRN \\
\hline CHEMBL1414585 & 688497 & 5.2 & 5.4789 & TRN \\
\hline CHEMBL1339281 & 688497 & 6.25 & 5.2337 & TRN \\
\hline CHEMBL1491728 & 688497 & 4.8 & 4.8893 & TRN \\
\hline CHEMBL1541260 & 688497 & 4.45 & 4.6628 & TRN \\
\hline CHEMBL1499190 & 688497 & 4.95 & 4.7346 & TRN \\
\hline CHEMBL1385759 & 688497 & 4.75 & 4.894 & TRN \\
\hline CHEMBL1507595 & 688497 & 4.8 & 4.6882 & TRN \\
\hline CHEMBL1403847 & 688497 & 4.45 & 5.2049 & TRN \\
\hline CHEMBL1543777 & 688497 & 4.45 & 5.1713 & TRN \\
\hline CHEMBL1380983 & 688497 & 5.05 & 5.3905 & TRN \\
\hline CHEMBL1447716 & 688497 & 4.5 & 5.1372 & TRN \\
\hline CHEMBL1433272 & 688497 & 6.2 & 5.0698 & TST \\
\hline CHEMBL3193835 & 688497 & 4.95 & 5.1514 & TST \\
\hline CHEMBL1582030 & 688497 & 5.0 & 5.1876 & TST \\
\hline CHEMBL1522058 & 688497 & 4.95 & 4.8507 & TRN \\
\hline CHEMBL1567829 & 688497 & 4.45 & 4.6557 & TRN \\
\hline CHEMBL1469054 & 688497 & 4.95 & 5.226 & TRN \\
\hline CHEMBL1486451 & 688497 & 5.3 & 4.8604 & TRN \\
\hline CHEMBL3192162 & 688497 & 4.95 & 5.33799 & 9999999999 \\
\hline CHEMBL1469032 & 688497 & 5.6 & 5.0327 & TRN \\
\hline CHEMBL1362893 & 688497 & 5.6 & 5.2073 & TST \\
\hline CHEMBL1575487 & 688497 & 4.45 & 4.9566 & TRN \\
\hline CHEMBL1503466 & 688497 & 4.45 & 5.4174 & TRN \\
\hline CHEMBL1580434 & 688497 & 5.3 & 4.8909 & TST \\
\hline CHEMBL1363914 & 688497 & 4.55 & 4.8293 & TST \\
\hline CHEMBL1368484 & 688497 & 4.8 & 4.5412 & TRN \\
\hline CHEMBL3198477 & 688497 & 4.95 & 4.6328 & TRN \\
\hline CHEMBL1346225 & 688497 & 4.45 & 4.6734 & TRN \\
\hline CHEMBL1612728 & 688497 & 4.75 & 5.5705 & TRN \\
\hline CHEMBL1520601 & 688497 & 4.75 & 4.9314 & TRN \\
\hline CHEMBL1346609 & 688497 & 4.75 & 5.0335 & TST \\
\hline CHEMBL1505549 & 688497 & 4.45 & 4.9077 & TRN \\
\hline CHEMBL1508526 & 688497 & 4.8 & 5.09 & TRN \\
\hline CHEMBL1399035 & 688497 & 5.45 & 5.0867 & TRN \\
\hline CHEMBL1376164 & 688497 & 4.45 & 4.6424 & TRN \\
\hline CHEMBL1422602 & 688497 & 4.65 & 4.8557 & TRN \\
\hline CHEMBL1420549 & 688497 & 4.45 & 4.7378 & TRN \\
\hline CHEMBL1480005 & 688497 & 4.45 & 4.9162 & TRN \\
\hline CHEMBL1346683 & 688497 & 5.75 & 5.0578 & TST \\
\hline CHEMBL1521681 & 688497 & 5.95 & 5.2634 & TST \\
\hline CHEMBL3192862 & 688497 & 4.45 & 4.5066 & TRN \\
\hline CHEMBL1305537 & 688497 & 4.45 & 4.7515 & TRN \\
\hline
\end{tabular}

TRN 


\begin{tabular}{|c|c|c|c|c|c|}
\hline & & & & & \\
\hline CHEMBL1439647 & 688497 & 4.9 & 4.976 & TRN & \\
\hline CHEMBL1469745 & 688497 & 4.45 & 5.3479 & TRN & \\
\hline CHEMBL1446966 & 688497 & 5.0 & 5.2514 & TRN & \\
\hline CHEMBL1453299 & 688497 & 4.7 & 5.0153 & TRN & \\
\hline CHEMBL1401259 & 688497 & 5.35 & 5.035 & TRN & \\
\hline CHEMBL1550633 & 688497 & 5.0 & 5.0247 & TRN & \\
\hline CHEMBL1407260 & 688497 & 4.45 & 4.8595 & TST & \\
\hline CHEMBL1450986 & 688497 & 5.5 & 5.0983 & TRN & \\
\hline CHEMBL1462041 & 688497 & 4.65 & 4.8719 & TRN & \\
\hline CHEMBL1525318 & 688497 & 4.6 & 4.9661 & TST & \\
\hline CHEMBL1363016 & 688497 & 5.85 & 4.8747 & TRN & \\
\hline CHEMBL1345564 & 688497 & 5.55 & 4.8903 & TRN & \\
\hline CHEMBL1352586 & 688497 & 4.5 & 4.8167 & TRN & \\
\hline CHEMBL3199324 & 688497 & 5.1 & 5.1018 & TRN & \\
\hline CHEMBL1577993 & 688497 & 4.8 & 4.9749 & TRN & \\
\hline CHEMBL1370314 & 688497 & 4.45 & 4.9104 & TRN & \\
\hline CHEMBL1079374 & 688497 & 4.95 & 4.8236 & TRN & \\
\hline CHEMBL3198885 & 688497 & 5.45 & 5.0732 & TST & \\
\hline CHEMBL1359838 & 688497 & 6.1 & 5.0680 & 00000000005 & TRN \\
\hline CHEMBL1378265 & 688497 & 5.9 & 4.9868 & TRN & \\
\hline CHEMBL1337038 & 688497 & 4.45 & 4.8779 & TST & \\
\hline CHEMBL1391824 & 688497 & 4.5 & 4.9121 & TRN & \\
\hline CHEMBL1606495 & 688497 & 4.8 & 5.0573 & TRN & \\
\hline CHEMBL1524400 & 688497 & 5.45 & 4.8516 & TRN & \\
\hline CHEMBL1414188 & 688497 & 4.6 & 4.4892 & TRN & \\
\hline CHEMBL592712 & 688497 & 4.6 & 4.8610 & 0000000001 & TRN \\
\hline CHEMBL1542051 & 688497 & 4.45 & 5.0116 & TRN & \\
\hline CHEMBL1347339 & 688497 & 4.85 & 4.8501 & TST & \\
\hline CHEMBL1585922 & 688497 & 4.95 & 5.2322 & TRN & \\
\hline CHEMBL3198526 & 688497 & 4.95 & 5.2733 & TRN & \\
\hline CHEMBL1448627 & 688497 & 5.25 & 5.2861 & TST & \\
\hline CHEMBL1577056 & 688497 & 4.6 & 4.9616 & TRN & \\
\hline CHEMBL1311812 & 688497 & 4.65 & 4.4942 & TRN & \\
\hline CHEMBL1505283 & 688497 & 4.85 & 5.0471 & TRN & \\
\hline CHEMBL1371912 & 688497 & 4.9 & 5.2839 & TST & \\
\hline CHEMBL1330515 & 688497 & 4.45 & 5.3007 & TST & \\
\hline CHEMBL1486253 & 688497 & 4.95 & 5.0993 & TST & \\
\hline CHEMBL1560904 & 688497 & 4.6 & 4.8534 & TRN & \\
\hline CHEMBL1349278 & 688497 & 4.9 & 4.9451 & TRN & \\
\hline CHEMBL3198332 & 688497 & 6.1 & 5.4421 & TRN & \\
\hline CHEMBL1540651 & 688497 & 5.25 & 4.9262 & TRN & \\
\hline CHEMBL 1445742 & 688497 & 4.6 & 4.7334 & TRN & \\
\hline CHEMBL1388127 & 688497 & 4.55 & 5.3616 & TRN & \\
\hline CHEMBL1993190 & 688497 & 5.25 & 5.4786 & TRN & \\
\hline CHEMBL1983104 & 688497 & 4.45 & 4.6097 & TRN & \\
\hline CHEMBL1366285 & 688497 & 6.25 & 5.1324 & TRN & \\
\hline CHEMBL 3198532 & 688497 & 4.75 & 4.8976 & TRN & \\
\hline CHEMBL1468099 & 688497 & 4.45 & 5.0511 & TST & \\
\hline
\end{tabular}




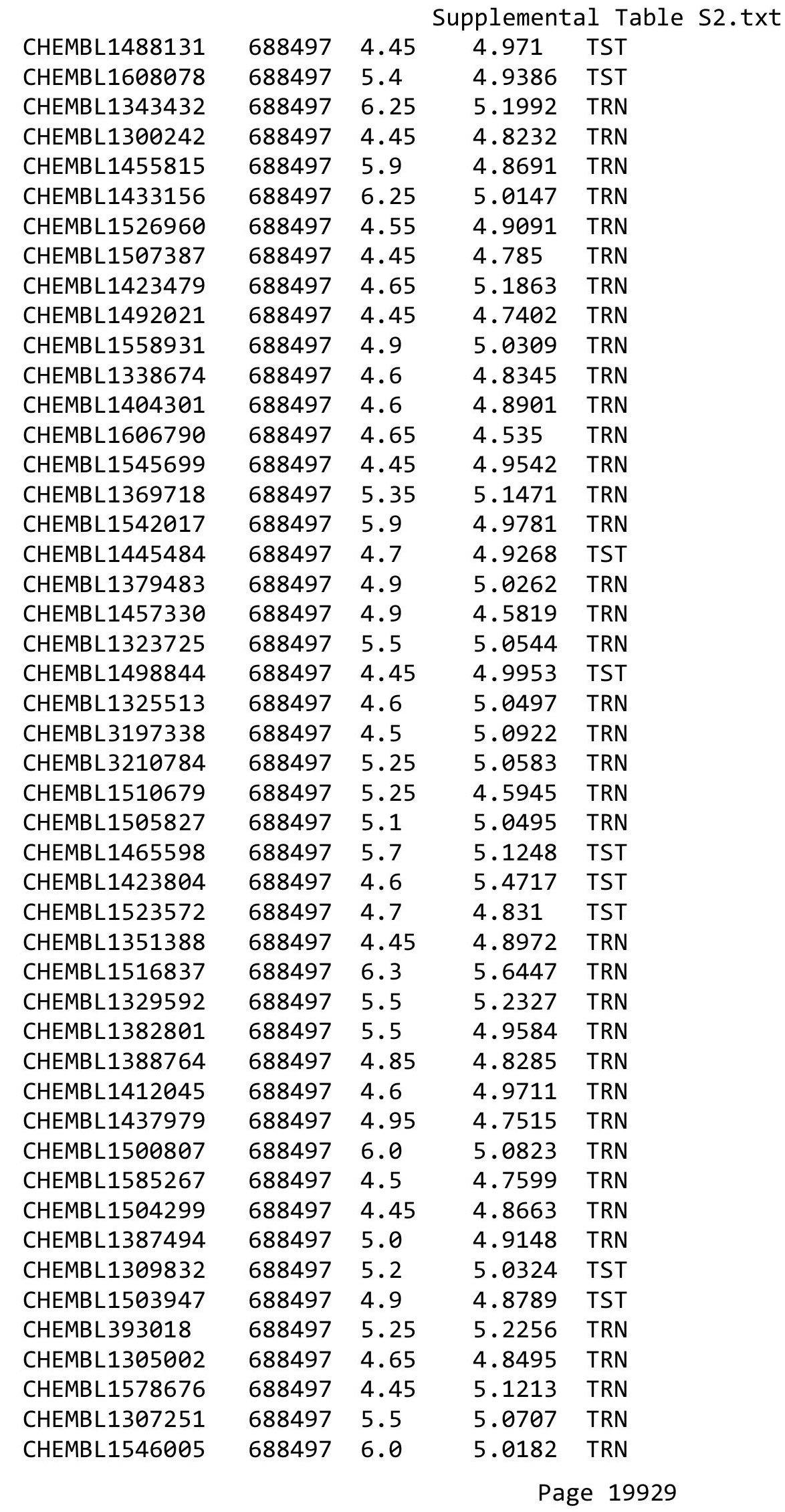




\begin{tabular}{|c|c|c|c|c|}
\hline & & & pplement & al Table S \\
\hline CHEMBL1404230 & 688497 & 5.0 & 5.1198 & TRN \\
\hline CHEMBL1327168 & 688497 & 4.9 & 5.12200 & 0000000001 \\
\hline CHEMBL1998229 & 688497 & 5.65 & 5.1038 & TRN \\
\hline CHEMBL1577466 & 688497 & 6.25 & 5.2943 & TRN \\
\hline CHEMBL1382985 & 688497 & 4.5 & 4.9911 & TRN \\
\hline CHEMBL1392258 & 688497 & 4.95 & 5.0654 & TRN \\
\hline CHEMBL1300780 & 688497 & 5.5 & 4.9322 & TRN \\
\hline CHEMBL1327034 & 688497 & 4.65 & 4.957 & TRN \\
\hline CHEMBL1300063 & 688497 & 4.85 & 5.0783 & TRN \\
\hline CHEMBL1378495 & 688497 & 5.05 & 5.1221 & TRN \\
\hline CHEMBL1523483 & 688497 & 4.9 & 4.9551 & TRN \\
\hline CHEMBL1350974 & 688497 & 4.9 & 4.9269 & TRN \\
\hline CHEMBL1362247 & 688497 & 5.0 & 4.704 & TRN \\
\hline CHEMBL1416497 & 688497 & 4.55 & 4.6461 & TRN \\
\hline CHEMBL1559622 & 688497 & 4.45 & 4.7694 & TRN \\
\hline CHEMBL1340799 & 688497 & 4.9 & 5.1217 & TRN \\
\hline CHEMBL1570774 & 688497 & 4.55 & 4.8727 & TST \\
\hline CHEMBL3208560 & 688497 & 5.85 & 4.7122 & TRN \\
\hline CHEMBL1538479 & 688497 & 5.05 & 5.1098 & TST \\
\hline CHEMBL1305562 & 688497 & 5.15 & 5.0282 & TRN \\
\hline CHEMBL1423690 & 688497 & 4.65 & 5.0808 & TRN \\
\hline CHEMBL1469446 & 688497 & 4.7 & 4.6966 & TST \\
\hline CHEMBL1326937 & 688497 & 4.85 & 4.7518 & TRN \\
\hline CHEMBL1543855 & 688497 & 6.95 & 4.9678 & TST \\
\hline CHEMBL1353885 & 688497 & 4.9 & 5.0715 & TRN \\
\hline CHEMBL1526212 & 688497 & 5.4 & 5.0449 & TRN \\
\hline CHEMBL1364723 & 688497 & 4.6 & 5.0039 & TST \\
\hline CHEMBL1569175 & 688497 & 6.3 & 5.3215 & TST \\
\hline CHEMBL1412074 & 688497 & 5.2 & 4.9615 & TRN \\
\hline CHEMBL1320446 & 688497 & 4.95 & 4.8913 & TRN \\
\hline CHEMBL1502945 & 688497 & 4.9 & 4.9817 & TRN \\
\hline CHEMBL1986073 & 688497 & 4.45 & 4.7817 & TST \\
\hline CHEMBL1416062 & 688497 & 6.25 & 5.2569 & TRN \\
\hline CHEMBL1299582 & 688497 & 4.9 & 5.0792 & TRN \\
\hline CHEMBL1578363 & 688497 & 4.85 & 4.9164 & TST \\
\hline CHEMBL1431928 & 688497 & 5.0 & 5.3981 & TRN \\
\hline CHEMBL1572901 & 688497 & 4.7 & 4.9698 & TRN \\
\hline CHEMBL1331844 & 688497 & 4.5 & 5.2022 & TST \\
\hline CHEMBL1413053 & 688497 & 5.1 & 5.0973 & TST \\
\hline CHEMBL1578239 & 688497 & 5.9 & 5.2963 & TRN \\
\hline CHEMBL1577123 & 688497 & 4.65 & 5.1479 & TRN \\
\hline CHEMBL1308307 & 688497 & 4.5 & 5.04 & TRN \\
\hline CHEMBL1428961 & 688497 & 4.45 & 4.7822 & TRN \\
\hline CHEMBL1413121 & 688497 & 4.8 & 5.0691 & TRN \\
\hline CHEMBL1445327 & 688497 & 4.65 & 5.0212 & TRN \\
\hline CHEMBL1439089 & 688497 & 5.55 & 5.3678 & TRN \\
\hline CHEMBL107639 & 688497 & 5.05 & 5.1246 & TRN \\
\hline CHEMBL3192463 & 688497 & 4.9 & 5.1654 & TRN \\
\hline
\end{tabular}

TRN 


\begin{tabular}{|c|c|c|c|c|}
\hline \multicolumn{5}{|c|}{ Supplemental Table S2.txt } \\
\hline CHEMBL1460755 & 688497 & 4.45 & 5.1473 & TRN \\
\hline CHEMBL1365219 & 688497 & 5.35 & 5.29799 & 9999999999 \\
\hline CHEMBL1472464 & 688497 & 4.45 & 4.808 & TRN \\
\hline CHEMBL1324121 & 688497 & 4.45 & 4.8692 & TRN \\
\hline CHEMBL1337247 & 688497 & 5.25 & 5.1714 & TRN \\
\hline CHEMBL1426948 & 688497 & 4.45 & 5.0638 & TST \\
\hline CHEMBL1550792 & 688497 & 5.05 & 4.9019 & TRN \\
\hline CHEMBL1324993 & 688497 & 5.8 & 5.3061 & TST \\
\hline CHEMBL1452944 & 688497 & 4.45 & 4.9786 & TRN \\
\hline CHEMBL1399093 & 688497 & 4.45 & 4.9931 & TRN \\
\hline CHEMBL1562591 & 688497 & 6.0 & 5.2279 & TST \\
\hline CHEMBL1307964 & 688497 & 5.55 & 4.9196 & TST \\
\hline CHEMBL1541490 & 688497 & 4.95 & 4.8066 & TST \\
\hline CHEMBL1558925 & 688497 & 6.3 & 4.8679 & TRN \\
\hline CHEMBL3192188 & 688497 & 5.0 & 5.002 & TST \\
\hline CHEMBL1465554 & 688497 & 4.45 & 4.8685 & TRN \\
\hline CHEMBL1495233 & 688497 & 6.25 & 5.3406 & TRN \\
\hline CHEMBL1469700 & 688497 & 5.45 & 5.1109 & TRN \\
\hline CHEMBL1336727 & 688497 & 4.45 & 5.1908 & TST \\
\hline CHEMBL1605785 & 688497 & 6.25 & 5.9862 & TRN \\
\hline CHEMBL3197610 & 688497 & 7.0501 & 5.2558 & TRN \\
\hline CHEMBL1562333 & 688497 & 4.6 & 4.9365 & TRN \\
\hline CHEMBL1443398 & 688497 & 6.25 & 5.546 & TST \\
\hline CHEMBL1423034 & 688497 & 4.9 & 5.0079 & TRN \\
\hline CHEMBL1506414 & 688497 & 4.5 & 5.1214 & TRN \\
\hline CHEMBL1320881 & 688497 & 5.5 & 5.0602 & TST \\
\hline CHEMBL1523568 & 688497 & 4.45 & 4.7106 & TRN \\
\hline CHEMBL1493439 & 688497 & 5.0 & 4.7235 & TRN \\
\hline CHEMBL1365968 & 688497 & 6.3 & 5.0519 & TST \\
\hline CHEMBL1579256 & 688497 & 4.85 & 4.6597 & TST \\
\hline CHEMBL1496972 & 688497 & 4.75 & 4.9132 & TRN \\
\hline CHEMBL1789998 & 688497 & 4.55 & 5.4179 & TRN \\
\hline CHEMBL1471186 & 688497 & 6.0 & 5.3399 & TST \\
\hline CHEMBL1372880 & 688497 & 4.95 & 5.1705 & TRN \\
\hline CHEMBL1301877 & 688497 & 5.9 & 5.0322 & TRN \\
\hline CHEMBL1306816 & 688497 & 4.45 & 4.6968 & TST \\
\hline CHEMBL1359384 & 688497 & 4.45 & 4.6436 & TRN \\
\hline CHEMBL40439 & 688497 & 6.15 & 5.0851 & TRN \\
\hline CHEMBL3208212 & 688497 & 4.45 & 4.9123 & TRN \\
\hline CHEMBL1471846 & 688497 & 4.45 & 4.9705 & TRN \\
\hline CHEMBL1544063 & 688497 & 4.6 & 4.8103 & TST \\
\hline CHEMBL1361883 & 688497 & 5.25 & 5.0217 & TRN \\
\hline CHEMBL1308492 & 688497 & 5.15 & 4.8232 & TRN \\
\hline CHEMBL1607958 & 688497 & 5.6 & 4.9648 & TST \\
\hline CHEMBL1445282 & 688497 & 4.5 & 4.9259 & TRN \\
\hline CHEMBL1351629 & 688497 & 5.25 & 5.3873 & TST \\
\hline CHEMBL3198511 & 688497 & 4.45 & 5.0112 & TRN \\
\hline CHEMBL1574263 & 688497 & 4.9 & 4.9084 & TRN \\
\hline
\end{tabular}

TRN 


\begin{tabular}{|c|c|c|c|c|}
\hline & & & pplement & al $\mathrm{Ta}$ \\
\hline CHEMBL1304078 & 688497 & 5.3 & 4.9792 & TST \\
\hline CHEMBL3199605 & 688497 & 4.95 & 4.9886 & TRN \\
\hline CHEMBL1338882 & 688497 & 4.8 & 4.8345 & TST \\
\hline CHEMBL1531987 & 688497 & 4.75 & 4.9162 & TST \\
\hline CHEMBL1584799 & 688497 & 4.45 & 5.1136 & TST \\
\hline CHEMBL1481887 & 688497 & 4.9 & 5.0846 & TRN \\
\hline CHEMBL1510202 & 688497 & 6.15 & 5.2205 & TST \\
\hline CHEMBL1534193 & 688497 & 4.9 & 5.1228 & TRN \\
\hline CHEMBL1586359 & 688497 & 4.45 & 5.0394 & TST \\
\hline CHEMBL1409291 & 688497 & 4.8 & 5.0035 & TRN \\
\hline CHEMBL1386052 & 688497 & 6.25 & 5.2744 & TRN \\
\hline CHEMBL533602 & 688497 & 6.05 & 5.1158 & TRN \\
\hline CHEMBL1445241 & 688497 & 4.45 & 5.2059 & TRN \\
\hline CHEMBL1388000 & 688497 & 5.4 & 4.752 & TRN \\
\hline CHEMBL1550570 & 688497 & 4.9 & 5.29 & TRN \\
\hline CHEMBL1496004 & 688497 & 5.05 & 5.0244 & TRN \\
\hline CHEMBL1510888 & 688497 & 4.6 & 5.0467 & TST \\
\hline CHEMBL1336997 & 688497 & 5.25 & 4.8611 & TST \\
\hline CHEMBL1364464 & 688497 & 4.45 & 5.1528 & TRN \\
\hline CHEMBL1594440 & 688497 & 5.35 & 5.0287 & TRN \\
\hline CHEMBL1558065 & 688497 & 5.0 & 5.2798 & TRN \\
\hline CHEMBL1362999 & 688497 & 5.0 & 5.0657 & TST \\
\hline CHEMBL1609908 & 688497 & 5.65 & 4.8272 & TRN \\
\hline CHEMBL1504833 & 688497 & 4.6 & 4.8653 & TRN \\
\hline CHEMBL1348435 & 688497 & 6.2 & 5.3458 & TRN \\
\hline CHEMBL584759 & 688497 & 5.6 & 5.6588 & TRN \\
\hline CHEMBL1532840 & 688497 & 4.45 & 5.1647 & TRN \\
\hline CHEMBL1569596 & 688497 & 4.45 & 5.0136 & TRN \\
\hline CHEMBL1492246 & 688497 & 4.45 & 4.7828 & TRN \\
\hline CHEMBL3190603 & 688497 & 4.9 & 5.1297 & TRN \\
\hline CHEMBL3196592 & 688497 & 4.6 & 5.0516 & TRN \\
\hline CHEMBL1501904 & 688497 & 4.65 & 4.9142 & TRN \\
\hline CHEMBL1599089 & 688497 & 4.65 & 4.8641 & TRN \\
\hline CHEMBL1348195 & 688497 & 5.25 & 5.1396 & TST \\
\hline CHEMBL1539891 & 688497 & 4.7 & 5.1718 & TST \\
\hline CHEMBL1540319 & 688497 & 4.45 & 5.0286 & TRN \\
\hline CHEMBL1464174 & 688497 & 4.65 & 5.0413 & TST \\
\hline CHEMBL533388 & 688497 & 4.7 & 4.7927 & TST \\
\hline CHEMBL1499376 & 688497 & 4.45 & 5.2119 & TST \\
\hline CHEMBL1966952 & 688497 & 4.9 & 4.9044 & TRN \\
\hline CHEMBL1353259 & 688497 & 4.25 & 4.956 & TRN \\
\hline CHEMBL1578922 & 688497 & 4.45 & 4.902 & TST \\
\hline CHEMBL1346399 & 688497 & 4.45 & 5.572 & TRN \\
\hline CHEMBL1540434 & 688497 & 6.1 & 4.9039 & TST \\
\hline CHEMBL1484818 & 688497 & 5.0 & 4.8474 & TST \\
\hline CHEMBL1322589 & 688497 & 4.95 & 4.8854 & TST \\
\hline CHEMBL1501121 & 688497 & 4.45 & 5.0958 & TST \\
\hline CHEMBL1583364 & 688497 & 4.45 & 4.9611 & TRN \\
\hline
\end{tabular}




\begin{tabular}{|c|c|c|c|c|c|}
\hline & & \multicolumn{4}{|c|}{ Supplemental Table S2.txt } \\
\hline CHEMBL1392164 & 688497 & 4.65 & 4.7897 & TRN & \\
\hline CHEMBL1596681 & 688497 & 5.9 & 5.5558 & TRN & \\
\hline CHEMBL3209251 & 688497 & 5.25 & 4.8683 & TRN & \\
\hline CHEMBL1371882 & 688497 & 4.95 & 4.8308 & TST & \\
\hline CHEMBL1484623 & 688497 & 5.5 & 5.2394 & TRN & \\
\hline CHEMBL1300100 & 688497 & 6.1 & 5.1172 & TST & \\
\hline CHEMBL1565773 & 688497 & 5.25 & 4.8085 & TRN & \\
\hline CHEMBL1484636 & 688497 & 6.05 & 4.8354 & TRN & \\
\hline CHEMBL1310734 & 688497 & 5.9 & 5.2031 & TST & \\
\hline CHEMBL1324298 & 688497 & 5.25 & 5.1335 & TRN & \\
\hline CHEMBL 3191962 & 688497 & 5.45 & 5.4415 & TRN & \\
\hline CHEMBL3199166 & 688497 & 4.45 & 5.0571 & TRN & \\
\hline CHEMBL1594299 & 688497 & 4.95 & 4.8511 & TRN & \\
\hline CHEMBL1571840 & 688497 & 4.45 & 5.1497 & TRN & \\
\hline CHEMBL3196754 & 688497 & 5.05 & 5.0217 & TRN & \\
\hline CHEMBL1608149 & 688497 & 5.5 & 4.8868 & TRN & \\
\hline CHEMBL1340593 & 688497 & 4.45 & 4.7346 & TRN & \\
\hline CHEMBL1398777 & 688497 & 6.25 & 5.2562 & TRN & \\
\hline CHEMBL1322090 & 688497 & 4.95 & 4.7994 & TST & \\
\hline CHEMBL1350782 & 688497 & 5.25 & 5.1601 & TRN & \\
\hline CHEMBL1430138 & 688497 & 4.65 & 4.9028 & TRN & \\
\hline CHEMBL1350744 & 688497 & 5.1 & 4.9402 & TST & \\
\hline CHEMBL1496421 & 688497 & 6.3 & 5.3422 & TRN & \\
\hline CHEMBL1332931 & 688497 & 4.65 & 5.0103 & TRN & \\
\hline CHEMBL1506076 & 688497 & 5.0 & 5.2837 & TRN & \\
\hline CHEMBL1525213 & 688497 & 4.7 & 4.87 & TST & \\
\hline CHEMBL1381433 & 688497 & 6.25 & 4.64199 & 99999999995 & TRN \\
\hline CHEMBL1562181 & 688497 & 5.5 & 5.0022 & TRN & \\
\hline CHEMBL1320148 & 688497 & 4.85 & 4.9552 & TRN & \\
\hline CHEMBL1469415 & 688497 & 5.6 & 5.3075 & TRN & \\
\hline CHEMBL1389657 & 688497 & 4.7 & 5.1569 & TRN & \\
\hline CHEMBL1464192 & 688497 & 4.65 & 5.0621 & TRN & \\
\hline CHEMBL1550962 & 688497 & 4.8 & 5.0149 & TRN & \\
\hline CHEMBL3191242 & 688497 & 5.2 & 5.3169 & TRN & \\
\hline CHEMBL1548769 & 688497 & 4.45 & 4.7051 & TRN & \\
\hline CHEMBL1494135 & 688497 & 5.9 & 4.9463 & TRN & \\
\hline CHEMBL1478216 & 688497 & 5.5 & 4.9905 & TRN & \\
\hline CHEMBL3196550 & 688497 & 4.65 & 5.0777 & TRN & \\
\hline CHEMBL1505342 & 688497 & 4.45 & 4.89199 & 99999999995 & TRN \\
\hline CHEMBL1547627 & 688497 & 5.2 & 5.0294 & TRN & \\
\hline CHEMBL1535700 & 688497 & 4.6 & 5.0314 & TRN & \\
\hline CHEMBL1595785 & 688497 & 5.9 & 5.0086 & TST & \\
\hline CHEMBL1504768 & 688497 & 4.95 & 5.3652 & TRN & \\
\hline CHEMBL1516865 & 688497 & 4.5 & 4.7231 & TRN & \\
\hline CHEMBL1384784 & 688497 & 5.25 & 4.8768 & TRN & \\
\hline CHEMBL346323 & 688497 & 4.55 & 5.0638 & TRN & \\
\hline CHEMBL1439992 & 688497 & 4.75 & 5.0562 & TRN & \\
\hline CHEMBL1530630 & 688497 & 4.45 & 4.8641 & TRN & \\
\hline
\end{tabular}




\begin{tabular}{|c|c|c|c|c|}
\hline & & & pplement & al $\mathrm{Ta}$ \\
\hline CHEMBL1541009 & 688497 & 4.5 & 4.7808 & TRN \\
\hline CHEMBL1308607 & 688497 & 4.85 & 5.0448 & TRN \\
\hline CHEMBL3194845 & 688497 & 6.05 & 4.8788 & TRN \\
\hline CHEMBL1574898 & 688497 & 4.95 & 5.1304 & TRN \\
\hline CHEMBL1517623 & 688497 & 5.95 & 4.7762 & TRN \\
\hline CHEMBL1386418 & 688497 & 4.65 & 4.6744 & TRN \\
\hline CHEMBL1307406 & 688497 & 4.75 & 4.9597 & TRN \\
\hline CHEMBL1386412 & 688497 & 4.5 & 5.2106 & TRN \\
\hline CHEMBL1524440 & 688497 & 5.25 & 5.1486 & TRN \\
\hline CHEMBL1508674 & 688497 & 4.45 & 4.6708 & TRN \\
\hline CHEMBL1430686 & 688497 & 4.45 & 4.9249 & TRN \\
\hline CHEMBL1453432 & 688497 & 4.45 & 5.0949 & TST \\
\hline CHEMBL1589688 & 688497 & 5.7 & 5.038 & TRN \\
\hline CHEMBL1541530 & 688497 & 4.45 & 4.7058 & TRN \\
\hline CHEMBL3196381 & 688497 & 4.75 & 5.1083 & TRN \\
\hline CHEMBL1410027 & 688497 & 5.5 & 5.0984 & TRN \\
\hline CHEMBL1389318 & 688497 & 4.8 & 5.2512 & TST \\
\hline CHEMBL1491990 & 688497 & 4.95 & 5.0092 & TST \\
\hline CHEMBL1509617 & 688497 & 5.15 & 4.9288 & TST \\
\hline CHEMBL1525906 & 688497 & 5.9 & 5.4356 & TRN \\
\hline CHEMBL3199145 & 688497 & 5.1 & 5.0211 & TRN \\
\hline CHEMBL1524076 & 688497 & 4.45 & 4.8601 & TRN \\
\hline CHEMBL1543776 & 688497 & 4.9 & 5.001 & TRN \\
\hline CHEMBL1605133 & 688497 & 4.45 & 5.1003 & TRN \\
\hline CHEMBL1531039 & 688497 & 4.45 & 4.9258 & TRN \\
\hline CHEMBL1362917 & 688497 & 6.5 & 5.3411 & TST \\
\hline CHEMBL1378292 & 688497 & 4.45 & 4.8299 & TRN \\
\hline CHEMBL1340937 & 688497 & 4.8 & 5.3833 & TRN \\
\hline CHEMBL1502658 & 688497 & 5.25 & 5.1919 & TRN \\
\hline CHEMBL3190423 & 688497 & 5.1 & 5.1575 & TST \\
\hline CHEMBL1448277 & 688497 & 4.8 & 4.8346 & TRN \\
\hline CHEMBL1612250 & 688497 & 4.95 & 4.9655 & TRN \\
\hline CHEMBL1360597 & 688497 & 5.75 & 4.9691 & TRN \\
\hline CHEMBL1312849 & 688497 & 4.45 & 5.0973 & TRN \\
\hline CHEMBL1485976 & 688497 & 5.55 & 4.8274 & TRN \\
\hline CHEMBL1497527 & 688497 & 4.9 & 5.1414 & TRN \\
\hline CHEMBL1324894 & 688497 & 5.05 & 4.8909 & TRN \\
\hline CHEMBL1501184 & 688497 & 4.45 & 4.9219 & TRN \\
\hline CHEMBL1600763 & 688497 & 4.65 & 4.8396 & TRN \\
\hline CHEMBL1502200 & 688497 & 4.8 & 5.0025 & TST \\
\hline CHEMBL1360354 & 688497 & 6.8 & 5.0847 & TRN \\
\hline CHEMBL1464519 & 688497 & 5.25 & 5.0306 & TRN \\
\hline CHEMBL1430931 & 688497 & 4.45 & 4.7746 & TRN \\
\hline CHEMBL1313252 & 688497 & 4.45 & 4.7528 & TRN \\
\hline CHEMBL1980684 & 688497 & 4.9 & 5.3927 & TRN \\
\hline CHEMBL1454728 & 688497 & 4.45 & 4.9507 & TRN \\
\hline CHEMBL1373385 & 688497 & 4.7 & 4.8247 & TRN \\
\hline CHEMBL1430124 & 688497 & 5.6 & 4.5689 & TRN \\
\hline
\end{tabular}




\begin{tabular}{|c|c|c|c|c|}
\hline \multicolumn{5}{|c|}{ Supplemental Table S2.txt } \\
\hline CHEMBL1311651 & 688497 & 5.4 & 5.2961 & TRN \\
\hline CHEMBL1547901 & 688497 & 4.95 & 4.6127 & TRN \\
\hline CHEMBL3196751 & 688497 & 4.45 & 5.3047 & TRN \\
\hline CHEMBL1524299 & 688497 & 4.45 & 5.1582 & TRN \\
\hline CHEMBL1442504 & 688497 & 4.95 & 5.1002 & TRN \\
\hline CHEMBL1464166 & 688497 & 4.45 & 5.1916 & TST \\
\hline CHEMBL1348052 & 688497 & 4.45 & 4.909 & TRN \\
\hline CHEMBL1347771 & 688497 & 4.45 & 5.0012 & TRN \\
\hline CHEMBL1361939 & 688497 & 5.8 & 4.9505 & TRN \\
\hline CHEMBL1379729 & 688497 & 4.45 & 5.1605 & TRN \\
\hline CHEMBL1388239 & 688497 & 4.45 & 5.0483 & TST \\
\hline CHEMBL1456075 & 688497 & 4.55 & 4.982 & TRN \\
\hline CHEMBL1571026 & 688497 & 6.25 & 5.2537 & TRN \\
\hline CHEMBL1343613 & 688497 & 4.45 & 5.1846 & TRN \\
\hline CHEMBL1408439 & 688497 & 5.2 & 5.0731 & TST \\
\hline CHEMBL3196495 & 688497 & 4.5 & 4.7879 & TRN \\
\hline CHEMBL1422916 & 688497 & 4.45 & 5.0355 & TST \\
\hline CHEMBL1505757 & 688497 & 5.45 & 5.233 & TRN \\
\hline CHEMBL1329738 & 688497 & 5.9 & 5.0389 & TRN \\
\hline CHEMBL1448094 & 688497 & 4.45 & 4.8822 & TRN \\
\hline CHEMBL1493085 & 688497 & 4.8 & 5.12 & TST \\
\hline CHEMBL1386350 & 688497 & 5.0 & 5.0844 & TRN \\
\hline CHEMBL1557683 & 688497 & 5.5 & 4.96 & TRN \\
\hline CHEMBL1372035 & 688497 & 4.45 & 4.9457 & TRN \\
\hline CHEMBL1337826 & 688497 & 6.05 & 5.1328 & TST \\
\hline CHEMBL1364834 & 688497 & 5.2 & 5.1557 & TRN \\
\hline CHEMBL1402783 & 688497 & 5.05 & 5.2036 & TST \\
\hline CHEMBL1605852 & 688497 & 4.85 & 5.3465 & TRN \\
\hline CHEMBL1388691 & 688497 & 4.7 & 4.553 & TRN \\
\hline CHEMBL1511150 & 688497 & 4.45 & 4.8605 & TRN \\
\hline CHEMBL1384313 & 688497 & 4.6 & 5.2867 & TST \\
\hline CHEMBL2003869 & 688497 & 5.0 & 5.2629 & TRN \\
\hline CHEMBL1463272 & 688497 & 5.5 & 5.0534 & TRN \\
\hline CHEMBL1325451 & 688497 & 4.45 & 4.6007 & TST \\
\hline CHEMBL1372064 & 688497 & 4.6 & 4.9161 & TRN \\
\hline CHEMBL1352394 & 688497 & 4.45 & 5.6594 & TRN \\
\hline CHEMBL 1488056 & 688497 & 4.95 & 4.9022 & TRN \\
\hline CHEMBL1564537 & 688497 & 4.45 & 4.9906 & TRN \\
\hline CHEMBL1359087 & 688497 & 4.45 & 5.1 & TRN \\
\hline CHEMBL1379560 & 688497 & 5.45 & 5.3718 & TST \\
\hline CHEMBL3211514 & 688497 & 5.9 & 5.1312 & TST \\
\hline CHEMBL1578228 & 688497 & 4.6 & 5.3543 & TST \\
\hline CHEMBL1460966 & 688497 & 6.2 & 5.4618 & TRN \\
\hline CHEMBL1460029 & 688497 & 5.45 & 5.1511 & TRN \\
\hline CHEMBL1482041 & 688497 & 4.45 & 4.905 & TRN \\
\hline CHEMBL1370422 & 688497 & 4.7 & 5.2145 & TRN \\
\hline CHEMBL1330896 & 688497 & 4.45 & 4.9117 & TST \\
\hline CHEMBL1600913 & 688497 & 5.0 & 5.0247 & TRN \\
\hline
\end{tabular}




\begin{tabular}{|c|c|c|c|c|}
\hline & & & & \\
\hline CHEMBL1351680 & 688497 & 4.9 & 5.1618 & TRN \\
\hline CHEMBL1981614 & 688497 & 5.45 & 5.2715 & TST \\
\hline CHEMBL1351353 & 688497 & 5.0 & 4.859 & TST \\
\hline CHEMBL 3195351 & 688497 & 4.45 & 4.9771 & TRN \\
\hline CHEMBL1440436 & 688497 & 4.55 & 5.1033 & TRN \\
\hline CHEMBL1533131 & 688497 & 5.05 & 4.9969 & TRN \\
\hline CHEMBL1574921 & 688497 & 4.65 & 5.0014 & TRN \\
\hline CHEMBL586061 & 688497 & 4.5 & 4.7955 & TRN \\
\hline CHEMBL1562040 & 688497 & 4.9 & 4.5575 & TRN \\
\hline CHEMBL1565498 & 688497 & 4.75 & 4.7281 & TRN \\
\hline CHEMBL1541593 & 688497 & 4.45 & 4.8858 & TRN \\
\hline CHEMBL1350379 & 688497 & 4.9 & 4.9733 & TRN \\
\hline CHEMBL1413718 & 688497 & 5.5 & 5.2258 & TRN \\
\hline CHEMBL1605698 & 688497 & 4.45 & 4.7071 & TRN \\
\hline CHEMBL1522033 & 688497 & 4.45 & 4.921 & TRN \\
\hline CHEMBL1607497 & 688497 & 5.35 & 5.1699 & TRN \\
\hline CHEMBL1580845 & 688497 & 4.45 & 4.6138 & TRN \\
\hline CHEMBL1495746 & 688497 & 5.65 & 4.9403 & TST \\
\hline CHEMBL1448168 & 688497 & 5.05 & 4.941 & TST \\
\hline CHEMBL3197399 & 688497 & 4.95 & 5.0718 & TRN \\
\hline CHEMBL1530571 & 688497 & 6.5501 & 5.2653 & TRN \\
\hline CHEMBL1346301 & 688497 & 4.85 & 5.2172 & TRN \\
\hline CHEMBL 3192124 & 688497 & 4.45 & 5.1446 & TRN \\
\hline CHEMBL1508199 & 688497 & 4.45 & 4.9858 & TRN \\
\hline CHEMBL1345334 & 688497 & 4.6 & 4.803 & TRN \\
\hline CHEMBL 1458975 & 688497 & 5.45 & 5.0974 & TRN \\
\hline CHEMBL1377747 & 688497 & 5.5 & 5.0284 & TST \\
\hline CHEMBL1565743 & 688497 & 5.9 & 5.2795 & TST \\
\hline CHEMBL1503736 & 688497 & 4.55 & 4.9124 & TRN \\
\hline CHEMBL1346506 & 688497 & 5.25 & 4.8565 & TRN \\
\hline CHEMBL 1578780 & 688497 & 6.7001 & 5.3597 & TRN \\
\hline CHEMBL1421233 & 688497 & 4.95 & 5.026 & TRN \\
\hline CHEMBL1401002 & 688497 & 4.9 & 5.0883 & TST \\
\hline CHEMBL 3198094 & 688497 & 5.3 & 4.98 & TRN \\
\hline CHEMBL1498202 & 688497 & 5.25 & 4.793 & TRN \\
\hline CHEMBL3211290 & 688497 & 5.25 & 4.971 & TRN \\
\hline CHEMBL1373410 & 688497 & 4.95 & 4.9656 & TST \\
\hline CHEMBL1386372 & 688497 & 5.35 & 4.8663 & TRN \\
\hline CHEMBL1384026 & 688497 & 4.6 & 5.0309 & TST \\
\hline CHEMBL1531070 & 688497 & 4.45 & 4.745 & TST \\
\hline CHEMBL1414204 & 688497 & 4.85 & 4.707 & TST \\
\hline CHEMBL1345933 & 688497 & 4.95 & 5.1043 & TRN \\
\hline CHEMBL1483975 & 688497 & 5.2 & 5.0635 & TRN \\
\hline CHEMBL1580728 & 688497 & 5.75 & $5.5920 e$ & 00000000005 \\
\hline CHEMBL1483908 & 688497 & 4.45 & 4.9039 & TRN \\
\hline CHEMBL1595724 & 688497 & 4.6 & 4.8065 & TRN \\
\hline CHEMBL 2002162 & 688497 & 5.45 & 5.5191 & TRN \\
\hline CHEMBL1585641 & 688497 & 4.6 & 4.8531 & TRN \\
\hline
\end{tabular}




\begin{tabular}{|c|c|c|c|c|}
\hline \multicolumn{5}{|c|}{ Supplemental Table } \\
\hline CHEMBL1419954 & 688497 & 4.85 & 4.65 & TRN \\
\hline CHEMBL1582859 & 688497 & 5.0 & 4.8303 & TRN \\
\hline CHEMBL1505936 & 688497 & 5.8 & 5.1476 & TST \\
\hline CHEMBL1417197 & 688497 & 4.45 & 4.8737 & TRN \\
\hline CHEMBL1497547 & 688497 & 5.5 & 4.7485 & TST \\
\hline CHEMBL1304364 & 688497 & 4.45 & 4.5565 & TRN \\
\hline CHEMBL 3193864 & 688497 & 5.2 & 5.0191 & TST \\
\hline CHEMBL1306142 & 688497 & 5.25 & 4.9641 & TRN \\
\hline CHEMBL1339860 & 688497 & 4.45 & 4.9716 & TRN \\
\hline CHEMBL1571568 & 688497 & 4.45 & 5.1125 & TRN \\
\hline CHEMBL1574815 & 688497 & 4.9 & 5.0019 & TRN \\
\hline CHEMBL1326316 & 688497 & 5.4 & 5.0174 & TST \\
\hline CHEMBL1559053 & 688497 & 6.0 & 5.0936 & TRN \\
\hline CHEMBL1413510 & 688497 & 5.0 & 4.9429 & TRN \\
\hline CHEMBL1534547 & 688497 & 4.45 & 5.0801 & TRN \\
\hline CHEMBL3196107 & 688497 & 4.45 & 4.8442 & TRN \\
\hline CHEMBL1393820 & 688497 & 4.8 & 5.0151 & TRN \\
\hline CHEMBL1527616 & 688497 & 4.9 & 4.985 & TST \\
\hline CHEMBL1357562 & 688497 & 6.0 & 5.4704 & TRN \\
\hline CHEMBL1596654 & 688497 & 4.8 & 5.3492 & TST \\
\hline CHEMBL1558955 & 688497 & 4.45 & 5.1901 & TRN \\
\hline CHEMBL1304402 & 688497 & 4.95 & 5.4001 & TRN \\
\hline CHEMBL1403419 & 688497 & 6.05 & 5.1238 & TRN \\
\hline CHEMBL1340418 & 688497 & 4.95 & 4.8525 & TRN \\
\hline CHEMBL1455993 & 688497 & 5.4 & 5.0884 & TRN \\
\hline CHEMBL3194214 & 688497 & 5.25 & 5.1755 & TRN \\
\hline CHEMBL589715 & 688497 & 4.45 & 4.7636 & TST \\
\hline CHEMBL1324949 & 688497 & 4.65 & 5.103 & TRN \\
\hline CHEMBL1373611 & 688497 & 5.35 & 5.2439 & TST \\
\hline CHEMBL1416561 & 688497 & 4.45 & 4.7366 & TRN \\
\hline CHEMBL1429733 & 688497 & 4.75 & 5.1469 & TST \\
\hline CHEMBL1578037 & 688497 & 5.25 & 5.2378 & TRN \\
\hline CHEMBL1999595 & 688497 & 4.45 & 5.2137 & TRN \\
\hline CHEMBL1331573 & 688497 & 4.9 & 4.8411 & TST \\
\hline CHEMBL1532742 & 688497 & 5.35 & 4.9298 & TRN \\
\hline CHEMBL1610604 & 688497 & 4.9 & 4.7785 & TRN \\
\hline CHEMBL1519374 & 688497 & 5.4 & 4.7372 & TRN \\
\hline CHEMBL1421670 & 688497 & 4.9 & 4.9214 & TRN \\
\hline CHEMBL1387863 & 688497 & 5.9 & 5.291 & TST \\
\hline CHEMBL1441916 & 688497 & 5.4 & 5.1833 & TRN \\
\hline CHEMBL1368649 & 688497 & 5.95 & 4.9466 & TRN \\
\hline CHEMBL1472386 & 688497 & 5.2 & 4.8752 & TRN \\
\hline CHEMBL1338585 & 688497 & 5.55 & 5.1534 & TRN \\
\hline CHEMBL1382411 & 688497 & 4.95 & 4.8796 & TRN \\
\hline CHEMBL1562623 & 688497 & 4.45 & 4.8537 & TRN \\
\hline CHEMBL3213519 & 688497 & 5.4 & 4.7577 & TRN \\
\hline CHEMBL1570881 & 688497 & 5.25 & 5.0109 & TRN \\
\hline CHEMBL1465581 & 688497 & 4.45 & 4.9009 & TRN \\
\hline
\end{tabular}




\begin{tabular}{|c|c|c|c|c|}
\hline \multicolumn{5}{|c|}{ Supplemental Table S2.txt } \\
\hline CHEMBL1347208 & 688497 & 4.65 & 4.9225 & TRN \\
\hline CHEMBL1979574 & 688497 & 5.55 & 5.0277 & TRN \\
\hline CHEMBL1550422 & 688497 & 4.45 & 5.1393 & TST \\
\hline CHEMBL1544309 & 688497 & 4.85 & 5.0115 & TST \\
\hline CHEMBL1412534 & 688497 & 5.0 & 4.9816 & TRN \\
\hline CHEMBL1367260 & 688497 & 4.45 & 5.1271 & TRN \\
\hline CHEMBL1578080 & 688497 & 4.45 & 4.8559 & TRN \\
\hline CHEMBL3211133 & 688497 & 5.0 & 4.8433 & TRN \\
\hline CHEMBL1487808 & 688497 & 4.45 & 5.1524 & TRN \\
\hline CHEMBL1352025 & 688497 & 5.95 & 5.0653 & TRN \\
\hline CHEMBL1303524 & 688497 & 5.7 & 4.9944 & TRN \\
\hline CHEMBL1429850 & 688497 & 5.2 & 5.2781 & TST \\
\hline CHEMBL1453263 & 688497 & 5.5 & 4.7579 & TRN \\
\hline CHEMBL1581639 & 688497 & 4.8 & 4.8972 & TST \\
\hline CHEMBL1558761 & 688497 & 4.55 & 4.8304 & TRN \\
\hline CHEMBL1570798 & 688497 & 5.4 & 5.1935 & TST \\
\hline CHEMBL1572129 & 688497 & 4.45 & 4.8154 & TRN \\
\hline CHEMBL1500282 & 688497 & 6.25 & 5.3315 & TST \\
\hline CHEMBL1405423 & 688497 & 5.25 & 5.0184 & TRN \\
\hline CHEMBL1969867 & 688497 & 4.45 & 5.2092 & TRN \\
\hline CHEMBL1462610 & 688497 & 4.75 & 5.0142 & TRN \\
\hline CHEMBL1573887 & 688497 & 5.45 & 5.0468 & TRN \\
\hline CHEMBL1322677 & 688497 & 4.55 & 4.9061 & TRN \\
\hline CHEMBL 3902037 & 688497 & 4.8 & 5.0243 & TRN \\
\hline CHEMBL1561133 & 688497 & 4.45 & 4.376 & TRN \\
\hline CHEMBL3210325 & 688497 & 4.7 & 4.8923 & TST \\
\hline CHEMBL1423370 & 688497 & 4.8 & 4.739 & TRN \\
\hline CHEMBL1300458 & 688497 & 4.55 & 5.3234 & TST \\
\hline CHEMBL1577420 & 688497 & 4.45 & 4.8904 & TRN \\
\hline CHEMBL539027 & 688497 & 4.45 & 4.8361 & TST \\
\hline CHEMBL1556134 & 688497 & 4.65 & 4.9941 & TRN \\
\hline CHEMBL1989294 & 688497 & 6.9 & 5.1623 & TRN \\
\hline CHEMBL1430328 & 688497 & 4.5 & 5.2077 & TRN \\
\hline CHEMBL1348060 & 688497 & 4.65 & 4.8577 & TRN \\
\hline CHEMBL1382167 & 688497 & 4.75 & 5.1869 & TRN \\
\hline CHEMBL1511705 & 688497 & 4.45 & 5.0745 & TST \\
\hline CHEMBL1546202 & 688497 & 4.5 & 5.34 & TRN \\
\hline CHEMBL1452607 & 688497 & 4.45 & 4.7701 & TRN \\
\hline CHEMBL1528114 & 688497 & 4.65 & 4.9699 & TRN \\
\hline CHEMBL3192415 & 688497 & 4.45 & 5.3112 & TRN \\
\hline CHEMBL1338958 & 688497 & 4.6 & 4.695 & TRN \\
\hline CHEMBL1595824 & 688497 & 5.0 & 5.0457 & TST \\
\hline CHEMBL1588046 & 688497 & 5.25 & 5.3193 & TRN \\
\hline CHEMBL1414534 & 688497 & 4.45 & 4.6438 & TST \\
\hline CHEMBL1582902 & 688497 & 4.95 & 5.1973 & TST \\
\hline CHEMBL1484051 & 688497 & 4.45 & 4.9217 & TRN \\
\hline CHEMBL1480831 & 688497 & 4.45 & 4.8073 & TRN \\
\hline CHEMBL3191919 & 688497 & 4.85 & 5.2095 & TRN \\
\hline
\end{tabular}




\begin{tabular}{|c|c|c|c|c|c|}
\hline & & \multicolumn{4}{|c|}{ Supplemental Table s2.txt } \\
\hline CHEMBL3189792 & 688497 & 4.45 & 4.7847 & TRN & \\
\hline CHEMBL1353689 & 688497 & 5.55 & 5.2197 & TST & \\
\hline CHEMBL1425108 & 688497 & 4.9 & 4.8959 & TRN & \\
\hline CHEMBL1302121 & 688497 & 4.6 & 4.8269 & TRN & \\
\hline CHEMBL1549879 & 688497 & 5.0 & 4.8963 & TRN & \\
\hline CHEMBL1565435 & 688497 & 5.0 & 4.8073 & TST & \\
\hline CHEMBL1604527 & 688497 & 5.55 & 4.8893 & TRN & \\
\hline CHEMBL3194133 & 688497 & 4.5 & 4.6578 & TRN & \\
\hline CHEMBL1345948 & 688497 & 4.9 & 4.9339 & TRN & \\
\hline CHEMBL1348933 & 688497 & 4.45 & 4.7512 & TST & \\
\hline CHEMBL1538192 & 688497 & 5.5 & 4.9645 & TST & \\
\hline CHEMBL1564980 & 688497 & 4.8 & 5.3916 & TRN & \\
\hline CHEMBL1537047 & 688497 & 5.4 & 4.7551 & TST & \\
\hline CHEMBL1409954 & 688497 & 4.55 & 4.8434 & TRN & \\
\hline CHEMBL 2000686 & 688497 & 4.45 & 4.9886 & TRN & \\
\hline CHEMBL1422610 & 688497 & 4.45 & 5.1643 & TRN & \\
\hline CHEMBL1460007 & 688497 & 4.9 & 4.8931 & TRN & \\
\hline CHEMBL1547071 & 688497 & 4.7 & 5.16299 & 9999999999 & TRN \\
\hline CHEMBL1523467 & 688497 & 4.45 & 4.9088 & TRN & \\
\hline CHEMBL1445070 & 688497 & 4.5 & 5.0735 & TRN & \\
\hline CHEMBL1448942 & 688497 & 6.1 & 5.1328 & TST & \\
\hline CHEMBL1501305 & 688497 & 4.9 & 4.8959 & TRN & \\
\hline CHEMBL579318 & 688497 & 5.45 & 4.9516 & TRN & \\
\hline CHEMBL1516586 & 688497 & 4.55 & 4.8253 & TRN & \\
\hline CHEMBL3190402 & 688497 & 4.9 & 4.779 & TRN & \\
\hline CHEMBL1484980 & 688497 & 5.5 & 5.1049 & TRN & \\
\hline CHEMBL1388094 & 688497 & 4.9 & 5.1121 & TST & \\
\hline CHEMBL1975032 & 688497 & 4.9 & 4.6972 & TST & \\
\hline CHEMBL1426974 & 688497 & 5.0 & 5.2363 & TST & \\
\hline CHEMBL1516718 & 688497 & 7.5498 & 5.2445 & TST & \\
\hline CHEMBL1534254 & 688497 & 4.95 & 5.2279 & TRN & \\
\hline CHEMBL1335703 & 688497 & 4.9 & 4.8718 & TST & \\
\hline CHEMBL1325890 & 688497 & 4.9 & 4.8363 & TRN & \\
\hline CHEMBL1485818 & 688497 & 5.15 & 4.843 & TRN & \\
\hline CHEMBL1498784 & 688497 & 5.55 & 4.8931 & TRN & \\
\hline CHEMBL1508669 & 688497 & 4.65 & 5.2103 & TRN & \\
\hline CHEMBL1464553 & 688497 & 4.6 & 4.6092 & TRN & \\
\hline CHEMBL1503057 & 688497 & 4.45 & 5.0116 & TRN & \\
\hline CHEMBL1544175 & 688497 & 5.15 & 4.9161 & TRN & \\
\hline CHEMBL1521905 & 688497 & 4.9 & 5.2331 & TRN & \\
\hline CHEMBL1327238 & 688497 & 4.45 & 5.3322 & TST & \\
\hline CHEMBL1532550 & 688497 & 4.95 & 4.9323 & TRN & \\
\hline CHEMBL1299995 & 688497 & 4.95 & 4.9163 & TRN & \\
\hline CHEMBL 2000440 & 688497 & 6.1 & 5.4421 & TRN & \\
\hline CHEMBL1408107 & 688497 & 5.15 & 4.8652 & TRN & \\
\hline CHEMBL1414449 & 688497 & 4.9 & 5.17299 & 9999999999 & TRN \\
\hline CHEMBL1378473 & 688497 & 5.75 & 4.8936 & TRN & \\
\hline CHEMBL1433382 & 688497 & 4.45 & 4.9306 & TRN & \\
\hline
\end{tabular}




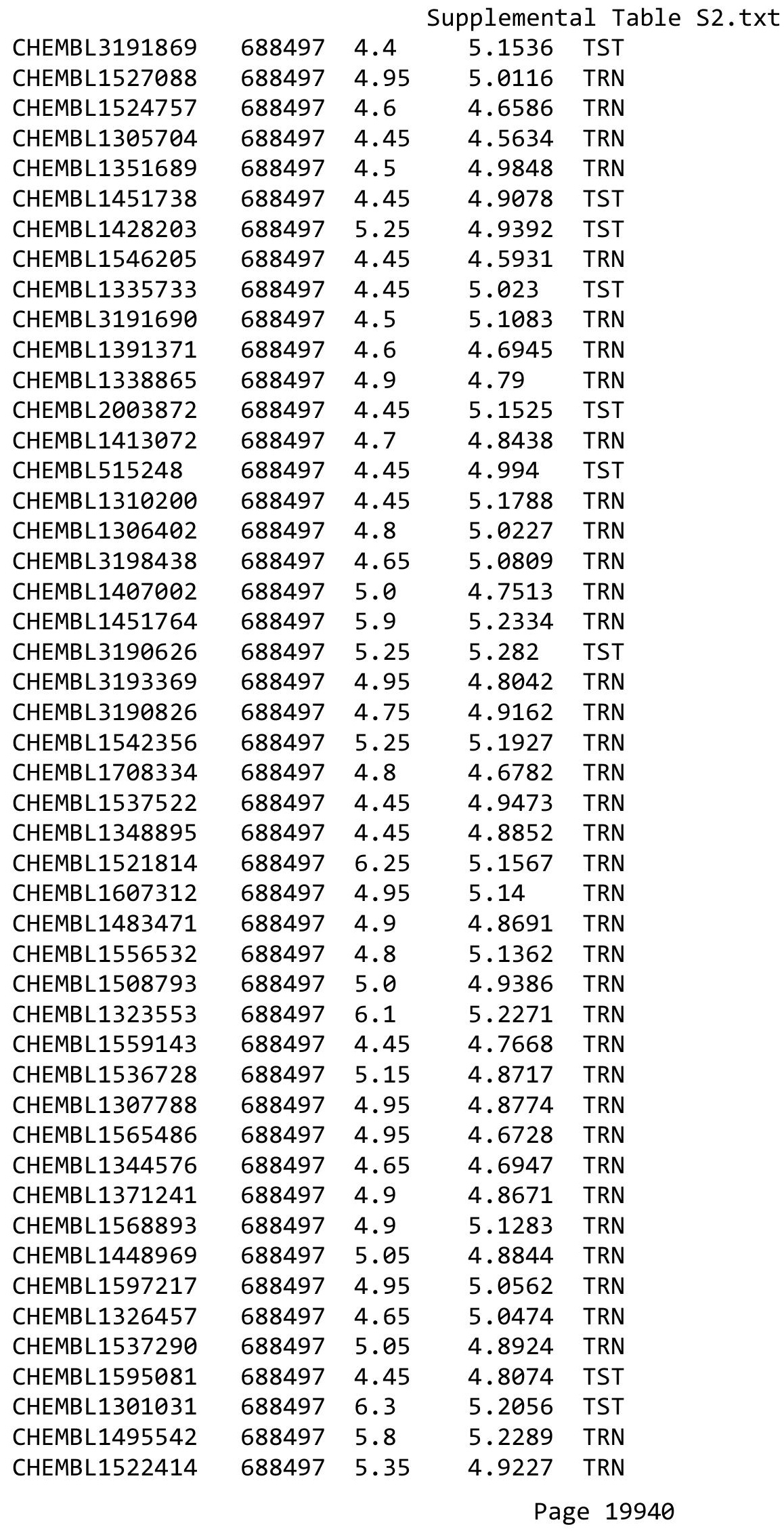




\begin{tabular}{|c|c|c|c|c|c|}
\hline \multicolumn{6}{|c|}{ Supplemental Table S2.txt } \\
\hline CHEMBL1612933 & 688497 & 5.2 & 4.7964 & TRN & \\
\hline CHEMBL1528973 & 688497 & 4.8 & 4.9602 & TRN & \\
\hline CHEMBL1584737 & 688497 & 5.85 & 5.2521 & TRN & \\
\hline CHEMBL1491959 & 688497 & 4.45 & 5.0389 & TRN & \\
\hline CHEMBL1440137 & 688497 & 5.25 & 5.0646 & TRN & \\
\hline CHEMBL1375217 & 688497 & 5.25 & 4.9331 & TRN & \\
\hline CHEMBL1343506 & 688497 & 4.55 & 4.7249 & TRN & \\
\hline CHEMBL1502571 & 688497 & 5.5 & 5.3879 & TRN & \\
\hline CHEMBL1325823 & 688497 & 4.95 & 4.8977 & TRN & \\
\hline CHEMBL1530090 & 688497 & 5.65 & 5.1197 & TRN & \\
\hline CHEMBL1350329 & 688497 & 6.05 & 5.0585 & TST & \\
\hline CHEMBL1607650 & 688497 & 4.45 & 4.5481 & TRN & \\
\hline CHEMBL1387501 & 688497 & 6.25 & 5.2166 & TST & \\
\hline CHEMBL1567589 & 688497 & 4.6 & 4.8822 & TRN & \\
\hline CHEMBL1412046 & 688497 & 4.65 & 5.2525 & TRN & \\
\hline CHEMBL1306199 & 688497 & 4.5 & 4.7506 & TRN & \\
\hline CHEMBL1423154 & 688497 & 4.45 & 5.1593 & TRN & \\
\hline CHEMBL1459784 & 688497 & 4.9 & 4.8779 & TRN & \\
\hline CHEMBL1503459 & 688497 & 5.05 & 4.9423 & TRN & \\
\hline CHEMBL1553978 & 688497 & 4.5 & 4.9261 & TRN & \\
\hline CHEMBL1387100 & 688497 & 5.0 & 4.9288 & TRN & \\
\hline CHEMBL1510327 & 688497 & 4.45 & 5.16799 & 9999999999 & TRN \\
\hline CHEMBL1524734 & 688497 & 4.85 & 5.4669 & TRN & \\
\hline CHEMBL1497589 & 688497 & 5.05 & 5.1093 & TRN & \\
\hline CHEMBL1458268 & 688497 & 4.9 & 4.9654 & TRN & \\
\hline CHEMBL1302054 & 688497 & 4.45 & 4.5035 & TRN & \\
\hline CHEMBL1353928 & 688497 & 4.65 & 5.048 & TST & \\
\hline CHEMBL1487284 & 688497 & 5.15 & 4.8661 & TRN & \\
\hline CHEMBL1464385 & 688497 & 4.75 & 4.7108 & TRN & \\
\hline CHEMBL1549996 & 688497 & 4.45 & 4.9389 & TRN & \\
\hline CHEMBL1428856 & 688497 & 5.4 & 5.199 & TRN & \\
\hline CHEMBL1463157 & 688497 & 5.1 & 5.3121 & TRN & \\
\hline CHEMBL1532342 & 688497 & 6.05 & 5.1262 & TRN & \\
\hline CHEMBL1425990 & 688497 & 5.25 & 4.8449 & TRN & \\
\hline CHEMBL1610207 & 688497 & 5.75 & 5.5162 & TST & \\
\hline CHEMBL1444790 & 688497 & 6.25 & 5.0792 & TRN & \\
\hline CHEMBL597857 & 688497 & 4.8 & 5.1003 & TRN & \\
\hline CHEMBL1393491 & 688497 & 4.9 & 5.1509 & TRN & \\
\hline CHEMBL1360203 & 688497 & 4.65 & 4.8788 & TRN & \\
\hline CHEMBL1609830 & 688497 & 4.9 & 5.1486 & TRN & \\
\hline CHEMBL1301614 & 688497 & 4.85 & 5.1659 & TRN & \\
\hline CHEMBL1344852 & 688497 & 4.45 & 4.9611 & TRN & \\
\hline CHEMBL1424289 & 688497 & 4.9 & 4.8992 & TST & \\
\hline CHEMBL1323214 & 688497 & 4.75 & 4.9175 & TRN & \\
\hline CHEMBL1578516 & 688497 & 5.9 & 5.3104 & TST & \\
\hline CHEMBL1327172 & 688497 & 5.0 & 5.5287 & TRN & \\
\hline CHEMBL1612398 & 688497 & 4.45 & 5.0595 & TST & \\
\hline CHEMBL1303190 & 688497 & 5.55 & 5.3982 & TST & \\
\hline
\end{tabular}




\begin{tabular}{|c|c|c|c|c|c|}
\hline \multirow{3}{*}{$\begin{array}{l}\text { CHEMBL1452939 } \\
\text { CHEMBL } 1305426\end{array}$} & \multirow{3}{*}{$\begin{array}{l}688497 \\
688497\end{array}$} & \multicolumn{4}{|c|}{ Supplemental Table S2.txt } \\
\hline & & 4.95 & 4.55399 & 9999999999 & TRN \\
\hline & & 4.65 & 4.9783 & TRN & \\
\hline CHEMBL1524184 & 688497 & 4.95 & 4.9269 & TRN & \\
\hline CHEMBL1492794 & 688497 & 5.45 & 5.2369 & TRN & \\
\hline CHEMBL1546805 & 688497 & 4.95 & 5.0272 & TRN & \\
\hline CHEMBL1441618 & 688497 & 4.8 & 4.8393 & TRN & \\
\hline CHEMBL1415371 & 688497 & 4.7 & 4.9082 & TRN & \\
\hline CHEMBL1359381 & 688497 & 5.1 & 5.0872 & TRN & \\
\hline CHEMBL1393574 & 688497 & 4.95 & 4.967 & TRN & \\
\hline CHEMBL582081 & 688497 & 4.7 & 5.0781 & TRN & \\
\hline CHEMBL1567635 & 688497 & 4.45 & 4.8336 & TRN & \\
\hline CHEMBL1419902 & 688497 & 4.5 & 5.0381 & TRN & \\
\hline CHEMBL1360344 & 688497 & 6.15 & 5.0578 & TST & \\
\hline CHEMBL1470236 & 688497 & 4.85 & 4.8967 & TST & \\
\hline CHEMBL1453232 & 688497 & 5.0 & 4.9814 & TRN & \\
\hline CHEMBL1588176 & 688497 & 5.9 & 5.2921 & TST & \\
\hline CHEMBL3194794 & 688497 & 4.45 & 4.8593 & TST & \\
\hline CHEMBL1345215 & 688497 & 4.45 & 5.2375 & TRN & \\
\hline CHEMBL1306182 & 688497 & 4.65 & 4.9401 & TST & \\
\hline CHEMBL1339641 & 688497 & 6.2 & 4.9569 & TRN & \\
\hline CHEMBL1493661 & 688497 & 4.8 & 5.2022 & TRN & \\
\hline CHEMBL1450671 & 688497 & 4.85 & 5.2802 & TST & \\
\hline CHEMBL1533856 & 688497 & 4.35 & 5.1419 & TRN & \\
\hline CHEMBL1607693 & 688497 & 4.45 & 4.9515 & TRN & \\
\hline CHEMBL1368819 & 688497 & 4.45 & 5.0839 & TRN & \\
\hline CHEMBL1431209 & 688497 & 5.45 & 5.1024 & TRN & \\
\hline CHEMBL1352016 & 688497 & 4.8 & 4.7921 & TRN & \\
\hline CHEMBL1365988 & 688497 & 5.15 & 5.4583 & TRN & \\
\hline CHEMBL1607362 & 688497 & 5.1 & 5.0831 & TRN & \\
\hline CHEMBL1509674 & 688497 & 5.6 & 5.1694 & TRN & \\
\hline CHEMBL1300443 & 688497 & 5.55 & 5.0505 & TRN & \\
\hline CHEMBL1451379 & 688497 & 4.95 & 4.8174 & TRN & \\
\hline CHEMBL1464930 & 688497 & 4.8 & 4.7667 & TRN & \\
\hline CHEMBL1336674 & 688497 & 5.25 & 5.7781 & TRN & \\
\hline CHEMBL1485156 & 688497 & 6.3 & 4.9145 & TST & \\
\hline CHEMBL1527830 & 688497 & 4.45 & 5.0321 & TRN & \\
\hline CHEMBL1603609 & 688497 & 4.45 & 4.8455 & TRN & \\
\hline CHEMBL3213842 & 688497 & 4.65 & 4.9714 & TRN & \\
\hline CHEMBL1463665 & 688497 & 4.45 & 5.0793 & TRN & \\
\hline CHEMBL1303835 & 688497 & 4.8 & 5.2876 & TRN & \\
\hline CHEMBL1352701 & 688497 & 5.5 & 5.3442 & TRN & \\
\hline CHEMBL 1347563 & 688497 & 5.25 & 4.712 & TRN & \\
\hline CHEMBL1342541 & 688497 & 4.45 & 5.1773 & TST & \\
\hline CHEMBL1557101 & 688497 & 4.8 & 5.0741 & TRN & \\
\hline CHEMBL1387221 & 688497 & 6.25 & 5.3759 & TRN & \\
\hline CHEMBL1410412 & 688497 & 4.55 & 4.6181 & TRN & \\
\hline CHEMBL 1485640 & 688497 & 6.1 & 5.1079 & TST & \\
\hline CHEMBL1522275 & 688497 & 5.05 & 4.8414 & TRN & \\
\hline
\end{tabular}




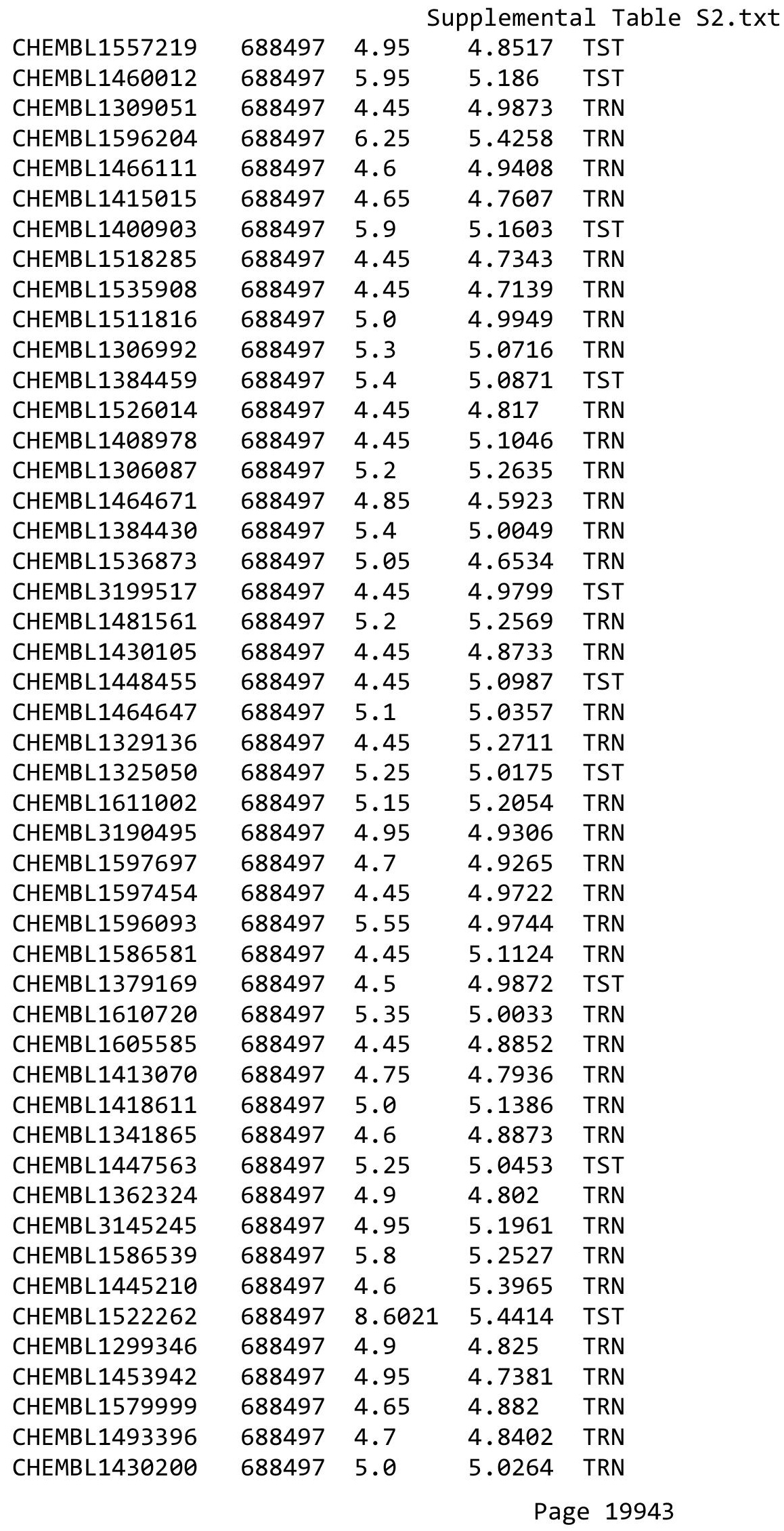




\begin{tabular}{|c|c|c|c|c|}
\hline \multicolumn{5}{|c|}{ Supplemental Table S2.txt } \\
\hline CHEMBL1379951 & 688497 & 5.65 & 4.7923 & TRN \\
\hline CHEMBL1546547 & 688497 & 5.5 & 5.073 & TRN \\
\hline CHEMBL1531362 & 688497 & 4.95 & 4.8612 & TST \\
\hline CHEMBL1565204 & 688497 & 4.85 & 5.0825 & TRN \\
\hline CHEMBL 1457825 & 688497 & 4.9 & 4.9654 & TST \\
\hline CHEMBL1524792 & 688497 & 4.65 & 4.9565 & TST \\
\hline CHEMBL1530687 & 688497 & 4.8 & 4.9528 & TST \\
\hline CHEMBL1543804 & 688497 & 4.85 & 5.3181 & TRN \\
\hline CHEMBL3196056 & 688497 & 4.7 & 5.0743 & TRN \\
\hline CHEMBL1603596 & 688497 & 4.45 & 5.3433 & TRN \\
\hline CHEMBL1415081 & 688497 & 7.0501 & 5.2621 & TRN \\
\hline CHEMBL1378175 & 688497 & 5.95 & 5.4038 & TST \\
\hline CHEMBL1609110 & 688497 & 4.45 & 4.8285 & TRN \\
\hline CHEMBL1303576 & 688497 & 5.3 & 5.1327 & TRN \\
\hline CHEMBL1425718 & 688497 & 5.0 & 5.0728 & TRN \\
\hline CHEMBL1346613 & 688497 & 4.55 & 4.9892 & TRN \\
\hline CHEMBL1468164 & 688497 & 5.4 & 5.1242 & TST \\
\hline CHEMBL1445776 & 688497 & 5.4 & 5.0382 & TRN \\
\hline CHEMBL1300769 & 688497 & 4.9 & 4.8166 & TST \\
\hline CHEMBL1406488 & 688497 & 4.8 & 4.7119 & TRN \\
\hline CHEMBL1557948 & 688497 & 4.95 & 5.1187 & TRN \\
\hline CHEMBL1431507 & 688497 & 5.8 & 5.2631 & TRN \\
\hline CHEMBL1575795 & 688497 & 4.9 & 4.8076 & TRN \\
\hline CHEMBL1389210 & 688497 & 5.0 & 4.9174 & TRN \\
\hline CHEMBL1304579 & 688497 & 4.95 & 4.8128 & TRN \\
\hline CHEMBL3208223 & 688497 & 4.95 & 5.1441 & TRN \\
\hline CHEMBL1541329 & 688497 & 4.85 & 5.0303 & TRN \\
\hline CHEMBL600773 & 688497 & 5.15 & 5.1471 & TRN \\
\hline CHEMBL1454332 & 688497 & 4.9 & 4.9405 & TRN \\
\hline CHEMBL3198449 & 688497 & 4.95 & 5.2748 & TRN \\
\hline CHEMBL1414048 & 688497 & 5.9 & 4.8856 & TST \\
\hline CHEMBL1535580 & 688497 & 5.0 & 5.2227 & TRN \\
\hline CHEMBL1504907 & 688497 & 4.45 & 4.7529 & TRN \\
\hline CHEMBL1530893 & 688497 & 4.8 & 5.2329 & TRN \\
\hline CHEMBL1461601 & 688497 & 4.95 & 4.7369 & TRN \\
\hline CHEMBL1351516 & 688497 & 4.8 & 4.7515 & TRN \\
\hline CHEMBL3191541 & 688497 & 6.05 & 5.3221 & TRN \\
\hline CHEMBL1493929 & 688497 & 5.25 & 4.8481 & TRN \\
\hline CHEMBL1444289 & 688497 & 4.9 & 4.9269 & TRN \\
\hline CHEMBL1348280 & 688497 & 4.95 & 4.9313 & TRN \\
\hline CHEMBL1581627 & 688497 & 5.75 & 5.0828 & TRN \\
\hline CHEMBL1604389 & 688497 & 4.45 & 5.0086 & TRN \\
\hline CHEMBL1437869 & 688497 & 5.15 & 5.0602 & TST \\
\hline CHEMBL1401122 & 688497 & 5.15 & 5.1604 & TRN \\
\hline CHEMBL1431585 & 688497 & 4.45 & 5.0305 & TST \\
\hline CHEMBL1423596 & 688497 & 4.45 & 4.6314 & TRN \\
\hline CHEMBL1445458 & 688497 & 4.6 & 4.9792 & TRN \\
\hline CHEMBL1533428 & 688497 & 4.45 & 4.7148 & TST \\
\hline
\end{tabular}




\begin{tabular}{|c|c|c|c|c|c|}
\hline \multicolumn{6}{|c|}{ Supplemental Table S2.txt } \\
\hline CHEMBL1336541 & 688497 & 5.15 & 5.0984 & TRN & \\
\hline CHEMBL1568884 & 688497 & 5.25 & 5.3205 & TRN & \\
\hline CHEMBL1545290 & 688497 & 5.25 & 5.5203 & TRN & \\
\hline CHEMBL1348994 & 688497 & 5.9 & 5.0527 & TRN & \\
\hline CHEMBL 1530538 & 688497 & 6.15 & 5.4173 & TRN & \\
\hline CHEMBL1537953 & 688497 & 4.45 & 5.1144 & TST & \\
\hline CHEMBL1336931 & 688497 & 5.4 & 5.1664 & TRN & \\
\hline CHEMBL1563145 & 688497 & 5.55 & 5.1067 & TST & \\
\hline CHEMBL1501645 & 688497 & 4.45 & 4.8506 & TRN & \\
\hline CHEMBL3195409 & 688497 & 5.15 & 5.0545 & TRN & \\
\hline CHEMBL1371715 & 688497 & 5.45 & 5.3348 & TRN & \\
\hline CHEMBL1595087 & 688497 & 4.7 & 5.2836 & TST & \\
\hline CHEMBL333767 & 688497 & 5.4 & 4.8157 & TRN & \\
\hline CHEMBL3192459 & 688497 & 4.45 & 4.90300 & 00000000005 & TRN \\
\hline CHEMBL1548028 & 688497 & 4.45 & 4.8464 & TRN & \\
\hline CHEMBL1365970 & 688497 & 4.95 & 4.8881 & TRN & \\
\hline CHEMBL1556335 & 688497 & 6.5 & 5.2929 & TST & \\
\hline CHEMBL1534287 & 688497 & 7.4498 & 5.4596 & TRN & \\
\hline CHEMBL1509209 & 688497 & 4.9 & 5.0675 & TRN & \\
\hline CHEMBL1388698 & 688497 & 4.8 & 4.9581 & TRN & \\
\hline CHEMBL1308006 & 688497 & 4.9 & 4.8112 & TRN & \\
\hline CHEMBL1490874 & 688497 & 5.0 & 5.0483 & TRN & \\
\hline CHEMBL1519268 & 688497 & 5.4 & 5.2644 & TRN & \\
\hline CHEMBL1450621 & 688497 & 4.8 & 4.9571 & TRN & \\
\hline CHEMBL1332111 & 688497 & 4.95 & 5.0703 & TRN & \\
\hline CHEMBL1332545 & 688497 & 4.5 & 4.8465 & TRN & \\
\hline CHEMBL1467691 & 688497 & 6.25 & 5.2308 & TST & \\
\hline CHEMBL1406531 & 688497 & 5.2 & 5.2832 & TRN & \\
\hline CHEMBL1462773 & 688497 & 4.9 & 4.801 & TST & \\
\hline CHEMBL1607684 & 688497 & 5.4 & 4.9143 & TRN & \\
\hline CHEMBL3214334 & 688497 & 5.55 & 5.1883 & TRN & \\
\hline CHEMBL1425635 & 688497 & 5.85 & 5.5505 & TRN & \\
\hline CHEMBL1320517 & 688497 & 4.45 & 4.9049 & TST & \\
\hline CHEMBL1304442 & 688497 & 4.65 & 4.8001 & TRN & \\
\hline CHEMBL1410682 & 688497 & 4.45 & 4.9232 & TRN & \\
\hline CHEMBL1485676 & 688497 & 4.75 & 4.9513 & TRN & \\
\hline CHEMBL1972029 & 688497 & 5.8 & 5.301 & TRN & \\
\hline CHEMBL1300235 & 688497 & 6.25 & 5.2456 & TRN & \\
\hline CHEMBL1542479 & 688497 & 4.7 & 4.8407 & TST & \\
\hline CHEMBL1448178 & 688497 & 6.25 & 5.1703 & TRN & \\
\hline CHEMBL1505849 & 688497 & 5.5 & 5.1711 & TRN & \\
\hline CHEMBL1467860 & 688497 & 4.45 & 4.5421 & TRN & \\
\hline CHEMBL3189740 & 688497 & 4.45 & 5.0115 & TRN & \\
\hline CHEMBL1351052 & 688497 & 4.45 & 4.9315 & TRN & \\
\hline CHEMBL3192207 & 688497 & 6.5 & 5.0181 & TST & \\
\hline CHEMBL1484150 & 688497 & 4.45 & 5.4756 & TRN & \\
\hline CHEMBL1330196 & 688497 & 5.25 & 4.9196 & TST & \\
\hline CHEMBL1333228 & 688497 & 4.45 & 4.9182 & TRN & \\
\hline
\end{tabular}




\begin{tabular}{|c|c|c|c|c|}
\hline \multicolumn{5}{|c|}{ Supplemental Table S2.txt } \\
\hline CHEMBL1454167 & 688497 & 5.4 & 5.2352 & TRN \\
\hline CHEMBL3197094 & 688497 & 4.75 & 4.7783 & TRN \\
\hline CHEMBL1602385 & 688497 & 6.4 & 5.3226 & TRN \\
\hline CHEMBL1423516 & 688497 & 4.45 & 4.792 & TST \\
\hline CHEMBL1531948 & 688497 & 4.45 & 5.1129 & TRN \\
\hline CHEMBL1353508 & 688497 & 5.0 & 4.7208 & TRN \\
\hline CHEMBL1587027 & 688497 & 5.05 & 5.244 & TRN \\
\hline CHEMBL1331960 & 688497 & 5.8 & 5.0106 & TRN \\
\hline CHEMBL1368391 & 688497 & 5.15 & 5.2029 & TST \\
\hline CHEMBL1543799 & 688497 & 6.25 & 5.0233 & TRN \\
\hline CHEMBL1491556 & 688497 & 4.45 & 5.0063 & TRN \\
\hline CHEMBL1565490 & 688497 & 9.699 & 5.3343 & TRN \\
\hline CHEMBL1417496 & 688497 & 5.45 & 4.4599 & TRN \\
\hline CHEMBL1561835 & 688497 & 4.55 & 4.8044 & TRN \\
\hline CHEMBL1497139 & 688497 & 4.45 & 4.8465 & TRN \\
\hline CHEMBL1605446 & 688497 & 4.9 & 5.1843 & TST \\
\hline CHEMBL1556666 & 688497 & 6.25 & 5.0566 & TST \\
\hline CHEMBL1362821 & 688497 & 7.0501 & 4.9346 & TRN \\
\hline CHEMBL1549000 & 688497 & 4.75 & 4.9845 & TRN \\
\hline CHEMBL1444186 & 688497 & 7.4498 & 5.1631 & TST \\
\hline CHEMBL1384368 & 688497 & 5.0 & 4.9391 & TRN \\
\hline CHEMBL1990786 & 688497 & 5.4 & 5.3772 & TRN \\
\hline CHEMBL1486330 & 688497 & 4.7 & 5.0568 & TRN \\
\hline CHEMBL1597877 & 688497 & 4.45 & 5.1273 & TRN \\
\hline CHEMBL1609072 & 688497 & 4.4 & 5.0874 & TRN \\
\hline CHEMBL1599200 & 688497 & 5.25 & 5.1667 & TRN \\
\hline CHEMBL3191417 & 688497 & 5.05 & 4.8543 & TRN \\
\hline CHEMBL 3194892 & 688497 & 4.45 & 5.0244 & TRN \\
\hline CHEMBL1565844 & 688497 & 4.85 & 5.1419 & TST \\
\hline CHEMBL1338390 & 688497 & 4.8 & 4.9759 & TRN \\
\hline CHEMBL1304678 & 688497 & 5.85 & 5.1642 & TST \\
\hline CHEMBL1454495 & 688497 & 4.45 & 4.9685 & TRN \\
\hline CHEMBL1557493 & 688497 & 5.0 & 5.2433 & TST \\
\hline CHEMBL1313162 & 688497 & 5.25 & 4.9959 & TST \\
\hline CHEMBL1339728 & 688497 & 4.85 & 4.6243 & TRN \\
\hline CHEMBL1545771 & 688497 & 4.45 & 4.9281 & TRN \\
\hline CHEMBL533226 & 688497 & 5.45 & 4.9856 & TRN \\
\hline CHEMBL1570509 & 688497 & 4.45 & 4.8694 & TRN \\
\hline CHEMBL1338533 & 688497 & 5.05 & 4.8208 & TRN \\
\hline CHEMBL1308821 & 688497 & 4.55 & 4.9553 & TRN \\
\hline CHEMBL3199182 & 688497 & 5.6 & 5.2143 & TST \\
\hline CHEMBL1337739 & 688497 & 6.25 & 5.0158 & TRN \\
\hline CHEMBL1602875 & 688497 & 5.05 & 5.1215 & TRN \\
\hline CHEMBL1520438 & 688497 & 5.3 & 4.8544 & TRN \\
\hline CHEMBL1518154 & 688497 & 5.25 & 5.9985 & TRN \\
\hline CHEMBL1339595 & 688497 & 6.25 & 5.091 & TRN \\
\hline CHEMBL1586434 & 688497 & 5.5 & 4.8062 & TST \\
\hline CHEMBL1320591 & 688497 & 4.45 & 4.9496 & TRN \\
\hline
\end{tabular}




\begin{tabular}{|c|c|c|c|c|}
\hline \multicolumn{5}{|c|}{ Supplemental Table S2.txt } \\
\hline CHEMBL1389637 & 688497 & 4.9 & 5.0217 & TRN \\
\hline CHEMBL1610002 & 688497 & 4.8 & 4.8326 & TST \\
\hline CHEMBL1506670 & 688497 & 4.75 & 4.9799 & TRN \\
\hline CHEMBL1348738 & 688497 & 4.45 & 5.1293 & TRN \\
\hline CHEMBL1346421 & 688497 & 4.95 & 4.8662 & TRN \\
\hline CHEMBL1570546 & 688497 & 5.15 & 4.8805 & TRN \\
\hline CHEMBL1608471 & 688497 & 4.45 & 4.8086 & TRN \\
\hline CHEMBL1352555 & 688497 & 4.6 & 4.898 & TST \\
\hline CHEMBL3192616 & 688497 & 4.45 & 5.1449 & TRN \\
\hline CHEMBL1403005 & 688497 & 4.85 & 4.6637 & TRN \\
\hline CHEMBL1326844 & 688497 & 6.45 & 5.1002 & TRN \\
\hline CHEMBL1559713 & 688497 & 4.9 & 4.7811 & TRN \\
\hline CHEMBL1566499 & 688497 & 4.9 & 5.2491 & TRN \\
\hline CHEMBL1407054 & 688497 & 5.0 & 4.9854 & TRN \\
\hline CHEMBL1563151 & 688497 & 4.8 & 5.1249 & TRN \\
\hline CHEMBL3189667 & 688497 & 4.95 & 5.0847 & TRN \\
\hline CHEMBL1428730 & 688497 & 4.95 & 4.5929 & TST \\
\hline CHEMBL1479719 & 688497 & 7.5003 & 4.9852 & TRN \\
\hline CHEMBL1371119 & 688497 & 5.55 & 4.735 & TRN \\
\hline CHEMBL1455421 & 688497 & 5.05 & 5.0888 & TRN \\
\hline CHEMBL1589463 & 688497 & 4.45 & 4.9438 & TST \\
\hline CHEMBL1608411 & 688497 & 4.6 & 4.8563 & TRN \\
\hline CHEMBL1543124 & 688497 & 4.45 & 5.5253 & TST \\
\hline CHEMBL1365550 & 688497 & 5.55 & 5.1347 & TRN \\
\hline CHEMBL1463463 & 688497 & 4.55 & 4.8307 & TRN \\
\hline CHEMBL1374115 & 688497 & 4.95 & 5.1017 & TRN \\
\hline CHEMBL1324510 & 688497 & 5.3 & 4.8729 & TST \\
\hline CHEMBL1569349 & 688497 & 4.45 & 5.0158 & TRN \\
\hline CHEMBL1526778 & 688497 & 4.6 & 4.8862 & TRN \\
\hline CHEMBL1374685 & 688497 & 4.45 & 4.5589 & TRN \\
\hline CHEMBL1288799 & 688497 & 4.8 & 5.1232 & TRN \\
\hline CHEMBL1345518 & 688497 & 4.6 & 4.784 & TRN \\
\hline CHEMBL1408861 & 688497 & 4.95 & 5.3461 & TRN \\
\hline CHEMBL1446430 & 688497 & 4.95 & 5.1361 & TST \\
\hline CHEMBL1391484 & 688497 & 4.95 & 4.5242 & TRN \\
\hline CHEMBL1528172 & 688497 & 4.8 & 4.8895 & TRN \\
\hline CHEMBL1544266 & 688497 & 6.25 & 5.0055 & TRN \\
\hline CHEMBL3214503 & 688497 & 6.95 & 5.0384 & TST \\
\hline CHEMBL1428995 & 688497 & 5.1 & 4.6945 & TRN \\
\hline CHEMBL1471605 & 688497 & 6.25 & 4.9537 & TST \\
\hline CHEMBL1465177 & 688497 & 4.45 & 5.0021 & TRN \\
\hline CHEMBL1458822 & 688497 & 4.9 & 5.0751 & TRN \\
\hline CHEMBL1556915 & 688497 & 4.45 & 5.0586 & TRN \\
\hline CHEMBL3190201 & 688497 & 5.5 & 4.9467 & TRN \\
\hline CHEMBL1369262 & 688497 & 5.45 & 4.9289 & TRN \\
\hline CHEMBL1418437 & 688497 & 4.7 & 5.1857 & TST \\
\hline CHEMBL1531512 & 688497 & 5.3 & 4.9032 & TRN \\
\hline CHEMBL1379480 & 688497 & 5.15 & 4.8387 & TRN \\
\hline
\end{tabular}




\begin{tabular}{|c|c|c|c|c|}
\hline \multicolumn{5}{|c|}{ Supplemental Table S2.txt } \\
\hline CHEMBL1305701 & 688497 & 4.45 & 4.8939 & TRN \\
\hline CHEMBL1611008 & 688497 & 4.85 & 5.018 & TRN \\
\hline CHEMBL1510649 & 688497 & 4.45 & 4.7741 & TRN \\
\hline CHEMBL1449265 & 688497 & 5.55 & 5.1256 & TRN \\
\hline CHEMBL601335 & 688497 & 6.0 & 5.6327 & TRN \\
\hline CHEMBL1599150 & 688497 & 5.9 & 5.3268 & TRN \\
\hline CHEMBL1341722 & 688497 & 6.0 & 5.4298 & TRN \\
\hline CHEMBL3194457 & 688497 & 4.45 & 4.8554 & TRN \\
\hline CHEMBL1587467 & 688497 & 4.45 & 4.9574 & TRN \\
\hline CHEMBL1322290 & 688497 & 5.5 & 5.3469 & TST \\
\hline CHEMBL1526377 & 688497 & 4.95 & 4.8949 & TRN \\
\hline CHEMBL1373822 & 688497 & 4.7 & 5.1428 & TST \\
\hline CHEMBL1349610 & 688497 & 4.7 & 4.7549 & TRN \\
\hline CHEMBL1584502 & 688497 & 4.45 & 4.9467 & TRN \\
\hline CHEMBL 3195222 & 688497 & 4.95 & 4.771 & TRN \\
\hline CHEMBL1564354 & 688497 & 5.55 & 5.0507 & TST \\
\hline CHEMBL3214426 & 688497 & 4.9 & 4.9727 & TRN \\
\hline CHEMBL1429129 & 688497 & 4.45 & 5.0305 & TST \\
\hline CHEMBL1486232 & 688497 & 4.45 & 5.2242 & TRN \\
\hline CHEMBL1605248 & 688497 & 4.95 & 4.955 & TRN \\
\hline CHEMBL1413872 & 688497 & 4.45 & 4.7317 & TRN \\
\hline CHEMBL1409593 & 688497 & 6.15 & 5.0632 & TRN \\
\hline CHEMBL1533030 & 688497 & 4.55 & 4.9314 & TRN \\
\hline CHEMBL1387726 & 688497 & 4.95 & 5.2783 & TRN \\
\hline CHEMBL1565121 & 688497 & 5.45 & 5.1913 & TRN \\
\hline CHEMBL1546938 & 688497 & 4.9 & 4.9348 & TST \\
\hline CHEMBL1543886 & 688497 & 4.85 & 5.2172 & TST \\
\hline CHEMBL1548371 & 688497 & 4.9 & 4.8564 & TRN \\
\hline CHEMBL1559586 & 688497 & 4.7 & 4.9433 & TRN \\
\hline CHEMBL1574187 & 688497 & 4.45 & 5.0723 & TRN \\
\hline CHEMBL3197978 & 688497 & 6.0 & 5.4036 & TRN \\
\hline CHEMBL1432514 & 688497 & 6.5 & 5.3323 & TRN \\
\hline CHEMBL1471198 & 688497 & 4.5 & 4.9229 & TRN \\
\hline CHEMBL1504168 & 688497 & 4.6 & 5.0357 & TST \\
\hline CHEMBL1328321 & 688497 & 4.45 & 5.1122 & TST \\
\hline CHEMBL1330983 & 688497 & 6.2 & 4.958 & TRN \\
\hline CHEMBL580609 & 688497 & 5.0 & 4.9548 & TRN \\
\hline CHEMBL1577179 & 688497 & 4.7 & 4.71 & TRN \\
\hline CHEMBL600495 & 688497 & 5.1 & 5.2338 & TRN \\
\hline CHEMBL1496639 & 688497 & 5.9 & 5.2919 & TRN \\
\hline CHEMBL1365075 & 688497 & 4.9 & 5.1348 & TST \\
\hline CHEMBL1964614 & 688497 & 5.55 & 5.4697 & TRN \\
\hline CHEMBL1445942 & 688497 & 4.95 & 5.1843 & TRN \\
\hline CHEMBL1427061 & 688497 & 5.0 & 5.1283 & TRN \\
\hline CHEMBL1531527 & 688497 & 6.3 & 5.2069 & TST \\
\hline CHEMBL1483312 & 688497 & 4.45 & 4.6623 & TST \\
\hline CHEMBL1542126 & 688497 & 4.8 & 4.8425 & TRN \\
\hline CHEMBL1343508 & 688497 & 6.1 & 4.8621 & TRN \\
\hline
\end{tabular}




\begin{tabular}{|c|c|c|c|c|c|}
\hline \multicolumn{6}{|c|}{ Supplemental Table S2.txt } \\
\hline CHEMBL1520346 & 688497 & 6.2 & 5.1285 & TRN & \\
\hline CHEMBL1487978 & 688497 & 5.45 & 5.077 & TST & \\
\hline CHEMBL1541719 & 688497 & 4.6 & 4.9291 & TRN & \\
\hline CHEMBL1346458 & 688497 & 6.3 & 5.1154 & TRN & \\
\hline CHEMBL3190974 & 688497 & 4.45 & 5.121 & TRN & \\
\hline CHEMBL1503131 & 688497 & 4.8 & 4.8858 & TRN & \\
\hline CHEMBL1509540 & 688497 & 4.9 & 5.0163 & TRN & \\
\hline CHEMBL1364625 & 688497 & 4.85 & 5.1102 & TRN & \\
\hline CHEMBL1339915 & 688497 & 4.65 & 5.0982 & TRN & \\
\hline CHEMBL3194506 & 688497 & 4.5 & 4.9599 & TRN & \\
\hline CHEMBL1345448 & 688497 & 4.85 & 5.0685 & TST & \\
\hline CHEMBL1425765 & 688497 & 4.85 & 4.7656 & TRN & \\
\hline CHEMBL1499788 & 688497 & 4.95 & 5.0579 & TRN & \\
\hline CHEMBL1384289 & 688497 & 5.5 & $4.9860 e$ & $\partial 000000001$ & TRN \\
\hline CHEMBL1331822 & 688497 & 4.45 & 4.7851 & TST & \\
\hline CHEMBL1557668 & 688497 & 5.45 & 4.9357 & TRN & \\
\hline CHEMBL1414671 & 688497 & 4.85 & 5.2512 & TRN & \\
\hline CHEMBL1336722 & 688497 & 4.7 & 4.9065 & TRN & \\
\hline CHEMBL1580479 & 688497 & 4.5 & 4.8798 & TRN & \\
\hline CHEMBL1429574 & 688497 & 5.05 & 4.9748 & TRN & \\
\hline CHEMBL1526471 & 688497 & 4.45 & 4.8969 & TRN & \\
\hline CHEMBL1478936 & 688497 & 5.15 & 5.0922 & TST & \\
\hline CHEMBL1519843 & 688497 & 4.45 & 4.7036 & TRN & \\
\hline CHEMBL1546211 & 688497 & 4.6 & 4.8799 & TRN & \\
\hline CHEMBL1416824 & 688497 & 4.95 & 4.987 & TRN & \\
\hline CHEMBL1569910 & 688497 & 4.45 & $4.8610 e$ & 0000000001 & TRN \\
\hline CHEMBL1418716 & 688497 & 6.15 & 4.9537 & TRN & \\
\hline CHEMBL585656 & 688497 & 5.15 & 4.9626 & TRN & \\
\hline CHEMBL1530707 & 688497 & 5.0 & 4.9435 & TRN & \\
\hline CHEMBL1373997 & 688497 & 4.9 & 5.1338 & TRN & \\
\hline CHEMBL1597278 & 688497 & 4.8 & 4.6919 & TRN & \\
\hline CHEMBL1344089 & 688497 & 4.45 & 4.9841 & TRN & \\
\hline CHEMBL1527755 & 688497 & 5.0 & 5.0897 & TST & \\
\hline CHEMBL1411449 & 688497 & 4.45 & 5.038 & TST & \\
\hline CHEMBL1305281 & 688497 & 7.5003 & 4.985 & TRN & \\
\hline CHEMBL1532996 & 688497 & 4.95 & 4.7747 & TRN & \\
\hline CHEMBL1584667 & 688497 & 6.45 & 5.0615 & TRN & \\
\hline CHEMBL1384935 & 688497 & 5.25 & 5.159 & TRN & \\
\hline CHEMBL1518696 & 688497 & 4.85 & 4.7463 & TRN & \\
\hline CHEMBL1521125 & 688497 & 5.05 & 4.845 & TRN & \\
\hline CHEMBL1349012 & 688497 & 5.25 & 5.1311 & TRN & \\
\hline CHEMBL1509614 & 688497 & 4.95 & 5.2134 & TST & \\
\hline CHEMBL1371286 & 688497 & 4.95 & 5.0374 & TRN & \\
\hline CHEMBL1572753 & 688497 & 4.45 & 4.9396 & TRN & \\
\hline CHEMBL1324200 & 688497 & 4.45 & 4.8455 & TRN & \\
\hline CHEMBL1368717 & 688497 & 4.85 & 5.2122 & TST & \\
\hline CHEMBL1466404 & 688497 & 4.85 & 4.6566 & TRN & \\
\hline CHEMBL1412381 & 688497 & 4.65 & 5.1088 & TRN & \\
\hline
\end{tabular}




\begin{tabular}{|c|c|c|c|c|}
\hline \multicolumn{5}{|c|}{ Supplemental Table S2.txt } \\
\hline CHEMBL1414113 & 688497 & 4.45 & 4.8347 & TRN \\
\hline CHEMBL1345839 & 688497 & 4.8 & 5.3014 & TRN \\
\hline CHEMBL3199423 & 688497 & 5.0 & 4.8402 & TST \\
\hline CHEMBL1493812 & 688497 & 4.45 & 4.8218 & TRN \\
\hline CHEMBL1570025 & 688497 & 4.6 & 4.8184 & TRN \\
\hline CHEMBL1608893 & 688497 & 5.0 & 4.9942 & TRN \\
\hline CHEMBL1422305 & 688497 & 7.0 & 5.143 & TRN \\
\hline CHEMBL1607661 & 688497 & 4.95 & 4.9387 & TRN \\
\hline CHEMBL1256910 & 688497 & 4.45 & 5.2971 & TST \\
\hline CHEMBL1361797 & 688497 & 4.65 & 4.8806 & TRN \\
\hline CHEMBL1599242 & 688497 & 5.05 & 5.1775 & TST \\
\hline CHEMBL1498473 & 688497 & 5.0 & 4.9128 & TRN \\
\hline CHEMBL1384028 & 688497 & 5.5 & 4.8868 & TRN \\
\hline CHEMBL1405447 & 688497 & 4.55 & 5.1066 & TRN \\
\hline CHEMBL1440258 & 688497 & 4.95 & 5.1457 & TRN \\
\hline CHEMBL1537810 & 688497 & 5.45 & 4.9888 & TRN \\
\hline CHEMBL1990571 & 688497 & 5.25 & 5.149 & TRN \\
\hline CHEMBL1568631 & 688497 & 4.6 & 5.008 & TRN \\
\hline CHEMBL1408695 & 688497 & 5.5 & 5.012 & TST \\
\hline CHEMBL1497520 & 688497 & 4.45 & 4.6228 & TRN \\
\hline CHEMBL1445151 & 688497 & 4.5 & 5.0352 & TRN \\
\hline CHEMBL1330143 & 688497 & 4.45 & 5.2531 & TRN \\
\hline CHEMBL3198896 & 688497 & 4.8 & 5.1422 & TST \\
\hline CHEMBL1540546 & 688497 & 4.45 & 5.3867 & TST \\
\hline CHEMBL486706 & 688497 & 5.15 & 5.131 & TST \\
\hline CHEMBL1546113 & 688497 & 5.25 & 5.1613 & TRN \\
\hline CHEMBL1419149 & 688497 & 5.0 & 5.2124 & TRN \\
\hline CHEMBL1580335 & 688497 & 6.25 & 4.9703 & TRN \\
\hline CHEMBL1585072 & 688497 & 4.45 & 4.9662 & TRN \\
\hline CHEMBL1429186 & 688497 & 4.6 & 5.0885 & TRN \\
\hline CHEMBL1369983 & 688497 & 4.95 & 4.8933 & TST \\
\hline CHEMBL 1300326 & 688497 & 4.7 & 4.9018 & TRN \\
\hline CHEMBL1581420 & 688497 & 4.45 & 4.8278 & TRN \\
\hline CHEMBL1404620 & 688497 & 5.0 & 4.8559 & TRN \\
\hline CHEMBL1571662 & 688497 & 5.45 & 4.8301 & TST \\
\hline CHEMBL1490638 & 688497 & 4.45 & 4.9793 & TRN \\
\hline CHEMBL1578267 & 688497 & 4.95 & 5.1333 & TRN \\
\hline CHEMBL1404573 & 688497 & 5.9 & 5.3429 & TST \\
\hline CHEMBL591126 & 688497 & 5.25 & 5.7253 & TRN \\
\hline CHEMBL1383315 & 688497 & 5.55 & 5.0602 & TRN \\
\hline CHEMBL3210043 & 688497 & 4.5 & 4.6393 & TRN \\
\hline CHEMBL1469609 & 688497 & 5.45 & 5.0607 & TRN \\
\hline CHEMBL1585192 & 688497 & 4.45 & 5.1394 & TRN \\
\hline CHEMBL 1334376 & 688497 & 4.45 & 5.1056 & TRN \\
\hline CHEMBL1493890 & 688497 & 4.45 & 5.3016 & TRN \\
\hline CHEMBL1561858 & 688497 & 5.25 & 4.9306 & TRN \\
\hline CHEMBL1509138 & 688497 & 4.6 & 4.9157 & TRN \\
\hline CHEMBL1609419 & 688497 & 5.55 & 4.8587 & TRN \\
\hline
\end{tabular}




\begin{tabular}{|c|c|c|c|c|c|}
\hline \multicolumn{6}{|c|}{ Supplemental Table S2.txt } \\
\hline CHEMBL1414429 & 688497 & 4.45 & 5.1233 & TRN & \\
\hline CHEMBL1545702 & 688497 & 4.45 & 5.3756 & TST & \\
\hline CHEMBL1454677 & 688497 & 4.65 & 4.6625 & TRN & \\
\hline CHEMBL1584058 & 688497 & 5.2 & 5.1552 & TRN & \\
\hline CHEMBL1301142 & 688497 & 5.6 & 5.2405 & TST & \\
\hline CHEMBL1609314 & 688497 & 4.45 & 5.135 & TST & \\
\hline CHEMBL3195995 & 688497 & 4.85 & 5.2715 & TRN & \\
\hline CHEMBL1582077 & 688497 & 4.95 & 5.0399 & TRN & \\
\hline CHEMBL1581367 & 688497 & 6.1 & 5.2876 & TRN & \\
\hline CHEMBL1602269 & 688497 & 5.6 & 5.1098 & TRN & \\
\hline CHEMBL1528715 & 688497 & 4.5 & 4.921 & TST & \\
\hline CHEMBL1334802 & 688497 & 5.35 & 5.434 & TST & \\
\hline CHEMBL1406121 & 688497 & 5.25 & 5.2834 & TST & \\
\hline CHEMBL1460700 & 688497 & 5.75 & 5.0543 & TST & \\
\hline CHEMBL1424847 & 688497 & 4.8 & 5.2748 & TRN & \\
\hline CHEMBL1588014 & 688497 & 4.85 & 4.8417 & TRN & \\
\hline CHEMBL1302135 & 688497 & 6.1 & 5.32299 & 99999999995 & TST \\
\hline CHEMBL1601555 & 688497 & 6.1 & 5.3411 & TRN & \\
\hline CHEMBL1517264 & 688497 & 4.45 & 4.8672 & TRN & \\
\hline CHEMBL1362799 & 688497 & 4.6 & 4.7163 & TRN & \\
\hline CHEMBL1462196 & 688497 & 7.5003 & 5.0416 & TRN & \\
\hline CHEMBL1568037 & 688497 & 5.4 & 5.0863 & TRN & \\
\hline CHEMBL1487582 & 688497 & 5.0 & 4.75 & TRN & \\
\hline CHEMBL1571397 & 688497 & 5.15 & 4.9536 & TRN & \\
\hline CHEMBL1506325 & 688497 & 6.05 & 5.1487 & TST & \\
\hline CHEMBL1445844 & 688497 & 6.25 & 5.334 & TRN & \\
\hline CHEMBL1426411 & 688497 & 4.45 & 5.0496 & TRN & \\
\hline CHEMBL1602914 & 688497 & 4.45 & 5.5277 & TRN & \\
\hline CHEMBL1313644 & 688497 & 4.65 & 4.8827 & TRN & \\
\hline CHEMBL1498860 & 688497 & 5.55 & 5.0083 & TRN & \\
\hline CHEMBL1577207 & 688497 & 4.45 & 5.0993 & TRN & \\
\hline CHEMBL1306348 & 688497 & 5.05 & 5.1148 & TRN & \\
\hline CHEMBL1971267 & 688497 & 7.0 & 5.0919 & TRN & \\
\hline CHEMBL1548533 & 688497 & 4.45 & 4.9764 & TRN & \\
\hline CHEMBL1571807 & 688497 & 4.7 & 4.6932 & TRN & \\
\hline CHEMBL1361685 & 688497 & 4.8 & 5.1538 & TST & \\
\hline CHEMBL1576555 & 688497 & 4.45 & 4.7498 & TRN & \\
\hline CHEMBL1572120 & 688497 & 5.65 & 5.1267 & TRN & \\
\hline CHEMBL3197396 & 688497 & 6.35 & 5.2635 & TRN & \\
\hline CHEMBL1541037 & 688497 & 5.0 & 4.7818 & TRN & \\
\hline CHEMBL1310710 & 688497 & 4.45 & 4.8731 & TRN & \\
\hline CHEMBL1589137 & 688497 & 4.65 & 5.1025 & TST & \\
\hline CHEMBL1390748 & 688497 & 4.45 & 4.5792 & TST & \\
\hline CHEMBL1313101 & 688497 & 4.85 & 4.7898 & TRN & \\
\hline CHEMBL1579152 & 688497 & 5.15 & 4.7369 & TRN & \\
\hline CHEMBL1608787 & 688497 & 5.55 & 5.1861 & TRN & \\
\hline CHEMBL1332910 & 688497 & 4.9 & 5.0378 & TRN & \\
\hline CHEMBL1416127 & 688497 & 4.95 & 4.8491 & TRN & \\
\hline
\end{tabular}




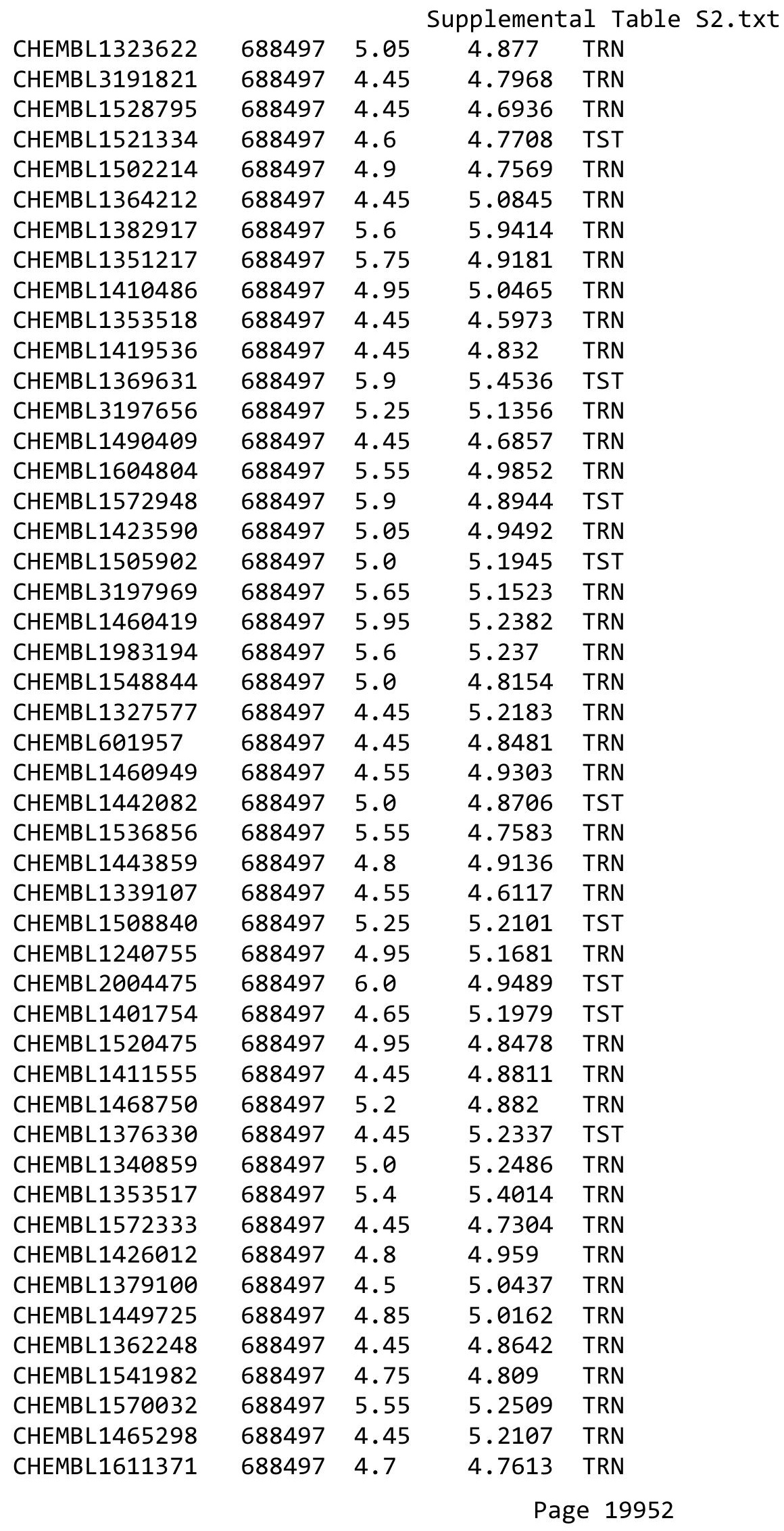




\begin{tabular}{|c|c|c|c|c|}
\hline \multicolumn{5}{|c|}{ Supplemental Table S2.txt } \\
\hline CHEMBL1580910 & 688497 & 4.45 & 4.8102 & TST \\
\hline CHEMBL1379586 & 688497 & 5.45 & 5.3937 & TST \\
\hline CHEMBL1332404 & 688497 & 6.0 & 5.5858 & TRN \\
\hline CHEMBL460602 & 688497 & 5.6 & 5.3059 & TRN \\
\hline CHEMBL1381461 & 688497 & 4.6 & 4.9083 & TRN \\
\hline CHEMBL1497298 & 688497 & 4.9 & 5.2301 & TST \\
\hline CHEMBL1465773 & 688497 & 6.25 & 5.1902 & TRN \\
\hline CHEMBL1452678 & 688497 & 6.0 & 5.0185 & TRN \\
\hline CHEMBL1533740 & 688497 & 4.5 & 4.8919 & TRN \\
\hline CHEMBL1382535 & 688497 & 4.8 & 5.0206 & TRN \\
\hline CHEMBL1303401 & 688497 & 7.0501 & 4.9618 & TRN \\
\hline CHEMBL3199132 & 688497 & 4.45 & 4.9106 & TST \\
\hline CHEMBL1499077 & 688497 & 4.45 & 4.9531 & TRN \\
\hline CHEMBL1308223 & 688497 & 5.4 & 5.3966 & TRN \\
\hline CHEMBL1399788 & 688497 & 5.5 & 5.2564 & TRN \\
\hline CHEMBL1459254 & 688497 & 5.5 & 5.1279 & TRN \\
\hline CHEMBL1319715 & 688497 & 4.9 & 5.0777 & TRN \\
\hline CHEMBL1450615 & 688497 & 6.0 & 5.2894 & TRN \\
\hline CHEMBL1528288 & 688497 & 6.45 & 5.2004 & TRN \\
\hline CHEMBL1422261 & 688497 & 5.0 & 4.8934 & TRN \\
\hline CHEMBL1493613 & 688497 & 5.05 & 5.2596 & TST \\
\hline CHEMBL1451772 & 688497 & 4.85 & 4.7808 & TRN \\
\hline CHEMBL1557920 & 688497 & 4.7 & 5.0724 & TRN \\
\hline CHEMBL1329710 & 688497 & 5.55 & 5.1087 & TRN \\
\hline CHEMBL1485422 & 688497 & 5.8 & 5.3289 & TST \\
\hline CHEMBL1492095 & 688497 & 4.75 & 4.726 & TRN \\
\hline CHEMBL1461171 & 688497 & 4.95 & 4.8883 & TRN \\
\hline CHEMBL1596269 & 688497 & 6.3 & 5.303 & TRN \\
\hline CHEMBL1393455 & 688497 & 5.45 & 5.3928 & TST \\
\hline CHEMBL1346079 & 688497 & 4.45 & 5.2054 & TRN \\
\hline CHEMBL1455378 & 688497 & 4.7 & 5.1293 & TRN \\
\hline CHEMBL1574323 & 688497 & 4.6 & 4.9435 & TRN \\
\hline CHEMBL1584454 & 688497 & 5.0 & 4.8832 & TRN \\
\hline CHEMBL1426723 & 688497 & 4.55 & 4.7551 & TRN \\
\hline CHEMBL1539178 & 688497 & 4.45 & 5.0376 & TRN \\
\hline CHEMBL1392564 & 688497 & 4.9 & 4.8512 & TRN \\
\hline CHEMBL1594781 & 688497 & 4.85 & 4.8444 & TRN \\
\hline CHEMBL1612954 & 688497 & 4.5 & 4.7969 & TRN \\
\hline CHEMBL1339696 & 688497 & 4.65 & 4.7735 & TST \\
\hline CHEMBL3194518 & 688497 & 5.35 & 4.9917 & TST \\
\hline CHEMBL1458132 & 688497 & 5.25 & 4.7629 & TST \\
\hline CHEMBL1526680 & 688497 & 5.2 & 5.0607 & TRN \\
\hline CHEMBL1479884 & 688497 & 4.85 & 5.4363 & TRN \\
\hline CHEMBL1302241 & 688497 & 5.5 & 4.9704 & TRN \\
\hline CHEMBL1604884 & 688497 & 4.95 & 5.0519 & TRN \\
\hline CHEMBL3193805 & 688497 & 4.45 & 5.2098 & TST \\
\hline CHEMBL1504413 & 688497 & 5.9 & 5.289 & TRN \\
\hline CHEMBL1352335 & 688497 & 4.45 & 4.9165 & TRN \\
\hline
\end{tabular}




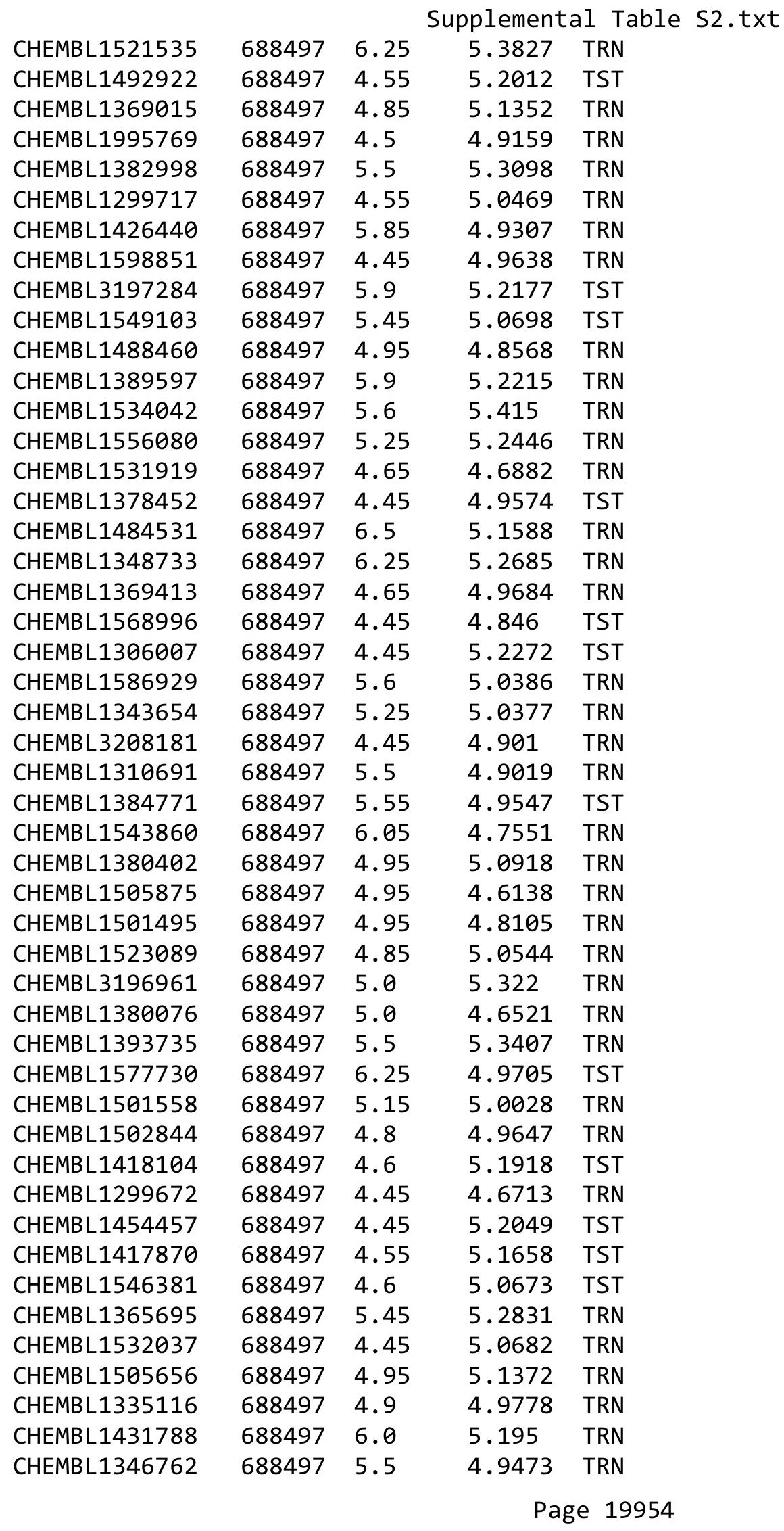




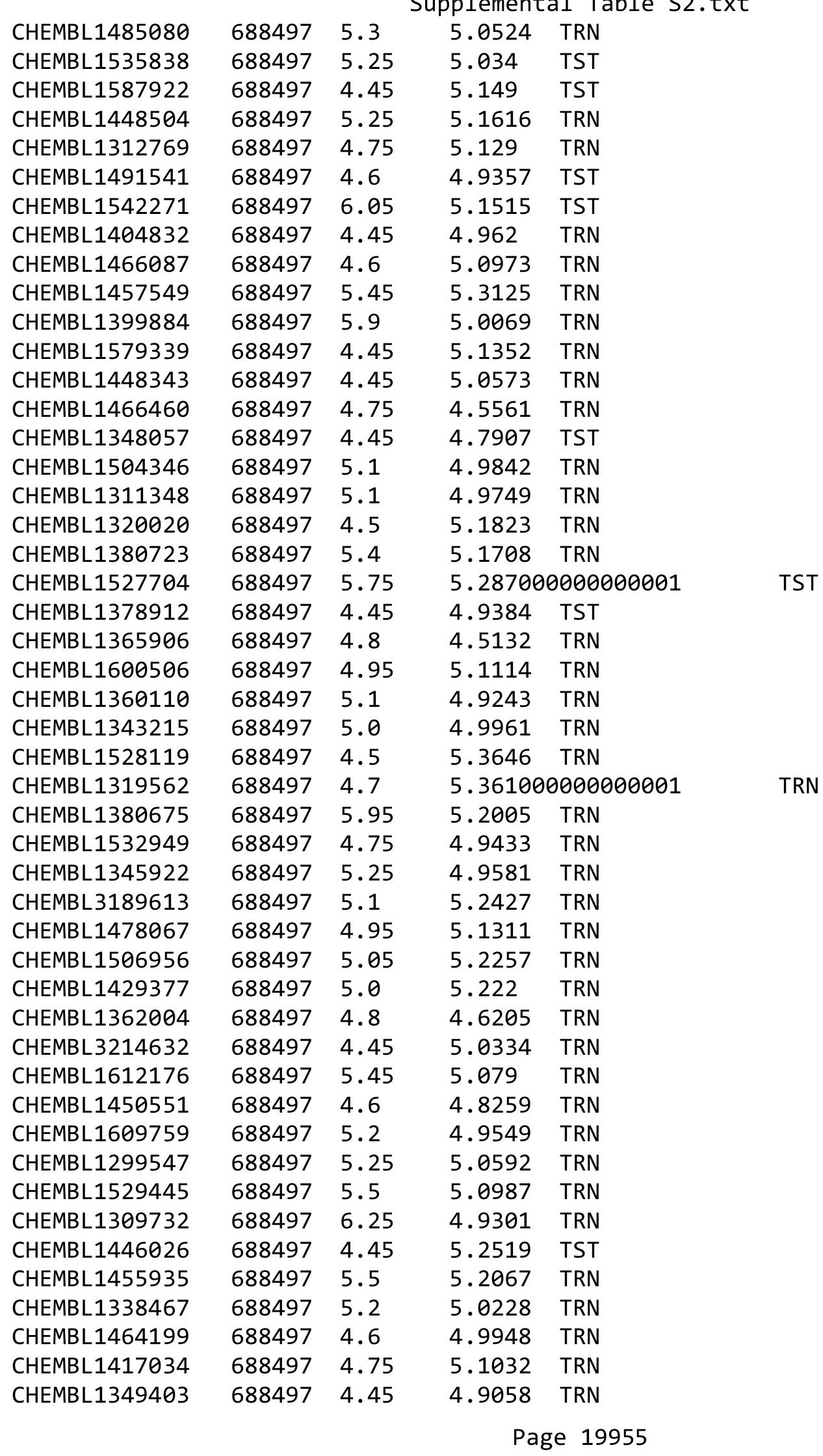




\begin{tabular}{|c|c|c|c|c|}
\hline \multicolumn{5}{|c|}{ Supplemental Table S2.txt } \\
\hline CHEMBL1423622 & 688497 & 4.45 & 4.7947 & TRN \\
\hline CHEMBL1564110 & 688497 & 4.9 & 4.8855 & TST \\
\hline CHEMBL1450076 & 688497 & 4.45 & 4.8718 & TRN \\
\hline CHEMBL1521481 & 688497 & 4.45 & 5.1426 & TRN \\
\hline CHEMBL1371946 & 688497 & 4.7 & 4.8267 & TRN \\
\hline CHEMBL1580220 & 688497 & 4.95 & 4.8868 & TRN \\
\hline CHEMBL1302395 & 688497 & 5.65 & 5.0568 & TRN \\
\hline CHEMBL1583277 & 688497 & 5.9 & 4.9164 & TRN \\
\hline CHEMBL1470463 & 688497 & 6.15 & 4.9524 & TRN \\
\hline CHEMBL565269 & 688497 & 4.65 & 5.0854 & TRN \\
\hline CHEMBL1321333 & 688497 & 4.65 & 4.5658 & TRN \\
\hline CHEMBL1403539 & 688497 & 5.0 & 5.09 & TRN \\
\hline CHEMBL1360793 & 688497 & 5.25 & 4.9376 & TRN \\
\hline CHEMBL1981770 & 688497 & 4.95 & 4.9127 & TRN \\
\hline CHEMBL1510977 & 688497 & 6.1 & 5.0681 & TRN \\
\hline CHEMBL1332860 & 688497 & 5.2 & 4.9371 & TRN \\
\hline CHEMBL1404653 & 688497 & 6.45 & 5.2592 & TRN \\
\hline CHEMBL1598620 & 688497 & 6.2 & 5.1808 & TRN \\
\hline CHEMBL1403351 & 688497 & 6.0 & 4.9061 & TRN \\
\hline CHEMBL1411164 & 688497 & 4.55 & 4.9981 & TRN \\
\hline CHEMBL1342674 & 688497 & 4.55 & 5.1402 & TST \\
\hline CHEMBL1346881 & 688497 & 5.25 & 4.9244 & TRN \\
\hline CHEMBL3210366 & 688497 & 4.8 & 5.1718 & TST \\
\hline CHEMBL1324243 & 688497 & 4.45 & 5.1013 & TST \\
\hline CHEMBL1401909 & 688497 & 6.35 & 5.2657 & TST \\
\hline CHEMBL1519289 & 688497 & 4.7 & 4.708 & TRN \\
\hline CHEMBL1423626 & 688497 & 5.25 & 4.9657 & TST \\
\hline CHEMBL1546915 & 688497 & 4.8 & 5.231 & TRN \\
\hline CHEMBL1391353 & 688497 & 4.65 & 4.8202 & TRN \\
\hline CHEMBL3195689 & 688497 & 4.45 & 5.086 & TRN \\
\hline CHEMBL3199822 & 688497 & 4.85 & 4.7651 & TRN \\
\hline CHEMBL1384903 & 688497 & 4.55 & 5.0359 & TST \\
\hline CHEMBL1331857 & 688497 & 4.45 & 4.9372 & TRN \\
\hline CHEMBL1368794 & 688497 & 4.65 & 4.9865 & TRN \\
\hline CHEMBL1462972 & 688497 & 4.95 & 5.0517 & TRN \\
\hline CHEMBL1468344 & 688497 & 4.95 & 5.1279 & TRN \\
\hline CHEMBL1550752 & 688497 & 5.25 & 4.8016 & TRN \\
\hline CHEMBL1391541 & 688497 & 5.1 & 4.9494 & TST \\
\hline CHEMBL3144885 & 688497 & 5.35 & 5.3243 & TRN \\
\hline CHEMBL3195336 & 688497 & 5.2 & 5.1539 & TRN \\
\hline CHEMBL1392360 & 688497 & 4.9 & 4.9797 & TRN \\
\hline CHEMBL1346092 & 688497 & 4.9 & 4.9427 & TRN \\
\hline CHEMBL1588380 & 688497 & 4.8 & 4.8252 & TRN \\
\hline CHEMBL3207875 & 688497 & 5.0 & 5.3485 & TST \\
\hline CHEMBL1531935 & 688497 & 4.45 & 4.9617 & TRN \\
\hline CHEMBL1523728 & 688497 & 4.65 & 5.0509 & TRN \\
\hline CHEMBL1602957 & 688497 & 4.65 & 4.9095 & TRN \\
\hline CHEMBL1510763 & 688497 & 4.65 & 4.9463 & TST \\
\hline
\end{tabular}




\begin{tabular}{|c|c|c|c|c|c|}
\hline \\
\hline CHEMBL1386370 & 688497 & 6.2 & 5.1083 & TST & \\
\hline CHEMBL1583224 & 688497 & 6.25 & 4.9116 & TRN & \\
\hline CHEMBL1407741 & 688497 & 4.55 & 5.019 & TRN & \\
\hline CHEMBL1446277 & 688497 & 4.8 & 4.7582 & TRN & \\
\hline CHEMBL1354156 & 688497 & 4.45 & 4.9112 & TRN & \\
\hline CHEMBL1570140 & 688497 & 4.5 & 5.0045 & TRN & \\
\hline CHEMBL1463914 & 688497 & 5.5 & 5.0341 & TRN & \\
\hline CHEMBL1335132 & 688497 & 5.2 & 5.1424 & TRN & \\
\hline CHEMBL1488422 & 688497 & 5.5 & 5.3174 & TST & \\
\hline CHEMBL1371815 & 688497 & 4.45 & 5.2408 & TRN & \\
\hline CHEMBL3189786 & 688497 & 4.45 & 5.13200 & $\partial 000000001$ & TRN \\
\hline CHEMBL1560350 & 688497 & 5.0 & 4.9566 & TRN & \\
\hline CHEMBL1439732 & 688497 & 4.45 & 4.7156 & TRN & \\
\hline CHEMBL1544694 & 688497 & 4.8 & 4.9093 & TST & \\
\hline CHEMBL1544111 & 688497 & 4.9 & 5.2643 & TRN & \\
\hline CHEMBL1387077 & 688497 & 4.7 & 4.9266 & TRN & \\
\hline CHEMBL1325826 & 688497 & 4.45 & 4.9845 & TRN & \\
\hline CHEMBL1380557 & 688497 & 4.95 & 5.0955 & TRN & \\
\hline CHEMBL1437809 & 688497 & 5.8 & 5.07600 & 00000000005 & TST \\
\hline CHEMBL1519023 & 688497 & 5.0 & 5.0203 & TRN & \\
\hline CHEMBL1471633 & 688497 & 4.65 & 5.05699 & 99999999995 & TST \\
\hline CHEMBL 207714 & 688497 & 4.7 & 4.9874 & TRN & \\
\hline CHEMBL1319166 & 688497 & 6.3 & 5.1781 & TRN & \\
\hline CHEMBL1400598 & 688497 & 6.1 & 4.9787 & TST & \\
\hline CHEMBL1977653 & 688497 & 5.0 & 5.1758 & TRN & \\
\hline CHEMBL1966241 & 688497 & 6.15 & 5.4266 & TRN & \\
\hline CHEMBL1510973 & 688497 & 5.45 & 4.9635 & TRN & \\
\hline CHEMBL1411948 & 688497 & 4.45 & 5.0743 & TST & \\
\hline CHEMBL1489418 & 688497 & 4.6 & 4.9648 & TRN & \\
\hline CHEMBL 306946 & 688497 & 4.95 & 5.2949 & TRN & \\
\hline CHEMBL1594211 & 688497 & 6.15 & 4.93199 & 99999999995 & TRN \\
\hline CHEMBL1381601 & 688497 & 5.55 & 4.9515 & TRN & \\
\hline CHEMBL1529581 & 688497 & 4.75 & 4.9968 & TRN & \\
\hline CHEMBL3199763 & 688497 & 4.8 & 4.9201 & TRN & \\
\hline CHEMBL1528990 & 688497 & 4.6 & 4.8093 & TST & \\
\hline CHEMBL1510964 & 688497 & 4.45 & 4.6963 & TRN & \\
\hline CHEMBL1490191 & 688497 & 4.45 & 5.336 & TST & \\
\hline CHEMBL1486546 & 688497 & 4.95 & 4.7954 & TRN & \\
\hline CHEMBL 2006634 & 688497 & 4.5 & 5.0446 & TRN & \\
\hline CHEMBL1379510 & 688497 & 5.7 & 5.2829 & TRN & \\
\hline CHEMBL1309655 & 688497 & 5.2 & 5.0081 & TRN & \\
\hline CHEMBL1350777 & 688497 & 5.0 & 4.8218 & TRN & \\
\hline CHEMBL1484842 & 688497 & 5.45 & 5.2013 & TRN & \\
\hline CHEMBL1448733 & 688497 & 4.8 & 4.7963 & TRN & \\
\hline CHEMBL1517737 & 688497 & 5.0 & 4.7375 & TRN & \\
\hline CHEMBL1528383 & 688497 & 4.45 & 4.9082 & TRN & \\
\hline CHEMBL1391325 & 688497 & 4.45 & 4.9047 & TST & \\
\hline CHEMBL3199549 & 688497 & 4.45 & 4.9104 & TRN & \\
\hline
\end{tabular}




\begin{tabular}{|c|c|c|c|c|}
\hline & & & upplement & al \\
\hline CHEMBL1302170 & 688497 & 4.45 & 4.7327 & TST \\
\hline CHEMBL1479060 & 688497 & 4.95 & 5.0152 & TRN \\
\hline CHEMBL1536702 & 688497 & 4.6 & 5.0996 & TRN \\
\hline CHEMBL1452967 & 688497 & 5.55 & 5.0288 & TRN \\
\hline CHEMBL1389482 & 688497 & 4.45 & 5.1864 & TRN \\
\hline CHEMBL1376397 & 688497 & 4.45 & 4.9489 & TRN \\
\hline CHEMBL1489226 & 688497 & 4.5 & 4.6737 & TRN \\
\hline CHEMBL1309888 & 688497 & 4.6 & 5.0508 & TST \\
\hline CHEMBL1381446 & 688497 & 6.25 & 5.0453 & TST \\
\hline CHEMBL1581818 & 688497 & 5.45 & 4.9432 & TST \\
\hline CHEMBL1508400 & 688497 & 6.1 & 5.4966 & TST \\
\hline CHEMBL1599874 & 688497 & 4.95 & 5.0544 & TRN \\
\hline CHEMBL1400185 & 688497 & 4.95 & 4.9637 & TRN \\
\hline CHEMBL1529479 & 688497 & 5.4 & 5.0244 & TST \\
\hline CHEMBL1996315 & 688497 & 4.9 & 5.1118 & TRN \\
\hline CHEMBL3194785 & 688497 & 4.85 & 4.7768 & TST \\
\hline CHEMBL1308118 & 688497 & 4.95 & 5.2656 & TST \\
\hline CHEMBL1542811 & 688497 & 4.45 & 4.7968 & TRN \\
\hline CHEMBL1482990 & 688497 & 4.7 & 5.0614 & TRN \\
\hline CHEMBL3207314 & 688497 & 4.65 & 5.0366 & TRN \\
\hline CHEMBL1336738 & 688497 & 4.75 & 4.851 & TRN \\
\hline CHEMBL1304114 & 688497 & 4.45 & 5.0479 & TRN \\
\hline CHEMBL1301504 & 688497 & 4.7 & 5.1295 & TRN \\
\hline CHEMBL1463786 & 688497 & 5.0 & 5.1741 & TRN \\
\hline CHEMBL1612470 & 688497 & 6.05 & 5.2789 & TRN \\
\hline CHEMBL1578853 & 688497 & 5.2 & 5.3931 & TRN \\
\hline CHEMBL1361727 & 688497 & 4.45 & 4.9111 & TRN \\
\hline CHEMBL1605419 & 688497 & 4.45 & 4.605 & TRN \\
\hline CHEMBL1415422 & 688497 & 4.45 & 5.2099 & TRN \\
\hline CHEMBL1604970 & 688497 & 4.95 & 5.016 & TST \\
\hline CHEMBL1478478 & 688497 & 5.25 & 4.9384 & TRN \\
\hline CHEMBL 260148 & 688497 & 5.0 & 4.7981 & TRN \\
\hline CHEMBL1596725 & 688497 & 4.6 & 5.1922 & TRN \\
\hline CHEMBL1486503 & 688497 & 4.45 & 4.5608 & TRN \\
\hline CHEMBL1549419 & 688497 & 4.5 & 4.6552 & TRN \\
\hline CHEMBL1527445 & 688497 & 4.85 & 5.0262 & TRN \\
\hline CHEMBL1577635 & 688497 & 4.9 & 5.0587 & TRN \\
\hline CHEMBL1537419 & 688497 & 4.75 & 5.0337 & TRN \\
\hline CHEMBL1431230 & 688497 & 5.2 & 5.441 & TRN \\
\hline CHEMBL1494390 & 688497 & 4.65 & 4.4875 & TRN \\
\hline CHEMBL1403345 & 688497 & 4.75 & 4.7243 & TST \\
\hline CHEMBL1612072 & 688497 & 4.45 & 4.9095 & TRN \\
\hline CHEMBL1561688 & 688497 & 4.8 & 5.0516 & TST \\
\hline CHEMBL3198178 & 688497 & 4.65 & 4.9718 & TRN \\
\hline CHEMBL1362552 & 688497 & 4.45 & 4.9945 & TRN \\
\hline CHEMBL1584594 & 688497 & 4.45 & 5.0268 & TRN \\
\hline CHEMBL1303953 & 688497 & 4.75 & 4.6909 & TRN \\
\hline CHEMBL1346063 & 688497 & 5.25 & 5.1344 & TRN \\
\hline
\end{tabular}




\begin{tabular}{|c|c|c|c|c|c|}
\hline \multicolumn{6}{|c|}{ Supplemental Table S2.txt } \\
\hline CHEMBL1566938 & 688497 & 4.45 & 4.7555 & TST & \\
\hline CHEMBL 2001685 & 688497 & 5.75 & 5.0919 & TST & \\
\hline CHEMBL3197498 & 688497 & 5.05 & 5.1897 & TST & \\
\hline CHEMBL1477379 & 688497 & 5.5 & 5.3309 & TRN & \\
\hline CHEMBL1550584 & 688497 & 5.05 & 4.6054 & TST & \\
\hline CHEMBL1427702 & 688497 & 4.45 & 4.7654 & TRN & \\
\hline CHEMBL1501864 & 688497 & 4.45 & 4.7721 & TRN & \\
\hline CHEMBL1511882 & 688497 & 5.0 & 5.0461 & TST & \\
\hline CHEMBL1521239 & 688497 & 4.75 & 4.9011 & TRN & \\
\hline CHEMBL1542693 & 688497 & 4.65 & 4.9428 & TRN & \\
\hline CHEMBL1468183 & 688497 & 4.8 & 4.9482 & TRN & \\
\hline CHEMBL1543745 & 688497 & 6.25 & 5.3122 & TRN & \\
\hline CHEMBL1381283 & 688497 & 6.45 & 5.0652 & TST & \\
\hline CHEMBL1596702 & 688497 & 5.05 & 5.0218 & TRN & \\
\hline CHEMBL1439648 & 688497 & 6.0 & 5.0831 & TST & \\
\hline CHEMBL1467052 & 688497 & 4.45 & 5.1709 & TRN & \\
\hline CHEMBL1452708 & 688497 & 4.85 & 4.8951 & TRN & \\
\hline CHEMBL1345717 & 688497 & 4.6 & 4.8312 & TRN & \\
\hline CHEMBL1359336 & 688497 & 4.45 & 5.0907 & TRN & \\
\hline CHEMBL1567481 & 688497 & 4.45 & 5.3158 & TRN & \\
\hline CHEMBL1406396 & 688497 & 4.6 & 5.1352 & TST & \\
\hline CHEMBL1333900 & 688497 & 4.45 & 4.6872 & TRN & \\
\hline CHEMBL1574132 & 688497 & 5.15 & 5.2761 & TRN & \\
\hline CHEMBL1416494 & 688497 & 5.1 & 5.2754 & TRN & \\
\hline CHEMBL1302488 & 688497 & 4.7 & 4.8495 & TRN & \\
\hline CHEMBL1582269 & 688497 & 5.25 & 4.7334 & TRN & \\
\hline CHEMBL1525932 & 688497 & 5.25 & 5.1257 & TRN & \\
\hline CHEMBL1366190 & 688497 & 6.25 & 5.6403 & TRN & \\
\hline CHEMBL1457472 & 688497 & 4.5 & 4.8564 & TST & \\
\hline CHEMBL1497078 & 688497 & 5.0 & 5.0079 & TRN & \\
\hline CHEMBL1419452 & 688497 & 5.2 & 5.0981 & TRN & \\
\hline CHEMBL1409705 & 688497 & 4.95 & 5.2517 & TST & \\
\hline CHEMBL1509460 & 688497 & 5.2 & 5.05699 & 99999999995 & TRN \\
\hline CHEMBL3197626 & 688497 & 4.95 & 5.1531 & TRN & \\
\hline CHEMBL1531392 & 688497 & 5.0 & 5.1371 & TRN & \\
\hline CHEMBL1505838 & 688497 & 4.45 & 4.9725 & TRN & \\
\hline CHEMBL1256686 & 688497 & 6.05 & 5.1214 & TST & \\
\hline CHEMBL1548195 & 688497 & 6.25 & 5.2653 & TST & \\
\hline CHEMBL1402324 & 688497 & 4.85 & 5.022 & TRN & \\
\hline CHEMBL1302009 & 688497 & 4.65 & 5.0652 & TRN & \\
\hline CHEMBL1519513 & 688497 & 4.65 & 4.9301 & TRN & \\
\hline CHEMBL1458928 & 688497 & 5.25 & 5.2504 & TRN & \\
\hline CHEMBL1978908 & 688497 & 4.5 & 5.1076 & TRN & \\
\hline CHEMBL1505601 & 688497 & 4.7 & 5.0966 & TRN & \\
\hline CHEMBL1602088 & 688497 & 4.85 & 4.9496 & TRN & \\
\hline CHEMBL1568308 & 688497 & 5.25 & 5.1574 & TRN & \\
\hline CHEMBL1534436 & 688497 & 4.6 & 4.9837 & TRN & \\
\hline CHEMBL1498138 & 688497 & 4.8 & 4.6781 & TRN & \\
\hline
\end{tabular}




\begin{tabular}{|c|c|c|c|c|}
\hline & & & pplement & al $\mathrm{Ta}$ \\
\hline CHEMBL1544899 & 688497 & 6.25 & 5.0996 & TRN \\
\hline CHEMBL1458707 & 688497 & 5.1 & 4.9046 & TRN \\
\hline CHEMBL 3190070 & 688497 & 4.45 & 5.0903 & TRN \\
\hline CHEMBL1565563 & 688497 & 4.65 & 4.7775 & TRN \\
\hline CHEMBL3192605 & 688497 & 4.6 & 5.0862 & TRN \\
\hline CHEMBL1324805 & 688497 & 4.45 & 4.7844 & TST \\
\hline CHEMBL1370352 & 688497 & 6.35 & 5.2528 & TRN \\
\hline CHEMBL1501489 & 688497 & 4.65 & 4.8147 & TRN \\
\hline CHEMBL1299439 & 688497 & 4.9 & 4.9571 & TRN \\
\hline CHEMBL1340077 & 688497 & 5.25 & 5.1356 & TST \\
\hline CHEMBL1337370 & 688497 & 4.55 & 5.0781 & TRN \\
\hline CHEMBL1541195 & 688497 & 4.9 & 4.942 & TRN \\
\hline CHEMBL1326972 & 688497 & 5.25 & 5.0859 & TRN \\
\hline CHEMBL1584374 & 688497 & 5.0 & 4.8328 & TRN \\
\hline CHEMBL1576185 & 688497 & 5.15 & 4.7615 & TRN \\
\hline CHEMBL1335377 & 688497 & 4.45 & 5.2617 & TRN \\
\hline CHEMBL1458653 & 688497 & 5.4 & 5.0932 & TRN \\
\hline CHEMBL1525986 & 688497 & 5.2 & 5.0334 & TRN \\
\hline CHEMBL1422252 & 688497 & 4.45 & 5.2702 & TST \\
\hline CHEMBL1421183 & 688497 & 4.45 & 4.7814 & TRN \\
\hline CHEMBL1544212 & 688497 & 4.95 & 4.7529 & TRN \\
\hline CHEMBL1568732 & 688497 & 4.55 & 5.0751 & TRN \\
\hline CHEMBL 1467250 & 688497 & 4.45 & 5.0485 & TRN \\
\hline CHEMBL1980982 & 688497 & 4.5 & 5.0277 & TRN \\
\hline CHEMBL1347599 & 688497 & 5.65 & 5.2348 & TST \\
\hline CHEMBL1455956 & 688497 & 4.45 & 4.8783 & TRN \\
\hline CHEMBL1579752 & 688497 & 5.15 & 4.9731 & TRN \\
\hline CHEMBL1432330 & 688497 & 4.6 & 4.9073 & TST \\
\hline CHEMBL1602376 & 688497 & 4.7 & 4.9726 & TST \\
\hline CHEMBL1310294 & 688497 & 4.45 & 4.7397 & TRN \\
\hline CHEMBL1499214 & 688497 & 4.6 & 4.9674 & TRN \\
\hline CHEMBL1441088 & 688497 & 4.8 & 4.6355 & TRN \\
\hline CHEMBL1381941 & 688497 & 4.95 & 5.3195 & TRN \\
\hline CHEMBL1327183 & 688497 & 5.9 & 5.0834 & TST \\
\hline CHEMBL1608983 & 688497 & 4.9 & 4.8655 & TST \\
\hline CHEMBL1427155 & 688497 & 4.8 & 5.2302 & TRN \\
\hline CHEMBL1481464 & 688497 & 5.05 & 5.1879 & TRN \\
\hline CHEMBL 2005317 & 688497 & 4.5 & 4.9956 & TRN \\
\hline CHEMBL 3198813 & 688497 & 4.95 & 4.7926 & TRN \\
\hline CHEMBL1336054 & 688497 & 5.15 & 4.8178 & TRN \\
\hline CHEMBL1403470 & 688497 & 4.45 & 5.0826 & TRN \\
\hline CHEMBL1601701 & 688497 & 4.5 & 5.2265 & TST \\
\hline CHEMBL3144895 & 688497 & 4.6 & 4.7482 & TRN \\
\hline CHEMBL1492700 & 688497 & 4.55 & 4.9641 & TRN \\
\hline CHEMBL1425067 & 688497 & 4.95 & 5.062 & TST \\
\hline CHEMBL1392358 & 688497 & 5.25 & 4.7336 & TST \\
\hline CHEMBL1549224 & 688497 & 4.45 & 4.9173 & TRN \\
\hline CHEMBL1325723 & 688497 & 4.9 & 4.8962 & TST \\
\hline
\end{tabular}




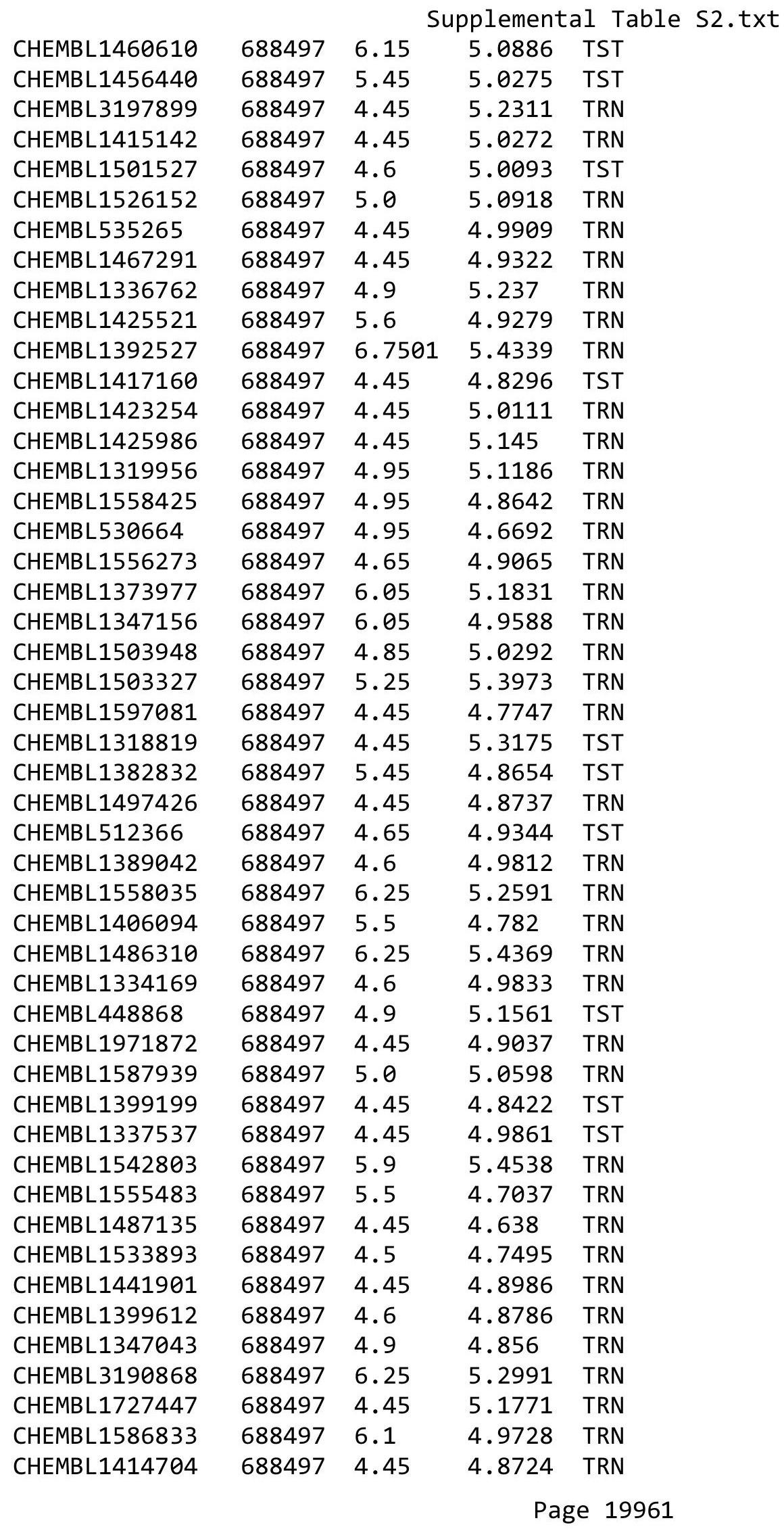




\begin{tabular}{|c|c|c|c|c|c|}
\hline \multicolumn{6}{|c|}{ Supplemental Table S2.txt } \\
\hline CHEMBL1402986 & 688497 & 6.25 & 5.3731 & TRN & \\
\hline CHEMBL1371339 & 688497 & 4.45 & 5.2624 & TRN & \\
\hline CHEMBL1537300 & 688497 & 4.45 & 5.0325 & TRN & \\
\hline CHEMBL1409708 & 688497 & 5.8 & 5.3539 & TRN & \\
\hline CHEMBL1300497 & 688497 & 5.0 & 5.1385 & TRN & \\
\hline CHEMBL1497771 & 688497 & 4.45 & 4.8825 & TRN & \\
\hline CHEMBL1521414 & 688497 & 4.45 & 4.6777 & TRN & \\
\hline CHEMBL1348119 & 688497 & 5.05 & 4.8772 & TRN & \\
\hline CHEMBL1380507 & 688497 & 5.75 & 4.9575 & TRN & \\
\hline CHEMBL1566687 & 688497 & 5.0 & 5.2318 & TRN & \\
\hline CHEMBL1496738 & 688497 & 4.8 & 5.4279 & TST & \\
\hline CHEMBL1511080 & 688497 & 4.6 & 5.1568 & TST & \\
\hline CHEMBL1321193 & 688497 & 4.45 & 4.7606 & TRN & \\
\hline CHEMBL571700 & 688497 & 5.5 & 5.3856 & TST & \\
\hline CHEMBL1549267 & 688497 & 4.45 & 4.6592 & TST & \\
\hline CHEMBL1526115 & 688497 & 4.45 & 5.1581 & TRN & \\
\hline CHEMBL1503011 & 688497 & 7.0501 & 5.4721 & TRN & \\
\hline CHEMBL1465422 & 688497 & 5.1 & 4.978 & TRN & \\
\hline CHEMBL1323854 & 688497 & 4.45 & 4.7029 & TRN & \\
\hline CHEMBL1323186 & 688497 & 4.45 & 4.7032 & TRN & \\
\hline CHEMBL1321662 & 688497 & 4.95 & 4.71399 & 99999999995 & TRN \\
\hline CHEMBL1562875 & 688497 & 4.45 & 5.1002 & TRN & \\
\hline CHEMBL1299591 & 688497 & 4.45 & 4.9045 & TRN & \\
\hline CHEMBL1485369 & 688497 & 5.4 & 4.8239 & TRN & \\
\hline CHEMBL1524035 & 688497 & 4.6 & 5.4005 & TRN & \\
\hline CHEMBL1424419 & 688497 & 4.45 & 4.9377 & TST & \\
\hline CHEMBL1369339 & 688497 & 4.8 & 4.8927 & TRN & \\
\hline CHEMBL1416484 & 688497 & 4.45 & 4.687 & TRN & \\
\hline CHEMBL1471737 & 688497 & 4.65 & 4.80399 & 9999999999 & TRN \\
\hline CHEMBL 3212448 & 688497 & 4.45 & 4.9528 & TRN & \\
\hline CHEMBL1359215 & 688497 & 5.1 & 5.1216 & TRN & \\
\hline CHEMBL1588976 & 688497 & 4.45 & 4.8042 & TRN & \\
\hline CHEMBL1537509 & 688497 & 6.3 & 5.3838 & TST & \\
\hline CHEMBL1548122 & 688497 & 4.45 & 5.0283 & TST & \\
\hline CHEMBL1468838 & 688497 & 4.45 & 4.7178 & TRN & \\
\hline CHEMBL1543657 & 688497 & 5.9 & 5.2089 & TRN & \\
\hline CHEMBL1559776 & 688497 & 4.95 & 5.2188 & TRN & \\
\hline CHEMBL1351173 & 688497 & 5.45 & 5.0647 & TRN & \\
\hline CHEMBL1488174 & 688497 & 6.0 & 5.3661 & TST & \\
\hline CHEMBL1364268 & 688497 & 5.05 & 4.89199 & 99999999995 & TRN \\
\hline CHEMBL1559459 & 688497 & 4.45 & 4.7403 & TRN & \\
\hline CHEMBL3194606 & 688497 & 5.25 & 4.9753 & TRN & \\
\hline CHEMBL1571433 & 688497 & 5.15 & 4.8663 & TRN & \\
\hline CHEMBL1984764 & 688497 & 4.85 & 4.9244 & TRN & \\
\hline CHEMBL1976567 & 688497 & 4.45 & 4.88 & TRN & \\
\hline CHEMBL1596985 & 688497 & 5.15 & 5.0946 & TRN & \\
\hline CHEMBL602969 & 688497 & 4.9 & 5.1462 & TST & \\
\hline CHEMBL1537008 & 688497 & 5.95 & 5.0731 & TST & \\
\hline
\end{tabular}




\begin{tabular}{|c|c|c|c|c|}
\hline \multicolumn{5}{|c|}{ Supplemental Table S2.txt } \\
\hline CHEMBL1369594 & 688497 & 5.3 & 4.8461 & TST \\
\hline CHEMBL1546822 & 688497 & 4.45 & 5.131 & TRN \\
\hline CHEMBL1385284 & 688497 & 5.15 & 5.3917 & TRN \\
\hline CHEMBL1371837 & 688497 & 4.95 & 5.3247 & TST \\
\hline CHEMBL1302626 & 688497 & 4.7 & 4.9897 & TRN \\
\hline CHEMBL1420393 & 688497 & 4.45 & 4.9134 & TRN \\
\hline CHEMBL1602222 & 688497 & 4.45 & 4.8506 & TST \\
\hline CHEMBL1449705 & 688497 & 4.45 & 5.0649 & TST \\
\hline CHEMBL1611206 & 688497 & 6.25 & 5.2608 & TRN \\
\hline CHEMBL3197784 & 688497 & 7.0 & 5.1352 & TST \\
\hline CHEMBL1520103 & 688497 & 6.3 & 5.2212 & TRN \\
\hline CHEMBL1458892 & 688497 & 4.8 & 5.3331 & TRN \\
\hline CHEMBL1613298 & 688497 & 4.45 & 4.9303 & TRN \\
\hline CHEMBL1370343 & 688497 & 4.8 & 5.1195 & TRN \\
\hline CHEMBL1380900 & 688497 & 4.95 & 4.7577 & TRN \\
\hline CHEMBL1465431 & 688497 & 4.45 & 5.3233 & TRN \\
\hline CHEMBL1320102 & 688497 & 4.45 & 4.6186 & TRN \\
\hline CHEMBL1429737 & 688497 & 5.6 & 5.466 & TRN \\
\hline CHEMBL1568173 & 688497 & 4.9 & 5.1527 & TRN \\
\hline CHEMBL1390711 & 688497 & 4.95 & 5.0062 & TRN \\
\hline CHEMBL1431256 & 688497 & 5.15 & 5.0774 & TST \\
\hline CHEMBL1508480 & 688497 & 5.45 & 4.9843 & TRN \\
\hline CHEMBL1566654 & 688497 & 4.45 & 5.2104 & TST \\
\hline CHEMBL1450935 & 688497 & 4.85 & 5.181 & TRN \\
\hline CHEMBL1334167 & 688497 & 4.45 & 5.1505 & TST \\
\hline CHEMBL1505293 & 688497 & 4.85 & 4.9694 & TRN \\
\hline CHEMBL1498231 & 688497 & 4.45 & 5.1058 & TRN \\
\hline CHEMBL3198239 & 688497 & 4.8 & 4.8666 & TRN \\
\hline CHEMBL1507201 & 688497 & 4.45 & 4.9967 & TST \\
\hline CHEMBL1300591 & 688497 & 6.3 & 5.2423 & TRN \\
\hline CHEMBL1490852 & 688497 & 4.85 & 4.9769 & TRN \\
\hline CHEMBL1398660 & 688497 & 4.8 & 5.0654 & TST \\
\hline CHEMBL 3189856 & 688497 & 4.65 & 4.9082 & TRN \\
\hline CHEMBL1379687 & 688497 & 5.25 & 4.7912 & TRN \\
\hline CHEMBL1360296 & 688497 & 5.1 & 5.0184 & TRN \\
\hline CHEMBL1441493 & 688497 & 4.45 & 5.0826 & TRN \\
\hline CHEMBL1430979 & 688497 & 5.45 & 5.0561 & TST \\
\hline CHEMBL3190606 & 688497 & 4.5 & 4.9342 & TRN \\
\hline CHEMBL1432490 & 688497 & 4.8 & 5.188 & TRN \\
\hline CHEMBL1581233 & 688497 & 4.9 & 4.8788 & TRN \\
\hline CHEMBL1335676 & 688497 & 4.45 & 5.1304 & TST \\
\hline CHEMBL1344930 & 688497 & 5.5 & 5.2791 & TRN \\
\hline CHEMBL1427308 & 688497 & 5.45 & 4.9579 & TRN \\
\hline CHEMBL3210134 & 688497 & 5.25 & 5.1647 & TST \\
\hline CHEMBL3213061 & 688497 & 5.45 & 5.2353 & TRN \\
\hline CHEMBL1992631 & 688497 & 4.45 & 4.9302 & TRN \\
\hline CHEMBL1471271 & 688497 & 4.45 & 5.1309 & TST \\
\hline CHEMBL3194563 & 688497 & 5.4 & 5.0492 & TRN \\
\hline
\end{tabular}




\begin{tabular}{|c|c|c|c|c|}
\hline \multicolumn{5}{|c|}{ Supplemental Table S2.txt } \\
\hline CHEMBL1324638 & 688497 & 4.45 & 4.9148 & TRN \\
\hline CHEMBL3193168 & 688497 & 4.45 & 4.6594 & TRN \\
\hline CHEMBL1351145 & 688497 & 4.85 & 4.9864 & TRN \\
\hline CHEMBL 3196124 & 688497 & 5.85 & 5.2376 & TRN \\
\hline CHEMBL 1464738 & 688497 & 5.25 & 4.7946 & TRN \\
\hline CHEMBL1501233 & 688497 & 4.45 & 5.0968 & TRN \\
\hline CHEMBL1493956 & 688497 & 4.45 & 5.02 & TRN \\
\hline CHEMBL1350513 & 688497 & 6.2 & 4.8124 & TRN \\
\hline CHEMBL1562852 & 688497 & 4.85 & 5.1779 & TRN \\
\hline CHEMBL1393096 & 688497 & 4.45 & 4.869 & TRN \\
\hline CHEMBL1545200 & 688497 & 6.2 & 4.8809 & TST \\
\hline CHEMBL536375 & 688497 & 4.8 & 4.72 & TRN \\
\hline CHEMBL1492570 & 688497 & 4.6 & 5.2292 & TRN \\
\hline CHEMBL1442170 & 688497 & 5.2 & 4.8442 & TRN \\
\hline CHEMBL1543636 & 688497 & 4.45 & 4.8955 & TRN \\
\hline CHEMBL1412095 & 688497 & 6.0 & 5.4571 & TRN \\
\hline CHEMBL1502014 & 688497 & 5.1 & 4.7307 & TRN \\
\hline CHEMBL1420460 & 688497 & 5.5 & 4.9702 & TRN \\
\hline CHEMBL1458412 & 688497 & 4.6 & 4.997 & TRN \\
\hline CHEMBL1407008 & 688497 & 4.45 & 4.9217 & TST \\
\hline CHEMBL1533045 & 688497 & 5.25 & 5.0911 & TST \\
\hline CHEMBL1417347 & 688497 & 6.25 & 4.8119 & TRN \\
\hline CHEMBL1351340 & 688497 & 4.45 & 5.0205 & TST \\
\hline CHEMBL1460315 & 688497 & 4.95 & 5.0467 & TRN \\
\hline CHEMBL1611041 & 688497 & 4.6 & 4.5985 & TST \\
\hline CHEMBL1493843 & 688497 & 5.95 & 5.1347 & TRN \\
\hline CHEMBL1303089 & 688497 & 4.45 & 4.6747 & TRN \\
\hline CHEMBL1603776 & 688497 & 4.75 & 5.2045 & TST \\
\hline CHEMBL1302681 & 688497 & 4.55 & 4.9742 & TRN \\
\hline CHEMBL1305645 & 688497 & 5.0 & 5.0261 & TRN \\
\hline CHEMBL1363815 & 688497 & 4.7 & 4.9282 & TRN \\
\hline CHEMBL1518570 & 688497 & 4.5 & 5.2073 & TRN \\
\hline CHEMBL1412538 & 688497 & 4.95 & 4.6273 & TRN \\
\hline CHEMBL1573909 & 688497 & 4.6 & 4.8662 & TRN \\
\hline CHEMBL1362152 & 688497 & 4.65 & 5.2134 & TRN \\
\hline CHEMBL1372119 & 688497 & 5.35 & 5.0535 & TRN \\
\hline CHEMBL 1450825 & 688497 & 4.75 & 4.7471 & TRN \\
\hline CHEMBL1332603 & 688497 & 5.25 & 5.0989 & TST \\
\hline CHEMBL1437829 & 688497 & 5.5 & 4.9946 & TRN \\
\hline CHEMBL1352660 & 688497 & 4.45 & 5.2952 & TRN \\
\hline CHEMBL1477515 & 688497 & 6.25 & 4.834 & TRN \\
\hline CHEMBL1417992 & 688497 & 4.95 & 5.3774 & TRN \\
\hline CHEMBL1599003 & 688497 & 5.25 & 5.2967 & TRN \\
\hline CHEMBL1411892 & 688497 & 4.45 & 5.2557 & TRN \\
\hline CHEMBL1387205 & 688497 & 5.1 & 4.8865 & TRN \\
\hline CHEMBL1422562 & 688497 & 5.25 & 5.2133 & TRN \\
\hline CHEMBL1413274 & 688497 & 4.6 & 4.9186 & TRN \\
\hline CHEMBL1347487 & 688497 & 4.7 & 5.1877 & TST \\
\hline
\end{tabular}




\begin{tabular}{|c|c|c|c|c|c|}
\hline \multicolumn{6}{|c|}{ Supplemental Table S2.txt } \\
\hline CHEMBL1496706 & 688497 & 4.5 & 4.9795 & TRN & \\
\hline CHEMBL3211392 & 688497 & 4.45 & 5.0906 & TRN & \\
\hline CHEMBL3199537 & 688497 & 5.5 & 5.1938 & TRN & \\
\hline CHEMBL1421894 & 688497 & 4.6 & 5.1778 & TRN & \\
\hline CHEMBL1341395 & 688497 & 4.45 & 4.8596 & TRN & \\
\hline CHEMBL1540576 & 688497 & 4.65 & 4.7683 & TRN & \\
\hline CHEMBL530361 & 688497 & 5.0 & $4.9510 e$ & 00000000005 & TRN \\
\hline CHEMBL1538215 & 688497 & 4.45 & 4.9026 & TRN & \\
\hline CHEMBL1496007 & 688497 & 4.75 & 4.9319 & TRN & \\
\hline CHEMBL1544060 & 688497 & 4.55 & 5.0138 & TRN & \\
\hline CHEMBL1336397 & 688497 & 4.45 & 4.6742 & TRN & \\
\hline CHEMBL1320669 & 688497 & 5.95 & 5.4695 & TRN & \\
\hline CHEMBL1388170 & 688497 & 4.85 & 5.3451 & TRN & \\
\hline CHEMBL1334872 & 688497 & 4.45 & 4.668 & TRN & \\
\hline CHEMBL1349745 & 688497 & 4.45 & 5.0485 & TRN & \\
\hline CHEMBL1402229 & 688497 & 6.3 & 5.2154 & TST & \\
\hline CHEMBL1491064 & 688497 & 4.65 & 4.9008 & TRN & \\
\hline CHEMBL1582852 & 688497 & 4.85 & 4.9424 & TRN & \\
\hline CHEMBL1454029 & 688497 & 5.25 & 5.1775 & TST & \\
\hline CHEMBL1487566 & 688497 & 4.45 & 5.2391 & TRN & \\
\hline CHEMBL1310878 & 688497 & 4.45 & 4.8313 & TRN & \\
\hline CHEMBL1504866 & 688497 & 5.15 & 4.9497 & TRN & \\
\hline CHEMBL1481019 & 688497 & 4.85 & 5.0616 & TRN & \\
\hline CHEMBL1370995 & 688497 & 4.45 & 4.68 & TST & \\
\hline CHEMBL1571950 & 688497 & 5.9 & 5.1545 & TRN & \\
\hline CHEMBL1487624 & 688497 & 5.85 & 5.12799 & 9999999999 & TRN \\
\hline CHEMBL1432981 & 688497 & 4.45 & 4.9488 & TRN & \\
\hline CHEMBL1404846 & 688497 & 4.6 & 4.8164 & TRN & \\
\hline CHEMBL1340976 & 688497 & 6.3 & 5.1113 & TRN & \\
\hline CHEMBL1389813 & 688497 & 4.85 & 5.1371 & TRN & \\
\hline CHEMBL1382858 & 688497 & 4.45 & 4.96399 & 99999999995 & TRN \\
\hline CHEMBL1493620 & 688497 & 4.75 & 4.7463 & TRN & \\
\hline CHEMBL1335725 & 688497 & 6.1 & 5.2324 & TRN & \\
\hline CHEMBL1486012 & 688497 & 4.65 & 4.8593 & TRN & \\
\hline CHEMBL585213 & 688497 & 5.0 & 4.9329 & TRN & \\
\hline CHEMBL1354014 & 688497 & 4.9 & 5.2149 & TST & \\
\hline CHEMBL1486325 & 688497 & 5.0 & 5.2294 & TRN & \\
\hline CHEMBL1374269 & 688497 & 5.4 & 5.2579 & TRN & \\
\hline CHEMBL1389438 & 688497 & 5.25 & 4.9435 & TRN & \\
\hline CHEMBL1345437 & 688497 & 4.8 & 4.9867 & TRN & \\
\hline CHEMBL1431036 & 688497 & 4.45 & 4.7672 & TST & \\
\hline CHEMBL1562926 & 688497 & 6.05 & $5.4520 e$ & 0000000001 & TRN \\
\hline CHEMBL1403180 & 688497 & 4.6 & 4.7436 & TRN & \\
\hline CHEMBL1392003 & 688497 & 4.45 & 4.7635 & TRN & \\
\hline CHEMBL1521733 & 688497 & 5.1 & 4.8446 & TST & \\
\hline CHEMBL1341560 & 688497 & 4.45 & 4.6498 & TRN & \\
\hline CHEMBL1347702 & 688497 & 5.55 & 5.5648 & TST & \\
\hline CHEMBL1303061 & 688497 & 4.8 & 5.1185 & TRN & \\
\hline
\end{tabular}




\begin{tabular}{|c|c|c|c|c|c|}
\hline \multicolumn{6}{|c|}{ Supplemental Table S2.txt } \\
\hline CHEMBL1409032 & 688497 & 5.0 & 5.0722 & TRN & \\
\hline CHEMBL1353980 & 688497 & 5.8 & 5.189 & TRN & \\
\hline CHEMBL1595573 & 688497 & 4.45 & 5.0262 & TRN & \\
\hline CHEMBL1517100 & 688497 & 4.95 & 4.9455 & TRN & \\
\hline CHEMBL1433119 & 688497 & 4.45 & 4.9371 & TRN & \\
\hline CHEMBL1529827 & 688497 & 4.45 & 5.0003 & TST & \\
\hline CHEMBL 3194379 & 688497 & 5.25 & 4.8861 & TST & \\
\hline CHEMBL1363360 & 688497 & 6.2 & 5.1905 & TST & \\
\hline CHEMBL1598091 & 688497 & 4.45 & 4.7455 & TRN & \\
\hline CHEMBL1442919 & 688497 & 4.95 & 4.8313 & TRN & \\
\hline CHEMBL1329031 & 688497 & 5.25 & 4.6562 & TRN & \\
\hline CHEMBL 1456900 & 688497 & 4.9 & 5.2615 & TRN & \\
\hline CHEMBL 3193534 & 688497 & 5.0 & 5.1402 & TRN & \\
\hline CHEMBL1323237 & 688497 & 5.45 & 4.92899 & 9999999999 & TST \\
\hline CHEMBL1488954 & 688497 & 4.9 & 4.7794 & TRN & \\
\hline CHEMBL1561229 & 688497 & 5.4 & 5.2812 & TRN & \\
\hline CHEMBL1505174 & 688497 & 4.45 & 4.8093 & TST & \\
\hline CHEMBL1488996 & 688497 & 4.45 & 4.8693 & TRN & \\
\hline CHEMBL1602367 & 688497 & 4.9 & 5.0737 & TRN & \\
\hline CHEMBL1312225 & 688497 & 5.25 & 4.9318 & TRN & \\
\hline CHEMBL 3192395 & 688497 & 4.5 & 5.4088 & TST & \\
\hline CHEMBL1558433 & 688497 & 4.45 & 4.9729 & TRN & \\
\hline CHEMBL1507704 & 688497 & 4.55 & 4.902 & TST & \\
\hline CHEMBL1613165 & 688497 & 5.45 & 5.2255 & TST & \\
\hline CHEMBL1340400 & 688497 & 5.7 & 4.9191 & TRN & \\
\hline CHEMBL1303049 & 688497 & 5.4 & 4.9874 & TRN & \\
\hline CHEMBL1572390 & 688497 & 4.45 & 5.1275 & TRN & \\
\hline CHEMBL1546439 & 688497 & 4.85 & 5.0521 & TRN & \\
\hline CHEMBL1345633 & 688497 & 6.25 & 4.8658 & TRN & \\
\hline CHEMBL1362388 & 688497 & 7.0501 & 4.9759 & TST & \\
\hline CHEMBL1510947 & 688497 & 5.25 & 5.153 & TRN & \\
\hline CHEMBL1505206 & 688497 & 5.2 & 4.8485 & TRN & \\
\hline CHEMBL1597600 & 688497 & 4.45 & 4.9196 & TRN & \\
\hline CHEMBL 3145287 & 688497 & 5.0 & $5.0310 e$ & 2000000001 & TRN \\
\hline CHEMBL 3196834 & 688497 & 4.8 & 5.0144 & TST & \\
\hline CHEMBL1371520 & 688497 & 4.45 & 4.5989 & TRN & \\
\hline CHEMBL1479729 & 688497 & 4.7 & 4.6681 & TRN & \\
\hline CHEMBL1975959 & 688497 & 5.45 & 5.0343 & TST & \\
\hline CHEMBL1422539 & 688497 & 4.7 & 4.6628 & TRN & \\
\hline CHEMBL1507474 & 688497 & 4.8 & 4.8667 & TRN & \\
\hline CHEMBL1337592 & 688497 & 4.45 & 4.5271 & TRN & \\
\hline CHEMBL1612290 & 688497 & 5.5 & 5.1952 & TRN & \\
\hline CHEMBL1305298 & 688497 & 5.95 & 5.2532 & TRN & \\
\hline CHEMBL1456749 & 688497 & 5.5 & 5.3459 & TRN & \\
\hline CHEMBL1336911 & 688497 & 4.75 & 4.7311 & TRN & \\
\hline CHEMBL1599740 & 688497 & 4.45 & 5.0548 & TRN & \\
\hline CHEMBL579424 & 688497 & 4.65 & 5.0299 & TRN & \\
\hline CHEMBL1997747 & 688497 & 5.4 & 4.9574 & TRN & \\
\hline
\end{tabular}




\begin{tabular}{|c|c|c|c|c|c|}
\hline \multicolumn{6}{|c|}{ Supplemental Table S2.txt } \\
\hline CHEMBL388676 & 688497 & 4.85 & 5.3451 & TST & \\
\hline CHEMBL564979 & 688497 & 4.95 & 5.0791 & TRN & \\
\hline CHEMBL1410350 & 688497 & 5.75 & 5.4208 & TRN & \\
\hline CHEMBL1420325 & 688497 & 5.25 & 4.9787 & TST & \\
\hline CHEMBL1449587 & 688497 & 5.0 & 5.2547 & TRN & \\
\hline CHEMBL1596732 & 688497 & 4.45 & 5.0191 & TRN & \\
\hline CHEMBL1563747 & 688497 & 4.6 & 4.8518 & TRN & \\
\hline CHEMBL1426498 & 688497 & 4.85 & 4.8623 & TST & \\
\hline CHEMBL1342035 & 688497 & 4.45 & 5.0215 & TRN & \\
\hline CHEMBL1539085 & 688497 & 4.45 & 4.8543 & TST & \\
\hline CHEMBL1299945 & 688497 & 4.95 & 4.8758 & TRN & \\
\hline CHEMBL1558506 & 688497 & 4.65 & 4.9163 & TST & \\
\hline CHEMBL1497876 & 688497 & 5.0 & 5.0795 & TRN & \\
\hline CHEMBL1500619 & 688497 & 4.9 & 4.9057 & TRN & \\
\hline CHEMBL3192970 & 688497 & 4.95 & 4.9973 & TST & \\
\hline CHEMBL1305572 & 688497 & 4.9 & 5.1084 & TRN & \\
\hline CHEMBL1310221 & 688497 & 4.95 & 5.0888 & TRN & \\
\hline CHEMBL1442312 & 688497 & 4.9 & 4.8397 & TRN & \\
\hline CHEMBL1362524 & 688497 & 4.45 & 4.8298 & TRN & \\
\hline CHEMBL1543659 & 688497 & 6.25 & 5.1986 & TRN & \\
\hline CHEMBL1468589 & 688497 & 4.45 & 5.4197 & TRN & \\
\hline CHEMBL1521617 & 688497 & 4.55 & 4.7961 & TRN & \\
\hline CHEMBL1449794 & 688497 & 5.35 & 4.7156 & TRN & \\
\hline CHEMBL1430289 & 688497 & 5.6 & 5.3382 & TRN & \\
\hline CHEMBL1543327 & 688497 & 4.45 & 5.2943 & TRN & \\
\hline CHEMBL1571834 & 688497 & 5.8 & 5.5769 & TRN & \\
\hline CHEMBL1311557 & 688497 & 5.65 & 5.0919 & TST & \\
\hline CHEMBL1532707 & 688497 & 4.75 & 4.9692 & TRN & \\
\hline CHEMBL1526624 & 688497 & 5.45 & 4.7127 & TRN & \\
\hline CHEMBL1369328 & 688497 & 4.45 & 5.3141 & TST & \\
\hline CHEMBL1322031 & 688497 & 4.45 & 4.8909 & TRN & \\
\hline CHEMBL1419201 & 688497 & 5.7 & 4.9884 & TRN & \\
\hline CHEMBL1380787 & 688497 & 5.2 & 4.8554 & TRN & \\
\hline CHEMBL1607657 & 688497 & 4.5 & 5.0474 & TRN & \\
\hline CHEMBL3210789 & 688497 & 4.9 & 5.2102 & TRN & \\
\hline CHEMBL602363 & 688497 & 4.7 & 5.1401 & TST & \\
\hline CHEMBL1450288 & 688497 & 4.45 & 4.9315 & TRN & \\
\hline CHEMBL1472183 & 688497 & 4.45 & 5.3201 & TST & \\
\hline CHEMBL1447915 & 688497 & 5.2 & 5.24100 & 00000000005 & TRN \\
\hline CHEMBL1578011 & 688497 & 4.45 & 4.8459 & TRN & \\
\hline CHEMBL1454742 & 688497 & 4.9 & 5.0103 & TRN & \\
\hline CHEMBL1381984 & 688497 & 5.45 & 4.8095 & TRN & \\
\hline CHEMBL1545945 & 688497 & 4.7 & 4.9513 & TRN & \\
\hline CHEMBL1439012 & 688497 & 4.85 & 5.5719 & TRN & \\
\hline CHEMBL1345981 & 688497 & 5.0 & 5.0206 & TRN & \\
\hline CHEMBL1479876 & 688497 & 4.45 & 4.8171 & TRN & \\
\hline CHEMBL1342018 & 688497 & 4.45 & 4.8947 & TRN & \\
\hline CHEMBL1488298 & 688497 & 5.0 & 5.2102 & TRN & \\
\hline
\end{tabular}




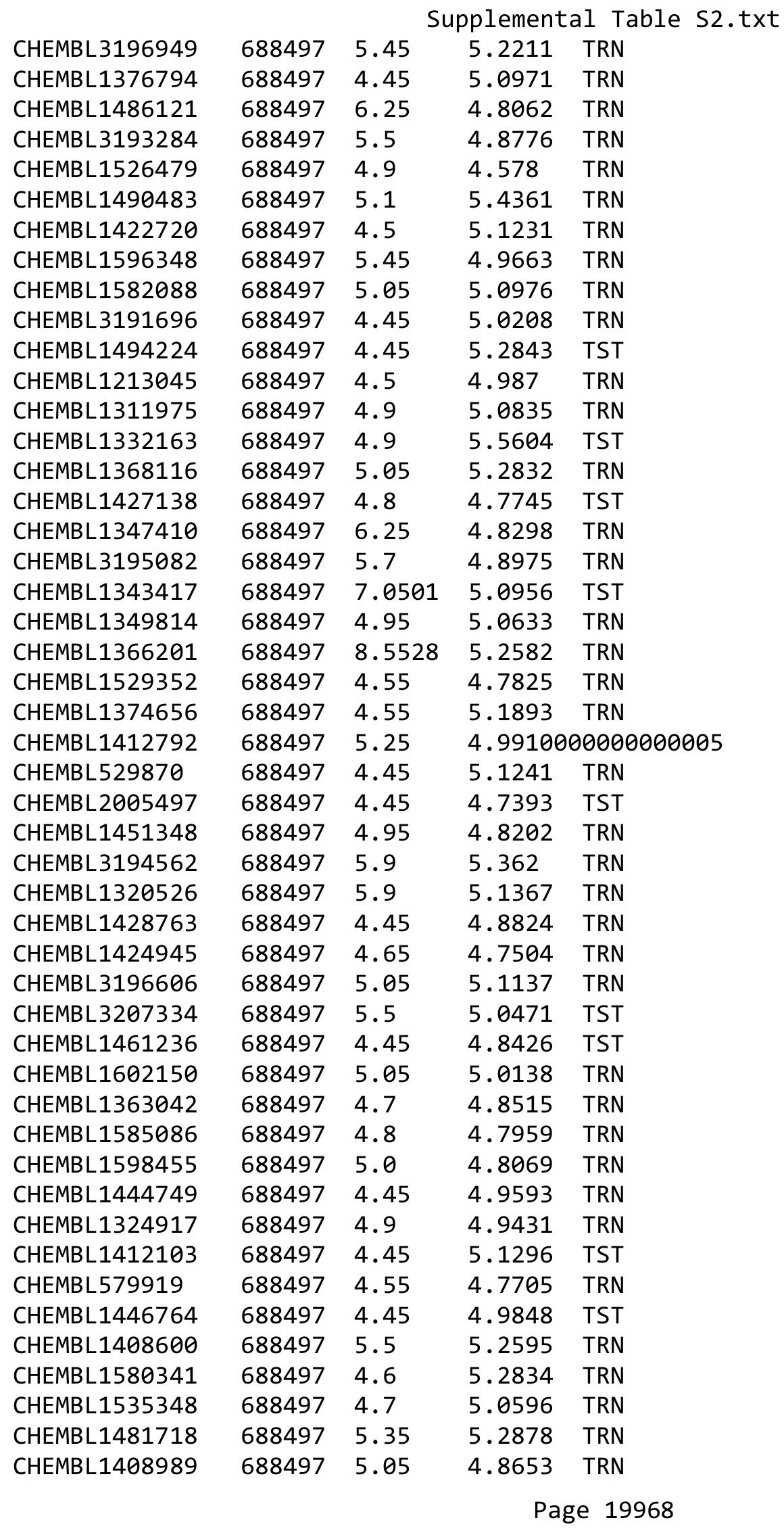

TRN 


\begin{tabular}{|c|c|c|c|c|}
\hline \multicolumn{5}{|c|}{ Supplemental Table S2.txt } \\
\hline CHEMBL1542668 & 688497 & 4.6 & 4.881 & TRN \\
\hline CHEMBL1483291 & 688497 & 4.95 & 5.0158 & TRN \\
\hline CHEMBL1603099 & 688497 & 4.45 & 5.0291 & TST \\
\hline CHEMBL1596363 & 688497 & 5.2 & 5.0951 & TRN \\
\hline CHEMBL1313756 & 688497 & 5.1 & 5.4637 & TRN \\
\hline CHEMBL1421685 & 688497 & 6.25 & 5.2156 & TST \\
\hline CHEMBL1323518 & 688497 & 5.25 & 4.9806 & TRN \\
\hline CHEMBL1518566 & 688497 & 5.4 & 4.8271 & TST \\
\hline CHEMBL1534154 & 688497 & 4.75 & 5.0447 & TRN \\
\hline CHEMBL1405039 & 688497 & 5.8 & 5.0398 & TRN \\
\hline CHEMBL 3211742 & 688497 & 4.5 & 5.1859 & TST \\
\hline CHEMBL1453108 & 688497 & 6.0 & 5.1768 & TRN \\
\hline CHEMBL1367319 & 688497 & 5.9 & 5.2708 & TRN \\
\hline CHEMBL1426384 & 688497 & 5.25 & 5.1603 & TST \\
\hline CHEMBL1526856 & 688497 & 5.4 & 4.9837 & TRN \\
\hline CHEMBL1612529 & 688497 & 4.95 & 5.1047 & TRN \\
\hline CHEMBL1344059 & 688497 & 4.75 & 4.625 & TRN \\
\hline CHEMBL1374415 & 688497 & 5.45 & 5.098 & TRN \\
\hline CHEMBL1539580 & 688497 & 6.25 & 5.0965 & TST \\
\hline CHEMBL1318998 & 688497 & 4.6 & 4.7362 & TRN \\
\hline CHEMBL65 & 688497 & 5.25 & 5.9797 & TRN \\
\hline CHEMBL1530125 & 688497 & 5.2 & 5.153 & TRN \\
\hline CHEMBL1547916 & 688497 & 5.4 & 5.0095 & TST \\
\hline CHEMBL1361490 & 688497 & 4.85 & 5.3152 & TRN \\
\hline CHEMBL1441983 & 688497 & 4.45 & 4.7608 & TRN \\
\hline CHEMBL1422494 & 688497 & 4.45 & 5.3249 & TST \\
\hline CHEMBL1586062 & 688497 & 4.95 & 4.8071 & TRN \\
\hline CHEMBL1335121 & 688497 & 4.6 & 4.9334 & TST \\
\hline CHEMBL1472235 & 688497 & 5.25 & 4.7782 & TRN \\
\hline CHEMBL193627 & 688497 & 6.0 & 5.7065 & TRN \\
\hline CHEMBL1309290 & 688497 & 4.6 & 4.635 & TRN \\
\hline CHEMBL1383944 & 688497 & 5.2 & 5.0542 & TRN \\
\hline CHEMBL1563269 & 688497 & 5.0 & 4.9393 & TRN \\
\hline CHEMBL1444632 & 688497 & 6.1 & 5.2856 & TST \\
\hline CHEMBL1385110 & 688497 & 5.55 & 5.3399 & TRN \\
\hline CHEMBL1422795 & 688497 & 4.7 & 5.151 & TRN \\
\hline CHEMBL 1455512 & 688497 & 4.45 & 4.9606 & TRN \\
\hline CHEMBL1388983 & 688497 & 5.45 & 4.6872 & TRN \\
\hline CHEMBL1350661 & 688497 & 4.65 & 5.5594 & TRN \\
\hline CHEMBL1345545 & 688497 & 6.0 & 5.2623 & TRN \\
\hline CHEMBL1453109 & 688497 & 4.95 & 4.6758 & TRN \\
\hline CHEMBL3197083 & 688497 & 6.25 & 5.2488 & TRN \\
\hline CHEMBL1482191 & 688497 & 4.8 & 4.8922 & TRN \\
\hline CHEMBL1425477 & 688497 & 4.6 & 5.1491 & TRN \\
\hline CHEMBL1303862 & 688497 & 4.95 & 5.2346 & TST \\
\hline CHEMBL1521914 & 688497 & 6.25 & 5.1812 & TRN \\
\hline CHEMBL1613136 & 688497 & 5.15 & 4.9782 & TRN \\
\hline CHEMBL1597921 & 688497 & 5.0 & 5.0592 & TRN \\
\hline
\end{tabular}




\begin{tabular}{|c|c|c|c|c|c|}
\hline \multicolumn{6}{|c|}{ Supplemental Table S2.txt } \\
\hline CHEMBL1450555 & 688497 & 4.65 & 4.7452 & TRN & \\
\hline CHEMBL1546624 & 688497 & 5.2 & 4.7162 & TRN & \\
\hline CHEMBL1982934 & 688497 & 4.6 & 5.188 & TRN & \\
\hline CHEMBL1564814 & 688497 & 4.45 & 5.0535 & TRN & \\
\hline CHEMBL1610067 & 688497 & 4.45 & 4.8773 & TRN & \\
\hline CHEMBL1489943 & 688497 & 5.55 & 4.8915 & TST & \\
\hline CHEMBL1450384 & 688497 & 5.85 & 5.0109 & TRN & \\
\hline CHEMBL1402887 & 688497 & 4.8 & 5.1481 & TRN & \\
\hline CHEMBL1599106 & 688497 & 4.45 & 5.33 & TRN & \\
\hline CHEMBL1348253 & 688497 & 5.2 & 5.1646 & TRN & \\
\hline CHEMBL236357 & 688497 & 4.75 & 5.0005 & TRN & \\
\hline CHEMBL1612603 & 688497 & 5.8 & 5.005 & TRN & \\
\hline CHEMBL1321895 & 688497 & 4.45 & 5.1295 & TRN & \\
\hline CHEMBL1306232 & 688497 & 4.45 & 4.8606 & TRN & \\
\hline CHEMBL1572265 & 688497 & 4.45 & 5.048 & TRN & \\
\hline CHEMBL1460277 & 688497 & 5.1 & 4.8749 & TRN & \\
\hline CHEMBL1504112 & 688497 & 5.2 & 4.6019 & TRN & \\
\hline CHEMBL1521656 & 688497 & 5.6 & 4.9258 & TRN & \\
\hline CHEMBL1571872 & 688497 & 5.35 & 5.1812 & TRN & \\
\hline CHEMBL1377866 & 688497 & 5.25 & 5.1896 & TST & \\
\hline CHEMBL1594236 & 688497 & 6.25 & 5.2831 & TRN & \\
\hline CHEMBL1523918 & 688497 & 4.45 & 4.8865 & TRN & \\
\hline CHEMBL1400003 & 688497 & 4.95 & 4.9425 & TRN & \\
\hline CHEMBL1507996 & 688497 & 4.65 & 4.9377 & TST & \\
\hline CHEMBL1428842 & 688497 & 6.3 & 5.3164 & TRN & \\
\hline CHEMBL1564696 & 688497 & 4.45 & 5.0809 & TRN & \\
\hline CHEMBL1380650 & 688497 & 7.6003 & 5.3283 & TRN & \\
\hline CHEMBL1398789 & 688497 & 5.25 & 5.0984 & TST & \\
\hline CHEMBL1421470 & 688497 & 4.95 & 4.995 & TRN & \\
\hline CHEMBL1324397 & 688497 & 4.6 & 4.6411 & TRN & \\
\hline CHEMBL1609696 & 688497 & 4.75 & 4.8312 & TRN & \\
\hline CHEMBL3194330 & 688497 & 5.05 & 5.0344 & TST & \\
\hline CHEMBL1336351 & 688497 & 4.9 & 5.0076 & TRN & \\
\hline CHEMBL3189725 & 688497 & 4.95 & 5.2541 & TRN & \\
\hline CHEMBL1424702 & 688497 & 5.0 & 5.1229 & TRN & \\
\hline CHEMBL1422435 & 688497 & 4.45 & 4.9674 & TRN & \\
\hline CHEMBL1609516 & 688497 & 4.95 & 5.3707 & TRN & \\
\hline CHEMBL1505153 & 688497 & 4.45 & 4.8199 & TRN & \\
\hline CHEMBL1563455 & 688497 & 4.45 & 4.8063 & TRN & \\
\hline CHEMBL1342990 & 688497 & 4.45 & 4.6401 & TRN & \\
\hline CHEMBL1345040 & 688497 & 4.9 & 5.2962 & TRN & \\
\hline CHEMBL1544203 & 688497 & 5.9 & 5.16100 & 00000000005 & TRN \\
\hline CHEMBL1341078 & 688497 & 5.0 & 5.0946 & TRN & \\
\hline CHEMBL3211859 & 688497 & 4.45 & 5.3605 & TRN & \\
\hline CHEMBL1311383 & 688497 & 4.45 & 4.7812 & TRN & \\
\hline CHEMBL1380630 & 688497 & 5.85 & 5.15799 & 99999999995 & TRN \\
\hline CHEMBL1611319 & 688497 & 4.45 & 5.2934 & TRN & \\
\hline CHEMBL3193225 & 688497 & 4.95 & 4.9769 & TRN & \\
\hline
\end{tabular}




\begin{tabular}{|c|c|c|c|c|c|}
\hline \multicolumn{6}{|c|}{ Supplemental Table S2.txt } \\
\hline CHEMBL1577665 & 688497 & 4.9 & 5.1126 & TRN & \\
\hline CHEMBL1382198 & 688497 & 4.55 & 4.9621 & TRN & \\
\hline CHEMBL1383072 & 688497 & 4.65 & 5.1463 & TRN & \\
\hline CHEMBL1505548 & 688497 & 4.8 & 4.7985 & TRN & \\
\hline CHEMBL1508437 & 688497 & 4.6 & 4.8781 & TST & \\
\hline CHEMBL1342894 & 688497 & 5.6 & 5.5357 & TRN & \\
\hline CHEMBL1990783 & 688497 & 5.55 & 5.4336 & TRN & \\
\hline CHEMBL1584477 & 688497 & 4.85 & 5.1148 & TRN & \\
\hline CHEMBL1585026 & 688497 & 4.95 & 4.9095 & TRN & \\
\hline CHEMBL1311101 & 688497 & 4.8 & 4.9004 & TRN & \\
\hline CHEMBL1341219 & 688497 & 4.55 & 5.2606 & TRN & \\
\hline CHEMBL1367685 & 688497 & 4.7 & 5.0716 & TST & \\
\hline CHEMBL1566471 & 688497 & 5.4 & 4.76399 & 9999999999 & TST \\
\hline CHEMBL1385436 & 688497 & 5.5 & 5.1418 & TRN & \\
\hline CHEMBL1580975 & 688497 & 5.25 & 5.2547 & TRN & \\
\hline CHEMBL1375326 & 688497 & 4.6 & 4.7234 & TRN & \\
\hline CHEMBL1462337 & 688497 & 4.45 & 4.9945 & TRN & \\
\hline CHEMBL1446126 & 688497 & 5.25 & 5.2685 & TST & \\
\hline CHEMBL1383376 & 688497 & 4.85 & 5.0432 & TRN & \\
\hline CHEMBL1383625 & 688497 & 4.65 & 4.9857 & TST & \\
\hline CHEMBL1351862 & 688497 & 4.45 & 4.8904 & TRN & \\
\hline CHEMBL1486191 & 688497 & 5.6 & 5.3466 & TRN & \\
\hline CHEMBL1421764 & 688497 & 4.45 & 4.6095 & TRN & \\
\hline CHEMBL1595841 & 688497 & 5.9 & 4.8596 & TST & \\
\hline CHEMBL1361432 & 688497 & 5.65 & 5.1405 & TRN & \\
\hline CHEMBL1422690 & 688497 & 4.45 & 4.9288 & TRN & \\
\hline CHEMBL1527005 & 688497 & 4.45 & 4.8847 & TRN & \\
\hline CHEMBL1326484 & 688497 & 4.45 & 5.1708 & TST & \\
\hline CHEMBL3144830 & 688497 & 4.45 & 5.066 & TRN & \\
\hline CHEMBL1583469 & 688497 & 6.05 & 5.2438 & TRN & \\
\hline CHEMBL1584673 & 688497 & 4.5 & 5.1057 & TRN & \\
\hline CHEMBL1412184 & 688497 & 6.0 & 4.6917 & TRN & \\
\hline CHEMBL1377168 & 688497 & 5.45 & 4.9086 & TRN & \\
\hline CHEMBL1992486 & 688497 & 5.25 & 5.2109 & TRN & \\
\hline CHEMBL1449107 & 688497 & 4.45 & 4.9604 & TRN & \\
\hline CHEMBL1598023 & 688497 & 4.45 & 4.9468 & TRN & \\
\hline CHEMBL1326829 & 688497 & 7.0501 & 5.3189 & TST & \\
\hline CHEMBL1546987 & 688497 & 4.45 & 4.8438 & TRN & \\
\hline CHEMBL1607013 & 688497 & 4.45 & 4.9032 & TRN & \\
\hline CHEMBL1418181 & 688497 & 4.45 & 5.2702 & TRN & \\
\hline CHEMBL3210266 & 688497 & 5.9 & 4.9646 & TRN & \\
\hline CHEMBL 3213748 & 688497 & 4.45 & 5.0879 & TST & \\
\hline CHEMBL1459835 & 688497 & 4.45 & 4.7989 & TRN & \\
\hline CHEMBL1406472 & 688497 & 4.45 & 4.77800 & 00000000005 & TRN \\
\hline CHEMBL1483321 & 688497 & 4.45 & 4.9767 & TRN & \\
\hline CHEMBL1385643 & 688497 & 6.45 & 5.1393 & TRN & \\
\hline CHEMBL1312946 & 688497 & 5.4 & 5.189 & TRN & \\
\hline CHEMBL1405342 & 688497 & 4.75 & 5.0559 & TRN & \\
\hline
\end{tabular}




\begin{tabular}{|c|c|c|c|c|c|}
\hline CHEMBL1485813 & 688497 & 5.6 & 4.9766 & TST & \\
\hline CHEMBL1419305 & 688497 & 5.5 & 5.2978 & TST & \\
\hline CHEMBL1413758 & 688497 & 5.9 & 4.8096 & TRN & \\
\hline CHEMBL1487031 & 688497 & 5.7 & 5.0817 & TRN & \\
\hline CHEMBL1353219 & 688497 & 4.95 & \multicolumn{2}{|c|}{5.0889999999999995} & TST \\
\hline CHEMBL1382993 & 688497 & 4.95 & 4.9102 & TRN & \\
\hline CHEMBL1448617 & 688497 & 5.05 & 4.8588 & TRN & \\
\hline CHEMBL1477416 & 688497 & 4.8 & 5.3928 & TRN & \\
\hline CHEMBL1321531 & 688497 & 4.45 & 5.1836 & TRN & \\
\hline CHEMBL1425652 & 688497 & 4.45 & 4.7403 & TST & \\
\hline CHEMBL1982304 & 688497 & 4.45 & \multicolumn{2}{|c|}{4.7780000000000005} & TRN \\
\hline CHEMBL1566731 & 688497 & 4.45 & 4.8551 & TRN & \\
\hline CHEMBL3194088 & 688497 & 5.6 & 5.1953 & TRN & \\
\hline CHEMBL1388001 & 688497 & 4.45 & 5.176 & TST & \\
\hline CHEMBL1437992 & 688497 & 4.85 & 5.3581 & TRN & \\
\hline CHEMBL1301271 & 688497 & 5.4 & 4.757 & TRN & \\
\hline CHEMBL1346547 & 688497 & 4.85 & 5.0289 & TRN & \\
\hline CHEMBL1351838 & 688497 & 5.0 & 5.0749 & TRN & \\
\hline CHEMBL1299579 & 688497 & 5.25 & 4.8916 & TRN & \\
\hline CHEMBL1545959 & 688497 & 4.45 & 4.9424 & TRN & \\
\hline CHEMBL600734 & 688497 & 5.05 & 5.0636 & TRN & \\
\hline CHEMBL1469715 & 688497 & 5.15 & 4.8736 & TRN & \\
\hline CHEMBL1446445 & 688497 & 4.75 & 4.7918 & TRN & \\
\hline CHEMBL1391123 & 688497 & 5.25 & 4.9091 & TRN & \\
\hline CHEMBL1388950 & 688497 & 4.45 & 4.8155 & TRN & \\
\hline CHEMBL1602759 & 688497 & 5.35 & 5.0725 & TRN & \\
\hline CHEMBL1401188 & 688497 & 4.45 & 5.0759 & TRN & \\
\hline CHEMBL1531932 & 688497 & 4.6 & 4.8531 & TST & \\
\hline CHEMBL1386146 & 688497 & 4.95 & 4.8948 & TRN & \\
\hline CHEMBL1391727 & 688497 & 4.55 & 5.1526 & TRN & \\
\hline CHEMBL1545676 & 688497 & 4.45 & 4.8466 & TRN & \\
\hline CHEMBL1489638 & 688497 & 5.45 & 5.1538 & TRN & \\
\hline CHEMBL1343883 & 688497 & 4.45 & 4.7876 & TRN & \\
\hline CHEMBL1560057 & 688497 & 6.0 & 5.2493 & TRN & \\
\hline CHEMBL1420356 & 688497 & 6.1 & 4.9701 & TRN & \\
\hline CHEMBL1323899 & 688497 & 5.05 & 5.1967 & TRN & \\
\hline CHEMBL1348126 & 688497 & 5.65 & 5.2633 & TRN & \\
\hline CHEMBL1578578 & 688497 & 4.55 & 4.8097 & TRN & \\
\hline CHEMBL1406480 & 688497 & 4.7 & 5.1661 & TRN & \\
\hline CHEMBL1600657 & 688497 & 4.8 & 4.8846 & TRN & \\
\hline CHEMBL1582440 & 688497 & 4.75 & 4.9227 & TST & \\
\hline CHEMBL1415926 & 688497 & 4.8 & 4.6671 & TRN & \\
\hline CHEMBL1469486 & 688497 & 5.6 & 5.0685 & TRN & \\
\hline CHEMBL1340133 & 688497 & 4.45 & 5.0048 & TRN & \\
\hline CHEMBL1504506 & 688497 & 4.45 & 5.2792 & TRN & \\
\hline CHEMBL1441589 & 688497 & 4.45 & 5.0928 & TST & \\
\hline CHEMBL1464823 & 688497 & 4.45 & 5.062 & TRN & \\
\hline CHEMBL 3144890 & 688497 & 4.45 & 4.822 & TST & \\
\hline
\end{tabular}




\begin{tabular}{|c|c|c|c|c|c|}
\hline \multicolumn{6}{|c|}{ Supplemental Table S2.txt } \\
\hline CHEMBL1533366 & 688497 & 5.0 & 5.0035 & TRN & \\
\hline CHEMBL324389 & 688497 & 4.45 & 4.8771 & TRN & \\
\hline CHEMBL1459671 & 688497 & 5.65 & 5.1428 & TST & \\
\hline CHEMBL1448592 & 688497 & 4.9 & $5.5520 e$ & 00000000005 & TRN \\
\hline CHEMBL1518454 & 688497 & 5.25 & 5.0336 & TRN & \\
\hline CHEMBL1331990 & 688497 & 6.4 & 5.4204 & TRN & \\
\hline CHEMBL1587526 & 688497 & 7.5498 & 5.2209 & TRN & \\
\hline CHEMBL1484185 & 688497 & 4.6 & 4.806 & TRN & \\
\hline CHEMBL1564517 & 688497 & 4.95 & 5.0801 & TST & \\
\hline CHEMBL1404213 & 688497 & 5.9 & $5.4520 e$ & 0000000001 & TRN \\
\hline CHEMBL1605275 & 688497 & 5.4 & 4.9641 & TST & \\
\hline CHEMBL 3190684 & 688497 & 4.9 & 5.0746 & TRN & \\
\hline CHEMBL1604229 & 688497 & 5.8 & 4.9119 & TRN & \\
\hline CHEMBL3211998 & 688497 & 5.0 & 5.0027 & TRN & \\
\hline CHEMBL1375808 & 688497 & 6.2 & 5.3114 & TRN & \\
\hline CHEMBL3212912 & 688497 & 4.9 & 5.0566 & TRN & \\
\hline CHEMBL1572095 & 688497 & 4.65 & 4.8204 & TRN & \\
\hline CHEMBL1556148 & 688497 & 4.45 & 5.0732 & TST & \\
\hline CHEMBL1611108 & 688497 & 5.9 & 5.317 & TRN & \\
\hline CHEMBL1527002 & 688497 & 6.3 & 5.3068 & TRN & \\
\hline CHEMBL1447733 & 688497 & 4.9 & 5.3753 & TST & \\
\hline CHEMBL1578993 & 688497 & 4.45 & 4.9316 & TRN & \\
\hline CHEMBL1500650 & 688497 & 4.95 & 4.7807 & TST & \\
\hline CHEMBL1509278 & 688497 & 4.45 & 4.9017 & TRN & \\
\hline CHEMBL1508519 & 688497 & 4.5 & 5.1472 & TRN & \\
\hline CHEMBL1520491 & 688497 & 4.85 & 4.967 & TRN & \\
\hline CHEMBL1438963 & 688497 & 5.9 & 5.5259 & TRN & \\
\hline CHEMBL1597416 & 688497 & 4.95 & 4.9315 & TRN & \\
\hline CHEMBL1520926 & 688497 & 6.9 & 5.3387 & TRN & \\
\hline CHEMBL1353915 & 688497 & 6.25 & 5.0813 & TRN & \\
\hline CHEMBL1412199 & 688497 & 5.25 & 4.9699 & TRN & \\
\hline CHEMBL3194469 & 688497 & 6.1 & 5.0488 & TRN & \\
\hline CHEMBL1447186 & 688497 & 5.05 & 5.2066 & TRN & \\
\hline CHEMBL1337583 & 688497 & 4.45 & 5.3872 & TST & \\
\hline CHEMBL1381498 & 688497 & 4.85 & 5.093 & TRN & \\
\hline CHEMBL1494874 & 688497 & 5.45 & 5.1576 & TST & \\
\hline CHEMBL1428190 & 688497 & 5.25 & 5.016 & TRN & \\
\hline CHEMBL1986557 & 688497 & 4.45 & 4.993 & TRN & \\
\hline CHEMBL1557465 & 688497 & 5.05 & 4.8469 & TRN & \\
\hline CHEMBL1452671 & 688497 & 4.9 & 4.8934 & TRN & \\
\hline CHEMBL1444354 & 688497 & 5.0 & 4.8514 & TRN & \\
\hline CHEMBL1492919 & 688497 & 5.65 & 4.9381 & TRN & \\
\hline CHEMBL1483882 & 688497 & 4.95 & 4.91 & TRN & \\
\hline CHEMBL1417379 & 688497 & 5.5 & 4.9363 & TST & \\
\hline CHEMBL1605218 & 688497 & 4.6 & 5.088 & TRN & \\
\hline CHEMBL1607011 & 688497 & 4.45 & 4.9657 & TRN & \\
\hline CHEMBL1573621 & 688497 & 6.05 & 5.0447 & TRN & \\
\hline CHEMBL1609326 & 688497 & 5.7 & 5.0493 & TRN & \\
\hline
\end{tabular}




\begin{tabular}{|c|c|c|c|c|c|}
\hline \multicolumn{6}{|c|}{ Supplemental Table s2.txt } \\
\hline CHEMBL1585695 & 688497 & 4.65 & 5.3007 & TRN & \\
\hline CHEMBL3207664 & 688497 & 4.9 & 5.0817 & TST & \\
\hline CHEMBL1303855 & 688497 & 6.3 & 5.3309 & TRN & \\
\hline CHEMBL1603054 & 688497 & 5.9 & 4.8231 & TRN & \\
\hline CHEMBL1495521 & 688497 & 4.9 & 4.9635 & TRN & \\
\hline CHEMBL1371666 & 688497 & 4.7 & 4.9353 & TST & \\
\hline CHEMBL1477919 & 688497 & 4.45 & 5.2214 & TRN & \\
\hline CHEMBL1422004 & 688497 & 4.9 & 5.3065 & TST & \\
\hline CHEMBL1495412 & 688497 & 4.9 & 5.1995 & TRN & \\
\hline CHEMBL1412008 & 688497 & 6.1 & 4.8221 & TRN & \\
\hline CHEMBL1470729 & 688497 & 5.55 & 4.9011 & TRN & \\
\hline CHEMBL1448251 & 688497 & 4.45 & 4.8621 & TRN & \\
\hline CHEMBL1588500 & 688497 & 4.8 & 4.8077 & TST & \\
\hline CHEMBL3197988 & 688497 & 6.45 & 4.8981 & TRN & \\
\hline CHEMBL1368728 & 688497 & 4.95 & 5.2881 & TRN & \\
\hline CHEMBL1571446 & 688497 & 5.0 & 5.0692 & TST & \\
\hline CHEMBL1352853 & 688497 & 5.0 & 4.8408 & TRN & \\
\hline CHEMBL1531094 & 688497 & 5.2 & 5.0923 & TRN & \\
\hline CHEMBL1608171 & 688497 & 4.9 & 4.9937 & TRN & \\
\hline CHEMBL 2007448 & 688497 & 5.45 & 4.7344 & TRN & \\
\hline CHEMBL1460296 & 688497 & 4.95 & 5.1898 & TST & \\
\hline CHEMBL3192850 & 688497 & 4.9 & 4.8681 & TRN & \\
\hline CHEMBL1335627 & 688497 & 4.45 & 5.0735 & TST & \\
\hline CHEMBL1467940 & 688497 & 4.95 & 5.0679 & TRN & \\
\hline CHEMBL1532909 & 688497 & 6.2 & 5.2252 & TST & \\
\hline CHEMBL1609296 & 688497 & 4.45 & 5.1131 & TRN & \\
\hline CHEMBL1548574 & 688497 & 4.45 & 5.104 & TRN & \\
\hline CHEMBL1598185 & 688497 & 4.45 & 5.0008 & TRN & \\
\hline CHEMBL1588016 & 688497 & 5.45 & 5.03 & TRN & \\
\hline CHEMBL1324123 & 688497 & 5.05 & 5.1593 & TRN & \\
\hline CHEMBL1332841 & 688497 & 5.3 & 5.1507 & TRN & \\
\hline CHEMBL1452636 & 688497 & 5.1 & 5.2084 & TST & \\
\hline CHEMBL1414053 & 688497 & 6.1 & 5.0602 & TRN & \\
\hline CHEMBL1456751 & 688497 & 5.0 & 5.5735 & TRN & \\
\hline CHEMBL1401596 & 688497 & 4.9 & 4.9032 & TRN & \\
\hline CHEMBL1587170 & 688497 & 4.95 & 5.1532 & TRN & \\
\hline CHEMBL3196761 & 688497 & 4.8 & 4.9705 & TRN & \\
\hline CHEMBL1400596 & 688497 & 4.45 & 4.913 & TRN & \\
\hline CHEMBL1594554 & 688497 & 6.8499 & 5.1546 & TRN & \\
\hline CHEMBL1384525 & 688497 & 4.45 & 5.0717 & TRN & \\
\hline CHEMBL1495227 & 688497 & 4.75 & 4.7968 & TRN & \\
\hline CHEMBL1545990 & 688497 & 4.6 & 5.0935 & TST & \\
\hline CHEMBL1411210 & 688497 & 5.45 & 4.9426 & TRN & \\
\hline CHEMBL1545291 & 688497 & 5.5 & 5.21299 & 9999999999 & TST \\
\hline CHEMBL1576168 & 688497 & 4.45 & 4.8436 & TRN & \\
\hline CHEMBL1346610 & 688497 & 4.95 & 4.7285 & TRN & \\
\hline CHEMBL1980204 & 688497 & 4.6 & 4.7342 & TRN & \\
\hline CHEMBL1308328 & 688497 & 4.85 & 5.29899 & 99999999995 & TRN \\
\hline & & & & 19974 & \\
\hline
\end{tabular}




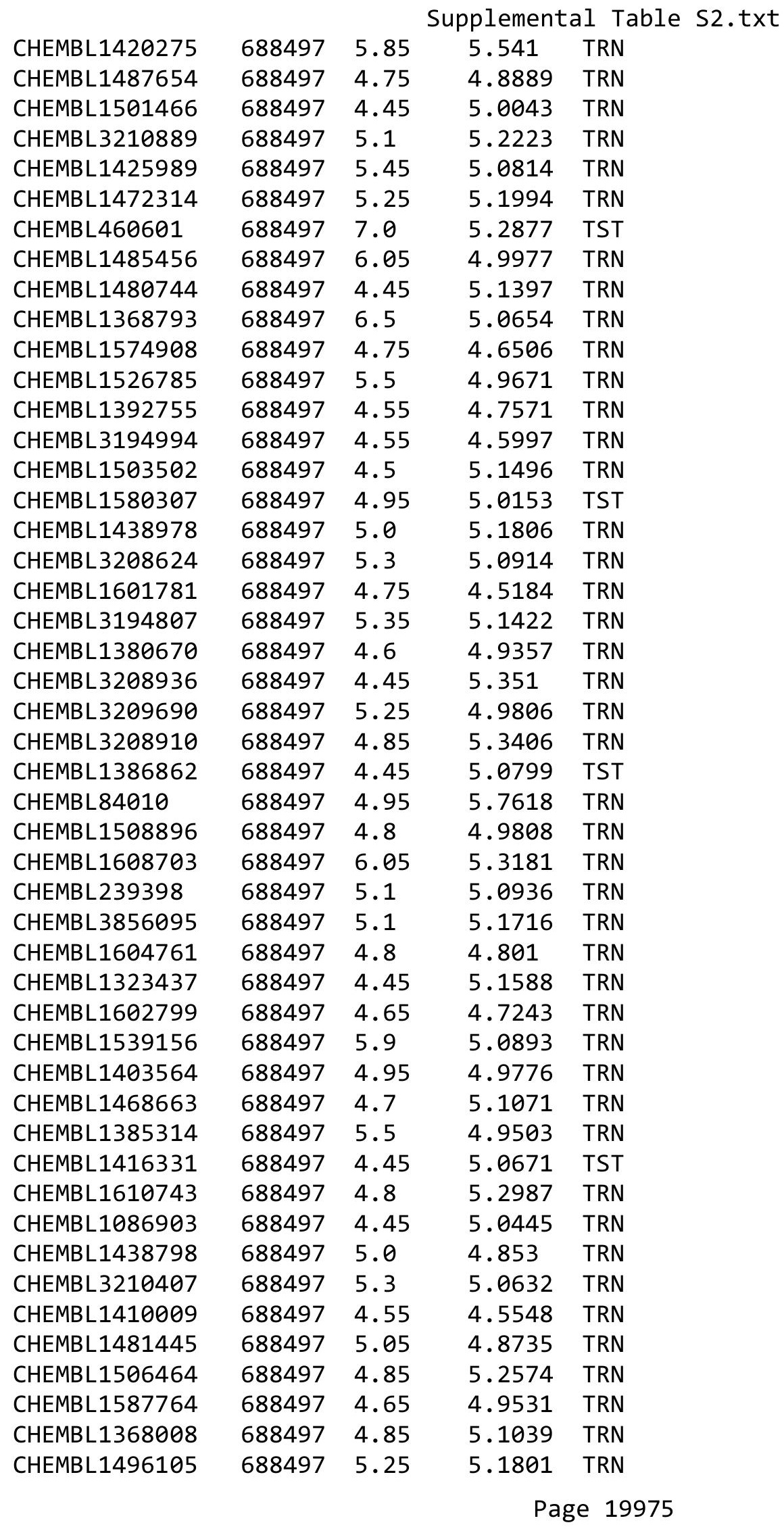




\begin{tabular}{|c|c|c|c|c|c|}
\hline \\
\hline CHEMBL1511041 & 688497 & 5.5 & 5.003 & TRN & \\
\hline CHEMBL1440630 & 688497 & 5.9 & 5.2831 & TRN & \\
\hline CHEMBL1429728 & 688497 & 4.9 & 4.7758 & TRN & \\
\hline CHEMBL1561866 & 688497 & 4.85 & 5.4321 & TRN & \\
\hline CHEMBL1508735 & 688497 & 4.45 & 4.7694 & TRN & \\
\hline CHEMBL1341674 & 688497 & 4.45 & 4.7987 & TST & \\
\hline CHEMBL1483468 & 688497 & 4.75 & 4.7214 & TRN & \\
\hline CHEMBL1565344 & 688497 & 5.25 & 5.1685 & TST & \\
\hline CHEMBL1510103 & 688497 & 4.5 & 4.8697 & TRN & \\
\hline CHEMBL1532104 & 688497 & 4.65 & 5.0473 & TRN & \\
\hline CHEMBL1503636 & 688497 & 4.45 & 5.0095 & TRN & \\
\hline CHEMBL1331247 & 688497 & 4.45 & 4.8934 & TST & \\
\hline CHEMBL1471669 & 688497 & 5.2 & 5.1504 & TRN & \\
\hline CHEMBL3193736 & 688497 & 4.7 & 4.9095 & TRN & \\
\hline CHEMBL1456662 & 688497 & 4.45 & 4.6837 & TRN & \\
\hline CHEMBL1603432 & 688497 & 6.2 & 5.3725 & TRN & \\
\hline CHEMBL1451973 & 688497 & 5.9 & 5.3259 & TRN & \\
\hline CHEMBL1582153 & 688497 & 6.45 & 4.8587 & TRN & \\
\hline CHEMBL1444767 & 688497 & 4.45 & 4.8219 & TRN & \\
\hline CHEMBL1442568 & 688497 & 8.3468 & 5.54799 & 9999999999 & TRN \\
\hline CHEMBL1380830 & 688497 & 5.05 & 4.9933 & TST & \\
\hline CHEMBL1498509 & 688497 & 5.35 & 5.0877 & TRN & \\
\hline CHEMBL1486590 & 688497 & 6.3 & 5.2564 & TST & \\
\hline CHEMBL1369251 & 688497 & 5.55 & 5.1288 & TRN & \\
\hline CHEMBL1602670 & 688497 & 4.45 & 4.7827 & TRN & \\
\hline CHEMBL1358946 & 688497 & 4.75 & 4.7242 & TRN & \\
\hline CHEMBL1990694 & 688497 & 4.8 & 4.6831 & TRN & \\
\hline CHEMBL1341476 & 688497 & 4.5 & 5.1412 & TRN & \\
\hline CHEMBL1391405 & 688497 & 5.25 & 5.0253 & TRN & \\
\hline CHEMBL1584367 & 688497 & 5.25 & 5.0468 & TST & \\
\hline CHEMBL1379816 & 688497 & 5.25 & 4.7296 & TRN & \\
\hline CHEMBL1509739 & 688497 & 4.75 & 4.9449 & TRN & \\
\hline CHEMBL1449513 & 688497 & 4.8 & 5.1654 & TRN & \\
\hline CHEMBL1467316 & 688497 & 6.25 & 4.8577 & TRN & \\
\hline CHEMBL1584571 & 688497 & 4.9 & 4.8545 & TRN & \\
\hline CHEMBL1462513 & 688497 & 5.45 & 4.8492 & TRN & \\
\hline CHEMBL1445583 & 688497 & 4.45 & 4.9958 & TRN & \\
\hline CHEMBL1505031 & 688497 & 5.05 & 4.9841 & TRN & \\
\hline CHEMBL1488059 & 688497 & 4.45 & 4.9931 & TST & \\
\hline CHEMBL1275655 & 688497 & 4.55 & 5.4676 & TST & \\
\hline CHEMBL1417750 & 688497 & 4.45 & 4.8666 & TRN & \\
\hline CHEMBL1343994 & 688497 & 5.45 & 4.9639 & TRN & \\
\hline CHEMBL1506819 & 688497 & 4.8 & 4.9804 & TRN & \\
\hline CHEMBL1411363 & 688497 & 5.15 & 4.8703 & TRN & \\
\hline CHEMBL1346614 & 688497 & 4.65 & 5.101 & TST & \\
\hline CHEMBL1589340 & 688497 & 4.8 & 5.2155 & TST & \\
\hline CHEMBL1496662 & 688497 & 4.9 & 4.8692 & TRN & \\
\hline CHEMBL1413054 & 688497 & 4.45 & 4.8631 & TRN & \\
\hline
\end{tabular}




\begin{tabular}{|c|c|c|c|c|c|}
\hline & & \multicolumn{4}{|c|}{ Supplemental Table s2.txt } \\
\hline CHEMBL1557521 & 688497 & 4.75 & 5.1144 & TRN & \\
\hline CHEMBL1964306 & 688497 & 4.45 & 4.9506 & TRN & \\
\hline CHEMBL1527550 & 688497 & 8.2007 & 5.4832 & TRN & \\
\hline CHEMBL1413275 & 688497 & 4.45 & 4.9659 & TRN & \\
\hline CHEMBL1331193 & 688497 & 4.95 & 5.1123 & TRN & \\
\hline CHEMBL1597211 & 688497 & 4.95 & 5.0658 & TST & \\
\hline CHEMBL1500219 & 688497 & 4.95 & 4.9256 & TST & \\
\hline CHEMBL1389449 & 688497 & 4.45 & 4.774 & TRN & \\
\hline CHEMBL1450523 & 688497 & 4.65 & 4.698 & TST & \\
\hline CHEMBL1540200 & 688497 & 4.65 & 4.7937 & TRN & \\
\hline CHEMBL1349387 & 688497 & 4.45 & 4.8565 & TRN & \\
\hline CHEMBL1331563 & 688497 & 4.65 & 4.8513 & TRN & \\
\hline CHEMBL1507951 & 688497 & 5.9 & 4.962 & TST & \\
\hline CHEMBL1400225 & 688497 & 4.8 & 4.8004 & TRN & \\
\hline CHEMBL1422794 & 688497 & 4.45 & 4.7496 & TRN & \\
\hline CHEMBL1489757 & 688497 & 4.85 & 4.8997 & TRN & \\
\hline CHEMBL1423956 & 688497 & 4.45 & 4.8526 & TRN & \\
\hline CHEMBL1410573 & 688497 & 5.65 & 5.0658 & TRN & \\
\hline CHEMBL1530686 & 688497 & 5.7 & 5.2824 & TRN & \\
\hline CHEMBL1311707 & 688497 & 4.95 & 4.7267 & TST & \\
\hline CHEMBL1573107 & 688497 & 6.25 & 5.555 & TRN & \\
\hline CHEMBL1520875 & 688497 & 6.5 & 5.4819 & TRN & \\
\hline CHEMBL1424369 & 688497 & 4.5 & 4.8965 & TRN & \\
\hline CHEMBL1313369 & 688497 & 5.25 & 5.0354 & TRN & \\
\hline CHEMBL1431128 & 688497 & 5.75 & 5.1481 & TRN & \\
\hline CHEMBL1465704 & 688497 & 7.5003 & 4.85 & TRN & \\
\hline CHEMBL1466750 & 688497 & 5.5 & 4.988 & TRN & \\
\hline CHEMBL1419335 & 688497 & 5.25 & 5.0019 & TRN & \\
\hline CHEMBL1374398 & 688497 & 4.45 & 5.1139 & TRN & \\
\hline CHEMBL1416660 & 688497 & 5.9 & 5.2281 & TRN & \\
\hline CHEMBL1391356 & 688497 & 5.2 & 4.9685 & TRN & \\
\hline CHEMBL1320124 & 688497 & 6.25 & 5.0307 & TRN & \\
\hline CHEMBL1322791 & 688497 & 5.45 & 5.0418 & TRN & \\
\hline CHEMBL1321952 & 688497 & 4.7 & 4.84399 & 9999999999 & TRN \\
\hline CHEMBL1601116 & 688497 & 5.0 & 5.0916 & TRN & \\
\hline CHEMBL1530025 & 688497 & 4.45 & 4.9043 & TRN & \\
\hline CHEMBL1301972 & 688497 & 4.45 & 5.0918 & TRN & \\
\hline CHEMBL1517197 & 688497 & 4.75 & 4.9467 & TRN & \\
\hline CHEMBL1484316 & 688497 & 4.9 & 5.0665 & TRN & \\
\hline CHEMBL1428417 & 688497 & 4.45 & 4.8562 & TRN & \\
\hline CHEMBL1563851 & 688497 & 4.45 & 4.7037 & TRN & \\
\hline CHEMBL1361034 & 688497 & 5.0 & 5.0626 & TST & \\
\hline CHEMBL1320911 & 688497 & 4.6 & 4.9699 & TRN & \\
\hline CHEMBL3210072 & 688497 & 5.0 & 5.4596 & TRN & \\
\hline CHEMBL1493649 & 688497 & 4.45 & 4.9346 & TRN & \\
\hline CHEMBL3196688 & 688497 & 4.65 & 4.7606 & TRN & \\
\hline CHEMBL22075 & 688497 & 4.5 & 5.0157 & TST & \\
\hline CHEMBL1438785 & 688497 & 4.8 & 4.878 & TST & \\
\hline
\end{tabular}




\begin{tabular}{|c|c|c|c|c|}
\hline \multicolumn{5}{|c|}{ Supplemental Table S2.txt } \\
\hline CHEMBL1610146 & 688497 & 6.25 & 5.0291 & TRN \\
\hline CHEMBL1503014 & 688497 & 5.5 & 5.2742 & TRN \\
\hline CHEMBL1477790 & 688497 & 5.95 & 5.4911 & TRN \\
\hline CHEMBL1604041 & 688497 & 4.95 & 4.7669 & TRN \\
\hline CHEMBL1603373 & 688497 & 4.95 & 4.7764 & TRN \\
\hline CHEMBL1521764 & 688497 & 4.85 & 5.0452 & TRN \\
\hline CHEMBL1349217 & 688497 & 4.9 & 4.9499 & TRN \\
\hline CHEMBL1582580 & 688497 & 5.2 & 5.1976 & TRN \\
\hline CHEMBL1444834 & 688497 & 6.25 & 5.0522 & TRN \\
\hline CHEMBL1603040 & 688497 & 4.9 & 5.0032 & TRN \\
\hline CHEMBL1603760 & 688497 & 5.0 & 4.7007 & TRN \\
\hline CHEMBL1393581 & 688497 & 4.45 & 4.7435 & TRN \\
\hline CHEMBL1976917 & 688497 & 4.85 & 5.0672 & TST \\
\hline CHEMBL1594951 & 688497 & 4.9 & 5.1387 & TRN \\
\hline CHEMBL1586067 & 688497 & 5.1 & 4.9886 & TRN \\
\hline CHEMBL336280 & 688497 & 4.65 & 4.8044 & TRN \\
\hline CHEMBL1557816 & 688497 & 5.15 & 5.1501 & TST \\
\hline CHEMBL1445973 & 688497 & 5.25 & 5.0559 & TRN \\
\hline CHEMBL3192217 & 688497 & 4.45 & 4.7442 & TRN \\
\hline CHEMBL1427079 & 688497 & 4.65 & 4.7288 & TST \\
\hline CHEMBL 2000619 & 688497 & 5.0 & 5.0456 & TRN \\
\hline CHEMBL1370645 & 688497 & 5.75 & 5.4307 & TST \\
\hline CHEMBL1545734 & 688497 & 4.6 & 4.9309 & TRN \\
\hline CHEMBL1486387 & 688497 & 4.45 & 4.7091 & TRN \\
\hline CHEMBL1346801 & 688497 & 5.0 & 4.9382 & TRN \\
\hline CHEMBL1503678 & 688497 & 4.45 & 5.013 & TRN \\
\hline CHEMBL1339976 & 688497 & 5.6 & 5.1947 & TRN \\
\hline CHEMBL1511114 & 688497 & 5.35 & 4.7531 & TRN \\
\hline CHEMBL1470321 & 688497 & 4.7 & 4.5212 & TRN \\
\hline CHEMBL1327434 & 688497 & 7.0501 & 5.3154 & TRN \\
\hline CHEMBL1384116 & 688497 & 4.65 & 5.1653 & TRN \\
\hline CHEMBL1586937 & 688497 & 4.45 & 4.855 & TRN \\
\hline CHEMBL1502001 & 688497 & 5.2 & 4.97 & TRN \\
\hline CHEMBL1350240 & 688497 & 5.0 & 4.7379 & TRN \\
\hline CHEMBL1500674 & 688497 & 5.9 & 5.3785 & TRN \\
\hline CHEMBL1550652 & 688497 & 4.45 & 4.9787 & TST \\
\hline CHEMBL1584036 & 688497 & 4.65 & 5.2084 & TRN \\
\hline CHEMBL1563241 & 688497 & 5.5 & 5.2272 & TRN \\
\hline CHEMBL1359057 & 688497 & 6.1 & 4.9927 & TST \\
\hline CHEMBL3190544 & 688497 & 6.25 & 5.2552 & TRN \\
\hline CHEMBL1543087 & 688497 & 4.6 & 5.0145 & TRN \\
\hline CHEMBL1384119 & 688497 & 4.85 & 5.1488 & TRN \\
\hline CHEMBL1430684 & 688497 & 4.9 & 4.9063 & TRN \\
\hline CHEMBL1300321 & 688497 & 4.6 & 5.3022 & TRN \\
\hline CHEMBL1557752 & 688497 & 4.7 & 5.1605 & TRN \\
\hline CHEMBL1169627 & 688497 & 6.0 & 5.4367 & TRN \\
\hline CHEMBL340807 & 688497 & 4.8 & 5.1954 & TST \\
\hline CHEMBL1569018 & 688497 & 4.45 & 4.7834 & TRN \\
\hline
\end{tabular}




\begin{tabular}{|c|c|c|c|c|}
\hline \multicolumn{5}{|c|}{ Supplemental Table S2.txt } \\
\hline CHEMBL1429513 & 688497 & 4.9 & 5.1293 & TRN \\
\hline CHEMBL1527529 & 688497 & 5.25 & 5.1841 & TRN \\
\hline CHEMBL3209943 & 688497 & 4.45 & 4.8802 & TRN \\
\hline CHEMBL1417204 & 688497 & 4.45 & 5.0304 & TRN \\
\hline CHEMBL1338172 & 688497 & 5.65 & 5.3608 & TRN \\
\hline CHEMBL1379866 & 688497 & 5.05 & 5.3658 & TST \\
\hline CHEMBL1322658 & 688497 & 5.25 & 4.9554 & TST \\
\hline CHEMBL1339537 & 688497 & 4.45 & 4.8373 & TRN \\
\hline CHEMBL1420492 & 688497 & 5.55 & 5.3401 & TRN \\
\hline CHEMBL1602561 & 688497 & 6.25 & 4.7356 & TRN \\
\hline CHEMBL1299600 & 688497 & 4.45 & 4.9128 & TRN \\
\hline CHEMBL1416050 & 688497 & 4.9 & 5.2164 & TRN \\
\hline CHEMBL1450784 & 688497 & 4.75 & 5.1459 & TST \\
\hline CHEMBL1511305 & 688497 & 4.6 & 4.9949 & TRN \\
\hline CHEMBL1312969 & 688497 & 4.7 & 5.1297 & TRN \\
\hline CHEMBL1586153 & 688497 & 4.6 & 4.9239 & TRN \\
\hline CHEMBL1498028 & 688497 & 4.95 & 5.1971 & TRN \\
\hline CHEMBL3145329 & 688497 & 4.65 & 5.18 & TRN \\
\hline CHEMBL1365088 & 688497 & 4.45 & 4.9947 & TRN \\
\hline CHEMBL1481361 & 688497 & 4.75 & 5.1598 & TST \\
\hline CHEMBL1430456 & 688497 & 4.7 & 5.0979 & TRN \\
\hline CHEMBL1511663 & 688497 & 5.25 & 4.7863 & TRN \\
\hline CHEMBL1520980 & 688497 & 4.45 & 5.129 & TRN \\
\hline CHEMBL1399258 & 688497 & 5.9 & 5.3591 & TRN \\
\hline CHEMBL492267 & 688497 & 5.0 & 5.0808 & TRN \\
\hline CHEMBL1349706 & 688497 & 4.95 & 4.9558 & TRN \\
\hline CHEMBL1404211 & 688497 & 4.45 & 4.8527 & TRN \\
\hline CHEMBL 2297588 & 688497 & 4.85 & 5.2754 & TST \\
\hline CHEMBL3194719 & 688497 & 4.9 & 5.0197 & TRN \\
\hline CHEMBL1379623 & 688497 & 4.95 & 4.8952 & TRN \\
\hline CHEMBL1484885 & 688497 & 5.5 & 4.8795 & TRN \\
\hline CHEMBL3199421 & 688497 & 4.45 & 4.9749 & TRN \\
\hline CHEMBL1573589 & 688497 & 4.45 & 5.1129 & TRN \\
\hline CHEMBL1490763 & 688497 & 4.9 & 4.6693 & TRN \\
\hline CHEMBL1372711 & 688497 & 6.5 & 5.4788 & TRN \\
\hline CHEMBL1300344 & 688497 & 5.35 & 5.0388 & TRN \\
\hline CHEMBL1421325 & 688497 & 5.25 & 5.1835 & TRN \\
\hline CHEMBL1498988 & 688497 & 5.05 & 4.8205 & TRN \\
\hline CHEMBL1977369 & 688497 & 4.65 & 4.8064 & TRN \\
\hline CHEMBL1361273 & 688497 & 4.95 & 5.1168 & TRN \\
\hline CHEMBL1349609 & 688497 & 5.55 & 4.6906 & TRN \\
\hline CHEMBL1312042 & 688497 & 4.45 & 4.9169 & TRN \\
\hline CHEMBL1305558 & 688497 & 4.7 & 4.8999 & TRN \\
\hline CHEMBL1300626 & 688497 & 5.0 & 4.8414 & TRN \\
\hline CHEMBL1378746 & 688497 & 5.05 & 5.0222 & TRN \\
\hline CHEMBL1559446 & 688497 & 6.2 & 5.4683 & TRN \\
\hline CHEMBL1607143 & 688497 & 5.15 & 5.2864 & TRN \\
\hline CHEMBL1437997 & 688497 & 4.6 & 5.0286 & TST \\
\hline
\end{tabular}




\begin{tabular}{|c|c|c|c|c|c|}
\hline \\
\hline CHEMBL518494 & 688497 & 4.9 & 5.5256 & TST & \\
\hline CHEMBL1439817 & 688497 & 5.2 & 4.8495 & TRN & \\
\hline CHEMBL1480344 & 688497 & 6.15 & 5.1905 & TST & \\
\hline CHEMBL1500929 & 688497 & 5.1 & 5.2896 & TRN & \\
\hline CHEMBL1370479 & 688497 & 5.15 & 5.0783 & TRN & \\
\hline CHEMBL1446840 & 688497 & 5.55 & 4.9254 & TST & \\
\hline CHEMBL1345789 & 688497 & 4.65 & 4.9174 & TST & \\
\hline CHEMBL1582519 & 688497 & 5.1 & 4.7492 & TST & \\
\hline CHEMBL1458809 & 688497 & 5.0 & 4.936 & TRN & \\
\hline CHEMBL1516549 & 688497 & 4.45 & 5.0306 & TRN & \\
\hline CHEMBL1595169 & 688497 & 5.9 & 5.3179 & TRN & \\
\hline CHEMBL1423888 & 688497 & 5.0 & 4.9693 & TST & \\
\hline CHEMBL1478418 & 688497 & 5.25 & 5.2175 & TST & \\
\hline CHEMBL1324699 & 688497 & 4.85 & 4.7212 & TRN & \\
\hline CHEMBL1537588 & 688497 & 4.65 & 4.7152 & TST & \\
\hline CHEMBL1378668 & 688497 & 5.0 & 4.6908 & TRN & \\
\hline CHEMBL1546087 & 688497 & 4.45 & 5.0258 & TRN & \\
\hline CHEMBL589694 & 688497 & 4.55 & 4.5639 & TRN & \\
\hline CHEMBL1328478 & 688497 & 5.25 & 4.9852 & TRN & \\
\hline CHEMBL1603475 & 688497 & 5.2 & 5.4519 & TST & \\
\hline CHEMBL1398645 & 688497 & 5.45 & 5.3288 & TRN & \\
\hline CHEMBL1401629 & 688497 & 4.6 & 4.873 & TRN & \\
\hline CHEMBL3191271 & 688497 & 6.15 & 5.0164 & TST & \\
\hline CHEMBL1416311 & 688497 & 6.25 & 5.15600 & 0000000001 & TRN \\
\hline CHEMBL1303719 & 688497 & 4.6 & 4.9099 & TRN & \\
\hline CHEMBL1597934 & 688497 & 4.6 & 4.8064 & TRN & \\
\hline CHEMBL1340213 & 688497 & 4.95 & 5.0719 & TST & \\
\hline CHEMBL1527177 & 688497 & 5.25 & 5.0023 & TRN & \\
\hline CHEMBL1459231 & 688497 & 6.25 & 5.3182 & TRN & \\
\hline CHEMBL1598791 & 688497 & 5.25 & 4.9934 & TST & \\
\hline CHEMBL1458319 & 688497 & 4.85 & 5.1283 & TRN & \\
\hline CHEMBL1308940 & 688497 & 4.45 & 5.077 & TRN & \\
\hline CHEMBL3198417 & 688497 & 4.45 & 5.0505 & TRN & \\
\hline CHEMBL1571717 & 688497 & 4.45 & 4.9811 & TRN & \\
\hline CHEMBL1334442 & 688497 & 4.75 & 4.9601 & TRN & \\
\hline CHEMBL1347260 & 688497 & 4.65 & 5.3965 & TRN & \\
\hline CHEMBL1446068 & 688497 & 4.8 & 5.3591 & TRN & \\
\hline CHEMBL1479438 & 688497 & 4.45 & 4.7674 & TRN & \\
\hline CHEMBL1980322 & 688497 & 5.6 & 5.4707 & TRN & \\
\hline CHEMBL1446013 & 688497 & 4.95 & 5.0287 & TRN & \\
\hline CHEMBL1609504 & 688497 & 4.45 & 5.1352 & TST & \\
\hline CHEMBL3190149 & 688497 & 4.45 & 4.9665 & TST & \\
\hline CHEMBL1544658 & 688497 & 4.95 & 4.9954 & TST & \\
\hline CHEMBL1492559 & 688497 & 6.25 & 4.9177 & TRN & \\
\hline CHEMBL1371231 & 688497 & 4.95 & 5.1628 & TRN & \\
\hline CHEMBL1301920 & 688497 & 4.45 & 5.0226 & TST & \\
\hline CHEMBL1384167 & 688497 & 6.05 & 5.0836 & TRN & \\
\hline CHEMBL1410132 & 688497 & 4.45 & 5.0873 & TST & \\
\hline
\end{tabular}




\begin{tabular}{|c|c|c|c|c|c|}
\hline & & \multicolumn{4}{|c|}{ Supplemental Table S2.txt } \\
\hline CHEMBL1600649 & 688497 & 5.35 & 4.7842 & TRN & \\
\hline CHEMBL1307167 & 688497 & 5.0 & 5.0827 & TST & \\
\hline CHEMBL1480529 & 688497 & 4.75 & 4.9768 & TRN & \\
\hline CHEMBL1351837 & 688497 & 4.85 & 4.9508 & TRN & \\
\hline CHEMBL1351951 & 688497 & 4.45 & 4.7973 & TRN & \\
\hline CHEMBL1495932 & 688497 & 6.25 & 5.13700 & 00000000005 & TRN \\
\hline CHEMBL1304718 & 688497 & 5.5 & 5.1229 & TRN & \\
\hline CHEMBL1625031 & 688497 & 4.9 & 4.913 & TRN & \\
\hline CHEMBL1439383 & 688497 & 5.35 & 5.0366 & TRN & \\
\hline CHEMBL1312788 & 688497 & 6.0 & 4.8259 & TRN & \\
\hline CHEMBL1430166 & 688497 & 4.95 & 4.9595 & TST & \\
\hline CHEMBL1324567 & 688497 & 4.95 & 4.8929 & TRN & \\
\hline CHEMBL1377261 & 688497 & 4.55 & 4.8079 & TRN & \\
\hline CHEMBL1429723 & 688497 & 5.25 & 5.0847 & TRN & \\
\hline CHEMBL1991779 & 688497 & 5.9 & 5.4505 & TRN & \\
\hline CHEMBL1333483 & 688497 & 4.45 & 4.8017 & TRN & \\
\hline CHEMBL1481091 & 688497 & 5.55 & 4.9757 & TRN & \\
\hline CHEMBL1557815 & 688497 & 4.65 & 4.9879 & TRN & \\
\hline CHEMBL1336792 & 688497 & 6.35 & 5.1119 & TST & \\
\hline CHEMBL1341008 & 688497 & 4.65 & 4.9454 & TST & \\
\hline CHEMBL1607967 & 688497 & 5.1 & 5.066 & TRN & \\
\hline CHEMBL1438983 & 688497 & 4.45 & 4.7103 & TST & \\
\hline CHEMBL1507817 & 688497 & 4.6 & 4.8084 & TRN & \\
\hline CHEMBL1486435 & 688497 & 4.45 & 4.9319 & TRN & \\
\hline CHEMBL1360322 & 688497 & 5.9 & 5.0147 & TRN & \\
\hline CHEMBL1331162 & 688497 & 5.0 & 5.07600 & 00000000005 & TRN \\
\hline CHEMBL1509034 & 688497 & 5.65 & 5.1099 & TRN & \\
\hline CHEMBL1427897 & 688497 & 4.85 & 5.0752 & TRN & \\
\hline CHEMBL 3189476 & 688497 & 4.95 & 4.933 & TRN & \\
\hline CHEMBL1404866 & 688497 & 5.5 & 4.7982 & TRN & \\
\hline CHEMBL1310553 & 688497 & 4.45 & 5.3936 & TST & \\
\hline CHEMBL1530081 & 688497 & 5.4 & 5.2148 & TST & \\
\hline CHEMBL1571034 & 688497 & 5.4 & 5.1492 & TRN & \\
\hline CHEMBL1505511 & 688497 & 4.65 & 5.0714 & TST & \\
\hline CHEMBL1497645 & 688497 & 4.45 & 4.91100 & 00000000005 & TRN \\
\hline CHEMBL1490764 & 688497 & 4.45 & 4.7992 & TRN & \\
\hline CHEMBL1333011 & 688497 & 5.3 & 5.1644 & TRN & \\
\hline CHEMBL3194618 & 688497 & 5.05 & 5.1285 & TRN & \\
\hline CHEMBL1609537 & 688497 & 5.35 & 5.2972 & TST & \\
\hline CHEMBL1539328 & 688497 & 4.85 & 4.8694 & TRN & \\
\hline CHEMBL1528348 & 688497 & 7.0 & 5.2225 & TRN & \\
\hline CHEMBL3210194 & 688497 & 6.05 & 5.2585 & TRN & \\
\hline CHEMBL1518926 & 688497 & 4.9 & 4.8963 & TRN & \\
\hline CHEMBL334707 & 688497 & 4.6 & 5.2074 & TRN & \\
\hline CHEMBL1576658 & 688497 & 5.25 & 4.956 & TST & \\
\hline CHEMBL1579134 & 688497 & 4.6 & 4.7653 & TRN & \\
\hline CHEMBL1323069 & 688497 & 4.75 & 4.9283 & TST & \\
\hline CHEMBL1380772 & 688497 & 5.35 & 5.4745 & TRN & \\
\hline
\end{tabular}




\begin{tabular}{|c|c|c|c|c|}
\hline \multicolumn{5}{|c|}{ Supplemental Table S2.txt } \\
\hline CHEMBL1383806 & 688497 & 4.45 & 4.6584 & TRN \\
\hline CHEMBL1519912 & 688497 & 5.25 & 5.2284 & TRN \\
\hline CHEMBL1383333 & 688497 & 4.9 & 4.8608 & TRN \\
\hline CHEMBL1449731 & 688497 & 4.8 & 5.3261 & TRN \\
\hline CHEMBL1472507 & 688497 & 4.65 & 4.9516 & TRN \\
\hline CHEMBL1540418 & 688497 & 4.65 & 4.7681 & TRN \\
\hline CHEMBL1511267 & 688497 & 5.4 & 5.2766 & TRN \\
\hline CHEMBL1576882 & 688497 & 4.5 & 4.9645 & TRN \\
\hline CHEMBL1387562 & 688497 & 5.45 & 4.8034 & TRN \\
\hline CHEMBL3191114 & 688497 & 4.45 & 5.2942 & TRN \\
\hline CHEMBL1427463 & 688497 & 4.9 & 4.8729 & TRN \\
\hline CHEMBL1385701 & 688497 & 6.25 & 4.9081 & TRN \\
\hline CHEMBL1471671 & 688497 & 4.45 & 4.8771 & TRN \\
\hline CHEMBL1442229 & 688497 & 4.8 & 4.7672 & TRN \\
\hline CHEMBL1433208 & 688497 & 5.9 & 5.188 & TRN \\
\hline CHEMBL1582747 & 688497 & 5.0 & 5.1057 & TRN \\
\hline CHEMBL1379642 & 688497 & 4.45 & 5.6867 & TST \\
\hline CHEMBL1307866 & 688497 & 4.55 & 5.3634 & TRN \\
\hline CHEMBL1328827 & 688497 & 4.6 & 4.7234 & TRN \\
\hline CHEMBL 250840 & 688497 & 4.45 & 5.0718 & TRN \\
\hline CHEMBL1557476 & 688497 & 5.45 & 4.9554 & TRN \\
\hline CHEMBL1507146 & 688497 & 4.45 & 5.1746 & TST \\
\hline CHEMBL1490894 & 688497 & 4.95 & 5.1187 & TRN \\
\hline CHEMBL1560558 & 688497 & 5.5 & 5.0198 & TRN \\
\hline CHEMBL1465707 & 688497 & 4.45 & 4.8002 & TRN \\
\hline CHEMBL1339522 & 688497 & 4.95 & 4.8284 & TRN \\
\hline CHEMBL1508930 & 688497 & 4.45 & 4.7926 & TST \\
\hline CHEMBL1372347 & 688497 & 5.45 & 5.1521 & TRN \\
\hline CHEMBL1465040 & 688497 & 5.25 & 5.266 & TRN \\
\hline CHEMBL1460461 & 688497 & 4.65 & 4.7829 & TST \\
\hline CHEMBL1565649 & 688497 & 5.15 & 4.9549 & TRN \\
\hline CHEMBL1200471 & 688497 & 6.05 & 5.8959 & TST \\
\hline CHEMBL1449309 & 688497 & 4.45 & 5.1346 & TRN \\
\hline CHEMBL1605078 & 688497 & 4.6 & 5.0488 & TRN \\
\hline CHEMBL1372071 & 688497 & 4.8 & 5.4148 & TRN \\
\hline CHEMBL1379002 & 688497 & 5.5 & 5.1764 & TRN \\
\hline CHEMBL1359516 & 688497 & 4.45 & 5.1778 & TRN \\
\hline CHEMBL1613648 & 688497 & 5.4 & 5.0954 & TRN \\
\hline CHEMBL1486780 & 688497 & 4.45 & 5.2396 & TRN \\
\hline CHEMBL1506967 & 688497 & 4.85 & 4.8676 & TRN \\
\hline CHEMBL1388369 & 688497 & 4.6 & 5.0537 & TRN \\
\hline CHEMBL1338975 & 688497 & 4.95 & 5.1498 & TST \\
\hline CHEMBL1444560 & 688497 & 5.6 & 5.0019 & TRN \\
\hline CHEMBL1393715 & 688497 & 5.25 & 5.0257 & TRN \\
\hline CHEMBL1353522 & 688497 & 5.0 & 5.0687 & TRN \\
\hline CHEMBL 2004809 & 688497 & 5.1 & 5.3223 & TRN \\
\hline CHEMBL1339924 & 688497 & 6.1 & 4.9568 & TRN \\
\hline CHEMBL1561726 & 688497 & 5.25 & 5.0522 & TRN \\
\hline
\end{tabular}




\begin{tabular}{|c|c|c|c|c|}
\hline \multicolumn{5}{|c|}{ Supplemental Table } \\
\hline CHEMBL1373833 & 688497 & 4.45 & 4.9564 & TRN \\
\hline CHEMBL1420234 & 688497 & 5.4 & 4.824 & TRN \\
\hline CHEMBL1331227 & 688497 & 5.8 & 5.1511 & TRN \\
\hline CHEMBL3209299 & 688497 & 4.45 & 5.4739 & TRN \\
\hline CHEMBL 1457045 & 688497 & 2.95 & 4.9514 & TRN \\
\hline CHEMBL1446678 & 688497 & 4.9 & 5.0347 & TRN \\
\hline CHEMBL3196469 & 688497 & 5.4 & 5.0802 & TRN \\
\hline CHEMBL1559811 & 688497 & 5.0 & 5.3348 & TRN \\
\hline CHEMBL1517900 & 688497 & 7.15 & 5.5673 & TST \\
\hline CHEMBL1571055 & 688497 & 4.9 & 5.0731 & TST \\
\hline CHEMBL1484741 & 688497 & 5.15 & 5.0938 & TRN \\
\hline CHEMBL1423143 & 688497 & 4.95 & 5.0111 & TRN \\
\hline CHEMBL1560307 & 688497 & 4.45 & 5.0435 & TST \\
\hline CHEMBL 3194223 & 688497 & 4.75 & 4.9593 & TRN \\
\hline CHEMBL1613104 & 688497 & 4.45 & 5.2124 & TST \\
\hline CHEMBL1365963 & 688497 & 4.45 & 4.8603 & TRN \\
\hline CHEMBL1453563 & 688497 & 5.2 & 5.3192 & TST \\
\hline CHEMBL1331206 & 688497 & 4.95 & 4.7646 & TRN \\
\hline CHEMBL1609925 & 688497 & 5.25 & 5.2703 & TST \\
\hline CHEMBL1565796 & 688497 & 5.05 & 5.7732 & TRN \\
\hline CHEMBL1544508 & 688497 & 4.45 & 4.7042 & TRN \\
\hline CHEMBL1464482 & 688497 & 5.7 & 5.1153 & TST \\
\hline CHEMBL1338962 & 688497 & 4.5 & 4.8985 & TRN \\
\hline CHEMBL1599998 & 688497 & 6.25 & 5.1821 & TRN \\
\hline CHEMBL1790007 & 688497 & 5.55 & 5.4704 & TRN \\
\hline CHEMBL1501983 & 688497 & 5.7 & 5.1493 & TRN \\
\hline CHEMBL1607065 & 688497 & 4.7 & 5.1407 & TST \\
\hline CHEMBL3197314 & 688497 & 5.15 & 4.902 & TRN \\
\hline CHEMBL1594312 & 688497 & 4.45 & 4.9854 & TRN \\
\hline CHEMBL3213002 & 688497 & 4.75 & 5.4297 & TRN \\
\hline CHEMBL1449997 & 688497 & 4.95 & 5.3976 & TRN \\
\hline CHEMBL1490244 & 688497 & 4.5 & 4.8466 & TRN \\
\hline CHEMBL3195280 & 688497 & 4.95 & 4.8901 & TRN \\
\hline CHEMBL1366840 & 688497 & 4.7 & 5.1238 & TRN \\
\hline CHEMBL1528901 & 688497 & 5.45 & 5.3281 & TRN \\
\hline CHEMBL1457525 & 688497 & 6.3 & 5.0553 & TRN \\
\hline CHEMBL1348969 & 688497 & 4.5 & 4.8653 & TRN \\
\hline CHEMBL1304694 & 688497 & 4.85 & 4.8587 & TRN \\
\hline CHEMBL3208782 & 688497 & 5.55 & 5.0925 & TRN \\
\hline CHEMBL1313972 & 688497 & 4.8 & 5.0433 & TRN \\
\hline CHEMBL1330989 & 688497 & 5.8 & 5.0822 & TRN \\
\hline CHEMBL1381627 & 688497 & 4.45 & 5.185 & TRN \\
\hline CHEMBL1428181 & 688497 & 4.95 & 4.9396 & TRN \\
\hline CHEMBL1405494 & 688497 & 4.95 & 5.0146 & TST \\
\hline CHEMBL1311641 & 688497 & 4.95 & 4.8637 & TRN \\
\hline CHEMBL1350854 & 688497 & 4.5 & 4.8118 & TST \\
\hline CHEMBL1385558 & 688497 & 5.1 & 4.9219 & TRN \\
\hline CHEMBL1406000 & 688497 & 5.7 & 5.2225 & TST \\
\hline
\end{tabular}




\begin{tabular}{|c|c|c|c|c|c|}
\hline \multicolumn{6}{|c|}{ Supplemental Table S2.txt } \\
\hline CHEMBL1564755 & 688497 & 4.45 & 4.7641 & TRN & \\
\hline CHEMBL1459672 & 688497 & 5.35 & 5.312 & TRN & \\
\hline CHEMBL1561140 & 688497 & 6.25 & 5.1348 & TRN & \\
\hline CHEMBL1365299 & 688497 & 4.8 & 4.8054 & TRN & \\
\hline CHEMBL3199036 & 688497 & 4.45 & 5.0309 & TRN & \\
\hline CHEMBL1523827 & 688497 & 4.6 & 5.1326 & TST & \\
\hline CHEMBL1339398 & 688497 & 5.65 & 5.3063 & TRN & \\
\hline CHEMBL1376842 & 688497 & 6.3 & 4.9999 & TST & \\
\hline CHEMBL3145205 & 688497 & 4.9 & 5.273 & TRN & \\
\hline CHEMBL1504174 & 688497 & 4.65 & 5.1943 & TRN & \\
\hline CHEMBL1375741 & 688497 & 4.8 & 4.75 & TRN & \\
\hline CHEMBL1338854 & 688497 & 4.45 & 5.1393 & TRN & \\
\hline CHEMBL1564143 & 688497 & 4.45 & 4.6064 & TRN & \\
\hline CHEMBL1361455 & 688497 & 6.0 & 5.4481 & TRN & \\
\hline CHEMBL1568705 & 688497 & 4.55 & 4.9821 & TRN & \\
\hline CHEMBL1470346 & 688497 & 4.6 & 5.1218 & TRN & \\
\hline CHEMBL1608847 & 688497 & 4.45 & 5.0289 & TST & \\
\hline CHEMBL1900055 & 688497 & 5.5 & 4.9633 & TST & \\
\hline CHEMBL1382429 & 688497 & 5.0 & 4.7192 & TRN & \\
\hline CHEMBL1423102 & 688497 & 5.1 & 5.0456 & TRN & \\
\hline CHEMBL1574015 & 688497 & 4.6 & 5.0334 & TRN & \\
\hline CHEMBL1602607 & 688497 & 4.95 & 5.0317 & TRN & \\
\hline CHEMBL 2005411 & 688497 & 5.1 & 5.0788 & TRN & \\
\hline CHEMBL1500090 & 688497 & 4.45 & 5.0251 & TRN & \\
\hline CHEMBL1446233 & 688497 & 4.9 & 5.0738 & TRN & \\
\hline CHEMBL1604690 & 688497 & 5.25 & 4.7661 & TRN & \\
\hline CHEMBL1457257 & 688497 & 4.55 & 4.9787 & TST & \\
\hline CHEMBL1347351 & 688497 & 4.45 & 5.4003 & TRN & \\
\hline CHEMBL1531551 & 688497 & 4.75 & 5.0346 & TRN & \\
\hline CHEMBL1366524 & 688497 & 4.65 & 4.8878 & TRN & \\
\hline CHEMBL1609566 & 688497 & 5.0 & 5.1134 & TRN & \\
\hline CHEMBL1353378 & 688497 & 6.1 & 5.0133 & TRN & \\
\hline CHEMBL1549738 & 688497 & 5.35 & 5.0171 & TST & \\
\hline CHEMBL1383774 & 688497 & 6.35 & 4.9666 & TRN & \\
\hline CHEMBL1400907 & 688497 & 5.45 & 4.8055 & TRN & \\
\hline CHEMBL1586363 & 688497 & 5.2 & 5.3286 & TRN & \\
\hline CHEMBL1306681 & 688497 & 4.45 & 5.2504 & TRN & \\
\hline CHEMBL1366722 & 688497 & 4.7 & 4.8252 & TRN & \\
\hline CHEMBL2000750 & 688497 & 5.85 & 5.0935 & TRN & \\
\hline CHEMBL1533755 & 688497 & 5.6 & 5.2599 & TRN & \\
\hline CHEMBL1465924 & 688497 & 4.45 & 5.0939 & TRN & \\
\hline CHEMBL1545898 & 688497 & 4.45 & 5.0524 & TRN & \\
\hline CHEMBL1373252 & 688497 & 5.15 & 4.8687 & TRN & \\
\hline CHEMBL1441776 & 688497 & 5.4 & 5.0604 & TST & \\
\hline CHEMBL1482081 & 688497 & 5.25 & 4.8106 & TRN & \\
\hline CHEMBL1439390 & 688497 & 4.45 & 4.8105 & TRN & \\
\hline CHEMBL1544904 & 688497 & 4.45 & 4.8452 & TRN & \\
\hline CHEMBL1571642 & 688497 & 6.25 & 5.16100 & 000000000 & TRN \\
\hline
\end{tabular}




\begin{tabular}{|c|c|c|c|c|}
\hline \multicolumn{5}{|c|}{ Supplemental Table S2.txt } \\
\hline CHEMBL1389288 & 688497 & 4.65 & 4.9041 & TRN \\
\hline CHEMBL1469440 & 688497 & 5.05 & 5.0257 & TRN \\
\hline CHEMBL1559708 & 688497 & 5.9 & 4.6858 & TRN \\
\hline CHEMBL3198917 & 688497 & 4.55 & 5.0985 & TST \\
\hline CHEMBL 1375206 & 688497 & 6.25 & 5.2676 & TST \\
\hline CHEMBL1536192 & 688497 & 4.5 & 5.4288 & TST \\
\hline CHEMBL1561675 & 688497 & 4.45 & 5.0928 & TRN \\
\hline CHEMBL1333993 & 688497 & 4.65 & 4.8428 & TRN \\
\hline CHEMBL1403890 & 688497 & 5.2 & 4.9974 & TST \\
\hline CHEMBL398476 & 688497 & 6.25 & 5.1228 & TRN \\
\hline CHEMBL3197910 & 688497 & 4.75 & 4.854 & TRN \\
\hline CHEMBL1559226 & 688497 & 4.45 & 4.9301 & TRN \\
\hline CHEMBL1303124 & 688497 & 6.0 & 5.2659 & TST \\
\hline CHEMBL1504963 & 688497 & 4.95 & 5.0626 & TRN \\
\hline CHEMBL487356 & 688497 & 5.05 & 5.0567 & TRN \\
\hline CHEMBL1520122 & 688497 & 4.55 & 4.8729 & TRN \\
\hline CHEMBL1339050 & 688497 & 5.15 & 4.9772 & TRN \\
\hline CHEMBL3213694 & 688497 & 4.9 & 4.8109 & TRN \\
\hline CHEMBL1347360 & 688497 & 5.0 & 4.9915 & TST \\
\hline CHEMBL1550628 & 688497 & 4.45 & 4.9201 & TRN \\
\hline CHEMBL1601890 & 688497 & 5.2 & 5.0744 & TST \\
\hline CHEMBL1990804 & 688497 & 4.65 & 5.285 & TRN \\
\hline CHEMBL1462522 & 688497 & 5.9 & 4.9671 & TRN \\
\hline CHEMBL1458768 & 688497 & 4.45 & 4.9952 & TRN \\
\hline CHEMBL1437883 & 688497 & 4.45 & 4.7738 & TRN \\
\hline CHEMBL578872 & 688497 & 5.5 & 5.1574 & TST \\
\hline CHEMBL 1377250 & 688497 & 4.6 & 4.874 & TRN \\
\hline CHEMBL1343298 & 688497 & 3.95 & 5.1101 & TST \\
\hline CHEMBL1484335 & 688497 & 4.95 & 5.041 & TRN \\
\hline CHEMBL1572107 & 688497 & 5.0 & 4.6542 & TRN \\
\hline CHEMBL1392024 & 688497 & 5.35 & 5.305 & TST \\
\hline CHEMBL586024 & 688497 & 4.95 & 4.7978 & TRN \\
\hline CHEMBL1529668 & 688497 & 5.55 & 5.2563 & TRN \\
\hline CHEMBL1399909 & 688497 & 4.9 & 5.1783 & TRN \\
\hline CHEMBL1388701 & 688497 & 4.45 & 4.9607 & TRN \\
\hline CHEMBL1490064 & 688497 & 4.85 & 4.7805 & TRN \\
\hline CHEMBL1586590 & 688497 & 5.0 & 5.2355 & TRN \\
\hline CHEMBL1577740 & 688497 & 5.8 & 5.4381 & TRN \\
\hline CHEMBL1550489 & 688497 & 4.65 & 5.0142 & TST \\
\hline CHEMBL1491908 & 688497 & 5.3 & 5.2985 & TST \\
\hline CHEMBL3193816 & 688497 & 4.65 & 4.9356 & TRN \\
\hline CHEMBL1531625 & 688497 & 4.45 & 5.3951 & TRN \\
\hline CHEMBL1503851 & 688497 & 4.9 & 4.8021 & TRN \\
\hline CHEMBL1520809 & 688497 & 4.45 & 5.1072 & TRN \\
\hline CHEMBL1490927 & 688497 & 5.25 & 4.9521 & TRN \\
\hline CHEMBL1430788 & 688497 & 4.5 & 4.85 & TRN \\
\hline CHEMBL 1495788 & 688497 & 5.15 & 4.8835 & TRN \\
\hline CHEMBL1364352 & 688497 & 4.95 & 5.1379 & TST \\
\hline
\end{tabular}




\begin{tabular}{|c|c|c|c|c|}
\hline \multicolumn{5}{|c|}{ Supplemental Table S2.txt } \\
\hline CHEMBL 3144947 & 688497 & 4.6 & 4.7751 & TST \\
\hline CHEMBL1384550 & 688497 & 4.45 & 4.9455 & TRN \\
\hline CHEMBL1345831 & 688497 & 4.65 & 4.9742 & TRN \\
\hline CHEMBL3210739 & 688497 & 5.0 & 5.1405 & TRN \\
\hline CHEMBL1529960 & 688497 & 5.9 & 5.3351 & TRN \\
\hline CHEMBL1336938 & 688497 & 4.45 & 5.0142 & TRN \\
\hline CHEMBL3210193 & 688497 & 4.45 & 4.955 & TRN \\
\hline CHEMBL1528007 & 688497 & 6.45 & 4.9795 & TRN \\
\hline CHEMBL1299352 & 688497 & 5.25 & 5.1899 & TRN \\
\hline CHEMBL1313660 & 688497 & 4.45 & 5.034 & TRN \\
\hline CHEMBL1412314 & 688497 & 5.2 & 5.0273 & TST \\
\hline CHEMBL1973904 & 688497 & 4.5 & 4.6709 & TRN \\
\hline CHEMBL1604945 & 688497 & 5.5 & 5.2113 & TRN \\
\hline CHEMBL1444414 & 688497 & 6.25 & 5.1255 & TRN \\
\hline CHEMBL1606097 & 688497 & 5.0 & 4.9215 & TRN \\
\hline CHEMBL1349928 & 688497 & 5.2 & 5.1282 & TRN \\
\hline CHEMBL1583262 & 688497 & 4.5 & 5.1192 & TRN \\
\hline CHEMBL1320685 & 688497 & 4.85 & 4.9158 & TRN \\
\hline CHEMBL1445153 & 688497 & 5.9 & 4.9324 & TRN \\
\hline CHEMBL1421868 & 688497 & 4.75 & 4.9596 & TRN \\
\hline CHEMBL1544803 & 688497 & 5.0 & 5.0086 & TRN \\
\hline CHEMBL1519022 & 688497 & 4.45 & 4.7339 & TRN \\
\hline CHEMBL1305166 & 688497 & 5.15 & 4.8729 & TRN \\
\hline CHEMBL1426745 & 688497 & 5.25 & 5.1046 & TST \\
\hline CHEMBL1449083 & 688497 & 5.0 & 5.0097 & TRN \\
\hline CHEMBL1390746 & 688497 & 4.45 & 4.8525 & TRN \\
\hline CHEMBL1400481 & 688497 & 4.45 & 4.8655 & TST \\
\hline CHEMBL1312885 & 688497 & 4.7 & 4.95 & TST \\
\hline CHEMBL1393862 & 688497 & 4.5 & 4.8162 & TRN \\
\hline CHEMBL1459880 & 688497 & 4.5 & 5.1372 & TRN \\
\hline CHEMBL1332598 & 688497 & 4.85 & 4.9344 & TST \\
\hline CHEMBL1526223 & 688497 & 4.45 & 5.2148 & TST \\
\hline CHEMBL1426243 & 688497 & 5.45 & 5.471 & TRN \\
\hline CHEMBL591370 & 688497 & 4.9 & 4.9913 & TRN \\
\hline CHEMBL1377071 & 688497 & 6.25 & 5.3696 & TRN \\
\hline CHEMBL1565180 & 688497 & 5.1 & 4.8216 & TRN \\
\hline CHEMBL1523377 & 688497 & 5.25 & 5.0388 & TST \\
\hline CHEMBL1411172 & 688497 & 5.9 & 4.974 & TRN \\
\hline CHEMBL1470077 & 688497 & 4.45 & 5.2592 & TRN \\
\hline CHEMBL1425407 & 688497 & 4.65 & 4.784 & TRN \\
\hline CHEMBL1540057 & 688497 & 5.9 & 4.9986 & TRN \\
\hline CHEMBL1301555 & 688497 & 4.45 & 4.9885 & TST \\
\hline CHEMBL3195032 & 688497 & 4.45 & 5.1109 & TST \\
\hline CHEMBL1484487 & 688497 & 4.95 & 5.4217 & TRN \\
\hline CHEMBL1543893 & 688497 & 4.8 & 4.9114 & TRN \\
\hline CHEMBL1306269 & 688497 & 4.9 & 5.1413 & TST \\
\hline CHEMBL1594699 & 688497 & 4.9 & 4.9191 & TST \\
\hline CHEMBL1470880 & 688497 & 4.45 & 4.893 & TST \\
\hline
\end{tabular}




\begin{tabular}{|c|c|c|c|c|c|}
\hline \multicolumn{6}{|c|}{ Supplemental Table S2.txt } \\
\hline CHEMBL1362088 & 688497 & 5.4 & 5.3795 & TRN & \\
\hline CHEMBL3198694 & 688497 & 4.5 & 5.1463 & TST & \\
\hline CHEMBL 2002223 & 688497 & 4.9 & 4.9264 & TST & \\
\hline CHEMBL1470391 & 688497 & 4.45 & 5.0229 & TRN & \\
\hline CHEMBL1311028 & 688497 & 4.75 & 5.01699 & 99999999995 & TRN \\
\hline CHEMBL1607637 & 688497 & 4.9 & 4.9096 & TRN & \\
\hline CHEMBL1389466 & 688497 & 5.45 & 5.5165 & TST & \\
\hline CHEMBL3207659 & 688497 & 5.25 & 5.1035 & TRN & \\
\hline CHEMBL1382264 & 688497 & 4.6 & 4.7859 & TRN & \\
\hline CHEMBL1518733 & 688497 & 5.2 & 5.1601 & TRN & \\
\hline CHEMBL1466570 & 688497 & 5.4 & 5.1697 & TRN & \\
\hline CHEMBL1364726 & 688497 & 4.45 & 5.2126 & TRN & \\
\hline CHEMBL1390151 & 688497 & 4.45 & 5.0673 & TRN & \\
\hline CHEMBL1490872 & 688497 & 6.25 & 5.0125 & TRN & \\
\hline CHEMBL1344339 & 688497 & 4.95 & 4.6718 & TST & \\
\hline CHEMBL3193885 & 688497 & 5.45 & 5.0681 & TRN & \\
\hline CHEMBL1453858 & 688497 & 5.6 & 5.399 & TRN & \\
\hline CHEMBL1330034 & 688497 & 4.45 & 4.7057 & TRN & \\
\hline CHEMBL1490832 & 688497 & 5.2 & 5.2259 & TRN & \\
\hline CHEMBL1301094 & 688497 & 5.7 & 5.1114 & TRN & \\
\hline CHEMBL1432300 & 688497 & 4.5 & 4.8826 & TRN & \\
\hline CHEMBL1326118 & 688497 & 4.65 & 4.692 & TRN & \\
\hline CHEMBL1537961 & 688497 & 5.45 & 4.9354 & TST & \\
\hline CHEMBL1460348 & 688497 & 4.95 & 5.5853 & TRN & \\
\hline CHEMBL1504057 & 688497 & 4.7 & 4.9971 & TRN & \\
\hline CHEMBL1353535 & 688497 & 4.45 & 4.9648 & TRN & \\
\hline CHEMBL1406910 & 688497 & 4.75 & 4.9833 & TRN & \\
\hline CHEMBL1438123 & 688497 & 4.45 & 4.8233 & TRN & \\
\hline CHEMBL1451865 & 688497 & 5.4 & 5.0048 & TRN & \\
\hline CHEMBL1386366 & 688497 & 4.75 & 4.6865 & TRN & \\
\hline CHEMBL1387015 & 688497 & 5.05 & 5.0318 & TRN & \\
\hline CHEMBL1413299 & 688497 & 4.6 & 5.1139 & TST & \\
\hline CHEMBL1504630 & 688497 & 5.9 & 5.0469 & TRN & \\
\hline CHEMBL1450606 & 688497 & 4.45 & 4.9032 & TRN & \\
\hline CHEMBL1608355 & 688497 & 5.9 & 4.8706 & TST & \\
\hline CHEMBL1611300 & 688497 & 4.85 & 4.9458 & TRN & \\
\hline CHEMBL1478053 & 688497 & 4.45 & 5.3475 & TST & \\
\hline CHEMBL1518851 & 688497 & 4.75 & 4.9399 & TRN & \\
\hline CHEMBL1492498 & 688497 & 5.0 & 4.9985 & TRN & \\
\hline CHEMBL1437145 & 688497 & 4.7 & 4.9011 & TRN & \\
\hline CHEMBL1521433 & 688497 & 4.45 & 5.0937 & TRN & \\
\hline CHEMBL1384369 & 688497 & 4.95 & 5.2921 & TRN & \\
\hline CHEMBL1538118 & 688497 & 4.5 & 4.9416 & TRN & \\
\hline CHEMBL1313696 & 688497 & 4.45 & 5.1704 & TRN & \\
\hline CHEMBL1974450 & 688497 & 5.0 & 4.9535 & TRN & \\
\hline CHEMBL1505239 & 688497 & 6.8499 & 5.2303 & TST & \\
\hline CHEMBL1312088 & 688497 & 5.85 & 5.1261 & TRN & \\
\hline CHEMBL1465873 & 688497 & 5.0 & 4.8993 & TRN & \\
\hline
\end{tabular}




\begin{tabular}{|c|c|c|c|c|c|}
\hline \multicolumn{6}{|c|}{ Supplemental Table S2.txt } \\
\hline CHEMBL1347071 & 688497 & 5.6 & 5.5023 & TRN & \\
\hline CHEMBL1303016 & 688497 & 6.25 & 5.1449 & TRN & \\
\hline CHEMBL1391333 & 688497 & 4.85 & 4.9088 & TRN & \\
\hline CHEMBL1608910 & 688497 & 4.65 & 5.0255 & TRN & \\
\hline CHEMBL1324988 & 688497 & 4.45 & 5.0793 & TRN & \\
\hline CHEMBL373839 & 688497 & 4.45 & 5.0077 & TRN & \\
\hline CHEMBL1587473 & 688497 & 5.3 & 4.6331 & TRN & \\
\hline CHEMBL1409967 & 688497 & 5.85 & 5.0821 & TRN & \\
\hline CHEMBL1611549 & 688497 & 4.45 & 5.0224 & TRN & \\
\hline CHEMBL1361020 & 688497 & 5.0 & 5.187 & TST & \\
\hline CHEMBL1976198 & 688497 & 4.6 & 4.687 & TRN & \\
\hline CHEMBL1380279 & 688497 & 4.45 & 5.1028 & TRN & \\
\hline CHEMBL1517410 & 688497 & 6.3 & 4.9639 & TST & \\
\hline CHEMBL1333052 & 688497 & 4.9 & 4.772 & TRN & \\
\hline CHEMBL1589502 & 688497 & 4.45 & 5.0349 & TRN & \\
\hline CHEMBL1352405 & 688497 & 4.55 & 5.0391 & TRN & \\
\hline CHEMBL1580735 & 688497 & 5.6 & 5.146 & TST & \\
\hline CHEMBL1346003 & 688497 & 4.45 & 4.78600 & 00000000005 & TRN \\
\hline CHEMBL1307715 & 688497 & 5.05 & 4.8153 & TRN & \\
\hline CHEMBL1454887 & 688497 & 4.85 & 4.7927 & TRN & \\
\hline CHEMBL1536981 & 688497 & 6.0 & 5.2429 & TRN & \\
\hline CHEMBL1365620 & 688497 & 5.45 & 4.9319 & TRN & \\
\hline CHEMBL1348181 & 688497 & 4.65 & 4.7236 & TRN & \\
\hline CHEMBL1299956 & 688497 & 4.45 & 4.8275 & TST & \\
\hline CHEMBL1312377 & 688497 & 5.15 & 5.228 & TST & \\
\hline CHEMBL1371372 & 688497 & 7.3002 & 5.5185 & TRN & \\
\hline CHEMBL1390963 & 688497 & 4.45 & 5.048 & TRN & \\
\hline CHEMBL1415148 & 688497 & 5.9 & 5.2238 & TRN & \\
\hline CHEMBL1385433 & 688497 & 4.95 & 5.2267 & TST & \\
\hline CHEMBL1367163 & 688497 & 4.75 & 5.0704 & TRN & \\
\hline CHEMBL1393502 & 688497 & 4.7 & 5.2131 & TRN & \\
\hline CHEMBL1499291 & 688497 & 4.45 & 4.7733 & TRN & \\
\hline CHEMBL1602307 & 688497 & 4.45 & 5.1685 & TRN & \\
\hline CHEMBL1606071 & 688497 & 5.6 & 5.4024 & TRN & \\
\hline CHEMBL1422187 & 688497 & 6.0 & 5.2512 & TRN & \\
\hline CHEMBL1375630 & 688497 & 4.6 & 4.6739 & TRN & \\
\hline CHEMBL 1458205 & 688497 & 4.45 & 4.716 & TRN & \\
\hline CHEMBL1408781 & 688497 & 4.85 & 4.8282 & TRN & \\
\hline CHEMBL1502840 & 688497 & 4.45 & 4.7212 & TRN & \\
\hline CHEMBL1583886 & 688497 & 5.05 & 4.9086 & TRN & \\
\hline CHEMBL1344880 & 688497 & 4.45 & 5.0812 & TST & \\
\hline CHEMBL1377838 & 688497 & 6.6 & 5.0827 & TST & \\
\hline CHEMBL1564349 & 688497 & 5.25 & 5.4468 & TRN & \\
\hline CHEMBL1384412 & 688497 & 4.65 & 4.9515 & TRN & \\
\hline CHEMBL1351643 & 688497 & 4.45 & 5.3536 & TST & \\
\hline CHEMBL3194240 & 688497 & 6.1 & 5.2965 & TST & \\
\hline CHEMBL1370165 & 688497 & 4.45 & 5.0826 & TRN & \\
\hline CHEMBL1364553 & 688497 & 4.45 & 4.7958 & TRN & \\
\hline
\end{tabular}




\begin{tabular}{|c|c|c|c|c|c|}
\hline \multicolumn{6}{|c|}{ Supplemental Table s2.txt } \\
\hline CHEMBL1419982 & 688497 & 6.0 & 5.316 & TRN & \\
\hline CHEMBL1598561 & 688497 & 4.65 & 4.4666 & TRN & \\
\hline CHEMBL1482407 & 688497 & 4.95 & 5.5929 & TRN & \\
\hline CHEMBL1588187 & 688497 & 4.45 & 5.0804 & TRN & \\
\hline CHEMBL1545877 & 688497 & 4.8 & 5.3351 & TRN & \\
\hline CHEMBL1539409 & 688497 & 4.6 & 5.1058 & TRN & \\
\hline CHEMBL1470135 & 688497 & 4.45 & 4.6957 & TRN & \\
\hline CHEMBL1584152 & 688497 & 6.25 & 5.0777 & TST & \\
\hline CHEMBL1305861 & 688497 & 4.9 & 4.8007 & TRN & \\
\hline CHEMBL147514 & 688497 & 5.0 & 4.9492 & TRN & \\
\hline CHEMBL1411054 & 688497 & 4.75 & 4.8614 & TRN & \\
\hline CHEMBL1321273 & 688497 & 5.8 & 4.8382 & TRN & \\
\hline CHEMBL3191858 & 688497 & 4.45 & 4.6322 & TRN & \\
\hline CHEMBL1410008 & 688497 & 5.4 & 5.3819 & TST & \\
\hline CHEMBL1606259 & 688497 & 4.45 & 4.7195 & TRN & \\
\hline CHEMBL1545872 & 688497 & 4.45 & 4.8542 & TRN & \\
\hline CHEMBL1379454 & 688497 & 4.45 & 5.0027 & TRN & \\
\hline CHEMBL1588463 & 688497 & 4.95 & 4.8797 & TST & \\
\hline CHEMBL1343437 & 688497 & 5.0 & 4.8592 & TRN & \\
\hline CHEMBL1421739 & 688497 & 4.95 & 5.0894 & TRN & \\
\hline CHEMBL1497467 & 688497 & 4.95 & 4.8307 & TRN & \\
\hline CHEMBL1418633 & 688497 & 4.9 & 4.8372 & TRN & \\
\hline CHEMBL1562136 & 688497 & 6.0 & 5.1238 & TRN & \\
\hline CHEMBL1607899 & 688497 & 4.45 & 4.8942 & TRN & \\
\hline CHEMBL1517374 & 688497 & 4.45 & 4.9061 & TST & \\
\hline CHEMBL3190677 & 688497 & 6.2 & 5.1174 & TRN & \\
\hline CHEMBL1303886 & 688497 & 5.1 & 5.0088 & TRN & \\
\hline CHEMBL1427087 & 688497 & 4.45 & 4.9078 & TRN & \\
\hline CHEMBL1430225 & 688497 & 4.9 & 5.2319 & TST & \\
\hline CHEMBL1343349 & 688497 & 5.4 & 4.8078 & TRN & \\
\hline CHEMBL1517974 & 688497 & 6.0 & 4.9122 & TRN & \\
\hline CHEMBL1302628 & 688497 & 4.45 & 4.8719 & TRN & \\
\hline CHEMBL1568714 & 688497 & 4.9 & 4.9522 & TRN & \\
\hline CHEMBL1310143 & 688497 & 4.75 & 4.907 & TRN & \\
\hline CHEMBL1312972 & 688497 & 5.25 & 4.8464 & TST & \\
\hline CHEMBL1412378 & 688497 & 4.45 & 5.2622 & TRN & \\
\hline CHEMBL1423708 & 688497 & 5.6 & 5.6227 & TST & \\
\hline CHEMBL3191286 & 688497 & 4.45 & 4.9803 & TST & \\
\hline CHEMBL1418225 & 688497 & 6.0 & 5.1933 & TST & \\
\hline CHEMBL1300156 & 688497 & 5.45 & 5.1285 & TRN & \\
\hline CHEMBL1380327 & 688497 & 4.95 & 5.1110 & 0000000001 & TRN \\
\hline CHEMBL1341744 & 688497 & 4.45 & 4.9465 & TRN & \\
\hline CHEMBL1984924 & 688497 & 4.95 & 5.0073 & TRN & \\
\hline CHEMBL1581094 & 688497 & 4.45 & 5.3056 & TRN & \\
\hline CHEMBL1540525 & 688497 & 4.85 & 4.6113 & TRN & \\
\hline CHEMBL1410698 & 688497 & 4.9 & 4.9364 & TST & \\
\hline CHEMBL1383873 & 688497 & 4.65 & 5.1394 & TST & \\
\hline CHEMBL3196987 & 688497 & 4.45 & 5.1844 & TST & \\
\hline
\end{tabular}




\begin{tabular}{|c|c|c|c|c|c|}
\hline \\
\hline CHEMBL1389959 & 688497 & 6.2 & 4.9215 & TST & \\
\hline CHEMBL1536628 & 688497 & 4.45 & 5.1447 & TRN & \\
\hline CHEMBL1611751 & 688497 & 5.85 & 5.3907 & TST & \\
\hline CHEMBL1524223 & 688497 & 5.5 & 5.2753 & TRN & \\
\hline CHEMBL1359573 & 688497 & 4.95 & 4.7524 & TRN & \\
\hline CHEMBL1595318 & 688497 & 6.25 & 4.9993 & TST & \\
\hline CHEMBL1346752 & 688497 & 4.95 & 5.0657 & TST & \\
\hline CHEMBL1588292 & 688497 & 5.35 & 5.0989 & TRN & \\
\hline CHEMBL3190629 & 688497 & 4.55 & 5.2032 & TRN & \\
\hline CHEMBL1464121 & 688497 & 6.45 & 5.25899 & 99999999995 & TRN \\
\hline CHEMBL1468519 & 688497 & 4.45 & 5.0194 & TRN & \\
\hline CHEMBL1373577 & 688497 & 5.0 & 4.9544 & TRN & \\
\hline CHEMBL1322002 & 688497 & 4.45 & 4.5577 & TRN & \\
\hline CHEMBL1605886 & 688497 & 4.45 & 5.2539 & TRN & \\
\hline CHEMBL1580342 & 688497 & 4.45 & 4.978 & TRN & \\
\hline CHEMBL1527779 & 688497 & 4.45 & 4.641 & TST & \\
\hline CHEMBL1459140 & 688497 & 6.0 & 5.106 & TRN & \\
\hline CHEMBL1994402 & 688497 & 5.1 & 5.015 & TRN & \\
\hline CHEMBL1508894 & 688497 & 6.2 & 5.3487 & TRN & \\
\hline CHEMBL1520421 & 688497 & 4.45 & 4.97 & TRN & \\
\hline CHEMBL1456201 & 688497 & 4.45 & 4.7897 & TRN & \\
\hline CHEMBL3195818 & 688497 & 5.35 & 5.0339 & TST & \\
\hline CHEMBL1556187 & 688497 & 4.95 & 4.9922 & TST & \\
\hline CHEMBL1448041 & 688497 & 4.45 & 4.9858 & TRN & \\
\hline CHEMBL1425438 & 688497 & 6.0 & 5.1663 & TRN & \\
\hline CHEMBL1382871 & 688497 & 4.65 & 5.0518 & TST & \\
\hline CHEMBL1605316 & 688497 & 5.05 & 4.817 & TRN & \\
\hline CHEMBL1499475 & 688497 & 4.45 & 4.8807 & TST & \\
\hline CHEMBL1390785 & 688497 & 5.0 & 5.0073 & TRN & \\
\hline CHEMBL1306573 & 688497 & 4.45 & 5.0423 & TRN & \\
\hline CHEMBL1309890 & 688497 & 5.35 & 5.3245 & TRN & \\
\hline CHEMBL1539970 & 688497 & 5.8 & 4.9144 & TST & \\
\hline CHEMBL3210583 & 688497 & 4.45 & 4.7954 & TRN & \\
\hline CHEMBL1505253 & 688497 & 5.55 & 5.2059 & TRN & \\
\hline CHEMBL1602847 & 688497 & 5.5 & 5.0804 & TRN & \\
\hline CHEMBL1350092 & 688497 & 5.0 & 5.5333 & TRN & \\
\hline CHEMBL1544996 & 688497 & 4.7 & 4.8129 & TST & \\
\hline CHEMBL1374288 & 688497 & 4.9 & 5.12299 & 9999999999 & TRN \\
\hline CHEMBL1480251 & 688497 & 4.65 & 4.967 & TRN & \\
\hline CHEMBL1462315 & 688497 & 4.6 & 4.7316 & TST & \\
\hline CHEMBL1322180 & 688497 & 4.45 & 5.0139 & TRN & \\
\hline CHEMBL1362660 & 688497 & 5.35 & 5.2581 & TST & \\
\hline CHEMBL1604234 & 688497 & 4.6 & 5.1042 & TRN & \\
\hline CHEMBL1584418 & 688497 & 4.45 & 4.8869 & TRN & \\
\hline CHEMBL1501263 & 688497 & 4.45 & 5.20299 & 9999999999 & TRN \\
\hline CHEMBL1566388 & 688497 & 6.1 & 5.2959 & TRN & \\
\hline CHEMBL1390237 & 688497 & 4.75 & 5.3086 & TST & \\
\hline CHEMBL1380946 & 688497 & 5.7 & 5.1482 & TRN & \\
\hline
\end{tabular}




\begin{tabular}{|c|c|c|c|c|c|}
\hline \multicolumn{6}{|c|}{ Supplemental Table S2.txt } \\
\hline CHEMBL1555540 & 688497 & 5.95 & 5.2982 & TRN & \\
\hline CHEMBL1456595 & 688497 & 4.7 & 4.7686 & TRN & \\
\hline CHEMBL1415344 & 688497 & 5.5 & 5.1433 & TRN & \\
\hline CHEMBL1549691 & 688497 & 4.95 & 4.9515 & TST & \\
\hline CHEMBL1450159 & 688497 & 5.95 & 5.0105 & TRN & \\
\hline CHEMBL1377977 & 688497 & 4.45 & 4.8466 & TRN & \\
\hline CHEMBL1440115 & 688497 & 5.25 & 5.266 & TST & \\
\hline CHEMBL1506563 & 688497 & 5.45 & 5.5294 & TRN & \\
\hline CHEMBL1531825 & 688497 & 4.45 & 4.9825 & TRN & \\
\hline CHEMBL1532309 & 688497 & 4.65 & 5.15799 & 99999999995 & TRN \\
\hline CHEMBL1530018 & 688497 & 4.45 & 4.6511 & TRN & \\
\hline CHEMBL1302326 & 688497 & 5.5 & 4.9878 & TRN & \\
\hline CHEMBL1989179 & 688497 & 4.6 & 4.7667 & TRN & \\
\hline CHEMBL 3196881 & 688497 & 5.1 & 5.3271 & TRN & \\
\hline CHEMBL1385094 & 688497 & 5.15 & 5.0263 & TRN & \\
\hline CHEMBL1543444 & 688497 & 4.45 & 4.949 & TRN & \\
\hline CHEMBL1472331 & 688497 & 7.5003 & 5.1347 & TRN & \\
\hline CHEMBL1609780 & 688497 & 6.0 & 5.4357 & TRN & \\
\hline CHEMBL1599674 & 688497 & 5.15 & 5.1483 & TRN & \\
\hline CHEMBL1524797 & 688497 & 4.45 & 4.9606 & TST & \\
\hline CHEMBL1458004 & 688497 & 5.7 & 5.1299 & TRN & \\
\hline CHEMBL1424902 & 688497 & 4.8 & 4.8752 & TRN & \\
\hline CHEMBL1443732 & 688497 & 4.5 & 5.0639 & TRN & \\
\hline CHEMBL1418742 & 688497 & 4.9 & 4.774 & TRN & \\
\hline CHEMBL1565542 & 688497 & 4.6 & 5.0244 & TRN & \\
\hline CHEMBL1613237 & 688497 & 4.95 & 4.7875 & TRN & \\
\hline CHEMBL1969672 & 688497 & 4.9 & 5.01 & TST & \\
\hline CHEMBL1567544 & 688497 & 4.45 & 5.0885 & TRN & \\
\hline CHEMBL1301741 & 688497 & 4.45 & 5.0976 & TRN & \\
\hline CHEMBL1342155 & 688497 & 6.0 & 5.4424 & TRN & \\
\hline CHEMBL1303810 & 688497 & 4.45 & 4.8417 & TRN & \\
\hline CHEMBL1559138 & 688497 & 4.45 & 5.1802 & TST & \\
\hline CHEMBL3189528 & 688497 & 4.45 & 4.8266 & TRN & \\
\hline CHEMBL1370977 & 688497 & 7.0 & 4.9587 & TRN & \\
\hline CHEMBL1531885 & 688497 & 4.45 & 5.0737 & TRN & \\
\hline CHEMBL1462431 & 688497 & 5.45 & 5.1615 & TRN & \\
\hline CHEMBL1584309 & 688497 & 4.6 & 5.0496 & TRN & \\
\hline CHEMBL1528593 & 688497 & 4.65 & 4.851 & TRN & \\
\hline CHEMBL1422078 & 688497 & 5.6 & 5.485 & TRN & \\
\hline CHEMBL1379832 & 688497 & 5.25 & 5.1972 & TRN & \\
\hline CHEMBL1363194 & 688497 & 4.5 & 4.9049 & TRN & \\
\hline CHEMBL1543172 & 688497 & 4.95 & 4.8752 & TRN & \\
\hline CHEMBL1565991 & 688497 & 5.55 & 4.9526 & TRN & \\
\hline CHEMBL1308461 & 688497 & 4.6 & 4.816 & TRN & \\
\hline CHEMBL1510843 & 688497 & 5.75 & 5.4422 & TST & \\
\hline CHEMBL1582573 & 688497 & 4.5 & 5.0412 & TST & \\
\hline CHEMBL1433385 & 688497 & 5.35 & 4.6837 & TRN & \\
\hline CHEMBL1367211 & 688497 & 5.5 & 5.4033 & TST & \\
\hline
\end{tabular}




\begin{tabular}{|c|c|c|c|c|}
\hline \multicolumn{5}{|c|}{ Supplemental Table S2.txt } \\
\hline CHEMBL1456841 & 688497 & 4.85 & 4.7597 & TRN \\
\hline CHEMBL1479822 & 688497 & 4.45 & 4.8374 & TRN \\
\hline CHEMBL1321836 & 688497 & 4.65 & 5.1383 & TRN \\
\hline CHEMBL1490379 & 688497 & 5.55 & 4.8545 & TRN \\
\hline CHEMBL1557301 & 688497 & 4.45 & 4.8471 & TRN \\
\hline CHEMBL1529236 & 688497 & 4.45 & 4.6812 & TRN \\
\hline CHEMBL1557584 & 688497 & 5.0 & 4.8394 & TRN \\
\hline CHEMBL1558177 & 688497 & 4.85 & 5.1398 & TRN \\
\hline CHEMBL1401985 & 688497 & 6.95 & 5.2401 & TST \\
\hline CHEMBL1576984 & 688497 & 5.0 & 4.7746 & TRN \\
\hline CHEMBL1502167 & 688497 & 4.8 & 4.9362 & TRN \\
\hline CHEMBL1444064 & 688497 & 7.5498 & 4.9334 & TRN \\
\hline CHEMBL1573534 & 688497 & 4.8 & 5.0261 & TRN \\
\hline CHEMBL1340021 & 688497 & 4.8 & 4.9688 & TST \\
\hline CHEMBL1555902 & 688497 & 5.9 & 5.223 & TRN \\
\hline CHEMBL1236872 & 688497 & 5.9 & 5.8217 & TRN \\
\hline CHEMBL1363140 & 688497 & 4.45 & 4.6237 & TRN \\
\hline CHEMBL1300502 & 688497 & 4.65 & 4.8255 & TRN \\
\hline CHEMBL1343555 & 688497 & 4.5 & 5.0974 & TRN \\
\hline CHEMBL1455214 & 688497 & 4.95 & 4.993 & TRN \\
\hline CHEMBL1407588 & 688497 & 4.8 & 4.8634 & TRN \\
\hline CHEMBL3190739 & 688497 & 4.45 & 4.8233 & TRN \\
\hline CHEMBL1517137 & 688497 & 4.95 & 4.9314 & TRN \\
\hline CHEMBL1517085 & 688497 & 4.45 & 4.8591 & TRN \\
\hline CHEMBL1341485 & 688497 & 5.05 & 5.1874 & TRN \\
\hline CHEMBL1334287 & 688497 & 5.45 & 4.9672 & TRN \\
\hline CHEMBL1485860 & 688497 & 5.65 & 5.1335 & TRN \\
\hline CHEMBL1391358 & 688497 & 4.9 & 5.3098 & TRN \\
\hline CHEMBL1374320 & 688497 & 6.1 & 5.5152 & TRN \\
\hline CHEMBL580918 & 688497 & 5.85 & 5.5767 & TRN \\
\hline CHEMBL3209727 & 688497 & 4.45 & 5.0797 & TRN \\
\hline CHEMBL1455547 & 688497 & 5.1 & 4.763 & TRN \\
\hline CHEMBL1539968 & 688497 & 4.45 & 4.9123 & TRN \\
\hline CHEMBL1596446 & 688497 & 5.55 & 5.0585 & TST \\
\hline CHEMBL1600173 & 688497 & 4.45 & 4.9081 & TRN \\
\hline CHEMBL1567791 & 688497 & 6.0 & 5.0569 & TRN \\
\hline CHEMBL197014 & 688497 & 4.45 & 4.8559 & TRN \\
\hline CHEMBL1520715 & 688497 & 4.75 & 4.9366 & TRN \\
\hline CHEMBL1343352 & 688497 & 4.75 & 5.2294 & TRN \\
\hline CHEMBL1425104 & 688497 & 5.25 & 5.1301 & TST \\
\hline CHEMBL1426370 & 688497 & 4.95 & 5.0136 & TRN \\
\hline CHEMBL1582147 & 688497 & 4.45 & 4.9056 & TRN \\
\hline CHEMBL1594717 & 688497 & 4.45 & 5.0015 & TRN \\
\hline CHEMBL1468484 & 688497 & 5.45 & 5.1556 & TST \\
\hline CHEMBL2004739 & 688497 & 4.75 & 4.6309 & TRN \\
\hline CHEMBL1558648 & 688497 & 5.75 & 4.9563 & TRN \\
\hline CHEMBL1444392 & 688497 & 4.7 & 4.8685 & TRN \\
\hline CHEMBL1383831 & 688497 & 6.45 & 5.2178 & TRN \\
\hline
\end{tabular}




\begin{tabular}{|c|c|c|c|c|}
\hline \multicolumn{5}{|c|}{ Supplemental Table S2.txt } \\
\hline CHEMBL1420829 & 688497 & 5.75 & 5.1205 & TRN \\
\hline CHEMBL1555566 & 688497 & 4.5 & 4.8365 & TRN \\
\hline CHEMBL1372242 & 688497 & 6.05 & 4.9678 & TRN \\
\hline CHEMBL1565369 & 688497 & 4.95 & 5.1594 & TRN \\
\hline CHEMBL1596917 & 688497 & 4.95 & 4.8947 & TRN \\
\hline CHEMBL1431939 & 688497 & 5.9 & 4.8555 & TRN \\
\hline CHEMBL1503193 & 688497 & 4.45 & 4.922 & TRN \\
\hline CHEMBL1306838 & 688497 & 4.6 & 4.7135 & TRN \\
\hline CHEMBL1605210 & 688497 & 6.5 & 4.9052 & TST \\
\hline CHEMBL1466376 & 688497 & 4.45 & 5.3452 & TST \\
\hline CHEMBL1462765 & 688497 & 5.2 & 5.2183 & TRN \\
\hline CHEMBL1541511 & 688497 & 4.45 & 4.7447 & TST \\
\hline CHEMBL1487758 & 688497 & 5.65 & 4.9664 & TRN \\
\hline CHEMBL1507645 & 688497 & 5.05 & 4.9338 & TRN \\
\hline CHEMBL1307222 & 688497 & 6.3 & 5.0213 & TRN \\
\hline CHEMBL1587624 & 688497 & 5.4 & 5.1271 & TRN \\
\hline CHEMBL1499305 & 688497 & 4.6 & 5.0824 & TRN \\
\hline CHEMBL1328544 & 688497 & 4.95 & 5.0119 & TRN \\
\hline CHEMBL1325753 & 688497 & 4.45 & 4.8782 & TST \\
\hline CHEMBL1499436 & 688497 & 5.5 & 4.7061 & TST \\
\hline CHEMBL1579305 & 688497 & 4.8 & 4.9836 & TRN \\
\hline CHEMBL1539539 & 688497 & 5.25 & 5.0004 & TRN \\
\hline CHEMBL1578575 & 688497 & 5.15 & 5.0283 & TRN \\
\hline CHEMBL1302293 & 688497 & 4.45 & 5.0065 & TRN \\
\hline CHEMBL1425821 & 688497 & 4.8 & 4.9067 & TST \\
\hline CHEMBL1366934 & 688497 & 5.5 & 4.7866 & TRN \\
\hline CHEMBL1374250 & 688497 & 6.2 & 5.1089 & TRN \\
\hline CHEMBL1332219 & 688497 & 5.4 & 5.4937 & TRN \\
\hline CHEMBL1575385 & 688497 & 4.45 & 4.8757 & TRN \\
\hline CHEMBL1341472 & 688497 & 4.95 & 4.9146 & TST \\
\hline CHEMBL 3193771 & 688497 & 4.45 & 5.2843 & TRN \\
\hline CHEMBL1418827 & 688497 & 4.95 & 5.1076 & TRN \\
\hline CHEMBL1341239 & 688497 & 5.05 & 5.1899 & TRN \\
\hline CHEMBL1352186 & 688497 & 6.35 & 5.2048 & TRN \\
\hline CHEMBL1581182 & 688497 & 4.8 & 4.9914 & TRN \\
\hline CHEMBL1440902 & 688497 & 4.55 & 4.4718 & TRN \\
\hline CHEMBL1366988 & 688497 & 5.35 & 5.1199 & TRN \\
\hline CHEMBL3194931 & 688497 & 4.45 & 4.7266 & TRN \\
\hline CHEMBL1532584 & 688497 & 4.55 & 4.8798 & TRN \\
\hline CHEMBL1404976 & 688497 & 5.1 & 5.0149 & TRN \\
\hline CHEMBL1325446 & 688497 & 4.45 & 4.7557 & TRN \\
\hline CHEMBL1510765 & 688497 & 4.6 & 4.838 & TRN \\
\hline CHEMBL3199312 & 688497 & 4.45 & 4.8282 & TRN \\
\hline CHEMBL1451283 & 688497 & 5.6 & 4.9708 & TRN \\
\hline CHEMBL1374126 & 688497 & 4.9 & 5.2507 & TRN \\
\hline CHEMBL1967474 & 688497 & 5.4 & 5.3778 & TST \\
\hline CHEMBL 1493490 & 688497 & 5.0 & 5.2076 & TRN \\
\hline CHEMBL1462185 & 688497 & 4.6 & 4.8973 & TRN \\
\hline
\end{tabular}




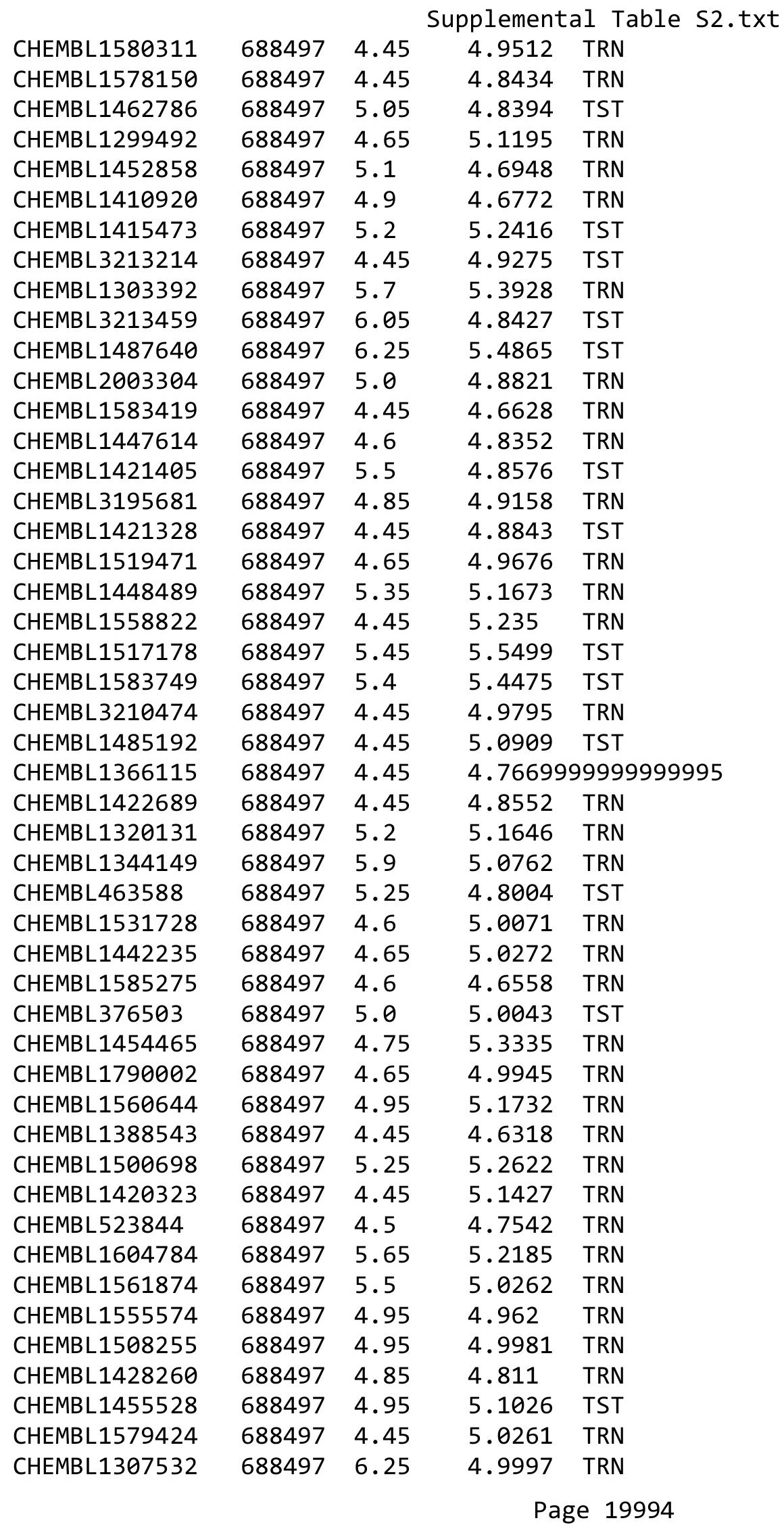




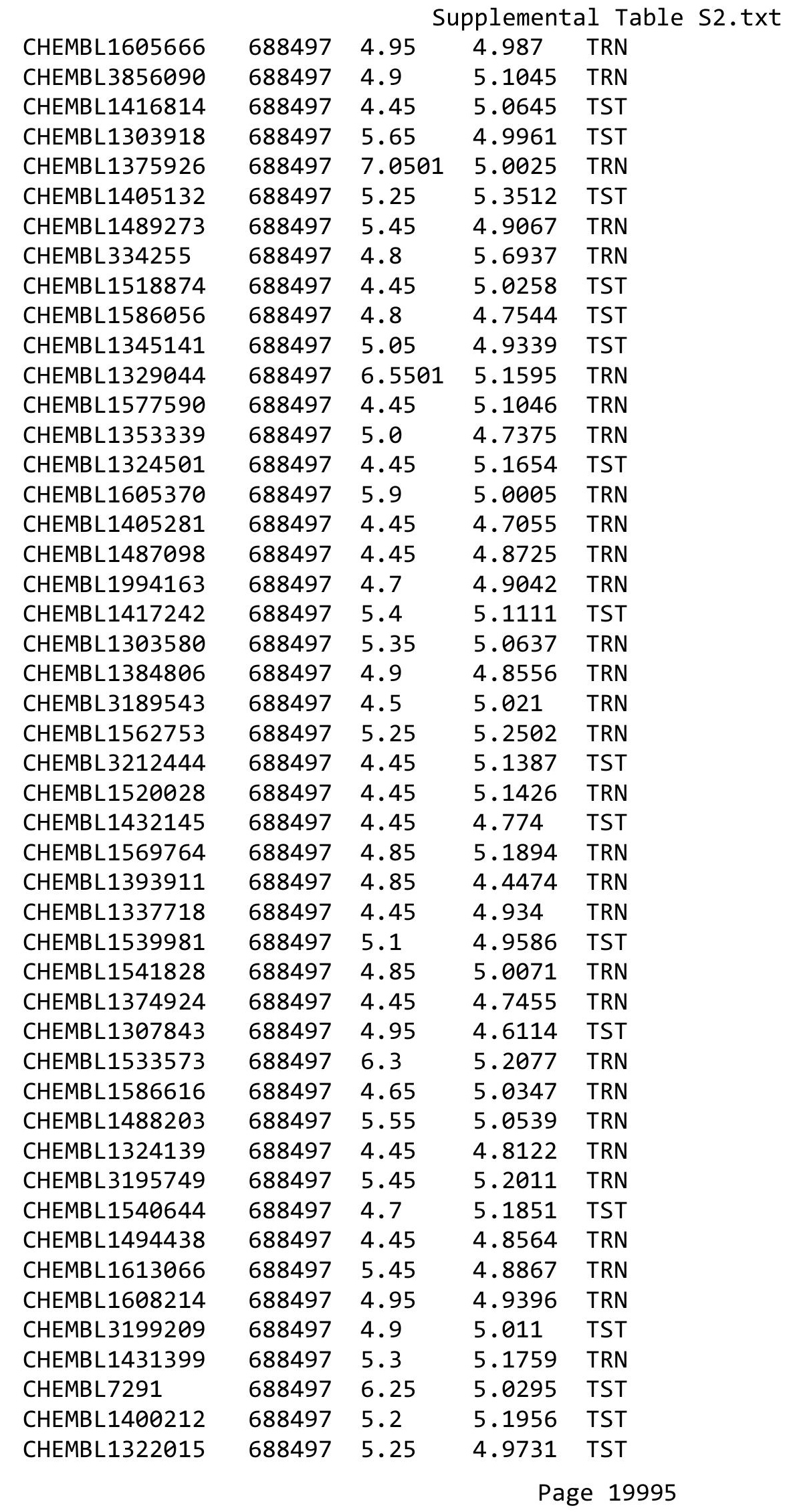




\begin{tabular}{|c|c|c|c|c|}
\hline \multicolumn{5}{|c|}{ Supplemental Table S2.txt } \\
\hline CHEMBL1455507 & 688497 & 4.5 & 4.7174 & TRN \\
\hline CHEMBL1487730 & 688497 & 4.85 & 4.8388 & TRN \\
\hline CHEMBL1605023 & 688497 & 5.4 & 5.3731 & TRN \\
\hline CHEMBL1487719 & 688497 & 5.5 & 5.1945 & TRN \\
\hline CHEMBL1467697 & 688497 & 5.35 & 5.011 & TRN \\
\hline CHEMBL1490152 & 688497 & 6.1 & 4.9896 & TRN \\
\hline CHEMBL1377824 & 688497 & 4.6 & 4.8959 & TRN \\
\hline CHEMBL1557796 & 688497 & 5.55 & 5.0694 & TST \\
\hline CHEMBL3195237 & 688497 & 5.5 & 5.112 & TRN \\
\hline CHEMBL1432897 & 688497 & 4.95 & 4.9054 & TRN \\
\hline CHEMBL1303342 & 688497 & 5.05 & 5.4947 & TRN \\
\hline CHEMBL1352052 & 688497 & 6.25 & 4.9775 & TRN \\
\hline CHEMBL1534772 & 688497 & 4.65 & 4.9676 & TRN \\
\hline CHEMBL1595701 & 688497 & 4.65 & 4.9602 & TST \\
\hline CHEMBL1368657 & 688497 & 4.45 & 5.1125 & TRN \\
\hline CHEMBL 2003964 & 688497 & 5.05 & 5.2024 & TRN \\
\hline CHEMBL1613033 & 688497 & 5.9 & 5.1535 & TRN \\
\hline CHEMBL1588979 & 688497 & 5.1 & 4.8663 & TRN \\
\hline CHEMBL1558382 & 688497 & 5.55 & 5.0147 & TST \\
\hline CHEMBL1423723 & 688497 & 4.45 & 4.863 & TRN \\
\hline CHEMBL1453355 & 688497 & 4.85 & 4.8221 & TRN \\
\hline CHEMBL1527578 & 688497 & 4.8 & 5.0382 & TRN \\
\hline CHEMBL3189810 & 688497 & 4.9 & 5.1716 & TRN \\
\hline CHEMBL1472103 & 688497 & 4.45 & 5.2325 & TRN \\
\hline CHEMBL1306267 & 688497 & 5.95 & 5.4151 & TRN \\
\hline CHEMBL1364399 & 688497 & 5.0 & 5.0398 & TRN \\
\hline CHEMBL1501998 & 688497 & 4.45 & 5.0538 & TRN \\
\hline CHEMBL1299376 & 688497 & 5.45 & 5.3296 & TST \\
\hline CHEMBL1393064 & 688497 & 5.15 & 5.0821 & TRN \\
\hline CHEMBL1387767 & 688497 & 5.0 & 4.6318 & TST \\
\hline CHEMBL1517473 & 688497 & 4.85 & 5.0589 & TRN \\
\hline CHEMBL1415851 & 688497 & 4.45 & 4.9018 & TRN \\
\hline CHEMBL1572001 & 688497 & 5.3 & 4.9142 & TRN \\
\hline CHEMBL609628 & 688497 & 5.05 & 4.8287 & TRN \\
\hline CHEMBL1584771 & 688497 & 4.45 & 5.0668 & TRN \\
\hline CHEMBL1345078 & 688497 & 4.95 & 5.0035 & TRN \\
\hline CHEMBL1300612 & 688497 & 4.45 & 4.6553 & TRN \\
\hline CHEMBL3190029 & 688497 & 5.55 & 4.8676 & TST \\
\hline CHEMBL1347672 & 688497 & 4.95 & 5.1129 & TST \\
\hline CHEMBL1610687 & 688497 & 4.45 & 4.8304 & TRN \\
\hline CHEMBL1481353 & 688497 & 5.1 & 5.0116 & TRN \\
\hline CHEMBL1572263 & 688497 & 4.45 & 4.8285 & TRN \\
\hline CHEMBL1336876 & 688497 & 4.45 & 4.9047 & TRN \\
\hline CHEMBL1461940 & 688497 & 4.45 & 4.9794 & TST \\
\hline CHEMBL1373429 & 688497 & 6.5 & 5.0789 & TST \\
\hline CHEMBL1612809 & 688497 & 5.0 & 5.2291 & TST \\
\hline CHEMBL3209184 & 688497 & 6.25 & 4.9605 & TRN \\
\hline CHEMBL1520241 & 688497 & 6.0 & 5.0243 & TRN \\
\hline
\end{tabular}




\begin{tabular}{|c|c|c|c|c|}
\hline \multicolumn{5}{|c|}{ Supplemental Table S2.txt } \\
\hline CHEMBL1472423 & 688497 & 5.7 & 5.3721 & TRN \\
\hline CHEMBL1368714 & 688497 & 5.5 & 5.2403 & TRN \\
\hline CHEMBL3194760 & 688497 & 5.6 & 4.9639 & TST \\
\hline CHEMBL1363982 & 688497 & 6.2 & 4.7633 & TRN \\
\hline CHEMBL1338045 & 688497 & 4.9 & 4.9213 & TRN \\
\hline CHEMBL1520222 & 688497 & 5.0 & 4.8821 & TRN \\
\hline CHEMBL1518107 & 688497 & 4.45 & 4.7763 & TRN \\
\hline CHEMBL1401272 & 688497 & 6.15 & 4.9633 & TRN \\
\hline CHEMBL1403160 & 688497 & 5.3 & 4.9456 & TRN \\
\hline CHEMBL1384253 & 688497 & 5.3 & 5.3161 & TST \\
\hline CHEMBL1312079 & 688497 & 5.45 & 4.9654 & TRN \\
\hline CHEMBL1443258 & 688497 & 4.65 & 4.5846 & TRN \\
\hline CHEMBL1461648 & 688497 & 6.05 & 5.0627 & TRN \\
\hline CHEMBL1520541 & 688497 & 4.45 & 4.959 & TRN \\
\hline CHEMBL1415960 & 688497 & 5.5 & 4.8284 & TRN \\
\hline CHEMBL1578360 & 688497 & 4.45 & 5.0834 & TRN \\
\hline CHEMBL1347466 & 688497 & 4.45 & 5.2815 & TRN \\
\hline CHEMBL1388376 & 688497 & 5.25 & 5.2055 & TST \\
\hline CHEMBL1334062 & 688497 & 4.45 & 4.8959 & TRN \\
\hline CHEMBL1563788 & 688497 & 4.45 & 5.0258 & TRN \\
\hline CHEMBL1984065 & 688497 & 4.45 & 5.0934 & TST \\
\hline CHEMBL389162 & 688497 & 4.45 & 5.0574 & TRN \\
\hline CHEMBL1344528 & 688497 & 4.6 & 4.7617 & TST \\
\hline CHEMBL1447010 & 688497 & 4.65 & 4.8918 & TST \\
\hline CHEMBL1337096 & 688497 & 5.2 & 5.1444 & TRN \\
\hline CHEMBL1584461 & 688497 & 4.55 & 4.6979 & TRN \\
\hline CHEMBL1579620 & 688497 & 6.25 & 5.0263 & TST \\
\hline CHEMBL1398981 & 688497 & 4.45 & 5.1244 & TRN \\
\hline CHEMBL1391560 & 688497 & 4.7 & 4.8734 & TRN \\
\hline CHEMBL1387589 & 688497 & 4.6 & 5.2788 & TRN \\
\hline CHEMBL1452506 & 688497 & 6.25 & 4.9472 & TST \\
\hline CHEMBL1601153 & 688497 & 4.45 & 4.8997 & TRN \\
\hline CHEMBL1573287 & 688497 & 5.25 & 5.0336 & TST \\
\hline CHEMBL1344965 & 688497 & 6.05 & 5.1897 & TRN \\
\hline CHEMBL3191789 & 688497 & 5.15 & 5.2739 & TRN \\
\hline CHEMBL1331314 & 688497 & 5.55 & 5.3004 & TRN \\
\hline CHEMBL1346489 & 688497 & 5.55 & 5.0607 & TRN \\
\hline CHEMBL1461471 & 688497 & 5.25 & 5.08 & TST \\
\hline CHEMBL1994877 & 688497 & 4.9 & 4.9616 & TRN \\
\hline CHEMBL1579839 & 688497 & 4.8 & 5.0829 & TRN \\
\hline CHEMBL1429172 & 688497 & 6.0 & 5.3086 & TST \\
\hline CHEMBL1550184 & 688497 & 5.9 & 5.3947 & TRN \\
\hline CHEMBL1584452 & 688497 & 5.2 & 4.9592 & TST \\
\hline CHEMBL1544553 & 688497 & 5.0 & 5.2838 & TST \\
\hline CHEMBL3190941 & 688497 & 4.9 & 5.0323 & TRN \\
\hline CHEMBL1329659 & 688497 & 5.45 & 4.4406 & TRN \\
\hline CHEMBL3192160 & 688497 & 5.5 & 4.8949 & TRN \\
\hline CHEMBL3213245 & 688497 & 4.75 & 4.9745 & TRN \\
\hline
\end{tabular}




\begin{tabular}{|c|c|c|c|c|c|}
\hline \multicolumn{6}{|c|}{ Supplemental Table s2.txt } \\
\hline CHEMBL1477337 & 688497 & 4.6 & 5.3052 & TRN & \\
\hline CHEMBL1467004 & 688497 & 4.45 & 5.0293 & TRN & \\
\hline CHEMBL1544969 & 688497 & 5.5 & 5.0674 & TST & \\
\hline CHEMBL1560437 & 688497 & 6.05 & 5.0975 & TST & \\
\hline CHEMBL1567269 & 688497 & 5.05 & 4.9337 & TRN & \\
\hline CHEMBL1371374 & 688497 & 4.7 & 5.1265 & TRN & \\
\hline CHEMBL1343076 & 688497 & 5.5 & 4.9669 & TRN & \\
\hline CHEMBL574583 & 688497 & 5.25 & 5.0419 & TST & \\
\hline CHEMBL1462215 & 688497 & 5.65 & \multicolumn{2}{|c|}{5.593999999999999} & TRN \\
\hline CHEMBL1543795 & 688497 & 6.25 & 5.2282 & TRN & \\
\hline CHEMBL1494304 & 688497 & 5.15 & 4.9299 & TRN & \\
\hline CHEMBL3189154 & 688497 & 4.45 & 4.7686 & TST & \\
\hline CHEMBL1405700 & 688497 & 4.45 & \multicolumn{2}{|c|}{4.7410000000000005} & TRN \\
\hline CHEMBL1400703 & 688497 & 4.45 & 4.9176 & TRN & \\
\hline CHEMBL1380524 & 688497 & 4.8 & 4.8801 & TST & \\
\hline CHEMBL3208474 & 688497 & 5.55 & 5.2206 & TRN & \\
\hline CHEMBL1373388 & 688497 & 4.95 & 4.9349 & TRN & \\
\hline CHEMBL1502980 & 688497 & 4.5 & 4.8801 & TRN & \\
\hline CHEMBL1409415 & 688497 & 5.9 & 5.3533 & TRN & \\
\hline CHEMBL1608182 & 688497 & 4.65 & 5.3977 & TST & \\
\hline CHEMBL1539964 & 688497 & 5.9 & 5.1626 & TST & \\
\hline CHEMBL1576942 & 688497 & 4.9 & 4.8886 & TRN & \\
\hline CHEMBL1414557 & 688497 & 4.95 & 4.9511 & TRN & \\
\hline CHEMBL1322969 & 688497 & 5.0 & 5.0201 & TRN & \\
\hline CHEMBL1415518 & 688497 & 4.7 & \multicolumn{2}{|c|}{5.071000000000001} & TRN \\
\hline CHEMBL1570622 & 688497 & 5.25 & 5.3495 & TST & \\
\hline CHEMBL1477399 & 688497 & 4.45 & 4.9096 & TRN & \\
\hline CHEMBL3189566 & 688497 & 5.05 & 4.8956 & TRN & \\
\hline CHEMBL1347013 & 688497 & 5.4 & 5.3737 & TRN & \\
\hline CHEMBL1386577 & 688497 & 4.45 & 5.1111 & TRN & \\
\hline CHEMBL1409207 & 688497 & 4.45 & 5.0325 & TRN & \\
\hline CHEMBL1402556 & 688497 & 4.6 & 5.1559 & TST & \\
\hline CHEMBL1585300 & 688497 & 4.9 & 4.9127 & TRN & \\
\hline CHEMBL1439318 & 688497 & 5.45 & 5.2139 & TRN & \\
\hline CHEMBL1429592 & 688497 & 5.25 & 4.9608 & TRN & \\
\hline CHEMBL3191406 & 688497 & 4.6 & 4.9121 & TRN & \\
\hline CHEMBL1732967 & 688497 & 5.45 & 4.8928 & TRN & \\
\hline CHEMBL1504497 & 688497 & 4.95 & 4.9231 & TRN & \\
\hline CHEMBL1594242 & 688497 & 4.45 & 4.8572 & TRN & \\
\hline CHEMBL1336098 & 688497 & 4.9 & 5.1073 & TRN & \\
\hline CHEMBL1490400 & 688497 & 6.25 & 5.1208 & TRN & \\
\hline CHEMBL1461661 & 688497 & 4.65 & 4.6837 & TRN & \\
\hline CHEMBL1523963 & 688497 & 5.2 & 5.1053 & TRN & \\
\hline CHEMBL1549308 & 688497 & 5.4 & 4.5916 & TRN & \\
\hline CHEMBL1377871 & 688497 & 6.25 & 5.0134 & TST & \\
\hline CHEMBL1546530 & 688497 & 5.15 & 5.1706 & TRN & \\
\hline CHEMBL1444294 & 688497 & 5.0 & 4.8034 & TST & \\
\hline CHEMBL1462497 & 688497 & 5.25 & 4.9396 & TST & \\
\hline
\end{tabular}




\begin{tabular}{|c|c|c|c|c|}
\hline \multicolumn{5}{|c|}{ Supplemental Table S2.txt } \\
\hline CHEMBL1454326 & 688497 & 5.55 & 5.0329 & TRN \\
\hline CHEMBL1967901 & 688497 & 5.6 & 4.8156 & TST \\
\hline CHEMBL1461283 & 688497 & 4.55 & 4.8408 & TRN \\
\hline CHEMBL1486786 & 688497 & 4.95 & 5.37299 & 9999999999 \\
\hline CHEMBL1607320 & 688497 & 4.45 & 4.8843 & TRN \\
\hline CHEMBL1579416 & 688497 & 4.95 & 4.8591 & TRN \\
\hline CHEMBL1381564 & 688497 & 4.95 & 4.6276 & TST \\
\hline CHEMBL1503282 & 688497 & 4.8 & 4.9698 & TRN \\
\hline CHEMBL1325081 & 688497 & 6.25 & 5.0153 & TRN \\
\hline CHEMBL1362902 & 688497 & 4.45 & 4.9151 & TST \\
\hline CHEMBL1451566 & 688497 & 6.95 & 4.9302 & TRN \\
\hline CHEMBL1407572 & 688497 & 5.5 & 4.933 & TRN \\
\hline CHEMBL3190429 & 688497 & 4.45 & 5.0321 & TRN \\
\hline CHEMBL1536767 & 688497 & 4.45 & 5.0134 & TRN \\
\hline CHEMBL3189209 & 688497 & 4.45 & 5.1671 & TRN \\
\hline CHEMBL1496208 & 688497 & 4.6 & 4.9179 & TRN \\
\hline CHEMBL1584620 & 688497 & 6.25 & 5.0084 & TST \\
\hline CHEMBL1509623 & 688497 & 4.8 & 4.7673 & TRN \\
\hline CHEMBL3193392 & 688497 & 4.95 & 5.0294 & TRN \\
\hline CHEMBL1399298 & 688497 & 4.7 & 5.2789 & TRN \\
\hline CHEMBL3198961 & 688497 & 5.15 & 5.2239 & TRN \\
\hline CHEMBL1341524 & 688497 & 4.65 & 5.1195 & TST \\
\hline CHEMBL1303428 & 688497 & 4.45 & 4.9248 & TST \\
\hline CHEMBL1542307 & 688497 & 4.8 & 4.831 & TRN \\
\hline CHEMBL1319208 & 688497 & 4.25 & 4.8122 & TRN \\
\hline CHEMBL1369720 & 688497 & 5.45 & 4.9832 & TRN \\
\hline CHEMBL1504701 & 688497 & 6.9 & 5.6251 & TRN \\
\hline CHEMBL1970469 & 688497 & 4.45 & 4.7224 & TRN \\
\hline CHEMBL 238188 & 688497 & 4.8 & 4.8533 & TST \\
\hline CHEMBL1481061 & 688497 & 5.5 & 5.1792 & TRN \\
\hline CHEMBL1479211 & 688497 & 5.0 & 5.0349 & TRN \\
\hline CHEMBL1491782 & 688497 & 5.3 & 5.0183 & TRN \\
\hline CHEMBL1598935 & 688497 & 4.45 & 5.052 & TST \\
\hline CHEMBL1578440 & 688497 & 5.45 & 4.7908 & TRN \\
\hline CHEMBL1567380 & 688497 & 4.45 & 5.1669 & TRN \\
\hline CHEMBL1361889 & 688497 & 5.0 & 4.6548 & TRN \\
\hline CHEMBL1546043 & 688497 & 4.45 & 4.96 & TRN \\
\hline CHEMBL1489737 & 688497 & 4.45 & 4.885 & TST \\
\hline CHEMBL1549663 & 688497 & 4.45 & 5.0817 & TRN \\
\hline CHEMBL1343214 & 688497 & 5.55 & 4.9926 & TST \\
\hline CHEMBL1362966 & 688497 & 5.0 & 4.8837 & TRN \\
\hline CHEMBL1606586 & 688497 & 4.45 & 4.7817 & TRN \\
\hline CHEMBL1350239 & 688497 & 4.95 & 4.9373 & TST \\
\hline CHEMBL1580537 & 688497 & 5.5 & 5.0587 & TRN \\
\hline CHEMBL1432251 & 688497 & 4.45 & 4.9986 & TRN \\
\hline CHEMBL1524664 & 688497 & 6.5 & 5.0614 & TRN \\
\hline CHEMBL3192892 & 688497 & 5.0 & 5.001 & TRN \\
\hline CHEMBL1381119 & 688497 & 4.45 & 5.3437 & TRN \\
\hline
\end{tabular}

TRN 


\begin{tabular}{|c|c|c|c|c|}
\hline \multicolumn{5}{|c|}{ Supplemental Table } \\
\hline CHEMBL1391064 & 688497 & 5.8 & 4.863 & TST \\
\hline CHEMBL1573124 & 688497 & 5.5 & 5.4479 & TRN \\
\hline CHEMBL1305930 & 688497 & 5.55 & 5.0722 & TRN \\
\hline CHEMBL1568500 & 688497 & 4.45 & 5.2038 & TRN \\
\hline CHEMBL1311527 & 688497 & 4.6 & 4.8295 & TRN \\
\hline CHEMBL1610049 & 688497 & 4.8 & 4.8784 & TRN \\
\hline CHEMBL1322923 & 688497 & 5.65 & 5.0536 & TRN \\
\hline CHEMBL1376784 & 688497 & 4.5 & 4.9796 & TRN \\
\hline CHEMBL3189686 & 688497 & 4.95 & 5.3279 & TRN \\
\hline CHEMBL1509985 & 688497 & 5.25 & 5.2775 & TST \\
\hline CHEMBL1342336 & 688497 & 4.85 & 5.6205 & TRN \\
\hline CHEMBL1478460 & 688497 & 4.45 & 5.1713 & TRN \\
\hline CHEMBL1530260 & 688497 & 4.45 & 4.7945 & TRN \\
\hline CHEMBL1391337 & 688497 & 4.5 & 4.8116 & TRN \\
\hline CHEMBL1457209 & 688497 & 4.45 & 4.9576 & TRN \\
\hline CHEMBL1419641 & 688497 & 4.45 & 4.7373 & TRN \\
\hline CHEMBL1333617 & 688497 & 4.9 & 4.8431 & TST \\
\hline CHEMBL3196108 & 688497 & 4.45 & 4.9762 & TRN \\
\hline CHEMBL1374205 & 688497 & 4.65 & 4.6402 & TRN \\
\hline CHEMBL1571934 & 688497 & 5.25 & 4.7878 & TRN \\
\hline CHEMBL1309799 & 688497 & 4.45 & 4.7487 & TRN \\
\hline CHEMBL1312232 & 688497 & 4.45 & 4.7262 & TRN \\
\hline CHEMBL1405615 & 688497 & 5.75 & 5.0186 & TRN \\
\hline CHEMBL1300973 & 688497 & 5.45 & 5.0811 & TRN \\
\hline CHEMBL1449736 & 688497 & 4.7 & 4.9553 & TST \\
\hline CHEMBL1969647 & 688497 & 5.3 & 4.9865 & TRN \\
\hline CHEMBL1538920 & 688497 & 4.95 & 4.8755 & TRN \\
\hline CHEMBL1461992 & 688497 & 4.45 & 4.931 & TRN \\
\hline CHEMBL1331491 & 688497 & 4.45 & 4.9491 & TRN \\
\hline CHEMBL1572253 & 688497 & 4.5 & 5.0878 & TRN \\
\hline CHEMBL1555583 & 688497 & 4.95 & 4.988 & TRN \\
\hline CHEMBL1520073 & 688497 & 6.6 & 5.2002 & TST \\
\hline CHEMBL1597345 & 688497 & 4.9 & 5.095 & TRN \\
\hline CHEMBL1366987 & 688497 & 5.05 & 4.6358 & TRN \\
\hline CHEMBL3190824 & 688497 & 4.45 & 5.1197 & TRN \\
\hline CHEMBL1471742 & 688497 & 4.45 & 5.1634 & TST \\
\hline CHEMBL1452379 & 688497 & 4.45 & 4.6766 & TRN \\
\hline CHEMBL3197188 & 688497 & 5.55 & 5.0391 & TRN \\
\hline CHEMBL1378698 & 688497 & 5.1 & 5.1129 & TRN \\
\hline CHEMBL1569472 & 688497 & 4.65 & 4.6932 & TRN \\
\hline CHEMBL1459633 & 688497 & 4.8 & 5.0899 & TRN \\
\hline CHEMBL1468328 & 688497 & 4.45 & 5.0556 & TRN \\
\hline CHEMBL1311806 & 688497 & 4.45 & 4.9939 & TRN \\
\hline CHEMBL1457972 & 688497 & 5.4 & 5.3522 & TRN \\
\hline CHEMBL1572266 & 688497 & 4.85 & 5.1082 & TST \\
\hline CHEMBL1516636 & 688497 & 5.25 & 5.2038 & TRN \\
\hline CHEMBL1332829 & 688497 & 4.95 & 5.0617 & TRN \\
\hline CHEMBL1300875 & 688497 & 6.95 & 5.088 & TST \\
\hline
\end{tabular}




\begin{tabular}{|c|c|c|c|c|}
\hline \multicolumn{5}{|c|}{ Supplemental Table S2.txt } \\
\hline CHEMBL1458755 & 688497 & 5.55 & 5.3081 & TRN \\
\hline CHEMBL1471612 & 688497 & 4.45 & 4.6723 & TRN \\
\hline CHEMBL1511879 & 688497 & 4.95 & 4.6582 & TRN \\
\hline CHEMBL1531520 & 688497 & 5.8 & 5.0954 & TST \\
\hline CHEMBL1585437 & 688497 & 4.45 & 5.1306 & TST \\
\hline CHEMBL1494353 & 688497 & 4.7 & 4.8117 & TRN \\
\hline CHEMBL1380459 & 688497 & 4.8 & 5.0279 & TRN \\
\hline CHEMBL1362027 & 688497 & 4.45 & 5.0768 & TRN \\
\hline CHEMBL1371991 & 688497 & 4.95 & 4.6667 & TRN \\
\hline CHEMBL1486779 & 688497 & 4.6 & 5.2683 & TRN \\
\hline CHEMBL1445393 & 688497 & 5.25 & 5.5958 & TRN \\
\hline CHEMBL1411912 & 688497 & 5.55 & 5.2821 & TRN \\
\hline CHEMBL1405360 & 688497 & 5.9 & 5.2357 & TST \\
\hline CHEMBL1467614 & 688497 & 5.25 & 5.2601 & TST \\
\hline CHEMBL3199359 & 688497 & 4.45 & 4.9501 & TRN \\
\hline CHEMBL1399198 & 688497 & 5.15 & 5.1007 & TRN \\
\hline CHEMBL1391340 & 688497 & 4.65 & 5.0649 & TRN \\
\hline CHEMBL1484167 & 688497 & 4.7 & 5.0811 & TRN \\
\hline CHEMBL1335358 & 688497 & 4.6 & 4.8522 & TRN \\
\hline CHEMBL1430872 & 688497 & 4.8 & 4.6665 & TST \\
\hline CHEMBL1430218 & 688497 & 6.0 & 5.4168 & TRN \\
\hline CHEMBL1413066 & 688497 & 5.2 & 5.1695 & TRN \\
\hline CHEMBL1972235 & 688497 & 4.95 & 4.9175 & TST \\
\hline CHEMBL1302785 & 688497 & 4.45 & 4.7604 & TRN \\
\hline CHEMBL1323368 & 688497 & 4.45 & 5.0267 & TRN \\
\hline CHEMBL1454019 & 688497 & 5.2 & 5.0332 & TRN \\
\hline CHEMBL1595905 & 688497 & 4.9 & 4.8652 & TRN \\
\hline CHEMBL1609941 & 688497 & 6.25 & 4.9097 & TST \\
\hline CHEMBL1304819 & 688497 & 5.0 & 4.9081 & TST \\
\hline CHEMBL1577854 & 688497 & 4.85 & 5.1886 & TRN \\
\hline CHEMBL1588173 & 688497 & 4.45 & 4.5716 & TRN \\
\hline CHEMBL1366214 & 688497 & 4.45 & 5.3026 & TST \\
\hline CHEMBL1465485 & 688497 & 5.4 & 5.1509 & TRN \\
\hline CHEMBL1516594 & 688497 & 5.55 & 5.2251 & TST \\
\hline CHEMBL1404375 & 688497 & 5.4 & 4.9884 & TRN \\
\hline CHEMBL1567859 & 688497 & 4.45 & 4.8009 & TRN \\
\hline CHEMBL1332687 & 688497 & 5.8 & 4.7763 & TRN \\
\hline CHEMBL1299666 & 688497 & 4.6 & 4.922 & TRN \\
\hline CHEMBL1609438 & 688497 & 6.05 & 5.2151 & TRN \\
\hline CHEMBL1542536 & 688497 & 5.6 & 5.2104 & TRN \\
\hline CHEMBL1410932 & 688497 & 4.95 & 5.0037 & TRN \\
\hline CHEMBL1466882 & 688497 & 5.3 & 5.2596 & TRN \\
\hline CHEMBL1519558 & 688497 & 4.8 & 5.1049 & TRN \\
\hline CHEMBL1550841 & 688497 & 4.8 & 4.9587 & TRN \\
\hline CHEMBL1346315 & 688497 & 4.45 & 5.0614 & TRN \\
\hline CHEMBL3207894 & 688497 & 4.45 & 4.835 & TRN \\
\hline CHEMBL1364963 & 688497 & 5.2 & 5.1489 & TRN \\
\hline CHEMBL1540446 & 688497 & 5.5 & 4.6119 & TRN \\
\hline
\end{tabular}




\begin{tabular}{|c|c|c|c|c|c|}
\hline \multirow[b]{2}{*}{ CHEMBL1333179 } & \multirow[b]{2}{*}{688497} & \\
\hline & & 4.8 & 5.0474 & TRN & \\
\hline CHEMBL1525787 & 688497 & 5.25 & 4.7751 & TST & \\
\hline CHEMBL1335270 & 688497 & 5.9 & 5.2356 & TRN & \\
\hline CHEMBL1535716 & 688497 & 5.5 & 5.6921 & TRN & \\
\hline CHEMBL1557105 & 688497 & 4.45 & 5.1412 & TRN & \\
\hline CHEMBL1539163 & 688497 & 5.25 & 5.1541 & TRN & \\
\hline CHEMBL1481341 & 688497 & 5.25 & 5.1782 & TRN & \\
\hline CHEMBL3192804 & 688497 & 5.4 & 5.0277 & TST & \\
\hline CHEMBL1524458 & 688497 & 4.85 & 4.9601 & TRN & \\
\hline CHEMBL1323813 & 688497 & 5.5 & 5.3922 & TRN & \\
\hline CHEMBL3194857 & 688497 & 4.65 & \multicolumn{2}{|c|}{4.7589999999999995} & TRN \\
\hline CHEMBL1572782 & 688497 & 6.15 & 5.186 & TST & \\
\hline CHEMBL1407051 & 688497 & 4.75 & 5.0165 & TRN & \\
\hline CHEMBL1376279 & 688497 & 6.0 & 5.0833 & TRN & \\
\hline CHEMBL1582900 & 688497 & 5.6 & 5.2462 & TRN & \\
\hline CHEMBL1536768 & 688497 & 5.8 & 5.016 & TRN & \\
\hline CHEMBL1488028 & 688497 & 5.4 & 5.4214 & TRN & \\
\hline CHEMBL1594437 & 688497 & 4.45 & \multicolumn{2}{|c|}{5.0169999999999995} & TRN \\
\hline CHEMBL1600573 & 688497 & 4.45 & 4.8271 & TRN & \\
\hline CHEMBL1339736 & 688497 & 6.1 & 5.1578 & TRN & \\
\hline CHEMBL1566174 & 688497 & 4.7 & 4.7521 & TRN & \\
\hline CHEMBL1537575 & 688497 & 4.45 & 5.1592 & TRN & \\
\hline CHEMBL1588856 & 688497 & 4.7 & 5.0555 & TRN & \\
\hline CHEMBL1601617 & 688497 & 5.8 & 4.9849 & TRN & \\
\hline CHEMBL1385608 & 688497 & 4.95 & 5.1534 & TST & \\
\hline CHEMBL1538246 & 688497 & 4.95 & 5.194 & TRN & \\
\hline CHEMBL1522156 & 688497 & 5.0 & 5.0337 & TRN & \\
\hline CHEMBL1406911 & 688497 & 4.8 & 4.9763 & TRN & \\
\hline CHEMBL3189462 & 688497 & 5.45 & 5.2328 & TRN & \\
\hline CHEMBL1403593 & 688497 & 4.45 & 5.1584 & TRN & \\
\hline CHEMBL1521820 & 688497 & 6.7501 & 5.4039 & TST & \\
\hline CHEMBL1594354 & 688497 & 4.45 & 5.084 & TRN & \\
\hline CHEMBL1538533 & 688497 & 5.25 & 5.0615 & TRN & \\
\hline CHEMBL1521719 & 688497 & 4.55 & 4.7382 & TRN & \\
\hline CHEMBL1547683 & 688497 & 4.45 & 5.1503 & TRN & \\
\hline CHEMBL1439484 & 688497 & 4.9 & 5.0541 & TST & \\
\hline CHEMBL3208229 & 688497 & 4.45 & 5.1664 & TRN & \\
\hline CHEMBL1547813 & 688497 & 4.6 & 4.7568 & TRN & \\
\hline CHEMBL1380418 & 688497 & 4.7 & 5.0787 & TRN & \\
\hline CHEMBL1345132 & 688497 & 5.25 & 4.9922 & TRN & \\
\hline CHEMBL1501390 & 688497 & 4.75 & 4.9138 & TRN & \\
\hline CHEMBL1600588 & 688497 & 6.25 & 5.17899 & 9999999999 & TRN \\
\hline CHEMBL1312168 & 688497 & 4.9 & 5.0647 & TST & \\
\hline CHEMBL1398779 & 688497 & 4.45 & 5.1304 & TST & \\
\hline CHEMBL3193474 & 688497 & 5.45 & 4.8717 & TRN & \\
\hline CHEMBL1412368 & 688497 & 6.4 & 5.0189 & TST & \\
\hline CHEMBL1305147 & 688497 & 6.45 & 5.3059 & TRN & \\
\hline \multirow[t]{2}{*}{ CHEMBL1345932 } & 688497 & 5.85 & 5.0191 & TRN & \\
\hline & & \multicolumn{4}{|c|}{ Page 20002} \\
\hline
\end{tabular}




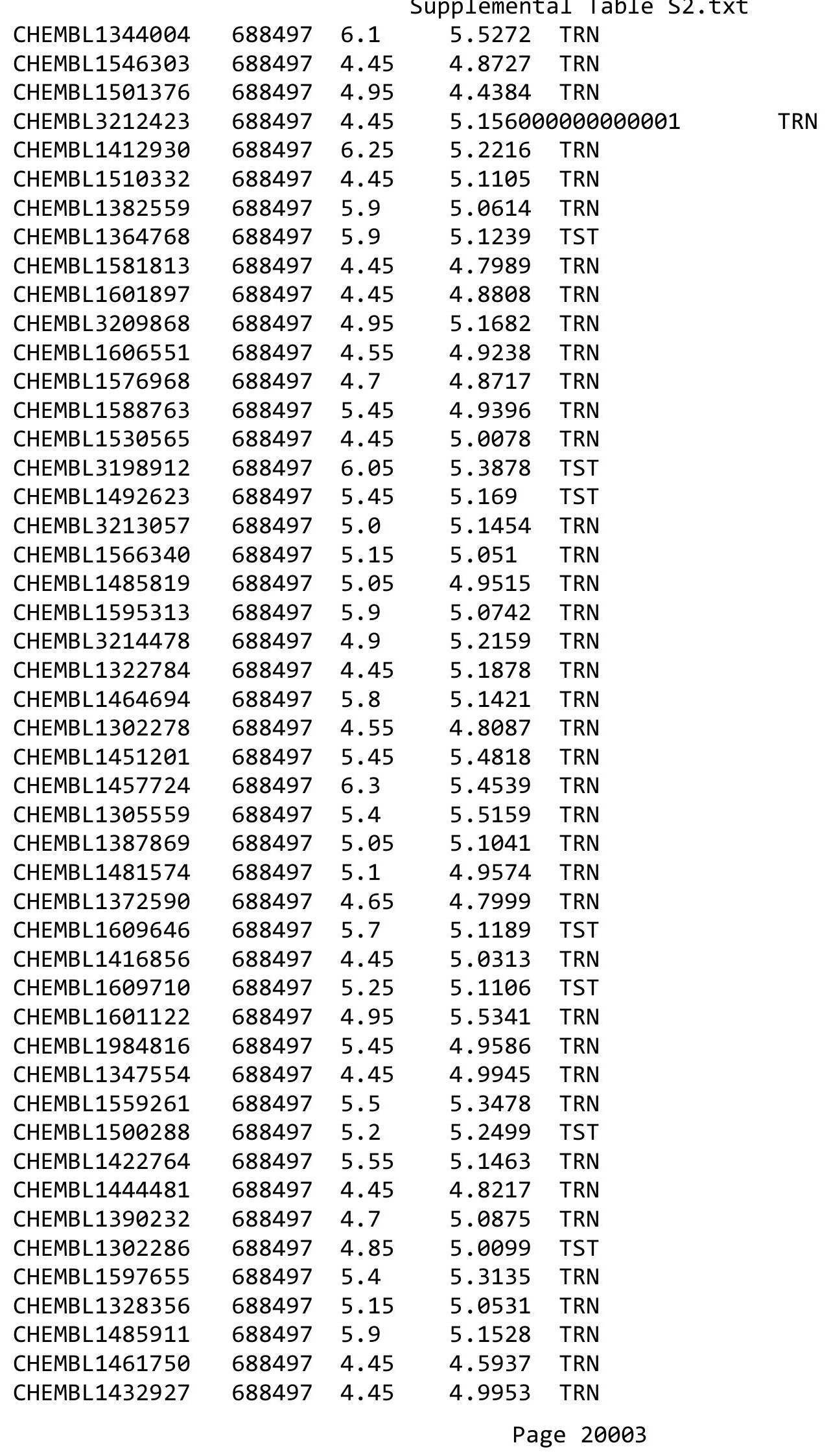




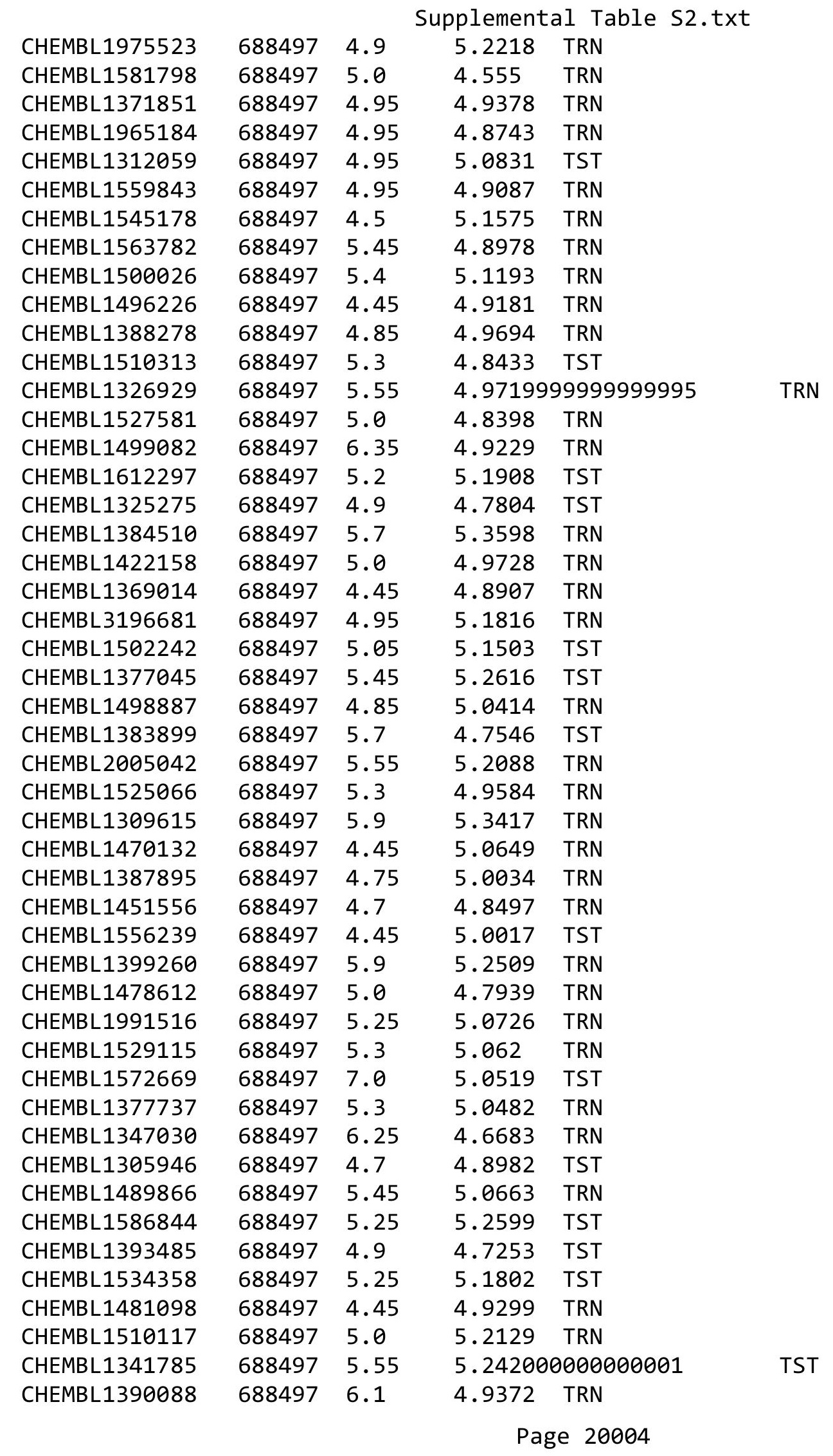




\begin{tabular}{|c|c|c|c|c|c|}
\hline \multicolumn{6}{|c|}{ Supplemental Table S2.txt } \\
\hline CHEMBL1351081 & 688497 & 4.8 & 5.0416 & TRN & \\
\hline CHEMBL3189416 & 688497 & 5.1 & 5.1081 & TRN & \\
\hline CHEMBL1508699 & 688497 & 5.45 & 5.0308 & TRN & \\
\hline CHEMBL1548869 & 688497 & 4.7 & 4.7596 & TRN & \\
\hline CHEMBL1582847 & 688497 & 5.0 & 4.9199 & TRN & \\
\hline CHEMBL1468537 & 688497 & 5.35 & 4.7357 & TRN & \\
\hline CHEMBL1524804 & 688497 & 4.85 & 4.9664 & TRN & \\
\hline CHEMBL1235568 & 688497 & 5.25 & 5.3196 & TRN & \\
\hline CHEMBL1391746 & 688497 & 4.9 & 5.0351 & TRN & \\
\hline CHEMBL1373217 & 688497 & 4.45 & 5.03100 & 0000000001 & TRN \\
\hline CHEMBL1502228 & 688497 & 5.55 & 4.822 & TRN & \\
\hline CHEMBL1392500 & 688497 & 5.4 & 4.8805 & TRN & \\
\hline CHEMBL1350019 & 688497 & 5.0 & 4.9314 & TRN & \\
\hline CHEMBL3207547 & 688497 & 4.95 & 4.996 & TST & \\
\hline CHEMBL1556670 & 688497 & 4.5 & 4.8373 & TST & \\
\hline CHEMBL1526899 & 688497 & 4.45 & 4.7363 & TRN & \\
\hline CHEMBL1460806 & 688497 & 8.9586 & 5.1124 & TST & \\
\hline CHEMBL1303002 & 688497 & 4.45 & 5.1509 & TRN & \\
\hline CHEMBL1393866 & 688497 & 4.8 & 4.9606 & TRN & \\
\hline CHEMBL1313323 & 688497 & 6.95 & 5.1908 & TRN & \\
\hline CHEMBL1453613 & 688497 & 4.6 & 4.945 & TRN & \\
\hline CHEMBL1351184 & 688497 & 4.65 & 4.6643 & TRN & \\
\hline CHEMBL1571389 & 688497 & 6.1 & 5.2066 & TRN & \\
\hline CHEMBL1438641 & 688497 & 4.95 & 4.8783 & TRN & \\
\hline CHEMBL1313522 & 688497 & 4.95 & 5.1086 & TRN & \\
\hline CHEMBL1385394 & 688497 & 5.25 & 5.0104 & TRN & \\
\hline CHEMBL1452956 & 688497 & 4.85 & 4.9395 & TRN & \\
\hline CHEMBL1484934 & 688497 & 4.45 & 4.4442 & TRN & \\
\hline CHEMBL1444874 & 688497 & 5.5 & 5.269 & TRN & \\
\hline CHEMBL1419104 & 688497 & 5.0 & 5.1271 & TST & \\
\hline CHEMBL1564313 & 688497 & 4.95 & 5.096 & TST & \\
\hline CHEMBL1510317 & 688497 & 5.45 & 4.9197 & TST & \\
\hline CHEMBL1342527 & 688497 & 4.55 & 4.8188 & TRN & \\
\hline CHEMBL1328443 & 688497 & 4.45 & 4.9027 & TRN & \\
\hline CHEMBL526673 & 688497 & 5.95 & 5.1107 & TRN & \\
\hline CHEMBL1975147 & 688497 & 4.9 & 5.2012 & TST & \\
\hline CHEMBL1441819 & 688497 & 5.05 & 5.0012 & TRN & \\
\hline CHEMBL1556333 & 688497 & 4.45 & 4.9945 & TRN & \\
\hline CHEMBL1331823 & 688497 & 4.4 & 5.1261 & TST & \\
\hline CHEMBL1585673 & 688497 & 4.45 & 5.1726 & TST & \\
\hline CHEMBL1499978 & 688497 & 4.65 & 4.9708 & TRN & \\
\hline CHEMBL1426402 & 688497 & 5.15 & 5.0147 & TRN & \\
\hline CHEMBL1534516 & 688497 & 5.25 & 5.0507 & TRN & \\
\hline CHEMBL1467766 & 688497 & 5.25 & 5.0101 & TRN & \\
\hline CHEMBL1415303 & 688497 & 5.95 & 4.9411 & TRN & \\
\hline CHEMBL1336191 & 688497 & 4.95 & 5.1782 & TRN & \\
\hline CHEMBL1541247 & 688497 & 4.45 & 5.1362 & TRN & \\
\hline CHEMBL1530762 & 688497 & 6.25 & 5.568 & TRN & \\
\hline
\end{tabular}




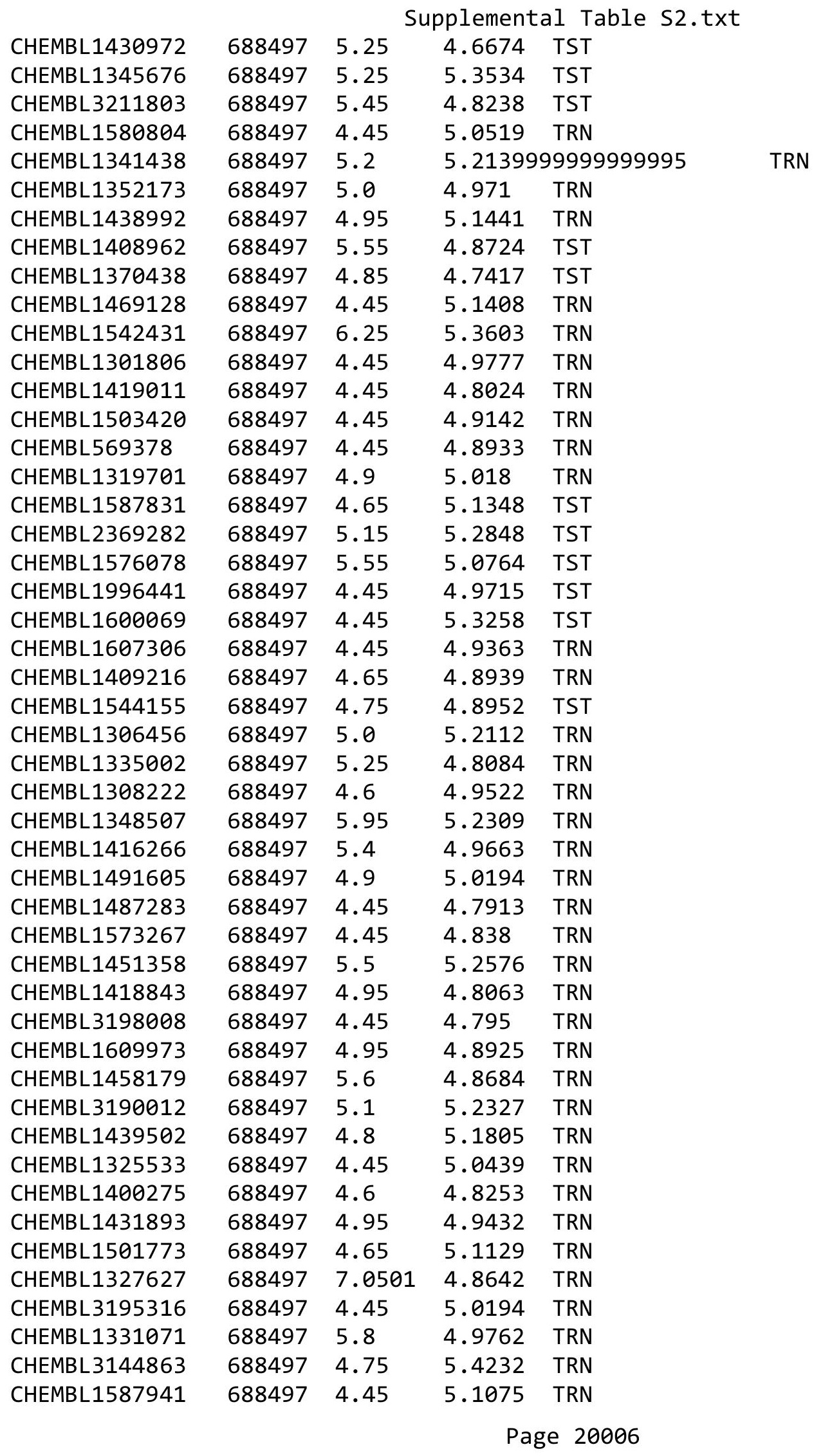




\begin{tabular}{|c|c|c|c|c|c|}
\hline \\
\hline CHEMBL1547967 & 688497 & 4.9 & 5.2577 & TRN & \\
\hline CHEMBL1543939 & 688497 & 4.45 & 4.8909 & TST & \\
\hline CHEMBL1303106 & 688497 & 4.65 & 4.8953 & TRN & \\
\hline CHEMBL1613090 & 688497 & 4.9 & 5.1867 & TRN & \\
\hline CHEMBL1347348 & 688497 & 6.1 & 5.1058 & TRN & \\
\hline CHEMBL 2006441 & 688497 & 5.0 & 4.7621 & TRN & \\
\hline CHEMBL1497095 & 688497 & 4.95 & 4.9118 & TRN & \\
\hline CHEMBL1400273 & 688497 & 5.25 & 5.04 & TRN & \\
\hline CHEMBL1484330 & 688497 & 5.0 & 5.21399 & 99999999995 & TRN \\
\hline CHEMBL1453272 & 688497 & 5.45 & 5.061 & TRN & \\
\hline CHEMBL1510047 & 688497 & 5.25 & 4.8632 & TRN & \\
\hline CHEMBL1459394 & 688497 & 6.0 & 5.0025 & TRN & \\
\hline CHEMBL1352373 & 688497 & 6.25 & 5.0928 & TST & \\
\hline CHEMBL1303176 & 688497 & 9.3979 & 5.1516 & TRN & \\
\hline CHEMBL1511152 & 688497 & 5.95 & 5.115 & TRN & \\
\hline CHEMBL1612097 & 688497 & 5.05 & 5.0709 & TRN & \\
\hline CHEMBL1340321 & 688497 & 4.45 & 4.7946 & TRN & \\
\hline CHEMBL3207804 & 688497 & 5.55 & 5.0328 & TRN & \\
\hline CHEMBL1561439 & 688497 & 4.45 & 4.905 & TRN & \\
\hline CHEMBL1322196 & 688497 & 5.05 & 4.5337 & TRN & \\
\hline CHEMBL1403181 & 688497 & 4.45 & 5.16700 & $\partial 000000001$ & TST \\
\hline CHEMBL1459983 & 688497 & 4.75 & 4.9345 & TRN & \\
\hline CHEMBL1542260 & 688497 & 4.9 & 5.1636 & TRN & \\
\hline CHEMBL1499576 & 688497 & 4.45 & 5.2239 & TRN & \\
\hline CHEMBL1536993 & 688497 & 5.0 & 4.9744 & TRN & \\
\hline CHEMBL1346311 & 688497 & 5.0 & 4.8405 & TRN & \\
\hline CHEMBL495005 & 688497 & 5.2 & 5.0826 & TRN & \\
\hline CHEMBL1412017 & 688497 & 6.1 & 5.1487 & TST & \\
\hline CHEMBL1323504 & 688497 & 4.45 & 4.7322 & TRN & \\
\hline CHEMBL1312639 & 688497 & 5.45 & 5.0256 & TRN & \\
\hline CHEMBL1330308 & 688497 & 4.9 & 4.9095 & TRN & \\
\hline CHEMBL1361612 & 688497 & 6.2 & 4.8456 & TRN & \\
\hline CHEMBL1367702 & 688497 & 4.8 & 4.7311 & TRN & \\
\hline CHEMBL1470624 & 688497 & 5.25 & 4.8009 & TST & \\
\hline CHEMBL1300999 & 688497 & 4.95 & 4.9597 & TRN & \\
\hline CHEMBL1579994 & 688497 & 4.75 & 4.9634 & TRN & \\
\hline CHEMBL1422517 & 688497 & 5.55 & 5.2162 & TRN & \\
\hline CHEMBL1539364 & 688497 & 4.9 & 4.7351 & TST & \\
\hline CHEMBL3196143 & 688497 & 4.9 & 5.4362 & TRN & \\
\hline CHEMBL1540016 & 688497 & 6.25 & 4.9726 & TST & \\
\hline CHEMBL1505466 & 688497 & 4.45 & 4.8169 & TRN & \\
\hline CHEMBL1572956 & 688497 & 4.85 & 4.9362 & TST & \\
\hline CHEMBL1320111 & 688497 & 4.45 & 5.4177 & TRN & \\
\hline CHEMBL1517713 & 688497 & 6.3 & 5.1063 & TRN & \\
\hline CHEMBL1359498 & 688497 & 4.45 & 5.1746 & TST & \\
\hline CHEMBL3210153 & 688497 & 5.25 & 5.2709 & TST & \\
\hline CHEMBL1377336 & 688497 & 4.45 & 4.7086 & TST & \\
\hline CHEMBL3190825 & 688497 & 4.9 & 5.175 & TRN & \\
\hline
\end{tabular}




\begin{tabular}{|c|c|c|c|c|}
\hline & & & ıpplement & al $\mathrm{T}$ \\
\hline CHEMBL1484881 & 688497 & 4.85 & 4.9736 & TST \\
\hline CHEMBL3198967 & 688497 & 4.5 & 5.0344 & TRN \\
\hline CHEMBL1430152 & 688497 & 4.95 & 4.8328 & TRN \\
\hline CHEMBL1501146 & 688497 & 5.2 & 4.9809 & TRN \\
\hline CHEMBL1453583 & 688497 & 5.4 & 4.9759 & TRN \\
\hline CHEMBL1498884 & 688497 & 4.6 & 4.9228 & TST \\
\hline CHEMBL1498876 & 688497 & 4.65 & 5.29 & TRN \\
\hline CHEMBL1362899 & 688497 & 5.95 & 5.0853 & TRN \\
\hline CHEMBL1425871 & 688497 & 5.5 & 4.6829 & TRN \\
\hline CHEMBL1490775 & 688497 & 5.6 & 4.9057 & TST \\
\hline CHEMBL1349437 & 688497 & 6.9 & 5.1543 & TRN \\
\hline CHEMBL1420748 & 688497 & 5.7 & 5.026 & TRN \\
\hline CHEMBL1341668 & 688497 & 4.75 & 4.746 & TRN \\
\hline CHEMBL3199737 & 688497 & 5.15 & 5.1783 & TRN \\
\hline CHEMBL3193709 & 688497 & 4.95 & 5.0241 & TRN \\
\hline CHEMBL1323644 & 688497 & 4.45 & 4.7935 & TRN \\
\hline CHEMBL1561595 & 688497 & 6.3 & 5.5871 & TST \\
\hline CHEMBL585443 & 688497 & 4.9 & 4.8912 & TRN \\
\hline CHEMBL1455877 & 688497 & 4.9 & 5.1301 & TRN \\
\hline CHEMBL1399490 & 688497 & 4.9 & 4.9417 & TRN \\
\hline CHEMBL1381854 & 688497 & 4.45 & 5.1191 & TST \\
\hline CHEMBL1327548 & 688497 & 4.45 & 5.0186 & TRN \\
\hline CHEMBL 3191433 & 688497 & 6.1 & 4.8738 & TST \\
\hline CHEMBL1578997 & 688497 & 5.35 & 4.7096 & TRN \\
\hline CHEMBL1430574 & 688497 & 4.6 & 5.2494 & TRN \\
\hline CHEMBL1374837 & 688497 & 5.7 & 4.7511 & TST \\
\hline CHEMBL1380918 & 688497 & 6.25 & 5.2451 & TRN \\
\hline CHEMBL1418081 & 688497 & 4.95 & 5.0186 & TRN \\
\hline CHEMBL1461576 & 688497 & 6.1 & 5.1891 & TRN \\
\hline CHEMBL1999906 & 688497 & 4.95 & 4.8793 & TRN \\
\hline CHEMBL1378398 & 688497 & 4.95 & 4.936 & TRN \\
\hline CHEMBL1339740 & 688497 & 4.75 & 5.1275 & TRN \\
\hline CHEMBL 3212708 & 688497 & 4.45 & 4.6248 & TRN \\
\hline CHEMBL1392427 & 688497 & 5.8 & 4.9751 & TRN \\
\hline CHEMBL1303722 & 688497 & 5.0 & 4.8989 & TST \\
\hline CHEMBL1351926 & 688497 & 5.45 & 5.0575 & TRN \\
\hline CHEMBL1467893 & 688497 & 4.45 & 4.9339 & TST \\
\hline CHEMBL1502929 & 688497 & 4.45 & 4.8911 & TST \\
\hline CHEMBL1418351 & 688497 & 4.45 & 5.0984 & TST \\
\hline CHEMBL1532729 & 688497 & 5.25 & 4.8107 & TRN \\
\hline CHEMBL1502027 & 688497 & 4.9 & 5.1364 & TRN \\
\hline CHEMBL1580532 & 688497 & 4.9 & 4.4624 & TRN \\
\hline CHEMBL1493953 & 688497 & 4.45 & 4.7042 & TRN \\
\hline CHEMBL1367252 & 688497 & 4.75 & 4.6362 & TRN \\
\hline CHEMBL1432468 & 688497 & 4.8 & 4.9326 & TRN \\
\hline CHEMBL1465617 & 688497 & 4.6 & 4.8912 & TRN \\
\hline CHEMBL1606140 & 688497 & 4.8 & 5.2211 & TRN \\
\hline CHEMBL1578728 & 688497 & 4.9 & 4.8532 & TRN \\
\hline
\end{tabular}




\begin{tabular}{|c|c|c|c|c|c|}
\hline \multicolumn{6}{|c|}{ Supplemental Table S2.txt } \\
\hline CHEMBL1527551 & 688497 & 5.1 & 4.9095 & TRN & \\
\hline CHEMBL151252 & 688497 & 4.45 & 5.0946 & TST & \\
\hline CHEMBL1335146 & 688497 & 4.9 & 5.0692 & TRN & \\
\hline CHEMBL1598383 & 688497 & 4.45 & 5.0613 & TST & \\
\hline CHEMBL2003351 & 688497 & 4.65 & 5.0713 & TST & \\
\hline CHEMBL1485674 & 688497 & 4.9 & 4.8472 & TRN & \\
\hline CHEMBL1488367 & 688497 & 5.45 & 5.4236 & TST & \\
\hline CHEMBL1416115 & 688497 & 4.45 & 5.2299 & TRN & \\
\hline CHEMBL1300494 & 688497 & 5.3 & 4.9697 & TST & \\
\hline CHEMBL1451345 & 688497 & 5.6 & 5.0512 & TRN & \\
\hline CHEMBL1439871 & 688497 & 6.6499 & 4.9893 & TST & \\
\hline CHEMBL1586726 & 688497 & 4.5 & 5.3074 & TST & \\
\hline CHEMBL1533459 & 688497 & 5.0 & 4.9669 & TRN & \\
\hline CHEMBL1430619 & 688497 & 5.0 & 4.8982 & TRN & \\
\hline CHEMBL1430540 & 688497 & 4.45 & 4.8845 & TRN & \\
\hline CHEMBL1563069 & 688497 & 5.9 & 5.1215 & TRN & \\
\hline CHEMBL1299210 & 688497 & 6.0 & 5.3113 & TRN & \\
\hline CHEMBL1609354 & 688497 & 4.45 & 5.0149 & TRN & \\
\hline CHEMBL1313978 & 688497 & 4.8 & 4.8513 & TRN & \\
\hline CHEMBL1428269 & 688497 & 6.05 & 5.1108 & TRN & \\
\hline CHEMBL1483085 & 688497 & 4.85 & $5.3370 e$ & 0000000001 & TST \\
\hline CHEMBL1463161 & 688497 & 4.45 & 5.1703 & TRN & \\
\hline CHEMBL1329874 & 688497 & 4.45 & 4.8631 & TST & \\
\hline CHEMBL1312247 & 688497 & 4.9 & 5.0812 & TRN & \\
\hline CHEMBL1489148 & 688497 & 4.9 & 4.9413 & TRN & \\
\hline CHEMBL1440010 & 688497 & 6.15 & 5.0193 & TRN & \\
\hline CHEMBL1524292 & 688497 & 4.45 & 4.7224 & TST & \\
\hline CHEMBL1587432 & 688497 & 4.65 & 5.0077 & TST & \\
\hline CHEMBL1511191 & 688497 & 4.45 & 4.8624 & TRN & \\
\hline CHEMBL1366494 & 688497 & 4.9 & 4.9757 & TST & \\
\hline CHEMBL1453212 & 688497 & 4.95 & 4.9568 & TST & \\
\hline CHEMBL1452123 & 688497 & 4.9 & 5.2505 & TRN & \\
\hline CHEMBL1388544 & 688497 & 4.55 & 4.6598 & TRN & \\
\hline CHEMBL1326747 & 688497 & 6.25 & 4.96899 & 9999999999 & TRN \\
\hline CHEMBL1405099 & 688497 & 4.9 & 5.0967 & TST & \\
\hline CHEMBL1555693 & 688497 & 5.3 & 4.9525 & TRN & \\
\hline CHEMBL1430385 & 688497 & 4.45 & $4.9030 e$ & 00000000005 & TRN \\
\hline CHEMBL3197903 & 688497 & 4.65 & 4.6832 & TRN & \\
\hline CHEMBL1348555 & 688497 & 5.7 & 5.0533 & TRN & \\
\hline CHEMBL1362863 & 688497 & 6.1 & 5.3291 & TRN & \\
\hline CHEMBL1338736 & 688497 & 4.9 & 4.7066 & TRN & \\
\hline CHEMBL1492371 & 688497 & 6.2 & 5.2492 & TST & \\
\hline CHEMBL1471657 & 688497 & 5.65 & 5.1821 & TRN & \\
\hline CHEMBL1578348 & 688497 & 4.7 & 4.9463 & TRN & \\
\hline CHEMBL1488364 & 688497 & 6.2 & 5.2145 & TRN & \\
\hline CHEMBL1568875 & 688497 & 4.45 & 5.1578 & TRN & \\
\hline CHEMBL1500506 & 688497 & 4.45 & 5.1074 & TRN & \\
\hline CHEMBL1371720 & 688497 & 4.95 & 4.8731 & TRN & \\
\hline
\end{tabular}




\begin{tabular}{|c|c|c|c|c|c|}
\hline \multirow[b]{2}{*}{ CHEMBL1423742 } & & \multicolumn{4}{|c|}{ Supplemental Table S2.txt } \\
\hline & 688497 & 4.45 & 5.24200 & 2000000001 & TRN \\
\hline CHEMBL1446031 & 688497 & 4.8 & 5.26399 & 9999999999 & TRN \\
\hline CHEMBL1565520 & 688497 & 4.45 & 4.59 & TRN & \\
\hline CHEMBL1312456 & 688497 & 4.65 & 4.6531 & TRN & \\
\hline CHEMBL3196559 & 688497 & 5.45 & 5.0536 & TST & \\
\hline CHEMBL1565910 & 688497 & 7.0 & 5.2637 & TRN & \\
\hline CHEMBL1348955 & 688497 & 4.8 & 5.2074 & TST & \\
\hline CHEMBL1330055 & 688497 & 4.55 & 4.8691 & TRN & \\
\hline CHEMBL1399915 & 688497 & 4.45 & 5.1226 & TST & \\
\hline CHEMBL1370259 & 688497 & 5.25 & 5.0116 & TRN & \\
\hline CHEMBL1347016 & 688497 & 5.25 & 5.0655 & TST & \\
\hline CHEMBL1556498 & 688497 & 4.9 & 4.666 & TST & \\
\hline CHEMBL1450222 & 688497 & 5.15 & 5.1622 & TST & \\
\hline CHEMBL1524865 & 688497 & 4.45 & 4.8152 & TRN & \\
\hline CHEMBL 362531 & 688497 & 5.6 & 5.0204 & TRN & \\
\hline CHEMBL1413672 & 688497 & 4.9 & 5.0123 & TRN & \\
\hline CHEMBL1466445 & 688497 & 4.65 & 5.0055 & TRN & \\
\hline CHEMBL1493193 & 688497 & 5.4 & 5.6376 & TRN & \\
\hline CHEMBL1371070 & 688497 & 6.05 & 4.9185 & TRN & \\
\hline CHEMBL1574979 & 688497 & 5.05 & 4.9214 & TST & \\
\hline CHEMBL1530926 & 688497 & 4.45 & 4.9665 & TRN & \\
\hline CHEMBL1548109 & 688497 & 4.6 & 4.901 & TRN & \\
\hline CHEMBL1418909 & 688497 & 4.45 & 4.9939 & TST & \\
\hline CHEMBL1508528 & 688497 & 4.6 & 4.8436 & TRN & \\
\hline CHEMBL1302899 & 688497 & 6.25 & 4.9974 & TRN & \\
\hline CHEMBL1413680 & 688497 & 5.25 & 5.0197 & TST & \\
\hline CHEMBL1431295 & 688497 & 4.45 & 5.1948 & TRN & \\
\hline CHEMBL1496483 & 688497 & 4.95 & 5.4213 & TRN & \\
\hline CHEMBL3208556 & 688497 & 4.95 & 4.9574 & TRN & \\
\hline CHEMBL1491821 & 688497 & 4.55 & 5.2413 & TST & \\
\hline CHEMBL1309225 & 688497 & 4.45 & 4.8445 & TRN & \\
\hline CHEMBL1441975 & 688497 & 5.05 & 5.2155 & TST & \\
\hline CHEMBL3198793 & 688497 & 4.45 & 5.1307 & TRN & \\
\hline CHEMBL1306451 & 688497 & 7.5003 & 5.1519 & TRN & \\
\hline CHEMBL1439190 & 688497 & 4.45 & 5.2782 & TST & \\
\hline CHEMBL1461692 & 688497 & 6.2 & 5.0856 & TRN & \\
\hline CHEMBL1538360 & 688497 & 4.45 & 4.7684 & TRN & \\
\hline CHEMBL1427757 & 688497 & 4.65 & 4.8894 & TST & \\
\hline CHEMBL1532544 & 688497 & 5.85 & 4.9866 & TRN & \\
\hline CHEMBL3193460 & 688497 & 6.25 & 4.9526 & TRN & \\
\hline CHEMBL1502030 & 688497 & 5.25 & 5.1833 & TRN & \\
\hline CHEMBL1352034 & 688497 & 4.45 & 4.9748 & TST & \\
\hline CHEMBL1489735 & 688497 & 4.8 & 4.9599 & TRN & \\
\hline CHEMBL1588513 & 688497 & 5.35 & 5.4076 & TST & \\
\hline CHEMBL1416833 & 688497 & 5.2 & 5.2322 & TRN & \\
\hline CHEMBL3199067 & 688497 & 5.5 & 5.0138 & TST & \\
\hline CHEMBL1465958 & 688497 & 4.8 & 4.8721 & TST & \\
\hline CHEMBL1456643 & 688497 & 4.55 & 5.1337 & TST & \\
\hline
\end{tabular}




\begin{tabular}{|c|c|c|c|c|c|}
\hline \multicolumn{6}{|c|}{ Supplemental Table S2.txt } \\
\hline CHEMBL3189759 & 688497 & 4.45 & 5.0664 & TRN & \\
\hline CHEMBL1430019 & 688497 & 4.85 & 5.0719 & TRN & \\
\hline CHEMBL3192408 & 688497 & 4.7 & 4.9559 & TST & \\
\hline CHEMBL1526167 & 688497 & 5.6 & 4.9825 & TRN & \\
\hline CHEMBL1327755 & 688497 & 5.4 & 5.29799 & 9999999999 & TRN \\
\hline CHEMBL550826 & 688497 & 4.95 & 4.7377 & TRN & \\
\hline CHEMBL1540343 & 688497 & 4.5 & 5.1303 & TRN & \\
\hline CHEMBL1535778 & 688497 & 5.25 & 5.6023 & TST & \\
\hline CHEMBL1510278 & 688497 & 4.7 & 4.9637 & TRN & \\
\hline CHEMBL1302436 & 688497 & 5.55 & 5.188 & TRN & \\
\hline CHEMBL1423702 & 688497 & 4.6 & 4.6797 & TRN & \\
\hline CHEMBL1486894 & 688497 & 5.0 & 4.8 & TRN & \\
\hline CHEMBL1408258 & 688497 & 5.6 & 4.9709 & TRN & \\
\hline CHEMBL1519057 & 688497 & 4.7 & 4.7809 & TRN & \\
\hline CHEMBL1443320 & 688497 & 5.35 & 5.2642 & TRN & \\
\hline CHEMBL1459485 & 688497 & 4.8 & 4.9122 & TRN & \\
\hline CHEMBL1463148 & 688497 & 6.25 & 5.1699 & TRN & \\
\hline CHEMBL1561196 & 688497 & 5.3 & 5.0291 & TRN & \\
\hline CHEMBL1392114 & 688497 & 4.95 & 5.3527 & TST & \\
\hline CHEMBL1441952 & 688497 & 5.6 & 5.2105 & TRN & \\
\hline CHEMBL1506673 & 688497 & 4.8 & 4.7677 & TRN & \\
\hline CHEMBL1309939 & 688497 & 4.45 & 5.1852 & TRN & \\
\hline CHEMBL1480581 & 688497 & 6.95 & 5.2937 & TST & \\
\hline CHEMBL1575051 & 688497 & 4.45 & 4.82 & TRN & \\
\hline CHEMBL1443059 & 688497 & 4.75 & 4.7378 & TRN & \\
\hline CHEMBL1533922 & 688497 & 4.45 & 4.9072 & TRN & \\
\hline CHEMBL1380359 & 688497 & 4.65 & 4.7791 & TRN & \\
\hline CHEMBL1321392 & 688497 & 5.35 & 5.1173 & TRN & \\
\hline CHEMBL1493442 & 688497 & 5.25 & 4.931 & TRN & \\
\hline CHEMBL1578861 & 688497 & 4.45 & 4.8679 & TRN & \\
\hline CHEMBL1502862 & 688497 & 4.5 & 4.8311 & TRN & \\
\hline CHEMBL1459330 & 688497 & 4.45 & 4.7023 & TRN & \\
\hline CHEMBL1337783 & 688497 & 4.7 & 5.3221 & TRN & \\
\hline CHEMBL1469895 & 688497 & 4.9 & 4.928 & TRN & \\
\hline CHEMBL1342462 & 688497 & 4.95 & 4.9815 & TRN & \\
\hline CHEMBL1587368 & 688497 & 4.85 & 5.0295 & TRN & \\
\hline CHEMBL1567016 & 688497 & 4.8 & 4.5217 & TRN & \\
\hline CHEMBL1387500 & 688497 & 4.6 & 5.0208 & TST & \\
\hline CHEMBL1449493 & 688497 & 4.45 & 4.9466 & TRN & \\
\hline CHEMBL1583292 & 688497 & 5.9 & 5.28799 & 9999999999 & TRN \\
\hline CHEMBL1379592 & 688497 & 5.3 & 5.3455 & TRN & \\
\hline CHEMBL1333235 & 688497 & 5.45 & 5.0403 & TRN & \\
\hline CHEMBL1411878 & 688497 & 4.45 & 4.7767 & TRN & \\
\hline CHEMBL1543597 & 688497 & 5.45 & 5.36 & TST & \\
\hline CHEMBL1482777 & 688497 & 4.85 & 4.7888 & TRN & \\
\hline CHEMBL3212247 & 688497 & 4.6 & 4.8824 & TRN & \\
\hline CHEMBL3798869 & 1575136 & 4.4067 & 4.5095 & TRN & \\
\hline CHEMBL3798472 & 1575136 & 4.475 & 4.1829 & TRN & \\
\hline
\end{tabular}


Supplemental Table S2.txt

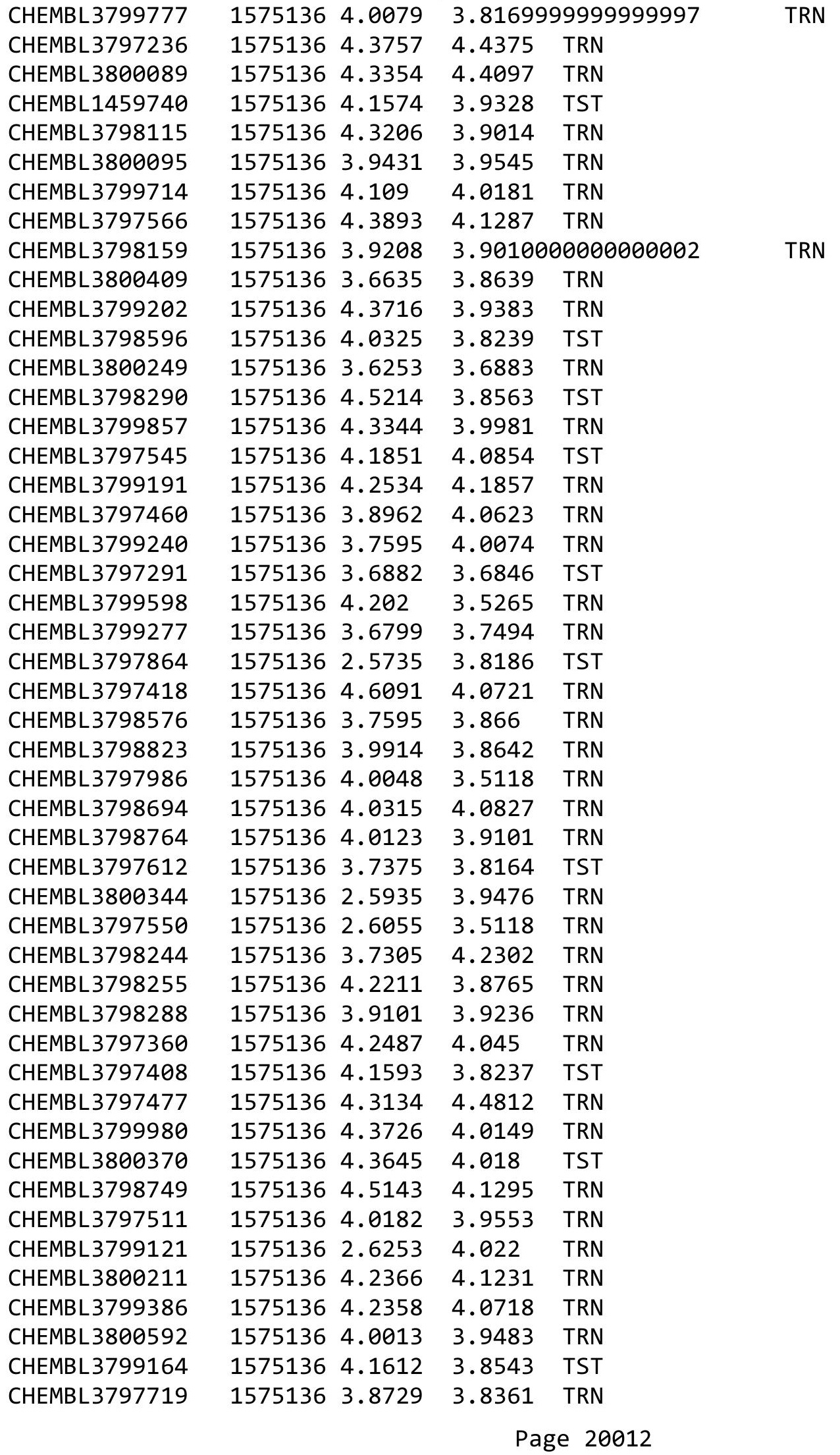


Supplemental Table S2.txt

\begin{tabular}{|c|c|c|c|c|c|c|}
\hline CHEMBL3798252 & 1575136 & 4.1475 & 3.9073 & TRN & & \\
\hline CHEMBL 3800083 & 1575136 & 2.58 & 3.8739 & TST & & \\
\hline CHEMBL3799110 & 1575136 & 4.0405 & 3.7889 & TST & & \\
\hline CHEMBL 3800520 & 1575136 & 3.6402 & 3.5509 & TRN & & \\
\hline CHEMBL 3799384 & 1575136 & 4.1851 & 4.0097 & TRN & & \\
\hline CHEMBL 3798920 & 1575136 & 3.6126 & 3.6697 & TST & & \\
\hline CHEMBL3799518 & 1575136 & 4.4737 & 4.4069 & TRN & & \\
\hline CHEMBL 3800501 & 1575136 & 3.6144 & 3.7578 & TRN & & \\
\hline CHEMBL3797262 & 1575136 & 4.475 & 4.0925 & TST & & \\
\hline CHEMBL 3798077 & 1575136 & 4.1612 & 3.8775 & TRN & & \\
\hline CHEMBL 3798621 & 1575136 & 4.752 & 4.4626 & TRN & & \\
\hline CHEMBL 3799963 & 1575136 & 3.8827 & 4.1135 & TRN & & \\
\hline CHEMBL 3800117 & 1575136 & 4.5045 & 4.5026 & TRN & & \\
\hline CHEMBL3799989 & 1575136 & 3.7721 & 3.9877 & TST & & \\
\hline CHEMBL 3799479 & 1575136 & 4.2848 & 4.092 & TRN & & \\
\hline CHEMBL1499901 & 1575136 & 4.0218 & 3.9234 & TST & & \\
\hline CHEMBL3798246 & 1575136 & 4.1024 & 4.0691 & TRN & & \\
\hline CHEMBL 3797414 & 1575136 & 2.5901 & 3.9743 & TRN & & \\
\hline CHEMBL3799302 & 1575136 & 4.3556 & 4.0327 & TRN & & \\
\hline CHEMBL 3800173 & 1575136 & 4.0487 & 3.8478 & TST & & \\
\hline CHEMBL 3798783 & 1575136 & 3.6073 & 4.1044 & TRN & & \\
\hline CHEMBL3799915 & 1575136 & 4.1986 & 3.9433 & TST & & \\
\hline CHEMBL 3798262 & 1575136 & 3.6055 & 3.9387 & TRN & & \\
\hline CHEMBL3799413 & 1575136 & 3.6946 & 3.6318 & TST & & \\
\hline CHEMBL 3798890 & 1575136 & 4.05699 & 999999999 & 95 & 3.9659 & $1 \mathrm{no}$ \\
\hline CHEMBL3798683 & 1575136 & 4.3089 & 3.9993 & TRN & & \\
\hline CHEMBL 3800464 & 1575136 & 4.644 & 4.4475 & TRN & & \\
\hline CHEMBL 3800484 & 1575136 & 4.1599 & 4.0419 & TRN & & \\
\hline CHEMBL 3800010 & 1575136 & 3.7905 & 3.9807 & TRN & & \\
\hline CHEMBL 3797231 & 1575136 & \multicolumn{3}{|c|}{4.4510000000000005} & 4.1758 & TRN \\
\hline CHEMBL3797234 & 1575136 & 3.8239 & 3.9441 & TST & & \\
\hline CHEMBL 3800126 & 1575136 & \multicolumn{3}{|c|}{3.6839999999999997} & 3.8648 & TRN \\
\hline CHEMBL 3800201 & 1575136 & 2.556 & 3.676 & TST & & \\
\hline CHEMBL145741 & 49333 & 5.699 & 5.3755 & TRN & & \\
\hline CHEMBL145795 & 49333 & 4.569 & 4.4969 & TRN & & \\
\hline CHEMBL357211 & 49333 & 4.77 & 4.7621 & TRN & & \\
\hline CHEMBL435423 & 49333 & 4.19 & 4.6568 & TST & & \\
\hline CHEMBL1161260 & 49333 & 3.886 & 3.9602 & TRN & & \\
\hline CHEMBL1161256 & 49333 & 3.886 & 4.4119 & TST & & \\
\hline CHEMBL142241 & 49333 & \multicolumn{3}{|c|}{ 4.0969999999999995 } & 4.8596 & TST \\
\hline CHEMBL145517 & 49333 & 4.745 & 4.5887 & TRN & & \\
\hline CHEMBL1161253 & 49333 & 4.42 & 4.3376 & TRN & & \\
\hline CHEMBL358508 & 49333 & 3.638 & 4.4154 & TST & & \\
\hline CHEMBL358970 & 49333 & 4.387 & 4.3355 & TRN & & \\
\hline CHEMBL356580 & 49333 & 4.796 & 4.7597 & TRN & & \\
\hline CHEMBL358999 & 49333 & 3.0 & 4.6885 & TST & & \\
\hline CHEMBL358110 & 49333 & 5.17 & 5.1533 & TRN & & \\
\hline CHEMBL356711 & 49333 & 5.638 & 4.8017 & TST & & \\
\hline
\end{tabular}




\begin{tabular}{|c|c|c|c|c|c|c|}
\hline & & \multicolumn{5}{|c|}{ Supplemental Table S2.txt } \\
\hline CHEMBL144847 & 49333 & 3.721 & 3.9793 & TST & & \\
\hline CHEMBL344552 & 49333 & 4.921 & 4.9935 & TRN & & \\
\hline CHEMBL145504 & 49333 & 4.42 & 4.5855 & TRN & & \\
\hline CHEMBL145250 & 49333 & 4.22 & 4.2314 & TRN & & \\
\hline CHEMBL1161263 & 49333 & 4.387 & 4.2401 & TST & & \\
\hline CHEMBL323101 & 49333 & 4.658 & 4.5174 & TRN & & \\
\hline CHEMBL145108 & 49333 & 4.721 & 4.7221 & TRN & & \\
\hline CHEMBL358491 & 49333 & 4.119 & 4.2759 & TRN & & \\
\hline CHEMBL1161245 & 49333 & 4.363 & 4.2152 & TRN & & \\
\hline CHEMBL358961 & 49333 & 6.046 & 6.0604 & TRN & & \\
\hline CHEMBL359422 & 49333 & 3.444 & 4.567 & TST & & \\
\hline CHEMBL609410 & 49333 & 4.658 & 4.6271 & TRN & & \\
\hline CHEMBL145630 & 49333 & 4.585 & 4.5855 & TRN & & \\
\hline CHEMBL143067 & 49333 & 4.0 & 3.8833 & TRN & & \\
\hline CHEMBL342542 & 49333 & 5.585 & 5.4859 & TRN & & \\
\hline CHEMBL356348 & 49333 & 5.013 & 4.7787 & TRN & & \\
\hline CHEMBL143594 & 49333 & 4.11 & 4.1387 & TRN & & \\
\hline CHEMBL435621 & 49333 & 5.638 & 5.6538 & TRN & & \\
\hline CHEMBL358366 & 49333 & 4.745 & 4.7315 & TRN & & \\
\hline CHEMBL357635 & 49333 & 4.456 & 4.4212 & TRN & & \\
\hline CHEMBL344104 & 49333 & 4.77 & 4.817 & TRN & & \\
\hline CHEMBL358526 & 49333 & 4.02 & 3.9946 & TRN & & \\
\hline CHEMBL145211 & 49333 & 4.301 & 4.4357 & TRN & & \\
\hline CHEMBL 344790 & 49333 & 5.456 & 4.6183 & TST & & \\
\hline CHEMBL356792 & 49333 & 4.569 & 4.6913 & TRN & & \\
\hline CHEMBL344283 & 49333 & 4.456 & 4.4603 & TRN & & \\
\hline CHEMBL342764 & 49333 & 3.745 & 3.8127 & TRN & & \\
\hline CHEMBL143205 & 49333 & 4.119 & 4.1652 & TRN & & \\
\hline CHEMBL 356071 & 49333 & 4.699 & 4.6865 & TRN & & \\
\hline CHEMBL145223 & 49333 & 5.6 & 5.6157 & TRN & & \\
\hline CHEMBL342722 & 49333 & $5.508 \mathrm{~s}$ & 99999995 & 995 & 4.6178 & TST \\
\hline CHEMBL423555 & 49333 & 4.337 & 4.3501 & TRN & & \\
\hline CHEMBL318352 & 49333 & 4.62 & 4.5693 & TRN & & \\
\hline CHEMBL142924 & 49333 & 5.6 & 4.4693 & TST & & \\
\hline CHEMBL145132 & 49333 & $3.958 \mathrm{~s}$ & 99999995 & 996 & 4.0033 & TRN \\
\hline CHEMBL145343 & 49333 & 5.0 & 4.9303 & TST & & \\
\hline CHEMBL142747 & 49333 & 4.886 & 4.9469 & TRN & & \\
\hline CHEMBL439810 & 49333 & 4.585 & 4.4187 & TST & & \\
\hline CHEMBL1161255 & 49333 & 4.886 & 5.1055 & TRN & & \\
\hline CHEMBL359184 & 49333 & 3.194 & 4.0646 & TST & & \\
\hline CHEMBL141782 & 49333 & 4.13 & 4.9797 & TST & & \\
\hline CHEMBL145148 & 49333 & 5.657 & 99999995 & 995 & 5.0862 & TST \\
\hline CHEMBL343254 & 49333 & 5.82 & 5.6159 & TRN & & \\
\hline CHEMBL343892 & 49333 & 4.37 & 4.4623 & TRN & & \\
\hline CHEMBL145655 & 49333 & 4.08 & 4.1382 & TRN & & \\
\hline CHEMBL358081 & 49333 & 4.377 & 4.5499 & TRN & & \\
\hline CHEMBL1161247 & 49333 & 4.382 & 4.4607 & TRN & & \\
\hline CHEMBL145173 & 49333 & 5.119 & 5.1282 & TRN & & \\
\hline
\end{tabular}




\begin{tabular}{|c|c|c|c|c|c|c|}
\hline & & \multicolumn{5}{|c|}{ Supplemental Table S2.txt } \\
\hline CHEMBL142312 & 49333 & 4.48 & 4.5514 & TRN & & \\
\hline CHEMBL320512 & 49333 & 4.523 & 4.5024 & TRN & & \\
\hline CHEMBL144993 & 49333 & 5.066 & 5.197 & TRN & & \\
\hline CHEMBL143501 & 49333 & 4.398 & 4.3509 & TST & & \\
\hline CHEMBL1161248 & 49333 & 4.268 & 4.4922 & TST & & \\
\hline CHEMBL358077 & 49333 & 5.092 & 5.0825 & TRN & & \\
\hline CHEMBL356295 & 49333 & 4.284 & 4.3721 & TRN & & \\
\hline CHEMBL142417 & 49333 & 4.149 & 4.3014 & TRN & & \\
\hline CHEMBL1161244 & 49333 & 4.678 & 4.6535 & TRN & & \\
\hline CHEMBL145206 & 49333 & 4.658 & 4.5855 & TRN & & \\
\hline CHEMBL357210 & 49333 & 4.85 & 4.9762 & TST & & \\
\hline CHEMBL356094 & 49333 & 4.444 & 4.3933 & TRN & & \\
\hline CHEMBL143910 & 49333 & 4.96 & 5.4745 & TST & & \\
\hline CHEMBL145664 & 49333 & 5.41 & 5.4821 & TRN & & \\
\hline CHEMBL423195 & 49333 & \multicolumn{3}{|c|}{3.9210000000000003} & 3.9933 & TRN \\
\hline CHEMBL142447 & 49333 & 4.796 & 4.624 & TRN & & \\
\hline CHEMBL1161250 & 49333 & 4.36 & 4.3008 & TRN & & \\
\hline CHEMBL341636 & 49333 & 4.6 & 4.6186 & TRN & & \\
\hline CHEMBL104815 & 49333 & 4.319 & 4.2666 & TRN & & \\
\hline CHEMBL357660 & 49333 & 4.237 & 4.203 & TRN & & \\
\hline CHEMBL429002 & 49333 & 5.495 & 5.5852 & TRN & & \\
\hline CHEMBL348255 & 49333 & 5.131 & 5.4057 & TRN & & \\
\hline CHEMBL146492 & 49333 & 4.82 & 4.4586 & TRN & & \\
\hline CHEMBL444601 & 49333 & 4.33 & 4.5237 & TST & & \\
\hline CHEMBL358085 & 49333 & 5.11 & 5.1252 & TRN & & \\
\hline CHEMBL 2181164 & 878513 & 7.3251 & 7.2915 & TRN & & \\
\hline CHEMBL 2180909 & 878513 & 6.289 & 6.9911 & TST & & \\
\hline CHEMBL 2181142 & 878513 & 6.51 & 6.5217 & TRN & & \\
\hline CHEMBL 2180925 & 878513 & 6.3936 & 7.4281 & TST & & \\
\hline CHEMBL 2181146 & 878513 & 6.7399 & 6.7586 & TRN & & \\
\hline CHEMBL 2180933 & 878513 & 8.9706 & 8.9227 & TRN & & \\
\hline CHEMBL 2181159 & 878513 & 7.7545 & 7.79700 & 0000000001 & & TRN \\
\hline CHEMBL 2181156 & 878513 & 8.4179 & 8.4318 & TRN & & \\
\hline CHEMBL 2180918 & 878513 & 7.4134 & 7.4307 & TRN & & \\
\hline CHEMBL 2180916 & 878513 & 6.3936 & 6.3386 & TRN & & \\
\hline CHEMBL 2181155 & 878513 & 7.6234 & 7.7614 & TRN & & \\
\hline CHEMBL 2181161 & 878513 & 8.067 & 7.9307 & TRN & & \\
\hline CHEMBL 2180922 & 878513 & 6.0841 & 7.4703 & TST & & \\
\hline CHEMBL 2180927 & 878513 & 7.4498 & 7.5646 & TST & & \\
\hline CHEMBL 2180919 & 878513 & 6.4045 & 6.5264 & TST & & \\
\hline CHEMBL 2180935 & 878513 & 8.7011 & 8.7346 & TRN & & \\
\hline CHEMBL 2181160 & 878513 & 8.1146 & 8.0075 & TRN & & \\
\hline CHEMBL 2180913 & 878513 & 6.5986 & 6.7326 & TRN & & \\
\hline CHEMBL 2181145 & 878513 & 6.0851 & 6.0903 & TRN & & \\
\hline CHEMBL 2180940 & 878513 & 7.2774 & 7.3032 & TRN & & \\
\hline CHEMBL 2180915 & 878513 & 6.8069 & 6.7549 & TRN & & \\
\hline CHEMBL 2180910 & 878513 & 6.4486 & 6.4414 & TRN & & \\
\hline CHEMBL 2181153 & 878513 & 7.8356 & 7.8368 & TRN & & \\
\hline
\end{tabular}




\begin{tabular}{|c|c|c|c|c|c|c|}
\hline & & \multicolumn{5}{|c|}{ Supplemental Table S2.txt } \\
\hline CHEMBL 2181141 & 878513 & 7.51 & 7.3453 & TST & & \\
\hline CHEMBL 2180938 & 878513 & 7.6757 & 7.7242 & TRN & & \\
\hline CHEMBL 2180908 & 878513 & 5.8761 & 6.7719 & TST & & \\
\hline CHEMBL 2181144 & 878513 & 6.4353 & 6.4164 & TRN & & \\
\hline CHEMBL 2181157 & 878513 & 6.8861 & 6.8575 & TRN & & \\
\hline CHEMBL 2181163 & 878513 & 7.8097 & 7.9307 & TRN & & \\
\hline CHEMBL 2181158 & 878513 & 7.1593 & 7.1411 & TRN & & \\
\hline CHEMBL 2181139 & 878513 & 7.4248 & 7.3958 & TRN & & \\
\hline CHEMBL 2180917 & 878513 & 6.6091 & 6.6172 & TRN & & \\
\hline CHEMBL2180939 & 878513 & 6.7282 & 6.7406 & TRN & & \\
\hline CHEMBL 2181162 & 878513 & 7.8125 & 7.9307 & TRN & & \\
\hline CHEMBL 2180924 & 878513 & 7.7447 & 7.2933 & TST & & \\
\hline CHEMBL 2181149 & 878513 & 7.4672 & 7.5033 & TRN & & \\
\hline CHEMBL 2181154 & 878513 & 8.0645 & 7.893 & TRN & & \\
\hline CHEMBL 2180929 & 878513 & 7.7258 & 7.7317 & TRN & & \\
\hline CHEMBL 2180934 & 878513 & 8.1599 & 8.1462 & TRN & & \\
\hline CHEMBL2180930 & 878513 & 8.6038 & 8.5628 & TRN & & \\
\hline CHEMBL 2181148 & 878513 & 7.3526 & 7.3512 & TRN & & \\
\hline CHEMBL 2180907 & 878513 & 7.4191 & 7.5733 & TST & & \\
\hline CHEMBL 2181165 & 878513 & 5.2774 & 6.1481 & TST & & \\
\hline CHEMBL 2180923 & 878513 & 7.4855 & 7.3717 & TST & & \\
\hline CHEMBL 2180937 & 878513 & 7.8268 & 7.815 & TRN & & \\
\hline CHEMBL 2181143 & 878513 & \multicolumn{3}{|c|}{6.617999999999999} & 6.6369 & TRN \\
\hline CHEMBL 2180926 & 878513 & 5.8665 & 6.523 & TST & & \\
\hline CHEMBL 2180906 & 878513 & 9.0809 & 9.0742 & TRN & & \\
\hline CHEMBL 2180921 & 878513 & 7.0164 & 7.0381 & TST & & \\
\hline CHEMBL 2181140 & 878513 & 7.4225 & 7.4205 & TRN & & \\
\hline CHEMBL 2180912 & 878513 & 6.2708 & 6.2631 & TRN & & \\
\hline CHEMBL 2180928 & 878513 & 7.4225 & 7.2946 & TST & & \\
\hline CHEMBL 2180920 & 878513 & 7.4353 & 7.5681 & TST & & \\
\hline CHEMBL 2180936 & 878513 & 8.3072 & 8.3399 & TRN & & \\
\hline CHEMBL 2181147 & 878513 & 7.1979 & 7.2074 & TRN & & \\
\hline CHEMBL 2180914 & 878513 & 6.8665 & 6.7549 & TRN & & \\
\hline CHEMBL 2180911 & 878513 & 7.2013 & 7.2495 & TRN & & \\
\hline CHEMBL1309228 & 688155 & 4.95 & 5.0583 & TST & & \\
\hline CHEMBL1609757 & 688155 & 5.1 & 5.0422 & TRN & & \\
\hline CHEMBL538965 & 688155 & 5.6 & 5.1366 & TST & & \\
\hline CHEMBL1363080 & 688155 & 4.55 & 5.1455 & TRN & & \\
\hline CHEMBL1323931 & 688155 & 6.0 & 5.1149 & TRN & & \\
\hline CHEMBL1527152 & 688155 & 4.85 & 5.0633 & TST & & \\
\hline CHEMBL1438937 & 688155 & 6.35 & 5.1363 & TST & & \\
\hline CHEMBL1362829 & 688155 & 5.0 & 5.0209 & TST & & \\
\hline CHEMBL1530244 & 688155 & 4.55 & 5.0659 & TRN & & \\
\hline CHEMBL1344373 & 688155 & 5.35 & 5.2962 & TRN & & \\
\hline CHEMBL1505680 & 688155 & 4.55 & 5.3043 & TRN & & \\
\hline CHEMBL1457371 & 688155 & 4.95 & 5.0044 & TST & & \\
\hline CHEMBL1507211 & 688155 & 4.95 & 5.0945 & TRN & & \\
\hline CHEMBL1577251 & 688155 & 4.6 & 5.1906 & TRN & & \\
\hline
\end{tabular}




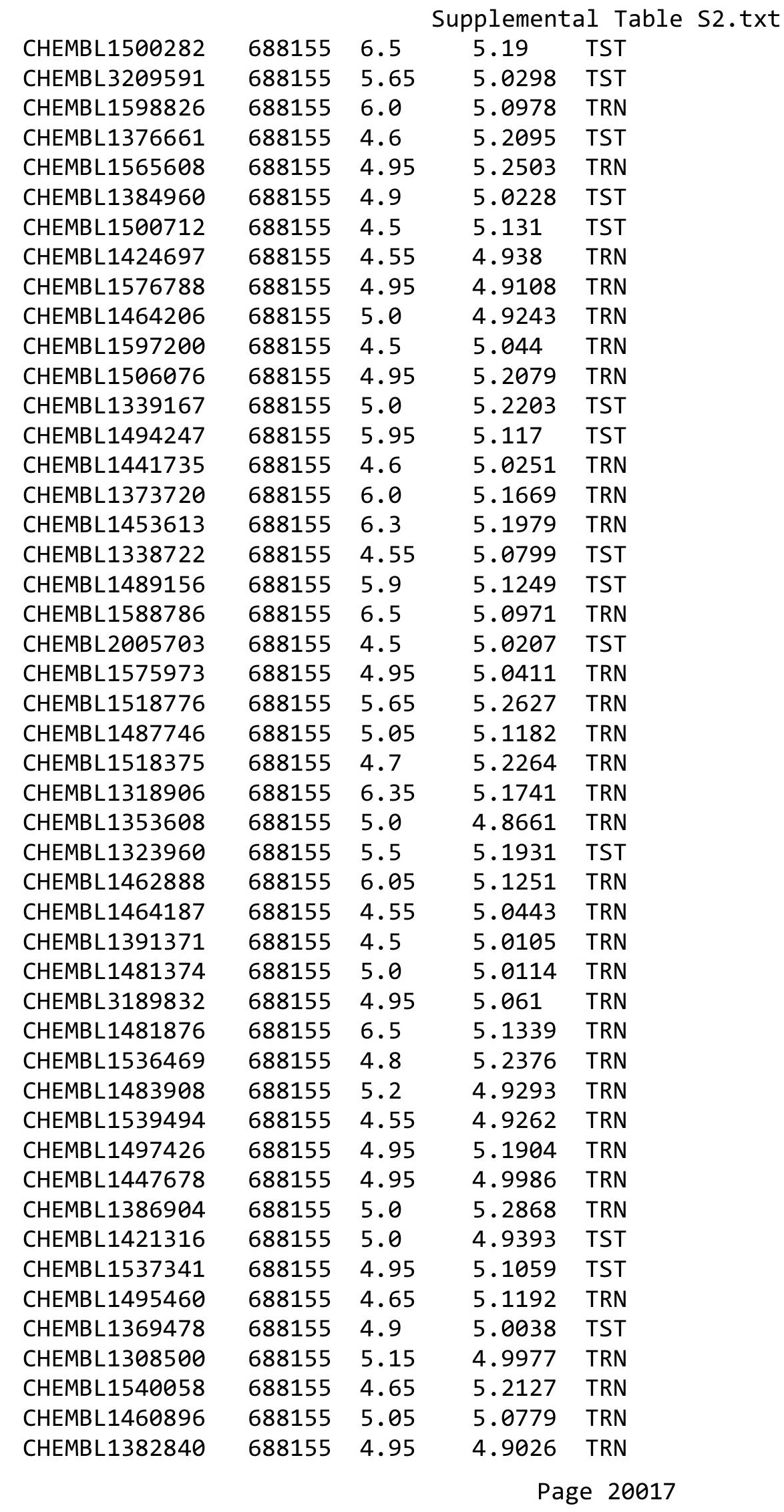




\begin{tabular}{|c|c|c|c|c|c|}
\hline \multicolumn{6}{|c|}{ Supplemental Table s2.txt } \\
\hline CHEMBL1422894 & 688155 & 4.5 & 5.0637 & TRN & \\
\hline CHEMBL459727 & 688155 & 4.5 & 5.2118 & TRN & \\
\hline CHEMBL547924 & 688155 & 4.55 & 4.9338 & TRN & \\
\hline CHEMBL1571324 & 688155 & 4.95 & 5.0776 & TRN & \\
\hline CHEMBL1493869 & 688155 & 5.05 & 5.029 & TRN & \\
\hline CHEMBL1543217 & 688155 & 4.95 & 5.1683 & TRN & \\
\hline CHEMBL1312613 & 688155 & 4.9 & 4.883 & TRN & \\
\hline CHEMBL1580527 & 688155 & 5.1 & 5.1083 & TRN & \\
\hline CHEMBL1351089 & 688155 & 4.55 & 5.1171 & TRN & \\
\hline CHEMBL1342047 & 688155 & 5.95 & 5.1412 & TRN & \\
\hline CHEMBL1369097 & 688155 & 4.9 & 5.1619 & TRN & \\
\hline CHEMBL1305806 & 688155 & 4.5 & 5.2444 & TRN & \\
\hline CHEMBL1499654 & 688155 & 5.5 & 5.0784 & TRN & \\
\hline CHEMBL1558055 & 688155 & 5.0 & 5.0511 & TRN & \\
\hline CHEMBL1537530 & 688155 & 4.95 & 4.9825 & TST & \\
\hline CHEMBL1425991 & 688155 & 5.05 & 4.9967 & TRN & \\
\hline CHEMBL1446788 & 688155 & 4.55 & 5.0322 & TRN & \\
\hline CHEMBL1604331 & 688155 & 4.55 & 5.0882 & TRN & \\
\hline CHEMBL1339412 & 688155 & 5.1 & 5.1427 & TRN & \\
\hline CHEMBL1974063 & 688155 & 4.85 & 5.018 & TRN & \\
\hline CHEMBL3193133 & 688155 & 4.55 & 5.0168 & TST & \\
\hline CHEMBL1454327 & 688155 & 5.5 & 5.2333 & TRN & \\
\hline CHEMBL1554723 & 688155 & 4.55 & 5.1749 & TRN & \\
\hline CHEMBL1455279 & 688155 & 5.0 & 5.0325 & TST & \\
\hline CHEMBL3192181 & 688155 & 4.95 & 4.9592 & TRN & \\
\hline CHEMBL1504364 & 688155 & 4.5 & 5.1956 & TRN & \\
\hline CHEMBL1546492 & 688155 & 4.5 & 5.1432 & TRN & \\
\hline CHEMBL1484625 & 688155 & 5.75 & 5.0624 & TRN & \\
\hline CHEMBL1300392 & 688155 & 5.1 & 5.15799 & 99999999995 & TRN \\
\hline CHEMBL1301737 & 688155 & 5.4 & 5.25799 & 9999999999 & TRN \\
\hline CHEMBL1380609 & 688155 & 4.8 & 5.0888 & TRN & \\
\hline CHEMBL1374203 & 688155 & 5.1 & 5.157 & TST & \\
\hline CHEMBL1543462 & 688155 & 4.9 & 5.0945 & TRN & \\
\hline CHEMBL1389155 & 688155 & 5.05 & 5.1595 & TRN & \\
\hline CHEMBL1372044 & 688155 & 6.5 & 5.1095 & TST & \\
\hline CHEMBL3192500 & 688155 & 4.95 & 4.9829 & TRN & \\
\hline CHEMBL1563754 & 688155 & 4.95 & 5.0886 & TRN & \\
\hline CHEMBL1612115 & 688155 & 5.0 & 5.0543 & TRN & \\
\hline CHEMBL1431373 & 688155 & 5.0 & 4.9528 & TRN & \\
\hline CHEMBL1609296 & 688155 & 4.95 & 5.0845 & TRN & \\
\hline CHEMBL1339156 & 688155 & 5.15 & 5.0648 & TRN & \\
\hline CHEMBL1363550 & 688155 & 4.95 & 5.0223 & TRN & \\
\hline CHEMBL1595950 & 688155 & 4.95 & 4.9775 & TRN & \\
\hline CHEMBL1301028 & 688155 & 4.95 & 4.9989 & TRN & \\
\hline CHEMBL1427245 & 688155 & 4.55 & 4.9793 & TST & \\
\hline CHEMBL1578822 & 688155 & 4.5 & 5.1964 & TRN & \\
\hline CHEMBL1320915 & 688155 & 5.0 & 5.1155 & TRN & \\
\hline CHEMBL1518008 & 688155 & 5.3 & 4.9452 & TST & \\
\hline
\end{tabular}




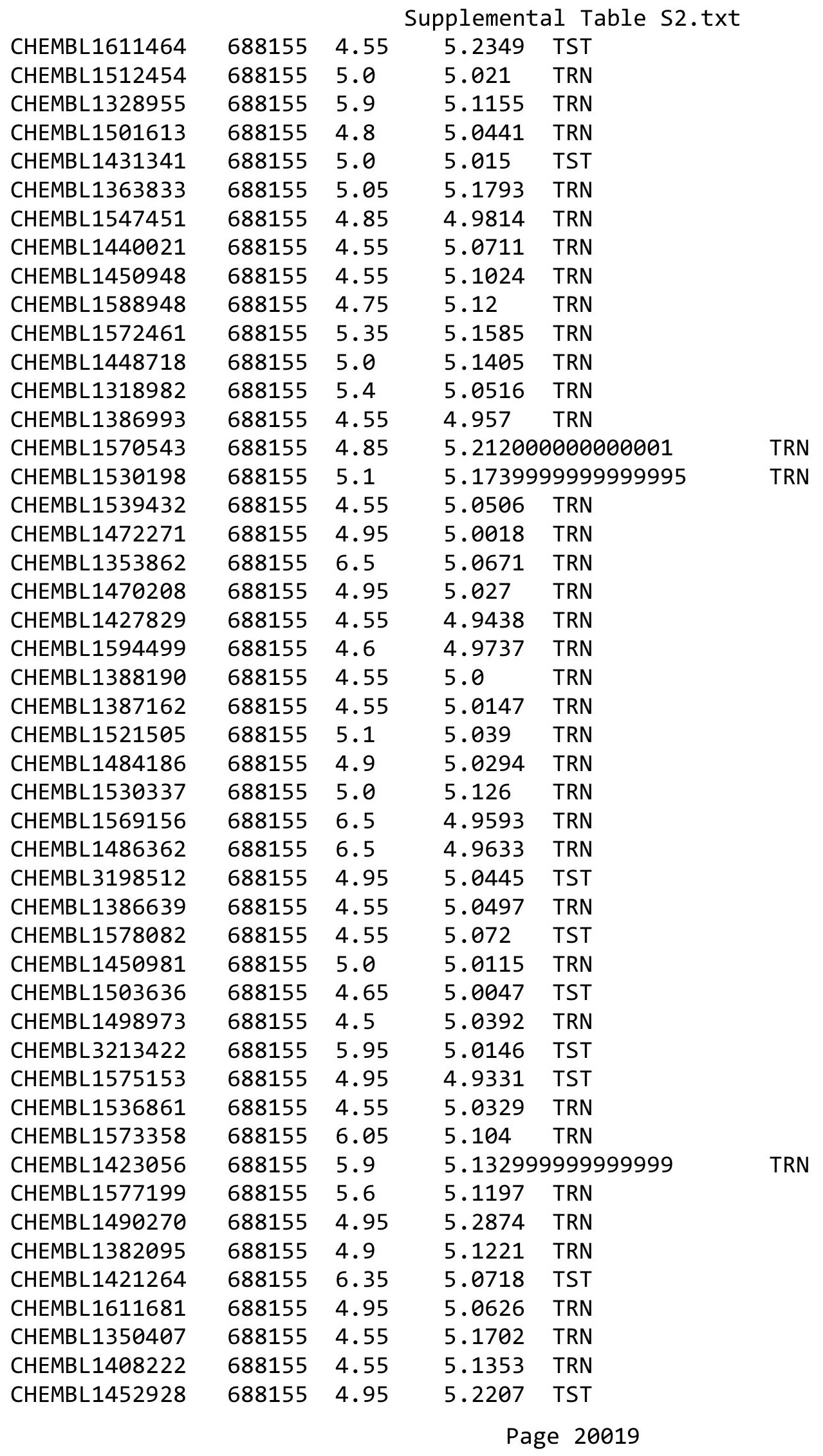




\begin{tabular}{|c|c|c|c|c|c|}
\hline \multicolumn{6}{|c|}{ Supplemental Table s2.txt } \\
\hline CHEMBL1363101 & 688155 & 4.55 & 5.0234 & TRN & \\
\hline CHEMBL1596259 & 688155 & 4.5 & 5.1173 & TRN & \\
\hline CHEMBL1529358 & 688155 & 4.9 & 5.0518 & TRN & \\
\hline CHEMBL1583312 & 688155 & 4.9 & 5.0384 & TRN & \\
\hline CHEMBL1547336 & 688155 & 5.5 & 5.1389 & TRN & \\
\hline CHEMBL1317761 & 688155 & 4.85 & 4.9873 & TRN & \\
\hline CHEMBL1569113 & 688155 & 4.9 & 4.9658 & TRN & \\
\hline CHEMBL1500955 & 688155 & 5.5 & 5.1951 & TRN & \\
\hline CHEMBL1365814 & 688155 & 6.5 & \multicolumn{2}{|c|}{5.031000000000001} & TST \\
\hline CHEMBL1572874 & 688155 & 4.55 & 4.89 & TRN & \\
\hline CHEMBL1345063 & 688155 & 5.2 & 4.9815 & TST & \\
\hline CHEMBL3195313 & 688155 & 6.5501 & 5.013 & TST & \\
\hline CHEMBL1300214 & 688155 & 4.95 & 5.1477 & TRN & \\
\hline CHEMBL1571206 & 688155 & 6.15 & 4.9724 & TRN & \\
\hline CHEMBL3193273 & 688155 & 4.5 & 4.9651 & TRN & \\
\hline CHEMBL1302670 & 688155 & 4.55 & 5.0601 & TST & \\
\hline CHEMBL1517304 & 688155 & 4.85 & 5.0045 & TRN & \\
\hline CHEMBL1321633 & 688155 & 4.65 & 4.9165 & TRN & \\
\hline CHEMBL1369777 & 688155 & 6.5 & 5.0929 & TRN & \\
\hline CHEMBL1330661 & 688155 & 5.0 & 5.0575 & TRN & \\
\hline CHEMBL1489810 & 688155 & 4.85 & 5.0706 & TRN & \\
\hline CHEMBL1377272 & 688155 & 5.15 & 5.0773 & TRN & \\
\hline CHEMBL1350591 & 688155 & 4.55 & 4.9829 & TRN & \\
\hline CHEMBL1452610 & 688155 & 5.3 & 5.1689 & TRN & \\
\hline CHEMBL1442238 & 688155 & 4.85 & 5.1461 & TST & \\
\hline CHEMBL1343237 & 688155 & 4.95 & 4.9447 & TST & \\
\hline CHEMBL1568168 & 688155 & 4.55 & 5.0779 & TRN & \\
\hline CHEMBL1405588 & 688155 & 5.65 & 4.9925 & TRN & \\
\hline CHEMBL1379364 & 688155 & 4.95 & 4.9807 & TRN & \\
\hline CHEMBL3190677 & 688155 & 6.45 & 5.0596 & TST & \\
\hline CHEMBL106437 & 688155 & 4.9 & 5.2363 & TRN & \\
\hline CHEMBL1335914 & 688155 & 4.65 & 5.1079 & TST & \\
\hline CHEMBL1612425 & 688155 & 4.9 & \multicolumn{2}{|c|}{5.111000000000001} & TST \\
\hline CHEMBL1337652 & 688155 & 5.0 & 5.0465 & TRN & \\
\hline CHEMBL1433027 & 688155 & 4.55 & 4.9127 & TRN & \\
\hline CHEMBL1558390 & 688155 & 4.5 & 5.0957 & TST & \\
\hline CHEMBL1324395 & 688155 & 4.55 & 5.1749 & TRN & \\
\hline CHEMBL1299866 & 688155 & 4.55 & 5.1162 & TRN & \\
\hline CHEMBL1490285 & 688155 & 5.45 & 5.1849 & TRN & \\
\hline CHEMBL1449066 & 688155 & 4.5 & 5.0887 & TRN & \\
\hline CHEMBL3196248 & 688155 & 4.9 & 4.8642 & TRN & \\
\hline CHEMBL1256659 & 688155 & 5.8 & 5.1834 & TST & \\
\hline CHEMBL1584889 & 688155 & 5.8 & 5.0109 & TRN & \\
\hline CHEMBL1566508 & 688155 & 5.15 & 5.2403 & TRN & \\
\hline CHEMBL1513392 & 688155 & 4.65 & 5.246 & TRN & \\
\hline CHEMBL1578019 & 688155 & 5.45 & 5.0385 & TRN & \\
\hline CHEMBL1440595 & 688155 & 4.55 & 5.0154 & TRN & \\
\hline CHEMBL1504227 & 688155 & 6.5 & 4.9631 & TST & \\
\hline
\end{tabular}




\begin{tabular}{|c|c|c|c|c|c|}
\hline \multicolumn{6}{|c|}{ Supplemental Table S2.txt } \\
\hline CHEMBL1390016 & 688155 & 4.7 & 5.0222 & TST & \\
\hline CHEMBL1310645 & 688155 & 5.45 & 5.1615 & TRN & \\
\hline CHEMBL1430238 & 688155 & 4.55 & 5.1269 & TRN & \\
\hline CHEMBL1579739 & 688155 & 5.1 & 5.0845 & TST & \\
\hline CHEMBL1612810 & 688155 & 4.9 & 5.0224 & TRN & \\
\hline CHEMBL1348866 & 688155 & 4.95 & 4.9125 & TRN & \\
\hline CHEMBL1487728 & 688155 & 5.1 & 4.9524 & TST & \\
\hline CHEMBL1590645 & 688155 & 4.9 & 4.9159 & TRN & \\
\hline CHEMBL1597469 & 688155 & 4.5 & 5.1398 & TST & \\
\hline CHEMBL3194159 & 688155 & 4.55 & 4.8861 & TRN & \\
\hline CHEMBL1504660 & 688155 & 4.95 & 4.9755 & TRN & \\
\hline CHEMBL1492815 & 688155 & 4.95 & 4.99 & TRN & \\
\hline CHEMBL1303217 & 688155 & 4.55 & 4.9794 & TST & \\
\hline CHEMBL1326154 & 688155 & 5.3 & 5.0296 & TRN & \\
\hline CHEMBL1544648 & 688155 & 5.0 & 5.0306 & TRN & \\
\hline CHEMBL1497800 & 688155 & 4.55 & 5.2896 & TRN & \\
\hline CHEMBL1389888 & 688155 & 4.8 & 4.9812 & TRN & \\
\hline CHEMBL 76904 & 688155 & 6.0 & 5.0556 & TRN & \\
\hline CHEMBL1561382 & 688155 & 4.65 & 5.0762 & TRN & \\
\hline CHEMBL3199401 & 688155 & 4.55 & 5.0198 & TRN & \\
\hline CHEMBL1605597 & 688155 & 4.95 & 4.9724 & TRN & \\
\hline CHEMBL1311847 & 688155 & 4.95 & 5.0538 & TST & \\
\hline CHEMBL1457525 & 688155 & 4.95 & 5.1597 & TRN & \\
\hline CHEMBL1355604 & 688155 & 5.0 & 5.1796 & TRN & \\
\hline CHEMBL1399406 & 688155 & 5.25 & 5.0236 & TST & \\
\hline CHEMBL1527604 & 688155 & 5.3 & 5.1925 & TRN & \\
\hline CHEMBL1507131 & 688155 & 4.9 & 5.1079 & TRN & \\
\hline CHEMBL1603006 & 688155 & 4.65 & 5.0783 & TRN & \\
\hline CHEMBL1476546 & 688155 & 4.9 & 5.062 & TST & \\
\hline CHEMBL1483373 & 688155 & 4.45 & 5.1117 & TRN & \\
\hline CHEMBL1255649 & 688155 & 6.0 & 5.232 & TRN & \\
\hline CHEMBL1470415 & 688155 & 4.95 & 5.0664 & TST & \\
\hline CHEMBL1578010 & 688155 & 6.1 & 5.2118 & TST & \\
\hline CHEMBL1364924 & 688155 & 5.55 & 5.0467 & TRN & \\
\hline CHEMBL1492324 & 688155 & 4.9 & 4.9549 & TRN & \\
\hline CHEMBL1582311 & 688155 & 5.65 & 5.3371 & TRN & \\
\hline CHEMBL1500777 & 688155 & 5.05 & 5.15799 & 99999999995 & TRN \\
\hline CHEMBL1470299 & 688155 & 4.5 & 5.1462 & TRN & \\
\hline CHEMBL1388237 & 688155 & 5.15 & 5.083 & TRN & \\
\hline CHEMBL1532755 & 688155 & 4.95 & 4.9883 & TRN & \\
\hline CHEMBL1456771 & 688155 & 4.55 & 4.936 & TRN & \\
\hline CHEMBL1572577 & 688155 & 5.3 & 5.0931 & TST & \\
\hline CHEMBL1420511 & 688155 & 4.95 & 5.1111 & TRN & \\
\hline CHEMBL1541308 & 688155 & 4.95 & 4.9978 & TRN & \\
\hline CHEMBL1341560 & 688155 & 4.55 & 4.9818 & TRN & \\
\hline CHEMBL1549469 & 688155 & 4.85 & 5.1842 & TRN & \\
\hline CHEMBL1364786 & 688155 & 5.85 & 5.1592 & TRN & \\
\hline CHEMBL1613002 & 688155 & 4.5 & 5.1422 & TST & \\
\hline
\end{tabular}




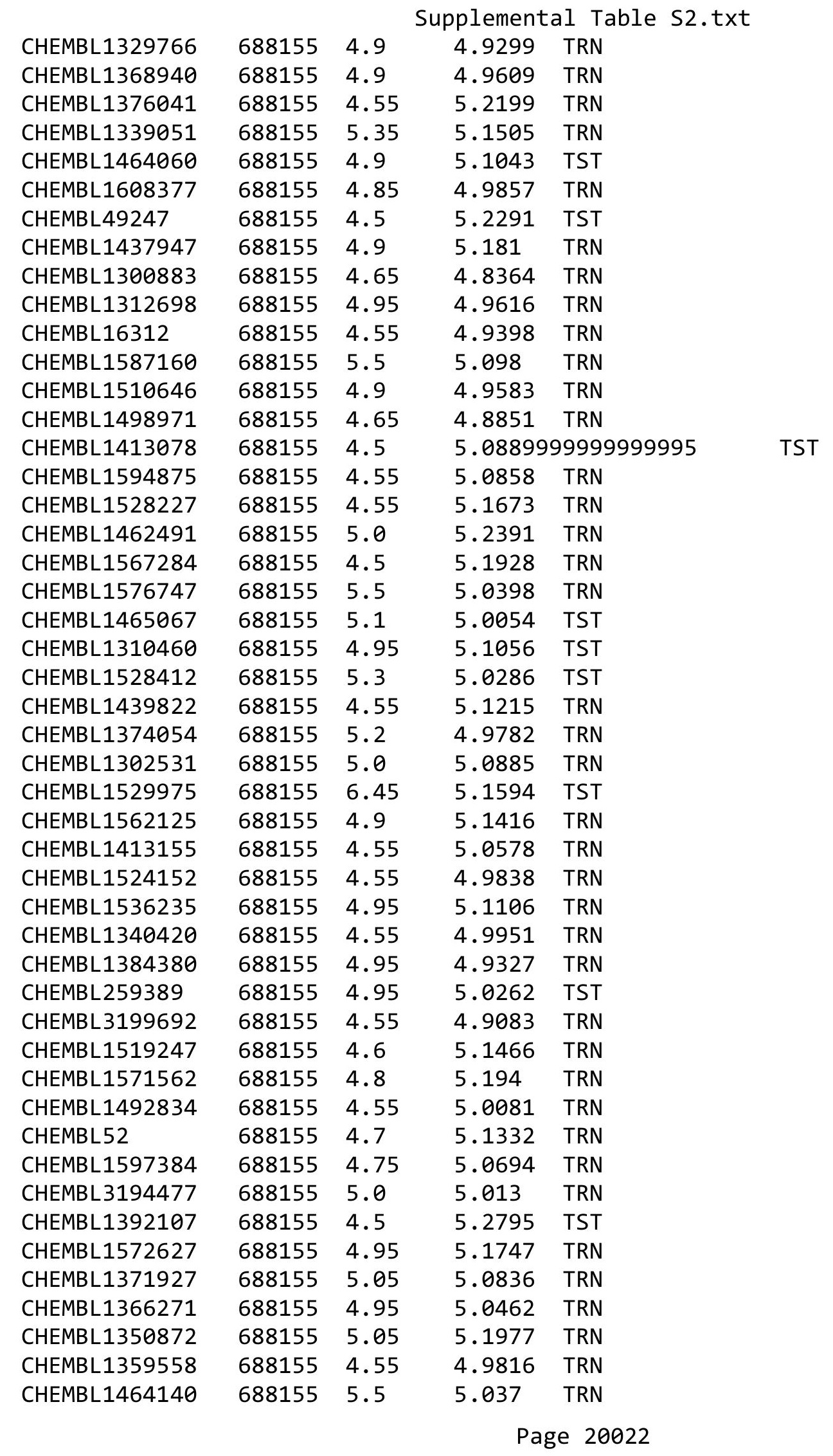




\begin{tabular}{|c|c|c|c|c|c|}
\hline & & \multicolumn{4}{|c|}{ Supplemental Table S2.txt } \\
\hline CHEMBL1526566 & 688155 & 5.9 & 4.9859 & TRN & \\
\hline CHEMBL1586041 & 688155 & 5.0 & 5.0697 & TRN & \\
\hline CHEMBL1380266 & 688155 & 4.6 & 5.1913 & TRN & \\
\hline CHEMBL1442610 & 688155 & 4.55 & 4.925 & TRN & \\
\hline CHEMBL3194432 & 688155 & 5.0 & 4.959 & TRN & \\
\hline CHEMBL1307492 & 688155 & 4.5 & 5.0531 & TRN & \\
\hline CHEMBL1577817 & 688155 & 4.85 & 5.0403 & TRN & \\
\hline CHEMBL1577539 & 688155 & 5.05 & 4.9233 & TRN & \\
\hline CHEMBL1332169 & 688155 & 4.8 & 5.0353 & TST & \\
\hline CHEMBL1370391 & 688155 & 4.6 & 5.0964 & TRN & \\
\hline CHEMBL1468594 & 688155 & 4.9 & 4.9386 & TRN & \\
\hline CHEMBL1346710 & 688155 & 4.65 & 5.0622 & TRN & \\
\hline CHEMBL1548526 & 688155 & 5.9 & 5.1761 & TRN & \\
\hline CHEMBL1519720 & 688155 & 5.7 & 4.9771 & TST & \\
\hline CHEMBL1515658 & 688155 & 5.0 & 5.0913 & TST & \\
\hline CHEMBL1483156 & 688155 & 5.25 & 5.07 & TRN & \\
\hline CHEMBL1605354 & 688155 & 5.0 & 5.2576 & TRN & \\
\hline CHEMBL1333585 & 688155 & 4.5 & 5.0281 & TRN & \\
\hline CHEMBL1598249 & 688155 & 5.25 & 4.8579 & TRN & \\
\hline CHEMBL1515945 & 688155 & 4.9 & 4.9751 & TRN & \\
\hline CHEMBL1456701 & 688155 & 5.0 & 5.0458 & TRN & \\
\hline CHEMBL1360539 & 688155 & 5.5 & 5.0988 & TRN & \\
\hline CHEMBL1348471 & 688155 & 4.9 & 5.0043 & TST & \\
\hline CHEMBL1564201 & 688155 & 5.5 & 5.0964 & TST & \\
\hline CHEMBL1462793 & 688155 & 5.0 & 5.0214 & TRN & \\
\hline CHEMBL1383415 & 688155 & 5.0 & 5.1623 & TRN & \\
\hline CHEMBL1337200 & 688155 & 4.95 & 5.2072 & TST & \\
\hline CHEMBL3190452 & 688155 & 4.9 & 5.0075 & TST & \\
\hline CHEMBL1401860 & 688155 & 4.55 & 5.0834 & TST & \\
\hline CHEMBL1407028 & 688155 & 5.1 & 5.0269 & TRN & \\
\hline CHEMBL1352560 & 688155 & 5.25 & 5.12 & TRN & \\
\hline CHEMBL1318305 & 688155 & 4.55 & 4.9634 & TRN & \\
\hline CHEMBL1590223 & 688155 & 4.95 & 5.1854 & TRN & \\
\hline CHEMBL1588285 & 688155 & 4.55 & 5.0463 & TRN & \\
\hline CHEMBL1387692 & 688155 & 5.05 & 4.9751 & TRN & \\
\hline CHEMBL1510817 & 688155 & 5.0 & 5.1268 & TST & \\
\hline CHEMBL1393136 & 688155 & 4.65 & 4.9702 & TRN & \\
\hline CHEMBL1303553 & 688155 & 4.55 & 5.00899 & 99999999995 & TRN \\
\hline CHEMBL1349490 & 688155 & 5.5 & 5.1683 & TRN & \\
\hline CHEMBL1378908 & 688155 & 6.0 & 5.1077 & TRN & \\
\hline CHEMBL1444360 & 688155 & 4.5 & 5.0254 & TRN & \\
\hline CHEMBL1361167 & 688155 & 5.8 & 4.96399 & 99999999995 & TRN \\
\hline CHEMBL1353413 & 688155 & 6.45 & 5.0573 & TST & \\
\hline CHEMBL1605788 & 688155 & 4.75 & 4.9421 & TRN & \\
\hline CHEMBL1588822 & 688155 & 6.15 & 5.2070 & 2000000001 & TRN \\
\hline CHEMBL1547437 & 688155 & 5.9 & 5.1133 & TRN & \\
\hline CHEMBL1364397 & 688155 & 5.0 & 5.1031 & TST & \\
\hline CHEMBL1545440 & 688155 & 5.05 & 5.1392 & TRN & \\
\hline
\end{tabular}




\begin{tabular}{|c|c|c|c|c|}
\hline \multicolumn{5}{|c|}{ Supplemental Table S2.txt } \\
\hline CHEMBL1343715 & 688155 & 6.1 & 5.0533 & TRN \\
\hline CHEMBL1349003 & 688155 & 5.25 & 4.982 & TRN \\
\hline CHEMBL1605210 & 688155 & 5.9 & 4.9815 & TST \\
\hline CHEMBL1349797 & 688155 & 5.5 & 5.2891 & TST \\
\hline CHEMBL1450042 & 688155 & 4.55 & 5.0183 & TRN \\
\hline CHEMBL1337490 & 688155 & 5.1 & 5.1073 & TRN \\
\hline CHEMBL1505993 & 688155 & 4.95 & 5.0993 & TRN \\
\hline CHEMBL1442237 & 688155 & 4.55 & 4.9282 & TRN \\
\hline CHEMBL1544131 & 688155 & 4.95 & 5.0461 & TRN \\
\hline CHEMBL1498013 & 688155 & 4.65 & 4.9925 & TRN \\
\hline CHEMBL1543705 & 688155 & 4.95 & 5.229 & TRN \\
\hline CHEMBL1384184 & 688155 & 4.9 & 5.2028 & TST \\
\hline CHEMBL1507987 & 688155 & 4.55 & 5.1107 & TST \\
\hline CHEMBL1307248 & 688155 & 5.0 & 5.0614 & TRN \\
\hline CHEMBL1429566 & 688155 & 6.0 & 5.1671 & TRN \\
\hline CHEMBL1522129 & 688155 & 4.55 & 5.1183 & TRN \\
\hline CHEMBL1467523 & 688155 & 5.0 & 5.0833 & TRN \\
\hline CHEMBL1536171 & 688155 & 5.95 & 4.9678 & TRN \\
\hline CHEMBL1311873 & 688155 & 4.75 & 5.0651 & TRN \\
\hline CHEMBL1499951 & 688155 & 4.95 & 5.0873 & TRN \\
\hline CHEMBL1405932 & 688155 & 5.0 & 4.9944 & TRN \\
\hline CHEMBL1330166 & 688155 & 4.55 & 4.9793 & TRN \\
\hline CHEMBL1348813 & 688155 & 4.9 & 5.0478 & TRN \\
\hline CHEMBL1529441 & 688155 & 4.65 & 5.0309 & TRN \\
\hline CHEMBL1602761 & 688155 & 4.95 & 5.1832 & TRN \\
\hline CHEMBL1564718 & 688155 & 5.65 & 5.1974 & TRN \\
\hline CHEMBL1363127 & 688155 & 6.5 & 5.0764 & TRN \\
\hline CHEMBL1490988 & 688155 & 4.5 & 5.1811 & TRN \\
\hline CHEMBL1522570 & 688155 & 4.55 & 5.0781 & TRN \\
\hline CHEMBL1307804 & 688155 & 4.5 & 4.9698 & TRN \\
\hline CHEMBL1341614 & 688155 & 5.7 & 5.0635 & TST \\
\hline CHEMBL1451957 & 688155 & 4.95 & 5.0061 & TRN \\
\hline CHEMBL1418330 & 688155 & 6.05 & 5.0035 & TRN \\
\hline CHEMBL1442139 & 688155 & 6.05 & 5.1267 & TRN \\
\hline CHEMBL1468332 & 688155 & 4.9 & 5.0185 & TRN \\
\hline CHEMBL1319810 & 688155 & 5.05 & 5.0307 & TRN \\
\hline CHEMBL1500976 & 688155 & 5.15 & 5.1527 & TST \\
\hline CHEMBL1365850 & 688155 & 5.0 & 5.0246 & TRN \\
\hline CHEMBL1428336 & 688155 & 6.5 & 4.9357 & TRN \\
\hline CHEMBL1536296 & 688155 & 4.9 & 5.2101 & TST \\
\hline CHEMBL1526356 & 688155 & 4.95 & 5.1022 & TST \\
\hline CHEMBL1520712 & 688155 & 5.75 & 5.1076 & TST \\
\hline CHEMBL1418697 & 688155 & 6.3 & 5.1086 & TRN \\
\hline CHEMBL1505044 & 688155 & 5.0 & 4.971 & TST \\
\hline CHEMBL1299470 & 688155 & 4.9 & 5.0864 & TRN \\
\hline CHEMBL1519051 & 688155 & 4.55 & 5.0413 & TRN \\
\hline CHEMBL1391966 & 688155 & 5.0 & 5.1906 & TRN \\
\hline CHEMBL1506482 & 688155 & 5.45 & 5.2374 & TRN \\
\hline
\end{tabular}




\begin{tabular}{|c|c|c|c|c|c|}
\hline \multicolumn{6}{|c|}{ Supplemental Table s2.txt } \\
\hline CHEMBL1414416 & 688155 & 4.5 & 5.0392 & TRN & \\
\hline CHEMBL1508441 & 688155 & 4.55 & 4.9154 & TRN & \\
\hline CHEMBL1390206 & 688155 & 4.8 & 5.0954 & TST & \\
\hline CHEMBL1429289 & 688155 & 5.05 & 5.0666 & TRN & \\
\hline CHEMBL1570608 & 688155 & 5.2 & 5.1705 & TST & \\
\hline CHEMBL 2001857 & 688155 & 4.9 & 5.0556 & TRN & \\
\hline CHEMBL1539024 & 688155 & 4.55 & 5.0348 & TRN & \\
\hline CHEMBL1397308 & 688155 & 5.05 & 5.1052 & TRN & \\
\hline CHEMBL1350211 & 688155 & 5.0 & 4.9992 & TRN & \\
\hline CHEMBL1992834 & 688155 & 5.65 & 4.9855 & TRN & \\
\hline CHEMBL1344800 & 688155 & 4.55 & 4.8818 & TRN & \\
\hline CHEMBL 8488 & 688155 & 5.0 & 5.0993 & TRN & \\
\hline CHEMBL1386288 & 688155 & 4.9 & 5.175 & TRN & \\
\hline CHEMBL1459671 & 688155 & 5.1 & 5.0397 & TRN & \\
\hline CHEMBL1363641 & 688155 & 5.95 & 5.1207 & TRN & \\
\hline CHEMBL1440703 & 688155 & 4.85 & 5.0516 & TRN & \\
\hline CHEMBL1389163 & 688155 & 5.3 & 5.0467 & TRN & \\
\hline CHEMBL1479477 & 688155 & 4.95 & 4.9063 & TRN & \\
\hline CHEMBL1362137 & 688155 & 4.5 & 5.1693 & TST & \\
\hline CHEMBL3197686 & 688155 & 4.55 & 5.0675 & TST & \\
\hline CHEMBL1419217 & 688155 & 4.5 & 5.0476 & TRN & \\
\hline CHEMBL 297784 & 688155 & 4.55 & 5.0672 & TST & \\
\hline CHEMBL1503380 & 688155 & 5.95 & 5.0599 & TST & \\
\hline CHEMBL1540180 & 688155 & 4.6 & 5.0439 & TRN & \\
\hline CHEMBL1472341 & 688155 & 5.85 & 4.9145 & TRN & \\
\hline CHEMBL1505221 & 688155 & 5.7 & 4.8822 & TST & \\
\hline CHEMBL1302227 & 688155 & 5.0 & 5.1753 & TRN & \\
\hline CHEMBL1541462 & 688155 & 5.3 & 5.1424 & TRN & \\
\hline CHEMBL1405234 & 688155 & 4.55 & 5.1597 & TRN & \\
\hline CHEMBL1389051 & 688155 & 4.5 & 5.1229 & TRN & \\
\hline CHEMBL1516444 & 688155 & 4.55 & 5.1045 & TST & \\
\hline CHEMBL1555535 & 688155 & 4.8 & 5.1073 & TRN & \\
\hline CHEMBL1423527 & 688155 & 4.55 & 4.9652 & TRN & \\
\hline CHEMBL1482145 & 688155 & 4.5 & 5.0255 & TRN & \\
\hline CHEMBL1508743 & 688155 & 4.95 & 5.1504 & TRN & \\
\hline CHEMBL1380232 & 688155 & 6.3 & 5.225 & TRN & \\
\hline CHEMBL1352124 & 688155 & 5.1 & 5.0285 & TRN & \\
\hline CHEMBL1438040 & 688155 & 5.5 & $5.1610 e$ & 00000000005 & TS \\
\hline CHEMBL1341833 & 688155 & 5.05 & 4.9752 & TRN & \\
\hline CHEMBL1487367 & 688155 & 5.4 & 5.0092 & TRN & \\
\hline CHEMBL1515997 & 688155 & 5.4 & 5.3079 & TST & \\
\hline CHEMBL1528306 & 688155 & 4.85 & 4.9819 & TRN & \\
\hline CHEMBL1463696 & 688155 & 5.0 & 5.0957 & TRN & \\
\hline CHEMBL1485606 & 688155 & 4.95 & 4.9884 & TST & \\
\hline CHEMBL1516572 & 688155 & 4.65 & 5.0157 & TRN & \\
\hline CHEMBL1515374 & 688155 & 5.65 & 4.9527 & TRN & \\
\hline CHEMBL1311223 & 688155 & 6.15 & 5.1463 & TRN & \\
\hline CHEMBL1414575 & 688155 & 4.95 & 4.9509 & TRN & \\
\hline
\end{tabular}




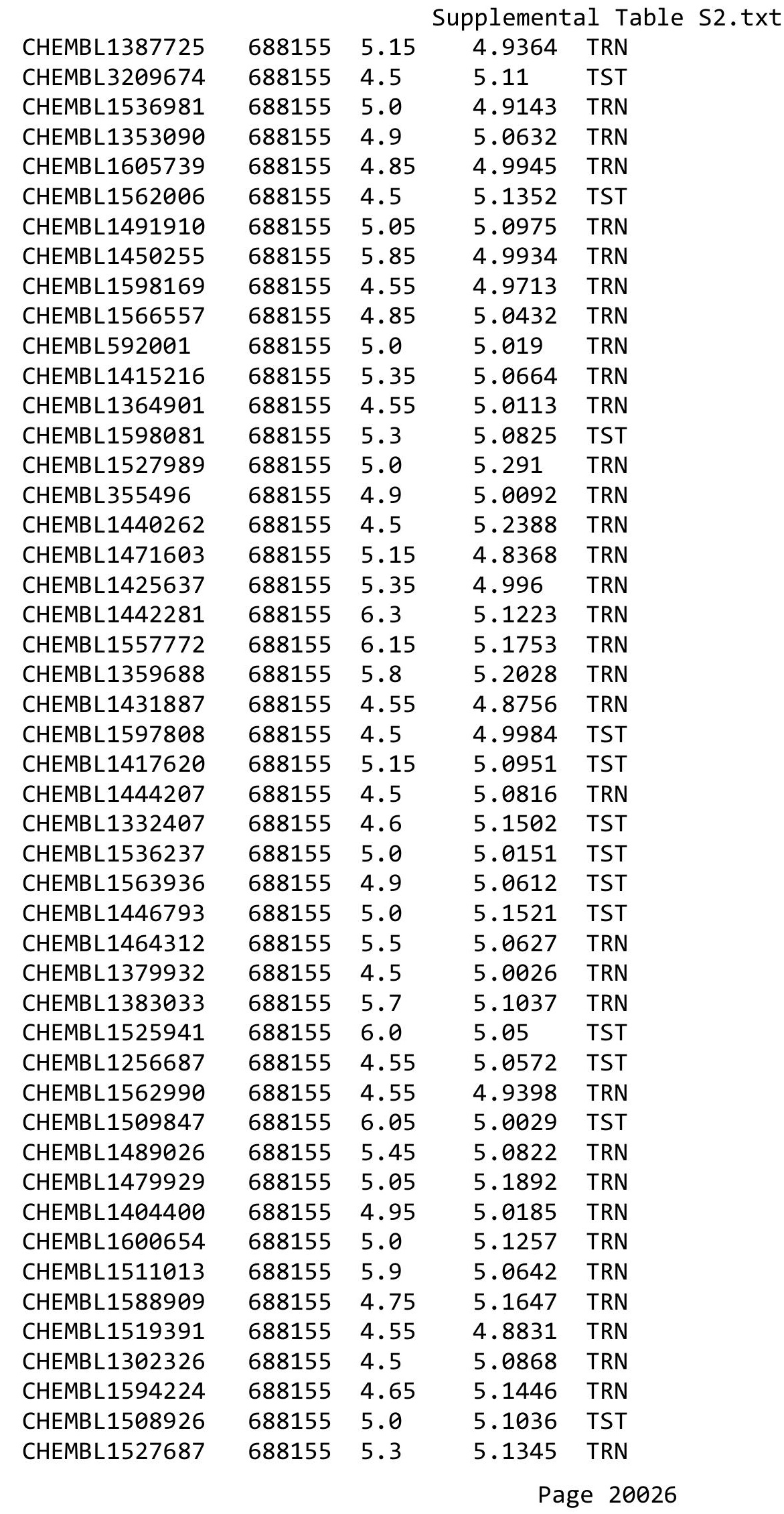




\begin{tabular}{|c|c|c|c|c|c|}
\hline \multicolumn{6}{|c|}{ Supplemental Table S2.txt } \\
\hline CHEMBL1388036 & 688155 & 4.9 & 5.0876 & TRN & \\
\hline CHEMBL1462892 & 688155 & 5.85 & 5.1022 & TRN & \\
\hline CHEMBL1391500 & 688155 & 6.0 & 5.2401 & TST & \\
\hline CHEMBL1347286 & 688155 & 5.45 & 5.1674 & TRN & \\
\hline CHEMBL1526497 & 688155 & 5.15 & 5.0114 & TRN & \\
\hline CHEMBL1376494 & 688155 & 4.5 & 4.9864 & TRN & \\
\hline CHEMBL1568707 & 688155 & 4.95 & 5.0215 & TRN & \\
\hline CHEMBL1440244 & 688155 & 4.5 & 5.0477 & TRN & \\
\hline CHEMBL1609813 & 688155 & 4.55 & 5.1549 & TST & \\
\hline CHEMBL1430244 & 688155 & 4.95 & 5.2164 & TRN & \\
\hline CHEMBL1452986 & 688155 & 5.3 & 5.0725 & TST & \\
\hline CHEMBL1375704 & 688155 & 4.95 & 5.0688 & TRN & \\
\hline CHEMBL1457599 & 688155 & 4.7 & 4.9524 & TRN & \\
\hline CHEMBL1456442 & 688155 & 6.05 & 5.1515 & TRN & \\
\hline CHEMBL1313988 & 688155 & 5.45 & 5.013 & TRN & \\
\hline CHEMBL1583007 & 688155 & 6.35 & 5.0958 & TST & \\
\hline CHEMBL1539938 & 688155 & 4.95 & 5.0816 & TRN & \\
\hline CHEMBL1539921 & 688155 & 4.85 & 5.1839 & TRN & \\
\hline CHEMBL1381455 & 688155 & 4.5 & 5.1569 & TRN & \\
\hline CHEMBL1583365 & 688155 & 4.95 & 4.9754 & TRN & \\
\hline CHEMBL1385347 & 688155 & 4.95 & 5.0551 & TST & \\
\hline CHEMBL1431153 & 688155 & 4.95 & 5.2337 & TST & \\
\hline CHEMBL1322563 & 688155 & 4.5 & 5.1537 & TRN & \\
\hline CHEMBL1311916 & 688155 & 4.6 & 5.05699 & 99999999995 & TRN \\
\hline CHEMBL301707 & 688155 & 5.1 & 5.1147 & TRN & \\
\hline CHEMBL1333768 & 688155 & 5.05 & 5.0928 & TRN & \\
\hline CHEMBL1606031 & 688155 & 4.55 & 4.9172 & TRN & \\
\hline CHEMBL1256667 & 688155 & 4.55 & 5.0493 & TST & \\
\hline CHEMBL1540779 & 688155 & 5.0 & 4.971 & TST & \\
\hline CHEMBL 1242180 & 688155 & 5.0 & 5.0771 & TRN & \\
\hline CHEMBL1459857 & 688155 & 5.15 & 5.0914 & TRN & \\
\hline CHEMBL1482803 & 688155 & 4.6 & 5.2045 & TRN & \\
\hline CHEMBL474933 & 688155 & 4.85 & 5.1143 & TRN & \\
\hline CHEMBL1509029 & 688155 & 5.8 & 5.0641 & TRN & \\
\hline CHEMBL1417357 & 688155 & 5.15 & 5.1081 & TRN & \\
\hline CHEMBL1977007 & 688155 & 5.0 & 4.9163 & TST & \\
\hline CHEMBL1351228 & 688155 & 5.95 & 5.3093 & TRN & \\
\hline CHEMBL1312914 & 688155 & 5.0 & 4.9949 & TST & \\
\hline CHEMBL1392289 & 688155 & 5.95 & 5.1928 & TST & \\
\hline CHEMBL1486847 & 688155 & 4.95 & 5.0189 & TRN & \\
\hline CHEMBL1352167 & 688155 & 4.85 & 5.0302 & TRN & \\
\hline CHEMBL1386032 & 688155 & 5.0 & 4.9267 & TST & \\
\hline CHEMBL1500192 & 688155 & 4.95 & 4.9758 & TST & \\
\hline CHEMBL1468608 & 688155 & 4.55 & 5.2192 & TRN & \\
\hline CHEMBL1498138 & 688155 & 6.1 & 5.0228 & TRN & \\
\hline CHEMBL1427587 & 688155 & 5.0 & 5.0501 & TRN & \\
\hline CHEMBL1308988 & 688155 & 6.0 & 5.3169 & TRN & \\
\hline CHEMBL1590484 & 688155 & 4.95 & 5.2189 & TRN & \\
\hline
\end{tabular}




\begin{tabular}{|c|c|c|c|c|c|}
\hline \multicolumn{6}{|c|}{ Supplemental Table S2.txt } \\
\hline CHEMBL1608811 & 688155 & 4.55 & 5.0837 & TRN & \\
\hline CHEMBL1583974 & 688155 & 5.0 & 5.0789 & TRN & \\
\hline CHEMBL1468981 & 688155 & 5.55 & 5.2029 & TST & \\
\hline CHEMBL1414005 & 688155 & 4.85 & 5.0128 & TRN & \\
\hline CHEMBL1488998 & 688155 & 5.45 & 5.0047 & TST & \\
\hline CHEMBL1591357 & 688155 & 5.25 & 5.2122 & TST & \\
\hline CHEMBL1467702 & 688155 & 4.55 & 5.0089 & TST & \\
\hline CHEMBL1349654 & 688155 & 5.0 & 5.0371 & TRN & \\
\hline CHEMBL1326511 & 688155 & 4.5 & 4.9711 & TRN & \\
\hline CHEMBL1463698 & 688155 & 4.5 & 5.0638 & TRN & \\
\hline CHEMBL1580188 & 688155 & 4.7 & 4.9913 & TRN & \\
\hline CHEMBL1469660 & 688155 & 4.9 & 4.9071 & TRN & \\
\hline CHEMBL1528620 & 688155 & 4.5 & 5.0422 & TRN & \\
\hline CHEMBL1348458 & 688155 & 4.5 & 5.1018 & TRN & \\
\hline CHEMBL42529 & 688155 & 5.65 & 5.1232 & TRN & \\
\hline CHEMBL1600003 & 688155 & 4.5 & 4.8979 & TRN & \\
\hline CHEMBL1607562 & 688155 & 4.55 & 4.98 & TST & \\
\hline CHEMBL1577092 & 688155 & 4.95 & 5.1697 & TRN & \\
\hline CHEMBL581417 & 688155 & 4.55 & 5.0004 & TRN & \\
\hline CHEMBL1410006 & 688155 & 6.0 & 4.9399 & TRN & \\
\hline CHEMBL1312539 & 688155 & 4.7 & 4.9941 & TRN & \\
\hline CHEMBL3212093 & 688155 & 4.6 & 5.1014 & TST & \\
\hline CHEMBL1506533 & 688155 & 6.3 & 4.97199 & 99999999995 & TRN \\
\hline CHEMBL1540554 & 688155 & 5.05 & 5.1949 & TRN & \\
\hline CHEMBL1306181 & 688155 & 4.95 & 4.9547 & TRN & \\
\hline CHEMBL1612447 & 688155 & 4.9 & 5.0319 & TRN & \\
\hline CHEMBL17127 & 688155 & 4.55 & 5.0174 & TST & \\
\hline CHEMBL1582113 & 688155 & 5.95 & 5.0423 & TST & \\
\hline CHEMBL3192085 & 688155 & 4.95 & 5.1312 & TST & \\
\hline CHEMBL1414335 & 688155 & 5.05 & 5.0923 & TRN & \\
\hline CHEMBL1494031 & 688155 & 5.55 & 5.0652 & TRN & \\
\hline CHEMBL1315609 & 688155 & 5.5 & 4.9571 & TRN & \\
\hline CHEMBL1582722 & 688155 & 5.3 & 5.2496 & TRN & \\
\hline CHEMBL1349822 & 688155 & 4.5 & 5.1727 & TST & \\
\hline CHEMBL1545160 & 688155 & 6.05 & 5.0562 & TRN & \\
\hline CHEMBL1480602 & 688155 & 5.3 & 5.23600 & 0000000001 & TRN \\
\hline CHEMBL1610441 & 688155 & 5.55 & 5.1694 & TRN & \\
\hline CHEMBL3210097 & 688155 & 4.95 & 5.106 & TST & \\
\hline CHEMBL1560888 & 688155 & 5.1 & 5.1457 & TRN & \\
\hline CHEMBL1338277 & 688155 & 5.05 & 5.2 & TRN & \\
\hline CHEMBL1573586 & 688155 & 4.85 & 5.0589 & TST & \\
\hline CHEMBL1414223 & 688155 & 5.3 & 5.2273 & TRN & \\
\hline CHEMBL1478518 & 688155 & 6.3 & 4.973 & TRN & \\
\hline CHEMBL1486759 & 688155 & 4.9 & 4.9445 & TST & \\
\hline CHEMBL1531745 & 688155 & 4.55 & 4.8992 & TRN & \\
\hline CHEMBL1605014 & 688155 & 4.9 & 5.1756 & TRN & \\
\hline CHEMBL1608266 & 688155 & 5.0 & 4.9875 & TRN & \\
\hline CHEMBL1542732 & 688155 & 4.55 & 5.1427 & TRN & \\
\hline
\end{tabular}




\begin{tabular}{|c|c|c|c|c|c|}
\hline \\
\hline CHEMBL1580670 & 688155 & 5.8 & 5.2157 & TRN & \\
\hline CHEMBL3212923 & 688155 & 4.5 & 4.9718 & TRN & \\
\hline CHEMBL1329255 & 688155 & 4.9 & 4.9767 & TRN & \\
\hline CHEMBL1413144 & 688155 & 5.15 & 5.0993 & TRN & \\
\hline CHEMBL1348719 & 688155 & 5.3 & 5.1623 & TST & \\
\hline CHEMBL1332989 & 688155 & 5.5 & 4.9682 & TRN & \\
\hline CHEMBL1413611 & 688155 & 4.65 & 5.0262 & TRN & \\
\hline CHEMBL1444800 & 688155 & 4.95 & 4.9717 & TRN & \\
\hline CHEMBL1565193 & 688155 & 5.1 & 4.9283 & TRN & \\
\hline CHEMBL468471 & 688155 & 5.55 & 5.0704 & TRN & \\
\hline CHEMBL1605236 & 688155 & 4.95 & 4.97199 & 99999999995 & TRN \\
\hline CHEMBL1527447 & 688155 & 5.55 & 5.0387 & TRN & \\
\hline CHEMBL1370078 & 688155 & 4.85 & 4.9584 & TRN & \\
\hline CHEMBL1410434 & 688155 & 4.65 & 5.1077 & TRN & \\
\hline CHEMBL1370884 & 688155 & 5.6 & 4.9261 & TRN & \\
\hline CHEMBL1496373 & 688155 & 5.3 & 5.0378 & TRN & \\
\hline CHEMBL1561667 & 688155 & 5.0 & 5.0507 & TRN & \\
\hline CHEMBL1373906 & 688155 & 4.65 & 4.9426 & TRN & \\
\hline CHEMBL1439642 & 688155 & 5.45 & 5.0331 & TRN & \\
\hline CHEMBL1361362 & 688155 & 5.7 & 4.9853 & TRN & \\
\hline CHEMBL1362711 & 688155 & 5.0 & 5.0824 & TRN & \\
\hline CHEMBL1469511 & 688155 & 4.7 & 5.273 & TRN & \\
\hline CHEMBL1400467 & 688155 & 4.6 & 4.9985 & TRN & \\
\hline CHEMBL1605702 & 688155 & 5.45 & 5.2086 & TRN & \\
\hline CHEMBL1521746 & 688155 & 4.9 & 5.1174 & TRN & \\
\hline CHEMBL1301524 & 688155 & 4.55 & 5.1668 & TRN & \\
\hline CHEMBL1439657 & 688155 & 5.5 & 5.1019 & TST & \\
\hline CHEMBL1465084 & 688155 & 5.0 & 5.2064 & TRN & \\
\hline CHEMBL1490918 & 688155 & 4.85 & 4.9514 & TRN & \\
\hline CHEMBL1572145 & 688155 & 5.5 & 4.9264 & TRN & \\
\hline CHEMBL1459370 & 688155 & 4.9 & 4.9705 & TST & \\
\hline CHEMBL1399860 & 688155 & 6.05 & 5.0993 & TRN & \\
\hline CHEMBL1490926 & 688155 & 4.55 & 5.1491 & TST & \\
\hline CHEMBL1598041 & 688155 & 5.1 & 5.0817 & TRN & \\
\hline CHEMBL1321232 & 688155 & 4.85 & 5.1458 & TRN & \\
\hline CHEMBL1305825 & 688155 & 4.5 & 4.9345 & TRN & \\
\hline CHEMBL1538570 & 688155 & 4.95 & 5.1072 & TST & \\
\hline CHEMBL1371955 & 688155 & 4.85 & 5.035 & TRN & \\
\hline CHEMBL1455466 & 688155 & 5.05 & 5.2212 & TRN & \\
\hline CHEMBL3198198 & 688155 & 5.65 & 4.9444 & TST & \\
\hline CHEMBL1509961 & 688155 & 5.0 & 5.1631 & TRN & \\
\hline CHEMBL1322685 & 688155 & 4.65 & 5.0711 & TRN & \\
\hline CHEMBL3199747 & 688155 & 5.05 & 5.0653 & TRN & \\
\hline CHEMBL1575504 & 688155 & 4.55 & 4.9357 & TRN & \\
\hline CHEMBL1383190 & 688155 & 4.5 & 5.148 & TST & \\
\hline CHEMBL1438278 & 688155 & 5.8 & 5.2001 & TRN & \\
\hline CHEMBL3194435 & 688155 & 4.5 & 4.944 & TRN & \\
\hline CHEMBL1419567 & 688155 & 5.1 & 5.0534 & TRN & \\
\hline & & & & 20029 & \\
\hline
\end{tabular}




\begin{tabular}{|c|c|c|c|c|c|}
\hline \multicolumn{6}{|c|}{ Supplemental Table S2.txt } \\
\hline CHEMBL1503060 & 688155 & 5.0 & 5.1341 & TRN & \\
\hline CHEMBL1495163 & 688155 & 4.95 & 5.0413 & TRN & \\
\hline CHEMBL1353794 & 688155 & 5.1 & 5.0939 & TRN & \\
\hline CHEMBL1376443 & 688155 & 4.85 & 4.9477 & TST & \\
\hline CHEMBL1406274 & 688155 & 6.1 & 5.0794 & TRN & \\
\hline CHEMBL1438978 & 688155 & 5.25 & 5.14 & TRN & \\
\hline CHEMBL1325976 & 688155 & 5.0 & 5.1263 & TRN & \\
\hline CHEMBL1456898 & 688155 & 4.5 & 5.1397 & TST & \\
\hline CHEMBL1307208 & 688155 & 4.95 & 5.1174 & TRN & \\
\hline CHEMBL1423919 & 688155 & 4.5 & 5.0271 & TRN & \\
\hline CHEMBL1575588 & 688155 & 5.6 & 4.9839 & TST & \\
\hline CHEMBL1449736 & 688155 & 4.6 & 5.13299 & 9999999999 & TRN \\
\hline CHEMBL1545343 & 688155 & 5.45 & 5.1315 & TRN & \\
\hline CHEMBL1441964 & 688155 & 5.0 & 5.0691 & TRN & \\
\hline CHEMBL1466023 & 688155 & 4.95 & 5.1575 & TST & \\
\hline CHEMBL1500615 & 688155 & 4.95 & 4.9729 & TRN & \\
\hline CHEMBL1414524 & 688155 & 5.1 & 5.2097 & TST & \\
\hline CHEMBL1462769 & 688155 & 4.9 & 5.0566 & TRN & \\
\hline CHEMBL1504575 & 688155 & 4.95 & 5.0075 & TST & \\
\hline CHEMBL1367866 & 688155 & 5.0 & 5.151 & TRN & \\
\hline CHEMBL1321006 & 688155 & 6.0 & 5.1342 & TRN & \\
\hline CHEMBL1569315 & 688155 & 5.05 & 5.0793 & TRN & \\
\hline CHEMBL3199005 & 688155 & 4.85 & 5.151 & TRN & \\
\hline CHEMBL1611036 & 688155 & 4.85 & 5.1399 & TRN & \\
\hline CHEMBL1496141 & 688155 & 4.95 & 5.0706 & TRN & \\
\hline CHEMBL602828 & 688155 & 5.7 & 5.0989 & TST & \\
\hline CHEMBL1609538 & 688155 & 4.75 & 4.9627 & TRN & \\
\hline CHEMBL1427719 & 688155 & 5.0 & 5.0778 & TRN & \\
\hline CHEMBL1344967 & 688155 & 5.95 & 5.0031 & TRN & \\
\hline CHEMBL1491580 & 688155 & 4.5 & 5.0182 & TRN & \\
\hline CHEMBL1430395 & 688155 & 4.55 & 5.0736 & TRN & \\
\hline CHEMBL1397230 & 688155 & 4.9 & 5.0564 & TRN & \\
\hline CHEMBL1429259 & 688155 & 4.85 & 5.067 & TRN & \\
\hline CHEMBL1612846 & 688155 & 5.05 & 5.0348 & TRN & \\
\hline CHEMBL3208553 & 688155 & 5.45 & 5.1075 & TST & \\
\hline CHEMBL1556642 & 688155 & 4.95 & 4.9009 & TRN & \\
\hline CHEMBL1517409 & 688155 & 5.0 & 4.9952 & TRN & \\
\hline CHEMBL1482109 & 688155 & 4.75 & 5.0353 & TRN & \\
\hline CHEMBL1318873 & 688155 & 5.45 & 5.0962 & TRN & \\
\hline CHEMBL1480380 & 688155 & 4.9 & 5.2047 & TRN & \\
\hline CHEMBL1571286 & 688155 & 4.5 & 5.0431 & TST & \\
\hline CHEMBL1489194 & 688155 & 4.5 & 4.9106 & TRN & \\
\hline CHEMBL1448950 & 688155 & 4.85 & 5.1779 & TRN & \\
\hline CHEMBL1426976 & 688155 & 4.55 & 4.8612 & TST & \\
\hline CHEMBL1571811 & 688155 & 6.5 & 5.1092 & TRN & \\
\hline CHEMBL1567631 & 688155 & 4.95 & 4.8695 & TRN & \\
\hline CHEMBL1967837 & 688155 & 4.5 & 4.9854 & TRN & \\
\hline CHEMBL1461569 & 688155 & 4.5 & 5.0933 & TRN & \\
\hline
\end{tabular}




\begin{tabular}{|c|c|c|c|c|c|}
\hline & & \multicolumn{4}{|c|}{ Supplemental Table S2.txt } \\
\hline CHEMBL1342635 & 688155 & 4.95 & 4.9373 & TRN & \\
\hline CHEMBL1610834 & 688155 & 6.0 & 5.0266 & TRN & \\
\hline CHEMBL1470946 & 688155 & 5.65 & 4.9853 & TRN & \\
\hline CHEMBL1320503 & 688155 & 5.4 & 5.0356 & TST & \\
\hline CHEMBL1539138 & 688155 & 4.55 & 5.1872 & TRN & \\
\hline CHEMBL3199298 & 688155 & 4.85 & 4.9784 & TRN & \\
\hline CHEMBL1401720 & 688155 & 5.0 & 5.1532 & TRN & \\
\hline CHEMBL1307376 & 688155 & 4.5 & 5.2744 & TRN & \\
\hline CHEMBL1388636 & 688155 & 6.5 & 5.126 & TST & \\
\hline CHEMBL1611004 & 688155 & 5.0 & 5.037 & TST & \\
\hline CHEMBL1310109 & 688155 & 4.55 & 5.0833 & TST & \\
\hline CHEMBL1381425 & 688155 & 4.5 & 5.0909 & TRN & \\
\hline CHEMBL1432309 & 688155 & 4.65 & 4.9948 & TRN & \\
\hline CHEMBL1576746 & 688155 & 4.95 & 5.1159 & TRN & \\
\hline CHEMBL3192352 & 688155 & 5.95 & 5.12200 & 0000000001 & TRN \\
\hline CHEMBL1488000 & 688155 & 4.55 & 5.2218 & TRN & \\
\hline CHEMBL1530502 & 688155 & 5.0 & 5.0514 & TRN & \\
\hline CHEMBL1396241 & 688155 & 5.35 & 5.0896 & TST & \\
\hline CHEMBL1486911 & 688155 & 5.7 & 5.0505 & TRN & \\
\hline CHEMBL1536388 & 688155 & 5.0 & 5.05 & TRN & \\
\hline CHEMBL1501079 & 688155 & 4.6 & 4.9653 & TRN & \\
\hline CHEMBL1482064 & 688155 & 4.6 & 4.9898 & TRN & \\
\hline CHEMBL1528011 & 688155 & 4.5 & 5.3086 & TRN & \\
\hline CHEMBL1464254 & 688155 & 6.35 & 5.2409 & TST & \\
\hline CHEMBL1579325 & 688155 & 5.55 & 5.1713 & TST & \\
\hline CHEMBL1528116 & 688155 & 5.55 & 5.08899 & 99999999995 & TRN \\
\hline CHEMBL1376094 & 688155 & 4.7 & 5.0182 & TRN & \\
\hline CHEMBL1570050 & 688155 & 5.25 & 5.24 & TRN & \\
\hline CHEMBL1439684 & 688155 & 4.55 & 4.98 & TRN & \\
\hline CHEMBL1541507 & 688155 & 5.05 & 5.1053 & TRN & \\
\hline CHEMBL1303810 & 688155 & 4.95 & 5.1023 & TRN & \\
\hline CHEMBL1456917 & 688155 & 5.05 & 5.1522 & TRN & \\
\hline CHEMBL1581469 & 688155 & 5.0 & 4.9997 & TRN & \\
\hline CHEMBL1874415 & 688155 & 4.95 & 4.9944 & TST & \\
\hline CHEMBL1605638 & 688155 & 5.25 & 5.0839 & TRN & \\
\hline CHEMBL1490257 & 688155 & 4.9 & 5.0703 & TRN & \\
\hline CHEMBL1353085 & 688155 & 5.65 & 5.0348 & TRN & \\
\hline CHEMBL1587593 & 688155 & 4.95 & 5.0729 & TST & \\
\hline CHEMBL1540648 & 688155 & 5.05 & 5.0089 & TRN & \\
\hline CHEMBL1347872 & 688155 & 5.6 & 5.1381 & TST & \\
\hline CHEMBL1453177 & 688155 & 4.95 & 5.2328 & TRN & \\
\hline CHEMBL1429651 & 688155 & 5.9 & 5.1004 & TRN & \\
\hline CHEMBL1544051 & 688155 & 4.65 & 5.1279 & TRN & \\
\hline CHEMBL1313522 & 688155 & 5.0 & 5.0383 & TRN & \\
\hline CHEMBL1470470 & 688155 & 4.9 & 5.2026 & TRN & \\
\hline CHEMBL1421293 & 688155 & 4.55 & 5.0442 & TRN & \\
\hline CHEMBL1349459 & 688155 & 4.95 & 5.0506 & TRN & \\
\hline CHEMBL1569363 & 688155 & 5.55 & 5.1433 & TRN & \\
\hline
\end{tabular}




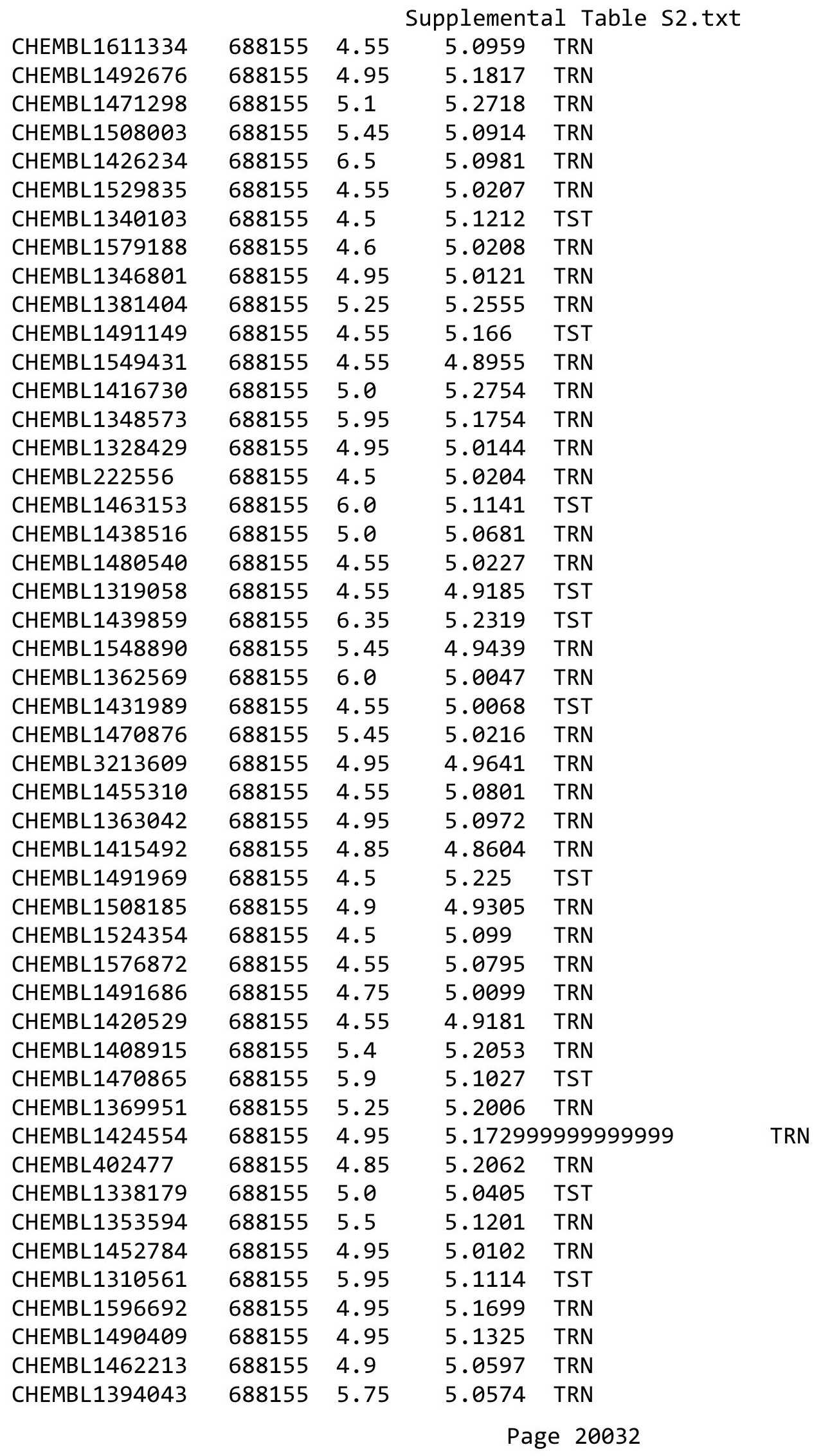




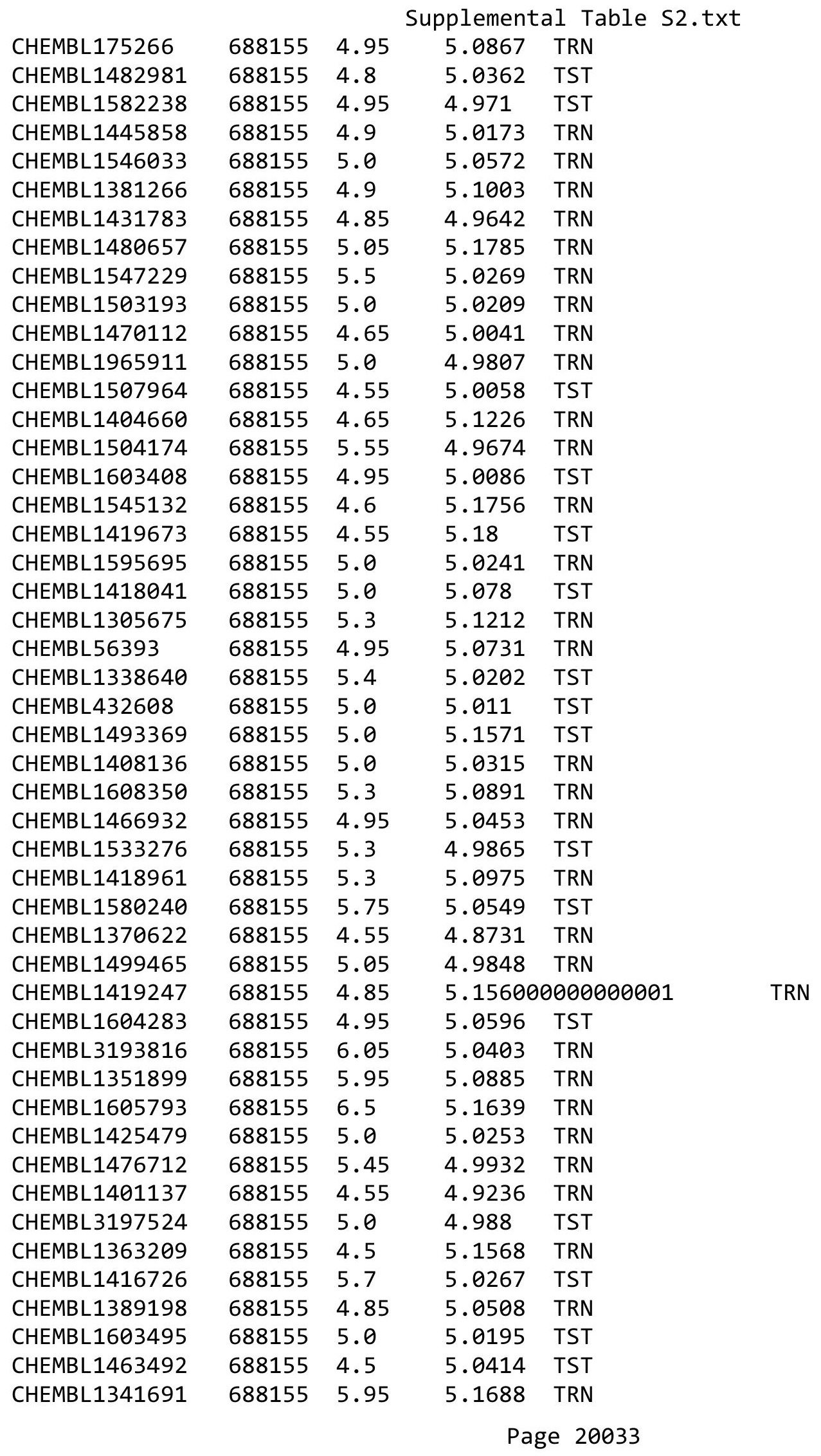




\begin{tabular}{|c|c|c|c|c|c|}
\hline \multicolumn{6}{|c|}{ Supplemental Table S2.txt } \\
\hline CHEMBL1351124 & 688155 & 4.65 & 4.9124 & TRN & \\
\hline CHEMBL1173522 & 688155 & 4.6 & 5.1305 & TRN & \\
\hline CHEMBL1336608 & 688155 & 6.0 & 5.1709 & TRN & \\
\hline CHEMBL1519395 & 688155 & 4.95 & 5.1317 & TRN & \\
\hline CHEMBL1432555 & 688155 & 5.75 & 5.0563 & TST & \\
\hline CHEMBL1534097 & 688155 & 4.55 & 5.0377 & TRN & \\
\hline CHEMBL1450036 & 688155 & 5.0 & 4.9571 & TRN & \\
\hline CHEMBL1427968 & 688155 & 5.1 & 5.1173 & TRN & \\
\hline CHEMBL3196506 & 688155 & 5.5 & 5.1169 & TST & \\
\hline CHEMBL1560296 & 688155 & 5.0 & 5.0 & TRN & \\
\hline CHEMBL1413785 & 688155 & 6.5 & 5.0208 & TST & \\
\hline CHEMBL1996724 & 688155 & 4.9 & 5.0491 & TRN & \\
\hline CHEMBL1352286 & 688155 & 5.85 & 5.2716 & TRN & \\
\hline CHEMBL1464296 & 688155 & 5.9 & 5.0051 & TRN & \\
\hline CHEMBL1486565 & 688155 & 4.9 & $4.9910 e$ & 00000000005 & TRN \\
\hline CHEMBL1403136 & 688155 & 5.9 & 4.9991 & TST & \\
\hline CHEMBL1456820 & 688155 & 5.3 & 4.9484 & TRN & \\
\hline CHEMBL1343232 & 688155 & 5.35 & 4.9633 & TRN & \\
\hline CHEMBL3212396 & 688155 & 4.5 & 5.04899 & 99999999995 & TRN \\
\hline CHEMBL1442570 & 688155 & 5.5 & 5.0562 & TST & \\
\hline CHEMBL1549101 & 688155 & 5.05 & 5.0926 & TRN & \\
\hline CHEMBL 3144906 & 688155 & 5.75 & 5.1287 & TRN & \\
\hline CHEMBL1573613 & 688155 & 4.55 & 5.0254 & TRN & \\
\hline CHEMBL1402909 & 688155 & 4.9 & 5.0722 & TST & \\
\hline CHEMBL1342405 & 688155 & 5.95 & 5.1001 & TRN & \\
\hline CHEMBL1612541 & 688155 & 4.55 & 4.8792 & TRN & \\
\hline CHEMBL1255747 & 688155 & 4.55 & 5.1253 & TRN & \\
\hline CHEMBL1497369 & 688155 & 4.5 & 4.9241 & TRN & \\
\hline CHEMBL1342379 & 688155 & 4.85 & 4.9728 & TRN & \\
\hline CHEMBL1431468 & 688155 & 6.0 & 5.0432 & TRN & \\
\hline CHEMBL601528 & 688155 & 4.5 & 5.1168 & TST & \\
\hline CHEMBL1612778 & 688155 & 4.65 & 4.9502 & TRN & \\
\hline CHEMBL1370151 & 688155 & 6.0 & 5.1519 & TRN & \\
\hline CHEMBL1383706 & 688155 & 5.0 & 4.9761 & TST & \\
\hline CHEMBL1486064 & 688155 & 4.9 & 5.0184 & TRN & \\
\hline CHEMBL1416154 & 688155 & 4.5 & 5.0002 & TRN & \\
\hline CHEMBL1503559 & 688155 & 4.85 & 5.0247 & TRN & \\
\hline CHEMBL165 & 688155 & 5.0 & 5.1047 & TST & \\
\hline CHEMBL1374526 & 688155 & 6.45 & 5.0382 & TST & \\
\hline CHEMBL1583026 & 688155 & 5.95 & 5.0266 & TRN & \\
\hline CHEMBL1424628 & 688155 & 4.55 & 4.9891 & TRN & \\
\hline CHEMBL1572547 & 688155 & 4.8 & 5.0623 & TST & \\
\hline CHEMBL1344555 & 688155 & 5.0 & 4.9811 & TRN & \\
\hline CHEMBL1404404 & 688155 & 4.5 & 5.0895 & TRN & \\
\hline CHEMBL1375753 & 688155 & 4.55 & 4.904 & TRN & \\
\hline CHEMBL1492433 & 688155 & 4.95 & $5.1320 e$ & 0000000001 & TST \\
\hline CHEMBL1410479 & 688155 & 4.95 & 5.093 & TST & \\
\hline CHEMBL1301723 & 688155 & 4.95 & 5.0408 & TST & \\
\hline
\end{tabular}




\begin{tabular}{|c|c|c|c|c|}
\hline \multicolumn{5}{|c|}{ Supplemental Table S2.txt } \\
\hline CHEMBL1448764 & 688155 & 4.95 & 5.0369 & TRN \\
\hline CHEMBL1449884 & 688155 & 5.95 & 5.1358 & TRN \\
\hline CHEMBL1381636 & 688155 & 5.9 & 5.0402 & TRN \\
\hline CHEMBL1472209 & 688155 & 4.7 & 5.0031 & TST \\
\hline CHEMBL3214510 & 688155 & 4.5 & 5.0186 & TRN \\
\hline CHEMBL1399701 & 688155 & 5.1 & 5.1541 & TRN \\
\hline CHEMBL1448127 & 688155 & 4.55 & 5.1134 & TST \\
\hline CHEMBL1594437 & 688155 & 4.9 & 4.9493 & TRN \\
\hline CHEMBL1370031 & 688155 & 4.55 & 5.1024 & TRN \\
\hline CHEMBL1376529 & 688155 & 4.6 & 5.0531 & TRN \\
\hline CHEMBL1363429 & 688155 & 4.95 & 5.0286 & TRN \\
\hline CHEMBL1373843 & 688155 & 4.55 & 5.0007 & TST \\
\hline CHEMBL1530284 & 688155 & 4.7 & 5.1597 & TST \\
\hline CHEMBL1391437 & 688155 & 4.9 & 5.0651 & TRN \\
\hline CHEMBL1549880 & 688155 & 5.3 & 5.1288 & TRN \\
\hline CHEMBL1576571 & 688155 & 4.95 & 5.04 & TST \\
\hline CHEMBL1350331 & 688155 & 6.3 & 5.1061 & TRN \\
\hline CHEMBL1460698 & 688155 & 5.2 & 5.0431 & TRN \\
\hline CHEMBL1489351 & 688155 & 4.5 & 5.1107 & TRN \\
\hline CHEMBL1323372 & 688155 & 4.95 & 5.0916 & TRN \\
\hline CHEMBL1498530 & 688155 & 4.55 & 5.1633 & TRN \\
\hline CHEMBL1353287 & 688155 & 5.95 & 5.0541 & TRN \\
\hline CHEMBL3211679 & 688155 & 5.05 & 5.0963 & TST \\
\hline CHEMBL1329965 & 688155 & 4.55 & 4.9582 & TRN \\
\hline CHEMBL1467181 & 688155 & 4.55 & 5.1956 & TRN \\
\hline CHEMBL3192590 & 688155 & 5.0 & 5.0591 & TRN \\
\hline CHEMBL1497016 & 688155 & 4.9 & 5.0686 & TRN \\
\hline CHEMBL1499027 & 688155 & 4.55 & 5.0559 & TRN \\
\hline CHEMBL1988339 & 688155 & 4.95 & 4.9696 & TST \\
\hline CHEMBL1360719 & 688155 & 5.65 & 5.0523 & TST \\
\hline CHEMBL1424727 & 688155 & 5.45 & 5.1855 & TST \\
\hline CHEMBL1541956 & 688155 & 4.5 & 5.1274 & TRN \\
\hline CHEMBL1512077 & 688155 & 4.95 & 5.0933 & TRN \\
\hline CHEMBL1394783 & 688155 & 5.7 & 4.9575 & TRN \\
\hline CHEMBL1432205 & 688155 & 4.95 & 5.0597 & TRN \\
\hline CHEMBL1427221 & 688155 & 4.55 & 4.9426 & TRN \\
\hline CHEMBL1352936 & 688155 & 5.0 & 5.0205 & TRN \\
\hline CHEMBL1301385 & 688155 & 4.95 & 4.9821 & TST \\
\hline CHEMBL1600823 & 688155 & 4.55 & 5.2257 & TRN \\
\hline CHEMBL1579942 & 688155 & 4.55 & 5.0395 & TRN \\
\hline CHEMBL1531396 & 688155 & 4.55 & 4.9971 & TST \\
\hline CHEMBL1992262 & 688155 & 5.4 & 5.1111 & TRN \\
\hline CHEMBL1502771 & 688155 & 5.6 & 4.9109 & TST \\
\hline CHEMBL1511598 & 688155 & 6.0 & 5.1742 & TST \\
\hline CHEMBL1491533 & 688155 & 4.55 & 4.9147 & TRN \\
\hline CHEMBL1378104 & 688155 & 4.95 & 5.0531 & TRN \\
\hline CHEMBL356688 & 688155 & 6.0 & 5.2265 & TRN \\
\hline CHEMBL1481495 & 688155 & 4.55 & 5.0447 & TRN \\
\hline
\end{tabular}




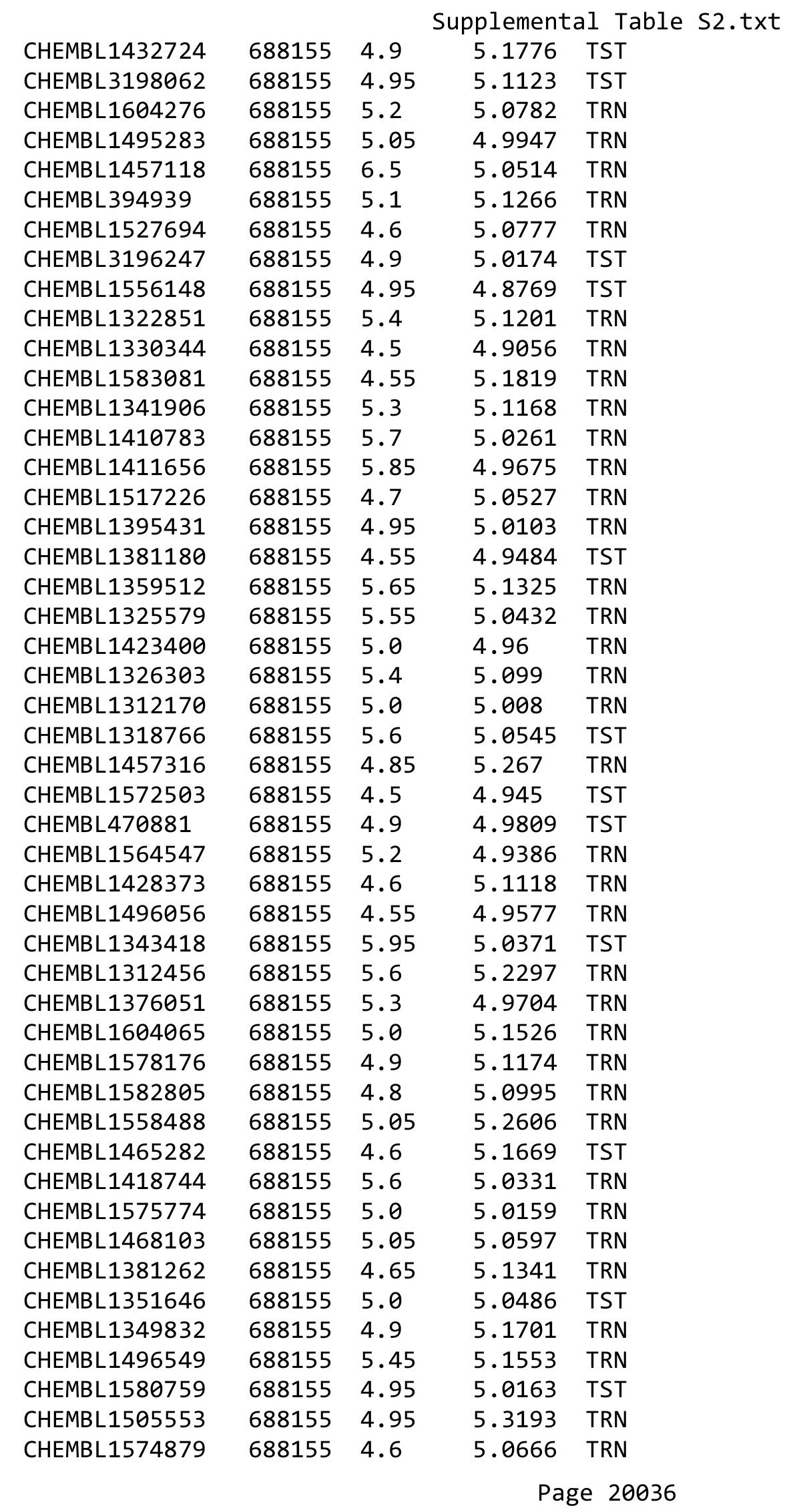




\begin{tabular}{|c|c|c|c|c|c|}
\hline \multicolumn{6}{|c|}{ Supplemental Table S2.txt } \\
\hline CHEMBL1312649 & 688155 & 3.95 & 5.2308 & TST & \\
\hline CHEMBL588859 & 688155 & 4.55 & 5.1148 & TST & \\
\hline CHEMBL1489342 & 688155 & 4.95 & 5.2258 & TST & \\
\hline CHEMBL1547316 & 688155 & 4.95 & 5.1133 & TRN & \\
\hline CHEMBL1341238 & 688155 & 4.55 & 5.1248 & TRN & \\
\hline CHEMBL1412450 & 688155 & 4.55 & 5.0373 & TRN & \\
\hline CHEMBL1480661 & 688155 & 6.2 & 5.09 & TRN & \\
\hline CHEMBL3213005 & 688155 & 5.2 & 4.9222 & TST & \\
\hline CHEMBL1376368 & 688155 & 4.95 & 4.8534 & TRN & \\
\hline CHEMBL1527784 & 688155 & 4.55 & 5.2918 & TRN & \\
\hline CHEMBL1310132 & 688155 & 4.55 & 5.0482 & TRN & \\
\hline CHEMBL1403397 & 688155 & 4.55 & 5.1433 & TST & \\
\hline CHEMBL 3197125 & 688155 & 5.45 & 5.0863 & TRN & \\
\hline CHEMBL1478696 & 688155 & 4.65 & 5.1948 & TRN & \\
\hline CHEMBL1531917 & 688155 & 4.95 & 5.2307 & TRN & \\
\hline CHEMBL1523690 & 688155 & 5.25 & 5.0609 & TRN & \\
\hline CHEMBL1504139 & 688155 & 4.8 & 5.12700 & 0000000001 & TST \\
\hline CHEMBL1339947 & 688155 & 4.6 & 5.0979 & TST & \\
\hline CHEMBL1493981 & 688155 & 5.45 & 5.1604 & TRN & \\
\hline CHEMBL1587764 & 688155 & 5.0 & 5.0824 & TRN & \\
\hline CHEMBL394385 & 688155 & 5.95 & 5.0715 & TRN & \\
\hline CHEMBL1438119 & 688155 & 4.55 & 5.0537 & TRN & \\
\hline CHEMBL1428466 & 688155 & 4.7 & 4.9673 & TRN & \\
\hline CHEMBL1347531 & 688155 & 5.1 & 5.1029 & TST & \\
\hline CHEMBL3207344 & 688155 & 5.3 & 5.1166 & TST & \\
\hline CHEMBL1496268 & 688155 & 4.65 & 5.1295 & TRN & \\
\hline CHEMBL1607431 & 688155 & 4.5 & 5.13399 & 99999999995 & TST \\
\hline CHEMBL1386922 & 688155 & 4.55 & 4.9488 & TRN & \\
\hline CHEMBL1362589 & 688155 & 4.95 & 5.1141 & TRN & \\
\hline CHEMBL1311641 & 688155 & 4.9 & 5.0433 & TRN & \\
\hline CHEMBL1312714 & 688155 & 5.15 & 5.1184 & TRN & \\
\hline CHEMBL1585011 & 688155 & 4.8 & 5.0536 & TST & \\
\hline CHEMBL1362256 & 688155 & 4.55 & 4.9357 & TRN & \\
\hline CHEMBL1409658 & 688155 & 4.55 & 4.8875 & TRN & \\
\hline CHEMBL1349809 & 688155 & 4.5 & 5.1818 & TRN & \\
\hline CHEMBL1361880 & 688155 & 4.5 & 5.0323 & TRN & \\
\hline CHEMBL1487191 & 688155 & 4.65 & 4.8924 & TRN & \\
\hline CHEMBL1463869 & 688155 & 4.55 & 4.9807 & TRN & \\
\hline CHEMBL1450888 & 688155 & 4.55 & 4.9514 & TST & \\
\hline CHEMBL1423812 & 688155 & 4.55 & 5.215 & TST & \\
\hline CHEMBL1472880 & 688155 & 5.0 & 5.061 & TRN & \\
\hline CHEMBL1465867 & 688155 & 4.9 & 4.9779 & TRN & \\
\hline CHEMBL1438070 & 688155 & 5.1 & 5.0233 & TRN & \\
\hline CHEMBL1483336 & 688155 & 5.0 & 5.1048 & TRN & \\
\hline CHEMBL1408881 & 688155 & 5.0 & 5.2859 & TRN & \\
\hline CHEMBL1996376 & 688155 & 4.95 & 5.1278 & TST & \\
\hline CHEMBL1300462 & 688155 & 5.25 & 4.98300 & 20000000005 & TST \\
\hline CHEMBL1521536 & 688155 & 5.3 & 5.0962 & TRN & \\
\hline
\end{tabular}




\begin{tabular}{|c|c|c|c|c|c|}
\hline \multicolumn{6}{|c|}{ Supplemental Table S2.txt } \\
\hline CHEMBL1494683 & 688155 & 5.0 & 5.0654 & TRN & \\
\hline CHEMBL1506546 & 688155 & 4.5 & 5.0614 & TRN & \\
\hline CHEMBL1406969 & 688155 & 5.2 & 5.1417 & TRN & \\
\hline CHEMBL1407298 & 688155 & 5.05 & 5.1494 & TRN & \\
\hline CHEMBL1489437 & 688155 & 5.4 & 5.1393 & TRN & \\
\hline CHEMBL1310889 & 688155 & 5.75 & 5.1698 & TRN & \\
\hline CHEMBL1362759 & 688155 & 4.65 & 5.0788 & TRN & \\
\hline CHEMBL1347314 & 688155 & 4.55 & 5.0564 & TRN & \\
\hline CHEMBL1372441 & 688155 & 4.6 & 5.0927 & TRN & \\
\hline CHEMBL1313044 & 688155 & 5.1 & 5.1136 & TRN & \\
\hline CHEMBL1311437 & 688155 & 5.0 & 5.003 & TRN & \\
\hline CHEMBL1408627 & 688155 & 5.2 & 5.1798 & TRN & \\
\hline CHEMBL1327135 & 688155 & 4.95 & 5.1993 & TST & \\
\hline CHEMBL1577378 & 688155 & 6.5 & 5.21200 & 0000000001 & TST \\
\hline CHEMBL1546698 & 688155 & 4.9 & 4.9843 & TRN & \\
\hline CHEMBL1508216 & 688155 & 4.5 & 5.0081 & TRN & \\
\hline CHEMBL3193297 & 688155 & 4.55 & 4.9859 & TRN & \\
\hline CHEMBL1537871 & 688155 & 4.85 & 4.9659 & TRN & \\
\hline CHEMBL1450992 & 688155 & 5.55 & 5.0423 & TRN & \\
\hline CHEMBL1366264 & 688155 & 5.8 & 5.1225 & TRN & \\
\hline CHEMBL1527705 & 688155 & 5.95 & 5.0603 & TRN & \\
\hline CHEMBL1381540 & 688155 & 4.5 & 4.9412 & TRN & \\
\hline CHEMBL1613382 & 688155 & 5.05 & 5.1005 & TST & \\
\hline CHEMBL1414224 & 688155 & 4.95 & 5.1377 & TRN & \\
\hline CHEMBL1313993 & 688155 & 5.0 & 5.2297 & TST & \\
\hline CHEMBL1498211 & 688155 & 6.5 & 5.2356 & TRN & \\
\hline CHEMBL1584364 & 688155 & 5.0 & 5.0254 & TRN & \\
\hline CHEMBL1502505 & 688155 & 4.95 & 5.0518 & TRN & \\
\hline CHEMBL1547611 & 688155 & 4.5 & 5.1021 & TST & \\
\hline CHEMBL3194214 & 688155 & 4.55 & 5.0289 & TST & \\
\hline CHEMBL1465738 & 688155 & 4.95 & 4.9283 & TRN & \\
\hline CHEMBL1378090 & 688155 & 5.3 & 5.0736 & TST & \\
\hline CHEMBL1405977 & 688155 & 5.4 & 5.0746 & TRN & \\
\hline CHEMBL1429929 & 688155 & 4.9 & 5.0345 & TRN & \\
\hline CHEMBL1517370 & 688155 & 4.8 & 5.0613 & TRN & \\
\hline CHEMBL1581644 & 688155 & 4.5 & 5.0908 & TST & \\
\hline CHEMBL1330506 & 688155 & 5.65 & 5.0472 & TST & \\
\hline CHEMBL1559107 & 688155 & 4.9 & 4.9316 & TST & \\
\hline CHEMBL1580952 & 688155 & 4.65 & 5.2486 & TRN & \\
\hline CHEMBL1364002 & 688155 & 4.95 & 4.9987 & TRN & \\
\hline CHEMBL1391989 & 688155 & 5.1 & 5.0514 & TST & \\
\hline CHEMBL1412731 & 688155 & 5.1 & 5.0229 & TST & \\
\hline CHEMBL1577441 & 688155 & 5.1 & 5.193 & TRN & \\
\hline CHEMBL1498006 & 688155 & 5.45 & 5.0321 & TRN & \\
\hline CHEMBL1304667 & 688155 & 4.55 & 4.9804 & TRN & \\
\hline CHEMBL1458584 & 688155 & 5.05 & 5.1757 & TRN & \\
\hline CHEMBL1587369 & 688155 & 4.55 & 5.1319 & TRN & \\
\hline CHEMBL1589587 & 688155 & 4.5 & 5.1774 & TRN & \\
\hline
\end{tabular}




\begin{tabular}{|c|c|c|c|c|c|}
\hline & & \multicolumn{4}{|c|}{ Supplemental Table S2.txt } \\
\hline CHEMBL1588902 & 688155 & 6.0 & 5.0938 & TRN & \\
\hline CHEMBL1478545 & 688155 & 5.0 & 5.1396 & TRN & \\
\hline CHEMBL1610057 & 688155 & 4.8 & 5.2213 & TRN & \\
\hline CHEMBL1309085 & 688155 & 4.9 & 5.2471 & TRN & \\
\hline CHEMBL1497505 & 688155 & 6.05 & 5.1373 & TRN & \\
\hline CHEMBL1586602 & 688155 & 4.9 & 4.9772 & TRN & \\
\hline CHEMBL 2078862 & 688155 & 5.65 & 5.2344 & TRN & \\
\hline CHEMBL1445744 & 688155 & 4.95 & 5.1429 & TST & \\
\hline CHEMBL1449647 & 688155 & 6.05 & 5.1745 & TST & \\
\hline CHEMBL1486603 & 688155 & 5.0 & 5.2608 & TRN & \\
\hline CHEMBL1600266 & 688155 & 4.55 & 5.0147 & TRN & \\
\hline CHEMBL1421453 & 688155 & 4.55 & 5.00899 & 99999999995 & TRN \\
\hline CHEMBL1576902 & 688155 & 4.95 & 5.1789 & TRN & \\
\hline CHEMBL1501151 & 688155 & 6.05 & 5.0761 & TRN & \\
\hline CHEMBL1506013 & 688155 & 5.7 & 5.1187 & TRN & \\
\hline CHEMBL1586280 & 688155 & 4.95 & 5.0516 & TRN & \\
\hline CHEMBL1608748 & 688155 & 4.9 & 5.0482 & TRN & \\
\hline CHEMBL3351063 & 688155 & 6.1 & 5.0889 & TRN & \\
\hline CHEMBL1307638 & 688155 & 4.95 & 5.1368 & TRN & \\
\hline CHEMBL1497964 & 688155 & 4.5 & 5.1497 & TRN & \\
\hline CHEMBL1450611 & 688155 & 5.0 & 5.192 & TST & \\
\hline CHEMBL1440834 & 688155 & 6.05 & 5.1343 & TRN & \\
\hline CHEMBL1322938 & 688155 & 5.65 & 5.1968 & TRN & \\
\hline CHEMBL1381946 & 688155 & 4.55 & 5.0394 & TRN & \\
\hline CHEMBL1594507 & 688155 & 5.0 & 5.1311 & TRN & \\
\hline CHEMBL1602759 & 688155 & 5.0 & 5.0045 & TRN & \\
\hline CHEMBL1433248 & 688155 & 4.95 & 4.9985 & TRN & \\
\hline CHEMBL1486980 & 688155 & 4.85 & 5.0949 & TST & \\
\hline CHEMBL1446756 & 688155 & 4.5 & 5.0701 & TRN & \\
\hline CHEMBL1321156 & 688155 & 4.55 & 5.0304 & TRN & \\
\hline CHEMBL1451483 & 688155 & 5.35 & 5.0914 & TST & \\
\hline CHEMBL1330139 & 688155 & 5.0 & 5.0912 & TRN & \\
\hline CHEMBL1360533 & 688155 & 4.95 & 5.2008 & TRN & \\
\hline CHEMBL1299521 & 688155 & 4.55 & 5.0341 & TRN & \\
\hline CHEMBL1372729 & 688155 & 4.55 & 5.1394 & TST & \\
\hline CHEMBL1341157 & 688155 & 4.9 & 5.0066 & TRN & \\
\hline CHEMBL1366602 & 688155 & 4.95 & 5.1374 & TRN & \\
\hline CHEMBL1463069 & 688155 & 6.1 & 5.0532 & TRN & \\
\hline CHEMBL1478432 & 688155 & 4.5 & 5.0763 & TRN & \\
\hline CHEMBL1374609 & 688155 & 5.9 & 5.0283 & TRN & \\
\hline CHEMBL1469521 & 688155 & 5.15 & 5.1573 & TST & \\
\hline CHEMBL1454765 & 688155 & 5.65 & 5.2522 & TRN & \\
\hline CHEMBL1486395 & 688155 & 5.55 & 5.1707 & TRN & \\
\hline CHEMBL1543224 & 688155 & 4.9 & 5.0578 & TRN & \\
\hline CHEMBL1565487 & 688155 & 5.0 & 5.0589 & TST & \\
\hline CHEMBL1454035 & 688155 & 4.9 & 4.9843 & TRN & \\
\hline CHEMBL1419490 & 688155 & 6.2 & 5.1162 & TRN & \\
\hline CHEMBL1256759 & 688155 & 4.7 & 5.171 & TST & \\
\hline
\end{tabular}




\begin{tabular}{|c|c|c|c|c|}
\hline \multicolumn{5}{|c|}{ Supplemental Table S2.txt } \\
\hline CHEMBL1337319 & 688155 & 5.6 & 5.1097 & TRN \\
\hline CHEMBL1409221 & 688155 & 5.95 & 5.2505 & TRN \\
\hline CHEMBL1343462 & 688155 & 4.55 & 5.1281 & TRN \\
\hline CHEMBL1984348 & 688155 & 4.95 & 5.0074 & TST \\
\hline CHEMBL1503113 & 688155 & 4.95 & 5.0799 & TRN \\
\hline CHEMBL1450551 & 688155 & 5.25 & 5.1386 & TRN \\
\hline CHEMBL488803 & 688155 & 5.85 & 5.0247 & TST \\
\hline CHEMBL1532584 & 688155 & 4.5 & 4.9746 & TST \\
\hline CHEMBL1538920 & 688155 & 4.85 & 5.0901 & TRN \\
\hline CHEMBL1385212 & 688155 & 5.05 & 5.2038 & TST \\
\hline CHEMBL1447384 & 688155 & 4.75 & 5.24799 & 9999999999 \\
\hline CHEMBL1310187 & 688155 & 5.0 & 5.0602 & TST \\
\hline CHEMBL1488997 & 688155 & 4.55 & 5.003 & TRN \\
\hline CHEMBL1569391 & 688155 & 4.9 & 5.1089 & TST \\
\hline CHEMBL1364136 & 688155 & 4.55 & 5.0101 & TRN \\
\hline CHEMBL1588424 & 688155 & 4.9 & 4.9505 & TRN \\
\hline CHEMBL3194195 & 688155 & 4.5 & 5.0751 & TST \\
\hline CHEMBL1567861 & 688155 & 4.9 & 5.1555 & TRN \\
\hline CHEMBL1574321 & 688155 & 6.05 & 5.2178 & TRN \\
\hline CHEMBL1384685 & 688155 & 5.6 & 5.2367 & TRN \\
\hline CHEMBL1383547 & 688155 & 6.5 & 5.1029 & TST \\
\hline CHEMBL1441397 & 688155 & 4.8 & 5.0915 & TRN \\
\hline CHEMBL1356171 & 688155 & 4.6 & 5.1055 & TRN \\
\hline CHEMBL1459178 & 688155 & 5.0 & 4.9053 & TRN \\
\hline CHEMBL1312321 & 688155 & 5.25 & 5.1666 & TST \\
\hline CHEMBL1528515 & 688155 & 5.45 & 4.9302 & TRN \\
\hline CHEMBL1560050 & 688155 & 5.95 & 5.1286 & TST \\
\hline CHEMBL1361935 & 688155 & 4.5 & 5.1149 & TRN \\
\hline CHEMBL1419477 & 688155 & 5.3 & 5.1767 & TRN \\
\hline CHEMBL1311583 & 688155 & 5.9 & 5.0339 & TST \\
\hline CHEMBL1564569 & 688155 & 5.0 & 5.0779 & TST \\
\hline CHEMBL1338317 & 688155 & 5.3 & 5.2053 & TST \\
\hline CHEMBL1532189 & 688155 & 4.7 & 5.1065 & TRN \\
\hline CHEMBL3207920 & 688155 & 5.95 & 5.0254 & TST \\
\hline CHEMBL1481095 & 688155 & 4.8 & 4.8815 & TRN \\
\hline CHEMBL1382184 & 688155 & 4.55 & 5.0668 & TRN \\
\hline CHEMBL1351054 & 688155 & 4.9 & 5.1135 & TRN \\
\hline CHEMBL1609651 & 688155 & 5.0 & 5.0279 & TST \\
\hline CHEMBL1377151 & 688155 & 5.55 & 5.0755 & TST \\
\hline CHEMBL1333090 & 688155 & 5.2 & 5.1152 & TRN \\
\hline CHEMBL1519329 & 688155 & 5.95 & 5.1466 & TRN \\
\hline CHEMBL1346826 & 688155 & 6.5 & 5.087 & TRN \\
\hline CHEMBL1613560 & 688155 & 5.15 & 5.0655 & TRN \\
\hline CHEMBL1408793 & 688155 & 4.85 & 5.065 & TRN \\
\hline CHEMBL 3190630 & 688155 & 5.5 & 5.0418 & TRN \\
\hline CHEMBL1468177 & 688155 & 5.0 & 5.2841 & TST \\
\hline CHEMBL1505501 & 688155 & 4.7 & 5.0547 & TRN \\
\hline CHEMBL1424346 & 688155 & 4.55 & 5.0031 & TST \\
\hline
\end{tabular}




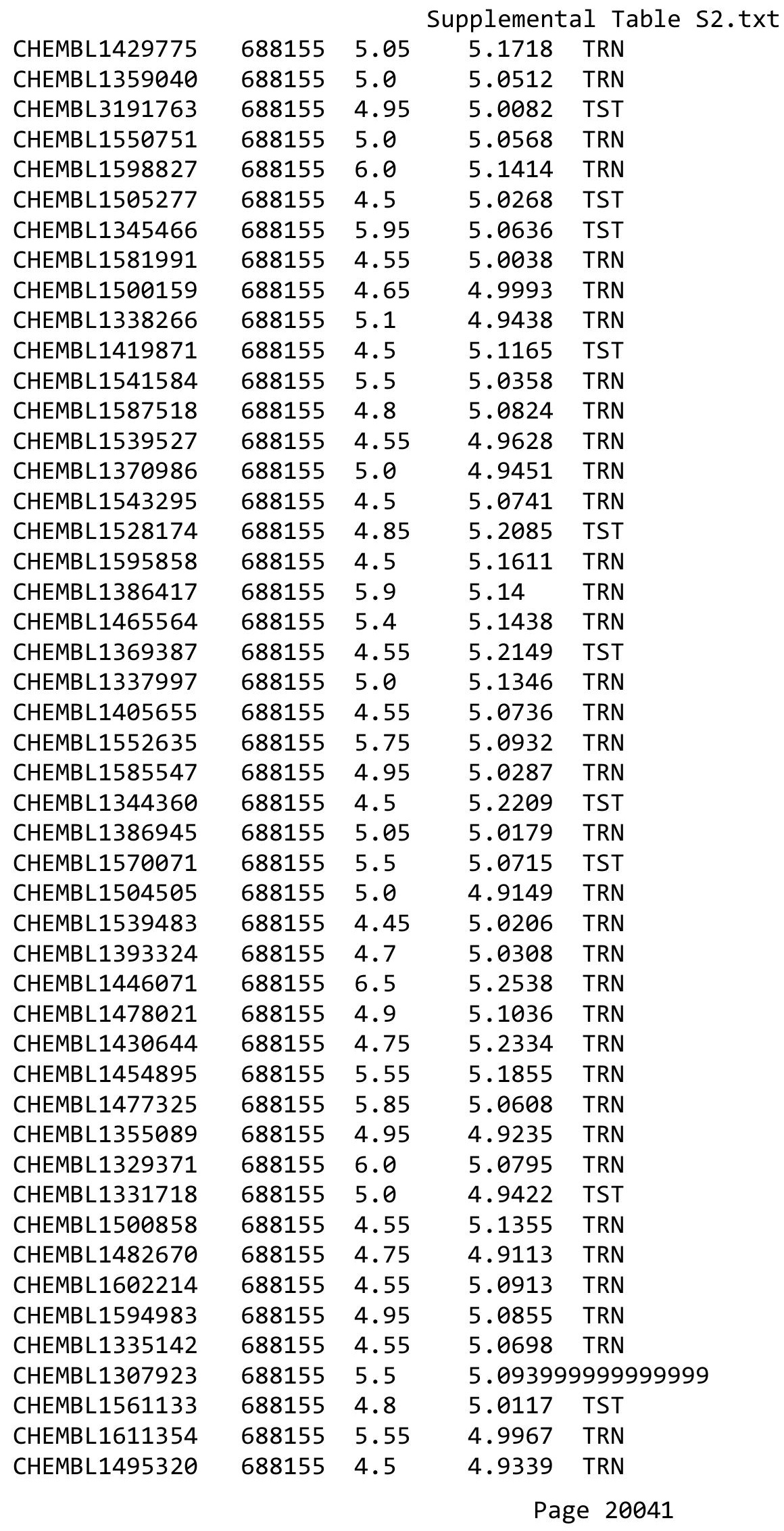




\begin{tabular}{|c|c|c|c|c|c|}
\hline \multicolumn{6}{|c|}{ Supplemental Table s2.txt } \\
\hline CHEMBL1511346 & 688155 & 6.0 & 5.083 & TRN & \\
\hline CHEMBL1365995 & 688155 & 4.55 & 5.1123 & TRN & \\
\hline CHEMBL1507344 & 688155 & 5.0 & 5.0621 & TST & \\
\hline CHEMBL1451056 & 688155 & 4.95 & 5.1486 & TST & \\
\hline CHEMBL1367213 & 688155 & 5.0 & 5.1677 & TRN & \\
\hline CHEMBL1307549 & 688155 & 5.35 & 5.1479 & TRN & \\
\hline CHEMBL1340053 & 688155 & 4.95 & 5.2364 & TRN & \\
\hline CHEMBL1378449 & 688155 & 4.0 & 4.9715 & TST & \\
\hline CHEMBL 3207820 & 688155 & 5.45 & 5.0473 & TRN & \\
\hline CHEMBL1330989 & 688155 & 4.95 & 4.9706 & TRN & \\
\hline CHEMBL1335412 & 688155 & 5.6 & 5.2465 & TRN & \\
\hline CHEMBL1472705 & 688155 & 4.95 & 5.0157 & TRN & \\
\hline CHEMBL 3214100 & 688155 & 4.55 & 5.0979 & TRN & \\
\hline CHEMBL1408781 & 688155 & 4.95 & 5.2116 & TRN & \\
\hline CHEMBL1341003 & 688155 & 5.05 & 5.1521 & TRN & \\
\hline CHEMBL1488355 & 688155 & 6.0 & 5.2171 & TRN & \\
\hline CHEMBL1441375 & 688155 & 4.9 & 4.9899 & TRN & \\
\hline CHEMBL1324947 & 688155 & 4.55 & 4.9806 & TRN & \\
\hline CHEMBL1370788 & 688155 & 6.45 & 5.0667 & TRN & \\
\hline CHEMBL1521129 & 688155 & 5.0 & 5.1478 & TRN & \\
\hline CHEMBL3209479 & 688155 & 4.65 & $5.0280 e$ & 00000000005 & TRN \\
\hline CHEMBL1398576 & 688155 & 5.95 & 5.2428 & TRN & \\
\hline CHEMBL1427878 & 688155 & 5.8 & 5.1734 & TRN & \\
\hline CHEMBL1600801 & 688155 & 5.4 & 5.0398 & TRN & \\
\hline CHEMBL1587791 & 688155 & 4.5 & 4.9608 & TRN & \\
\hline CHEMBL1472649 & 688155 & 6.15 & 5.2003 & TRN & \\
\hline CHEMBL1414258 & 688155 & 5.3 & 5.0434 & TRN & \\
\hline CHEMBL1402903 & 688155 & 6.0 & 5.2523 & TRN & \\
\hline CHEMBL 270299 & 688155 & 4.8 & 5.1717 & TRN & \\
\hline CHEMBL1306007 & 688155 & 4.5 & 5.2151 & TRN & \\
\hline CHEMBL1411054 & 688155 & 5.1 & 4.9602 & TRN & \\
\hline CHEMBL1304011 & 688155 & 4.6 & 5.1008 & TST & \\
\hline CHEMBL1350581 & 688155 & 5.05 & 4.9361 & TRN & \\
\hline CHEMBL1384034 & 688155 & 4.65 & 5.0432 & TRN & \\
\hline CHEMBL1425117 & 688155 & 5.1 & 5.2009 & TRN & \\
\hline CHEMBL1498919 & 688155 & 5.0 & 5.0089 & TST & \\
\hline CHEMBL 206483 & 688155 & 5.0 & 5.0029 & TRN & \\
\hline CHEMBL1550215 & 688155 & 4.55 & 4.9904 & TRN & \\
\hline CHEMBL1453141 & 688155 & 4.6 & 5.1583 & TRN & \\
\hline CHEMBL1370911 & 688155 & 5.15 & 5.1153 & TRN & \\
\hline CHEMBL1992800 & 688155 & 6.1 & 5.048 & TRN & \\
\hline CHEMBL1301611 & 688155 & 4.95 & 4.9924 & TRN & \\
\hline CHEMBL1581304 & 688155 & 4.55 & 5.1117 & TRN & \\
\hline CHEMBL1572650 & 688155 & 4.9 & 5.0179 & TRN & \\
\hline CHEMBL1604435 & 688155 & 4.5 & 5.1464 & TRN & \\
\hline CHEMBL1374191 & 688155 & 6.05 & 5.0329 & TST & \\
\hline CHEMBL1485746 & 688155 & 5.2 & 4.965 & TRN & \\
\hline CHEMBL1432568 & 688155 & 4.5 & 5.0528 & TST & \\
\hline
\end{tabular}




\begin{tabular}{|c|c|c|c|c|c|}
\hline & & \multicolumn{4}{|c|}{ Supplemental Table S2.txt } \\
\hline CHEMBL1466716 & 688155 & 4.55 & 4.9542 & TRN & \\
\hline CHEMBL1380028 & 688155 & 5.2 & 5.0233 & TRN & \\
\hline CHEMBL1539091 & 688155 & 4.95 & 5.0706 & TRN & \\
\hline CHEMBL1387559 & 688155 & 4.95 & 5.1282 & TRN & \\
\hline CHEMBL1442444 & 688155 & 4.9 & 5.074 & TRN & \\
\hline CHEMBL1522275 & 688155 & 5.0 & 5.0953 & TRN & \\
\hline CHEMBL1313362 & 688155 & 5.0 & 5.0364 & TRN & \\
\hline CHEMBL1374913 & 688155 & 4.9 & 5.2243 & TRN & \\
\hline CHEMBL1560048 & 688155 & 5.1 & 4.9497 & TRN & \\
\hline CHEMBL1366240 & 688155 & 5.25 & 5.065 & TRN & \\
\hline CHEMBL1477779 & 688155 & 6.0 & 5.0869 & TRN & \\
\hline CHEMBL328710 & 688155 & 4.95 & 5.1161 & TRN & \\
\hline CHEMBL3194236 & 688155 & 4.55 & 5.0185 & TRN & \\
\hline CHEMBL1532250 & 688155 & 6.0 & 5.1399 & TRN & \\
\hline CHEMBL1579757 & 688155 & 5.45 & 5.2299 & TRN & \\
\hline CHEMBL1519379 & 688155 & 6.0 & 5.1603 & TRN & \\
\hline CHEMBL1411729 & 688155 & 5.0 & 5.1744 & TRN & \\
\hline CHEMBL1493366 & 688155 & 4.55 & 5.2268 & TRN & \\
\hline CHEMBL1509267 & 688155 & 4.65 & 5.0753 & TST & \\
\hline CHEMBL1438117 & 688155 & 5.05 & 5.0029 & TRN & \\
\hline CHEMBL541585 & 688155 & 4.85 & 5.146 & TST & \\
\hline CHEMBL1410734 & 688155 & 4.65 & 4.9856 & TRN & \\
\hline CHEMBL 3191874 & 688155 & 5.0 & 5.0719 & TRN & \\
\hline CHEMBL1422634 & 688155 & 6.05 & 5.0928 & TRN & \\
\hline CHEMBL1370620 & 688155 & 5.95 & 5.0312 & TST & \\
\hline CHEMBL1427447 & 688155 & 4.9 & 5.0167 & TRN & \\
\hline CHEMBL1312030 & 688155 & 4.65 & 4.9336 & TRN & \\
\hline CHEMBL1330042 & 688155 & 4.95 & 4.9914 & TRN & \\
\hline CHEMBL1523989 & 688155 & 5.35 & 5.1096 & TST & \\
\hline CHEMBL1491077 & 688155 & 4.55 & 5.0125 & TRN & \\
\hline CHEMBL1496177 & 688155 & 4.55 & 5.2279 & TRN & \\
\hline CHEMBL1330120 & 688155 & 4.55 & 5.1372 & TRN & \\
\hline CHEMBL1548157 & 688155 & 6.0 & 5.1174 & TRN & \\
\hline CHEMBL1347786 & 688155 & 6.0 & 5.151 & TST & \\
\hline CHEMBL473313 & 688155 & 4.55 & 5.1294 & TRN & \\
\hline CHEMBL1556161 & 688155 & 4.9 & 5.1085 & TRN & \\
\hline CHEMBL1422429 & 688155 & 4.9 & 4.96899 & 9999999999 & TRN \\
\hline CHEMBL1506379 & 688155 & 5.0 & 4.9347 & TRN & \\
\hline CHEMBL1572041 & 688155 & 4.55 & 5.0895 & TRN & \\
\hline CHEMBL1440554 & 688155 & 5.5 & 5.0993 & TRN & \\
\hline CHEMBL1349906 & 688155 & 5.2 & 4.9263 & TRN & \\
\hline CHEMBL1610051 & 688155 & 5.2 & 5.0701 & TRN & \\
\hline CHEMBL1520645 & 688155 & 5.7 & 5.1324 & TRN & \\
\hline CHEMBL578741 & 688155 & 5.0 & 4.9469 & TRN & \\
\hline CHEMBL1320049 & 688155 & 4.55 & 4.9898 & TST & \\
\hline CHEMBL1487155 & 688155 & 5.3 & 5.0234 & TRN & \\
\hline CHEMBL1309202 & 688155 & 6.5 & 5.1617 & TRN & \\
\hline CHEMBL1580650 & 688155 & 5.55 & 5.2237 & TRN & \\
\hline
\end{tabular}




\begin{tabular}{|c|c|c|c|c|c|}
\hline \multicolumn{6}{|c|}{ Supplemental Table S2.txt } \\
\hline CHEMBL1409738 & 688155 & 4.5 & 5.1004 & TST & \\
\hline CHEMBL1597900 & 688155 & 5.25 & 5.1836 & TRN & \\
\hline CHEMBL1423146 & 688155 & 5.0 & 5.0024 & TRN & \\
\hline CHEMBL1523413 & 688155 & 6.1 & 5.019 & TST & \\
\hline CHEMBL1485461 & 688155 & 4.65 & 5.0563 & TRN & \\
\hline CHEMBL1465235 & 688155 & 5.2 & 5.081 & TRN & \\
\hline CHEMBL1511786 & 688155 & 4.95 & 5.1115 & TRN & \\
\hline CHEMBL1427637 & 688155 & 5.05 & 5.0342 & TRN & \\
\hline CHEMBL 8197 & 688155 & 4.5 & 5.1624 & TRN & \\
\hline CHEMBL1496552 & 688155 & 4.95 & 4.9588 & TRN & \\
\hline CHEMBL1447245 & 688155 & 5.0 & 5.0315 & TRN & \\
\hline CHEMBL1452537 & 688155 & 4.5 & 5.1394 & TRN & \\
\hline CHEMBL607299 & 688155 & 4.5 & 5.1605 & TST & \\
\hline CHEMBL1557239 & 688155 & 5.55 & 5.1085 & TRN & \\
\hline CHEMBL1256737 & 688155 & 5.0 & 5.1505 & TRN & \\
\hline CHEMBL1525955 & 688155 & 4.65 & 5.0984 & TST & \\
\hline CHEMBL1547459 & 688155 & 4.55 & 5.2373 & TRN & \\
\hline CHEMBL1485466 & 688155 & 4.65 & 4.9642 & TRN & \\
\hline CHEMBL1581693 & 688155 & 5.85 & 5.0104 & TST & \\
\hline CHEMBL1506878 & 688155 & 4.9 & 4.9939 & TRN & \\
\hline CHEMBL1546439 & 688155 & 5.1 & 5.1885 & TST & \\
\hline CHEMBL1486794 & 688155 & 4.9 & 5.1373 & TRN & \\
\hline CHEMBL1391498 & 688155 & 4.85 & 5.1567 & TST & \\
\hline CHEMBL1329712 & 688155 & 5.25 & 4.9427 & TRN & \\
\hline CHEMBL1376513 & 688155 & 4.65 & 5.1085 & TRN & \\
\hline CHEMBL 38832 & 688155 & 4.6 & 5.0079 & TST & \\
\hline CHEMBL1557816 & 688155 & 5.6 & 5.0015 & TST & \\
\hline CHEMBL1376120 & 688155 & 5.1 & 5.0995 & TRN & \\
\hline CHEMBL3189916 & 688155 & 6.15 & 5.0832 & TRN & \\
\hline CHEMBL1488908 & 688155 & 5.05 & 5.1525 & TST & \\
\hline CHEMBL1596587 & 688155 & 4.95 & 5.1951 & TRN & \\
\hline CHEMBL1580668 & 688155 & 5.45 & 5.1242 & TRN & \\
\hline CHEMBL1613612 & 688155 & 5.8 & 5.2506 & TST & \\
\hline CHEMBL1576881 & 688155 & 4.5 & 5.1467 & TST & \\
\hline CHEMBL1379164 & 688155 & 4.95 & 5.2283 & TST & \\
\hline CHEMBL1539014 & 688155 & 5.35 & 5.0079 & TST & \\
\hline CHEMBL1365455 & 688155 & 4.85 & 5.1755 & TRN & \\
\hline CHEMBL1477476 & 688155 & 5.3 & 5.3437 & TRN & \\
\hline CHEMBL 3196327 & 688155 & 4.8 & 5.0611 & TST & \\
\hline CHEMBL1574974 & 688155 & 5.65 & 5.1932 & TST & \\
\hline CHEMBL1538764 & 688155 & 4.55 & 5.00899 & 99999999995 & TRN \\
\hline CHEMBL1411434 & 688155 & 4.6 & 5.15 & TRN & \\
\hline CHEMBL1311769 & 688155 & 5.0 & 5.2134 & TRN & \\
\hline CHEMBL1521875 & 688155 & 4.55 & 5.143 & TRN & \\
\hline CHEMBL1563201 & 688155 & 4.85 & 4.9854 & TST & \\
\hline CHEMBL1575852 & 688155 & 4.6 & 4.9329 & TRN & \\
\hline CHEMBL1420469 & 688155 & 6.5 & 5.0679 & TRN & \\
\hline CHEMBL1374735 & 688155 & 6.5 & 5.1022 & TRN & \\
\hline
\end{tabular}




\begin{tabular}{|c|c|c|c|c|}
\hline \multicolumn{5}{|c|}{ Supplemental Table S2.txt } \\
\hline CHEMBL1323117 & 688155 & 5.0 & 5.0606 & TRN \\
\hline CHEMBL1341829 & 688155 & 5.5 & 5.1338 & TST \\
\hline CHEMBL1547257 & 688155 & 5.6 & 5.003 & TRN \\
\hline CHEMBL1504612 & 688155 & 5.45 & 5.0299 & TRN \\
\hline CHEMBL1339651 & 688155 & 5.15 & 5.081 & TRN \\
\hline CHEMBL1332317 & 688155 & 5.2 & 5.2765 & TRN \\
\hline CHEMBL1363710 & 688155 & 4.95 & 5.1119 & TRN \\
\hline CHEMBL1508208 & 688155 & 4.55 & 4.9953 & TRN \\
\hline CHEMBL1528004 & 688155 & 4.95 & 5.0187 & TRN \\
\hline CHEMBL1599400 & 688155 & 5.3 & 5.0224 & TRN \\
\hline CHEMBL1448743 & 688155 & 4.55 & 4.9712 & TRN \\
\hline CHEMBL1392813 & 688155 & 4.55 & 5.0144 & TRN \\
\hline CHEMBL1427497 & 688155 & 5.2 & 5.1648 & TRN \\
\hline CHEMBL146525 & 688155 & 5.7 & 5.0285 & TRN \\
\hline CHEMBL1561030 & 688155 & 4.5 & 5.1328 & TRN \\
\hline CHEMBL1461036 & 688155 & 4.65 & 5.0155 & TST \\
\hline CHEMBL1302121 & 688155 & 4.55 & 5.1335 & TRN \\
\hline CHEMBL1440031 & 688155 & 4.55 & 4.997 & TRN \\
\hline CHEMBL1381345 & 688155 & 5.0 & 5.0302 & TRN \\
\hline CHEMBL1407294 & 688155 & 4.7 & 5.0313 & TRN \\
\hline CHEMBL1416713 & 688155 & 5.0 & 5.0479 & TST \\
\hline CHEMBL1459968 & 688155 & 5.0 & 4.9836 & TRN \\
\hline CHEMBL1564023 & 688155 & 5.0 & 4.8732 & TST \\
\hline CHEMBL1607435 & 688155 & 5.8 & 5.0698 & TRN \\
\hline CHEMBL1351119 & 688155 & 4.75 & 5.0375 & TRN \\
\hline CHEMBL1467045 & 688155 & 5.0 & 5.1442 & TRN \\
\hline CHEMBL1341919 & 688155 & 4.5 & 5.1442 & TRN \\
\hline CHEMBL1400510 & 688155 & 4.95 & 5.015 & TRN \\
\hline CHEMBL1442920 & 688155 & 4.85 & 5.0992 & TRN \\
\hline CHEMBL1521211 & 688155 & 5.0 & 5.0789 & TRN \\
\hline CHEMBL1305838 & 688155 & 5.0 & 4.9864 & TST \\
\hline CHEMBL1521739 & 688155 & 4.9 & 4.9718 & TST \\
\hline CHEMBL1561668 & 688155 & 4.95 & 4.8712 & TRN \\
\hline CHEMBL1555744 & 688155 & 4.5 & 5.1058 & TRN \\
\hline CHEMBL1357076 & 688155 & 5.05 & 4.8936 & TRN \\
\hline CHEMBL1582393 & 688155 & 5.2 & 5.0574 & TRN \\
\hline CHEMBL1412323 & 688155 & 6.3 & 5.1821 & TRN \\
\hline CHEMBL1576276 & 688155 & 4.85 & 5.0713 & TRN \\
\hline CHEMBL1322784 & 688155 & 4.95 & 4.976 & TRN \\
\hline CHEMBL1410441 & 688155 & 4.95 & 4.9374 & TST \\
\hline CHEMBL1481391 & 688155 & 6.45 & 5.2172 & TST \\
\hline CHEMBL1408183 & 688155 & 5.1 & 5.0646 & TRN \\
\hline CHEMBL3199873 & 688155 & 4.85 & 5.1039 & TRN \\
\hline CHEMBL1608126 & 688155 & 4.5 & 5.0706 & TRN \\
\hline CHEMBL1393421 & 688155 & 5.8 & 5.2222 & TRN \\
\hline CHEMBL1543954 & 688155 & 5.35 & 5.0155 & TRN \\
\hline CHEMBL1362625 & 688155 & 5.45 & 5.0804 & TST \\
\hline CHEMBL1369837 & 688155 & 5.45 & 5.0031 & TRN \\
\hline
\end{tabular}




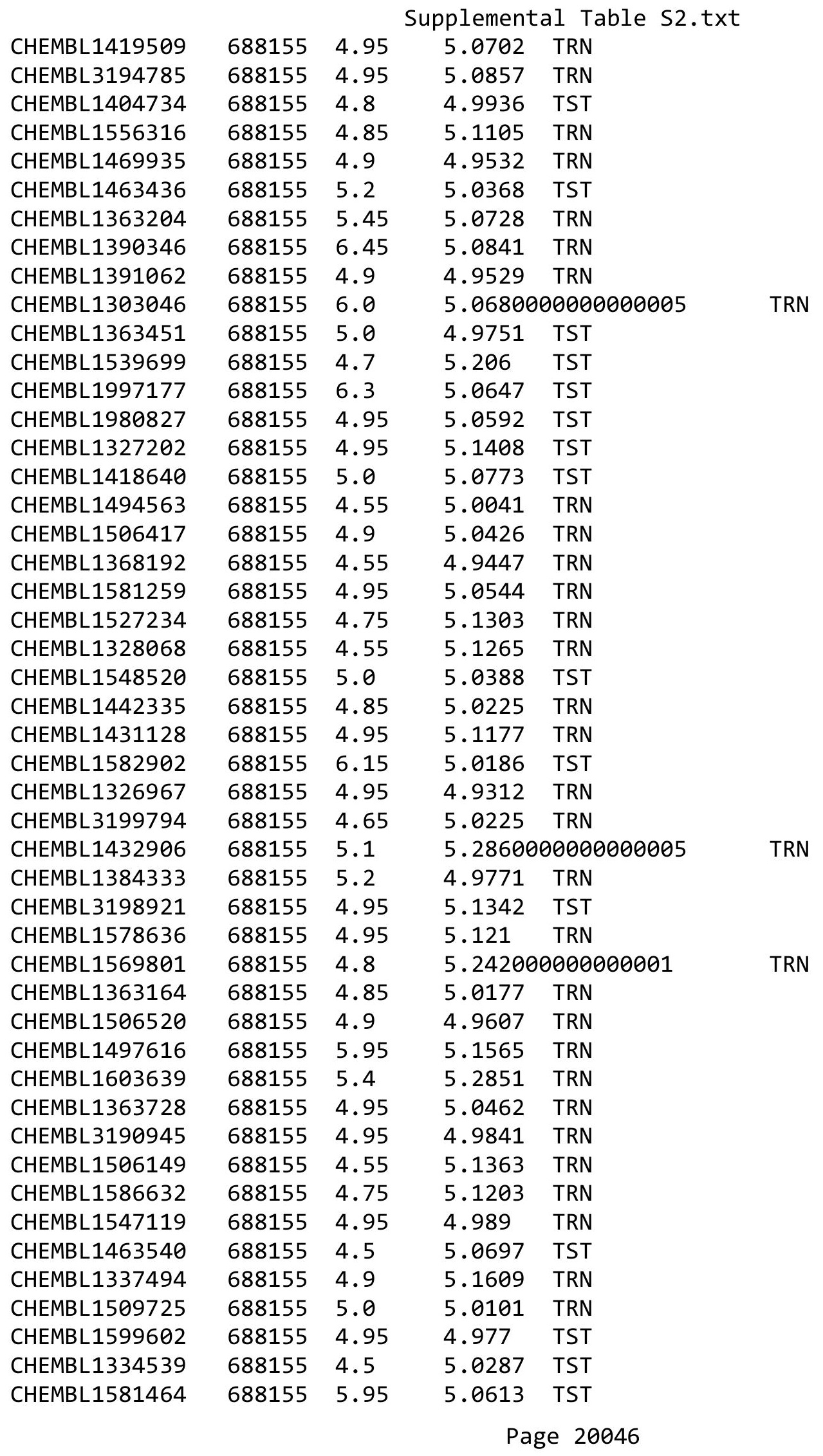




\begin{tabular}{|c|c|c|c|c|c|}
\hline \multicolumn{6}{|c|}{ Supplemental Table S2.txt } \\
\hline CHEMBL1390307 & 688155 & 5.75 & 5.2756 & TST & \\
\hline CHEMBL1430230 & 688155 & 5.35 & 5.0954 & TRN & \\
\hline CHEMBL1550382 & 688155 & 4.55 & 4.9493 & TRN & \\
\hline CHEMBL1547074 & 688155 & 5.05 & 4.8624 & TRN & \\
\hline CHEMBL1578790 & 688155 & 4.9 & 5.1076 & TST & \\
\hline CHEMBL1387862 & 688155 & 6.05 & 4.9992 & TST & \\
\hline CHEMBL1582832 & 688155 & 4.95 & 5.2414 & TRN & \\
\hline CHEMBL1467582 & 688155 & 4.85 & 5.01399 & 9999999999 & TRN \\
\hline CHEMBL1352352 & 688155 & 5.3 & 5.0859 & TRN & \\
\hline CHEMBL1605516 & 688155 & 6.35 & 5.0394 & TRN & \\
\hline CHEMBL1395792 & 688155 & 4.7 & 4.9798 & TRN & \\
\hline CHEMBL1519984 & 688155 & 4.55 & 5.105 & TRN & \\
\hline CHEMBL1587944 & 688155 & 5.0 & 5.1996 & TRN & \\
\hline CHEMBL1578769 & 688155 & 5.0 & 5.0525 & TRN & \\
\hline CHEMBL1333147 & 688155 & 4.65 & 5.0158 & TRN & \\
\hline CHEMBL3197358 & 688155 & 4.95 & 5.0564 & TRN & \\
\hline CHEMBL1425785 & 688155 & 5.3 & 5.21899 & 9999999999 & TRN \\
\hline CHEMBL1419604 & 688155 & 6.2 & 5.2196 & TRN & \\
\hline CHEMBL1503479 & 688155 & 5.25 & 5.2524 & TRN & \\
\hline CHEMBL1379188 & 688155 & 5.9 & 5.0415 & TRN & \\
\hline CHEMBL1375790 & 688155 & 4.9 & 5.0105 & TRN & \\
\hline CHEMBL1558820 & 688155 & 4.9 & 4.9692 & TRN & \\
\hline CHEMBL1256655 & 688155 & 5.25 & 5.0308 & TST & \\
\hline CHEMBL1491837 & 688155 & 4.55 & 4.9995 & TRN & \\
\hline CHEMBL1472232 & 688155 & 5.5 & 5.0231 & TRN & \\
\hline CHEMBL1578763 & 688155 & 4.95 & 5.0426 & TRN & \\
\hline CHEMBL1542741 & 688155 & 4.55 & 5.1336 & TRN & \\
\hline CHEMBL1374154 & 688155 & 4.5 & 5.0682 & TRN & \\
\hline CHEMBL1312953 & 688155 & 5.9 & 5.0491 & TRN & \\
\hline CHEMBL1577049 & 688155 & 5.45 & 5.1321 & TRN & \\
\hline CHEMBL 2007425 & 688155 & 5.2 & 4.9682 & TRN & \\
\hline CHEMBL3212402 & 688155 & 5.0 & 5.0403 & TST & \\
\hline CHEMBL1463231 & 688155 & 5.0 & 5.0895 & TRN & \\
\hline CHEMBL1604154 & 688155 & 5.85 & 5.1378 & TST & \\
\hline CHEMBL1465825 & 688155 & 5.0 & 5.1801 & TRN & \\
\hline CHEMBL1608729 & 688155 & 5.0 & 5.034 & TST & \\
\hline CHEMBL1558011 & 688155 & 4.55 & 5.0535 & TST & \\
\hline CHEMBL1411916 & 688155 & 5.4 & 5.0985 & TRN & \\
\hline CHEMBL1348690 & 688155 & 6.3 & 5.13200 & 0000000001 & TST \\
\hline CHEMBL1440599 & 688155 & 5.6 & 4.9425 & TRN & \\
\hline CHEMBL1352301 & 688155 & 4.5 & 5.0566 & TRN & \\
\hline CHEMBL1412504 & 688155 & 4.55 & 4.92399 & 99999999995 & TRN \\
\hline CHEMBL1480259 & 688155 & 5.6 & 5.1894 & TRN & \\
\hline CHEMBL1558301 & 688155 & 5.0 & 5.1525 & TRN & \\
\hline CHEMBL1345377 & 688155 & 4.9 & 5.0196 & TRN & \\
\hline CHEMBL1471837 & 688155 & 5.5 & 5.2258 & TST & \\
\hline CHEMBL3209531 & 688155 & 6.3 & 5.1651 & TST & \\
\hline CHEMBL1367949 & 688155 & 4.5 & 5.1622 & TRN & \\
\hline
\end{tabular}




\begin{tabular}{|c|c|c|c|c|c|}
\hline \multicolumn{6}{|c|}{ Supplemental Table S2.txt } \\
\hline CHEMBL1564034 & 688155 & 5.2 & 5.0489 & TRN & \\
\hline CHEMBL1537858 & 688155 & 5.05 & 4.9859 & TRN & \\
\hline CHEMBL3191409 & 688155 & 4.55 & 5.0076 & TRN & \\
\hline CHEMBL1371935 & 688155 & 4.55 & 5.2238 & TRN & \\
\hline CHEMBL1588046 & 688155 & 5.25 & 5.0388 & TRN & \\
\hline CHEMBL1511120 & 688155 & 4.55 & 4.9698 & TRN & \\
\hline CHEMBL405358 & 688155 & 4.95 & 5.0345 & TST & \\
\hline CHEMBL1575245 & 688155 & 4.7 & 5.1835 & TRN & \\
\hline CHEMBL1490755 & 688155 & 4.95 & 5.2281 & TRN & \\
\hline CHEMBL1607917 & 688155 & 6.0 & 5.1412 & TRN & \\
\hline CHEMBL1437950 & 688155 & 4.75 & 4.90300 & 00000000005 & TRN \\
\hline CHEMBL1496198 & 688155 & 6.0 & 5.2692 & TRN & \\
\hline CHEMBL1448129 & 688155 & 4.95 & 5.1401 & TST & \\
\hline CHEMBL1534197 & 688155 & 4.95 & 5.016 & TRN & \\
\hline CHEMBL1368677 & 688155 & 6.5 & 5.2498 & TRN & \\
\hline CHEMBL1481094 & 688155 & 4.5 & 4.9375 & TRN & \\
\hline CHEMBL1523568 & 688155 & 4.95 & 5.2063 & TRN & \\
\hline CHEMBL1464360 & 688155 & 4.55 & 4.9048 & TRN & \\
\hline CHEMBL1477178 & 688155 & 5.55 & 5.0663 & TRN & \\
\hline CHEMBL68534 & 688155 & 5.15 & 5.0284 & TRN & \\
\hline CHEMBL1479061 & 688155 & 4.6 & 5.1935 & TRN & \\
\hline CHEMBL1385237 & 688155 & 5.45 & 5.2925 & TRN & \\
\hline CHEMBL1594696 & 688155 & 4.9 & 5.0434 & TRN & \\
\hline CHEMBL1485733 & 688155 & 4.95 & 5.0259 & TRN & \\
\hline CHEMBL1378390 & 688155 & 5.1 & 5.1591 & TRN & \\
\hline CHEMBL1569956 & 688155 & 5.75 & 5.3256 & TRN & \\
\hline CHEMBL1576459 & 688155 & 6.05 & 5.0628 & TRN & \\
\hline CHEMBL1568340 & 688155 & 4.55 & 4.9793 & TRN & \\
\hline CHEMBL1598321 & 688155 & 5.0 & 5.0964 & TRN & \\
\hline CHEMBL1578939 & 688155 & 5.05 & 5.1039 & TST & \\
\hline CHEMBL1522502 & 688155 & 5.55 & 5.1724 & TST & \\
\hline CHEMBL 30432 & 688155 & 4.95 & 5.0175 & TST & \\
\hline CHEMBL1164316 & 688155 & 4.95 & 5.0419 & TST & \\
\hline CHEMBL1517986 & 688155 & 4.9 & 5.1234 & TRN & \\
\hline CHEMBL1422158 & 688155 & 5.85 & 4.9115 & TST & \\
\hline CHEMBL448515 & 688155 & 4.5 & 5.1408 & TST & \\
\hline CHEMBL1533894 & 688155 & 6.0 & 5.2879 & TRN & \\
\hline CHEMBL1526969 & 688155 & 5.0 & 5.1306 & TRN & \\
\hline CHEMBL1415369 & 688155 & 5.5 & 5.1862 & TRN & \\
\hline CHEMBL1442617 & 688155 & 4.55 & 4.9279 & TRN & \\
\hline CHEMBL1345952 & 688155 & 6.5 & 5.0338 & TRN & \\
\hline CHEMBL1428442 & 688155 & 4.95 & 5.0734 & TRN & \\
\hline CHEMBL1439520 & 688155 & 4.55 & 5.0254 & TRN & \\
\hline CHEMBL1506835 & 688155 & 5.4 & 5.0193 & TST & \\
\hline CHEMBL153072 & 688155 & 4.95 & 4.9897 & TRN & \\
\hline CHEMBL1550028 & 688155 & 4.9 & 4.9759 & TST & \\
\hline CHEMBL1517746 & 688155 & 5.0 & 5.0842 & TRN & \\
\hline CHEMBL1586056 & 688155 & 5.0 & 4.939 & TRN & \\
\hline
\end{tabular}




\begin{tabular}{|c|c|c|c|c|c|}
\hline \multicolumn{6}{|c|}{ Supplemental Table S2.txt } \\
\hline CHEMBL1423649 & 688155 & 5.0 & 4.9507 & TRN & \\
\hline CHEMBL 3145070 & 688155 & 5.75 & 5.1055 & TRN & \\
\hline CHEMBL1528916 & 688155 & 4.6 & 5.1362 & TST & \\
\hline CHEMBL1413421 & 688155 & 5.8 & 5.0219 & TRN & \\
\hline CHEMBL1608305 & 688155 & 4.45 & 5.2377 & TRN & \\
\hline CHEMBL1563950 & 688155 & 4.55 & 4.8756 & TRN & \\
\hline CHEMBL1523972 & 688155 & 4.55 & 4.974 & TRN & \\
\hline CHEMBL1438501 & 688155 & 5.1 & 5.0562 & TRN & \\
\hline CHEMBL 3196260 & 688155 & 6.5 & 5.0648 & TST & \\
\hline CHEMBL1370707 & 688155 & 5.55 & 5.1558 & TRN & \\
\hline CHEMBL1464246 & 688155 & 5.45 & 5.0397 & TST & \\
\hline CHEMBL1339467 & 688155 & 5.5 & 5.0566 & TRN & \\
\hline CHEMBL1346848 & 688155 & 4.55 & 5.1149 & TRN & \\
\hline CHEMBL1537872 & 688155 & 4.55 & 5.0552 & TRN & \\
\hline CHEMBL1302123 & 688155 & 5.05 & 5.0367 & TRN & \\
\hline CHEMBL1367307 & 688155 & 5.65 & 5.0293 & TST & \\
\hline CHEMBL1439588 & 688155 & 4.95 & 5.1765 & TST & \\
\hline CHEMBL1300254 & 688155 & 4.55 & 5.2523 & TRN & \\
\hline CHEMBL1443500 & 688155 & 5.0 & 5.2268 & TRN & \\
\hline CHEMBL1374329 & 688155 & 4.9 & 5.01699 & 99999999995 & TRN \\
\hline CHEMBL1337763 & 688155 & 5.0 & 5.0564 & TRN & \\
\hline CHEMBL1408033 & 688155 & 5.15 & 5.2205 & TRN & \\
\hline CHEMBL584452 & 688155 & 5.0 & 5.09699 & 99999999995 & TRN \\
\hline CHEMBL3210375 & 688155 & 4.95 & 5.0381 & TRN & \\
\hline CHEMBL1338594 & 688155 & 4.55 & 5.0833 & TRN & \\
\hline CHEMBL1523389 & 688155 & 5.85 & 5.1832 & TRN & \\
\hline CHEMBL 258767 & 688155 & 4.55 & 5.0686 & TRN & \\
\hline CHEMBL1594882 & 688155 & 5.35 & 5.0324 & TRN & \\
\hline CHEMBL586830 & 688155 & 4.7 & 5.0666 & TRN & \\
\hline CHEMBL1489733 & 688155 & 4.5 & 5.1236 & TRN & \\
\hline CHEMBL1483815 & 688155 & 5.0 & 5.0057 & TRN & \\
\hline CHEMBL1466026 & 688155 & 4.55 & 4.9986 & TRN & \\
\hline CHEMBL1256624 & 688155 & 4.55 & 5.13 & TST & \\
\hline CHEMBL1345456 & 688155 & 4.95 & 5.2203 & TRN & \\
\hline CHEMBL1309698 & 688155 & 4.55 & 5.1453 & TRN & \\
\hline CHEMBL1549348 & 688155 & 4.95 & 5.0531 & TST & \\
\hline CHEMBL1524567 & 688155 & 4.5 & 5.1456 & TRN & \\
\hline CHEMBL1349980 & 688155 & 4.9 & 5.0686 & TRN & \\
\hline CHEMBL1458935 & 688155 & 5.3 & 4.9183 & TST & \\
\hline CHEMBL484385 & 688155 & 4.95 & 4.9485 & TST & \\
\hline CHEMBL1391913 & 688155 & 5.8 & 5.0416 & TRN & \\
\hline CHEMBL 90472 & 688155 & 6.25 & 5.1769 & TST & \\
\hline CHEMBL1333019 & 688155 & 6.3 & 5.0598 & TST & \\
\hline CHEMBL1399828 & 688155 & 4.55 & 5.0 & TRN & \\
\hline CHEMBL1333679 & 688155 & 6.0 & 5.2593 & TRN & \\
\hline CHEMBL1420333 & 688155 & 4.85 & 4.9248 & TST & \\
\hline CHEMBL1563489 & 688155 & 5.4 & 5.2558 & TST & \\
\hline CHEMBL1585002 & 688155 & 5.0 & 5.1274 & TRN & \\
\hline
\end{tabular}




\begin{tabular}{|c|c|c|c|c|c|}
\hline CHEMBL1541969 & 688155 & 6.0 & \multicolumn{2}{|c|}{5.212000000000001} & TST \\
\hline CHEMBL1577449 & 688155 & 4.8 & 5.1668 & TRN & \\
\hline CHEMBL3196285 & 688155 & 5.0 & 5.0444 & TST & \\
\hline CHEMBL1423865 & 688155 & 4.95 & 4.9596 & TST & \\
\hline CHEMBL1428188 & 688155 & 4.55 & 4.9262 & TRN & \\
\hline CHEMBL1423198 & 688155 & 4.8 & 5.0337 & TRN & \\
\hline CHEMBL587856 & 688155 & 4.9 & 4.9973 & TRN & \\
\hline CHEMBL3213989 & 688155 & 4.9 & 5.0543 & TST & \\
\hline CHEMBL1412226 & 688155 & 4.85 & 5.0641 & TRN & \\
\hline CHEMBL1313483 & 688155 & 5.1 & 5.0668 & TRN & \\
\hline CHEMBL1565765 & 688155 & 5.0 & 4.9674 & TRN & \\
\hline CHEMBL1527680 & 688155 & 6.3 & 5.2572 & TRN & \\
\hline CHEMBL1497427 & 688155 & 4.85 & 5.0299 & TRN & \\
\hline CHEMBL18618 & 688155 & 4.55 & \multicolumn{2}{|c|}{5.1579999999999995} & TST \\
\hline CHEMBL1585428 & 688155 & 4.7 & 5.1767 & TRN & \\
\hline CHEMBL1429787 & 688155 & 5.7 & 5.1453 & TRN & \\
\hline CHEMBL1525864 & 688155 & 4.6 & 5.1489 & TRN & \\
\hline CHEMBL1308607 & 688155 & 5.5 & 5.1098 & TRN & \\
\hline CHEMBL1609513 & 688155 & 5.25 & 5.07 & TST & \\
\hline CHEMBL1491573 & 688155 & 6.35 & 5.0515 & TST & \\
\hline CHEMBL1604704 & 688155 & 4.8 & 4.975 & TRN & \\
\hline CHEMBL1426781 & 688155 & 4.95 & 5.1305 & TST & \\
\hline CHEMBL1304261 & 688155 & 5.5 & 5.1034 & TRN & \\
\hline CHEMBL3190027 & 688155 & 4.5 & 5.1268 & TRN & \\
\hline CHEMBL1505646 & 688155 & 5.55 & 5.1152 & TST & \\
\hline CHEMBL1460669 & 688155 & 4.55 & 5.1127 & TRN & \\
\hline CHEMBL1544443 & 688155 & 5.3 & 5.0089 & TRN & \\
\hline CHEMBL1599313 & 688155 & 5.0 & 5.0431 & TRN & \\
\hline CHEMBL1430284 & 688155 & 6.0 & 5.1954 & TST & \\
\hline CHEMBL1451260 & 688155 & 4.5 & 5.1257 & TST & \\
\hline CHEMBL1494577 & 688155 & 5.0 & 4.9851 & TST & \\
\hline CHEMBL1466046 & 688155 & 4.95 & 5.1075 & TST & \\
\hline CHEMBL1257024 & 688155 & 5.8 & 5.1629 & TRN & \\
\hline CHEMBL1373490 & 688155 & 5.7 & 4.979 & TRN & \\
\hline CHEMBL1560561 & 688155 & 4.9 & 5.0159 & TRN & \\
\hline CHEMBL1520858 & 688155 & 4.9 & 4.8778 & TRN & \\
\hline CHEMBL1401031 & 688155 & 5.3 & 4.9087 & TRN & \\
\hline CHEMBL1523295 & 688155 & 4.55 & 5.1179 & TRN & \\
\hline CHEMBL1462378 & 688155 & 4.55 & 5.0038 & TRN & \\
\hline CHEMBL1528093 & 688155 & 4.5 & \multicolumn{2}{|c|}{5.1080000000000005} & TRN \\
\hline CHEMBL1426911 & 688155 & 5.2 & 4.9773 & TST & \\
\hline CHEMBL1444726 & 688155 & 4.65 & 5.0882 & TRN & \\
\hline CHEMBL1389530 & 688155 & 4.8 & \multicolumn{2}{|c|}{5.1339999999999995} & TRN \\
\hline CHEMBL1439016 & 688155 & 4.55 & 4.9983 & TRN & \\
\hline CHEMBL1318721 & 688155 & 4.55 & 5.2357 & TRN & \\
\hline CHEMBL1490351 & 688155 & 4.55 & 4.9718 & TST & \\
\hline CHEMBL1403971 & 688155 & 5.15 & 5.1367 & TRN & \\
\hline CHEMBL1463034 & 688155 & 4.5 & 5.1307 & TRN & \\
\hline
\end{tabular}




\begin{tabular}{|c|c|c|c|c|c|}
\hline & & \multicolumn{4}{|c|}{ Supplemental Table s2.txt } \\
\hline CHEMBL441948 & 688155 & 4.55 & 5.0832 & TST & \\
\hline CHEMBL1362375 & 688155 & 4.65 & 4.9563 & TRN & \\
\hline CHEMBL3195564 & 688155 & 5.4 & 5.0532 & TST & \\
\hline CHEMBL1568579 & 688155 & 4.9 & 5.0662 & TRN & \\
\hline CHEMBL1567503 & 688155 & 4.5 & 5.0251 & TRN & \\
\hline CHEMBL1327627 & 688155 & 5.8 & 5.0968 & TRN & \\
\hline CHEMBL1460476 & 688155 & 5.05 & 5.1338 & TST & \\
\hline CHEMBL1547292 & 688155 & 5.15 & 5.1323 & TRN & \\
\hline CHEMBL1586435 & 688155 & 4.5 & 5.1685 & TRN & \\
\hline CHEMBL1305963 & 688155 & 4.5 & 4.9176 & TRN & \\
\hline CHEMBL1402277 & 688155 & 5.85 & 5.1557 & TRN & \\
\hline CHEMBL1569872 & 688155 & 5.55 & 4.9173 & TRN & \\
\hline CHEMBL1578721 & 688155 & 5.0 & 5.0474 & TRN & \\
\hline CHEMBL1561625 & 688155 & 5.3 & 5.0778 & TRN & \\
\hline CHEMBL1579616 & 688155 & 5.45 & 5.1012 & TRN & \\
\hline CHEMBL1532234 & 688155 & 4.7 & 5.0839 & TRN & \\
\hline CHEMBL1371040 & 688155 & 5.9 & 5.1606 & TRN & \\
\hline CHEMBL1544670 & 688155 & 5.1 & 5.1402 & TRN & \\
\hline CHEMBL1431800 & 688155 & 4.55 & 5.1438 & TST & \\
\hline CHEMBL1382743 & 688155 & 6.0 & 5.0246 & TRN & \\
\hline CHEMBL1570134 & 688155 & 4.8 & 5.1593 & TRN & \\
\hline CHEMBL1306274 & 688155 & 5.0 & 5.0607 & TRN & \\
\hline CHEMBL1301289 & 688155 & 4.95 & 4.9792 & TRN & \\
\hline CHEMBL1543566 & 688155 & 6.0 & 5.1081 & TST & \\
\hline CHEMBL1539513 & 688155 & 4.55 & 5.17899 & 9999999999 & TST \\
\hline CHEMBL1503289 & 688155 & 4.95 & 5.07100 & 0000000001 & TRN \\
\hline CHEMBL1579790 & 688155 & 4.8 & 5.0305 & TST & \\
\hline CHEMBL1501669 & 688155 & 4.95 & 5.048 & TRN & \\
\hline CHEMBL1464968 & 688155 & 5.95 & 5.1266 & TRN & \\
\hline CHEMBL1609127 & 688155 & 5.35 & 5.0748 & TRN & \\
\hline CHEMBL1441801 & 688155 & 4.9 & 5.0196 & TRN & \\
\hline CHEMBL1463302 & 688155 & 4.95 & 5.1435 & TRN & \\
\hline CHEMBL396366 & 688155 & 4.55 & 5.2709 & TRN & \\
\hline CHEMBL1567985 & 688155 & 4.5 & 4.9438 & TRN & \\
\hline CHEMBL1526624 & 688155 & 5.0 & 4.913 & TRN & \\
\hline CHEMBL1576451 & 688155 & 4.55 & 5.1104 & TRN & \\
\hline CHEMBL1416184 & 688155 & 4.9 & 4.9246 & TST & \\
\hline CHEMBL1393309 & 688155 & 4.9 & 5.1457 & TRN & \\
\hline CHEMBL3193785 & 688155 & 4.9 & 5.0803 & TRN & \\
\hline CHEMBL1520318 & 688155 & 4.55 & 5.1611 & TRN & \\
\hline CHEMBL1567262 & 688155 & 5.2 & 5.155 & TST & \\
\hline CHEMBL1451869 & 688155 & 4.55 & 5.0057 & TRN & \\
\hline CHEMBL1342517 & 688155 & 4.65 & 4.9741 & TRN & \\
\hline CHEMBL1486995 & 688155 & 5.0 & 5.0425 & TST & \\
\hline CHEMBL1452996 & 688155 & 5.25 & 5.1533 & TRN & \\
\hline CHEMBL1462713 & 688155 & 4.65 & 4.98300 & 00000000005 & TRN \\
\hline CHEMBL1596759 & 688155 & 4.95 & 5.1182 & TRN & \\
\hline CHEMBL1301297 & 688155 & 5.05 & 5.0897 & TRN & \\
\hline
\end{tabular}




\begin{tabular}{|c|c|c|c|c|c|}
\hline & & \multicolumn{4}{|c|}{ Supplemental Table S2.txt } \\
\hline CHEMBL1518801 & 688155 & 4.85 & 5.0077 & TRN & \\
\hline CHEMBL1507481 & 688155 & 4.9 & 4.9315 & TRN & \\
\hline CHEMBL1607122 & 688155 & 4.95 & 5.2479 & TRN & \\
\hline CHEMBL1431591 & 688155 & 5.1 & 5.0392 & TRN & \\
\hline CHEMBL 3192374 & 688155 & 4.9 & 5.0498 & TRN & \\
\hline CHEMBL1480508 & 688155 & 6.0 & 5.06800 & 00000000005 & TST \\
\hline CHEMBL1581638 & 688155 & 4.55 & 5.0764 & TRN & \\
\hline CHEMBL1348849 & 688155 & 4.55 & 5.1436 & TRN & \\
\hline CHEMBL1499332 & 688155 & 5.1 & 5.2541 & TRN & \\
\hline CHEMBL1458912 & 688155 & 4.8 & 5.0378 & TRN & \\
\hline CHEMBL1445752 & 688155 & 5.4 & 5.21200 & 0000000001 & TRN \\
\hline CHEMBL1505324 & 688155 & 4.55 & 4.9047 & TRN & \\
\hline CHEMBL1447441 & 688155 & 4.55 & 4.8862 & TRN & \\
\hline CHEMBL1416887 & 688155 & 5.2 & 5.0014 & TRN & \\
\hline CHEMBL1542146 & 688155 & 5.0 & 5.1748 & TRN & \\
\hline CHEMBL1605072 & 688155 & 4.9 & 5.0118 & TRN & \\
\hline CHEMBL492267 & 688155 & 5.0 & 5.1039 & TST & \\
\hline CHEMBL1589923 & 688155 & 5.5 & 5.2459 & TRN & \\
\hline CHEMBL1422564 & 688155 & 4.65 & 5.0578 & TST & \\
\hline CHEMBL453019 & 688155 & 4.95 & 5.1306 & TST & \\
\hline CHEMBL3211903 & 688155 & 5.2 & 4.9487 & TRN & \\
\hline CHEMBL1567921 & 688155 & 5.55 & 5.0826 & TST & \\
\hline CHEMBL1386763 & 688155 & 4.8 & 5.0589 & TRN & \\
\hline CHEMBL1605529 & 688155 & 4.6 & 5.2289 & TRN & \\
\hline CHEMBL1335639 & 688155 & 5.45 & 4.987 & TRN & \\
\hline CHEMBL1540811 & 688155 & 6.0 & 4.9741 & TRN & \\
\hline CHEMBL1308362 & 688155 & 4.55 & 5.1158 & TRN & \\
\hline CHEMBL3209166 & 688155 & 5.0 & 5.0149 & TST & \\
\hline CHEMBL1343024 & 688155 & 4.9 & 4.9629 & TRN & \\
\hline CHEMBL1319545 & 688155 & 6.5 & 5.1687 & TST & \\
\hline CHEMBL1420448 & 688155 & 5.3 & 5.0445 & TRN & \\
\hline CHEMBL1467309 & 688155 & 4.95 & 4.9027 & TRN & \\
\hline CHEMBL1556666 & 688155 & 4.55 & 4.9884 & TRN & \\
\hline CHEMBL1360282 & 688155 & 5.0 & 5.0217 & TRN & \\
\hline CHEMBL451748 & 688155 & 4.95 & 4.9806 & TRN & \\
\hline CHEMBL1986418 & 688155 & 4.5 & 5.0018 & TST & \\
\hline CHEMBL3210722 & 688155 & 4.85 & 5.1315 & TRN & \\
\hline CHEMBL1542152 & 688155 & 4.55 & 5.2511 & TST & \\
\hline CHEMBL1460262 & 688155 & 4.55 & 5.0651 & TST & \\
\hline CHEMBL1526738 & 688155 & 4.9 & 4.8752 & TRN & \\
\hline CHEMBL1546706 & 688155 & 5.1 & 5.05 & TRN & \\
\hline CHEMBL1329756 & 688155 & 6.5 & 5.0305 & TRN & \\
\hline CHEMBL3194851 & 688155 & 4.55 & 4.9497 & TRN & \\
\hline CHEMBL1484741 & 688155 & 4.95 & 5.1442 & TRN & \\
\hline CHEMBL1577894 & 688155 & 4.55 & 4.9986 & TRN & \\
\hline CHEMBL1386383 & 688155 & 5.1 & 5.142 & TRN & \\
\hline CHEMBL1383014 & 688155 & 4.55 & 4.9899 & TST & \\
\hline CHEMBL1503964 & 688155 & 4.55 & 5.1395 & TRN & \\
\hline
\end{tabular}




\begin{tabular}{|c|c|c|c|c|c|}
\hline \multicolumn{6}{|c|}{ Supplemental Table S2.txt } \\
\hline CHEMBL1307022 & 688155 & 4.75 & 5.1467 & TRN & \\
\hline CHEMBL1576889 & 688155 & 4.9 & 4.9832 & TRN & \\
\hline CHEMBL1442399 & 688155 & 5.9 & 5.1815 & TRN & \\
\hline CHEMBL430266 & 688155 & 7.4001 & 5.002 & TST & \\
\hline CHEMBL1489009 & 688155 & 5.85 & 5.1168 & TST & \\
\hline CHEMBL1374594 & 688155 & 4.75 & 5.0602 & TRN & \\
\hline CHEMBL1533196 & 688155 & 4.9 & 5.0832 & TRN & \\
\hline CHEMBL1440035 & 688155 & 5.5 & 5.0884 & TST & \\
\hline CHEMBL1483462 & 688155 & 4.75 & 5.1761 & TRN & \\
\hline CHEMBL1579287 & 688155 & 4.95 & 5.0016 & TRN & \\
\hline CHEMBL1450485 & 688155 & 5.0 & 5.2276 & TST & \\
\hline CHEMBL1320314 & 688155 & 4.95 & 5.1455 & TRN & \\
\hline CHEMBL75267 & 688155 & 4.8 & 5.0489 & TRN & \\
\hline CHEMBL1457793 & 688155 & 4.5 & 5.0164 & TRN & \\
\hline CHEMBL1533390 & 688155 & 4.55 & 5.0899 & TRN & \\
\hline CHEMBL1496282 & 688155 & 5.8 & 5.2217 & TRN & \\
\hline CHEMBL3392068 & 688155 & 4.5 & 5.12 & TRN & \\
\hline CHEMBL1347023 & 688155 & 5.45 & 5.1102 & TRN & \\
\hline CHEMBL1548472 & 688155 & 4.95 & 5.0592 & TRN & \\
\hline CHEMBL1415997 & 688155 & 4.5 & 5.0757 & TRN & \\
\hline CHEMBL1411867 & 688155 & 5.05 & 5.1873 & TRN & \\
\hline CHEMBL225012 & 688155 & 4.5 & 5.102 & TRN & \\
\hline CHEMBL1543916 & 688155 & 5.95 & 5.0694 & TRN & \\
\hline CHEMBL1403639 & 688155 & 4.55 & 5.03100 & 0000000001 & TRN \\
\hline CHEMBL1370725 & 688155 & 6.5 & 5.1231 & TRN & \\
\hline CHEMBL1611128 & 688155 & 4.9 & 5.1024 & TRN & \\
\hline CHEMBL1324977 & 688155 & 4.55 & 5.1973 & TST & \\
\hline CHEMBL1303767 & 688155 & 4.5 & 5.0063 & TST & \\
\hline CHEMBL1419046 & 688155 & 4.55 & 5.0997 & TRN & \\
\hline CHEMBL1482680 & 688155 & 5.0 & 5.1532 & TRN & \\
\hline CHEMBL1440090 & 688155 & 4.95 & 4.9932 & TRN & \\
\hline CHEMBL1540274 & 688155 & 5.45 & 5.13399 & 99999999995 & TST \\
\hline CHEMBL1546703 & 688155 & 4.55 & 5.0969 & TST & \\
\hline CHEMBL1496647 & 688155 & 5.3 & 5.0782 & TRN & \\
\hline CHEMBL1597425 & 688155 & 4.5 & 5.0029 & TRN & \\
\hline CHEMBL1416694 & 688155 & 4.55 & 5.1879 & TRN & \\
\hline CHEMBL1447542 & 688155 & 4.5 & 5.012 & TRN & \\
\hline CHEMBL1392870 & 688155 & 5.3 & 5.04 & TRN & \\
\hline CHEMBL1351820 & 688155 & 6.0 & 5.1055 & TRN & \\
\hline CHEMBL1342288 & 688155 & 5.7 & 5.0025 & TST & \\
\hline CHEMBL1466180 & 688155 & 4.5 & 5.0543 & TRN & \\
\hline CHEMBL1505036 & 688155 & 4.95 & 5.1822 & TRN & \\
\hline CHEMBL1339372 & 688155 & 4.95 & 5.0992 & TST & \\
\hline CHEMBL1470175 & 688155 & 5.4 & 5.1609 & TRN & \\
\hline CHEMBL1378603 & 688155 & 5.65 & 5.2465 & TST & \\
\hline CHEMBL1371890 & 688155 & 4.55 & 5.0369 & TRN & \\
\hline CHEMBL1559983 & 688155 & 4.95 & 5.0837 & TRN & \\
\hline CHEMBL1549553 & 688155 & 4.55 & 4.944 & TRN & \\
\hline
\end{tabular}




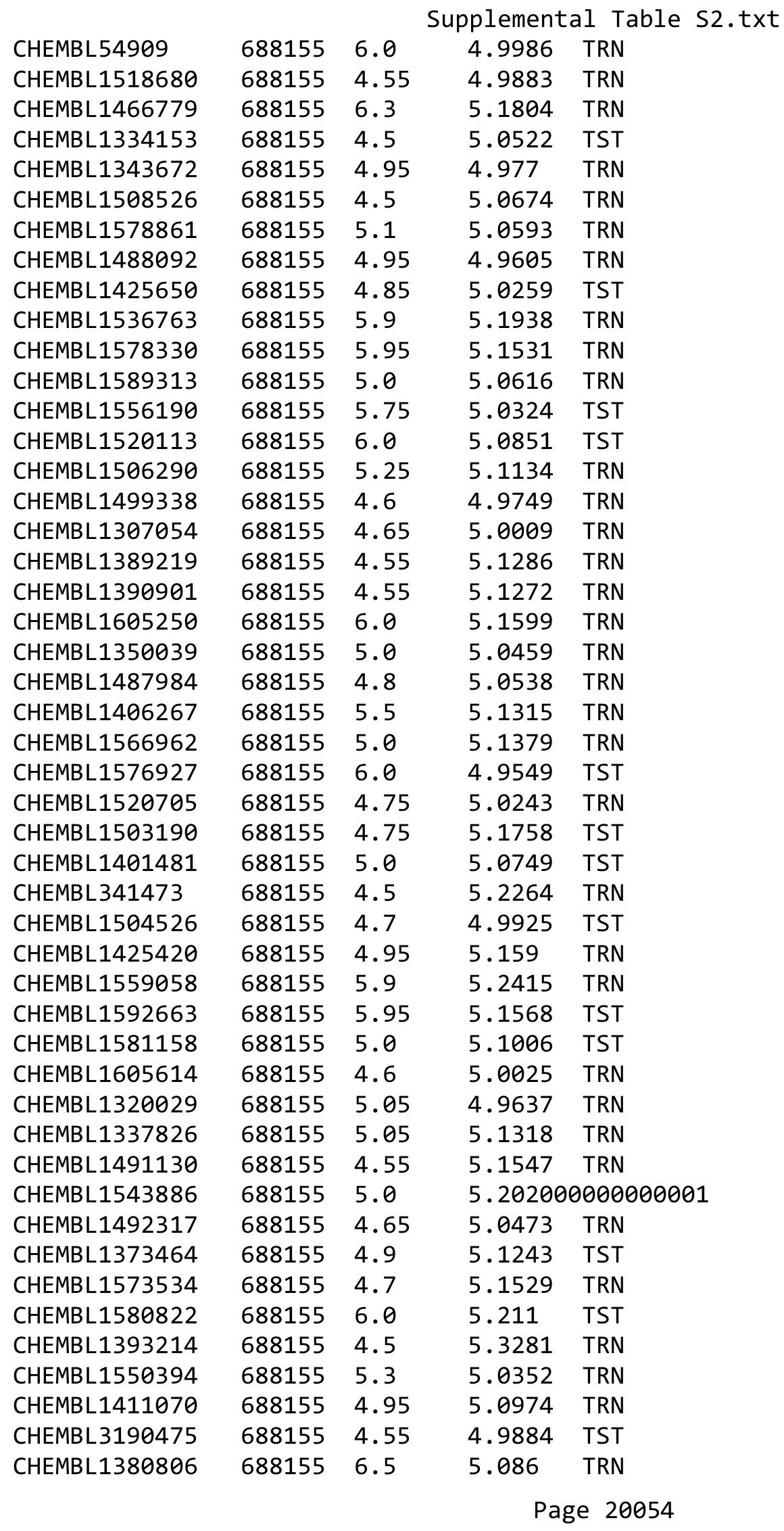




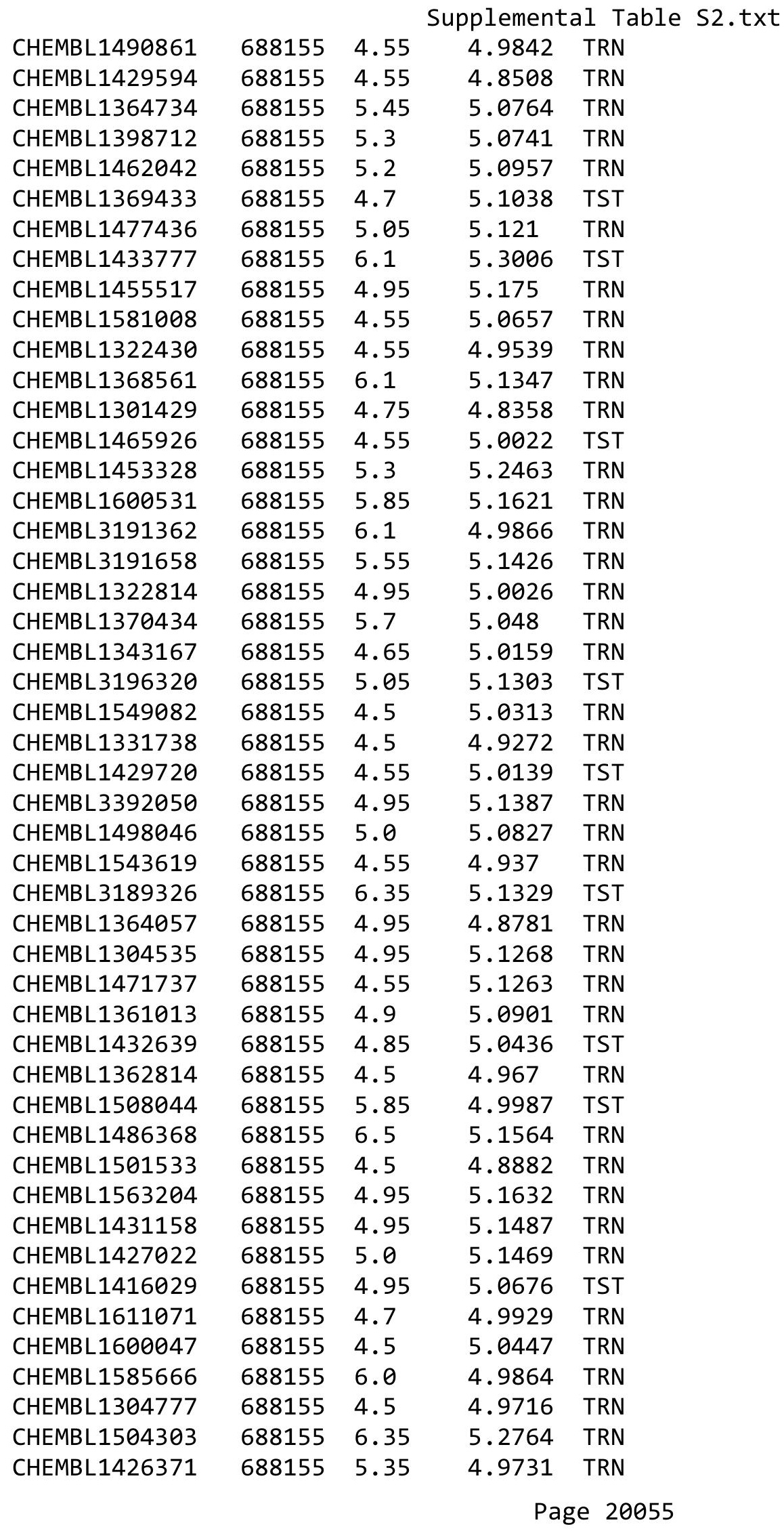




\begin{tabular}{|c|c|c|c|c|c|}
\hline \multicolumn{6}{|c|}{ Supplemental Table s2.txt } \\
\hline CHEMBL1432342 & 688155 & 5.0 & 5.0271 & TST & \\
\hline CHEMBL1986805 & 688155 & 6.0 & 4.9455 & TRN & \\
\hline CHEMBL1533009 & 688155 & 4.9 & 5.0789 & TRN & \\
\hline CHEMBL1387843 & 688155 & 4.95 & 5.0715 & TST & \\
\hline CHEMBL1390622 & 688155 & 4.95 & 5.0846 & TST & \\
\hline CHEMBL1540577 & 688155 & 5.8 & 4.8854 & TRN & \\
\hline CHEMBL1548047 & 688155 & 4.95 & 5.0029 & TST & \\
\hline CHEMBL1555967 & 688155 & 4.65 & 5.0647 & TRN & \\
\hline CHEMBL1305293 & 688155 & 5.0 & 5.0747 & TRN & \\
\hline CHEMBL1304528 & 688155 & 4.6 & 5.0554 & TRN & \\
\hline CHEMBL1380310 & 688155 & 5.15 & 5.026 & TRN & \\
\hline CHEMBL1352598 & 688155 & 5.7 & 5.0117 & TRN & \\
\hline CHEMBL1604499 & 688155 & 5.25 & 4.9934 & TST & \\
\hline CHEMBL1571701 & 688155 & 5.75 & 4.9254 & TST & \\
\hline CHEMBL1507682 & 688155 & 4.55 & 5.0284 & TST & \\
\hline CHEMBL1604196 & 688155 & 5.0 & 4.9631 & TRN & \\
\hline CHEMBL463783 & 688155 & 6.45 & 4.9977 & TRN & \\
\hline CHEMBL1600295 & 688155 & 4.95 & 5.0003 & TST & \\
\hline CHEMBL1337212 & 688155 & 6.5 & 5.1691 & TRN & \\
\hline CHEMBL1456868 & 688155 & 5.0 & 4.9393 & TRN & \\
\hline CHEMBL1372579 & 688155 & 4.6 & 5.0544 & TRN & \\
\hline CHEMBL1470672 & 688155 & 4.55 & 5.1172 & TST & \\
\hline CHEMBL1575216 & 688155 & 4.95 & 5.371 & TRN & \\
\hline CHEMBL1613113 & 688155 & 4.85 & 5.183 & TRN & \\
\hline CHEMBL1487237 & 688155 & 5.1 & 5.0554 & TRN & \\
\hline CHEMBL1451970 & 688155 & 4.95 & 5.1794 & TRN & \\
\hline CHEMBL1311686 & 688155 & 5.45 & 5.2635 & TRN & \\
\hline CHEMBL1481856 & 688155 & 6.0 & 5.1086 & TST & \\
\hline CHEMBL1363506 & 688155 & 5.0 & 4.9944 & TRN & \\
\hline CHEMBL1479816 & 688155 & 5.65 & 5.0595 & TRN & \\
\hline CHEMBL1498048 & 688155 & 5.3 & 5.2074 & TST & \\
\hline CHEMBL1539570 & 688155 & 5.0 & 5.0221 & TRN & \\
\hline CHEMBL1464275 & 688155 & 6.5 & 5.2832 & TRN & \\
\hline CHEMBL1419668 & 688155 & 5.95 & 5.1704 & TRN & \\
\hline CHEMBL1445871 & 688155 & 5.05 & 4.9836 & TRN & \\
\hline CHEMBL1534384 & 688155 & 5.0 & 5.1049 & TRN & \\
\hline CHEMBL1447164 & 688155 & 4.55 & 5.0111 & TRN & \\
\hline CHEMBL1445004 & 688155 & 5.0 & 5.0665 & TRN & \\
\hline CHEMBL1379478 & 688155 & 6.35 & 5.12799 & 9999999999 & TRN \\
\hline CHEMBL1589488 & 688155 & 4.95 & 4.9472 & TRN & \\
\hline CHEMBL1461308 & 688155 & 5.5 & 5.1359 & TST & \\
\hline CHEMBL1331087 & 688155 & 5.0 & 5.0163 & TRN & \\
\hline CHEMBL1420600 & 688155 & 5.05 & 5.032 & TRN & \\
\hline CHEMBL1499477 & 688155 & 4.55 & 4.9843 & TRN & \\
\hline CHEMBL1979383 & 688155 & 4.95 & 5.0259 & TRN & \\
\hline CHEMBL1572779 & 688155 & 5.95 & 5.1462 & TRN & \\
\hline CHEMBL1523223 & 688155 & 5.05 & 5.1498 & TRN & \\
\hline CHEMBL1420430 & 688155 & 4.85 & 4.9747 & TRN & \\
\hline
\end{tabular}




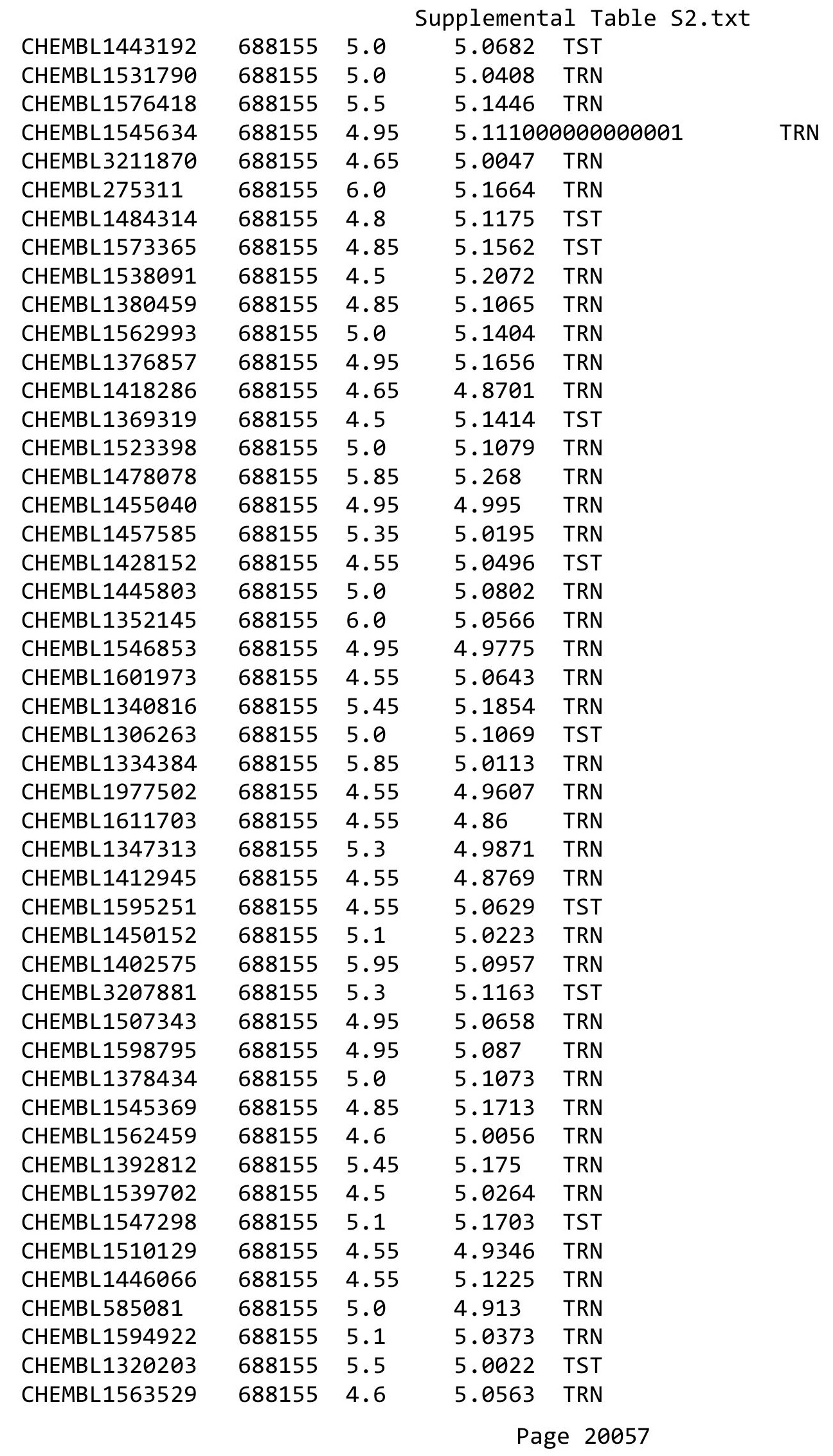




\begin{tabular}{|c|c|c|c|c|c|}
\hline \multicolumn{6}{|c|}{ Supplemental Table S2.txt } \\
\hline CHEMBL1345345 & 688155 & 5.5 & 5.1789 & TRN & \\
\hline CHEMBL1337387 & 688155 & 5.0 & 5.0326 & TRN & \\
\hline CHEMBL1528097 & 688155 & 4.95 & 5.235 & TRN & \\
\hline CHEMBL1488940 & 688155 & 4.55 & 4.9593 & TRN & \\
\hline CHEMBL1352752 & 688155 & 4.8 & 5.1467 & TRN & \\
\hline CHEMBL1537569 & 688155 & 4.5 & 5.0839 & TRN & \\
\hline CHEMBL1308878 & 688155 & 4.95 & 5.0567 & TST & \\
\hline CHEMBL1342657 & 688155 & 5.2 & 5.0645 & TRN & \\
\hline CHEMBL1426340 & 688155 & 4.55 & 4.9579 & TST & \\
\hline CHEMBL1391455 & 688155 & 4.95 & 4.908 & TRN & \\
\hline CHEMBL1374860 & 688155 & 4.9 & 5.1733 & TRN & \\
\hline CHEMBL1507785 & 688155 & 5.0 & 5.0464 & TRN & \\
\hline CHEMBL1310680 & 688155 & 5.95 & 5.0109 & TRN & \\
\hline CHEMBL1594263 & 688155 & 6.35 & 5.1037 & TST & \\
\hline CHEMBL 1605220 & 688155 & 5.0 & 5.1721 & TRN & \\
\hline CHEMBL1324123 & 688155 & 5.35 & 5.04899 & 99999999995 & TRN \\
\hline CHEMBL1565281 & 688155 & 4.55 & 5.2217 & TST & \\
\hline CHEMBL1458442 & 688155 & 6.05 & 5.2333 & TRN & \\
\hline CHEMBL1566660 & 688155 & 4.5 & 5.2232 & TST & \\
\hline CHEMBL1503589 & 688155 & 5.1 & 5.0752 & TRN & \\
\hline CHEMBL3189272 & 688155 & 4.85 & 5.1811 & TST & \\
\hline CHEMBL1555469 & 688155 & 5.05 & 5.0537 & TRN & \\
\hline CHEMBL1463416 & 688155 & 4.95 & 5.1142 & TST & \\
\hline CHEMBL1541339 & 688155 & 4.9 & 5.1627 & TRN & \\
\hline CHEMBL3197207 & 688155 & 4.95 & 5.0659 & TST & \\
\hline CHEMBL1432866 & 688155 & 6.0 & 5.1573 & TRN & \\
\hline CHEMBL1372968 & 688155 & 5.65 & 5.0459 & TRN & \\
\hline CHEMBL1370601 & 688155 & 5.4 & 4.9171 & TRN & \\
\hline CHEMBL1427957 & 688155 & 5.6 & 5.2252 & TRN & \\
\hline CHEMBL1346418 & 688155 & 4.55 & 5.0209 & TST & \\
\hline CHEMBL1378826 & 688155 & 4.9 & 4.9887 & TST & \\
\hline CHEMBL1425597 & 688155 & 4.95 & 4.9817 & TRN & \\
\hline CHEMBL1560125 & 688155 & 4.5 & 5.0751 & TST & \\
\hline CHEMBL501711 & 688155 & 5.75 & 5.1195 & TST & \\
\hline CHEMBL1424017 & 688155 & 4.95 & 4.9306 & TST & \\
\hline CHEMBL1300317 & 688155 & 4.8 & 5.0331 & TST & \\
\hline CHEMBL1595336 & 688155 & 4.55 & 5.0128 & TRN & \\
\hline CHEMBL1418632 & 688155 & 4.55 & 5.0024 & TRN & \\
\hline CHEMBL1530323 & 688155 & 5.0 & 5.0859 & TRN & \\
\hline CHEMBL1451594 & 688155 & 5.5 & 5.1451 & TRN & \\
\hline CHEMBL1498524 & 688155 & 5.05 & 5.1544 & TRN & \\
\hline CHEMBL1399968 & 688155 & 4.5 & 4.9108 & TRN & \\
\hline CHEMBL1431093 & 688155 & 5.75 & 5.1345 & TRN & \\
\hline CHEMBL3196455 & 688155 & 4.5 & 5.0992 & TRN & \\
\hline CHEMBL1388113 & 688155 & 5.75 & 4.9981 & TRN & \\
\hline CHEMBL1524631 & 688155 & 4.55 & 5.0288 & TRN & \\
\hline CHEMBL1503253 & 688155 & 5.95 & 4.9921 & TRN & \\
\hline CHEMBL1380362 & 688155 & 5.1 & 5.2354 & TST & \\
\hline
\end{tabular}




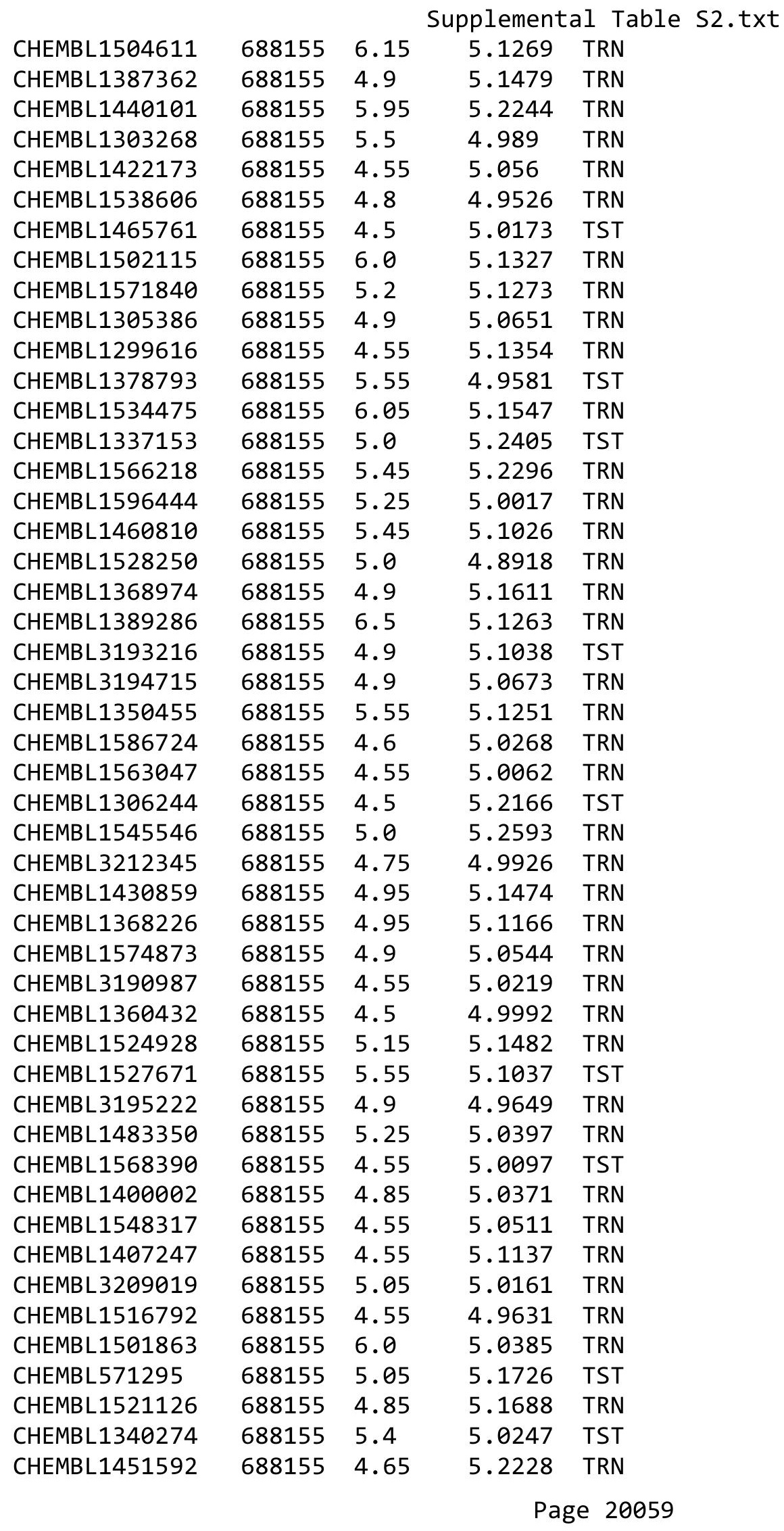




\begin{tabular}{|c|c|c|c|c|c|}
\hline \multicolumn{6}{|c|}{ Supplemental Table s2.txt } \\
\hline CHEMBL1563904 & 688155 & 5.0 & 5.0597 & TRN & \\
\hline CHEMBL532504 & 688155 & 4.9 & 5.1119 & TRN & \\
\hline CHEMBL1350535 & 688155 & 5.5 & 5.2348 & TRN & \\
\hline CHEMBL1540492 & 688155 & 4.55 & 5.169 & TRN & \\
\hline CHEMBL1389685 & 688155 & 4.55 & 5.2255 & TST & \\
\hline CHEMBL1383856 & 688155 & 5.0 & 5.0774 & TRN & \\
\hline CHEMBL1556571 & 688155 & 4.65 & 5.0083 & TRN & \\
\hline CHEMBL1330235 & 688155 & 5.0 & 5.0666 & TRN & \\
\hline CHEMBL1479509 & 688155 & 5.0 & 4.9964 & TRN & \\
\hline CHEMBL1480529 & 688155 & 4.6 & 4.9396 & TRN & \\
\hline CHEMBL1359407 & 688155 & 4.5 & 4.963 & TRN & \\
\hline CHEMBL1589547 & 688155 & 5.0 & 5.1243 & TRN & \\
\hline CHEMBL1422690 & 688155 & 5.25 & 4.9965 & TST & \\
\hline CHEMBL1378920 & 688155 & 4.6 & 4.9972 & TST & \\
\hline CHEMBL1418584 & 688155 & 4.55 & 4.9579 & TRN & \\
\hline CHEMBL1516759 & 688155 & 5.0 & 5.1663 & TRN & \\
\hline CHEMBL1433153 & 688155 & 4.55 & 4.919 & TST & \\
\hline CHEMBL1319441 & 688155 & 4.85 & 5.0182 & TST & \\
\hline CHEMBL1595799 & 688155 & 6.3 & 5.0095 & TRN & \\
\hline CHEMBL1509344 & 688155 & 4.95 & 5.1621 & TRN & \\
\hline CHEMBL1533607 & 688155 & 4.55 & 4.9652 & TRN & \\
\hline CHEMBL1302526 & 688155 & 6.3 & 5.3271 & TRN & \\
\hline CHEMBL1397885 & 688155 & 6.15 & 5.274 & TRN & \\
\hline CHEMBL1588880 & 688155 & 4.55 & 4.9336 & TRN & \\
\hline CHEMBL1312413 & 688155 & 4.95 & 5.1363 & TRN & \\
\hline CHEMBL1363485 & 688155 & 4.65 & 5.0319 & TRN & \\
\hline CHEMBL1530521 & 688155 & 4.9 & 5.1451 & TRN & \\
\hline CHEMBL1499495 & 688155 & 5.0 & 5.029 & TRN & \\
\hline CHEMBL1490175 & 688155 & 4.5 & 5.183 & TST & \\
\hline CHEMBL1604068 & 688155 & 5.0 & 5.0162 & TRN & \\
\hline CHEMBL1433489 & 688155 & 4.95 & 5.086 & TST & \\
\hline CHEMBL543557 & 688155 & 5.05 & 5.3182 & TST & \\
\hline CHEMBL1390558 & 688155 & 4.55 & 4.9816 & TRN & \\
\hline CHEMBL1568508 & 688155 & 4.55 & 4.994 & TRN & \\
\hline CHEMBL1379690 & 688155 & 4.55 & 5.0294 & TRN & \\
\hline CHEMBL1539156 & 688155 & 5.05 & 5.1535 & TRN & \\
\hline CHEMBL1322098 & 688155 & 6.0 & 5.1419 & TRN & \\
\hline CHEMBL1490264 & 688155 & 4.5 & 5.1088 & TRN & \\
\hline CHEMBL1449110 & 688155 & 4.55 & 4.8914 & TRN & \\
\hline CHEMBL1534309 & 688155 & 5.0 & 5.0292 & TRN & \\
\hline CHEMBL1367702 & 688155 & 5.2 & 5.1959 & TRN & \\
\hline CHEMBL1572571 & 688155 & 4.55 & 5.007 & TRN & \\
\hline CHEMBL1421811 & 688155 & 5.65 & 4.9675 & TRN & \\
\hline CHEMBL1467815 & 688155 & 4.9 & 4.9007 & TRN & \\
\hline CHEMBL3209706 & 688155 & 4.55 & 5.0394 & TST & \\
\hline CHEMBL1541824 & 688155 & 5.0 & 5.15799 & 99999999995 & TRN \\
\hline CHEMBL1484092 & 688155 & 4.5 & 5.2481 & TRN & \\
\hline CHEMBL1549886 & 688155 & 5.45 & 5.1127 & TRN & \\
\hline
\end{tabular}




\begin{tabular}{|c|c|c|c|c|c|}
\hline & & \multicolumn{4}{|c|}{ Supplemental Table s2.txt } \\
\hline CHEMBL1380037 & 688155 & 4.45 & 5.0413 & TRN & \\
\hline CHEMBL1604335 & 688155 & 5.0 & 5.104 & TRN & \\
\hline CHEMBL1537974 & 688155 & 4.95 & 5.1086 & TST & \\
\hline CHEMBL1391136 & 688155 & 5.1 & 5.0673 & TRN & \\
\hline CHEMBL1352884 & 688155 & 5.1 & 5.1635 & TST & \\
\hline CHEMBL1352546 & 688155 & 4.55 & 5.0373 & TST & \\
\hline CHEMBL1428882 & 688155 & 5.05 & 5.0924 & TRN & \\
\hline CHEMBL3199263 & 688155 & 4.7 & 4.9992 & TST & \\
\hline CHEMBL1315794 & 688155 & 4.55 & 4.9415 & TRN & \\
\hline CHEMBL1453098 & 688155 & 4.55 & 4.9475 & TRN & \\
\hline CHEMBL1300424 & 688155 & 4.55 & 4.9775 & TRN & \\
\hline CHEMBL1485370 & 688155 & 6.5 & 4.9463 & TRN & \\
\hline CHEMBL1469075 & 688155 & 5.7 & 5.0546 & TST & \\
\hline CHEMBL1428859 & 688155 & 4.55 & 4.9976 & TRN & \\
\hline CHEMBL1555362 & 688155 & 5.8 & 4.9819 & TRN & \\
\hline CHEMBL1302595 & 688155 & 4.6 & 4.8832 & TRN & \\
\hline CHEMBL1328537 & 688155 & 6.05 & 5.1408 & TRN & \\
\hline CHEMBL1507471 & 688155 & 4.9 & 4.9822 & TRN & \\
\hline CHEMBL1501939 & 688155 & 5.95 & 5.0134 & TRN & \\
\hline CHEMBL1412163 & 688155 & 4.55 & 5.0682 & TST & \\
\hline CHEMBL1446949 & 688155 & 5.3 & 5.2199 & TRN & \\
\hline CHEMBL1546992 & 688155 & 4.85 & 5.0405 & TRN & \\
\hline CHEMBL1539122 & 688155 & 4.95 & 5.1055 & TST & \\
\hline CHEMBL1584806 & 688155 & 4.65 & 5.1317 & TST & \\
\hline CHEMBL1567663 & 688155 & 4.95 & 4.8879 & TRN & \\
\hline CHEMBL440084 & 688155 & 5.6 & 4.9255 & TRN & \\
\hline CHEMBL1600415 & 688155 & 6.5 & 5.09399 & 9999999999 & TRN \\
\hline CHEMBL1492092 & 688155 & 5.3 & 5.0398 & TRN & \\
\hline CHEMBL179763 & 688155 & 4.85 & 5.0871 & TST & \\
\hline CHEMBL1566290 & 688155 & 5.0 & 4.9758 & TST & \\
\hline CHEMBL1460806 & 688155 & 5.4 & 5.087 & TRN & \\
\hline CHEMBL1499877 & 688155 & 4.95 & 5.03600 & 00000000005 & TST \\
\hline CHEMBL1973050 & 688155 & 4.9 & 5.1196 & TRN & \\
\hline CHEMBL1345007 & 688155 & 6.3 & 5.3109 & TRN & \\
\hline CHEMBL1353081 & 688155 & 4.55 & 5.0872 & TRN & \\
\hline CHEMBL1460077 & 688155 & 5.8 & 5.1057 & TRN & \\
\hline CHEMBL1329906 & 688155 & 5.2 & 5.0507 & TRN & \\
\hline CHEMBL1341875 & 688155 & 5.3 & 5.091 & TRN & \\
\hline CHEMBL1480178 & 688155 & 5.2 & 4.9816 & TRN & \\
\hline CHEMBL1415709 & 688155 & 5.3 & 4.9063 & TRN & \\
\hline CHEMBL71851 & 688155 & 6.0 & 5.0248 & TRN & \\
\hline CHEMBL1348859 & 688155 & 5.85 & 4.9701 & TRN & \\
\hline CHEMBL1379871 & 688155 & 5.1 & 5.1538 & TRN & \\
\hline CHEMBL1530893 & 688155 & 5.75 & 5.0985 & TRN & \\
\hline CHEMBL1535397 & 688155 & 6.05 & 5.1034 & TST & \\
\hline CHEMBL1565101 & 688155 & 5.0 & 4.9422 & TRN & \\
\hline CHEMBL1348141 & 688155 & 4.9 & 5.0083 & TRN & \\
\hline CHEMBL1465659 & 688155 & 4.55 & 5.0101 & TST & \\
\hline
\end{tabular}




\begin{tabular}{|c|c|c|c|c|c|}
\hline & & \multicolumn{4}{|c|}{ Supplemental Table S2.txt } \\
\hline CHEMBL1346170 & 688155 & 4.55 & 4.9693 & TRN & \\
\hline CHEMBL1491602 & 688155 & 4.55 & 4.9884 & TRN & \\
\hline CHEMBL1383886 & 688155 & 4.95 & 5.059 & TRN & \\
\hline CHEMBL1613298 & 688155 & 5.3 & 4.8689 & TRN & \\
\hline CHEMBL1558902 & 688155 & 4.85 & 5.2497 & TRN & \\
\hline CHEMBL1466799 & 688155 & 4.65 & 4.9825 & TST & \\
\hline CHEMBL1576321 & 688155 & 4.55 & 4.9052 & TRN & \\
\hline CHEMBL1532356 & 688155 & 5.0 & 5.3116 & TST & \\
\hline CHEMBL1309071 & 688155 & 5.7 & 5.0899 & TST & \\
\hline CHEMBL 1383376 & 688155 & 6.0 & \multicolumn{2}{|c|}{5.372000000000001} & TRN \\
\hline CHEMBL1965713 & 688155 & 5.05 & 5.0408 & TRN & \\
\hline CHEMBL1484738 & 688155 & 4.95 & 5.1809 & TST & \\
\hline CHEMBL1491728 & 688155 & 4.5 & 5.13 & TRN & \\
\hline CHEMBL3145174 & 688155 & 5.75 & 5.1631 & TRN & \\
\hline CHEMBL1454003 & 688155 & 5.3 & 5.1533 & TRN & \\
\hline CHEMBL1370423 & 688155 & 5.75 & 5.0953 & TRN & \\
\hline CHEMBL1323916 & 688155 & 6.4 & 5.1177 & TRN & \\
\hline CHEMBL1566213 & 688155 & 5.55 & 5.1523 & TST & \\
\hline CHEMBL1311661 & 688155 & 5.2 & 5.1898 & TRN & \\
\hline CHEMBL1562974 & 688155 & 4.95 & \multicolumn{2}{|c|}{5.0360000000000005} & TRN \\
\hline CHEMBL1613656 & 688155 & 4.75 & 5.1774 & TRN & \\
\hline CHEMBL1602927 & 688155 & 5.3 & 5.0761 & TST & \\
\hline CHEMBL1536338 & 688155 & 5.75 & 5.2915 & TST & \\
\hline CHEMBL1373557 & 688155 & 6.05 & 5.0363 & TST & \\
\hline CHEMBL1487438 & 688155 & 5.0 & 5.0192 & TRN & \\
\hline CHEMBL1343969 & 688155 & 5.0 & 5.1364 & TRN & \\
\hline CHEMBL1494458 & 688155 & 4.85 & 5.1011 & TRN & \\
\hline CHEMBL1583472 & 688155 & 5.0 & 5.1063 & TST & \\
\hline CHEMBL1343957 & 688155 & 6.2 & 5.1119 & TRN & \\
\hline CHEMBL1343825 & 688155 & 5.3 & 5.0173 & TRN & \\
\hline CHEMBL1331727 & 688155 & 4.95 & 5.0776 & TST & \\
\hline CHEMBL1543331 & 688155 & 4.9 & 5.1322 & TST & \\
\hline CHEMBL1603214 & 688155 & 4.55 & 5.1766 & TRN & \\
\hline CHEMBL1488541 & 688155 & 6.5 & 5.0481 & TRN & \\
\hline CHEMBL605185 & 688155 & 4.8 & 5.142 & TRN & \\
\hline CHEMBL1479211 & 688155 & 5.7 & 5.0053 & TRN & \\
\hline CHEMBL1566877 & 688155 & 4.9 & 4.9142 & TRN & \\
\hline CHEMBL1402323 & 688155 & 4.5 & 5.3177 & TRN & \\
\hline CHEMBL1535192 & 688155 & 6.35 & 4.8635 & TRN & \\
\hline CHEMBL1376741 & 688155 & 5.35 & 5.1193 & TRN & \\
\hline CHEMBL1579808 & 688155 & 5.9 & 4.974 & TST & \\
\hline CHEMBL 1448020 & 688155 & 4.55 & 4.9575 & TRN & \\
\hline CHEMBL1375994 & 688155 & 4.45 & 5.0591 & TRN & \\
\hline CHEMBL1346421 & 688155 & 4.9 & 4.8878 & TRN & \\
\hline CHEMBL1577334 & 688155 & 4.55 & 4.8666 & TRN & \\
\hline CHEMBL1455177 & 688155 & 4.85 & 5.1317 & TRN & \\
\hline CHEMBL1402035 & 688155 & 4.75 & 5.2206 & TRN & \\
\hline CHEMBL1416661 & 688155 & 4.95 & 5.0493 & TRN & \\
\hline
\end{tabular}




\begin{tabular}{|c|c|c|c|c|}
\hline \multicolumn{5}{|c|}{ Supplemental Table } \\
\hline CHEMBL1327772 & 688155 & 5.25 & 4.96 & TRN \\
\hline CHEMBL1445776 & 688155 & 5.0 & 5.149 & TRN \\
\hline CHEMBL1359019 & 688155 & 4.95 & 4.9117 & TRN \\
\hline CHEMBL1500857 & 688155 & 5.0 & 5.2233 & TRN \\
\hline CHEMBL1300906 & 688155 & 4.5 & 5.1694 & TRN \\
\hline CHEMBL1432072 & 688155 & 4.9 & 5.0863 & TRN \\
\hline CHEMBL1415963 & 688155 & 4.5 & 5.1777 & TRN \\
\hline CHEMBL1576390 & 688155 & 5.75 & 5.0536 & TRN \\
\hline CHEMBL1480329 & 688155 & 4.75 & 5.0707 & TRN \\
\hline CHEMBL1467730 & 688155 & 5.55 & 5.03 & TRN \\
\hline CHEMBL1406804 & 688155 & 4.55 & 5.1815 & TRN \\
\hline CHEMBL1599431 & 688155 & 5.2 & 4.9825 & TRN \\
\hline CHEMBL1363254 & 688155 & 5.55 & 5.0967 & TRN \\
\hline CHEMBL1376685 & 688155 & 5.1 & 5.0496 & TRN \\
\hline CHEMBL1376954 & 688155 & 5.3 & 5.0292 & TRN \\
\hline CHEMBL1416985 & 688155 & 6.0 & 5.0116 & TRN \\
\hline CHEMBL1475999 & 688155 & 6.0 & 5.0992 & TRN \\
\hline CHEMBL1987798 & 688155 & 6.5 & 4.9697 & TRN \\
\hline CHEMBL1414671 & 688155 & 4.95 & 4.9665 & TST \\
\hline CHEMBL1416947 & 688155 & 4.35 & 4.9076 & TRN \\
\hline CHEMBL1483315 & 688155 & 4.55 & 5.0617 & TRN \\
\hline CHEMBL1432055 & 688155 & 4.5 & 5.1706 & TRN \\
\hline CHEMBL1390254 & 688155 & 4.55 & 4.9925 & TRN \\
\hline CHEMBL1458891 & 688155 & 5.0 & 4.9301 & TRN \\
\hline CHEMBL1366254 & 688155 & 4.55 & 4.9837 & TRN \\
\hline CHEMBL155563 & 688155 & 5.0 & 5.1287 & TRN \\
\hline CHEMBL1525979 & 688155 & 4.5 & 4.9384 & TRN \\
\hline CHEMBL1347378 & 688155 & 6.1 & 5.0307 & TRN \\
\hline CHEMBL3213656 & 688155 & 4.9 & 5.066 & TST \\
\hline CHEMBL1321938 & 688155 & 5.55 & 5.1726 & TRN \\
\hline CHEMBL1540273 & 688155 & 4.85 & 5.0731 & TST \\
\hline CHEMBL1567207 & 688155 & 4.95 & 4.9562 & TRN \\
\hline CHEMBL1612905 & 688155 & 5.4 & 5.1609 & TST \\
\hline CHEMBL1313604 & 688155 & 6.5 & 5.0999 & TRN \\
\hline CHEMBL1484142 & 688155 & 5.0 & 5.1236 & TST \\
\hline CHEMBL1417430 & 688155 & 4.8 & 5.0241 & TRN \\
\hline CHEMBL1469785 & 688155 & 6.45 & 5.1698 & TRN \\
\hline CHEMBL1349215 & 688155 & 5.25 & 5.0271 & TRN \\
\hline CHEMBL1529463 & 688155 & 4.55 & 5.0671 & TRN \\
\hline CHEMBL1492286 & 688155 & 4.65 & 5.0618 & TST \\
\hline CHEMBL78150 & 688155 & 6.0 & 5.0687 & TRN \\
\hline CHEMBL1331857 & 688155 & 5.0 & 5.1021 & TRN \\
\hline CHEMBL1578147 & 688155 & 4.7 & 5.1978 & TST \\
\hline CHEMBL1323143 & 688155 & 4.55 & 5.0885 & TST \\
\hline CHEMBL1367095 & 688155 & 5.2 & 4.9913 & TRN \\
\hline CHEMBL1483923 & 688155 & 5.45 & 5.2372 & TST \\
\hline CHEMBL1379222 & 688155 & 5.0 & 5.0999 & TRN \\
\hline CHEMBL3209819 & 688155 & 4.5 & 5.1283 & TRN \\
\hline
\end{tabular}




\begin{tabular}{|c|c|c|c|c|c|}
\hline \multicolumn{6}{|c|}{ Supplemental Table S2.txt } \\
\hline CHEMBL1527349 & 688155 & 6.0 & 5.1096 & TRN & \\
\hline CHEMBL1325228 & 688155 & 5.0 & 5.0376 & TRN & \\
\hline CHEMBL1408969 & 688155 & 5.1 & 4.92399 & 99999999995 & TRN \\
\hline CHEMBL193627 & 688155 & 4.55 & 5.0035 & TST & \\
\hline CHEMBL1369446 & 688155 & 4.55 & 4.9613 & TRN & \\
\hline CHEMBL1566627 & 688155 & 5.95 & 5.145 & TRN & \\
\hline CHEMBL1401180 & 688155 & 5.5 & 5.1675 & TST & \\
\hline CHEMBL1578720 & 688155 & 4.95 & 5.1063 & TRN & \\
\hline CHEMBL1540929 & 688155 & 5.55 & 4.945 & TRN & \\
\hline CHEMBL1595934 & 688155 & 6.5 & 5.0435 & TST & \\
\hline CHEMBL1382010 & 688155 & 5.15 & 5.0522 & TRN & \\
\hline CHEMBL1336934 & 688155 & 4.95 & 5.0418 & TRN & \\
\hline CHEMBL1479240 & 688155 & 5.0 & 5.1401 & TST & \\
\hline CHEMBL1339708 & 688155 & 5.4 & 5.1203 & TRN & \\
\hline CHEMBL1571764 & 688155 & 4.55 & 5.0239 & TRN & \\
\hline CHEMBL1528858 & 688155 & 5.0 & 5.0848 & TST & \\
\hline CHEMBL1535910 & 688155 & 4.95 & 5.0523 & TRN & \\
\hline CHEMBL1381551 & 688155 & 4.75 & 5.113 & TST & \\
\hline CHEMBL1547182 & 688155 & 6.35 & 5.0527 & TST & \\
\hline CHEMBL1386928 & 688155 & 5.65 & 4.9727 & TRN & \\
\hline CHEMBL1426607 & 688155 & 6.0 & 5.0414 & TRN & \\
\hline CHEMBL1558287 & 688155 & 4.55 & 4.9914 & TST & \\
\hline CHEMBL1339840 & 688155 & 4.55 & 5.0148 & TRN & \\
\hline CHEMBL1558843 & 688155 & 5.4 & 4.9351 & TST & \\
\hline CHEMBL1418852 & 688155 & 5.5 & 4.9987 & TRN & \\
\hline CHEMBL1335833 & 688155 & 4.55 & 5.136 & TST & \\
\hline CHEMBL1384195 & 688155 & 4.6 & 5.1649 & TRN & \\
\hline CHEMBL1372293 & 688155 & 4.5 & 5.0376 & TRN & \\
\hline CHEMBL1602801 & 688155 & 6.0 & 5.20799 & 9999999999 & TST \\
\hline CHEMBL1430910 & 688155 & 4.75 & 5.1397 & TRN & \\
\hline CHEMBL1446940 & 688155 & 4.95 & 5.1572 & TST & \\
\hline CHEMBL1606736 & 688155 & 5.9 & 5.1136 & TST & \\
\hline CHEMBL1486934 & 688155 & 4.95 & 5.0871 & TRN & \\
\hline CHEMBL1408894 & 688155 & 4.95 & 5.0683 & TST & \\
\hline CHEMBL1607686 & 688155 & 4.55 & 5.1492 & TRN & \\
\hline CHEMBL1347795 & 688155 & 4.6 & 4.9409 & TRN & \\
\hline CHEMBL1409901 & 688155 & 5.0 & 4.9305 & TST & \\
\hline CHEMBL1382113 & 688155 & 5.0 & 5.1429 & TST & \\
\hline CHEMBL1517061 & 688155 & 4.7 & 4.9962 & TRN & \\
\hline CHEMBL1326280 & 688155 & 4.95 & 5.1767 & TRN & \\
\hline CHEMBL3209494 & 688155 & 5.0 & 4.9548 & TST & \\
\hline CHEMBL1379817 & 688155 & 4.95 & 5.0187 & TRN & \\
\hline CHEMBL1505849 & 688155 & 4.75 & 5.1431 & TRN & \\
\hline CHEMBL3209207 & 688155 & 4.8 & 5.0753 & TST & \\
\hline CHEMBL1311532 & 688155 & 4.55 & 4.9582 & TRN & \\
\hline CHEMBL1986151 & 688155 & 4.9 & 5.0799 & TST & \\
\hline CHEMBL1326350 & 688155 & 5.0 & 5.0906 & TST & \\
\hline CHEMBL1555832 & 688155 & 5.0 & 4.9353 & TST & \\
\hline
\end{tabular}




\begin{tabular}{|c|c|c|c|c|}
\hline \multicolumn{5}{|c|}{ Supplemental Table S2.txt } \\
\hline CHEMBL1613144 & 688155 & 4.9 & 5.0364 & TST \\
\hline CHEMBL1485420 & 688155 & 4.9 & 5.0495 & TRN \\
\hline CHEMBL1275655 & 688155 & 5.65 & 5.164 & TST \\
\hline CHEMBL1339433 & 688155 & 5.45 & 5.1554 & TRN \\
\hline CHEMBL1504167 & 688155 & 6.35 & 5.1898 & TRN \\
\hline CHEMBL1488124 & 688155 & 5.9 & 5.1581 & TRN \\
\hline CHEMBL1312568 & 688155 & 6.0 & 5.0052 & TRN \\
\hline CHEMBL1431505 & 688155 & 4.9 & 5.0324 & TRN \\
\hline CHEMBL1375060 & 688155 & 5.0 & 5.2181 & TRN \\
\hline CHEMBL1416104 & 688155 & 6.1 & 4.9328 & TRN \\
\hline CHEMBL1568848 & 688155 & 5.25 & 5.1245 & TST \\
\hline CHEMBL1508101 & 688155 & 4.5 & 5.2276 & TST \\
\hline CHEMBL1496315 & 688155 & 4.55 & 4.9267 & TRN \\
\hline CHEMBL1546088 & 688155 & 5.5 & 5.1234 & TST \\
\hline CHEMBL1411764 & 688155 & 5.2 & 4.9979 & TRN \\
\hline CHEMBL1381318 & 688155 & 4.95 & 5.1197 & TRN \\
\hline CHEMBL1577888 & 688155 & 4.55 & 4.9496 & TST \\
\hline CHEMBL1457420 & 688155 & 5.15 & 5.1863 & TRN \\
\hline CHEMBL1571483 & 688155 & 5.45 & 4.8569 & TRN \\
\hline CHEMBL1449215 & 688155 & 4.95 & 5.0586 & TRN \\
\hline CHEMBL1404714 & 688155 & 5.0 & 5.0176 & TRN \\
\hline CHEMBL1609833 & 688155 & 6.3 & 5.0219 & TRN \\
\hline CHEMBL1480050 & 688155 & 5.2 & 5.0957 & TRN \\
\hline CHEMBL1405359 & 688155 & 5.05 & 5.1504 & TRN \\
\hline CHEMBL1308815 & 688155 & 4.55 & 4.9262 & TST \\
\hline CHEMBL1456262 & 688155 & 4.9 & 5.1949 & TRN \\
\hline CHEMBL1314039 & 688155 & 5.0 & 5.0394 & TRN \\
\hline CHEMBL1544216 & 688155 & 4.9 & 5.0694 & TRN \\
\hline CHEMBL1533529 & 688155 & 4.55 & 5.0558 & TRN \\
\hline CHEMBL15192 & 688155 & 4.95 & 5.1747 & TST \\
\hline CHEMBL1442411 & 688155 & 5.0 & 5.013 & TRN \\
\hline CHEMBL1404682 & 688155 & 4.5 & 4.9851 & TRN \\
\hline CHEMBL1417290 & 688155 & 4.5 & 5.0089 & TRN \\
\hline CHEMBL1467822 & 688155 & 6.3 & 5.2125 & TRN \\
\hline CHEMBL1561641 & 688155 & 4.95 & 5.0114 & TRN \\
\hline CHEMBL1439499 & 688155 & 5.1 & 4.9861 & TRN \\
\hline CHEMBL1431350 & 688155 & 5.2 & 4.9563 & TRN \\
\hline CHEMBL1394490 & 688155 & 4.9 & 5.0401 & TST \\
\hline CHEMBL1370265 & 688155 & 4.8 & 4.9558 & TRN \\
\hline CHEMBL1478238 & 688155 & 5.3 & 5.0742 & TST \\
\hline CHEMBL1535712 & 688155 & 4.5 & 4.9605 & TST \\
\hline CHEMBL1329328 & 688155 & 4.55 & 5.0791 & TRN \\
\hline CHEMBL1438982 & 688155 & 6.45 & 5.0411 & TRN \\
\hline CHEMBL1550252 & 688155 & 4.9 & 5.102 & TRN \\
\hline CHEMBL1344127 & 688155 & 4.95 & 5.2435 & TRN \\
\hline CHEMBL1481718 & 688155 & 4.55 & 5.0293 & TRN \\
\hline CHEMBL1319858 & 688155 & 5.3 & 5.1359 & TST \\
\hline CHEMBL1581083 & 688155 & 5.95 & 5.0466 & TRN \\
\hline
\end{tabular}




\begin{tabular}{|c|c|c|c|c|c|}
\hline \multicolumn{6}{|c|}{ Supplemental Table S2.txt } \\
\hline CHEMBL1341119 & 688155 & 5.4 & 5.0226 & TRN & \\
\hline CHEMBL1419794 & 688155 & 5.25 & 4.9547 & TRN & \\
\hline CHEMBL1490429 & 688155 & 4.95 & 5.0153 & TRN & \\
\hline CHEMBL1432234 & 688155 & 5.9 & 5.0898 & TST & \\
\hline CHEMBL1550580 & 688155 & 5.4 & 4.9332 & TRN & \\
\hline CHEMBL1351651 & 688155 & 4.5 & 4.9341 & TRN & \\
\hline CHEMBL1369250 & 688155 & 6.0 & 5.1073 & TST & \\
\hline CHEMBL1308994 & 688155 & 5.85 & 5.1292 & TRN & \\
\hline CHEMBL1313074 & 688155 & 4.9 & 5.1272 & TST & \\
\hline CHEMBL1333181 & 688155 & 4.85 & 4.8926 & TRN & \\
\hline CHEMBL1312263 & 688155 & 4.95 & 5.0115 & TRN & \\
\hline CHEMBL1462433 & 688155 & 4.85 & 5.1536 & TST & \\
\hline CHEMBL1609516 & 688155 & 4.55 & 5.2263 & TRN & \\
\hline CHEMBL1455756 & 688155 & 4.6 & 4.8955 & TRN & \\
\hline CHEMBL1348732 & 688155 & 5.35 & 5.1444 & TST & \\
\hline CHEMBL1426964 & 688155 & 5.95 & 5.0389 & TST & \\
\hline CHEMBL1468104 & 688155 & 5.4 & 5.1175 & TST & \\
\hline CHEMBL1490629 & 688155 & 4.5 & 5.03600 & 00000000005 & TRN \\
\hline CHEMBL1505276 & 688155 & 4.75 & 5.0573 & TRN & \\
\hline CHEMBL1566428 & 688155 & 4.65 & 4.9264 & TRN & \\
\hline CHEMBL130867 & 688155 & 5.0 & 5.0522 & TST & \\
\hline CHEMBL1547807 & 688155 & 5.2 & 5.0913 & TST & \\
\hline CHEMBL1351741 & 688155 & 4.55 & 4.984 & TRN & \\
\hline CHEMBL1445788 & 688155 & 4.45 & 5.0123 & TRN & \\
\hline CHEMBL1336386 & 688155 & 5.0 & 5.0755 & TRN & \\
\hline CHEMBL1416213 & 688155 & 4.65 & 4.9159 & TRN & \\
\hline CHEMBL1392641 & 688155 & 4.95 & 5.1728 & TRN & \\
\hline CHEMBL1407146 & 688155 & 5.8 & 5.2517 & TRN & \\
\hline CHEMBL1564688 & 688155 & 6.1 & 5.3507 & TRN & \\
\hline CHEMBL1537669 & 688155 & 5.75 & 5.1904 & TRN & \\
\hline CHEMBL1479557 & 688155 & 5.45 & 5.0086 & TST & \\
\hline CHEMBL1369522 & 688155 & 5.5 & 5.1442 & TRN & \\
\hline CHEMBL1603702 & 688155 & 5.3 & 5.0428 & TRN & \\
\hline CHEMBL1438643 & 688155 & 4.5 & 5.1577 & TRN & \\
\hline CHEMBL1405692 & 688155 & 5.65 & 5.0517 & TRN & \\
\hline CHEMBL1460719 & 688155 & 4.5 & 4.9383 & TRN & \\
\hline CHEMBL1595919 & 688155 & 5.0 & 5.0229 & TRN & \\
\hline CHEMBL1569235 & 688155 & 4.95 & 4.9203 & TRN & \\
\hline CHEMBL1571622 & 688155 & 5.0 & 5.0072 & TRN & \\
\hline CHEMBL1598358 & 688155 & 5.45 & 5.0238 & TRN & \\
\hline CHEMBL1335967 & 688155 & 5.0 & 4.9895 & TRN & \\
\hline CHEMBL1312889 & 688155 & 5.4 & 5.184 & TST & \\
\hline CHEMBL1344476 & 688155 & 5.45 & 5.0124 & TRN & \\
\hline CHEMBL1303898 & 688155 & 5.05 & 5.0959 & TRN & \\
\hline CHEMBL1341497 & 688155 & 4.85 & 5.1339 & TST & \\
\hline CHEMBL1462865 & 688155 & 5.4 & 5.0398 & TRN & \\
\hline CHEMBL1353455 & 688155 & 5.15 & 5.0708 & TST & \\
\hline CHEMBL1605155 & 688155 & 6.5 & 5.098 & TRN & \\
\hline
\end{tabular}




\begin{tabular}{|c|c|c|c|c|}
\hline \multicolumn{5}{|c|}{ Supplemental Table S2.txt } \\
\hline CHEMBL1481335 & 688155 & 5.0 & 5.0497 & TRN \\
\hline CHEMBL1400027 & 688155 & 4.55 & 4.9873 & TST \\
\hline CHEMBL1311883 & 688155 & 4.75 & 5.0654 & TRN \\
\hline CHEMBL1389122 & 688155 & 4.95 & 5.0135 & TRN \\
\hline CHEMBL1549459 & 688155 & 4.6 & 5.1006 & TRN \\
\hline CHEMBL1352737 & 688155 & 5.3 & 5.0775 & TRN \\
\hline CHEMBL1473925 & 688155 & 5.35 & 5.1511 & TRN \\
\hline CHEMBL1424902 & 688155 & 6.15 & 5.1013 & TRN \\
\hline CHEMBL3212137 & 688155 & 4.95 & 5.1319 & TST \\
\hline CHEMBL3210929 & 688155 & 4.95 & 5.0563 & TST \\
\hline CHEMBL1472701 & 688155 & 5.0 & 5.0647 & TRN \\
\hline CHEMBL1502014 & 688155 & 5.5 & 4.9802 & TRN \\
\hline CHEMBL1472502 & 688155 & 5.15 & 5.1628 & TRN \\
\hline CHEMBL1541720 & 688155 & 5.8 & 4.9659 & TRN \\
\hline CHEMBL1368621 & 688155 & 5.0 & 4.9684 & TRN \\
\hline CHEMBL1338362 & 688155 & 4.95 & 5.0476 & TRN \\
\hline CHEMBL1585404 & 688155 & 4.9 & 4.9086 & TRN \\
\hline CHEMBL1345955 & 688155 & 4.9 & 5.0552 & TRN \\
\hline CHEMBL1580611 & 688155 & 5.55 & 5.0025 & TST \\
\hline CHEMBL1470374 & 688155 & 5.0 & 5.1967 & TRN \\
\hline CHEMBL1310672 & 688155 & 5.3 & 4.9478 & TRN \\
\hline CHEMBL3192174 & 688155 & 4.95 & 5.1312 & TRN \\
\hline CHEMBL1376724 & 688155 & 4.95 & 4.9896 & TRN \\
\hline CHEMBL1386124 & 688155 & 4.75 & 5.0717 & TRN \\
\hline CHEMBL1555806 & 688155 & 5.0 & 5.0689 & TRN \\
\hline CHEMBL1506765 & 688155 & 5.0 & 5.0717 & TRN \\
\hline CHEMBL3213805 & 688155 & 5.1 & 5.2287 & TRN \\
\hline CHEMBL1566386 & 688155 & 4.55 & 5.0428 & TRN \\
\hline CHEMBL1342710 & 688155 & 6.5 & 5.0236 & TRN \\
\hline CHEMBL1309854 & 688155 & 4.65 & 4.9593 & TRN \\
\hline CHEMBL1610515 & 688155 & 4.95 & 5.0651 & TRN \\
\hline CHEMBL1443573 & 688155 & 4.9 & 5.1862 & TST \\
\hline CHEMBL1557079 & 688155 & 4.8 & 5.0183 & TRN \\
\hline CHEMBL1411217 & 688155 & 4.65 & 5.2024 & TRN \\
\hline CHEMBL1373299 & 688155 & 4.85 & 5.1197 & TRN \\
\hline CHEMBL1330442 & 688155 & 4.5 & 5.0091 & TST \\
\hline CHEMBL1541687 & 688155 & 4.95 & 5.2254 & TRN \\
\hline CHEMBL1370943 & 688155 & 5.95 & 5.2062 & TRN \\
\hline CHEMBL1492025 & 688155 & 4.95 & 5.0791 & TST \\
\hline CHEMBL1410782 & 688155 & 4.55 & 5.0391 & TRN \\
\hline CHEMBL1382306 & 688155 & 5.55 & 5.1292 & TST \\
\hline CHEMBL1546366 & 688155 & 6.5 & 5.1278 & TRN \\
\hline CHEMBL1534897 & 688155 & 4.5 & 5.2579 & TRN \\
\hline CHEMBL1517387 & 688155 & 4.9 & 4.9205 & TRN \\
\hline CHEMBL1320071 & 688155 & 5.45 & 5.1311 & TRN \\
\hline CHEMBL1572132 & 688155 & 4.5 & 5.0355 & TRN \\
\hline CHEMBL1506932 & 688155 & 4.95 & 5.0805 & TRN \\
\hline CHEMBL1580154 & 688155 & 5.5 & 5.1127 & TRN \\
\hline
\end{tabular}




\begin{tabular}{|c|c|c|c|c|c|}
\hline \multicolumn{6}{|c|}{ Supplemental Table S2.txt } \\
\hline CHEMBL1409217 & 688155 & 4.7 & 5.0317 & TRN & \\
\hline CHEMBL1372535 & 688155 & 4.95 & 5.0533 & TRN & \\
\hline CHEMBL1449223 & 688155 & 5.9 & 5.1476 & TRN & \\
\hline CHEMBL 3193432 & 688155 & 5.55 & 5.0281 & TRN & \\
\hline CHEMBL1480089 & 688155 & 5.0 & 5.0893 & TRN & \\
\hline CHEMBL1347502 & 688155 & 5.3 & 5.1217 & TRN & \\
\hline CHEMBL1398972 & 688155 & 5.0 & 5.1202 & TRN & \\
\hline CHEMBL1306182 & 688155 & 5.1 & 5.0558 & TRN & \\
\hline CHEMBL1507058 & 688155 & 4.65 & 4.9521 & TRN & \\
\hline CHEMBL1478825 & 688155 & 4.8 & 4.9117 & TRN & \\
\hline CHEMBL1444347 & 688155 & 5.5 & 5.0709 & TRN & \\
\hline CHEMBL1508582 & 688155 & 5.85 & 4.9068 & TRN & \\
\hline CHEMBL1478935 & 688155 & 4.95 & 5.1608 & TST & \\
\hline CHEMBL1463712 & 688155 & 4.55 & 5.0212 & TRN & \\
\hline CHEMBL1324140 & 688155 & 5.7 & 5.0759 & TRN & \\
\hline CHEMBL1301207 & 688155 & 4.95 & 5.1773 & TRN & \\
\hline CHEMBL3189398 & 688155 & 5.95 & 5.0186 & TST & \\
\hline CHEMBL1594935 & 688155 & 5.25 & 5.1978 & TST & \\
\hline CHEMBL1447963 & 688155 & 4.5 & 5.2743 & TRN & \\
\hline CHEMBL1493014 & 688155 & 5.0 & 5.1348 & TRN & \\
\hline CHEMBL1387072 & 688155 & 4.75 & 4.9143 & TRN & \\
\hline CHEMBL1588138 & 688155 & 4.95 & 5.1551 & TRN & \\
\hline CHEMBL 21823 & 688155 & 5.45 & 5.1393 & TRN & \\
\hline CHEMBL1373988 & 688155 & 4.5 & 4.9428 & TRN & \\
\hline CHEMBL1299756 & 688155 & 4.95 & 4.9674 & TRN & \\
\hline CHEMBL1458448 & 688155 & 4.9 & 5.1695 & TRN & \\
\hline CHEMBL1529236 & 688155 & 4.85 & 5.0955 & TRN & \\
\hline CHEMBL1499047 & 688155 & 5.85 & 5.0786 & TST & \\
\hline CHEMBL1587324 & 688155 & 4.8 & 5.0339 & TRN & \\
\hline CHEMBL1466867 & 688155 & 4.55 & 5.1167 & TST & \\
\hline CHEMBL1388204 & 688155 & 5.45 & 5.1332 & TRN & \\
\hline CHEMBL1419885 & 688155 & 5.4 & 5.2771 & TRN & \\
\hline CHEMBL1477710 & 688155 & 4.95 & 5.20799 & 9999999999 & TRN \\
\hline CHEMBL1491484 & 688155 & 6.05 & 5.1118 & TST & \\
\hline CHEMBL1363721 & 688155 & 5.25 & 5.2676 & TRN & \\
\hline CHEMBL1429375 & 688155 & 4.55 & 5.0248 & TRN & \\
\hline CHEMBL1386204 & 688155 & 4.9 & 4.9898 & TRN & \\
\hline CHEMBL3191951 & 688155 & 5.0 & 4.9908 & TRN & \\
\hline CHEMBL1303908 & 688155 & 5.5 & 5.1148 & TRN & \\
\hline CHEMBL1411085 & 688155 & 4.55 & 5.0704 & TRN & \\
\hline CHEMBL1505494 & 688155 & 4.5 & 5.0574 & TST & \\
\hline CHEMBL1290409 & 688155 & 6.3 & 5.2618 & TRN & \\
\hline CHEMBL3184468 & 688155 & 5.0 & 5.1355 & TST & \\
\hline CHEMBL1368626 & 688155 & 6.3 & 5.1793 & TRN & \\
\hline CHEMBL1527912 & 688155 & 5.65 & 5.039 & TRN & \\
\hline CHEMBL1523672 & 688155 & 4.95 & 5.0572 & TRN & \\
\hline CHEMBL1335367 & 688155 & 4.75 & 5.1916 & TRN & \\
\hline CHEMBL1426040 & 688155 & 4.55 & 4.9922 & TRN & \\
\hline
\end{tabular}




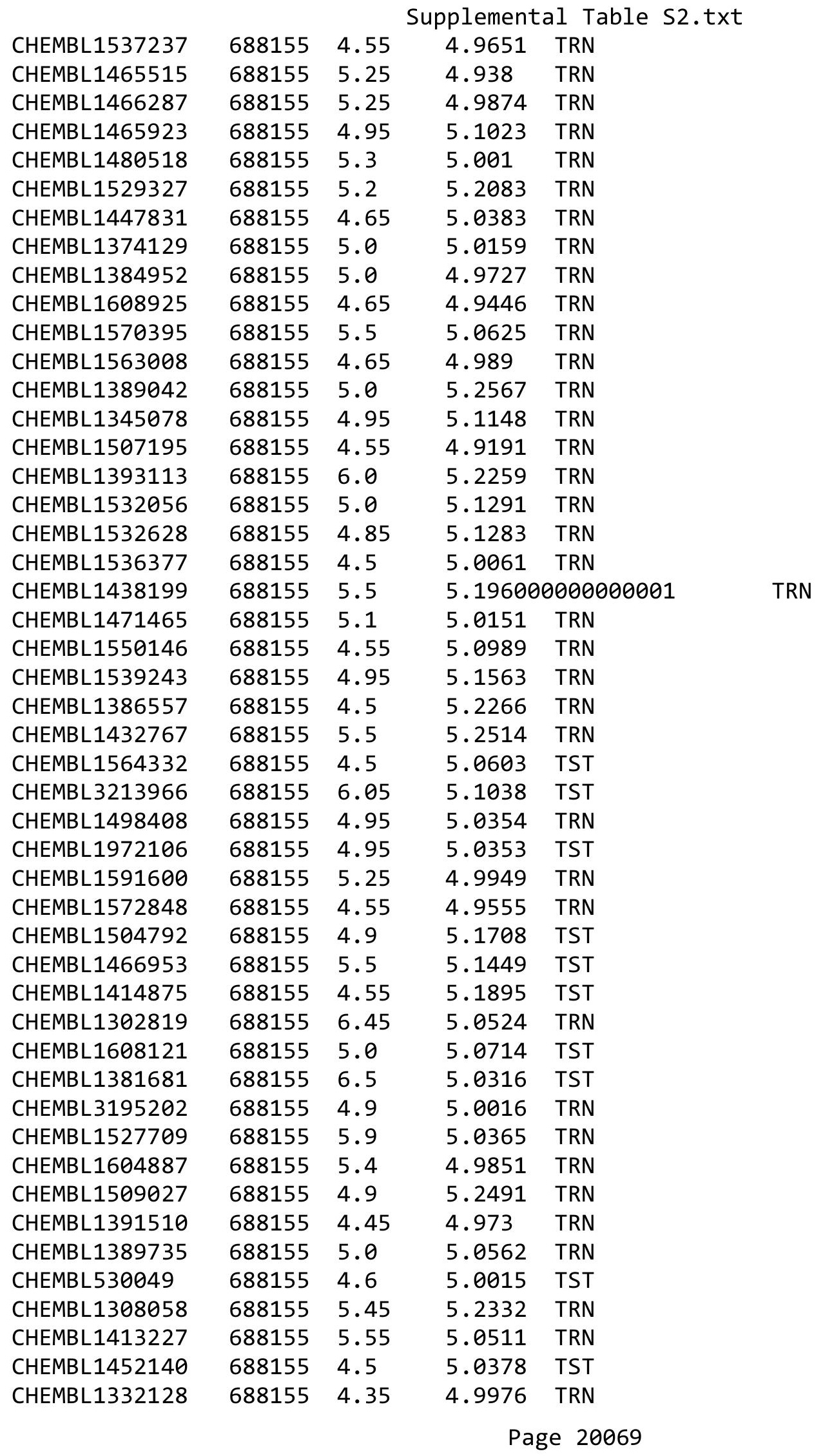




\begin{tabular}{|c|c|c|c|c|}
\hline \multicolumn{5}{|c|}{ Supplemental Table S2.txt } \\
\hline CHEMBL1550670 & 688155 & 5.9 & 4.9405 & TRN \\
\hline CHEMBL1308649 & 688155 & 6.5 & 5.078 & TRN \\
\hline CHEMBL1712082 & 688155 & 5.1 & 5.1394 & TST \\
\hline CHEMBL3211329 & 688155 & 6.0 & 5.0979 & TRN \\
\hline CHEMBL1610772 & 688155 & 6.35 & 5.18 & TRN \\
\hline CHEMBL1307373 & 688155 & 4.9 & 5.1082 & TST \\
\hline CHEMBL1430047 & 688155 & 4.9 & 5.0929 & TST \\
\hline CHEMBL1579841 & 688155 & 4.95 & 4.9418 & TRN \\
\hline CHEMBL1499817 & 688155 & 4.55 & 5.224 & TRN \\
\hline CHEMBL1507049 & 688155 & 4.55 & 5.1425 & TRN \\
\hline CHEMBL1309120 & 688155 & 4.95 & 5.0265 & TRN \\
\hline CHEMBL3192393 & 688155 & 5.0 & 4.921 & TST \\
\hline CHEMBL1522067 & 688155 & 4.65 & 5.1379 & TRN \\
\hline CHEMBL1542470 & 688155 & 5.75 & 5.1666 & TST \\
\hline CHEMBL1583656 & 688155 & 5.0 & 5.0734 & TRN \\
\hline CHEMBL1337096 & 688155 & 5.15 & 5.2353 & TRN \\
\hline CHEMBL1416679 & 688155 & 4.95 & 5.0807 & TRN \\
\hline CHEMBL1504991 & 688155 & 4.75 & 4.9506 & TRN \\
\hline CHEMBL587728 & 688155 & 5.55 & 5.0443 & TRN \\
\hline CHEMBL1463984 & 688155 & 6.5 & 5.1431 & TRN \\
\hline CHEMBL1329826 & 688155 & 5.0 & 5.101 & TST \\
\hline CHEMBL1310523 & 688155 & 5.45 & 5.1857 & TRN \\
\hline CHEMBL3195544 & 688155 & 4.55 & 5.0054 & TST \\
\hline CHEMBL1416168 & 688155 & 4.55 & 5.1591 & TRN \\
\hline CHEMBL1576394 & 688155 & 6.5501 & 5.1042 & TRN \\
\hline CHEMBL1330994 & 688155 & 4.8 & 4.9927 & TRN \\
\hline CHEMBL1390716 & 688155 & 4.95 & 5.0043 & TST \\
\hline CHEMBL1453034 & 688155 & 6.6 & 5.0291 & TRN \\
\hline CHEMBL1575649 & 688155 & 4.9 & 5.0421 & TRN \\
\hline CHEMBL1256661 & 688155 & 5.2 & 5.1512 & TRN \\
\hline CHEMBL1326239 & 688155 & 4.95 & 5.066 & TRN \\
\hline CHEMBL1302022 & 688155 & 5.55 & 4.9955 & TRN \\
\hline CHEMBL1388477 & 688155 & 4.8 & 5.2153 & TRN \\
\hline CHEMBL1570889 & 688155 & 5.25 & 5.1658 & TST \\
\hline CHEMBL1550961 & 688155 & 5.0 & 5.072 & TRN \\
\hline CHEMBL1455557 & 688155 & 4.55 & 5.0267 & TRN \\
\hline CHEMBL1374214 & 688155 & 4.75 & 5.0484 & TRN \\
\hline CHEMBL1463091 & 688155 & 5.35 & 5.1021 & TRN \\
\hline CHEMBL1603525 & 688155 & 5.9 & 5.2467 & TRN \\
\hline CHEMBL1366148 & 688155 & 5.0 & 5.2121 & TRN \\
\hline CHEMBL1392651 & 688155 & 5.0 & 5.0655 & TST \\
\hline CHEMBL1308471 & 688155 & 4.95 & 4.9976 & TRN \\
\hline CHEMBL1559525 & 688155 & 4.8 & 5.0959 & TRN \\
\hline CHEMBL1365553 & 688155 & 5.0 & 5.0155 & TRN \\
\hline CHEMBL1333962 & 688155 & 5.3 & 4.9222 & TRN \\
\hline CHEMBL1375326 & 688155 & 4.9 & 5.0475 & TRN \\
\hline CHEMBL1597827 & 688155 & 5.1 & 5.1247 & TST \\
\hline CHEMBL1462162 & 688155 & 4.55 & 4.9721 & TRN \\
\hline
\end{tabular}




\begin{tabular}{|c|c|c|c|c|c|}
\hline & & \multicolumn{4}{|c|}{ Supplemental Table s2.txt } \\
\hline CHEMBL1427723 & 688155 & 5.05 & 5.0771 & TRN & \\
\hline CHEMBL1479574 & 688155 & 4.55 & 5.021 & TRN & \\
\hline CHEMBL1366804 & 688155 & 5.3 & 4.9811 & TRN & \\
\hline CHEMBL1539934 & 688155 & 4.85 & 5.0149 & TRN & \\
\hline CHEMBL1497945 & 688155 & 4.5 & 5.1811 & TRN & \\
\hline CHEMBL1532111 & 688155 & 4.85 & 5.1011 & TST & \\
\hline CHEMBL573524 & 688155 & 4.95 & 4.994 & TRN & \\
\hline CHEMBL1415351 & 688155 & 5.5 & 4.9655 & TST & \\
\hline CHEMBL1353342 & 688155 & 4.55 & 5.0837 & TST & \\
\hline CHEMBL1350706 & 688155 & 4.7 & 4.8905 & TRN & \\
\hline CHEMBL1582104 & 688155 & 4.65 & 5.2803 & TST & \\
\hline CHEMBL1309255 & 688155 & 6.5 & 5.085 & TST & \\
\hline CHEMBL1328778 & 688155 & 5.0 & 5.0392 & TRN & \\
\hline CHEMBL1446667 & 688155 & 5.0 & 5.0377 & TST & \\
\hline CHEMBL1562996 & 688155 & 4.9 & 4.9925 & TRN & \\
\hline CHEMBL1313675 & 688155 & 4.55 & 5.07100 & 0000000001 & TST \\
\hline CHEMBL1558851 & 688155 & 4.95 & 5.0435 & TRN & \\
\hline CHEMBL1537436 & 688155 & 4.55 & 4.9004 & TRN & \\
\hline CHEMBL1400292 & 688155 & 4.95 & 4.9867 & TST & \\
\hline CHEMBL1427520 & 688155 & 5.0 & 5.1258 & TRN & \\
\hline CHEMBL1521599 & 688155 & 5.0 & 5.1119 & TRN & \\
\hline CHEMBL1351826 & 688155 & 4.9 & 5.1474 & TST & \\
\hline CHEMBL1362087 & 688155 & 4.55 & 4.974 & TRN & \\
\hline CHEMBL 2449003 & 688155 & 4.85 & 5.2191 & TRN & \\
\hline CHEMBL3211476 & 688155 & 5.1 & 5.074 & TRN & \\
\hline CHEMBL1594521 & 688155 & 4.95 & 5.0208 & TRN & \\
\hline CHEMBL1412509 & 688155 & 5.65 & 5.2551 & TRN & \\
\hline CHEMBL1380816 & 688155 & 4.9 & 4.9196 & TRN & \\
\hline CHEMBL1309310 & 688155 & 4.85 & 5.016 & TRN & \\
\hline CHEMBL1446535 & 688155 & 5.3 & 5.2112 & TRN & \\
\hline CHEMBL1334040 & 688155 & 4.85 & 5.1841 & TRN & \\
\hline CHEMBL1338665 & 688155 & 4.5 & 4.9687 & TRN & \\
\hline CHEMBL1340256 & 688155 & 5.05 & 5.2824 & TST & \\
\hline CHEMBL1454651 & 688155 & 4.95 & 5.1546 & TRN & \\
\hline CHEMBL1447405 & 688155 & 4.75 & 5.2525 & TRN & \\
\hline CHEMBL1301780 & 688155 & 4.55 & 5.1087 & TST & \\
\hline CHEMBL1463906 & 688155 & 5.0 & 5.0387 & TST & \\
\hline CHEMBL1578738 & 688155 & 5.0 & 4.9937 & TRN & \\
\hline CHEMBL1397653 & 688155 & 4.95 & 5.1228 & TRN & \\
\hline CHEMBL1532513 & 688155 & 5.0 & 5.0403 & TRN & \\
\hline CHEMBL1499629 & 688155 & 4.95 & 5.091 & TRN & \\
\hline CHEMBL1572214 & 688155 & 5.05 & 4.9841 & TST & \\
\hline CHEMBL1580183 & 688155 & 5.95 & 5.2723 & TRN & \\
\hline CHEMBL1497000 & 688155 & 4.9 & 5.1386 & TRN & \\
\hline CHEMBL1582767 & 688155 & 5.7 & 5.0108 & TST & \\
\hline CHEMBL1603602 & 688155 & 5.2 & 4.9971 & TRN & \\
\hline CHEMBL1569696 & 688155 & 5.1 & 5.044 & TRN & \\
\hline CHEMBL1516868 & 688155 & 4.8 & 5.1061 & TRN & \\
\hline
\end{tabular}




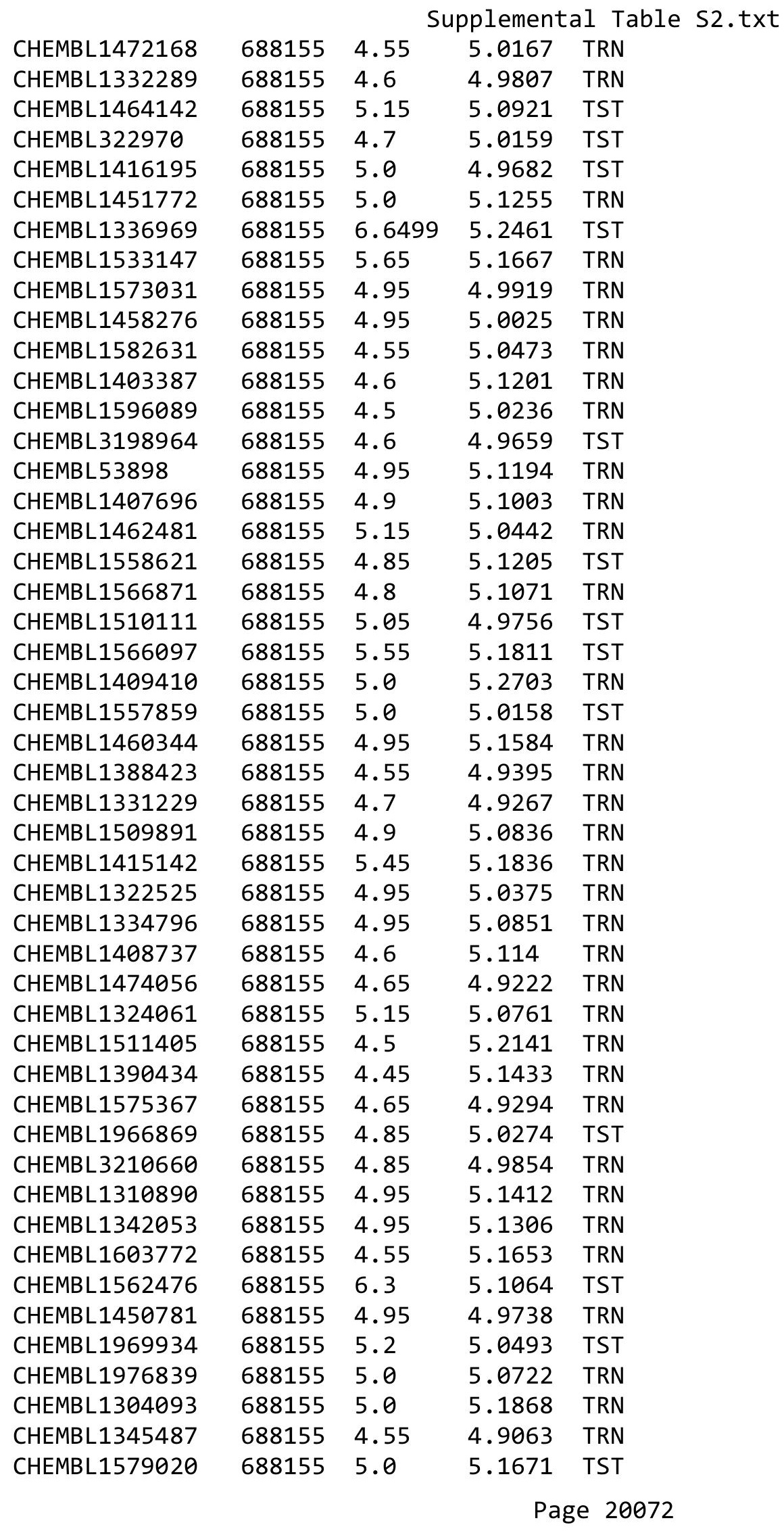




\begin{tabular}{|c|c|c|c|c|c|}
\hline \multicolumn{6}{|c|}{ Supplemental Table S2.txt } \\
\hline CHEMBL1375364 & 688155 & 4.95 & 5.229 & TRN & \\
\hline CHEMBL1450470 & 688155 & 5.15 & 5.0457 & TRN & \\
\hline CHEMBL1578765 & 688155 & 5.7 & 5.0341 & TRN & \\
\hline CHEMBL1509842 & 688155 & 5.0 & 4.9283 & TRN & \\
\hline CHEMBL275938 & 688155 & 4.95 & 5.0844 & TST & \\
\hline CHEMBL1455375 & 688155 & 5.45 & 5.0054 & TST & \\
\hline CHEMBL1410195 & 688155 & 5.0 & 5.0544 & TRN & \\
\hline CHEMBL1335943 & 688155 & 6.5501 & 5.2103 & TST & \\
\hline CHEMBL1544655 & 688155 & 4.9 & 5.0689 & TRN & \\
\hline CHEMBL1464112 & 688155 & 4.5 & 5.11100 & 0000000001 & TRN \\
\hline CHEMBL1586484 & 688155 & 4.5 & 5.1488 & TRN & \\
\hline CHEMBL1379196 & 688155 & 4.6 & 5.1065 & TRN & \\
\hline CHEMBL1590821 & 688155 & 4.85 & 5.0322 & TRN & \\
\hline CHEMBL1599437 & 688155 & 5.6 & 5.2162 & TST & \\
\hline CHEMBL1304601 & 688155 & 4.9 & 5.0223 & TST & \\
\hline CHEMBL441473 & 688155 & 5.3 & 4.9467 & TRN & \\
\hline CHEMBL1539590 & 688155 & 5.45 & 5.3227 & TRN & \\
\hline CHEMBL1587883 & 688155 & 5.25 & 5.0239 & TRN & \\
\hline CHEMBL1455980 & 688155 & 4.55 & 5.098 & TST & \\
\hline CHEMBL1557598 & 688155 & 5.0 & 5.0079 & TRN & \\
\hline CHEMBL1404328 & 688155 & 4.55 & 5.0219 & TRN & \\
\hline CHEMBL1360226 & 688155 & 5.05 & 5.0653 & TST & \\
\hline CHEMBL1443475 & 688155 & 5.0 & 5.1528 & TRN & \\
\hline CHEMBL1340131 & 688155 & 5.05 & 5.1925 & TRN & \\
\hline CHEMBL1478054 & 688155 & 4.95 & 5.1127 & TST & \\
\hline CHEMBL1334125 & 688155 & 5.95 & 5.1478 & TRN & \\
\hline CHEMBL1352828 & 688155 & 4.65 & 5.0922 & TRN & \\
\hline CHEMBL1605874 & 688155 & 4.5 & 5.2731 & TRN & \\
\hline CHEMBL1417790 & 688155 & 4.55 & 4.8767 & TST & \\
\hline CHEMBL1526433 & 688155 & 5.5 & 5.0202 & TRN & \\
\hline CHEMBL1491177 & 688155 & 5.0 & 5.1869 & TRN & \\
\hline CHEMBL1499476 & 688155 & 4.9 & 5.0919 & TRN & \\
\hline CHEMBL1466049 & 688155 & 6.0 & 5.1485 & TST & \\
\hline CHEMBL1380503 & 688155 & 4.5 & 5.1216 & TST & \\
\hline CHEMBL1325849 & 688155 & 5.0 & 5.2144 & TRN & \\
\hline CHEMBL1608956 & 688155 & 4.9 & 5.0471 & TST & \\
\hline CHEMBL1477468 & 688155 & 5.3 & 5.1866 & TST & \\
\hline CHEMBL1531900 & 688155 & 4.9 & 5.2332 & TRN & \\
\hline CHEMBL1422825 & 688155 & 4.65 & 5.1367 & TRN & \\
\hline CHEMBL1484007 & 688155 & 5.05 & 5.065 & TST & \\
\hline CHEMBL1605962 & 688155 & 4.85 & 4.9416 & TRN & \\
\hline CHEMBL1481361 & 688155 & 5.0 & 5.1383 & TST & \\
\hline CHEMBL1340078 & 688155 & 5.05 & 5.0356 & TRN & \\
\hline CHEMBL1586600 & 688155 & 4.6 & 5.0728 & TRN & \\
\hline CHEMBL3209060 & 688155 & 6.0 & 5.0475 & TRN & \\
\hline CHEMBL1380850 & 688155 & 5.1 & 5.0949 & TRN & \\
\hline CHEMBL1410614 & 688155 & 5.6 & 5.3384 & TRN & \\
\hline CHEMBL1407494 & 688155 & 5.2 & 5.1387 & TST & \\
\hline
\end{tabular}




\begin{tabular}{|c|c|c|c|c|}
\hline \multicolumn{5}{|c|}{ Supplemental Table S2.txt } \\
\hline CHEMBL1487706 & 688155 & 4.5 & 5.2179 & TST \\
\hline CHEMBL1584975 & 688155 & 5.45 & 4.9963 & TRN \\
\hline CHEMBL1370837 & 688155 & 4.95 & 4.9697 & TRN \\
\hline CHEMBL1570812 & 688155 & 5.95 & 5.0753 & TRN \\
\hline CHEMBL1401431 & 688155 & 4.55 & 5.0399 & TRN \\
\hline CHEMBL1582197 & 688155 & 4.65 & 5.0448 & TRN \\
\hline CHEMBL1300588 & 688155 & 4.6 & 5.1096 & TST \\
\hline CHEMBL1599652 & 688155 & 5.0 & 4.9939 & TRN \\
\hline CHEMBL1425738 & 688155 & 4.9 & 4.9806 & TRN \\
\hline CHEMBL1575331 & 688155 & 6.0 & 4.9531 & TRN \\
\hline CHEMBL1582768 & 688155 & 5.1 & 4.9515 & TRN \\
\hline CHEMBL1303808 & 688155 & 5.65 & 5.2707 & TRN \\
\hline CHEMBL3211567 & 688155 & 5.2 & 5.1177 & TST \\
\hline CHEMBL1967697 & 688155 & 5.3 & 5.0786 & TRN \\
\hline CHEMBL391877 & 688155 & 4.95 & 4.9596 & TRN \\
\hline CHEMBL1456481 & 688155 & 4.85 & 5.0188 & TRN \\
\hline CHEMBL1579992 & 688155 & 5.3 & 5.2132 & TRN \\
\hline CHEMBL1562655 & 688155 & 4.95 & 5.1336 & TST \\
\hline CHEMBL1556330 & 688155 & 4.9 & 5.038 & TRN \\
\hline CHEMBL1571454 & 688155 & 4.8 & 5.0456 & TRN \\
\hline CHEMBL1372495 & 688155 & 4.5 & 5.0823 & TRN \\
\hline CHEMBL1468803 & 688155 & 4.95 & 4.9344 & TRN \\
\hline CHEMBL1350539 & 688155 & 4.9 & 5.1127 & TST \\
\hline CHEMBL1498247 & 688155 & 5.1 & 5.0387 & TRN \\
\hline CHEMBL1432842 & 688155 & 5.45 & 4.9929 & TST \\
\hline CHEMBL1305868 & 688155 & 4.6 & 4.9549 & TRN \\
\hline CHEMBL1442709 & 688155 & 5.8 & 5.0026 & TRN \\
\hline CHEMBL1525939 & 688155 & 5.35 & 5.0108 & TRN \\
\hline CHEMBL1479144 & 688155 & 5.0 & 4.8397 & TRN \\
\hline CHEMBL1542030 & 688155 & 4.55 & 5.2853 & TRN \\
\hline CHEMBL1327864 & 688155 & 5.0 & 5.0791 & TRN \\
\hline CHEMBL1493355 & 688155 & 4.9 & 4.9473 & TRN \\
\hline CHEMBL1331535 & 688155 & 5.25 & 5.1966 & TST \\
\hline CHEMBL1413220 & 688155 & 4.95 & 4.8425 & TRN \\
\hline CHEMBL1445620 & 688155 & 5.2 & 5.0761 & TRN \\
\hline CHEMBL1568679 & 688155 & 5.9 & 5.0894 & TRN \\
\hline CHEMBL1563669 & 688155 & 4.55 & 4.9931 & TRN \\
\hline CHEMBL1401159 & 688155 & 5.0 & 5.0322 & TRN \\
\hline CHEMBL1403102 & 688155 & 4.55 & 4.9889 & TST \\
\hline CHEMBL1441215 & 688155 & 4.55 & 4.9556 & TRN \\
\hline CHEMBL1597040 & 688155 & 4.55 & 5.0998 & TRN \\
\hline CHEMBL1411986 & 688155 & 5.55 & 5.0239 & TRN \\
\hline CHEMBL1594650 & 688155 & 4.7 & 4.9417 & TRN \\
\hline CHEMBL1480005 & 688155 & 5.0 & 5.1687 & TRN \\
\hline CHEMBL1970265 & 688155 & 5.05 & 5.1165 & TRN \\
\hline CHEMBL1337347 & 688155 & 4.9 & 4.9907 & TRN \\
\hline CHEMBL1504692 & 688155 & 4.55 & 4.982 & TST \\
\hline CHEMBL1506817 & 688155 & 5.05 & 5.26 & TRN \\
\hline
\end{tabular}




\begin{tabular}{|c|c|c|c|c|}
\hline \multicolumn{5}{|c|}{ Supplemental Table S2.txt } \\
\hline CHEMBL1337039 & 688155 & 6.5 & 4.999 & TRN \\
\hline CHEMBL1430854 & 688155 & 5.25 & 5.1281 & TST \\
\hline CHEMBL1463735 & 688155 & 5.8 & 5.0057 & TRN \\
\hline CHEMBL1379717 & 688155 & 4.45 & 5.0283 & TRN \\
\hline CHEMBL 1350020 & 688155 & 4.55 & 4.9987 & TST \\
\hline CHEMBL1419387 & 688155 & 4.85 & 5.0136 & TRN \\
\hline CHEMBL3190033 & 688155 & 5.95 & 5.0318 & TRN \\
\hline CHEMBL1592557 & 688155 & 4.55 & 4.8854 & TRN \\
\hline CHEMBL1346130 & 688155 & 4.8 & 5.1986 & TST \\
\hline CHEMBL1319314 & 688155 & 4.65 & 5.0008 & TRN \\
\hline CHEMBL1606315 & 688155 & 4.9 & 4.9872 & TRN \\
\hline CHEMBL1318837 & 688155 & 5.2 & 5.1865 & TRN \\
\hline CHEMBL1386382 & 688155 & 5.15 & 5.1498 & TRN \\
\hline CHEMBL1452308 & 688155 & 4.9 & 5.2082 & TST \\
\hline CHEMBL1414653 & 688155 & 4.55 & 5.1008 & TST \\
\hline CHEMBL1418456 & 688155 & 5.75 & 5.1817 & TRN \\
\hline CHEMBL1595645 & 688155 & 4.65 & 5.0133 & TRN \\
\hline CHEMBL3208502 & 688155 & 5.2 & 5.0046 & TST \\
\hline CHEMBL1498658 & 688155 & 5.45 & 5.0564 & TRN \\
\hline CHEMBL1327600 & 688155 & 5.35 & 5.0587 & TST \\
\hline CHEMBL1305498 & 688155 & 6.4 & 5.2597 & TST \\
\hline CHEMBL1329436 & 688155 & 4.85 & 5.3214 & TRN \\
\hline CHEMBL1548598 & 688155 & 5.85 & 5.0529 & TRN \\
\hline CHEMBL1440640 & 688155 & 6.0 & 5.2508 & TRN \\
\hline CHEMBL1302577 & 688155 & 4.85 & 5.0934 & TRN \\
\hline CHEMBL1578905 & 688155 & 5.85 & 5.169 & TRN \\
\hline CHEMBL1353116 & 688155 & 4.95 & 5.1277 & TRN \\
\hline CHEMBL3194766 & 688155 & 4.9 & 4.9496 & TRN \\
\hline CHEMBL1328450 & 688155 & 6.0 & 5.1996 & TRN \\
\hline CHEMBL1474732 & 688155 & 5.0 & 5.1058 & TST \\
\hline CHEMBL1327040 & 688155 & 4.65 & 4.9611 & TRN \\
\hline CHEMBL1379443 & 688155 & 6.0 & 4.912 & TST \\
\hline CHEMBL1440818 & 688155 & 4.9 & 5.1619 & TRN \\
\hline CHEMBL3192732 & 688155 & 6.45 & 5.0934 & TST \\
\hline CHEMBL1538896 & 688155 & 5.0 & 5.1122 & TRN \\
\hline CHEMBL1428225 & 688155 & 4.9 & 5.0265 & TRN \\
\hline CHEMBL 1414410 & 688155 & 5.95 & 5.0471 & TST \\
\hline CHEMBL1349213 & 688155 & 6.0 & 5.1595 & TRN \\
\hline CHEMBL1324524 & 688155 & 5.85 & 5.1308 & TRN \\
\hline CHEMBL1360458 & 688155 & 4.9 & 4.9912 & TRN \\
\hline CHEMBL1383198 & 688155 & 5.3 & 5.1102 & TRN \\
\hline CHEMBL1518881 & 688155 & 5.2 & 5.1049 & TST \\
\hline CHEMBL1467202 & 688155 & 5.55 & 5.0796 & TST \\
\hline CHEMBL2373604 & 688155 & 5.8 & 5.1339 & TST \\
\hline CHEMBL1533988 & 688155 & 4.95 & 5.0684 & TRN \\
\hline CHEMBL1464025 & 688155 & 4.95 & 5.0845 & TRN \\
\hline CHEMBL1350297 & 688155 & 5.3 & 5.1265 & TRN \\
\hline CHEMBL1399363 & 688155 & 5.5 & 5.0725 & TST \\
\hline
\end{tabular}




\begin{tabular}{|c|c|c|c|c|c|}
\hline \multicolumn{6}{|c|}{ Supplemental Table S2.txt } \\
\hline CHEMBL1500474 & 688155 & 5.65 & 5.0937 & TRN & \\
\hline CHEMBL 221137 & 688155 & 5.8 & 5.1448 & TST & \\
\hline CHEMBL1600916 & 688155 & 4.5 & 5.0233 & TRN & \\
\hline CHEMBL 2140526 & 688155 & 4.9 & 4.9214 & TST & \\
\hline CHEMBL 2007593 & 688155 & 6.15 & 4.9253 & TST & \\
\hline CHEMBL1497600 & 688155 & 6.0 & 5.1111 & TST & \\
\hline CHEMBL1361461 & 688155 & 5.45 & 5.0144 & TST & \\
\hline CHEMBL1539013 & 688155 & 5.4 & 5.05699 & 99999999995 & TRN \\
\hline CHEMBL1482412 & 688155 & 5.9 & 5.1032 & TST & \\
\hline CHEMBL1459851 & 688155 & 4.9 & 4.8653 & TRN & \\
\hline CHEMBL1586951 & 688155 & 4.55 & 4.9719 & TRN & \\
\hline CHEMBL1462208 & 688155 & 4.75 & 5.0494 & TST & \\
\hline CHEMBL1344344 & 688155 & 5.45 & 5.1085 & TRN & \\
\hline CHEMBL1366241 & 688155 & 5.45 & 5.1032 & TRN & \\
\hline CHEMBL1430056 & 688155 & 5.85 & 5.1406 & TRN & \\
\hline CHEMBL 3197008 & 688155 & 4.9 & 4.9986 & TRN & \\
\hline CHEMBL1595015 & 688155 & 5.7 & 5.0593 & TRN & \\
\hline CHEMBL1388164 & 688155 & 4.55 & 4.9701 & TRN & \\
\hline CHEMBL1597829 & 688155 & 4.9 & 4.9789 & TRN & \\
\hline CHEMBL1366674 & 688155 & 4.55 & 5.1826 & TRN & \\
\hline CHEMBL1467862 & 688155 & 5.5 & 5.0738 & TRN & \\
\hline CHEMBL1349943 & 688155 & 5.0 & 5.1445 & TRN & \\
\hline CHEMBL1455993 & 688155 & 5.0 & 4.9456 & TRN & \\
\hline CHEMBL1584136 & 688155 & 5.05 & 5.1499 & TST & \\
\hline CHEMBL1454799 & 688155 & 4.95 & 4.9962 & TRN & \\
\hline CHEMBL1470469 & 688155 & 6.5 & 5.1338 & TRN & \\
\hline CHEMBL1528937 & 688155 & 4.6 & 5.2402 & TRN & \\
\hline CHEMBL1379928 & 688155 & 5.95 & 5.2707 & TRN & \\
\hline CHEMBL 3198962 & 688155 & 5.65 & 5.1102 & TRN & \\
\hline CHEMBL1423138 & 688155 & 4.95 & 5.0227 & TST & \\
\hline CHEMBL1599879 & 688155 & 6.05 & 5.0552 & TRN & \\
\hline CHEMBL3211709 & 688155 & 5.05 & 5.1403 & TRN & \\
\hline CHEMBL 29898 & 688155 & 4.9 & 5.1197 & TRN & \\
\hline CHEMBL1352006 & 688155 & 6.5 & 5.2721 & TRN & \\
\hline CHEMBL1564660 & 688155 & 4.5 & 5.0327 & TST & \\
\hline CHEMBL1504516 & 688155 & 5.45 & 5.0587 & TRN & \\
\hline CHEMBL1500169 & 688155 & 6.05 & 5.0402 & TRN & \\
\hline CHEMBL3192166 & 688155 & 5.0 & 5.0643 & TRN & \\
\hline CHEMBL1531188 & 688155 & 5.45 & 5.2011 & TRN & \\
\hline CHEMBL1432742 & 688155 & 4.95 & 5.0934 & TST & \\
\hline CHEMBL1575401 & 688155 & 4.95 & 5.1952 & TST & \\
\hline CHEMBL1357674 & 688155 & 5.25 & 5.1603 & TST & \\
\hline CHEMBL1579369 & 688155 & 4.5 & 5.0545 & TRN & \\
\hline CHEMBL1506774 & 688155 & 5.1 & 4.9436 & TRN & \\
\hline CHEMBL1324817 & 688155 & 4.8 & 5.0605 & TRN & \\
\hline CHEMBL1456621 & 688155 & 4.85 & 4.9181 & TRN & \\
\hline CHEMBL1401315 & 688155 & 5.0 & 4.974 & TST & \\
\hline CHEMBL3193510 & 688155 & 4.5 & 4.9138 & TRN & \\
\hline
\end{tabular}




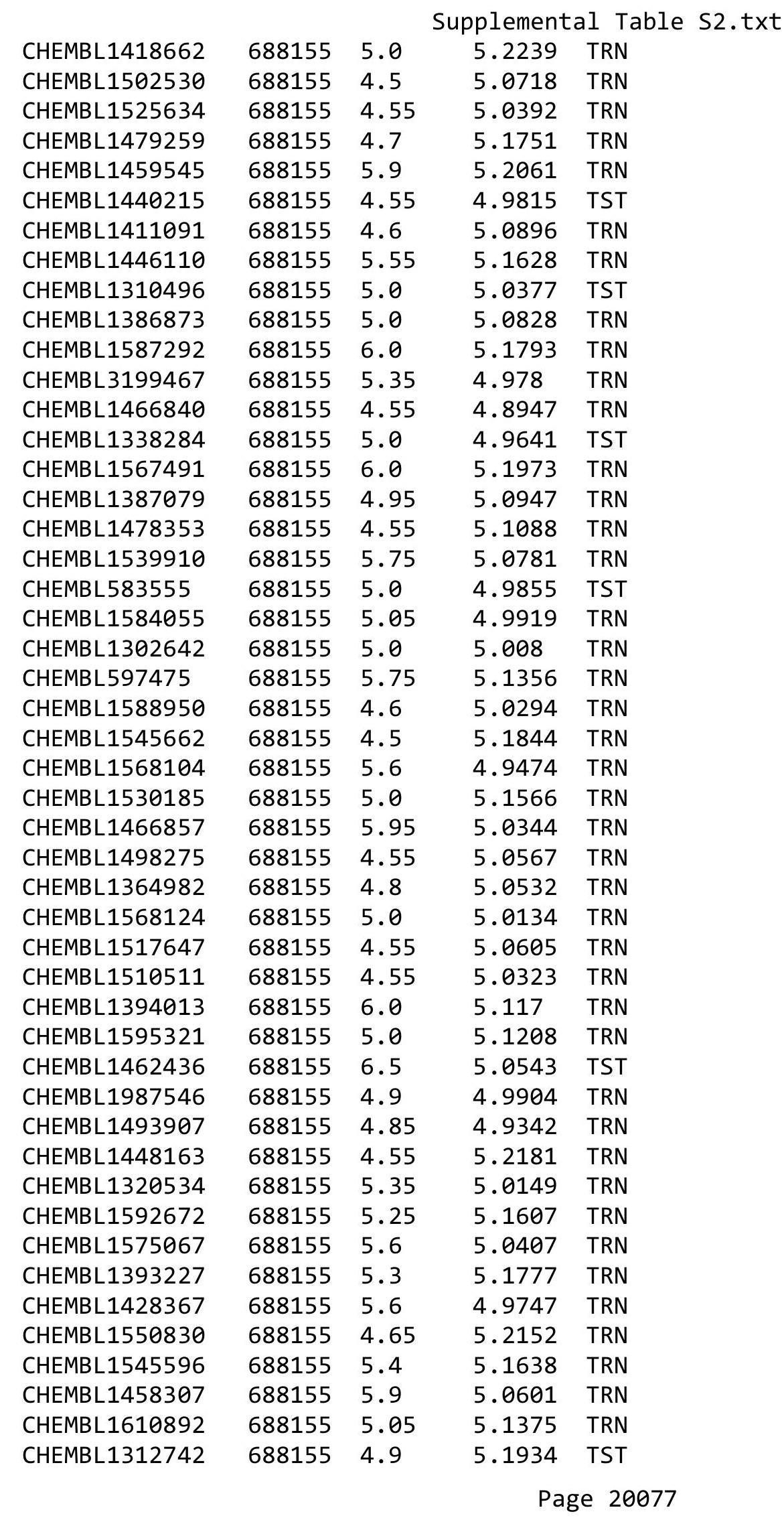




\begin{tabular}{|c|c|c|c|c|}
\hline & & & pplement & al $\mathrm{T}$ \\
\hline CHEMBL1361260 & 688155 & 4.55 & 5.04 & TST \\
\hline CHEMBL3197910 & 688155 & 4.55 & 5.016 & TST \\
\hline CHEMBL3208997 & 688155 & 5.55 & 4.9532 & TST \\
\hline CHEMBL1426250 & 688155 & 4.6 & 5.1405 & TRN \\
\hline CHEMBL1385822 & 688155 & 4.85 & 5.0355 & TRN \\
\hline CHEMBL3210838 & 688155 & 5.55 & 5.0815 & TST \\
\hline CHEMBL1468171 & 688155 & 4.95 & 5.0705 & TRN \\
\hline CHEMBL1452649 & 688155 & 4.5 & 5.074 & TRN \\
\hline CHEMBL1567255 & 688155 & 4.5 & 5.0792 & TRN \\
\hline CHEMBL1606495 & 688155 & 5.0 & 5.1869 & TRN \\
\hline CHEMBL1366864 & 688155 & 4.55 & 5.1051 & TRN \\
\hline CHEMBL1529664 & 688155 & 4.55 & 5.0572 & TST \\
\hline CHEMBL1469799 & 688155 & 5.25 & 5.3036 & TRN \\
\hline CHEMBL1326385 & 688155 & 4.5 & 5.0469 & TST \\
\hline CHEMBL1550135 & 688155 & 4.9 & 4.9908 & TRN \\
\hline CHEMBL1381683 & 688155 & 4.65 & 5.0236 & TRN \\
\hline CHEMBL1426386 & 688155 & 4.5 & 5.2352 & TRN \\
\hline CHEMBL1495560 & 688155 & 5.0 & 5.0183 & TRN \\
\hline CHEMBL1560232 & 688155 & 4.85 & 4.9283 & TRN \\
\hline CHEMBL1558400 & 688155 & 4.95 & 5.0402 & TST \\
\hline CHEMBL1573799 & 688155 & 4.9 & 5.0973 & TRN \\
\hline CHEMBL1311061 & 688155 & 4.9 & 4.9916 & TRN \\
\hline CHEMBL1304888 & 688155 & 4.55 & 5.0552 & TRN \\
\hline CHEMBL1550692 & 688155 & 4.85 & 5.2426 & TRN \\
\hline CHEMBL1477555 & 688155 & 6.1 & 5.176 & TRN \\
\hline CHEMBL1411530 & 688155 & 6.1 & 5.0862 & TRN \\
\hline CHEMBL1536748 & 688155 & 5.55 & 5.0983 & TRN \\
\hline CHEMBL1445990 & 688155 & 5.75 & 5.2199 & TRN \\
\hline CHEMBL1337466 & 688155 & 5.95 & 5.1709 & TST \\
\hline CHEMBL 3189145 & 688155 & 4.95 & 4.8859 & TRN \\
\hline CHEMBL1305115 & 688155 & 5.5 & 5.0458 & TRN \\
\hline CHEMBL1462479 & 688155 & 4.5 & 5.0068 & TRN \\
\hline CHEMBL1499484 & 688155 & 5.0 & 5.1478 & TRN \\
\hline CHEMBL1497122 & 688155 & 4.95 & 5.0678 & TRN \\
\hline CHEMBL1383736 & 688155 & 4.5 & 5.2629 & TRN \\
\hline CHEMBL1429565 & 688155 & 4.95 & 5.0229 & TST \\
\hline CHEMBL1422174 & 688155 & 4.5 & 5.1806 & TST \\
\hline CHEMBL1431316 & 688155 & 5.65 & 5.0982 & TRN \\
\hline CHEMBL1350396 & 688155 & 4.5 & 5.1288 & TRN \\
\hline CHEMBL1404799 & 688155 & 5.0 & 5.0477 & TRN \\
\hline CHEMBL473136 & 688155 & 5.0 & 5.1397 & TRN \\
\hline CHEMBL1490587 & 688155 & 5.0 & 5.0296 & TRN \\
\hline CHEMBL1466983 & 688155 & 5.85 & 5.1149 & TRN \\
\hline CHEMBL1545894 & 688155 & 5.0 & 5.0295 & TRN \\
\hline CHEMBL1360799 & 688155 & 4.85 & 4.8856 & TRN \\
\hline CHEMBL3210339 & 688155 & 4.9 & 5.0046 & TRN \\
\hline CHEMBL1497896 & 688155 & 5.15 & 5.113 & TRN \\
\hline CHEMBL1460863 & 688155 & 4.65 & 4.9285 & TRN \\
\hline
\end{tabular}




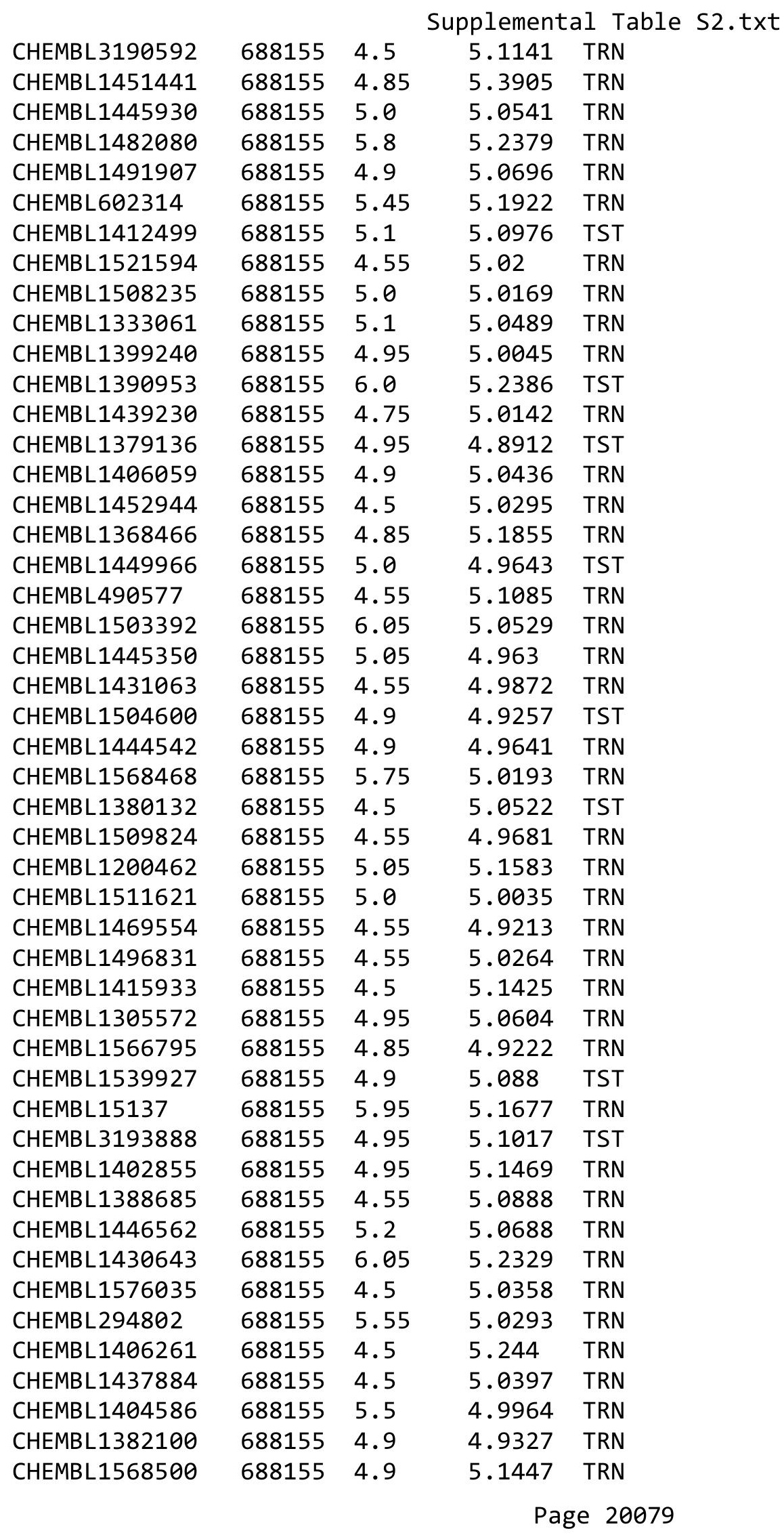




\begin{tabular}{|c|c|c|c|c|}
\hline \multicolumn{5}{|c|}{ Supplemental Table S2.txt } \\
\hline CHEMBL1610353 & 688155 & 4.95 & 5.0229 & TRN \\
\hline CHEMBL1461732 & 688155 & 4.55 & 4.9994 & TRN \\
\hline CHEMBL1532811 & 688155 & 5.9 & 5.0099 & TRN \\
\hline CHEMBL1457311 & 688155 & 5.0 & 4.9242 & TRN \\
\hline CHEMBL1495687 & 688155 & 4.85 & 5.0947 & TRN \\
\hline CHEMBL1331659 & 688155 & 5.0 & 5.0817 & TRN \\
\hline CHEMBL1299587 & 688155 & 4.55 & 4.8981 & TRN \\
\hline CHEMBL1577393 & 688155 & 4.55 & 5.0724 & TRN \\
\hline CHEMBL1306886 & 688155 & 5.0 & 5.0331 & TRN \\
\hline CHEMBL1564115 & 688155 & 4.5 & 5.1152 & TST \\
\hline CHEMBL1347131 & 688155 & 4.55 & 5.0853 & TRN \\
\hline CHEMBL1353816 & 688155 & 4.6 & 5.0321 & TRN \\
\hline CHEMBL1309385 & 688155 & 5.1 & 5.1186 & TRN \\
\hline CHEMBL1559520 & 688155 & 4.5 & 5.0824 & TRN \\
\hline CHEMBL1324133 & 688155 & 4.55 & 4.9638 & TRN \\
\hline CHEMBL578675 & 688155 & 5.3 & 4.9855 & TRN \\
\hline CHEMBL1524664 & 688155 & 5.45 & 5.1413 & TRN \\
\hline CHEMBL1400950 & 688155 & 5.0 & 5.2557 & TRN \\
\hline CHEMBL1601093 & 688155 & 4.9 & 5.1255 & TRN \\
\hline CHEMBL3199351 & 688155 & 5.7 & 5.0993 & TRN \\
\hline CHEMBL1342297 & 688155 & 5.0 & 5.1464 & TRN \\
\hline CHEMBL1380013 & 688155 & 4.5 & 5.1582 & TST \\
\hline CHEMBL1527578 & 688155 & 4.9 & 5.1073 & TRN \\
\hline CHEMBL1517881 & 688155 & 5.5 & 5.0802 & TRN \\
\hline CHEMBL3196468 & 688155 & 4.95 & 5.0694 & TST \\
\hline CHEMBL1440482 & 688155 & 4.9 & 5.1716 & TRN \\
\hline CHEMBL1374812 & 688155 & 5.5 & 5.0634 & TRN \\
\hline CHEMBL1519321 & 688155 & 4.55 & 4.9587 & TRN \\
\hline CHEMBL1360081 & 688155 & 4.6 & 5.03 & TRN \\
\hline CHEMBL 274844 & 688155 & 4.8 & 5.2506 & TST \\
\hline CHEMBL587819 & 688155 & 4.9 & 4.9048 & TRN \\
\hline CHEMBL1441709 & 688155 & 4.95 & 5.1545 & TST \\
\hline CHEMBL1415825 & 688155 & 5.4 & 5.0807 & TRN \\
\hline CHEMBL 3214188 & 688155 & 6.0 & 5.0714 & TST \\
\hline CHEMBL1529883 & 688155 & 4.95 & 5.0141 & TRN \\
\hline CHEMBL1536915 & 688155 & 6.35 & 5.1571 & TRN \\
\hline CHEMBL1527741 & 688155 & 4.9 & 5.136 & TRN \\
\hline CHEMBL1451865 & 688155 & 5.95 & 5.0923 & TRN \\
\hline CHEMBL1449705 & 688155 & 6.45 & 5.1405 & TST \\
\hline CHEMBL1461643 & 688155 & 4.55 & 5.2143 & TST \\
\hline CHEMBL1504655 & 688155 & 6.45 & 5.1459 & TST \\
\hline CHEMBL1571157 & 688155 & 6.05 & 5.0263 & TRN \\
\hline CHEMBL1493960 & 688155 & 4.45 & 5.159 & TRN \\
\hline CHEMBL1384115 & 688155 & 5.95 & 5.0318 & TRN \\
\hline CHEMBL1328509 & 688155 & 4.95 & 4.9718 & TRN \\
\hline CHEMBL 260676 & 688155 & 4.95 & 4.9801 & TRN \\
\hline CHEMBL1411446 & 688155 & 5.3 & 5.2048 & TRN \\
\hline CHEMBL1564674 & 688155 & 4.55 & 4.9687 & TRN \\
\hline
\end{tabular}




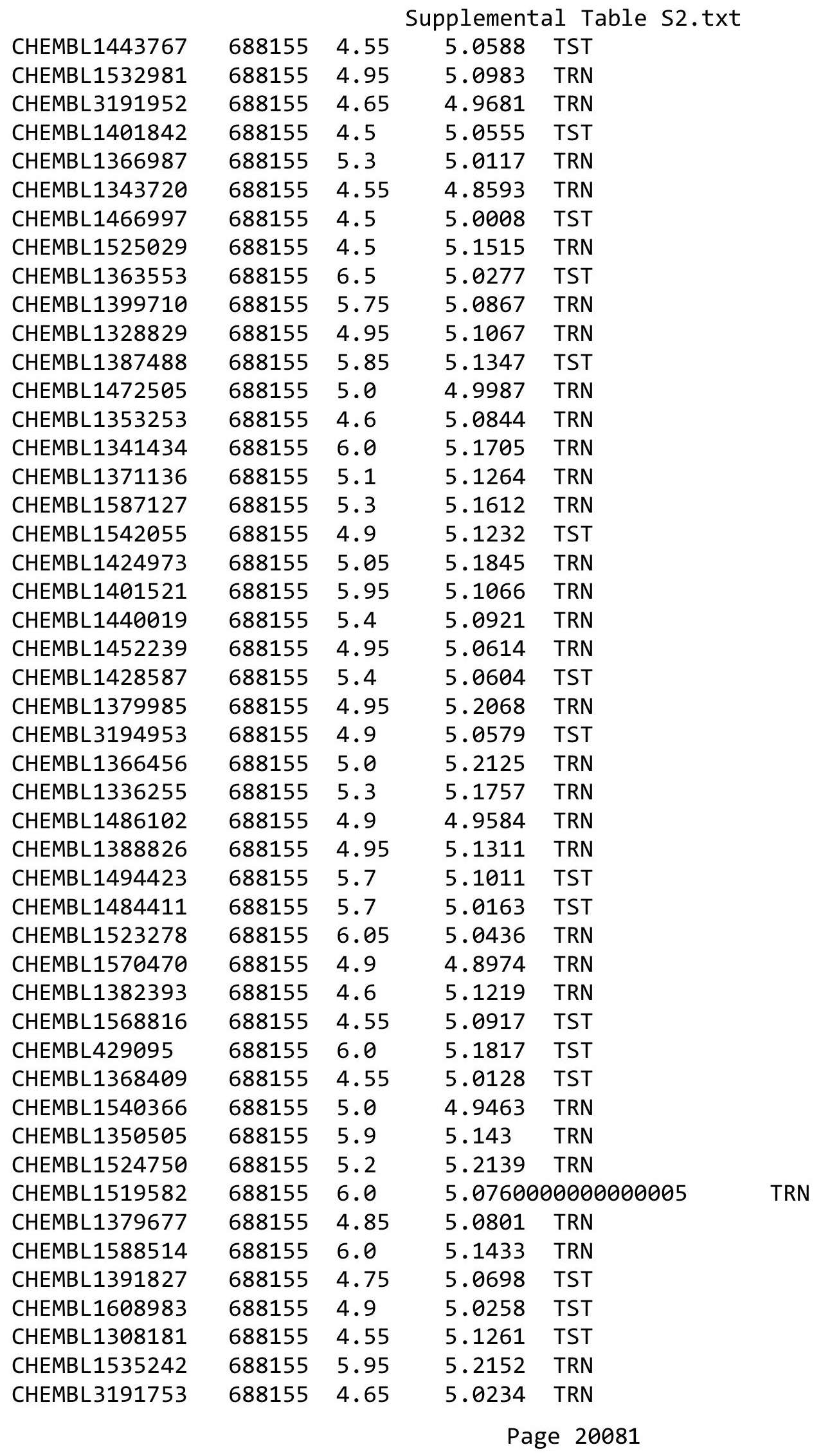




\begin{tabular}{|c|c|c|c|c|c|}
\hline \multicolumn{6}{|c|}{ Supplemental Table s2.txt } \\
\hline CHEMBL1338744 & 688155 & 4.6 & 5.1562 & TRN & \\
\hline CHEMBL1526471 & 688155 & 4.5 & 4.9449 & TRN & \\
\hline CHEMBL593120 & 688155 & 4.95 & 5.0949 & TST & \\
\hline CHEMBL1577567 & 688155 & 4.5 & 5.0358 & TST & \\
\hline CHEMBL1477611 & 688155 & 4.5 & 5.0365 & TRN & \\
\hline CHEMBL1557209 & 688155 & 4.65 & 5.2059 & TRN & \\
\hline CHEMBL1381932 & 688155 & 4.9 & 5.0545 & TRN & \\
\hline CHEMBL1332139 & 688155 & 4.85 & 5.0061 & TRN & \\
\hline CHEMBL1400936 & 688155 & 4.55 & 5.0283 & TST & \\
\hline CHEMBL1343978 & 688155 & 4.8 & 5.2108 & TRN & \\
\hline CHEMBL1384509 & 688155 & 6.0 & 5.2442 & TRN & \\
\hline CHEMBL1484835 & 688155 & 4.55 & 5.045 & TRN & \\
\hline CHEMBL1447301 & 688155 & 4.9 & 5.0712 & TST & \\
\hline CHEMBL1399626 & 688155 & 4.45 & 5.1461 & TRN & \\
\hline CHEMBL1606581 & 688155 & 4.9 & 5.1518 & TRN & \\
\hline CHEMBL1498155 & 688155 & 4.5 & 5.0214 & TRN & \\
\hline CHEMBL1540911 & 688155 & 4.5 & 5.0247 & TRN & \\
\hline CHEMBL1302298 & 688155 & 4.75 & 5.1478 & TRN & \\
\hline CHEMBL151937 & 688155 & 6.3 & 5.1742 & TST & \\
\hline CHEMBL1383806 & 688155 & 4.9 & 4.954 & TRN & \\
\hline CHEMBL1359971 & 688155 & 4.75 & 5.0842 & TRN & \\
\hline CHEMBL1491590 & 688155 & 5.55 & 5.0184 & TST & \\
\hline CHEMBL1305451 & 688155 & 5.5 & 4.8976 & TRN & \\
\hline CHEMBL1967562 & 688155 & 4.95 & 5.1058 & TRN & \\
\hline CHEMBL1442235 & 688155 & 4.95 & 5.1148 & TRN & \\
\hline CHEMBL1342384 & 688155 & 4.55 & 5.1721 & TRN & \\
\hline CHEMBL1306907 & 688155 & 6.05 & 5.1676 & TST & \\
\hline CHEMBL1375641 & 688155 & 4.55 & 5.1735 & TRN & \\
\hline CHEMBL1456318 & 688155 & 5.0 & 5.082 & TST & \\
\hline CHEMBL1603690 & 688155 & 6.3 & 5.0609 & TRN & \\
\hline CHEMBL1460161 & 688155 & 5.2 & 5.2109 & TST & \\
\hline CHEMBL1559474 & 688155 & 4.5 & 5.0263 & TRN & \\
\hline CHEMBL1459425 & 688155 & 4.55 & 5.1754 & TRN & \\
\hline CHEMBL1558332 & 688155 & 6.0 & 5.33200 & 0000000001 & TRN \\
\hline CHEMBL1565091 & 688155 & 5.45 & 5.1707 & TRN & \\
\hline CHEMBL1608085 & 688155 & 4.9 & 5.0142 & TST & \\
\hline CHEMBL1482308 & 688155 & 5.1 & 5.1149 & TRN & \\
\hline CHEMBL1544503 & 688155 & 6.45 & 5.2265 & TST & \\
\hline CHEMBL1469736 & 688155 & 4.9 & 4.9739 & TRN & \\
\hline CHEMBL1607188 & 688155 & 5.0 & 5.0979 & TRN & \\
\hline CHEMBL1360090 & 688155 & 4.5 & 5.2545 & TST & \\
\hline CHEMBL1373534 & 688155 & 6.5 & 5.1979 & TRN & \\
\hline CHEMBL1313066 & 688155 & 5.25 & 5.01399 & 9999999999 & TRN \\
\hline CHEMBL1423207 & 688155 & 5.0 & 5.0949 & TST & \\
\hline CHEMBL1320328 & 688155 & 5.75 & 5.1755 & TRN & \\
\hline CHEMBL296407 & 688155 & 4.95 & 5.0637 & TRN & \\
\hline CHEMBL1387922 & 688155 & 4.95 & 5.1409 & TRN & \\
\hline CHEMBL1528299 & 688155 & 4.95 & 5.1127 & TST & \\
\hline
\end{tabular}




\begin{tabular}{|c|c|c|c|c|c|}
\hline \multicolumn{6}{|c|}{ Supplemental Table S2.txt } \\
\hline CHEMBL1536905 & 688155 & 6.5 & 5.1626 & TRN & \\
\hline CHEMBL1545589 & 688155 & 6.45 & 5.2079 & TST & \\
\hline CHEMBL1455547 & 688155 & 5.25 & 5.1156 & TRN & \\
\hline CHEMBL1370953 & 688155 & 5.3 & 5.1934 & TRN & \\
\hline CHEMBL1529600 & 688155 & 4.5 & 5.1484 & TRN & \\
\hline CHEMBL1453160 & 688155 & 5.0 & 4.8919 & TRN & \\
\hline CHEMBL1586970 & 688155 & 4.9 & 5.1056 & TST & \\
\hline CHEMBL1521722 & 688155 & 4.85 & 5.2265 & TRN & \\
\hline CHEMBL1574127 & 688155 & 5.0 & 5.13 & TRN & \\
\hline CHEMBL1415875 & 688155 & 4.55 & 4.9689 & TRN & \\
\hline CHEMBL1406204 & 688155 & 5.0 & 4.9612 & TRN & \\
\hline CHEMBL3195099 & 688155 & 4.55 & 5.0598 & TST & \\
\hline CHEMBL1432627 & 688155 & 4.95 & 4.9848 & TRN & \\
\hline CHEMBL1307313 & 688155 & 4.65 & 4.974 & TRN & \\
\hline CHEMBL1612026 & 688155 & 4.5 & 5.0328 & TRN & \\
\hline CHEMBL1396757 & 688155 & 4.85 & 4.9664 & TRN & \\
\hline CHEMBL1504406 & 688155 & 4.85 & 5.2444 & TRN & \\
\hline CHEMBL1461190 & 688155 & 5.1 & 5.1426 & TST & \\
\hline CHEMBL1478344 & 688155 & 4.95 & 5.2072 & TRN & \\
\hline CHEMBL119264 & 688155 & 4.85 & 4.9811 & TST & \\
\hline CHEMBL3213335 & 688155 & 4.85 & 4.9848 & TRN & \\
\hline CHEMBL1588024 & 688155 & 5.65 & 5.1154 & TRN & \\
\hline CHEMBL1453446 & 688155 & 4.5 & 5.1156 & TRN & \\
\hline CHEMBL1550267 & 688155 & 4.65 & 5.0808 & TRN & \\
\hline CHEMBL1441823 & 688155 & 4.55 & 4.9245 & TRN & \\
\hline CHEMBL1376580 & 688155 & 4.55 & 4.9358 & TRN & \\
\hline CHEMBL1310099 & 688155 & 5.85 & 4.9211 & TRN & \\
\hline CHEMBL1477659 & 688155 & 4.85 & 5.05699 & 99999999995 & TRN \\
\hline CHEMBL1323268 & 688155 & 4.95 & 4.9651 & TRN & \\
\hline CHEMBL1562009 & 688155 & 5.95 & 5.0667 & TRN & \\
\hline CHEMBL1526617 & 688155 & 4.55 & 5.0629 & TRN & \\
\hline CHEMBL1334582 & 688155 & 4.5 & 5.1035 & TRN & \\
\hline CHEMBL1527405 & 688155 & 4.55 & 5.0095 & TRN & \\
\hline CHEMBL162808 & 688155 & 4.8 & 5.0884 & TRN & \\
\hline CHEMBL1549706 & 688155 & 5.1 & 5.14 & TRN & \\
\hline CHEMBL1595150 & 688155 & 5.0 & 5.3153 & TST & \\
\hline CHEMBL1544909 & 688155 & 5.15 & 5.0559 & TRN & \\
\hline CHEMBL1360528 & 688155 & 4.55 & 5.0706 & TRN & \\
\hline CHEMBL1342459 & 688155 & 5.4 & 5.2434 & TRN & \\
\hline CHEMBL1327816 & 688155 & 4.9 & 5.1382 & TRN & \\
\hline CHEMBL1455998 & 688155 & 5.9 & 4.9525 & TRN & \\
\hline CHEMBL1459855 & 688155 & 4.9 & 5.2301 & TRN & \\
\hline CHEMBL1570225 & 688155 & 6.0 & 5.0332 & TST & \\
\hline CHEMBL1399486 & 688155 & 5.0 & 4.9697 & TST & \\
\hline CHEMBL1496786 & 688155 & 4.5 & 4.9163 & TRN & \\
\hline CHEMBL1328792 & 688155 & 4.95 & 5.0307 & TRN & \\
\hline CHEMBL1503234 & 688155 & 5.0 & 5.0152 & TRN & \\
\hline CHEMBL1381109 & 688155 & 5.55 & 5.0399 & TST & \\
\hline
\end{tabular}




\begin{tabular}{|c|c|c|c|c|c|}
\hline \multicolumn{6}{|c|}{ Supplemental Table S2.txt } \\
\hline CHEMBL1479945 & 688155 & 4.55 & 5.0882 & TRN & \\
\hline CHEMBL1442116 & 688155 & 4.5 & 5.1033 & TRN & \\
\hline CHEMBL1351951 & 688155 & 6.0 & 5.0909 & TRN & \\
\hline CHEMBL3208403 & 688155 & 4.85 & 4.9455 & TST & \\
\hline CHEMBL 1482195 & 688155 & 6.0 & 5.2045 & TRN & \\
\hline CHEMBL1456240 & 688155 & 4.95 & 5.078 & TRN & \\
\hline CHEMBL1610186 & 688155 & 5.0 & 5.2261 & TST & \\
\hline CHEMBL1540114 & 688155 & 5.0 & 4.9902 & TRN & \\
\hline CHEMBL1390386 & 688155 & 4.6 & 5.053 & TRN & \\
\hline CHEMBL1402874 & 688155 & 4.9 & 5.0329 & TRN & \\
\hline CHEMBL1484513 & 688155 & 5.05 & 5.0549 & TST & \\
\hline CHEMBL1336532 & 688155 & 5.25 & 5.1451 & TRN & \\
\hline CHEMBL1305639 & 688155 & 4.55 & 4.9684 & TRN & \\
\hline CHEMBL1365866 & 688155 & 5.3 & 5.1007 & TRN & \\
\hline CHEMBL1561918 & 688155 & 5.0 & 5.1431 & TST & \\
\hline CHEMBL1530125 & 688155 & 5.25 & 5.2167 & TRN & \\
\hline CHEMBL1380901 & 688155 & 6.0 & 5.0512 & TRN & \\
\hline CHEMBL1500821 & 688155 & 5.0 & 5.03600 & 00000000005 & TRN \\
\hline CHEMBL1550080 & 688155 & 5.7 & 5.0144 & TRN & \\
\hline CHEMBL1594543 & 688155 & 5.0 & 4.9685 & TST & \\
\hline CHEMBL1591544 & 688155 & 4.85 & 5.043 & TRN & \\
\hline CHEMBL1505616 & 688155 & 4.55 & 5.1019 & TRN & \\
\hline CHEMBL1328233 & 688155 & 4.55 & 4.9844 & TRN & \\
\hline CHEMBL1482973 & 688155 & 4.55 & 5.2367 & TRN & \\
\hline CHEMBL3197141 & 688155 & 4.85 & 5.0307 & TRN & \\
\hline CHEMBL1256996 & 688155 & 4.85 & 5.1628 & TRN & \\
\hline CHEMBL1611768 & 688155 & 4.5 & 5.17700 & 00000000005 & TRN \\
\hline CHEMBL1336848 & 688155 & 4.9 & 4.8927 & TRN & \\
\hline CHEMBL1421626 & 688155 & 4.95 & 5.0181 & TRN & \\
\hline CHEMBL1541457 & 688155 & 5.45 & 5.0984 & TRN & \\
\hline CHEMBL1549580 & 688155 & 4.5 & 5.1516 & TRN & \\
\hline CHEMBL1381435 & 688155 & 4.55 & 4.9504 & TRN & \\
\hline CHEMBL1493188 & 688155 & 5.45 & 5.095 & TST & \\
\hline CHEMBL1507026 & 688155 & 5.35 & 5.0291 & TRN & \\
\hline CHEMBL1573572 & 688155 & 4.9 & 4.98 & TRN & \\
\hline CHEMBL1319736 & 688155 & 4.55 & 5.1862 & TST & \\
\hline CHEMBL1439783 & 688155 & 4.5 & 5.0531 & TRN & \\
\hline CHEMBL1414633 & 688155 & 4.55 & 5.0333 & TRN & \\
\hline CHEMBL1329604 & 688155 & 4.65 & 4.8746 & TRN & \\
\hline CHEMBL 2002522 & 688155 & 5.0 & 5.0392 & TST & \\
\hline CHEMBL1569057 & 688155 & 4.55 & 5.1804 & TRN & \\
\hline CHEMBL1450129 & 688155 & 5.3 & 5.0892 & TRN & \\
\hline CHEMBL1451912 & 688155 & 5.55 & 4.9494 & TRN & \\
\hline CHEMBL1378802 & 688155 & 4.65 & 4.9813 & TRN & \\
\hline CHEMBL582030 & 688155 & 5.35 & 5.1297 & TST & \\
\hline CHEMBL1602109 & 688155 & 4.65 & 5.0288 & TRN & \\
\hline CHEMBL 1348738 & 688155 & 4.5 & 5.0852 & TRN & \\
\hline CHEMBL1468575 & 688155 & 4.85 & 5.0181 & TRN & \\
\hline
\end{tabular}




\begin{tabular}{|c|c|c|c|c|c|}
\hline & & \multicolumn{4}{|c|}{ Supplemental Table S2.txt } \\
\hline CHEMBL1368214 & 688155 & 4.55 & 4.9289 & TRN & \\
\hline CHEMBL1526294 & 688155 & 4.9 & 5.0029 & TRN & \\
\hline CHEMBL1527811 & 688155 & 5.0 & 5.1093 & TRN & \\
\hline CHEMBL1584207 & 688155 & 5.3 & 5.0407 & TRN & \\
\hline CHEMBL1516476 & 688155 & 4.5 & 5.0642 & TST & \\
\hline CHEMBL1600096 & 688155 & 5.0 & 5.1304 & TST & \\
\hline CHEMBL1308784 & 688155 & 5.0 & 5.1878 & TRN & \\
\hline CHEMBL592124 & 688155 & 5.0 & 5.0393 & TRN & \\
\hline CHEMBL1375429 & 688155 & 4.95 & 5.1507 & TRN & \\
\hline CHEMBL1428315 & 688155 & 6.05 & 5.0666 & TRN & \\
\hline CHEMBL1376649 & 688155 & 6.45 & 5.2455 & TRN & \\
\hline CHEMBL1385206 & 688155 & 4.75 & 5.1673 & TST & \\
\hline CHEMBL1353102 & 688155 & 6.15 & 5.2539 & TRN & \\
\hline CHEMBL1529364 & 688155 & 5.55 & 5.1281 & TRN & \\
\hline CHEMBL1484334 & 688155 & 5.0 & 5.0374 & TRN & \\
\hline CHEMBL1445534 & 688155 & 4.75 & 5.0328 & TRN & \\
\hline CHEMBL1321848 & 688155 & 6.5 & 5.246 & TRN & \\
\hline CHEMBL1541315 & 688155 & 5.05 & 5.12299 & 7999999999 & TRN \\
\hline CHEMBL1524277 & 688155 & 5.65 & 5.1143 & TST & \\
\hline CHEMBL1377010 & 688155 & 4.65 & 5.0008 & TRN & \\
\hline CHEMBL1498005 & 688155 & 5.8 & 5.1089 & TRN & \\
\hline CHEMBL1310920 & 688155 & 5.85 & 5.1128 & TST & \\
\hline CHEMBL1469733 & 688155 & 4.85 & 4.8824 & TRN & \\
\hline CHEMBL1438449 & 688155 & 5.05 & 5.1595 & TRN & \\
\hline CHEMBL1393994 & 688155 & 4.9 & 4.9778 & TRN & \\
\hline CHEMBL1581803 & 688155 & 4.55 & 5.0487 & TRN & \\
\hline CHEMBL1596156 & 688155 & 4.9 & 5.0835 & TRN & \\
\hline CHEMBL1408982 & 688155 & 4.6 & 5.0276 & TRN & \\
\hline CHEMBL1583426 & 688155 & 5.7 & 5.1696 & TRN & \\
\hline CHEMBL1399572 & 688155 & 5.0 & 5.1411 & TST & \\
\hline CHEMBL1388510 & 688155 & 4.55 & 5.0497 & TRN & \\
\hline CHEMBL261122 & 688155 & 5.0 & 5.1309 & TST & \\
\hline CHEMBL1928491 & 688155 & 4.45 & 4.9802 & TRN & \\
\hline CHEMBL1407760 & 688155 & 4.65 & 5.0573 & TRN & \\
\hline CHEMBL1334339 & 688155 & 4.95 & 5.1147 & TRN & \\
\hline CHEMBL1371274 & 688155 & 5.4 & 5.1016 & TRN & \\
\hline CHEMBL3213380 & 688155 & 5.05 & 4.9839 & TST & \\
\hline CHEMBL1608990 & 688155 & 4.5 & 5.0266 & TRN & \\
\hline CHEMBL1595374 & 688155 & 4.55 & 5.0573 & TRN & \\
\hline CHEMBL3195955 & 688155 & 5.25 & 5.0105 & TRN & \\
\hline CHEMBL18132 & 688155 & 4.55 & 5.0024 & TST & \\
\hline CHEMBL1580643 & 688155 & 5.1 & 5.0674 & TRN & \\
\hline CHEMBL1579521 & 688155 & 6.45 & 4.9884 & TRN & \\
\hline CHEMBL1448286 & 688155 & 5.95 & 5.2471 & TRN & \\
\hline CHEMBL478960 & 688155 & 4.95 & 5.0443 & TST & \\
\hline CHEMBL1398151 & 688155 & 5.0 & 5.0183 & TST & \\
\hline CHEMBL1332550 & 688155 & 5.25 & 5.1403 & TRN & \\
\hline CHEMBL1471371 & 688155 & 5.15 & 5.2485 & TRN & \\
\hline
\end{tabular}




\begin{tabular}{|c|c|c|c|c|}
\hline & & & pplement & \\
\hline CHEMBL228078 & 688155 & 4.9 & 4.9368 & TRN \\
\hline CHEMBL1510990 & 688155 & 5.0 & 4.9905 & TRN \\
\hline CHEMBL1605299 & 688155 & 4.95 & 4.9053 & TST \\
\hline CHEMBL1481089 & 688155 & 4.95 & 5.1853 & TRN \\
\hline CHEMBL1707275 & 688155 & 4.5 & 4.9603 & TRN \\
\hline CHEMBL1496947 & 688155 & 5.0 & 5.096 & TRN \\
\hline CHEMBL1398884 & 688155 & 4.9 & 5.0654 & TRN \\
\hline CHEMBL1615433 & 688155 & 6.0 & 5.1969 & TRN \\
\hline CHEMBL1580886 & 688155 & 4.5 & 5.0372 & TST \\
\hline CHEMBL1362880 & 688155 & 5.0 & 5.175 & TRN \\
\hline CHEMBL1562295 & 688155 & 5.95 & 5.052 & TRN \\
\hline CHEMBL1369567 & 688155 & 4.55 & 5.0637 & TST \\
\hline CHEMBL1604962 & 688155 & 4.95 & 5.2041 & TRN \\
\hline CHEMBL1530530 & 688155 & 5.4 & 5.1919 & TST \\
\hline CHEMBL1526858 & 688155 & 4.9 & 4.9733 & TRN \\
\hline CHEMBL1454301 & 688155 & 5.3 & 5.166 & TST \\
\hline CHEMBL1381904 & 688155 & 6.35 & 4.9379 & TRN \\
\hline CHEMBL1467705 & 688155 & 4.65 & 5.1064 & TRN \\
\hline CHEMBL1455013 & 688155 & 4.55 & 5.1948 & TST \\
\hline CHEMBL1334457 & 688155 & 5.1 & 5.1277 & TST \\
\hline CHEMBL1302776 & 688155 & 4.85 & 5.1418 & TRN \\
\hline CHEMBL3196198 & 688155 & 5.05 & 5.0164 & TRN \\
\hline CHEMBL1604395 & 688155 & 4.55 & 5.2003 & TST \\
\hline CHEMBL1606047 & 688155 & 5.85 & 5.1281 & TRN \\
\hline CHEMBL1570114 & 688155 & 4.5 & 5.2431 & TRN \\
\hline CHEMBL1312848 & 688155 & 4.55 & 5.2278 & TRN \\
\hline CHEMBL1383429 & 688155 & 4.6 & 5.1543 & TST \\
\hline CHEMBL 3199837 & 688155 & 4.95 & 5.0722 & TRN \\
\hline CHEMBL1509699 & 688155 & 4.7 & 5.0805 & TST \\
\hline CHEMBL 3194891 & 688155 & 5.0 & 4.9861 & TRN \\
\hline CHEMBL1506214 & 688155 & 5.85 & 5.1069 & TST \\
\hline CHEMBL1532533 & 688155 & 5.3 & 4.962 & TRN \\
\hline CHEMBL1564786 & 688155 & 4.55 & 4.9804 & TRN \\
\hline CHEMBL1519253 & 688155 & 4.45 & 4.9657 & TRN \\
\hline CHEMBL1426242 & 688155 & 4.95 & 4.9821 & TRN \\
\hline CHEMBL3199253 & 688155 & 4.65 & 5.093 & TST \\
\hline CHEMBL1436956 & 688155 & 4.5 & 4.9095 & TRN \\
\hline CHEMBL1578912 & 688155 & 5.25 & 5.1253 & TRN \\
\hline CHEMBL1407262 & 688155 & 4.65 & 4.83 & TRN \\
\hline CHEMBL1309265 & 688155 & 4.95 & 5.1171 & TRN \\
\hline CHEMBL1540728 & 688155 & 4.9 & 5.2333 & TRN \\
\hline CHEMBL1482431 & 688155 & 5.0 & 5.0201 & TRN \\
\hline CHEMBL1537686 & 688155 & 4.55 & 5.1448 & TST \\
\hline CHEMBL1441333 & 688155 & 4.6 & 5.1558 & TRN \\
\hline CHEMBL3191291 & 688155 & 4.85 & 5.0988 & TRN \\
\hline CHEMBL1580112 & 688155 & 5.1 & 5.2137 & TRN \\
\hline CHEMBL1405142 & 688155 & 5.0 & 5.1232 & TRN \\
\hline CHEMBL1563086 & 688155 & 4.55 & 4.9919 & TRN \\
\hline
\end{tabular}




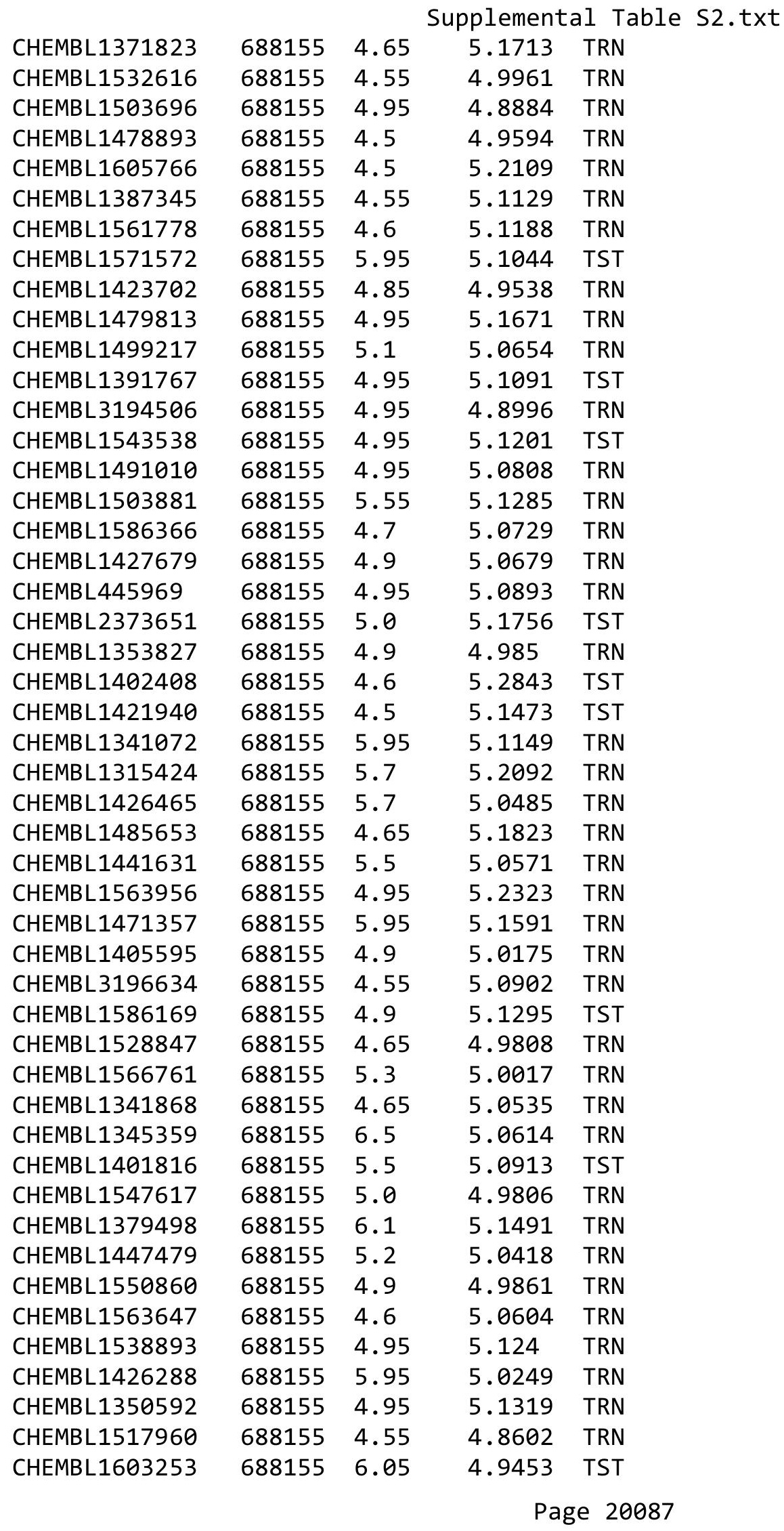




\begin{tabular}{|c|c|c|c|c|}
\hline \multicolumn{5}{|c|}{ Supplemental Table S2.txt } \\
\hline CHEMBL1597968 & 688155 & 6.5 & 4.9423 & TRN \\
\hline CHEMBL1409778 & 688155 & 5.25 & 5.1429 & TRN \\
\hline CHEMBL1454351 & 688155 & 4.5 & 5.0932 & TST \\
\hline CHEMBL1558049 & 688155 & 4.5 & 5.1714 & TRN \\
\hline CHEMBL1378467 & 688155 & 4.85 & 5.0761 & TRN \\
\hline CHEMBL1588821 & 688155 & 6.35 & 5.2565 & TRN \\
\hline CHEMBL1426004 & 688155 & 5.4 & 5.0249 & TST \\
\hline CHEMBL1445570 & 688155 & 6.0 & 5.1135 & TRN \\
\hline CHEMBL3195582 & 688155 & 5.05 & 5.0747 & TRN \\
\hline CHEMBL3209776 & 688155 & 4.6 & 4.9304 & TRN \\
\hline CHEMBL1450088 & 688155 & 4.95 & 5.129 & TRN \\
\hline CHEMBL1561308 & 688155 & 6.3 & 5.0774 & TST \\
\hline CHEMBL1307757 & 688155 & 5.3 & 5.0692 & TRN \\
\hline CHEMBL1566170 & 688155 & 5.0 & 5.1238 & TRN \\
\hline CHEMBL1495778 & 688155 & 5.0 & 5.1193 & TST \\
\hline CHEMBL1422503 & 688155 & 5.45 & 5.1572 & TST \\
\hline CHEMBL1510676 & 688155 & 4.55 & 5.0569 & TST \\
\hline CHEMBL1532925 & 688155 & 4.5 & 4.9458 & TST \\
\hline CHEMBL1359089 & 688155 & 5.2 & 5.0962 & TRN \\
\hline CHEMBL1333696 & 688155 & 4.9 & 5.0993 & TRN \\
\hline CHEMBL1460095 & 688155 & 5.0 & 5.1164 & TRN \\
\hline CHEMBL1400763 & 688155 & 6.2 & 5.0192 & TST \\
\hline CHEMBL1416636 & 688155 & 5.25 & 5.1169 & TST \\
\hline CHEMBL1420984 & 688155 & 5.0 & 5.0092 & TRN \\
\hline CHEMBL1332230 & 688155 & 5.75 & 5.1315 & TRN \\
\hline CHEMBL1376888 & 688155 & 4.5 & 4.9652 & TRN \\
\hline CHEMBL1347404 & 688155 & 5.0 & 4.9714 & TRN \\
\hline CHEMBL1596946 & 688155 & 5.15 & 5.3566 & TRN \\
\hline CHEMBL1401048 & 688155 & 4.6 & 4.9906 & TRN \\
\hline CHEMBL1342748 & 688155 & 5.95 & 5.0489 & TRN \\
\hline CHEMBL1353303 & 688155 & 6.0 & 5.0379 & TRN \\
\hline CHEMBL1305396 & 688155 & 4.45 & 5.1633 & TRN \\
\hline CHEMBL 3208175 & 688155 & 5.8 & 5.0053 & TST \\
\hline CHEMBL1516388 & 688155 & 4.9 & 5.1362 & TST \\
\hline CHEMBL1483054 & 688155 & 4.55 & 5.0133 & TST \\
\hline CHEMBL1463826 & 688155 & 5.7 & 5.109 & TRN \\
\hline CHEMBL1385309 & 688155 & 4.9 & 5.1542 & TRN \\
\hline CHEMBL1349942 & 688155 & 5.0 & 5.2289 & TRN \\
\hline CHEMBL1603570 & 688155 & 5.2 & 5.3004 & TRN \\
\hline CHEMBL1531658 & 688155 & 6.45 & 4.9892 & TRN \\
\hline CHEMBL1492366 & 688155 & 5.35 & 5.0375 & TRN \\
\hline CHEMBL1407555 & 688155 & 5.15 & 5.0701 & TRN \\
\hline CHEMBL1508863 & 688155 & 4.95 & 5.1079 & TRN \\
\hline CHEMBL1491365 & 688155 & 6.0 & 5.1353 & TRN \\
\hline CHEMBL1400266 & 688155 & 4.55 & 5.1768 & TRN \\
\hline CHEMBL1446078 & 688155 & 4.85 & 5.0839 & TRN \\
\hline CHEMBL 1486462 & 688155 & 4.95 & 5.0971 & TST \\
\hline CHEMBL1372292 & 688155 & 5.25 & 5.1523 & TRN \\
\hline
\end{tabular}




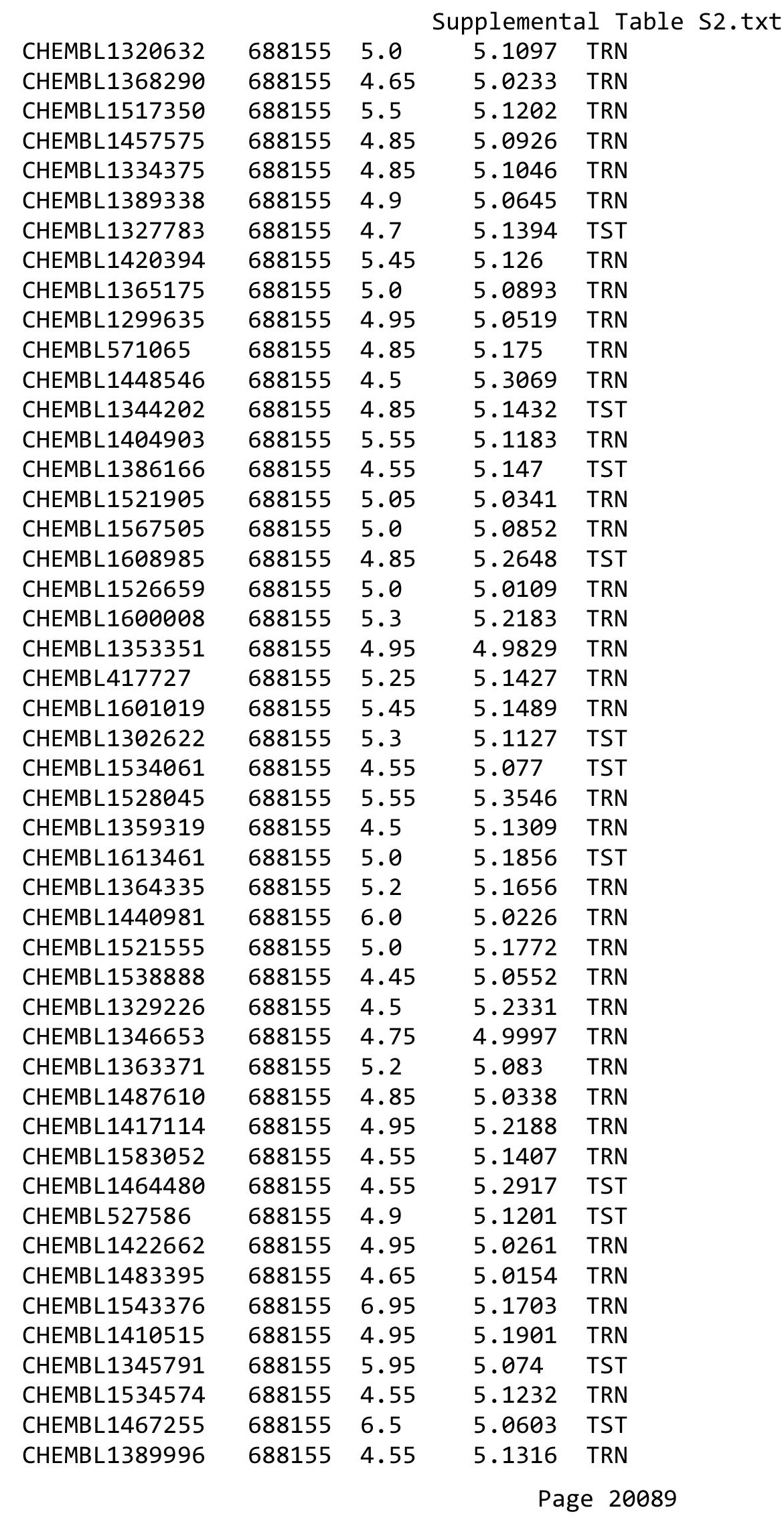




\begin{tabular}{|c|c|c|c|c|c|}
\hline \multicolumn{6}{|c|}{ Supplemental Table S2.txt } \\
\hline CHEMBL92309 & 688155 & 6.4 & 5.256 & TST & \\
\hline CHEMBL1412965 & 688155 & 4.55 & 5.0074 & TRN & \\
\hline CHEMBL3196957 & 688155 & 5.5 & 5.0213 & TRN & \\
\hline CHEMBL1486671 & 688155 & 5.55 & 5.066 & TRN & \\
\hline CHEMBL1539706 & 688155 & 5.45 & 5.1262 & TST & \\
\hline CHEMBL1579216 & 688155 & 5.95 & 5.1389 & TST & \\
\hline CHEMBL1503362 & 688155 & 4.95 & 5.0386 & TRN & \\
\hline CHEMBL1585668 & 688155 & 5.0 & 4.9675 & TST & \\
\hline CHEMBL1368420 & 688155 & 4.55 & 4.9679 & TRN & \\
\hline CHEMBL1527325 & 688155 & 5.75 & 5.2736 & TRN & \\
\hline CHEMBL1567336 & 688155 & 6.5 & 5.1092 & TRN & \\
\hline CHEMBL1404111 & 688155 & 5.4 & 4.9572 & TRN & \\
\hline CHEMBL1384035 & 688155 & 4.95 & 5.0665 & TRN & \\
\hline CHEMBL1595702 & 688155 & 4.55 & 4.9397 & TRN & \\
\hline CHEMBL1486192 & 688155 & 6.05 & 5.1611 & TRN & \\
\hline CHEMBL1601043 & 688155 & 4.55 & 4.8578 & TRN & \\
\hline CHEMBL3193329 & 688155 & 4.9 & 4.9688 & TRN & \\
\hline CHEMBL1533502 & 688155 & 4.95 & 5.018 & TRN & \\
\hline CHEMBL 217920 & 688155 & 4.85 & 5.0431 & TRN & \\
\hline CHEMBL3211566 & 688155 & 5.3 & 5.03100 & 0000000001 & TRN \\
\hline CHEMBL3210765 & 688155 & 4.95 & 5.0324 & TRN & \\
\hline CHEMBL1384654 & 688155 & 4.9 & 5.0764 & TRN & \\
\hline CHEMBL1306626 & 688155 & 5.25 & 5.1601 & TRN & \\
\hline CHEMBL533082 & 688155 & 5.55 & 5.0917 & TRN & \\
\hline CHEMBL1411809 & 688155 & 5.0 & 5.1027 & TRN & \\
\hline CHEMBL1365652 & 688155 & 4.55 & 4.9328 & TRN & \\
\hline CHEMBL1543308 & 688155 & 6.0 & 5.1805 & TST & \\
\hline CHEMBL1430815 & 688155 & 4.55 & 4.8712 & TRN & \\
\hline CHEMBL1328768 & 688155 & 6.0 & 5.1077 & TST & \\
\hline CHEMBL3198356 & 688155 & 5.25 & 4.9471 & TRN & \\
\hline CHEMBL1486441 & 688155 & 4.85 & 5.0118 & TRN & \\
\hline CHEMBL1563359 & 688155 & 4.95 & 5.164 & TRN & \\
\hline CHEMBL1419947 & 688155 & 5.55 & 5.1869 & TRN & \\
\hline CHEMBL1331469 & 688155 & 4.95 & 5.1083 & TRN & \\
\hline CHEMBL1564991 & 688155 & 4.8 & 5.0541 & TST & \\
\hline CHEMBL1327034 & 688155 & 5.5 & 5.1098 & TRN & \\
\hline CHEMBL1520615 & 688155 & 5.45 & 5.1213 & TRN & \\
\hline CHEMBL1344342 & 688155 & 4.55 & 5.0618 & TST & \\
\hline CHEMBL1495473 & 688155 & 4.55 & 5.0624 & TST & \\
\hline CHEMBL1408478 & 688155 & 5.45 & 4.9345 & TST & \\
\hline CHEMBL1413106 & 688155 & 4.6 & 5.1395 & TST & \\
\hline CHEMBL530788 & 688155 & 4.55 & 5.0427 & TRN & \\
\hline CHEMBL1319011 & 688155 & 4.55 & 5.0061 & TRN & \\
\hline CHEMBL3198587 & 688155 & 5.65 & 5.0133 & TRN & \\
\hline CHEMBL 2143919 & 688155 & 4.55 & 4.9743 & TRN & \\
\hline CHEMBL1539694 & 688155 & 4.9 & 5.0416 & TRN & \\
\hline CHEMBL1571478 & 688155 & 5.8 & 5.1761 & TRN & \\
\hline CHEMBL1328258 & 688155 & 5.25 & 5.2487 & TRN & \\
\hline
\end{tabular}




\begin{tabular}{|c|c|c|c|c|c|}
\hline \multicolumn{6}{|c|}{ Supplemental Table S2.txt } \\
\hline CHEMBL1477426 & 688155 & 5.0 & 4.9615 & TRN & \\
\hline CHEMBL1509321 & 688155 & 4.5 & 4.9996 & TRN & \\
\hline CHEMBL1310101 & 688155 & 5.0 & 5.044 & TST & \\
\hline CHEMBL1564945 & 688155 & 5.0 & 5.0754 & TRN & \\
\hline CHEMBL1333142 & 688155 & 5.0 & 4.9491 & TRN & \\
\hline CHEMBL1385852 & 688155 & 5.15 & $5.0710 e$ & 0000000001 & TRN \\
\hline CHEMBL1586545 & 688155 & 4.9 & 5.1262 & TRN & \\
\hline CHEMBL1579259 & 688155 & 6.5 & 5.0888 & TST & \\
\hline CHEMBL1447306 & 688155 & 4.55 & 5.0364 & TST & \\
\hline CHEMBL1093246 & 688155 & 4.95 & 5.0524 & TST & \\
\hline CHEMBL1376337 & 688155 & 4.65 & 5.0258 & TST & \\
\hline CHEMBL1373912 & 688155 & 5.45 & 5.0741 & TST & \\
\hline CHEMBL1304444 & 688155 & 4.5 & 5.0227 & TST & \\
\hline CHEMBL1305272 & 688155 & 5.15 & 5.2173 & TST & \\
\hline CHEMBL1422033 & 688155 & 4.95 & 5.1215 & TRN & \\
\hline CHEMBL3194826 & 688155 & 4.55 & 5.0164 & TRN & \\
\hline CHEMBL1526027 & 688155 & 4.85 & 4.9544 & TST & \\
\hline CHEMBL1423199 & 688155 & 6.35 & 4.9787 & TRN & \\
\hline CHEMBL1579143 & 688155 & 6.3 & 5.1872 & TRN & \\
\hline CHEMBL1415791 & 688155 & 4.95 & 5.1767 & TRN & \\
\hline CHEMBL1572251 & 688155 & 4.95 & 5.1032 & TST & \\
\hline CHEMBL1581809 & 688155 & 4.5 & 4.9855 & TST & \\
\hline CHEMBL1503611 & 688155 & 5.05 & 4.9623 & TST & \\
\hline CHEMBL1523763 & 688155 & 4.85 & 5.249 & TST & \\
\hline CHEMBL164813 & 688155 & 4.95 & 5.1579 & TST & \\
\hline CHEMBL1437438 & 688155 & 6.3 & 5.027 & TST & \\
\hline CHEMBL1564964 & 688155 & 5.3 & 5.2826 & TST & \\
\hline CHEMBL1458374 & 688155 & 4.65 & 5.1887 & TRN & \\
\hline CHEMBL3192271 & 688155 & 5.2 & 5.0698 & TRN & \\
\hline CHEMBL1350764 & 688155 & 5.0 & 5.2577 & TRN & \\
\hline CHEMBL1504980 & 688155 & 4.9 & $5.1370 e$ & 00000000005 & TRN \\
\hline CHEMBL3196407 & 688155 & 4.55 & 5.0476 & TST & \\
\hline CHEMBL1422277 & 688155 & 5.05 & 5.1364 & TRN & \\
\hline CHEMBL1518557 & 688155 & 4.95 & 5.1097 & TST & \\
\hline CHEMBL1427609 & 688155 & 4.55 & 4.9702 & TRN & \\
\hline CHEMBL375629 & 688155 & 4.55 & 5.1584 & TRN & \\
\hline CHEMBL1416387 & 688155 & 4.9 & 4.8734 & TRN & \\
\hline CHEMBL1325709 & 688155 & 4.65 & 4.8445 & TRN & \\
\hline CHEMBL1479965 & 688155 & 5.0 & 5.0734 & TST & \\
\hline CHEMBL1458941 & 688155 & 5.0 & 4.9563 & TST & \\
\hline CHEMBL1350427 & 688155 & 5.0 & 4.9341 & TRN & \\
\hline CHEMBL1382174 & 688155 & 6.0 & 5.0961 & TRN & \\
\hline CHEMBL1453603 & 688155 & 5.0 & 5.0996 & TRN & \\
\hline CHEMBL1458479 & 688155 & 4.9 & 5.0698 & TRN & \\
\hline CHEMBL1373892 & 688155 & 4.7 & 5.1484 & TRN & \\
\hline CHEMBL1309370 & 688155 & 4.85 & 5.0093 & TST & \\
\hline CHEMBL1501701 & 688155 & 4.8 & 4.9303 & TST & \\
\hline CHEMBL1594171 & 688155 & 5.05 & 5.1391 & TRN & \\
\hline
\end{tabular}




\begin{tabular}{|c|c|c|c|c|c|}
\hline \multicolumn{6}{|c|}{ Supplemental Table S2.txt } \\
\hline CHEMBL1418222 & 688155 & 4.5 & 5.0522 & TST & \\
\hline CHEMBL1504624 & 688155 & 4.55 & 5.029 & TST & \\
\hline CHEMBL1457068 & 688155 & 4.65 & 4.9148 & TST & \\
\hline CHEMBL1516428 & 688155 & 5.0 & 5.0199 & TRN & \\
\hline CHEMBL1465165 & 688155 & 4.95 & 5.02 & TST & \\
\hline CHEMBL1334872 & 688155 & 4.5 & 5.0229 & TRN & \\
\hline CHEMBL1492064 & 688155 & 5.9 & 5.1148 & TRN & \\
\hline CHEMBL1527195 & 688155 & 6.2 & 5.0067 & TRN & \\
\hline CHEMBL1343115 & 688155 & 5.05 & 5.1347 & TRN & \\
\hline CHEMBL1555615 & 688155 & 5.05 & 5.3202 & TST & \\
\hline CHEMBL1468209 & 688155 & 4.95 & 5.2614 & TRN & \\
\hline CHEMBL1419733 & 688155 & 4.65 & $4.8210 e$ & 0000000001 & TRN \\
\hline CHEMBL1487259 & 688155 & 4.55 & 5.1698 & TRN & \\
\hline CHEMBL1374320 & 688155 & 5.6 & 5.072 & TRN & \\
\hline CHEMBL1305809 & 688155 & 5.9 & 5.0842 & TRN & \\
\hline CHEMBL1993447 & 688155 & 4.5 & 4.9446 & TRN & \\
\hline CHEMBL1439668 & 688155 & 4.5 & 4.9729 & TRN & \\
\hline CHEMBL1485372 & 688155 & 5.15 & 5.2246 & TRN & \\
\hline CHEMBL1305848 & 688155 & 4.7 & $4.9830 e$ & 00000000005 & TRN \\
\hline CHEMBL3208346 & 688155 & 5.05 & 4.9625 & TRN & \\
\hline CHEMBL190328 & 688155 & 4.65 & 5.1437 & TST & \\
\hline CHEMBL1540513 & 688155 & 4.5 & 4.8773 & TRN & \\
\hline CHEMBL1423121 & 688155 & 5.25 & 5.0276 & TRN & \\
\hline CHEMBL1333531 & 688155 & 6.05 & 5.2243 & TRN & \\
\hline CHEMBL1412528 & 688155 & 5.9 & 5.0991 & TRN & \\
\hline CHEMBL1322245 & 688155 & 4.55 & 4.9717 & TRN & \\
\hline CHEMBL1597803 & 688155 & 4.95 & 5.1786 & TST & \\
\hline CHEMBL1608909 & 688155 & 4.5 & 5.0442 & TRN & \\
\hline CHEMBL1388529 & 688155 & 5.0 & 5.0716 & TRN & \\
\hline CHEMBL1419730 & 688155 & 5.0 & 4.9195 & TRN & \\
\hline CHEMBL1463795 & 688155 & 5.0 & 5.2085 & TRN & \\
\hline CHEMBL1503819 & 688155 & 4.55 & 5.1704 & TRN & \\
\hline CHEMBL1555899 & 688155 & 4.85 & 5.0254 & TST & \\
\hline CHEMBL1485401 & 688155 & 5.3 & 5.2518 & TRN & \\
\hline CHEMBL1387617 & 688155 & 4.85 & 5.1469 & TRN & \\
\hline CHEMBL1343242 & 688155 & 4.55 & 4.9641 & TST & \\
\hline CHEMBL1457021 & 688155 & 5.0 & 5.1901 & TRN & \\
\hline CHEMBL260148 & 688155 & 4.8 & 5.1094 & TRN & \\
\hline CHEMBL1511541 & 688155 & 4.65 & 5.3014 & TST & \\
\hline CHEMBL3195842 & 688155 & 5.0 & 5.0618 & TRN & \\
\hline CHEMBL1510608 & 688155 & 4.85 & 5.0966 & TRN & \\
\hline CHEMBL1390766 & 688155 & 5.3 & 5.027 & TRN & \\
\hline CHEMBL1510509 & 688155 & 5.7 & 5.0583 & TRN & \\
\hline CHEMBL1448594 & 688155 & 4.55 & 5.0312 & TRN & \\
\hline CHEMBL1595612 & 688155 & 5.15 & 5.1184 & TRN & \\
\hline CHEMBL1333566 & 688155 & 4.6 & 5.069 & TRN & \\
\hline CHEMBL3191374 & 688155 & 4.9 & 4.9599 & TRN & \\
\hline CHEMBL1330142 & 688155 & 5.1 & 5.0825 & TST & \\
\hline
\end{tabular}




\begin{tabular}{|c|c|c|c|c|}
\hline \multicolumn{5}{|c|}{ Supplemental Table } \\
\hline CHEMBL1342666 & 688155 & 4.55 & 5.0086 & TST \\
\hline CHEMBL1427788 & 688155 & 5.0 & 5.2465 & TRN \\
\hline CHEMBL1547311 & 688155 & 5.0 & 5.0714 & TRN \\
\hline CHEMBL1383603 & 688155 & 5.0 & 5.0629 & TRN \\
\hline CHEMBL1377099 & 688155 & 4.95 & 4.9217 & TST \\
\hline CHEMBL1419933 & 688155 & 5.5 & 5.1758 & TRN \\
\hline CHEMBL1327935 & 688155 & 4.65 & 4.9082 & TRN \\
\hline CHEMBL1570262 & 688155 & 4.65 & 4.9326 & TRN \\
\hline CHEMBL1462936 & 688155 & 5.0 & 4.915 & TST \\
\hline CHEMBL1477651 & 688155 & 4.95 & 5.1393 & TRN \\
\hline CHEMBL1573374 & 688155 & 5.0 & 5.0329 & TRN \\
\hline CHEMBL1412474 & 688155 & 4.95 & 4.9689 & TRN \\
\hline CHEMBL1421372 & 688155 & 5.05 & 5.2347 & TRN \\
\hline CHEMBL 3194756 & 688155 & 4.85 & 5.0298 & TRN \\
\hline CHEMBL3189942 & 688155 & 5.15 & 4.912 & TRN \\
\hline CHEMBL1604975 & 688155 & 4.95 & 5.0333 & TRN \\
\hline CHEMBL1087460 & 688155 & 4.55 & 5.1805 & TST \\
\hline CHEMBL1318867 & 688155 & 4.55 & 5.095 & TRN \\
\hline CHEMBL1344136 & 688155 & 4.95 & 5.1376 & TRN \\
\hline CHEMBL1373740 & 688155 & 4.55 & 5.0397 & TRN \\
\hline CHEMBL1449105 & 688155 & 5.05 & 5.0382 & TRN \\
\hline CHEMBL1461568 & 688155 & 5.0 & 4.9827 & TRN \\
\hline CHEMBL1698217 & 688155 & 4.95 & 5.0 & TRN \\
\hline CHEMBL1379765 & 688155 & 4.9 & 4.9832 & TRN \\
\hline CHEMBL1461424 & 688155 & 5.0 & 5.1314 & TRN \\
\hline CHEMBL1414931 & 688155 & 5.05 & 4.9298 & TST \\
\hline CHEMBL1420638 & 688155 & 4.55 & 5.0621 & TRN \\
\hline CHEMBL1529842 & 688155 & 4.5 & 5.021 & TRN \\
\hline CHEMBL1387455 & 688155 & 4.5 & 5.2066 & TRN \\
\hline CHEMBL1580291 & 688155 & 4.95 & 4.9117 & TST \\
\hline CHEMBL1370526 & 688155 & 6.15 & 5.1707 & TST \\
\hline CHEMBL1401134 & 688155 & 4.55 & 5.0455 & TRN \\
\hline CHEMBL1332955 & 688155 & 4.75 & 5.0331 & TST \\
\hline CHEMBL460433 & 688155 & 4.55 & 4.9827 & TST \\
\hline CHEMBL1424929 & 688155 & 4.9 & 4.8971 & TRN \\
\hline CHEMBL1453976 & 688155 & 5.9 & 5.0695 & TRN \\
\hline CHEMBL1303036 & 688155 & 5.8 & 5.0823 & TRN \\
\hline CHEMBL1311259 & 688155 & 5.2 & 5.3328 & TRN \\
\hline CHEMBL1365661 & 688155 & 5.0 & 5.1661 & TST \\
\hline CHEMBL1330049 & 688155 & 4.95 & 5.2433 & TST \\
\hline CHEMBL1425383 & 688155 & 5.0 & 5.1299 & TRN \\
\hline CHEMBL1600173 & 688155 & 5.35 & 5.0797 & TRN \\
\hline CHEMBL1368778 & 688155 & 5.05 & 5.0224 & TST \\
\hline CHEMBL1327690 & 688155 & 5.25 & 5.0816 & TRN \\
\hline CHEMBL1546828 & 688155 & 4.55 & 4.978 & TRN \\
\hline CHEMBL1547196 & 688155 & 5.1 & 5.1256 & TRN \\
\hline CHEMBL1487468 & 688155 & 4.55 & 5.0143 & TRN \\
\hline CHEMBL1559595 & 688155 & 5.65 & 5.1548 & TRN \\
\hline
\end{tabular}




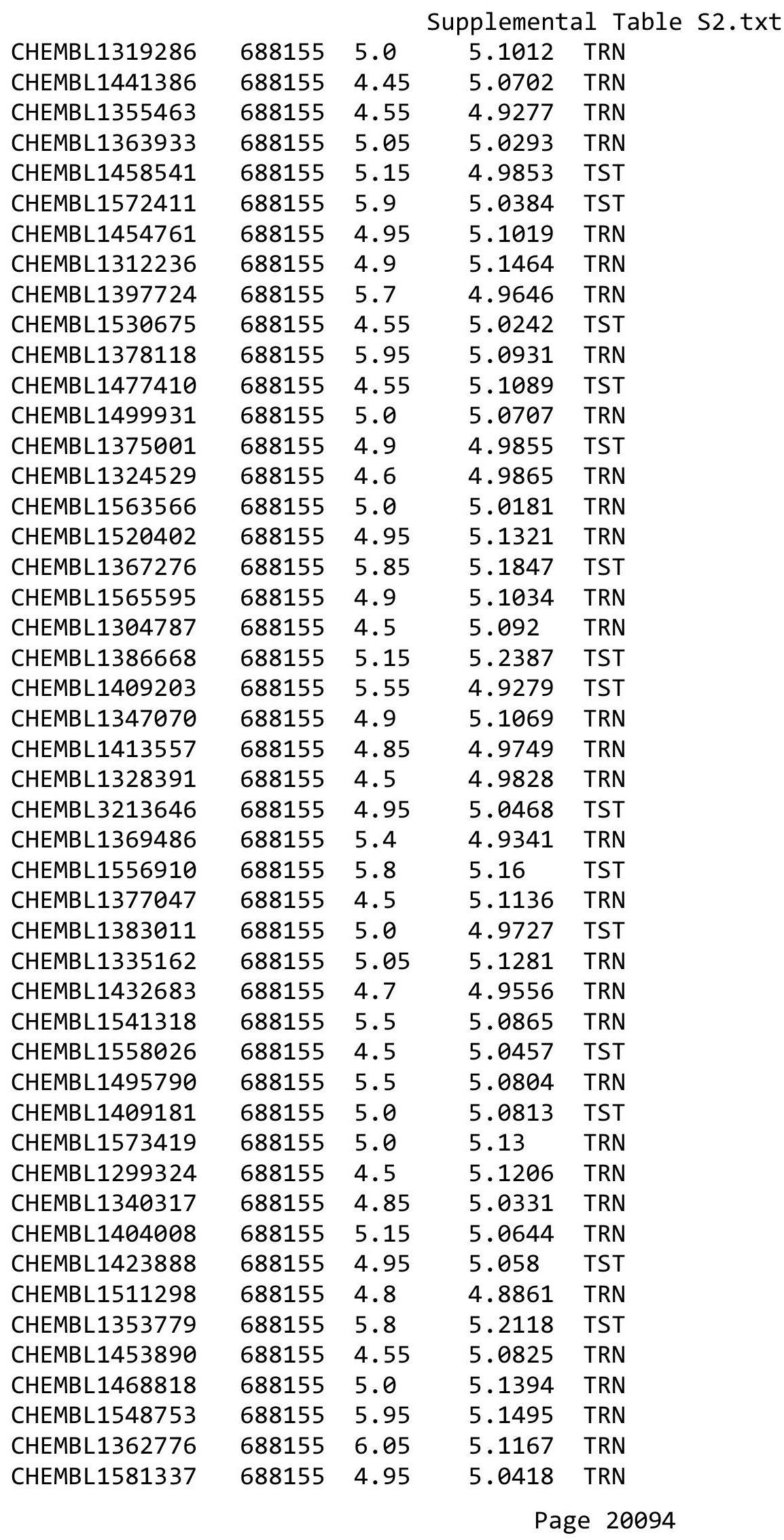




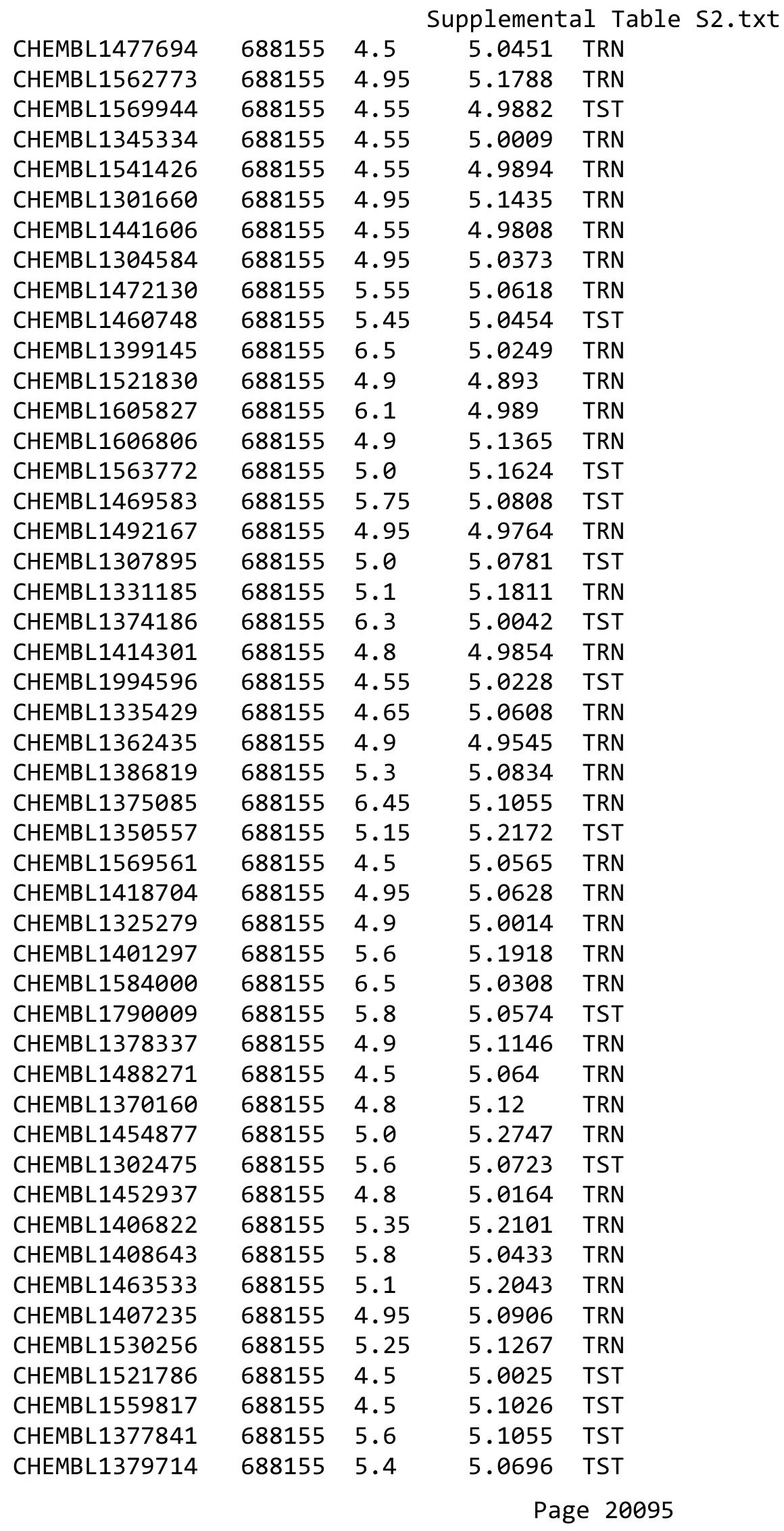




\begin{tabular}{|c|c|c|c|c|c|}
\hline \multicolumn{6}{|c|}{ Supplemental Table s2.txt } \\
\hline CHEMBL1429464 & 688155 & 6.4 & 5.0125 & TRN & \\
\hline CHEMBL1446442 & 688155 & 4.8 & 5.0382 & TRN & \\
\hline CHEMBL1379878 & 688155 & 5.4 & 5.2288 & TST & \\
\hline CHEMBL462880 & 688155 & 4.85 & 5.0957 & TRN & \\
\hline CHEMBL71492 & 688155 & 6.3 & 5.2078 & TST & \\
\hline CHEMBL1410970 & 688155 & 6.5 & 5.0542 & TRN & \\
\hline CHEMBL1598353 & 688155 & 5.55 & 5.2419 & TRN & \\
\hline CHEMBL1351896 & 688155 & 5.0 & 4.9946 & TRN & \\
\hline CHEMBL3193479 & 688155 & 5.0 & 5.0063 & TRN & \\
\hline CHEMBL1406306 & 688155 & 4.5 & 5.1023 & TST & \\
\hline CHEMBL1354142 & 688155 & 4.95 & 5.2068 & TST & \\
\hline CHEMBL 3198838 & 688155 & 5.2 & 5.1578 & TST & \\
\hline CHEMBL1312839 & 688155 & 4.5 & 5.1226 & TRN & \\
\hline CHEMBL1504342 & 688155 & 4.95 & 4.978 & TRN & \\
\hline CHEMBL1561316 & 688155 & 4.65 & 4.9594 & TRN & \\
\hline CHEMBL1449353 & 688155 & 4.55 & 4.9573 & TRN & \\
\hline CHEMBL1386874 & 688155 & 4.95 & 5.0001 & TRN & \\
\hline CHEMBL1344875 & 688155 & 4.95 & 5.0431 & TRN & \\
\hline CHEMBL1540077 & 688155 & 4.5 & 5.2328 & TRN & \\
\hline CHEMBL1363585 & 688155 & 4.95 & 4.984 & TST & \\
\hline CHEMBL1405769 & 688155 & 4.55 & 4.9966 & TRN & \\
\hline CHEMBL1495539 & 688155 & 4.7 & 5.1613 & TRN & \\
\hline CHEMBL1348807 & 688155 & 5.6 & 5.0241 & TRN & \\
\hline CHEMBL1354051 & 688155 & 5.9 & 5.0975 & TRN & \\
\hline CHEMBL1478082 & 688155 & 5.2 & 4.9945 & TST & \\
\hline CHEMBL1398171 & 688155 & 5.15 & 4.9797 & TRN & \\
\hline CHEMBL3193330 & 688155 & 4.95 & 5.1455 & TRN & \\
\hline CHEMBL1448235 & 688155 & 5.85 & 5.0976 & TST & \\
\hline CHEMBL1431810 & 688155 & 5.0 & 5.0872 & TRN & \\
\hline CHEMBL1311214 & 688155 & 5.05 & 5.0511 & TRN & \\
\hline CHEMBL1511190 & 688155 & 4.9 & 5.0104 & TST & \\
\hline CHEMBL1438918 & 688155 & 4.9 & 4.9542 & TRN & \\
\hline CHEMBL1567960 & 688155 & 5.95 & 4.9826 & TRN & \\
\hline CHEMBL1542477 & 688155 & 5.1 & 4.8912 & TRN & \\
\hline CHEMBL117405 & 688155 & 5.0 & 5.0949 & TRN & \\
\hline CHEMBL1520178 & 688155 & 6.0 & 5.1252 & TST & \\
\hline CHEMBL1422960 & 688155 & 5.0 & 4.9582 & TRN & \\
\hline CHEMBL1518888 & 688155 & 5.65 & 4.9909 & TRN & \\
\hline CHEMBL1490805 & 688155 & 4.9 & 5.0658 & TRN & \\
\hline CHEMBL1424112 & 688155 & 4.55 & 4.9693 & TRN & \\
\hline CHEMBL1510701 & 688155 & 5.85 & 5.1413 & TRN & \\
\hline CHEMBL1312337 & 688155 & 4.65 & 4.962 & TST & \\
\hline CHEMBL1510451 & 688155 & 5.75 & 5.0919 & TST & \\
\hline CHEMBL1413484 & 688155 & 4.55 & $5.0710 e$ & 3000000001 & TRN \\
\hline CHEMBL1347274 & 688155 & 4.55 & 5.1315 & TRN & \\
\hline CHEMBL1492517 & 688155 & 4.55 & 5.0269 & TST & \\
\hline CHEMBL1586929 & 688155 & 4.9 & 4.9617 & TST & \\
\hline CHEMBL263972 & 688155 & 5.0 & 5.1108 & TST & \\
\hline
\end{tabular}




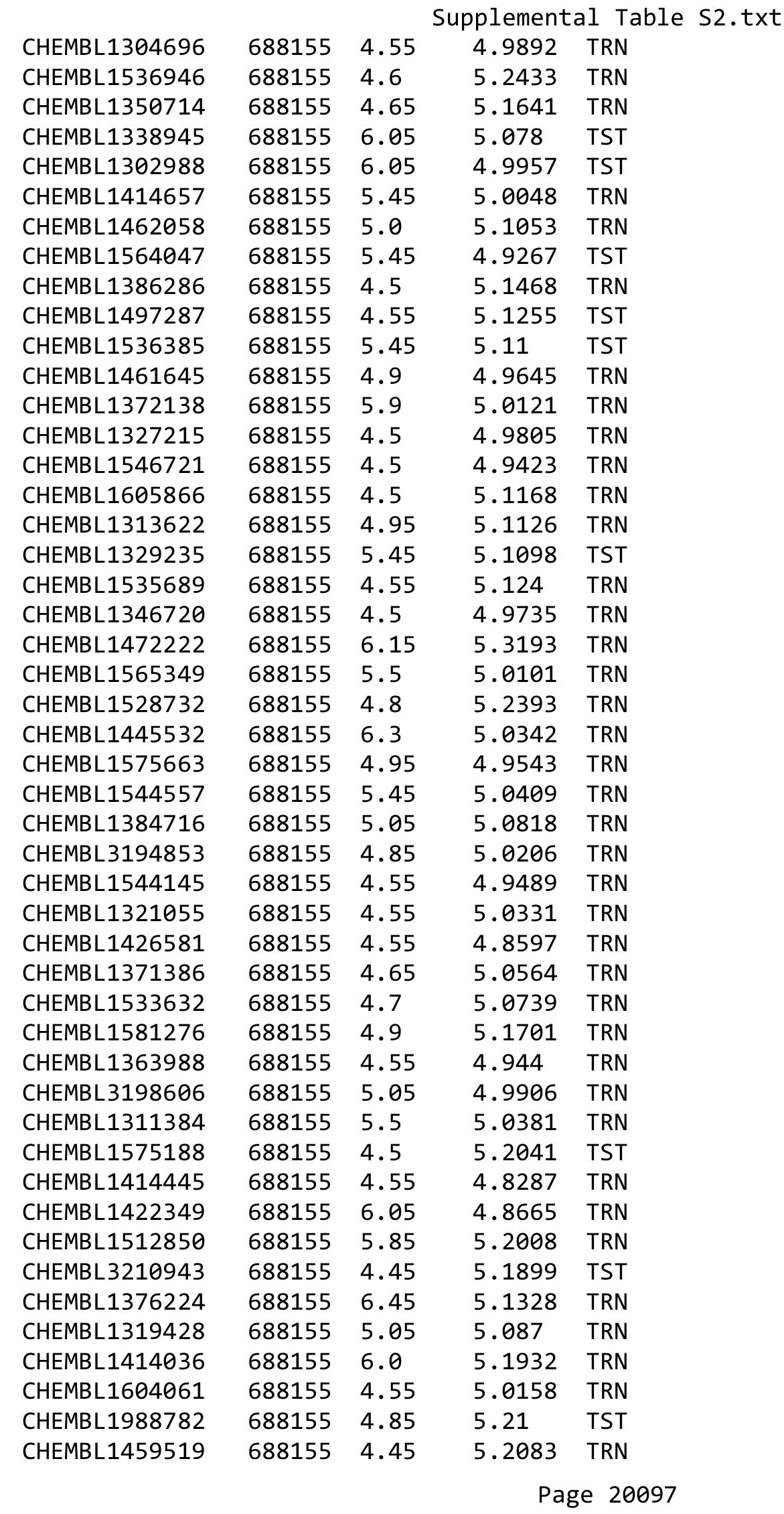




\begin{tabular}{|c|c|c|c|c|}
\hline \multicolumn{5}{|c|}{ Supplemental Table S2.txt } \\
\hline CHEMBL1448248 & 688155 & 4.5 & 5.0883 & TRN \\
\hline CHEMBL1384748 & 688155 & 5.25 & 5.0949 & TRN \\
\hline CHEMBL1610742 & 688155 & 6.05 & 4.8306 & TRN \\
\hline CHEMBL3209526 & 688155 & 6.0 & 5.1018 & TRN \\
\hline CHEMBL1610831 & 688155 & 4.85 & 5.1481 & TST \\
\hline CHEMBL1432472 & 688155 & 4.85 & 5.1016 & TST \\
\hline CHEMBL3189574 & 688155 & 4.55 & 5.0067 & TRN \\
\hline CHEMBL1580041 & 688155 & 6.0 & 5.1105 & TRN \\
\hline CHEMBL1393460 & 688155 & 4.85 & 4.971 & TRN \\
\hline CHEMBL1432095 & 688155 & 4.9 & 5.0005 & TRN \\
\hline CHEMBL1497497 & 688155 & 6.35 & 5.1673 & TRN \\
\hline CHEMBL1352465 & 688155 & 4.95 & 5.0005 & TRN \\
\hline CHEMBL3207353 & 688155 & 5.0 & 5.0481 & TST \\
\hline CHEMBL1517917 & 688155 & 5.95 & 5.0685 & TRN \\
\hline CHEMBL1596728 & 688155 & 4.5 & 5.1784 & TST \\
\hline CHEMBL1417433 & 688155 & 4.55 & 5.0847 & TST \\
\hline CHEMBL1582392 & 688155 & 5.0 & 5.1916 & TRN \\
\hline CHEMBL1499135 & 688155 & 5.0 & 5.1123 & TST \\
\hline CHEMBL1391259 & 688155 & 5.3 & 5.0325 & TRN \\
\hline CHEMBL3212771 & 688155 & 4.9 & 5.0838 & TRN \\
\hline CHEMBL1489593 & 688155 & 5.95 & 4.9781 & TRN \\
\hline CHEMBL1364435 & 688155 & 4.9 & 5.0612 & TST \\
\hline CHEMBL1313650 & 688155 & 4.5 & 5.0792 & TRN \\
\hline CHEMBL1307390 & 688155 & 4.65 & 4.9652 & TRN \\
\hline CHEMBL1461766 & 688155 & 4.5 & 5.0687 & TRN \\
\hline CHEMBL3189203 & 688155 & 4.95 & 5.1036 & TRN \\
\hline CHEMBL1445229 & 688155 & 5.15 & 5.0114 & TRN \\
\hline CHEMBL1461973 & 688155 & 4.55 & 4.9884 & TST \\
\hline CHEMBL1549982 & 688155 & 4.85 & 5.1824 & TRN \\
\hline CHEMBL1567997 & 688155 & 4.55 & 5.1778 & TST \\
\hline CHEMBL1357283 & 688155 & 5.5 & 5.1114 & TST \\
\hline CHEMBL1300770 & 688155 & 5.85 & 5.2167 & TRN \\
\hline CHEMBL1468763 & 688155 & 5.2 & 5.0571 & TST \\
\hline CHEMBL3207395 & 688155 & 4.5 & 5.0958 & TST \\
\hline CHEMBL1336881 & 688155 & 5.0 & 5.0077 & TST \\
\hline CHEMBL1483885 & 688155 & 5.45 & 5.0124 & TRN \\
\hline CHEMBL1444519 & 688155 & 4.55 & 5.1527 & TRN \\
\hline CHEMBL1481914 & 688155 & 4.5 & 5.0053 & TST \\
\hline CHEMBL1542466 & 688155 & 4.55 & 5.1024 & TST \\
\hline CHEMBL1460852 & 688155 & 5.05 & 5.0521 & TRN \\
\hline CHEMBL1460264 & 688155 & 4.55 & 4.9446 & TRN \\
\hline CHEMBL1575418 & 688155 & 4.55 & 5.2409 & TST \\
\hline CHEMBL1582006 & 688155 & 5.45 & 5.0409 & TST \\
\hline CHEMBL317757 & 688155 & 4.75 & 5.1752 & TRN \\
\hline CHEMBL1470058 & 688155 & 4.55 & 5.0387 & TRN \\
\hline CHEMBL1534639 & 688155 & 4.7 & 5.0247 & TST \\
\hline CHEMBL1324995 & 688155 & 5.2 & 4.867 & TRN \\
\hline CHEMBL1431126 & 688155 & 5.1 & 5.0217 & TRN \\
\hline
\end{tabular}




\begin{tabular}{|c|c|c|c|c|}
\hline \multicolumn{5}{|c|}{ Supplemental Table S2.txt } \\
\hline CHEMBL1425749 & 688155 & 5.4 & 5.1021 & TST \\
\hline CHEMBL1528526 & 688155 & 4.9 & 5.1659 & TRN \\
\hline CHEMBL1581818 & 688155 & 4.95 & 5.0437 & TST \\
\hline CHEMBL1338448 & 688155 & 4.65 & 4.9979 & TRN \\
\hline CHEMBL1301530 & 688155 & 4.9 & 5.0555 & TRN \\
\hline CHEMBL1477811 & 688155 & 4.95 & 5.2351 & TRN \\
\hline CHEMBL1607072 & 688155 & 5.35 & 5.2841 & TRN \\
\hline CHEMBL1487007 & 688155 & 4.5 & 5.2572 & TRN \\
\hline CHEMBL1431501 & 688155 & 4.95 & 5.0841 & TRN \\
\hline CHEMBL1338021 & 688155 & 4.5 & 5.1245 & TRN \\
\hline CHEMBL1466539 & 688155 & 5.25 & 4.9049 & TRN \\
\hline CHEMBL1601223 & 688155 & 4.9 & 5.0669 & TRN \\
\hline CHEMBL1543282 & 688155 & 4.5 & 5.0171 & TRN \\
\hline CHEMBL1564461 & 688155 & 5.05 & 5.0636 & TRN \\
\hline CHEMBL1318425 & 688155 & 4.95 & 5.0115 & TRN \\
\hline CHEMBL1439672 & 688155 & 5.15 & 4.9795 & TST \\
\hline CHEMBL1367426 & 688155 & 4.95 & 5.1115 & TRN \\
\hline CHEMBL1303635 & 688155 & 4.55 & 4.9913 & TRN \\
\hline CHEMBL1551015 & 688155 & 4.95 & 5.1371 & TRN \\
\hline CHEMBL1371706 & 688155 & 4.5 & 5.0422 & TRN \\
\hline CHEMBL1423342 & 688155 & 5.75 & 5.0963 & TRN \\
\hline CHEMBL1408324 & 688155 & 5.8 & 5.2096 & TRN \\
\hline CHEMBL1588295 & 688155 & 6.0 & 5.1977 & TST \\
\hline CHEMBL1350949 & 688155 & 4.9 & 4.993 & TRN \\
\hline CHEMBL1442671 & 688155 & 4.85 & 5.2771 & TRN \\
\hline CHEMBL1300365 & 688155 & 4.5 & 5.1852 & TST \\
\hline CHEMBL1544903 & 688155 & 4.75 & 5.1263 & TRN \\
\hline CHEMBL1458210 & 688155 & 4.9 & 5.0169 & TRN \\
\hline CHEMBL1487863 & 688155 & 6.3 & 5.274 & TST \\
\hline CHEMBL1408106 & 688155 & 4.85 & 5.0613 & TST \\
\hline CHEMBL1496854 & 688155 & 4.55 & 4.9439 & TST \\
\hline CHEMBL1382710 & 688155 & 4.6 & 5.1947 & TRN \\
\hline CHEMBL1492518 & 688155 & 4.95 & 5.0048 & TRN \\
\hline CHEMBL1299250 & 688155 & 5.0 & 5.1089 & TRN \\
\hline CHEMBL1366072 & 688155 & 4.55 & 5.1708 & TRN \\
\hline CHEMBL1365260 & 688155 & 4.5 & 4.9909 & TRN \\
\hline CHEMBL3213742 & 688155 & 4.95 & 5.0588 & TST \\
\hline CHEMBL1541206 & 688155 & 4.95 & 5.0102 & TRN \\
\hline CHEMBL1416630 & 688155 & 4.5 & 5.0021 & TRN \\
\hline CHEMBL3196954 & 688155 & 4.9 & 5.0097 & TRN \\
\hline CHEMBL1604539 & 688155 & 4.6 & 5.1187 & TRN \\
\hline CHEMBL1589698 & 688155 & 4.55 & 4.9944 & TRN \\
\hline CHEMBL1337075 & 688155 & 4.55 & 4.8058 & TRN \\
\hline CHEMBL1589063 & 688155 & 4.9 & 5.186 & TRN \\
\hline CHEMBL1387385 & 688155 & 4.9 & 5.0609 & TST \\
\hline CHEMBL1306193 & 688155 & 6.05 & 5.0634 & TRN \\
\hline CHEMBL1452608 & 688155 & 4.95 & 5.0759 & TRN \\
\hline CHEMBL1421913 & 688155 & 4.55 & 4.9854 & TRN \\
\hline
\end{tabular}




\begin{tabular}{|c|c|c|c|c|}
\hline \multicolumn{5}{|c|}{ Supplemental Table } \\
\hline CHEMBL1343311 & 688155 & 4.9 & 4.8849 & TRN \\
\hline CHEMBL1325634 & 688155 & 5.0 & 5.0008 & TRN \\
\hline CHEMBL1535291 & 688155 & 4.55 & 4.9598 & TRN \\
\hline CHEMBL1500539 & 688155 & 4.95 & 5.0528 & TRN \\
\hline CHEMBL1386316 & 688155 & 4.55 & 4.9792 & TST \\
\hline CHEMBL1542203 & 688155 & 5.45 & 5.2666 & TST \\
\hline CHEMBL1533245 & 688155 & 5.55 & 5.0379 & TRN \\
\hline CHEMBL1383884 & 688155 & 4.55 & 5.0943 & TST \\
\hline CHEMBL1574852 & 688155 & 4.55 & 5.0477 & TRN \\
\hline CHEMBL1418094 & 688155 & 5.9 & 5.0699 & TST \\
\hline CHEMBL1604143 & 688155 & 5.0 & 4.9449 & TRN \\
\hline CHEMBL1471055 & 688155 & 5.6 & 5.0045 & TRN \\
\hline CHEMBL1472426 & 688155 & 4.8 & 4.9323 & TRN \\
\hline CHEMBL1509918 & 688155 & 4.55 & 4.9483 & TRN \\
\hline CHEMBL1601565 & 688155 & 4.5 & 5.0767 & TRN \\
\hline CHEMBL1503412 & 688155 & 4.55 & 5.0551 & TST \\
\hline CHEMBL1304979 & 688155 & 4.95 & 5.0899 & TRN \\
\hline CHEMBL1325184 & 688155 & 4.55 & 5.0938 & TST \\
\hline CHEMBL1510177 & 688155 & 5.15 & 5.2064 & TRN \\
\hline CHEMBL 38288 & 688155 & 4.6 & 5.1625 & TRN \\
\hline CHEMBL1374622 & 688155 & 5.0 & 5.0848 & TRN \\
\hline CHEMBL1613238 & 688155 & 4.95 & 5.1184 & TRN \\
\hline CHEMBL1487131 & 688155 & 4.5 & 4.9244 & TRN \\
\hline CHEMBL1464657 & 688155 & 4.9 & 5.0575 & TRN \\
\hline CHEMBL1312498 & 688155 & 5.95 & 5.0079 & TST \\
\hline CHEMBL1566044 & 688155 & 6.0 & 5.2933 & TRN \\
\hline CHEMBL1362914 & 688155 & 4.95 & 5.073 & TST \\
\hline CHEMBL1534352 & 688155 & 5.95 & 5.2975 & TRN \\
\hline CHEMBL1526507 & 688155 & 5.05 & 4.998 & TRN \\
\hline CHEMBL90124 & 688155 & 6.0 & 4.8439 & TRN \\
\hline CHEMBL1369948 & 688155 & 5.2 & 5.1654 & TST \\
\hline CHEMBL1439360 & 688155 & 5.0 & 5.3437 & TRN \\
\hline CHEMBL1418818 & 688155 & 5.0 & 4.9791 & TRN \\
\hline CHEMBL1560530 & 688155 & 4.9 & 5.0236 & TRN \\
\hline CHEMBL1374838 & 688155 & 5.95 & 5.0757 & TRN \\
\hline CHEMBL1469841 & 688155 & 5.05 & 5.1126 & TRN \\
\hline CHEMBL1453905 & 688155 & 4.55 & 4.9869 & TRN \\
\hline CHEMBL1304915 & 688155 & 6.3 & 4.9848 & TST \\
\hline CHEMBL1609211 & 688155 & 5.55 & 5.1523 & TST \\
\hline CHEMBL1438136 & 688155 & 4.55 & 5.1818 & TST \\
\hline CHEMBL1484386 & 688155 & 4.95 & 5.107 & TRN \\
\hline CHEMBL1352807 & 688155 & 5.1 & 5.0502 & TRN \\
\hline CHEMBL3212026 & 688155 & 5.0 & 5.0709 & TST \\
\hline CHEMBL1510860 & 688155 & 4.55 & 4.8601 & TRN \\
\hline CHEMBL1420233 & 688155 & 5.0 & 5.1649 & TRN \\
\hline CHEMBL1457512 & 688155 & 6.0 & 5.0892 & TST \\
\hline CHEMBL1489841 & 688155 & 5.65 & 5.0748 & TRN \\
\hline CHEMBL1363762 & 688155 & 5.0 & 4.9039 & TRN \\
\hline
\end{tabular}




\begin{tabular}{|c|c|c|c|c|}
\hline \multicolumn{5}{|c|}{ Supplemental Table S2.txt } \\
\hline CHEMBL1312803 & 688155 & 5.6 & 5.1442 & TRN \\
\hline CHEMBL1425475 & 688155 & 4.8 & 5.0334 & TRN \\
\hline CHEMBL1449494 & 688155 & 5.25 & 5.0907 & TST \\
\hline CHEMBL1543078 & 688155 & 6.05 & 4.936 & TRN \\
\hline CHEMBL1347839 & 688155 & 5.05 & 5.0648 & TST \\
\hline CHEMBL1388808 & 688155 & 4.55 & 5.0653 & TST \\
\hline CHEMBL1602122 & 688155 & 5.3 & 4.9826 & TRN \\
\hline CHEMBL1442082 & 688155 & 4.5 & 5.1207 & TRN \\
\hline CHEMBL1341090 & 688155 & 4.95 & 5.1678 & TST \\
\hline CHEMBL1487246 & 688155 & 4.85 & 5.0226 & TST \\
\hline CHEMBL1467708 & 688155 & 4.55 & 5.1798 & TST \\
\hline CHEMBL1541655 & 688155 & 5.85 & 5.0563 & TRN \\
\hline CHEMBL1454080 & 688155 & 4.95 & 5.0108 & TST \\
\hline CHEMBL1468428 & 688155 & 4.5 & 5.075 & TST \\
\hline CHEMBL1448318 & 688155 & 6.5 & 5.0688 & TRN \\
\hline CHEMBL1424393 & 688155 & 5.45 & 5.1508 & TRN \\
\hline CHEMBL1353238 & 688155 & 4.55 & 5.1474 & TST \\
\hline CHEMBL 3212937 & 688155 & 4.5 & 5.1019 & TRN \\
\hline CHEMBL1507392 & 688155 & 4.55 & 4.9875 & TST \\
\hline CHEMBL1452794 & 688155 & 5.0 & 5.1511 & TST \\
\hline CHEMBL1534999 & 688155 & 4.55 & 5.0215 & TRN \\
\hline CHEMBL1333441 & 688155 & 4.85 & 5.0885 & TRN \\
\hline CHEMBL3192365 & 688155 & 5.45 & 5.0438 & TST \\
\hline CHEMBL1425554 & 688155 & 6.5 & 5.109 & TRN \\
\hline CHEMBL3196016 & 688155 & 4.5 & 5.0188 & TRN \\
\hline CHEMBL313163 & 688155 & 4.9 & 4.9373 & TRN \\
\hline CHEMBL1373271 & 688155 & 4.85 & 4.9386 & TRN \\
\hline CHEMBL1357500 & 688155 & 5.5 & 5.1864 & TRN \\
\hline CHEMBL1573297 & 688155 & 4.55 & 5.0532 & TST \\
\hline CHEMBL1471308 & 688155 & 4.95 & 4.9831 & TRN \\
\hline CHEMBL1572616 & 688155 & 4.5 & 5.2794 & TRN \\
\hline CHEMBL3192485 & 688155 & 4.55 & 5.0828 & TRN \\
\hline CHEMBL1467593 & 688155 & 4.9 & 5.1947 & TST \\
\hline CHEMBL358644 & 688155 & 5.5 & 5.0396 & TRN \\
\hline CHEMBL1456405 & 688155 & 6.05 & 5.0851 & TRN \\
\hline CHEMBL1427503 & 688155 & 4.9 & 5.0513 & TRN \\
\hline CHEMBL1497238 & 688155 & 4.55 & 5.0936 & TRN \\
\hline CHEMBL1535525 & 688155 & 5.35 & 5.0571 & TRN \\
\hline CHEMBL1522405 & 688155 & 5.45 & 5.1513 & TRN \\
\hline CHEMBL1349444 & 688155 & 4.95 & 5.2081 & TRN \\
\hline CHEMBL485907 & 688155 & 6.5501 & 5.2977 & TRN \\
\hline CHEMBL1367925 & 688155 & 4.65 & 5.1067 & TRN \\
\hline CHEMBL1423633 & 688155 & 4.55 & 5.0527 & TRN \\
\hline CHEMBL1409369 & 688155 & 4.55 & 4.8872 & TRN \\
\hline CHEMBL1425616 & 688155 & 5.4 & 5.1602 & TRN \\
\hline CHEMBL1507968 & 688155 & 5.6 & 5.1715 & TST \\
\hline CHEMBL1505824 & 688155 & 5.0 & 5.1231 & TRN \\
\hline CHEMBL1463247 & 688155 & 4.7 & 4.9729 & TRN \\
\hline
\end{tabular}




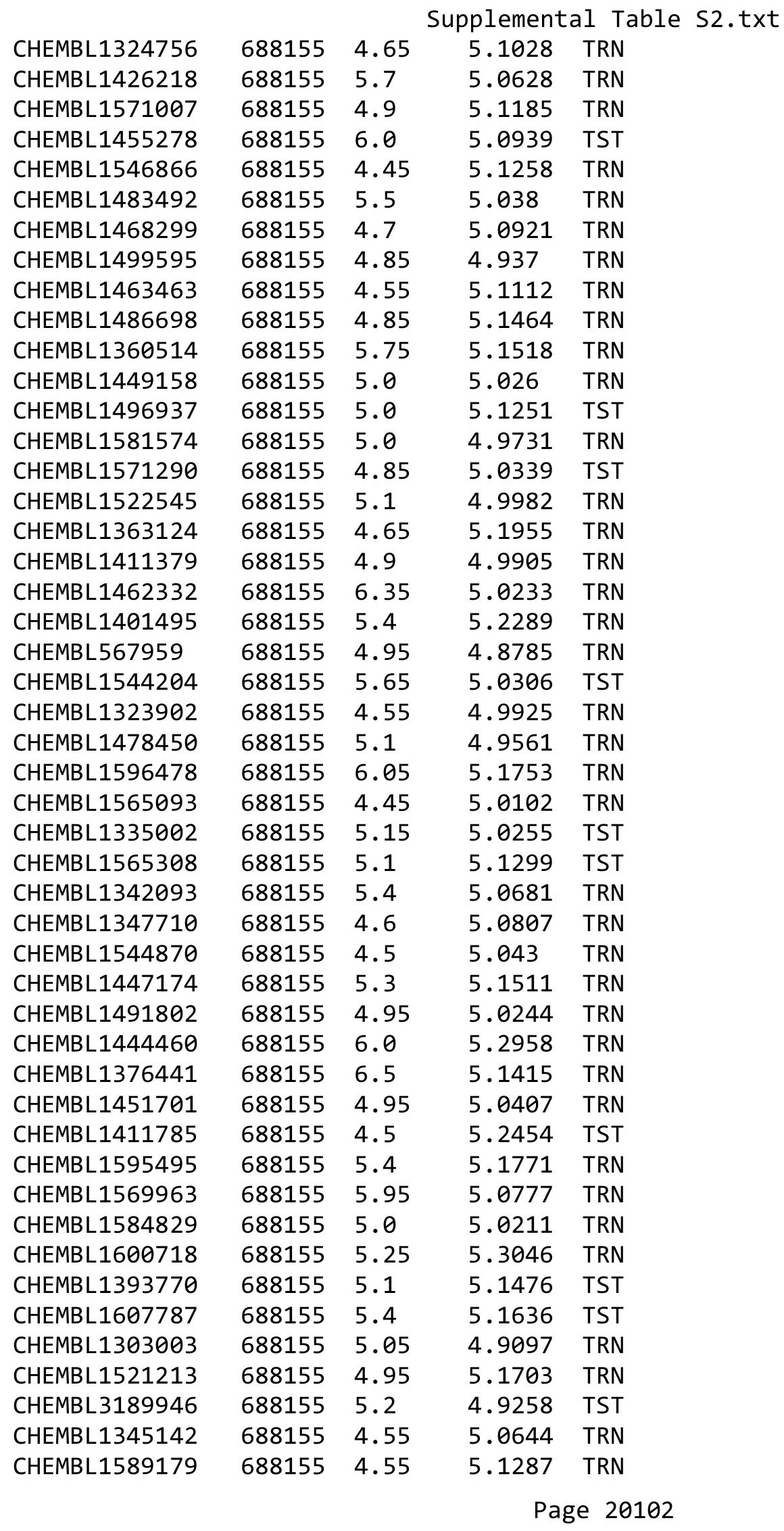




\begin{tabular}{|c|c|c|c|c|c|}
\hline \multicolumn{6}{|c|}{ Supplemental Table S2.txt } \\
\hline CHEMBL1332883 & 688155 & 5.25 & 5.3236 & TRN & \\
\hline CHEMBL1385701 & 688155 & 4.8 & 5.1174 & TRN & \\
\hline CHEMBL1306204 & 688155 & 4.55 & 4.9477 & TRN & \\
\hline CHEMBL1609110 & 688155 & 5.55 & 5.0872 & TRN & \\
\hline CHEMBL1438785 & 688155 & 4.95 & 5.0584 & TRN & \\
\hline CHEMBL1402931 & 688155 & 5.25 & 5.0493 & TST & \\
\hline CHEMBL1349394 & 688155 & 4.5 & 4.86600 & 00000000005 & TRN \\
\hline CHEMBL1455777 & 688155 & 4.7 & 5.2062 & TST & \\
\hline CHEMBL1545865 & 688155 & 4.55 & 4.874 & TRN & \\
\hline CHEMBL1405949 & 688155 & 4.55 & 5.0526 & TRN & \\
\hline CHEMBL1375120 & 688155 & 4.95 & 5.109 & TST & \\
\hline CHEMBL1516369 & 688155 & 4.6 & 4.9364 & TRN & \\
\hline CHEMBL1309016 & 688155 & 6.0 & 5.0887 & TRN & \\
\hline CHEMBL1580537 & 688155 & 5.15 & 5.0668 & TRN & \\
\hline CHEMBL1611622 & 688155 & 5.0 & 5.015 & TRN & \\
\hline CHEMBL1604659 & 688155 & 5.15 & 5.0812 & TRN & \\
\hline CHEMBL13790 & 688155 & 5.1 & 5.0691 & TRN & \\
\hline CHEMBL3192362 & 688155 & 5.3 & 4.9343 & TRN & \\
\hline CHEMBL1393494 & 688155 & 4.9 & 5.1328 & TST & \\
\hline CHEMBL1594527 & 688155 & 4.5 & 4.9871 & TST & \\
\hline CHEMBL1579817 & 688155 & 4.5 & 5.0317 & TST & \\
\hline CHEMBL1559662 & 688155 & 4.6 & 5.0424 & TRN & \\
\hline CHEMBL1495170 & 688155 & 4.55 & 5.0881 & TST & \\
\hline CHEMBL1317748 & 688155 & 5.0 & 4.9984 & TRN & \\
\hline CHEMBL1572455 & 688155 & 6.5501 & 5.1974 & TRN & \\
\hline CHEMBL1457257 & 688155 & 5.0 & 5.0689 & TRN & \\
\hline CHEMBL1498977 & 688155 & 5.0 & 5.038 & TST & \\
\hline CHEMBL1342771 & 688155 & 4.5 & 5.2366 & TRN & \\
\hline CHEMBL1530449 & 688155 & 4.95 & 5.1039 & TST & \\
\hline CHEMBL1370564 & 688155 & 4.95 & 4.9783 & TST & \\
\hline CHEMBL3212050 & 688155 & 5.0 & 5.0149 & TRN & \\
\hline CHEMBL1601698 & 688155 & 4.9 & 4.9979 & TRN & \\
\hline CHEMBL1407584 & 688155 & 5.85 & 5.1251 & TRN & \\
\hline CHEMBL1559853 & 688155 & 4.65 & 4.9382 & TRN & \\
\hline CHEMBL1346984 & 688155 & 4.95 & 4.9028 & TRN & \\
\hline CHEMBL 2373578 & 688155 & 5.3 & 5.2044 & TST & \\
\hline CHEMBL1557200 & 688155 & 6.45 & 5.23 & TRN & \\
\hline CHEMBL1365331 & 688155 & 5.35 & 5.11100 & 0000000001 & TRN \\
\hline CHEMBL3144955 & 688155 & 4.95 & 5.0786 & TST & \\
\hline CHEMBL1503693 & 688155 & 5.95 & 5.2076 & TRN & \\
\hline CHEMBL1365588 & 688155 & 4.5 & 5.3627 & TRN & \\
\hline CHEMBL1584137 & 688155 & 4.75 & 5.1698 & TRN & \\
\hline CHEMBL 251055 & 688155 & 4.9 & 5.0445 & TST & \\
\hline CHEMBL1408754 & 688155 & 5.45 & 4.9799 & TRN & \\
\hline CHEMBL1321376 & 688155 & 4.55 & 5.0364 & TRN & \\
\hline CHEMBL1493273 & 688155 & 4.5 & 5.0286 & TRN & \\
\hline CHEMBL1567738 & 688155 & 4.9 & 4.9245 & TRN & \\
\hline CHEMBL1362741 & 688155 & 4.7 & 5.0787 & TRN & \\
\hline
\end{tabular}




\begin{tabular}{|c|c|c|c|c|c|}
\hline & & \multicolumn{4}{|c|}{ Supplemental Table S2.txt } \\
\hline CHEMBL1561876 & 688155 & 4.95 & 5.1247 & TRN & \\
\hline CHEMBL1352497 & 688155 & 4.55 & 5.0508 & TRN & \\
\hline CHEMBL1560691 & 688155 & 5.65 & 5.1651 & TRN & \\
\hline CHEMBL 3213517 & 688155 & 4.55 & 4.9776 & TRN & \\
\hline CHEMBL1374672 & 688155 & 5.25 & 5.1262 & TST & \\
\hline CHEMBL1468835 & 688155 & 4.55 & 5.1617 & TRN & \\
\hline CHEMBL1484152 & 688155 & 4.5 & 5.0632 & TRN & \\
\hline CHEMBL1386496 & 688155 & 5.0 & 4.9315 & TRN & \\
\hline CHEMBL1380330 & 688155 & 4.55 & 5.0667 & TRN & \\
\hline CHEMBL3190827 & 688155 & 5.05 & 4.981 & TRN & \\
\hline CHEMBL1359820 & 688155 & 5.1 & 5.1251 & TRN & \\
\hline CHEMBL1307389 & 688155 & 5.55 & 5.0615 & TST & \\
\hline CHEMBL1334551 & 688155 & 4.55 & 5.0879 & TRN & \\
\hline CHEMBL1407002 & 688155 & 4.95 & 5.1354 & TST & \\
\hline CHEMBL1487041 & 688155 & 5.0 & 4.9312 & TRN & \\
\hline CHEMBL1496968 & 688155 & 5.55 & 5.1697 & TRN & \\
\hline CHEMBL1606572 & 688155 & 4.85 & 5.0619 & TST & \\
\hline CHEMBL1580473 & 688155 & 4.95 & 5.1065 & TRN & \\
\hline CHEMBL1565576 & 688155 & 4.55 & 4.9406 & TRN & \\
\hline CHEMBL1374436 & 688155 & 4.55 & 5.0419 & TRN & \\
\hline CHEMBL1454428 & 688155 & 5.65 & 5.1785 & TST & \\
\hline CHEMBL1578303 & 688155 & 4.65 & 4.9071 & TRN & \\
\hline CHEMBL1583723 & 688155 & 4.55 & 4.9081 & TRN & \\
\hline CHEMBL1464093 & 688155 & 4.9 & 4.896 & TRN & \\
\hline CHEMBL1353469 & 688155 & 5.3 & 5.1508 & TRN & \\
\hline CHEMBL1568022 & 688155 & 4.55 & 4.9623 & TRN & \\
\hline CHEMBL1574238 & 688155 & 5.0 & 5.0433 & TRN & \\
\hline CHEMBL1466564 & 688155 & 5.0 & 4.9977 & TST & \\
\hline CHEMBL1461201 & 688155 & 5.4 & 5.0433 & TST & \\
\hline CHEMBL1301984 & 688155 & 4.5 & 5.06800 & 00000000005 & TRN \\
\hline CHEMBL1270953 & 688155 & 5.65 & 4.9519 & TRN & \\
\hline CHEMBL1386680 & 688155 & 4.55 & 5.0002 & TST & \\
\hline CHEMBL1310129 & 688155 & 4.95 & 5.0354 & TST & \\
\hline CHEMBL1459159 & 688155 & 5.0 & 5.0183 & TRN & \\
\hline CHEMBL1353133 & 688155 & 4.55 & 5.0297 & TRN & \\
\hline CHEMBL491991 & 688155 & 4.55 & 5.0439 & TRN & \\
\hline CHEMBL1503650 & 688155 & 5.95 & 5.1918 & TRN & \\
\hline CHEMBL3199045 & 688155 & 5.7 & 4.9729 & TST & \\
\hline CHEMBL1588627 & 688155 & 4.65 & 4.9583 & TRN & \\
\hline CHEMBL1312029 & 688155 & 5.4 & 5.2544 & TST & \\
\hline CHEMBL1539535 & 688155 & 5.0 & 5.112 & TRN & \\
\hline CHEMBL1322491 & 688155 & 5.6 & 5.0997 & TRN & \\
\hline CHEMBL 2006503 & 688155 & 5.1 & 5.0048 & TRN & \\
\hline CHEMBL1970152 & 688155 & 5.0 & 4.9655 & TST & \\
\hline CHEMBL1561378 & 688155 & 5.55 & 5.3081 & TRN & \\
\hline CHEMBL1546975 & 688155 & 4.5 & 5.098 & TST & \\
\hline CHEMBL1347163 & 688155 & 4.9 & 5.0594 & TST & \\
\hline CHEMBL3214495 & 688155 & 5.1 & 5.1443 & TRN & \\
\hline
\end{tabular}




\begin{tabular}{|c|c|c|c|c|c|}
\hline \multicolumn{6}{|c|}{ Supplemental Table S2.txt } \\
\hline CHEMBL1536819 & 688155 & 4.9 & 5.016 & TRN & \\
\hline CHEMBL1548412 & 688155 & 4.55 & 5.1138 & TRN & \\
\hline CHEMBL1460607 & 688155 & 5.45 & 5.2316 & TST & \\
\hline CHEMBL1580626 & 688155 & 5.55 & 5.1923 & TRN & \\
\hline CHEMBL1413326 & 688155 & 5.85 & 5.0326 & TRN & \\
\hline CHEMBL1368428 & 688155 & 4.55 & 5.1228 & TRN & \\
\hline CHEMBL1613302 & 688155 & 4.55 & 4.9667 & TRN & \\
\hline CHEMBL1488272 & 688155 & 4.5 & 5.1834 & TST & \\
\hline CHEMBL1301760 & 688155 & 5.45 & 5.1627 & TRN & \\
\hline CHEMBL1342176 & 688155 & 6.0 & 4.9572 & TRN & \\
\hline CHEMBL1460761 & 688155 & 4.5 & 5.1167 & TRN & \\
\hline CHEMBL1446207 & 688155 & 4.5 & 5.0733 & TST & \\
\hline CHEMBL1495860 & 688155 & 4.55 & 5.0366 & TRN & \\
\hline CHEMBL1563504 & 688155 & 4.55 & 4.9296 & TRN & \\
\hline CHEMBL1575022 & 688155 & 5.0 & 5.2197 & TRN & \\
\hline CHEMBL1383064 & 688155 & 4.9 & 5.1616 & TST & \\
\hline CHEMBL1470542 & 688155 & 5.25 & 5.0399 & TRN & \\
\hline CHEMBL1604179 & 688155 & 5.25 & 5.0737 & TRN & \\
\hline CHEMBL1479705 & 688155 & 4.5 & 5.1177 & TRN & \\
\hline CHEMBL1610431 & 688155 & 6.1 & 5.0126 & TST & \\
\hline CHEMBL3199125 & 688155 & 4.9 & 4.9401 & TRN & \\
\hline CHEMBL3196552 & 688155 & 4.9 & 5.1128 & TRN & \\
\hline CHEMBL1496536 & 688155 & 5.3 & 5.2223 & TRN & \\
\hline CHEMBL1347674 & 688155 & 4.55 & 4.9860 & 0000000001 & TST \\
\hline CHEMBL1539886 & 688155 & 4.95 & 5.0123 & TRN & \\
\hline CHEMBL1342894 & 688155 & 5.0 & 5.0851 & TRN & \\
\hline CHEMBL1495845 & 688155 & 4.55 & 5.0403 & TST & \\
\hline CHEMBL1508801 & 688155 & 5.8 & 5.0923 & TRN & \\
\hline CHEMBL1309684 & 688155 & 4.95 & 4.9452 & TRN & \\
\hline CHEMBL589235 & 688155 & 4.65 & 5.1686 & TRN & \\
\hline CHEMBL1312064 & 688155 & 4.5 & 4.9035 & TRN & \\
\hline CHEMBL1583070 & 688155 & 5.0 & 5.0757 & TRN & \\
\hline CHEMBL1422379 & 688155 & 6.5 & 5.2025 & TRN & \\
\hline CHEMBL1406485 & 688155 & 4.85 & 5.0026 & TRN & \\
\hline CHEMBL1450710 & 688155 & 5.0 & 5.0431 & TRN & \\
\hline CHEMBL1479266 & 688155 & 5.1 & 5.1368 & TRN & \\
\hline CHEMBL1459732 & 688155 & 4.55 & 5.0119 & TST & \\
\hline CHEMBL412010 & 688155 & 4.95 & 5.0143 & TRN & \\
\hline CHEMBL1416774 & 688155 & 4.5 & 5.1670 & 0000000001 & TRN \\
\hline CHEMBL1329912 & 688155 & 4.55 & 4.9535 & TRN & \\
\hline CHEMBL1380555 & 688155 & 4.95 & 5.045 & TRN & \\
\hline CHEMBL1425305 & 688155 & 6.5 & 5.0624 & TST & \\
\hline CHEMBL1508375 & 688155 & 5.15 & 5.0805 & TRN & \\
\hline CHEMBL1510689 & 688155 & 4.55 & 5.0781 & TRN & \\
\hline CHEMBL1420144 & 688155 & 4.55 & 5.0588 & TRN & \\
\hline CHEMBL475376 & 688155 & 4.6 & 4.9438 & TRN & \\
\hline CHEMBL1601252 & 688155 & 5.3 & 4.9749 & TRN & \\
\hline CHEMBL1549548 & 688155 & 4.5 & 5.1038 & TRN & \\
\hline
\end{tabular}




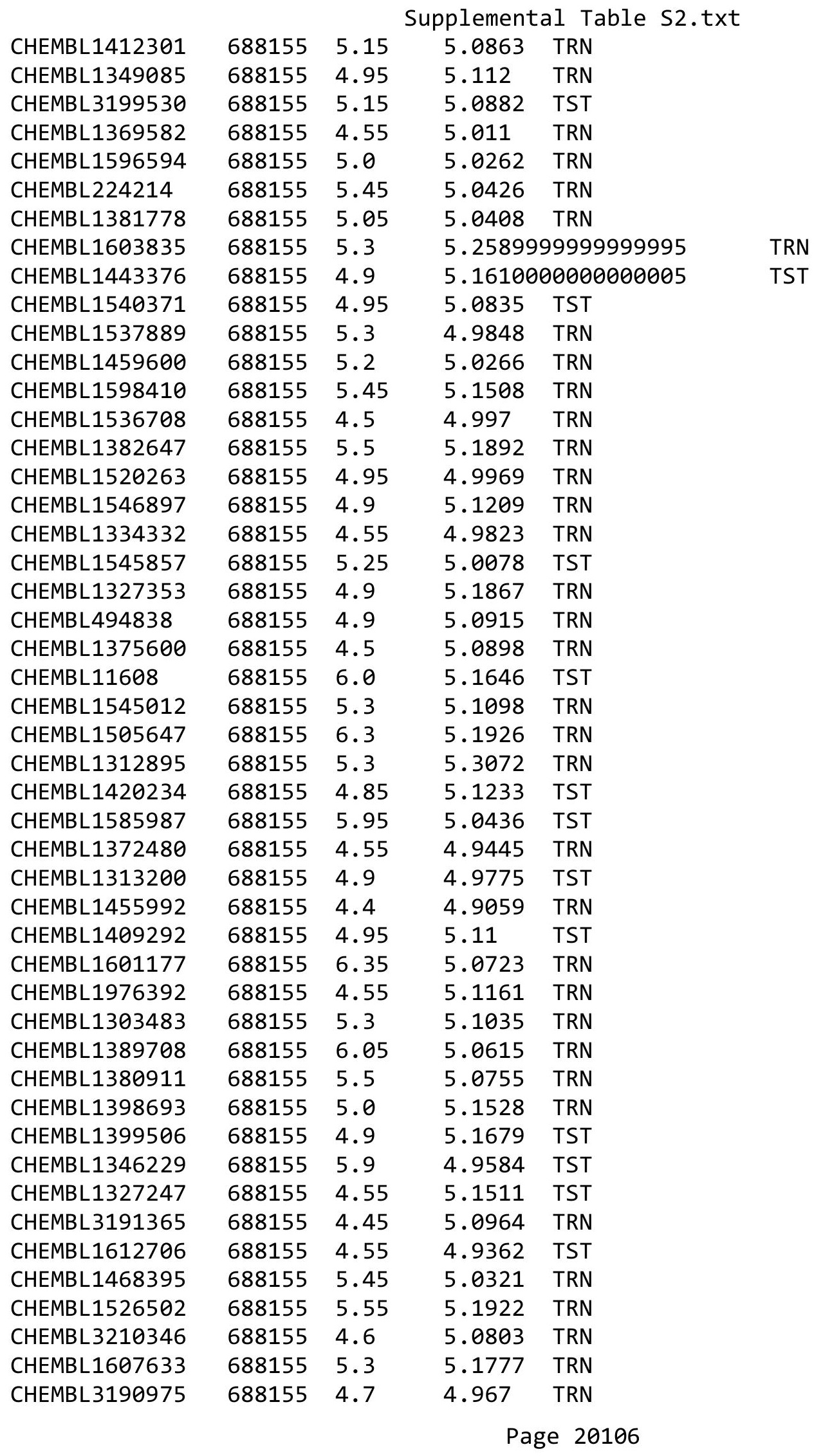




\begin{tabular}{|c|c|c|c|c|c|}
\hline \multicolumn{6}{|c|}{ Supplemental Table S2.txt } \\
\hline CHEMBL3198603 & 688155 & 5.55 & 4.9696 & TRN & \\
\hline CHEMBL1420034 & 688155 & 4.55 & 5.1707 & TRN & \\
\hline CHEMBL1512413 & 688155 & 4.55 & 4.8997 & TRN & \\
\hline CHEMBL1457309 & 688155 & 4.95 & 4.9424 & TRN & \\
\hline CHEMBL1399516 & 688155 & 4.95 & 5.0226 & TST & \\
\hline CHEMBL1451522 & 688155 & 4.5 & 5.0179 & TRN & \\
\hline CHEMBL1479116 & 688155 & 4.55 & 4.9779 & TRN & \\
\hline CHEMBL1547536 & 688155 & 4.95 & 5.1437 & TRN & \\
\hline CHEMBL1433291 & 688155 & 4.55 & 5.1167 & TRN & \\
\hline CHEMBL1478163 & 688155 & 4.8 & 5.0266 & TRN & \\
\hline CHEMBL1518516 & 688155 & 4.95 & 5.0721 & TRN & \\
\hline CHEMBL1572717 & 688155 & 4.85 & 5.0254 & TST & \\
\hline CHEMBL1594688 & 688155 & 4.95 & 5.2556 & TRN & \\
\hline CHEMBL1456132 & 688155 & 5.0 & 5.0269 & TST & \\
\hline CHEMBL1545965 & 688155 & 4.5 & 4.9289 & TRN & \\
\hline CHEMBL1532922 & 688155 & 6.5 & 5.1435 & TST & \\
\hline CHEMBL1302272 & 688155 & 5.25 & 5.0518 & TRN & \\
\hline CHEMBL1314469 & 688155 & 4.95 & 4.9689 & TST & \\
\hline CHEMBL1392443 & 688155 & 4.7 & 5.1122 & TRN & \\
\hline CHEMBL1417364 & 688155 & 4.9 & 5.0725 & TRN & \\
\hline CHEMBL1442120 & 688155 & 4.55 & 5.0987 & TST & \\
\hline CHEMBL1402628 & 688155 & 4.9 & 5.0907 & TRN & \\
\hline CHEMBL1463513 & 688155 & 5.0 & 5.0801 & TST & \\
\hline CHEMBL1503584 & 688155 & 5.1 & 4.9981 & TRN & \\
\hline CHEMBL1611361 & 688155 & 5.0 & 5.0989 & TST & \\
\hline CHEMBL1442979 & 688155 & 5.2 & 5.1333 & TRN & \\
\hline CHEMBL1501426 & 688155 & 5.85 & 5.1716 & TRN & \\
\hline CHEMBL1350562 & 688155 & 5.4 & 5.1128 & TST & \\
\hline CHEMBL1478602 & 688155 & 5.1 & 4.9352 & TRN & \\
\hline CHEMBL1368277 & 688155 & 5.7 & 5.1337 & TRN & \\
\hline CHEMBL1485010 & 688155 & 5.15 & 5.0619 & TRN & \\
\hline CHEMBL1312372 & 688155 & 4.5 & 5.2377 & TRN & \\
\hline CHEMBL1409402 & 688155 & 5.0 & 4.98 & TST & \\
\hline CHEMBL1526744 & 688155 & 4.8 & 5.1943 & TST & \\
\hline CHEMBL1340151 & 688155 & 4.55 & 4.9809 & TRN & \\
\hline CHEMBL1578674 & 688155 & 4.55 & 5.0257 & TST & \\
\hline CHEMBL1380000 & 688155 & 4.5 & 5.1612 & TRN & \\
\hline CHEMBL1312602 & 688155 & 4.95 & 5.0826 & TST & \\
\hline CHEMBL1332574 & 688155 & 5.0 & 5.0931 & TRN & \\
\hline CHEMBL1606805 & 688155 & 4.65 & 5.1788 & TRN & \\
\hline CHEMBL1353603 & 688155 & 4.55 & 5.0801 & TRN & \\
\hline CHEMBL1610361 & 688155 & 6.5501 & 5.0379 & TRN & \\
\hline CHEMBL1502852 & 688155 & 4.85 & 5.0387 & TRN & \\
\hline CHEMBL1557972 & 688155 & 5.05 & 4.9814 & TRN & \\
\hline CHEMBL1522044 & 688155 & 4.65 & 5.2286 & TRN & \\
\hline CHEMBL1457150 & 688155 & 4.55 & 4.9645 & TRN & \\
\hline CHEMBL1362768 & 688155 & 4.85 & 5.17700 & 00000000005 & TRN \\
\hline CHEMBL1541040 & 688155 & 5.9 & 5.0302 & TRN & \\
\hline & & & & 20107 & \\
\hline
\end{tabular}




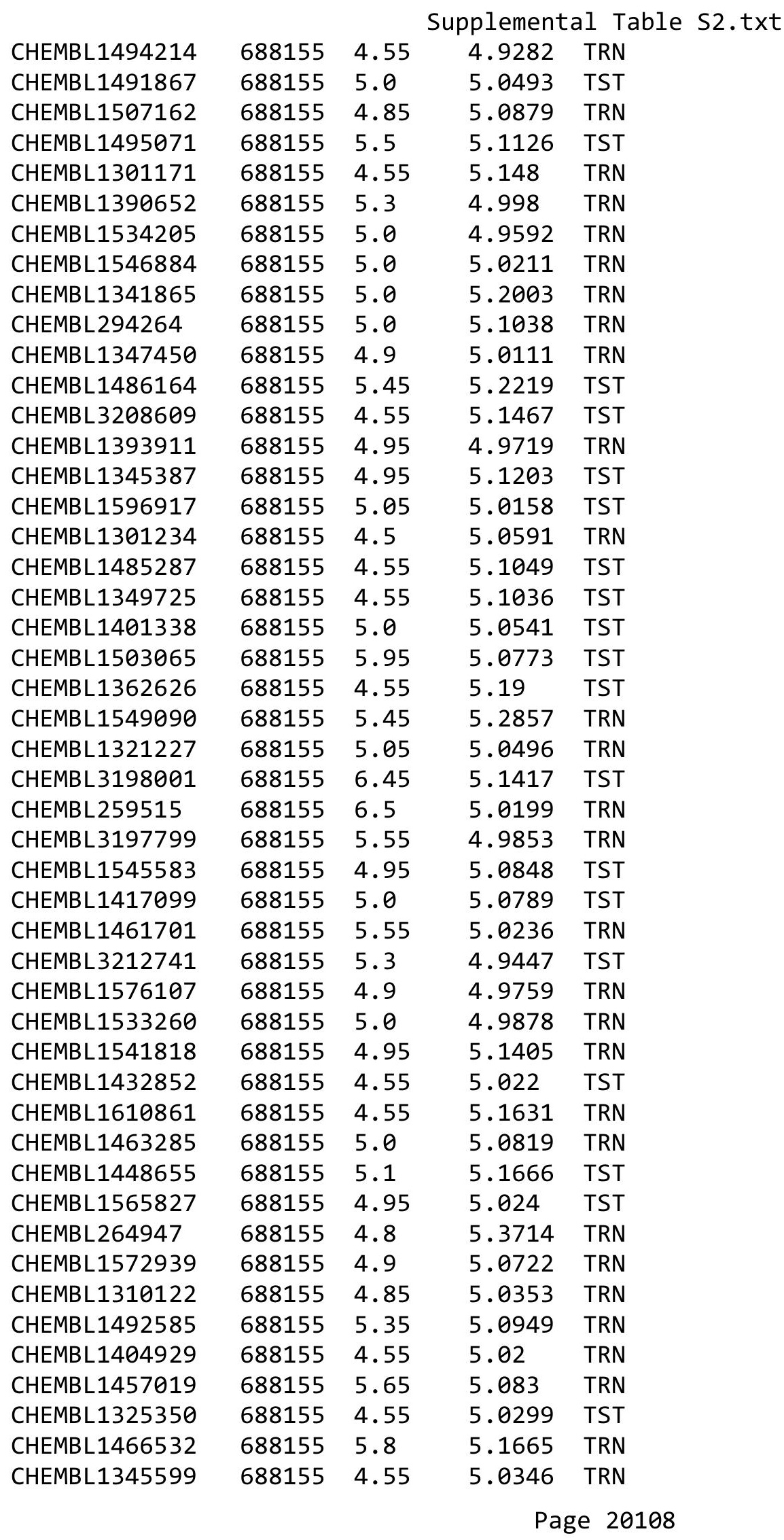




\begin{tabular}{|c|c|c|c|c|}
\hline \multicolumn{5}{|c|}{ Supplemental Table } \\
\hline CHEMBL1541016 & 688155 & 5.75 & 5.2361 & TRN \\
\hline CHEMBL1425949 & 688155 & 4.6 & 4.8441 & TST \\
\hline CHEMBL1305450 & 688155 & 4.95 & 4.9259 & TST \\
\hline CHEMBL3198670 & 688155 & 6.0 & 5.0047 & TST \\
\hline CHEMBL1471924 & 688155 & 5.35 & 5.0148 & TRN \\
\hline CHEMBL1484261 & 688155 & 4.5 & 4.8855 & TRN \\
\hline CHEMBL1585396 & 688155 & 4.55 & 5.1823 & TST \\
\hline CHEMBL1472187 & 688155 & 4.85 & 5.3198 & TST \\
\hline CHEMBL1494182 & 688155 & 5.05 & 5.2273 & TST \\
\hline CHEMBL1310782 & 688155 & 4.9 & 5.0198 & TRN \\
\hline CHEMBL1586282 & 688155 & 4.95 & 5.0213 & TRN \\
\hline CHEMBL1379839 & 688155 & 5.1 & 5.2147 & TST \\
\hline CHEMBL1522805 & 688155 & 5.0 & 5.2119 & TST \\
\hline CHEMBL1335254 & 688155 & 4.95 & 5.0126 & TRN \\
\hline CHEMBL1559260 & 688155 & 5.1 & 5.0769 & TRN \\
\hline CHEMBL1445182 & 688155 & 4.55 & 4.9885 & TRN \\
\hline CHEMBL1461176 & 688155 & 4.95 & 5.0831 & TRN \\
\hline CHEMBL1485984 & 688155 & 6.0 & 5.1411 & TRN \\
\hline CHEMBL1523365 & 688155 & 4.95 & 5.0896 & TRN \\
\hline CHEMBL1401209 & 688155 & 5.0 & 5.0724 & TRN \\
\hline CHEMBL1372348 & 688155 & 4.55 & 4.9844 & TRN \\
\hline CHEMBL1391432 & 688155 & 5.3 & 5.2033 & TST \\
\hline CHEMBL1466130 & 688155 & 4.5 & 5.0755 & TST \\
\hline CHEMBL1454006 & 688155 & 5.25 & 4.9804 & TRN \\
\hline CHEMBL1458939 & 688155 & 5.05 & 5.0448 & TRN \\
\hline CHEMBL1324242 & 688155 & 4.95 & 5.0659 & TRN \\
\hline CHEMBL1399556 & 688155 & 4.95 & 5.1186 & TST \\
\hline CHEMBL1584183 & 688155 & 5.2 & 5.0063 & TRN \\
\hline CHEMBL1427785 & 688155 & 6.5 & 4.9896 & TST \\
\hline CHEMBL1415442 & 688155 & 5.0 & 4.9948 & TRN \\
\hline CHEMBL1526381 & 688155 & 6.0 & 5.0979 & TRN \\
\hline CHEMBL1587132 & 688155 & 4.55 & 5.0052 & TRN \\
\hline CHEMBL1461327 & 688155 & 4.55 & 5.1051 & TRN \\
\hline CHEMBL1402728 & 688155 & 5.95 & 5.0916 & TRN \\
\hline CHEMBL1404934 & 688155 & 5.7 & 5.2668 & TRN \\
\hline CHEMBL1579949 & 688155 & 5.95 & 5.1275 & TST \\
\hline CHEMBL1353508 & 688155 & 5.1 & 5.0942 & TRN \\
\hline CHEMBL1397558 & 688155 & 4.55 & 5.2039 & TRN \\
\hline CHEMBL1599520 & 688155 & 4.95 & 5.0241 & TRN \\
\hline CHEMBL1452151 & 688155 & 5.3 & 5.0783 & TST \\
\hline CHEMBL1232258 & 688155 & 5.3 & 5.2281 & TST \\
\hline CHEMBL1364667 & 688155 & 4.55 & 4.9492 & TRN \\
\hline CHEMBL1448750 & 688155 & 4.9 & 4.927 & TRN \\
\hline CHEMBL1347327 & 688155 & 5.55 & 5.0217 & TST \\
\hline CHEMBL1429785 & 688155 & 4.5 & 5.1753 & TRN \\
\hline CHEMBL1428403 & 688155 & 4.55 & 5.1033 & TST \\
\hline CHEMBL1577332 & 688155 & 5.0 & 4.9816 & TST \\
\hline CHEMBL1337204 & 688155 & 5.95 & 5.1367 & TRN \\
\hline
\end{tabular}




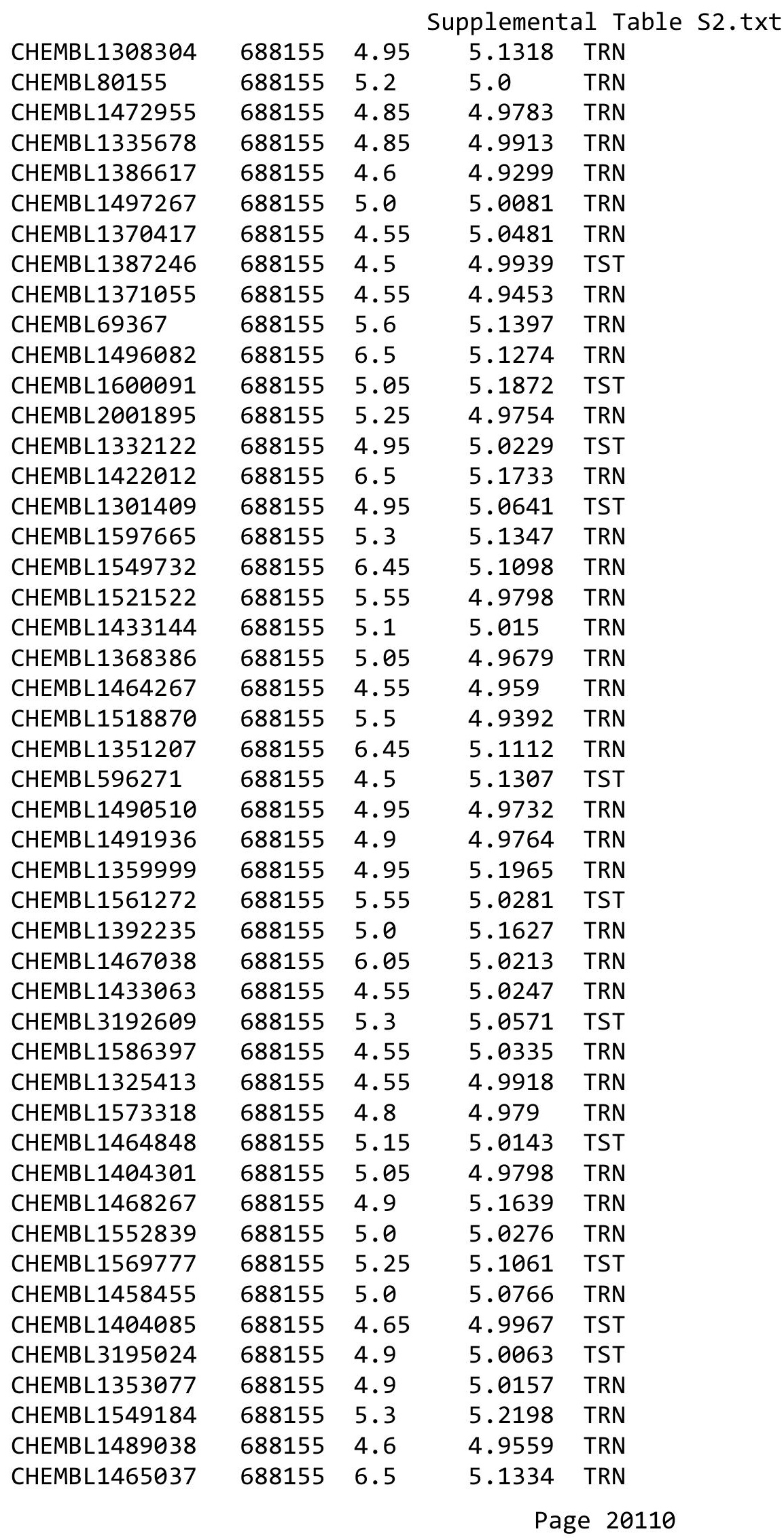




\begin{tabular}{|c|c|c|c|c|c|}
\hline \multicolumn{6}{|c|}{ Supplemental Table S2.txt } \\
\hline CHEMBL1387104 & 688155 & 4.9 & 5.2095 & TRN & \\
\hline CHEMBL1400244 & 688155 & 4.55 & 5.136 & TRN & \\
\hline CHEMBL1344055 & 688155 & 4.9 & 4.9814 & TRN & \\
\hline CHEMBL590186 & 688155 & 5.7 & 5.136 & TST & \\
\hline CHEMBL1340749 & 688155 & 4.95 & 5.0282 & TRN & \\
\hline CHEMBL1439186 & 688155 & 4.5 & 5.0472 & TRN & \\
\hline CHEMBL1578334 & 688155 & 5.05 & 5.0704 & TRN & \\
\hline CHEMBL1351342 & 688155 & 5.0 & 5.0086 & TRN & \\
\hline CHEMBL1531249 & 688155 & 5.05 & 5.0214 & TRN & \\
\hline CHEMBL1489973 & 688155 & 4.5 & 5.0234 & TRN & \\
\hline CHEMBL1571692 & 688155 & 4.95 & 5.1586 & TST & \\
\hline CHEMBL494081 & 688155 & 5.2 & 5.2052 & TRN & \\
\hline CHEMBL1197556 & 688155 & 4.95 & 5.0746 & TST & \\
\hline CHEMBL1487951 & 688155 & 5.55 & 5.2295 & TRN & \\
\hline CHEMBL1543035 & 688155 & 5.7 & 5.0307 & TST & \\
\hline CHEMBL1429013 & 688155 & 4.5 & 5.0221 & TRN & \\
\hline CHEMBL1487275 & 688155 & 5.3 & 5.2676 & TRN & \\
\hline CHEMBL1543163 & 688155 & 5.0 & 4.9864 & TST & \\
\hline CHEMBL606166 & 688155 & 5.05 & 5.0289 & TST & \\
\hline CHEMBL1602290 & 688155 & 4.5 & 5.0786 & TST & \\
\hline CHEMBL1358911 & 688155 & 4.85 & 4.9914 & TRN & \\
\hline CHEMBL1425822 & 688155 & 4.9 & 5.0601 & TST & \\
\hline CHEMBL1312176 & 688155 & 6.0 & 5.15 & TRN & \\
\hline CHEMBL1410279 & 688155 & 5.4 & 5.0146 & TRN & \\
\hline CHEMBL1527731 & 688155 & 6.0 & 5.216 & TRN & \\
\hline CHEMBL1577905 & 688155 & 4.75 & 5.1184 & TST & \\
\hline CHEMBL1300379 & 688155 & 5.25 & 5.1424 & TST & \\
\hline CHEMBL1494386 & 688155 & 6.25 & 4.9187 & TRN & \\
\hline CHEMBL1530757 & 688155 & 4.55 & 4.9597 & TRN & \\
\hline CHEMBL1311159 & 688155 & 6.3 & 5.1146 & TST & \\
\hline CHEMBL1480936 & 688155 & 5.0 & 5.07600 & 00000000005 & TRN \\
\hline CHEMBL1351436 & 688155 & 4.55 & 4.9844 & TRN & \\
\hline CHEMBL 3212145 & 688155 & 4.55 & 5.021 & TST & \\
\hline CHEMBL1329126 & 688155 & 4.5 & 5.2065 & TRN & \\
\hline CHEMBL1446704 & 688155 & 4.7 & 4.9902 & TST & \\
\hline CHEMBL283130 & 688155 & 4.65 & 5.1967 & TST & \\
\hline CHEMBL1308665 & 688155 & 4.85 & 5.1011 & TRN & \\
\hline CHEMBL1471958 & 688155 & 5.0 & 5.0024 & TRN & \\
\hline CHEMBL1311164 & 688155 & 4.85 & 5.0821 & TRN & \\
\hline CHEMBL1402087 & 688155 & 6.45 & 5.2328 & TRN & \\
\hline CHEMBL1472314 & 688155 & 5.95 & 5.0253 & TRN & \\
\hline CHEMBL1611338 & 688155 & 4.95 & 5.1212 & TRN & \\
\hline CHEMBL1584700 & 688155 & 4.65 & 5.1897 & TST & \\
\hline CHEMBL1451537 & 688155 & 6.45 & 5.143 & TRN & \\
\hline CHEMBL1378258 & 688155 & 4.5 & 5.0596 & TRN & \\
\hline CHEMBL1497289 & 688155 & 5.2 & 5.0775 & TRN & \\
\hline CHEMBL1499611 & 688155 & 4.9 & 5.0707 & TRN & \\
\hline CHEMBL1542538 & 688155 & 5.45 & 5.1547 & TRN & \\
\hline
\end{tabular}




\begin{tabular}{|c|c|c|c|c|c|}
\hline & & \multicolumn{4}{|c|}{ Supplemental Table S2.txt } \\
\hline CHEMBL1432801 & 688155 & 4.55 & 4.8669 & TRN & \\
\hline CHEMBL1587962 & 688155 & 4.55 & 5.1927 & TRN & \\
\hline CHEMBL1564669 & 688155 & 4.95 & 5.0406 & TRN & \\
\hline CHEMBL121229 & 688155 & 5.55 & 5.1592 & TST & \\
\hline CHEMBL1441873 & 688155 & 4.55 & 5.03600 & 00000000005 & TRN \\
\hline CHEMBL1518360 & 688155 & 5.0 & 5.0347 & TRN & \\
\hline CHEMBL1547203 & 688155 & 5.05 & 5.1871 & TRN & \\
\hline CHEMBL1426726 & 688155 & 5.0 & 5.0812 & TRN & \\
\hline CHEMBL1403983 & 688155 & 4.55 & 5.0304 & TST & \\
\hline CHEMBL1306075 & 688155 & 5.9 & 5.3069 & TRN & \\
\hline CHEMBL 2006511 & 688155 & 4.5 & 5.1105 & TST & \\
\hline CHEMBL1425956 & 688155 & 4.55 & 4.9522 & TRN & \\
\hline CHEMBL1468397 & 688155 & 5.2 & 5.1327 & TRN & \\
\hline CHEMBL1568064 & 688155 & 6.45 & 5.1151 & TRN & \\
\hline CHEMBL1405990 & 688155 & 4.5 & 5.0309 & TST & \\
\hline CHEMBL1393863 & 688155 & 4.55 & 4.9506 & TRN & \\
\hline CHEMBL1494934 & 688155 & 4.55 & 5.0672 & TRN & \\
\hline CHEMBL1441270 & 688155 & 4.75 & 5.13200 & 0000000001 & TRN \\
\hline CHEMBL1571534 & 688155 & 5.0 & 5.2218 & TRN & \\
\hline CHEMBL1583967 & 688155 & 5.3 & 5.0179 & TRN & \\
\hline CHEMBL1384261 & 688155 & 5.0 & 5.0054 & TRN & \\
\hline CHEMBL1508593 & 688155 & 4.95 & 4.9287 & TST & \\
\hline CHEMBL1509120 & 688155 & 4.55 & 4.9617 & TRN & \\
\hline CHEMBL1352496 & 688155 & 4.85 & 5.2828 & TST & \\
\hline CHEMBL1578314 & 688155 & 4.55 & 4.9365 & TRN & \\
\hline CHEMBL1338796 & 688155 & 6.45 & 5.2161 & TRN & \\
\hline CHEMBL253570 & 688155 & 4.65 & 5.0257 & TRN & \\
\hline CHEMBL1502723 & 688155 & 4.95 & 4.9997 & TRN & \\
\hline CHEMBL1479052 & 688155 & 4.55 & 5.0546 & TRN & \\
\hline CHEMBL1577466 & 688155 & 4.9 & 4.8979 & TRN & \\
\hline CHEMBL1310248 & 688155 & 5.0 & 4.957 & TST & \\
\hline CHEMBL1332963 & 688155 & 4.6 & 4.9811 & TRN & \\
\hline CHEMBL1495053 & 688155 & 4.55 & 5.1657 & TST & \\
\hline CHEMBL3212497 & 688155 & 5.0 & 5.0451 & TRN & \\
\hline CHEMBL1340832 & 688155 & 5.1 & 4.9498 & TRN & \\
\hline CHEMBL1465138 & 688155 & 5.65 & 4.9497 & TRN & \\
\hline CHEMBL1336910 & 688155 & 4.95 & 5.05 & TRN & \\
\hline CHEMBL1463012 & 688155 & 4.65 & 4.9315 & TRN & \\
\hline CHEMBL1320239 & 688155 & 4.9 & 5.1977 & TRN & \\
\hline CHEMBL1501170 & 688155 & 6.15 & 5.2169 & TRN & \\
\hline CHEMBL1536011 & 688155 & 4.8 & 5.0971 & TRN & \\
\hline CHEMBL1346860 & 688155 & 6.35 & 4.9473 & TRN & \\
\hline CHEMBL1429129 & 688155 & 4.55 & 5.0725 & TRN & \\
\hline CHEMBL1301246 & 688155 & 5.85 & 5.1073 & TRN & \\
\hline CHEMBL1412940 & 688155 & 5.5 & 5.0575 & TRN & \\
\hline CHEMBL1378922 & 688155 & 4.9 & 5.1542 & TRN & \\
\hline CHEMBL1384987 & 688155 & 4.5 & 4.9934 & TRN & \\
\hline CHEMBL1558735 & 688155 & 4.65 & 5.0976 & TRN & \\
\hline
\end{tabular}




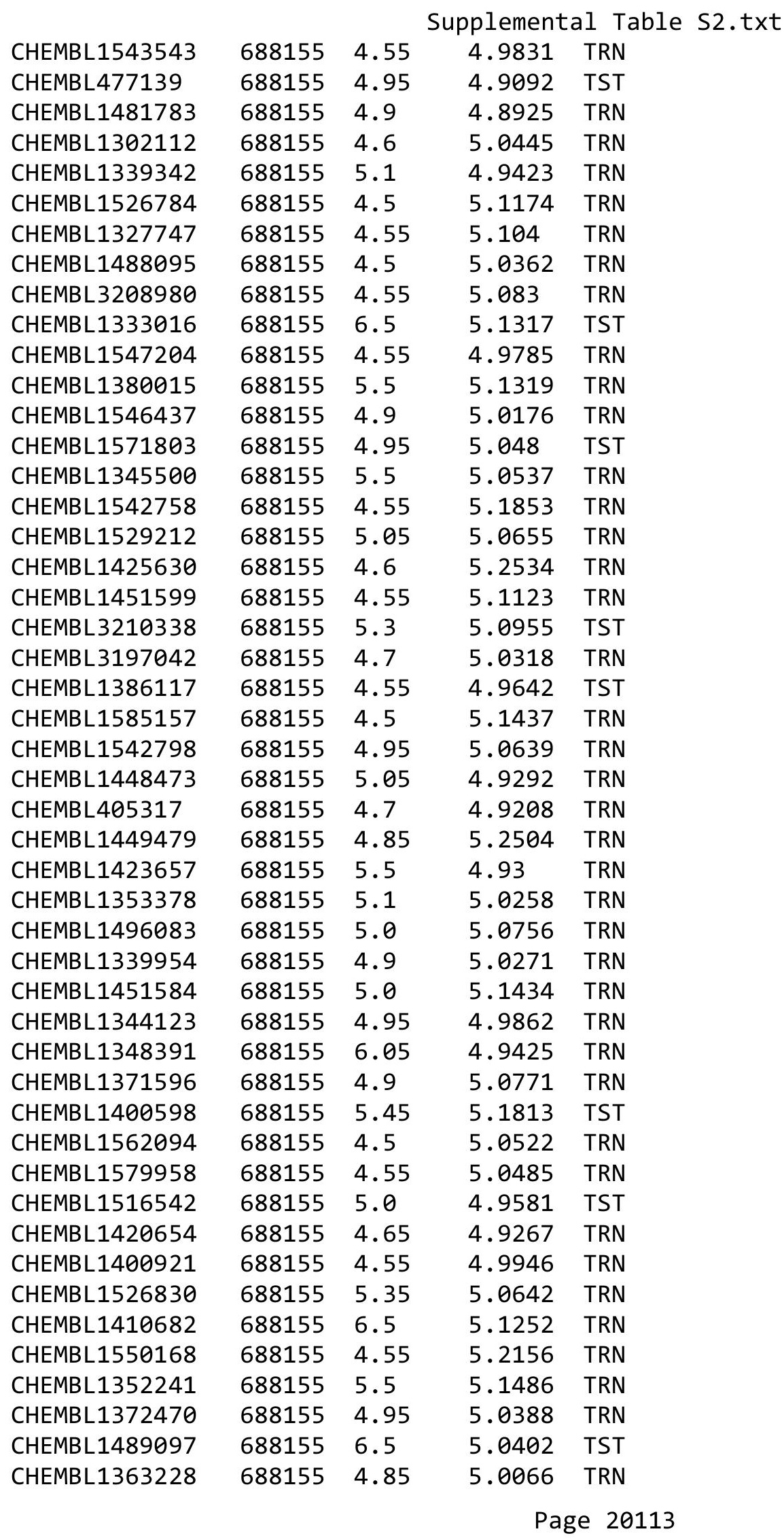




\begin{tabular}{|c|c|c|c|c|c|}
\hline & & \multicolumn{4}{|c|}{ Supplemental Table s2.txt } \\
\hline CHEMBL1392186 & 688155 & 6.35 & 4.9504 & TST & \\
\hline CHEMBL 3187596 & 688155 & 4.9 & 5.149 & TST & \\
\hline CHEMBL1428001 & 688155 & 4.7 & 5.1063 & TRN & \\
\hline CHEMBL1518914 & 688155 & 4.55 & 5.0149 & TRN & \\
\hline CHEMBL2003806 & 688155 & 4.95 & 4.973 & TRN & \\
\hline CHEMBL1406685 & 688155 & 4.5 & 5.1907 & TRN & \\
\hline CHEMBL1313510 & 688155 & 4.85 & 5.0275 & TRN & \\
\hline CHEMBL1380365 & 688155 & 4.5 & 5.0572 & TRN & \\
\hline CHEMBL1398894 & 688155 & 4.55 & 5.1292 & TRN & \\
\hline CHEMBL1426711 & 688155 & 5.0 & 4.9542 & TRN & \\
\hline CHEMBL1404704 & 688155 & 5.0 & 5.041 & TRN & \\
\hline CHEMBL1429692 & 688155 & 4.85 & 5.0749 & TRN & \\
\hline CHEMBL1352202 & 688155 & 4.55 & 4.9445 & TRN & \\
\hline CHEMBL1464879 & 688155 & 4.65 & 5.0774 & TRN & \\
\hline CHEMBL1309785 & 688155 & 4.55 & 5.0134 & TRN & \\
\hline CHEMBL1586132 & 688155 & 5.3 & 5.0479 & TST & \\
\hline CHEMBL1407969 & 688155 & 5.0 & 5.0843 & TRN & \\
\hline CHEMBL3195874 & 688155 & 6.0 & 5.1235 & TST & \\
\hline CHEMBL1556428 & 688155 & 5.9 & 5.0249 & TRN & \\
\hline CHEMBL1468582 & 688155 & 4.85 & 5.2288 & TST & \\
\hline CHEMBL1403145 & 688155 & 4.9 & 5.043 & TRN & \\
\hline CHEMBL1507807 & 688155 & 4.95 & 5.0198 & TRN & \\
\hline CHEMBL3191109 & 688155 & 4.55 & 5.03600 & 00000000005 & TRN \\
\hline CHEMBL1409796 & 688155 & 5.05 & 5.1666 & TRN & \\
\hline CHEMBL1366084 & 688155 & 4.55 & 4.9793 & TRN & \\
\hline CHEMBL1311474 & 688155 & 4.85 & 5.2258 & TRN & \\
\hline CHEMBL1454334 & 688155 & 4.95 & 5.1928 & TRN & \\
\hline CHEMBL1605735 & 688155 & 5.7 & 5.2737 & TRN & \\
\hline CHEMBL1562667 & 688155 & 4.55 & 5.3051 & TRN & \\
\hline CHEMBL1373698 & 688155 & 5.5 & 5.032 & TST & \\
\hline CHEMBL1386429 & 688155 & 4.9 & 5.0849 & TRN & \\
\hline CHEMBL1315346 & 688155 & 4.95 & 5.1447 & TST & \\
\hline CHEMBL1587044 & 688155 & 4.6 & 5.0405 & TRN & \\
\hline CHEMBL1382622 & 688155 & 4.55 & 4.9999 & TRN & \\
\hline CHEMBL1384647 & 688155 & 5.0 & 4.9982 & TST & \\
\hline CHEMBL1462994 & 688155 & 5.0 & 5.0955 & TRN & \\
\hline CHEMBL1369056 & 688155 & 6.35 & 5.1001 & TRN & \\
\hline CHEMBL1499500 & 688155 & 4.75 & 4.9887 & TRN & \\
\hline CHEMBL1607242 & 688155 & 6.0 & 5.1779 & TRN & \\
\hline CHEMBL1484851 & 688155 & 4.6 & 4.9945 & TRN & \\
\hline CHEMBL1461832 & 688155 & 5.0 & 5.1865 & TRN & \\
\hline CHEMBL1307418 & 688155 & 5.35 & 4.963 & TRN & \\
\hline CHEMBL1348452 & 688155 & 4.95 & 5.0224 & TST & \\
\hline CHEMBL1583710 & 688155 & 6.05 & 5.1061 & TRN & \\
\hline CHEMBL1507612 & 688155 & 5.0 & 5.1314 & TRN & \\
\hline CHEMBL1310421 & 688155 & 4.5 & 5.0804 & TST & \\
\hline CHEMBL1465358 & 688155 & 4.9 & 5.0116 & TRN & \\
\hline CHEMBL1562313 & 688155 & 5.45 & 5.1081 & TST & \\
\hline
\end{tabular}




\begin{tabular}{|c|c|c|c|c|}
\hline \multicolumn{5}{|c|}{ Supplemental Table S2.txt } \\
\hline CHEMBL1483568 & 688155 & 5.65 & 5.1914 & TRN \\
\hline CHEMBL1584333 & 688155 & 5.3 & 5.0916 & TST \\
\hline CHEMBL1584299 & 688155 & 4.9 & 4.958 & TRN \\
\hline CHEMBL1318859 & 688155 & 4.5 & 5.0593 & TST \\
\hline CHEMBL1535666 & 688155 & 4.5 & 5.0498 & TRN \\
\hline CHEMBL 256367 & 688155 & 4.5 & 5.0546 & TRN \\
\hline CHEMBL1450048 & 688155 & 6.0 & 5.1262 & TST \\
\hline CHEMBL1524180 & 688155 & 6.05 & 5.0304 & TRN \\
\hline CHEMBL1447522 & 688155 & 6.45 & 5.1488 & TST \\
\hline CHEMBL3199347 & 688155 & 5.0 & 5.0608 & TST \\
\hline CHEMBL1299919 & 688155 & 5.0 & 5.2106 & TRN \\
\hline CHEMBL1382433 & 688155 & 4.95 & 5.1766 & TST \\
\hline CHEMBL1590378 & 688155 & 6.0 & 5.1815 & TST \\
\hline CHEMBL1368008 & 688155 & 5.3 & 5.0978 & TRN \\
\hline CHEMBL3193341 & 688155 & 4.5 & 5.0912 & TST \\
\hline CHEMBL1585426 & 688155 & 4.7 & 5.0306 & TRN \\
\hline CHEMBL1558519 & 688155 & 5.0 & 5.0434 & TRN \\
\hline CHEMBL1340439 & 688155 & 4.95 & 5.1358 & TST \\
\hline CHEMBL1533983 & 688155 & 4.75 & 5.2308 & TRN \\
\hline CHEMBL1471554 & 688155 & 4.55 & 4.8987 & TRN \\
\hline CHEMBL1556995 & 688155 & 4.9 & 5.1273 & TRN \\
\hline CHEMBL1462380 & 688155 & 5.0 & 5.1264 & TST \\
\hline CHEMBL1991885 & 688155 & 5.0 & 5.0509 & TRN \\
\hline CHEMBL1536779 & 688155 & 5.05 & 5.0405 & TST \\
\hline CHEMBL1613374 & 688155 & 4.55 & 4.9013 & TRN \\
\hline CHEMBL1468346 & 688155 & 6.1 & 5.117 & TRN \\
\hline CHEMBL1410654 & 688155 & 5.0 & 5.0956 & TRN \\
\hline CHEMBL503763 & 688155 & 6.0 & 5.0231 & TST \\
\hline CHEMBL1550162 & 688155 & 6.05 & 4.9794 & TST \\
\hline CHEMBL1342156 & 688155 & 5.05 & 4.8736 & TRN \\
\hline CHEMBL1537230 & 688155 & 5.05 & 5.0448 & TRN \\
\hline CHEMBL1321345 & 688155 & 5.85 & 5.1395 & TRN \\
\hline CHEMBL1389486 & 688155 & 4.55 & 5.037 & TST \\
\hline CHEMBL1487016 & 688155 & 4.5 & 5.0157 & TRN \\
\hline CHEMBL1528171 & 688155 & 6.05 & 5.1463 & TRN \\
\hline CHEMBL1426998 & 688155 & 4.9 & 5.1785 & TRN \\
\hline CHEMBL1491096 & 688155 & 5.95 & 5.2248 & TRN \\
\hline CHEMBL1478557 & 688155 & 4.9 & 4.9086 & TRN \\
\hline CHEMBL1348663 & 688155 & 5.1 & 5.1422 & TST \\
\hline CHEMBL1572746 & 688155 & 5.9 & 5.0996 & TRN \\
\hline CHEMBL1432151 & 688155 & 4.85 & 5.1828 & TST \\
\hline CHEMBL1443128 & 688155 & 4.85 & 5.1775 & TRN \\
\hline CHEMBL8145 & 688155 & 6.3 & 5.0379 & TRN \\
\hline CHEMBL1300612 & 688155 & 5.3 & 5.0499 & TST \\
\hline CHEMBL1461283 & 688155 & 4.85 & 5.0675 & TRN \\
\hline CHEMBL1489312 & 688155 & 6.0 & 5.1873 & TST \\
\hline CHEMBL1440876 & 688155 & 4.7 & 5.1339 & TRN \\
\hline CHEMBL1508182 & 688155 & 5.05 & 5.1365 & TRN \\
\hline
\end{tabular}




\begin{tabular}{|c|c|c|c|c|c|}
\hline & & \multicolumn{4}{|c|}{ Supplemental Table S2.txt } \\
\hline CHEMBL1375821 & 688155 & 4.95 & 5.18 & TRN & \\
\hline CHEMBL1408880 & 688155 & 5.0 & 5.2325 & TST & \\
\hline CHEMBL1569649 & 688155 & 6.35 & 5.0805 & TST & \\
\hline CHEMBL1324098 & 688155 & 4.95 & 4.90600 & 0000000001 & TRN \\
\hline CHEMBL1507669 & 688155 & 4.6 & 4.9694 & TRN & \\
\hline CHEMBL1457549 & 688155 & 4.55 & 4.9552 & TRN & \\
\hline CHEMBL1365578 & 688155 & 4.55 & 4.9307 & TRN & \\
\hline CHEMBL1427880 & 688155 & 4.55 & 5.1238 & TRN & \\
\hline CHEMBL115225 & 688155 & 4.65 & 5.0832 & TST & \\
\hline CHEMBL1544235 & 688155 & 4.6 & 5.0689 & TRN & \\
\hline CHEMBL1392177 & 688155 & 4.85 & 5.0457 & TST & \\
\hline CHEMBL 1424278 & 688155 & 5.5 & 5.1716 & TST & \\
\hline CHEMBL1441575 & 688155 & 5.05 & 5.0683 & TRN & \\
\hline CHEMBL60718 & 688155 & 4.9 & 5.1745 & TST & \\
\hline CHEMBL1420151 & 688155 & 5.65 & 5.0529 & TRN & \\
\hline CHEMBL1518629 & 688155 & 5.15 & 5.066 & TRN & \\
\hline CHEMBL1468333 & 688155 & 5.6 & 5.1014 & TRN & \\
\hline CHEMBL1325061 & 688155 & 4.95 & 5.0404 & TRN & \\
\hline CHEMBL1494607 & 688155 & 4.45 & 4.8971 & TRN & \\
\hline CHEMBL1256914 & 688155 & 4.8 & 5.1232 & TRN & \\
\hline CHEMBL1393047 & 688155 & 4.95 & 5.0185 & TRN & \\
\hline CHEMBL1361287 & 688155 & 4.55 & 4.9638 & TRN & \\
\hline CHEMBL1462946 & 688155 & 5.0 & 5.0889 & TRN & \\
\hline CHEMBL1439758 & 688155 & 4.7 & 4.9297 & TRN & \\
\hline CHEMBL1535328 & 688155 & 5.3 & 5.2036 & TRN & \\
\hline CHEMBL1501269 & 688155 & 4.55 & 5.1562 & TRN & \\
\hline CHEMBL1372300 & 688155 & 6.35 & 5.1996 & TRN & \\
\hline CHEMBL1579195 & 688155 & 5.15 & 4.9643 & TRN & \\
\hline CHEMBL1495980 & 688155 & 5.35 & 5.1174 & TST & \\
\hline CHEMBL1607935 & 688155 & 5.0 & 5.0993 & TST & \\
\hline CHEMBL1532878 & 688155 & 4.95 & 4.9228 & TRN & \\
\hline CHEMBL1537577 & 688155 & 5.05 & 5.2229 & TST & \\
\hline CHEMBL1533768 & 688155 & 4.5 & 5.0166 & TST & \\
\hline CHEMBL1604829 & 688155 & 4.95 & 5.2201 & TRN & \\
\hline CHEMBL1581326 & 688155 & 5.0 & 5.1261 & TRN & \\
\hline CHEMBL1399380 & 688155 & 4.55 & 4.96399 & 99999999995 & TRN \\
\hline CHEMBL1575795 & 688155 & 4.8 & 4.9439 & TRN & \\
\hline CHEMBL1548080 & 688155 & 4.55 & 4.9758 & TRN & \\
\hline CHEMBL1464401 & 688155 & 4.95 & 5.2225 & TRN & \\
\hline CHEMBL1567793 & 688155 & 5.8 & 5.0212 & TRN & \\
\hline CHEMBL1361276 & 688155 & 4.85 & 5.082 & TST & \\
\hline CHEMBL1574891 & 688155 & 5.95 & 5.0595 & TRN & \\
\hline CHEMBL1578785 & 688155 & 5.2 & 5.0745 & TST & \\
\hline CHEMBL1567022 & 688155 & 4.55 & 5.1956 & TST & \\
\hline CHEMBL1340609 & 688155 & 5.5 & 4.9612 & TRN & \\
\hline CHEMBL1352043 & 688155 & 4.95 & 4.9032 & TRN & \\
\hline CHEMBL1527599 & 688155 & 4.85 & 4.9476 & TRN & \\
\hline CHEMBL1369045 & 688155 & 4.95 & 5.0327 & TRN & \\
\hline
\end{tabular}




\begin{tabular}{|c|c|c|c|c|c|}
\hline & & \multicolumn{4}{|c|}{ Supplemental Table S2.txt } \\
\hline CHEMBL3190426 & 688155 & 4.95 & 4.8963 & TST & \\
\hline CHEMBL1548577 & 688155 & 5.55 & 5.1547 & TRN & \\
\hline CHEMBL1448142 & 688155 & 5.0 & 5.0927 & TRN & \\
\hline CHEMBL1458724 & 688155 & 5.1 & 5.0575 & TRN & \\
\hline CHEMBL1313842 & 688155 & 5.0 & 5.1488 & TRN & \\
\hline CHEMBL1337235 & 688155 & 5.0 & 5.1223 & TRN & \\
\hline CHEMBL1585567 & 688155 & 4.7 & 5.0781 & TRN & \\
\hline CHEMBL 3198875 & 688155 & 5.0 & 5.1181 & TRN & \\
\hline CHEMBL1998652 & 688155 & 5.0 & 5.025 & TRN & \\
\hline CHEMBL1602717 & 688155 & 4.9 & 4.9628 & TRN & \\
\hline CHEMBL1494753 & 688155 & 4.95 & 5.3187 & TRN & \\
\hline CHEMBL1499379 & 688155 & 4.5 & 5.1065 & TST & \\
\hline CHEMBL1421296 & 688155 & 5.1 & 5.0273 & TST & \\
\hline CHEMBL1367447 & 688155 & 4.9 & 5.0773 & TRN & \\
\hline CHEMBL1308051 & 688155 & 4.7 & 4.9937 & TST & \\
\hline CHEMBL1537004 & 688155 & 6.5 & 5.0517 & TRN & \\
\hline CHEMBL1467451 & 688155 & 4.55 & 4.9363 & TST & \\
\hline CHEMBL1518255 & 688155 & 4.9 & 5.2222 & TST & \\
\hline CHEMBL1385489 & 688155 & 4.9 & 5.0535 & TST & \\
\hline CHEMBL1419519 & 688155 & 5.95 & 5.0844 & TST & \\
\hline CHEMBL1370925 & 688155 & 5.0 & 5.0038 & TST & \\
\hline CHEMBL1373252 & 688155 & 5.4 & 4.9401 & TRN & \\
\hline CHEMBL1373115 & 688155 & 6.5 & 5.1231 & TRN & \\
\hline CHEMBL1555483 & 688155 & 5.35 & 4.9841 & TST & \\
\hline CHEMBL1563323 & 688155 & 5.1 & 5.0538 & TRN & \\
\hline CHEMBL1583067 & 688155 & 4.55 & 4.9751 & TRN & \\
\hline CHEMBL1391038 & 688155 & 6.45 & 5.1134 & TRN & \\
\hline CHEMBL1579189 & 688155 & 4.5 & 5.1953 & TRN & \\
\hline CHEMBL1368188 & 688155 & 4.95 & 5.28299 & 99999999995 & TST \\
\hline CHEMBL1353504 & 688155 & 4.95 & 5.1029 & TST & \\
\hline CHEMBL582701 & 688155 & 5.2 & 5.0385 & TRN & \\
\hline CHEMBL1350152 & 688155 & 4.85 & 5.1257 & TRN & \\
\hline CHEMBL1333292 & 688155 & 4.95 & 5.0326 & TRN & \\
\hline CHEMBL1379761 & 688155 & 6.35 & 5.2513 & TST & \\
\hline CHEMBL1340363 & 688155 & 4.95 & 4.9192 & TRN & \\
\hline CHEMBL1461369 & 688155 & 5.05 & 5.129 & TRN & \\
\hline CHEMBL1550049 & 688155 & 4.95 & 4.9782 & TST & \\
\hline CHEMBL1550942 & 688155 & 4.55 & 5.093 & TRN & \\
\hline CHEMBL1384020 & 688155 & 4.9 & 5.0341 & TRN & \\
\hline CHEMBL1497803 & 688155 & 5.7 & 5.0701 & TRN & \\
\hline CHEMBL1511282 & 688155 & 5.5 & 5.2006 & TRN & \\
\hline CHEMBL1527416 & 688155 & 5.75 & 5.1533 & TST & \\
\hline CHEMBL1602220 & 688155 & 5.05 & 5.0786 & TST & \\
\hline CHEMBL1440650 & 688155 & 5.0 & 4.9701 & TRN & \\
\hline CHEMBL1387480 & 688155 & 4.95 & 5.11 & TRN & \\
\hline CHEMBL1344865 & 688155 & 4.7 & 5.086 & TST & \\
\hline CHEMBL1400414 & 688155 & 4.65 & 5.0019 & TRN & \\
\hline CHEMBL1424762 & 688155 & 4.55 & 5.1324 & TST & \\
\hline
\end{tabular}




\begin{tabular}{|c|c|c|c|c|}
\hline \multicolumn{5}{|c|}{ Supplemental Table S2.txt } \\
\hline CHEMBL1560199 & 688155 & 6.5 & 5.1869 & TRN \\
\hline CHEMBL1602177 & 688155 & 4.55 & 4.9271 & TST \\
\hline CHEMBL1601959 & 688155 & 5.9 & 5.1826 & TST \\
\hline CHEMBL1519630 & 688155 & 4.9 & 5.0473 & TST \\
\hline CHEMBL1324163 & 688155 & 5.0 & 4.9874 & TRN \\
\hline CHEMBL1586916 & 688155 & 5.9 & 5.0569 & TST \\
\hline CHEMBL1463969 & 688155 & 6.0 & 5.0919 & TRN \\
\hline CHEMBL1405008 & 688155 & 5.3 & 5.1817 & TRN \\
\hline CHEMBL1569535 & 688155 & 5.05 & 5.0227 & TRN \\
\hline CHEMBL3191487 & 688155 & 4.5 & 5.0241 & TRN \\
\hline CHEMBL1322923 & 688155 & 5.75 & 5.0285 & TRN \\
\hline CHEMBL1542119 & 688155 & 4.55 & 4.9987 & TRN \\
\hline CHEMBL1524956 & 688155 & 4.95 & 5.0977 & TST \\
\hline CHEMBL1370709 & 688155 & 4.9 & 5.0026 & TRN \\
\hline CHEMBL1548911 & 688155 & 4.9 & 5.1103 & TST \\
\hline CHEMBL1544579 & 688155 & 4.6 & 5.0086 & TST \\
\hline CHEMBL1386208 & 688155 & 4.65 & 5.1829 & TRN \\
\hline CHEMBL1338570 & 688155 & 4.95 & 5.0193 & TRN \\
\hline CHEMBL1326812 & 688155 & 6.0 & 4.9599 & TRN \\
\hline CHEMBL1517623 & 688155 & 6.45 & 5.1052 & TRN \\
\hline CHEMBL1515331 & 688155 & 5.45 & 5.1788 & TRN \\
\hline CHEMBL1596182 & 688155 & 5.45 & 5.0263 & TRN \\
\hline CHEMBL1332841 & 688155 & 4.55 & 5.1655 & TRN \\
\hline CHEMBL1306269 & 688155 & 4.55 & 5.081 & TRN \\
\hline CHEMBL1523619 & 688155 & 4.7 & 5.2266 & TRN \\
\hline CHEMBL3212985 & 688155 & 4.95 & 4.8874 & TRN \\
\hline CHEMBL1584344 & 688155 & 4.95 & 5.0463 & TRN \\
\hline CHEMBL1505422 & 688155 & 4.55 & 5.0726 & TST \\
\hline CHEMBL1565621 & 688155 & 4.9 & 4.9963 & TRN \\
\hline CHEMBL1334164 & 688155 & 5.05 & 5.0773 & TST \\
\hline CHEMBL1546597 & 688155 & 4.95 & 4.995 & TST \\
\hline CHEMBL1375116 & 688155 & 5.0 & 4.9589 & TRN \\
\hline CHEMBL1602143 & 688155 & 6.0 & 4.9224 & TST \\
\hline CHEMBL1508669 & 688155 & 5.3 & 5.0184 & TRN \\
\hline CHEMBL1461872 & 688155 & 4.55 & 4.8684 & TST \\
\hline CHEMBL1399919 & 688155 & 5.2 & 5.0089 & TRN \\
\hline CHEMBL1421462 & 688155 & 4.5 & 5.0732 & TRN \\
\hline CHEMBL1313191 & 688155 & 5.75 & 5.1158 & TST \\
\hline CHEMBL1468639 & 688155 & 6.5 & 5.0131 & TRN \\
\hline CHEMBL1408284 & 688155 & 4.95 & 5.2385 & TST \\
\hline CHEMBL1440154 & 688155 & 4.75 & 5.1305 & TRN \\
\hline CHEMBL1404753 & 688155 & 4.85 & 5.1175 & TST \\
\hline CHEMBL1414769 & 688155 & 4.95 & 5.1264 & TRN \\
\hline CHEMBL1401194 & 688155 & 4.9 & 4.9465 & TRN \\
\hline CHEMBL1318923 & 688155 & 4.7 & 4.9017 & TRN \\
\hline CHEMBL1501112 & 688155 & 4.9 & 5.2069 & TRN \\
\hline CHEMBL1309767 & 688155 & 4.9 & 4.9877 & TRN \\
\hline CHEMBL1432476 & 688155 & 5.1 & 5.1206 & TRN \\
\hline
\end{tabular}




\begin{tabular}{|c|c|c|c|c|}
\hline \multicolumn{5}{|c|}{ Supplemental Table S2.txt } \\
\hline CHEMBL1350915 & 688155 & 6.0 & 5.0385 & TRN \\
\hline CHEMBL1301287 & 688155 & 4.65 & 5.0587 & TRN \\
\hline CHEMBL1399345 & 688155 & 4.55 & 5.0838 & TRN \\
\hline CHEMBL1391341 & 688155 & 5.95 & 5.0547 & TRN \\
\hline CHEMBL258699 & 688155 & 4.95 & 5.2551 & TST \\
\hline CHEMBL1518710 & 688155 & 5.5 & 5.1101 & TRN \\
\hline CHEMBL1324880 & 688155 & 5.5 & 4.9883 & TRN \\
\hline CHEMBL1523338 & 688155 & 5.15 & 5.0268 & TST \\
\hline CHEMBL1543703 & 688155 & 5.0 & 5.0966 & TRN \\
\hline CHEMBL1568683 & 688155 & 4.95 & 4.9282 & TRN \\
\hline CHEMBL1332342 & 688155 & 4.55 & 5.0444 & TST \\
\hline CHEMBL1454397 & 688155 & 4.55 & 4.9944 & TST \\
\hline CHEMBL1521742 & 688155 & 4.55 & 5.0948 & TST \\
\hline CHEMBL1465693 & 688155 & 4.95 & 5.1987 & TST \\
\hline CHEMBL1472049 & 688155 & 5.65 & 5.0244 & TRN \\
\hline CHEMBL1449018 & 688155 & 4.5 & 5.1836 & TRN \\
\hline CHEMBL1503134 & 688155 & 4.55 & 5.1204 & TST \\
\hline CHEMBL1313374 & 688155 & 5.1 & 5.0709 & TRN \\
\hline CHEMBL1488701 & 688155 & 4.55 & 4.96 & TRN \\
\hline CHEMBL530291 & 688155 & 4.9 & 5.1899 & TRN \\
\hline CHEMBL1493207 & 688155 & 4.9 & 5.0865 & TRN \\
\hline CHEMBL1561533 & 688155 & 5.0 & 4.9539 & TRN \\
\hline CHEMBL1307177 & 688155 & 4.55 & 5.0558 & TRN \\
\hline CHEMBL577887 & 688155 & 6.1 & 5.1307 & TST \\
\hline CHEMBL1466594 & 688155 & 6.5 & 5.1078 & TRN \\
\hline CHEMBL1377491 & 688155 & 5.05 & 5.0744 & TRN \\
\hline CHEMBL1313459 & 688155 & 5.65 & 5.0368 & TRN \\
\hline CHEMBL3194415 & 688155 & 4.55 & 5.1791 & TRN \\
\hline CHEMBL1306512 & 688155 & 5.6 & 5.0618 & TRN \\
\hline CHEMBL1582446 & 688155 & 4.5 & 4.9379 & TST \\
\hline CHEMBL1430166 & 688155 & 4.9 & 5.0752 & TRN \\
\hline CHEMBL525337 & 688155 & 5.15 & 5.0751 & TRN \\
\hline CHEMBL1490887 & 688155 & 4.9 & 5.229 & TST \\
\hline CHEMBL1567125 & 688155 & 5.75 & 5.249 & TRN \\
\hline CHEMBL1368847 & 688155 & 4.55 & 4.9666 & TRN \\
\hline CHEMBL1531250 & 688155 & 5.0 & 5.1288 & TST \\
\hline CHEMBL1389776 & 688155 & 4.5 & 5.1447 & TRN \\
\hline CHEMBL1414117 & 688155 & 4.55 & 5.1106 & TST \\
\hline CHEMBL1413595 & 688155 & 5.9 & 5.1034 & TRN \\
\hline CHEMBL1302995 & 688155 & 4.55 & 5.0627 & TRN \\
\hline CHEMBL1449923 & 688155 & 4.95 & 5.0782 & TRN \\
\hline CHEMBL1388295 & 688155 & 5.45 & 4.9706 & TRN \\
\hline CHEMBL1386439 & 688155 & 4.55 & 4.9762 & TRN \\
\hline CHEMBL1602989 & 688155 & 5.8 & 5.2364 & TST \\
\hline CHEMBL1303139 & 688155 & 4.75 & 5.1291 & TST \\
\hline CHEMBL1590831 & 688155 & 4.9 & 4.9976 & TRN \\
\hline CHEMBL1401341 & 688155 & 4.9 & 5.1045 & TST \\
\hline CHEMBL1569151 & 688155 & 5.7 & 5.2538 & TST \\
\hline
\end{tabular}




\begin{tabular}{|c|c|c|c|c|}
\hline \multicolumn{5}{|c|}{ Supplemental Table s2.txt } \\
\hline CHEMBL1340418 & 688155 & 5.35 & 5.0095 & TRN \\
\hline CHEMBL1408758 & 688155 & 5.3 & 5.2147 & TRN \\
\hline CHEMBL1496863 & 688155 & 5.2 & 5.178 & TST \\
\hline CHEMBL1351160 & 688155 & 4.55 & 5.1044 & TRN \\
\hline CHEMBL1567869 & 688155 & 5.0 & 4.8386 & TST \\
\hline CHEMBL1336570 & 688155 & 5.5 & 5.2097 & TRN \\
\hline CHEMBL1580157 & 688155 & 4.95 & 5.0366 & TRN \\
\hline CHEMBL1571201 & 688155 & 4.5 & 4.9804 & TRN \\
\hline CHEMBL1375106 & 688155 & 4.6 & 5.1994 & TST \\
\hline CHEMBL1320366 & 688155 & 6.0 & 5.0408 & TRN \\
\hline CHEMBL1339087 & 688155 & 6.5 & 5.1359 & TST \\
\hline CHEMBL1538602 & 688155 & 5.8 & 5.106 & TRN \\
\hline CHEMBL1369691 & 688155 & 4.8 & 5.0281 & TRN \\
\hline CHEMBL1341237 & 688155 & 4.5 & 5.199 & TRN \\
\hline CHEMBL1602709 & 688155 & 4.65 & 5.1337 & TST \\
\hline CHEMBL1546820 & 688155 & 4.9 & 5.1525 & TST \\
\hline CHEMBL3195176 & 688155 & 5.25 & 5.1121 & TRN \\
\hline CHEMBL1569752 & 688155 & 4.95 & 5.0039 & TRN \\
\hline CHEMBL1564712 & 688155 & 4.6 & 5.1444 & TRN \\
\hline CHEMBL1463175 & 688155 & 4.75 & 4.9987 & TRN \\
\hline CHEMBL1373385 & 688155 & 4.55 & 5.1733 & TRN \\
\hline CHEMBL1365604 & 688155 & 6.05 & 5.1431 & TST \\
\hline CHEMBL1321116 & 688155 & 5.05 & 5.13299 & 9999999999 \\
\hline CHEMBL1522344 & 688155 & 5.35 & 4.8863 & TRN \\
\hline CHEMBL1407723 & 688155 & 5.7 & 5.0484 & TRN \\
\hline CHEMBL1411543 & 688155 & 5.0 & 5.0253 & TRN \\
\hline CHEMBL1532062 & 688155 & 4.9 & 4.933 & TST \\
\hline CHEMBL1603358 & 688155 & 5.35 & 5.1409 & TST \\
\hline CHEMBL1349436 & 688155 & 5.2 & 5.211 & TRN \\
\hline CHEMBL1427779 & 688155 & 5.55 & 5.2299 & TRN \\
\hline CHEMBL1537400 & 688155 & 4.95 & 5.109 & TRN \\
\hline CHEMBL1352380 & 688155 & 5.5 & 5.0946 & TRN \\
\hline CHEMBL1504012 & 688155 & 4.8 & 5.0591 & TRN \\
\hline CHEMBL1353531 & 688155 & 5.1 & 5.1927 & TRN \\
\hline CHEMBL1450020 & 688155 & 4.55 & 4.9698 & TRN \\
\hline CHEMBL1363336 & 688155 & 6.5 & 5.1586 & TRN \\
\hline CHEMBL1300343 & 688155 & 5.85 & 5.0941 & TRN \\
\hline CHEMBL1564532 & 688155 & 5.0 & 4.9119 & TRN \\
\hline CHEMBL3195232 & 688155 & 4.5 & 5.1256 & TRN \\
\hline CHEMBL1447633 & 688155 & 4.9 & 5.1992 & TRN \\
\hline CHEMBL1501085 & 688155 & 4.5 & 5.1652 & TST \\
\hline CHEMBL1400954 & 688155 & 6.15 & 5.0807 & TRN \\
\hline CHEMBL1529659 & 688155 & 4.5 & 5.069 & TRN \\
\hline CHEMBL1600693 & 688155 & 6.15 & 5.1845 & TRN \\
\hline CHEMBL1388428 & 688155 & 5.85 & 4.9499 & TRN \\
\hline CHEMBL1400176 & 688155 & 4.55 & 4.9877 & TRN \\
\hline CHEMBL1606699 & 688155 & 5.05 & 5.0091 & TRN \\
\hline CHEMBL1365381 & 688155 & 6.0 & 5.1298 & TRN \\
\hline
\end{tabular}




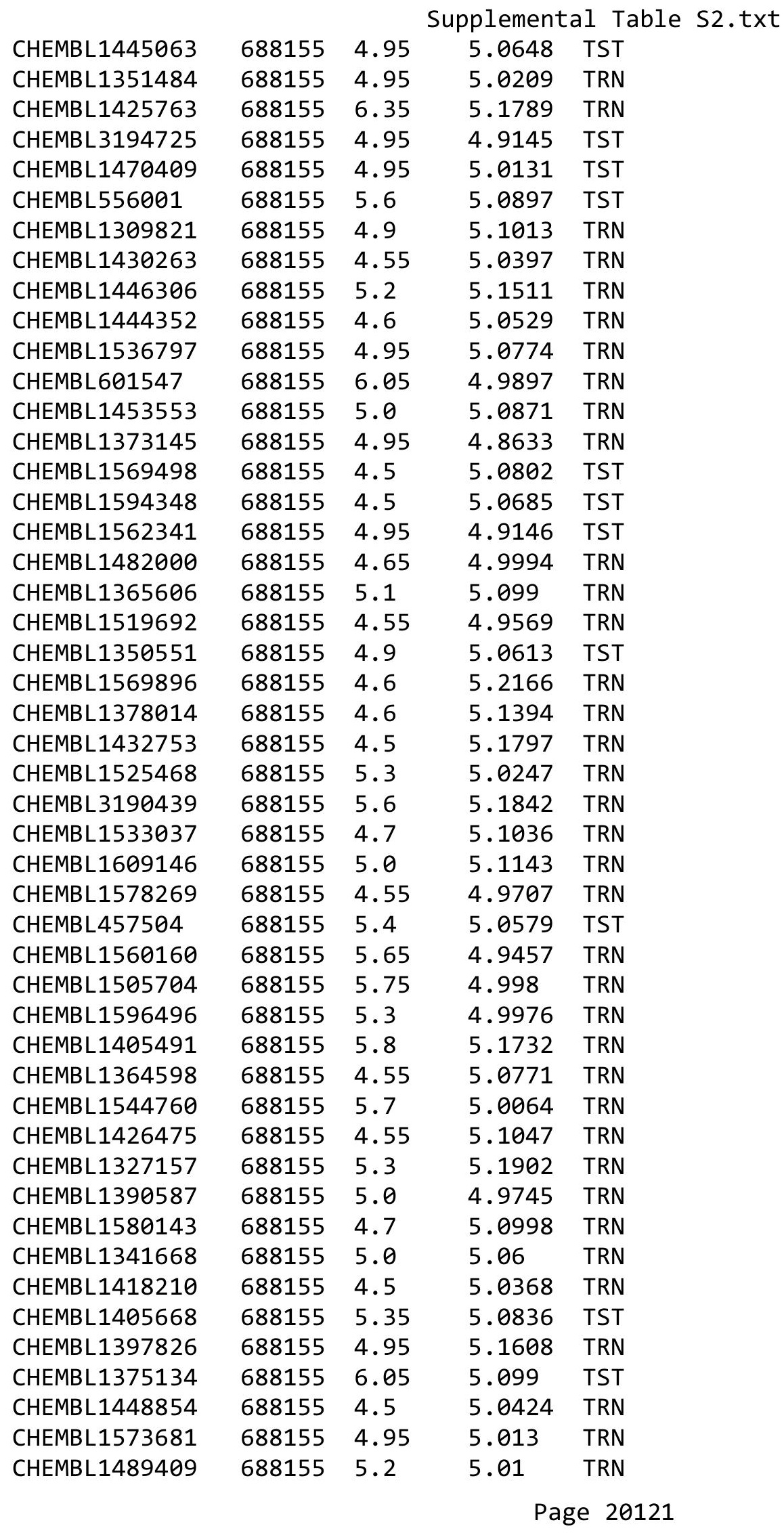




\begin{tabular}{|c|c|c|c|c|c|}
\hline \multicolumn{6}{|c|}{ Supplemental Table S2.txt } \\
\hline CHEMBL3195589 & 688155 & 5.3 & 5.1038 & TRN & \\
\hline CHEMBL1499514 & 688155 & 4.55 & 4.9088 & TRN & \\
\hline CHEMBL1556878 & 688155 & 4.95 & 5.1143 & TST & \\
\hline CHEMBL1585189 & 688155 & 5.45 & 5.1266 & TRN & \\
\hline CHEMBL1363056 & 688155 & 4.5 & 4.9589 & TRN & \\
\hline CHEMBL1324506 & 688155 & 4.6 & 5.0429 & TRN & \\
\hline CHEMBL1387594 & 688155 & 4.55 & 4.9966 & TRN & \\
\hline CHEMBL1414675 & 688155 & 4.55 & 5.1179 & TRN & \\
\hline CHEMBL1308850 & 688155 & 4.5 & 5.118 & TST & \\
\hline CHEMBL1577908 & 688155 & 4.9 & 5.006 & TRN & \\
\hline CHEMBL1507860 & 688155 & 5.1 & 4.9716 & TRN & \\
\hline CHEMBL1516900 & 688155 & 6.45 & 4.9921 & TRN & \\
\hline CHEMBL1339618 & 688155 & 4.55 & 5.2845 & TRN & \\
\hline CHEMBL1385608 & 688155 & 5.25 & 5.1726 & TRN & \\
\hline CHEMBL1353200 & 688155 & 5.05 & 5.0128 & TST & \\
\hline CHEMBL1484269 & 688155 & 4.8 & 5.0286 & TRN & \\
\hline CHEMBL1313176 & 688155 & 6.0 & 5.255 & TRN & \\
\hline CHEMBL1352531 & 688155 & 5.5 & 4.908 & TRN & \\
\hline CHEMBL1423071 & 688155 & 4.95 & 4.9194 & TST & \\
\hline CHEMBL1309139 & 688155 & 5.0 & 5.0486 & TRN & \\
\hline CHEMBL1452503 & 688155 & 4.5 & 5.0382 & TRN & \\
\hline CHEMBL3214155 & 688155 & 4.95 & 4.9409 & TRN & \\
\hline CHEMBL1565261 & 688155 & 5.0 & 5.0633 & TRN & \\
\hline CHEMBL1524666 & 688155 & 5.45 & 5.0465 & TST & \\
\hline CHEMBL1477670 & 688155 & 4.75 & 5.0187 & TST & \\
\hline CHEMBL1369655 & 688155 & 4.95 & 5.0715 & TRN & \\
\hline CHEMBL1380533 & 688155 & 4.55 & 5.0509 & TRN & \\
\hline CHEMBL1437258 & 688155 & 4.5 & 5.0399 & TRN & \\
\hline CHEMBL1429250 & 688155 & 4.5 & 5.1072 & TRN & \\
\hline CHEMBL1484219 & 688155 & 5.1 & 4.91100 & 00000000005 & TRN \\
\hline CHEMBL1325765 & 688155 & 5.3 & 5.0711 & TRN & \\
\hline CHEMBL 3212785 & 688155 & 5.9 & 5.1463 & TRN & \\
\hline CHEMBL1544595 & 688155 & 4.6 & 5.0886 & TRN & \\
\hline CHEMBL1497295 & 688155 & 4.95 & 5.0933 & TST & \\
\hline CHEMBL1306015 & 688155 & 5.55 & 4.9819 & TRN & \\
\hline CHEMBL67535 & 688155 & 4.85 & 5.0953 & TRN & \\
\hline CHEMBL 3213214 & 688155 & 5.15 & 4.9945 & TRN & \\
\hline CHEMBL1384973 & 688155 & 4.8 & 5.1008 & TRN & \\
\hline CHEMBL1608569 & 688155 & 5.25 & 5.0405 & TRN & \\
\hline CHEMBL1451666 & 688155 & 5.8 & 4.9868 & TST & \\
\hline CHEMBL244948 & 688155 & 4.55 & 5.0682 & TST & \\
\hline CHEMBL1339768 & 688155 & 4.55 & 4.9472 & TST & \\
\hline CHEMBL1308106 & 688155 & 4.5 & 5.0552 & TRN & \\
\hline CHEMBL1337839 & 688155 & 5.0 & 4.9518 & TRN & \\
\hline CHEMBL1480497 & 688155 & 4.95 & 5.0395 & TRN & \\
\hline CHEMBL1428206 & 688155 & 5.15 & 4.9801 & TRN & \\
\hline CHEMBL1399879 & 688155 & 4.95 & 4.9246 & TST & \\
\hline CHEMBL1546584 & 688155 & 4.95 & 4.8547 & TRN & \\
\hline
\end{tabular}




\begin{tabular}{|c|c|c|c|c|}
\hline \multicolumn{5}{|c|}{ Supplemental Table S2.txt } \\
\hline CHEMBL1341061 & 688155 & 5.4 & 5.0417 & TST \\
\hline CHEMBL3192939 & 688155 & 5.8 & 4.9791 & TST \\
\hline CHEMBL1984772 & 688155 & 4.65 & 4.9962 & TRN \\
\hline CHEMBL1371896 & 688155 & 5.65 & 5.0444 & TRN \\
\hline CHEMBL1489534 & 688155 & 4.95 & 5.1937 & TRN \\
\hline CHEMBL1359411 & 688155 & 4.55 & 4.9526 & TST \\
\hline CHEMBL1509076 & 688155 & 6.45 & 5.0216 & TRN \\
\hline CHEMBL114544 & 688155 & 5.15 & 5.0643 & TST \\
\hline CHEMBL1537948 & 688155 & 4.9 & 5.1152 & TRN \\
\hline CHEMBL1413820 & 688155 & 4.55 & 4.9872 & TRN \\
\hline CHEMBL1441179 & 688155 & 6.1 & 5.13 & TRN \\
\hline CHEMBL3199463 & 688155 & 4.9 & 5.1428 & TRN \\
\hline CHEMBL1574711 & 688155 & 4.5 & 5.0865 & TRN \\
\hline CHEMBL1561943 & 688155 & 4.9 & 5.0055 & TRN \\
\hline CHEMBL1372813 & 688155 & 4.8 & 5.0339 & TRN \\
\hline CHEMBL1406368 & 688155 & 5.85 & 5.0913 & TST \\
\hline CHEMBL1570119 & 688155 & 4.55 & 4.9872 & TRN \\
\hline CHEMBL1537860 & 688155 & 4.95 & 5.1999 & TRN \\
\hline CHEMBL1593068 & 688155 & 4.55 & 4.8966 & TRN \\
\hline CHEMBL1345722 & 688155 & 4.65 & 5.1029 & TRN \\
\hline CHEMBL1425787 & 688155 & 5.55 & 5.1061 & TRN \\
\hline CHEMBL1384089 & 688155 & 5.85 & 5.0708 & TST \\
\hline CHEMBL1304273 & 688155 & 4.95 & 5.0863 & TST \\
\hline CHEMBL577758 & 688155 & 6.3 & 4.9083 & TRN \\
\hline CHEMBL1582893 & 688155 & 5.25 & 5.1329 & TST \\
\hline CHEMBL1562706 & 688155 & 4.65 & 5.0845 & TRN \\
\hline CHEMBL1364557 & 688155 & 5.05 & 5.1119 & TRN \\
\hline CHEMBL1488375 & 688155 & 4.55 & 5.1139 & TRN \\
\hline CHEMBL1389572 & 688155 & 4.55 & 5.1434 & TRN \\
\hline CHEMBL1423457 & 688155 & 4.55 & 5.0677 & TRN \\
\hline CHEMBL1321684 & 688155 & 6.0 & 5.2861 & TRN \\
\hline CHEMBL1301522 & 688155 & 4.55 & 5.0381 & TRN \\
\hline CHEMBL1430905 & 688155 & 5.45 & 5.0772 & TRN \\
\hline CHEMBL1507648 & 688155 & 4.9 & 5.1039 & TRN \\
\hline CHEMBL1450931 & 688155 & 4.95 & 5.0367 & TRN \\
\hline CHEMBL1588926 & 688155 & 5.2 & 5.0377 & TRN \\
\hline CHEMBL1464725 & 688155 & 5.95 & 5.1247 & TRN \\
\hline CHEMBL1488942 & 688155 & 5.1 & 5.0793 & TRN \\
\hline CHEMBL1520388 & 688155 & 5.0 & 5.0818 & TRN \\
\hline CHEMBL599552 & 688155 & 5.5 & 5.1805 & TRN \\
\hline CHEMBL1536588 & 688155 & 5.2 & 4.9876 & TRN \\
\hline CHEMBL1344515 & 688155 & 5.55 & 4.8735 & TST \\
\hline CHEMBL3189455 & 688155 & 4.65 & 5.039 & TST \\
\hline CHEMBL1363046 & 688155 & 4.55 & 4.9591 & TRN \\
\hline CHEMBL1344130 & 688155 & 4.5 & 5.1042 & TRN \\
\hline CHEMBL3208208 & 688155 & 6.05 & 5.0436 & TRN \\
\hline CHEMBL1466889 & 688155 & 5.45 & 5.0659 & TST \\
\hline CHEMBL1392855 & 688155 & 5.45 & 5.0466 & TST \\
\hline
\end{tabular}




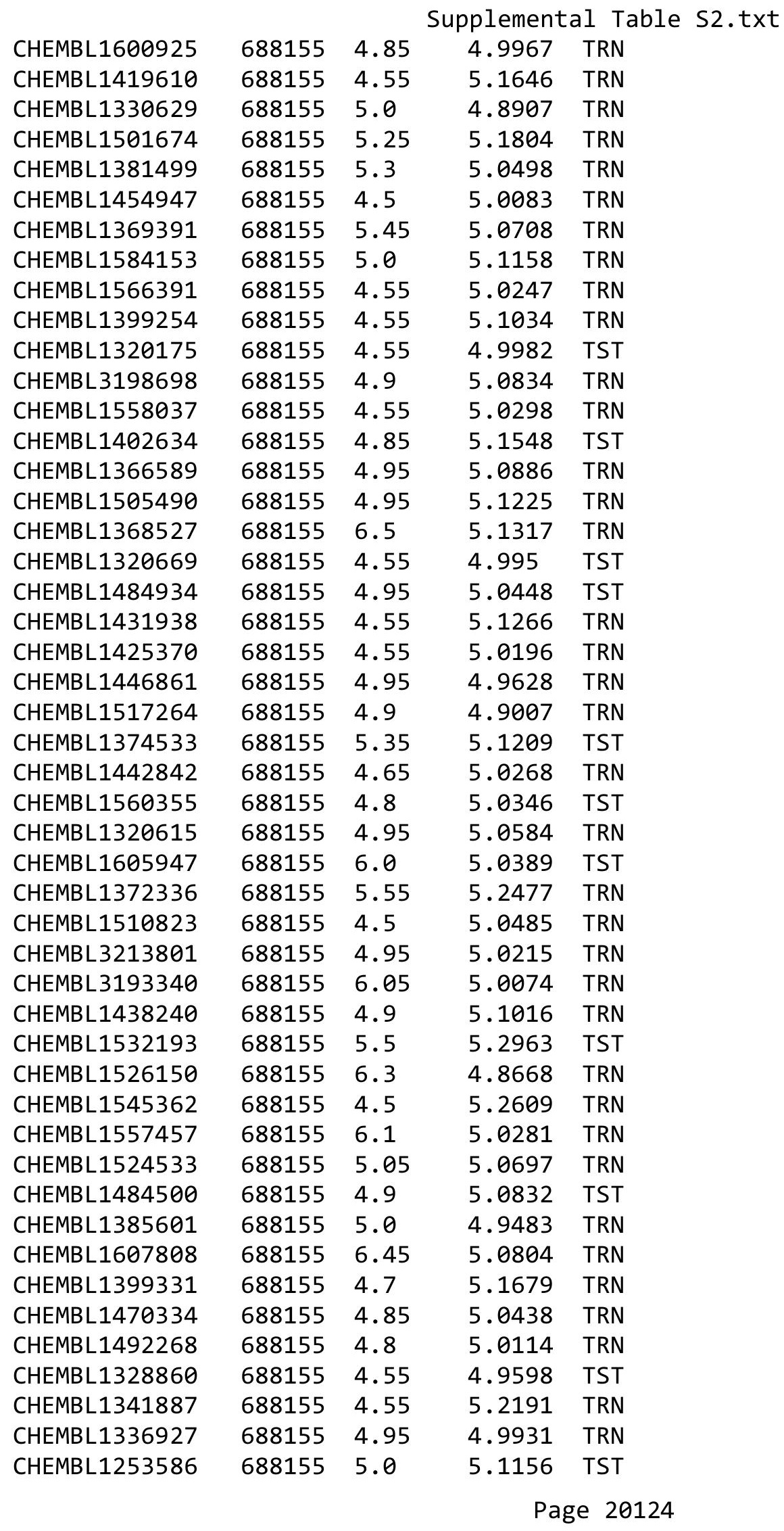




\begin{tabular}{|c|c|c|c|c|c|}
\hline \\
\hline CHEMBL1546678 & 688155 & 5.0 & 4.9911 & TRN & \\
\hline CHEMBL1373571 & 688155 & 5.0 & 5.0 & TST & \\
\hline CHEMBL1432963 & 688155 & 4.55 & 5.2192 & TRN & \\
\hline CHEMBL1523856 & 688155 & 4.55 & 5.1207 & TST & \\
\hline CHEMBL1493801 & 688155 & 5.0 & 5.0887 & TST & \\
\hline CHEMBL588038 & 688155 & 5.45 & 4.9655 & TRN & \\
\hline CHEMBL3210933 & 688155 & 4.65 & 5.0381 & TST & \\
\hline CHEMBL1566928 & 688155 & 4.9 & 5.0479 & TRN & \\
\hline CHEMBL1342837 & 688155 & 6.0 & 5.0155 & TRN & \\
\hline CHEMBL1390514 & 688155 & 4.55 & 5.0839 & TRN & \\
\hline CHEMBL1353692 & 688155 & 4.5 & 4.973 & TST & \\
\hline CHEMBL1433074 & 688155 & 5.05 & 4.9087 & TRN & \\
\hline CHEMBL1536770 & 688155 & 4.6 & 4.9612 & TST & \\
\hline CHEMBL1509290 & 688155 & 5.05 & 5.1268 & TST & \\
\hline CHEMBL3192760 & 688155 & 5.0 & 5.1266 & TST & \\
\hline CHEMBL1550145 & 688155 & 6.45 & 5.0181 & TRN & \\
\hline CHEMBL1380862 & 688155 & 5.85 & 5.0516 & TRN & \\
\hline CHEMBL1506445 & 688155 & 4.45 & 5.1446 & TRN & \\
\hline CHEMBL1556914 & 688155 & 5.05 & 5.0608 & TST & \\
\hline CHEMBL1348606 & 688155 & 4.55 & 4.9421 & TRN & \\
\hline CHEMBL1409857 & 688155 & 6.0 & 5.0711 & TST & \\
\hline CHEMBL3193629 & 688155 & 4.95 & 4.9744 & TRN & \\
\hline CHEMBL1441619 & 688155 & 4.95 & 4.9265 & TRN & \\
\hline CHEMBL1309436 & 688155 & 5.0 & 5.2141 & TRN & \\
\hline CHEMBL1581740 & 688155 & 5.9 & 5.04899 & 99999999995 & TRN \\
\hline CHEMBL1381247 & 688155 & 5.3 & 5.114 & TRN & \\
\hline CHEMBL1603191 & 688155 & 5.9 & 5.0793 & TRN & \\
\hline CHEMBL1393617 & 688155 & 4.9 & 5.0754 & TRN & \\
\hline CHEMBL1403729 & 688155 & 5.55 & 5.1386 & TST & \\
\hline CHEMBL3192706 & 688155 & 5.05 & 5.0411 & TRN & \\
\hline CHEMBL1988679 & 688155 & 5.0 & 5.0983 & TST & \\
\hline CHEMBL1451680 & 688155 & 4.95 & 5.106 & TST & \\
\hline CHEMBL1470784 & 688155 & 5.15 & 5.0532 & TST & \\
\hline CHEMBL1532249 & 688155 & 5.1 & 5.1151 & TST & \\
\hline CHEMBL1417481 & 688155 & 5.5 & 5.1492 & TST & \\
\hline CHEMBL1582262 & 688155 & 4.5 & 5.0105 & TRN & \\
\hline CHEMBL1588131 & 688155 & 4.65 & 5.0393 & TST & \\
\hline CHEMBL1484536 & 688155 & 5.3 & 5.1248 & TRN & \\
\hline CHEMBL1605816 & 688155 & 6.5 & 5.051 & TST & \\
\hline CHEMBL1601172 & 688155 & 4.9 & 5.1619 & TRN & \\
\hline CHEMBL1499295 & 688155 & 4.95 & 4.9769 & TRN & \\
\hline CHEMBL3197928 & 688155 & 4.95 & 5.0689 & TRN & \\
\hline CHEMBL 2369244 & 688155 & 6.3 & 5.05699 & 99999999995 & TST \\
\hline CHEMBL1598735 & 688155 & 5.95 & 5.1313 & TRN & \\
\hline CHEMBL3197685 & 688155 & 4.85 & 5.0589 & TRN & \\
\hline CHEMBL1380697 & 688155 & 4.65 & 4.9516 & TRN & \\
\hline CHEMBL1566829 & 688155 & 4.6 & 5.1662 & TRN & \\
\hline CHEMBL1393325 & 688155 & 4.85 & 5.1785 & TRN & \\
\hline
\end{tabular}




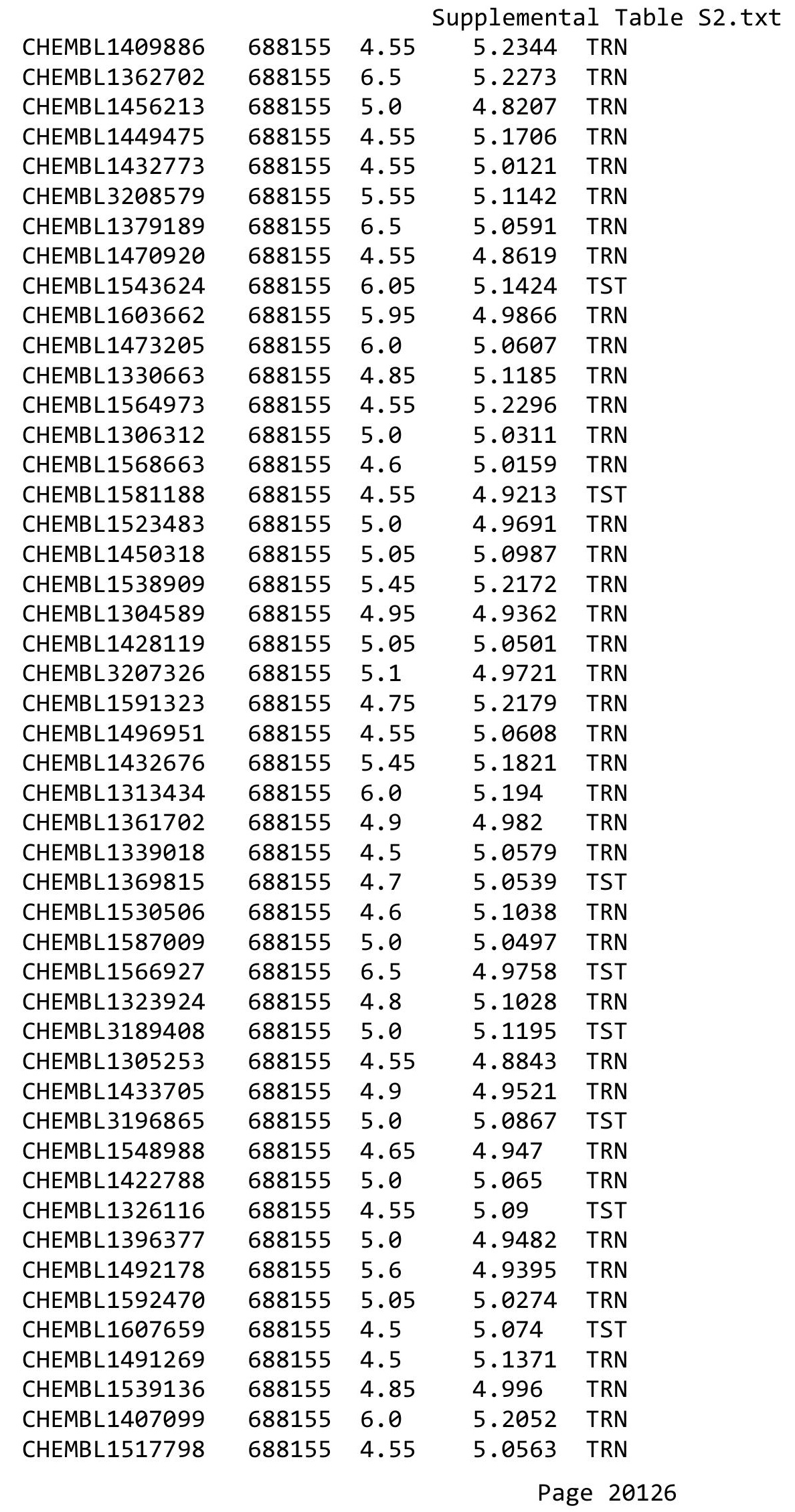




\begin{tabular}{|c|c|c|c|c|c|}
\hline \multicolumn{6}{|c|}{ Supplemental Table s2.txt } \\
\hline CHEMBL429023 & 688155 & 6.0 & 5.0433 & TST & \\
\hline CHEMBL1542362 & 688155 & 4.9 & 4.9497 & TRN & \\
\hline CHEMBL1418577 & 688155 & 5.6 & 5.1634 & TST & \\
\hline CHEMBL1568783 & 688155 & 5.4 & 5.1562 & TST & \\
\hline CHEMBL1524181 & 688155 & 4.9 & 5.1685 & TST & \\
\hline CHEMBL1598147 & 688155 & 5.95 & 5.1567 & TRN & \\
\hline CHEMBL582644 & 688155 & 5.4 & 5.1685 & TRN & \\
\hline CHEMBL1523129 & 688155 & 4.5 & 4.9978 & TRN & \\
\hline CHEMBL1471128 & 688155 & 4.55 & 5.0275 & TRN & \\
\hline CHEMBL1583917 & 688155 & 5.5 & 4.8871 & TRN & \\
\hline CHEMBL1256666 & 688155 & 6.0 & 5.0787 & TRN & \\
\hline CHEMBL1557785 & 688155 & 5.0 & 5.0379 & TRN & \\
\hline CHEMBL3210066 & 688155 & 4.55 & 4.9836 & TRN & \\
\hline CHEMBL1539288 & 688155 & 4.95 & 4.8927 & TRN & \\
\hline CHEMBL1331248 & 688155 & 4.95 & 5.2403 & TRN & \\
\hline CHEMBL1432679 & 688155 & 5.05 & 5.1301 & TRN & \\
\hline CHEMBL1351131 & 688155 & 4.7 & 5.0409 & TRN & \\
\hline CHEMBL1501189 & 688155 & 4.65 & 4.9732 & TRN & \\
\hline CHEMBL3211279 & 688155 & 6.3 & 5.1891 & TST & \\
\hline CHEMBL1378831 & 688155 & 5.0 & 4.9391 & TRN & \\
\hline CHEMBL1608471 & 688155 & 4.95 & 4.9824 & TST & \\
\hline CHEMBL1418862 & 688155 & 5.05 & 5.0696 & TRN & \\
\hline CHEMBL1597021 & 688155 & 4.95 & 5.004 & TRN & \\
\hline CHEMBL1484199 & 688155 & 6.3 & 5.1997 & TST & \\
\hline CHEMBL1461648 & 688155 & 4.9 & 4.9211 & TRN & \\
\hline CHEMBL1603599 & 688155 & 4.55 & 5.0364 & TRN & \\
\hline CHEMBL1344571 & 688155 & 4.95 & 4.9746 & TRN & \\
\hline CHEMBL1603099 & 688155 & 4.75 & 4.9978 & TRN & \\
\hline CHEMBL1381564 & 688155 & 5.3 & 4.984 & TRN & \\
\hline CHEMBL1406292 & 688155 & 4.55 & 5.1815 & TST & \\
\hline CHEMBL1538195 & 688155 & 5.1 & 5.0665 & TRN & \\
\hline CHEMBL1561813 & 688155 & 4.55 & 5.064 & TRN & \\
\hline CHEMBL1541807 & 688155 & 4.55 & 5.03600 & 00000000005 & TRN \\
\hline CHEMBL1543667 & 688155 & 4.85 & 4.9417 & TRN & \\
\hline CHEMBL1547968 & 688155 & 4.65 & 4.9869 & TRN & \\
\hline CHEMBL1427302 & 688155 & 4.55 & 4.9363 & TRN & \\
\hline CHEMBL1419028 & 688155 & 5.0 & 5.21299 & 9999999999 & TRN \\
\hline CHEMBL1487431 & 688155 & 4.55 & 5.1285 & TRN & \\
\hline CHEMBL1494025 & 688155 & 4.9 & 5.0672 & TRN & \\
\hline CHEMBL1334230 & 688155 & 6.5 & 4.9961 & TRN & \\
\hline CHEMBL1312002 & 688155 & 4.55 & 5.1194 & TRN & \\
\hline CHEMBL1470641 & 688155 & 5.6 & 5.1745 & TRN & \\
\hline CHEMBL1426427 & 688155 & 4.65 & 5.0362 & TST & \\
\hline CHEMBL1387226 & 688155 & 6.5 & 5.0776 & TST & \\
\hline CHEMBL1335658 & 688155 & 4.65 & 5.0497 & TST & \\
\hline CHEMBL1405934 & 688155 & 5.25 & 5.1537 & TRN & \\
\hline CHEMBL1363221 & 688155 & 6.5 & 5.0679 & TST & \\
\hline CHEMBL1508629 & 688155 & 4.55 & 5.1491 & TRN & \\
\hline
\end{tabular}




\begin{tabular}{|c|c|c|c|c|c|}
\hline \multicolumn{6}{|c|}{ Supplemental Table S2.txt } \\
\hline CHEMBL1330391 & 688155 & 5.1 & 5.0189 & TST & \\
\hline CHEMBL1328220 & 688155 & 5.3 & 5.1561 & TRN & \\
\hline CHEMBL1608824 & 688155 & 5.0 & 5.0921 & TRN & \\
\hline CHEMBL3194658 & 688155 & 4.95 & 4.9572 & TRN & \\
\hline CHEMBL1479690 & 688155 & 4.65 & 5.0867 & TRN & \\
\hline CHEMBL1576867 & 688155 & 5.05 & 5.0962 & TRN & \\
\hline CHEMBL1491019 & 688155 & 4.9 & 5.0071 & TRN & \\
\hline CHEMBL1387368 & 688155 & 4.9 & 4.9932 & TRN & \\
\hline CHEMBL1392878 & 688155 & 4.45 & 4.9159 & TST & \\
\hline CHEMBL1548150 & 688155 & 5.0 & 5.1574 & TRN & \\
\hline CHEMBL1447212 & 688155 & 5.8 & 5.1533 & TRN & \\
\hline CHEMBL1343030 & 688155 & 4.95 & 5.0192 & TRN & \\
\hline CHEMBL1374596 & 688155 & 4.9 & 5.0934 & TRN & \\
\hline CHEMBL3192160 & 688155 & 5.0 & 5.0273 & TRN & \\
\hline CHEMBL1426275 & 688155 & 6.0 & 5.2332 & TRN & \\
\hline CHEMBL1342903 & 688155 & 5.0 & 5.0842 & TRN & \\
\hline CHEMBL1505714 & 688155 & 4.95 & 5.0697 & TRN & \\
\hline CHEMBL1408720 & 688155 & 4.95 & 5.0378 & TRN & \\
\hline CHEMBL1487430 & 688155 & 5.3 & 4.99 & TRN & \\
\hline CHEMBL1557372 & 688155 & 5.75 & 5.0375 & TRN & \\
\hline CHEMBL1391422 & 688155 & 6.35 & 4.9773 & TRN & \\
\hline CHEMBL1451193 & 688155 & 6.45 & $5.0680 e$ & 00000000005 & TRN \\
\hline CHEMBL1412236 & 688155 & 4.55 & 5.0195 & TRN & \\
\hline CHEMBL1432322 & 688155 & 4.85 & 5.1537 & TRN & \\
\hline CHEMBL1410470 & 688155 & 5.4 & 5.1859 & TRN & \\
\hline CHEMBL1585080 & 688155 & 5.05 & 5.1756 & TRN & \\
\hline CHEMBL1368168 & 688155 & 5.55 & 5.0219 & TRN & \\
\hline CHEMBL1353679 & 688155 & 4.95 & 4.9329 & TRN & \\
\hline CHEMBL1424725 & 688155 & 4.7 & 4.9162 & TRN & \\
\hline CHEMBL1499911 & 688155 & 5.1 & 4.9874 & TRN & \\
\hline CHEMBL1467335 & 688155 & 4.95 & 4.9863 & TRN & \\
\hline CHEMBL1482362 & 688155 & 6.15 & 5.0953 & TST & \\
\hline CHEMBL1334074 & 688155 & 4.65 & 5.01399 & 9999999999 & TRN \\
\hline CHEMBL1509746 & 688155 & 5.5 & 5.0993 & TST & \\
\hline CHEMBL1393077 & 688155 & 5.75 & 5.0207 & TST & \\
\hline CHEMBL1418545 & 688155 & 4.6 & 5.1822 & TST & \\
\hline CHEMBL1358085 & 688155 & 6.4 & 5.2643 & TRN & \\
\hline CHEMBL1540729 & 688155 & 4.85 & 5.2378 & TST & \\
\hline CHEMBL1501662 & 688155 & 4.95 & 4.9479 & TRN & \\
\hline CHEMBL 278295 & 688155 & 5.05 & 5.1359 & TST & \\
\hline CHEMBL1532846 & 688155 & 4.95 & 5.0339 & TST & \\
\hline CHEMBL1561363 & 688155 & 4.55 & 4.957 & TRN & \\
\hline CHEMBL3195042 & 688155 & 4.65 & 5.0429 & TST & \\
\hline CHEMBL1344888 & 688155 & 4.9 & $5.0710 e$ & $\partial 000000001$ & TST \\
\hline CHEMBL3213811 & 688155 & 5.05 & 5.0317 & TRN & \\
\hline CHEMBL1607196 & 688155 & 5.65 & 5.1335 & TST & \\
\hline CHEMBL1325008 & 688155 & 5.0 & 5.1947 & TST & \\
\hline CHEMBL1304189 & 688155 & 4.5 & 5.0814 & TST & \\
\hline
\end{tabular}




\begin{tabular}{|c|c|c|c|c|}
\hline \multicolumn{5}{|c|}{ Supplemental Table S2.txt } \\
\hline CHEMBL1419896 & 688155 & 5.45 & 5.2211 & TRN \\
\hline CHEMBL1301962 & 688155 & 5.35 & 5.0702 & TRN \\
\hline CHEMBL1491815 & 688155 & 4.95 & 5.034 & TRN \\
\hline CHEMBL1599688 & 688155 & 5.45 & 5.1244 & TRN \\
\hline CHEMBL1577601 & 688155 & 5.05 & 5.0125 & TRN \\
\hline CHEMBL1601477 & 688155 & 4.9 & 5.0195 & TST \\
\hline CHEMBL1400845 & 688155 & 4.8 & 5.2052 & TST \\
\hline CHEMBL1440529 & 688155 & 5.0 & 4.9839 & TRN \\
\hline CHEMBL1448094 & 688155 & 5.0 & 4.9384 & TRN \\
\hline CHEMBL1568220 & 688155 & 4.5 & 5.1473 & TRN \\
\hline CHEMBL1323072 & 688155 & 6.45 & 5.0902 & TST \\
\hline CHEMBL1430641 & 688155 & 5.55 & 5.032 & TST \\
\hline CHEMBL1361335 & 688155 & 5.7 & 5.0039 & TRN \\
\hline CHEMBL1520325 & 688155 & 5.1 & 4.9859 & TRN \\
\hline CHEMBL3208825 & 688155 & 5.0 & 5.0214 & TRN \\
\hline CHEMBL1612927 & 688155 & 5.6 & 5.0577 & TRN \\
\hline CHEMBL1565414 & 688155 & 4.6 & 4.9501 & TRN \\
\hline CHEMBL1529356 & 688155 & 5.7 & 5.0745 & TST \\
\hline CHEMBL1311617 & 688155 & 4.85 & 5.0963 & TRN \\
\hline CHEMBL1464344 & 688155 & 5.0 & 5.0861 & TRN \\
\hline CHEMBL1479515 & 688155 & 4.55 & 4.916 & TST \\
\hline CHEMBL1393783 & 688155 & 5.2 & 5.0763 & TRN \\
\hline CHEMBL1312925 & 688155 & 5.1 & 5.1942 & TRN \\
\hline CHEMBL1369861 & 688155 & 5.55 & 4.9958 & TRN \\
\hline CHEMBL3213231 & 688155 & 4.95 & 4.9825 & TRN \\
\hline CHEMBL1362971 & 688155 & 4.65 & 5.0785 & TST \\
\hline CHEMBL3212655 & 688155 & 4.95 & 5.0048 & TRN \\
\hline CHEMBL1507469 & 688155 & 4.9 & 5.007 & TRN \\
\hline CHEMBL1383370 & 688155 & 6.05 & 4.9453 & TRN \\
\hline CHEMBL1559212 & 688155 & 4.95 & 5.1214 & TRN \\
\hline CHEMBL1432388 & 688155 & 5.35 & 5.1569 & TRN \\
\hline CHEMBL1544119 & 688155 & 5.9 & 5.0692 & TRN \\
\hline CHEMBL1529011 & 688155 & 6.35 & 5.0678 & TRN \\
\hline CHEMBL236554 & 688155 & 4.55 & 5.1719 & TRN \\
\hline CHEMBL1451357 & 688155 & 6.5 & 5.0262 & TRN \\
\hline CHEMBL1479887 & 688155 & 4.55 & 5.016 & TRN \\
\hline CHEMBL1585982 & 688155 & 6.5501 & 5.1004 & TST \\
\hline CHEMBL1307585 & 688155 & 4.9 & 5.0953 & TST \\
\hline CHEMBL3192282 & 688155 & 5.0 & 5.0369 & TRN \\
\hline CHEMBL1532510 & 688155 & 4.5 & 4.9572 & TRN \\
\hline CHEMBL1346986 & 688155 & 4.85 & 5.021 & TST \\
\hline CHEMBL1413816 & 688155 & 5.05 & 5.1663 & TRN \\
\hline CHEMBL1606476 & 688155 & 5.7 & 5.188 & TST \\
\hline CHEMBL1547161 & 688155 & 5.0 & 5.0323 & TRN \\
\hline CHEMBL1524927 & 688155 & 4.9 & 4.9813 & TRN \\
\hline CHEMBL1359092 & 688155 & 4.65 & 5.0639 & TRN \\
\hline CHEMBL1580619 & 688155 & 4.6 & 4.7965 & TRN \\
\hline CHEMBL 76589 & 688155 & 5.05 & 5.0697 & TRN \\
\hline
\end{tabular}




\begin{tabular}{|c|c|c|c|c|c|}
\hline \multicolumn{6}{|c|}{ Supplemental Table S2.txt } \\
\hline CHEMBL1313265 & 688155 & 5.0 & 5.0755 & TRN & \\
\hline CHEMBL1517888 & 688155 & 4.9 & 4.9822 & TRN & \\
\hline CHEMBL3195451 & 688155 & 4.65 & 5.0766 & TST & \\
\hline CHEMBL1308901 & 688155 & 5.95 & 5.2531 & TRN & \\
\hline CHEMBL1367228 & 688155 & 4.85 & 4.9648 & TST & \\
\hline CHEMBL1558131 & 688155 & 4.9 & 4.8405 & TRN & \\
\hline CHEMBL1441675 & 688155 & 4.5 & 5.0962 & TST & \\
\hline CHEMBL1399463 & 688155 & 4.55 & 4.9525 & TRN & \\
\hline CHEMBL1561073 & 688155 & 4.85 & 5.1071 & TRN & \\
\hline CHEMBL1531870 & 688155 & 5.85 & 4.8781 & TRN & \\
\hline CHEMBL1424579 & 688155 & 5.15 & 5.1838 & TRN & \\
\hline CHEMBL1366706 & 688155 & 5.45 & 5.2699 & TRN & \\
\hline CHEMBL1548510 & 688155 & 5.0 & 4.9628 & TRN & \\
\hline CHEMBL1306392 & 688155 & 5.8 & 5.1709 & TRN & \\
\hline CHEMBL1568856 & 688155 & 5.95 & 5.1503 & TRN & \\
\hline CHEMBL1505301 & 688155 & 4.85 & 5.3296 & TRN & \\
\hline CHEMBL1459632 & 688155 & 5.1 & 5.0486 & TRN & \\
\hline CHEMBL1543405 & 688155 & 5.5 & 5.1818 & TRN & \\
\hline CHEMBL1460186 & 688155 & 4.9 & 5.0489 & TRN & \\
\hline CHEMBL1308633 & 688155 & 5.05 & 5.0858 & TRN & \\
\hline CHEMBL1422326 & 688155 & 5.15 & 5.0127 & TRN & \\
\hline CHEMBL1424726 & 688155 & 4.95 & 5.0906 & TRN & \\
\hline CHEMBL1525564 & 688155 & 5.55 & 5.1716 & TRN & \\
\hline CHEMBL1316158 & 688155 & 4.95 & 5.0336 & TRN & \\
\hline CHEMBL1540762 & 688155 & 4.9 & 5.1947 & TRN & \\
\hline CHEMBL1607547 & 688155 & 5.15 & 5.1816 & TRN & \\
\hline CHEMBL1470376 & 688155 & 4.95 & 5.1659 & TST & \\
\hline CHEMBL1517536 & 688155 & 4.55 & 5.0322 & TRN & \\
\hline CHEMBL2374259 & 688155 & 5.15 & 5.0783 & TRN & \\
\hline CHEMBL 3210294 & 688155 & 4.55 & 5.1747 & TST & \\
\hline CHEMBL1391064 & 688155 & 6.05 & 5.002 & TRN & \\
\hline CHEMBL1542876 & 688155 & 4.85 & 4.9726 & TRN & \\
\hline CHEMBL1467740 & 688155 & 4.55 & 5.102 & TRN & \\
\hline CHEMBL1389901 & 688155 & 6.05 & 5.3057 & TRN & \\
\hline CHEMBL1444156 & 688155 & 4.75 & 5.2272 & TRN & \\
\hline CHEMBL1458376 & 688155 & 4.95 & 5.1153 & TRN & \\
\hline CHEMBL1335540 & 688155 & 5.05 & 5.13299 & 9999999999 & TRN \\
\hline CHEMBL1557479 & 688155 & 4.85 & 5.2262 & TST & \\
\hline CHEMBL1344089 & 688155 & 6.15 & 5.0498 & TRN & \\
\hline CHEMBL1566655 & 688155 & 5.0 & 5.0773 & TST & \\
\hline CHEMBL1422212 & 688155 & 4.55 & 4.9877 & TRN & \\
\hline CHEMBL1535282 & 688155 & 4.95 & 5.0874 & TRN & \\
\hline CHEMBL1374591 & 688155 & 6.0 & 5.0186 & TRN & \\
\hline CHEMBL1300064 & 688155 & 4.95 & 5.1159 & TST & \\
\hline CHEMBL1346240 & 688155 & 5.1 & 4.9728 & TRN & \\
\hline CHEMBL1608019 & 688155 & 5.25 & 5.2015 & TST & \\
\hline CHEMBL1489236 & 688155 & 5.3 & 5.0933 & TST & \\
\hline CHEMBL1563035 & 688155 & 4.5 & 5.1412 & TRN & \\
\hline
\end{tabular}




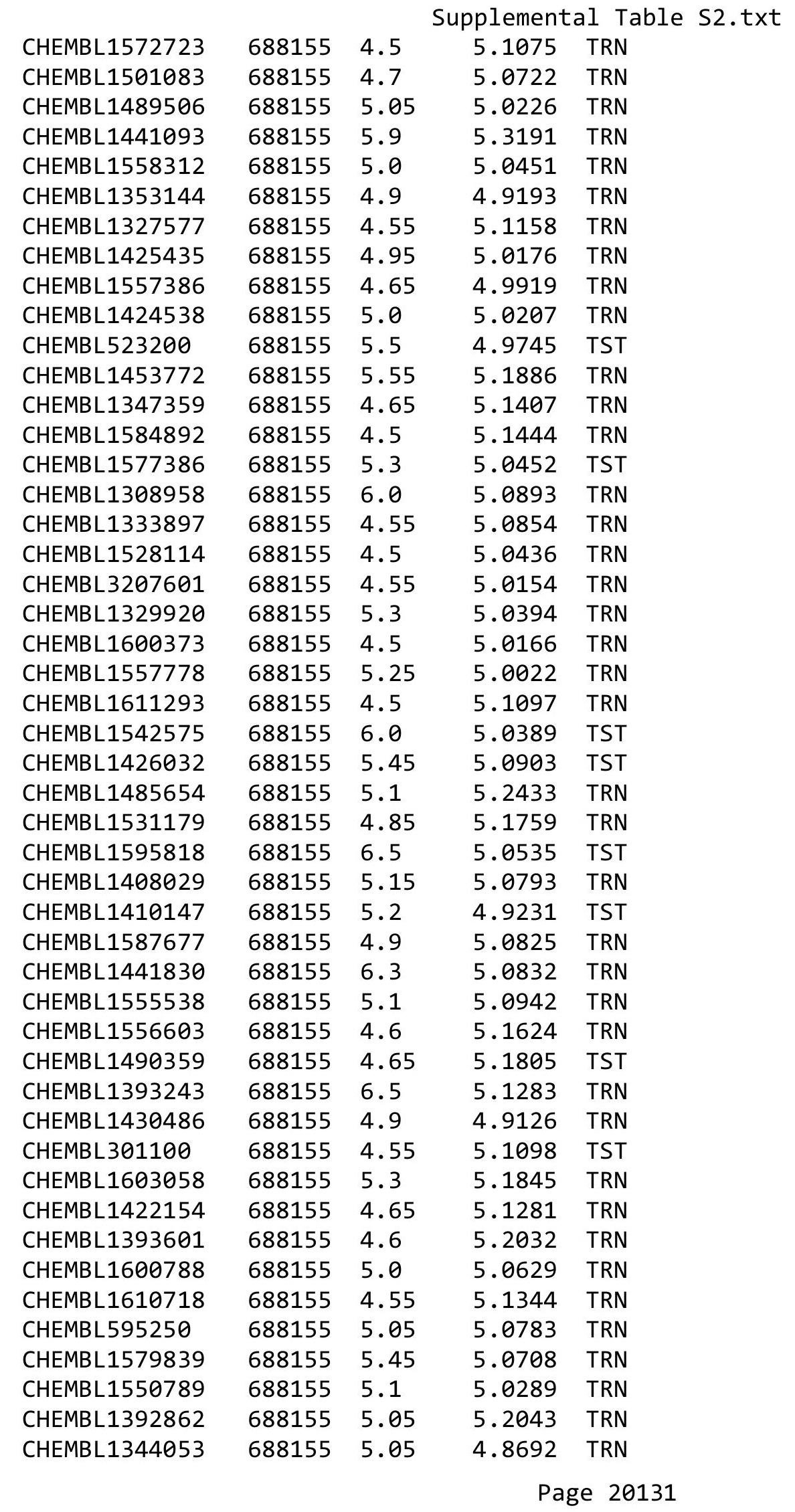




\begin{tabular}{|c|c|c|c|c|}
\hline \multicolumn{5}{|c|}{ Supplemental Table S2.txt } \\
\hline CHEMBL1511386 & 688155 & 4.5 & 5.1253 & TRN \\
\hline CHEMBL1447863 & 688155 & 4.95 & 5.0012 & TRN \\
\hline CHEMBL1349787 & 688155 & 4.55 & 5.1495 & TRN \\
\hline CHEMBL1353018 & 688155 & 5.5 & 4.9497 & TRN \\
\hline CHEMBL1409656 & 688155 & 6.5 & 5.0951 & TST \\
\hline CHEMBL1336351 & 688155 & 4.5 & 5.0864 & TST \\
\hline CHEMBL1466145 & 688155 & 4.55 & 5.1333 & TRN \\
\hline CHEMBL1497883 & 688155 & 5.0 & 4.9894 & TRN \\
\hline CHEMBL1328983 & 688155 & 5.35 & 5.2389 & TRN \\
\hline CHEMBL1590048 & 688155 & 4.7 & 5.1434 & TST \\
\hline CHEMBL3198896 & 688155 & 5.3 & 5.117 & TST \\
\hline CHEMBL1468653 & 688155 & 4.9 & 5.1579 & TRN \\
\hline CHEMBL1581024 & 688155 & 5.05 & 5.2254 & TRN \\
\hline CHEMBL1440508 & 688155 & 4.9 & 5.0498 & TRN \\
\hline CHEMBL1559987 & 688155 & 4.55 & 5.1284 & TST \\
\hline CHEMBL1453483 & 688155 & 4.55 & 5.083 & TST \\
\hline CHEMBL1570336 & 688155 & 4.6 & 5.1863 & TRN \\
\hline CHEMBL1540097 & 688155 & 5.5 & 5.2309 & TRN \\
\hline CHEMBL1458732 & 688155 & 4.95 & 5.1176 & TST \\
\hline CHEMBL1510408 & 688155 & 5.4 & 5.0882 & TRN \\
\hline CHEMBL1439912 & 688155 & 5.95 & 5.2785 & TRN \\
\hline CHEMBL1568864 & 688155 & 4.55 & 5.2781 & TRN \\
\hline CHEMBL1364339 & 688155 & 6.0 & 4.9013 & TRN \\
\hline CHEMBL1716038 & 688155 & 5.0 & 4.945 & TRN \\
\hline CHEMBL1463888 & 688155 & 5.0 & 5.1213 & TRN \\
\hline CHEMBL1552688 & 688155 & 4.95 & 4.9459 & TRN \\
\hline CHEMBL1428296 & 688155 & 4.65 & 4.9778 & TRN \\
\hline CHEMBL1530638 & 688155 & 5.8 & 5.0024 & TRN \\
\hline CHEMBL1375391 & 688155 & 4.95 & 5.273 & TRN \\
\hline CHEMBL1347213 & 688155 & 6.5 & 5.0975 & TST \\
\hline CHEMBL1385010 & 688155 & 4.5 & 4.9916 & TRN \\
\hline CHEMBL1319481 & 688155 & 5.9 & 5.1061 & TRN \\
\hline CHEMBL1374064 & 688155 & 5.65 & 5.0833 & TST \\
\hline CHEMBL1324766 & 688155 & 4.55 & 5.1623 & TRN \\
\hline CHEMBL1597660 & 688155 & 6.0 & 5.1381 & TRN \\
\hline CHEMBL1587995 & 688155 & 4.95 & 5.1148 & TRN \\
\hline CHEMBL1588937 & 688155 & 5.85 & 5.1943 & TRN \\
\hline CHEMBL1533225 & 688155 & 4.55 & 4.939 & TST \\
\hline CHEMBL1365288 & 688155 & 4.85 & 4.9645 & TRN \\
\hline CHEMBL1384238 & 688155 & 6.5 & 5.0842 & TST \\
\hline CHEMBL1354736 & 688155 & 4.5 & 5.1664 & TRN \\
\hline CHEMBL1387298 & 688155 & 4.55 & 4.9399 & TRN \\
\hline CHEMBL1303479 & 688155 & 5.1 & 5.2043 & TST \\
\hline CHEMBL1382228 & 688155 & 4.65 & 5.3318 & TRN \\
\hline CHEMBL1592982 & 688155 & 4.95 & 4.8421 & TRN \\
\hline CHEMBL1457677 & 688155 & 4.85 & 5.0354 & TST \\
\hline CHEMBL1387914 & 688155 & 5.1 & 5.1051 & TRN \\
\hline CHEMBL1504868 & 688155 & 4.95 & 5.0386 & TRN \\
\hline
\end{tabular}




\begin{tabular}{|c|c|c|c|c|c|}
\hline \multirow{3}{*}{$\begin{array}{l}\text { CHEMBL3211259 } \\
\text { CHEMBL } 1430531\end{array}$} & & \multicolumn{4}{|c|}{ Supplemental Table S2.txt } \\
\hline & & 4.95 & 5.1320 & 0000000001 & TST \\
\hline & 688155 & 6.45 & 5.1618 & TRN & \\
\hline CHEMBL1606368 & 688155 & 5.5 & 5.2336 & TRN & \\
\hline CHEMBL 2005437 & 688155 & 6.1 & 4.9866 & TRN & \\
\hline CHEMBL1378245 & 688155 & 5.5 & 5.1537 & TRN & \\
\hline CHEMBL3190471 & 688155 & 4.95 & 5.1489 & TRN & \\
\hline CHEMBL3145367 & 688155 & 4.9 & 5.0749 & TST & \\
\hline CHEMBL1427849 & 688155 & 4.6 & 5.0508 & TRN & \\
\hline CHEMBL1346946 & 688155 & 4.9 & 5.1198 & TST & \\
\hline CHEMBL1568144 & 688155 & 5.55 & 5.1593 & TRN & \\
\hline CHEMBL1561281 & 688155 & 5.1 & 5.0746 & TRN & \\
\hline CHEMBL1602811 & 688155 & 4.95 & 4.9964 & TRN & \\
\hline CHEMBL1350806 & 688155 & 4.9 & 5.0264 & TST & \\
\hline CHEMBL1564175 & 688155 & 4.85 & 4.9477 & TRN & \\
\hline CHEMBL1364027 & 688155 & 5.0 & 5.1884 & TRN & \\
\hline CHEMBL1559829 & 688155 & 5.0 & 4.9411 & TRN & \\
\hline CHEMBL1604187 & 688155 & 5.1 & 4.9968 & TRN & \\
\hline CHEMBL1558781 & 688155 & 4.9 & 5.043 & TRN & \\
\hline CHEMBL1503046 & 688155 & 4.9 & 5.0572 & TST & \\
\hline CHEMBL1973629 & 688155 & 4.85 & 5.1057 & TST & \\
\hline CHEMBL1331799 & 688155 & 5.1 & 4.9849 & TRN & \\
\hline CHEMBL1340945 & 688155 & 5.45 & 5.1317 & TRN & \\
\hline CHEMBL1582890 & 688155 & 4.5 & 5.0447 & TRN & \\
\hline CHEMBL1453558 & 688155 & 5.0 & 5.2479 & TRN & \\
\hline CHEMBL1586641 & 688155 & 4.55 & 4.8914 & TRN & \\
\hline CHEMBL1564496 & 688155 & 5.0 & 5.047 & TRN & \\
\hline CHEMBL1604364 & 688155 & 5.3 & 5.0225 & TRN & \\
\hline CHEMBL1490850 & 688155 & 5.0 & 5.1714 & TRN & \\
\hline CHEMBL1498576 & 688155 & 4.5 & 5.1779 & TRN & \\
\hline CHEMBL1604928 & 688155 & 4.95 & 5.1141 & TRN & \\
\hline CHEMBL1583411 & 688155 & 5.25 & 5.2403 & TRN & \\
\hline CHEMBL1486411 & 688155 & 4.5 & 5.115 & TRN & \\
\hline CHEMBL1399561 & 688155 & 5.55 & 4.9211 & TRN & \\
\hline CHEMBL1388223 & 688155 & 4.5 & 5.0737 & TRN & \\
\hline CHEMBL1468288 & 688155 & 5.3 & 5.1792 & TST & \\
\hline CHEMBL1349450 & 688155 & 4.5 & 5.0243 & TRN & \\
\hline CHEMBL1570796 & 688155 & 4.9 & 4.9969 & TRN & \\
\hline CHEMBL1316563 & 688155 & 4.55 & 5.1825 & TST & \\
\hline CHEMBL1573153 & 688155 & 4.85 & 5.0949 & TRN & \\
\hline CHEMBL3196917 & 688155 & 4.5 & 5.1196 & TRN & \\
\hline CHEMBL1595094 & 688155 & 4.5 & 5.0196 & TRN & \\
\hline CHEMBL1580748 & 688155 & 5.0 & 5.0543 & TST & \\
\hline CHEMBL1338081 & 688155 & 5.15 & 5.1281 & TRN & \\
\hline CHEMBL133576 & 688155 & 5.0 & 5.1036 & TRN & \\
\hline CHEMBL1424440 & 688155 & 5.1 & 4.9952 & TST & \\
\hline CHEMBL1467966 & 688155 & 5.65 & 5.1912 & TRN & \\
\hline CHEMBL1451268 & 688155 & 4.6 & 5.1738 & TRN & \\
\hline CHEMBL1379012 & 688155 & 5.05 & 5.2521 & TST & \\
\hline
\end{tabular}




\begin{tabular}{|c|c|c|c|c|c|}
\hline & & \multicolumn{4}{|c|}{ Supplemental Table S2.txt } \\
\hline CHEMBL1382766 & 688155 & 4.95 & 4.978 & TRN & \\
\hline CHEMBL1565777 & 688155 & 5.0 & 4.9949 & TRN & \\
\hline CHEMBL1471031 & 688155 & 4.55 & 4.978 & TST & \\
\hline CHEMBL1602730 & 688155 & 5.6 & 5.1965 & TRN & \\
\hline CHEMBL1349484 & 688155 & 4.65 & 4.9745 & TRN & \\
\hline CHEMBL1324564 & 688155 & 5.75 & 5.1109 & TRN & \\
\hline CHEMBL1542185 & 688155 & 5.0 & 5.2395 & TST & \\
\hline CHEMBL1429381 & 688155 & 4.9 & 4.9796 & TST & \\
\hline CHEMBL1611972 & 688155 & 5.1 & 5.0002 & TRN & \\
\hline CHEMBL1586107 & 688155 & 5.0 & 4.9476 & TRN & \\
\hline CHEMBL1526117 & 688155 & 4.55 & 5.01699 & 99999999995 & TST \\
\hline CHEMBL1612087 & 688155 & 5.45 & 4.9243 & TRN & \\
\hline CHEMBL578504 & 688155 & 4.55 & 5.1453 & TRN & \\
\hline CHEMBL1544552 & 688155 & 5.1 & 5.2328 & TST & \\
\hline CHEMBL1427322 & 688155 & 5.3 & 5.0868 & TST & \\
\hline CHEMBL1330373 & 688155 & 5.0 & 5.1006 & TRN & \\
\hline CHEMBL1369038 & 688155 & 5.65 & 5.2676 & TRN & \\
\hline CHEMBL3209132 & 688155 & 4.75 & 4.896 & TST & \\
\hline CHEMBL1423234 & 688155 & 5.0 & 5.1657 & TRN & \\
\hline CHEMBL1401610 & 688155 & 5.25 & 5.0656 & TRN & \\
\hline CHEMBL1301436 & 688155 & 4.55 & 5.17200 & 0000000001 & TRN \\
\hline CHEMBL1399498 & 688155 & 4.9 & 5.0818 & TRN & \\
\hline CHEMBL1602194 & 688155 & 4.5 & 4.9813 & TRN & \\
\hline CHEMBL1330131 & 688155 & 5.45 & 4.996 & TST & \\
\hline CHEMBL1302752 & 688155 & 4.95 & 5.0289 & TRN & \\
\hline CHEMBL1359902 & 688155 & 4.95 & 5.0916 & TST & \\
\hline CHEMBL1306640 & 688155 & 5.3 & 5.0448 & TST & \\
\hline CHEMBL1382775 & 688155 & 4.55 & 5.1959 & TST & \\
\hline CHEMBL336296 & 688155 & 4.55 & 5.1223 & TRN & \\
\hline CHEMBL1559833 & 688155 & 4.95 & 5.1899 & TST & \\
\hline CHEMBL1332797 & 688155 & 4.6 & 5.0042 & TST & \\
\hline CHEMBL3191780 & 688155 & 5.3 & 5.0021 & TRN & \\
\hline CHEMBL1399774 & 688155 & 5.55 & 5.1851 & TST & \\
\hline CHEMBL1490682 & 688155 & 4.55 & 5.2025 & TRN & \\
\hline CHEMBL1374122 & 688155 & 5.5 & 5.0364 & TRN & \\
\hline CHEMBL1531439 & 688155 & 5.4 & 5.1826 & TRN & \\
\hline CHEMBL3198465 & 688155 & 5.75 & 4.9821 & TRN & \\
\hline CHEMBL1556063 & 688155 & 4.8 & 4.8304 & TRN & \\
\hline CHEMBL 1378742 & 688155 & 4.55 & 5.0293 & TST & \\
\hline CHEMBL1520774 & 688155 & 4.95 & 5.2105 & TRN & \\
\hline CHEMBL1311440 & 688155 & 5.0 & 5.1824 & TRN & \\
\hline CHEMBL1994460 & 688155 & 5.9 & 5.1221 & TRN & \\
\hline CHEMBL1600215 & 688155 & 5.45 & 5.2699 & TST & \\
\hline CHEMBL1375963 & 688155 & 5.0 & 5.1122 & TST & \\
\hline CHEMBL1542972 & 688155 & 4.95 & 5.22 & TRN & \\
\hline CHEMBL1577158 & 688155 & 4.9 & 4.9937 & TRN & \\
\hline CHEMBL1451202 & 688155 & 5.05 & 5.0763 & TRN & \\
\hline CHEMBL1990336 & 688155 & 5.0 & 5.0748 & TST & \\
\hline
\end{tabular}




\begin{tabular}{|c|c|c|c|c|c|}
\hline \multicolumn{6}{|c|}{ Supplemental Table S2.txt } \\
\hline CHEMBL1491506 & 688155 & 5.95 & 5.0854 & TRN & \\
\hline CHEMBL1555814 & 688155 & 4.5 & 4.9782 & TRN & \\
\hline CHEMBL1331090 & 688155 & 4.75 & 4.9272 & TRN & \\
\hline CHEMBL 3189940 & 688155 & 4.5 & 5.2543 & TRN & \\
\hline CHEMBL1411452 & 688155 & 5.0 & 5.1736 & TRN & \\
\hline CHEMBL1497545 & 688155 & 5.5 & 5.3409 & TRN & \\
\hline CHEMBL1432430 & 688155 & 4.55 & 5.17899 & 9999999999 & TRN \\
\hline CHEMBL1489370 & 688155 & 4.8 & 5.1889 & TRN & \\
\hline CHEMBL1441645 & 688155 & 5.0 & 4.9912 & TRN & \\
\hline CHEMBL1303031 & 688155 & 4.55 & 4.9626 & TRN & \\
\hline CHEMBL1413233 & 688155 & 5.0 & 4.9342 & TRN & \\
\hline CHEMBL1421862 & 688155 & 6.5 & 5.1655 & TRN & \\
\hline CHEMBL1438711 & 688155 & 4.9 & 5.0937 & TRN & \\
\hline CHEMBL1359056 & 688155 & 4.55 & 5.1234 & TRN & \\
\hline CHEMBL1332151 & 688155 & 5.4 & 5.0231 & TRN & \\
\hline CHEMBL1585630 & 688155 & 5.95 & 5.1315 & TRN & \\
\hline CHEMBL1605363 & 688155 & 4.6 & 4.9594 & TRN & \\
\hline CHEMBL1505687 & 688155 & 4.95 & 5.0244 & TRN & \\
\hline CHEMBL1365185 & 688155 & 4.55 & 5.0406 & TRN & \\
\hline CHEMBL1576895 & 688155 & 4.95 & 5.2223 & TRN & \\
\hline CHEMBL1318262 & 688155 & 5.0 & 5.2351 & TST & \\
\hline CHEMBL1580100 & 688155 & 4.5 & 5.1386 & TRN & \\
\hline CHEMBL261508 & 688155 & 5.3 & 5.1366 & TRN & \\
\hline CHEMBL1575478 & 688155 & 4.9 & 5.3583 & TST & \\
\hline CHEMBL1309850 & 688155 & 4.65 & 4.9198 & TRN & \\
\hline CHEMBL1449802 & 688155 & 4.95 & 4.9298 & TRN & \\
\hline CHEMBL1559551 & 688155 & 5.25 & 5.1473 & TRN & \\
\hline CHEMBL1409207 & 688155 & 5.05 & 4.8663 & TRN & \\
\hline CHEMBL1402539 & 688155 & 5.1 & 5.084 & TST & \\
\hline CHEMBL1313346 & 688155 & 5.45 & 4.9767 & TST & \\
\hline CHEMBL1612363 & 688155 & 6.05 & 5.1812 & TRN & \\
\hline CHEMBL1505909 & 688155 & 4.5 & 5.1429 & TRN & \\
\hline CHEMBL1430160 & 688155 & 6.45 & 4.9824 & TRN & \\
\hline CHEMBL1352839 & 688155 & 5.1 & 5.0752 & TRN & \\
\hline CHEMBL1388862 & 688155 & 4.85 & 5.0688 & TST & \\
\hline CHEMBL1574375 & 688155 & 4.5 & 4.9777 & TRN & \\
\hline CHEMBL1535759 & 688155 & 5.25 & 5.0022 & TST & \\
\hline CHEMBL1533555 & 688155 & 5.1 & 5.2522 & TRN & \\
\hline CHEMBL1446238 & 688155 & 5.0 & 5.0646 & TRN & \\
\hline CHEMBL1303333 & 688155 & 4.9 & 5.1634 & TRN & \\
\hline CHEMBL1472451 & 688155 & 4.55 & 5.0766 & TRN & \\
\hline CHEMBL 1307850 & 688155 & 4.95 & 5.2024 & TRN & \\
\hline CHEMBL1525683 & 688155 & 5.85 & 5.2352 & TRN & \\
\hline CHEMBL1414006 & 688155 & 4.6 & 5.0455 & TST & \\
\hline CHEMBL1340480 & 688155 & 6.25 & 5.1327 & TST & \\
\hline CHEMBL1325453 & 688155 & 4.5 & 5.1573 & TRN & \\
\hline CHEMBL509256 & 688155 & 4.55 & 4.9647 & TRN & \\
\hline CHEMBL43383 & 688155 & 6.15 & 5.1823 & TRN & \\
\hline
\end{tabular}




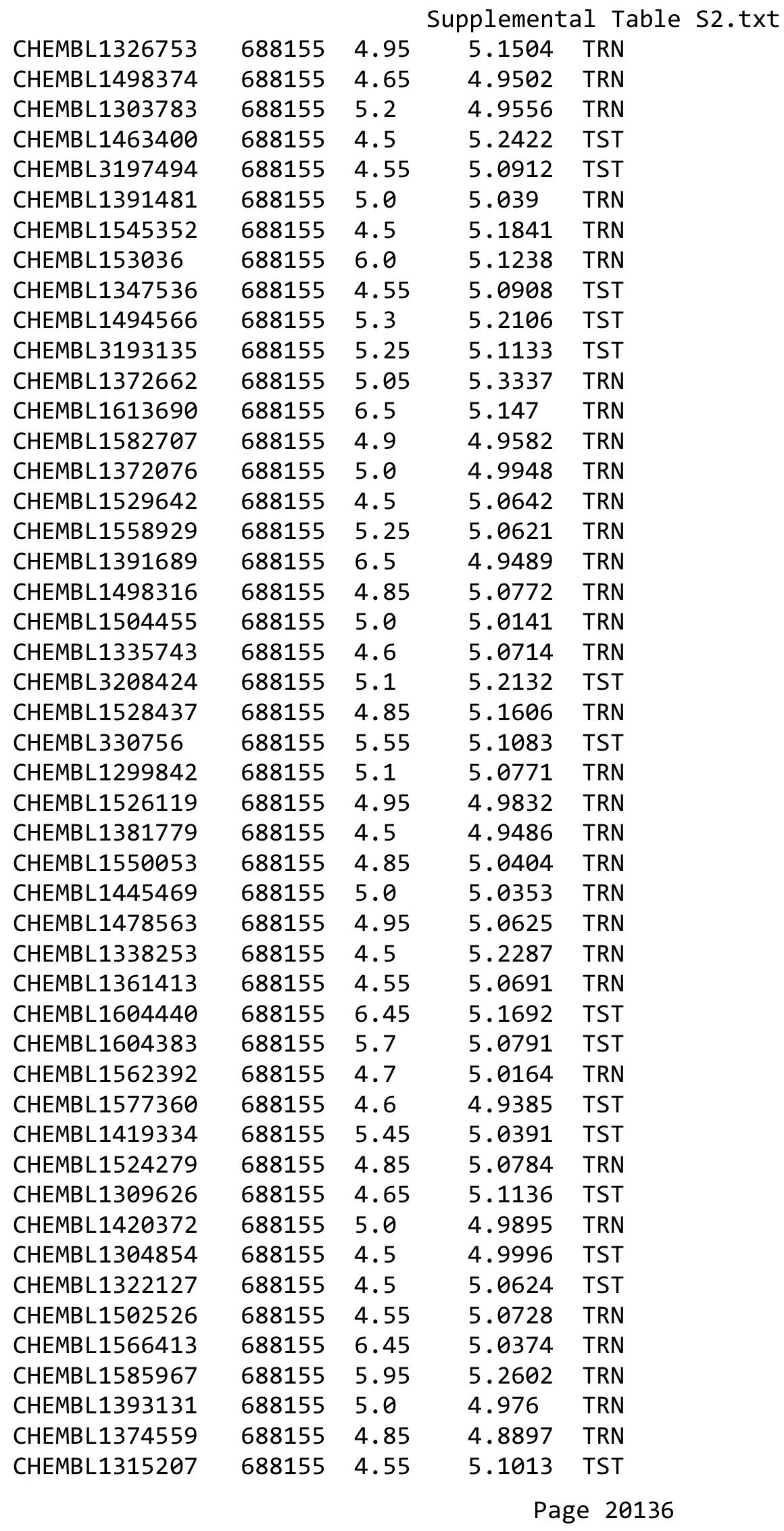




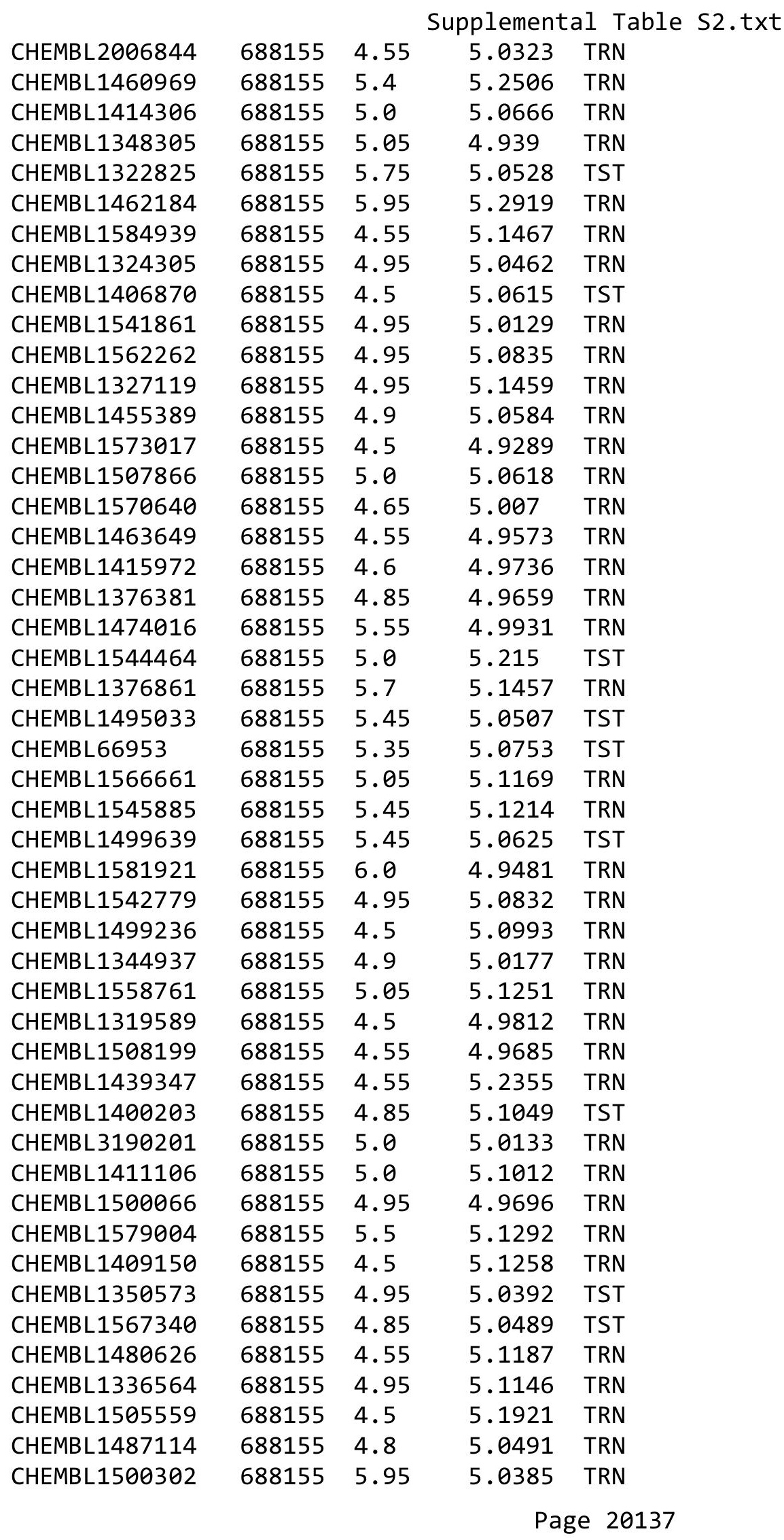




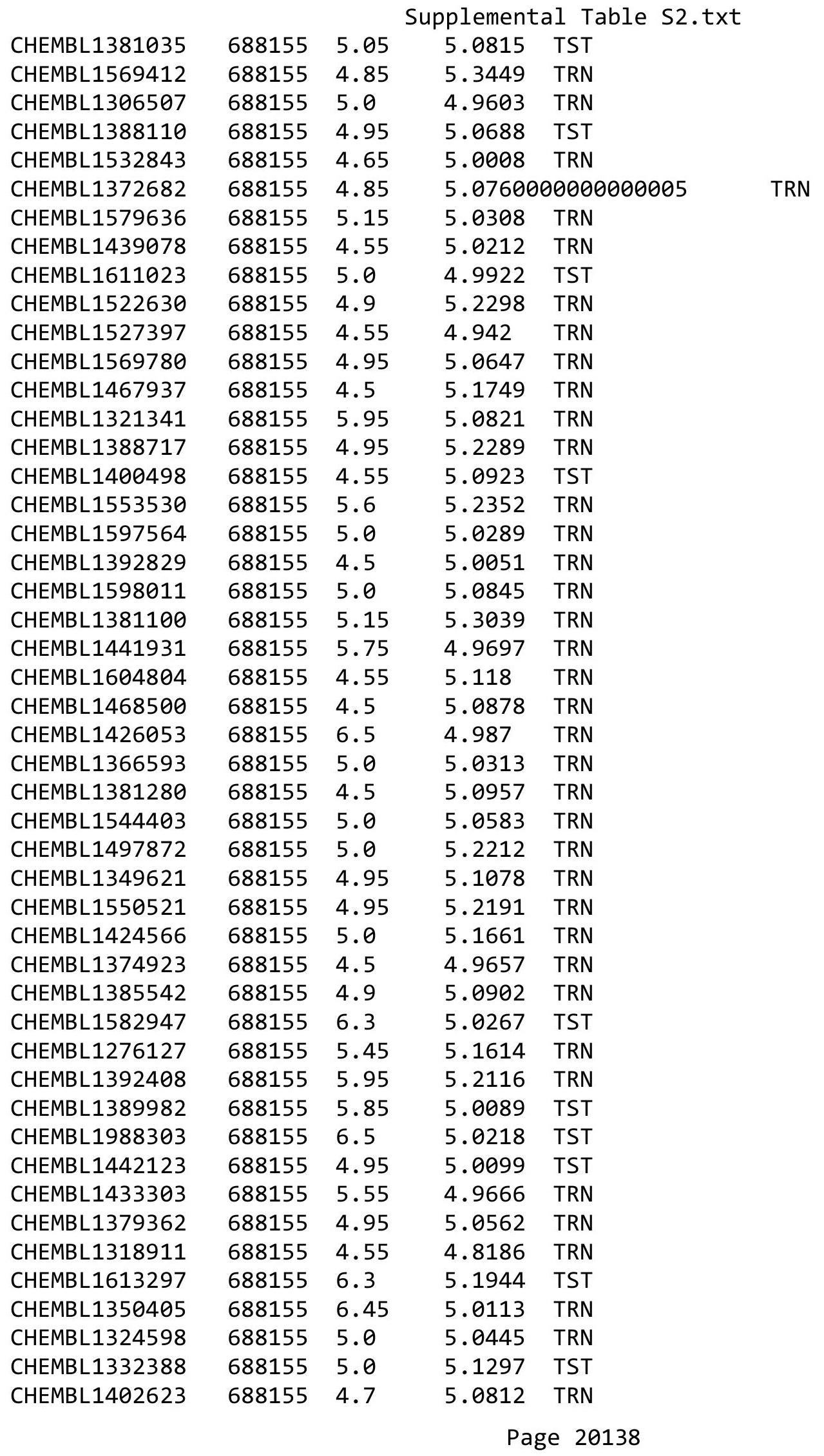




\begin{tabular}{|c|c|c|c|c|c|}
\hline \multicolumn{6}{|c|}{ Supplemental Table S2.txt } \\
\hline CHEMBL3210603 & 688155 & 6.5 & 5.0855 & TRN & \\
\hline CHEMBL1321062 & 688155 & 5.25 & 5.1086 & TRN & \\
\hline CHEMBL1387035 & 688155 & 5.1 & 5.2197 & TST & \\
\hline CHEMBL1313453 & 688155 & 4.95 & 5.2274 & TRN & \\
\hline CHEMBL1327607 & 688155 & 4.55 & 5.0763 & TRN & \\
\hline CHEMBL1588672 & 688155 & 4.8 & 5.0168 & TRN & \\
\hline CHEMBL1582416 & 688155 & 5.0 & 4.9591 & TST & \\
\hline CHEMBL1372946 & 688155 & 6.35 & 5.2034 & TRN & \\
\hline CHEMBL1371889 & 688155 & 4.9 & 5.0924 & TST & \\
\hline CHEMBL1321428 & 688155 & 4.95 & 5.1857 & TST & \\
\hline CHEMBL1419438 & 688155 & 4.5 & 5.1824 & TRN & \\
\hline CHEMBL1409686 & 688155 & 4.55 & 5.0294 & TST & \\
\hline CHEMBL1320152 & 688155 & 4.85 & 5.0478 & TST & \\
\hline CHEMBL1461212 & 688155 & 5.1 & 5.0407 & TRN & \\
\hline CHEMBL 1537780 & 688155 & 4.6 & 5.0451 & TRN & \\
\hline CHEMBL1382264 & 688155 & 5.3 & 4.9612 & TRN & \\
\hline CHEMBL1581960 & 688155 & 5.45 & 5.075 & TRN & \\
\hline CHEMBL1498561 & 688155 & 4.95 & 5.1343 & TST & \\
\hline CHEMBL1371186 & 688155 & 5.05 & 5.1736 & TST & \\
\hline CHEMBL1377071 & 688155 & 6.35 & 5.3461 & TRN & \\
\hline CHEMBL1969984 & 688155 & 4.85 & 5.0163 & TST & \\
\hline CHEMBL1533904 & 688155 & 5.0 & 5.032 & TRN & \\
\hline CHEMBL1531536 & 688155 & 4.6 & 4.9538 & TRN & \\
\hline CHEMBL1329073 & 688155 & 4.95 & 5.1195 & TRN & \\
\hline CHEMBL1338045 & 688155 & 4.5 & 5.0807 & TRN & \\
\hline CHEMBL1570355 & 688155 & 5.0 & 5.0694 & TRN & \\
\hline CHEMBL1718398 & 688155 & 4.8 & 5.1378 & TST & \\
\hline CHEMBL1562794 & 688155 & 4.95 & 5.029 & TRN & \\
\hline CHEMBL1372242 & 688155 & 4.95 & 5.1904 & TRN & \\
\hline CHEMBL1369904 & 688155 & 5.5 & 5.13399 & 99999999995 & TRN \\
\hline CHEMBL1352405 & 688155 & 5.4 & 5.0093 & TRN & \\
\hline CHEMBL1423552 & 688155 & 5.4 & 5.2982 & TRN & \\
\hline CHEMBL609027 & 688155 & 4.5 & 5.1123 & TRN & \\
\hline CHEMBL 289277 & 688155 & 4.5 & 5.0741 & TST & \\
\hline CHEMBL1509555 & 688155 & 5.65 & 4.9229 & TST & \\
\hline CHEMBL3198938 & 688155 & 4.7 & 5.1007 & TST & \\
\hline CHEMBL1334036 & 688155 & 5.65 & 5.1627 & TRN & \\
\hline CHEMBL1545200 & 688155 & 5.4 & 5.1761 & TRN & \\
\hline CHEMBL1303538 & 688155 & 4.85 & 5.0129 & TRN & \\
\hline CHEMBL340807 & 688155 & 5.0 & 5.0005 & TRN & \\
\hline CHEMBL1542785 & 688155 & 6.0 & 5.1564 & TRN & \\
\hline CHEMBL1563334 & 688155 & 4.75 & 5.2278 & TRN & \\
\hline CHEMBL1349724 & 688155 & 5.0 & 5.2195 & TRN & \\
\hline CHEMBL1405468 & 688155 & 5.9 & 5.1514 & TRN & \\
\hline CHEMBL1528492 & 688155 & 4.95 & 4.9372 & TRN & \\
\hline CHEMBL1416218 & 688155 & 5.1 & 5.0947 & TST & \\
\hline CHEMBL1530571 & 688155 & 5.55 & 5.1861 & TRN & \\
\hline CHEMBL1612476 & 688155 & 4.95 & 5.0872 & TRN & \\
\hline
\end{tabular}




\begin{tabular}{|c|c|c|c|c|c|}
\hline \multicolumn{6}{|c|}{ Supplemental Table S2.txt } \\
\hline CHEMBL1423190 & 688155 & 5.2 & 5.1271 & TRN & \\
\hline CHEMBL3207865 & 688155 & 4.85 & 5.0172 & TRN & \\
\hline CHEMBL3190273 & 688155 & 4.5 & 5.0601 & TST & \\
\hline CHEMBL1419359 & 688155 & 4.55 & 4.9912 & TRN & \\
\hline CHEMBL1339476 & 688155 & 5.0 & 5.0145 & TRN & \\
\hline CHEMBL1300089 & 688155 & 6.5 & 5.0654 & TRN & \\
\hline CHEMBL1612514 & 688155 & 4.5 & 5.1937 & TRN & \\
\hline CHEMBL1596929 & 688155 & 5.8 & 5.093 & TST & \\
\hline CHEMBL1510991 & 688155 & 4.55 & 4.9828 & TST & \\
\hline CHEMBL1605635 & 688155 & 5.05 & 5.0765 & TRN & \\
\hline CHEMBL1580278 & 688155 & 4.5 & 5.1908 & TRN & \\
\hline CHEMBL1341120 & 688155 & 5.6 & 5.1273 & TRN & \\
\hline CHEMBL1529087 & 688155 & 4.95 & 5.1714 & TRN & \\
\hline CHEMBL1522133 & 688155 & 5.0 & 5.1193 & TST & \\
\hline CHEMBL579621 & 688155 & 6.1 & 5.0162 & TRN & \\
\hline CHEMBL1497676 & 688155 & 4.9 & 5.2057 & TST & \\
\hline CHEMBL1597416 & 688155 & 4.8 & 5.1716 & TRN & \\
\hline CHEMBL1391825 & 688155 & 5.0 & 5.0606 & TST & \\
\hline CHEMBL1569509 & 688155 & 4.55 & 5.1146 & TST & \\
\hline CHEMBL1301193 & 688155 & 4.5 & 4.9875 & TST & \\
\hline CHEMBL1385062 & 688155 & 4.55 & 5.077 & TRN & \\
\hline CHEMBL1603514 & 688155 & 5.5 & 5.0205 & TRN & \\
\hline CHEMBL1481291 & 688155 & 6.05 & 5.0324 & TST & \\
\hline CHEMBL1519514 & 688155 & 5.2 & 5.0207 & TRN & \\
\hline CHEMBL1303471 & 688155 & 5.5 & 5.1806 & TRN & \\
\hline CHEMBL1382808 & 688155 & 4.5 & 5.09399 & 9999999999 & TST \\
\hline CHEMBL1540621 & 688155 & 5.25 & 5.0362 & TRN & \\
\hline CHEMBL1547122 & 688155 & 5.3 & 5.0467 & TRN & \\
\hline CHEMBL1367935 & 688155 & 5.45 & 5.13200 & 0000000001 & TRN \\
\hline CHEMBL1348135 & 688155 & 5.2 & 5.0879 & TST & \\
\hline CHEMBL1421575 & 688155 & 4.55 & 4.9479 & TRN & \\
\hline CHEMBL1560895 & 688155 & 6.3 & 5.1379 & TRN & \\
\hline CHEMBL1387599 & 688155 & 5.0 & 5.064 & TRN & \\
\hline CHEMBL1444181 & 688155 & 4.6 & 5.0407 & TST & \\
\hline CHEMBL1348100 & 688155 & 4.55 & 4.8985 & TST & \\
\hline CHEMBL362919 & 688155 & 4.4 & 5.0578 & TST & \\
\hline CHEMBL1318773 & 688155 & 5.65 & 5.0173 & TRN & \\
\hline CHEMBL1575033 & 688155 & 5.3 & 4.904 & TST & \\
\hline CHEMBL1577394 & 688155 & 4.9 & 4.8943 & TRN & \\
\hline CHEMBL1356501 & 688155 & 4.95 & 4.938 & TRN & \\
\hline CHEMBL1352240 & 688155 & 5.8 & 5.0649 & TRN & \\
\hline CHEMBL1431983 & 688155 & 4.85 & 4.9435 & TRN & \\
\hline CHEMBL1407724 & 688155 & 5.45 & 5.0292 & TRN & \\
\hline CHEMBL1338238 & 688155 & 5.6 & 5.1507 & TRN & \\
\hline CHEMBL1353113 & 688155 & 6.05 & 4.9956 & TST & \\
\hline CHEMBL1387610 & 688155 & 4.75 & 4.917 & TRN & \\
\hline CHEMBL597035 & 688155 & 4.5 & 4.9317 & TRN & \\
\hline CHEMBL1536148 & 688155 & 4.75 & 5.1226 & TRN & \\
\hline
\end{tabular}




\begin{tabular}{|c|c|c|c|c|c|}
\hline \multicolumn{6}{|c|}{ Supplemental Table s2.txt } \\
\hline CHEMBL1584691 & 688155 & 4.55 & 5.0368 & TRN & \\
\hline CHEMBL1377261 & 688155 & 5.0 & 4.9384 & TRN & \\
\hline CHEMBL1535806 & 688155 & 4.5 & 5.0484 & TST & \\
\hline CHEMBL1367166 & 688155 & 5.1 & 5.2408 & TRN & \\
\hline CHEMBL1607132 & 688155 & 4.9 & 5.056 & TRN & \\
\hline CHEMBL1385115 & 688155 & 6.5501 & 5.2628 & TRN & \\
\hline CHEMBL1546307 & 688155 & 4.95 & 5.0631 & TST & \\
\hline CHEMBL1550112 & 688155 & 5.1 & 5.1336 & TST & \\
\hline CHEMBL1986032 & 688155 & 5.1 & 4.9912 & TST & \\
\hline CHEMBL1503771 & 688155 & 6.45 & 5.131 & TRN & \\
\hline CHEMBL1390453 & 688155 & 4.45 & 5.0524 & TRN & \\
\hline CHEMBL1485612 & 688155 & 5.95 & 5.0404 & TST & \\
\hline CHEMBL584031 & 688155 & 4.55 & 5.2704 & TRN & \\
\hline CHEMBL1394472 & 688155 & 5.35 & 5.2008 & TST & \\
\hline CHEMBL1529366 & 688155 & 4.9 & 5.0153 & TST & \\
\hline CHEMBL1405975 & 688155 & 4.5 & 5.0681 & TRN & \\
\hline CHEMBL1442716 & 688155 & 4.7 & 4.9636 & TRN & \\
\hline CHEMBL1387917 & 688155 & 4.55 & 5.0223 & TRN & \\
\hline CHEMBL1599705 & 688155 & 5.9 & 5.0658 & TST & \\
\hline CHEMBL1594540 & 688155 & 5.15 & 4.9627 & TRN & \\
\hline CHEMBL1509744 & 688155 & 5.0 & 4.9627 & TRN & \\
\hline CHEMBL1326773 & 688155 & 4.55 & 4.982 & TRN & \\
\hline CHEMBL1410258 & 688155 & 4.95 & 5.1448 & TST & \\
\hline CHEMBL1562977 & 688155 & 4.5 & 5.0639 & TRN & \\
\hline CHEMBL1523209 & 688155 & 4.95 & 5.0046 & TRN & \\
\hline CHEMBL1566709 & 688155 & 4.95 & 5.1744 & TST & \\
\hline CHEMBL1581315 & 688155 & 4.6 & 5.0391 & TRN & \\
\hline CHEMBL1586196 & 688155 & 5.0 & 5.16100 & 00000000005 & TST \\
\hline CHEMBL1363989 & 688155 & 4.95 & 5.0414 & TRN & \\
\hline CHEMBL1383675 & 688155 & 4.9 & 5.0594 & TRN & \\
\hline CHEMBL1431295 & 688155 & 5.4 & 5.2079 & TST & \\
\hline CHEMBL1532473 & 688155 & 5.05 & 5.2816 & TRN & \\
\hline CHEMBL1076559 & 688155 & 4.6 & 4.8813 & TRN & \\
\hline CHEMBL1585201 & 688155 & 5.85 & 5.2074 & TRN & \\
\hline CHEMBL1455194 & 688155 & 5.4 & 5.0428 & TRN & \\
\hline CHEMBL1399422 & 688155 & 5.4 & 5.1044 & TST & \\
\hline CHEMBL1416834 & 688155 & 5.25 & 5.0628 & TST & \\
\hline CHEMBL1499144 & 688155 & 5.55 & 5.0407 & TRN & \\
\hline CHEMBL1583200 & 688155 & 4.95 & 5.1117 & TST & \\
\hline CHEMBL1505785 & 688155 & 5.45 & 5.0877 & TRN & \\
\hline CHEMBL1497900 & 688155 & 4.95 & 5.0891 & TRN & \\
\hline CHEMBL3214105 & 688155 & 6.3 & 5.1181 & TRN & \\
\hline CHEMBL1384766 & 688155 & 5.0 & 5.2565 & TRN & \\
\hline CHEMBL1584205 & 688155 & 5.25 & 4.9874 & TST & \\
\hline CHEMBL1548743 & 688155 & 5.9 & 5.0429 & TRN & \\
\hline CHEMBL1456863 & 688155 & 5.95 & 5.2398 & TST & \\
\hline CHEMBL1406222 & 688155 & 4.5 & 5.2093 & TRN & \\
\hline CHEMBL1540684 & 688155 & 4.95 & 5.1253 & TST & \\
\hline
\end{tabular}




\begin{tabular}{|c|c|c|c|c|}
\hline \multicolumn{5}{|c|}{ Supplemental Table S2.txt } \\
\hline CHEMBL1585246 & 688155 & 5.65 & 5.1499 & TRN \\
\hline CHEMBL1348410 & 688155 & 4.55 & 5.0022 & TRN \\
\hline CHEMBL1577266 & 688155 & 5.1 & 5.0897 & TST \\
\hline CHEMBL1602236 & 688155 & 4.55 & 4.9473 & TRN \\
\hline CHEMBL1503032 & 688155 & 4.55 & 4.9738 & TRN \\
\hline CHEMBL1569293 & 688155 & 4.55 & 5.0696 & TST \\
\hline CHEMBL1464837 & 688155 & 5.95 & 5.0113 & TRN \\
\hline CHEMBL1562147 & 688155 & 5.05 & 5.1499 & TST \\
\hline CHEMBL1600107 & 688155 & 5.0 & 5.1247 & TRN \\
\hline CHEMBL1320536 & 688155 & 4.95 & 5.0877 & TRN \\
\hline CHEMBL1599174 & 688155 & 5.8 & 4.9904 & TRN \\
\hline CHEMBL1544337 & 688155 & 4.55 & 4.9956 & TRN \\
\hline CHEMBL1322630 & 688155 & 5.5 & 5.2067 & TST \\
\hline CHEMBL1301655 & 688155 & 5.0 & 5.117 & TST \\
\hline CHEMBL1351638 & 688155 & 6.5 & 5.0986 & TRN \\
\hline CHEMBL1387110 & 688155 & 4.95 & 4.8683 & TRN \\
\hline CHEMBL1333548 & 688155 & 5.85 & 4.9564 & TRN \\
\hline CHEMBL1544176 & 688155 & 4.95 & 5.1578 & TRN \\
\hline CHEMBL1308037 & 688155 & 5.0 & 5.015 & TRN \\
\hline CHEMBL1429158 & 688155 & 5.0 & 5.0513 & TST \\
\hline CHEMBL1609233 & 688155 & 7.4498 & 5.0788 & TRN \\
\hline CHEMBL1598797 & 688155 & 5.95 & 5.1925 & TRN \\
\hline CHEMBL1318737 & 688155 & 6.6499 & 5.1803 & TST \\
\hline CHEMBL1303775 & 688155 & 4.55 & 5.2026 & TRN \\
\hline CHEMBL1550141 & 688155 & 4.5 & 5.0882 & TST \\
\hline CHEMBL1611654 & 688155 & 4.5 & 5.2222 & TST \\
\hline CHEMBL1549602 & 688155 & 4.95 & 5.2288 & TRN \\
\hline CHEMBL1351658 & 688155 & 4.55 & 5.1171 & TRN \\
\hline CHEMBL1521972 & 688155 & 4.55 & 4.9121 & TRN \\
\hline CHEMBL1453797 & 688155 & 5.3 & 5.1031 & TRN \\
\hline CHEMBL1417231 & 688155 & 4.55 & 4.9542 & TRN \\
\hline CHEMBL1562945 & 688155 & 4.55 & 5.0523 & TRN \\
\hline CHEMBL1498571 & 688155 & 5.05 & 5.1973 & TRN \\
\hline CHEMBL1391168 & 688155 & 4.95 & 5.1535 & TST \\
\hline CHEMBL1545632 & 688155 & 4.85 & 5.0941 & TST \\
\hline CHEMBL1377866 & 688155 & 4.55 & 4.9756 & TRN \\
\hline CHEMBL1546971 & 688155 & 5.1 & 5.0339 & TST \\
\hline CHEMBL3192606 & 688155 & 4.9 & 5.0322 & TST \\
\hline CHEMBL1505139 & 688155 & 5.0 & 5.1669 & TRN \\
\hline CHEMBL1491556 & 688155 & 4.5 & 5.0067 & TRN \\
\hline CHEMBL1405278 & 688155 & 4.95 & 4.9182 & TRN \\
\hline CHEMBL 1577532 & 688155 & 5.4 & 5.0543 & TST \\
\hline CHEMBL1453263 & 688155 & 5.1 & 5.1073 & TRN \\
\hline CHEMBL1303576 & 688155 & 6.05 & 5.1301 & TRN \\
\hline CHEMBL1517106 & 688155 & 4.9 & 5.016 & TRN \\
\hline CHEMBL1334572 & 688155 & 4.95 & 5.0063 & TRN \\
\hline CHEMBL 1577871 & 688155 & 5.8 & 5.1287 & TRN \\
\hline CHEMBL1342038 & 688155 & 4.55 & 5.0517 & TRN \\
\hline
\end{tabular}




\begin{tabular}{|c|c|c|c|c|c|}
\hline \\
\hline CHEMBL1470598 & 688155 & 4.7 & 4.9111 & TRN & \\
\hline CHEMBL1411370 & 688155 & 4.55 & 5.1482 & TST & \\
\hline CHEMBL1308380 & 688155 & 4.5 & 5.0494 & TST & \\
\hline CHEMBL50112 & 688155 & 5.05 & 5.2767 & TRN & \\
\hline CHEMBL1448284 & 688155 & 4.5 & 5.0196 & TRN & \\
\hline CHEMBL1440422 & 688155 & 4.95 & 4.9775 & TRN & \\
\hline CHEMBL1361889 & 688155 & 4.95 & 5.1229 & TRN & \\
\hline CHEMBL1375393 & 688155 & 4.55 & 5.0322 & TRN & \\
\hline CHEMBL1464473 & 688155 & 5.8 & 5.1189 & TST & \\
\hline CHEMBL1508261 & 688155 & 4.5 & 5.0138 & TRN & \\
\hline CHEMBL1323641 & 688155 & 5.3 & 5.1089 & TRN & \\
\hline CHEMBL1389174 & 688155 & 5.7 & 5.004 & TRN & \\
\hline CHEMBL1392054 & 688155 & 5.0 & 4.9559 & TRN & \\
\hline CHEMBL1352835 & 688155 & 6.15 & 5.1323 & TRN & \\
\hline CHEMBL1583438 & 688155 & 5.3 & 5.0573 & TST & \\
\hline CHEMBL1392606 & 688155 & 5.45 & 5.0824 & TRN & \\
\hline CHEMBL1521261 & 688155 & 4.8 & 5.0945 & TST & \\
\hline CHEMBL1608897 & 688155 & 5.5 & 4.97199 & 99999999995 & TST \\
\hline CHEMBL1583911 & 688155 & 4.75 & 5.0138 & TST & \\
\hline CHEMBL1408686 & 688155 & 4.55 & 5.211 & TST & \\
\hline CHEMBL1300246 & 688155 & 4.55 & 5.0533 & TRN & \\
\hline CHEMBL1464608 & 688155 & 4.55 & 4.9541 & TRN & \\
\hline CHEMBL1600445 & 688155 & 4.55 & 4.9122 & TRN & \\
\hline CHEMBL1477841 & 688155 & 4.85 & 5.1861 & TRN & \\
\hline CHEMBL1522188 & 688155 & 4.9 & 5.2197 & TRN & \\
\hline CHEMBL1501716 & 688155 & 5.0 & 5.2635 & TRN & \\
\hline CHEMBL1366408 & 688155 & 4.55 & 5.1389 & TST & \\
\hline CHEMBL1255650 & 688155 & 4.95 & 5.1767 & TRN & \\
\hline CHEMBL1379558 & 688155 & 5.25 & 5.232 & TST & \\
\hline CHEMBL1305020 & 688155 & 4.95 & 5.05399 & 9999999999 & TRN \\
\hline CHEMBL1483349 & 688155 & 5.3 & 5.17299 & 9999999999 & TRN \\
\hline CHEMBL1322740 & 688155 & 5.45 & 4.9973 & TRN & \\
\hline CHEMBL1500613 & 688155 & 5.45 & 5.1351 & TRN & \\
\hline CHEMBL1500854 & 688155 & 5.3 & 5.0516 & TST & \\
\hline CHEMBL1352168 & 688155 & 4.5 & 5.0211 & TRN & \\
\hline CHEMBL1320404 & 688155 & 6.0 & 5.0832 & TRN & \\
\hline CHEMBL1352687 & 688155 & 4.95 & 5.1331 & TST & \\
\hline CHEMBL1500090 & 688155 & 4.95 & 5.1775 & TRN & \\
\hline CHEMBL1507598 & 688155 & 4.8 & 5.1877 & TST & \\
\hline CHEMBL1471323 & 688155 & 5.95 & 5.0886 & TST & \\
\hline CHEMBL1332925 & 688155 & 5.45 & 5.1265 & TRN & \\
\hline CHEMBL3191427 & 688155 & 4.95 & 5.0758 & TST & \\
\hline CHEMBL1498474 & 688155 & 4.65 & 4.9336 & TRN & \\
\hline CHEMBL1580490 & 688155 & 4.9 & 4.9843 & TRN & \\
\hline CHEMBL3212427 & 688155 & 4.95 & 4.9916 & TRN & \\
\hline CHEMBL1609705 & 688155 & 4.5 & 5.0845 & TRN & \\
\hline CHEMBL1391131 & 688155 & 4.45 & 5.2066 & TST & \\
\hline CHEMBL1561190 & 688155 & 4.55 & 4.8828 & TRN & \\
\hline
\end{tabular}




\begin{tabular}{|c|c|c|c|c|c|}
\hline & & \multicolumn{4}{|c|}{ Supplemental Table S2.txt } \\
\hline CHEMBL1419623 & 688155 & 4.55 & 4.9894 & TRN & \\
\hline CHEMBL1356428 & 688155 & 5.1 & 5.1656 & TST & \\
\hline CHEMBL1312182 & 688155 & 5.25 & 5.1177 & TRN & \\
\hline CHEMBL1494266 & 688155 & 5.65 & 5.1214 & TRN & \\
\hline CHEMBL1510954 & 688155 & 4.9 & 4.9411 & TST & \\
\hline CHEMBL1605044 & 688155 & 5.85 & 4.9314 & TRN & \\
\hline CHEMBL1318988 & 688155 & 4.6 & 4.988 & TRN & \\
\hline CHEMBL1438358 & 688155 & 4.55 & 5.0638 & TRN & \\
\hline CHEMBL1322835 & 688155 & 4.5 & 5.2862 & TRN & \\
\hline CHEMBL1429387 & 688155 & 4.55 & 4.9715 & TRN & \\
\hline CHEMBL1325208 & 688155 & 4.5 & 5.0711 & TST & \\
\hline CHEMBL1468770 & 688155 & 5.55 & 4.9328 & TRN & \\
\hline CHEMBL83899 & 688155 & 4.5 & 5.2153 & TST & \\
\hline CHEMBL1444033 & 688155 & 5.95 & 5.2116 & TRN & \\
\hline CHEMBL1341842 & 688155 & 4.8 & 4.9828 & TRN & \\
\hline CHEMBL3212936 & 688155 & 5.15 & 4.9999 & TRN & \\
\hline CHEMBL1468890 & 688155 & 4.95 & 5.102 & TRN & \\
\hline CHEMBL1311563 & 688155 & 4.95 & 5.0154 & TRN & \\
\hline CHEMBL1610955 & 688155 & 5.85 & 5.16799 & 9999999999 & TRN \\
\hline CHEMBL1324653 & 688155 & 4.55 & 4.9411 & TRN & \\
\hline CHEMBL1390549 & 688155 & 4.95 & 5.1952 & TRN & \\
\hline CHEMBL1459963 & 688155 & 5.3 & 5.1311 & TRN & \\
\hline CHEMBL1600493 & 688155 & 5.75 & 5.0982 & TRN & \\
\hline CHEMBL 77387 & 688155 & 5.1 & 5.0635 & TRN & \\
\hline CHEMBL1344787 & 688155 & 4.55 & 4.9462 & TRN & \\
\hline CHEMBL1585332 & 688155 & 4.95 & 5.0279 & TRN & \\
\hline CHEMBL1589010 & 688155 & 4.55 & 4.9913 & TRN & \\
\hline CHEMBL592842 & 688155 & 5.0 & 4.9859 & TST & \\
\hline CHEMBL 1498068 & 688155 & 4.5 & 5.0324 & TRN & \\
\hline CHEMBL1319389 & 688155 & 5.0 & 5.1384 & TRN & \\
\hline CHEMBL1393364 & 688155 & 5.4 & 5.1531 & TRN & \\
\hline CHEMBL1308462 & 688155 & 5.25 & 5.0361 & TST & \\
\hline CHEMBL1311001 & 688155 & 5.8 & 4.9074 & TST & \\
\hline CHEMBL1596504 & 688155 & 6.0 & 4.9904 & TST & \\
\hline CHEMBL3213103 & 688155 & 5.1 & 5.1075 & TST & \\
\hline CHEMBL1590261 & 688155 & 4.85 & 4.8964 & TRN & \\
\hline CHEMBL474703 & 688155 & 6.5 & 5.0972 & TRN & \\
\hline CHEMBL1463934 & 688155 & 5.9 & 4.9623 & TRN & \\
\hline CHEMBL1508485 & 688155 & 5.0 & 4.9692 & TRN & \\
\hline CHEMBL1449761 & 688155 & 4.5 & 5.1077 & TRN & \\
\hline CHEMBL1587500 & 688155 & 4.7 & 4.976 & TST & \\
\hline CHEMBL1331261 & 688155 & 5.0 & 4.9057 & TRN & \\
\hline CHEMBL1514906 & 688155 & 4.85 & 5.1654 & TRN & \\
\hline CHEMBL1532411 & 688155 & 5.4 & 5.231 & TRN & \\
\hline CHEMBL1563518 & 688155 & 4.9 & 5.0251 & TRN & \\
\hline CHEMBL3191439 & 688155 & 4.8 & 5.0499 & TRN & \\
\hline CHEMBL1535972 & 688155 & 4.45 & 4.9714 & TST & \\
\hline CHEMBL1540912 & 688155 & 5.1 & 4.941 & TRN & \\
\hline
\end{tabular}




\begin{tabular}{|c|c|c|c|c|c|}
\hline & & \multicolumn{4}{|c|}{ Supplemental Table s2.txt } \\
\hline CHEMBL1564359 & 688155 & 6.45 & 5.0577 & TRN & \\
\hline CHEMBL198666 & 688155 & 5.9 & 5.1371 & TRN & \\
\hline CHEMBL1416105 & 688155 & 4.9 & 5.3019 & TRN & \\
\hline CHEMBL1345077 & 688155 & 4.5 & 5.2851 & TRN & \\
\hline CHEMBL8916 & 688155 & 5.0 & 5.1318 & TST & \\
\hline CHEMBL1272150 & 688155 & 5.5 & 5.0211 & TRN & \\
\hline CHEMBL1373948 & 688155 & 4.95 & 5.0216 & TST & \\
\hline CHEMBL 3145160 & 688155 & 5.0 & 4.978 & TRN & \\
\hline CHEMBL1377177 & 688155 & 4.5 & 5.1252 & TRN & \\
\hline CHEMBL1416879 & 688155 & 4.55 & 5.1345 & TRN & \\
\hline CHEMBL1548475 & 688155 & 4.95 & 5.1374 & TRN & \\
\hline CHEMBL1536301 & 688155 & 5.0 & 5.1007 & TRN & \\
\hline CHEMBL1517297 & 688155 & 4.85 & 5.2583 & TST & \\
\hline CHEMBL1581447 & 688155 & 5.05 & 5.2304 & TST & \\
\hline CHEMBL1970286 & 688155 & 4.85 & 4.9856 & TRN & \\
\hline CHEMBL1462734 & 688155 & 6.3 & 5.1437 & TST & \\
\hline CHEMBL1606816 & 688155 & 6.0 & 4.9788 & TRN & \\
\hline CHEMBL1364412 & 688155 & 5.15 & 5.0804 & TST & \\
\hline CHEMBL188 & 688155 & 5.6 & 5.1859 & TST & \\
\hline CHEMBL1430019 & 688155 & 5.6 & 5.0387 & TST & \\
\hline CHEMBL1490108 & 688155 & 4.55 & 5.0228 & TRN & \\
\hline CHEMBL1728023 & 688155 & 4.95 & 5.0171 & TRN & \\
\hline CHEMBL1491062 & 688155 & 5.95 & 4.8706 & TRN & \\
\hline CHEMBL1600853 & 688155 & 5.05 & 5.0185 & TRN & \\
\hline CHEMBL1366058 & 688155 & 4.5 & 4.921 & TRN & \\
\hline CHEMBL1596115 & 688155 & 4.9 & 5.045 & TRN & \\
\hline CHEMBL1613651 & 688155 & 4.55 & 5.0421 & TRN & \\
\hline CHEMBL1522396 & 688155 & 4.95 & 5.2003 & TRN & \\
\hline CHEMBL1612102 & 688155 & 5.0 & 5.1337 & TRN & \\
\hline CHEMBL1492664 & 688155 & 5.0 & 5.3209 & TRN & \\
\hline CHEMBL1470905 & 688155 & 4.55 & 4.9379 & TRN & \\
\hline CHEMBL1401784 & 688155 & 5.1 & 5.0769 & TST & \\
\hline CHEMBL1527170 & 688155 & 4.5 & 5.0336 & TRN & \\
\hline CHEMBL1606859 & 688155 & 5.6 & 5.1366 & TST & \\
\hline CHEMBL1340454 & 688155 & 5.0 & 5.105 & TRN & \\
\hline CHEMBL1303738 & 688155 & 4.7 & 5.0585 & TRN & \\
\hline CHEMBL1603881 & 688155 & 4.5 & 5.2248 & TRN & \\
\hline CHEMBL1331691 & 688155 & 5.5 & 5.2472 & TRN & \\
\hline CHEMBL1336860 & 688155 & 5.0 & 4.9973 & TRN & \\
\hline CHEMBL3192682 & 688155 & 4.9 & 5.0310 & 0000000001 & TRN \\
\hline CHEMBL3190659 & 688155 & 6.5 & 5.1133 & TST & \\
\hline CHEMBL3208328 & 688155 & 5.2 & 5.0151 & TRN & \\
\hline CHEMBL1366129 & 688155 & 5.0 & 5.0095 & TRN & \\
\hline CHEMBL1535864 & 688155 & 4.95 & 5.0952 & TRN & \\
\hline CHEMBL1513825 & 688155 & 4.9 & 4.8861 & TRN & \\
\hline CHEMBL1528496 & 688155 & 4.85 & 5.0569 & 99999999995 & TRN \\
\hline CHEMBL1422818 & 688155 & 4.95 & 5.2774 & TST & \\
\hline CHEMBL268291 & 688155 & 5.2 & 5.2244 & TST & \\
\hline
\end{tabular}




\begin{tabular}{|c|c|c|c|c|}
\hline \multicolumn{5}{|c|}{ Supplemental Table S2.txt } \\
\hline CHEMBL1354901 & 688155 & 4.95 & 5.0204 & TRN \\
\hline CHEMBL1351845 & 688155 & 4.9 & 5.1924 & TRN \\
\hline CHEMBL1503673 & 688155 & 4.55 & 4.8746 & TRN \\
\hline CHEMBL492127 & 688155 & 4.5 & 4.9784 & TRN \\
\hline CHEMBL 1425036 & 688155 & 5.9 & 5.0807 & TRN \\
\hline CHEMBL1504065 & 688155 & 4.95 & 5.0438 & TRN \\
\hline CHEMBL1601077 & 688155 & 5.0 & 5.021 & TRN \\
\hline CHEMBL1447467 & 688155 & 5.9 & 5.0238 & TST \\
\hline CHEMBL1534106 & 688155 & 5.0 & 5.044 & TRN \\
\hline CHEMBL1465843 & 688155 & 6.5 & 5.0981 & TST \\
\hline CHEMBL1418750 & 688155 & 4.95 & 5.0488 & TRN \\
\hline CHEMBL1509674 & 688155 & 5.75 & 5.0924 & TRN \\
\hline CHEMBL1425438 & 688155 & 5.1 & 5.0151 & TRN \\
\hline CHEMBL1577853 & 688155 & 6.5 & 5.0632 & TRN \\
\hline CHEMBL1568077 & 688155 & 5.0 & 5.1492 & TRN \\
\hline CHEMBL1505844 & 688155 & 4.55 & 4.9492 & TRN \\
\hline CHEMBL1534878 & 688155 & 4.55 & 5.1266 & TST \\
\hline CHEMBL1491308 & 688155 & 5.6 & 5.0857 & TRN \\
\hline CHEMBL1443300 & 688155 & 4.5 & 5.1241 & TRN \\
\hline CHEMBL1505932 & 688155 & 6.0 & 5.1764 & TRN \\
\hline CHEMBL1350197 & 688155 & 5.15 & 5.1129 & TST \\
\hline CHEMBL1600524 & 688155 & 4.95 & 5.0329 & TRN \\
\hline CHEMBL1529651 & 688155 & 4.85 & 5.1449 & TRN \\
\hline CHEMBL1426865 & 688155 & 6.0 & 5.1152 & TRN \\
\hline CHEMBL1371405 & 688155 & 4.9 & 5.1212 & TRN \\
\hline CHEMBL3213638 & 688155 & 4.7 & 5.0683 & TRN \\
\hline CHEMBL1325506 & 688155 & 5.0 & 4.9991 & TST \\
\hline CHEMBL582507 & 688155 & 4.55 & 4.9403 & TRN \\
\hline CHEMBL1500773 & 688155 & 5.0 & 5.0364 & TRN \\
\hline CHEMBL 9470 & 688155 & 5.15 & 5.0745 & TST \\
\hline CHEMBL1328930 & 688155 & 4.95 & 4.9869 & TRN \\
\hline CHEMBL1606130 & 688155 & 5.65 & 5.0347 & TRN \\
\hline CHEMBL1428417 & 688155 & 5.65 & 4.9641 & TRN \\
\hline CHEMBL1568834 & 688155 & 5.9 & 5.047 & TST \\
\hline CHEMBL1420552 & 688155 & 5.65 & 5.1779 & TRN \\
\hline CHEMBL1583216 & 688155 & 4.95 & 4.996 & TRN \\
\hline CHEMBL1411349 & 688155 & 4.9 & 4.9722 & TRN \\
\hline CHEMBL1429906 & 688155 & 4.95 & 4.9725 & TRN \\
\hline CHEMBL3197610 & 688155 & 5.5 & 5.0307 & TST \\
\hline CHEMBL1405834 & 688155 & 5.05 & 5.0527 & TST \\
\hline CHEMBL1439184 & 688155 & 5.05 & 5.1176 & TRN \\
\hline CHEMBL1338476 & 688155 & 5.5 & 5.001 & TRN \\
\hline CHEMBL1384049 & 688155 & 5.0 & 4.9603 & TRN \\
\hline CHEMBL1461602 & 688155 & 4.55 & 5.2236 & TRN \\
\hline CHEMBL1479543 & 688155 & 4.75 & 5.1046 & TRN \\
\hline CHEMBL1431924 & 688155 & 6.05 & 4.9996 & TRN \\
\hline CHEMBL1399825 & 688155 & 4.55 & 4.9413 & TRN \\
\hline CHEMBL1562771 & 688155 & 4.55 & 5.0016 & TRN \\
\hline
\end{tabular}




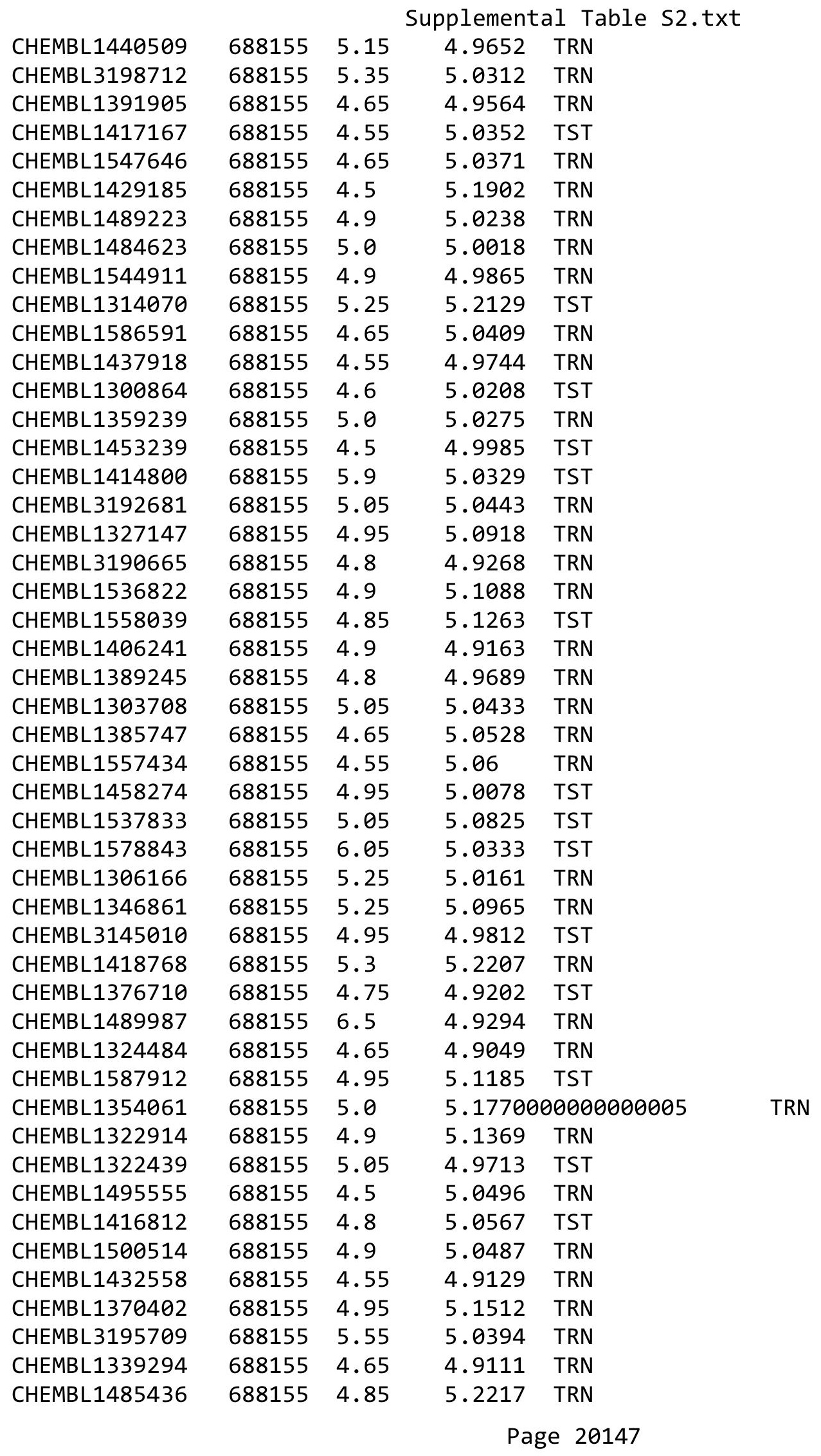




\begin{tabular}{|c|c|c|c|c|c|}
\hline \multicolumn{6}{|c|}{ Supplemental Table S2.txt } \\
\hline CHEMBL41920 & 688155 & 5.0 & 5.091 & TST & \\
\hline CHEMBL1413739 & 688155 & 4.6 & 5.1526 & TRN & \\
\hline CHEMBL1534168 & 688155 & 6.0 & 4.8931 & TRN & \\
\hline CHEMBL1419348 & 688155 & 5.6 & 5.0578 & TST & \\
\hline CHEMBL1304585 & 688155 & 4.55 & 4.9481 & TRN & \\
\hline CHEMBL1452913 & 688155 & 4.8 & 5.0594 & TRN & \\
\hline CHEMBL1497605 & 688155 & 5.0 & 4.9917 & TST & \\
\hline CHEMBL1341913 & 688155 & 4.85 & 4.9837 & TRN & \\
\hline CHEMBL1372654 & 688155 & 5.55 & 5.2483 & TRN & \\
\hline CHEMBL1517525 & 688155 & 4.95 & 5.0303 & TRN & \\
\hline CHEMBL1459965 & 688155 & 5.0 & 5.1728 & TRN & \\
\hline CHEMBL1505143 & 688155 & 4.95 & 5.1384 & TRN & \\
\hline CHEMBL1330533 & 688155 & 6.45 & 5.1832 & TRN & \\
\hline CHEMBL1499085 & 688155 & 4.95 & 4.9845 & TRN & \\
\hline CHEMBL1412670 & 688155 & 4.65 & 5.0395 & TRN & \\
\hline CHEMBL1413479 & 688155 & 4.55 & 5.0158 & TRN & \\
\hline CHEMBL1304762 & 688155 & 4.95 & 5.1054 & TRN & \\
\hline CHEMBL1306480 & 688155 & 4.85 & 5.0533 & TRN & \\
\hline CHEMBL1381217 & 688155 & 4.5 & 5.1505 & TST & \\
\hline CHEMBL1721986 & 688155 & 5.1 & 5.0187 & TRN & \\
\hline CHEMBL1485734 & 688155 & 4.9 & 5.0403 & TST & \\
\hline CHEMBL1459912 & 688155 & 5.0 & 5.109 & TRN & \\
\hline CHEMBL1548680 & 688155 & 5.0 & 5.0525 & TRN & \\
\hline CHEMBL586061 & 688155 & 5.45 & 4.8976 & TRN & \\
\hline CHEMBL 3190756 & 688155 & 4.95 & 4.9042 & TST & \\
\hline CHEMBL1426332 & 688155 & 5.45 & 5.1227 & TST & \\
\hline CHEMBL1548813 & 688155 & 4.55 & 4.9517 & TST & \\
\hline CHEMBL1372515 & 688155 & 5.2 & 5.0388 & TRN & \\
\hline CHEMBL1334299 & 688155 & 5.2 & 5.2617 & TRN & \\
\hline CHEMBL1461378 & 688155 & 4.95 & 5.0595 & TRN & \\
\hline CHEMBL1319047 & 688155 & 6.4 & 5.0855 & TST & \\
\hline CHEMBL1311812 & 688155 & 4.8 & 5.1347 & TRN & \\
\hline CHEMBL3193619 & 688155 & 5.9 & 5.0294 & TRN & \\
\hline CHEMBL1353975 & 688155 & 4.5 & 5.2603 & TRN & \\
\hline CHEMBL1975257 & 688155 & 5.0 & 4.9577 & TRN & \\
\hline CHEMBL1367897 & 688155 & 5.95 & 5.2258 & TRN & \\
\hline CHEMBL1609080 & 688155 & 6.3 & 5.037 & TRN & \\
\hline CHEMBL1607684 & 688155 & 6.3 & 5.21399 & 99999999995 & TRN \\
\hline CHEMBL1441576 & 688155 & 5.05 & 5.2149 & TRN & \\
\hline CHEMBL1410007 & 688155 & 5.0 & 5.1311 & TRN & \\
\hline CHEMBL3189467 & 688155 & 6.0 & 5.0576 & TST & \\
\hline CHEMBL1442639 & 688155 & 4.95 & 5.0281 & TRN & \\
\hline CHEMBL1507121 & 688155 & 4.95 & 5.1181 & TRN & \\
\hline CHEMBL1353804 & 688155 & 5.15 & 4.9519 & TST & \\
\hline CHEMBL 3190816 & 688155 & 4.95 & 5.0604 & TST & \\
\hline CHEMBL1446862 & 688155 & 6.0 & 5.0144 & TRN & \\
\hline CHEMBL1579570 & 688155 & 4.85 & 5.0291 & TRN & \\
\hline CHEMBL1492946 & 688155 & 5.0 & 5.0376 & TRN & \\
\hline
\end{tabular}




\begin{tabular}{|c|c|c|c|c|}
\hline \multicolumn{5}{|c|}{ Supplemental Table S2.txt } \\
\hline CHEMBL1347137 & 688155 & 4.5 & 5.1227 & TST \\
\hline CHEMBL1576308 & 688155 & 4.8 & 4.9559 & TST \\
\hline CHEMBL1408421 & 688155 & 5.4 & 5.0705 & TST \\
\hline CHEMBL1600962 & 688155 & 4.85 & 5.1145 & TRN \\
\hline CHEMBL1530018 & 688155 & 4.95 & 4.9538 & TRN \\
\hline CHEMBL1584754 & 688155 & 5.1 & 4.9976 & TST \\
\hline CHEMBL1341254 & 688155 & 5.05 & 5.1282 & TRN \\
\hline CHEMBL1530797 & 688155 & 4.55 & 5.1584 & TST \\
\hline CHEMBL1450025 & 688155 & 5.0 & 5.0512 & TRN \\
\hline CHEMBL1539256 & 688155 & 5.8 & 5.0463 & TRN \\
\hline CHEMBL1362838 & 688155 & 4.65 & 5.1213 & TRN \\
\hline CHEMBL1440247 & 688155 & 5.0 & 5.1444 & TRN \\
\hline CHEMBL1478852 & 688155 & 4.5 & 4.9799 & TRN \\
\hline CHEMBL1339926 & 688155 & 4.55 & 5.0829 & TRN \\
\hline CHEMBL1426945 & 688155 & 5.0 & 5.0199 & TRN \\
\hline CHEMBL1730100 & 688155 & 4.95 & 5.0873 & TST \\
\hline CHEMBL1314031 & 688155 & 4.85 & 5.0439 & TRN \\
\hline CHEMBL3210209 & 688155 & 6.45 & 5.135 & TRN \\
\hline CHEMBL1344706 & 688155 & 6.45 & 5.1232 & TRN \\
\hline CHEMBL1567162 & 688155 & 4.5 & 4.9865 & TRN \\
\hline CHEMBL1509238 & 688155 & 5.05 & 5.0628 & TST \\
\hline CHEMBL1448631 & 688155 & 4.5 & 5.1333 & TRN \\
\hline CHEMBL1574086 & 688155 & 4.55 & 5.23 & TRN \\
\hline CHEMBL1352600 & 688155 & 5.25 & 5.0283 & TRN \\
\hline CHEMBL1593582 & 688155 & 5.0 & 4.9225 & TRN \\
\hline CHEMBL3195849 & 688155 & 4.55 & 5.001 & TST \\
\hline CHEMBL1412510 & 688155 & 4.55 & 4.9984 & TRN \\
\hline CHEMBL1505504 & 688155 & 5.45 & 5.0877 & TRN \\
\hline CHEMBL1479470 & 688155 & 6.45 & 5.2354 & TRN \\
\hline CHEMBL1380243 & 688155 & 4.95 & 5.1332 & TRN \\
\hline CHEMBL1362505 & 688155 & 5.45 & 5.1173 & TST \\
\hline CHEMBL1441299 & 688155 & 4.9 & 5.0646 & TRN \\
\hline CHEMBL 2006260 & 688155 & 4.55 & 5.0418 & TRN \\
\hline CHEMBL1422094 & 688155 & 4.5 & 5.2179 & TST \\
\hline CHEMBL1338853 & 688155 & 4.5 & 4.91 & TRN \\
\hline CHEMBL1426514 & 688155 & 5.75 & 5.2858 & TRN \\
\hline CHEMBL1410063 & 688155 & 5.1 & 4.904 & TST \\
\hline CHEMBL1340809 & 688155 & 6.0 & 5.1086 & TRN \\
\hline CHEMBL1579336 & 688155 & 5.3 & 5.1752 & TST \\
\hline CHEMBL1565204 & 688155 & 5.25 & 5.0661 & TST \\
\hline CHEMBL1542688 & 688155 & 4.75 & 5.2305 & TRN \\
\hline CHEMBL1390323 & 688155 & 4.55 & 5.0688 & TRN \\
\hline CHEMBL1364957 & 688155 & 4.65 & 4.9857 & TRN \\
\hline CHEMBL3189751 & 688155 & 4.95 & 5.05 & TRN \\
\hline CHEMBL1547863 & 688155 & 6.4 & 5.101 & TRN \\
\hline CHEMBL1356466 & 688155 & 6.2 & 5.2673 & TRN \\
\hline CHEMBL1469400 & 688155 & 5.65 & 5.1424 & TRN \\
\hline CHEMBL1413946 & 688155 & 4.95 & 5.0121 & TRN \\
\hline
\end{tabular}




\begin{tabular}{|c|c|c|c|c|c|}
\hline \multicolumn{6}{|c|}{ Supplemental Table S2.txt } \\
\hline CHEMBL1556711 & 688155 & 5.0 & 5.2095 & TRN & \\
\hline CHEMBL1511078 & 688155 & 5.9 & 5.1069 & TRN & \\
\hline CHEMBL1421867 & 688155 & 4.95 & 5.157 & TRN & \\
\hline CHEMBL1367346 & 688155 & 4.6 & 5.1547 & TRN & \\
\hline CHEMBL1496732 & 688155 & 4.9 & 5.113 & TRN & \\
\hline CHEMBL473735 & 688155 & 4.5 & 4.8972 & TRN & \\
\hline CHEMBL1529669 & 688155 & 5.0 & 5.1556 & TRN & \\
\hline CHEMBL1309378 & 688155 & 4.6 & 4.9447 & TRN & \\
\hline CHEMBL1342725 & 688155 & 4.5 & 5.1034 & TRN & \\
\hline CHEMBL1534021 & 688155 & 4.55 & 5.0685 & TRN & \\
\hline CHEMBL1559419 & 688155 & 4.9 & 5.1823 & TRN & \\
\hline CHEMBL1331927 & 688155 & 4.95 & 5.0473 & TRN & \\
\hline CHEMBL1491054 & 688155 & 4.95 & 5.1595 & TRN & \\
\hline CHEMBL1559601 & 688155 & 4.95 & 5.1153 & TST & \\
\hline CHEMBL1564045 & 688155 & 4.55 & 5.0435 & TST & \\
\hline CHEMBL1382865 & 688155 & 5.5 & 5.0586 & TRN & \\
\hline CHEMBL1467646 & 688155 & 4.5 & 5.0166 & TRN & \\
\hline CHEMBL1583671 & 688155 & 4.55 & 4.9143 & TRN & \\
\hline CHEMBL3212468 & 688155 & 4.95 & 5.1603 & TRN & \\
\hline CHEMBL1300720 & 688155 & 4.65 & 5.0139 & TRN & \\
\hline CHEMBL1343458 & 688155 & 4.95 & 4.9462 & TRN & \\
\hline CHEMBL1413305 & 688155 & 4.9 & 5.1533 & TRN & \\
\hline CHEMBL1320133 & 688155 & 4.95 & 5.1029 & TRN & \\
\hline CHEMBL1479186 & 688155 & 4.45 & 5.2035 & TST & \\
\hline CHEMBL1427657 & 688155 & 4.85 & 4.9671 & TRN & \\
\hline CHEMBL1509360 & 688155 & 5.05 & 4.8899 & TRN & \\
\hline CHEMBL1393833 & 688155 & 5.45 & 4.9965 & TST & \\
\hline CHEMBL1989697 & 688155 & 5.95 & 4.9803 & TST & \\
\hline CHEMBL1360274 & 688155 & 5.5 & 5.1304 & TRN & \\
\hline CHEMBL1416455 & 688155 & 4.65 & 5.0956 & TRN & \\
\hline CHEMBL1300914 & 688155 & 4.5 & 5.181 & TRN & \\
\hline CHEMBL1371168 & 688155 & 5.0 & 5.0621 & TRN & \\
\hline CHEMBL1511344 & 688155 & 5.45 & 5.0663 & TST & \\
\hline CHEMBL1428848 & 688155 & 4.65 & 5.1368 & TRN & \\
\hline CHEMBL1426937 & 688155 & 4.95 & 5.1446 & TST & \\
\hline CHEMBL3191476 & 688155 & 4.95 & 5.1589 & TST & \\
\hline CHEMBL 1445626 & 688155 & 4.9 & 4.9802 & TRN & \\
\hline CHEMBL1457262 & 688155 & 4.95 & 5.21299 & 9999999999 & TRN \\
\hline CHEMBL1334794 & 688155 & 4.5 & 5.1087 & TRN & \\
\hline CHEMBL1589279 & 688155 & 4.95 & 4.9433 & TRN & \\
\hline CHEMBL1353177 & 688155 & 5.15 & 5.0873 & TST & \\
\hline CHEMBL1343080 & 688155 & 5.9 & 5.2625 & TRN & \\
\hline CHEMBL1404683 & 688155 & 5.1 & 5.1079 & TST & \\
\hline CHEMBL1308028 & 688155 & 5.0 & 4.9803 & TRN & \\
\hline CHEMBL1500130 & 688155 & 4.75 & 5.1795 & TRN & \\
\hline CHEMBL1402898 & 688155 & 4.5 & 4.9583 & TST & \\
\hline CHEMBL1469859 & 688155 & 5.05 & 5.1172 & TRN & \\
\hline CHEMBL1536967 & 688155 & 6.05 & 5.2037 & TRN & \\
\hline
\end{tabular}




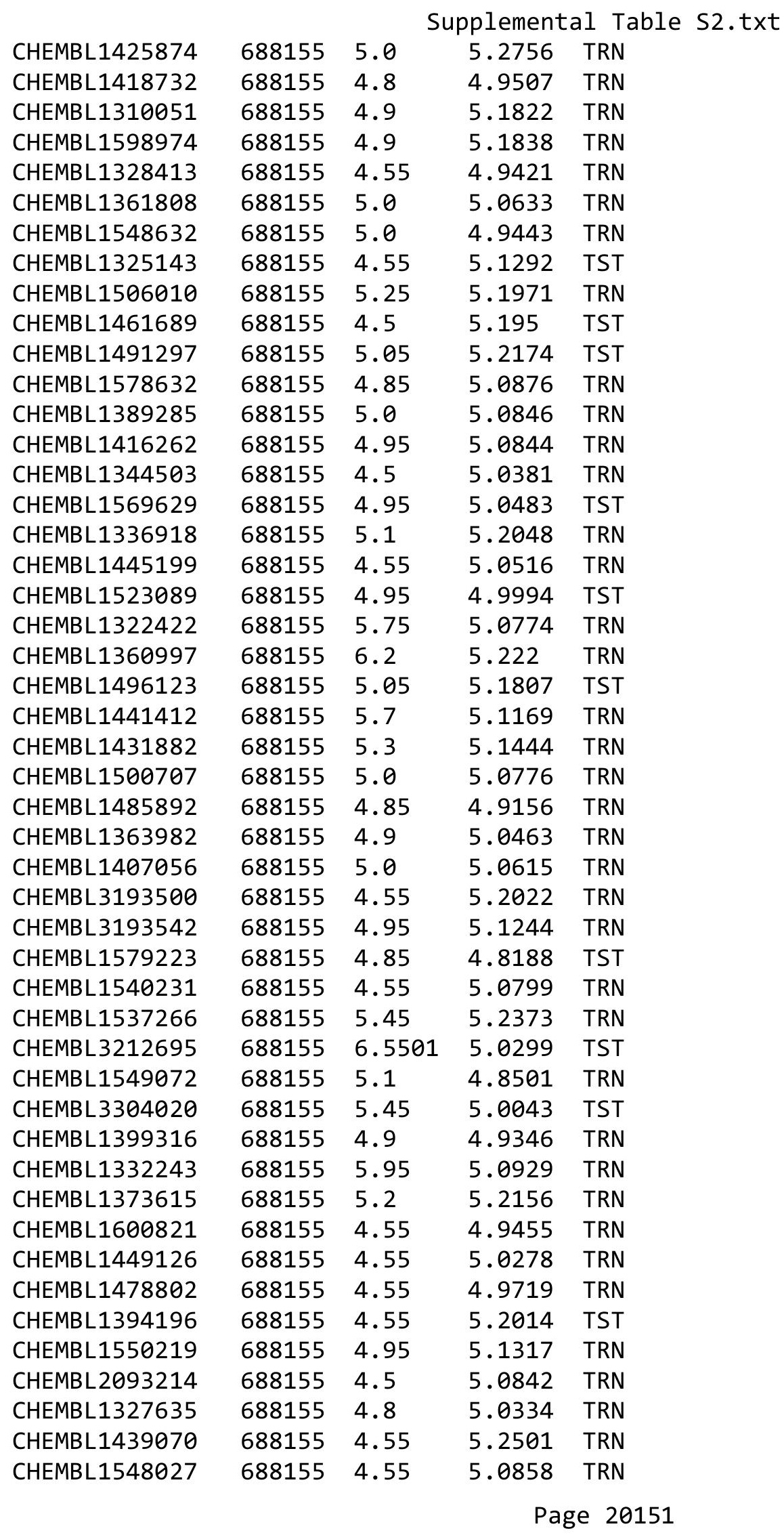




\begin{tabular}{|c|c|c|c|c|c|}
\hline \multicolumn{6}{|c|}{ Supplemental Table S2.txt } \\
\hline CHEMBL1467097 & 688155 & 4.9 & 4.9722 & TRN & \\
\hline CHEMBL 26320 & 688155 & 6.0 & 5.2595 & TRN & \\
\hline CHEMBL1406114 & 688155 & 4.95 & 5.1109 & TRN & \\
\hline CHEMBL1488995 & 688155 & 4.55 & 4.8972 & TRN & \\
\hline CHEMBL1398683 & 688155 & 4.95 & \multicolumn{2}{|c|}{5.138999999999999} & TST \\
\hline CHEMBL1499384 & 688155 & 4.95 & 5.1106 & TRN & \\
\hline CHEMBL1503309 & 688155 & 5.6 & 5.029 & TST & \\
\hline CHEMBL1545979 & 688155 & 5.65 & 5.0995 & TRN & \\
\hline CHEMBL1385373 & 688155 & 4.95 & 4.9733 & TRN & \\
\hline CHEMBL1444779 & 688155 & 4.5 & 5.0634 & TRN & \\
\hline CHEMBL 3192043 & 688155 & 5.05 & 5.1248 & TRN & \\
\hline CHEMBL1552098 & 688155 & 5.55 & 5.1178 & TRN & \\
\hline CHEMBL1353693 & 688155 & 4.95 & 4.9314 & TRN & \\
\hline CHEMBL1387514 & 688155 & 4.95 & 4.9961 & TST & \\
\hline CHEMBL539947 & 688155 & 5.25 & 5.061 & TRN & \\
\hline CHEMBL1410592 & 688155 & 6.1 & 5.0827 & TRN & \\
\hline CHEMBL 1370874 & 688155 & 4.95 & 5.0695 & TRN & \\
\hline CHEMBL1560642 & 688155 & 5.0 & 4.99 & TRN & \\
\hline CHEMBL1334893 & 688155 & 4.55 & 5.044 & TRN & \\
\hline CHEMBL1429297 & 688155 & 4.65 & 5.1348 & TRN & \\
\hline CHEMBL1576518 & 688155 & 4.8 & 5.1165 & TRN & \\
\hline CHEMBL517444 & 688155 & 5.1 & 4.949 & TRN & \\
\hline CHEMBL1599024 & 688155 & 4.65 & 5.0553 & TRN & \\
\hline CHEMBL1526030 & 688155 & 4.5 & 4.9787 & TRN & \\
\hline CHEMBL1455554 & 688155 & 5.0 & 4.9853 & TRN & \\
\hline CHEMBL1434848 & 688155 & 4.55 & 5.0543 & TRN & \\
\hline CHEMBL1586159 & 688155 & 5.0 & 5.0686 & TST & \\
\hline CHEMBL1408990 & 688155 & 4.95 & 5.176 & TRN & \\
\hline CHEMBL1450434 & 688155 & 5.65 & 5.0318 & TRN & \\
\hline CHEMBL1325036 & 688155 & 6.0 & 5.0998 & TRN & \\
\hline CHEMBL1502059 & 688155 & 5.3 & 5.0006 & TRN & \\
\hline CHEMBL1492635 & 688155 & 5.35 & 5.0558 & TRN & \\
\hline CHEMBL1523185 & 688155 & 6.1 & 5.129 & TRN & \\
\hline CHEMBL546597 & 688155 & 5.5 & 5.2065 & TST & \\
\hline CHEMBL1419672 & 688155 & 5.05 & 5.0982 & TRN & \\
\hline CHEMBL3195003 & 688155 & 4.75 & 5.1344 & TST & \\
\hline CHEMBL1300404 & 688155 & 6.5 & 5.0486 & TRN & \\
\hline CHEMBL1432711 & 688155 & 4.9 & 5.0224 & TRN & \\
\hline CHEMBL1341104 & 688155 & 4.55 & 5.0302 & TRN & \\
\hline CHEMBL1514486 & 688155 & 5.0 & 5.0892 & TST & \\
\hline CHEMBL1471980 & 688155 & 4.9 & 5.0958 & TRN & \\
\hline CHEMBL1561547 & 688155 & 4.5 & 5.1055 & TRN & \\
\hline CHEMBL1348824 & 688155 & 4.9 & 5.244 & TRN & \\
\hline CHEMBL1305455 & 688155 & 4.5 & 5.1109 & TRN & \\
\hline CHEMBL1583776 & 688155 & 4.95 & 5.0554 & TST & \\
\hline CHEMBL1401058 & 688155 & 4.95 & 5.1165 & TRN & \\
\hline CHEMBL1564105 & 688155 & 5.2 & 5.0679 & TRN & \\
\hline CHEMBL1308605 & 688155 & 4.9 & 5.17299 & 999999999 & TRN \\
\hline & & & & 2015 & \\
\hline
\end{tabular}




\begin{tabular}{|c|c|c|c|c|c|}
\hline \multirow[b]{2}{*}{ CHEMBL1312836 } & \multirow[b]{2}{*}{688155} & \multicolumn{4}{|c|}{ Supplemental Table S2.txt } \\
\hline & & 4.55 & 5.0826 & TRN & \\
\hline CHEMBL1335680 & 688155 & 5.0 & 5.20799 & 9999999999 & TRN \\
\hline CHEMBL1504140 & 688155 & 5.2 & 5.1418 & TRN & \\
\hline CHEMBL1579677 & 688155 & 5.15 & 5.2293 & TRN & \\
\hline CHEMBL1594201 & 688155 & 5.1 & 5.0139 & TRN & \\
\hline CHEMBL1599588 & 688155 & 6.0 & 5.0656 & TRN & \\
\hline CHEMBL1487309 & 688155 & 5.45 & 5.0742 & TRN & \\
\hline CHEMBL1200450 & 688155 & 5.5 & 5.1359 & TST & \\
\hline CHEMBL1569537 & 688155 & 4.5 & 5.1196 & TRN & \\
\hline CHEMBL1481585 & 688155 & 5.25 & 5.0542 & TRN & \\
\hline CHEMBL1410146 & 688155 & 4.95 & 5.0971 & TRN & \\
\hline CHEMBL3198551 & 688155 & 5.05 & 4.9849 & TRN & \\
\hline CHEMBL1409985 & 688155 & 4.9 & 5.2201 & TST & \\
\hline CHEMBL1313862 & 688155 & 4.95 & 4.9524 & TRN & \\
\hline CHEMBL1378932 & 688155 & 6.1 & 5.0605 & TRN & \\
\hline CHEMBL3193517 & 688155 & 4.55 & 5.0198 & TST & \\
\hline CHEMBL1611920 & 688155 & 4.6 & 5.0389 & TRN & \\
\hline CHEMBL1334844 & 688155 & 4.85 & 5.0563 & TST & \\
\hline CHEMBL1439130 & 688155 & 5.25 & 5.1469 & TST & \\
\hline CHEMBL1327237 & 688155 & 4.95 & 4.9465 & TRN & \\
\hline CHEMBL1389963 & 688155 & 4.8 & 5.0118 & TRN & \\
\hline CHEMBL1559291 & 688155 & 4.55 & 4.981 & TRN & \\
\hline CHEMBL1389491 & 688155 & 5.3 & 4.975 & TRN & \\
\hline CHEMBL8565 & 688155 & 4.95 & 5.1055 & TRN & \\
\hline CHEMBL1340230 & 688155 & 5.7 & 5.0597 & TRN & \\
\hline CHEMBL1483687 & 688155 & 4.95 & 5.2867 & TRN & \\
\hline CHEMBL1457456 & 688155 & 4.9 & 5.2903 & TRN & \\
\hline CHEMBL3189384 & 688155 & 4.9 & 5.1207 & TRN & \\
\hline CHEMBL1517907 & 688155 & 4.55 & 4.9365 & TRN & \\
\hline CHEMBL1463148 & 688155 & 4.5 & 5.2008 & TRN & \\
\hline CHEMBL1611543 & 688155 & 4.65 & 4.9871 & TRN & \\
\hline CHEMBL 258893 & 688155 & 5.3 & 5.0115 & TST & \\
\hline CHEMBL1427848 & 688155 & 4.95 & 5.0015 & TRN & \\
\hline CHEMBL1342969 & 688155 & 4.95 & 5.0692 & TRN & \\
\hline CHEMBL1505466 & 688155 & 4.55 & 5.1001 & TRN & \\
\hline CHEMBL1458942 & 688155 & 5.0 & 5.0871 & TRN & \\
\hline CHEMBL3213625 & 688155 & 5.9 & 5.0431 & TRN & \\
\hline CHEMBL1507156 & 688155 & 4.95 & 4.9376 & TRN & \\
\hline CHEMBL1542552 & 688155 & 6.05 & 5.0936 & TRN & \\
\hline CHEMBL1325565 & 688155 & 4.75 & 5.0196 & TRN & \\
\hline CHEMBL1607138 & 688155 & 4.55 & 4.9623 & TRN & \\
\hline CHEMBL1398959 & 688155 & 5.5 & 5.1918 & TRN & \\
\hline CHEMBL3196514 & 688155 & 4.5 & 5.0775 & TST & \\
\hline CHEMBL1466738 & 688155 & 4.55 & 5.1733 & TRN & \\
\hline CHEMBL1428582 & 688155 & 4.9 & 4.9229 & TRN & \\
\hline CHEMBL1432223 & 688155 & 5.2 & 5.0788 & TST & \\
\hline CHEMBL1578014 & 688155 & 5.15 & 5.0377 & TRN & \\
\hline CHEMBL1364866 & 688155 & 6.3 & 5.0198 & TRN & \\
\hline
\end{tabular}




\begin{tabular}{|c|c|c|c|c|}
\hline \multicolumn{5}{|c|}{ Supplemental Table S2.txt } \\
\hline CHEMBL1525320 & 688155 & 4.95 & 5.0607 & TRN \\
\hline CHEMBL1372245 & 688155 & 4.95 & 4.9192 & TRN \\
\hline CHEMBL1384201 & 688155 & 6.3 & 5.1276 & TRN \\
\hline CHEMBL1483839 & 688155 & 4.55 & 5.0697 & TST \\
\hline CHEMBL1565079 & 688155 & 4.55 & 4.9199 & TRN \\
\hline CHEMBL1416070 & 688155 & 4.55 & 5.1281 & TRN \\
\hline CHEMBL1498529 & 688155 & 4.55 & 5.0407 & TRN \\
\hline CHEMBL1520355 & 688155 & 5.0 & 5.1 & TRN \\
\hline CHEMBL1582075 & 688155 & 4.5 & 5.0118 & TRN \\
\hline CHEMBL34704 & 688155 & 5.3 & 5.126 & TST \\
\hline CHEMBL609606 & 688155 & 4.85 & 5.0871 & TRN \\
\hline CHEMBL1333917 & 688155 & 5.0 & 5.1414 & TRN \\
\hline CHEMBL1607657 & 688155 & 5.0 & 5.1121 & TST \\
\hline CHEMBL1592186 & 688155 & 4.65 & 4.9195 & TRN \\
\hline CHEMBL1403733 & 688155 & 5.25 & 5.1806 & TRN \\
\hline CHEMBL1549437 & 688155 & 4.95 & 5.0379 & TRN \\
\hline CHEMBL 242711 & 688155 & 5.6 & 5.0741 & TRN \\
\hline CHEMBL1422766 & 688155 & 4.95 & 5.1483 & TRN \\
\hline CHEMBL1549689 & 688155 & 4.95 & 5.0412 & TST \\
\hline CHEMBL285479 & 688155 & 6.35 & 5.1975 & TST \\
\hline CHEMBL1320460 & 688155 & 4.85 & 5.0861 & TRN \\
\hline CHEMBL1440872 & 688155 & 5.3 & 4.9773 & TRN \\
\hline CHEMBL1469242 & 688155 & 4.95 & 5.0551 & TRN \\
\hline CHEMBL1548496 & 688155 & 4.5 & 4.93 & TRN \\
\hline CHEMBL1515526 & 688155 & 4.85 & 4.9539 & TRN \\
\hline CHEMBL1400344 & 688155 & 4.95 & 5.0393 & TRN \\
\hline CHEMBL1410467 & 688155 & 5.2 & 5.2798 & TST \\
\hline CHEMBL1343623 & 688155 & 5.25 & 5.0897 & TRN \\
\hline CHEMBL1340446 & 688155 & 4.6 & 5.0881 & TRN \\
\hline CHEMBL1605115 & 688155 & 6.1 & 5.2157 & TRN \\
\hline CHEMBL1392634 & 688155 & 4.9 & 5.2267 & TRN \\
\hline CHEMBL1392626 & 688155 & 5.1 & 5.1124 & TRN \\
\hline CHEMBL1331702 & 688155 & 5.2 & 4.9974 & TST \\
\hline CHEMBL1498181 & 688155 & 4.55 & 5.091 & TRN \\
\hline CHEMBL1527083 & 688155 & 5.25 & 5.2094 & TST \\
\hline CHEMBL1498496 & 688155 & 5.75 & 5.093 & TRN \\
\hline CHEMBL1581736 & 688155 & 6.4 & 5.0015 & TRN \\
\hline CHEMBL1376134 & 688155 & 4.65 & 5.2151 & TRN \\
\hline CHEMBL1405619 & 688155 & 4.95 & 4.9689 & TRN \\
\hline CHEMBL1562280 & 688155 & 4.75 & 5.1044 & TST \\
\hline CHEMBL3199870 & 688155 & 5.45 & 5.0005 & TRN \\
\hline CHEMBL1359444 & 688155 & 6.5501 & 5.2558 & TRN \\
\hline CHEMBL1563235 & 688155 & 4.95 & 5.1441 & TST \\
\hline CHEMBL1409272 & 688155 & 4.55 & 5.0733 & TST \\
\hline CHEMBL1528957 & 688155 & 4.55 & 5.1979 & TRN \\
\hline CHEMBL1508147 & 688155 & 5.0 & 5.0941 & TRN \\
\hline CHEMBL1607661 & 688155 & 6.45 & 5.0222 & TRN \\
\hline CHEMBL1384065 & 688155 & 5.0 & 5.17 & TRN \\
\hline
\end{tabular}




\begin{tabular}{|c|c|c|c|c|}
\hline \multicolumn{5}{|c|}{ Supplemental Table S2.txt } \\
\hline CHEMBL1566035 & 688155 & 6.5 & 5.0894 & TRN \\
\hline CHEMBL1431343 & 688155 & 6.5 & 5.1578 & TRN \\
\hline CHEMBL1351746 & 688155 & 5.5 & 5.0879 & TRN \\
\hline CHEMBL3189190 & 688155 & 5.2 & 5.0379 & TST \\
\hline CHEMBL1538793 & 688155 & 5.95 & 5.0304 & TRN \\
\hline CHEMBL3212866 & 688155 & 5.95 & 5.1697 & TRN \\
\hline CHEMBL1446200 & 688155 & 4.9 & 5.1196 & TRN \\
\hline CHEMBL1303817 & 688155 & 6.7501 & 5.0724 & TRN \\
\hline CHEMBL3213366 & 688155 & 4.55 & 5.056 & TRN \\
\hline CHEMBL1368597 & 688155 & 4.55 & 4.9466 & TST \\
\hline CHEMBL3207507 & 688155 & 4.5 & 4.9914 & TST \\
\hline CHEMBL1605437 & 688155 & 4.5 & 4.9919 & TRN \\
\hline CHEMBL1518965 & 688155 & 5.1 & 5.1166 & TRN \\
\hline CHEMBL1570442 & 688155 & 5.0 & 5.0737 & TRN \\
\hline CHEMBL1451991 & 688155 & 5.0 & 5.1724 & TRN \\
\hline CHEMBL1528857 & 688155 & 5.55 & 5.099 & TRN \\
\hline CHEMBL1478185 & 688155 & 6.0 & 5.2632 & TRN \\
\hline CHEMBL1601532 & 688155 & 5.3 & 5.1065 & TST \\
\hline CHEMBL1579585 & 688155 & 5.05 & 5.2732 & TRN \\
\hline CHEMBL1372545 & 688155 & 4.55 & 5.2339 & TST \\
\hline CHEMBL1507559 & 688155 & 4.6 & 5.0818 & TST \\
\hline CHEMBL1465522 & 688155 & 5.0 & 5.0159 & TST \\
\hline CHEMBL1359269 & 688155 & 4.8 & 5.0649 & TRN \\
\hline CHEMBL1543938 & 688155 & 6.5 & 5.018 & TRN \\
\hline CHEMBL1613233 & 688155 & 5.55 & 5.2666 & TRN \\
\hline CHEMBL1525574 & 688155 & 4.7 & 4.9749 & TRN \\
\hline CHEMBL1409209 & 688155 & 4.65 & 4.9375 & TRN \\
\hline CHEMBL1548754 & 688155 & 4.55 & 4.926 & TRN \\
\hline CHEMBL1306651 & 688155 & 5.9 & 5.2215 & TRN \\
\hline CHEMBL1349347 & 688155 & 5.0 & 5.1372 & TST \\
\hline CHEMBL 2005807 & 688155 & 5.0 & 5.0572 & TRN \\
\hline CHEMBL1378063 & 688155 & 4.5 & 5.1242 & TRN \\
\hline CHEMBL1559467 & 688155 & 5.95 & 5.0397 & TST \\
\hline CHEMBL1367252 & 688155 & 5.35 & 5.0675 & TRN \\
\hline CHEMBL1486635 & 688155 & 4.6 & 5.1814 & TST \\
\hline CHEMBL1448587 & 688155 & 4.95 & 5.1227 & TRN \\
\hline CHEMBL3199304 & 688155 & 4.5 & 5.2231 & TRN \\
\hline CHEMBL1305440 & 688155 & 4.55 & 4.8901 & TRN \\
\hline CHEMBL1380268 & 688155 & 4.55 & 4.999 & TRN \\
\hline CHEMBL1310504 & 688155 & 5.3 & 5.1766 & TRN \\
\hline CHEMBL1520349 & 688155 & 4.85 & 5.1277 & TRN \\
\hline CHEMBL1593589 & 688155 & 5.55 & 5.2306 & TRN \\
\hline CHEMBL1457162 & 688155 & 4.55 & 5.2499 & TRN \\
\hline CHEMBL1325888 & 688155 & 4.5 & 5.0876 & TRN \\
\hline CHEMBL3195210 & 688155 & 5.7 & 5.0096 & TRN \\
\hline CHEMBL3190449 & 688155 & 6.35 & 4.9891 & TRN \\
\hline CHEMBL1524034 & 688155 & 5.15 & 5.1782 & TRN \\
\hline CHEMBL1379359 & 688155 & 4.55 & 4.9711 & TRN \\
\hline
\end{tabular}




\begin{tabular}{|c|c|c|c|c|c|}
\hline \multicolumn{6}{|c|}{ Supplemental Table S2.txt } \\
\hline CHEMBL1559930 & 688155 & 4.95 & 5.2289 & TRN & \\
\hline CHEMBL1335711 & 688155 & 5.65 & 5.1673 & TRN & \\
\hline CHEMBL1410132 & 688155 & 5.55 & 5.20100 & 00000000005 & TRN \\
\hline CHEMBL1420453 & 688155 & 4.65 & 5.2154 & TST & \\
\hline CHEMBL1482188 & 688155 & 5.0 & 5.0467 & TRN & \\
\hline CHEMBL7917 & 688155 & 6.0 & 4.9103 & TRN & \\
\hline CHEMBL1333519 & 688155 & 5.2 & 5.0673 & TRN & \\
\hline CHEMBL3208060 & 688155 & 4.55 & 5.0013 & TRN & \\
\hline CHEMBL1445358 & 688155 & 4.95 & 4.8893 & TRN & \\
\hline CHEMBL1376556 & 688155 & 4.9 & 5.1539 & TRN & \\
\hline CHEMBL1412692 & 688155 & 6.0 & 5.0027 & TRN & \\
\hline CHEMBL1307725 & 688155 & 4.85 & 5.1606 & TRN & \\
\hline CHEMBL1300502 & 688155 & 4.9 & 5.0818 & TRN & \\
\hline CHEMBL1300160 & 688155 & 4.55 & 5.1229 & TRN & \\
\hline CHEMBL1334328 & 688155 & 4.65 & 4.8791 & TRN & \\
\hline CHEMBL1352833 & 688155 & 4.55 & 5.2475 & TRN & \\
\hline CHEMBL1346936 & 688155 & 4.95 & 5.0128 & TST & \\
\hline CHEMBL 2134693 & 688155 & 6.1 & 5.0205 & TRN & \\
\hline CHEMBL1579892 & 688155 & 5.5 & 5.0542 & TST & \\
\hline CHEMBL1422698 & 688155 & 4.5 & 5.2271 & TST & \\
\hline CHEMBL1503211 & 688155 & 5.25 & 5.0272 & TRN & \\
\hline CHEMBL1523313 & 688155 & 4.95 & 5.0743 & TRN & \\
\hline CHEMBL1348906 & 688155 & 5.95 & 4.9814 & TRN & \\
\hline CHEMBL1325483 & 688155 & 4.95 & 5.1255 & TRN & \\
\hline CHEMBL1501964 & 688155 & 5.05 & 4.8904 & TRN & \\
\hline CHEMBL1404538 & 688155 & 5.15 & 5.0629 & TST & \\
\hline CHEMBL1375544 & 688155 & 5.0 & 5.1336 & TRN & \\
\hline CHEMBL1517866 & 688155 & 6.5 & 5.0428 & TST & \\
\hline CHEMBL1577218 & 688155 & 4.5 & 5.0819 & TRN & \\
\hline CHEMBL1577861 & 688155 & 5.05 & 5.0484 & TRN & \\
\hline CHEMBL1316470 & 688155 & 4.85 & 5.0958 & TRN & \\
\hline CHEMBL1383310 & 688155 & 5.2 & 5.2717 & TRN & \\
\hline CHEMBL1456928 & 688155 & 5.05 & 5.0902 & TRN & \\
\hline CHEMBL1389886 & 688155 & 4.55 & 4.9751 & TRN & \\
\hline CHEMBL1574214 & 688155 & 5.05 & 5.2688 & TRN & \\
\hline CHEMBL1375971 & 688155 & 5.6 & 5.21899 & 9999999999 & TRN \\
\hline CHEMBL1534533 & 688155 & 4.55 & 5.0513 & TST & \\
\hline CHEMBL1300499 & 688155 & 4.55 & 5.1288 & TRN & \\
\hline CHEMBL1555931 & 688155 & 5.0 & 5.2116 & TRN & \\
\hline CHEMBL1610743 & 688155 & 5.65 & 5.1366 & TRN & \\
\hline CHEMBL1333143 & 688155 & 5.0 & 5.2705 & TRN & \\
\hline CHEMBL581044 & 688155 & 5.0 & 5.1331 & TRN & \\
\hline CHEMBL1546812 & 688155 & 5.0 & 5.2648 & TRN & \\
\hline CHEMBL3190069 & 688155 & 4.9 & 4.9715 & TRN & \\
\hline CHEMBL1348553 & 688155 & 4.6 & 5.1172 & TST & \\
\hline CHEMBL1528416 & 688155 & 5.0 & 5.0595 & TRN & \\
\hline CHEMBL1606106 & 688155 & 5.4 & 5.0338 & TRN & \\
\hline CHEMBL1351426 & 688155 & 5.5 & 5.0995 & TRN & \\
\hline
\end{tabular}




\begin{tabular}{|c|c|c|c|c|c|}
\hline \multicolumn{6}{|c|}{ Supplemental Table s2.txt } \\
\hline CHEMBL1481034 & 688155 & 5.9 & 5.0387 & TST & \\
\hline CHEMBL1300942 & 688155 & 4.8 & 4.9768 & TRN & \\
\hline CHEMBL3199476 & 688155 & 4.55 & 5.1745 & TST & \\
\hline CHEMBL1558299 & 688155 & 5.55 & 5.0576 & TRN & \\
\hline CHEMBL1430128 & 688155 & 4.9 & 4.9902 & TST & \\
\hline CHEMBL1421993 & 688155 & 5.0 & 5.0389 & TST & \\
\hline CHEMBL1438881 & 688155 & 5.0 & 5.1117 & TRN & \\
\hline CHEMBL1375436 & 688155 & 5.2 & 4.9744 & TRN & \\
\hline CHEMBL1500092 & 688155 & 4.9 & 5.1477 & TST & \\
\hline CHEMBL1596744 & 688155 & 5.55 & 5.0408 & TRN & \\
\hline CHEMBL1537160 & 688155 & 4.55 & 4.9692 & TST & \\
\hline CHEMBL3199032 & 688155 & 5.25 & 5.1522 & TST & \\
\hline CHEMBL1573864 & 688155 & 4.55 & 5.0847 & TST & \\
\hline CHEMBL1373704 & 688155 & 6.1 & 5.3061 & TRN & \\
\hline CHEMBL1502372 & 688155 & 4.95 & 5.0663 & TST & \\
\hline CHEMBL1447291 & 688155 & 5.6 & 5.0166 & TRN & \\
\hline CHEMBL1489694 & 688155 & 4.55 & 4.8962 & TRN & \\
\hline CHEMBL1594673 & 688155 & 4.55 & 5.33200 & 0000000001 & TST \\
\hline CHEMBL1497388 & 688155 & 6.0 & 5.0872 & TRN & \\
\hline CHEMBL1988579 & 688155 & 4.85 & 5.0986 & TST & \\
\hline CHEMBL1392487 & 688155 & 6.45 & 5.1017 & TRN & \\
\hline CHEMBL1200567 & 688155 & 5.0 & 5.1032 & TRN & \\
\hline CHEMBL1256869 & 688155 & 4.7 & 5.011 & TST & \\
\hline CHEMBL1432099 & 688155 & 5.3 & 5.1341 & TRN & \\
\hline CHEMBL1343363 & 688155 & 4.9 & 5.0607 & TRN & \\
\hline CHEMBL1485791 & 688155 & 4.95 & 5.0938 & TRN & \\
\hline CHEMBL1468255 & 688155 & 4.85 & 4.9514 & TRN & \\
\hline CHEMBL1331122 & 688155 & 5.45 & 5.2285 & TST & \\
\hline CHEMBL1416862 & 688155 & 6.45 & 4.9993 & TRN & \\
\hline CHEMBL1392524 & 688155 & 4.5 & 4.987 & TRN & \\
\hline CHEMBL1499816 & 688155 & 5.25 & 4.9483 & TRN & \\
\hline CHEMBL1503475 & 688155 & 4.65 & 5.1686 & TRN & \\
\hline CHEMBL1556256 & 688155 & 4.95 & 5.1196 & TRN & \\
\hline CHEMBL1460877 & 688155 & 4.85 & 5.0853 & TRN & \\
\hline CHEMBL3209422 & 688155 & 5.5 & 5.1652 & TST & \\
\hline CHEMBL1370750 & 688155 & 5.1 & 5.0133 & TRN & \\
\hline CHEMBL1450416 & 688155 & 4.85 & 5.0059 & TST & \\
\hline CHEMBL1334930 & 688155 & 5.45 & 5.0057 & TRN & \\
\hline CHEMBL1312622 & 688155 & 5.0 & 4.9766 & TRN & \\
\hline CHEMBL449081 & 688155 & 4.5 & 5.1255 & TST & \\
\hline CHEMBL1579416 & 688155 & 4.95 & 4.9687 & TRN & \\
\hline CHEMBL1999959 & 688155 & 4.5 & 4.9401 & TRN & \\
\hline CHEMBL1424703 & 688155 & 5.2 & 5.0959 & TRN & \\
\hline CHEMBL1549879 & 688155 & 5.0 & 4.9783 & TRN & \\
\hline CHEMBL1558865 & 688155 & 5.65 & 5.0534 & TRN & \\
\hline CHEMBL1509167 & 688155 & 5.3 & 5.1273 & TRN & \\
\hline CHEMBL1492018 & 688155 & 4.9 & 4.9942 & TST & \\
\hline CHEMBL1504348 & 688155 & 6.1 & 5.1577 & TRN & \\
\hline
\end{tabular}




\begin{tabular}{|c|c|c|c|c|c|}
\hline & & \multicolumn{4}{|c|}{ Supplemental Table s2.txt } \\
\hline CHEMBL1469246 & 688155 & 5.45 & 5.141 & TRN & \\
\hline CHEMBL1454636 & 688155 & 4.95 & 4.967 & TST & \\
\hline CHEMBL1548370 & 688155 & 4.5 & 5.0132 & TRN & \\
\hline CHEMBL1562436 & 688155 & 4.55 & 5.2321 & TRN & \\
\hline CHEMBL1327906 & 688155 & 5.7 & 5.0732 & TRN & \\
\hline CHEMBL1375853 & 688155 & 5.3 & 5.1264 & TST & \\
\hline CHEMBL1375940 & 688155 & 6.05 & 5.2484 & TST & \\
\hline CHEMBL1349585 & 688155 & 5.0 & 4.9299 & TST & \\
\hline CHEMBL542493 & 688155 & 5.3 & 5.1534 & TST & \\
\hline CHEMBL1350046 & 688155 & 5.15 & 5.2544 & TST & \\
\hline CHEMBL1311187 & 688155 & 4.55 & 5.0647 & TRN & \\
\hline CHEMBL1576351 & 688155 & 5.3 & 5.0887 & TST & \\
\hline CHEMBL1468869 & 688155 & 4.55 & 5.0056 & TRN & \\
\hline CHEMBL1609153 & 688155 & 5.1 & 5.2813 & TRN & \\
\hline CHEMBL1494752 & 688155 & 5.15 & 5.1907 & TRN & \\
\hline CHEMBL1413736 & 688155 & 4.95 & 5.0002 & TRN & \\
\hline CHEMBL286494 & 688155 & 6.0 & 5.1066 & TST & \\
\hline CHEMBL1544592 & 688155 & 4.95 & 5.021 & TST & \\
\hline CHEMBL1506591 & 688155 & 4.55 & 5.1151 & TRN & \\
\hline CHEMBL1524230 & 688155 & 5.3 & 5.1357 & TST & \\
\hline CHEMBL1344999 & 688155 & 5.2 & 4.9961 & TRN & \\
\hline CHEMBL1484837 & 688155 & 4.95 & 5.1735 & TST & \\
\hline CHEMBL1459796 & 688155 & 4.55 & 5.1584 & TRN & \\
\hline CHEMBL1602207 & 688155 & 4.8 & 5.0303 & TRN & \\
\hline CHEMBL1449305 & 688155 & 4.95 & 5.0365 & TRN & \\
\hline CHEMBL1441207 & 688155 & 4.5 & 5.1685 & TST & \\
\hline CHEMBL1557175 & 688155 & 4.95 & 5.1778 & TRN & \\
\hline CHEMBL1458667 & 688155 & 5.0 & 5.1848 & TRN & \\
\hline CHEMBL1548451 & 688155 & 5.25 & 4.9059 & TST & \\
\hline CHEMBL1471078 & 688155 & 4.95 & 5.23799 & 99999999995 & TRN \\
\hline CHEMBL1335354 & 688155 & 5.0 & 5.1861 & TRN & \\
\hline CHEMBL1400336 & 688155 & 5.35 & 5.2061 & TRN & \\
\hline CHEMBL1443522 & 688155 & 5.25 & 5.1767 & TST & \\
\hline CHEMBL1302003 & 688155 & 4.55 & 5.0509 & TRN & \\
\hline CHEMBL1976499 & 688155 & 4.9 & 4.9609 & TRN & \\
\hline CHEMBL1342612 & 688155 & 6.5 & 4.925 & TRN & \\
\hline CHEMBL1399095 & 688155 & 4.5 & 5.1179 & TST & \\
\hline CHEMBL1481480 & 688155 & 4.5 & 5.0547 & TRN & \\
\hline CHEMBL1608631 & 688155 & 5.95 & 5.0371 & TRN & \\
\hline CHEMBL1469424 & 688155 & 5.0 & 5.0444 & TRN & \\
\hline CHEMBL1378591 & 688155 & 5.75 & 5.2854 & TRN & \\
\hline CHEMBL1365773 & 688155 & 4.95 & 5.147 & TRN & \\
\hline CHEMBL1378863 & 688155 & 4.5 & 5.0171 & TRN & \\
\hline CHEMBL1173475 & 688155 & 6.0 & 5.0316 & TRN & \\
\hline CHEMBL1472575 & 688155 & 5.35 & 5.136 & TRN & \\
\hline CHEMBL1350969 & 688155 & 4.5 & 5.09699 & 99999999995 & TRN \\
\hline CHEMBL1405695 & 688155 & 4.55 & 5.0712 & TRN & \\
\hline CHEMBL1602246 & 688155 & 5.0 & 4.9716 & TRN & \\
\hline
\end{tabular}




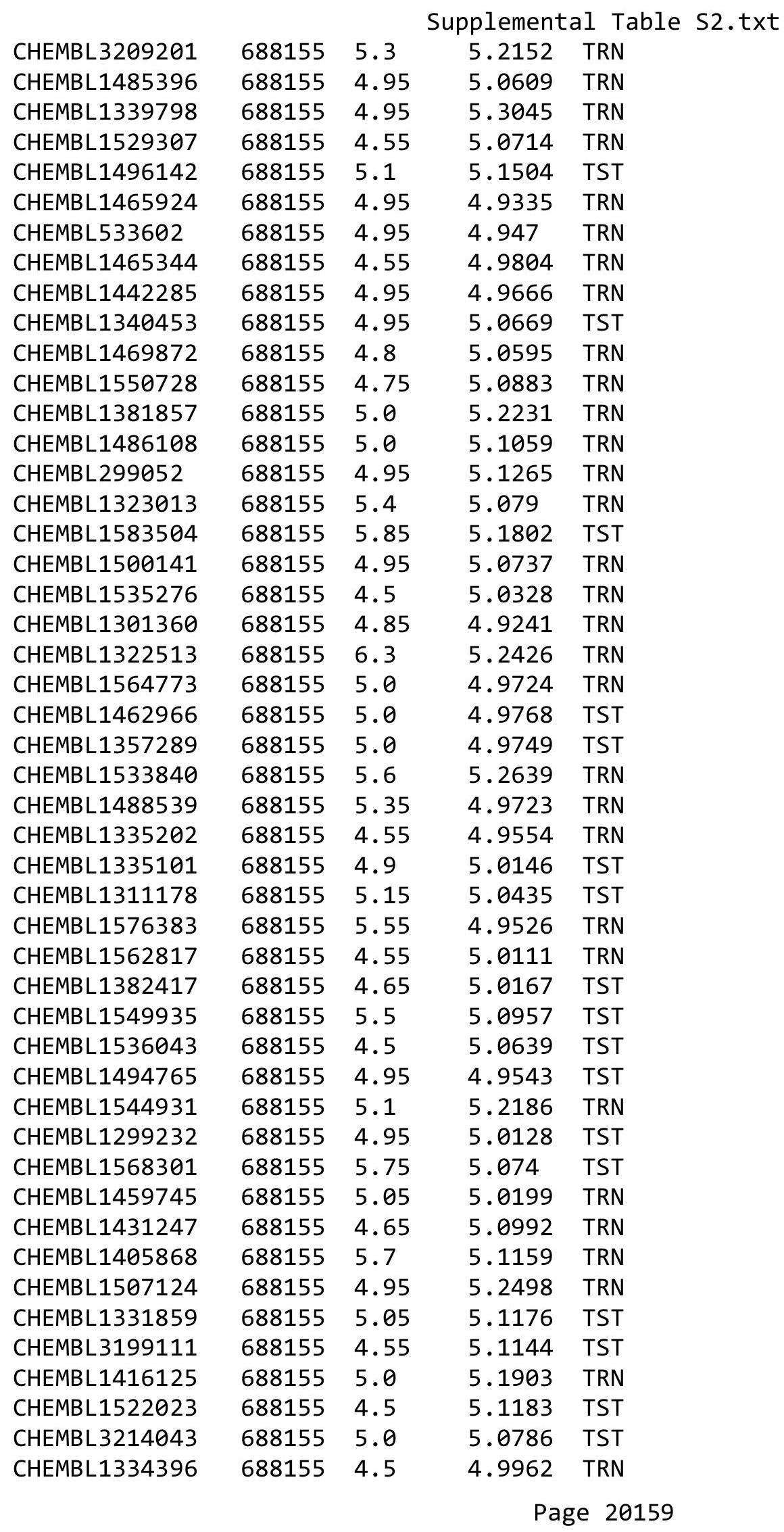




\begin{tabular}{|c|c|c|c|c|c|}
\hline & & \multicolumn{4}{|c|}{ Supplemental Table s2.txt } \\
\hline CHEMBL1367845 & 688155 & 4.85 & 4.902 & TRN & \\
\hline CHEMBL1556470 & 688155 & 4.9 & 5.2733 & TST & \\
\hline CHEMBL1531873 & 688155 & 5.9 & 5.1491 & TRN & \\
\hline CHEMBL1409201 & 688155 & 5.9 & 5.1346 & TRN & \\
\hline CHEMBL1465195 & 688155 & 4.65 & 5.0289 & TRN & \\
\hline CHEMBL1337227 & 688155 & 4.55 & 5.1847 & TRN & \\
\hline CHEMBL1386142 & 688155 & 4.9 & 4.9738 & TRN & \\
\hline CHEMBL1546403 & 688155 & 4.55 & 4.9822 & TRN & \\
\hline CHEMBL1431003 & 688155 & 4.95 & 5.1335 & TRN & \\
\hline CHEMBL1998944 & 688155 & 5.0 & 4.9905 & TRN & \\
\hline CHEMBL3213209 & 688155 & 5.25 & 5.0795 & TST & \\
\hline CHEMBL1480371 & 688155 & 4.9 & 5.1396 & TRN & \\
\hline CHEMBL1466140 & 688155 & 5.5 & 5.1368 & TRN & \\
\hline CHEMBL1301906 & 688155 & 4.9 & 5.1699 & TRN & \\
\hline CHEMBL3208775 & 688155 & 4.85 & 5.0093 & TRN & \\
\hline CHEMBL1471643 & 688155 & 5.05 & 5.1533 & TRN & \\
\hline CHEMBL1472413 & 688155 & 5.45 & 5.08899 & 99999999995 & TST \\
\hline CHEMBL1991388 & 688155 & 4.95 & 4.9162 & TRN & \\
\hline CHEMBL1302366 & 688155 & 5.0 & 5.145 & TRN & \\
\hline CHEMBL1546674 & 688155 & 4.75 & 4.9714 & TRN & \\
\hline CHEMBL3198822 & 688155 & 4.65 & 5.0303 & TRN & \\
\hline CHEMBL3211303 & 688155 & 5.0 & 5.0987 & TST & \\
\hline CHEMBL1457519 & 688155 & 4.9 & 5.0198 & TRN & \\
\hline CHEMBL1454178 & 688155 & 4.55 & 5.1919 & TRN & \\
\hline CHEMBL1403684 & 688155 & 4.95 & 5.1003 & TST & \\
\hline CHEMBL1476170 & 688155 & 6.0 & 5.1266 & TRN & \\
\hline CHEMBL1499969 & 688155 & 4.95 & 4.9501 & TST & \\
\hline CHEMBL1530356 & 688155 & 4.5 & 5.0516 & TRN & \\
\hline CHEMBL1313158 & 688155 & 5.3 & 5.1918 & TST & \\
\hline CHEMBL1493594 & 688155 & 4.95 & 5.0537 & TRN & \\
\hline CHEMBL1466281 & 688155 & 5.5 & 5.0165 & TRN & \\
\hline CHEMBL1550575 & 688155 & 6.3 & 5.0323 & TRN & \\
\hline CHEMBL1319276 & 688155 & 5.6 & 5.1259 & TRN & \\
\hline CHEMBL1538068 & 688155 & 5.3 & 5.0451 & TRN & \\
\hline CHEMBL1410376 & 688155 & 4.95 & 5.0833 & TRN & \\
\hline CHEMBL600769 & 688155 & 6.0 & 5.1281 & TRN & \\
\hline CHEMBL1442271 & 688155 & 4.95 & 5.0036 & TRN & \\
\hline CHEMBL1410633 & 688155 & 4.55 & 5.0669 & TRN & \\
\hline CHEMBL1322965 & 688155 & 4.55 & 5.0405 & TST & \\
\hline CHEMBL1494256 & 688155 & 4.55 & 4.9487 & TST & \\
\hline CHEMBL1602472 & 688155 & 4.95 & 5.1321 & TRN & \\
\hline CHEMBL1389175 & 688155 & 4.55 & 5.1392 & TRN & \\
\hline CHEMBL1536945 & 688155 & 4.85 & 5.0056 & TRN & \\
\hline CHEMBL1342506 & 688155 & 5.2 & 5.01 & TRN & \\
\hline CHEMBL1382616 & 688155 & 4.55 & 4.9515 & TRN & \\
\hline CHEMBL1420081 & 688155 & 4.55 & 4.8792 & TRN & \\
\hline CHEMBL1331234 & 688155 & 4.95 & 5.1438 & TST & \\
\hline CHEMBL3197468 & 688155 & 4.95 & 5.0368 & TRN & \\
\hline
\end{tabular}




\begin{tabular}{|c|c|c|c|c|c|}
\hline \multicolumn{6}{|c|}{ Supplemental Table S2.txt } \\
\hline CHEMBL1313019 & 688155 & 4.55 & 5.1991 & TST & \\
\hline CHEMBL1455315 & 688155 & 4.9 & 5.1705 & TST & \\
\hline CHEMBL1429541 & 688155 & 5.3 & 5.0379 & TRN & \\
\hline CHEMBL1454223 & 688155 & 4.5 & 5.0263 & TRN & \\
\hline CHEMBL579583 & 688155 & 6.0 & 4.973 & TRN & \\
\hline CHEMBL3195797 & 688155 & 5.4 & 5.1152 & TRN & \\
\hline CHEMBL1468072 & 688155 & 5.0 & 5.0469 & TRN & \\
\hline CHEMBL1567514 & 688155 & 4.95 & 5.2374 & TRN & \\
\hline CHEMBL1550974 & 688155 & 4.5 & 5.0718 & TST & \\
\hline CHEMBL1582048 & 688155 & 4.55 & 4.9526 & TRN & \\
\hline CHEMBL1464502 & 688155 & 4.95 & 4.9001 & TRN & \\
\hline CHEMBL1568911 & 688155 & 4.95 & 5.2045 & TRN & \\
\hline CHEMBL1516687 & 688155 & 5.95 & 5.1209 & TST & \\
\hline CHEMBL 92387 & 688155 & 5.0 & 5.1482 & TST & \\
\hline CHEMBL1571026 & 688155 & 4.95 & 5.2319 & TRN & \\
\hline CHEMBL1360309 & 688155 & 4.65 & 5.086 & TST & \\
\hline CHEMBL1602451 & 688155 & 5.0 & 5.0796 & TRN & \\
\hline CHEMBL495069 & 688155 & 5.05 & 4.9923 & TRN & \\
\hline CHEMBL1527381 & 688155 & 5.5 & 5.0867 & TST & \\
\hline CHEMBL1541330 & 688155 & 4.5 & 5.0696 & TRN & \\
\hline CHEMBL1603295 & 688155 & 4.65 & 5.1425 & TRN & \\
\hline CHEMBL1568171 & 688155 & 5.0 & 5.0242 & TRN & \\
\hline CHEMBL3210295 & 688155 & 5.2 & 5.0727 & TST & \\
\hline CHEMBL1565372 & 688155 & 4.75 & 5.1331 & TST & \\
\hline CHEMBL1497769 & 688155 & 4.55 & 4.9441 & TRN & \\
\hline CHEMBL1613363 & 688155 & 4.95 & 4.9499 & TRN & \\
\hline CHEMBL1611586 & 688155 & 4.95 & 5.2342 & TRN & \\
\hline CHEMBL1364025 & 688155 & 4.55 & 4.9828 & TRN & \\
\hline CHEMBL1532182 & 688155 & 4.85 & 4.9508 & TRN & \\
\hline CHEMBL1342537 & 688155 & 4.6 & 5.0385 & TST & \\
\hline CHEMBL1411889 & 688155 & 4.5 & 5.2582 & TRN & \\
\hline CHEMBL1386067 & 688155 & 5.0 & 5.1699 & TRN & \\
\hline CHEMBL1578343 & 688155 & 5.05 & 5.1075 & TST & \\
\hline CHEMBL3193307 & 688155 & 4.55 & 5.07600 & 00000000005 & TST \\
\hline CHEMBL1549816 & 688155 & 5.3 & 5.1129 & TST & \\
\hline CHEMBL1528565 & 688155 & 4.95 & 5.0748 & TST & \\
\hline CHEMBL1505364 & 688155 & 4.85 & 4.9714 & TRN & \\
\hline CHEMBL1362901 & 688155 & 4.6 & 5.0316 & TST & \\
\hline CHEMBL1417728 & 688155 & 5.55 & 4.9813 & TST & \\
\hline CHEMBL1584351 & 688155 & 4.5 & 5.0304 & TRN & \\
\hline CHEMBL1415008 & 688155 & 4.5 & 5.0274 & TRN & \\
\hline CHEMBL1536738 & 688155 & 4.9 & 5.1462 & TRN & \\
\hline CHEMBL1328154 & 688155 & 5.05 & 5.004 & TRN & \\
\hline CHEMBL126077 & 688155 & 4.9 & 5.0688 & TRN & \\
\hline CHEMBL1543273 & 688155 & 4.55 & 5.1393 & TST & \\
\hline CHEMBL1495262 & 688155 & 5.2 & 5.1421 & TRN & \\
\hline CHEMBL579219 & 688155 & 4.55 & 4.9673 & TRN & \\
\hline CHEMBL1491724 & 688155 & 4.6 & 4.996 & TRN & \\
\hline
\end{tabular}




\begin{tabular}{|c|c|c|c|c|c|}
\hline \multirow[b]{2}{*}{ CHEMBL1373402 } & & \multicolumn{4}{|c|}{ Supplemental Table S2.txt } \\
\hline & 688155 & 4.55 & \multicolumn{2}{|c|}{4.986000000000001} & TRN \\
\hline CHEMBL1550204 & 688155 & 4.65 & 5.0457 & TRN & \\
\hline CHEMBL1561809 & 688155 & 4.85 & 4.90600 & 0000000001 & TRN \\
\hline CHEMBL1350430 & 688155 & 5.35 & 5.1043 & TRN & \\
\hline CHEMBL1466728 & 688155 & 4.85 & 4.999 & TRN & \\
\hline CHEMBL1608059 & 688155 & 6.1 & 5.1392 & TRN & \\
\hline CHEMBL1328245 & 688155 & 4.6 & 5.2354 & TRN & \\
\hline CHEMBL1497732 & 688155 & 4.55 & 4.9422 & TRN & \\
\hline CHEMBL1326937 & 688155 & 6.1 & 5.121 & TRN & \\
\hline CHEMBL1397322 & 688155 & 6.05 & 5.2098 & TRN & \\
\hline CHEMBL3212191 & 688155 & 4.6 & 4.9303 & TST & \\
\hline CHEMBL1309229 & 688155 & 4.55 & 5.0631 & TRN & \\
\hline CHEMBL1428087 & 688155 & 5.15 & 4.9587 & TRN & \\
\hline CHEMBL1451761 & 688155 & 5.0 & 5.0699 & TST & \\
\hline CHEMBL375905 & 688155 & 4.85 & 5.0917 & TRN & \\
\hline CHEMBL1517284 & 688155 & 4.85 & 4.9397 & TRN & \\
\hline CHEMBL3192640 & 688155 & 6.15 & 5.1184 & TRN & \\
\hline CHEMBL1607508 & 688155 & 6.05 & 5.1033 & TRN & \\
\hline CHEMBL3192734 & 688155 & 4.9 & 5.0191 & TRN & \\
\hline CHEMBL1547006 & 688155 & 4.55 & 5.0534 & TST & \\
\hline CHEMBL1538097 & 688155 & 5.05 & 5.0463 & TRN & \\
\hline CHEMBL1472067 & 688155 & 4.55 & 5.0013 & TRN & \\
\hline CHEMBL1534571 & 688155 & 4.7 & 5.0017 & TRN & \\
\hline CHEMBL16410 & 688155 & 4.9 & 5.1555 & TST & \\
\hline CHEMBL1376781 & 688155 & 5.7 & 5.1432 & TRN & \\
\hline CHEMBL1336372 & 688155 & 5.2 & 5.0569 & TST & \\
\hline CHEMBL1509254 & 688155 & 4.95 & 5.1468 & TRN & \\
\hline CHEMBL1570144 & 688155 & 6.05 & 5.1089 & TRN & \\
\hline CHEMBL1444991 & 688155 & 4.75 & 5.0719 & TST & \\
\hline CHEMBL1596039 & 688155 & 4.95 & 5.0498 & TRN & \\
\hline CHEMBL1424229 & 688155 & 5.9 & 5.0803 & TRN & \\
\hline CHEMBL1488203 & 688155 & 5.2 & 5.037 & TRN & \\
\hline CHEMBL1478947 & 688155 & 5.0 & 5.091 & TRN & \\
\hline CHEMBL1546186 & 688155 & 4.55 & 5.0598 & TRN & \\
\hline CHEMBL1462838 & 688155 & 4.9 & 5.07 & TRN & \\
\hline CHEMBL1320109 & 688155 & 4.95 & 5.0884 & TRN & \\
\hline CHEMBL1546685 & 688155 & 5.45 & 5.1001 & TRN & \\
\hline CHEMBL1468767 & 688155 & 4.55 & 5.1048 & TRN & \\
\hline CHEMBL1347217 & 688155 & 4.95 & 5.0973 & TRN & \\
\hline CHEMBL1517431 & 688155 & 4.75 & 5.1389 & TST & \\
\hline CHEMBL1459300 & 688155 & 4.5 & 5.1206 & TRN & \\
\hline CHEMBL1528702 & 688155 & 4.95 & 5.1868 & TRN & \\
\hline CHEMBL1576839 & 688155 & 6.35 & 5.1747 & TRN & \\
\hline CHEMBL 26001 & 688155 & 6.3 & 5.0727 & TST & \\
\hline CHEMBL1595835 & 688155 & 4.9 & 4.981 & TRN & \\
\hline CHEMBL1388589 & 688155 & 4.95 & 5.1141 & TRN & \\
\hline CHEMBL1544436 & 688155 & 4.95 & 4.9822 & TRN & \\
\hline CHEMBL1965975 & 688155 & 5.95 & 5.0202 & TRN & \\
\hline
\end{tabular}




\begin{tabular}{|c|c|c|c|c|c|}
\hline \multicolumn{6}{|c|}{ Supplemental Table S2.txt } \\
\hline CHEMBL1382365 & 688155 & 5.35 & 5.2586 & TRN & \\
\hline CHEMBL1452540 & 688155 & 4.65 & 5.1478 & TST & \\
\hline CHEMBL1466134 & 688155 & 4.95 & 4.9943 & TRN & \\
\hline CHEMBL1419743 & 688155 & 4.85 & 5.1467 & TST & \\
\hline CHEMBL1391501 & 688155 & 4.55 & 5.0316 & TRN & \\
\hline CHEMBL1370794 & 688155 & 4.55 & 5.0003 & TRN & \\
\hline CHEMBL1426211 & 688155 & 6.0 & 5.0407 & TRN & \\
\hline CHEMBL1587272 & 688155 & 5.7 & 4.98600 & 0000000001 & TRN \\
\hline CHEMBL1387767 & 688155 & 4.65 & 5.1662 & TST & \\
\hline CHEMBL1312425 & 688155 & 4.55 & 4.9868 & TRN & \\
\hline CHEMBL1333910 & 688155 & 5.45 & 5.0588 & TRN & \\
\hline CHEMBL1302340 & 688155 & 5.35 & 5.2282 & TRN & \\
\hline CHEMBL1424299 & 688155 & 5.55 & 5.0375 & TRN & \\
\hline CHEMBL1404109 & 688155 & 4.9 & 4.9424 & TRN & \\
\hline CHEMBL1458002 & 688155 & 4.95 & 5.1312 & TRN & \\
\hline CHEMBL1402615 & 688155 & 5.0 & 4.8771 & TRN & \\
\hline CHEMBL1377448 & 688155 & 5.0 & 5.0838 & TRN & \\
\hline CHEMBL1423900 & 688155 & 4.55 & 5.0005 & TRN & \\
\hline CHEMBL1464497 & 688155 & 5.3 & 5.2086 & TRN & \\
\hline CHEMBL1528765 & 688155 & 4.5 & 5.0379 & TST & \\
\hline CHEMBL1400868 & 688155 & 5.0 & 4.9022 & TRN & \\
\hline CHEMBL1374416 & 688155 & 5.25 & 5.0183 & TRN & \\
\hline CHEMBL1607092 & 688155 & 4.65 & 4.9159 & TRN & \\
\hline CHEMBL1369320 & 688155 & 5.0 & 5.2051 & TRN & \\
\hline CHEMBL1340020 & 688155 & 5.45 & 5.0488 & TRN & \\
\hline CHEMBL1572026 & 688155 & 4.8 & 4.993 & TRN & \\
\hline CHEMBL1384702 & 688155 & 5.2 & 4.9944 & TRN & \\
\hline CHEMBL1401792 & 688155 & 4.95 & 5.0148 & TST & \\
\hline CHEMBL1498274 & 688155 & 5.1 & 5.067 & TRN & \\
\hline CHEMBL1533888 & 688155 & 4.95 & 5.0025 & TST & \\
\hline CHEMBL1550669 & 688155 & 4.7 & 4.9858 & TRN & \\
\hline CHEMBL1446649 & 688155 & 4.75 & 5.0842 & TRN & \\
\hline CHEMBL1508072 & 688155 & 4.9 & 4.9566 & TRN & \\
\hline CHEMBL1559481 & 688155 & 5.1 & 5.2081 & TRN & \\
\hline CHEMBL1461940 & 688155 & 4.95 & 5.0882 & TST & \\
\hline CHEMBL1583585 & 688155 & 4.95 & 5.0333 & TRN & \\
\hline CHEMBL 1341760 & 688155 & 5.75 & 5.0165 & TST & \\
\hline CHEMBL1446957 & 688155 & 4.9 & 5.0605 & TRN & \\
\hline CHEMBL1554574 & 688155 & 5.0 & 5.2109 & TRN & \\
\hline CHEMBL1610979 & 688155 & 5.1 & 5.1376 & TRN & \\
\hline CHEMBL1361939 & 688155 & 5.0 & 5.1324 & TRN & \\
\hline CHEMBL1596567 & 688155 & 5.3 & 5.1041 & TRN & \\
\hline CHEMBL1565471 & 688155 & 5.0 & 5.1518 & TRN & \\
\hline CHEMBL 1370328 & 688155 & 4.95 & 5.1155 & TST & \\
\hline CHEMBL1521729 & 688155 & 4.65 & 5.0063 & TRN & \\
\hline CHEMBL1481836 & 688155 & 4.6 & 4.9708 & TST & \\
\hline CHEMBL1531639 & 688155 & 5.0 & 5.0273 & TRN & \\
\hline CHEMBL1336550 & 688155 & 5.5 & 5.2047 & TRN & \\
\hline
\end{tabular}




\begin{tabular}{|c|c|c|c|c|}
\hline \multicolumn{5}{|c|}{ Supplemental Table S2.txt } \\
\hline CHEMBL1409329 & 688155 & 4.75 & 4.9671 & TRN \\
\hline CHEMBL1313480 & 688155 & 5.05 & 5.0991 & TRN \\
\hline CHEMBL1323046 & 688155 & 5.85 & 5.2293 & TRN \\
\hline CHEMBL1522003 & 688155 & 5.6 & 4.9436 & TST \\
\hline CHEMBL1309556 & 688155 & 6.05 & 5.0829 & TRN \\
\hline CHEMBL1337264 & 688155 & 5.0 & 5.0174 & TRN \\
\hline CHEMBL1500866 & 688155 & 4.55 & 5.1317 & TST \\
\hline CHEMBL1324908 & 688155 & 4.9 & 5.2291 & TRN \\
\hline CHEMBL1545540 & 688155 & 5.3 & 5.1098 & TRN \\
\hline CHEMBL1418569 & 688155 & 4.6 & 5.1071 & TRN \\
\hline CHEMBL1412904 & 688155 & 4.95 & 4.9699 & TRN \\
\hline CHEMBL3196616 & 688155 & 4.95 & 5.0473 & TRN \\
\hline CHEMBL1516749 & 688155 & 4.95 & 5.1616 & TRN \\
\hline CHEMBL1509352 & 688155 & 4.75 & 5.0557 & TST \\
\hline CHEMBL1452820 & 688155 & 5.05 & 5.0253 & TRN \\
\hline CHEMBL1582252 & 688155 & 4.55 & 5.013 & TRN \\
\hline CHEMBL1331554 & 688155 & 5.25 & 5.0819 & TRN \\
\hline CHEMBL3197687 & 688155 & 4.95 & 5.0196 & TRN \\
\hline CHEMBL1575730 & 688155 & 4.5 & 5.1541 & TRN \\
\hline CHEMBL1328135 & 688155 & 4.55 & 5.1819 & TRN \\
\hline CHEMBL3193311 & 688155 & 4.85 & 5.1132 & TST \\
\hline CHEMBL1327190 & 688155 & 5.0 & 5.0291 & TRN \\
\hline CHEMBL1482639 & 688155 & 4.6 & 4.8887 & TRN \\
\hline CHEMBL1402196 & 688155 & 5.85 & 4.9522 & TRN \\
\hline CHEMBL1466356 & 688155 & 5.0 & 5.0155 & TRN \\
\hline CHEMBL1445619 & 688155 & 4.95 & 4.8972 & TST \\
\hline CHEMBL1530827 & 688155 & 5.4 & 5.2246 & TST \\
\hline CHEMBL1527737 & 688155 & 5.05 & 4.9986 & TST \\
\hline CHEMBL1353934 & 688155 & 5.2 & 5.0401 & TRN \\
\hline CHEMBL1390006 & 688155 & 4.55 & 5.1378 & TRN \\
\hline CHEMBL1433215 & 688155 & 5.1 & 5.1213 & TST \\
\hline CHEMBL1500673 & 688155 & 4.65 & 4.9592 & TRN \\
\hline CHEMBL1448341 & 688155 & 4.65 & 4.8932 & TST \\
\hline CHEMBL497939 & 688155 & 5.5 & 5.2053 & TST \\
\hline CHEMBL1318822 & 688155 & 6.0 & 5.2426 & TST \\
\hline CHEMBL1611086 & 688155 & 4.55 & 5.0889 & TRN \\
\hline CHEMBL3189462 & 688155 & 4.8 & 4.9959 & TST \\
\hline CHEMBL1505045 & 688155 & 4.5 & 5.17 & TST \\
\hline CHEMBL1430132 & 688155 & 5.1 & 5.0695 & TST \\
\hline CHEMBL1302492 & 688155 & 4.55 & 5.0681 & TST \\
\hline CHEMBL1373300 & 688155 & 6.0 & 5.2448 & TST \\
\hline CHEMBL1491622 & 688155 & 4.9 & 4.934 & TRN \\
\hline CHEMBL1462729 & 688155 & 5.15 & 5.2016 & TST \\
\hline CHEMBL1560789 & 688155 & 4.5 & 4.9572 & TRN \\
\hline CHEMBL1418524 & 688155 & 4.5 & 4.9983 & TST \\
\hline CHEMBL1487819 & 688155 & 4.55 & 5.245 & TRN \\
\hline CHEMBL1363121 & 688155 & 5.4 & 5.0311 & TRN \\
\hline CHEMBL1411213 & 688155 & 4.95 & 5.1288 & TRN \\
\hline
\end{tabular}




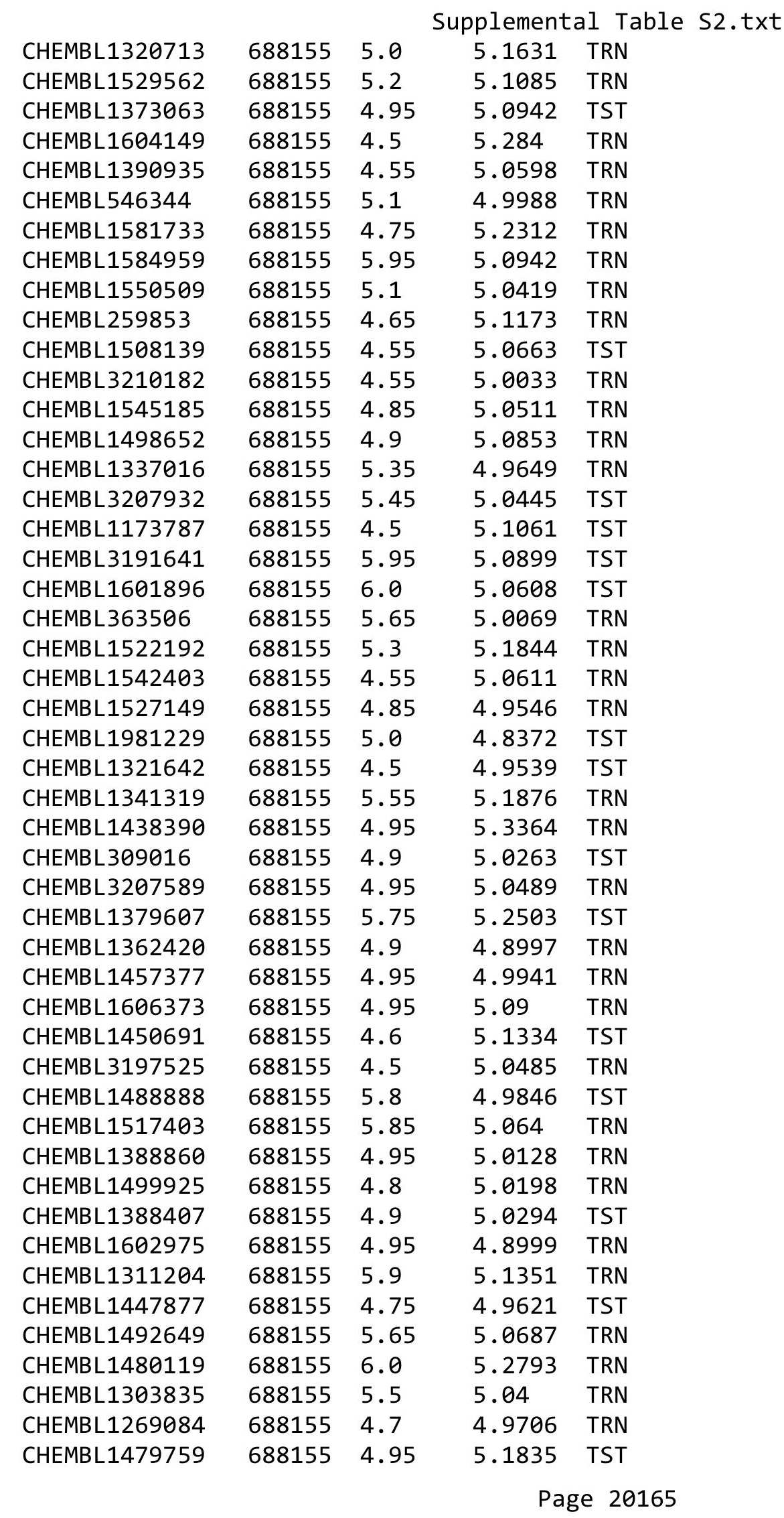




\begin{tabular}{|c|c|c|c|c|c|}
\hline \multirow[b]{2}{*}{ CHEMBL1579404 } & & \multicolumn{4}{|c|}{ Supplemental Table s2.txt } \\
\hline & 688155 & 5.95 & 4.962 & TST & \\
\hline CHEMBL1308381 & 688155 & 4.45 & 4.9722 & TRN & \\
\hline CHEMBL1319177 & 688155 & 5.5 & 5.0297 & TRN & \\
\hline CHEMBL1611615 & 688155 & 4.65 & 5.0229 & TRN & \\
\hline CHEMBL1572096 & 688155 & 6.45 & 5.1059 & TRN & \\
\hline CHEMBL1595001 & 688155 & 4.95 & 5.0408 & TST & \\
\hline CHEMBL1378666 & 688155 & 4.55 & 5.0706 & TST & \\
\hline CHEMBL3209297 & 688155 & 5.35 & 5.1224 & TST & \\
\hline CHEMBL1388414 & 688155 & 4.55 & 5.0273 & TST & \\
\hline CHEMBL3209610 & 688155 & 6.35 & 5.0869 & TST & \\
\hline CHEMBL1493604 & 688155 & 5.0 & 4.8839 & TRN & \\
\hline CHEMBL1350350 & 688155 & 5.0 & 4.9724 & TRN & \\
\hline CHEMBL1488722 & 688155 & 5.95 & 5.0997 & TRN & \\
\hline CHEMBL1342271 & 688155 & 4.5 & 5.0451 & TRN & \\
\hline CHEMBL1388895 & 688155 & 4.6 & 5.0905 & TST & \\
\hline CHEMBL1401641 & 688155 & 5.85 & 5.1992 & TRN & \\
\hline CHEMBL1581079 & 688155 & 4.95 & 5.2141 & TRN & \\
\hline CHEMBL1405208 & 688155 & 4.95 & 5.1184 & TRN & \\
\hline CHEMBL1327501 & 688155 & 4.5 & 5.0912 & TRN & \\
\hline CHEMBL1519055 & 688155 & 4.55 & 5.1666 & TST & \\
\hline CHEMBL1430204 & 688155 & 4.8 & 5.0662 & TST & \\
\hline CHEMBL1582676 & 688155 & 4.5 & 5.1114 & TST & \\
\hline CHEMBL1476762 & 688155 & 4.95 & 5.1551 & TRN & \\
\hline CHEMBL1365522 & 688155 & 5.35 & 5.0706 & TRN & \\
\hline CHEMBL1548891 & 688155 & 5.1 & 5.2871 & TRN & \\
\hline CHEMBL1399093 & 688155 & 5.0 & 5.1623 & TRN & \\
\hline CHEMBL601952 & 688155 & 4.85 & 5.2493 & TRN & \\
\hline CHEMBL1302448 & 688155 & 5.15 & 5.0735 & TRN & \\
\hline CHEMBL1304951 & 688155 & 4.5 & 5.0805 & TRN & \\
\hline CHEMBL1531784 & 688155 & 4.9 & 5.1488 & TRN & \\
\hline CHEMBL1464171 & 688155 & 5.1 & 5.1647 & TRN & \\
\hline CHEMBL1400958 & 688155 & 4.9 & 5.1249 & TST & \\
\hline CHEMBL1595989 & 688155 & 4.9 & 5.0088 & TST & \\
\hline CHEMBL1598529 & 688155 & 4.9 & 5.03 & TRN & \\
\hline CHEMBL1604844 & 688155 & 4.85 & 5.0887 & TRN & \\
\hline CHEMBL3194843 & 688155 & 5.85 & 5.0399 & TST & \\
\hline CHEMBL1454167 & 688155 & 6.0 & 5.03600 & 00000000005 & TRN \\
\hline CHEMBL15060 & 688155 & 4.5 & 5.0181 & TST & \\
\hline CHEMBL1540417 & 688155 & 5.9 & 4.9854 & TST & \\
\hline CHEMBL1607116 & 688155 & 4.8 & 5.113 & TRN & \\
\hline CHEMBL1539360 & 688155 & 4.95 & 5.1281 & TST & \\
\hline CHEMBL1582866 & 688155 & 5.8 & 4.9965 & TST & \\
\hline CHEMBL1306491 & 688155 & 5.3 & 4.8797 & TRN & \\
\hline CHEMBL1401753 & 688155 & 4.9 & 5.0517 & TST & \\
\hline CHEMBL12019 & 688155 & 4.95 & 5.04899 & 99999999995 & TRN \\
\hline CHEMBL 2001433 & 688155 & 4.8 & 5.0505 & TRN & \\
\hline CHEMBL1302592 & 688155 & 4.85 & 5.1832 & TRN & \\
\hline CHEMBL1337704 & 688155 & 4.5 & 5.1421 & TRN & \\
\hline
\end{tabular}




\begin{tabular}{|c|c|c|c|c|c|}
\hline & & \multicolumn{4}{|c|}{ Supplemental Table S2.txt } \\
\hline CHEMBL1491154 & 688155 & 4.65 & 4.9276 & TRN & \\
\hline CHEMBL1557440 & 688155 & 5.05 & 5.2207 & TRN & \\
\hline CHEMBL1369641 & 688155 & 4.9 & 4.935 & TRN & \\
\hline CHEMBL1585446 & 688155 & 4.55 & 5.0352 & TRN & \\
\hline CHEMBL1382215 & 688155 & 4.55 & 5.0474 & TST & \\
\hline CHEMBL 3210955 & 688155 & 5.2 & 5.0218 & TST & \\
\hline CHEMBL1525290 & 688155 & 5.05 & 5.1735 & TRN & \\
\hline CHEMBL3197076 & 688155 & 5.9 & 5.2532 & TST & \\
\hline CHEMBL1577526 & 688155 & 5.1 & 5.2398 & TRN & \\
\hline CHEMBL1419004 & 688155 & 5.05 & 5.1994 & TRN & \\
\hline CHEMBL1489063 & 688155 & 4.9 & 5.0506 & TRN & \\
\hline CHEMBL1449354 & 688155 & 4.5 & 5.0721 & TRN & \\
\hline CHEMBL3197284 & 688155 & 5.0 & 5.1622 & TST & \\
\hline CHEMBL1582569 & 688155 & 4.65 & 4.9843 & TRN & \\
\hline CHEMBL1373175 & 688155 & 4.65 & 4.9887 & TRN & \\
\hline CHEMBL1611902 & 688155 & 5.45 & 4.9634 & TST & \\
\hline CHEMBL1402421 & 688155 & 5.85 & 5.0051 & TST & \\
\hline CHEMBL1339474 & 688155 & 4.6 & 5.0818 & TST & \\
\hline CHEMBL1470611 & 688155 & 4.5 & 5.1983 & TRN & \\
\hline CHEMBL1559459 & 688155 & 4.85 & 4.9852 & TRN & \\
\hline CHEMBL1560954 & 688155 & 4.95 & 5.0058 & TRN & \\
\hline CHEMBL1410697 & 688155 & 4.9 & 5.06800 & 00000000005 & TRN \\
\hline CHEMBL1358821 & 688155 & 5.85 & 5.059 & TRN & \\
\hline CHEMBL1440409 & 688155 & 4.95 & 5.1206 & TST & \\
\hline CHEMBL1347663 & 688155 & 6.1 & 4.9654 & TRN & \\
\hline CHEMBL1378602 & 688155 & 4.55 & 5.2425 & TRN & \\
\hline CHEMBL1323216 & 688155 & 5.5 & 5.1701 & TRN & \\
\hline CHEMBL1383753 & 688155 & 4.55 & 5.1526 & TRN & \\
\hline CHEMBL1425534 & 688155 & 6.3 & 5.2545 & TRN & \\
\hline CHEMBL1489612 & 688155 & 4.95 & 5.2111 & TRN & \\
\hline CHEMBL1426468 & 688155 & 4.8 & 4.9576 & TRN & \\
\hline CHEMBL1365230 & 688155 & 4.55 & 5.016 & TRN & \\
\hline CHEMBL1432447 & 688155 & 5.4 & 5.2574 & TRN & \\
\hline CHEMBL1300458 & 688155 & 5.35 & 5.0992 & TST & \\
\hline CHEMBL1363350 & 688155 & 4.9 & 4.9799 & TST & \\
\hline CHEMBL1312946 & 688155 & 5.7 & 5.1683 & TRN & \\
\hline CHEMBL1326768 & 688155 & 4.9 & 5.1056 & TRN & \\
\hline CHEMBL1347842 & 688155 & 4.55 & 4.9845 & TRN & \\
\hline CHEMBL1543833 & 688155 & 4.75 & 5.231 & TRN & \\
\hline CHEMBL1338117 & 688155 & 4.55 & 4.917 & TRN & \\
\hline CHEMBL1487260 & 688155 & 6.0 & 4.9635 & TST & \\
\hline CHEMBL1549074 & 688155 & 5.2 & 5.1207 & TRN & \\
\hline CHEMBL1457503 & 688155 & 4.85 & 4.979 & TRN & \\
\hline CHEMBL1555917 & 688155 & 4.55 & 4.9363 & TRN & \\
\hline CHEMBL1351976 & 688155 & 5.9 & 5.0721 & TRN & \\
\hline CHEMBL1459324 & 688155 & 4.5 & 5.0502 & TRN & \\
\hline CHEMBL1311225 & 688155 & 6.5 & 5.1774 & TRN & \\
\hline CHEMBL1586557 & 688155 & 5.3 & 5.0874 & TST & \\
\hline
\end{tabular}




\begin{tabular}{|c|c|c|c|c|}
\hline & & & pplemen & al $\mathrm{T}$ \\
\hline CHEMBL1335031 & 688155 & 4.55 & 5.215 & TRN \\
\hline CHEMBL1520496 & 688155 & 5.3 & 5.1309 & TRN \\
\hline CHEMBL1417990 & 688155 & 5.95 & 5.1487 & TRN \\
\hline CHEMBL1410705 & 688155 & 4.9 & 4.9872 & TRN \\
\hline CHEMBL3199816 & 688155 & 5.0 & 5.083 & TRN \\
\hline CHEMBL1445260 & 688155 & 4.55 & 5.0779 & TRN \\
\hline CHEMBL1484565 & 688155 & 5.1 & 4.9915 & TRN \\
\hline CHEMBL1467152 & 688155 & 4.5 & 5.0063 & TRN \\
\hline CHEMBL1327647 & 688155 & 4.85 & 5.0517 & TST \\
\hline CHEMBL1586870 & 688155 & 5.0 & 5.1206 & TRN \\
\hline CHEMBL 3194890 & 688155 & 4.55 & 4.9826 & TRN \\
\hline CHEMBL1561287 & 688155 & 5.0 & 4.9919 & TRN \\
\hline CHEMBL1332890 & 688155 & 4.55 & 5.0335 & TRN \\
\hline CHEMBL1417249 & 688155 & 4.55 & 4.9707 & TRN \\
\hline CHEMBL1448292 & 688155 & 4.95 & 5.1714 & TRN \\
\hline CHEMBL1369578 & 688155 & 4.95 & 5.1568 & TRN \\
\hline CHEMBL1420681 & 688155 & 6.45 & 5.1642 & TRN \\
\hline CHEMBL1454124 & 688155 & 4.55 & 4.9227 & TRN \\
\hline CHEMBL1567533 & 688155 & 5.95 & 5.0111 & TST \\
\hline CHEMBL3197118 & 688155 & 4.6 & 5.0344 & TST \\
\hline CHEMBL1350917 & 688155 & 6.05 & 5.1964 & TRN \\
\hline CHEMBL1389638 & 688155 & 5.8 & 5.2401 & TRN \\
\hline CHEMBL1324724 & 688155 & 4.55 & 4.9577 & TRN \\
\hline CHEMBL1426049 & 688155 & 5.1 & 5.1273 & TRN \\
\hline CHEMBL1603530 & 688155 & 5.4 & 4.9848 & TRN \\
\hline CHEMBL1370208 & 688155 & 4.55 & 5.0212 & TST \\
\hline CHEMBL1601711 & 688155 & 5.95 & 4.9891 & TRN \\
\hline CHEMBL1422402 & 688155 & 4.55 & 5.0941 & TRN \\
\hline CHEMBL1518159 & 688155 & 5.0 & 5.0774 & TST \\
\hline CHEMBL1478597 & 688155 & 4.5 & 5.0424 & TRN \\
\hline CHEMBL1470063 & 688155 & 5.0 & 4.9901 & TRN \\
\hline CHEMBL1457894 & 688155 & 5.25 & 5.0972 & TRN \\
\hline CHEMBL1504676 & 688155 & 4.95 & 4.8749 & TRN \\
\hline CHEMBL1533246 & 688155 & 4.95 & 5.0398 & TRN \\
\hline CHEMBL1494096 & 688155 & 4.55 & 4.9853 & TRN \\
\hline CHEMBL1501185 & 688155 & 4.5 & 4.9652 & TST \\
\hline CHEMBL1348924 & 688155 & 4.85 & 5.2033 & TRN \\
\hline CHEMBL1463392 & 688155 & 5.8 & 5.2583 & TRN \\
\hline CHEMBL1547537 & 688155 & 5.15 & 5.0167 & TRN \\
\hline CHEMBL1447715 & 688155 & 5.1 & 5.061 & TRN \\
\hline CHEMBL1547272 & 688155 & 5.0 & 4.9471 & TRN \\
\hline CHEMBL1365325 & 688155 & 4.55 & 5.2053 & TRN \\
\hline CHEMBL1455408 & 688155 & 6.35 & 5.1497 & TRN \\
\hline CHEMBL1407515 & 688155 & 5.2 & 4.9977 & TST \\
\hline CHEMBL1510490 & 688155 & 4.9 & 4.9879 & TRN \\
\hline CHEMBL1354600 & 688155 & 5.2 & 4.9861 & TST \\
\hline CHEMBL1415700 & 688155 & 4.5 & 5.023 & TRN \\
\hline CHEMBL1537595 & 688155 & 5.7 & 5.1689 & TRN \\
\hline
\end{tabular}




\begin{tabular}{|c|c|c|c|c|c|}
\hline \multicolumn{6}{|c|}{ Supplemental Table S2.txt } \\
\hline CHEMBL1391126 & 688155 & 5.8 & 5.153 & TRN & \\
\hline CHEMBL1534554 & 688155 & 4.55 & 5.1889 & TST & \\
\hline CHEMBL1530807 & 688155 & 4.85 & 5.1204 & TRN & \\
\hline CHEMBL1608119 & 688155 & 4.95 & 5.0498 & TRN & \\
\hline CHEMBL1524932 & 688155 & 4.7 & 5.0086 & TRN & \\
\hline CHEMBL1370193 & 688155 & 4.9 & 5.1448 & TST & \\
\hline CHEMBL1331364 & 688155 & 4.5 & 5.2478 & TRN & \\
\hline CHEMBL1539384 & 688155 & 5.8 & 5.0669 & TST & \\
\hline CHEMBL1308632 & 688155 & 5.0 & 5.0149 & TRN & \\
\hline CHEMBL1564867 & 688155 & 4.9 & 4.9569 & TRN & \\
\hline CHEMBL579503 & 688155 & 4.95 & 5.061 & TRN & \\
\hline CHEMBL1441453 & 688155 & 4.55 & 4.9487 & TRN & \\
\hline CHEMBL1563765 & 688155 & 4.5 & 5.0676 & TRN & \\
\hline CHEMBL 3208787 & 688155 & 5.55 & 5.0647 & TRN & \\
\hline CHEMBL1418893 & 688155 & 5.0 & 5.1444 & TST & \\
\hline CHEMBL 2136569 & 688155 & 4.5 & 4.948 & TST & \\
\hline CHEMBL1464931 & 688155 & 4.5 & 5.1932 & TRN & \\
\hline CHEMBL1571034 & 688155 & 5.3 & 5.0027 & TRN & \\
\hline CHEMBL1498060 & 688155 & 4.95 & 5.1632 & TRN & \\
\hline CHEMBL1581750 & 688155 & 5.5 & 5.1643 & TRN & \\
\hline CHEMBL1385175 & 688155 & 4.65 & 4.9786 & TRN & \\
\hline CHEMBL1337428 & 688155 & 4.95 & 5.0251 & TRN & \\
\hline CHEMBL1458017 & 688155 & 4.6 & 5.0306 & TRN & \\
\hline CHEMBL1587876 & 688155 & 4.9 & 5.0595 & TRN & \\
\hline CHEMBL1453673 & 688155 & 5.0 & 4.9327 & TST & \\
\hline CHEMBL1311324 & 688155 & 4.75 & 5.0907 & TST & \\
\hline CHEMBL3199079 & 688155 & 4.85 & 5.0177 & TRN & \\
\hline CHEMBL1377930 & 688155 & 5.1 & 5.1081 & TRN & \\
\hline CHEMBL1588162 & 688155 & 4.65 & 5.1907 & TRN & \\
\hline CHEMBL1466901 & 688155 & 4.6 & 5.0957 & TRN & \\
\hline CHEMBL1381673 & 688155 & 4.95 & 4.9156 & TRN & \\
\hline CHEMBL1547165 & 688155 & 4.9 & 5.0408 & TRN & \\
\hline CHEMBL1532311 & 688155 & 4.55 & 4.9962 & TST & \\
\hline CHEMBL3199722 & 688155 & 5.55 & 5.0964 & TST & \\
\hline CHEMBL1443527 & 688155 & 5.3 & 5.086 & TRN & \\
\hline CHEMBL1356055 & 688155 & 5.95 & 5.0954 & TST & \\
\hline CHEMBL1329763 & 688155 & 5.85 & $5.1370 e$ & 00000000005 & TRN \\
\hline CHEMBL1498953 & 688155 & 4.85 & 5.2145 & TRN & \\
\hline CHEMBL1311703 & 688155 & 4.9 & 4.9889 & TRN & \\
\hline CHEMBL1306627 & 688155 & 6.0 & 5.1596 & TRN & \\
\hline CHEMBL1419534 & 688155 & 4.55 & 5.0849 & TST & \\
\hline CHEMBL1224512 & 688155 & 4.95 & 5.0457 & TST & \\
\hline CHEMBL1496914 & 688155 & 5.95 & 5.1377 & TRN & \\
\hline CHEMBL1305607 & 688155 & 4.95 & 5.1667 & TST & \\
\hline CHEMBL1326010 & 688155 & 5.2 & 5.0169 & TRN & \\
\hline CHEMBL1457159 & 688155 & 4.9 & 4.9359 & TST & \\
\hline CHEMBL1563013 & 688155 & 5.15 & 5.3571 & TRN & \\
\hline CHEMBL1501091 & 688155 & 4.95 & 5.1086 & TRN & \\
\hline
\end{tabular}




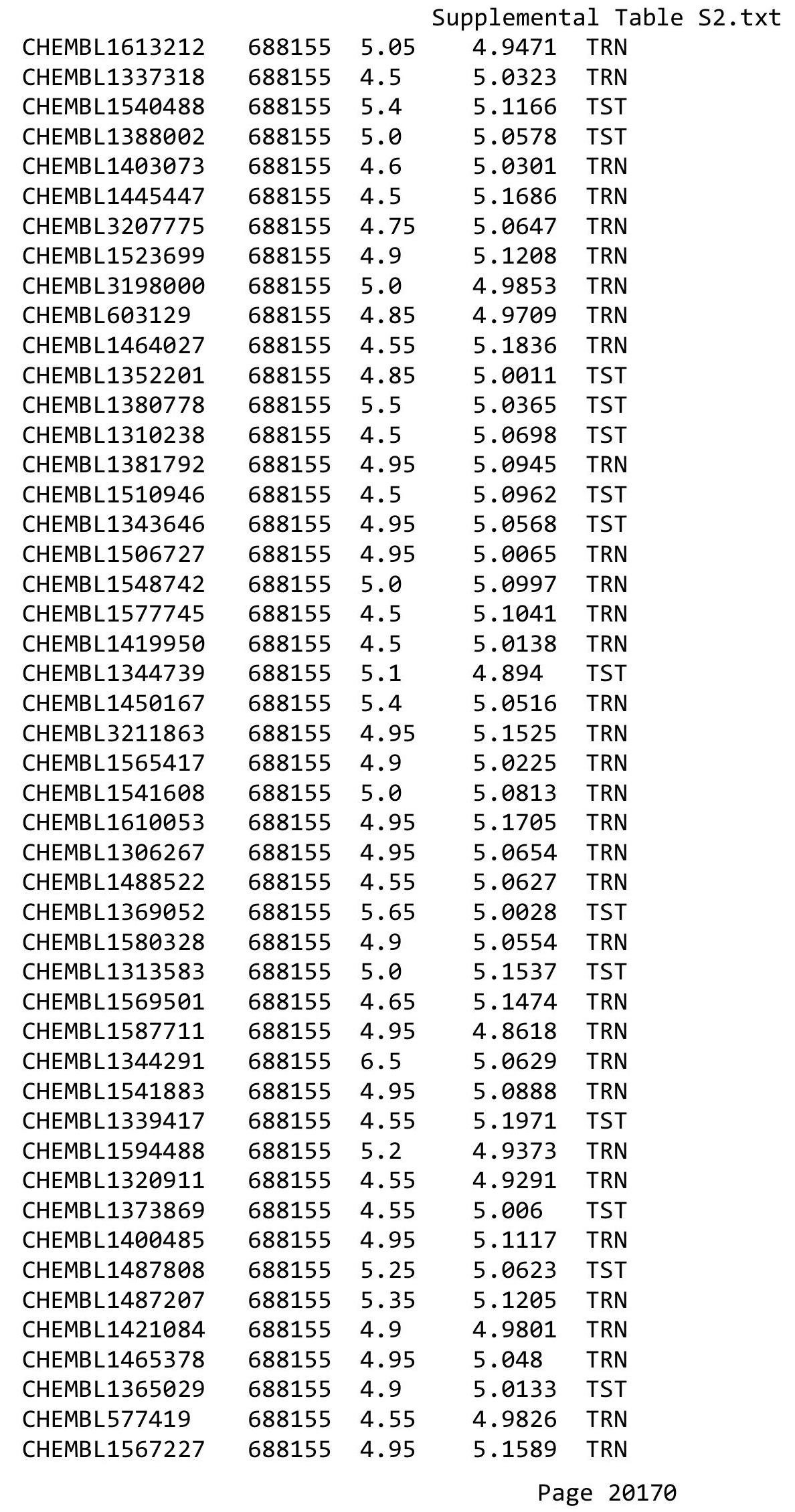




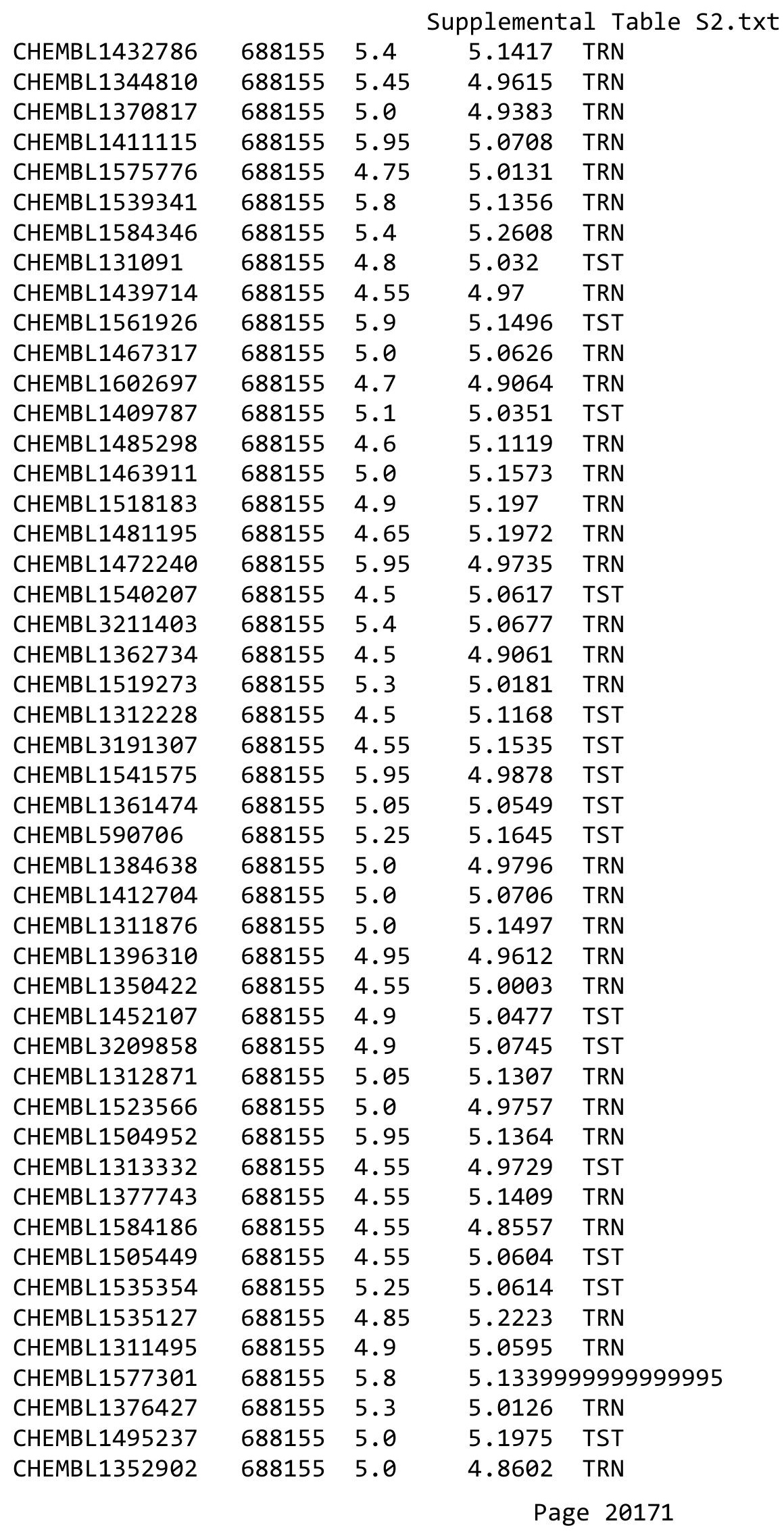




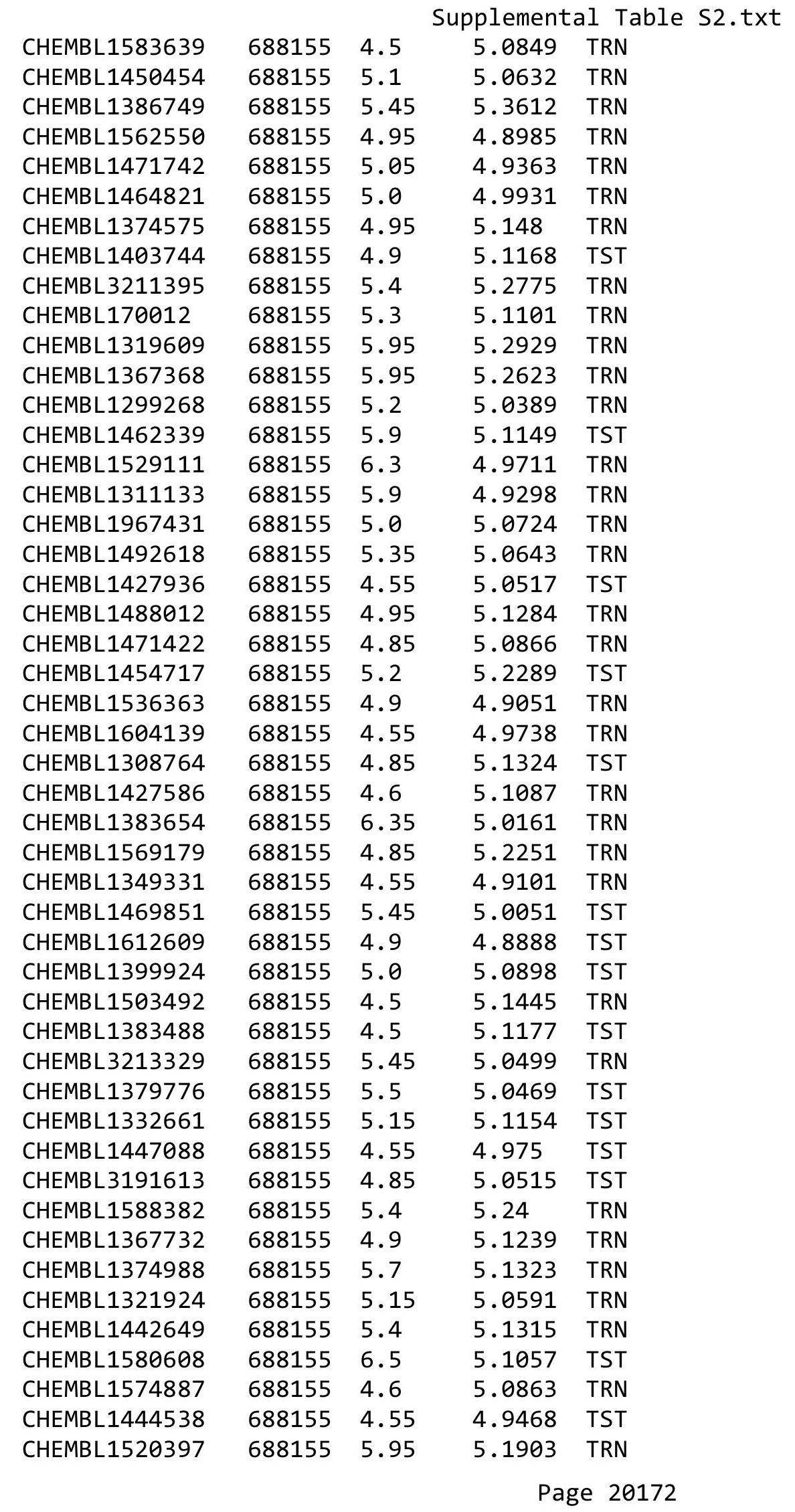




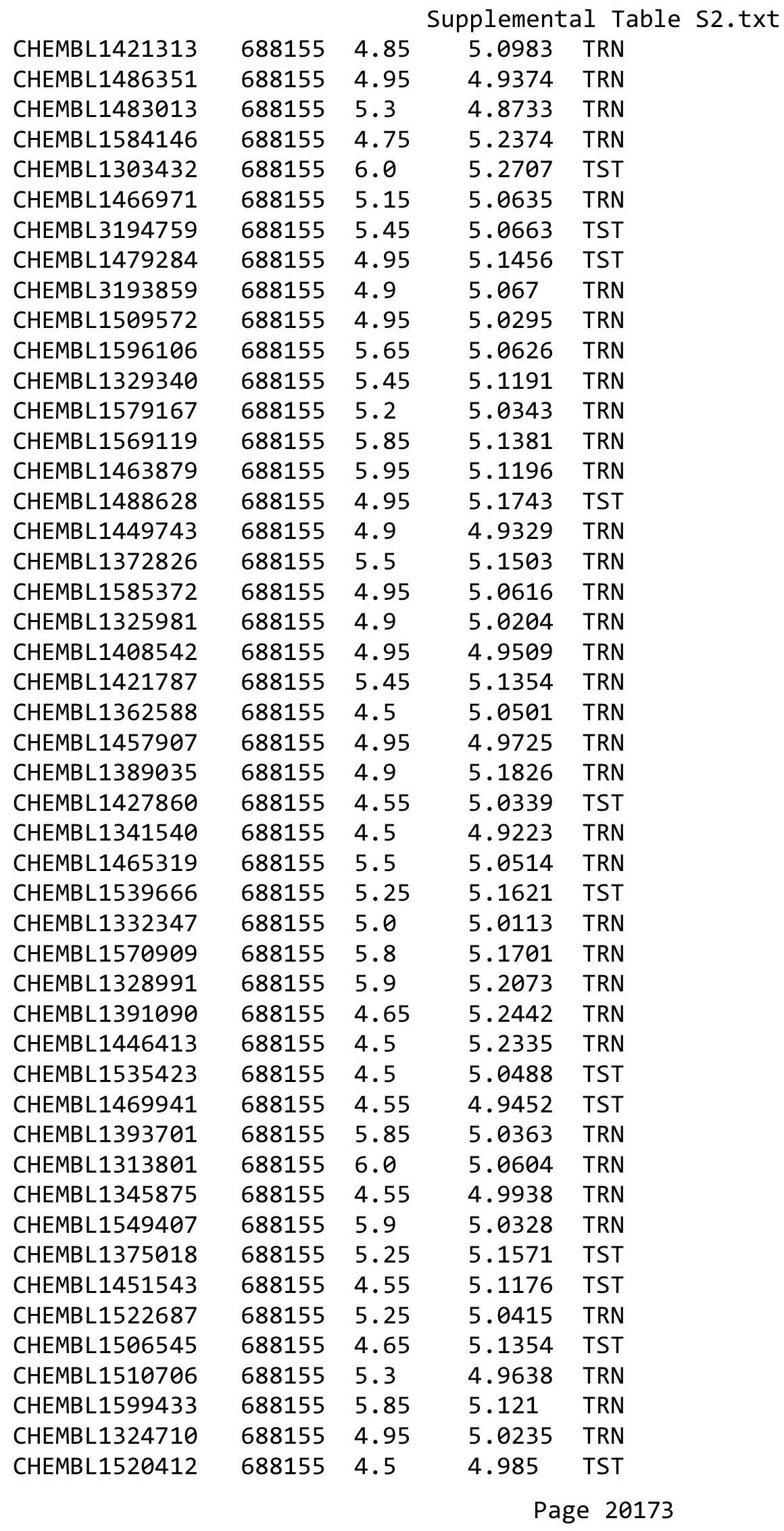




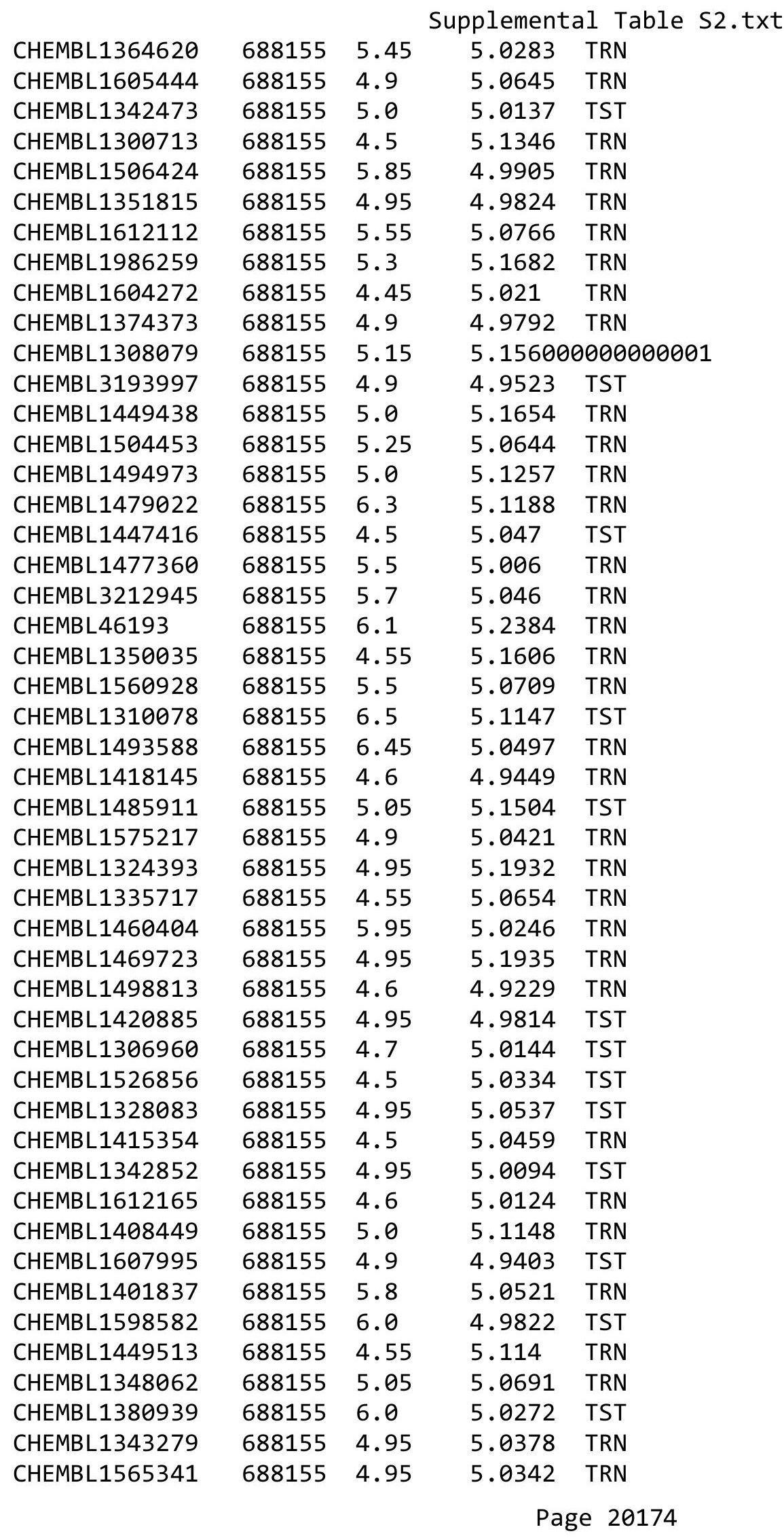




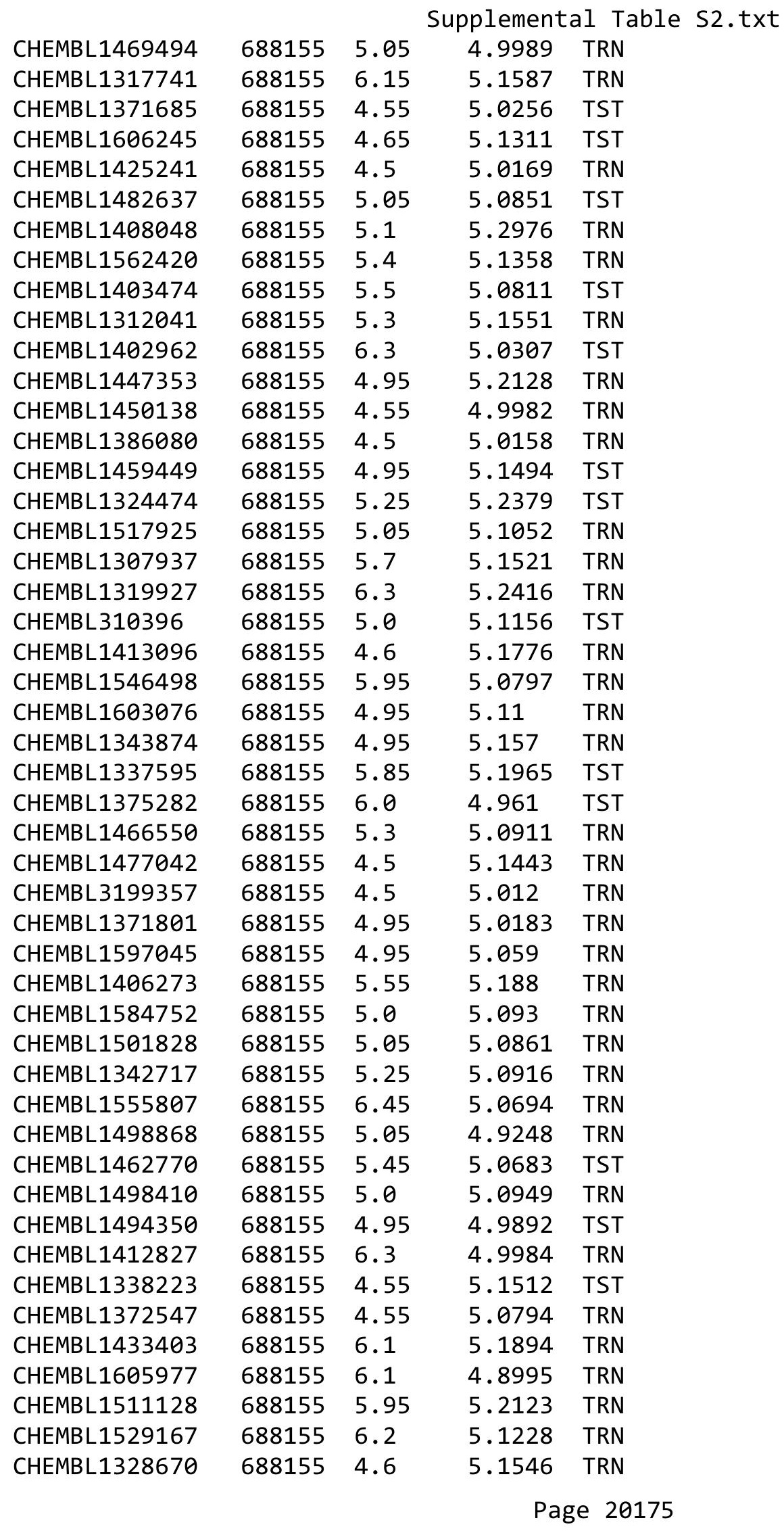




\begin{tabular}{|c|c|c|c|c|c|}
\hline \multicolumn{6}{|c|}{ Supplemental Table S2.txt } \\
\hline CHEMBL1377200 & 688155 & 5.5 & 5.07 & TST & \\
\hline CHEMBL1447343 & 688155 & 5.25 & 5.0648 & TRN & \\
\hline CHEMBL1582270 & 688155 & 6.0 & 5.1707 & TRN & \\
\hline CHEMBL1488226 & 688155 & 5.0 & 5.084 & TST & \\
\hline CHEMBL1594570 & 688155 & 4.65 & 5.0595 & TRN & \\
\hline CHEMBL1607089 & 688155 & 5.25 & 5.0424 & TRN & \\
\hline CHEMBL117966 & 688155 & 4.95 & 4.9605 & TRN & \\
\hline CHEMBL1522972 & 688155 & 5.75 & 5.2276 & TRN & \\
\hline CHEMBL1452476 & 688155 & 4.95 & 5.1656 & TST & \\
\hline CHEMBL1453095 & 688155 & 5.9 & 5.2008 & TST & \\
\hline CHEMBL1443398 & 688155 & 5.0 & 5.1302 & TST & \\
\hline CHEMBL1588735 & 688155 & 5.2 & 5.0625 & TRN & \\
\hline CHEMBL1391898 & 688155 & 5.95 & 5.0681 & TST & \\
\hline CHEMBL1349743 & 688155 & 5.25 & 5.0076 & TRN & \\
\hline CHEMBL3199895 & 688155 & 4.95 & 5.0925 & TST & \\
\hline CHEMBL1443903 & 688155 & 5.0 & 5.0693 & TRN & \\
\hline CHEMBL1529799 & 688155 & 4.9 & 5.0941 & TRN & \\
\hline CHEMBL1425736 & 688155 & 4.65 & 4.9728 & TST & \\
\hline CHEMBL1307984 & 688155 & 5.25 & 5.2048 & TRN & \\
\hline CHEMBL1587200 & 688155 & 6.0 & 4.9633 & TRN & \\
\hline CHEMBL1498473 & 688155 & 4.45 & 5.0523 & TRN & \\
\hline CHEMBL1338371 & 688155 & 5.05 & 4.9477 & TRN & \\
\hline CHEMBL1377563 & 688155 & 4.5 & 5.0471 & TRN & \\
\hline CHEMBL1502154 & 688155 & 5.0 & 5.0532 & TRN & \\
\hline CHEMBL1532807 & 688155 & 5.25 & 5.1101 & TRN & \\
\hline CHEMBL1543855 & 688155 & 5.5 & 5.2606 & TST & \\
\hline CHEMBL1510082 & 688155 & 4.5 & 4.98300 & 00000000005 & TRN \\
\hline CHEMBL1443763 & 688155 & 4.65 & 5.103 & TRN & \\
\hline CHEMBL1539842 & 688155 & 4.85 & 5.1158 & TRN & \\
\hline CHEMBL1334465 & 688155 & 4.8 & 5.0165 & TST & \\
\hline CHEMBL1380488 & 688155 & 5.85 & 5.0745 & TRN & \\
\hline CHEMBL1525902 & 688155 & 5.0 & 5.0627 & TRN & \\
\hline CHEMBL1532663 & 688155 & 4.5 & 5.0873 & TRN & \\
\hline CHEMBL1307578 & 688155 & 5.95 & 5.13700 & 00000000005 & TRN \\
\hline CHEMBL1440077 & 688155 & 5.05 & 5.2007 & TRN & \\
\hline CHEMBL1508177 & 688155 & 4.55 & 4.9884 & TRN & \\
\hline CHEMBL1503758 & 688155 & 4.95 & 5.1576 & TRN & \\
\hline CHEMBL1342255 & 688155 & 5.0 & 5.1013 & TRN & \\
\hline CHEMBL1494334 & 688155 & 4.5 & 4.8969 & TST & \\
\hline CHEMBL1464180 & 688155 & 6.45 & 4.9455 & TRN & \\
\hline CHEMBL1595916 & 688155 & 4.55 & 5.0749 & TRN & \\
\hline CHEMBL1509018 & 688155 & 4.55 & 4.9379 & TRN & \\
\hline CHEMBL1507963 & 688155 & 4.95 & 4.9939 & TRN & \\
\hline CHEMBL1556284 & 688155 & 4.65 & 5.0999 & TRN & \\
\hline CHEMBL1539787 & 688155 & 5.35 & 5.0047 & TRN & \\
\hline CHEMBL1326364 & 688155 & 4.95 & 5.0154 & TRN & \\
\hline CHEMBL1442810 & 688155 & 4.95 & 5.0701 & TRN & \\
\hline CHEMBL1601542 & 688155 & 6.0 & 5.1415 & TRN & \\
\hline
\end{tabular}




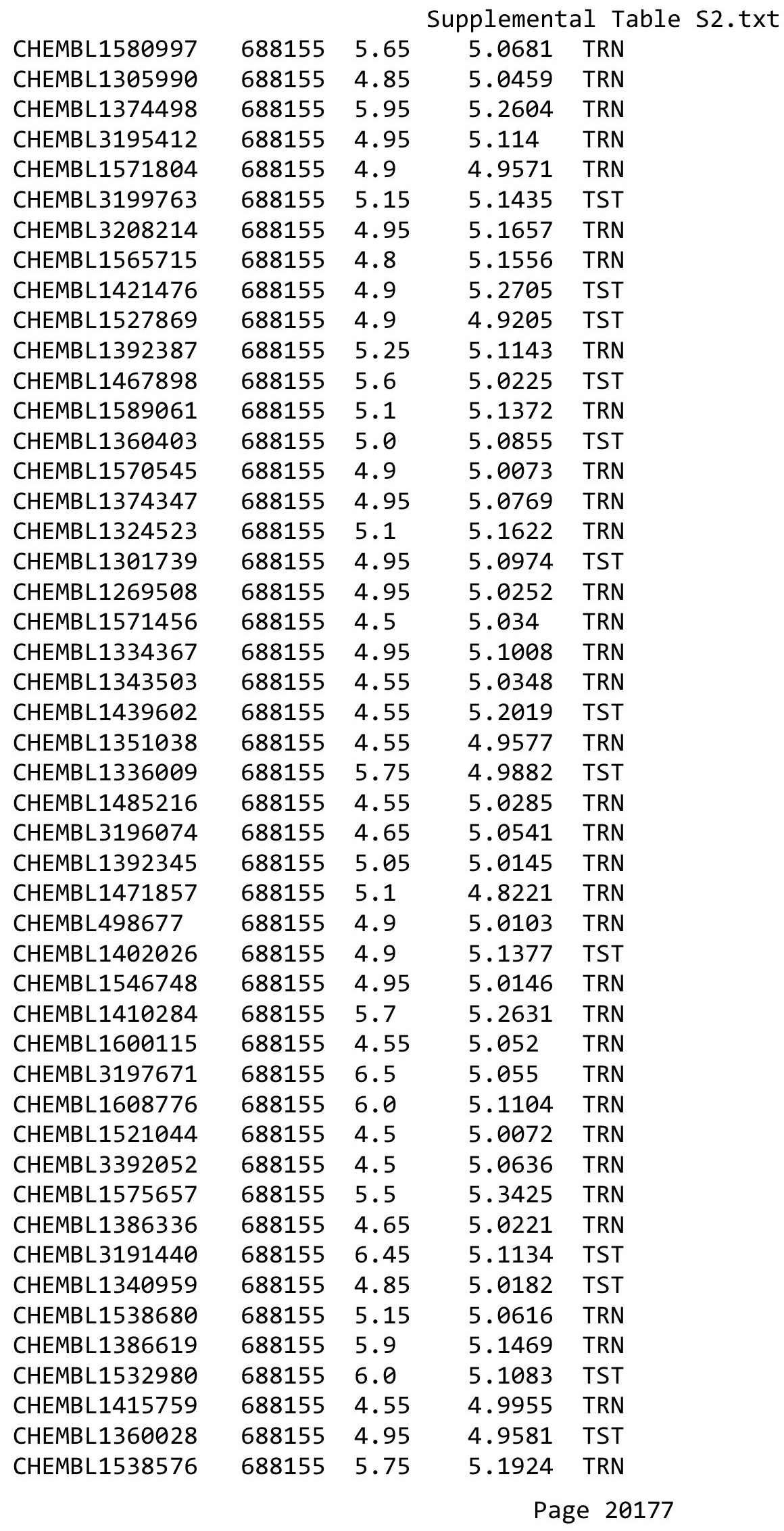




\begin{tabular}{|c|c|c|c|c|c|}
\hline \multicolumn{6}{|c|}{ Supplemental Table S2.txt } \\
\hline CHEMBL1525587 & 688155 & 5.35 & 5.0803 & TST & \\
\hline CHEMBL1495504 & 688155 & 6.35 & 5.0493 & TRN & \\
\hline CHEMBL1349807 & 688155 & 5.95 & 5.2274 & TRN & \\
\hline CHEMBL1471196 & 688155 & 4.7 & 5.1436 & TRN & \\
\hline CHEMBL1473715 & 688155 & 5.5 & 5.1845 & TST & \\
\hline CHEMBL1605232 & 688155 & 5.1 & 5.0188 & TRN & \\
\hline CHEMBL1602466 & 688155 & 4.55 & 5.1704 & TRN & \\
\hline CHEMBL 3195286 & 688155 & 4.95 & 5.0515 & TRN & \\
\hline CHEMBL1375676 & 688155 & 5.8 & 5.0944 & TRN & \\
\hline CHEMBL1414086 & 688155 & 4.5 & 5.1356 & TRN & \\
\hline CHEMBL1442655 & 688155 & 4.65 & 4.9645 & TRN & \\
\hline CHEMBL1494713 & 688155 & 4.65 & 5.1126 & TRN & \\
\hline CHEMBL1349226 & 688155 & 4.95 & 4.933 & TRN & \\
\hline CHEMBL1311918 & 688155 & 6.05 & 5.1875 & TST & \\
\hline CHEMBL1525195 & 688155 & 5.45 & 5.0624 & TRN & \\
\hline CHEMBL1560645 & 688155 & 4.85 & 5.1853 & TST & \\
\hline CHEMBL1596225 & 688155 & 4.5 & 5.0848 & TST & \\
\hline CHEMBL1501033 & 688155 & 4.8 & 5.2244 & TST & \\
\hline CHEMBL1495975 & 688155 & 5.0 & 5.0562 & TRN & \\
\hline CHEMBL1447960 & 688155 & 4.95 & 5.0795 & TST & \\
\hline CHEMBL1589491 & 688155 & 5.3 & 5.0687 & TST & \\
\hline CHEMBL1441047 & 688155 & 5.0 & 5.0686 & TRN & \\
\hline CHEMBL1555421 & 688155 & 5.05 & 4.975 & TST & \\
\hline CHEMBL1559119 & 688155 & 4.5 & 5.1198 & TST & \\
\hline CHEMBL1566957 & 688155 & 4.55 & 5.0555 & TRN & \\
\hline CHEMBL416657 & 688155 & 4.55 & 5.1051 & TST & \\
\hline CHEMBL1566599 & 688155 & 5.55 & 5.2182 & TST & \\
\hline CHEMBL1504392 & 688155 & 4.55 & 5.0089 & TRN & \\
\hline CHEMBL1464237 & 688155 & 4.95 & 4.885 & TRN & \\
\hline CHEMBL1408395 & 688155 & 5.0 & 5.1732 & TST & \\
\hline CHEMBL1584013 & 688155 & 4.95 & 5.1713 & TRN & \\
\hline CHEMBL1350301 & 688155 & 6.5 & 5.225 & TST & \\
\hline CHEMBL1583101 & 688155 & 4.9 & 4.9824 & TRN & \\
\hline CHEMBL1548511 & 688155 & 4.5 & 5.0379 & TST & \\
\hline CHEMBL1380059 & 688155 & 4.55 & 4.9142 & TRN & \\
\hline CHEMBL 3195749 & 688155 & 4.45 & 5.0514 & TRN & \\
\hline CHEMBL845 & 688155 & 6.0 & 5.1107 & TST & \\
\hline CHEMBL1510704 & 688155 & 4.85 & 5.0445 & TST & \\
\hline CHEMBL 3210922 & 688155 & 4.5 & 5.07600 & 00000000005 & TRN \\
\hline CHEMBL1541408 & 688155 & 5.0 & 5.1911 & TRN & \\
\hline CHEMBL1574831 & 688155 & 5.05 & 5.0733 & TRN & \\
\hline CHEMBL1345530 & 688155 & 5.0 & 5.1379 & TST & \\
\hline CHEMBL1346879 & 688155 & 6.0 & 5.0028 & TRN & \\
\hline CHEMBL1562801 & 688155 & 5.3 & 5.0595 & TST & \\
\hline CHEMBL1484983 & 688155 & 5.1 & 5.117 & TRN & \\
\hline CHEMBL1317923 & 688155 & 5.75 & 5.2084 & TRN & \\
\hline CHEMBL88621 & 688155 & 5.55 & 5.2081 & TRN & \\
\hline CHEMBL1320486 & 688155 & 4.5 & 5.124 & TRN & \\
\hline
\end{tabular}




\begin{tabular}{|c|c|c|c|c|}
\hline \multicolumn{5}{|c|}{ Supplemental Table S2.txt } \\
\hline CHEMBL1343481 & 688155 & 4.6 & 4.9872 & TRN \\
\hline CHEMBL1412298 & 688155 & 5.25 & 5.3209 & TST \\
\hline CHEMBL 2138770 & 688155 & 4.5 & 5.221 & TRN \\
\hline CHEMBL334255 & 688155 & 5.65 & 5.1623 & TST \\
\hline CHEMBL1604733 & 688155 & 5.7 & 4.9707 & TRN \\
\hline CHEMBL 3193878 & 688155 & 5.3 & 5.1477 & TRN \\
\hline CHEMBL1596723 & 688155 & 5.0 & 5.0427 & TST \\
\hline CHEMBL1541210 & 688155 & 4.9 & 5.2059 & TRN \\
\hline CHEMBL1402489 & 688155 & 4.5 & 5.0794 & TST \\
\hline CHEMBL1568227 & 688155 & 5.45 & 5.0644 & TRN \\
\hline CHEMBL1996766 & 688155 & 4.85 & 5.2452 & TST \\
\hline CHEMBL1541671 & 688155 & 4.5 & 5.1449 & TST \\
\hline CHEMBL1315257 & 688155 & 4.55 & 5.0254 & TRN \\
\hline CHEMBL1367313 & 688155 & 5.25 & 4.982 & TRN \\
\hline CHEMBL1487852 & 688155 & 5.0 & 5.2672 & TRN \\
\hline CHEMBL1388053 & 688155 & 5.1 & 5.2503 & TRN \\
\hline CHEMBL1429745 & 688155 & 5.65 & 5.1188 & TRN \\
\hline CHEMBL1444218 & 688155 & 5.0 & 5.0226 & TRN \\
\hline CHEMBL1391017 & 688155 & 5.25 & 5.0324 & TRN \\
\hline CHEMBL1592584 & 688155 & 4.8 & 5.0141 & TRN \\
\hline CHEMBL1451087 & 688155 & 4.95 & 5.1407 & TRN \\
\hline CHEMBL3196976 & 688155 & 5.0 & 5.1771 & TRN \\
\hline CHEMBL1587212 & 688155 & 5.05 & 4.9454 & TRN \\
\hline CHEMBL1383937 & 688155 & 4.95 & 5.0598 & TST \\
\hline CHEMBL1478986 & 688155 & 4.95 & 5.1785 & TRN \\
\hline CHEMBL1486010 & 688155 & 5.0 & 4.9656 & TRN \\
\hline CHEMBL1491509 & 688155 & 4.55 & 5.0652 & TRN \\
\hline CHEMBL1992689 & 688155 & 4.95 & 5.1245 & TRN \\
\hline CHEMBL1471269 & 688155 & 5.0 & 5.0831 & TRN \\
\hline CHEMBL1526978 & 688155 & 4.9 & 5.0766 & TRN \\
\hline CHEMBL1471468 & 688155 & 5.0 & 4.997 & TST \\
\hline CHEMBL1374089 & 688155 & 5.8 & 5.0307 & TRN \\
\hline CHEMBL1332802 & 688155 & 4.5 & 5.1916 & TRN \\
\hline CHEMBL1361955 & 688155 & 4.85 & 5.0025 & TRN \\
\hline CHEMBL1401005 & 688155 & 6.35 & 5.2278 & TRN \\
\hline CHEMBL1500582 & 688155 & 4.9 & 5.1729 & TST \\
\hline CHEMBL1323526 & 688155 & 5.5 & 5.1662 & TST \\
\hline CHEMBL1342553 & 688155 & 4.95 & 5.159 & TST \\
\hline CHEMBL1465748 & 688155 & 4.55 & 5.2282 & TRN \\
\hline CHEMBL3198451 & 688155 & 4.95 & 5.0824 & TST \\
\hline CHEMBL1363347 & 688155 & 5.8 & 5.221 & TRN \\
\hline CHEMBL1425885 & 688155 & 4.8 & 5.1816 & TRN \\
\hline CHEMBL1520988 & 688155 & 4.55 & 5.0965 & TRN \\
\hline CHEMBL1346325 & 688155 & 6.0 & 5.0966 & TST \\
\hline CHEMBL1402783 & 688155 & 5.45 & 4.9412 & TST \\
\hline CHEMBL1569932 & 688155 & 4.85 & 5.0802 & TST \\
\hline CHEMBL1409917 & 688155 & 4.5 & 4.9732 & TRN \\
\hline CHEMBL1327817 & 688155 & 5.0 & $5.0680 e$ & 00000000005 \\
\hline & & & & 20179 \\
\hline
\end{tabular}




\begin{tabular}{|c|c|c|c|c|c|}
\hline \multicolumn{6}{|c|}{ Supplemental Table S2.txt } \\
\hline CHEMBL1300901 & 688155 & 5.1 & 5.1796 & TST & \\
\hline CHEMBL1444096 & 688155 & 4.55 & 5.1271 & TST & \\
\hline CHEMBL1523189 & 688155 & 4.95 & 5.1128 & TRN & \\
\hline CHEMBL1510929 & 688155 & 4.9 & 5.1344 & TRN & \\
\hline CHEMBL1449527 & 688155 & 5.5 & 4.9884 & TST & \\
\hline CHEMBL1423129 & 688155 & 5.0 & 4.9767 & TRN & \\
\hline CHEMBL1517136 & 688155 & 6.05 & 4.9832 & TST & \\
\hline CHEMBL1565449 & 688155 & 6.0 & 5.1023 & TRN & \\
\hline CHEMBL1547693 & 688155 & 4.55 & 5.0454 & TRN & \\
\hline CHEMBL1564344 & 688155 & 5.1 & 5.1004 & TRN & \\
\hline CHEMBL1463752 & 688155 & 5.25 & 5.2201 & TRN & \\
\hline CHEMBL1374884 & 688155 & 4.95 & 5.1372 & TRN & \\
\hline CHEMBL1510964 & 688155 & 4.6 & 5.1176 & TRN & \\
\hline CHEMBL1445552 & 688155 & 6.0 & 5.0177 & TRN & \\
\hline CHEMBL1467628 & 688155 & 6.5 & 5.1924 & TRN & \\
\hline CHEMBL1462394 & 688155 & 5.3 & 5.1196 & TRN & \\
\hline CHEMBL1319364 & 688155 & 5.15 & 5.1069 & TRN & \\
\hline CHEMBL1307792 & 688155 & 5.45 & 4.9046 & TST & \\
\hline CHEMBL1455127 & 688155 & 4.55 & 4.9774 & TRN & \\
\hline CHEMBL1595823 & 688155 & 4.95 & 5.0597 & TST & \\
\hline CHEMBL1526655 & 688155 & 5.45 & 5.046 & TRN & \\
\hline CHEMBL1311577 & 688155 & 4.5 & 5.1715 & TRN & \\
\hline CHEMBL1544334 & 688155 & 4.55 & 5.0307 & TRN & \\
\hline CHEMBL1600351 & 688155 & 5.0 & 5.0692 & TRN & \\
\hline CHEMBL1506363 & 688155 & 4.9 & 5.0266 & TST & \\
\hline CHEMBL1385766 & 688155 & 5.0 & 5.1173 & TST & \\
\hline CHEMBL1336044 & 688155 & 4.95 & 5.1912 & TST & \\
\hline CHEMBL1364180 & 688155 & 4.85 & 5.2427 & TRN & \\
\hline CHEMBL1604403 & 688155 & 5.55 & 5.1394 & TRN & \\
\hline CHEMBL1388368 & 688155 & 5.2 & 5.1092 & TST & \\
\hline CHEMBL1429530 & 688155 & 5.45 & 5.3206 & TRN & \\
\hline CHEMBL1306978 & 688155 & 5.1 & 5.1406 & TST & \\
\hline CHEMBL1309266 & 688155 & 5.45 & 5.0135 & TST & \\
\hline CHEMBL1374482 & 688155 & 5.65 & $5.0710 e$ & 3000000001 & TRN \\
\hline CHEMBL1491356 & 688155 & 4.45 & 5.0611 & TRN & \\
\hline CHEMBL1438319 & 688155 & 4.9 & 4.9871 & TRN & \\
\hline CHEMBL590457 & 688155 & 4.65 & 5.0119 & TRN & \\
\hline CHEMBL1603533 & 688155 & 5.0 & 4.9982 & TRN & \\
\hline CHEMBL1313817 & 688155 & 5.0 & 5.1517 & TRN & \\
\hline CHEMBL1425426 & 688155 & 6.0 & 5.1412 & TRN & \\
\hline CHEMBL1509766 & 688155 & 4.55 & 5.2151 & TRN & \\
\hline CHEMBL1533900 & 688155 & 5.4 & 5.2715 & TST & \\
\hline CHEMBL1540459 & 688155 & 4.65 & 4.8898 & TST & \\
\hline CHEMBL1304420 & 688155 & 5.75 & 5.0573 & TRN & \\
\hline CHEMBL1343813 & 688155 & 4.55 & 5.1296 & TST & \\
\hline CHEMBL1460751 & 688155 & 4.85 & 5.0027 & TRN & \\
\hline CHEMBL1389665 & 688155 & 5.35 & 5.0582 & TRN & \\
\hline CHEMBL1364569 & 688155 & 4.95 & 5.0269 & TST & \\
\hline
\end{tabular}




\begin{tabular}{|c|c|c|c|c|}
\hline \multicolumn{5}{|c|}{ Supplemental Table S2.txt } \\
\hline CHEMBL1323031 & 688155 & 4.65 & 5.1484 & TRN \\
\hline CHEMBL1337175 & 688155 & 4.5 & 5.2334 & TRN \\
\hline CHEMBL1375046 & 688155 & 5.7 & 4.9043 & TRN \\
\hline CHEMBL1409789 & 688155 & 4.55 & 4.8737 & TRN \\
\hline CHEMBL1381523 & 688155 & 4.9 & 5.0476 & TST \\
\hline CHEMBL1378189 & 688155 & 6.5 & 5.0957 & TRN \\
\hline CHEMBL1452494 & 688155 & 5.05 & 5.0502 & TRN \\
\hline CHEMBL1607798 & 688155 & 5.6 & 5.2843 & TST \\
\hline CHEMBL1549641 & 688155 & 4.95 & 4.9497 & TST \\
\hline CHEMBL1536768 & 688155 & 5.0 & 4.9233 & TRN \\
\hline CHEMBL1583591 & 688155 & 6.5 & 4.9563 & TST \\
\hline CHEMBL1301224 & 688155 & 4.55 & 5.0972 & TRN \\
\hline CHEMBL1502760 & 688155 & 4.55 & 5.0514 & TRN \\
\hline CHEMBL3212392 & 688155 & 4.95 & 5.1029 & TRN \\
\hline CHEMBL1420044 & 688155 & 5.0 & 5.0537 & TRN \\
\hline CHEMBL1371241 & 688155 & 6.5 & 5.0972 & TST \\
\hline CHEMBL1518519 & 688155 & 4.55 & 5.1365 & TRN \\
\hline CHEMBL1523061 & 688155 & 5.5 & 5.1876 & TRN \\
\hline CHEMBL1452886 & 688155 & 4.55 & 4.9801 & TRN \\
\hline CHEMBL1418583 & 688155 & 4.95 & 5.0 & TRN \\
\hline CHEMBL1577771 & 688155 & 4.75 & 4.9723 & TRN \\
\hline CHEMBL1530382 & 688155 & 4.95 & 5.0341 & TRN \\
\hline CHEMBL1973866 & 688155 & 4.65 & 4.9182 & TST \\
\hline CHEMBL1330787 & 688155 & 5.0 & 4.9303 & TST \\
\hline CHEMBL1312000 & 688155 & 4.55 & 5.2199 & TRN \\
\hline CHEMBL1577271 & 688155 & 5.95 & 5.1231 & TRN \\
\hline CHEMBL1459146 & 688155 & 4.5 & 5.073 & TRN \\
\hline CHEMBL1348840 & 688155 & 4.55 & 4.982 & TRN \\
\hline CHEMBL1340976 & 688155 & 4.8 & 5.2248 & TRN \\
\hline CHEMBL1337889 & 688155 & 5.25 & 5.0669 & TRN \\
\hline CHEMBL1368310 & 688155 & 5.85 & 5.1646 & TRN \\
\hline CHEMBL1386481 & 688155 & 6.5 & 5.0312 & TST \\
\hline CHEMBL1306228 & 688155 & 5.85 & 5.1681 & TST \\
\hline CHEMBL1504471 & 688155 & 4.95 & 5.2632 & TRN \\
\hline CHEMBL1583724 & 688155 & 5.25 & 5.0902 & TRN \\
\hline CHEMBL1377666 & 688155 & 5.65 & 5.2139 & TRN \\
\hline CHEMBL1468383 & 688155 & 5.0 & 5.1104 & TRN \\
\hline CHEMBL1470594 & 688155 & 4.55 & 4.9981 & TRN \\
\hline CHEMBL1372443 & 688155 & 4.5 & 5.0372 & TRN \\
\hline CHEMBL50267 & 688155 & 5.0 & 5.0662 & TST \\
\hline CHEMBL1485112 & 688155 & 4.55 & 5.0153 & TRN \\
\hline CHEMBL1328133 & 688155 & 5.95 & 5.1282 & TRN \\
\hline CHEMBL580421 & 688155 & 5.0 & 5.1192 & TST \\
\hline CHEMBL1587951 & 688155 & 5.1 & 5.2413 & TRN \\
\hline CHEMBL468167 & 688155 & 4.6 & 5.1277 & TST \\
\hline CHEMBL1375747 & 688155 & 4.55 & 5.0915 & TRN \\
\hline CHEMBL3209072 & 688155 & 4.5 & 5.045 & TST \\
\hline CHEMBL1604627 & 688155 & 4.5 & 5.0849 & TRN \\
\hline
\end{tabular}




\begin{tabular}{|c|c|c|c|c|c|}
\hline \multicolumn{6}{|c|}{ Supplemental Table S2.txt } \\
\hline CHEMBL15193 & 688155 & 4.9 & 5.1338 & TST & \\
\hline CHEMBL1303124 & 688155 & 4.95 & 5.2527 & TRN & \\
\hline CHEMBL1328078 & 688155 & 4.95 & 5.1318 & TST & \\
\hline CHEMBL1389013 & 688155 & 5.0 & 5.1128 & TRN & \\
\hline CHEMBL1489221 & 688155 & 4.45 & 5.0261 & TRN & \\
\hline CHEMBL1386843 & 688155 & 5.85 & 5.0366 & TRN & \\
\hline CHEMBL1377813 & 688155 & 5.3 & 5.17 & TST & \\
\hline CHEMBL1481174 & 688155 & 5.8 & 5.055 & TST & \\
\hline CHEMBL1568200 & 688155 & 4.55 & 5.0135 & TRN & \\
\hline CHEMBL1366121 & 688155 & 5.0 & 5.0476 & TRN & \\
\hline CHEMBL1410656 & 688155 & 5.0 & 5.1406 & TRN & \\
\hline CHEMBL1318829 & 688155 & 4.95 & 4.9694 & TRN & \\
\hline CHEMBL1490912 & 688155 & 6.0 & 5.2186 & TRN & \\
\hline CHEMBL1443601 & 688155 & 4.55 & 5.1056 & TRN & \\
\hline CHEMBL1548600 & 688155 & 4.5 & 5.0664 & TRN & \\
\hline CHEMBL1438188 & 688155 & 4.85 & 5.1046 & TRN & \\
\hline CHEMBL1501751 & 688155 & 4.55 & 5.1285 & TST & \\
\hline CHEMBL1395412 & 688155 & 6.0 & 5.2325 & TRN & \\
\hline CHEMBL1192187 & 688155 & 6.0 & 5.197 & TRN & \\
\hline CHEMBL1578260 & 688155 & 4.85 & 5.1948 & TRN & \\
\hline CHEMBL1530551 & 688155 & 5.05 & 4.9781 & TRN & \\
\hline CHEMBL1409898 & 688155 & 5.7 & 5.2173 & TST & \\
\hline CHEMBL1441242 & 688155 & 5.0 & 5.0964 & TRN & \\
\hline CHEMBL1386914 & 688155 & 5.95 & 4.9574 & TRN & \\
\hline CHEMBL448847 & 688155 & 5.5 & 5.1337 & TST & \\
\hline CHEMBL1601712 & 688155 & 6.0 & 4.9686 & TRN & \\
\hline CHEMBL1529360 & 688155 & 4.5 & 5.2007 & TRN & \\
\hline CHEMBL1387945 & 688155 & 4.9 & 4.9648 & TRN & \\
\hline CHEMBL1377478 & 688155 & 5.0 & 5.204 & TST & \\
\hline CHEMBL3212833 & 688155 & 4.9 & 5.0698 & TST & \\
\hline CHEMBL312487 & 688155 & 5.8 & 5.0695 & TST & \\
\hline CHEMBL1598114 & 688155 & 4.55 & 5.0258 & TRN & \\
\hline CHEMBL1446630 & 688155 & 4.9 & 5.0419 & TST & \\
\hline CHEMBL1508872 & 688155 & 5.75 & 4.9492 & TRN & \\
\hline CHEMBL201305 & 688155 & 4.55 & 5.1016 & TST & \\
\hline CHEMBL1424653 & 688155 & 5.8 & 5.0286 & TRN & \\
\hline CHEMBL1504592 & 688155 & 6.5 & 5.1034 & TST & \\
\hline CHEMBL1501575 & 688155 & 5.9 & 5.1369 & TRN & \\
\hline CHEMBL1384088 & 688155 & 4.95 & 5.0803 & TRN & \\
\hline CHEMBL1525187 & 688155 & 5.0 & 5.0645 & TST & \\
\hline CHEMBL1467089 & 688155 & 4.95 & 4.9092 & TRN & \\
\hline CHEMBL1447311 & 688155 & 6.1 & 5.25799 & 9999999999 & TRN \\
\hline CHEMBL1583364 & 688155 & 4.95 & 5.2919 & TRN & \\
\hline CHEMBL1389385 & 688155 & 6.45 & 5.0667 & TRN & \\
\hline CHEMBL1585554 & 688155 & 4.5 & 5.0705 & TRN & \\
\hline CHEMBL1302324 & 688155 & 4.55 & 4.9987 & TRN & \\
\hline CHEMBL1353757 & 688155 & 4.5 & 4.9162 & TST & \\
\hline CHEMBL1409216 & 688155 & 4.9 & 4.9977 & TRN & \\
\hline
\end{tabular}




\begin{tabular}{|c|c|c|c|c|c|}
\hline & & \multicolumn{4}{|c|}{ Supplemental Table s2.txt } \\
\hline CHEMBL1610573 & 688155 & 5.45 & 5.1349 & TST & \\
\hline CHEMBL1518765 & 688155 & 4.65 & 5.0941 & TRN & \\
\hline CHEMBL1455185 & 688155 & 5.05 & 5.1329 & TRN & \\
\hline CHEMBL 3197702 & 688155 & 4.75 & 4.9811 & TST & \\
\hline CHEMBL1302664 & 688155 & 4.9 & 5.2093 & TST & \\
\hline CHEMBL1373577 & 688155 & 5.45 & 5.0857 & TRN & \\
\hline CHEMBL1544802 & 688155 & 5.2 & 5.0035 & TST & \\
\hline CHEMBL1414987 & 688155 & 5.95 & 4.9978 & TRN & \\
\hline CHEMBL1567092 & 688155 & 5.15 & 5.0819 & TST & \\
\hline CHEMBL1594349 & 688155 & 5.05 & 5.1615 & TRN & \\
\hline CHEMBL1510014 & 688155 & 5.75 & 5.1821 & TRN & \\
\hline CHEMBL1447498 & 688155 & 4.8 & 4.9318 & TRN & \\
\hline CHEMBL1562103 & 688155 & 5.3 & 5.0744 & TRN & \\
\hline CHEMBL1566564 & 688155 & 4.55 & 5.23799 & 99999999995 & TRN \\
\hline CHEMBL1601300 & 688155 & 4.85 & 5.0346 & TRN & \\
\hline CHEMBL1430507 & 688155 & 6.05 & 4.9864 & TRN & \\
\hline CHEMBL1505880 & 688155 & 5.05 & 5.0242 & TRN & \\
\hline CHEMBL1529901 & 688155 & 5.65 & 5.1548 & TRN & \\
\hline CHEMBL1202936 & 688155 & 4.7 & 5.2353 & TRN & \\
\hline CHEMBL1450531 & 688155 & 4.85 & 4.9082 & TRN & \\
\hline CHEMBL1392825 & 688155 & 5.1 & 5.0666 & TRN & \\
\hline CHEMBL1603951 & 688155 & 4.55 & 5.0217 & TRN & \\
\hline CHEMBL1311072 & 688155 & 4.95 & 5.1133 & TST & \\
\hline CHEMBL1321663 & 688155 & 5.15 & 5.0222 & TRN & \\
\hline CHEMBL1502516 & 688155 & 5.5 & 4.9702 & TRN & \\
\hline CHEMBL1403470 & 688155 & 4.55 & 5.1597 & TRN & \\
\hline CHEMBL1591556 & 688155 & 4.55 & 5.0725 & TST & \\
\hline CHEMBL1368018 & 688155 & 4.95 & 5.0167 & TRN & \\
\hline CHEMBL1522120 & 688155 & 5.5 & 5.1674 & TRN & \\
\hline CHEMBL1437123 & 688155 & 4.6 & 5.0513 & TRN & \\
\hline CHEMBL1325641 & 688155 & 4.75 & 5.2087 & TRN & \\
\hline CHEMBL1539070 & 688155 & 5.05 & 4.9293 & TRN & \\
\hline CHEMBL1379365 & 688155 & 5.4 & 5.1003 & TRN & \\
\hline CHEMBL1420683 & 688155 & 4.9 & 5.0689 & TRN & \\
\hline CHEMBL1399669 & 688155 & 4.5 & 5.0089 & TRN & \\
\hline CHEMBL1606732 & 688155 & 4.9 & 4.973 & TRN & \\
\hline CHEMBL1554829 & 688155 & 4.95 & 5.1204 & TST & \\
\hline CHEMBL1608355 & 688155 & 4.65 & 5.0252 & TST & \\
\hline CHEMBL1348442 & 688155 & 5.25 & 5.1671 & TRN & \\
\hline CHEMBL1340321 & 688155 & 4.85 & 4.9638 & TRN & \\
\hline CHEMBL1332156 & 688155 & 4.55 & 5.1053 & TRN & \\
\hline CHEMBL1460730 & 688155 & 4.95 & 5.1568 & TRN & \\
\hline CHEMBL1606360 & 688155 & 6.5 & 4.9816 & TRN & \\
\hline CHEMBL1537419 & 688155 & 4.65 & 5.2735 & TRN & \\
\hline CHEMBL1405306 & 688155 & 4.85 & 4.8817 & TRN & \\
\hline CHEMBL1589797 & 688155 & 4.9 & 5.0003 & TST & \\
\hline CHEMBL1335083 & 688155 & 4.9 & 5.0024 & TRN & \\
\hline CHEMBL1358019 & 688155 & 6.0 & 5.1196 & TST & \\
\hline
\end{tabular}




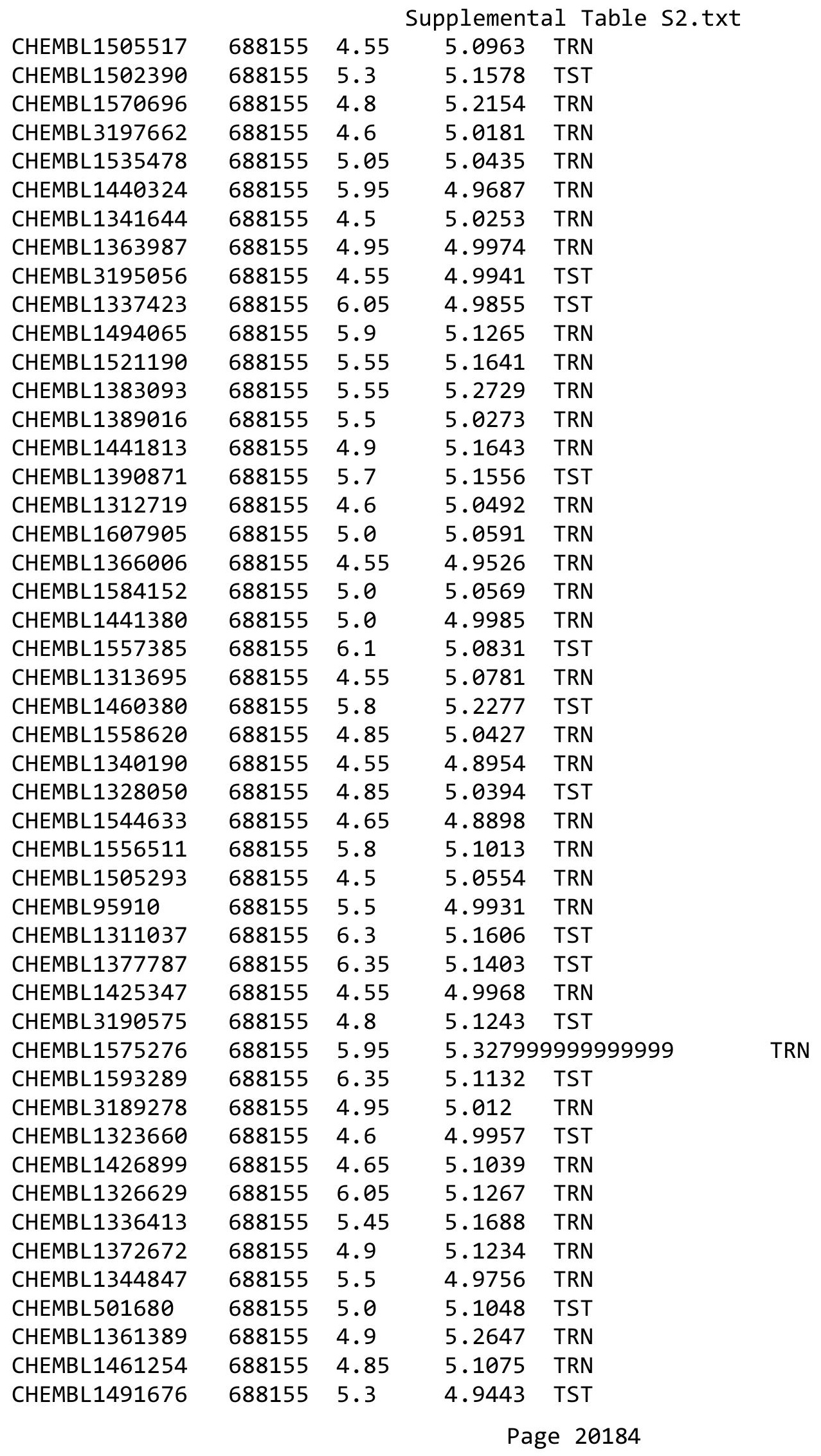




\begin{tabular}{|c|c|c|c|c|c|}
\hline \multirow{3}{*}{$\begin{array}{l}\text { CHEMBL1415594 } \\
\text { CHEMBL } 3192632\end{array}$} & \multirow[b]{2}{*}{688155} & \multicolumn{4}{|c|}{ Supplemental Table S2.txt } \\
\hline & & 4.6 & \multicolumn{2}{|c|}{5.2139999999999995} & TRN \\
\hline & 688155 & 4.7 & 4.9295 & TRN & \\
\hline CHEMBL314639 & 688155 & 4.95 & 5.1045 & TST & \\
\hline CHEMBL1498284 & 688155 & 4.95 & 5.0994 & TST & \\
\hline CHEMBL1407141 & 688155 & 5.25 & 5.2168 & TRN & \\
\hline CHEMBL1343750 & 688155 & 4.55 & 4.97199 & 99999999995 & TRN \\
\hline CHEMBL1610323 & 688155 & 5.3 & 5.0927 & TST & \\
\hline CHEMBL1347130 & 688155 & 4.9 & 4.9956 & TRN & \\
\hline CHEMBL1387210 & 688155 & 4.95 & 4.9834 & TRN & \\
\hline CHEMBL1423274 & 688155 & 4.65 & 5.022 & TRN & \\
\hline CHEMBL1558288 & 688155 & 4.85 & 5.1515 & TRN & \\
\hline CHEMBL1360343 & 688155 & 5.9 & 5.08 & TST & \\
\hline CHEMBL1461215 & 688155 & 4.55 & 5.1151 & TRN & \\
\hline CHEMBL1300579 & 688155 & 6.3 & 5.2878 & TRN & \\
\hline CHEMBL1360383 & 688155 & 4.95 & 4.9762 & TRN & \\
\hline CHEMBL1472170 & 688155 & 4.55 & 4.9803 & TRN & \\
\hline CHEMBL1511707 & 688155 & 4.9 & 5.086 & TST & \\
\hline CHEMBL1472338 & 688155 & 4.95 & 5.2413 & TRN & \\
\hline CHEMBL1542748 & 688155 & 4.95 & 5.0421 & TRN & \\
\hline CHEMBL1454045 & 688155 & 5.35 & 5.1495 & TRN & \\
\hline CHEMBL1405149 & 688155 & 5.65 & 5.2625 & TST & \\
\hline CHEMBL578896 & 688155 & 4.5 & 5.1936 & TRN & \\
\hline CHEMBL1562183 & 688155 & 4.5 & 5.1885 & TRN & \\
\hline CHEMBL1341196 & 688155 & 5.0 & 5.1074 & TRN & \\
\hline CHEMBL1299945 & 688155 & 4.55 & 4.9434 & TRN & \\
\hline CHEMBL1448140 & 688155 & 5.0 & 5.0072 & TRN & \\
\hline CHEMBL1353807 & 688155 & 5.1 & 5.2081 & TST & \\
\hline CHEMBL 2002830 & 688155 & 5.95 & 4.9813 & TRN & \\
\hline CHEMBL1409595 & 688155 & 7.1002 & 5.2143 & TRN & \\
\hline CHEMBL3195235 & 688155 & 4.5 & 4.9797 & TST & \\
\hline CHEMBL1489716 & 688155 & 4.55 & 4.9918 & TRN & \\
\hline CHEMBL1412461 & 688155 & 5.55 & 5.0804 & TRN & \\
\hline CHEMBL1431447 & 688155 & 4.95 & 5.0452 & TRN & \\
\hline CHEMBL1602229 & 688155 & 6.45 & 5.1715 & TRN & \\
\hline CHEMBL520107 & 688155 & 4.5 & 5.1014 & TST & \\
\hline CHEMBL492886 & 688155 & 5.65 & 5.0814 & TST & \\
\hline CHEMBL1350866 & 688155 & 4.95 & 4.9686 & TRN & \\
\hline CHEMBL1990096 & 688155 & 4.7 & 5.0359 & TRN & \\
\hline CHEMBL539027 & 688155 & 4.5 & 5.1713 & TRN & \\
\hline CHEMBL1478783 & 688155 & 5.3 & 5.1326 & TRN & \\
\hline CHEMBL1611179 & 688155 & 6.45 & 5.15799 & 99999999995 & TST \\
\hline CHEMBL1528205 & 688155 & 4.55 & 4.9972 & TRN & \\
\hline CHEMBL1489090 & 688155 & 5.0 & 5.0695 & TRN & \\
\hline CHEMBL1526977 & 688155 & 4.55 & 5.0824 & TRN & \\
\hline CHEMBL1345097 & 688155 & 4.8 & 5.1609 & TRN & \\
\hline CHEMBL1577592 & 688155 & 4.55 & 5.1858 & TRN & \\
\hline CHEMBL1521879 & 688155 & 4.5 & 5.1222 & TRN & \\
\hline CHEMBL1593765 & 688155 & 4.6 & 5.1101 & TRN & \\
\hline
\end{tabular}




\begin{tabular}{|c|c|c|c|c|c|}
\hline & & \multicolumn{4}{|c|}{ Supplemental Table s2.txt } \\
\hline CHEMBL1563818 & 688155 & 5.85 & 5.21 & TST & \\
\hline CHEMBL1586975 & 688155 & 4.6 & 5.1164 & TST & \\
\hline CHEMBL1600944 & 688155 & 4.8 & 4.9023 & TRN & \\
\hline CHEMBL1557808 & 688155 & 5.5 & 5.087 & TRN & \\
\hline CHEMBL1565267 & 688155 & 5.3 & 5.0448 & TST & \\
\hline CHEMBL1568735 & 688155 & 4.5 & 4.9096 & TRN & \\
\hline CHEMBL1421591 & 688155 & 4.5 & 5.1204 & TST & \\
\hline CHEMBL1482899 & 688155 & 5.05 & 5.0901 & TRN & \\
\hline CHEMBL1401322 & 688155 & 4.5 & 5.0132 & TRN & \\
\hline CHEMBL1468746 & 688155 & 4.55 & 4.9466 & TST & \\
\hline CHEMBL1565242 & 688155 & 4.7 & 4.9886 & TRN & \\
\hline CHEMBL1333135 & 688155 & 4.55 & 5.1391 & TST & \\
\hline CHEMBL1588769 & 688155 & 4.9 & 4.9829 & TRN & \\
\hline CHEMBL1522033 & 688155 & 4.55 & 5.0917 & TRN & \\
\hline CHEMBL1321356 & 688155 & 5.0 & 5.0027 & TRN & \\
\hline CHEMBL1460526 & 688155 & 4.6 & 5.0926 & TRN & \\
\hline CHEMBL1557562 & 688155 & 5.1 & 5.0527 & TRN & \\
\hline CHEMBL1409554 & 688155 & 6.45 & 5.0523 & TST & \\
\hline CHEMBL1448066 & 688155 & 6.35 & 5.12 & TRN & \\
\hline CHEMBL1414766 & 688155 & 4.85 & 5.1629 & TST & \\
\hline CHEMBL1299808 & 688155 & 6.35 & 5.0692 & TRN & \\
\hline CHEMBL1393920 & 688155 & 4.6 & 5.046 & TRN & \\
\hline CHEMBL1349609 & 688155 & 5.85 & 4.8943 & TRN & \\
\hline CHEMBL1460619 & 688155 & 4.95 & 4.8987 & TRN & \\
\hline CHEMBL1330034 & 688155 & 5.25 & 5.2622 & TRN & \\
\hline CHEMBL1526693 & 688155 & 4.95 & 4.9866 & TRN & \\
\hline CHEMBL1388802 & 688155 & 6.05 & 4.9426 & TRN & \\
\hline CHEMBL1348280 & 688155 & 5.95 & 4.9876 & TRN & \\
\hline CHEMBL1403813 & 688155 & 5.75 & 5.0999 & TRN & \\
\hline CHEMBL1498456 & 688155 & 5.8 & 5.1291 & TST & \\
\hline CHEMBL1435259 & 688155 & 5.1 & 4.9108 & TRN & \\
\hline CHEMBL1370630 & 688155 & 4.8 & 5.0742 & TRN & \\
\hline CHEMBL1391985 & 688155 & 5.25 & 5.1842 & TRN & \\
\hline CHEMBL1413032 & 688155 & 4.5 & 5.1025 & TRN & \\
\hline CHEMBL1470135 & 688155 & 4.65 & 5.1177 & TRN & \\
\hline CHEMBL1528698 & 688155 & 4.65 & 5.0961 & TRN & \\
\hline CHEMBL1609279 & 688155 & 4.85 & 5.0883 & TRN & \\
\hline CHEMBL1477452 & 688155 & 4.95 & 5.1061 & TST & \\
\hline CHEMBL1505913 & 688155 & 5.0 & 5.0332 & TRN & \\
\hline CHEMBL1319229 & 688155 & 5.85 & 5.0463 & TRN & \\
\hline CHEMBL1316779 & 688155 & 4.9 & 4.9386 & TRN & \\
\hline CHEMBL1445430 & 688155 & 4.5 & 5.0626 & TST & \\
\hline CHEMBL1384190 & 688155 & 4.55 & 4.8878 & TRN & \\
\hline CHEMBL1586139 & 688155 & 4.5 & 5.0579 & TRN & \\
\hline CHEMBL1551578 & 688155 & 6.15 & 5.1718 & TRN & \\
\hline CHEMBL1536204 & 688155 & 4.95 & 4.994 & TRN & \\
\hline CHEMBL1353968 & 688155 & 6.2 & 5.23600 & 0000000001 & TRN \\
\hline CHEMBL1559168 & 688155 & 4.95 & 5.0371 & TRN & \\
\hline
\end{tabular}




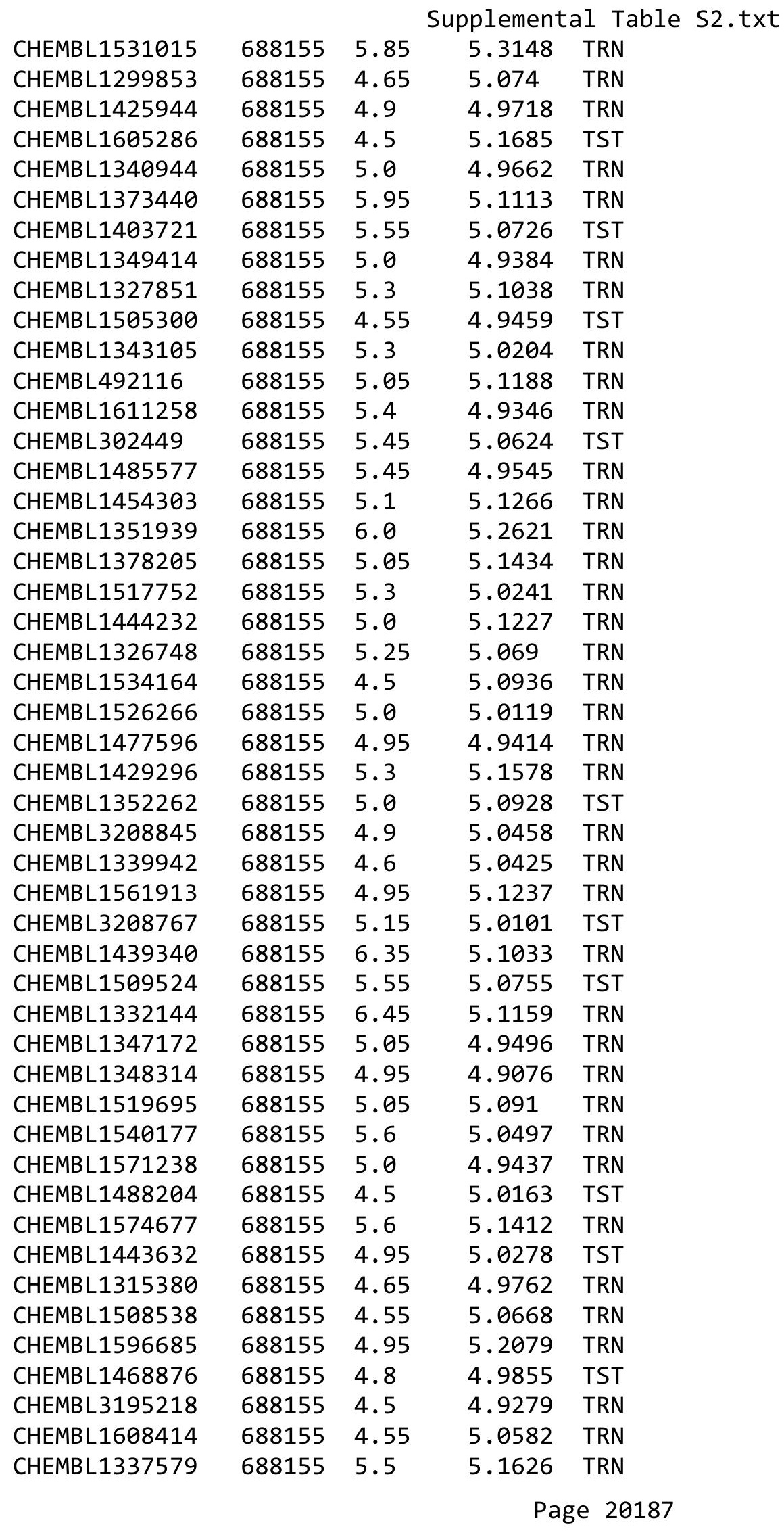




\begin{tabular}{|c|c|c|c|c|}
\hline \multicolumn{5}{|c|}{ Supplemental Table S2.txt } \\
\hline CHEMBL1328410 & 688155 & 4.5 & 5.0937 & TRN \\
\hline CHEMBL1508303 & 688155 & 5.6 & 5.15799 & 99999999995 \\
\hline CHEMBL1335318 & 688155 & 5.0 & 5.1624 & TRN \\
\hline CHEMBL1453502 & 688155 & 5.0 & 4.9359 & TRN \\
\hline CHEMBL1446626 & 688155 & 5.5 & 4.9462 & TRN \\
\hline CHEMBL1609703 & 688155 & 5.25 & 5.0522 & TST \\
\hline CHEMBL1338611 & 688155 & 5.9 & 5.1473 & TRN \\
\hline CHEMBL1468369 & 688155 & 5.25 & 4.933 & TST \\
\hline CHEMBL1993380 & 688155 & 5.0 & 4.8545 & TRN \\
\hline CHEMBL1338747 & 688155 & 4.9 & 5.0338 & TST \\
\hline CHEMBL1326506 & 688155 & 4.65 & 5.1681 & TRN \\
\hline CHEMBL1550393 & 688155 & 4.55 & 5.1676 & TST \\
\hline CHEMBL1378944 & 688155 & 5.0 & 5.0706 & TRN \\
\hline CHEMBL1519930 & 688155 & 5.3 & 5.0095 & TRN \\
\hline CHEMBL1400298 & 688155 & 5.05 & 5.0064 & TST \\
\hline CHEMBL1368261 & 688155 & 4.95 & 5.0156 & TRN \\
\hline CHEMBL1353573 & 688155 & 5.35 & 5.0601 & TRN \\
\hline CHEMBL1525898 & 688155 & 5.15 & 5.0918 & TST \\
\hline CHEMBL1330556 & 688155 & 4.95 & 4.9483 & TRN \\
\hline CHEMBL1346140 & 688155 & 4.5 & 5.1028 & TRN \\
\hline CHEMBL1610240 & 688155 & 4.55 & 5.0544 & TRN \\
\hline CHEMBL1412288 & 688155 & 4.55 & 4.967 & TRN \\
\hline CHEMBL1413983 & 688155 & 5.45 & 5.0121 & TRN \\
\hline CHEMBL1592796 & 688155 & 5.2 & 5.1128 & TRN \\
\hline CHEMBL1439536 & 688155 & 4.9 & 5.0154 & TST \\
\hline CHEMBL1470199 & 688155 & 4.6 & 4.9753 & TRN \\
\hline CHEMBL1422439 & 688155 & 4.55 & 4.9925 & TST \\
\hline CHEMBL1371616 & 688155 & 5.9 & 5.0443 & TRN \\
\hline CHEMBL1381520 & 688155 & 4.65 & 5.0719 & TRN \\
\hline CHEMBL1533107 & 688155 & 5.1 & 4.9195 & TRN \\
\hline CHEMBL1373910 & 688155 & 5.6 & 4.9114 & TRN \\
\hline CHEMBL1479203 & 688155 & 6.1 & 5.2576 & TST \\
\hline CHEMBL525826 & 688155 & 4.9 & 4.9507 & TRN \\
\hline CHEMBL1383602 & 688155 & 5.45 & 5.2957 & TRN \\
\hline CHEMBL1486177 & 688155 & 7.0501 & 5.0523 & TST \\
\hline CHEMBL3212702 & 688155 & 4.7 & 5.0132 & TRN \\
\hline CHEMBL1382650 & 688155 & 4.9 & 5.0709 & TRN \\
\hline CHEMBL1460986 & 688155 & 6.3 & 4.9974 & TST \\
\hline CHEMBL1506331 & 688155 & 4.9 & 5.289 & TST \\
\hline CHEMBL1492655 & 688155 & 5.0 & 5.081 & TRN \\
\hline CHEMBL1976046 & 688155 & 4.95 & 4.9023 & TST \\
\hline CHEMBL1494716 & 688155 & 5.5 & 5.1532 & TRN \\
\hline CHEMBL3196786 & 688155 & 5.05 & 5.1049 & TST \\
\hline CHEMBL1560379 & 688155 & 4.65 & 4.9251 & TRN \\
\hline CHEMBL1418168 & 688155 & 4.85 & 4.998 & TST \\
\hline CHEMBL1325897 & 688155 & 4.5 & 4.992 & TRN \\
\hline CHEMBL1368381 & 688155 & 5.5 & 5.1707 & TRN \\
\hline CHEMBL1333667 & 688155 & 4.5 & 4.9819 & TRN \\
\hline
\end{tabular}




\begin{tabular}{|c|c|c|c|c|c|}
\hline \multicolumn{6}{|c|}{ Supplemental Table S2.txt } \\
\hline CHEMBL1501393 & 688155 & 4.9 & 5.1735 & TRN & \\
\hline CHEMBL1585274 & 688155 & 5.5 & 5.1948 & TST & \\
\hline CHEMBL1492422 & 688155 & 5.2 & 5.0492 & TRN & \\
\hline CHEMBL1582684 & 688155 & 4.5 & 4.9706 & TRN & \\
\hline CHEMBL1499903 & 688155 & 6.05 & 5.1213 & TRN & \\
\hline CHEMBL1562408 & 688155 & 5.1 & 4.9853 & TRN & \\
\hline CHEMBL1456743 & 688155 & 6.5 & 5.0253 & TRN & \\
\hline CHEMBL1374003 & 688155 & 5.7 & 4.9436 & TST & \\
\hline CHEMBL1543965 & 688155 & 5.15 & 4.9453 & TST & \\
\hline CHEMBL1517172 & 688155 & 6.0 & 5.1742 & TRN & \\
\hline CHEMBL1965669 & 688155 & 4.7 & 5.0789 & TRN & \\
\hline CHEMBL1607082 & 688155 & 5.0 & 5.0254 & TRN & \\
\hline CHEMBL1611786 & 688155 & 4.55 & 4.9846 & TST & \\
\hline CHEMBL1465433 & 688155 & 4.6 & 4.8909 & TRN & \\
\hline CHEMBL1584378 & 688155 & 5.15 & 5.2817 & TST & \\
\hline CHEMBL1490166 & 688155 & 4.5 & 5.0641 & TRN & \\
\hline CHEMBL1404472 & 688155 & 5.0 & 5.0674 & TRN & \\
\hline CHEMBL1574426 & 688155 & 5.6 & 5.1712 & TRN & \\
\hline CHEMBL1476078 & 688155 & 5.7 & 5.2501 & TRN & \\
\hline CHEMBL1599874 & 688155 & 4.55 & 5.1253 & TRN & \\
\hline CHEMBL1331801 & 688155 & 5.1 & 5.1317 & TST & \\
\hline CHEMBL1536035 & 688155 & 4.5 & 5.1058 & TRN & \\
\hline CHEMBL1698283 & 688155 & 4.5 & 4.9965 & TST & \\
\hline CHEMBL1329962 & 688155 & 4.5 & 5.0831 & TRN & \\
\hline CHEMBL1517620 & 688155 & 4.5 & 5.1192 & TRN & \\
\hline CHEMBL1447628 & 688155 & 5.95 & 4.9598 & TRN & \\
\hline CHEMBL1603856 & 688155 & 4.95 & 5.04899 & 99999999995 & TRN \\
\hline CHEMBL1579729 & 688155 & 6.0 & 5.1378 & TRN & \\
\hline CHEMBL1416493 & 688155 & 4.85 & 4.9097 & TRN & \\
\hline CHEMBL1602137 & 688155 & 4.55 & 5.2111 & TRN & \\
\hline CHEMBL1354143 & 688155 & 6.05 & 4.9787 & TRN & \\
\hline CHEMBL1302669 & 688155 & 4.85 & 4.9994 & TRN & \\
\hline CHEMBL1459818 & 688155 & 6.5 & 5.246 & TST & \\
\hline CHEMBL1326178 & 688155 & 5.8 & 5.2206 & TRN & \\
\hline CHEMBL1469557 & 688155 & 5.0 & 5.0754 & TRN & \\
\hline CHEMBL587884 & 688155 & 4.85 & 5.1712 & TST & \\
\hline CHEMBL1612732 & 688155 & 4.55 & 4.8447 & TST & \\
\hline CHEMBL1493130 & 688155 & 4.85 & 5.21200 & 0000000001 & TRN \\
\hline CHEMBL1328648 & 688155 & 4.9 & 4.9648 & TRN & \\
\hline CHEMBL1525698 & 688155 & 4.9 & 4.9585 & TRN & \\
\hline CHEMBL1315457 & 688155 & 4.9 & 5.1116 & TST & \\
\hline CHEMBL1353778 & 688155 & 4.9 & 5.1889 & TST & \\
\hline CHEMBL1306131 & 688155 & 6.0 & 5.0946 & TST & \\
\hline CHEMBL1440147 & 688155 & 5.1 & 5.11100 & 0000000001 & TRN \\
\hline CHEMBL1571208 & 688155 & 4.9 & 5.0898 & TRN & \\
\hline CHEMBL1394040 & 688155 & 6.05 & 5.07 & TRN & \\
\hline CHEMBL1353510 & 688155 & 4.5 & 5.0666 & TRN & \\
\hline CHEMBL1599591 & 688155 & 4.55 & 5.1592 & TST & \\
\hline
\end{tabular}




\begin{tabular}{|c|c|c|c|c|}
\hline \multicolumn{5}{|c|}{ Supplemental Table s2.txt } \\
\hline CHEMBL1578405 & 688155 & 5.6 & 5.0166 & TRN \\
\hline CHEMBL1457094 & 688155 & 4.5 & 5.0947 & TRN \\
\hline CHEMBL1423125 & 688155 & 4.95 & 4.9691 & TRN \\
\hline CHEMBL1465539 & 688155 & 6.3 & 5.0008 & TRN \\
\hline CHEMBL1549896 & 688155 & 5.8 & 5.1536 & TRN \\
\hline CHEMBL1394437 & 688155 & 5.35 & 5.194 & TRN \\
\hline CHEMBL1365118 & 688155 & 5.0 & 5.0877 & TRN \\
\hline CHEMBL1404247 & 688155 & 5.1 & 5.2283 & TRN \\
\hline CHEMBL1603820 & 688155 & 5.0 & 5.1808 & TRN \\
\hline CHEMBL1550794 & 688155 & 4.5 & 5.0084 & TRN \\
\hline CHEMBL3189322 & 688155 & 4.9 & 5.0309 & TRN \\
\hline CHEMBL1365800 & 688155 & 4.5 & 5.0291 & TRN \\
\hline CHEMBL1486570 & 688155 & 4.85 & 5.0604 & TRN \\
\hline CHEMBL1484258 & 688155 & 4.55 & 5.0608 & TRN \\
\hline CHEMBL1981058 & 688155 & 4.95 & 5.0264 & TRN \\
\hline CHEMBL1607565 & 688155 & 4.95 & 5.0044 & TRN \\
\hline CHEMBL3210686 & 688155 & 6.5 & 5.142 & TST \\
\hline CHEMBL1612261 & 688155 & 4.95 & 5.0962 & TRN \\
\hline CHEMBL1416465 & 688155 & 4.85 & 5.051 & TRN \\
\hline CHEMBL1374034 & 688155 & 5.0 & 5.1764 & TRN \\
\hline CHEMBL1488357 & 688155 & 4.95 & 5.1578 & TRN \\
\hline CHEMBL1432737 & 688155 & 5.55 & 5.1537 & TRN \\
\hline CHEMBL1384539 & 688155 & 6.0 & 5.1337 & TRN \\
\hline CHEMBL1584574 & 688155 & 5.95 & 5.0696 & TRN \\
\hline CHEMBL1450308 & 688155 & 5.0 & 5.0585 & TRN \\
\hline CHEMBL1323952 & 688155 & 5.65 & 5.0196 & TST \\
\hline CHEMBL1326901 & 688155 & 5.0 & 5.0727 & TRN \\
\hline CHEMBL1529405 & 688155 & 5.1 & 5.0245 & TST \\
\hline CHEMBL 3208753 & 688155 & 4.9 & 5.0301 & TRN \\
\hline CHEMBL1505101 & 688155 & 5.75 & 5.1711 & TRN \\
\hline CHEMBL1556882 & 688155 & 4.55 & 4.9616 & TRN \\
\hline CHEMBL1495378 & 688155 & 4.9 & 5.1386 & TRN \\
\hline CHEMBL1549973 & 688155 & 5.45 & 5.0269 & TRN \\
\hline CHEMBL1540578 & 688155 & 4.5 & 5.1216 & TRN \\
\hline CHEMBL1518887 & 688155 & 5.0 & 5.0482 & TRN \\
\hline CHEMBL 259474 & 688155 & 4.95 & 5.0051 & TRN \\
\hline CHEMBL1460479 & 688155 & 6.0 & 5.2583 & TRN \\
\hline CHEMBL1531004 & 688155 & 5.25 & 5.064 & TRN \\
\hline CHEMBL1452275 & 688155 & 5.25 & 5.1139 & TRN \\
\hline CHEMBL1580220 & 688155 & 4.95 & 5.2626 & TRN \\
\hline CHEMBL1487320 & 688155 & 5.2 & 4.9759 & TRN \\
\hline CHEMBL1597383 & 688155 & 5.0 & 5.0751 & TRN \\
\hline CHEMBL1335467 & 688155 & 4.9 & 5.2104 & TST \\
\hline CHEMBL1468864 & 688155 & 4.85 & 4.9697 & TRN \\
\hline CHEMBL1577121 & 688155 & 4.85 & 5.13200 & 0000000001 \\
\hline CHEMBL1367790 & 688155 & 5.0 & 5.0122 & TRN \\
\hline CHEMBL1387562 & 688155 & 5.1 & 5.1456 & TRN \\
\hline CHEMBL1458514 & 688155 & 4.55 & 4.9581 & TRN \\
\hline
\end{tabular}




\begin{tabular}{|c|c|c|c|c|c|}
\hline \multicolumn{6}{|c|}{ Supplemental Table S2.txt } \\
\hline CHEMBL1421252 & 688155 & 4.5 & 5.0639 & TRN & \\
\hline CHEMBL1393645 & 688155 & 4.55 & 4.9649 & TST & \\
\hline CHEMBL3193241 & 688155 & 5.05 & 5.0358 & TRN & \\
\hline CHEMBL1445436 & 688155 & 4.65 & 4.9453 & TRN & \\
\hline CHEMBL1564530 & 688155 & 4.7 & 5.0853 & TRN & \\
\hline CHEMBL1369680 & 688155 & 4.55 & 5.1026 & TST & \\
\hline CHEMBL1598226 & 688155 & 4.65 & \multicolumn{2}{|c|}{4.9830000000000005} & TST \\
\hline CHEMBL1565187 & 688155 & 4.45 & 4.8703 & TRN & \\
\hline CHEMBL1521196 & 688155 & 4.5 & 5.1048 & TRN & \\
\hline CHEMBL3192403 & 688155 & 5.05 & 5.0943 & TST & \\
\hline CHEMBL1484562 & 688155 & 5.05 & 4.9655 & TST & \\
\hline CHEMBL1344478 & 688155 & 4.75 & \multicolumn{2}{|c|}{5.202000000000001} & TRN \\
\hline CHEMBL1339512 & 688155 & 5.1 & 5.1877 & TRN & \\
\hline CHEMBL1613469 & 688155 & 5.0 & 5.0353 & TST & \\
\hline CHEMBL1381891 & 688155 & 4.5 & 5.1637 & TST & \\
\hline CHEMBL1313254 & 688155 & 4.55 & 5.006 & TRN & \\
\hline CHEMBL1543380 & 688155 & 4.55 & 4.9595 & TRN & \\
\hline CHEMBL1453527 & 688155 & 4.9 & 5.1677 & TRN & \\
\hline CHEMBL1342523 & 688155 & 5.5 & 5.1458 & TRN & \\
\hline CHEMBL1461576 & 688155 & 4.85 & 5.0761 & TRN & \\
\hline CHEMBL1431342 & 688155 & 4.95 & 5.1363 & TST & \\
\hline CHEMBL1611913 & 688155 & 5.9 & 5.0353 & TRN & \\
\hline CHEMBL1302581 & 688155 & 4.95 & 4.9955 & TRN & \\
\hline CHEMBL1425702 & 688155 & 5.15 & 4.9784 & TRN & \\
\hline CHEMBL1470439 & 688155 & 4.95 & 5.1478 & TRN & \\
\hline CHEMBL1479585 & 688155 & 4.6 & 5.0814 & TRN & \\
\hline CHEMBL1479713 & 688155 & 4.55 & \multicolumn{2}{|c|}{5.111000000000001} & TRN \\
\hline CHEMBL1490278 & 688155 & 4.45 & 4.8233 & TRN & \\
\hline CHEMBL1492215 & 688155 & 5.25 & 4.9104 & TRN & \\
\hline CHEMBL1401711 & 688155 & 5.5 & 5.1634 & TRN & \\
\hline CHEMBL1387592 & 688155 & 5.15 & 5.0511 & TRN & \\
\hline CHEMBL1369149 & 688155 & 4.5 & 5.185 & TRN & \\
\hline CHEMBL1517988 & 688155 & 4.7 & 5.1954 & TRN & \\
\hline CHEMBL1457940 & 688155 & 5.0 & 5.1721 & TRN & \\
\hline CHEMBL603156 & 688155 & 4.75 & 5.0941 & TST & \\
\hline CHEMBL1308287 & 688155 & 4.55 & 5.0075 & TRN & \\
\hline CHEMBL1460461 & 688155 & 4.5 & 5.0109 & TST & \\
\hline CHEMBL471401 & 688155 & 5.9 & 5.1555 & TRN & \\
\hline CHEMBL1509077 & 688155 & 4.8 & 5.0812 & TRN & \\
\hline CHEMBL3213337 & 688155 & 4.5 & 5.0081 & TST & \\
\hline CHEMBL1529955 & 688155 & 5.55 & 5.1369 & TRN & \\
\hline CHEMBL1580414 & 688155 & 4.9 & 5.1594 & TST & \\
\hline CHEMBL1346617 & 688155 & 5.0 & 4.9121 & TRN & \\
\hline CHEMBL1528874 & 688155 & 4.55 & \multicolumn{2}{|c|}{4.9830000000000005} & TRN \\
\hline CHEMBL1427926 & 688155 & 4.55 & 4.9868 & TRN & \\
\hline CHEMBL1348954 & 688155 & 4.95 & 5.0437 & TST & \\
\hline CHEMBL1447180 & 688155 & 5.6 & 5.1225 & TRN & \\
\hline CHEMBL1353157 & 688155 & 5.5 & 4.9999 & TRN & \\
\hline
\end{tabular}




\begin{tabular}{|c|c|c|c|c|c|}
\hline \multicolumn{6}{|c|}{ Supplemental Table S2.txt } \\
\hline CHEMBL1499350 & 688155 & 4.55 & 5.0082 & TRN & \\
\hline CHEMBL1425406 & 688155 & 6.3 & 5.0356 & TRN & \\
\hline CHEMBL1607143 & 688155 & 4.9 & 4.9912 & TRN & \\
\hline CHEMBL1308759 & 688155 & 5.2 & 5.067 & TST & \\
\hline CHEMBL1360240 & 688155 & 5.35 & 4.958 & TRN & \\
\hline CHEMBL1381650 & 688155 & 5.1 & 4.9657 & TRN & \\
\hline CHEMBL1323505 & 688155 & 6.0 & 4.9789 & TRN & \\
\hline CHEMBL1361153 & 688155 & 5.6 & 5.0719 & TRN & \\
\hline CHEMBL1389229 & 688155 & 4.75 & 5.0054 & TRN & \\
\hline CHEMBL1332541 & 688155 & 4.9 & 4.992 & TST & \\
\hline CHEMBL 3209727 & 688155 & 5.3 & 4.9937 & TST & \\
\hline CHEMBL1330325 & 688155 & 5.3 & 4.9791 & TRN & \\
\hline CHEMBL1317461 & 688155 & 5.5 & 4.9583 & TRN & \\
\hline CHEMBL1499736 & 688155 & 5.15 & 5.0557 & TRN & \\
\hline CHEMBL1500128 & 688155 & 5.05 & 5.0431 & TRN & \\
\hline CHEMBL1299319 & 688155 & 6.05 & 5.07 & TRN & \\
\hline CHEMBL1418845 & 688155 & 4.55 & 5.1241 & TRN & \\
\hline CHEMBL1305574 & 688155 & 6.0 & 5.2286 & TRN & \\
\hline CHEMBL1493025 & 688155 & 4.85 & 5.021 & TST & \\
\hline CHEMBL1530789 & 688155 & 5.0 & 5.1143 & TRN & \\
\hline CHEMBL1986459 & 688155 & 4.6 & 5.0099 & TRN & \\
\hline CHEMBL1508430 & 688155 & 4.55 & 5.0318 & TRN & \\
\hline CHEMBL1527476 & 688155 & 5.1 & 4.9916 & TRN & \\
\hline CHEMBL1542308 & 688155 & 4.55 & 5.2437 & TRN & \\
\hline CHEMBL1310951 & 688155 & 4.55 & 4.9539 & TRN & \\
\hline CHEMBL1366198 & 688155 & 5.95 & 5.1468 & TRN & \\
\hline CHEMBL1349515 & 688155 & 5.45 & 4.9559 & TRN & \\
\hline CHEMBL1341089 & 688155 & 4.95 & 5.1674 & TRN & \\
\hline CHEMBL1488743 & 688155 & 5.15 & 5.04899 & 99999999995 & TRN \\
\hline CHEMBL1372855 & 688155 & 5.45 & 5.2508 & TRN & \\
\hline CHEMBL1459350 & 688155 & 5.0 & 4.9852 & TRN & \\
\hline CHEMBL1601668 & 688155 & 4.95 & 5.0618 & TST & \\
\hline CHEMBL3212962 & 688155 & 4.95 & 5.0112 & TRN & \\
\hline CHEMBL1566163 & 688155 & 5.2 & 5.1129 & TST & \\
\hline CHEMBL1379603 & 688155 & 4.65 & 5.1481 & TST & \\
\hline CHEMBL1390310 & 688155 & 5.25 & 5.0799 & TST & \\
\hline CHEMBL1531942 & 688155 & 6.0 & 5.1147 & TST & \\
\hline CHEMBL1419421 & 688155 & 4.95 & 5.1241 & TRN & \\
\hline CHEMBL1302967 & 688155 & 5.05 & 5.0831 & TRN & \\
\hline CHEMBL1536074 & 688155 & 5.6 & 5.0777 & TRN & \\
\hline CHEMBL1426008 & 688155 & 4.9 & 5.1201 & TST & \\
\hline CHEMBL1537195 & 688155 & 4.9 & 5.0423 & TRN & \\
\hline CHEMBL3198520 & 688155 & 5.0 & 5.0193 & TRN & \\
\hline CHEMBL1519298 & 688155 & 5.1 & 5.1319 & TRN & \\
\hline CHEMBL1345919 & 688155 & 4.65 & 4.9938 & TRN & \\
\hline CHEMBL1324220 & 688155 & 7.6003 & 5.0433 & TST & \\
\hline CHEMBL1497305 & 688155 & 4.9 & 5.1381 & TRN & \\
\hline CHEMBL1609121 & 688155 & 4.65 & 4.9963 & TST & \\
\hline
\end{tabular}




\begin{tabular}{|c|c|c|c|c|c|}
\hline & & \multicolumn{4}{|c|}{ Supplemental Table s2.txt } \\
\hline CHEMBL1391895 & 688155 & 5.25 & 4.933 & TRN & \\
\hline CHEMBL1532780 & 688155 & 4.55 & 5.1338 & TRN & \\
\hline CHEMBL1506635 & 688155 & 4.55 & 5.0438 & TST & \\
\hline CHEMBL1449590 & 688155 & 4.5 & 5.0342 & TRN & \\
\hline CHEMBL1574961 & 688155 & 5.0 & 5.0647 & TRN & \\
\hline CHEMBL1331431 & 688155 & 6.0 & 5.1839 & TRN & \\
\hline CHEMBL1549015 & 688155 & 4.95 & 5.1097 & TRN & \\
\hline CHEMBL1565040 & 688155 & 5.95 & 4.9457 & TST & \\
\hline CHEMBL132222 & 688155 & 5.0 & 5.1239 & TST & \\
\hline CHEMBL144614 & 688155 & 5.0 & 5.1964 & TST & \\
\hline CHEMBL487203 & 688155 & 5.0 & 5.0456 & TST & \\
\hline CHEMBL1611753 & 688155 & 4.5 & 5.0567 & TRN & \\
\hline CHEMBL1343250 & 688155 & 5.95 & 5.1863 & TRN & \\
\hline CHEMBL1587438 & 688155 & 5.3 & 5.1415 & TRN & \\
\hline CHEMBL1484715 & 688155 & 4.5 & 5.0457 & TRN & \\
\hline CHEMBL1535827 & 688155 & 5.05 & 5.0279 & TRN & \\
\hline CHEMBL1488806 & 688155 & 5.25 & 5.2168 & TRN & \\
\hline CHEMBL1417914 & 688155 & 4.9 & 5.0789 & TRN & \\
\hline CHEMBL1508431 & 688155 & 4.55 & 4.9228 & TRN & \\
\hline CHEMBL1550486 & 688155 & 5.45 & 4.917 & TRN & \\
\hline CHEMBL1486451 & 688155 & 5.1 & 5.1187 & TRN & \\
\hline CHEMBL1545043 & 688155 & 6.5 & 5.0722 & TST & \\
\hline CHEMBL1574832 & 688155 & 4.75 & 5.2848 & TRN & \\
\hline CHEMBL 227086 & 688155 & 4.9 & 5.0808 & TRN & \\
\hline CHEMBL1572438 & 688155 & 4.95 & 4.988 & TRN & \\
\hline CHEMBL1312199 & 688155 & 4.55 & 4.9174 & TRN & \\
\hline CHEMBL1613195 & 688155 & 5.0 & 5.2148 & TRN & \\
\hline CHEMBL1596779 & 688155 & 4.95 & 5.1274 & TRN & \\
\hline CHEMBL1531320 & 688155 & 4.6 & 5.0435 & TRN & \\
\hline CHEMBL1492196 & 688155 & 4.55 & 5.2198 & TRN & \\
\hline CHEMBL1313167 & 688155 & 5.3 & 5.1537 & TRN & \\
\hline CHEMBL1419488 & 688155 & 4.55 & 5.0881 & TRN & \\
\hline CHEMBL1430582 & 688155 & 5.6 & 5.1915 & TST & \\
\hline CHEMBL1522822 & 688155 & 4.6 & 5.1829 & TRN & \\
\hline CHEMBL1430843 & 688155 & 5.5 & 5.1431 & TRN & \\
\hline CHEMBL3209680 & 688155 & 5.7 & 5.0146 & TRN & \\
\hline CHEMBL1332551 & 688155 & 5.0 & 5.1758 & TRN & \\
\hline CHEMBL1375950 & 688155 & 4.55 & 4.979 & TRN & \\
\hline CHEMBL1531905 & 688155 & 6.0 & 4.9329 & TRN & \\
\hline CHEMBL3193453 & 688155 & 4.5 & 5.1174 & TST & \\
\hline CHEMBL1562534 & 688155 & 5.0 & 5.1468 & TRN & \\
\hline CHEMBL1360834 & 688155 & 4.55 & 5.0393 & TST & \\
\hline CHEMBL1367611 & 688155 & 5.7 & 5.0924 & TRN & \\
\hline CHEMBL1424022 & 688155 & 4.8 & 4.9861 & TRN & \\
\hline CHEMBL1498753 & 688155 & 4.55 & 5.0003 & TRN & \\
\hline CHEMBL1533990 & 688155 & 5.0 & 5.2522 & TRN & \\
\hline CHEMBL1569761 & 688155 & 6.35 & 5.3171 & TST & \\
\hline CHEMBL1550763 & 688155 & 4.5 & $5.0710 e$ & 0000000001 & TRN \\
\hline & & & & 20193 & \\
\hline
\end{tabular}




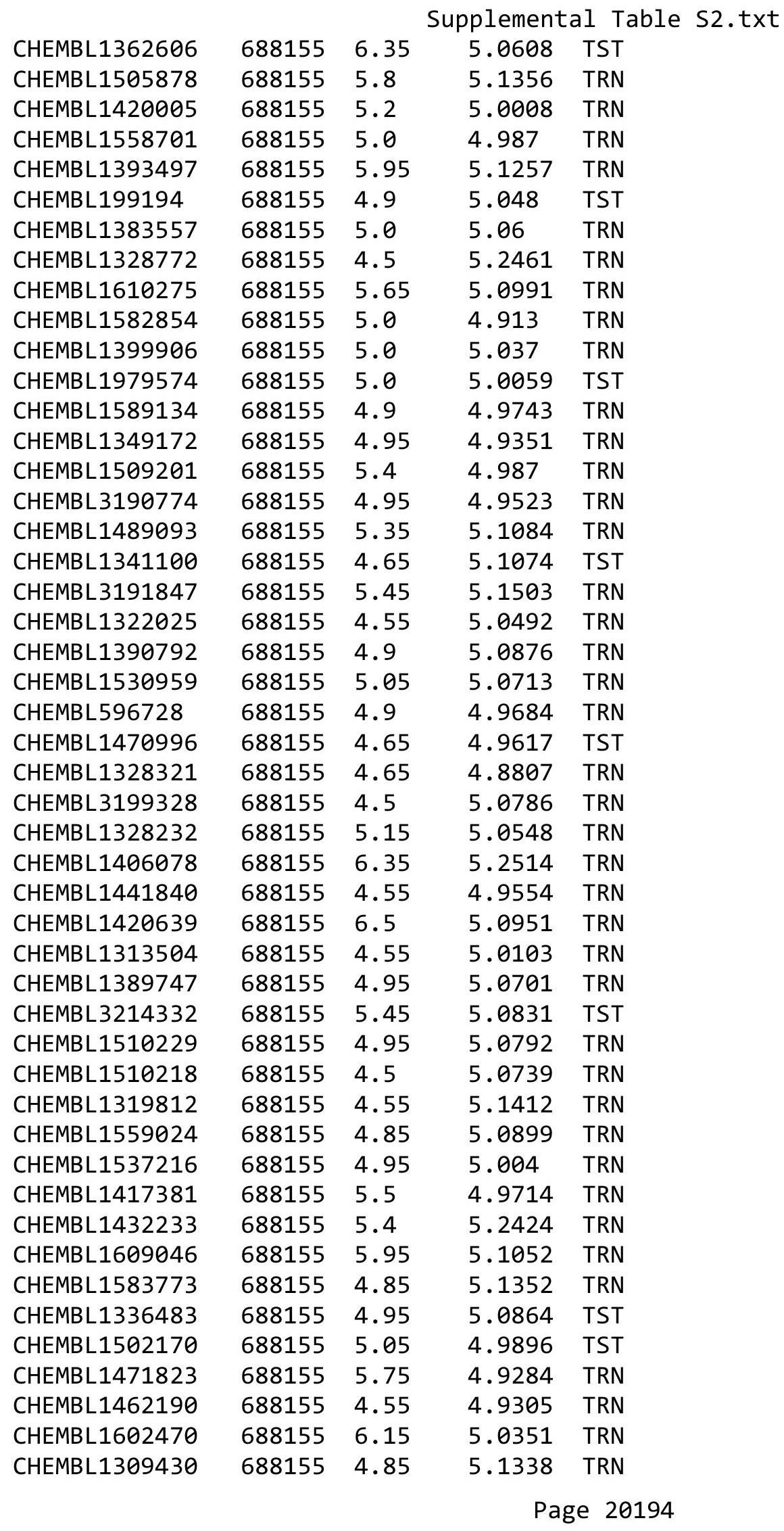




\begin{tabular}{|c|c|c|c|c|}
\hline \multicolumn{5}{|c|}{ Supplemental Table s2.txt } \\
\hline CHEMBL1382034 & 688155 & 5.1 & 5.234 & TST \\
\hline CHEMBL1307168 & 688155 & 4.95 & 5.0878 & TST \\
\hline CHEMBL1577921 & 688155 & 4.55 & 4.9982 & TRN \\
\hline CHEMBL1320722 & 688155 & 5.3 & 5.1005 & TRN \\
\hline CHEMBL1470316 & 688155 & 5.0 & 5.003 & TRN \\
\hline CHEMBL1452704 & 688155 & 5.65 & 5.1143 & TST \\
\hline CHEMBL1571331 & 688155 & 4.65 & 4.9436 & TRN \\
\hline CHEMBL1416841 & 688155 & 5.9 & 5.0234 & TRN \\
\hline CHEMBL1567607 & 688155 & 4.55 & 4.9252 & TRN \\
\hline CHEMBL1300125 & 688155 & 4.85 & 4.9223 & TST \\
\hline CHEMBL1490816 & 688155 & 4.65 & 4.9132 & TRN \\
\hline CHEMBL3189906 & 688155 & 5.35 & 5.1207 & TRN \\
\hline CHEMBL1484873 & 688155 & 5.5 & 5.0906 & TST \\
\hline CHEMBL1612250 & 688155 & 4.8 & 5.0124 & TRN \\
\hline CHEMBL1442728 & 688155 & 6.5 & 5.0808 & TRN \\
\hline CHEMBL1497165 & 688155 & 4.95 & 4.9308 & TRN \\
\hline CHEMBL1325825 & 688155 & 4.55 & 4.9485 & TRN \\
\hline CHEMBL1525433 & 688155 & 4.95 & 5.318 & TRN \\
\hline CHEMBL1385456 & 688155 & 4.95 & 5.1041 & TST \\
\hline CHEMBL1341019 & 688155 & 6.35 & 5.2722 & TRN \\
\hline CHEMBL1319469 & 688155 & 4.95 & 5.1816 & TRN \\
\hline CHEMBL1339110 & 688155 & 4.55 & 4.9477 & TRN \\
\hline CHEMBL1333043 & 688155 & 6.05 & 5.1299 & TRN \\
\hline CHEMBL1597346 & 688155 & 4.85 & 5.0773 & TRN \\
\hline CHEMBL1390202 & 688155 & 5.85 & 5.1529 & TRN \\
\hline CHEMBL1569073 & 688155 & 5.65 & 5.0781 & TRN \\
\hline CHEMBL1372071 & 688155 & 5.0 & 5.0439 & TST \\
\hline CHEMBL1483762 & 688155 & 4.55 & 5.0325 & TRN \\
\hline CHEMBL1320489 & 688155 & 4.95 & 5.0594 & TRN \\
\hline CHEMBL1458083 & 688155 & 4.95 & 4.9974 & TRN \\
\hline CHEMBL1423797 & 688155 & 5.0 & 4.955 & TRN \\
\hline CHEMBL1604402 & 688155 & 4.95 & 4.9785 & TRN \\
\hline CHEMBL1568623 & 688155 & 4.5 & 5.1549 & TRN \\
\hline CHEMBL3210914 & 688155 & 5.65 & 5.0761 & TRN \\
\hline CHEMBL1509792 & 688155 & 5.9 & 5.0258 & TRN \\
\hline CHEMBL1427080 & 688155 & 5.7 & 5.1349 & TRN \\
\hline CHEMBL1553179 & 688155 & 5.65 & 5.0128 & TRN \\
\hline CHEMBL3194716 & 688155 & 6.3 & 5.2258 & TST \\
\hline CHEMBL310798 & 688155 & 6.0 & 5.0777 & TRN \\
\hline CHEMBL1604265 & 688155 & 5.25 & 4.9952 & TRN \\
\hline CHEMBL3212201 & 688155 & 4.75 & 5.1994 & TRN \\
\hline CHEMBL1359390 & 688155 & 4.95 & 5.0827 & TRN \\
\hline CHEMBL1339743 & 688155 & 4.95 & 4.9045 & TRN \\
\hline CHEMBL1418548 & 688155 & 5.25 & 4.9864 & TRN \\
\hline CHEMBL1326180 & 688155 & 4.65 & 5.0529 & TST \\
\hline CHEMBL1347042 & 688155 & 6.45 & 5.1007 & TRN \\
\hline CHEMBL1335077 & 688155 & 4.55 & 5.0477 & TRN \\
\hline CHEMBL1588149 & 688155 & 5.9 & 5.2313 & TRN \\
\hline
\end{tabular}




\begin{tabular}{|c|c|c|c|c|}
\hline & & \multicolumn{3}{|c|}{ Supplemental Table S2.txt } \\
\hline CHEMBL1499916 & 688155 & 4.65 & 5.0659 & TRN \\
\hline CHEMBL1544381 & 688155 & 4.65 & 5.0124 & TST \\
\hline CHEMBL1534267 & 688155 & 5.8 & 5.1578 & TST \\
\hline CHEMBL1545691 & 688155 & 4.45 & 5.1441 & TRN \\
\hline CHEMBL1459388 & 688155 & 5.95 & 5.0174 & TRN \\
\hline CHEMBL1537062 & 688155 & 5.85 & 5.1906 & TST \\
\hline CHEMBL 2000517 & 688155 & 5.05 & 5.0322 & TRN \\
\hline CHEMBL1428000 & 688155 & 5.0 & 4.9835 & TST \\
\hline CHEMBL1522538 & 688155 & 5.1 & 4.9672 & TST \\
\hline CHEMBL1611030 & 688155 & 4.8 & 4.9506 & TRN \\
\hline CHEMBL1525816 & 688155 & 5.0 & 5.0915 & TST \\
\hline CHEMBL1459240 & 688155 & 4.95 & 4.9743 & TRN \\
\hline CHEMBL1450163 & 688155 & 5.0 & 5.0317 & TRN \\
\hline CHEMBL1447421 & 688155 & 6.35 & 5.0024 & TRN \\
\hline CHEMBL1589184 & 688155 & 4.6 & 4.9934 & TRN \\
\hline CHEMBL1561460 & 688155 & 5.6 & 5.272 & TRN \\
\hline CHEMBL1549500 & 688155 & 4.55 & 5.1174 & TRN \\
\hline CHEMBL1424490 & 688155 & 4.65 & 4.9793 & TST \\
\hline CHEMBL1487002 & 688155 & 4.65 & 5.113 & TRN \\
\hline CHEMBL1444887 & 688155 & 5.1 & 5.0722 & TST \\
\hline CHEMBL1488926 & 688155 & 5.0 & 5.1343 & TRN \\
\hline CHEMBL1299307 & 688155 & 5.25 & 5.1348 & TRN \\
\hline CHEMBL1549266 & 688155 & 5.55 & 5.1763 & TRN \\
\hline CHEMBL1345152 & 688155 & 4.5 & 5.2376 & TST \\
\hline CHEMBL1520457 & 688155 & 4.7 & 4.9437 & TST \\
\hline CHEMBL1414025 & 688155 & 4.8 & 5.1014 & TST \\
\hline CHEMBL476668 & 688155 & 5.75 & 5.0745 & TRN \\
\hline CHEMBL1441479 & 688155 & 6.0 & 4.9601 & TRN \\
\hline CHEMBL1592812 & 688155 & 6.0 & 5.1894 & TRN \\
\hline CHEMBL1489432 & 688155 & 4.95 & 5.1467 & TST \\
\hline CHEMBL1538246 & 688155 & 4.95 & 5.0614 & TRN \\
\hline CHEMBL1451938 & 688155 & 4.5 & 5.0358 & TRN \\
\hline CHEMBL1304471 & 688155 & 4.55 & 5.1751 & TRN \\
\hline CHEMBL1453652 & 688155 & 5.3 & 5.0363 & TST \\
\hline CHEMBL1404563 & 688155 & 5.3 & 5.0504 & TRN \\
\hline CHEMBL1309604 & 688155 & 4.55 & 5.1255 & TST \\
\hline CHEMBL1375381 & 688155 & 5.2 & 5.155 & TRN \\
\hline CHEMBL1304588 & 688155 & 4.95 & 5.0363 & TRN \\
\hline CHEMBL1340713 & 688155 & 4.5 & 5.0391 & TRN \\
\hline CHEMBL1448958 & 688155 & 4.9 & 5.1041 & TRN \\
\hline CHEMBL1470324 & 688155 & 4.9 & 5.0382 & TRN \\
\hline CHEMBL1502735 & 688155 & 4.95 & 5.1766 & TRN \\
\hline CHEMBL1506443 & 688155 & 6.0 & 4.8755 & TRN \\
\hline CHEMBL1986381 & 688155 & 5.25 & 4.9885 & TST \\
\hline CHEMBL1438733 & 688155 & 4.55 & 4.9494 & TRN \\
\hline CHEMBL1418440 & 688155 & 4.55 & 4.9817 & TST \\
\hline CHEMBL1570765 & 688155 & 4.55 & 5.0773 & TST \\
\hline CHEMBL1565614 & 688155 & 4.65 & 5.01399 & 9999999999 \\
\hline & & & & 20196 \\
\hline
\end{tabular}




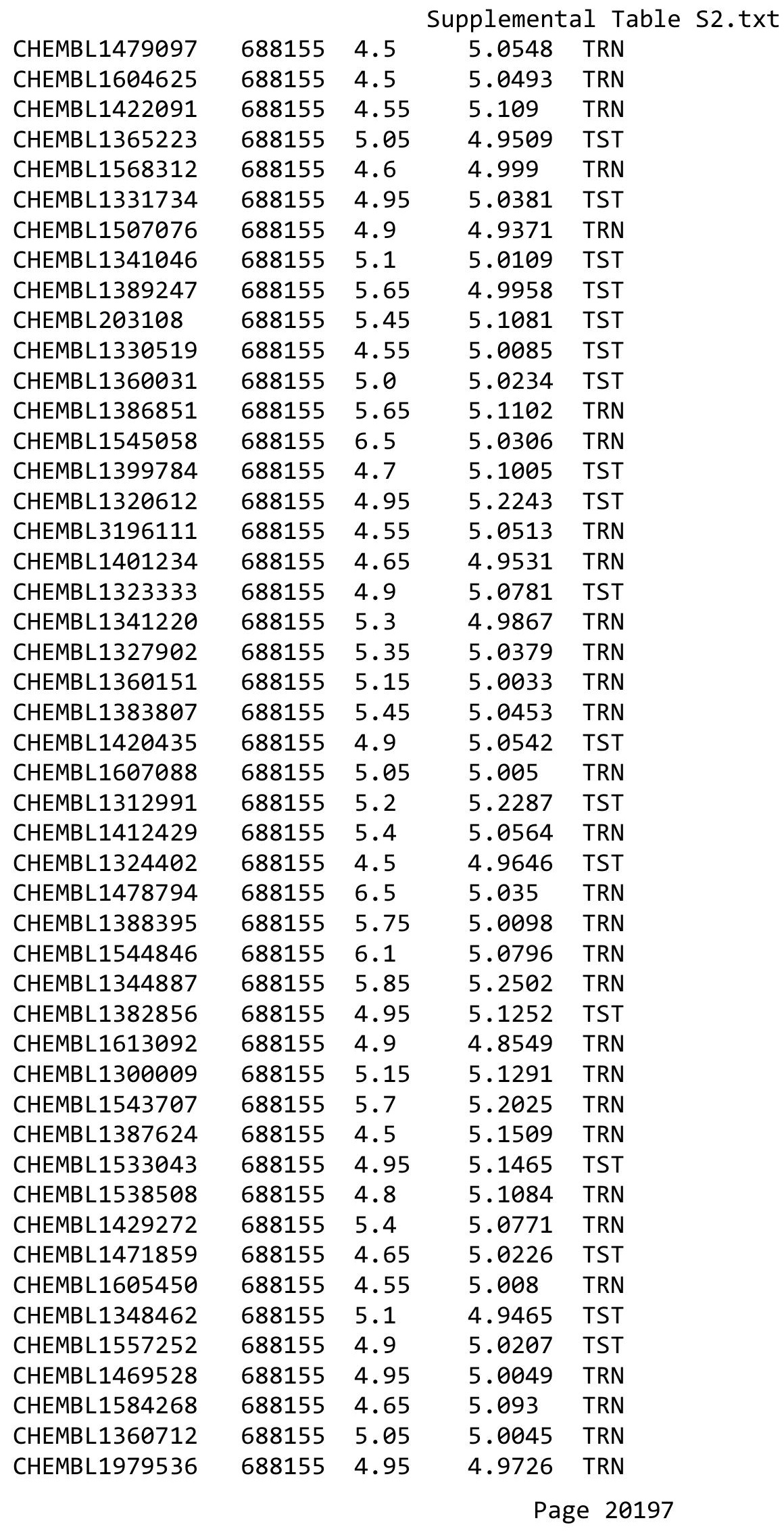




\begin{tabular}{|c|c|c|c|c|c|}
\hline \multicolumn{6}{|c|}{ Supplemental Table S2.txt } \\
\hline CHEMBL3191716 & 688155 & 5.3 & 5.016 & TST & \\
\hline CHEMBL1305042 & 688155 & 4.7 & 5.1019 & TRN & \\
\hline CHEMBL1440612 & 688155 & 4.95 & 5.1567 & TRN & \\
\hline CHEMBL1978236 & 688155 & 4.9 & 5.0757 & TRN & \\
\hline CHEMBL1491541 & 688155 & 5.0 & 5.1823 & TRN & \\
\hline CHEMBL1502752 & 688155 & 4.95 & 5.0434 & TST & \\
\hline CHEMBL1521618 & 688155 & 5.1 & 5.0464 & TST & \\
\hline CHEMBL1505922 & 688155 & 4.5 & 5.1293 & TST & \\
\hline CHEMBL1438695 & 688155 & 4.7 & 5.0776 & TRN & \\
\hline CHEMBL1511586 & 688155 & 4.65 & 4.9277 & TRN & \\
\hline CHEMBL1460497 & 688155 & 4.9 & 5.0712 & TRN & \\
\hline CHEMBL1413213 & 688155 & 4.75 & 4.9758 & TRN & \\
\hline CHEMBL1421240 & 688155 & 5.05 & 5.1104 & TST & \\
\hline CHEMBL1446421 & 688155 & 4.65 & 4.9622 & TRN & \\
\hline CHEMBL1311933 & 688155 & 4.5 & 4.9847 & TRN & \\
\hline CHEMBL1375382 & 688155 & 5.6 & 5.24299 & 9999999999 & TRN \\
\hline CHEMBL1609194 & 688155 & 4.55 & 5.1488 & TST & \\
\hline CHEMBL1386866 & 688155 & 4.55 & 5.0252 & TRN & \\
\hline CHEMBL581870 & 688155 & 5.5 & 5.1914 & TRN & \\
\hline CHEMBL1532751 & 688155 & 5.3 & 4.9631 & TRN & \\
\hline CHEMBL1557458 & 688155 & 4.5 & 4.9581 & TRN & \\
\hline CHEMBL1565717 & 688155 & 4.65 & 4.9488 & TRN & \\
\hline CHEMBL1410191 & 688155 & 5.25 & 5.0886 & TRN & \\
\hline CHEMBL1602491 & 688155 & 4.55 & 4.8998 & TRN & \\
\hline CHEMBL310310 & 688155 & 6.0 & 5.1846 & TRN & \\
\hline CHEMBL1531788 & 688155 & 4.8 & 4.9784 & TRN & \\
\hline CHEMBL1346837 & 688155 & 5.95 & 5.2063 & TRN & \\
\hline CHEMBL1542457 & 688155 & 5.0 & 5.1614 & TRN & \\
\hline CHEMBL1480470 & 688155 & 4.5 & 5.2303 & TST & \\
\hline CHEMBL1421979 & 688155 & 5.2 & 5.112 & TRN & \\
\hline CHEMBL1470394 & 688155 & 5.0 & 5.1326 & TRN & \\
\hline CHEMBL1560329 & 688155 & 5.4 & 4.9598 & TRN & \\
\hline CHEMBL1523892 & 688155 & 5.1 & 5.0741 & TRN & \\
\hline CHEMBL1490768 & 688155 & 5.25 & 5.0781 & TRN & \\
\hline CHEMBL1427360 & 688155 & 5.65 & 5.1096 & TRN & \\
\hline CHEMBL1562535 & 688155 & 4.5 & 5.0284 & TST & \\
\hline CHEMBL1345174 & 688155 & 5.0 & 4.9985 & TRN & \\
\hline CHEMBL1514176 & 688155 & 6.3 & 5.1533 & TST & \\
\hline CHEMBL1503922 & 688155 & 4.7 & 4.9347 & TRN & \\
\hline CHEMBL1595048 & 688155 & 4.95 & $4.9510 e$ & 00000000005 & TRN \\
\hline CHEMBL1572973 & 688155 & 4.9 & 5.0575 & TRN & \\
\hline CHEMBL1391519 & 688155 & 4.6 & 4.9549 & TRN & \\
\hline CHEMBL1548486 & 688155 & 5.2 & 5.1028 & TST & \\
\hline CHEMBL1335379 & 688155 & 5.15 & 5.2677 & TRN & \\
\hline CHEMBL1609322 & 688155 & 5.25 & 4.9935 & TRN & \\
\hline CHEMBL1369487 & 688155 & 5.0 & 4.9654 & TRN & \\
\hline CHEMBL1347084 & 688155 & 4.55 & 5.1461 & TRN & \\
\hline CHEMBL1452609 & 688155 & 4.55 & 5.2469 & TST & \\
\hline
\end{tabular}




\begin{tabular}{|c|c|c|c|c|c|}
\hline & & \multicolumn{4}{|c|}{ Supplemental Table S2.txt } \\
\hline CHEMBL1362281 & 688155 & 4.55 & 4.8855 & TST & \\
\hline CHEMBL1319259 & 688155 & 4.55 & 5.0858 & TRN & \\
\hline CHEMBL1351226 & 688155 & 4.6 & 5.1616 & TST & \\
\hline CHEMBL1546502 & 688155 & 5.8 & 5.0167 & TRN & \\
\hline CHEMBL1467099 & 688155 & 5.3 & 5.107 & TRN & \\
\hline CHEMBL1369049 & 688155 & 4.55 & 5.0529 & TRN & \\
\hline CHEMBL1405911 & 688155 & 4.5 & 5.0253 & TRN & \\
\hline CHEMBL1467824 & 688155 & 4.55 & 4.9324 & TRN & \\
\hline CHEMBL1449674 & 688155 & 5.05 & 5.0971 & TST & \\
\hline CHEMBL1375112 & 688155 & 5.5 & 5.1111 & TST & \\
\hline CHEMBL1503197 & 688155 & 6.0 & 5.3056 & TRN & \\
\hline CHEMBL1584470 & 688155 & 4.55 & 5.1308 & TRN & \\
\hline CHEMBL1530541 & 688155 & 6.45 & 4.9986 & TRN & \\
\hline CHEMBL1451386 & 688155 & 5.0 & 5.2201 & TST & \\
\hline CHEMBL1379511 & 688155 & 5.3 & 4.8545 & TRN & \\
\hline CHEMBL1563832 & 688155 & 6.5 & 5.0643 & TRN & \\
\hline CHEMBL1568054 & 688155 & 5.35 & 5.2491 & TRN & \\
\hline CHEMBL1471923 & 688155 & 5.5 & 5.0853 & TRN & \\
\hline CHEMBL1608513 & 688155 & 4.55 & 5.1374 & TRN & \\
\hline CHEMBL1539087 & 688155 & 4.95 & 4.9474 & TST & \\
\hline CHEMBL1308547 & 688155 & 4.95 & 5.1191 & TRN & \\
\hline CHEMBL1527549 & 688155 & 4.5 & 5.1317 & TST & \\
\hline CHEMBL1978903 & 688155 & 4.55 & 5.0429 & TRN & \\
\hline CHEMBL1561261 & 688155 & 4.55 & 4.988 & TRN & \\
\hline CHEMBL1971613 & 688155 & 5.8 & 5.0109 & TST & \\
\hline CHEMBL1333512 & 688155 & 4.55 & 5.1658 & TRN & \\
\hline CHEMBL1520088 & 688155 & 5.8 & 5.2005 & TRN & \\
\hline CHEMBL1604532 & 688155 & 5.35 & 5.0722 & TRN & \\
\hline CHEMBL1454459 & 688155 & 5.9 & 5.0638 & TRN & \\
\hline CHEMBL1549099 & 688155 & 4.55 & 4.8956 & TST & \\
\hline CHEMBL1571640 & 688155 & 5.7 & 5.187 & TRN & \\
\hline CHEMBL1233714 & 688155 & 5.2 & 5.2015 & TRN & \\
\hline CHEMBL1369466 & 688155 & 6.35 & 5.1006 & TRN & \\
\hline CHEMBL1561383 & 688155 & 4.95 & 5.0214 & TRN & \\
\hline CHEMBL1504567 & 688155 & 6.35 & 5.1476 & TST & \\
\hline CHEMBL1613684 & 688155 & 4.55 & 4.9314 & TST & \\
\hline CHEMBL1500705 & 688155 & 4.95 & 5.09699 & 99999999995 & TRN \\
\hline CHEMBL3198706 & 688155 & 4.9 & 5.0199 & TST & \\
\hline CHEMBL1495246 & 688155 & 5.65 & 5.0793 & TST & \\
\hline CHEMBL1442040 & 688155 & 5.9 & 5.146 & TRN & \\
\hline CHEMBL1373811 & 688155 & 5.55 & 4.9509 & TRN & \\
\hline CHEMBL1501249 & 688155 & 4.55 & 5.044 & TRN & \\
\hline CHEMBL1305800 & 688155 & 6.0 & 5.0247 & TRN & \\
\hline CHEMBL1425135 & 688155 & 4.95 & 4.98300 & 00000000005 & TRN \\
\hline CHEMBL1578056 & 688155 & 4.9 & 5.1199 & TST & \\
\hline CHEMBL1463954 & 688155 & 5.9 & 5.1434 & TRN & \\
\hline CHEMBL1489697 & 688155 & 4.5 & 5.0753 & TST & \\
\hline CHEMBL1559515 & 688155 & 4.55 & 4.9563 & TRN & \\
\hline
\end{tabular}




\begin{tabular}{|c|c|c|c|c|c|}
\hline \multicolumn{6}{|c|}{ Supplemental Table S2.txt } \\
\hline CHEMBL1351686 & 688155 & 4.5 & 4.9576 & TRN & \\
\hline CHEMBL3210696 & 688155 & 5.5 & 5.0305 & TRN & \\
\hline CHEMBL1403290 & 688155 & 5.85 & 5.0423 & TST & \\
\hline CHEMBL1404487 & 688155 & 4.65 & 5.1574 & TRN & \\
\hline CHEMBL1555893 & 688155 & 4.95 & 5.20299 & 9999999999 & TRN \\
\hline CHEMBL1434042 & 688155 & 6.0 & 5.0833 & TRN & \\
\hline CHEMBL1561638 & 688155 & 6.3 & 4.9453 & TST & \\
\hline CHEMBL1568603 & 688155 & 4.85 & 4.9709 & TST & \\
\hline CHEMBL1532782 & 688155 & 5.3 & 5.1865 & TRN & \\
\hline CHEMBL1522586 & 688155 & 5.0 & 5.0932 & TRN & \\
\hline CHEMBL1448874 & 688155 & 6.3 & 5.0677 & TRN & \\
\hline CHEMBL1498539 & 688155 & 4.55 & 5.1677 & TRN & \\
\hline CHEMBL1409718 & 688155 & 4.5 & 5.0703 & TRN & \\
\hline CHEMBL1439522 & 688155 & 5.0 & 4.9705 & TRN & \\
\hline CHEMBL1328256 & 688155 & 4.85 & 5.1596 & TRN & \\
\hline CHEMBL1553939 & 688155 & 6.2 & 5.2854 & TRN & \\
\hline CHEMBL1588714 & 688155 & 4.8 & 5.0879 & TRN & \\
\hline CHEMBL1430475 & 688155 & 4.85 & 5.211 & TRN & \\
\hline CHEMBL1306003 & 688155 & 4.65 & 4.9825 & TST & \\
\hline CHEMBL1344099 & 688155 & 4.5 & 5.0202 & TRN & \\
\hline CHEMBL1544668 & 688155 & 6.3 & 5.0289 & TST & \\
\hline CHEMBL1455634 & 688155 & 4.6 & 5.0141 & TRN & \\
\hline CHEMBL1456663 & 688155 & 4.65 & 5.1457 & TRN & \\
\hline CHEMBL1364336 & 688155 & 4.9 & 5.2559 & TRN & \\
\hline CHEMBL1302114 & 688155 & 5.8 & 5.0421 & TRN & \\
\hline CHEMBL1341967 & 688155 & 4.5 & 5.2343 & TRN & \\
\hline CHEMBL1548165 & 688155 & 5.3 & 5.2169 & TRN & \\
\hline CHEMBL1549427 & 688155 & 5.25 & 5.0993 & TRN & \\
\hline CHEMBL1418118 & 688155 & 5.0 & 5.0508 & TRN & \\
\hline CHEMBL1558797 & 688155 & 4.55 & 4.8947 & TRN & \\
\hline CHEMBL1583872 & 688155 & 4.75 & 5.232 & TRN & \\
\hline CHEMBL1579588 & 688155 & 4.6 & 5.2794 & TRN & \\
\hline CHEMBL1369736 & 688155 & 5.55 & 5.0349 & TRN & \\
\hline CHEMBL1466088 & 688155 & 4.9 & 4.9164 & TRN & \\
\hline CHEMBL1379542 & 688155 & 4.65 & 5.1356 & TRN & \\
\hline CHEMBL1536766 & 688155 & 4.95 & 5.1707 & TRN & \\
\hline CHEMBL1482574 & 688155 & 4.55 & 5.0976 & TRN & \\
\hline CHEMBL1540028 & 688155 & 5.0 & 5.0705 & TST & \\
\hline CHEMBL1497431 & 688155 & 5.55 & 5.0066 & TRN & \\
\hline CHEMBL1389655 & 688155 & 4.55 & 5.2024 & TRN & \\
\hline CHEMBL1388197 & 688155 & 4.55 & 5.1557 & TRN & \\
\hline CHEMBL1337400 & 688155 & 6.35 & 5.114 & TRN & \\
\hline CHEMBL2003351 & 688155 & 4.6 & 5.0477 & TRN & \\
\hline CHEMBL1385074 & 688155 & 5.05 & 5.0401 & TRN & \\
\hline CHEMBL1547186 & 688155 & 5.35 & 5.0106 & TRN & \\
\hline CHEMBL1583344 & 688155 & 4.55 & 5.0689 & TRN & \\
\hline CHEMBL1299586 & 688155 & 4.65 & 4.9091 & TRN & \\
\hline CHEMBL1372414 & 688155 & 4.95 & 4.9539 & TRN & \\
\hline
\end{tabular}




\begin{tabular}{|c|c|c|c|c|}
\hline \multicolumn{5}{|c|}{ Supplemental Table S2.txt } \\
\hline CHEMBL1401328 & 688155 & 4.5 & 5.0701 & TRN \\
\hline CHEMBL1344430 & 688155 & 5.0 & 5.0418 & TRN \\
\hline CHEMBL1421559 & 688155 & 5.0 & 5.083 & TRN \\
\hline CHEMBL1613701 & 688155 & 4.55 & 4.9984 & TST \\
\hline CHEMBL1449970 & 688155 & 4.55 & 5.1016 & TRN \\
\hline CHEMBL1569337 & 688155 & 5.15 & 4.9913 & TRN \\
\hline CHEMBL1576596 & 688155 & 4.8 & 5.1013 & TRN \\
\hline CHEMBL1334320 & 688155 & 5.45 & 4.9547 & TRN \\
\hline CHEMBL3212818 & 688155 & 4.6 & 5.1742 & TRN \\
\hline CHEMBL1465823 & 688155 & 5.0 & 5.1577 & TRN \\
\hline CHEMBL1528901 & 688155 & 4.95 & 5.1027 & TRN \\
\hline CHEMBL1498624 & 688155 & 4.95 & 5.1123 & TRN \\
\hline CHEMBL1365867 & 688155 & 6.5 & 5.1223 & TST \\
\hline CHEMBL1972986 & 688155 & 4.9 & 5.1121 & TRN \\
\hline CHEMBL1608931 & 688155 & 5.95 & 4.9865 & TRN \\
\hline CHEMBL1566345 & 688155 & 4.55 & 4.9453 & TRN \\
\hline CHEMBL1331543 & 688155 & 5.6 & 5.1742 & TST \\
\hline CHEMBL1572883 & 688155 & 5.05 & 4.9157 & TRN \\
\hline CHEMBL1334996 & 688155 & 4.95 & 4.9932 & TRN \\
\hline CHEMBL3197932 & 688155 & 4.95 & 5.0239 & TST \\
\hline CHEMBL1576833 & 688155 & 5.0 & 4.9126 & TRN \\
\hline CHEMBL1361173 & 688155 & 4.85 & 5.1616 & TRN \\
\hline CHEMBL1311684 & 688155 & 6.3 & 5.2539 & TRN \\
\hline CHEMBL1489172 & 688155 & 4.85 & 5.2125 & TRN \\
\hline CHEMBL1476521 & 688155 & 5.45 & 5.1899 & TRN \\
\hline CHEMBL1589790 & 688155 & 5.0 & 4.9064 & TRN \\
\hline CHEMBL1410641 & 688155 & 4.95 & 5.0313 & TST \\
\hline CHEMBL1331513 & 688155 & 4.45 & 5.1387 & TST \\
\hline CHEMBL1536380 & 688155 & 5.0 & 5.0154 & TST \\
\hline CHEMBL1366718 & 688155 & 5.1 & 5.2285 & TRN \\
\hline CHEMBL1550591 & 688155 & 5.2 & 5.0767 & TST \\
\hline CHEMBL3214418 & 688155 & 5.3 & 5.0392 & TRN \\
\hline CHEMBL1491996 & 688155 & 5.45 & 4.9572 & TST \\
\hline CHEMBL1353913 & 688155 & 5.8 & 5.1264 & TRN \\
\hline CHEMBL1451732 & 688155 & 6.45 & 5.0898 & TST \\
\hline CHEMBL1449269 & 688155 & 4.55 & 5.0675 & TRN \\
\hline CHEMBL1320806 & 688155 & 4.95 & 5.2036 & TRN \\
\hline CHEMBL3209466 & 688155 & 6.0 & 5.0028 & TST \\
\hline CHEMBL1557915 & 688155 & 4.85 & 5.3444 & TRN \\
\hline CHEMBL1568366 & 688155 & 4.9 & 5.1021 & TRN \\
\hline CHEMBL1547723 & 688155 & 5.3 & 5.0245 & TST \\
\hline CHEMBL1443231 & 688155 & 5.5 & 5.1443 & TRN \\
\hline CHEMBL1529928 & 688155 & 4.8 & 5.0288 & TRN \\
\hline CHEMBL1608911 & 688155 & 4.5 & 5.2205 & TRN \\
\hline CHEMBL1446619 & 688155 & 5.05 & 5.0008 & TRN \\
\hline CHEMBL1369091 & 688155 & 4.9 & 5.0557 & TST \\
\hline CHEMBL1321656 & 688155 & 5.1 & 5.0133 & TRN \\
\hline CHEMBL1327618 & 688155 & 4.95 & 5.2209 & TRN \\
\hline
\end{tabular}




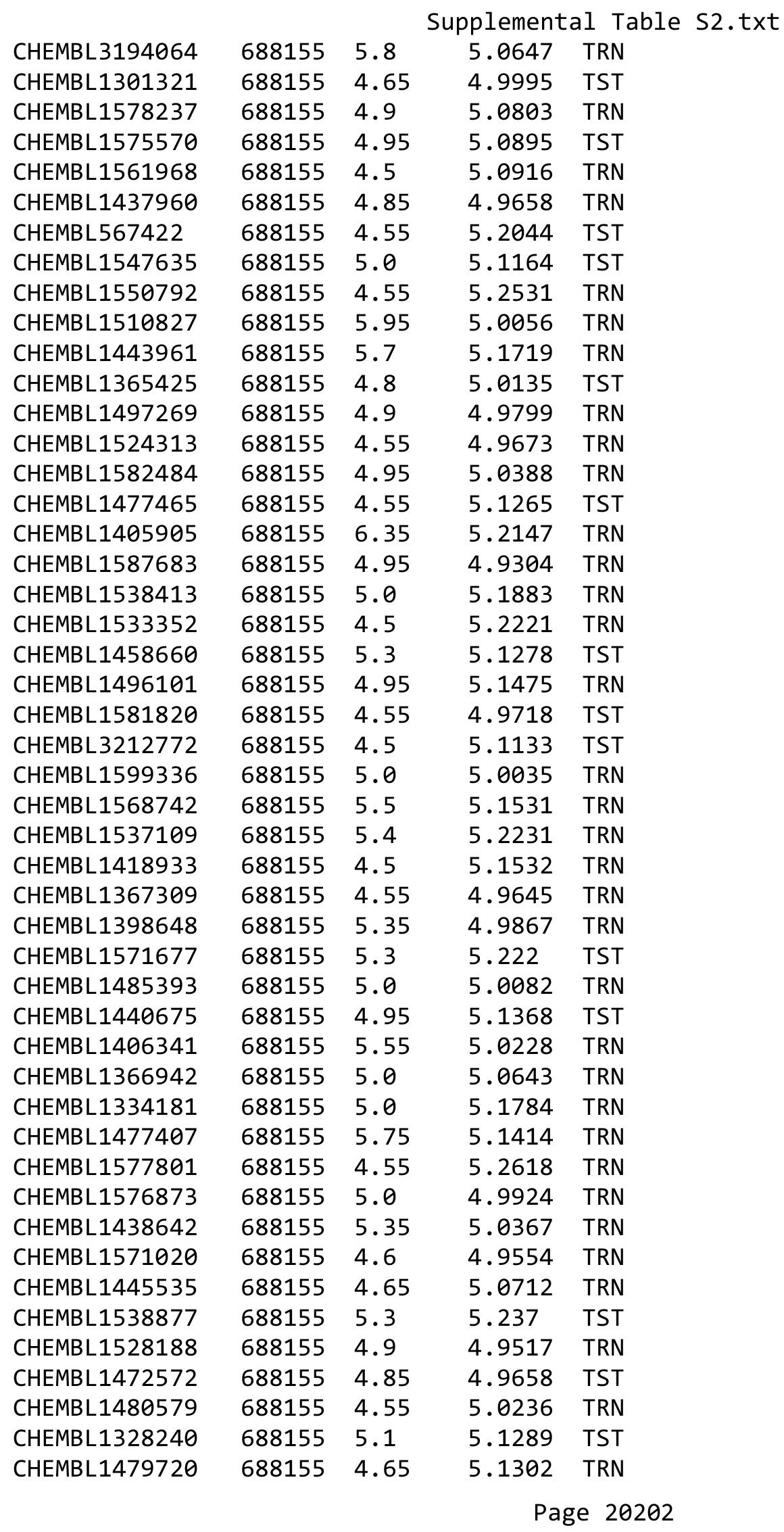




\begin{tabular}{|c|c|c|c|c|}
\hline \multicolumn{5}{|c|}{ Supplemental Table S2.txt } \\
\hline CHEMBL1442998 & 688155 & 5.35 & 5.2449 & TRN \\
\hline CHEMBL1448758 & 688155 & 4.5 & 5.1186 & TRN \\
\hline CHEMBL555689 & 688155 & 4.65 & 4.9614 & TST \\
\hline CHEMBL1570853 & 688155 & 4.5 & 5.0314 & TRN \\
\hline CHEMBL1547372 & 688155 & 5.25 & 4.9586 & TST \\
\hline CHEMBL1499262 & 688155 & 5.0 & 5.0614 & TRN \\
\hline CHEMBL1519359 & 688155 & 5.1 & 5.1802 & TRN \\
\hline CHEMBL1511177 & 688155 & 4.8 & 5.2799 & TRN \\
\hline CHEMBL1304144 & 688155 & 4.5 & 5.0713 & TRN \\
\hline CHEMBL1404832 & 688155 & 4.9 & 5.1436 & TST \\
\hline CHEMBL1303974 & 688155 & 5.0 & 5.1538 & TRN \\
\hline CHEMBL1382438 & 688155 & 4.9 & 5.0487 & TRN \\
\hline CHEMBL1328266 & 688155 & 6.45 & 5.0624 & TST \\
\hline CHEMBL1322106 & 688155 & 4.9 & 5.1196 & TST \\
\hline CHEMBL1594328 & 688155 & 4.5 & 5.0263 & TRN \\
\hline CHEMBL1360045 & 688155 & 4.9 & 5.0558 & TRN \\
\hline CHEMBL1319093 & 688155 & 4.65 & 5.0713 & TRN \\
\hline CHEMBL1331684 & 688155 & 4.85 & 5.0867 & TRN \\
\hline CHEMBL1527563 & 688155 & 4.6 & 5.1346 & TRN \\
\hline CHEMBL1327583 & 688155 & 4.65 & 4.9698 & TST \\
\hline CHEMBL1537746 & 688155 & 4.95 & 5.0276 & TST \\
\hline CHEMBL1378539 & 688155 & 6.05 & 5.0966 & TRN \\
\hline CHEMBL55814 & 688155 & 4.9 & 5.1253 & TRN \\
\hline CHEMBL1600572 & 688155 & 5.2 & 5.1174 & TRN \\
\hline CHEMBL1598080 & 688155 & 5.75 & 5.0443 & TST \\
\hline CHEMBL1557690 & 688155 & 4.55 & 5.0126 & TST \\
\hline CHEMBL 3191778 & 688155 & 5.45 & 5.0162 & TRN \\
\hline CHEMBL1372808 & 688155 & 4.85 & 5.1912 & TST \\
\hline CHEMBL1581003 & 688155 & 4.95 & 5.0993 & TRN \\
\hline CHEMBL1568530 & 688155 & 6.0 & 5.1812 & TRN \\
\hline CHEMBL1601910 & 688155 & 6.0 & 5.1019 & TRN \\
\hline CHEMBL1588451 & 688155 & 4.5 & 5.0538 & TRN \\
\hline CHEMBL1344041 & 688155 & 4.9 & 4.9541 & TRN \\
\hline CHEMBL1412661 & 688155 & 5.2 & 4.9917 & TRN \\
\hline CHEMBL1605178 & 688155 & 4.5 & 4.9847 & TRN \\
\hline CHEMBL1600302 & 688155 & 4.55 & 5.0085 & TRN \\
\hline CHEMBL1426944 & 688155 & 4.75 & 5.1492 & TRN \\
\hline CHEMBL1579191 & 688155 & 5.0 & 5.101 & TRN \\
\hline CHEMBL1561581 & 688155 & 4.8 & 4.9969 & TST \\
\hline CHEMBL36296 & 688155 & 4.85 & 5.155 & TRN \\
\hline CHEMBL1518885 & 688155 & 5.4 & 5.052 & TRN \\
\hline CHEMBL1368991 & 688155 & 4.95 & 5.2761 & TRN \\
\hline CHEMBL1306967 & 688155 & 4.55 & 4.9333 & TRN \\
\hline CHEMBL1307259 & 688155 & 5.0 & 5.2078 & TRN \\
\hline CHEMBL600523 & 688155 & 5.1 & 5.0278 & TRN \\
\hline CHEMBL1314303 & 688155 & 4.5 & 5.1354 & TRN \\
\hline CHEMBL1597115 & 688155 & 6.1 & 5.1603 & TRN \\
\hline CHEMBL1468417 & 688155 & 4.55 & 5.0216 & TRN \\
\hline
\end{tabular}




\begin{tabular}{|c|c|c|c|c|}
\hline \multicolumn{5}{|c|}{ Supplemental Table S2.txt } \\
\hline CHEMBL538664 & 688155 & 5.6 & 5.0159 & TRN \\
\hline CHEMBL1978488 & 688155 & 4.5 & 5.0486 & TRN \\
\hline CHEMBL1466362 & 688155 & 5.0 & 5.0481 & TRN \\
\hline CHEMBL1330144 & 688155 & 4.55 & 4.8767 & TRN \\
\hline CHEMBL 285843 & 688155 & 4.65 & 5.2212 & TRN \\
\hline CHEMBL1484451 & 688155 & 4.75 & 5.1452 & TRN \\
\hline CHEMBL1563339 & 688155 & 5.75 & 5.0864 & TRN \\
\hline CHEMBL3195957 & 688155 & 5.8 & 4.9897 & TRN \\
\hline CHEMBL1411208 & 688155 & 4.55 & 5.0643 & TST \\
\hline CHEMBL1382040 & 688155 & 5.0 & 4.9433 & TST \\
\hline CHEMBL1535436 & 688155 & 4.55 & 4.9829 & TRN \\
\hline CHEMBL1572290 & 688155 & 5.95 & 5.3534 & TRN \\
\hline CHEMBL536375 & 688155 & 6.45 & 5.0306 & TRN \\
\hline CHEMBL1369838 & 688155 & 4.5 & 4.9368 & TRN \\
\hline CHEMBL1449339 & 688155 & 4.85 & 5.0718 & TRN \\
\hline CHEMBL1550292 & 688155 & 5.0 & 5.1257 & TRN \\
\hline CHEMBL1494208 & 688155 & 4.95 & 5.2512 & TRN \\
\hline CHEMBL1488194 & 688155 & 4.5 & 5.1434 & TST \\
\hline CHEMBL1520891 & 688155 & 4.7 & 5.0414 & TRN \\
\hline CHEMBL1365983 & 688155 & 5.0 & 5.0407 & TRN \\
\hline CHEMBL1445887 & 688155 & 4.9 & 5.011 & TRN \\
\hline CHEMBL 267160 & 688155 & 4.55 & 4.8698 & TRN \\
\hline CHEMBL1428460 & 688155 & 4.95 & 4.9978 & TRN \\
\hline CHEMBL1327066 & 688155 & 4.85 & 5.0913 & TRN \\
\hline CHEMBL1421014 & 688155 & 4.55 & 5.1142 & TRN \\
\hline CHEMBL1338544 & 688155 & 5.1 & 5.0987 & TST \\
\hline CHEMBL1162107 & 688155 & 5.45 & 5.038 & TST \\
\hline CHEMBL1489869 & 688155 & 5.35 & 5.0311 & TRN \\
\hline CHEMBL1391033 & 688155 & 5.25 & 5.0077 & TST \\
\hline CHEMBL1309620 & 688155 & 4.95 & 5.0061 & TRN \\
\hline CHEMBL1385971 & 688155 & 4.55 & 5.07 & TRN \\
\hline CHEMBL1301232 & 688155 & 5.0 & 4.9703 & TRN \\
\hline CHEMBL1426005 & 688155 & 4.95 & 5.1696 & TRN \\
\hline CHEMBL1361839 & 688155 & 5.9 & 5.2188 & TRN \\
\hline CHEMBL1556840 & 688155 & 4.5 & 5.0555 & TST \\
\hline CHEMBL1531863 & 688155 & 5.8 & 5.1762 & TRN \\
\hline CHEMBL1571785 & 688155 & 4.9 & 5.0492 & TRN \\
\hline CHEMBL1448784 & 688155 & 5.05 & 5.1687 & TRN \\
\hline CHEMBL1440688 & 688155 & 4.55 & 4.9697 & TRN \\
\hline CHEMBL1471995 & 688155 & 4.95 & 5.1825 & TRN \\
\hline CHEMBL1355762 & 688155 & 5.4 & 5.1099 & TRN \\
\hline CHEMBL1372390 & 688155 & 5.0 & 5.0583 & TRN \\
\hline CHEMBL1508562 & 688155 & 6.0 & 5.2029 & TRN \\
\hline CHEMBL1340986 & 688155 & 5.2 & 5.0232 & TST \\
\hline CHEMBL1365362 & 688155 & 5.95 & 5.101 & TRN \\
\hline CHEMBL1446922 & 688155 & 5.0 & 5.2593 & TRN \\
\hline CHEMBL1416018 & 688155 & 4.95 & 4.9447 & TRN \\
\hline CHEMBL1377800 & 688155 & 5.05 & 5.1042 & TST \\
\hline
\end{tabular}




\begin{tabular}{|c|c|c|c|c|}
\hline \multicolumn{5}{|c|}{ Supplemental Table S2.txt } \\
\hline CHEMBL1578093 & 688155 & 4.95 & 5.0592 & TRN \\
\hline CHEMBL1492877 & 688155 & 4.75 & 5.2214 & TRN \\
\hline CHEMBL1607708 & 688155 & 5.0 & 5.1501 & TRN \\
\hline CHEMBL1417242 & 688155 & 4.8 & 5.0264 & TRN \\
\hline CHEMBL1385084 & 688155 & 4.55 & 4.9668 & TRN \\
\hline CHEMBL1532984 & 688155 & 5.05 & 5.0934 & TST \\
\hline CHEMBL1382813 & 688155 & 4.9 & 5.1262 & TRN \\
\hline CHEMBL1430198 & 688155 & 4.55 & 5.1549 & TST \\
\hline CHEMBL395978 & 688155 & 4.55 & 5.1496 & TRN \\
\hline CHEMBL1604563 & 688155 & 5.0 & 5.1208 & TST \\
\hline CHEMBL1340874 & 688155 & 5.85 & 5.1222 & TST \\
\hline CHEMBL1577167 & 688155 & 5.25 & 5.1481 & TRN \\
\hline CHEMBL1595366 & 688155 & 5.6 & 5.0892 & TRN \\
\hline CHEMBL1438484 & 688155 & 4.5 & 5.0047 & TRN \\
\hline CHEMBL3189713 & 688155 & 4.95 & 5.117 & TST \\
\hline CHEMBL1369555 & 688155 & 5.55 & 5.1641 & TRN \\
\hline CHEMBL1448295 & 688155 & 5.95 & 5.0814 & TST \\
\hline CHEMBL1538474 & 688155 & 4.65 & 5.1268 & TST \\
\hline CHEMBL1533007 & 688155 & 4.9 & 5.1692 & TRN \\
\hline CHEMBL1425465 & 688155 & 5.95 & 5.1116 & TRN \\
\hline CHEMBL1566308 & 688155 & 4.5 & 4.9962 & TRN \\
\hline CHEMBL1599405 & 688155 & 5.35 & 5.1754 & TST \\
\hline CHEMBL1603217 & 688155 & 5.95 & 5.2191 & TRN \\
\hline CHEMBL1479761 & 688155 & 4.55 & 5.1096 & TRN \\
\hline CHEMBL1410769 & 688155 & 5.95 & 4.9443 & TST \\
\hline CHEMBL1580594 & 688155 & 4.6 & 5.1369 & TRN \\
\hline CHEMBL1583932 & 688155 & 5.0 & 5.0236 & TST \\
\hline CHEMBL1432613 & 688155 & 6.05 & 5.1191 & TRN \\
\hline CHEMBL1360629 & 688155 & 4.95 & 5.1689 & TRN \\
\hline CHEMBL58033 & 688155 & 6.0 & 5.2495 & TRN \\
\hline CHEMBL1471364 & 688155 & 5.0 & 4.9485 & TRN \\
\hline CHEMBL1508121 & 688155 & 4.95 & 5.0817 & TRN \\
\hline CHEMBL1506877 & 688155 & 6.3 & 5.0804 & TRN \\
\hline CHEMBL1437811 & 688155 & 5.65 & 4.9795 & TRN \\
\hline CHEMBL345124 & 688155 & 4.55 & 5.0504 & TST \\
\hline CHEMBL1607229 & 688155 & 4.95 & 5.2484 & TST \\
\hline CHEMBL1595349 & 688155 & 5.9 & 5.1444 & TST \\
\hline CHEMBL1367530 & 688155 & 4.95 & 5.1198 & TRN \\
\hline CHEMBL1526457 & 688155 & 4.95 & 5.1553 & TRN \\
\hline CHEMBL1318851 & 688155 & 4.95 & 5.1672 & TRN \\
\hline CHEMBL1432510 & 688155 & 5.9 & 5.0834 & TRN \\
\hline CHEMBL1508508 & 688155 & 5.1 & 4.9341 & TRN \\
\hline CHEMBL1612159 & 688155 & 4.9 & 5.2267 & TRN \\
\hline CHEMBL1343301 & 688155 & 5.55 & 5.1609 & TRN \\
\hline CHEMBL1496776 & 688155 & 4.5 & 5.1543 & TST \\
\hline CHEMBL1328003 & 688155 & 4.9 & 5.0278 & TST \\
\hline CHEMBL1307548 & 688155 & 5.45 & 4.9961 & TRN \\
\hline CHEMBL1557721 & 688155 & 4.55 & 5.0244 & TRN \\
\hline
\end{tabular}




\begin{tabular}{|c|c|c|c|c|}
\hline \multicolumn{5}{|c|}{ Supplemental Table S2.txt } \\
\hline CHEMBL1524405 & 688155 & 4.95 & 5.0917 & TST \\
\hline CHEMBL1393872 & 688155 & 4.55 & 4.88 & TRN \\
\hline CHEMBL1493515 & 688155 & 5.95 & 5.1034 & TRN \\
\hline CHEMBL562192 & 688155 & 5.15 & 4.9728 & TRN \\
\hline CHEMBL1551915 & 688155 & 4.95 & 5.1414 & TRN \\
\hline CHEMBL3145073 & 688155 & 6.35 & 4.9867 & TST \\
\hline CHEMBL428496 & 688155 & 6.0 & 5.1099 & TST \\
\hline CHEMBL1572540 & 688155 & 4.95 & 5.0314 & TST \\
\hline CHEMBL3197060 & 688155 & 5.25 & 5.0783 & TRN \\
\hline CHEMBL1305054 & 688155 & 4.95 & 5.0024 & TRN \\
\hline CHEMBL1341984 & 688155 & 5.6 & 5.2666 & TRN \\
\hline CHEMBL449690 & 688155 & 5.8 & 5.0643 & TST \\
\hline CHEMBL1479201 & 688155 & 6.05 & 5.1775 & TST \\
\hline CHEMBL1571397 & 688155 & 4.55 & 5.0734 & TRN \\
\hline CHEMBL1587097 & 688155 & 5.75 & 5.1369 & TST \\
\hline CHEMBL1452509 & 688155 & 4.55 & 5.1658 & TRN \\
\hline CHEMBL1412295 & 688155 & 4.65 & 5.0861 & TRN \\
\hline CHEMBL1510330 & 688155 & 4.95 & 4.9995 & TRN \\
\hline CHEMBL77030 & 688155 & 6.0 & 5.0512 & TRN \\
\hline CHEMBL1543121 & 688155 & 5.2 & 5.1906 & TST \\
\hline CHEMBL1498390 & 688155 & 6.3 & 5.0173 & TST \\
\hline CHEMBL1383082 & 688155 & 6.0 & 5.0727 & TRN \\
\hline CHEMBL1416904 & 688155 & 6.0 & 5.1281 & TRN \\
\hline CHEMBL1580978 & 688155 & 5.0 & 4.8872 & TRN \\
\hline CHEMBL1351653 & 688155 & 4.5 & 5.1614 & TRN \\
\hline CHEMBL1520265 & 688155 & 5.0 & 5.0958 & TRN \\
\hline CHEMBL1484849 & 688155 & 4.5 & 5.1498 & TRN \\
\hline CHEMBL1329033 & 688155 & 4.85 & 5.1475 & TRN \\
\hline CHEMBL1322960 & 688155 & 4.55 & 5.0467 & TST \\
\hline CHEMBL1333435 & 688155 & 6.0 & 5.0528 & TRN \\
\hline CHEMBL1422331 & 688155 & 5.4 & 5.1662 & TST \\
\hline CHEMBL51931 & 688155 & 4.75 & 5.1834 & TST \\
\hline CHEMBL1538268 & 688155 & 6.45 & 5.1967 & TRN \\
\hline CHEMBL1492633 & 688155 & 4.95 & 5.1912 & TRN \\
\hline CHEMBL1315183 & 688155 & 4.45 & 5.0421 & TRN \\
\hline CHEMBL3198666 & 688155 & 4.9 & 5.0838 & TST \\
\hline CHEMBL3208662 & 688155 & 5.3 & 5.0632 & TRN \\
\hline CHEMBL1387338 & 688155 & 4.5 & 5.1205 & TRN \\
\hline CHEMBL1372843 & 688155 & 6.5 & 4.9892 & TRN \\
\hline CHEMBL1304775 & 688155 & 4.95 & 5.2469 & TRN \\
\hline CHEMBL1384241 & 688155 & 4.95 & 5.2071 & TRN \\
\hline CHEMBL1341586 & 688155 & 5.1 & 5.0626 & TST \\
\hline CHEMBL3195844 & 688155 & 4.75 & 5.1042 & TRN \\
\hline CHEMBL1477713 & 688155 & 5.65 & 5.1004 & TST \\
\hline CHEMBL1581407 & 688155 & 4.5 & 5.0811 & TRN \\
\hline CHEMBL1549968 & 688155 & 4.9 & 5.2166 & TRN \\
\hline CHEMBL1498484 & 688155 & 5.95 & 5.1866 & TRN \\
\hline CHEMBL1334175 & 688155 & 4.5 & 5.0917 & TRN \\
\hline
\end{tabular}




\begin{tabular}{|c|c|c|c|c|c|}
\hline \multirow[b]{2}{*}{ CHEMBL1611370 } & \multirow{2}{*}{688155} & \multicolumn{4}{|c|}{ olemental } \\
\hline & & 5.8 & 4.9681 & TRN & \\
\hline CHEMBL583969 & 688155 & 4.6 & \multicolumn{2}{|c|}{5.0889999999999995} & TRN \\
\hline CHEMBL1526216 & 688155 & 4.7 & 5.0236 & TRN & \\
\hline CHEMBL1573218 & 688155 & 6.25 & 5.0513 & TST & \\
\hline CHEMBL1399600 & 688155 & 4.5 & 4.9611 & TRN & \\
\hline CHEMBL1522959 & 688155 & 5.05 & 5.0908 & TRN & \\
\hline CHEMBL1299933 & 688155 & 4.55 & 4.9294 & TRN & \\
\hline CHEMBL1542646 & 688155 & 4.95 & 4.9519 & TRN & \\
\hline CHEMBL1484927 & 688155 & 4.9 & 5.0168 & TST & \\
\hline CHEMBL1521545 & 688155 & 4.85 & 5.117 & TRN & \\
\hline CHEMBL1509159 & 688155 & 5.0 & 5.1613 & TRN & \\
\hline CHEMBL1426586 & 688155 & 4.95 & 5.0362 & TRN & \\
\hline CHEMBL1465049 & 688155 & 4.55 & 5.0915 & TRN & \\
\hline CHEMBL1563111 & 688155 & 4.95 & 5.026 & TST & \\
\hline CHEMBL1558786 & 688155 & 4.95 & 5.0795 & TRN & \\
\hline CHEMBL1332598 & 688155 & 5.7 & 5.0542 & TST & \\
\hline CHEMBL1488030 & 688155 & 4.8 & 5.0852 & TRN & \\
\hline CHEMBL1466988 & 688155 & 5.0 & 5.1711 & TRN & \\
\hline CHEMBL1581440 & 688155 & 5.15 & 5.0962 & TRN & \\
\hline CHEMBL1407226 & 688155 & 4.55 & 5.084 & TRN & \\
\hline CHEMBL1556157 & 688155 & 4.65 & 5.1984 & TRN & \\
\hline CHEMBL1411860 & 688155 & 5.0 & 4.9231 & TST & \\
\hline CHEMBL1502040 & 688155 & 5.15 & 5.0976 & TRN & \\
\hline CHEMBL1504701 & 688155 & 6.5 & 4.9188 & TRN & \\
\hline CHEMBL1237212 & 688155 & 4.55 & 5.2163 & TST & \\
\hline CHEMBL1582302 & 688155 & 4.5 & 5.0455 & TRN & \\
\hline CHEMBL1370269 & 688155 & 5.25 & 5.2499 & TRN & \\
\hline CHEMBL1347985 & 688155 & 4.85 & 5.0504 & TRN & \\
\hline CHEMBL1468903 & 688155 & 5.45 & 4.9349 & TRN & \\
\hline CHEMBL1547207 & 688155 & 5.65 & 5.1208 & TRN & \\
\hline CHEMBL1525668 & 688155 & 5.6 & 5.2375 & TRN & \\
\hline CHEMBL1539280 & 688155 & 5.45 & 4.974 & TRN & \\
\hline CHEMBL1345245 & 688155 & 4.8 & 5.081 & TRN & \\
\hline CHEMBL1328529 & 688155 & 4.85 & 4.8243 & TRN & \\
\hline CHEMBL1425105 & 688155 & 5.0 & 4.9141 & TRN & \\
\hline CHEMBL1330991 & 688155 & 4.55 & 5.0925 & TRN & \\
\hline CHEMBL1457373 & 688155 & 4.5 & 5.1295 & TRN & \\
\hline CHEMBL1446156 & 688155 & 5.75 & 5.0947 & TRN & \\
\hline CHEMBL3196256 & 688155 & 5.55 & 5.0362 & TST & \\
\hline CHEMBL1339457 & 688155 & 6.15 & 5.1747 & TRN & \\
\hline CHEMBL1484706 & 688155 & 4.95 & 5.1643 & TRN & \\
\hline CHEMBL1568402 & 688155 & 4.5 & 5.2256 & TRN & \\
\hline CHEMBL1347440 & 688155 & 4.95 & 5.1179 & TRN & \\
\hline CHEMBL1412417 & 688155 & 4.95 & 5.0777 & TRN & \\
\hline CHEMBL1303841 & 688155 & 6.5 & 5.1585 & TRN & \\
\hline CHEMBL3214139 & 688155 & 4.95 & 4.9937 & TRN & \\
\hline CHEMBL1376846 & 688155 & 4.95 & 4.8724 & TRN & \\
\hline CHEMBL1462100 & 688155 & 6.0 & 5.2411 & TRN & \\
\hline & & & & 20207 & \\
\hline
\end{tabular}




\begin{tabular}{|c|c|c|c|c|c|}
\hline \multicolumn{6}{|c|}{ Supplemental Table S2.txt } \\
\hline CHEMBL1415494 & 688155 & 4.9 & 5.118 & TRN & \\
\hline CHEMBL1586622 & 688155 & 5.1 & 5.2353 & TRN & \\
\hline CHEMBL1418528 & 688155 & 5.65 & 5.0105 & TST & \\
\hline CHEMBL3193761 & 688155 & 5.55 & 5.0286 & TRN & \\
\hline CHEMBL1999451 & 688155 & 6.5 & $5.1080 e$ & 00000000005 & TRN \\
\hline CHEMBL1509017 & 688155 & 4.95 & 4.9449 & TRN & \\
\hline CHEMBL1530823 & 688155 & 4.5 & 4.9765 & TRN & \\
\hline CHEMBL1449518 & 688155 & 4.95 & 5.0886 & TRN & \\
\hline CHEMBL1336810 & 688155 & 4.95 & 5.2333 & TRN & \\
\hline CHEMBL1539858 & 688155 & 5.9 & 5.1534 & TST & \\
\hline CHEMBL1456826 & 688155 & 6.0 & 5.1274 & TRN & \\
\hline CHEMBL1537106 & 688155 & 4.85 & 5.0839 & TRN & \\
\hline CHEMBL1414878 & 688155 & 4.55 & 5.109 & TST & \\
\hline CHEMBL1329861 & 688155 & 5.95 & 5.0663 & TRN & \\
\hline CHEMBL1330383 & 688155 & 5.15 & 5.0712 & TRN & \\
\hline CHEMBL1353167 & 688155 & 4.9 & 5.0817 & TRN & \\
\hline CHEMBL1578407 & 688155 & 5.0 & 5.0198 & TST & \\
\hline CHEMBL1558034 & 688155 & 4.5 & 5.0451 & TRN & \\
\hline CHEMBL1573754 & 688155 & 5.05 & 5.015 & TST & \\
\hline CHEMBL1519839 & 688155 & 5.1 & 5.0985 & TRN & \\
\hline CHEMBL1509263 & 688155 & 4.8 & 5.0853 & TRN & \\
\hline CHEMBL1565033 & 688155 & 5.05 & 5.0218 & TRN & \\
\hline CHEMBL1322656 & 688155 & 4.9 & 5.102 & TRN & \\
\hline CHEMBL1460159 & 688155 & 4.55 & 5.0331 & TRN & \\
\hline CHEMBL459302 & 688155 & 5.5 & 5.0728 & TRN & \\
\hline CHEMBL1541620 & 688155 & 4.55 & 5.1266 & TST & \\
\hline CHEMBL1528425 & 688155 & 5.0 & 5.0056 & TRN & \\
\hline CHEMBL1526372 & 688155 & 4.55 & 5.1496 & TRN & \\
\hline CHEMBL1587206 & 688155 & 5.95 & 4.9023 & TRN & \\
\hline CHEMBL1574614 & 688155 & 5.55 & 5.1269 & TRN & \\
\hline CHEMBL1609556 & 688155 & 5.0 & 5.0933 & TST & \\
\hline CHEMBL1602615 & 688155 & 6.0 & 5.0909 & TST & \\
\hline CHEMBL1496459 & 688155 & 4.9 & 4.9507 & TRN & \\
\hline CHEMBL1599665 & 688155 & 5.9 & 5.0666 & TRN & \\
\hline CHEMBL1333841 & 688155 & 5.9 & 4.9597 & TRN & \\
\hline CHEMBL1572037 & 688155 & 5.5 & 5.1949 & TST & \\
\hline CHEMBL1585275 & 688155 & 5.05 & 4.9127 & TRN & \\
\hline CHEMBL1363571 & 688155 & 4.55 & 5.023 & TRN & \\
\hline CHEMBL1459543 & 688155 & 5.1 & 5.2206 & TRN & \\
\hline CHEMBL1549514 & 688155 & 5.5 & 5.1351 & TST & \\
\hline CHEMBL1576939 & 688155 & 4.45 & 5.0016 & TRN & \\
\hline CHEMBL1520242 & 688155 & 4.65 & 5.1384 & TRN & \\
\hline CHEMBL1508682 & 688155 & 5.3 & 5.0075 & TST & \\
\hline CHEMBL1451642 & 688155 & 4.55 & 5.2275 & TST & \\
\hline CHEMBL1452524 & 688155 & 4.85 & 5.0902 & TRN & \\
\hline CHEMBL1339411 & 688155 & 4.95 & 5.0823 & TRN & \\
\hline CHEMBL3197891 & 688155 & 4.9 & 5.0589 & TRN & \\
\hline CHEMBL1489318 & 688155 & 4.85 & 5.2937 & TRN & \\
\hline
\end{tabular}




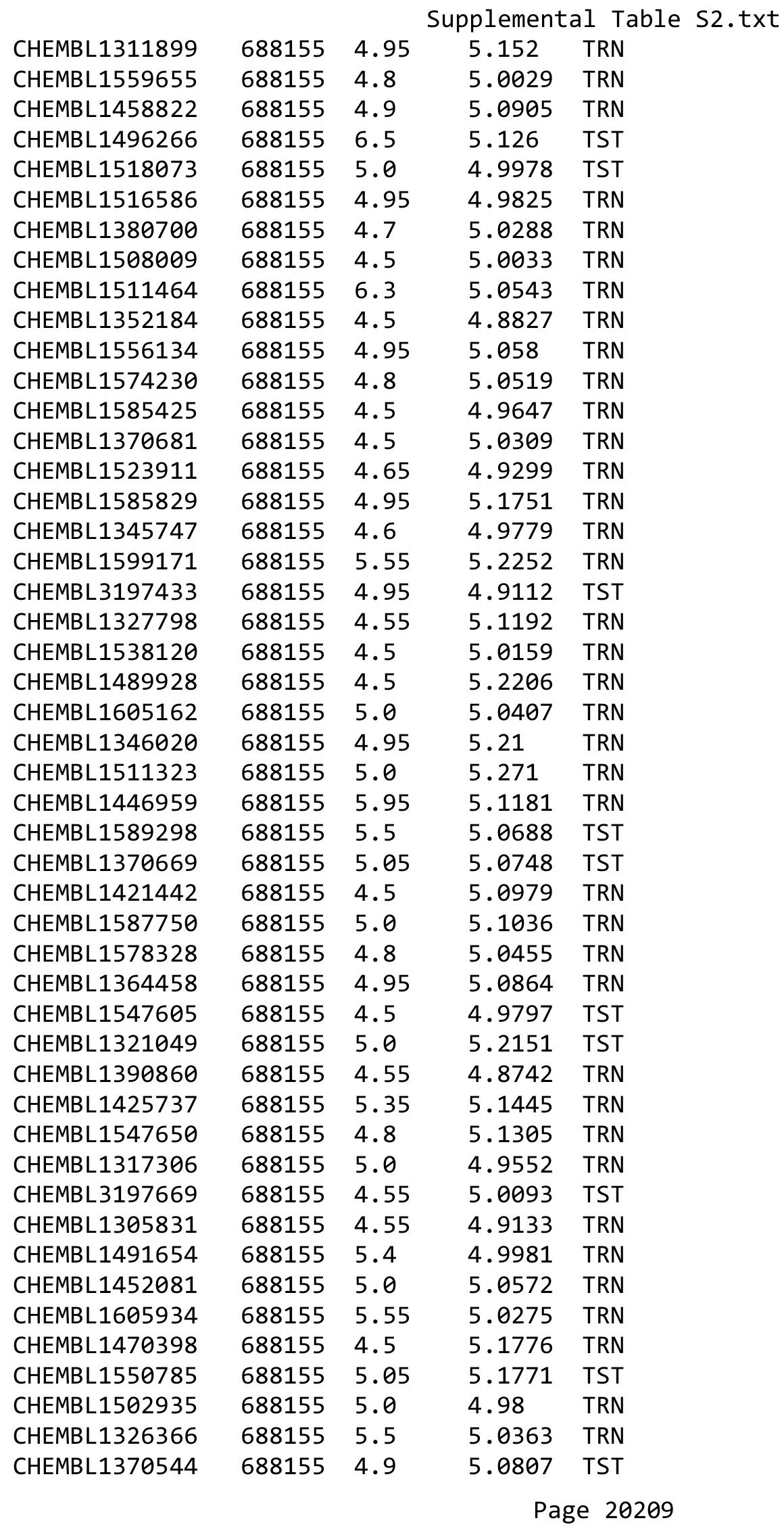




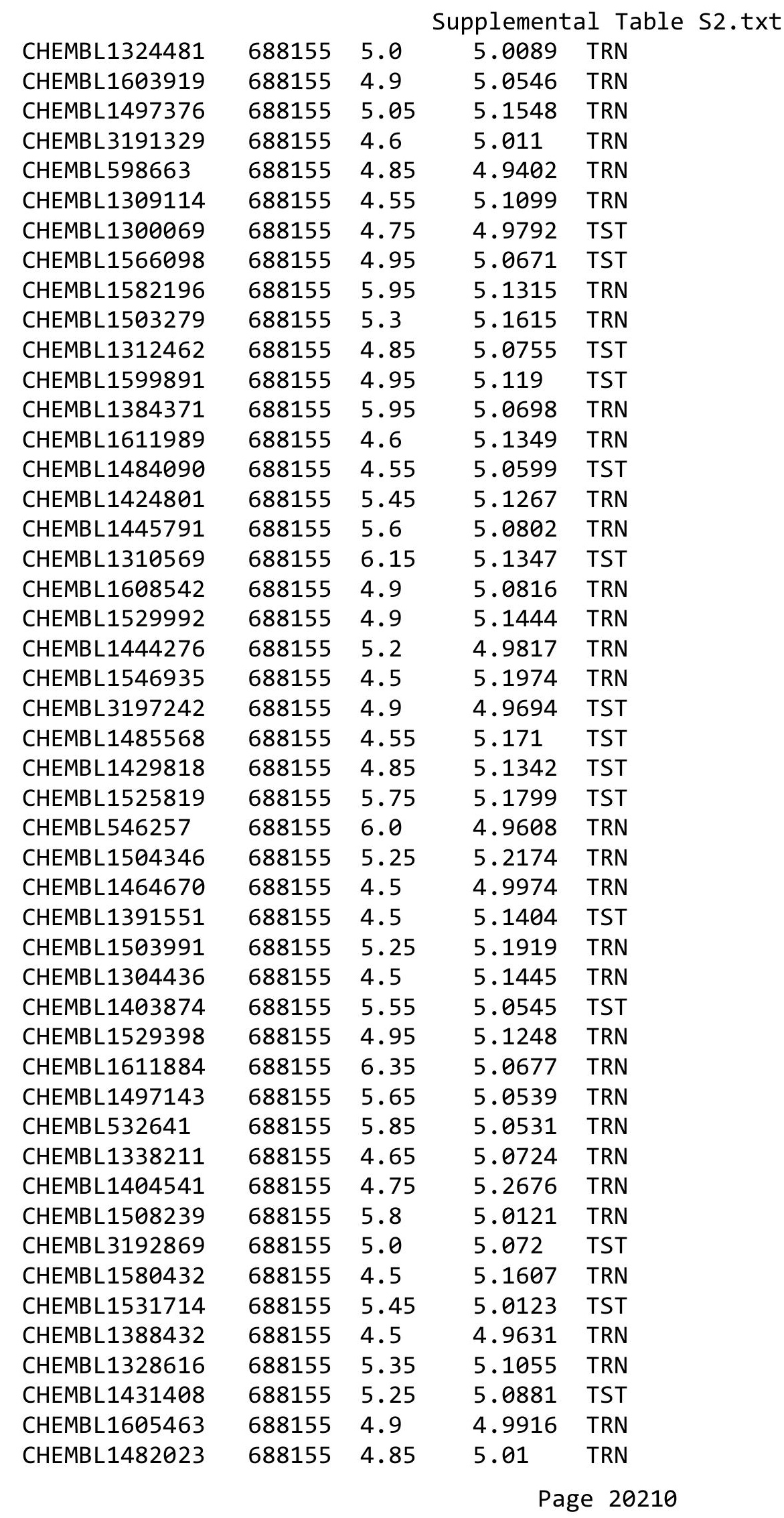




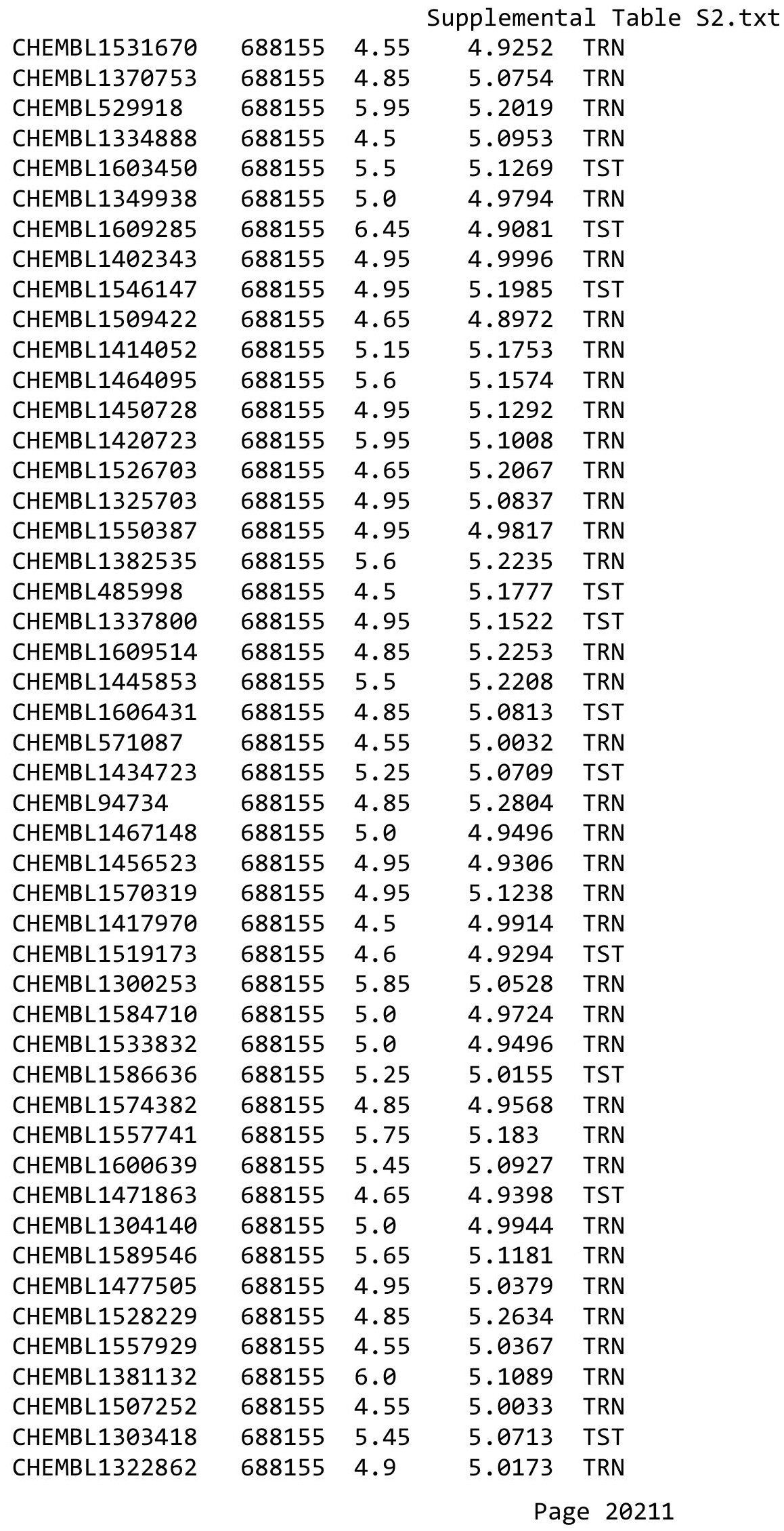




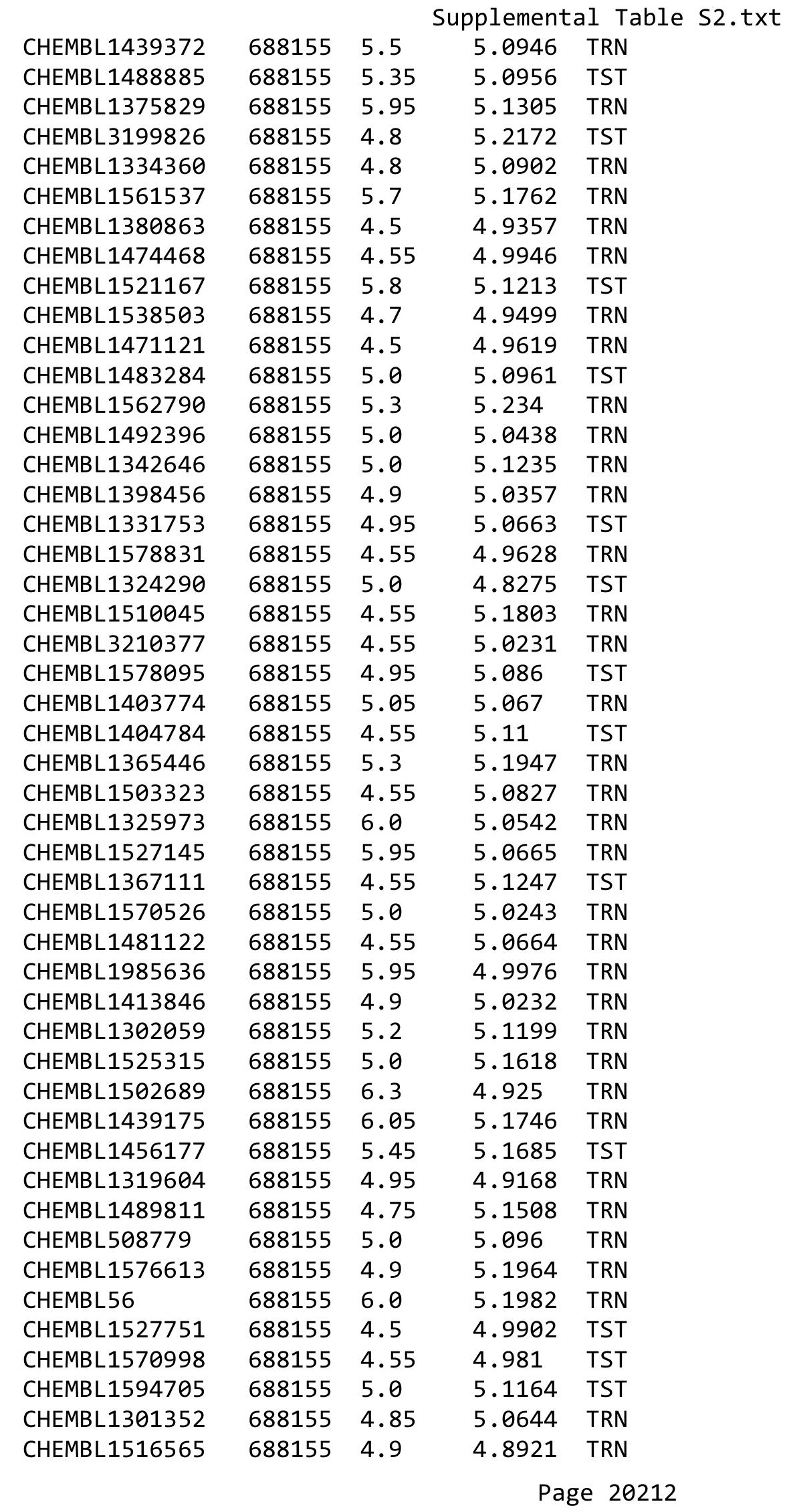




\begin{tabular}{|c|c|c|c|c|c|}
\hline \multicolumn{6}{|c|}{ Supplemental Table S2.txt } \\
\hline CHEMBL1548532 & 688155 & 5.5 & 4.9532 & TRN & \\
\hline CHEMBL1334984 & 688155 & 5.05 & 5.0961 & TRN & \\
\hline CHEMBL1534846 & 688155 & 4.55 & 5.0194 & TRN & \\
\hline CHEMBL1333745 & 688155 & 4.85 & 5.0807 & TST & \\
\hline CHEMBL1390374 & 688155 & 4.9 & 5.015 & TRN & \\
\hline CHEMBL181633 & 688155 & 4.5 & 5.0696 & TST & \\
\hline CHEMBL1574014 & 688155 & 4.85 & 4.9056 & TST & \\
\hline CHEMBL1599746 & 688155 & 6.0 & 5.0037 & TRN & \\
\hline CHEMBL1528076 & 688155 & 5.15 & 5.1282 & TRN & \\
\hline CHEMBL1485625 & 688155 & 6.35 & 5.232 & TRN & \\
\hline CHEMBL 3197475 & 688155 & 5.0 & 5.0504 & TRN & \\
\hline CHEMBL1569493 & 688155 & 4.95 & 5.1535 & TRN & \\
\hline CHEMBL1496528 & 688155 & 4.5 & 4.8208 & TRN & \\
\hline CHEMBL1545606 & 688155 & 4.5 & 5.085 & TRN & \\
\hline CHEMBL1303072 & 688155 & 4.65 & 5.1295 & TRN & \\
\hline CHEMBL1426569 & 688155 & 5.15 & 5.1007 & TRN & \\
\hline CHEMBL1382443 & 688155 & 4.8 & 5.2006 & TST & \\
\hline CHEMBL1440367 & 688155 & 4.7 & 4.9375 & TRN & \\
\hline CHEMBL1362160 & 688155 & 4.95 & 5.0716 & TRN & \\
\hline CHEMBL1409659 & 688155 & 5.5 & 5.1358 & TRN & \\
\hline CHEMBL1447350 & 688155 & 5.0 & 5.0109 & TRN & \\
\hline CHEMBL1538027 & 688155 & 4.6 & 5.0434 & TRN & \\
\hline CHEMBL3195827 & 688155 & 5.0 & 5.0782 & TRN & \\
\hline CHEMBL1576495 & 688155 & 5.2 & 5.0821 & TRN & \\
\hline CHEMBL1343401 & 688155 & 5.5 & 5.2908 & TRN & \\
\hline CHEMBL1377250 & 688155 & 4.5 & 4.9332 & TRN & \\
\hline CHEMBL1497050 & 688155 & 5.5 & 5.1645 & TRN & \\
\hline CHEMBL1566598 & 688155 & 6.45 & 5.2391 & TRN & \\
\hline CHEMBL1582129 & 688155 & 4.5 & 5.13399 & 99999999995 & TRN \\
\hline CHEMBL1402926 & 688155 & 6.05 & 4.9661 & TRN & \\
\hline CHEMBL1549361 & 688155 & 4.95 & 5.0246 & TRN & \\
\hline CHEMBL1443722 & 688155 & 5.2 & 5.088 & TRN & \\
\hline CHEMBL1462978 & 688155 & 4.9 & 5.0005 & TRN & \\
\hline CHEMBL1507052 & 688155 & 4.55 & 4.9994 & TRN & \\
\hline CHEMBL1340822 & 688155 & 5.2 & 5.0373 & TRN & \\
\hline CHEMBL1501121 & 688155 & 5.9 & 4.97199 & 99999999995 & TRN \\
\hline CHEMBL1412471 & 688155 & 4.55 & 5.016 & TRN & \\
\hline CHEMBL1382150 & 688155 & 5.75 & 5.1565 & TRN & \\
\hline CHEMBL1377850 & 688155 & 4.55 & 4.9753 & TRN & \\
\hline CHEMBL1344591 & 688155 & 5.2 & 5.1659 & TRN & \\
\hline CHEMBL1365620 & 688155 & 5.55 & 5.0522 & TST & \\
\hline CHEMBL1312087 & 688155 & 5.0 & 5.0849 & TRN & \\
\hline CHEMBL3212503 & 688155 & 4.6 & 5.0505 & TRN & \\
\hline CHEMBL1569232 & 688155 & 4.95 & 5.0518 & TRN & \\
\hline CHEMBL1305744 & 688155 & 4.5 & 5.0211 & TRN & \\
\hline CHEMBL1511731 & 688155 & 5.35 & 5.0045 & TST & \\
\hline CHEMBL1463781 & 688155 & 5.0 & 4.9929 & TRN & \\
\hline CHEMBL1522138 & 688155 & 5.3 & 4.89199 & 99999999995 & TRN \\
\hline & & & & 20213 & \\
\hline
\end{tabular}




\begin{tabular}{|c|c|c|c|c|c|}
\hline \multicolumn{6}{|c|}{ Supplemental Table S2.txt } \\
\hline CHEMBL1477836 & 688155 & 4.5 & 5.1553 & TST & \\
\hline CHEMBL1458647 & 688155 & 4.9 & 5.0137 & TRN & \\
\hline CHEMBL3208369 & 688155 & 5.1 & 4.9198 & TRN & \\
\hline CHEMBL1423646 & 688155 & 4.95 & 5.2614 & TRN & \\
\hline CHEMBL1432655 & 688155 & 5.0 & 5.0332 & TST & \\
\hline CHEMBL1584016 & 688155 & 4.95 & 5.1519 & TRN & \\
\hline CHEMBL1425940 & 688155 & 4.5 & 5.0809 & TRN & \\
\hline CHEMBL1327168 & 688155 & 5.0 & 5.1213 & TRN & \\
\hline CHEMBL1504995 & 688155 & 4.95 & 4.9453 & TRN & \\
\hline CHEMBL1573874 & 688155 & 6.35 & 4.9937 & TRN & \\
\hline CHEMBL1411387 & 688155 & 5.0 & 5.1007 & TRN & \\
\hline CHEMBL1529320 & 688155 & 5.6 & 4.93199 & 99999999995 & TST \\
\hline CHEMBL1463485 & 688155 & 4.5 & 5.0166 & TRN & \\
\hline CHEMBL1482435 & 688155 & 5.6 & 5.1949 & TRN & \\
\hline CHEMBL1384631 & 688155 & 4.95 & 5.0811 & TRN & \\
\hline CHEMBL1342889 & 688155 & 5.0 & 4.9739 & TST & \\
\hline CHEMBL1410652 & 688155 & 4.55 & 5.1055 & TRN & \\
\hline CHEMBL1344796 & 688155 & 4.95 & 4.9663 & TRN & \\
\hline CHEMBL1478755 & 688155 & 5.25 & 5.0953 & TRN & \\
\hline CHEMBL1377744 & 688155 & 5.9 & 5.0738 & TST & \\
\hline CHEMBL1484070 & 688155 & 6.0 & 5.1932 & TRN & \\
\hline CHEMBL1337695 & 688155 & 4.6 & 5.0452 & TRN & \\
\hline CHEMBL1407945 & 688155 & 5.1 & 4.9389 & TRN & \\
\hline CHEMBL1337523 & 688155 & 4.55 & 5.1869 & TRN & \\
\hline CHEMBL1423986 & 688155 & 5.1 & 5.0336 & TST & \\
\hline CHEMBL1319580 & 688155 & 4.95 & 4.933 & TRN & \\
\hline CHEMBL1560747 & 688155 & 4.5 & 5.1715 & TRN & \\
\hline CHEMBL271023 & 688155 & 4.55 & 5.1199 & TST & \\
\hline CHEMBL1414494 & 688155 & 5.5 & 5.2042 & TRN & \\
\hline CHEMBL1344621 & 688155 & 4.55 & $5.1720 e$ & 0000000001 & TRN \\
\hline CHEMBL1506016 & 688155 & 4.5 & 4.9398 & TRN & \\
\hline CHEMBL1561828 & 688155 & 4.65 & 4.9852 & TRN & \\
\hline CHEMBL1468928 & 688155 & 6.45 & 4.9636 & TRN & \\
\hline CHEMBL1576460 & 688155 & 5.95 & 5.2245 & TRN & \\
\hline CHEMBL1470471 & 688155 & 4.9 & 4.9887 & TST & \\
\hline CHEMBL1537893 & 688155 & 5.05 & 5.1073 & TRN & \\
\hline CHEMBL1381238 & 688155 & 5.4 & 5.0473 & TST & \\
\hline CHEMBL1550985 & 688155 & 6.5 & 5.0815 & TST & \\
\hline CHEMBL1361462 & 688155 & 5.0 & 5.0773 & TRN & \\
\hline CHEMBL1507266 & 688155 & 4.55 & 5.1914 & TST & \\
\hline CHEMBL1457583 & 688155 & 5.95 & 5.0793 & TST & \\
\hline CHEMBL1331186 & 688155 & 5.65 & 5.1279 & TST & \\
\hline CHEMBL1522268 & 688155 & 5.65 & 5.2814 & TRN & \\
\hline CHEMBL1375070 & 688155 & 4.55 & 5.0421 & TRN & \\
\hline CHEMBL3192933 & 688155 & 4.9 & 5.0466 & TRN & \\
\hline CHEMBL1465744 & 688155 & 6.05 & 5.1547 & TRN & \\
\hline CHEMBL1585870 & 688155 & 5.4 & 5.1765 & TRN & \\
\hline CHEMBL1491854 & 688155 & 5.3 & 5.1682 & TRN & \\
\hline
\end{tabular}




\begin{tabular}{|c|c|c|c|c|c|}
\hline \multicolumn{6}{|c|}{ Supplemental Table S2.txt } \\
\hline CHEMBL1444145 & 688155 & 4.5 & 4.9902 & TRN & \\
\hline CHEMBL1369587 & 688155 & 5.0 & 5.0449 & TRN & \\
\hline CHEMBL1332677 & 688155 & 4.55 & 4.9795 & TRN & \\
\hline CHEMBL1505571 & 688155 & 4.5 & 5.0689 & TRN & \\
\hline CHEMBL1309256 & 688155 & 5.0 & 5.0927 & TST & \\
\hline CHEMBL1302436 & 688155 & 4.55 & 5.0141 & TRN & \\
\hline CHEMBL1435045 & 688155 & 5.3 & 4.9575 & TRN & \\
\hline CHEMBL1539841 & 688155 & 5.9 & 5.0717 & TRN & \\
\hline CHEMBL1327915 & 688155 & 6.1 & 5.0518 & TRN & \\
\hline CHEMBL1377509 & 688155 & 5.1 & 5.2113 & TRN & \\
\hline CHEMBL1438436 & 688155 & 4.55 & 5.0799 & TRN & \\
\hline CHEMBL1365582 & 688155 & 5.85 & 5.2287 & TRN & \\
\hline CHEMBL1589723 & 688155 & 5.0 & 5.1121 & TRN & \\
\hline CHEMBL1589289 & 688155 & 4.65 & 4.9896 & TRN & \\
\hline CHEMBL1453272 & 688155 & 5.8 & 5.1879 & TRN & \\
\hline CHEMBL1414452 & 688155 & 6.0 & 5.11600 & 30000000005 & TRN \\
\hline CHEMBL1560709 & 688155 & 5.0 & 4.9777 & TRN & \\
\hline CHEMBL1399917 & 688155 & 4.75 & 5.012 & TRN & \\
\hline CHEMBL1725983 & 688155 & 5.45 & 4.9967 & TRN & \\
\hline CHEMBL1546413 & 688155 & 4.95 & 4.9684 & TRN & \\
\hline CHEMBL1500639 & 688155 & 5.8 & 5.2478 & TRN & \\
\hline CHEMBL1467743 & 688155 & 5.0 & 5.1816 & TRN & \\
\hline CHEMBL1345018 & 688155 & 5.0 & 5.0943 & TRN & \\
\hline CHEMBL1485071 & 688155 & 5.0 & 5.1736 & TST & \\
\hline CHEMBL1613327 & 688155 & 5.0 & 5.0513 & TST & \\
\hline CHEMBL1257125 & 688155 & 5.65 & 5.2217 & TRN & \\
\hline CHEMBL1560313 & 688155 & 4.65 & 5.1615 & TRN & \\
\hline CHEMBL1379663 & 688155 & 4.9 & 4.9499 & TRN & \\
\hline CHEMBL1571407 & 688155 & 5.05 & 5.2535 & TRN & \\
\hline CHEMBL1528223 & 688155 & 5.25 & 5.0616 & TRN & \\
\hline CHEMBL1401211 & 688155 & 4.45 & 5.092 & TRN & \\
\hline CHEMBL1425334 & 688155 & 4.55 & 5.0304 & TST & \\
\hline CHEMBL1505268 & 688155 & 4.95 & 4.9857 & TRN & \\
\hline CHEMBL1466241 & 688155 & 5.8 & 4.9801 & TST & \\
\hline CHEMBL1517426 & 688155 & 4.7 & 5.0805 & TRN & \\
\hline CHEMBL1382347 & 688155 & 5.7 & 5.1079 & TRN & \\
\hline CHEMBL1483204 & 688155 & 5.55 & 5.1884 & TRN & \\
\hline CHEMBL1421358 & 688155 & 5.85 & 5.0177 & TRN & \\
\hline CHEMBL1579187 & 688155 & 4.9 & 5.1566 & TST & \\
\hline CHEMBL1320427 & 688155 & 5.9 & 5.0706 & TRN & \\
\hline CHEMBL1465814 & 688155 & 5.05 & 4.9515 & TRN & \\
\hline CHEMBL1466961 & 688155 & 4.9 & 5.1882 & TST & \\
\hline CHEMBL1388224 & 688155 & 4.9 & 5.0518 & TRN & \\
\hline CHEMBL1353408 & 688155 & 5.0 & 5.0425 & TRN & \\
\hline CHEMBL1427890 & 688155 & 4.85 & 5.0844 & TST & \\
\hline CHEMBL1426817 & 688155 & 4.9 & 5.1047 & TST & \\
\hline CHEMBL1485609 & 688155 & 4.95 & 4.8616 & TRN & \\
\hline CHEMBL1572056 & 688155 & 4.9 & 5.0619 & TRN & \\
\hline
\end{tabular}




\begin{tabular}{|c|c|c|c|c|}
\hline \multicolumn{5}{|c|}{ Supplemental Table S2.txt } \\
\hline CHEMBL1487236 & 688155 & 4.8 & 5.1003 & TRN \\
\hline CHEMBL1318967 & 688155 & 5.3 & 5.1509 & TRN \\
\hline CHEMBL1454046 & 688155 & 4.5 & 5.0175 & TRN \\
\hline CHEMBL1424991 & 688155 & 5.7 & 5.2726 & TRN \\
\hline CHEMBL1468368 & 688155 & 4.55 & 5.0541 & TST \\
\hline CHEMBL1383029 & 688155 & 4.5 & 4.9235 & TRN \\
\hline CHEMBL1338342 & 688155 & 4.55 & 5.0891 & TRN \\
\hline CHEMBL1530190 & 688155 & 4.9 & 5.0419 & TRN \\
\hline CHEMBL1507369 & 688155 & 4.5 & 5.1493 & TST \\
\hline CHEMBL1305152 & 688155 & 4.9 & 5.0417 & TST \\
\hline CHEMBL1462804 & 688155 & 4.55 & 4.9408 & TRN \\
\hline CHEMBL1609786 & 688155 & 5.4 & 5.1155 & TRN \\
\hline CHEMBL1609093 & 688155 & 6.5 & 5.0308 & TRN \\
\hline CHEMBL1354068 & 688155 & 5.45 & 5.2009 & TRN \\
\hline CHEMBL3191587 & 688155 & 4.95 & 4.8794 & TRN \\
\hline CHEMBL1352024 & 688155 & 5.4 & 5.1516 & TRN \\
\hline CHEMBL1506181 & 688155 & 4.55 & 5.1564 & TST \\
\hline CHEMBL1966241 & 688155 & 5.0 & 5.0615 & TRN \\
\hline CHEMBL1533664 & 688155 & 4.8 & 5.2293 & TST \\
\hline CHEMBL1492497 & 688155 & 5.15 & 5.1481 & TRN \\
\hline CHEMBL377295 & 688155 & 4.8 & 5.0494 & TRN \\
\hline CHEMBL1479135 & 688155 & 4.7 & 5.0867 & TRN \\
\hline CHEMBL1386430 & 688155 & 4.5 & 5.0016 & TRN \\
\hline CHEMBL1388961 & 688155 & 6.0 & 5.1604 & TRN \\
\hline CHEMBL1572952 & 688155 & 6.0 & 5.1512 & TRN \\
\hline CHEMBL1301464 & 688155 & 5.75 & 5.0621 & TST \\
\hline CHEMBL1332912 & 688155 & 5.0 & 5.193 & TRN \\
\hline CHEMBL1526171 & 688155 & 4.65 & 5.0789 & TST \\
\hline CHEMBL1332655 & 688155 & 4.95 & 5.2711 & TRN \\
\hline CHEMBL1576790 & 688155 & 4.55 & 5.1121 & TRN \\
\hline CHEMBL1595221 & 688155 & 4.5 & 5.0704 & TRN \\
\hline CHEMBL1409587 & 688155 & 5.4 & 5.0733 & TRN \\
\hline CHEMBL1391679 & 688155 & 4.9 & 4.9077 & TRN \\
\hline CHEMBL1423477 & 688155 & 4.55 & 4.8697 & TRN \\
\hline CHEMBL1507562 & 688155 & 6.45 & 5.0015 & TST \\
\hline CHEMBL1312234 & 688155 & 4.55 & 4.9301 & TRN \\
\hline CHEMBL1304139 & 688155 & 4.9 & 4.8987 & TRN \\
\hline CHEMBL1364483 & 688155 & 6.05 & 4.9947 & TRN \\
\hline CHEMBL1299321 & 688155 & 4.55 & 5.0313 & TST \\
\hline CHEMBL20377 & 688155 & 4.55 & 5.2225 & TRN \\
\hline CHEMBL1534885 & 688155 & 5.2 & 5.1247 & TRN \\
\hline CHEMBL1465211 & 688155 & 5.0 & 5.0503 & TRN \\
\hline CHEMBL1542698 & 688155 & 4.95 & 4.9848 & TRN \\
\hline CHEMBL1336784 & 688155 & 6.05 & 5.0193 & TRN \\
\hline CHEMBL1569439 & 688155 & 6.45 & 5.2211 & TST \\
\hline CHEMBL1378704 & 688155 & 6.1 & 5.1925 & TRN \\
\hline CHEMBL1536978 & 688155 & 4.55 & 5.1058 & TST \\
\hline CHEMBL1319070 & 688155 & 4.9 & 5.0228 & TRN \\
\hline
\end{tabular}




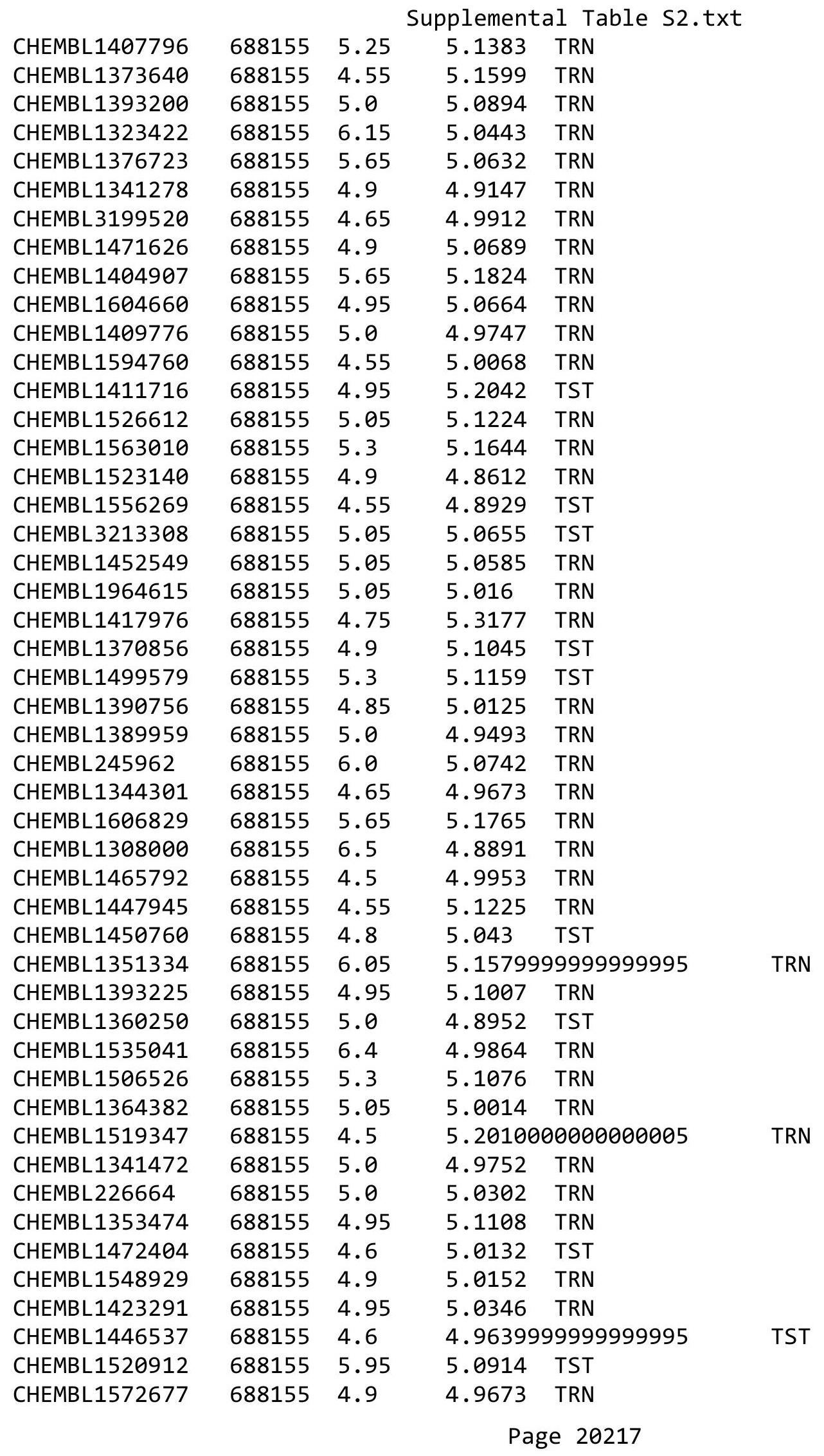




\begin{tabular}{|c|c|c|c|c|c|}
\hline & & & pplement & Table S2. & \\
\hline CHEMBL1472303 & 688155 & 4.9 & 5.1834 & TRN & \\
\hline CHEMBL1385837 & 688155 & 5.45 & 5.20299 & 9999999999 & TST \\
\hline CHEMBL1501602 & 688155 & 4.55 & 5.1431 & TRN & \\
\hline CHEMBL1464800 & 688155 & 4.55 & 5.1254 & TRN & \\
\hline CHEMBL1319912 & 688155 & 5.3 & 5.1441 & TST & \\
\hline CHEMBL1545293 & 688155 & 4.65 & 5.3398 & TRN & \\
\hline CHEMBL1347542 & 688155 & 4.95 & 5.084 & TST & \\
\hline CHEMBL1450165 & 688155 & 5.0 & 5.085 & TST & \\
\hline CHEMBL1606858 & 688155 & 6.5 & 5.1483 & TRN & \\
\hline CHEMBL1302919 & 688155 & 4.85 & 5.1832 & TRN & \\
\hline CHEMBL1535811 & 688155 & 5.0 & 5.1574 & TRN & \\
\hline CHEMBL1607103 & 688155 & 4.5 & 5.047 & TRN & \\
\hline CHEMBL1527049 & 688155 & 5.15 & 4.8998 & TRN & \\
\hline CHEMBL1386573 & 688155 & 4.55 & 5.1519 & TRN & \\
\hline CHEMBL1550345 & 688155 & 5.4 & 5.13299 & 9999999999 & TRN \\
\hline CHEMBL1562110 & 688155 & 5.05 & 5.0312 & TRN & \\
\hline CHEMBL1568081 & 688155 & 4.95 & 4.919 & TRN & \\
\hline CHEMBL1323774 & 688155 & 4.9 & 4.9422 & TRN & \\
\hline CHEMBL1399035 & 688155 & 5.1 & 4.9686 & TRN & \\
\hline CHEMBL1544704 & 688155 & 6.0 & 5.1597 & TRN & \\
\hline CHEMBL1559140 & 688155 & 5.0 & 5.0391 & TRN & \\
\hline CHEMBL549208 & 688155 & 4.9 & 5.0215 & TRN & \\
\hline CHEMBL1526403 & 688155 & 5.0 & 5.1643 & TRN & \\
\hline CHEMBL1414368 & 688155 & 5.4 & 5.0374 & TST & \\
\hline CHEMBL1300912 & 688155 & 5.35 & 4.8392 & TRN & \\
\hline CHEMBL1378658 & 688155 & 4.9 & 5.1263 & TST & \\
\hline CHEMBL1457248 & 688155 & 4.85 & 5.0145 & TRN & \\
\hline CHEMBL1300483 & 688155 & 5.2 & 5.1718 & TST & \\
\hline CHEMBL1331930 & 688155 & 4.95 & $5.1080 e$ & 00000000005 & TRN \\
\hline CHEMBL1402849 & 688155 & 5.35 & 5.3029 & TRN & \\
\hline CHEMBL1460905 & 688155 & 5.45 & 5.1165 & TRN & \\
\hline CHEMBL1388514 & 688155 & 4.55 & 5.1747 & TRN & \\
\hline CHEMBL1095796 & 688155 & 4.75 & 5.1795 & TST & \\
\hline CHEMBL1327735 & 688155 & 4.5 & 5.11 & TST & \\
\hline CHEMBL1337886 & 688155 & 5.05 & 4.8989 & TRN & \\
\hline CHEMBL1521215 & 688155 & 4.7 & 4.9946 & TRN & \\
\hline CHEMBL1529824 & 688155 & 4.95 & 5.1804 & TST & \\
\hline CHEMBL1346709 & 688155 & 4.55 & 5.2634 & TRN & \\
\hline CHEMBL1449491 & 688155 & 4.5 & 5.2834 & TRN & \\
\hline CHEMBL1377242 & 688155 & 5.45 & 5.0351 & TRN & \\
\hline CHEMBL1381706 & 688155 & 6.15 & 5.1283 & TST & \\
\hline CHEMBL1322742 & 688155 & 5.45 & 5.1768 & TRN & \\
\hline CHEMBL1352186 & 688155 & 5.1 & 5.1465 & TRN & \\
\hline CHEMBL1408420 & 688155 & 5.65 & 5.0707 & TST & \\
\hline CHEMBL75691 & 688155 & 5.6 & 5.0498 & TST & \\
\hline CHEMBL1500409 & 688155 & 4.95 & 5.0337 & TRN & \\
\hline CHEMBL1502765 & 688155 & 5.95 & 5.2233 & TRN & \\
\hline CHEMBL1385759 & 688155 & 5.5 & 5.1472 & TST & \\
\hline & & & & 2021 & \\
\hline
\end{tabular}




\begin{tabular}{|c|c|c|c|c|c|}
\hline \multicolumn{6}{|c|}{ Supplemental Table s2.txt } \\
\hline CHEMBL1368951 & 688155 & 4.55 & 5.0359 & TRN & \\
\hline CHEMBL1354561 & 688155 & 4.55 & 4.9223 & TRN & \\
\hline CHEMBL1499443 & 688155 & 5.5 & 5.021 & TRN & \\
\hline CHEMBL1605984 & 688155 & 6.5 & 4.952 & TRN & \\
\hline CHEMBL1311808 & 688155 & 4.95 & 5.0182 & TRN & \\
\hline CHEMBL1536383 & 688155 & 6.05 & 5.2597 & TST & \\
\hline CHEMBL1494612 & 688155 & 5.95 & 4.9786 & TRN & \\
\hline CHEMBL1406145 & 688155 & 4.95 & 5.0915 & TST & \\
\hline CHEMBL1381578 & 688155 & 5.5 & 4.959 & TRN & \\
\hline CHEMBL1573353 & 688155 & 4.55 & 5.1439 & TRN & \\
\hline CHEMBL1376872 & 688155 & 4.65 & 4.9562 & TRN & \\
\hline CHEMBL1393452 & 688155 & 4.5 & 5.0393 & TRN & \\
\hline CHEMBL1997195 & 688155 & 5.95 & 4.975 & TRN & \\
\hline CHEMBL1344811 & 688155 & 4.45 & 5.0789 & TRN & \\
\hline CHEMBL1517177 & 688155 & 4.55 & 5.0861 & TRN & \\
\hline CHEMBL1430358 & 688155 & 5.0 & 5.1077 & TRN & \\
\hline CHEMBL1388102 & 688155 & 4.5 & 5.1131 & TRN & \\
\hline CHEMBL3192888 & 688155 & 5.2 & 5.0006 & TST & \\
\hline CHEMBL120806 & 688155 & 5.65 & 5.1612 & TST & \\
\hline CHEMBL1334736 & 688155 & 5.4 & 5.0915 & TRN & \\
\hline CHEMBL1544664 & 688155 & 4.95 & 4.9726 & TST & \\
\hline CHEMBL1339659 & 688155 & 4.95 & 5.0848 & TRN & \\
\hline CHEMBL1403420 & 688155 & 4.5 & 4.9808 & TRN & \\
\hline CHEMBL1579885 & 688155 & 5.95 & 5.0355 & TRN & \\
\hline CHEMBL1393918 & 688155 & 5.05 & 5.0774 & TRN & \\
\hline CHEMBL1504015 & 688155 & 4.95 & 5.3447 & TRN & \\
\hline CHEMBL1606494 & 688155 & 4.75 & 5.0542 & TST & \\
\hline CHEMBL1417204 & 688155 & 5.05 & 5.0818 & TRN & \\
\hline CHEMBL1307228 & 688155 & 4.5 & 5.2252 & TRN & \\
\hline CHEMBL1543763 & 688155 & 4.55 & 5.0409 & TST & \\
\hline CHEMBL3198781 & 688155 & 4.55 & 4.9748 & TST & \\
\hline CHEMBL1449749 & 688155 & 4.45 & 4.9909 & TRN & \\
\hline CHEMBL1399142 & 688155 & 4.5 & 5.1475 & TST & \\
\hline CHEMBL1313418 & 688155 & 4.65 & 5.0616 & TRN & \\
\hline CHEMBL3213359 & 688155 & 4.55 & 4.9719 & TRN & \\
\hline CHEMBL1489863 & 688155 & 5.0 & 5.0141 & TRN & \\
\hline CHEMBL1301821 & 688155 & 5.9 & 5.1228 & TRN & \\
\hline CHEMBL1585355 & 688155 & 4.7 & 5.2277 & TRN & \\
\hline CHEMBL1327708 & 688155 & 4.9 & 5.0821 & TRN & \\
\hline CHEMBL1332653 & 688155 & 4.9 & 4.98 & TRN & \\
\hline CHEMBL1304295 & 688155 & 6.0 & 5.2668 & TRN & \\
\hline CHEMBL1459221 & 688155 & 5.5 & 5.1524 & TRN & \\
\hline CHEMBL1302716 & 688155 & 5.0 & 5.0987 & TRN & \\
\hline CHEMBL1458873 & 688155 & 4.55 & 5.0365 & TRN & \\
\hline CHEMBL1462562 & 688155 & 4.55 & 5.0022 & TRN & \\
\hline CHEMBL1577258 & 688155 & 5.0 & 4.9906 & TRN & \\
\hline CHEMBL1354056 & 688155 & 5.05 & 5.13899 & 9999999999 & TRN \\
\hline CHEMBL1608446 & 688155 & 4.95 & 4.9021 & TRN & \\
\hline & & & & 20219 & \\
\hline
\end{tabular}




\begin{tabular}{|c|c|c|c|c|c|}
\hline \multicolumn{6}{|c|}{ Supplemental Table s2.txt } \\
\hline CHEMBL1408148 & 688155 & 4.7 & 5.1058 & TST & \\
\hline CHEMBL1541646 & 688155 & 5.65 & 5.2349 & TRN & \\
\hline CHEMBL1331311 & 688155 & 5.15 & 5.0611 & TRN & \\
\hline CHEMBL1385751 & 688155 & 4.5 & 5.0995 & TRN & \\
\hline CHEMBL1341873 & 688155 & 5.7 & 4.9468 & TRN & \\
\hline CHEMBL1385192 & 688155 & 4.9 & 5.1494 & TRN & \\
\hline CHEMBL1409954 & 688155 & 4.95 & 4.9998 & TRN & \\
\hline CHEMBL1342955 & 688155 & 5.5 & 5.1757 & TST & \\
\hline CHEMBL 293749 & 688155 & 4.95 & 5.1197 & TRN & \\
\hline CHEMBL1328279 & 688155 & 4.9 & 4.9864 & TRN & \\
\hline CHEMBL1492543 & 688155 & 4.55 & 5.2744 & TRN & \\
\hline CHEMBL1589567 & 688155 & 4.95 & 4.9322 & TRN & \\
\hline CHEMBL1543459 & 688155 & 6.0 & 5.1741 & TRN & \\
\hline CHEMBL1411212 & 688155 & 4.95 & 5.1067 & TRN & \\
\hline CHEMBL1576634 & 688155 & 6.5 & 5.03 & TRN & \\
\hline CHEMBL1327643 & 688155 & 4.95 & $5.0280 e$ & 00000000005 & TST \\
\hline CHEMBL1556539 & 688155 & 5.2 & 5.0206 & TRN & \\
\hline CHEMBL3210226 & 688155 & 6.3 & 5.0796 & TST & \\
\hline CHEMBL1368425 & 688155 & 6.4 & 5.0257 & TST & \\
\hline CHEMBL88147 & 688155 & 4.55 & 4.9357 & TST & \\
\hline CHEMBL3189951 & 688155 & 4.95 & 5.0343 & TST & \\
\hline CHEMBL1367707 & 688155 & 4.55 & 5.0048 & TRN & \\
\hline CHEMBL186526 & 688155 & 6.5 & 5.0042 & TST & \\
\hline CHEMBL1564380 & 688155 & 4.7 & 5.1454 & TRN & \\
\hline CHEMBL1383461 & 688155 & 4.9 & 5.0591 & TRN & \\
\hline CHEMBL1583381 & 688155 & 5.95 & 5.0877 & TRN & \\
\hline CHEMBL1545558 & 688155 & 5.95 & 5.1172 & TST & \\
\hline CHEMBL601110 & 688155 & 5.0 & 5.0744 & TST & \\
\hline CHEMBL1608598 & 688155 & 5.0 & 5.0325 & TRN & \\
\hline CHEMBL1389537 & 688155 & 5.2 & 5.1354 & TRN & \\
\hline CHEMBL1380671 & 688155 & 4.95 & 5.0631 & TST & \\
\hline CHEMBL1573867 & 688155 & 4.95 & 5.1006 & TRN & \\
\hline CHEMBL192627 & 688155 & 6.0 & 5.1812 & TST & \\
\hline CHEMBL1493251 & 688155 & 5.5 & 5.1428 & TRN & \\
\hline CHEMBL1456319 & 688155 & 5.9 & 4.9277 & TRN & \\
\hline CHEMBL1609445 & 688155 & 4.5 & 5.0841 & TRN & \\
\hline CHEMBL1541699 & 688155 & 4.9 & 5.1746 & TRN & \\
\hline CHEMBL1481987 & 688155 & 4.55 & 5.026 & TRN & \\
\hline CHEMBL1485993 & 688155 & 4.9 & 4.9233 & TRN & \\
\hline CHEMBL1364651 & 688155 & 5.05 & 5.1125 & TRN & \\
\hline CHEMBL1591258 & 688155 & 5.0 & 5.0944 & TST & \\
\hline CHEMBL1450813 & 688155 & 5.0 & 5.0871 & TST & \\
\hline CHEMBL1475131 & 688155 & 4.55 & 4.9374 & TST & \\
\hline CHEMBL1573159 & 688155 & 5.55 & 5.1406 & TRN & \\
\hline CHEMBL1479708 & 688155 & 5.45 & 5.0578 & TRN & \\
\hline CHEMBL1348169 & 688155 & 5.1 & 4.8928 & TRN & \\
\hline CHEMBL1597229 & 688155 & 4.65 & 5.0227 & TRN & \\
\hline CHEMBL1389021 & 688155 & 4.5 & 5.011 & TRN & \\
\hline
\end{tabular}




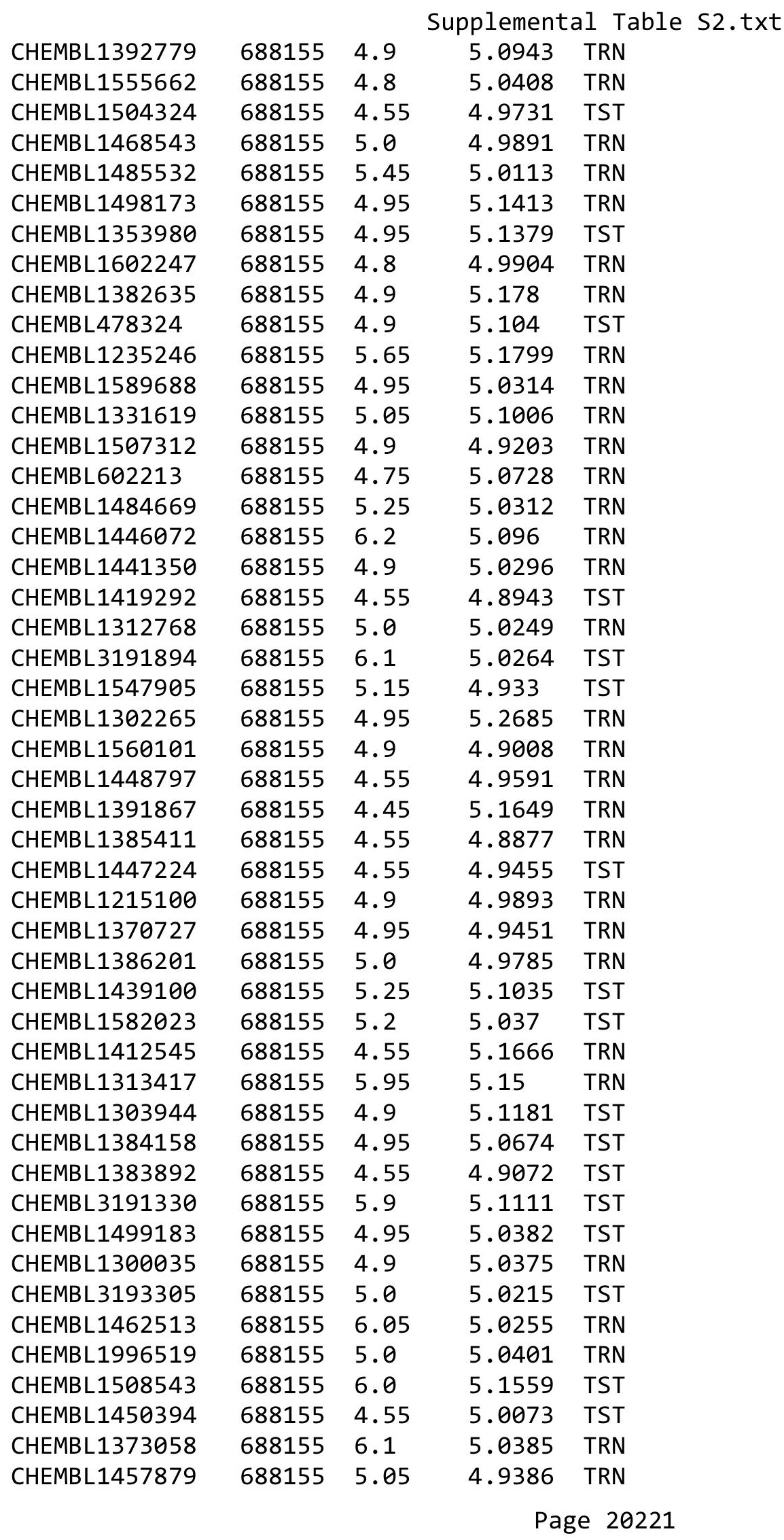




\begin{tabular}{|c|c|c|c|c|c|}
\hline \multicolumn{6}{|c|}{ Supplemental Table s2.txt } \\
\hline CHEMBL1366945 & 688155 & 4.45 & 5.0963 & TRN & \\
\hline CHEMBL1596090 & 688155 & 4.65 & 5.0741 & TRN & \\
\hline CHEMBL1349528 & 688155 & 5.05 & 5.0056 & TRN & \\
\hline CHEMBL1500024 & 688155 & 5.05 & 5.1654 & TRN & \\
\hline CHEMBL1497225 & 688155 & 4.95 & 5.0542 & TRN & \\
\hline CHEMBL3138730 & 688155 & 5.85 & 5.0978 & TST & \\
\hline CHEMBL3212311 & 688155 & 4.95 & 4.9885 & TRN & \\
\hline CHEMBL1346293 & 688155 & 4.8 & 5.1203 & TST & \\
\hline CHEMBL1367446 & 688155 & 6.5 & 5.19799 & 99999999995 & TST \\
\hline CHEMBL1423417 & 688155 & 4.55 & 5.0598 & TRN & \\
\hline CHEMBL1498785 & 688155 & 4.5 & 5.0493 & TRN & \\
\hline CHEMBL1546086 & 688155 & 5.3 & 5.2117 & TST & \\
\hline CHEMBL1504186 & 688155 & 4.8 & 5.1039 & TRN & \\
\hline CHEMBL1521639 & 688155 & 4.95 & 5.0392 & TRN & \\
\hline CHEMBL3194881 & 688155 & 4.9 & 5.082 & TRN & \\
\hline CHEMBL1572969 & 688155 & 6.2 & 5.0946 & TRN & \\
\hline CHEMBL1467557 & 688155 & 4.85 & 5.0194 & TRN & \\
\hline CHEMBL1492442 & 688155 & 6.35 & 5.0356 & TST & \\
\hline CHEMBL1539870 & 688155 & 4.55 & 5.0787 & TRN & \\
\hline CHEMBL1612606 & 688155 & 4.55 & 5.0284 & TRN & \\
\hline CHEMBL1454682 & 688155 & 5.2 & 5.0645 & TRN & \\
\hline CHEMBL1608727 & 688155 & 5.6 & 5.141 & TST & \\
\hline CHEMBL1423531 & 688155 & 5.35 & 5.0678 & TRN & \\
\hline CHEMBL1388695 & 688155 & 4.55 & 4.9471 & TRN & \\
\hline CHEMBL1589342 & 688155 & 4.95 & 5.1082 & TRN & \\
\hline CHEMBL1572892 & 688155 & 5.3 & 5.0563 & TRN & \\
\hline CHEMBL1493968 & 688155 & 4.7 & 4.9701 & TRN & \\
\hline CHEMBL1571599 & 688155 & 4.55 & 5.0203 & TRN & \\
\hline CHEMBL1506399 & 688155 & 4.7 & 5.1053 & TRN & \\
\hline CHEMBL1516894 & 688155 & 4.5 & 5.13700 & 00000000005 & TST \\
\hline CHEMBL1520340 & 688155 & 4.5 & 5.0244 & TRN & \\
\hline CHEMBL1353799 & 688155 & 5.05 & 4.9502 & TRN & \\
\hline CHEMBL1407614 & 688155 & 5.8 & 5.0276 & TRN & \\
\hline CHEMBL1335324 & 688155 & 4.95 & 5.0814 & TRN & \\
\hline CHEMBL1534140 & 688155 & 4.55 & 5.1434 & TRN & \\
\hline CHEMBL1459978 & 688155 & 4.9 & 5.0685 & TRN & \\
\hline CHEMBL1308149 & 688155 & 4.95 & 5.0707 & TRN & \\
\hline CHEMBL1449878 & 688155 & 6.5 & 5.1351 & TST & \\
\hline CHEMBL1584956 & 688155 & 4.9 & 5.1154 & TRN & \\
\hline CHEMBL1999046 & 688155 & 4.9 & 4.9753 & TST & \\
\hline CHEMBL1416521 & 688155 & 5.0 & 5.0536 & TRN & \\
\hline CHEMBL1351020 & 688155 & 5.25 & 4.9722 & TST & \\
\hline CHEMBL1613534 & 688155 & 4.6 & 5.0713 & TST & \\
\hline CHEMBL1504492 & 688155 & 4.5 & 5.0528 & TRN & \\
\hline CHEMBL1449664 & 688155 & 4.5 & 5.0332 & TST & \\
\hline CHEMBL145725 & 688155 & 4.5 & 5.1527 & TST & \\
\hline CHEMBL1417539 & 688155 & 5.35 & 5.0196 & TRN & \\
\hline CHEMBL1543800 & 688155 & 4.95 & 5.0082 & TRN & \\
\hline
\end{tabular}




\begin{tabular}{|c|c|c|c|c|c|}
\hline & & \multicolumn{4}{|c|}{ Supplemental Table s2.txt } \\
\hline CHEMBL1455049 & 688155 & 4.95 & 5.1077 & TRN & \\
\hline CHEMBL1395026 & 688155 & 4.85 & 4.9467 & TRN & \\
\hline CHEMBL1538560 & 688155 & 4.55 & 4.9076 & TRN & \\
\hline CHEMBL1360504 & 688155 & 4.9 & 5.1752 & TRN & \\
\hline CHEMBL1365794 & 688155 & 5.55 & 5.1667 & TRN & \\
\hline CHEMBL1419679 & 688155 & 4.95 & 5.0093 & TRN & \\
\hline CHEMBL1560872 & 688155 & 4.65 & 5.0009 & TST & \\
\hline CHEMBL1569744 & 688155 & 5.0 & 4.9587 & TRN & \\
\hline CHEMBL1710 & 688155 & 5.5 & 5.1765 & TRN & \\
\hline CHEMBL1469146 & 688155 & 4.55 & 5.2413 & TRN & \\
\hline CHEMBL1570559 & 688155 & 4.6 & 5.0349 & TRN & \\
\hline CHEMBL1432372 & 688155 & 4.5 & 5.051 & TRN & \\
\hline CHEMBL1527264 & 688155 & 6.05 & 5.2574 & TRN & \\
\hline CHEMBL1480787 & 688155 & 4.55 & 5.1462 & TRN & \\
\hline CHEMBL1336951 & 688155 & 6.1 & 4.9461 & TST & \\
\hline CHEMBL1391566 & 688155 & 4.95 & 5.083 & TRN & \\
\hline CHEMBL1332891 & 688155 & 6.35 & 5.1875 & TST & \\
\hline CHEMBL1362307 & 688155 & 4.6 & 4.967 & TST & \\
\hline CHEMBL1549128 & 688155 & 4.55 & 5.0235 & TST & \\
\hline CHEMBL1340638 & 688155 & 4.7 & 5.0789 & TST & \\
\hline CHEMBL1370119 & 688155 & 4.55 & 5.0 & TST & \\
\hline CHEMBL1308790 & 688155 & 4.55 & 4.9077 & TRN & \\
\hline CHEMBL1510840 & 688155 & 4.55 & 5.1504 & TRN & \\
\hline CHEMBL1510869 & 688155 & 4.95 & 5.0711 & TRN & \\
\hline CHEMBL1496149 & 688155 & 4.65 & 5.0899 & TST & \\
\hline CHEMBL1498569 & 688155 & 4.95 & 5.2327 & TRN & \\
\hline CHEMBL405110 & 688155 & 5.7 & 4.94300 & 00000000005 & TST \\
\hline CHEMBL1491944 & 688155 & 5.1 & 5.1036 & TRN & \\
\hline CHEMBL1611934 & 688155 & 5.9 & 5.2356 & TST & \\
\hline CHEMBL1404093 & 688155 & 4.5 & 5.0345 & TRN & \\
\hline CHEMBL1439553 & 688155 & 5.3 & 5.17299 & 9999999999 & TST \\
\hline CHEMBL1578505 & 688155 & 5.1 & 5.1024 & TRN & \\
\hline CHEMBL1450150 & 688155 & 4.55 & 5.0129 & TRN & \\
\hline CHEMBL1606077 & 688155 & 4.5 & 5.0971 & TRN & \\
\hline CHEMBL1548764 & 688155 & 5.6 & 5.1861 & TRN & \\
\hline CHEMBL1377706 & 688155 & 4.95 & 4.92 & TRN & \\
\hline CHEMBL1342429 & 688155 & 4.55 & 5.07 & TRN & \\
\hline CHEMBL1381608 & 688155 & 6.5 & 5.2233 & TRN & \\
\hline CHEMBL3195177 & 688155 & 5.0 & 5.0051 & TRN & \\
\hline CHEMBL1497925 & 688155 & 4.95 & 5.1123 & TST & \\
\hline CHEMBL1578960 & 688155 & 6.5 & 5.0178 & TST & \\
\hline CHEMBL1321693 & 688155 & 4.8 & 4.8939 & TRN & \\
\hline CHEMBL1453802 & 688155 & 4.55 & 5.0921 & TRN & \\
\hline CHEMBL1426009 & 688155 & 4.9 & 5.1389 & TRN & \\
\hline CHEMBL1384477 & 688155 & 4.55 & 5.1342 & TRN & \\
\hline CHEMBL1557499 & 688155 & 4.95 & 5.0496 & TRN & \\
\hline CHEMBL1602808 & 688155 & 6.5 & 5.2344 & TRN & \\
\hline CHEMBL1550381 & 688155 & 4.9 & 4.9854 & TST & \\
\hline
\end{tabular}




\begin{tabular}{|c|c|c|c|c|c|}
\hline \multicolumn{6}{|c|}{ Supplemental Table S2.txt } \\
\hline CHEMBL1983791 & 688155 & 4.95 & 5.0031 & TRN & \\
\hline CHEMBL1599622 & 688155 & 4.55 & 5.2407 & TRN & \\
\hline CHEMBL1498110 & 688155 & 4.95 & 5.0709 & TRN & \\
\hline CHEMBL1540335 & 688155 & 5.3 & 5.0277 & TRN & \\
\hline CHEMBL1609088 & 688155 & 5.45 & 5.1241 & TRN & \\
\hline CHEMBL1467241 & 688155 & 4.95 & 4.8798 & TRN & \\
\hline CHEMBL48449 & 688155 & 5.0 & 5.222 & TST & \\
\hline CHEMBL1536471 & 688155 & 4.5 & 5.1317 & TRN & \\
\hline CHEMBL1432271 & 688155 & 5.1 & 5.1744 & TRN & \\
\hline CHEMBL603020 & 688155 & 5.0 & 5.0876 & TRN & \\
\hline CHEMBL1458591 & 688155 & 5.3 & 5.1016 & TST & \\
\hline CHEMBL1487270 & 688155 & 5.0 & 5.2411 & TRN & \\
\hline CHEMBL1498159 & 688155 & 5.35 & 5.1018 & TRN & \\
\hline CHEMBL1581648 & 688155 & 4.65 & 4.9914 & TST & \\
\hline CHEMBL1303320 & 688155 & 4.55 & 4.9966 & TRN & \\
\hline CHEMBL1345083 & 688155 & 4.85 & 5.0013 & TRN & \\
\hline CHEMBL222519 & 688155 & 4.6 & 5.0397 & TST & \\
\hline CHEMBL1545624 & 688155 & 6.35 & 5.2238 & TRN & \\
\hline CHEMBL1377154 & 688155 & 4.95 & 5.0674 & TRN & \\
\hline CHEMBL1310487 & 688155 & 4.95 & 5.0304 & TRN & \\
\hline CHEMBL1335945 & 688155 & 4.85 & 5.0779 & TST & \\
\hline CHEMBL1481788 & 688155 & 5.9 & 5.2966 & TST & \\
\hline CHEMBL1586964 & 688155 & 4.55 & 4.8652 & TRN & \\
\hline CHEMBL1598791 & 688155 & 4.95 & 5.0969 & TST & \\
\hline CHEMBL1580553 & 688155 & 5.0 & 5.2006 & TST & \\
\hline CHEMBL1403484 & 688155 & 5.5 & 5.1684 & TRN & \\
\hline CHEMBL1301654 & 688155 & 4.85 & 4.9787 & TRN & \\
\hline CHEMBL1438193 & 688155 & 4.6 & 5.0011 & TRN & \\
\hline CHEMBL1332402 & 688155 & 5.05 & 5.0148 & TST & \\
\hline CHEMBL1360140 & 688155 & 5.0 & 5.20200 & 0000000001 & TRN \\
\hline CHEMBL337173 & 688155 & 5.0 & 5.1473 & TRN & \\
\hline CHEMBL1489100 & 688155 & 5.15 & 5.1042 & TST & \\
\hline CHEMBL1493336 & 688155 & 4.5 & 5.0765 & TRN & \\
\hline CHEMBL1330004 & 688155 & 6.5 & 5.1913 & TRN & \\
\hline CHEMBL1584878 & 688155 & 4.55 & 5.0195 & TST & \\
\hline CHEMBL1331341 & 688155 & 6.5 & 4.9557 & TRN & \\
\hline CHEMBL1315733 & 688155 & 4.9 & 5.1273 & TST & \\
\hline CHEMBL1422524 & 688155 & 5.85 & 5.0753 & TRN & \\
\hline CHEMBL1527444 & 688155 & 5.2 & 5.117 & TST & \\
\hline CHEMBL581052 & 688155 & 4.5 & 4.997 & TRN & \\
\hline CHEMBL1377484 & 688155 & 5.2 & 5.0613 & TRN & \\
\hline CHEMBL1439562 & 688155 & 4.55 & 4.798 & TRN & \\
\hline CHEMBL1438450 & 688155 & 4.6 & 5.2645 & TRN & \\
\hline CHEMBL1386739 & 688155 & 4.55 & 4.978 & TST & \\
\hline CHEMBL1256750 & 688155 & 5.6 & 5.141 & TRN & \\
\hline CHEMBL1547817 & 688155 & 4.95 & 5.0087 & TRN & \\
\hline CHEMBL583594 & 688155 & 5.3 & 5.2211 & TRN & \\
\hline CHEMBL1595903 & 688155 & 5.25 & 5.2799 & TRN & \\
\hline
\end{tabular}




\begin{tabular}{|c|c|c|c|c|c|}
\hline \multicolumn{6}{|c|}{ Supplemental Table S2.txt } \\
\hline CHEMBL1329592 & 688155 & 4.5 & 5.1215 & TRN & \\
\hline CHEMBL1504221 & 688155 & 5.0 & 5.0956 & TRN & \\
\hline CHEMBL1581084 & 688155 & 5.55 & 5.04 & TST & \\
\hline CHEMBL1513648 & 688155 & 6.45 & 5.1896 & TRN & \\
\hline CHEMBL1403921 & 688155 & 4.5 & 5.1763 & TRN & \\
\hline CHEMBL1558814 & 688155 & 4.85 & 5.0054 & TST & \\
\hline CHEMBL1414220 & 688155 & 4.65 & 5.0774 & TRN & \\
\hline CHEMBL1351544 & 688155 & 4.9 & 4.9934 & TST & \\
\hline CHEMBL1570265 & 688155 & 6.3 & 5.1261 & TRN & \\
\hline CHEMBL1607706 & 688155 & 4.55 & 5.0991 & TRN & \\
\hline CHEMBL 3208330 & 688155 & 5.5 & 4.9597 & TST & \\
\hline CHEMBL1399595 & 688155 & 4.95 & 5.1503 & TST & \\
\hline CHEMBL1477690 & 688155 & 4.8 & 4.8656 & TRN & \\
\hline CHEMBL1567220 & 688155 & 5.7 & 5.0919 & TRN & \\
\hline CHEMBL1346173 & 688155 & 2.75 & 5.0493 & TRN & \\
\hline CHEMBL1604821 & 688155 & 5.1 & 5.2157 & TRN & \\
\hline CHEMBL1449261 & 688155 & 4.9 & 5.2258 & TRN & \\
\hline CHEMBL1423374 & 688155 & 4.65 & 4.9525 & TRN & \\
\hline CHEMBL1527692 & 688155 & 4.5 & $5.1620 e$ & 0000000001 & TST \\
\hline CHEMBL1510650 & 688155 & 6.5 & 4.9205 & TRN & \\
\hline CHEMBL1365545 & 688155 & 4.5 & 5.0554 & TST & \\
\hline CHEMBL1388915 & 688155 & 4.55 & 5.0789 & TRN & \\
\hline CHEMBL1600437 & 688155 & 5.0 & 5.035 & TRN & \\
\hline CHEMBL1610292 & 688155 & 5.0 & 5.0922 & TRN & \\
\hline CHEMBL1583579 & 688155 & 4.55 & 5.0048 & TRN & \\
\hline CHEMBL1312984 & 688155 & 4.75 & 5.2107 & TRN & \\
\hline CHEMBL1450555 & 688155 & 4.9 & 4.9247 & TRN & \\
\hline CHEMBL576997 & 688155 & 5.3 & 5.0489 & TST & \\
\hline CHEMBL 1465678 & 688155 & 5.05 & 5.1871 & TST & \\
\hline CHEMBL1440527 & 688155 & 4.95 & 5.1373 & TRN & \\
\hline CHEMBL1521366 & 688155 & 4.95 & 5.0948 & TRN & \\
\hline CHEMBL1450063 & 688155 & 4.6 & 5.1116 & TST & \\
\hline CHEMBL1362267 & 688155 & 4.95 & 5.0865 & TRN & \\
\hline CHEMBL1388836 & 688155 & 4.55 & 5.1667 & TRN & \\
\hline CHEMBL1364115 & 688155 & 5.0 & 5.1232 & TRN & \\
\hline CHEMBL1562395 & 688155 & 4.55 & 5.2618 & TRN & \\
\hline CHEMBL1609472 & 688155 & 4.95 & 5.1142 & TST & \\
\hline CHEMBL1521209 & 688155 & 4.55 & 5.1155 & TRN & \\
\hline CHEMBL1415609 & 688155 & 4.55 & 5.1587 & TRN & \\
\hline CHEMBL1327325 & 688155 & 5.0 & 4.9768 & TRN & \\
\hline CHEMBL1313891 & 688155 & 4.85 & 5.0981 & TRN & \\
\hline CHEMBL1439066 & 688155 & 4.55 & 5.0232 & TRN & \\
\hline CHEMBL1523777 & 688155 & 5.45 & 5.044 & TST & \\
\hline CHEMBL1981833 & 688155 & 6.5 & 5.0391 & TST & \\
\hline CHEMBL1507174 & 688155 & 4.55 & 5.0224 & TRN & \\
\hline CHEMBL1391735 & 688155 & 4.55 & 5.0878 & TRN & \\
\hline CHEMBL1572195 & 688155 & 4.65 & 5.0866 & TRN & \\
\hline CHEMBL3145205 & 688155 & 4.9 & 5.0509 & TRN & \\
\hline
\end{tabular}




\begin{tabular}{|c|c|c|c|c|}
\hline \multicolumn{5}{|c|}{ Supplemental Table } \\
\hline CHEMBL1582801 & 688155 & 4.95 & 5.1355 & TRN \\
\hline CHEMBL1342934 & 688155 & 5.7 & 5.1073 & TRN \\
\hline CHEMBL1307543 & 688155 & 4.9 & 5.2386 & TRN \\
\hline CHEMBL 3213458 & 688155 & 6.0 & 5.0206 & TRN \\
\hline CHEMBL1417459 & 688155 & 5.75 & 5.1196 & TRN \\
\hline CHEMBL1570874 & 688155 & 4.65 & 4.9835 & TRN \\
\hline CHEMBL1337644 & 688155 & 4.95 & 5.1023 & TRN \\
\hline CHEMBL1571597 & 688155 & 5.1 & 5.1917 & TRN \\
\hline CHEMBL1313295 & 688155 & 5.55 & 5.047 & TST \\
\hline CHEMBL1336010 & 688155 & 5.3 & 5.1188 & TRN \\
\hline CHEMBL1417820 & 688155 & 4.9 & 5.1677 & TRN \\
\hline CHEMBL3211692 & 688155 & 6.0 & 5.0541 & TST \\
\hline CHEMBL3210965 & 688155 & 4.95 & 4.9898 & TST \\
\hline CHEMBL1989372 & 688155 & 4.55 & 5.03 & TRN \\
\hline CHEMBL1550366 & 688155 & 4.9 & 5.0731 & TST \\
\hline CHEMBL1469864 & 688155 & 5.0 & 5.1978 & TRN \\
\hline CHEMBL1419763 & 688155 & 4.8 & 5.0187 & TRN \\
\hline CHEMBL1993627 & 688155 & 5.0 & 5.0484 & TRN \\
\hline CHEMBL1488212 & 688155 & 4.5 & 5.1706 & TST \\
\hline CHEMBL1444767 & 688155 & 5.5 & 5.1418 & TRN \\
\hline CHEMBL3189613 & 688155 & 5.2 & 5.0187 & TRN \\
\hline CHEMBL1321146 & 688155 & 4.55 & 5.1575 & TST \\
\hline CHEMBL392515 & 688155 & 5.0 & 5.1106 & TRN \\
\hline CHEMBL1497897 & 688155 & 4.6 & 4.9548 & TRN \\
\hline CHEMBL1522566 & 688155 & 4.55 & 5.0299 & TST \\
\hline CHEMBL1345701 & 688155 & 4.95 & 5.0195 & TRN \\
\hline CHEMBL3392072 & 688155 & 4.5 & 5.1387 & TRN \\
\hline CHEMBL1398645 & 688155 & 5.0 & 5.0701 & TRN \\
\hline CHEMBL1478073 & 688155 & 5.0 & 4.9852 & TRN \\
\hline CHEMBL1339553 & 688155 & 4.95 & 5.067 & TRN \\
\hline CHEMBL1374742 & 688155 & 4.5 & 5.1017 & TRN \\
\hline CHEMBL1511413 & 688155 & 4.55 & 5.0375 & TRN \\
\hline CHEMBL352690 & 688155 & 5.95 & 5.0399 & TRN \\
\hline CHEMBL1426578 & 688155 & 4.8 & 5.1007 & TST \\
\hline CHEMBL1595468 & 688155 & 4.55 & 5.0662 & TST \\
\hline CHEMBL1589537 & 688155 & 6.5 & 5.2574 & TRN \\
\hline CHEMBL 1424588 & 688155 & 5.0 & 5.0228 & TRN \\
\hline CHEMBL1584930 & 688155 & 4.5 & 4.9848 & TRN \\
\hline CHEMBL1389097 & 688155 & 4.55 & 4.9827 & TRN \\
\hline CHEMBL1573098 & 688155 & 5.0 & 5.0867 & TRN \\
\hline CHEMBL1371115 & 688155 & 5.45 & 5.0945 & TST \\
\hline CHEMBL1994372 & 688155 & 5.2 & 4.9992 & TRN \\
\hline CHEMBL1301143 & 688155 & 5.0 & 4.9966 & TRN \\
\hline CHEMBL1446390 & 688155 & 5.65 & 5.2196 & TRN \\
\hline CHEMBL1339463 & 688155 & 4.55 & 5.0551 & TRN \\
\hline CHEMBL1422809 & 688155 & 4.55 & 4.9107 & TRN \\
\hline CHEMBL1444990 & 688155 & 4.55 & 4.9985 & TST \\
\hline CHEMBL1421143 & 688155 & 5.0 & 5.1804 & TST \\
\hline
\end{tabular}




\begin{tabular}{|c|c|c|c|c|c|}
\hline \multicolumn{6}{|c|}{ Supplemental Table S2.txt } \\
\hline CHEMBL1384800 & 688155 & 4.5 & 4.9777 & TRN & \\
\hline CHEMBL1418746 & 688155 & 4.55 & 5.1169 & TST & \\
\hline CHEMBL1381243 & 688155 & 5.0 & 5.056 & TRN & \\
\hline CHEMBL1361750 & 688155 & 6.0 & 5.0477 & TRN & \\
\hline CHEMBL1528973 & 688155 & 5.0 & 5.0628 & TRN & \\
\hline CHEMBL1482927 & 688155 & 6.5 & 5.0722 & TRN & \\
\hline CHEMBL1488928 & 688155 & 5.0 & 4.9761 & TRN & \\
\hline CHEMBL1486316 & 688155 & 6.05 & 5.0895 & TRN & \\
\hline CHEMBL1415464 & 688155 & 5.0 & 5.0219 & TRN & \\
\hline CHEMBL1485694 & 688155 & 5.0 & 5.0773 & TRN & \\
\hline CHEMBL1569892 & 688155 & 5.0 & 5.0192 & TRN & \\
\hline CHEMBL1433200 & 688155 & 4.95 & 5.0756 & TRN & \\
\hline CHEMBL1387679 & 688155 & 4.55 & 5.1259 & TRN & \\
\hline CHEMBL1489505 & 688155 & 5.9 & 5.0518 & TST & \\
\hline CHEMBL1571516 & 688155 & 4.95 & 4.9359 & TRN & \\
\hline CHEMBL1299343 & 688155 & 5.3 & 5.1362 & TRN & \\
\hline CHEMBL1608540 & 688155 & 5.1 & 4.9565 & TST & \\
\hline CHEMBL1343246 & 688155 & 5.95 & 5.151 & TRN & \\
\hline CHEMBL 3198140 & 688155 & 5.7 & 5.1044 & TST & \\
\hline CHEMBL1450744 & 688155 & 5.05 & 5.1504 & TRN & \\
\hline CHEMBL1542813 & 688155 & 4.55 & 5.0605 & TRN & \\
\hline CHEMBL1557566 & 688155 & 4.6 & 4.9242 & TRN & \\
\hline CHEMBL1589180 & 688155 & 5.0 & 4.9305 & TRN & \\
\hline CHEMBL1389925 & 688155 & 6.0 & 4.9939 & TRN & \\
\hline CHEMBL1466198 & 688155 & 4.9 & 5.1011 & TST & \\
\hline CHEMBL1326508 & 688155 & 4.55 & 4.9452 & TRN & \\
\hline CHEMBL1378005 & 688155 & 5.6 & 5.1273 & TRN & \\
\hline CHEMBL1323092 & 688155 & 5.95 & 4.9966 & TST & \\
\hline CHEMBL1487782 & 688155 & 4.95 & 5.1082 & TRN & \\
\hline CHEMBL1602411 & 688155 & 5.3 & 5.1376 & TRN & \\
\hline CHEMBL1533279 & 688155 & 4.75 & 5.0379 & TRN & \\
\hline CHEMBL1583248 & 688155 & 5.0 & 5.0503 & TST & \\
\hline CHEMBL1354079 & 688155 & 4.65 & 5.24100 & 00000000005 & TST \\
\hline CHEMBL1372064 & 688155 & 5.65 & 4.8905 & TRN & \\
\hline CHEMBL1423588 & 688155 & 5.65 & 5.1724 & TRN & \\
\hline CHEMBL1585861 & 688155 & 4.55 & 5.018 & TRN & \\
\hline CHEMBL1466430 & 688155 & 4.75 & 5.0697 & TRN & \\
\hline CHEMBL473314 & 688155 & 4.95 & 4.8468 & TRN & \\
\hline CHEMBL1519874 & 688155 & 4.6 & 5.0356 & TST & \\
\hline CHEMBL1360597 & 688155 & 4.55 & 5.004 & TST & \\
\hline CHEMBL1568298 & 688155 & 4.95 & 5.0936 & TRN & \\
\hline CHEMBL1516808 & 688155 & 4.9 & 5.0838 & TST & \\
\hline CHEMBL1576970 & 688155 & 4.5 & 5.1027 & TRN & \\
\hline CHEMBL1508190 & 688155 & 5.0 & 5.0072 & TST & \\
\hline CHEMBL1452558 & 688155 & 5.1 & 5.063 & TRN & \\
\hline CHEMBL3196331 & 688155 & 5.25 & 5.1376 & TST & \\
\hline CHEMBL1337685 & 688155 & 5.0 & 5.0387 & TST & \\
\hline CHEMBL1576207 & 688155 & 4.65 & 5.0098 & TRN & \\
\hline
\end{tabular}




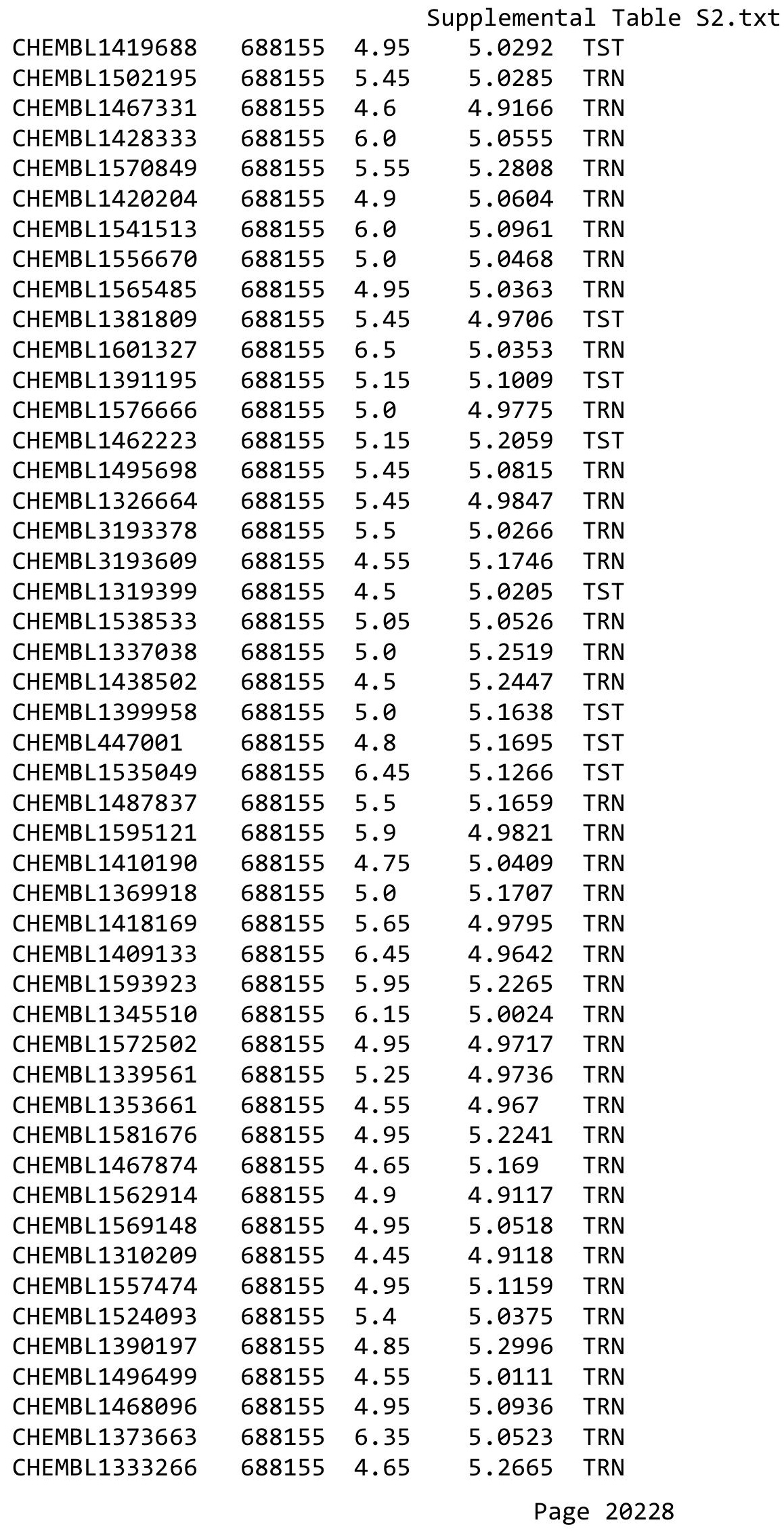




\begin{tabular}{|c|c|c|c|c|}
\hline \multicolumn{5}{|c|}{ Supplemental Table S2.txt } \\
\hline CHEMBL1375985 & 688155 & 4.55 & 5.102 & TST \\
\hline CHEMBL1599948 & 688155 & 5.0 & 4.9378 & TRN \\
\hline CHEMBL1334189 & 688155 & 4.75 & 5.0296 & TRN \\
\hline CHEMBL1565371 & 688155 & 5.2 & 5.0158 & TRN \\
\hline CHEMBL 1350778 & 688155 & 5.45 & 5.0367 & TRN \\
\hline CHEMBL1497370 & 688155 & 4.55 & 5.0051 & TRN \\
\hline CHEMBL1419262 & 688155 & 5.0 & 5.1133 & TRN \\
\hline CHEMBL1319156 & 688155 & 4.55 & 5.0149 & TRN \\
\hline CHEMBL1400165 & 688155 & 5.95 & 5.0406 & TRN \\
\hline CHEMBL1489972 & 688155 & 4.95 & 5.0448 & TRN \\
\hline CHEMBL1511948 & 688155 & 4.65 & 5.0547 & TRN \\
\hline CHEMBL1527014 & 688155 & 5.25 & 5.1214 & TRN \\
\hline CHEMBL1442406 & 688155 & 4.5 & 5.0813 & TST \\
\hline CHEMBL1506506 & 688155 & 5.0 & 4.9677 & TST \\
\hline CHEMBL1370759 & 688155 & 4.5 & 5.0154 & TRN \\
\hline CHEMBL3209962 & 688155 & 4.65 & 5.0663 & TRN \\
\hline CHEMBL1569503 & 688155 & 5.05 & 5.1811 & TRN \\
\hline CHEMBL3198543 & 688155 & 5.0 & 4.9771 & TRN \\
\hline CHEMBL1459416 & 688155 & 5.0 & 4.9501 & TRN \\
\hline CHEMBL1555238 & 688155 & 4.95 & 5.0658 & TRN \\
\hline CHEMBL3196404 & 688155 & 4.95 & 5.1164 & TRN \\
\hline CHEMBL1545747 & 688155 & 4.55 & 4.9988 & TRN \\
\hline CHEMBL1604488 & 688155 & 5.0 & 5.1322 & TRN \\
\hline CHEMBL1570564 & 688155 & 4.95 & 5.3018 & TRN \\
\hline CHEMBL1373582 & 688155 & 4.6 & 5.0929 & TRN \\
\hline CHEMBL1542726 & 688155 & 4.55 & 4.9852 & TRN \\
\hline CHEMBL1455526 & 688155 & 4.5 & 5.2253 & TRN \\
\hline CHEMBL1504480 & 688155 & 5.0 & 5.1748 & TRN \\
\hline CHEMBL1318943 & 688155 & 5.0 & 5.1299 & TRN \\
\hline CHEMBL1604724 & 688155 & 4.55 & 4.9223 & TRN \\
\hline CHEMBL1507587 & 688155 & 4.9 & 5.3134 & TRN \\
\hline CHEMBL1486156 & 688155 & 4.5 & 5.0134 & TRN \\
\hline CHEMBL1497405 & 688155 & 4.95 & 5.1189 & TRN \\
\hline CHEMBL1346881 & 688155 & 6.05 & 5.114 & TRN \\
\hline CHEMBL1393166 & 688155 & 5.0 & 4.931 & TRN \\
\hline CHEMBL1412410 & 688155 & 4.95 & 4.8918 & TRN \\
\hline CHEMBL1431129 & 688155 & 5.3 & 5.0196 & TRN \\
\hline CHEMBL1410820 & 688155 & 6.5 & 5.2743 & TRN \\
\hline CHEMBL1579590 & 688155 & 4.5 & 5.1429 & TRN \\
\hline CHEMBL1479671 & 688155 & 4.65 & 4.958 & TST \\
\hline CHEMBL1302139 & 688155 & 5.05 & 5.1206 & TRN \\
\hline CHEMBL1305339 & 688155 & 6.15 & 4.8879 & TRN \\
\hline CHEMBL1500964 & 688155 & 4.9 & 5.0637 & TST \\
\hline CHEMBL1349987 & 688155 & 4.9 & 5.0954 & TRN \\
\hline CHEMBL3197077 & 688155 & 4.6 & 5.092 & TST \\
\hline CHEMBL1570137 & 688155 & 5.5 & 5.1981 & TRN \\
\hline CHEMBL1316953 & 688155 & 5.25 & 5.1453 & TST \\
\hline CHEMBL1600661 & 688155 & 5.0 & 5.1904 & TST \\
\hline
\end{tabular}




\begin{tabular}{|c|c|c|c|c|c|}
\hline \multicolumn{6}{|c|}{ Supplemental Table S2.txt } \\
\hline CHEMBL1573466 & 688155 & 5.2 & 5.0728 & TST & \\
\hline CHEMBL1331695 & 688155 & 5.35 & 5.042 & TRN & \\
\hline CHEMBL1581006 & 688155 & 5.25 & 5.0166 & TRN & \\
\hline CHEMBL1383876 & 688155 & 5.2 & 4.9705 & TST & \\
\hline CHEMBL1596675 & 688155 & 4.55 & 5.119 & TST & \\
\hline CHEMBL1539630 & 688155 & 5.25 & 5.1147 & TRN & \\
\hline CHEMBL1367648 & 688155 & 4.95 & 4.9816 & TST & \\
\hline CHEMBL1430586 & 688155 & 5.0 & 5.1054 & TRN & \\
\hline CHEMBL1548896 & 688155 & 5.9 & 5.1897 & TST & \\
\hline CHEMBL1511867 & 688155 & 4.95 & 5.1821 & TST & \\
\hline CHEMBL1309478 & 688155 & 4.9 & 4.9076 & TRN & \\
\hline CHEMBL1412617 & 688155 & 5.05 & 5.0994 & TRN & \\
\hline CHEMBL1562003 & 688155 & 4.95 & 4.9142 & TRN & \\
\hline CHEMBL1375987 & 688155 & 5.05 & 5.2291 & TRN & \\
\hline CHEMBL1459185 & 688155 & 5.15 & 5.0164 & TST & \\
\hline CHEMBL1581848 & 688155 & 4.55 & 5.124 & TST & \\
\hline CHEMBL1304064 & 688155 & 5.0 & 5.0045 & TRN & \\
\hline CHEMBL1378470 & 688155 & 6.05 & 5.0687 & TRN & \\
\hline CHEMBL1564722 & 688155 & 4.6 & 5.1142 & TRN & \\
\hline CHEMBL1308489 & 688155 & 4.55 & 5.1142 & TRN & \\
\hline CHEMBL1467999 & 688155 & 6.05 & 4.9575 & TRN & \\
\hline CHEMBL1303565 & 688155 & 4.8 & 5.0727 & TRN & \\
\hline CHEMBL1299836 & 688155 & 5.2 & 5.1958 & TRN & \\
\hline CHEMBL1390786 & 688155 & 4.85 & 5.2535 & TRN & \\
\hline CHEMBL1543571 & 688155 & 5.5 & 5.1735 & TRN & \\
\hline CHEMBL1525957 & 688155 & 5.2 & 5.1566 & TRN & \\
\hline CHEMBL1383601 & 688155 & 4.6 & 4.8335 & TRN & \\
\hline CHEMBL1371615 & 688155 & 4.65 & 5.0717 & TRN & \\
\hline CHEMBL1358962 & 688155 & 5.45 & 5.0727 & TRN & \\
\hline CHEMBL1465714 & 688155 & 4.95 & 5.2564 & TRN & \\
\hline CHEMBL1493432 & 688155 & 4.55 & 5.1585 & TRN & \\
\hline CHEMBL1460399 & 688155 & 5.0 & 5.007 & TRN & \\
\hline CHEMBL3198729 & 688155 & 5.0 & 5.1008 & TRN & \\
\hline CHEMBL1364995 & 688155 & 4.65 & 4.9503 & TRN & \\
\hline CHEMBL1529052 & 688155 & 4.45 & 5.1145 & TRN & \\
\hline CHEMBL1375485 & 688155 & 5.0 & 4.9718 & TRN & \\
\hline CHEMBL1347071 & 688155 & 5.0 & 5.08899 & 99999999995 & TRN \\
\hline CHEMBL1494074 & 688155 & 5.0 & 4.92 & TRN & \\
\hline CHEMBL1576462 & 688155 & 4.75 & 5.1842 & TRN & \\
\hline CHEMBL1344225 & 688155 & 5.5 & 5.0088 & TRN & \\
\hline CHEMBL1329324 & 688155 & 5.1 & 5.0125 & TST & \\
\hline CHEMBL1310999 & 688155 & 4.95 & 5.0016 & TRN & \\
\hline CHEMBL1503962 & 688155 & 5.65 & 5.0359 & TRN & \\
\hline CHEMBL1468461 & 688155 & 5.9 & 4.9784 & TST & \\
\hline CHEMBL1600260 & 688155 & 5.0 & 5.0033 & TRN & \\
\hline CHEMBL1494636 & 688155 & 5.75 & 5.0314 & TRN & \\
\hline CHEMBL1455126 & 688155 & 4.5 & 5.2759 & TRN & \\
\hline CHEMBL1540836 & 688155 & 5.55 & 4.9599 & TRN & \\
\hline
\end{tabular}




\begin{tabular}{|c|c|c|c|c|c|}
\hline \multicolumn{6}{|c|}{ Supplemental Table s2.txt } \\
\hline CHEMBL1519259 & 688155 & 4.65 & 5.0902 & TRN & \\
\hline CHEMBL3194371 & 688155 & 6.05 & 5.0594 & TRN & \\
\hline CHEMBL1421520 & 688155 & 4.55 & 5.0177 & TRN & \\
\hline CHEMBL1308043 & 688155 & 4.55 & 5.0613 & TRN & \\
\hline CHEMBL1410100 & 688155 & 5.4 & 5.1476 & TRN & \\
\hline CHEMBL1454096 & 688155 & 4.55 & 4.9428 & TRN & \\
\hline CHEMBL1550363 & 688155 & 4.55 & 4.9237 & TRN & \\
\hline CHEMBL1547494 & 688155 & 4.9 & 5.0002 & TRN & \\
\hline CHEMBL1302332 & 688155 & 5.95 & 5.0364 & TST & \\
\hline CHEMBL1424053 & 688155 & 4.55 & 5.0383 & TRN & \\
\hline CHEMBL1521893 & 688155 & 5.0 & 4.9551 & TRN & \\
\hline CHEMBL1351180 & 688155 & 5.4 & \multicolumn{2}{|c|}{5.127999999999999} & TST \\
\hline CHEMBL1500954 & 688155 & 4.9 & 5.1905 & TST & \\
\hline CHEMBL1536557 & 688155 & 4.95 & 5.0665 & TST & \\
\hline CHEMBL1534296 & 688155 & 5.05 & 5.0856 & TRN & \\
\hline CHEMBL1602202 & 688155 & 5.05 & 5.0668 & TST & \\
\hline CHEMBL1392205 & 688155 & 5.2 & 5.1688 & TRN & \\
\hline CHEMBL1337389 & 688155 & 4.6 & 5.1072 & TRN & \\
\hline CHEMBL1714915 & 688155 & 5.95 & \multicolumn{2}{|c|}{4.968999999999999} & TST \\
\hline CHEMBL1305633 & 688155 & 6.5 & 5.0988 & TRN & \\
\hline CHEMBL1566336 & 688155 & 4.6 & 5.0418 & TRN & \\
\hline CHEMBL1443333 & 688155 & 4.85 & \multicolumn{2}{|c|}{4.9239999999999995} & TRN \\
\hline CHEMBL1374654 & 688155 & 4.75 & 5.1516 & TRN & \\
\hline CHEMBL1612474 & 688155 & 4.6 & 5.0807 & TST & \\
\hline CHEMBL1608028 & 688155 & 4.55 & 5.0648 & TRN & \\
\hline CHEMBL1343596 & 688155 & 4.9 & 4.843 & TRN & \\
\hline CHEMBL1391265 & 688155 & 4.75 & 5.1201 & TRN & \\
\hline CHEMBL1372109 & 688155 & 4.95 & 5.0693 & TST & \\
\hline CHEMBL1536373 & 688155 & 5.0 & 5.0212 & TRN & \\
\hline CHEMBL1501159 & 688155 & 5.45 & 5.0584 & TRN & \\
\hline CHEMBL1411257 & 688155 & 6.5 & 4.9677 & TRN & \\
\hline CHEMBL1506936 & 688155 & 4.95 & 5.1367 & TST & \\
\hline CHEMBL1367064 & 688155 & 4.65 & 5.0292 & TRN & \\
\hline CHEMBL1560049 & 688155 & 5.95 & 4.9723 & TRN & \\
\hline CHEMBL1563965 & 688155 & 4.75 & 5.0307 & TRN & \\
\hline CHEMBL578177 & 688155 & 4.9 & 5.0192 & TST & \\
\hline CHEMBL1460386 & 688155 & 6.05 & \multicolumn{2}{|c|}{5.122999999999999} & TST \\
\hline CHEMBL1455895 & 688155 & 6.2 & 5.2863 & TRN & \\
\hline CHEMBL1375669 & 688155 & 4.55 & 4.794 & TRN & \\
\hline CHEMBL1489710 & 688155 & 4.95 & 5.0207 & TRN & \\
\hline CHEMBL1561710 & 688155 & 4.5 & 5.0619 & TRN & \\
\hline CHEMBL1330431 & 688155 & 4.7 & 5.135 & TRN & \\
\hline CHEMBL1459500 & 688155 & 4.45 & 5.1831 & TST & \\
\hline CHEMBL1368234 & 688155 & 6.0 & 4.9948 & TRN & \\
\hline CHEMBL1484920 & 688155 & 4.9 & 5.0501 & TRN & \\
\hline CHEMBL1345236 & 688155 & 5.0 & 5.3025 & TRN & \\
\hline CHEMBL1558458 & 688155 & 4.55 & 5.1094 & TRN & \\
\hline \multirow[t]{2}{*}{ CHEMBL1585708 } & 688155 & 5.0 & 5.0224 & TST & \\
\hline & & \multicolumn{4}{|c|}{ Page 20231} \\
\hline
\end{tabular}




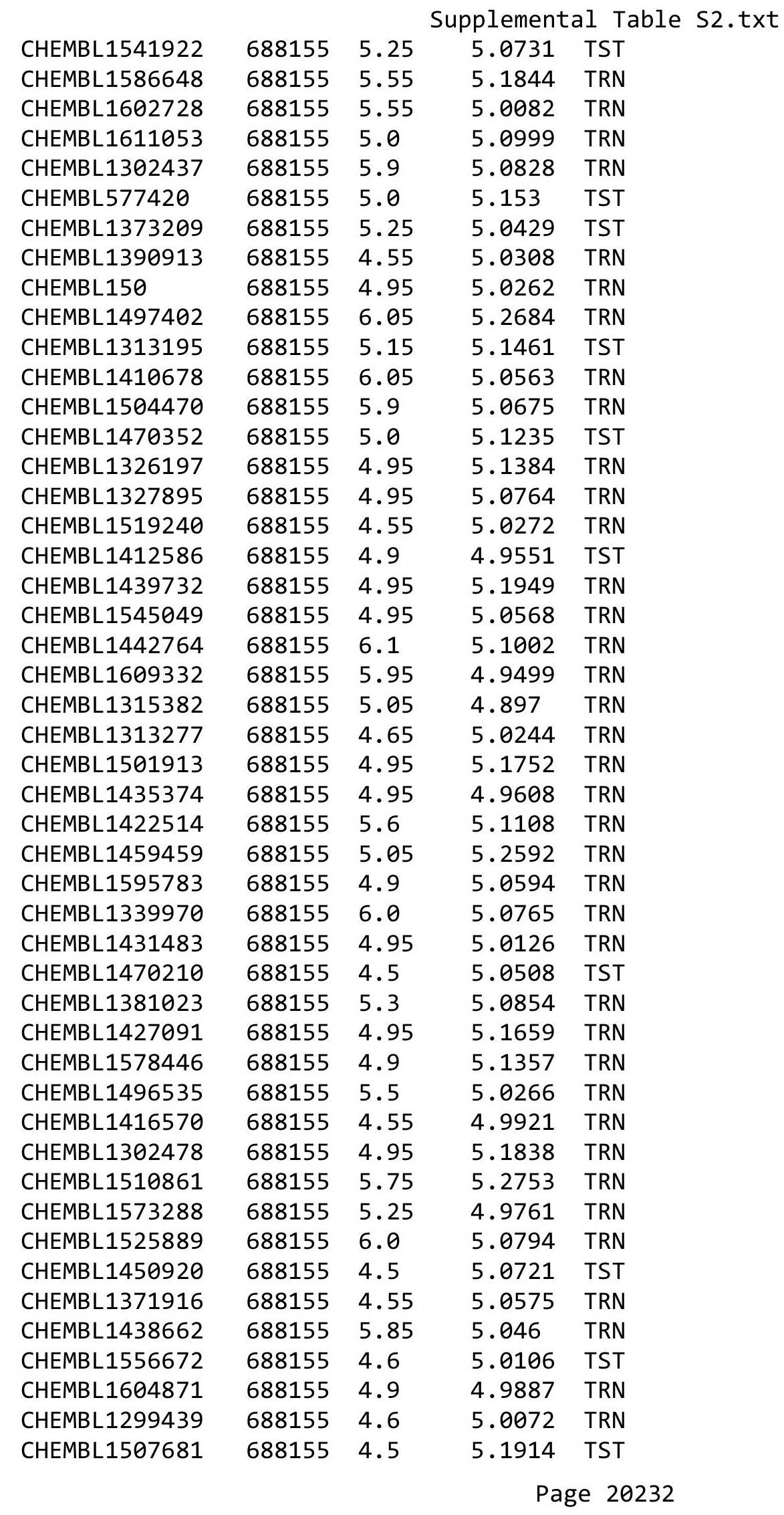




\begin{tabular}{|c|c|c|c|c|}
\hline \multicolumn{5}{|c|}{ Supplemental Table } \\
\hline CHEMBL1981398 & 688155 & 4.55 & 4.9336 & TRN \\
\hline CHEMBL1504653 & 688155 & 4.55 & 5.1061 & TRN \\
\hline CHEMBL1460397 & 688155 & 4.5 & 5.0661 & TRN \\
\hline CHEMBL1606087 & 688155 & 5.2 & 5.0125 & TRN \\
\hline CHEMBL1389758 & 688155 & 5.0 & 5.1044 & TRN \\
\hline CHEMBL1331828 & 688155 & 5.0 & 5.2179 & TRN \\
\hline CHEMBL1340140 & 688155 & 4.55 & 5.1347 & TRN \\
\hline CHEMBL436913 & 688155 & 4.55 & 4.982 & TRN \\
\hline CHEMBL1610545 & 688155 & 4.5 & 5.1787 & TRN \\
\hline CHEMBL1473216 & 688155 & 5.0 & 5.1125 & TRN \\
\hline CHEMBL1327566 & 688155 & 4.9 & 5.0983 & TRN \\
\hline CHEMBL1400479 & 688155 & 4.55 & 5.1114 & TST \\
\hline CHEMBL1577928 & 688155 & 5.05 & 5.1003 & TRN \\
\hline CHEMBL1346504 & 688155 & 4.95 & 5.1666 & TRN \\
\hline CHEMBL1588807 & 688155 & 4.95 & 5.0832 & TRN \\
\hline CHEMBL1341057 & 688155 & 4.85 & 5.1467 & TRN \\
\hline CHEMBL3207804 & 688155 & 4.9 & 5.1046 & TRN \\
\hline CHEMBL1477332 & 688155 & 4.55 & 4.9186 & TRN \\
\hline CHEMBL1455091 & 688155 & 4.9 & 5.0681 & TRN \\
\hline CHEMBL1536626 & 688155 & 5.0 & 5.1197 & TRN \\
\hline CHEMBL1304965 & 688155 & 5.65 & 5.0768 & TRN \\
\hline CHEMBL3194261 & 688155 & 5.95 & 5.0253 & TRN \\
\hline CHEMBL1589565 & 688155 & 4.95 & 4.9962 & TRN \\
\hline CHEMBL1411684 & 688155 & 5.2 & 5.2386 & TST \\
\hline CHEMBL1532047 & 688155 & 4.65 & 4.9995 & TST \\
\hline CHEMBL1349286 & 688155 & 4.55 & 5.0288 & TRN \\
\hline CHEMBL1440801 & 688155 & 6.5 & 5.1106 & TRN \\
\hline CHEMBL1516967 & 688155 & 4.9 & 4.9367 & TRN \\
\hline CHEMBL1570885 & 688155 & 4.95 & 5.0303 & TRN \\
\hline CHEMBL1547269 & 688155 & 6.1 & 5.0131 & TRN \\
\hline CHEMBL1465340 & 688155 & 5.05 & 5.1488 & TRN \\
\hline CHEMBL1383179 & 688155 & 5.85 & 5.2344 & TRN \\
\hline CHEMBL1305029 & 688155 & 6.5 & 5.0859 & TST \\
\hline CHEMBL1359749 & 688155 & 6.0 & 5.0389 & TRN \\
\hline CHEMBL1343226 & 688155 & 6.35 & 4.9863 & TRN \\
\hline CHEMBL1450481 & 688155 & 5.3 & 5.1728 & TST \\
\hline CHEMBL1495049 & 688155 & 5.05 & 5.1233 & TRN \\
\hline CHEMBL1426758 & 688155 & 5.0 & 5.2308 & TRN \\
\hline CHEMBL1586847 & 688155 & 6.35 & 4.9889 & TRN \\
\hline CHEMBL1447541 & 688155 & 6.05 & 4.9406 & TRN \\
\hline CHEMBL1339340 & 688155 & 4.95 & 4.9488 & TST \\
\hline CHEMBL1351184 & 688155 & 4.5 & 4.9585 & TRN \\
\hline CHEMBL1329706 & 688155 & 4.95 & 5.1654 & TRN \\
\hline CHEMBL1609569 & 688155 & 5.0 & 5.1991 & TRN \\
\hline CHEMBL 260374 & 688155 & 6.05 & 5.2424 & TST \\
\hline CHEMBL1499883 & 688155 & 5.0 & 4.9703 & TRN \\
\hline CHEMBL1451343 & 688155 & 4.55 & 5.0306 & TST \\
\hline CHEMBL1523093 & 688155 & 4.55 & 5.0717 & TRN \\
\hline
\end{tabular}




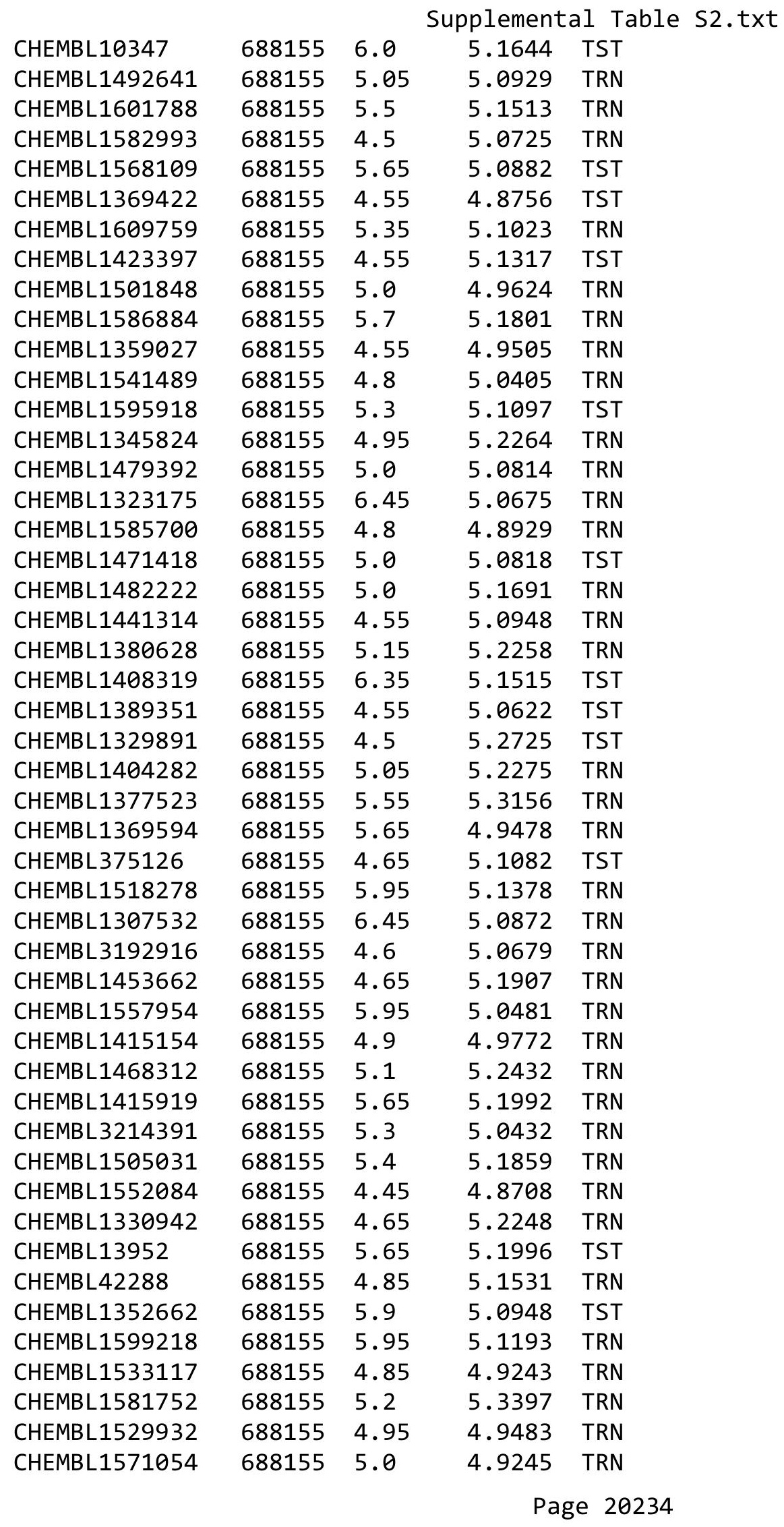




\begin{tabular}{|c|c|c|c|c|}
\hline \multicolumn{5}{|c|}{ Supplemental Table S2.txt } \\
\hline CHEMBL1575674 & 688155 & 4.85 & 5.2159 & TRN \\
\hline CHEMBL1527530 & 688155 & 5.5 & 4.9688 & TRN \\
\hline CHEMBL1586934 & 688155 & 4.55 & 5.0958 & TRN \\
\hline CHEMBL1347852 & 688155 & 4.5 & 5.1693 & TRN \\
\hline CHEMBL1306957 & 688155 & 5.35 & 5.0421 & TST \\
\hline CHEMBL570844 & 688155 & 4.65 & 5.0272 & TRN \\
\hline CHEMBL1413869 & 688155 & 4.55 & 5.0611 & TRN \\
\hline CHEMBL1456204 & 688155 & 4.65 & 5.0336 & TRN \\
\hline CHEMBL 3189499 & 688155 & 4.9 & 4.9573 & TRN \\
\hline CHEMBL1539102 & 688155 & 4.55 & 5.1162 & TST \\
\hline CHEMBL1431481 & 688155 & 5.0 & 5.1533 & TST \\
\hline CHEMBL1417030 & 688155 & 4.5 & 5.1877 & TST \\
\hline CHEMBL1579263 & 688155 & 4.5 & 5.1307 & TRN \\
\hline CHEMBL1336722 & 688155 & 6.05 & 4.9911 & TST \\
\hline CHEMBL1361956 & 688155 & 5.5 & 5.0982 & TRN \\
\hline CHEMBL1587284 & 688155 & 5.6 & 5.0455 & TRN \\
\hline CHEMBL1538765 & 688155 & 5.15 & 5.1046 & TRN \\
\hline CHEMBL1578391 & 688155 & 4.6 & 4.9869 & TST \\
\hline CHEMBL1320193 & 688155 & 4.55 & 4.9142 & TRN \\
\hline CHEMBL1523317 & 688155 & 5.15 & 5.0357 & TRN \\
\hline CHEMBL1508573 & 688155 & 4.95 & 5.0272 & TRN \\
\hline CHEMBL1609156 & 688155 & 5.0 & 5.0055 & TRN \\
\hline CHEMBL1493825 & 688155 & 4.9 & 5.0703 & TRN \\
\hline CHEMBL1482885 & 688155 & 5.3 & 5.1094 & TRN \\
\hline CHEMBL1559745 & 688155 & 5.1 & 4.9283 & TRN \\
\hline CHEMBL1399495 & 688155 & 4.5 & 5.0716 & TRN \\
\hline CHEMBL1492271 & 688155 & 4.8 & 4.9916 & TST \\
\hline CHEMBL1335679 & 688155 & 5.95 & 5.1765 & TST \\
\hline CHEMBL1570017 & 688155 & 4.8 & 5.1389 & TRN \\
\hline CHEMBL1390900 & 688155 & 6.05 & 5.1232 & TST \\
\hline CHEMBL1366112 & 688155 & 4.75 & 4.9414 & TRN \\
\hline CHEMBL1501889 & 688155 & 4.5 & 5.0821 & TRN \\
\hline CHEMBL1500087 & 688155 & 4.95 & 5.3162 & TRN \\
\hline CHEMBL1517637 & 688155 & 6.45 & 5.1017 & TRN \\
\hline CHEMBL1403995 & 688155 & 4.95 & 5.0773 & TST \\
\hline CHEMBL1371277 & 688155 & 6.0 & 5.0013 & TRN \\
\hline CHEMBL1450806 & 688155 & 4.85 & 5.1829 & TRN \\
\hline CHEMBL3190009 & 688155 & 4.5 & 5.0244 & TRN \\
\hline CHEMBL1508295 & 688155 & 6.2 & 5.0901 & TST \\
\hline CHEMBL3208039 & 688155 & 4.9 & 5.0156 & TST \\
\hline CHEMBL1353472 & 688155 & 5.15 & 4.9513 & TRN \\
\hline CHEMBL1573602 & 688155 & 4.8 & 5.1693 & TRN \\
\hline CHEMBL1392860 & 688155 & 4.5 & 4.9567 & TRN \\
\hline CHEMBL1309619 & 688155 & 4.9 & 5.1133 & TRN \\
\hline CHEMBL1364493 & 688155 & 4.8 & 5.0405 & TRN \\
\hline CHEMBL1476061 & 688155 & 4.55 & 5.1483 & TRN \\
\hline CHEMBL1576037 & 688155 & 4.95 & 5.0796 & TRN \\
\hline CHEMBL1363409 & 688155 & 4.55 & 4.9883 & TRN \\
\hline
\end{tabular}




\begin{tabular}{|c|c|c|c|c|c|}
\hline \multicolumn{6}{|c|}{ Supplemental Table S2.txt } \\
\hline CHEMBL1527838 & 688155 & 4.55 & 5.0762 & TST & \\
\hline CHEMBL1545790 & 688155 & 4.65 & 4.9833 & TRN & \\
\hline CHEMBL1610143 & 688155 & 4.8 & 5.1261 & TST & \\
\hline CHEMBL1312379 & 688155 & 5.05 & 4.9988 & TRN & \\
\hline CHEMBL1415866 & 688155 & 5.45 & 5.0472 & TRN & \\
\hline CHEMBL1479425 & 688155 & 4.55 & 5.1036 & TRN & \\
\hline CHEMBL1364610 & 688155 & 4.55 & 5.0884 & TRN & \\
\hline CHEMBL1408635 & 688155 & 4.5 & 4.9912 & TRN & \\
\hline CHEMBL1466788 & 688155 & 4.95 & 5.09399 & 9999999999 & TRN \\
\hline CHEMBL1501367 & 688155 & 5.3 & 5.2286 & TST & \\
\hline CHEMBL1570107 & 688155 & 5.0 & 5.1557 & TRN & \\
\hline CHEMBL 3189611 & 688155 & 5.85 & 5.0856 & TRN & \\
\hline CHEMBL1509203 & 688155 & 5.5 & 4.94 & TST & \\
\hline CHEMBL 3210456 & 688155 & 5.25 & 4.9368 & TRN & \\
\hline CHEMBL 1405803 & 688155 & 5.35 & 5.1047 & TRN & \\
\hline CHEMBL1604351 & 688155 & 4.6 & 5.2243 & TRN & \\
\hline CHEMBL1561004 & 688155 & 6.5 & 5.1035 & TRN & \\
\hline CHEMBL1410886 & 688155 & 5.55 & 5.2023 & TRN & \\
\hline CHEMBL1349466 & 688155 & 4.55 & 5.273 & TRN & \\
\hline CHEMBL1322917 & 688155 & 6.0 & 5.0844 & TRN & \\
\hline CHEMBL1427455 & 688155 & 5.1 & 5.10800 & 00000000005 & TRN \\
\hline CHEMBL1400197 & 688155 & 5.65 & 5.1464 & TRN & \\
\hline CHEMBL1540601 & 688155 & 6.35 & 4.9727 & TRN & \\
\hline CHEMBL1333947 & 688155 & 4.95 & 5.2075 & TRN & \\
\hline CHEMBL1372982 & 688155 & 4.65 & 5.0544 & TST & \\
\hline CHEMBL1471439 & 688155 & 5.0 & 4.887 & TRN & \\
\hline CHEMBL1496159 & 688155 & 5.0 & 5.0992 & TRN & \\
\hline CHEMBL1407732 & 688155 & 4.5 & 5.1753 & TRN & \\
\hline CHEMBL 3198639 & 688155 & 4.5 & 5.083 & TST & \\
\hline CHEMBL1342386 & 688155 & 6.0 & 5.1798 & TRN & \\
\hline CHEMBL1311290 & 688155 & 5.0 & 5.0905 & TRN & \\
\hline CHEMBL3207915 & 688155 & 6.35 & 5.1318 & TST & \\
\hline CHEMBL1344884 & 688155 & 5.0 & 5.1795 & TRN & \\
\hline CHEMBL1999900 & 688155 & 4.95 & 5.0167 & TST & \\
\hline CHEMBL1451687 & 688155 & 6.3 & 5.0501 & TRN & \\
\hline CHEMBL 3194665 & 688155 & 4.9 & 5.0471 & TST & \\
\hline CHEMBL1385553 & 688155 & 5.55 & 5.0377 & TST & \\
\hline CHEMBL1328951 & 688155 & 4.55 & 4.9661 & TRN & \\
\hline CHEMBL 60518 & 688155 & 5.6 & 5.1099 & TRN & \\
\hline CHEMBL1429859 & 688155 & 6.5 & 4.9898 & TRN & \\
\hline CHEMBL1323347 & 688155 & 4.5 & 5.074 & TRN & \\
\hline CHEMBL1576281 & 688155 & 4.85 & 5.0958 & TST & \\
\hline CHEMBL1499734 & 688155 & 5.5 & 5.101 & TRN & \\
\hline CHEMBL1460618 & 688155 & 4.65 & 4.9675 & TRN & \\
\hline CHEMBL3192607 & 688155 & 5.15 & 5.0969 & TRN & \\
\hline CHEMBL1532931 & 688155 & 4.9 & 4.9529 & TRN & \\
\hline CHEMBL1501407 & 688155 & 4.95 & 5.0581 & TRN & \\
\hline CHEMBL1344814 & 688155 & 6.1 & 5.1118 & TRN & \\
\hline
\end{tabular}




\begin{tabular}{|c|c|c|c|c|}
\hline \multicolumn{5}{|c|}{ Supplemental Table S2.txt } \\
\hline CHEMBL1443318 & 688155 & 4.8 & 5.0894 & TRN \\
\hline CHEMBL1602422 & 688155 & 5.0 & 5.0678 & TST \\
\hline CHEMBL1489456 & 688155 & 5.15 & 5.0926 & TRN \\
\hline CHEMBL1432463 & 688155 & 5.15 & 5.0638 & TRN \\
\hline CHEMBL1424200 & 688155 & 4.9 & 5.0692 & TRN \\
\hline CHEMBL1459316 & 688155 & 4.5 & 5.1958 & TRN \\
\hline CHEMBL1422959 & 688155 & 4.55 & 4.9978 & TST \\
\hline CHEMBL1486681 & 688155 & 5.2 & 5.1259 & TRN \\
\hline CHEMBL 1604380 & 688155 & 4.7 & 4.8956 & TRN \\
\hline CHEMBL1444185 & 688155 & 4.55 & 5.0011 & TST \\
\hline CHEMBL1466534 & 688155 & 5.0 & 5.0549 & TRN \\
\hline CHEMBL1445961 & 688155 & 5.95 & 5.064 & TRN \\
\hline CHEMBL1568145 & 688155 & 4.55 & 5.0159 & TRN \\
\hline CHEMBL1596371 & 688155 & 4.8 & 5.0825 & TRN \\
\hline CHEMBL1328728 & 688155 & 5.65 & 5.0572 & TRN \\
\hline CHEMBL1417921 & 688155 & 5.0 & 5.1537 & TRN \\
\hline CHEMBL1481697 & 688155 & 4.95 & 5.0727 & TRN \\
\hline CHEMBL1336978 & 688155 & 6.0 & 5.0901 & TST \\
\hline CHEMBL1547153 & 688155 & 6.3 & 5.0755 & TRN \\
\hline CHEMBL1608686 & 688155 & 6.0 & 5.1378 & TST \\
\hline CHEMBL1511471 & 688155 & 5.85 & 4.9905 & TRN \\
\hline CHEMBL1416669 & 688155 & 6.0 & 5.1135 & TRN \\
\hline CHEMBL1328788 & 688155 & 4.55 & 4.9155 & TRN \\
\hline CHEMBL1341412 & 688155 & 4.5 & 5.1436 & TRN \\
\hline CHEMBL1501197 & 688155 & 4.95 & 4.953 & TRN \\
\hline CHEMBL1370872 & 688155 & 4.8 & 5.093 & TRN \\
\hline CHEMBL1213073 & 688155 & 5.3 & 5.0798 & TRN \\
\hline CHEMBL1581778 & 688155 & 5.75 & 4.9278 & TRN \\
\hline CHEMBL1548208 & 688155 & 6.0 & 5.1036 & TRN \\
\hline CHEMBL1489704 & 688155 & 5.8 & 5.1067 & TRN \\
\hline CHEMBL1381093 & 688155 & 4.55 & 5.0935 & TRN \\
\hline CHEMBL1337806 & 688155 & 4.85 & 4.9628 & TST \\
\hline CHEMBL1256709 & 688155 & 4.55 & 5.187 & TRN \\
\hline CHEMBL1398596 & 688155 & 5.0 & 4.9344 & TRN \\
\hline CHEMBL1327391 & 688155 & 5.75 & 5.1712 & TRN \\
\hline CHEMBL1392042 & 688155 & 4.9 & 5.0105 & TRN \\
\hline CHEMBL1348841 & 688155 & 5.2 & 4.9344 & TRN \\
\hline CHEMBL1405991 & 688155 & 5.0 & 5.1095 & TRN \\
\hline CHEMBL3193160 & 688155 & 5.25 & 5.0943 & TRN \\
\hline CHEMBL1340894 & 688155 & 6.45 & 5.066 & TST \\
\hline CHEMBL1470907 & 688155 & 4.5 & 4.9762 & TRN \\
\hline CHEMBL1423095 & 688155 & 5.7 & 5.0997 & TRN \\
\hline CHEMBL1388744 & 688155 & 4.95 & 5.04 & TRN \\
\hline CHEMBL1492193 & 688155 & 4.95 & 5.2296 & TRN \\
\hline CHEMBL1610457 & 688155 & 5.35 & 4.9421 & TRN \\
\hline CHEMBL1466770 & 688155 & 4.9 & 4.9974 & TRN \\
\hline CHEMBL1448394 & 688155 & 4.5 & 4.9141 & TRN \\
\hline CHEMBL1299448 & 688155 & 4.9 & 5.14 & TRN \\
\hline
\end{tabular}




\begin{tabular}{|c|c|c|c|c|}
\hline \multicolumn{5}{|c|}{ Supplemental Table S2.txt } \\
\hline CHEMBL1393087 & 688155 & 4.95 & 5.0458 & TRN \\
\hline CHEMBL1579750 & 688155 & 4.55 & 5.1974 & TRN \\
\hline CHEMBL1327709 & 688155 & 5.45 & 4.9726 & TRN \\
\hline CHEMBL1305466 & 688155 & 6.3 & 5.3277 & TRN \\
\hline CHEMBL 1438082 & 688155 & 4.55 & 5.0574 & TST \\
\hline CHEMBL1352626 & 688155 & 4.5 & 5.1525 & TRN \\
\hline CHEMBL1439681 & 688155 & 5.0 & 5.1989 & TRN \\
\hline CHEMBL1582213 & 688155 & 5.85 & 5.2535 & TRN \\
\hline CHEMBL1337123 & 688155 & 5.75 & 5.1193 & TRN \\
\hline CHEMBL1526339 & 688155 & 5.9 & 5.0844 & TRN \\
\hline CHEMBL1367089 & 688155 & 5.5 & 4.9923 & TRN \\
\hline CHEMBL1339520 & 688155 & 4.5 & 5.0159 & TRN \\
\hline CHEMBL1392436 & 688155 & 5.35 & 5.1869 & TRN \\
\hline CHEMBL1559097 & 688155 & 4.6 & 5.0485 & TST \\
\hline CHEMBL1466193 & 688155 & 4.55 & 5.0787 & TRN \\
\hline CHEMBL1306504 & 688155 & 5.0 & 5.0274 & TRN \\
\hline CHEMBL1468919 & 688155 & 5.45 & 5.0611 & TRN \\
\hline CHEMBL1442697 & 688155 & 5.8 & 5.1053 & TRN \\
\hline CHEMBL1440162 & 688155 & 5.45 & 5.0788 & TRN \\
\hline CHEMBL1333692 & 688155 & 4.5 & 4.9015 & TRN \\
\hline CHEMBL1501268 & 688155 & 6.0 & 5.2482 & TRN \\
\hline CHEMBL1470735 & 688155 & 4.65 & 5.1882 & TRN \\
\hline CHEMBL1450791 & 688155 & 5.2 & 4.9529 & TRN \\
\hline CHEMBL1400407 & 688155 & 4.9 & 5.0296 & TRN \\
\hline CHEMBL1534294 & 688155 & 4.65 & 4.9307 & TRN \\
\hline CHEMBL1486135 & 688155 & 6.35 & 5.1359 & TRN \\
\hline CHEMBL1540420 & 688155 & 4.65 & 4.9194 & TRN \\
\hline CHEMBL1598267 & 688155 & 5.8 & 5.119 & TRN \\
\hline CHEMBL1557933 & 688155 & 6.5 & 5.0341 & TRN \\
\hline CHEMBL1542364 & 688155 & 5.65 & 5.2157 & TRN \\
\hline CHEMBL1493965 & 688155 & 4.9 & 4.9111 & TRN \\
\hline CHEMBL576607 & 688155 & 4.85 & 5.0456 & TRN \\
\hline CHEMBL1338176 & 688155 & 5.05 & 5.0252 & TRN \\
\hline CHEMBL1554088 & 688155 & 4.55 & 5.0031 & TRN \\
\hline CHEMBL1422217 & 688155 & 4.95 & 5.0904 & TRN \\
\hline CHEMBL1577391 & 688155 & 5.85 & 5.2093 & TRN \\
\hline CHEMBL 1331573 & 688155 & 5.55 & 5.0427 & TRN \\
\hline CHEMBL1613288 & 688155 & 5.6 & 5.0734 & TST \\
\hline CHEMBL1417966 & 688155 & 6.35 & 5.1263 & TRN \\
\hline CHEMBL1315920 & 688155 & 4.95 & 4.9836 & TRN \\
\hline CHEMBL1981008 & 688155 & 4.9 & 5.1168 & TST \\
\hline CHEMBL1349135 & 688155 & 5.8 & 5.0378 & TST \\
\hline CHEMBL1581340 & 688155 & 4.6 & 5.1051 & TRN \\
\hline CHEMBL1349695 & 688155 & 5.85 & 4.9518 & TRN \\
\hline CHEMBL1329868 & 688155 & 6.35 & 5.0794 & TST \\
\hline CHEMBL1993711 & 688155 & 4.55 & 5.0303 & TRN \\
\hline CHEMBL 1304892 & 688155 & 4.7 & 5.0422 & TRN \\
\hline CHEMBL1521122 & 688155 & 5.1 & 4.9544 & TRN \\
\hline
\end{tabular}




\begin{tabular}{|c|c|c|c|c|c|}
\hline \multicolumn{6}{|c|}{ Supplemental Table S2.txt } \\
\hline CHEMBL1364516 & 688155 & 4.55 & 5.0744 & TST & \\
\hline CHEMBL1343580 & 688155 & 4.5 & 5.2148 & TRN & \\
\hline CHEMBL1414453 & 688155 & 4.9 & 4.9705 & TRN & \\
\hline CHEMBL1382032 & 688155 & 4.9 & 5.0841 & TRN & \\
\hline CHEMBL1322531 & 688155 & 5.0 & 5.0233 & TRN & \\
\hline CHEMBL1531060 & 688155 & 5.0 & 5.0206 & TRN & \\
\hline CHEMBL1471506 & 688155 & 5.9 & 5.0318 & TRN & \\
\hline CHEMBL1502534 & 688155 & 5.05 & 5.12299 & 9999999999 & TRN \\
\hline CHEMBL1573293 & 688155 & 4.75 & 5.1579 & TRN & \\
\hline CHEMBL1582659 & 688155 & 5.0 & 5.0422 & TRN & \\
\hline CHEMBL1580762 & 688155 & 4.5 & 5.0617 & TRN & \\
\hline CHEMBL1535161 & 688155 & 6.0 & 5.0375 & TRN & \\
\hline CHEMBL1389484 & 688155 & 4.5 & 5.1428 & TRN & \\
\hline CHEMBL1338833 & 688155 & 5.9 & 5.149 & TST & \\
\hline CHEMBL1468909 & 688155 & 4.95 & 5.0704 & TRN & \\
\hline CHEMBL1459141 & 688155 & 5.7 & 5.1453 & TRN & \\
\hline CHEMBL1441159 & 688155 & 4.65 & 5.053 & TRN & \\
\hline CHEMBL3194256 & 688155 & 4.95 & 5.1155 & TRN & \\
\hline CHEMBL1323989 & 688155 & 4.9 & 4.883 & TRN & \\
\hline CHEMBL1547487 & 688155 & 4.55 & 4.9385 & TRN & \\
\hline CHEMBL1965060 & 688155 & 5.0 & 4.8918 & TRN & \\
\hline CHEMBL1340012 & 688155 & 5.2 & 5.0796 & TRN & \\
\hline CHEMBL1588171 & 688155 & 4.5 & 5.2143 & TRN & \\
\hline CHEMBL1562116 & 688155 & 4.65 & 5.0955 & TRN & \\
\hline CHEMBL1505194 & 688155 & 5.55 & 5.0712 & TRN & \\
\hline CHEMBL1447828 & 688155 & 5.0 & 5.0203 & TRN & \\
\hline CHEMBL1569277 & 688155 & 4.55 & 4.8982 & TRN & \\
\hline CHEMBL1607505 & 688155 & 5.4 & 5.169 & TST & \\
\hline CHEMBL1439659 & 688155 & 5.75 & 5.0336 & TRN & \\
\hline CHEMBL87791 & 688155 & 5.05 & 4.8561 & TRN & \\
\hline CHEMBL597047 & 688155 & 4.7 & 5.0973 & TRN & \\
\hline CHEMBL1503639 & 688155 & 4.65 & 5.048 & TRN & \\
\hline CHEMBL1582833 & 688155 & 4.95 & 5.0337 & TRN & \\
\hline CHEMBL1608045 & 688155 & 4.55 & 5.1259 & TRN & \\
\hline CHEMBL343002 & 688155 & 4.9 & 5.0013 & TRN & \\
\hline CHEMBL1527484 & 688155 & 4.55 & 5.061 & TRN & \\
\hline CHEMBL1499213 & 688155 & 4.8 & 5.0204 & TRN & \\
\hline CHEMBL1427426 & 688155 & 4.7 & 5.1174 & TRN & \\
\hline CHEMBL1440137 & 688155 & 4.55 & 4.9711 & TRN & \\
\hline CHEMBL1521358 & 688155 & 5.8 & 5.1992 & TRN & \\
\hline CHEMBL1499636 & 688155 & 5.95 & 5.2465 & TRN & \\
\hline CHEMBL1590855 & 688155 & 4.55 & 4.9983 & TRN & \\
\hline CHEMBL1408807 & 688155 & 4.95 & 5.2396 & TRN & \\
\hline CHEMBL1373918 & 688155 & 5.4 & 5.0001 & TST & \\
\hline CHEMBL1529511 & 688155 & 4.85 & 5.1014 & TRN & \\
\hline CHEMBL1438567 & 688155 & 5.45 & 5.0678 & TRN & \\
\hline CHEMBL1585204 & 688155 & 4.95 & 5.0076 & TRN & \\
\hline CHEMBL1344668 & 688155 & 5.0 & 5.1339 & TST & \\
\hline
\end{tabular}




\begin{tabular}{|c|c|c|c|c|c|}
\hline \multicolumn{6}{|c|}{ Supplemental Table S2.txt } \\
\hline CHEMBL1448476 & 688155 & 4.95 & 5.0466 & TRN & \\
\hline CHEMBL1393118 & 688155 & 5.0 & 5.04899 & 99999999995 & TST \\
\hline CHEMBL1585766 & 688155 & 5.7 & 5.0603 & TRN & \\
\hline CHEMBL1399873 & 688155 & 4.95 & 5.0877 & TRN & \\
\hline CHEMBL1428170 & 688155 & 4.55 & 5.0288 & TRN & \\
\hline CHEMBL1592160 & 688155 & 4.55 & 4.9775 & TRN & \\
\hline CHEMBL1355693 & 688155 & 5.95 & 4.9678 & TST & \\
\hline CHEMBL1376263 & 688155 & 4.55 & 5.0007 & TRN & \\
\hline CHEMBL1446203 & 688155 & 5.7 & 5.1424 & TRN & \\
\hline CHEMBL1447563 & 688155 & 5.45 & 4.9973 & TRN & \\
\hline CHEMBL 3212114 & 688155 & 5.3 & 5.0713 & TST & \\
\hline CHEMBL1522749 & 688155 & 4.6 & 4.9861 & TST & \\
\hline CHEMBL1596898 & 688155 & 5.0 & 4.9267 & TRN & \\
\hline CHEMBL1599903 & 688155 & 4.95 & 5.1606 & TRN & \\
\hline CHEMBL1519409 & 688155 & 4.95 & 5.0845 & TRN & \\
\hline CHEMBL1330922 & 688155 & 4.95 & 4.9793 & TRN & \\
\hline CHEMBL1499487 & 688155 & 4.5 & 5.2408 & TRN & \\
\hline CHEMBL1379268 & 688155 & 5.2 & 5.07 & TRN & \\
\hline CHEMBL1339394 & 688155 & 4.65 & 4.9016 & TRN & \\
\hline CHEMBL1599901 & 688155 & 5.65 & 5.0857 & TRN & \\
\hline CHEMBL1408587 & 688155 & 6.35 & 4.9711 & TRN & \\
\hline CHEMBL1516984 & 688155 & 4.55 & 4.9727 & TRN & \\
\hline CHEMBL1405839 & 688155 & 4.6 & 5.0561 & TRN & \\
\hline CHEMBL1319911 & 688155 & 5.9 & 5.16200 & 0000000001 & TRN \\
\hline CHEMBL1450504 & 688155 & 5.0 & 5.0826 & TST & \\
\hline CHEMBL1556722 & 688155 & 5.25 & 5.1772 & TRN & \\
\hline CHEMBL1605449 & 688155 & 4.55 & 5.0222 & TRN & \\
\hline CHEMBL1423637 & 688155 & 4.55 & 4.9906 & TRN & \\
\hline CHEMBL1521747 & 688155 & 5.4 & 5.1658 & TRN & \\
\hline CHEMBL1418907 & 688155 & 5.5 & 5.0637 & TRN & \\
\hline CHEMBL1585541 & 688155 & 6.2 & 5.2419 & TRN & \\
\hline CHEMBL1569403 & 688155 & 5.05 & 5.2049 & TRN & \\
\hline CHEMBL1534520 & 688155 & 4.5 & 4.9861 & TRN & \\
\hline CHEMBL1500105 & 688155 & 4.95 & 5.1023 & TRN & \\
\hline CHEMBL1412789 & 688155 & 4.9 & 4.9655 & TST & \\
\hline CHEMBL1600688 & 688155 & 4.95 & 5.0095 & TRN & \\
\hline CHEMBL 1445383 & 688155 & 6.5 & 4.9944 & TRN & \\
\hline CHEMBL1538117 & 688155 & 5.9 & 4.9923 & TRN & \\
\hline CHEMBL1352138 & 688155 & 5.6 & 5.0345 & TRN & \\
\hline CHEMBL1527752 & 688155 & 4.95 & 5.0787 & TST & \\
\hline CHEMBL1371586 & 688155 & 4.55 & 5.0302 & TRN & \\
\hline CHEMBL 1571628 & 688155 & 5.0 & 5.0711 & TST & \\
\hline CHEMBL1405700 & 688155 & 4.9 & 5.0742 & TRN & \\
\hline CHEMBL1468051 & 688155 & 5.9 & 5.1471 & TST & \\
\hline CHEMBL1603532 & 688155 & 4.55 & 4.9585 & TRN & \\
\hline CHEMBL1378168 & 688155 & 4.55 & 5.0454 & TRN & \\
\hline CHEMBL1353585 & 688155 & 5.05 & 5.0927 & TST & \\
\hline CHEMBL1445900 & 688155 & 4.85 & 5.0199 & TRN & \\
\hline
\end{tabular}




\begin{tabular}{|c|c|c|c|c|}
\hline \multicolumn{5}{|c|}{ Supplemental Table S2.txt } \\
\hline CHEMBL1548879 & 688155 & 5.75 & 5.3143 & TRN \\
\hline CHEMBL 3199314 & 688155 & 5.25 & 5.0878 & TRN \\
\hline CHEMBL1545191 & 688155 & 4.55 & 4.9759 & TRN \\
\hline CHEMBL1408514 & 688155 & 4.9 & 5.0617 & TRN \\
\hline CHEMBL1970478 & 688155 & 4.55 & 5.1056 & TRN \\
\hline CHEMBL1570577 & 688155 & 6.5 & 5.0583 & TRN \\
\hline CHEMBL1432565 & 688155 & 4.8 & 4.9827 & TRN \\
\hline CHEMBL1542967 & 688155 & 4.5 & 5.1121 & TST \\
\hline CHEMBL1484163 & 688155 & 5.0 & 5.0394 & TRN \\
\hline CHEMBL1458125 & 688155 & 5.5 & 5.0576 & TRN \\
\hline CHEMBL1602269 & 688155 & 6.3 & 5.2635 & TRN \\
\hline CHEMBL1377688 & 688155 & 5.0 & 4.9822 & TRN \\
\hline CHEMBL1578369 & 688155 & 4.65 & 5.1564 & TRN \\
\hline CHEMBL1583529 & 688155 & 5.0 & 5.2904 & TRN \\
\hline CHEMBL1498596 & 688155 & 4.95 & 5.1015 & TRN \\
\hline CHEMBL1508612 & 688155 & 6.05 & 5.0636 & TRN \\
\hline CHEMBL1502360 & 688155 & 5.0 & 5.2128 & TRN \\
\hline CHEMBL1593545 & 688155 & 4.55 & 4.9916 & TRN \\
\hline CHEMBL1372909 & 688155 & 4.95 & 5.1829 & TST \\
\hline CHEMBL1336287 & 688155 & 5.0 & 5.0521 & TST \\
\hline CHEMBL1391527 & 688155 & 4.95 & 5.0482 & TRN \\
\hline CHEMBL1572932 & 688155 & 4.55 & 5.0671 & TRN \\
\hline CHEMBL1359384 & 688155 & 4.5 & 5.1362 & TRN \\
\hline CHEMBL1530553 & 688155 & 5.0 & 4.9174 & TRN \\
\hline CHEMBL1566161 & 688155 & 5.35 & 5.249 & TRN \\
\hline CHEMBL1408363 & 688155 & 4.5 & 5.1693 & TRN \\
\hline CHEMBL1374853 & 688155 & 4.6 & 5.0782 & TRN \\
\hline CHEMBL1505521 & 688155 & 5.95 & 5.0663 & TST \\
\hline CHEMBL1339079 & 688155 & 4.55 & 5.1128 & TRN \\
\hline CHEMBL1350986 & 688155 & 4.9 & 5.0496 & TRN \\
\hline CHEMBL1442469 & 688155 & 4.75 & 5.0189 & TRN \\
\hline CHEMBL1604333 & 688155 & 4.95 & 5.0898 & TST \\
\hline CHEMBL1501481 & 688155 & 4.55 & 5.0479 & TST \\
\hline CHEMBL1329684 & 688155 & 4.5 & 4.9962 & TRN \\
\hline CHEMBL1350295 & 688155 & 5.05 & 5.2097 & TST \\
\hline CHEMBL1589202 & 688155 & 4.55 & 4.9302 & TRN \\
\hline CHEMBL1577228 & 688155 & 4.55 & 5.007 & TRN \\
\hline CHEMBL1375859 & 688155 & 5.2 & 5.2521 & TRN \\
\hline CHEMBL1453136 & 688155 & 5.0 & 4.9308 & TRN \\
\hline CHEMBL1411179 & 688155 & 4.65 & 4.9675 & TRN \\
\hline CHEMBL1536530 & 688155 & 5.95 & 5.0854 & TRN \\
\hline CHEMBL1404154 & 688155 & 4.5 & 5.0977 & TRN \\
\hline CHEMBL1304617 & 688155 & 4.55 & 5.2122 & TRN \\
\hline CHEMBL1459050 & 688155 & 4.95 & 5.129 & TRN \\
\hline CHEMBL1608565 & 688155 & 5.25 & 5.0615 & TRN \\
\hline CHEMBL1518304 & 688155 & 5.0 & 4.8683 & TRN \\
\hline CHEMBL1465686 & 688155 & 4.5 & 5.0771 & TRN \\
\hline CHEMBL1571927 & 688155 & 4.85 & 5.0625 & TST \\
\hline
\end{tabular}




\begin{tabular}{|c|c|c|c|c|c|}
\hline \multirow[b]{2}{*}{ CHEMBL1446050 } & \multicolumn{5}{|c|}{ Supplemental Table S2.txt } \\
\hline & 688155 & 6.45 & 5.2269 & TST & \\
\hline CHEMBL1558431 & 688155 & 4.8 & 4.9060 & 0000000001 & TRN \\
\hline CHEMBL1491181 & 688155 & 4.95 & 5.2525 & TRN & \\
\hline CHEMBL1471677 & 688155 & 5.2 & 5.0386 & TRN & \\
\hline CHEMBL1495662 & 688155 & 4.5 & 5.1827 & TRN & \\
\hline CHEMBL14830 & 688155 & 4.55 & 5.088 & TRN & \\
\hline CHEMBL1417955 & 688155 & 4.65 & 5.064 & TRN & \\
\hline CHEMBL1213837 & 688155 & 4.85 & 5.022 & TRN & \\
\hline CHEMBL1383668 & 688155 & 5.5 & 5.1352 & TRN & \\
\hline CHEMBL1529297 & 688155 & 4.95 & 5.1338 & TRN & \\
\hline CHEMBL1450879 & 688155 & 5.0 & 5.0143 & TST & \\
\hline CHEMBL1407303 & 688155 & 6.35 & 5.0981 & TST & \\
\hline CHEMBL1429883 & 688155 & 4.55 & 5.0721 & TST & \\
\hline CHEMBL1430906 & 688155 & 5.85 & 5.0669 & TRN & \\
\hline CHEMBL1307207 & 688155 & 5.4 & 5.2332 & TRN & \\
\hline CHEMBL1506790 & 688155 & 4.5 & 5.1031 & TRN & \\
\hline CHEMBL1493472 & 688155 & 5.25 & 5.1038 & TRN & \\
\hline CHEMBL1549476 & 688155 & 5.0 & 5.0438 & TRN & \\
\hline CHEMBL1353719 & 688155 & 5.45 & 5.0782 & TST & \\
\hline CHEMBL1386366 & 688155 & 5.95 & 5.1063 & TRN & \\
\hline CHEMBL1382772 & 688155 & 5.55 & 4.9460 & 0000000001 & TRN \\
\hline CHEMBL1333559 & 688155 & 4.75 & 4.9971 & TRN & \\
\hline CHEMBL 1427340 & 688155 & 5.0 & 4.9925 & TST & \\
\hline CHEMBL564708 & 688155 & 4.85 & 5.0224 & TRN & \\
\hline CHEMBL1368995 & 688155 & 4.95 & 4.9829 & TRN & \\
\hline CHEMBL1489906 & 688155 & 4.9 & 5.1524 & TRN & \\
\hline CHEMBL1444789 & 688155 & 4.65 & 5.0787 & TRN & \\
\hline CHEMBL1384227 & 688155 & 4.5 & 4.9218 & TRN & \\
\hline CHEMBL 3214432 & 688155 & 4.65 & 5.0218 & TRN & \\
\hline CHEMBL1457936 & 688155 & 5.05 & 4.9958 & TRN & \\
\hline CHEMBL1380091 & 688155 & 5.45 & 5.1745 & TRN & \\
\hline CHEMBL1329352 & 688155 & 4.95 & 5.1551 & TRN & \\
\hline CHEMBL1307499 & 688155 & 5.0 & 5.1544 & TRN & \\
\hline CHEMBL1415264 & 688155 & 5.25 & 5.1839 & TRN & \\
\hline CHEMBL1489749 & 688155 & 4.55 & 5.0489 & TRN & \\
\hline CHEMBL441282 & 688155 & 4.7 & 5.0652 & TST & \\
\hline CHEMBL1332328 & 688155 & 4.95 & 5.0116 & TRN & \\
\hline CHEMBL1375483 & 688155 & 5.55 & 5.2829 & 99999999995 & TRN \\
\hline CHEMBL1578821 & 688155 & 4.7 & 5.1327 & TST & \\
\hline CHEMBL1334105 & 688155 & 4.55 & 4.9607 & TRN & \\
\hline CHEMBL1387453 & 688155 & 4.6 & 5.005 & TRN & \\
\hline CHEMBL1477100 & 688155 & 4.9 & 5.0943 & TRN & \\
\hline CHEMBL1534925 & 688155 & 5.25 & 5.165 & TRN & \\
\hline CHEMBL1376690 & 688155 & 5.85 & 4.9781 & TRN & \\
\hline CHEMBL1371101 & 688155 & 5.4 & 5.1719 & TRN & \\
\hline CHEMBL1591674 & 688155 & 4.65 & 5.0426 & TRN & \\
\hline CHEMBL398363 & 688155 & 4.8 & 5.0147 & TRN & \\
\hline CHEMBL1556667 & 688155 & 4.9 & 5.0529 & TRN & \\
\hline
\end{tabular}




\begin{tabular}{|c|c|c|c|c|}
\hline \multicolumn{5}{|c|}{ Supplemental Table S2.txt } \\
\hline CHEMBL1345652 & 688155 & 5.5 & 5.1181 & TRN \\
\hline CHEMBL1509558 & 688155 & 6.0 & 4.9882 & TRN \\
\hline CHEMBL1428950 & 688155 & 4.75 & 5.0391 & TRN \\
\hline CHEMBL1549345 & 688155 & 4.5 & 4.9536 & TRN \\
\hline CHEMBL1328005 & 688155 & 5.0 & 5.0114 & TRN \\
\hline CHEMBL3145244 & 688155 & 4.95 & 5.0203 & TST \\
\hline CHEMBL1524617 & 688155 & 4.9 & 5.1595 & TST \\
\hline CHEMBL1520729 & 688155 & 4.55 & 5.1299 & TST \\
\hline CHEMBL1321886 & 688155 & 6.0 & 5.261 & TRN \\
\hline CHEMBL1538245 & 688155 & 5.55 & 5.1675 & TRN \\
\hline CHEMBL1596681 & 688155 & 5.4 & 5.1899 & TRN \\
\hline CHEMBL1502758 & 688155 & 4.9 & 5.1726 & TST \\
\hline CHEMBL1391890 & 688155 & 4.95 & 5.0633 & TRN \\
\hline CHEMBL3193639 & 688155 & 5.0 & 5.114 & TRN \\
\hline CHEMBL1508020 & 688155 & 5.75 & 5.1488 & TRN \\
\hline CHEMBL1463583 & 688155 & 4.55 & 5.046 & TRN \\
\hline CHEMBL1401433 & 688155 & 6.5 & 5.1579 & TRN \\
\hline CHEMBL1536571 & 688155 & 4.85 & 5.0398 & TRN \\
\hline CHEMBL1334059 & 688155 & 5.95 & 5.0177 & TRN \\
\hline CHEMBL1588226 & 688155 & 4.45 & 5.0144 & TRN \\
\hline CHEMBL1474326 & 688155 & 4.95 & 4.9924 & TRN \\
\hline CHEMBL1569209 & 688155 & 5.5 & 5.0661 & TRN \\
\hline CHEMBL1500937 & 688155 & 4.5 & 5.0985 & TST \\
\hline CHEMBL1545316 & 688155 & 5.5 & 5.0795 & TRN \\
\hline CHEMBL1370379 & 688155 & 4.95 & 5.1015 & TRN \\
\hline CHEMBL1599438 & 688155 & 5.45 & 4.9793 & TRN \\
\hline CHEMBL1600837 & 688155 & 4.5 & 4.9581 & TRN \\
\hline CHEMBL1576254 & 688155 & 4.9 & 5.16299 & 7999999999 \\
\hline CHEMBL1378830 & 688155 & 5.0 & 5.0206 & TST \\
\hline CHEMBL1377164 & 688155 & 4.55 & 5.074 & TRN \\
\hline CHEMBL1461242 & 688155 & 4.55 & 5.0214 & TRN \\
\hline CHEMBL1341087 & 688155 & 4.95 & 5.0514 & TST \\
\hline CHEMBL1340568 & 688155 & 5.2 & 5.0151 & TRN \\
\hline CHEMBL1393249 & 688155 & 4.55 & 5.1783 & TRN \\
\hline CHEMBL1344433 & 688155 & 4.55 & 5.0426 & TRN \\
\hline CHEMBL1372179 & 688155 & 5.45 & 5.0892 & TRN \\
\hline CHEMBL1421748 & 688155 & 5.0 & 4.9899 & TRN \\
\hline CHEMBL1359057 & 688155 & 5.5 & 5.0165 & TST \\
\hline CHEMBL1440679 & 688155 & 5.0 & 4.9618 & TST \\
\hline CHEMBL1438230 & 688155 & 5.2 & 5.1903 & TRN \\
\hline CHEMBL1310294 & 688155 & 5.05 & 4.97 & TRN \\
\hline CHEMBL1544096 & 688155 & 4.95 & 5.129 & TRN \\
\hline CHEMBL1529418 & 688155 & 4.55 & 5.0081 & TST \\
\hline CHEMBL1496330 & 688155 & 5.0 & 4.9867 & TRN \\
\hline CHEMBL1432957 & 688155 & 5.05 & 5.1155 & TRN \\
\hline CHEMBL1374684 & 688155 & 5.35 & 4.9666 & TST \\
\hline CHEMBL1463563 & 688155 & 4.5 & 5.0241 & TRN \\
\hline CHEMBL1500341 & 688155 & 4.5 & 5.0317 & TST \\
\hline
\end{tabular}




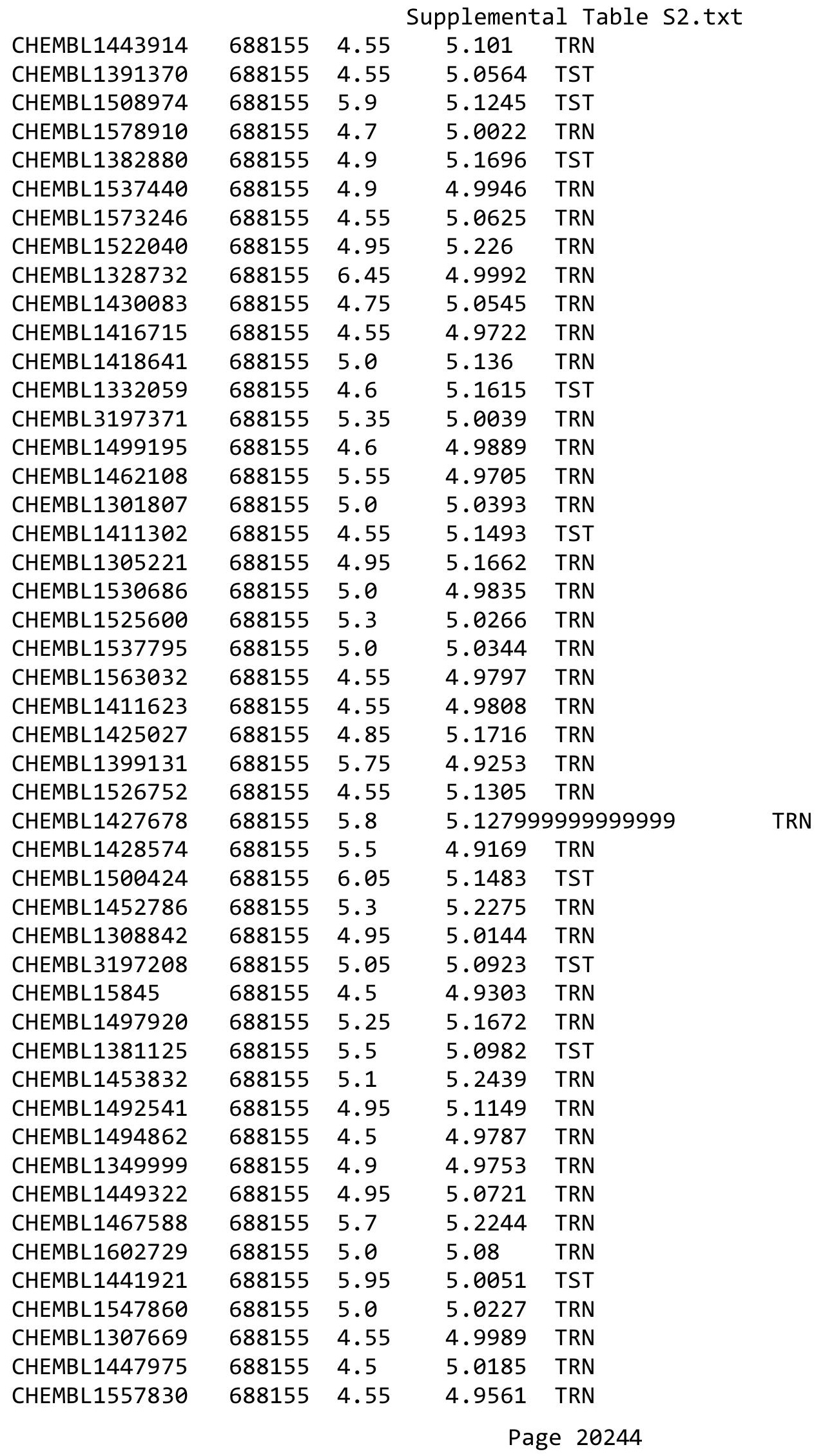




\begin{tabular}{|c|c|c|c|c|c|}
\hline \multicolumn{6}{|c|}{ Supplemental Table S2.txt } \\
\hline CHEMBL1340716 & 688155 & 5.05 & 4.9019 & TRN & \\
\hline CHEMBL1523661 & 688155 & 4.65 & 5.0551 & TRN & \\
\hline CHEMBL1402957 & 688155 & 4.55 & 5.1488 & TRN & \\
\hline CHEMBL1567856 & 688155 & 4.55 & 5.1294 & TST & \\
\hline CHEMBL1449350 & 688155 & 4.75 & 4.9731 & TRN & \\
\hline CHEMBL1442978 & 688155 & 4.5 & 5.2192 & TST & \\
\hline CHEMBL1477431 & 688155 & 4.95 & 5.0974 & TRN & \\
\hline CHEMBL1439075 & 688155 & 5.85 & 5.0939 & TRN & \\
\hline CHEMBL1387087 & 688155 & 4.5 & 5.1421 & TRN & \\
\hline CHEMBL1575065 & 688155 & 5.9 & 5.0609 & TRN & \\
\hline CHEMBL1421842 & 688155 & 6.5 & 5.2914 & TRN & \\
\hline CHEMBL1503756 & 688155 & 5.2 & 5.0043 & TRN & \\
\hline CHEMBL1386988 & 688155 & 5.1 & 5.03600 & 00000000005 & TRN \\
\hline CHEMBL1483147 & 688155 & 6.0 & 5.1044 & TRN & \\
\hline CHEMBL1576245 & 688155 & 5.0 & 5.0812 & TRN & \\
\hline CHEMBL1318957 & 688155 & 5.0 & 5.1284 & TRN & \\
\hline CHEMBL1590123 & 688155 & 4.85 & 4.8878 & TRN & \\
\hline CHEMBL1392332 & 688155 & 5.6 & 5.1148 & TRN & \\
\hline CHEMBL1586726 & 688155 & 5.25 & 5.1079 & TST & \\
\hline CHEMBL1499032 & 688155 & 5.05 & 5.1838 & TRN & \\
\hline CHEMBL1319204 & 688155 & 4.85 & 5.0262 & TRN & \\
\hline CHEMBL1600998 & 688155 & 4.8 & 5.1388 & TRN & \\
\hline CHEMBL600287 & 688155 & 5.2 & 4.9039 & TRN & \\
\hline CHEMBL1495686 & 688155 & 5.0 & 5.0182 & TRN & \\
\hline CHEMBL1326308 & 688155 & 4.55 & 5.0917 & TRN & \\
\hline CHEMBL1609827 & 688155 & 5.05 & 5.0355 & TRN & \\
\hline CHEMBL1509460 & 688155 & 5.4 & 4.9355 & TRN & \\
\hline CHEMBL1493330 & 688155 & 4.55 & 5.0118 & TRN & \\
\hline CHEMBL1362562 & 688155 & 4.6 & 5.0268 & TST & \\
\hline CHEMBL1532082 & 688155 & 4.55 & 5.0429 & TRN & \\
\hline CHEMBL1378741 & 688155 & 4.65 & 4.9697 & TRN & \\
\hline CHEMBL1990545 & 688155 & 5.6 & 4.9242 & TRN & \\
\hline CHEMBL1495515 & 688155 & 6.35 & 5.0939 & TRN & \\
\hline CHEMBL1585572 & 688155 & 4.55 & 4.9554 & TRN & \\
\hline CHEMBL1467525 & 688155 & 5.85 & 4.9422 & TRN & \\
\hline CHEMBL1307897 & 688155 & 4.95 & 5.1106 & TST & \\
\hline CHEMBL3193035 & 688155 & 5.9 & 4.9607 & TRN & \\
\hline CHEMBL1515253 & 688155 & 5.5 & 4.9338 & TRN & \\
\hline CHEMBL1489578 & 688155 & 5.0 & 5.2769 & TRN & \\
\hline CHEMBL1340361 & 688155 & 5.0 & 5.1351 & TST & \\
\hline CHEMBL1439904 & 688155 & 5.0 & 4.9323 & TRN & \\
\hline CHEMBL1377307 & 688155 & 5.1 & 5.1692 & TRN & \\
\hline CHEMBL1534306 & 688155 & 4.65 & 4.9224 & TRN & \\
\hline CHEMBL1566845 & 688155 & 4.55 & 5.1001 & TRN & \\
\hline CHEMBL1416381 & 688155 & 6.05 & 5.0631 & TRN & \\
\hline CHEMBL1558464 & 688155 & 5.8 & 4.9705 & TRN & \\
\hline CHEMBL1550616 & 688155 & 4.5 & 5.0955 & TRN & \\
\hline CHEMBL1566327 & 688155 & 4.95 & 5.234 & TRN & \\
\hline
\end{tabular}




\begin{tabular}{|c|c|c|c|c|}
\hline \multicolumn{5}{|c|}{ Supplemental Table S2.txt } \\
\hline CHEMBL1612715 & 688155 & 6.05 & 5.0261 & TRN \\
\hline CHEMBL1527779 & 688155 & 5.0 & 5.176 & TRN \\
\hline CHEMBL1410076 & 688155 & 6.4 & 5.0892 & TRN \\
\hline CHEMBL1431309 & 688155 & 4.9 & 5.0417 & TRN \\
\hline CHEMBL1523844 & 688155 & 5.3 & 4.9454 & TRN \\
\hline CHEMBL1434308 & 688155 & 5.7 & 4.9543 & TRN \\
\hline CHEMBL1307806 & 688155 & 5.4 & 4.9979 & TRN \\
\hline CHEMBL1307740 & 688155 & 6.5 & 5.0143 & TRN \\
\hline CHEMBL1535358 & 688155 & 4.9 & 5.1428 & TRN \\
\hline CHEMBL1568089 & 688155 & 4.6 & 5.0501 & TRN \\
\hline CHEMBL1471920 & 688155 & 4.55 & 5.0538 & TRN \\
\hline CHEMBL1544100 & 688155 & 5.9 & 5.1696 & TRN \\
\hline CHEMBL582674 & 688155 & 4.5 & 5.1155 & TRN \\
\hline CHEMBL1498608 & 688155 & 4.8 & 4.9537 & TRN \\
\hline CHEMBL1313570 & 688155 & 5.4 & 5.1549 & TST \\
\hline CHEMBL1452066 & 688155 & 4.65 & 5.2645 & TRN \\
\hline CHEMBL1586438 & 688155 & 4.9 & 5.1515 & TST \\
\hline CHEMBL1557116 & 688155 & 4.75 & 5.0942 & TST \\
\hline CHEMBL1342314 & 688155 & 4.95 & 5.1661 & TRN \\
\hline CHEMBL1351836 & 688155 & 4.8 & 4.9705 & TRN \\
\hline CHEMBL1594988 & 688155 & 4.55 & 5.0519 & TRN \\
\hline CHEMBL39 & 688155 & 4.7 & 5.0662 & TRN \\
\hline CHEMBL1332060 & 688155 & 4.85 & 4.9611 & TST \\
\hline CHEMBL1311625 & 688155 & 4.55 & 5.1055 & TRN \\
\hline CHEMBL1326361 & 688155 & 4.7 & 4.976 & TRN \\
\hline CHEMBL1319513 & 688155 & 4.55 & 4.9913 & TRN \\
\hline CHEMBL1383982 & 688155 & 4.55 & 4.8891 & TRN \\
\hline CHEMBL1587831 & 688155 & 5.3 & 5.0255 & TST \\
\hline CHEMBL1471844 & 688155 & 4.55 & 4.8433 & TRN \\
\hline CHEMBL1385735 & 688155 & 5.0 & 5.145 & TRN \\
\hline CHEMBL1328747 & 688155 & 6.0 & 5.2693 & TST \\
\hline CHEMBL1584570 & 688155 & 4.8 & 5.0991 & TRN \\
\hline CHEMBL1572162 & 688155 & 5.3 & 5.0605 & TRN \\
\hline CHEMBL1988684 & 688155 & 4.85 & 5.0211 & TRN \\
\hline CHEMBL1341260 & 688155 & 6.0 & 4.9888 & TRN \\
\hline CHEMBL1585113 & 688155 & 6.5501 & 5.2356 & TRN \\
\hline CHEMBL1594622 & 688155 & 5.0 & 5.1594 & TRN \\
\hline CHEMBL3192495 & 688155 & 4.5 & 4.8474 & TST \\
\hline CHEMBL3208831 & 688155 & 4.55 & 5.0849 & TRN \\
\hline CHEMBL1456012 & 688155 & 4.55 & 5.16799 & 9999999999 \\
\hline CHEMBL1418611 & 688155 & 5.4 & 4.8513 & TRN \\
\hline CHEMBL1576742 & 688155 & 4.6 & 5.0477 & TRN \\
\hline CHEMBL1597014 & 688155 & 4.75 & 5.0425 & TRN \\
\hline CHEMBL1393498 & 688155 & 4.9 & 5.1948 & TRN \\
\hline CHEMBL1499052 & 688155 & 6.5 & 5.0258 & TRN \\
\hline CHEMBL1478659 & 688155 & 4.55 & 5.0011 & TRN \\
\hline CHEMBL1596460 & 688155 & 5.1 & 5.1202 & TRN \\
\hline CHEMBL1585175 & 688155 & 4.9 & 5.2212 & TST \\
\hline
\end{tabular}




\begin{tabular}{|c|c|c|c|c|c|}
\hline \multicolumn{6}{|c|}{ Supplemental Table S2.txt } \\
\hline CHEMBL1556028 & 688155 & 6.4 & 5.053 & TRN & \\
\hline CHEMBL1492224 & 688155 & 6.35 & 5.2635 & TRN & \\
\hline CHEMBL1367025 & 688155 & 5.1 & 5.1423 & TRN & \\
\hline CHEMBL1571307 & 688155 & 4.95 & 4.9091 & TRN & \\
\hline CHEMBL1504899 & 688155 & 4.95 & 4.9514 & TRN & \\
\hline CHEMBL1464305 & 688155 & 4.95 & 5.2023 & TRN & \\
\hline CHEMBL1320682 & 688155 & 4.6 & 5.0756 & TST & \\
\hline CHEMBL1523343 & 688155 & 5.0 & 5.1871 & TRN & \\
\hline CHEMBL1325255 & 688155 & 5.05 & 5.0142 & TRN & \\
\hline CHEMBL3198590 & 688155 & 4.5 & 5.0672 & TST & \\
\hline CHEMBL1370473 & 688155 & 4.65 & 5.0026 & TRN & \\
\hline CHEMBL1440351 & 688155 & 4.5 & 5.0927 & TRN & \\
\hline CHEMBL1454742 & 688155 & 4.95 & 5.1785 & TRN & \\
\hline CHEMBL1607878 & 688155 & 5.0 & 5.1571 & TST & \\
\hline CHEMBL1526448 & 688155 & 4.6 & 5.0021 & TRN & \\
\hline CHEMBL3190658 & 688155 & 5.15 & 5.0018 & TRN & \\
\hline CHEMBL1535724 & 688155 & 5.55 & $4.9060 e$ & 0000000001 & TRN \\
\hline CHEMBL1385738 & 688155 & 5.0 & 5.0332 & TRN & \\
\hline CHEMBL1524217 & 688155 & 4.5 & 5.2065 & TST & \\
\hline CHEMBL1456488 & 688155 & 4.95 & 5.175 & TRN & \\
\hline CHEMBL1506415 & 688155 & 4.55 & 5.2457 & TRN & \\
\hline CHEMBL1378357 & 688155 & 4.95 & 5.0442 & TRN & \\
\hline CHEMBL73824 & 688155 & 5.0 & 5.186 & TRN & \\
\hline CHEMBL3195513 & 688155 & 4.9 & 4.9369 & TRN & \\
\hline CHEMBL602777 & 688155 & 5.05 & 5.1684 & TRN & \\
\hline CHEMBL1556085 & 688155 & 5.0 & 5.0539 & TRN & \\
\hline CHEMBL1526960 & 688155 & 4.85 & 5.1507 & TRN & \\
\hline CHEMBL1516412 & 688155 & 4.9 & 5.1358 & TRN & \\
\hline CHEMBL1561621 & 688155 & 4.85 & 4.9946 & TRN & \\
\hline CHEMBL1485049 & 688155 & 5.5 & 5.2637 & TRN & \\
\hline CHEMBL1989690 & 688155 & 5.6 & 5.2335 & TRN & \\
\hline CHEMBL1543254 & 688155 & 5.45 & 5.0941 & TRN & \\
\hline CHEMBL1373356 & 688155 & 5.9 & 5.0484 & TRN & \\
\hline CHEMBL1493178 & 688155 & 4.95 & 4.8976 & TRN & \\
\hline CHEMBL1412408 & 688155 & 5.15 & 5.0647 & TST & \\
\hline CHEMBL1431645 & 688155 & 5.0 & 5.1567 & TRN & \\
\hline CHEMBL3189714 & 688155 & 4.85 & 5.0464 & TRN & \\
\hline CHEMBL1386980 & 688155 & 5.1 & 5.0982 & TRN & \\
\hline CHEMBL1559109 & 688155 & 4.55 & 4.9959 & TST & \\
\hline CHEMBL1402842 & 688155 & 5.0 & 4.9383 & TRN & \\
\hline CHEMBL1447338 & 688155 & 5.65 & 5.093 & TRN & \\
\hline CHEMBL579956 & 688155 & 6.3 & 5.1456 & TRN & \\
\hline CHEMBL1501130 & 688155 & 5.05 & 5.0284 & TST & \\
\hline CHEMBL1570880 & 688155 & 4.6 & 5.1358 & TRN & \\
\hline CHEMBL1546342 & 688155 & 4.5 & 5.0123 & TRN & \\
\hline CHEMBL1561655 & 688155 & 4.9 & 5.0265 & TRN & \\
\hline CHEMBL1371581 & 688155 & 4.65 & 4.9921 & TRN & \\
\hline CHEMBL1367765 & 688155 & 4.7 & 4.9481 & TRN & \\
\hline
\end{tabular}




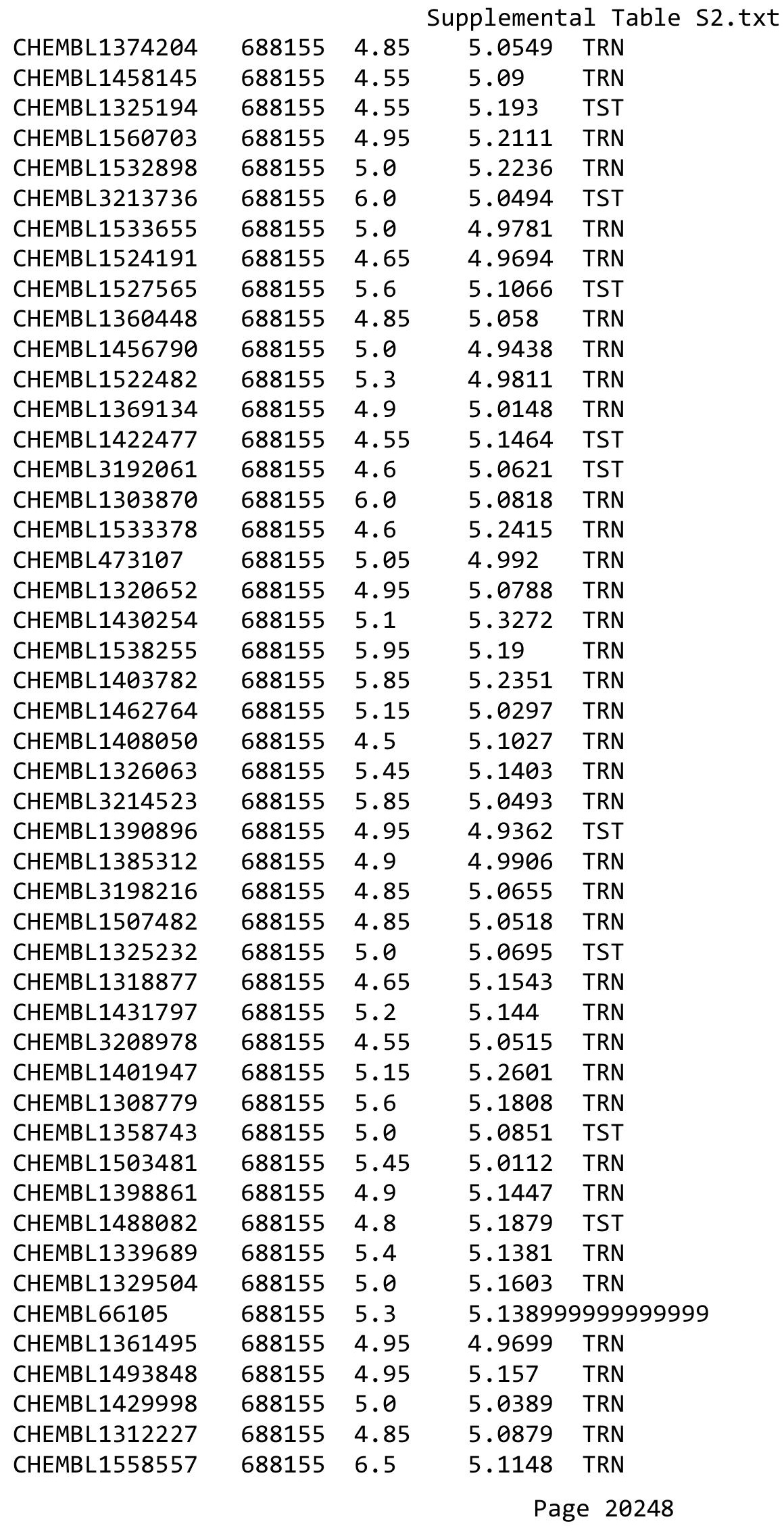




\begin{tabular}{|c|c|c|c|c|}
\hline \multicolumn{5}{|c|}{ Supplemental Table S2.txt } \\
\hline CHEMBL1505265 & 688155 & 4.9 & 5.0701 & TRN \\
\hline CHEMBL1565025 & 688155 & 4.95 & 5.093 & TRN \\
\hline CHEMBL1484754 & 688155 & 4.9 & 5.035 & TRN \\
\hline CHEMBL1560598 & 688155 & 4.65 & 5.0546 & TRN \\
\hline CHEMBL1366712 & 688155 & 5.25 & 5.0192 & TRN \\
\hline CHEMBL1416653 & 688155 & 4.55 & 5.1072 & TST \\
\hline CHEMBL1344654 & 688155 & 4.6 & 5.072 & TRN \\
\hline CHEMBL1542934 & 688155 & 6.3 & 5.1163 & TST \\
\hline CHEMBL1452293 & 688155 & 4.6 & 5.0302 & TRN \\
\hline CHEMBL1587910 & 688155 & 4.55 & 5.0812 & TRN \\
\hline CHEMBL1376040 & 688155 & 5.5 & 4.9829 & TRN \\
\hline CHEMBL1407488 & 688155 & 4.85 & 5.1056 & TRN \\
\hline CHEMBL1305032 & 688155 & 5.3 & 5.2952 & TST \\
\hline CHEMBL1338568 & 688155 & 6.05 & 5.2047 & TRN \\
\hline CHEMBL1531646 & 688155 & 5.85 & 5.1725 & TRN \\
\hline CHEMBL1463130 & 688155 & 4.95 & 5.2373 & TRN \\
\hline CHEMBL1304037 & 688155 & 5.35 & 5.0762 & TRN \\
\hline CHEMBL1458569 & 688155 & 6.5 & 5.1542 & TST \\
\hline CHEMBL1531409 & 688155 & 4.95 & 5.2005 & TRN \\
\hline CHEMBL1517167 & 688155 & 5.8 & 5.0598 & TRN \\
\hline CHEMBL1375663 & 688155 & 4.55 & 5.1298 & TRN \\
\hline CHEMBL1482653 & 688155 & 5.25 & 5.0285 & TRN \\
\hline CHEMBL1528561 & 688155 & 4.55 & 5.1392 & TRN \\
\hline CHEMBL1571275 & 688155 & 5.3 & 5.1797 & TRN \\
\hline CHEMBL1364998 & 688155 & 6.15 & 5.0748 & TRN \\
\hline CHEMBL1343999 & 688155 & 4.55 & 5.1333 & TRN \\
\hline CHEMBL1531956 & 688155 & 4.9 & 5.157 & TST \\
\hline CHEMBL1478458 & 688155 & 4.9 & 5.1421 & TRN \\
\hline CHEMBL1707911 & 688155 & 5.55 & 5.0456 & TRN \\
\hline CHEMBL1541068 & 688155 & 4.6 & 4.9797 & TST \\
\hline CHEMBL1372431 & 688155 & 4.55 & 5.0802 & TRN \\
\hline CHEMBL1462702 & 688155 & 5.05 & 5.1742 & TRN \\
\hline CHEMBL 3212543 & 688155 & 4.5 & 5.0044 & TST \\
\hline CHEMBL3207320 & 688155 & 5.25 & 5.0603 & TRN \\
\hline CHEMBL1399210 & 688155 & 5.95 & 5.1493 & TRN \\
\hline CHEMBL1451209 & 688155 & 4.9 & 4.9599 & TRN \\
\hline CHEMBL1549606 & 688155 & 6.1 & 4.9776 & TRN \\
\hline CHEMBL 256202 & 688155 & 5.7 & 5.1702 & TRN \\
\hline CHEMBL1310333 & 688155 & 5.85 & 5.2443 & TRN \\
\hline CHEMBL1320013 & 688155 & 5.25 & 4.9129 & TRN \\
\hline CHEMBL1410528 & 688155 & 5.55 & 5.0853 & TRN \\
\hline CHEMBL1480222 & 688155 & 4.8 & 4.9668 & TRN \\
\hline CHEMBL1540116 & 688155 & 4.55 & 5.1502 & TRN \\
\hline CHEMBL1309939 & 688155 & 5.55 & 5.2416 & TRN \\
\hline CHEMBL1606911 & 688155 & 4.9 & 5.0634 & TRN \\
\hline CHEMBL1418551 & 688155 & 4.5 & 4.9871 & TRN \\
\hline CHEMBL 1465040 & 688155 & 4.55 & 5.1109 & TRN \\
\hline CHEMBL1380975 & 688155 & 4.95 & 4.9466 & TRN \\
\hline
\end{tabular}




\begin{tabular}{|c|c|c|c|c|}
\hline \multicolumn{5}{|c|}{ Supplemental Table s2.txt } \\
\hline CHEMBL1448387 & 688155 & 5.35 & 5.1153 & TST \\
\hline CHEMBL1414234 & 688155 & 5.0 & 4.9937 & TRN \\
\hline CHEMBL1480530 & 688155 & 5.2 & 5.2039 & TST \\
\hline CHEMBL1418562 & 688155 & 4.55 & 5.0043 & TRN \\
\hline CHEMBL1467921 & 688155 & 4.5 & 5.0742 & TST \\
\hline CHEMBL572806 & 688155 & 4.65 & 5.1875 & TST \\
\hline CHEMBL1613638 & 1301786 & 5.4789 & 4.8976 & TRN \\
\hline CHEMBL1900893 & 1301786 & 4.5662 & 5.0527 & TRN \\
\hline CHEMBL1331911 & 1301786 & 4.658 & 4.9132 & TRN \\
\hline CHEMBL3189985 & 1301786 & 4.6002 & 4.9982 & TRN \\
\hline CHEMBL1423524 & 1301786 & 4.8576 & 5.2933 & TRN \\
\hline CHEMBL 3190368 & 1301786 & 5.2984 & 4.8833 & TRN \\
\hline CHEMBL1723968 & 1301786 & 5.4123 & 5.2566 & TRN \\
\hline CHEMBL1535503 & 1301786 & 5.2518 & 5.3627 & TST \\
\hline CHEMBL 2134784 & 1301786 & 5.6615 & 4.9874 & TRN \\
\hline CHEMBL1719605 & 1301786 & 5.4908 & 5.1406 & TRN \\
\hline CHEMBL1473982 & 1301786 & 5.3468 & 5.1067 & TRN \\
\hline CHEMBL1397359 & 1301786 & 5.3233 & 5.0805 & TRN \\
\hline CHEMBL1982441 & 1301786 & 5.1506 & 5.0589 & TRN \\
\hline CHEMBL179611 & 1301786 & 5.1618 & 5.2753 & TRN \\
\hline CHEMBL 3199944 & 1301786 & 5.2007 & 4.8836 & TRN \\
\hline CHEMBL1608768 & 1301786 & 4.5167 & 5.106 & TST \\
\hline CHEMBL1539909 & 1301786 & 4.2861 & 5.0432 & TRN \\
\hline CHEMBL460366 & 1301786 & 4.4641 & 4.7645 & TRN \\
\hline CHEMBL1400929 & 1301786 & 4.8798 & 5.6297 & TRN \\
\hline CHEMBL1377211 & 1301786 & 4.8202 & 4.7445 & TRN \\
\hline CHEMBL1349079 & 1301786 & 4.8854 & 5.0486 & TST \\
\hline CHEMBL1475629 & 1301786 & 5.5391 & 5.5457 & TRN \\
\hline CHEMBL1397916 & 1301786 & 5.9208 & 5.0056 & TRN \\
\hline CHEMBL1322708 & 1301786 & 5.699 & 5.067 & TRN \\
\hline CHEMBL1411228 & 1301786 & 4.6712 & 4.877 & TST \\
\hline CHEMBL1483840 & 1301786 & 5.0141 & 5.074 & TST \\
\hline CHEMBL1731574 & 1301786 & 4.2862 & 4.9255 & TST \\
\hline CHEMBL1442500 & 1301786 & 5.8013 & 5.6054 & TRN \\
\hline CHEMBL1972470 & 1301786 & 4.7178 & 4.9746 & TRN \\
\hline CHEMBL1700038 & 1301786 & 4.9527 & 4.9926 & TST \\
\hline CHEMBL1559307 & 1301786 & 5.0706 & 4.9261 & TRN \\
\hline CHEMBL1870238 & 1301786 & 4.5918 & 5.3329 & TRN \\
\hline CHEMBL1721177 & 1301786 & 4.3075 & 4.8478 & TRN \\
\hline CHEMBL1357139 & 1301786 & 4.5719 & 4.8627 & TRN \\
\hline CHEMBL1454531 & 1301786 & 5.8097 & 4.9081 & TRN \\
\hline CHEMBL1904453 & 1301786 & 5.2182 & 5.1701 & TRN \\
\hline CHEMBL1580664 & 1301786 & 4.971 & 5.1835 & TRN \\
\hline CHEMBL3192665 & 1301786 & 5.7258 & 5.2532 & TRN \\
\hline CHEMBL1374603 & 1301786 & 5.3536 & 4.8839 & TRN \\
\hline CHEMBL1468277 & 1301786 & 4.7277 & 4.9947 & TRN \\
\hline CHEMBL1332605 & 1301786 & 5.0737 & 5.2183 & TRN \\
\hline CHEMBL1532198 & 1301786 & 4.8904 & 4.9394 & TRN \\
\hline
\end{tabular}


Supplemental Table S2.txt

\begin{tabular}{|c|c|c|c|c|}
\hline CHEMBL1492995 & 1301786 & 5.1445 & 5.4382 & TRN \\
\hline CHEMBL1410602 & 1301786 & 4.3461 & 5.0956 & TRN \\
\hline CHEMBL505670 & 1301786 & 5.1421 & 5.1883 & TRN \\
\hline CHEMBL1594374 & 1301786 & 6.5591 & 5.6857 & TST \\
\hline CHEMBL 2000633 & 1301786 & 4.3652 & 5.4045 & TRN \\
\hline CHEMBL1406996 & 1301786 & 4.8091 & 4.83 & TRN \\
\hline CHEMBL1532300 & 1301786 & 4.4256 & 4.9126 & TRN \\
\hline CHEMBL1429570 & 1301786 & 5.5331 & 5.2914 & TRN \\
\hline CHEMBL1320799 & 1301786 & 5.684 & 5.1963 & TRN \\
\hline CHEMBL1417701 & 1301786 & 5.4353 & 5.1157 & TRN \\
\hline CHEMBL1476798 & 1301786 & 4.8864 & 4.6739 & TRN \\
\hline CHEMBL1467623 & 1301786 & 5.1457 & 5.0738 & TRN \\
\hline CHEMBL1707215 & 1301786 & 5.0044 & 5.0556 & TRN \\
\hline CHEMBL1708263 & 1301786 & 4.4676 & 4.5072 & TRN \\
\hline CHEMBL1878046 & 1301786 & 5.4365 & 5.0446 & TRN \\
\hline CHEMBL1306943 & 1301786 & 5.0721 & 5.0608 & TRN \\
\hline CHEMBL3186240 & 1301786 & 4.706 & 5.2943 & TST \\
\hline CHEMBL3187005 & 1301786 & 5.1688 & 5.1325 & TRN \\
\hline CHEMBL1550032 & 1301786 & 5.8601 & 4.9982 & TRN \\
\hline CHEMBL1702854 & 1301786 & 4.335 & 4.8951 & TRN \\
\hline CHEMBL1565805 & 1301786 & 4.7817 & 5.234 & TRN \\
\hline CHEMBL1414432 & 1301786 & 6.7033 & 5.053 & TRN \\
\hline CHEMBL1357064 & 1301786 & 5.8182 & 5.2272 & TRN \\
\hline CHEMBL1712572 & 1301786 & 4.4528 & 4.5051 & TRN \\
\hline CHEMBL1346909 & 1301786 & 5.3872 & 5.1254 & TRN \\
\hline CHEMBL3193134 & 1301786 & 5.9547 & 5.5718 & TRN \\
\hline CHEMBL1594542 & 1301786 & 4.706 & 5.1289 & TRN \\
\hline CHEMBL1480962 & 1301786 & 4.4974 & 4.8002 & TRN \\
\hline CHEMBL1458444 & 1301786 & 5.4776 & 5.0835 & TRN \\
\hline CHEMBL1335844 & 1301786 & 6.0405 & 5.2985 & TRN \\
\hline CHEMBL1329888 & 1301786 & 4.6959 & 4.9382 & TRN \\
\hline CHEMBL1586383 & 1301786 & 4.3949 & 4.9992 & TRN \\
\hline CHEMBL1330558 & 1301786 & 4.763 & 5.3307 & TRN \\
\hline CHEMBL1530824 & 1301786 & 4.7875 & 4.8746 & TRN \\
\hline CHEMBL1570497 & 1301786 & 4.4089 & 4.9842 & TRN \\
\hline CHEMBL1565057 & 1301786 & 5.2573 & 5.0259 & TRN \\
\hline CHEMBL1504853 & 1301786 & 5.6038 & 5.1249 & TRN \\
\hline CHEMBL 1897178 & 1301786 & 5.2708 & 5.0616 & TRN \\
\hline CHEMBL210208 & 1301786 & 6.7167 & 6.3051 & TRN \\
\hline CHEMBL1399676 & 1301786 & 4.8474 & 5.2803 & TST \\
\hline CHEMBL1409628 & 1301786 & 5.6536 & 5.26399 & 9999999999 \\
\hline CHEMBL1498137 & 1301786 & 4.3273 & 4.8163 & TRN \\
\hline CHEMBL1540929 & 1301786 & 6.0009 & 5.279 & TRN \\
\hline CHEMBL3188710 & 1301786 & 4.2972 & 5.0201 & TRN \\
\hline CHEMBL1704382 & 1301786 & 5.3915 & 5.0538 & TST \\
\hline CHEMBL1550788 & 1301786 & 4.9197 & 5.125 & TST \\
\hline CHEMBL1323546 & 1301786 & 4.6492 & 4.9756 & TST \\
\hline CHEMBL 2137636 & 1301786 & 5.7959 & 5.0151 & TST \\
\hline
\end{tabular}


Supplemental Table S2.txt

\begin{tabular}{|c|c|c|c|c|c|c|}
\hline CHEMBL1417159 & 1301786 & 5.8794 & 5.3028 & TST & & \\
\hline CHEMBL1972346 & 1301786 & 5.9208 & 5.7213 & TRN & & \\
\hline CHEMBL3183797 & 1301786 & 5.17200 & 00000000 & & 5.1296 & TRN \\
\hline CHEMBL1383240 & 1301786 & 5.9355 & 4.8256 & TRN & & \\
\hline CHEMBL1399900 & 1301786 & 4.6291 & 4.9559 & TRN & & \\
\hline CHEMBL1443996 & 1301786 & 4.3461 & 5.0391 & TST & & \\
\hline CHEMBL478754 & 1301786 & 5.2495 & 5.1074 & TRN & & \\
\hline CHEMBL1534986 & 1301786 & 4.9851 & 5.0917 & TRN & & \\
\hline CHEMBL1302463 & 1301786 & 4.7962 & 4.8531 & TRN & & \\
\hline CHEMBL1400127 & 1301786 & 4.8462 & 4.8956 & TRN & & \\
\hline CHEMBL3183216 & 1301786 & 4.3776 & 5.1388 & TST & & \\
\hline CHEMBL1355177 & 1301786 & 4.6171 & 4.9189 & TRN & & \\
\hline CHEMBL1419792 & 1301786 & 5.2411 & 4.8931 & TRN & & \\
\hline CHEMBL258756 & 1301786 & 5.5686 & 5.0366 & TRN & & \\
\hline CHEMBL1591246 & 1301786 & 4.4167 & 5.0511 & TRN & & \\
\hline CHEMBL1463659 & 1301786 & 6.6596 & 5.8483 & TRN & & \\
\hline CHEMBL1587422 & 1301786 & 4.6847 & 4.8677 & TRN & & \\
\hline CHEMBL1492590 & 1301786 & 5.317 & 5.0201 & TRN & & \\
\hline CHEMBL1545792 & 1301786 & 4.9234 & 4.8768 & TRN & & \\
\hline CHEMBL3191867 & 1301786 & 4.3998 & 5.176 & TRN & & \\
\hline CHEMBL1318277 & 1301786 & 5.4179 & 4.9599 & TRN & & \\
\hline CHEMBL1382999 & 1301786 & 4.6084 & 4.8923 & TRN & & \\
\hline CHEMBL1381758 & 1301786 & 4.4628 & 4.9007 & TST & & \\
\hline CHEMBL1576896 & 1301786 & 5.2636 & 5.215 & TRN & & \\
\hline CHEMBL1421034 & 1301786 & 5.0362 & 4.6488 & TRN & & \\
\hline CHEMBL3182623 & 1301786 & 5.1085 & 5.1371 & TST & & \\
\hline CHEMBL1567670 & 1301786 & 4.9278 & 5.1004 & TRN & & \\
\hline CHEMBL1994094 & 1301786 & 4.56 & 5.5128 & TRN & & \\
\hline CHEMBL2001761 & 1301786 & 4.6158 & 5.4104 & TRN & & \\
\hline CHEMBL1730653 & 1301786 & 4.6114 & 5.0739 & TRN & & \\
\hline CHEMBL1384930 & 1301786 & 4.8564 & 5.0721 & TRN & & \\
\hline CHEMBL1326647 & 1301786 & 4.3949 & 5.1835 & TRN & & \\
\hline CHEMBL1879872 & 1301786 & 4.3973 & 4.8676 & TRN & & \\
\hline CHEMBL1518924 & 1301786 & 4.523 & 4.7734 & TRN & & \\
\hline CHEMBL3184830 & 1301786 & 4.9706 & 4.9587 & TRN & & \\
\hline CHEMBL1314122 & 1301786 & 4.2895 & 5.0962 & TRN & & \\
\hline CHEMBL171632 & 1301786 & 5.9706 & 5.2532 & TST & & \\
\hline CHEMBL1342038 & 1301786 & 4.4192 & 5.0745 & TRN & & \\
\hline CHEMBL1568867 & 1301786 & 4.4683 & 4.7296 & TRN & & \\
\hline CHEMBL1390521 & 1301786 & 5.6144 & 6.1428 & TRN & & \\
\hline CHEMBL3192569 & 1301786 & 4.9492 & 5.0592 & TRN & & \\
\hline CHEMBL1308497 & 1301786 & 5.3575 & 4.9635 & TRN & & \\
\hline CHEMBL11875 & 1301786 & 4.3759 & 5.0284 & TRN & & \\
\hline CHEMBL1364567 & 1301786 & 5.7258 & 5.0805 & TRN & & \\
\hline CHEMBL1985664 & 1301786 & 6.059 & 5.5474 & TRN & & \\
\hline CHEMBL3191063 & 1301786 & 5.8069 & 5.7506 & TRN & & \\
\hline CHEMBL1364175 & 1301786 & 4.9519 & 4.7888 & TRN & & \\
\hline CHEMBL3199718 & 1301786 & 5.4672 & 5.2151 & TRN & & \\
\hline
\end{tabular}


Supplemental Table S2.txt

\begin{tabular}{|c|c|c|c|c|}
\hline 6 & & 585 & & \\
\hline & & 5.1215 & 5.1974 & \\
\hline EMR 1 & 01786 & 9965 & & \\
\hline IEMBL: & 86 & 218 & & \\
\hline AEMBL1334020 & 301786 & 6343 & 8804 & \\
\hline HEMBL1882729 & 301786 & 4.3235 & 1327 & \\
\hline 21993 & 86 & 327 & 268 & \\
\hline AEMBL1477749 & & & 1536 & \\
\hline HEMBL1556121 & 301786 & 5.2373 & 9164 & \\
\hline HEMBL 272465 & 301786 & 4.7095 & 7808 & \\
\hline HEMBL1526687 & 36 & 4.9809 & 9597 & \\
\hline 365 & 36 & 56 & 816 & \\
\hline HEMBL1 & & & 507 & \\
\hline HEMBL1719459 & 301786 & 5.426 & 3369 & \\
\hline AEMBL1497838 & 86 & 5.5544 & & \\
\hline HEMBL1 & J & 4 & 087 & \\
\hline HEMBL2 & 0 & & 203 & RN \\
\hline HEMBL1 & 36 & 52 & 441 & \\
\hline HEMBL1342821 & 86 & 4.852 & 3346 & \\
\hline HEMBL1503050 & & 4. & & I KIV \\
\hline HEMBL & 30 & 4 & 387 & RN \\
\hline HEM & & & & TIV \\
\hline AEMBL & 6 & 31 & 607 & RN \\
\hline HEMBL1 & & & 3535 & I RIV \\
\hline HEMBL3182498 & & 58 & 643 & | \\
\hline HEMBL1 & 30 & 59 & 626 & RN \\
\hline HEMBL & 6 & & 23 & KIV \\
\hline 178 & & 79 & 909 & RN \\
\hline AEMBL1 & & & 26 & IK \\
\hline HEMBL1383118 & 30 & 99 & 47 & TRN \\
\hline HEMB & 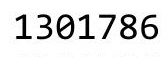 & 59 & 13 & ST \\
\hline 5 & & & & 「RN \\
\hline - וחבית & & & 718 & RN \\
\hline HEMBL1 & & & & 「RN \\
\hline HEMBL3191761 & 30 & & 704 & ГRN \\
\hline IFMDI- & 30 & 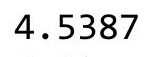 & 15 & TRN \\
\hline 2 & & 6. & & ГRN \\
\hline HEMBL1 & & & & 「RN \\
\hline HEMBL1 & 36 & & 932 & TST \\
\hline EMBL & & & 919 & RN \\
\hline HFMRI 1 & & 55 & 548 & R \\
\hline & & & 3671 & 「RN \\
\hline HEMBL1 & & 4.6538 & 9181 & TRN \\
\hline HEMBL 2 & 30 & 09 & 937 & TS \\
\hline 03 & & & & \\
\hline HEMBL173530 & & 6.0878 & 5155 & \\
\hline HEMBL318315 & 30 & 4.3253 & 9575 & RN \\
\hline CHEMBL1541890 & 130178 & 5.1451 & 5.1695 & TRN \\
\hline
\end{tabular}

Page 20253 
Supplemental Table S2.txt

\begin{tabular}{|c|c|c|c|c|c|}
\hline CHEMBL591137 & 1301786 & 4.4717 & 5.4364 & TRN & \\
\hline CHEMBL1897987 & 1301786 & 4.4192 & 5.2456 & TST & \\
\hline CHEMBL1902287 & 1301786 & 5.4342 & 5.5325 & TST & \\
\hline CHEMBL1497070 & 1301786 & 6.0334 & 5.1622 & TRN & \\
\hline CHEMBL1523328 & 1301786 & 6.0434 & 5.064 & TRN & \\
\hline CHEMBL1562896 & 1301786 & 5.426 & 4.9428 & TRN & \\
\hline CHEMBL1601846 & 1301786 & 6.3152 & 6.542999 & 9999999999 & TRN \\
\hline CHEMBL1325326 & 1301786 & 4.4479 & 5.1545 & TRN & \\
\hline CHEMBL1570982 & 1301786 & 4.6278 & 5.1614 & TRN & \\
\hline CHEMBL1997668 & 1301786 & 4.8761 & 5.3363 & TRN & \\
\hline CHEMBL3184317 & 1301786 & 4.3724 & 5.1966 & TST & \\
\hline CHEMBL1873953 & 1301786 & 4.8716 & 5.143 & TRN & \\
\hline CHEMBL172350 & 1301786 & 4.5328 & 5.5633 & TRN & \\
\hline CHEMBL3190083 & 1301786 & 5.3747 & 5.127000 & 0000000001 & TRN \\
\hline CHEMBL1712631 & 1301786 & 5.1818 & 5.3065 & TRN & \\
\hline CHEMBL1335030 & 1301786 & 4.4618 & 5.52 & TRN & \\
\hline CHEMBL1435948 & 1301786 & 6.1643 & 5.0447 & TRN & \\
\hline CHEMBL1469043 & 1301786 & 4.434 & 4.8288 & TRN & \\
\hline CHEMBL1307247 & 1301786 & 5.0311 & 4.7728 & TRN & \\
\hline CHEMBL1456035 & 1301786 & 5.699 & 5.4209 & TST & \\
\hline CHEMBL1442893 & 1301786 & 4.3662 & 4.7413 & TRN & \\
\hline CHEMBL1520133 & 1301786 & 4.6165 & 4.9273 & TRN & \\
\hline CHEMBL1428705 & 1301786 & 4.5126 & 4.8837 & TRN & \\
\hline CHEMBL1891071 & 1301786 & 4.8969 & 4.8402 & TRN & \\
\hline CHEMBL1528737 & 1301786 & 5.767 & 5.0562 & TRN & \\
\hline CHEMBL1376200 & 1301786 & 5.3487 & 5.5869 & TRN & \\
\hline CHEMBL1548326 & 1301786 & 4.9622 & 4.9166 & TRN & \\
\hline CHEMBL1355983 & 1301786 & 5.7496 & 5.3953 & TRN & \\
\hline CHEMBL1553446 & 1301786 & 5.0467 & 4.8557 & TRN & \\
\hline CHEMBL1453503 & 1301786 & 5.21899 & 999999999 & 5.3246 & TRN \\
\hline CHEMBL1489693 & 1301786 & 4.9248 & 5.155 & TRN & \\
\hline CHEMBL1522941 & 1301786 & 6.0259 & 5.2035 & TRN & \\
\hline CHEMBL1980204 & 1301786 & 4.9574 & 5.2152 & TRN & \\
\hline CHEMBL1703689 & 1301786 & 4.5291 & 5.0891 & TST & \\
\hline CHEMBL1434792 & 1301786 & 5.3665 & 5.1134 & TRN & \\
\hline CHEMBL1334889 & 1301786 & 4.658 & 5.1306 & TRN & \\
\hline CHEMBL1875561 & 1301786 & 5.4056 & 5.0609 & TRN & \\
\hline CHEMBL1888617 & 1301786 & 5.5884 & 5.0907 & TRN & \\
\hline CHEMBL1521600 & 1301786 & 5.3401 & 5.0602 & TRN & \\
\hline CHEMBL1476707 & 1301786 & 4.7513 & 4.8853 & TRN & \\
\hline CHEMBL1453409 & 1301786 & 4.7238 & 5.0344 & TRN & \\
\hline CHEMBL1705326 & 1301786 & 4.9978 & 5.2254 & TRN & \\
\hline CHEMBL1520233 & 1301786 & 5.4449 & 5.064 & TRN & \\
\hline CHEMBL3188527 & 1301786 & 4.9169 & 5.0724 & TST & \\
\hline CHEMBL1456412 & 1301786 & 5.7696 & 5.2094 & TST & \\
\hline CHEMBL1517788 & 1301786 & 4.7773 & 4.818000 & 00000000005 & TRN \\
\hline CHEMBL1611833 & 1301786 & 5.2299 & 5.4204 & TRN & \\
\hline CHEMBL1582755 & 1301786 & 5.3936 & 4.9591 & TST & \\
\hline
\end{tabular}


Supplemental Table S2.txt

\begin{tabular}{|c|c|c|c|c|}
\hline AEMBL 3191236 & & & & \\
\hline & & 5.1904 & 5.3756 & \\
\hline$=M I_{1}$ & 01 & 3377 & & \\
\hline IEMBL1 & 36 & 3391 & & \\
\hline HEMBL2143726 & 301786 & 7428 & 2761 & \\
\hline AEMBL15 & 301786 & 4.8854 & 98 & \\
\hline AEMBL1 & 301 & & & \\
\hline IEMBL164 & 36 & & & \\
\hline IEMBL132 & 301786 & 6496 & 8813 & \\
\hline HEMBL144 & 301786 & 4.9539 & 4.8368 & \\
\hline HEMBL & 301 & & & \\
\hline EMBL: & 30 & 24 & 616 & \\
\hline AEMBL & 36 & & & \\
\hline AEMBL: & 86 & 2388 & 5.0708 & \\
\hline HEMBL & 301 & & & \\
\hline AEMBL: & ש & 4 & 85 & \\
\hline IEMBL & De & & 341 & \\
\hline AEMBL & 30 & 55 & 5.5876 & \\
\hline EMBL & 36 & 328 & 203 & \\
\hline AEMBL: & 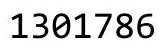 & & & \\
\hline AEMBL & 36 & & 56 & \\
\hline IEMBL & 36 & & & 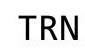 \\
\hline IEMBL & 36 & 77 & & \\
\hline IEMBL & م & & & \\
\hline AEMBL & 301 & & & \\
\hline IEMBL: & 0 & & & \\
\hline EMB & $3 e$ & 18 & & \\
\hline 79 & 20 & 83 & & \\
\hline IEMBL & סח & & & \\
\hline EMBL: & 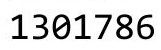 & 526 & & \\
\hline IEMBL & 30 & & & $m$ \\
\hline 5 & 0 & & & \\
\hline & & 54 & & \\
\hline IEMBL: & 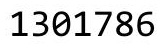 & 6 . & 5 . & RI \\
\hline AEMBL: & 301 & & & RI \\
\hline EMR & 30 & 15 & 61 & 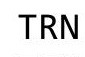 \\
\hline 17 & 201 & & 76 & RN \\
\hline AEMBL & & & 5.2248 & $\mathrm{RI}$ \\
\hline AEMBL: & 30 & & 4.9954 & $\Gamma R$ \\
\hline IEMB & 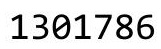 & & & \\
\hline HEMBL & & & & \\
\hline HEMBL & 201 & 39 & 5.1728 & \\
\hline AEMBL & 3901 & & 5.2027 & RN \\
\hline AEMBL & 30 & & 79 & $\mathrm{~F}$ \\
\hline 4 & & & & \\
\hline CHEMBLI & 301 & & 4.9773 & \\
\hline CHEMBLI & 391 & 4.3278 & 4.7662 & \\
\hline CHEMBL1530147 & 130178 & 4.9846 & 5.1073 & \\
\hline
\end{tabular}

Page 20255 
Supplemental Table S2.txt

\begin{tabular}{|c|c|c|c|c|c|}
\hline CHEMBL1368901 & 1301786 & 5.0106 & 5.4288 & TRN & \\
\hline CHEMBL1325203 & 1301786 & 5.4425 & 4.8652 & TRN & \\
\hline CHEMBL1972037 & 1301786 & 6.4547 & 5.8448 & TRN & \\
\hline CHEMBL1537106 & 1301786 & 5.2034 & 5.0638 & TST & \\
\hline CHEMBL1707033 & 1301786 & 5.6126 & 5.2403 & TRN & \\
\hline CHEMBL1604925 & 1301786 & 4.6631 & 4.8649 & TST & \\
\hline CHEMBL1978925 & 1301786 & 5.9547 & 5.5232 & TRN & \\
\hline CHEMBL1409844 & 1301786 & 4.7383 & 4.8134 & TRN & \\
\hline CHEMBL1356373 & 1301786 & 4.4153 & 4.8447 & TRN & \\
\hline CHEMBL 2141749 & 1301786 & 4.582 & 5.0134 & TST & \\
\hline CHEMBL1481417 & 1301786 & 4.481 & 5.1316 & TRN & \\
\hline CHEMBL 2007178 & 1301786 & 6.0964 & 5.4405 & TRN & \\
\hline CHEMBL1496441 & 1301786 & 5.2343 & 5.0866 & TRN & \\
\hline CHEMBL 2358974 & 1301786 & 4.3372 & 5.0047 & TST & \\
\hline CHEMBL66953 & 1301786 & 7.0947 & 6.54799 & & TRN \\
\hline CHEMBL1271266 & 1301786 & 6.3947 & 5.5651 & TRN & \\
\hline CHEMBL1364573 & 1301786 & 5.2204 & 4.9177 & TRN & \\
\hline CHEMBL1464949 & 1301786 & 5.71 & 5.096 & TRN & \\
\hline CHEMBL1874279 & 1301786 & 4.4752 & 5.1245 & TRN & \\
\hline CHEMBL1576766 & 1301786 & 4.9363 & 5.1455 & TRN & \\
\hline CHEMBL1905733 & 1301786 & 4.3745 & 4.5313 & TRN & \\
\hline CHEMBL1370674 & 1301786 & 4.4222 & 5.012 & TRN & \\
\hline CHEMBL1517216 & 1301786 & 6.3635 & 4.9623 & TRN & \\
\hline CHEMBL2356380 & 1301786 & 4.9144 & 4.8144 & TRN & \\
\hline CHEMBL1388036 & 1301786 & 4.5746 & 4.7406 & TRN & \\
\hline CHEMBL1601302 & 1301786 & 4.7249 & 4.6118 & TRN & \\
\hline CHEMBL1484234 & 1301786 & 4.9059 & 5.0276 & TRN & \\
\hline CHEMBL1359190 & 1301786 & 5.0259 & 5.1388 & TRN & \\
\hline CHEMBL1551717 & 1301786 & 4.6457 & 5.0268 & TRN & \\
\hline CHEMBL 3191689 & 1301786 & 6.1255 & 5.2594 & TRN & \\
\hline CHEMBL3193295 & 1301786 & 5.7496 & 4.9555 & TRN & \\
\hline CHEMBL1563939 & 1301786 & 4.7724 & 5.0591 & TST & \\
\hline CHEMBL1507743 & 1301786 & 4.5869 & \multicolumn{2}{|c|}{5.2170000000000005} & TRN \\
\hline CHEMBL2131054 & 1301786 & 5.1959 & 5.2577 & TST & \\
\hline CHEMBL1591913 & 1301786 & 5.0737 & 4.7439 & TRN & \\
\hline CHEMBL1703515 & 1301786 & 5.1512 & 5.3012 & TST & \\
\hline CHEMBL 88811 & 1301786 & 4.6165 & 4.9201 & TRN & \\
\hline CHEMBL1485949 & 1301786 & 4.6055 & 4.8052 & TRN & \\
\hline CHEMBL1312514 & 1301786 & 5.1675 & 5.5037 & TRN & \\
\hline CHEMBL1459258 & 1301786 & 4.4063 & 5.0687 & TST & \\
\hline CHEMBL1407263 & 1301786 & 4.4827 & 4.9779 & TRN & \\
\hline CHEMBL1555216 & 1301786 & 4.6185 & 4.5093 & TRN & \\
\hline CHEMBL1577151 & 1301786 & 4.7206 & 5.1181 & TRN & \\
\hline CHEMBL1500335 & 1301786 & 5.2291 & 4.8471 & TRN & \\
\hline CHEMBL1983033 & 1301786 & 5.9706 & \multicolumn{2}{|c|}{5.0569999999999995} & TST \\
\hline CHEMBL1700270 & 1301786 & 5.6126 & 5.6393 & TRN & \\
\hline CHEMBL1475596 & 1301786 & 5.5171 & 4.9771 & TRN & \\
\hline CHEMBL1310928 & 1301786 & 4.8038 & 4.9771 & TST & \\
\hline
\end{tabular}


Supplemental Table S2.txt

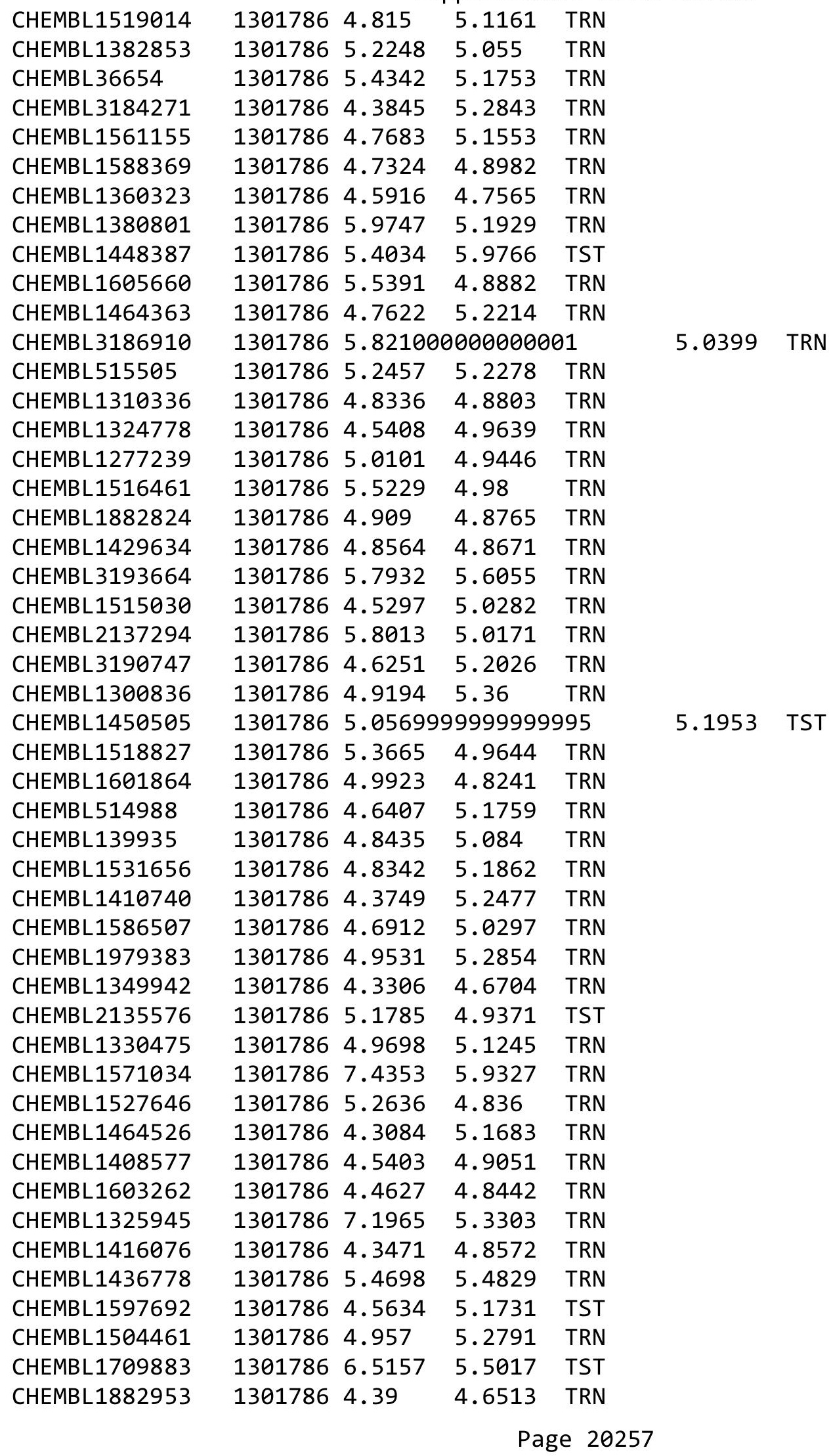


Supplemental Table S2.txt

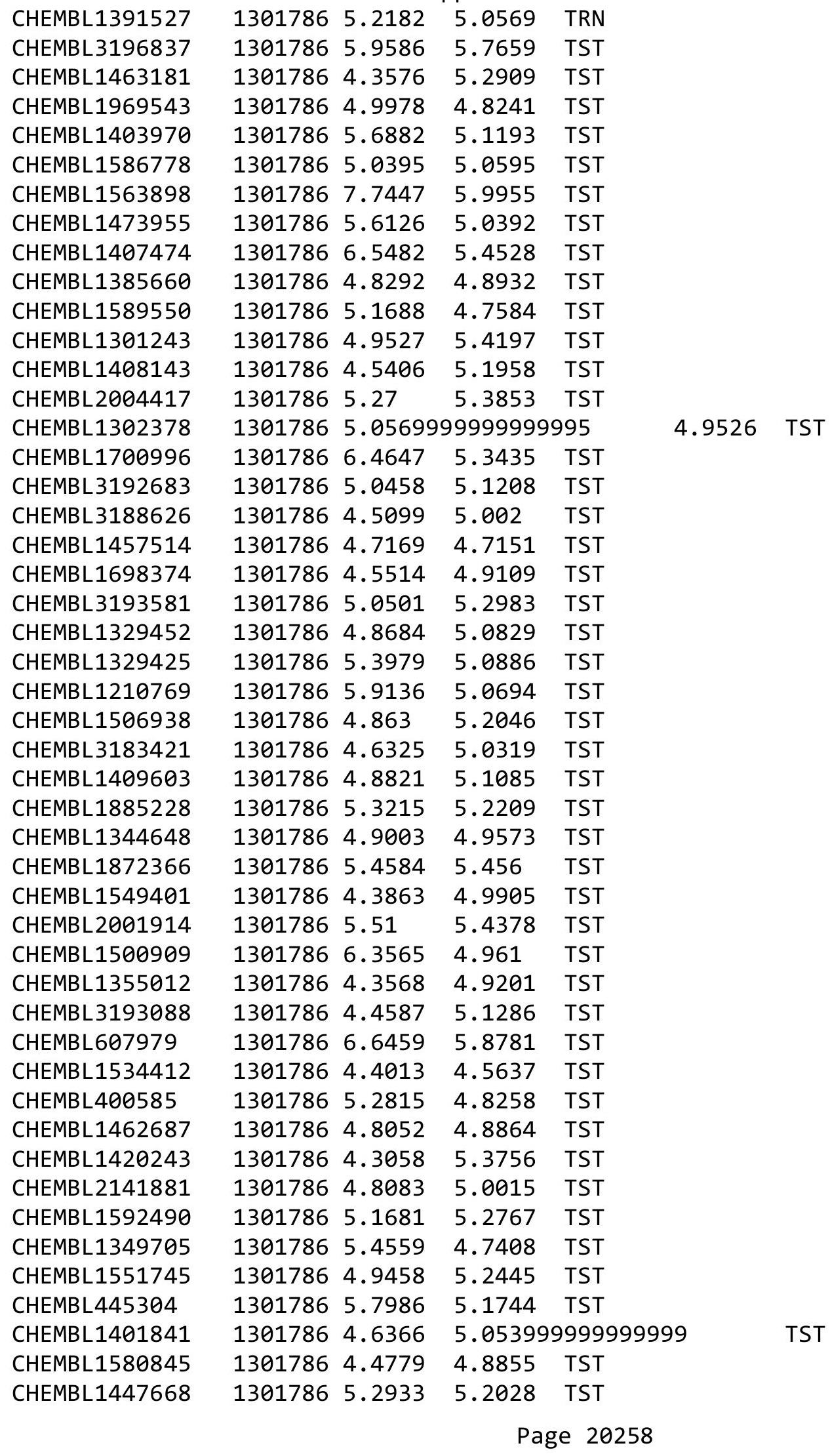


Supplemental Table S2.txt

\begin{tabular}{|c|c|c|c|c|}
\hline CHEMBL1485159 & 1301786 & 5.475 & 5.2026 & TST \\
\hline CHEMBL994 & 1301786 & 5.7212 & 5.3956 & TST \\
\hline CHEMBL1377417 & 1301786 & 4.3148 & 5.24299 & 999999999 \\
\hline CHEMBL366434 & 1301786 & 4.8058 & 5.1356 & TST \\
\hline CHEMBL1347633 & 1301786 & 5.4535 & 5.2167 & TST \\
\hline CHEMBL1512376 & 1301786 & 5.3391 & 4.967 & TST \\
\hline CHEMBL1515663 & 1301786 & 4.7208 & 5.025 & TST \\
\hline CHEMBL1994036 & 688242 & 3.2527 & 3.7685 & TRN \\
\hline CHEMBL1428810 & 688242 & 4.9128 & 4.3063 & TST \\
\hline CHEMBL1333989 & 688242 & 5.0128 & 5.1478 & TRN \\
\hline CHEMBL1596609 & 688242 & 3.2521 & 4.2033 & TRN \\
\hline CHEMBL1363152 & 688242 & 4.6782 & 4.5474 & TRN \\
\hline CHEMBL1414359 & 688242 & 5.1722 & 4.6101 & TRN \\
\hline CHEMBL1587291 & 688242 & 3.2522 & 4.2707 & TRN \\
\hline CHEMBL1371792 & 688242 & 5.8425 & 6.2216 & TRN \\
\hline CHEMBL1503134 & 688242 & 4.2063 & 4.2689 & TST \\
\hline CHEMBL3198810 & 688242 & 4.6588 & 5.2712 & TRN \\
\hline CHEMBL1375130 & 688242 & 4.6744 & 4.5468 & TRN \\
\hline CHEMBL 3189447 & 688242 & 3.7292 & 3.6893 & TRN \\
\hline CHEMBL597857 & 688242 & 4.9644 & 4.6118 & TRN \\
\hline CHEMBL1464398 & 688242 & 5.1551 & 5.6341 & TRN \\
\hline CHEMBL1570108 & 688242 & 4.7968 & 3.7188 & TST \\
\hline CHEMBL1440160 & 688242 & 4.9373 & 3.7884 & TRN \\
\hline CHEMBL1382246 & 688242 & 5.5252 & 4.3861 & TRN \\
\hline CHEMBL1588953 & 688242 & 3.2519 & 4.4443 & TST \\
\hline CHEMBL1607933 & 688242 & 5.3151 & 4.1738 & TRN \\
\hline CHEMBL1483555 & 688242 & 5.5904 & 4.9146 & TRN \\
\hline CHEMBL1332860 & 688242 & 4.5325 & 3.8381 & TRN \\
\hline CHEMBL1491402 & 688242 & 3.2523 & 4.0116 & TRN \\
\hline CHEMBL1557186 & 688242 & 5.0115 & 4.7302 & TRN \\
\hline CHEMBL1420311 & 688242 & 4.8918 & 4.5117 & TRN \\
\hline CHEMBL1408792 & 688242 & 4.6547 & 4.3272 & TRN \\
\hline CHEMBL1451796 & 688242 & 5.3979 & 4.5891 & TRN \\
\hline CHEMBL1410800 & 688242 & 3.2522 & 4.2625 & TST \\
\hline CHEMBL 2000525 & 688242 & 3.2523 & 3.5322 & TRN \\
\hline CHEMBL1388069 & 688242 & 4.2066 & 3.7582 & TRN \\
\hline CHEMBL1366394 & 688242 & 4.7609 & 5.2305 & TRN \\
\hline CHEMBL1538176 & 688242 & 3.2524 & 3.1594 & TRN \\
\hline CHEMBL1424188 & 688242 & 4.3718 & 5.0096 & TRN \\
\hline CHEMBL1522277 & 688242 & 3.2523 & 4.2277 & TRN \\
\hline CHEMBL1310158 & 688242 & 3.2524 & 3.9663 & TRN \\
\hline CHEMBL1437947 & 688242 & 5.0593 & 4.6515 & TRN \\
\hline CHEMBL1408874 & 688242 & 5.0491 & 5.1647 & TRN \\
\hline CHEMBL1333860 & 688242 & 4.6696 & 4.5049 & TRN \\
\hline CHEMBL1608223 & 688242 & 4.5964 & 4.4841 & TRN \\
\hline CHEMBL1363026 & 688242 & 5.3651 & 4.7518 & TRN \\
\hline CHEMBL1488626 & 688242 & 4.7508 & 4.9424 & TRN \\
\hline CHEMBL 2005518 & 688242 & 3.2523 & 3.3479 & TRN \\
\hline
\end{tabular}


Supplemental Table S2.txt

\begin{tabular}{|c|c|c|c|c|}
\hline & & & & \\
\hline CHEMBL1559626 & 88242 & 3.2523 & 3.952 & \\
\hline HEMBL1472879 & 242 & 97 & & \\
\hline 625 & 242 & & & \\
\hline EMBL13 & 3242 & & & \\
\hline IEMBL117121 & 88242 & 2726 & $\partial 8$ & \\
\hline HEMBL1609236 & 88242 & .2522 & 9734 & \\
\hline HEMBL1978101 & 242 & & & \\
\hline IEMBL32 & 242 & & & \\
\hline IEMBL1 & 242 & & & \\
\hline AEMBL1344703 & 88242 & 6537 & 14 & \\
\hline HEMBL1333250 & 88242 & 5.6774 & 98 & \\
\hline HEMBL13 & 12 & 3 & & \\
\hline IEMBL] & 242 & & & \\
\hline AEMBL & 242 & & & \\
\hline AEMBL3: & 88242 & & & \\
\hline HEMBL14 & 242 & & & \\
\hline HEMBL1 & 242 & 4.7 & & \\
\hline AEMBL: & 242 & 41 & & \\
\hline HEMBL: & 242 & & & \\
\hline IEMBL] & 242 & & & \\
\hline AEMBL13 & & & & \\
\hline HEMBLI & 242 & 3.2 & & \\
\hline AEMBL: & 242 & & & \\
\hline 950 & 242 & & & \\
\hline 102 & 242 & & & \\
\hline IEMBL14 & & & & \\
\hline AEMBL1: & 42 & 4. & & \\
\hline EMB & & 3. & & \\
\hline 533 & 42 & & & \\
\hline 256 & & & & $\mathrm{RI}$ \\
\hline AEMBL15 & 242 & 4. & & ST \\
\hline AEMBL & & & & \\
\hline EME & 2 & & & \\
\hline 48 & 42 & & & RIV \\
\hline IEMBL1: & & & & \\
\hline AEMBL1: & 88242 & 3. & & \\
\hline 55 & & & & $\mathrm{RN}$ \\
\hline 29 & & 5 & & \\
\hline 321 & & 12 & & RN \\
\hline AEMBL32 & 8242 & & & \\
\hline AEMBL: & & & & \\
\hline CHEME & & & & \\
\hline HEMBLI & & & & \\
\hline HEMBL 2 & & & & $\mathrm{RI}$ \\
\hline AEMBL3: & 42 & 3.2522 & 581 & \\
\hline HEMBL2 & & 3.2 & 11 & \\
\hline CHEMBL15487 & & & 4.4319 & \\
\hline
\end{tabular}

Page 20260 
Supplemental Table S2.txt

\begin{tabular}{|c|c|c|c|c|c|}
\hline CHEMBL1995565 & 688242 & 4.4178 & 4.1975 & TRN & \\
\hline CHEMBL1538650 & 688242 & 3.2523 & 4.2014 & TRN & \\
\hline CHEMBL1487402 & 688242 & 5.568 & 5.0724 & TRN & \\
\hline CHEMBL3193527 & 688242 & 4.2066 & 3.9706 & TRN & \\
\hline CHEMBL1536626 & 688242 & 4.7922 & 4.8138 & TST & \\
\hline CHEMBL1366556 & 688242 & 4.7243 & 4.3775 & TRN & \\
\hline CHEMBL1364419 & 688242 & 3.2523 & 4.3257 & TRN & \\
\hline CHEMBL1342644 & 688242 & 4.7471 & 4.5865 & TRN & \\
\hline CHEMBL1549566 & 688242 & 4.6776 & 3.9374 & TRN & \\
\hline CHEMBL3189228 & 688242 & 3.2525 & 3.9583 & TRN & \\
\hline CHEMBL1372672 & 688242 & 4.8799 & 4.5774 & TRN & \\
\hline CHEMBL1458192 & 688242 & 4.7177 & 4.6847 & TRN & \\
\hline CHEMBL1526622 & 688242 & 5.2467 & 5.1313 & TRN & \\
\hline CHEMBL1499996 & 688242 & 5.1453 & 4.8306 & TRN & \\
\hline CHEMBL1399939 & 688242 & 4.5132 & 4.39 & TRN & \\
\hline CHEMBL1445779 & 688242 & 3.7297 & 4.5969 & TRN & \\
\hline CHEMBL393287 & 688242 & 3.2523 & 4.2446 & TST & \\
\hline CHEMBL1561847 & 688242 & 5.0538 & 4.474 & TRN & \\
\hline CHEMBL1489113 & 688242 & 3.2523 & 4.3744 & TST & \\
\hline CHEMBL1598813 & 688242 & 4.7313 & 4.5181 & TRN & \\
\hline CHEMBL1377807 & 688242 & 5.0385 & 4.3059 & TST & \\
\hline CHEMBL1329496 & 688242 & 3.2523 & 4.5068 & TST & \\
\hline CHEMBL1510798 & 688242 & 4.2067 & 4.1539 & TST & \\
\hline CHEMBL395808 & 688242 & 4.207 & 3.8516 & TST & \\
\hline CHEMBL1369585 & 688242 & 3.2526 & 4.1569 & TST & \\
\hline CHEMBL1424237 & 688242 & 4.5009 & 4.498 & TST & \\
\hline CHEMBL1533557 & 688242 & 4.2068 & 3.9917 & TST & \\
\hline CHEMBL1375264 & 688242 & 5.0816 & 4.6782 & TST & \\
\hline CHEMBL1425837 & 688242 & 5.3433 & 4.7758 & TST & \\
\hline CHEMBL1388661 & 688242 & 3.2523 & 4.0576 & TST & \\
\hline CHEMBL1306708 & 688242 & 4.9818 & 4.4945 & TST & \\
\hline CHEMBL1546527 & 688242 & 4.5265 & 3.5681 & TST & \\
\hline CHEMBL1390206 & 688242 & 4.9113 & 4.48 & TST & \\
\hline CHEMBL1443120 & 688242 & 4.8548 & 4.3057 & TST & \\
\hline CHEMBL1327785 & 688242 & 3.2524 & 4.6524 & TST & \\
\hline CHEMBL1981990 & 688242 & 4.9036 & 4.3134 & TST & \\
\hline CHEMBL1970896 & 688242 & 3.2523 & 3.9842 & TST & \\
\hline CHEMBL1514082 & 688242 & 3.2525 & 4.8723 & TST & \\
\hline CHEMBL3663387 & 1642540 & 5.9586 & 4.6749 & TST & \\
\hline CHEMBL 3659237 & 1642540 & 7.3979 & 7.1749 & TRN & \\
\hline CHEMBL 3663420 & 1642540 & 6.8477 & 7.0473 & TRN & \\
\hline CHEMBL3659202 & 1642540 & 7.8239 & 8.0913 & TRN & \\
\hline CHEMBL3663402 & 1642540 & 6.6073 & 6.8984 & TRN & \\
\hline CHEMBL3659219 & 1642540 & 6.0114 & 6.1904 & TRN & \\
\hline CHEMBL3663513 & 1642540 & 6.5901 & 5.9837 & TRN & \\
\hline CHEMBL 3663551 & 1642540 & 7.4815 & 7.415 & TRN & \\
\hline CHEMBL3663430 & 1642540 & 7.6383 & 7.4833 & TRN & \\
\hline CHEMBL 3663534 & 1642540 & 5.24799 & 99999999 & 99 & 4.819 \\
\hline
\end{tabular}


Supplemental Table S2.txt

\begin{tabular}{|c|c|c|c|c|}
\hline CHEMBL 3659240 & 1642540 & 6.8633 & 6.8297 & TST \\
\hline CHEMBL3663479 & 1642540 & 5.8239 & 6.3227 & TRN \\
\hline CHEMBL3659216 & 1642540 & 5.4089 & 5.785 & TRN \\
\hline CHEMBL 3663410 & 1642540 & 5.9586 & 5.6749 & TRN \\
\hline CHEMBL3663413 & 1642540 & 8.0 & 7.989 & TRN \\
\hline CHEMBL339286 & 1642540 & 7.8539 & 6.1462 & TST \\
\hline CHEMBL3663398 & 1642540 & 6.2048 & 6.5585 & TST \\
\hline CHEMBL 3663523 & 1642540 & 7.6576 & \multicolumn{2}{|c|}{ 7.718999999999999 } \\
\hline CHEMBL 3659225 & 1642540 & 6.0 & 5.8675 & TRN \\
\hline CHEMBL3663539 & 1642540 & 7.4949 & 7.8502 & TRN \\
\hline CHEMBL 3663531 & 1642540 & 6.3768 & 6.6248 & TRN \\
\hline CHEMBL3663396 & 1642540 & 7.9586 & 8.8255 & TST \\
\hline CHEMBL 3663427 & 1642540 & 6.3979 & 6.6522 & TRN \\
\hline CHEMBL 3663549 & 1642540 & 7.699 & 7.8842 & TRN \\
\hline CHEMBL3663428 & 1642540 & 7.0809 & 6.8227 & TRN \\
\hline CHEMBL3663546 & 1642540 & 6.9747 & 6.8856 & TRN \\
\hline CHEMBL3663559 & 1642540 & 4.0 & 4.1985 & TRN \\
\hline CHEMBL3663519 & 1642540 & 6.2757 & 6.7674 & TRN \\
\hline CHEMBL3663508 & 1642540 & 6.301 & 6.4156 & TRN \\
\hline CHEMBL3659229 & 1642540 & 5.5528 & 5.4554 & TRN \\
\hline CHEMBL3659239 & 1642540 & 5.9208 & 6.1854 & TST \\
\hline CHEMBL3663570 & 1642540 & 7.8861 & 7.6776 & TRN \\
\hline CHEMBL3663419 & 1642540 & 7.2441 & 7.4886 & TRN \\
\hline CHEMBL3663557 & 1642540 & 7.7696 & 7.9934 & TRN \\
\hline CHEMBL 3663395 & 1642540 & 7.3279 & 7.3794 & TST \\
\hline CHEMBL3663507 & 1642540 & 5.5528 & 5.7148 & TRN \\
\hline CHEMBL3663511 & 1642540 & 7.2291 & 7.3015 & TRN \\
\hline CHEMBL3663498 & 1642540 & 7.4815 & 7.2024 & TRN \\
\hline CHEMBL 3659221 & 1642540 & 5.6576 & \multicolumn{2}{|c|}{5.622000000000001} \\
\hline CHEMBL 3663480 & 1642540 & 6.8729 & 6.8722 & TRN \\
\hline CHEMBL 3663484 & 1642540 & 6.2299 & 6.7004 & TRN \\
\hline CHEMBL 3663421 & 1642540 & 7.2076 & 7.1325 & TRN \\
\hline CHEMBL3663552 & 1642540 & 6.3468 & 6.3623 & TRN \\
\hline CHEMBL 3663530 & 1642540 & 7.5376 & 7.5657 & TRN \\
\hline CHEMBL 3663529 & 1642540 & 8.0 & 8.0904 & TRN \\
\hline CHEMBL3659177 & 1642540 & 7.5086 & 7.2247 & TRN \\
\hline CHEMBL 3663572 & 1642540 & 7.8239 & 7.9553 & TRN \\
\hline CHEMBL 3663562 & 1642540 & 7.0605 & 6.6492 & TRN \\
\hline CHEMBL3663544 & 1642540 & 7.8539 & 7.9208 & TRN \\
\hline CHEMBL 3663426 & 1642540 & 6.9281 & 6.8406 & TRN \\
\hline CHEMBL3663405 & 1642540 & 4.0 & 4.3106 & TRN \\
\hline CHEMBL3663461 & 1642540 & 5.5331 & 6.888 & TST \\
\hline CHEMBL3663558 & 1642540 & 4.0 & 6.7308 & TST \\
\hline CHEMBL3663547 & 1642540 & 7.3565 & 7.4812 & TRN \\
\hline CHEMBL3659242 & 1642540 & 6.4449 & 6.8787 & TST \\
\hline CHEMBL3663505 & 1642540 & 6.9586 & 6.767 & TRN \\
\hline CHEMBL 3663490 & 1642540 & 7.2291 & 7.0163 & TRN \\
\hline CHEMBL3659236 & 1642540 & 7.5686 & 7.3117 & TRN \\
\hline
\end{tabular}

Page 20262 
Supplemental Table S2.txt

\begin{tabular}{|c|c|c|c|c|}
\hline CHEMBL 3663406 & 1642540 & 5.8239 & 5.6003 & TRN \\
\hline CHEMBL3663496 & 1642540 & 6.1192 & 5.6052 & TRN \\
\hline CHEMBL3663417 & 1642540 & 5.4685 & 5.6904 & TRN \\
\hline CHEMBL 3663383 & 1642540 & 4.0 & 5.5024 & TST \\
\hline CHEMBL3663463 & 1642540 & 5.0605 & 5.937 & TST \\
\hline CHEMBL3962823 & 1642540 & 7.699 & 7.3823 & TRN \\
\hline CHEMBL3659224 & 1642540 & 4.0 & 3.9761 & TRN \\
\hline CHEMBL 3663401 & 1642540 & 6.7696 & 6.8621 & TRN \\
\hline CHEMBL 3663550 & 1642540 & 8.301 & 8.4447 & TRN \\
\hline CHEMBL3659180 & 1642540 & 6.0 & 6.3643 & TRN \\
\hline CHEMBL129596 & 1642540 & 4.0 & 4.9195 & TST \\
\hline CHEMBL3659235 & 1642540 & 7.3188 & 7.5277 & TRN \\
\hline CHEMBL 3663397 & 1642540 & 5.5229 & 5.6426 & TRN \\
\hline CHEMBL3663571 & 1642540 & 7.6778 & 7.8399 & TRN \\
\hline CHEMBL3663485 & 1642540 & 6.5901 & 6.5114 & TRN \\
\hline CHEMBL3663521 & 1642540 & 4.0 & 4.2023 & TRN \\
\hline CHEMBL3931862 & 1642540 & 4.0 & 3.8565 & TRN \\
\hline CHEMBL 3663408 & 1642540 & 6.1871 & 6.2011 & TRN \\
\hline CHEMBL3663506 & 1642540 & 6.1343 & 6.1674 & TRN \\
\hline CHEMBL3663422 & 1642540 & 6.3565 & 5.6035 & TRN \\
\hline CHEMBL3663487 & 1642540 & 5.5376 & 5.1888 & TRN \\
\hline CHEMBL3659223 & 1642540 & 6.9245 & 7.0927 & TRN \\
\hline CHEMBL3663509 & 1642540 & 5.7696 & 5.7857 & TRN \\
\hline CHEMBL 3663385 & 1642540 & 6.3788 & 6.76399 & 9999999999 \\
\hline CHEMBL 3663489 & 1642540 & 7.2441 & 7.2607 & TRN \\
\hline CHEMBL 3663425 & 1642540 & 7.1079 & 6.9528 & TRN \\
\hline CHEMBL3663465 & 1642540 & 5.0706 & 6.07 & TST \\
\hline CHEMBL 3663567 & 1642540 & 7.5376 & 7.4284 & TRN \\
\hline CHEMBL3663503 & 1642540 & 5.9586 & 6.0355 & TRN \\
\hline CHEMBL 3663392 & 1642540 & 4.0 & 4.1155 & TRN \\
\hline CHEMBL 3663473 & 1642540 & 5.6021 & 5.6707 & TRN \\
\hline CHEMBL3663399 & 1642540 & 7.699 & 7.6565 & TST \\
\hline CHEMBL 3663524 & 1642540 & 6.3979 & 6.3891 & TRN \\
\hline CHEMBL3663536 & 1642540 & 7.3468 & 7.6094 & TRN \\
\hline CHEMBL 3663477 & 1642540 & 7.3279 & 7.2289 & TRN \\
\hline CHEMBL 3663545 & 1642540 & 4.0 & 4.0396 & TRN \\
\hline CHEMBL3663502 & 1642540 & 7.585 & 7.5295 & TRN \\
\hline CHEMBL 3659232 & 1642540 & 7.7447 & 7.5281 & TRN \\
\hline CHEMBL3659231 & 1642540 & 7.6021 & 7.1917 & TRN \\
\hline CHEMBL 3663414 & 1642540 & 7.5376 & 6.9906 & TST \\
\hline CHEMBL3663409 & 1642540 & 5.7696 & 5.6157 & TRN \\
\hline CHEMBL 3663540 & 1642540 & 7.0757 & 7.3248 & TRN \\
\hline CHEMBL3663400 & 1642540 & 7.3979 & 7.4719 & TRN \\
\hline CHEMBL3659176 & 1642540 & 7.6021 & 7.8693 & TRN \\
\hline CHEMBL 3659243 & 1642540 & 7.7447 & 8.3072 & TST \\
\hline CHEMBL 3663474 & 1642540 & 6.2716 & 6.2837 & TRN \\
\hline CHEMBL3663566 & 1642540 & 7.8539 & 7.9443 & TRN \\
\hline CHEMBL 3663564 & 1642540 & 7.6778 & 7.5659 & TRN \\
\hline
\end{tabular}

Page 20263 
Supplemental Table S2.txt

\begin{tabular}{|c|c|c|c|c|c|}
\hline CHEMBL3663538 & 1642540 & 7.6383 & 7.5749 & TRN & \\
\hline CHEMBL3659238 & 1642540 & 7.0555 & 7.0904 & TRN & \\
\hline CHEMBL3663528 & 1642540 & 7.1308 & 7.1848 & TST & \\
\hline CHEMBL3659241 & 1642540 & 6.556 & 6.7509 & TRN & \\
\hline CHEMBL3659233 & 1642540 & 5.8416 & 5.8813 & TRN & \\
\hline CHEMBL3663537 & 1642540 & 6.8097 & 6.7038 & TRN & \\
\hline CHEMBL3663515 & 1642540 & 6.7645 & 6.8605 & TRN & \\
\hline CHEMBL3663429 & 1642540 & 7.3279 & 7.2546 & TRN & \\
\hline CHEMBL3663533 & 1642540 & 7.2441 & 7.0649 & TRN & \\
\hline CHEMBL3663569 & 1642540 & 7.0269 & 7.0814 & TRN & \\
\hline CHEMBL3663391 & 1642540 & 5.585 & 5.7223 & TST & \\
\hline CHEMBL3663464 & 1642540 & 6.3206 & 7.3683 & TST & \\
\hline CHEMBL3663390 & 1642540 & 6.0 & 7.6114 & TST & \\
\hline CHEMBL3663542 & 1642540 & 7.3768 & 7.572 & TRN & \\
\hline CHEMBL3663561 & 1642540 & 6.3401 & 6.4625 & TRN & \\
\hline CHEMBL3663526 & 1642540 & 7.5086 & 7.5388 & TRN & \\
\hline CHEMBL3663407 & 1642540 & 6.0223 & 5.9168 & TRN & \\
\hline CHEMBL3663388 & 1642540 & 6.0381 & 6.1807 & TST & \\
\hline CHEMBL3659234 & 1642540 & 6.7055 & 6.809 & TRN & \\
\hline CHEMBL3663394 & 1642540 & 5.3768 & 5.4827 & TRN & \\
\hline CHEMBL3663541 & 1642540 & 7.0706 & 6.9672 & TRN & \\
\hline CHEMBL3663411 & 1642540 & 6.5229 & 6.92 & TRN & \\
\hline CHEMBL3659220 & 1642540 & 6.4559 & 6.5537 & TRN & \\
\hline CHEMBL3659204 & 1642540 & 7.1612 & 7.1023 & TRN & \\
\hline CHEMBL3663481 & 1642540 & 7.0915 & 6.8668 & TRN & \\
\hline CHEMBL3663415 & 1642540 & 7.2676 & 7.0362 & TRN & \\
\hline CHEMBL3663389 & 1642540 & 4.0 & 5.6147 & TST & \\
\hline CHEMBL3663574 & 1642540 & 7.6383 & 7.5457 & TRN & \\
\hline CHEMBL3663403 & 1642540 & 7.1549 & 7.2263 & TRN & \\
\hline CHEMBL3663424 & 1642540 & 7.8239 & 7.7331 & TRN & \\
\hline CHEMBL3663478 & 1642540 & 6.7235 & 6.1 & TRN & \\
\hline CHEMBL3663416 & 1642540 & 6.3188 & 6.3132 & TRN & \\
\hline CHEMBL3663525 & 1642540 & 6.8729 & 6.7941 & TRN & \\
\hline CHEMBL3663466 & 1642540 & 6.8239 & 7.8539 & TST & \\
\hline CHEMBL3659228 & 1642540 & 5.1079 & 5.2803 & TRN & \\
\hline CHEMBL3659217 & 1642540 & 7.0915 & 7.584 & TRN & \\
\hline CHEMBL3659230 & 1642540 & 7.1308 & 6.987999 & 99999999995 & TRN \\
\hline CHEMBL3663482 & 1642540 & 6.5302 & 6.3203 & TRN & \\
\hline CHEMBL3663554 & 1642540 & 6.4881 & 6.8734 & TST & \\
\hline CHEMBL3663460 & 1642540 & 7.0269 & 7.4263 & TST & \\
\hline CHEMBL3663475 & 1642540 & 6.0159 & 5.7938 & TST & \\
\hline CHEMBL3663520 & 1642540 & 4.0 & 4.757 & TRN & \\
\hline CHEMBL3663497 & 1642540 & 4.0 & 4.6742 & TRN & \\
\hline CHEMBL3659218 & 1642540 & 6.3372 & 6.3435 & TST & \\
\hline CHEMBL3663535 & 1642540 & 6.284 & 6.6414 & TST & \\
\hline CHEMBL3663483 & 1642540 & 6.1158 & 6.3257 & TRN & \\
\hline CHEMBL3663548 & 1642540 & 5.8539 & 5.8178 & TRN & \\
\hline CHEMBL3659222 & 1642540 & 5.4559 & 6.4147 & TST & \\
\hline
\end{tabular}


Supplemental Table S2.txt

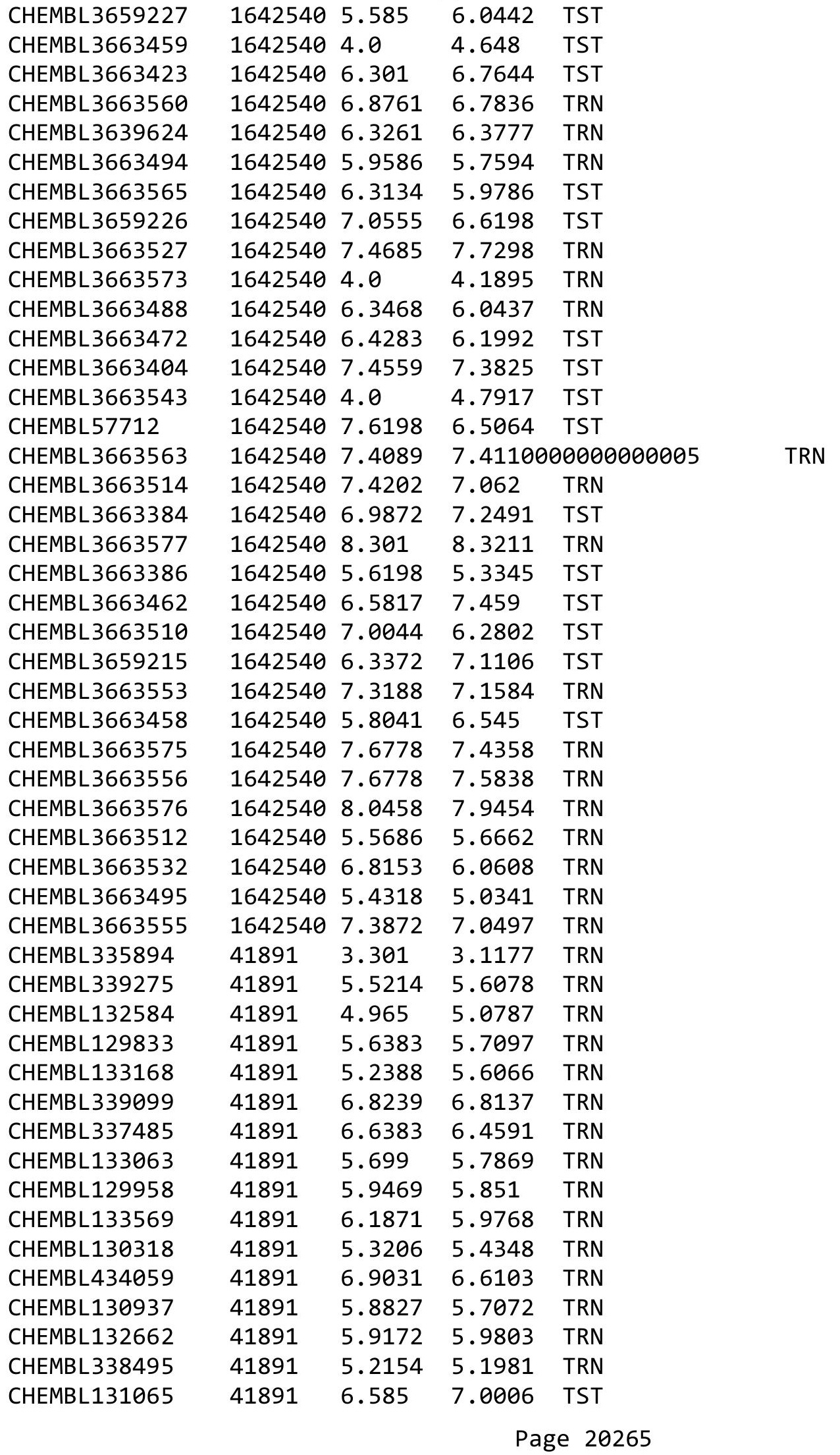




\begin{tabular}{|c|c|c|c|c|c|}
\hline \multicolumn{6}{|c|}{ Supplemental Table S2.txt } \\
\hline CHEMBL336399 & 41891 & 5.7696 & 5.8542 & TRN & \\
\hline CHEMBL130608 & 41891 & 6.4685 & 6.3225 & TRN & \\
\hline CHEMBL130598 & 41891 & 6.301 & 5.9226 & TRN & \\
\hline CHEMBL130065 & 41891 & 4.8996 & 5.2533 & TRN & \\
\hline CHEMBL133111 & 41891 & 5.4112 & 5.6105 & TRN & \\
\hline CHEMBL336143 & 41891 & 4.5686 & 4.5453 & TRN & \\
\hline CHEMBL131493 & 41891 & 4.8962 & 4.9978 & TRN & \\
\hline CHEMBL130467 & 41891 & 6.4685 & 6.6623 & TRN & \\
\hline CHEMBL130947 & 41891 & 6.4318 & 5.9552 & TRN & \\
\hline CHEMBL133748 & 41891 & 5.8962 & 5.8558 & TRN & \\
\hline CHEMBL134072 & 41891 & 7.0458 & 6.8277 & TRN & \\
\hline CHEMBL134230 & 41891 & 5.7852 & 5.9523 & TRN & \\
\hline CHEMBL338782 & 41891 & 3.301 & 4.6878 & TST & \\
\hline CHEMBL133839 & 41891 & 6.9586 & 7.0672 & TRN & \\
\hline CHEMBL339842 & 41891 & 5.8297 & 6.546 & TST & \\
\hline CHEMBL130724 & 41891 & 5.9245 & 6.3567 & TRN & \\
\hline CHEMBL129881 & 41891 & 6.5528 & 6.4238 & TRN & \\
\hline CHEMBL334766 & 41891 & 6.6576 & 6.4983 & TRN & \\
\hline CHEMBL133075 & 41891 & 7.0177 & 6.7587 & TST & \\
\hline CHEMBL336421 & 41891 & 6.1135 & 6.9122 & TST & \\
\hline CHEMBL340450 & 41891 & 6.3872 & 6.3393 & TRN & \\
\hline CHEMBL339670 & 41891 & 6.5229 & 6.74 & TST & \\
\hline CHEMBL340072 & 41891 & 4.9101 & 4.8096 & TRN & \\
\hline CHEMBL132664 & 41891 & 6.6383 & 6.4553 & TRN & \\
\hline CHEMBL424638 & 41891 & 7.2518 & 7.3615 & TRN & \\
\hline CHEMBL130936 & 41891 & 6.4089 & 6.5315 & TRN & \\
\hline CHEMBL128640 & 41891 & 5.9914 & 4.8593 & TST & \\
\hline CHEMBL339851 & 41891 & 6.7696 & 6.9842 & TRN & \\
\hline CHEMBL130008 & 41891 & 7.0044 & 6.934 & TRN & \\
\hline CHEMBL132725 & 41891 & 5.8665 & 6.0114 & TRN & \\
\hline CHEMBL130403 & 41891 & 6.9208 & 6.9427 & TST & \\
\hline CHEMBL337857 & 41891 & 5.0655 & 5.5052 & TST & \\
\hline CHEMBL337720 & 41891 & 6.1938 & 5.8551 & TST & \\
\hline CHEMBL 335378 & 41891 & 5.9788 & 6.3397 & TST & \\
\hline CHEMBL131885 & 41891 & 5.6576 & 5.9078 & TST & \\
\hline CHEMBL132719 & 41891 & 3.301 & 4.4413 & TST & \\
\hline CHEMBL131087 & 41891 & 5.9872 & 5.5068 & TST & \\
\hline CHEMBL3657903 & 1528911 & 7.0969 & 7.0254 & TRN & \\
\hline CHEMBL 3654178 & 1528911 & 5.0 & 6.5868 & TST & \\
\hline CHEMBL 3657831 & 1528911 & 8.0458 & 7.36600 & 00000000005 & TST \\
\hline CHEMBL3657913 & 1528911 & 6.6383 & 6.1799 & TST & \\
\hline CHEMBL3662176 & 1528911 & 8.1549 & 7.9789 & TRN & \\
\hline CHEMBL3657953 & 1528911 & 8.5229 & 7.6706 & TRN & \\
\hline CHEMBL 3657927 & 1528911 & 6.5229 & 6.4492 & TRN & \\
\hline CHEMBL3657966 & 1528911 & 7.9208 & 7.0837 & TRN & \\
\hline CHEMBL3657939 & 1528911 & 8.301 & 7.7576 & TRN & \\
\hline CHEMBL3657855 & 1528911 & 8.699 & 8.8891 & TRN & \\
\hline CHEMBL3654181 & 1528911 & 5.0 & 4.6683 & TRN & \\
\hline
\end{tabular}


Supplemental Table S2.txt

\begin{tabular}{|c|c|c|c|c|}
\hline HEM & 528911 & 7.3665 & & \\
\hline HEMBL3662097 & 528911 & 7.7212 & 7.5985 & \\
\hline 67 & & 7447 & & \\
\hline AEMBL & 28911 & 8539 & 57 & $\mathrm{MI}$ \\
\hline AEMBL3662145 & 528911 & 3665 & 4813 & \\
\hline HEMBL3928384 & 528911 & 6.0 & . 1627 & \\
\hline 79 & 528911 & 172 & & \\
\hline 96 & 528911 & & & \\
\hline AEMBL3 & 528911 & 959 & 8404 & \\
\hline HEMBL366 & 528911 & 969 & .5252 & \\
\hline AEMBL 365 & 528911 & 5021 & .8984 & \\
\hline IEMBL: & 528911 & 12 & 814 & \\
\hline AEMBL & & & & \\
\hline HEMBL3 & 528911 & 586 & 6268 & \\
\hline AEMBL3 & 911 & & 7073 & \\
\hline IEMBL365 & 528911 & & .8499 & \\
\hline HEMBL & 911 & 76 & 45 & . \\
\hline HEMBL & & & & \\
\hline HEMBL3 & 528911 & & & \\
\hline AEMBL3 & 11 & & & \\
\hline AEMIBL & 5285 & 32 & 46 & וב \\
\hline AEMBL & L & & & RN \\
\hline HEMBL & 11 & 218 & 79 & \\
\hline HEMBL & 911 & & & \\
\hline AEMBL3 & & & & I RIV \\
\hline HEMBL; & 1 & & 124 & KIV \\
\hline AEMBL & 11 & & & ST \\
\hline HFMRI & 11 & & 62 & RN \\
\hline HEMBL3 & & & & I \\
\hline HEMBL 365 & 528911 & & & IK \\
\hline HEMBL3 & 3911 & & 7329 & ST \\
\hline HEMBL & 11 & & 45 & RN \\
\hline HEMBL & 11 & 76 & 7.5395 & RN \\
\hline HEMBL 3657 & 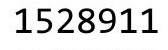 & & 615 & IRN \\
\hline HEMBL3662202 & 528911 & & .2874 & TRN \\
\hline HEMBL & 3911 & & 489 & TRN \\
\hline HCMDI & & & $\partial 8$ & ST \\
\hline HEMBL & & & 319 & IRN \\
\hline HEMBL3662230 & 528911 & & 7.5548 & TRN \\
\hline IEMBL: & 528911 & 32 & 3684 & TST \\
\hline HEMBL3 & 528911 & & .0332 & n \\
\hline EHEMBL3 & 1528911 & & 7.9591 & RN \\
\hline HEMBL3 & 528911 & 805 & 7.0404 & RN \\
\hline AEMBL3657905 & 528911 & 475 & 6.7244 & ГST \\
\hline$M B L 3$ & $=208$ & & 7 & TST \\
\hline HEMBL3 & & r & 5.8785 & \\
\hline HEMBL365 & 528911 & & 8.6907 & \\
\hline LHEMBL 3658001 & 1528911 & 30 & 8.1708 & . \\
\hline
\end{tabular}

Page 20267 
Supplemental Table S2.txt

\begin{tabular}{|c|c|c|c|c|}
\hline CHEMBL3662158 & 1528911 & 7.3565 & 7.3029 & TRN \\
\hline CHEMBL 3662218 & 1528911 & 8.699 & 8.3661 & TRN \\
\hline CHEMBL3959871 & 1528911 & 6.0 & 5.8709 & TST \\
\hline CHEMBL 3657847 & 1528911 & 6.3188 & 5.9964 & TRN \\
\hline CHEMBL 3662134 & 1528911 & 6.7212 & 6.3389 & TRN \\
\hline CHEMBL3639567 & 1528911 & 6.0531 & 6.0455 & TRN \\
\hline CHEMBL3657988 & 1528911 & 7.9208 & 8.1669 & TRN \\
\hline CHEMBL3658009 & 1528911 & 7.3372 & 7.5573 & TRN \\
\hline CHEMBL3657906 & 1528911 & 5.8794 & 7.12299 & 99 \\
\hline CHEMBL3662129 & 1528911 & 6.0 & 6.7231 & TRN \\
\hline CHEMBL3662190 & 1528911 & 8.5229 & 9.2077 & TRN \\
\hline CHEMBL 3924008 & 1528911 & 6.0 & 6.8499 & TRN \\
\hline CHEMBL 3658011 & 1528911 & 7.5229 & 7.8884 & TRN \\
\hline CHEMBL3662228 & 1528911 & 6.0 & 6.8857 & TRN \\
\hline CHEMBL 3657944 & 1528911 & 5.7852 & 6.5465 & TST \\
\hline CHEMBL3657892 & 1528911 & 6.1726 & 6.2949 & TRN \\
\hline CHEMBL3654179 & 1528911 & 5.0 & 6.431 & TST \\
\hline CHEMBL 3657874 & 1528911 & 6.9747 & 6.9567 & TST \\
\hline CHEMBL3657841 & 1528911 & 7.5376 & 7.4807 & TRN \\
\hline CHEMBL3911051 & 1528911 & 6.6498 & 7.3178 & TST \\
\hline CHEMBL3662136 & 1528911 & 7.6198 & 8.0449 & TRN \\
\hline CHEMBL3657984 & 1528911 & 6.2676 & 6.0526 & TRN \\
\hline CHEMBL3657899 & 1528911 & 7.7696 & 7.9316 & TRN \\
\hline CHEMBL3657862 & 1528911 & 6.4318 & 7.0274 & TST \\
\hline CHEMBL3662073 & 1528911 & 6.8861 & 7.1722 & TRN \\
\hline CHEMBL 3657971 & 1528911 & 8.5086 & 8.6913 & TRN \\
\hline CHEMBL3657910 & 1528911 & 7.0315 & 7.3259 & TRN \\
\hline CHEMBL 3942782 & 1528911 & 8.3979 & 8.1137 & TRN \\
\hline CHEMBL3657887 & 1528911 & 7.2924 & 7.5042 & TRN \\
\hline CHEMBL3658012 & 1528911 & 7.4437 & 7.4145 & TRN \\
\hline CHEMBL3657830 & 1528911 & 6.2197 & 6.3205 & TRN \\
\hline CHEMBL3662152 & 1528911 & 7.8239 & 7.3835 & TRN \\
\hline CHEMBL3662166 & 1528911 & 8.3979 & 8.2745 & TRN \\
\hline CHEMBL3657835 & 1528911 & 8.301 & 8.0005 & TST \\
\hline CHEMBL3662098 & 1528911 & 7.585 & 7.6801 & TRN \\
\hline CHEMBL3662126 & 1528911 & 6.0 & 6.1789 & TRN \\
\hline CHEMBL 3662147 & 1528911 & 6.5086 & 6.524 & TRN \\
\hline CHEMBL3657876 & 1528911 & 7.7959 & 6.8394 & TST \\
\hline CHEMBL 3658002 & 1528911 & 8.5229 & 8.4652 & TRN \\
\hline CHEMBL3657951 & 1528911 & 7.9208 & 7.9112 & TRN \\
\hline CHEMBL 3662198 & 1528911 & 8.2218 & 7.6079 & TRN \\
\hline CHEMBL 3657918 & 1528911 & 6.8601 & 6.5733 & TRN \\
\hline CHEMBL3657867 & 1528911 & 6.7212 & 6.6622 & TST \\
\hline CHEMBL3662120 & 1528911 & 7.0757 & 7.2063 & TRN \\
\hline CHEMBL3662168 & 1528911 & 8.2007 & 7.5231 & TRN \\
\hline CHEMBL3658018 & 1528911 & 7.1739 & 7.4435 & TRN \\
\hline CHEMBL3657931 & 1528911 & 8.0 & 7.4336 & TRN \\
\hline CHEMBL3658016 & 1528911 & 8.5229 & 8.0742 & TRN \\
\hline
\end{tabular}

Page 20268 
Supplemental Table S2.txt

\begin{tabular}{|c|c|c|c|c|}
\hline CHEMBL3657943 & 1528911 & 8.0 & 8.0842 & TRN \\
\hline CHEMBL3662092 & 1528911 & 7.3098 & 7.3009 & TRN \\
\hline CHEMBL3658015 & 1528911 & 7.5229 & 7.0262 & TRN \\
\hline CHEMBL3657865 & 1528911 & 7.2596 & 6.7466 & TRN \\
\hline CHEMBL3639609 & 1528911 & 7.3279 & 7.551 & TRN \\
\hline CHEMBL3657886 & 1528911 & 6.7852 & 7.1984 & TST \\
\hline CHEMBL3657979 & 1528911 & 7.8539 & 7.6901 & TRN \\
\hline CHEMBL 3662229 & 1528911 & 8.7959 & 8.8175 & TRN \\
\hline CHEMBL3662208 & 1528911 & 8.301 & 7.6717 & TRN \\
\hline CHEMBL3662164 & 1528911 & 7.9208 & 8.0069 & TRN \\
\hline CHEMBL3657909 & 1528911 & 7.2441 & 7.0135 & TRN \\
\hline CHEMBL3662169 & 1528911 & 6.0 & 6.7611 & TRN \\
\hline CHEMBL3662090 & 1528911 & 8.5229 & 8.9047 & TRN \\
\hline CHEMBL3657928 & 1528911 & 6.7799 & 7.0242 & TRN \\
\hline CHEMBL 3662170 & 1528911 & 8.3979 & 7.8988 & TRN \\
\hline CHEMBL3657997 & 1528911 & 7.3665 & 7.1594 & TRN \\
\hline CHEMBL3657969 & 1528911 & 6.0555 & 6.3098 & TRN \\
\hline CHEMBL 3657853 & 1528911 & 7.2366 & 7.3084 & TRN \\
\hline CHEMBL3657973 & 1528911 & 8.301 & 8.2212 & TRN \\
\hline CHEMBL 3657807 & 1528911 & 7.5376 & 7.62200 & 0000000001 \\
\hline CHEMBL3662237 & 1528911 & 6.6289 & 6.5713 & TRN \\
\hline CHEMBL3662116 & 1528911 & 5.8861 & 5.5646 & TRN \\
\hline CHEMBL3657934 & 1528911 & 9.0 & 8.3743 & TRN \\
\hline CHEMBL3657821 & 1528911 & 5.0 & 6.0221 & TST \\
\hline CHEMBL 3657825 & 1528911 & 6.8539 & 6.5466 & TRN \\
\hline CHEMBL3662119 & 1528911 & 8.2218 & 7.6962 & TRN \\
\hline CHEMBL3662122 & 1528911 & 6.0 & 7.186 & TRN \\
\hline CHEMBL3662130 & 1528911 & 7.7696 & 7.8873 & TST \\
\hline CHEMBL3662144 & 1528911 & 6.9586 & 6.959 & TRN \\
\hline CHEMBL3657999 & 1528911 & 8.0 & 7.0394 & TST \\
\hline CHEMBL 3662227 & 1528911 & 8.0 & 8.019 & TRN \\
\hline CHEMBL3657915 & 1528911 & 6.4698 & 6.1936 & TRN \\
\hline CHEMBL3657900 & 1528911 & 7.0655 & 7.0606 & TST \\
\hline CHEMBL3657861 & 1528911 & 7.6778 & 7.5399 & TRN \\
\hline CHEMBL 3657885 & 1528911 & 7.7696 & 7.7968 & TRN \\
\hline CHEMBL3662072 & 1528911 & 8.3979 & 7.9783 & TRN \\
\hline CHEMBL3935463 & 1528911 & 6.0 & 6.6963 & TRN \\
\hline CHEMBL3658006 & 1528911 & 7.0 & 7.1783 & TRN \\
\hline CHEMBL3662140 & 1528911 & 8.3979 & 8.2058 & TRN \\
\hline CHEMBL 3658017 & 1528911 & 7.4559 & 7.7873 & TRN \\
\hline CHEMBL3662173 & 1528911 & 6.7167 & 7.1134 & TST \\
\hline CHEMBL3657938 & 1528911 & 8.3979 & 8.7582 & TRN \\
\hline CHEMBL3657852 & 1528911 & 7.2924 & 6.96299 & 9999999999 \\
\hline CHEMBL3657902 & 1528911 & 6.9318 & 7.3401 & TST \\
\hline CHEMBL3657992 & 1528911 & 8.699 & 9.0188 & TRN \\
\hline CHEMBL 3662235 & 1528911 & 6.0 & 6.8436 & TRN \\
\hline CHEMBL 3662075 & 1528911 & 7.0 & 7.0231 & TRN \\
\hline CHEMBL 3658014 & 1528911 & 8.301 & 8.1768 & TRN \\
\hline
\end{tabular}


Supplemental Table S2.txt

\begin{tabular}{|c|c|c|c|c|c|}
\hline CHEMBL 3662197 & 1528911 & 7.4949 & 7.6843 & TRN & \\
\hline CHEMBL3657932 & 1528911 & 9.0 & 9.1458 & TRN & \\
\hline CHEMBL3662094 & 1528911 & 6.5376 & 6.9504 & TST & \\
\hline CHEMBL 3657925 & 1528911 & 6.5513 & 6.7683 & TRN & \\
\hline CHEMBL 3662125 & 1528911 & 7.7212 & 8.0223 & TRN & \\
\hline CHEMBL 3662128 & 1528911 & 8.3979 & 8.1436 & TRN & \\
\hline CHEMBL 3657964 & 1528911 & 6.0506 & 6.48 & TRN & \\
\hline CHEMBL3662191 & 1528911 & 8.5229 & 8.5892 & TRN & \\
\hline CHEMBL 3890625 & 1528911 & 7.8539 & 7.2997 & TRN & \\
\hline CHEMBL 3657985 & 1528911 & 7.9208 & 8.1624 & TRN & \\
\hline CHEMBL 3657970 & 1528911 & 6.5086 & 6.6352 & TRN & \\
\hline CHEMBL 3657858 & 1528911 & 6.8861 & 7.1186 & TRN & \\
\hline CHEMBL3662091 & 1528911 & 6.8861 & 6.6545 & TRN & \\
\hline CHEMBL 3662093 & 1528911 & 8.2218 & 8.1409 & TRN & \\
\hline CHEMBL 3662151 & 1528911 & 8.0969 & 8.0371 & TRN & \\
\hline CHEMBL 3662225 & 1528911 & 7.5528 & 7.7838 & TRN & \\
\hline CHEMBL3658019 & 1528911 & 7.699 & 7.9624 & TRN & \\
\hline CHEMBL 3657854 & 1528911 & 8.6778 & 8.2595 & TRN & \\
\hline CHEMBL 3657864 & 1528911 & 6.7212 & 7.5008 & TST & \\
\hline CHEMBL 3657981 & 1528911 & 8.301 & 8.2668 & TRN & \\
\hline CHEMBL 3662165 & 1528911 & 8.1549 & 7.71899 & 9999999999 & TRN \\
\hline CHEMBL 3662205 & 1528911 & 8.3979 & 7.9315 & TRN & \\
\hline CHEMBL 3657987 & 1528911 & 6.7959 & 6.5231 & TRN & \\
\hline CHEMBL 3657889 & 1528911 & 6.2534 & 6.7516 & TRN & \\
\hline CHEMBL 3662177 & 1528911 & 8.3979 & 8.7846 & TRN & \\
\hline CHEMBL 3662148 & 1528911 & 7.6778 & 7.7747 & TRN & \\
\hline CHEMBL 3662149 & 1528911 & 7.6383 & 7.7343 & TRN & \\
\hline CHEMBL 3658005 & 1528911 & 8.0458 & 7.7787 & TRN & \\
\hline CHEMBL 3657833 & 1528911 & 7.3565 & 6.8436 & TRN & \\
\hline CHEMBL3657958 & 1528911 & 7.301 & 7.2883 & TRN & \\
\hline CHEMBL 3657888 & 1528911 & 6.4179 & 6.5694 & TRN & \\
\hline CHEMBL 3662080 & 1528911 & 8.301 & 8.3326 & TRN & \\
\hline CHEMBL 3657922 & 1528911 & 6.6778 & 6.1936 & TRN & \\
\hline CHEMBL 3658008 & 1528911 & 7.2218 & 7.5156 & TRN & \\
\hline CHEMBL3662105 & 1528911 & 6.9208 & 7.0862 & TRN & \\
\hline CHEMBL3657982 & 1528911 & 6.0 & 6.7024 & TRN & \\
\hline CHEMBL 3662163 & 1528911 & 7.7959 & 7.879 & TRN & \\
\hline CHEMBL 3657840 & 1528911 & 8.5229 & 8.11399 & 9999999999 & TRN \\
\hline CHEMBL3657933 & 1528911 & 6.4522 & 6.7723 & TRN & \\
\hline CHEMBL 3662131 & 1528911 & 6.4318 & 6.4814 & TRN & \\
\hline CHEMBL3657916 & 1528911 & 6.0 & 6.1064 & TRN & \\
\hline CHEMBL 3662216 & 1528911 & 7.9586 & 7.6474 & TRN & \\
\hline CHEMBL 3657941 & 1528911 & 7.9208 & 7.5375 & TRN & \\
\hline CHEMBL 3657881 & 1528911 & 5.9172 & 6.7959 & TST & \\
\hline CHEMBL 3662214 & 1528911 & 8.3979 & 8.2962 & TRN & \\
\hline CHEMBL 3658007 & 1528911 & 7.5229 & 7.3 & TRN & \\
\hline CHEMBL 3657919 & 1528911 & 6.9031 & 7.2021 & TRN & \\
\hline CHEMBL 3654177 & 1528911 & 5.1637 & 5.6319 & TRN & \\
\hline
\end{tabular}




\begin{tabular}{|c|c|c|c|c|c|}
\hline \multicolumn{6}{|c|}{ Supplemental Table s2.txt } \\
\hline CHEMBL3662189 & 1528911 & 6.0 & 6.7274 & TRN & \\
\hline CHEMBL 3657809 & 1528911 & 6.0 & 6.4966 & TST & \\
\hline CHEMBL3662156 & 1528911 & 6.1367 & 5.9608 & TRN & \\
\hline CHEMBL 3657893 & 1528911 & 6.2197 & 6.8451 & TRN & \\
\hline CHEMBL 3657978 & 1528911 & 7.6576 & 7.9926 & TRN & \\
\hline CHEMBL3662194 & 1528911 & 7.9586 & 6.8973 & TRN & \\
\hline CHEMBL 3657890 & 1528911 & 6.5243 & 6.3362 & TRN & \\
\hline CHEMBL 3657848 & 1528911 & 7.1135 & 7.0634 & TST & \\
\hline CHEMBL 3662100 & 1528911 & 5.8239 & 5.3643 & TST & \\
\hline CHEMBL3662112 & 1528911 & 6.6383 & 7.0802 & TRN & \\
\hline CHEMBL3657911 & 1528911 & 6.7799 & 6.7955 & TRN & \\
\hline CHEMBL 3657824 & 1528911 & 5.8539 & 7.004 & TST & \\
\hline CHEMBL 3939334 & 1528911 & 6.0 & 5.7511 & TST & \\
\hline CHEMBL 3657942 & 1528911 & 8.699 & 8.1705 & TRN & \\
\hline CHEMBL 3657980 & 1528911 & 7.8239 & 8.3606 & TRN & \\
\hline CHEMBL3662150 & 1528911 & 7.6778 & 7.4808 & TRN & \\
\hline CHEMBL 3657846 & 1528911 & 8.0458 & 8.138 & TST & \\
\hline CHEMBL 3657883 & 1528911 & 6.0 & 5.9521 & TRN & \\
\hline CHEMBL3910018 & 1528911 & 6.0 & 7.0726 & TRN & \\
\hline CHEMBL 3657875 & 1528911 & 7.7905 & 7.5058 & TRN & \\
\hline CHEMBL3662193 & 1528911 & 8.301 & 8.12 & TRN & \\
\hline CHEMBL 3654180 & 1528911 & 6.8239 & 7.0542 & TRN & \\
\hline CHEMBL3662133 & 1528911 & 6.5686 & 6.6294 & TRN & \\
\hline CHEMBL 3662089 & 1528911 & 7.3979 & 7.2772 & TRN & \\
\hline CHEMBL3662121 & 1528911 & 7.5229 & 6.6431 & TRN & \\
\hline CHEMBL 3657870 & 1528911 & 6.7959 & 6.3579 & TRN & \\
\hline CHEMBL 3657872 & 1528911 & 6.9136 & 7.1565 & TRN & \\
\hline CHEMBL3658013 & 1528911 & 7.0969 & 7.6023 & TRN & \\
\hline CHEMBL 3658000 & 1528911 & 8.1549 & 7.9859 & TRN & \\
\hline CHEMBL3657895 & 1528911 & 6.5784 & 6.7939 & TRN & \\
\hline CHEMBL 3658020 & 1528911 & 8.3979 & 7.8783 & TRN & \\
\hline CHEMBL3657961 & 1528911 & 5.7696 & 5.9145 & TST & \\
\hline CHEMBL 3662234 & 1528911 & 7.7447 & 7.4915 & TRN & \\
\hline CHEMBL 3657995 & 1528911 & 6.0458 & 6.1099 & TST & \\
\hline CHEMBL3654176 & 1528911 & 5.0004 & 4.89199 & 99999999995 & TST \\
\hline CHEMBL 3662201 & 1528911 & 6.0 & 6.2198 & TRN & \\
\hline CHEMBL 3657836 & 1528911 & 8.301 & 8.0077 & TRN & \\
\hline CHEMBL3662213 & 1528911 & 8.3979 & 8.4368 & TRN & \\
\hline CHEMBL 3657813 & 1528911 & 5.9208 & 6.6569 & TST & \\
\hline CHEMBL3657963 & 1528911 & 8.3979 & 8.2532 & TRN & \\
\hline CHEMBL3662106 & 1528911 & 6.7447 & 7.1397 & TRN & \\
\hline CHEMBL3657959 & 1528911 & 7.1549 & 6.7045 & TST & \\
\hline CHEMBL3657937 & 1528911 & 9.0 & 8.6319 & TRN & \\
\hline CHEMBL 3657898 & 1528911 & 6.0953 & 6.7508 & TST & \\
\hline CHEMBL 3657873 & 1528911 & 6.5317 & 6.7081 & TRN & \\
\hline CHEMBL 3657878 & 1528911 & 7.0915 & 7.312 & TRN & \\
\hline CHEMBL3657945 & 1528911 & 7.8539 & 7.5601 & TRN & \\
\hline CHEMBL3657991 & 1528911 & 8.0969 & 7.1934 & TRN & \\
\hline
\end{tabular}


Supplemental Table S2.txt

\begin{tabular}{|c|c|c|c|c|}
\hline CHEMBL3662221 & 1528911 & 6.0 & 6.4667 & TRN \\
\hline CHEMBL3961343 & 1528911 & 7.4202 & 7.0258 & TST \\
\hline CHEMBL3657843 & 1528911 & 8.2218 & 7.1389 & TST \\
\hline CHEMBL3662099 & 1528911 & 8.3979 & 8.116 & TRN \\
\hline CHEMBL 3657954 & 1528911 & 8.3979 & 8.6203 & TRN \\
\hline CHEMBL3639610 & 1528911 & 8.3979 & 8.1571 & TRN \\
\hline CHEMBL3662139 & 1528911 & 6.0 & 6.397 & TRN \\
\hline CHEMBL3658010 & 1528911 & 6.2007 & 7.476 & TRN \\
\hline CHEMBL3662087 & 1528911 & 7.699 & 8.0115 & TRN \\
\hline CHEMBL3895995 & 1528911 & 6.6576 & 6.6727 & TST \\
\hline CHEMBL3662081 & 1528911 & 8.3979 & 8.5329 & TRN \\
\hline CHEMBL3662182 & 1528911 & 8.301 & 7.4645 & TRN \\
\hline CHEMBL3662162 & 1528911 & 7.1308 & 6.765 & TRN \\
\hline CHEMBL 3657849 & 1528911 & 7.585 & 7.1038 & TST \\
\hline CHEMBL 3662220 & 1528911 & 6.0 & 7.1521 & TRN \\
\hline CHEMBL3657917 & 1528911 & 6.266 & 6.1219 & TRN \\
\hline CHEMBL3657923 & 1528911 & 6.5302 & 6.5049 & TRN \\
\hline CHEMBL3657921 & 1528911 & 6.2716 & 6.4286 & TST \\
\hline CHEMBL3657859 & 1528911 & 6.1367 & 6.4362 & TRN \\
\hline CHEMBL3657998 & 1528911 & 8.2218 & 8.0754 & TRN \\
\hline CHEMBL 3657838 & 1528911 & 8.1549 & 8.1443 & TRN \\
\hline CHEMBL3662199 & 1528911 & 8.2218 & 8.0884 & TRN \\
\hline CHEMBL3662083 & 1528911 & 7.4437 & 7.4898 & TRN \\
\hline CHEMBL3657860 & 1528911 & 7.0132 & 7.1296 & TRN \\
\hline CHEMBL 3657822 & 1528911 & 5.0 & 5.5497 & TRN \\
\hline CHEMBL3662086 & 1528911 & 7.9586 & 8.1554 & TRN \\
\hline CHEMBL3662185 & 1528911 & 7.9208 & 7.8079 & TRN \\
\hline CHEMBL3657834 & 1528911 & 7.1427 & 7.3035 & TST \\
\hline CHEMBL3955528 & 1528911 & 6.7773 & 5.7914 & TST \\
\hline CHEMBL 3662154 & 1528911 & 8.0458 & 7.6487 & TRN \\
\hline CHEMBL 3657820 & 1528911 & 6.9208 & 6.9234 & TRN \\
\hline CHEMBL3658003 & 1528911 & 8.0458 & 7.7772 & TRN \\
\hline CHEMBL3657901 & 1528911 & 6.7423 & 6.4238 & TST \\
\hline CHEMBL 3662155 & 1528911 & 6.0 & 7.8639 & TRN \\
\hline CHEMBL3662172 & 1528911 & 6.4437 & 6.0253 & TRN \\
\hline CHEMBL3662079 & 1528911 & 7.7447 & 7.9088 & TRN \\
\hline CHEMBL3657863 & 1528911 & 7.1192 & 7.0996 & TRN \\
\hline CHEMBL 3657924 & 1528911 & 6.0 & 5.5703 & TRN \\
\hline CHEMBL 3657817 & 1528911 & 7.8861 & 7.4524 & TRN \\
\hline CHEMBL3657823 & 1528911 & 6.0 & 7.2229 & TST \\
\hline CHEMBL3657935 & 1528911 & 7.6778 & 7.3898 & TRN \\
\hline CHEMBL3657868 & 1528911 & 7.0655 & 6.7965 & TST \\
\hline CHEMBL3657816 & 1528911 & 6.7212 & 6.4575 & TST \\
\hline CHEMBL3923789 & 1528911 & 7.9586 & \multicolumn{2}{|c|}{7.656000000000001} \\
\hline CHEMBL3662078 & 1528911 & 8.0 & 8.1988 & TRN \\
\hline CHEMBL3657891 & 1528911 & 6.4921 & 6.3362 & TRN \\
\hline CHEMBL3657950 & 1528911 & 7.5686 & 7.6997 & TRN \\
\hline CHEMBL3905386 & 1528911 & 6.0 & 6.3043 & TST \\
\hline
\end{tabular}


Supplemental Table S2.txt

\begin{tabular}{|c|c|c|c|c|}
\hline HEN & 528911 & & & \\
\hline HEMPI 2662119 & 528911 & 6.0088 & 0684 & \\
\hline 52 & 28911 & & & \\
\hline IEMBL & 28911 & 59 & & $\mathrm{MI}$ \\
\hline AEMBL3657844 & 528911 & 7.0 & 2691 & \\
\hline HEMBL3657880 & 528911 & 6.6308 & 3879 & \\
\hline 432 & 528911 & 6.0 & 16 & \\
\hline 211 & 528911 & 79 & & RN \\
\hline AEMBL3662187 & 528911 & 7.4685 & 3672 & \\
\hline HEMBL3894925 & 528911 & 6.0 & 1346 & \\
\hline HEMBL3657993 & 528911 & 5.63 & 9956 & \\
\hline AEMBL3 & 528911 & 51 & 896 & \\
\hline IEMBL: & 8911 & & & RN \\
\hline HEMBL 366 & 528911 & $6.8 \varepsilon$ & 5446 & \\
\hline HEMBL366 & 528911 & 8 & 796 & \\
\hline IEMBL 366 & 528911 & 6. & 738 & \\
\hline HEMBL36 & 911 & 99 & 003 & m \\
\hline HEMBL3 & & 979 & 356 & \\
\hline HEMBL366 & 528911 & 6.0 & 4794 & \\
\hline HEMBL 366 & & 29 & & \\
\hline HEMBL & 1 & & 82 & IRN \\
\hline AEMBL & 911 & & & RI \\
\hline HEMBL & 911 & & 43 & \\
\hline AEMBL & & & & \\
\hline HEMBL 365 & & 5 & & $\mid$ \\
\hline HEMBL & 11 & & 906 & RN \\
\hline HEMBL & 11 & & 98 & ST \\
\hline HFMRI & 11 & & 196 & RN \\
\hline HEMBL3 & & & 475 & I \\
\hline HEMBL3657871 & & 5.77 & & IK \\
\hline HEMBL3 & 11 & 6 & 779 & RN \\
\hline HEMBL & 1 & & 88 & RN \\
\hline HEMBL & 11 & 8 & 159 & N \\
\hline HEMBL3657929 & 528911 & 6 & .74 & IRN \\
\hline HEMBL3662226 & 528911 & 7.95 & 158 & TRN \\
\hline HEMBL3 & 911 & & 94 & ST \\
\hline HFMRI: & 1 & & 434 & $\Gamma \mathrm{RN}$ \\
\hline HEMBL & & 79 & & RN \\
\hline HEMBL3657850 & 528911 & 7.1871 & 175 & TST \\
\hline AEMBL3 & 528911 & 1 & & TRN \\
\hline HEMBL3 & 11 & 8 & 673 & \\
\hline EHEMBL3 & 528911 & & 104 & RN \\
\hline HEMBL3 & 528911 & 7.4437 & 2531 & TST \\
\hline HEMBL3662138 & 528911 & 7.6021 & 31 & TRN \\
\hline 39 & 1 & & & RN \\
\hline HEMBL3 & & & 3636 & \\
\hline CHEMBL 3662082 & 528911 & & 8.0437 & \\
\hline CHEMBL3662196 & 1528911 & 7.6021 & 7.303 & ГRN \\
\hline
\end{tabular}

Page 20273 
Supplemental Table S2.txt

\begin{tabular}{|c|c|c|c|c|}
\hline 9 & & & 8.2907 & \\
\hline & 528911 & & 6.4791 & \\
\hline AEM & 28911 & & & \\
\hline IEMBL & 8911 & & & \\
\hline AEMBL3662132 & 528911 & 3372 & 6751 & \\
\hline HEMBL3662127 & 528911 & 6.0 & .7334 & \\
\hline 37 & 911 & 79 & 3707 & \\
\hline AEMBL & 911 & & & \\
\hline HEMBL3662175 & 528911 & 6.6576 & 6.8815 & \\
\hline HEMBL 365 & 528911 & 6.0 & 8039 & \\
\hline HEMBL36 & 911 & & 5712 & \\
\hline IEME & 911 & 8 & 3986 & \\
\hline HEMBL; & & & & \\
\hline HEMBL 392 & 528911 & & 9324 & \\
\hline HEMBL365 & 528911 & 8 . & & \\
\hline HEMBL3 & 1 & 8 & 62 & \\
\hline HEMBL & 11 & & & \\
\hline AEMBL. & 11 & & & \\
\hline HFMBL $=$ & 911 & & & \\
\hline AEMBL3 & & & & (ב) \\
\hline HEMBL & 1 & & & IST \\
\hline HEM & & & & \\
\hline AEMBL & 11 & 36 & 31 & \\
\hline HEMBL & & & & IST \\
\hline AEMBL3 & 11 & & 28 & I \\
\hline HEMBL3 & & 8 & 34 & 5T \\
\hline HFM & & 39 & & ST \\
\hline 85 & & 76 & & \\
\hline AEMBL & & & & IST \\
\hline AEMBL 365 & 11 & 5 . & 96 & TST \\
\hline AEMBL & 1 & 18 & 17 & ST \\
\hline HFM & & & & \\
\hline 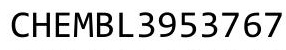 & & & & \\
\hline HEMBL3 & & & & is \\
\hline HEMBL 365 & 911 & 6. & 573 & ГST \\
\hline AEMR 1 & 1 & 39 & 02 & RN \\
\hline 9 & & & & \\
\hline HEMBL 128 & & & & RN \\
\hline HEMBL128 & 1 & 5 . & & TRN \\
\hline 0 & & & & RN \\
\hline HEMBL1 & & & 95 & \\
\hline HEMBL1 & & & 68 & RN \\
\hline HEMBL 128 & & 5.4437 & 3579 & TRN \\
\hline HEMBL 128 & 1 & & & $\mathrm{TR}$ \\
\hline CHFMRI 128 & & & & \\
\hline HEMBL128 & & & 3.3338 & \\
\hline HEMBL 128 & 41 & 4.7645 & 4.9025 & \\
\hline CHEMBL1288127 & 687741 & 5.7959 & 6.0154 & $n$ \\
\hline
\end{tabular}

Page 20274 
Supplemental Table S2.txt

\begin{tabular}{|c|c|c|c|c|}
\hline $\mathrm{HEl}$ & 741 & 59 & 29 & TS \\
\hline HEMBL1288993 & 87741 & .3565 & 5.2896 & \\
\hline 13 & 7741 & & & \\
\hline AEMBL1 & 7741 & 01 & & \\
\hline AEMBL12ع & 87741 & 576 & 737 & \\
\hline HEMBL1288214 & 87741 & .8996 & 0595 & \\
\hline HEMBL1288188 & 741 & 239 & & \\
\hline IEMBL12 & & & & \\
\hline HEMBL1288930 & & 5686 & & \\
\hline HEMBL1287888 & 87741 & .757 & & \\
\hline AEMBL1288128 & 87741 & 862 & 14 & \\
\hline IEMBL12ع & 41 & 01 & & \\
\hline AEMBL12 & & & & \\
\hline HEMBL1288004 & & 269 & & \\
\hline JEMBL12 & 41 & 86 & & $5 T$ \\
\hline AEMBL128 & 41 & 676 & & \\
\hline HEMBL 12 & & & & \\
\hline HEMBL 12 & & 959 & & \\
\hline HEMBL12ع & & & & \\
\hline JEMBL12 & & & & \\
\hline HEMBL12 & & & & \\
\hline HEMBL12 & & & & \\
\hline HEMBL 12 & & & & RN \\
\hline JEMBL12 & & 778 & & \\
\hline JEMBL12 & & & & IRN \\
\hline HEMBL12 & & & & RN \\
\hline HEMBL12 & & & & RIV \\
\hline AEMBL12 & & & & RN \\
\hline HEMBL12 & & & & $2 \mathrm{~N}$ \\
\hline HEMBL 128 & & & & RN \\
\hline HEMBL12 & & & & ST \\
\hline HFMRI 12 & & & & ST \\
\hline HEMBL1 & 1 & & & RN \\
\hline HEMBL1288037 & & & & $\Gamma R$ \\
\hline HEMBL1288272 & & & 102 & TRN \\
\hline HEMBL 128 & & & 93 & ST \\
\hline 1 & & & & RN \\
\hline HEMBL $12 \varepsilon$ & & & & $\mathrm{RN}$ \\
\hline HEMBL1288098 & & & 5.4402 & IST \\
\hline IEMBL128 & & & & RN \\
\hline HEMBL1288099 & & & 57 & \\
\hline HEMBL1287945 & & & & IST \\
\hline HEMBL1288215 & & & & TRN \\
\hline AEMBL1288005 & 7741 & & 88 & TRN \\
\hline EMBL206 & & & & \\
\hline CHEMBL 202721 & & & 5.3912 & \\
\hline CHEMBL $20 \Theta$ & 809226 & 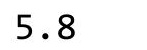 & 5.1044 & \\
\hline LHEMBL 200709 & 809226 & 4.2 & 4.1754 & ГRN \\
\hline
\end{tabular}

Page 20275 


\begin{tabular}{|c|c|c|c|c|c|}
\hline & & & & & \\
\hline CHEMBL1825138 & 809226 & 4.7 & 5.4618 & TST & \\
\hline CHEMBL1974328 & 809226 & 6.4 & 5.6859 & TRN & \\
\hline CHEMBL509032 & 809226 & 6.5 & 6.2707 & TRN & \\
\hline CHEMBL143703 & 809226 & 3.1 & 3.3106 & TRN & \\
\hline CHEMBL388311 & 809226 & 8.5 & 8.1264 & TRN & \\
\hline CHEMBL1964948 & 809226 & 4.7 & 4.9875 & TRN & \\
\hline CHEMBL1973013 & 809226 & 5.9 & 5.8584 & TRN & \\
\hline CHEMBL1989834 & 809226 & 3.7 & 3.45 & TRN & \\
\hline CHEMBL1987430 & 809226 & 4.7 & 4.534 & TRN & \\
\hline CHEMBL205415 & 809226 & 4.7 & 4.7083 & TRN & \\
\hline CHEMBL1975927 & 809226 & 6.6 & 6.88399 & 99999999995 & TRN \\
\hline CHEMBL1986943 & 809226 & 4.7 & 5.7374 & TRN & \\
\hline CHEMBL289959 & 809226 & 3.1 & 2.8297 & TRN & \\
\hline CHEMBL1997119 & 809226 & 4.7 & 4.0557 & TRN & \\
\hline CHEMBL1977138 & 809226 & 5.9 & 6.0096 & TRN & \\
\hline CHEMBL 2000879 & 809226 & 3.1 & 4.1883 & TRN & \\
\hline CHEMBL1978448 & 809226 & 4.7 & 4.6984 & TST & \\
\hline CHEMBL1980329 & 809226 & 7.4 & 6.8965 & TRN & \\
\hline CHEMBL 2004515 & 809226 & 3.1 & 5.0038 & TRN & \\
\hline CHEMBL1992042 & 809226 & 5.8 & 5.4574 & TRN & \\
\hline CHEMBL1986265 & 809226 & 4.7 & 5.0244 & TRN & \\
\hline CHEMBL1967211 & 809226 & 3.1 & 3.5351 & TRN & \\
\hline CHEMBL1991734 & 809226 & 6.4 & 5.8067 & TST & \\
\hline CHEMBL21156 & 809226 & 4.7 & 4.3396 & TRN & \\
\hline CHEMBL1994724 & 809226 & 4.7 & 4.5037 & TRN & \\
\hline CHEMBL1989267 & 809226 & 7.5 & 7.5506 & TRN & \\
\hline CHEMBL1991782 & 809226 & 3.4 & 2.9924 & TRN & \\
\hline CHEMBL 2002105 & 809226 & 3.1 & 4.3111 & TRN & \\
\hline CHEMBL1983348 & 809226 & 6.0 & 6.1333 & TRN & \\
\hline CHEMBL1970290 & 809226 & 6.5 & 5.8493 & TRN & \\
\hline CHEMBL1968394 & 809226 & 3.1 & 3.2566 & TRN & \\
\hline CHEMBL1993877 & 809226 & 4.7 & 5.7945 & TRN & \\
\hline CHEMBL1974480 & 809226 & 5.7 & 6.0262 & TRN & \\
\hline CHEMBL1996500 & 809226 & 4.7 & 4.9315 & TRN & \\
\hline CHEMBL1980671 & 809226 & 5.2 & 5.0684 & TRN & \\
\hline CHEMBL1973363 & 809226 & 5.7 & 5.3539 & TRN & \\
\hline CHEMBL1986177 & 809226 & 4.7 & 5.0477 & TRN & \\
\hline CHEMBL1989708 & 809226 & 9.0 & 8.9977 & TRN & \\
\hline CHEMBL1976420 & 809226 & 4.7 & 5.4671 & TRN & \\
\hline CHEMBL1981744 & 809226 & 4.7 & 4.6848 & TRN & \\
\hline CHEMBL1989423 & 809226 & 3.1 & 3.2391 & TRN & \\
\hline CHEMBL1985367 & 809226 & 4.7 & 5.1588 & TRN & \\
\hline CHEMBL 2000029 & 809226 & 4.7 & 4.7805 & TRN & \\
\hline CHEMBL1995172 & 809226 & 4.1 & 4.1924 & TRN & \\
\hline CHEMBL2001584 & 809226 & 4.7 & 4.4751 & TRN & \\
\hline CHEMBL1973961 & 809226 & 4.7 & 4.9233 & TRN & \\
\hline CHEMBL1978562 & 809226 & 6.1 & 6.1997 & TRN & \\
\hline CHEMBL1974875 & 809226 & 3.1 & 3.245 & TRN & \\
\hline & & & & 20276 & \\
\hline
\end{tabular}




\begin{tabular}{|c|c|c|c|c|c|}
\hline & & & & & \\
\hline CHEMBL 2005478 & 809226 & 5.8 & 6.2295 & TRN & \\
\hline CHEMBL1996646 & 809226 & 8.0 & 7.6441 & TRN & \\
\hline CHEMBL1979773 & 809226 & 4.7 & 5.1695 & TRN & \\
\hline CHEMBL1989471 & 809226 & 4.7 & 5.7701 & TST & \\
\hline CHEMBL2002099 & 809226 & 4.7 & 4.85 & TRN & \\
\hline CHEMBL1992723 & 809226 & 3.1 & 3.7157 & TRN & \\
\hline CHEMBL1996702 & 809226 & 5.9 & 5.6783 & TRN & \\
\hline CHEMBL 2007124 & 809226 & 6.4 & 5.3079 & TRN & \\
\hline CHEMBL1978195 & 809226 & 4.7 & 4.5392 & TRN & \\
\hline CHEMBL1985681 & 809226 & 6.5 & 5.9049 & TRN & \\
\hline CHEMBL1982711 & 809226 & 4.7 & 4.63899 & 7999999999 & TRN \\
\hline CHEMBL262623 & 809226 & 4.3 & 3.7824 & TRN & \\
\hline CHEMBL1984842 & 809226 & 4.7 & 5.0218 & TRN & \\
\hline CHEMBL 2004118 & 809226 & 4.7 & 5.3501 & TRN & \\
\hline CHEMBL1996345 & 809226 & 4.7 & 5.0667 & TRN & \\
\hline CHEMBL 2004025 & 809226 & 6.2 & 5.8908 & TRN & \\
\hline CHEMBL1996048 & 809226 & 6.3 & 5.4854 & TRN & \\
\hline CHEMBL50894 & 809226 & 4.7 & 5.1906 & TRN & \\
\hline CHEMBL1965033 & 809226 & 6.3 & 5.6537 & TRN & \\
\hline CHEMBL461876 & 809226 & 4.7 & 4.7335 & TRN & \\
\hline CHEMBL 2006299 & 809226 & 4.7 & 4.5312 & TRN & \\
\hline CHEMBL1971519 & 809226 & 5.2 & 5.0371 & TRN & \\
\hline CHEMBL1997335 & 809226 & 4.7 & 4.4928 & TRN & \\
\hline CHEMBL1965169 & 809226 & 4.7 & 5.2544 & TRN & \\
\hline CHEMBL1081312 & 809226 & 6.4 & 6.6048 & TRN & \\
\hline CHEMBL1965170 & 809226 & 9.3 & 9.8406 & TRN & \\
\hline CHEMBL1994808 & 809226 & 4.2 & 4.2981 & TST & \\
\hline CHEMBL 2005792 & 809226 & 4.7 & 4.9309 & TRN & \\
\hline CHEMBL1991867 & 809226 & 3.1 & 3.35100 & 00000000004 & TRN \\
\hline CHEMBL1972355 & 809226 & 6.1 & 6.03100 & 0000000001 & TRN \\
\hline CHEMBL1997892 & 809226 & 6.8 & 6.5355 & TRN & \\
\hline CHEMBL 2001641 & 809226 & 4.3 & 4.4256 & TRN & \\
\hline CHEMBL1997193 & 809226 & 5.8 & 6.25299 & 9999999999 & TST \\
\hline CHEMBL1964902 & 809226 & 4.7 & 4.6417 & TRN & \\
\hline CHEMBL1973868 & 809226 & 4.7 & 4.5682 & TRN & \\
\hline CHEMBL1983715 & 809226 & 6.6 & 6.6254 & TRN & \\
\hline CHEMBL 2002992 & 809226 & 4.7 & 4.4263 & TRN & \\
\hline CHEMBL1982700 & 809226 & 4.7 & 4.6481 & TRN & \\
\hline CHEMBL10 & 809226 & 4.7 & 5.0701 & TRN & \\
\hline CHEMBL1980763 & 809226 & 4.7 & 5.8391 & TRN & \\
\hline CHEMBL1977931 & 809226 & 4.5 & 4.3527 & TRN & \\
\hline CHEMBL1976872 & 809226 & 3.1 & 2.9636 & TRN & \\
\hline CHEMBL1969156 & 809226 & 3.1 & 3.3004 & TRN & \\
\hline CHEMBL 2007479 & 809226 & 4.7 & 4.6592 & TRN & \\
\hline CHEMBL1999120 & 809226 & 3.1 & 3.9869 & TST & \\
\hline CHEMBL1972220 & 809226 & 9.1 & 9.5324 & TRN & \\
\hline CHEMBL1981215 & 809226 & 4.7 & 4.6877 & TRN & \\
\hline CHEMBL 2003785 & 809226 & 4.9 & 4.8818 & TRN & \\
\hline & & & & 20277 & \\
\hline
\end{tabular}




\begin{tabular}{|c|c|c|c|c|c|}
\hline \\
\hline CHEMBL1973720 & 809226 & 6.3 & 5.6869 & TRN & \\
\hline CHEMBL354676 & 809226 & 3.1 & 3.2455 & TRN & \\
\hline CHEMBL1999414 & 809226 & 9.5 & 9.4398 & TRN & \\
\hline CHEMBL1967336 & 809226 & 4.7 & 4.7633 & TRN & \\
\hline CHEMBL 2003514 & 809226 & 4.7 & 4.6101 & TRN & \\
\hline CHEMBL1970340 & 809226 & 5.1 & 4.6761 & TRN & \\
\hline CHEMBL1967992 & 809226 & 4.7 & 4.6219 & TRN & \\
\hline CHEMBL1989043 & 809226 & 4.7 & 4.5267 & TRN & \\
\hline CHEMBL 2001987 & 809226 & 4.7 & 4.4711 & TRN & \\
\hline CHEMBL1994555 & 809226 & 4.7 & 4.9177 & TRN & \\
\hline CHEMBL1164180 & 809226 & 6.2 & 6.215 & TST & \\
\hline CHEMBL1975121 & 809226 & 4.7 & 4.60800 & 00000000005 & TRN \\
\hline CHEMBL1983640 & 809226 & 8.7 & 9.0534 & TRN & \\
\hline CHEMBL2002723 & 809226 & 5.7 & 5.4281 & TRN & \\
\hline CHEMBL1984686 & 809226 & 4.7 & 4.7069 & TST & \\
\hline CHEMBL1973793 & 809226 & 4.7 & 4.5118 & TRN & \\
\hline CHEMBL1990254 & 809226 & 4.7 & 4.5074 & TRN & \\
\hline CHEMBL1986143 & 809226 & 4.7 & 4.5892 & TRN & \\
\hline CHEMBL1972934 & 809226 & 4.6 & 4.6675 & TRN & \\
\hline CHEMBL2007559 & 809226 & 4.7 & 4.8824 & TRN & \\
\hline CHEMBL1992581 & 809226 & 5.7 & 5.9737 & TRN & \\
\hline CHEMBL 2004290 & 809226 & 8.9 & 9.4195 & TRN & \\
\hline CHEMBL1975921 & 809226 & 4.5 & 4.1809 & TRN & \\
\hline CHEMBL1983573 & 809226 & 5.2 & 4.1025 & TRN & \\
\hline CHEMBL1975923 & 809226 & 6.1 & 5.0738 & TST & \\
\hline CHEMBL2004033 & 809226 & 5.7 & 4.1981 & TST & \\
\hline CHEMBL1984402 & 809226 & 3.1 & 4.0195 & TRN & \\
\hline CHEMBL1996576 & 809226 & 4.7 & 5.0166 & TST & \\
\hline CHEMBL2005449 & 809226 & 5.9 & 6.0911 & TRN & \\
\hline CHEMBL1991678 & 809226 & 4.7 & 4.9968 & TRN & \\
\hline CHEMBL1987998 & 809226 & 4.7 & 4.5853 & TRN & \\
\hline CHEMBL1971534 & 809226 & 3.1 & 3.5702 & TRN & \\
\hline CHEMBL1990496 & 809226 & 4.7 & 5.0274 & TRN & \\
\hline CHEMBL242865 & 809226 & 4.7 & 4.0634 & TRN & \\
\hline CHEMBL2004159 & 809226 & 4.7 & 4.6251 & TRN & \\
\hline CHEMBL1978371 & 809226 & 4.7 & 5.144 & TST & \\
\hline CHEMBL1998110 & 809226 & 4.7 & 4.7639 & TRN & \\
\hline CHEMBL1978166 & 809226 & 8.1 & 8.4178 & TRN & \\
\hline CHEMBL1972454 & 809226 & 3.1 & 3.4629 & TRN & \\
\hline CHEMBL1974617 & 809226 & 4.3 & 4.2685 & TRN & \\
\hline CHEMBL1977814 & 809226 & 5.7 & 5.4117 & TST & \\
\hline CHEMBL1992125 & 809226 & 5.8 & 5.9508 & TRN & \\
\hline CHEMBL1966175 & 809226 & 4.7 & 5.4473 & TRN & \\
\hline CHEMBL 2007375 & 809226 & 4.7 & 4.6071 & TRN & \\
\hline CHEMBL379975 & 809226 & 4.7 & 4.7855 & TST & \\
\hline CHEMBL1965387 & 809226 & 7.7 & 7.9451 & TRN & \\
\hline CHEMBL 388978 & 809226 & 9.1 & 7.6016 & TST & \\
\hline CHEMBL550418 & 809226 & 4.7 & 4.3402 & TRN & \\
\hline & & & & 20278 & \\
\hline
\end{tabular}




\begin{tabular}{|c|c|c|c|c|c|}
\hline \\
\hline CHEMBL1971289 & 809226 & 4.7 & 4.7821 & TST & \\
\hline CHEMBL1988437 & 809226 & 9.2 & 7.6501 & TRN & \\
\hline CHEMBL1421720 & 809226 & 4.7 & 4.8983 & TRN & \\
\hline CHEMBL1233887 & 809226 & 4.7 & 4.8022 & TRN & \\
\hline CHEMBL1968130 & 809226 & 4.3 & 4.0676 & TRN & \\
\hline CHEMBL1996649 & 809226 & 9.4 & 8.8613 & TRN & \\
\hline CHEMBL1986756 & 809226 & 4.7 & 4.4684 & TRN & \\
\hline CHEMBL1949855 & 809226 & 4.6 & 4.1662 & TRN & \\
\hline CHEMBL3109278 & 809226 & 9.0 & 8.1894 & TRN & \\
\hline CHEMBL1727312 & 809226 & 3.1 & 3.0309 & TRN & \\
\hline CHEMBL 2004438 & 809226 & 7.6 & 7.9676 & TRN & \\
\hline CHEMBL1964382 & 809226 & 5.8 & 5.3 & TST & \\
\hline CHEMBL101311 & 809226 & 6.4 & 5.871 & TRN & \\
\hline CHEMBL191003 & 809226 & 4.7 & 5.3886 & TRN & \\
\hline CHEMBL1973359 & 809226 & 6.0 & 5.2673 & TST & \\
\hline CHEMBL1988581 & 809226 & 7.2 & 6.6885 & TST & \\
\hline CHEMBL2005699 & 809226 & 4.7 & 4.6951 & TRN & \\
\hline CHEMBL2006564 & 809226 & 6.7 & 6.1726 & TRN & \\
\hline CHEMBL1979690 & 809226 & 7.4 & 7.6893 & TRN & \\
\hline CHEMBL 234085 & 809226 & 4.7 & 4.9896 & TRN & \\
\hline CHEMBL1978167 & 809226 & 4.7 & 5.6525 & TRN & \\
\hline CHEMBL418203 & 809226 & 4.7 & 4.2868 & TST & \\
\hline CHEMBL225519 & 809226 & 4.7 & 4.421 & TRN & \\
\hline CHEMBL1994159 & 809226 & 3.1 & 3.8624 & TRN & \\
\hline CHEMBL1976376 & 809226 & 6.4 & 6.0861 & TRN & \\
\hline CHEMBL1988622 & 809226 & 3.1 & 3.4047 & TRN & \\
\hline CHEMBL1983575 & 809226 & 6.2 & 5.8106 & TRN & \\
\hline CHEMBL1968868 & 809226 & 4.7 & 4.8234 & TRN & \\
\hline CHEMBL1981047 & 809226 & 5.0 & 5.5161 & TRN & \\
\hline CHEMBL1976196 & 809226 & 4.7 & 4.9656 & TRN & \\
\hline CHEMBL2002432 & 809226 & 7.8 & 5.904 & TRN & \\
\hline CHEMBL1997197 & 809226 & 4.7 & 4.6677 & TRN & \\
\hline CHEMBL1975903 & 809226 & 5.8 & 5.1935 & TRN & \\
\hline CHEMBL1983630 & 809226 & 4.3 & 4.0412 & TRN & \\
\hline CHEMBL1522508 & 809226 & 3.1 & 3.5134 & TRN & \\
\hline CHEMBL1973795 & 809226 & 3.1 & 3.0641 & TRN & \\
\hline CHEMBL1988805 & 809226 & 4.7 & 4.8033 & TRN & \\
\hline CHEMBL458997 & 809226 & 6.0 & 5.3271 & TRN & \\
\hline CHEMBL1969942 & 809226 & 6.3 & 5.3776 & TRN & \\
\hline CHEMBL1978567 & 809226 & 4.7 & 4.7639 & TRN & \\
\hline CHEMBL1982660 & 809226 & 4.7 & 5.1325 & TRN & \\
\hline CHEMBL1976290 & 809226 & 3.1 & 3.2785 & TRN & \\
\hline CHEMBL1995765 & 809226 & 4.5 & 4.4441 & TRN & \\
\hline CHEMBL1984760 & 809226 & 4.7 & 5.21899 & 9999999999 & TRN \\
\hline CHEMBL360847 & 809226 & 4.7 & 4.5947 & TST & \\
\hline CHEMBL1995811 & 809226 & 4.7 & 5.0762 & TRN & \\
\hline CHEMBL1983111 & 809226 & 7.2 & 7.1576 & TRN & \\
\hline CHEMBL1995916 & 809226 & 4.2 & 3.4371 & TRN & \\
\hline & & & & 2027 & \\
\hline
\end{tabular}




\begin{tabular}{|c|c|c|c|c|c|}
\hline & & & & & \\
\hline CHEMBL1992937 & 809226 & 6.1 & 5.5499 & TRN & \\
\hline CHEMBL1988141 & 809226 & 6.5 & 6.1788 & TST & \\
\hline CHEMBL1977134 & 809226 & 8.1 & 8.3316 & TRN & \\
\hline CHEMBL1970873 & 809226 & 3.1 & 3.3136 & TRN & \\
\hline CHEMBL1985206 & 809226 & 6.2 & 5.7292 & TRN & \\
\hline CHEMBL1977749 & 809226 & 4.7 & 4.5458 & TST & \\
\hline CHEMBL 2002450 & 809226 & 3.1 & 3.3129 & TRN & \\
\hline CHEMBL1975212 & 809226 & 6.4 & 6.2897 & TRN & \\
\hline CHEMBL 2001613 & 809226 & 4.2 & 4.1016 & TRN & \\
\hline CHEMBL261849 & 809226 & 4.7 & 6.0003 & TST & \\
\hline CHEMBL1983923 & 809226 & 7.2 & 7.0123 & TRN & \\
\hline CHEMBL1993904 & 809226 & 4.7 & $5.8270 e$ & 0000000001 & TRN \\
\hline CHEMBL1997275 & 809226 & 6.2 & 5.6035 & TRN & \\
\hline CHEMBL1967513 & 809226 & 5.8 & 4.5256 & TRN & \\
\hline CHEMBL1980376 & 809226 & 5.1 & 4.2587 & TRN & \\
\hline CHEMBL1982413 & 809226 & 5.7 & 5.2062 & TRN & \\
\hline CHEMBL1981792 & 809226 & 4.7 & 4.7316 & TRN & \\
\hline CHEMBL1987535 & 809226 & 4.7 & 4.67399 & 99999999995 & TRN \\
\hline CHEMBL1983393 & 809226 & 5.8 & 5.0951 & TRN & \\
\hline CHEMBL 2002586 & 809226 & 4.7 & 4.7655 & TRN & \\
\hline CHEMBL1987815 & 809226 & 3.1 & 3.4593 & TRN & \\
\hline CHEMBL 2006674 & 809226 & 4.7 & 4.8113 & TST & \\
\hline CHEMBL1992371 & 809226 & 4.7 & 4.9 & TST & \\
\hline CHEMBL1984236 & 809226 & 6.8 & 5.3379 & TST & \\
\hline CHEMBL 2002599 & 809226 & 4.7 & 5.0048 & TST & \\
\hline CHEMBL1992673 & 809226 & 4.9 & 4.3426 & TST & \\
\hline CHEMBL1973138 & 809226 & 4.7 & 4.4986 & TST & \\
\hline CHEMBL1969151 & 809226 & 6.0 & 5.1578 & TST & \\
\hline CHEMBL1967252 & 809226 & 4.6 & 4.3377 & TST & \\
\hline CHEMBL1993335 & 809226 & 6.2 & 6.8793 & TST & \\
\hline CHEMBL1981492 & 809226 & 3.1 & 3.7042 & TST & \\
\hline CHEMBL1988692 & 809226 & 6.7 & 6.3615 & TST & \\
\hline CHEMBL 2004637 & 809226 & 6.4 & 5.3324 & TST & \\
\hline CHEMBL1993374 & 809226 & 4.7 & 5.4539 & TST & \\
\hline CHEMBL1998680 & 809226 & 4.7 & 4.8255 & TST & \\
\hline CHEMBL592030 & 809226 & 4.7 & 5.1668 & TST & \\
\hline CHEMBL1605605 & 809226 & 4.7 & 4.5929 & TST & \\
\hline CHEMBL1997007 & 809226 & 4.7 & 4.7184 & TST & \\
\hline CHEMBL1970352 & 809226 & 5.8 & 4.6874 & TST & \\
\hline CHEMBL 2002690 & 809226 & 4.7 & 5.6323 & TST & \\
\hline CHEMBL1980167 & 809226 & 5.8 & 6.0375 & TST & \\
\hline CHEMBL1975503 & 809226 & 3.1 & 3.7007 & TST & \\
\hline CHEMBL 278041 & 809226 & 4.7 & 4.919 & TST & \\
\hline CHEMBL 215152 & 809226 & 6.2 & 6.1909 & TST & \\
\hline CHEMBL 2006765 & 809226 & 5.9 & 5.0402 & TST & \\
\hline CHEMBL1986590 & 809226 & 6.4 & 5.9029 & TST & \\
\hline CHEMBL406845 & 809226 & 6.7 & 5.5518 & TST & \\
\hline CHEMBL1980246 & 809226 & 5.8 & $4.8580 e$ & 00000000005 & TST \\
\hline & & & & 20280 & \\
\hline
\end{tabular}




\begin{tabular}{|c|c|c|c|c|}
\hline & & & pplement & al $\mathrm{Ta}$ \\
\hline CHEMBL1983980 & 809226 & 6.0 & 6.0851 & TST \\
\hline CHEMBL1999484 & 809226 & 6.9 & 6.4551 & TST \\
\hline CHEMBL482538 & 809226 & 3.1 & 4.4969 & TST \\
\hline CHEMBL1973399 & 809226 & 3.1 & 3.3087 & TST \\
\hline CHEMBL196363 & 809226 & 9.9 & 9.3919 & TST \\
\hline CHEMBL1986899 & 809226 & 6.7 & 6.4486 & TST \\
\hline CHEMBL1996837 & 809226 & 3.1 & 3.1933 & TST \\
\hline CHEMBL1984038 & 809226 & 4.7 & 4.7926 & TST \\
\hline CHEMBL1968606 & 809226 & 5.9 & 5.6023 & TST \\
\hline CHEMBL1993661 & 809226 & 7.1 & 6.5921 & TST \\
\hline CHEMBL1964718 & 809226 & 3.1 & 3.425 & TST \\
\hline CHEMBL1964441 & 809226 & 8.5 & 8.794 & TST \\
\hline CHEMBL546797 & 809226 & 5.8 & 5.6855 & TST \\
\hline CHEMBL3731605 & 1537621 & 5.9355 & 6.0123 & TRN \\
\hline CHEMBL 3731415 & 1537621 & 6.7212 & 6.1269 & TRN \\
\hline CHEMBL3730434 & 1537621 & 6.301 & 6.4014 & TST \\
\hline CHEMBL3729947 & 1537621 & 5.0357 & 5.9393 & TST \\
\hline CHEMBL3731990 & 1537621 & 5.4634 & 5.8324 & TRN \\
\hline CHEMBL 3727485 & 1537621 & 5.6696 & 5.2816 & TRN \\
\hline CHEMBL3729270 & 1537621 & 6.3768 & 6.0328 & TRN \\
\hline CHEMBL3732142 & 1537621 & 6.6576 & 6.8597 & TRN \\
\hline CHEMBL 3732247 & 1537621 & 6.8861 & 6.4415 & TRN \\
\hline CHEMBL3728444 & 1537621 & 4.7373 & 6.0811 & TRN \\
\hline CHEMBL 3732250 & 1537621 & 5.8477 & 5.63 & TRN \\
\hline CHEMBL3728723 & 1537621 & 6.0132 & 6.0941 & TRN \\
\hline CHEMBL3727973 & 1537621 & 5.3936 & 6.2117 & TRN \\
\hline CHEMBL3730703 & 1537621 & 5.3625 & 5.4902 & TRN \\
\hline CHEMBL3732974 & 1537621 & 5.7055 & 5.2746 & TRN \\
\hline CHEMBL3731950 & 1537621 & 5.9066 & 5.4898 & TRN \\
\hline CHEMBL3728889 & 1537621 & 5.2526 & 6.0694 & TRN \\
\hline CHEMBL3729571 & 1537621 & 5.9706 & 6.0141 & TRN \\
\hline CHEMBL3730889 & 1537621 & 5.6635 & 5.5094 & TRN \\
\hline CHEMBL3728312 & 1537621 & 5.9318 & 6.0024 & TRN \\
\hline CHEMBL3728101 & 1537621 & 5.9747 & 6.5469 & TRN \\
\hline CHEMBL3729382 & 1537621 & 5.767 & 5.4921 & TRN \\
\hline CHEMBL3730916 & 1537621 & 6.301 & 6.3008 & TST \\
\hline CHEMBL 3730642 & 1537621 & 6.8539 & 6.496 & TRN \\
\hline CHEMBL3732268 & 1537621 & 6.1871 & 6.3157 & TRN \\
\hline CHEMBL3733269 & 1537621 & 6.7696 & 5.8245 & TRN \\
\hline CHEMBL3730376 & 1537621 & 5.9747 & 5.6921 & TRN \\
\hline CHEMBL3732733 & 1537621 & 8.0 & 6.3068 & TRN \\
\hline CHEMBL3730948 & 1537621 & 5.7825 & 6.0097 & TRN \\
\hline CHEMBL3728091 & 1537621 & 5.2104 & 5.7738 & TRN \\
\hline CHEMBL3728849 & 1537621 & 5.6421 & 5.7954 & TRN \\
\hline CHEMBL3729470 & 1537621 & 7.699 & 7.1165 & TRN \\
\hline CHEMBL3731620 & 1537621 & 6.2076 & 5.8856 & TRN \\
\hline CHEMBL3730997 & 1537621 & 5.5986 & 6.5236 & TST \\
\hline CHEMBL3728349 & 1537621 & 5.5243 & 5.3828 & TRN \\
\hline
\end{tabular}


Supplemental Table S2.txt

\begin{tabular}{|c|c|c|c|c|c|}
\hline CHEMBL 3728048 & 1537621 & 6.1938 & 5.494 & TRN & \\
\hline CHEMBL 3729991 & 1537621 & 5.3019 & 5.0986 & TRN & \\
\hline CHEMBL 3732687 & 1537621 & 5.9393 & 6.0701 & TRN & \\
\hline CHEMBL 3728810 & 1537621 & 6.1612 & 6.1529 & TRN & \\
\hline CHEMBL 3732489 & 1537621 & 5.1568 & 5.9923 & TRN & \\
\hline CHEMBL3727498 & 1537621 & 5.8827 & 5.8146 & TRN & \\
\hline CHEMBL3728763 & 1537621 & 6.4815 & \multicolumn{2}{|c|}{6.0360000000000005} & TRN \\
\hline CHEMBL 3727957 & 1537621 & 6.0088 & 5.982 & TRN & \\
\hline CHEMBL 3731842 & 1537621 & 5.567 & 5.7411 & TRN & \\
\hline CHEMBL 3732545 & 1537621 & 6.2076 & 6.0972 & TRN & \\
\hline CHEMBL 3731681 & 1537621 & 4.766 & 5.9238 & TRN & \\
\hline CHEMBL3729123 & 1537621 & 6.2596 & 5.3959 & TRN & \\
\hline CHEMBL3730972 & 1537621 & 8.0 & 6.6916 & TRN & \\
\hline CHEMBL3729469 & 1537621 & \multicolumn{3}{|c|}{5.718999999999999} & TRN \\
\hline CHEMBL 3732318 & 1537621 & 6.0458 & 6.3614 & TRN & \\
\hline CHEMBL 3730165 & 1537621 & 6.6021 & 6.1273 & TRN & \\
\hline CHEMBL3732815 & 1537621 & 5.2967 & 6.6643 & TST & \\
\hline CHEMBL3730729 & 1537621 & 4.9622 & \multicolumn{2}{|c|}{5.207000000000001} & TRN \\
\hline CHEMBL3729528 & 1537621 & 5.5361 & 6.6881 & TST & \\
\hline CHEMBL 3733222 & 1537621 & 4.757 & 5.9611 & TST & \\
\hline CHEMBL 3729941 & 1537621 & 5.7258 & 6.1579 & TRN & \\
\hline CHEMBL3731768 & 1537621 & 5.5952 & 6.4488 & TST & \\
\hline CHEMBL3727716 & 1537621 & 6.6198 & 5.8111 & TRN & \\
\hline CHEMBL3730355 & 1537621 & 7.0458 & 6.06 & TST & \\
\hline CHEMBL 3730313 & 1537621 & 4.4944 & 5.6758 & TST & \\
\hline CHEMBL 3728298 & 1537621 & 6.1612 & 6.0473 & TRN & \\
\hline CHEMBL3729638 & 1537621 & 6.4815 & 5.825 & TRN & \\
\hline CHEMBL 3732023 & 1537621 & 6.2007 & 6.2954 & TRN & \\
\hline CHEMBL3732211 & 1537621 & 6.2518 & 6.5998 & TST & \\
\hline CHEMBL 3727757 & 1537621 & 4.5107 & 5.6391 & TRN & \\
\hline CHEMBL 3732259 & 1537621 & 6.1487 & 6.1212 & TRN & \\
\hline CHEMBL3728529 & 1537621 & 4.5391 & 5.7682 & TST & \\
\hline CHEMBL3730406 & 1537621 & 5.7878 & 5.9372 & TRN & \\
\hline CHEMBL3730420 & 1537621 & 5.8665 & 5.9583 & TRN & \\
\hline CHEMBL 3730566 & 1537621 & 5.9666 & 5.8994 & TRN & \\
\hline CHEMBL 3731748 & 1537621 & 5.7305 & 5.4225 & TRN & \\
\hline CHEMBL 3728544 & 1537621 & 4.7226 & 5.7635 & TRN & \\
\hline CHEMBL3731878 & 1537621 & 6.3188 & 5.5115 & TRN & \\
\hline CHEMBL3728396 & 1537621 & 6.5528 & 5.9244 & TRN & \\
\hline CHEMBL3728951 & 1537621 & 5.5406 & 6.2323 & TRN & \\
\hline CHEMBL 3733350 & 1537621 & 6.6778 & 6.2107 & TRN & \\
\hline CHEMBL 3730473 & 1537621 & 6.301 & 5.9391 & TRN & \\
\hline CHEMBL3730936 & 1537621 & 5.5086 & 6.2696 & TRN & \\
\hline CHEMBL3727831 & 1537621 & 5.34200 & 00000000 & 6.1907 & TRN \\
\hline CHEMBL 3730855 & 1537621 & 7.301 & 6.5284 & TRN & \\
\hline CHEMBL 3729928 & 1537621 & 4.7894 & 5.3988 & TRN & \\
\hline CHEMBL 3731934 & 1537621 & 7.301 & 6.1901 & TST & \\
\hline CHEMBL3731129 & 1537621 & 6.585 & 5.9985 & TST & \\
\hline
\end{tabular}


Supplemental Table S2.txt

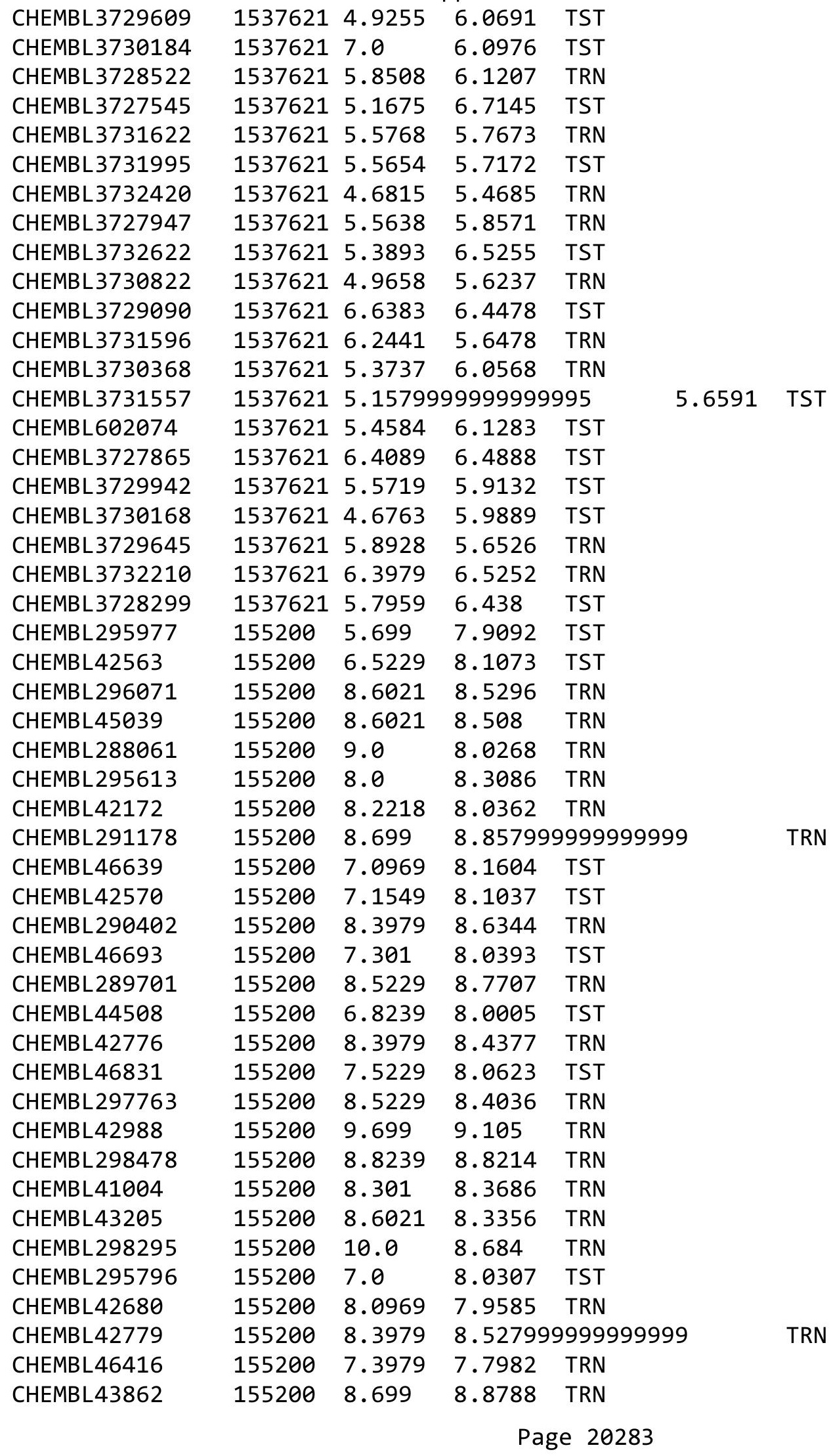




\begin{tabular}{|c|c|c|c|c|c|}
\hline \multicolumn{6}{|c|}{ Supplemental Table S2.txt } \\
\hline CHEMBL45367 & 155200 & 8.5229 & 8.6275 & TRN & \\
\hline CHEMBL46771 & 155200 & 8.699 & 8.904 & TRN & \\
\hline CHEMBL43617 & 155200 & 7.0 & 8.0435 & TST & \\
\hline CHEMBL 290694 & 155200 & 8.699 & 8.5748 & TRN & \\
\hline CHEMBL296294 & 155200 & 8.7696 & 8.413 & TRN & \\
\hline CHEMBL47108 & 155200 & 7.5229 & 7.9015 & TRN & \\
\hline CHEMBL43443 & 155200 & 9.0969 & 8.8531 & TRN & \\
\hline CHEMBL42435 & 155200 & 7.2218 & 8.0995 & TST & \\
\hline CHEMBL44467 & 155200 & 7.699 & 7.9579 & TRN & \\
\hline CHEMBL42713 & 155200 & 7.0969 & 8.0006 & TST & \\
\hline CHEMBL 298294 & 155200 & 8.3979 & 8.676 & TRN & \\
\hline CHEMBL46621 & 155200 & 8.4559 & 8.89200 & 0000000001 & TRN \\
\hline CHEMBL295614 & 155200 & 8.5229 & 8.4738 & TRN & \\
\hline CHEMBL 295329 & 155200 & 8.699 & 8.5325 & TRN & \\
\hline CHEMBL43225 & 155200 & 8.5229 & 8.9138 & TRN & \\
\hline CHEMBL43320 & 155200 & 8.1549 & 8.0483 & TRN & \\
\hline CHEMBL 295224 & 155200 & 8.301 & 8.6464 & TRN & \\
\hline CHEMBL416267 & 155200 & 8.699 & 8.8946 & TRN & \\
\hline CHEMBL 297864 & 155200 & 9.0 & 8.8105 & TRN & \\
\hline CHEMBL42272 & 155200 & 8.5229 & 8.5993 & TRN & \\
\hline CHEMBL43795 & 155200 & 7.301 & 8.0596 & TST & \\
\hline CHEMBL439923 & 155200 & 8.1549 & 8.3761 & TRN & \\
\hline CHEMBL42886 & 155200 & 8.699 & 8.8536 & TRN & \\
\hline CHEMBL 289344 & 155200 & 8.301 & 8.3855 & TRN & \\
\hline CHEMBL42796 & 155200 & 7.1549 & 7.92 & TRN & \\
\hline CHEMBL46714 & 155200 & 8.699 & 8.033 & TRN & \\
\hline CHEMBL43665 & 155200 & 7.699 & 8.3255 & TST & \\
\hline CHEMBL298282 & 155200 & 8.3979 & 8.4849 & TST & \\
\hline CHEMBL3690161 & 1527697 & 9.699 & 9.8769 & TST & \\
\hline CHEMBL3690157 & 1527697 & 9.5229 & 9.4237 & TRN & \\
\hline CHEMBL3690166 & 1527697 & 9.0 & 9.0983 & TRN & \\
\hline CHEMBL 3690171 & 1527697 & 9.5229 & 9.5521 & TRN & \\
\hline CHEMBL3690195 & 1527697 & 8.4202 & 8.2913 & TST & \\
\hline CHEMBL3690173 & 1527697 & 8.6576 & 8.6316 & TRN & \\
\hline CHEMBL3690160 & 1527697 & 8.0044 & 8.8559 & TST & \\
\hline CHEMBL 3690174 & 1527697 & 9.2218 & 9.3283 & TRN & \\
\hline CHEMBL3690177 & 1527697 & 10.0 & 10.038 & TRN & \\
\hline CHEMBL3685839 & 1527697 & 8.9208 & 8.9202 & TRN & \\
\hline CHEMBL3690193 & 1527697 & 8.0555 & 8.988 & TST & \\
\hline CHEMBL3685838 & 1527697 & 9.5229 & 9.499 & TRN & \\
\hline CHEMBL3690184 & 1527697 & 8.9208 & 8.8845 & TRN & \\
\hline CHEMBL3690159 & 1527697 & 9.5229 & 9.9606 & TST & \\
\hline CHEMBL3690155 & 1527697 & 9.699 & 9.7455 & TRN & \\
\hline CHEMBL 3690170 & 1527697 & 9.5229 & 9.54 & TRN & \\
\hline CHEMBL3690186 & 1527697 & 9.3979 & 9.3861 & TRN & \\
\hline CHEMBL3690179 & 1527697 & 8.6383 & 8.684 & TRN & \\
\hline CHEMBL3690172 & 1527697 & 9.699 & 9.7942 & TRN & \\
\hline CHEMBL3690192 & 1527697 & 9.699 & 9.5588 & TRN & \\
\hline
\end{tabular}


Supplemental Table S2.txt

\begin{tabular}{|c|c|c|c|c|}
\hline $\mathrm{E}$ & 97 & & 49 & TST \\
\hline & 527697 & 9.1549 & 9.1606 & \\
\hline 76 & 697 & & & \\
\hline AEMBL & 7697 & $\partial 969$ & & \\
\hline AEMBL3639847 & 527697 & 10.0 & 142 & \\
\hline HEMBL3690165 & 527697 & 10.0 & 9996 & \\
\hline 81 & & 9.5229 & 59 & \\
\hline IFMBI 3690167 & & & & \\
\hline AEMBL3685834 & 697 & 9.0969 & 43 & \\
\hline HEMBL3690169 & 527697 & 8.6576 & 303 & \\
\hline HEMBL3690178 & 697 & 10.0 & 82 & \\
\hline IEMBL369 & 97 & 9.699 & 42 & \\
\hline AEMBL & & & & \\
\hline HEMBL3690187 & 97 & 9.3979 & & \\
\hline AEMBL 369 & 97 & 9.699 & & \\
\hline AEMBL3685842 & 97 & 9.699 & 351 & \\
\hline AEMBL36 & 31 & 229 & & \\
\hline HEMBL 36 & & 969 & & \\
\hline HEMBL3685847 & 97 & 11.0 & & \\
\hline HEMBL369 & & & & \\
\hline HEIMBL3t & 1 & & 572 & RIN \\
\hline AEMBL & & 9. & & $\mathrm{RN}$ \\
\hline HEMBL & & 9. & & \\
\hline HEMBL $369 €$ & & 9.3979 & & \\
\hline HEMBL369 & & & & RN \\
\hline HEMBL3 & & 9. & & RN \\
\hline HEMBL; & & 945 & & וד \\
\hline HFMBI 3 & & 979 & & \\
\hline HEMBL $369 €$ & & 458 & & 「RN \\
\hline HEMBL3690191 & & & & $\Gamma \mathrm{RN}$ \\
\hline HEMBL 368 & & 9. & & RN \\
\hline HEMBL & & 229 & & ST \\
\hline HEMBL & & 9. & & ST \\
\hline HEMBL3690182 & & 8.3468 & & $\mathrm{RN}$ \\
\hline HEMBL3685831 & 97 & 9.0969 & & TST \\
\hline HEMBL3685836 & & 218 & & RN \\
\hline HEMPI & & & & RN \\
\hline HEMBL3 & & 861 & & RN \\
\hline HEMBL3690194 & 597 & 7.4295 & 76 & TST \\
\hline AEMBL172 & a & 083 & & TST \\
\hline HEMBL133 & 0 & 696 & & RN \\
\hline HEMBL169 & & & & TST \\
\hline HEMBL1704084 & 10 & 5.7033 & & TST \\
\hline AEMBL1728454 & 10 & 4.7471 & 95 & TST \\
\hline $\mathrm{MB} \mid 1$ & & & & RN \\
\hline HEMBL1703 & & 1948 & & \\
\hline LHEMBL1698983 & 10 & 5.0623 & 5.2859 & \\
\hline CHEMBL170824 & 737710 & 5.38 & 999 & \\
\hline
\end{tabular}

Page 20285 
Supplemental Table S2.txt

\begin{tabular}{|c|c|c|c|c|}
\hline CHEMBL1725686 & 737710 & 5.7799 & 5.7418 & TRN \\
\hline CHEMBL1729479 & 737710 & 5.1481 & 4.5757 & TST \\
\hline CHEMBL1726224 & 737710 & 5.4461 & 5.5664 & TRN \\
\hline CHEMBL1703772 & 737710 & 5.0635 & 4.5721 & TST \\
\hline CHEMBL1713770 & 737710 & 5.4486 & 5.6459 & TRN \\
\hline CHEMBL1534425 & 737710 & 5.3215 & 5.4639 & TRN \\
\hline CHEMBL1443900 & 737710 & 5.4572 & 5.5611 & TST \\
\hline CHEMBL1703285 & 737710 & 5.1765 & 5.151 & TRN \\
\hline CHEMBL1484306 & 737710 & 5.4989 & 5.4808 & TRN \\
\hline CHEMBL1702412 & 737710 & 4.8761 & 4.9548 & TRN \\
\hline CHEMBL1586567 & 737710 & 4.5017 & 4.6141 & TRN \\
\hline CHEMBL1730381 & 737710 & 4.7986 & 4.65 & TRN \\
\hline CHEMBL1734939 & 737710 & 5.6757 & 5.6223 & TST \\
\hline CHEMBL1722450 & 737710 & 6.0605 & 5.8577 & TRN \\
\hline CHEMBL1713756 & 737710 & 5.983 & 5.8016 & TRN \\
\hline CHEMBL1700716 & 737710 & 3.4948 & 3.545 & TRN \\
\hline CHEMBL1420151 & 737710 & 7.1612 & 7.1459 & TRN \\
\hline CHEMBL1721827 & 737710 & 4.7471 & 4.8278 & TRN \\
\hline CHEMBL1542448 & 737710 & 5.7747 & 5.8093 & TRN \\
\hline CHEMBL1586706 & 737710 & 5.0391 & 5.0109 & TRN \\
\hline CHEMBL1382214 & 737710 & 4.9914 & 4.9511 & TRN \\
\hline CHEMBL1386647 & 737710 & 5.4045 & 5.4503 & TRN \\
\hline CHEMBL1736309 & 737710 & 4.9318 & 5.4545 & TST \\
\hline CHEMBL1705807 & 737710 & 3.4948 & 3.3751 & TRN \\
\hline CHEMBL1729109 & 737710 & 5.3363 & 5.221 & TRN \\
\hline CHEMBL1730076 & 737710 & 5.8327 & 5.9358 & TRN \\
\hline CHEMBL1710129 & 737710 & 4.8314 & 4.7808 & TRN \\
\hline CHEMBL1715275 & 737710 & 5.7747 & 5.7324 & TRN \\
\hline CHEMBL1416169 & 737710 & 5.6517 & 5.6195 & TRN \\
\hline CHEMBL1733320 & 737710 & 3.4948 & 3.58699 & 99999999997 \\
\hline CHEMBL1726562 & 737710 & 5.4225 & 5.4543 & TST \\
\hline CHEMBL1709480 & 737710 & 4.8013 & 5.3572 & TST \\
\hline CHEMBL1719526 & 737710 & 5.1146 & 5.4528 & TST \\
\hline CHEMBL1705660 & 737710 & 3.4948 & 3.5369 & TRN \\
\hline CHEMBL1727434 & 737710 & 5.3883 & 5.3178 & TRN \\
\hline CHEMBL1707517 & 737710 & 5.5867 & 5.4689 & TRN \\
\hline CHEMBL1701998 & 737710 & 5.4737 & 5.54700 & 0000000001 \\
\hline CHEMBL1430124 & 737710 & 5.308 & 5.2789 & TRN \\
\hline CHEMBL1715078 & 737710 & 3.4948 & 3.5227 & TRN \\
\hline CHEMBL1305795 & 737710 & 4.6108 & 4.591 & TRN \\
\hline CHEMBL1721058 & 737710 & 3.4948 & 3.5422 & TRN \\
\hline CHEMBL1718220 & 737710 & 6.1798 & 6.1496 & TRN \\
\hline CHEMBL1310336 & 737710 & 4.6091 & 4.6195 & TRN \\
\hline CHEMBL1719423 & 737710 & 5.4802 & 4.9651 & TST \\
\hline CHEMBL1411573 & 737710 & 6.0241 & 6.0206 & TST \\
\hline CHEMBL1449870 & 737710 & 3.4948 & 3.4007 & TRN \\
\hline CHEMBL1481494 & 737710 & 4.7721 & 4.7653 & TRN \\
\hline CHEMBL1736438 & 737710 & 5.4401 & 5.4968 & TST \\
\hline
\end{tabular}




\begin{tabular}{|c|c|c|c|c|c|c|}
\hline & & \multicolumn{5}{|c|}{ Supplemental Table S2.txt } \\
\hline CHEMBL1718537 & 737710 & 5.5157 & 5.5154 & TRN & & \\
\hline CHEMBL1717402 & 737710 & 3.4948 & 3.5025 & TRN & & \\
\hline CHEMBL1402210 & 737710 & 4.7258 & 4.7412 & TRN & & \\
\hline CHEMBL1706882 & 737710 & 4.7077 & 4.6919 & TRN & & \\
\hline CHEMBL1368569 & 737710 & 6.4535 & 6.4168 & TRN & & \\
\hline CHEMBL1698745 & 737710 & 4.6038 & 4.5129 & TRN & & \\
\hline CHEMBL1727053 & 737710 & 6.3242 & 5.4286 & TST & & \\
\hline CHEMBL1465869 & 737710 & 5.27 & 5.28600 & 2000 & 05 & TP \\
\hline CHEMBL1720072 & 737710 & 3.4948 & 3.5006 & TRN & & \\
\hline CHEMBL3698903 & 1640306 & 8.3188 & 7.1834 & TRN & & \\
\hline CHEMBL 3695258 & 1640306 & \multicolumn{3}{|c|}{6.2620000000000005} & 6.7506 & RN \\
\hline CHEMBL3698891 & 1640306 & 6.8416 & 7.3293 & TST & & \\
\hline CHEMBL3695276 & 1640306 & 7.433 & 7.05 & TRN & & \\
\hline CHEMBL3698784 & 1640306 & 6.2165 & 6.6475 & TRN & & \\
\hline CHEMBL3698897 & 1640306 & 7.6676 & 7.5154 & TRN & & \\
\hline CHEMBL3695287 & 1640306 & 6.4789 & 6.2437 & TRN & & \\
\hline CHEMBL3698902 & 1640306 & 8.6021 & 7.865 & TRN & & \\
\hline CHEMBL3695254 & 1640306 & 7.9626 & 7.5478 & TST & & \\
\hline CHEMBL3695260 & 1640306 & 7.4535 & 7.5599 & TRN & & \\
\hline CHEMBL3698857 & 1640306 & 6.7462 & 7.4326 & TST & & \\
\hline CHEMBL3698787 & 1640306 & 6.8268 & 6.4787 & TRN & & \\
\hline CHEMBL3698860 & 1640306 & 6.1051 & 6.8847 & TRN & & \\
\hline CHEMBL 3695240 & 1640306 & 7.9208 & 7.4114 & TRN & & \\
\hline CHEMBL3898898 & 1640306 & 7.3595 & 6.8115 & TST & & \\
\hline CHEMBL3698770 & 1640306 & 7.2924 & 6.9754 & TRN & & \\
\hline CHEMBL3698795 & 1640306 & 7.4461 & 8.0401 & TRN & & \\
\hline CHEMBL3698789 & 1640306 & 6.7696 & 7.6839 & TRN & & \\
\hline CHEMBL 3698805 & 1640306 & 6.4001 & 6.433 & TST & & \\
\hline CHEMBL3698775 & 1640306 & 7.8962 & 7.4633 & TRN & & \\
\hline CHEMBL3698758 & 1640306 & 6.3585 & 7.0769 & TST & & \\
\hline CHEMBL3698882 & 1640306 & 6.585 & 7.1901 & TRN & & \\
\hline CHEMBL3698845 & 1640306 & 6.5214 & 6.5281 & TRN & & \\
\hline CHEMBL 3698826 & 1640306 & 6.6021 & 6.8164 & TRN & & \\
\hline CHEMBL3698833 & 1640306 & 6.7258 & 7.2942 & TRN & & \\
\hline CHEMBL 3698840 & 1640306 & 7.8477 & 7.195 & TRN & & \\
\hline CHEMBL3698873 & 1640306 & 6.9918 & 7.1435 & TRN & & \\
\hline CHEMBL3698874 & 1640306 & 7.9747 & 7.7682 & TRN & & \\
\hline CHEMBL3698771 & 1640306 & 7.8633 & 7.7032 & TST & & \\
\hline CHEMBL3698753 & 1640306 & 7.8297 & 7.0961 & TRN & & \\
\hline CHEMBL3698850 & 1640306 & 7.5686 & 7.0304 & TRN & & \\
\hline CHEMBL3698867 & 1640306 & 6.6247 & 7.2031 & TRN & & \\
\hline CHEMBL3698767 & 1640306 & 6.426 & 7.2921 & TRN & & \\
\hline CHEMBL3695248 & 1640306 & 7.3507 & 7.1985 & TST & & \\
\hline CHEMBL3695222 & 1640306 & 6.9205 & 6.9898 & TRN & & \\
\hline CHEMBL3695226 & 1640306 & 6.3072 & 6.5507 & TRN & & \\
\hline CHEMBL3698798 & 1640306 & 6.8041 & 7.308 & TST & & \\
\hline CHEMBL3698859 & 1640306 & 6.301 & 6.7704 & TRN & & \\
\hline CHEMBL3698855 & 1640306 & 7.2774 & 7.3343 & TRN & & \\
\hline
\end{tabular}

Page 20287 
Supplemental Table S2.txt

\begin{tabular}{|c|c|c|c|c|c|c|}
\hline CHEMBL 3944932 & 1640306 & 7.8097 & 7.0749 & TRN & & \\
\hline CHEMBL 3698847 & 1640306 & 6.7404 & 7.0608 & TRN & & \\
\hline CHEMBL3698830 & 1640306 & 6.0 & 7.1291 & TRN & & \\
\hline CHEMBL 3695270 & 1640306 & 6.8153 & 7.4947 & TST & & \\
\hline CHEMBL 3698814 & 1640306 & 8.4437 & 7.9039 & TRN & & \\
\hline CHEMBL 3695281 & 1640306 & 7.3726 & 7.0551 & TRN & & \\
\hline CHEMBL 3984664 & 1640306 & 7.9788 & 7.1452 & TST & & \\
\hline CHEMBL 3698887 & 1640306 & 6.1308 & 6.0105 & TRN & & \\
\hline CHEMBL 3695217 & 1640306 & 6.0 & 6.9279 & TRN & & \\
\hline CHEMBL 3698864 & 1640306 & 7.3363 & 7.3011 & TRN & & \\
\hline CHEMBL 3695215 & 1640306 & 6.4866 & 6.8781 & TRN & & \\
\hline CHEMBL 3695262 & 1640306 & 8.1487 & 7.0643 & TRN & & \\
\hline CHEMBL 3698856 & 1640306 & 7.0353 & 7.2172 & TST & & \\
\hline CHEMBL3698773 & 1640306 & 7.7905 & 7.7086 & TRN & & \\
\hline CHEMBL 3698766 & 1640306 & 6.5638 & 7.044 & TRN & & \\
\hline CHEMBL 3698827 & 1640306 & 8.8539 & 6.4785 & TST & & \\
\hline CHEMBL3939135 & 1640306 & 7.4597 & 6.6657 & TRN & & \\
\hline CHEMBL 3698889 & 1640306 & 7.2832 & 6.3879 & TST & & \\
\hline CHEMBL 3698907 & 1640306 & 7.9393 & 8.1608 & TRN & & \\
\hline CHEMBL3698904 & 1640306 & 8.699 & 7.865 & TRN & & \\
\hline CHEMBL 3695219 & 1640306 & 6.9626 & 7.0989 & TRN & & \\
\hline CHEMBL 3695234 & 1640306 & 7.1355 & 7.0 & TST & & \\
\hline CHEMBL 3698862 & 1640306 & 7.9747 & 7.0562 & TRN & & \\
\hline CHEMBL 3698885 & 1640306 & 6.2248 & 6.6333 & TRN & & \\
\hline CHEMBL 3698828 & 1640306 & 7.301 & 6.5867 & TRN & & \\
\hline CHEMBL 3695261 & 1640306 & 7.2161 & 6.6628 & TRN & & \\
\hline CHEMBL3698756 & 1640306 & 6.8861 & 6.8279 & TST & & \\
\hline CHEMBL 3695249 & 1640306 & 8.3565 & 7.2261 & TRN & & \\
\hline CHEMBL 3695267 & 1640306 & 7.433 & 7.224 & TRN & & \\
\hline CHEMBL 3695280 & 1640306 & 7.4935 & 6.9062 & TRN & & \\
\hline CHEMBL 3698842 & 1640306 & 6.9397 & 6.765 & TRN & & \\
\hline CHEMBL 3698757 & 1640306 & 6.4342 & 6.7312 & TRN & & \\
\hline CHEMBL 3698852 & 1640306 & 6.9626 & 7.0594 & TRN & & \\
\hline CHEMBL3698869 & 1640306 & 7.8013 & 7.5171 & TRN & & \\
\hline CHEMBL 3698890 & 1640306 & 7.7423 & 7.303 & TRN & & \\
\hline CHEMBL3698796 & 1640306 & 7.224 & 6.9586 & TRN & & \\
\hline CHEMBL 3698883 & 1640306 & 5.4823 & 7.3533 & TRN & & \\
\hline CHEMBL 3698825 & 1640306 & 7.9355 & 7.9039 & TRN & & \\
\hline CHEMBL 3695255 & 1640306 & 7.21899 & 99999999 & 99 & 6.9371 & TRN \\
\hline CHEMBL 3985983 & 1640306 & 6.806 & 6.5418 & TRN & & \\
\hline CHEMBL 3695233 & 1640306 & 6.251 & 6.6939 & TRN & & \\
\hline CHEMBL 3695263 & 1640306 & 7.3143 & 6.7736 & TRN & & \\
\hline CHEMBL 3698774 & 1640306 & 7.3565 & 7.2388 & TRN & & \\
\hline CHEMBL 3698778 & 1640306 & 6.0 & 7.2894 & TRN & & \\
\hline CHEMBL 3695224 & 1640306 & 6.0 & 6.9298 & TRN & & \\
\hline CHEMBL 3695245 & 1640306 & 6.0 & 6.4264 & TST & & \\
\hline CHEMBL 3698861 & 1640306 & 7.8356 & 7.5091 & TRN & & \\
\hline CHEMBL 3698816 & 1640306 & 8.0458 & 8.3317 & TRN & & \\
\hline
\end{tabular}

Page 20288 
Supplemental Table S2.txt

\begin{tabular}{|c|c|c|c|c|c|c|}
\hline CHEMBL 3945015 & 1640306 & 6.3706 & 6.7701 & TRN & & \\
\hline CHEMBL 3639941 & 1640306 & 7.6904 & 7.1184 & TRN & & \\
\hline CHEMBL3698841 & 1640306 & 7.1421 & 7.1689 & TRN & & \\
\hline CHEMBL3698755 & 1640306 & 6.8861 & 7.0464 & TRN & & \\
\hline CHEMBL 3698762 & 1640306 & \multicolumn{3}{|c|}{ 7.718999999999999 } & 6.8875 & TRN \\
\hline CHEMBL 3695229 & 1640306 & 7.2832 & 7.1734 & TRN & & \\
\hline CHEMBL3695250 & 640306 & 6.3595 & 7.245 & TRN & & \\
\hline CHEMBL 3698776 & 1640306 & 7.6819 & 7.1551 & TST & & \\
\hline CHEMBL3698751 & 1640306 & 7.4377 & 6.7538 & TRN & & \\
\hline CHEMBL 3698800 & 1640306 & \multicolumn{3}{|c|}{6.2139999999999995} & 7.4847 & TRN \\
\hline CHEMBL3698875 & 1640306 & 6.2692 & 7.3439 & TST & & \\
\hline CHEMBL3698879 & 1640306 & 6.0 & 6.6702 & TRN & & \\
\hline CHEMBL3698802 & 1640306 & 3.699 & 5.3876 & TRN & & \\
\hline CHEMBL3698772 & 1640306 & 7.3565 & 7.5083 & TRN & & \\
\hline CHEMBL3698781 & 1640306 & 7.9702 & 7.5183 & TRN & & \\
\hline CHEMBL3695273 & 1640306 & 6.0 & 7.2907 & TRN & & \\
\hline CHEMBL3695279 & 1640306 & 7.3344 & 7.2276 & TRN & & \\
\hline CHEMBL 3698901 & 1640306 & 8.0706 & 7.1827 & TRN & & \\
\hline CHEMBL 3698821 & 1640306 & 7.6402 & 7.4943 & TRN & & \\
\hline CHEMBL 3698819 & 1640306 & \multicolumn{3}{|c|}{7.4510000000000005} & 7.0854 & TRN \\
\hline CHEMBL3698858 & 1640306 & 6.0 & 6.6658 & TRN & & \\
\hline CHEMBL3698792 & 1640306 & 6.8941 & 7.9496 & TRN & & \\
\hline CHEMBL 3695243 & 1640306 & 7.8041 & \multicolumn{3}{|c|}{7.0920000000000005} & TST \\
\hline CHEMBL3698843 & 1640306 & 7.6799 & 7.4683 & TRN & & \\
\hline CHEMBL 3698844 & 1640306 & 7.0155 & 6.9678 & TRN & & \\
\hline CHEMBL 3698900 & 1640306 & 8.8539 & 8.0689 & TRN & & \\
\hline CHEMBL3698836 & 1640306 & 7.7122 & 7.4218 & TRN & & \\
\hline CHEMBL 3695251 & 1640306 & 7.4023 & 7.1861 & TRN & & \\
\hline CHEMBL3698899 & 1640306 & 8.7447 & 8.0689 & TRN & & \\
\hline CHEMBL3698785 & 1640306 & 6.8668 & 7.0388 & TRN & & \\
\hline CHEMBL 3698754 & 1640306 & 6.0 & 6.6704 & TRN & & \\
\hline CHEMBL3900785 & 1640306 & 6.04 & 6.3542 & TST & & \\
\hline CHEMBL 3698884 & 1640306 & 7.6536 & 7.5065 & TRN & & \\
\hline CHEMBL3933973 & 1640306 & 6.3069 & 5.657 & TRN & & \\
\hline CHEMBL3698894 & 1640306 & \multicolumn{3}{|c|}{7.3420000000000005} & 6.9502 & TRN \\
\hline CHEMBL3698854 & 1640306 & 6.6576 & 6.8871 & TRN & & \\
\hline CHEMBL 3695244 & 1640306 & 7.8697 & 7.80200 & 0000000000 & 05 & TRN \\
\hline CHEMBL3909917 & 1640306 & 7.1238 & 5.6956 & TST & & \\
\hline CHEMBL3695266 & 1640306 & 7.2373 & 7.1334 & TRN & & \\
\hline CHEMBL 3698834 & 1640306 & 7.1726 & 7.7553 & TST & & \\
\hline CHEMBL 3698908 & 1640306 & \multicolumn{3}{|c|}{5.7379999999999995} & 5.8853 & TRN \\
\hline CHEMBL 3698835 & 1640306 & 6.8133 & 6.9661 & TRN & & \\
\hline CHEMBL3698876 & 1640306 & 7.2097 & 7.5565 & TST & & \\
\hline CHEMBL3930169 & 1640306 & 6.9821 & 6.8226 & TRN & & \\
\hline CHEMBL 3698817 & 1640306 & 7.5258 & 7.091 & TRN & & \\
\hline CHEMBL 3698888 & 1640306 & 6.4168 & 5.54 & TRN & & \\
\hline CHEMBL 3698848 & 1640306 & 6.7399 & 6.9338 & TRN & & \\
\hline CHEMBL 3698881 & 1640306 & 6.0405 & 7.1165 & TRN & & \\
\hline
\end{tabular}




$$
\text { Supplemental Table S2.txt }
$$

\begin{tabular}{|c|c|c|c|c|c|}
\hline CHEMBL3698809 & 1640306 & 8.1135 & 7.8403 & TRN & \\
\hline CHEMBL3698906 & 1640306 & 7.475 & 7.6736 & TRN & \\
\hline CHEMBL3695256 & 1640306 & 7.9547 & 7.7586 & TRN & \\
\hline CHEMBL3698872 & 1640306 & 7.1463 & 6.9823 & TRN & \\
\hline CHEMBL3698870 & 1640306 & 6.8539 & 6.9361 & TRN & \\
\hline CHEMBL3698811 & 1640306 & 7.1798 & 7.0322 & TRN & \\
\hline CHEMBL3695253 & 1640306 & 7.7878 & 7.3769 & TRN & \\
\hline CHEMBL 3698760 & 1640306 & 7.0691 & 6.9211 & TST & \\
\hline CHEMBL3695228 & 1640306 & 6.7235 & 7.2397 & TRN & \\
\hline CHEMBL3695277 & 1640306 & 7.3737 & 6.8672 & TRN & \\
\hline CHEMBL3698866 & 1640306 & 7.1278 & 6.87200 & 2000000001 & TRN \\
\hline CHEMBL3695274 & 1640306 & 6.51 & 6.9014 & TRN & \\
\hline CHEMBL3695278 & 1640306 & 6.9547 & 6.3551 & TRN & \\
\hline CHEMBL3698868 & 1640306 & 7.3487 & 7.2119 & TRN & \\
\hline CHEMBL3698818 & 1640306 & 8.0044 & 7.1116 & TRN & \\
\hline CHEMBL3698896 & 1640306 & 6.2993 & 7.4798 & TST & \\
\hline CHEMBL3698829 & 1640306 & 6.4271 & 7.0624 & TRN & \\
\hline CHEMBL3698813 & 1640306 & 8.0655 & 7.2649 & TRN & \\
\hline CHEMBL3698849 & 1640306 & 7.7747 & 6.855 & TRN & \\
\hline CHEMBL3698763 & 1640306 & 6.0 & 6.8216 & TRN & \\
\hline CHEMBL3698786 & 1640306 & 7.5768 & 7.3966 & TRN & \\
\hline CHEMBL3695238 & 1640306 & 6.8938 & 7.8902 & TST & \\
\hline CHEMBL3698797 & 1640306 & 6.1993 & 7.2956 & TRN & \\
\hline CHEMBL3698759 & 1640306 & 7.2612 & 5.9895 & TST & \\
\hline CHEMBL 3698877 & 1640306 & 7.3947 & 7.7439 & TRN & \\
\hline CHEMBL3698838 & 1640306 & 6.8069 & 6.2858 & TRN & \\
\hline CHEMBL3698832 & 1640306 & 6.3045 & 6.3949 & TRN & \\
\hline CHEMBL3698768 & 1640306 & 7.9626 & 7.7672 & TRN & \\
\hline CHEMBL3698839 & 1640306 & 6.4921 & 6.4926 & TRN & \\
\hline CHEMBL3647959 & 1640306 & 6.0 & 6.9244 & TRN & \\
\hline CHEMBL3698831 & 1640306 & 5.8861 & 6.2575 & TRN & \\
\hline CHEMBL3698790 & 1640306 & 7.1107 & 7.3811 & TRN & \\
\hline CHEMBL3698823 & 1640306 & 6.8928 & 6.4234 & TST & \\
\hline CHEMBL3698769 & 1640306 & 7.3904 & 7.4704 & TRN & \\
\hline CHEMBL3698806 & 1640306 & 7.0862 & 6.6655 & TST & \\
\hline CHEMBL3698803 & 1640306 & 5.5465 & 5.5938 & TST & \\
\hline CHEMBL3698871 & 1640306 & 6.341 & 6.6032 & TRN & \\
\hline CHEMBL3695231 & 1640306 & 6.0778 & 5.7598 & TST & \\
\hline CHEMBL3695218 & 1640306 & 8.3546 & 8.224 & TRN & \\
\hline CHEMBL 3695283 & 1640306 & 7.1494 & 6.9007 & TRN & \\
\hline CHEMBL3647958 & 1640306 & 6.0 & 7.0228 & TRN & \\
\hline CHEMBL3698878 & 1640306 & \multicolumn{2}{|c|}{7.752000000000001} & 8.0689 & TRN \\
\hline CHEMBL3647961 & 1640306 & 7.52 & 6.8144 & TST & \\
\hline CHEMBL3698820 & 1640306 & 7.8601 & 7.1098 & TRN & \\
\hline CHEMBL3698794 & 1640306 & 7.4449 & 7.8593 & TRN & \\
\hline CHEMBL3698898 & 1640306 & 8.5528 & 5.6054 & TST & \\
\hline CHEMBL3900892 & 1640306 & 6.0 & 6.32299 & 99999999995 & TRN \\
\hline CHEMBL3698791 & 1640306 & 7.2013 & 7.7671 & TRN & \\
\hline
\end{tabular}




\begin{tabular}{|c|c|c|c|c|c|}
\hline \multicolumn{6}{|c|}{ Supplemental Table s2.txt } \\
\hline CHEMBL3698865 & 1640306 & 7.7747 & 7.4322 & TRN & \\
\hline CHEMBL3695216 & 1640306 & 6.93 & 6.5576 & TRN & \\
\hline CHEMBL3647963 & 1640306 & 7.3655 & 7.865 & TRN & \\
\hline CHEMBL 3698846 & 1640306 & 7.8125 & 7.9221 & TRN & \\
\hline CHEMBL3698788 & 1640306 & 6.9397 & 7.6125 & TRN & \\
\hline CHEMBL 3695220 & 1640306 & 6.0 & 7.0161 & TRN & \\
\hline CHEMBL3695221 & 1640306 & 8.7959 & 8.0535 & TRN & \\
\hline CHEMBL3695265 & 1640306 & 7.4001 & 7.0943 & TRN & \\
\hline CHEMBL 3695268 & 1640306 & 7.4271 & 7.1071 & TRN & \\
\hline CHEMBL3695269 & 1640306 & 7.6402 & 6.8657 & TRN & \\
\hline CHEMBL 3698837 & 1640306 & 6.8182 & 7.3606 & TRN & \\
\hline CHEMBL3695232 & 1640306 & 5.8722 & 6.5638 & TST & \\
\hline CHEMBL 3695257 & 1640306 & 7.0097 & 6.6875 & TRN & \\
\hline CHEMBL 3698752 & 1640306 & 7.3468 & 6.5045 & TRN & \\
\hline CHEMBL3695236 & 1640306 & 7.7235 & 7.6536 & TRN & \\
\hline CHEMBL3695242 & 1640306 & 8.5686 & 8.0299 & TRN & \\
\hline CHEMBL3695286 & 1640306 & 7.0362 & 7.0703 & TRN & \\
\hline CHEMBL3698851 & 1640306 & 6.0 & 6.6432 & TRN & \\
\hline CHEMBL 3698764 & 1640306 & 8.3768 & 7.8256 & TST & \\
\hline CHEMBL3889570 & 1640306 & 7.52 & 6.9261 & TRN & \\
\hline CHEMBL3698880 & 1640306 & 6.0 & 6.4001 & TST & \\
\hline CHEMBL3698895 & 1640306 & 7.5243 & 7.12299 & 9999999999 & TST \\
\hline CHEMBL3695282 & 1640306 & 6.4498 & 7.33799 & 9999999999 & TST \\
\hline CHEMBL3698804 & 1640306 & 6.6882 & 4.8422 & TST & \\
\hline CHEMBL3695237 & 1640306 & 6.0 & 7.9213 & TST & \\
\hline CHEMBL3695235 & 1640306 & 8.5086 & 7.8363 & TST & \\
\hline CHEMBL3698793 & 1640306 & 7.6091 & 8.1039 & TST & \\
\hline CHEMBL3698799 & 1640306 & 7.2161 & 6.7809 & TST & \\
\hline CHEMBL3695259 & 1640306 & 7.1261 & 6.4095 & TST & \\
\hline CHEMBL3695272 & 1640306 & 8.2441 & 7.3367 & TST & \\
\hline CHEMBL3695284 & 1640306 & 7.4535 & 7.38700 & 00000000005 & TST \\
\hline CHEMBL3695252 & 1640306 & 7.1035 & 7.2764 & TST & \\
\hline CHEMBL3698765 & 1640306 & 6.0 & 7.865 & TST & \\
\hline CHEMBL3698853 & 1640306 & 6.9547 & 7.3425 & TST & \\
\hline CHEMBL3698801 & 1640306 & 6.0 & 6.2506 & TST & \\
\hline CHEMBL3698863 & 1640306 & 6.8013 & 7.2975 & TST & \\
\hline CHEMBL3698905 & 1640306 & 6.4179 & 7.5923 & TST & \\
\hline CHEMBL3695247 & 1640306 & 3.0 & 7.1071 & TST & \\
\hline CHEMBL3917702 & 1640306 & 6.5391 & 6.9842 & TST & \\
\hline CHEMBL3647960 & 1640306 & 8.0458 & 7.865 & TST & \\
\hline CHEMBL1604429 & 688270 & 4.4 & 4.6972 & TRN & \\
\hline CHEMBL1319452 & 688270 & 4.9 & 4.5119 & TRN & \\
\hline CHEMBL362919 & 688270 & 4.7 & 4.5285 & TRN & \\
\hline CHEMBL1489568 & 688270 & 4.4 & 4.3426 & TRN & \\
\hline CHEMBL167513 & 688270 & 4.5 & 4.3755 & TRN & \\
\hline CHEMBL1562104 & 688270 & 5.6 & 5.46899 & 9999999999 & TRN \\
\hline CHEMBL1303139 & 688270 & 5.5 & 5.2563 & TRN & \\
\hline CHEMBL1391326 & 688270 & 4.6 & 4.4006 & TRN & \\
\hline
\end{tabular}




\begin{tabular}{|c|c|c|c|c|}
\hline \multicolumn{5}{|c|}{ Supplemental Table S2.txt } \\
\hline CHEMBL1304981 & 688270 & 4.3 & 4.2417 & TST \\
\hline CHEMBL1600998 & 688270 & 5.3 & 5.5448 & TRN \\
\hline CHEMBL1558796 & 688270 & 4.4 & 4.6456 & TRN \\
\hline CHEMBL510539 & 688270 & 4.2 & 4.705 & TRN \\
\hline CHEMBL1236200 & 688270 & 4.1 & 4.4481 & TRN \\
\hline CHEMBL1439332 & 688270 & 8.8861 & 4.7148 & TRN \\
\hline CHEMBL1330518 & 688270 & 4.3 & 4.3751 & TRN \\
\hline CHEMBL433721 & 688270 & 4.6 & 4.4788 & TRN \\
\hline CHEMBL1492884 & 688270 & 4.4 & 4.4364 & TRN \\
\hline CHEMBL486193 & 688270 & 4.3 & 4.7847 & TRN \\
\hline CHEMBL1414154 & 688270 & 4.3 & 4.2212 & TRN \\
\hline CHEMBL289277 & 688270 & 4.3 & 4.4309 & TRN \\
\hline CHEMBL1524617 & 688270 & 5.4 & 5.2006 & TST \\
\hline CHEMBL1510786 & 688270 & 4.4 & 4.5108 & TST \\
\hline CHEMBL1309179 & 688270 & 5.1 & 4.8682 & TRN \\
\hline CHEMBL1530684 & 688270 & 4.4 & 4.4577 & TRN \\
\hline CHEMBL1522486 & 688270 & 4.8 & 4.6531 & TRN \\
\hline CHEMBL1519327 & 688270 & 6.3 & 6.4885 & TRN \\
\hline CHEMBL1142 & 688270 & 4.6 & 4.4228 & TRN \\
\hline CHEMBL1612246 & 688270 & 4.5 & 4.5517 & TRN \\
\hline CHEMBL1585396 & 688270 & 4.3 & 4.3895 & TRN \\
\hline CHEMBL 28 & 688270 & 4.3 & 4.348 & TRN \\
\hline CHEMBL1566369 & 688270 & 4.5 & 4.4558 & TRN \\
\hline CHEMBL1235157 & 688270 & 4.3 & 4.4386 & TRN \\
\hline CHEMBL 70582 & 688270 & 4.8 & 4.542 & TRN \\
\hline CHEMBL144530 & 688270 & 4.5 & 4.3667 & TRN \\
\hline CHEMBL1492729 & 688270 & 4.8 & 4.7521 & TRN \\
\hline CHEMBL1369243 & 688270 & 4.3 & 4.4169 & TRN \\
\hline CHEMBL1448387 & 688270 & 4.4 & 4.6451 & TRN \\
\hline CHEMBL454173 & 688270 & 6.0 & 4.7313 & TRN \\
\hline CHEMBL1545634 & 688270 & 6.6 & 6.6791 & TRN \\
\hline CHEMBL 140 & 688270 & 4.6 & 4.4338 & TRN \\
\hline CHEMBL1531716 & 688270 & 4.4 & 4.435 & TRN \\
\hline CHEMBL1526319 & 688270 & 4.5 & 4.4385 & TRN \\
\hline CHEMBL1609459 & 688270 & 5.1 & 5.2371 & TRN \\
\hline CHEMBL1430204 & 688270 & 4.5 & 4.4815 & TRN \\
\hline CHEMBL540851 & 688270 & 4.8 & 4.4842 & TST \\
\hline CHEMBL1456906 & 688270 & 4.4 & 4.6473 & TRN \\
\hline CHEMBL443949 & 688270 & 4.4 & 4.507 & TRN \\
\hline CHEMBL194399 & 688270 & 4.3 & 4.3548 & TRN \\
\hline CHEMBL1462419 & 688270 & 4.3 & 4.4628 & TST \\
\hline CHEMBL509531 & 688270 & 4.7 & 4.9372 & TRN \\
\hline CHEMBL1373184 & 688270 & 4.4 & 4.4083 & TRN \\
\hline CHEMBL1366408 & 688270 & 4.3 & 4.6504 & TRN \\
\hline CHEMBL1308088 & 688270 & 4.9 & 4.928 & TRN \\
\hline CHEMBL1452158 & 688270 & 4.3 & 4.3339 & TRN \\
\hline CHEMBL1393325 & 688270 & 4.3 & 4.4061 & TRN \\
\hline CHEMBL334255 & 688270 & 4.8 & 5.0629 & TRN \\
\hline
\end{tabular}




\begin{tabular}{|c|c|c|c|c|}
\hline & & & pplement & $\mathrm{a} \perp \mathrm{Ta}$ \\
\hline CHEMBL2373279 & 688270 & 4.3 & 4.6142 & TRN \\
\hline CHEMBL329673 & 688270 & 4.3 & 4.4048 & TRN \\
\hline CHEMBL1576086 & 688270 & 4.5 & 4.4576 & TRN \\
\hline CHEMBL1569493 & 688270 & 6.2 & 6.0174 & TRN \\
\hline CHEMBL 242080 & 688270 & 4.3 & 4.5834 & TRN \\
\hline CHEMBL 364900 & 688270 & 4.3 & 4.7172 & TRN \\
\hline CHEMBL1523215 & 688270 & 4.4 & 4.5229 & TRN \\
\hline CHEMBL462576 & 688270 & 4.3 & 4.5186 & TRN \\
\hline CHEMBL1565705 & 688270 & 4.1 & 4.3559 & TRN \\
\hline CHEMBL1566504 & 688270 & 4.4 & 4.4122 & TRN \\
\hline CHEMBL91732 & 688270 & 4.1 & 4.7039 & TST \\
\hline CHEMBL389950 & 688270 & 4.1 & 4.2824 & TST \\
\hline CHEMBL1338613 & 688270 & 4.5 & 4.407 & TST \\
\hline CHEMBL31425 & 688270 & 4.1 & 4.4342 & TRN \\
\hline CHEMBL1408847 & 688270 & 5.4 & 5.3962 & TRN \\
\hline CHEMBL1465793 & 688270 & 4.3 & 4.4069 & TST \\
\hline CHEMBL1418603 & 688270 & 4.1 & 4.2622 & TRN \\
\hline CHEMBL318275 & 688270 & 4.3 & 4.4957 & TRN \\
\hline CHEMBL40274 & 688270 & 4.3 & 4.621 & TRN \\
\hline CHEMBL1331245 & 688270 & 4.3 & 4.271 & TRN \\
\hline CHEMBL346918 & 688270 & 4.1 & 4.4509 & TST \\
\hline CHEMBL1549844 & 688270 & 4.7 & 4.6922 & TST \\
\hline CHEMBL1472377 & 688270 & 4.3 & 4.4649 & TRN \\
\hline CHEMBL195953 & 688270 & 4.3 & 4.2827 & TRN \\
\hline CHEMBL196537 & 688270 & 4.3 & 4.3175 & TRN \\
\hline CHEMBL1602699 & 688270 & 5.4 & 5.3839 & TRN \\
\hline CHEMBL1492104 & 688270 & 4.9 & 4.7853 & TST \\
\hline CHEMBL167423 & 688270 & 4.3 & 4.3201 & TRN \\
\hline CHEMBL1458681 & 688270 & 4.4 & 4.4332 & TRN \\
\hline CHEMBL1447588 & 688270 & 4.9 & 5.1098 & TST \\
\hline CHEMBL1450123 & 688270 & 4.3 & 4.3891 & TST \\
\hline CHEMBL1409985 & 688270 & 5.5 & 5.3817 & TRN \\
\hline CHEMBL8739 & 688270 & 4.4 & 4.3032 & TRN \\
\hline CHEMBL1569226 & 688270 & 5.6 & 5.3096 & TRN \\
\hline CHEMBL 280998 & 688270 & 4.7 & 4.4691 & TRN \\
\hline CHEMBL1562553 & 688270 & 4.4 & 4.5166 & TRN \\
\hline CHEMBL1484480 & 688270 & 4.1 & 4.1678 & TRN \\
\hline CHEMBL84685 & 688270 & 4.6 & 4.4132 & TRN \\
\hline CHEMBL28319 & 688270 & 4.7 & 4.4201 & TRN \\
\hline CHEMBL440287 & 688270 & 4.4 & 4.5647 & TRN \\
\hline CHEMBL58835 & 688270 & 4.3 & 4.4872 & TRN \\
\hline CHEMBL1462995 & 688270 & 4.3 & 4.6082 & TST \\
\hline CHEMBL538146 & 688270 & 4.5 & 4.8137 & TRN \\
\hline CHEMBL28517 & 688270 & 4.1 & 4.3922 & TST \\
\hline CHEMBL36296 & 688270 & 4.3 & 4.2899 & TRN \\
\hline CHEMBL251389 & 688270 & 5.0 & 4.5269 & TRN \\
\hline CHEMBL513678 & 688270 & 4.5 & 4.801 & TST \\
\hline CHEMBL1535689 & 688270 & 4.5 & 4.3829 & TRN \\
\hline
\end{tabular}




\begin{tabular}{|c|c|c|c|c|c|}
\hline & & & pplement & al Table S2 & \\
\hline CHEMBL175193 & 688270 & 4.1 & 4.2273 & TRN & \\
\hline CHEMBL935 & 688270 & 4.4 & 4.4245 & TRN & \\
\hline CHEMBL1221925 & 688270 & 4.3 & 4.4159 & TRN & \\
\hline CHEMBL1517425 & 688270 & 4.3 & 4.204 & TRN & \\
\hline CHEMBL1489064 & 688270 & 4.4 & 4.2777 & TRN & \\
\hline CHEMBL1559341 & 688270 & 4.4 & 4.5003 & TRN & \\
\hline CHEMBL8320 & 688270 & 4.4 & 4.3973 & TRN & \\
\hline CHEMBL1449018 & 688270 & 4.6 & 4.6793 & TRN & \\
\hline CHEMBL1471289 & 688270 & 4.4 & 4.5172 & TRN & \\
\hline CHEMBL192627 & 688270 & 4.9 & 4.6677 & TRN & \\
\hline CHEMBL1407826 & 688270 & 4.7 & 4.776 & TST & \\
\hline CHEMBL1330194 & 688270 & 4.4 & 4.5257 & TST & \\
\hline CHEMBL44 & 688270 & 4.2 & 4.46399 & 99999999995 & TRN \\
\hline CHEMBL1526721 & 688270 & 5.3 & 5.1703 & TRN & \\
\hline CHEMBL1344952 & 688270 & 4.3 & 4.3188 & TRN & \\
\hline CHEMBL114070 & 688270 & 4.1 & 4.4425 & TRN & \\
\hline CHEMBL445957 & 688270 & 4.4 & 4.479 & TRN & \\
\hline CHEMBL 263376 & 688270 & 4.1 & 4.981 & TRN & \\
\hline CHEMBL 220845 & 688270 & 4.5 & 4.3079 & TRN & \\
\hline CHEMBL443436 & 688270 & 4.5 & 4.3962 & TRN & \\
\hline CHEMBL1485974 & 688270 & 4.5 & 4.4277 & TRN & \\
\hline CHEMBL1496957 & 688270 & 4.8 & 4.7521 & TRN & \\
\hline CHEMBL105712 & 688270 & 5.1 & 5.0872 & TRN & \\
\hline CHEMBL468037 & 688270 & 4.1 & 4.5913 & TRN & \\
\hline CHEMBL 224282 & 688270 & 4.4 & 4.2874 & TRN & \\
\hline CHEMBL1371285 & 688270 & 4.3 & 4.5166 & TST & \\
\hline CHEMBL1450607 & 688270 & 4.8 & 4.6556 & TST & \\
\hline CHEMBL85811 & 688270 & 4.3 & 4.2539 & TST & \\
\hline CHEMBL1485360 & 688270 & 4.9 & 4.6492 & TST & \\
\hline CHEMBL 267476 & 688270 & 4.3 & 4.5135 & TST & \\
\hline CHEMBL402063 & 688270 & 6.0 & 5.52 & TST & \\
\hline CHEMBL1451833 & 688270 & 4.5 & 4.5083 & TST & \\
\hline CHEMBL1200471 & 688270 & 6.6 & 6.7469 & TST & \\
\hline CHEMBL1518369 & 688270 & 4.6 & 4.4579 & TST & \\
\hline CHEMBL3391990 & 688270 & 4.3 & 4.4991 & TST & \\
\hline CHEMBL 29878 & 688270 & 4.4 & 4.273 & TST & \\
\hline CHEMBL44072 & 688270 & 4.3 & 4.41100 & 00000000005 & TST \\
\hline CHEMBL1499545 & 688270 & 5.5 & 5.3992 & TST & \\
\hline CHEMBL162598 & 688270 & 4.4 & 4.3599 & TST & \\
\hline CHEMBL172064 & 688270 & 4.3 & 4.4378 & TST & \\
\hline CHEMBL1527567 & 688270 & 4.6 & 4.354 & TST & \\
\hline CHEMBL230156 & 688270 & 4.3 & 4.3104 & TST & \\
\hline CHEMBL194400 & 688270 & 4.3 & 4.2887 & TST & \\
\hline CHEMBL3644960 & 1527772 & 5.523 & 5.2704 & TRN & \\
\hline CHEMBL 3642353 & 1527772 & 5.523 & 5.7321 & TRN & \\
\hline CHEMBL3645033 & 1527772 & 5.0 & 5.3235 & TRN & \\
\hline CHEMBL 3642401 & 1527772 & 5.0 & 5.5451 & TRN & \\
\hline CHEMBL3645015 & 1527772 & 5.8619 & 6.0876 & TRN & \\
\hline
\end{tabular}


Supplemental Table S2.txt

\begin{tabular}{|c|c|c|c|c|c|}
\hline CHEMBL 3645018 & 1527772 & 5.523 & 5.5291 & TRN & \\
\hline CHEMBL3645115 & 1527772 & 5.0 & 4.9204 & TST & \\
\hline CHEMBL3642380 & 1527772 & 6.5236 & 6.1998 & TRN & \\
\hline CHEMBL 3645075 & 1527772 & 5.0 & 5.051 & TRN & \\
\hline CHEMBL 3642287 & 1527772 & 6.245 & 6.2516 & TRN & \\
\hline CHEMBL 3642361 & 1527772 & 6.7001 & 6.9175 & TRN & \\
\hline CHEMBL 2062798 & 1527772 & 5.8681 & 5.9621 & TRN & \\
\hline CHEMBL 3642285 & 1527772 & 5.7649 & 5.7807 & TRN & \\
\hline CHEMBL3642397 & 1527772 & 5.523 & 5.7447 & TRN & \\
\hline CHEMBL3645092 & 1527772 & 5.9504 & 5.8764 & TRN & \\
\hline CHEMBL3645055 & 1527772 & 5.8647 & 5.5521 & TRN & \\
\hline CHEMBL 3642425 & 1527772 & 5.0 & 5.1449 & TRN & \\
\hline CHEMBL 2062804 & 1527772 & 5.9762 & 5.9606 & TRN & \\
\hline CHEMBL 3645074 & 1527772 & 5.523 & 5.3958 & TRN & \\
\hline CHEMBL3644989 & 1527772 & 6.3177 & 6.0377 & TRN & \\
\hline CHEMBL3642406 & 1527772 & 7.2039 & 7.3145 & TRN & \\
\hline CHEMBL3644955 & 1527772 & 5.523 & 5.7099 & TRN & \\
\hline CHEMBL 3642348 & 1527772 & 5.6885 & 5.9531 & TRN & \\
\hline CHEMBL3642413 & 1527772 & 5.6155 & 5.7536 & TRN & \\
\hline CHEMBL3645080 & 1527772 & 5.614 & 5.3996 & TRN & \\
\hline CHEMBL3644994 & 1527772 & 5.5913 & 6.2827 & TST & \\
\hline CHEMBL3644985 & 1527772 & 5.7701 & 5.4966 & TST & \\
\hline CHEMBL3644975 & 1527772 & 5.9943 & 6.0454 & TRN & \\
\hline CHEMBL3642313 & 1527772 & 5.6413 & 6.3392 & TST & \\
\hline CHEMBL3642280 & 1527772 & 6.2946 & 5.6247 & TST & \\
\hline CHEMBL3642376 & 1527772 & 5.1872 & 5.1216 & TRN & \\
\hline CHEMBL3642399 & 1527772 & 6.0004 & 5.8202 & TRN & \\
\hline CHEMBL3642335 & 1527772 & 5.4718 & 5.7136 & TST & \\
\hline CHEMBL 3642410 & 1527772 & 6.2825 & 6.0844 & TRN & \\
\hline CHEMBL3642370 & 1527772 & 7.9435 & 7.8715 & TRN & \\
\hline CHEMBL 2062809 & 1527772 & 6.5766 & 6.2595 & TRN & \\
\hline CHEMBL 3642342 & 1527772 & 5.5432 & 6.2012 & TST & \\
\hline CHEMBL3642404 & 1527772 & 5.1872 & 5.5855 & TRN & \\
\hline CHEMBL3645029 & 1527772 & 5.0 & 5.2254 & TRN & \\
\hline CHEMBL3645090 & 1527772 & 5.6992 & 5.983 & TRN & \\
\hline CHEMBL3644963 & 1527772 & 5.0 & 5.0068 & TRN & \\
\hline CHEMBL3645104 & 1527772 & 5.0 & 5.3804 & TST & \\
\hline CHEMBL3642330 & 1527772 & 5.0 & 5.0873 & TRN & \\
\hline CHEMBL3645021 & 1527772 & 5.61700 & 000000000 & 5.8215 & TRN \\
\hline CHEMBL3645017 & 1527772 & 5.6078 & \multicolumn{3}{|c|}{$\begin{array}{ll}5.406000000000001 & \text { TST }\end{array}$} \\
\hline CHEMBL3645076 & 1527772 & 5.523 & \multicolumn{2}{|c|}{5.486000000000001} & TRN \\
\hline CHEMBL3645061 & 1527772 & 5.8305 & 5.9438 & TRN & \\
\hline CHEMBL3642331 & 1527772 & 6.1744 & 5.5631 & TRN & \\
\hline CHEMBL3644986 & 1527772 & 5.9658 & 5.9589 & TRN & \\
\hline CHEMBL3642317 & 1527772 & 5.9866 & 6.1882 & TST & \\
\hline CHEMBL3645083 & 1527772 & 5.0 & 5.2498 & TRN & \\
\hline CHEMBL3645052 & 1527772 & 6.0004 & 5.8089 & TRN & \\
\hline CHEMBL3644981 & 1527772 & 5.1872 & 5.4953 & TST & \\
\hline
\end{tabular}


Supplemental Table S2.txt

\begin{tabular}{|c|c|c|c|c|c|}
\hline CHEMBL 3645026 & 1527772 & 5.9858 & 5.256 & TST & \\
\hline CHEMBL 3645081 & 1527772 & 6.0004 & 5.5066 & TRN & \\
\hline CHEMBL 3642251 & 1527772 & 5.0 & \multicolumn{2}{|c|}{5.1370000000000005} & TST \\
\hline CHEMBL 3642277 & 1527772 & 5.0 & 4.9944 & TRN & \\
\hline CHEMBL 3642327 & 1527772 & 5.0 & 5.14 & TST & \\
\hline CHEMBL 3645101 & 1527772 & 5.0 & 4.7681 & TST & \\
\hline CHEMBL 3642293 & 1527772 & 5.5874 & 6.1461 & TRN & \\
\hline CHEMBL 3645095 & 1527772 & 6.0217 & 6.2958 & TRN & \\
\hline CHEMBL 3645041 & 1527772 & 5.523 & 5.3476 & TRN & \\
\hline CHEMBL 3645040 & 1527772 & 6.1607 & 5.9161 & TRN & \\
\hline CHEMBL 3645067 & 1527772 & 5.0 & 5.23 & TRN & \\
\hline CHEMBL 3645099 & 1527772 & 5.0 & 5.0103 & TRN & \\
\hline CHEMBL 3642418 & 1527772 & 6.0004 & 6.2588 & TST & \\
\hline CHEMBL 3645071 & 1527772 & 5.523 & 5.4763 & TRN & \\
\hline CHEMBL 3645069 & 1527772 & 5.7941 & 5.7838 & TRN & \\
\hline CHEMBL 3642386 & 1527772 & 5.6992 & 5.6259 & TRN & \\
\hline CHEMBL 3644978 & 1527772 & 5.0 & 4.7377 & TRN & \\
\hline CHEMBL 3642382 & 1527772 & 6.2692 & 6.2083 & TRN & \\
\hline CHEMBL 3645053 & 1527772 & 5.0 & 5.2641 & TRN & \\
\hline CHEMBL 3642341 & 1527772 & 5.8332 & 6.2363 & TST & \\
\hline CHEMBL 3642411 & 1527772 & 6.2363 & 6.0477 & TRN & \\
\hline CHEMBL 3642409 & 1527772 & 5.7121 & 5.8168 & TRN & \\
\hline CHEMBL 3642403 & 1527772 & 5.9989 & 6.0324 & TRN & \\
\hline CHEMBL2062811 & 1527772 & 6.0004 & 5.7095 & TRN & \\
\hline CHEMBL 3642368 & 1527772 & 6.1733 & 6.1409 & TRN & \\
\hline CHEMBL 3645065 & 1527772 & 5.523 & 5.3856 & TRN & \\
\hline CHEMBL 3645068 & 1527772 & 5.7197 & 5.6539 & TRN & \\
\hline CHEMBL 3642400 & 1527772 & 5.0 & 5.0939 & TRN & \\
\hline CHEMBL 3642407 & 1527772 & 5.524 & 5.393 & TRN & \\
\hline CHEMBL 3644991 & 1527772 & 5.4695 & 6.2761 & TST & \\
\hline CHEMBL 3644980 & 1527772 & 5.0 & 4.7915 & TST & \\
\hline CHEMBL 3642408 & 1527772 & 5.6131 & 5.5445 & TRN & \\
\hline CHEMBL 3645005 & 1527772 & 6.0004 & 5.4327 & TRN & \\
\hline CHEMBL 3642347 & 1527772 & 7.2238 & 7.0491 & TRN & \\
\hline CHEMBL 3645066 & 1527772 & 5.523 & 5.5032 & TRN & \\
\hline CHEMBL 3642255 & 1527772 & 5.8305 & 5.3501 & TST & \\
\hline CHEMBL 3642349 & 1527772 & 5.8868 & 6.1715 & TRN & \\
\hline CHEMBL 3642303 & 1527772 & \multicolumn{3}{|c|}{6.2989999999999995} & TST \\
\hline CHEMBL 3645093 & 1527772 & 5.0 & 5.2364 & TST & \\
\hline CHEMBL 3642343 & 1527772 & 5.0 & 5.3643 & TRN & \\
\hline CHEMBL 3642300 & 1527772 & 6.2158 & 5.6214 & TRN & \\
\hline CHEMBL 3642302 & 1527772 & 6.5361 & 6.5804 & TST & \\
\hline CHEMBL 3645020 & 1527772 & 5.523 & 5.7999 & TRN & \\
\hline CHEMBL 3642373 & 1527772 & 7.8874 & 7.8144 & TRN & \\
\hline CHEMBL 3642296 & 1527772 & 5.8696 & 5.5902 & TRN & \\
\hline CHEMBL 3644964 & 1527772 & 5.0 & 5.3734 & TRN & \\
\hline CHEMBL 3645050 & 1527772 & 5.0 & 5.17899 & 9999999999 & TRN \\
\hline CHEMBL3642295 & 1527772 & 6.0004 & 5.7805 & TRN & \\
\hline
\end{tabular}


Supplemental Table S2.txt

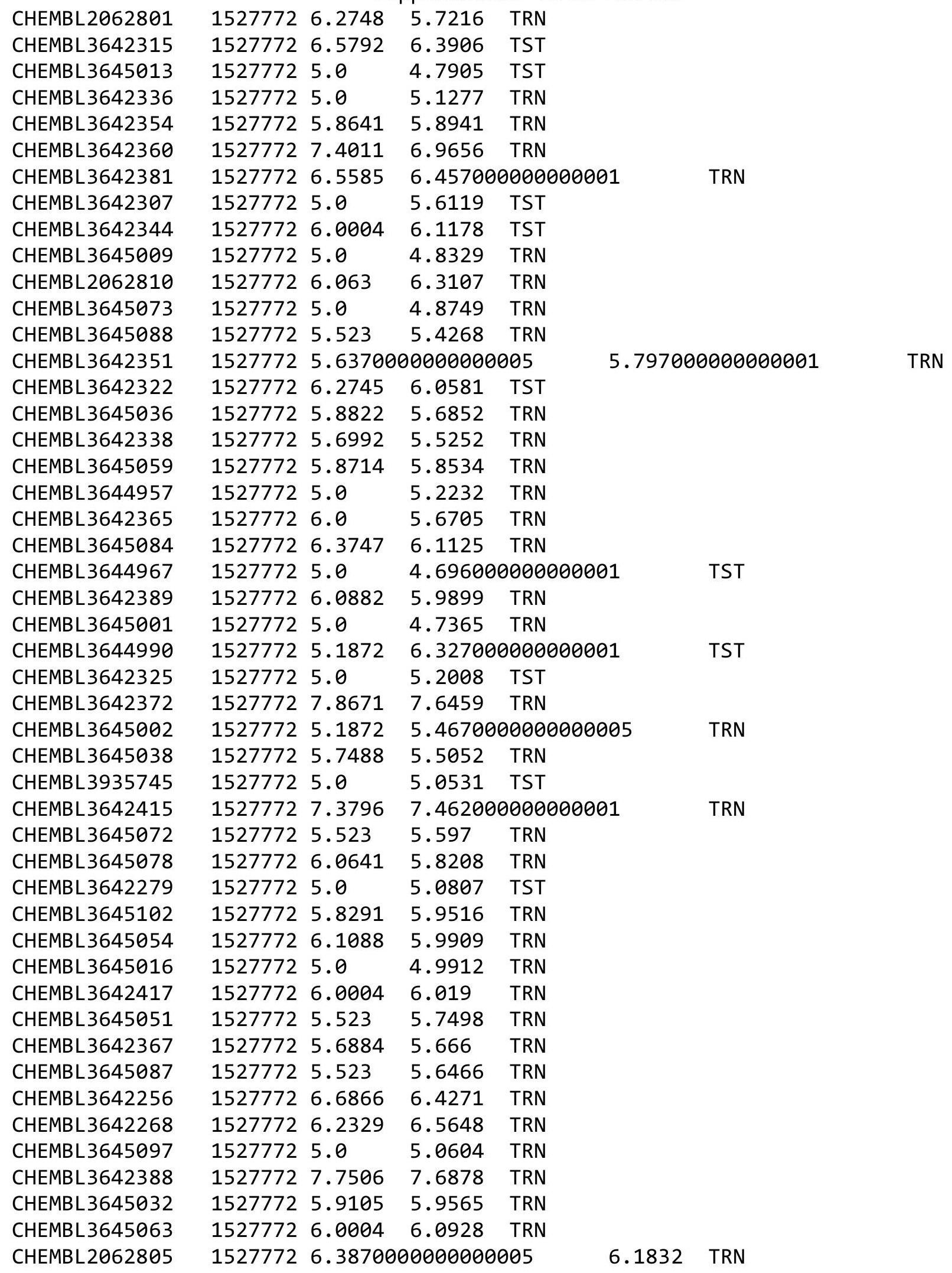

Page 20297 


\begin{tabular}{|c|c|c|c|c|c|}
\hline \multicolumn{6}{|c|}{ Supplemental Table s2.txt } \\
\hline CHEMBL3644966 & 1527772 & 5.0 & 5.4807 & TRN & \\
\hline CHEMBL3644983 & 1527772 & 5.0 & 5.0815 & TRN & \\
\hline CHEMBL3645094 & 1527772 & 6.2576 & 6.5463 & TRN & \\
\hline CHEMBL 3642286 & 1527772 & 6.6008 & 6.2462 & TRN & \\
\hline CHEMBL3642363 & 1527772 & 6.9073 & 6.7022 & TRN & \\
\hline CHEMBL 2062800 & 1527772 & 6.159 & 5.5887 & TRN & \\
\hline CHEMBL3642333 & 1527772 & 5.523 & 5.6102 & TRN & \\
\hline CHEMBL3642281 & 1527772 & 5.9315 & 6.0061 & TRN & \\
\hline CHEMBL3642356 & 1527772 & 5.685 & 5.775 & TRN & \\
\hline CHEMBL3644959 & 1527772 & 5.0 & 5.1569 & TRN & \\
\hline CHEMBL 3642340 & 1527772 & 5.9776 & 6.2748 & TST & \\
\hline CHEMBL3644971 & 1527772 & 5.523 & 5.5338 & TRN & \\
\hline CHEMBL3642306 & 1527772 & 6.4444 & 5.8343 & TST & \\
\hline CHEMBL 3645037 & 1527772 & 5.523 & 5.4904 & TRN & \\
\hline CHEMBL3644995 & 1527772 & 5.523 & 6.0613 & TST & \\
\hline CHEMBL3645014 & 1527772 & 6.0004 & 5.9733 & TRN & \\
\hline CHEMBL 3645047 & 1527772 & 5.523 & 5.5771 & TRN & \\
\hline CHEMBL 2414547 & 1527772 & 6.3755 & 6.3659 & TST & \\
\hline CHEMBL 3645003 & 1527772 & 5.0 & 5.052 & TRN & \\
\hline CHEMBL3645019 & 1527772 & 5.0 & 5.0115 & TRN & \\
\hline CHEMBL3642383 & 1527772 & 5.0 & 4.9625 & TRN & \\
\hline CHEMBL3642390 & 1527772 & 5.1872 & 5.1569 & TRN & \\
\hline CHEMBL3642392 & 1527772 & 6.0004 & 5.724 & TRN & \\
\hline CHEMBL 3645064 & 1527772 & 5.0 & 4.8632 & TRN & \\
\hline CHEMBL3645060 & 1527772 & 6.0004 & 5.9832 & TST & \\
\hline CHEMBL3644958 & 1527772 & 5.0 & 5.4621 & TST & \\
\hline CHEMBL 2062802 & 1527772 & 5.6942 & 5.8106 & TRN & \\
\hline CHEMBL 3642420 & 1527772 & 7.7404 & 7.5628 & TST & \\
\hline CHEMBL3639439 & 1527772 & 5.0 & 4.9498 & TRN & \\
\hline CHEMBL3645048 & 1527772 & 5.1872 & 5.2557 & TRN & \\
\hline CHEMBL 3645034 & 1527772 & 5.0 & 5.3038 & TRN & \\
\hline CHEMBL3645117 & 1527772 & 6.1816 & 6.0223 & TRN & \\
\hline CHEMBL 3642378 & 1527772 & 6.4211 & 6.7939 & TRN & \\
\hline CHEMBL3642305 & 1527772 & 6.6442 & 6.6819 & TST & \\
\hline CHEMBL 3645025 & 1527772 & 5.523 & 5.2141 & TRN & \\
\hline CHEMBL 2062808 & 1527772 & 5.9288 & 6.0104 & TRN & \\
\hline CHEMBL 2062803 & 1527772 & 6.3361 & 6.0082 & TRN & \\
\hline CHEMBL3642379 & 1527772 & 6.7472 & 6.4963 & TRN & \\
\hline CHEMBL 3645105 & 1527772 & 5.0 & 4.7155 & TST & \\
\hline CHEMBL3642299 & 1527772 & 5.0 & 5.0913 & TRN & \\
\hline CHEMBL3642412 & 1527772 & 6.0004 & 5.8241 & TRN & \\
\hline CHEMBL3642405 & 1527772 & 6.4154 & 6.0691 & TRN & \\
\hline CHEMBL3642357 & 1527772 & 6.124 & 6.6997 & TRN & \\
\hline CHEMBL 3645118 & 1527772 & 5.7299 & 6.1062 & TST & \\
\hline CHEMBL3645085 & 1527772 & 6.3539 & 6.3985 & TRN & \\
\hline CHEMBL 3644982 & 1527772 & 5.0 & 5.0313 & TRN & \\
\hline CHEMBL3645042 & 1527772 & 5.6992 & 5.61700 & 0000000001 & TRN \\
\hline CHEMBL2062812 & 1527772 & 6.0004 & 5.7726 & TRN & \\
\hline
\end{tabular}


Supplemental Table S2.txt

\begin{tabular}{|c|c|c|c|c|c|c|}
\hline CHEMBL 3645086 & 1527772 & 5.9032 & 5.8097 & TRN & & \\
\hline CHEMBL3645006 & 1527772 & 5.0 & 4.6083 & TST & & \\
\hline CHEMBL 3642284 & 1527772 & 5.523 & 5.5196 & TRN & & \\
\hline CHEMBL3645089 & 1527772 & 6.3622 & 6.0546 & TRN & & \\
\hline CHEMBL3645022 & 1527772 & 5.0 & 5.2233 & TRN & & \\
\hline CHEMBL3645114 & 1527772 & 5.0 & 5.0344 & TST & & \\
\hline CHEMBL3642359 & 1527772 & 7.1483 & 6.9908 & TRN & & \\
\hline CHEMBL 3642385 & 1527772 & 5.8924 & 5.7953 & TRN & & \\
\hline CHEMBL3645113 & 1527772 & 5.0 & 5.2346 & TST & & \\
\hline CHEMBL3645110 & 1527772 & 5.7252 & 6.4919 & TST & & \\
\hline CHEMBL3644972 & 1527772 & 5.6992 & 5.497006 & 000000000 & & TRN \\
\hline CHEMBL 3645027 & 1527772 & 6.0004 & 5.4697 & TRN & & \\
\hline CHEMBL 3645044 & 1527772 & 5.523 & 5.7741 & TRN & & \\
\hline CHEMBL3644992 & 1527772 & 5.9569 & 6.1527 & TST & & \\
\hline CHEMBL 3644987 & 1527772 & 5.9154 & 5.8746 & TRN & & \\
\hline CHEMBL3642332 & 1527772 & 5.9776 & 5.1191 & TST & & \\
\hline CHEMBL3645107 & 1527772 & 5.5064 & 5.9753 & TST & & \\
\hline CHEMBL 3642314 & 1527772 & 6.76200 & 0000000 & 005 & 6.4352 & TST \\
\hline CHEMBL3645039 & 1527772 & 6.2425 & 5.9399 & TRN & & \\
\hline CHEMBL 3642387 & 1527772 & 7.3176 & 7.0445 & TRN & & \\
\hline CHEMBL3642288 & 1527772 & 6.7739 & 6.2827 & TRN & & \\
\hline CHEMBL 3645058 & 1527772 & 5.0 & 5.1833 & TRN & & \\
\hline CHEMBL 3642423 & 1527772 & 5.0 & 5.2017 & TRN & & \\
\hline CHEMBL3645028 & 1527772 & 5.5545 & 5.4804 & TRN & & \\
\hline CHEMBL 3642391 & 1527772 & 6.0594 & 6.1489 & TST & & \\
\hline CHEMBL 2062807 & 1527772 & 5.6992 & 5.7762 & TRN & & \\
\hline CHEMBL3645031 & 1527772 & 6.024 & 5.8097 & TRN & & \\
\hline CHEMBL 3642362 & 1527772 & \multicolumn{3}{|c|}{6.6979999999999995} & 6.6407 & TRN \\
\hline CHEMBL3645112 & 1527772 & 5.0 & 5.3465 & TST & & \\
\hline CHEMBL 3645070 & 1527772 & 5.0 & 4.9394 & TRN & & \\
\hline CHEMBL3642309 & 1527772 & 5.815 & 6.1937 & TST & & \\
\hline CHEMBL3642316 & 1527772 & \multicolumn{3}{|c|}{6.4670000000000005} & 6.2906 & TST \\
\hline CHEMBL 3642419 & 1527772 & 5.0 & 4.9556 & TST & & \\
\hline CHEMBL3645012 & 1527772 & 5.0 & 5.0814 & TRN & & \\
\hline CHEMBL 3642374 & 1527772 & 5.1872 & 5.2651 & TRN & & \\
\hline CHEMBL3645043 & 1527772 & 5.2597 & 5.6292 & TRN & & \\
\hline CHEMBL 2062529 & 1527772 & 5.6225 & 6.0139 & TRN & & \\
\hline CHEMBL 3644984 & 1527772 & 5.6992 & 5.37 & TST & & \\
\hline CHEMBL2062799 & 1527772 & 5.8011 & 5.9231 & TRN & & \\
\hline CHEMBL 3642312 & 1527772 & 6.2575 & 6.0126 & TST & & \\
\hline CHEMBL 3642282 & 1527772 & 5.9484 & 6.0073 & TRN & & \\
\hline CHEMBL3645106 & 1527772 & 5.0 & 4.5564 & TST & & \\
\hline CHEMBL3642384 & 1527772 & 5.0 & 5.4871 & TST & & \\
\hline CHEMBL3639412 & 1527772 & 5.0 & 5.0419 & TRN & & \\
\hline CHEMBL 3645082 & 1527772 & 5.0 & 5.4743 & TRN & & \\
\hline CHEMBL3645096 & 1527772 & 5.9752 & 6.6809 & TRN & & \\
\hline CHEMBL 3645057 & 1527772 & 5.523 & 5.6059 & TRN & & \\
\hline CHEMBL3645077 & 1527772 & 5.7573 & 5.6664 & TRN & & \\
\hline
\end{tabular}


Supplemental Table S2.txt

\begin{tabular}{|c|c|c|c|c|c|c|}
\hline CHEMBL 3642421 & 1527772 & 6.7766 & 6.8071 & TRN & & \\
\hline CHEMBL3645108 & 1527772 & 5.1872 & 5.796 & TST & & \\
\hline CHEMBL3642259 & 1527772 & 6.2809 & 6.4043 & TRN & & \\
\hline CHEMBL 3644962 & 1527772 & 5.0 & 5.6889 & TRN & & \\
\hline CHEMBL3645024 & 1527772 & 5.523 & 6.0112 & TRN & & \\
\hline CHEMBL 3642320 & 1527772 & 5.5851 & 6.1869 & TST & & \\
\hline CHEMBL3644993 & 1527772 & 5.79799 & 99999999 & 99 & 6.0811 & TST \\
\hline CHEMBL 2414545 & 1527772 & 6.2336 & 6.2838 & TST & & \\
\hline CHEMBL 3642398 & 1527772 & 5.523 & 5.8828 & TRN & & \\
\hline CHEMBL3644996 & 1527772 & 5.0 & 5.3119 & TST & & \\
\hline CHEMBL 3642326 & 1527772 & 5.0 & 5.0115 & TST & & \\
\hline CHEMBL3645103 & 1527772 & 5.0 & 5.1271 & TRN & & \\
\hline CHEMBL 3645091 & 1527772 & 5.968 & 6.1564 & TRN & & \\
\hline CHEMBL 3642395 & 1527772 & 5.0 & 5.5707 & TRN & & \\
\hline CHEMBL3639438 & 1527772 & 5.0 & 4.5724 & TRN & & \\
\hline CHEMBL 3644956 & 1527772 & 5.0 & 4.7265 & TRN & & \\
\hline CHEMBL3642290 & 1527772 & 6.1039 & 6.0545 & TRN & & \\
\hline CHEMBL3645079 & 1527772 & 5.72 & 5.6673 & TRN & & \\
\hline CHEMBL 3642337 & 1527772 & 5.523 & 4.9666 & TRN & & \\
\hline CHEMBL 3645046 & 1527772 & 6.0004 & 5.7978 & TRN & & \\
\hline CHEMBL 3642321 & 1527772 & 5.8968 & 6.2038 & TST & & \\
\hline CHEMBL 3642352 & 1527772 & 6.1196 & 5.8968 & TRN & & \\
\hline CHEMBL 3642324 & 1527772 & 5.6992 & 6.2867 & TST & & \\
\hline CHEMBL 3642283 & 1527772 & 5.0 & 5.095 & TRN & & \\
\hline CHEMBL 3642276 & 1527772 & 5.0 & 5.7078 & TST & & \\
\hline CHEMBL 3642355 & 1527772 & 5.523 & 5.7889 & TRN & & \\
\hline CHEMBL3642396 & 1527772 & 5.523 & 5.7458 & TRN & & \\
\hline CHEMBL 3645011 & 1527772 & 5.0 & 5.2301 & TRN & & \\
\hline CHEMBL 3645007 & 1527772 & 5.6992 & 5.5569 & TRN & & \\
\hline CHEMBL 3642318 & 1527772 & 5.0539 & 5.836 & TST & & \\
\hline CHEMBL 3642393 & 1527772 & 5.523 & 5.3432 & TRN & & \\
\hline CHEMBL 3645056 & 1527772 & 5.6992 & 5.4915 & TRN & & \\
\hline CHEMBL 3642270 & 1527772 & 5.87 & 5.8311 & TRN & & \\
\hline CHEMBL 3645116 & 1527772 & 5.0 & 5.3329 & TST & & \\
\hline CHEMBL 3644977 & 1527772 & 5.7105 & 5.9555 & TRN & & \\
\hline CHEMBL3642350 & 1527772 & 5.5038 & 5.6742 & TRN & & \\
\hline CHEMBL 3642334 & 1527772 & 6.0682 & 5.7044 & TST & & \\
\hline CHEMBL 3642297 & 1527772 & 5.9038 & 5.8399 & TRN & & \\
\hline CHEMBL 3645004 & 1527772 & 5.0 & 5.223 & TRN & & \\
\hline CHEMBL 3645098 & 1527772 & 5.0 & 5.0521 & TRN & & \\
\hline CHEMBL3644970 & 1527772 & 5.0 & 5.2178 & TRN & & \\
\hline CHEMBL 3644997 & 1527772 & 5.0 & 5.0305 & TRN & & \\
\hline CHEMBL 3644961 & 1527772 & 5.523 & 5.5484 & TRN & & \\
\hline CHEMBL 3642416 & 1527772 & 7.6613 & 7.5444 & TRN & & \\
\hline CHEMBL 3642319 & 1527772 & 5.0 & 5.7208 & TST & & \\
\hline CHEMBL 3642345 & 1527772 & 7.523 & 7.2352 & TRN & & \\
\hline CHEMBL 3642291 & 1527772 & 5.523 & 5.5439 & TRN & & \\
\hline CHEMBL 3642369 & 1527772 & 6.9757 & 7.1392 & TRN & & \\
\hline
\end{tabular}

Page 20300 
Supplemental Table S2.txt

\begin{tabular}{|c|c|c|c|c|c|c|}
\hline CHEMBL 3645035 & 1527772 & 5.6992 & 5.8386 & TRN & & \\
\hline CHEMBL 3642278 & 1527772 & 5.6275 & 5.6805 & TST & & \\
\hline CHEMBL3644968 & 1527772 & 5.0 & 5.2059 & TST & & \\
\hline CHEMBL3642294 & 1527772 & 5.9013 & 6.0962 & TRN & & \\
\hline CHEMBL3645109 & 1527772 & 5.523 & 6.04 & TST & & \\
\hline CHEMBL3645100 & 1527772 & 5.0 & 4.8751 & TRN & & \\
\hline CHEMBL3642298 & 1527772 & 5.0 & 5.3291 & TRN & & \\
\hline CHEMBL3644999 & 1527772 & 5.0 & 4.9139 & TRN & & \\
\hline CHEMBL3644973 & 1527772 & \multicolumn{3}{|c|}{6.2620000000000005} & 6.5116 & TRN \\
\hline CHEMBL3644965 & 1527772 & 5.9125 & 5.5143 & TRN & & \\
\hline CHEMBL3642394 & 1527772 & 5.6992 & 5.7527 & TRN & & \\
\hline CHEMBL3644976 & 1527772 & 6.1462 & 6.3547 & TRN & & \\
\hline CHEMBL 3642257 & 1527772 & 5.1872 & 5.3187 & TRN & & \\
\hline CHEMBL3645062 & 1527772 & 6.0004 & 6.0101 & TRN & & \\
\hline CHEMBL3642377 & 1527772 & 5.0 & 5.4961 & TST & & \\
\hline CHEMBL3642304 & 1527772 & 6.4204 & 6.0189 & TRN & & \\
\hline CHEMBL3639411 & 1527772 & 6.0208 & 5.9656 & TRN & & \\
\hline CHEMBL 3645000 & 1527772 & 6.0004 & 5.9971 & TRN & & \\
\hline CHEMBL3642328 & 1527772 & 5.0 & 5.2385 & TST & & \\
\hline CHEMBL3645023 & 1527772 & 5.6992 & 5.1498 & TRN & & \\
\hline CHEMBL3645008 & 1527772 & 5.0 & 5.0901 & TST & & \\
\hline CHEMBL 3642402 & 1527772 & \multicolumn{3}{|c|}{5.9479999999999995} & 5.7988 & TRN \\
\hline CHEMBL 3644974 & 1527772 & 6.8683 & 6.9446 & TRN & & \\
\hline CHEMBL3645030 & 1527772 & 5.9797 & 5.9658 & TRN & & \\
\hline CHEMBL3645010 & 1527772 & 5.0 & 5.1489 & TRN & & \\
\hline CHEMBL3642289 & 1527772 & 6.5137 & 6.5236 & TRN & & \\
\hline CHEMBL3642323 & 1527772 & 5.523 & 5.8577 & TST & & \\
\hline CHEMBL3645045 & 1527772 & 6.0004 & 6.0564 & TRN & & \\
\hline CHEMBL3642301 & 1527772 & 5.1872 & 4.9103 & TRN & & \\
\hline CHEMBL3645049 & 1527772 & 5.6992 & 5.7633 & TRN & & \\
\hline CHEMBL 3642329 & 1527772 & 5.0 & 5.0883 & TRN & & \\
\hline CHEMBL3644988 & 1527772 & 5.0 & 5.3504 & TST & & \\
\hline CHEMBL3642375 & 1527772 & 6.0004 & 5.706 & TRN & & \\
\hline CHEMBL3642253 & 1527772 & 5.1872 & 5.3272 & TRN & & \\
\hline CHEMBL 3642371 & 1527772 & 7.8348 & 7.5749 & TRN & & \\
\hline CHEMBL2062806 & 1527772 & 5.523 & 5.8367 & TRN & & \\
\hline CHEMBL3642364 & 1527772 & 7.0053 & 7.0031 & TRN & & \\
\hline CHEMBL3642339 & 1527772 & 5.8303 & 5.8755 & TRN & & \\
\hline CHEMBL2062813 & 1527772 & 5.0 & 5.3855 & TRN & & \\
\hline CHEMBL 3642254 & 1527772 & 5.523 & 5.5122 & TRN & & \\
\hline CHEMBL3642275 & 1527772 & 5.0 & 5.4391 & TST & & \\
\hline CHEMBL3644969 & 1527772 & 5.0 & 4.97 & TST & & \\
\hline CHEMBL3645111 & 1527772 & 5.5876 & 6.5822 & TST & & \\
\hline CHEMBL3642424 & 1527772 & 5.0 & 5.3671 & TRN & & \\
\hline CHEMBL 3644998 & 1527772 & 5.7784 & 6.13899 & 9999999999 & & TST \\
\hline CHEMBL3642258 & 1527772 & 6.3625 & 6.324 & TST & & \\
\hline CHEMBL 3642414 & 1527772 & 5.523 & 5.6661 & TRN & & \\
\hline CHEMBL3642358 & 1527772 & 6.6673 & 6.5773 & TRN & & \\
\hline
\end{tabular}


Supplemental Table S2.txt

\begin{tabular}{|c|c|c|c|c|}
\hline HEMBL3642422 & 1527772 & 6.7225 & 6.9439 & TRN \\
\hline HEMBL 3642346 & 1527772 & 7.1117 & 7.0548 & TRN \\
\hline HEMBL3642292 & 527772 & 5.523 & 5.4122 & RN \\
\hline HEMBL 74236 & 5562 & 7.699 & 7.859 & PN \\
\hline HEMBL115021 & 5562 & 5.0 & 2531 & $T$ \\
\hline HEMBL 70370 & 5562 & 8.699 & 8.7185 & \\
\hline HEMBL305239 & 5562 & 6.699 & 7.5516 & \\
\hline HEMBL 302964 & 5562 & 8.699 & 8.7129 & DN \\
\hline HEMBL306923 & 5562 & 5.5229 & 7.2718 & CT \\
\hline HEMBL69839 & 5562 & 7.699 & 7.7503 & $\mathrm{RN}$ \\
\hline HEMBL306435 & 5562 & 8.0 & 7.8796 & \\
\hline HEMBL430792 & 5562 & 8.301 & 8.4166 & \\
\hline HEMBL311625 & 5562 & 9.0 & 9.0637 & RN \\
\hline HEMBL311018 & 5562 & 8.0 & 8.2645 & \\
\hline HEMBL 307008 & 5562 & 8.5229 & 8.3764 & \\
\hline HEMBL 70868 & 35562 & 8.301 & 8.3949 & IIV \\
\hline HEMBL 70935 & 5562 & 8.699 & 8.6438 & RIV \\
\hline HEMBL 72249 & 5562 & 6.0 & 7.6606 & זוס \\
\hline HEMBL306638 & 35562 & 8.7212 & 8.6572 & RN \\
\hline HEMBL 309455 & 5562 & 979 & 7.6342 & 151 \\
\hline HEMBL306340 & 35562 & 8.0458 & 8.0163 & RIV \\
\hline HEMBL 70793 & 5562 & 8.0458 & 8.1166 & RN \\
\hline HEMBL 70726 & 35562 & 8.7959 & 8.9405 & RN \\
\hline JEMBL 306473 & 35562 & 6.5229 & 7.4326 & TST \\
\hline HEMBL 72595 & 55 & 9.0 & 9.1677 & $2 \mathrm{~N}$ \\
\hline HEMBL 74514 & 5562 & 8.5229 & 8.5693 & RN \\
\hline HEMBL 70843 & 5562 & 8.5229 & 8.3337 & RN \\
\hline HEMBL69721 & 5562 & 8. & 8.6948 & RN \\
\hline HEMBL303647 & 5562 & 29 & 8.5447 & $\mathrm{RN}$ \\
\hline HEMBL 73283 & 5562 & 8.699 & 8.6621 & TRN \\
\hline CHEMBL70867 & 5562 & 9 . & 9.0874 & rRN \\
\hline CHEMBL 303427 & 5562 & 8.3979 & 8.3852 & RN \\
\hline HEMBL 70161 & 35562 & 8 & 8.436 & TRN \\
\hline HEMBL 70100 & 5562 & 78 & 8.4327 & TRI \\
\hline HEMBL 306924 & 5562 & 5.699 & 7.3196 & TS \\
\hline HEMBL311253 & 55 & 49 & 8.2491 & rRN \\
\hline CHEMBL307359 & 5562 & 29 & 8.4603 & TRN \\
\hline CHEMBL74069 & 35562 & 8.5229 & 8.6682 & TRN \\
\hline CHEMBL302485 & 35562 & 5.699 & 7.4621 & TST \\
\hline CHEMBL419073 & 35562 & 8.301 & 8.4241 & TR \\
\hline CHEMBL309081 & 35562 & 6.6 & 7.2477 & $S$ \\
\hline CHEMBL 70353 & 35562 & 6.5229 & 8.1819 & 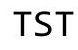 \\
\hline CHEMBL302579 & 35562 & 9.0 & 8.9159 & $\mathrm{RI}$ \\
\hline CHEMBL 71220 & 35562 & 9.0458 & 8.6072 & $\mathrm{RI}$ \\
\hline CHEMBL73369 & 35562 & 6.2218 & 7.2823 & S \\
\hline CHEMBL305369 & 35562 & 6.5229 & 7.5296 & TS \\
\hline CHEMBL 70789 & 35562 & 9.0 & 8.6326 & h \\
\hline CHEMBL 74573 & 35562 & 9.1549 & 9.2555 & $1 \mathrm{~K}$ \\
\hline
\end{tabular}

Page 20302 


\begin{tabular}{|c|c|c|c|c|c|c|}
\hline \multicolumn{7}{|c|}{ Supplemental Table s2.txt } \\
\hline CHEMBL307866 & 35562 & 8.0 & 8.1903 & TRN & & \\
\hline CHEMBL71286 & 35562 & 7.699 & 7.5643 & TRN & & \\
\hline CHEMBL72099 & 35562 & 8.5229 & 8.543 & TRN & & \\
\hline CHEMBL 307318 & 35562 & 9.0 & 8.5056 & TRN & & \\
\hline CHEMBL304065 & 35562 & 8.0 & 8.1286 & TRN & & \\
\hline CHEMBL 308482 & 35562 & 8.0 & 8.4028 & TRN & & \\
\hline CHEMBL71125 & 35562 & 9.1612 & 9.0841 & TRN & & \\
\hline CHEMBL71639 & 35562 & 8.699 & 8.6943 & TRN & & \\
\hline CHEMBL 305017 & 35562 & 8.699 & 8.5278 & TRN & & \\
\hline CHEMBL305238 & 35562 & 8.5229 & 8.5834 & TRN & & \\
\hline CHEMBL312301 & 35562 & 8.301 & 8.3922 & TRN & & \\
\hline CHEMBL306186 & 35562 & 6.301 & 7.2343 & TST & & \\
\hline CHEMBL 308323 & 35562 & 8.699 & 8.6241 & TRN & & \\
\hline CHEMBL 309790 & 35562 & 8.5229 & 8.9788 & TST & & \\
\hline CHEMBL71172 & 35562 & 9.0458 & 9.0907 & TST & & \\
\hline CHEMBL 306761 & 35562 & 8.699 & 8.5771 & TST & & \\
\hline CHEMBL1643959 & 955059 & 3.2866 & 3.2878 & TRN & & \\
\hline CHEMBL585951 & 955059 & 6.1452 & 6.147 & TRN & & \\
\hline CHEMBL180127 & 955059 & 4.6502 & 4.6554 & TRN & & \\
\hline CHEMBL379975 & 955059 & 5.5501 & 5.5455 & TRN & & \\
\hline CHEMBL1230020 & 955059 & 4.6738 & 4.675 & TRN & & \\
\hline CHEMBL1357247 & 955059 & 3.4651 & 3.4699 & TRN & & \\
\hline CHEMBL1242367 & 955059 & 2.8908 & 2.886 & TRN & & \\
\hline CHEMBL1673039 & 955059 & 4.4372 & 4.4384 & TRN & & \\
\hline CHEMBL189584 & 955059 & 4.4409 & 4.4425 & TRN & & \\
\hline CHEMBL 379300 & 955059 & 6.88299 & 99999999 & 99 & 6.8858 & TRN \\
\hline CHEMBL65 & 955059 & 8.7916 & 8.7927 & TRN & & \\
\hline CHEMBL472940 & 955059 & 4.8538 & 4.8536 & TRN & & \\
\hline CHEMBL192566 & 955059 & 7.4034 & 8.1597 & TST & & \\
\hline CHEMBL392695 & 955059 & 5.3679 & 5.3659 & TRN & & \\
\hline CHEMBL 373751 & 955059 & 3.1607 & 3.1646 & TRN & & \\
\hline CHEMBL92309 & 955059 & 3.1439 & 3.0487 & TST & & \\
\hline CHEMBL1788116 & 955059 & 3.4317 & 3.4327 & TRN & & \\
\hline CHEMBL558642 & 955059 & 4.3788 & 4.3743 & TRN & & \\
\hline CHEMBL1909414 & 955059 & 4.5398 & 4.5372 & TRN & & \\
\hline CHEMBL 210618 & 955059 & 4.2881 & 4.2857 & TRN & & \\
\hline CHEMBL573107 & 955059 & 5.4697 & 5.4638 & TRN & & \\
\hline CHEMBL1516890 & 955059 & 4.704 & 4.702 & TRN & & \\
\hline CHEMBL 209148 & 955059 & 3.3838 & 3.3905 & TRN & & \\
\hline CHEMBL3186408 & 955059 & 4.73600 & 00000000 & $\partial 1$ & 3.7425 & TST \\
\hline CHEMBL 300389 & 955059 & 6.1733 & 6.1696 & TRN & & \\
\hline CHEMBL1190711 & 955059 & 5.2359 & 5.2349 & TRN & & \\
\hline CHEMBL412142 & 955059 & 3.6176 & 3.6192 & TRN & & \\
\hline CHEMBL188678 & 955059 & 5.6539 & 5.6518 & TRN & & \\
\hline CHEMBL213100 & 955059 & 4.2849 & 4.2858 & TRN & & \\
\hline CHEMBL1256459 & 955059 & 7.1801 & 7.1818 & TRN & & \\
\hline CHEMBL221137 & 955059 & 4.974 & 4.8165 & TST & & \\
\hline CHEMBL449158 & 955059 & 6.0554 & 6.655 & TST & & \\
\hline
\end{tabular}




\begin{tabular}{|c|c|c|c|c|c|}
\hline \multicolumn{6}{|c|}{ Supplemental Table S2.txt } \\
\hline CHEMBL258844 & 955059 & 4.4164 & 4.4191 & TRN & \\
\hline CHEMBL191334 & 955059 & 5.6329 & 5.6307 & TRN & \\
\hline CHEMBL514499 & 955059 & 7.5694 & 7.5759 & TRN & \\
\hline CHEMBL512504 & 955059 & 6.9413 & 6.9435 & TRN & \\
\hline CHEMBL 202721 & 955059 & 6.0459 & 6.0417 & TRN & \\
\hline CHEMBL 2363137 & 955059 & 4.4318 & 4.4273 & TRN & \\
\hline CHEMBL3349342 & 955059 & 3.8349 & 3.833 & TRN & \\
\hline CHEMBL577784 & 955059 & 5.9861 & 5.9823 & TRN & \\
\hline CHEMBL1970879 & 955059 & 3.4178 & 3.4186 & TRN & \\
\hline CHEMBL 222102 & 955059 & 4.2833 & 4.2932 & TRN & \\
\hline CHEMBL220241 & 955059 & 4.8413 & 4.8386 & TRN & \\
\hline CHEMBL259181 & 955059 & 4.7111 & 4.7113 & TRN & \\
\hline CHEMBL483847 & 955059 & 3.5818 & 3.5805 & TRN & \\
\hline CHEMBL515416 & 955059 & 3.9107 & 3.9076 & TRN & \\
\hline CHEMBL1404918 & 955059 & 2.7426 & 2.7401 & TRN & \\
\hline CHEMBL393929 & 955059 & 4.539 & 4.5382 & TRN & \\
\hline CHEMBL102714 & 955059 & 4.4419 & 4.44600 & 0000000001 & TRN \\
\hline CHEMBL1590308 & 955059 & 2.6095 & 3.0333 & TST & \\
\hline CHEMBL483849 & 955059 & 3.3147 & 2.4343 & TST & \\
\hline CHEMBL 2005886 & 955059 & 5.3388 & 4.2542 & TST & \\
\hline CHEMBL135561 & 955059 & 4.654 & 4.2217 & TST & \\
\hline CHEMBL 3392440 & 955059 & 3.4834 & 3.6679 & TST & \\
\hline CHEMBL 2144069 & 955059 & 5.0701 & 4.3859 & TST & \\
\hline CHEMBL3199475 & 955059 & 5.0656 & 4.9995 & TST & \\
\hline CHEMBL240954 & 955059 & 4.4481 & 4.1846 & TST & \\
\hline CHEMBL509032 & 955059 & 5.2909 & 4.539 & TST & \\
\hline CHEMBL 9470 & 955059 & 6.3871 & 6.0678 & TST & \\
\hline CHEMBL1357429 & 688839 & 6.1 & 6.0824 & TRN & \\
\hline CHEMBL1592323 & 688839 & 5.8 & 5.3582 & TRN & \\
\hline CHEMBL1554937 & 688839 & 4.8 & 4.7616 & TRN & \\
\hline CHEMBL1552985 & 688839 & 6.0 & 6.1545 & TRN & \\
\hline CHEMBL1315666 & 688839 & 5.5 & 5.1875 & TRN & \\
\hline CHEMBL1513439 & 688839 & 4.9 & 4.9329 & TRN & \\
\hline CHEMBL1317884 & 688839 & 5.0 & 5.0388 & TRN & \\
\hline CHEMBL422942 & 688839 & 6.0 & 5.206 & TST & \\
\hline CHEMBL1517635 & 688839 & 5.1 & 5.0438 & TRN & \\
\hline CHEMBL1528491 & 688839 & 5.5 & 5.4535 & TRN & \\
\hline CHEMBL1328374 & 688839 & 4.8 & 5.1485 & TRN & \\
\hline CHEMBL1356068 & 688839 & 6.0 & 4.9857 & TRN & \\
\hline CHEMBL1527221 & 688839 & 5.7 & 5.8317 & TRN & \\
\hline CHEMBL63426 & 688839 & 5.2 & 5.2072 & TST & \\
\hline CHEMBL 1474890 & 688839 & 5.0 & 5.0411 & TRN & \\
\hline CHEMBL1398031 & 688839 & 4.6 & 4.7896 & TST & \\
\hline CHEMBL509256 & 688839 & 5.0 & 5.1964 & TRN & \\
\hline CHEMBL1551090 & 688839 & 4.8 & 4.8566 & TRN & \\
\hline CHEMBL1434747 & 688839 & 5.6 & 5.4 & TRN & \\
\hline CHEMBL1395297 & 688839 & 5.5 & 5.3192 & TRN & \\
\hline CHEMBL1315743 & 688839 & 6.0 & 5.7001 & TST & \\
\hline
\end{tabular}




\begin{tabular}{|c|c|c|c|c|c|}
\hline & & \\
\hline CHEMBL1412519 & 688839 & 5.4 & 5.3385 & TRN & \\
\hline CHEMBL1551274 & 688839 & 5.4 & 5.3472 & TST & \\
\hline CHEMBL137498 & 688839 & 5.4 & 5.0391 & TRN & \\
\hline CHEMBL1438371 & 688839 & 5.1 & 5.0907 & TRN & \\
\hline CHEMBL1591758 & 688839 & 4.9 & 4.8895 & TRN & \\
\hline CHEMBL1434975 & 688839 & 5.4 & 5.3315 & TST & \\
\hline CHEMBL1483801 & 688839 & 5.4 & 5.4516 & TRN & \\
\hline CHEMBL1473842 & 688839 & 4.4 & 5.4395 & TRN & \\
\hline CHEMBL1373007 & 688839 & 7.5003 & 5.2948 & TRN & \\
\hline CHEMBL1479767 & 688839 & 5.0 & 5.1123 & TRN & \\
\hline CHEMBL1318799 & 688839 & 5.5 & 5.7846 & TRN & \\
\hline CHEMBL490744 & 688839 & 5.6 & 5.8486 & TRN & \\
\hline CHEMBL1524305 & 688839 & 4.9 & 4.8807 & TRN & \\
\hline CHEMBL1366926 & 688839 & 4.9 & 4.9105 & TRN & \\
\hline CHEMBL1358276 & 688839 & 5.9 & 5.9392 & TRN & \\
\hline CHEMBL1319672 & 688839 & 5.3 & 5.2258 & TST & \\
\hline CHEMBL1564957 & 688839 & 5.4 & 5.1284 & TST & \\
\hline CHEMBL1597277 & 688839 & 4.4 & 4.5535 & TRN & \\
\hline CHEMBL1413489 & 688839 & 6.0 & 5.8918 & TRN & \\
\hline CHEMBL1437962 & 688839 & 5.4 & 5.3299 & TST & \\
\hline CHEMBL1409996 & 688839 & 5.7 & 5.8352 & TRN & \\
\hline CHEMBL83552 & 688839 & 5.3 & 4.9899 & TRN & \\
\hline CHEMBL465226 & 688839 & 4.9 & 5.1966 & TST & \\
\hline CHEMBL269362 & 688839 & 6.0 & 5.7629 & TST & \\
\hline CHEMBL1354372 & 688839 & 4.9 & 4.8717 & TRN & \\
\hline CHEMBL1395351 & 688839 & 5.6 & 5.2114 & TRN & \\
\hline CHEMBL1333783 & 688839 & 6.1 & 5.9585 & TRN & \\
\hline CHEMBL1331122 & 688839 & 5.4 & 5.2991 & TST & \\
\hline CHEMBL1517982 & 688839 & 4.7 & 5.0975 & TRN & \\
\hline CHEMBL1486289 & 688839 & 6.0 & 5.9747 & TRN & \\
\hline CHEMBL19259 & 688839 & 4.6 & 5.0477 & TRN & \\
\hline CHEMBL1611302 & 688839 & 5.9 & 5.36100 & 0000000001 & TST \\
\hline CHEMBL1593774 & 688839 & 5.2 & 5.1883 & TRN & \\
\hline CHEMBL491547 & 688839 & 5.7 & 5.7159 & TRN & \\
\hline CHEMBL1453244 & 688839 & 5.3 & 5.33899 & 99999999995 & TRN \\
\hline CHEMBL1395429 & 688839 & 4.9 & 4.9612 & TRN & \\
\hline CHEMBL1474483 & 688839 & 5.3 & 5.1454 & TRN & \\
\hline CHEMBL1491899 & 688839 & 4.6 & 5.1166 & TRN & \\
\hline CHEMBL1613544 & 688839 & 5.5 & 5.1256 & TRN & \\
\hline CHEMBL1560551 & 688839 & 5.8 & 5.5554 & TST & \\
\hline CHEMBL1315184 & 688839 & 5.1 & 5.2412 & TRN & \\
\hline CHEMBL1592835 & 688839 & 4.8 & 4.8418 & TRN & \\
\hline CHEMBL530115 & 688839 & 5.1 & 5.0202 & TST & \\
\hline CHEMBL1356713 & 688839 & 4.4 & 5.3522 & TST & \\
\hline CHEMBL31970 & 688839 & 4.8 & 4.9692 & TST & \\
\hline CHEMBL1334784 & 688839 & 6.0 & 4.9615 & TST & \\
\hline CHEMBL1256646 & 688839 & 4.8 & 4.8929 & TRN & \\
\hline CHEMBL2373679 & 688839 & 6.2 & 5.2373 & TST & \\
\hline & & & & 236 & \\
\hline
\end{tabular}




\begin{tabular}{|c|c|c|c|c|}
\hline & & & pplement & $a+1$ \\
\hline CHEMBL1515568 & 688839 & 5.6 & 5.4244 & TRN \\
\hline CHEMBL93655 & 688839 & 6.3 & 5.7322 & TST \\
\hline CHEMBL1365979 & 688839 & 4.9 & 4.9166 & TRN \\
\hline CHEMBL1359780 & 688839 & 4.9 & 5.1922 & TRN \\
\hline CHEMBL1554791 & 688839 & 4.8 & 4.8275 & TRN \\
\hline CHEMBL1316831 & 688839 & 4.8 & 4.857 & TST \\
\hline CHEMBL1256876 & 688839 & 6.0 & 5.6624 & TST \\
\hline CHEMBL117405 & 688839 & 5.1 & 5.0692 & TST \\
\hline CHEMBL3190029 & 688839 & 5.6 & 5.2224 & TST \\
\hline CHEMBL1593997 & 688839 & 5.7 & 5.8345 & TRN \\
\hline CHEMBL 28449 & 688839 & 6.0 & 5.8496 & TRN \\
\hline CHEMBL1405464 & 688839 & 5.3 & 5.2427 & TRN \\
\hline CHEMBL1256668 & 688839 & 4.8 & 4.9829 & TST \\
\hline CHEMBL1451788 & 688839 & 5.5 & 5.7144 & TRN \\
\hline CHEMBL1512199 & 688839 & 4.5 & 4.6851 & TST \\
\hline CHEMBL1315777 & 688839 & 5.5 & 5.2181 & TST \\
\hline CHEMBL1593663 & 688839 & 5.2 & 5.1623 & TRN \\
\hline CHEMBL1533932 & 688839 & 5.1 & 5.3318 & TRN \\
\hline CHEMBL131921 & 688839 & 4.7 & 5.1288 & TRN \\
\hline CHEMBL1480516 & 688839 & 6.0 & 5.8573 & TST \\
\hline CHEMBL51697 & 688839 & 6.0 & 5.8227 & TRN \\
\hline CHEMBL513116 & 688839 & 6.0 & 5.6911 & TRN \\
\hline CHEMBL1320943 & 688839 & 5.4 & 4.9866 & TRN \\
\hline CHEMBL1357151 & 688839 & 4.4 & 5.2091 & TST \\
\hline CHEMBL1356657 & 688839 & 5.3 & 5.2279 & TRN \\
\hline CHEMBL1495854 & 688839 & 5.3 & 5.2072 & TRN \\
\hline CHEMBL194805 & 688839 & 4.7 & 5.0784 & TRN \\
\hline CHEMBL173395 & 688839 & 4.9 & 5.0713 & TRN \\
\hline CHEMBL1329372 & 688839 & 5.3 & 4.9403 & TRN \\
\hline CHEMBL1496596 & 688839 & 4.8 & 4.8185 & TRN \\
\hline CHEMBL491976 & 688839 & 6.4 & 6.6072 & TRN \\
\hline CHEMBL1354172 & 688839 & 6.1 & 5.8694 & TST \\
\hline CHEMBL1570788 & 688839 & 4.9 & 5.0217 & TST \\
\hline CHEMBL1590382 & 688839 & 5.0 & 4.9624 & TRN \\
\hline CHEMBL1593371 & 688839 & 4.8 & 4.8803 & TRN \\
\hline CHEMBL18701 & 688839 & 4.8 & 4.9087 & TRN \\
\hline CHEMBL1437491 & 688839 & 4.8 & 4.8299 & TRN \\
\hline CHEMBL83899 & 688839 & 4.8 & 4.9112 & TRN \\
\hline CHEMBL1610735 & 688839 & 6.0 & 5.5386 & TRN \\
\hline CHEMBL1434111 & 688839 & 4.8 & 4.7956 & TRN \\
\hline CHEMBL1397913 & 688839 & 5.1 & 5.2014 & TRN \\
\hline CHEMBL1472880 & 688839 & 5.5 & 5.3502 & TRN \\
\hline CHEMBL1991126 & 688839 & 4.6 & 5.0313 & TRN \\
\hline CHEMBL1451526 & 688839 & 5.5 & 5.386 & TRN \\
\hline CHEMBL11458 & 688839 & 5.3 & 5.3067 & TST \\
\hline CHEMBL1445084 & 688839 & 4.8 & 5.0259 & TRN \\
\hline CHEMBL1362880 & 688839 & 5.2 & 4.7073 & TRN \\
\hline CHEMBL1513241 & 688839 & 4.7 & 4.6676 & TRN \\
\hline
\end{tabular}




\begin{tabular}{|c|c|c|c|c|}
\hline & & & pplement & al $\mathrm{Ta}$ \\
\hline CHEMBL1314477 & 688839 & 6.9 & 6.1909 & TRN \\
\hline CHEMBL1398540 & 688839 & 4.8 & 4.823 & TRN \\
\hline CHEMBL1671904 & 688839 & 4.6 & 5.0354 & TST \\
\hline CHEMBL1256735 & 688839 & 4.8 & 5.0032 & TRN \\
\hline CHEMBL348856 & 688839 & 4.9 & 5.1037 & TRN \\
\hline CHEMBL72631 & 688839 & 5.3 & 5.2811 & TRN \\
\hline CHEMBL1374108 & 688839 & 5.1 & 5.1646 & TRN \\
\hline CHEMBL411492 & 688839 & 5.1 & 5.0593 & TRN \\
\hline CHEMBL1435912 & 688839 & 4.9 & 5.0569 & TRN \\
\hline CHEMBL1553626 & 688839 & 5.1 & 5.3266 & TST \\
\hline CHEMBL1523286 & 688839 & 5.4 & 5.2657 & TST \\
\hline CHEMBL1354262 & 688839 & 4.9 & 4.9249 & TRN \\
\hline CHEMBL1553328 & 688839 & 5.3 & 5.0681 & TRN \\
\hline CHEMBL1563497 & 688839 & 5.6 & 5.5959 & TRN \\
\hline CHEMBL1404317 & 688839 & 5.5 & 5.4804 & TRN \\
\hline CHEMBL1438674 & 688839 & 5.4 & 5.5475 & TRN \\
\hline CHEMBL1606574 & 688839 & 6.0 & 5.8654 & TRN \\
\hline CHEMBL1086446 & 688839 & 4.8 & 5.007 & TRN \\
\hline CHEMBL487186 & 688839 & 6.3 & 5.2325 & TST \\
\hline CHEMBL1339340 & 688839 & 4.5 & 5.2492 & TST \\
\hline CHEMBL1525456 & 688839 & 5.3 & 5.3131 & TRN \\
\hline CHEMBL1406556 & 688839 & 5.6 & 5.563 & TRN \\
\hline CHEMBL239439 & 688839 & 5.8 & 5.5402 & TST \\
\hline CHEMBL1368643 & 688839 & 4.6 & 4.6938 & TRN \\
\hline CHEMBL1526987 & 688839 & 4.8 & 5.1495 & TST \\
\hline CHEMBL1522552 & 688839 & 6.0 & 5.0593 & TRN \\
\hline CHEMBL1553404 & 688839 & 5.1 & 5.008 & TRN \\
\hline CHEMBL335231 & 688839 & 5.5 & 5.3267 & TST \\
\hline CHEMBL1356022 & 688839 & 5.4 & 5.2458 & TRN \\
\hline CHEMBL1435319 & 688839 & 4.4 & 5.0954 & TST \\
\hline CHEMBL1358120 & 688839 & 5.4 & 5.3612 & TRN \\
\hline CHEMBL1328943 & 688839 & 5.3 & 5.3801 & TRN \\
\hline CHEMBL1396462 & 688839 & 4.5 & 4.5494 & TRN \\
\hline CHEMBL1322207 & 688839 & 5.5 & 5.3704 & TST \\
\hline CHEMBL345124 & 688839 & 4.8 & 4.9582 & TST \\
\hline CHEMBL1570285 & 688839 & 5.6 & 5.6095 & TRN \\
\hline CHEMBL1515804 & 688839 & 5.3 & 5.2621 & TRN \\
\hline CHEMBL1315093 & 688839 & 4.9 & 4.7507 & TRN \\
\hline CHEMBL1358614 & 688839 & 6.0 & 6.1444 & TRN \\
\hline CHEMBL1371221 & 688839 & 5.4 & 5.313 & TRN \\
\hline CHEMBL131199 & 688839 & 5.8 & 5.1837 & TRN \\
\hline CHEMBL1597410 & 688839 & 6.0 & 6.0714 & TRN \\
\hline CHEMBL1440056 & 688839 & 4.8 & 5.1891 & TST \\
\hline CHEMBL1357850 & 688839 & 6.0 & 6.0949 & TRN \\
\hline CHEMBL1409547 & 688839 & 5.3 & 5.2366 & TRN \\
\hline CHEMBL1450521 & 688839 & 6.6 & 6.6853 & TRN \\
\hline CHEMBL1998893 & 688839 & 5.4 & 5.3294 & TRN \\
\hline CHEMBL1552667 & 688839 & 5.4 & 5.144 & TRN \\
\hline
\end{tabular}




\begin{tabular}{|c|c|c|c|c|}
\hline & & & pplement & $\mathrm{a} \perp \mathrm{Ta}$ \\
\hline CHEMBL1435086 & 688839 & 4.8 & 4.8134 & TRN \\
\hline CHEMBL1316979 & 688839 & 5.9 & 5.9986 & TRN \\
\hline CHEMBL1527579 & 688839 & 5.4 & 5.4558 & TRN \\
\hline CHEMBL1442011 & 688839 & 5.7 & 5.5787 & TRN \\
\hline CHEMBL1473480 & 688839 & 5.3 & 5.2141 & TRN \\
\hline CHEMBL1513392 & 688839 & 5.3 & 5.2016 & TST \\
\hline CHEMBL1316616 & 688839 & 5.6 & 5.7151 & TRN \\
\hline CHEMBL1526032 & 688839 & 4.8 & 4.7795 & TRN \\
\hline CHEMBL1356624 & 688839 & 4.8 & 4.9269 & TRN \\
\hline CHEMBL296586 & 688839 & 4.9 & 4.9832 & TST \\
\hline CHEMBL1440943 & 688839 & 6.3 & 6.4478 & TRN \\
\hline CHEMBL1373918 & 688839 & 5.4 & 5.115 & TRN \\
\hline CHEMBL1256186 & 688839 & 5.5 & 5.3972 & TST \\
\hline CHEMBL1611550 & 688839 & 5.6 & 5.1511 & TRN \\
\hline CHEMBL1485984 & 688839 & 4.7 & 5.1322 & TST \\
\hline CHEMBL1314582 & 688839 & 5.1 & 5.2354 & TST \\
\hline CHEMBL1331657 & 688839 & 4.6 & 4.8783 & TRN \\
\hline CHEMBL1356336 & 688839 & 5.8 & 5.8755 & TRN \\
\hline CHEMBL1256695 & 688839 & 6.0 & 5.7618 & TST \\
\hline CHEMBL1553731 & 688839 & 5.4 & 5.1689 & TST \\
\hline CHEMBL1317378 & 688839 & 4.8 & 4.742 & TRN \\
\hline CHEMBL1337781 & 688839 & 5.4 & 5.3574 & TRN \\
\hline CHEMBL1552588 & 688839 & 5.0 & 4.9528 & TRN \\
\hline CHEMBL1433598 & 688839 & 5.5 & 5.3104 & TRN \\
\hline CHEMBL1488845 & 688839 & 5.0 & 4.8913 & TST \\
\hline CHEMBL1612620 & 688839 & 5.2 & 5.0924 & TRN \\
\hline CHEMBL1318461 & 688839 & 5.3 & 5.2438 & TRN \\
\hline CHEMBL567175 & 688839 & 6.0 & 5.7616 & TST \\
\hline CHEMBL1489659 & 688839 & 6.2 & 6.1336 & TRN \\
\hline CHEMBL1256360 & 688839 & 5.0 & 4.9823 & TRN \\
\hline CHEMBL1415488 & 688839 & 5.4 & 5.2539 & TRN \\
\hline CHEMBL1555118 & 688839 & 5.5 & 5.4076 & TRN \\
\hline CHEMBL1355139 & 688839 & 6.3 & 6.4533 & TRN \\
\hline CHEMBL1476981 & 688839 & 4.8 & 4.775 & TRN \\
\hline CHEMBL1231544 & 688839 & 5.1 & 4.8529 & TRN \\
\hline CHEMBL1452520 & 688839 & 6.3 & 5.2089 & TRN \\
\hline CHEMBL1413566 & 688839 & 6.6 & 6.5417 & TRN \\
\hline CHEMBL1521133 & 688839 & 5.5 & 5.4345 & TRN \\
\hline CHEMBL1333264 & 688839 & 5.4 & 5.1148 & TRN \\
\hline CHEMBL1591712 & 688839 & 4.9 & 4.8954 & TRN \\
\hline CHEMBL1356304 & 688839 & 5.5 & 5.275 & TST \\
\hline CHEMBL1555316 & 688839 & 4.8 & 4.8033 & TRN \\
\hline CHEMBL1490863 & 688839 & 5.5 & 5.3258 & TRN \\
\hline CHEMBL1494592 & 688839 & 4.8 & 4.8159 & TRN \\
\hline CHEMBL1357781 & 688839 & 5.4 & 5.489 & TRN \\
\hline CHEMBL1365122 & 688839 & 5.4 & 5.1562 & TRN \\
\hline CHEMBL1415175 & 688839 & 6.0 & 5.2137 & TRN \\
\hline CHEMBL1375049 & 688839 & 6.0 & 5.1154 & TRN \\
\hline
\end{tabular}




\begin{tabular}{|c|c|c|c|c|}
\hline & & & pplement & al $\mathrm{Ta}$ \\
\hline CHEMBL1329026 & 688839 & 5.5 & 5.3927 & TST \\
\hline CHEMBL1405913 & 688839 & 5.4 & 5.4348 & TRN \\
\hline CHEMBL1551200 & 688839 & 5.4 & 5.3467 & TRN \\
\hline CHEMBL1561561 & 688839 & 5.9 & 5.3259 & TRN \\
\hline CHEMBL 1400788 & 688839 & 5.4 & 5.2952 & TST \\
\hline CHEMBL16671 & 688839 & 6.0 & 4.8327 & TST \\
\hline CHEMBL1436475 & 688839 & 4.9 & 5.1438 & TRN \\
\hline CHEMBL1371944 & 688839 & 5.5 & 5.7392 & TRN \\
\hline CHEMBL1579501 & 688839 & 5.3 & 5.1949 & TST \\
\hline CHEMBL1446649 & 688839 & 5.3 & 5.2463 & TRN \\
\hline CHEMBL1555537 & 688839 & 5.3 & 5.2219 & TST \\
\hline CHEMBL492132 & 688839 & 6.4 & 6.5082 & TRN \\
\hline CHEMBL1487111 & 688839 & 5.8 & 5.7976 & TRN \\
\hline CHEMBL1590877 & 688839 & 5.4 & 4.9431 & TRN \\
\hline CHEMBL1574608 & 688839 & 4.8 & 4.8992 & TRN \\
\hline CHEMBL1398321 & 688839 & 4.9 & 4.9425 & TST \\
\hline CHEMBL1407497 & 688839 & 4.9 & 5.0685 & TRN \\
\hline CHEMBL1367159 & 688839 & 4.6 & 5.1014 & TRN \\
\hline CHEMBL1365271 & 688839 & 5.0 & 5.0518 & TRN \\
\hline CHEMBL1594947 & 688839 & 5.6 & 5.6745 & TRN \\
\hline CHEMBL1368286 & 688839 & 5.4 & 5.3411 & TRN \\
\hline CHEMBL1331105 & 688839 & 5.4 & 5.3586 & TRN \\
\hline CHEMBL1553990 & 688839 & 4.8 & 4.934 & TRN \\
\hline CHEMBL1441255 & 688839 & 5.3 & 5.2483 & TST \\
\hline CHEMBL1610144 & 688839 & 4.8 & 5.0823 & TRN \\
\hline CHEMBL1442425 & 688839 & 4.6 & 4.6977 & TRN \\
\hline CHEMBL90124 & 688839 & 4.9 & 5.1609 & TST \\
\hline CHEMBL1369863 & 688839 & 5.0 & 4.9234 & TRN \\
\hline CHEMBL1319789 & 688839 & 5.0 & 5.3817 & TRN \\
\hline CHEMBL1554408 & 688839 & 6.9 & 5.2123 & TRN \\
\hline CHEMBL1534630 & 688839 & 5.0 & 5.0269 & TST \\
\hline CHEMBL1561691 & 688839 & 5.4 & 5.0423 & TRN \\
\hline CHEMBL1600620 & 688839 & 5.3 & 5.1991 & TRN \\
\hline CHEMBL1592547 & 688839 & 6.1 & 5.7708 & TRN \\
\hline CHEMBL1601163 & 688839 & 6.4 & 6.591 & TRN \\
\hline CHEMBL1516701 & 688839 & 4.7 & 4.7857 & TRN \\
\hline CHEMBL1434643 & 688839 & 5.1 & 5.1628 & TRN \\
\hline CHEMBL1405043 & 688839 & 5.4 & 5.3129 & TRN \\
\hline CHEMBL1314906 & 688839 & 4.9 & 4.9285 & TRN \\
\hline CHEMBL1434057 & 688839 & 5.0 & 5.0508 & TRN \\
\hline CHEMBL1355010 & 688839 & 4.7 & 4.6944 & TRN \\
\hline CHEMBL1165239 & 688839 & 5.6 & 5.0323 & TST \\
\hline CHEMBL1371095 & 688839 & 5.0 & 5.1535 & TST \\
\hline CHEMBL1512701 & 688839 & 5.6 & 5.6121 & TRN \\
\hline CHEMBL1474875 & 688839 & 4.8 & 4.8102 & TRN \\
\hline CHEMBL1200921 & 688839 & 4.4 & 4.9449 & TST \\
\hline CHEMBL585481 & 688839 & 4.5 & 5.0871 & TRN \\
\hline CHEMBL1317932 & 688839 & 5.8 & 5.5736 & TRN \\
\hline
\end{tabular}




\begin{tabular}{|c|c|c|c|c|c|}
\hline \\
\hline CHEMBL1410865 & 688839 & 6.0 & 6.074 & TRN & \\
\hline CHEMBL1529665 & 688839 & 5.5 & 5.3856 & TST & \\
\hline CHEMBL467706 & 688839 & 6.0 & 5.7924 & TST & \\
\hline CHEMBL1355201 & 688839 & 5.2 & 5.2571 & TRN & \\
\hline CHEMBL1436121 & 688839 & 6.9 & 5.0928 & TST & \\
\hline CHEMBL1412863 & 688839 & 4.9 & 5.0931 & TRN & \\
\hline CHEMBL1401214 & 688839 & 5.5 & 5.6921 & TRN & \\
\hline CHEMBL1452561 & 688839 & 5.6 & 5.4639 & TRN & \\
\hline CHEMBL 2373655 & 688839 & 4.7 & 5.1537 & TST & \\
\hline CHEMBL1434369 & 688839 & 5.5 & 5.3422 & TRN & \\
\hline CHEMBL1563032 & 688839 & 4.8 & 4.9883 & TRN & \\
\hline CHEMBL1417448 & 688839 & 4.9 & 4.8272 & TRN & \\
\hline CHEMBL1601305 & 688839 & 5.1 & 5.022 & TRN & \\
\hline CHEMBL443462 & 688839 & 4.5 & 5.0464 & TST & \\
\hline CHEMBL1514257 & 688839 & 5.3 & 5.34399 & 9999999999 & TRN \\
\hline CHEMBL994 & 688839 & 4.9 & 4.9924 & TST & \\
\hline CHEMBL1318104 & 688839 & 4.8 & 4.8814 & TRN & \\
\hline CHEMBL1567295 & 688839 & 6.8 & 6.7617 & TRN & \\
\hline CHEMBL1375525 & 688839 & 6.0 & 5.3695 & TRN & \\
\hline CHEMBL1317214 & 688839 & 5.5 & 5.5767 & TRN & \\
\hline CHEMBL1329590 & 688839 & 4.8 & 5.0337 & TRN & \\
\hline CHEMBL1361855 & 688839 & 5.5 & 5.4172 & TST & \\
\hline CHEMBL1552329 & 688839 & 4.9 & 4.9332 & TRN & \\
\hline CHEMBL1592975 & 688839 & 5.1 & 5.1917 & TST & \\
\hline CHEMBL1531899 & 688839 & 5.0 & 4.9976 & TRN & \\
\hline CHEMBL1607517 & 688839 & 4.4 & 5.1919 & TRN & \\
\hline CHEMBL319244 & 688839 & 6.0 & 4.8559 & TRN & \\
\hline CHEMBL1443360 & 688839 & 5.0 & 4.9634 & TRN & \\
\hline CHEMBL1592631 & 688839 & 5.4 & 5.1515 & TRN & \\
\hline CHEMBL1481984 & 688839 & 4.9 & 4.967 & TST & \\
\hline CHEMBL1302739 & 688839 & 7.8996 & 5.1473 & TST & \\
\hline CHEMBL1394048 & 688839 & 5.5 & 4.9846 & TRN & \\
\hline CHEMBL1452389 & 688839 & 5.7 & 5.5463 & TRN & \\
\hline CHEMBL1607623 & 688839 & 5.5 & 5.5319 & TRN & \\
\hline CHEMBL587849 & 688839 & 5.8 & 5.5699 & TRN & \\
\hline CHEMBL1256663 & 688839 & 4.8 & 4.8524 & TRN & \\
\hline CHEMBL87285 & 688839 & 6.0 & 4.9353 & TRN & \\
\hline CHEMBL1414988 & 688839 & 4.9 & 5.2305 & TRN & \\
\hline CHEMBL1479470 & 688839 & 4.8 & 4.8129 & TRN & \\
\hline CHEMBL1315609 & 688839 & 5.4 & 5.38899 & 9999999999 & TRN \\
\hline CHEMBL1395235 & 688839 & 6.0 & 5.2193 & TRN & \\
\hline CHEMBL1434646 & 688839 & 4.8 & 5.0984 & TRN & \\
\hline CHEMBL291057 & 688839 & 4.5 & 5.0829 & TST & \\
\hline CHEMBL1481847 & 688839 & 5.0 & 5.0233 & TRN & \\
\hline CHEMBL1512845 & 688839 & 4.7 & 5.3018 & TRN & \\
\hline CHEMBL1322216 & 688839 & 5.0 & 4.9973 & TRN & \\
\hline CHEMBL1592160 & 688839 & 4.9 & 5.0771 & TRN & \\
\hline CHEMBL1514390 & 688839 & 4.8 & 4.8976 & TRN & \\
\hline
\end{tabular}




\begin{tabular}{|c|c|c|c|c|c|}
\hline & & & & & \\
\hline CHEMBL1566552 & 688839 & 4.8 & 5.2834 & TRN & \\
\hline CHEMBL554311 & 688839 & 4.4 & 5.086 & TST & \\
\hline CHEMBL1603803 & 688839 & 6.0 & 5.9751 & TRN & \\
\hline CHEMBL432608 & 688839 & 6.1 & 5.9116 & TST & \\
\hline CHEMBL1322026 & 688839 & 5.4 & 5.3225 & TST & \\
\hline CHEMBL1256660 & 688839 & 4.7 & 4.9492 & TST & \\
\hline CHEMBL1370135 & 688839 & 5.3 & 5.1649 & TRN & \\
\hline CHEMBL3195553 & 688839 & 6.0 & 6.0094 & TRN & \\
\hline CHEMBL1359157 & 688839 & 5.5 & 5.4093 & TRN & \\
\hline CHEMBL1440653 & 688839 & 4.6 & 5.4728 & TRN & \\
\hline CHEMBL596674 & 688839 & 6.0 & $5.7620 e$ & 30000000005 & TRN \\
\hline CHEMBL1612582 & 688839 & 5.1 & 5.1046 & TRN & \\
\hline CHEMBL1560502 & 688839 & 5.9 & 5.9278 & TRN & \\
\hline CHEMBL1356941 & 688839 & 5.9 & 5.6251 & TRN & \\
\hline CHEMBL1368773 & 688839 & 5.8 & 6.0306 & TST & \\
\hline CHEMBL1435296 & 688839 & 4.8 & 4.8753 & TRN & \\
\hline CHEMBL1406274 & 688839 & 6.0 & 4.7544 & TST & \\
\hline CHEMBL115121 & 688839 & 5.2 & $5.1960 e$ & 3000000001 & TST \\
\hline CHEMBL1602568 & 688839 & 5.0 & 4.9892 & TRN & \\
\hline CHEMBL1565311 & 688839 & 6.0 & 6.0183 & TRN & \\
\hline CHEMBL1079460 & 688839 & 5.3 & 5.2612 & TST & \\
\hline CHEMBL1445706 & 688839 & 5.4 & 5.1641 & TRN & \\
\hline CHEMBL1413827 & 688839 & 5.4 & 5.1747 & TST & \\
\hline CHEMBL1316974 & 688839 & 4.8 & 5.0652 & TRN & \\
\hline CHEMBL1358272 & 688839 & 5.0 & 5.0505 & TRN & \\
\hline CHEMBL 2374082 & 688839 & 4.4 & 5.0423 & TST & \\
\hline CHEMBL1595401 & 688839 & 4.4 & 5.0089 & TRN & \\
\hline CHEMBL1560633 & 688839 & 4.5 & 5.0759 & TRN & \\
\hline CHEMBL1405922 & 688839 & 6.0 & 5.0011 & TST & \\
\hline CHEMBL285932 & 688839 & 5.0 & 5.0243 & TST & \\
\hline CHEMBL1317163 & 688839 & 4.8 & 4.8713 & TRN & \\
\hline CHEMBL1558729 & 688839 & 4.8 & 5.1216 & TRN & \\
\hline CHEMBL1476670 & 688839 & 4.9 & 5.0431 & TRN & \\
\hline CHEMBL484662 & 688839 & 6.1 & 5.357 & TRN & \\
\hline CHEMBL1473990 & 688839 & 6.0 & 5.7994 & TRN & \\
\hline CHEMBL1595328 & 688839 & 4.6 & 4.626 & TRN & \\
\hline CHEMBL1496494 & 688839 & 5.0 & 5.1051 & TRN & \\
\hline CHEMBL1316754 & 688839 & 5.5 & 5.2989 & TRN & \\
\hline CHEMBL276618 & 688839 & 4.6 & 5.0538 & TRN & \\
\hline CHEMBL239047 & 688839 & 4.4 & 5.4719 & TRN & \\
\hline CHEMBL 2112207 & 688839 & 5.0 & 5.211 & TST & \\
\hline CHEMBL1323167 & 688839 & 5.5 & 5.3251 & TST & \\
\hline CHEMBL1517581 & 688839 & 5.4 & 5.1841 & TRN & \\
\hline CHEMBL1358266 & 688839 & 4.8 & 4.9542 & TRN & \\
\hline CHEMBL470671 & 688839 & 4.9 & 4.9918 & TRN & \\
\hline CHEMBL362051 & 688839 & 4.8 & 5.0183 & TRN & \\
\hline CHEMBL1574626 & 688839 & 4.8 & 4.882 & TRN & \\
\hline CHEMBL1396203 & 688839 & 5.5 & 5.3898 & TRN & \\
\hline & & & & 20311 & \\
\hline
\end{tabular}




\begin{tabular}{|c|c|c|c|c|c|}
\hline & & & & & \\
\hline CHEMBL1445979 & 688839 & 5.1 & 4.7242 & TRN & \\
\hline CHEMBL1397999 & 688839 & 5.2 & 5.1194 & TST & \\
\hline CHEMBL77287 & 688839 & 4.4 & 4.6362 & TRN & \\
\hline CHEMBL159096 & 688839 & 4.7 & 4.8671 & TST & \\
\hline CHEMBL1394964 & 688839 & 4.7 & $4.7410 e$ & 00000000005 & TRN \\
\hline CHEMBL1417648 & 688839 & 4.8 & 5.0789 & TRN & \\
\hline CHEMBL1515290 & 688839 & 5.7 & 5.2386 & TST & \\
\hline CHEMBL1374524 & 688839 & 5.4 & 5.3201 & TST & \\
\hline CHEMBL1611471 & 688839 & 6.0 & 5.205 & TRN & \\
\hline CHEMBL1590321 & 688839 & 4.7 & 4.7523 & TRN & \\
\hline CHEMBL1396407 & 688839 & 5.9 & 5.9703 & TRN & \\
\hline CHEMBL1356721 & 688839 & 5.4 & 5.3456 & TRN & \\
\hline CHEMBL1396559 & 688839 & 5.1 & 5.0959 & TRN & \\
\hline CHEMBL1476129 & 688839 & 5.6 & 5.4563 & TRN & \\
\hline CHEMBL1590270 & 688839 & 4.8 & 5.0624 & TRN & \\
\hline CHEMBL1333104 & 688839 & 5.1 & 5.1211 & TRN & \\
\hline CHEMBL1554693 & 688839 & 6.2 & 6.1172 & TRN & \\
\hline CHEMBL1532597 & 688839 & 5.7 & 5.7916 & TRN & \\
\hline CHEMBL1397490 & 688839 & 4.8 & 4.9634 & TRN & \\
\hline CHEMBL1450499 & 688839 & 5.3 & 5.0125 & TST & \\
\hline CHEMBL1607202 & 688839 & 4.8 & 5.04 & TRN & \\
\hline CHEMBL1513654 & 688839 & 4.7 & 4.8295 & TST & \\
\hline CHEMBL1605496 & 688839 & 5.1 & 5.0102 & TRN & \\
\hline CHEMBL1520411 & 688839 & 4.7 & 5.1767 & TRN & \\
\hline CHEMBL1518159 & 688839 & 4.7 & 4.8167 & TRN & \\
\hline CHEMBL1605426 & 688839 & 4.7 & 4.7374 & TST & \\
\hline CHEMBL1514639 & 688839 & 5.6 & 5.4743 & TST & \\
\hline CHEMBL1355146 & 688839 & 5.1 & 5.0171 & TRN & \\
\hline CHEMBL1560109 & 688839 & 4.7 & 5.1523 & TRN & \\
\hline CHEMBL110739 & 688839 & 5.1 & 5.3547 & TRN & \\
\hline CHEMBL1323684 & 688839 & 6.0 & 5.9998 & TRN & \\
\hline CHEMBL1394738 & 688839 & 4.4 & 5.2562 & TRN & \\
\hline CHEMBL1444914 & 688839 & 6.5 & 6.5759 & TRN & \\
\hline CHEMBL1591729 & 688839 & 4.9 & 5.2431 & TST & \\
\hline CHEMBL170408 & 688839 & 4.5 & 5.0402 & TRN & \\
\hline CHEMBL184450 & 688839 & 4.8 & 4.9812 & TRN & \\
\hline CHEMBL1414885 & 688839 & 4.9 & 5.2282 & TRN & \\
\hline CHEMBL1357199 & 688839 & 4.7 & 4.808 & TRN & \\
\hline CHEMBL82846 & 688839 & 5.3 & 5.0251 & TRN & \\
\hline CHEMBL1406408 & 688839 & 5.4 & 5.2353 & TRN & \\
\hline CHEMBL1515961 & 688839 & 5.5 & 5.4295 & TST & \\
\hline CHEMBL1375363 & 688839 & 5.0 & 5.2444 & TST & \\
\hline CHEMBL1354563 & 688839 & 5.5 & 5.4337 & TRN & \\
\hline CHEMBL1514416 & 688839 & 5.1 & 5.2041 & TRN & \\
\hline CHEMBL1600780 & 688839 & 6.0 & 5.8012 & TRN & \\
\hline CHEMBL1374334 & 688839 & 6.2 & 5.9887 & TST & \\
\hline CHEMBL1474625 & 688839 & 6.0 & 5.727 & TRN & \\
\hline CHEMBL1357157 & 688839 & 4.7 & 4.8593 & TRN & \\
\hline & & & & 20312 & \\
\hline
\end{tabular}




\begin{tabular}{|c|c|c|c|c|}
\hline & & & pplement & $d \perp$ \\
\hline CHEMBL 294878 & 688839 & 5.1 & 5.1965 & TRN \\
\hline CHEMBL1569585 & 688839 & 5.1 & 5.2014 & TRN \\
\hline CHEMBL1453764 & 688839 & 4.6 & 4.8043 & TRN \\
\hline CHEMBL1404660 & 688839 & 5.9 & 5.8797 & TRN \\
\hline CHEMBL1355835 & 688839 & 6.3 & 6.0817 & TRN \\
\hline CHEMBL1361725 & 688839 & 5.5 & 5.3196 & TRN \\
\hline CHEMBL1514719 & 688839 & 4.6 & 4.7058 & TRN \\
\hline CHEMBL1433805 & 688839 & 4.8 & 4.8044 & TRN \\
\hline CHEMBL1396010 & 688839 & 4.7 & 4.7295 & TRN \\
\hline CHEMBL1551584 & 688839 & 6.0 & 5.9946 & TRN \\
\hline CHEMBL 263893 & 688839 & 4.8 & 5.1039 & TRN \\
\hline CHEMBL1451973 & 688839 & 4.6 & 5.2276 & TRN \\
\hline CHEMBL1590550 & 688839 & 6.4 & 6.5312 & TRN \\
\hline CHEMBL1315455 & 688839 & 5.3 & 5.2045 & TST \\
\hline CHEMBL88961 & 688839 & 6.1 & 5.1652 & TRN \\
\hline CHEMBL1489663 & 688839 & 5.4 & 5.3504 & TST \\
\hline CHEMBL1456688 & 688839 & 4.6 & 4.7115 & TRN \\
\hline CHEMBL1330422 & 688839 & 5.5 & 5.4389 & TRN \\
\hline CHEMBL 307341 & 688839 & 4.4 & 5.083 & TRN \\
\hline CHEMBL1596952 & 688839 & 5.3 & 5.1722 & TRN \\
\hline CHEMBL1473317 & 688839 & 5.4 & 5.2549 & TRN \\
\hline CHEMBL1354841 & 688839 & 5.5 & 5.4191 & TRN \\
\hline CHEMBL1531056 & 688839 & 4.6 & 4.7487 & TRN \\
\hline CHEMBL1256836 & 688839 & 6.0 & 5.4467 & TST \\
\hline CHEMBL1318679 & 688839 & 6.0 & 5.2485 & TRN \\
\hline CHEMBL1865649 & 688839 & 6.0 & 6.0328 & TRN \\
\hline CHEMBL1576153 & 688839 & 4.5 & 5.1918 & TRN \\
\hline CHEMBL1516675 & 688839 & 4.8 & 5.0488 & TST \\
\hline CHEMBL1552294 & 688839 & 4.8 & 4.9414 & TRN \\
\hline CHEMBL1437488 & 688839 & 6.0 & 6.0216 & TRN \\
\hline CHEMBL 305195 & 688839 & 5.0 & 5.166 & TRN \\
\hline CHEMBL1564927 & 688839 & 5.4 & 5.2808 & TST \\
\hline CHEMBL1329033 & 688839 & 5.5 & 5.4281 & TST \\
\hline CHEMBL 98350 & 688839 & 6.0 & 5.7622 & TRN \\
\hline CHEMBL1534872 & 688839 & 5.6 & 5.3574 & TST \\
\hline CHEMBL1334465 & 688839 & 5.2 & 5.2066 & TST \\
\hline CHEMBL546257 & 688839 & 6.0 & 5.7422 & TST \\
\hline CHEMBL1477727 & 688839 & 5.5 & 5.496 & TRN \\
\hline CHEMBL1612246 & 688839 & 4.8 & 5.1113 & TRN \\
\hline CHEMBL1555314 & 688839 & 5.6 & 5.6913 & TRN \\
\hline CHEMBL1592506 & 688839 & 4.8 & 4.7808 & TRN \\
\hline CHEMBL1473965 & 688839 & 6.7001 & 6.1256 & TRN \\
\hline CHEMBL38832 & 688839 & 5.9 & 5.6405 & TST \\
\hline CHEMBL1330459 & 688839 & 6.0 & 5.2396 & TRN \\
\hline CHEMBL1567150 & 688839 & 4.8 & 5.0005 & TRN \\
\hline CHEMBL1319452 & 688839 & 4.6 & 4.9666 & TRN \\
\hline CHEMBL1607751 & 688839 & 5.5 & 5.2015 & TST \\
\hline CHEMBL1488225 & 688839 & 4.8 & 5.0541 & TRN \\
\hline
\end{tabular}




\begin{tabular}{|c|c|c|c|c|c|}
\hline & & & & & \\
\hline CHEMBL 265943 & 688839 & 5.0 & 5.0293 & TRN & \\
\hline CHEMBL1490322 & 688839 & 5.2 & 5.3604 & TST & \\
\hline CHEMBL1554654 & 688839 & 5.5 & 5.4931 & TRN & \\
\hline CHEMBL 285843 & 688839 & 4.4 & 5.4292 & TST & \\
\hline CHEMBL 1475574 & 688839 & 5.6 & 4.8157 & TRN & \\
\hline CHEMBL1434848 & 688839 & 5.5 & 5.6638 & TRN & \\
\hline CHEMBL1441649 & 688839 & 4.7 & 4.8376 & TRN & \\
\hline CHEMBL1337379 & 688839 & 4.4 & 5.1933 & TRN & \\
\hline CHEMBL1354190 & 688839 & 5.5 & 5.3602 & TST & \\
\hline CHEMBL1319316 & 688839 & 4.8 & 5.1234 & TST & \\
\hline CHEMBL67535 & 688839 & 5.7 & 5.5283 & TRN & \\
\hline CHEMBL 280998 & 688839 & 5.0 & 4.80399 & 9999999999 & TST \\
\hline CHEMBL1402827 & 688839 & 4.6 & 4.7356 & TRN & \\
\hline CHEMBL 240963 & 688839 & 4.6 & 4.9455 & TRN & \\
\hline CHEMBL1592215 & 688839 & 5.0 & 4.9429 & TRN & \\
\hline CHEMBL1450395 & 688839 & 5.6 & 5.4549 & TST & \\
\hline CHEMBL586058 & 688839 & 5.0 & 5.2184 & TST & \\
\hline CHEMBL1447894 & 688839 & 5.4 & 5.3981 & TRN & \\
\hline CHEMBL491548 & 688839 & 5.7 & $5.6560 e$ & 3000000001 & TRN \\
\hline CHEMBL1395009 & 688839 & 5.3 & 5.2632 & TST & \\
\hline CHEMBL1529151 & 688839 & 4.8 & 4.8287 & TRN & \\
\hline CHEMBL1474708 & 688839 & 5.4 & 5.4526 & TRN & \\
\hline CHEMBL337173 & 688839 & 5.6 & 4.9594 & TRN & \\
\hline CHEMBL1590855 & 688839 & 5.2 & 5.1903 & TRN & \\
\hline CHEMBL1315417 & 688839 & 4.9 & 4.9569 & TST & \\
\hline CHEMBL1394089 & 688839 & 6.0 & 4.9948 & TST & \\
\hline CHEMBL1354734 & 688839 & 4.9 & 5.0219 & TST & \\
\hline CHEMBL1591009 & 688839 & 6.0 & 4.9699 & TST & \\
\hline CHEMBL1395882 & 688839 & 4.5 & 4.7177 & TRN & \\
\hline CHEMBL1331037 & 688839 & 5.7 & 5.8333 & TRN & \\
\hline CHEMBL291829 & 688839 & 5.1 & 5.0102 & TRN & \\
\hline CHEMBL450493 & 688839 & 6.5 & 6.5842 & TRN & \\
\hline CHEMBL1397009 & 688839 & 5.0 & 4.8475 & TRN & \\
\hline CHEMBL1571545 & 688839 & 4.8 & 5.1558 & TRN & \\
\hline CHEMBL1451733 & 688839 & 5.4 & 5.2858 & TST & \\
\hline CHEMBL1551051 & 688839 & 5.4 & 5.3967 & TRN & \\
\hline CHEMBL1410367 & 688839 & 6.0 & 5.7062 & TRN & \\
\hline CHEMBL1472761 & 688839 & 5.7 & 5.4013 & TRN & \\
\hline CHEMBL1593796 & 688839 & 5.4 & 5.381 & TRN & \\
\hline CHEMBL1332532 & 688839 & 5.8 & 5.3934 & TRN & \\
\hline CHEMBL55814 & 688839 & 6.0 & 5.0686 & TRN & \\
\hline CHEMBL164 & 688839 & 6.0 & $5.8020 e$ & 00000000005 & TRN \\
\hline CHEMBL1362657 & 688839 & 5.4 & 5.4138 & TST & \\
\hline CHEMBL1515253 & 688839 & 4.8 & 4.788 & TRN & \\
\hline CHEMBL1481399 & 688839 & 4.9 & 4.8565 & TRN & \\
\hline CHEMBL1321660 & 688839 & 5.6 & 5.4637 & TRN & \\
\hline CHEMBL1563075 & 688839 & 5.1 & 5.4446 & TRN & \\
\hline CHEMBL1316401 & 688839 & 5.4 & 5.4637 & TRN & \\
\hline & & & & 20314 & \\
\hline
\end{tabular}




\begin{tabular}{|c|c|c|c|c|}
\hline & & & Supplement & \\
\hline CHEMBL1590639 & 688839 & 4.6 & 4.6985 & TRN \\
\hline CHEMBL1475787 & 688839 & 4.6 & 5.1368 & TRN \\
\hline CHEMBL1606796 & 688839 & 5.2 & 5.1312 & TRN \\
\hline CHEMBL1598680 & 688839 & 6.0 & 5.8842 & TRN \\
\hline CHEMBL1335220 & 688839 & 5.2 & 5.178 & TRN \\
\hline CHEMBL1606094 & 688839 & 6.0 & 5.8498 & TST \\
\hline CHEMBL490756 & 688839 & 5.9 & 5.8745 & TRN \\
\hline CHEMBL1355963 & 688839 & 4.8 & 4.9723 & TST \\
\hline CHEMBL1558843 & 688839 & 6.0 & 5.9934 & TRN \\
\hline CHEMBL1366433 & 688839 & 5.1 & 5.0894 & TRN \\
\hline CHEMBL1335332 & 688839 & 4.8 & 4.8502 & TRN \\
\hline CHEMBL1338378 & 688839 & 5.6 & 5.0953 & TRN \\
\hline CHEMBL1512413 & 688839 & 5.1 & 5.0127 & TRN \\
\hline CHEMBL1559341 & 688839 & 4.6 & 5.2549 & TST \\
\hline CHEMBL1516254 & 688839 & 4.8 & 4.7224 & TRN \\
\hline CHEMBL1320730 & 688839 & 4.8 & 4.9059 & TRN \\
\hline CHEMBL1403982 & 688839 & 5.5 & 5.4698 & TRN \\
\hline CHEMBL102714 & 688839 & 5.7 & 5.4506 & TST \\
\hline CHEMBL1479593 & 688839 & 4.6 & 5.1282 & TRN \\
\hline CHEMBL1604095 & 688839 & 4.8 & 4.869 & TRN \\
\hline CHEMBL 3189483 & 688839 & 6.0 & 5.934 & TRN \\
\hline CHEMBL1373587 & 688839 & 5.4 & 5.3397 & TRN \\
\hline CHEMBL1516154 & 688839 & 4.9 & 5.4897 & TRN \\
\hline CHEMBL1561474 & 688839 & 5.9 & 5.6238 & TST \\
\hline CHEMBL1370705 & 688839 & 5.4 & 5.1181 & TRN \\
\hline CHEMBL192627 & 688839 & 5.7 & 4.8973 & TST \\
\hline CHEMBL1527466 & 688839 & 6.0 & 6.0893 & TRN \\
\hline CHEMBL1410627 & 688839 & 5.4 & 5.2989 & TST \\
\hline CHEMBL154580 & 688839 & 4.6 & 5.1461 & TRN \\
\hline CHEMBL1475945 & 688839 & 5.4 & 5.4544 & TRN \\
\hline CHEMBL1598686 & 688839 & 5.0 & 5.1086 & TRN \\
\hline CHEMBL1321561 & 688839 & 5.5 & 5.0487 & TRN \\
\hline CHEMBL1475131 & 688839 & 6.4 & 6.3452 & TRN \\
\hline CHEMBL1435702 & 688839 & 5.0 & 4.963 & TRN \\
\hline CHEMBL553503 & 688839 & 6.0 & 4.9159 & TRN \\
\hline CHEMBL1407271 & 688839 & 5.5 & 5.1363 & TRN \\
\hline CHEMBL1474684 & 688839 & 4.6 & 5.2371 & TST \\
\hline CHEMBL1489708 & 688839 & 4.9 & 4.9994 & TRN \\
\hline CHEMBL1320922 & 688839 & 5.3 & 5.4006 & TST \\
\hline CHEMBL95606 & 688839 & 4.5 & 4.6348 & TRN \\
\hline CHEMBL1354713 & 688839 & 5.2 & 5.1102 & TRN \\
\hline CHEMBL1436821 & 688839 & 4.4 & 5.2387 & TST \\
\hline CHEMBL1513812 & 688839 & 4.8 & 4.843 & TRN \\
\hline CHEMBL101168 & 688839 & 5.2 & 5.0958 & TST \\
\hline CHEMBL1495395 & 688839 & 5.5 & 5.3929 & TRN \\
\hline CHEMBL1457550 & 688839 & 6.0 & 5.852 & TRN \\
\hline CHEMBL1493002 & 688839 & 5.2 & 5.0884 & TRN \\
\hline CHEMBL34241 & 688839 & 5.2 & 4.9738 & TRN \\
\hline
\end{tabular}




\begin{tabular}{|c|c|c|c|c|c|}
\hline & & & & & \\
\hline CHEMBL1435823 & 688839 & 5.0 & 4.9451 & TRN & \\
\hline CHEMBL1472926 & 688839 & 5.7 & 5.5059 & TRN & \\
\hline CHEMBL1557696 & 688839 & 4.9 & 4.9122 & TRN & \\
\hline CHEMBL15594 & 688839 & 6.0 & 4.7288 & TRN & \\
\hline CHEMBL1356166 & 688839 & 5.4 & 5.2992 & TRN & \\
\hline CHEMBL1436733 & 688839 & 4.4 & 5.1929 & TST & \\
\hline CHEMBL597744 & 688839 & 5.0 & 5.0927 & TRN & \\
\hline CHEMBL1405001 & 688839 & 5.0 & 4.9527 & TRN & \\
\hline CHEMBL15134 & 688839 & 4.6 & 5.0589 & TST & \\
\hline CHEMBL1365983 & 688839 & 5.5 & 5.2356 & TRN & \\
\hline CHEMBL1371217 & 688839 & 5.4 & 5.4937 & TRN & \\
\hline CHEMBL1440487 & 688839 & 5.6 & 5.46200 & 2000000001 & TRN \\
\hline CHEMBL1358664 & 688839 & 5.4 & 5.4433 & TRN & \\
\hline CHEMBL1356808 & 688839 & 5.8 & 5.9075 & TRN & \\
\hline CHEMBL484901 & 688839 & 4.9 & 4.9581 & TRN & \\
\hline CHEMBL1476521 & 688839 & 5.2 & 5.1673 & TRN & \\
\hline CHEMBL1594439 & 688839 & 5.3 & 5.1452 & TST & \\
\hline CHEMBL1473834 & 688839 & 5.2 & 5.2114 & TRN & \\
\hline CHEMBL1375573 & 688839 & 5.6 & 5.3206 & TST & \\
\hline CHEMBL485349 & 688839 & 4.6 & 5.1006 & TRN & \\
\hline CHEMBL1378901 & 688839 & 4.6 & 4.6768 & TRN & \\
\hline CHEMBL1097940 & 688839 & 4.9 & 4.921 & TST & \\
\hline CHEMBL1444413 & 688839 & 5.4 & 5.3932 & TRN & \\
\hline CHEMBL1313005 & 688839 & 5.0 & 5.1245 & TST & \\
\hline CHEMBL1568071 & 688839 & 5.8 & 5.8725 & TRN & \\
\hline CHEMBL393136 & 688839 & 4.5 & 5.0889 & TRN & \\
\hline CHEMBL1551009 & 688839 & 5.1 & 5.087 & TRN & \\
\hline CHEMBL1401324 & 688839 & 5.5 & 5.5827 & TST & \\
\hline CHEMBL1551534 & 688839 & 4.8 & 4.8375 & TRN & \\
\hline CHEMBL1395417 & 688839 & 5.0 & 4.9576 & TRN & \\
\hline CHEMBL1516477 & 688839 & 6.0 & 5.7422 & TRN & \\
\hline CHEMBL1410759 & 688839 & 5.5 & 5.4017 & TST & \\
\hline CHEMBL1396595 & 688839 & 6.0 & 6.1454 & TRN & \\
\hline CHEMBL1335471 & 688839 & 5.1 & 5.013 & TST & \\
\hline CHEMBL1316075 & 688839 & 5.7 & 5.6042 & TRN & \\
\hline CHEMBL1235966 & 688839 & 4.9 & 5.0083 & TRN & \\
\hline CHEMBL1554278 & 688839 & 5.5 & 5.1807 & TST & \\
\hline CHEMBL1356501 & 688839 & 4.7 & 4.9452 & TRN & \\
\hline CHEMBL1712082 & 688839 & 4.6 & 5.16 & TST & \\
\hline CHEMBL1452049 & 688839 & 5.8 & 5.6924 & TRN & \\
\hline CHEMBL1255655 & 688839 & 4.9 & 4.9495 & TST & \\
\hline CHEMBL1475036 & 688839 & 6.0 & 6.0089 & TRN & \\
\hline CHEMBL1358384 & 688839 & 8.8861 & 7.815 & TST & \\
\hline CHEMBL1512511 & 688839 & 4.9 & 5.0037 & TST & \\
\hline CHEMBL1445913 & 688839 & 5.6 & 5.4573 & TST & \\
\hline CHEMBL1593288 & 688839 & 5.3 & 5.062 & TRN & \\
\hline CHEMBL1533516 & 688839 & 4.5 & 4.6213 & TRN & \\
\hline CHEMBL1371789 & 688839 & 5.4 & 5.1814 & TRN & \\
\hline & & & & 20316 & \\
\hline
\end{tabular}




\begin{tabular}{|c|c|c|c|c|}
\hline \multicolumn{5}{|c|}{ emental T } \\
\hline CHEMBL1513115 & 688839 & 5.4 & 5.2356 & TRN \\
\hline CHEMBL29197 & 688839 & 5.3 & 5.2907 & TRN \\
\hline CHEMBL1475257 & 688839 & 4.4 & 4.5024 & TRN \\
\hline CHEMBL1401243 & 688839 & 5.0 & 5.0714 & TRN \\
\hline CHEMBL1558834 & 688839 & 4.6 & 4.7116 & TRN \\
\hline CHEMBL1457493 & 688839 & 4.9 & 5.0169 & TST \\
\hline CHEMBL 238188 & 688839 & 4.6 & 5.0662 & TRN \\
\hline CHEMBL1338329 & 688839 & 6.0 & 5.8844 & TRN \\
\hline CHEMBL1610082 & 688839 & 4.9 & 4.8571 & TRN \\
\hline CHEMBL1337713 & 688839 & 5.2 & 5.1698 & TRN \\
\hline CHEMBL 1443376 & 688839 & 5.1 & 5.0935 & TST \\
\hline CHEMBL1473307 & 688839 & 4.5 & 5.2242 & TST \\
\hline CHEMBL1479506 & 688839 & 5.1 & 5.138 & TRN \\
\hline CHEMBL1324418 & 688839 & 4.7 & 4.7397 & TRN \\
\hline CHEMBL1396170 & 688839 & 4.4 & 5.1048 & TRN \\
\hline CHEMBL1316956 & 688839 & 6.9 & 6.8858 & TRN \\
\hline CHEMBL1363594 & 688839 & 4.8 & 4.7805 & TRN \\
\hline CHEMBL399491 & 688839 & 4.5 & 4.6324 & TST \\
\hline CHEMBL1602812 & 688839 & 5.9 & 5.9961 & TRN \\
\hline CHEMBL1325931 & 688839 & 4.4 & 5.0687 & TRN \\
\hline CHEMBL1521490 & 688839 & 6.1 & 6.0891 & TRN \\
\hline CHEMBL60718 & 688839 & 5.5 & 5.3576 & TRN \\
\hline CHEMBL1558245 & 688839 & 5.4 & 5.477 & TRN \\
\hline CHEMBL1396225 & 688839 & 4.9 & 4.8272 & TRN \\
\hline CHEMBL 1370510 & 688839 & 5.5 & 5.1259 & TRN \\
\hline CHEMBL1526053 & 688839 & 5.5 & 4.8859 & TRN \\
\hline CHEMBL1491966 & 688839 & 5.6 & 5.6231 & TRN \\
\hline CHEMBL369142 & 688839 & 4.8 & 5.0031 & TRN \\
\hline CHEMBL1484120 & 688839 & 5.4 & 5.2003 & TRN \\
\hline CHEMBL1449726 & 688839 & 5.5 & 5.5104 & TRN \\
\hline CHEMBL1452250 & 688839 & 5.9 & 5.9503 & TRN \\
\hline CHEMBL1398600 & 688839 & 5.5 & 5.3628 & TRN \\
\hline CHEMBL1515948 & 688839 & 4.9 & 5.0093 & TST \\
\hline CHEMBL1446139 & 688839 & 5.2 & 5.3507 & TRN \\
\hline CHEMBL104264 & 688839 & 5.8 & 5.7238 & TRN \\
\hline CHEMBL1337381 & 688839 & 4.8 & 5.0081 & TRN \\
\hline CHEMBL1527029 & 688839 & 4.6 & 4.6867 & TRN \\
\hline CHEMBL137648 & 688839 & 4.5 & 4.6481 & TRN \\
\hline CHEMBL1474989 & 688839 & 5.2 & 5.1391 & TRN \\
\hline CHEMBL1403280 & 688839 & 4.8 & 4.8013 & TRN \\
\hline CHEMBL1560567 & 688839 & 6.0 & 5.3853 & TRN \\
\hline CHEMBL1317885 & 688839 & 4.8 & 4.9071 & TRN \\
\hline CHEMBL497170 & 688839 & 4.9 & 5.079 & TRN \\
\hline CHEMBL1592517 & 688839 & 4.8 & 4.8029 & TRN \\
\hline CHEMBL 2374058 & 688839 & 4.6 & 4.7835 & TST \\
\hline CHEMBL1437990 & 688839 & 5.6 & 5.5434 & TRN \\
\hline CHEMBL1520907 & 688839 & 5.4 & 5.3269 & TST \\
\hline CHEMBL1513280 & 688839 & 4.6 & 4.5884 & TRN \\
\hline
\end{tabular}




\begin{tabular}{|c|c|c|c|c|c|}
\hline \multirow{2}{*}{ CHEMBL1603393 } & \multirow{2}{*}{688839} & \multirow[b]{2}{*}{4.8} & \\
\hline & & & 4.9524 & TRN & \\
\hline CHEMBL1516005 & 688839 & 5.3 & 5.2357 & TRN & \\
\hline CHEMBL1314288 & 688839 & 5.6 & 5.7543 & TRN & \\
\hline CHEMBL1554459 & 688839 & 5.4 & 5.4301 & TRN & \\
\hline CHEMBL 1455880 & 688839 & 6.2 & 5.1578 & TRN & \\
\hline CHEMBL490717 & 688839 & 6.2 & 6.3558 & TRN & \\
\hline CHEMBL1256797 & 688839 & 6.0 & 5.7911 & TRN & \\
\hline CHEMBL1465244 & 688839 & 4.9 & 5.1196 & TRN & \\
\hline CHEMBL1493496 & 688839 & 5.8 & 5.9161 & TRN & \\
\hline CHEMBL1610375 & 688839 & 5.4 & 5.3442 & TRN & \\
\hline CHEMBL1436578 & 688839 & 5.6 & 5.0927 & TRN & \\
\hline CHEMBL1489064 & 688839 & 4.8 & \multicolumn{2}{|c|}{5.0680000000000005} & TST \\
\hline CHEMBL1533139 & 688839 & 5.1 & 5.1793 & TRN & \\
\hline CHEMBL 30432 & 688839 & 5.3 & 5.2485 & TST & \\
\hline CHEMBL1484360 & 688839 & 5.3 & 5.1209 & TRN & \\
\hline CHEMBL1437408 & 688839 & 5.4 & 5.4024 & TRN & \\
\hline CHEMBL1255940 & 688839 & 4.8 & 4.8642 & TRN & \\
\hline CHEMBL1320569 & 688839 & 5.7 & 5.2936 & TRN & \\
\hline CHEMBL1435198 & 688839 & 5.7 & 5.3734 & TRN & \\
\hline CHEMBL1448726 & 688839 & 5.7 & 5.9103 & TRN & \\
\hline CHEMBL1560764 & 688839 & 6.0 & 5.8379 & TRN & \\
\hline CHEMBL1437906 & 688839 & 4.9 & 4.961 & TRN & \\
\hline CHEMBL1554194 & 688839 & 5.4 & 5.4445 & TRN & \\
\hline CHEMBL1519435 & 688839 & 5.7 & 5.7121 & TRN & \\
\hline CHEMBL1439689 & 688839 & 5.3 & 5.1894 & TST & \\
\hline CHEMBL 323354 & 688839 & 5.3 & 5.4222 & TST & \\
\hline CHEMBL1338229 & 688839 & 5.8 & 5.1636 & TRN & \\
\hline CHEMBL1483625 & 688839 & 4.9 & 4.904 & TRN & \\
\hline CHEMBL321820 & 688839 & 4.9 & 5.0112 & TST & \\
\hline CHEMBL303516 & 688839 & 4.8 & 4.9108 & TST & \\
\hline CHEMBL1377706 & 688839 & 4.6 & 4.7998 & TRN & \\
\hline CHEMBL1478153 & 688839 & 5.5 & 5.1712 & TRN & \\
\hline CHEMBL1496315 & 688839 & 6.4 & 6.0895 & TRN & \\
\hline CHEMBL1494064 & 688839 & 5.7 & 5.1601 & TST & \\
\hline CHEMBL1551915 & 688839 & 4.6 & 5.235 & TST & \\
\hline CHEMBL1256718 & 688839 & 4.9 & 4.9509 & TST & \\
\hline CHEMBL1595404 & 688839 & 6.1 & 6.1567 & TRN & \\
\hline CHEMBL1552314 & 688839 & 5.0 & 5.38399 & 99999999995 & TRN \\
\hline CHEMBL3351080 & 688839 & 5.5 & 5.358 & TST & \\
\hline CHEMBL1369406 & 688839 & 5.1 & $5.1370 e$ & 00000000005 & TST \\
\hline CHEMBL3351063 & 688839 & 5.5 & 5.1994 & TRN & \\
\hline CHEMBL47940 & 688839 & 5.5 & 5.329 & TRN & \\
\hline CHEMBL1394854 & 688839 & 6.3 & 6.3395 & TRN & \\
\hline CHEMBL1572173 & 688839 & 4.8 & 4.7772 & TRN & \\
\hline CHEMBL1355547 & 688839 & 5.3 & 5.4308 & TRN & \\
\hline CHEMBL1415701 & 688839 & 4.9 & 5.1473 & TRN & \\
\hline CHEMBL1491455 & 688839 & 5.4 & 5.3216 & TST & \\
\hline CHEMBL1472899 & 688839 & 4.6 & 4.6293 & TRN & \\
\hline & & & & 20318 & \\
\hline
\end{tabular}




\begin{tabular}{|c|c|c|c|c|}
\hline & & & IET & al Ta \\
\hline CHEMBL1514782 & 688839 & 5.4 & 5.2514 & TRN \\
\hline CHEMBL1607885 & 688839 & 5.9 & 6.0023 & TRN \\
\hline CHEMBL1395605 & 688839 & 4.8 & 4.8098 & TRN \\
\hline CHEMBL1330623 & 688839 & 6.0 & 6.0339 & TRN \\
\hline CHEMBL1335595 & 688839 & 6.3 & 5.9164 & TRN \\
\hline CHEMBL1396611 & 688839 & 4.9 & 4.985 & TRN \\
\hline CHEMBL67378 & 688839 & 6.0 & 5.7915 & TST \\
\hline CHEMBL1440619 & 688839 & 5.0 & 5.1258 & TRN \\
\hline CHEMBL1573844 & 688839 & 4.7 & 5.153 & TST \\
\hline CHEMBL1488067 & 688839 & 4.6 & 5.1731 & TST \\
\hline CHEMBL1594704 & 688839 & 5.1 & 5.2171 & TRN \\
\hline CHEMBL1439893 & 688839 & 5.3 & 5.3824 & TRN \\
\hline CHEMBL1256995 & 688839 & 6.0 & 5.7074 & TST \\
\hline CHEMBL1435200 & 688839 & 5.3 & 5.1772 & TRN \\
\hline CHEMBL1552752 & 688839 & 5.6 & 5.6215 & TRN \\
\hline CHEMBL1412710 & 688839 & 5.9 & 5.0124 & TRN \\
\hline CHEMBL1255737 & 688839 & 5.9 & 5.1009 & TRN \\
\hline CHEMBL1361226 & 688839 & 6.0 & 5.9971 & TRN \\
\hline CHEMBL1592465 & 688839 & 4.8 & 4.7953 & TRN \\
\hline CHEMBL1398810 & 688839 & 4.8 & 4.8239 & TRN \\
\hline CHEMBL1483422 & 688839 & 5.6 & 5.239 & TRN \\
\hline CHEMBL1514122 & 688839 & 5.2 & 5.5447 & TST \\
\hline CHEMBL1557167 & 688839 & 4.9 & 4.9287 & TST \\
\hline CHEMBL 372227 & 688839 & 5.1 & 5.1231 & TST \\
\hline CHEMBL1483672 & 688839 & 6.0 & 5.6163 & TRN \\
\hline CHEMBL503938 & 688839 & 4.5 & 5.0624 & TST \\
\hline CHEMBL68997 & 688839 & 5.4 & 5.4749 & TST \\
\hline CHEMBL1412825 & 688839 & 4.7 & 5.2304 & TST \\
\hline CHEMBL1324494 & 688839 & 5.5 & 5.4069 & TRN \\
\hline CHEMBL1484869 & 688839 & 6.5 & 4.9013 & TRN \\
\hline CHEMBL1597572 & 688839 & 5.6 & 5.3478 & TRN \\
\hline CHEMBL1327708 & 688839 & 4.6 & 4.6476 & TRN \\
\hline CHEMBL1473868 & 688839 & 5.4 & 5.4305 & TRN \\
\hline CHEMBL1336803 & 688839 & 4.6 & 4.7289 & TRN \\
\hline CHEMBL1363077 & 688839 & 5.1 & 5.3781 & TRN \\
\hline CHEMBL1321421 & 688839 & 4.7 & 4.8899 & TST \\
\hline CHEMBL1484438 & 688839 & 6.6 & 5.2152 & TST \\
\hline CHEMBL1476184 & 688839 & 4.9 & 4.8252 & TRN \\
\hline CHEMBL1555156 & 688839 & 4.9 & 4.9658 & TRN \\
\hline CHEMBL1406936 & 688839 & 4.7 & 4.74 & TRN \\
\hline CHEMBL 275809 & 688839 & 5.1 & 5.1008 & TRN \\
\hline CHEMBL1516459 & 688839 & 4.4 & 5.0527 & TST \\
\hline CHEMBL607536 & 688839 & 4.4 & 5.0372 & TRN \\
\hline CHEMBL1525774 & 688839 & 4.8 & 5.0586 & TRN \\
\hline CHEMBL1553001 & 688839 & 4.8 & 4.7403 & TRN \\
\hline CHEMBL1344070 & 688839 & 5.1 & 5.0724 & TRN \\
\hline CHEMBL1485360 & 688839 & 4.5 & 4.9627 & TST \\
\hline CHEMBL1478034 & 688839 & 6.0 & 5.0843 & TRN \\
\hline
\end{tabular}




\begin{tabular}{|c|c|c|c|c|}
\hline \multicolumn{5}{|c|}{ Supplemental Table S2.txt } \\
\hline CHEMBL54907 & 688839 & 4.4 & 5.0111 & TRN \\
\hline CHEMBL1433883 & 688839 & 4.9 & 4.922 & TRN \\
\hline CHEMBL1366732 & 688839 & 5.8 & 5.9824 & TRN \\
\hline CHEMBL1437012 & 688839 & 5.5 & 5.3735 & TST \\
\hline CHEMBL1391326 & 688839 & 5.0 & 5.1034 & TRN \\
\hline CHEMBL1553488 & 688839 & 5.5 & 5.0537 & TST \\
\hline CHEMBL1368887 & 688839 & 6.0 & 5.9801 & TRN \\
\hline CHEMBL1398878 & 688839 & 6.0 & 5.1579 & TRN \\
\hline CHEMBL1355410 & 688839 & 4.5 & 5.3827 & TST \\
\hline CHEMBL1314286 & 688839 & 6.0 & 5.7046 & TST \\
\hline CHEMBL1445772 & 688839 & 5.3 & 5.3247 & TRN \\
\hline CHEMBL522600 & 688839 & 6.7001 & 6.8091 & TRN \\
\hline CHEMBL1406513 & 688839 & 4.9 & 5.1302 & TRN \\
\hline CHEMBL 243677 & 688839 & 4.8 & 5.1569 & TRN \\
\hline CHEMBL384903 & 688839 & 4.8 & 4.9081 & TST \\
\hline CHEMBL1453749 & 688839 & 5.1 & 5.3524 & TRN \\
\hline CHEMBL1366699 & 688839 & 4.5 & 4.6325 & TRN \\
\hline CHEMBL1321655 & 688839 & 5.9 & 5.9533 & TRN \\
\hline CHEMBL1315833 & 688839 & 5.3 & 5.3613 & TRN \\
\hline CHEMBL1367485 & 688839 & 4.4 & 4.7066 & TST \\
\hline CHEMBL1514804 & 688839 & 4.8 & 4.691 & TRN \\
\hline CHEMBL1473996 & 688839 & 6.0 & 5.9746 & TRN \\
\hline CHEMBL1395275 & 688839 & 4.6 & 5.2784 & TST \\
\hline CHEMBL1595524 & 688839 & 4.4 & 4.5708 & TST \\
\hline CHEMBL1403769 & 688839 & 4.5 & 4.6101 & TRN \\
\hline CHEMBL1356505 & 688839 & 6.4 & 6.4046 & TRN \\
\hline CHEMBL577455 & 688839 & 4.8 & 4.9656 & TST \\
\hline CHEMBL 3213748 & 688839 & 5.4 & 5.4374 & TRN \\
\hline CHEMBL1316562 & 688839 & 5.2 & 5.0877 & TRN \\
\hline CHEMBL 297784 & 688839 & 6.0 & 5.8326 & TST \\
\hline CHEMBL1316353 & 688839 & 4.8 & 4.8006 & TRN \\
\hline CHEMBL1590360 & 688839 & 4.8 & 5.107 & TRN \\
\hline CHEMBL1394638 & 688839 & 4.6 & 4.6611 & TRN \\
\hline CHEMBL1553745 & 688839 & 5.2 & 5.2494 & TST \\
\hline CHEMBL1435654 & 688839 & 5.3 & 5.265 & TRN \\
\hline CHEMBL32579 & 688839 & 5.5 & 5.3605 & TRN \\
\hline CHEMBL1487121 & 688839 & 4.9 & 4.9783 & TRN \\
\hline CHEMBL1415656 & 688839 & 4.8 & 4.7075 & TRN \\
\hline CHEMBL 85728 & 688839 & 4.6 & 5.1752 & TRN \\
\hline CHEMBL1408604 & 688839 & 5.5 & 5.3953 & TST \\
\hline CHEMBL523283 & 688839 & 6.4 & 6.6242 & TRN \\
\hline CHEMBL1330355 & 688839 & 6.8 & 5.0583 & TRN \\
\hline CHEMBL1315141 & 688839 & 4.6 & 4.6778 & TRN \\
\hline CHEMBL 2373668 & 688839 & 4.9 & 5.2937 & TST \\
\hline CHEMBL1395241 & 688839 & 6.0 & 6.0866 & TRN \\
\hline CHEMBL1398197 & 688839 & 4.5 & 5.1661 & TST \\
\hline CHEMBL1314185 & 688839 & 4.4 & 4.5714 & TRN \\
\hline CHEMBL1472703 & 688839 & 6.0 & 5.184 & TRN \\
\hline
\end{tabular}




\begin{tabular}{|c|c|c|c|c|}
\hline \multicolumn{5}{|c|}{ Supplemental Table S2.txt } \\
\hline CHEMBL1445572 & 688839 & 4.7 & 4.8069 & TRN \\
\hline CHEMBL1338601 & 688839 & 5.2 & 5.1875 & TRN \\
\hline CHEMBL1334650 & 688839 & 5.7 & 5.2024 & TRN \\
\hline CHEMBL1331734 & 688839 & 5.1 & 5.1192 & TST \\
\hline CHEMBL1256998 & 688839 & 5.5 & 5.4214 & TRN \\
\hline CHEMBL1606176 & 688839 & 5.7 & 5.3572 & TST \\
\hline CHEMBL1452722 & 688839 & 5.4 & 5.2287 & TST \\
\hline CHEMBL1395915 & 688839 & 5.5 & 5.4048 & TRN \\
\hline CHEMBL1475617 & 688839 & 4.7 & 4.7285 & TRN \\
\hline CHEMBL1476170 & 688839 & 6.0 & 5.8424 & TST \\
\hline CHEMBL1359267 & 688839 & 5.0 & 5.17299 & 9999999999 \\
\hline CHEMBL1434739 & 688839 & 4.9 & 5.0512 & TRN \\
\hline CHEMBL1314367 & 688839 & 6.3 & 6.4145 & TRN \\
\hline CHEMBL1316447 & 688839 & 5.4 & 5.5115 & TRN \\
\hline CHEMBL1355515 & 688839 & 5.4 & 5.4808 & TRN \\
\hline CHEMBL1515614 & 688839 & 4.8 & 4.9832 & TRN \\
\hline CHEMBL507122 & 688839 & 4.7 & 4.8666 & TST \\
\hline CHEMBL444309 & 688839 & 4.8 & 5.1894 & TRN \\
\hline CHEMBL1563066 & 688839 & 5.4 & 5.3304 & TRN \\
\hline CHEMBL1322959 & 688839 & 6.0 & 5.7279 & TST \\
\hline CHEMBL253786 & 688839 & 4.9 & 5.1015 & TRN \\
\hline CHEMBL1411424 & 688839 & 5.3 & 5.1595 & TRN \\
\hline CHEMBL 9843 & 688839 & 5.1 & 5.1038 & TST \\
\hline CHEMBL1358568 & 688839 & 6.0 & 6.0818 & TRN \\
\hline CHEMBL1317302 & 688839 & 5.1 & 5.0313 & TRN \\
\hline CHEMBL1078384 & 688839 & 4.8 & 5.1494 & TRN \\
\hline CHEMBL1515280 & 688839 & 4.8 & 4.803 & TRN \\
\hline CHEMBL1415080 & 688839 & 4.7 & 4.7354 & TRN \\
\hline CHEMBL 338314 & 688839 & 4.6 & 4.7507 & TST \\
\hline CHEMBL1355262 & 688839 & 5.0 & 4.9772 & TRN \\
\hline CHEMBL1593859 & 688839 & 4.6 & 4.6644 & TRN \\
\hline CHEMBL1330614 & 688839 & 5.5 & 5.3407 & TRN \\
\hline CHEMBL3199282 & 688839 & 5.4 & 5.4802 & TRN \\
\hline CHEMBL1317749 & 688839 & 5.4 & 5.3649 & TST \\
\hline CHEMBL1403793 & 688839 & 5.1 & 5.1795 & TRN \\
\hline CHEMBL1395862 & 688839 & 5.4 & 5.4291 & TRN \\
\hline CHEMBL1434411 & 688839 & 4.8 & 4.7404 & TRN \\
\hline CHEMBL1593707 & 688839 & 5.1 & 4.98 & TRN \\
\hline CHEMBL1318588 & 688839 & 4.5 & 5.0142 & TRN \\
\hline CHEMBL1375214 & 688839 & 5.4 & 5.148 & TST \\
\hline CHEMBL1372744 & 688839 & 5.1 & 5.1013 & TRN \\
\hline CHEMBL1491258 & 688839 & 4.8 & 4.9147 & TRN \\
\hline CHEMBL405357 & 688839 & 5.5 & 5.2478 & TRN \\
\hline CHEMBL1598717 & 688839 & 5.6 & 5.7986 & TRN \\
\hline CHEMBL1473707 & 688839 & 5.5 & 5.136 & TRN \\
\hline CHEMBL1512702 & 688839 & 5.1 & 5.0679 & TRN \\
\hline CHEMBL1409720 & 688839 & 5.2 & 5.2498 & TRN \\
\hline CHEMBL516616 & 688839 & 5.4 & 5.3558 & TST \\
\hline
\end{tabular}




\begin{tabular}{|c|c|c|c|c|c|}
\hline \multicolumn{6}{|c|}{ plemental lable S2. } \\
\hline CHEMBL1380684 & 688839 & 6.0 & 5.5883 & TRN & \\
\hline CHEMBL1457317 & 688839 & 5.1 & 5.1931 & TRN & \\
\hline CHEMBL1325775 & 688839 & 5.5 & 5.5083 & TRN & \\
\hline CHEMBL1487929 & 688839 & 5.5 & 5.2208 & TRN & \\
\hline CHEMBL1317358 & 688839 & 4.6 & 4.6921 & TRN & \\
\hline CHEMBL1332719 & 688839 & 5.4 & 5.3808 & TST & \\
\hline CHEMBL1373004 & 688839 & 5.6 & 5.5243 & TRN & \\
\hline CHEMBL172064 & 688839 & 6.0 & 4.9819 & TST & \\
\hline CHEMBL 242341 & 688839 & 4.8 & 4.9754 & TRN & \\
\hline CHEMBL1435301 & 688839 & 4.7 & 4.7351 & TRN & \\
\hline CHEMBL1256656 & 688839 & 6.1 & 5.0845 & TST & \\
\hline CHEMBL1518415 & 688839 & 6.5 & 6.4519 & TRN & \\
\hline CHEMBL1396986 & 688839 & 6.0 & 5.3562 & TRN & \\
\hline CHEMBL573214 & 688839 & 5.7 & 5.6604 & TST & \\
\hline CHEMBL1364990 & 688839 & 5.1 & 5.3514 & TRN & \\
\hline CHEMBL1236602 & 688839 & 6.6 & 6.1539 & TRN & \\
\hline CHEMBL 328710 & 688839 & 5.0 & 5.0908 & TST & \\
\hline CHEMBL1396721 & 688839 & 5.5 & 5.36299 & 99999999995 & TST \\
\hline CHEMBL1515034 & 688839 & 5.7 & 5.9037 & TRN & \\
\hline CHEMBL260316 & 688839 & 4.8 & 5.2538 & TRN & \\
\hline CHEMBL1569400 & 688839 & 4.7 & 4.7464 & TRN & \\
\hline CHEMBL1479224 & 688839 & 4.7 & 5.0877 & TRN & \\
\hline CHEMBL1395431 & 688839 & 4.8 & 4.8329 & TRN & \\
\hline CHEMBL465843 & 688839 & 7.3002 & 5.0698 & TRN & \\
\hline CHEMBL118902 & 688839 & 6.0 & 5.7089 & TST & \\
\hline CHEMBL1356106 & 688839 & 4.9 & 4.9585 & TRN & \\
\hline CHEMBL1494529 & 688839 & 4.8 & 4.8793 & TRN & \\
\hline CHEMBL 239276 & 688839 & 4.9 & 5.1266 & TRN & \\
\hline CHEMBL1611225 & 688839 & 5.3 & 5.3434 & TRN & \\
\hline CHEMBL1434789 & 688839 & 4.4 & 4.5559 & TRN & \\
\hline CHEMBL1397279 & 688839 & 5.7 & 5.3621 & TRN & \\
\hline CHEMBL1447538 & 688839 & 6.0 & 5.9519 & TRN & \\
\hline CHEMBL1516530 & 688839 & 4.8 & 4.8479 & TRN & \\
\hline CHEMBL1515352 & 688839 & 5.3 & 5.0405 & TRN & \\
\hline CHEMBL1364473 & 688839 & 4.9 & 4.9146 & TRN & \\
\hline CHEMBL1606866 & 688839 & 6.0 & 6.0062 & TRN & \\
\hline CHEMBL1371435 & 688839 & 4.6 & 5.2041 & TRN & \\
\hline CHEMBL1355710 & 688839 & 5.0 & 4.9286 & TRN & \\
\hline CHEMBL1358402 & 688839 & 6.0 & 5.7708 & TST & \\
\hline CHEMBL1361552 & 688839 & 5.0 & 5.0229 & TRN & \\
\hline CHEMBL1322979 & 688839 & 5.5 & 5.13299 & 9999999999 & TST \\
\hline CHEMBL1324667 & 688839 & 5.7 & 5.9543 & TRN & \\
\hline CHEMBL1554531 & 688839 & 4.7 & 5.2232 & TRN & \\
\hline CHEMBL195008 & 688839 & 5.2 & 5.1502 & TRN & \\
\hline CHEMBL1514735 & 688839 & 5.4 & 5.2478 & TST & \\
\hline CHEMBL1517765 & 688839 & 5.4 & 5.5611 & TRN & \\
\hline CHEMBL1358654 & 688839 & 5.6 & 5.4576 & TRN & \\
\hline CHEMBL1590266 & 688839 & 5.1 & 5.0886 & TRN & \\
\hline
\end{tabular}




\begin{tabular}{|c|c|c|c|c|}
\hline & & & & al lable \\
\hline CHEMBL1486474 & 688839 & 4.8 & 5.2535 & TRN \\
\hline CHEMBL1399136 & 688839 & 5.1 & 5.1381 & TRN \\
\hline CHEMBL1496590 & 688839 & 4.8 & 5.0014 & TRN \\
\hline CHEMBL1489432 & 688839 & 5.0 & 5.1435 & TST \\
\hline CHEMBL484663 & 688839 & 5.5 & 5.1778 & TRN \\
\hline CHEMBL1396358 & 688839 & 5.3 & 5.1635 & TRN \\
\hline CHEMBL1485000 & 688839 & 5.4 & 5.3158 & TST \\
\hline CHEMBL1481361 & 688839 & 5.8 & 5.7764 & TRN \\
\hline CHEMBL1596796 & 688839 & 5.5 & 5.3722 & TST \\
\hline CHEMBL1551068 & 688839 & 4.8 & 5.0646 & TRN \\
\hline CHEMBL1396108 & 688839 & 4.9 & 5.0505 & TRN \\
\hline CHEMBL1560685 & 688839 & 5.1 & 5.1475 & TRN \\
\hline CHEMBL1357356 & 688839 & 4.4 & 5.1393 & TST \\
\hline CHEMBL1574196 & 688839 & 4.9 & 4.9805 & TRN \\
\hline CHEMBL1413343 & 688839 & 4.8 & 4.8176 & TRN \\
\hline CHEMBL1360725 & 688839 & 6.0 & 5.7482 & TST \\
\hline CHEMBL1611646 & 688839 & 5.2 & 5.0952 & TRN \\
\hline CHEMBL1607289 & 688839 & 4.5 & 5.2935 & TRN \\
\hline CHEMBL72365 & 688839 & 5.3 & 5.2476 & TST \\
\hline CHEMBL1452710 & 688839 & 4.6 & 5.0795 & TRN \\
\hline CHEMBL93353 & 688839 & 6.0 & 5.432 & TST \\
\hline CHEMBL1358562 & 688839 & 5.6 & 4.8605 & TRN \\
\hline CHEMBL1513669 & 688839 & 5.4 & 5.2981 & TRN \\
\hline CHEMBL1526486 & 688839 & 5.0 & 4.9601 & TST \\
\hline CHEMBL1531299 & 688839 & 4.9 & 5.0128 & TRN \\
\hline CHEMBL1605941 & 688839 & 5.6 & 5.3072 & TST \\
\hline CHEMBL1513134 & 688839 & 4.7 & 4.7542 & TRN \\
\hline CHEMBL1434198 & 688839 & 4.9 & 4.9472 & TRN \\
\hline CHEMBL1411201 & 688839 & 5.7 & 5.7909 & TRN \\
\hline CHEMBL197027 & 688839 & 6.9 & 6.4056 & TST \\
\hline CHEMBL1394620 & 688839 & 4.8 & 5.2091 & TST \\
\hline CHEMBL52387 & 688839 & 4.9 & 5.0073 & TRN \\
\hline CHEMBL1477982 & 688839 & 5.3 & 5.4383 & TRN \\
\hline CHEMBL153062 & 688839 & 4.5 & 5.0075 & TRN \\
\hline CHEMBL1436908 & 688839 & 4.7 & 5.2845 & TST \\
\hline CHEMBL428814 & 688839 & 5.6 & 5.6851 & TRN \\
\hline CHEMBL1208858 & 688839 & 4.8 & 4.9476 & TRN \\
\hline CHEMBL 2373584 & 688839 & 5.5 & $5.5310 e$ & 0000000001 \\
\hline CHEMBL1598111 & 688839 & 4.8 & 5.1902 & TST \\
\hline CHEMBL1481127 & 688839 & 5.0 & 4.9746 & TRN \\
\hline CHEMBL1381098 & 688839 & 4.6 & 5.0952 & TRN \\
\hline CHEMBL1394272 & 688839 & 5.2 & 5.3062 & TRN \\
\hline CHEMBL356688 & 688839 & 5.0 & 5.0534 & TRN \\
\hline CHEMBL1355351 & 688839 & 4.9 & 4.9612 & TRN \\
\hline CHEMBL1553262 & 688839 & 4.5 & 4.6592 & TRN \\
\hline CHEMBL1555368 & 688839 & 5.5 & 5.6592 & TRN \\
\hline CHEMBL1327772 & 688839 & 5.3 & 5.1065 & TRN \\
\hline CHEMBL1440774 & 688839 & 4.8 & 5.4465 & TRN \\
\hline
\end{tabular}

TRN 


\begin{tabular}{|c|c|c|c|c|}
\hline & & & IETाL & al Ta \\
\hline CHEMBL1435210 & 688839 & 5.5 & 5.414 & TRN \\
\hline CHEMBL1395219 & 688839 & 4.8 & 4.801 & TRN \\
\hline CHEMBL1608948 & 688839 & 4.5 & 5.1995 & TST \\
\hline CHEMBL1554590 & 688839 & 5.5 & 5.0683 & TRN \\
\hline CHEMBL1601416 & 688839 & 4.5 & 4.534 & TRN \\
\hline CHEMBL1482446 & 688839 & 4.8 & 5.2369 & TRN \\
\hline CHEMBL1411438 & 688839 & 5.5 & 5.5926 & TRN \\
\hline CHEMBL1393926 & 688839 & 5.3 & 5.0907 & TRN \\
\hline CHEMBL1476055 & 688839 & 5.2 & 5.184 & TRN \\
\hline CHEMBL1454793 & 688839 & 5.2 & 5.2808 & TRN \\
\hline CHEMBL1592110 & 688839 & 4.5 & 4.9123 & TRN \\
\hline CHEMBL1533537 & 688839 & 4.8 & 4.7775 & TRN \\
\hline CHEMBL1435079 & 688839 & 5.0 & 5.1334 & TRN \\
\hline CHEMBL1377526 & 688839 & 5.4 & 5.3787 & TRN \\
\hline CHEMBL1334817 & 688839 & 4.5 & 4.666 & TST \\
\hline CHEMBL1451411 & 688839 & 6.1 & 5.8668 & TRN \\
\hline CHEMBL1446815 & 688839 & 4.9 & 4.9034 & TRN \\
\hline CHEMBL2373604 & 688839 & 5.8 & 5.043 & TST \\
\hline CHEMBL1605632 & 688839 & 6.0 & 5.9869 & TRN \\
\hline CHEMBL1358735 & 688839 & 4.6 & 5.1263 & TST \\
\hline CHEMBL406256 & 688839 & 5.0 & 5.2101 & TRN \\
\hline CHEMBL1439455 & 688839 & 5.4 & 5.2701 & TST \\
\hline CHEMBL1317537 & 688839 & 5.1 & 5.0009 & TRN \\
\hline CHEMBL1553808 & 688839 & 5.8 & 5.4527 & TRN \\
\hline CHEMBL145 & 688839 & 4.6 & 4.9995 & TRN \\
\hline CHEMBL457504 & 688839 & 5.3 & 5.1045 & TRN \\
\hline CHEMBL1513578 & 688839 & 5.4 & 5.1816 & TRN \\
\hline CHEMBL1319626 & 688839 & 5.4 & 5.3205 & TRN \\
\hline CHEMBL1554348 & 688839 & 4.9 & 4.965 & TRN \\
\hline CHEMBL1592493 & 688839 & 6.0 & 5.5619 & TST \\
\hline CHEMBL1404408 & 688839 & 4.9 & 4.8745 & TRN \\
\hline CHEMBL1314422 & 688839 & 4.9 & 4.8763 & TRN \\
\hline CHEMBL1394499 & 688839 & 4.8 & 4.8449 & TRN \\
\hline CHEMBL1318020 & 688839 & 5.2 & 5.1371 & TRN \\
\hline CHEMBL1320469 & 688839 & 5.4 & 5.5329 & TRN \\
\hline CHEMBL1594078 & 688839 & 4.9 & 5.0056 & TRN \\
\hline CHEMBL1317353 & 688839 & 5.2 & 5.312 & TST \\
\hline CHEMBL1398886 & 688839 & 5.0 & 5.2437 & TST \\
\hline CHEMBL1366754 & 688839 & 4.9 & 4.8728 & TRN \\
\hline CHEMBL1394533 & 688839 & 5.1 & 5.0251 & TRN \\
\hline CHEMBL1496664 & 688839 & 4.8 & 4.6705 & TRN \\
\hline CHEMBL1593547 & 688839 & 4.7 & 4.8597 & TRN \\
\hline CHEMBL1434882 & 688839 & 6.0 & 6.0192 & TRN \\
\hline CHEMBL1414073 & 688839 & 5.9 & 5.7138 & TRN \\
\hline CHEMBL1360401 & 688839 & 5.2 & 5.1568 & TRN \\
\hline CHEMBL1591635 & 688839 & 4.8 & 4.8678 & TRN \\
\hline CHEMBL1355879 & 688839 & 4.9 & 4.9661 & TRN \\
\hline CHEMBL1324151 & 688839 & 4.9 & 4.8801 & TRN \\
\hline
\end{tabular}




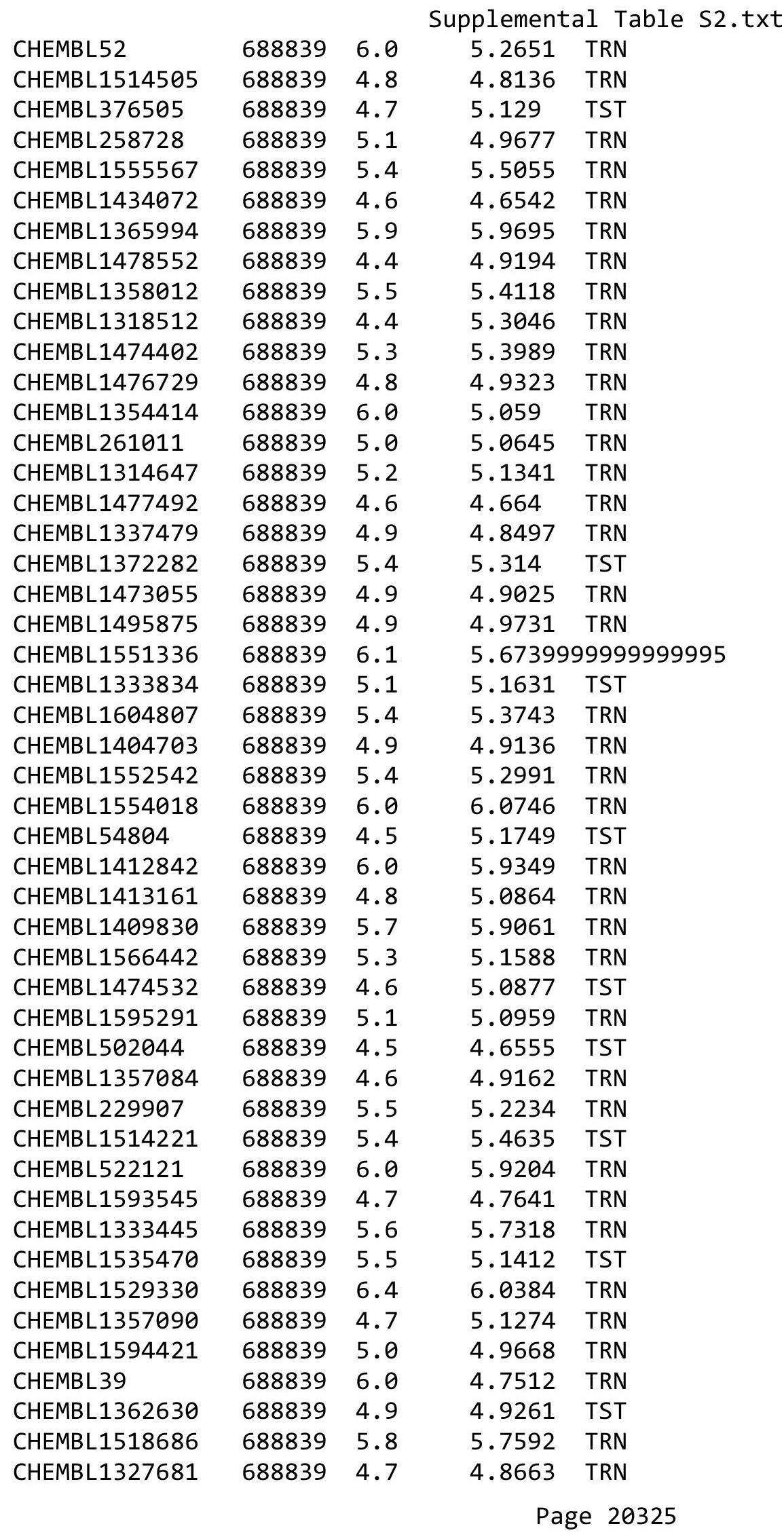




\begin{tabular}{|c|c|c|c|c|c|}
\hline \multicolumn{6}{|c|}{ Supplemental Table S2.txt } \\
\hline CHEMBL1323905 & 688839 & 5.0 & 5.0722 & TRN & \\
\hline CHEMBL1440534 & 688839 & 5.4 & 5.4367 & TRN & \\
\hline CHEMBL1377805 & 688839 & 6.0 & 5.1316 & TRN & \\
\hline CHEMBL1316294 & 688839 & 5.5 & 5.4976 & TRN & \\
\hline CHEMBL1590354 & 688839 & 5.7 & 5.7964 & TRN & \\
\hline CHEMBL1474241 & 688839 & 5.5 & 5.4137 & TRN & \\
\hline CHEMBL1526043 & 688839 & 4.4 & 4.4797 & TRN & \\
\hline CHEMBL107251 & 688839 & 5.0 & 4.9887 & TRN & \\
\hline CHEMBL1320485 & 688839 & 5.0 & 5.0527 & TRN & \\
\hline CHEMBL1486821 & 688839 & 6.0 & 5.9848 & TRN & \\
\hline CHEMBL1594044 & 688839 & 5.9 & 5.6297 & TRN & \\
\hline CHEMBL1360011 & 688839 & 5.9 & 5.184 & TRN & \\
\hline CHEMBL227298 & 688839 & 5.3 & 5.2403 & TST & \\
\hline CHEMBL1316408 & 688839 & 5.5 & 5.5962 & TRN & \\
\hline CHEMBL1316496 & 688839 & 7.5003 & 6.7541 & TRN & \\
\hline CHEMBL1514626 & 688839 & 4.8 & 4.8415 & TRN & \\
\hline CHEMBL1599096 & 688839 & 4.8 & 5.1886 & TST & \\
\hline CHEMBL1257080 & 688839 & 5.0 & 5.1337 & TST & \\
\hline CHEMBL1343453 & 688839 & 5.1 & 5.101 & TRN & \\
\hline CHEMBL1354941 & 688839 & 5.0 & 4.9466 & TRN & \\
\hline CHEMBL1489182 & 688839 & 5.9 & 5.9541 & TRN & \\
\hline CHEMBL1397196 & 688839 & 5.7 & 5.2886 & TRN & \\
\hline CHEMBL1512190 & 688839 & 5.3 & 5.1831 & TRN & \\
\hline CHEMBL3391702 & 688839 & 6.4 & 5.7345 & TST & \\
\hline CHEMBL1561402 & 688839 & 4.9 & 4.9069 & TRN & \\
\hline CHEMBL1436222 & 688839 & 4.9 & 4.8898 & TRN & \\
\hline CHEMBL1485406 & 688839 & 4.6 & 5.1501 & TRN & \\
\hline CHEMBL1323666 & 688839 & 4.8 & 5.1404 & TRN & \\
\hline CHEMBL1316897 & 688839 & 5.0 & 4.9689 & TRN & \\
\hline CHEMBL1315820 & 688839 & 4.8 & 4.8083 & TRN & \\
\hline CHEMBL1373204 & 688839 & 5.4 & 5.4963 & TRN & \\
\hline CHEMBL1558511 & 688839 & 5.0 & 5.0372 & TRN & \\
\hline CHEMBL1610811 & 688839 & 5.5 & 5.107 & TRN & \\
\hline CHEMBL1324508 & 688839 & 7.2 & 5.7291 & TST & \\
\hline CHEMBL1476546 & 688839 & 4.9 & 5.4533 & TST & \\
\hline CHEMBL1572683 & 688839 & 4.9 & 4.8576 & TRN & \\
\hline CHEMBL49247 & 688839 & 4.6 & 5.105 & TST & \\
\hline CHEMBL1476895 & 688839 & 4.5 & 5.3082 & TRN & \\
\hline CHEMBL1444367 & 688839 & 4.8 & 5.0603 & TRN & \\
\hline CHEMBL1450493 & 688839 & 5.3 & 5.21299 & 9999999999 & TST \\
\hline CHEMBL1533853 & 688839 & 6.1 & 6.1854 & TRN & \\
\hline CHEMBL74913 & 688839 & 4.9 & 5.0671 & TRN & \\
\hline CHEMBL1590059 & 688839 & 5.2 & 4.9824 & TRN & \\
\hline CHEMBL1403134 & 688839 & 5.0 & 5.1175 & TRN & \\
\hline CHEMBL1600561 & 688839 & 4.8 & 4.79 & TRN & \\
\hline CHEMBL407874 & 688839 & 5.1 & 5.1467 & TRN & \\
\hline CHEMBL1602263 & 688839 & 5.4 & 5.0642 & TST & \\
\hline CHEMBL1514430 & 688839 & 5.0 & 5.16799 & 9999999999 & TST \\
\hline & & & & 2032 & \\
\hline
\end{tabular}




\begin{tabular}{|c|c|c|c|c|c|}
\hline \multirow[b]{2}{*}{ CHEMBL 72410} & \multirow[b]{2}{*}{688839} & \\
\hline & & 4.6 & 4.7805 & TRN & \\
\hline CHEMBL1449224 & 688839 & 4.5 & \multicolumn{2}{|c|}{4.5489999999999995} & TRN \\
\hline CHEMBL1317741 & 688839 & 4.8 & 4.7797 & TRN & \\
\hline CHEMBL1256869 & 688839 & 4.5 & 4.7098 & TST & \\
\hline CHEMBL 286722 & 688839 & 5.2 & 5.1436 & TRN & \\
\hline CHEMBL1500995 & 688839 & 4.5 & 5.0124 & TRN & \\
\hline CHEMBL1449987 & 688839 & 5.0 & 5.1251 & TST & \\
\hline CHEMBL1437690 & 688839 & 5.7 & 5.7177 & TRN & \\
\hline CHEMBL1514569 & 688839 & 4.5 & 5.1738 & TRN & \\
\hline CHEMBL1533388 & 688839 & 5.4 & 5.2404 & TST & \\
\hline CHEMBL1256364 & 688839 & 4.8 & 4.9171 & TRN & \\
\hline CHEMBL1357759 & 688839 & 4.8 & 4.7985 & TRN & \\
\hline CHEMBL1554888 & 688839 & 5.6 & 5.6189 & TRN & \\
\hline CHEMBL1418023 & 688839 & 4.5 & 5.0599 & TST & \\
\hline CHEMBL1559654 & 688839 & 5.6 & 5.843 & TRN & \\
\hline CHEMBL1436049 & 688839 & 5.2 & 5.2715 & TRN & \\
\hline CHEMBL1450993 & 688839 & 4.7 & 4.7149 & TRN & \\
\hline CHEMBL1591964 & 688839 & 5.3 & \multicolumn{2}{|c|}{4.718999999999999} & TRN \\
\hline CHEMBL1553902 & 688839 & 4.9 & 4.93 & TRN & \\
\hline CHEMBL365739 & 688839 & 5.5 & 5.2857 & TST & \\
\hline CHEMBL 25308 & 688839 & 4.9 & 4.9257 & TST & \\
\hline CHEMBL1475010 & 688839 & 5.2 & 5.0668 & TRN & \\
\hline CHEMBL1473448 & 688839 & 4.8 & 4.9332 & TRN & \\
\hline CHEMBL1354751 & 688839 & 5.3 & 5.2513 & TRN & \\
\hline CHEMBL1594648 & 688839 & 5.2 & 5.0886 & TRN & \\
\hline CHEMBL1598334 & 688839 & 5.4 & 5.5097 & TRN & \\
\hline CHEMBL1358007 & 688839 & 5.5 & 5.3976 & TST & \\
\hline CHEMBL1443323 & 688839 & 4.9 & 4.8767 & TRN & \\
\hline CHEMBL1555164 & 688839 & 5.4 & 5.4679 & TRN & \\
\hline CHEMBL1256851 & 688839 & 6.4 & 6.017 & TRN & \\
\hline CHEMBL1333454 & 688839 & 5.2 & 5.1851 & TRN & \\
\hline CHEMBL1437778 & 688839 & 4.8 & 4.8506 & TRN & \\
\hline CHEMBL1404954 & 688839 & 4.5 & 4.5864 & TRN & \\
\hline CHEMBL1528756 & 688839 & 5.1 & 5.2092 & TRN & \\
\hline CHEMBL196537 & 688839 & 4.8 & 5.0179 & TST & \\
\hline CHEMBL521970 & 688839 & 5.7 & 5.5955 & TRN & \\
\hline CHEMBL1535635 & 688839 & 4.8 & 4.8429 & TRN & \\
\hline CHEMBL1436441 & 688839 & 5.5 & 5.5655 & TRN & \\
\hline CHEMBL1399249 & 688839 & 5.9 & 5.8012 & TST & \\
\hline CHEMBL1521440 & 688839 & 5.4 & 5.7177 & TRN & \\
\hline CHEMBL1173475 & 688839 & 6.0 & 5.811 & TRN & \\
\hline CHEMBL1371096 & 688839 & 4.8 & 4.9651 & TRN & \\
\hline CHEMBL1475589 & 688839 & 4.6 & 4.6658 & TRN & \\
\hline CHEMBL1436811 & 688839 & 4.8 & 4.7895 & TRN & \\
\hline CHEMBL1398392 & 688839 & 5.4 & 5.1921 & TST & \\
\hline CHEMBL1406622 & 688839 & 5.5 & 5.4467 & TRN & \\
\hline CHEMBL1356299 & 688839 & 5.7 & 5.7942 & TRN & \\
\hline \multirow[t]{2}{*}{ CHEMBL1730100 } & 688839 & 6.0 & 5.1194 & TST & \\
\hline & & \multicolumn{4}{|c|}{ Page 20327} \\
\hline
\end{tabular}




\begin{tabular}{|c|c|c|c|c|}
\hline & & & ipplemen & at \\
\hline CHEMBL1553136 & 688839 & 5.1 & 5.1499 & TRN \\
\hline CHEMBL1318708 & 688839 & 5.0 & 5.0404 & TST \\
\hline CHEMBL1554976 & 688839 & 6.2 & 6.0021 & TRN \\
\hline CHEMBL1515706 & 688839 & 5.5 & 5.4754 & TRN \\
\hline CHEMBL 280074 & 688839 & 4.8 & 4.9132 & TRN \\
\hline CHEMBL1593134 & 688839 & 4.9 & 4.9264 & TRN \\
\hline CHEMBL1235001 & 688839 & 5.0 & 5.0399 & TST \\
\hline CHEMBL1330456 & 688839 & 5.4 & 5.0962 & TST \\
\hline CHEMBL1606380 & 688839 & 6.0 & 5.9813 & TRN \\
\hline CHEMBL 2373557 & 688839 & 6.0 & 5.2074 & TRN \\
\hline CHEMBL1436272 & 688839 & 4.8 & 4.9903 & TRN \\
\hline CHEMBL1591971 & 688839 & 6.4 & 6.5375 & TRN \\
\hline CHEMBL1378440 & 688839 & 5.6 & 5.4946 & TRN \\
\hline CHEMBL1527324 & 688839 & 4.6 & 5.2615 & TST \\
\hline CHEMBL1593926 & 688839 & 4.9 & 4.61 & TRN \\
\hline CHEMBL1519326 & 688839 & 4.8 & 4.805 & TRN \\
\hline CHEMBL1357551 & 688839 & 4.7 & 4.79 & TRN \\
\hline CHEMBL73711 & 688839 & 5.5 & 5.1765 & TRN \\
\hline CHEMBL1551380 & 688839 & 4.7 & 4.7385 & TRN \\
\hline CHEMBL446021 & 688839 & 4.6 & 4.9424 & TST \\
\hline CHEMBL1594030 & 688839 & 4.6 & 4.6684 & TRN \\
\hline CHEMBL1356041 & 688839 & 5.6 & 5.644 & TRN \\
\hline CHEMBL1444396 & 688839 & 5.5 & 5.3001 & TRN \\
\hline CHEMBL 76232 & 688839 & 4.6 & 4.8907 & TST \\
\hline CHEMBL 286721 & 688839 & 6.5 & 6.0427 & TRN \\
\hline CHEMBL1363413 & 688839 & 6.0 & 6.0603 & TRN \\
\hline CHEMBL1482342 & 688839 & 5.5 & 5.3331 & TRN \\
\hline CHEMBL1314545 & 688839 & 6.0 & 5.7783 & TST \\
\hline CHEMBL1328324 & 688839 & 6.0 & 4.9679 & TST \\
\hline CHEMBL1516346 & 688839 & 5.2 & 5.2945 & TST \\
\hline CHEMBL1315508 & 688839 & 4.8 & 4.8304 & TRN \\
\hline CHEMBL1512740 & 688839 & 5.8 & 5.8704 & TRN \\
\hline CHEMBL198159 & 688839 & 4.9 & 4.9887 & TRN \\
\hline CHEMBL1328907 & 688839 & 4.8 & 4.9654 & TRN \\
\hline CHEMBL1355665 & 688839 & 5.9 & 5.5459 & TRN \\
\hline CHEMBL568379 & 688839 & 5.0 & 5.0272 & TRN \\
\hline CHEMBL 2373626 & 688839 & 4.8 & 5.1952 & TST \\
\hline CHEMBL186526 & 688839 & 5.6 & 5.4959 & TST \\
\hline CHEMBL1397914 & 688839 & 4.6 & 4.6992 & TRN \\
\hline CHEMBL1515449 & 688839 & 6.2 & 6.2538 & TRN \\
\hline CHEMBL1358263 & 688839 & 6.6 & 6.7004 & TRN \\
\hline CHEMBL173530 & 688839 & 4.9 & 5.1258 & TRN \\
\hline CHEMBL1515315 & 688839 & 5.3 & 5.3944 & TRN \\
\hline CHEMBL1399553 & 688839 & 5.0 & 5.2926 & TST \\
\hline CHEMBL1520285 & 688839 & 5.9 & 5.6869 & TRN \\
\hline CHEMBL1358659 & 688839 & 4.5 & 4.734 & TST \\
\hline CHEMBL1515194 & 688839 & 4.8 & 4.7781 & TRN \\
\hline CHEMBL1369874 & 688839 & 6.0 & 1.2039 & TRN \\
\hline
\end{tabular}




\begin{tabular}{|c|c|c|c|c|c|}
\hline \\
\hline CHEMBL 280822 & 688839 & 6.0 & 5.7113 & TST & \\
\hline CHEMBL601534 & 688839 & 4.7 & 5.3335 & TRN & \\
\hline CHEMBL1357857 & 688839 & 4.7 & 4.7694 & TRN & \\
\hline CHEMBL1594487 & 688839 & 5.4 & 5.4506 & TRN & \\
\hline CHEMBL1326092 & 688839 & 4.9 & 5.0011 & TRN & \\
\hline CHEMBL1435744 & 688839 & 4.9 & 5.1991 & TRN & \\
\hline CHEMBL1224512 & 688839 & 5.5 & 5.3254 & TRN & \\
\hline CHEMBL1514836 & 688839 & 4.5 & 4.6729 & TRN & \\
\hline CHEMBL15060 & 688839 & 4.9 & 4.9958 & TRN & \\
\hline CHEMBL1499330 & 688839 & 5.2 & 5.1999 & TRN & \\
\hline CHEMBL1331923 & 688839 & 5.4 & 5.2166 & TST & \\
\hline CHEMBL1324882 & 688839 & 6.0 & 6.0535 & TRN & \\
\hline CHEMBL1516187 & 688839 & 5.5 & 5.4078 & TRN & \\
\hline CHEMBL3198657 & 688839 & 6.0 & 6.0061 & TRN & \\
\hline CHEMBL1396577 & 688839 & 4.9 & 4.9353 & TRN & \\
\hline CHEMBL1434895 & 688839 & 5.3 & 5.5105 & TRN & \\
\hline CHEMBL1396309 & 688839 & 5.0 & 5.3398 & TST & \\
\hline CHEMBL1361750 & 688839 & 5.3 & 5.2499 & TRN & \\
\hline CHEMBL475198 & 688839 & 5.4 & 5.4274 & TRN & \\
\hline CHEMBL1590106 & 688839 & 4.7 & 4.9962 & TRN & \\
\hline CHEMBL1555028 & 688839 & 4.7 & 4.7598 & TRN & \\
\hline CHEMBL1592186 & 688839 & 5.0 & 4.9792 & TRN & \\
\hline CHEMBL1397175 & 688839 & 6.0 & 6.0032 & TRN & \\
\hline CHEMBL1524520 & 688839 & 6.2 & 6.11600 & 00000000005 & TRN \\
\hline CHEMBL1514359 & 688839 & 4.8 & 4.873 & TRN & \\
\hline CHEMBL42485 & 688839 & 4.7 & 4.7813 & TST & \\
\hline CHEMBL1446731 & 688839 & 5.4 & 5.57799 & 9999999999 & TST \\
\hline CHEMBL1320904 & 688839 & 6.2 & 6.3616 & TRN & \\
\hline CHEMBL 278332 & 688839 & 4.7 & 4.8118 & TST & \\
\hline CHEMBL1484614 & 688839 & 4.6 & 4.7516 & TRN & \\
\hline CHEMBL1447528 & 688839 & 5.4 & 5.3695 & TRN & \\
\hline CHEMBL1369966 & 688839 & 5.8 & 5.9434 & TRN & \\
\hline CHEMBL1486465 & 688839 & 5.6 & 5.0647 & TRN & \\
\hline CHEMBL1395049 & 688839 & 5.4 & 5.4469 & TRN & \\
\hline CHEMBL1256984 & 688839 & 5.6 & 5.6627 & TST & \\
\hline CHEMBL1475689 & 688839 & 4.4 & 4.5102 & TRN & \\
\hline CHEMBL1314222 & 688839 & 5.5 & 5.4384 & TRN & \\
\hline CHEMBL1445984 & 688839 & 4.8 & 4.8364 & TRN & \\
\hline CHEMBL1601895 & 688839 & 5.4 & 5.235 & TRN & \\
\hline CHEMBL1496934 & 688839 & 5.5 & 4.7912 & TRN & \\
\hline CHEMBL1565169 & 688839 & 5.4 & 5.2374 & TRN & \\
\hline CHEMBL1571391 & 688839 & 5.5 & 5.1325 & TRN & \\
\hline CHEMBL1593068 & 688839 & 5.1 & 5.0654 & TRN & \\
\hline CHEMBL77387 & 688839 & 5.8 & 5.4499 & TRN & \\
\hline CHEMBL1603406 & 688839 & 4.6 & 4.6648 & TRN & \\
\hline CHEMBL1416646 & 688839 & 4.5 & 5.1522 & TRN & \\
\hline CHEMBL1475550 & 688839 & 4.8 & 5.1681 & TST & \\
\hline CHEMBL1472786 & 688839 & 5.4 & 5.1396 & TST & \\
\hline
\end{tabular}




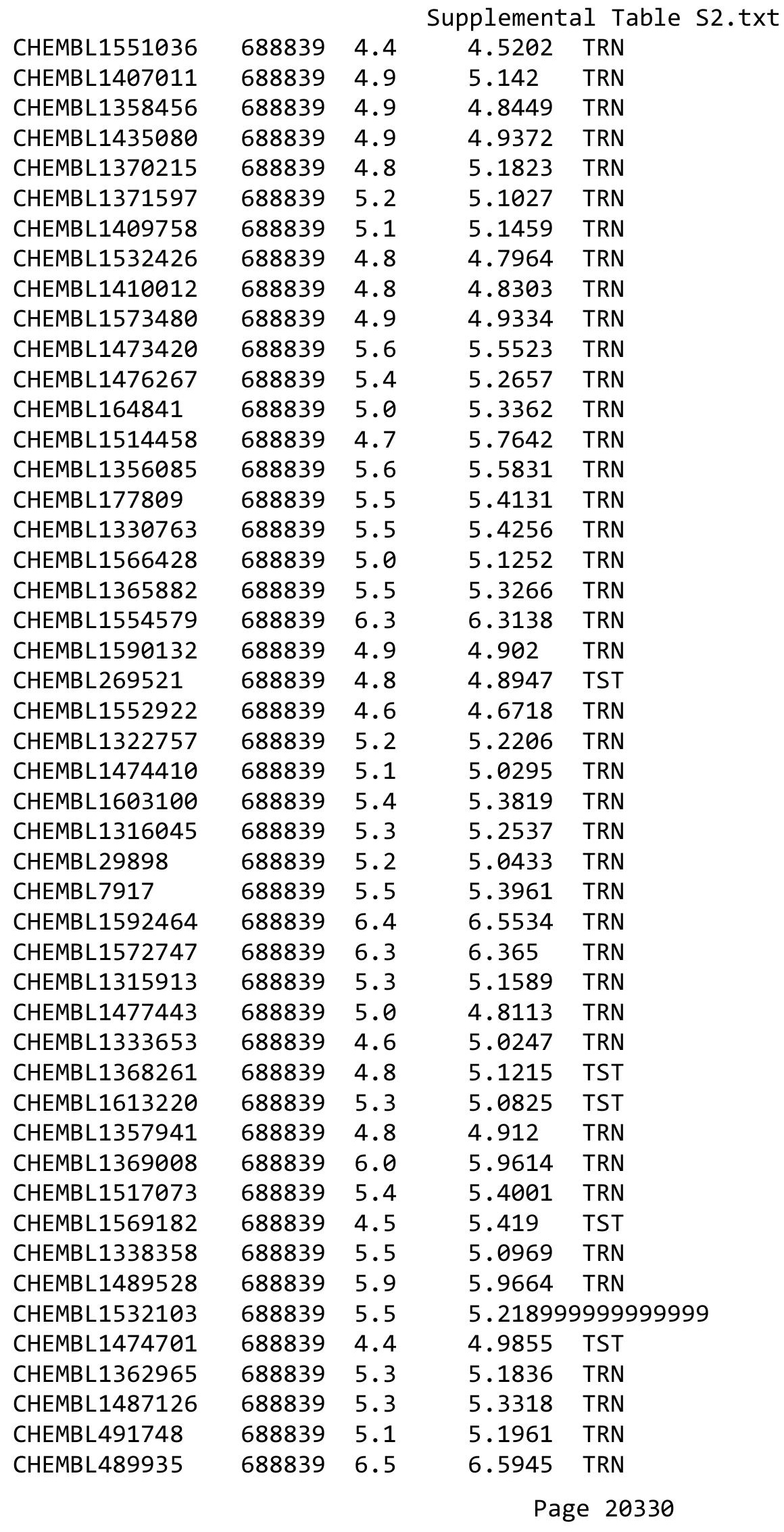




\begin{tabular}{|c|c|c|c|c|}
\hline \multicolumn{5}{|c|}{ olemental Table s } \\
\hline CHEMBL1552051 & 688839 & 4.6 & 4.7001 & TRN \\
\hline CHEMBL1357338 & 688839 & 4.9 & 4.8488 & TRN \\
\hline CHEMBL1398543 & 688839 & 6.0 & 5.7893 & TRN \\
\hline CHEMBL1397177 & 688839 & 5.5 & 5.5065 & TRN \\
\hline CHEMBL1409986 & 688839 & 5.4 & 5.4043 & TRN \\
\hline CHEMBL1368113 & 688839 & 4.8 & 4.8366 & TRN \\
\hline CHEMBL1322608 & 688839 & 6.0 & 4.922 & TRN \\
\hline CHEMBL1512198 & 688839 & 4.9 & 4.9581 & TST \\
\hline CHEMBL1374799 & 688839 & 5.9 & 5.1276 & TRN \\
\hline CHEMBL1454949 & 688839 & 5.6 & 5.4384 & TST \\
\hline CHEMBL1517241 & 688839 & 4.8 & 4.9421 & TRN \\
\hline CHEMBL1475737 & 688839 & 5.2 & 5.2801 & TRN \\
\hline CHEMBL244746 & 688839 & 4.6 & 5.0828 & TRN \\
\hline CHEMBL1360610 & 688839 & 4.9 & 5.1811 & TRN \\
\hline CHEMBL1358388 & 688839 & 5.1 & 5.0191 & TRN \\
\hline CHEMBL1321343 & 688839 & 4.8 & 5.1555 & TRN \\
\hline CHEMBL1357558 & 688839 & 4.6 & 4.789 & TST \\
\hline CHEMBL398673 & 688839 & 4.5 & 4.7202 & TST \\
\hline CHEMBL43612 & 688839 & 4.4 & 4.9613 & TRN \\
\hline CHEMBL293341 & 688839 & 4.9 & 5.0518 & TRN \\
\hline CHEMBL1556035 & 688839 & 4.8 & 5.0029 & TRN \\
\hline CHEMBL1532000 & 688839 & 5.3 & 5.3706 & TRN \\
\hline CHEMBL1330729 & 688839 & 4.8 & 5.25700 & 0000000001 \\
\hline CHEMBL1476511 & 688839 & 5.1 & 5.0216 & TRN \\
\hline CHEMBL1455018 & 688839 & 4.7 & 4.7991 & TRN \\
\hline CHEMBL1590909 & 688839 & 5.5 & 5.5751 & TRN \\
\hline CHEMBL1411146 & 688839 & 5.1 & 5.0955 & TRN \\
\hline CHEMBL1413572 & 688839 & 5.1 & 5.4147 & TRN \\
\hline CHEMBL1516249 & 688839 & 5.1 & 4.7473 & TRN \\
\hline CHEMBL1315373 & 688839 & 5.4 & 5.4954 & TRN \\
\hline CHEMBL167513 & 688839 & 4.6 & 4.9705 & TRN \\
\hline CHEMBL1317458 & 688839 & 4.6 & 5.0375 & TRN \\
\hline CHEMBL1332314 & 688839 & 4.7 & 5.1152 & TST \\
\hline CHEMBL1597690 & 688839 & 4.9 & 5.3036 & TST \\
\hline CHEMBL1575015 & 688839 & 6.0 & 5.1585 & TRN \\
\hline CHEMBL1562085 & 688839 & 4.9 & 4.8867 & TRN \\
\hline CHEMBL1316056 & 688839 & 5.5 & 5.4127 & TRN \\
\hline CHEMBL166161 & 688839 & 4.5 & 4.7657 & TST \\
\hline CHEMBL1531342 & 688839 & 5.5 & 5.4837 & TST \\
\hline CHEMBL1435313 & 688839 & 5.4 & 5.4768 & TRN \\
\hline CHEMBL1318560 & 688839 & 5.7 & 5.4693 & TRN \\
\hline CHEMBL1314465 & 688839 & 4.8 & 4.811 & TRN \\
\hline CHEMBL 1410006 & 688839 & 5.5 & 5.1671 & TRN \\
\hline CHEMBL1529538 & 688839 & 4.9 & 4.9474 & TST \\
\hline CHEMBL1318927 & 688839 & 5.4 & 5.3712 & TRN \\
\hline CHEMBL258942 & 688839 & 5.6 & 5.2345 & TRN \\
\hline CHEMBL1591537 & 688839 & 5.2 & 5.3996 & TRN \\
\hline CHEMBL1447318 & 688839 & 5.6 & 5.2766 & TST \\
\hline
\end{tabular}




\begin{tabular}{|c|c|c|c|c|c|}
\hline & & & & & \\
\hline CHEMBL1482968 & 688839 & 5.5 & 4.7138 & TRN & \\
\hline CHEMBL1517852 & 688839 & 5.4 & 4.822 & TRN & \\
\hline CHEMBL1316222 & 688839 & 5.8 & 5.6009 & TST & \\
\hline CHEMBL1474468 & 688839 & 5.7 & 5.6886 & TRN & \\
\hline CHEMBL3211338 & 688839 & 6.0 & 6.0182 & TRN & \\
\hline CHEMBL1318042 & 688839 & 5.4 & 5.557 & TRN & \\
\hline CHEMBL1597812 & 688839 & 6.0 & 5.7535 & TST & \\
\hline CHEMBL1412163 & 688839 & 5.4 & 4.997 & TRN & \\
\hline CHEMBL1532921 & 688839 & 5.5 & 5.4307 & TRN & \\
\hline CHEMBL1334016 & 688839 & 5.2 & 5.1639 & TRN & \\
\hline CHEMBL1556828 & 688839 & 5.4 & 5.4616 & TRN & \\
\hline CHEMBL1316893 & 688839 & 5.1 & 5.0614 & TRN & \\
\hline CHEMBL1590259 & 688839 & 4.9 & 4.9476 & TRN & \\
\hline CHEMBL1568735 & 688839 & 5.6 & 5.5296 & TRN & \\
\hline CHEMBL1490919 & 688839 & 4.8 & 5.1413 & TST & \\
\hline CHEMBL1450619 & 688839 & 5.5 & 5.6114 & TRN & \\
\hline CHEMBL1476426 & 688839 & 4.7 & 5.317 & TRN & \\
\hline CHEMBL299613 & 688839 & 6.0 & 5.7434 & TRN & \\
\hline CHEMBL1327915 & 688839 & 4.8 & 4.8507 & TRN & \\
\hline CHEMBL1371726 & 688839 & 6.0 & 6.0353 & TRN & \\
\hline CHEMBL1515526 & 688839 & 5.4 & 5.3621 & TRN & \\
\hline CHEMBL1488679 & 688839 & 5.8 & 5.6708 & TRN & \\
\hline CHEMBL194399 & 688839 & 5.6 & 5.0642 & TST & \\
\hline CHEMBL1318261 & 688839 & 5.0 & 4.9988 & TRN & \\
\hline CHEMBL1357500 & 688839 & 4.8 & 4.8398 & TRN & \\
\hline CHEMBL1552098 & 688839 & 4.5 & 4.5928 & TRN & \\
\hline CHEMBL1437713 & 688839 & 4.9 & 5.2269 & TRN & \\
\hline CHEMBL1411389 & 688839 & 5.2 & 5.3849 & TRN & \\
\hline CHEMBL1567944 & 688839 & 6.0 & $6.1170 e$ & 0000000001 & TRN \\
\hline CHEMBL 280065 & 688839 & 4.5 & 4.5649 & TRN & \\
\hline CHEMBL1488305 & 688839 & 5.2 & 5.2791 & TRN & \\
\hline CHEMBL1364808 & 688839 & 4.7 & 4.832 & TST & \\
\hline CHEMBL1201074 & 688839 & 5.0 & 5.0674 & TST & \\
\hline CHEMBL1593592 & 688839 & 5.8 & 5.7317 & TRN & \\
\hline CHEMBL94734 & 688839 & 4.9 & 4.938 & TRN & \\
\hline CHEMBL1488728 & 688839 & 4.4 & 5.1327 & TRN & \\
\hline CHEMBL1551049 & 688839 & 5.3 & 5.2121 & TRN & \\
\hline CHEMBL1452910 & 688839 & 5.3 & 5.1533 & TST & \\
\hline CHEMBL1357044 & 688839 & 5.4 & 5.1215 & TST & \\
\hline CHEMBL1515858 & 688839 & 4.9 & 4.8552 & TRN & \\
\hline CHEMBL1593923 & 688839 & 5.2 & 5.0347 & TRN & \\
\hline CHEMBL552439 & 688839 & 5.4 & 5.3227 & TST & \\
\hline CHEMBL1552332 & 688839 & 5.9 & 4.8107 & TRN & \\
\hline CHEMBL77030 & 688839 & 6.0 & 5.6744 & TRN & \\
\hline CHEMBL1526213 & 688839 & 5.9 & 5.6771 & TRN & \\
\hline CHEMBL1434762 & 688839 & 4.6 & 5.5291 & TRN & \\
\hline CHEMBL1323290 & 688839 & 4.9 & 5.3056 & TRN & \\
\hline CHEMBL1315328 & 688839 & 5.2 & 5.0041 & TRN & \\
\hline & & & & 20332 & \\
\hline
\end{tabular}




\begin{tabular}{|c|c|c|c|c|}
\hline & & & ipplemen & $\mathrm{a} \perp \mathrm{T}$ \\
\hline CHEMBL1436743 & 688839 & 5.4 & 5.6145 & TRN \\
\hline CHEMBL1365701 & 688839 & 5.6 & 5.9257 & TRN \\
\hline CHEMBL116438 & 688839 & 4.6 & 4.934 & TRN \\
\hline CHEMBL3392050 & 688839 & 4.4 & 4.5874 & TST \\
\hline CHEMBL1447746 & 688839 & 5.5 & 5.4325 & TST \\
\hline CHEMBL127421 & 688839 & 4.8 & 4.8435 & TRN \\
\hline CHEMBL428768 & 688839 & 6.0 & 5.7918 & TRN \\
\hline CHEMBL1441593 & 688839 & 5.6 & 5.5863 & TST \\
\hline CHEMBL576997 & 688839 & 6.0 & 5.056 & TST \\
\hline CHEMBL1477240 & 688839 & 5.9 & 5.6043 & TST \\
\hline CHEMBL243676 & 688839 & 4.9 & 5.0853 & TRN \\
\hline CHEMBL1256913 & 688839 & 5.0 & 5.0047 & TRN \\
\hline CHEMBL 293749 & 688839 & 5.4 & 5.4231 & TRN \\
\hline CHEMBL338115 & 688839 & 5.3 & 5.3111 & TRN \\
\hline CHEMBL1472995 & 688839 & 5.3 & 5.0565 & TRN \\
\hline CHEMBL1318710 & 688839 & 5.5 & 5.0442 & TST \\
\hline CHEMBL123 & 688839 & 6.0 & 6.4186 & TRN \\
\hline CHEMBL1590458 & 688839 & 4.9 & 5.0181 & TRN \\
\hline CHEMBL275084 & 688839 & 6.0 & 5.3308 & TST \\
\hline CHEMBL21241 & 688839 & 5.4 & 5.2972 & TST \\
\hline CHEMBL1256749 & 688839 & 6.0 & 5.7048 & TST \\
\hline CHEMBL1444973 & 688839 & 4.9 & 5.1893 & TRN \\
\hline CHEMBL1435384 & 688839 & 5.6 & 5.624 & TRN \\
\hline CHEMBL1396384 & 688839 & 5.3 & 5.5603 & TRN \\
\hline CHEMBL1512460 & 688839 & 5.6 & 5.1727 & TST \\
\hline CHEMBL1592760 & 688839 & 5.0 & 4.9857 & TRN \\
\hline CHEMBL1408730 & 688839 & 4.8 & 5.1056 & TRN \\
\hline CHEMBL1565060 & 688839 & 5.3 & 5.2584 & TRN \\
\hline CHEMBL1407012 & 688839 & 4.9 & 5.1154 & TRN \\
\hline CHEMBL1553422 & 688839 & 5.5 & 5.4288 & TRN \\
\hline CHEMBL1513944 & 688839 & 5.0 & 5.2295 & TST \\
\hline CHEMBL1452517 & 688839 & 4.8 & 5.4152 & TRN \\
\hline CHEMBL1396080 & 688839 & 4.9 & 4.8949 & TRN \\
\hline CHEMBL1526319 & 688839 & 5.4 & 5.1767 & TST \\
\hline CHEMBL1566621 & 688839 & 4.8 & 4.7583 & TRN \\
\hline CHEMBL1319292 & 688839 & 4.4 & 4.4867 & TRN \\
\hline CHEMBL258893 & 688839 & 4.5 & 4.8027 & TST \\
\hline CHEMBL1396377 & 688839 & 4.6 & 4.7814 & TRN \\
\hline CHEMBL1611235 & 688839 & 4.8 & 4.8858 & TRN \\
\hline CHEMBL124267 & 688839 & 5.3 & 5.2271 & TRN \\
\hline CHEMBL3197283 & 688839 & 5.4 & 5.4273 & TRN \\
\hline CHEMBL1314211 & 688839 & 5.6 & 5.6781 & TRN \\
\hline CHEMBL1593440 & 688839 & 5.2 & 5.1229 & TRN \\
\hline CHEMBL1591080 & 688839 & 4.9 & 5.1638 & TRN \\
\hline CHEMBL1319093 & 688839 & 6.3 & 6.2011 & TRN \\
\hline CHEMBL1473429 & 688839 & 4.9 & 4.9853 & TST \\
\hline CHEMBL1316213 & 688839 & 5.3 & 5.3954 & TRN \\
\hline CHEMBL1554577 & 688839 & 6.5 & 6.5938 & TRN \\
\hline
\end{tabular}




\begin{tabular}{|c|c|c|c|c|}
\hline & & & pplement & al $\mathrm{T}$ \\
\hline CHEMBL1479912 & 688839 & 5.5 & 5.5147 & TRN \\
\hline CHEMBL1315292 & 688839 & 5.9 & 6.1174 & TRN \\
\hline CHEMBL1317451 & 688839 & 4.8 & 4.7842 & TRN \\
\hline CHEMBL15712 & 688839 & 4.9 & 4.8211 & TRN \\
\hline CHEMBL1317055 & 688839 & 6.0 & 5.1506 & TRN \\
\hline CHEMBL294590 & 688839 & 7.4001 & 6.7189 & TRN \\
\hline CHEMBL1397257 & 688839 & 4.8 & 4.7562 & TRN \\
\hline CHEMBL1333531 & 688839 & 4.6 & 4.6919 & TRN \\
\hline CHEMBL440084 & 688839 & 5.0 & 5.1592 & TRN \\
\hline CHEMBL418509 & 688839 & 4.7 & 5.0087 & TRN \\
\hline CHEMBL1445094 & 688839 & 5.0 & 5.143 & TRN \\
\hline CHEMBL1476230 & 688839 & 4.6 & 4.6802 & TRN \\
\hline CHEMBL1318316 & 688839 & 5.4 & 5.3777 & TST \\
\hline CHEMBL1326944 & 688839 & 5.1 & 5.1334 & TRN \\
\hline CHEMBL1613260 & 688839 & 4.9 & 5.1273 & TRN \\
\hline CHEMBL1436295 & 688839 & 5.4 & 5.1614 & TRN \\
\hline CHEMBL1475686 & 688839 & 5.0 & 5.0137 & TRN \\
\hline CHEMBL1590060 & 688839 & 4.9 & 4.8347 & TRN \\
\hline CHEMBL 2373622 & 688839 & 4.8 & 4.9515 & TST \\
\hline CHEMBL1357222 & 688839 & 4.9 & 5.0537 & TRN \\
\hline CHEMBL225513 & 688839 & 4.8 & 5.0548 & TRN \\
\hline CHEMBL1371756 & 688839 & 5.0 & 5.1655 & TRN \\
\hline CHEMBL1442770 & 688839 & 4.7 & 4.785 & TST \\
\hline CHEMBL1565360 & 688839 & 4.7 & 4.7385 & TRN \\
\hline CHEMBL1553428 & 688839 & 5.0 & 5.0753 & TRN \\
\hline CHEMBL1213187 & 688839 & 4.5 & 4.7452 & TST \\
\hline CHEMBL 254218 & 688839 & 4.8 & 5.0736 & TRN \\
\hline CHEMBL1377781 & 688839 & 5.0 & 4.8965 & TRN \\
\hline CHEMBL140796 & 688839 & 5.7 & 5.0078 & TRN \\
\hline CHEMBL1593596 & 688839 & 5.5 & 5.0983 & TST \\
\hline CHEMBL1525691 & 688839 & 5.8 & 5.3962 & TRN \\
\hline CHEMBL12252 & 688839 & 5.2 & 5.3023 & TRN \\
\hline CHEMBL1605942 & 688839 & 4.9 & 5.0869 & TRN \\
\hline CHEMBL 23731 & 688839 & 6.0 & 5.7638 & TST \\
\hline CHEMBL1441287 & 688839 & 4.8 & 4.9114 & TRN \\
\hline CHEMBL1317294 & 688839 & 4.9 & 5.0498 & TRN \\
\hline CHEMBL1476155 & 688839 & 4.6 & 5.0917 & TST \\
\hline CHEMBL495068 & 688839 & 5.5 & 5.4715 & TRN \\
\hline CHEMBL1398536 & 688839 & 5.3 & 5.402 & TRN \\
\hline CHEMBL 1437650 & 688839 & 4.6 & 4.6864 & TRN \\
\hline CHEMBL1327466 & 688839 & 5.6 & 5.6631 & TRN \\
\hline CHEMBL1372873 & 688839 & 5.5 & 5.1211 & TST \\
\hline CHEMBL1491288 & 688839 & 5.5 & 5.4011 & TRN \\
\hline CHEMBL1397634 & 688839 & 5.5 & 5.5041 & TRN \\
\hline CHEMBL91153 & 688839 & 5.1 & 5.0969 & TRN \\
\hline CHEMBL1355089 & 688839 & 5.5 & 5.4644 & TRN \\
\hline CHEMBL1439882 & 688839 & 6.1 & 5.8705 & TRN \\
\hline CHEMBL3210161 & 688839 & 5.4 & 5.4618 & TRN \\
\hline
\end{tabular}




\begin{tabular}{|c|c|c|c|c|c|}
\hline \\
\hline CHEMBL1315941 & 688839 & 6.0 & 5.2671 & TST & \\
\hline CHEMBL1555122 & 688839 & 4.8 & 4.8601 & TRN & \\
\hline CHEMBL1591460 & 688839 & 5.1 & 5.091 & TRN & \\
\hline CHEMBL1552066 & 688839 & 5.4 & 5.4022 & TRN & \\
\hline CHEMBL586946 & 688839 & 5.7 & 5.5013 & TRN & \\
\hline CHEMBL1367976 & 688839 & 4.6 & 5.1811 & TRN & \\
\hline CHEMBL1526697 & 688839 & 5.5 & 5.4676 & TRN & \\
\hline CHEMBL278164 & 688839 & 4.9 & 5.1178 & TRN & \\
\hline CHEMBL1446323 & 688839 & 4.7 & 4.7893 & TRN & \\
\hline CHEMBL1535201 & 688839 & 4.9 & 5.15600 & 0000000001 & TST \\
\hline CHEMBL664 & 688839 & 4.7 & 4.8723 & TST & \\
\hline CHEMBL21260 & 688839 & 6.0 & 5.8073 & TST & \\
\hline CHEMBL1574543 & 688839 & 7.5003 & 5.1896 & TRN & \\
\hline CHEMBL68423 & 688839 & 6.5 & 6.2163 & TST & \\
\hline CHEMBL1321846 & 688839 & 5.5 & 5.6375 & TRN & \\
\hline CHEMBL1556608 & 688839 & 4.8 & 5.0416 & TRN & \\
\hline CHEMBL1552970 & 688839 & 5.0 & 5.0613 & TRN & \\
\hline CHEMBL1533214 & 688839 & 5.2 & 5.1384 & TRN & \\
\hline CHEMBL1554199 & 688839 & 5.7 & 5.2037 & TRN & \\
\hline CHEMBL1343187 & 688839 & 5.9 & 5.3063 & TRN & \\
\hline CHEMBL1362420 & 688839 & 5.4 & 4.9927 & TRN & \\
\hline CHEMBL1320190 & 688839 & 5.0 & 4.9287 & TRN & \\
\hline CHEMBL1315690 & 688839 & 4.7 & 4.6942 & TRN & \\
\hline CHEMBL1256325 & 688839 & 4.5 & 4.7008 & TRN & \\
\hline CHEMBL1515131 & 688839 & 5.5 & 5.4307 & TST & \\
\hline CHEMBL1317373 & 688839 & 5.9 & 5.9278 & TRN & \\
\hline CHEMBL1588831 & 688839 & 4.5 & 5.0127 & TRN & \\
\hline CHEMBL453797 & 688839 & 4.4 & 5.1698 & TST & \\
\hline CHEMBL1591258 & 688839 & 4.8 & 5.1455 & TRN & \\
\hline CHEMBL1256020 & 688839 & 5.0 & 5.0482 & TRN & \\
\hline CHEMBL 236789 & 688839 & 6.0 & 5.7807 & TRN & \\
\hline CHEMBL1492229 & 688839 & 5.4 & 5.2764 & TRN & \\
\hline CHEMBL1358560 & 688839 & 5.4 & 5.5637 & TRN & \\
\hline CHEMBL1363873 & 688839 & 5.0 & 4.8413 & TRN & \\
\hline CHEMBL1557091 & 688839 & 4.9 & 4.942 & TST & \\
\hline CHEMBL1515137 & 688839 & 4.5 & 5.2059 & TST & \\
\hline CHEMBL1336796 & 688839 & 6.2 & 5.8876 & TST & \\
\hline CHEMBL1591757 & 688839 & 5.4 & 5.3694 & TRN & \\
\hline CHEMBL1358395 & 688839 & 5.4 & 5.3448 & TST & \\
\hline CHEMBL1512123 & 688839 & 5.1 & 5.1489 & TRN & \\
\hline CHEMBL1526170 & 688839 & 5.4 & 5.5447 & TRN & \\
\hline CHEMBL1609209 & 688839 & 4.7 & 4.763 & TRN & \\
\hline CHEMBL1489085 & 688839 & 5.4 & 5.4941 & TRN & \\
\hline CHEMBL1487748 & 688839 & 6.0 & 6.0729 & TRN & \\
\hline CHEMBL1256737 & 688839 & 6.0 & 5.67700 & 20000000005 & TST \\
\hline CHEMBL 283130 & 688839 & 4.8 & 4.8556 & TRN & \\
\hline CHEMBL137803 & 688839 & 5.0 & 5.0973 & TST & \\
\hline CHEMBL1473188 & 688839 & 5.0 & 4.9895 & TRN & \\
\hline
\end{tabular}




\begin{tabular}{|c|c|c|c|c|c|}
\hline & & & & & \\
\hline CHEMBL1256173 & 688839 & 4.5 & 4.6407 & TRN & \\
\hline CHEMBL1374280 & 688839 & 5.4 & 5.3006 & TRN & \\
\hline CHEMBL1255653 & 688839 & 6.5 & 6.1683 & TST & \\
\hline CHEMBL1442250 & 688839 & 4.9 & 4.9414 & TRN & \\
\hline CHEMBL1613725 & 688839 & 4.9 & 4.9395 & TRN & \\
\hline CHEMBL1488467 & 688839 & 4.9 & 5.0401 & TRN & \\
\hline CHEMBL93403 & 688839 & 4.8 & 4.8548 & TRN & \\
\hline CHEMBL1290347 & 688839 & 4.5 & 5.0311 & TRN & \\
\hline CHEMBL1317620 & 688839 & 4.7 & 4.6941 & TRN & \\
\hline CHEMBL1473133 & 688839 & 5.4 & 5.32799 & 9999999999 & TRN \\
\hline CHEMBL1475788 & 688839 & 4.9 & 4.8785 & TRN & \\
\hline CHEMBL1404884 & 688839 & 5.1 & 5.1083 & TRN & \\
\hline CHEMBL1438226 & 688839 & 4.9 & 5.131 & TRN & \\
\hline CHEMBL1490869 & 688839 & 5.4 & 5.4994 & TRN & \\
\hline CHEMBL1327256 & 688839 & 4.9 & 5.1 & TRN & \\
\hline CHEMBL1331476 & 688839 & 4.6 & 4.8302 & TST & \\
\hline CHEMBL1374591 & 688839 & 4.8 & 5.1927 & TST & \\
\hline CHEMBL1519167 & 688839 & 5.4 & 5.2606 & TRN & \\
\hline CHEMBL1384154 & 688839 & 4.8 & 5.2176 & TRN & \\
\hline CHEMBL1553740 & 688839 & 5.3 & 5.2738 & TRN & \\
\hline CHEMBL1475667 & 688839 & 4.9 & 5.0303 & TRN & \\
\hline CHEMBL1601477 & 688839 & 5.1 & 5.0035 & TRN & \\
\hline CHEMBL1563507 & 688839 & 5.6 & 5.6434 & TRN & \\
\hline CHEMBL1475541 & 688839 & 5.0 & 5.1947 & TRN & \\
\hline CHEMBL 307893 & 688839 & 4.4 & 5.0813 & TRN & \\
\hline CHEMBL1512250 & 688839 & 4.7 & 4.735 & TRN & \\
\hline CHEMBL1315109 & 688839 & 5.1 & 5.0799 & TRN & \\
\hline CHEMBL489934 & 688839 & 6.5 & 6.4967 & TRN & \\
\hline CHEMBL1597366 & 688839 & 4.9 & 5.0179 & TRN & \\
\hline CHEMBL1594058 & 688839 & 6.7001 & 6.3675 & TRN & \\
\hline CHEMBL1402049 & 688839 & 5.5 & 5.4242 & TRN & \\
\hline CHEMBL1562290 & 688839 & 4.8 & 5.074 & TRN & \\
\hline CHEMBL 36148 & 688839 & 6.0 & 5.9669 & TRN & \\
\hline CHEMBL1592812 & 688839 & 5.1 & 5.0172 & TRN & \\
\hline CHEMBL1597474 & 688839 & 5.4 & 5.279 & TRN & \\
\hline CHEMBL1590103 & 688839 & 4.4 & 5.2003 & TST & \\
\hline CHEMBL1456420 & 688839 & 5.4 & 5.3914 & TRN & \\
\hline CHEMBL1565927 & 688839 & 4.8 & 4.9141 & TRN & \\
\hline CHEMBL1480740 & 688839 & 4.8 & 5.2307 & TST & \\
\hline CHEMBL522311 & 688839 & 7.0 & 6.9797 & TRN & \\
\hline CHEMBL1481510 & 688839 & 4.9 & 4.9126 & TRN & \\
\hline CHEMBL1603788 & 688839 & 4.5 & 5.0798 & TRN & \\
\hline CHEMBL1443390 & 688839 & 4.8 & 4.9189 & TRN & \\
\hline CHEMBL1410676 & 688839 & 6.9 & 6.8936 & TRN & \\
\hline CHEMBL1328979 & 688839 & 5.3 & 5.5343 & TRN & \\
\hline CHEMBL1436536 & 688839 & 4.6 & 4.8857 & TRN & \\
\hline CHEMBL1318454 & 688839 & 4.9 & 4.836 & TRN & \\
\hline CHEMBL1318259 & 688839 & 4.8 & 5.1661 & TST & \\
\hline & & & & 20336 & \\
\hline
\end{tabular}




\begin{tabular}{|c|c|c|c|c|}
\hline \multicolumn{5}{|c|}{ Supplemental Table S2.txt } \\
\hline CHEMBL1523104 & 688839 & 4.5 & 5.0682 & TRN \\
\hline CHEMBL1559126 & 688839 & 5.8 & 5.8964 & TRN \\
\hline CHEMBL1590601 & 688839 & 5.5 & 5.5745 & TRN \\
\hline CHEMBL1435698 & 688839 & 4.8 & 4.8046 & TRN \\
\hline CHEMBL1476722 & 688839 & 4.9 & 5.4379 & TRN \\
\hline CHEMBL1328319 & 688839 & 5.1 & 5.3038 & TRN \\
\hline CHEMBL571087 & 688839 & 5.2 & 5.1003 & TRN \\
\hline CHEMBL1318847 & 688839 & 4.6 & 4.6962 & TRN \\
\hline CHEMBL1409261 & 688839 & 5.0 & 5.1572 & TRN \\
\hline CHEMBL1436053 & 688839 & 4.9 & 5.24700 & 0000000001 \\
\hline CHEMBL1358208 & 688839 & 5.6 & 5.5209 & TST \\
\hline CHEMBL1514671 & 688839 & 4.6 & 5.1912 & TST \\
\hline CHEMBL1512614 & 688839 & 6.3 & 5.4233 & TRN \\
\hline CHEMBL1440857 & 688839 & 5.1 & 5.1194 & TST \\
\hline CHEMBL1561366 & 688839 & 6.6 & 6.6456 & TRN \\
\hline CHEMBL1597023 & 688839 & 5.5 & 4.9511 & TRN \\
\hline CHEMBL1521527 & 688839 & 5.0 & 4.9982 & TRN \\
\hline CHEMBL1518301 & 688839 & 5.9 & 5.8919 & TRN \\
\hline CHEMBL1559465 & 688839 & 4.9 & 4.9744 & TRN \\
\hline CHEMBL1354600 & 688839 & 4.6 & 4.652 & TRN \\
\hline CHEMBL1329110 & 688839 & 5.0 & 5.0718 & TRN \\
\hline CHEMBL1407923 & 688839 & 4.8 & 5.2358 & TST \\
\hline CHEMBL1495634 & 688839 & 5.5 & 5.4953 & TRN \\
\hline CHEMBL1435404 & 688839 & 7.6003 & 6.7059 & TRN \\
\hline CHEMBL1256719 & 688839 & 5.0 & 4.9988 & TST \\
\hline CHEMBL1516331 & 688839 & 4.9 & 4.8837 & TRN \\
\hline CHEMBL1370594 & 688839 & 4.8 & 5.4559 & TRN \\
\hline CHEMBL62 & 688839 & 5.0 & 5.0217 & TRN \\
\hline CHEMBL 1475120 & 688839 & 5.0 & 5.0316 & TRN \\
\hline CHEMBL1552897 & 688839 & 4.6 & 4.9535 & TRN \\
\hline CHEMBL1444270 & 688839 & 5.8 & 5.9019 & TRN \\
\hline CHEMBL6634 & 688839 & 7.4001 & 6.4546 & TST \\
\hline CHEMBL1326341 & 688839 & 5.0 & 4.9966 & TRN \\
\hline CHEMBL1572834 & 688839 & 6.1 & 6.2549 & TRN \\
\hline CHEMBL491 & 688839 & 4.6 & 5.1672 & TST \\
\hline CHEMBL1378235 & 688839 & 5.2 & 5.4705 & TRN \\
\hline CHEMBL1515792 & 688839 & 4.8 & 5.1821 & TST \\
\hline CHEMBL 267458 & 688839 & 4.7 & 4.8556 & TST \\
\hline CHEMBL443127 & 688839 & 4.4 & 4.9937 & TRN \\
\hline CHEMBL489943 & 688839 & 6.5 & 6.7527 & TRN \\
\hline CHEMBL3348998 & 688839 & 5.1 & 5.0817 & TRN \\
\hline CHEMBL1710 & 688839 & 4.5 & 5.1368 & TST \\
\hline CHEMBL1513119 & 688839 & 6.0 & 5.2565 & TST \\
\hline CHEMBL1356844 & 688839 & 4.6 & 4.7179 & TRN \\
\hline CHEMBL1316178 & 688839 & 6.0 & 5.2048 & TST \\
\hline CHEMBL1333019 & 688839 & 6.0 & 5.7919 & TST \\
\hline CHEMBL1551444 & 688839 & 4.6 & 4.7479 & TRN \\
\hline CHEMBL1436110 & 688839 & 4.6 & 5.0576 & TRN \\
\hline
\end{tabular}




\begin{tabular}{|c|c|c|c|c|c|}
\hline & & & & & \\
\hline CHEMBL1526240 & 688839 & 4.7 & 5.1574 & TRN & \\
\hline CHEMBL1406307 & 688839 & 5.5 & 5.3682 & TST & \\
\hline CHEMBL1593805 & 688839 & 5.4 & 5.1512 & TST & \\
\hline CHEMBL1515018 & 688839 & 5.4 & 5.1457 & TST & \\
\hline CHEMBL1450169 & 688839 & 5.5 & 5.2219 & TRN & \\
\hline CHEMBL1476640 & 688839 & 5.1 & 4.7922 & TRN & \\
\hline CHEMBL1483285 & 688839 & 5.5 & 5.7017 & TRN & \\
\hline CHEMBL1373621 & 688839 & 4.8 & 4.793 & TRN & \\
\hline CHEMBL1595910 & 688839 & 5.5 & 5.2971 & TRN & \\
\hline CHEMBL109037 & 688839 & 4.8 & 5.13200 & 0000000001 & TRN \\
\hline CHEMBL1418449 & 688839 & 5.6 & 5.2226 & TST & \\
\hline CHEMBL1395450 & 688839 & 5.4 & 5.3131 & TST & \\
\hline CHEMBL1354626 & 688839 & 5.5 & 5.4446 & TRN & \\
\hline CHEMBL1378758 & 688839 & 5.5 & 5.4343 & TRN & \\
\hline CHEMBL77456 & 688839 & 4.7 & 4.73600 & 0000000001 & TRN \\
\hline CHEMBL1473755 & 688839 & 5.6 & 5.5504 & TRN & \\
\hline CHEMBL1475924 & 688839 & 7.1002 & 6.6219 & TRN & \\
\hline CHEMBL418971 & 688839 & 6.0 & 5.052 & TRN & \\
\hline CHEMBL1515874 & 688839 & 4.9 & 5.0093 & TRN & \\
\hline CHEMBL1412047 & 688839 & 4.8 & 5.0835 & TRN & \\
\hline CHEMBL1435947 & 688839 & 4.7 & 4.8 & TRN & \\
\hline CHEMBL408982 & 688839 & 4.6 & 5.1182 & TST & \\
\hline CHEMBL542700 & 688839 & 4.9 & 5.1184 & TRN & \\
\hline CHEMBL1525856 & 688839 & 4.8 & 5.2486 & TRN & \\
\hline CHEMBL1609624 & 688839 & 4.9 & 4.8835 & TRN & \\
\hline CHEMBL1434484 & 688839 & 4.9 & 4.9875 & TRN & \\
\hline CHEMBL1358122 & 688839 & 4.9 & 4.8834 & TRN & \\
\hline CHEMBL1357598 & 688839 & 4.8 & 5.1855 & TRN & \\
\hline CHEMBL1356094 & 688839 & 4.5 & 4.604 & TST & \\
\hline CHEMBL1256750 & 688839 & 4.6 & 4.808 & TRN & \\
\hline CHEMBL1485777 & 688839 & 5.2 & 5.1203 & TRN & \\
\hline CHEMBL1415521 & 688839 & 6.0 & 6.0903 & TRN & \\
\hline CHEMBL1474498 & 688839 & 5.0 & 5.2361 & TRN & \\
\hline CHEMBL489534 & 688839 & 6.3 & 6.4837 & TRN & \\
\hline CHEMBL155265 & 688839 & 4.6 & 4.7558 & TRN & \\
\hline CHEMBL1474435 & 688839 & 5.5 & 5.4509 & TRN & \\
\hline CHEMBL1528820 & 688839 & 4.5 & 4.9211 & TRN & \\
\hline CHEMBL1395869 & 688839 & 5.5 & 5.4868 & TRN & \\
\hline CHEMBL1484032 & 688839 & 5.8 & 5.5951 & TST & \\
\hline CHEMBL554041 & 688839 & 4.6 & 5.1419 & TRN & \\
\hline CHEMBL447876 & 688839 & 5.1 & 5.4034 & TST & \\
\hline CHEMBL1288014 & 688839 & 5.4 & 5.4871 & TST & \\
\hline CHEMBL1436575 & 688839 & 5.5 & 4.7784 & TRN & \\
\hline CHEMBL1591674 & 688839 & 4.6 & 4.6428 & TRN & \\
\hline CHEMBL85139 & 688839 & 5.4 & 5.2837 & TST & \\
\hline CHEMBL1518947 & 688839 & 4.8 & 4.8274 & TRN & \\
\hline CHEMBL1318222 & 688839 & 4.5 & 4.8054 & TRN & \\
\hline CHEMBL259359 & 688839 & 5.7 & 5.2665 & TRN & \\
\hline & & & & 2033 & \\
\hline
\end{tabular}




\begin{tabular}{|c|c|c|c|c|c|}
\hline & & & & & \\
\hline CHEMBL1527567 & 688839 & 5.0 & 4.7637 & TRN & \\
\hline CHEMBL1492205 & 688839 & 5.5 & 5.6256 & TRN & \\
\hline CHEMBL1567160 & 688839 & 5.7 & 5.5262 & TST & \\
\hline CHEMBL1322711 & 688839 & 5.5 & 5.1512 & TRN & \\
\hline CHEMBL1452816 & 688839 & 4.6 & 5.17399 & 99999999995 & TRN \\
\hline CHEMBL1356234 & 688839 & 4.8 & 4.857 & TRN & \\
\hline CHEMBL1321459 & 688839 & 5.4 & 5.5482 & TRN & \\
\hline CHEMBL1515918 & 688839 & 4.5 & 4.5476 & TRN & \\
\hline CHEMBL1257123 & 688839 & 5.1 & 5.0194 & TRN & \\
\hline CHEMBL1480687 & 688839 & 4.6 & 4.6518 & TRN & \\
\hline CHEMBL1453358 & 688839 & 5.0 & 5.545 & TRN & \\
\hline CHEMBL1359843 & 688839 & 4.9 & 4.8902 & TRN & \\
\hline CHEMBL1597037 & 688839 & 5.5 & 5.4297 & TRN & \\
\hline CHEMBL1256751 & 688839 & 5.0 & 5.0379 & TRN & \\
\hline CHEMBL1377408 & 688839 & 5.8 & $5.7570 €$ & 0000000001 & TRN \\
\hline CHEMBL1476791 & 688839 & 5.1 & 5.1765 & TRN & \\
\hline CHEMBL1330394 & 688839 & 6.0 & 6.0048 & TRN & \\
\hline CHEMBL1570983 & 688839 & 4.9 & 5.0911 & TRN & \\
\hline CHEMBL388054 & 688839 & 4.3 & 4.5166 & TST & \\
\hline CHEMBL1569497 & 688839 & 5.4 & 5.5089 & TRN & \\
\hline CHEMBL1320141 & 688839 & 5.3 & 5.4378 & TRN & \\
\hline CHEMBL1367020 & 688839 & 4.7 & 4.7076 & TRN & \\
\hline CHEMBL1596872 & 688839 & 4.8 & 4.7914 & TRN & \\
\hline CHEMBL1437054 & 688839 & 5.8 & 5.5216 & TST & \\
\hline CHEMBL1406764 & 688839 & 5.4 & 5.2673 & TRN & \\
\hline CHEMBL1592964 & 688839 & 5.2 & 5.2565 & TRN & \\
\hline CHEMBL1357089 & 688839 & 5.3 & 5.1451 & TRN & \\
\hline CHEMBL1395792 & 688839 & 5.2 & 5.4077 & TRN & \\
\hline CHEMBL1256844 & 688839 & 6.0 & 5.7167 & TST & \\
\hline CHEMBL1435916 & 688839 & 5.3 & 5.4604 & TRN & \\
\hline CHEMBL1314641 & 688839 & 5.3 & 5.1211 & TST & \\
\hline CHEMBL1399927 & 688839 & 4.6 & 5.1749 & TST & \\
\hline CHEMBL1593981 & 688839 & 5.3 & 5.2877 & TRN & \\
\hline CHEMBL1523579 & 688839 & 4.8 & 4.7609 & TRN & \\
\hline CHEMBL541543 & 688839 & 4.7 & 4.9673 & TST & \\
\hline CHEMBL1511986 & 688839 & 5.7 & 5.5869 & TRN & \\
\hline CHEMBL315348 & 688839 & 4.7 & 4.9088 & TRN & \\
\hline CHEMBL103469 & 688839 & 4.8 & 5.0319 & TRN & \\
\hline CHEMBL16312 & 688839 & 5.7 & 5.0891 & TRN & \\
\hline CHEMBL429095 & 688839 & 4.6 & 4.6886 & TST & \\
\hline CHEMBL1355408 & 688839 & 6.2 & 6.2056 & TRN & \\
\hline CHEMBL1481747 & 688839 & 4.8 & 4.8952 & TRN & \\
\hline CHEMBL1557007 & 688839 & 5.4 & 5.3128 & TRN & \\
\hline CHEMBL1589897 & 688839 & 5.6 & 4.8842 & TRN & \\
\hline CHEMBL1472732 & 688839 & 4.8 & 4.7846 & TRN & \\
\hline CHEMBL 1480558 & 688839 & 6.7001 & 5.1491 & TST & \\
\hline CHEMBL1441237 & 688839 & 5.1 & 4.996 & TRN & \\
\hline CHEMBL1495077 & 688839 & 4.9 & 4.8669 & TRN & \\
\hline & & & & 20339 & \\
\hline
\end{tabular}




\begin{tabular}{|c|c|c|c|c|c|}
\hline \multirow{2}{*}{ CHEMBL1527132 } & \multirow{2}{*}{688839} & \multirow[b]{2}{*}{5.7} & \\
\hline & & & 5.7571 & TRN & \\
\hline CHEMBL434063 & 688839 & 5.5 & 5.0655 & TST & \\
\hline CHEMBL1601019 & 688839 & 4.9 & 5.1106 & TRN & \\
\hline CHEMBL1335140 & 688839 & 5.4 & 5.1746 & TRN & \\
\hline CHEMBL1524760 & 688839 & 5.0 & 5.1228 & TRN & \\
\hline CHEMBL1373773 & 688839 & 6.5 & 6.3067 & TRN & \\
\hline CHEMBL157351 & 688839 & 4.9 & 4.9569 & TST & \\
\hline CHEMBL1590975 & 688839 & 5.0 & 4.9462 & TRN & \\
\hline CHEMBL1560095 & 688839 & 4.5 & \multicolumn{2}{|c|}{4.6530000000000005} & TRN \\
\hline CHEMBL1568358 & 688839 & 5.3 & 5.0266 & TRN & \\
\hline CHEMBL1609002 & 688839 & 4.9 & 5.0841 & TRN & \\
\hline CHEMBL1591543 & 688839 & 5.4 & 5.3263 & TRN & \\
\hline CHEMBL1596987 & 688839 & 6.0 & 6.0733 & TRN & \\
\hline CHEMBL1409320 & 688839 & 5.7 & 5.7812 & TRN & \\
\hline CHEMBL1319047 & 688839 & 4.5 & 4.9294 & TRN & \\
\hline CHEMBL399121 & 688839 & 6.0 & 5.0345 & TRN & \\
\hline CHEMBL1569985 & 688839 & 5.5 & 5.4185 & TRN & \\
\hline CHEMBL1593269 & 688839 & 5.3 & 5.3091 & TRN & \\
\hline CHEMBL1326322 & 688839 & 4.9 & 4.9451 & TRN & \\
\hline CHEMBL1317982 & 688839 & 4.4 & 4.5041 & TRN & \\
\hline CHEMBL1566987 & 688839 & 6.8 & 6.3977 & TRN & \\
\hline CHEMBL1320765 & 688839 & 4.9 & 4.947 & TRN & \\
\hline CHEMBL1327204 & 688839 & 4.8 & 4.8319 & TRN & \\
\hline CHEMBL1565567 & 688839 & 5.4 & 5.2329 & TRN & \\
\hline CHEMBL1520783 & 688839 & 4.6 & 5.0786 & TST & \\
\hline CHEMBL1566452 & 688839 & 5.4 & 5.0962 & TRN & \\
\hline CHEMBL1513030 & 688839 & 5.1 & 5.0531 & TRN & \\
\hline CHEMBL1554664 & 688839 & 5.5 & 5.4658 & TRN & \\
\hline CHEMBL1590391 & 688839 & 4.3 & 5.0123 & TST & \\
\hline CHEMBL1398467 & 688839 & 4.6 & 4.6741 & TRN & \\
\hline CHEMBL1369882 & 688839 & 4.7 & 4.9766 & TRN & \\
\hline CHEMBL 75267 & 688839 & 4.4 & 4.9736 & TRN & \\
\hline CHEMBL1325701 & 688839 & 5.3 & 5.1853 & TRN & \\
\hline CHEMBL1357770 & 688839 & 5.2 & \multicolumn{2}{|c|}{5.2010000000000005} & TRN \\
\hline CHEMBL1475191 & 688839 & 4.8 & 4.935 & TRN & \\
\hline CHEMBL1355387 & 688839 & 5.4 & 5.3805 & TRN & \\
\hline CHEMBL 1445026 & 688839 & 5.6 & 5.5091 & TRN & \\
\hline CHEMBL1327247 & 688839 & 6.1 & 5.8671 & TRN & \\
\hline CHEMBL1565302 & 688839 & 5.8 & 5.772 & TRN & \\
\hline CHEMBL1335669 & 688839 & 4.9 & 5.3785 & TRN & \\
\hline CHEMBL1608125 & 688839 & 5.6 & 5.5196 & TRN & \\
\hline CHEMBL1513966 & 688839 & 5.4 & 5.4112 & TRN & \\
\hline CHEMBL1567365 & 688839 & 5.5 & 5.4718 & TRN & \\
\hline CHEMBL1318400 & 688839 & 6.0 & 6.0996 & TRN & \\
\hline CHEMBL1360799 & 688839 & 5.4 & 5.3709 & TRN & \\
\hline CHEMBL1605356 & 688839 & 5.6 & 5.7081 & TRN & \\
\hline CHEMBL1314989 & 688839 & 4.4 & 4.5246 & TST & \\
\hline \multirow[t]{2}{*}{ CHEMBL1322702 } & 688839 & 5.4 & 5.3505 & TST & \\
\hline & & \multicolumn{4}{|c|}{ Page 20340} \\
\hline
\end{tabular}




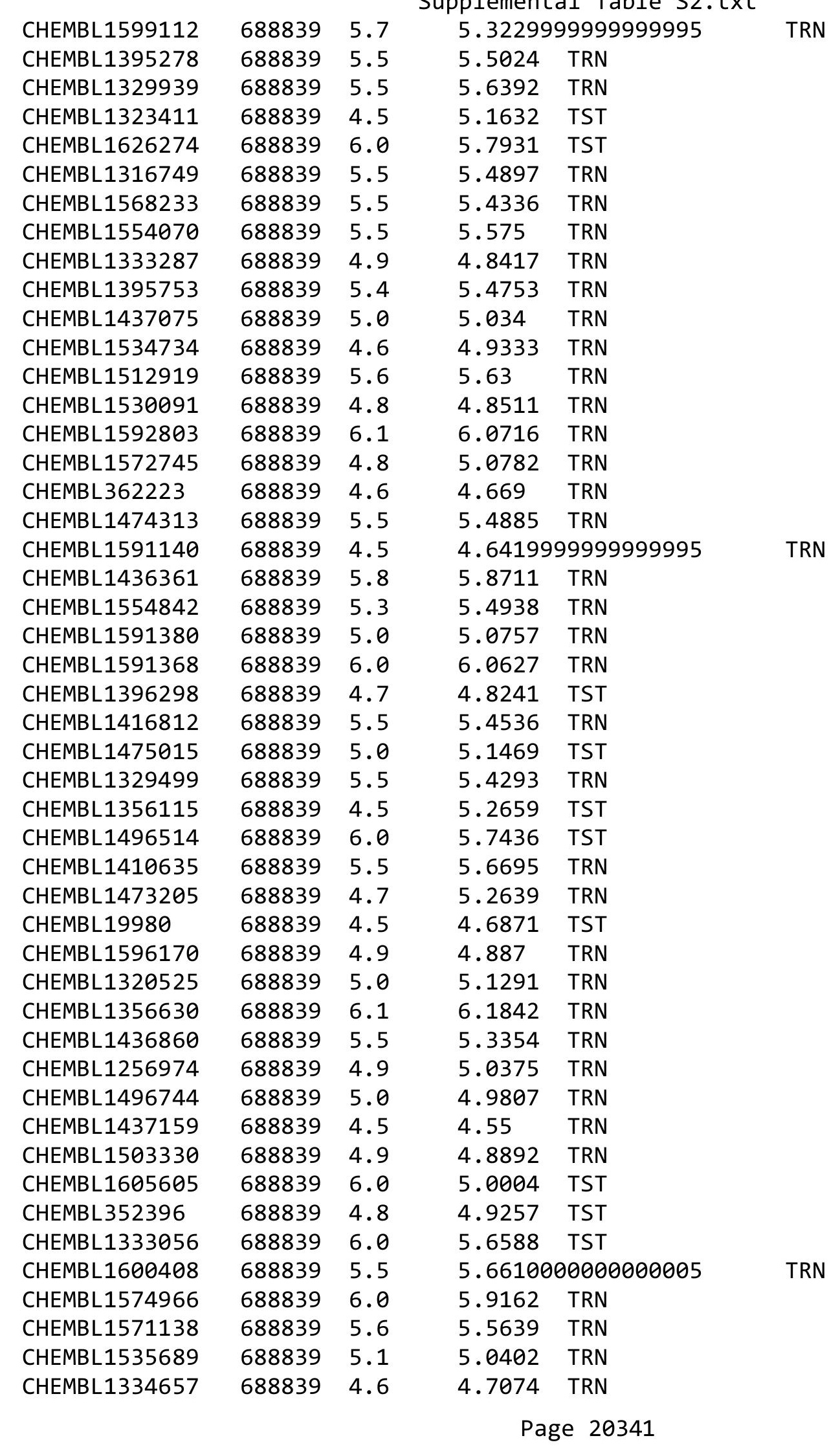




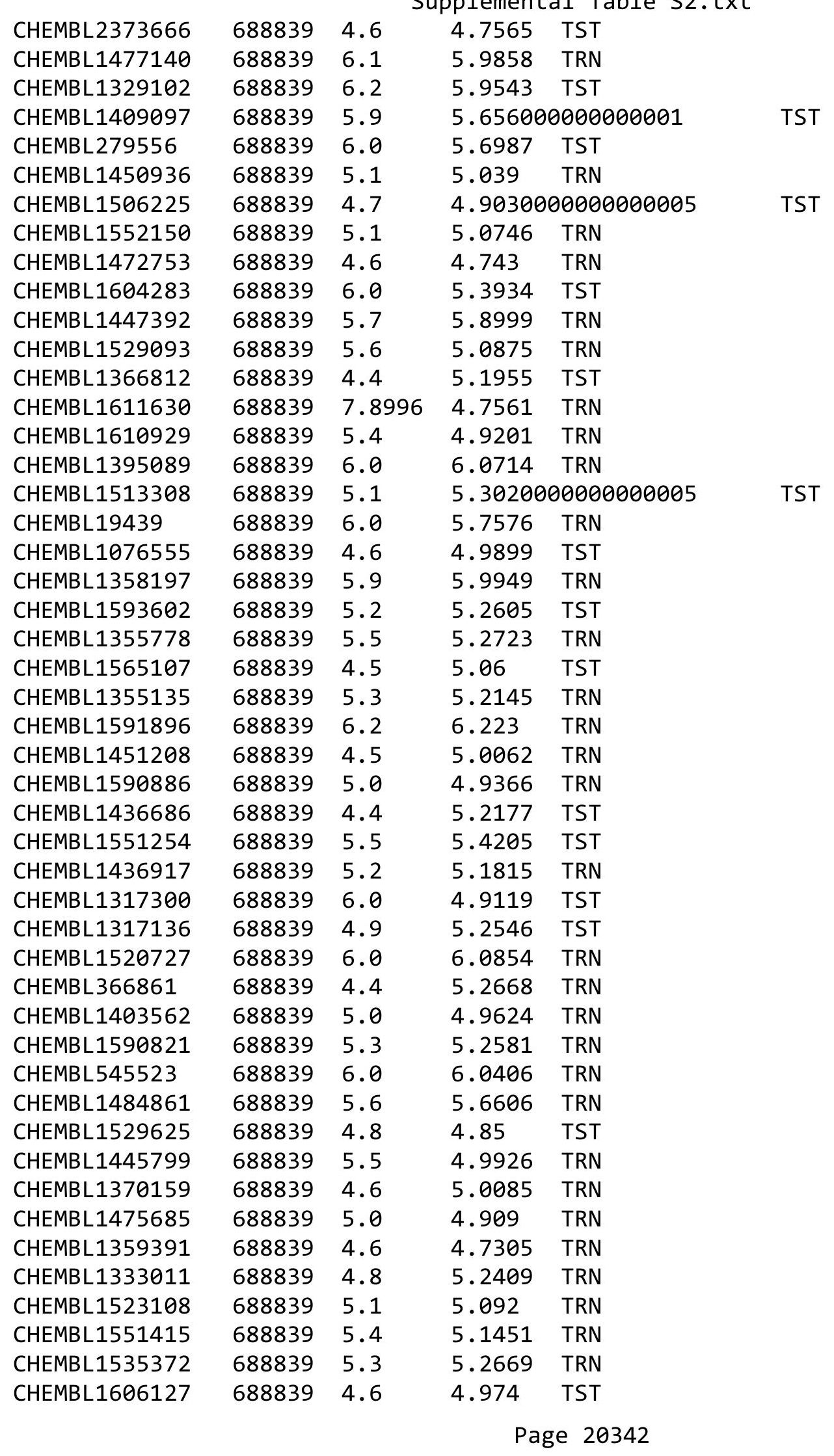




\begin{tabular}{|c|c|c|c|c|}
\hline \multicolumn{5}{|c|}{ Supplemental Table S2.txt } \\
\hline CHEMBL1593321 & 688839 & 5.7 & 5.3435 & TRN \\
\hline CHEMBL1435120 & 688839 & 5.0 & 5.0213 & TRN \\
\hline CHEMBL1516080 & 688839 & 5.0 & 5.065 & TST \\
\hline CHEMBL287327 & 688839 & 4.6 & 4.7368 & TST \\
\hline CHEMBL 1415100 & 688839 & 5.5 & 5.1172 & TRN \\
\hline CHEMBL1270169 & 688839 & 5.7 & 5.5563 & TST \\
\hline CHEMBL1399338 & 688839 & 5.5 & 5.3484 & TRN \\
\hline CHEMBL1513800 & 688839 & 4.6 & 4.7431 & TRN \\
\hline CHEMBL 225230 & 688839 & 4.9 & 4.9842 & TRN \\
\hline CHEMBL1317148 & 688839 & 5.0 & 5.1052 & TRN \\
\hline CHEMBL1402495 & 688839 & 5.4 & 5.4461 & TRN \\
\hline CHEMBL1406175 & 688839 & 4.8 & 4.8274 & TRN \\
\hline CHEMBL1474817 & 688839 & 5.4 & 5.0298 & TRN \\
\hline CHEMBL1566458 & 688839 & 5.4 & 5.0285 & TRN \\
\hline CHEMBL189438 & 688839 & 5.3 & 5.3357 & TST \\
\hline CHEMBL1593001 & 688839 & 4.9 & 4.9073 & TRN \\
\hline CHEMBL1328576 & 688839 & 6.0 & 4.9667 & TST \\
\hline CHEMBL1553530 & 688839 & 4.7 & 4.8069 & TRN \\
\hline CHEMBL1373907 & 688839 & 4.6 & 4.739 & TRN \\
\hline CHEMBL1531982 & 688839 & 4.8 & 5.2112 & TST \\
\hline CHEMBL1338708 & 688839 & 6.2 & 5.3863 & TRN \\
\hline CHEMBL1529879 & 688839 & 5.4 & 5.4068 & TRN \\
\hline CHEMBL1439673 & 688839 & 4.9 & 4.8893 & TRN \\
\hline CHEMBL 258767 & 688839 & 6.0 & 5.7073 & TRN \\
\hline CHEMBL1435899 & 688839 & 4.8 & 4.7284 & TRN \\
\hline CHEMBL1590813 & 688839 & 4.8 & 4.8773 & TRN \\
\hline CHEMBL 1445578 & 688839 & 5.3 & 5.3971 & TRN \\
\hline CHEMBL1358602 & 688839 & 5.4 & 5.125 & TRN \\
\hline CHEMBL1405627 & 688839 & 6.1 & 6.1904 & TRN \\
\hline CHEMBL1396403 & 688839 & 4.6 & 4.6473 & TRN \\
\hline CHEMBL1473252 & 688839 & 5.0 & 5.2059 & TST \\
\hline CHEMBL1556045 & 688839 & 6.7001 & 6.5546 & TRN \\
\hline CHEMBL140220 & 688839 & 5.1 & 5.0742 & TRN \\
\hline CHEMBL1599378 & 688839 & 4.9 & 5.1327 & TRN \\
\hline CHEMBL1472523 & 688839 & 5.5 & 5.3149 & TRN \\
\hline CHEMBL1329517 & 688839 & 4.6 & 5.291 & TST \\
\hline CHEMBL1530505 & 688839 & 4.7 & 4.8117 & TRN \\
\hline CHEMBL1359108 & 688839 & 6.6 & 6.3959 & TRN \\
\hline CHEMBL1593430 & 688839 & 4.8 & 4.7894 & TRN \\
\hline CHEMBL1434156 & 688839 & 4.8 & 4.7886 & TRN \\
\hline CHEMBL1436763 & 688839 & 5.5 & 4.8725 & TRN \\
\hline CHEMBL1318120 & 688839 & 5.5 & 5.5315 & TRN \\
\hline CHEMBL1476939 & 688839 & 5.4 & 5.4295 & TST \\
\hline CHEMBL1566012 & 688839 & 5.8 & 5.6062 & TRN \\
\hline CHEMBL1406782 & 688839 & 4.6 & 4.6586 & TRN \\
\hline CHEMBL1603582 & 688839 & 6.0 & 5.345 & TRN \\
\hline CHEMBL1512624 & 688839 & 5.3 & 5.3371 & TRN \\
\hline CHEMBL1590156 & 688839 & 6.5 & 6.5857 & TRN \\
\hline
\end{tabular}




\begin{tabular}{|c|c|c|c|c|}
\hline & & & ipplemen & al $\mathrm{T}$ \\
\hline CHEMBL1325975 & 688839 & 5.1 & 5.0688 & TRN \\
\hline CHEMBL375126 & 688839 & 5.1 & 5.0886 & TST \\
\hline CHEMBL1534573 & 688839 & 4.6 & 4.6424 & TRN \\
\hline CHEMBL1315268 & 688839 & 4.9 & 4.901 & TRN \\
\hline CHEMBL1438439 & 688839 & 4.6 & 5.0977 & TRN \\
\hline CHEMBL38576 & 688839 & 5.2 & 5.2138 & TRN \\
\hline CHEMBL1371604 & 688839 & 5.6 & 5.4943 & TRN \\
\hline CHEMBL1486915 & 688839 & 5.4 & 5.5179 & TRN \\
\hline CHEMBL1555153 & 688839 & 5.7 & 5.2098 & TST \\
\hline CHEMBL1475241 & 688839 & 4.7 & 4.6682 & TRN \\
\hline CHEMBL1436935 & 688839 & 4.5 & 4.7027 & TRN \\
\hline CHEMBL1256839 & 688839 & 6.0 & 5.8591 & TRN \\
\hline CHEMBL1361513 & 688839 & 4.9 & 4.9174 & TRN \\
\hline CHEMBL1474578 & 688839 & 4.9 & 4.8349 & TRN \\
\hline CHEMBL169233 & 688839 & 4.9 & 4.9352 & TST \\
\hline CHEMBL1591992 & 688839 & 4.8 & 4.8433 & TRN \\
\hline CHEMBL1604074 & 688839 & 5.0 & 5.1412 & TST \\
\hline CHEMBL 309490 & 688839 & 4.8 & 5.4688 & TRN \\
\hline CHEMBL1317603 & 688839 & 5.4 & 5.1512 & TRN \\
\hline CHEMBL1396583 & 688839 & 5.3 & 5.0925 & TRN \\
\hline CHEMBL1435908 & 688839 & 6.0 & 6.0265 & TRN \\
\hline CHEMBL1528531 & 688839 & 6.1 & 5.0348 & TST \\
\hline CHEMBL1443741 & 688839 & 4.6 & 4.6907 & TRN \\
\hline CHEMBL1371458 & 688839 & 5.1 & 4.949 & TRN \\
\hline CHEMBL1480350 & 688839 & 4.8 & 4.8709 & TRN \\
\hline CHEMBL1408138 & 688839 & 6.2 & 5.9388 & TST \\
\hline CHEMBL1369796 & 688839 & 4.6 & 4.6761 & TRN \\
\hline CHEMBL 295316 & 688839 & 4.5 & 4.9755 & TRN \\
\hline CHEMBL1568854 & 688839 & 5.0 & 5.1122 & TRN \\
\hline CHEMBL1400612 & 688839 & 4.8 & 5.0319 & TST \\
\hline CHEMBL445102 & 688839 & 5.6 & 5.0882 & TRN \\
\hline CHEMBL1334321 & 688839 & 4.8 & 4.819 & TRN \\
\hline CHEMBL1554717 & 688839 & 5.6 & 5.4586 & TRN \\
\hline CHEMBL1417552 & 688839 & 4.9 & 5.0901 & TRN \\
\hline CHEMBL1323529 & 688839 & 4.4 & 4.8307 & TRN \\
\hline CHEMBL1316108 & 688839 & 4.6 & 4.6439 & TRN \\
\hline CHEMBL1591956 & 688839 & 5.6 & 5.7005 & TRN \\
\hline CHEMBL1474509 & 688839 & 5.1 & 5.0 & TRN \\
\hline CHEMBL1357553 & 688839 & 4.8 & 4.8184 & TRN \\
\hline CHEMBL1436386 & 688839 & 5.8 & 5.1072 & TST \\
\hline CHEMBL1535931 & 688839 & 4.8 & 4.8411 & TRN \\
\hline CHEMBL1332591 & 688839 & 5.8 & 5.7966 & TRN \\
\hline CHEMBL1474272 & 688839 & 5.1 & 5.1868 & TRN \\
\hline CHEMBL1396109 & 688839 & 5.3 & 5.1816 & TRN \\
\hline CHEMBL1528565 & 688839 & 5.7 & 5.6011 & TST \\
\hline CHEMBL1554099 & 688839 & 5.4 & 5.4807 & TRN \\
\hline CHEMBL1314386 & 688839 & 4.9 & 4.8936 & TRN \\
\hline CHEMBL1397221 & 688839 & 4.5 & 4.7762 & TRN \\
\hline
\end{tabular}




\begin{tabular}{|c|c|c|c|c|c|}
\hline & & & & & \\
\hline CHEMBL1480806 & 688839 & 5.7 & 5.8198 & TRN & \\
\hline CHEMBL 243664 & 688839 & 6.0 & 5.5883 & TRN & \\
\hline CHEMBL1436976 & 688839 & 4.8 & 4.7967 & TRN & \\
\hline CHEMBL26915 & 688839 & 4.4 & 4.6171 & TST & \\
\hline CHEMBL97797 & 688839 & 4.5 & 4.9523 & TRN & \\
\hline CHEMBL1403464 & 688839 & 5.4 & 5.2033 & TRN & \\
\hline CHEMBL1402381 & 688839 & 5.0 & 5.1465 & TRN & \\
\hline CHEMBL1257075 & 688839 & 6.0 & 5.711 & TRN & \\
\hline CHEMBL1513149 & 688839 & 5.8 & 5.2016 & TST & \\
\hline CHEMBL1600998 & 688839 & 4.7 & 4.8564 & TRN & \\
\hline CHEMBL1395138 & 688839 & 6.0 & 5.0832 & TRN & \\
\hline CHEMBL1437804 & 688839 & 4.8 & 4.8874 & TST & \\
\hline CHEMBL1376212 & 688839 & 5.5 & 5.5362 & TRN & \\
\hline CHEMBL1316828 & 688839 & 4.5 & 4.7533 & TST & \\
\hline CHEMBL1256776 & 688839 & 5.5 & 5.4802 & TRN & \\
\hline CHEMBL606675 & 688839 & 4.5 & 4.9482 & TST & \\
\hline CHEMBL1377727 & 688839 & 6.2 & 6.0731 & TRN & \\
\hline CHEMBL1411360 & 688839 & 6.0 & 5.8519 & TST & \\
\hline CHEMBL 3716478 & 688839 & 6.2 & 5.189 & TST & \\
\hline CHEMBL1512850 & 688839 & 4.6 & 4.6568 & TRN & \\
\hline CHEMBL1373326 & 688839 & 4.9 & 4.8597 & TRN & \\
\hline CHEMBL1601121 & 688839 & 5.6 & 5.5416 & TRN & \\
\hline CHEMBL1373464 & 688839 & 6.0 & 6.0602 & TRN & \\
\hline CHEMBL1316210 & 688839 & 4.6 & 4.73300 & 00000000005 & TRN \\
\hline CHEMBL1456454 & 688839 & 5.4 & 5.58 & TRN & \\
\hline CHEMBL1532186 & 688839 & 4.6 & 5.1085 & TRN & \\
\hline CHEMBL1395737 & 688839 & 4.6 & 4.7489 & TRN & \\
\hline CHEMBL453376 & 688839 & 5.6 & 5.3199 & TRN & \\
\hline CHEMBL1564178 & 688839 & 6.7001 & 5.3242 & TRN & \\
\hline CHEMBL1255867 & 688839 & 6.0 & 4.9025 & TRN & \\
\hline CHEMBL1601768 & 688839 & 4.4 & 5.24100 & 00000000005 & TRN \\
\hline CHEMBL1527332 & 688839 & 5.6 & 5.5002 & TRN & \\
\hline CHEMBL1613209 & 688839 & 6.1 & 4.9578 & TRN & \\
\hline CHEMBL 344127 & 688839 & 4.8 & 4.9693 & TRN & \\
\hline CHEMBL106265 & 688839 & 4.4 & 5.2697 & TST & \\
\hline CHEMBL1453240 & 688839 & 4.8 & 4.9749 & TST & \\
\hline CHEMBL1552227 & 688839 & 5.0 & 4.8767 & TRN & \\
\hline CHEMBL1557255 & 688839 & 4.8 & 5.0259 & TRN & \\
\hline CHEMBL1574924 & 688839 & 5.5 & 5.2019 & TRN & \\
\hline CHEMBL1316858 & 688839 & 5.6 & 5.13700 & 00000000005 & TST \\
\hline CHEMBL1317986 & 688839 & 5.3 & 5.2688 & TST & \\
\hline CHEMBL1511042 & 688839 & 5.7 & 5.4984 & TRN & \\
\hline CHEMBL1324493 & 688839 & 4.8 & 4.9176 & TST & \\
\hline CHEMBL1402088 & 688839 & 5.4 & 5.1603 & TRN & \\
\hline CHEMBL1269022 & 688839 & 5.6 & 5.5441 & TRN & \\
\hline CHEMBL1371285 & 688839 & 4.5 & 5.0294 & TST & \\
\hline CHEMBL1208903 & 688839 & 5.4 & 5.4588 & TRN & \\
\hline CHEMBL1395054 & 688839 & 5.0 & 5.0848 & TRN & \\
\hline
\end{tabular}




\begin{tabular}{|c|c|c|c|c|}
\hline \multicolumn{5}{|c|}{ Supplemental Table S2.txt } \\
\hline CHEMBL1396661 & 688839 & 5.6 & 5.4105 & TRN \\
\hline CHEMBL48278 & 688839 & 4.6 & 4.7555 & TRN \\
\hline CHEMBL13647 & 688839 & 6.0 & 5.7223 & TRN \\
\hline CHEMBL1331045 & 688839 & 5.6 & 5.1716 & TST \\
\hline CHEMBL429023 & 688839 & 6.0 & 4.7318 & TRN \\
\hline CHEMBL1473752 & 688839 & 4.7 & 4.6876 & TRN \\
\hline CHEMBL1450209 & 688839 & 5.2 & 5.1785 & TST \\
\hline CHEMBL1357247 & 688839 & 4.8 & 4.9072 & TST \\
\hline CHEMBL1395215 & 688839 & 5.6 & 5.1612 & TST \\
\hline CHEMBL1317344 & 688839 & 5.0 & 5.1252 & TRN \\
\hline CHEMBL1517425 & 688839 & 4.8 & 5.0997 & TST \\
\hline CHEMBL1316432 & 688839 & 5.4 & 5.0409 & TRN \\
\hline CHEMBL1373610 & 688839 & 5.7 & 5.7158 & TRN \\
\hline CHEMBL1317124 & 688839 & 5.1 & 5.1242 & TST \\
\hline CHEMBL1303139 & 688839 & 4.9 & 5.0339 & TRN \\
\hline CHEMBL419045 & 688839 & 4.8 & 5.1758 & TST \\
\hline CHEMBL1394258 & 688839 & 4.9 & 4.9492 & TRN \\
\hline CHEMBL1399561 & 688839 & 4.9 & 4.8429 & TRN \\
\hline CHEMBL1606199 & 688839 & 5.6 & 5.7496 & TRN \\
\hline CHEMBL1603186 & 688839 & 5.6 & 5.5152 & TRN \\
\hline CHEMBL1516107 & 688839 & 5.5 & 5.1052 & TRN \\
\hline CHEMBL1337108 & 688839 & 5.3 & 5.191 & TRN \\
\hline CHEMBL75967 & 688839 & 5.6 & 4.8641 & TRN \\
\hline CHEMBL1572770 & 688839 & 5.5 & 5.3622 & TST \\
\hline CHEMBL1330396 & 688839 & 4.7 & 4.7587 & TRN \\
\hline CHEMBL1369013 & 688839 & 5.1 & 4.9362 & TRN \\
\hline CHEMBL1600586 & 688839 & 5.3 & 5.3459 & TRN \\
\hline CHEMBL1325197 & 688839 & 5.6 & 5.2489 & TRN \\
\hline CHEMBL1357067 & 688839 & 5.0 & 5.251 & TRN \\
\hline CHEMBL1591677 & 688839 & 5.5 & 5.4145 & TRN \\
\hline CHEMBL1448728 & 688839 & 4.9 & 4.8378 & TRN \\
\hline CHEMBL1448490 & 688839 & 6.0 & 5.13 & TRN \\
\hline CHEMBL1571785 & 688839 & 6.1 & 5.1362 & TRN \\
\hline CHEMBL1418420 & 688839 & 5.4 & 5.3836 & TRN \\
\hline CHEMBL168461 & 688839 & 6.7001 & 6.1856 & TST \\
\hline CHEMBL1512708 & 688839 & 5.8 & 6.0116 & TRN \\
\hline CHEMBL1395038 & 688839 & 4.7 & 5.0834 & TRN \\
\hline CHEMBL1320565 & 688839 & 5.1 & 5.0125 & TRN \\
\hline CHEMBL1364243 & 688839 & 6.0 & 6.0742 & TRN \\
\hline CHEMBL1487898 & 688839 & 5.0 & 5.1054 & TRN \\
\hline CHEMBL1529478 & 688839 & 5.4 & 5.3491 & TRN \\
\hline CHEMBL1551749 & 688839 & 4.5 & 4.5441 & TRN \\
\hline CHEMBL1433687 & 688839 & 5.1 & 5.1477 & TRN \\
\hline CHEMBL1335961 & 688839 & 5.9 & 5.0688 & TRN \\
\hline CHEMBL1395523 & 688839 & 6.0 & 6.0374 & TRN \\
\hline CHEMBL1369374 & 688839 & 5.5 & 5.3863 & TST \\
\hline CHEMBL1553185 & 688839 & 6.1 & 6.0472 & TRN \\
\hline CHEMBL1256873 & 688839 & 4.9 & 4.9631 & TST \\
\hline
\end{tabular}




\begin{tabular}{|c|c|c|c|c|c|}
\hline \multirow[b]{2}{*}{ CHEMBL1319049 } & \multirow[b]{2}{*}{688839} & \\
\hline & & 6.0 & 6.0667 & TRN & \\
\hline CHEMBL1517965 & 688839 & 5.5 & 5.0822 & TST & \\
\hline CHEMBL1613534 & 688839 & 5.1 & 5.1512 & TRN & \\
\hline CHEMBL420060 & 688839 & 4.7 & 4.8036 & TRN & \\
\hline CHEMBL1568520 & 688839 & 4.9 & 5.0424 & TRN & \\
\hline CHEMBL1434535 & 688839 & 5.1 & 5.3393 & TRN & \\
\hline CHEMBL1592352 & 688839 & 5.0 & 5.1709 & TST & \\
\hline CHEMBL1476159 & 688839 & 5.5 & 5.5021 & TRN & \\
\hline CHEMBL227725 & 688839 & 5.7 & 5.5871 & TST & \\
\hline CHEMBL1400637 & 688839 & 5.1 & 5.0508 & TRN & \\
\hline CHEMBL1317946 & 688839 & 4.6 & 5.1661 & TRN & \\
\hline CHEMBL39317 & 688839 & 4.8 & 4.8909 & TRN & \\
\hline CHEMBL1356439 & 688839 & 5.2 & 5.3003 & TRN & \\
\hline CHEMBL1714574 & 688839 & 5.8 & 5.7038 & TST & \\
\hline CHEMBL1482582 & 688839 & 4.8 & 4.7964 & TRN & \\
\hline CHEMBL1529205 & 688839 & 5.4 & 5.2039 & TRN & \\
\hline CHEMBL313244 & 688839 & 4.8 & 5.0401 & TRN & \\
\hline CHEMBL1316092 & 688839 & 5.4 & 5.2507 & TST & \\
\hline CHEMBL1512023 & 688839 & 4.8 & 4.8266 & TRN & \\
\hline CHEMBL1593645 & 688839 & 5.4 & 5.6074 & TRN & \\
\hline CHEMBL1414185 & 688839 & 6.5 & $6.2810 e$ & 2000000001 & TST \\
\hline CHEMBL608109 & 688839 & 5.5 & 5.4746 & TRN & \\
\hline CHEMBL1565373 & 688839 & 4.9 & 5.2672 & TRN & \\
\hline CHEMBL1476430 & 688839 & 5.3 & $5.4170 e$ & 0000000001 & TRN \\
\hline CHEMBL1326815 & 688839 & 5.5 & 5.5036 & TRN & \\
\hline CHEMBL1356777 & 688839 & 4.5 & 4.7152 & TST & \\
\hline CHEMBL1484253 & 688839 & 4.5 & 4.6171 & TRN & \\
\hline CHEMBL1372363 & 688839 & 4.8 & 4.819 & TRN & \\
\hline CHEMBL1488918 & 688839 & 6.1 & 6.0508 & TRN & \\
\hline CHEMBL1397596 & 688839 & 4.9 & 4.9046 & TRN & \\
\hline CHEMBL87385 & 688839 & 4.9 & 5.0705 & TST & \\
\hline CHEMBL1449821 & 688839 & 4.9 & 4.9387 & TST & \\
\hline CHEMBL1315207 & 688839 & 4.6 & 4.8662 & TST & \\
\hline CHEMBL1570480 & 688839 & 5.2 & 5.1676 & TST & \\
\hline CHEMBL1551064 & 688839 & 5.3 & 5.3115 & TRN & \\
\hline CHEMBL1370467 & 688839 & 6.0 & 6.0629 & TRN & \\
\hline CHEMBL1593523 & 688839 & 5.7 & 5.3223 & TST & \\
\hline CHEMBL1445792 & 688839 & 6.0 & 5.1622 & TRN & \\
\hline CHEMBL1406485 & 688839 & 4.7 & 4.7838 & TRN & \\
\hline CHEMBL1371710 & 688839 & 5.2 & 5.1709 & TRN & \\
\hline CHEMBL1591893 & 688839 & 4.9 & 5.1255 & TRN & \\
\hline CHEMBL1476831 & 688839 & 4.8 & 4.815 & TRN & \\
\hline CHEMBL268609 & 688839 & 6.0 & 5.8954 & TRN & \\
\hline CHEMBL1380212 & 688839 & 5.9 & 5.9469 & TRN & \\
\hline CHEMBL1318262 & 688839 & 4.7 & 4.7351 & TRN & \\
\hline CHEMBL1317056 & 688839 & 5.9 & 5.9407 & TRN & \\
\hline CHEMBL1408878 & 688839 & 5.1 & 5.0511 & TRN & \\
\hline CHEMBL1434220 & 688839 & 5.9 & 5.1647 & TST & \\
\hline & & & & 20347 & \\
\hline
\end{tabular}




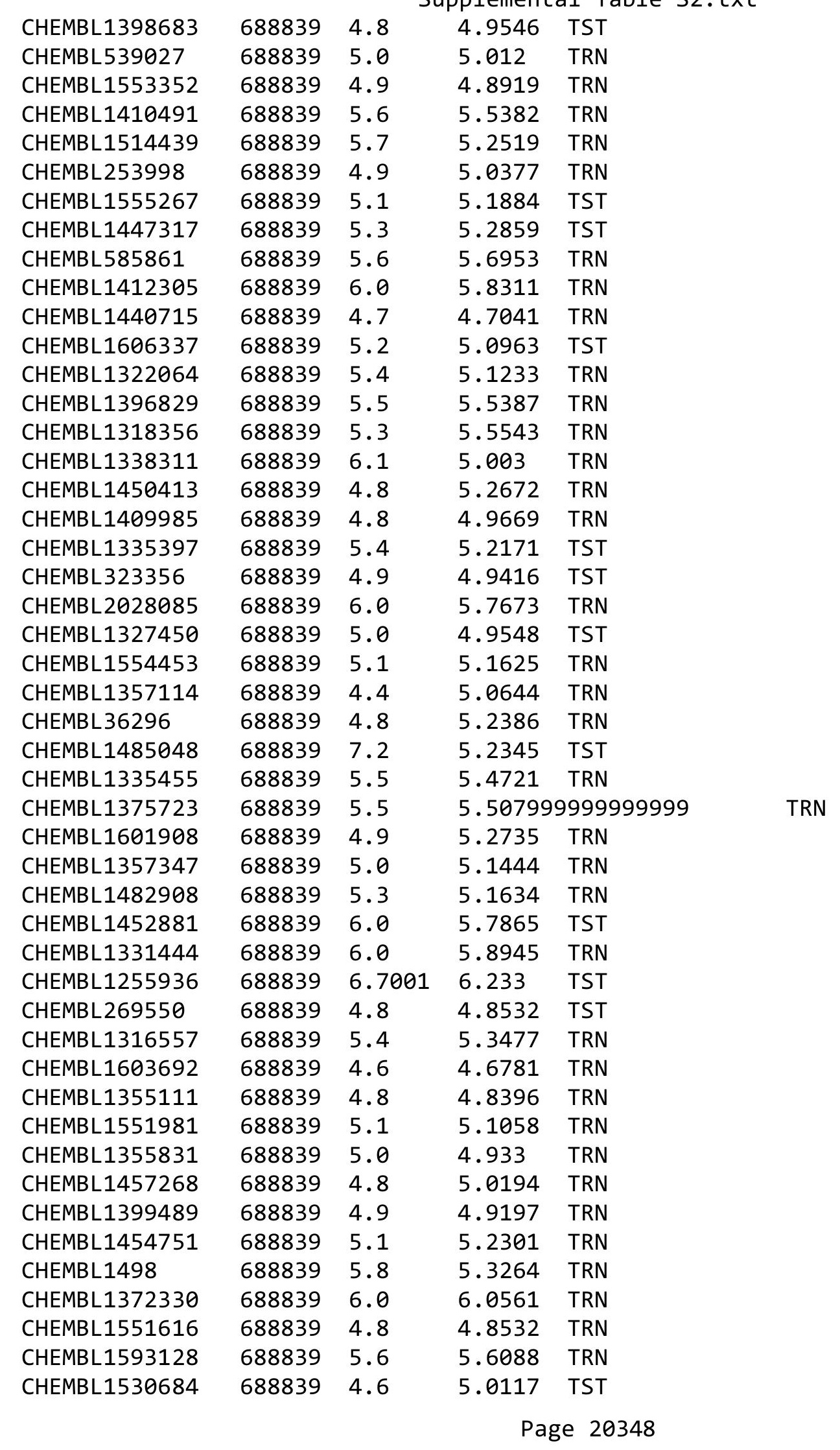




\begin{tabular}{|c|c|c|c|c|}
\hline \multicolumn{5}{|c|}{ Supplemental Table S2.txt } \\
\hline CHEMBL510539 & 688839 & 5.1 & 5.2167 & TRN \\
\hline CHEMBL1597209 & 688839 & 4.6 & 4.7349 & TRN \\
\hline CHEMBL66105 & 688839 & 6.0 & 5.734 & TST \\
\hline CHEMBL1522525 & 688839 & 4.5 & 5.1226 & TST \\
\hline CHEMBL1611192 & 688839 & 4.8 & 4.9137 & TST \\
\hline CHEMBL1355909 & 688839 & 4.6 & 4.6629 & TRN \\
\hline CHEMBL1357381 & 688839 & 5.9 & 4.8293 & TRN \\
\hline CHEMBL1314388 & 688839 & 6.0 & 6.0425 & TRN \\
\hline CHEMBL1180 & 688839 & 4.5 & 5.0164 & TST \\
\hline CHEMBL1436237 & 688839 & 5.4 & 5.4449 & TRN \\
\hline CHEMBL1414950 & 688839 & 4.7 & 5.0133 & TRN \\
\hline CHEMBL1323524 & 688839 & 4.9 & 4.7446 & TRN \\
\hline CHEMBL1515899 & 688839 & 6.0 & 5.9422 & TRN \\
\hline CHEMBL1443628 & 688839 & 5.5 & 5.441 & TRN \\
\hline CHEMBL565654 & 688839 & 5.1 & 5.1777 & TRN \\
\hline CHEMBL1314799 & 688839 & 5.6 & 5.5147 & TRN \\
\hline CHEMBL1316292 & 688839 & 4.9 & 5.1343 & TRN \\
\hline CHEMBL1590341 & 688839 & 4.6 & 4.7315 & TRN \\
\hline CHEMBL30024 & 688839 & 4.8 & 4.8748 & TST \\
\hline CHEMBL1402656 & 688839 & 5.0 & 4.9505 & TST \\
\hline CHEMBL1551066 & 688839 & 4.6 & 4.6823 & TRN \\
\hline CHEMBL 2374020 & 688839 & 4.7 & 5.1479 & TST \\
\hline CHEMBL1591714 & 688839 & 6.0 & 5.4803 & TRN \\
\hline CHEMBL60518 & 688839 & 4.4 & 4.5857 & TRN \\
\hline CHEMBL1369212 & 688839 & 6.0 & 6.0574 & TRN \\
\hline CHEMBL1319251 & 688839 & 5.4 & 5.1675 & TST \\
\hline CHEMBL1457622 & 688839 & 6.1 & 5.8673 & TRN \\
\hline CHEMBL595227 & 688839 & 4.6 & 5.0491 & TST \\
\hline CHEMBL1555392 & 688839 & 4.6 & 4.6895 & TRN \\
\hline CHEMBL1612050 & 688839 & 5.5 & 5.528 & TRN \\
\hline CHEMBL1256666 & 688839 & 5.0 & 5.0026 & TRN \\
\hline CHEMBL1566571 & 688839 & 5.0 & 4.9919 & TRN \\
\hline CHEMBL1376200 & 688839 & 4.7 & 5.0682 & TRN \\
\hline CHEMBL1473760 & 688839 & 5.2 & 5.224 & TRN \\
\hline CHEMBL1451562 & 688839 & 5.4 & 5.5492 & TRN \\
\hline CHEMBL1436540 & 688839 & 4.8 & 4.8342 & TRN \\
\hline CHEMBL1415185 & 688839 & 4.7 & 4.9745 & TRN \\
\hline CHEMBL98572 & 688839 & 4.9 & 5.1089 & TST \\
\hline CHEMBL1454512 & 688839 & 5.5 & 5.2817 & TRN \\
\hline CHEMBL1429478 & 688839 & 5.6 & 5.1874 & TRN \\
\hline CHEMBL 2374045 & 688839 & 5.5 & 5.1846 & TRN \\
\hline CHEMBL45176 & 688839 & 5.5 & 5.1201 & TRN \\
\hline CHEMBL1475366 & 688839 & 5.9 & 5.8955 & TRN \\
\hline CHEMBL1439400 & 688839 & 6.0 & 5.1203 & TRN \\
\hline CHEMBL1452080 & 688839 & 4.9 & 5.0939 & TRN \\
\hline CHEMBL1606591 & 688839 & 4.9 & 4.8582 & TRN \\
\hline CHEMBL1551979 & 688839 & 4.8 & 4.8667 & TRN \\
\hline CHEMBL1483693 & 688839 & 6.0 & 6.0439 & TRN \\
\hline
\end{tabular}




\begin{tabular}{|c|c|c|c|c|c|}
\hline \\
\hline CHEMBL467085 & 688839 & 4.5 & 4.6502 & TST & \\
\hline CHEMBL1417771 & 688839 & 6.3 & 6.4032 & TRN & \\
\hline CHEMBL289277 & 688839 & 5.0 & 5.0885 & TRN & \\
\hline CHEMBL1512478 & 688839 & 5.4 & $5.1270 e$ & 0000000001 & TRN \\
\hline CHEMBL1446743 & 688839 & 5.1 & 5.1627 & TST & \\
\hline CHEMBL1335889 & 688839 & 4.6 & 4.8045 & TRN & \\
\hline CHEMBL1435028 & 688839 & 4.9 & 4.9313 & TRN & \\
\hline CHEMBL1568575 & 688839 & 4.7 & 4.8524 & TRN & \\
\hline CHEMBL1361731 & 688839 & 4.9 & 4.8807 & TRN & \\
\hline CHEMBL1321919 & 688839 & 6.4 & 5.4656 & TRN & \\
\hline CHEMBL1408427 & 688839 & 5.8 & 5.822 & TRN & \\
\hline CHEMBL1527565 & 688839 & 5.8 & 5.506 & TST & \\
\hline CHEMBL1403101 & 688839 & 5.3 & 5.232 & TRN & \\
\hline CHEMBL1514634 & 688839 & 4.6 & 5.0973 & TST & \\
\hline CHEMBL1476107 & 688839 & 5.5 & 4.9714 & TST & \\
\hline CHEMBL1590077 & 688839 & 6.0 & 6.0128 & TRN & \\
\hline CHEMBL1514129 & 688839 & 4.9 & 4.9972 & TRN & \\
\hline CHEMBL490913 & 688839 & 6.8 & 6.7756 & TRN & \\
\hline CHEMBL 281622 & 688839 & 4.8 & 4.8763 & TST & \\
\hline CHEMBL1411246 & 688839 & 4.6 & 4.9983 & TST & \\
\hline CHEMBL1478772 & 688839 & 4.7 & 4.7801 & TRN & \\
\hline CHEMBL1557272 & 688839 & 5.3 & 5.1299 & TRN & \\
\hline CHEMBL 313737 & 688839 & 5.3 & 5.3272 & TST & \\
\hline CHEMBL1590038 & 688839 & 5.1 & 5.1778 & TRN & \\
\hline CHEMBL1596756 & 688839 & 5.7 & 5.5896 & TRN & \\
\hline CHEMBL1410841 & 688839 & 5.3 & 5.3429 & TST & \\
\hline CHEMBL3194627 & 688839 & 5.5 & 5.5027 & TRN & \\
\hline CHEMBL 2110371 & 688839 & 5.1 & 5.0977 & TST & \\
\hline CHEMBL398363 & 688839 & 4.9 & 4.9281 & TRN & \\
\hline CHEMBL1485361 & 688839 & 5.5 & 5.6098 & TRN & \\
\hline CHEMBL1488197 & 688839 & 6.0 & 5.9703 & TRN & \\
\hline CHEMBL1357982 & 688839 & 5.7 & 5.8665 & TRN & \\
\hline CHEMBL1355293 & 688839 & 5.5 & $5.3260 e$ & 00000000005 & TST \\
\hline CHEMBL 297687 & 688839 & 5.0 & 5.188 & TRN & \\
\hline CHEMBL1332709 & 688839 & 5.9 & 5.2146 & TRN & \\
\hline CHEMBL1513740 & 688839 & 4.8 & 4.8914 & TRN & \\
\hline CHEMBL1524211 & 688839 & 4.9 & 4.8934 & TRN & \\
\hline CHEMBL1316629 & 688839 & 5.4 & 5.2536 & TST & \\
\hline CHEMBL1456312 & 688839 & 5.1 & 5.0992 & TST & \\
\hline CHEMBL1408445 & 688839 & 4.8 & 5.2067 & TRN & \\
\hline CHEMBL1332518 & 688839 & 4.6 & 5.062 & TST & \\
\hline CHEMBL1400667 & 688839 & 5.1 & 5.0748 & TST & \\
\hline CHEMBL1374696 & 688839 & 4.8 & 4.8597 & TRN & \\
\hline CHEMBL1568086 & 688839 & 5.3 & 5.3302 & TRN & \\
\hline CHEMBL1606369 & 688839 & 5.0 & 5.0328 & TRN & \\
\hline CHEMBL1405187 & 688839 & 5.4 & 5.2387 & TST & \\
\hline CHEMBL1574106 & 688839 & 6.3 & 6.3848 & TRN & \\
\hline CHEMBL1358161 & 688839 & 4.8 & 4.984 & TRN & \\
\hline
\end{tabular}




\begin{tabular}{|c|c|c|c|c|c|}
\hline \multicolumn{6}{|c|}{ Supplemental Table S2.txt } \\
\hline CHEMBL275260 & 688839 & 4.6 & 4.9043 & TRN & \\
\hline CHEMBL1256667 & 688839 & 5.5 & 5.3984 & TST & \\
\hline CHEMBL510275 & 688839 & 4.7 & 5.117 & TST & \\
\hline CHEMBL1455670 & 688839 & 5.4 & 5.4072 & TRN & \\
\hline CHEMBL1417646 & 688839 & 6.7001 & 6.6314 & TRN & \\
\hline CHEMBL520107 & 688839 & 5.5 & 5.3682 & TST & \\
\hline CHEMBL1603627 & 688839 & 4.7 & 4.7635 & TRN & \\
\hline CHEMBL1336469 & 688839 & 5.0 & 5.0323 & TRN & \\
\hline CHEMBL56331 & 688839 & 4.8 & 4.9249 & TRN & \\
\hline CHEMBL1317931 & 688839 & 6.0 & 5.2011 & TST & \\
\hline CHEMBL1435032 & 688839 & 5.9 & 5.8894 & TRN & \\
\hline CHEMBL1437226 & 688839 & 5.9 & 5.9192 & TRN & \\
\hline CHEMBL1439262 & 688839 & 4.6 & 4.9931 & TRN & \\
\hline CHEMBL1600325 & 688839 & 5.7 & 5.1704 & TST & \\
\hline CHEMBL 252722 & 688839 & 4.6 & 5.5056 & TRN & \\
\hline CHEMBL1417789 & 688839 & 5.4 & 5.4308 & TRN & \\
\hline CHEMBL1513876 & 688839 & 5.2 & 5.045 & TRN & \\
\hline CHEMBL1365712 & 688839 & 5.4 & 5.3284 & TRN & \\
\hline CHEMBL1490139 & 688839 & 5.0 & 4.9849 & TRN & \\
\hline CHEMBL1554745 & 688839 & 5.6 & 5.7224 & TRN & \\
\hline CHEMBL1512434 & 688839 & 6.0 & 6.0313 & TRN & \\
\hline CHEMBL1496243 & 688839 & 4.7 & 4.6569 & TRN & \\
\hline CHEMBL1611806 & 688839 & 5.3 & 5.1829 & TRN & \\
\hline CHEMBL 228132 & 688839 & 5.5 & 5.1056 & TRN & \\
\hline CHEMBL1489769 & 688839 & 6.0 & 5.1298 & TST & \\
\hline CHEMBL1407035 & 688839 & 5.1 & 5.0898 & TRN & \\
\hline CHEMBL1484944 & 688839 & 4.9 & 4.9147 & TRN & \\
\hline CHEMBL1552172 & 688839 & 5.5 & 5.562 & TRN & \\
\hline CHEMBL1472900 & 688839 & 4.6 & 4.6633 & TRN & \\
\hline CHEMBL1516103 & 688839 & 5.4 & 5.2059 & TRN & \\
\hline CHEMBL399705 & 688839 & 4.9 & 4.9648 & TST & \\
\hline CHEMBL1511998 & 688839 & 6.0 & 5.8742 & TST & \\
\hline CHEMBL1554411 & 688839 & 5.5 & 5.4259 & TRN & \\
\hline CHEMBL1554465 & 688839 & 5.4 & $5.2570 e$ & 0000000001 & TRN \\
\hline CHEMBL1434334 & 688839 & 6.0 & 5.2497 & TRN & \\
\hline CHEMBL490577 & 688839 & 5.5 & 5.5457 & TRN & \\
\hline CHEMBL1358738 & 688839 & 5.5 & 5.3953 & TRN & \\
\hline CHEMBL1535431 & 688839 & 4.9 & 4.9144 & TRN & \\
\hline CHEMBL1552442 & 688839 & 4.8 & 5.1814 & TRN & \\
\hline CHEMBL1433785 & 688839 & 4.5 & 4.672 & TRN & \\
\hline CHEMBL845 & 688839 & 5.3 & 5.225 & TRN & \\
\hline CHEMBL1356748 & 688839 & 5.6 & 5.2817 & TRN & \\
\hline CHEMBL1516068 & 688839 & 6.0 & 4.9374 & TRN & \\
\hline CHEMBL1466168 & 688839 & 4.5 & 4.9778 & TRN & \\
\hline CHEMBL1450327 & 688839 & 5.0 & 5.0599 & TRN & \\
\hline CHEMBL1395137 & 688839 & 4.9 & 4.8233 & TRN & \\
\hline CHEMBL1487070 & 688839 & 5.6 & 5.7182 & TRN & \\
\hline CHEMBL1519649 & 688839 & 6.3 & 6.0505 & TRN & \\
\hline
\end{tabular}




\begin{tabular}{|c|c|c|c|c|}
\hline & & & pplement & al $\mathrm{Ta}$ \\
\hline CHEMBL1562088 & 688839 & 5.3 & 5.2877 & TST \\
\hline CHEMBL492610 & 688839 & 5.6 & 5.4858 & TRN \\
\hline CHEMBL1342932 & 688839 & 5.5 & 5.5065 & TRN \\
\hline CHEMBL1517051 & 688839 & 4.6 & 4.6799 & TRN \\
\hline CHEMBL17127 & 688839 & 4.5 & 5.0649 & TST \\
\hline CHEMBL1408954 & 688839 & 5.6 & 5.4481 & TST \\
\hline CHEMBL1329889 & 688839 & 5.1 & 5.1269 & TRN \\
\hline CHEMBL1487503 & 688839 & 5.4 & 5.4133 & TST \\
\hline CHEMBL1327881 & 688839 & 5.0 & 4.9849 & TRN \\
\hline CHEMBL1516007 & 688839 & 4.7 & 4.9934 & TRN \\
\hline CHEMBL1451071 & 688839 & 5.4 & 5.4631 & TRN \\
\hline CHEMBL1315374 & 688839 & 5.5 & 5.1322 & TST \\
\hline CHEMBL1593219 & 688839 & 5.0 & 4.9694 & TRN \\
\hline CHEMBL67311 & 688839 & 5.3 & 5.2529 & TST \\
\hline CHEMBL1436661 & 688839 & 5.0 & 4.9795 & TRN \\
\hline CHEMBL1514910 & 688839 & 4.6 & 5.2526 & TST \\
\hline CHEMBL1452850 & 688839 & 5.4 & 5.5126 & TRN \\
\hline CHEMBL1358586 & 688839 & 4.8 & 4.8041 & TRN \\
\hline CHEMBL1396822 & 688839 & 5.5 & 5.4285 & TST \\
\hline CHEMBL34155 & 688839 & 5.7 & 5.0027 & TST \\
\hline CHEMBL1362225 & 688839 & 4.9 & 4.9867 & TRN \\
\hline CHEMBL1378237 & 688839 & 5.9 & 5.935 & TRN \\
\hline CHEMBL1496350 & 688839 & 6.0 & 5.7723 & TRN \\
\hline CHEMBL1554680 & 688839 & 5.7 & 5.2426 & TRN \\
\hline CHEMBL1515024 & 688839 & 4.8 & 4.8072 & TRN \\
\hline CHEMBL1452158 & 688839 & 4.6 & 5.2093 & TRN \\
\hline CHEMBL1590397 & 688839 & 5.5 & 5.5427 & TRN \\
\hline CHEMBL1527923 & 688839 & 5.7 & 5.5695 & TRN \\
\hline CHEMBL1590213 & 688839 & 5.4 & 5.2707 & TRN \\
\hline CHEMBL1256775 & 688839 & 4.4 & 4.6034 & TRN \\
\hline CHEMBL1493117 & 688839 & 5.4 & 5.3643 & TST \\
\hline CHEMBL1489016 & 688839 & 4.5 & 4.6482 & TRN \\
\hline CHEMBL453019 & 688839 & 4.6 & 5.5166 & TRN \\
\hline CHEMBL1434146 & 688839 & 5.4 & 5.5153 & TRN \\
\hline CHEMBL1357796 & 688839 & 5.0 & 5.4907 & TST \\
\hline CHEMBL 244743 & 688839 & 4.9 & 4.9341 & TRN \\
\hline CHEMBL1486924 & 688839 & 5.6 & 5.1159 & TRN \\
\hline CHEMBL1332937 & 688839 & 5.7 & 5.7639 & TRN \\
\hline CHEMBL1516514 & 688839 & 5.4 & 5.1725 & TRN \\
\hline CHEMBL1356690 & 688839 & 4.6 & 4.6284 & TRN \\
\hline CHEMBL450288 & 688839 & 4.6 & 5.0564 & TRN \\
\hline CHEMBL1589879 & 688839 & 5.2 & 5.3274 & TRN \\
\hline CHEMBL2373286 & 688839 & 6.0 & 5.8299 & TST \\
\hline CHEMBL1439183 & 688839 & 4.8 & 4.9134 & TRN \\
\hline CHEMBL141690 & 688839 & 4.9 & 5.0406 & TRN \\
\hline CHEMBL1527443 & 688839 & 5.7 & 5.7926 & TRN \\
\hline CHEMBL1338985 & 688839 & 5.1 & 5.1265 & TRN \\
\hline CHEMBL1565578 & 688839 & 4.8 & 4.8101 & TRN \\
\hline
\end{tabular}




\begin{tabular}{|c|c|c|c|c|c|}
\hline \multirow{3}{*}{$\begin{array}{l}\text { CHEMBL1433886 } \\
\text { CHEMBL1371698 }\end{array}$} & \multirow{3}{*}{$\begin{array}{l}688839 \\
688839\end{array}$} & \multicolumn{4}{|c|}{ Supplemental Table S2.txt } \\
\hline & & 5.4 & \multicolumn{2}{|c|}{5.4239999999999995} & TRN \\
\hline & & 6.0 & 5.9811 & TRN & \\
\hline CHEMBL1592327 & 688839 & 5.5 & 5.3688 & TRN & \\
\hline CHEMBL1394223 & 688839 & 4.8 & 4.8031 & TRN & \\
\hline CHEMBL1406851 & 688839 & 6.4 & 6.4382 & TRN & \\
\hline CHEMBL1551578 & 688839 & 5.6 & 5.3273 & TRN & \\
\hline CHEMBL1528170 & 688839 & 4.9 & 4.9022 & TRN & \\
\hline CHEMBL1455073 & 688839 & 5.4 & 5.2934 & TST & \\
\hline CHEMBL 2374040 & 688839 & 5.4 & 5.2707 & TRN & \\
\hline CHEMBL1591847 & 688839 & 4.8 & 4.8267 & TRN & \\
\hline CHEMBL1593853 & 688839 & 5.7 & 5.5337 & TRN & \\
\hline CHEMBL1370726 & 688839 & 5.5 & 5.3051 & TST & \\
\hline CHEMBL1400309 & 688839 & 5.3 & 5.2112 & TRN & \\
\hline CHEMBL1488771 & 688839 & 5.4 & 5.3638 & TST & \\
\hline CHEMBL1437002 & 688839 & 5.4 & 5.2611 & TST & \\
\hline CHEMBL45068 & 688839 & 6.0 & 5.0533 & TRN & \\
\hline CHEMBL1489359 & 688839 & 5.3 & 5.1739 & TRN & \\
\hline CHEMBL1553555 & 688839 & 5.7 & 5.0973 & TRN & \\
\hline CHEMBL1456346 & 688839 & 4.9 & 5.005 & TST & \\
\hline CHEMBL1488329 & 688839 & 4.7 & 5.1013 & TRN & \\
\hline CHEMBL1532720 & 688839 & 4.9 & 4.887 & TRN & \\
\hline CHEMBL1357735 & 688839 & 5.3 & 4.9655 & TST & \\
\hline CHEMBL1439788 & 688839 & 4.8 & 4.9858 & TRN & \\
\hline CHEMBL1321094 & 688839 & 4.9 & 4.8532 & TRN & \\
\hline CHEMBL1598994 & 688839 & 4.7 & 4.9106 & TRN & \\
\hline CHEMBL1530445 & 688839 & 5.5 & 5.4846 & TRN & \\
\hline CHEMBL1448896 & 688839 & 5.3 & 5.1727 & TRN & \\
\hline CHEMBL1406078 & 688839 & 4.9 & 4.8118 & TRN & \\
\hline CHEMBL1355881 & 688839 & 4.5 & 4.5859 & TRN & \\
\hline CHEMBL1567183 & 688839 & 4.6 & 4.7109 & TRN & \\
\hline CHEMBL1441415 & 688839 & 5.1 & 5.2822 & TRN & \\
\hline CHEMBL1356060 & 688839 & 6.1 & 6.2351 & TRN & \\
\hline CHEMBL1256654 & 688839 & 6.0 & 5.6717 & TST & \\
\hline CHEMBL76904 & 688839 & 4.5 & 4.6781 & TRN & \\
\hline CHEMBL1396142 & 688839 & 4.8 & 4.8403 & TRN & \\
\hline CHEMBL1306920 & 688839 & 6.0 & 5.2147 & TRN & \\
\hline CHEMBL544115 & 688839 & 4.8 & 5.0701 & TRN & \\
\hline CHEMBL457583 & 688839 & 4.6 & 5.0663 & TRN & \\
\hline CHEMBL1473171 & 688839 & 5.6 & 5.3154 & TST & \\
\hline CHEMBL491978 & 688839 & 6.3 & 6.3209 & TRN & \\
\hline CHEMBL1256693 & 688839 & 5.1 & 5.1047 & TST & \\
\hline CHEMBL1476449 & 688839 & 4.9 & 5.1153 & TRN & \\
\hline CHEMBL260283 & 688839 & 5.0 & 5.0602 & TRN & \\
\hline CHEMBL1608337 & 688839 & 5.4 & 5.3931 & TRN & \\
\hline CHEMBL1608975 & 688839 & 5.4 & 5.3349 & TRN & \\
\hline CHEMBL1437013 & 688839 & 5.0 & 5.1295 & TRN & \\
\hline CHEMBL63102 & 688839 & 4.4 & 4.6466 & TST & \\
\hline CHEMBL1332182 & 688839 & 6.2 & 5.896 & TST & \\
\hline
\end{tabular}




\begin{tabular}{|c|c|c|c|c|}
\hline & & & ient & al Ta \\
\hline CHEMBL1378691 & 688839 & 5.1 & 5.0269 & TRN \\
\hline CHEMBL1434390 & 688839 & 5.2 & 5.2099 & TST \\
\hline CHEMBL1558303 & 688839 & 5.0 & 4.9038 & TRN \\
\hline CHEMBL1356256 & 688839 & 4.9 & 4.9977 & TRN \\
\hline CHEMBL1316491 & 688839 & 4.8 & 4.8372 & TRN \\
\hline CHEMBL1524331 & 688839 & 5.8 & 5.6517 & TRN \\
\hline CHEMBL1456785 & 688839 & 5.4 & 5.2032 & TST \\
\hline CHEMBL1486459 & 688839 & 5.6 & 5.2528 & TRN \\
\hline CHEMBL1330057 & 688839 & 5.5 & 5.4213 & TST \\
\hline CHEMBL 274189 & 688839 & 4.4 & 5.1099 & TST \\
\hline CHEMBL1314808 & 688839 & 5.0 & 5.4499 & TRN \\
\hline CHEMBL1318419 & 688839 & 5.4 & 5.1162 & TRN \\
\hline CHEMBL1369822 & 688839 & 6.0 & 6.0041 & TRN \\
\hline CHEMBL1528479 & 688839 & 4.9 & 4.8969 & TRN \\
\hline CHEMBL1434817 & 688839 & 4.6 & 4.7383 & TRN \\
\hline CHEMBL1519225 & 688839 & 5.4 & 5.2911 & TRN \\
\hline CHEMBL1315716 & 688839 & 6.0 & 6.1084 & TRN \\
\hline CHEMBL1437007 & 688839 & 4.8 & 4.8162 & TRN \\
\hline CHEMBL1591592 & 688839 & 5.4 & 5.4499 & TRN \\
\hline CHEMBL1484995 & 688839 & 4.4 & 5.1739 & TRN \\
\hline CHEMBL1520681 & 688839 & 5.3 & 5.1768 & TRN \\
\hline CHEMBL192509 & 688839 & 5.2 & 5.1724 & TRN \\
\hline CHEMBL604119 & 688839 & 5.6 & 5.4649 & TST \\
\hline CHEMBL1449082 & 688839 & 4.7 & 4.7493 & TRN \\
\hline CHEMBL1490024 & 688839 & 4.9 & 4.89 & TRN \\
\hline CHEMBL1479727 & 688839 & 5.1 & 5.056 & TRN \\
\hline CHEMBL1355537 & 688839 & 4.9 & 4.9268 & TRN \\
\hline CHEMBL1316656 & 688839 & 5.4 & 5.3873 & TRN \\
\hline CHEMBL1394833 & 688839 & 4.7 & 4.7433 & TRN \\
\hline CHEMBL1553751 & 688839 & 5.1 & 5.3987 & TRN \\
\hline CHEMBL1517999 & 688839 & 4.8 & 4.8309 & TRN \\
\hline CHEMBL1369085 & 688839 & 5.2 & 5.1749 & TRN \\
\hline CHEMBL1438224 & 688839 & 4.6 & 5.2584 & TRN \\
\hline CHEMBL6291 & 688839 & 5.2 & 5.1618 & TST \\
\hline CHEMBL1416429 & 688839 & 5.5 & 5.3866 & TRN \\
\hline CHEMBL1566105 & 688839 & 5.3 & 5.2139 & TST \\
\hline CHEMBL 301707 & 688839 & 4.8 & 4.9001 & TRN \\
\hline CHEMBL1597612 & 688839 & 4.9 & 5.0084 & TRN \\
\hline CHEMBL1592117 & 688839 & 5.1 & 5.032 & TRN \\
\hline CHEMBL471728 & 688839 & 5.5 & 5.4672 & TST \\
\hline CHEMBL559612 & 688839 & 5.3 & 5.3133 & TST \\
\hline CHEMBL1418144 & 688839 & 5.4 & 5.1543 & TST \\
\hline CHEMBL1564802 & 688839 & 5.0 & 5.1418 & TRN \\
\hline CHEMBL1398425 & 688839 & 4.8 & 4.961 & TRN \\
\hline CHEMBL1356292 & 688839 & 5.4 & 5.3961 & TRN \\
\hline CHEMBL1554622 & 688839 & 5.5 & 5.4109 & TRN \\
\hline CHEMBL1447808 & 688839 & 4.8 & 5.1719 & TRN \\
\hline CHEMBL1332033 & 688839 & 4.6 & 4.6883 & TRN \\
\hline
\end{tabular}




\begin{tabular}{|c|c|c|c|c|}
\hline \multicolumn{5}{|c|}{ Supplemental Ta } \\
\hline CHEMBL1554725 & 688839 & 5.5 & 5.4951 & TRN \\
\hline CHEMBL1415728 & 688839 & 4.9 & 4.9475 & TRN \\
\hline CHEMBL1316628 & 688839 & 4.8 & 4.8954 & TRN \\
\hline CHEMBL1433762 & 688839 & 4.9 & 5.0205 & TRN \\
\hline CHEMBL1358807 & 688839 & 5.6 & 5.5371 & TRN \\
\hline CHEMBL1376723 & 688839 & 4.6 & 4.766 & TRN \\
\hline CHEMBL1142 & 688839 & 4.6 & 5.1773 & TRN \\
\hline CHEMBL1445522 & 688839 & 4.8 & 4.8942 & TRN \\
\hline CHEMBL1559279 & 688839 & 4.8 & 4.7303 & TRN \\
\hline CHEMBL1354913 & 688839 & 5.2 & 5.2146 & TST \\
\hline CHEMBL1493039 & 688839 & 5.5 & 5.4419 & TRN \\
\hline CHEMBL1561579 & 688839 & 5.5 & 5.4851 & TRN \\
\hline CHEMBL104255 & 688839 & 4.8 & 5.065 & TRN \\
\hline CHEMBL1561888 & 688839 & 4.9 & 4.8684 & TRN \\
\hline CHEMBL1331128 & 688839 & 4.6 & 4.878 & TRN \\
\hline CHEMBL1366061 & 688839 & 5.0 & 5.1588 & TRN \\
\hline CHEMBL400875 & 688839 & 5.3 & 5.3394 & TRN \\
\hline CHEMBL1357360 & 688839 & 5.4 & 5.3789 & TRN \\
\hline CHEMBL1368832 & 688839 & 5.5 & 5.1776 & TRN \\
\hline CHEMBL1321552 & 688839 & 7.3002 & 6.5562 & TST \\
\hline CHEMBL 245121 & 688839 & 4.9 & 5.2478 & TRN \\
\hline CHEMBL1515334 & 688839 & 6.0 & 5.7322 & TRN \\
\hline CHEMBL13662 & 688839 & 4.5 & 4.5982 & TST \\
\hline CHEMBL1315636 & 688839 & 5.4 & 5.4741 & TRN \\
\hline CHEMBL1491340 & 688839 & 6.0 & 5.7139 & TST \\
\hline CHEMBL1354388 & 688839 & 4.9 & 4.894 & TRN \\
\hline CHEMBL1359135 & 688839 & 4.7 & 5.2706 & TRN \\
\hline CHEMBL1452413 & 688839 & 5.1 & 5.087 & TRN \\
\hline CHEMBL1359917 & 688839 & 6.7001 & 6.5314 & TRN \\
\hline CHEMBL 1600520 & 688839 & 5.5 & 5.1751 & TRN \\
\hline CHEMBL1474816 & 688839 & 5.0 & 4.8932 & TRN \\
\hline CHEMBL1318544 & 688839 & 5.6 & 5.7947 & TRN \\
\hline CHEMBL1574231 & 688839 & 5.3 & 5.4225 & TRN \\
\hline CHEMBL1558620 & 688839 & 5.1 & 5.0467 & TRN \\
\hline CHEMBL310396 & 688839 & 4.5 & 4.9012 & TRN \\
\hline CHEMBL1437442 & 688839 & 5.4 & 5.3601 & TRN \\
\hline CHEMBL1378659 & 688839 & 4.5 & 4.6327 & TRN \\
\hline CHEMBL1356744 & 688839 & 6.5 & 6.3369 & TRN \\
\hline CHEMBL1612590 & 688839 & 5.4 & 5.1259 & TST \\
\hline CHEMBL1565867 & 688839 & 5.6 & 5.1841 & TRN \\
\hline CHEMBL1417135 & 688839 & 4.8 & 4.8593 & TRN \\
\hline CHEMBL1314505 & 688839 & 5.0 & 4.999 & TRN \\
\hline CHEMBL1474230 & 688839 & 5.5 & 5.0786 & TST \\
\hline CHEMBL370761 & 688839 & 4.8 & 5.2821 & TST \\
\hline CHEMBL 1405649 & 688839 & 5.3 & 5.0759 & TRN \\
\hline CHEMBL1600973 & 688839 & 4.8 & 4.7542 & TRN \\
\hline CHEMBL88272 & 688839 & 4.8 & 4.8735 & TST \\
\hline CHEMBL1397079 & 688839 & 4.6 & 4.6756 & TRN \\
\hline
\end{tabular}




\begin{tabular}{|c|c|c|c|c|c|}
\hline & & & & & \\
\hline CHEMBL1514517 & 688839 & 5.0 & 4.982 & TRN & \\
\hline CHEMBL1407670 & 688839 & 4.8 & 4.8535 & TRN & \\
\hline CHEMBL1566017 & 688839 & 5.1 & 5.2733 & TRN & \\
\hline CHEMBL1476206 & 688839 & 5.8 & 5.9374 & TRN & \\
\hline CHEMBL498770 & 688839 & 6.1 & 5.9359 & TST & \\
\hline CHEMBL235658 & 688839 & 4.5 & 5.1426 & TRN & \\
\hline CHEMBL1376253 & 688839 & 5.1 & 5.0496 & TRN & \\
\hline CHEMBL1551308 & 688839 & 4.8 & 4.8305 & TRN & \\
\hline CHEMBL1571692 & 688839 & 6.0 & 5.7122 & TST & \\
\hline CHEMBL1557234 & 688839 & 5.1 & 5.119 & TRN & \\
\hline CHEMBL1316779 & 688839 & 5.7 & 5.6419 & TRN & \\
\hline CHEMBL486817 & 688839 & 4.4 & 5.1421 & TST & \\
\hline CHEMBL326967 & 688839 & 4.6 & 4.7474 & TST & \\
\hline CHEMBL1479741 & 688839 & 4.9 & 4.9693 & TRN & \\
\hline CHEMBL1436024 & 688839 & 4.6 & 4.7117 & TRN & \\
\hline CHEMBL1558135 & 688839 & 4.8 & 4.8991 & TRN & \\
\hline CHEMBL1323768 & 688839 & 4.5 & 5.1781 & TST & \\
\hline CHEMBL1499545 & 688839 & 4.9 & 4.8748 & TST & \\
\hline CHEMBL1449782 & 688839 & 5.5 & 5.2728 & TST & \\
\hline CHEMBL1601824 & 688839 & 7.8013 & 5.1929 & TRN & \\
\hline CHEMBL1515341 & 688839 & 5.4 & 5.3173 & TRN & \\
\hline CHEMBL1512817 & 688839 & 4.9 & 5.0363 & TRN & \\
\hline CHEMBL3392051 & 688839 & 5.4 & 5.2935 & TRN & \\
\hline CHEMBL3212919 & 688839 & 5.2 & 5.2765 & TRN & \\
\hline CHEMBL1526455 & 688839 & 4.6 & 5.0836 & TRN & \\
\hline CHEMBL190259 & 688839 & 6.0 & 5.0798 & TRN & \\
\hline CHEMBL1395252 & 688839 & 4.8 & 4.8853 & TRN & \\
\hline CHEMBL1364404 & 688839 & 5.2 & 5.1356 & TST & \\
\hline CHEMBL1477506 & 688839 & 5.5 & 5.4445 & TST & \\
\hline CHEMBL1484006 & 688839 & 6.0 & 6.0857 & TRN & \\
\hline CHEMBL1256625 & 688839 & 4.6 & 4.7209 & TRN & \\
\hline CHEMBL1512722 & 688839 & 5.1 & 5.0286 & TRN & \\
\hline CHEMBL1316470 & 688839 & 4.7 & 4.9761 & TRN & \\
\hline CHEMBL1560541 & 688839 & 4.5 & 4.9691 & TRN & \\
\hline CHEMBL575073 & 688839 & 4.6 & 4.9276 & TRN & \\
\hline CHEMBL1590378 & 688839 & 4.6 & 4.7911 & TST & \\
\hline CHEMBL1358467 & 688839 & 5.6 & 5.1259 & TRN & \\
\hline CHEMBL1535074 & 688839 & 4.8 & 5.0163 & TRN & \\
\hline CHEMBL1357930 & 688839 & 6.0 & 5.0411 & TST & \\
\hline CHEMBL1394855 & 688839 & 5.4 & 5.46399 & 99999999995 & TRN \\
\hline CHEMBL1603852 & 688839 & 6.4 & 6.2802 & TRN & \\
\hline CHEMBL1356318 & 688839 & 5.5 & 5.1778 & TST & \\
\hline CHEMBL565856 & 688839 & 5.7 & 5.8303 & TRN & \\
\hline CHEMBL1407887 & 688839 & 5.4 & 5.21899 & 9999999999 & TST \\
\hline CHEMBL1448668 & 688839 & 5.7 & 5.6509 & TRN & \\
\hline CHEMBL1421016 & 688839 & 4.8 & 4.9154 & TST & \\
\hline CHEMBL580421 & 688839 & 4.5 & 4.6672 & TST & \\
\hline CHEMBL1594086 & 688839 & 5.0 & 5.0303 & TRN & \\
\hline & & & & 20356 & \\
\hline
\end{tabular}




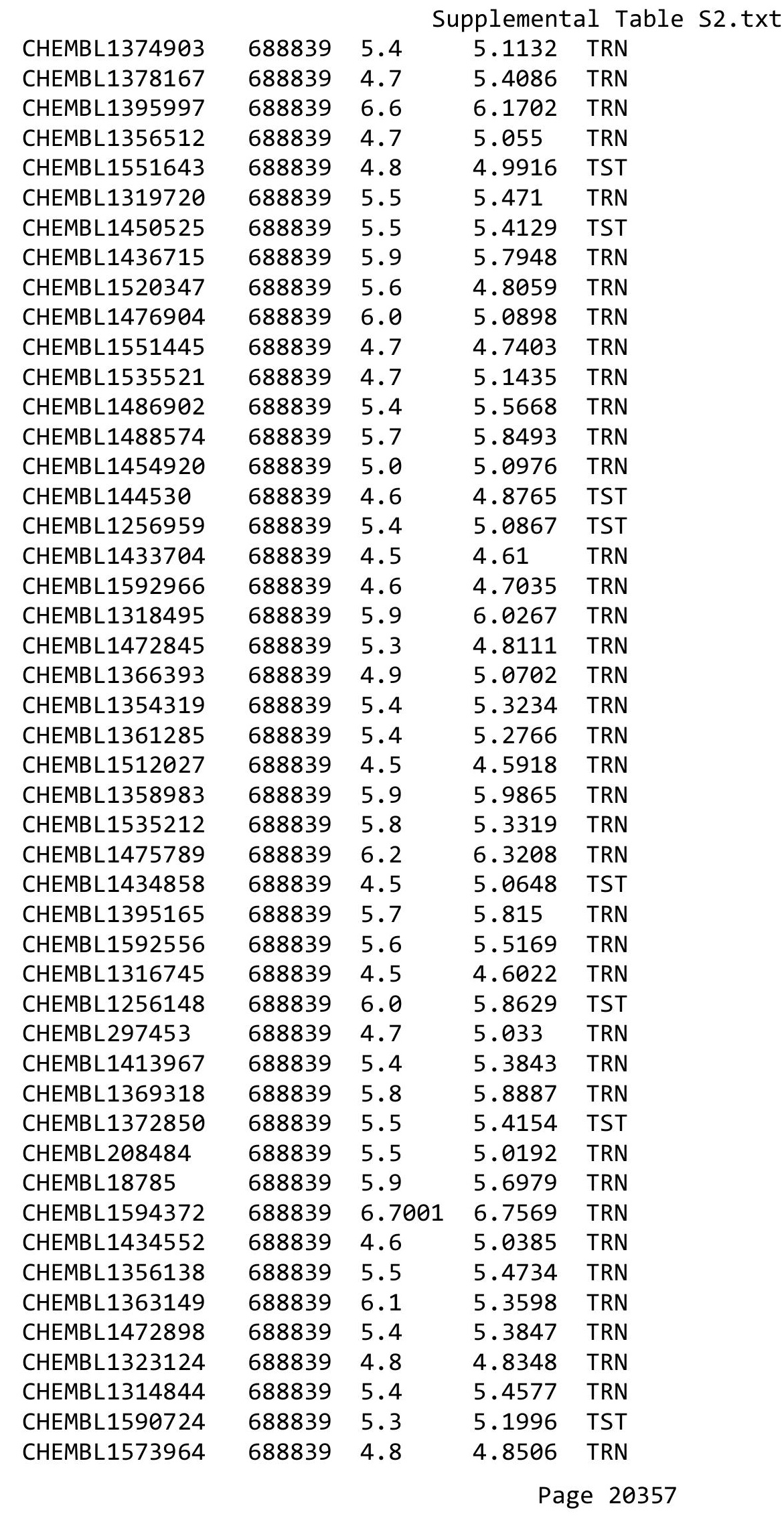




\begin{tabular}{|c|c|c|c|c|c|}
\hline \\
\hline CHEMBL1525438 & 688839 & 5.4 & 5.0219 & TST & \\
\hline CHEMBL1552165 & 688839 & 5.0 & 5.1096 & TRN & \\
\hline CHEMBL1401859 & 688839 & 5.1 & 5.0755 & TRN & \\
\hline CHEMBL1317761 & 688839 & 4.8 & 4.7822 & TRN & \\
\hline CHEMBL1316647 & 688839 & 4.7 & 4.7182 & TRN & \\
\hline CHEMBL1569638 & 688839 & 5.5 & 5.4349 & TRN & \\
\hline CHEMBL1481921 & 688839 & 5.5 & 5.2052 & TRN & \\
\hline CHEMBL1397782 & 688839 & 5.7 & 5.5045 & TST & \\
\hline CHEMBL1435227 & 688839 & 4.6 & 4.5982 & TRN & \\
\hline CHEMBL1534566 & 688839 & 4.9 & 4.9395 & TRN & \\
\hline CHEMBL1526411 & 688839 & 5.5 & 5.4536 & TRN & \\
\hline CHEMBL1327945 & 688839 & 6.3 & 6.42299 & 9999999999 & TRN \\
\hline CHEMBL1366616 & 688839 & 5.4 & 5.3171 & TRN & \\
\hline CHEMBL1361839 & 688839 & 4.8 & 4.8491 & TRN & \\
\hline CHEMBL1337995 & 688839 & 4.9 & 5.4887 & TRN & \\
\hline CHEMBL1367917 & 688839 & 5.8 & 5.55 & TRN & \\
\hline CHEMBL 2374076 & 688839 & 4.4 & 5.2566 & TST & \\
\hline CHEMBL1314971 & 688839 & 5.3 & 5.2067 & TRN & \\
\hline CHEMBL1396754 & 688839 & 5.4 & 5.0527 & TRN & \\
\hline CHEMBL8739 & 688839 & 4.8 & 4.7768 & TRN & \\
\hline CHEMBL66 & 688839 & 6.0 & 5.0168 & TRN & \\
\hline CHEMBL1323956 & 688839 & 4.6 & 4.6007 & TRN & \\
\hline CHEMBL57394 & 688839 & 4.5 & 5.1377 & TRN & \\
\hline CHEMBL1321988 & 688839 & 5.5 & 5.0169 & TST & \\
\hline CHEMBL1565133 & 688839 & 4.9 & 5.0537 & TST & \\
\hline CHEMBL1447438 & 688839 & 5.6 & 5.5183 & TRN & \\
\hline CHEMBL241858 & 688839 & 4.9 & 5.2301 & TRN & \\
\hline CHEMBL1357676 & 688839 & 5.1 & 5.16 & TRN & \\
\hline CHEMBL277525 & 688839 & 6.2 & 6.1712 & TRN & \\
\hline CHEMBL1534951 & 688839 & 5.0 & 4.8292 & TRN & \\
\hline CHEMBL1611348 & 688839 & 4.9 & 4.8703 & TRN & \\
\hline CHEMBL520992 & 688839 & 5.6 & 5.1363 & TRN & \\
\hline CHEMBL1396261 & 688839 & 6.4 & 6.5725 & TRN & \\
\hline CHEMBL323197 & 688839 & 4.4 & 5.1572 & TRN & \\
\hline CHEMBL1160544 & 688839 & 6.3 & 5.8905 & TRN & \\
\hline CHEMBL1490477 & 688839 & 5.5 & 5.4546 & TRN & \\
\hline CHEMBL587714 & 688839 & 4.9 & 5.0019 & TRN & \\
\hline CHEMBL1373723 & 688839 & 5.9 & 5.9068 & TRN & \\
\hline CHEMBL1317010 & 688839 & 5.4 & 5.4459 & TRN & \\
\hline CHEMBL1524085 & 688839 & 4.9 & 5.0077 & TRN & \\
\hline CHEMBL1513063 & 688839 & 4.8 & 4.8667 & TRN & \\
\hline CHEMBL1594008 & 688839 & 5.5 & 5.4764 & TRN & \\
\hline CHEMBL1452111 & 688839 & 5.0 & 5.4579 & TRN & \\
\hline CHEMBL490706 & 688839 & 5.7 & 5.6776 & TRN & \\
\hline CHEMBL1591374 & 688839 & 5.7 & 5.6107 & TRN & \\
\hline CHEMBL1355156 & 688839 & 5.5 & 5.5114 & TRN & \\
\hline CHEMBL1594075 & 688839 & 5.3 & 5.2289 & TRN & \\
\hline CHEMBL351772 & 688839 & 5.9 & 5.695 & TST & \\
\hline
\end{tabular}




\begin{tabular}{|c|c|c|c|c|c|}
\hline \\
\hline CHEMBL1436179 & 688839 & 4.8 & 4.8948 & TRN & \\
\hline CHEMBL406835 & 688839 & 4.5 & 5.1667 & TRN & \\
\hline CHEMBL1491313 & 688839 & 4.5 & 5.2693 & TRN & \\
\hline CHEMBL1404598 & 688839 & 6.2 & 6.3229 & TRN & \\
\hline CHEMBL1328088 & 688839 & 5.6 & 5.0369 & TST & \\
\hline CHEMBL1359691 & 688839 & 5.3 & 5.3223 & TRN & \\
\hline CHEMBL1478614 & 688839 & 5.5 & 5.4324 & TRN & \\
\hline CHEMBL1476271 & 688839 & 4.4 & 5.2119 & TST & \\
\hline CHEMBL1323438 & 688839 & 4.9 & 4.9831 & TRN & \\
\hline CHEMBL1579749 & 688839 & 4.6 & 5.0707 & TRN & \\
\hline CHEMBL1593511 & 688839 & 5.5 & 5.381 & TRN & \\
\hline CHEMBL1333968 & 688839 & 4.9 & 4.9053 & TRN & \\
\hline CHEMBL1601630 & 688839 & 4.9 & 4.9162 & TRN & \\
\hline CHEMBL1326152 & 688839 & 4.8 & 4.6716 & TRN & \\
\hline CHEMBL275097 & 688839 & 5.1 & 5.2065 & TRN & \\
\hline CHEMBL1370938 & 688839 & 5.4 & 5.08899 & 99999999995 & TRN \\
\hline CHEMBL1448345 & 688839 & 5.9 & 5.4677 & TRN & \\
\hline CHEMBL1398335 & 688839 & 5.5 & 5.4354 & TST & \\
\hline CHEMBL1362068 & 688839 & 5.5 & 5.4997 & TRN & \\
\hline CHEMBL1553741 & 688839 & 4.9 & 5.0089 & TRN & \\
\hline CHEMBL454431 & 688839 & 4.9 & 5.0253 & TRN & \\
\hline CHEMBL1332667 & 688839 & 5.7 & 5.3729 & TRN & \\
\hline CHEMBL1514931 & 688839 & 4.5 & 4.6475 & TST & \\
\hline CHEMBL1435889 & 688839 & 4.6 & 4.6212 & TRN & \\
\hline CHEMBL1318340 & 688839 & 4.9 & 4.921 & TRN & \\
\hline CHEMBL1531727 & 688839 & 5.4 & 5.3536 & TRN & \\
\hline CHEMBL346516 & 688839 & 5.4 & 5.0109 & TST & \\
\hline CHEMBL1371311 & 688839 & 5.4 & 5.3582 & TST & \\
\hline CHEMBL1436054 & 688839 & 4.9 & 4.976 & TRN & \\
\hline CHEMBL1475562 & 688839 & 4.9 & 4.9104 & TRN & \\
\hline CHEMBL1402435 & 688839 & 4.8 & 4.9189 & TST & \\
\hline CHEMBL1396997 & 688839 & 5.0 & 4.72 & TRN & \\
\hline CHEMBL486193 & 688839 & 4.6 & 5.3392 & TST & \\
\hline CHEMBL1567725 & 688839 & 5.4 & 5.4544 & TRN & \\
\hline CHEMBL15901 & 688839 & 4.6 & 5.0685 & TRN & \\
\hline CHEMBL1551286 & 688839 & 4.8 & 5.3446 & TRN & \\
\hline CHEMBL 27403 & 688839 & 4.6 & 4.6637 & TRN & \\
\hline CHEMBL490745 & 688839 & 5.6 & 5.7133 & TRN & \\
\hline CHEMBL33103 & 688839 & 6.0 & 5.055 & TRN & \\
\hline CHEMBL1554763 & 688839 & 4.5 & 4.6328 & TRN & \\
\hline CHEMBL363332 & 688839 & 5.8 & 5.8306 & TST & \\
\hline CHEMBL1515717 & 688839 & 5.4 & 5.3911 & TRN & \\
\hline CHEMBL1327492 & 688839 & 6.1 & 5.1666 & TST & \\
\hline CHEMBL1376290 & 688839 & 4.9 & 4.947 & TRN & \\
\hline CHEMBL50378 & 688839 & 6.0 & 5.8629 & TST & \\
\hline CHEMBL1443713 & 688839 & 4.6 & 4.6886 & TRN & \\
\hline CHEMBL1332453 & 688839 & 5.5 & 5.1151 & TRN & \\
\hline CHEMBL1520512 & 688839 & 4.4 & 5.1552 & TRN & \\
\hline
\end{tabular}




\begin{tabular}{|c|c|c|c|c|c|}
\hline \multicolumn{6}{|c|}{ Supplemental Table S2.txt } \\
\hline CHEMBL1606751 & 688839 & 4.7 & 5.0658 & TRN & \\
\hline CHEMBL1522796 & 688839 & 5.4 & 5.3089 & TST & \\
\hline CHEMBL512908 & 688839 & 6.3 & 5.9729 & TRN & \\
\hline CHEMBL541229 & 688839 & 4.4 & 4.9217 & TRN & \\
\hline CHEMBL1496345 & 688839 & 4.8 & 4.9506 & TRN & \\
\hline CHEMBL1399760 & 688839 & 4.8 & 4.859 & TRN & \\
\hline CHEMBL1222498 & 688839 & 4.8 & 4.8734 & TST & \\
\hline CHEMBL1372037 & 688839 & 6.1 & 6.2448 & TRN & \\
\hline CHEMBL1437047 & 688839 & 4.7 & 5.1959 & TST & \\
\hline CHEMBL1482575 & 688839 & 6.1 & 6.0888 & TRN & \\
\hline CHEMBL1331913 & 688839 & 6.0 & 5.7583 & TST & \\
\hline CHEMBL1610778 & 688839 & 6.0 & 5.4016 & TST & \\
\hline CHEMBL1552286 & 688839 & 4.8 & 5.0464 & TRN & \\
\hline CHEMBL1440842 & 688839 & 6.6 & 6.3606 & TST & \\
\hline CHEMBL1437354 & 688839 & 5.4 & 5.1958 & TRN & \\
\hline CHEMBL 75978 & 688839 & 5.0 & 5.1532 & TRN & \\
\hline CHEMBL1368942 & 688839 & 5.7 & 5.7005 & TRN & \\
\hline CHEMBL1401483 & 688839 & 5.2 & 4.9832 & TRN & \\
\hline CHEMBL1568539 & 688839 & 5.7 & 5.2288 & TRN & \\
\hline CHEMBL1513324 & 688839 & 5.2 & 5.048 & TRN & \\
\hline CHEMBL1509442 & 688839 & 4.6 & 5.0564 & TST & \\
\hline CHEMBL1414232 & 688839 & 6.0 & 5.9597 & TRN & \\
\hline CHEMBL1573532 & 688839 & 5.5 & 5.5623 & TRN & \\
\hline CHEMBL1613338 & 688839 & 4.7 & 4.7015 & TRN & \\
\hline CHEMBL1318220 & 688839 & 4.5 & 5.2016 & TST & \\
\hline CHEMBL471226 & 688839 & 5.4 & 5.3879 & TRN & \\
\hline CHEMBL1395344 & 688839 & 6.7001 & 6.58700 & 0000000001 & TRN \\
\hline CHEMBL1316055 & 688839 & 5.0 & 5.1187 & TRN & \\
\hline CHEMBL1481412 & 688839 & 5.4 & 5.1747 & TRN & \\
\hline CHEMBL1435435 & 688839 & 4.8 & 5.0347 & TRN & \\
\hline CHEMBL1356004 & 688839 & 4.9 & 4.8533 & TRN & \\
\hline CHEMBL1434801 & 688839 & 4.9 & 4.9861 & TRN & \\
\hline CHEMBL42115 & 688839 & 4.5 & 5.0979 & TRN & \\
\hline CHEMBL1572988 & 688839 & 5.7 & 5.8476 & TRN & \\
\hline CHEMBL578741 & 688839 & 7.2 & 5.3106 & TRN & \\
\hline CHEMBL1318480 & 688839 & 4.9 & 4.979 & TRN & \\
\hline CHEMBL1447160 & 688839 & 5.5 & 5.3775 & TST & \\
\hline CHEMBL1327394 & 688839 & 4.7 & 4.6884 & TRN & \\
\hline CHEMBL1554325 & 688839 & 4.7 & 4.95100 & 00000000005 & TRN \\
\hline CHEMBL1495773 & 688839 & 4.6 & 4.6855 & TRN & \\
\hline CHEMBL1408808 & 688839 & 4.4 & 5.2421 & TST & \\
\hline CHEMBL1604523 & 688839 & 4.4 & 5.2107 & TST & \\
\hline CHEMBL1595856 & 688839 & 5.4 & 5.5094 & TRN & \\
\hline CHEMBL1408519 & 688839 & 5.0 & 5.0483 & TST & \\
\hline CHEMBL1364182 & 688839 & 5.4 & 5.4618 & TRN & \\
\hline CHEMBL1520292 & 688839 & 5.9 & 6.1556 & TRN & \\
\hline CHEMBL1435754 & 688839 & 6.0 & 5.4865 & TST & \\
\hline CHEMBL1515540 & 688839 & 5.1 & 4.9652 & TRN & \\
\hline
\end{tabular}




\begin{tabular}{|c|c|c|c|c|c|}
\hline \\
\hline CHEMBL1554550 & 688839 & 5.5 & 5.3403 & TRN & \\
\hline CHEMBL1438748 & 688839 & 4.6 & 4.8579 & TRN & \\
\hline CHEMBL1604421 & 688839 & 6.5 & 6.5475 & TRN & \\
\hline CHEMBL1330272 & 688839 & 6.1 & 6.2615 & TRN & \\
\hline CHEMBL1377189 & 688839 & 4.5 & 5.2415 & TST & \\
\hline CHEMBL1317712 & 688839 & 4.6 & 4.6841 & TRN & \\
\hline CHEMBL1373634 & 688839 & 5.4 & 5.3518 & TRN & \\
\hline CHEMBL1357085 & 688839 & 5.5 & 5.5176 & TRN & \\
\hline CHEMBL1360310 & 688839 & 5.0 & 5.0951 & TRN & \\
\hline CHEMBL1592974 & 688839 & 4.8 & 5.0749 & TRN & \\
\hline CHEMBL1323164 & 688839 & 6.0 & 6.061 & TRN & \\
\hline CHEMBL1552984 & 688839 & 5.5 & 5.3579 & TST & \\
\hline CHEMBL1606292 & 688839 & 5.9 & 5.9814 & TRN & \\
\hline CHEMBL1363331 & 688839 & 5.3 & 5.2804 & TRN & \\
\hline CHEMBL1555014 & 688839 & 5.0 & 4.9785 & TRN & \\
\hline CHEMBL1524001 & 688839 & 5.1 & 4.9411 & TRN & \\
\hline CHEMBL1458 & 688839 & 5.5 & 4.966 & TST & \\
\hline CHEMBL1336443 & 688839 & 6.0 & 6.0639 & TRN & \\
\hline CHEMBL1476274 & 688839 & 5.3 & 5.2397 & TRN & \\
\hline CHEMBL1528708 & 688839 & 4.8 & 4.7983 & TRN & \\
\hline CHEMBL1357168 & 688839 & 5.5 & 5.5271 & TRN & \\
\hline CHEMBL1360916 & 688839 & 4.4 & 5.3276 & TRN & \\
\hline CHEMBL1564552 & 688839 & 4.4 & 5.0101 & TST & \\
\hline CHEMBL1395338 & 688839 & 7.1002 & 6.4112 & TRN & \\
\hline CHEMBL1325511 & 688839 & 5.4 & 5.2943 & TST & \\
\hline CHEMBL1474056 & 688839 & 5.6 & 5.4667 & TRN & \\
\hline CHEMBL1527222 & 688839 & 4.6 & 5.1532 & TST & \\
\hline CHEMBL1593466 & 688839 & 5.4 & 5.3723 & TRN & \\
\hline CHEMBL1437088 & 688839 & 4.9 & 4.9497 & TRN & \\
\hline CHEMBL1551151 & 688839 & 4.8 & 4.9074 & TRN & \\
\hline CHEMBL1368904 & 688839 & 5.1 & 5.3883 & TRN & \\
\hline CHEMBL125569 & 688839 & 4.6 & 4.704 & TST & \\
\hline CHEMBL1362553 & 688839 & 5.4 & 5.1585 & TRN & \\
\hline CHEMBL1568178 & 688839 & 5.9 & 5.95700 & 0000000001 & TRN \\
\hline CHEMBL1453542 & 688839 & 4.7 & 4.6963 & TST & \\
\hline CHEMBL1401642 & 688839 & 4.8 & 5.48799 & 99999999995 & TRN \\
\hline CHEMBL1402957 & 688839 & 6.0 & 5.5386 & TST & \\
\hline CHEMBL309917 & 688839 & 4.5 & 4.942 & TRN & \\
\hline CHEMBL1319992 & 688839 & 5.6 & 5.3704 & TRN & \\
\hline CHEMBL 1475258 & 688839 & 4.7 & 4.7558 & TRN & \\
\hline CHEMBL1590081 & 688839 & 6.1 & 6.2486 & TRN & \\
\hline CHEMBL 2062333 & 688839 & 4.6 & 4.7469 & TST & \\
\hline CHEMBL497781 & 688839 & 4.9 & 5.0664 & TRN & \\
\hline CHEMBL1323656 & 688839 & 5.4 & 5.4469 & TRN & \\
\hline CHEMBL487603 & 688839 & 4.6 & 5.3959 & TRN & \\
\hline CHEMBL1440509 & 688839 & 5.0 & 5.0358 & TRN & \\
\hline CHEMBL 325238 & 688839 & 4.5 & 5.0029 & TRN & \\
\hline CHEMBL1435033 & 688839 & 5.5 & 5.5432 & TST & \\
\hline
\end{tabular}




\begin{tabular}{|c|c|c|c|c|}
\hline & & & & \\
\hline CHEMBL1366591 & 688839 & 5.4 & 5.4205 & TRN \\
\hline CHEMBL1567569 & 688839 & 4.6 & 4.7361 & TRN \\
\hline CHEMBL1512444 & 688839 & 4.6 & 4.666 & TRN \\
\hline CHEMBL402468 & 688839 & 4.7 & 4.8317 & TRN \\
\hline CHEMBL398755 & 688839 & 4.5 & 4.9051 & TRN \\
\hline CHEMBL1572239 & 688839 & 5.2 & 5.3238 & TRN \\
\hline CHEMBL259849 & 688839 & 4.8 & 5.0653 & TRN \\
\hline CHEMBL1314469 & 688839 & 4.4 & 5.2227 & TST \\
\hline CHEMBL1372900 & 688839 & 4.9 & 5.2158 & TRN \\
\hline CHEMBL1335436 & 688839 & 5.6 & 5.4662 & TST \\
\hline CHEMBL1435509 & 688839 & 5.4 & 5.3578 & TRN \\
\hline CHEMBL1442440 & 688839 & 6.3 & 6.2414 & TRN \\
\hline CHEMBL1558153 & 688839 & 4.6 & 5.1155 & TST \\
\hline CHEMBL276140 & 688839 & 5.4 & 5.4403 & TST \\
\hline CHEMBL22870 & 688839 & 5.1 & 4.9042 & TRN \\
\hline CHEMBL1513174 & 688839 & 5.6 & 4.8662 & TRN \\
\hline CHEMBL446452 & 688839 & 4.4 & 5.0156 & TRN \\
\hline CHEMBL1448010 & 688839 & 5.9 & 4.9863 & TST \\
\hline CHEMBL1514375 & 688839 & 4.8 & 4.9999 & TST \\
\hline CHEMBL1591544 & 688839 & 4.5 & 4.5238 & TRN \\
\hline CHEMBL1397860 & 688839 & 6.3 & 6.2519 & TRN \\
\hline CHEMBL1439866 & 688839 & 4.5 & 5.1965 & TRN \\
\hline CHEMBL150 & 688839 & 6.0 & 5.3521 & TRN \\
\hline CHEMBL1514748 & 688839 & 5.6 & 5.4 & TRN \\
\hline CHEMBL1395402 & 688839 & 5.1 & 5.0971 & TRN \\
\hline CHEMBL1326360 & 688839 & 5.8 & 5.978 & TRN \\
\hline CHEMBL195953 & 688839 & 5.5 & 5.0493 & TST \\
\hline CHEMBL354663 & 688839 & 4.5 & 5.1478 & TRN \\
\hline CHEMBL1475200 & 688839 & 6.0 & 5.9954 & TRN \\
\hline CHEMBL1356623 & 688839 & 5.7 & 5.1921 & TRN \\
\hline CHEMBL13097 & 688839 & 4.7 & 5.1666 & TRN \\
\hline CHEMBL168279 & 688839 & 6.0 & 5.7548 & TST \\
\hline CHEMBL1480219 & 688839 & 4.8 & 4.8691 & TRN \\
\hline CHEMBL 3208052 & 688839 & 5.5 & 5.2757 & TST \\
\hline CHEMBL1410859 & 688839 & 5.1 & 5.0885 & TRN \\
\hline CHEMBL1484337 & 688839 & 5.8 & 5.8845 & TRN \\
\hline CHEMBL119841 & 688839 & 5.8 & 5.8984 & TRN \\
\hline CHEMBL1612893 & 688839 & 4.7 & 4.7759 & TRN \\
\hline CHEMBL1493644 & 688839 & 5.5 & 4.6143 & TRN \\
\hline CHEMBL1394520 & 688839 & 4.4 & 4.4905 & TRN \\
\hline CHEMBL1396693 & 688839 & 5.8 & 5.75799 & 9999999999 \\
\hline CHEMBL56543 & 688839 & 4.8 & 4.9879 & TRN \\
\hline CHEMBL1522370 & 688839 & 4.6 & 4.6792 & TRN \\
\hline CHEMBL1593443 & 688839 & 5.2 & 5.3119 & TRN \\
\hline CHEMBL1475428 & 688839 & 5.2 & 5.0095 & TRN \\
\hline CHEMBL1400594 & 688839 & 6.0 & 5.6993 & TRN \\
\hline CHEMBL1458713 & 688839 & 6.8 & 6.1593 & TST \\
\hline CHEMBL1370770 & 688839 & 6.0 & 5.7473 & TRN \\
\hline
\end{tabular}




\begin{tabular}{|c|c|c|c|c|c|}
\hline \\
\hline CHEMBL1517986 & 688839 & 5.3 & 5.051 & TST & \\
\hline CHEMBL1456015 & 688839 & 4.8 & 4.8296 & TRN & \\
\hline CHEMBL394171 & 688839 & 4.8 & 4.934 & TRN & \\
\hline CHEMBL1324697 & 688839 & 4.9 & 4.8425 & TST & \\
\hline CHEMBL1611906 & 688839 & 5.5 & 5.4266 & TRN & \\
\hline CHEMBL1450004 & 688839 & 6.0 & 5.045 & TST & \\
\hline CHEMBL 273807 & 688839 & 6.0 & 5.8194 & TST & \\
\hline CHEMBL45281 & 688839 & 4.9 & 4.8434 & TST & \\
\hline CHEMBL1531837 & 688839 & 6.6 & 6.4631 & TRN & \\
\hline CHEMBL1473632 & 688839 & 5.9 & 5.3853 & TRN & \\
\hline CHEMBL540848 & 688839 & 6.0 & 5.7585 & TRN & \\
\hline CHEMBL1322414 & 688839 & 5.6 & 5.5586 & TRN & \\
\hline CHEMBL1414592 & 688839 & 4.7 & 4.7298 & TRN & \\
\hline CHEMBL1513928 & 688839 & 5.0 & 5.2986 & TRN & \\
\hline CHEMBL1590738 & 688839 & 5.1 & 5.0148 & TRN & \\
\hline CHEMBL 38508 & 688839 & 5.1 & 5.2621 & TST & \\
\hline CHEMBL1332471 & 688839 & 5.6 & 5.7453 & TRN & \\
\hline CHEMBL1362416 & 688839 & 5.8 & 5.5693 & TRN & \\
\hline CHEMBL1590450 & 688839 & 5.5 & 4.9907 & TRN & \\
\hline CHEMBL1455462 & 688839 & 5.5 & 5.46899 & 9999999999 & TRN \\
\hline CHEMBL1314453 & 688839 & 5.5 & 5.4656 & TRN & \\
\hline CHEMBL133930 & 688839 & 4.9 & 5.0923 & TST & \\
\hline CHEMBL1569001 & 688839 & 4.7 & 5.117 & TRN & \\
\hline CHEMBL1315236 & 688839 & 4.5 & 4.5715 & TRN & \\
\hline CHEMBL445969 & 688839 & 5.8 & 5.3088 & TST & \\
\hline CHEMBL1552643 & 688839 & 5.0 & 4.9421 & TRN & \\
\hline CHEMBL1533465 & 688839 & 4.8 & 4.9172 & TRN & \\
\hline CHEMBL1555369 & 688839 & 5.4 & 5.4132 & TRN & \\
\hline CHEMBL1322818 & 688839 & 4.6 & 4.9601 & TRN & \\
\hline CHEMBL1367935 & 688839 & 5.4 & 5.3399 & TRN & \\
\hline CHEMBL1607830 & 688839 & 5.5 & 5.476 & TST & \\
\hline CHEMBL1610228 & 688839 & 4.6 & 4.633 & TRN & \\
\hline CHEMBL1513562 & 688839 & 4.8 & 5.1046 & TRN & \\
\hline CHEMBL3212160 & 688839 & 5.4 & 5.4403 & TRN & \\
\hline CHEMBL1256392 & 688839 & 4.6 & 4.7593 & TRN & \\
\hline CHEMBL221300 & 688839 & 4.8 & 4.958 & TRN & \\
\hline CHEMBL1418387 & 688839 & 4.7 & 4.7235 & TRN & \\
\hline CHEMBL228281 & 688839 & 4.4 & 5.1254 & TRN & \\
\hline CHEMBL1473430 & 688839 & 5.9 & 5.754 & TRN & \\
\hline CHEMBL1394840 & 688839 & 4.7 & 4.7727 & TRN & \\
\hline CHEMBL1321008 & 688839 & 4.8 & 5.1501 & TST & \\
\hline CHEMBL1256573 & 688839 & 6.0 & 5.7229 & TST & \\
\hline CHEMBL1255749 & 688839 & 4.6 & 4.7207 & TST & \\
\hline CHEMBL1394887 & 688839 & 5.9 & 5.5984 & TRN & \\
\hline CHEMBL1514819 & 688839 & 4.8 & 4.882 & TRN & \\
\hline CHEMBL1318565 & 688839 & 5.5 & 5.4896 & TRN & \\
\hline CHEMBL1514486 & 688839 & 5.1 & 5.1179 & TST & \\
\hline CHEMBL1611261 & 688839 & 4.8 & 4.8577 & TRN & \\
\hline & & & & 20363 & \\
\hline
\end{tabular}




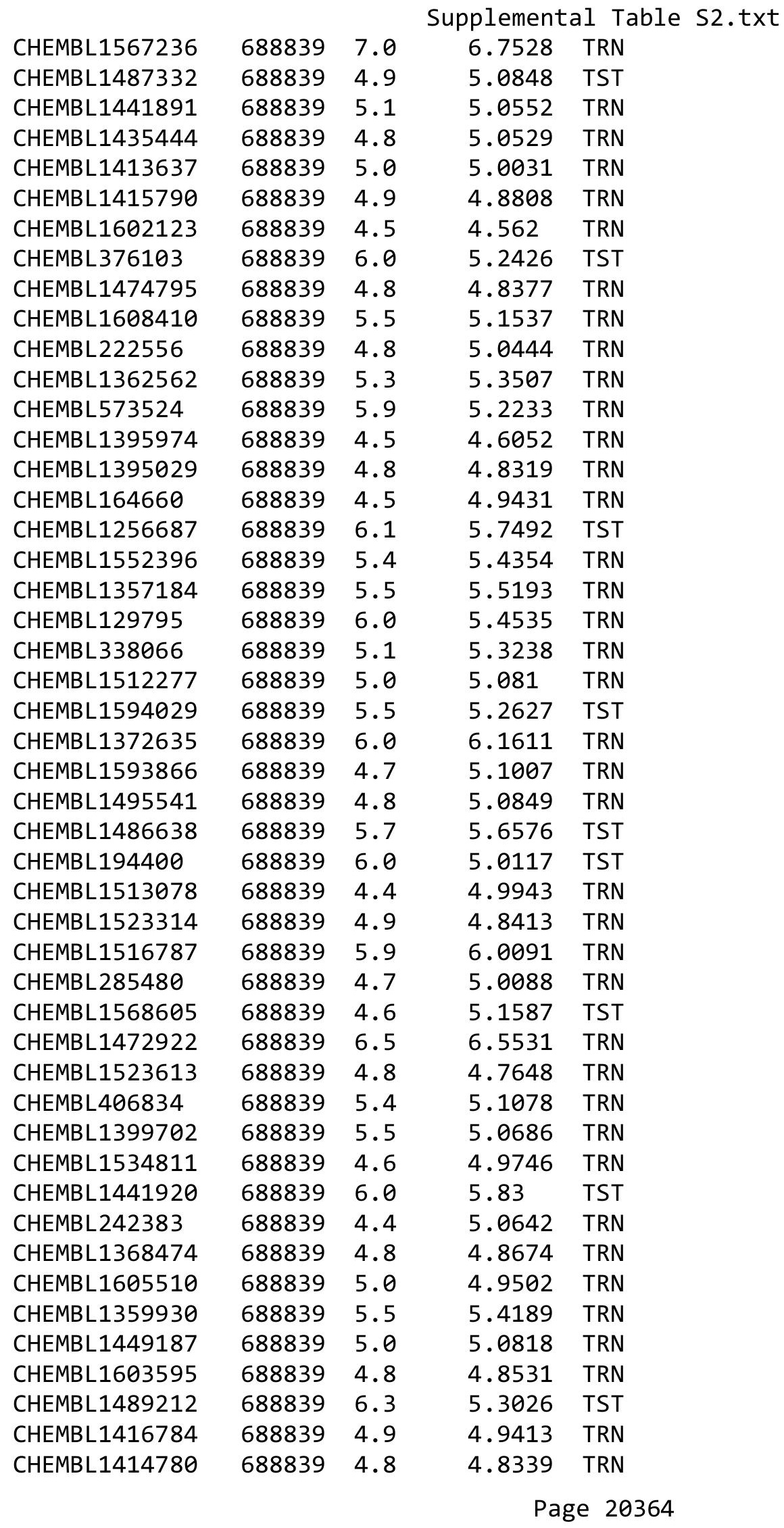




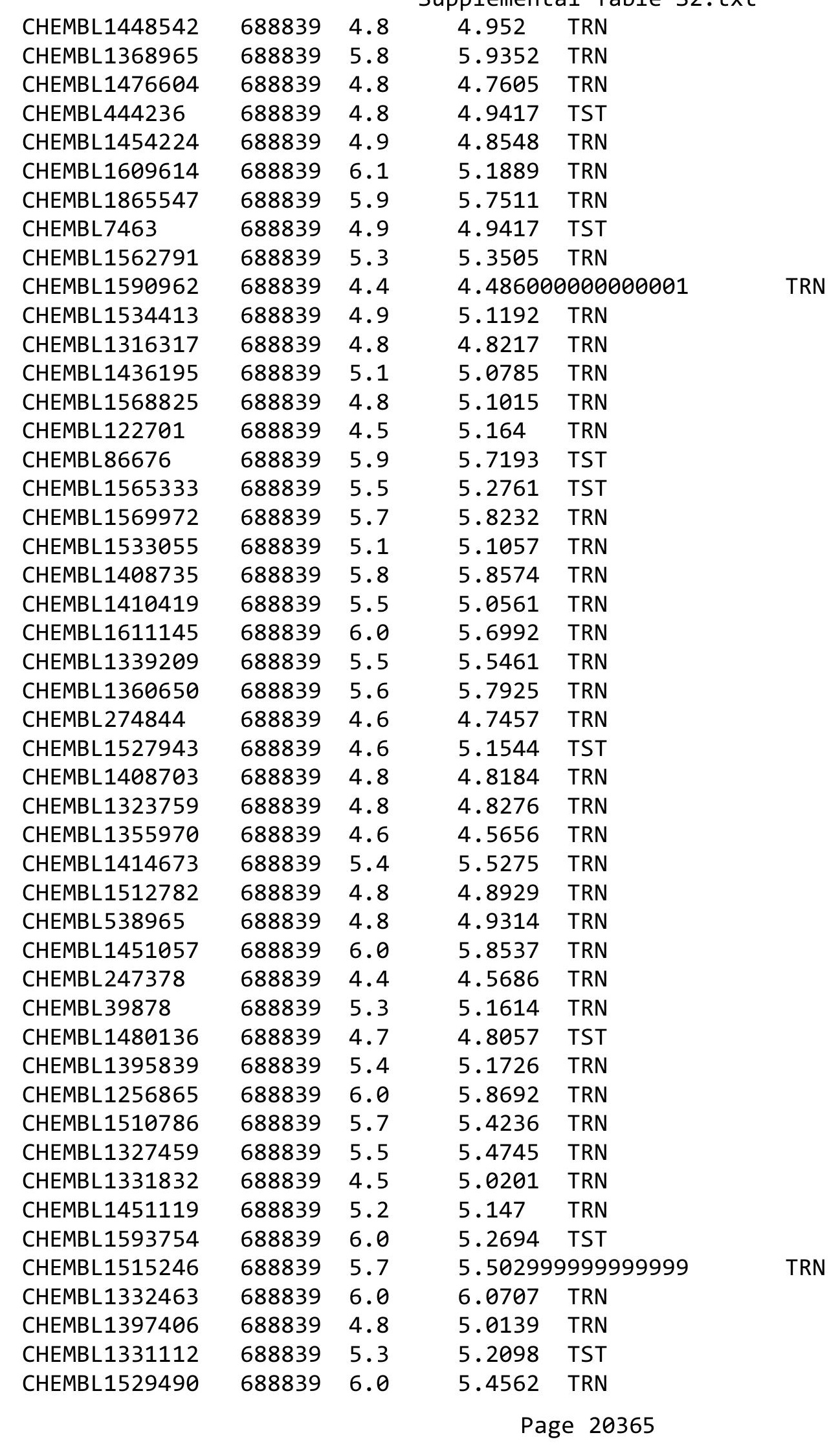




\begin{tabular}{|c|c|c|c|c|}
\hline \multicolumn{5}{|c|}{ Supplement } \\
\hline CHEMBL1411094 & 688839 & 5.6 & 5.7307 & TRN \\
\hline CHEMBL1609528 & 688839 & 5.1 & 5.1431 & TRN \\
\hline CHEMBL1569485 & 688839 & 5.6 & 5.7658 & TRN \\
\hline CHEMBL1567676 & 688839 & 4.8 & 5.2193 & TRN \\
\hline CHEMBL1394348 & 688839 & 6.0 & 5.8277 & TRN \\
\hline CHEMBL1357834 & 688839 & 5.4 & 5.2489 & TST \\
\hline CHEMBL1566283 & 688839 & 4.8 & 5.0852 & TRN \\
\hline CHEMBL1317747 & 688839 & 5.5 & 5.5023 & TRN \\
\hline CHEMBL464176 & 688839 & 5.0 & \multicolumn{2}{|c|}{5.287000000000001} \\
\hline CHEMBL1330587 & 688839 & 5.6 & 5.401 & TRN \\
\hline CHEMBL1315637 & 688839 & 4.9 & 4.8209 & TRN \\
\hline CHEMBL1455438 & 688839 & 4.6 & 4.6413 & TRN \\
\hline CHEMBL327708 & 688839 & 5.5 & 5.4464 & TST \\
\hline CHEMBL1515366 & 688839 & 5.3 & 5.1763 & TRN \\
\hline CHEMBL1611999 & 688839 & 5.5 & 5.0262 & TRN \\
\hline CHEMBL1476437 & 688839 & 4.6 & 4.7547 & TRN \\
\hline CHEMBL1403041 & 688839 & 5.6 & 5.4854 & TRN \\
\hline CHEMBL 1256746 & 688839 & 4.9 & 5.0514 & TRN \\
\hline CHEMBL489738 & 688839 & 6.7001 & 6.7025 & TRN \\
\hline CHEMBL553181 & 688839 & 4.5 & 4.887 & TRN \\
\hline CHEMBL1515401 & 688839 & 4.9 & 4.9517 & TRN \\
\hline CHEMBL258465 & 688839 & 5.5 & 5.3934 & TST \\
\hline CHEMBL226968 & 688839 & 5.4 & 5.072 & TST \\
\hline CHEMBL1551639 & 688839 & 5.0 & 5.1241 & TRN \\
\hline CHEMBL1533572 & 688839 & 5.0 & 4.9688 & TRN \\
\hline CHEMBL1518338 & 688839 & 4.8 & 4.8206 & TRN \\
\hline CHEMBL1455972 & 688839 & 5.3 & 5.2289 & TST \\
\hline CHEMBL47814 & 688839 & 5.0 & 5.0276 & TRN \\
\hline CHEMBL1322958 & 688839 & 5.4 & 4.9701 & TST \\
\hline CHEMBL1414353 & 688839 & 4.6 & 5.0175 & TRN \\
\hline CHEMBL1385840 & 688839 & 5.9 & 5.5868 & TST \\
\hline CHEMBL472994 & 688839 & 6.5 & 6.2275 & TST \\
\hline CHEMBL1434082 & 688839 & 6.8 & 6.8349 & TRN \\
\hline CHEMBL1450573 & 688839 & 6.4 & 6.1017 & TRN \\
\hline CHEMBL 2373587 & 688839 & 5.6 & 5.2352 & TRN \\
\hline CHEMBL1488477 & 688839 & 4.7 & 4.7205 & TRN \\
\hline CHEMBL1514640 & 688839 & 4.6 & 4.6124 & TRN \\
\hline CHEMBL90882 & 688839 & 4.5 & 4.6368 & TST \\
\hline CHEMBL1434460 & 688839 & 5.5 & 5.6525 & TRN \\
\hline CHEMBL1525767 & 688839 & 4.4 & 4.5343 & TRN \\
\hline CHEMBL1521739 & 688839 & 5.1 & 5.1902 & TST \\
\hline CHEMBL 305881 & 688839 & 6.0 & 5.6687 & TRN \\
\hline CHEMBL275638 & 688839 & 4.9 & 5.0141 & TRN \\
\hline CHEMBL1188431 & 688839 & 5.2 & 5.2455 & TRN \\
\hline CHEMBL1357195 & 688839 & 6.0 & 5.0465 & TST \\
\hline CHEMBL1552100 & 688839 & 5.3 & 5.0474 & TRN \\
\hline CHEMBL1561544 & 688839 & 4.4 & 5.0915 & TST \\
\hline CHEMBL1371140 & 688839 & 5.0 & 4.9634 & TRN \\
\hline
\end{tabular}




\begin{tabular}{|c|c|c|c|c|c|}
\hline \multicolumn{6}{|c|}{ Supplemental Table S2.txt } \\
\hline CHEMBL389390 & 688839 & 6.0 & 4.8734 & TRN & \\
\hline CHEMBL1333368 & 688839 & 4.7 & 5.102 & TRN & \\
\hline CHEMBL1448288 & 688839 & 5.6 & 5.6444 & TRN & \\
\hline CHEMBL58353 & 688839 & 4.4 & 4.6289 & TST & \\
\hline CHEMBL1436925 & 688839 & 5.8 & 5.7481 & TRN & \\
\hline CHEMBL1485541 & 688839 & 4.6 & 5.0823 & TRN & \\
\hline CHEMBL1527442 & 688839 & 4.6 & 4.8455 & TST & \\
\hline CHEMBL1410926 & 688839 & 5.2 & 5.1981 & TRN & \\
\hline CHEMBL1374863 & 688839 & 5.5 & 5.4004 & TRN & \\
\hline CHEMBL1331351 & 688839 & 4.8 & 4.8985 & TRN & \\
\hline CHEMBL1400342 & 688839 & 4.8 & 4.82600 & 00000000005 & TRN \\
\hline CHEMBL1611590 & 688839 & 5.2 & 4.9964 & TST & \\
\hline CHEMBL362863 & 688839 & 6.5 & 6.188 & TST & \\
\hline CHEMBL2373582 & 688839 & 5.4 & 4.8458 & TST & \\
\hline CHEMBL1395415 & 688839 & 4.9 & 4.9411 & TRN & \\
\hline CHEMBL1454153 & 688839 & 4.7 & 4.7392 & TRN & \\
\hline CHEMBL1401672 & 688839 & 4.8 & 4.8531 & TRN & \\
\hline CHEMBL44 & 688839 & 6.0 & 5.0032 & TRN & \\
\hline CHEMBL270299 & 688839 & 4.6 & 4.657 & TST & \\
\hline CHEMBL1449417 & 688839 & 4.9 & 4.8908 & TRN & \\
\hline CHEMBL1552293 & 688839 & 4.7 & 4.7307 & TRN & \\
\hline CHEMBL1318580 & 688839 & 4.8 & 4.8191 & TRN & \\
\hline CHEMBL1486399 & 688839 & 4.7 & 4.7544 & TRN & \\
\hline CHEMBL1362931 & 688839 & 5.5 & 5.3867 & TRN & \\
\hline CHEMBL1361596 & 688839 & 6.0 & 5.7243 & TST & \\
\hline CHEMBL1555884 & 688839 & 5.1 & 5.1785 & TST & \\
\hline CHEMBL1435558 & 688839 & 5.2 & 5.1181 & TRN & \\
\hline CHEMBL1531070 & 688839 & 5.0 & 5.0936 & TRN & \\
\hline CHEMBL1512208 & 688839 & 5.1 & 5.0576 & TRN & \\
\hline CHEMBL1499077 & 688839 & 6.3 & 6.1588 & TRN & \\
\hline CHEMBL1356485 & 688839 & 5.1 & 5.1598 & TRN & \\
\hline CHEMBL1486578 & 688839 & 5.4 & 5.3035 & TST & \\
\hline CHEMBL1450805 & 688839 & 5.1 & 4.989 & TRN & \\
\hline CHEMBL1552194 & 688839 & 5.1 & 5.1016 & TRN & \\
\hline CHEMBL1495665 & 688839 & 5.2 & 5.1804 & TRN & \\
\hline CHEMBL1255832 & 688839 & 4.9 & 4.9695 & TRN & \\
\hline CHEMBL1611218 & 688839 & 5.0 & 5.0095 & TST & \\
\hline CHEMBL1529009 & 688839 & 6.0 & 5.7163 & TRN & \\
\hline CHEMBL1551575 & 688839 & 5.2 & 5.1248 & TST & \\
\hline CHEMBL 74675 & 688839 & 5.6 & 5.3105 & TRN & \\
\hline CHEMBL1318499 & 688839 & 4.6 & 5.1719 & TST & \\
\hline CHEMBL1493851 & 688839 & 5.5 & 5.4837 & TRN & \\
\hline CHEMBL472656 & 688839 & 5.5 & 5.4121 & TST & \\
\hline CHEMBL1532895 & 688839 & 4.9 & 5.2773 & TST & \\
\hline CHEMBL1565724 & 688839 & 5.0 & 5.25799 & 9999999999 & TRN \\
\hline CHEMBL1554935 & 688839 & 5.5 & 5.4684 & TRN & \\
\hline CHEMBL1360944 & 688839 & 4.6 & 4.7312 & TST & \\
\hline CHEMBL123040 & 688839 & 4.4 & 4.981 & TST & \\
\hline
\end{tabular}




\begin{tabular}{|c|c|c|c|c|}
\hline & & & 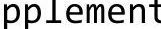 & \\
\hline CHEMBL318275 & 688839 & 4.5 & 5.0441 & TRN \\
\hline CHEMBL258485 & 688839 & 5.5 & 5.2028 & TRN \\
\hline CHEMBL1290409 & 688839 & 4.7 & 4.78 & TRN \\
\hline CHEMBL1355125 & 688839 & 4.9 & 5.2047 & TRN \\
\hline CHEMBL1418097 & 688839 & 5.3 & 5.2249 & TST \\
\hline CHEMBL 261919 & 688839 & 6.0 & 5.0313 & TST \\
\hline CHEMBL 25230 & 688839 & 4.9 & 5.1703 & TST \\
\hline CHEMBL1534082 & 688839 & 5.3 & 5.3395 & TRN \\
\hline CHEMBL112816 & 688839 & 4.9 & 4.8258 & TST \\
\hline CHEMBL1512391 & 688839 & 4.6 & 4.8956 & TRN \\
\hline CHEMBL1242017 & 688839 & 4.8 & 5.1754 & TRN \\
\hline CHEMBL1518035 & 688839 & 4.8 & 4.8454 & TRN \\
\hline CHEMBL1325879 & 688839 & 4.9 & 4.9665 & TRN \\
\hline CHEMBL491939 & 688839 & 5.8 & 5.8043 & TRN \\
\hline CHEMBL1404501 & 688839 & 4.8 & 4.8085 & TRN \\
\hline CHEMBL 303579 & 688839 & 5.9 & 5.6209 & TRN \\
\hline CHEMBL1318064 & 688839 & 4.8 & 5.0381 & TRN \\
\hline CHEMBL1408475 & 688839 & 4.8 & 5.023 & TRN \\
\hline CHEMBL454802 & 688839 & 6.6 & 6.2354 & TRN \\
\hline CHEMBL1552753 & 688839 & 5.4 & 5.5443 & TRN \\
\hline CHEMBL1522104 & 688839 & 5.7 & 5.0248 & TST \\
\hline CHEMBL11348 & 688839 & 5.4 & 5.3952 & TST \\
\hline CHEMBL1395472 & 688839 & 5.5 & 5.324 & TRN \\
\hline CHEMBL1336793 & 688839 & 5.0 & 4.9801 & TRN \\
\hline CHEMBL1357872 & 688839 & 4.6 & 4.6839 & TRN \\
\hline CHEMBL1600269 & 688839 & 4.9 & 4.9391 & TRN \\
\hline CHEMBL1366408 & 688839 & 5.0 & 4.9676 & TRN \\
\hline CHEMBL407864 & 688839 & 5.9 & 5.2498 & TRN \\
\hline CHEMBL1324032 & 688839 & 5.3 & 5.2412 & TST \\
\hline CHEMBL1397752 & 688839 & 5.5 & 5.4882 & TRN \\
\hline CHEMBL1574956 & 688839 & 5.3 & 5.3698 & TRN \\
\hline CHEMBL1590616 & 688839 & 4.6 & 4.774 & TRN \\
\hline CHEMBL1590789 & 688839 & 5.0 & 4.9314 & TRN \\
\hline CHEMBL1553072 & 688839 & 6.3 & 5.1671 & TST \\
\hline CHEMBL1476227 & 688839 & 4.6 & 4.5906 & TRN \\
\hline CHEMBL34730 & 688839 & 4.8 & 4.8484 & TRN \\
\hline CHEMBL210276 & 688839 & 4.4 & 5.0613 & TRN \\
\hline CHEMBL1366020 & 688839 & 5.7 & 5.6018 & TRN \\
\hline CHEMBL1512909 & 688839 & 5.5 & 5.1408 & TST \\
\hline CHEMBL371811 & 688839 & 4.5 & 4.5965 & TST \\
\hline CHEMBL540989 & 688839 & 4.9 & 5.3603 & TST \\
\hline CHEMBL1476266 & 688839 & 5.5 & 5.6352 & TRN \\
\hline CHEMBL1409518 & 688839 & 4.9 & 5.2929 & TST \\
\hline CHEMBL290914 & 688839 & 4.8 & 5.1074 & TRN \\
\hline CHEMBL1513614 & 688839 & 6.2 & 5.7083 & TRN \\
\hline CHEMBL1554844 & 688839 & 6.0 & 5.1555 & TST \\
\hline CHEMBL1489220 & 688839 & 4.6 & 5.2301 & TST \\
\hline CHEMBL 25028 & 688839 & 4.7 & 4.8583 & TST \\
\hline
\end{tabular}




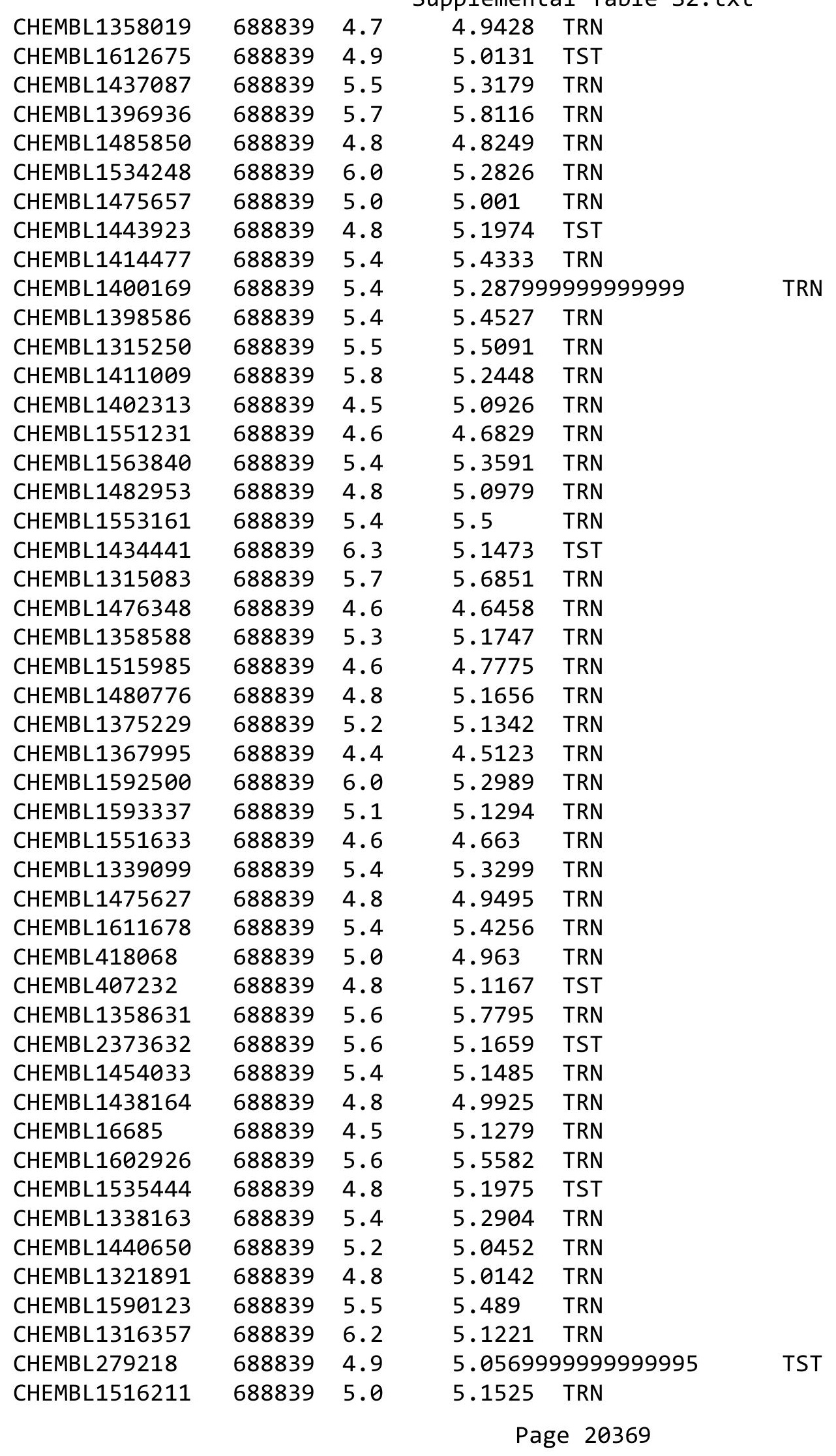




\begin{tabular}{|c|c|c|c|c|c|}
\hline \\
\hline CHEMBL1232474 & 688839 & 6.5 & 6.5905 & TRN & \\
\hline CHEMBL1728023 & 688839 & 6.0 & 5.2372 & TRN & \\
\hline CHEMBL254348 & 688839 & 6.0 & 5.3462 & TRN & \\
\hline CHEMBL1489353 & 688839 & 5.0 & 5.0397 & TRN & \\
\hline CHEMBL1416476 & 688839 & 5.6 & 5.6039 & TRN & \\
\hline CHEMBL1594329 & 688839 & 5.7 & 5.8335 & TRN & \\
\hline CHEMBL1593765 & 688839 & 4.5 & 4.7586 & TRN & \\
\hline CHEMBL1435276 & 688839 & 5.0 & 5.0205 & TRN & \\
\hline CHEMBL1439202 & 688839 & 4.5 & 5.1056 & TST & \\
\hline CHEMBL63154 & 688839 & 5.6 & 5.3879 & TST & \\
\hline CHEMBL1356628 & 688839 & 4.6 & 4.6874 & TST & \\
\hline CHEMBL1435907 & 688839 & 5.6 & 5.472 & TRN & \\
\hline CHEMBL1361449 & 688839 & 5.3 & 5.4235 & TRN & \\
\hline CHEMBL175858 & 688839 & 4.9 & 5.1615 & TRN & \\
\hline CHEMBL1452221 & 688839 & 5.6 & 5.6614 & TRN & \\
\hline CHEMBL 247484 & 688839 & 4.7 & 5.5439 & TRN & \\
\hline CHEMBL1366302 & 688839 & 5.0 & 4.7598 & TRN & \\
\hline CHEMBL1568181 & 688839 & 4.5 & 5.0873 & TRN & \\
\hline CHEMBL3186408 & 688839 & 6.0 & 5.7864 & TST & \\
\hline CHEMBL1315380 & 688839 & 5.6 & 5.4212 & TRN & \\
\hline CHEMBL1371160 & 688839 & 5.2 & 5.1488 & TST & \\
\hline CHEMBL338790 & 688839 & 5.5 & 5.3638 & TRN & \\
\hline CHEMBL1605399 & 688839 & 5.2 & 4.8179 & TRN & \\
\hline CHEMBL1482155 & 688839 & 4.9 & 4.9748 & TRN & \\
\hline CHEMBL1561023 & 688839 & 5.2 & 5.1512 & TRN & \\
\hline CHEMBL1395112 & 688839 & 4.6 & 4.9759 & TRN & \\
\hline CHEMBL1611800 & 688839 & 4.4 & 5.2895 & TRN & \\
\hline CHEMBL73930 & 688839 & 4.9 & 5.227 & TRN & \\
\hline CHEMBL1371510 & 688839 & 5.5 & 5.3307 & TST & \\
\hline CHEMBL1354596 & 688839 & 4.6 & 4.7185 & TRN & \\
\hline CHEMBL1457332 & 688839 & 5.6 & 5.5909 & TRN & \\
\hline CHEMBL1433725 & 688839 & 4.6 & 4.6192 & TRN & \\
\hline CHEMBL1534710 & 688839 & 4.9 & 4.8284 & TRN & \\
\hline CHEMBL1364372 & 688839 & 5.5 & 5.5124 & TRN & \\
\hline CHEMBL1529308 & 688839 & 5.6 & 5.5429 & TRN & \\
\hline CHEMBL1368892 & 688839 & 5.4 & 5.305 & TRN & \\
\hline CHEMBL1445893 & 688839 & 4.9 & $4.9830 e$ & 20000000005 & TRN \\
\hline CHEMBL1443425 & 688839 & 4.6 & 4.5827 & TRN & \\
\hline CHEMBL1453944 & 688839 & 6.0 & 5.2792 & TST & \\
\hline CHEMBL1593335 & 688839 & 5.0 & 5.1982 & TRN & \\
\hline CHEMBL1480008 & 688839 & 5.7 & 5.4387 & TRN & \\
\hline CHEMBL1369940 & 688839 & 5.0 & 5.0429 & TRN & \\
\hline CHEMBL1376952 & 688839 & 5.5 & 5.4 & TRN & \\
\hline CHEMBL468167 & 688839 & 5.5 & 4.9142 & TST & \\
\hline CHEMBL1327355 & 688839 & 4.5 & 4.6739 & TRN & \\
\hline CHEMBL510009 & 688839 & 5.6 & 5.5058 & TRN & \\
\hline CHEMBL1369824 & 688839 & 5.4 & 5.2763 & TRN & \\
\hline CHEMBL86931 & 688839 & 4.5 & 4.6707 & TST & \\
\hline & & & & 20370 & \\
\hline
\end{tabular}




\begin{tabular}{|c|c|c|c|c|c|}
\hline \\
\hline CHEMBL1372870 & 688839 & 4.8 & 5.2471 & TST & \\
\hline CHEMBL1468832 & 688839 & 4.9 & 4.9201 & TRN & \\
\hline CHEMBL490718 & 688839 & 6.2 & 6.3772 & TRN & \\
\hline CHEMBL1358462 & 688839 & 4.8 & 4.8195 & TST & \\
\hline CHEMBL1551479 & 688839 & 6.1 & 5.8502 & TRN & \\
\hline CHEMBL1357724 & 688839 & 5.3 & 5.3933 & TRN & \\
\hline CHEMBL1373998 & 688839 & 5.2 & 5.2065 & TRN & \\
\hline CHEMBL25719 & 688839 & 4.8 & 4.9214 & TST & \\
\hline CHEMBL1408286 & 688839 & 4.6 & 4.7604 & TRN & \\
\hline CHEMBL1356391 & 688839 & 5.5 & 5.49200 & 0000000001 & TRN \\
\hline CHEMBL1370610 & 688839 & 6.0 & 5.0147 & TST & \\
\hline CHEMBL1565914 & 688839 & 5.4 & 5.2996 & TST & \\
\hline CHEMBL408501 & 688839 & 5.4 & 5.2393 & TRN & \\
\hline CHEMBL1483427 & 688839 & 4.7 & 4.7289 & TRN & \\
\hline CHEMBL1363467 & 688839 & 4.8 & 4.7734 & TRN & \\
\hline CHEMBL1411081 & 688839 & 6.0 & 6.0146 & TRN & \\
\hline CHEMBL1400043 & 688839 & 4.8 & 4.8862 & TRN & \\
\hline CHEMBL1568080 & 688839 & 5.5 & 5.49 & TRN & \\
\hline CHEMBL1369140 & 688839 & 5.5 & 5.3602 & TST & \\
\hline CHEMBL1569529 & 688839 & 4.9 & 4.9815 & TRN & \\
\hline CHEMBL1434266 & 688839 & 4.6 & 4.6144 & TRN & \\
\hline CHEMBL289233 & 688839 & 4.8 & 4.8843 & TRN & \\
\hline CHEMBL491909 & 688839 & 7.1002 & 7.1026 & TRN & \\
\hline CHEMBL1409756 & 688839 & 5.5 & 5.4037 & TRN & \\
\hline CHEMBL1437436 & 688839 & 5.4 & 5.4035 & TST & \\
\hline CHEMBL15766 & 688839 & 5.0 & 5.1825 & TST & \\
\hline CHEMBL1607106 & 688839 & 5.5 & 5.5069 & TRN & \\
\hline CHEMBL1590556 & 688839 & 4.8 & 4.9382 & TRN & \\
\hline CHEMBL521971 & 688839 & 6.6 & 6.6989 & TRN & \\
\hline CHEMBL 876 & 688839 & 6.0 & 4.9935 & TST & \\
\hline CHEMBL1595973 & 688839 & 5.8 & 5.1171 & TRN & \\
\hline CHEMBL1443163 & 688839 & 5.6 & 5.4209 & TST & \\
\hline CHEMBL1557383 & 688839 & 6.0 & 4.9826 & TRN & \\
\hline CHEMBL1520442 & 688839 & 5.5 & 5.5132 & TRN & \\
\hline CHEMBL1600187 & 688839 & 5.4 & 5.2474 & TRN & \\
\hline CHEMBL1518689 & 688839 & 5.6 & 5.7644 & TRN & \\
\hline CHEMBL1553070 & 688839 & 6.4 & 6.4217 & TRN & \\
\hline CHEMBL47529 & 688839 & 4.8 & 4.9043 & TRN & \\
\hline CHEMBL1556431 & 688839 & 4.8 & 4.7603 & TRN & \\
\hline CHEMBL1395408 & 688839 & 4.8 & 5.1648 & TST & \\
\hline CHEMBL1363801 & 688839 & 5.5 & 4.8101 & TRN & \\
\hline CHEMBL1475004 & 688839 & 4.8 & 4.7904 & TRN & \\
\hline CHEMBL54277 & 688839 & 4.9 & 5.0753 & TRN & \\
\hline CHEMBL1378704 & 688839 & 4.9 & 5.0026 & TRN & \\
\hline CHEMBL1476504 & 688839 & 5.3 & 5.2299 & TRN & \\
\hline CHEMBL 286204 & 688839 & 5.8 & 4.8333 & TST & \\
\hline CHEMBL1362729 & 688839 & 5.4 & 5.4634 & TRN & \\
\hline CHEMBL1255583 & 688839 & 4.4 & 4.659 & TRN & \\
\hline
\end{tabular}




\begin{tabular}{|c|c|c|c|c|c|}
\hline & & & & & \\
\hline CHEMBL1526543 & 688839 & 6.0 & 5.7565 & TRN & \\
\hline CHEMBL1599299 & 688839 & 6.3 & 5.1202 & TRN & \\
\hline CHEMBL454761 & 688839 & 5.5 & 5.312 & TRN & \\
\hline CHEMBL1374585 & 688839 & 4.4 & 4.5299 & TRN & \\
\hline CHEMBL1316731 & 688839 & 5.1 & 4.9649 & TRN & \\
\hline CHEMBL1394899 & 688839 & 5.4 & 5.4606 & TRN & \\
\hline CHEMBL1366297 & 688839 & 4.9 & 5.056 & TRN & \\
\hline CHEMBL1372514 & 688839 & 4.9 & 5.005 & TRN & \\
\hline CHEMBL1595002 & 688839 & 5.3 & 4.8698 & TRN & \\
\hline CHEMBL395808 & 688839 & 4.8 & 5.0801 & TRN & \\
\hline CHEMBL1330251 & 688839 & 5.7 & 5.6653 & TRN & \\
\hline CHEMBL1543632 & 688839 & 4.6 & 5.1668 & TRN & \\
\hline CHEMBL10009 & 688839 & 5.6 & 5.58899 & 99999999995 & TRN \\
\hline CHEMBL1489438 & 688839 & 4.8 & 4.841 & TRN & \\
\hline CHEMBL1328109 & 688839 & 5.5 & 5.3733 & TRN & \\
\hline CHEMBL1443413 & 688839 & 4.4 & 4.994 & TRN & \\
\hline CHEMBL1480885 & 688839 & 5.4 & 5.4019 & TRN & \\
\hline CHEMBL1490268 & 688839 & 4.9 & 5.0248 & TST & \\
\hline CHEMBL1394112 & 688839 & 4.8 & 4.7463 & TRN & \\
\hline CHEMBL1473472 & 688839 & 5.4 & 5.4564 & TRN & \\
\hline CHEMBL1361758 & 688839 & 5.0 & 5.0913 & TRN & \\
\hline CHEMBL1474185 & 688839 & 4.9 & 4.8408 & TRN & \\
\hline CHEMBL1397559 & 688839 & 5.4 & 5.3467 & TRN & \\
\hline CHEMBL1467058 & 688839 & 5.1 & 5.325 & TST & \\
\hline CHEMBL1437138 & 688839 & 6.0 & 5.9276 & TRN & \\
\hline CHEMBL1172911 & 688839 & 5.4 & 5.2239 & TST & \\
\hline CHEMBL1400491 & 688839 & 5.6 & 5.4659 & TRN & \\
\hline CHEMBL188641 & 688839 & 5.4 & 5.3125 & TST & \\
\hline CHEMBL 102740 & 688839 & 4.4 & 5.1393 & TST & \\
\hline CHEMBL1356794 & 688839 & 5.2 & 5.188 & TRN & \\
\hline CHEMBL1370296 & 688839 & 5.4 & 5.4418 & TRN & \\
\hline CHEMBL1448331 & 688839 & 4.4 & 4.9218 & TST & \\
\hline CHEMBL1328533 & 688839 & 6.1 & 6.1031 & TRN & \\
\hline CHEMBL430893 & 688839 & 6.0 & 5.8106 & TST & \\
\hline CHEMBL1373071 & 688839 & 5.6 & 5.1925 & TRN & \\
\hline CHEMBL1553274 & 688839 & 4.4 & 5.2319 & TST & \\
\hline CHEMBL1594258 & 688839 & 5.4 & 5.0377 & TRN & \\
\hline CHEMBL1317853 & 688839 & 5.1 & 5.0756 & TRN & \\
\hline CHEMBL405760 & 688839 & 5.1 & 5.3268 & TRN & \\
\hline CHEMBL1557170 & 688839 & 5.4 & 5.4448 & TRN & \\
\hline CHEMBL1403488 & 688839 & 5.6 & 5.476 & TRN & \\
\hline CHEMBL1373259 & 688839 & 5.6 & 5.4231 & TRN & \\
\hline CHEMBL2374036 & 688839 & 5.2 & 5.2834 & TST & \\
\hline CHEMBL1556456 & 688839 & 5.1 & 5.1225 & TRN & \\
\hline CHEMBL1520593 & 688839 & 5.4 & 5.2024 & TRN & \\
\hline CHEMBL1554851 & 688839 & 5.2 & 5.1555 & TRN & \\
\hline CHEMBL 2373593 & 688839 & 5.4 & 5.2048 & TRN & \\
\hline CHEMBL1551925 & 688839 & 5.3 & 5.2935 & TRN & \\
\hline & & & & 20372 & \\
\hline
\end{tabular}




\begin{tabular}{|c|c|c|c|c|c|}
\hline \\
\hline CHEMBL1514923 & 688839 & 6.6 & 6.1515 & TRN & \\
\hline CHEMBL1554569 & 688839 & 4.8 & 4.938 & TRN & \\
\hline CHEMBL1331521 & 688839 & 4.5 & 5.1458 & TRN & \\
\hline CHEMBL1358666 & 688839 & 5.4 & 5.3895 & TRN & \\
\hline CHEMBL1449371 & 688839 & 5.8 & 5.5545 & TRN & \\
\hline CHEMBL1356113 & 688839 & 5.5 & 5.5237 & TRN & \\
\hline CHEMBL1338909 & 688839 & 4.9 & 5.1019 & TRN & \\
\hline CHEMBL1561922 & 688839 & 5.1 & 4.7468 & TRN & \\
\hline CHEMBL1490938 & 688839 & 4.8 & 5.4304 & TRN & \\
\hline CHEMBL508494 & 688839 & 6.3 & 4.9941 & TRN & \\
\hline CHEMBL1555991 & 688839 & 4.8 & 4.8298 & TRN & \\
\hline CHEMBL1357520 & 688839 & 5.1 & 5.1237 & TRN & \\
\hline CHEMBL1532023 & 688839 & 5.4 & 5.4198 & TRN & \\
\hline CHEMBL1435886 & 688839 & 4.9 & 4.9029 & TRN & \\
\hline CHEMBL1256816 & 688839 & 4.8 & 4.9059 & TST & \\
\hline CHEMBL1256674 & 688839 & 4.8 & 5.0676 & TST & \\
\hline CHEMBL1475142 & 688839 & 5.5 & 5.1079 & TRN & \\
\hline CHEMBL1518067 & 688839 & 4.8 & 4.8632 & TRN & \\
\hline CHEMBL1355982 & 688839 & 5.3 & 5.2906 & TST & \\
\hline CHEMBL1396630 & 688839 & 5.4 & 5.1838 & TRN & \\
\hline CHEMBL1356775 & 688839 & 4.6 & 4.8423 & TST & \\
\hline CHEMBL1357231 & 688839 & 5.4 & 5.42 & TRN & \\
\hline CHEMBL1512025 & 688839 & 5.4 & 5.2254 & TST & \\
\hline CHEMBL1354864 & 688839 & 5.5 & 5.3818 & TRN & \\
\hline CHEMBL1315504 & 688839 & 6.1 & 6.0643 & TRN & \\
\hline CHEMBL1551122 & 688839 & 5.7 & 5.8125 & TRN & \\
\hline CHEMBL1570971 & 688839 & 5.4 & 5.341 & TRN & \\
\hline CHEMBL1480880 & 688839 & 5.4 & 5.4316 & TRN & \\
\hline CHEMBL1368062 & 688839 & 5.8 & 5.1801 & TRN & \\
\hline CHEMBL1477870 & 688839 & 5.4 & 4.9819 & TRN & \\
\hline CHEMBL1355088 & 688839 & 5.7 & $5.3610 e$ & 2000000001 & TRN \\
\hline CHEMBL 28626 & 688839 & 4.5 & 5.5041 & TRN & \\
\hline CHEMBL402063 & 688839 & 6.0 & 5.2426 & TRN & \\
\hline CHEMBL24909 & 688839 & 6.2 & 6.1224 & TRN & \\
\hline CHEMBL1530654 & 688839 & 5.1 & 4.8667 & TRN & \\
\hline CHEMBL1564545 & 688839 & 4.8 & 4.8132 & TRN & \\
\hline CHEMBL1372997 & 688839 & 5.5 & 5.4109 & TST & \\
\hline CHEMBL1358359 & 688839 & 5.4 & 5.2993 & TRN & \\
\hline CHEMBL1552540 & 688839 & 5.0 & 5.0973 & TRN & \\
\hline CHEMBL1474523 & 688839 & 4.4 & 5.37799 & 9999999999 & TRN \\
\hline CHEMBL1473761 & 688839 & 4.9 & 5.0448 & TRN & \\
\hline CHEMBL1513121 & 688839 & 5.1 & 5.0944 & TRN & \\
\hline CHEMBL1435477 & 688839 & 6.0 & $5.7120 e$ & 0000000001 & TST \\
\hline CHEMBL1594436 & 688839 & 5.4 & 5.1179 & TRN & \\
\hline CHEMBL1371397 & 688839 & 5.1 & 5.2202 & TST & \\
\hline CHEMBL1553768 & 688839 & 6.0 & 5.8775 & TST & \\
\hline CHEMBL423081 & 688839 & 4.5 & 5.1307 & TST & \\
\hline CHEMBL1733652 & 688839 & 6.4 & 5.0756 & TST & \\
\hline & & & & 2037 & \\
\hline
\end{tabular}




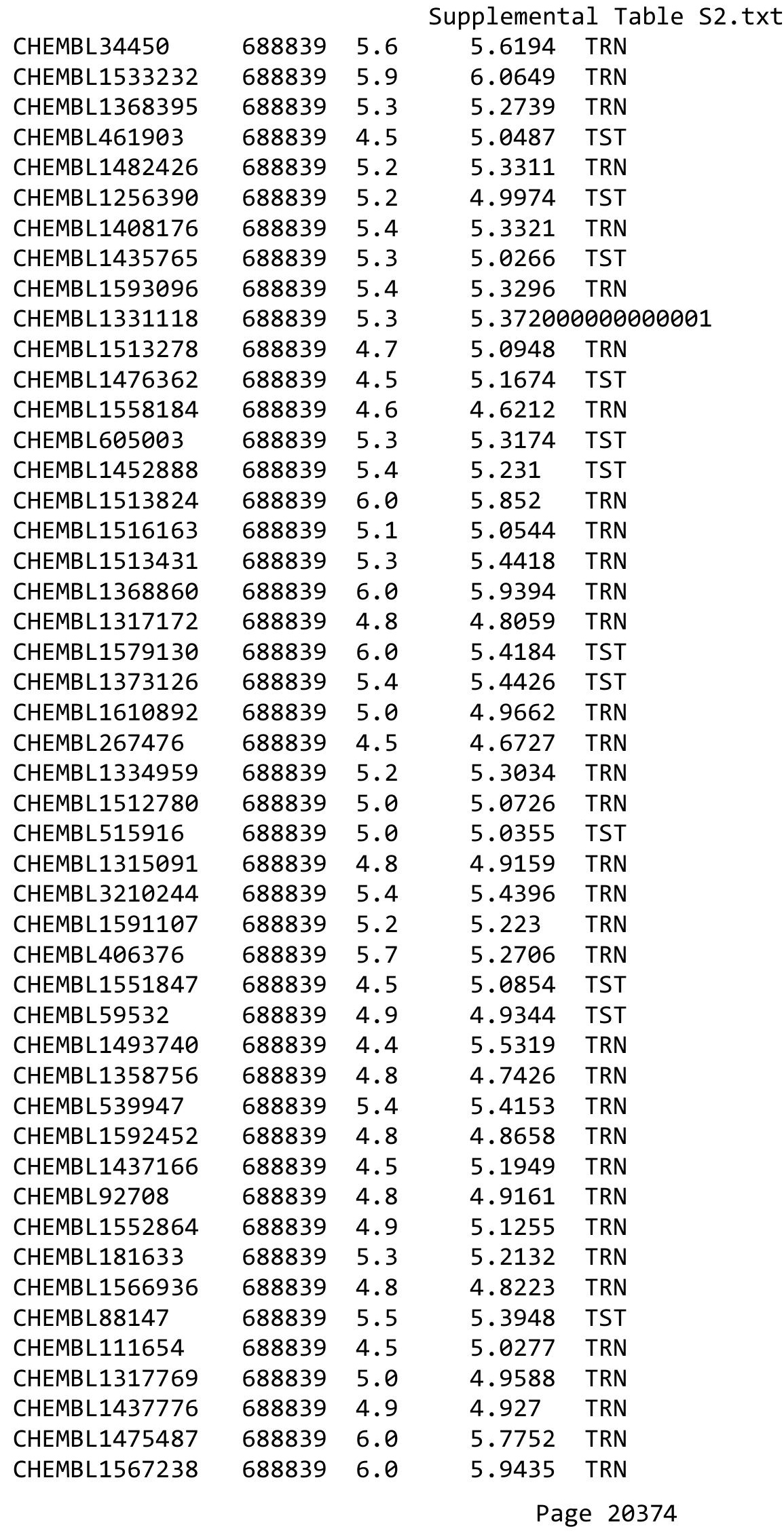

TRN 


\begin{tabular}{|c|c|c|c|c|}
\hline \multicolumn{5}{|c|}{ Supplemental Tab } \\
\hline CHEMBL1592672 & 688839 & 4.8 & 4.8537 & TRN \\
\hline CHEMBL118109 & 688839 & 5.4 & 5.3637 & TRN \\
\hline CHEMBL1405759 & 688839 & 4.9 & 4.9594 & TST \\
\hline CHEMBL1400050 & 688839 & 6.0 & 5.99 & TRN \\
\hline CHEMBL1472837 & 688839 & 5.2 & 5.2838 & TRN \\
\hline CHEMBL1434085 & 688839 & 4.9 & 4.919 & TRN \\
\hline CHEMBL1451483 & 688839 & 4.6 & 5.1322 & TRN \\
\hline CHEMBL1406971 & 688839 & 5.5 & 5.1472 & TRN \\
\hline CHEMBL1327619 & 688839 & 5.1 & 5.2314 & TRN \\
\hline CHEMBL1417025 & 688839 & 4.7 & 4.7824 & TRN \\
\hline CHEMBL3209838 & 688839 & 5.5 & 5.5248 & TRN \\
\hline CHEMBL1447149 & 688839 & 5.3 & 5.1845 & TRN \\
\hline CHEMBL1481465 & 688839 & 5.4 & 5.4979 & TRN \\
\hline CHEMBL1316368 & 688839 & 5.0 & 5.0507 & TST \\
\hline CHEMBL1354186 & 688839 & 5.5 & 5.1143 & TRN \\
\hline CHEMBL 1527622 & 688839 & 5.8 & 5.5933 & TST \\
\hline CHEMBL1435118 & 688839 & 4.4 & 5.2277 & TRN \\
\hline CHEMBL1516545 & 688839 & 4.8 & 5.2306 & TST \\
\hline CHEMBL1314564 & 688839 & 5.4 & 5.2721 & TRN \\
\hline CHEMBL1327358 & 688839 & 5.0 & 5.2096 & TRN \\
\hline CHEMBL 1370553 & 688839 & 4.6 & 4.6454 & TRN \\
\hline CHEMBL1568019 & 688839 & 5.5 & 5.5595 & TRN \\
\hline CHEMBL1607133 & 688839 & 5.9 & 6.0027 & TRN \\
\hline CHEMBL1326015 & 688839 & 4.9 & 4.9485 & TST \\
\hline CHEMBL1736254 & 688839 & 5.5 & 5.4576 & TST \\
\hline CHEMBL1552353 & 688839 & 4.5 & 4.5662 & TRN \\
\hline CHEMBL1513478 & 688839 & 4.7 & 4.6957 & TRN \\
\hline CHEMBL1403310 & 688839 & 5.9 & 5.2298 & TRN \\
\hline CHEMBL1445399 & 688839 & 4.8 & 4.9336 & TST \\
\hline CHEMBL 229908 & 688839 & 4.7 & 5.1066 & TRN \\
\hline CHEMBL1521167 & 688839 & 6.0 & 5.4071 & TRN \\
\hline CHEMBL1409369 & 688839 & 5.5 & 5.4043 & TRN \\
\hline CHEMBL1519490 & 688839 & 6.0 & 5.6854 & TRN \\
\hline CHEMBL1474695 & 688839 & 5.2 & 5.2598 & TRN \\
\hline CHEMBL538146 & 688839 & 5.0 & 5.0457 & TST \\
\hline CHEMBL1358731 & 688839 & 5.4 & 5.2376 & TRN \\
\hline CHEMBL34704 & 688839 & 6.0 & 5.7134 & TST \\
\hline CHEMBL 1494832 & 688839 & 4.9 & 4.8875 & TRN \\
\hline CHEMBL1357491 & 688839 & 4.6 & 4.6111 & TRN \\
\hline CHEMBL1474664 & 688839 & 4.8 & 5.0796 & TRN \\
\hline CHEMBL1456076 & 688839 & 5.2 & 5.1197 & TRN \\
\hline CHEMBL1402369 & 688839 & 5.6 & 5.4903 & TRN \\
\hline CHEMBL1569962 & 688839 & 5.5 & 5.4164 & TRN \\
\hline CHEMBL1358758 & 688839 & 5.2 & 5.4038 & TRN \\
\hline CHEMBL1357956 & 688839 & 4.8 & 4.816 & TRN \\
\hline CHEMBL1355292 & 688839 & 4.5 & 4.5543 & TRN \\
\hline CHEMBL1366106 & 688839 & 5.1 & 4.9152 & TRN \\
\hline CHEMBL 274438 & 688839 & 5.9 & 5.6955 & TRN \\
\hline
\end{tabular}




\begin{tabular}{|c|c|c|c|c|}
\hline \multicolumn{5}{|c|}{ Supplemental Table S2.txt } \\
\hline CHEMBL1356196 & 688839 & 5.3 & 5.2849 & TRN \\
\hline CHEMBL1603418 & 688839 & 4.8 & 4.8436 & TRN \\
\hline CHEMBL1554826 & 688839 & 4.8 & 4.7847 & TRN \\
\hline CHEMBL1554637 & 688839 & 4.6 & 4.7003 & TRN \\
\hline CHEMBL1450334 & 688839 & 4.8 & 4.9162 & TST \\
\hline CHEMBL1288013 & 688839 & 5.6 & 5.5722 & TRN \\
\hline CHEMBL1438138 & 688839 & 5.4 & 5.211 & TRN \\
\hline CHEMBL1441843 & 688839 & 4.7 & 4.6789 & TRN \\
\hline CHEMBL428130 & 688839 & 5.6 & 5.2544 & TRN \\
\hline CHEMBL1552720 & 688839 & 5.3 & 5.1878 & TRN \\
\hline CHEMBL53898 & 688839 & 5.6 & 5.5958 & TRN \\
\hline CHEMBL1594132 & 688839 & 5.0 & 5.1452 & TRN \\
\hline CHEMBL1358449 & 688839 & 7.5003 & 6.8529 & TRN \\
\hline CHEMBL12014 & 688839 & 5.4 & 5.2932 & TRN \\
\hline CHEMBL1316953 & 688839 & 6.0 & 5.3169 & TRN \\
\hline CHEMBL1399058 & 688839 & 5.1 & 5.1635 & TRN \\
\hline CHEMBL154533 & 688839 & 4.9 & 5.0795 & TRN \\
\hline CHEMBL148296 & 688839 & 4.6 & 4.6454 & TRN \\
\hline CHEMBL1592211 & 688839 & 6.1 & 6.2515 & TRN \\
\hline CHEMBL1515508 & 688839 & 4.5 & 4.5831 & TRN \\
\hline CHEMBL1561408 & 688839 & 4.4 & 5.0036 & TRN \\
\hline CHEMBL1476043 & 688839 & 5.1 & 5.1663 & TRN \\
\hline CHEMBL251647 & 688839 & 6.0 & 5.8577 & TST \\
\hline CHEMBL1557053 & 688839 & 5.7 & 5.442 & TRN \\
\hline CHEMBL1435053 & 688839 & 5.0 & 5.0254 & TST \\
\hline CHEMBL1592227 & 688839 & 5.7 & 5.8334 & TRN \\
\hline CHEMBL1560798 & 688839 & 5.1 & 5.1917 & TRN \\
\hline CHEMBL1335406 & 688839 & 4.8 & 4.9194 & TST \\
\hline CHEMBL1554723 & 688839 & 5.4 & 5.3046 & TRN \\
\hline CHEMBL1597107 & 688839 & 5.1 & 5.0841 & TRN \\
\hline CHEMBL1433752 & 688839 & 5.4 & 5.4944 & TRN \\
\hline CHEMBL1437006 & 688839 & 5.2 & 5.1443 & TST \\
\hline CHEMBL476135 & 688839 & 6.0 & 5.7846 & TST \\
\hline CHEMBL1256940 & 688839 & 5.7 & 5.7873 & TRN \\
\hline CHEMBL1591860 & 688839 & 5.8 & 5.5979 & TRN \\
\hline CHEMBL1552854 & 688839 & 5.7 & 5.6823 & TRN \\
\hline CHEMBL 1450080 & 688839 & 4.7 & 5.1922 & TST \\
\hline CHEMBL1591336 & 688839 & 4.8 & 4.8271 & TRN \\
\hline CHEMBL497939 & 688839 & 6.0 & 4.7244 & TST \\
\hline CHEMBL1475083 & 688839 & 5.6 & 5.6495 & TRN \\
\hline CHEMBL1559127 & 688839 & 5.1 & 5.2144 & TRN \\
\hline CHEMBL1433593 & 688839 & 5.2 & 5.1869 & TRN \\
\hline CHEMBL1570413 & 688839 & 4.8 & 4.712 & TRN \\
\hline CHEMBL1397552 & 688839 & 4.9 & 5.2572 & TRN \\
\hline CHEMBL1359613 & 688839 & 4.8 & 5.0102 & TRN \\
\hline CHEMBL1526572 & 688839 & 5.6 & 5.5136 & TRN \\
\hline CHEMBL310798 & 688839 & 5.0 & 4.9498 & TRN \\
\hline CHEMBL1316464 & 688839 & 5.4 & 5.3231 & TRN \\
\hline
\end{tabular}




\begin{tabular}{|c|c|c|c|c|c|}
\hline & & & & & \\
\hline CHEMBL1487836 & 688839 & 5.4 & 5.2195 & TRN & \\
\hline CHEMBL560020 & 688839 & 4.5 & 5.0182 & TST & \\
\hline CHEMBL1369871 & 688839 & 4.8 & 4.9069 & TRN & \\
\hline CHEMBL1355335 & 688839 & 4.8 & 5.0402 & TRN & \\
\hline CHEMBL1595576 & 688839 & 5.4 & 5.3734 & TRN & \\
\hline CHEMBL1315926 & 688839 & 5.6 & 4.95 & TRN & \\
\hline CHEMBL1479661 & 688839 & 5.8 & 5.1909 & TRN & \\
\hline CHEMBL1394765 & 688839 & 5.0 & 5.01 & TRN & \\
\hline CHEMBL1357401 & 688839 & 4.6 & 4.7274 & TRN & \\
\hline CHEMBL1327059 & 688839 & 4.6 & 4.7027 & TRN & \\
\hline CHEMBL1316709 & 688839 & 4.8 & 4.7578 & TRN & \\
\hline CHEMBL1413858 & 688839 & 5.1 & 5.0691 & TRN & \\
\hline CHEMBL1437294 & 688839 & 5.2 & 5.3207 & TRN & \\
\hline CHEMBL1486930 & 688839 & 4.9 & 5.0148 & TRN & \\
\hline CHEMBL1355340 & 688839 & 5.5 & 5.1384 & TRN & \\
\hline CHEMBL1596847 & 688839 & 5.1 & 4.96 & TST & \\
\hline CHEMBL 375270 & 688839 & 4.6 & 4.723 & TRN & \\
\hline CHEMBL1355896 & 688839 & 6.5 & 6.396 & TRN & \\
\hline CHEMBL1554183 & 688839 & 4.8 & 4.8753 & TST & \\
\hline CHEMBL1611856 & 688839 & 5.3 & 5.1879 & TRN & \\
\hline CHEMBL28 & 688839 & 6.0 & 5.7937 & TRN & \\
\hline CHEMBL1447239 & 688839 & 6.1 & 5.4857 & TRN & \\
\hline CHEMBL1552677 & 688839 & 4.5 & 4.76699 & 99999999995 & TRN \\
\hline CHEMBL1335890 & 688839 & 6.0 & 6.1071 & TRN & \\
\hline CHEMBL1526849 & 688839 & 5.3 & 5.2882 & TST & \\
\hline CHEMBL399249 & 688839 & 4.9 & 5.0885 & TRN & \\
\hline CHEMBL1441981 & 688839 & 6.0 & 6.0645 & TRN & \\
\hline CHEMBL1573063 & 688839 & 5.9 & 6.0138 & TRN & \\
\hline CHEMBL1605152 & 688839 & 5.5 & 5.5066 & TRN & \\
\hline CHEMBL1489211 & 688839 & 5.7 & 5.6879 & TRN & \\
\hline CHEMBL1363622 & 688839 & 4.5 & 4.6318 & TRN & \\
\hline CHEMBL1496378 & 688839 & 6.0 & 5.0323 & TRN & \\
\hline CHEMBL1325833 & 688839 & 5.7 & 5.6018 & TRN & \\
\hline CHEMBL1336812 & 688839 & 4.9 & 5.0154 & TST & \\
\hline CHEMBL1604387 & 688839 & 5.3 & 5.102 & TST & \\
\hline CHEMBL1512312 & 688839 & 4.8 & 4.885 & TRN & \\
\hline CHEMBL388342 & 688839 & 6.0 & 4.9316 & TRN & \\
\hline CHEMBL1533197 & 688839 & 5.1 & 5.0883 & TRN & \\
\hline CHEMBL1394661 & 688839 & 5.5 & 5.4797 & TRN & \\
\hline CHEMBL1475075 & 688839 & 5.8 & 5.7174 & TRN & \\
\hline CHEMBL1521453 & 688839 & 6.0 & 5.7859 & TST & \\
\hline CHEMBL1364611 & 688839 & 5.9 & 5.8223 & TRN & \\
\hline CHEMBL1598394 & 688839 & 4.9 & 5.1219 & TRN & \\
\hline CHEMBL1595166 & 688839 & 6.5 & 6.28299 & 99999999995 & TRN \\
\hline CHEMBL1441737 & 688839 & 5.1 & 5.1415 & TRN & \\
\hline CHEMBL1592220 & 688839 & 5.3 & 5.086 & TRN & \\
\hline CHEMBL1523816 & 688839 & 4.6 & 4.9208 & TRN & \\
\hline CHEMBL1376378 & 688839 & 4.5 & 5.0105 & TST & \\
\hline & & & & 20377 & \\
\hline
\end{tabular}




\begin{tabular}{|c|c|c|c|c|c|}
\hline & & & & & \\
\hline CHEMBL1554960 & 688839 & 4.8 & 4.8122 & TRN & \\
\hline CHEMBL1331634 & 688839 & 6.0 & 6.0631 & TRN & \\
\hline CHEMBL1435261 & 688839 & 4.6 & 5.2369 & TST & \\
\hline CHEMBL1590968 & 688839 & 4.8 & 4.8043 & TRN & \\
\hline CHEMBL1610387 & 688839 & 4.9 & 4.9656 & TRN & \\
\hline CHEMBL1496203 & 688839 & 5.5 & 5.3669 & TRN & \\
\hline CHEMBL1405325 & 688839 & 5.2 & 5.1632 & TST & \\
\hline CHEMBL1447909 & 688839 & 5.7 & 5.897 & TRN & \\
\hline CHEMBL1609896 & 688839 & 5.5 & 5.3356 & TRN & \\
\hline CHEMBL583849 & 688839 & 5.0 & 5.081 & TRN & \\
\hline CHEMBL440687 & 688839 & 4.6 & 5.1034 & TRN & \\
\hline CHEMBL1358200 & 688839 & 4.9 & 5.1204 & TRN & \\
\hline CHEMBL1317059 & 688839 & 4.8 & 5.0964 & TST & \\
\hline CHEMBL1358708 & 688839 & 4.9 & 4.9748 & TST & \\
\hline CHEMBL491991 & 688839 & 5.4 & 5.0991 & TRN & \\
\hline CHEMBL1434783 & 688839 & 4.6 & 4.6494 & TRN & \\
\hline CHEMBL1551777 & 688839 & 6.5 & 6.4554 & TRN & \\
\hline CHEMBL1593998 & 688839 & 4.7 & 5.0811 & TRN & \\
\hline CHEMBL1433731 & 688839 & 5.2 & 4.9637 & TRN & \\
\hline CHEMBL 1357530 & 688839 & 4.7 & 4.7537 & TRN & \\
\hline CHEMBL1456755 & 688839 & 5.4 & 5.3408 & TST & \\
\hline CHEMBL1491744 & 688839 & 5.4 & 5.5255 & TRN & \\
\hline CHEMBL1375862 & 688839 & 5.0 & 5.2959 & TST & \\
\hline CHEMBL1481781 & 688839 & 5.5 & 5.4195 & TRN & \\
\hline CHEMBL1319286 & 688839 & 4.9 & 4.9755 & TRN & \\
\hline CHEMBL1433724 & 688839 & 6.2 & 6.20299 & 9999999999 & TRN \\
\hline CHEMBL1374710 & 688839 & 4.9 & 4.9156 & TRN & \\
\hline CHEMBL322970 & 688839 & 4.9 & 4.8105 & TST & \\
\hline CHEMBL1591910 & 688839 & 4.9 & 5.2021 & TST & \\
\hline CHEMBL1443480 & 688839 & 4.6 & 4.8191 & TRN & \\
\hline CHEMBL175296 & 688839 & 4.7 & 5.1139 & TRN & \\
\hline CHEMBL1324110 & 688839 & 4.8 & 5.0411 & TRN & \\
\hline CHEMBL1435788 & 688839 & 5.4 & 5.2465 & TRN & \\
\hline CHEMBL1408259 & 688839 & 6.0 & 5.9551 & TRN & \\
\hline CHEMBL536480 & 688839 & 5.2 & 5.1397 & TRN & \\
\hline CHEMBL1415465 & 688839 & 4.7 & 4.7163 & TRN & \\
\hline CHEMBL 258860 & 688839 & 5.2 & 5.1929 & TRN & \\
\hline CHEMBL187216 & 688839 & 5.5 & 5.4174 & TST & \\
\hline CHEMBL458765 & 688839 & 5.5 & 5.3203 & TST & \\
\hline CHEMBL1409682 & 688839 & 6.1 & 5.8168 & TST & \\
\hline CHEMBL1405461 & 688839 & 6.0 & 5.9863 & TRN & \\
\hline CHEMBL1487191 & 688839 & 5.4 & 5.3645 & TRN & \\
\hline CHEMBL1355634 & 688839 & 4.8 & 4.8574 & TRN & \\
\hline CHEMBL1555238 & 688839 & 4.7 & 4.7119 & TRN & \\
\hline CHEMBL1473925 & 688839 & 4.8 & 4.8369 & TRN & \\
\hline CHEMBL1569421 & 688839 & 5.5 & $4.7360 e$ & 0000000001 & TRN \\
\hline CHEMBL1512719 & 688839 & 6.0 & 5.2467 & TST & \\
\hline CHEMBL10284 & 688839 & 5.1 & 5.1288 & TST & \\
\hline & & & & 20378 & \\
\hline
\end{tabular}




\begin{tabular}{|c|c|c|c|c|c|}
\hline & & & & & \\
\hline CHEMBL1447383 & 688839 & 6.0 & 5.1823 & TST & \\
\hline CHEMBL1255934 & 688839 & 5.9 & 5.6645 & TST & \\
\hline CHEMBL1317237 & 688839 & 5.4 & 5.2261 & TRN & \\
\hline CHEMBL1332204 & 688839 & 4.8 & 5.1841 & TRN & \\
\hline CHEMBL1316158 & 688839 & 4.7 & 4.6925 & TRN & \\
\hline CHEMBL1436075 & 688839 & 5.2 & 5.2103 & TRN & \\
\hline CHEMBL1362482 & 688839 & 5.1 & 5.0328 & TRN & \\
\hline CHEMBL1433798 & 688839 & 5.1 & 5.0869 & TRN & \\
\hline CHEMBL509150 & 688839 & 6.7001 & 6.67200 & 0000000001 & TRN \\
\hline CHEMBL1561076 & 688839 & 4.5 & 5.1182 & TRN & \\
\hline CHEMBL1372588 & 688839 & 4.9 & 5.1217 & TST & \\
\hline CHEMBL334378 & 688839 & 5.0 & 5.1356 & TST & \\
\hline CHEMBL1339029 & 688839 & 5.3 & 5.2764 & TRN & \\
\hline CHEMBL1532555 & 688839 & 4.9 & 4.8615 & TRN & \\
\hline CHEMBL1436037 & 688839 & 5.4 & 5.4749 & TRN & \\
\hline CHEMBL1554308 & 688839 & 5.5 & 5.3608 & TRN & \\
\hline CHEMBL1355855 & 688839 & 5.5 & 5.4275 & TST & \\
\hline CHEMBL44072 & 688839 & 4.9 & 5.052 & TST & \\
\hline CHEMBL85811 & 688839 & 4.5 & 4.9442 & TRN & \\
\hline CHEMBL1525886 & 688839 & 5.4 & 5.3371 & TST & \\
\hline CHEMBL1315318 & 688839 & 5.4 & 5.4978 & TRN & \\
\hline CHEMBL1559269 & 688839 & 4.8 & 5.0204 & TRN & \\
\hline CHEMBL1336060 & 688839 & 4.8 & 4.8599 & TRN & \\
\hline CHEMBL1337755 & 688839 & 6.0 & 5.7461 & TST & \\
\hline CHEMBL1605255 & 688839 & 5.0 & 5.0311 & TRN & \\
\hline CHEMBL1484261 & 688839 & 6.3 & 6.3745 & TRN & \\
\hline CHEMBL1514027 & 688839 & 4.5 & 4.5933 & TRN & \\
\hline CHEMBL1330692 & 688839 & 5.4 & 5.4887 & TRN & \\
\hline CHEMBL1513821 & 688839 & 4.9 & 5.1694 & TST & \\
\hline CHEMBL244948 & 688839 & 4.9 & 4.9295 & TRN & \\
\hline CHEMBL1356998 & 688839 & 5.0 & 4.9153 & TRN & \\
\hline CHEMBL447507 & 688839 & 6.4 & 6.527 & TRN & \\
\hline CHEMBL1483716 & 688839 & 7.5003 & 5.1589 & TRN & \\
\hline CHEMBL1591508 & 688839 & 4.8 & 4.873 & TST & \\
\hline CHEMBL1591238 & 688839 & 5.9 & 5.9906 & TRN & \\
\hline CHEMBL36028 & 688839 & 4.6 & 4.8422 & TRN & \\
\hline CHEMBL1486734 & 688839 & 5.8 & 5.9288 & TRN & \\
\hline CHEMBL10347 & 688839 & 6.0 & 5.8134 & TST & \\
\hline CHEMBL1356652 & 688839 & 6.2 & 6.2236 & TRN & \\
\hline CHEMBL24510 & 688839 & 4.6 & 4.7239 & TRN & \\
\hline CHEMBL 8145 & 688839 & 6.0 & 4.8427 & TRN & \\
\hline CHEMBL1606038 & 688839 & 5.5 & 5.5016 & TRN & \\
\hline CHEMBL1484689 & 688839 & 5.4 & 5.5632 & TRN & \\
\hline CHEMBL1314674 & 688839 & 4.8 & 4.8659 & TRN & \\
\hline CHEMBL1336025 & 688839 & 6.0 & 5.20200 & 2000000001 & TRN \\
\hline CHEMBL1533335 & 688839 & 5.5 & 5.4927 & TRN & \\
\hline CHEMBL1366629 & 688839 & 5.3 & 5.131 & TRN & \\
\hline CHEMBL1356463 & 688839 & 5.4 & 5.5868 & TRN & \\
\hline & & & & 20379 & \\
\hline
\end{tabular}




\begin{tabular}{|c|c|c|c|c|c|}
\hline & & & & & \\
\hline CHEMBL1335862 & 688839 & 5.9 & 5.6537 & TST & \\
\hline CHEMBL1396546 & 688839 & 5.6 & 5.1257 & TRN & \\
\hline CHEMBL1200765 & 688839 & 6.0 & 5.0814 & TST & \\
\hline CHEMBL1414251 & 688839 & 5.1 & 5.4388 & TRN & \\
\hline CHEMBL1371677 & 688839 & 4.8 & 5.6632 & TRN & \\
\hline CHEMBL1317016 & 688839 & 5.6 & 5.2668 & TST & \\
\hline CHEMBL105739 & 688839 & 5.1 & 5.1267 & TST & \\
\hline CHEMBL1356783 & 688839 & 4.9 & 5.3248 & TRN & \\
\hline CHEMBL1514440 & 688839 & 6.0 & 5.8376 & TRN & \\
\hline CHEMBL1317998 & 688839 & 5.3 & 5.3191 & TRN & \\
\hline CHEMBL1591381 & 688839 & 4.8 & 4.7524 & TRN & \\
\hline CHEMBL1597911 & 688839 & 5.8 & 5.0271 & TST & \\
\hline CHEMBL1474318 & 688839 & 5.1 & 5.0877 & TRN & \\
\hline CHEMBL518494 & 688839 & 4.4 & $5.1770 e$ & 00000000005 & TST \\
\hline CHEMBL1334895 & 688839 & 4.6 & 5.0016 & TST & \\
\hline CHEMBL1331579 & 688839 & 5.5 & 5.4658 & TRN & \\
\hline CHEMBL1553114 & 688839 & 5.3 & 5.2871 & TRN & \\
\hline CHEMBL1354398 & 688839 & 4.5 & 4.7048 & TST & \\
\hline CHEMBL1322719 & 688839 & 5.8 & 5.7511 & TST & \\
\hline CHEMBL8618 & 688839 & 6.0 & 5.7101 & TRN & \\
\hline CHEMBL1571264 & 688839 & 5.0 & 5.0026 & TRN & \\
\hline CHEMBL1371587 & 688839 & 4.7 & 5.1245 & TRN & \\
\hline CHEMBL574181 & 688839 & 5.5 & 5.395 & TRN & \\
\hline CHEMBL1473123 & 688839 & 5.2 & 5.1175 & TRN & \\
\hline CHEMBL1317802 & 688839 & 4.9 & 4.9349 & TRN & \\
\hline CHEMBL1403333 & 688839 & 5.3 & 5.1726 & TRN & \\
\hline CHEMBL1319120 & 688839 & 5.6 & 5.8588 & TRN & \\
\hline CHEMBL1404315 & 688839 & 5.4 & 5.4126 & TRN & \\
\hline CHEMBL28517 & 688839 & 4.5 & 5.149 & TST & \\
\hline CHEMBL1318293 & 688839 & 4.8 & 4.9069 & TRN & \\
\hline CHEMBL1396664 & 688839 & 4.4 & 4.6653 & TRN & \\
\hline CHEMBL1314486 & 688839 & 6.1 & 6.2658 & TRN & \\
\hline CHEMBL1370480 & 688839 & 4.5 & 4.7233 & TRN & \\
\hline CHEMBL1079421 & 688839 & 4.6 & 4.8548 & TRN & \\
\hline CHEMBL1592202 & 688839 & 4.9 & 4.893 & TRN & \\
\hline CHEMBL1325732 & 688839 & 6.2 & 5.9344 & TST & \\
\hline CHEMBL1591903 & 688839 & 5.4 & 5.4323 & TRN & \\
\hline CHEMBL 267014 & 688839 & 4.9 & 4.857 & TRN & \\
\hline CHEMBL1497006 & 688839 & 4.8 & 5.067 & TRN & \\
\hline CHEMBL1515410 & 688839 & 5.1 & 4.8739 & TRN & \\
\hline CHEMBL1481741 & 688839 & 4.5 & 4.7124 & TRN & \\
\hline CHEMBL3207903 & 688839 & 5.5 & 5.5395 & TRN & \\
\hline CHEMBL491960 & 688839 & 6.2 & 5.9281 & TST & \\
\hline CHEMBL1317066 & 688839 & 4.9 & 4.9616 & TRN & \\
\hline CHEMBL1317058 & 688839 & 4.4 & 5.1557 & TST & \\
\hline CHEMBL1554170 & 688839 & 5.6 & 5.784 & TRN & \\
\hline CHEMBL1434513 & 688839 & 4.5 & 5.1328 & TRN & \\
\hline CHEMBL1592963 & 688839 & 5.4 & 5.3992 & TRN & \\
\hline & & & & 20380 & \\
\hline
\end{tabular}




\begin{tabular}{|c|c|c|c|c|}
\hline \multicolumn{5}{|c|}{ pplemental $\mathrm{T}$} \\
\hline CHEMBL1603884 & 688839 & 5.4 & 5.2026 & TRN \\
\hline CHEMBL1513247 & 688839 & 4.9 & 5.1319 & TRN \\
\hline CHEMBL1449528 & 688839 & 5.8 & 5.7599 & TRN \\
\hline CHEMBL1441052 & 688839 & 4.5 & 4.5691 & TRN \\
\hline CHEMBL1512222 & 688839 & 4.7 & 4.6858 & TRN \\
\hline CHEMBL1590242 & 688839 & 4.7 & 4.6872 & TRN \\
\hline CHEMBL2373656 & 688839 & 5.8 & 5.2403 & TST \\
\hline CHEMBL 29097 & 688839 & 4.8 & 4.7822 & TRN \\
\hline CHEMBL1317943 & 688839 & 4.5 & 4.5963 & TRN \\
\hline CHEMBL1552949 & 688839 & 5.4 & 5.4754 & TRN \\
\hline CHEMBL1325766 & 688839 & 5.5 & 5.4374 & TRN \\
\hline CHEMBL1512895 & 688839 & 4.8 & 4.7281 & TRN \\
\hline CHEMBL1476642 & 688839 & 4.6 & 5.0745 & TRN \\
\hline CHEMBL1435409 & 688839 & 6.3 & 6.3307 & TRN \\
\hline CHEMBL1490313 & 688839 & 4.8 & 5.2262 & TRN \\
\hline CHEMBL1529384 & 688839 & 5.4 & 5.4585 & TRN \\
\hline CHEMBL1403121 & 688839 & 5.2 & 5.3236 & TRN \\
\hline CHEMBL492611 & 688839 & 5.6 & 5.5635 & TRN \\
\hline CHEMBL1358743 & 688839 & 6.4 & 5.2364 & TST \\
\hline CHEMBL1355718 & 688839 & 4.8 & 4.8838 & TRN \\
\hline CHEMBL1443393 & 688839 & 4.8 & 4.8457 & TRN \\
\hline CHEMBL77971 & 688839 & 6.4 & 6.0566 & TST \\
\hline CHEMBL1476134 & 688839 & 5.3 & 5.1947 & TRN \\
\hline CHEMBL1610003 & 688839 & 4.6 & 4.5866 & TRN \\
\hline CHEMBL1364366 & 688839 & 5.1 & 5.2411 & TRN \\
\hline CHEMBL1437095 & 688839 & 6.2 & 6.2114 & TRN \\
\hline CHEMBL1618718 & 688839 & 4.7 & 4.7967 & TST \\
\hline CHEMBL1336932 & 688839 & 5.0 & 4.9423 & TRN \\
\hline CHEMBL412010 & 688839 & 5.4 & 5.5521 & TRN \\
\hline CHEMBL131171 & 688839 & 5.5 & 5.3758 & TST \\
\hline CHEMBL1451364 & 688839 & 4.7 & 4.7608 & TRN \\
\hline CHEMBL1602710 & 688839 & 5.1 & 5.2364 & TRN \\
\hline CHEMBL1476288 & 688839 & 4.5 & 4.5603 & TRN \\
\hline CHEMBL1530965 & 688839 & 5.1 & 5.1343 & TRN \\
\hline CHEMBL1484447 & 688839 & 4.8 & 4.7896 & TST \\
\hline CHEMBL1332726 & 688839 & 4.8 & 4.9141 & TRN \\
\hline CHEMBL1257014 & 688839 & 4.6 & 4.7437 & TRN \\
\hline CHEMBL1552303 & 688839 & 5.3 & 5.3966 & TRN \\
\hline CHEMBL1369373 & 688839 & 5.2 & 5.487 & TRN \\
\hline CHEMBL1363411 & 688839 & 4.5 & 4.8067 & TRN \\
\hline CHEMBL1489589 & 688839 & 4.6 & 4.7207 & TRN \\
\hline CHEMBL 2373610 & 688839 & 5.3 & 5.1826 & TRN \\
\hline CHEMBL1487677 & 688839 & 4.9 & 5.0807 & TRN \\
\hline CHEMBL17468 & 688839 & 4.8 & 4.9148 & TST \\
\hline CHEMBL353971 & 688839 & 4.6 & 5.1754 & TRN \\
\hline CHEMBL1596675 & 688839 & 4.8 & 5.1588 & TST \\
\hline CHEMBL1330296 & 688839 & 4.6 & 4.7349 & TRN \\
\hline CHEMBL1442987 & 688839 & 6.0 & 6.1052 & TRN \\
\hline
\end{tabular}




\begin{tabular}{|c|c|c|c|c|}
\hline \multicolumn{5}{|r|}{$1 \mathrm{e} s$} \\
\hline CHEMBL1325297 & 688839 & 4.9 & 5.061 & TRN \\
\hline CHEMBL1367222 & 688839 & 5.5 & 5.6091 & TRN \\
\hline CHEMBL1555011 & 688839 & 5.0 & 4.7879 & TRN \\
\hline CHEMBL1440617 & 688839 & 4.8 & 4.8443 & TRN \\
\hline CHEMBL1328879 & 688839 & 5.5 & 5.1565 & TRN \\
\hline CHEMBL1435373 & 688839 & 6.6 & 6.5257 & TRN \\
\hline CHEMBL1335654 & 688839 & 4.6 & 4.6543 & TRN \\
\hline CHEMBL1438690 & 688839 & 6.0 & 6.239 & TRN \\
\hline CHEMBL1317494 & 688839 & 5.7 & 5.7355 & TRN \\
\hline CHEMBL1434149 & 688839 & 5.1 & 5.0594 & TRN \\
\hline CHEMBL1338520 & 688839 & 4.9 & 5.2163 & TST \\
\hline CHEMBL489737 & 688839 & 6.7001 & 6.7704 & TRN \\
\hline CHEMBL1592571 & 688839 & 5.1 & 5.081 & TRN \\
\hline CHEMBL1590974 & 688839 & 5.4 & 5.2908 & TRN \\
\hline CHEMBL1398608 & 688839 & 5.4 & 5.2932 & TRN \\
\hline CHEMBL1446335 & 688839 & 4.8 & 4.9537 & TRN \\
\hline CHEMBL288174 & 688839 & 5.5 & 5.4558 & TST \\
\hline CHEMBL1590262 & 688839 & 4.8 & 4.8213 & TRN \\
\hline CHEMBL600715 & 688839 & 4.9 & 5.2107 & TST \\
\hline CHEMBL1398528 & 688839 & 4.7 & 4.9962 & TRN \\
\hline CHEMBL598952 & 688839 & 5.0 & 4.6697 & TST \\
\hline CHEMBL313833 & 688839 & 5.1 & 5.0598 & TST \\
\hline CHEMBL16751 & 688839 & 5.1 & 5.2093 & TRN \\
\hline CHEMBL1365537 & 688839 & 5.4 & 5.43 & TRN \\
\hline CHEMBL336467 & 688839 & 4.9 & 4.93199 & 99999999995 \\
\hline CHEMBL1565160 & 688839 & 5.4 & 5.3514 & TRN \\
\hline CHEMBL1397192 & 688839 & 4.8 & 4.9207 & TRN \\
\hline CHEMBL242385 & 688839 & 5.4 & 5.4336 & TRN \\
\hline CHEMBL85194 & 688839 & 5.0 & 5.1103 & TST \\
\hline CHEMBL1562090 & 688839 & 4.7 & 5.0564 & TRN \\
\hline CHEMBL80155 & 688839 & 5.0 & 4.9757 & TRN \\
\hline CHEMBL1314225 & 688839 & 4.8 & 4.8517 & TRN \\
\hline CHEMBL1318553 & 688839 & 6.0 & 5.7742 & TST \\
\hline CHEMBL 140 & 688839 & 6.0 & 5.0699 & TRN \\
\hline CHEMBL192566 & 688839 & 5.4 & 5.2809 & TST \\
\hline CHEMBL1479088 & 688839 & 5.6 & 5.8285 & TRN \\
\hline CHEMBL1397225 & 688839 & 6.0 & 6.0625 & TRN \\
\hline CHEMBL1553058 & 688839 & 6.4 & 5.2313 & TRN \\
\hline CHEMBL1316348 & 688839 & 4.8 & 4.8353 & TRN \\
\hline CHEMBL1314935 & 688839 & 5.6 & 5.4728 & TRN \\
\hline CHEMBL1610944 & 688839 & 6.0 & 6.0571 & TRN \\
\hline CHEMBL518252 & 688839 & 5.5 & 5.1138 & TRN \\
\hline CHEMBL1357498 & 688839 & 4.8 & 4.8108 & TRN \\
\hline CHEMBL1314279 & 688839 & 5.6 & 5.105 & TRN \\
\hline CHEMBL1567101 & 688839 & 5.6 & 5.3256 & TRN \\
\hline CHEMBL1590261 & 688839 & 4.8 & 4.8946 & TRN \\
\hline CHEMBL1369967 & 688839 & 4.5 & 5.0584 & TRN \\
\hline CHEMBL1457390 & 688839 & 4.6 & 4.6835 & TRN \\
\hline
\end{tabular}




\begin{tabular}{|c|c|c|c|c|}
\hline \multicolumn{5}{|c|}{ lemental Table s } \\
\hline CHEMBL1355224 & 688839 & 4.9 & 4.9971 & TRN \\
\hline CHEMBL55285 & 688839 & 4.6 & 4.9109 & TST \\
\hline CHEMBL1528605 & 688839 & 4.4 & 5.0083 & TST \\
\hline CHEMBL1316314 & 688839 & 5.7 & 5.5203 & TST \\
\hline CHEMBL1255659 & 688839 & 4.6 & 4.7438 & TRN \\
\hline CHEMBL1434272 & 688839 & 5.0 & \multicolumn{2}{|c|}{5.013999999999999} \\
\hline CHEMBL 2375170 & 688839 & 4.5 & 5.2221 & TST \\
\hline CHEMBL1318045 & 688839 & 4.7 & 4.8068 & TRN \\
\hline CHEMBL1475902 & 688839 & 4.9 & 4.9829 & TRN \\
\hline CHEMBL 3198273 & 688839 & 5.4 & 5.4407 & TRN \\
\hline CHEMBL 1450460 & 688839 & 4.8 & 5.11 & TST \\
\hline CHEMBL1396615 & 688839 & 4.8 & 4.915 & TRN \\
\hline CHEMBL1555348 & 688839 & 4.8 & 4.9935 & TRN \\
\hline CHEMBL491742 & 688839 & 6.9 & 6.919 & TRN \\
\hline CHEMBL1552201 & 688839 & 5.8 & 4.9036 & TRN \\
\hline CHEMBL 1599647 & 688839 & 6.7001 & 5.1937 & TST \\
\hline CHEMBL490749 & 688839 & 6.7001 & 6.8054 & TRN \\
\hline CHEMBL492130 & 688839 & 4.8 & 4.9271 & TRN \\
\hline CHEMBL1478 & 688839 & 4.5 & 5.5647 & TRN \\
\hline CHEMBL1527366 & 688839 & 4.9 & 5.1394 & TRN \\
\hline CHEMBL1334021 & 688839 & 4.6 & 4.6889 & TRN \\
\hline CHEMBL1363513 & 688839 & 6.0 & 5.8407 & TRN \\
\hline CHEMBL3208495 & 688839 & 5.0 & 5.2787 & TST \\
\hline CHEMBL95431 & 688839 & 5.5 & 5.3933 & TST \\
\hline CHEMBL1596499 & 688839 & 4.8 & 4.8557 & TRN \\
\hline CHEMBL1434833 & 688839 & 5.0 & 5.0509 & TRN \\
\hline CHEMBL1474302 & 688839 & 5.0 & 5.0575 & TRN \\
\hline CHEMBL48310 & 688839 & 6.2 & 5.0896 & TST \\
\hline CHEMBL1394983 & 688839 & 4.8 & 4.8074 & TRN \\
\hline CHEMBL1517885 & 688839 & 4.8 & 4.7449 & TRN \\
\hline CHEMBL1372077 & 688839 & 4.9 & 5.0057 & TRN \\
\hline CHEMBL1374218 & 688839 & 5.4 & 5.3762 & TRN \\
\hline CHEMBL115225 & 688839 & 8.4949 & 7.6047 & TST \\
\hline CHEMBL1405546 & 688839 & 5.5 & 5.4143 & TRN \\
\hline CHEMBL1372627 & 688839 & 4.8 & 4.9141 & TRN \\
\hline CHEMBL1450455 & 688839 & 4.6 & 4.6436 & TRN \\
\hline CHEMBL1476383 & 688839 & 5.2 & 5.2289 & TRN \\
\hline CHEMBL1529256 & 688839 & 4.8 & 5.1801 & TRN \\
\hline CHEMBL1355242 & 688839 & 4.9 & 4.9891 & TRN \\
\hline CHEMBL611494 & 688839 & 6.0 & 5.7254 & TST \\
\hline CHEMBL1449458 & 688839 & 4.6 & 4.7189 & TRN \\
\hline CHEMBL1357294 & 688839 & 4.8 & 4.9265 & TRN \\
\hline CHEMBL1558777 & 688839 & 4.8 & 4.9428 & TRN \\
\hline CHEMBL1357674 & 688839 & 4.5 & 4.6934 & TST \\
\hline CHEMBL1436980 & 688839 & 4.6 & 5.1753 & TRN \\
\hline CHEMBL75773 & 688839 & 4.9 & 5.0544 & TRN \\
\hline CHEMBL1590992 & 688839 & 5.3 & 5.1017 & TRN \\
\hline CHEMBL1433559 & 688839 & 5.1 & 5.186 & TRN \\
\hline
\end{tabular}




\begin{tabular}{|c|c|c|c|c|}
\hline & & \multicolumn{3}{|c|}{ Supplemental Table S2.txt } \\
\hline CHEMBL491910 & 688839 & 7.1002 & 7.0945 & TRN \\
\hline CHEMBL1496560 & 688839 & 4.9 & 4.9291 & TRN \\
\hline CHEMBL1354648 & 688839 & 5.4 & 5.4865 & TST \\
\hline CHEMBL1400976 & 688839 & 6.0 & 6.0663 & TRN \\
\hline CHEMBL1324022 & 688839 & 4.8 & 4.9004 & TST \\
\hline CHEMBL566899 & 688839 & 6.0 & 6.0167 & TRN \\
\hline CHEMBL1400280 & 688839 & 5.0 & 5.4605 & TRN \\
\hline CHEMBL1514153 & 688839 & 4.9 & 4.8611 & TRN \\
\hline CHEMBL1317135 & 688839 & 6.4 & 6.1518 & TST \\
\hline CHEMBL1566325 & 688839 & 5.3 & 5.1549 & TST \\
\hline CHEMBL1434108 & 688839 & 5.5 & 5.2038 & TST \\
\hline CHEMBL1567483 & 688839 & 4.8 & 5.2529 & TRN \\
\hline CHEMBL479689 & 688839 & 6.4 & 5.2222 & TRN \\
\hline CHEMBL1455301 & 688839 & 4.9 & 5.191 & TST \\
\hline CHEMBL1158 & 688839 & 4.4 & 4.9114 & TST \\
\hline CHEMBL1570716 & 688839 & 6.0 & 5.9507 & TRN \\
\hline CHEMBL1487381 & 688839 & 6.0 & 5.1121 & TRN \\
\hline CHEMBL1397308 & 688839 & 5.1 & 5.0066 & TRN \\
\hline CHEMBL1513643 & 688839 & 5.4 & 5.3719 & TST \\
\hline CHEMBL 259847 & 688839 & 5.3 & 5.2606 & TRN \\
\hline CHEMBL 286077 & 688839 & 6.8 & 6.1842 & TST \\
\hline CHEMBL1486596 & 688839 & 5.1 & 5.1332 & TRN \\
\hline CHEMBL437450 & 688839 & 5.5 & 5.2318 & TRN \\
\hline CHEMBL9352 & 688839 & 6.0 & 5.1762 & TRN \\
\hline CHEMBL478 & 688839 & 7.4001 & 6.7623 & TRN \\
\hline CHEMBL265177 & 688839 & 5.4 & 5.4059 & TRN \\
\hline CHEMBL1318421 & 688839 & 5.5 & 5.2991 & TRN \\
\hline CHEMBL1436042 & 688839 & 4.7 & 4.6946 & TRN \\
\hline CHEMBL1529361 & 688839 & 5.1 & 5.0761 & TRN \\
\hline CHEMBL1370169 & 688839 & 6.1 & 5.834 & TRN \\
\hline CHEMBL1591209 & 688839 & 4.9 & 4.9075 & TRN \\
\hline CHEMBL1335634 & 688839 & 6.0 & 5.1451 & TRN \\
\hline CHEMBL1404112 & 688839 & 5.4 & 5.3577 & TRN \\
\hline CHEMBL1562612 & 688839 & 5.3 & 5.2306 & TST \\
\hline CHEMBL1473438 & 688839 & 4.5 & 4.5909 & TRN \\
\hline CHEMBL1362517 & 688839 & 4.9 & 4.9342 & TRN \\
\hline CHEMBL370152 & 688839 & 5.1 & 5.0126 & TRN \\
\hline CHEMBL1335213 & 688839 & 5.1 & 5.09399 & 9999999999 \\
\hline CHEMBL1411411 & 688839 & 6.0 & 5.1836 & TRN \\
\hline CHEMBL1454855 & 688839 & 5.8 & 5.7355 & TRN \\
\hline CHEMBL 8747 & 688839 & 4.9 & 5.0242 & TRN \\
\hline CHEMBL1397454 & 688839 & 4.8 & 4.7854 & TRN \\
\hline CHEMBL1372371 & 688839 & 5.0 & 4.9611 & TRN \\
\hline CHEMBL1529543 & 688839 & 5.4 & 5.3949 & TRN \\
\hline CHEMBL1356134 & 688839 & 5.2 & 4.6809 & TRN \\
\hline CHEMBL1318448 & 688839 & 5.2 & 5.2562 & TRN \\
\hline CHEMBL1475284 & 688839 & 4.6 & 4.7071 & TRN \\
\hline CHEMBL404313 & 688839 & 4.8 & 5.2701 & TST \\
\hline
\end{tabular}




\begin{tabular}{|c|c|c|c|c|}
\hline & & & 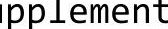 & al Table \\
\hline CHEMBL 368700 & 688839 & 5.0 & 5.0275 & TST \\
\hline CHEMBL1514465 & 688839 & 5.0 & 4.9104 & TRN \\
\hline CHEMBL1594134 & 688839 & 5.6 & 5.6813 & TRN \\
\hline CHEMBL1320919 & 688839 & 5.4 & 5.0017 & TRN \\
\hline CHEMBL1332346 & 688839 & 5.9 & 6.0251 & TRN \\
\hline CHEMBL1516428 & 688839 & 4.7 & 5.0911 & TST \\
\hline CHEMBL1593438 & 688839 & 4.7 & 4.7224 & TRN \\
\hline CHEMBL1554721 & 688839 & 5.8 & 5.9049 & TRN \\
\hline CHEMBL1451823 & 688839 & 5.5 & 5.0202 & TRN \\
\hline CHEMBL 295652 & 688839 & 4.6 & 5.0446 & TRN \\
\hline CHEMBL1398262 & 688839 & 4.5 & 5.2748 & TST \\
\hline CHEMBL1364859 & 688839 & 4.9 & 4.9023 & TRN \\
\hline CHEMBL1551970 & 688839 & 4.8 & 5.2646 & TRN \\
\hline CHEMBL1513300 & 688839 & 4.7 & 4.9099 & TRN \\
\hline CHEMBL1399528 & 688839 & 4.9 & 4.8668 & TRN \\
\hline CHEMBL1321338 & 688839 & 4.8 & 4.9842 & TRN \\
\hline CHEMBL1395098 & 688839 & 4.5 & 4.6477 & TRN \\
\hline CHEMBL1452868 & 688839 & 5.4 & 5.0899 & TRN \\
\hline CHEMBL3965817 & 688839 & 4.5 & 5.0271 & TRN \\
\hline CHEMBL1514272 & 688839 & 4.8 & 4.8268 & TRN \\
\hline CHEMBL1554982 & 688839 & 5.5 & 5.6806 & TRN \\
\hline CHEMBL1447959 & 688839 & 5.1 & 5.0614 & TRN \\
\hline CHEMBL220087 & 688839 & 4.8 & 4.9221 & TRN \\
\hline CHEMBL1433668 & 688839 & 4.8 & 4.8809 & TRN \\
\hline CHEMBL1474854 & 688839 & 4.8 & 4.7302 & TRN \\
\hline CHEMBL1412847 & 688839 & 5.5 & 5.4452 & TRN \\
\hline CHEMBL1564426 & 688839 & 5.4 & 5.2043 & TRN \\
\hline CHEMBL1600908 & 688839 & 5.4 & 5.2926 & TRN \\
\hline CHEMBL1396862 & 688839 & 5.4 & 5.3606 & TRN \\
\hline CHEMBL 2373602 & 688839 & 6.0 & 5.825 & TST \\
\hline CHEMBL1437448 & 688839 & 4.9 & 4.8716 & TST \\
\hline CHEMBL1568722 & 688839 & 4.7 & 5.0642 & TRN \\
\hline CHEMBL1396698 & 688839 & 4.6 & 4.6493 & TRN \\
\hline CHEMBL1436997 & 688839 & 5.6 & 5.1011 & TRN \\
\hline CHEMBL1373151 & 688839 & 5.0 & 4.9403 & TRN \\
\hline CHEMBL1603371 & 688839 & 5.0 & 5.1986 & TRN \\
\hline CHEMBL37081 & 688839 & 4.7 & 4.8415 & TRN \\
\hline CHEMBL1321439 & 688839 & 4.8 & 4.8194 & TRN \\
\hline CHEMBL1322137 & 688839 & 6.1 & 5.74700 & 0000000001 \\
\hline CHEMBL1490307 & 688839 & 4.4 & 4.6123 & TRN \\
\hline CHEMBL1562729 & 688839 & 4.6 & 5.2342 & TST \\
\hline CHEMBL105310 & 688839 & 5.8 & 5.2828 & TRN \\
\hline CHEMBL1324889 & 688839 & 5.9 & 6.0364 & TRN \\
\hline CHEMBL1446539 & 688839 & 4.9 & 4.8611 & TRN \\
\hline CHEMBL 88402 & 688839 & 5.1 & 5.154 & TST \\
\hline CHEMBL1316945 & 688839 & 4.8 & 5.185 & TST \\
\hline CHEMBL1515417 & 688839 & 5.2 & 5.1492 & TRN \\
\hline CHEMBL1374335 & 688839 & 5.5 & 5.348 & TRN \\
\hline
\end{tabular}




\begin{tabular}{|c|c|c|c|c|}
\hline \multicolumn{5}{|c|}{ lemental T } \\
\hline CHEMBL1479372 & 688839 & 4.7 & 4.8305 & TRN \\
\hline CHEMBL15927 & 688839 & 4.3 & 4.5227 & TRN \\
\hline CHEMBL1476280 & 688839 & 5.4 & 5.6883 & TRN \\
\hline CHEMBL1529147 & 688839 & 4.5 & 5.2216 & TST \\
\hline CHEMBL1514016 & 688839 & 4.6 & 4.6466 & TRN \\
\hline CHEMBL1436355 & 688839 & 5.3 & 5.3056 & TRN \\
\hline CHEMBL1370526 & 688839 & 5.3 & 5.2114 & TST \\
\hline CHEMBL2373630 & 688839 & 5.3 & 5.2308 & TST \\
\hline CHEMBL433461 & 688839 & 6.1 & 5.8429 & TRN \\
\hline CHEMBL1592376 & 688839 & 5.2 & 5.3008 & TRN \\
\hline CHEMBL 363207 & 688839 & 5.1 & 4.8656 & TST \\
\hline CHEMBL1446716 & 688839 & 6.2 & 6.3295 & TRN \\
\hline CHEMBL1317498 & 688839 & 4.8 & 4.7832 & TRN \\
\hline CHEMBL1594612 & 688839 & 6.5 & 6.5124 & TRN \\
\hline CHEMBL491943 & 688839 & 6.6 & 6.6828 & TRN \\
\hline CHEMBL1356834 & 688839 & 5.0 & 4.9871 & TRN \\
\hline CHEMBL1453347 & 688839 & 4.4 & 4.9986 & TST \\
\hline CHEMBL126804 & 688839 & 5.8 & 5.2966 & TRN \\
\hline CHEMBL1485069 & 688839 & 5.3 & 5.4187 & TRN \\
\hline CHEMBL1358142 & 688839 & 4.6 & 4.6564 & TRN \\
\hline CHEMBL1526121 & 688839 & 4.8 & 5.0309 & TRN \\
\hline CHEMBL1412232 & 688839 & 5.1 & 5.0171 & TRN \\
\hline CHEMBL333985 & 688839 & 4.9 & 4.9164 & TST \\
\hline CHEMBL448602 & 688839 & 5.5 & 5.5006 & TRN \\
\hline CHEMBL1591425 & 688839 & 4.5 & 5.1244 & TST \\
\hline CHEMBL 3212722 & 688839 & 5.4 & 5.5025 & TRN \\
\hline CHEMBL259073 & 688839 & 5.0 & 5.0393 & TRN \\
\hline CHEMBL1530613 & 688839 & 6.1 & 5.9403 & TST \\
\hline CHEMBL1317962 & 688839 & 5.4 & 4.8998 & TST \\
\hline CHEMBL1329823 & 688839 & 4.9 & 5.0938 & TRN \\
\hline CHEMBL1436488 & 688839 & 5.1 & 5.0102 & TRN \\
\hline CHEMBL1435216 & 688839 & 4.9 & 4.9653 & TRN \\
\hline CHEMBL1409148 & 688839 & 6.0 & 6.0448 & TRN \\
\hline CHEMBL1442173 & 688839 & 5.8 & 5.9025 & TRN \\
\hline CHEMBL1399103 & 688839 & 5.3 & 5.1396 & TST \\
\hline CHEMBL355496 & 688839 & 5.1 & 5.0437 & TST \\
\hline CHEMBL1438566 & 688839 & 6.0 & 5.9644 & TRN \\
\hline CHEMBL1331525 & 688839 & 6.4 & 6.4571 & TRN \\
\hline CHEMBL1516388 & 688839 & 4.5 & 4.7433 & TST \\
\hline CHEMBL1408013 & 688839 & 6.0 & 6.0502 & TRN \\
\hline CHEMBL1320662 & 688839 & 4.9 & 4.9318 & TRN \\
\hline CHEMBL1396146 & 688839 & 4.8 & 4.8933 & TRN \\
\hline CHEMBL259389 & 688839 & 6.9 & 6.3411 & TST \\
\hline CHEMBL1377686 & 688839 & 5.4 & 5.2397 & TRN \\
\hline CHEMBL1085765 & 688839 & 6.0 & 4.9288 & TRN \\
\hline CHEMBL1434022 & 688839 & 4.8 & 4.8177 & TRN \\
\hline CHEMBL542493 & 688839 & 4.5 & 4.8105 & TRN \\
\hline CHEMBL1590173 & 688839 & 5.5 & 5.5116 & TRN \\
\hline
\end{tabular}




\begin{tabular}{|c|c|c|c|c|}
\hline \multicolumn{5}{|c|}{ lemental T } \\
\hline CHEMBL1413956 & 688839 & 5.1 & 5.2052 & TST \\
\hline CHEMBL1434228 & 688839 & 5.1 & 5.1906 & TST \\
\hline CHEMBL250711 & 688839 & 5.5 & 5.3544 & TRN \\
\hline CHEMBL1482880 & 688839 & 4.5 & 4.645 & TRN \\
\hline CHEMBL1530314 & 688839 & 5.5 & 5.4668 & TST \\
\hline CHEMBL76589 & 688839 & 4.4 & 4.6971 & TRN \\
\hline CHEMBL1446922 & 688839 & 5.0 & 5.0394 & TRN \\
\hline CHEMBL1366766 & 688839 & 5.3 & 5.3882 & TRN \\
\hline CHEMBL1555320 & 688839 & 5.0 & 4.9243 & TRN \\
\hline CHEMBL1356764 & 688839 & 5.3 & 5.3536 & TRN \\
\hline CHEMBL1605950 & 688839 & 5.5 & 5.2988 & TRN \\
\hline CHEMBL1591876 & 688839 & 4.8 & 4.7875 & TRN \\
\hline CHEMBL448515 & 688839 & 4.6 & 5.0511 & TST \\
\hline CHEMBL1435885 & 688839 & 5.0 & 5.0941 & TRN \\
\hline CHEMBL1514149 & 688839 & 4.9 & 4.9727 & TRN \\
\hline CHEMBL1413701 & 688839 & 6.1 & 5.8068 & TRN \\
\hline CHEMBL1314625 & 688839 & 5.6 & 5.7354 & TRN \\
\hline CHEMBL1370675 & 688839 & 4.8 & 5.1761 & TRN \\
\hline CHEMBL1314371 & 688839 & 5.4 & 5.3841 & TRN \\
\hline CHEMBL261836 & 688839 & 5.4 & 5.2304 & TRN \\
\hline CHEMBL1599163 & 688839 & 4.6 & 4.6483 & TRN \\
\hline CHEMBL493032 & 688839 & 4.4 & 5.0158 & TRN \\
\hline CHEMBL1474471 & 688839 & 4.8 & 4.7812 & TRN \\
\hline CHEMBL1513463 & 688839 & 4.8 & 5.1255 & TST \\
\hline CHEMBL1372133 & 688839 & 4.6 & 4.5895 & TRN \\
\hline CHEMBL1455200 & 688839 & 5.7 & 5.7928 & TRN \\
\hline CHEMBL1395277 & 688839 & 5.6 & 5.4708 & TRN \\
\hline CHEMBL 2374044 & 688839 & 6.5 & 5.1774 & TST \\
\hline CHEMBL1593601 & 688839 & 5.9 & 5.9664 & TRN \\
\hline CHEMBL1200717 & 688839 & 4.8 & 4.8617 & TST \\
\hline CHEMBL1433485 & 688839 & 5.5 & 5.4831 & TRN \\
\hline CHEMBL1407307 & 688839 & 5.0 & 4.9857 & TRN \\
\hline CHEMBL1395485 & 688839 & 5.6 & 4.9636 & TRN \\
\hline CHEMBL1559745 & 688839 & 5.7 & 4.9754 & TRN \\
\hline CHEMBL1370456 & 688839 & 4.5 & 5.147 & TST \\
\hline CHEMBL1329927 & 688839 & 6.0 & 4.9777 & TST \\
\hline CHEMBL16807 & 688839 & 6.0 & 5.0825 & TRN \\
\hline CHEMBL1434308 & 688839 & 5.8 & 4.8513 & TRN \\
\hline CHEMBL1397325 & 688839 & 4.9 & 4.9402 & TRN \\
\hline CHEMBL1443614 & 688839 & 6.0 & 5.0611 & TRN \\
\hline CHEMBL1317950 & 688839 & 7.0 & 6.7295 & TRN \\
\hline CHEMBL1483700 & 688839 & 5.5 & 5.4863 & TRN \\
\hline CHEMBL1323563 & 688839 & 4.9 & 4.913 & TRN \\
\hline CHEMBL1489223 & 688839 & 5.0 & 5.0897 & TRN \\
\hline CHEMBL1355307 & 688839 & 5.4 & 5.2407 & TRN \\
\hline CHEMBL1514717 & 688839 & 4.6 & 4.7101 & TRN \\
\hline CHEMBL1448138 & 688839 & 5.3 & 4.9025 & TRN \\
\hline CHEMBL343732 & 688839 & 4.5 & 4.9531 & TST \\
\hline
\end{tabular}




\begin{tabular}{|c|c|c|c|c|c|}
\hline \multicolumn{6}{|c|}{ Supplemental Table S2.txt } \\
\hline CHEMBL1398216 & 688839 & 5.5 & 5.5302 & TRN & \\
\hline CHEMBL164921 & 688839 & 4.6 & 5.1062 & TRN & \\
\hline CHEMBL1325965 & 688839 & 4.4 & 5.0893 & TST & \\
\hline CHEMBL1613194 & 688839 & 5.3 & 5.2616 & TST & \\
\hline CHEMBL1570894 & 688839 & 5.4 & 5.2823 & TRN & \\
\hline CHEMBL1559418 & 688839 & 4.7 & 5.0754 & TRN & \\
\hline CHEMBL1368577 & 688839 & 5.5 & 5.2266 & TRN & \\
\hline CHEMBL1523594 & 688839 & 5.2 & 5.1358 & TRN & \\
\hline CHEMBL1515555 & 688839 & 5.0 & 5.1433 & TRN & \\
\hline CHEMBL1455965 & 688839 & 4.9 & 5.101 & TRN & \\
\hline CHEMBL1397443 & 688839 & 5.5 & 5.4644 & TRN & \\
\hline CHEMBL1554609 & 688839 & 5.5 & 5.5318 & TRN & \\
\hline CHEMBL1314833 & 688839 & 5.4 & 5.5873 & TRN & \\
\hline CHEMBL1437263 & 688839 & 5.4 & 5.4096 & TRN & \\
\hline CHEMBL1484896 & 688839 & 4.8 & 4.8063 & TRN & \\
\hline CHEMBL1395303 & 688839 & 4.8 & 4.7533 & TRN & \\
\hline CHEMBL1575052 & 688839 & 5.0 & 5.1763 & TST & \\
\hline CHEMBL1417837 & 688839 & 5.4 & 5.3375 & TRN & \\
\hline CHEMBL1377507 & 688839 & 6.0 & 5.80200 & 00000000005 & TRN \\
\hline CHEMBL1524370 & 688839 & 4.4 & 5.1939 & TRN & \\
\hline CHEMBL1592819 & 688839 & 4.9 & 5.1142 & TRN & \\
\hline CHEMBL1602394 & 688839 & 5.5 & 5.4982 & TRN & \\
\hline CHEMBL1365082 & 688839 & 5.3 & 5.2976 & TST & \\
\hline CHEMBL77098 & 688839 & 4.7 & 5.1173 & TRN & \\
\hline CHEMBL1590545 & 688839 & 5.0 & 5.2466 & TST & \\
\hline CHEMBL1366737 & 688839 & 4.8 & 4.7748 & TRN & \\
\hline CHEMBL3348827 & 688839 & 4.8 & 5.3876 & TRN & \\
\hline CHEMBL230056 & 688839 & 4.9 & 5.0172 & TST & \\
\hline CHEMBL1413770 & 688839 & 4.9 & 4.8906 & TRN & \\
\hline CHEMBL 2374266 & 688839 & 4.6 & 4.9361 & TRN & \\
\hline CHEMBL410873 & 688839 & 4.8 & 4.9598 & TRN & \\
\hline CHEMBL279564 & 688839 & 5.0 & 5.0165 & TRN & \\
\hline CHEMBL1554588 & 688839 & 4.9 & 5.008 & TRN & \\
\hline CHEMBL1324529 & 688839 & 4.6 & 4.6894 & TRN & \\
\hline CHEMBL1358796 & 688839 & 5.7 & 5.7341 & TRN & \\
\hline CHEMBL1553173 & 688839 & 5.6 & 5.562 & TRN & \\
\hline CHEMBL1609324 & 688839 & 4.9 & 4.8731 & TRN & \\
\hline CHEMBL1411743 & 688839 & 5.6 & 5.7678 & TRN & \\
\hline CHEMBL1559578 & 688839 & 5.4 & 5.3199 & TRN & \\
\hline CHEMBL1359713 & 688839 & 6.7001 & 6.6875 & TRN & \\
\hline CHEMBL1433726 & 688839 & 5.0 & 5.0845 & TST & \\
\hline CHEMBL1319432 & 688839 & 5.7 & 5.6807 & TST & \\
\hline CHEMBL1484196 & 688839 & 5.9 & 5.9476 & TRN & \\
\hline CHEMBL1366925 & 688839 & 5.0 & 5.5602 & TRN & \\
\hline CHEMBL1474681 & 688839 & 6.3 & 6.4604 & TRN & \\
\hline CHEMBL1395935 & 688839 & 5.4 & 5.3655 & TRN & \\
\hline CHEMBL1325735 & 688839 & 5.6 & 5.5917 & TRN & \\
\hline CHEMBL1374841 & 688839 & 5.0 & 5.1524 & TST & \\
\hline
\end{tabular}




\begin{tabular}{|c|c|c|c|c|}
\hline & & & & $a \perp 1 a$ \\
\hline CHEMBL1564985 & 688839 & 5.9 & 5.4013 & TRN \\
\hline CHEMBL1372368 & 688839 & 5.3 & 5.2511 & TRN \\
\hline CHEMBL1256814 & 688839 & 5.0 & 4.948 & TRN \\
\hline CHEMBL1591205 & 688839 & 5.5 & 5.4318 & TRN \\
\hline CHEMBL1395226 & 688839 & 5.1 & 5.0572 & TRN \\
\hline CHEMBL1476996 & 688839 & 4.8 & 5.2248 & TST \\
\hline CHEMBL1418542 & 688839 & 5.6 & 5.4875 & TRN \\
\hline CHEMBL291536 & 688839 & 5.0 & 5.025 & TST \\
\hline CHEMBL 3209943 & 688839 & 5.4 & 5.4565 & TRN \\
\hline CHEMBL1439746 & 688839 & 5.5 & 5.274 & TRN \\
\hline CHEMBL1486447 & 688839 & 4.6 & 4.9815 & TRN \\
\hline CHEMBL1451315 & 688839 & 4.8 & 4.8496 & TRN \\
\hline CHEMBL1357180 & 688839 & 5.2 & 5.0831 & TRN \\
\hline CHEMBL1397466 & 688839 & 4.9 & 4.9701 & TRN \\
\hline CHEMBL1592213 & 688839 & 4.8 & 4.8543 & TRN \\
\hline CHEMBL1087126 & 688839 & 4.4 & 5.0649 & TRN \\
\hline CHEMBL1561927 & 688839 & 5.4 & 5.7146 & TRN \\
\hline CHEMBL1323927 & 688839 & 4.5 & 4.6346 & TRN \\
\hline CHEMBL1525813 & 688839 & 5.5 & 5.5225 & TST \\
\hline CHEMBL1317339 & 688839 & 4.9 & 5.2792 & TST \\
\hline CHEMBL1395337 & 688839 & 5.4 & 5.6266 & TRN \\
\hline CHEMBL1408343 & 688839 & 5.4 & 5.4394 & TRN \\
\hline CHEMBL1368895 & 688839 & 4.8 & 4.7588 & TST \\
\hline CHEMBL 70141 & 688839 & 5.0 & 5.0757 & TRN \\
\hline CHEMBL1317461 & 688839 & 6.3 & 6.2806 & TRN \\
\hline CHEMBL1435447 & 688839 & 4.9 & 5.0296 & TRN \\
\hline CHEMBL1439401 & 688839 & 5.7 & 5.7572 & TRN \\
\hline CHEMBL1554817 & 688839 & 5.5 & 5.4996 & TRN \\
\hline CHEMBL1318066 & 688839 & 5.4 & 5.2756 & TRN \\
\hline CHEMBL261782 & 688839 & 5.5 & 5.2663 & TRN \\
\hline CHEMBL1411519 & 688839 & 5.0 & 5.0693 & TRN \\
\hline CHEMBL1407769 & 688839 & 4.9 & 5.0151 & TRN \\
\hline CHEMBL1602633 & 688839 & 5.7 & 5.724 & TRN \\
\hline CHEMBL1558526 & 688839 & 5.0 & 5.0507 & TRN \\
\hline CHEMBL1591772 & 688839 & 5.2 & 5.0894 & TRN \\
\hline CHEMBL1600612 & 688839 & 4.4 & 4.5145 & TRN \\
\hline CHEMBL1257002 & 688839 & 6.0 & 5.8241 & TST \\
\hline CHEMBL1487454 & 688839 & 4.8 & 4.9942 & TRN \\
\hline CHEMBL153036 & 688839 & 6.0 & 5.825 & TST \\
\hline CHEMBL1368566 & 688839 & 4.8 & 4.8377 & TRN \\
\hline CHEMBL1355762 & 688839 & 4.4 & 4.971 & TRN \\
\hline CHEMBL1356780 & 688839 & 5.6 & 5.4553 & TST \\
\hline CHEMBL1570134 & 688839 & 5.0 & 5.1253 & TRN \\
\hline CHEMBL1435450 & 688839 & 5.6 & 5.6541 & TRN \\
\hline CHEMBL1336826 & 688839 & 4.9 & 5.0689 & TRN \\
\hline CHEMBL1475338 & 688839 & 6.0 & 5.932 & TRN \\
\hline CHEMBL1473331 & 688839 & 4.8 & 4.8052 & TRN \\
\hline CHEMBL1608470 & 688839 & 5.3 & 5.2726 & TST \\
\hline
\end{tabular}




\begin{tabular}{|c|c|c|c|c|c|}
\hline \multicolumn{6}{|c|}{ Supplemental Table S2.txt } \\
\hline CHEMBL1473117 & 688839 & 4.7 & 4.8066 & TRN & \\
\hline CHEMBL1590767 & 688839 & 5.4 & 5.2426 & TRN & \\
\hline CHEMBL1365512 & 688839 & 5.5 & 5.5878 & TRN & \\
\hline CHEMBL1314828 & 688839 & 4.4 & 5.1181 & TST & \\
\hline CHEMBL1357293 & 688839 & 5.9 & 5.6737 & TRN & \\
\hline CHEMBL1590598 & 688839 & 5.2 & 5.0982 & TRN & \\
\hline CHEMBL1358503 & 688839 & 5.5 & 5.644 & TRN & \\
\hline CHEMBL400777 & 688839 & 5.2 & 5.2384 & TRN & \\
\hline CHEMBL1474987 & 688839 & 4.7 & 5.1289 & TRN & \\
\hline CHEMBL1317069 & 688839 & 5.0 & 5.2294 & TST & \\
\hline CHEMBL1558420 & 688839 & 4.8 & 4.74100 & 00000000005 & TRN \\
\hline CHEMBL1512562 & 688839 & 5.3 & 5.2402 & TRN & \\
\hline CHEMBL1437846 & 688839 & 5.4 & 5.2496 & TST & \\
\hline CHEMBL1358724 & 688839 & 4.9 & 5.1195 & TST & \\
\hline CHEMBL 216504 & 688839 & 5.8 & 5.6092 & TST & \\
\hline CHEMBL1551518 & 688839 & 4.9 & 5.0202 & TRN & \\
\hline CHEMBL1370043 & 688839 & 4.7 & 4.8431 & TRN & \\
\hline CHEMBL1521391 & 688839 & 6.0 & 6.0494 & TRN & \\
\hline CHEMBL1394596 & 688839 & 4.9 & 4.7599 & TRN & \\
\hline CHEMBL1354316 & 688839 & 4.9 & 5.0867 & TRN & \\
\hline CHEMBL1374784 & 688839 & 5.4 & 5.4663 & TRN & \\
\hline CHEMBL1365553 & 688839 & 4.6 & 5.2571 & TST & \\
\hline CHEMBL243663 & 688839 & 4.4 & 4.9727 & TRN & \\
\hline CHEMBL1331060 & 688839 & 4.8 & 4.9164 & TRN & \\
\hline CHEMBL1520216 & 688839 & 5.5 & 5.626 & TRN & \\
\hline CHEMBL1566650 & 688839 & 4.6 & 5.2828 & TRN & \\
\hline CHEMBL1335465 & 688839 & 4.8 & 4.80699 & 99999999995 & TRN \\
\hline CHEMBL56393 & 688839 & 4.8 & 4.904 & TRN & \\
\hline CHEMBL1536007 & 688839 & 4.9 & 4.9564 & TRN & \\
\hline CHEMBL1477964 & 688839 & 4.8 & 4.7602 & TRN & \\
\hline CHEMBL1374337 & 688839 & 4.9 & 5.0062 & TRN & \\
\hline CHEMBL1374028 & 688839 & 5.4 & 5.3126 & TST & \\
\hline CHEMBL1255837 & 688839 & 6.0 & 5.9277 & TST & \\
\hline CHEMBL397209 & 688839 & 4.4 & 4.6052 & TST & \\
\hline CHEMBL1476480 & 688839 & 4.9 & 5.1316 & TRN & \\
\hline CHEMBL1593861 & 688839 & 4.8 & 4.8439 & TRN & \\
\hline CHEMBL1595371 & 688839 & 5.5 & 5.3404 & TRN & \\
\hline CHEMBL1402241 & 688839 & 5.4 & 5.4256 & TRN & \\
\hline CHEMBL462576 & 688839 & 6.0 & 5.0363 & TST & \\
\hline CHEMBL1473753 & 688839 & 5.3 & 5.2452 & TRN & \\
\hline CHEMBL 6640 & 688839 & 4.4 & 4.9747 & TRN & \\
\hline CHEMBL1592651 & 688839 & 5.0 & 5.0291 & TRN & \\
\hline CHEMBL1487405 & 688839 & 6.5 & 5.1722 & TRN & \\
\hline CHEMBL1366539 & 688839 & 4.7 & 5.2204 & TST & \\
\hline CHEMBL1355712 & 688839 & 5.8 & 5.8937 & TRN & \\
\hline CHEMBL1332759 & 688839 & 6.2 & 6.2694 & TRN & \\
\hline CHEMBL1594350 & 688839 & 5.2 & 5.2856 & TRN & \\
\hline CHEMBL1354355 & 688839 & 4.8 & 4.9348 & TRN & \\
\hline
\end{tabular}




\begin{tabular}{|c|c|c|c|c|}
\hline \multicolumn{5}{|c|}{ Supplemental Table S2.txt } \\
\hline CHEMBL1318056 & 688839 & 5.5 & 5.5894 & TRN \\
\hline CHEMBL1436865 & 688839 & 4.9 & 4.8482 & TRN \\
\hline CHEMBL106437 & 688839 & 4.9 & 5.0617 & TRN \\
\hline CHEMBL1596241 & 688839 & 4.9 & 5.0298 & TRN \\
\hline CHEMBL1512833 & 688839 & 4.8 & 4.8227 & TRN \\
\hline CHEMBL1359181 & 688839 & 4.4 & 4.6537 & TRN \\
\hline CHEMBL1318765 & 688839 & 6.0 & 5.3319 & TRN \\
\hline CHEMBL1331679 & 688839 & 5.3 & 5.1503 & TRN \\
\hline CHEMBL1551913 & 688839 & 5.4 & 5.3394 & TRN \\
\hline CHEMBL1256686 & 688839 & 5.3 & 5.2836 & TST \\
\hline CHEMBL1599248 & 688839 & 4.9 & 5.2013 & TRN \\
\hline CHEMBL268868 & 688839 & 5.8 & 4.9439 & TRN \\
\hline CHEMBL 8151 & 688839 & 4.4 & 5.0738 & TST \\
\hline CHEMBL1598565 & 688839 & 5.5 & 4.708 & TRN \\
\hline CHEMBL1371652 & 688839 & 4.7 & 5.1832 & TRN \\
\hline CHEMBL1552623 & 688839 & 6.3 & 6.3863 & TRN \\
\hline CHEMBL1329649 & 688839 & 4.8 & 5.1233 & TST \\
\hline CHEMBL1319312 & 688839 & 5.3 & 5.194 & TRN \\
\hline CHEMBL1476084 & 688839 & 5.4 & 5.4489 & TRN \\
\hline CHEMBL1332235 & 688839 & 5.5 & 5.2455 & TST \\
\hline CHEMBL1487219 & 688839 & 5.5 & 5.5348 & TST \\
\hline CHEMBL1358810 & 688839 & 5.5 & 5.3226 & TRN \\
\hline CHEMBL1526429 & 688839 & 6.0 & 5.9038 & TRN \\
\hline CHEMBL1363408 & 688839 & 5.1 & 5.0122 & TRN \\
\hline CHEMBL1398713 & 688839 & 5.2 & 5.2084 & TST \\
\hline CHEMBL1396326 & 688839 & 5.0 & 5.0581 & TRN \\
\hline CHEMBL1365616 & 688839 & 4.9 & 5.0326 & TRN \\
\hline CHEMBL1456872 & 688839 & 6.4 & 6.3572 & TRN \\
\hline CHEMBL1523894 & 688839 & 4.8 & 4.893 & TST \\
\hline CHEMBL242384 & 688839 & 4.8 & 5.2384 & TRN \\
\hline CHEMBL182461 & 688839 & 7.4001 & 5.0448 & TST \\
\hline CHEMBL1492454 & 688839 & 4.7 & 5.0997 & TST \\
\hline CHEMBL1436333 & 688839 & 4.6 & 5.206 & TST \\
\hline CHEMBL1474977 & 688839 & 5.0 & 5.0334 & TRN \\
\hline CHEMBL1596743 & 688839 & 5.2 & 5.2159 & TRN \\
\hline CHEMBL1566670 & 688839 & 4.6 & 4.7285 & TRN \\
\hline CHEMBL1409536 & 688839 & 5.5 & 5.3265 & TST \\
\hline CHEMBL1378800 & 688839 & 5.4 & 5.3647 & TST \\
\hline CHEMBL1530832 & 688839 & 5.6 & 5.7589 & TRN \\
\hline CHEMBL1368340 & 688839 & 4.4 & 4.5628 & TST \\
\hline CHEMBL12998 & 688839 & 5.1 & 5.307 & TST \\
\hline CHEMBL1332636 & 688839 & 5.4 & 5.4509 & TRN \\
\hline CHEMBL1396460 & 688839 & 6.0 & 5.3292 & TRN \\
\hline CHEMBL1491099 & 688839 & 5.8 & 5.1123 & TST \\
\hline CHEMBL1573319 & 688839 & 4.9 & 5.1202 & TRN \\
\hline CHEMBL 258512 & 688839 & 5.3 & 5.3162 & TRN \\
\hline CHEMBL1316389 & 688839 & 4.7 & 4.8568 & TRN \\
\hline CHEMBL 276727 & 688839 & 7.2 & 6.5125 & TST \\
\hline
\end{tabular}




\begin{tabular}{|c|c|c|c|c|c|}
\hline & & & & & \\
\hline CHEMBL1491435 & 688839 & 5.8 & 5.2811 & TRN & \\
\hline CHEMBL1394135 & 688839 & 4.9 & 4.9872 & TST & \\
\hline CHEMBL1592474 & 688839 & 4.9 & 5.0845 & TST & \\
\hline CHEMBL1473405 & 688839 & 5.3 & $5.2120 e$ & 0000000001 & TRN \\
\hline CHEMBL1512385 & 688839 & 5.4 & 5.4256 & TRN & \\
\hline CHEMBL479014 & 688839 & 4.9 & 4.9048 & TRN & \\
\hline CHEMBL491555 & 688839 & 6.3 & 6.4873 & TRN & \\
\hline CHEMBL278041 & 688839 & 6.0 & 6.1669 & TST & \\
\hline CHEMBL1515355 & 688839 & 6.2 & 6.1728 & TRN & \\
\hline CHEMBL1611820 & 688839 & 4.8 & 4.8092 & TRN & \\
\hline CHEMBL1320619 & 688839 & 5.0 & 4.9253 & TRN & \\
\hline CHEMBL1530645 & 688839 & 6.3 & 6.4688 & TRN & \\
\hline CHEMBL1367486 & 688839 & 4.6 & 5.2186 & TRN & \\
\hline CHEMBL1596246 & 688839 & 5.6 & 4.9694 & TRN & \\
\hline CHEMBL1565965 & 688839 & 4.8 & 4.7548 & TRN & \\
\hline CHEMBL1318789 & 688839 & 4.5 & 4.6876 & TST & \\
\hline CHEMBL475375 & 688839 & 5.4 & 5.5168 & TRN & \\
\hline CHEMBL1357574 & 688839 & 6.5 & 6.1258 & TRN & \\
\hline CHEMBL1412900 & 688839 & 6.1 & 6.0879 & TRN & \\
\hline CHEMBL1361133 & 688839 & 5.4 & 5.4226 & TST & \\
\hline CHEMBL1394731 & 688839 & 5.1 & 5.117 & TRN & \\
\hline CHEMBL1559023 & 688839 & 4.8 & 4.8248 & TRN & \\
\hline CHEMBL1557657 & 688839 & 4.9 & 4.8748 & TRN & \\
\hline CHEMBL1356372 & 688839 & 4.7 & 4.7064 & TRN & \\
\hline CHEMBL448966 & 688839 & 6.6 & 6.7211 & TRN & \\
\hline CHEMBL294009 & 688839 & 4.6 & 5.0683 & TRN & \\
\hline CHEMBL1590663 & 688839 & 4.9 & 4.8436 & TRN & \\
\hline CHEMBL3084891 & 688839 & 4.9 & 5.1178 & TRN & \\
\hline CHEMBL1591619 & 688839 & 5.0 & 5.0395 & TRN & \\
\hline CHEMBL1474479 & 688839 & 4.4 & 4.5631 & TRN & \\
\hline CHEMBL1439635 & 688839 & 6.0 & 5.2725 & TST & \\
\hline CHEMBL1491809 & 688839 & 5.0 & 4.9793 & TRN & \\
\hline CHEMBL1493284 & 688839 & 4.6 & 4.6465 & TRN & \\
\hline CHEMBL119264 & 688839 & 5.9 & 5.8193 & TST & \\
\hline CHEMBL1567292 & 688839 & 4.9 & 4.835 & TRN & \\
\hline CHEMBL66654 & 688839 & 6.0 & 4.9599 & TST & \\
\hline CHEMBL1589942 & 688839 & 5.9 & 5.7741 & TST & \\
\hline CHEMBL1552953 & 688839 & 5.4 & 5.4902 & TRN & \\
\hline CHEMBL1371686 & 688839 & 7.0 & 5.0595 & TRN & \\
\hline CHEMBL1493308 & 688839 & 5.8 & 5.2375 & TRN & \\
\hline CHEMBL1499 & 688839 & 5.0 & 5.0724 & TRN & \\
\hline CHEMBL1490195 & 688839 & 5.0 & 5.1508 & TRN & \\
\hline CHEMBL1453980 & 688839 & 4.8 & 4.8047 & TRN & \\
\hline CHEMBL1322976 & 688839 & 5.4 & 5.1278 & TST & \\
\hline CHEMBL3213894 & 688839 & 6.0 & 6.0619 & TRN & \\
\hline CHEMBL1318635 & 688839 & 5.4 & 5.32799 & 9999999999 & TST \\
\hline CHEMBL1515452 & 688839 & 6.1 & 5.2481 & TRN & \\
\hline CHEMBL1591487 & 688839 & 4.5 & 4.5454 & TRN & \\
\hline & & & & 20392 & \\
\hline
\end{tabular}




\begin{tabular}{|c|c|c|c|c|}
\hline \multicolumn{5}{|c|}{$\mathrm{E}$} \\
\hline CHEMBL1591874 & 688839 & 4.9 & 4.83 & TRN \\
\hline CHEMBL1451697 & 688839 & 5.5 & 5.3449 & TRN \\
\hline CHEMBL1474561 & 688839 & 5.3 & 5.1338 & TRN \\
\hline CHEMBL1334477 & 688839 & 5.0 & 5.0672 & TRN \\
\hline CHEMBL551154 & 688839 & 4.7 & 5.0188 & TRN \\
\hline CHEMBL307639 & 688839 & 5.9 & 5.7303 & TST \\
\hline CHEMBL83154 & 688839 & 4.8 & 5.1135 & TRN \\
\hline CHEMBL1628207 & 688839 & 5.1 & 5.152 & TRN \\
\hline CHEMBL1316463 & 688839 & 4.9 & 4.908 & TRN \\
\hline CHEMBL15193 & 688839 & 4.6 & 4.9956 & TST \\
\hline CHEMBL1331148 & 688839 & 5.6 & 5.6911 & TRN \\
\hline CHEMBL1316528 & 688839 & 5.5 & 5.3797 & TRN \\
\hline CHEMBL1444862 & 688839 & 4.9 & 5.2084 & TST \\
\hline CHEMBL1430204 & 688839 & 4.8 & 5.0455 & TRN \\
\hline CHEMBL 299683 & 688839 & 6.0 & 4.9341 & TRN \\
\hline CHEMBL1472651 & 688839 & 4.6 & 4.5918 & TRN \\
\hline CHEMBL1396778 & 688839 & 5.0 & 5.1766 & TRN \\
\hline CHEMBL1566504 & 688839 & 5.3 & 5.0939 & TST \\
\hline CHEMBL1474363 & 688839 & 5.5 & 5.0752 & TST \\
\hline CHEMBL1365609 & 688839 & 4.8 & 4.883 & TRN \\
\hline CHEMBL1407527 & 688839 & 5.4 & 5.395 & TRN \\
\hline CHEMBL1516252 & 688839 & 4.8 & 5.0378 & TRN \\
\hline CHEMBL1411164 & 688839 & 5.7 & 5.8306 & TRN \\
\hline CHEMBL69710 & 688839 & 4.5 & 4.7439 & TST \\
\hline CHEMBL1551962 & 688839 & 5.6 & 5.4787 & TRN \\
\hline CHEMBL1413787 & 688839 & 5.3 & 5.0331 & TRN \\
\hline CHEMBL1333711 & 688839 & 4.8 & 4.9905 & TRN \\
\hline CHEMBL1512756 & 688839 & 4.8 & 4.6627 & TRN \\
\hline CHEMBL1606892 & 688839 & 4.9 & 4.9821 & TRN \\
\hline CHEMBL1482527 & 688839 & 5.3 & 5.2409 & TRN \\
\hline CHEMBL1333156 & 688839 & 5.5 & 5.5108 & TRN \\
\hline CHEMBL1435727 & 688839 & 7.1002 & 5.096 & TRN \\
\hline CHEMBL1270168 & 688839 & 5.4 & 5.3533 & TRN \\
\hline CHEMBL1333038 & 688839 & 4.6 & 4.9564 & TRN \\
\hline CHEMBL 35482 & 688839 & 5.1 & 5.1009 & TRN \\
\hline CHEMBL563919 & 688839 & 4.4 & 5.0309 & TRN \\
\hline CHEMBL1495893 & 688839 & 5.6 & 5.0379 & TST \\
\hline CHEMBL1592371 & 688839 & 5.1 & 5.1084 & TRN \\
\hline CHEMBL1552270 & 688839 & 5.6 & 5.5674 & TRN \\
\hline CHEMBL1435481 & 688839 & 4.7 & 4.7296 & TRN \\
\hline CHEMBL1450079 & 688839 & 5.5 & 5.1975 & TRN \\
\hline CHEMBL1327793 & 688839 & 5.4 & 5.3186 & TRN \\
\hline CHEMBL1363367 & 688839 & 5.4 & 5.3434 & TRN \\
\hline CHEMBL1563147 & 688839 & 4.6 & 4.684 & TRN \\
\hline CHEMBL340807 & 688839 & 6.0 & 5.4772 & TRN \\
\hline CHEMBL1356069 & 688839 & 5.0 & 5.2672 & TRN \\
\hline CHEMBL1561383 & 688839 & 4.9 & 4.8379 & TRN \\
\hline CHEMBL1476099 & 688839 & 4.4 & 5.0816 & TRN \\
\hline
\end{tabular}




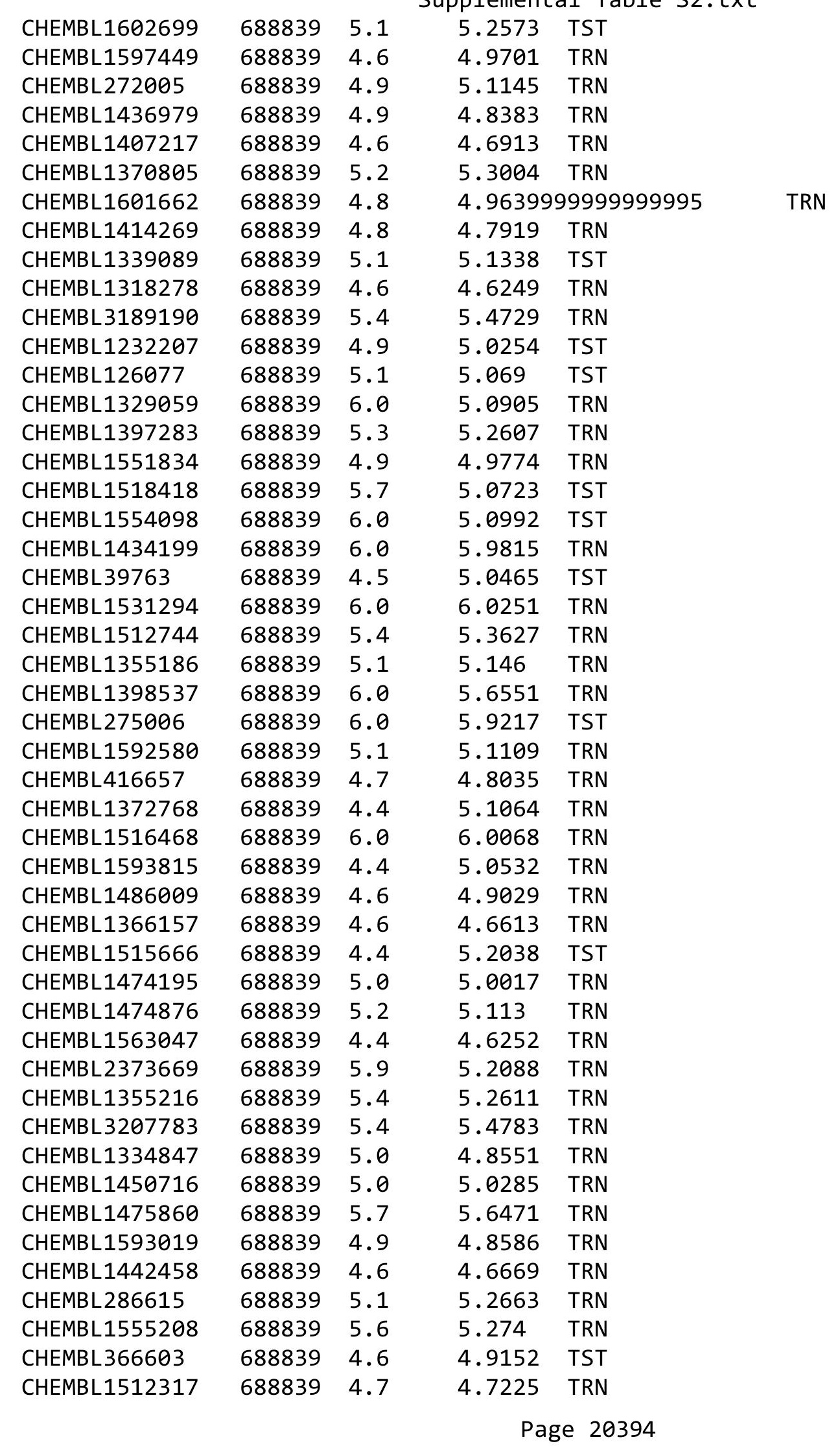




\begin{tabular}{|c|c|c|c|c|}
\hline \\
\hline CHEMBL1437314 & 688839 & 5.4 & 5.4849 & TRN \\
\hline CHEMBL1394698 & 688839 & 5.7 & 5.3221 & TRN \\
\hline CHEMBL117 & 688839 & 6.0 & 5.4814 & TRN \\
\hline CHEMBL1552405 & 688839 & 5.0 & 4.8987 & TRN \\
\hline CHEMBL1519978 & 688839 & 5.4 & 5.4155 & TRN \\
\hline CHEMBL1568744 & 688839 & 6.0 & 5.8785 & TRN \\
\hline CHEMBL134291 & 688839 & 5.0 & 5.0103 & TRN \\
\hline CHEMBL1573058 & 688839 & 4.8 & 4.7447 & TRN \\
\hline CHEMBL1557498 & 688839 & 5.6 & 5.3556 & TRN \\
\hline CHEMBL1574390 & 688839 & 4.5 & 4.5723 & TRN \\
\hline CHEMBL1411543 & 688839 & 7.6003 & 6.7315 & TRN \\
\hline CHEMBL1338367 & 688839 & 4.8 & 5.188 & TRN \\
\hline CHEMBL1483855 & 688839 & 5.5 & 5.6131 & TRN \\
\hline CHEMBL1610129 & 688839 & 4.8 & 4.8032 & TST \\
\hline CHEMBL1553322 & 688839 & 4.8 & 4.8133 & TRN \\
\hline CHEMBL1408854 & 688839 & 5.5 & 4.825 & TRN \\
\hline CHEMBL1521010 & 688839 & 6.0 & 5.8666 & TRN \\
\hline CHEMBL1330385 & 688839 & 5.6 & 5.6523 & TRN \\
\hline CHEMBL1331288 & 688839 & 5.6 & 5.649 & TRN \\
\hline CHEMBL1395634 & 688839 & 6.0 & 5.048 & TRN \\
\hline CHEMBL1518164 & 688839 & 4.9 & 5.0604 & TRN \\
\hline CHEMBL1452894 & 688839 & 5.5 & 5.6254 & TRN \\
\hline CHEMBL1314587 & 688839 & 5.3 & 5.4122 & TRN \\
\hline CHEMBL1514455 & 688839 & 5.5 & 5.3503 & TRN \\
\hline CHEMBL1490495 & 688839 & 4.4 & 5.0718 & TRN \\
\hline CHEMBL1495954 & 688839 & 4.6 & 5.2349 & TRN \\
\hline CHEMBL1571975 & 688839 & 5.8 & 5.7009 & TST \\
\hline CHEMBL1493835 & 688839 & 5.0 & 5.0019 & TST \\
\hline CHEMBL1603264 & 688839 & 5.6 & 5.0277 & TST \\
\hline CHEMBL520897 & 688839 & 6.1 & 5.2548 & TST \\
\hline CHEMBL1314434 & 688839 & 4.8 & 4.7864 & TRN \\
\hline CHEMBL1256916 & 688839 & 4.6 & 5.0365 & TRN \\
\hline CHEMBL1357221 & 688839 & 4.8 & 4.8417 & TRN \\
\hline CHEMBL1602112 & 688839 & 5.9 & 5.9405 & TRN \\
\hline CHEMBL 23832 & 688839 & 4.5 & 4.769 & TRN \\
\hline CHEMBL1484480 & 688839 & 4.9 & 4.9565 & TRN \\
\hline CHEMBL1592584 & 688839 & 5.4 & 5.3548 & TRN \\
\hline CHEMBL1456767 & 688839 & 5.1 & 5.1064 & TRN \\
\hline CHEMBL1400190 & 688839 & 5.5 & 5.1556 & TRN \\
\hline CHEMBL1356135 & 688839 & 4.9 & 4.9637 & TRN \\
\hline CHEMBL1590048 & 688839 & 5.0 & 5.0453 & TRN \\
\hline CHEMBL1516028 & 688839 & 5.5 & 5.5727 & TRN \\
\hline CHEMBL1535796 & 688839 & 5.2 & 5.0638 & TRN \\
\hline CHEMBL1596172 & 688839 & 4.8 & 5.1214 & TRN \\
\hline CHEMBL1358215 & 688839 & 5.1 & 4.9832 & TRN \\
\hline CHEMBL1378755 & 688839 & 5.9 & 6.0009 & TRN \\
\hline CHEMBL1355840 & 688839 & 6.5 & 6.485 & TRN \\
\hline CHEMBL1600436 & 688839 & 4.4 & 5.3037 & TST \\
\hline
\end{tabular}




\begin{tabular}{|c|c|c|c|c|c|}
\hline \\
\hline CHEMBL1551841 & 688839 & 5.5 & 5.4515 & TRN & \\
\hline CHEMBL1570196 & 688839 & 5.6 & 5.4897 & TRN & \\
\hline CHEMBL1592589 & 688839 & 5.9 & 5.3223 & TST & \\
\hline CHEMBL1475484 & 688839 & 5.3 & 5.1605 & TRN & \\
\hline CHEMBL1595377 & 688839 & 5.0 & 4.9907 & TRN & \\
\hline CHEMBL1480742 & 688839 & 5.5 & 5.5734 & TRN & \\
\hline CHEMBL1320947 & 688839 & 6.2 & 5.9382 & TRN & \\
\hline CHEMBL18879 & 688839 & 4.6 & 4.831 & TST & \\
\hline CHEMBL1474927 & 688839 & 5.7 & 5.6917 & TRN & \\
\hline CHEMBL1522486 & 688839 & 5.3 & 4.9734 & TST & \\
\hline CHEMBL1476892 & 688839 & 6.0 & 6.0434 & TRN & \\
\hline CHEMBL1488112 & 688839 & 4.5 & 5.0341 & TRN & \\
\hline CHEMBL1256659 & 688839 & 4.7 & 5.1045 & TRN & \\
\hline CHEMBL1590982 & 688839 & 5.5 & 5.3205 & TRN & \\
\hline CHEMBL1572915 & 688839 & 5.4 & 5.3361 & TRN & \\
\hline CHEMBL1450026 & 688839 & 4.7 & 4.7577 & TRN & \\
\hline CHEMBL186366 & 688839 & 4.5 & 5.1098 & TRN & \\
\hline CHEMBL1403626 & 688839 & 5.5 & 5.4728 & TRN & \\
\hline CHEMBL1369825 & 688839 & 4.8 & 5.101 & TST & \\
\hline CHEMBL1490209 & 688839 & 4.5 & 4.824 & TRN & \\
\hline CHEMBL1456923 & 688839 & 4.6 & 5.2208 & TRN & \\
\hline CHEMBL1475108 & 688839 & 5.4 & 5.0752 & TRN & \\
\hline CHEMBL1561500 & 688839 & 4.5 & 4.5701 & TRN & \\
\hline CHEMBL1376736 & 688839 & 4.8 & 4.8799 & TRN & \\
\hline CHEMBL491940 & 688839 & 5.8 & 5.6763 & TRN & \\
\hline CHEMBL1316456 & 688839 & 5.4 & 5.3237 & TRN & \\
\hline CHEMBL 267373 & 688839 & 8.301 & 4.80699 & 99999999995 & TRN \\
\hline CHEMBL1473191 & 688839 & 5.4 & 5.4012 & TST & \\
\hline CHEMBL1396090 & 688839 & 4.8 & 4.7768 & TRN & \\
\hline CHEMBL1516224 & 688839 & 5.0 & 5.1014 & TRN & \\
\hline CHEMBL1408520 & 688839 & 4.9 & 4.9935 & TRN & \\
\hline CHEMBL1476712 & 688839 & 5.5 & 5.33700 & $\partial 000000001$ & TRN \\
\hline CHEMBL1477557 & 688839 & 4.8 & 4.8254 & TRN & \\
\hline CHEMBL404613 & 688839 & 5.4 & 5.4211 & TST & \\
\hline CHEMBL517186 & 688839 & 5.5 & 5.4051 & TST & \\
\hline CHEMBL259807 & 688839 & 5.6 & 5.2383 & TRN & \\
\hline CHEMBL1552707 & 688839 & 6.2 & 6.0658 & TRN & \\
\hline CHEMBL1526852 & 688839 & 4.4 & 4.6219 & TRN & \\
\hline CHEMBL1334106 & 688839 & 6.0 & 6.0307 & TRN & \\
\hline CHEMBL1330087 & 688839 & 6.0 & 6.0676 & TRN & \\
\hline CHEMBL1451874 & 688839 & 4.9 & 5.0742 & TRN & \\
\hline CHEMBL1491242 & 688839 & 5.9 & 5.3344 & TST & \\
\hline CHEMBL1450903 & 688839 & 5.7 & 5.7929 & TRN & \\
\hline CHEMBL1553179 & 688839 & 5.3 & 5.1505 & TRN & \\
\hline CHEMBL1256697 & 688839 & 5.6 & 5.4219 & TRN & \\
\hline CHEMBL1255662 & 688839 & 6.0 & 5.5094 & TST & \\
\hline CHEMBL1559009 & 688839 & 5.5 & 5.5085 & TRN & \\
\hline CHEMBL1608678 & 688839 & 5.5 & 5.4836 & TRN & \\
\hline
\end{tabular}




\begin{tabular}{|c|c|c|c|c|c|}
\hline & & & & & \\
\hline CHEMBL1515724 & 688839 & 5.1 & 5.0272 & TRN & \\
\hline CHEMBL1455942 & 688839 & 5.5 & 5.3508 & TRN & \\
\hline CHEMBL1350617 & 688839 & 4.5 & 5.1252 & TRN & \\
\hline CHEMBL1454052 & 688839 & 4.9 & 4.9759 & TRN & \\
\hline CHEMBL287689 & 688839 & 5.5 & 5.3624 & TST & \\
\hline CHEMBL1407576 & 688839 & 5.4 & 5.3024 & TRN & \\
\hline CHEMBL1395058 & 688839 & 4.7 & 5.037 & TRN & \\
\hline CHEMBL1569592 & 688839 & 6.6 & 6.4455 & TRN & \\
\hline CHEMBL1590818 & 688839 & 4.5 & 4.6259 & TRN & \\
\hline CHEMBL375629 & 688839 & 5.0 & 5.1219 & TST & \\
\hline CHEMBL491952 & 688839 & 5.0 & 5.0425 & TRN & \\
\hline CHEMBL1374544 & 688839 & 5.6 & 5.6301 & TRN & \\
\hline CHEMBL1336727 & 688839 & 4.9 & 4.9843 & TST & \\
\hline CHEMBL1374913 & 688839 & 4.8 & 4.8832 & TRN & \\
\hline CHEMBL1604877 & 688839 & 4.8 & 5.0609 & TRN & \\
\hline CHEMBL113142 & 688839 & 4.8 & 4.8894 & TST & \\
\hline CHEMBL1613233 & 688839 & 4.5 & 4.6535 & TRN & \\
\hline CHEMBL1436160 & 688839 & 4.8 & 4.7227 & TRN & \\
\hline CHEMBL1455661 & 688839 & 5.0 & 5.0815 & TRN & \\
\hline CHEMBL1475698 & 688839 & 6.0 & 5.2753 & TRN & \\
\hline CHEMBL1603860 & 688839 & 5.0 & 5.09699 & 99999999995 & TRN \\
\hline CHEMBL1512440 & 688839 & 4.8 & 5.2009 & TRN & \\
\hline CHEMBL1436521 & 688839 & 5.1 & 5.1513 & TRN & \\
\hline CHEMBL1434447 & 688839 & 5.4 & 5.4463 & TRN & \\
\hline CHEMBL 76447 & 688839 & 4.6 & 5.1257 & TRN & \\
\hline CHEMBL1358380 & 688839 & 5.5 & 5.3807 & TRN & \\
\hline CHEMBL1449575 & 688839 & 4.6 & 5.1477 & TRN & \\
\hline CHEMBL1523822 & 688839 & 5.4 & 5.4579 & TST & \\
\hline CHEMBL1565830 & 688839 & 4.9 & 5.1331 & TST & \\
\hline CHEMBL1397671 & 688839 & 5.1 & 5.1721 & TRN & \\
\hline CHEMBL1591731 & 688839 & 5.6 & 5.5352 & TST & \\
\hline CHEMBL1364717 & 688839 & 5.1 & 5.0157 & TRN & \\
\hline CHEMBL391997 & 688839 & 5.5 & 5.3666 & TST & \\
\hline CHEMBL1562786 & 688839 & 5.3 & 5.3808 & TRN & \\
\hline CHEMBL1412390 & 688839 & 5.5 & 5.5848 & TRN & \\
\hline CHEMBL1356395 & 688839 & 5.5 & 5.415 & TST & \\
\hline CHEMBL1377111 & 688839 & 6.0 & 5.8375 & TST & \\
\hline CHEMBL1255747 & 688839 & 4.4 & 5.2053 & TRN & \\
\hline CHEMBL1413371 & 688839 & 5.0 & 5.0931 & TRN & \\
\hline CHEMBL1435544 & 688839 & 4.8 & 4.785 & TRN & \\
\hline CHEMBL1328490 & 688839 & 5.5 & 5.5402 & TRN & \\
\hline CHEMBL164269 & 688839 & 5.5 & 5.4438 & TST & \\
\hline CHEMBL1482759 & 688839 & 5.1 & 5.0313 & TRN & \\
\hline CHEMBL1435604 & 688839 & 4.8 & 4.819 & TRN & \\
\hline CHEMBL1516015 & 688839 & 4.6 & 4.7455 & TST & \\
\hline CHEMBL332898 & 688839 & 5.1 & 5.0863 & TRN & \\
\hline CHEMBL1437259 & 688839 & 5.0 & $4.7810 e$ & 0000000001 & TRN \\
\hline CHEMBL1365367 & 688839 & 5.4 & 5.5417 & TRN & \\
\hline & & & & 20397 & \\
\hline
\end{tabular}




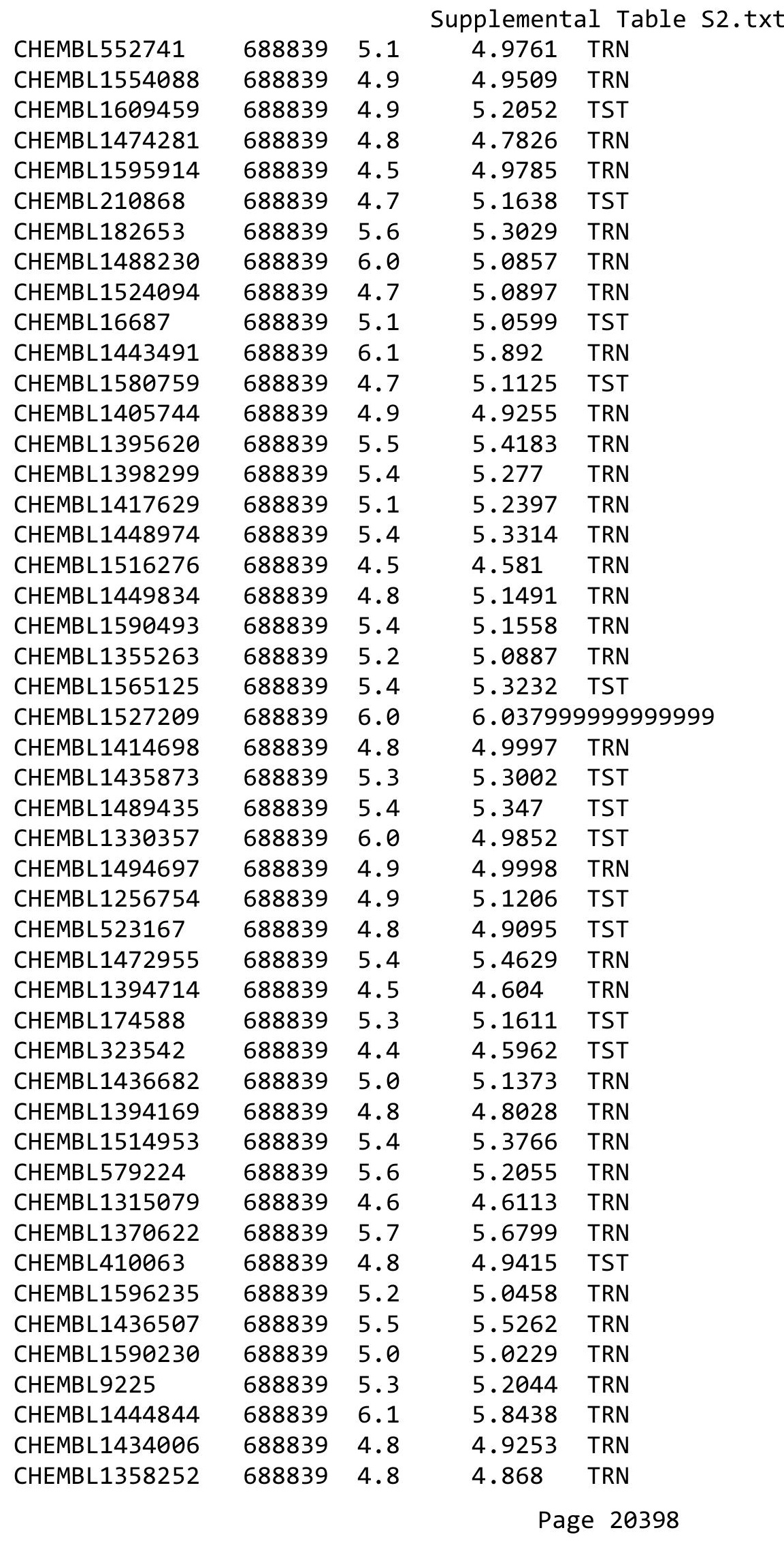




\begin{tabular}{|c|c|c|c|c|c|}
\hline & & & & & \\
\hline CHEMBL1455767 & 688839 & 4.4 & 4.475 & TRN & \\
\hline CHEMBL1395567 & 688839 & 5.7 & 5.6656 & TRN & \\
\hline CHEMBL1318310 & 688839 & 5.4 & 5.4629 & TRN & \\
\hline CHEMBL1405410 & 688839 & 4.9 & 4.998 & TRN & \\
\hline CHEMBL 260374 & 688839 & 6.0 & 5.7843 & TST & \\
\hline CHEMBL1561374 & 688839 & 5.6 & 5.1633 & TST & \\
\hline CHEMBL1436726 & 688839 & 5.7 & 5.0896 & TRN & \\
\hline CHEMBL1256290 & 688839 & 4.5 & 4.691 & TST & \\
\hline CHEMBL534084 & 688839 & 5.1 & 5.2428 & TRN & \\
\hline CHEMBL1515777 & 688839 & 4.9 & 4.8974 & TRN & \\
\hline CHEMBL1567600 & 688839 & 4.9 & 4.874 & TRN & \\
\hline CHEMBL1531163 & 688839 & 5.4 & 5.25299 & 9999999999 & TRN \\
\hline CHEMBL1318114 & 688839 & 5.5 & 5.5661 & TRN & \\
\hline CHEMBL1557564 & 688839 & 7.1002 & 6.75899 & 99999999995 & TRN \\
\hline CHEMBL 22373 & 688839 & 5.1 & 5.1181 & TST & \\
\hline CHEMBL1405909 & 688839 & 4.6 & 4.812 & TRN & \\
\hline CHEMBL1560835 & 688839 & 4.5 & 5.1604 & TRN & \\
\hline CHEMBL1355644 & 688839 & 6.0 & 6.0531 & TRN & \\
\hline CHEMBL1377106 & 688839 & 4.9 & 4.9694 & TRN & \\
\hline CHEMBL1320607 & 688839 & 4.8 & 4.7693 & TRN & \\
\hline CHEMBL1514071 & 688839 & 5.0 & 4.9684 & TRN & \\
\hline CHEMBL1512594 & 688839 & 5.1 & 5.14 & TRN & \\
\hline CHEMBL1334652 & 688839 & 5.1 & 5.0884 & TRN & \\
\hline CHEMBL1355935 & 688839 & 4.8 & 4.9411 & TRN & \\
\hline CHEMBL1453992 & 688839 & 5.7 & 5.6085 & TRN & \\
\hline CHEMBL1450162 & 688839 & 5.2 & 5.1335 & TRN & \\
\hline CHEMBL1565842 & 688839 & 4.8 & 4.8515 & TST & \\
\hline CHEMBL1435293 & 688839 & 5.5 & 5.8496 & TRN & \\
\hline CHEMBL1482809 & 688839 & 5.3 & 5.244 & TRN & \\
\hline CHEMBL1438323 & 688839 & 6.0 & 5.9908 & TRN & \\
\hline CHEMBL1356262 & 688839 & 5.0 & 5.0223 & TRN & \\
\hline CHEMBL1559246 & 688839 & 4.8 & 4.7874 & TRN & \\
\hline CHEMBL3207894 & 688839 & 6.0 & 5.9627 & TRN & \\
\hline CHEMBL1476298 & 688839 & 5.6 & 5.6757 & TRN & \\
\hline CHEMBL1374355 & 688839 & 4.9 & 4.9022 & TRN & \\
\hline CHEMBL1492215 & 688839 & 5.5 & 5.441 & TRN & \\
\hline CHEMBL1434625 & 688839 & 5.1 & 4.816 & TRN & \\
\hline CHEMBL1555480 & 688839 & 4.8 & 4.8405 & TRN & \\
\hline CHEMBL1402799 & 688839 & 4.8 & 4.9079 & TRN & \\
\hline CHEMBL1354154 & 688839 & 5.7 & 5.8883 & TRN & \\
\hline CHEMBL1473073 & 688839 & 5.4 & 5.1211 & TRN & \\
\hline CHEMBL1411045 & 688839 & 5.5 & 5.5917 & TST & \\
\hline CHEMBL1474196 & 688839 & 5.9 & 5.24299 & 9999999999 & TST \\
\hline CHEMBL1591429 & 688839 & 4.8 & 5.0364 & TRN & \\
\hline CHEMBL1492669 & 688839 & 5.4 & 5.3197 & TST & \\
\hline CHEMBL1514398 & 688839 & 5.4 & 5.5829 & TRN & \\
\hline CHEMBL1406879 & 688839 & 4.8 & 4.873 & TRN & \\
\hline CHEMBL406120 & 688839 & 5.0 & 5.2305 & TRN & \\
\hline & & & & 20399 & \\
\hline
\end{tabular}




\begin{tabular}{|c|c|c|c|c|}
\hline & & & pplement & al $\mathrm{Ta}$ \\
\hline CHEMBL1487604 & 688839 & 6.0 & 5.0903 & TRN \\
\hline CHEMBL1401780 & 688839 & 5.7 & 5.1501 & TRN \\
\hline CHEMBL1535573 & 688839 & 5.0 & 5.2153 & TST \\
\hline CHEMBL1474114 & 688839 & 6.1 & 6.2707 & TRN \\
\hline CHEMBL1363568 & 688839 & 4.6 & 4.6148 & TRN \\
\hline CHEMBL1369062 & 688839 & 4.6 & 4.6938 & TRN \\
\hline CHEMBL1573862 & 688839 & 4.9 & 4.9553 & TRN \\
\hline CHEMBL 38288 & 688839 & 6.1 & 5.732 & TRN \\
\hline CHEMBL44201 & 688839 & 4.9 & 5.0041 & TRN \\
\hline CHEMBL1358092 & 688839 & 5.7 & 5.574 & TRN \\
\hline CHEMBL1435381 & 688839 & 4.6 & 4.56 & TST \\
\hline CHEMBL 2373658 & 688839 & 5.1 & 5.102 & TST \\
\hline CHEMBL1317039 & 688839 & 5.7 & 5.8345 & TRN \\
\hline CHEMBL 243250 & 688839 & 5.4 & 5.065 & TRN \\
\hline CHEMBL1318447 & 688839 & 4.6 & 4.6743 & TRN \\
\hline CHEMBL1317232 & 688839 & 4.8 & 4.8394 & TRN \\
\hline CHEMBL1479817 & 688839 & 5.1 & 5.0527 & TRN \\
\hline CHEMBL1473029 & 688839 & 5.5 & 5.1327 & TST \\
\hline CHEMBL1511972 & 688839 & 4.4 & 4.5179 & TRN \\
\hline CHEMBL1449490 & 688839 & 6.0 & 5.2298 & TST \\
\hline CHEMBL536950 & 688839 & 4.5 & 4.573 & TST \\
\hline CHEMBL1367076 & 688839 & 4.6 & 5.0932 & TRN \\
\hline CHEMBL1513990 & 688839 & 5.7 & 5.851 & TRN \\
\hline CHEMBL1320310 & 688839 & 4.8 & 4.8907 & TRN \\
\hline CHEMBL1454049 & 688839 & 5.9 & 5.9484 & TRN \\
\hline CHEMBL1527944 & 688839 & 4.4 & 5.5474 & TRN \\
\hline CHEMBL1364168 & 688839 & 4.8 & 4.9006 & TRN \\
\hline CHEMBL48449 & 688839 & 6.0 & 5.7571 & TST \\
\hline CHEMBL1395497 & 688839 & 5.0 & 4.8997 & TRN \\
\hline CHEMBL 342375 & 688839 & 6.3 & 6.1064 & TST \\
\hline CHEMBL 273094 & 688839 & 5.6 & 5.6323 & TST \\
\hline CHEMBL1480554 & 688839 & 5.5 & 4.8947 & TRN \\
\hline CHEMBL1476139 & 688839 & 4.9 & 4.855 & TRN \\
\hline CHEMBL252721 & 688839 & 5.2 & 5.5529 & TRN \\
\hline CHEMBL12129 & 688839 & 6.2 & 6.0506 & TRN \\
\hline CHEMBL1573756 & 688839 & 5.5 & 5.1717 & TST \\
\hline CHEMBL64569 & 688839 & 5.5 & 5.4326 & TRN \\
\hline CHEMBL1590095 & 688839 & 4.6 & 5.0252 & TRN \\
\hline CHEMBL1318622 & 688839 & 5.6 & 5.5526 & TRN \\
\hline CHEMBL1449018 & 688839 & 4.6 & 4.9482 & TRN \\
\hline CHEMBL1603825 & 688839 & 4.7 & 5.0852 & TRN \\
\hline CHEMBL1552747 & 688839 & 5.1 & 5.0563 & TRN \\
\hline CHEMBL475376 & 688839 & 5.2 & 5.1957 & TRN \\
\hline CHEMBL1551284 & 688839 & 5.0 & 5.12 & TRN \\
\hline CHEMBL1551515 & 688839 & 4.7 & 4.7733 & TRN \\
\hline CHEMBL1457544 & 688839 & 5.0 & 5.0167 & TRN \\
\hline CHEMBL1450553 & 688839 & 6.0 & 5.8435 & TRN \\
\hline CHEMBL1517187 & 688839 & 4.5 & 4.56 & TST \\
\hline
\end{tabular}




\begin{tabular}{|c|c|c|c|c|}
\hline \multicolumn{5}{|c|}{ Supplemental Table S2.txt } \\
\hline CHEMBL1592804 & 688839 & 5.1 & 4.96 & TRN \\
\hline CHEMBL1162521 & 688839 & 5.4 & 5.3689 & TRN \\
\hline CHEMBL1301177 & 688839 & 5.3 & 5.0818 & TRN \\
\hline CHEMBL1357167 & 688839 & 5.0 & 4.9936 & TRN \\
\hline CHEMBL1591533 & 688839 & 4.4 & 4.5144 & TRN \\
\hline CHEMBL1487735 & 688839 & 4.8 & 4.7846 & TRN \\
\hline CHEMBL489525 & 688839 & 4.6 & 5.1498 & TRN \\
\hline CHEMBL1492385 & 688839 & 4.5 & 5.1343 & TST \\
\hline CHEMBL1590857 & 688839 & 5.2 & 5.1685 & TRN \\
\hline CHEMBL1355720 & 688839 & 5.8 & 5.6221 & TRN \\
\hline CHEMBL 371523 & 688839 & 4.9 & 4.8874 & TRN \\
\hline CHEMBL1435647 & 688839 & 4.6 & 4.6726 & TST \\
\hline CHEMBL1513511 & 688839 & 6.3 & 6.1494 & TRN \\
\hline CHEMBL1554236 & 688839 & 4.7 & 4.6723 & TRN \\
\hline CHEMBL1483862 & 688839 & 4.4 & 5.1499 & TST \\
\hline CHEMBL1590590 & 688839 & 5.4 & 4.8804 & TRN \\
\hline CHEMBL1565192 & 688839 & 4.5 & 5.006 & TRN \\
\hline CHEMBL1568111 & 688839 & 5.9 & 6.0435 & TRN \\
\hline CHEMBL1565190 & 688839 & 5.5 & 4.897 & TRN \\
\hline CHEMBL454173 & 688839 & 6.0 & 5.1133 & TST \\
\hline CHEMBL259140 & 688839 & 5.3 & 5.5629 & TRN \\
\hline CHEMBL490742 & 688839 & 5.9 & 6.1159 & TRN \\
\hline CHEMBL41092 & 688839 & 4.6 & 4.9665 & TRN \\
\hline CHEMBL1355651 & 688839 & 4.7 & 4.8102 & TRN \\
\hline CHEMBL1399481 & 688839 & 5.9 & 6.0652 & TRN \\
\hline CHEMBL1317177 & 688839 & 4.5 & 4.6177 & TRN \\
\hline CHEMBL44628 & 688839 & 7.3002 & 4.813 & TRN \\
\hline CHEMBL1355788 & 688839 & 4.8 & 4.8407 & TRN \\
\hline CHEMBL1454730 & 688839 & 5.7 & 5.6025 & TST \\
\hline CHEMBL1481608 & 688839 & 5.3 & 5.1638 & TRN \\
\hline CHEMBL1475381 & 688839 & 5.0 & 4.9864 & TRN \\
\hline CHEMBL1435254 & 688839 & 5.8 & 5.7787 & TRN \\
\hline CHEMBL66953 & 688839 & 4.5 & 5.1616 & TST \\
\hline CHEMBL1395863 & 688839 & 5.4 & 5.2191 & TST \\
\hline CHEMBL18132 & 688839 & 5.8 & 5.5771 & TRN \\
\hline CHEMBL1325152 & 688839 & 4.6 & 5.1177 & TRN \\
\hline CHEMBL1323355 & 688839 & 5.1 & 5.1645 & TST \\
\hline CHEMBL1358628 & 688839 & 6.0 & 5.7289 & TRN \\
\hline CHEMBL1398137 & 688839 & 5.1 & 5.1398 & TRN \\
\hline CHEMBL1478221 & 688839 & 4.8 & 4.8496 & TRN \\
\hline CHEMBL1589925 & 688839 & 4.8 & 4.8179 & TRN \\
\hline CHEMBL1476407 & 688839 & 4.8 & 4.8295 & TRN \\
\hline CHEMBL1435077 & 688839 & 5.9 & 5.9452 & TRN \\
\hline CHEMBL484928 & 688839 & 4.8 & 4.9909 & TRN \\
\hline CHEMBL2373639 & 688839 & 5.5 & 5.3837 & TST \\
\hline CHEMBL1489541 & 688839 & 6.0 & 5.9322 & TRN \\
\hline CHEMBL1341844 & 688839 & 4.8 & 4.9424 & TRN \\
\hline CHEMBL1256709 & 688839 & 4.7 & 4.8178 & TRN \\
\hline
\end{tabular}




\begin{tabular}{|c|c|c|c|c|c|}
\hline \multicolumn{6}{|c|}{ Supplemental Table S2.txt } \\
\hline CHEMBL58033 & 688839 & 6.0 & 5.7782 & TRN & \\
\hline CHEMBL1395850 & 688839 & 4.8 & 4.8575 & TRN & \\
\hline CHEMBL1437273 & 688839 & 5.2 & 5.0517 & TRN & \\
\hline CHEMBL1608876 & 688839 & 5.7 & 5.2192 & TRN & \\
\hline CHEMBL1552607 & 688839 & 4.8 & 4.7577 & TRN & \\
\hline CHEMBL1516170 & 688839 & 6.7001 & 6.6101 & TRN & \\
\hline CHEMBL1358547 & 688839 & 5.8 & 5.3515 & TRN & \\
\hline CHEMBL1475151 & 688839 & 5.5 & 5.5243 & TRN & \\
\hline CHEMBL1562777 & 688839 & 5.2 & 4.9608 & TRN & \\
\hline CHEMBL1411578 & 688839 & 4.8 & 4.8252 & TST & \\
\hline CHEMBL1337128 & 688839 & 6.0 & 6.0023 & TRN & \\
\hline CHEMBL1592876 & 688839 & 5.4 & $5.4510 €$ & 00000000005 & TRN \\
\hline CHEMBL1436169 & 688839 & 6.2 & 6.0999 & TRN & \\
\hline CHEMBL1610945 & 688839 & 5.4 & 5.3214 & TST & \\
\hline CHEMBL1591548 & 688839 & 5.1 & 5.138 & TRN & \\
\hline CHEMBL1475620 & 688839 & 5.8 & 5.7672 & TRN & \\
\hline CHEMBL1375285 & 688839 & 6.0 & 6.0091 & TRN & \\
\hline CHEMBL1397825 & 688839 & 5.0 & 4.9531 & TRN & \\
\hline CHEMBL1512540 & 688839 & 5.0 & 5.0819 & TRN & \\
\hline CHEMBL1375046 & 688839 & 4.9 & 4.9213 & TRN & \\
\hline CHEMBL1515287 & 688839 & 5.3 & 5.1642 & TRN & \\
\hline CHEMBL1355227 & 688839 & 4.9 & 4.8397 & TRN & \\
\hline CHEMBL1355701 & 688839 & 5.3 & 5.2363 & TRN & \\
\hline CHEMBL1727680 & 688839 & 5.4 & 5.437 & TRN & \\
\hline CHEMBL1404882 & 688839 & 5.6 & 5.6511 & TRN & \\
\hline CHEMBL1317913 & 688839 & 5.2 & 5.0861 & TRN & \\
\hline CHEMBL1452716 & 688839 & 6.0 & 5.2164 & TST & \\
\hline CHEMBL 80941 & 688839 & 4.9 & 4.9346 & TRN & \\
\hline CHEMBL1354725 & 688839 & 5.6 & 5.34206 & 00000000005 & TRN \\
\hline CHEMBL1602508 & 688839 & 4.6 & 4.7694 & TRN & \\
\hline CHEMBL1612363 & 688839 & 5.0 & 5.0163 & TRN & \\
\hline CHEMBL1595709 & 688839 & 6.0 & 5.7837 & TST & \\
\hline CHEMBL50112 & 688839 & 5.1 & 4.9898 & TRN & \\
\hline CHEMBL1593071 & 688839 & 4.8 & 4.9462 & TRN & \\
\hline CHEMBL107131 & 688839 & 4.9 & 5.1128 & TRN & \\
\hline CHEMBL1556218 & 688839 & 4.9 & 4.9351 & TRN & \\
\hline CHEMBL1320206 & 688839 & 4.9 & 4.9383 & TRN & \\
\hline CHEMBL1363362 & 688839 & 4.8 & 5.0633 & TRN & \\
\hline CHEMBL1370891 & 688839 & 6.0 & 5.3155 & TRN & \\
\hline CHEMBL405912 & 688839 & 6.0 & 6.0366 & TRN & \\
\hline CHEMBL1515033 & 688839 & 5.1 & 5.0813 & TRN & \\
\hline CHEMBL1594020 & 688839 & 4.8 & 4.8995 & TRN & \\
\hline CHEMBL1397427 & 688839 & 4.8 & 4.8532 & TRN & \\
\hline CHEMBL1594405 & 688839 & 6.2 & 6.4598 & TRN & \\
\hline CHEMBL1439945 & 688839 & 4.8 & 4.8036 & TRN & \\
\hline CHEMBL1409689 & 688839 & 6.3 & 6.3432 & TRN & \\
\hline CHEMBL1551503 & 688839 & 4.9 & 4.9269 & TRN & \\
\hline CHEMBL1331363 & 688839 & 7.2 & 6.8176 & TRN & \\
\hline
\end{tabular}




\begin{tabular}{|c|c|c|c|c|c|}
\hline \multirow[b]{2}{*}{ CHEMBL1256283 } & \multirow{2}{*}{688839} & \\
\hline & & 5.5 & 5.3889 & TST & \\
\hline CHEMBL1361905 & 688839 & 4.9 & 4.9204 & TRN & \\
\hline CHEMBL1396124 & 688839 & 4.8 & 5.261 & TRN & \\
\hline CHEMBL1553694 & 688839 & 5.8 & 5.8772 & TRN & \\
\hline CHEMBL1397089 & 688839 & 5.2 & 5.223 & TST & \\
\hline CHEMBL411481 & 688839 & 5.4 & 5.1185 & TRN & \\
\hline CHEMBL1256835 & 688839 & 6.0 & 5.8259 & TRN & \\
\hline CHEMBL1317748 & 688839 & 5.0 & 4.9615 & TRN & \\
\hline CHEMBL1442106 & 688839 & 4.8 & 4.8154 & TRN & \\
\hline CHEMBL1494609 & 688839 & 4.8 & 4.8386 & TRN & \\
\hline CHEMBL1474125 & 688839 & 4.4 & 4.4821 & TRN & \\
\hline CHEMBL1324334 & 688839 & 5.1 & 5.1679 & TRN & \\
\hline CHEMBL1488612 & 688839 & 4.8 & 5.2074 & TST & \\
\hline CHEMBL1479036 & 688839 & 5.4 & 5.2446 & TST & \\
\hline CHEMBL1600394 & 688839 & 4.7 & 4.7124 & TRN & \\
\hline CHEMBL1452946 & 688839 & 5.9 & 5.2308 & TST & \\
\hline CHEMBL1338095 & 688839 & 5.4 & 5.3925 & TRN & \\
\hline CHEMBL1489568 & 688839 & 4.8 & 4.9515 & TRN & \\
\hline CHEMBL1377908 & 688839 & 4.9 & 4.8912 & TRN & \\
\hline CHEMBL1397636 & 688839 & 5.5 & 5.5549 & TRN & \\
\hline CHEMBL1398066 & 688839 & 4.9 & 4.9976 & TRN & \\
\hline CHEMBL1451739 & 688839 & 7.3002 & 4.9895 & TST & \\
\hline CHEMBL495069 & 688839 & 5.5 & 5.43 & TRN & \\
\hline CHEMBL1410816 & 688839 & 5.0 & 5.1647 & TRN & \\
\hline CHEMBL1571634 & 688839 & 5.5 & 5.13200 & 0000000001 & TRN \\
\hline CHEMBL1528606 & 688839 & 6.0 & 5.9476 & TRN & \\
\hline CHEMBL45244 & 688839 & 4.5 & 4.6754 & TRN & \\
\hline CHEMBL3192742 & 688839 & 5.2 & 5.2842 & TRN & \\
\hline CHEMBL1476049 & 688839 & 4.6 & 4.6555 & TRN & \\
\hline CHEMBL1318349 & 688839 & 4.9 & 4.9955 & TRN & \\
\hline CHEMBL1517884 & 688839 & 5.5 & 4.8264 & TRN & \\
\hline CHEMBL14690 & 688839 & 5.8 & 5.6462 & TRN & \\
\hline CHEMBL1358297 & 688839 & 5.0 & 5.0426 & TST & \\
\hline CHEMBL1570996 & 688839 & 5.6 & 5.5915 & TRN & \\
\hline CHEMBL1316796 & 688839 & 4.9 & 4.8875 & TRN & \\
\hline CHEMBL1442996 & 688839 & 4.9 & 5.0304 & TRN & \\
\hline CHEMBL1473754 & 688839 & 4.7 & 4.7897 & TRN & \\
\hline CHEMBL1408856 & 688839 & 5.3 & 5.2259 & TRN & \\
\hline CHEMBL1516476 & 688839 & 6.0 & 5.8128 & TRN & \\
\hline CHEMBL1605130 & 688839 & 5.0 & 4.8389 & TRN & \\
\hline CHEMBL1374151 & 688839 & 4.4 & 5.0327 & TRN & \\
\hline CHEMBL1398800 & 688839 & 4.9 & 4.9685 & TRN & \\
\hline CHEMBL1592717 & 688839 & 5.2 & 5.2823 & TRN & \\
\hline CHEMBL1514075 & 688839 & 4.8 & 4.8659 & TRN & \\
\hline CHEMBL1408334 & 688839 & 6.0 & 6.0802 & TRN & \\
\hline CHEMBL1524650 & 688839 & 5.0 & 4.9625 & TRN & \\
\hline CHEMBL1396374 & 688839 & 6.4 & 6.3284 & TRN & \\
\hline CHEMBL1554362 & 688839 & 5.5 & 5.1158 & TRN & \\
\hline & & & & 0403 & \\
\hline
\end{tabular}




\begin{tabular}{|c|c|c|c|c|}
\hline \multicolumn{5}{|c|}{ Supplemental Table s2.txt } \\
\hline CHEMBL409902 & 688839 & 5.0 & 5.0064 & TRN \\
\hline CHEMBL405081 & 688839 & 5.6 & 5.175 & TRN \\
\hline CHEMBL470881 & 688839 & 5.6 & 5.2254 & TST \\
\hline CHEMBL166112 & 688839 & 5.0 & 5.0058 & TST \\
\hline CHEMBL1527317 & 688839 & 5.9 & 5.6488 & TST \\
\hline CHEMBL1323385 & 688839 & 5.1 & 5.1262 & TRN \\
\hline CHEMBL2374096 & 688839 & 5.1 & 5.2412 & TST \\
\hline CHEMBL565755 & 688839 & 4.8 & 4.9147 & TRN \\
\hline CHEMBL1493707 & 688839 & 5.5 & 5.4928 & TST \\
\hline CHEMBL1609913 & 688839 & 4.8 & 5.2471 & TST \\
\hline CHEMBL1335668 & 688839 & 5.5 & 5.4709 & TRN \\
\hline CHEMBL52229 & 688839 & 4.8 & 5.0066 & TRN \\
\hline CHEMBL1448839 & 688839 & 4.9 & 4.8783 & TRN \\
\hline CHEMBL1591263 & 688839 & 4.4 & 5.2234 & TST \\
\hline CHEMBL1316219 & 688839 & 5.3 & 5.266 & TST \\
\hline CHEMBL1604672 & 688839 & 5.9 & 5.2825 & TST \\
\hline CHEMBL13952 & 688839 & 4.4 & 4.9185 & TRN \\
\hline CHEMBL1256910 & 688839 & 6.0 & 4.9707 & TST \\
\hline CHEMBL1370136 & 688839 & 5.4 & 5.5262 & TRN \\
\hline CHEMBL1396539 & 688839 & 5.1 & 5.2081 & TRN \\
\hline CHEMBL1437119 & 688839 & 4.7 & 4.7173 & TRN \\
\hline CHEMBL1520940 & 688839 & 7.8996 & 7.1384 & TRN \\
\hline CHEMBL1357577 & 688839 & 5.1 & 5.1201 & TRN \\
\hline CHEMBL481537 & 688839 & 4.7 & 4.8496 & TST \\
\hline CHEMBL1551732 & 688839 & 5.4 & 5.5976 & TRN \\
\hline CHEMBL1408836 & 688839 & 5.4 & 5.3118 & TST \\
\hline CHEMBL1591673 & 688839 & 4.5 & 4.596 & TRN \\
\hline CHEMBL1553491 & 688839 & 4.9 & 4.9049 & TRN \\
\hline CHEMBL1473260 & 688839 & 4.7 & 4.9169 & TRN \\
\hline CHEMBL1597434 & 688839 & 4.9 & 4.8622 & TRN \\
\hline CHEMBL1612347 & 688839 & 4.8 & 5.0549 & TRN \\
\hline CHEMBL1331583 & 688839 & 5.4 & 5.1028 & TRN \\
\hline CHEMBL244707 & 688839 & 4.5 & 5.0192 & TRN \\
\hline CHEMBL1452408 & 688839 & 4.8 & 4.8524 & TRN \\
\hline CHEMBL1394118 & 688839 & 4.9 & 4.8961 & TRN \\
\hline CHEMBL1494966 & 688839 & 4.6 & 5.129 & TRN \\
\hline CHEMBL1488990 & 688839 & 5.4 & 5.3841 & TRN \\
\hline CHEMBL1478279 & 688839 & 4.9 & 4.8363 & TRN \\
\hline CHEMBL1447143 & 688839 & 5.2 & 5.261 & TRN \\
\hline CHEMBL 14276 & 688839 & 5.6 & 5.5169 & TST \\
\hline CHEMBL1325119 & 688839 & 5.0 & 5.1469 & TST \\
\hline CHEMBL1457212 & 688839 & 4.9 & $5.0680 e$ & 00000000005 \\
\hline CHEMBL1457256 & 688839 & 5.1 & 5.1472 & TRN \\
\hline CHEMBL1358527 & 688839 & 4.8 & 5.3991 & TRN \\
\hline CHEMBL1482184 & 688839 & 6.0 & 5.355 & TST \\
\hline CHEMBL462880 & 688839 & 4.7 & 4.9675 & TRN \\
\hline CHEMBL1454280 & 688839 & 5.5 & 4.982 & TRN \\
\hline CHEMBL1322549 & 688839 & 5.6 & 5.465 & TST \\
\hline
\end{tabular}




\begin{tabular}{|c|c|c|c|c|}
\hline \multicolumn{5}{|c|}{ Supplemental Table S2.txt } \\
\hline CHEMBL1477081 & 688839 & 4.4 & 5.2375 & TRN \\
\hline CHEMBL1489140 & 688839 & 4.7 & 4.743 & TST \\
\hline CHEMBL37312 & 688839 & 5.4 & 5.3771 & TRN \\
\hline CHEMBL 2374057 & 688839 & 6.0 & 5.2813 & TST \\
\hline CHEMBL1442087 & 688839 & 6.0 & 5.7791 & TRN \\
\hline CHEMBL1318425 & 688839 & 4.5 & 5.3009 & TST \\
\hline CHEMBL3212645 & 688839 & 5.5 & 5.459 & TRN \\
\hline CHEMBL1319741 & 688839 & 4.4 & 4.588 & TST \\
\hline CHEMBL1703229 & 688839 & 5.1 & 5.0767 & TRN \\
\hline CHEMBL574985 & 688839 & 4.4 & 4.6243 & TST \\
\hline CHEMBL1436125 & 688839 & 6.1 & 6.0361 & TRN \\
\hline CHEMBL1437128 & 688839 & 6.5 & 6.0252 & TRN \\
\hline CHEMBL492127 & 688839 & 6.5 & 6.7053 & TRN \\
\hline CHEMBL1551139 & 688839 & 5.2 & 5.2253 & TRN \\
\hline CHEMBL1398019 & 688839 & 5.4 & 5.2564 & TRN \\
\hline CHEMBL465339 & 688839 & 5.6 & 5.3156 & TRN \\
\hline CHEMBL1490299 & 688839 & 4.5 & 5.0969 & TRN \\
\hline CHEMBL453066 & 688839 & 4.8 & 5.05399 & 7999999999 \\
\hline CHEMBL1316461 & 688839 & 5.9 & 5.6904 & TRN \\
\hline CHEMBL1474244 & 688839 & 4.7 & 4.7314 & TRN \\
\hline CHEMBL171064 & 688839 & 4.5 & 4.6326 & TST \\
\hline CHEMBL1516262 & 688839 & 4.8 & 4.7899 & TRN \\
\hline CHEMBL1593743 & 688839 & 4.9 & 5.0344 & TST \\
\hline CHEMBL 8867 & 688839 & 6.0 & 5.1822 & TST \\
\hline CHEMBL1332361 & 688839 & 4.5 & 4.7341 & TRN \\
\hline CHEMBL1315991 & 688839 & 4.8 & 4.8612 & TRN \\
\hline CHEMBL153 & 688839 & 4.9 & 4.9097 & TST \\
\hline CHEMBL1599014 & 688839 & 6.1 & 6.0475 & TRN \\
\hline CHEMBL1554683 & 688839 & 4.7 & 5.0278 & TRN \\
\hline CHEMBL1478761 & 688839 & 5.3 & 5.1763 & TRN \\
\hline CHEMBL1555389 & 688839 & 4.8 & 5.0273 & TRN \\
\hline CHEMBL3213163 & 688839 & 5.5 & 5.5253 & TRN \\
\hline CHEMBL516075 & 688839 & 5.3 & 5.2814 & TRN \\
\hline CHEMBL1395899 & 688839 & 5.3 & 5.2469 & TRN \\
\hline CHEMBL1475166 & 688839 & 5.0 & 5.2668 & TRN \\
\hline CHEMBL1593751 & 688839 & 7.6003 & 5.2437 & TRN \\
\hline CHEMBL1396236 & 688839 & 5.3 & 5.2488 & TST \\
\hline CHEMBL500996 & 688839 & 5.0 & 5.0113 & TRN \\
\hline CHEMBL1517644 & 688839 & 5.4 & 5.449 & TRN \\
\hline CHEMBL1591908 & 688839 & 5.1 & 5.1096 & TRN \\
\hline CHEMBL13790 & 688839 & 6.0 & 4.292 & TRN \\
\hline CHEMBL1604925 & 688839 & 6.0 & 5.0944 & TST \\
\hline CHEMBL1437133 & 688839 & 4.8 & 5.0109 & TRN \\
\hline CHEMBL 261642 & 688839 & 4.7 & 5.1294 & TST \\
\hline CHEMBL1442538 & 688839 & 4.5 & 4.6335 & TRN \\
\hline CHEMBL19032 & 688839 & 5.9 & 5.2371 & TRN \\
\hline CHEMBL1444489 & 688839 & 4.5 & 4.6451 & TRN \\
\hline CHEMBL1321975 & 688839 & 4.6 & 5.2445 & TRN \\
\hline
\end{tabular}




\begin{tabular}{|c|c|c|c|c|c|}
\hline & & \multicolumn{4}{|c|}{ Supplemental Table S2.txt } \\
\hline CHEMBL77705 & 688839 & 5.5 & 5.17299 & 9999999999 & TRN \\
\hline CHEMBL1491397 & 688839 & 4.8 & 4.9865 & TST & \\
\hline CHEMBL1256740 & 688839 & 6.0 & 5.8505 & TST & \\
\hline CHEMBL1336787 & 688839 & 5.1 & 5.1173 & TRN & \\
\hline CHEMBL1553635 & 688839 & 5.3 & 5.3512 & TST & \\
\hline CHEMBL1555396 & 688839 & 5.8 & 5.5171 & TRN & \\
\hline CHEMBL1607868 & 688839 & 5.9 & 6.0907 & TRN & \\
\hline CHEMBL428496 & 688839 & 5.1 & 5.118 & TST & \\
\hline CHEMBL287045 & 688839 & 4.5 & 4.691 & TRN & \\
\hline CHEMBL1317626 & 688839 & 4.8 & 4.8213 & TRN & \\
\hline CHEMBL1524453 & 688839 & 6.0 & 5.9713 & TRN & \\
\hline CHEMBL1323619 & 688839 & 6.2 & 5.0349 & TST & \\
\hline CHEMBL388676 & 688839 & 6.0 & 5.093 & TST & \\
\hline CHEMBL1357444 & 688839 & 5.7 & 5.76200 & 00000000005 & TRN \\
\hline CHEMBL1514779 & 688839 & 4.8 & 4.7551 & TRN & \\
\hline CHEMBL1417349 & 688839 & 5.5 & 5.6381 & TRN & \\
\hline CHEMBL1319213 & 688839 & 4.4 & 4.9329 & TRN & \\
\hline CHEMBL276473 & 688839 & 4.4 & 5.1169 & TRN & \\
\hline CHEMBL1476082 & 688839 & 4.8 & 4.7669 & TRN & \\
\hline CHEMBL1322319 & 688839 & 6.0 & 5.9915 & TRN & \\
\hline CHEMBL1357018 & 688839 & 6.0 & 6.1132 & TRN & \\
\hline CHEMBL242171 & 688839 & 4.7 & 5.1102 & TRN & \\
\hline CHEMBL551842 & 688839 & 4.6 & 5.2303 & TST & \\
\hline CHEMBL1334327 & 688839 & 5.4 & 5.3694 & TRN & \\
\hline CHEMBL1494452 & 688839 & 4.9 & 5.0569 & TRN & \\
\hline CHEMBL1475079 & 688839 & 4.9 & 4.882 & TRN & \\
\hline CHEMBL1570633 & 688839 & 5.4 & 5.4955 & TRN & \\
\hline CHEMBL283196 & 688839 & 4.9 & 5.104 & TRN & \\
\hline CHEMBL1256924 & 688839 & 5.4 & 5.2797 & TRN & \\
\hline CHEMBL523464 & 688839 & 6.2 & 6.14 & TRN & \\
\hline CHEMBL1553804 & 688839 & 4.8 & 4.9036 & TRN & \\
\hline CHEMBL1562093 & 688839 & 5.6 & 5.2009 & TST & \\
\hline CHEMBL294264 & 688839 & 6.0 & 4.9959 & TRN & \\
\hline CHEMBL1494408 & 688839 & 5.5 & 5.7352 & TRN & \\
\hline CHEMBL 7162 & 688839 & 4.7 & 4.8492 & TST & \\
\hline CHEMBL1517329 & 688839 & 5.1 & 4.9605 & TRN & \\
\hline CHEMBL1445173 & 688839 & 4.9 & 5.1749 & TST & \\
\hline CHEMBL78573 & 688839 & 4.6 & 5.0918 & TRN & \\
\hline CHEMBL1555610 & 688839 & 4.6 & 4.6375 & TRN & \\
\hline CHEMBL1355849 & 688839 & 5.5 & 5.1102 & TST & \\
\hline CHEMBL1404451 & 688839 & 5.9 & 5.8929 & TRN & \\
\hline CHEMBL1474633 & 688839 & 5.7 & 5.767 & TRN & \\
\hline CHEMBL1410016 & 688839 & 6.0 & 5.9637 & TRN & \\
\hline CHEMBL 2373608 & 688839 & 6.0 & 5.1937 & TRN & \\
\hline CHEMBL1333915 & 688839 & 5.0 & 5.2802 & TRN & \\
\hline CHEMBL164747 & 688839 & 4.8 & 4.8968 & TST & \\
\hline CHEMBL1400902 & 688839 & 4.9 & 5.0772 & TRN & \\
\hline CHEMBL1519482 & 688839 & 4.5 & 4.9959 & TRN & \\
\hline
\end{tabular}




\begin{tabular}{|c|c|c|c|c|c|}
\hline & & & & & \\
\hline CHEMBL1556023 & 688839 & 6.4 & 6.0315 & TRN & \\
\hline CHEMBL1513107 & 688839 & 5.1 & 5.2138 & TRN & \\
\hline CHEMBL 78150 & 688839 & 5.5 & 5.3533 & TRN & \\
\hline CHEMBL1515802 & 688839 & 5.3 & 5.3257 & TRN & \\
\hline CHEMBL1417139 & 688839 & 5.7 & 5.3465 & TRN & \\
\hline CHEMBL1395088 & 688839 & 5.4 & 5.2866 & TRN & \\
\hline CHEMBL1316337 & 688839 & 5.3 & 5.21200 & 0000000001 & TRN \\
\hline CHEMBL1439625 & 688839 & 4.4 & 5.4654 & TRN & \\
\hline CHEMBL1394640 & 688839 & 6.0 & 6.0517 & TRN & \\
\hline CHEMBL3207394 & 688839 & 5.4 & 5.4396 & TRN & \\
\hline CHEMBL1474440 & 688839 & 4.9 & 5.1209 & TRN & \\
\hline CHEMBL1335826 & 688839 & 4.8 & 4.9084 & TRN & \\
\hline CHEMBL1522460 & 688839 & 4.8 & 4.845 & TRN & \\
\hline CHEMBL1553941 & 688839 & 4.8 & 4.9152 & TRN & \\
\hline CHEMBL1477383 & 688839 & 5.3 & 5.2399 & TST & \\
\hline CHEMBL1552727 & 688839 & 4.7 & 4.7892 & TRN & \\
\hline CHEMBL1496576 & 688839 & 6.2 & 6.272 & TRN & \\
\hline CHEMBL1415957 & 688839 & 5.5 & 5.4407 & TRN & \\
\hline CHEMBL1494196 & 688839 & 4.5 & 4.7122 & TRN & \\
\hline CHEMBL1569718 & 688839 & 4.7 & 4.7367 & TRN & \\
\hline CHEMBL1331627 & 688839 & 5.4 & 5.3196 & TST & \\
\hline CHEMBL1492346 & 688839 & 6.0 & 5.8179 & TRN & \\
\hline CHEMBL1474326 & 688839 & 5.1 & 5.0082 & TRN & \\
\hline CHEMBL1417636 & 688839 & 5.9 & 6.0105 & TRN & \\
\hline CHEMBL1515945 & 688839 & 7.3002 & 6.5499 & TRN & \\
\hline CHEMBL1475395 & 688839 & 5.2 & 5.3721 & TRN & \\
\hline CHEMBL1256291 & 688839 & 4.7 & 4.76 & TST & \\
\hline CHEMBL540294 & 688839 & 6.0 & 5.8072 & TST & \\
\hline CHEMBL1437176 & 688839 & 5.2 & 5.1357 & TRN & \\
\hline CHEMBL1362892 & 688839 & 4.8 & 4.8316 & TRN & \\
\hline CHEMBL1360778 & 688839 & 4.6 & 5.1183 & TRN & \\
\hline CHEMBL1332998 & 688839 & 6.0 & 5.0835 & TRN & \\
\hline CHEMBL1496569 & 688839 & 4.5 & 4.5442 & TRN & \\
\hline CHEMBL1256914 & 688839 & 5.0 & 5.0212 & TRN & \\
\hline CHEMBL1397595 & 688839 & 4.9 & 5.3423 & TRN & \\
\hline CHEMBL1332832 & 688839 & 4.7 & 5.17399 & 99999999995 & TRN \\
\hline CHEMBL 1488390 & 688839 & 5.0 & 5.1759 & TST & \\
\hline CHEMBL1358178 & 688839 & 5.6 & 5.4343 & TST & \\
\hline CHEMBL1610400 & 688839 & 4.9 & 4.8033 & TRN & \\
\hline CHEMBL1338613 & 688839 & 4.8 & 5.0147 & TST & \\
\hline CHEMBL1483133 & 688839 & 4.6 & 4.6577 & TRN & \\
\hline CHEMBL1318285 & 688839 & 5.5 & 5.4117 & TST & \\
\hline CHEMBL1534237 & 688839 & 4.9 & 4.958 & TRN & \\
\hline CHEMBL1448192 & 688839 & 6.5 & 5.4522 & TRN & \\
\hline CHEMBL136906 & 688839 & 5.5 & 5.2891 & TST & \\
\hline CHEMBL1459078 & 688839 & 5.6 & 5.3593 & TRN & \\
\hline CHEMBL 2374027 & 688839 & 6.0 & 5.7681 & TST & \\
\hline CHEMBL1356870 & 688839 & 6.0 & 5.722 & TRN & \\
\hline & & & & 20407 & \\
\hline
\end{tabular}




\begin{tabular}{|c|c|c|c|c|c|}
\hline & & & & & \\
\hline CHEMBL1473442 & 688839 & 5.4 & 5.4363 & TRN & \\
\hline CHEMBL1449914 & 688839 & 5.6 & 5.2612 & TRN & \\
\hline CHEMBL1407257 & 688839 & 5.1 & 5.0969 & TRN & \\
\hline CHEMBL1256770 & 688839 & 5.5 & 5.4644 & TRN & \\
\hline CHEMBL1437011 & 688839 & 5.1 & 5.1218 & TRN & \\
\hline CHEMBL1361977 & 688839 & 5.3 & 4.9121 & TRN & \\
\hline CHEMBL3207899 & 688839 & 5.5 & 5.5242 & TRN & \\
\hline CHEMBL1357182 & 688839 & 4.9 & 4.7538 & TRN & \\
\hline CHEMBL1415180 & 688839 & 6.1 & 6.1205 & TRN & \\
\hline CHEMBL1455570 & 688839 & 4.9 & 4.9528 & TRN & \\
\hline CHEMBL146855 & 688839 & 6.0 & 4.9278 & TST & \\
\hline CHEMBL1417375 & 688839 & 6.3 & 6.063 & TRN & \\
\hline CHEMBL1473099 & 688839 & 6.2 & 6.3589 & TRN & \\
\hline CHEMBL1361656 & 688839 & 5.8 & 6.0018 & TRN & \\
\hline CHEMBL1512693 & 688839 & 4.8 & 4.8152 & TRN & \\
\hline CHEMBL1318518 & 688839 & 4.9 & 4.8287 & TRN & \\
\hline CHEMBL1397517 & 688839 & 5.1 & 5.0651 & TRN & \\
\hline CHEMBL1609007 & 688839 & 4.8 & 5.0357 & TRN & \\
\hline CHEMBL1554587 & 688839 & 4.9 & 5.17399 & 99999999995 & TRN \\
\hline CHEMBL1486304 & 688839 & 5.4 & 5.3314 & TRN & \\
\hline CHEMBL1553797 & 688839 & 4.7 & 4.746 & TRN & \\
\hline CHEMBL1369515 & 688839 & 4.7 & 4.7299 & TRN & \\
\hline CHEMBL406255 & 688839 & 5.5 & 5.2781 & TRN & \\
\hline CHEMBL1515675 & 688839 & 6.7001 & 5.2308 & TRN & \\
\hline CHEMBL1354547 & 688839 & 5.7 & 5.7326 & TRN & \\
\hline CHEMBL1476526 & 688839 & 4.8 & 4.8511 & TRN & \\
\hline CHEMBL1316190 & 688839 & 4.8 & 5.0289 & TRN & \\
\hline CHEMBL1355359 & 688839 & 5.6 & 5.1836 & TST & \\
\hline CHEMBL1394302 & 688839 & 6.5 & 6.4838 & TRN & \\
\hline CHEMBL1374610 & 688839 & 5.5 & 5.2148 & TRN & \\
\hline CHEMBL1396792 & 688839 & 5.5 & 5.4031 & TRN & \\
\hline CHEMBL1331980 & 688839 & 6.0 & 5.8134 & TST & \\
\hline CHEMBL1531250 & 688839 & 6.0 & 5.3737 & TRN & \\
\hline CHEMBL1436045 & 688839 & 6.1 & 6.1981 & TRN & \\
\hline CHEMBL1610350 & 688839 & 5.5 & 5.4092 & TRN & \\
\hline CHEMBL1553700 & 688839 & 6.0 & 5.7378 & TST & \\
\hline CHEMBL 1473620 & 688839 & 4.6 & 4.6867 & TRN & \\
\hline CHEMBL481044 & 688839 & 5.0 & 5.4283 & TRN & \\
\hline CHEMBL1405538 & 688839 & 5.8 & 5.8007 & TRN & \\
\hline CHEMBL1474294 & 688839 & 6.2 & 5.8747 & TRN & \\
\hline CHEMBL1513659 & 688839 & 4.6 & 4.6821 & TRN & \\
\hline CHEMBL1573555 & 688839 & 5.2 & 5.1861 & TRN & \\
\hline CHEMBL1367960 & 688839 & 4.7 & 5.2305 & TRN & \\
\hline CHEMBL1451434 & 688839 & 4.8 & 4.9771 & TRN & \\
\hline CHEMBL1418190 & 688839 & 5.8 & 5.53799 & 9999999999 & TRN \\
\hline CHEMBL556001 & 688839 & 6.0 & 5.7831 & TRN & \\
\hline CHEMBL1565342 & 688839 & 6.0 & 6.0004 & TRN & \\
\hline CHEMBL1552635 & 688839 & 5.9 & 5.9462 & TRN & \\
\hline & & & & 20408 & \\
\hline
\end{tabular}




\begin{tabular}{|c|c|c|c|c|}
\hline & & & & $a \perp 1 a$ \\
\hline CHEMBL1475377 & 688839 & 5.5 & 4.7871 & TRN \\
\hline CHEMBL1445473 & 688839 & 4.9 & 4.8435 & TRN \\
\hline CHEMBL1256647 & 688839 & 5.4 & 5.2684 & TRN \\
\hline CHEMBL1570350 & 688839 & 4.6 & 4.7547 & TST \\
\hline CHEMBL1529028 & 688839 & 5.8 & 5.1547 & TRN \\
\hline CHEMBL1606727 & 688839 & 5.6 & 5.7133 & TRN \\
\hline CHEMBL1396809 & 688839 & 5.6 & 5.4591 & TRN \\
\hline CHEMBL1317810 & 688839 & 5.4 & 5.1773 & TST \\
\hline CHEMBL1363883 & 688839 & 6.0 & 5.8838 & TST \\
\hline CHEMBL1437667 & 688839 & 5.8 & 5.6767 & TRN \\
\hline CHEMBL1407454 & 688839 & 5.4 & 5.1499 & TST \\
\hline CHEMBL1492558 & 688839 & 4.5 & 4.5428 & TRN \\
\hline CHEMBL1359320 & 688839 & 4.9 & 4.944 & TRN \\
\hline CHEMBL1514740 & 688839 & 5.7 & 5.9377 & TRN \\
\hline CHEMBL1317400 & 688839 & 4.9 & 4.83 & TRN \\
\hline CHEMBL1435638 & 688839 & 5.7 & 5.7525 & TRN \\
\hline CHEMBL1493037 & 688839 & 4.5 & 4.6557 & TST \\
\hline CHEMBL21396 & 688839 & 6.0 & 5.0778 & TST \\
\hline CHEMBL1408822 & 688839 & 5.3 & 5.4622 & TRN \\
\hline CHEMBL1514110 & 688839 & 5.1 & 5.0345 & TRN \\
\hline CHEMBL1355002 & 688839 & 4.9 & 4.8969 & TRN \\
\hline CHEMBL1574160 & 688839 & 5.3 & 5.1079 & TRN \\
\hline CHEMBL1566556 & 688839 & 4.8 & 4.8673 & TRN \\
\hline CHEMBL1607228 & 688839 & 6.0 & 5.7445 & TRN \\
\hline CHEMBL1473715 & 688839 & 4.8 & 5.27 & TRN \\
\hline CHEMBL1591965 & 688839 & 5.2 & 5.1388 & TRN \\
\hline CHEMBL1330323 & 688839 & 5.6 & 5.5148 & TST \\
\hline CHEMBL1561363 & 688839 & 5.2 & 5.1371 & TRN \\
\hline CHEMBL1437732 & 688839 & 5.4 & 5.4593 & TRN \\
\hline CHEMBL1496125 & 688839 & 5.5 & 5.5347 & TST \\
\hline CHEMBL1079227 & 688839 & 5.9 & 5.0349 & TRN \\
\hline CHEMBL1435252 & 688839 & 4.8 & 5.1138 & TRN \\
\hline CHEMBL 242172 & 688839 & 4.8 & 5.1906 & TRN \\
\hline CHEMBL1449218 & 688839 & 5.7 & 5.5805 & TRN \\
\hline CHEMBL1322864 & 688839 & 5.5 & 5.3564 & TST \\
\hline CHEMBL1551133 & 688839 & 5.4 & 5.4463 & TRN \\
\hline CHEMBL1355432 & 688839 & 4.5 & 4.6268 & TRN \\
\hline CHEMBL1358018 & 688839 & 5.5 & 5.188 & TRN \\
\hline CHEMBL1594610 & 688839 & 4.8 & 5.4381 & TST \\
\hline CHEMBL1611893 & 688839 & 4.6 & 4.6717 & TRN \\
\hline CHEMBL 343822 & 688839 & 4.8 & 5.2213 & TST \\
\hline CHEMBL8260 & 688839 & 4.5 & 4.7838 & TRN \\
\hline CHEMBL1525024 & 688839 & 5.4 & 5.3669 & TST \\
\hline CHEMBL1513665 & 688839 & 4.7 & 4.6956 & TRN \\
\hline CHEMBL1437056 & 688839 & 4.7 & 4.7276 & TRN \\
\hline CHEMBL1361149 & 688839 & 4.9 & 4.9274 & TRN \\
\hline CHEMBL1356466 & 688839 & 4.5 & 4.5733 & TRN \\
\hline CHEMBL1314745 & 688839 & 4.9 & 4.9692 & TRN \\
\hline
\end{tabular}




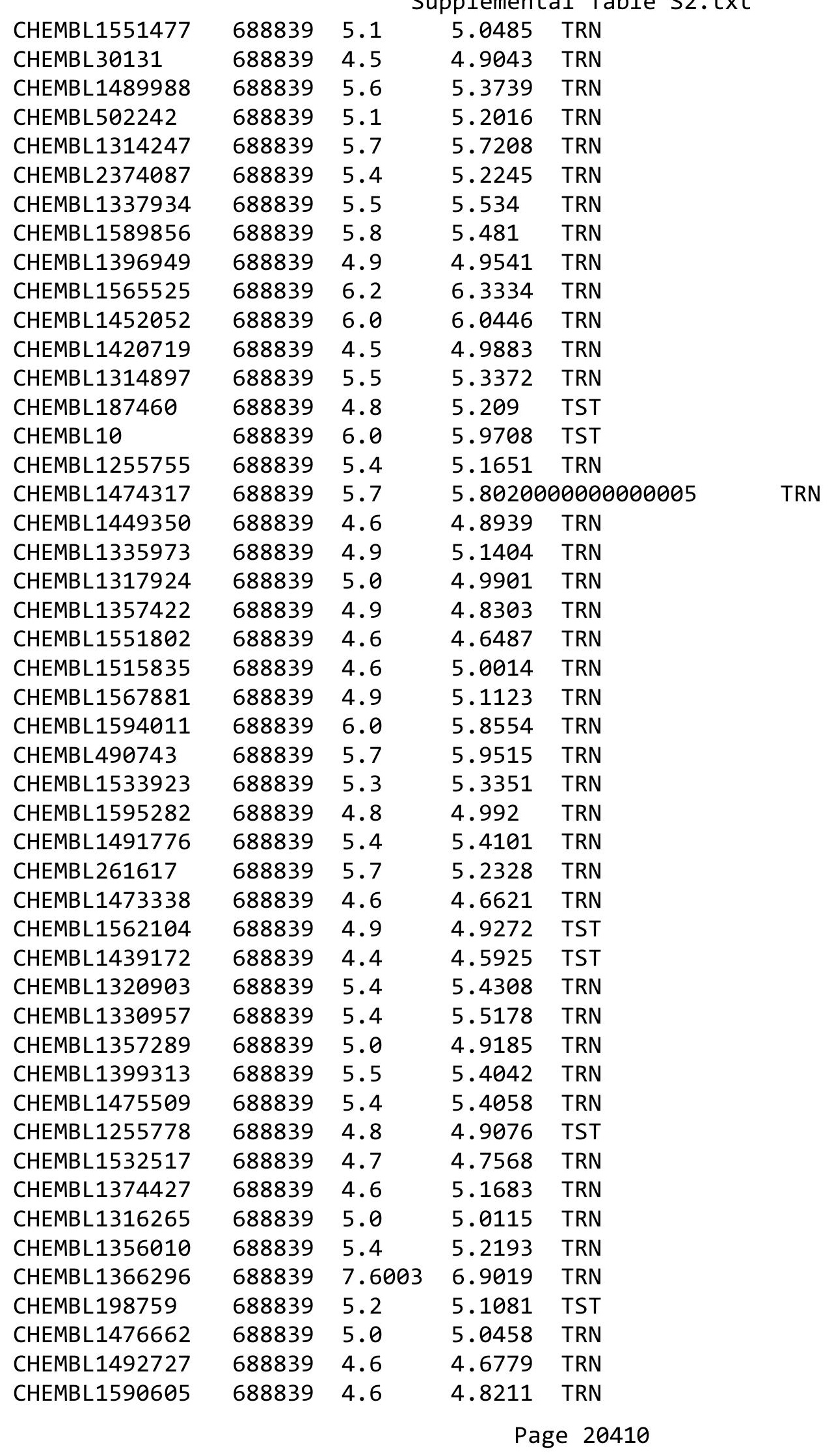




\begin{tabular}{|c|c|c|c|c|}
\hline & & & ipplement & al Table S \\
\hline CHEMBL1473149 & 688839 & 4.7 & 4.7312 & TRN \\
\hline CHEMBL1516342 & 688839 & 6.2 & 6.09399 & 9999999999 \\
\hline CHEMBL1532230 & 688839 & 4.5 & 4.7179 & TRN \\
\hline CHEMBL1561132 & 688839 & 5.4 & 5.3426 & TST \\
\hline CHEMBL1357512 & 688839 & 4.9 & 5.2315 & TST \\
\hline CHEMBL1316156 & 688839 & 5.9 & 5.1654 & TRN \\
\hline CHEMBL1334709 & 688839 & 4.9 & 5.4353 & TRN \\
\hline CHEMBL84685 & 688839 & 5.6 & 5.2382 & TRN \\
\hline CHEMBL1417140 & 688839 & 5.7 & 5.535 & TRN \\
\hline CHEMBL1330718 & 688839 & 5.1 & 5.0957 & TRN \\
\hline CHEMBL1375431 & 688839 & 4.8 & 4.8699 & TRN \\
\hline CHEMBL1512570 & 688839 & 4.6 & 5.1518 & TST \\
\hline CHEMBL1445754 & 688839 & 4.7 & 5.1823 & TRN \\
\hline CHEMBL1590980 & 688839 & 6.6 & 6.4972 & TRN \\
\hline CHEMBL446315 & 688839 & 6.0 & 5.6625 & TST \\
\hline CHEMBL1533575 & 688839 & 4.5 & 4.5563 & TRN \\
\hline CHEMBL324642 & 688839 & 4.5 & 4.9546 & TRN \\
\hline CHEMBL1401793 & 688839 & 5.4 & 5.2894 & TST \\
\hline CHEMBL 286136 & 688839 & 4.8 & 4.7885 & TRN \\
\hline CHEMBL1435902 & 688839 & 5.9 & 5.3542 & TRN \\
\hline CHEMBL1592212 & 688839 & 4.5 & 4.6248 & TRN \\
\hline CHEMBL90769 & 688839 & 4.7 & 4.7289 & TST \\
\hline CHEMBL1414358 & 688839 & 5.3 & 5.5145 & TRN \\
\hline CHEMBL1489424 & 688839 & 6.5 & 6.0815 & TST \\
\hline CHEMBL15192 & 688839 & 4.8 & 4.8794 & TST \\
\hline CHEMBL1522015 & 688839 & 5.5 & 5.2371 & TST \\
\hline CHEMBL1556803 & 688839 & 4.8 & 5.0497 & TRN \\
\hline CHEMBL261237 & 688839 & 5.9 & 5.1667 & TST \\
\hline CHEMBL1443445 & 688839 & 5.6 & 5.2066 & TST \\
\hline CHEMBL1592388 & 688839 & 5.7 & 5.8278 & TRN \\
\hline CHEMBL1400162 & 688839 & 5.5 & 5.1348 & TST \\
\hline CHEMBL1398476 & 688839 & 5.1 & 5.0399 & TST \\
\hline CHEMBL1528540 & 688839 & 5.4 & 5.1981 & TRN \\
\hline CHEMBL1457494 & 688839 & 5.0 & 5.0239 & TRN \\
\hline CHEMBL1474475 & 688839 & 5.3 & 5.2831 & TRN \\
\hline CHEMBL1517998 & 688839 & 4.8 & 5.4544 & TRN \\
\hline CHEMBL1416203 & 688839 & 4.7 & 5.0702 & TRN \\
\hline CHEMBL3213210 & 688839 & 5.5 & 5.4891 & TRN \\
\hline CHEMBL1332504 & 688839 & 6.4 & 6.0888 & TRN \\
\hline CHEMBL1499536 & 688839 & 4.8 & 4.9893 & TRN \\
\hline CHEMBL1413340 & 688839 & 5.7 & 5.6175 & TRN \\
\hline CHEMBL1473809 & 688839 & 4.9 & 4.9078 & TRN \\
\hline CHEMBL1325335 & 688839 & 4.6 & 4.5929 & TRN \\
\hline CHEMBL1416207 & 688839 & 5.0 & 4.8983 & TRN \\
\hline CHEMBL1490998 & 688839 & 5.1 & 5.1535 & TRN \\
\hline CHEMBL1256923 & 688839 & 5.2 & 5.1753 & TST \\
\hline CHEMBL1435934 & 688839 & 4.9 & 5.1803 & TRN \\
\hline CHEMBL1357164 & 688839 & 5.0 & 5.1915 & TRN \\
\hline
\end{tabular}

TRN 


\begin{tabular}{|c|c|c|c|c|}
\hline \multicolumn{5}{|c|}{ Supplemental Table S2.txt } \\
\hline CHEMBL1516118 & 688839 & 4.6 & 5.0921 & TRN \\
\hline CHEMBL1476705 & 688839 & 4.6 & 5.2017 & TST \\
\hline CHEMBL1315521 & 688839 & 5.3 & 5.2337 & TRN \\
\hline CHEMBL1593827 & 688839 & 5.7 & 5.69600 & 0000000001 \\
\hline CHEMBL1316355 & 688839 & 5.4 & 5.689 & TRN \\
\hline CHEMBL508779 & 688839 & 5.9 & 5.2974 & TST \\
\hline CHEMBL1357130 & 688839 & 6.0 & 5.0316 & TRN \\
\hline CHEMBL444422 & 688839 & 5.7 & 5.1455 & TRN \\
\hline CHEMBL1555713 & 688839 & 5.7 & 5.8631 & TRN \\
\hline CHEMBL1327203 & 688839 & 6.4 & 6.5444 & TRN \\
\hline CHEMBL1414841 & 688839 & 5.4 & 5.3979 & TRN \\
\hline CHEMBL1475255 & 688839 & 6.2 & 6.184 & TRN \\
\hline CHEMBL471225 & 688839 & 5.1 & 5.1228 & TST \\
\hline CHEMBL495067 & 688839 & 4.8 & 5.0828 & TST \\
\hline CHEMBL 2373647 & 688839 & 5.2 & 5.2799 & TST \\
\hline CHEMBL1358234 & 688839 & 5.8 & 5.8897 & TRN \\
\hline CHEMBL1436817 & 688839 & 4.9 & 4.9564 & TRN \\
\hline CHEMBL1613347 & 688839 & 5.1 & 5.2716 & TRN \\
\hline CHEMBL1358033 & 688839 & 5.0 & 5.0384 & TRN \\
\hline CHEMBL1591121 & 688839 & 4.8 & 4.8422 & TRN \\
\hline CHEMBL1355051 & 688839 & 4.4 & 5.2336 & TRN \\
\hline CHEMBL1398013 & 688839 & 5.1 & 5.0774 & TRN \\
\hline CHEMBL165 & 688839 & 6.0 & 5.6745 & TRN \\
\hline CHEMBL 3208021 & 688839 & 5.4 & 5.4594 & TRN \\
\hline CHEMBL1490970 & 688839 & 5.1 & 5.0978 & TRN \\
\hline CHEMBL1476293 & 688839 & 5.0 & 4.9217 & TRN \\
\hline CHEMBL544713 & 688839 & 5.6 & 5.5599 & TRN \\
\hline CHEMBL1397888 & 688839 & 4.5 & 5.2129 & TRN \\
\hline CHEMBL1551557 & 688839 & 4.8 & 4.7552 & TRN \\
\hline CHEMBL1528648 & 688839 & 4.8 & 5.1375 & TRN \\
\hline CHEMBL1365427 & 688839 & 5.5 & 5.3103 & TRN \\
\hline CHEMBL 259851 & 688839 & 5.0 & 5.2479 & TRN \\
\hline CHEMBL1315277 & 688839 & 4.6 & 5.0216 & TRN \\
\hline CHEMBL1315845 & 688839 & 4.7 & 4.685 & TRN \\
\hline CHEMBL 272682 & 688839 & 4.9 & 5.164 & TRN \\
\hline CHEMBL1491545 & 688839 & 5.3 & 5.4727 & TRN \\
\hline CHEMBL1474209 & 688839 & 5.4 & 5.5871 & TRN \\
\hline CHEMBL1520025 & 688839 & 6.0 & 5.1582 & TRN \\
\hline CHEMBL1532016 & 688839 & 6.0 & 6.0681 & TRN \\
\hline CHEMBL1356132 & 688839 & 5.3 & 5.2249 & TRN \\
\hline CHEMBL1397169 & 688839 & 4.8 & 5.1515 & TRN \\
\hline CHEMBL1491853 & 688839 & 5.5 & 5.4961 & TST \\
\hline CHEMBL1374763 & 688839 & 5.5 & 5.4107 & TRN \\
\hline CHEMBL1433551 & 688839 & 5.5 & 5.5101 & TRN \\
\hline CHEMBL 2373653 & 688839 & 5.4 & 5.178 & TRN \\
\hline CHEMBL1545942 & 688839 & 4.5 & 5.2031 & TST \\
\hline CHEMBL1474151 & 688839 & 4.5 & 4.6302 & TRN \\
\hline CHEMBL1439903 & 688839 & 5.4 & 5.1508 & TRN \\
\hline
\end{tabular}




\begin{tabular}{|c|c|c|c|c|}
\hline \\
\hline CHEMBL1552277 & 688839 & 5.6 & 5.6553 & TRN \\
\hline CHEMBL1370189 & 688839 & 5.7 & 5.5273 & TRN \\
\hline CHEMBL1318067 & 688839 & 4.8 & 4.771 & TRN \\
\hline CHEMBL 3196930 & 688839 & 5.7 & 5.3204 & TST \\
\hline CHEMBL1334357 & 688839 & 5.5 & 5.3425 & TST \\
\hline CHEMBL1514976 & 688839 & 4.9 & 4.8399 & TRN \\
\hline CHEMBL 3207752 & 688839 & 5.1 & 5.2745 & TST \\
\hline CHEMBL1562477 & 688839 & 4.5 & 4.5296 & TRN \\
\hline CHEMBL1473211 & 688839 & 5.4 & 5.1322 & TST \\
\hline CHEMBL1326787 & 688839 & 5.8 & 5.2294 & TST \\
\hline CHEMBL541847 & 688839 & 5.7 & 5.7689 & TRN \\
\hline CHEMBL1473489 & 688839 & 5.5 & 5.3143 & TRN \\
\hline CHEMBL1396211 & 688839 & 4.9 & 4.949 & TRN \\
\hline CHEMBL1721226 & 688839 & 4.6 & 5.078 & TRN \\
\hline CHEMBL 3350578 & 688839 & 5.5 & 5.3908 & TST \\
\hline CHEMBL1553785 & 688839 & 4.7 & 4.7222 & TRN \\
\hline CHEMBL1552519 & 688839 & 4.8 & 4.8809 & TRN \\
\hline CHEMBL1358090 & 688839 & 5.3 & 5.3072 & TRN \\
\hline CHEMBL1445323 & 688839 & 5.1 & 4.9624 & TST \\
\hline CHEMBL1534376 & 688839 & 5.1 & 5.3254 & TRN \\
\hline CHEMBL202752 & 688839 & 5.8 & 5.5876 & TST \\
\hline CHEMBL1446112 & 688839 & 6.1 & 5.9015 & TRN \\
\hline CHEMBL1338803 & 688839 & 5.3 & 5.3126 & TRN \\
\hline CHEMBL1610955 & 688839 & 5.4 & 5.3031 & TRN \\
\hline CHEMBL1512307 & 688839 & 5.4 & 5.4563 & TRN \\
\hline CHEMBL1330388 & 688839 & 5.5 & 5.1831 & TST \\
\hline CHEMBL186784 & 688839 & 4.9 & 5.0433 & TRN \\
\hline CHEMBL1408422 & 688839 & 6.0 & 6.1079 & TRN \\
\hline CHEMBL 20963 & 688839 & 4.8 & 4.9011 & TST \\
\hline CHEMBL1341097 & 688839 & 5.0 & 5.0432 & TST \\
\hline CHEMBL1402894 & 688839 & 5.4 & 5.3958 & TRN \\
\hline CHEMBL1355090 & 688839 & 4.6 & 4.7129 & TRN \\
\hline CHEMBL1523215 & 688839 & 4.8 & 4.873 & TRN \\
\hline CHEMBL1725279 & 688839 & 5.4 & 5.2839 & TST \\
\hline CHEMBL1513537 & 688839 & 4.6 & 5.2276 & TST \\
\hline CHEMBL1361847 & 688839 & 5.7 & 5.7893 & TRN \\
\hline CHEMBL1589976 & 688839 & 4.9 & 4.8961 & TRN \\
\hline CHEMBL1554743 & 688839 & 4.8 & 4.7916 & TRN \\
\hline CHEMBL1560118 & 688839 & 5.1 & 5.2262 & TRN \\
\hline CHEMBL1436644 & 688839 & 4.8 & 4.8082 & TRN \\
\hline CHEMBL1474261 & 688839 & 4.5 & 4.6658 & TRN \\
\hline CHEMBL1406230 & 688839 & 4.6 & 5.1031 & TRN \\
\hline CHEMBL1409852 & 688839 & 4.9 & 4.9324 & TRN \\
\hline CHEMBL1161461 & 688839 & 4.7 & 5.1389 & 9999999999 \\
\hline CHEMBL1472765 & 688839 & 5.3 & 5.2384 & TRN \\
\hline CHEMBL1473793 & 688839 & 4.6 & 4.6 & TRN \\
\hline CHEMBL145725 & 688839 & 4.5 & 5.1505 & TST \\
\hline CHEMBL1316033 & 688839 & 5.0 & 4.9481 & TRN \\
\hline
\end{tabular}




\begin{tabular}{|c|c|c|c|c|}
\hline & & & & $a \perp 1 a$ \\
\hline CHEMBL1316402 & 688839 & 5.5 & 5.4598 & TRN \\
\hline CHEMBL1433596 & 688839 & 4.8 & 4.9546 & TRN \\
\hline CHEMBL1513686 & 688839 & 5.1 & 5.1084 & TRN \\
\hline CHEMBL1332964 & 688839 & 5.6 & 5.8891 & TRN \\
\hline CHEMBL153648 & 688839 & 5.6 & 5.5575 & TST \\
\hline CHEMBL1404907 & 688839 & 5.3 & 5.1816 & TRN \\
\hline CHEMBL1593486 & 688839 & 5.3 & 5.3129 & TRN \\
\hline CHEMBL1530168 & 688839 & 4.9 & 4.8162 & TRN \\
\hline CHEMBL1447946 & 688839 & 5.4 & 5.1948 & TRN \\
\hline CHEMBL1591275 & 688839 & 4.8 & 4.8412 & TRN \\
\hline CHEMBL1397369 & 688839 & 4.8 & 5.4102 & TST \\
\hline CHEMBL1606022 & 688839 & 5.1 & 5.1316 & TRN \\
\hline CHEMBL1257003 & 688839 & 4.9 & 4.9965 & TRN \\
\hline CHEMBL1435809 & 688839 & 4.6 & 4.825 & TRN \\
\hline CHEMBL292477 & 688839 & 4.5 & 4.9485 & TRN \\
\hline CHEMBL1368572 & 688839 & 5.6 & 5.5363 & TRN \\
\hline CHEMBL1354424 & 688839 & 4.5 & 5.3226 & TST \\
\hline CHEMBL1534591 & 688839 & 5.3 & 5.2136 & TRN \\
\hline CHEMBL1513050 & 688839 & 5.9 & 5.3028 & TST \\
\hline CHEMBL1446905 & 688839 & 5.3 & 5.2773 & TRN \\
\hline CHEMBL1403505 & 688839 & 5.8 & 5.9546 & TRN \\
\hline CHEMBL1366586 & 688839 & 5.1 & 5.3136 & TRN \\
\hline CHEMBL1490740 & 688839 & 5.0 & 5.3539 & TRN \\
\hline CHEMBL1399301 & 688839 & 4.6 & 4.6945 & TRN \\
\hline CHEMBL1593867 & 688839 & 6.0 & 5.0292 & TRN \\
\hline CHEMBL1597692 & 688839 & 5.7 & 5.5876 & TST \\
\hline CHEMBL1316760 & 688839 & 5.3 & 5.2876 & TRN \\
\hline CHEMBL441282 & 688839 & 5.6 & 5.4506 & TST \\
\hline CHEMBL3209702 & 688839 & 6.0 & 6.0105 & TRN \\
\hline CHEMBL1394353 & 688839 & 6.0 & 6.1705 & TRN \\
\hline CHEMBL2373284 & 688839 & 5.5 & 5.4039 & TST \\
\hline CHEMBL1526068 & 688839 & 5.9 & 5.1888 & TST \\
\hline CHEMBL1590763 & 688839 & 4.7 & 4.7882 & TRN \\
\hline CHEMBL1437648 & 688839 & 5.2 & 5.1921 & TST \\
\hline CHEMBL510698 & 688839 & 5.9 & 5.5512 & TRN \\
\hline CHEMBL1394923 & 688839 & 4.8 & 4.8723 & TRN \\
\hline CHEMBL1448398 & 688839 & 5.5 & 5.4347 & TRN \\
\hline CHEMBL543767 & 688839 & 4.9 & 5.2917 & TRN \\
\hline CHEMBL232801 & 688839 & 4.8 & 5.0105 & TST \\
\hline CHEMBL1568250 & 688839 & 5.0 & 5.1618 & TRN \\
\hline CHEMBL1444856 & 688839 & 4.7 & 4.7183 & TRN \\
\hline CHEMBL1314516 & 688839 & 4.8 & 5.0974 & TRN \\
\hline CHEMBL1523827 & 688839 & 5.0 & 4.9663 & TST \\
\hline CHEMBL1603446 & 688839 & 5.2 & 5.2423 & TRN \\
\hline CHEMBL1358255 & 688839 & 4.5 & 5.1612 & TST \\
\hline CHEMBL1354455 & 688839 & 4.5 & 4.6009 & TRN \\
\hline CHEMBL312163 & 688839 & 4.4 & 5.4549 & TRN \\
\hline CHEMBL1591190 & 688839 & 4.8 & 4.922 & TRN \\
\hline
\end{tabular}




\begin{tabular}{|c|c|c|c|c|}
\hline & & & pplement & al $\mathrm{Ta}$ \\
\hline CHEMBL158507 & 688839 & 5.6 & 5.5387 & TST \\
\hline CHEMBL1396301 & 688839 & 4.9 & 5.1311 & TRN \\
\hline CHEMBL1354672 & 688839 & 4.6 & 5.0116 & TRN \\
\hline CHEMBL1256760 & 688839 & 6.0 & 5.6929 & TRN \\
\hline CHEMBL1436532 & 688839 & 5.5 & 5.5813 & TRN \\
\hline CHEMBL1415804 & 688839 & 5.1 & 5.2598 & TRN \\
\hline CHEMBL1324530 & 688839 & 4.9 & 5.0404 & TRN \\
\hline CHEMBL1551567 & 688839 & 5.2 & 5.3134 & TRN \\
\hline CHEMBL1564813 & 688839 & 5.6 & 5.6794 & TRN \\
\hline CHEMBL1520489 & 688839 & 4.7 & 5.1004 & TRN \\
\hline CHEMBL1521278 & 688839 & 5.6 & 5.3298 & TST \\
\hline CHEMBL1523959 & 688839 & 4.6 & 4.7161 & TRN \\
\hline CHEMBL1438719 & 688839 & 4.8 & 5.3786 & TRN \\
\hline CHEMBL1592364 & 688839 & 5.0 & 4.9911 & TRN \\
\hline CHEMBL1456417 & 688839 & 5.1 & 5.1381 & TRN \\
\hline CHEMBL1558146 & 688839 & 4.7 & 4.8433 & TRN \\
\hline CHEMBL1368937 & 688839 & 5.3 & 5.3574 & TRN \\
\hline CHEMBL1326251 & 688839 & 5.4 & 5.2833 & TRN \\
\hline CHEMBL1335967 & 688839 & 5.0 & 4.8097 & TRN \\
\hline CHEMBL1515565 & 688839 & 4.6 & 4.6694 & TRN \\
\hline CHEMBL1590919 & 688839 & 4.5 & 4.5555 & TRN \\
\hline CHEMBL1484422 & 688839 & 5.5 & 5.4953 & TRN \\
\hline CHEMBL1591958 & 688839 & 4.4 & 4.6712 & TRN \\
\hline CHEMBL1475951 & 688839 & 5.9 & 6.0674 & TRN \\
\hline CHEMBL1336166 & 688839 & 4.9 & 5.0289 & TST \\
\hline CHEMBL1331410 & 688839 & 5.7 & 5.7856 & TRN \\
\hline CHEMBL188 & 688839 & 5.9 & 5.7258 & TRN \\
\hline CHEMBL1356842 & 688839 & 6.3 & 5.9533 & TRN \\
\hline CHEMBL1552957 & 688839 & 4.6 & 4.8109 & TRN \\
\hline CHEMBL1590432 & 688839 & 4.8 & 5.1631 & TST \\
\hline CHEMBL1551021 & 688839 & 5.3 & 5.3636 & TRN \\
\hline CHEMBL1494481 & 688839 & 5.2 & 5.0462 & TRN \\
\hline CHEMBL1512676 & 688839 & 4.9 & 4.9075 & TRN \\
\hline CHEMBL1330951 & 688839 & 5.3 & 5.296 & TRN \\
\hline CHEMBL 70880 & 688839 & 6.2 & 5.9689 & TRN \\
\hline CHEMBL1565564 & 688839 & 4.5 & 4.652 & TRN \\
\hline CHEMBL1394113 & 688839 & 5.1 & 5.1623 & TRN \\
\hline CHEMBL1594054 & 688839 & 5.5 & 5.4936 & TRN \\
\hline CHEMBL1451477 & 688839 & 5.8 & 5.3975 & TRN \\
\hline CHEMBL1438688 & 688839 & 5.5 & 5.5618 & TRN \\
\hline CHEMBL1489446 & 688839 & 4.7 & 4.7326 & TRN \\
\hline CHEMBL1446324 & 688839 & 4.8 & 4.9405 & TRN \\
\hline CHEMBL1474568 & 688839 & 6.2 & 5.8335 & TRN \\
\hline CHEMBL1453872 & 688839 & 6.0 & 5.9317 & TRN \\
\hline CHEMBL1366762 & 688839 & 5.3 & 5.3819 & TRN \\
\hline CHEMBL1394757 & 688839 & 6.0 & 5.8321 & TST \\
\hline CHEMBL1487944 & 688839 & 5.7 & 5.6535 & TST \\
\hline CHEMBL1395107 & 688839 & 4.4 & 4.5896 & TRN \\
\hline
\end{tabular}




\begin{tabular}{|c|c|c|c|c|}
\hline \multicolumn{5}{|c|}{ Supplemental Table S2.txt } \\
\hline CHEMBL1395162 & 688839 & 4.6 & 4.685 & TRN \\
\hline CHEMBL1361406 & 688839 & 4.9 & 4.9524 & TRN \\
\hline CHEMBL1436816 & 688839 & 5.4 & 5.5476 & TRN \\
\hline CHEMBL1574476 & 688839 & 5.1 & 5.0516 & TRN \\
\hline CHEMBL1410175 & 688839 & 5.4 & 5.3313 & TST \\
\hline CHEMBL242711 & 688839 & 4.8 & 4.9942 & TRN \\
\hline CHEMBL1515295 & 688839 & 4.9 & 5.0077 & TRN \\
\hline CHEMBL1610995 & 688839 & 5.5 & 5.3424 & TRN \\
\hline CHEMBL1319813 & 688839 & 4.6 & 5.0744 & TRN \\
\hline CHEMBL1354678 & 688839 & 4.6 & 4.6157 & TRN \\
\hline CHEMBL1304407 & 688839 & 5.7 & 5.1116 & TRN \\
\hline CHEMBL1405339 & 688839 & 4.9 & 5.1397 & TRN \\
\hline CHEMBL448741 & 688839 & 4.5 & 4.6981 & TST \\
\hline CHEMBL441618 & 688839 & 5.0 & 5.0434 & TST \\
\hline CHEMBL1512878 & 688839 & 5.8 & 5.9375 & TRN \\
\hline CHEMBL1256971 & 688839 & 4.8 & 4.9421 & TST \\
\hline CHEMBL1370284 & 688839 & 5.8 & 5.2508 & TST \\
\hline CHEMBL 2374062 & 688839 & 6.0 & 5.6681 & TST \\
\hline CHEMBL1356879 & 688839 & 5.7 & 5.5532 & TST \\
\hline CHEMBL1557129 & 688839 & 6.0 & 5.1813 & TST \\
\hline CHEMBL1589893 & 688839 & 5.1 & 4.9748 & TRN \\
\hline CHEMBL1363920 & 688839 & 5.8 & 4.7734 & TRN \\
\hline CHEMBL1562589 & 688839 & 5.8 & 5.6933 & TST \\
\hline CHEMBL1441222 & 688839 & 5.6 & 5.5372 & TRN \\
\hline CHEMBL1413165 & 688839 & 6.4 & 6.3036 & TRN \\
\hline CHEMBL1527413 & 688839 & 5.3 & 5.3394 & TRN \\
\hline CHEMBL1415927 & 688839 & 5.5 & 5.2232 & TST \\
\hline CHEMBL1253351 & 688839 & 5.7 & 5.5427 & TST \\
\hline CHEMBL1325964 & 688839 & 4.8 & 4.9345 & TRN \\
\hline CHEMBL1436992 & 688839 & 4.8 & 4.7869 & TST \\
\hline CHEMBL1409461 & 688839 & 4.5 & 4.6612 & TST \\
\hline CHEMBL367741 & 688839 & 4.6 & 4.9762 & TRN \\
\hline CHEMBL1558480 & 688839 & 5.6 & 5.4637 & TRN \\
\hline CHEMBL1552071 & 688839 & 5.2 & 5.2131 & TRN \\
\hline CHEMBL1442997 & 688839 & 4.8 & 4.8802 & TRN \\
\hline CHEMBL1320820 & 688839 & 4.9 & 4.8453 & TRN \\
\hline CHEMBL1589923 & 688839 & 4.7 & 4.876 & TRN \\
\hline CHEMBL299052 & 688839 & 5.5 & 5.5142 & TST \\
\hline CHEMBL1374849 & 688839 & 5.8 & 5.8449 & TRN \\
\hline CHEMBL1592982 & 688839 & 5.7 & 5.7483 & TRN \\
\hline CHEMBL1476789 & 688839 & 4.8 & 4.9932 & TRN \\
\hline CHEMBL1332074 & 688839 & 5.2 & 5.1575 & TRN \\
\hline CHEMBL1609583 & 688839 & 4.9 & 4.8453 & TRN \\
\hline CHEMBL1256359 & 688839 & 5.1 & 5.0642 & TRN \\
\hline CHEMBL1330317 & 688839 & 4.8 & 4.7841 & TRN \\
\hline CHEMBL 1437578 & 688839 & 4.9 & 4.8749 & TRN \\
\hline CHEMBL1439839 & 688839 & 5.9 & 5.9971 & TRN \\
\hline CHEMBL492122 & 688839 & 4.8 & 4.9327 & TRN \\
\hline
\end{tabular}




\begin{tabular}{|c|c|c|c|c|c|}
\hline & & & & & \\
\hline CHEMBL1480779 & 688839 & 5.9 & 5.6472 & TRN & \\
\hline CHEMBL1355256 & 688839 & 5.2 & 5.1444 & TRN & \\
\hline CHEMBL491578 & 688839 & 6.9 & 6.9341 & TRN & \\
\hline CHEMBL1356733 & 688839 & 4.9 & 4.8922 & TRN & \\
\hline CHEMBL161343 & 688839 & 4.6 & 4.7059 & TRN & \\
\hline CHEMBL1203772 & 688839 & 4.5 & 4.8687 & TST & \\
\hline CHEMBL1416055 & 688839 & 5.2 & 5.4227 & TRN & \\
\hline CHEMBL1600340 & 688839 & 4.6 & 4.6354 & TRN & \\
\hline CHEMBL1484738 & 688839 & 4.8 & 4.9172 & TST & \\
\hline CHEMBL1494227 & 688839 & 5.5 & 5.5003 & TRN & \\
\hline CHEMBL1416639 & 688839 & 4.6 & 4.6533 & TRN & \\
\hline CHEMBL1255664 & 688839 & 5.6 & 5.0717 & TRN & \\
\hline CHEMBL1568970 & 688839 & 4.8 & 4.8192 & TRN & \\
\hline CHEMBL1515774 & 688839 & 5.4 & 5.279 & TST & \\
\hline CHEMBL1355463 & 688839 & 5.8 & 5.5771 & TRN & \\
\hline CHEMBL1607905 & 688839 & 4.8 & 5.0304 & TST & \\
\hline CHEMBL1611496 & 688839 & 5.3 & 5.4211 & TRN & \\
\hline CHEMBL1358009 & 688839 & 5.3 & 5.2569 & TRN & \\
\hline CHEMBL311158 & 688839 & 6.0 & 5.0285 & TRN & \\
\hline CHEMBL1331031 & 688839 & 5.5 & 5.5239 & TRN & \\
\hline CHEMBL1490786 & 688839 & 5.8 & 5.88399 & 99999999995 & TRN \\
\hline CHEMBL1374504 & 688839 & 4.6 & 5.1619 & TRN & \\
\hline CHEMBL1512454 & 688839 & 5.9 & 5.7099 & TRN & \\
\hline CHEMBL1490528 & 688839 & 4.8 & 4.7639 & TRN & \\
\hline CHEMBL1322756 & 688839 & 4.8 & 4.838 & TRN & \\
\hline CHEMBL1449517 & 688839 & 5.4 & 5.32 & TRN & \\
\hline CHEMBL1379031 & 688839 & 4.9 & 4.7506 & TRN & \\
\hline CHEMBL1562420 & 688839 & 4.4 & 4.55399 & 9999999999 & TST \\
\hline CHEMBL1414605 & 688839 & 5.4 & $5.2860 e$ & 00000000005 & TRN \\
\hline CHEMBL1337419 & 688839 & 6.6 & 6.1266 & TST & \\
\hline CHEMBL1362852 & 688839 & 6.0 & 6.0004 & TRN & \\
\hline CHEMBL1514023 & 688839 & 5.4 & 5.3896 & TRN & \\
\hline CHEMBL474415 & 688839 & 5.1 & 5.2564 & TRN & \\
\hline CHEMBL1314982 & 688839 & 6.7001 & 5.564 & TRN & \\
\hline CHEMBL1433464 & 688839 & 5.2 & 5.2573 & TRN & \\
\hline CHEMBL151 & 688839 & 6.0 & 5.4367 & TRN & \\
\hline CHEMBL1455203 & 688839 & 5.4 & 5.4576 & TRN & \\
\hline CHEMBL1438689 & 688839 & 5.4 & 5.4753 & TRN & \\
\hline CHEMBL252744 & 688839 & 4.5 & 5.4731 & TST & \\
\hline CHEMBL44297 & 688839 & 4.8 & 4.8993 & TST & \\
\hline CHEMBL1435859 & 688839 & 4.7 & 5.0331 & TRN & \\
\hline CHEMBL1378731 & 688839 & 5.3 & 5.2833 & TST & \\
\hline CHEMBL56731 & 688839 & 4.8 & 4.8933 & TRN & \\
\hline CHEMBL1433776 & 688839 & 4.9 & 4.9322 & TRN & \\
\hline CHEMBL1490904 & 688839 & 6.0 & 5.8025 & TRN & \\
\hline CHEMBL1337092 & 688839 & 4.7 & 4.7946 & TRN & \\
\hline CHEMBL1525602 & 688839 & 5.1 & 5.1184 & TRN & \\
\hline CHEMBL1613623 & 688839 & 4.9 & 5.4805 & TST & \\
\hline & & & & 20417 & \\
\hline
\end{tabular}




\begin{tabular}{|c|c|c|c|c|c|}
\hline \\
\hline CHEMBL1398390 & 688839 & 5.3 & 5.3643 & TRN & \\
\hline CHEMBL1356003 & 688839 & 4.5 & 4.6253 & TRN & \\
\hline CHEMBL1488179 & 688839 & 4.9 & 4.9502 & TRN & \\
\hline CHEMBL393417 & 688839 & 6.0 & 4.8849 & TRN & \\
\hline CHEMBL250892 & 688839 & 5.0 & 5.0503 & TRN & \\
\hline CHEMBL1593850 & 688839 & 4.9 & 5.0759 & TST & \\
\hline CHEMBL1397050 & 688839 & 4.4 & 4.9631 & TRN & \\
\hline CHEMBL1322233 & 688839 & 4.7 & 4.8003 & TRN & \\
\hline CHEMBL1592557 & 688839 & 5.7 & 5.4875 & TRN & \\
\hline CHEMBL363506 & 688839 & 6.0 & 5.024 & TST & \\
\hline CHEMBL1434973 & 688839 & 4.8 & 4.7817 & TRN & \\
\hline CHEMBL1448387 & 688839 & 6.0 & 5.1027 & TST & \\
\hline CHEMBL1512083 & 688839 & 5.1 & 5.0276 & TRN & \\
\hline CHEMBL 261134 & 688839 & 5.4 & 5.2623 & TRN & \\
\hline CHEMBL1488668 & 688839 & 4.9 & 4.9659 & TRN & \\
\hline CHEMBL1515787 & 688839 & 5.4 & 5.2986 & TRN & \\
\hline CHEMBL1302867 & 688839 & 4.7 & 5.0627 & TRN & \\
\hline CHEMBL1454270 & 688839 & 4.8 & 4.7786 & TRN & \\
\hline CHEMBL1591459 & 688839 & 5.4 & 5.4307 & TRN & \\
\hline CHEMBL1434655 & 688839 & 4.5 & 4.5985 & TRN & \\
\hline CHEMBL1451097 & 688839 & 4.9 & 4.8256 & TST & \\
\hline CHEMBL508030 & 688839 & 6.0 & 5.0217 & TST & \\
\hline CHEMBL17331 & 688839 & 6.8 & 5.8651 & TST & \\
\hline CHEMBL1409109 & 688839 & 5.0 & 5.0284 & TST & \\
\hline CHEMBL1475358 & 688839 & 5.6 & 5.75700 & 0000000001 & TRN \\
\hline CHEMBL1461491 & 688839 & 7.3002 & 6.4926 & TRN & \\
\hline CHEMBL39947 & 688839 & 6.0 & 5.0331 & TST & \\
\hline CHEMBL259331 & 688839 & 6.0 & 5.2605 & TRN & \\
\hline CHEMBL1366068 & 688839 & 4.5 & 4.6661 & TRN & \\
\hline CHEMBL 25236 & 688839 & 5.1 & 5.084 & TRN & \\
\hline CHEMBL1411135 & 688839 & 6.0 & 5.1994 & TRN & \\
\hline CHEMBL1490386 & 688839 & 5.8 & 5.8309 & TRN & \\
\hline CHEMBL1316808 & 688839 & 4.9 & 4.8347 & TRN & \\
\hline CHEMBL1567353 & 688839 & 4.7 & 4.8219 & TRN & \\
\hline CHEMBL1378132 & 688839 & 4.6 & 4.6747 & TRN & \\
\hline CHEMBL1558796 & 688839 & 4.6 & 5.0426 & TRN & \\
\hline CHEMBL1515559 & 688839 & 4.8 & 4.8213 & TRN & \\
\hline CHEMBL1411049 & 688839 & 5.6 & 5.7569 & TRN & \\
\hline CHEMBL1315457 & 688839 & 5.0 & 5.0532 & TST & \\
\hline CHEMBL1256191 & 688839 & 4.8 & 4.836 & TRN & \\
\hline CHEMBL1599728 & 688839 & 4.6 & 5.1685 & TRN & \\
\hline CHEMBL429711 & 688839 & 4.4 & 4.5393 & TRN & \\
\hline CHEMBL1553123 & 688839 & 4.8 & 5.1018 & TRN & \\
\hline CHEMBL 310310 & 688839 & 6.0 & 5.6427 & TRN & \\
\hline CHEMBL1552181 & 688839 & 5.0 & 4.9831 & TRN & \\
\hline CHEMBL1594425 & 688839 & 5.2 & 5.2054 & TST & \\
\hline CHEMBL1317314 & 688839 & 5.1 & 5.0858 & TRN & \\
\hline CHEMBL1530982 & 688839 & 5.9 & 6.0543 & TRN & \\
\hline
\end{tabular}




\begin{tabular}{|c|c|c|c|c|c|}
\hline \multicolumn{6}{|c|}{ Supplemental Table S2.txt } \\
\hline CHEMBL1452326 & 688839 & 4.8 & 5.2024 & TRN & \\
\hline CHEMBL1486091 & 688839 & 5.1 & 5.1535 & TST & \\
\hline CHEMBL1433719 & 688839 & 5.0 & 5.1176 & TRN & \\
\hline CHEMBL73933 & 688839 & 4.6 & 5.1418 & TRN & \\
\hline CHEMBL111545 & 688839 & 5.0 & 5.0202 & TST & \\
\hline CHEMBL1440157 & 688839 & 6.7001 & $6.7620 e$ & 00000000005 & TRN \\
\hline CHEMBL406119 & 688839 & 5.1 & 5.3276 & TRN & \\
\hline CHEMBL1433486 & 688839 & 5.0 & 4.9399 & TRN & \\
\hline CHEMBL1574786 & 688839 & 5.7 & 5.3982 & TRN & \\
\hline CHEMBL1555037 & 688839 & 5.6 & 5.2524 & TRN & \\
\hline CHEMBL1435996 & 688839 & 5.5 & 5.1219 & TRN & \\
\hline CHEMBL1256911 & 688839 & 4.9 & $4.9510 e$ & 00000000005 & TRN \\
\hline CHEMBL1396975 & 688839 & 5.1 & 5.0142 & TRN & \\
\hline CHEMBL1355349 & 688839 & 5.4 & 5.2621 & TST & \\
\hline CHEMBL1334278 & 688839 & 5.1 & $5.2810 e$ & $\partial 000000001$ & TRN \\
\hline CHEMBL1362935 & 688839 & 4.4 & 5.0957 & TRN & \\
\hline CHEMBL68534 & 688839 & 5.1 & 5.0541 & TRN & \\
\hline CHEMBL1518718 & 688839 & 4.4 & 4.5913 & TRN & \\
\hline CHEMBL1493476 & 688839 & 4.5 & 4.567 & TRN & \\
\hline CHEMBL1446523 & 688839 & 6.0 & 5.7817 & TRN & \\
\hline CHEMBL576349 & 688839 & 5.6 & 5.4489 & TST & \\
\hline CHEMBL1456906 & 688839 & 4.8 & 5.3329 & TST & \\
\hline CHEMBL 308688 & 688839 & 4.8 & 5.1608 & TRN & \\
\hline CHEMBL73310 & 688839 & 4.9 & 4.973 & TRN & \\
\hline CHEMBL1593589 & 688839 & 4.9 & 4.9181 & TRN & \\
\hline CHEMBL1598062 & 688839 & 5.9 & 5.9263 & TRN & \\
\hline CHEMBL1567098 & 688839 & 6.0 & 5.9488 & TRN & \\
\hline CHEMBL1376143 & 688839 & 4.8 & 4.8371 & TRN & \\
\hline CHEMBL1496246 & 688839 & 5.4 & 5.5763 & TRN & \\
\hline CHEMBL177820 & 688839 & 6.0 & 5.078 & TST & \\
\hline CHEMBL1514484 & 688839 & 5.8 & 4.7512 & TRN & \\
\hline CHEMBL1446009 & 688839 & 4.9 & 4.9456 & TRN & \\
\hline CHEMBL1568917 & 688839 & 5.5 & 5.1887 & TRN & \\
\hline CHEMBL1236872 & 688839 & 4.9 & 5.521 & TRN & \\
\hline CHEMBL1475990 & 688839 & 5.2 & 5.2891 & TRN & \\
\hline CHEMBL1394181 & 688839 & 5.0 & 4.9391 & TRN & \\
\hline CHEMBL1409816 & 688839 & 4.7 & 5.099 & TRN & \\
\hline CHEMBL1314911 & 688839 & 5.5 & 5.2521 & TRN & \\
\hline CHEMBL1456388 & 688839 & 4.8 & 5.029 & TRN & \\
\hline CHEMBL1318163 & 688839 & 4.8 & 4.9802 & TST & \\
\hline CHEMBL326958 & 688839 & 4.6 & 4.7943 & TRN & \\
\hline CHEMBL1592470 & 688839 & 4.4 & 4.4643 & TRN & \\
\hline CHEMBL1314446 & 688839 & 5.1 & 5.0365 & TRN & \\
\hline CHEMBL1449457 & 688839 & 5.3 & 5.4273 & TRN & \\
\hline CHEMBL1231330 & 688839 & 7.5003 & 6.8857 & TST & \\
\hline CHEMBL1389138 & 688839 & 5.4 & 5.2505 & TRN & \\
\hline CHEMBL1513684 & 688839 & 4.4 & 4.5538 & TRN & \\
\hline CHEMBL491953 & 688839 & 4.9 & 4.9908 & TRN & \\
\hline
\end{tabular}




\begin{tabular}{|c|c|c|c|c|c|}
\hline \\
\hline CHEMBL1487687 & 688839 & 5.7 & 5.6516 & TST & \\
\hline CHEMBL278755 & 688839 & 4.8 & 4.8694 & TRN & \\
\hline CHEMBL1415406 & 688839 & 5.1 & 5.2258 & TRN & \\
\hline CHEMBL1407783 & 688839 & 5.5 & 5.5378 & TRN & \\
\hline CHEMBL1304981 & 688839 & 4.6 & 5.2519 & TST & \\
\hline CHEMBL1531754 & 688839 & 6.0 & 5.6872 & TST & \\
\hline CHEMBL1552814 & 688839 & 4.6 & 4.5986 & TST & \\
\hline CHEMBL1483739 & 688839 & 4.8 & 5.0198 & TST & \\
\hline CHEMBL1453655 & 688839 & 5.4 & 5.0208 & TST & \\
\hline CHEMBL1354529 & 688839 & 4.4 & 5.0432 & TST & \\
\hline CHEMBL1482847 & 688839 & 4.9 & 4.8764 & TST & \\
\hline CHEMBL1445946 & 688839 & 5.5 & 5.0716 & TST & \\
\hline CHEMBL184074 & 688839 & 6.2 & 5.1792 & TST & \\
\hline CHEMBL1531108 & 688839 & 4.7 & 4.8583 & TST & \\
\hline CHEMBL1317096 & 688839 & 5.5 & 5.0856 & TST & \\
\hline CHEMBL1338623 & 688839 & 5.5 & 5.5213 & TST & \\
\hline CHEMBL1518075 & 688839 & 4.6 & 5.1271 & TST & \\
\hline CHEMBL1375753 & 688839 & 5.5 & 5.4304 & TST & \\
\hline CHEMBL51085 & 688839 & 6.0 & 4.9894 & TST & \\
\hline CHEMBL1517172 & 688839 & 4.8 & 4.8914 & TST & \\
\hline CHEMBL1518618 & 688839 & 4.8 & 4.7539 & TST & \\
\hline CHEMBL1354693 & 688839 & 4.7 & 4.732 & TST & \\
\hline CHEMBL1515001 & 688839 & 4.8 & 4.9226 & TST & \\
\hline CHEMBL1474211 & 688839 & 4.7 & 4.7463 & TST & \\
\hline CHEMBL1331312 & 688839 & 4.9 & 5.0715 & TST & \\
\hline CHEMBL1396989 & 688839 & 4.9 & 4.8888 & TST & \\
\hline CHEMBL1567472 & 688839 & 5.3 & 5.3775 & TST & \\
\hline CHEMBL329673 & 688839 & 4.9 & 5.1625 & TST & \\
\hline CHEMBL1519261 & 688839 & 5.6 & 5.6301 & TST & \\
\hline CHEMBL1571027 & 688839 & 5.4 & 5.5074 & TST & \\
\hline CHEMBL1567251 & 688839 & 4.6 & 4.6731 & TST & \\
\hline CHEMBL1513633 & 688839 & 6.3 & 6.32799 & 9999999999 & TST \\
\hline CHEMBL1531699 & 688839 & 5.6 & 5.5826 & TST & \\
\hline CHEMBL1320518 & 688839 & 5.4 & 5.3483 & TST & \\
\hline CHEMBL1358525 & 688839 & 4.5 & 4.6548 & TST & \\
\hline CHEMBL1558938 & 688839 & 4.7 & 5.1221 & TST & \\
\hline CHEMBL1397902 & 688839 & 5.4 & 5.4695 & TST & \\
\hline CHEMBL1564477 & 688839 & 4.8 & 4.8223 & TST & \\
\hline CHEMBL1435713 & 688839 & 4.8 & 4.8793 & TST & \\
\hline CHEMBL 282489 & 688839 & 4.8 & 4.8992 & TST & \\
\hline CHEMBL1552095 & 688839 & 6.0 & 5.9446 & TST & \\
\hline CHEMBL1439665 & 688839 & 4.8 & 4.9339 & TST & \\
\hline CHEMBL1559912 & 688839 & 5.4 & 5.2675 & TST & \\
\hline CHEMBL492121 & 688839 & 4.9 & 4.9659 & TST & \\
\hline CHEMBL 1373160 & 688839 & 4.9 & 4.9138 & TST & \\
\hline CHEMBL1484176 & 688839 & 4.9 & 5.2363 & TST & \\
\hline CHEMBL1357016 & 688839 & 4.7 & 4.7631 & TST & \\
\hline CHEMBL1437164 & 688839 & 4.8 & 4.8639 & TST & \\
\hline
\end{tabular}




\begin{tabular}{|c|c|c|c|c|c|}
\hline & & & & & \\
\hline CHEMBL1396561 & 688839 & 5.8 & 5.7715 & TST & \\
\hline CHEMBL1358116 & 688839 & 6.0 & 5.1484 & TST & \\
\hline CHEMBL1597873 & 688839 & 5.3 & 5.20799 & 9999999999 & TST \\
\hline CHEMBL452477 & 688839 & 5.5 & 5.0254 & TST & \\
\hline CHEMBL1484127 & 688839 & 4.9 & 4.908 & TST & \\
\hline CHEMBL1481378 & 688839 & 5.4 & 5.61 & TST & \\
\hline CHEMBL1515221 & 688839 & 4.9 & 5.0277 & TST & \\
\hline CHEMBL1314416 & 688839 & 4.8 & 4.8146 & TST & \\
\hline CHEMBL1605366 & 688839 & 6.1 & 5.4545 & TST & \\
\hline CHEMBL1713992 & 688839 & 4.5 & 4.633 & TST & \\
\hline CHEMBL 75035 & 688839 & 4.5 & 4.7097 & TST & \\
\hline CHEMBL1612252 & 688839 & 4.9 & 4.9624 & TST & \\
\hline CHEMBL1972346 & 688839 & 4.7 & 5.0092 & TST & \\
\hline CHEMBL 224214 & 688839 & 5.9 & 5.145 & TST & \\
\hline CHEMBL1559163 & 688839 & 5.4 & 5.3887 & TST & \\
\hline CHEMBL1552551 & 688839 & 5.6 & 5.5181 & TST & \\
\hline CHEMBL1473934 & 688839 & 4.5 & 4.6049 & TST & \\
\hline CHEMBL1605233 & 688839 & 4.8 & 4.851 & TST & \\
\hline CHEMBL1566780 & 688839 & 6.1 & 6.2435 & TST & \\
\hline CHEMBL1476632 & 688839 & 6.5 & 6.3222 & TST & \\
\hline CHEMBL1330334 & 688839 & 4.9 & 4.9337 & TST & \\
\hline CHEMBL1523957 & 688839 & 5.3 & 5.27 & TST & \\
\hline CHEMBL1433898 & 688839 & 5.0 & 4.9544 & TST & \\
\hline CHEMBL65 & 688839 & 5.2 & 5.1907 & TST & \\
\hline CHEMBL1514765 & 688839 & 5.5 & 5.4475 & TST & \\
\hline CHEMBL1396463 & 688839 & 4.5 & 4.6464 & TST & \\
\hline CHEMBL1599118 & 688839 & 5.0 & 5.0479 & TST & \\
\hline CHEMBL1452057 & 688839 & 4.9 & 5.0608 & TST & \\
\hline CHEMBL1354281 & 688839 & 5.8 & 5.7454 & TST & \\
\hline CHEMBL405358 & 688839 & 5.3 & 4.9526 & TST & \\
\hline CHEMBL1492577 & 688839 & 5.8 & 5.2064 & TST & \\
\hline CHEMBL1356771 & 688839 & 5.0 & 4.9875 & TST & \\
\hline CHEMBL1560999 & 688839 & 5.0 & 5.2692 & TST & \\
\hline CHEMBL83954 & 688839 & 4.6 & 4.7426 & TST & \\
\hline CHEMBL1322584 & 688839 & 4.8 & 4.8624 & TST & \\
\hline CHEMBL1573712 & 688839 & 4.9 & 5.1282 & TST & \\
\hline CHEMBL1517234 & 688839 & 5.8 & 5.5185 & TST & \\
\hline CHEMBL1601166 & 688839 & 4.6 & 5.0061 & TST & \\
\hline CHEMBL481049 & 688839 & 4.5 & 5.0852 & TST & \\
\hline CHEMBL1453216 & 688839 & 5.3 & 5.3136 & TST & \\
\hline CHEMBL1304918 & 688839 & 5.8 & 5.574 & TST & \\
\hline CHEMBL1433897 & 688839 & 4.7 & 4.783 & TST & \\
\hline CHEMBL1364980 & 688839 & 5.5 & 5.4883 & TST & \\
\hline CHEMBL1318509 & 688839 & 4.9 & 5.0496 & TST & \\
\hline CHEMBL1451087 & 688839 & 5.9 & 5.6427 & TST & \\
\hline CHEMBL1592041 & 688839 & 4.9 & 5.1116 & TST & \\
\hline CHEMBL 1357148 & 688839 & 5.0 & 5.15799 & 99999999995 & TST \\
\hline CHEMBL1396917 & 688839 & 4.8 & 5.0432 & TST & \\
\hline & & & & 20421 & \\
\hline
\end{tabular}




\begin{tabular}{|c|c|c|c|c|}
\hline & & & 170 & \\
\hline CHEMBL1415777 & 688839 & 6.0 & 4.9578 & TST \\
\hline CHEMBL1569213 & 688839 & 5.4 & 5.32299 & 99999999995 \\
\hline CHEMBL1257078 & 688839 & 6.0 & 4.9895 & TST \\
\hline CHEMBL1435917 & 688839 & 4.9 & 4.8985 & TST \\
\hline CHEMBL1513870 & 688839 & 5.3 & 5.0335 & TST \\
\hline CHEMBL1474286 & 688839 & 4.8 & 5.0282 & TST \\
\hline CHEMBL1317009 & 688839 & 5.0 & 4.978 & TST \\
\hline CHEMBL1609142 & 688839 & 5.5 & 5.5334 & TST \\
\hline CHEMBL1471289 & 688839 & 4.6 & 5.0137 & TST \\
\hline CHEMBL1316165 & 688839 & 4.9 & 4.7397 & TST \\
\hline CHEMBL1455699 & 688839 & 5.5 & 5.073 & TST \\
\hline CHEMBL 2374259 & 688839 & 5.1 & 5.2026 & TST \\
\hline CHEMBL1444266 & 688839 & 5.6 & 5.0634 & TST \\
\hline CHEMBL1600347 & 688839 & 4.9 & 4.9438 & TST \\
\hline CHEMBL 3192674 & 688839 & 5.3 & 5.3791 & TST \\
\hline CHEMBL1363142 & 688839 & 5.6 & 5.6994 & TST \\
\hline CHEMBL1337829 & 688839 & 5.0 & 4.9033 & TST \\
\hline CHEMBL1475695 & 688839 & 5.1 & 5.0709 & TST \\
\hline CHEMBL1326907 & 688839 & 5.5 & 5.2692 & TST \\
\hline CHEMBL1517718 & 688839 & 4.8 & 4.8814 & TST \\
\hline CHEMBL1411750 & 688839 & 4.9 & 5.1563 & TST \\
\hline CHEMBL1409613 & 688839 & 6.5 & 6.1416 & TST \\
\hline CHEMBL1515691 & 688839 & 4.8 & 4.8575 & TST \\
\hline CHEMBL1592560 & 688839 & 4.4 & 4.5015 & TST \\
\hline CHEMBL1321887 & 688839 & 5.4 & 5.4096 & TST \\
\hline CHEMBL1551919 & 688839 & 5.0 & 4.9478 & TST \\
\hline CHEMBL1515209 & 688839 & 5.4 & 5.3133 & TST \\
\hline CHEMBL1376070 & 688839 & 5.5 & 5.33 & TST \\
\hline CHEMBL1447659 & 688839 & 5.7 & 5.245 & TST \\
\hline CHEMBL23327 & 688839 & 4.9 & 5.2006 & TST \\
\hline CHEMBL1603870 & 688839 & 5.0 & 4.7922 & TST \\
\hline CHEMBL 1533680 & 688839 & 4.8 & 4.9161 & TST \\
\hline CHEMBL1397877 & 688839 & 4.8 & 4.8358 & TST \\
\hline CHEMBL1454544 & 688839 & 5.6 & 5.6563 & TST \\
\hline CHEMBL1515361 & 688839 & 4.8 & 4.9421 & TST \\
\hline CHEMBL1317900 & 688839 & 5.1 & 5.4223 & TST \\
\hline CHEMBL64119 & 688839 & 4.8 & 4.88 & TST \\
\hline CHEMBL3209999 & 688839 & 5.4 & 5.4395 & TST \\
\hline CHEMBL1357968 & 688839 & 4.8 & 4.8291 & TST \\
\hline CHEMBL567332 & 688839 & 6.1 & 5.9356 & TST \\
\hline CHEMBL1517935 & 688839 & 5.5 & 5.4964 & TST \\
\hline CHEMBL1355467 & 688839 & 5.6 & 5.0567 & TST \\
\hline CHEMBL1321470 & 688839 & 5.3 & 5.1548 & TST \\
\hline CHEMBL1356497 & 688839 & 5.0 & 4.9985 & TST \\
\hline CHEMBL1481745 & 688839 & 5.7 & 5.3919 & TST \\
\hline CHEMBL1404977 & 688839 & 5.5 & 5.0813 & TST \\
\hline CHEMBL1590645 & 688839 & 5.2 & 5.2639 & TST \\
\hline CHEMBL 264141 & 688839 & 5.3 & 5.0671 & TST \\
\hline
\end{tabular}




\begin{tabular}{|c|c|c|c|c|}
\hline & & & & \\
\hline CHEMBL1480574 & 688839 & 5.4 & 5.1384 & TST \\
\hline CHEMBL1192187 & 688839 & 4.7 & 4.8542 & TST \\
\hline CHEMBL1477833 & 688839 & 6.0 & 6.0171 & TST \\
\hline CHEMBL1413962 & 688839 & 6.1 & 6.1119 & TST \\
\hline CHEMBL3210890 & 688839 & 5.5 & 5.5117 & TST \\
\hline CHEMBL1571929 & 688839 & 6.0 & 4.9319 & TST \\
\hline CHEMBL582444 & 688839 & 5.0 & 5.0078 & TST \\
\hline CHEMBL1333249 & 688839 & 4.6 & 5.0787 & TST \\
\hline CHEMBL1590484 & 688839 & 4.6 & 4.7588 & TST \\
\hline CHEMBL1512786 & 688839 & 5.2 & 4.9535 & TST \\
\hline CHEMBL491771 & 688839 & 5.8 & 5.7636 & TST \\
\hline CHEMBL1318041 & 688839 & 4.9 & 4.868 & TST \\
\hline CHEMBL1456714 & 688839 & 5.1 & 4.9887 & TST \\
\hline CHEMBL1495004 & 688839 & 5.4 & 5.4329 & TST \\
\hline CHEMBL263972 & 688839 & 5.6 & 5.4612 & TST \\
\hline CHEMBL1357465 & 688839 & 4.7 & 5.2063 & TST \\
\hline CHEMBL1314273 & 688839 & 5.5 & 5.5278 & TST \\
\hline CHEMBL1513347 & 688839 & 4.9 & 4.8787 & TST \\
\hline CHEMBL602575 & 688839 & 4.9 & 5.019 & TST \\
\hline CHEMBL70582 & 688839 & 4.7 & 4.8343 & TST \\
\hline CHEMBL1374536 & 688839 & 4.8 & 5.1108 & TST \\
\hline CHEMBL1397151 & 688839 & 5.6 & 5.1534 & TST \\
\hline CHEMBL1315530 & 688839 & 4.7 & 4.6956 & TST \\
\hline CHEMBL1369650 & 688839 & 4.8 & 4.7592 & TST \\
\hline CHEMBL1571679 & 688839 & 5.6 & 5.4745 & TST \\
\hline CHEMBL1545634 & 688839 & 4.9 & 5.1174 & TST \\
\hline CHEMBL1433930 & 688839 & 5.8 & 5.6386 & TST \\
\hline CHEMBL1376005 & 688839 & 5.3 & 5.2824 & TST \\
\hline CHEMBL1525112 & 688839 & 4.6 & 4.6895 & TST \\
\hline CHEMBL1516054 & 688839 & 5.9 & 5.9448 & TST \\
\hline CHEMBL1552478 & 688839 & 4.5 & 4.7136 & TST \\
\hline CHEMBL1476051 & 688839 & 6.2 & 6.2155 & TST \\
\hline CHEMBL1551295 & 688839 & 4.4 & 4.5417 & TST \\
\hline CHEMBL1515698 & 688839 & 5.5 & 5.459 & TST \\
\hline CHEMBL1574278 & 688839 & 6.5 & 6.0598 & TST \\
\hline CHEMBL1332929 & 688839 & 6.2 & 6.284 & TST \\
\hline CHEMBL1609440 & 688839 & 4.7 & 4.646 & TST \\
\hline CHEMBL1381 & 688839 & 4.6 & 4.8445 & TST \\
\hline CHEMBL1522030 & 688839 & 6.0 & 5.1111 & TST \\
\hline CHEMBL1363319 & 688839 & 4.9 & 5.0346 & TST \\
\hline CHEMBL1488393 & 688839 & 4.7 & 5.0888 & TST \\
\hline CHEMBL1602632 & 688839 & 5.4 & 5.0935 & TST \\
\hline CHEMBL1356843 & 688839 & 4.4 & 4.5505 & TST \\
\hline CHEMBL1329526 & 688839 & 5.0 & 5.044 & TST \\
\hline CHEMBL1603113 & 688839 & 5.6 & 5.5802 & TST \\
\hline CHEMBL491977 & 688839 & 6.4 & 6.4283 & TST \\
\hline CHEMBL1332054 & 688839 & 4.5 & 5.4551 & TST \\
\hline CHEMBL1479744 & 688839 & 5.0 & 5.0528 & TST \\
\hline
\end{tabular}




\begin{tabular}{|c|c|c|c|c|c|}
\hline \multicolumn{6}{|c|}{ Supplemental Table S2.txt } \\
\hline CHEMBL1213139 & 688839 & 5.2 & 5.0322 & TST & \\
\hline CHEMBL1433950 & 688839 & 4.8 & 4.805 & TST & \\
\hline CHEMBL1439334 & 688839 & 6.0 & 6.0607 & TST & \\
\hline CHEMBL265699 & 688839 & 5.4 & 5.2908 & TST & \\
\hline CHEMBL1375469 & 688839 & 6.0 & 5.9882 & TST & \\
\hline CHEMBL465423 & 688839 & 5.4 & 5.1868 & TST & \\
\hline CHEMBL1491574 & 688839 & 5.6 & 5.6149 & TST & \\
\hline CHEMBL1551610 & 688839 & 4.4 & 5.3471 & TST & \\
\hline CHEMBL1447663 & 688839 & 5.6 & 5.5421 & TST & \\
\hline CHEMBL1515324 & 688839 & 5.4 & 5.4038 & TST & \\
\hline CHEMBL1533413 & 688839 & 5.4 & 5.3558 & TST & \\
\hline CHEMBL1318307 & 688839 & 4.8 & 4.9303 & TST & \\
\hline CHEMBL1086539 & 688197 & 4.95 & 5.8748 & TRN & \\
\hline CHEMBL1086349 & 688197 & 5.85 & 5.9509 & TRN & \\
\hline CHEMBL1091057 & 688197 & 7.699 & 6.8856 & TRN & \\
\hline CHEMBL1093361 & 688197 & 4.5 & 6.7903 & TRN & \\
\hline CHEMBL1090756 & 688197 & 4.85 & 6.8165 & TRN & \\
\hline CHEMBL1085412 & 688197 & 8.7959 & 5.9236 & TRN & \\
\hline CHEMBL1085413 & 688197 & 5.9 & 5.9481 & TRN & \\
\hline CHEMBL1091055 & 688197 & 4.75 & 6.6978 & TST & \\
\hline CHEMBL1082457 & 688197 & 6.0 & 5.9423 & TRN & \\
\hline CHEMBL1086566 & 688197 & 5.95 & 5.9373 & TRN & \\
\hline CHEMBL1093061 & 688197 & 6.8 & 6.86299 & 99999999995 & TRN \\
\hline CHEMBL1085340 & 688197 & 5.25 & 5.8645 & TRN & \\
\hline CHEMBL1086540 & 688197 & 5.85 & 5.8168 & TRN & \\
\hline CHEMBL1085648 & 688197 & 5.95 & 5.8417 & TRN & \\
\hline CHEMBL1082796 & 688197 & 8.7959 & 5.9123 & TRN & \\
\hline CHEMBL1093091 & 688197 & 8.7447 & 6.7664 & TST & \\
\hline CHEMBL1092462 & 688197 & 7.6003 & 6.9569 & TRN & \\
\hline CHEMBL1092472 & 688197 & 5.1 & 6.9544 & TRN & \\
\hline CHEMBL1092463 & 688197 & 7.0501 & 6.8926 & TRN & \\
\hline CHEMBL1092297 & 688197 & 6.0 & 6.8767 & TRN & \\
\hline CHEMBL1085215 & 688197 & 4.45 & 5.8476 & TRN & \\
\hline CHEMBL1090774 & 688197 & 7.3497 & 6.8939 & TRN & \\
\hline CHEMBL1396401 & 688197 & 6.25 & 5.9786 & TRN & \\
\hline CHEMBL1084057 & 688197 & 6.2 & 5.9965 & TST & \\
\hline CHEMBL1475784 & 688197 & 4.6 & 5.8867 & TRN & \\
\hline CHEMBL1084625 & 688197 & 5.7 & 5.8499 & TRN & \\
\hline CHEMBL1082454 & 688197 & 4.9 & 5.8832 & TRN & \\
\hline CHEMBL1083165 & 688197 & 5.25 & 5.8705 & TRN & \\
\hline CHEMBL1092471 & 688197 & 10.0 & 6.9711 & TRN & \\
\hline CHEMBL1094006 & 688197 & 6.3 & 6.9043 & TRN & \\
\hline CHEMBL1092121 & 688197 & 8.6576 & 6.9906 & TRN & \\
\hline CHEMBL1085586 & 688197 & 6.2 & 5.9263 & TRN & \\
\hline CHEMBL1551624 & 688197 & 9.2218 & 6.1065 & TST & \\
\hline CHEMBL1360157 & 688197 & 4.6 & 5.774 & TRN & \\
\hline CHEMBL1085647 & 688197 & 6.4 & 5.8943 & TRN & \\
\hline CHEMBL1090776 & 688197 & 6.6 & 6.8376 & TRN & \\
\hline
\end{tabular}




\begin{tabular}{|c|c|c|c|c|c|}
\hline & & \multicolumn{4}{|c|}{ Supplemental Table S2.txt } \\
\hline CHEMBL1091458 & 688197 & 7.6498 & 6.8137 & TST & \\
\hline CHEMBL1093092 & 688197 & 5.5 & 6.7664 & TST & \\
\hline CHEMBL1091457 & 688197 & 4.4 & 6.8352 & TRN & \\
\hline CHEMBL1086565 & 688197 & 6.15 & 5.8438 & TRN & \\
\hline CHEMBL1084058 & 688197 & 8.8861 & 6.0899 & TRN & \\
\hline CHEMBL1094007 & 688197 & 5.65 & 6.7724 & TRN & \\
\hline CHEMBL1091502 & 688197 & 4.65 & 6.9352 & TST & \\
\hline CHEMBL1315562 & 688197 & 8.2007 & 6.8233 & TRN & \\
\hline CHEMBL1093049 & 688197 & 5.3 & 7.0066 & TST & \\
\hline CHEMBL1323190 & 688197 & 9.0 & 6.2979 & TRN & \\
\hline CHEMBL1591871 & 688197 & 7.3497 & 5.9628 & TRN & \\
\hline CHEMBL1089603 & 688197 & 7.6498 & 6.8716 & TST & \\
\hline CHEMBL1085794 & 688197 & 6.35 & 5.9307 & TRN & \\
\hline CHEMBL1083475 & 688197 & 4.85 & 5.8416 & TRN & \\
\hline CHEMBL1085411 & 688197 & 4.8 & 5.8923 & TRN & \\
\hline CHEMBL1093688 & 688197 & 6.0 & 6.7486 & TST & \\
\hline CHEMBL1083166 & 688197 & 5.35 & 5.8248 & TRN & \\
\hline CHEMBL1091078 & 688197 & 7.8996 & 6.9011 & TST & \\
\hline CHEMBL1093096 & 688197 & 8.4949 & 6.7919 & TST & \\
\hline CHEMBL1083882 & 688197 & 5.95 & 5.95 & TRN & \\
\hline CHEMBL1093360 & 688197 & 6.5501 & 6.8454 & TST & \\
\hline CHEMBL1084899 & 688197 & 6.2 & 5.8065 & TRN & \\
\hline CHEMBL1513933 & 688197 & 6.15 & 6.6131 & TST & \\
\hline CHEMBL1085649 & 688197 & 5.35 & 5.8314 & TRN & \\
\hline CHEMBL1085873 & 688197 & 6.6 & 5.9743 & TRN & \\
\hline CHEMBL1083137 & 688197 & 5.4 & 5.8569 & TRN & \\
\hline CHEMBL1435175 & 688197 & 5.6 & 5.8176 & TRN & \\
\hline CHEMBL1086538 & 688197 & 5.25 & 5.8608 & TRN & \\
\hline CHEMBL1083728 & 688197 & 6.6 & 5.86 & TRN & \\
\hline CHEMBL1085410 & 688197 & 6.0 & 5.9522 & TST & \\
\hline CHEMBL1091794 & 688197 & 5.15 & 6.7868 & TST & \\
\hline CHEMBL1085147 & 688197 & 5.55 & 5.81 & TRN & \\
\hline CHEMBL1089059 & 688197 & 7.7496 & 6.78 & TST & \\
\hline CHEMBL1091795 & 688197 & 7.5003 & 6.7729 & TST & \\
\hline CHEMBL1082456 & 688197 & 6.2 & 5.95700 & 0000000001 & TRN \\
\hline CHEMBL1084029 & 688197 & 6.2 & 5.9111 & TRN & \\
\hline CHEMBL1089364 & 688197 & 8.4559 & 6.8781 & TST & \\
\hline CHEMBL1082455 & 688197 & 6.35 & 5.8165 & TRN & \\
\hline CHEMBL1524808 & 688197 & 5.1 & 5.8616 & TRN & \\
\hline CHEMBL1093996 & 688197 & 4.6 & 6.756 & TST & \\
\hline CHEMBL1086350 & 688197 & 5.35 & 5.8866 & TRN & \\
\hline CHEMBL1086320 & 688197 & 4.9 & 5.8628 & TRN & \\
\hline CHEMBL2180918 & 878515 & 6.1898 & 6.1914 & TRN & \\
\hline CHEMBL 2181163 & 878515 & 6.3152 & 6.5849 & TRN & \\
\hline CHEMBL 2180927 & 878515 & 6.4841 & 6.0327 & TST & \\
\hline CHEMBL 2180940 & 878515 & 6.1349 & 6.1366 & TRN & \\
\hline CHEMBL2181162 & 878515 & 6.6517 & 6.5849 & TRN & \\
\hline CHEMBL2180908 & 878515 & 4.8182 & 5.5762 & TST & \\
\hline
\end{tabular}


Supplemental Table S2.txt

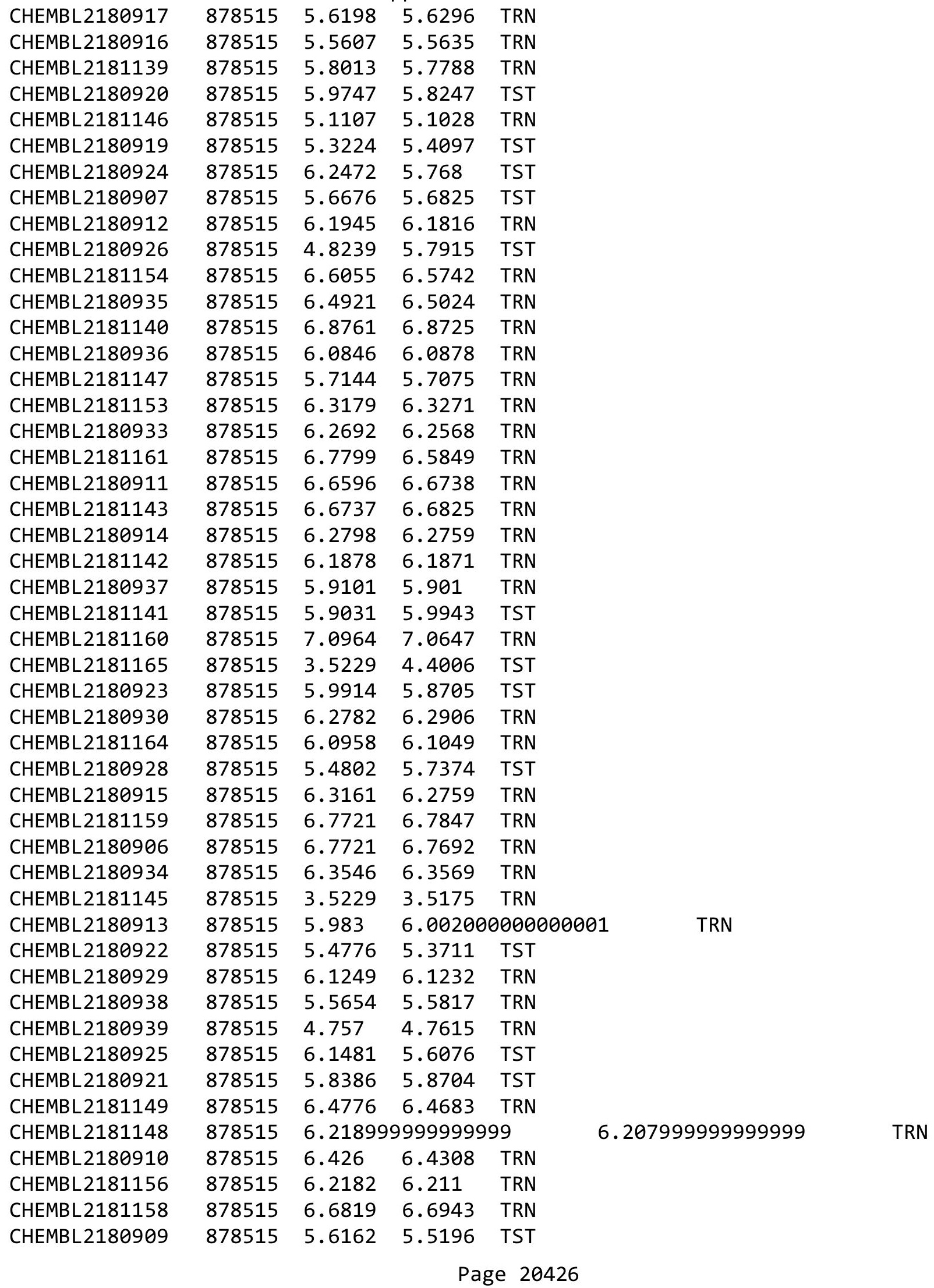


Supplemental Table S2.txt

\begin{tabular}{|c|c|c|c|c|c|c|}
\hline CHEMBL 2181157 & 878515 & 6.0079 & 6.0136 & TRN & & \\
\hline CHEMBL2181155 & 878515 & 6.5768 & 6.6179 & TRN & & \\
\hline CHEMBL 2181144 & 878515 & 5.1831 & 5.1938 & TRN & & \\
\hline CHEMBL3671502 & 1528896 & 6.2636 & 6.4683 & TRN & & \\
\hline CHEMBL3671560 & 1528896 & 6.3215 & 6.4122 & TST & & \\
\hline CHEMBL 3671525 & 1528896 & \multicolumn{3}{|c|}{6.4510000000000005} & 6.4736 & TRN \\
\hline CHEMBL 3676360 & 1528896 & 6.1244 & 6.0836 & TRN & & \\
\hline CHEMBL3671509 & 1528896 & \multicolumn{3}{|c|}{6.4510000000000005} & 6.4023 & TRN \\
\hline CHEMBL 3676387 & 1528896 & 6.8665 & 6.3111 & TST & & \\
\hline CHEMBL3671566 & 1528896 & 6.4461 & 6.4072 & TRN & & \\
\hline CHEMBL3671583 & 1528896 & 5.0 & 6.039 & TRN & & \\
\hline CHEMBL3671482 & 1528896 & 6.8297 & 6.1522 & TST & & \\
\hline CHEMBL 3671585 & 1528896 & 6.1203 & 6.1902 & TRN & & \\
\hline CHEMBL3671497 & 1528896 & 6.6021 & 6.454 & TRN & & \\
\hline CHEMBL3671530 & 1528896 & 6.0205 & 6.355 & TRN & & \\
\hline CHEMBL3671492 & 1528896 & 6.3468 & 6.3718 & TRN & & \\
\hline CHEMBL3676351 & 1528896 & 6.1215 & 6.2628 & TRN & & \\
\hline CHEMBL 3671491 & 1528896 & 7.0177 & 6.3225 & TRN & & \\
\hline CHEMBL3671500 & 1528896 & 6.6021 & 6.4585 & TRN & & \\
\hline CHEMBL 3671544 & 1528896 & 6.4295 & 6.2998 & TRN & & \\
\hline CHEMBL3671514 & 1528896 & 6.8729 & 6.9892 & TRN & & \\
\hline CHEMBL 3671563 & 1528896 & 6.7055 & 6.4826 & TRN & & \\
\hline CHEMBL 3676342 & 1528896 & 6.1029 & 5.7236 & TRN & & \\
\hline CHEMBL3676346 & 1528896 & 6.8539 & 6.7254 & TRN & & \\
\hline CHEMBL 3671515 & 1528896 & \multicolumn{3}{|c|}{6.162999999999999} & 6.3456 & TRN \\
\hline CHEMBL3671510 & 1528896 & 6.0482 & 6.4166 & TRN & & \\
\hline CHEMBL3671534 & 1528896 & 6.1255 & 6.4225 & TRN & & \\
\hline CHEMBL3671532 & 1528896 & 6.1643 & 6.385 & TRN & & \\
\hline CHEMBL3676388 & 1528896 & 7.0458 & 5.7543 & TRN & & \\
\hline CHEMBL 3676383 & 1528896 & 6.3354 & 6.4368 & TRN & & \\
\hline CHEMBL 3676348 & 1528896 & 6.0846 & 5.8106 & TST & & \\
\hline CHEMBL3671549 & 1528896 & 5.8441 & 6.0819 & TRN & & \\
\hline CHEMBL 3671479 & 1528896 & 6.6925 & 6.3296 & TST & & \\
\hline CHEMBL3671570 & 1528896 & 6.067 & 6.4653 & TRN & & \\
\hline CHEMBL3671495 & 1528896 & 6.2815 & 6.4747 & TRN & & \\
\hline CHEMBL3671485 & 1528896 & 7.301 & 6.2608 & TST & & \\
\hline CHEMBL3671519 & 1528896 & 6.1972 & 6.3982 & TRN & & \\
\hline CHEMBL3671565 & 1528896 & 6.1068 & 6.34 & TRN & & \\
\hline CHEMBL3676350 & 1528896 & 6.0691 & 5.66799 & 9999999999 & & TST \\
\hline CHEMBL 3671584 & 1528896 & 6.0685 & 6.0407 & TRN & & \\
\hline CHEMBL3671490 & 1528896 & 6.8125 & 6.4914 & TRN & & \\
\hline CHEMBL3676365 & 1528896 & 7.0555 & 7.0275 & TRN & & \\
\hline CHEMBL3676394 & 1528896 & 5.0 & 6.3744 & TST & & \\
\hline CHEMBL3671520 & 1528896 & 6.6799 & 6.3107 & TRN & & \\
\hline CHEMBL 3671489 & 1528896 & 6.6819 & 6.5172 & TRN & & \\
\hline CHEMBL3676379 & 1528896 & 5.9519 & 6.3136 & TRN & & \\
\hline CHEMBL3671580 & 1528896 & 5.0 & 5.8382 & TRN & & \\
\hline CHEMBL3671480 & 1528896 & 6.301 & 6.3765 & TST & & \\
\hline
\end{tabular}


Supplemental Table S2.txt

\begin{tabular}{|c|c|c|c|c|c|}
\hline CHEMBL3671488 & 1528896 & 6.2284 & 6.3943 & TRN & \\
\hline CHEMBL3676373 & 1528896 & 5.0 & 6.2388 & TST & \\
\hline CHEMBL3676344 & 1528896 & 6.8665 & 6.4773 & TRN & \\
\hline CHEMBL3671581 & 1528896 & 6.9431 & 6.2327 & TRN & \\
\hline CHEMBL3676362 & 1528896 & 6.9747 & 6.9622 & TRN & \\
\hline CHEMBL3671558 & 1528896 & 5.0 & 6.2013 & TST & \\
\hline CHEMBL3676358 & 1528896 & 6.0846 & 6.1757 & TRN & \\
\hline CHEMBL3671559 & 1528896 & 5.0 & 6.2039 & TST & \\
\hline CHEMBL3671499 & 1528896 & 6.6021 & 6.4512 & TRN & \\
\hline CHEMBL3671516 & 1528896 & 6.1051 & 6.3343 & TST & \\
\hline CHEMBL3671550 & 1528896 & 7.1135 & 6.2849 & TST & \\
\hline CHEMBL3671504 & 1528896 & 6.2815 & 6.41200 & 0000000001 & TRN \\
\hline CHEMBL3671501 & 1528896 & 6.301 & 6.3423 & TRN & \\
\hline CHEMBL3671541 & 1528896 & 6.6003 & 6.2942 & TRN & \\
\hline CHEMBL 3676384 & 1528896 & 7.4202 & 6.9881 & TRN & \\
\hline CHEMBL3671539 & 1528896 & 6.6676 & 6.49 & TRN & \\
\hline CHEMBL3671562 & 1528896 & 6.8894 & 6.4978 & TST & \\
\hline CHEMBL 3671573 & 1528896 & 6.0246 & 6.606 & TRN & \\
\hline CHEMBL 3671478 & 1528896 & 6.8665 & 6.3421 & TST & \\
\hline CHEMBL 3671554 & 1528896 & 7.0269 & 6.5161 & TRN & \\
\hline CHEMBL3671557 & 1528896 & 6.1561 & 6.4989 & TRN & \\
\hline CHEMBL 3671494 & 1528896 & 6.2899 & 6.4313 & TRN & \\
\hline CHEMBL3671567 & 1528896 & 6.1818 & 6.2223 & TRN & \\
\hline CHEMBL 3676338 & 1528896 & 6.0246 & 6.1464 & TST & \\
\hline CHEMBL 3676372 & 1528896 & 5.0 & 5.9136 & TRN & \\
\hline CHEMBL3676357 & 1528896 & 6.0205 & 6.234 & TRN & \\
\hline CHEMBL 3671487 & 1528896 & 6.8041 & 6.3809 & TRN & \\
\hline CHEMBL3671505 & 1528896 & 6.5867 & 6.3654 & TRN & \\
\hline CHEMBL3671506 & 1528896 & 6.433 & 6.3161 & TRN & \\
\hline CHEMBL 3676363 & 1528896 & 7.0605 & 6.8213 & TRN & \\
\hline CHEMBL3676367 & 1528896 & 7.1024 & 7.0519 & TRN & \\
\hline CHEMBL 3671542 & 1528896 & 7.0757 & 6.3741 & TRN & \\
\hline CHEMBL3676371 & 1528896 & 6.51 & 6.9452 & TRN & \\
\hline CHEMBL3676368 & 1528896 & 6.6861 & 6.9567 & TRN & \\
\hline CHEMBL3671572 & 1528896 & 6.1068 & 6.4584 & TRN & \\
\hline CHEMBL3671523 & 1528896 & 7.1805 & 6.4744 & TRN & \\
\hline CHEMBL3671574 & 1528896 & 6.1844 & 6.2947 & TST & \\
\hline CHEMBL 3676345 & 1528896 & 6.6615 & 6.7078 & TRN & \\
\hline CHEMBL 3676343 & 1528896 & 6.5719 & 6.2112 & TRN & \\
\hline CHEMBL3676393 & 1528896 & 6.3635 & 6.2795 & TST & \\
\hline CHEMBL3676391 & 1528896 & 6.0066 & 6.4008 & TST & \\
\hline CHEMBL3676374 & 1528896 & 6.6038 & 6.523 & TST & \\
\hline CHEMBL 3671476 & 1528896 & 6.6021 & 6.2976 & TST & \\
\hline CHEMBL3671576 & 1528896 & 6.699 & 6.4272 & TRN & \\
\hline CHEMBL3676354 & 1528896 & 6.7645 & \multicolumn{2}{|c|}{6.428999999999999} & TRN \\
\hline CHEMBL3671568 & 1528896 & 6.0 & 6.2835 & TST & \\
\hline CHEMBL3676339 & 1528896 & 6.3107 & 6.2956 & TRN & \\
\hline CHEMBL 3671508 & 1528896 & 6.3401 & 6.348 & TRN & \\
\hline
\end{tabular}


Supplemental Table S2.txt

\begin{tabular}{|c|c|c|c|c|c|}
\hline CHEMBL 3671577 & 1528896 & 6.3134 & 6.4595 & TRN & \\
\hline CHEMBL 3671546 & 1528896 & 5.0 & 5.9596 & TRN & \\
\hline CHEMBL 3671486 & 1528896 & 6.4597 & 6.3936 & TRN & \\
\hline CHEMBL 3671556 & 1528896 & 7.0088 & 6.3686 & TST & \\
\hline CHEMBL 3676389 & 1528896 & 6.7825 & 6.4386 & TRN & \\
\hline CHEMBL 3671511 & 1528896 & 6.4895 & 6.4697 & TRN & \\
\hline CHEMBL 3671484 & 1528896 & 7.2596 & 6.2494 & TST & \\
\hline CHEMBL 3671527 & 1528896 & 6.3737 & 6.9036 & TRN & \\
\hline CHEMBL 3676369 & 1528896 & 6.8327 & 6.9487 & TRN & \\
\hline CHEMBL 3676385 & 1528896 & 6.8928 & 6.9125 & TRN & \\
\hline CHEMBL 3671547 & 1528896 & 6.4377 & 6.0922 & TRN & \\
\hline CHEMBL 3671555 & 1528896 & 6.1057 & 6.404 & TRN & \\
\hline CHEMBL 3671582 & 1528896 & 6.5719 & 5.9238 & TRN & \\
\hline CHEMBL 3676366 & 1528896 & 6.5901 & 6.8835 & TRN & \\
\hline CHEMBL 3671512 & 1528896 & 6.5784 & 6.4274 & TRN & \\
\hline CHEMBL 3671540 & 1528896 & 6.16299 & 999999999 & 6.1382 & TRN \\
\hline CHEMBL 3676340 & 1528896 & 6.8962 & 6.225 & TRN & \\
\hline CHEMBL 3639703 & 1528896 & 6.4815 & 6.3624 & TRN & \\
\hline CHEMBL 3671538 & 1528896 & 6.9031 & 6.4438 & TRN & \\
\hline CHEMBL 3671569 & 1528896 & 6.0013 & 6.4168 & TST & \\
\hline CHEMBL 3671545 & 1528896 & 6.1818 & 6.3381 & TRN & \\
\hline CHEMBL 3676370 & 1528896 & 6.556 & 6.9615 & TRN & \\
\hline CHEMBL 3671561 & 1528896 & 6.2314 & 6.3966 & TST & \\
\hline CHEMBL 3671518 & 1528896 & 6.4881 & 6.4071 & TRN & \\
\hline CHEMBL 3671528 & 1528896 & 6.1844 & 6.3016 & TRN & \\
\hline CHEMBL 3671531 & 1528896 & 6.7033 & 6.5205 & TRN & \\
\hline CHEMBL 3671529 & 1528896 & 6.6289 & 6.4319 & TRN & \\
\hline CHEMBL 3676347 & 1528896 & 6.0186 & 6.5879 & TRN & \\
\hline CHEMBL 3671533 & 1528896 & 6.45100 & \multirow{2}{*}{\multicolumn{3}{|c|}{$\begin{array}{ccc}00000000005 & 6.4303 & \text { TRN } \\
6.922000000000001 & \text { TRN }\end{array}$}} \\
\hline CHEMBL 3676386 & 1528896 & 6.7235 & & & \\
\hline CHEMBL 3639752 & 1528896 & 6.1068 & 6.2483 & TRN & \\
\hline CHEMBL 3671522 & 1528896 & 6.0685 & \multicolumn{2}{|c|}{6.257999999999999} & TRN \\
\hline CHEMBL 3671537 & 1528896 & 6.0205 & 6.3774 & TRN & \\
\hline CHEMBL 3671498 & 1528896 & 6.2336 & 6.329 & TRN & \\
\hline CHEMBL 3671564 & 1528896 & 6.1561 & 6.3723 & TRN & \\
\hline CHEMBL 3676352 & 1528896 & 5.0 & 5.7253 & TRN & \\
\hline CHEMBL 3671535 & 1528896 & 7.0757 & 6.352 & TRN & \\
\hline CHEMBL 3676356 & 1528896 & 6.0675 & 6.1038 & TST & \\
\hline CHEMBL 3676359 & 1528896 & 6.1824 & 6.106 & TRN & \\
\hline CHEMBL 3676341 & 1528896 & 6.8153 & 6.095 & TRN & \\
\hline CHEMBL 3671521 & 1528896 & 6.1561 & 6.3871 & TRN & \\
\hline CHEMBL 3671493 & 1528896 & 6.2636 & 6.3674 & TRN & \\
\hline CHEMBL 3671483 & 1528896 & 7.3468 & 6.2979 & TST & \\
\hline CHEMBL 3671548 & 1528896 & 5.0 & 6.0802 & TST & \\
\hline CHEMBL 3676380 & 1528896 & 6.0985 & 6.3737 & TRN & \\
\hline CHEMBL 3671536 & 1528896 & 6.6364 & 6.4266 & TRN & \\
\hline CHEMBL 3676378 & 1528896 & 6.00700 & 000000000 & 6.3876 & TST \\
\hline CHEMBL 3671475 & 1528896 & 6.8827 & 6.2591 & TST & \\
\hline
\end{tabular}


Supplemental Table S2.txt

\begin{tabular}{|c|c|c|c|c|c|}
\hline CHEMBL3676364 & 1528896 & 7.2676 & 7.0557 & TRN & \\
\hline CHEMBL 3671543 & 1528896 & 6.1752 & 6.3018 & TRN & \\
\hline CHEMBL3671517 & 1528896 & 6.7932 & 6.3884 & TRN & \\
\hline CHEMBL 3671507 & 1528896 & 6.3391 & 6.3841 & TRN & \\
\hline CHEMBL3671524 & 1528896 & 6.0205 & 6.4434 & TRN & \\
\hline CHEMBL3676353 & 1528896 & 6.3778 & 6.2928 & TRN & \\
\hline CHEMBL 3676390 & 1528896 & $6.32700 e$ & $20000000 t$ & & 6.3389999999999995 \\
\hline CHEMBL3671575 & 1528896 & 6.0691 & 6.3532 & TST & \\
\hline CHEMBL 3676392 & 1528896 & 6.5544 & 6.4421 & TST & \\
\hline CHEMBL3671571 & 1528896 & 6.1844 & 6.3644 & TRN & \\
\hline CHEMBL 3671578 & 1528896 & 6.3206 & 6.3887 & TST & \\
\hline CHEMBL3671513 & 1528896 & 6.8097 & 6.4869 & TRN & \\
\hline CHEMBL3676349 & 1528896 & 6.4473 & 6.0276 & TRN & \\
\hline CHEMBL3671503 & 1528896 & 6.2899 & 6.3839 & TRN & \\
\hline CHEMBL 3671477 & 1528896 & 6.9666 & 6.3124 & TST & \\
\hline CHEMBL3676381 & 1528896 & 7.1024 & 6.8837 & TRN & \\
\hline CHEMBL3671496 & 1528896 & 6.6021 & 6.4744 & TRN & \\
\hline CHEMBL 3671481 & 1528896 & 6.6021 & 6.2161 & TST & \\
\hline CHEMBL3676382 & 1528896 & 5.0 & 5.7747 & TRN & \\
\hline CHEMBL3671579 & 1528896 & 6.0218 & 6.3537 & TST & \\
\hline CHEMBL 3676361 & 1528896 & 7.2518 & 6.8315 & TST & \\
\hline CHEMBL3676355 & 1528896 & 6.1057 & 6.2959 & TST & \\
\hline CHEMBL3671526 & 1528896 & 6.058 & 6.3919 & TST & \\
\hline CHEMBL437331 & 420098 & 7.3768 & 7.1563 & TRN & \\
\hline CHEMBL215012 & 420098 & 6.6021 & 6.9234 & TRN & \\
\hline CHEMBL387184 & 420098 & 6.4789 & 6.7834 & TRN & \\
\hline CHEMBL217416 & 420098 & 6.4559 & 6.4611 & TRN & \\
\hline CHEMBL214613 & 420098 & 7.3768 & 7.2405 & TRN & \\
\hline CHEMBL 214683 & 420098 & 7.3665 & 7.3347 & TRN & \\
\hline CHEMBL214734 & 420098 & 5.8386 & 6.0496 & TRN & \\
\hline CHEMBL216833 & 420098 & 7.3279 & 7.3876 & TRN & \\
\hline CHEMBL263039 & 420098 & 7.6576 & 7.6213 & TRN & \\
\hline CHEMBL217414 & 420098 & 7.0555 & 6.9865 & TRN & \\
\hline CHEMBL 217130 & 420098 & 7.0 & 7.0903 & TRN & \\
\hline CHEMBL385059 & 420098 & 6.1586 & 6.1506 & TRN & \\
\hline CHEMBL216201 & 420098 & 6.2487 & 6.2044 & TRN & \\
\hline CHEMBL425980 & 420098 & 7.5229 & 7.4034 & TRN & \\
\hline CHEMBL385203 & 420098 & 6.699 & 6.7686 & TRN & \\
\hline CHEMBL214425 & 420098 & 6.585 & 6.7317 & TRN & \\
\hline CHEMBL383858 & 420098 & 6.9469 & 7.0437 & TRN & \\
\hline CHEMBL269696 & 420098 & 7.0 & 7.027 & TRN & \\
\hline CHEMBL253116 & 420098 & 7.3468 & 6.574 & TST & \\
\hline CHEMBL213992 & 420098 & 4.0 & 6.0855 & TST & \\
\hline CHEMBL217415 & 420098 & 6.4815 & 6.7242 & TRN & \\
\hline CHEMBL216449 & 420098 & 7.1871 & 7.2252 & TST & \\
\hline CHEMBL217126 & 420098 & 7.1549 & 7.1718 & TRN & \\
\hline CHEMBL217117 & 420098 & 6.556 & 6.5779 & TRN & \\
\hline CHEMBL385703 & 420098 & 5.8239 & 5.8049 & TRN & \\
\hline
\end{tabular}

Page 20430 


\begin{tabular}{|c|c|c|c|c|c|}
\hline CHEMBL214614 & 420098 & 7.0 & 7.03100 & 0000000001 & TRN \\
\hline CHEMBL215011 & 420098 & 6.8928 & 7.2289 & TRN & \\
\hline CHEMBL217833 & 420098 & 7.0223 & 6.9437 & TRN & \\
\hline CHEMBL386230 & 420098 & 6.1871 & 6.1425 & TRN & \\
\hline CHEMBL424897 & 420098 & 6.6021 & 6.5211 & TRN & \\
\hline CHEMBL214636 & 420098 & 6.5467 & 6.78299 & 99999999995 & TRN \\
\hline CHEMBL385905 & 420098 & 7.1249 & 7.0622 & TRN & \\
\hline CHEMBL 375609 & 420098 & 6.426 & 6.3517 & TST & \\
\hline CHEMBL216500 & 420098 & 5.2083 & 6.3729 & TST & \\
\hline CHEMBL385446 & 420098 & 6.6576 & 6.6675 & TRN & \\
\hline CHEMBL215193 & 420098 & 6.8861 & 6.5058 & TRN & \\
\hline CHEMBL413636 & 420098 & 6.8861 & 6.901 & TRN & \\
\hline CHEMBL 384012 & 420098 & 7.2676 & 7.3061 & TRN & \\
\hline CHEMBL217832 & 420098 & 6.9101 & 7.0134 & TRN & \\
\hline CHEMBL211359 & 420098 & 5.8297 & 6.0757 & TST & \\
\hline CHEMBL 216832 & 420098 & 7.3098 & 7.3839 & TRN & \\
\hline CHEMBL214032 & 420098 & 7.0 & 6.8024 & TRN & \\
\hline CHEMBL 384784 & 420098 & 7.4318 & 7.1224 & TRN & \\
\hline CHEMBL214977 & 420098 & 6.9281 & 6.8358 & TRN & \\
\hline CHEMBL 214587 & 420098 & 7.4559 & 7.1422 & TRN & \\
\hline CHEMBL 217355 & 420098 & 6.4559 & 6.3614 & TRN & \\
\hline CHEMBL215038 & 420098 & 7.1079 & 6.846 & TRN & \\
\hline CHEMBL 214901 & 420098 & 7.3279 & 7.4716 & TRN & \\
\hline CHEMBL214752 & 420098 & 6.8239 & 7.0827 & TST & \\
\hline CHEMBL386469 & 420098 & 6.3526 & 7.1716 & TST & \\
\hline CHEMBL265478 & 420098 & 6.8539 & 7.1855 & TST & \\
\hline CHEMBL386457 & 420098 & 6.2182 & 6.473 & TST & \\
\hline CHEMBL214816 & 420098 & 6.8539 & 6.5958 & TST & \\
\hline CHEMBL209868 & 420098 & 5.0798 & 6.4824 & TST & \\
\hline CHEMBL216325 & 420098 & 6.9208 & 6.7596 & TST & \\
\hline CHEMBL 217310 & 420098 & 6.8861 & 6.4291 & TST & \\
\hline CHEMBL3392440 & 954774 & 5.0066 & 4.4089 & TRN & \\
\hline CHEMBL1516890 & 954774 & 4.3552 & 4.4976 & TRN & \\
\hline CHEMBL373751 & 954774 & 3.5046 & 3.9632 & TRN & \\
\hline CHEMBL240954 & 954774 & 4.011 & 4.6416 & TST & \\
\hline CHEMBL558642 & 954774 & 4.711 & 4.6216 & TRN & \\
\hline CHEMBL573107 & 954774 & 6.3199 & 5.8721 & TRN & \\
\hline CHEMBL 379300 & 954774 & 6.4905 & 6.4328 & TRN & \\
\hline CHEMBL483849 & 954774 & 3.5753 & 3.1851 & TRN & \\
\hline CHEMBL210618 & 954774 & 3.4054 & 3.875 & TRN & \\
\hline CHEMBL 202721 & 954774 & 5.6843 & 5.7035 & TRN & \\
\hline CHEMBL1242367 & 954774 & 3.5315 & 4.2872 & TRN & \\
\hline CHEMBL209148 & 954774 & 5.2007 & 4.7798 & TRN & \\
\hline CHEMBL392695 & 954774 & 6.1036 & 5.5196 & TRN & \\
\hline CHEMBL258844 & 954774 & 4.8648 & 4.8402 & TRN & \\
\hline CHEMBL9470 & 954774 & 4.4848 & 6.5999 & TST & \\
\hline CHEMBL 259181 & 954774 & 4.6184 & 5.0451 & TRN & \\
\hline CHEMBL1357247 & 954774 & 3.9102 & 3.5696 & TRN & \\
\hline
\end{tabular}

Page 20431 


\begin{tabular}{|c|c|c|c|c|c|}
\hline & & \multicolumn{4}{|c|}{ Supplemental Table s2.txt } \\
\hline CHEMBL509032 & 954774 & 6.2547 & 5.6732 & TRN & \\
\hline CHEMBL512504 & 954774 & 7.1365 & 6.9944 & TRN & \\
\hline CHEMBL514499 & 954774 & 7.5173 & 7.1227 & TRN & \\
\hline CHEMBL191334 & 954774 & 5.3894 & 5.1022 & TRN & \\
\hline CHEMBL192566 & 954774 & 8.2843 & 8.6284 & TST & \\
\hline CHEMBL585951 & 954774 & 6.3923 & 6.858 & TRN & \\
\hline CHEMBL1190711 & 954774 & 5.825 & 5.8879 & TRN & \\
\hline CHEMBL1256459 & 954774 & 7.1839 & \multicolumn{2}{|c|}{7.167000000000001} & TRN \\
\hline CHEMBL1788116 & 954774 & 5.5453 & 4.9063 & TRN & \\
\hline CHEMBL189584 & 954774 & 4.6652 & 5.1128 & TRN & \\
\hline CHEMBL449158 & 954774 & 5.9802 & 7.2967 & TST & \\
\hline CHEMBL3349342 & 954774 & 5.3044 & 5.1186 & TRN & \\
\hline CHEMBL1643959 & 954774 & 4.1485 & 3.8224 & TRN & \\
\hline CHEMBL393929 & 954774 & 4.1451 & 4.4552 & TRN & \\
\hline CHEMBL135561 & 954774 & 3.8229 & 4.6173 & TRN & \\
\hline CHEMBL65 & 954774 & 9.0432 & 9.4056 & TRN & \\
\hline CHEMBL180127 & 954774 & 4.6663 & 4.6436 & TRN & \\
\hline CHEMBL379975 & 954774 & 4.9343 & 5.9294 & TRN & \\
\hline CHEMBL472940 & 954774 & 5.0286 & 4.9282 & TRN & \\
\hline CHEMBL483847 & 954774 & 3.4936 & 4.2351 & TRN & \\
\hline CHEMBL92309 & 954774 & 3.3301 & 3.4521 & TST & \\
\hline CHEMBL102714 & 954774 & 3.7215 & 4.2354 & TRN & \\
\hline CHEMBL221137 & 954774 & 5.0282 & 5.3329 & TST & \\
\hline CHEMBL412142 & 954774 & 5.0251 & 4.5195 & TRN & \\
\hline CHEMBL515416 & 954774 & 5.1383 & 4.8927 & TRN & \\
\hline CHEMBL3186408 & 954774 & 4.1299 & 4.4082 & TST & \\
\hline CHEMBL3199475 & 954774 & 5.7073 & 5.4091 & TRN & \\
\hline CHEMBL2363137 & 954774 & 5.2959 & 5.034 & TRN & \\
\hline CHEMBL1404918 & 954774 & 3.3862 & 3.389 & TRN & \\
\hline CHEMBL1590308 & 954774 & 4.2918 & 3.967 & TST & \\
\hline CHEMBL 2005886 & 954774 & 5.5405 & 5.4025 & TRN & \\
\hline CHEMBL1230020 & 954774 & 4.1977 & 4.4181 & TRN & \\
\hline CHEMBL 300389 & 954774 & 7.1805 & 7.0893 & TRN & \\
\hline CHEMBL1673039 & 954774 & 4.7883 & 5.1263 & TST & \\
\hline CHEMBL213100 & 954774 & 10.4973 & 4.4941 & TST & \\
\hline CHEMBL 220241 & 954774 & 4.6213 & 5.0782 & TST & \\
\hline CHEMBL2144069 & 954774 & 5.9206 & 4.9295 & TST & \\
\hline CHEMBL1970879 & 954774 & 10.3096 & 4.4628 & TST & \\
\hline CHEMBL1909414 & 954774 & 5.2876 & 4.7614 & TST & \\
\hline CHEMBL412142 & 954501 & 5.3671 & 5.4296 & TRN & \\
\hline CHEMBL558642 & 954501 & 3.0319 & 2.9715 & TRN & \\
\hline CHEMBL1970879 & 954501 & 4.8832 & 4.9439 & TRN & \\
\hline CHEMBL3199475 & 954501 & 3.9928 & 3.9486 & TRN & \\
\hline CHEMBL217354 & 954501 & 4.8589 & 4.7637 & TRN & \\
\hline CHEMBL192566 & 954501 & 5.7322 & 6.1628 & TST & \\
\hline CHEMBL1909414 & 954501 & 3.2666 & 3.15100 & 00000000002 & TRN \\
\hline CHEMBL1190711 & 954501 & 4.602 & 4.5005 & TRN & \\
\hline CHEMBL585951 & 954501 & 6.0513 & 5.9383 & TRN & \\
\hline
\end{tabular}


Supplemental Table S2.txt

\begin{tabular}{|c|c|c|c|c|c|c|}
\hline CHEMBL509032 & 954501 & 5.1409 & 5.2109 & TRN & & \\
\hline CHEMBL221137 & 954501 & 3.9611 & 4.1242 & TST & & \\
\hline CHEMBL3392440 & 954501 & 4.1599 & 4.0696 & TRN & & \\
\hline CHEMBL1590308 & 954501 & 3.3372 & 4.2341 & TST & & \\
\hline CHEMBL2363137 & 954501 & 4.0991 & 4.1081 & TRN & & \\
\hline CHEMBL202721 & 954501 & 3.6955 & 3.6746 & TRN & & \\
\hline CHEMBL514499 & 954501 & 5.2075 & 5.19799 & 999999999 & TRN & \\
\hline CHEMBL102714 & 954501 & 4.0452 & 4.1053 & TRN & & \\
\hline CHEMBL 3186408 & 954501 & 4.1069 & 4.1436 & TST & & \\
\hline CHEMBL255342 & 954501 & \multicolumn{3}{|c|}{3.6260000000000003} & 3.7481 TRN & \\
\hline CHEMBL373751 & 954501 & 3.3112 & 3.4664 & TRN & & \\
\hline CHEMBL240954 & 954501 & 3.3997 & 3.9054 & TST & & \\
\hline CHEMBL483849 & 954501 & 1.2193 & 2.6276 & TST & & \\
\hline CHEMBL1230020 & 954501 & 3.6413 & 3.7642 & TRN & & \\
\hline CHEMBL577784 & 954501 & 4.6425 & 4.623 & TRN & & \\
\hline CHEMBL180127 & 954501 & 4.6456 & 4.5967 & TRN & & \\
\hline CHEMBL1242367 & 954501 & 3.938 & 3.9022 & TRN & & \\
\hline CHEMBL65 & 954501 & 6.9445 & 7.0878 & TRN & & \\
\hline CHEMBL512504 & 954501 & 4.5024 & 4.5158 & TRN & & \\
\hline CHEMBL9470 & 954501 & 5.8058 & 5.4255 & TST & & \\
\hline CHEMBL213100 & 954501 & 6.3703 & 6.3944 & TRN & & \\
\hline CHEMBL 2134202 & 954501 & 3.7592 & 3.8273 & TRN & & \\
\hline CHEMBL393929 & 954501 & 4.7457 & 4.5174 & TRN & & \\
\hline CHEMBL135561 & 954501 & \multicolumn{3}{|c|}{5.502999999999999} & 5.132999999999999 & TRN \\
\hline CHEMBL1788116 & 954501 & 5.087 & 5.0263 & TRN & & \\
\hline CHEMBL379300 & 954501 & 4.7934 & 4.562 & TRN & & \\
\hline CHEMBL189584 & 954501 & 3.8544 & 3.7969 & TRN & & \\
\hline CHEMBL1186585 & 954501 & 4.0237 & 3.9581 & TRN & & \\
\hline CHEMBL379975 & 954501 & 5.2393 & 5.2454 & TRN & & \\
\hline CHEMBL449158 & 954501 & 7.2276 & 6.2385 & TST & & \\
\hline CHEMBL3349342 & 954501 & 4.5135 & 4.6557 & TRN & & \\
\hline CHEMBL259181 & 954501 & 3.1109 & 2.9978 & TRN & & \\
\hline CHEMBL300389 & 954501 & 6.9537 & 6.9906 & TRN & & \\
\hline CHEMBL210618 & 954501 & 3.2305 & 3.3131 & TRN & & \\
\hline CHEMBL 2144069 & 954501 & 3.7943 & 3.9887 & TRN & & \\
\hline CHEMBL399530 & 954501 & 3.7802 & 3.9769 & TRN & & \\
\hline CHEMBL222102 & 954501 & 3.5588 & 3.62 & TRN & & \\
\hline CHEMBL92309 & 954501 & 2.9813 & 3.3846 & TST & & \\
\hline CHEMBL483847 & 954501 & 4.7325 & 4.6569 & TRN & & \\
\hline CHEMBL1673039 & 954501 & 4.5606 & 4.632 & TRN & & \\
\hline CHEMBL220241 & 954501 & 4.7235 & 4.6846 & TRN & & \\
\hline CHEMBL1256459 & 954501 & 4.8754 & 4.9172 & TRN & & \\
\hline CHEMBL1404918 & 954501 & 3.2619 & 3.1875 & TRN & & \\
\hline CHEMBL392695 & 954501 & 4.4591 & 4.5735 & TRN & & \\
\hline CHEMBL209148 & 954501 & 4.2125 & 4.1788 & TRN & & \\
\hline CHEMBL1516890 & 954501 & 3.688 & 3.847 & TRN & & \\
\hline CHEMBL1357247 & 954501 & 3.9317 & 4.0053 & TRN & & \\
\hline CHEMBL515416 & 954501 & 4.9007 & 4.9132 & TRN & & \\
\hline
\end{tabular}

Page 20433 


\begin{tabular}{|c|c|c|c|c|c|c|}
\hline & & \multicolumn{5}{|c|}{ Supplemental Table S2.txt } \\
\hline CHEMBL2005886 & 954501 & 5.4474 & 5.2488 & TST & & \\
\hline CHEMBL191334 & 954501 & 5.0522 & 4.4183 & TST & & \\
\hline CHEMBL188678 & 954501 & 4.6846 & 4.0384 & TST & & \\
\hline CHEMBL1643959 & 954501 & 3.7847 & 3.679 & TST & & \\
\hline CHEMBL573107 & 954501 & 4.4692 & 4.4371 & TST & & \\
\hline CHEMBL472940 & 954501 & \multicolumn{3}{|c|}{3.9360000000000004} & 3.4944 & TST \\
\hline CHEMBL 258844 & 954501 & 4.4128 & 4.1701 & TST & & \\
\hline CHEMBL2137530 & 954501 & 3.8846 & 4.5813 & TST & & \\
\hline CHEMBL 3672622 & 1534711 & 6.0348 & 6.61700 & 0000000001 & & TRN \\
\hline CHEMBL 3677533 & 1534711 & 5.0 & 5.4898 & TRN & & \\
\hline CHEMBL3672649 & 1534711 & 6.0 & 6.5143 & TRN & & \\
\hline CHEMBL 3682489 & 1534711 & 7.0857 & 7.18 & TRN & & \\
\hline CHEMBL3682446 & 1534711 & 6.8649 & 6.8653 & TRN & & \\
\hline CHEMBL 3682487 & 1534711 & 6.1041 & 5.6532 & TRN & & \\
\hline CHEMBL3672636 & 1534711 & 6.284 & 6.6183 & TRN & & \\
\hline CHEMBL3677599 & 1534711 & 5.9983 & 5.9093 & TRN & & \\
\hline CHEMBL3677624 & 1534711 & 6.0626 & 6.7195 & TRN & & \\
\hline CHEMBL3672656 & 1534711 & 6.9872 & 6.6282 & TRN & & \\
\hline CHEMBL 3677513 & 1534711 & 6.9281 & 7.2842 & TRN & & \\
\hline CHEMBL3677511 & 1534711 & 7.4949 & 7.5595 & TRN & & \\
\hline CHEMBL3682475 & 1534711 & 5.9097 & 5.8933 & TRN & & \\
\hline CHEMBL3677468 & 1534711 & 6.0809 & 6.1363 & TRN & & \\
\hline CHEMBL3677637 & 1534711 & 6.8162 & 6.5025 & TRN & & \\
\hline CHEMBL3677499 & 1534711 & 9.0 & 8.0432 & TRN & & \\
\hline CHEMBL3677452 & 1534711 & 7.6383 & 6.8234 & TRN & & \\
\hline CHEMBL3672659 & 1534711 & 6.2132 & 6.6432 & TST & & \\
\hline CHEMBL 3677463 & 1534711 & 7.9586 & 8.6346 & TRN & & \\
\hline CHEMBL3682452 & 1534711 & 7.0013 & 7.0886 & TRN & & \\
\hline CHEMBL 3672634 & 1534711 & 6.8297 & 6.8558 & TRN & & \\
\hline CHEMBL3677621 & 1534711 & 6.8526 & 6.7063 & TRN & & \\
\hline CHEMBL 3677457 & 1534711 & 6.0 & 5.9852 & TRN & & \\
\hline CHEMBL 3677588 & 1534711 & 5.8713 & 6.0121 & TRN & & \\
\hline CHEMBL3677609 & 1534711 & 6.9598 & 6.8857 & TRN & & \\
\hline CHEMBL3682467 & 1534711 & 7.7328 & 6.585 & TRN & & \\
\hline CHEMBL3677605 & 1534711 & 7.0711 & 7.1398 & TRN & & \\
\hline CHEMBL3672631 & 1534711 & 7.7696 & 7.3932 & TRN & & \\
\hline CHEMBL3639763 & 1534711 & 4.6861 & 5.6483 & TRN & & \\
\hline CHEMBL 3677600 & 1534711 & 6.2135 & 6.2469 & TRN & & \\
\hline CHEMBL3682459 & 1534711 & 6.6716 & 7.0244 & TRN & & \\
\hline CHEMBL3677603 & 1534711 & 6.6605 & 8.2527 & TST & & \\
\hline CHEMBL 3677640 & 1534711 & 5.0 & 4.7361 & TST & & \\
\hline CHEMBL 3677486 & 1534711 & 7.1135 & 7.1574 & TRN & & \\
\hline CHEMBL3639764 & 1534711 & 6.9473 & 7.027 & TRN & & \\
\hline CHEMBL3677528 & 1534711 & 6.6234 & 6.0812 & TRN & & \\
\hline CHEMBL3677509 & 1534711 & 7.2218 & 7.4736 & TRN & & \\
\hline CHEMBL3677636 & 1534711 & 7.6162 & 7.11700 & 0000000001 & & TRN \\
\hline CHEMBL 3677483 & 1534711 & 5.6799 & 5.8832 & TRN & & \\
\hline CHEMBL3677611 & 1534711 & 6.8983 & 7.4449 & TRN & & \\
\hline
\end{tabular}


Supplemental Table S2.txt

\begin{tabular}{|c|c|c|c|c|c|}
\hline CHEMBL 3682496 & 1534711 & 6.0822 & 6.3904 & TST & \\
\hline CHEMBL 3677537 & 1534711 & 8.5528 & 8.4904 & TRN & \\
\hline CHEMBL3677433 & 1534711 & 8.585 & 8.227 & TRN & \\
\hline CHEMBL3677573 & 1534711 & 6.8847 & \multicolumn{2}{|c|}{7.382000000000001} & TRN \\
\hline CHEMBL3677466 & 1534711 & 6.2 & 5.7868 & TST & \\
\hline CHEMBL3677462 & 1534711 & 8.0 & 8.4385 & TRN & \\
\hline CHEMBL3682503 & 1534711 & 5.7972 & 6.0409 & TST & \\
\hline CHEMBL3677529 & 1534711 & 7.0223 & 6.6609 & TRN & \\
\hline CHEMBL3677615 & 1534711 & 7.6635 & 7.2037 & TRN & \\
\hline CHEMBL3677478 & 1534711 & 7.7447 & 8.4463 & TST & \\
\hline CHEMBL3677591 & 1534711 & 5.0 & 5.9576 & TRN & \\
\hline CHEMBL 3677646 & 1534711 & \multicolumn{2}{|c|}{6.757000000000001} & 7.1149 & TRN \\
\hline CHEMBL 3677626 & 1534711 & 7.0701 & 6.8671 & TRN & \\
\hline CHEMBL3677510 & 1534711 & 7.041 & 7.5872 & TRN & \\
\hline CHEMBL3682500 & 1534711 & 5.2004 & 6.6634 & TST & \\
\hline CHEMBL3677484 & 1534711 & 5.0561 & 5.5642 & TRN & \\
\hline CHEMBL3682485 & 1534711 & 7.3401 & 7.2571 & TRN & \\
\hline CHEMBL3677474 & 1534711 & 7.8861 & 7.8039 & TRN & \\
\hline CHEMBL3677612 & 1534711 & 7.2557 & 7.5366 & TRN & \\
\hline CHEMBL 3677430 & 1534711 & 6.4559 & 6.8743 & TST & \\
\hline CHEMBL3677525 & 1534711 & 7.8861 & 6.8527 & TRN & \\
\hline CHEMBL3672657 & 1534711 & 7.3872 & 7.6748 & TST & \\
\hline CHEMBL3682450 & 1534711 & 7.6459 & 7.0525 & TRN & \\
\hline CHEMBL3677606 & 1534711 & 6.4496 & 5.2614 & TST & \\
\hline CHEMBL 3677527 & 1534711 & 6.3516 & 6.7012 & TRN & \\
\hline CHEMBL3677610 & 1534711 & 8.585 & 8.3991 & TRN & \\
\hline CHEMBL3682492 & 1534711 & 7.7328 & 7.6956 & TRN & \\
\hline CHEMBL3677595 & 1534711 & 6.5391 & 6.1006 & TRN & \\
\hline CHEMBL3672662 & 1534711 & 7.1675 & 7.4933 & TRN & \\
\hline CHEMBL3677618 & 1534711 & 6.9508 & 6.2055 & TRN & \\
\hline CHEMBL3677568 & 1534711 & 7.1158 & 7.2106 & TRN & \\
\hline CHEMBL3677616 & 1534711 & 6.9412 & 7.2309 & TRN & \\
\hline CHEMBL3677467 & 1534711 & 6.3979 & 6.2427 & TST & \\
\hline CHEMBL3672624 & 1534711 & 6.5045 & 6.5809 & TST & \\
\hline CHEMBL3677602 & 1534711 & 8.2924 & 8.9445 & TRN & \\
\hline CHEMBL 3682442 & 1534711 & 6.0 & 5.8453 & TRN & \\
\hline CHEMBL3677576 & 1534711 & 7.7545 & 8.0065 & TRN & \\
\hline CHEMBL3672666 & 1534711 & 7.6778 & 8.2034 & TST & \\
\hline CHEMBL3677631 & 1534711 & 6.8259 & 6.6182 & TRN & \\
\hline CHEMBL3677492 & 1534711 & 7.8861 & 8.2258 & TRN & \\
\hline CHEMBL3672623 & 1534711 & 7.6576 & 7.6411 & TRN & \\
\hline CHEMBL3677617 & 1534711 & 7.4535 & 7.4701 & TRN & \\
\hline CHEMBL3682484 & 1534711 & 6.9059 & 7.2455 & TRN & \\
\hline CHEMBL3677488 & 1534711 & 7.4815 & 8.4207 & TRN & \\
\hline CHEMBL3677530 & 1534711 & 6.9788 & 6.4195 & TRN & \\
\hline CHEMBL 3677642 & 1534711 & 6.4075 & 6.7413 & TST & \\
\hline CHEMBL3682465 & 1534711 & 7.8268 & 7.67899 & 9999999999 & TRN \\
\hline CHEMBL3677432 & 1534711 & 6.3063 & 6.6404 & TRN & \\
\hline
\end{tabular}


Supplemental Table S2.txt

\begin{tabular}{|c|c|c|c|c|c|c|}
\hline CHEMBL 3677446 & 1534711 & 5.2767 & 5.968 & TRN & & \\
\hline CHEMBL 3682462 & 1534711 & 7.4306 & 7.9188 & TRN & & \\
\hline CHEMBL 3677571 & 1534711 & 8.6198 & 8.9995 & TRN & & \\
\hline CHEMBL 3672627 & 1534711 & 9.0 & 8.7548 & TRN & & \\
\hline CHEMBL 3677502 & 1534711 & 7.6576 & 6.7238 & TRN & & \\
\hline CHEMBL 3677429 & 1534711 & 6.6402 & 6.2485 & TST & & \\
\hline CHEMBL 3682448 & 1534711 & 7.21899 & 999999999 & & 6.8864 & TRN \\
\hline CHEMBL 3677453 & 1534711 & 6.71899 & 999999999 & & 6.6992 & TRN \\
\hline CHEMBL 3682444 & 1534711 & 7.3307 & 7.2502 & TRN & & \\
\hline CHEMBL 3677562 & 1534711 & 9.0969 & 7.8348 & TST & & \\
\hline CHEMBL 3682463 & 1534711 & 6.4594 & 6.4747 & TRN & & \\
\hline CHEMBL 3677471 & 1534711 & 6.0301 & 6.6582 & TST & & \\
\hline CHEMBL 3672650 & 1534711 & 7.2147 & 7.244 & TRN & & \\
\hline CHEMBL 3677546 & 1534711 & 6.8099 & 7.2054 & TRN & & \\
\hline CHEMBL 3677596 & 1534711 & 6.3917 & 6.1772 & TRN & & \\
\hline CHEMBL 3941137 & 1534711 & 7.8447 & 8.2725 & TST & & \\
\hline CHEMBL 3677594 & 1534711 & 6.0234 & 6.3213 & TRN & & \\
\hline CHEMBL 3677572 & 1534711 & 7.9208 & 8.0557 & TRN & & \\
\hline CHEMBL 3677497 & 1534711 & 7.4089 & 7.3555 & TRN & & \\
\hline CHEMBL 3677569 & 1534711 & 6.2168 & 7.015 & TRN & & \\
\hline CHEMBL 3682480 & 1534711 & 5.65600 & 000000000 & & 5.5497 & TRN \\
\hline CHEMBL 3677548 & 1534711 & 8.28399 & 999999999 & & 8.2447 & TRN \\
\hline CHEMBL 3672641 & 1534711 & 9.0 & 8.7323 & TRN & & \\
\hline CHEMBL 3677470 & 1534711 & 7.2924 & 7.2269 & TRN & & \\
\hline CHEMBL 3677479 & 1534711 & 7.2518 & 7.2575 & TRN & & \\
\hline CHEMBL 3672630 & 1534711 & 7.7212 & 6.7603 & TRN & & \\
\hline CHEMBL 3677456 & 1534711 & 5.0792 & 6.9237 & TRN & & \\
\hline CHEMBL 3677447 & 1534711 & 9.0 & 8.7307 & TRN & & \\
\hline CHEMBL 3672629 & 1534711 & 9.0 & 8.7313 & TRN & & \\
\hline CHEMBL 3677549 & 1534711 & 6.8483 & 7.5727 & TRN & & \\
\hline CHEMBL 3677630 & 1534711 & 9.0 & 8.5624 & TRN & & \\
\hline CHEMBL 3677559 & 1534711 & 6.6156 & 6.8501 & TRN & & \\
\hline CHEMBL 3672654 & 1534711 & 8.7212 & 8.368 & TRN & & \\
\hline CHEMBL 3682476 & 1534711 & 7.5186 & 6.7935 & TRN & & \\
\hline CHEMBL 3682502 & 1534711 & 5.2406 & 5.4645 & TRN & & \\
\hline CHEMBL 3672653 & 1534711 & 8.585 & 8.1123 & TRN & & \\
\hline CHEMBL 3682437 & 1534711 & 7.0878 & 6.6571 & TRN & & \\
\hline CHEMBL 3677523 & 1534711 & 5.0 & 7.2531 & TST & & \\
\hline CHEMBL 3677440 & 1534711 & 6.9101 & 6.7228 & TRN & & \\
\hline CHEMBL 3672664 & 1534711 & 9.0 & 8.6116 & TRN & & \\
\hline CHEMBL 3639762 & 1534711 & 6.75200 & 000000000 & 1 & 7.5755 & $1 \mathrm{KI}$ \\
\hline CHEMBL 3677454 & 1534711 & 6.7447 & 6.8897 & TRN & & \\
\hline CHEMBL 3677580 & 1534711 & 8.8539 & 7.8744 & TST & & \\
\hline CHEMBL 3672667 & 1534711 & 5.6457 & 6.3134 & TST & & \\
\hline CHEMBL 3672652 & 1534711 & 9.0 & 8.5208 & TST & & \\
\hline CHEMBL 3682458 & 1534711 & 6.0 & 6.5051 & TRN & & \\
\hline CHEMBL 3677505 & 1534711 & 5.5928 & 6.8195 & TST & & \\
\hline CHEMBL3677449 & 1534711 & 9.0 & 8.4413 & TRN & & \\
\hline
\end{tabular}


Supplemental Table S2.txt

\begin{tabular}{|c|c|c|c|c|}
\hline th & 534711 & 6.7962 & & \\
\hline & & 6.9614 & 7.0615 & \\
\hline & & 997 & & \\
\hline AEMBL & 711 & 857 & & \\
\hline AEMBL3672635 & 34711 & 1202 & & \\
\hline HEMBL3677518 & 534711 & 6.8386 & 6951 & \\
\hline HEMBL & & 1089 & & \\
\hline IEMBL 367 & & & & \\
\hline HEMBL3677581 & 711 & 9269 & & \\
\hline HEMBL3677442 & 711 & 6003 & 1744 & \\
\hline HEMBL3672639 & 111 & 6.8182 & 267 & \\
\hline IEMBL: & 11 & 286 & & \\
\hline AEMBL & & 229 & & \\
\hline HEMBL3 & 11 & 7.6882 & & \\
\hline AEMBL3 & 11 & 5826 & & \\
\hline AEMBL36 & 1 & 7328 & 04 & \\
\hline HEMBL & & 01 & & \\
\hline HEMBL; & & 212 & & \\
\hline HEMBL3E & & 6.734 & & \\
\hline AEMBL3 & & 166 & & \\
\hline HEMBL & 1 & 79 & 37 & 1SI \\
\hline HEMBL & & 871 & & RN \\
\hline HEMBL & & 82 & & \\
\hline 51 & & 467 & & \\
\hline AEMBL36 & & 39 & & I RIV \\
\hline HEMBL & & 45 & & RIV \\
\hline HEMBL. & & 96 & & RN \\
\hline HFMRI & & 29 & & \\
\hline HEMBL36 & & & & IRIN \\
\hline HEMBL 367 & & 74 & & $\mid$ \\
\hline HEMBL3 & & 926 & & RN \\
\hline HEMBL & & 75 & & ST \\
\hline HEMBL3 & & 27 & & IST \\
\hline HEMBL3672632 & & & & ISI \\
\hline HEMBL3677643 & & 35 & & TRN \\
\hline HEMBL3 & & 47 & & TST \\
\hline HEMRI & & & & \\
\hline HEMBL & & & & IRN \\
\hline HEMBL3682464 & & 7. & & TRN \\
\hline HEMBL367 & & & & $\mathrm{RN}$ \\
\hline HEMBL36 & & & 21 & \\
\hline CHEMBL 36 & & & & TRN \\
\hline HEMBL3677485 & 11 & 5.6554 & 5.9097 & RN \\
\hline HEMBL3677567 & 11 & 8.1367 & 63 & TR \\
\hline Fu & & & & $\mathrm{N}$ \\
\hline HEMBL367 & & & . 7916 & \\
\hline CHEMBL 3677491 & 534711 & & 8.7264 & \\
\hline CHEMBL3682455 & 1534711 & 6.9516 & 7.0895 & ГRN \\
\hline
\end{tabular}

Page 20437 
Supplemental Table S2.txt

\begin{tabular}{|c|c|c|c|c|c|c|}
\hline CHEMBL 3677556 & 1534711 & 7.1308 & 7.2399 & TRN & & \\
\hline CHEMBL 3677644 & 1534711 & 5.9996 & 6.3714 & TRN & & \\
\hline CHEMBL 3677455 & 1534711 & 6.0 & 6.4798 & TRN & & \\
\hline CHEMBL3677459 & 1534711 & 6.9706 & 6.9522 & TRN & & \\
\hline CHEMBL 3677575 & 1534711 & 6.8952 & 7.0896 & TRN & & \\
\hline CHEMBL3677472 & 1534711 & 6.5376 & 6.7567 & TST & & \\
\hline CHEMBL3682495 & 1534711 & 7.8861 & 7.7773 & TRN & & \\
\hline CHEMBL 3682477 & 1534711 & 5.0 & 6.372999 & 99999999 & & TST \\
\hline CHEMBL3677582 & 1534711 & 6.5862 & 6.369 & TST & & \\
\hline CHEMBL3672647 & 1534711 & 6.8416 & 7.1164 & TRN & & \\
\hline CHEMBL3639813 & 1534711 & 5.0 & 5.3057 & TRN & & \\
\hline CHEMBL3677503 & 1534711 & 7.699 & 6.6521 & TST & & \\
\hline CHEMBL 3677627 & 1534711 & 7.284 & 6.9734 & TRN & & \\
\hline CHEMBL3682438 & 1534711 & 7.2358 & 7.4365 & TRN & & \\
\hline CHEMBL3677515 & 1534711 & 6.3054 & 6.6017 & TRN & & \\
\hline CHEMBL3677625 & 1534711 & 7.1296 & 6.9928 & TRN & & \\
\hline CHEMBL 3677543 & 1534711 & 8.5229 & 8.3869 & TRN & & \\
\hline CHEMBL 3682474 & 1534711 & 6.3266 & 6.9368 & TRN & & \\
\hline CHEMBL3682436 & 1534711 & 7.4271 & 6.4881 & TRN & & \\
\hline CHEMBL3677632 & 1534711 & 8.8239 & 8.3942 & TRN & & \\
\hline CHEMBL 3682494 & 1534711 & 7.4377 & 8.1846 & TST & & \\
\hline CHEMBL 3677451 & 1534711 & 9.0 & 8.8626 & TRN & & \\
\hline CHEMBL 3677473 & 1534711 & 9.0 & 7.9153 & TRN & & \\
\hline CHEMBL 3682445 & 1534711 & 6.6692 & 6.5388 & TRN & & \\
\hline CHEMBL 3677514 & 1534711 & 7.0362 & 7.2359 & TRN & & \\
\hline CHEMBL 3682454 & 1534711 & 7.0996 & 6.8216 & TRN & & \\
\hline CHEMBL 3677608 & 1534711 & 8.5376 & 8.0298 & TST & & \\
\hline CHEMBL 3677535 & 1534711 & \multicolumn{3}{|c|}{7.757000000000001} & 8.291 & TST \\
\hline CHEMBL 3682457 & 1534711 & 7.4191 & 7.2572 & TRN & & \\
\hline CHEMBL 3677622 & 1534711 & 6.574 & 6.5688 & TRN & & \\
\hline CHEMBL 3677555 & 1534711 & 7.8125 & 7.6137 & TST & & \\
\hline CHEMBL 3677553 & 1534711 & 8.1135 & 7.6352 & TRN & & \\
\hline CHEMBL 3682461 & 1534711 & 6.2369 & 6.1146 & TRN & & \\
\hline CHEMBL3677427 & 1534711 & 9.0 & 7.8005 & TST & & \\
\hline CHEMBL 3677444 & 1534711 & \multicolumn{3}{|c|}{5.9079999999999995} & 6.7192 & TRN \\
\hline CHEMBL 3677450 & 1534711 & 9.0 & 8.6774 & TRN & & \\
\hline CHEMBL 3677524 & 1534711 & 6.4001 & 6.8746 & TRN & & \\
\hline CHEMBL 3677614 & 1534711 & 6.9083 & 7.4498 & TRN & & \\
\hline CHEMBL3677512 & 1534711 & 7.7212 & 7.4904 & TRN & & \\
\hline CHEMBL 3672661 & 1534711 & 9.0 & 8.4007 & TRN & & \\
\hline CHEMBL3677490 & 1534711 & 6.0381 & 6.34 & TRN & & \\
\hline CHEMBL 3677635 & 1534711 & 7.289 & 7.1629 & TRN & & \\
\hline CHEMBL 3677552 & 1534711 & 7.5003 & 7.3116 & TRN & & \\
\hline CHEMBL3672660 & 1534711 & 9.0 & 9.3287 & TRN & & \\
\hline CHEMBL 3677558 & 1534711 & 6.6028 & 6.5993 & TRN & & \\
\hline CHEMBL 3677620 & 1534711 & 6.74299 & 999999999 & 9 & 6.401 & TRN \\
\hline CHEMBL 3677507 & 1534711 & 6.4989 & 6.6602 & TST & & \\
\hline CHEMBL 3677623 & 1534711 & 6.2552 & 6.0834 & TRN & & \\
\hline
\end{tabular}

Page 20438 
Supplemental Table S2.txt

\begin{tabular}{|c|c|c|c|c|}
\hline AEMBL3677633 & 534711 & 6.7122 & 0404 & \\
\hline & 534711 & 7.8633 & 8.6676 & \\
\hline & & & & \\
\hline IEMBL 3682501 & 534711 & 5.0 & & \\
\hline AEMBL3677531 & 711 & 053 & 416 & \\
\hline AEMBL3677538 & 534711 & 9.0969 & .3982 & \\
\hline IEMBL & & 5576 & 551 & \\
\hline EMBL & & 021 & & \\
\hline AEMBL3677604 & 711 & 9.0969 & & \\
\hline AEMBL3677445 & 711 & 7.2007 & 6.7189 & \\
\hline AEMBL3682488 & 53 & 5.3284 & 5.6382 & \\
\hline IEMBL & 11 & 989 & 88 & \\
\hline IEMBL & & & & \\
\hline AEMBL. & 11 & 5959 & & \\
\hline AEMBL: & 11 & 066 & & \\
\hline AEMBL368 & 1 & 773 & 6.8756 & \\
\hline AEMBL & 1 & & & \\
\hline AEMBL & 11 & 239 & & \\
\hline AEMBL & 11 & 9.301 & & \\
\hline IEMBL & 11 & 9.0 & & $R /$ \\
\hline IEMBL & 1 & 733 & & (I \\
\hline EMB & 1 & 33 & & \\
\hline EMB & 11 & 72 & & 年 \\
\hline 625 & 1 & 3665 & & \\
\hline IEMBL: & 1 & 36 & 7. & NIV \\
\hline IEMBL & 53 & 654 & & RN \\
\hline IEMBL & 1 & 55 & & 4 \\
\hline EMB & 1 & & & RN \\
\hline IEMBL & 5. & 057 & & RN \\
\hline IEMBL3677 & 53 & 99 & & RN \\
\hline IEMBL3682 & & 234 & 82 & RN \\
\hline FMB & & 37 & 71 & ונה \\
\hline & 1 & 53 & 72 & RN \\
\hline IEMBL367 & 1 & 45 & & RN \\
\hline IEMBL36775 & 53 & 437 & & $S$ \\
\hline EMBL: & & 79 & & וב \\
\hline 1 & & & & ST \\
\hline & 1 & & & RN \\
\hline IEMBL3677560 & 1 & 7.4271 & & RI \\
\hline EMBL. & 53 & 247 & & RI \\
\hline HEMBL3682472 & 53 & 701 & 7.2902 & 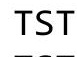 \\
\hline HEMBL3677477 & & & & ST \\
\hline HEMBL3677566 & 1 & 6.6312 & 6.72 & $\mathrm{RN}$ \\
\hline AEMBL3677436 & 53 & 7.0 & 7.3961 & $\mathrm{CT}$ \\
\hline EMB & & 1086 & & RA \\
\hline CHEMBL 3682460 & & .3975 & 6.2411 & \\
\hline CHEMBL 3677586 & $50-7$ & .0512 & 6.1669 & \\
\hline CHEMBL3677482 & 1534711 & 6.8477 & 6.4002 & TS \\
\hline
\end{tabular}

Page 20439 
Supplemental Table S2.txt

\begin{tabular}{|c|c|c|}
\hline . & & \\
\hline & & \\
\hline 726 & & 9 \\
\hline HEMBL3677628 & & 290 \\
\hline HEMBL3677448 & 711 & 9.0 \\
\hline HEMBL3677498 & 534711 & 7.95 \\
\hline HEMBL 367 & & \\
\hline AEMBL 3682470 & & \\
\hline HEMBL3677428 & & 6.707 \\
\hline HEMBL3677475 & 711 & 7.920 \\
\hline HEMBL3682479 & 11 & $65 c$ \\
\hline IEMBL36 & 11 & 0164 \\
\hline AEMBL3 & & 4835 \\
\hline HEMBL3672633 & & 9.0 \\
\hline HEMBL 367 & 711 & \\
\hline AEMBL3672648 & 11 & 7 \\
\hline HEMBL36 & $\perp \perp$ & 8.6778 \\
\hline HEMBL36 & & 8.5528 \\
\hline HEMBL36 & & 7.8539 \\
\hline AEMBL3 & & 3522 \\
\hline AEMBL3 & 11 & 3983 \\
\hline HEMBL3 & & 7447 \\
\hline HEMBL & & 0458 \\
\hline HEMBL3672637 & & 7.4559 \\
\hline HEMBL 367 & & סכ0. \\
\hline HEMBL3 & 11 & 0306 \\
\hline HEMBL & & 1487 \\
\hline HEMBL 3 & & 4437 \\
\hline HEMBL3677434 & & 8.6576 \\
\hline HEMBL3682493 & & 7.3958 \\
\hline HEMBL36824 & & 7.3279 \\
\hline HEMBL & 11 & $\partial 757$ \\
\hline HEMBL; & 11 & 7.9586 \\
\hline HEMBL3677545 & & 8.4437 \\
\hline HEMBL3677435 & 11 & 7.1549 \\
\hline HEMBL 367 & & 586 \\
\hline HEMBL & & 7967 \\
\hline HEMBL 3677532 & 11 & 5.4352 \\
\hline HEMBL3677634 & 11 & 7.1739 \\
\hline CHEMBL 36726 & 11 & 7.1675 \\
\hline CHEMBL3677 & 15 & .8327 \\
\hline CHEMBL3677574 & 153 & 7.025 \\
\hline CHEMBL3677577 & 711 & 7.5317 \\
\hline HEMBL3677629 & 711 & 7.7799 \\
\hline CHEMBL3677550 & 153 & 8.5528 \\
\hline CHEMBL3677506 & 15347 & 701 \\
\hline CHEMBL3672669 & 53471 & \\
\hline תר נחמבו & & \\
\hline
\end{tabular}

6.7854 TRN

5.6085 TRN

7.8437 TST

7.4279 TST

7.8518 TRN

8.0839 TST

7.6599 TST

6.7539 TRN

6.3672 TRN

7.8076 TRN

6.8787 TRN

7.017 TRN

6.1581 TRN

7.8538 TRN

8.7964 TRN

7.6974 TRN

8.1572 TRN

8.5001 TST

8.2524 TRN

6.5505 TST

6.4964 TRN

6.5739 TST

6.955 TRN

7.5851 TRN

7.2411 TRN

6.7784 TRN

7.2582 TRN

7.7763 TST

8.7538 TRN

6.9184 TRN

7.4241 TRN

8.1555 TST

8.042 TRN

8.0506 TRN

6.1885 TRN

8.8628 TST

5.5837 TRN

4.7125 TST

7.3016 TRN

8.2347 TST

7.1246 TRN

7.5117 TRN

7.5514 TRN

7.1977 TRN

7.502999999999999 TST

6.9705 TST

9.0939 TRN

6.4465 TST

Page 20440 
Supplemental Table S2.txt

\begin{tabular}{|c|c|c|c|c|}
\hline CHEMBL 3677443 & 1534711 & 7.2441 & 7.9563 & TST \\
\hline CHEMBL3682439 & 1534711 & 6.983 & 6.5799 & TRN \\
\hline CHEMBL3682482 & 1534711 & 7.8097 & 7.9381 & RN \\
\hline CHEMBL3682449 & 534711 & 7.8327 & .8068 & \\
\hline CHEMBL 3677578 & .534711 & 7.4157 & 6.7496 & RN \\
\hline CHEMBL3677583 & 534711 & 7.3615 & 7.0969 & ST \\
\hline CHEMBL3677554 & 534711 & 8.0 & 7.0341 & ST \\
\hline CHEMBL142738 & 417161 & 8.06 & 7.9276 & \\
\hline CHEMBL145781 & 417161 & 8.77 & 8.4039 & $\mathrm{RN}$ \\
\hline CHEMBL339565 & 417161 & 7.58 & 7.5861 & $\mathrm{~N}$ \\
\hline CHEMBL124935 & 417161 & 8.08 & 8.0088 & $\mathrm{RN}$ \\
\hline CHEMBL123895 & 417161 & 6.28 & 6.1552 & RN \\
\hline CHEMBL339429 & 417161 & 6.93 & 7.176 & \\
\hline CHEMBL339027 & 417161 & 7.48 & 7.4547 & RN \\
\hline CHEMBL127983 & 417161 & 8.27 & 8.3425 & $\mathrm{~N}$ \\
\hline CHEMBL127774 & 417 & 8.07 & 8 & KIV \\
\hline CHEMBL338094 & 17161 & 8.09 & 8.0594 & RN \\
\hline CHEMBL127622 & 417161 & 8.25 & 8.2241 & \\
\hline CHEMBL127517 & 417161 & 7.96 & 7.926 & RN \\
\hline CHEMBL339626 & 417161 & 8.34 & 8.2062 & $R / N$ \\
\hline CHEMBL127518 & 417 & 6.72 & 6 & RIN \\
\hline CHEMBL125921 & 61 & 8.3 & 8.2182 & RN \\
\hline CHEMBL340701 & 417161 & 7.83 & 7.8273 & RN \\
\hline CHEMBL127751 & 417161 & 7.37 & 7.5984 & TRN \\
\hline CHEMBL125044 & 417161 & 7.13 & & 15 \\
\hline CHEMBL125094 & 417161 & 7.37 & 7.6426 & TST \\
\hline CHEMBL127757 & 61 & 6.57 & 6 . & ST \\
\hline CHEMBL339561 & 61 & 6.22 & 7.4785 & TST \\
\hline CHEMBL420523 & 417161 & 5.57 & 6.6734 & $\mathrm{TS}$ \\
\hline CHEMBL127982 & 417161 & 8.2 & 7.7256 & TST \\
\hline CHEMBL125843 & 17161 & 7.58 & & ST \\
\hline CHEMBL126505 & 51 & 7.5 & 6. & ST \\
\hline CHEMBL338035 & 61 & 6.12 & 6.9621 & ST \\
\hline CHEMBL128029 & 417161 & 5.89 & 6.9141 & ST \\
\hline CHEMBL421088 & 417161 & 6.75 & 7.3335 & TST \\
\hline CHEMBL126504 & & 5.53 & 6. & ST \\
\hline CHEMBL341071 & 51 & 5.56 & 7.0481 & \\
\hline CHEMBL357614 & 417161 & 8.79 & 8.9055 & TRN \\
\hline CHEMBL142582 & 417161 & 8.95 & 9.0026 & TRN \\
\hline CHEMBL145792 & 417161 & 8.63 & 8.6027 & TRN \\
\hline CHEMBL274030 & 417 & 8.83 & 8.8317 & RN \\
\hline CHEMBL276076 & 417161 & 8.81 & 8.8788 & RN \\
\hline CHEMBL18966 & 417161 & 8.86 & 8.8085 & RN \\
\hline CHEMBL356977 & 17161 & 8.96 & 8.9803 & RN \\
\hline CHEMBL356714 & 417161 & 8.85 & 8.7673 & TRN \\
\hline CHEMBL143555 & 417161 & 8.37 & 8.5293 & RN \\
\hline CHEMBL109018 & 417161 & 8.67 & 8.8048 & \\
\hline CHEMBL108697 & 417161 & 9.04 & 8.8726 & \\
\hline
\end{tabular}

Page 20441 


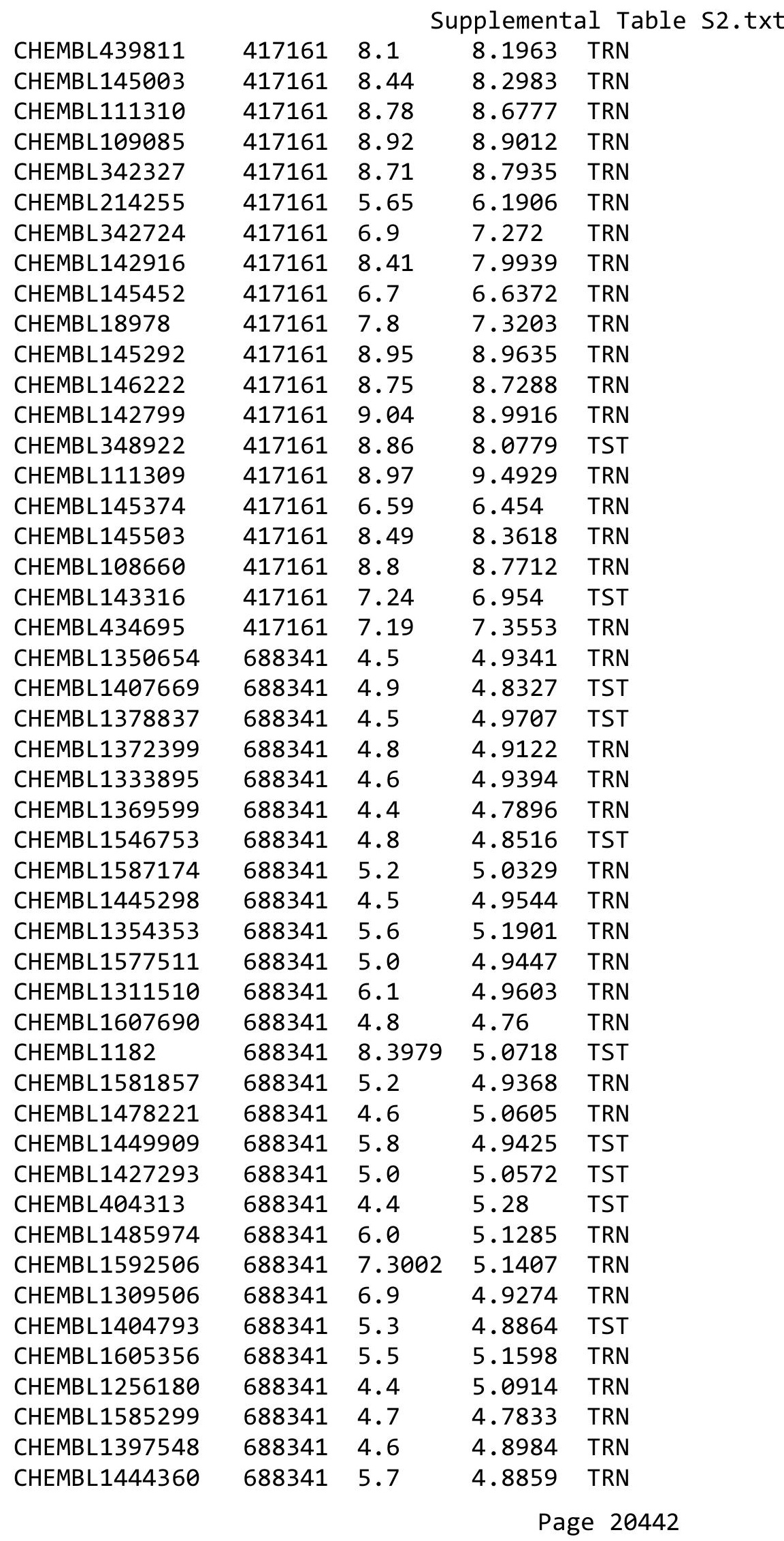




\begin{tabular}{|c|c|c|c|c|}
\hline \multicolumn{5}{|c|}{ Supplemental Table S2.txt } \\
\hline CHEMBL1448510 & 688341 & 6.1 & 4.9994 & TST \\
\hline CHEMBL1467636 & 688341 & 4.5 & 4.7906 & TRN \\
\hline CHEMBL1310739 & 688341 & 4.8 & 5.0167 & TRN \\
\hline CHEMBL1588307 & 688341 & 4.5 & 4.9143 & TST \\
\hline CHEMBL1391602 & 688341 & 5.6 & 4.9201 & TRN \\
\hline CHEMBL1323268 & 688341 & 4.6 & 4.7783 & TRN \\
\hline CHEMBL1456698 & 688341 & 5.2 & 4.9982 & TST \\
\hline CHEMBL1343376 & 688341 & 6.8 & 4.9376 & TRN \\
\hline CHEMBL1342419 & 688341 & 4.7 & 4.7948 & TRN \\
\hline CHEMBL1551284 & 688341 & 4.8 & 5.2795 & TRN \\
\hline CHEMBL1380000 & 688341 & 4.4 & 5.2355 & TRN \\
\hline CHEMBL1565345 & 688341 & 4.6 & 4.819 & TRN \\
\hline CHEMBL1505637 & 688341 & 4.5 & 5.1249 & TRN \\
\hline CHEMBL1613639 & 688341 & 4.5 & 4.8452 & TRN \\
\hline CHEMBL1595277 & 688341 & 5.2 & 4.8768 & TRN \\
\hline CHEMBL1423004 & 688341 & 5.2 & 4.9239 & TST \\
\hline CHEMBL1368232 & 688341 & 4.6 & 4.8576 & TST \\
\hline CHEMBL1365959 & 688341 & 4.8 & 4.7385 & TRN \\
\hline CHEMBL1523780 & 688341 & 4.5 & 4.8235 & TRN \\
\hline CHEMBL1329135 & 688341 & 4.5 & 4.8907 & TRN \\
\hline CHEMBL1535652 & 688341 & 4.4 & 4.7355 & TRN \\
\hline CHEMBL1326702 & 688341 & 5.4 & 4.9142 & TRN \\
\hline CHEMBL1359102 & 688341 & 4.5 & 4.8332 & TRN \\
\hline CHEMBL1611618 & 688341 & 5.2 & 4.6835 & TRN \\
\hline CHEMBL1589409 & 688341 & 5.4 & 4.8672 & TRN \\
\hline CHEMBL1504411 & 688341 & 4.4 & 4.8738 & TRN \\
\hline CHEMBL1515324 & 688341 & 6.8 & 5.0433 & TRN \\
\hline CHEMBL1333283 & 688341 & 4.5 & 4.9922 & TRN \\
\hline CHEMBL1550137 & 688341 & 5.9 & 4.7438 & TRN \\
\hline CHEMBL1558796 & 688341 & 6.2 & 5.1709 & TRN \\
\hline CHEMBL1502532 & 688341 & 4.8 & 5.0132 & TRN \\
\hline CHEMBL1491342 & 688341 & 4.7 & 4.8 & TRN \\
\hline CHEMBL1331691 & 688341 & 5.0 & 4.8124 & TST \\
\hline CHEMBL1511154 & 688341 & 4.4 & 4.9052 & TRN \\
\hline CHEMBL1343147 & 688341 & 4.4 & 5.1592 & TST \\
\hline CHEMBL1598344 & 688341 & 5.9 & 4.8599 & TRN \\
\hline CHEMBL1468639 & 688341 & 5.7 & 4.9637 & TRN \\
\hline CHEMBL15766 & 688341 & 4.7 & 5.1168 & TST \\
\hline CHEMBL1313496 & 688341 & 4.7 & 4.8836 & TRN \\
\hline CHEMBL1321325 & 688341 & 4.4 & 4.8647 & TRN \\
\hline CHEMBL1401648 & 688341 & 5.2 & 4.8393 & TRN \\
\hline CHEMBL1319185 & 688341 & 5.1 & 4.851 & TRN \\
\hline CHEMBL1335471 & 688341 & 5.4 & 5.1506 & TRN \\
\hline CHEMBL1423098 & 688341 & 5.2 & 4.8162 & TRN \\
\hline CHEMBL1519490 & 688341 & 5.5 & 5.1012 & TRN \\
\hline CHEMBL1448873 & 688341 & 5.4 & 4.8638 & TRN \\
\hline CHEMBL1412545 & 688341 & 5.2 & 4.8581 & TRN \\
\hline CHEMBL1526721 & 688341 & 5.5 & 5.1389 & TST \\
\hline
\end{tabular}




\begin{tabular}{|c|c|c|c|c|c|}
\hline \multicolumn{6}{|c|}{ Supplemental Table s2.txt } \\
\hline CHEMBL1593371 & 688341 & 4.8 & 5.1907 & TRN & \\
\hline CHEMBL1362051 & 688341 & 4.6 & 4.8779 & TST & \\
\hline CHEMBL1467186 & 688341 & 4.6 & 4.8945 & TRN & \\
\hline CHEMBL1548799 & 688341 & 5.2 & 4.989 & TST & \\
\hline CHEMBL1537246 & 688341 & 4.7 & 4.987 & TRN & \\
\hline CHEMBL1537665 & 688341 & 5.2 & 5.039 & TST & \\
\hline CHEMBL80941 & 688341 & 4.5 & 5.087 & TST & \\
\hline CHEMBL1339717 & 688341 & 5.2 & 4.8609 & TST & \\
\hline CHEMBL1346928 & 688341 & 4.9 & 5.0113 & TRN & \\
\hline CHEMBL1479727 & 688341 & 4.7 & 5.0014 & TRN & \\
\hline CHEMBL1353497 & 688341 & 5.8 & 4.928 & TST & \\
\hline CHEMBL1456417 & 688341 & 4.7 & 5.0562 & TST & \\
\hline CHEMBL1318400 & 688341 & 5.0 & 5.1081 & TRN & \\
\hline CHEMBL1401457 & 688341 & 4.8 & 4.9618 & TRN & \\
\hline CHEMBL1430524 & 688341 & 5.0 & 4.7747 & TRN & \\
\hline CHEMBL1306116 & 688341 & 5.2 & 4.909 & TRN & \\
\hline CHEMBL1429699 & 688341 & 4.5 & 4.9779 & TRN & \\
\hline CHEMBL1466018 & 688341 & 4.8 & 5.0911 & TRN & \\
\hline CHEMBL1444838 & 688341 & 4.7 & 5.0113 & TRN & \\
\hline CHEMBL1409131 & 688341 & 5.2 & 4.9537 & TRN & \\
\hline CHEMBL1602150 & 688341 & 4.5 & 5.0539 & TRN & \\
\hline CHEMBL1456433 & 688341 & 5.2 & 4.9149 & TST & \\
\hline CHEMBL1465781 & 688341 & 4.5 & 4.9108 & TRN & \\
\hline CHEMBL1485190 & 688341 & 5.0 & 4.9352 & TRN & \\
\hline CHEMBL1313676 & 688341 & 4.4 & 4.868 & TRN & \\
\hline CHEMBL1604421 & 688341 & 5.2 & 5.2496 & TRN & \\
\hline CHEMBL1592754 & 688341 & 5.5 & 5.0679 & TRN & \\
\hline CHEMBL1382994 & 688341 & 5.4 & 5.0456 & TRN & \\
\hline CHEMBL1582536 & 688341 & 5.2 & 4.8493 & TRN & \\
\hline CHEMBL1336572 & 688341 & 4.4 & 4.7837 & TST & \\
\hline CHEMBL3214458 & 688341 & 5.3 & 4.9279 & TST & \\
\hline CHEMBL1477287 & 688341 & 4.8 & 5.11600 & 00000000005 & TRN \\
\hline CHEMBL1532224 & 688341 & 5.2 & 4.9772 & TRN & \\
\hline CHEMBL1441417 & 688341 & 4.7 & 4.9029 & TRN & \\
\hline CHEMBL1413998 & 688341 & 7.4001 & 5.1794 & TRN & \\
\hline CHEMBL1565064 & 688341 & 4.5 & 4.8519 & TRN & \\
\hline CHEMBL1369350 & 688341 & 4.5 & 4.9959 & TRN & \\
\hline CHEMBL1499745 & 688341 & 4.4 & 4.9429 & TRN & \\
\hline CHEMBL1491128 & 688341 & 4.6 & 4.8721 & TST & \\
\hline CHEMBL1527209 & 688341 & 4.8 & 5.1779 & TRN & \\
\hline CHEMBL1601244 & 688341 & 4.5 & 4.8826 & TST & \\
\hline CHEMBL1603155 & 688341 & 4.5 & 4.9077 & TRN & \\
\hline CHEMBL1364184 & 688341 & 4.6 & 4.9821 & TST & \\
\hline CHEMBL1319718 & 688341 & 5.1 & 4.8782 & TRN & \\
\hline CHEMBL1521879 & 688341 & 5.4 & 5.1748 & TRN & \\
\hline CHEMBL1495577 & 688341 & 5.2 & 5.0191 & TRN & \\
\hline CHEMBL1456204 & 688341 & 4.6 & 4.8879 & TRN & \\
\hline CHEMBL1510097 & 688341 & 4.6 & 5.0088 & TRN & \\
\hline
\end{tabular}




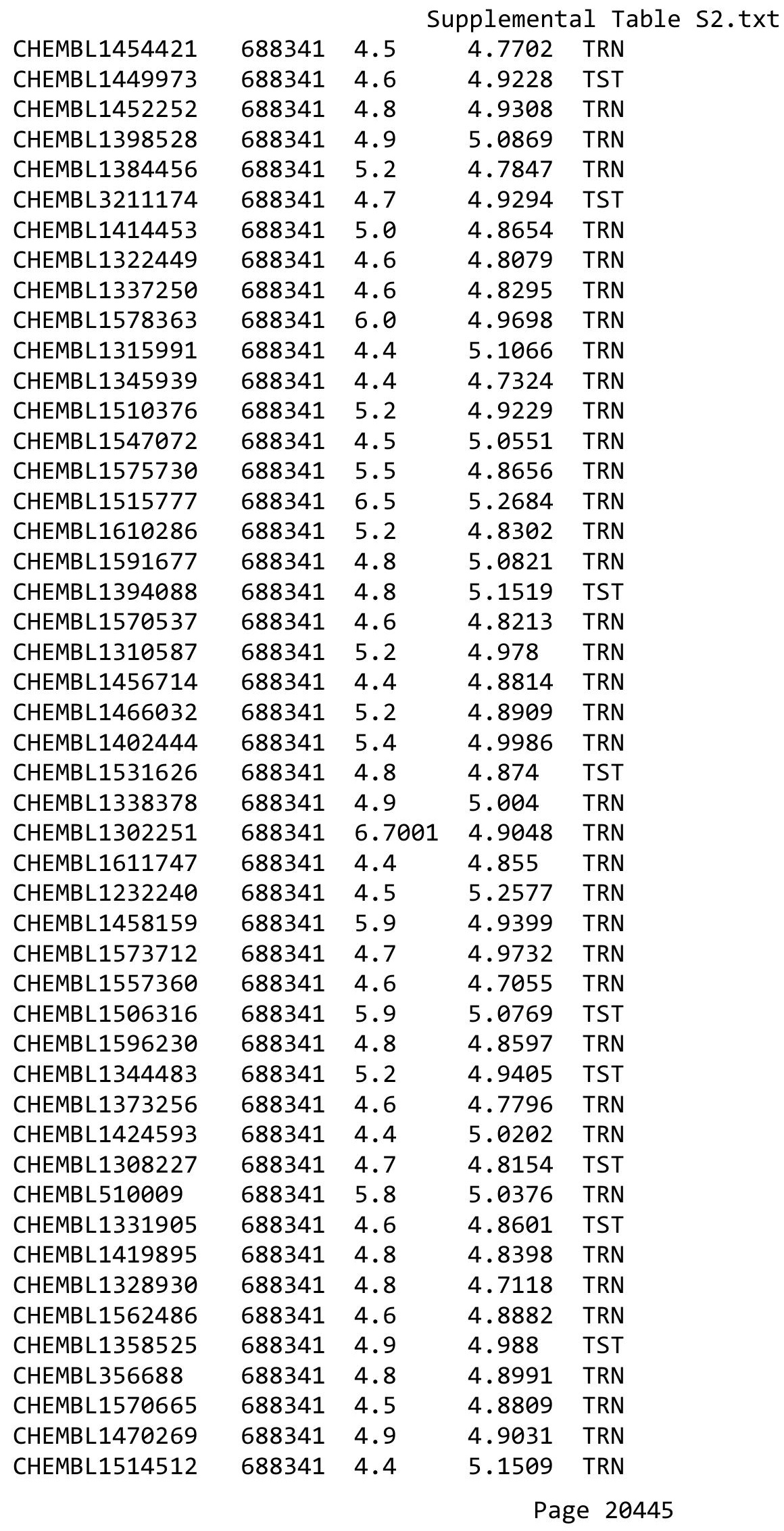




\begin{tabular}{|c|c|c|c|c|}
\hline & & & EI & al Ta \\
\hline CHEMBL1325152 & 688341 & 5.3 & 4.9324 & TRN \\
\hline CHEMBL1591374 & 688341 & 5.9 & 5.2051 & TRN \\
\hline CHEMBL1542677 & 688341 & 5.4 & 5.0445 & TST \\
\hline CHEMBL1385009 & 688341 & 4.9 & 4.8424 & TRN \\
\hline CHEMBL1418264 & 688341 & 4.6 & 4.7807 & TRN \\
\hline CHEMBL1412606 & 688341 & 4.5 & 4.8432 & TRN \\
\hline CHEMBL1467135 & 688341 & 4.4 & 4.9886 & TST \\
\hline CHEMBL1507911 & 688341 & 4.5 & 4.9403 & TST \\
\hline CHEMBL1607300 & 688341 & 4.5 & 4.9069 & TRN \\
\hline CHEMBL1589103 & 688341 & 5.1 & 4.8137 & TRN \\
\hline CHEMBL1311660 & 688341 & 6.1 & 4.7031 & TRN \\
\hline CHEMBL1485361 & 688341 & 4.9 & 5.1035 & TRN \\
\hline CHEMBL1371447 & 688341 & 5.2 & 4.8825 & TRN \\
\hline CHEMBL1382107 & 688341 & 4.4 & 4.9698 & TRN \\
\hline CHEMBL1327023 & 688341 & 5.5 & 4.9544 & TST \\
\hline CHEMBL1380991 & 688341 & 4.5 & 4.9445 & TRN \\
\hline CHEMBL1414091 & 688341 & 4.8 & 4.8145 & TRN \\
\hline CHEMBL1604728 & 688341 & 4.9 & 4.8811 & TRN \\
\hline CHEMBL1587663 & 688341 & 4.5 & 4.8733 & TRN \\
\hline CHEMBL1554664 & 688341 & 6.1 & 4.8805 & TRN \\
\hline CHEMBL1327903 & 688341 & 5.3 & 4.9713 & TRN \\
\hline CHEMBL1566213 & 688341 & 4.4 & 5.1196 & TRN \\
\hline CHEMBL1489430 & 688341 & 4.4 & 5.0556 & TST \\
\hline CHEMBL1608349 & 688341 & 5.5 & 5.0225 & TRN \\
\hline CHEMBL1503361 & 688341 & 4.7 & 5.0064 & TST \\
\hline CHEMBL1502012 & 688341 & 5.6 & 5.0099 & TST \\
\hline CHEMBL1442668 & 688341 & 4.8 & 4.9297 & TRN \\
\hline CHEMBL1449573 & 688341 & 4.6 & 5.0333 & TST \\
\hline CHEMBL1564730 & 688341 & 5.0 & 4.9895 & TST \\
\hline CHEMBL1500198 & 688341 & 4.4 & 4.9916 & TST \\
\hline CHEMBL1442201 & 688341 & 4.4 & 4.9057 & TST \\
\hline CHEMBL1534495 & 688341 & 4.5 & 4.9936 & TRN \\
\hline CHEMBL1462422 & 688341 & 4.4 & 4.9211 & TRN \\
\hline CHEMBL1384828 & 688341 & 6.9 & 5.1646 & TRN \\
\hline CHEMBL1354626 & 688341 & 5.6 & 5.0431 & TRN \\
\hline CHEMBL1416386 & 688341 & 4.8 & 5.1114 & TRN \\
\hline CHEMBL1391612 & 688341 & 4.7 & 4.6751 & TRN \\
\hline CHEMBL1556843 & 688341 & 5.0 & 4.7542 & TRN \\
\hline CHEMBL1497038 & 688341 & 4.4 & 5.1303 & TST \\
\hline CHEMBL1430533 & 688341 & 4.8 & 4.9698 & TRN \\
\hline CHEMBL1380260 & 688341 & 5.5 & 5.0321 & TST \\
\hline CHEMBL1529744 & 688341 & 5.5 & 4.8976 & TRN \\
\hline CHEMBL1405544 & 688341 & 4.5 & 4.7923 & TRN \\
\hline CHEMBL355014 & 688341 & 4.4 & 4.9395 & TRN \\
\hline CHEMBL1558283 & 688341 & 5.2 & 4.8515 & TST \\
\hline CHEMBL1375377 & 688341 & 4.8 & 4.888 & TRN \\
\hline CHEMBL1486217 & 688341 & 4.4 & 4.8901 & TRN \\
\hline CHEMBL1549972 & 688341 & 5.1 & 5.0855 & TST \\
\hline
\end{tabular}




\begin{tabular}{|c|c|c|c|c|}
\hline \multicolumn{5}{|c|}{ Supplemental Table S2.txt } \\
\hline CHEMBL233896 & 688341 & 4.9 & 4.8251 & TST \\
\hline CHEMBL259615 & 688341 & 4.4 & 4.7316 & TRN \\
\hline CHEMBL1514607 & 688341 & 4.4 & 5.1211 & TRN \\
\hline CHEMBL1375628 & 688341 & 4.7 & 4.8844 & TRN \\
\hline CHEMBL1555985 & 688341 & 4.5 & 4.8268 & TRN \\
\hline CHEMBL1426073 & 688341 & 4.5 & 4.9187 & TRN \\
\hline CHEMBL1346960 & 688341 & 4.6 & 4.8733 & TRN \\
\hline CHEMBL1314422 & 688341 & 4.4 & 4.9959 & TRN \\
\hline CHEMBL1590360 & 688341 & 4.4 & 4.8469 & TRN \\
\hline CHEMBL1335389 & 688341 & 4.4 & 4.9029 & TST \\
\hline CHEMBL1598028 & 688341 & 4.6 & 4.8761 & TRN \\
\hline CHEMBL1459111 & 688341 & 4.7 & 4.7121 & TRN \\
\hline CHEMBL1558115 & 688341 & 4.5 & 4.8853 & TST \\
\hline CHEMBL1418459 & 688341 & 4.8 & 4.7662 & TRN \\
\hline CHEMBL1495244 & 688341 & 4.6 & 4.8176 & TRN \\
\hline CHEMBL1378711 & 688341 & 5.6 & 4.8545 & TRN \\
\hline CHEMBL1409119 & 688341 & 4.7 & 4.7872 & TRN \\
\hline CHEMBL1599277 & 688341 & 4.5 & 4.9533 & TST \\
\hline CHEMBL1376163 & 688341 & 4.5 & 4.8866 & TRN \\
\hline CHEMBL1339031 & 688341 & 4.5 & 4.9059 & TRN \\
\hline CHEMBL1425168 & 688341 & 7.8996 & 5.1582 & TRN \\
\hline CHEMBL1547990 & 688341 & 5.0 & 4.9321 & TRN \\
\hline CHEMBL1322960 & 688341 & 4.6 & 4.8722 & TST \\
\hline CHEMBL1529105 & 688341 & 5.2 & 4.8992 & TRN \\
\hline CHEMBL1346683 & 688341 & 5.1 & 4.6971 & TRN \\
\hline CHEMBL1466714 & 688341 & 4.7 & 4.728 & TRN \\
\hline CHEMBL1540534 & 688341 & 4.6 & 4.8628 & TST \\
\hline CHEMBL1380864 & 688341 & 5.3 & 5.0185 & TRN \\
\hline CHEMBL1546087 & 688341 & 4.6 & 5.1317 & TRN \\
\hline CHEMBL1498941 & 688341 & 4.8 & 5.0249 & TRN \\
\hline CHEMBL1345725 & 688341 & 4.7 & 5.0188 & TRN \\
\hline CHEMBL1546388 & 688341 & 4.7 & 5.1995 & TRN \\
\hline CHEMBL1534925 & 688341 & 4.8 & 5.0573 & TST \\
\hline CHEMBL1353522 & 688341 & 4.5 & 5.0453 & TST \\
\hline CHEMBL1347243 & 688341 & 5.3 & 4.9617 & TRN \\
\hline CHEMBL1377909 & 688341 & 4.4 & 4.916 & TST \\
\hline CHEMBL1524804 & 688341 & 5.4 & 4.9089 & TRN \\
\hline CHEMBL1609067 & 688341 & 4.5 & 4.8903 & TRN \\
\hline CHEMBL1354644 & 688341 & 5.6 & 5.0022 & TRN \\
\hline CHEMBL1436049 & 688341 & 4.8 & 5.0163 & TRN \\
\hline CHEMBL1371805 & 688341 & 4.6 & 4.8023 & TST \\
\hline CHEMBL1612675 & 688341 & 4.7 & 5.1803 & TST \\
\hline CHEMBL1461912 & 688341 & 4.6 & $5.0310 e$ & 0000000001 \\
\hline CHEMBL1357148 & 688341 & 4.9 & 5.0561 & TRN \\
\hline CHEMBL1378019 & 688341 & 6.8 & 4.9158 & TST \\
\hline CHEMBL1558177 & 688341 & 5.2 & 5.0437 & TRN \\
\hline CHEMBL 252901 & 688341 & 4.8 & 4.7612 & TRN \\
\hline CHEMBL1308349 & 688341 & 5.0 & 4.8657 & TRN \\
\hline
\end{tabular}




\begin{tabular}{|c|c|c|c|c|c|}
\hline \multicolumn{6}{|c|}{ Supplemental Table S2.txt } \\
\hline CHEMBL1352335 & 688341 & 4.4 & 4.8895 & TRN & \\
\hline CHEMBL1455186 & 688341 & 4.4 & 5.0985 & TRN & \\
\hline CHEMBL1456549 & 688341 & 5.2 & 4.8977 & TRN & \\
\hline CHEMBL1369819 & 688341 & 5.1 & 4.8676 & TST & \\
\hline CHEMBL1610343 & 688341 & 4.4 & 4.8405 & TST & \\
\hline CHEMBL1367007 & 688341 & 4.7 & 4.8278 & TRN & \\
\hline CHEMBL1336173 & 688341 & 5.2 & 4.9542 & TST & \\
\hline CHEMBL1607988 & 688341 & 7.3002 & 5.0396 & TRN & \\
\hline CHEMBL1582760 & 688341 & 4.6 & 5.0296 & TRN & \\
\hline CHEMBL1568570 & 688341 & 4.8 & 4.8954 & TRN & \\
\hline CHEMBL1516342 & 688341 & 5.5 & 5.1542 & TRN & \\
\hline CHEMBL1539444 & 688341 & 6.0 & 4.921 & TST & \\
\hline CHEMBL1553322 & 688341 & 4.5 & 4.8214 & TRN & \\
\hline CHEMBL1448082 & 688341 & 4.4 & 4.9041 & TST & \\
\hline CHEMBL1453717 & 688341 & 5.2 & 5.0017 & TRN & \\
\hline CHEMBL1302217 & 688341 & 4.6 & 4.8407 & TRN & \\
\hline CHEMBL267476 & 688341 & 4.5 & 5.2376 & TRN & \\
\hline CHEMBL1424127 & 688341 & 4.6 & 4.9748 & TRN & \\
\hline CHEMBL1301940 & 688341 & 4.6 & 5.0431 & TST & \\
\hline CHEMBL1490886 & 688341 & 4.4 & 5.0504 & TST & \\
\hline CHEMBL1301904 & 688341 & 5.2 & 4.8836 & TRN & \\
\hline CHEMBL1382721 & 688341 & 4.6 & 4.9111 & TRN & \\
\hline CHEMBL1536202 & 688341 & 6.0 & 4.9998 & TRN & \\
\hline CHEMBL1599572 & 688341 & 4.9 & 4.9336 & TRN & \\
\hline CHEMBL1369929 & 688341 & 4.7 & 4.8802 & TRN & \\
\hline CHEMBL1411560 & 688341 & 4.5 & 4.6592 & TRN & \\
\hline CHEMBL1332866 & 688341 & 5.4 & 4.8589 & TRN & \\
\hline CHEMBL 206483 & 688341 & 4.6 & 4.945 & TRN & \\
\hline CHEMBL1374594 & 688341 & 4.8 & 4.9298 & TRN & \\
\hline CHEMBL1412842 & 688341 & 4.9 & 4.99100 & 00000000005 & TRN \\
\hline CHEMBL1390598 & 688341 & 6.1 & 4.8326 & TST & \\
\hline CHEMBL29197 & 688341 & 4.4 & 5.1043 & TST & \\
\hline CHEMBL1492073 & 688341 & 4.8 & 4.9419 & TRN & \\
\hline CHEMBL1470966 & 688341 & 4.6 & 4.7367 & TRN & \\
\hline CHEMBL1494592 & 688341 & 5.4 & 5.1301 & TRN & \\
\hline CHEMBL26318 & 688341 & 6.0 & 5.0705 & TRN & \\
\hline CHEMBL1327203 & 688341 & 4.8 & 4.9883 & TRN & \\
\hline CHEMBL1591543 & 688341 & 5.0 & 5.0636 & TRN & \\
\hline CHEMBL1451428 & 688341 & 4.8 & 4.9428 & TRN & \\
\hline CHEMBL137648 & 688341 & 4.4 & 5.0496 & TST & \\
\hline CHEMBL1351095 & 688341 & 4.7 & 4.7636 & TRN & \\
\hline CHEMBL1372129 & 688341 & 4.5 & 4.9471 & TRN & \\
\hline CHEMBL1412864 & 688341 & 5.9 & 5.01399 & 9999999999 & TRN \\
\hline CHEMBL1334035 & 688341 & 5.4 & 5.0744 & TRN & \\
\hline CHEMBL1324598 & 688341 & 4.6 & 5.0274 & TRN & \\
\hline CHEMBL1398800 & 688341 & 4.6 & 5.1687 & TRN & \\
\hline CHEMBL1329391 & 688341 & 4.4 & 4.8785 & TRN & \\
\hline CHEMBL1550771 & 688341 & 4.8 & 4.8919 & TST & \\
\hline
\end{tabular}




\begin{tabular}{|c|c|c|c|c|c|}
\hline \multicolumn{6}{|c|}{ Supplemental Table S2.txt } \\
\hline CHEMBL1499005 & 688341 & 5.1 & 4.7552 & TRN & \\
\hline CHEMBL1562297 & 688341 & 4.6 & 4.8359 & TRN & \\
\hline CHEMBL1302294 & 688341 & 4.4 & 4.9814 & TST & \\
\hline CHEMBL1581164 & 688341 & 4.8 & 4.8156 & TRN & \\
\hline CHEMBL1375274 & 688341 & 4.4 & 4.9182 & TST & \\
\hline CHEMBL1576798 & 688341 & 7.6003 & 5.1243 & TST & \\
\hline CHEMBL1318954 & 688341 & 4.4 & 5.0539 & TST & \\
\hline CHEMBL1384931 & 688341 & 5.1 & 4.9283 & TRN & \\
\hline CHEMBL1330469 & 688341 & 5.2 & 4.9575 & TST & \\
\hline CHEMBL1518469 & 688341 & 4.8 & 4.9691 & TRN & \\
\hline CHEMBL1305334 & 688341 & 4.6 & 4.8031 & TRN & \\
\hline CHEMBL1570525 & 688341 & 6.0 & 5.1464 & TRN & \\
\hline CHEMBL1200488 & 688341 & 4.7 & 5.1208 & TRN & \\
\hline CHEMBL262347 & 688341 & 4.4 & 4.8482 & TRN & \\
\hline CHEMBL1543187 & 688341 & 4.4 & 4.8468 & TRN & \\
\hline CHEMBL1357347 & 688341 & 4.8 & 5.0808 & TRN & \\
\hline CHEMBL1415094 & 688341 & 4.7 & 4.9804 & TRN & \\
\hline CHEMBL1387988 & 688341 & 6.0 & 5.012 & TRN & \\
\hline CHEMBL1502467 & 688341 & 4.6 & 4.654 & TRN & \\
\hline CHEMBL1426583 & 688341 & 5.2 & 4.7947 & TST & \\
\hline CHEMBL266084 & 688341 & 5.2 & 5.1144 & TRN & \\
\hline CHEMBL68253 & 688341 & 5.2 & 5.1227 & TRN & \\
\hline CHEMBL1518383 & 688341 & 4.5 & 4.9033 & TRN & \\
\hline CHEMBL1482174 & 688341 & 6.8 & 4.9093 & TST & \\
\hline CHEMBL1450869 & 688341 & 5.4 & 5.0673 & TRN & \\
\hline CHEMBL1559199 & 688341 & 4.5 & 4.9464 & TRN & \\
\hline CHEMBL1330293 & 688341 & 4.5 & 4.8853 & TRN & \\
\hline CHEMBL1339679 & 688341 & 4.8 & 4.9049 & TRN & \\
\hline CHEMBL1424680 & 688341 & 4.6 & 4.9458 & TST & \\
\hline CHEMBL1505091 & 688341 & 4.7 & 4.9259 & TRN & \\
\hline CHEMBL1566074 & 688341 & 6.0 & 4.9863 & TST & \\
\hline CHEMBL1419549 & 688341 & 4.7 & 4.8887 & TRN & \\
\hline CHEMBL1552187 & 688341 & 4.7 & 5.2085 & TRN & \\
\hline CHEMBL409695 & 688341 & 4.7 & 5.0789 & TRN & \\
\hline CHEMBL1583553 & 688341 & 5.2 & 4.9491 & TST & \\
\hline CHEMBL1570698 & 688341 & 4.5 & 4.9724 & TRN & \\
\hline CHEMBL1519488 & 688341 & 4.4 & 4.6826 & TRN & \\
\hline CHEMBL1609528 & 688341 & 5.8 & 5.0995 & TRN & \\
\hline CHEMBL1520065 & 688341 & 5.4 & 4.8054 & TRN & \\
\hline CHEMBL1441246 & 688341 & 5.9 & 4.6439 & TRN & \\
\hline CHEMBL1546479 & 688341 & 4.6 & 4.8228 & TRN & \\
\hline CHEMBL198759 & 688341 & 4.7 & 4.7526 & TST & \\
\hline CHEMBL1475810 & 688341 & 5.1 & 5.0184 & TRN & \\
\hline CHEMBL1589376 & 688341 & 4.5 & 5.0431 & TST & \\
\hline CHEMBL1605850 & 688341 & 5.9 & 4.8834 & TRN & \\
\hline CHEMBL577764 & 688341 & 4.5 & 4.9118 & TST & \\
\hline CHEMBL1560223 & 688341 & 5.3 & 4.92899 & 9999999999 & TRN \\
\hline CHEMBL1519830 & 688341 & 4.7 & 4.9785 & TRN & \\
\hline
\end{tabular}




\begin{tabular}{|c|c|c|c|c|c|}
\hline \multicolumn{6}{|c|}{ Supplemental Table S2.txt } \\
\hline CHEMBL1392205 & 688341 & 4.4 & 4.8912 & TST & \\
\hline CHEMBL1533687 & 688341 & 4.8 & 4.7888 & TRN & \\
\hline CHEMBL1566556 & 688341 & 4.8 & 5.0802 & TRN & \\
\hline CHEMBL1383317 & 688341 & 5.3 & 4.6606 & TRN & \\
\hline CHEMBL1569708 & 688341 & 4.6 & 4.8453 & TRN & \\
\hline CHEMBL1488416 & 688341 & 4.7 & 4.7782 & TRN & \\
\hline CHEMBL1462616 & 688341 & 5.2 & 4.9978 & TST & \\
\hline CHEMBL1575288 & 688341 & 4.4 & 4.8881 & TRN & \\
\hline CHEMBL1431888 & 688341 & 4.6 & 5.1003 & TRN & \\
\hline CHEMBL1356764 & 688341 & 5.3 & 5.0084 & TRN & \\
\hline CHEMBL1603902 & 688341 & 4.8 & 4.9012 & TRN & \\
\hline CHEMBL1380257 & 688341 & 4.9 & 5.0857 & TST & \\
\hline CHEMBL1503235 & 688341 & 5.1 & 5.1035 & TRN & \\
\hline CHEMBL1459853 & 688341 & 4.6 & 4.9079 & TRN & \\
\hline CHEMBL1435086 & 688341 & 4.5 & 4.9026 & TRN & \\
\hline CHEMBL1552403 & 688341 & 6.0 & 5.249 & TST & \\
\hline CHEMBL1569358 & 688341 & 6.5 & 5.0922 & TRN & \\
\hline CHEMBL1544295 & 688341 & 4.6 & 4.873 & TRN & \\
\hline CHEMBL1442060 & 688341 & 4.5 & 4.8482 & TRN & \\
\hline CHEMBL1383901 & 688341 & 4.8 & 4.9255 & TST & \\
\hline CHEMBL1562088 & 688341 & 5.0 & 4.9658 & TST & \\
\hline CHEMBL1563858 & 688341 & 4.4 & 4.8232 & TRN & \\
\hline CHEMBL1539718 & 688341 & 4.5 & 4.9013 & TRN & \\
\hline CHEMBL1374260 & 688341 & 4.6 & 5.0071 & TST & \\
\hline CHEMBL1351516 & 688341 & 4.9 & 4.9008 & TRN & \\
\hline CHEMBL1362547 & 688341 & 5.2 & 4.7473 & TRN & \\
\hline CHEMBL1414761 & 688341 & 4.5 & 4.856 & TRN & \\
\hline CHEMBL1504234 & 688341 & 4.7 & 4.9091 & TRN & \\
\hline CHEMBL1375563 & 688341 & 4.8 & 5.0447 & TRN & \\
\hline CHEMBL1547605 & 688341 & 4.8 & 4.8149 & TST & \\
\hline CHEMBL3208324 & 688341 & 4.6 & 4.7058 & TRN & \\
\hline CHEMBL1346885 & 688341 & 4.6 & 4.8506 & TRN & \\
\hline CHEMBL85251 & 688341 & 4.5 & 5.1057 & TST & \\
\hline CHEMBL1460023 & 688341 & 4.5 & 5.077 & TRN & \\
\hline CHEMBL1612854 & 688341 & 4.9 & 4.8159 & TRN & \\
\hline CHEMBL1373724 & 688341 & 4.4 & 4.7015 & TRN & \\
\hline CHEMBL521971 & 688341 & 4.5 & 5.12200 & 0000000001 & TRN \\
\hline CHEMBL1336826 & 688341 & 5.1 & 4.9937 & TRN & \\
\hline CHEMBL1304255 & 688341 & 4.9 & 4.9633 & TRN & \\
\hline CHEMBL1443979 & 688341 & 4.6 & 5.0324 & TRN & \\
\hline CHEMBL1527727 & 688341 & 4.8 & 4.7685 & TRN & \\
\hline CHEMBL1380287 & 688341 & 5.1 & 4.7547 & TRN & \\
\hline CHEMBL1487188 & 688341 & 5.4 & 5.0591 & TRN & \\
\hline CHEMBL1534864 & 688341 & 4.7 & 4.7729 & TRN & \\
\hline CHEMBL1393963 & 688341 & 5.1 & 4.8422 & TST & \\
\hline CHEMBL1425223 & 688341 & 5.2 & 5.0746 & TRN & \\
\hline CHEMBL1347853 & 688341 & 4.6 & 4.9116 & TRN & \\
\hline CHEMBL1476580 & 688341 & 5.4 & 5.0239 & TRN & \\
\hline
\end{tabular}




\begin{tabular}{|c|c|c|c|c|}
\hline & & & pplement & al $\mathrm{Ta}$ \\
\hline CHEMBL1484153 & 688341 & 5.4 & 4.9277 & TRN \\
\hline CHEMBL1369874 & 688341 & 6.0 & 5.1062 & TRN \\
\hline CHEMBL1458079 & 688341 & 4.9 & 4.905 & TST \\
\hline CHEMBL 3213281 & 688341 & 5.2 & 5.0164 & TRN \\
\hline CHEMBL1489716 & 688341 & 4.4 & 4.8779 & TRN \\
\hline CHEMBL1533335 & 688341 & 4.8 & 5.0453 & TRN \\
\hline CHEMBL1360419 & 688341 & 4.7 & 4.838 & TRN \\
\hline CHEMBL1332531 & 688341 & 5.4 & 4.9931 & TST \\
\hline CHEMBL1552970 & 688341 & 4.5 & 5.0502 & TRN \\
\hline CHEMBL1566195 & 688341 & 4.7 & 4.8879 & TRN \\
\hline CHEMBL1367332 & 688341 & 5.9 & 4.9196 & TRN \\
\hline CHEMBL1448862 & 688341 & 4.4 & 4.9707 & TRN \\
\hline CHEMBL1329219 & 688341 & 5.0 & 4.993 & TRN \\
\hline CHEMBL1356624 & 688341 & 7.0 & 4.9652 & TRN \\
\hline CHEMBL1347752 & 688341 & 4.9 & 4.8301 & TRN \\
\hline CHEMBL1478235 & 688341 & 5.2 & 4.9482 & TRN \\
\hline CHEMBL1389724 & 688341 & 5.9 & 4.7631 & TST \\
\hline CHEMBL1387526 & 688341 & 5.4 & 4.8121 & TRN \\
\hline CHEMBL1426027 & 688341 & 4.8 & 4.9334 & TST \\
\hline CHEMBL1316897 & 688341 & 5.1 & 4.9776 & TRN \\
\hline CHEMBL1521144 & 688341 & 5.1 & 4.958 & TRN \\
\hline CHEMBL1439561 & 688341 & 4.6 & 4.9218 & TST \\
\hline CHEMBL1592819 & 688341 & 4.8 & 4.9537 & TRN \\
\hline CHEMBL1608077 & 688341 & 4.5 & 4.8473 & TRN \\
\hline CHEMBL1578763 & 688341 & 4.9 & 4.8924 & TRN \\
\hline CHEMBL1312225 & 688341 & 4.8 & 4.9695 & TRN \\
\hline CHEMBL1412140 & 688341 & 4.4 & 4.8813 & TRN \\
\hline CHEMBL1306108 & 688341 & 4.4 & 4.8254 & TST \\
\hline CHEMBL1602790 & 688341 & 4.8 & 4.7592 & TRN \\
\hline CHEMBL1370379 & 688341 & 4.4 & 5.013 & TRN \\
\hline CHEMBL1343279 & 688341 & 4.7 & 4.8056 & TRN \\
\hline CHEMBL1475083 & 688341 & 5.3 & 5.1101 & TRN \\
\hline CHEMBL1399058 & 688341 & 4.9 & 4.91 & TRN \\
\hline CHEMBL1349134 & 688341 & 4.5 & 4.7161 & TRN \\
\hline CHEMBL1305742 & 688341 & 7.0 & 5.1553 & TST \\
\hline CHEMBL1536945 & 688341 & 4.6 & 4.9309 & TRN \\
\hline CHEMBL1496664 & 688341 & 4.4 & 4.9639 & TRN \\
\hline CHEMBL1596756 & 688341 & 4.8 & 5.0147 & TRN \\
\hline CHEMBL1389031 & 688341 & 4.4 & 4.8319 & TRN \\
\hline CHEMBL1419272 & 688341 & 4.8 & 4.9323 & TST \\
\hline CHEMBL1608147 & 688341 & 5.1 & 4.9732 & TRN \\
\hline CHEMBL1570222 & 688341 & 4.5 & 4.8882 & TRN \\
\hline CHEMBL1423291 & 688341 & 4.8 & 4.7729 & TRN \\
\hline CHEMBL1499393 & 688341 & 4.4 & 4.9294 & TRN \\
\hline CHEMBL409024 & 688341 & 4.6 & 5.0911 & TST \\
\hline CHEMBL1363718 & 688341 & 6.8 & 5.0227 & TRN \\
\hline CHEMBL1342643 & 688341 & 5.7 & 4.8699 & TRN \\
\hline CHEMBL1462419 & 688341 & 4.9 & 5.1353 & TST \\
\hline
\end{tabular}




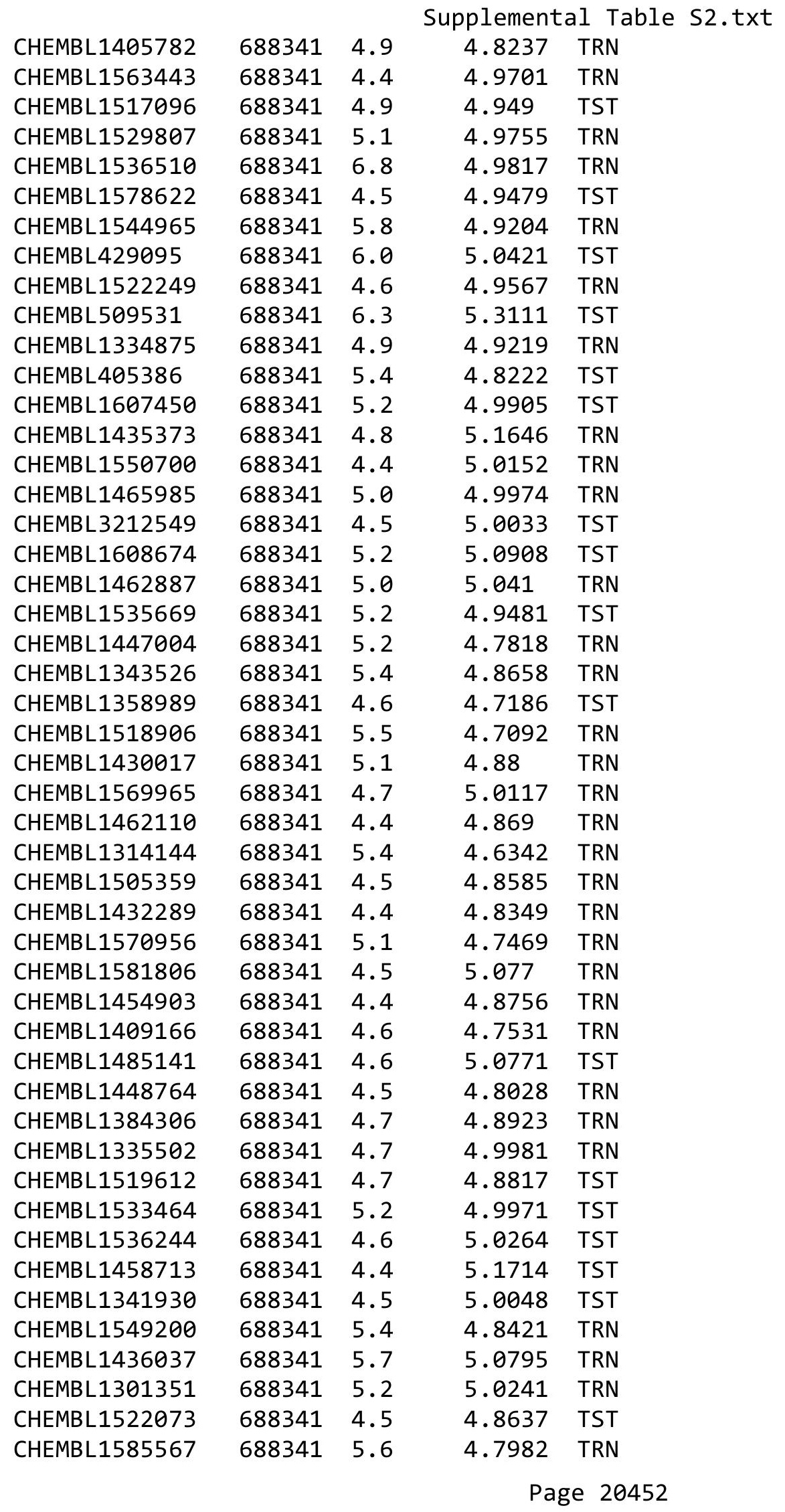




\begin{tabular}{|c|c|c|c|c|c|}
\hline \\
\hline CHEMBL1544687 & 688341 & 4.6 & 5.1403 & TRN & \\
\hline CHEMBL1299495 & 688341 & 4.8 & 4.9599 & TRN & \\
\hline CHEMBL1571250 & 688341 & 5.5 & 5.0603 & TST & \\
\hline CHEMBL1337450 & 688341 & 5.2 & 4.7278 & TRN & \\
\hline CHEMBL1489098 & 688341 & 4.5 & 4.907 & TRN & \\
\hline CHEMBL1451970 & 688341 & 4.8 & 4.8362 & TRN & \\
\hline CHEMBL1382640 & 688341 & 4.9 & 4.912 & TRN & \\
\hline CHEMBL13888 & 688341 & 4.4 & 5.0176 & TRN & \\
\hline CHEMBL1376242 & 688341 & 4.4 & 5.0329 & TRN & \\
\hline CHEMBL1443080 & 688341 & 5.5 & 4.9324 & TST & \\
\hline CHEMBL1413675 & 688341 & 5.2 & 4.787 & TRN & \\
\hline CHEMBL1423537 & 688341 & 4.8 & 4.7481 & TRN & \\
\hline CHEMBL1347264 & 688341 & 4.7 & 4.8846 & TRN & \\
\hline CHEMBL1523544 & 688341 & 5.3 & 5.0295 & TRN & \\
\hline CHEMBL1489438 & 688341 & 4.4 & 4.9437 & TRN & \\
\hline CHEMBL522311 & 688341 & 4.8 & 5.0586 & TRN & \\
\hline CHEMBL1548567 & 688341 & 4.6 & 4.9998 & TRN & \\
\hline CHEMBL1498785 & 688341 & 4.4 & 4.8858 & TRN & \\
\hline CHEMBL65 & 688341 & 4.4 & 5.4067 & TST & \\
\hline CHEMBL1309352 & 688341 & 4.7 & 4.8626 & TST & \\
\hline CHEMBL1436644 & 688341 & 4.6 & 5.1137 & TRN & \\
\hline CHEMBL1539540 & 688341 & 4.5 & 4.9016 & TRN & \\
\hline CHEMBL1429565 & 688341 & 4.8 & 5.0727 & TRN & \\
\hline CHEMBL1359463 & 688341 & 4.5 & 4.96 & TRN & \\
\hline CHEMBL1565446 & 688341 & 6.9 & 4.9757 & TRN & \\
\hline CHEMBL1435520 & 688341 & 5.4 & 5.2139 & TST & \\
\hline CHEMBL1539084 & 688341 & 4.5 & 4.8777 & TST & \\
\hline CHEMBL1361677 & 688341 & 5.1 & 5.1373 & TRN & \\
\hline CHEMBL1454438 & 688341 & 4.4 & 5.0262 & TRN & \\
\hline CHEMBL1409230 & 688341 & 4.6 & 4.9475 & TST & \\
\hline CHEMBL1534861 & 688341 & 4.8 & 4.9829 & TST & \\
\hline CHEMBL1428461 & 688341 & 4.4 & 4.9361 & TRN & \\
\hline CHEMBL1365271 & 688341 & 4.9 & 5.0159 & TRN & \\
\hline CHEMBL1412885 & 688341 & 5.4 & 5.178 & TRN & \\
\hline CHEMBL249669 & 688341 & 4.4 & 5.0613 & TST & \\
\hline CHEMBL1403474 & 688341 & 4.7 & 4.8028 & TRN & \\
\hline CHEMBL1451622 & 688341 & 4.5 & $5.0280 e$ & 00000000005 & TRN \\
\hline CHEMBL1509641 & 688341 & 4.6 & 5.1896 & TRN & \\
\hline CHEMBL1388950 & 688341 & 4.9 & 5.0164 & TRN & \\
\hline CHEMBL1401085 & 688341 & 5.0 & 4.894 & TRN & \\
\hline CHEMBL1558881 & 688341 & 5.4 & 4.683 & TRN & \\
\hline CHEMBL1545939 & 688341 & 4.9 & 4.9113 & TRN & \\
\hline CHEMBL1558155 & 688341 & 4.8 & 4.9435 & TST & \\
\hline CHEMBL1385459 & 688341 & 4.4 & 4.8928 & TRN & \\
\hline CHEMBL1479236 & 688341 & 4.6 & 4.8868 & TRN & \\
\hline CHEMBL1539570 & 688341 & 5.5 & 4.934 & TRN & \\
\hline CHEMBL1427049 & 688341 & 4.6 & 4.9779 & TRN & \\
\hline CHEMBL1488213 & 688341 & 5.0 & 4.7829 & TRN & \\
\hline & & & & 2453 & \\
\hline
\end{tabular}




\begin{tabular}{|c|c|c|c|c|}
\hline \multicolumn{5}{|c|}{ Supplemental Table S2.txt } \\
\hline CHEMBL1537166 & 688341 & 4.4 & 4.9654 & TRN \\
\hline CHEMBL166050 & 688341 & 5.0 & 5.0679 & TRN \\
\hline CHEMBL1365075 & 688341 & 5.3 & 4.8898 & TRN \\
\hline CHEMBL1422671 & 688341 & 4.8 & 5.13 & TRN \\
\hline CHEMBL1347057 & 688341 & 4.6 & 5.0935 & TST \\
\hline CHEMBL1581922 & 688341 & 4.5 & 4.7739 & TRN \\
\hline CHEMBL1320893 & 688341 & 4.4 & 5.1101 & TRN \\
\hline CHEMBL 28449 & 688341 & 6.6 & 5.0562 & TRN \\
\hline CHEMBL1458475 & 688341 & 4.6 & 5.0862 & TRN \\
\hline CHEMBL1589801 & 688341 & 4.7 & 4.9586 & TRN \\
\hline CHEMBL1530348 & 688341 & 4.5 & 4.8535 & TRN \\
\hline CHEMBL1553825 & 688341 & 5.6 & 5.1906 & TRN \\
\hline CHEMBL1606336 & 688341 & 4.8 & 5.1561 & TRN \\
\hline CHEMBL1580954 & 688341 & 5.0 & 4.7859 & TRN \\
\hline CHEMBL1594144 & 688341 & 5.5 & 5.0296 & TRN \\
\hline CHEMBL1372513 & 688341 & 4.5 & 4.9526 & TRN \\
\hline CHEMBL1342448 & 688341 & 5.5 & 4.8798 & TRN \\
\hline CHEMBL441282 & 688341 & 4.4 & 4.9982 & TST \\
\hline CHEMBL1340580 & 688341 & 4.5 & 4.7548 & TRN \\
\hline CHEMBL1302017 & 688341 & 4.4 & 4.9327 & TST \\
\hline CHEMBL1489478 & 688341 & 4.6 & 4.9355 & TRN \\
\hline CHEMBL1478445 & 688341 & 5.4 & 4.8948 & TRN \\
\hline CHEMBL1364243 & 688341 & 4.8 & 5.0978 & TRN \\
\hline CHEMBL1528209 & 688341 & 4.6 & 4.9481 & TRN \\
\hline CHEMBL1333631 & 688341 & 5.2 & 4.9913 & TST \\
\hline CHEMBL1497812 & 688341 & 4.7 & 5.0385 & TRN \\
\hline CHEMBL1324772 & 688341 & 4.6 & 4.7855 & TRN \\
\hline CHEMBL1382401 & 688341 & 5.5 & 4.9862 & TST \\
\hline CHEMBL1581648 & 688341 & 5.9 & 4.9591 & TRN \\
\hline CHEMBL1440238 & 688341 & 4.5 & 4.7447 & TRN \\
\hline CHEMBL 227726 & 688341 & 5.5 & 4.7699 & TRN \\
\hline CHEMBL1575586 & 688341 & 4.5 & 4.9092 & TRN \\
\hline CHEMBL1538798 & 688341 & 4.6 & 4.812 & TRN \\
\hline CHEMBL1505732 & 688341 & 4.4 & 4.9106 & TST \\
\hline CHEMBL1449118 & 688341 & 5.2 & 4.7555 & TRN \\
\hline CHEMBL1306273 & 688341 & 6.1 & 4.9543 & TRN \\
\hline CHEMBL1566472 & 688341 & 4.8 & 4.9455 & TRN \\
\hline CHEMBL1446591 & 688341 & 5.4 & 4.8528 & TRN \\
\hline CHEMBL1535530 & 688341 & 4.9 & 4.8068 & TRN \\
\hline CHEMBL1493816 & 688341 & 4.9 & 4.8529 & TRN \\
\hline CHEMBL1462034 & 688341 & 4.4 & 4.9802 & TRN \\
\hline CHEMBL1528116 & 688341 & 5.7 & 4.9328 & TRN \\
\hline CHEMBL1326186 & 688341 & 4.5 & 4.8159 & TRN \\
\hline CHEMBL1487747 & 688341 & 6.2 & 5.0223 & TRN \\
\hline CHEMBL1425968 & 688341 & 4.8 & 5.0772 & TRN \\
\hline CHEMBL1300640 & 688341 & 5.2 & 4.8286 & TRN \\
\hline CHEMBL1427272 & 688341 & 4.9 & 4.8583 & TST \\
\hline CHEMBL1557008 & 688341 & 4.5 & 4.8008 & TRN \\
\hline
\end{tabular}




\begin{tabular}{|c|c|c|c|c|}
\hline \multicolumn{5}{|c|}{ Supplemental Table s2.tx } \\
\hline CHEMBL1435834 & 688341 & 5.1 & 5.1805 & TRN \\
\hline CHEMBL1323547 & 688341 & 4.5 & 4.9086 & TST \\
\hline CHEMBL1575442 & 688341 & 4.4 & 4.7432 & TRN \\
\hline CHEMBL1580002 & 688341 & 4.7 & 4.8761 & TST \\
\hline CHEMBL1513654 & 688341 & 4.4 & 5.1133 & TST \\
\hline CHEMBL1531843 & 688341 & 4.4 & 4.9153 & TRN \\
\hline CHEMBL1327644 & 688341 & 4.5 & 4.9982 & TST \\
\hline CHEMBL1408013 & 688341 & 6.0 & 4.9609 & TRN \\
\hline CHEMBL1361020 & 688341 & 5.1 & 5.0678 & TST \\
\hline CHEMBL1472703 & 688341 & 6.0 & 5.2136 & TRN \\
\hline CHEMBL1435444 & 688341 & 4.5 & 5.0694 & TST \\
\hline CHEMBL1607579 & 688341 & 5.1 & 4.9671 & TRN \\
\hline CHEMBL1463911 & 688341 & 4.9 & 4.8696 & TRN \\
\hline CHEMBL1403733 & 688341 & 5.2 & 4.8886 & TRN \\
\hline CHEMBL491940 & 688341 & 5.3 & 5.0599 & TRN \\
\hline CHEMBL1609660 & 688341 & 5.1 & 4.8005 & TRN \\
\hline CHEMBL1499582 & 688341 & 6.4 & 4.9882 & TRN \\
\hline CHEMBL1316516 & 688341 & 4.6 & 5.1381 & TRN \\
\hline CHEMBL1511410 & 688341 & 5.4 & 5.1204 & TRN \\
\hline CHEMBL1523123 & 688341 & 4.8 & 4.9363 & TRN \\
\hline CHEMBL1334387 & 688341 & 4.4 & 4.9632 & TST \\
\hline CHEMBL1300779 & 688341 & 4.9 & 4.8847 & TST \\
\hline CHEMBL1587441 & 688341 & 5.1 & 5.0095 & TRN \\
\hline CHEMBL1448958 & 688341 & 4.6 & 4.9916 & TST \\
\hline CHEMBL1385762 & 688341 & 4.8 & 4.8734 & TRN \\
\hline CHEMBL1457417 & 688341 & 4.8 & 4.8178 & TRN \\
\hline CHEMBL1339424 & 688341 & 4.9 & 4.9858 & TRN \\
\hline CHEMBL1333157 & 688341 & 4.5 & 5.0795 & TRN \\
\hline CHEMBL1540020 & 688341 & 5.3 & 4.9703 & TRN \\
\hline CHEMBL 3207615 & 688341 & 4.7 & 5.051 & TST \\
\hline CHEMBL1453087 & 688341 & 5.1 & 5.1697 & TRN \\
\hline CHEMBL1469822 & 688341 & 4.6 & 4.7508 & TRN \\
\hline CHEMBL1582811 & 688341 & 5.2 & 4.846 & TRN \\
\hline CHEMBL1303172 & 688341 & 4.4 & 5.0955 & TRN \\
\hline CHEMBL1323436 & 688341 & 5.1 & 4.9496 & TRN \\
\hline CHEMBL1466652 & 688341 & 4.6 & 4.9357 & TST \\
\hline CHEMBL1491009 & 688341 & 5.8 & 5.0611 & TRN \\
\hline CHEMBL1609405 & 688341 & 4.9 & 5.0652 & TRN \\
\hline CHEMBL79824 & 688341 & 5.7 & 5.1052 & TST \\
\hline CHEMBL1531294 & 688341 & 5.2 & 5.1366 & TRN \\
\hline CHEMBL1378854 & 688341 & 5.2 & 5.0081 & TST \\
\hline CHEMBL1507132 & 688341 & 4.6 & 5.0034 & TRN \\
\hline CHEMBL1440656 & 688341 & 4.4 & 4.9081 & TST \\
\hline CHEMBL1525381 & 688341 & 4.7 & 4.768 & TRN \\
\hline CHEMBL1501221 & 688341 & 4.5 & 4.9004 & TRN \\
\hline CHEMBL1498248 & 688341 & 5.6 & 4.7559 & TRN \\
\hline CHEMBL1602353 & 688341 & 5.4 & 4.9768 & TRN \\
\hline CHEMBL1325054 & 688341 & 4.7 & 4.9567 & TRN \\
\hline
\end{tabular}




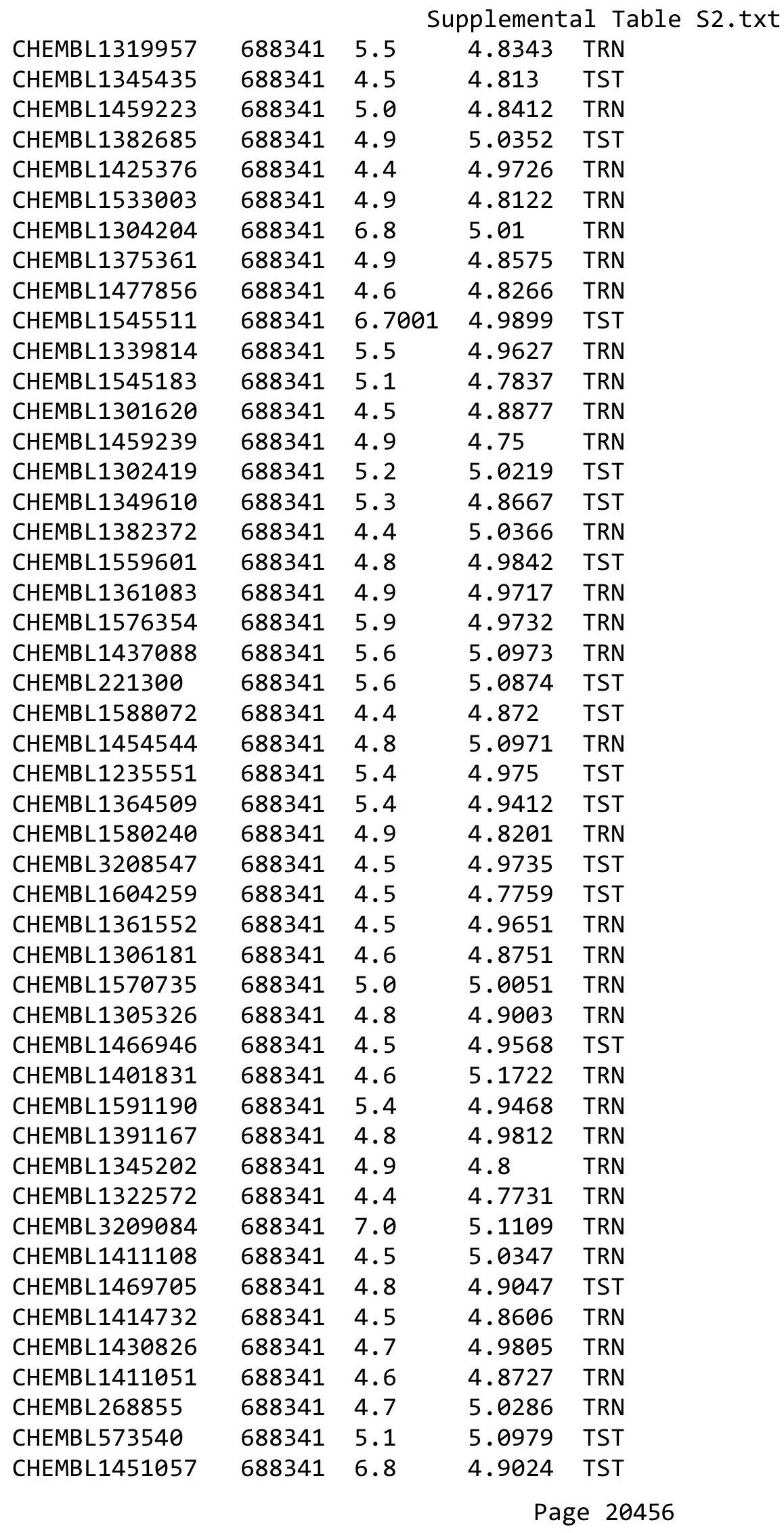




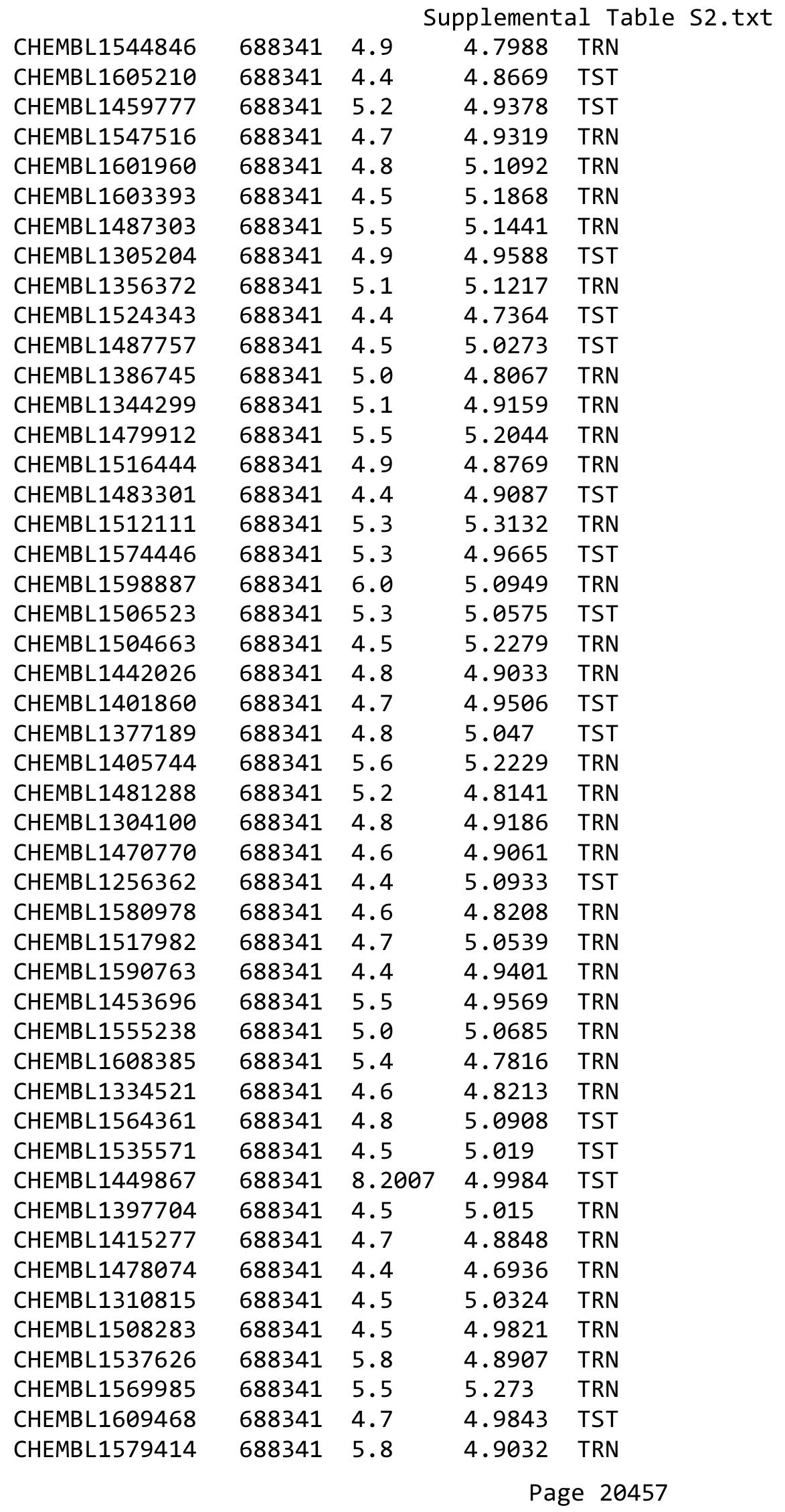




\begin{tabular}{|c|c|c|c|c|}
\hline \multicolumn{5}{|c|}{ Supplemental Table S2.txt } \\
\hline CHEMBL1480919 & 688341 & 5.0 & 4.7933 & TRN \\
\hline CHEMBL1357982 & 688341 & 5.2 & 5.3588 & TRN \\
\hline CHEMBL1480787 & 688341 & 4.8 & 4.8593 & TRN \\
\hline CHEMBL1385555 & 688341 & 4.9 & 4.768 & TRN \\
\hline CHEMBL1385337 & 688341 & 4.4 & 4.9893 & TRN \\
\hline CHEMBL1574985 & 688341 & 4.5 & 4.8022 & TRN \\
\hline CHEMBL1538584 & 688341 & 4.4 & 5.2034 & TST \\
\hline CHEMBL1492559 & 688341 & 5.0 & 4.7894 & TRN \\
\hline CHEMBL1582991 & 688341 & 5.3 & 5.0389 & TST \\
\hline CHEMBL1328732 & 688341 & 4.7 & 4.8957 & TRN \\
\hline CHEMBL1443697 & 688341 & 4.6 & 4.9737 & TRN \\
\hline CHEMBL1559946 & 688341 & 4.4 & 4.9181 & TRN \\
\hline CHEMBL1341220 & 688341 & 5.3 & 5.0084 & TRN \\
\hline CHEMBL1537100 & 688341 & 5.1 & 4.9078 & TRN \\
\hline CHEMBL1379374 & 688341 & 4.7 & 5.0271 & TRN \\
\hline CHEMBL1361276 & 688341 & 4.4 & 4.9276 & TST \\
\hline CHEMBL1320751 & 688341 & 5.3 & 4.8034 & TRN \\
\hline CHEMBL1402689 & 688341 & 7.3002 & 4.9299 & TRN \\
\hline CHEMBL1392144 & 688341 & 5.2 & 5.0037 & TRN \\
\hline CHEMBL1183 & 688341 & 4.9 & 5.1282 & TST \\
\hline CHEMBL1331836 & 688341 & 5.1 & 5.0194 & TRN \\
\hline CHEMBL1398792 & 688341 & 4.4 & 5.016 & TST \\
\hline CHEMBL1609282 & 688341 & 4.6 & 4.7981 & TRN \\
\hline CHEMBL1557284 & 688341 & 4.6 & 4.8395 & TRN \\
\hline CHEMBL1466691 & 688341 & 4.7 & 5.0564 & TST \\
\hline CHEMBL1464080 & 688341 & 4.6 & 4.8616 & TRN \\
\hline CHEMBL1560213 & 688341 & 4.4 & 4.8934 & TRN \\
\hline CHEMBL1539023 & 688341 & 5.0 & 4.9319 & TST \\
\hline CHEMBL3209285 & 688341 & 5.5 & 4.9762 & TST \\
\hline CHEMBL1407945 & 688341 & 4.5 & 4.8062 & TRN \\
\hline CHEMBL1378237 & 688341 & 5.3 & 5.0978 & TRN \\
\hline CHEMBL1554725 & 688341 & 4.4 & 5.1514 & TRN \\
\hline CHEMBL1572276 & 688341 & 4.7 & 5.1726 & TRN \\
\hline CHEMBL1512909 & 688341 & 5.9 & 5.1765 & TST \\
\hline CHEMBL1380725 & 688341 & 4.5 & 4.9951 & TRN \\
\hline CHEMBL463783 & 688341 & 5.6 & 5.0315 & TST \\
\hline CHEMBL1332661 & 688341 & 4.4 & 5.0726 & TST \\
\hline CHEMBL3190015 & 688341 & 4.4 & 5.1039 & TRN \\
\hline CHEMBL1415472 & 688341 & 4.8 & 4.8807 & TST \\
\hline CHEMBL1417004 & 688341 & 5.2 & 4.8344 & TRN \\
\hline CHEMBL1500715 & 688341 & 4.7 & 5.0399 & TRN \\
\hline CHEMBL1526135 & 688341 & 4.8 & 4.7973 & TRN \\
\hline CHEMBL1597656 & 688341 & 4.6 & 4.936 & TRN \\
\hline CHEMBL1576586 & 688341 & 5.5 & 4.8903 & TRN \\
\hline CHEMBL1318622 & 688341 & 5.6 & 5.1957 & TRN \\
\hline CHEMBL1366456 & 688341 & 5.0 & 4.8951 & TRN \\
\hline CHEMBL1328312 & 688341 & 5.2 & 4.8902 & TRN \\
\hline CHEMBL1543652 & 688341 & 4.5 & 4.8651 & TRN \\
\hline
\end{tabular}




\begin{tabular}{|c|c|c|c|c|}
\hline \multicolumn{5}{|c|}{ plemental } \\
\hline CHEMBL1353317 & 688341 & 4.4 & 4.8171 & TRN \\
\hline CHEMBL1365303 & 688341 & 4.4 & 4.9155 & TRN \\
\hline CHEMBL1307475 & 688341 & 4.8 & 5.1389 & TRN \\
\hline CHEMBL1414219 & 688341 & 6.1 & 5.025 & TST \\
\hline CHEMBL1559674 & 688341 & 4.4 & 4.9653 & TRN \\
\hline CHEMBL1484152 & 688341 & 5.1 & 5.0073 & TRN \\
\hline CHEMBL1338424 & 688341 & 5.4 & 5.0285 & TST \\
\hline CHEMBL1371779 & 688341 & 5.2 & 5.02800 & 00000000005 \\
\hline CHEMBL1409547 & 688341 & 4.6 & 4.9437 & TST \\
\hline CHEMBL1386337 & 688341 & 4.6 & 4.8327 & TRN \\
\hline CHEMBL1522303 & 688341 & 4.4 & 5.0349 & TST \\
\hline CHEMBL1439839 & 688341 & 4.7 & 5.1789 & TRN \\
\hline CHEMBL1372590 & 688341 & 4.5 & 4.6628 & TRN \\
\hline CHEMBL1329084 & 688341 & 6.8 & 4.9365 & TRN \\
\hline CHEMBL1490744 & 688341 & 4.5 & 4.811 & TRN \\
\hline CHEMBL1303813 & 688341 & 5.2 & 4.981 & TST \\
\hline CHEMBL1563235 & 688341 & 5.4 & 4.9905 & TST \\
\hline CHEMBL1471212 & 688341 & 5.4 & 4.8419 & TRN \\
\hline CHEMBL1587552 & 688341 & 4.6 & 5.1379 & TRN \\
\hline CHEMBL1351965 & 688341 & 4.5 & 4.6932 & TRN \\
\hline CHEMBL1368432 & 688341 & 5.2 & 4.8974 & TST \\
\hline CHEMBL1256291 & 688341 & 4.7 & 4.9846 & TST \\
\hline CHEMBL1584888 & 688341 & 5.1 & 4.9246 & TRN \\
\hline CHEMBL1591429 & 688341 & 5.8 & 5.0331 & TRN \\
\hline CHEMBL1360433 & 688341 & 4.5 & 4.9207 & TST \\
\hline CHEMBL1463919 & 688341 & 4.8 & 4.9465 & TRN \\
\hline CHEMBL1332509 & 688341 & 5.4 & 4.8558 & TRN \\
\hline CHEMBL1478447 & 688341 & 4.5 & 5.1061 & TRN \\
\hline CHEMBL1355778 & 688341 & 4.8 & 5.0952 & TRN \\
\hline CHEMBL1301849 & 688341 & 4.4 & 5.0417 & TRN \\
\hline CHEMBL1338672 & 688341 & 4.6 & 4.7627 & TRN \\
\hline CHEMBL1334094 & 688341 & 5.3 & 4.7311 & TRN \\
\hline CHEMBL1434762 & 688341 & 4.6 & 5.1046 & TRN \\
\hline CHEMBL1256866 & 688341 & 4.5 & 4.8916 & TRN \\
\hline CHEMBL 272005 & 688341 & 4.4 & 4.8592 & TRN \\
\hline CHEMBL1576613 & 688341 & 4.8 & 4.9673 & TRN \\
\hline CHEMBL195789 & 688341 & 4.8 & 5.0609 & TST \\
\hline CHEMBL1499044 & 688341 & 5.2 & 4.8626 & TRN \\
\hline CHEMBL3189828 & 688341 & 4.5 & 5.0391 & TRN \\
\hline CHEMBL1578301 & 688341 & 4.8 & 4.9409 & TRN \\
\hline CHEMBL1497853 & 688341 & 4.4 & 4.865 & TRN \\
\hline CHEMBL1378396 & 688341 & 8.301 & 4.8906 & TRN \\
\hline CHEMBL532641 & 688341 & 4.8 & 5.0474 & TST \\
\hline CHEMBL1478528 & 688341 & 5.3 & 4.8895 & TRN \\
\hline CHEMBL1387753 & 688341 & 6.4 & 4.7387 & TST \\
\hline CHEMBL1575737 & 688341 & 5.5 & 4.9134 & TST \\
\hline CHEMBL 1302390 & 688341 & 5.0 & 4.8957 & TST \\
\hline CHEMBL1580109 & 688341 & 5.2 & 4.8725 & TST \\
\hline
\end{tabular}




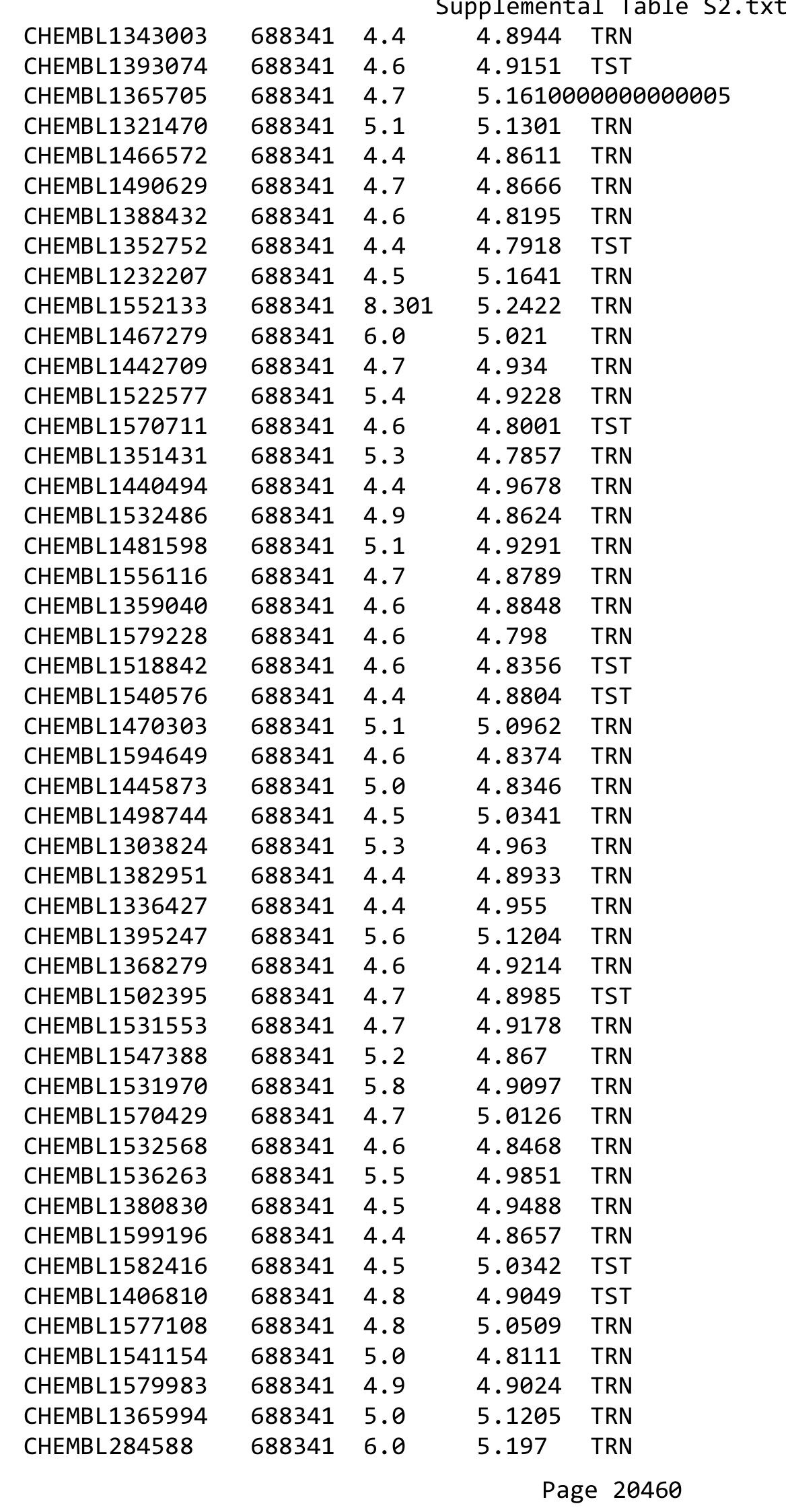

TRN 


\begin{tabular}{|c|c|c|c|c|}
\hline \multicolumn{5}{|c|}{ Supplemental Table S2.txt } \\
\hline CHEMBL1357192 & 688341 & 5.5 & 5.08 & TST \\
\hline CHEMBL1488168 & 688341 & 5.5 & 4.6597 & TST \\
\hline CHEMBL1355396 & 688341 & 4.7 & 5.0835 & TRN \\
\hline CHEMBL1517721 & 688341 & 4.9 & 5.0011 & TRN \\
\hline CHEMBL1605823 & 688341 & 4.8 & 4.9109 & TST \\
\hline CHEMBL1606871 & 688341 & 4.8 & 4.6571 & TRN \\
\hline CHEMBL1316595 & 688341 & 4.4 & 4.7861 & TST \\
\hline CHEMBL1506228 & 688341 & 7.8996 & 5.11100 & 0000000001 \\
\hline CHEMBL1589228 & 688341 & 4.5 & 4.7784 & TRN \\
\hline CHEMBL1517765 & 688341 & 4.8 & 5.0638 & TRN \\
\hline CHEMBL1359472 & 688341 & 5.2 & 5.0857 & TRN \\
\hline CHEMBL1521930 & 688341 & 4.7 & 4.8705 & TRN \\
\hline CHEMBL1476712 & 688341 & 4.9 & 4.9272 & TRN \\
\hline CHEMBL1537448 & 688341 & 5.2 & 4.9889 & TRN \\
\hline CHEMBL1359579 & 688341 & 6.7001 & 4.9533 & TRN \\
\hline CHEMBL1410385 & 688341 & 6.4 & 4.8344 & TRN \\
\hline CHEMBL1369817 & 688341 & 4.9 & 4.9584 & TRN \\
\hline CHEMBL1586195 & 688341 & 4.6 & 4.9783 & TST \\
\hline CHEMBL1511595 & 688341 & 6.8 & 4.9903 & TRN \\
\hline CHEMBL1351619 & 688341 & 6.1 & 5.0486 & TST \\
\hline CHEMBL1380598 & 688341 & 4.5 & 4.7537 & TRN \\
\hline CHEMBL1479372 & 688341 & 5.6 & 5.1325 & TRN \\
\hline CHEMBL1589171 & 688341 & 4.5 & 5.0517 & TRN \\
\hline CHEMBL1605812 & 688341 & 5.2 & 5.1246 & TST \\
\hline CHEMBL1573090 & 688341 & 4.9 & 4.8602 & TRN \\
\hline CHEMBL1411234 & 688341 & 4.8 & 4.8249 & TRN \\
\hline CHEMBL1416951 & 688341 & 5.0 & 4.8217 & TRN \\
\hline CHEMBL1506537 & 688341 & 6.4 & 5.2233 & TRN \\
\hline CHEMBL1316956 & 688341 & 5.5 & 5.2055 & TRN \\
\hline CHEMBL1460095 & 688341 & 4.6 & 5.0851 & TRN \\
\hline CHEMBL1491582 & 688341 & 4.7 & 4.8146 & TRN \\
\hline CHEMBL1500466 & 688341 & 4.5 & 4.8621 & TRN \\
\hline CHEMBL1533680 & 688341 & 4.9 & 5.0869 & TRN \\
\hline CHEMBL1365415 & 688341 & 4.7 & 4.7883 & TRN \\
\hline CHEMBL1610403 & 688341 & 4.4 & 4.7354 & TRN \\
\hline CHEMBL1491274 & 688341 & 4.6 & 5.0095 & TRN \\
\hline CHEMBL1437294 & 688341 & 6.0 & 5.1287 & TRN \\
\hline CHEMBL1485834 & 688341 & 4.8 & 4.7663 & TRN \\
\hline CHEMBL1607499 & 688341 & 4.4 & 5.1102 & TST \\
\hline CHEMBL1412576 & 688341 & 4.4 & 5.0093 & TST \\
\hline CHEMBL1612410 & 688341 & 4.4 & 5.0657 & TRN \\
\hline CHEMBL1309139 & 688341 & 4.8 & 4.7684 & TRN \\
\hline CHEMBL1439027 & 688341 & 6.5 & 5.0943 & TRN \\
\hline CHEMBL1590919 & 688341 & 4.9 & 5.0263 & TRN \\
\hline CHEMBL1482795 & 688341 & 5.1 & 4.8044 & TRN \\
\hline CHEMBL1543264 & 688341 & 5.2 & 4.8809 & TST \\
\hline CHEMBL1536838 & 688341 & 4.5 & 5.0111 & TRN \\
\hline CHEMBL1491677 & 688341 & 4.5 & 4.9063 & TST \\
\hline
\end{tabular}




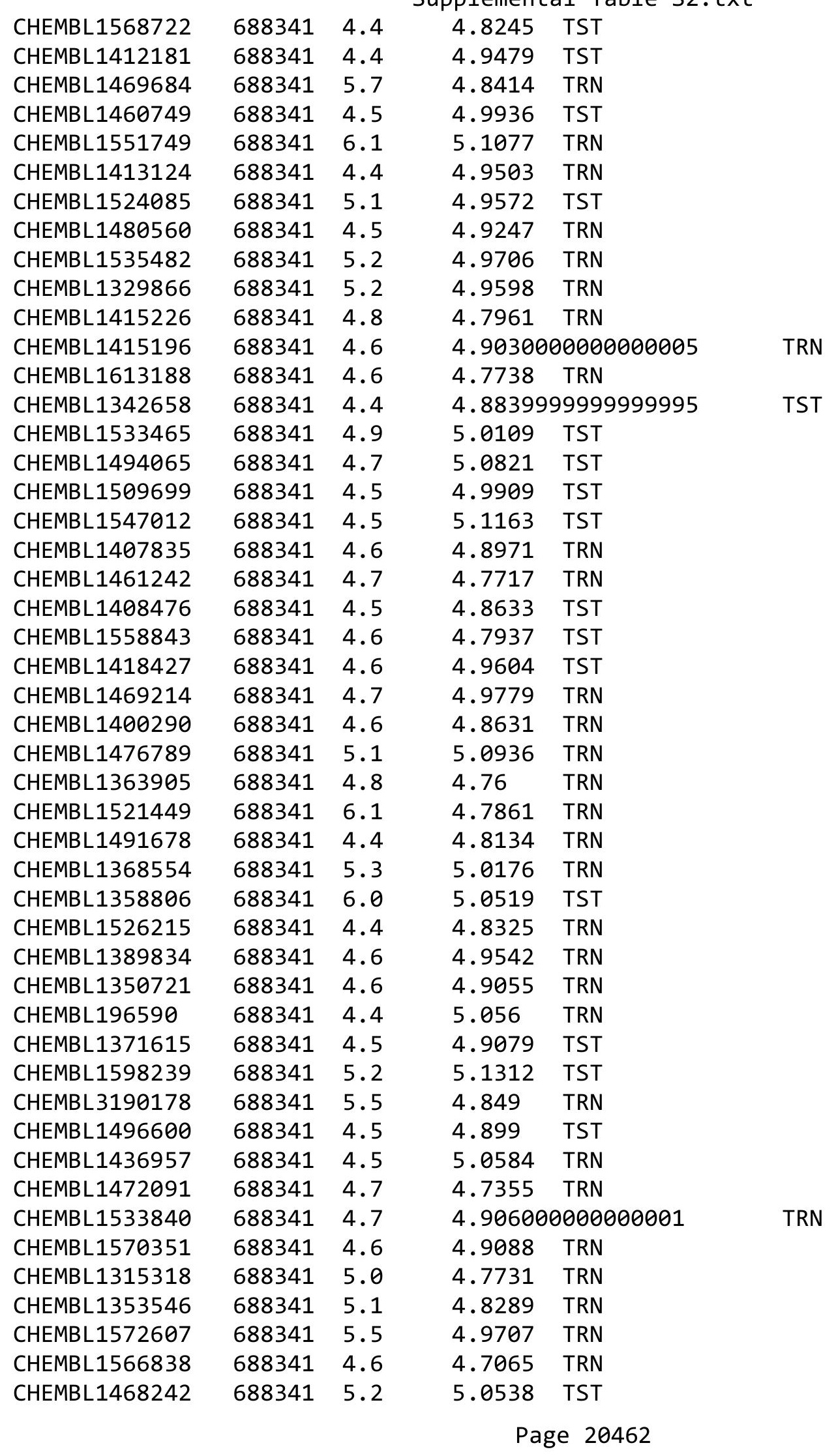




\begin{tabular}{|c|c|c|c|c|}
\hline & & & & \\
\hline CHEMBL1403787 & 688341 & 5.2 & 4.8332 & TRN \\
\hline CHEMBL1408061 & 688341 & 4.5 & 4.8649 & TRN \\
\hline CHEMBL1412260 & 688341 & 4.5 & 4.849 & TRN \\
\hline CHEMBL1361411 & 688341 & 4.4 & 4.841 & TST \\
\hline CHEMBL1373151 & 688341 & 4.5 & 5.1832 & TRN \\
\hline CHEMBL591834 & 688341 & 5.4 & 4.9717 & TST \\
\hline CHEMBL1535801 & 688341 & 4.6 & 5.01 & TRN \\
\hline CHEMBL1309571 & 688341 & 5.3 & 4.9995 & TRN \\
\hline CHEMBL1497924 & 688341 & 4.6 & 4.8018 & TRN \\
\hline CHEMBL1301013 & 688341 & 4.8 & 4.8427 & TRN \\
\hline CHEMBL3192608 & 688341 & 4.4 & 4.9188 & TRN \\
\hline CHEMBL1574201 & 688341 & 4.9 & 4.8355 & TST \\
\hline CHEMBL1518689 & 688341 & 5.0 & 5.1597 & TRN \\
\hline CHEMBL1543263 & 688341 & 5.4 & 4.9442 & TRN \\
\hline CHEMBL1388763 & 688341 & 4.4 & 5.0017 & TST \\
\hline CHEMBL1491100 & 688341 & 4.7 & 4.8604 & TRN \\
\hline CHEMBL1530548 & 688341 & 4.8 & 5.0232 & TRN \\
\hline CHEMBL1589088 & 688341 & 4.8 & 4.8124 & TST \\
\hline CHEMBL1413928 & 688341 & 4.8 & 4.8553 & TRN \\
\hline CHEMBL1521374 & 688341 & 5.3 & 4.8298 & TST \\
\hline CHEMBL1513517 & 688341 & 4.4 & 4.9802 & TRN \\
\hline CHEMBL1327014 & 688341 & 5.1 & 5.0468 & TRN \\
\hline CHEMBL1529470 & 688341 & 4.5 & 4.9959 & TRN \\
\hline CHEMBL1526284 & 688341 & 4.5 & 5.0325 & TST \\
\hline CHEMBL1299435 & 688341 & 5.2 & 4.8875 & TRN \\
\hline CHEMBL1554789 & 688341 & 6.0 & 4.9851 & TST \\
\hline CHEMBL1388477 & 688341 & 4.9 & 4.8731 & TRN \\
\hline CHEMBL1423123 & 688341 & 4.8 & 4.8523 & TST \\
\hline CHEMBL1367076 & 688341 & 4.8 & 5.0616 & TST \\
\hline CHEMBL1520634 & 688341 & 4.5 & 4.9043 & TRN \\
\hline CHEMBL1379259 & 688341 & 5.2 & 4.8555 & TRN \\
\hline CHEMBL1487121 & 688341 & 4.5 & 4.9344 & TRN \\
\hline CHEMBL1327143 & 688341 & 5.8 & 5.1355 & TST \\
\hline CHEMBL1403744 & 688341 & 4.5 & 5.0886 & TST \\
\hline CHEMBL1307245 & 688341 & 4.5 & 5.0161 & TRN \\
\hline CHEMBL1607462 & 688341 & 4.5 & 4.9267 & TST \\
\hline CHEMBL1504424 & 688341 & 4.5 & 4.7059 & TRN \\
\hline CHEMBL1477492 & 688341 & 4.7 & 4.9846 & TRN \\
\hline CHEMBL1434198 & 688341 & 4.8 & 4.9517 & TRN \\
\hline CHEMBL1349227 & 688341 & 5.3 & 4.9648 & TRN \\
\hline CHEMBL 1437873 & 688341 & 4.6 & 4.8033 & TRN \\
\hline CHEMBL600060 & 688341 & 4.7 & 5.0131 & TRN \\
\hline CHEMBL1483602 & 688341 & 4.6 & 4.8328 & TST \\
\hline CHEMBL1321686 & 688341 & 5.6 & 4.8292 & TRN \\
\hline CHEMBL 1342745 & 688341 & 4.5 & 4.8084 & TRN \\
\hline CHEMBL1448726 & 688341 & 4.7 & 5.1887 & TRN \\
\hline CHEMBL1362861 & 688341 & 5.1 & 4.954 & TRN \\
\hline CHEMBL1598104 & 688341 & 4.8 & 4.9988 & TRN \\
\hline
\end{tabular}




\begin{tabular}{|c|c|c|c|c|}
\hline \multicolumn{5}{|c|}{ Supplemental Table S2.txt } \\
\hline CHEMBL3196169 & 688341 & 5.2 & 5.1037 & TST \\
\hline CHEMBL1611258 & 688341 & 4.5 & 4.8475 & TRN \\
\hline CHEMBL1449117 & 688341 & 4.7 & 4.91 & TRN \\
\hline CHEMBL1393191 & 688341 & 4.5 & 4.9746 & TST \\
\hline CHEMBL1490721 & 688341 & 5.5 & 5.2352 & TRN \\
\hline CHEMBL1505867 & 688341 & 4.8 & 4.9635 & TST \\
\hline CHEMBL1591799 & 688341 & 5.5 & 5.0676 & TRN \\
\hline CHEMBL1507334 & 688341 & 4.9 & 4.8915 & TRN \\
\hline CHEMBL1355090 & 688341 & 8.301 & 5.2025 & TRN \\
\hline CHEMBL1457966 & 688341 & 5.1 & 5.0629 & TST \\
\hline CHEMBL1439247 & 688341 & 4.8 & 4.893 & TRN \\
\hline CHEMBL1590857 & 688341 & 4.6 & 4.9122 & TRN \\
\hline CHEMBL1419037 & 688341 & 4.6 & 4.9391 & TRN \\
\hline CHEMBL1498570 & 688341 & 5.0 & 5.1118 & TRN \\
\hline CHEMBL1308495 & 688341 & 5.2 & 4.8796 & TRN \\
\hline CHEMBL1497266 & 688341 & 4.5 & 5.0668 & TRN \\
\hline CHEMBL1506373 & 688341 & 5.0 & 4.8745 & TRN \\
\hline CHEMBL1459560 & 688341 & 4.6 & 4.8471 & TRN \\
\hline CHEMBL1463766 & 688341 & 4.8 & 4.8628 & TRN \\
\hline CHEMBL1407077 & 688341 & 4.4 & 4.8017 & TRN \\
\hline CHEMBL1613574 & 688341 & 5.7 & 4.9508 & TRN \\
\hline CHEMBL1561850 & 688341 & 4.5 & 4.8162 & TRN \\
\hline CHEMBL1609172 & 688341 & 4.5 & 4.8981 & TST \\
\hline CHEMBL1569562 & 688341 & 4.4 & 4.9083 & TRN \\
\hline CHEMBL1570622 & 688341 & 4.4 & 5.0408 & TRN \\
\hline CHEMBL1600935 & 688341 & 4.7 & 4.8589 & TRN \\
\hline CHEMBL1342930 & 688341 & 4.8 & 4.8024 & TRN \\
\hline CHEMBL1520418 & 688341 & 4.7 & 4.9212 & TRN \\
\hline CHEMBL1454662 & 688341 & 4.4 & 4.8014 & TRN \\
\hline CHEMBL1477191 & 688341 & 5.3 & 4.7865 & TRN \\
\hline CHEMBL1300586 & 688341 & 4.9 & 4.9372 & TRN \\
\hline CHEMBL1506437 & 688341 & 7.0 & 4.779 & TRN \\
\hline CHEMBL1545764 & 688341 & 4.8 & 4.8499 & TRN \\
\hline CHEMBL1466669 & 688341 & 6.1 & 5.0081 & TST \\
\hline CHEMBL3197234 & 688341 & 4.5 & 4.8961 & TRN \\
\hline CHEMBL1410374 & 688341 & 4.5 & 4.9035 & TRN \\
\hline CHEMBL1383499 & 688341 & 5.5 & 4.776 & TST \\
\hline CHEMBL1353833 & 688341 & 4.9 & 4.8503 & TST \\
\hline CHEMBL1424548 & 688341 & 4.8 & 4.9508 & TST \\
\hline CHEMBL1339697 & 688341 & 4.6 & 4.7557 & TRN \\
\hline CHEMBL1586326 & 688341 & 6.0 & 4.9231 & TST \\
\hline CHEMBL1305679 & 688341 & 4.5 & 4.8424 & TRN \\
\hline CHEMBL1555348 & 688341 & 4.8 & 4.9749 & TRN \\
\hline CHEMBL1371232 & 688341 & 4.6 & 4.8231 & TRN \\
\hline CHEMBL1470816 & 688341 & 4.4 & 4.8535 & TRN \\
\hline CHEMBL1438811 & 688341 & 5.2 & 5.0499 & TST \\
\hline CHEMBL1494982 & 688341 & 4.8 & 4.9097 & TRN \\
\hline CHEMBL1301702 & 688341 & 5.5 & 5.0346 & TST \\
\hline
\end{tabular}




\begin{tabular}{|c|c|c|c|c|}
\hline & & & pplement & $\mathrm{a} \perp \mathrm{Ta}$ \\
\hline CHEMBL1553808 & 688341 & 4.4 & 5.2077 & TRN \\
\hline CHEMBL1376926 & 688341 & 4.6 & 4.9779 & TRN \\
\hline CHEMBL1313504 & 688341 & 4.6 & 4.954 & TRN \\
\hline CHEMBL1427864 & 688341 & 4.5 & 5.0506 & TST \\
\hline CHEMBL1522803 & 688341 & 4.4 & 5.0706 & TST \\
\hline CHEMBL1595250 & 688341 & 4.4 & 4.8495 & TRN \\
\hline CHEMBL1302806 & 688341 & 5.2 & 5.0291 & TST \\
\hline CHEMBL1339120 & 688341 & 4.6 & 4.8179 & TRN \\
\hline CHEMBL1453216 & 688341 & 4.7 & 5.0792 & TRN \\
\hline CHEMBL1610924 & 688341 & 5.4 & 4.8141 & TRN \\
\hline CHEMBL1595480 & 688341 & 5.7 & 4.8677 & TRN \\
\hline CHEMBL1492058 & 688341 & 5.5 & 4.9301 & TRN \\
\hline CHEMBL1528449 & 688341 & 4.6 & 4.8451 & TRN \\
\hline CHEMBL1406024 & 688341 & 4.8 & 4.8387 & TRN \\
\hline CHEMBL1334650 & 688341 & 4.8 & 5.1483 & TRN \\
\hline CHEMBL1335140 & 688341 & 5.4 & 4.9858 & TRN \\
\hline CHEMBL56 & 688341 & 4.8 & 5.1309 & TRN \\
\hline CHEMBL1564891 & 688341 & 4.5 & 4.9466 & TRN \\
\hline CHEMBL3191143 & 688341 & 5.0 & 4.8746 & TST \\
\hline CHEMBL1363103 & 688341 & 4.8 & 4.8246 & TST \\
\hline CHEMBL1483757 & 688341 & 5.4 & 5.1413 & TRN \\
\hline CHEMBL1523277 & 688341 & 4.6 & 4.9445 & TRN \\
\hline CHEMBL1557553 & 688341 & 5.4 & 5.0338 & TRN \\
\hline CHEMBL1587370 & 688341 & 4.9 & 4.9117 & TST \\
\hline CHEMBL1444257 & 688341 & 4.8 & 4.8833 & TRN \\
\hline CHEMBL1460830 & 688341 & 4.8 & 4.9763 & TRN \\
\hline CHEMBL1532640 & 688341 & 4.5 & 4.8635 & TRN \\
\hline CHEMBL1347291 & 688341 & 4.7 & 4.9946 & TRN \\
\hline CHEMBL1435009 & 688341 & 5.7 & 5.0932 & TRN \\
\hline CHEMBL1487111 & 688341 & 5.3 & 5.1025 & TRN \\
\hline CHEMBL1536768 & 688341 & 4.5 & 5.0732 & TRN \\
\hline CHEMBL1343808 & 688341 & 5.4 & 4.867 & TRN \\
\hline CHEMBL1579463 & 688341 & 5.2 & 4.8172 & TRN \\
\hline CHEMBL1380300 & 688341 & 4.6 & 4.8314 & TRN \\
\hline CHEMBL1600302 & 688341 & 4.6 & 4.9274 & TRN \\
\hline CHEMBL1502958 & 688341 & 5.5 & 4.8351 & TRN \\
\hline CHEMBL1441062 & 688341 & 5.1 & 4.8839 & TRN \\
\hline CHEMBL1574041 & 688341 & 4.6 & 4.9196 & TRN \\
\hline CHEMBL1446407 & 688341 & 5.2 & 4.9284 & TRN \\
\hline CHEMBL1299374 & 688341 & 4.9 & 4.7486 & TST \\
\hline CHEMBL1423046 & 688341 & 4.8 & 5.0725 & TRN \\
\hline CHEMBL1549473 & 688341 & 5.2 & 5.1039 & TRN \\
\hline CHEMBL1586884 & 688341 & 5.2 & 4.978 & TRN \\
\hline CHEMBL1455094 & 688341 & 4.7 & 4.9345 & TRN \\
\hline CHEMBL1448607 & 688341 & 5.9 & 4.9964 & TRN \\
\hline CHEMBL1411543 & 688341 & 6.0 & 5.1279 & TRN \\
\hline CHEMBL1485328 & 688341 & 4.8 & 4.9125 & TRN \\
\hline CHEMBL1256656 & 688341 & 5.2 & 4.8398 & TST \\
\hline
\end{tabular}




\begin{tabular}{|c|c|c|c|c|c|}
\hline \multicolumn{6}{|c|}{ Supplemental Table S2.txt } \\
\hline CHEMBL1491107 & 688341 & 5.1 & 4.915 & TST & \\
\hline CHEMBL1576221 & 688341 & 4.8 & 4.9293 & TRN & \\
\hline CHEMBL1333013 & 688341 & 5.1 & 4.8634 & TRN & \\
\hline CHEMBL1409783 & 688341 & 7.0 & 5.0452 & TRN & \\
\hline CHEMBL1606289 & 688341 & 5.1 & 5.0215 & TRN & \\
\hline CHEMBL1529715 & 688341 & 4.6 & 4.9845 & TRN & \\
\hline CHEMBL1311151 & 688341 & 6.7001 & 5.0354 & TRN & \\
\hline CHEMBL1303637 & 688341 & 4.5 & 4.9149 & TRN & \\
\hline CHEMBL1319752 & 688341 & 4.6 & 4.8583 & TST & \\
\hline CHEMBL3214375 & 688341 & 4.8 & 5.021 & TRN & \\
\hline CHEMBL1605605 & 688341 & 6.0 & 5.0514 & TST & \\
\hline CHEMBL250969 & 688341 & 5.2 & 5.04 & TRN & \\
\hline CHEMBL1489035 & 688341 & 4.8 & 4.8704 & TST & \\
\hline CHEMBL1350634 & 688341 & 4.5 & 4.8683 & TRN & \\
\hline CHEMBL1471531 & 688341 & 5.2 & 4.9906 & TRN & \\
\hline CHEMBL1603264 & 688341 & 4.8 & 4.9843 & TST & \\
\hline CHEMBL1312533 & 688341 & 4.4 & 5.2085 & TST & \\
\hline CHEMBL1345083 & 688341 & 4.8 & 4.7977 & TRN & \\
\hline CHEMBL1332706 & 688341 & 5.4 & 4.8832 & TRN & \\
\hline CHEMBL1606087 & 688341 & 4.8 & 4.8655 & TST & \\
\hline CHEMBL1448617 & 688341 & 5.5 & 4.9484 & TRN & \\
\hline CHEMBL1402888 & 688341 & 5.0 & 5.0455 & TST & \\
\hline CHEMBL1456526 & 688341 & 5.8 & 4.7831 & TRN & \\
\hline CHEMBL3209382 & 688341 & 4.8 & 4.8316 & TRN & \\
\hline CHEMBL1545249 & 688341 & 4.6 & 4.9898 & TST & \\
\hline CHEMBL1399289 & 688341 & 4.5 & 4.669 & TRN & \\
\hline CHEMBL1536373 & 688341 & 4.6 & 4.9633 & TRN & \\
\hline CHEMBL1305663 & 688341 & 5.1 & 4.98306 & 00000000005 & TST \\
\hline CHEMBL1499224 & 688341 & 5.1 & 5.0043 & TRN & \\
\hline CHEMBL1435907 & 688341 & 4.6 & 4.9399 & TRN & \\
\hline CHEMBL1609428 & 688341 & 4.5 & 4.9621 & TRN & \\
\hline CHEMBL1336823 & 688341 & 4.9 & 4.9732 & TST & \\
\hline CHEMBL1537077 & 688341 & 5.2 & 4.9404 & TRN & \\
\hline CHEMBL1423358 & 688341 & 4.5 & 4.9711 & TRN & \\
\hline CHEMBL1318041 & 688341 & 5.0 & 5.0583 & TRN & \\
\hline CHEMBL1450380 & 688341 & 4.4 & 4.755 & TRN & \\
\hline CHEMBL1336686 & 688341 & 4.6 & 4.8104 & TRN & \\
\hline CHEMBL1469079 & 688341 & 4.8 & 4.9946 & TRN & \\
\hline CHEMBL1396298 & 688341 & 4.5 & 5.1557 & TRN & \\
\hline CHEMBL1470060 & 688341 & 5.9 & $4.7860 e$ & 00000000005 & TRN \\
\hline CHEMBL1474302 & 688341 & 5.0 & 4.9949 & TRN & \\
\hline CHEMBL1344551 & 688341 & 4.8 & 4.8862 & TST & \\
\hline CHEMBL1457138 & 688341 & 4.4 & 5.0513 & TRN & \\
\hline CHEMBL1409946 & 688341 & 4.7 & 4.825 & TRN & \\
\hline CHEMBL1602394 & 688341 & 5.8 & 5.0348 & TRN & \\
\hline CHEMBL1584027 & 688341 & 5.2 & 5.0202 & TST & \\
\hline CHEMBL1538542 & 688341 & 5.1 & 5.0438 & TRN & \\
\hline CHEMBL1520860 & 688341 & 4.8 & 4.8776 & TRN & \\
\hline
\end{tabular}




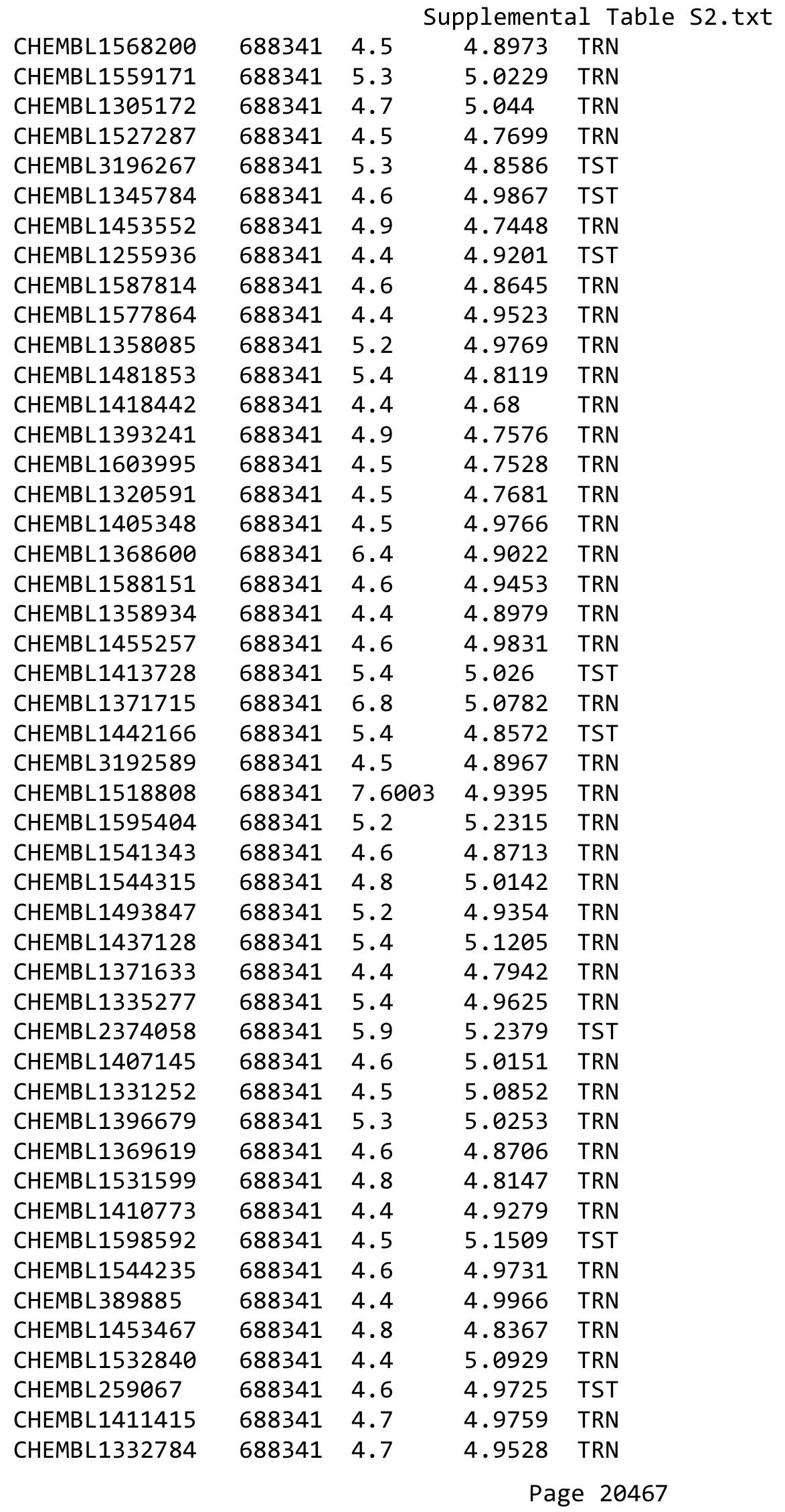




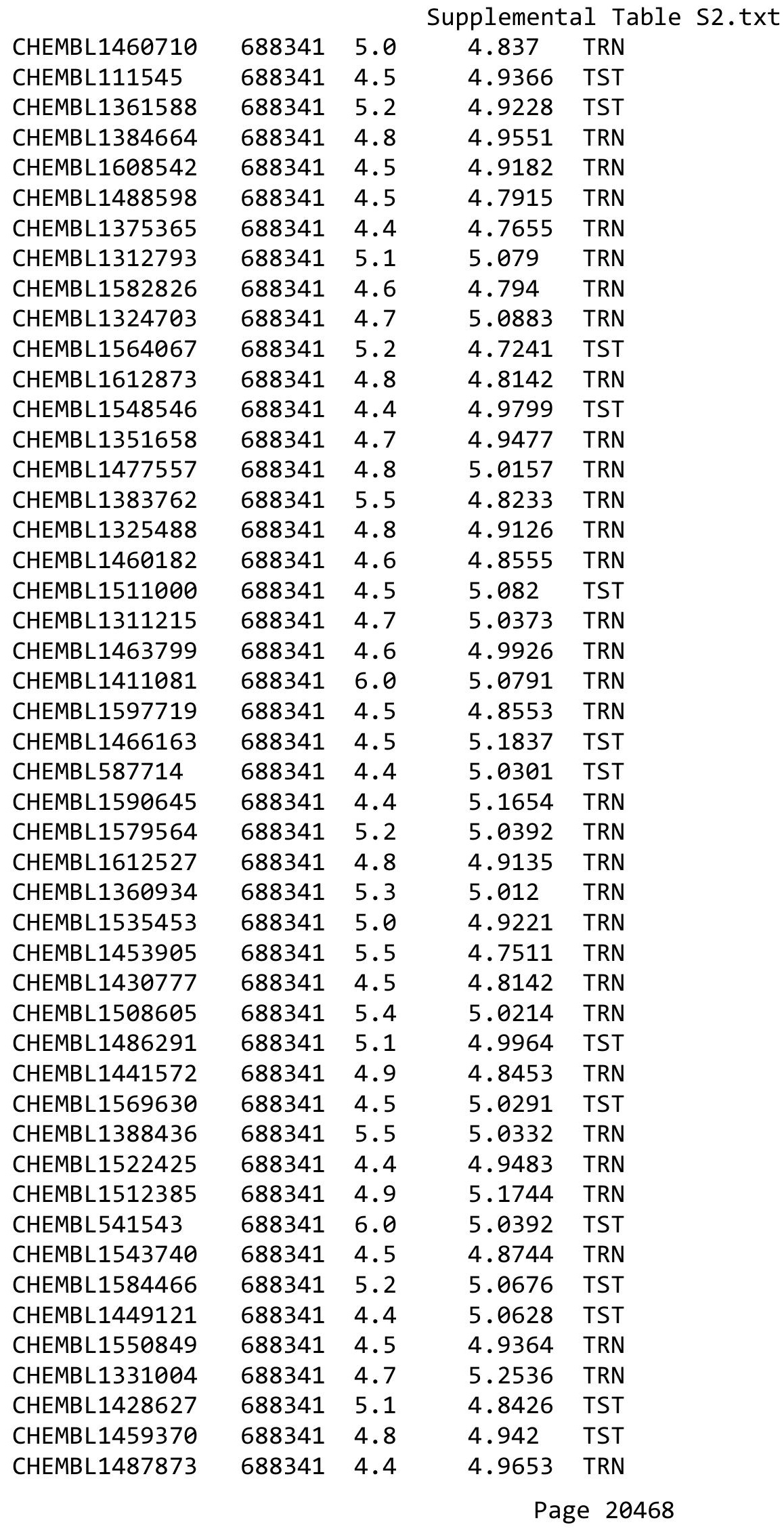




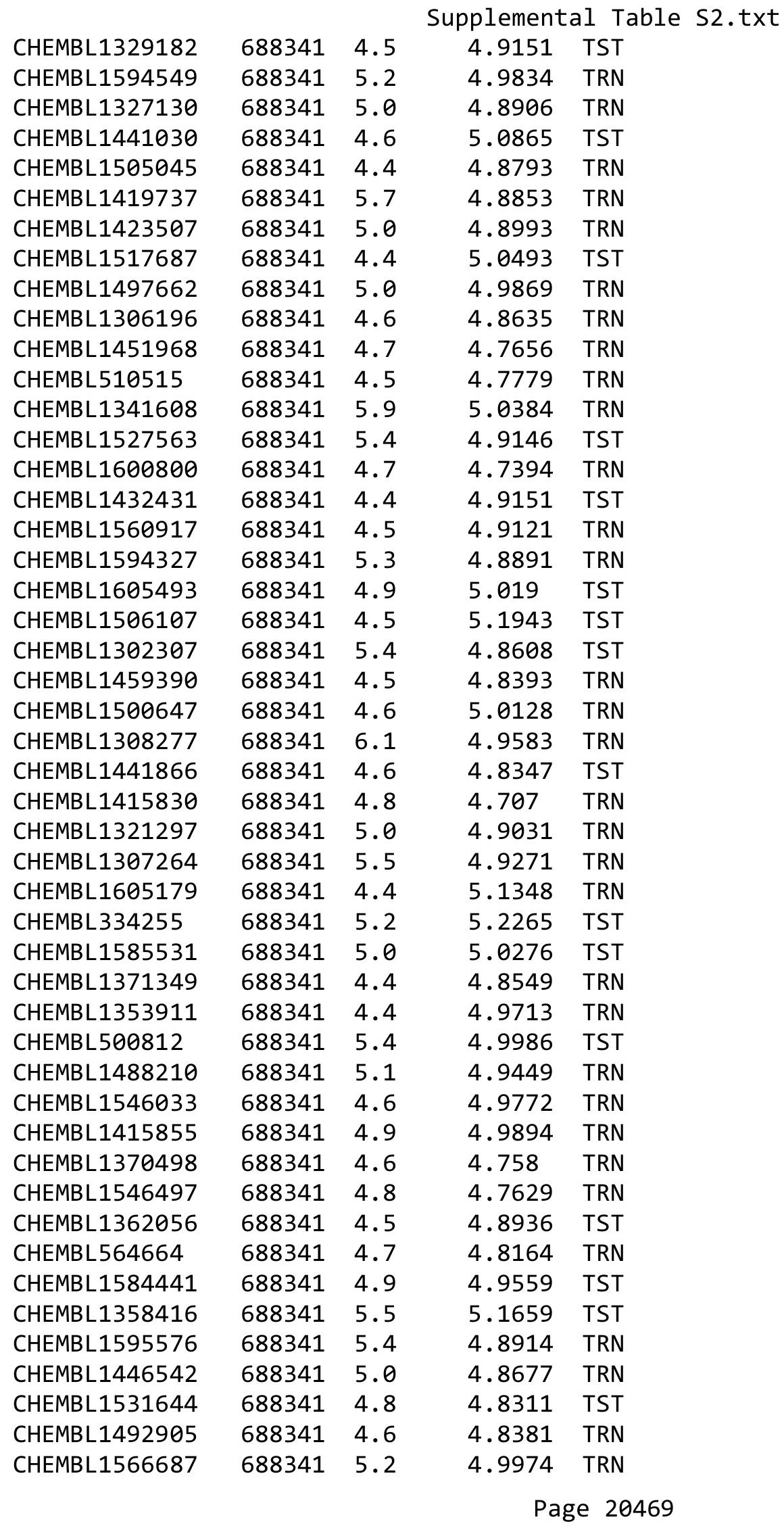




\begin{tabular}{|c|c|c|c|c|c|}
\hline & & & & & \\
\hline CHEMBL1384654 & 688341 & 5.2 & 4.7799 & TRN & \\
\hline CHEMBL1377929 & 688341 & 5.4 & 5.0305 & TRN & \\
\hline CHEMBL1530185 & 688341 & 5.1 & 4.8653 & TRN & \\
\hline CHEMBL1387014 & 688341 & 4.6 & 4.8307 & TRN & \\
\hline CHEMBL1608446 & 688341 & 4.4 & 4.819 & TRN & \\
\hline CHEMBL1558739 & 688341 & 4.4 & 4.9817 & TST & \\
\hline CHEMBL1302766 & 688341 & 4.9 & 5.1059 & TRN & \\
\hline CHEMBL1597471 & 688341 & 4.7 & 4.942 & TST & \\
\hline CHEMBL1299992 & 688341 & 4.6 & 4.8127 & TRN & \\
\hline CHEMBL1478630 & 688341 & 4.4 & 4.7844 & TRN & \\
\hline CHEMBL1494499 & 688341 & 5.1 & 4.882 & TST & \\
\hline CHEMBL1446926 & 688341 & 4.6 & 4.7367 & TRN & \\
\hline CHEMBL1479506 & 688341 & 5.7 & 5.0979 & TRN & \\
\hline CHEMBL1393221 & 688341 & 4.6 & $4.7810 e$ & 2000000001 & TRN \\
\hline CHEMBL1522352 & 688341 & 4.5 & 4.8358 & TRN & \\
\hline CHEMBL1353929 & 688341 & 4.8 & 4.9127 & TRN & \\
\hline CHEMBL1611235 & 688341 & 5.4 & 5.0072 & TRN & \\
\hline CHEMBL1430921 & 688341 & 4.4 & 4.8297 & TRN & \\
\hline CHEMBL579224 & 688341 & 4.4 & 5.0256 & TST & \\
\hline CHEMBL1376416 & 688341 & 4.8 & $4.8610 e$ & 0000000001 & TRN \\
\hline CHEMBL1405511 & 688341 & 4.7 & 5.0161 & TRN & \\
\hline CHEMBL1300519 & 688341 & 4.9 & 4.918 & TRN & \\
\hline CHEMBL12327 & 688341 & 5.4 & 5.0476 & TST & \\
\hline CHEMBL1444983 & 688341 & 4.5 & 4.9725 & TRN & \\
\hline CHEMBL82224 & 688341 & 6.5 & 4.9472 & TST & \\
\hline CHEMBL1341829 & 688341 & 4.7 & 4.8795 & TRN & \\
\hline CHEMBL1389688 & 688341 & 4.5 & 4.9341 & TRN & \\
\hline CHEMBL1256484 & 688341 & 4.5 & 5.1622 & TST & \\
\hline CHEMBL1599435 & 688341 & 6.3 & 4.9623 & TRN & \\
\hline CHEMBL1588463 & 688341 & 4.6 & 4.8287 & TRN & \\
\hline CHEMBL1455106 & 688341 & 4.6 & 5.0309 & TRN & \\
\hline CHEMBL1390006 & 688341 & 5.4 & 4.7641 & TRN & \\
\hline CHEMBL1341771 & 688341 & 6.0 & 4.9719 & TRN & \\
\hline CHEMBL1530275 & 688341 & 5.4 & 5.0257 & TRN & \\
\hline CHEMBL1305371 & 688341 & 6.0 & 4.8872 & TST & \\
\hline CHEMBL1485295 & 688341 & 4.4 & 4.9512 & TRN & \\
\hline CHEMBL1566094 & 688341 & 4.7 & 4.7879 & TST & \\
\hline CHEMBL1573269 & 688341 & 5.3 & 4.9119 & TRN & \\
\hline CHEMBL1334270 & 688341 & 4.6 & 4.9942 & TST & \\
\hline CHEMBL1612859 & 688341 & 4.5 & 4.7755 & TRN & \\
\hline CHEMBL1492834 & 688341 & 4.4 & 4.9251 & TRN & \\
\hline CHEMBL1512895 & 688341 & 5.2 & $5.1610 e$ & 00000000005 & TRN \\
\hline CHEMBL1389124 & 688341 & 4.9 & 4.8208 & TRN & \\
\hline CHEMBL1469918 & 688341 & 5.1 & 4.8674 & TRN & \\
\hline CHEMBL1588215 & 688341 & 6.0 & 5.0584 & TRN & \\
\hline CHEMBL1565242 & 688341 & 5.4 & 4.8053 & TRN & \\
\hline CHEMBL1483862 & 688341 & 4.8 & 5.2154 & TST & \\
\hline CHEMBL1432952 & 688341 & 4.8 & 4.9977 & TST & \\
\hline & & & & 20470 & \\
\hline
\end{tabular}




\begin{tabular}{|c|c|c|c|c|}
\hline \multicolumn{5}{|c|}{ Supplemental Table S2.txt } \\
\hline CHEMBL1496903 & 688341 & 4.5 & 4.8119 & TRN \\
\hline CHEMBL1540358 & 688341 & 4.5 & 5.0606 & TST \\
\hline CHEMBL1329728 & 688341 & 4.5 & 4.9764 & TST \\
\hline CHEMBL1383693 & 688341 & 4.6 & 4.9932 & TST \\
\hline CHEMBL1500506 & 688341 & 6.3 & 4.8566 & TST \\
\hline CHEMBL1528428 & 688341 & 5.3 & 4.9862 & TST \\
\hline CHEMBL1302506 & 688341 & 4.7 & 4.8804 & TRN \\
\hline CHEMBL1310445 & 688341 & 4.5 & 4.88 & TRN \\
\hline CHEMBL1599734 & 688341 & 6.7001 & 5.0227 & TRN \\
\hline CHEMBL1512780 & 688341 & 4.5 & 5.1463 & TRN \\
\hline CHEMBL1312203 & 688341 & 4.8 & 5.0267 & TRN \\
\hline CHEMBL1516373 & 688341 & 5.4 & 4.9966 & TRN \\
\hline CHEMBL1402797 & 688341 & 4.5 & 4.8448 & TRN \\
\hline CHEMBL1349982 & 688341 & 4.6 & 4.8468 & TRN \\
\hline CHEMBL376103 & 688341 & 6.0 & 5.0031 & TST \\
\hline CHEMBL1447214 & 688341 & 6.0 & 5.21200 & 0000000001 \\
\hline CHEMBL1449702 & 688341 & 5.5 & 4.8898 & TRN \\
\hline CHEMBL1464734 & 688341 & 4.4 & 4.9601 & TRN \\
\hline CHEMBL1573220 & 688341 & 4.6 & 4.9704 & TRN \\
\hline CHEMBL1454728 & 688341 & 4.6 & 4.9243 & TRN \\
\hline CHEMBL1529176 & 688341 & 4.4 & 4.7924 & TRN \\
\hline CHEMBL1325339 & 688341 & 4.7 & 4.9916 & TRN \\
\hline CHEMBL1350075 & 688341 & 5.1 & 4.7692 & TRN \\
\hline CHEMBL1501868 & 688341 & 4.9 & 5.0232 & TRN \\
\hline CHEMBL1405769 & 688341 & 4.6 & 4.8677 & TRN \\
\hline CHEMBL1505042 & 688341 & 5.4 & 5.0157 & TRN \\
\hline CHEMBL1489967 & 688341 & 5.1 & 5.0914 & TRN \\
\hline CHEMBL 296586 & 688341 & 4.4 & 5.1063 & TST \\
\hline CHEMBL1338771 & 688341 & 6.0 & 4.9407 & TRN \\
\hline CHEMBL1319310 & 688341 & 4.7 & 4.9118 & TRN \\
\hline CHEMBL1494655 & 688341 & 5.3 & 4.9754 & TRN \\
\hline CHEMBL1386350 & 688341 & 4.7 & 4.9006 & TRN \\
\hline CHEMBL1568982 & 688341 & 4.4 & 4.8074 & TRN \\
\hline CHEMBL1373648 & 688341 & 4.6 & 4.952 & TRN \\
\hline CHEMBL1559127 & 688341 & 5.9 & 5.1052 & TRN \\
\hline CHEMBL1560296 & 688341 & 4.5 & 4.9783 & TST \\
\hline CHEMBL1528654 & 688341 & 6.3 & 5.1098 & TST \\
\hline CHEMBL1360748 & 688341 & 4.5 & 4.9057 & TST \\
\hline CHEMBL1442312 & 688341 & 4.6 & 4.8304 & TRN \\
\hline CHEMBL1361777 & 688341 & 4.4 & 4.8211 & TRN \\
\hline CHEMBL1543382 & 688341 & 4.6 & 4.8602 & TRN \\
\hline CHEMBL310798 & 688341 & 4.4 & 5.0867 & TRN \\
\hline CHEMBL1482007 & 688341 & 4.5 & 4.8031 & TRN \\
\hline CHEMBL1407493 & 688341 & 4.6 & 4.849 & TRN \\
\hline CHEMBL1448658 & 688341 & 5.5 & 5.0012 & TST \\
\hline CHEMBL1485929 & 688341 & 4.4 & 4.8422 & TRN \\
\hline CHEMBL1542000 & 688341 & 4.4 & 4.9282 & TRN \\
\hline CHEMBL1525774 & 688341 & 4.6 & 4.999 & TRN \\
\hline
\end{tabular}




\begin{tabular}{|c|c|c|c|c|}
\hline & & & & \\
\hline CHEMBL1304744 & 688341 & 4.4 & 5.209 & TST \\
\hline CHEMBL 275809 & 688341 & 4.5 & 4.8156 & TST \\
\hline CHEMBL1326338 & 688341 & 5.3 & 5.069 & TST \\
\hline CHEMBL 3189201 & 688341 & 4.8 & 4.7586 & TST \\
\hline CHEMBL1316292 & 688341 & 4.7 & 4.94 & TRN \\
\hline CHEMBL1076555 & 688341 & 4.8 & 4.8559 & TRN \\
\hline CHEMBL1569606 & 688341 & 4.6 & 4.971 & TRN \\
\hline CHEMBL1541064 & 688341 & 5.1 & 4.9453 & TRN \\
\hline CHEMBL1370057 & 688341 & 4.8 & 5.0658 & TST \\
\hline CHEMBL1430798 & 688341 & 4.4 & 5.0417 & TST \\
\hline CHEMBL1361840 & 688341 & 4.9 & 4.9236 & TRN \\
\hline CHEMBL1408236 & 688341 & 5.5 & 4.8948 & TRN \\
\hline CHEMBL1411088 & 688341 & 4.6 & 4.8354 & TRN \\
\hline CHEMBL1324166 & 688341 & 4.5 & 4.9056 & TST \\
\hline CHEMBL1583433 & 688341 & 5.3 & 5.0111 & TRN \\
\hline CHEMBL46703 & 688341 & 4.5 & 5.1721 & TRN \\
\hline CHEMBL153658 & 688341 & 5.3 & 5.1428 & TST \\
\hline CHEMBL1445788 & 688341 & 6.8 & 4.7085 & TRN \\
\hline CHEMBL1319109 & 688341 & 5.2 & 4.8503 & TRN \\
\hline CHEMBL1400181 & 688341 & 4.9 & 5.0479 & TST \\
\hline CHEMBL1355186 & 688341 & 5.9 & 5.0223 & TRN \\
\hline CHEMBL1494165 & 688341 & 4.4 & 4.8771 & TRN \\
\hline CHEMBL1439987 & 688341 & 4.7 & 4.963 & TRN \\
\hline CHEMBL534084 & 688341 & 5.0 & 5.069 & TST \\
\hline CHEMBL1568497 & 688341 & 4.9 & 4.7382 & TRN \\
\hline CHEMBL1353426 & 688341 & 4.5 & 4.896 & TRN \\
\hline CHEMBL1460488 & 688341 & 4.6 & 4.9138 & TRN \\
\hline CHEMBL1567100 & 688341 & 4.6 & 4.7465 & TRN \\
\hline CHEMBL1496517 & 688341 & 4.7 & 4.9421 & TRN \\
\hline CHEMBL1592117 & 688341 & 4.5 & 5.0522 & TRN \\
\hline CHEMBL1459678 & 688341 & 4.6 & 4.9076 & TRN \\
\hline CHEMBL1571520 & 688341 & 4.9 & 5.0067 & TST \\
\hline CHEMBL1522582 & 688341 & 4.7 & 4.9959 & TRN \\
\hline CHEMBL1346183 & 688341 & 5.2 & 4.8917 & TST \\
\hline CHEMBL1424211 & 688341 & 4.6 & 4.9037 & TST \\
\hline CHEMBL389516 & 688341 & 5.3 & 4.8659 & TST \\
\hline CHEMBL1458653 & 688341 & 4.9 & 5.0493 & TRN \\
\hline CHEMBL1540621 & 688341 & 4.5 & 4.9149 & TRN \\
\hline CHEMBL1334475 & 688341 & 4.6 & 4.8541 & TRN \\
\hline CHEMBL1412662 & 688341 & 4.8 & 4.9535 & TRN \\
\hline CHEMBL1425896 & 688341 & 5.2 & 4.7657 & TRN \\
\hline CHEMBL1337075 & 688341 & 4.7 & 4.8228 & TRN \\
\hline CHEMBL1601980 & 688341 & 5.2 & 4.8109 & TRN \\
\hline CHEMBL3210295 & 688341 & 6.0 & 4.7972 & TRN \\
\hline CHEMBL1339727 & 688341 & 4.6 & 4.9926 & TRN \\
\hline CHEMBL472931 & 688341 & 5.2 & 4.8546 & TST \\
\hline CHEMBL1410347 & 688341 & 5.8 & 5.0294 & TST \\
\hline CHEMBL1402799 & 688341 & 4.6 & 5.0691 & TRN \\
\hline
\end{tabular}




\begin{tabular}{|c|c|c|c|c|c|}
\hline \\
\hline CHEMBL1543224 & 688341 & 4.4 & 4.8645 & TRN & \\
\hline CHEMBL1594460 & 688341 & 6.1 & 4.9197 & TRN & \\
\hline CHEMBL1340404 & 688341 & 5.3 & 5.0601 & TST & \\
\hline CHEMBL1432175 & 688341 & 4.5 & 4.7442 & TRN & \\
\hline CHEMBL1490572 & 688341 & 5.2 & 5.0072 & TST & \\
\hline CHEMBL137035 & 688341 & 8.0 & 5.0268 & TST & \\
\hline CHEMBL1526697 & 688341 & 4.9 & 5.0481 & TRN & \\
\hline CHEMBL1487536 & 688341 & 5.4 & 4.8649 & TRN & \\
\hline CHEMBL1426650 & 688341 & 5.5 & 4.9431 & TRN & \\
\hline CHEMBL1483913 & 688341 & 5.3 & 5.0041 & TRN & \\
\hline CHEMBL1406020 & 688341 & 5.3 & 4.9496 & TRN & \\
\hline CHEMBL1447444 & 688341 & 4.9 & 4.7586 & TRN & \\
\hline CHEMBL1545426 & 688341 & 4.6 & 4.8724 & TRN & \\
\hline CHEMBL1387832 & 688341 & 4.7 & 5.0031 & TRN & \\
\hline CHEMBL1331654 & 688341 & 5.5 & 4.9584 & TST & \\
\hline CHEMBL1606077 & 688341 & 4.4 & 5.0359 & TST & \\
\hline CHEMBL1592202 & 688341 & 5.4 & 4.9388 & TRN & \\
\hline CHEMBL1478700 & 688341 & 4.6 & 4.8463 & TRN & \\
\hline CHEMBL1327950 & 688341 & 5.7 & 5.0028 & TST & \\
\hline CHEMBL541585 & 688341 & 5.2 & 5.0531 & TRN & \\
\hline CHEMBL1537094 & 688341 & 4.4 & 5.0405 & TRN & \\
\hline CHEMBL1447026 & 688341 & 4.7 & 4.9606 & TRN & \\
\hline CHEMBL1488642 & 688341 & 4.5 & 4.9008 & TRN & \\
\hline CHEMBL1489891 & 688341 & 4.5 & 4.886 & TRN & \\
\hline CHEMBL411492 & 688341 & 4.5 & 4.9919 & TRN & \\
\hline CHEMBL1471814 & 688341 & 5.4 & 5.0597 & TST & \\
\hline CHEMBL1569486 & 688341 & 6.4 & 5.00899 & 99999999995 & TST \\
\hline CHEMBL1316745 & 688341 & 5.2 & 5.0028 & TRN & \\
\hline CHEMBL1479267 & 688341 & 4.4 & 5.0377 & TST & \\
\hline CHEMBL1425965 & 688341 & 4.6 & 4.8838 & TST & \\
\hline CHEMBL1498356 & 688341 & 4.7 & 4.8572 & TRN & \\
\hline CHEMBL1363566 & 688341 & 4.4 & 4.955 & TST & \\
\hline CHEMBL1613699 & 688341 & 5.2 & 4.9761 & TRN & \\
\hline CHEMBL1479211 & 688341 & 4.7 & 4.7645 & TRN & \\
\hline CHEMBL1360647 & 688341 & 4.9 & 4.9776 & TRN & \\
\hline CHEMBL1327326 & 688341 & 4.5 & 4.827 & TRN & \\
\hline CHEMBL1579944 & 688341 & 5.2 & 5.0415 & TRN & \\
\hline CHEMBL1308487 & 688341 & 5.0 & 4.8529 & TST & \\
\hline CHEMBL1420150 & 688341 & 4.9 & 4.9954 & TST & \\
\hline CHEMBL460515 & 688341 & 4.5 & 4.8744 & TST & \\
\hline CHEMBL1406645 & 688341 & 4.4 & 5.06800 & 20000000005 & TST \\
\hline CHEMBL1571828 & 688341 & 4.6 & 4.8856 & TRN & \\
\hline CHEMBL1402656 & 688341 & 4.9 & 5.0361 & TRN & \\
\hline CHEMBL1507422 & 688341 & 4.5 & 4.8696 & TRN & \\
\hline CHEMBL1354154 & 688341 & 5.4 & 5.1364 & TRN & \\
\hline CHEMBL1467064 & 688341 & 5.3 & 4.7525 & TST & \\
\hline CHEMBL1459188 & 688341 & 4.7 & 4.9834 & TST & \\
\hline CHEMBL393417 & 688341 & 4.7 & 5.1612 & TST & \\
\hline
\end{tabular}




\begin{tabular}{|c|c|c|c|c|}
\hline \multicolumn{5}{|c|}{ Supplemental Table S2.txt } \\
\hline CHEMBL1318799 & 688341 & 5.9 & 5.193 & TRN \\
\hline CHEMBL1381512 & 688341 & 4.7 & 4.9303 & TRN \\
\hline CHEMBL1414773 & 688341 & 4.6 & 4.9336 & TST \\
\hline CHEMBL1488613 & 688341 & 5.1 & 5.0425 & TRN \\
\hline CHEMBL1428337 & 688341 & 4.4 & 4.7752 & TST \\
\hline CHEMBL1450221 & 688341 & 4.9 & 4.9081 & TRN \\
\hline CHEMBL1326691 & 688341 & 4.7 & 4.9018 & TRN \\
\hline CHEMBL1375193 & 688341 & 5.2 & 4.8895 & TRN \\
\hline CHEMBL1368866 & 688341 & 4.4 & 4.8947 & TRN \\
\hline CHEMBL1567017 & 688341 & 4.6 & 4.9394 & TRN \\
\hline CHEMBL1521693 & 688341 & 4.4 & 5.1667 & TST \\
\hline CHEMBL1445500 & 688341 & 4.8 & 4.7095 & TRN \\
\hline CHEMBL1446139 & 688341 & 4.8 & 5.1121 & TRN \\
\hline CHEMBL1392136 & 688341 & 4.7 & 5.0547 & TRN \\
\hline CHEMBL1325541 & 688341 & 4.4 & 4.8663 & TRN \\
\hline CHEMBL1492494 & 688341 & 5.9 & 4.896 & TRN \\
\hline CHEMBL1584551 & 688341 & 5.2 & 4.8918 & TST \\
\hline CHEMBL1428821 & 688341 & 4.6 & 5.0715 & TRN \\
\hline CHEMBL1526213 & 688341 & 4.9 & 5.0791 & TRN \\
\hline CHEMBL1311085 & 688341 & 4.7 & 4.8629 & TRN \\
\hline CHEMBL1580259 & 688341 & 8.301 & 4.7395 & TST \\
\hline CHEMBL1422129 & 688341 & 6.1 & 5.1042 & TRN \\
\hline CHEMBL1384357 & 688341 & 5.1 & 4.8209 & TST \\
\hline CHEMBL1504749 & 688341 & 4.8 & 4.9697 & TRN \\
\hline CHEMBL1468741 & 688341 & 4.9 & 4.927 & TRN \\
\hline CHEMBL1407268 & 688341 & 4.6 & 4.9325 & TRN \\
\hline CHEMBL1441877 & 688341 & 4.4 & 5.0768 & TRN \\
\hline CHEMBL1576285 & 688341 & 4.4 & 5.0053 & TRN \\
\hline CHEMBL1330313 & 688341 & 4.4 & 4.8642 & TRN \\
\hline CHEMBL1305016 & 688341 & 4.4 & 5.0989 & TST \\
\hline CHEMBL1505202 & 688341 & 5.2 & 5.1295 & TST \\
\hline CHEMBL1532016 & 688341 & 4.8 & 5.1864 & TRN \\
\hline CHEMBL1584500 & 688341 & 4.8 & 4.8986 & TRN \\
\hline CHEMBL1368613 & 688341 & 5.1 & 4.8949 & TRN \\
\hline CHEMBL585081 & 688341 & 5.6 & 4.751 & TRN \\
\hline CHEMBL1470711 & 688341 & 4.6 & 4.8488 & TRN \\
\hline CHEMBL1588639 & 688341 & 4.8 & 4.9347 & TRN \\
\hline CHEMBL1472448 & 688341 & 5.2 & 5.0869 & TRN \\
\hline CHEMBL1308051 & 688341 & 4.5 & 4.8906 & TRN \\
\hline CHEMBL1363049 & 688341 & 5.2 & 4.8643 & TRN \\
\hline CHEMBL1335889 & 688341 & 4.9 & 4.9681 & TRN \\
\hline CHEMBL1427175 & 688341 & 4.6 & 5.0042 & TRN \\
\hline CHEMBL1316337 & 688341 & 5.4 & 5.1942 & TRN \\
\hline CHEMBL1447514 & 688341 & 4.4 & 4.8922 & TRN \\
\hline CHEMBL1395165 & 688341 & 4.5 & 5.0655 & TRN \\
\hline CHEMBL1482982 & 688341 & 4.5 & 4.9804 & TRN \\
\hline CHEMBL1304910 & 688341 & 4.4 & 4.9092 & TRN \\
\hline CHEMBL1536861 & 688341 & 4.6 & 4.7763 & TRN \\
\hline
\end{tabular}




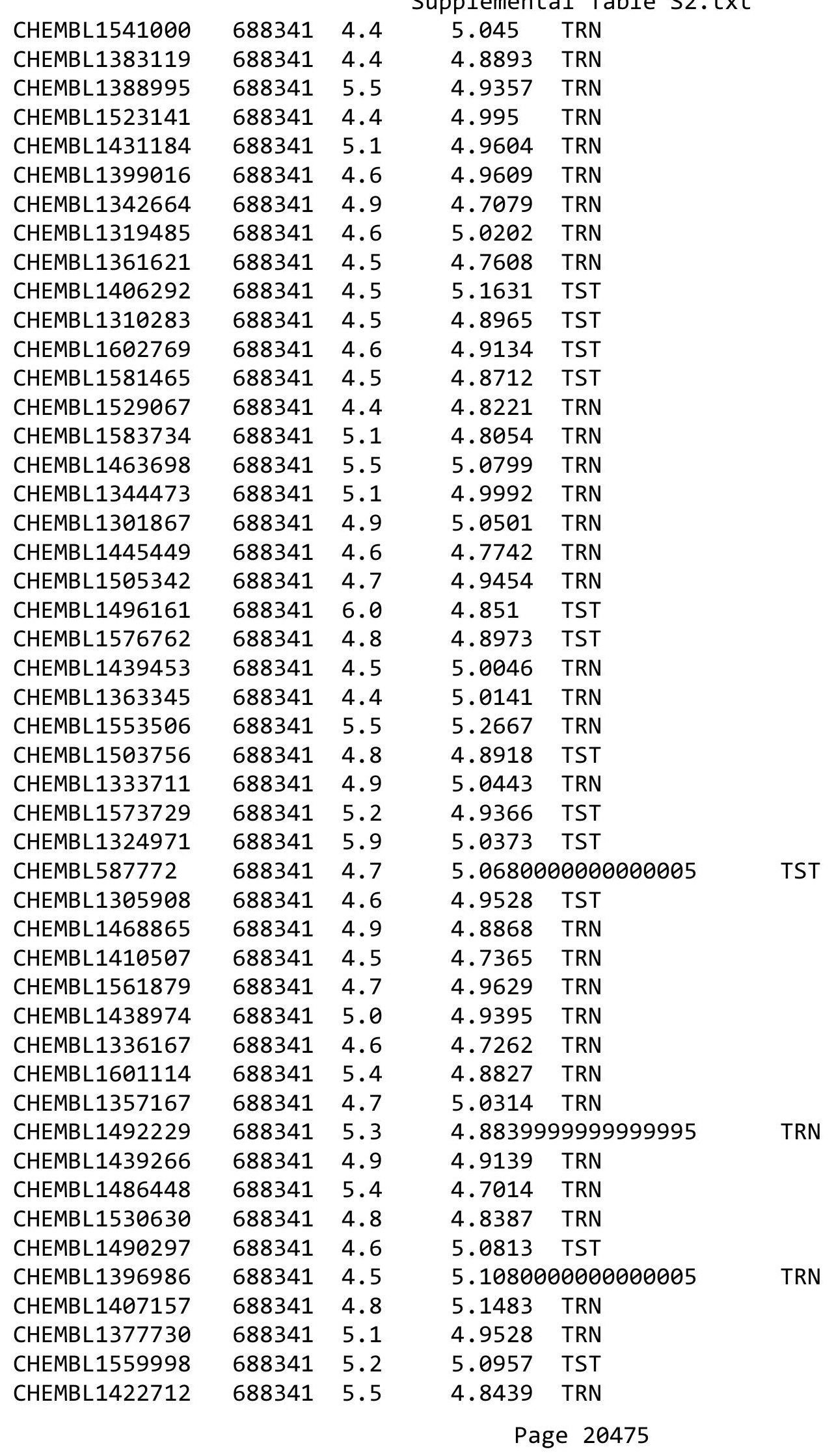




\begin{tabular}{|c|c|c|c|c|}
\hline & & & oplemen & \\
\hline CHEMBL1589365 & 688341 & 4.5 & 4.8575 & TRN \\
\hline CHEMBL1582406 & 688341 & 5.3 & 4.8689 & TRN \\
\hline CHEMBL1373006 & 688341 & 4.4 & 4.879 & TST \\
\hline CHEMBL1419849 & 688341 & 4.6 & 5.0037 & TRN \\
\hline CHEMBL1533461 & 688341 & 4.5 & 4.7717 & TRN \\
\hline CHEMBL1352388 & 688341 & 4.4 & 5.0511 & TST \\
\hline CHEMBL473736 & 688341 & 4.9 & 4.81 & TRN \\
\hline CHEMBL1459135 & 688341 & 4.5 & 4.9908 & TST \\
\hline CHEMBL1558122 & 688341 & 4.4 & 4.8015 & TST \\
\hline CHEMBL1444107 & 688341 & 6.6 & 4.9567 & TRN \\
\hline CHEMBL1526852 & 688341 & 5.2 & 5.0634 & TST \\
\hline CHEMBL1374715 & 688341 & 4.4 & 4.8347 & TRN \\
\hline CHEMBL1559310 & 688341 & 4.5 & 4.7708 & TRN \\
\hline CHEMBL1466679 & 688341 & 4.5 & 5.0949 & TST \\
\hline CHEMBL1605255 & 688341 & 4.8 & 5.0667 & TRN \\
\hline CHEMBL1371894 & 688341 & 4.4 & 4.8804 & TRN \\
\hline CHEMBL1579658 & 688341 & 6.1 & 4.9447 & TRN \\
\hline CHEMBL1518063 & 688341 & 4.4 & 4.8696 & TST \\
\hline CHEMBL1336166 & 688341 & 4.6 & 4.8823 & TRN \\
\hline CHEMBL1600612 & 688341 & 5.3 & 4.9517 & TRN \\
\hline CHEMBL1521868 & 688341 & 6.1 & 4.9449 & TRN \\
\hline CHEMBL1477362 & 688341 & 5.0 & 5.0261 & TRN \\
\hline CHEMBL1545440 & 688341 & 4.6 & 4.8173 & TRN \\
\hline CHEMBL1504894 & 688341 & 4.5 & 4.7802 & TRN \\
\hline CHEMBL1335760 & 688341 & 4.6 & 4.8268 & TRN \\
\hline CHEMBL1326700 & 688341 & 4.6 & 4.9462 & TRN \\
\hline CHEMBL1383638 & 688341 & 5.3 & 4.9481 & TRN \\
\hline CHEMBL1451974 & 688341 & 4.7 & 4.8207 & TRN \\
\hline CHEMBL1597481 & 688341 & 4.6 & 4.9024 & TRN \\
\hline CHEMBL1429242 & 688341 & 5.1 & 4.6908 & TRN \\
\hline CHEMBL1548444 & 688341 & 4.4 & 4.8923 & TST \\
\hline CHEMBL1255935 & 688341 & 6.8 & 5.0547 & TST \\
\hline CHEMBL1473755 & 688341 & 4.7 & 5.0165 & TRN \\
\hline CHEMBL1585190 & 688341 & 6.3 & 4.9328 & TRN \\
\hline CHEMBL1578130 & 688341 & 5.8 & 4.8267 & TRN \\
\hline CHEMBL1495846 & 688341 & 4.4 & 4.9792 & TRN \\
\hline CHEMBL1417270 & 688341 & 4.6 & 5.0851 & TRN \\
\hline CHEMBL1451755 & 688341 & 5.4 & 4.9586 & TRN \\
\hline CHEMBL1271881 & 688341 & 5.4 & 5.0177 & TRN \\
\hline CHEMBL1559957 & 688341 & 4.6 & 4.9275 & TRN \\
\hline CHEMBL1351330 & 688341 & 5.1 & 5.088 & TRN \\
\hline CHEMBL1471573 & 688341 & 7.0 & 5.0127 & TRN \\
\hline CHEMBL1433051 & 688341 & 4.8 & 4.7772 & TRN \\
\hline CHEMBL1505758 & 688341 & 5.4 & 5.0289 & TRN \\
\hline CHEMBL1442113 & 688341 & 4.4 & 5.1074 & TST \\
\hline CHEMBL1430804 & 688341 & 5.0 & 4.7765 & TRN \\
\hline CHEMBL1564036 & 688341 & 4.8 & 4.7896 & TRN \\
\hline CHEMBL1486138 & 688341 & 4.6 & 4.8306 & TRN \\
\hline
\end{tabular}




\begin{tabular}{|c|c|c|c|c|c|}
\hline \\
\hline CHEMBL1349977 & 688341 & 4.6 & 4.7847 & TRN & \\
\hline CHEMBL1501614 & 688341 & 4.4 & 5.041 & TST & \\
\hline CHEMBL1507108 & 688341 & 5.1 & 5.0497 & TRN & \\
\hline CHEMBL1607024 & 688341 & 4.8 & 4.6823 & TRN & \\
\hline CHEMBL1559728 & 688341 & 5.2 & 5.0478 & TST & \\
\hline CHEMBL285235 & 688341 & 5.7 & 5.0841 & TST & \\
\hline CHEMBL1367658 & 688341 & 4.7 & 4.802 & TRN & \\
\hline CHEMBL34450 & 688341 & 4.5 & 5.1556 & TST & \\
\hline CHEMBL1566147 & 688341 & 4.6 & 5.0493 & TRN & \\
\hline CHEMBL1526803 & 688341 & 4.9 & 4.9265 & TRN & \\
\hline CHEMBL1341352 & 688341 & 6.1 & 4.9979 & TRN & \\
\hline CHEMBL1363536 & 688341 & 4.9 & 4.9276 & TRN & \\
\hline CHEMBL1427957 & 688341 & 4.8 & 4.9834 & TRN & \\
\hline CHEMBL1486223 & 688341 & 5.0 & 5.12700 & 0000000001 & TST \\
\hline CHEMBL1386786 & 688341 & 4.6 & 4.689 & TRN & \\
\hline CHEMBL 1400190 & 688341 & 5.3 & 5.1248 & TRN & \\
\hline CHEMBL1431636 & 688341 & 5.4 & 4.9062 & TRN & \\
\hline CHEMBL1590259 & 688341 & 5.5 & 5.1569 & TRN & \\
\hline CHEMBL1521391 & 688341 & 4.8 & 5.1661 & TRN & \\
\hline CHEMBL1563143 & 688341 & 4.9 & 4.9714 & TRN & \\
\hline CHEMBL1351861 & 688341 & 4.7 & 4.7711 & TRN & \\
\hline CHEMBL1419395 & 688341 & 5.0 & 4.9968 & TRN & \\
\hline CHEMBL1481491 & 688341 & 4.9 & 4.8658 & TRN & \\
\hline CHEMBL1397079 & 688341 & 4.8 & 5.1176 & TRN & \\
\hline CHEMBL15625 & 688341 & 4.8 & 5.1098 & TST & \\
\hline CHEMBL1592584 & 688341 & 5.9 & 5.1422 & TRN & \\
\hline CHEMBL1350094 & 688341 & 5.0 & 4.9915 & TRN & \\
\hline CHEMBL1539824 & 688341 & 4.6 & 4.7251 & TRN & \\
\hline CHEMBL1489830 & 688341 & 4.7 & 4.63 & TRN & \\
\hline CHEMBL1359157 & 688341 & 4.9 & 5.0946 & TRN & \\
\hline CHEMBL1572696 & 688341 & 4.9 & 4.9644 & TST & \\
\hline CHEMBL1597691 & 688341 & 4.4 & 4.7294 & TRN & \\
\hline CHEMBL1550038 & 688341 & 4.4 & 4.7612 & TRN & \\
\hline CHEMBL1565612 & 688341 & 4.5 & 5.0146 & TRN & \\
\hline CHEMBL1451097 & 688341 & 5.6 & 5.1728 & TRN & \\
\hline CHEMBL3198538 & 688341 & 4.4 & 4.8672 & TRN & \\
\hline CHEMBL1453446 & 688341 & 4.4 & 4.9108 & TRN & \\
\hline CHEMBL3190407 & 688341 & 5.9 & 5.0004 & TRN & \\
\hline CHEMBL1411078 & 688341 & 4.5 & 4.7599 & TRN & \\
\hline CHEMBL1443713 & 688341 & 5.2 & 5.1287 & TRN & \\
\hline CHEMBL1421241 & 688341 & 4.8 & 4.7984 & TRN & \\
\hline CHEMBL1435120 & 688341 & 4.6 & 5.1325 & TRN & \\
\hline CHEMBL1368002 & 688341 & 5.2 & 5.0855 & TST & \\
\hline CHEMBL3214039 & 688341 & 5.2 & 5.0148 & TST & \\
\hline CHEMBL1588980 & 688341 & 5.4 & 4.9243 & TST & \\
\hline CHEMBL1461889 & 688341 & 4.8 & 4.9167 & TRN & \\
\hline CHEMBL1543601 & 688341 & 6.5 & 4.9052 & TST & \\
\hline CHEMBL1538628 & 688341 & 5.5 & 4.8506 & TRN & \\
\hline & & & & 20477 & \\
\hline
\end{tabular}




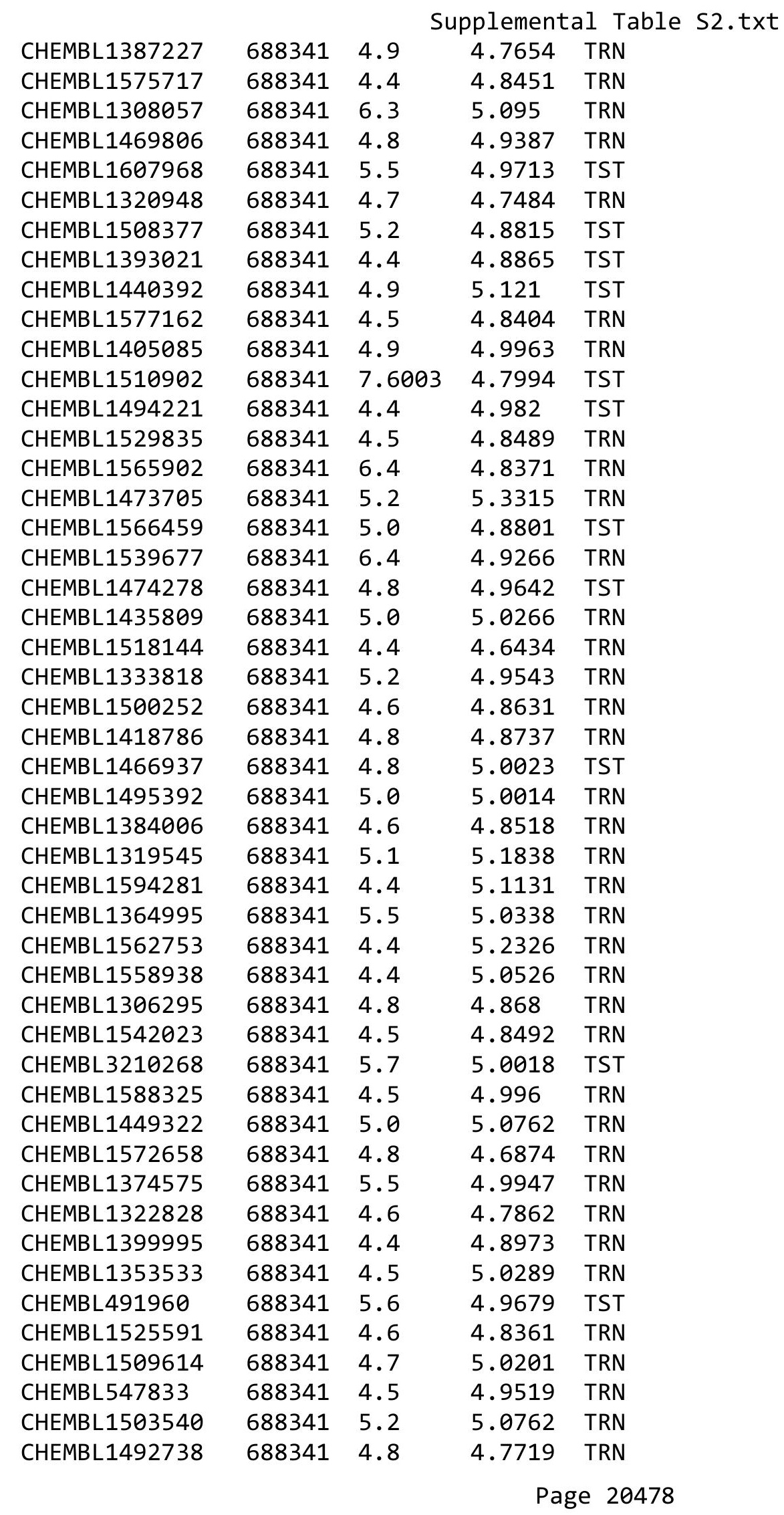




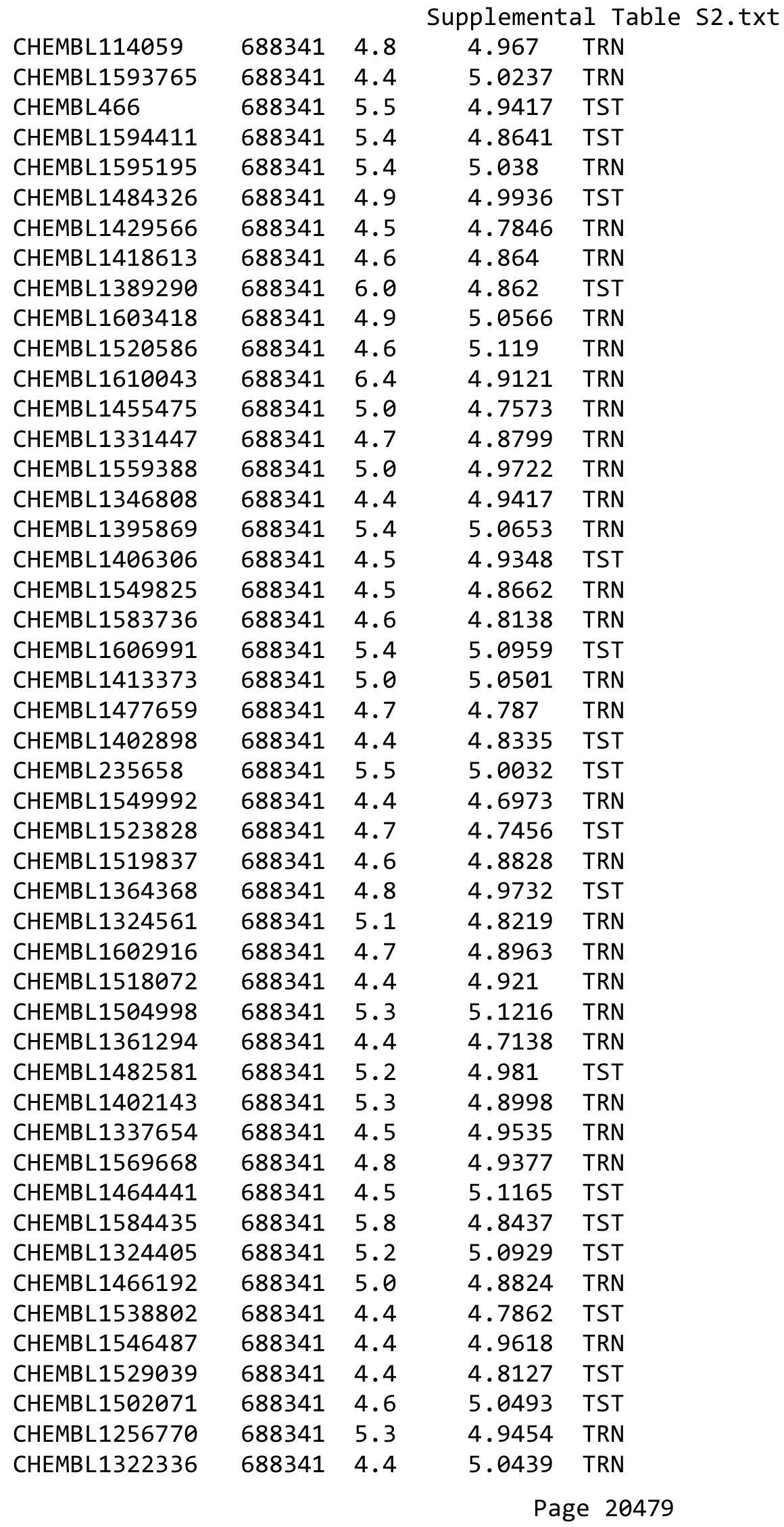




\begin{tabular}{|c|c|c|c|c|}
\hline \multicolumn{5}{|c|}{ Supplemental Table S2.txt } \\
\hline CHEMBL1507753 & 688341 & 4.4 & 4.757 & TRN \\
\hline CHEMBL1530468 & 688341 & 5.3 & 4.8601 & TRN \\
\hline CHEMBL1485434 & 688341 & 4.4 & 5.0073 & TRN \\
\hline CHEMBL289431 & 688341 & 5.5 & 5.0536 & TST \\
\hline CHEMBL1520845 & 688341 & 4.5 & 4.9381 & TST \\
\hline CHEMBL1492205 & 688341 & 4.5 & 5.09 & TRN \\
\hline CHEMBL1491899 & 688341 & 4.7 & 4.9262 & TRN \\
\hline CHEMBL1577024 & 688341 & 4.9 & 4.75 & TRN \\
\hline CHEMBL142735 & 688341 & 8.0 & 5.165 & TST \\
\hline CHEMBL1527923 & 688341 & 5.1 & 5.2073 & TRN \\
\hline CHEMBL1422012 & 688341 & 4.6 & 5.0175 & TRN \\
\hline CHEMBL175193 & 688341 & 5.7 & 5.0347 & TST \\
\hline CHEMBL1558035 & 688341 & 5.6 & 4.9628 & TRN \\
\hline CHEMBL1553768 & 688341 & 4.8 & 5.1113 & TST \\
\hline CHEMBL574181 & 688341 & 4.4 & 5.0344 & TST \\
\hline CHEMBL1421453 & 688341 & 4.5 & 4.9318 & TRN \\
\hline CHEMBL72631 & 688341 & 4.4 & 4.8525 & TRN \\
\hline CHEMBL1384025 & 688341 & 4.9 & 4.9737 & TRN \\
\hline CHEMBL1577514 & 688341 & 5.4 & 4.9141 & TRN \\
\hline CHEMBL1484376 & 688341 & 4.5 & 4.8434 & TRN \\
\hline CHEMBL1429577 & 688341 & 4.5 & 4.9344 & TST \\
\hline CHEMBL3207708 & 688341 & 5.0 & 4.9241 & TST \\
\hline CHEMBL1905194 & 688341 & 5.4 & 4.938 & TST \\
\hline CHEMBL1479744 & 688341 & 4.9 & 4.9632 & TRN \\
\hline CHEMBL1502745 & 688341 & 7.4001 & 4.8841 & TRN \\
\hline CHEMBL1303767 & 688341 & 4.6 & 4.7746 & TST \\
\hline CHEMBL1606283 & 688341 & 4.4 & 4.9392 & TRN \\
\hline CHEMBL1444987 & 688341 & 5.2 & 4.9318 & TRN \\
\hline CHEMBL1484743 & 688341 & 4.8 & 4.9841 & TRN \\
\hline CHEMBL1303091 & 688341 & 4.6 & 4.8335 & TRN \\
\hline CHEMBL1348399 & 688341 & 4.8 & 4.761 & TRN \\
\hline CHEMBL1342481 & 688341 & 4.7 & 4.8733 & TRN \\
\hline CHEMBL1555156 & 688341 & 5.4 & 5.0877 & TRN \\
\hline CHEMBL1563799 & 688341 & 4.5 & 4.8358 & TRN \\
\hline CHEMBL1323935 & 688341 & 4.9 & 4.8707 & TRN \\
\hline CHEMBL1441291 & 688341 & 4.4 & 4.8349 & TRN \\
\hline CHEMBL1406507 & 688341 & 4.6 & 4.7053 & TRN \\
\hline CHEMBL1401387 & 688341 & 5.2 & 4.989 & TRN \\
\hline CHEMBL1533734 & 688341 & 5.4 & 5.0678 & TRN \\
\hline CHEMBL1480237 & 688341 & 4.4 & 5.0331 & TRN \\
\hline CHEMBL244693 & 688341 & 5.2 & 4.9635 & TRN \\
\hline CHEMBL1338367 & 688341 & 4.5 & 4.8345 & TRN \\
\hline CHEMBL1481743 & 688341 & 4.5 & 4.8663 & TRN \\
\hline CHEMBL1488734 & 688341 & 4.7 & 4.8711 & TRN \\
\hline CHEMBL1384584 & 688341 & 5.3 & 4.9985 & TRN \\
\hline CHEMBL1310020 & 688341 & 4.7 & 5.0025 & TST \\
\hline CHEMBL1398921 & 688341 & 4.5 & 4.7467 & TRN \\
\hline CHEMBL1427142 & 688341 & 4.9 & 4.8918 & TRN \\
\hline
\end{tabular}




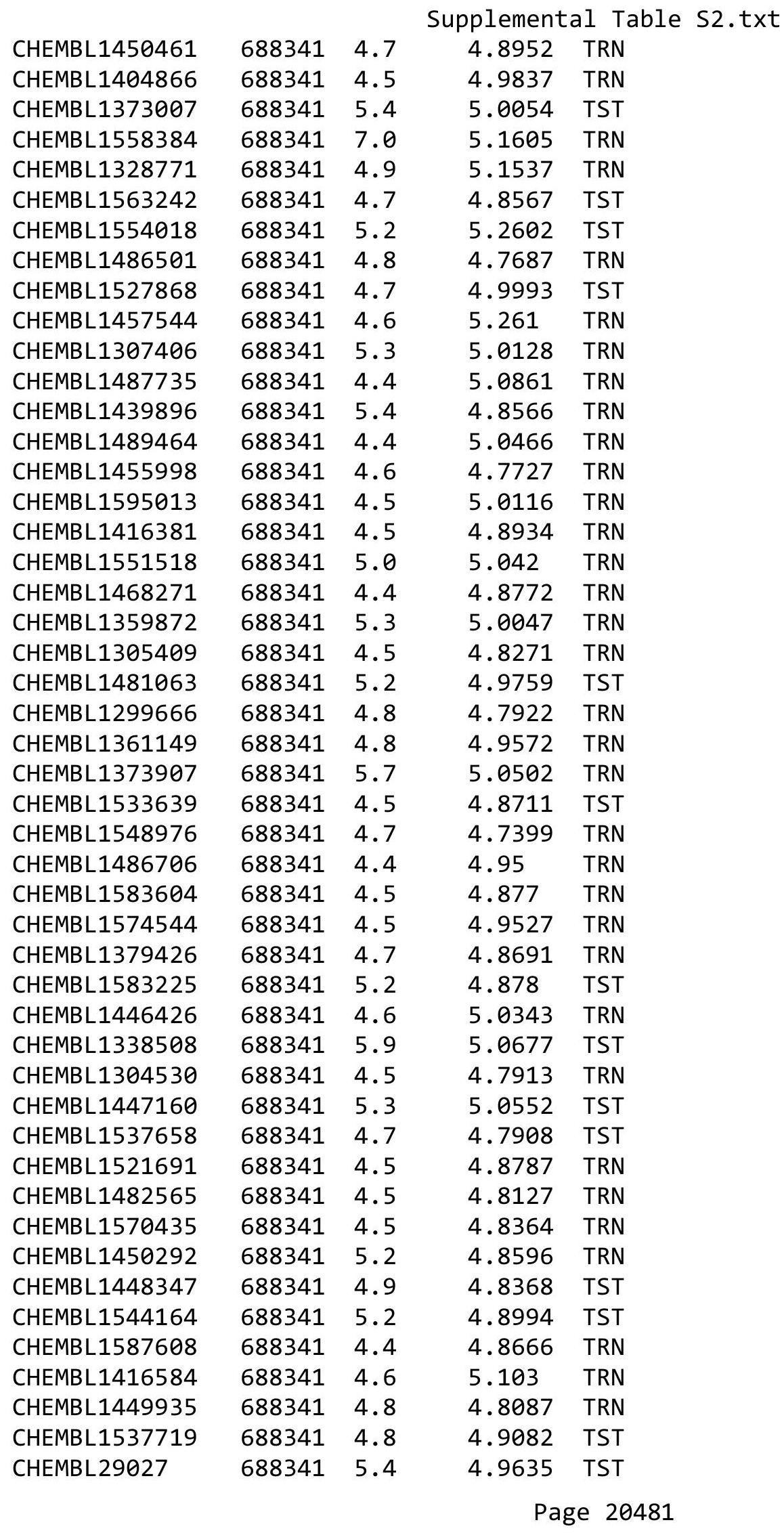




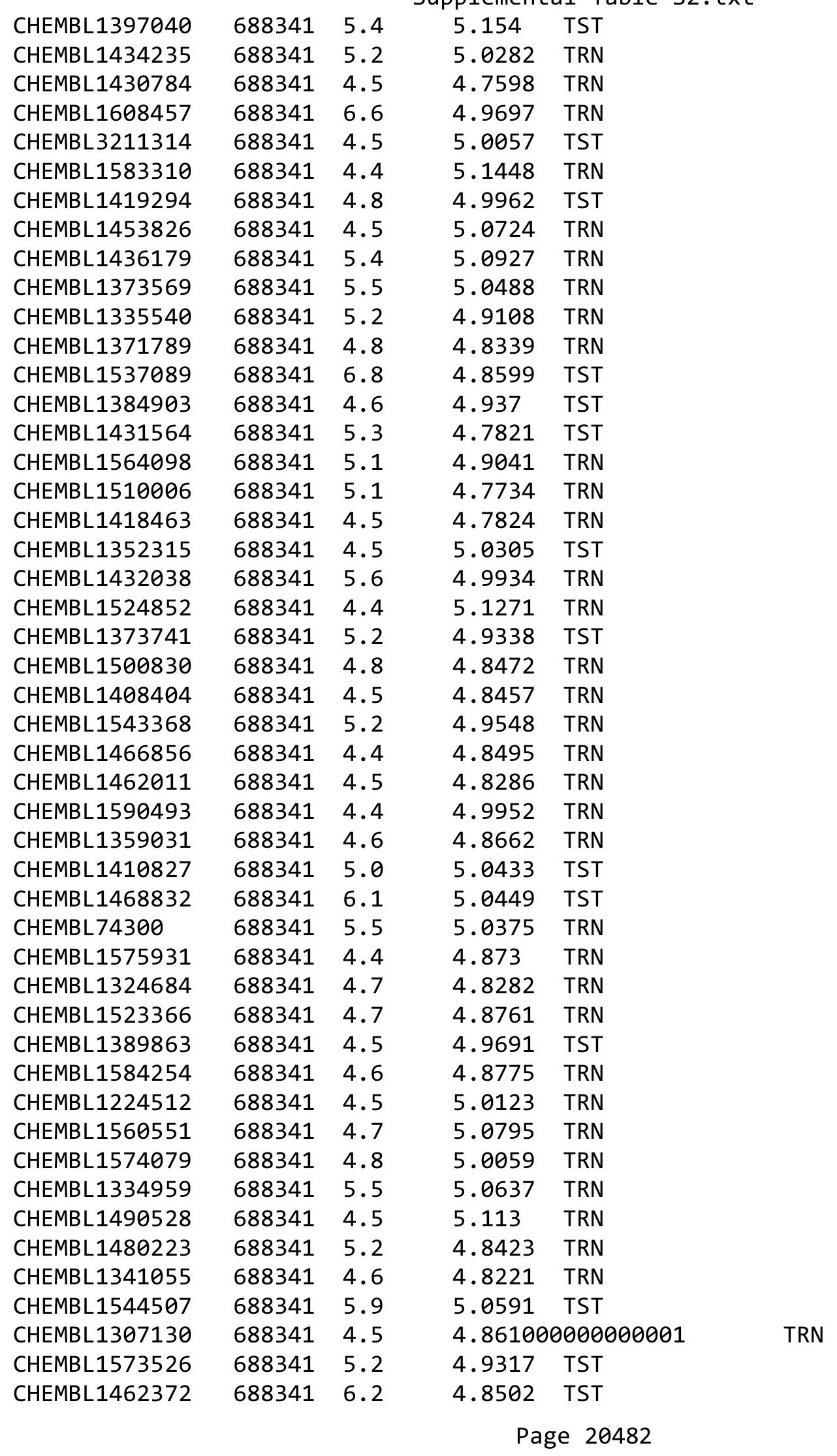




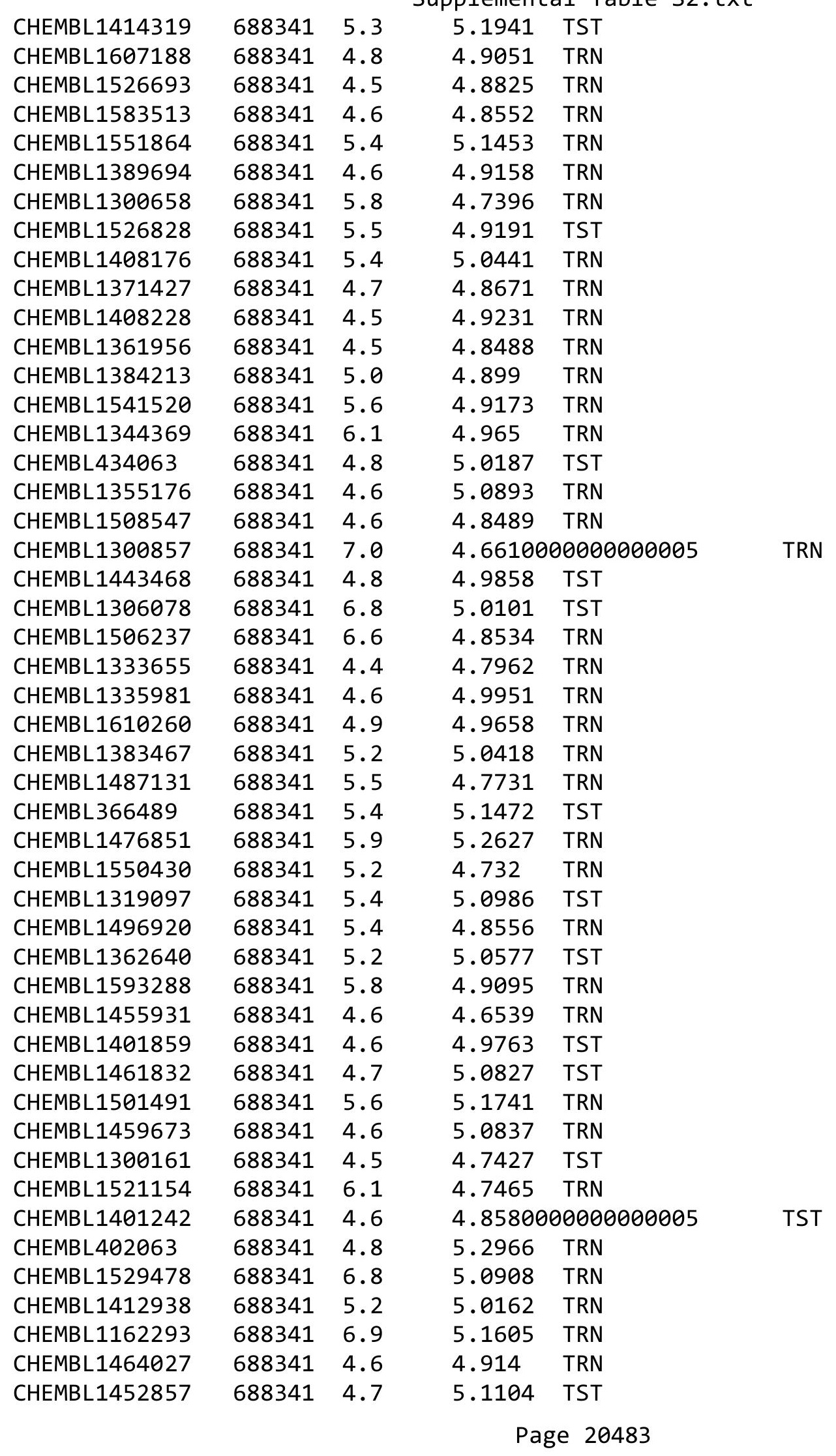




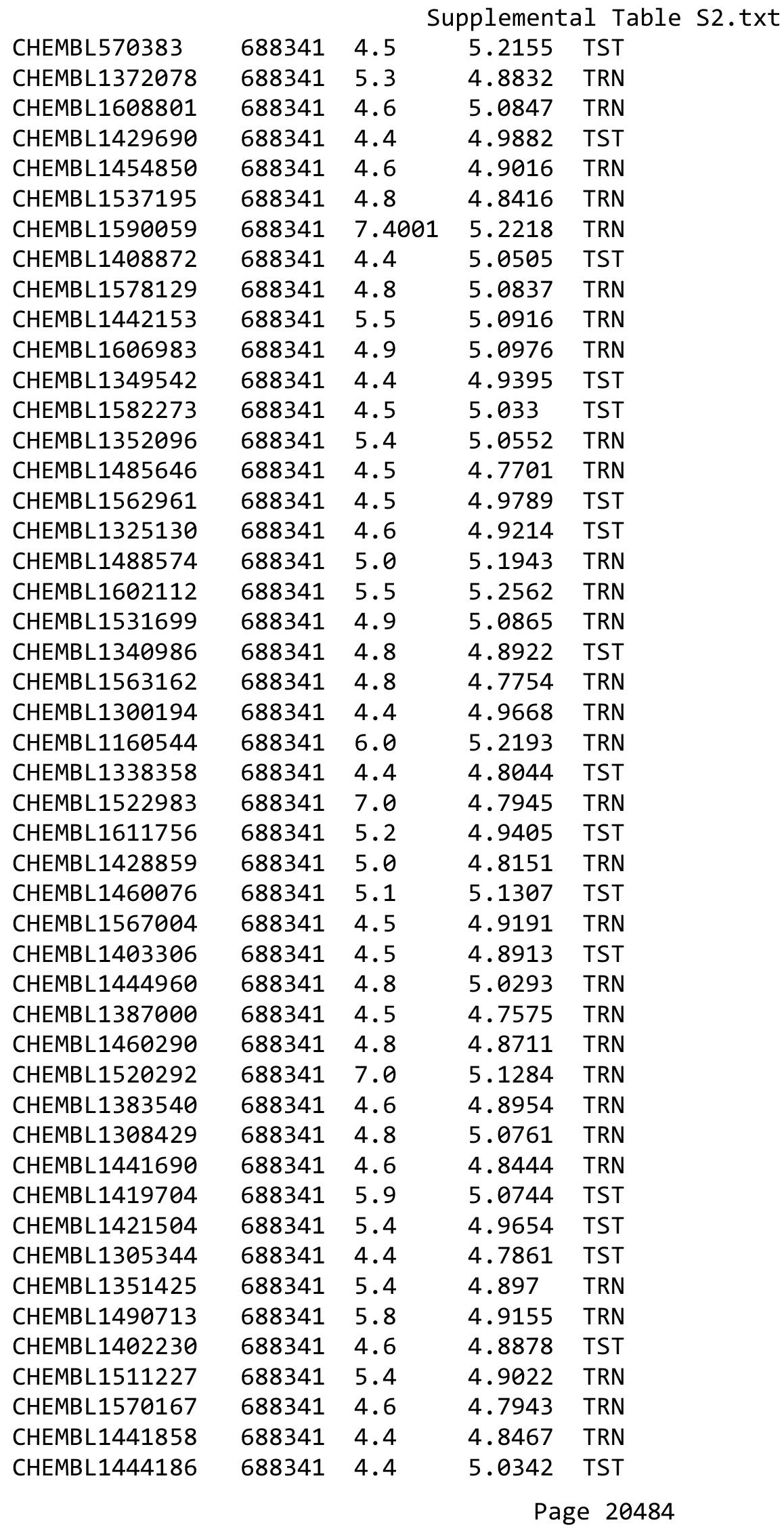




\begin{tabular}{|c|c|c|c|c|c|}
\hline & & & & & \\
\hline CHEMBL3192857 & 688341 & 5.5 & 4.949 & TRN & \\
\hline CHEMBL1369796 & 688341 & 4.8 & 4.9388 & TRN & \\
\hline CHEMBL1455566 & 688341 & 4.8 & 4.8342 & TRN & \\
\hline CHEMBL1401204 & 688341 & 4.9 & 4.9215 & TST & \\
\hline CHEMBL1440648 & 688341 & 5.1 & 4.846 & TRN & \\
\hline CHEMBL1503791 & 688341 & 4.8 & 5.0003 & TST & \\
\hline CHEMBL1468417 & 688341 & 4.6 & 5.2182 & TRN & \\
\hline CHEMBL1606761 & 688341 & 4.6 & 4.8614 & TRN & \\
\hline CHEMBL1560288 & 688341 & 4.6 & 5.1795 & TST & \\
\hline CHEMBL1507411 & 688341 & 5.4 & 5.0332 & TRN & \\
\hline CHEMBL1461844 & 688341 & 6.1 & 4.9152 & TRN & \\
\hline CHEMBL105457 & 688341 & 5.5 & 5.0658 & TST & \\
\hline CHEMBL 38576 & 688341 & 4.5 & 4.8499 & TRN & \\
\hline CHEMBL1613150 & 688341 & 4.6 & 5.0143 & TST & \\
\hline CHEMBL1517051 & 688341 & 4.5 & 4.9608 & TRN & \\
\hline CHEMBL1589673 & 688341 & 4.8 & 4.9071 & TRN & \\
\hline CHEMBL1565468 & 688341 & 4.8 & 4.8644 & TRN & \\
\hline CHEMBL1585000 & 688341 & 4.4 & 4.9686 & TST & \\
\hline CHEMBL3193842 & 688341 & 4.5 & 4.7432 & TST & \\
\hline CHEMBL1375619 & 688341 & 4.5 & 4.9089 & TRN & \\
\hline CHEMBL1322921 & 688341 & 4.7 & 4.7206 & TRN & \\
\hline CHEMBL1329377 & 688341 & 5.5 & 4.90600 & 2000000001 & TRN \\
\hline CHEMBL1507290 & 688341 & 4.8 & 4.8658 & TRN & \\
\hline CHEMBL1599012 & 688341 & 5.3 & 4.9291 & TRN & \\
\hline CHEMBL1303035 & 688341 & 4.5 & 5.1283 & TST & \\
\hline CHEMBL1565923 & 688341 & 4.5 & 4.7482 & TRN & \\
\hline CHEMBL1429998 & 688341 & 4.8 & 5.0517 & TST & \\
\hline CHEMBL1388070 & 688341 & 4.4 & 4.9153 & TRN & \\
\hline CHEMBL1587384 & 688341 & 4.6 & 4.8475 & TRN & \\
\hline CHEMBL1577611 & 688341 & 4.5 & 4.8643 & TST & \\
\hline CHEMBL1303052 & 688341 & 4.4 & 4.9104 & TRN & \\
\hline CHEMBL1474532 & 688341 & 4.8 & 5.155 & TRN & \\
\hline CHEMBL1462712 & 688341 & 4.4 & 5.0451 & TST & \\
\hline CHEMBL1547724 & 688341 & 5.2 & 5.0351 & TST & \\
\hline CHEMBL1511625 & 688341 & 5.0 & 4.9642 & TST & \\
\hline CHEMBL1313467 & 688341 & 5.2 & 4.7924 & TRN & \\
\hline CHEMBL1362121 & 688341 & 5.4 & 5.1172 & TST & \\
\hline CHEMBL1588470 & 688341 & 4.8 & 4.8752 & TRN & \\
\hline CHEMBL552272 & 688341 & 5.3 & 4.9087 & TRN & \\
\hline CHEMBL1372426 & 688341 & 5.2 & 4.8961 & TST & \\
\hline CHEMBL1595709 & 688341 & 5.0 & 5.06800 & 20000000005 & TST \\
\hline CHEMBL1422838 & 688341 & 4.8 & 4.8509 & TRN & \\
\hline CHEMBL1565304 & 688341 & 4.7 & 4.9315 & TRN & \\
\hline CHEMBL1398721 & 688341 & 5.0 & 5.0722 & TRN & \\
\hline CHEMBL1491709 & 688341 & 4.5 & 4.9902 & TRN & \\
\hline CHEMBL1609955 & 688341 & 5.2 & 4.9271 & TST & \\
\hline CHEMBL1521481 & 688341 & 4.6 & 4.9071 & TRN & \\
\hline CHEMBL1608888 & 688341 & 4.4 & 4.8588 & TRN & \\
\hline
\end{tabular}




\begin{tabular}{|c|c|c|c|c|c|}
\hline \multicolumn{6}{|c|}{ Supplemental Table S2.txt } \\
\hline CHEMBL1411259 & 688341 & 5.0 & 4.9172 & TRN & \\
\hline CHEMBL1429305 & 688341 & 5.6 & 4.9910 & 00000000005 & TRN \\
\hline CHEMBL1554194 & 688341 & 5.9 & 5.0017 & TRN & \\
\hline CHEMBL1313866 & 688341 & 4.5 & 4.7463 & TRN & \\
\hline CHEMBL1437018 & 688341 & 5.2 & 5.3523 & TRN & \\
\hline CHEMBL1490272 & 688341 & 5.2 & 4.8085 & TST & \\
\hline CHEMBL1356094 & 688341 & 4.4 & 5.1486 & TRN & \\
\hline CHEMBL1325766 & 688341 & 5.7 & 4.9899 & TRN & \\
\hline CHEMBL1374214 & 688341 & 4.8 & 4.9161 & TST & \\
\hline CHEMBL490706 & 688341 & 7.6003 & 5.0983 & TRN & \\
\hline CHEMBL3199819 & 688341 & 4.6 & 5.05 & TRN & \\
\hline CHEMBL1425396 & 688341 & 4.4 & 4.8723 & TST & \\
\hline CHEMBL1488603 & 688341 & 4.4 & 4.973 & TRN & \\
\hline CHEMBL1480405 & 688341 & 4.5 & 4.8397 & TRN & \\
\hline CHEMBL1412373 & 688341 & 4.7 & 4.6546 & TRN & \\
\hline CHEMBL1392655 & 688341 & 4.8 & 4.7879 & TRN & \\
\hline CHEMBL1572533 & 688341 & 6.5 & 5.0178 & TST & \\
\hline CHEMBL1497732 & 688341 & 5.4 & 4.8954 & TRN & \\
\hline CHEMBL1463134 & 688341 & 5.1 & 5.0253 & TRN & \\
\hline CHEMBL1304455 & 688341 & 5.2 & 4.8027 & TRN & \\
\hline CHEMBL1540088 & 688341 & 5.3 & 4.8698 & TRN & \\
\hline CHEMBL1346978 & 688341 & 6.8 & 5.0561 & TST & \\
\hline CHEMBL1468530 & 688341 & 5.0 & 5.0545 & TRN & \\
\hline CHEMBL1445650 & 688341 & 4.5 & 4.8681 & TRN & \\
\hline CHEMBL1566955 & 688341 & 6.4 & 4.9033 & TST & \\
\hline CHEMBL1524023 & 688341 & 4.5 & 4.8456 & TRN & \\
\hline CHEMBL1461649 & 688341 & 4.8 & 4.9460 & 0000000001 & TST \\
\hline CHEMBL1308582 & 688341 & 4.7 & 4.9987 & TRN & \\
\hline CHEMBL1383345 & 688341 & 4.9 & 5.1041 & TRN & \\
\hline CHEMBL1537116 & 688341 & 5.4 & 4.958 & TRN & \\
\hline CHEMBL1311376 & 688341 & 4.8 & 4.9379 & TRN & \\
\hline CHEMBL1368191 & 688341 & 4.4 & 5.1285 & TST & \\
\hline CHEMBL 3194851 & 688341 & 4.9 & 4.9595 & TST & \\
\hline CHEMBL1362088 & 688341 & 5.1 & 5.0895 & TST & \\
\hline CHEMBL1584751 & 688341 & 4.4 & 4.7797 & TRN & \\
\hline CHEMBL1364557 & 688341 & 5.0 & 4.8755 & TRN & \\
\hline CHEMBL1584415 & 688341 & 4.5 & 4.9572 & TRN & \\
\hline CHEMBL1484947 & 688341 & 4.3 & 5.0757 & TST & \\
\hline CHEMBL2374259 & 688341 & 7.8013 & 5.1865 & TRN & \\
\hline CHEMBL1312369 & 688341 & 4.8 & 4.7456 & TRN & \\
\hline CHEMBL1458509 & 688341 & 5.3 & 4.9565 & TST & \\
\hline CHEMBL1601176 & 688341 & 4.5 & 4.8611 & TST & \\
\hline CHEMBL1426192 & 688341 & 4.4 & 4.8783 & TRN & \\
\hline CHEMBL1603257 & 688341 & 5.5 & 4.9961 & TRN & \\
\hline CHEMBL1444727 & 688341 & 5.8 & 4.8595 & TRN & \\
\hline CHEMBL1440469 & 688341 & 4.6 & 4.8625 & TRN & \\
\hline CHEMBL1488752 & 688341 & 4.9 & 4.9699 & TST & \\
\hline CHEMBL1304272 & 688341 & 4.4 & 4.8595 & TRN & \\
\hline
\end{tabular}




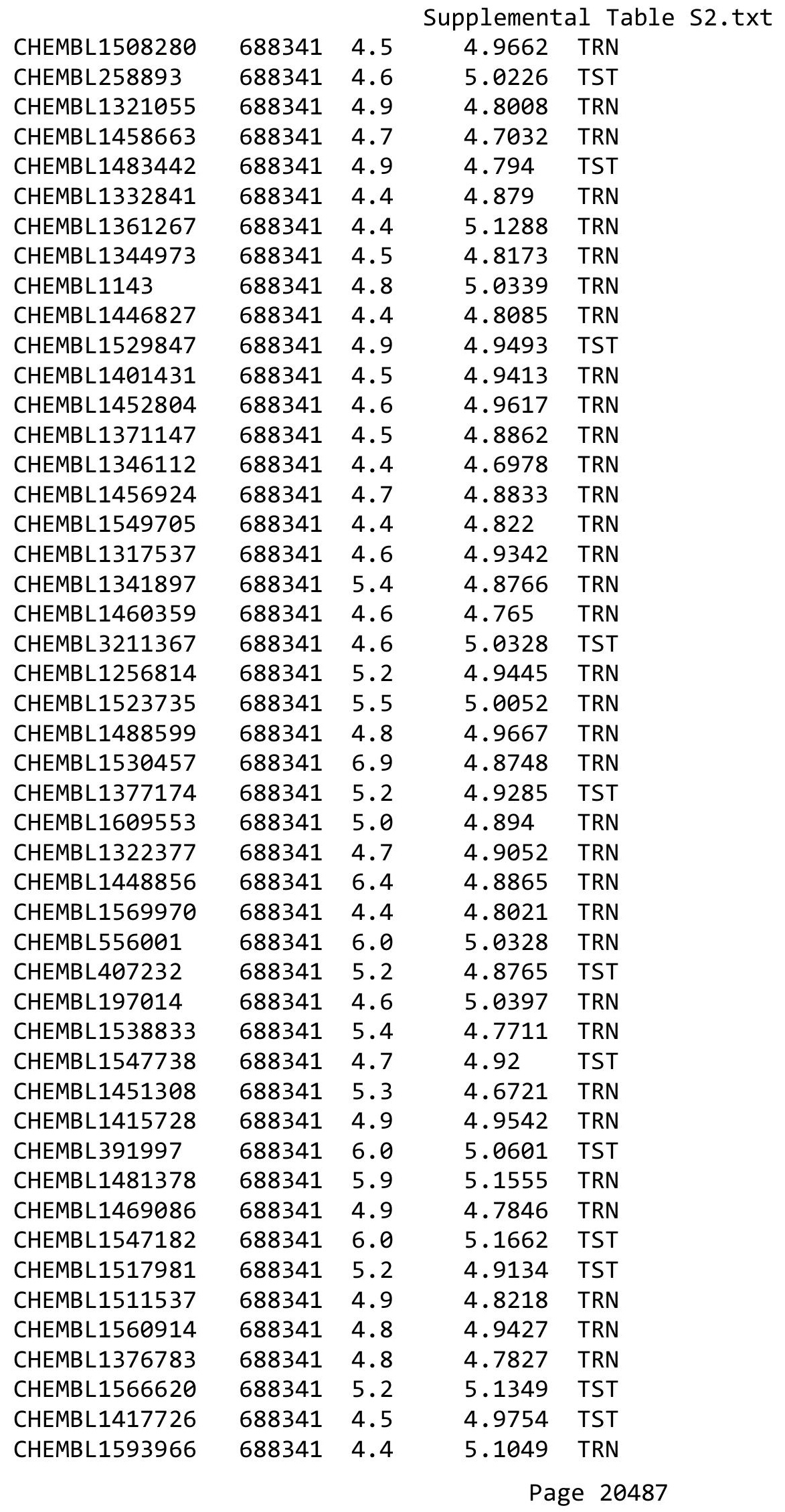




\begin{tabular}{|c|c|c|c|c|c|}
\hline \multicolumn{6}{|c|}{ Supplemental Table s2.txt } \\
\hline CHEMBL1256695 & 688341 & 4.5 & 5.1598 & TST & \\
\hline CHEMBL1338280 & 688341 & 5.1 & 4.955 & TRN & \\
\hline CHEMBL1399595 & 688341 & 4.6 & 5.0328 & TST & \\
\hline CHEMBL1413382 & 688341 & 5.0 & 4.9309 & TRN & \\
\hline CHEMBL1466416 & 688341 & 4.6 & 5.0395 & TST & \\
\hline CHEMBL1611022 & 688341 & 4.8 & 4.9644 & TST & \\
\hline CHEMBL1353549 & 688341 & 4.7 & 4.9311 & TRN & \\
\hline CHEMBL1367957 & 688341 & 4.6 & 4.8423 & TRN & \\
\hline CHEMBL1591381 & 688341 & 4.8 & 5.053 & TRN & \\
\hline CHEMBL1584770 & 688341 & 4.6 & 4.8236 & TRN & \\
\hline CHEMBL1521695 & 688341 & 4.8 & 4.8422 & TRN & \\
\hline CHEMBL1339237 & 688341 & 4.7 & 4.8867 & TRN & \\
\hline CHEMBL1338194 & 688341 & 4.7 & 4.8656 & TRN & \\
\hline CHEMBL1499837 & 688341 & 4.6 & 4.939 & TRN & \\
\hline CHEMBL1515918 & 688341 & 4.5 & 5.0217 & TRN & \\
\hline CHEMBL1561644 & 688341 & 5.3 & 4.8749 & TRN & \\
\hline CHEMBL1379280 & 688341 & 4.4 & 4.8199 & TRN & \\
\hline CHEMBL1488376 & 688341 & 5.0 & 5.0075 & TRN & \\
\hline CHEMBL1579038 & 688341 & 4.6 & 5.0242 & TRN & \\
\hline CHEMBL1576902 & 688341 & 4.6 & 4.9255 & TRN & \\
\hline CHEMBL1497987 & 688341 & 4.8 & 5.1858 & TST & \\
\hline CHEMBL1461504 & 688341 & 5.9 & 5.1935 & TRN & \\
\hline CHEMBL1421831 & 688341 & 5.5 & 4.9529 & TST & \\
\hline CHEMBL1368827 & 688341 & 4.6 & 4.812 & TST & \\
\hline CHEMBL1308361 & 688341 & 4.5 & 4.9205 & TST & \\
\hline CHEMBL1397225 & 688341 & 4.4 & 5.1656 & TRN & \\
\hline CHEMBL1609440 & 688341 & 4.8 & 5.069 & TRN & \\
\hline CHEMBL1522603 & 688341 & 4.6 & 4.7512 & TRN & \\
\hline CHEMBL1443694 & 688341 & 5.4 & 5.0261 & TRN & \\
\hline CHEMBL1527170 & 688341 & 5.1 & 4.8397 & TRN & \\
\hline CHEMBL1452558 & 688341 & 5.4 & 4.9268 & TRN & \\
\hline CHEMBL1342608 & 688341 & 4.7 & 4.9887 & TST & \\
\hline CHEMBL1541641 & 688341 & 8.2007 & 4.99100 & 00000000005 & TRN \\
\hline CHEMBL1974818 & 688341 & 5.2 & 4.9457 & TST & \\
\hline CHEMBL1609182 & 688341 & 4.8 & 4.8696 & TST & \\
\hline CHEMBL1569363 & 688341 & 6.1 & 5.0456 & TRN & \\
\hline CHEMBL1446489 & 688341 & 4.4 & 4.95 & TRN & \\
\hline CHEMBL1389322 & 688341 & 4.6 & 4.933 & TRN & \\
\hline CHEMBL1568714 & 688341 & 4.7 & 4.7636 & TST & \\
\hline CHEMBL1498604 & 688341 & 7.4001 & 4.8568 & TRN & \\
\hline CHEMBL1448182 & 688341 & 5.7 & 4.8402 & TST & \\
\hline CHEMBL1318796 & 688341 & 4.8 & 4.7413 & TRN & \\
\hline CHEMBL1448042 & 688341 & 5.3 & 5.1323 & TRN & \\
\hline CHEMBL1567121 & 688341 & 4.4 & 4.8539 & TRN & \\
\hline CHEMBL1411502 & 688341 & 4.4 & 4.8768 & TST & \\
\hline CHEMBL1483214 & 688341 & 4.6 & 4.8999 & TRN & \\
\hline CHEMBL1613331 & 688341 & 4.6 & 4.8234 & TRN & \\
\hline CHEMBL1506881 & 688341 & 5.3 & 4.9127 & TRN & \\
\hline
\end{tabular}




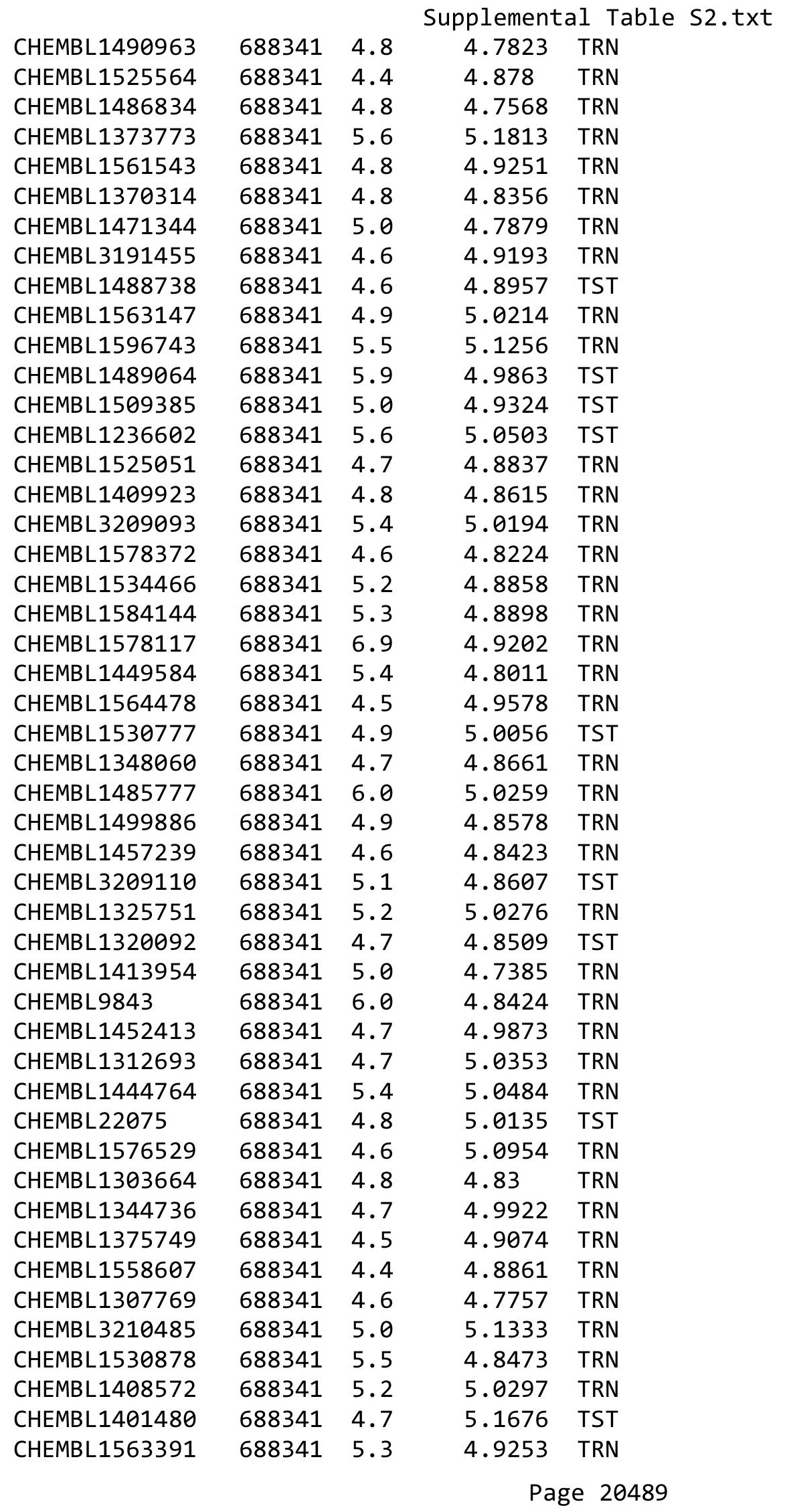




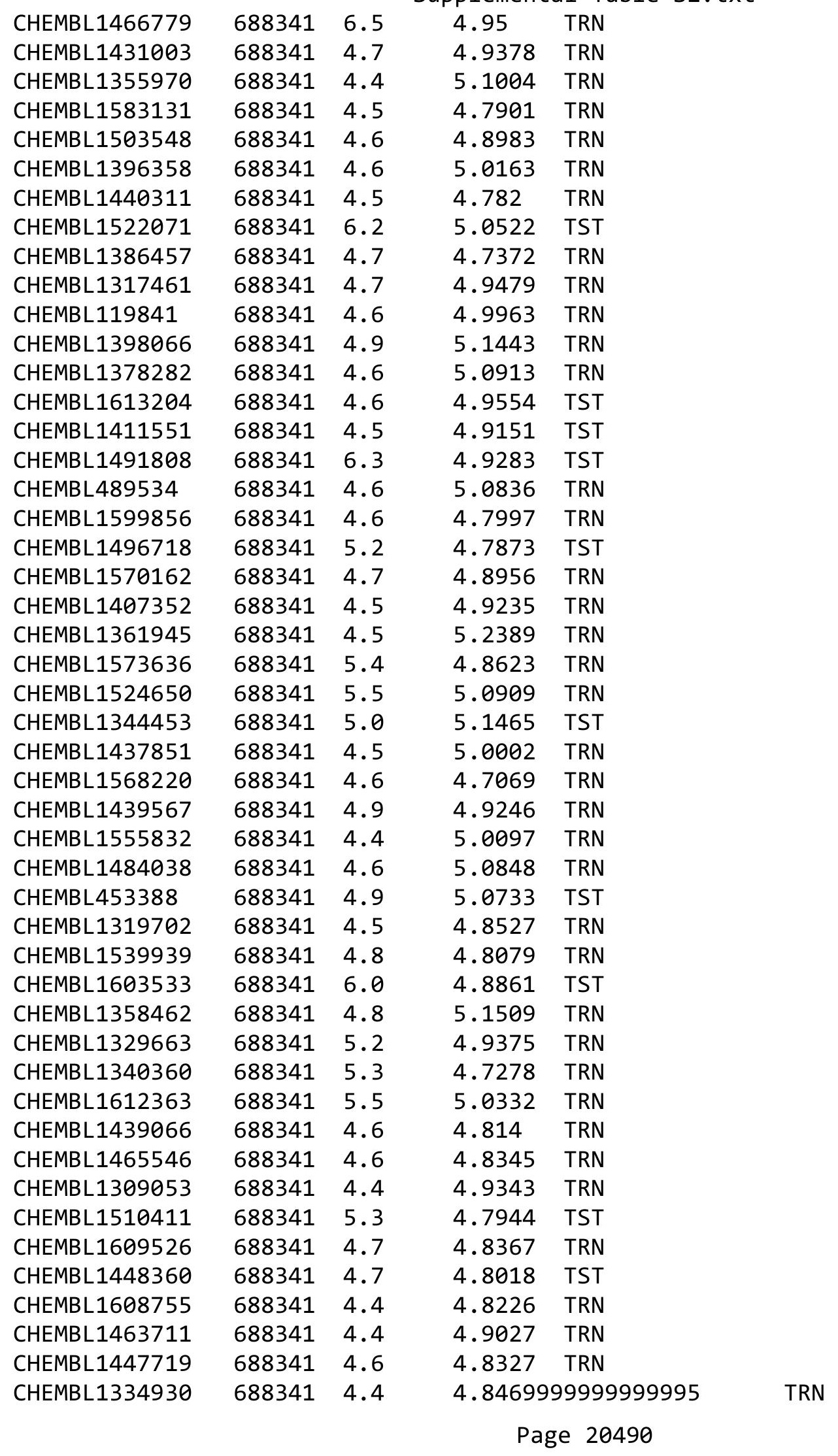




\begin{tabular}{|c|c|c|c|c|c|}
\hline & & & & & \\
\hline CHEMBL1551925 & 688341 & 5.3 & 5.1382 & TRN & \\
\hline CHEMBL1490103 & 688341 & 5.3 & 4.7974 & TST & \\
\hline CHEMBL1305152 & 688341 & 4.9 & 4.8775 & TST & \\
\hline CHEMBL1305217 & 688341 & 4.6 & 4.7864 & TRN & \\
\hline CHEMBL1399589 & 688341 & 6.8 & 4.7471 & TRN & \\
\hline CHEMBL50378 & 688341 & 4.5 & 5.1908 & TST & \\
\hline CHEMBL1464530 & 688341 & 4.8 & 4.834 & TRN & \\
\hline CHEMBL1376266 & 688341 & 4.7 & 4.9063 & TST & \\
\hline CHEMBL1480465 & 688341 & 4.5 & 4.9609 & TST & \\
\hline CHEMBL1412344 & 688341 & 4.5 & 4.7256 & TRN & \\
\hline CHEMBL1319055 & 688341 & 4.6 & 5.0108 & TRN & \\
\hline CHEMBL288998 & 688341 & 7.1002 & 5.1459 & TST & \\
\hline CHEMBL1399328 & 688341 & 4.5 & 4.905 & TRN & \\
\hline CHEMBL1447446 & 688341 & 4.6 & 5.1542 & TST & \\
\hline CHEMBL1352660 & 688341 & 4.6 & 4.9186 & TRN & \\
\hline CHEMBL1382502 & 688341 & 6.1 & 4.9991 & TRN & \\
\hline CHEMBL1466002 & 688341 & 4.6 & 4.86600 & 00000000005 & TST \\
\hline CHEMBL1394302 & 688341 & 4.5 & 5.0267 & TRN & \\
\hline CHEMBL1364507 & 688341 & 4.6 & 4.7966 & TST & \\
\hline CHEMBL1576107 & 688341 & 5.2 & 4.8942 & TRN & \\
\hline CHEMBL1538053 & 688341 & 5.3 & 5.0727 & TRN & \\
\hline CHEMBL1439079 & 688341 & 4.8 & 4.9706 & TRN & \\
\hline CHEMBL1436045 & 688341 & 4.5 & 4.9037 & TRN & \\
\hline CHEMBL1361066 & 688341 & 5.2 & 5.1226 & TRN & \\
\hline CHEMBL1346832 & 688341 & 4.4 & 5.0367 & TST & \\
\hline CHEMBL1332282 & 688341 & 4.6 & 5.0133 & TST & \\
\hline CHEMBL1483855 & 688341 & 5.6 & 5.16299 & 9999999999 & TRN \\
\hline CHEMBL1356346 & 688341 & 4.5 & 4.9989 & TST & \\
\hline CHEMBL1303003 & 688341 & 4.6 & 4.7913 & TRN & \\
\hline CHEMBL1521328 & 688341 & 4.4 & 5.0467 & TRN & \\
\hline CHEMBL1348792 & 688341 & 5.5 & 4.6724 & TRN & \\
\hline CHEMBL 302213 & 688341 & 5.4 & 5.0614 & TST & \\
\hline CHEMBL1471148 & 688341 & 4.4 & 4.9473 & TRN & \\
\hline CHEMBL1408541 & 688341 & 4.6 & 4.8115 & TRN & \\
\hline CHEMBL1570874 & 688341 & 5.0 & 4.771 & TRN & \\
\hline CHEMBL1419352 & 688341 & 5.2 & 4.9297 & TRN & \\
\hline CHEMBL1548581 & 688341 & 5.2 & 4.8487 & TST & \\
\hline CHEMBL1535429 & 688341 & 4.8 & 4.827 & TRN & \\
\hline CHEMBL1330692 & 688341 & 5.7 & 5.0571 & TRN & \\
\hline CHEMBL1300881 & 688341 & 4.8 & 4.7742 & TRN & \\
\hline CHEMBL1409830 & 688341 & 5.3 & 5.005 & TRN & \\
\hline CHEMBL1562269 & 688341 & 4.9 & 4.9366 & TRN & \\
\hline CHEMBL602807 & 688341 & 4.4 & 4.9213 & TRN & \\
\hline CHEMBL326958 & 688341 & 4.5 & 5.1653 & TRN & \\
\hline CHEMBL1499336 & 688341 & 4.8 & 4.9647 & TST & \\
\hline CHEMBL1380530 & 688341 & 4.4 & 4.7254 & TRN & \\
\hline CHEMBL1516077 & 688341 & 4.8 & 5.0192 & TST & \\
\hline CHEMBL1417671 & 688341 & 5.2 & 4.9141 & TST & \\
\hline & & & & 20491 & \\
\hline
\end{tabular}




\begin{tabular}{|c|c|c|c|c|}
\hline \multicolumn{5}{|c|}{ Supplemental Table S2.txt } \\
\hline CHEMBL1436169 & 688341 & 5.0 & 5.0663 & TRN \\
\hline CHEMBL148296 & 688341 & 4.4 & 4.9691 & TRN \\
\hline CHEMBL1468626 & 688341 & 5.2 & 4.8716 & TRN \\
\hline CHEMBL1577619 & 688341 & 4.4 & 4.9499 & TRN \\
\hline CHEMBL1462055 & 688341 & 4.6 & 4.8591 & TRN \\
\hline CHEMBL1364348 & 688341 & 4.6 & 4.9112 & TRN \\
\hline CHEMBL1388257 & 688341 & 4.5 & 4.7545 & TRN \\
\hline CHEMBL1596172 & 688341 & 4.7 & 4.918 & TRN \\
\hline CHEMBL1569821 & 688341 & 4.4 & 4.9677 & TST \\
\hline CHEMBL1534422 & 688341 & 4.4 & 4.8655 & TST \\
\hline CHEMBL1352569 & 688341 & 4.6 & 4.9135 & TRN \\
\hline CHEMBL1369405 & 688341 & 5.2 & 4.9737 & TST \\
\hline CHEMBL1381308 & 688341 & 5.2 & 5.1119 & TRN \\
\hline CHEMBL1320368 & 688341 & 4.6 & 4.9545 & TRN \\
\hline CHEMBL1498591 & 688341 & 5.2 & 4.7421 & TRN \\
\hline CHEMBL1476206 & 688341 & 4.6 & 5.1872 & TRN \\
\hline CHEMBL1579276 & 688341 & 5.3 & 4.9177 & TRN \\
\hline CHEMBL1611839 & 688341 & 4.6 & 4.8486 & TRN \\
\hline CHEMBL1455375 & 688341 & 4.4 & 4.7931 & TRN \\
\hline CHEMBL1407976 & 688341 & 4.6 & 4.9381 & TRN \\
\hline CHEMBL1400280 & 688341 & 5.3 & 5.147 & TRN \\
\hline CHEMBL1438222 & 688341 & 4.4 & 4.8712 & TRN \\
\hline CHEMBL1534239 & 688341 & 4.6 & 4.8353 & TST \\
\hline CHEMBL1531944 & 688341 & 4.6 & 4.8277 & TRN \\
\hline CHEMBL1419334 & 688341 & 4.6 & 4.9599 & TST \\
\hline CHEMBL1577343 & 688341 & 4.4 & 4.8866 & TST \\
\hline CHEMBL489737 & 688341 & 6.0 & 5.1066 & TRN \\
\hline CHEMBL1430781 & 688341 & 5.5 & 4.9744 & TRN \\
\hline CHEMBL 230056 & 688341 & 6.0 & 5.1991 & TST \\
\hline CHEMBL1399292 & 688341 & 4.6 & 5.0644 & TST \\
\hline CHEMBL1420841 & 688341 & 5.0 & 4.7539 & TRN \\
\hline CHEMBL1359135 & 688341 & 5.2 & 5.0764 & TST \\
\hline CHEMBL1558761 & 688341 & 4.4 & 4.9965 & TRN \\
\hline CHEMBL1493283 & 688341 & 4.8 & 4.6922 & TRN \\
\hline CHEMBL1346075 & 688341 & 5.5 & 4.9148 & TRN \\
\hline CHEMBL1561200 & 688341 & 5.3 & 4.8314 & TRN \\
\hline CHEMBL1447678 & 688341 & 5.4 & 4.8564 & TRN \\
\hline CHEMBL1511200 & 688341 & 4.4 & 4.8322 & TRN \\
\hline CHEMBL1372076 & 688341 & 4.7 & 5.0686 & TRN \\
\hline CHEMBL1332662 & 688341 & 5.9 & 4.721 & TRN \\
\hline CHEMBL1583163 & 688341 & 4.9 & 5.0445 & TRN \\
\hline CHEMBL1491726 & 688341 & 4.6 & 4.9144 & TRN \\
\hline CHEMBL1452671 & 688341 & 4.5 & 5.0487 & TRN \\
\hline CHEMBL1490895 & 688341 & 6.3 & 5.0818 & TRN \\
\hline CHEMBL1965138 & 688341 & 7.5003 & 5.0695 & TST \\
\hline CHEMBL1600522 & 688341 & 6.0 & 4.9003 & TRN \\
\hline CHEMBL1577452 & 688341 & 4.5 & 4.7759 & TRN \\
\hline CHEMBL1543818 & 688341 & 4.8 & 4.7836 & TRN \\
\hline
\end{tabular}




\begin{tabular}{|c|c|c|c|c|c|}
\hline \\
\hline CHEMBL1404633 & 688341 & 5.8 & 5.0044 & TRN & \\
\hline CHEMBL1331651 & 688341 & 4.4 & 4.9509 & TRN & \\
\hline CHEMBL1534654 & 688341 & 4.4 & 5.1316 & TST & \\
\hline CHEMBL1464123 & 688341 & 5.5 & 5.0172 & TST & \\
\hline CHEMBL1505786 & 688341 & 6.1 & 4.888 & TST & \\
\hline CHEMBL1528296 & 688341 & 4.7 & 4.8563 & TRN & \\
\hline CHEMBL1586648 & 688341 & 4.8 & 4.8125 & TRN & \\
\hline CHEMBL1363513 & 688341 & 4.5 & 5.1935 & TRN & \\
\hline CHEMBL1491547 & 688341 & 4.4 & 4.8264 & TRN & \\
\hline CHEMBL1310311 & 688341 & 4.5 & 4.7275 & TRN & \\
\hline CHEMBL1392265 & 688341 & 4.9 & 4.8647 & TRN & \\
\hline CHEMBL1401086 & 688341 & 5.2 & 4.7915 & TRN & \\
\hline CHEMBL1468448 & 688341 & 6.0 & 4.89199 & 99999999995 & TRN \\
\hline CHEMBL567531 & 688341 & 4.5 & 4.7238 & TRN & \\
\hline CHEMBL1311599 & 688341 & 5.2 & 5.0462 & TRN & \\
\hline CHEMBL1502625 & 688341 & 4.7 & 4.92899 & 9999999999 & TRN \\
\hline CHEMBL1580426 & 688341 & 4.8 & 4.9494 & TST & \\
\hline CHEMBL1502228 & 688341 & 4.4 & 4.9058 & TST & \\
\hline CHEMBL3191364 & 688341 & 4.5 & 5.0821 & TST & \\
\hline CHEMBL1370464 & 688341 & 4.6 & 4.8146 & TRN & \\
\hline CHEMBL1506459 & 688341 & 4.6 & 4.8883 & TRN & \\
\hline CHEMBL1336727 & 688341 & 4.5 & 4.9184 & TST & \\
\hline CHEMBL1412945 & 688341 & 4.7 & 4.9823 & TRN & \\
\hline CHEMBL1545690 & 688341 & 4.5 & 4.9259 & TST & \\
\hline CHEMBL 281622 & 688341 & 4.8 & 5.1161 & TST & \\
\hline CHEMBL1507941 & 688341 & 4.7 & 4.8455 & TRN & \\
\hline CHEMBL1340474 & 688341 & 4.4 & 5.0044 & TRN & \\
\hline CHEMBL1377745 & 688341 & 5.2 & 4.9498 & TRN & \\
\hline CHEMBL1491574 & 688341 & 4.5 & 5.1377 & TRN & \\
\hline CHEMBL1345131 & 688341 & 5.4 & 4.9596 & TRN & \\
\hline CHEMBL1428574 & 688341 & 4.6 & 4.8427 & TRN & \\
\hline CHEMBL513116 & 688341 & 4.5 & 5.1186 & TRN & \\
\hline CHEMBL1395431 & 688341 & 6.0 & 5.0963 & TRN & \\
\hline CHEMBL1460951 & 688341 & 4.6 & 5.0514 & TRN & \\
\hline CHEMBL1490788 & 688341 & 4.8 & 4.9299 & TRN & \\
\hline CHEMBL1439272 & 688341 & 5.5 & 4.9659 & TRN & \\
\hline CHEMBL1450981 & 688341 & 5.6 & 4.7777 & TRN & \\
\hline CHEMBL1468358 & 688341 & 4.4 & 5.0642 & TST & \\
\hline CHEMBL410873 & 688341 & 5.7 & 5.1237 & TST & \\
\hline CHEMBL1300784 & 688341 & 5.2 & 4.8789 & TRN & \\
\hline CHEMBL1441608 & 688341 & 4.5 & 5.1245 & TRN & \\
\hline CHEMBL1465372 & 688341 & 5.4 & 4.7608 & TST & \\
\hline CHEMBL1611371 & 688341 & 4.4 & 4.8417 & TRN & \\
\hline CHEMBL1510439 & 688341 & 5.8 & 5.0075 & TRN & \\
\hline CHEMBL 73711 & 688341 & 5.0 & 4.8609 & TST & \\
\hline CHEMBL1500158 & 688341 & 5.3 & 4.8342 & TRN & \\
\hline CHEMBL1303320 & 688341 & 4.6 & 4.8007 & TRN & \\
\hline CHEMBL592106 & 688341 & 4.8 & 5.0009 & TRN & \\
\hline
\end{tabular}




\begin{tabular}{|c|c|c|c|c|}
\hline & & & & \\
\hline CHEMBL1374999 & 688341 & 5.9 & 5.1265 & TST \\
\hline CHEMBL1300645 & 688341 & 4.6 & 4.9109 & TST \\
\hline CHEMBL1491558 & 688341 & 4.8 & 4.9588 & TRN \\
\hline CHEMBL1578190 & 688341 & 5.3 & 4.7741 & TST \\
\hline CHEMBL1464836 & 688341 & 5.8 & 4.8953 & TRN \\
\hline CHEMBL1473523 & 688341 & 4.8 & 5.2742 & TST \\
\hline CHEMBL1597692 & 688341 & 5.2 & 5.1717 & TRN \\
\hline CHEMBL1489461 & 688341 & 4.4 & 5.0457 & TRN \\
\hline CHEMBL1331229 & 688341 & 4.6 & 4.7345 & TRN \\
\hline CHEMBL1600003 & 688341 & 5.4 & 4.7846 & TRN \\
\hline CHEMBL1450307 & 688341 & 6.2 & 5.011 & TRN \\
\hline CHEMBL1525948 & 688341 & 4.9 & 5.0362 & TRN \\
\hline CHEMBL1393501 & 688341 & 4.4 & 5.1402 & TST \\
\hline CHEMBL155265 & 688341 & 5.3 & 5.021 & TST \\
\hline CHEMBL1376514 & 688341 & 4.9 & 5.0055 & TST \\
\hline CHEMBL1303389 & 688341 & 4.9 & 4.7022 & TRN \\
\hline CHEMBL1311758 & 688341 & 4.6 & 5.0218 & TRN \\
\hline CHEMBL1318878 & 688341 & 4.5 & 4.989 & TST \\
\hline CHEMBL1401720 & 688341 & 4.8 & 4.9369 & TRN \\
\hline CHEMBL1370951 & 688341 & 4.4 & 4.8981 & TRN \\
\hline CHEMBL1332937 & 688341 & 4.8 & 5.0668 & TRN \\
\hline CHEMBL1306305 & 688341 & 4.5 & 4.6812 & TRN \\
\hline CHEMBL1368302 & 688341 & 5.2 & 4.9598 & TRN \\
\hline CHEMBL1564034 & 688341 & 5.3 & 5.002 & TST \\
\hline CHEMBL1527556 & 688341 & 4.8 & 5.084 & TST \\
\hline CHEMBL1565146 & 688341 & 5.4 & 4.7801 & TRN \\
\hline CHEMBL1453232 & 688341 & 4.6 & 4.9287 & TRN \\
\hline CHEMBL3190009 & 688341 & 4.5 & 4.8449 & TRN \\
\hline CHEMBL1365455 & 688341 & 6.0 & 5.0466 & TRN \\
\hline CHEMBL1523844 & 688341 & 4.6 & 4.9335 & TRN \\
\hline CHEMBL1409572 & 688341 & 4.4 & 4.9983 & TRN \\
\hline CHEMBL1611225 & 688341 & 4.4 & 5.2502 & TST \\
\hline CHEMBL1431089 & 688341 & 5.4 & 4.9525 & TRN \\
\hline CHEMBL471397 & 688341 & 5.9 & 5.0124 & TST \\
\hline CHEMBL1372392 & 688341 & 4.7 & 4.9631 & TST \\
\hline CHEMBL1533560 & 688341 & 7.0 & 5.1975 & TST \\
\hline CHEMBL1598120 & 688341 & 4.8 & 4.8722 & TRN \\
\hline CHEMBL1547645 & 688341 & 4.6 & 5.0709 & TRN \\
\hline CHEMBL1573374 & 688341 & 4.5 & 4.7535 & TRN \\
\hline CHEMBL1583898 & 688341 & 4.9 & 5.004 & TRN \\
\hline CHEMBL1555567 & 688341 & 5.5 & 5.1337 & TRN \\
\hline CHEMBL1568116 & 688341 & 4.8 & 4.9616 & TRN \\
\hline CHEMBL1339255 & 688341 & 6.4 & 4.9355 & TRN \\
\hline CHEMBL1510819 & 688341 & 4.5 & 4.8624 & TRN \\
\hline CHEMBL1326130 & 688341 & 4.6 & 4.8526 & TRN \\
\hline CHEMBL1546324 & 688341 & 4.6 & 4.9362 & TRN \\
\hline CHEMBL 3211543 & 688341 & 4.8 & 4.9983 & TST \\
\hline CHEMBL1343892 & 688341 & 4.7 & 4.9741 & TRN \\
\hline
\end{tabular}




\begin{tabular}{|c|c|c|c|c|}
\hline & & & & \\
\hline CHEMBL1558580 & 688341 & 5.2 & 5.0566 & TST \\
\hline CHEMBL1386674 & 688341 & 4.7 & 4.8392 & TST \\
\hline CHEMBL3192087 & 688341 & 5.0 & 4.9257 & TRN \\
\hline CHEMBL1540995 & 688341 & 5.3 & 4.9092 & TRN \\
\hline CHEMBL1372254 & 688341 & 5.6 & 5.0478 & TST \\
\hline CHEMBL1548667 & 688341 & 4.8 & 4.8379 & TRN \\
\hline CHEMBL1466746 & 688341 & 4.7 & 4.9054 & TRN \\
\hline CHEMBL1563604 & 688341 & 4.8 & 5.1642 & TRN \\
\hline CHEMBL1440708 & 688341 & 4.9 & 4.7892 & TRN \\
\hline CHEMBL1460400 & 688341 & 5.2 & 4.945 & TRN \\
\hline CHEMBL1458607 & 688341 & 5.4 & 4.9348 & TRN \\
\hline CHEMBL1578928 & 688341 & 5.9 & 5.2223 & TRN \\
\hline CHEMBL1303974 & 688341 & 4.5 & 4.9823 & TRN \\
\hline CHEMBL1421059 & 688341 & 5.4 & 4.8979 & TRN \\
\hline CHEMBL1402227 & 688341 & 4.8 & 4.9584 & TRN \\
\hline CHEMBL1426183 & 688341 & 4.6 & 4.8608 & TRN \\
\hline CHEMBL1530831 & 688341 & 4.6 & 4.949 & TRN \\
\hline CHEMBL 274438 & 688341 & 5.1 & 5.0501 & TST \\
\hline CHEMBL1538036 & 688341 & 4.6 & 4.8498 & TRN \\
\hline CHEMBL1383479 & 688341 & 5.5 & 4.8966 & TRN \\
\hline CHEMBL1377430 & 688341 & 4.6 & 4.9448 & TRN \\
\hline CHEMBL1373723 & 688341 & 4.9 & 5.0846 & TRN \\
\hline CHEMBL1450089 & 688341 & 4.8 & 4.9382 & TRN \\
\hline CHEMBL1503284 & 688341 & 4.7 & 4.8177 & TRN \\
\hline CHEMBL1610904 & 688341 & 4.7 & 4.8335 & TRN \\
\hline CHEMBL1466896 & 688341 & 4.4 & 4.7581 & TRN \\
\hline CHEMBL1463277 & 688341 & 5.0 & 4.8717 & TRN \\
\hline CHEMBL1447333 & 688341 & 8.0 & 5.1467 & TST \\
\hline CHEMBL1419284 & 688341 & 5.2 & 4.917 & TRN \\
\hline CHEMBL1594330 & 688341 & 5.2 & 5.0227 & TRN \\
\hline CHEMBL1607363 & 688341 & 4.5 & 4.8344 & TRN \\
\hline CHEMBL3198180 & 688341 & 5.8 & 4.9439 & TRN \\
\hline CHEMBL530361 & 688341 & 5.2 & 5.0591 & TRN \\
\hline CHEMBL1370544 & 688341 & 4.5 & 5.0853 & TST \\
\hline CHEMBL1570175 & 688341 & 5.3 & 4.9108 & TRN \\
\hline CHEMBL1510990 & 688341 & 5.3 & 4.9273 & TST \\
\hline CHEMBL85139 & 688341 & 4.9 & 4.9105 & TST \\
\hline CHEMBL1396583 & 688341 & 5.4 & 5.004 & TRN \\
\hline CHEMBL1299291 & 688341 & 4.4 & 4.9904 & TRN \\
\hline CHEMBL1299446 & 688341 & 4.4 & 4.9037 & TRN \\
\hline CHEMBL1561768 & 688341 & 4.8 & 4.7333 & TRN \\
\hline CHEMBL3198096 & 688341 & 5.4 & 4.9593 & TRN \\
\hline CHEMBL1527710 & 688341 & 4.8 & 4.8469 & TRN \\
\hline CHEMBL1549683 & 688341 & 4.9 & 4.7884 & TRN \\
\hline CHEMBL375270 & 688341 & 5.3 & 4.9802 & TRN \\
\hline CHEMBL1585829 & 688341 & 5.3 & 4.8789 & TRN \\
\hline CHEMBL1610380 & 688341 & 5.2 & 5.0126 & TST \\
\hline CHEMBL581194 & 688341 & 4.6 & 4.7969 & TRN \\
\hline
\end{tabular}




\begin{tabular}{|c|c|c|c|c|c|}
\hline \multicolumn{6}{|c|}{ Supplemental Table S2.txt } \\
\hline CHEMBL1321286 & 688341 & 4.8 & 4.9941 & TRN & \\
\hline CHEMBL1606030 & 688341 & 4.4 & 4.7498 & TRN & \\
\hline CHEMBL1380133 & 688341 & 5.9 & 5.0167 & TST & \\
\hline CHEMBL1541679 & 688341 & 4.9 & 5.0825 & TST & \\
\hline CHEMBL3210299 & 688341 & 5.2 & 5.0211 & TRN & \\
\hline CHEMBL1529220 & 688341 & 4.5 & 4.7663 & TRN & \\
\hline CHEMBL1320841 & 688341 & 4.6 & 4.9017 & TRN & \\
\hline CHEMBL1568288 & 688341 & 5.5 & 4.8835 & TRN & \\
\hline CHEMBL491747 & 688341 & 4.5 & 4.9945 & TRN & \\
\hline CHEMBL1429196 & 688341 & 4.8 & 4.8949 & TRN & \\
\hline CHEMBL1567956 & 688341 & 5.0 & 4.8449 & TRN & \\
\hline CHEMBL1579840 & 688341 & 5.4 & \multicolumn{2}{|c|}{4.9319999999999995} & TST \\
\hline CHEMBL1484810 & 688341 & 4.7 & 4.9613 & TRN & \\
\hline CHEMBL1550675 & 688341 & 4.4 & 4.8437 & TRN & \\
\hline CHEMBL1332761 & 688341 & 5.4 & 4.9014 & TRN & \\
\hline CHEMBL1367565 & 688341 & 4.8 & 5.0712 & TST & \\
\hline CHEMBL1526115 & 688341 & 4.5 & 4.9753 & TRN & \\
\hline CHEMBL1309562 & 688341 & 4.6 & 4.7649 & TST & \\
\hline CHEMBL1500666 & 688341 & 4.4 & 4.9285 & TRN & \\
\hline CHEMBL1607456 & 688341 & 4.8 & 4.8617 & TRN & \\
\hline CHEMBL1465539 & 688341 & 5.5 & 4.84 & TRN & \\
\hline CHEMBL1533378 & 688341 & 5.1 & 4.9569 & TRN & \\
\hline CHEMBL1462331 & 688341 & 5.5 & 4.9326 & TRN & \\
\hline CHEMBL1578304 & 688341 & 4.6 & 4.8022 & TRN & \\
\hline CHEMBL1389906 & 688341 & 4.6 & 4.8471 & TRN & \\
\hline CHEMBL1548490 & 688341 & 4.5 & 4.697 & TRN & \\
\hline CHEMBL1330302 & 688341 & 4.4 & 4.9597 & TRN & \\
\hline CHEMBL1342777 & 688341 & 5.2 & 4.8419 & TRN & \\
\hline CHEMBL83294 & 688341 & 4.7 & 4.7735 & TRN & \\
\hline CHEMBL1449992 & 688341 & 4.6 & 4.7644 & TRN & \\
\hline CHEMBL1353231 & 688341 & 4.4 & 4.7862 & TRN & \\
\hline CHEMBL1365624 & 688341 & 4.7 & \multicolumn{2}{|c|}{4.9110000000000005} & TRN \\
\hline CHEMBL1525750 & 688341 & 4.9 & 4.6923 & TRN & \\
\hline CHEMBL1585014 & 688341 & 4.6 & 4.8899 & TRN & \\
\hline CHEMBL1600561 & 688341 & 5.5 & 5.0575 & TST & \\
\hline CHEMBL1369207 & 688341 & 4.6 & 4.89 & TRN & \\
\hline CHEMBL1517062 & 688341 & 5.8 & 5.0419 & TRN & \\
\hline CHEMBL1395138 & 688341 & 5.5 & 5.1307 & TRN & \\
\hline CHEMBL131199 & 688341 & 6.7001 & 5.0268 & TST & \\
\hline CHEMBL1532984 & 688341 & 4.4 & 4.9702 & TST & \\
\hline CHEMBL1587145 & 688341 & 4.7 & 4.7765 & TRN & \\
\hline CHEMBL1499425 & 688341 & 5.2 & 5.0754 & TST & \\
\hline CHEMBL1431517 & 688341 & 4.4 & 5.1824 & TST & \\
\hline CHEMBL1536615 & 688341 & 4.8 & 4.9087 & TRN & \\
\hline CHEMBL 3195620 & 688341 & 4.5 & 4.9407 & TST & \\
\hline CHEMBL1335627 & 688341 & 6.0 & 4.9728 & TST & \\
\hline CHEMBL1566365 & 688341 & 4.8 & 4.80399 & 9999999999 & TRN \\
\hline CHEMBL1415198 & 688341 & 4.7 & 4.9812 & TRN & \\
\hline
\end{tabular}




\begin{tabular}{|c|c|c|c|c|}
\hline \multicolumn{5}{|c|}{ Supplemental Table S2.txt } \\
\hline CHEMBL1380462 & 688341 & 5.1 & 5.1798 & TRN \\
\hline CHEMBL1572747 & 688341 & 4.8 & 4.9606 & TRN \\
\hline CHEMBL1355010 & 688341 & 5.6 & 5.1858 & TRN \\
\hline CHEMBL1421517 & 688341 & 4.6 & 5.0406 & TRN \\
\hline CHEMBL1432976 & 688341 & 4.8 & 4.931 & TRN \\
\hline CHEMBL1524752 & 688341 & 4.4 & 4.7762 & TRN \\
\hline CHEMBL1321887 & 688341 & 4.6 & 5.2203 & TRN \\
\hline CHEMBL1498839 & 688341 & 4.7 & 4.8857 & TRN \\
\hline CHEMBL1330394 & 688341 & 4.8 & 5.1207 & TRN \\
\hline CHEMBL1310499 & 688341 & 4.5 & 4.8719 & TRN \\
\hline CHEMBL1404747 & 688341 & 4.6 & 4.9345 & TRN \\
\hline CHEMBL1541513 & 688341 & 5.7 & 4.8775 & TRN \\
\hline CHEMBL1345974 & 688341 & 4.7 & 4.8704 & TST \\
\hline CHEMBL1510533 & 688341 & 4.8 & 4.7049 & TRN \\
\hline CHEMBL1589768 & 688341 & 4.7 & 4.8821 & TRN \\
\hline CHEMBL1448278 & 688341 & 4.4 & 4.8619 & TRN \\
\hline CHEMBL1587512 & 688341 & 7.8996 & 5.1716 & TST \\
\hline CHEMBL1568520 & 688341 & 4.4 & 4.9929 & TRN \\
\hline CHEMBL 3192945 & 688341 & 4.5 & 4.9258 & TST \\
\hline CHEMBL1447059 & 688341 & 4.7 & 4.8357 & TRN \\
\hline CHEMBL1369169 & 688341 & 5.4 & 4.9754 & TST \\
\hline CHEMBL1546428 & 688341 & 4.7 & 4.8101 & TRN \\
\hline CHEMBL1352430 & 688341 & 5.2 & 4.886 & TRN \\
\hline CHEMBL1417865 & 688341 & 4.9 & 5.0533 & TRN \\
\hline CHEMBL1583860 & 688341 & 4.9 & 4.9712 & TRN \\
\hline CHEMBL1354287 & 688341 & 5.3 & 5.1469 & TRN \\
\hline CHEMBL402477 & 688341 & 4.4 & 5.061 & TST \\
\hline CHEMBL1405410 & 688341 & 5.1 & 5.166 & TRN \\
\hline CHEMBL1568598 & 688341 & 4.6 & 5.0045 & TRN \\
\hline CHEMBL1460835 & 688341 & 4.7 & 4.8361 & TRN \\
\hline CHEMBL1446324 & 688341 & 4.5 & 5.1481 & TRN \\
\hline CHEMBL1422801 & 688341 & 5.3 & 4.9694 & TST \\
\hline CHEMBL1372200 & 688341 & 5.1 & 5.0052 & TRN \\
\hline CHEMBL1393786 & 688341 & 4.5 & 5.0631 & TST \\
\hline CHEMBL1370669 & 688341 & 5.4 & 4.9455 & TST \\
\hline CHEMBL1531299 & 688341 & 4.5 & 5.2427 & TRN \\
\hline CHEMBL1568990 & 688341 & 4.9 & 4.7906 & TST \\
\hline CHEMBL1388826 & 688341 & 5.1 & 4.8828 & TST \\
\hline CHEMBL1359940 & 688341 & 4.4 & 4.7704 & TRN \\
\hline CHEMBL1498256 & 688341 & 5.8 & 5.0508 & TRN \\
\hline CHEMBL1398607 & 688341 & 5.4 & 4.8971 & TST \\
\hline CHEMBL1469332 & 688341 & 4.9 & 4.9305 & TST \\
\hline CHEMBL1483878 & 688341 & 4.8 & 4.9885 & TST \\
\hline CHEMBL1585852 & 688341 & 5.2 & 4.8999 & TST \\
\hline CHEMBL1430402 & 688341 & 4.5 & 4.9054 & TRN \\
\hline CHEMBL1580791 & 688341 & 4.6 & 5.0163 & TST \\
\hline CHEMBL1376765 & 688341 & 5.0 & 4.8808 & TRN \\
\hline CHEMBL1424313 & 688341 & 5.4 & 4.9378 & TRN \\
\hline
\end{tabular}




\begin{tabular}{|c|c|c|c|c|}
\hline \multicolumn{5}{|c|}{ Supplemental Table S2.txt } \\
\hline CHEMBL1462049 & 688341 & 4.6 & 4.8737 & TRN \\
\hline CHEMBL1597574 & 688341 & 4.9 & 4.6687 & TRN \\
\hline CHEMBL1344408 & 688341 & 4.7 & 4.9725 & TRN \\
\hline CHEMBL1304625 & 688341 & 5.4 & 5.0152 & TST \\
\hline CHEMBL1593443 & 688341 & 4.8 & 4.9927 & TRN \\
\hline CHEMBL1465767 & 688341 & 7.2 & 4.8343 & TRN \\
\hline CHEMBL1545575 & 688341 & 4.8 & 4.8613 & TRN \\
\hline CHEMBL1302606 & 688341 & 4.4 & 4.8936 & TRN \\
\hline CHEMBL1545295 & 688341 & 5.1 & 4.8549 & TRN \\
\hline CHEMBL1432678 & 688341 & 5.1 & 4.762 & TRN \\
\hline CHEMBL1346069 & 688341 & 4.9 & 4.9289 & TRN \\
\hline CHEMBL1529042 & 688341 & 5.4 & 4.8309 & TRN \\
\hline CHEMBL1534772 & 688341 & 4.5 & 4.8861 & TRN \\
\hline CHEMBL1586489 & 688341 & 4.4 & 4.9055 & TRN \\
\hline CHEMBL1459568 & 688341 & 5.2 & 5.0548 & TRN \\
\hline CHEMBL1609337 & 688341 & 4.5 & 5.135 & TST \\
\hline CHEMBL1388435 & 688341 & 5.3 & 4.8167 & TRN \\
\hline CHEMBL1417269 & 688341 & 4.8 & 4.9311 & TST \\
\hline CHEMBL1365306 & 688341 & 4.9 & 4.9817 & TRN \\
\hline CHEMBL1420059 & 688341 & 5.6 & 5.1186 & TRN \\
\hline CHEMBL1534846 & 688341 & 4.9 & 4.7817 & TRN \\
\hline CHEMBL1572173 & 688341 & 7.5003 & 5.1262 & TRN \\
\hline CHEMBL1550840 & 688341 & 4.5 & 4.8559 & TRN \\
\hline CHEMBL1352971 & 688341 & 5.0 & 4.8976 & TRN \\
\hline CHEMBL1443391 & 688341 & 6.0 & 4.7888 & TRN \\
\hline CHEMBL1557303 & 688341 & 4.6 & 4.7082 & TRN \\
\hline CHEMBL1540094 & 688341 & 4.4 & 4.9554 & TST \\
\hline CHEMBL1501431 & 688341 & 4.7 & 4.8574 & TRN \\
\hline CHEMBL1379075 & 688341 & 5.4 & 5.0489 & TST \\
\hline CHEMBL1557481 & 688341 & 5.2 & 4.8793 & TRN \\
\hline CHEMBL1413938 & 688341 & 4.8 & 4.9611 & TRN \\
\hline CHEMBL1580903 & 688341 & 4.6 & 4.7518 & TRN \\
\hline CHEMBL1421178 & 688341 & 5.0 & 4.8368 & TRN \\
\hline CHEMBL1364538 & 688341 & 4.6 & 4.8686 & TRN \\
\hline CHEMBL1323569 & 688341 & 4.6 & 4.8386 & TST \\
\hline CHEMBL1336191 & 688341 & 6.0 & 4.9296 & TRN \\
\hline CHEMBL1517147 & 688341 & 4.5 & 4.7302 & TRN \\
\hline CHEMBL1578087 & 688341 & 4.4 & 4.7467 & TRN \\
\hline CHEMBL1583207 & 688341 & 4.5 & 4.8806 & TRN \\
\hline CHEMBL 228511 & 688341 & 7.1002 & 5.0761 & TST \\
\hline CHEMBL1373673 & 688341 & 4.9 & 5.1 & TRN \\
\hline CHEMBL1327910 & 688341 & 6.4 & 4.8543 & TST \\
\hline CHEMBL1488677 & 688341 & 4.5 & 5.0898 & TST \\
\hline CHEMBL1436817 & 688341 & 4.8 & 4.9853 & TRN \\
\hline CHEMBL 2006154 & 688341 & 5.4 & 5.0667 & TRN \\
\hline CHEMBL1604540 & 688341 & 5.4 & 4.9865 & TST \\
\hline CHEMBL1610323 & 688341 & 5.2 & 4.852 & TRN \\
\hline CHEMBL1488407 & 688341 & 4.8 & 5.0782 & TRN \\
\hline
\end{tabular}




\begin{tabular}{|c|c|c|c|c|c|}
\hline \multicolumn{6}{|c|}{ Supplemental Table S2.txt } \\
\hline CHEMBL1482818 & 688341 & 4.5 & 5.0428 & TST & \\
\hline CHEMBL1418843 & 688341 & 4.6 & 5.1149 & TRN & \\
\hline CHEMBL1313009 & 688341 & 4.9 & 4.8048 & TRN & \\
\hline CHEMBL1393586 & 688341 & 5.2 & 5.1361 & TRN & \\
\hline CHEMBL1432443 & 688341 & 4.8 & 4.6489 & TRN & \\
\hline CHEMBL1221925 & 688341 & 6.2 & 5.0425 & TST & \\
\hline CHEMBL1570154 & 688341 & 5.5 & 4.8746 & TRN & \\
\hline CHEMBL1411402 & 688341 & 4.4 & 4.8222 & TRN & \\
\hline CHEMBL1460876 & 688341 & 4.5 & 5.0361 & TST & \\
\hline CHEMBL1375946 & 688341 & 5.2 & 4.8636 & TRN & \\
\hline CHEMBL1396898 & 688341 & 4.9 & 5.131 & TRN & \\
\hline CHEMBL1538076 & 688341 & 4.7 & 5.013 & TST & \\
\hline CHEMBL1587305 & 688341 & 5.1 & 4.8326 & TST & \\
\hline CHEMBL1484309 & 688341 & 4.9 & 4.9278 & TRN & \\
\hline CHEMBL1441605 & 688341 & 5.5 & 4.8718 & TRN & \\
\hline CHEMBL1375381 & 688341 & 4.7 & 4.8605 & TST & \\
\hline CHEMBL1527459 & 688341 & 5.9 & 4.8972 & TRN & \\
\hline CHEMBL1539839 & 688341 & 5.4 & 4.80699 & 99999999995 & TRN \\
\hline CHEMBL1467086 & 688341 & 5.6 & 5.0234 & TST & \\
\hline CHEMBL1551090 & 688341 & 5.3 & 4.9767 & TRN & \\
\hline CHEMBL1402122 & 688341 & 5.6 & $5.0310 e$ & 0000000001 & TRN \\
\hline CHEMBL1378350 & 688341 & 4.4 & 4.8992 & TRN & \\
\hline CHEMBL1478073 & 688341 & 5.9 & 4.8544 & TRN & \\
\hline CHEMBL1527443 & 688341 & 4.7 & 5.1245 & TRN & \\
\hline CHEMBL1299476 & 688341 & 4.6 & 4.955 & TRN & \\
\hline CHEMBL1449288 & 688341 & 5.1 & 5.20299 & 9999999999 & TRN \\
\hline CHEMBL1480968 & 688341 & 5.1 & 4.8718 & TRN & \\
\hline CHEMBL1597625 & 688341 & 5.4 & 5.004 & TRN & \\
\hline CHEMBL1561449 & 688341 & 4.4 & 5.1088 & TST & \\
\hline CHEMBL1326527 & 688341 & 6.9 & 4.8673 & TRN & \\
\hline CHEMBL1391401 & 688341 & 4.4 & 4.8398 & TRN & \\
\hline CHEMBL1605965 & 688341 & 4.9 & 4.9933 & TRN & \\
\hline CHEMBL1466437 & 688341 & 4.4 & 4.8956 & TRN & \\
\hline CHEMBL1509355 & 688341 & 6.0 & 4.8041 & TRN & \\
\hline CHEMBL1462133 & 688341 & 4.8 & 4.9248 & TRN & \\
\hline CHEMBL1333934 & 688341 & 4.5 & 5.0535 & TRN & \\
\hline CHEMBL1427723 & 688341 & 4.5 & 4.9181 & TRN & \\
\hline CHEMBL1331314 & 688341 & 4.8 & 4.9363 & TRN & \\
\hline CHEMBL1535074 & 688341 & 4.7 & 5.0839 & TRN & \\
\hline CHEMBL1369878 & 688341 & 4.8 & 5.0685 & TRN & \\
\hline CHEMBL1560323 & 688341 & 4.6 & 5.0008 & TRN & \\
\hline CHEMBL1483770 & 688341 & 4.8 & 4.8505 & TRN & \\
\hline CHEMBL1605465 & 688341 & 5.7 & 5.0179 & TRN & \\
\hline CHEMBL1381093 & 688341 & 4.5 & 4.7035 & TRN & \\
\hline CHEMBL1346299 & 688341 & 5.2 & 4.837 & TRN & \\
\hline CHEMBL1359146 & 688341 & 5.4 & 4.8654 & TRN & \\
\hline CHEMBL1591600 & 688341 & 4.4 & 5.1891 & TRN & \\
\hline CHEMBL1494881 & 688341 & 4.6 & 5.0176 & TST & \\
\hline
\end{tabular}




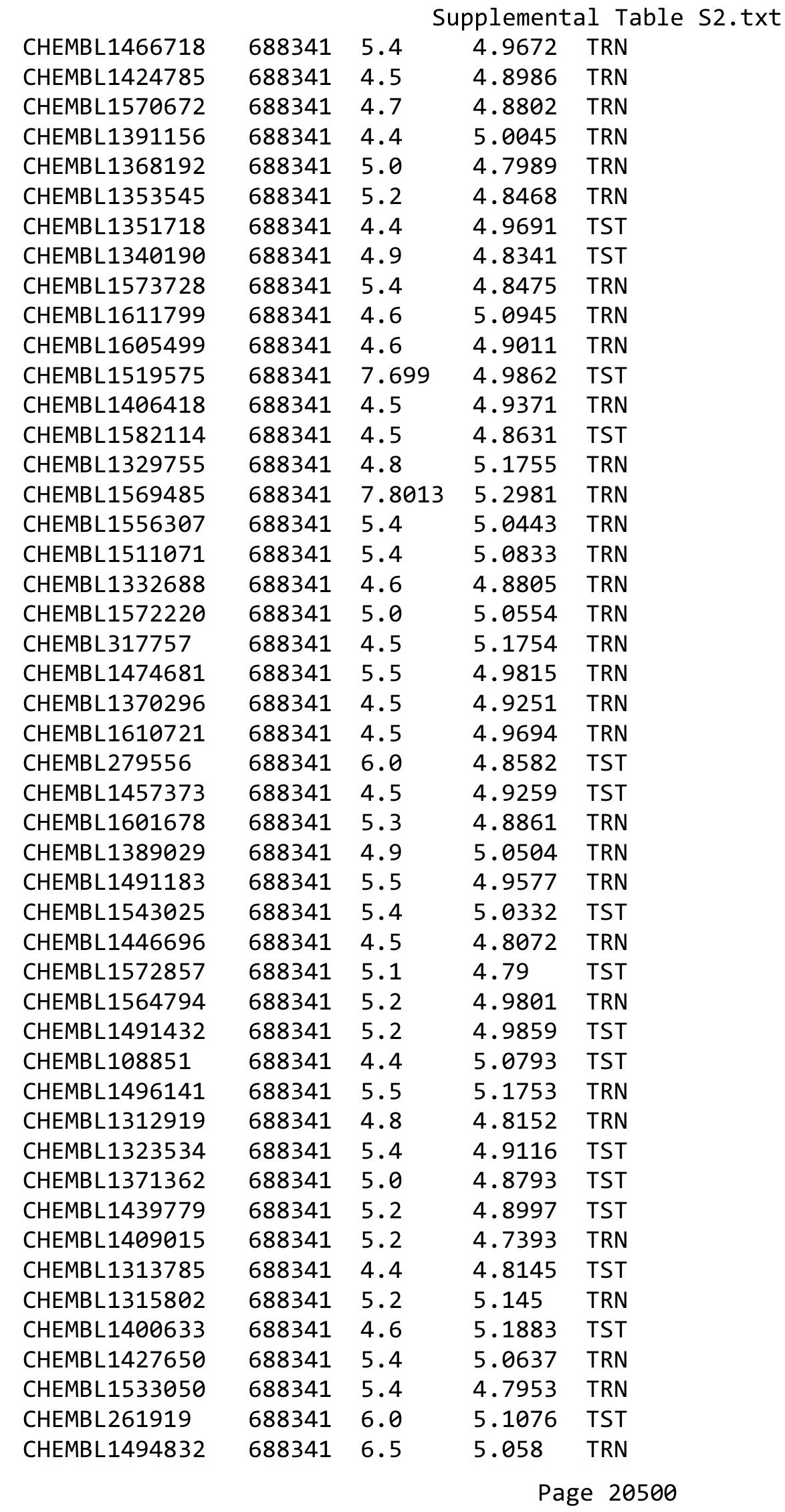




\begin{tabular}{|c|c|c|c|c|}
\hline \multicolumn{5}{|c|}{ plemental T } \\
\hline CHEMBL1404398 & 688341 & 4.4 & 4.9555 & TRN \\
\hline CHEMBL1491101 & 688341 & 4.5 & 4.9548 & TRN \\
\hline CHEMBL1451224 & 688341 & 5.5 & 5.1607 & TRN \\
\hline CHEMBL554311 & 688341 & 5.3 & 5.1895 & TRN \\
\hline CHEMBL50112 & 688341 & 5.1 & 4.9473 & TRN \\
\hline CHEMBL1528050 & 688341 & 5.4 & 5.044 & TRN \\
\hline CHEMBL1472379 & 688341 & 4.7 & 4.9862 & TST \\
\hline CHEMBL1604833 & 688341 & 6.0 & 4.7602 & TRN \\
\hline CHEMBL1312641 & 688341 & 6.1 & 4.9564 & TRN \\
\hline CHEMBL1602873 & 688341 & 5.1 & 4.8546 & TRN \\
\hline CHEMBL1489875 & 688341 & 4.8 & 4.9752 & TST \\
\hline CHEMBL1309884 & 688341 & 5.5 & 5.0494 & TRN \\
\hline CHEMBL1437833 & 688341 & 5.2 & 4.9076 & TRN \\
\hline CHEMBL1549880 & 688341 & 4.6 & 4.8448 & TRN \\
\hline CHEMBL1591635 & 688341 & 5.3 & 5.2231 & TRN \\
\hline CHEMBL1363472 & 688341 & 4.6 & 4.9635 & TRN \\
\hline CHEMBL1521729 & 688341 & 5.2 & 4.8203 & TRN \\
\hline CHEMBL1533805 & 688341 & 4.8 & 4.6773 & TRN \\
\hline CHEMBL1322549 & 688341 & 5.8 & 5.0966 & TST \\
\hline CHEMBL1338573 & 688341 & 4.6 & 4.9163 & TRN \\
\hline CHEMBL1457192 & 688341 & 4.9 & 4.9478 & TRN \\
\hline CHEMBL1475137 & 688341 & 4.4 & 5.0739 & TST \\
\hline CHEMBL1503927 & 688341 & 5.2 & 4.9863 & TRN \\
\hline CHEMBL1379819 & 688341 & 4.6 & 4.8436 & TRN \\
\hline CHEMBL1342633 & 688341 & 5.4 & 5.0866 & TRN \\
\hline CHEMBL1546569 & 688341 & 4.4 & 4.9339 & TST \\
\hline CHEMBL1468599 & 688341 & 4.5 & 4.8861 & TRN \\
\hline CHEMBL1470718 & 688341 & 5.1 & 4.9946 & TRN \\
\hline CHEMBL1460526 & 688341 & 4.8 & 4.7499 & TRN \\
\hline CHEMBL1445946 & 688341 & 5.4 & 5.0396 & TRN \\
\hline CHEMBL1595783 & 688341 & 4.6 & 4.9562 & TRN \\
\hline CHEMBL1452644 & 688341 & 5.5 & 4.8478 & TRN \\
\hline CHEMBL1584571 & 688341 & 4.5 & 4.8637 & TRN \\
\hline CHEMBL1331525 & 688341 & 6.8 & 4.9037 & TRN \\
\hline CHEMBL1480347 & 688341 & 4.4 & 4.9203 & TST \\
\hline CHEMBL1331017 & 688341 & 5.2 & 5.0703 & TST \\
\hline CHEMBL1478563 & 688341 & 5.7 & 4.7306 & TRN \\
\hline CHEMBL1449327 & 688341 & 4.5 & 4.8066 & TRN \\
\hline CHEMBL1375399 & 688341 & 4.5 & 4.803 & TRN \\
\hline CHEMBL1559230 & 688341 & 5.0 & 4.86 & TRN \\
\hline CHEMBL1470100 & 688341 & 4.6 & 4.8941 & TRN \\
\hline CHEMBL1527961 & 688341 & 4.7 & 4.9659 & TRN \\
\hline CHEMBL1463829 & 688341 & 5.2 & 4.7883 & TRN \\
\hline CHEMBL1465276 & 688341 & 4.6 & 4.827 & TRN \\
\hline CHEMBL1313394 & 688341 & 5.2 & 4.9917 & TST \\
\hline CHEMBL1375436 & 688341 & 4.4 & 4.7115 & TRN \\
\hline CHEMBL1315618 & 688341 & 7.0 & 4.9857 & TST \\
\hline CHEMBL1563972 & 688341 & 4.4 & 4.9014 & TRN \\
\hline
\end{tabular}




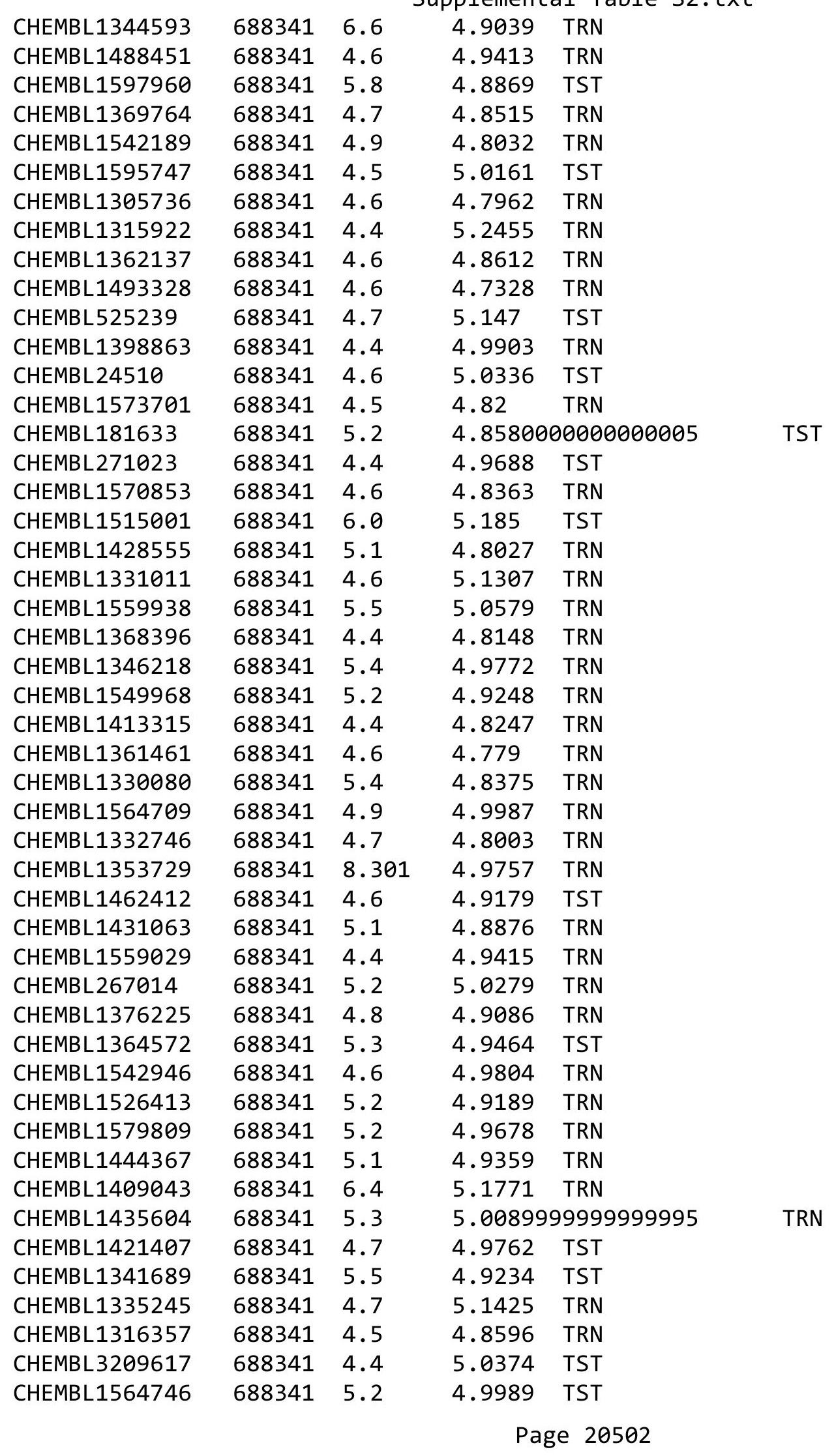




\begin{tabular}{|c|c|c|c|c|}
\hline & & & plement & \\
\hline CHEMBL1613088 & 688341 & 4.9 & 4.9121 & TRN \\
\hline CHEMBL1475358 & 688341 & 4.4 & 5.0531 & TRN \\
\hline CHEMBL1469785 & 688341 & 5.5 & 5.0271 & TRN \\
\hline CHEMBL1490013 & 688341 & 5.2 & 4.959 & TRN \\
\hline CHEMBL1348441 & 688341 & 5.4 & 4.9123 & TRN \\
\hline CHEMBL1326451 & 688341 & 4.9 & 5.0943 & TRN \\
\hline CHEMBL1587501 & 688341 & 4.7 & 4.7307 & TRN \\
\hline CHEMBL1426789 & 688341 & 5.4 & 4.817 & TRN \\
\hline CHEMBL335231 & 688341 & 4.4 & 5.091 & TST \\
\hline CHEMBL1314158 & 688341 & 5.7 & 5.0293 & TRN \\
\hline CHEMBL1439593 & 688341 & 5.7 & 4.8376 & TRN \\
\hline CHEMBL1417471 & 688341 & 4.4 & 4.9717 & TST \\
\hline CHEMBL1590663 & 688341 & 4.4 & 5.05 & TRN \\
\hline CHEMBL1569310 & 688341 & 4.5 & 4.8244 & TRN \\
\hline CHEMBL1563134 & 688341 & 4.5 & 4.7486 & TRN \\
\hline CHEMBL1598539 & 688341 & 4.4 & 4.8723 & TRN \\
\hline CHEMBL1392428 & 688341 & 4.7 & 5.0721 & TST \\
\hline CHEMBL1463780 & 688341 & 4.5 & 4.88 & TRN \\
\hline CHEMBL1344065 & 688341 & 4.7 & 4.8858 & TST \\
\hline CHEMBL1480806 & 688341 & 4.8 & 4.9958 & TRN \\
\hline CHEMBL1426235 & 688341 & 5.0 & 4.7554 & TRN \\
\hline CHEMBL1559279 & 688341 & 6.0 & 5.1984 & TRN \\
\hline CHEMBL1365166 & 688341 & 4.5 & 4.9045 & TST \\
\hline CHEMBL1579872 & 688341 & 4.5 & 4.7238 & TRN \\
\hline CHEMBL1612085 & 688341 & 5.4 & 4.8913 & TRN \\
\hline CHEMBL1405122 & 688341 & 6.0 & 5.1749 & TST \\
\hline CHEMBL1454868 & 688341 & 4.6 & 4.7686 & TRN \\
\hline CHEMBL1330729 & 688341 & 7.8996 & 5.2426 & TST \\
\hline CHEMBL1507268 & 688341 & 6.0 & 4.9662 & TRN \\
\hline CHEMBL1200765 & 688341 & 4.6 & 5.1091 & TST \\
\hline CHEMBL1500946 & 688341 & 4.4 & 4.9062 & TST \\
\hline CHEMBL1435654 & 688341 & 5.6 & 5.0083 & TRN \\
\hline CHEMBL1554158 & 688341 & 6.2 & 4.9588 & TRN \\
\hline CHEMBL1516148 & 688341 & 5.4 & 5.2336 & TRN \\
\hline CHEMBL1569975 & 688341 & 4.8 & 4.9297 & TRN \\
\hline CHEMBL1358276 & 688341 & 4.4 & 5.2301 & TRN \\
\hline CHEMBL1579268 & 688341 & 5.2 & 4.8724 & TRN \\
\hline CHEMBL1424914 & 688341 & 4.5 & 5.0104 & TRN \\
\hline CHEMBL1501637 & 688341 & 4.7 & 4.9213 & TST \\
\hline CHEMBL1492649 & 688341 & 7.0 & 5.0154 & TRN \\
\hline CHEMBL1450211 & 688341 & 5.2 & 4.7966 & TRN \\
\hline CHEMBL1502549 & 688341 & 5.1 & 4.8668 & TRN \\
\hline CHEMBL1447239 & 688341 & 4.5 & 5.0686 & TRN \\
\hline CHEMBL3191553 & 688341 & 5.4 & 5.0986 & TRN \\
\hline CHEMBL1429250 & 688341 & 4.7 & 4.9957 & TRN \\
\hline CHEMBL1451664 & 688341 & 4.9 & 4.7725 & TRN \\
\hline CHEMBL1586100 & 688341 & 4.8 & 4.8427 & TRN \\
\hline CHEMBL1356138 & 688341 & 4.8 & 5.0144 & TRN \\
\hline
\end{tabular}




\begin{tabular}{|c|c|c|c|c|}
\hline \multicolumn{5}{|c|}{ Supplemental Table S2.txt } \\
\hline CHEMBL1317009 & 688341 & 5.0 & 4.8491 & TRN \\
\hline CHEMBL1494607 & 688341 & 4.5 & 4.7392 & TRN \\
\hline CHEMBL1502592 & 688341 & 4.4 & 5.0724 & TST \\
\hline CHEMBL1382524 & 688341 & 5.3 & 5.08 & TRN \\
\hline CHEMBL429711 & 688341 & 5.4 & 4.9237 & TRN \\
\hline CHEMBL1463540 & 688341 & 4.4 & 4.9299 & TRN \\
\hline CHEMBL1417558 & 688341 & 5.1 & 4.8802 & TRN \\
\hline CHEMBL1431676 & 688341 & 5.1 & 4.8295 & TRN \\
\hline CHEMBL1376357 & 688341 & 4.6 & 5.0049 & TRN \\
\hline CHEMBL1586332 & 688341 & 4.4 & 4.7753 & TRN \\
\hline CHEMBL1526789 & 688341 & 4.7 & 4.834 & TRN \\
\hline CHEMBL1481034 & 688341 & 4.4 & 4.9932 & TRN \\
\hline CHEMBL1302993 & 688341 & 4.6 & 4.9628 & TRN \\
\hline CHEMBL1390396 & 688341 & 4.8 & 4.9002 & TRN \\
\hline CHEMBL1513077 & 688341 & 5.4 & 5.1225 & TRN \\
\hline CHEMBL1546342 & 688341 & 4.8 & 4.6577 & TRN \\
\hline CHEMBL1390074 & 688341 & 4.5 & 4.9805 & TST \\
\hline CHEMBL1557313 & 688341 & 4.8 & 4.9677 & TRN \\
\hline CHEMBL1256697 & 688341 & 4.4 & 5.1785 & TRN \\
\hline CHEMBL1542305 & 688341 & 5.2 & 4.8689 & TRN \\
\hline CHEMBL1373334 & 688341 & 6.2 & 4.9725 & TRN \\
\hline CHEMBL1492811 & 688341 & 5.2 & 4.9088 & TRN \\
\hline CHEMBL1578557 & 688341 & 4.6 & 4.9891 & TRN \\
\hline CHEMBL1368233 & 688341 & 5.1 & 4.9781 & TRN \\
\hline CHEMBL1389864 & 688341 & 4.6 & 4.7946 & TST \\
\hline CHEMBL1436024 & 688341 & 4.5 & 5.056 & TRN \\
\hline CHEMBL1547831 & 688341 & 4.5 & 4.9759 & TST \\
\hline CHEMBL1432238 & 688341 & 4.5 & 4.9795 & TRN \\
\hline CHEMBL1360981 & 688341 & 4.4 & 4.7823 & TRN \\
\hline CHEMBL1486645 & 688341 & 6.3 & 5.1134 & TRN \\
\hline CHEMBL1302187 & 688341 & 5.6 & 4.8496 & TRN \\
\hline CHEMBL 1475750 & 688341 & 5.3 & 5.1002 & TRN \\
\hline CHEMBL1603769 & 688341 & 4.7 & 5.0422 & TRN \\
\hline CHEMBL1341122 & 688341 & 4.5 & 4.8228 & TST \\
\hline CHEMBL1352543 & 688341 & 4.7 & 4.9033 & TRN \\
\hline CHEMBL1569972 & 688341 & 5.5 & 5.1031 & TRN \\
\hline CHEMBL 1304008 & 688341 & 4.8 & 4.6841 & TRN \\
\hline CHEMBL1353217 & 688341 & 5.2 & 5.0018 & TST \\
\hline CHEMBL1571614 & 688341 & 5.9 & 4.9107 & TRN \\
\hline CHEMBL1578196 & 688341 & 4.4 & 4.8038 & TRN \\
\hline CHEMBL1431585 & 688341 & 4.4 & 4.7983 & TRN \\
\hline CHEMBL1360343 & 688341 & 4.4 & 4.9227 & TST \\
\hline CHEMBL1406931 & 688341 & 5.0 & 4.9287 & TRN \\
\hline CHEMBL1400051 & 688341 & 5.4 & 4.9564 & TRN \\
\hline CHEMBL370152 & 688341 & 4.8 & 4.9219 & TST \\
\hline CHEMBL1541656 & 688341 & 5.4 & 4.9258 & TRN \\
\hline CHEMBL1362431 & 688341 & 4.4 & 5.1233 & TST \\
\hline CHEMBL1562745 & 688341 & 4.5 & 4.7811 & TRN \\
\hline
\end{tabular}




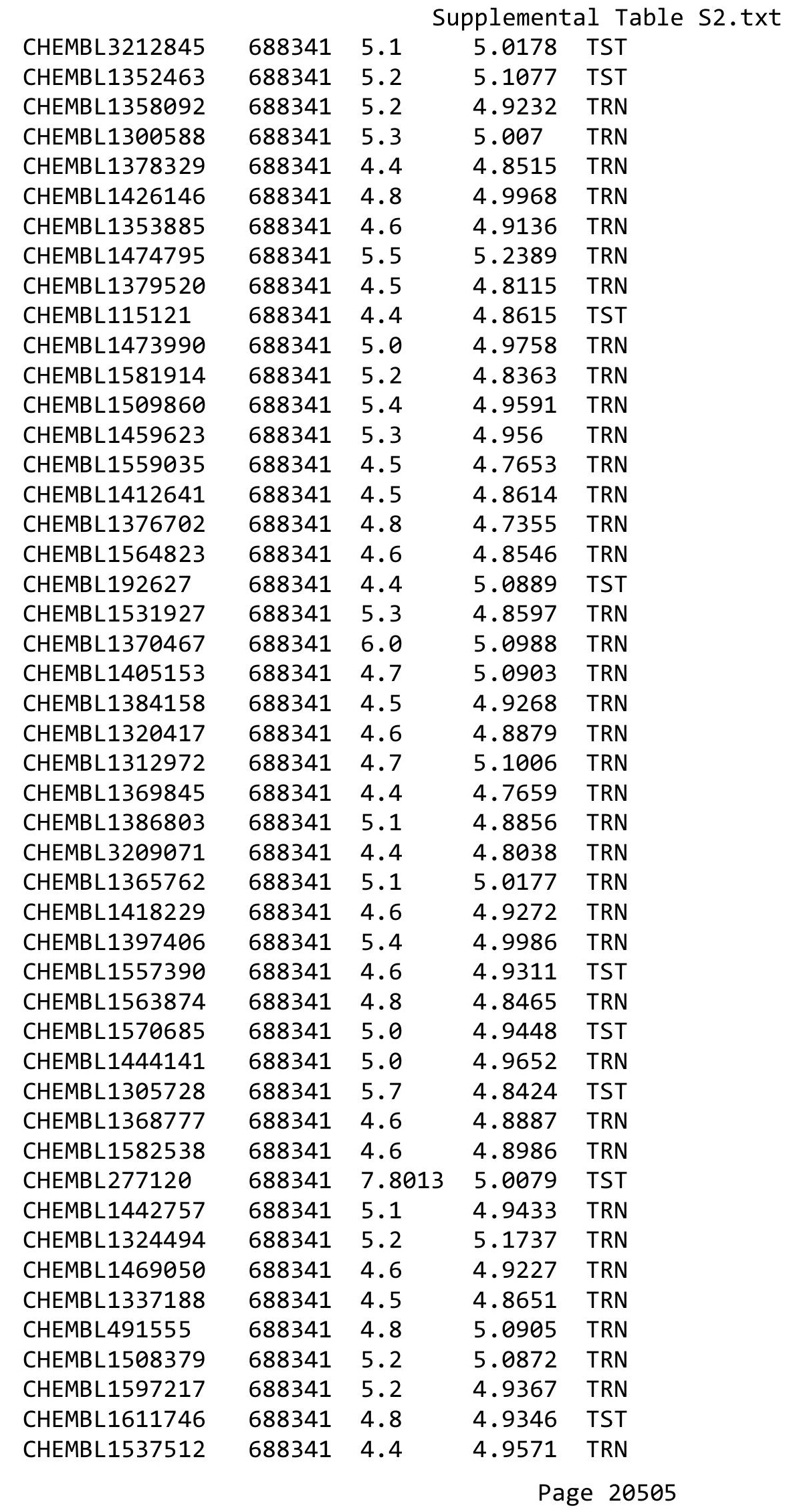




\begin{tabular}{|c|c|c|c|c|c|}
\hline \multicolumn{6}{|c|}{ Supplemental Table S2.txt } \\
\hline CHEMBL1542572 & 688341 & 4.9 & 4.9727 & TRN & \\
\hline CHEMBL1433742 & 688341 & 5.4 & 5.0485 & TST & \\
\hline CHEMBL1507538 & 688341 & 5.5 & 4.8409 & TRN & \\
\hline CHEMBL1403280 & 688341 & 5.4 & 4.8997 & TRN & \\
\hline CHEMBL1565462 & 688341 & 5.0 & 4.8267 & TRN & \\
\hline CHEMBL 2002522 & 688341 & 4.4 & 4.8923 & TST & \\
\hline CHEMBL1423205 & 688341 & 4.5 & 5.1001 & TRN & \\
\hline CHEMBL1359836 & 688341 & 5.4 & 5.191 & TST & \\
\hline CHEMBL1337619 & 688341 & 4.5 & 5.0239 & TRN & \\
\hline CHEMBL1383773 & 688341 & 5.2 & 4.8959 & TST & \\
\hline CHEMBL1366020 & 688341 & 4.4 & 4.925 & TRN & \\
\hline CHEMBL1485744 & 688341 & 4.5 & 4.8412 & TRN & \\
\hline CHEMBL1603638 & 688341 & 4.6 & 4.9119 & TRN & \\
\hline CHEMBL 258767 & 688341 & 6.0 & 5.0704 & TRN & \\
\hline CHEMBL1512444 & 688341 & 5.7 & 5.1754 & TRN & \\
\hline CHEMBL1370164 & 688341 & 5.9 & 5.0637 & TST & \\
\hline CHEMBL1449910 & 688341 & 5.2 & 4.9074 & TRN & \\
\hline CHEMBL1370794 & 688341 & 4.4 & 4.8154 & TRN & \\
\hline CHEMBL1340294 & 688341 & 4.9 & 5.0157 & TRN & \\
\hline CHEMBL1305828 & 688341 & 4.6 & 4.9432 & TRN & \\
\hline CHEMBL1380693 & 688341 & 5.0 & 4.9298 & TRN & \\
\hline CHEMBL1335363 & 688341 & 4.8 & 4.9402 & TRN & \\
\hline CHEMBL395915 & 688341 & 5.5 & 5.0515 & TRN & \\
\hline CHEMBL1612696 & 688341 & 5.9 & 4.9592 & TST & \\
\hline CHEMBL1522486 & 688341 & 6.0 & 4.9428 & TST & \\
\hline CHEMBL1579584 & 688341 & 6.5 & 4.8099 & TRN & \\
\hline CHEMBL1549470 & 688341 & 5.2 & 5.0068 & TST & \\
\hline CHEMBL1576049 & 688341 & 4.4 & 4.8914 & TRN & \\
\hline CHEMBL1607465 & 688341 & 5.3 & 5.07600 & 00000000005 & TRN \\
\hline CHEMBL 243652 & 688341 & 4.6 & 5.0285 & TST & \\
\hline CHEMBL1430299 & 688341 & 5.8 & 4.9825 & TST & \\
\hline CHEMBL1330336 & 688341 & 5.0 & 5.0605 & TRN & \\
\hline CHEMBL1302466 & 688341 & 5.3 & 4.9242 & TRN & \\
\hline CHEMBL1509507 & 688341 & 5.2 & 4.9625 & TRN & \\
\hline CHEMBL1488392 & 688341 & 4.5 & 4.9392 & TRN & \\
\hline CHEMBL1436865 & 688341 & 5.8 & 5.2069 & TRN & \\
\hline CHEMBL1557817 & 688341 & 5.4 & 5.0397 & TRN & \\
\hline CHEMBL1611830 & 688341 & 4.8 & 4.8992 & TRN & \\
\hline CHEMBL1512567 & 688341 & 5.1 & 5.16100 & 20000000005 & TST \\
\hline CHEMBL1354272 & 688341 & 5.0 & 4.9756 & TRN & \\
\hline CHEMBL1411082 & 688341 & 4.7 & 4.8062 & TRN & \\
\hline CHEMBL1567175 & 688341 & 4.8 & 4.8691 & TRN & \\
\hline CHEMBL1542050 & 688341 & 4.4 & 4.683 & TRN & \\
\hline CHEMBL1532770 & 688341 & 4.4 & 4.9726 & TRN & \\
\hline CHEMBL1412984 & 688341 & 5.5 & 4.8836 & TRN & \\
\hline CHEMBL1596661 & 688341 & 4.4 & 4.9492 & TRN & \\
\hline CHEMBL1196026 & 688341 & 4.8 & 5.119 & TST & \\
\hline CHEMBL1447573 & 688341 & 4.8 & 5.0293 & TST & \\
\hline
\end{tabular}




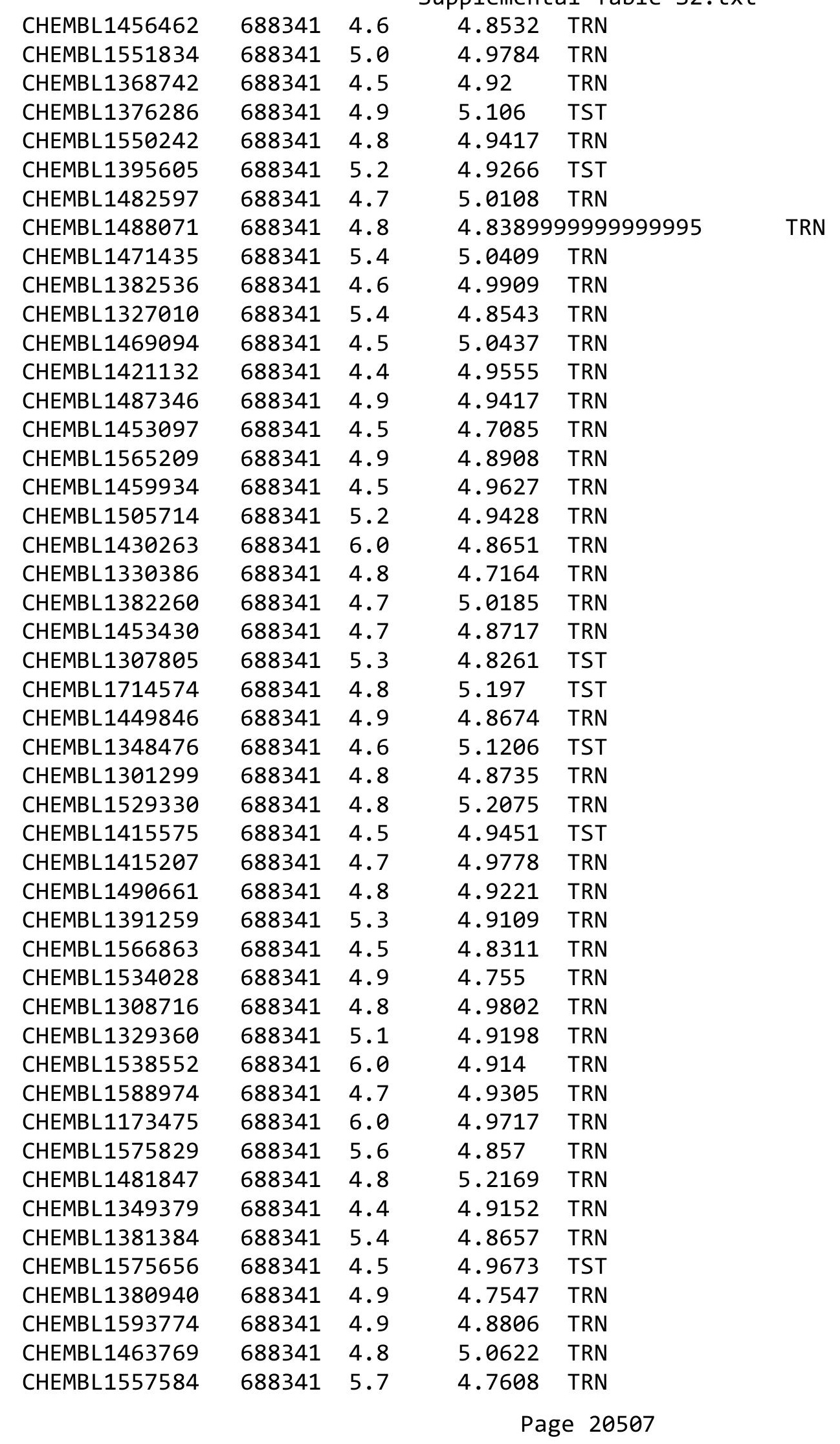




\begin{tabular}{|c|c|c|c|c|}
\hline \\
\hline CHEMBL1602127 & 688341 & 4.4 & 5.1319 & TRN \\
\hline CHEMBL3209348 & 688341 & 4.8 & 4.8558 & TST \\
\hline CHEMBL1477858 & 688341 & 4.5 & 4.7783 & TRN \\
\hline CHEMBL1517796 & 688341 & 4.6 & 5.0448 & TRN \\
\hline CHEMBL1507131 & 688341 & 5.3 & 4.882 & TRN \\
\hline CHEMBL1532004 & 688341 & 4.7 & 4.8423 & TRN \\
\hline CHEMBL1173823 & 688341 & 5.2 & 4.9349 & TRN \\
\hline CHEMBL1514748 & 688341 & 5.2 & 5.0518 & TRN \\
\hline CHEMBL1321863 & 688341 & 6.2 & 5.0909 & TRN \\
\hline CHEMBL1455689 & 688341 & 4.6 & 4.7219 & TRN \\
\hline CHEMBL1480855 & 688341 & 4.4 & 5.0075 & TRN \\
\hline CHEMBL602481 & 688341 & 5.1 & 4.8943 & TST \\
\hline CHEMBL1525602 & 688341 & 4.6 & 4.9587 & TRN \\
\hline CHEMBL1523881 & 688341 & 4.9 & 5.0936 & TRN \\
\hline CHEMBL1379266 & 688341 & 4.8 & 4.9326 & TRN \\
\hline CHEMBL1499300 & 688341 & 4.8 & 4.8933 & TRN \\
\hline CHEMBL1485377 & 688341 & 4.6 & 4.8268 & TRN \\
\hline CHEMBL1542758 & 688341 & 4.6 & 4.9532 & TRN \\
\hline CHEMBL1496315 & 688341 & 4.8 & 5.0866 & TRN \\
\hline CHEMBL1466047 & 688341 & 7.0 & 5.1117 & TRN \\
\hline CHEMBL1472338 & 688341 & 4.5 & 4.9264 & TRN \\
\hline CHEMBL1309051 & 688341 & 4.7 & 4.8193 & TRN \\
\hline CHEMBL1329927 & 688341 & 6.0 & 4.9651 & TST \\
\hline CHEMBL1480131 & 688341 & 4.6 & 4.8807 & TRN \\
\hline CHEMBL1374178 & 688341 & 4.7 & 4.8792 & TRN \\
\hline CHEMBL1507697 & 688341 & 5.2 & 4.9147 & TRN \\
\hline CHEMBL1429064 & 688341 & 4.4 & 4.771 & TRN \\
\hline CHEMBL1547421 & 688341 & 5.2 & 4.8945 & TST \\
\hline CHEMBL1546369 & 688341 & 5.2 & 4.712 & TRN \\
\hline CHEMBL1450252 & 688341 & 5.6 & 5.0072 & TRN \\
\hline CHEMBL1412045 & 688341 & 5.6 & 5.0758 & TRN \\
\hline CHEMBL1390422 & 688341 & 5.1 & 5.0277 & TRN \\
\hline CHEMBL1585534 & 688341 & 4.7 & 4.6981 & TRN \\
\hline CHEMBL467623 & 688341 & 4.9 & 5.0187 & TRN \\
\hline CHEMBL1309696 & 688341 & 4.7 & 4.8432 & TST \\
\hline CHEMBL1452608 & 688341 & 4.6 & 4.8839 & TRN \\
\hline CHEMBL1505567 & 688341 & 4.6 & 4.9664 & TRN \\
\hline CHEMBL1510681 & 688341 & 4.4 & 4.8283 & TRN \\
\hline CHEMBL259073 & 688341 & 4.6 & 4.9579 & TRN \\
\hline CHEMBL1480387 & 688341 & 4.9 & 4.9625 & TRN \\
\hline CHEMBL1418412 & 688341 & 4.5 & 5.2409 & TRN \\
\hline CHEMBL1452335 & 688341 & 5.2 & 4.9483 & TRN \\
\hline CHEMBL1605875 & 688341 & 4.7 & 4.9679 & TRN \\
\hline CHEMBL1504444 & 688341 & 4.5 & 4.8386 & TRN \\
\hline CHEMBL1412063 & 688341 & 5.1 & 4.9109 & TRN \\
\hline CHEMBL1417030 & 688341 & 4.5 & 4.9809 & TST \\
\hline CHEMBL1335759 & 688341 & 4.5 & 4.9648 & TRN \\
\hline CHEMBL1428299 & 688341 & 4.4 & 4.8698 & TRN \\
\hline
\end{tabular}




\begin{tabular}{|c|c|c|c|c|}
\hline \multicolumn{5}{|c|}{ Supplemental Table S2.txt } \\
\hline CHEMBL1428273 & 688341 & 8.301 & 5.069 & TST \\
\hline CHEMBL1528097 & 688341 & 4.5 & 4.9579 & TRN \\
\hline CHEMBL1306920 & 688341 & 6.0 & 5.1374 & TRN \\
\hline CHEMBL1256996 & 688341 & 4.4 & 5.2352 & TRN \\
\hline CHEMBL1539070 & 688341 & 5.2 & 4.8162 & TRN \\
\hline CHEMBL1427702 & 688341 & 4.4 & 4.8423 & TRN \\
\hline CHEMBL1401293 & 688341 & 5.0 & 4.8724 & TRN \\
\hline CHEMBL318275 & 688341 & 7.0 & 5.0051 & TRN \\
\hline CHEMBL1578159 & 688341 & 5.4 & 5.0 & TST \\
\hline CHEMBL1332366 & 688341 & 5.6 & 5.0037 & TRN \\
\hline CHEMBL1394622 & 688341 & 5.2 & 5.0203 & TRN \\
\hline CHEMBL39 & 688341 & 4.5 & 5.1504 & TRN \\
\hline CHEMBL1451927 & 688341 & 4.5 & 4.8134 & TRN \\
\hline CHEMBL1479781 & 688341 & 5.0 & 4.9089 & TRN \\
\hline CHEMBL490742 & 688341 & 5.4 & 5.0948 & TRN \\
\hline CHEMBL1334334 & 688341 & 4.8 & 4.8053 & TRN \\
\hline CHEMBL1584572 & 688341 & 7.5003 & 4.8817 & TRN \\
\hline CHEMBL1570863 & 688341 & 4.8 & 4.7653 & TRN \\
\hline CHEMBL1479661 & 688341 & 5.8 & 5.027 & TRN \\
\hline CHEMBL1559473 & 688341 & 4.5 & 4.9644 & TRN \\
\hline CHEMBL1536692 & 688341 & 4.4 & 4.9989 & TRN \\
\hline CHEMBL1575943 & 688341 & 5.4 & 4.9645 & TRN \\
\hline CHEMBL1444217 & 688341 & 5.3 & 4.9402 & TRN \\
\hline CHEMBL1511191 & 688341 & 5.4 & 4.8038 & TRN \\
\hline CHEMBL1405986 & 688341 & 4.4 & 5.1014 & TST \\
\hline CHEMBL1385428 & 688341 & 4.8 & 4.8947 & TRN \\
\hline CHEMBL1494256 & 688341 & 4.6 & 4.7541 & TRN \\
\hline CHEMBL46730 & 688341 & 6.0 & 4.9074 & TRN \\
\hline CHEMBL1419182 & 688341 & 4.5 & 4.8664 & TRN \\
\hline CHEMBL1382217 & 688341 & 4.4 & 4.9627 & TST \\
\hline CHEMBL1450975 & 688341 & 4.9 & 4.7496 & TRN \\
\hline CHEMBL1535373 & 688341 & 5.5 & 4.9903 & TST \\
\hline CHEMBL1300062 & 688341 & 4.4 & 4.9588 & TRN \\
\hline CHEMBL1432979 & 688341 & 5.6 & 4.9963 & TST \\
\hline CHEMBL1455866 & 688341 & 4.6 & 4.9747 & TRN \\
\hline CHEMBL1566386 & 688341 & 4.6 & 4.6323 & TRN \\
\hline CHEMBL1552294 & 688341 & 5.5 & 5.0653 & TRN \\
\hline CHEMBL1413572 & 688341 & 5.9 & 5.1162 & TRN \\
\hline CHEMBL1554654 & 688341 & 5.5 & 5.1127 & TRN \\
\hline CHEMBL1519188 & 688341 & 5.2 & 5.0284 & TST \\
\hline CHEMBL1466238 & 688341 & 4.8 & 4.8826 & TRN \\
\hline CHEMBL1387949 & 688341 & 4.4 & 4.9481 & TRN \\
\hline CHEMBL1579490 & 688341 & 4.6 & 4.9022 & TRN \\
\hline CHEMBL1707911 & 688341 & 4.7 & 4.9152 & TST \\
\hline CHEMBL1431312 & 688341 & 4.6 & 5.0828 & TRN \\
\hline CHEMBL1496691 & 688341 & 5.5 & 5.0834 & TRN \\
\hline CHEMBL1599037 & 688341 & 4.7 & 4.8968 & TRN \\
\hline CHEMBL1302244 & 688341 & 4.8 & 4.7555 & TRN \\
\hline
\end{tabular}




\begin{tabular}{|c|c|c|c|c|c|}
\hline & & & & & \\
\hline CHEMBL1408520 & 688341 & 5.3 & 5.1483 & TRN & \\
\hline CHEMBL1578861 & 688341 & 4.7 & 4.8895 & TRN & \\
\hline CHEMBL1532597 & 688341 & 6.0 & 5.1322 & TRN & \\
\hline CHEMBL1353598 & 688341 & 5.3 & $4.9510 e$ & 20000000005 & TST \\
\hline CHEMBL1556632 & 688341 & 5.0 & 5.1055 & TRN & \\
\hline CHEMBL1321807 & 688341 & 5.2 & 5.0652 & TST & \\
\hline CHEMBL3213638 & 688341 & 5.4 & 5.0267 & TST & \\
\hline CHEMBL1367444 & 688341 & 4.6 & 4.743 & TRN & \\
\hline CHEMBL1542500 & 688341 & 4.5 & 4.9255 & TRN & \\
\hline CHEMBL1600236 & 688341 & 4.4 & 4.8758 & TRN & \\
\hline CHEMBL1532193 & 688341 & 5.8 & 4.9862 & TRN & \\
\hline CHEMBL1455578 & 688341 & 4.7 & 4.9437 & TRN & \\
\hline CHEMBL1352766 & 688341 & 5.3 & 4.9934 & TRN & \\
\hline CHEMBL1563032 & 688341 & 5.1 & 5.1487 & TRN & \\
\hline CHEMBL1392180 & 688341 & 4.4 & 4.9637 & TRN & \\
\hline CHEMBL1519692 & 688341 & 4.5 & 4.8447 & TRN & \\
\hline CHEMBL1489445 & 688341 & 4.6 & 5.0481 & TST & \\
\hline CHEMBL1412386 & 688341 & 5.9 & 5.0175 & TST & \\
\hline CHEMBL1410921 & 688341 & 4.9 & 4.7585 & TRN & \\
\hline CHEMBL1513812 & 688341 & 4.6 & 5.0149 & TRN & \\
\hline CHEMBL1451340 & 688341 & 4.8 & 5.0483 & TRN & \\
\hline CHEMBL1520681 & 688341 & 4.7 & 5.1383 & TRN & \\
\hline CHEMBL1477471 & 688341 & 5.3 & 4.8537 & TRN & \\
\hline CHEMBL1521379 & 688341 & 4.6 & 4.7718 & TRN & \\
\hline CHEMBL1611789 & 688341 & 5.0 & 5.0279 & TRN & \\
\hline CHEMBL1402000 & 688341 & 4.6 & 4.8908 & TRN & \\
\hline CHEMBL1446593 & 688341 & 4.6 & 4.8807 & TST & \\
\hline CHEMBL1482692 & 688341 & 4.9 & 4.774 & TRN & \\
\hline CHEMBL1419223 & 688341 & 4.6 & 4.7007 & TRN & \\
\hline CHEMBL1341031 & 688341 & 5.0 & 5.2017 & TRN & \\
\hline CHEMBL1592803 & 688341 & 5.3 & 4.9937 & TRN & \\
\hline CHEMBL1566696 & 688341 & 4.6 & 4.8953 & TRN & \\
\hline CHEMBL1422539 & 688341 & 4.4 & 4.8496 & TST & \\
\hline CHEMBL1523589 & 688341 & 5.2 & 4.9435 & TRN & \\
\hline CHEMBL1500317 & 688341 & 4.4 & 4.859 & TRN & \\
\hline CHEMBL1423060 & 688341 & 4.7 & 4.8992 & TRN & \\
\hline CHEMBL1575772 & 688341 & 4.7 & 4.8134 & TRN & \\
\hline CHEMBL1416939 & 688341 & 4.4 & 4.8158 & TRN & \\
\hline CHEMBL1410947 & 688341 & 5.4 & 4.8754 & TRN & \\
\hline CHEMBL1505801 & 688341 & 5.3 & 5.1763 & TRN & \\
\hline CHEMBL1422682 & 688341 & 5.3 & 4.9026 & TST & \\
\hline CHEMBL15819 & 688341 & 5.2 & 5.0156 & TST & \\
\hline CHEMBL1326896 & 688341 & 4.6 & $4.8260 e$ & 20000000005 & TRN \\
\hline CHEMBL1547706 & 688341 & 4.7 & 4.8831 & TRN & \\
\hline CHEMBL1602645 & 688341 & 5.4 & 5.0105 & TRN & \\
\hline CHEMBL1497863 & 688341 & 4.5 & 4.9501 & TRN & \\
\hline CHEMBL 1440170 & 688341 & 4.4 & 4.7895 & TRN & \\
\hline CHEMBL1417724 & 688341 & 4.8 & 4.8351 & TRN & \\
\hline & & & & 20510 & \\
\hline
\end{tabular}


Supplemental Table S2.txt

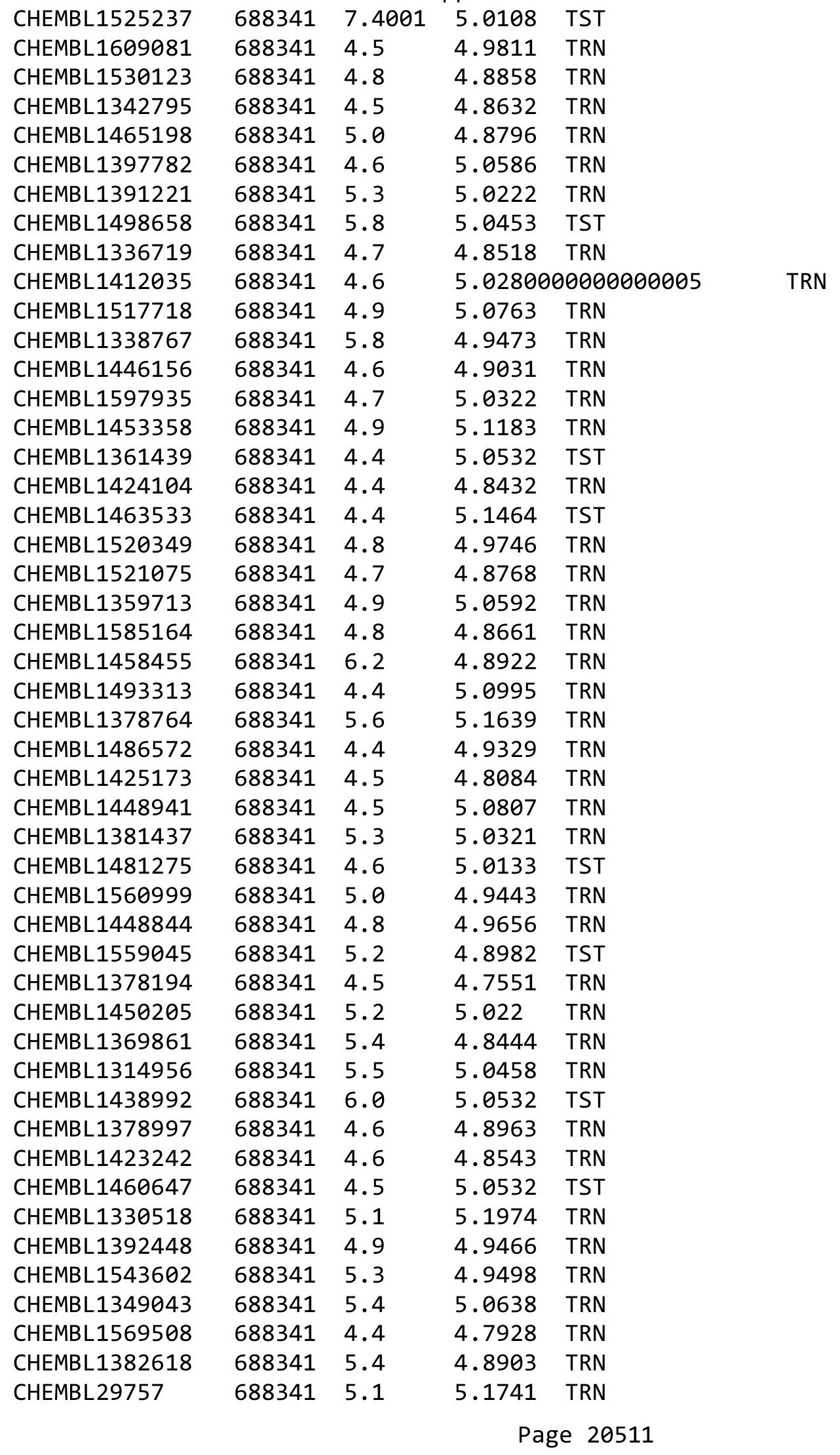




\begin{tabular}{|c|c|c|c|c|c|}
\hline \\
\hline CHEMBL1332529 & 688341 & 4.6 & 5.037 & TST & \\
\hline CHEMBL1402637 & 688341 & 4.6 & 5.0607 & TRN & \\
\hline CHEMBL1390926 & 688341 & 4.9 & 5.0494 & TRN & \\
\hline CHEMBL1590095 & 688341 & 5.0 & 4.9334 & TRN & \\
\hline CHEMBL1367630 & 688341 & 5.9 & 4.9891 & TRN & \\
\hline CHEMBL1589307 & 688341 & 4.5 & 4.9079 & TST & \\
\hline CHEMBL1491272 & 688341 & 4.5 & 4.7046 & TRN & \\
\hline CHEMBL1418640 & 688341 & 4.6 & 4.9277 & TST & \\
\hline CHEMBL1382175 & 688341 & 5.1 & 4.9876 & TRN & \\
\hline CHEMBL418068 & 688341 & 4.8 & 5.0314 & TRN & \\
\hline CHEMBL1576934 & 688341 & 4.4 & 4.9553 & TST & \\
\hline CHEMBL1388289 & 688341 & 4.5 & 4.8511 & TST & \\
\hline CHEMBL1461109 & 688341 & 5.2 & 4.8745 & TRN & \\
\hline CHEMBL1501719 & 688341 & 5.3 & 5.1562 & TRN & \\
\hline CHEMBL1499181 & 688341 & 4.5 & 4.9937 & TRN & \\
\hline CHEMBL1447064 & 688341 & 5.2 & 5.04 & TST & \\
\hline CHEMBL1446729 & 688341 & 5.2 & 4.8643 & TRN & \\
\hline CHEMBL1343438 & 688341 & 4.5 & 4.8777 & TRN & \\
\hline CHEMBL1504346 & 688341 & 5.3 & 4.8528 & TRN & \\
\hline CHEMBL1441574 & 688341 & 4.8 & 4.9493 & TRN & \\
\hline CHEMBL1421615 & 688341 & 4.4 & 4.9414 & TRN & \\
\hline CHEMBL1497763 & 688341 & 5.2 & 4.9692 & TRN & \\
\hline CHEMBL1548741 & 688341 & 5.3 & 5.0415 & TST & \\
\hline CHEMBL1332444 & 688341 & 4.4 & 4.898 & TRN & \\
\hline CHEMBL1366846 & 688341 & 4.5 & 5.0686 & TST & \\
\hline CHEMBL1428587 & 688341 & 5.1 & 5.0523 & TRN & \\
\hline CHEMBL1608918 & 688341 & 5.6 & 4.9556 & TRN & \\
\hline CHEMBL1502475 & 688341 & 5.5 & 5.0386 & TRN & \\
\hline CHEMBL1484413 & 688341 & 4.5 & 4.9989 & TRN & \\
\hline CHEMBL1466849 & 688341 & 4.7 & 4.7848 & TRN & \\
\hline CHEMBL1315417 & 688341 & 4.4 & 4.9918 & TST & \\
\hline CHEMBL1334439 & 688341 & 4.8 & 4.7782 & TRN & \\
\hline CHEMBL1360924 & 688341 & 5.4 & 5.0142 & TST & \\
\hline CHEMBL1501141 & 688341 & 4.4 & 4.8591 & TRN & \\
\hline CHEMBL1568586 & 688341 & 4.5 & 4.80699 & 99999999995 & TRN \\
\hline CHEMBL1483607 & 688341 & 4.4 & 4.8932 & TRN & \\
\hline CHEMBL1415281 & 688341 & 5.3 & 4.6626 & TRN & \\
\hline CHEMBL1542906 & 688341 & 4.7 & 5.1281 & TRN & \\
\hline CHEMBL1338787 & 688341 & 5.4 & 5.0614 & TST & \\
\hline CHEMBL1386458 & 688341 & 4.4 & 4.8773 & TST & \\
\hline CHEMBL1626274 & 688341 & 5.3 & 4.8993 & TST & \\
\hline CHEMBL1477801 & 688341 & 6.0 & 4.9505 & TST & \\
\hline CHEMBL1311188 & 688341 & 4.5 & 4.987 & TRN & \\
\hline CHEMBL1491091 & 688341 & 4.4 & 5.0671 & TRN & \\
\hline CHEMBL1319665 & 688341 & 5.1 & 4.9381 & TST & \\
\hline CHEMBL1424651 & 688341 & 4.5 & 4.8898 & TRN & \\
\hline CHEMBL23094 & 688341 & 4.9 & 5.1143 & TRN & \\
\hline CHEMBL3210745 & 688341 & 4.4 & 4.8161 & TST & \\
\hline & & & & 20512 & \\
\hline
\end{tabular}




\begin{tabular}{|c|c|c|c|c|}
\hline & & & pplemen & al Table \\
\hline CHEMBL1393510 & 688341 & 4.6 & 5.067 & TRN \\
\hline CHEMBL1520757 & 688341 & 4.5 & 4.88899 & 9999999999 \\
\hline CHEMBL1548548 & 688341 & 4.8 & 4.9359 & TRN \\
\hline CHEMBL1385618 & 688341 & 4.4 & 4.8658 & TRN \\
\hline CHEMBL1608513 & 688341 & 4.8 & 4.8239 & TRN \\
\hline CHEMBL1546958 & 688341 & 4.6 & 4.9085 & TRN \\
\hline CHEMBL1495107 & 688341 & 5.9 & 4.8576 & TRN \\
\hline CHEMBL530115 & 688341 & 4.4 & 4.8856 & TST \\
\hline CHEMBL1482575 & 688341 & 5.6 & 5.204 & TRN \\
\hline CHEMBL1452910 & 688341 & 4.7 & 5.1262 & TRN \\
\hline CHEMBL1390170 & 688341 & 4.9 & 5.0712 & TST \\
\hline CHEMBL1425067 & 688341 & 4.6 & 4.9982 & TST \\
\hline CHEMBL1363897 & 688341 & 4.9 & 4.9298 & TRN \\
\hline CHEMBL1338206 & 688341 & 4.5 & 5.0298 & TRN \\
\hline CHEMBL 1581898 & 688341 & 5.4 & 4.9798 & TRN \\
\hline CHEMBL1520976 & 688341 & 5.2 & 5.0549 & TST \\
\hline CHEMBL1521011 & 688341 & 4.6 & 5.0179 & TRN \\
\hline CHEMBL1521895 & 688341 & 5.0 & 5.044 & TRN \\
\hline CHEMBL1482542 & 688341 & 5.5 & 4.9543 & TRN \\
\hline CHEMBL1316714 & 688341 & 4.4 & 4.9755 & TRN \\
\hline CHEMBL1384708 & 688341 & 4.5 & 5.1865 & TST \\
\hline CHEMBL1500536 & 688341 & 5.3 & 4.9991 & TST \\
\hline CHEMBL1453274 & 688341 & 5.0 & 4.7909 & TRN \\
\hline CHEMBL1430875 & 688341 & 4.5 & 4.7606 & TRN \\
\hline CHEMBL 1573271 & 688341 & 4.7 & 5.0236 & TRN \\
\hline CHEMBL1318668 & 688341 & 5.2 & 4.9694 & TST \\
\hline CHEMBL1601824 & 688341 & 5.3 & 5.0168 & TRN \\
\hline CHEMBL1543893 & 688341 & 5.0 & 4.8707 & TST \\
\hline CHEMBL1521887 & 688341 & 4.5 & 4.9514 & TRN \\
\hline CHEMBL1462031 & 688341 & 4.5 & 4.8128 & TRN \\
\hline CHEMBL 1437863 & 688341 & 4.5 & 4.7913 & TRN \\
\hline CHEMBL 1427586 & 688341 & 4.6 & 4.8567 & TRN \\
\hline CHEMBL1435158 & 688341 & 5.4 & 5.2897 & TST \\
\hline CHEMBL1460507 & 688341 & 4.8 & 5.0607 & TST \\
\hline CHEMBL1575033 & 688341 & 4.5 & 4.8751 & TST \\
\hline CHEMBL1402503 & 688341 & 5.4 & 4.8758 & TST \\
\hline CHEMBL1535764 & 688341 & 4.4 & 5.0822 & TST \\
\hline CHEMBL1419981 & 688341 & 4.5 & 5.1346 & TST \\
\hline CHEMBL1430161 & 688341 & 4.4 & 4.815 & TRN \\
\hline CHEMBL1371533 & 688341 & 4.4 & 4.8857 & TRN \\
\hline CHEMBL1599249 & 688341 & 4.5 & 4.6993 & TST \\
\hline CHEMBL1427882 & 688341 & 4.8 & 4.7778 & TRN \\
\hline CHEMBL1568033 & 688341 & 5.6 & 4.9723 & TST \\
\hline CHEMBL1569116 & 688341 & 5.2 & 5.2202 & TRN \\
\hline CHEMBL1449890 & 688341 & 5.2 & 5.06 & TST \\
\hline CHEMBL1537491 & 688341 & 5.1 & 5.1529 & TST \\
\hline CHEMBL1397914 & 688341 & 4.4 & 5.0563 & TRN \\
\hline CHEMBL1407940 & 688341 & 4.7 & 4.9965 & TST \\
\hline
\end{tabular}

TRN 


\begin{tabular}{|c|c|c|c|c|c|}
\hline \multicolumn{6}{|c|}{ Supplemental Table S2.txt } \\
\hline CHEMBL1472594 & 688341 & 4.7 & 4.9475 & TRN & \\
\hline CHEMBL1459464 & 688341 & 4.8 & 5.0642 & TST & \\
\hline CHEMBL1528250 & 688341 & 4.5 & 4.8234 & TRN & \\
\hline CHEMBL1447497 & 688341 & 4.4 & 4.9944 & TST & \\
\hline CHEMBL1328870 & 688341 & 5.4 & 4.9372 & TRN & \\
\hline CHEMBL1455789 & 688341 & 4.5 & 4.8561 & TRN & \\
\hline CHEMBL1329093 & 688341 & 4.4 & 4.9314 & TRN & \\
\hline CHEMBL1565842 & 688341 & 4.7 & 5.0171 & TRN & \\
\hline CHEMBL1482449 & 688341 & 5.0 & 4.7623 & TRN & \\
\hline CHEMBL1407696 & 688341 & 5.2 & 5.1002 & TRN & \\
\hline CHEMBL1340418 & 688341 & 4.4 & 4.8558 & TRN & \\
\hline CHEMBL1601133 & 688341 & 4.8 & 4.9467 & TRN & \\
\hline CHEMBL1314041 & 688341 & 5.2 & 5.0778 & TST & \\
\hline CHEMBL1574558 & 688341 & 4.5 & 4.8492 & TRN & \\
\hline CHEMBL1415721 & 688341 & 5.5 & 4.8617 & TRN & \\
\hline CHEMBL1375509 & 688341 & 4.9 & 4.9804 & TRN & \\
\hline CHEMBL1489547 & 688341 & 4.7 & 4.985 & TST & \\
\hline CHEMBL1158 & 688341 & 4.4 & 5.0421 & TST & \\
\hline CHEMBL1496235 & 688341 & 6.8 & 4.8669 & TRN & \\
\hline CHEMBL1359994 & 688341 & 4.6 & 4.8919 & TRN & \\
\hline CHEMBL1486558 & 688341 & 4.5 & 4.9811 & TRN & \\
\hline CHEMBL1451787 & 688341 & 5.4 & 4.8885 & TRN & \\
\hline CHEMBL1564618 & 688341 & 5.1 & 4.8878 & TRN & \\
\hline CHEMBL1400764 & 688341 & 4.7 & 4.88 & TRN & \\
\hline CHEMBL1303423 & 688341 & 4.5 & 4.9203 & TRN & \\
\hline CHEMBL1542833 & 688341 & 5.2 & 4.8814 & TRN & \\
\hline CHEMBL1527977 & 688341 & 4.9 & 4.9712 & TRN & \\
\hline CHEMBL1462506 & 688341 & 5.1 & 4.8106 & TRN & \\
\hline CHEMBL1427976 & 688341 & 4.7 & 4.9625 & TRN & \\
\hline CHEMBL1516884 & 688341 & 4.5 & 4.9579 & TST & \\
\hline CHEMBL1570765 & 688341 & 5.3 & 4.8413 & TST & \\
\hline CHEMBL1347655 & 688341 & 4.4 & 5.0162 & TST & \\
\hline CHEMBL1348771 & 688341 & 4.9 & 4.74 & TRN & \\
\hline CHEMBL1563201 & 688341 & 5.9 & 4.8612 & TRN & \\
\hline CHEMBL3209603 & 688341 & 4.8 & 4.9497 & TRN & \\
\hline CHEMBL1483600 & 688341 & 4.9 & 5.0462 & TRN & \\
\hline CHEMBL1256916 & 688341 & 4.6 & 4.95100 & 00000000005 & TRN \\
\hline CHEMBL1564088 & 688341 & 5.1 & 4.9507 & TRN & \\
\hline CHEMBL1383741 & 688341 & 6.8 & 5.0521 & TRN & \\
\hline CHEMBL1540207 & 688341 & 4.6 & 4.8434 & TRN & \\
\hline CHEMBL1423429 & 688341 & 4.6 & 4.93199 & 99999999995 & TRN \\
\hline CHEMBL1568018 & 688341 & 4.6 & 5.0059 & TST & \\
\hline CHEMBL1256660 & 688341 & 4.5 & 4.9609 & TST & \\
\hline CHEMBL1347468 & 688341 & 4.7 & 4.8301 & TRN & \\
\hline CHEMBL1572043 & 688341 & 5.2 & 4.703 & TRN & \\
\hline CHEMBL1471203 & 688341 & 4.4 & 4.8624 & TRN & \\
\hline CHEMBL1612273 & 688341 & 4.7 & 4.8981 & TRN & \\
\hline CHEMBL1417018 & 688341 & 4.5 & 4.9824 & TRN & \\
\hline
\end{tabular}




\begin{tabular}{|c|c|c|c|c|}
\hline & & & ment & al Ta \\
\hline CHEMBL1447531 & 688341 & 6.0 & 5.0069 & TST \\
\hline CHEMBL1382529 & 688341 & 4.8 & 5.1033 & TRN \\
\hline CHEMBL1551980 & 688341 & 4.9 & 5.0297 & TRN \\
\hline CHEMBL1521829 & 688341 & 4.6 & 4.8123 & TRN \\
\hline CHEMBL324642 & 688341 & 7.2 & 5.0492 & TRN \\
\hline CHEMBL1324802 & 688341 & 5.4 & 4.8816 & TRN \\
\hline CHEMBL1333083 & 688341 & 4.7 & 5.0584 & TST \\
\hline CHEMBL1606698 & 688341 & 4.4 & 4.9386 & TRN \\
\hline CHEMBL1334238 & 688341 & 4.8 & 4.7813 & TRN \\
\hline CHEMBL1541330 & 688341 & 5.1 & 4.8725 & TRN \\
\hline CHEMBL1499502 & 688341 & 5.2 & 4.9274 & TRN \\
\hline CHEMBL1583499 & 688341 & 4.7 & 4.935 & TRN \\
\hline CHEMBL1416931 & 688341 & 5.1 & 4.9129 & TST \\
\hline CHEMBL1402528 & 688341 & 4.7 & 5.0017 & TRN \\
\hline CHEMBL1354648 & 688341 & 5.9 & 5.0266 & TST \\
\hline CHEMBL1535630 & 688341 & 5.5 & 4.8989 & TRN \\
\hline CHEMBL1312349 & 688341 & 5.2 & 5.0701 & TST \\
\hline CHEMBL1437747 & 688341 & 4.6 & 5.1259 & TRN \\
\hline CHEMBL1443931 & 688341 & 4.6 & 5.0976 & TST \\
\hline CHEMBL1419418 & 688341 & 4.7 & 4.809 & TRN \\
\hline CHEMBL1370480 & 688341 & 5.9 & 5.1388 & TRN \\
\hline CHEMBL293749 & 688341 & 4.4 & 5.0812 & TRN \\
\hline CHEMBL1344424 & 688341 & 5.4 & 4.9458 & TRN \\
\hline CHEMBL1529738 & 688341 & 4.8 & 4.9663 & TRN \\
\hline CHEMBL1378383 & 688341 & 5.0 & 4.9744 & TRN \\
\hline CHEMBL1587264 & 688341 & 4.5 & 4.7764 & TST \\
\hline CHEMBL1359572 & 688341 & 4.7 & 4.9097 & TRN \\
\hline CHEMBL1440326 & 688341 & 5.0 & 4.9798 & TST \\
\hline CHEMBL1594030 & 688341 & 5.4 & 4.9 & TRN \\
\hline CHEMBL1490295 & 688341 & 5.0 & 4.7419 & TRN \\
\hline CHEMBL1450956 & 688341 & 4.6 & 4.8503 & TRN \\
\hline CHEMBL1591548 & 688341 & 5.7 & 4.9562 & TRN \\
\hline CHEMBL1503542 & 688341 & 5.2 & 4.9013 & TRN \\
\hline CHEMBL1414984 & 688341 & 4.5 & 4.9161 & TRN \\
\hline CHEMBL1323851 & 688341 & 5.4 & 4.9032 & TRN \\
\hline CHEMBL2373595 & 688341 & 4.6 & 5.0769 & TRN \\
\hline CHEMBL1429506 & 688341 & 4.4 & 5.1361 & TST \\
\hline CHEMBL1475941 & 688341 & 5.0 & 5.0819 & TRN \\
\hline CHEMBL1488893 & 688341 & 4.9 & 4.6905 & TRN \\
\hline CHEMBL1442619 & 688341 & 4.6 & 4.7788 & TRN \\
\hline CHEMBL1489456 & 688341 & 4.5 & 4.9165 & TRN \\
\hline CHEMBL1300505 & 688341 & 4.4 & 4.8023 & TRN \\
\hline CHEMBL1570547 & 688341 & 5.0 & 4.945 & TRN \\
\hline CHEMBL1444847 & 688341 & 5.2 & 4.8021 & TRN \\
\hline CHEMBL1358263 & 688341 & 7.0 & 5.1786 & TRN \\
\hline CHEMBL1372549 & 688341 & 4.7 & 5.0601 & TRN \\
\hline CHEMBL1332378 & 688341 & 5.4 & 4.9247 & TRN \\
\hline CHEMBL1527558 & 688341 & 4.6 & 4.987 & TRN \\
\hline
\end{tabular}




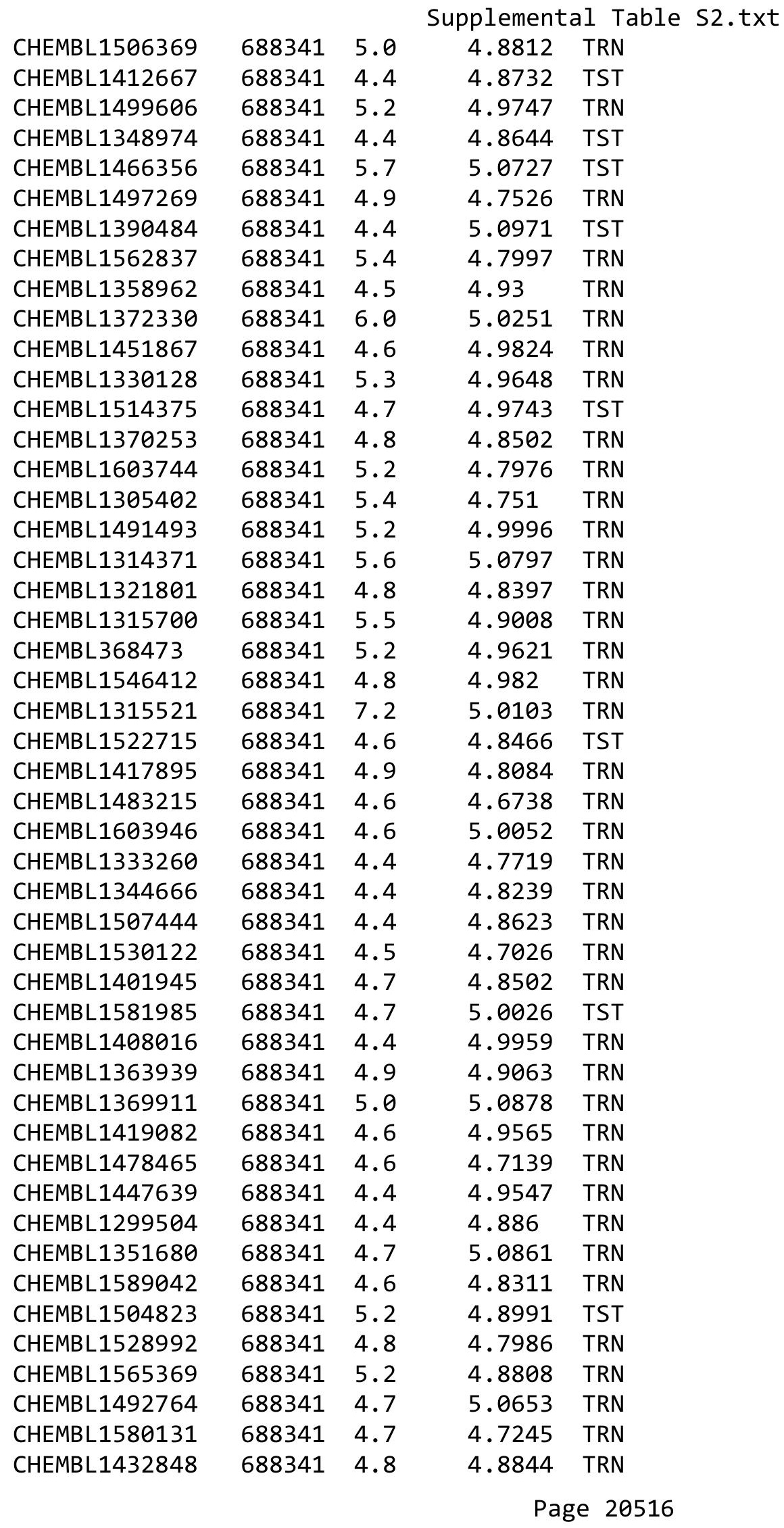




\begin{tabular}{|c|c|c|c|c|c|}
\hline & & & & & \\
\hline CHEMBL1557170 & 688341 & 5.9 & 4.8769 & TRN & \\
\hline CHEMBL1322600 & 688341 & 4.6 & 4.8965 & TRN & \\
\hline CHEMBL1449350 & 688341 & 4.4 & 5.0244 & TRN & \\
\hline CHEMBL1453742 & 688341 & 4.7 & 4.9002 & TRN & \\
\hline CHEMBL1595175 & 688341 & 4.5 & 4.745 & TRN & \\
\hline CHEMBL1518889 & 688341 & 4.4 & 4.9562 & TST & \\
\hline CHEMBL1308328 & 688341 & 4.7 & 4.9232 & TRN & \\
\hline CHEMBL1337635 & 688341 & 4.5 & 4.688 & TRN & \\
\hline CHEMBL1532465 & 688341 & 4.4 & 4.8502 & TST & \\
\hline CHEMBL1488221 & 688341 & 4.9 & 5.0674 & TRN & \\
\hline CHEMBL1398467 & 688341 & 4.9 & 5.0096 & TRN & \\
\hline CHEMBL1330979 & 688341 & 4.8 & 4.8111 & TRN & \\
\hline CHEMBL1501871 & 688341 & 4.4 & 4.9553 & TST & \\
\hline CHEMBL470671 & 688341 & 4.9 & 5.0138 & TST & \\
\hline CHEMBL1336941 & 688341 & 7.0 & 5.0717 & TRN & \\
\hline CHEMBL1537424 & 688341 & 4.7 & 4.9464 & TST & \\
\hline CHEMBL1476904 & 688341 & 5.4 & 4.8297 & TRN & \\
\hline CHEMBL1484411 & 688341 & 5.1 & 4.9543 & TST & \\
\hline CHEMBL1566288 & 688341 & 4.9 & 4.81 & TRN & \\
\hline CHEMBL1309404 & 688341 & 5.4 & 5.0051 & TST & \\
\hline CHEMBL1612155 & 688341 & 4.8 & 4.9715 & TRN & \\
\hline CHEMBL1331237 & 688341 & 4.6 & 5.0925 & TST & \\
\hline CHEMBL1403351 & 688341 & 5.4 & 4.8544 & TRN & \\
\hline CHEMBL1301325 & 688341 & 4.6 & $4.9060 e$ & 0000000001 & TRN \\
\hline CHEMBL1373704 & 688341 & 5.2 & 4.9648 & TST & \\
\hline CHEMBL1608868 & 688341 & 5.0 & 4.7261 & TRN & \\
\hline CHEMBL1536007 & 688341 & 4.6 & 5.0493 & TRN & \\
\hline CHEMBL1457207 & 688341 & 4.6 & 4.9457 & TRN & \\
\hline CHEMBL568379 & 688341 & 4.5 & 4.9417 & TRN & \\
\hline CHEMBL3208967 & 688341 & 5.1 & 4.8064 & TST & \\
\hline CHEMBL1337092 & 688341 & 5.2 & 5.0599 & TRN & \\
\hline CHEMBL1557361 & 688341 & 4.8 & 4.6895 & TRN & \\
\hline CHEMBL1309092 & 688341 & 4.7 & 5.0232 & TRN & \\
\hline CHEMBL1599089 & 688341 & 5.9 & 5.0088 & TRN & \\
\hline CHEMBL3211349 & 688341 & 4.4 & 5.0784 & TST & \\
\hline CHEMBL455491 & 688341 & 4.4 & 5.2729 & TST & \\
\hline CHEMBL1581555 & 688341 & 4.9 & 4.8506 & TST & \\
\hline CHEMBL1318908 & 688341 & 4.9 & 4.8365 & TRN & \\
\hline CHEMBL1340152 & 688341 & 4.5 & 5.043 & TRN & \\
\hline CHEMBL1610411 & 688341 & 5.5 & 5.2693 & TRN & \\
\hline CHEMBL1554683 & 688341 & 4.8 & 5.0055 & TRN & \\
\hline CHEMBL1469620 & 688341 & 4.5 & 4.7841 & TRN & \\
\hline CHEMBL1310155 & 688341 & 4.5 & 4.8846 & TRN & \\
\hline CHEMBL1548825 & 688341 & 5.0 & 4.9053 & TST & \\
\hline CHEMBL1308461 & 688341 & 4.6 & 4.8014 & TRN & \\
\hline CHEMBL1324146 & 688341 & 4.4 & 4.9328 & TRN & \\
\hline CHEMBL 3212191 & 688341 & 4.8 & 4.8754 & TST & \\
\hline CHEMBL1582818 & 688341 & 4.5 & 4.97199 & 99999999995 & TST \\
\hline & & & & 20517 & \\
\hline
\end{tabular}




\begin{tabular}{|c|c|c|c|c|}
\hline \multicolumn{5}{|c|}{ Supplemental Table S2.txt } \\
\hline CHEMBL1417771 & 688341 & 4.9 & 5.0546 & TRN \\
\hline CHEMBL445612 & 688341 & 4.4 & 5.1387 & TST \\
\hline CHEMBL1363623 & 688341 & 6.8 & 4.9781 & TRN \\
\hline CHEMBL1408965 & 688341 & 4.6 & 4.9203 & TRN \\
\hline CHEMBL76904 & 688341 & 4.4 & 5.0999 & TRN \\
\hline CHEMBL1374496 & 688341 & 4.9 & 4.8657 & TRN \\
\hline CHEMBL1468924 & 688341 & 5.3 & 4.8011 & TRN \\
\hline CHEMBL1610450 & 688341 & 5.4 & 4.9486 & TRN \\
\hline CHEMBL1385123 & 688341 & 4.7 & 4.9237 & TRN \\
\hline CHEMBL1486411 & 688341 & 4.6 & 4.8681 & TST \\
\hline CHEMBL1361174 & 688341 & 4.6 & 4.782 & TRN \\
\hline CHEMBL3214013 & 688341 & 4.7 & 5.0672 & TRN \\
\hline CHEMBL1375233 & 688341 & 7.5003 & 4.9589 & TRN \\
\hline CHEMBL1451750 & 688341 & 4.4 & 4.9867 & TRN \\
\hline CHEMBL1466589 & 688341 & 5.4 & 5.0884 & TRN \\
\hline CHEMBL1453542 & 688341 & 4.5 & 5.191 & TRN \\
\hline CHEMBL1361838 & 688341 & 4.6 & 4.8368 & TST \\
\hline CHEMBL27403 & 688341 & 4.5 & 5.0638 & TST \\
\hline CHEMBL1329020 & 688341 & 4.6 & 5.0574 & TST \\
\hline CHEMBL1353300 & 688341 & 8.1024 & 5.0287 & TRN \\
\hline CHEMBL1330864 & 688341 & 4.9 & 4.7374 & TRN \\
\hline CHEMBL1565048 & 688341 & 4.9 & 4.8631 & TRN \\
\hline CHEMBL1469243 & 688341 & 4.5 & 4.7161 & TRN \\
\hline CHEMBL1480089 & 688341 & 4.8 & 4.9459 & TRN \\
\hline CHEMBL1525066 & 688341 & 4.8 & 4.9978 & TRN \\
\hline CHEMBL1458374 & 688341 & 4.9 & 4.7837 & TRN \\
\hline CHEMBL1377686 & 688341 & 5.3 & 5.1362 & TRN \\
\hline CHEMBL1256020 & 688341 & 4.6 & 4.9958 & TRN \\
\hline CHEMBL1479028 & 688341 & 5.2 & 4.8668 & TRN \\
\hline CHEMBL1319971 & 688341 & 4.5 & 4.9417 & TST \\
\hline CHEMBL1353359 & 688341 & 4.6 & 4.8195 & TRN \\
\hline CHEMBL1396792 & 688341 & 4.8 & 5.0795 & TRN \\
\hline CHEMBL1424468 & 688341 & 4.5 & 4.9759 & TRN \\
\hline CHEMBL1391482 & 688341 & 5.0 & 4.9389 & TST \\
\hline CHEMBL1468840 & 688341 & 5.3 & 4.962 & TST \\
\hline CHEMBL1388344 & 688341 & 5.3 & 4.8949 & TRN \\
\hline CHEMBL 1374558 & 688341 & 4.6 & 4.968 & TRN \\
\hline CHEMBL1525177 & 688341 & 4.8 & 4.8181 & TRN \\
\hline CHEMBL1336101 & 688341 & 4.9 & 4.7944 & TRN \\
\hline CHEMBL1576558 & 688341 & 5.2 & 5.0157 & TRN \\
\hline CHEMBL1303906 & 688341 & 5.2 & 4.9164 & TRN \\
\hline CHEMBL1428970 & 688341 & 4.5 & 4.9337 & TRN \\
\hline CHEMBL1415585 & 688341 & 4.4 & 4.7888 & TRN \\
\hline CHEMBL1387489 & 688341 & 5.0 & 4.8946 & TRN \\
\hline CHEMBL1324586 & 688341 & 4.4 & 4.933 & TRN \\
\hline CHEMBL1481252 & 688341 & 5.6 & 4.9468 & TRN \\
\hline CHEMBL1483925 & 688341 & 4.8 & 4.798 & TRN \\
\hline CHEMBL 3214098 & 688341 & 4.4 & 4.8 & TRN \\
\hline
\end{tabular}




\begin{tabular}{|c|c|c|c|c|c|}
\hline \multicolumn{6}{|c|}{ Supplemental Table S2.txt } \\
\hline CHEMBL1508936 & 688341 & 5.2 & 4.8871 & TRN & \\
\hline CHEMBL1547250 & 688341 & 4.9 & 4.7864 & TRN & \\
\hline CHEMBL1373288 & 688341 & 4.5 & 4.9309 & TST & \\
\hline CHEMBL1555657 & 688341 & 4.5 & 4.8359 & TRN & \\
\hline CHEMBL1572142 & 688341 & 4.7 & 4.817 & TRN & \\
\hline CHEMBL1411672 & 688341 & 4.5 & 4.7746 & TRN & \\
\hline CHEMBL1526075 & 688341 & 5.5 & 4.9847 & TST & \\
\hline CHEMBL1304416 & 688341 & 5.2 & 4.7033 & TRN & \\
\hline CHEMBL1500473 & 688341 & 4.8 & 4.8363 & TRN & \\
\hline CHEMBL1360852 & 688341 & 4.9 & 4.9051 & TRN & \\
\hline CHEMBL1438748 & 688341 & 5.5 & 5.0508 & TRN & \\
\hline CHEMBL1453646 & 688341 & 5.5 & 5.0165 & TRN & \\
\hline CHEMBL1415642 & 688341 & 6.6 & 4.8213 & TRN & \\
\hline CHEMBL1313439 & 688341 & 5.2 & 5.1121 & TST & \\
\hline CHEMBL1508526 & 688341 & 5.2 & 5.0888 & TRN & \\
\hline CHEMBL1548834 & 688341 & 5.5 & 4.9702 & TRN & \\
\hline CHEMBL1484186 & 688341 & 4.6 & 4.9405 & TST & \\
\hline CHEMBL1422210 & 688341 & 4.4 & 4.7976 & TRN & \\
\hline CHEMBL1500549 & 688341 & 4.4 & 4.8431 & TRN & \\
\hline CHEMBL1543781 & 688341 & 5.4 & 4.7621 & TRN & \\
\hline CHEMBL1455269 & 688341 & 4.6 & 4.8101 & TRN & \\
\hline CHEMBL1541290 & 688341 & 5.4 & 4.9031 & TRN & \\
\hline CHEMBL105739 & 688341 & 5.8 & 5.0881 & TST & \\
\hline CHEMBL1461480 & 688341 & 4.6 & 5.0108 & TRN & \\
\hline CHEMBL1583810 & 688341 & 4.7 & 4.9967 & TST & \\
\hline CHEMBL1429463 & 688341 & 4.6 & 4.8907 & TST & \\
\hline CHEMBL1412222 & 688341 & 4.7 & 4.9034 & TRN & \\
\hline CHEMBL1437981 & 688341 & 4.7 & 4.7069 & TRN & \\
\hline CHEMBL1491676 & 688341 & 4.5 & 4.8525 & TRN & \\
\hline CHEMBL1454000 & 688341 & 4.6 & 4.8691 & TRN & \\
\hline CHEMBL1572490 & 688341 & 4.4 & 4.9571 & TRN & \\
\hline CHEMBL1415986 & 688341 & 5.1 & 4.8161 & TST & \\
\hline CHEMBL1433798 & 688341 & 4.4 & 5.0074 & TRN & \\
\hline CHEMBL1322401 & 688341 & 4.5 & 5.0076 & TRN & \\
\hline CHEMBL1584930 & 688341 & 4.6 & 4.8636 & TST & \\
\hline CHEMBL1537053 & 688341 & 4.4 & 4.9047 & TRN & \\
\hline CHEMBL292477 & 688341 & 4.5 & 4.9504 & TRN & \\
\hline CHEMBL1503684 & 688341 & 7.699 & 4.8641 & TST & \\
\hline CHEMBL1537325 & 688341 & 5.2 & 4.9522 & TRN & \\
\hline CHEMBL1481022 & 688341 & 4.6 & 4.8751 & TST & \\
\hline CHEMBL1520589 & 688341 & 4.6 & 4.93199 & 99999999995 & TST \\
\hline CHEMBL1480041 & 688341 & 4.6 & 4.9136 & TRN & \\
\hline CHEMBL1467937 & 688341 & 4.5 & 4.8689 & TRN & \\
\hline CHEMBL1583165 & 688341 & 5.3 & 4.8788 & TRN & \\
\hline CHEMBL1410255 & 688341 & 4.5 & 5.0124 & TRN & \\
\hline CHEMBL1494878 & 688341 & 5.1 & 4.9408 & TST & \\
\hline CHEMBL1433290 & 688341 & 5.1 & 4.8756 & TRN & \\
\hline CHEMBL1364473 & 688341 & 5.2 & 5.0258 & TRN & \\
\hline
\end{tabular}




\begin{tabular}{|c|c|c|c|c|}
\hline & & & upplement & al Table S \\
\hline CHEMBL1580188 & 688341 & 4.6 & 5.0744 & TRN \\
\hline CHEMBL1352013 & 688341 & 4.8 & 5.1121 & TRN \\
\hline CHEMBL1524002 & 688341 & 4.8 & 4.9584 & TRN \\
\hline CHEMBL1423564 & 688341 & 5.0 & 5.1062 & TRN \\
\hline CHEMBL1583655 & 688341 & 5.2 & 4.7546 & TRN \\
\hline CHEMBL1482759 & 688341 & 5.8 & 5.1111 & TRN \\
\hline CHEMBL1506140 & 688341 & 4.8 & 5.012 & TRN \\
\hline CHEMBL1379030 & 688341 & 4.8 & 4.8921 & TRN \\
\hline CHEMBL1440509 & 688341 & 4.5 & 5.0695 & TRN \\
\hline CHEMBL599705 & 688341 & 4.5 & 4.8065 & TRN \\
\hline CHEMBL 1409060 & 688341 & 4.4 & 4.9806 & TST \\
\hline CHEMBL1441911 & 688341 & 4.5 & 4.9644 & TST \\
\hline CHEMBL1397322 & 688341 & 4.8 & 5.1072 & TRN \\
\hline CHEMBL1427044 & 688341 & 4.5 & 4.8445 & TRN \\
\hline CHEMBL1540916 & 688341 & 4.7 & 4.999 & TRN \\
\hline CHEMBL1528358 & 688341 & 4.4 & 4.9942 & TRN \\
\hline CHEMBL1611298 & 688341 & 4.9 & 4.9309 & TRN \\
\hline CHEMBL1373761 & 688341 & 4.6 & 4.9233 & TRN \\
\hline CHEMBL1409320 & 688341 & 5.0 & 5.1569 & TRN \\
\hline CHEMBL1414507 & 688341 & 4.8 & 4.8985 & TRN \\
\hline CHEMBL1448062 & 688341 & 5.4 & 4.8425 & TRN \\
\hline CHEMBL1429805 & 688341 & 6.0 & 4.82 & TRN \\
\hline CHEMBL 1457150 & 688341 & 4.7 & $4.8210 e$ & 0000000001 \\
\hline CHEMBL1359569 & 688341 & 5.4 & 4.8344 & TST \\
\hline CHEMBL1483058 & 688341 & 4.9 & 5.0475 & TRN \\
\hline CHEMBL1594995 & 688341 & 4.8 & 4.9596 & TST \\
\hline CHEMBL1318480 & 688341 & 4.5 & 5.1794 & TRN \\
\hline CHEMBL1380742 & 688341 & 5.2 & 5.0282 & TST \\
\hline CHEMBL1428963 & 688341 & 5.4 & 4.9045 & TST \\
\hline CHEMBL1571553 & 688341 & 4.9 & 4.8509 & TRN \\
\hline CHEMBL1234848 & 688341 & 6.0 & 5.0586 & TST \\
\hline CHEMBL1503415 & 688341 & 4.5 & 4.9241 & TST \\
\hline CHEMBL555689 & 688341 & 5.5 & 4.9132 & TST \\
\hline CHEMBL1598208 & 688341 & 5.4 & 4.8501 & TRN \\
\hline CHEMBL1342717 & 688341 & 4.7 & 4.9972 & TRN \\
\hline CHEMBL1432842 & 688341 & 4.8 & 4.7652 & TST \\
\hline CHEMBL1471969 & 688341 & 5.5 & 4.8722 & TST \\
\hline CHEMBL1440226 & 688341 & 4.4 & 5.0986 & TST \\
\hline CHEMBL1568162 & 688341 & 4.8 & 4.8535 & TST \\
\hline CHEMBL1534353 & 688341 & 6.0 & 4.9266 & TRN \\
\hline CHEMBL1345307 & 688341 & 4.5 & 5.1303 & TRN \\
\hline CHEMBL1307843 & 688341 & 5.4 & 4.8477 & TST \\
\hline CHEMBL1324425 & 688341 & 4.4 & 4.8117 & TRN \\
\hline CHEMBL1353913 & 688341 & 4.7 & 4.9476 & TRN \\
\hline CHEMBL1386080 & 688341 & 4.4 & 4.7812 & TRN \\
\hline CHEMBL1411130 & 688341 & 5.0 & 4.8305 & TRN \\
\hline CHEMBL1443695 & 688341 & 4.8 & 5.0438 & TRN \\
\hline CHEMBL1331960 & 688341 & 4.5 & 4.7358 & TRN \\
\hline
\end{tabular}




\begin{tabular}{|c|c|c|c|c|}
\hline \multicolumn{5}{|c|}{ Supplemental Table S2.txt } \\
\hline CHEMBL1538165 & 688341 & 4.7 & 4.8705 & TRN \\
\hline CHEMBL1381808 & 688341 & 4.9 & 4.8616 & TRN \\
\hline CHEMBL1465532 & 688341 & 6.3 & 5.0105 & TRN \\
\hline CHEMBL1394020 & 688341 & 5.0 & 5.0507 & TRN \\
\hline CHEMBL1540591 & 688341 & 4.6 & 4.8956 & TRN \\
\hline CHEMBL131171 & 688341 & 4.8 & 5.11 & TST \\
\hline CHEMBL1309735 & 688341 & 5.0 & 4.8082 & TST \\
\hline CHEMBL1446909 & 688341 & 4.6 & 4.8278 & TRN \\
\hline CHEMBL1333773 & 688341 & 5.1 & 4.9244 & TRN \\
\hline CHEMBL1433704 & 688341 & 5.5 & 5.1035 & TRN \\
\hline CHEMBL1311410 & 688341 & 5.3 & 4.9598 & TRN \\
\hline CHEMBL1407524 & 688341 & 5.5 & 4.9311 & TRN \\
\hline CHEMBL1424022 & 688341 & 4.7 & 5.0419 & TRN \\
\hline CHEMBL1586097 & 688341 & 4.4 & 5.0847 & TST \\
\hline CHEMBL200309 & 688341 & 4.8 & 5.1168 & TST \\
\hline CHEMBL1456015 & 688341 & 5.0 & 5.121 & TRN \\
\hline CHEMBL1532340 & 688341 & 5.0 & 4.8599 & TST \\
\hline CHEMBL1381147 & 688341 & 5.4 & 4.8044 & TRN \\
\hline CHEMBL1569907 & 688341 & 4.7 & 4.8296 & TRN \\
\hline CHEMBL1556428 & 688341 & 5.1 & 4.8387 & TRN \\
\hline CHEMBL1559976 & 688341 & 4.4 & 4.8705 & TRN \\
\hline CHEMBL1512023 & 688341 & 4.9 & 5.2227 & TRN \\
\hline CHEMBL398673 & 688341 & 5.4 & 5.1379 & TST \\
\hline CHEMBL1454696 & 688341 & 5.4 & 4.8961 & TST \\
\hline CHEMBL1452716 & 688341 & 6.0 & 5.1371 & TRN \\
\hline CHEMBL1501180 & 688341 & 4.4 & 4.8221 & TRN \\
\hline CHEMBL1594858 & 688341 & 4.9 & 4.9054 & TRN \\
\hline CHEMBL1406467 & 688341 & 5.1 & 4.9904 & TST \\
\hline CHEMBL1573277 & 688341 & 5.4 & 4.8717 & TRN \\
\hline CHEMBL28319 & 688341 & 5.0 & 4.9865 & TST \\
\hline CHEMBL1587507 & 688341 & 4.5 & 4.8154 & TRN \\
\hline CHEMBL1607133 & 688341 & 5.5 & 5.1415 & TRN \\
\hline CHEMBL1570447 & 688341 & 4.4 & 4.8844 & TST \\
\hline CHEMBL1391326 & 688341 & 8.1024 & 5.0438 & TRN \\
\hline CHEMBL1471717 & 688341 & 6.2 & 4.8202 & TRN \\
\hline CHEMBL1322077 & 688341 & 5.2 & 4.9707 & TRN \\
\hline CHEMBL1488942 & 688341 & 4.8 & 4.9707 & TRN \\
\hline CHEMBL1581337 & 688341 & 4.6 & 5.0759 & TST \\
\hline CHEMBL1522929 & 688341 & 5.2 & 4.9862 & TRN \\
\hline CHEMBL1479591 & 688341 & 4.4 & 4.8786 & TRN \\
\hline CHEMBL1454146 & 688341 & 5.4 & 5.0616 & TRN \\
\hline CHEMBL462576 & 688341 & 6.0 & 5.191 & TST \\
\hline CHEMBL1533843 & 688341 & 5.3 & 5.0728 & TRN \\
\hline CHEMBL1487656 & 688341 & 4.5 & 5.1374 & TST \\
\hline CHEMBL1372908 & 688341 & 4.4 & 4.8106 & TST \\
\hline CHEMBL3195844 & 688341 & 4.5 & 4.8821 & TST \\
\hline CHEMBL1578133 & 688341 & 4.8 & 5.0144 & TST \\
\hline CHEMBL170781 & 688341 & 5.1 & 5.0665 & TRN \\
\hline
\end{tabular}




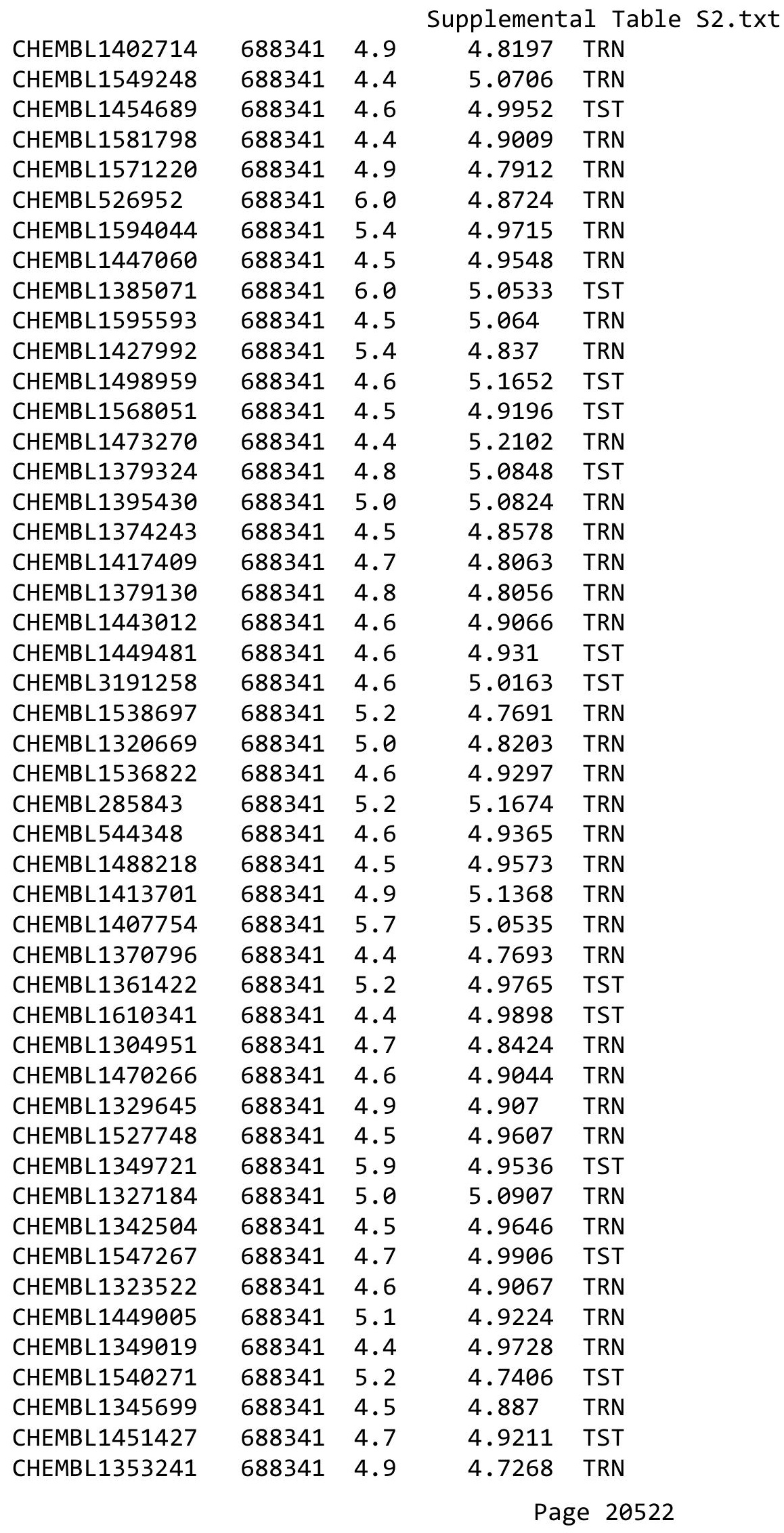




\begin{tabular}{|c|c|c|c|c|c|}
\hline & & & & & \\
\hline CHEMBL1409080 & 688341 & 5.3 & 4.9423 & TST & \\
\hline CHEMBL1306528 & 688341 & 5.0 & 4.6718 & TRN & \\
\hline CHEMBL1583045 & 688341 & 5.0 & 4.9878 & TST & \\
\hline CHEMBL1370812 & 688341 & 4.5 & 4.73600 & 0000000001 & TRN \\
\hline CHEMBL1434334 & 688341 & 4.4 & 5.2589 & TST & \\
\hline CHEMBL1560366 & 688341 & 4.5 & 5.0663 & TRN & \\
\hline CHEMBL1593866 & 688341 & 4.4 & 4.908 & TRN & \\
\hline CHEMBL1318739 & 688341 & 5.1 & 5.1062 & TST & \\
\hline CHEMBL539648 & 688341 & 7.5003 & 5.0794 & TRN & \\
\hline CHEMBL1383720 & 688341 & 4.9 & 4.9058 & TST & \\
\hline CHEMBL1383582 & 688341 & 5.0 & 4.8371 & TRN & \\
\hline CHEMBL1460848 & 688341 & 4.6 & 4.7846 & TRN & \\
\hline CHEMBL1500033 & 688341 & 4.8 & 4.9916 & TRN & \\
\hline CHEMBL1434098 & 688341 & 4.5 & 4.92899 & 9999999999 & TRN \\
\hline CHEMBL1568129 & 688341 & 5.0 & 4.9311 & TRN & \\
\hline CHEMBL1437428 & 688341 & 5.2 & 5.001 & TST & \\
\hline CHEMBL1383488 & 688341 & 4.8 & 5.16 & TST & \\
\hline CHEMBL1574534 & 688341 & 4.8 & 5.0962 & TRN & \\
\hline CHEMBL1549597 & 688341 & 4.6 & 4.7813 & TRN & \\
\hline CHEMBL1455644 & 688341 & 5.5 & 4.8919 & TRN & \\
\hline CHEMBL1559225 & 688341 & 4.7 & 4.9416 & TRN & \\
\hline CHEMBL1385227 & 688341 & 5.0 & 4.8922 & TRN & \\
\hline CHEMBL1364670 & 688341 & 4.7 & 5.001 & TRN & \\
\hline CHEMBL1362247 & 688341 & 4.5 & 4.8236 & TRN & \\
\hline CHEMBL1552286 & 688341 & 4.7 & 4.8994 & TRN & \\
\hline CHEMBL320820 & 688341 & 4.5 & 5.0922 & TST & \\
\hline CHEMBL1367996 & 688341 & 4.7 & 4.8572 & TRN & \\
\hline CHEMBL1415399 & 688341 & 4.7 & 4.8412 & TRN & \\
\hline CHEMBL1413610 & 688341 & 4.4 & 4.871 & TRN & \\
\hline CHEMBL1493660 & 688341 & 4.9 & 4.9185 & TRN & \\
\hline CHEMBL16435 & 688341 & 4.9 & 4.9387 & TRN & \\
\hline CHEMBL1327690 & 688341 & 5.1 & 4.8405 & TRN & \\
\hline CHEMBL1597435 & 688341 & 4.5 & 4.9742 & TRN & \\
\hline CHEMBL1506172 & 688341 & 4.4 & 5.0189 & TRN & \\
\hline CHEMBL1504889 & 688341 & 4.5 & 4.7773 & TRN & \\
\hline CHEMBL1372023 & 688341 & 4.7 & 4.9527 & TRN & \\
\hline CHEMBL1358807 & 688341 & 4.8 & 5.1271 & TRN & \\
\hline CHEMBL1431486 & 688341 & 5.2 & 4.9323 & TRN & \\
\hline CHEMBL1332712 & 688341 & 5.2 & 4.9192 & TRN & \\
\hline CHEMBL305978 & 688341 & 5.5 & 4.8773 & TRN & \\
\hline CHEMBL1411170 & 688341 & 5.2 & 4.8746 & TRN & \\
\hline CHEMBL1572611 & 688341 & 4.7 & 4.8813 & TRN & \\
\hline CHEMBL1320057 & 688341 & 4.7 & 4.916 & TST & \\
\hline CHEMBL1521116 & 688341 & 5.8 & 4.8812 & TRN & \\
\hline CHEMBL1423849 & 688341 & 5.8 & 4.6294 & TRN & \\
\hline CHEMBL1329068 & 688341 & 5.1 & 4.9481 & TRN & \\
\hline CHEMBL1439901 & 688341 & 4.7 & 5.0017 & TRN & \\
\hline CHEMBL1410889 & 688341 & 4.4 & 5.0055 & TST & \\
\hline & & & & 20523 & \\
\hline
\end{tabular}




\begin{tabular}{|c|c|c|c|c|c|}
\hline \multicolumn{6}{|c|}{ Supplemental Table S2.txt } \\
\hline CHEMBL1417665 & 688341 & 4.8 & 4.7629 & TRN & \\
\hline CHEMBL45079 & 688341 & 5.0 & 5.129 & TST & \\
\hline CHEMBL1469101 & 688341 & 6.7001 & 4.9228 & TST & \\
\hline CHEMBL1343237 & 688341 & 4.9 & 4.8774 & TRN & \\
\hline CHEMBL1386065 & 688341 & 4.6 & 4.8528 & TRN & \\
\hline CHEMBL490913 & 688341 & 4.5 & 5.0097 & TRN & \\
\hline CHEMBL1322827 & 688341 & 4.8 & 4.9632 & TRN & \\
\hline CHEMBL1450354 & 688341 & 5.2 & 4.8723 & TRN & \\
\hline CHEMBL1381589 & 688341 & 4.6 & 4.8561 & TST & \\
\hline CHEMBL1518075 & 688341 & 5.5 & 5.0837 & TRN & \\
\hline CHEMBL1341401 & 688341 & 4.6 & 4.9554 & TRN & \\
\hline CHEMBL1479805 & 688341 & 5.2 & 5.2274 & TST & \\
\hline CHEMBL1331245 & 688341 & 5.1 & 5.0239 & TST & \\
\hline CHEMBL1594885 & 688341 & 4.7 & 4.8223 & TRN & \\
\hline CHEMBL1499016 & 688341 & 4.6 & 4.7788 & TRN & \\
\hline CHEMBL1485204 & 688341 & 4.7 & 4.8635 & TRN & \\
\hline CHEMBL1426615 & 688341 & 4.8 & 5.042 & TRN & \\
\hline CHEMBL 721 & 688341 & 4.4 & 5.1132 & TST & \\
\hline CHEMBL 1607192 & 688341 & 5.4 & 5.0693 & TST & \\
\hline CHEMBL1500745 & 688341 & 4.4 & 4.9283 & TST & \\
\hline CHEMBL1428027 & 688341 & 4.8 & 4.7782 & TRN & \\
\hline CHEMBL1572608 & 688341 & 4.6 & 5.0651 & TST & \\
\hline CHEMBL1400900 & 688341 & 5.2 & 5.09699 & 99999999995 & TRN \\
\hline CHEMBL1399402 & 688341 & 4.5 & 4.8796 & TRN & \\
\hline CHEMBL1524790 & 688341 & 4.5 & 4.7666 & TRN & \\
\hline CHEMBL565856 & 688341 & 5.4 & 4.856 & TRN & \\
\hline CHEMBL1411940 & 688341 & 4.4 & 5.0416 & TST & \\
\hline CHEMBL1377491 & 688341 & 4.7 & 4.8028 & TRN & \\
\hline CHEMBL1509967 & 688341 & 4.5 & 4.7473 & TRN & \\
\hline CHEMBL1529399 & 688341 & 4.5 & 4.9993 & TRN & \\
\hline CHEMBL1327747 & 688341 & 5.2 & 5.0371 & TST & \\
\hline CHEMBL1421029 & 688341 & 4.5 & 4.8362 & TST & \\
\hline CHEMBL1421424 & 688341 & 5.3 & 4.9421 & TRN & \\
\hline CHEMBL1413855 & 688341 & 4.4 & 4.7872 & TRN & \\
\hline CHEMBL1494697 & 688341 & 4.6 & 5.0536 & TRN & \\
\hline CHEMBL1570238 & 688341 & 4.5 & 4.9077 & TRN & \\
\hline CHEMBL1420491 & 688341 & 5.6 & 4.9729 & TRN & \\
\hline CHEMBL1540830 & 688341 & 4.4 & 4.9901 & TRN & \\
\hline CHEMBL1556227 & 688341 & 4.6 & 4.7198 & TRN & \\
\hline CHEMBL1349313 & 688341 & 4.6 & 4.8907 & TRN & \\
\hline CHEMBL1462993 & 688341 & 5.1 & 4.8864 & TRN & \\
\hline CHEMBL1522912 & 688341 & 5.2 & 4.9407 & TRN & \\
\hline CHEMBL1469892 & 688341 & 4.5 & 4.9591 & TST & \\
\hline CHEMBL1299268 & 688341 & 4.9 & 4.7503 & TRN & \\
\hline CHEMBL1489308 & 688341 & 4.9 & 5.0199 & TRN & \\
\hline CHEMBL1349003 & 688341 & 4.8 & 4.9132 & TRN & \\
\hline CHEMBL1376741 & 688341 & 4.8 & 4.8352 & TRN & \\
\hline CHEMBL1600378 & 688341 & 5.9 & 4.9909 & TRN & \\
\hline
\end{tabular}




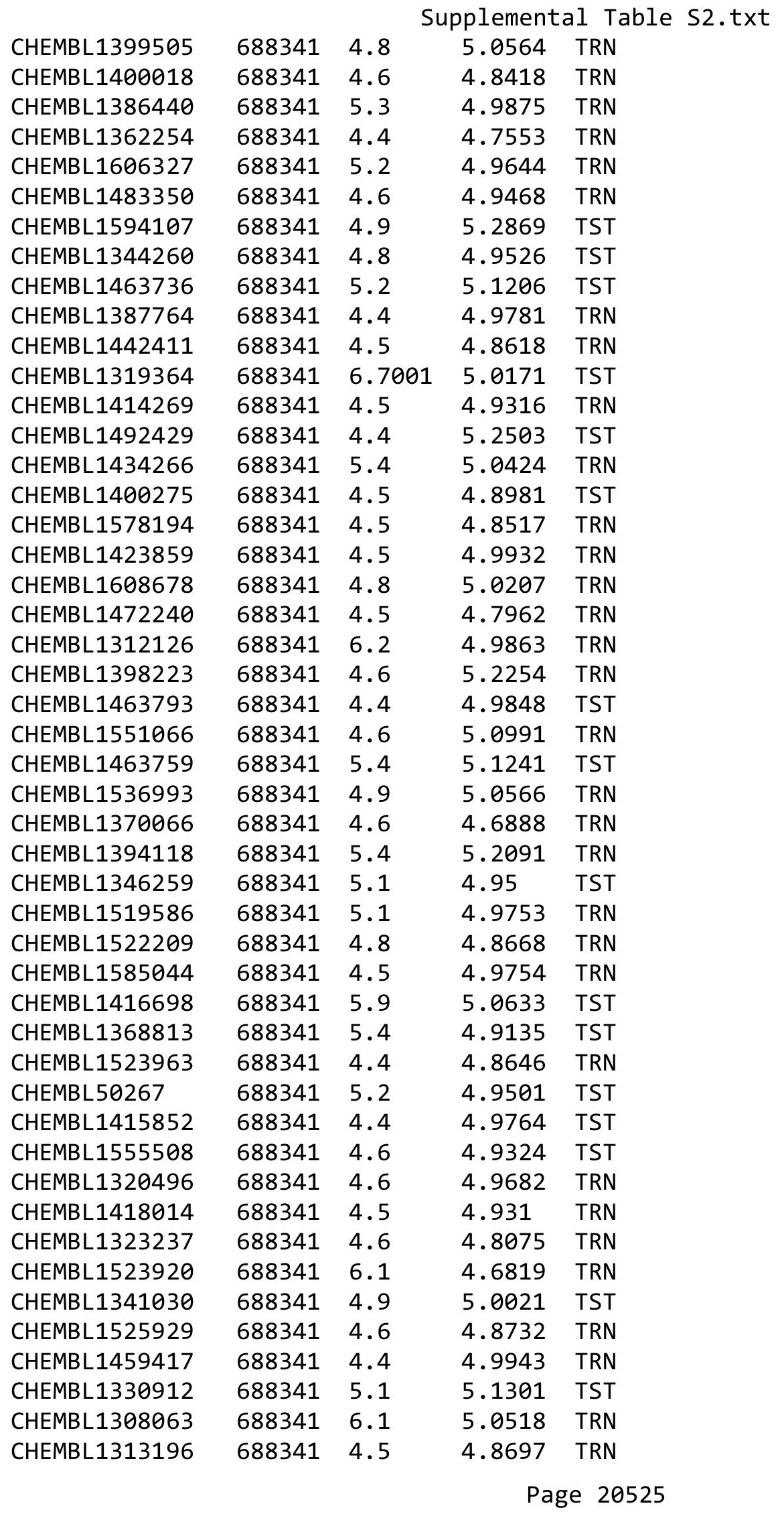




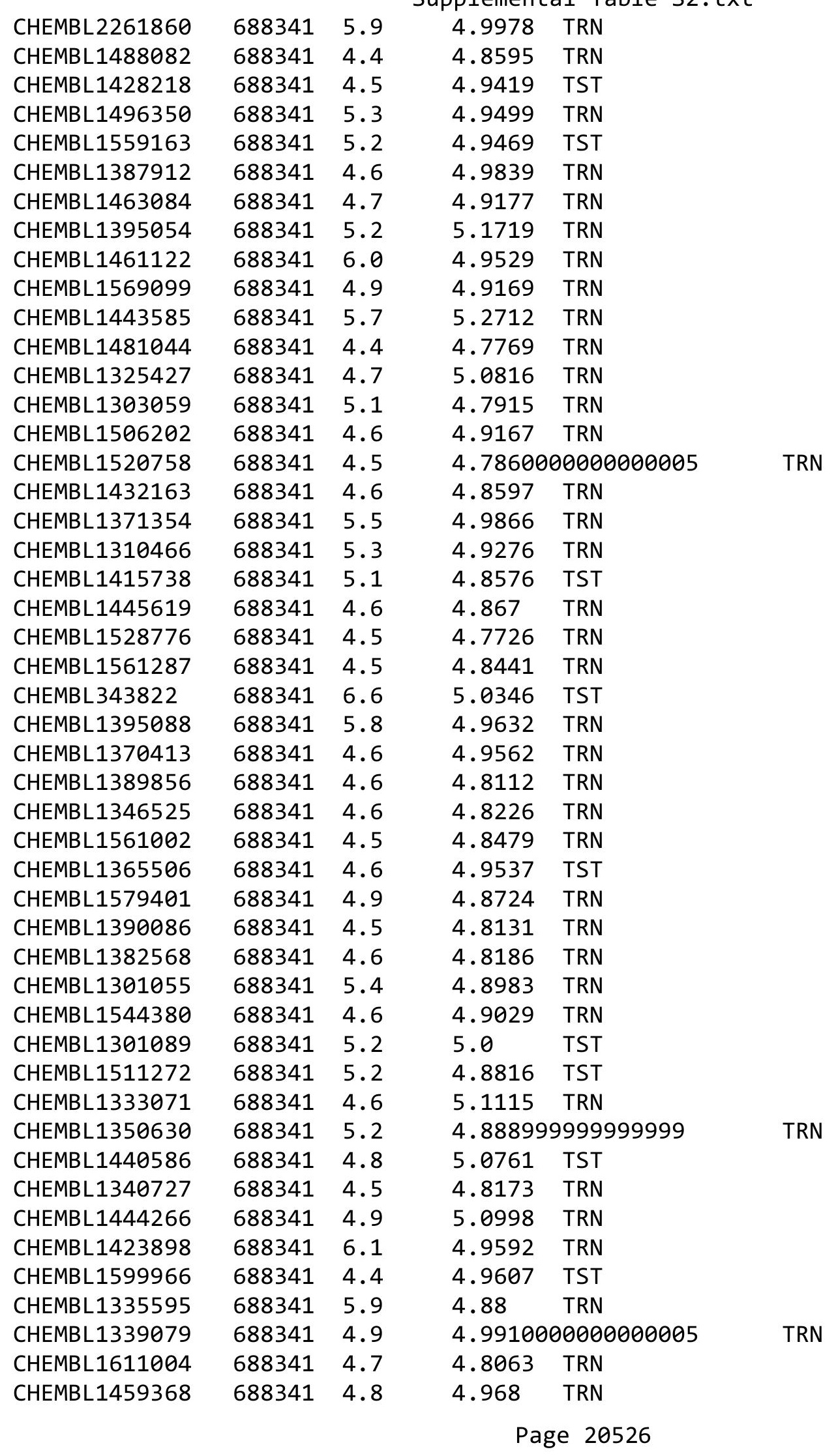




\begin{tabular}{|c|c|c|c|c|c|}
\hline \multicolumn{6}{|c|}{ Supplemental Table s2.txt } \\
\hline CHEMBL36148 & 688341 & 6.0 & 5.1953 & TST & \\
\hline CHEMBL1513241 & 688341 & 6.1 & 5.2025 & TRN & \\
\hline CHEMBL1549160 & 688341 & 4.9 & 4.9753 & TRN & \\
\hline CHEMBL1560329 & 688341 & 4.6 & 4.743 & TRN & \\
\hline CHEMBL1576563 & 688341 & 4.6 & 4.7923 & TRN & \\
\hline CHEMBL1301151 & 688341 & 4.5 & 4.9274 & TRN & \\
\hline CHEMBL1366954 & 688341 & 4.9 & 5.0606 & TRN & \\
\hline CHEMBL1540345 & 688341 & 5.4 & 5.0842 & TST & \\
\hline CHEMBL1466795 & 688341 & 4.7 & 4.8954 & TRN & \\
\hline CHEMBL1491959 & 688341 & 5.0 & 4.8036 & TRN & \\
\hline CHEMBL1349521 & 688341 & 4.8 & 4.9221 & TRN & \\
\hline CHEMBL1164301 & 688341 & 4.4 & 5.0791 & TST & \\
\hline CHEMBL1300020 & 688341 & 5.0 & 4.8365 & TST & \\
\hline CHEMBL1468116 & 688341 & 4.5 & 4.8299 & TRN & \\
\hline CHEMBL1529503 & 688341 & 4.6 & 5.1502 & TST & \\
\hline CHEMBL1601200 & 688341 & 4.4 & 4.9259 & TRN & \\
\hline CHEMBL1353804 & 688341 & 4.6 & 4.9199 & TST & \\
\hline CHEMBL1596952 & 688341 & 4.8 & 5.0814 & TRN & \\
\hline CHEMBL1508888 & 688341 & 4.6 & 5.0179 & TRN & \\
\hline CHEMBL1521714 & 688341 & 5.2 & 5.1309 & TST & \\
\hline CHEMBL1594803 & 688341 & 4.6 & 4.7556 & TRN & \\
\hline CHEMBL1256851 & 688341 & 4.6 & 4.9443 & TST & \\
\hline CHEMBL1518110 & 688341 & 4.8 & 4.9587 & TRN & \\
\hline CHEMBL1475689 & 688341 & 6.3 & 5.0791 & TRN & \\
\hline CHEMBL1361716 & 688341 & 5.1 & 4.9429 & TST & \\
\hline CHEMBL1605550 & 688341 & 5.4 & 4.9711 & TST & \\
\hline CHEMBL1543469 & 688341 & 4.6 & 4.9493 & TRN & \\
\hline CHEMBL1509065 & 688341 & 4.5 & 4.8422 & TRN & \\
\hline CHEMBL1321146 & 688341 & 4.7 & 5.1284 & TST & \\
\hline CHEMBL1500867 & 688341 & 4.8 & 4.7278 & TRN & \\
\hline CHEMBL299613 & 688341 & 4.5 & $5.2070 e$ & 0000000001 & TST \\
\hline CHEMBL1545920 & 688341 & 5.0 & 4.9638 & TRN & \\
\hline CHEMBL1542848 & 688341 & 4.7 & 4.8807 & TRN & \\
\hline CHEMBL1301641 & 688341 & 4.8 & 4.8165 & TRN & \\
\hline CHEMBL1606591 & 688341 & 4.9 & 5.0825 & TRN & \\
\hline CHEMBL1386385 & 688341 & 5.2 & 4.8666 & TRN & \\
\hline CHEMBL1407294 & 688341 & 4.8 & 4.8739 & TRN & \\
\hline CHEMBL1489529 & 688341 & 6.8 & 5.0346 & TST & \\
\hline CHEMBL1531635 & 688341 & 4.6 & 5.0879 & TRN & \\
\hline CHEMBL1460403 & 688341 & 4.4 & 4.9927 & TST & \\
\hline CHEMBL1374849 & 688341 & 4.9 & 5.0634 & TRN & \\
\hline CHEMBL1586893 & 688341 & 4.6 & 4.8089 & TRN & \\
\hline CHEMBL1355307 & 688341 & 4.8 & 4.8326 & TRN & \\
\hline CHEMBL1482430 & 688341 & 4.8 & 4.88 & TRN & \\
\hline CHEMBL1441012 & 688341 & 6.1 & 5.105 & TRN & \\
\hline CHEMBL1538849 & 688341 & 7.1002 & 4.8347 & TRN & \\
\hline CHEMBL1519435 & 688341 & 4.6 & 5.0773 & TRN & \\
\hline CHEMBL1546300 & 688341 & 5.2 & 5.0608 & TRN & \\
\hline
\end{tabular}




\begin{tabular}{|c|c|c|c|c|c|}
\hline \multicolumn{6}{|c|}{ Supplemental Table S2.txt } \\
\hline CHEMBL567332 & 688341 & 4.8 & 4.9757 & TRN & \\
\hline CHEMBL1256646 & 688341 & 4.5 & 5.1373 & TST & \\
\hline CHEMBL1491648 & 688341 & 4.9 & 5.1835 & TRN & \\
\hline CHEMBL1485783 & 688341 & 4.6 & 4.8857 & TRN & \\
\hline CHEMBL1520346 & 688341 & 6.9 & 4.8086 & TST & \\
\hline CHEMBL1331786 & 688341 & 4.6 & 4.9721 & TST & \\
\hline CHEMBL1516118 & 688341 & 4.9 & 5.0135 & TRN & \\
\hline CHEMBL1472416 & 688341 & 5.2 & 5.0165 & TST & \\
\hline CHEMBL1514272 & 688341 & 4.6 & 4.9573 & TRN & \\
\hline CHEMBL1498567 & 688341 & 4.7 & 4.7475 & TRN & \\
\hline CHEMBL1384108 & 688341 & 4.6 & 4.8624 & TRN & \\
\hline CHEMBL1303548 & 688341 & 4.8 & 4.7966 & TST & \\
\hline CHEMBL1383400 & 688341 & 4.6 & 4.9228 & TRN & \\
\hline CHEMBL1513188 & 688341 & 5.5 & 5.0622 & TRN & \\
\hline CHEMBL1586641 & 688341 & 4.5 & 4.9404 & TRN & \\
\hline CHEMBL1519225 & 688341 & 5.1 & 5.0937 & TRN & \\
\hline CHEMBL1432209 & 688341 & 4.5 & 4.9529 & TRN & \\
\hline CHEMBL1427968 & 688341 & 4.5 & 4.91 & TRN & \\
\hline CHEMBL1417000 & 688341 & 5.2 & 5.0859 & TST & \\
\hline CHEMBL1527225 & 688341 & 6.0 & 5.0039 & TRN & \\
\hline CHEMBL1539530 & 688341 & 4.9 & 4.8138 & TRN & \\
\hline CHEMBL1517842 & 688341 & 5.5 & 4.7924 & TRN & \\
\hline CHEMBL1302584 & 688341 & 4.8 & 4.97199 & 99999999995 & TRN \\
\hline CHEMBL1567274 & 688341 & 5.1 & 4.9558 & TRN & \\
\hline CHEMBL1526446 & 688341 & 4.9 & 4.8901 & TRN & \\
\hline CHEMBL1609406 & 688341 & 4.5 & 5.0706 & TRN & \\
\hline CHEMBL1499872 & 688341 & 5.3 & 4.8199 & TRN & \\
\hline CHEMBL1385522 & 688341 & 5.0 & 4.7342 & TRN & \\
\hline CHEMBL1465165 & 688341 & 4.4 & 5.0746 & TRN & \\
\hline CHEMBL1421826 & 688341 & 4.6 & 5.063 & TRN & \\
\hline CHEMBL1384617 & 688341 & 4.4 & 5.0076 & TST & \\
\hline CHEMBL1608949 & 688341 & 4.7 & 5.0167 & TST & \\
\hline CHEMBL1461076 & 688341 & 4.7 & 4.9895 & TST & \\
\hline CHEMBL1411799 & 688341 & 5.4 & 5.0365 & TRN & \\
\hline CHEMBL1478376 & 688341 & 4.4 & 5.0798 & TST & \\
\hline CHEMBL1556084 & 688341 & 5.3 & 4.8501 & TRN & \\
\hline CHEMBL1373568 & 688341 & 4.4 & 5.0938 & TST & \\
\hline CHEMBL1571377 & 688341 & 4.8 & 4.9859 & TRN & \\
\hline CHEMBL1521169 & 688341 & 4.8 & 5.0587 & TRN & \\
\hline CHEMBL177809 & 688341 & 4.4 & 5.1974 & TST & \\
\hline CHEMBL1528840 & 688341 & 4.6 & 4.8619 & TRN & \\
\hline CHEMBL1368292 & 688341 & 4.6 & 4.9568 & TRN & \\
\hline CHEMBL1356998 & 688341 & 6.2 & 4.9795 & TRN & \\
\hline CHEMBL1500041 & 688341 & 4.4 & 4.7786 & TRN & \\
\hline CHEMBL1606718 & 688341 & 4.8 & 4.9901 & TRN & \\
\hline CHEMBL1462714 & 688341 & 5.8 & 4.8965 & TRN & \\
\hline CHEMBL1299599 & 688341 & 4.5 & 4.9579 & TRN & \\
\hline CHEMBL1366325 & 688341 & 5.5 & 4.988 & TRN & \\
\hline
\end{tabular}




\begin{tabular}{|c|c|c|c|c|}
\hline & & & pplement & $\mathrm{a} \perp \mathrm{Ta}$ \\
\hline CHEMBL1449408 & 688341 & 4.4 & 5.0275 & TST \\
\hline CHEMBL1542797 & 688341 & 4.4 & 4.8645 & TRN \\
\hline CHEMBL1341471 & 688341 & 4.6 & 4.9418 & TRN \\
\hline CHEMBL1606181 & 688341 & 4.4 & 4.8059 & TST \\
\hline CHEMBL1406721 & 688341 & 4.6 & 4.9035 & TRN \\
\hline CHEMBL1457257 & 688341 & 4.9 & 4.7687 & TRN \\
\hline CHEMBL1497433 & 688341 & 5.2 & 5.0529 & TRN \\
\hline CHEMBL1409492 & 688341 & 4.9 & 4.8392 & TRN \\
\hline CHEMBL1380550 & 688341 & 6.2 & 4.7882 & TRN \\
\hline CHEMBL1338530 & 688341 & 5.2 & 4.9385 & TRN \\
\hline CHEMBL3212608 & 688341 & 4.6 & 4.9901 & TST \\
\hline CHEMBL1588916 & 688341 & 4.5 & 4.8536 & TST \\
\hline CHEMBL1482510 & 688341 & 5.5 & 4.8129 & TRN \\
\hline CHEMBL1580052 & 688341 & 4.7 & 5.053 & TRN \\
\hline CHEMBL1566888 & 688341 & 4.8 & 4.9936 & TRN \\
\hline CHEMBL1566158 & 688341 & 4.4 & 4.9635 & TRN \\
\hline CHEMBL1369023 & 688341 & 4.6 & 4.8459 & TRN \\
\hline CHEMBL1329809 & 688341 & 5.6 & 4.9001 & TST \\
\hline CHEMBL1392663 & 688341 & 5.5 & 4.9216 & TRN \\
\hline CHEMBL1500854 & 688341 & 4.5 & 5.0774 & TST \\
\hline CHEMBL1370398 & 688341 & 4.5 & 4.8379 & TST \\
\hline CHEMBL1302653 & 688341 & 4.6 & 4.8648 & TRN \\
\hline CHEMBL1361731 & 688341 & 4.9 & 5.1071 & TRN \\
\hline CHEMBL1463091 & 688341 & 4.4 & 4.859 & TRN \\
\hline CHEMBL1418551 & 688341 & 5.1 & 4.8095 & TRN \\
\hline CHEMBL1415858 & 688341 & 4.7 & 4.9342 & TRN \\
\hline CHEMBL1516418 & 688341 & 4.6 & 4.8508 & TRN \\
\hline CHEMBL1361477 & 688341 & 4.5 & 4.8004 & TRN \\
\hline CHEMBL1332964 & 688341 & 5.3 & 5.1628 & TRN \\
\hline CHEMBL1520584 & 688341 & 4.5 & 4.8989 & TST \\
\hline CHEMBL 3194228 & 688341 & 6.4 & 4.9523 & TST \\
\hline CHEMBL1405339 & 688341 & 4.8 & 5.0539 & TRN \\
\hline CHEMBL 363207 & 688341 & 6.0 & 5.0649 & TRN \\
\hline CHEMBL1461811 & 688341 & 4.5 & 4.8907 & TRN \\
\hline CHEMBL1404934 & 688341 & 4.4 & 4.9739 & TRN \\
\hline CHEMBL1385800 & 688341 & 4.8 & 4.8602 & TRN \\
\hline CHEMBL1487400 & 688341 & 4.8 & 4.913 & TRN \\
\hline CHEMBL1460658 & 688341 & 4.5 & 4.868 & TRN \\
\hline CHEMBL1405585 & 688341 & 5.9 & 4.9243 & TRN \\
\hline CHEMBL1450227 & 688341 & 6.0 & 5.0029 & TRN \\
\hline CHEMBL1972755 & 688341 & 5.0 & 4.9625 & TST \\
\hline CHEMBL1578584 & 688341 & 4.7 & 4.7742 & TRN \\
\hline CHEMBL1377706 & 688341 & 5.5 & 5.1845 & TRN \\
\hline CHEMBL1371626 & 688341 & 5.4 & 4.7645 & TRN \\
\hline CHEMBL1367594 & 688341 & 4.6 & 4.8918 & TRN \\
\hline CHEMBL1613671 & 688341 & 4.5 & 4.8971 & TST \\
\hline CHEMBL1566495 & 688341 & 4.6 & 4.8716 & TRN \\
\hline CHEMBL1347926 & 688341 & 4.4 & 5.1223 & TRN \\
\hline
\end{tabular}




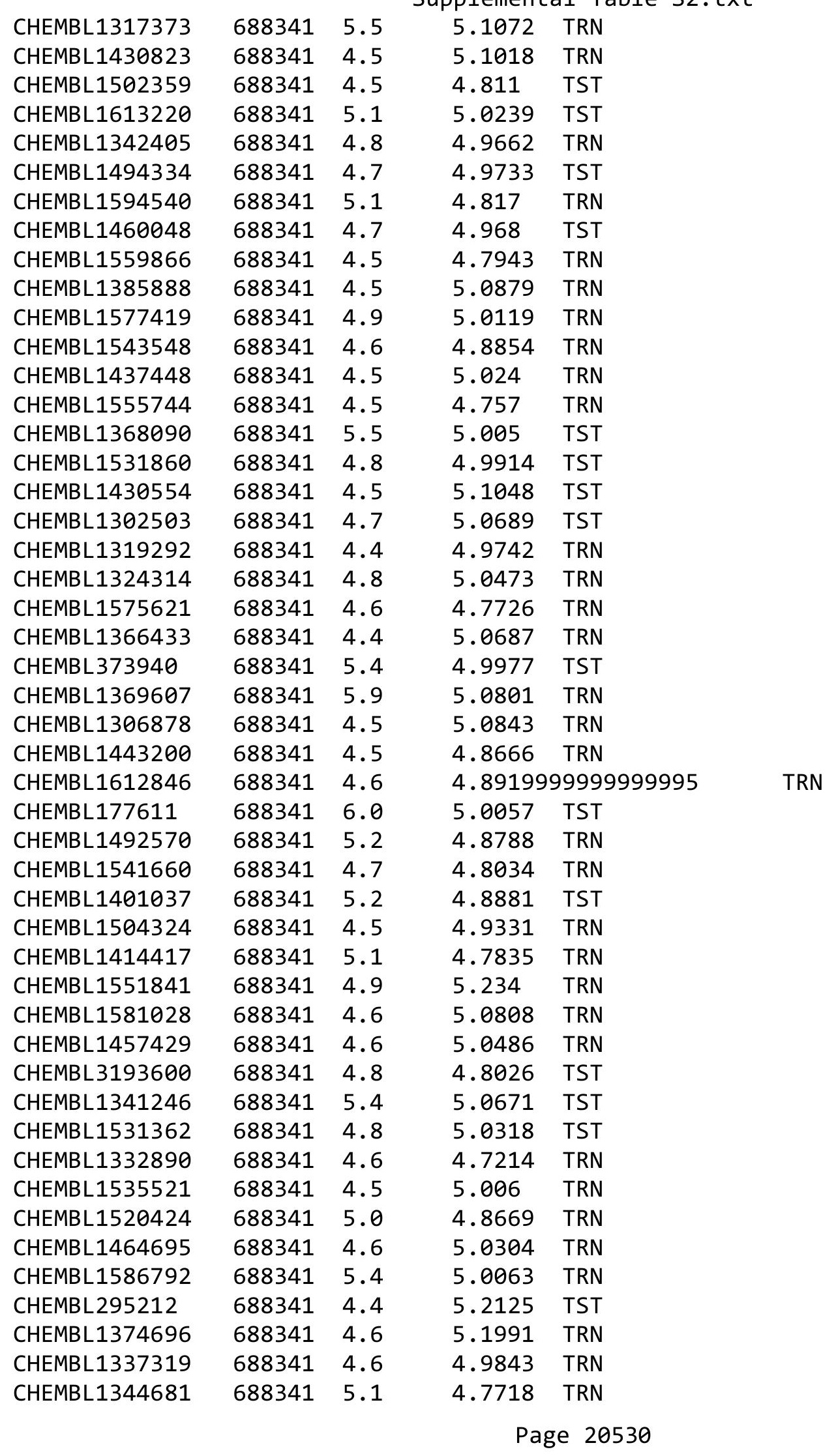




\begin{tabular}{|c|c|c|c|c|c|}
\hline \multirow{3}{*}{$\begin{array}{l}\text { CHEMBL1571725 } \\
\text { CHEMBL1373868 }\end{array}$} & \multirow{3}{*}{$\begin{array}{l}688341 \\
688341\end{array}$} & \multicolumn{4}{|c|}{ Supplemental Table S2.txt } \\
\hline & & 5.0 & \multicolumn{2}{|c|}{4.9030000000000005} & TRN \\
\hline & & 4.7 & 4.9091 & TRN & \\
\hline CHEMBL1417097 & 688341 & 6.8 & 4.7792 & TRN & \\
\hline CHEMBL1451229 & 688341 & 5.4 & 4.8908 & TST & \\
\hline CHEMBL1571727 & 688341 & 4.6 & 4.917 & TRN & \\
\hline CHEMBL1357247 & 688341 & 4.7 & 4.9442 & TST & \\
\hline CHEMBL1445792 & 688341 & 5.5 & 5.1574 & TST & \\
\hline CHEMBL1518015 & 688341 & 5.2 & 5.0493 & TST & \\
\hline CHEMBL1444488 & 688341 & 4.8 & 4.8576 & TRN & \\
\hline CHEMBL1526750 & 688341 & 4.6 & 4.8054 & TST & \\
\hline CHEMBL1420368 & 688341 & 5.2 & 4.9102 & TRN & \\
\hline CHEMBL1588179 & 688341 & 5.0 & 4.822 & TRN & \\
\hline CHEMBL1585386 & 688341 & 5.8 & 4.9129 & TRN & \\
\hline CHEMBL1494756 & 688341 & 4.8 & 4.8089 & TRN & \\
\hline CHEMBL1555438 & 688341 & 4.5 & 5.0425 & TST & \\
\hline CHEMBL1434535 & 688341 & 5.2 & 5.0233 & TRN & \\
\hline CHEMBL490749 & 688341 & 5.8 & 5.0 & TRN & \\
\hline CHEMBL1538347 & 688341 & 4.6 & 4.8431 & TRN & \\
\hline CHEMBL1330877 & 688341 & 6.4 & 5.0096 & TRN & \\
\hline CHEMBL16200 & 688341 & 6.9 & 4.9736 & TRN & \\
\hline CHEMBL1426925 & 688341 & 4.8 & 4.9982 & TRN & \\
\hline CHEMBL1507393 & 688341 & 4.6 & 4.9279 & TRN & \\
\hline CHEMBL1540153 & 688341 & 6.1 & 4.8892 & TRN & \\
\hline CHEMBL1462076 & 688341 & 5.1 & 5.16 & TRN & \\
\hline CHEMBL1396261 & 688341 & 5.1 & 5.1465 & TRN & \\
\hline CHEMBL1517745 & 688341 & 5.2 & 4.9802 & TRN & \\
\hline CHEMBL1526736 & 688341 & 5.0 & 5.035 & TRN & \\
\hline CHEMBL 364900 & 688341 & 4.4 & 5.0543 & TST & \\
\hline CHEMBL1432773 & 688341 & 5.1 & 4.837 & TRN & \\
\hline CHEMBL1425782 & 688341 & 7.8013 & 5.0841 & TRN & \\
\hline CHEMBL1557265 & 688341 & 4.5 & 4.9039 & TRN & \\
\hline CHEMBL1307241 & 688341 & 5.2 & 4.8318 & TRN & \\
\hline CHEMBL1328827 & 688341 & 4.5 & 4.7395 & TRN & \\
\hline CHEMBL1402961 & 688341 & 5.2 & 4.9087 & TRN & \\
\hline CHEMBL409902 & 688341 & 4.8 & 4.978 & TRN & \\
\hline CHEMBL1490991 & 688341 & 4.7 & 5.0307 & TST & \\
\hline CHEMBL1486905 & 688341 & 5.2 & 4.9044 & TRN & \\
\hline CHEMBL1453052 & 688341 & 4.5 & 4.9167 & TST & \\
\hline CHEMBL1407022 & 688341 & 4.4 & 4.8679 & TRN & \\
\hline CHEMBL1535626 & 688341 & 5.2 & 4.9509 & TST & \\
\hline CHEMBL3210221 & 688341 & 4.4 & 4.9937 & TST & \\
\hline CHEMBL1454533 & 688341 & 5.5 & 5.1703 & TRN & \\
\hline CHEMBL1545864 & 688341 & 4.5 & 4.7755 & TRN & \\
\hline CHEMBL1456650 & 688341 & 4.5 & 4.9261 & TRN & \\
\hline CHEMBL1455181 & 688341 & 5.1 & 4.8588 & TRN & \\
\hline CHEMBL1318544 & 688341 & 5.7 & 5.2946 & TRN & \\
\hline CHEMBL1591673 & 688341 & 4.8 & 5.0685 & TRN & \\
\hline CHEMBL1343239 & 688341 & 4.5 & 4.6613 & TRN & \\
\hline
\end{tabular}




\begin{tabular}{|c|c|c|c|c|}
\hline & & & plemen & \\
\hline CHEMBL1413296 & 688341 & 4.4 & 4.8295 & TRN \\
\hline CHEMBL1582419 & 688341 & 4.5 & 4.8416 & TRN \\
\hline CHEMBL375126 & 688341 & 4.4 & 4.8838 & TST \\
\hline CHEMBL1448929 & 688341 & 4.4 & 4.9898 & TRN \\
\hline CHEMBL1599971 & 688341 & 4.5 & 4.9228 & TST \\
\hline CHEMBL1504547 & 688341 & 4.5 & 4.8628 & TRN \\
\hline CHEMBL1401483 & 688341 & 4.5 & 5.0101 & TRN \\
\hline CHEMBL1411468 & 688341 & 5.2 & 4.8862 & TRN \\
\hline CHEMBL1308876 & 688341 & 5.3 & 5.1293 & TST \\
\hline CHEMBL1332051 & 688341 & 4.6 & 4.9789 & TRN \\
\hline CHEMBL414400 & 688341 & 5.1 & 5.1819 & TST \\
\hline CHEMBL1415596 & 688341 & 4.5 & 4.8272 & TRN \\
\hline CHEMBL1517643 & 688341 & 5.4 & 5.088 & TRN \\
\hline CHEMBL1586093 & 688341 & 5.0 & 4.8709 & TRN \\
\hline CHEMBL1537558 & 688341 & 5.5 & 4.7943 & TRN \\
\hline CHEMBL1469677 & 688341 & 5.4 & 4.7029 & TRN \\
\hline CHEMBL1346066 & 688341 & 5.2 & 5.0918 & TRN \\
\hline CHEMBL1485999 & 688341 & 5.2 & 5.0735 & TST \\
\hline CHEMBL1309044 & 688341 & 4.5 & 4.8586 & TRN \\
\hline CHEMBL1533572 & 688341 & 4.8 & 4.9072 & TRN \\
\hline CHEMBL445102 & 688341 & 5.5 & 4.988 & TRN \\
\hline CHEMBL1327767 & 688341 & 4.4 & 4.9484 & TRN \\
\hline CHEMBL1592500 & 688341 & 6.0 & 4.9986 & TRN \\
\hline CHEMBL1594761 & 688341 & 5.2 & 4.9762 & TRN \\
\hline CHEMBL592712 & 688341 & 4.8 & 4.9828 & TRN \\
\hline CHEMBL1431969 & 688341 & 4.7 & 4.9368 & TST \\
\hline CHEMBL1572642 & 688341 & 4.5 & 4.8905 & TRN \\
\hline CHEMBL1518739 & 688341 & 4.4 & 4.7595 & TRN \\
\hline CHEMBL1327534 & 688341 & 4.5 & 4.8002 & TRN \\
\hline CHEMBL1505023 & 688341 & 5.5 & 4.9419 & TRN \\
\hline CHEMBL481577 & 688341 & 5.1 & 4.9627 & TRN \\
\hline CHEMBL1406865 & 688341 & 6.4 & 5.1417 & TRN \\
\hline CHEMBL1391519 & 688341 & 5.0 & 5.0519 & TRN \\
\hline CHEMBL1344319 & 688341 & 6.0 & 5.0912 & TRN \\
\hline CHEMBL1494329 & 688341 & 4.6 & 4.9109 & TRN \\
\hline CHEMBL1540513 & 688341 & 4.6 & 4.8373 & TRN \\
\hline CHEMBL1593430 & 688341 & 4.5 & 5.0063 & TRN \\
\hline CHEMBL1364366 & 688341 & 4.5 & 5.105 & TRN \\
\hline CHEMBL 3197840 & 688341 & 4.5 & 4.9699 & TST \\
\hline CHEMBL1545746 & 688341 & 5.4 & 4.8863 & TRN \\
\hline CHEMBL1344803 & 688341 & 4.8 & 4.9866 & TRN \\
\hline CHEMBL1342654 & 688341 & 4.7 & 4.6499 & TRN \\
\hline CHEMBL1492489 & 688341 & 4.6 & 5.0566 & TRN \\
\hline CHEMBL1450653 & 688341 & 4.5 & 4.996 & TST \\
\hline CHEMBL1488815 & 688341 & 5.4 & 4.8944 & TRN \\
\hline CHEMBL1376210 & 688341 & 4.4 & 5.0063 & TRN \\
\hline CHEMBL1319007 & 688341 & 4.5 & 4.7495 & TRN \\
\hline CHEMBL1479675 & 688341 & 4.7 & 4.9868 & TST \\
\hline
\end{tabular}




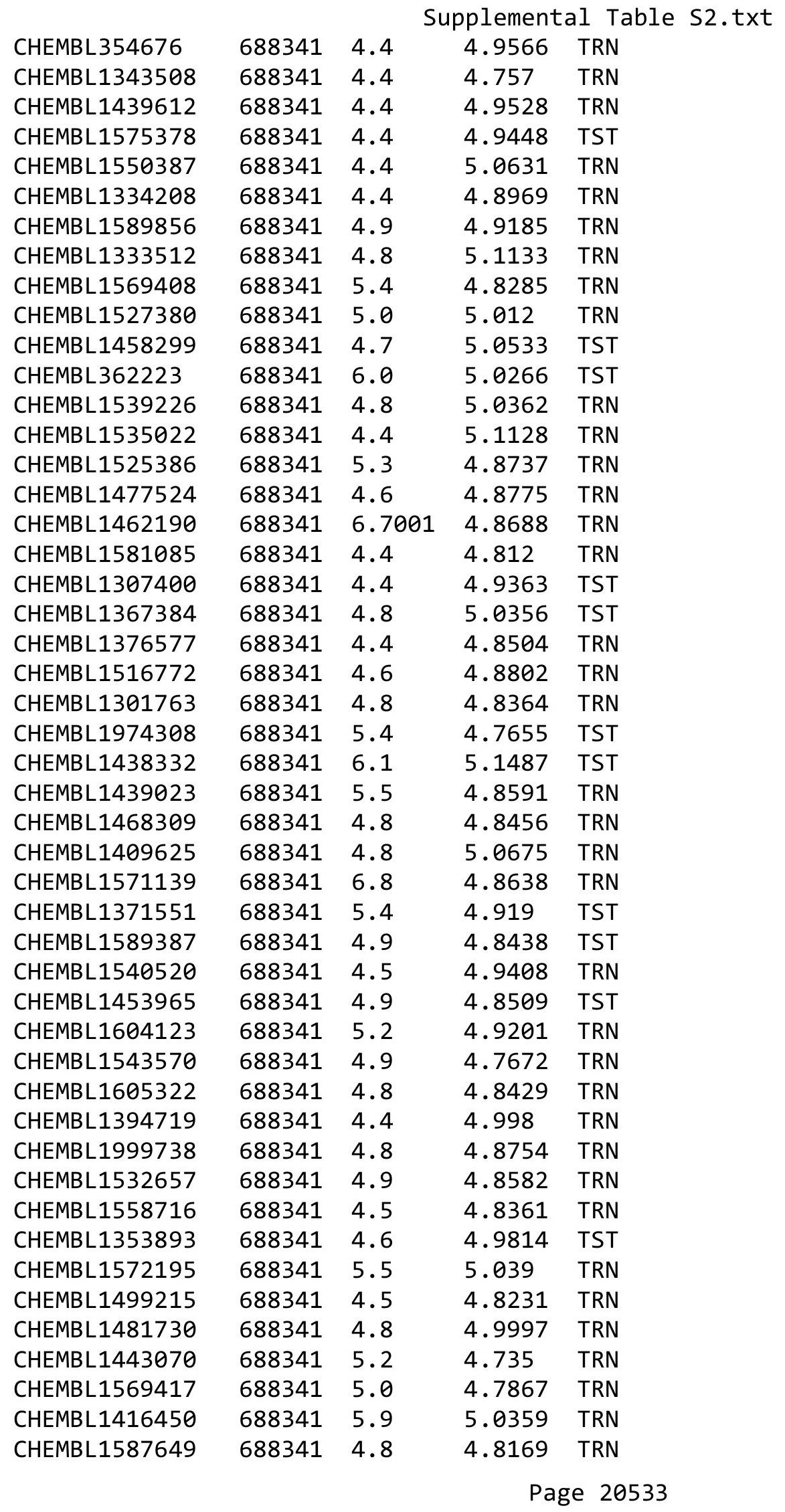




\begin{tabular}{|c|c|c|c|c|c|}
\hline \\
\hline CHEMBL1424916 & 688341 & 4.6 & 4.7424 & TRN & \\
\hline CHEMBL1481566 & 688341 & 4.6 & 4.7361 & TRN & \\
\hline CHEMBL1581199 & 688341 & 4.5 & 4.8884 & TRN & \\
\hline CHEMBL1305911 & 688341 & 4.6 & 4.9348 & TRN & \\
\hline CHEMBL1562995 & 688341 & 4.4 & 4.9604 & TST & \\
\hline CHEMBL1422233 & 688341 & 4.4 & 4.8899 & TST & \\
\hline CHEMBL1431076 & 688341 & 5.2 & 4.977 & TRN & \\
\hline CHEMBL1332759 & 688341 & 4.8 & 5.2343 & TRN & \\
\hline CHEMBL1330662 & 688341 & 4.5 & 4.8947 & TRN & \\
\hline CHEMBL1476430 & 688341 & 4.7 & 4.9141 & TRN & \\
\hline CHEMBL1471912 & 688341 & 4.8 & 4.694 & TRN & \\
\hline CHEMBL1411785 & 688341 & 4.4 & 4.9692 & TST & \\
\hline CHEMBL1476134 & 688341 & 4.7 & 5.0474 & TRN & \\
\hline CHEMBL1609522 & 688341 & 4.8 & 4.7945 & TRN & \\
\hline CHEMBL1371950 & 688341 & 5.8 & 5.0293 & TRN & \\
\hline CHEMBL1325335 & 688341 & 5.2 & 5.0687 & TRN & \\
\hline CHEMBL1588598 & 688341 & 4.5 & 5.0411 & TRN & \\
\hline CHEMBL1455514 & 688341 & 5.2 & 4.9917 & TRN & \\
\hline CHEMBL1507273 & 688341 & 4.9 & 5.0291 & TST & \\
\hline CHEMBL1445595 & 688341 & 5.3 & 4.9882 & TRN & \\
\hline CHEMBL1305665 & 688341 & 4.7 & 4.8303 & TRN & \\
\hline CHEMBL1408909 & 688341 & 4.4 & 4.8272 & TRN & \\
\hline CHEMBL 234926 & 688341 & 4.9 & 5.1436 & TST & \\
\hline CHEMBL1331593 & 688341 & 4.6 & 4.89199 & 99999999995 & TRN \\
\hline CHEMBL1471693 & 688341 & 4.5 & 4.8862 & TRN & \\
\hline CHEMBL1440095 & 688341 & 4.7 & 4.965 & TRN & \\
\hline CHEMBL1565338 & 688341 & 4.5 & 4.8734 & TRN & \\
\hline CHEMBL1605497 & 688341 & 4.6 & 5.0313 & TST & \\
\hline CHEMBL1408076 & 688341 & 5.5 & 4.939 & TRN & \\
\hline CHEMBL1398978 & 688341 & 5.5 & 5.0991 & TRN & \\
\hline CHEMBL1404128 & 688341 & 5.4 & 4.8317 & TRN & \\
\hline CHEMBL1369085 & 688341 & 5.7 & 5.1271 & TRN & \\
\hline CHEMBL1305046 & 688341 & 4.5 & 4.8165 & TRN & \\
\hline CHEMBL1380574 & 688341 & 4.6 & 4.8705 & TRN & \\
\hline CHEMBL1475004 & 688341 & 5.2 & 5.0809 & TRN & \\
\hline CHEMBL1550481 & 688341 & 4.4 & 4.8769 & TST & \\
\hline CHEMBL1323563 & 688341 & 5.0 & 4.9718 & TRN & \\
\hline CHEMBL1349707 & 688341 & 5.1 & 5.0989 & TRN & \\
\hline CHEMBL1522487 & 688341 & 5.5 & 4.7786 & TST & \\
\hline CHEMBL1531939 & 688341 & 4.7 & 4.9193 & TRN & \\
\hline CHEMBL1412585 & 688341 & 4.6 & 4.8647 & TRN & \\
\hline CHEMBL1350579 & 688341 & 4.4 & 4.8074 & TRN & \\
\hline CHEMBL1402468 & 688341 & 4.8 & 4.815 & TRN & \\
\hline CHEMBL1579034 & 688341 & 5.7 & 4.8293 & TRN & \\
\hline CHEMBL1395862 & 688341 & 5.0 & 4.808 & TST & \\
\hline CHEMBL1542674 & 688341 & 5.0 & 4.9944 & TST & \\
\hline CHEMBL3196148 & 688341 & 6.0 & 4.9855 & TST & \\
\hline CHEMBL1375326 & 688341 & 4.4 & 4.7368 & TRN & \\
\hline
\end{tabular}




\begin{tabular}{|c|c|c|c|c|c|}
\hline \multicolumn{6}{|c|}{ Supplemental Table S2.txt } \\
\hline CHEMBL1564263 & 688341 & 4.4 & 4.8699 & TST & \\
\hline CHEMBL1603249 & 688341 & 4.4 & 4.88399 & 99999999995 & TRN \\
\hline CHEMBL1406627 & 688341 & 5.3 & 4.8647 & TRN & \\
\hline CHEMBL1418235 & 688341 & 4.4 & 4.9092 & TRN & \\
\hline CHEMBL1586333 & 688341 & 5.2 & 4.7483 & TRN & \\
\hline CHEMBL1409865 & 688341 & 6.3 & 4.9421 & TRN & \\
\hline CHEMBL3198987 & 688341 & 5.3 & 4.9061 & TST & \\
\hline CHEMBL1544250 & 688341 & 4.7 & 5.1436 & TRN & \\
\hline CHEMBL1516103 & 688341 & 5.5 & 5.0619 & TRN & \\
\hline CHEMBL1424575 & 688341 & 4.4 & 4.8438 & TRN & \\
\hline CHEMBL1333420 & 688341 & 4.4 & 5.1025 & TRN & \\
\hline CHEMBL1457637 & 688341 & 4.6 & 4.9947 & TST & \\
\hline CHEMBL1549209 & 688341 & 4.6 & 4.8153 & TRN & \\
\hline CHEMBL30193 & 688341 & 4.5 & 5.0552 & TST & \\
\hline CHEMBL1371501 & 688341 & 4.5 & 4.9412 & TRN & \\
\hline CHEMBL1411518 & 688341 & 4.5 & 4.9744 & TRN & \\
\hline CHEMBL1518386 & 688341 & 4.4 & 4.8415 & TRN & \\
\hline CHEMBL1472108 & 688341 & 4.4 & 4.8666 & TRN & \\
\hline CHEMBL1450714 & 688341 & 5.2 & 4.8884 & TRN & \\
\hline CHEMBL1326154 & 688341 & 4.7 & 5.0813 & TST & \\
\hline CHEMBL1350197 & 688341 & 5.4 & 4.9142 & TST & \\
\hline CHEMBL1612543 & 688341 & 4.4 & 4.8834 & TRN & \\
\hline CHEMBL1557857 & 688341 & 4.6 & 4.9645 & TRN & \\
\hline CHEMBL1311399 & 688341 & 4.5 & 4.9108 & TRN & \\
\hline CHEMBL1429413 & 688341 & 5.2 & 4.8539 & TRN & \\
\hline CHEMBL1502398 & 688341 & 4.7 & 4.8225 & TRN & \\
\hline CHEMBL512649 & 688341 & 4.4 & 4.976 & TST & \\
\hline CHEMBL 75967 & 688341 & 6.0 & 5.1032 & TST & \\
\hline CHEMBL565654 & 688341 & 5.1 & 4.9393 & TRN & \\
\hline CHEMBL1475860 & 688341 & 5.0 & 4.957 & TRN & \\
\hline CHEMBL604119 & 688341 & 5.2 & 5.0251 & TST & \\
\hline CHEMBL1550204 & 688341 & 4.4 & 4.7591 & TRN & \\
\hline CHEMBL1309521 & 688341 & 4.6 & 4.7166 & TRN & \\
\hline CHEMBL1255660 & 688341 & 4.4 & 5.0377 & TST & \\
\hline CHEMBL1469425 & 688341 & 5.2 & 4.8934 & TRN & \\
\hline CHEMBL1484727 & 688341 & 4.9 & 4.8547 & TRN & \\
\hline CHEMBL1488671 & 688341 & 4.5 & 4.9102 & TRN & \\
\hline CHEMBL1606088 & 688341 & 5.5 & 4.9644 & TRN & \\
\hline CHEMBL1567209 & 688341 & 5.4 & 4.7779 & TRN & \\
\hline CHEMBL1575590 & 688341 & 4.7 & 4.8729 & TRN & \\
\hline CHEMBL1472402 & 688341 & 4.5 & 4.7408 & TRN & \\
\hline CHEMBL1419900 & 688341 & 7.1002 & 5.0452 & TRN & \\
\hline CHEMBL1564965 & 688341 & 4.6 & 4.9304 & TST & \\
\hline CHEMBL1514307 & 688341 & 5.5 & 5.0696 & TRN & \\
\hline CHEMBL1431729 & 688341 & 5.3 & 4.992 & TRN & \\
\hline CHEMBL1553123 & 688341 & 4.9 & 5.0099 & TRN & \\
\hline CHEMBL1348557 & 688341 & 5.3 & 4.8401 & TRN & \\
\hline CHEMBL1418350 & 688341 & 4.9 & 4.9357 & TRN & \\
\hline
\end{tabular}




\begin{tabular}{|c|c|c|c|c|}
\hline \multicolumn{5}{|c|}{ Supplemental Table s2.txt } \\
\hline CHEMBL1393017 & 688341 & 4.8 & 4.8447 & TRN \\
\hline CHEMBL1457763 & 688341 & 5.4 & 5.0691 & TRN \\
\hline CHEMBL1589310 & 688341 & 4.8 & 4.7174 & TRN \\
\hline CHEMBL1412240 & 688341 & 4.4 & 4.9737 & TST \\
\hline CHEMBL1310041 & 688341 & 4.5 & 4.8 & TRN \\
\hline CHEMBL1482054 & 688341 & 4.8 & 4.8471 & TRN \\
\hline CHEMBL1160509 & 688341 & 7.8013 & 5.2634 & TRN \\
\hline CHEMBL1557383 & 688341 & 5.1 & 5.1386 & TRN \\
\hline CHEMBL1321714 & 688341 & 4.8 & 4.7711 & TRN \\
\hline CHEMBL1483338 & 688341 & 4.6 & 4.9787 & TST \\
\hline CHEMBL491953 & 688341 & 5.6 & 5.0767 & TRN \\
\hline CHEMBL1534254 & 688341 & 4.6 & 4.8898 & TRN \\
\hline CHEMBL1429652 & 688341 & 5.2 & 5.0098 & TRN \\
\hline CHEMBL1559474 & 688341 & 4.7 & 4.7588 & TRN \\
\hline CHEMBL1475207 & 688341 & 5.6 & 5.0547 & TRN \\
\hline CHEMBL1559433 & 688341 & 4.4 & 4.9607 & TRN \\
\hline CHEMBL1484176 & 688341 & 5.3 & 4.9664 & TRN \\
\hline CHEMBL1495091 & 688341 & 4.6 & 4.8418 & TRN \\
\hline CHEMBL1361119 & 688341 & 4.6 & 4.8871 & TRN \\
\hline CHEMBL1577160 & 688341 & 4.5 & 4.9025 & TRN \\
\hline CHEMBL1348207 & 688341 & 4.4 & 4.7493 & TRN \\
\hline CHEMBL1544839 & 688341 & 4.7 & 5.0807 & TRN \\
\hline CHEMBL1333487 & 688341 & 5.2 & 5.0447 & TST \\
\hline CHEMBL1336638 & 688341 & 4.5 & 4.8125 & TRN \\
\hline CHEMBL 2141452 & 688341 & 4.4 & 4.9205 & TRN \\
\hline CHEMBL1479741 & 688341 & 4.6 & 4.9618 & TRN \\
\hline CHEMBL1386883 & 688341 & 4.4 & 4.9503 & TRN \\
\hline CHEMBL1578910 & 688341 & 4.8 & 4.9571 & TST \\
\hline CHEMBL93655 & 688341 & 4.4 & 4.9608 & TST \\
\hline CHEMBL3212505 & 688341 & 6.2 & 4.9075 & TST \\
\hline CHEMBL1409247 & 688341 & 4.9 & 4.9637 & TRN \\
\hline CHEMBL1375161 & 688341 & 4.5 & 4.981 & TRN \\
\hline CHEMBL1603174 & 688341 & 5.2 & 4.9193 & TRN \\
\hline CHEMBL1576582 & 688341 & 4.4 & 5.0661 & TRN \\
\hline CHEMBL1329764 & 688341 & 4.6 & 4.7579 & TRN \\
\hline CHEMBL1605525 & 688341 & 7.4001 & 4.7752 & TRN \\
\hline CHEMBL1557057 & 688341 & 4.4 & 4.9879 & TST \\
\hline CHEMBL1338384 & 688341 & 4.5 & 4.905 & TRN \\
\hline CHEMBL1362377 & 688341 & 5.3 & 4.9799 & TST \\
\hline CHEMBL1554325 & 688341 & 4.4 & 4.7645 & TRN \\
\hline CHEMBL1508369 & 688341 & 4.4 & 4.9473 & TST \\
\hline CHEMBL1458972 & 688341 & 4.5 & 4.7498 & TRN \\
\hline CHEMBL1528347 & 688341 & 4.5 & 4.8884 & TRN \\
\hline CHEMBL1078384 & 688341 & 5.6 & 5.0939 & 9999999999 \\
\hline CHEMBL1344942 & 688341 & 5.1 & 5.0389 & TST \\
\hline CHEMBL1336909 & 688341 & 4.9 & 4.9352 & TRN \\
\hline CHEMBL1515280 & 688341 & 4.4 & 5.0484 & TRN \\
\hline CHEMBL1309830 & 688341 & 5.3 & 4.8645 & TRN \\
\hline
\end{tabular}




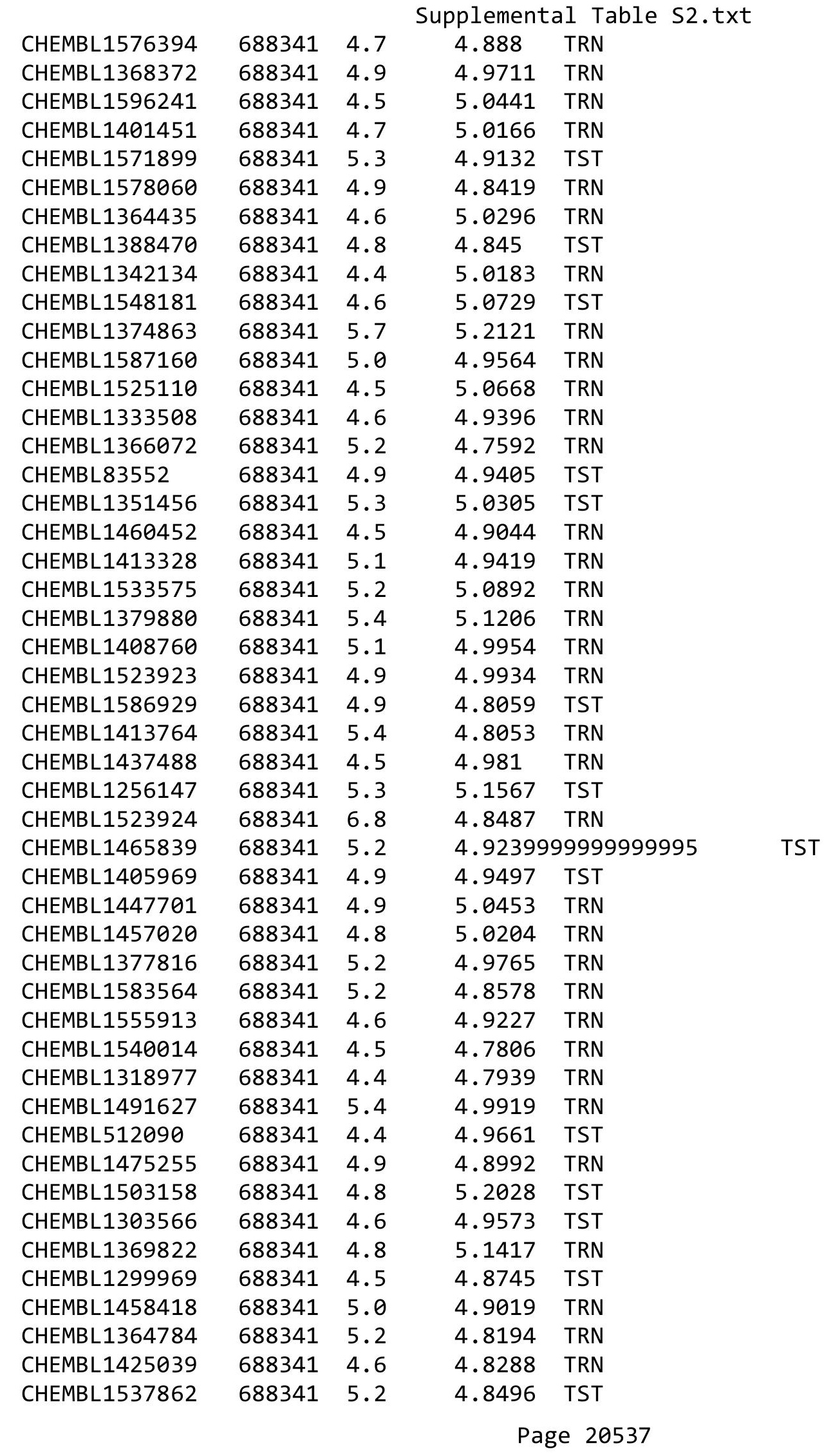




\begin{tabular}{|c|c|c|c|c|}
\hline \multicolumn{5}{|c|}{ Supplemental Table S2.txt } \\
\hline CHEMBL1611866 & 688341 & 4.5 & 4.6916 & TRN \\
\hline CHEMBL1324690 & 688341 & 4.6 & 4.8389 & TRN \\
\hline CHEMBL1382898 & 688341 & 5.3 & 4.9206 & TRN \\
\hline CHEMBL1499033 & 688341 & 4.7 & 5.0684 & TRN \\
\hline CHEMBL1532928 & 688341 & 4.4 & 4.7151 & TST \\
\hline CHEMBL1335001 & 688341 & 4.9 & 4.9691 & TST \\
\hline CHEMBL1306058 & 688341 & 4.6 & 4.8047 & TRN \\
\hline CHEMBL1399235 & 688341 & 4.4 & 4.854 & TST \\
\hline CHEMBL1532448 & 688341 & 5.4 & 5.1889 & TST \\
\hline CHEMBL1531643 & 688341 & 4.6 & 4.7263 & TRN \\
\hline CHEMBL1449987 & 688341 & 5.1 & 5.085 & TST \\
\hline CHEMBL1451562 & 688341 & 4.7 & 5.0543 & TRN \\
\hline CHEMBL1547554 & 688341 & 5.4 & 5.046 & TRN \\
\hline CHEMBL1374656 & 688341 & 4.6 & 4.9418 & TRN \\
\hline CHEMBL1318310 & 688341 & 4.8 & 4.9416 & TRN \\
\hline CHEMBL1404612 & 688341 & 4.4 & 4.9495 & TST \\
\hline CHEMBL1554680 & 688341 & 4.6 & 4.9722 & TRN \\
\hline CHEMBL1430198 & 688341 & 5.5 & 4.9713 & TST \\
\hline CHEMBL1255733 & 688341 & 4.6 & 5.2681 & TST \\
\hline CHEMBL1395415 & 688341 & 4.8 & 5.0442 & TRN \\
\hline CHEMBL1300689 & 688341 & 4.4 & 4.7785 & TRN \\
\hline CHEMBL1488375 & 688341 & 4.6 & 5.0809 & TRN \\
\hline CHEMBL1535709 & 688341 & 4.4 & 4.7352 & TRN \\
\hline CHEMBL1353210 & 688341 & 5.1 & 5.0987 & TST \\
\hline CHEMBL1532189 & 688341 & 4.6 & 5.0064 & TRN \\
\hline CHEMBL1305660 & 688341 & 4.5 & 4.6822 & TRN \\
\hline CHEMBL1360103 & 688341 & 5.2 & 5.0268 & TST \\
\hline CHEMBL1367109 & 688341 & 5.2 & 5.0047 & TST \\
\hline CHEMBL1410094 & 688341 & 5.5 & 4.8699 & TRN \\
\hline CHEMBL1526339 & 688341 & 4.9 & 5.0029 & TRN \\
\hline CHEMBL1589040 & 688341 & 4.6 & 4.9719 & TRN \\
\hline CHEMBL1390677 & 688341 & 4.6 & 5.0187 & TRN \\
\hline CHEMBL1578860 & 688341 & 4.5 & 4.9123 & TRN \\
\hline CHEMBL1374329 & 688341 & 4.8 & 4.8794 & TRN \\
\hline CHEMBL1330317 & 688341 & 4.9 & 4.8865 & TRN \\
\hline CHEMBL1591971 & 688341 & 4.6 & 5.021 & TRN \\
\hline CHEMBL1448275 & 688341 & 4.6 & 4.7477 & TRN \\
\hline CHEMBL1437871 & 688341 & 6.8 & 4.9129 & TRN \\
\hline CHEMBL1400517 & 688341 & 4.7 & 4.7187 & TRN \\
\hline CHEMBL1446384 & 688341 & 4.7 & 5.1858 & TST \\
\hline CHEMBL538 & 688341 & 5.9 & 5.0077 & TST \\
\hline CHEMBL1362477 & 688341 & 5.2 & 5.0829 & TST \\
\hline CHEMBL1406427 & 688341 & 4.7 & 4.886 & TST \\
\hline CHEMBL1388126 & 688341 & 4.5 & 4.992 & TRN \\
\hline CHEMBL1347808 & 688341 & 4.8 & 4.9071 & TRN \\
\hline CHEMBL 3190124 & 688341 & 5.2 & 4.9928 & TST \\
\hline CHEMBL1424702 & 688341 & 4.5 & 4.9793 & TRN \\
\hline CHEMBL1531727 & 688341 & 5.2 & 4.9529 & TST \\
\hline
\end{tabular}




\begin{tabular}{|c|c|c|c|c|c|}
\hline \multirow{3}{*}{$\begin{array}{l}\text { CHEMBL1528773 } \\
\text { CHEMBL1442918 }\end{array}$} & \multirow{3}{*}{$\begin{array}{l}688341 \\
688341\end{array}$} & \multicolumn{4}{|c|}{ Supplemental Table S2.txt } \\
\hline & & 4.5 & 4.9060 & 0000000001 & TST \\
\hline & & 4.5 & 4.7298 & TRN & \\
\hline CHEMBL1470122 & 688341 & 4.7 & 4.9124 & TRN & \\
\hline CHEMBL1378795 & 688341 & 5.2 & 4.9353 & TRN & \\
\hline CHEMBL1429289 & 688341 & 5.1 & 5.1738 & TRN & \\
\hline CHEMBL1299561 & 688341 & 5.9 & 4.9668 & TRN & \\
\hline CHEMBL3209543 & 688341 & 4.9 & 5.0396 & TRN & \\
\hline CHEMBL1379364 & 688341 & 4.5 & 4.7543 & TRN & \\
\hline CHEMBL1462058 & 688341 & 5.4 & 4.6935 & TRN & \\
\hline CHEMBL1499536 & 688341 & 4.4 & 4.8928 & TRN & \\
\hline CHEMBL1479761 & 688341 & 4.8 & 4.8025 & TRN & \\
\hline CHEMBL1371693 & 688341 & 4.9 & 4.8231 & TRN & \\
\hline CHEMBL1336301 & 688341 & 5.4 & 4.9863 & TRN & \\
\hline CHEMBL1324739 & 688341 & 4.6 & 4.9141 & TRN & \\
\hline CHEMBL1318635 & 688341 & 5.5 & 4.8713 & TST & \\
\hline CHEMBL1316775 & 688341 & 4.4 & 5.0375 & TRN & \\
\hline CHEMBL144530 & 688341 & 5.3 & 5.2111 & TST & \\
\hline CHEMBL1540606 & 688341 & 5.1 & 4.9373 & TST & \\
\hline CHEMBL1381022 & 688341 & 5.3 & 4.9137 & TST & \\
\hline CHEMBL1495167 & 688341 & 4.7 & 4.8787 & TRN & \\
\hline CHEMBL1369782 & 688341 & 4.6 & 4.8791 & TRN & \\
\hline CHEMBL1450327 & 688341 & 4.8 & 4.9588 & TRN & \\
\hline CHEMBL1443914 & 688341 & 5.1 & 4.8431 & TRN & \\
\hline CHEMBL1423290 & 688341 & 4.6 & 4.8289 & TRN & \\
\hline CHEMBL1595887 & 688341 & 7.5003 & 4.7279 & TRN & \\
\hline CHEMBL1387162 & 688341 & 4.7 & 5.0737 & TRN & \\
\hline CHEMBL1351715 & 688341 & 4.5 & 4.7661 & TRN & \\
\hline CHEMBL1481953 & 688341 & 5.9 & 4.8856 & TST & \\
\hline CHEMBL1348895 & 688341 & 5.0 & 4.7885 & TRN & \\
\hline CHEMBL1440173 & 688341 & 4.6 & 4.8295 & TRN & \\
\hline CHEMBL1596384 & 688341 & 5.3 & 4.8895 & TRN & \\
\hline CHEMBL1493939 & 688341 & 5.6 & 5.1518 & TRN & \\
\hline CHEMBL1463288 & 688341 & 4.6 & 4.9473 & TRN & \\
\hline CHEMBL1547376 & 688341 & 5.1 & 4.9989 & TST & \\
\hline CHEMBL1579385 & 688341 & 4.9 & 5.0428 & TRN & \\
\hline CHEMBL1315145 & 688341 & 5.0 & 5.1931 & TRN & \\
\hline CHEMBL1514560 & 688341 & 5.2 & 5.105 & TRN & \\
\hline CHEMBL1340419 & 688341 & 4.6 & 4.8074 & TRN & \\
\hline CHEMBL1303944 & 688341 & 6.1 & 5.1947 & TST & \\
\hline CHEMBL1421118 & 688341 & 4.5 & 4.9894 & TRN & \\
\hline CHEMBL1515559 & 688341 & 6.8 & 4.8664 & TST & \\
\hline CHEMBL1326261 & 688341 & 4.6 & 5.0692 & TRN & \\
\hline CHEMBL1560696 & 688341 & 4.6 & 4.8471 & TRN & \\
\hline CHEMBL1543611 & 688341 & 4.8 & 4.8268 & TRN & \\
\hline CHEMBL1505360 & 688341 & 5.2 & 4.8681 & TST & \\
\hline CHEMBL1391390 & 688341 & 4.4 & 4.8878 & TRN & \\
\hline CHEMBL1582756 & 688341 & 4.6 & 4.9808 & TST & \\
\hline CHEMBL1466645 & 688341 & 5.2 & 5.0492 & TST & \\
\hline
\end{tabular}




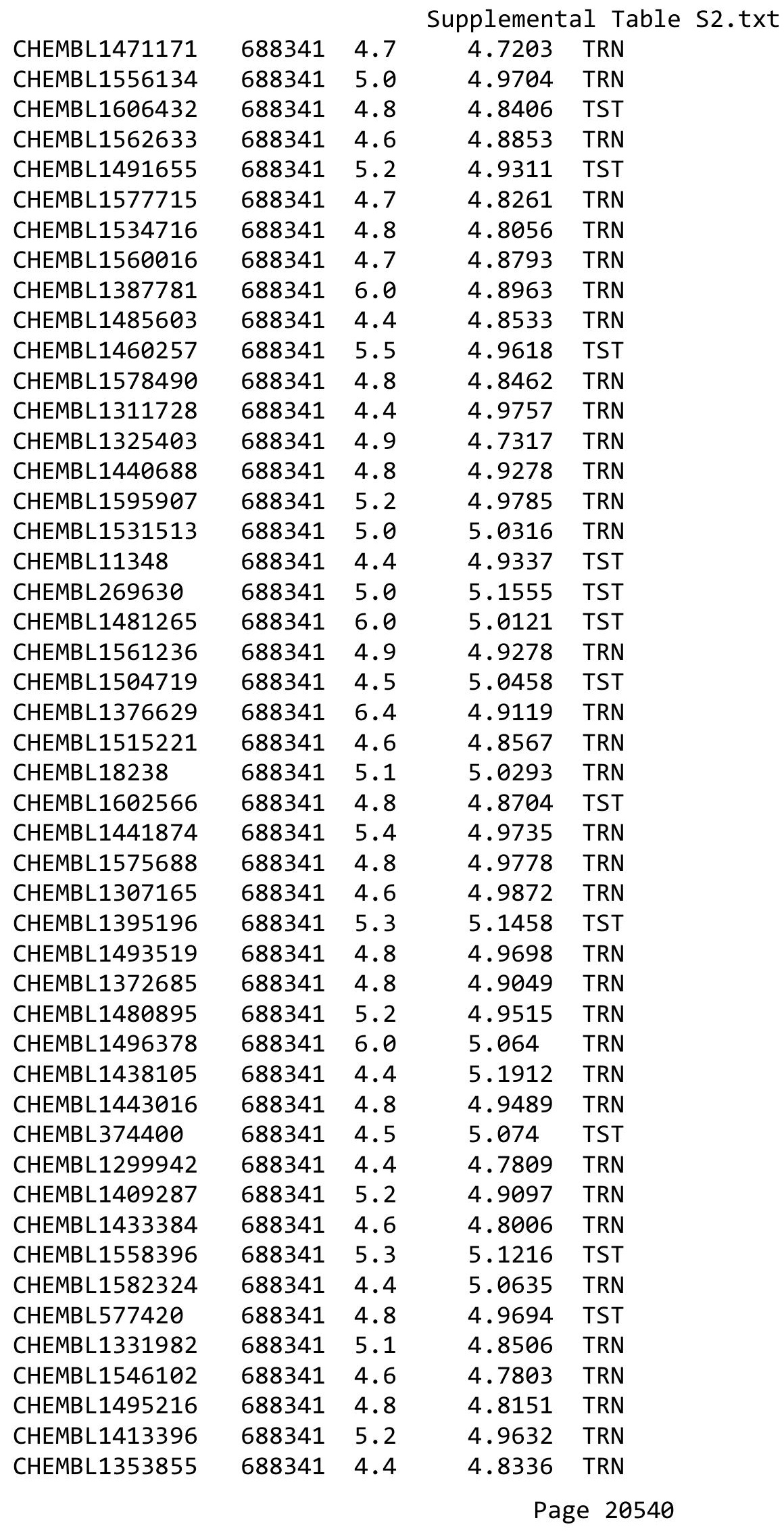




\begin{tabular}{|c|c|c|c|c|c|}
\hline CHEMBL1422735 & 688341 & 6.9 & 4.9914 & TST & \\
\hline CHEMBL1519622 & 688341 & 4.6 & 4.82600 & 00000000005 & TRN \\
\hline CHEMBL1522144 & 688341 & 5.3 & 4.9012 & TRN & \\
\hline CHEMBL1566378 & 688341 & 4.6 & 4.9101 & TRN & \\
\hline CHEMBL1350615 & 688341 & 5.4 & 4.9771 & TRN & \\
\hline CHEMBL118902 & 688341 & 5.0 & 5.1638 & TST & \\
\hline CHEMBL1526273 & 688341 & 4.6 & 4.8548 & TRN & \\
\hline CHEMBL1408644 & 688341 & 5.5 & 4.8207 & TRN & \\
\hline CHEMBL1329206 & 688341 & 5.7 & 4.9999 & TST & \\
\hline CHEMBL1562139 & 688341 & 4.5 & 4.8072 & TRN & \\
\hline CHEMBL1559014 & 688341 & 4.4 & 4.8309 & TST & \\
\hline CHEMBL1443226 & 688341 & 4.6 & 4.8402 & TRN & \\
\hline CHEMBL1552249 & 688341 & 5.0 & 5.1424 & TRN & \\
\hline CHEMBL1401352 & 688341 & 5.2 & 4.9414 & TST & \\
\hline CHEMBL1482920 & 688341 & 4.7 & 5.07 & TST & \\
\hline CHEMBL1546620 & 688341 & 4.6 & 5.0653 & TRN & \\
\hline CHEMBL1374609 & 688341 & 4.5 & 4.8273 & TRN & \\
\hline CHEMBL1393673 & 688341 & 4.8 & 4.9714 & TST & \\
\hline CHEMBL1353725 & 688341 & 4.4 & 4.9997 & TRN & \\
\hline CHEMBL1551415 & 688341 & 5.2 & 5.0031 & TRN & \\
\hline CHEMBL1510910 & 688341 & 6.2 & 5.1221 & TST & \\
\hline CHEMBL1474230 & 688341 & 5.2 & 5.1305 & TST & \\
\hline CHEMBL1311278 & 688341 & 4.4 & 4.8111 & TST & \\
\hline CHEMBL1572687 & 688341 & 4.5 & 4.8576 & TST & \\
\hline CHEMBL1480687 & 688341 & 5.2 & 4.9785 & TRN & \\
\hline CHEMBL1312222 & 688341 & 4.7 & 4.908 & TRN & \\
\hline CHEMBL1595166 & 688341 & 4.4 & 5.1234 & TRN & \\
\hline CHEMBL1581249 & 688341 & 4.8 & 4.9763 & TRN & \\
\hline CHEMBL1499726 & 688341 & 4.5 & 5.0227 & TST & \\
\hline CHEMBL1484049 & 688341 & 4.9 & 4.8895 & TRN & \\
\hline CHEMBL1503330 & 688341 & 4.4 & 5.0017 & TRN & \\
\hline CHEMBL1381145 & 688341 & 6.1 & 5.0419 & TST & \\
\hline CHEMBL1541899 & 688341 & 4.9 & 5.0652 & TRN & \\
\hline CHEMBL1570109 & 688341 & 4.8 & 5.0088 & TST & \\
\hline CHEMBL1432760 & 688341 & 4.6 & 4.739 & TRN & \\
\hline CHEMBL1302713 & 688341 & 4.8 & 4.8533 & TRN & \\
\hline CHEMBL1587968 & 688341 & 5.9 & 4.9216 & TRN & \\
\hline CHEMBL1601055 & 688341 & 4.4 & 4.9244 & TRN & \\
\hline CHEMBL1442558 & 688341 & 5.3 & 5.0334 & TST & \\
\hline CHEMBL1477509 & 688341 & 5.1 & 4.9551 & TST & \\
\hline CHEMBL1439291 & 688341 & 4.8 & 4.8923 & TST & \\
\hline CHEMBL1513643 & 688341 & 5.4 & 5.0292 & TST & \\
\hline CHEMBL1492346 & 688341 & 5.0 & 4.919 & TRN & \\
\hline CHEMBL1548533 & 688341 & 4.6 & 4.9901 & TRN & \\
\hline CHEMBL1516028 & 688341 & 4.5 & 5.0256 & TRN & \\
\hline CHEMBL1327119 & 688341 & 4.5 & 4.8625 & TRN & \\
\hline CHEMBL1594156 & 688341 & 4.6 & 4.9262 & TRN & \\
\hline CHEMBL1603859 & 688341 & 5.3 & 4.9683 & TRN & \\
\hline
\end{tabular}




\begin{tabular}{|c|c|c|c|c|c|}
\hline \multicolumn{6}{|c|}{ Supplemental Table S2.txt } \\
\hline CHEMBL1388275 & 688341 & 4.8 & 4.9304 & TRN & \\
\hline CHEMBL1545915 & 688341 & 4.6 & 4.931 & TRN & \\
\hline CHEMBL1574813 & 688341 & 4.6 & 4.956 & TRN & \\
\hline CHEMBL1370533 & 688341 & 4.5 & 4.9867 & TRN & \\
\hline CHEMBL1559680 & 688341 & 5.2 & 4.9811 & TST & \\
\hline CHEMBL1337117 & 688341 & 4.6 & 5.0003 & TRN & \\
\hline CHEMBL1359105 & 688341 & 5.4 & 4.9393 & TRN & \\
\hline CHEMBL1502655 & 688341 & 5.1 & 4.8982 & TRN & \\
\hline CHEMBL1368561 & 688341 & 4.4 & 4.9991 & TRN & \\
\hline CHEMBL1385229 & 688341 & 7.1002 & 5.1167 & TST & \\
\hline CHEMBL1371350 & 688341 & 4.4 & 5.0809 & TST & \\
\hline CHEMBL1327752 & 688341 & 4.4 & 5.1436 & TRN & \\
\hline CHEMBL1526397 & 688341 & 5.4 & 5.0056 & TRN & \\
\hline CHEMBL1490770 & 688341 & 5.5 & 4.9547 & TRN & \\
\hline CHEMBL1395226 & 688341 & 5.1 & 5.2236 & TRN & \\
\hline CHEMBL1388883 & 688341 & 4.5 & 4.7493 & TRN & \\
\hline CHEMBL1320713 & 688341 & 4.8 & 4.8864 & TRN & \\
\hline CHEMBL1371597 & 688341 & 4.5 & 5.0467 & TRN & \\
\hline CHEMBL1345294 & 688341 & 5.1 & 4.7646 & TRN & \\
\hline CHEMBL1413287 & 688341 & 5.1 & 5.0347 & TRN & \\
\hline CHEMBL1485627 & 688341 & 5.4 & 4.8412 & TRN & \\
\hline CHEMBL1520017 & 688341 & 4.6 & 4.85800 & 00000000005 & TRN \\
\hline CHEMBL1342687 & 688341 & 5.2 & 4.7119 & TRN & \\
\hline CHEMBL1457725 & 688341 & 6.9 & 5.0041 & TRN & \\
\hline CHEMBL1544342 & 688341 & 4.6 & 4.9543 & TRN & \\
\hline CHEMBL1480219 & 688341 & 5.3 & 5.0187 & TRN & \\
\hline CHEMBL250428 & 688341 & 4.4 & 4.8978 & TRN & \\
\hline CHEMBL3210248 & 688341 & 5.2 & 5.0162 & TRN & \\
\hline CHEMBL1424630 & 688341 & 4.5 & 5.0699 & TST & \\
\hline CHEMBL1446065 & 688341 & 4.9 & 4.8627 & TRN & \\
\hline CHEMBL1466923 & 688341 & 4.6 & 4.8908 & TRN & \\
\hline CHEMBL1558817 & 688341 & 5.2 & 4.8931 & TRN & \\
\hline CHEMBL1606892 & 688341 & 4.5 & 5.0316 & TST & \\
\hline CHEMBL1583579 & 688341 & 4.6 & 4.9228 & TST & \\
\hline CHEMBL1447657 & 688341 & 4.6 & 5.1678 & TST & \\
\hline CHEMBL1440005 & 688341 & 5.8 & 5.0578 & TST & \\
\hline CHEMBL1503436 & 688341 & 4.5 & 4.91 & TST & \\
\hline CHEMBL1335327 & 688341 & 4.7 & 4.8211 & TRN & \\
\hline CHEMBL1307312 & 688341 & 4.8 & 4.8954 & TRN & \\
\hline CHEMBL1430222 & 688341 & 4.4 & 4.8339 & TRN & \\
\hline CHEMBL1380789 & 688341 & 4.7 & 4.88399 & 99999999995 & TRN \\
\hline CHEMBL1494965 & 688341 & 4.7 & 4.9416 & TRN & \\
\hline CHEMBL1476526 & 688341 & 5.6 & 5.0903 & TRN & \\
\hline CHEMBL1541302 & 688341 & 4.4 & 5.0403 & TST & \\
\hline CHEMBL1508029 & 688341 & 4.4 & 4.9783 & TRN & \\
\hline CHEMBL1472444 & 688341 & 4.6 & 4.8274 & TRN & \\
\hline CHEMBL1539249 & 688341 & 5.0 & 4.8963 & TRN & \\
\hline CHEMBL1588857 & 688341 & 5.1 & 4.8838 & TRN & \\
\hline
\end{tabular}




\begin{tabular}{|c|c|c|c|c|c|}
\hline \multicolumn{6}{|c|}{ Supplemental Table S2.txt } \\
\hline CHEMBL1393088 & 688341 & 4.4 & 4.8986 & TST & \\
\hline CHEMBL1483413 & 688341 & 5.2 & 4.97199 & 99999999995 & TRN \\
\hline CHEMBL1600727 & 688341 & 4.5 & 4.6887 & TRN & \\
\hline CHEMBL1489120 & 688341 & 4.8 & 4.8888 & TRN & \\
\hline CHEMBL107498 & 688341 & 4.5 & 5.2247 & TRN & \\
\hline CHEMBL1464607 & 688341 & 4.4 & 4.8191 & TST & \\
\hline CHEMBL1354736 & 688341 & 5.4 & 5.2669 & TRN & \\
\hline CHEMBL1353501 & 688341 & 4.7 & 4.7455 & TRN & \\
\hline CHEMBL1467594 & 688341 & 5.0 & 5.0373 & TRN & \\
\hline CHEMBL1454074 & 688341 & 4.4 & 4.881 & TRN & \\
\hline CHEMBL1532602 & 688341 & 5.4 & 4.9691 & TRN & \\
\hline CHEMBL1580618 & 688341 & 5.9 & 4.9499 & TRN & \\
\hline CHEMBL1609128 & 688341 & 4.4 & 5.1643 & TST & \\
\hline CHEMBL1424034 & 688341 & 4.7 & 4.8425 & TRN & \\
\hline CHEMBL1489152 & 688341 & 4.8 & 4.8616 & TRN & \\
\hline CHEMBL1574848 & 688341 & 4.5 & 4.8036 & TRN & \\
\hline CHEMBL1569712 & 688341 & 4.6 & 4.7637 & TRN & \\
\hline CHEMBL1596231 & 688341 & 4.4 & 4.8862 & TRN & \\
\hline CHEMBL1374710 & 688341 & 4.4 & 4.9579 & TRN & \\
\hline CHEMBL1595142 & 688341 & 6.1 & 5.2119 & TRN & \\
\hline CHEMBL1353698 & 688341 & 4.5 & 4.8932 & TRN & \\
\hline CHEMBL1501933 & 688341 & 4.5 & 4.8648 & TRN & \\
\hline CHEMBL1546085 & 688341 & 6.1 & 4.9797 & TST & \\
\hline CHEMBL1315939 & 688341 & 4.8 & 5.0513 & TST & \\
\hline CHEMBL1551962 & 688341 & 5.6 & 5.1079 & TRN & \\
\hline CHEMBL1599150 & 688341 & 5.2 & 4.7458 & TST & \\
\hline CHEMBL1441232 & 688341 & 4.6 & 4.9432 & TST & \\
\hline CHEMBL1398488 & 688341 & 5.0 & 5.1336 & TRN & \\
\hline CHEMBL1542915 & 688341 & 4.6 & 4.7803 & TRN & \\
\hline CHEMBL1507227 & 688341 & 4.4 & 4.9135 & TRN & \\
\hline CHEMBL1546372 & 688341 & 4.6 & 4.7522 & TRN & \\
\hline CHEMBL164290 & 688341 & 7.3002 & 5.0881 & TST & \\
\hline CHEMBL23957 & 688341 & 5.2 & 5.1451 & TST & \\
\hline CHEMBL1321112 & 688341 & 4.8 & 4.8602 & TRN & \\
\hline CHEMBL1318375 & 688341 & 5.8 & 4.9377 & TST & \\
\hline CHEMBL1579151 & 688341 & 5.6 & 4.952 & TST & \\
\hline CHEMBL1330355 & 688341 & 6.0 & 5.2719 & TST & \\
\hline CHEMBL1361733 & 688341 & 4.5 & 4.9297 & TRN & \\
\hline CHEMBL1591556 & 688341 & 6.0 & 5.3142 & TST & \\
\hline CHEMBL1468103 & 688341 & 4.8 & 4.9238 & TRN & \\
\hline CHEMBL1466554 & 688341 & 4.6 & 4.9164 & TRN & \\
\hline CHEMBL1331634 & 688341 & 5.1 & 5.1598 & TRN & \\
\hline CHEMBL1341301 & 688341 & 5.1 & 4.8564 & TRN & \\
\hline CHEMBL1256759 & 688341 & 4.4 & 5.0573 & TRN & \\
\hline CHEMBL1347299 & 688341 & 4.8 & 5.0551 & TST & \\
\hline CHEMBL 35482 & 688341 & 5.2 & 4.919 & TRN & \\
\hline CHEMBL1384300 & 688341 & 5.4 & 5.0658 & TRN & \\
\hline CHEMBL1367453 & 688341 & 4.8 & 4.916 & TRN & \\
\hline
\end{tabular}




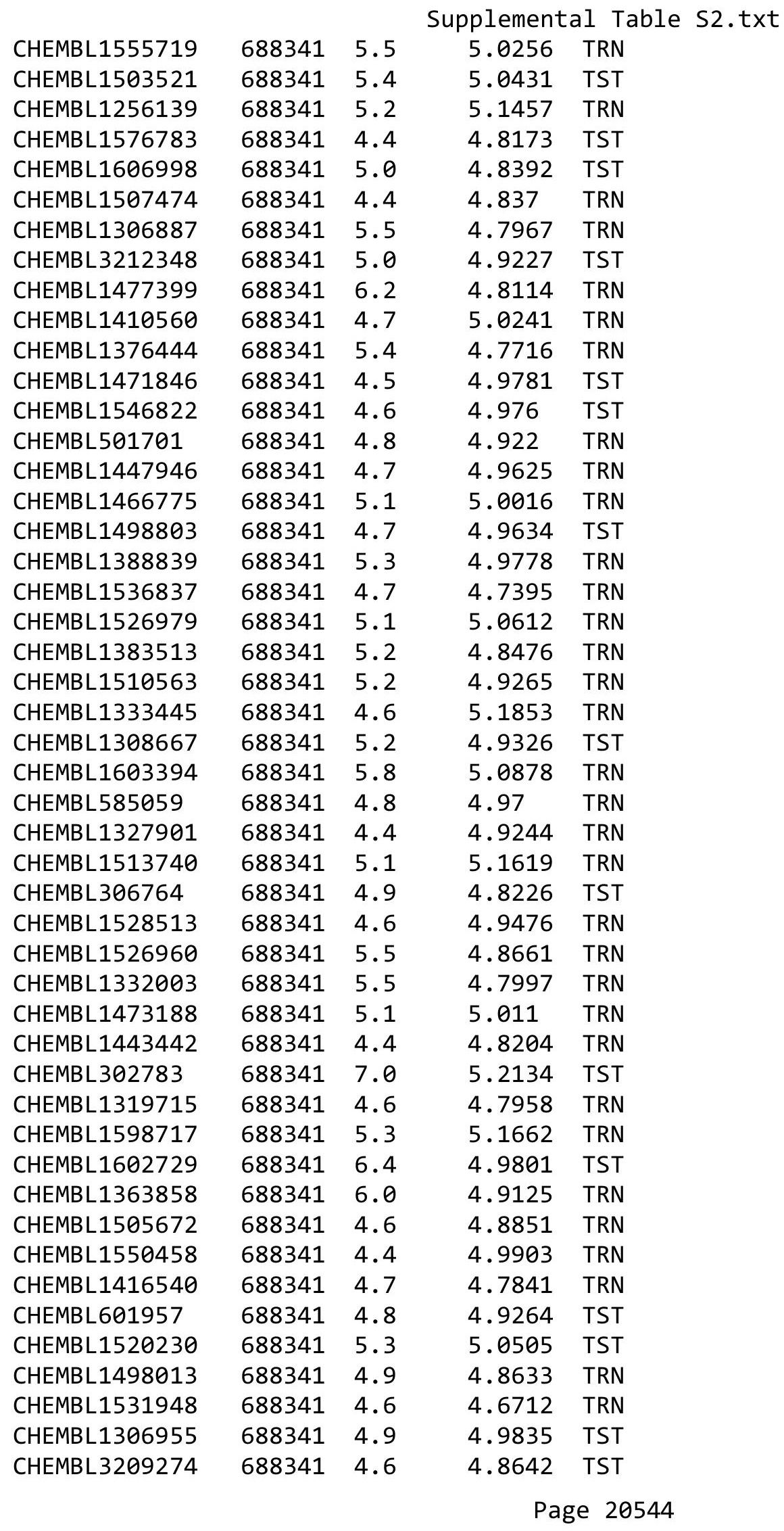




\begin{tabular}{|c|c|c|c|c|c|}
\hline \multicolumn{6}{|c|}{ Supplemental Table S2.txt } \\
\hline CHEMBL1603030 & 688341 & 4.5 & 4.8211 & TRN & \\
\hline CHEMBL1521445 & 688341 & 5.1 & 4.996 & TRN & \\
\hline CHEMBL1507550 & 688341 & 4.4 & 4.7933 & TST & \\
\hline CHEMBL1451476 & 688341 & 5.9 & 4.8026 & TRN & \\
\hline CHEMBL1433273 & 688341 & 4.5 & 4.7615 & TRN & \\
\hline CHEMBL1592212 & 688341 & 4.5 & 4.9306 & TRN & \\
\hline CHEMBL1494289 & 688341 & 5.5 & 4.8872 & TST & \\
\hline CHEMBL1351687 & 688341 & 4.9 & 4.9464 & TRN & \\
\hline CHEMBL1574894 & 688341 & 5.5 & 4.8267 & TRN & \\
\hline CHEMBL1319378 & 688341 & 4.5 & 4.7612 & TST & \\
\hline CHEMBL1506743 & 688341 & 6.1 & 4.7419 & TRN & \\
\hline CHEMBL1335392 & 688341 & 5.5 & 4.8673 & TRN & \\
\hline CHEMBL1331933 & 688341 & 4.8 & 4.9688 & TST & \\
\hline CHEMBL1412261 & 688341 & 4.5 & 5.0727 & TST & \\
\hline CHEMBL1328576 & 688341 & 4.8 & 5.34 & TST & \\
\hline CHEMBL1569370 & 688341 & 4.8 & 4.8984 & TRN & \\
\hline CHEMBL1405426 & 688341 & 5.2 & 4.8495 & TRN & \\
\hline CHEMBL3190916 & 688341 & 4.5 & 5.0379 & TST & \\
\hline CHEMBL1499999 & 688341 & 4.6 & 4.9049 & TRN & \\
\hline CHEMBL1327675 & 688341 & 5.1 & 4.9265 & TRN & \\
\hline CHEMBL1592289 & 688341 & 5.5 & 5.1062 & TRN & \\
\hline CHEMBL1348407 & 688341 & 4.6 & 4.9438 & TRN & \\
\hline CHEMBL1308000 & 688341 & 4.5 & 5.0698 & TRN & \\
\hline CHEMBL1495486 & 688341 & 4.8 & 4.69600 & $\partial 000000001$ & TRN \\
\hline CHEMBL1458525 & 688341 & 4.8 & 4.9564 & TRN & \\
\hline CHEMBL1320820 & 688341 & 4.8 & 4.9967 & TRN & \\
\hline CHEMBL1426807 & 688341 & 5.4 & 5.1453 & TRN & \\
\hline CHEMBL1320071 & 688341 & 4.8 & 4.9829 & TRN & \\
\hline CHEMBL1409258 & 688341 & 4.5 & 4.7588 & TRN & \\
\hline CHEMBL1305957 & 688341 & 6.2 & 5.0882 & TRN & \\
\hline CHEMBL1581088 & 688341 & 4.8 & 4.8891 & TST & \\
\hline CHEMBL1394353 & 688341 & 4.4 & 5.0531 & TRN & \\
\hline CHEMBL1569001 & 688341 & 4.5 & 4.95100 & 00000000005 & TRN \\
\hline CHEMBL1441900 & 688341 & 4.5 & 4.9851 & TRN & \\
\hline CHEMBL1410187 & 688341 & 4.7 & 5.0135 & TRN & \\
\hline CHEMBL1378707 & 688341 & 4.8 & 4.977 & TRN & \\
\hline CHEMBL1330055 & 688341 & 5.3 & 5.0942 & TRN & \\
\hline CHEMBL1556368 & 688341 & 4.6 & 5.0312 & TST & \\
\hline CHEMBL1400603 & 688341 & 5.2 & 4.8573 & TRN & \\
\hline CHEMBL1337025 & 688341 & 4.8 & 4.9022 & TRN & \\
\hline CHEMBL1465913 & 688341 & 4.6 & 4.8848 & TRN & \\
\hline CHEMBL1312599 & 688341 & 5.5 & 4.9718 & TRN & \\
\hline CHEMBL1399489 & 688341 & 5.1 & 4.9692 & TRN & \\
\hline CHEMBL1379136 & 688341 & 4.6 & 5.0097 & TST & \\
\hline CHEMBL1593108 & 688341 & 5.0 & 5.1082 & TRN & \\
\hline CHEMBL1570159 & 688341 & 5.5 & 5.0921 & TST & \\
\hline CHEMBL1359256 & 688341 & 7.0 & 5.0109 & TRN & \\
\hline CHEMBL228792 & 688341 & 5.3 & 5.0638 & TRN & \\
\hline
\end{tabular}




\begin{tabular}{|c|c|c|c|c|c|}
\hline \multicolumn{6}{|c|}{ Supplemental Table S2.txt } \\
\hline CHEMBL1230080 & 688341 & 4.9 & 5.1157 & TST & \\
\hline CHEMBL1529024 & 688341 & 5.3 & 4.894 & TRN & \\
\hline CHEMBL1361129 & 688341 & 5.2 & 5.1697 & TST & \\
\hline CHEMBL1488420 & 688341 & 5.4 & 4.9087 & TST & \\
\hline CHEMBL1361953 & 688341 & 5.3 & 4.8472 & TST & \\
\hline CHEMBL1391082 & 688341 & 4.5 & 5.0059 & TST & \\
\hline CHEMBL1475377 & 688341 & 4.7 & 5.0407 & TRN & \\
\hline CHEMBL1522003 & 688341 & 5.0 & 4.8235 & TRN & \\
\hline CHEMBL1591893 & 688341 & 5.2 & 4.979 & TRN & \\
\hline CHEMBL1434783 & 688341 & 4.4 & 5.1354 & TRN & \\
\hline CHEMBL1529166 & 688341 & 4.6 & 5.0492 & TRN & \\
\hline CHEMBL1558184 & 688341 & 5.4 & 4.8734 & TRN & \\
\hline CHEMBL1559096 & 688341 & 5.0 & 4.7695 & TRN & \\
\hline CHEMBL1565567 & 688341 & 6.8 & 5.0744 & TST & \\
\hline CHEMBL1586877 & 688341 & 5.2 & 4.9387 & TRN & \\
\hline CHEMBL1565741 & 688341 & 5.1 & 5.0484 & TRN & \\
\hline CHEMBL261663 & 688341 & 4.4 & 5.13899 & 9999999999 & TST \\
\hline CHEMBL1443514 & 688341 & 4.7 & 5.1686 & TRN & \\
\hline CHEMBL1431877 & 688341 & 4.7 & 4.739 & TRN & \\
\hline CHEMBL1416666 & 688341 & 4.5 & 4.7755 & TRN & \\
\hline CHEMBL1604212 & 688341 & 4.4 & 4.848 & TRN & \\
\hline CHEMBL1391258 & 688341 & 4.7 & 4.691 & TRN & \\
\hline CHEMBL1380137 & 688341 & 4.5 & 4.962 & TRN & \\
\hline CHEMBL 3212640 & 688341 & 4.5 & 4.8982 & TST & \\
\hline CHEMBL1490268 & 688341 & 4.8 & 5.0109 & TRN & \\
\hline CHEMBL225510 & 688341 & 4.5 & 4.9597 & TRN & \\
\hline CHEMBL1378650 & 688341 & 5.3 & 5.0652 & TRN & \\
\hline CHEMBL1366590 & 688341 & 5.4 & 4.9999 & TST & \\
\hline CHEMBL1301413 & 688341 & 5.2 & 4.7755 & TRN & \\
\hline CHEMBL1327833 & 688341 & 5.3 & 4.8576 & TRN & \\
\hline CHEMBL1501608 & 688341 & 4.8 & 4.8777 & TRN & \\
\hline CHEMBL1491667 & 688341 & 4.4 & 4.9718 & TRN & \\
\hline CHEMBL1420389 & 688341 & 4.4 & 5.1082 & TRN & \\
\hline CHEMBL1480520 & 688341 & 5.5 & 5.0541 & TRN & \\
\hline CHEMBL571295 & 688341 & 5.7 & 4.9601 & TST & \\
\hline CHEMBL1494177 & 688341 & 5.5 & 5.0572 & TRN & \\
\hline CHEMBL1548408 & 688341 & 4.8 & 4.8932 & TRN & \\
\hline CHEMBL1603323 & 688341 & 4.4 & 5.004 & TRN & \\
\hline CHEMBL1394923 & 688341 & 5.0 & 5.1089 & TRN & \\
\hline CHEMBL 94734 & 688341 & 4.5 & 4.9338 & TST & \\
\hline CHEMBL1341986 & 688341 & 5.1 & 5.0284 & TST & \\
\hline CHEMBL1414950 & 688341 & 7.1002 & 5.2582 & TRN & \\
\hline CHEMBL1373827 & 688341 & 5.0 & 4.887 & TST & \\
\hline CHEMBL1600736 & 688341 & 4.5 & 4.9989 & TRN & \\
\hline CHEMBL1342417 & 688341 & 4.6 & 4.9785 & TRN & \\
\hline CHEMBL1337502 & 688341 & 4.4 & 4.9239 & TST & \\
\hline CHEMBL1391432 & 688341 & 5.3 & 4.9864 & TST & \\
\hline CHEMBL1391020 & 688341 & 5.3 & 5.1279 & TRN & \\
\hline
\end{tabular}




\begin{tabular}{|c|c|c|c|c|}
\hline & & & Supplement & al Table \\
\hline CHEMBL1365104 & 688341 & 4.5 & 4.8569 & TST \\
\hline CHEMBL1585575 & 688341 & 4.4 & 4.9037 & TRN \\
\hline CHEMBL1445009 & 688341 & 4.5 & 4.9567 & TRN \\
\hline CHEMBL1349037 & 688341 & 4.4 & 5.0591 & TST \\
\hline CHEMBL1542927 & 688341 & 5.4 & 4.8993 & TRN \\
\hline CHEMBL1484051 & 688341 & 5.2 & 5.0053 & TST \\
\hline CHEMBL1353113 & 688341 & 5.3 & 4.9709 & TST \\
\hline CHEMBL1579219 & 688341 & 5.2 & 4.9792 & TRN \\
\hline CHEMBL1502286 & 688341 & 5.4 & 5.0845 & TST \\
\hline CHEMBL1407483 & 688341 & 5.0 & 4.9954 & TST \\
\hline CHEMBL1429403 & 688341 & 5.4 & 4.93 & TRN \\
\hline CHEMBL1409415 & 688341 & 5.2 & 4.9748 & TRN \\
\hline CHEMBL1454323 & 688341 & 4.5 & 4.8201 & TST \\
\hline CHEMBL1355242 & 688341 & 4.4 & 4.8697 & TRN \\
\hline CHEMBL1309006 & 688341 & 4.6 & 4.6459 & TRN \\
\hline CHEMBL1415887 & 688341 & 4.4 & 5.0863 & TST \\
\hline CHEMBL1488198 & 688341 & 4.6 & 4.8496 & TRN \\
\hline CHEMBL1085946 & 688341 & 8.0 & 5.0171 & TRN \\
\hline CHEMBL1508142 & 688341 & 4.9 & 4.9813 & TRN \\
\hline CHEMBL1559212 & 688341 & 4.8 & 4.846 & TRN \\
\hline CHEMBL1559653 & 688341 & 4.6 & 4.9968 & TRN \\
\hline CHEMBL1563284 & 688341 & 4.8 & 4.7803 & TRN \\
\hline CHEMBL1506646 & 688341 & 4.6 & 4.8304 & TRN \\
\hline CHEMBL1565244 & 688341 & 5.0 & 4.8679 & TST \\
\hline CHEMBL1347822 & 688341 & 4.7 & 4.9315 & TRN \\
\hline CHEMBL1579627 & 688341 & 4.5 & 5.2058 & TRN \\
\hline CHEMBL1492586 & 688341 & 4.5 & 4.9576 & TRN \\
\hline CHEMBL1405705 & 688341 & 4.7 & 5.0079 & TRN \\
\hline CHEMBL1470413 & 688341 & 5.5 & 5.0183 & TRN \\
\hline CHEMBL1497050 & 688341 & 4.5 & 5.0628 & TRN \\
\hline CHEMBL118765 & 688341 & 5.7 & 5.1723 & TST \\
\hline CHEMBL1342672 & 688341 & 5.4 & 5.1093 & TRN \\
\hline CHEMBL1471335 & 688341 & 5.0 & 4.9108 & TRN \\
\hline CHEMBL1306007 & 688341 & 4.6 & 4.9925 & TST \\
\hline CHEMBL1425972 & 688341 & 4.4 & 4.9257 & TST \\
\hline CHEMBL1482184 & 688341 & 6.0 & 5.1958 & TST \\
\hline CHEMBL1447630 & 688341 & 5.9 & 4.9968 & TST \\
\hline CHEMBL1484447 & 688341 & 4.6 & 5.0273 & TRN \\
\hline CHEMBL1321339 & 688341 & 4.9 & 5.0638 & TRN \\
\hline CHEMBL1575755 & 688341 & 6.1 & 4.7957 & TRN \\
\hline CHEMBL1550351 & 688341 & 4.5 & 4.6752 & TRN \\
\hline CHEMBL1451089 & 688341 & 4.6 & 5.0206 & TST \\
\hline CHEMBL1365031 & 688341 & 4.4 & 5.0127 & TRN \\
\hline CHEMBL1490905 & 688341 & 4.8 & 4.9118 & TRN \\
\hline CHEMBL1487748 & 688341 & 5.0 & 5.1112 & TRN \\
\hline CHEMBL1479899 & 688341 & 4.4 & 4.8935 & TRN \\
\hline CHEMBL1422415 & 688341 & 4.5 & 4.7276 & TST \\
\hline CHEMBL1595437 & 688341 & 4.7 & 4.8528 & TRN \\
\hline
\end{tabular}




\begin{tabular}{|c|c|c|c|c|c|}
\hline \multicolumn{6}{|c|}{ Supplemental Table S2.txt } \\
\hline CHEMBL1373348 & 688341 & 4.8 & 4.8325 & TST & \\
\hline CHEMBL1558539 & 688341 & 5.2 & 5.0684 & TST & \\
\hline CHEMBL1583293 & 688341 & 4.5 & 4.8656 & TST & \\
\hline CHEMBL1489367 & 688341 & 4.5 & 5.0953 & TRN & \\
\hline CHEMBL1365081 & 688341 & 4.8 & 4.9685 & TRN & \\
\hline CHEMBL1426084 & 688341 & 5.4 & 4.8707 & TRN & \\
\hline CHEMBL491910 & 688341 & 4.6 & 5.3082 & TRN & \\
\hline CHEMBL1464322 & 688341 & 5.3 & 4.853 & TRN & \\
\hline CHEMBL1565756 & 688341 & 4.5 & 4.8592 & TST & \\
\hline CHEMBL108766 & 688341 & 6.0 & 5.2247 & TRN & \\
\hline CHEMBL1334342 & 688341 & 4.4 & 4.8096 & TST & \\
\hline CHEMBL3196797 & 688341 & 5.5 & 5.0561 & TRN & \\
\hline CHEMBL1488009 & 688341 & 5.2 & 5.0688 & TRN & \\
\hline CHEMBL1505711 & 688341 & 4.8 & 4.7916 & TRN & \\
\hline CHEMBL1561293 & 688341 & 4.9 & 4.6723 & TRN & \\
\hline CHEMBL1380963 & 688341 & 4.5 & 4.7312 & TRN & \\
\hline CHEMBL1376935 & 688341 & 4.5 & 4.8861 & TRN & \\
\hline CHEMBL1321193 & 688341 & 4.8 & 4.7273 & TRN & \\
\hline CHEMBL1409996 & 688341 & 4.9 & 5.1606 & TRN & \\
\hline CHEMBL1501207 & 688341 & 4.6 & 4.926 & TST & \\
\hline CHEMBL1506214 & 688341 & 4.8 & 4.8125 & TRN & \\
\hline CHEMBL1490809 & 688341 & 4.6 & 4.9365 & TRN & \\
\hline CHEMBL1468806 & 688341 & 4.6 & 4.7856 & TST & \\
\hline CHEMBL1532542 & 688341 & 4.4 & 4.9241 & TST & \\
\hline CHEMBL1333464 & 688341 & 4.8 & 4.90300 & 00000000005 & TRN \\
\hline CHEMBL1574982 & 688341 & 5.1 & 5.0125 & TST & \\
\hline CHEMBL1505338 & 688341 & 4.6 & 4.982 & TRN & \\
\hline CHEMBL1538857 & 688341 & 5.4 & 4.9781 & TST & \\
\hline CHEMBL1456533 & 688341 & 5.5 & 4.9423 & TRN & \\
\hline CHEMBL1342725 & 688341 & 4.6 & 4.975 & TRN & \\
\hline CHEMBL1467552 & 688341 & 4.5 & 4.8743 & TRN & \\
\hline CHEMBL1463079 & 688341 & 4.9 & 4.9662 & TRN & \\
\hline CHEMBL1541839 & 688341 & 4.7 & 4.9211 & TRN & \\
\hline CHEMBL1313522 & 688341 & 5.3 & 4.9987 & TRN & \\
\hline CHEMBL1532342 & 688341 & 4.6 & 4.8117 & TRN & \\
\hline CHEMBL1588930 & 688341 & 4.5 & 4.8175 & TRN & \\
\hline CHEMBL1539118 & 688341 & 5.2 & 4.8714 & TRN & \\
\hline CHEMBL1255836 & 688341 & 5.4 & 5.2212 & TST & \\
\hline CHEMBL1256910 & 688341 & 6.0 & 5.0348 & TST & \\
\hline CHEMBL1386323 & 688341 & 4.8 & 4.757 & TRN & \\
\hline CHEMBL1439956 & 688341 & 4.8 & 4.905 & TRN & \\
\hline CHEMBL1476280 & 688341 & 4.8 & 5.1448 & TRN & \\
\hline CHEMBL1488711 & 688341 & 4.6 & 4.7949 & TRN & \\
\hline CHEMBL1393096 & 688341 & 4.4 & 4.952 & TRN & \\
\hline CHEMBL1341971 & 688341 & 4.9 & 5.0165 & TRN & \\
\hline CHEMBL1498011 & 688341 & 4.6 & 4.908 & TRN & \\
\hline CHEMBL1551979 & 688341 & 5.7 & 4.9704 & TRN & \\
\hline CHEMBL1335115 & 688341 & 4.9 & 4.9585 & TRN & \\
\hline
\end{tabular}




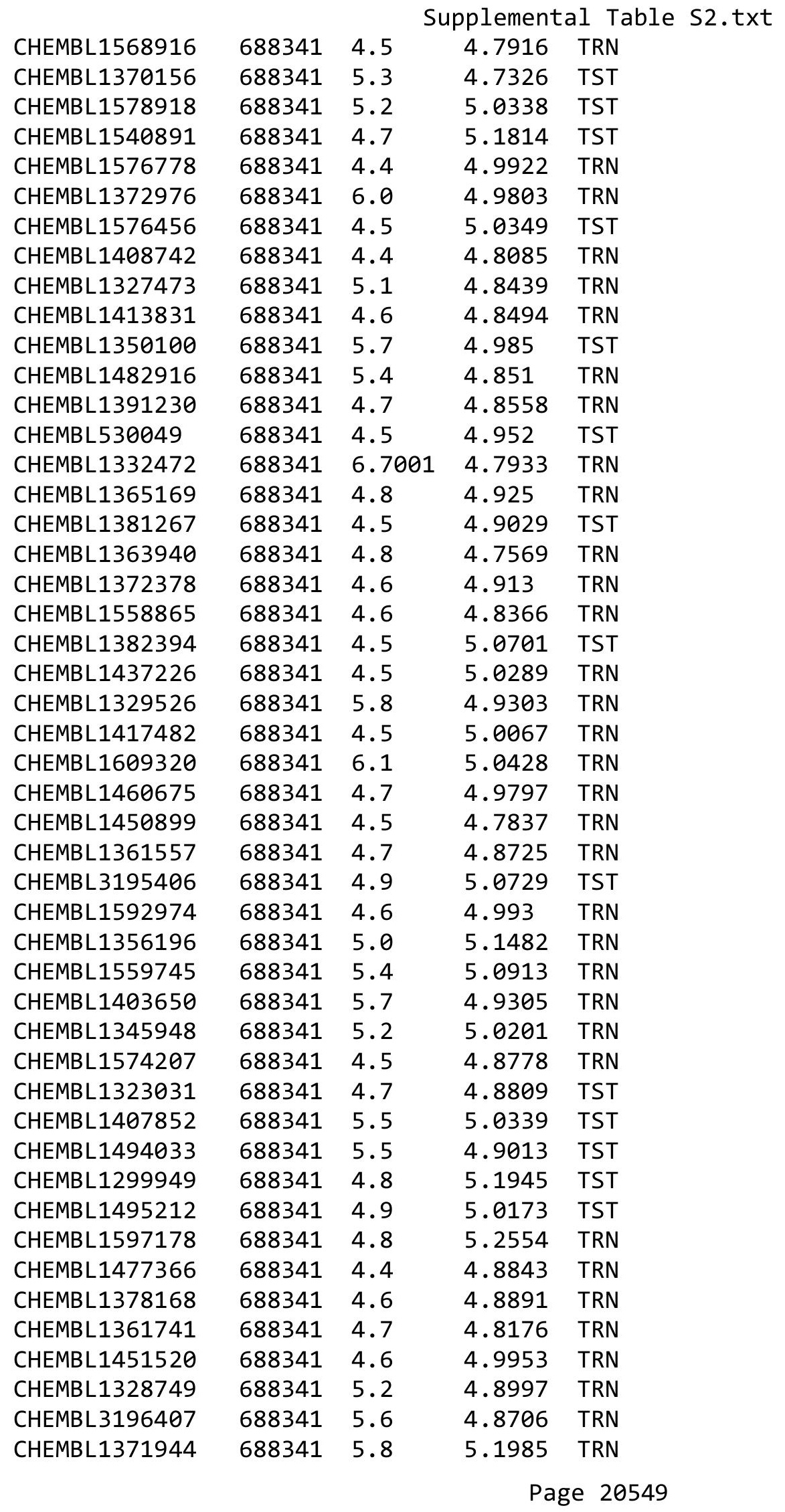




\begin{tabular}{|c|c|c|c|c|}
\hline \multicolumn{5}{|c|}{ Supplemental Table S2.txt } \\
\hline CHEMBL3212021 & 688341 & 4.5 & 4.9554 & TST \\
\hline CHEMBL1568030 & 688341 & 5.0 & 4.8183 & TRN \\
\hline CHEMBL1562478 & 688341 & 5.2 & 4.7908 & TRN \\
\hline CHEMBL1330357 & 688341 & 4.7 & 5.2532 & TRN \\
\hline CHEMBL1347024 & 688341 & 5.0 & 4.8414 & TRN \\
\hline CHEMBL1612861 & 688341 & 4.6 & 4.9246 & TST \\
\hline CHEMBL1453889 & 688341 & 5.2 & 4.8465 & TRN \\
\hline CHEMBL1581007 & 688341 & 4.7 & 4.8489 & TRN \\
\hline CHEMBL1515555 & 688341 & 4.9 & 5.0601 & TRN \\
\hline CHEMBL1368695 & 688341 & 4.4 & 4.8149 & TRN \\
\hline CHEMBL1387407 & 688341 & 4.9 & 5.0056 & TST \\
\hline CHEMBL1520748 & 688341 & 4.7 & 5.13 & TRN \\
\hline CHEMBL1560355 & 688341 & 8.2007 & 4.8104 & TST \\
\hline CHEMBL1351455 & 688341 & 4.7 & 5.0028 & TRN \\
\hline CHEMBL1415790 & 688341 & 5.0 & 4.8728 & TRN \\
\hline CHEMBL1503262 & 688341 & 4.8 & 4.8888 & TRN \\
\hline CHEMBL1300068 & 688341 & 4.5 & 4.8795 & TST \\
\hline CHEMBL1310609 & 688341 & 4.6 & 4.766 & TRN \\
\hline CHEMBL1499801 & 688341 & 4.4 & 4.7667 & TRN \\
\hline CHEMBL3211074 & 688341 & 4.4 & 4.9287 & TST \\
\hline CHEMBL1565677 & 688341 & 4.5 & 4.9764 & TRN \\
\hline CHEMBL1444971 & 688341 & 4.8 & 4.9259 & TRN \\
\hline CHEMBL1443218 & 688341 & 4.6 & 5.0268 & TST \\
\hline CHEMBL1435248 & 688341 & 4.4 & 5.0153 & TRN \\
\hline CHEMBL1369030 & 688341 & 4.5 & 5.1036 & TST \\
\hline CHEMBL1501225 & 688341 & 4.4 & 4.9796 & TRN \\
\hline CHEMBL1413982 & 688341 & 4.6 & 4.8855 & TRN \\
\hline CHEMBL1334487 & 688341 & 4.7 & 4.7955 & TRN \\
\hline CHEMBL1508674 & 688341 & 6.0 & 4.8616 & TST \\
\hline CHEMBL1528170 & 688341 & 6.0 & 4.9819 & TRN \\
\hline CHEMBL1414101 & 688341 & 5.4 & 4.9554 & TRN \\
\hline CHEMBL1583467 & 688341 & 8.2007 & 4.8629 & TRN \\
\hline CHEMBL1399648 & 688341 & 5.4 & 5.0858 & TRN \\
\hline CHEMBL1546642 & 688341 & 4.5 & 4.9197 & TRN \\
\hline CHEMBL1494309 & 688341 & 4.5 & 4.7664 & TST \\
\hline CHEMBL1460030 & 688341 & 4.4 & 4.8615 & TRN \\
\hline CHEMBL1411519 & 688341 & 4.6 & 5.1517 & TRN \\
\hline CHEMBL1381347 & 688341 & 4.8 & 4.9725 & TST \\
\hline CHEMBL1411201 & 688341 & 5.1 & 5.1759 & TRN \\
\hline CHEMBL1361262 & 688341 & 5.1 & 4.9312 & TRN \\
\hline CHEMBL1383218 & 688341 & 5.2 & 4.9632 & TRN \\
\hline CHEMBL1568879 & 688341 & 6.0 & 4.9297 & TST \\
\hline CHEMBL1548217 & 688341 & 5.1 & 4.8149 & TRN \\
\hline CHEMBL1451996 & 688341 & 4.5 & 4.907 & TRN \\
\hline CHEMBL1472042 & 688341 & 4.8 & 4.8807 & TRN \\
\hline CHEMBL1499667 & 688341 & 4.8 & 5.0036 & TRN \\
\hline CHEMBL1347556 & 688341 & 5.9 & 4.8314 & TST \\
\hline CHEMBL1462825 & 688341 & 4.4 & 4.765 & TRN \\
\hline
\end{tabular}




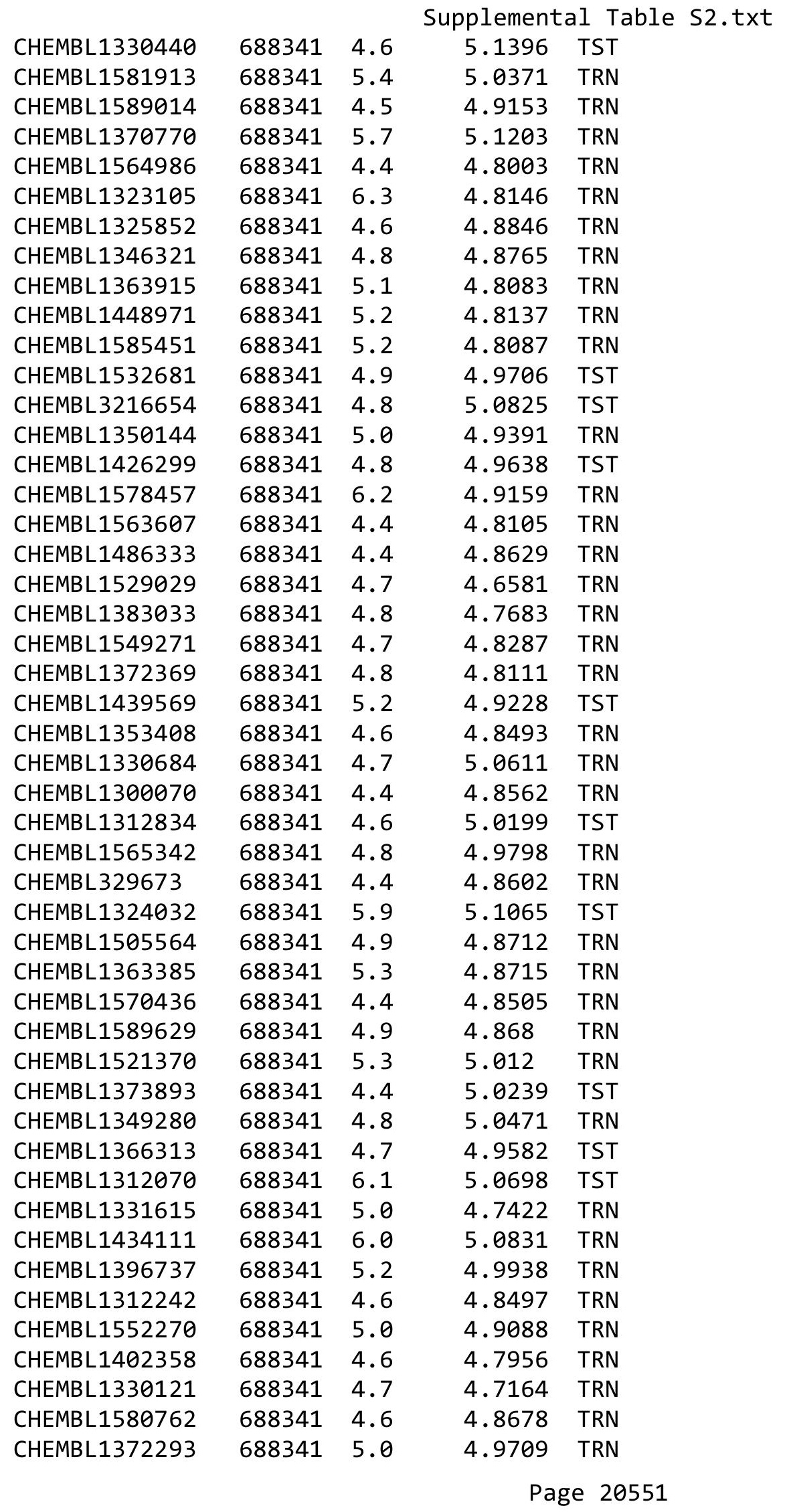




\begin{tabular}{|c|c|c|c|c|}
\hline \multicolumn{5}{|c|}{ Supplemental Table S2.txt } \\
\hline CHEMBL1612893 & 688341 & 5.1 & 4.8976 & TRN \\
\hline CHEMBL1369062 & 688341 & 4.6 & 5.1658 & TRN \\
\hline CHEMBL1362172 & 688341 & 4.6 & 4.8838 & TRN \\
\hline CHEMBL1382739 & 688341 & 5.2 & 4.9326 & TRN \\
\hline CHEMBL1479239 & 688341 & 4.8 & 4.8291 & TRN \\
\hline CHEMBL1339553 & 688341 & 4.9 & 4.8972 & TRN \\
\hline CHEMBL1603766 & 688341 & 4.6 & 4.7594 & TRN \\
\hline CHEMBL1527940 & 688341 & 5.2 & 4.9957 & TRN \\
\hline CHEMBL1580452 & 688341 & 4.7 & 4.8767 & TRN \\
\hline CHEMBL1558773 & 688341 & 4.7 & 4.9374 & TRN \\
\hline CHEMBL1392853 & 688341 & 4.5 & 4.8664 & TRN \\
\hline CHEMBL167869 & 688341 & 4.8 & 5.1266 & TRN \\
\hline CHEMBL1561241 & 688341 & 5.4 & 4.883 & TRN \\
\hline CHEMBL1349971 & 688341 & 5.5 & 4.9328 & TRN \\
\hline CHEMBL1428965 & 688341 & 4.4 & 4.9907 & TST \\
\hline CHEMBL1452755 & 688341 & 4.4 & 4.8681 & TRN \\
\hline CHEMBL1516845 & 688341 & 5.1 & 4.9901 & TRN \\
\hline CHEMBL1384120 & 688341 & 6.5 & 4.8344 & TST \\
\hline CHEMBL1505650 & 688341 & 4.5 & 5.0671 & TST \\
\hline CHEMBL1588491 & 688341 & 5.3 & 4.8328 & TRN \\
\hline CHEMBL1572383 & 688341 & 4.5 & 4.8664 & TRN \\
\hline CHEMBL1500591 & 688341 & 4.5 & 4.7657 & TRN \\
\hline CHEMBL1523566 & 688341 & 4.5 & 4.7616 & TRN \\
\hline CHEMBL1442367 & 688341 & 4.6 & 5.0114 & TRN \\
\hline CHEMBL1346059 & 688341 & 5.3 & 4.8922 & TRN \\
\hline CHEMBL8165 & 688341 & 4.4 & 5.2039 & TRN \\
\hline CHEMBL1500847 & 688341 & 5.1 & 5.035 & TST \\
\hline CHEMBL1343744 & 688341 & 5.2 & 4.8816 & TRN \\
\hline CHEMBL1570073 & 688341 & 4.8 & 4.8442 & TRN \\
\hline CHEMBL1326011 & 688341 & 5.3 & 4.791 & TRN \\
\hline CHEMBL1349350 & 688341 & 5.1 & 4.8133 & TRN \\
\hline CHEMBL1330994 & 688341 & 4.8 & 5.1115 & TRN \\
\hline CHEMBL1313221 & 688341 & 5.1 & 4.9218 & TST \\
\hline CHEMBL1365274 & 688341 & 5.4 & 4.8511 & TRN \\
\hline CHEMBL1349241 & 688341 & 5.5 & 4.9194 & TST \\
\hline CHEMBL1580655 & 688341 & 4.9 & 4.9258 & TRN \\
\hline CHEMBL1339493 & 688341 & 4.8 & 4.9421 & TRN \\
\hline CHEMBL192509 & 688341 & 4.9 & 5.0209 & TST \\
\hline CHEMBL1359297 & 688341 & 4.9 & 5.1612 & TST \\
\hline CHEMBL1446815 & 688341 & 4.9 & 5.0987 & TRN \\
\hline CHEMBL1400430 & 688341 & 4.7 & 4.9612 & TRN \\
\hline CHEMBL1455993 & 688341 & 4.9 & 4.8646 & TRN \\
\hline CHEMBL1559311 & 688341 & 4.4 & 4.8641 & TST \\
\hline CHEMBL1313319 & 688341 & 5.0 & 4.9782 & TRN \\
\hline CHEMBL1418567 & 688341 & 4.4 & 4.8245 & TRN \\
\hline CHEMBL1599179 & 688341 & 4.8 & 4.8119 & TRN \\
\hline CHEMBL1561429 & 688341 & 5.4 & 5.0693 & TST \\
\hline CHEMBL1468900 & 688341 & 4.8 & 4.8663 & TST \\
\hline
\end{tabular}




\begin{tabular}{|c|c|c|c|c|c|}
\hline \multicolumn{6}{|c|}{ Supplemental Table S2.txt } \\
\hline CHEMBL1429915 & 688341 & 4.6 & 4.9562 & TRN & \\
\hline CHEMBL1601228 & 688341 & 4.5 & 5.0548 & TRN & \\
\hline CHEMBL1301577 & 688341 & 5.2 & 4.8678 & TRN & \\
\hline CHEMBL1572103 & 688341 & 5.3 & 4.7926 & TRN & \\
\hline CHEMBL1416762 & 688341 & 5.2 & 4.9636 & TRN & \\
\hline CHEMBL398363 & 688341 & 5.2 & 5.0205 & TST & \\
\hline CHEMBL1457774 & 688341 & 4.6 & 4.8938 & TST & \\
\hline CHEMBL1601967 & 688341 & 5.4 & 5.0677 & TRN & \\
\hline CHEMBL1372859 & 688341 & 4.6 & 4.8667 & TRN & \\
\hline CHEMBL1396301 & 688341 & 4.4 & 4.8858 & TRN & \\
\hline CHEMBL1354122 & 688341 & 4.8 & 5.0434 & TRN & \\
\hline CHEMBL1537868 & 688341 & 4.8 & 4.7299 & TRN & \\
\hline CHEMBL1563315 & 688341 & 6.9 & 4.9395 & TRN & \\
\hline CHEMBL1325964 & 688341 & 4.4 & 4.9874 & TRN & \\
\hline CHEMBL1539969 & 688341 & 4.8 & 4.9155 & TRN & \\
\hline CHEMBL1364852 & 688341 & 4.6 & 4.8727 & TRN & \\
\hline CHEMBL1568850 & 688341 & 4.4 & 4.9963 & TRN & \\
\hline CHEMBL1559204 & 688341 & 4.5 & 4.6903 & TRN & \\
\hline CHEMBL1377510 & 688341 & 4.5 & 4.88399 & 99999999995 & TST \\
\hline CHEMBL1499741 & 688341 & 4.8 & 4.8588 & TRN & \\
\hline CHEMBL1311633 & 688341 & 4.7 & 4.8303 & TRN & \\
\hline CHEMBL52387 & 688341 & 4.5 & 5.1081 & TST & \\
\hline CHEMBL1595181 & 688341 & 4.5 & 4.9284 & TRN & \\
\hline CHEMBL1359354 & 688341 & 5.4 & 4.7494 & TRN & \\
\hline CHEMBL1468932 & 688341 & 4.7 & 5.1342 & TST & \\
\hline CHEMBL1393149 & 688341 & 5.3 & 4.8362 & TRN & \\
\hline CHEMBL1367636 & 688341 & 5.4 & 4.8542 & TRN & \\
\hline CHEMBL3198936 & 688341 & 5.2 & 5.1326 & TRN & \\
\hline CHEMBL1406690 & 688341 & 4.5 & 4.9227 & TST & \\
\hline CHEMBL1558511 & 688341 & 5.2 & 4.9205 & TRN & \\
\hline CHEMBL1438691 & 688341 & 5.3 & 4.7619 & TRN & \\
\hline CHEMBL1435823 & 688341 & 5.5 & 5.2393 & TRN & \\
\hline CHEMBL399760 & 688341 & 5.5 & 4.8446 & TRN & \\
\hline CHEMBL1340321 & 688341 & 4.5 & 4.8415 & TRN & \\
\hline CHEMBL1703229 & 688341 & 5.5 & 4.9864 & TST & \\
\hline CHEMBL1422872 & 688341 & 4.4 & 4.8667 & TRN & \\
\hline CHEMBL1393845 & 688341 & 4.4 & 5.0196 & TST & \\
\hline CHEMBL1613725 & 688341 & 4.4 & 5.0317 & TRN & \\
\hline CHEMBL1428499 & 688341 & 4.4 & 4.9922 & TRN & \\
\hline CHEMBL1471165 & 688341 & 6.3 & 4.9382 & TRN & \\
\hline CHEMBL1382146 & 688341 & 4.7 & 4.9767 & TST & \\
\hline CHEMBL1426762 & 688341 & 4.5 & 4.9623 & TST & \\
\hline CHEMBL1496951 & 688341 & 4.8 & 4.8646 & TRN & \\
\hline CHEMBL1572410 & 688341 & 4.8 & 4.9869 & TRN & \\
\hline CHEMBL1485366 & 688341 & 4.4 & 4.9539 & TRN & \\
\hline CHEMBL1602357 & 688341 & 4.6 & 4.9953 & TRN & \\
\hline CHEMBL1565158 & 688341 & 5.3 & 4.8092 & TRN & \\
\hline CHEMBL1464142 & 688341 & 5.2 & 4.8854 & TST & \\
\hline
\end{tabular}




\begin{tabular}{|c|c|c|c|c|c|}
\hline \multicolumn{6}{|c|}{ Supplemental Table S2.txt } \\
\hline CHEMBL1430579 & 688341 & 4.7 & 4.9821 & TRN & \\
\hline CHEMBL1358583 & 688341 & 5.1 & 5.0124 & TRN & \\
\hline CHEMBL1333817 & 688341 & 5.2 & 4.9955 & TST & \\
\hline CHEMBL1422096 & 688341 & 4.6 & 4.9522 & TST & \\
\hline CHEMBL1543759 & 688341 & 4.4 & 5.0847 & TRN & \\
\hline CHEMBL1471455 & 688341 & 4.6 & 4.8873 & TRN & \\
\hline CHEMBL1341329 & 688341 & 8.0 & 5.0914 & TST & \\
\hline CHEMBL1414010 & 688341 & 4.7 & 4.9307 & TRN & \\
\hline CHEMBL1328934 & 688341 & 4.6 & 4.788 & TRN & \\
\hline CHEMBL1400095 & 688341 & 4.6 & 4.8967 & TRN & \\
\hline CHEMBL1461993 & 688341 & 5.4 & 4.9687 & TST & \\
\hline CHEMBL1461973 & 688341 & 5.0 & 4.8713 & TRN & \\
\hline CHEMBL1606690 & 688341 & 4.5 & 4.9469 & TST & \\
\hline CHEMBL1352062 & 688341 & 4.5 & 5.0192 & TRN & \\
\hline CHEMBL1489620 & 688341 & 4.5 & 4.871 & TRN & \\
\hline CHEMBL1603357 & 688341 & 4.7 & 4.9637 & TRN & \\
\hline CHEMBL1404295 & 688341 & 4.4 & 5.1269 & TST & \\
\hline CHEMBL263893 & 688341 & 4.4 & 5.1061 & TRN & \\
\hline CHEMBL1328096 & 688341 & 4.6 & 4.9661 & TRN & \\
\hline CHEMBL1413391 & 688341 & 4.5 & 4.7783 & TRN & \\
\hline CHEMBL1443480 & 688341 & 4.7 & 5.1102 & TRN & \\
\hline CHEMBL1607661 & 688341 & 5.0 & 4.803 & TST & \\
\hline CHEMBL1563164 & 688341 & 4.4 & 4.8867 & TRN & \\
\hline CHEMBL1544371 & 688341 & 4.7 & 4.9293 & TST & \\
\hline CHEMBL1361955 & 688341 & 5.3 & 4.8499 & TRN & \\
\hline CHEMBL1350957 & 688341 & 5.4 & 4.868 & TRN & \\
\hline CHEMBL1525272 & 688341 & 5.2 & 4.966 & TST & \\
\hline CHEMBL1468479 & 688341 & 4.9 & 5.1133 & TRN & \\
\hline CHEMBL1606419 & 688341 & 4.5 & 4.8959 & TRN & \\
\hline CHEMBL1580537 & 688341 & 4.5 & 4.8773 & TRN & \\
\hline CHEMBL1444884 & 688341 & 4.4 & 4.8473 & TRN & \\
\hline CHEMBL1371499 & 688341 & 4.8 & 4.9259 & TRN & \\
\hline CHEMBL21260 & 688341 & 6.0 & 5.0941 & TST & \\
\hline CHEMBL1511332 & 688341 & 4.4 & 5.0329 & TST & \\
\hline CHEMBL1346244 & 688341 & 4.5 & 4.941 & TRN & \\
\hline CHEMBL1490390 & 688341 & 4.7 & 4.92899 & 9999999999 & TRN \\
\hline CHEMBL1392762 & 688341 & 4.7 & 4.7877 & TRN & \\
\hline CHEMBL1598549 & 688341 & 4.6 & 4.8145 & TRN & \\
\hline CHEMBL1460318 & 688341 & 4.4 & 5.1003 & TST & \\
\hline CHEMBL1442655 & 688341 & 5.9 & 4.9631 & TRN & \\
\hline CHEMBL1370872 & 688341 & 4.7 & 4.8566 & TRN & \\
\hline CHEMBL163970 & 688341 & 4.4 & 4.9977 & TRN & \\
\hline CHEMBL1372624 & 688341 & 5.4 & 4.9031 & TST & \\
\hline CHEMBL526034 & 688341 & 4.5 & 4.9865 & TST & \\
\hline CHEMBL1358252 & 688341 & 5.5 & 5.0665 & TRN & \\
\hline CHEMBL1372115 & 688341 & 4.9 & 4.8068 & TRN & \\
\hline CHEMBL1483419 & 688341 & 5.2 & 4.8964 & TRN & \\
\hline CHEMBL1490816 & 688341 & 4.5 & 4.8345 & TRN & \\
\hline
\end{tabular}




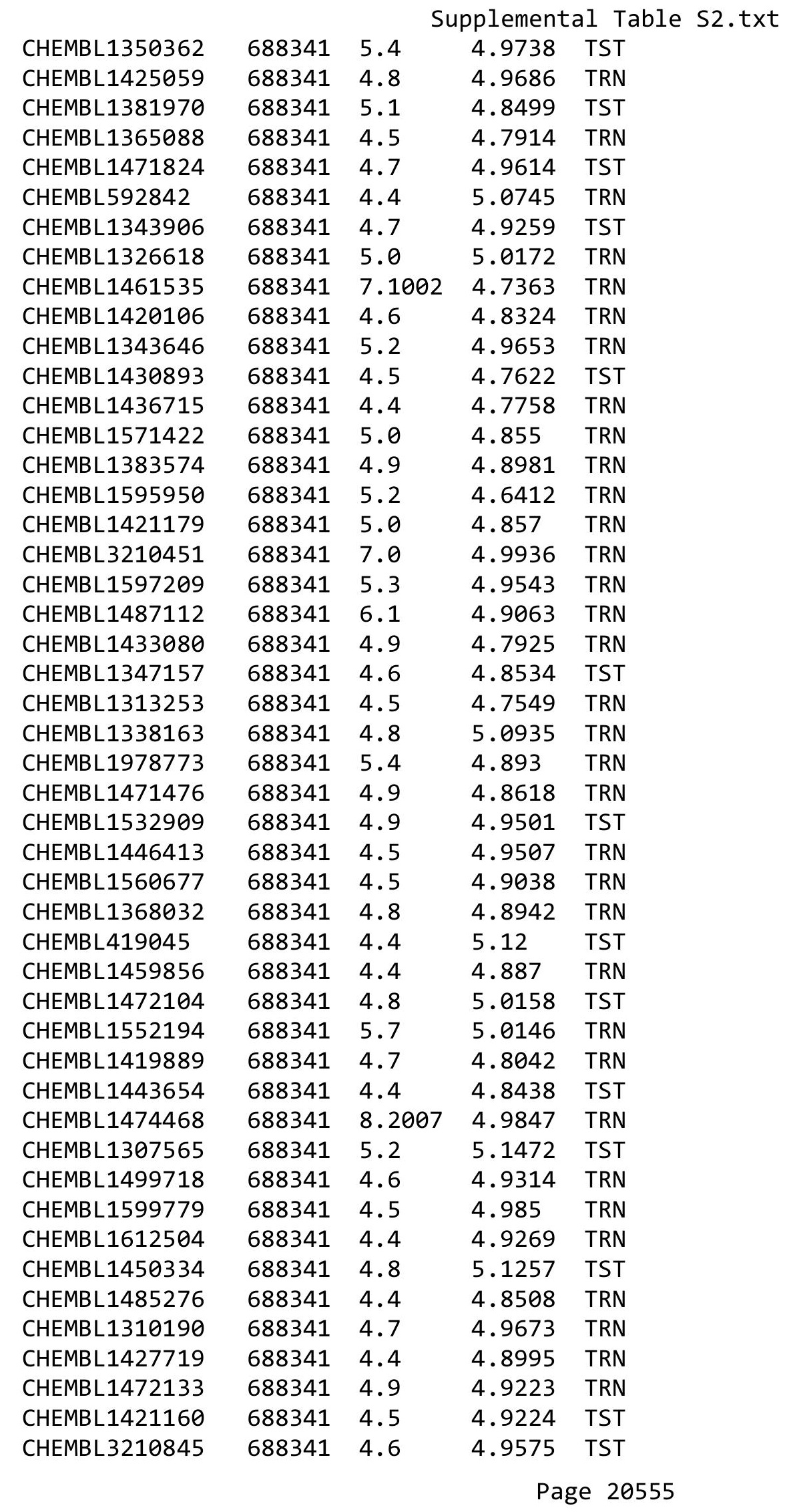




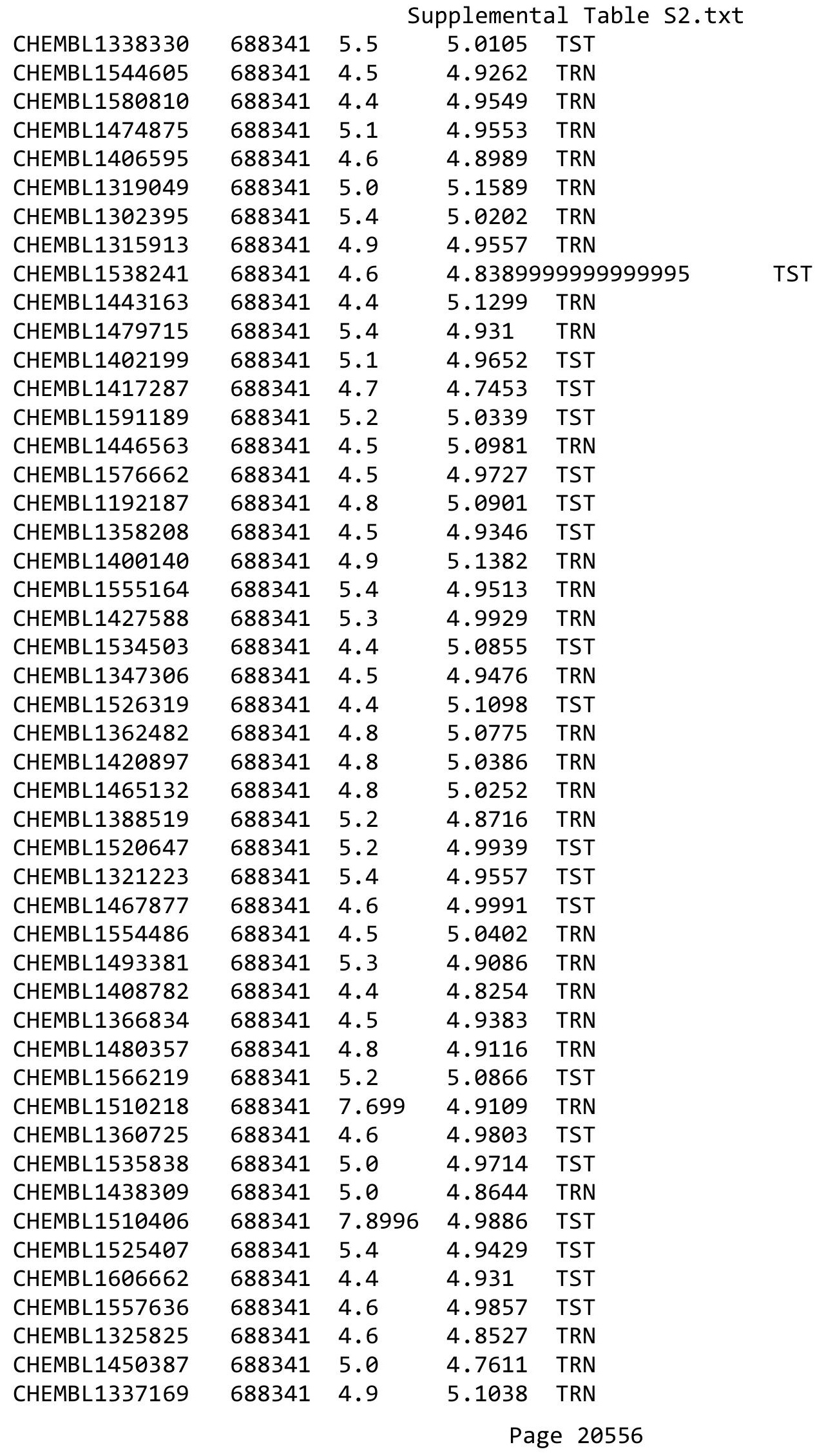




\begin{tabular}{|c|c|c|c|c|c|}
\hline \multicolumn{6}{|c|}{ Supplemental Table S2.txt } \\
\hline CHEMBL1583865 & 688341 & 4.6 & 4.9362 & TRN & \\
\hline CHEMBL1448251 & 688341 & 5.3 & 4.7519 & TRN & \\
\hline CHEMBL1420993 & 688341 & 5.2 & 4.7942 & TRN & \\
\hline CHEMBL1363109 & 688341 & 5.2 & 5.0962 & TRN & \\
\hline CHEMBL1351263 & 688341 & 4.8 & 5.0869 & TST & \\
\hline CHEMBL1452793 & 688341 & 4.7 & 4.9441 & TRN & \\
\hline CHEMBL 140 & 688341 & 6.0 & 5.1292 & TRN & \\
\hline CHEMBL1422946 & 688341 & 4.4 & 4.9717 & TST & \\
\hline CHEMBL1342901 & 688341 & 5.4 & 4.9064 & TRN & \\
\hline CHEMBL1503366 & 688341 & 4.7 & 4.7904 & TRN & \\
\hline CHEMBL1603812 & 688341 & 4.6 & 4.7948 & TRN & \\
\hline CHEMBL1519898 & 688341 & 4.6 & 5.0307 & TRN & \\
\hline CHEMBL1308058 & 688341 & 5.0 & 4.9708 & TRN & \\
\hline CHEMBL1410237 & 688341 & 6.1 & 5.1099 & TRN & \\
\hline CHEMBL1301656 & 688341 & 5.8 & 4.9175 & TST & \\
\hline CHEMBL1487963 & 688341 & 4.5 & 4.711 & TRN & \\
\hline CHEMBL1319229 & 688341 & 4.6 & 4.9768 & TRN & \\
\hline CHEMBL1412192 & 688341 & 4.4 & 4.938 & TRN & \\
\hline CHEMBL1524735 & 688341 & 4.5 & 4.9317 & TRN & \\
\hline CHEMBL1453299 & 688341 & 4.5 & 4.6903 & TRN & \\
\hline CHEMBL1444361 & 688341 & 4.9 & 4.9898 & TRN & \\
\hline CHEMBL1390434 & 688341 & 4.6 & 5.0231 & TRN & \\
\hline CHEMBL1416440 & 688341 & 4.9 & 4.8405 & TRN & \\
\hline CHEMBL1571018 & 688341 & 4.5 & 4.7706 & TRN & \\
\hline CHEMBL1569619 & 688341 & 4.7 & 5.0997 & TST & \\
\hline CHEMBL1579804 & 688341 & 7.0 & 4.8903 & TST & \\
\hline CHEMBL1352641 & 688341 & 6.1 & 4.96899 & 9999999999 & TRN \\
\hline CHEMBL1607693 & 688341 & 5.0 & 4.8839 & TRN & \\
\hline CHEMBL1575635 & 688341 & 4.4 & 4.9293 & TST & \\
\hline CHEMBL1426849 & 688341 & 5.5 & 4.9707 & TRN & \\
\hline CHEMBL1566779 & 688341 & 5.5 & 4.9337 & TST & \\
\hline CHEMBL1339536 & 688341 & 5.5 & 4.7146 & TRN & \\
\hline CHEMBL1333102 & 688341 & 4.7 & 4.9184 & TRN & \\
\hline CHEMBL1527995 & 688341 & 4.7 & 4.9495 & TST & \\
\hline CHEMBL1736239 & 688341 & 5.5 & 4.9563 & TST & \\
\hline CHEMBL1484261 & 688341 & 5.3 & 5.1637 & TRN & \\
\hline CHEMBL1335264 & 688341 & 4.6 & 4.9044 & TRN & \\
\hline CHEMBL1335045 & 688341 & 5.2 & 4.9221 & TST & \\
\hline CHEMBL1412538 & 688341 & 4.6 & 4.9057 & TST & \\
\hline CHEMBL1553373 & 688341 & 4.4 & 5.227 & TRN & \\
\hline CHEMBL1429381 & 688341 & 4.6 & 4.7439 & TRN & \\
\hline CHEMBL1300232 & 688341 & 6.1 & 4.9372 & TRN & \\
\hline CHEMBL1394464 & 688341 & 4.6 & 4.8722 & TST & \\
\hline CHEMBL1325178 & 688341 & 4.7 & 4.6971 & TRN & \\
\hline CHEMBL1308901 & 688341 & 5.4 & 5.0459 & TRN & \\
\hline CHEMBL1559578 & 688341 & 5.6 & 5.1609 & TRN & \\
\hline CHEMBL1430139 & 688341 & 4.5 & 4.8266 & TRN & \\
\hline CHEMBL1462869 & 688341 & 4.4 & 5.0297 & TST & \\
\hline
\end{tabular}




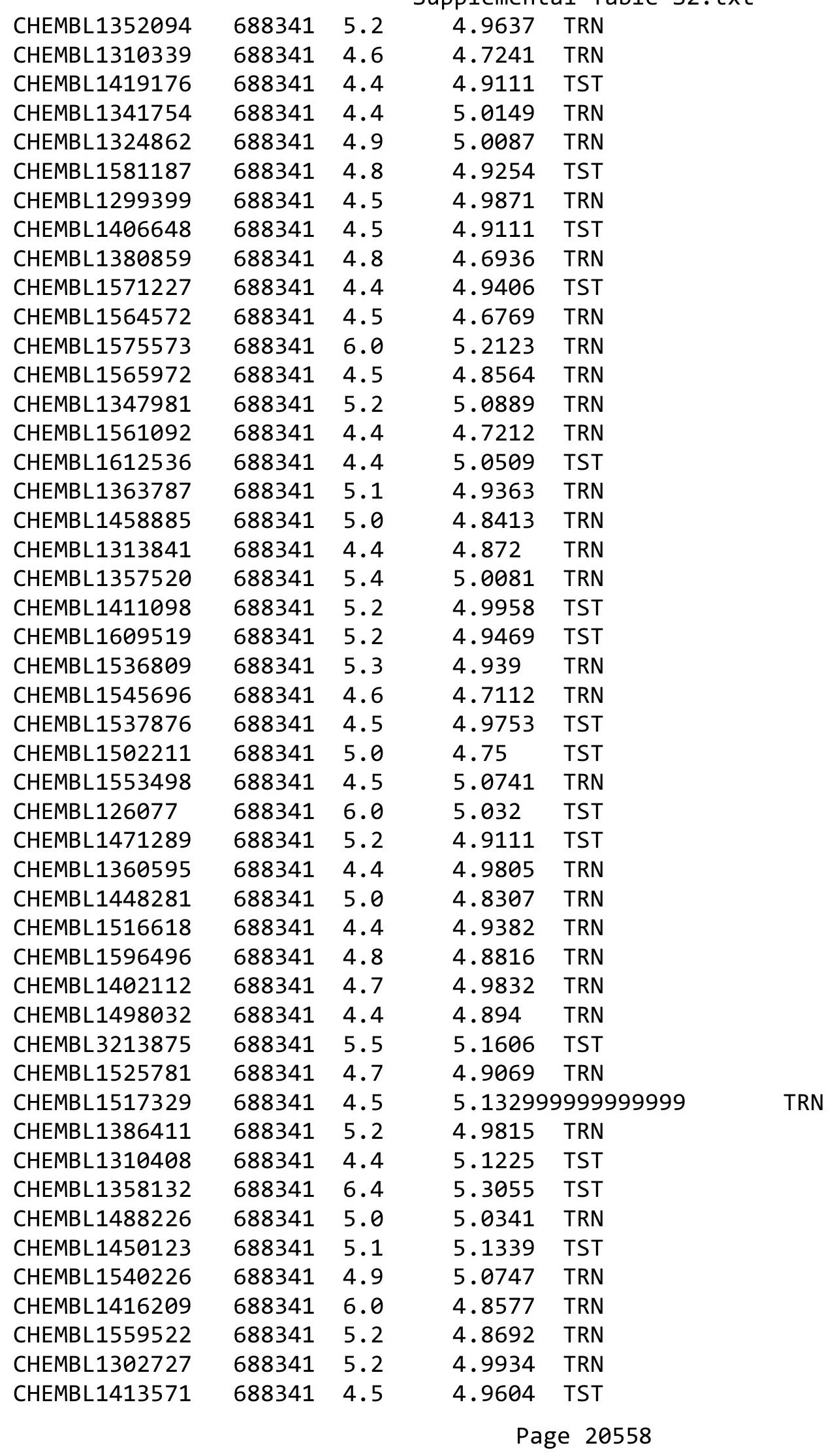




\begin{tabular}{|c|c|c|c|c|}
\hline \multicolumn{5}{|c|}{ Supplemental Table S2.txt } \\
\hline CHEMBL1333153 & 688341 & 4.4 & 5.0037 & TRN \\
\hline CHEMBL1400176 & 688341 & 4.5 & 4.6613 & TRN \\
\hline CHEMBL1399445 & 688341 & 4.8 & 4.7155 & TRN \\
\hline CHEMBL1369522 & 688341 & 5.2 & 4.9558 & TST \\
\hline CHEMBL1528069 & 688341 & 4.5 & 4.9753 & TST \\
\hline CHEMBL1497191 & 688341 & 4.4 & 4.9009 & TRN \\
\hline CHEMBL1557564 & 688341 & 4.6 & 5.1278 & TRN \\
\hline CHEMBL1304794 & 688341 & 4.5 & 5.0292 & TST \\
\hline CHEMBL1609952 & 688341 & 5.2 & 4.8744 & TRN \\
\hline CHEMBL1551321 & 688341 & 5.2 & 5.0173 & TRN \\
\hline CHEMBL1418494 & 688341 & 4.4 & 4.7809 & TRN \\
\hline CHEMBL1592556 & 688341 & 5.5 & 5.0629 & TRN \\
\hline CHEMBL1317633 & 688341 & 5.3 & 5.2534 & TRN \\
\hline CHEMBL1535690 & 688341 & 4.4 & 4.9231 & TRN \\
\hline CHEMBL1412900 & 688341 & 4.9 & 5.082 & TRN \\
\hline CHEMBL1606898 & 688341 & 4.5 & 4.8865 & TST \\
\hline CHEMBL1451728 & 688341 & 4.5 & 4.9298 & TRN \\
\hline CHEMBL1421619 & 688341 & 4.6 & 5.072 & TST \\
\hline CHEMBL1468652 & 688341 & 5.4 & 4.8737 & TRN \\
\hline CHEMBL1489236 & 688341 & 4.6 & 4.8966 & TST \\
\hline CHEMBL1385011 & 688341 & 4.9 & 4.6967 & TRN \\
\hline CHEMBL1528337 & 688341 & 4.4 & 4.8902 & TRN \\
\hline CHEMBL1447386 & 688341 & 4.7 & 4.8746 & TRN \\
\hline CHEMBL1602519 & 688341 & 4.4 & 5.0524 & TRN \\
\hline CHEMBL1399528 & 688341 & 4.8 & 4.9344 & TRN \\
\hline CHEMBL1493017 & 688341 & 5.2 & 4.8707 & TRN \\
\hline CHEMBL1439427 & 688341 & 4.4 & 4.8201 & TRN \\
\hline CHEMBL1425637 & 688341 & 4.5 & 4.7417 & TRN \\
\hline CHEMBL1392067 & 688341 & 5.0 & 4.856 & TRN \\
\hline CHEMBL1428162 & 688341 & 4.5 & 4.9024 & TRN \\
\hline CHEMBL1598414 & 688341 & 4.5 & 4.8695 & TRN \\
\hline CHEMBL1524640 & 688341 & 4.8 & 4.7968 & TST \\
\hline CHEMBL1313239 & 688341 & 5.2 & 5.0485 & TST \\
\hline CHEMBL1557919 & 688341 & 4.5 & 4.9027 & TRN \\
\hline CHEMBL1324727 & 688341 & 4.6 & 4.9783 & TRN \\
\hline CHEMBL1528604 & 688341 & 5.3 & 4.8922 & TRN \\
\hline CHEMBL1404884 & 688341 & 7.6003 & 5.1255 & TRN \\
\hline CHEMBL1595253 & 688341 & 4.4 & 4.9293 & TRN \\
\hline CHEMBL1613233 & 688341 & 4.9 & 4.9332 & TRN \\
\hline CHEMBL1256816 & 688341 & 4.4 & 5.1525 & TST \\
\hline CHEMBL1465543 & 688341 & 5.4 & 4.8108 & TST \\
\hline CHEMBL1451172 & 688341 & 5.4 & 5.0023 & TRN \\
\hline CHEMBL1348073 & 688341 & 5.5 & 4.9977 & TST \\
\hline CHEMBL428064 & 688341 & 5.0 & 4.9287 & TST \\
\hline CHEMBL1543857 & 688341 & 4.4 & 5.0332 & TRN \\
\hline CHEMBL1374687 & 688341 & 4.7 & 5.0192 & TST \\
\hline CHEMBL1256754 & 688341 & 4.9 & 5.1907 & TRN \\
\hline CHEMBL1532349 & 688341 & 4.6 & 4.9284 & TST \\
\hline
\end{tabular}




\begin{tabular}{|c|c|c|c|c|}
\hline \multicolumn{5}{|c|}{ Supplemental Table S2.txt } \\
\hline CHEMBL1359848 & 688341 & 4.8 & 4.8055 & TRN \\
\hline CHEMBL1447876 & 688341 & 4.6 & 4.942 & TRN \\
\hline CHEMBL1362542 & 688341 & 4.9 & 4.7909 & TRN \\
\hline CHEMBL1609626 & 688341 & 4.4 & 5.1262 & TRN \\
\hline CHEMBL1324415 & 688341 & 4.7 & 4.8623 & TRN \\
\hline CHEMBL1352504 & 688341 & 5.2 & 4.9544 & TRN \\
\hline CHEMBL1611982 & 688341 & 4.8 & 4.9327 & TRN \\
\hline CHEMBL1528419 & 688341 & 4.6 & 5.092 & TST \\
\hline CHEMBL1451908 & 688341 & 5.1 & 4.9879 & TRN \\
\hline CHEMBL1568834 & 688341 & 5.7 & 4.8282 & TST \\
\hline CHEMBL1610827 & 688341 & 4.5 & 5.0157 & TRN \\
\hline CHEMBL1443397 & 688341 & 5.2 & 4.8611 & TST \\
\hline CHEMBL1609846 & 688341 & 5.2 & 4.9198 & TRN \\
\hline CHEMBL1394874 & 688341 & 4.7 & 5.0456 & TRN \\
\hline CHEMBL1607125 & 688341 & 4.5 & 4.9604 & TST \\
\hline CHEMBL1487138 & 688341 & 5.2 & 4.9337 & TRN \\
\hline CHEMBL1496623 & 688341 & 4.6 & 4.8607 & TRN \\
\hline CHEMBL1431949 & 688341 & 4.5 & 4.852 & TRN \\
\hline CHEMBL1606835 & 688341 & 4.7 & 5.0638 & TST \\
\hline CHEMBL1595002 & 688341 & 4.9 & 5.0612 & TRN \\
\hline CHEMBL1409920 & 688341 & 6.2 & 5.0115 & TST \\
\hline CHEMBL1575532 & 688341 & 5.4 & 4.9452 & TRN \\
\hline CHEMBL1468993 & 688341 & 5.2 & 4.9603 & TST \\
\hline CHEMBL1607736 & 688341 & 4.6 & 5.0018 & TST \\
\hline CHEMBL1321749 & 688341 & 4.5 & 4.8467 & TRN \\
\hline CHEMBL1534811 & 688341 & 4.9 & 5.1753 & TRN \\
\hline CHEMBL1437778 & 688341 & 5.4 & 4.9918 & TRN \\
\hline CHEMBL1596063 & 688341 & 4.8 & 5.0339 & TST \\
\hline CHEMBL1506830 & 688341 & 4.8 & 4.9581 & TST \\
\hline CHEMBL1524664 & 688341 & 4.4 & 4.9593 & TRN \\
\hline CHEMBL1402435 & 688341 & 4.7 & 5.0611 & TST \\
\hline CHEMBL1333857 & 688341 & 4.8 & 5.0398 & TRN \\
\hline CHEMBL1329965 & 688341 & 4.5 & 4.8736 & TRN \\
\hline CHEMBL1451932 & 688341 & 4.6 & 4.8366 & TRN \\
\hline CHEMBL69086 & 688341 & 4.4 & 5.0597 & TST \\
\hline CHEMBL1564368 & 688341 & 4.7 & 5.0677 & TRN \\
\hline CHEMBL1300270 & 688341 & 4.8 & 4.7749 & TRN \\
\hline CHEMBL1455926 & 688341 & 4.4 & 5.1112 & TRN \\
\hline CHEMBL1486887 & 688341 & 4.5 & 4.7713 & TRN \\
\hline CHEMBL1581045 & 688341 & 4.7 & 4.7616 & TRN \\
\hline CHEMBL1482847 & 688341 & 5.2 & 5.0653 & TRN \\
\hline CHEMBL1339052 & 688341 & 4.4 & 5.0135 & TST \\
\hline CHEMBL1406206 & 688341 & 5.3 & 5.0636 & TRN \\
\hline CHEMBL1353637 & 688341 & 5.0 & 4.7873 & TRN \\
\hline CHEMBL1476741 & 688341 & 4.4 & 4.9306 & TRN \\
\hline CHEMBL1380900 & 688341 & 5.1 & 4.9451 & TRN \\
\hline CHEMBL1610903 & 688341 & 4.8 & 4.8263 & TRN \\
\hline CHEMBL1389378 & 688341 & 5.2 & 4.8994 & TRN \\
\hline
\end{tabular}




\begin{tabular}{|c|c|c|c|c|}
\hline \multicolumn{5}{|c|}{ Supplemental Table S2.txt } \\
\hline CHEMBL3184468 & 688341 & 4.8 & 5.0681 & TST \\
\hline CHEMBL1560562 & 688341 & 4.5 & 4.7839 & TRN \\
\hline CHEMBL1378995 & 688341 & 4.9 & 4.7535 & TRN \\
\hline CHEMBL1354281 & 688341 & 5.0 & 5.1582 & TRN \\
\hline CHEMBL1458917 & 688341 & 4.4 & 4.9673 & TST \\
\hline CHEMBL1558676 & 688341 & 4.7 & 4.9667 & TST \\
\hline CHEMBL1376888 & 688341 & 4.5 & 4.5975 & TRN \\
\hline CHEMBL1377511 & 688341 & 4.8 & 4.7249 & TRN \\
\hline CHEMBL1488179 & 688341 & 5.9 & 5.0234 & TRN \\
\hline CHEMBL1610686 & 688341 & 5.2 & 4.8453 & TRN \\
\hline CHEMBL1533466 & 688341 & 4.5 & 5.0249 & TRN \\
\hline CHEMBL490756 & 688341 & 4.6 & 4.9654 & TRN \\
\hline CHEMBL1462315 & 688341 & 4.5 & 4.9872 & TST \\
\hline CHEMBL1355840 & 688341 & 5.2 & 5.0912 & TRN \\
\hline CHEMBL1372733 & 688341 & 5.4 & 5.0424 & TRN \\
\hline CHEMBL1517099 & 688341 & 4.8 & 5.0827 & TST \\
\hline CHEMBL1478530 & 688341 & 7.8996 & 5.3073 & TST \\
\hline CHEMBL1598228 & 688341 & 5.4 & 5.1339 & TST \\
\hline CHEMBL1529490 & 688341 & 4.8 & 4.9774 & TRN \\
\hline CHEMBL1422256 & 688341 & 5.0 & 4.7807 & TRN \\
\hline CHEMBL1370445 & 688341 & 4.8 & 4.7843 & TRN \\
\hline CHEMBL1402400 & 688341 & 4.6 & 4.7174 & TRN \\
\hline CHEMBL582444 & 688341 & 5.1 & 5.2924 & TST \\
\hline CHEMBL33171 & 688341 & 5.3 & 5.07 & TRN \\
\hline CHEMBL1362314 & 688341 & 4.5 & 4.9868 & TRN \\
\hline CHEMBL1527886 & 688341 & 5.4 & 5.0295 & TRN \\
\hline CHEMBL1608733 & 688341 & 4.9 & 4.7997 & TRN \\
\hline CHEMBL1606811 & 688341 & 4.4 & 4.9737 & TRN \\
\hline CHEMBL1452784 & 688341 & 4.5 & 4.8506 & TRN \\
\hline CHEMBL1450404 & 688341 & 6.1 & 4.9803 & TST \\
\hline CHEMBL1354614 & 688341 & 5.2 & 5.0721 & TRN \\
\hline CHEMBL1439255 & 688341 & 4.9 & 4.7373 & TRN \\
\hline CHEMBL1574543 & 688341 & 5.5 & 5.0561 & TRN \\
\hline CHEMBL1351630 & 688341 & 5.0 & 4.7853 & TRN \\
\hline CHEMBL1438566 & 688341 & 6.0 & 5.0836 & TRN \\
\hline CHEMBL1407552 & 688341 & 5.2 & 4.8633 & TST \\
\hline CHEMBL 1409676 & 688341 & 5.1 & 4.9546 & TST \\
\hline CHEMBL1408518 & 688341 & 4.7 & 4.9884 & TRN \\
\hline CHEMBL1595300 & 688341 & 4.4 & 4.8861 & TRN \\
\hline CHEMBL3392072 & 688341 & 4.5 & 5.2657 & TRN \\
\hline CHEMBL1549600 & 688341 & 5.2 & 5.0833 & TRN \\
\hline CHEMBL1469625 & 688341 & 4.5 & 4.9674 & TRN \\
\hline CHEMBL1393919 & 688341 & 4.5 & 4.7065 & TRN \\
\hline CHEMBL 1455980 & 688341 & 5.4 & 4.7852 & TST \\
\hline CHEMBL1518722 & 688341 & 5.2 & 4.851 & TST \\
\hline CHEMBL1355146 & 688341 & 5.2 & 5.0864 & TRN \\
\hline CHEMBL1608621 & 688341 & 6.3 & 4.9939 & TRN \\
\hline CHEMBL1346094 & 688341 & 4.6 & 4.8808 & TST \\
\hline
\end{tabular}




\begin{tabular}{|c|c|c|c|c|c|}
\hline \multicolumn{6}{|c|}{ Supplemental Table S2.txt } \\
\hline CHEMBL1493329 & 688341 & 5.2 & 4.7987 & TRN & \\
\hline CHEMBL1520624 & 688341 & 5.2 & 4.8859 & TRN & \\
\hline CHEMBL1387519 & 688341 & 4.9 & 4.942 & TRN & \\
\hline CHEMBL1612736 & 688341 & 4.5 & 4.8617 & TRN & \\
\hline CHEMBL1335371 & 688341 & 4.6 & 5.1306 & TRN & \\
\hline CHEMBL1317900 & 688341 & 4.8 & 5.17 & TRN & \\
\hline CHEMBL1507657 & 688341 & 4.8 & 4.8567 & TST & \\
\hline CHEMBL1562069 & 688341 & 4.6 & 4.9634 & TRN & \\
\hline CHEMBL1474633 & 688341 & 4.5 & 5.0882 & TRN & \\
\hline CHEMBL1489244 & 688341 & 5.7 & 4.9514 & TRN & \\
\hline CHEMBL1354561 & 688341 & 4.7 & 4.9973 & TRN & \\
\hline CHEMBL1417800 & 688341 & 4.6 & 5.1879 & TST & \\
\hline CHEMBL1387850 & 688341 & 4.4 & 4.987 & TRN & \\
\hline CHEMBL1421053 & 688341 & 4.5 & 4.9035 & TRN & \\
\hline CHEMBL1497235 & 688341 & 4.6 & 4.888 & TST & \\
\hline CHEMBL1473754 & 688341 & 5.7 & 4.9801 & TRN & \\
\hline CHEMBL1604556 & 688341 & 5.2 & 4.7628 & TRN & \\
\hline CHEMBL1486638 & 688341 & 4.4 & 5.1645 & TST & \\
\hline CHEMBL1609198 & 688341 & 6.7001 & 5.0705 & TRN & \\
\hline CHEMBL1340795 & 688341 & 4.7 & 4.9591 & TRN & \\
\hline CHEMBL1361406 & 688341 & 5.0 & 5.1012 & TRN & \\
\hline CHEMBL1591336 & 688341 & 4.8 & 4.85800 & 00000000005 & TRN \\
\hline CHEMBL3211567 & 688341 & 4.8 & 4.9879 & TST & \\
\hline CHEMBL1340896 & 688341 & 4.5 & 4.9099 & TST & \\
\hline CHEMBL1567179 & 688341 & 4.4 & 5.11100 & 2000000001 & TRN \\
\hline CHEMBL1425267 & 688341 & 5.6 & 4.8941 & TRN & \\
\hline CHEMBL3191187 & 688341 & 5.0 & 5.0051 & TRN & \\
\hline CHEMBL1606924 & 688341 & 4.6 & 5.0695 & TST & \\
\hline CHEMBL1524331 & 688341 & 5.2 & 5.1573 & TRN & \\
\hline CHEMBL1509745 & 688341 & 6.0 & 4.9395 & TST & \\
\hline CHEMBL1486233 & 688341 & 4.4 & 4.868 & TRN & \\
\hline CHEMBL1489360 & 688341 & 4.5 & 4.8733 & TRN & \\
\hline CHEMBL1344409 & 688341 & 4.5 & 4.8196 & TRN & \\
\hline CHEMBL1528664 & 688341 & 4.7 & 4.8502 & TRN & \\
\hline CHEMBL1362206 & 688341 & 4.6 & 4.9742 & TST & \\
\hline CHEMBL1485979 & 688341 & 4.4 & 4.8604 & TRN & \\
\hline CHEMBL335900 & 688341 & 5.5 & 5.2252 & TRN & \\
\hline CHEMBL1305310 & 688341 & 4.5 & 4.7407 & TRN & \\
\hline CHEMBL1585023 & 688341 & 4.4 & 4.8918 & TRN & \\
\hline CHEMBL1482002 & 688341 & 5.0 & 4.8535 & TRN & \\
\hline CHEMBL1532177 & 688341 & 4.5 & 4.7194 & TRN & \\
\hline CHEMBL1475737 & 688341 & 6.3 & 4.9659 & TRN & \\
\hline CHEMBL1550834 & 688341 & 5.0 & 4.9457 & TRN & \\
\hline CHEMBL1573605 & 688341 & 4.6 & 4.8146 & TRN & \\
\hline CHEMBL1326920 & 688341 & 4.6 & 4.8168 & TRN & \\
\hline CHEMBL1549176 & 688341 & 5.0 & 5.1067 & TRN & \\
\hline CHEMBL1511361 & 688341 & 4.8 & 4.9112 & TRN & \\
\hline CHEMBL216504 & 688341 & 5.2 & 5.0236 & TST & \\
\hline
\end{tabular}




\begin{tabular}{|c|c|c|c|c|c|}
\hline \multicolumn{6}{|c|}{ Supplemental Table S2.txt } \\
\hline CHEMBL1499986 & 688341 & 4.8 & 4.958 & TRN & \\
\hline CHEMBL1304586 & 688341 & 4.4 & 4.7571 & TRN & \\
\hline CHEMBL1609183 & 688341 & 5.1 & 4.907 & TST & \\
\hline CHEMBL1505662 & 688341 & 5.5 & 5.1118 & TRN & \\
\hline CHEMBL1426676 & 688341 & 4.4 & 4.7444 & TRN & \\
\hline CHEMBL1430716 & 688341 & 5.3 & 4.9569 & TST & \\
\hline CHEMBL1532973 & 688341 & 4.6 & 4.8717 & TRN & \\
\hline CHEMBL1442247 & 688341 & 6.0 & 5.0497 & TRN & \\
\hline CHEMBL1448542 & 688341 & 4.4 & 4.9076 & TRN & \\
\hline CHEMBL1409763 & 688341 & 4.4 & 4.9242 & TRN & \\
\hline CHEMBL1442987 & 688341 & 4.8 & 5.106 & TRN & \\
\hline CHEMBL1566938 & 688341 & 5.3 & 4.7845 & TRN & \\
\hline CHEMBL1509309 & 688341 & 6.4 & 5.0125 & TST & \\
\hline CHEMBL1370720 & 688341 & 4.5 & 4.9795 & TST & \\
\hline CHEMBL1322270 & 688341 & 5.2 & 4.8658 & TRN & \\
\hline CHEMBL1301871 & 688341 & 4.5 & 4.8071 & TRN & \\
\hline CHEMBL1533139 & 688341 & 4.5 & 5.0212 & TRN & \\
\hline CHEMBL1613623 & 688341 & 4.8 & 5.0822 & TRN & \\
\hline CHEMBL1563455 & 688341 & 4.6 & 4.9248 & TRN & \\
\hline CHEMBL1568071 & 688341 & 4.8 & 5.2292 & TRN & \\
\hline CHEMBL1588609 & 688341 & 6.9 & 5.0227 & TST & \\
\hline CHEMBL405616 & 688341 & 4.7 & 4.835 & TRN & \\
\hline CHEMBL1411743 & 688341 & 6.3 & 5.1337 & TRN & \\
\hline CHEMBL1365783 & 688341 & 4.7 & 5.0215 & TRN & \\
\hline CHEMBL1567236 & 688341 & 5.4 & 5.1781 & TRN & \\
\hline CHEMBL1593504 & 688341 & 5.2 & 5.1805 & TRN & \\
\hline CHEMBL1504219 & 688341 & 4.9 & 5.0041 & TRN & \\
\hline CHEMBL1356336 & 688341 & 6.6 & 5.1766 & TRN & \\
\hline CHEMBL1306917 & 688341 & 4.5 & 5.0256 & TST & \\
\hline CHEMBL1421632 & 688341 & 4.8 & 4.8683 & TRN & \\
\hline CHEMBL1319909 & 688341 & 5.1 & 5.0502 & TST & \\
\hline CHEMBL1420531 & 688341 & 4.8 & 5.0176 & TRN & \\
\hline CHEMBL1348395 & 688341 & 4.8 & 4.7778 & TRN & \\
\hline CHEMBL1301130 & 688341 & 6.7001 & 4.8502 & TRN & \\
\hline CHEMBL1573063 & 688341 & 4.6 & 5.00899 & 99999999995 & TRN \\
\hline CHEMBL62 & 688341 & 4.6 & 4.987 & TRN & \\
\hline CHEMBL1469635 & 688341 & 4.4 & 5.1196 & TST & \\
\hline CHEMBL1384385 & 688341 & 4.4 & 5.0878 & TRN & \\
\hline CHEMBL 3212537 & 688341 & 5.2 & 4.8847 & TRN & \\
\hline CHEMBL1412263 & 688341 & 4.7 & 4.8876 & TRN & \\
\hline CHEMBL1541876 & 688341 & 4.6 & 4.8026 & TRN & \\
\hline CHEMBL1525979 & 688341 & 4.7 & 4.82 & TRN & \\
\hline CHEMBL1256869 & 688341 & 5.1 & 4.7864 & TST & \\
\hline CHEMBL1518599 & 688341 & 4.9 & 4.822 & TST & \\
\hline CHEMBL1531037 & 688341 & 4.7 & 4.7885 & TRN & \\
\hline CHEMBL1527332 & 688341 & 6.1 & 5.0089 & TRN & \\
\hline CHEMBL1332471 & 688341 & 5.5 & 5.1863 & TRN & \\
\hline CHEMBL395269 & 688341 & 5.2 & 4.9953 & TRN & \\
\hline
\end{tabular}




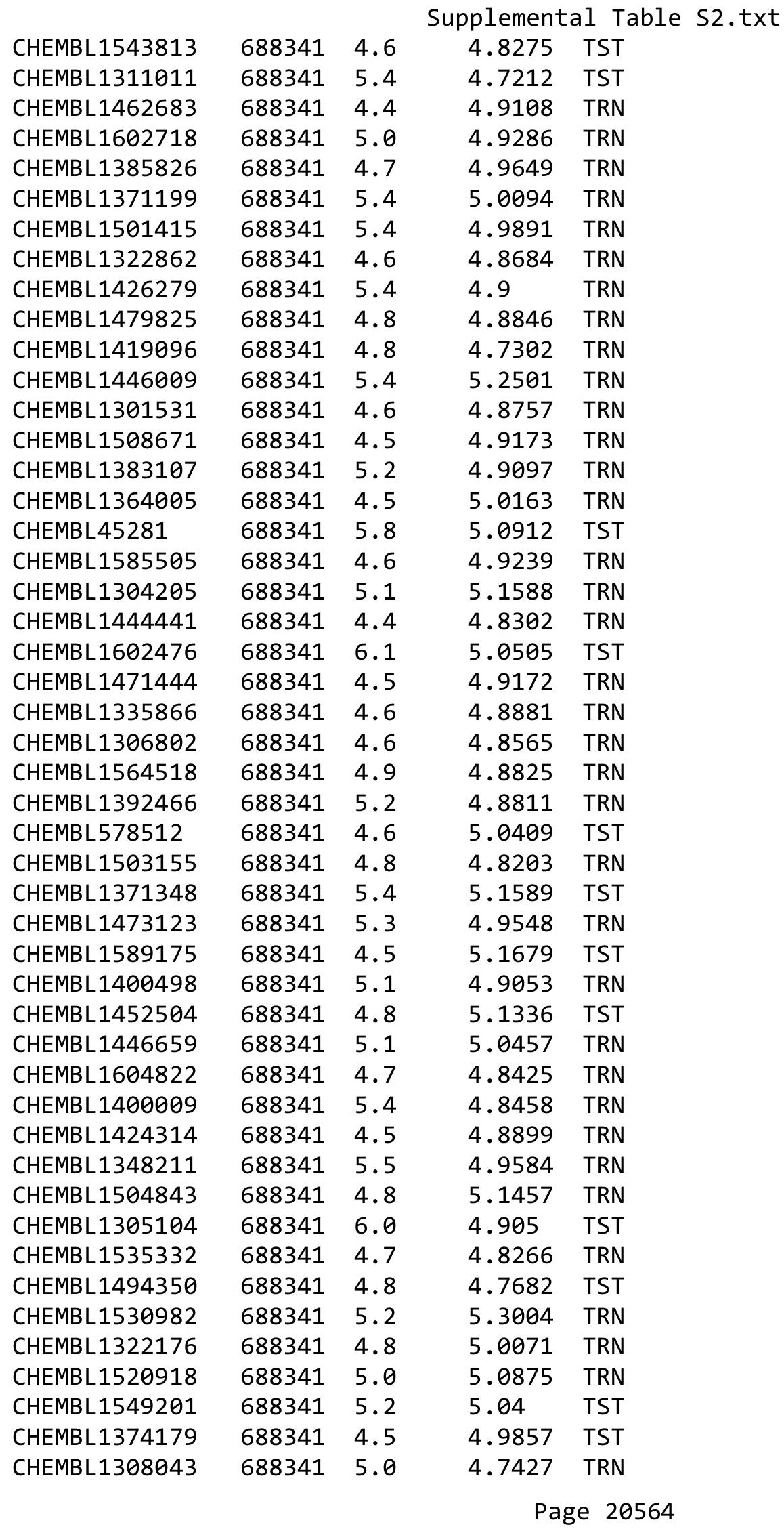




\begin{tabular}{|c|c|c|c|c|}
\hline & & & & \\
\hline CHEMBL1361876 & 688341 & 5.9 & 4.9199 & TRN \\
\hline CHEMBL1598686 & 688341 & 4.6 & 4.8943 & TRN \\
\hline CHEMBL1510347 & 688341 & 4.8 & 4.9117 & TST \\
\hline CHEMBL 328710 & 688341 & 6.0 & 5.0892 & TST \\
\hline CHEMBL1491340 & 688341 & 4.5 & 5.2041 & TST \\
\hline CHEMBL1413235 & 688341 & 4.7 & 4.7685 & TRN \\
\hline CHEMBL1479729 & 688341 & 5.0 & 4.9782 & TRN \\
\hline CHEMBL1563648 & 688341 & 4.5 & 4.8138 & TRN \\
\hline CHEMBL1353922 & 688341 & 5.2 & 4.8377 & TRN \\
\hline CHEMBL1460426 & 688341 & 4.4 & 4.9919 & TRN \\
\hline CHEMBL1418024 & 688341 & 4.5 & 5.1327 & TST \\
\hline CHEMBL1338618 & 688341 & 4.5 & 4.7609 & TRN \\
\hline CHEMBL1593545 & 688341 & 5.2 & 5.209 & TRN \\
\hline CHEMBL3193715 & 688341 & 5.4 & 4.9043 & TST \\
\hline CHEMBL3193785 & 688341 & 5.3 & 4.9817 & TST \\
\hline CHEMBL1411681 & 688341 & 5.2 & 4.7611 & TRN \\
\hline CHEMBL1595583 & 688341 & 4.5 & 4.9062 & TRN \\
\hline CHEMBL1321566 & 688341 & 4.6 & 4.9266 & TRN \\
\hline CHEMBL1607966 & 688341 & 5.6 & 4.8692 & TRN \\
\hline CHEMBL1560952 & 688341 & 4.5 & 5.053 & TST \\
\hline CHEMBL1528790 & 688341 & 4.9 & 4.9055 & TRN \\
\hline CHEMBL1412076 & 688341 & 5.4 & 4.8378 & TST \\
\hline CHEMBL1521594 & 688341 & 4.8 & 4.6957 & TRN \\
\hline CHEMBL1493825 & 688341 & 4.7 & 4.9836 & TRN \\
\hline CHEMBL1520615 & 688341 & 5.3 & 5.0619 & TST \\
\hline CHEMBL1481781 & 688341 & 6.4 & 5.013 & TRN \\
\hline CHEMBL1409619 & 688341 & 4.4 & 4.7753 & TRN \\
\hline CHEMBL1492495 & 688341 & 4.4 & 4.8409 & TRN \\
\hline CHEMBL1330034 & 688341 & 4.7 & 4.8138 & TRN \\
\hline CHEMBL1325495 & 688341 & 4.6 & 4.7002 & TRN \\
\hline CHEMBL389390 & 688341 & 6.0 & 5.1526 & TRN \\
\hline CHEMBL1540280 & 688341 & 4.8 & 4.9284 & TRN \\
\hline CHEMBL1460192 & 688341 & 4.4 & 5.1767 & TST \\
\hline CHEMBL1407030 & 688341 & 4.4 & 5.0221 & TRN \\
\hline CHEMBL1379708 & 688341 & 4.6 & 4.8539 & TRN \\
\hline CHEMBL1352318 & 688341 & 4.6 & 4.9508 & TRN \\
\hline CHEMBL1456465 & 688341 & 4.8 & 4.9176 & TST \\
\hline CHEMBL1399001 & 688341 & 4.7 & 4.7685 & TRN \\
\hline CHEMBL1343333 & 688341 & 4.5 & 4.8794 & TRN \\
\hline CHEMBL1566950 & 688341 & 4.4 & 4.877 & TST \\
\hline CHEMBL1332486 & 688341 & 4.7 & 4.8924 & TST \\
\hline CHEMBL1429079 & 688341 & 4.5 & 4.9892 & TRN \\
\hline CHEMBL1332367 & 688341 & 4.6 & 4.8731 & TRN \\
\hline CHEMBL1557436 & 688341 & 4.4 & 4.9349 & TST \\
\hline CHEMBL1463264 & 688341 & 4.8 & 4.9097 & TRN \\
\hline CHEMBL1518987 & 688341 & 4.5 & 4.6096 & TRN \\
\hline CHEMBL1581430 & 688341 & 4.9 & 5.1602 & TST \\
\hline CHEMBL1414084 & 688341 & 4.7 & 4.9498 & TST \\
\hline
\end{tabular}




\begin{tabular}{|c|c|c|c|c|}
\hline & & & & $a \perp 1 a$ \\
\hline CHEMBL1565777 & 688341 & 4.5 & 4.8999 & TRN \\
\hline CHEMBL1528477 & 688341 & 5.6 & 4.9503 & TRN \\
\hline CHEMBL1464394 & 688341 & 5.2 & 4.834 & TST \\
\hline CHEMBL1607965 & 688341 & 4.9 & 4.9813 & TRN \\
\hline CHEMBL1391847 & 688341 & 4.6 & 5.0321 & TRN \\
\hline CHEMBL1400836 & 688341 & 4.8 & 5.0393 & TRN \\
\hline CHEMBL1609115 & 688341 & 5.6 & 4.9687 & TST \\
\hline CHEMBL1323579 & 688341 & 4.8 & 5.0036 & TRN \\
\hline CHEMBL1521263 & 688341 & 4.9 & 4.9347 & TST \\
\hline CHEMBL1595905 & 688341 & 4.6 & 4.734 & TRN \\
\hline CHEMBL1426529 & 688341 & 4.4 & 4.8923 & TRN \\
\hline CHEMBL1599836 & 688341 & 4.4 & 4.8267 & TRN \\
\hline CHEMBL1525880 & 688341 & 5.4 & 5.0642 & TST \\
\hline CHEMBL1381039 & 688341 & 4.4 & 4.8596 & TRN \\
\hline CHEMBL1593663 & 688341 & 6.0 & 5.2519 & TRN \\
\hline CHEMBL1507052 & 688341 & 4.7 & 4.8493 & TRN \\
\hline CHEMBL1438667 & 688341 & 4.7 & 5.0078 & TRN \\
\hline CHEMBL1545132 & 688341 & 5.3 & 5.0548 & TRN \\
\hline CHEMBL1349867 & 688341 & 5.2 & 4.6765 & TRN \\
\hline CHEMBL1498135 & 688341 & 4.5 & 4.7837 & TRN \\
\hline CHEMBL1456269 & 688341 & 4.5 & 4.8905 & TRN \\
\hline CHEMBL1530684 & 688341 & 5.6 & 5.1972 & TRN \\
\hline CHEMBL1434895 & 688341 & 4.4 & 5.0265 & TRN \\
\hline CHEMBL1428942 & 688341 & 5.8 & 5.0157 & TRN \\
\hline CHEMBL1363142 & 688341 & 5.9 & 5.1094 & TRN \\
\hline CHEMBL 286721 & 688341 & 4.9 & 5.1641 & TST \\
\hline CHEMBL1535610 & 688341 & 4.6 & 4.831 & TRN \\
\hline CHEMBL1585095 & 688341 & 5.4 & 4.9264 & TRN \\
\hline CHEMBL1332915 & 688341 & 4.6 & 4.9086 & TRN \\
\hline CHEMBL1490386 & 688341 & 4.7 & 5.1123 & TRN \\
\hline CHEMBL1462904 & 688341 & 5.3 & 5.13 & TRN \\
\hline CHEMBL1417368 & 688341 & 4.6 & 4.8618 & TRN \\
\hline CHEMBL1441745 & 688341 & 5.8 & 4.9183 & TRN \\
\hline CHEMBL1360489 & 688341 & 4.5 & 5.0413 & TRN \\
\hline CHEMBL1386383 & 688341 & 4.4 & 5.0822 & TRN \\
\hline CHEMBL1409307 & 688341 & 4.5 & 4.8132 & TRN \\
\hline CHEMBL1386716 & 688341 & 5.2 & 4.9686 & TRN \\
\hline CHEMBL1594781 & 688341 & 4.8 & 4.8854 & TRN \\
\hline CHEMBL1327906 & 688341 & 4.6 & 4.8029 & TRN \\
\hline CHEMBL1448511 & 688341 & 5.4 & 5.0296 & TRN \\
\hline CHEMBL1538508 & 688341 & 4.4 & 4.8964 & TRN \\
\hline CHEMBL1363381 & 688341 & 6.6 & 4.9223 & TRN \\
\hline CHEMBL1321885 & 688341 & 4.5 & 4.8335 & TRN \\
\hline CHEMBL1391377 & 688341 & 4.8 & 4.9306 & TST \\
\hline CHEMBL1603491 & 688341 & 4.4 & 5.0811 & TRN \\
\hline CHEMBL1455209 & 688341 & 4.4 & 4.8328 & TRN \\
\hline CHEMBL1386257 & 688341 & 4.8 & 4.9209 & TST \\
\hline CHEMBL1302741 & 688341 & 4.4 & 4.8147 & TST \\
\hline
\end{tabular}




\begin{tabular}{|c|c|c|c|c|c|}
\hline \multirow{3}{*}{$\begin{array}{l}\text { CHEMBL1364362 } \\
\text { CHEMBL1493623 }\end{array}$} & \multirow{3}{*}{$\begin{array}{l}688341 \\
688341\end{array}$} & \multicolumn{4}{|c|}{ Supplemental Table S2.txt } \\
\hline & & 5.2 & 4.8889 & 9999999999 & TRN \\
\hline & & 5.7 & 4.919 & TST & \\
\hline CHEMBL3199884 & 688341 & 4.4 & 5.0831 & TST & \\
\hline CHEMBL1418209 & 688341 & 4.5 & 4.7297 & TRN & \\
\hline CHEMBL1544736 & 688341 & 5.3 & 5.0191 & TST & \\
\hline CHEMBL1353065 & 688341 & 4.8 & 4.8704 & TRN & \\
\hline CHEMBL1321132 & 688341 & 4.6 & 4.8648 & TRN & \\
\hline CHEMBL1534514 & 688341 & 5.0 & 4.7227 & TRN & \\
\hline CHEMBL1413071 & 688341 & 4.6 & 4.8315 & TRN & \\
\hline CHEMBL1310208 & 688341 & 6.0 & 4.9908 & TST & \\
\hline CHEMBL1542307 & 688341 & 5.7 & 4.6903 & TRN & \\
\hline CHEMBL1306110 & 688341 & 4.8 & 4.8928 & TRN & \\
\hline CHEMBL1362939 & 688341 & 4.5 & 4.8474 & TRN & \\
\hline CHEMBL1363801 & 688341 & 5.1 & 4.942 & TRN & \\
\hline CHEMBL1576666 & 688341 & 4.5 & 4.8591 & TST & \\
\hline CHEMBL1468353 & 688341 & 4.7 & 5.0093 & TRN & \\
\hline CHEMBL1463699 & 688341 & 4.8 & 4.9557 & TRN & \\
\hline CHEMBL1577615 & 688341 & 5.5 & 5.1764 & TRN & \\
\hline CHEMBL1599665 & 688341 & 4.7 & 5.008 & TRN & \\
\hline CHEMBL1417338 & 688341 & 4.8 & 4.8826 & TRN & \\
\hline CHEMBL1355835 & 688341 & 5.4 & 5.0075 & TRN & \\
\hline CHEMBL1556539 & 688341 & 4.6 & 4.7863 & TRN & \\
\hline CHEMBL1447549 & 688341 & 4.6 & 4.7715 & TRN & \\
\hline CHEMBL1299531 & 688341 & 4.4 & 4.8908 & TRN & \\
\hline CHEMBL1599147 & 688341 & 5.1 & 5.069 & TRN & \\
\hline CHEMBL1604542 & 688341 & 4.4 & 4.769 & TRN & \\
\hline CHEMBL1309684 & 688341 & 4.8 & 4.8621 & TRN & \\
\hline CHEMBL1525784 & 688341 & 5.0 & 4.9239 & TRN & \\
\hline CHEMBL1585541 & 688341 & 5.5 & 4.9603 & TRN & \\
\hline CHEMBL1593269 & 688341 & 5.5 & 5.1545 & TRN & \\
\hline CHEMBL1435079 & 688341 & 5.6 & 4.9984 & TRN & \\
\hline CHEMBL1435252 & 688341 & 4.8 & 5.0058 & TRN & \\
\hline CHEMBL3207899 & 688341 & 5.4 & 5.1501 & TST & \\
\hline CHEMBL1311755 & 688341 & 4.8 & 5.0765 & TST & \\
\hline CHEMBL1372824 & 688341 & 4.7 & 4.9335 & TRN & \\
\hline CHEMBL1529415 & 688341 & 5.3 & 4.9172 & TRN & \\
\hline CHEMBL1544334 & 688341 & 5.6 & 4.8206 & TRN & \\
\hline CHEMBL1331632 & 688341 & 4.7 & 4.9536 & TRN & \\
\hline CHEMBL1313005 & 688341 & 4.5 & 4.9839 & TST & \\
\hline CHEMBL185885 & 688341 & 5.1 & 5.0061 & TST & \\
\hline CHEMBL1302867 & 688341 & 4.6 & 5.0419 & TST & \\
\hline CHEMBL1390841 & 688341 & 5.2 & 4.8246 & TRN & \\
\hline CHEMBL375629 & 688341 & 4.4 & 5.051 & TRN & \\
\hline CHEMBL1471728 & 688341 & 4.6 & 4.9524 & TRN & \\
\hline CHEMBL1558048 & 688341 & 4.5 & 4.8961 & TRN & \\
\hline CHEMBL1482889 & 688341 & 4.8 & 4.7561 & TRN & \\
\hline CHEMBL1481297 & 688341 & 5.3 & 4.9119 & TRN & \\
\hline CHEMBL1470619 & 688341 & 4.8 & 4.9709 & TRN & \\
\hline
\end{tabular}




\begin{tabular}{|c|c|c|c|c|c|}
\hline \\
\hline CHEMBL1604288 & 688341 & 4.7 & 5.0444 & TRN & \\
\hline CHEMBL1453244 & 688341 & 5.5 & 5.1435 & TRN & \\
\hline CHEMBL1469134 & 688341 & 5.1 & 4.9003 & TST & \\
\hline CHEMBL1546986 & 688341 & 5.9 & 4.9746 & TST & \\
\hline CHEMBL1519736 & 688341 & 4.6 & 4.7796 & TRN & \\
\hline CHEMBL1570016 & 688341 & 4.9 & 4.9013 & TRN & \\
\hline CHEMBL1467611 & 688341 & 4.7 & 4.9742 & TRN & \\
\hline CHEMBL1601630 & 688341 & 5.2 & 5.2034 & TRN & \\
\hline CHEMBL1469915 & 688341 & 4.8 & 5.0262 & TST & \\
\hline CHEMBL1608269 & 688341 & 5.4 & 4.9471 & TRN & \\
\hline CHEMBL3210205 & 688341 & 6.5 & 5.2557 & TST & \\
\hline CHEMBL1365000 & 688341 & 4.6 & 4.9139 & TRN & \\
\hline CHEMBL1566132 & 688341 & 4.4 & 5.1311 & TST & \\
\hline CHEMBL1328045 & 688341 & 4.8 & 4.83 & TRN & \\
\hline CHEMBL1399394 & 688341 & 4.8 & 4.9276 & TRN & \\
\hline CHEMBL1570008 & 688341 & 4.7 & 4.8688 & TRN & \\
\hline CHEMBL1540498 & 688341 & 4.6 & 4.9904 & TRN & \\
\hline CHEMBL 1557078 & 688341 & 4.4 & 4.9081 & TRN & \\
\hline CHEMBL1375229 & 688341 & 4.4 & 5.1438 & TRN & \\
\hline CHEMBL1535790 & 688341 & 5.3 & 5.0166 & TRN & \\
\hline CHEMBL1362304 & 688341 & 4.7 & 5.0085 & TRN & \\
\hline CHEMBL1496811 & 688341 & 4.6 & 4.908 & TRN & \\
\hline CHEMBL1509281 & 688341 & 4.8 & 4.7434 & TRN & \\
\hline CHEMBL1510397 & 688341 & 6.8 & 4.891 & TRN & \\
\hline CHEMBL1538976 & 688341 & 4.5 & 4.914 & TRN & \\
\hline CHEMBL1306731 & 688341 & 4.7 & 4.9088 & TST & \\
\hline CHEMBL1360322 & 688341 & 5.4 & 4.9059 & TRN & \\
\hline CHEMBL1308116 & 688341 & 4.8 & 4.801 & TRN & \\
\hline CHEMBL93496 & 688341 & 5.2 & 5.0876 & TST & \\
\hline CHEMBL1521937 & 688341 & 5.4 & 4.9714 & TRN & \\
\hline CHEMBL1529294 & 688341 & 5.3 & 4.9981 & TRN & \\
\hline CHEMBL1410676 & 688341 & 4.8 & 4.9761 & TRN & \\
\hline CHEMBL 1327772 & 688341 & 5.3 & 5.0276 & TRN & \\
\hline CHEMBL1424385 & 688341 & 5.3 & 4.863 & TRN & \\
\hline CHEMBL1569961 & 688341 & 5.2 & 5.0819 & TRN & \\
\hline CHEMBL1603598 & 688341 & 6.4 & 5.0494 & TST & \\
\hline CHEMBL1325831 & 688341 & 4.5 & 4.8929 & TST & \\
\hline CHEMBL1415251 & 688341 & 5.1 & 4.9557 & TST & \\
\hline CHEMBL1313118 & 688341 & 5.2 & 5.09399 & 9999999999 & TRN \\
\hline CHEMBL1345225 & 688341 & 4.6 & 4.9886 & TRN & \\
\hline CHEMBL1563833 & 688341 & 5.4 & 4.9757 & TRN & \\
\hline CHEMBL1339542 & 688341 & 4.6 & 4.8054 & TST & \\
\hline CHEMBL1368924 & 688341 & 5.0 & 4.8887 & TRN & \\
\hline CHEMBL 84963 & 688341 & 6.3 & 4.959 & TST & \\
\hline CHEMBL1550141 & 688341 & 4.5 & 5.0263 & TST & \\
\hline CHEMBL1493710 & 688341 & 5.2 & 5.04 & TRN & \\
\hline CHEMBL1354123 & 688341 & 5.4 & 4.76699 & 99999999995 & TRN \\
\hline CHEMBL1436536 & 688341 & 5.4 & 5.1042 & TRN & \\
\hline
\end{tabular}




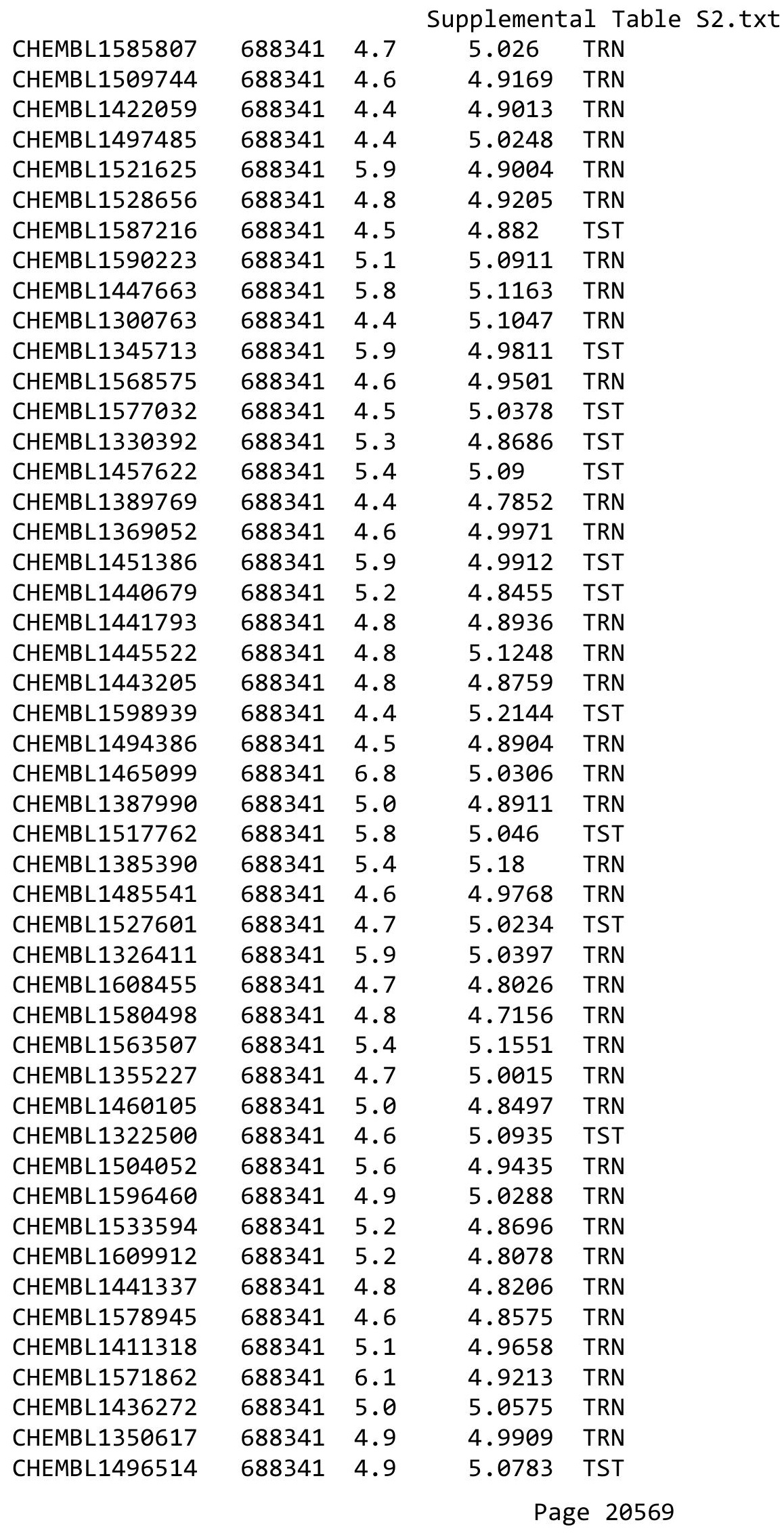




\begin{tabular}{|c|c|c|c|c|c|}
\hline \\
\hline CHEMBL1363413 & 688341 & 6.0 & 5.1119 & TRN & \\
\hline CHEMBL1504506 & 688341 & 5.0 & 5.0082 & TRN & \\
\hline CHEMBL1374846 & 688341 & 4.9 & 4.7985 & TRN & \\
\hline CHEMBL1417435 & 688341 & 4.5 & 4.8273 & TRN & \\
\hline CHEMBL1502008 & 688341 & 4.8 & 4.6831 & TRN & \\
\hline CHEMBL13670 & 688341 & 6.1 & 4.9325 & TST & \\
\hline CHEMBL1529174 & 688341 & 4.4 & 5.1173 & TST & \\
\hline CHEMBL1583200 & 688341 & 4.5 & 4.8148 & TRN & \\
\hline CHEMBL1425032 & 688341 & 4.5 & 4.8608 & TRN & \\
\hline CHEMBL1312246 & 688341 & 4.7 & 5.0054 & TRN & \\
\hline CHEMBL1365748 & 688341 & 4.4 & 4.8151 & TRN & \\
\hline CHEMBL1454093 & 688341 & 5.1 & 4.8694 & TST & \\
\hline CHEMBL1608831 & 688341 & 5.2 & 4.8482 & TST & \\
\hline CHEMBL1484266 & 688341 & 5.4 & 4.8498 & TRN & \\
\hline CHEMBL1383630 & 688341 & 4.5 & 4.936 & TRN & \\
\hline CHEMBL1541009 & 688341 & 4.6 & 4.7214 & TRN & \\
\hline CHEMBL1609167 & 688341 & 4.8 & 4.9007 & TRN & \\
\hline CHEMBL1432187 & 688341 & 4.6 & 5.1438 & TST & \\
\hline CHEMBL1363056 & 688341 & 4.8 & 4.7166 & TRN & \\
\hline CHEMBL1505633 & 688341 & 4.6 & 5.0059 & TST & \\
\hline CHEMBL106437 & 688341 & 5.2 & 5.00899 & 99999999995 & TRN \\
\hline CHEMBL1453158 & 688341 & 5.2 & 4.9068 & TRN & \\
\hline CHEMBL1540098 & 688341 & 4.7 & 4.6923 & TST & \\
\hline CHEMBL1472271 & 688341 & 4.8 & 4.8245 & TRN & \\
\hline CHEMBL1580917 & 688341 & 4.7 & 4.8314 & TRN & \\
\hline CHEMBL1318349 & 688341 & 4.4 & 5.0323 & TRN & \\
\hline CHEMBL1564753 & 688341 & 4.6 & 4.8149 & TRN & \\
\hline CHEMBL1308088 & 688341 & 4.4 & 4.9375 & TRN & \\
\hline CHEMBL1305232 & 688341 & 4.4 & 4.9408 & TRN & \\
\hline CHEMBL1568806 & 688341 & 4.5 & 4.8276 & TST & \\
\hline CHEMBL1450455 & 688341 & 4.5 & 5.0919 & TRN & \\
\hline CHEMBL1334194 & 688341 & 4.6 & 5.0007 & TST & \\
\hline CHEMBL1589326 & 688341 & 5.2 & 5.0241 & TRN & \\
\hline CHEMBL1523254 & 688341 & 4.7 & 4.9649 & TRN & \\
\hline CHEMBL1607364 & 688341 & 4.6 & 4.8554 & TRN & \\
\hline CHEMBL1474461 & 688341 & 4.5 & 5.0018 & TRN & \\
\hline CHEMBL1493493 & 688341 & 4.8 & 5.0522 & TRN & \\
\hline CHEMBL1488104 & 688341 & 4.7 & 4.6765 & TRN & \\
\hline CHEMBL1506771 & 688341 & 4.8 & 4.9695 & TRN & \\
\hline CHEMBL1311100 & 688341 & 5.2 & 4.872 & TST & \\
\hline CHEMBL1543009 & 688341 & 4.7 & 4.9601 & TRN & \\
\hline CHEMBL1464287 & 688341 & 6.5 & 4.9484 & TST & \\
\hline CHEMBL1483601 & 688341 & 4.4 & 5.0445 & TRN & \\
\hline CHEMBL1563782 & 688341 & 4.4 & 4.9366 & TST & \\
\hline CHEMBL1569610 & 688341 & 4.9 & 5.1868 & TST & \\
\hline CHEMBL1327896 & 688341 & 4.7 & 4.9056 & TRN & \\
\hline CHEMBL1368892 & 688341 & 5.4 & 5.12700 & 0000000001 & TRN \\
\hline CHEMBL1480680 & 688341 & 5.4 & 4.8411 & TST & \\
\hline
\end{tabular}




\begin{tabular}{|c|c|c|c|c|c|}
\hline \multicolumn{6}{|c|}{ Supplemental Table S2.txt } \\
\hline CHEMBL1427602 & 688341 & 5.0 & 4.9239 & TRN & \\
\hline CHEMBL1371170 & 688341 & 4.6 & 5.0422 & TRN & \\
\hline CHEMBL1459485 & 688341 & 4.8 & 4.99100 & 00000000005 & TRN \\
\hline CHEMBL1345583 & 688341 & 4.4 & 4.5909 & TRN & \\
\hline CHEMBL1507580 & 688341 & 5.2 & 4.917 & TRN & \\
\hline CHEMBL1499245 & 688341 & 4.8 & 5.1055 & TST & \\
\hline CHEMBL1471211 & 688341 & 4.6 & 4.8323 & TRN & \\
\hline CHEMBL 370458 & 688341 & 6.3 & 4.9596 & TRN & \\
\hline CHEMBL1613159 & 688341 & 5.4 & 5.063 & TRN & \\
\hline CHEMBL1609622 & 688341 & 4.7 & 4.8704 & TRN & \\
\hline CHEMBL1367465 & 688341 & 4.4 & 5.0474 & TRN & \\
\hline CHEMBL1307951 & 688341 & 5.0 & 4.7804 & TRN & \\
\hline CHEMBL1346813 & 688341 & 4.4 & 5.0551 & TST & \\
\hline CHEMBL1340880 & 688341 & 4.8 & 4.9474 & TRN & \\
\hline CHEMBL1567013 & 688341 & 4.4 & 4.7641 & TRN & \\
\hline CHEMBL1570650 & 688341 & 5.2 & 4.8909 & TST & \\
\hline CHEMBL1464511 & 688341 & 4.5 & 4.863 & TST & \\
\hline CHEMBL1478888 & 688341 & 5.0 & 4.8954 & TRN & \\
\hline CHEMBL1324414 & 688341 & 7.4001 & 4.8838 & TRN & \\
\hline CHEMBL1583117 & 688341 & 4.7 & 5.0174 & TRN & \\
\hline CHEMBL1429375 & 688341 & 4.9 & 4.8452 & TRN & \\
\hline CHEMBL1334437 & 688341 & 5.1 & 4.9225 & TST & \\
\hline CHEMBL1442547 & 688341 & 4.6 & 4.7916 & TST & \\
\hline CHEMBL1257013 & 688341 & 4.6 & 5.136 & TRN & \\
\hline CHEMBL1410245 & 688341 & 4.7 & 5.1008 & TRN & \\
\hline CHEMBL1601711 & 688341 & 5.3 & 4.7284 & TRN & \\
\hline CHEMBL1454529 & 688341 & 4.6 & 4.6845 & TRN & \\
\hline CHEMBL1339798 & 688341 & 5.2 & 4.9678 & TRN & \\
\hline CHEMBL1594090 & 688341 & 4.6 & 5.0075 & TST & \\
\hline CHEMBL1500081 & 688341 & 4.5 & 4.8571 & TST & \\
\hline CHEMBL1354563 & 688341 & 4.6 & 4.9705 & TRN & \\
\hline CHEMBL1510242 & 688341 & 4.4 & 4.8159 & TRN & \\
\hline CHEMBL1471414 & 688341 & 4.6 & 5.0169 & TST & \\
\hline CHEMBL1582621 & 688341 & 5.8 & 4.9452 & TRN & \\
\hline CHEMBL1462195 & 688341 & 4.6 & 4.8248 & TRN & \\
\hline CHEMBL1589925 & 688341 & 5.5 & 4.9662 & TRN & \\
\hline CHEMBL1590261 & 688341 & 5.5 & 5.2445 & TRN & \\
\hline CHEMBL1603115 & 688341 & 4.7 & 4.9342 & TRN & \\
\hline CHEMBL1354100 & 688341 & 4.5 & 5.0066 & TST & \\
\hline CHEMBL1414481 & 688341 & 4.9 & 4.9827 & TRN & \\
\hline CHEMBL1383968 & 688341 & 4.6 & 5.0366 & TST & \\
\hline CHEMBL1592936 & 688341 & 4.9 & 5.1943 & TRN & \\
\hline CHEMBL1597126 & 688341 & 5.2 & 5.1616 & TRN & \\
\hline CHEMBL1574074 & 688341 & 4.5 & 4.8376 & TRN & \\
\hline CHEMBL1336204 & 688341 & 4.4 & 4.8642 & TRN & \\
\hline CHEMBL1603371 & 688341 & 5.2 & 5.03100 & 0000000001 & TRN \\
\hline CHEMBL1455965 & 688341 & 5.3 & 4.9411 & TRN & \\
\hline CHEMBL313493 & 688341 & 4.7 & 5.0911 & TST & \\
\hline
\end{tabular}




\begin{tabular}{|c|c|c|c|c|c|}
\hline \multicolumn{6}{|c|}{ Supplemental Table S2.txt } \\
\hline CHEMBL1563090 & 688341 & 4.8 & 4.9668 & TRN & \\
\hline CHEMBL1497370 & 688341 & 4.6 & 4.7984 & TRN & \\
\hline CHEMBL1384728 & 688341 & 5.0 & 4.88899 & 9999999999 & TRN \\
\hline CHEMBL1450269 & 688341 & 4.6 & 4.948 & TRN & \\
\hline CHEMBL1450210 & 688341 & 5.1 & 4.9495 & TRN & \\
\hline CHEMBL1441397 & 688341 & 4.9 & 4.8176 & TRN & \\
\hline CHEMBL1321357 & 688341 & 5.9 & 5.0693 & TRN & \\
\hline CHEMBL552741 & 688341 & 4.8 & 5.0248 & TRN & \\
\hline CHEMBL1455056 & 688341 & 4.6 & 4.8537 & TST & \\
\hline CHEMBL1344285 & 688341 & 4.6 & 4.9374 & TRN & \\
\hline CHEMBL1593019 & 688341 & 5.1 & 5.0726 & TRN & \\
\hline CHEMBL1319369 & 688341 & 5.9 & 5.0905 & TRN & \\
\hline CHEMBL1412695 & 688341 & 4.5 & 4.981 & TRN & \\
\hline CHEMBL1499097 & 688341 & 7.8013 & 4.9552 & TST & \\
\hline CHEMBL1331193 & 688341 & 4.6 & 4.8726 & TRN & \\
\hline CHEMBL1383931 & 688341 & 4.6 & 4.9295 & TST & \\
\hline CHEMBL1445418 & 688341 & 5.0 & 4.9639 & TRN & \\
\hline CHEMBL1532531 & 688341 & 4.7 & 4.9798 & TRN & \\
\hline CHEMBL1377856 & 688341 & 8.2007 & 4.7908 & TRN & \\
\hline CHEMBL1392280 & 688341 & 5.5 & 4.9612 & TRN & \\
\hline CHEMBL1407829 & 688341 & 4.4 & 4.7713 & TRN & \\
\hline CHEMBL1541021 & 688341 & 4.8 & 4.9876 & TRN & \\
\hline CHEMBL1541509 & 688341 & 4.4 & 4.923 & TRN & \\
\hline CHEMBL1489357 & 688341 & 5.4 & 5.21 & TST & \\
\hline CHEMBL1455098 & 688341 & 4.7 & 4.8452 & TRN & \\
\hline CHEMBL1419340 & 688341 & 4.5 & 5.0047 & TRN & \\
\hline CHEMBL1389599 & 688341 & 6.0 & 4.9393 & TST & \\
\hline CHEMBL1562425 & 688341 & 4.5 & 4.7458 & TRN & \\
\hline CHEMBL1302694 & 688341 & 4.7 & 4.8221 & TRN & \\
\hline CHEMBL1452508 & 688341 & 4.5 & 4.9878 & TRN & \\
\hline CHEMBL1363603 & 688341 & 4.6 & 4.9752 & TST & \\
\hline CHEMBL307639 & 688341 & 4.4 & 5.0936 & TST & \\
\hline CHEMBL1549430 & 688341 & 4.8 & 4.8075 & TRN & \\
\hline CHEMBL1487744 & 688341 & 6.1 & 4.9122 & TST & \\
\hline CHEMBL1367427 & 688341 & 5.4 & 4.9578 & TRN & \\
\hline CHEMBL3198078 & 688341 & 5.3 & 5.1014 & TST & \\
\hline CHEMBL1445388 & 688341 & 5.2 & 4.8625 & TRN & \\
\hline CHEMBL1415580 & 688341 & 4.6 & 4.8124 & TRN & \\
\hline CHEMBL1381496 & 688341 & 4.8 & 4.9568 & TRN & \\
\hline CHEMBL1552753 & 688341 & 5.4 & 5.0315 & TRN & \\
\hline CHEMBL1389179 & 688341 & 4.6 & 4.8723 & TRN & \\
\hline CHEMBL1472779 & 688341 & 5.4 & 5.1189 & TRN & \\
\hline CHEMBL1400183 & 688341 & 4.5 & 4.967 & TRN & \\
\hline CHEMBL1427266 & 688341 & 4.8 & 4.8677 & TST & \\
\hline CHEMBL1573425 & 688341 & 4.6 & 4.9605 & TRN & \\
\hline CHEMBL1607475 & 688341 & 4.8 & 4.9177 & TRN & \\
\hline CHEMBL1495657 & 688341 & 5.4 & 5.0057 & TST & \\
\hline CHEMBL1330487 & 688341 & 4.8 & 4.8644 & TRN & \\
\hline
\end{tabular}




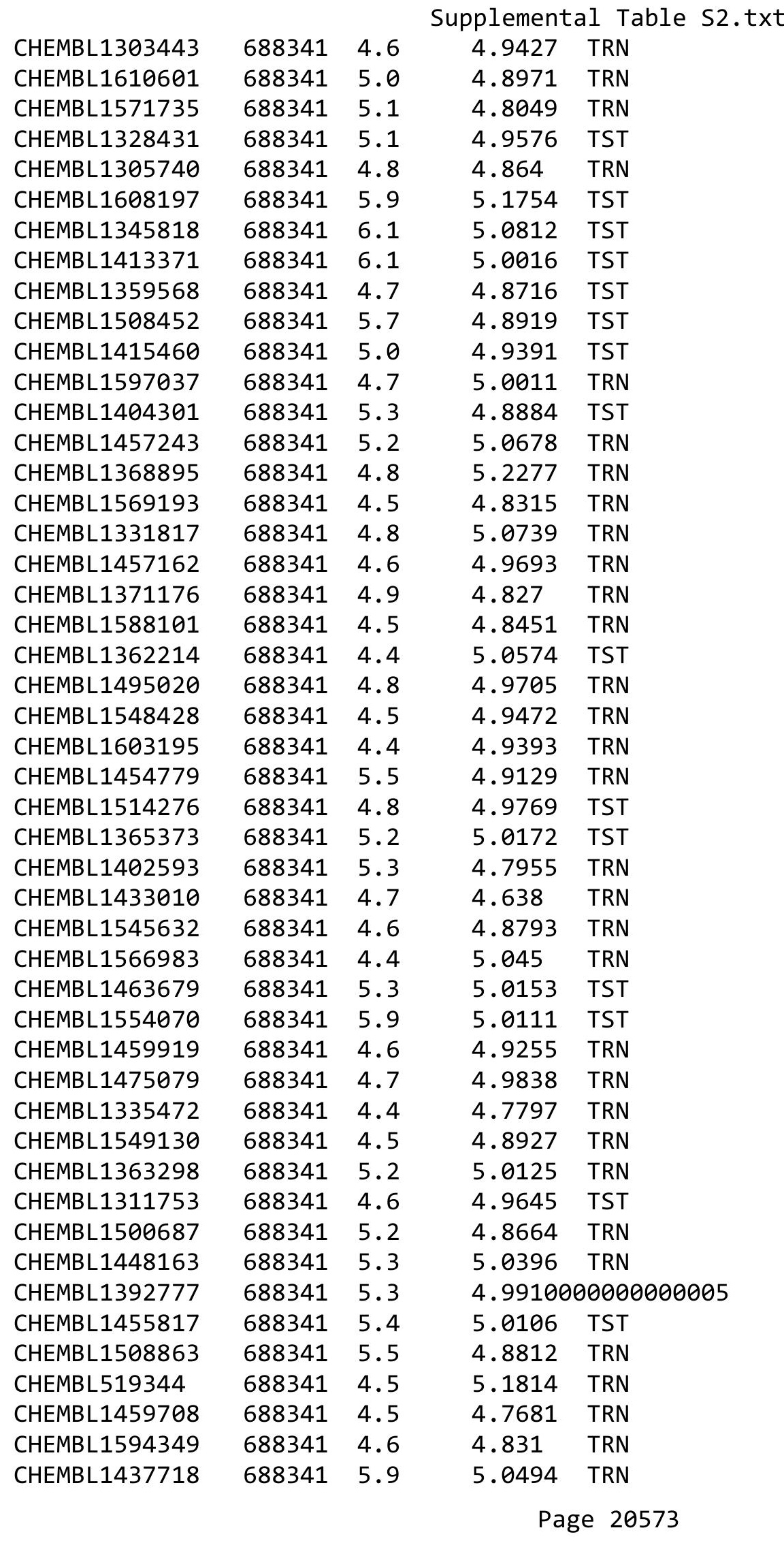




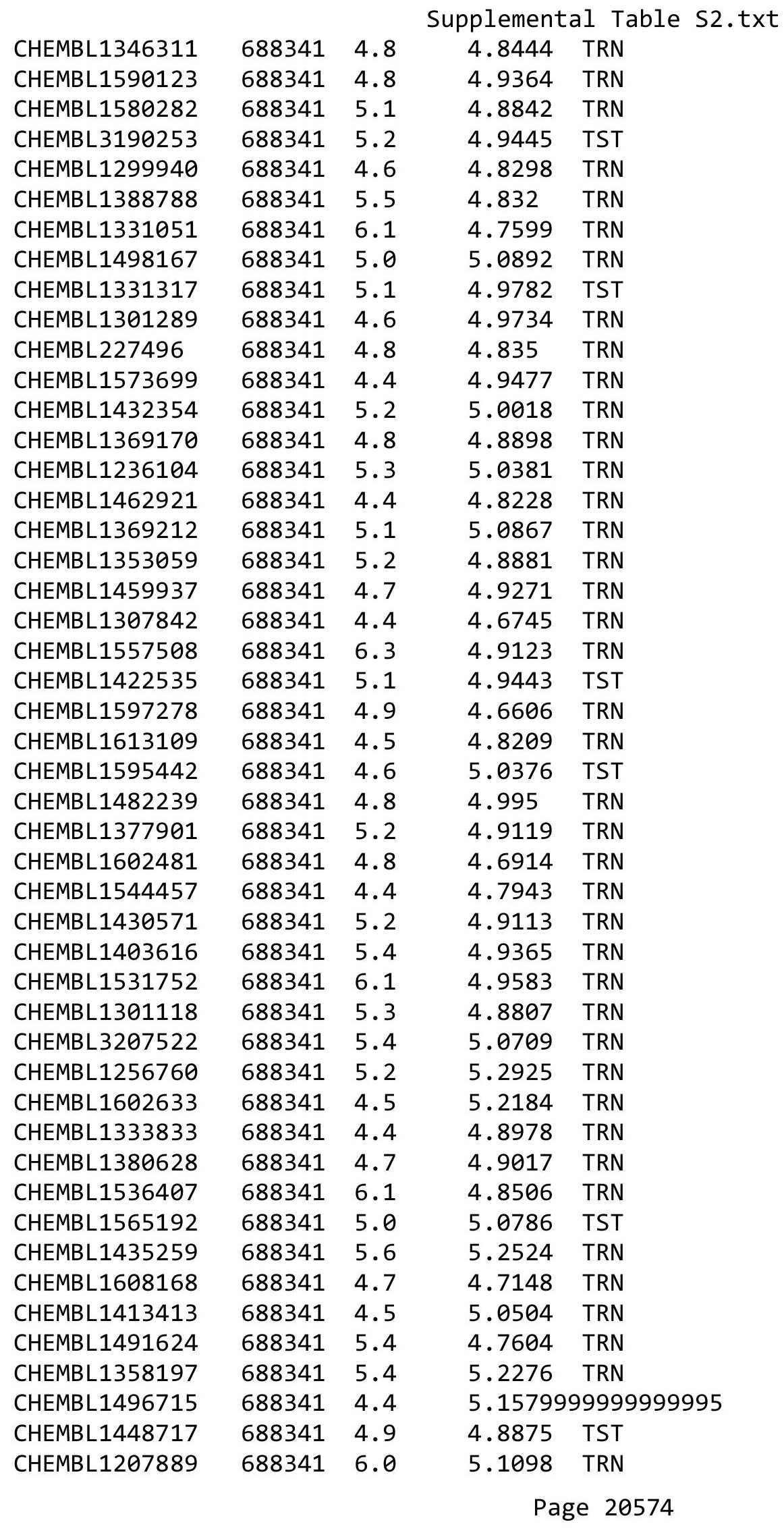




\begin{tabular}{|c|c|c|c|c|}
\hline \multicolumn{5}{|c|}{ Supplemental Table S2.txt } \\
\hline CHEMBL1306249 & 688341 & 4.7 & 4.8019 & TRN \\
\hline CHEMBL1330272 & 688341 & 4.5 & 5.0507 & TRN \\
\hline CHEMBL1411864 & 688341 & 4.9 & 4.9145 & TRN \\
\hline CHEMBL1613260 & 688341 & 5.0 & 5.0551 & TRN \\
\hline CHEMBL1387406 & 688341 & 5.5 & 4.8959 & TST \\
\hline CHEMBL1372838 & 688341 & 6.5 & 5.1003 & TRN \\
\hline CHEMBL1332898 & 688341 & 4.6 & 4.8399 & TRN \\
\hline CHEMBL1514779 & 688341 & 4.4 & 5.1981 & TRN \\
\hline CHEMBL1442250 & 688341 & 5.4 & 5.0529 & TRN \\
\hline CHEMBL1556195 & 688341 & 4.6 & 4.9071 & TRN \\
\hline CHEMBL1392518 & 688341 & 4.8 & 4.939 & TRN \\
\hline CHEMBL1412163 & 688341 & 4.4 & 4.995 & TST \\
\hline CHEMBL1557465 & 688341 & 4.6 & 5.0271 & TST \\
\hline CHEMBL1272096 & 688341 & 4.7 & 4.6957 & TRN \\
\hline CHEMBL1492497 & 688341 & 4.7 & 4.8264 & TRN \\
\hline CHEMBL1391476 & 688341 & 5.5 & 5.0434 & TRN \\
\hline CHEMBL1597046 & 688341 & 8.3979 & 4.9699 & TST \\
\hline CHEMBL1359493 & 688341 & 4.4 & 4.9926 & TRN \\
\hline CHEMBL1493069 & 688341 & 5.0 & 4.8318 & TRN \\
\hline CHEMBL1483824 & 688341 & 4.5 & 4.8579 & TRN \\
\hline CHEMBL1430277 & 688341 & 4.4 & 4.8587 & TRN \\
\hline CHEMBL1472466 & 688341 & 5.2 & 4.9082 & TST \\
\hline CHEMBL1429292 & 688341 & 4.4 & 4.7082 & TST \\
\hline CHEMBL1534995 & 688341 & 6.2 & 4.83 & TST \\
\hline CHEMBL1426683 & 688341 & 4.4 & 4.9231 & TRN \\
\hline CHEMBL1484715 & 688341 & 4.8 & 4.8379 & TRN \\
\hline CHEMBL1400566 & 688341 & 4.6 & 5.0035 & TST \\
\hline CHEMBL1414675 & 688341 & 6.9 & 4.8975 & TRN \\
\hline CHEMBL1331504 & 688341 & 5.2 & 4.9464 & TST \\
\hline CHEMBL1345487 & 688341 & 4.4 & 4.8484 & TST \\
\hline CHEMBL1499545 & 688341 & 4.8 & 5.2439 & TRN \\
\hline CHEMBL1311969 & 688341 & 4.4 & 4.7979 & TRN \\
\hline CHEMBL1575051 & 688341 & 4.5 & 4.7269 & TRN \\
\hline CHEMBL1526723 & 688341 & 4.5 & 5.0454 & TRN \\
\hline CHEMBL1606971 & 688341 & 5.1 & 4.8104 & TRN \\
\hline CHEMBL1537884 & 688341 & 4.4 & 4.8061 & TRN \\
\hline CHEMBL1467815 & 688341 & 4.8 & 4.7266 & TRN \\
\hline CHEMBL1606763 & 688341 & 4.5 & 5.1623 & TRN \\
\hline CHEMBL1353585 & 688341 & 4.5 & 5.0497 & TRN \\
\hline CHEMBL1553766 & 688341 & 5.8 & 5.067 & TRN \\
\hline CHEMBL1379420 & 688341 & 5.2 & 4.8998 & TRN \\
\hline CHEMBL1501233 & 688341 & 4.5 & 4.9285 & TRN \\
\hline CHEMBL1309150 & 688341 & 4.7 & 4.6302 & TRN \\
\hline CHEMBL1364836 & 688341 & 6.5 & 5.1033 & TRN \\
\hline CHEMBL1314152 & 688341 & 4.5 & 4.8957 & TRN \\
\hline CHEMBL1605353 & 688341 & 4.6 & 4.9313 & TST \\
\hline CHEMBL1425011 & 688341 & 4.4 & 5.0054 & TST \\
\hline CHEMBL1461098 & 688341 & 4.6 & 4.7993 & TRN \\
\hline
\end{tabular}




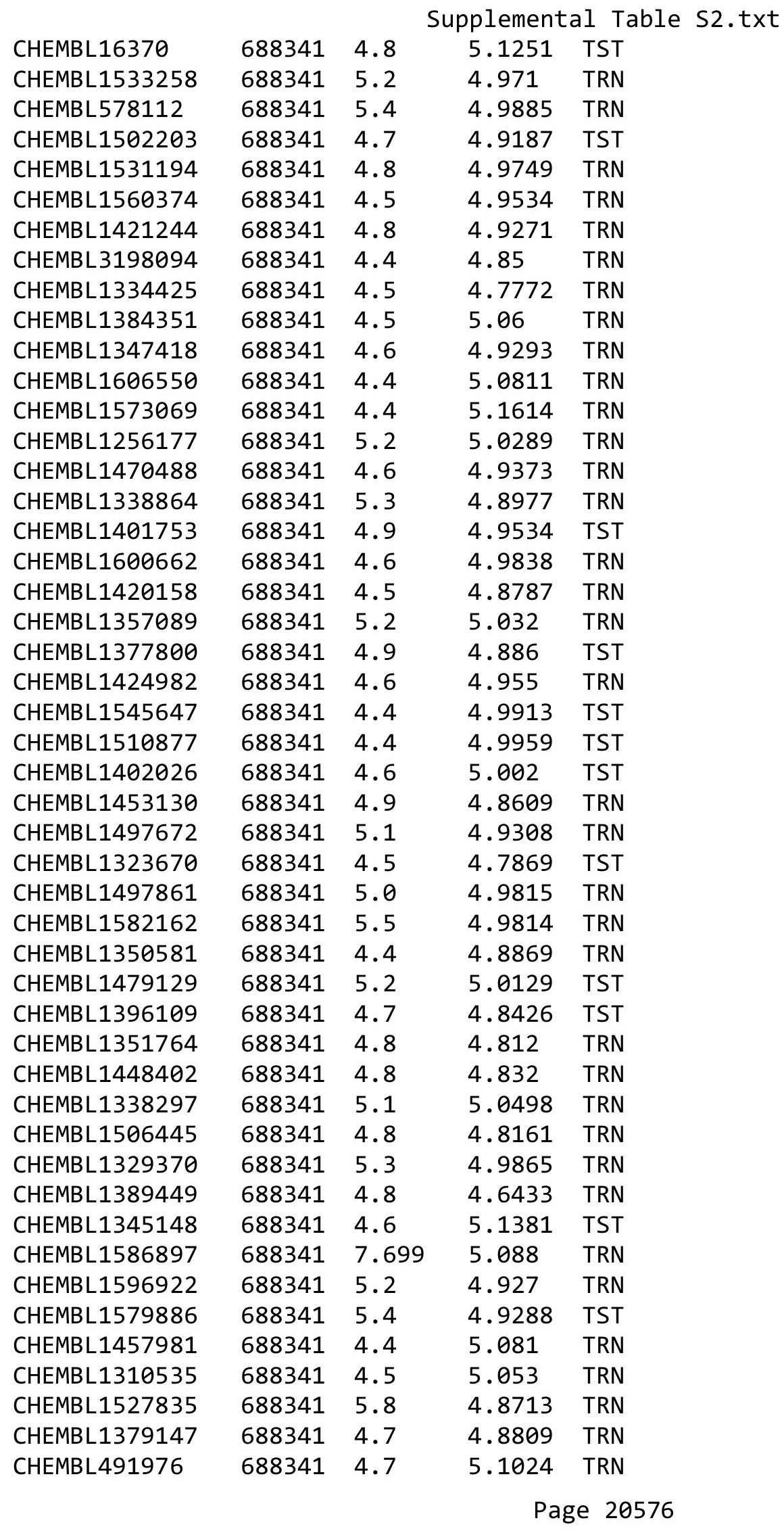




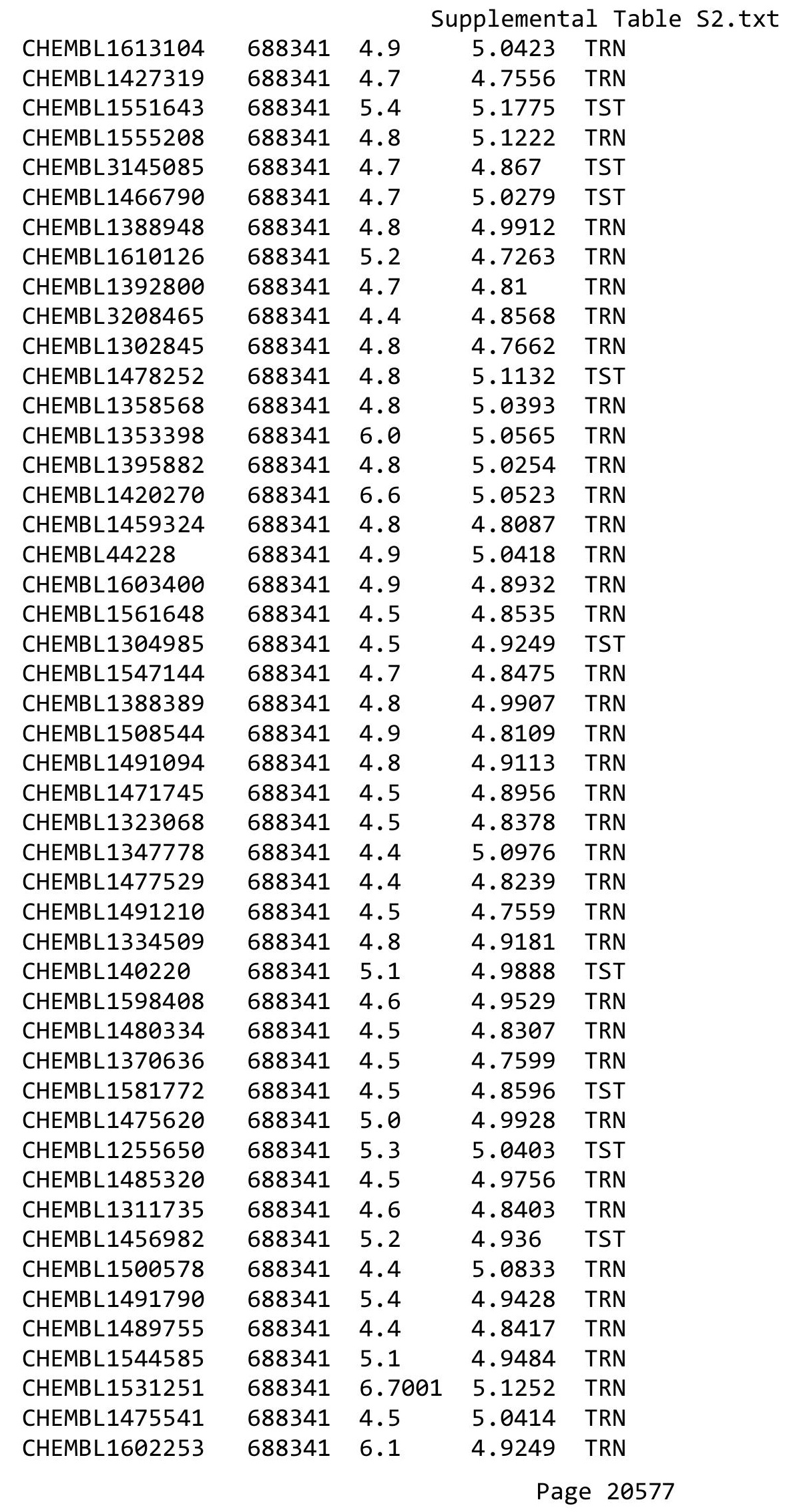




\begin{tabular}{|c|c|c|c|c|c|}
\hline \multicolumn{6}{|c|}{ Supplemental Table S2.txt } \\
\hline CHEMBL1479969 & 688341 & 5.9 & 5.008 & TRN & \\
\hline CHEMBL1402796 & 688341 & 4.4 & 5.0034 & TRN & \\
\hline CHEMBL1580636 & 688341 & 4.7 & 4.7387 & TRN & \\
\hline CHEMBL1423860 & 688341 & 4.5 & 5.0861 & TRN & \\
\hline CHEMBL1334728 & 688341 & 4.8 & 4.8828 & TRN & \\
\hline CHEMBL1456194 & 688341 & 4.4 & 4.8822 & TRN & \\
\hline CHEMBL1402777 & 688341 & 4.6 & 5.0245 & TST & \\
\hline CHEMBL1358796 & 688341 & 5.9 & 4.9046 & TRN & \\
\hline CHEMBL1375370 & 688341 & 4.4 & 5.2052 & TST & \\
\hline CHEMBL1545220 & 688341 & 4.5 & 5.0449 & TRN & \\
\hline CHEMBL1540890 & 688341 & 4.5 & 5.0053 & TRN & \\
\hline CHEMBL1488247 & 688341 & 4.9 & 4.8796 & TST & \\
\hline CHEMBL1433762 & 688341 & 8.8861 & 5.2282 & TRN & \\
\hline CHEMBL1422866 & 688341 & 4.7 & 4.7216 & TRN & \\
\hline CHEMBL1589056 & 688341 & 5.4 & 4.8833 & TST & \\
\hline CHEMBL1541546 & 688341 & 4.9 & $5.0710 €$ & 0000000001 & TRN \\
\hline CHEMBL1489221 & 688341 & 4.6 & 4.7431 & TRN & \\
\hline CHEMBL1432339 & 688341 & 4.7 & 4.7901 & TRN & \\
\hline CHEMBL1395038 & 688341 & 4.5 & 4.9639 & TST & \\
\hline CHEMBL1529272 & 688341 & 5.2 & 5.0574 & TST & \\
\hline CHEMBL1607264 & 688341 & 5.2 & 5.0619 & TRN & \\
\hline CHEMBL1477328 & 688341 & 4.6 & 4.88899 & 9999999999 & TRN \\
\hline CHEMBL1460357 & 688341 & 5.2 & 4.8533 & TRN & \\
\hline CHEMBL1571785 & 688341 & 4.9 & 5.0467 & TST & \\
\hline CHEMBL1394477 & 688341 & 5.6 & 5.2627 & TRN & \\
\hline CHEMBL1603952 & 688341 & 4.5 & 4.8353 & TRN & \\
\hline CHEMBL1439004 & 688341 & 4.6 & 4.7367 & TST & \\
\hline CHEMBL1420707 & 688341 & 5.2 & 4.8887 & TRN & \\
\hline CHEMBL1492317 & 688341 & 4.7 & 4.9928 & TST & \\
\hline CHEMBL1256325 & 688341 & 4.4 & 4.9825 & TRN & \\
\hline CHEMBL1386182 & 688341 & 5.1 & 4.8225 & TRN & \\
\hline CHEMBL1307845 & 688341 & 4.8 & 4.8729 & TRN & \\
\hline CHEMBL1324780 & 688341 & 4.6 & 4.8049 & TRN & \\
\hline CHEMBL1372617 & 688341 & 5.4 & 4.8864 & TRN & \\
\hline CHEMBL1322263 & 688341 & 4.6 & 4.8186 & TRN & \\
\hline CHEMBL1490144 & 688341 & 4.6 & 4.8753 & TRN & \\
\hline CHEMBL1362398 & 688341 & 4.6 & 4.7326 & TRN & \\
\hline CHEMBL1582030 & 688341 & 4.4 & 4.8857 & TST & \\
\hline CHEMBL279998 & 688341 & 5.2 & 5.1203 & TST & \\
\hline CHEMBL1568024 & 688341 & 4.4 & 5.0623 & TRN & \\
\hline CHEMBL1316735 & 688341 & 5.5 & 4.9883 & TRN & \\
\hline CHEMBL1503009 & 688341 & 5.1 & 4.8668 & TRN & \\
\hline CHEMBL1583670 & 688341 & 4.8 & 5.0986 & TRN & \\
\hline CHEMBL1489512 & 688341 & 5.5 & 4.9691 & TRN & \\
\hline CHEMBL1359027 & 688341 & 4.9 & 4.7241 & TRN & \\
\hline CHEMBL1522938 & 688341 & 4.5 & 5.0457 & TST & \\
\hline CHEMBL1588844 & 688341 & 4.4 & 4.9411 & TRN & \\
\hline CHEMBL1496062 & 688341 & 4.8 & 4.8488 & TRN & \\
\hline
\end{tabular}




\begin{tabular}{|c|c|c|c|c|c|}
\hline \multicolumn{6}{|c|}{ Supplemental Table S2.txt } \\
\hline CHEMBL1583259 & 688341 & 4.5 & 4.7486 & TRN & \\
\hline CHEMBL1450262 & 688341 & 5.2 & 5.0223 & TRN & \\
\hline CHEMBL1479274 & 688341 & 5.2 & 4.9882 & TRN & \\
\hline CHEMBL1305455 & 688341 & 4.9 & 4.8294 & TRN & \\
\hline CHEMBL1334175 & 688341 & 5.0 & 4.9869 & TRN & \\
\hline CHEMBL1558886 & 688341 & 4.4 & 4.7258 & TRN & \\
\hline CHEMBL1463777 & 688341 & 4.6 & 4.9758 & TRN & \\
\hline CHEMBL1448192 & 688341 & 5.2 & 5.0466 & TST & \\
\hline CHEMBL1541805 & 688341 & 6.9 & 4.9351 & TRN & \\
\hline CHEMBL1323526 & 688341 & 5.3 & 5.1658 & TRN & \\
\hline CHEMBL1486698 & 688341 & 4.4 & 4.891 & TST & \\
\hline CHEMBL1471361 & 688341 & 4.4 & 4.7539 & TST & \\
\hline CHEMBL1413339 & 688341 & 4.5 & 4.9862 & TRN & \\
\hline CHEMBL1462359 & 688341 & 4.5 & 4.8941 & TRN & \\
\hline CHEMBL1310502 & 688341 & 4.4 & 5.0172 & TRN & \\
\hline CHEMBL1500773 & 688341 & 4.4 & 4.9319 & TST & \\
\hline CHEMBL45462 & 688341 & 5.1 & 5.185 & TST & \\
\hline CHEMBL1535088 & 688341 & 5.4 & 5.0662 & TRN & \\
\hline CHEMBL1532637 & 688341 & 4.8 & 4.7104 & TRN & \\
\hline CHEMBL1572599 & 688341 & 5.2 & 4.8471 & TRN & \\
\hline CHEMBL1446316 & 688341 & 4.6 & 4.74100 & 00000000005 & TST \\
\hline CHEMBL1319745 & 688341 & 4.4 & 4.7681 & TST & \\
\hline CHEMBL1575489 & 688341 & 4.9 & 4.8776 & TST & \\
\hline CHEMBL1160730 & 688341 & 4.8 & 5.0998 & TRN & \\
\hline CHEMBL1408322 & 688341 & 4.6 & 4.7596 & TRN & \\
\hline CHEMBL1311514 & 688341 & 4.8 & 4.864 & TRN & \\
\hline CHEMBL1466951 & 688341 & 4.8 & 4.9094 & TRN & \\
\hline CHEMBL1552680 & 688341 & 4.6 & 5.0212 & TRN & \\
\hline CHEMBL1404553 & 688341 & 4.7 & 4.88399 & 79999999995 & TRN \\
\hline CHEMBL1587603 & 688341 & 4.4 & 5.0565 & TRN & \\
\hline CHEMBL1488982 & 688341 & 4.4 & 5.1495 & TST & \\
\hline CHEMBL1603817 & 688341 & 4.8 & 4.8095 & TRN & \\
\hline CHEMBL1557018 & 688341 & 4.8 & 4.7833 & TRN & \\
\hline CHEMBL1446905 & 688341 & 4.8 & 4.9249 & TRN & \\
\hline CHEMBL1327766 & 688341 & 5.4 & 4.8481 & TRN & \\
\hline CHEMBL1421485 & 688341 & 5.9 & 4.7317 & TRN & \\
\hline CHEMBL1400435 & 688341 & 6.2 & 5.0315 & TRN & \\
\hline CHEMBL1328534 & 688341 & 4.6 & 4.9582 & TRN & \\
\hline CHEMBL1503853 & 688341 & 4.4 & 5.05699 & 79999999995 & TRN \\
\hline CHEMBL1305819 & 688341 & 4.4 & 5.0353 & TST & \\
\hline CHEMBL1506218 & 688341 & 4.7 & 4.783 & TRN & \\
\hline CHEMBL1317344 & 688341 & 4.6 & 5.0476 & TRN & \\
\hline CHEMBL1566451 & 688341 & 4.7 & 4.9554 & TST & \\
\hline CHEMBL1492783 & 688341 & 4.5 & 4.7741 & TRN & \\
\hline CHEMBL1456688 & 688341 & 5.0 & 4.9766 & TRN & \\
\hline CHEMBL1363362 & 688341 & 4.4 & 4.9201 & TRN & \\
\hline CHEMBL1502967 & 688341 & 4.4 & 4.9826 & TRN & \\
\hline CHEMBL63426 & 688341 & 5.0 & 5.1147 & TST & \\
\hline
\end{tabular}




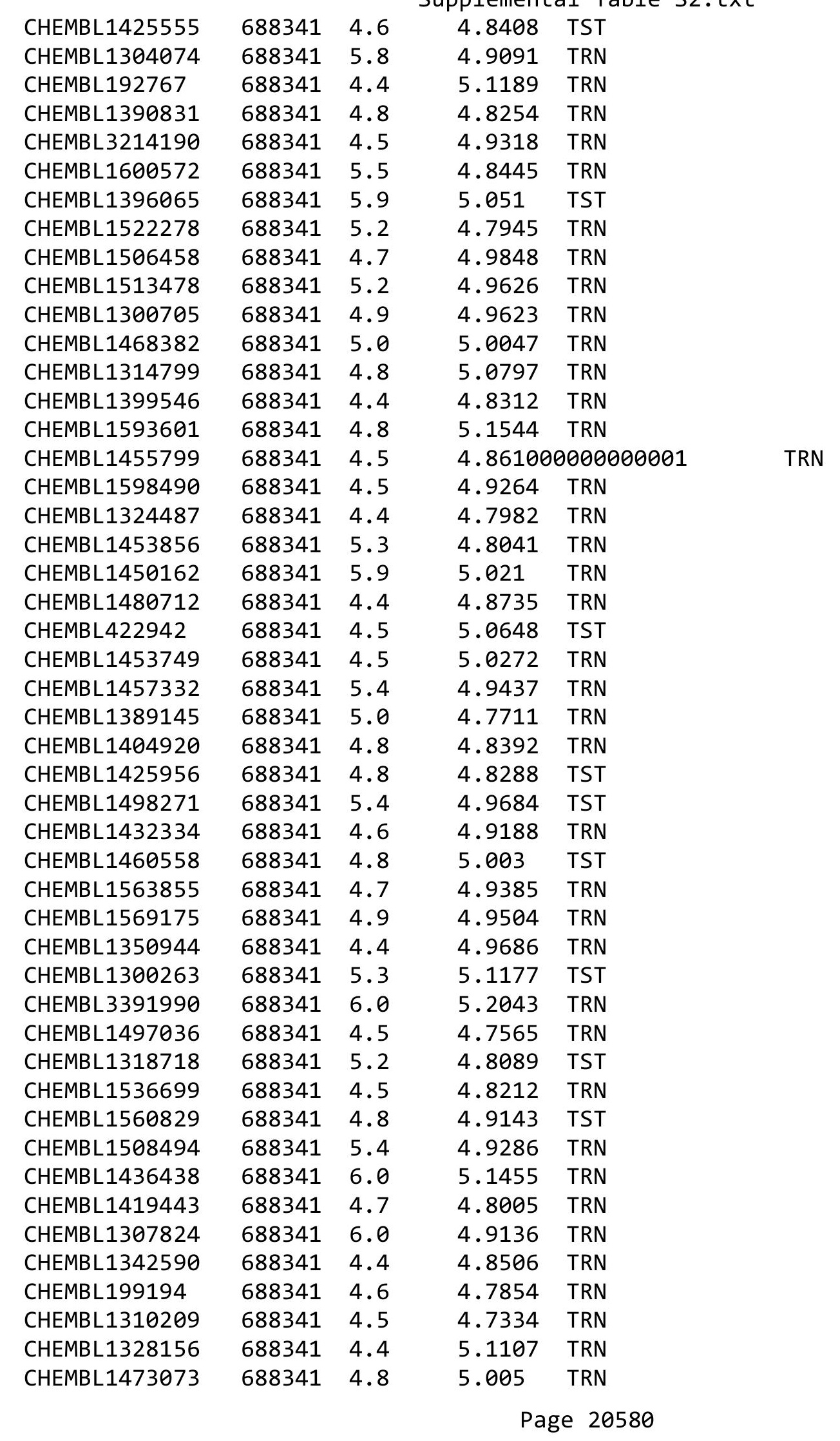




\begin{tabular}{|c|c|c|c|c|}
\hline \multicolumn{5}{|c|}{ Supplemental Table S2.txt } \\
\hline CHEMBL1572017 & 688341 & 4.7 & 4.8746 & TRN \\
\hline CHEMBL1554659 & 688341 & 4.6 & 5.1539 & TRN \\
\hline CHEMBL23507 & 688341 & 5.2 & 5.0293 & TST \\
\hline CHEMBL1536269 & 688341 & 5.2 & 4.9275 & TRN \\
\hline CHEMBL 1380327 & 688341 & 4.4 & 4.9443 & TRN \\
\hline CHEMBL1364980 & 688341 & 4.9 & 5.1287 & TRN \\
\hline CHEMBL1453739 & 688341 & 4.4 & 4.9554 & TRN \\
\hline CHEMBL1462954 & 688341 & 4.4 & 4.9016 & TST \\
\hline CHEMBL1369303 & 688341 & 4.4 & 4.867 & TRN \\
\hline CHEMBL1410470 & 688341 & 5.4 & 4.7281 & TRN \\
\hline CHEMBL1374420 & 688341 & 4.6 & 4.9799 & TRN \\
\hline CHEMBL1320662 & 688341 & 7.0 & 5.0714 & TRN \\
\hline CHEMBL1547678 & 688341 & 4.9 & 4.9013 & TRN \\
\hline CHEMBL1506109 & 688341 & 5.2 & 4.8611 & TRN \\
\hline CHEMBL1518825 & 688341 & 5.7 & 4.8032 & TRN \\
\hline CHEMBL3193145 & 688341 & 4.6 & 4.8088 & TRN \\
\hline CHEMBL1451286 & 688341 & 4.6 & 4.7739 & TRN \\
\hline CHEMBL1511444 & 688341 & 5.5 & 4.957 & TRN \\
\hline CHEMBL1372635 & 688341 & 5.0 & 5.1527 & TRN \\
\hline CHEMBL1606828 & 688341 & 4.8 & 4.9739 & TRN \\
\hline CHEMBL293341 & 688341 & 4.5 & 4.862 & TRN \\
\hline CHEMBL1350082 & 688341 & 4.7 & 4.9357 & TRN \\
\hline CHEMBL1300448 & 688341 & 4.7 & 4.9954 & TRN \\
\hline CHEMBL1509961 & 688341 & 4.5 & 4.8552 & TST \\
\hline CHEMBL1539840 & 688341 & 5.4 & 4.7696 & TST \\
\hline CHEMBL1527343 & 688341 & 5.2 & 5.0715 & TST \\
\hline CHEMBL1409737 & 688341 & 4.5 & 4.9486 & TRN \\
\hline CHEMBL3212239 & 688341 & 4.7 & 4.9829 & TRN \\
\hline CHEMBL1299672 & 688341 & 4.6 & 4.9655 & TRN \\
\hline CHEMBL1326962 & 688341 & 4.8 & 5.0315 & TST \\
\hline CHEMBL1323417 & 688341 & 4.6 & 4.8457 & TRN \\
\hline CHEMBL1332220 & 688341 & 4.5 & 4.9281 & TRN \\
\hline CHEMBL1389692 & 688341 & 4.6 & 4.7994 & TRN \\
\hline CHEMBL3211120 & 688341 & 4.4 & 4.834 & TST \\
\hline CHEMBL1365057 & 688341 & 5.4 & 4.7775 & TRN \\
\hline CHEMBL1597921 & 688341 & 4.6 & 4.757 & TRN \\
\hline CHEMBL 283196 & 688341 & 4.5 & 4.8541 & TRN \\
\hline CHEMBL1484127 & 688341 & 4.8 & 4.9949 & TRN \\
\hline CHEMBL1360485 & 688341 & 4.6 & 4.7772 & TRN \\
\hline CHEMBL1327150 & 688341 & 4.4 & 4.9913 & TST \\
\hline CHEMBL1371515 & 688341 & 4.7 & 4.8303 & TRN \\
\hline CHEMBL1356166 & 688341 & 4.8 & 5.0756 & TRN \\
\hline CHEMBL1399185 & 688341 & 4.6 & 4.8612 & TRN \\
\hline CHEMBL 2373666 & 688341 & 4.4 & 5.1303 & TRN \\
\hline CHEMBL1411288 & 688341 & 4.7 & 4.8071 & TRN \\
\hline CHEMBL1389095 & 688341 & 5.4 & 5.1422 & TRN \\
\hline CHEMBL1524299 & 688341 & 4.6 & 4.7471 & TRN \\
\hline CHEMBL1447207 & 688341 & 5.1 & 4.9203 & TRN \\
\hline
\end{tabular}




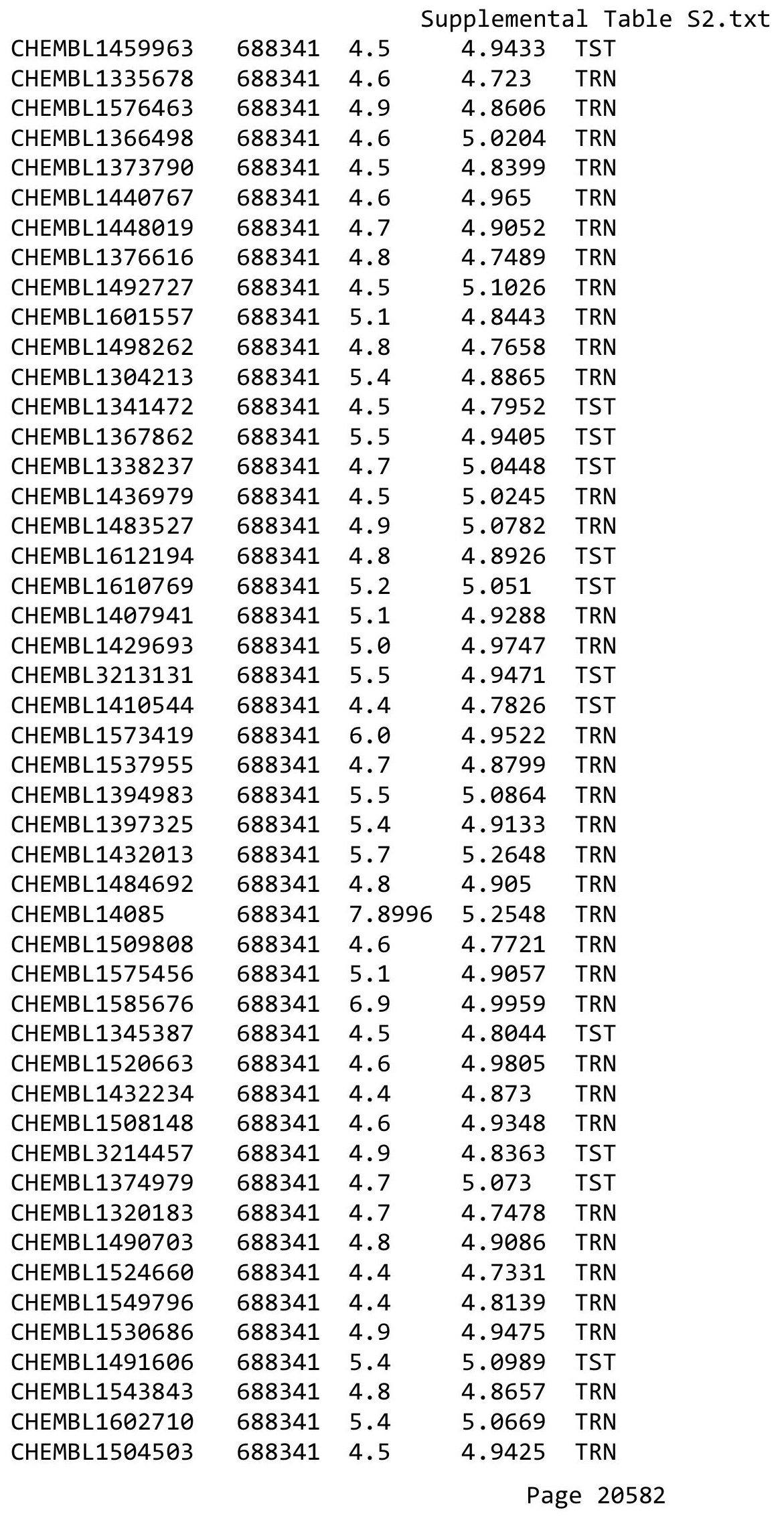




\begin{tabular}{|c|c|c|c|c|c|}
\hline \multicolumn{6}{|c|}{ Supplemental Table S2.txt } \\
\hline CHEMBL92824 & 688341 & 4.8 & 5.1846 & TST & \\
\hline CHEMBL1315743 & 688341 & 4.8 & 5.1261 & TST & \\
\hline CHEMBL328910 & 688341 & 6.0 & 4.9024 & TST & \\
\hline CHEMBL1564927 & 688341 & 5.4 & 5.0244 & TST & \\
\hline CHEMBL1419472 & 688341 & 4.5 & 4.9484 & TRN & \\
\hline CHEMBL1358588 & 688341 & 5.5 & 5.0343 & TST & \\
\hline CHEMBL1352422 & 688341 & 4.4 & 4.8226 & TST & \\
\hline CHEMBL1469736 & 688341 & 4.4 & 4.9205 & TRN & \\
\hline CHEMBL1557806 & 688341 & 5.3 & 4.97199 & 99999999995 & TRN \\
\hline CHEMBL1366796 & 688341 & 4.4 & 5.0687 & TRN & \\
\hline CHEMBL1386928 & 688341 & 5.5 & 4.7782 & TRN & \\
\hline CHEMBL1301462 & 688341 & 4.7 & 4.9774 & TRN & \\
\hline CHEMBL1414327 & 688341 & 4.5 & 4.8812 & TRN & \\
\hline CHEMBL1371599 & 688341 & 4.7 & 4.9679 & TRN & \\
\hline CHEMBL1598711 & 688341 & 4.7 & 4.8465 & TRN & \\
\hline CHEMBL1591757 & 688341 & 5.5 & 5.0272 & TRN & \\
\hline CHEMBL1599234 & 688341 & 4.8 & 4.859 & TRN & \\
\hline CHEMBL1522235 & 688341 & 4.4 & 4.7761 & TRN & \\
\hline CHEMBL117405 & 688341 & 4.6 & 5.1709 & TST & \\
\hline CHEMBL1413966 & 688341 & 6.4 & 5.0513 & TST & \\
\hline CHEMBL1380311 & 688341 & 4.4 & 4.8588 & TRN & \\
\hline CHEMBL1353055 & 688341 & 4.4 & 4.8787 & TRN & \\
\hline CHEMBL1404282 & 688341 & 5.0 & 5.0407 & TRN & \\
\hline CHEMBL1608915 & 688341 & 4.6 & 4.9729 & TRN & \\
\hline CHEMBL1445963 & 688341 & 5.4 & 4.9316 & TRN & \\
\hline CHEMBL1505683 & 688341 & 4.6 & 4.8811 & TRN & \\
\hline CHEMBL1545197 & 688341 & 5.5 & 4.7958 & TRN & \\
\hline CHEMBL1486613 & 688341 & 5.2 & 4.9399 & TRN & \\
\hline CHEMBL1465045 & 688341 & 5.1 & 4.8565 & TRN & \\
\hline CHEMBL1543317 & 688341 & 6.1 & 4.7861 & TRN & \\
\hline CHEMBL1448444 & 688341 & 4.7 & 4.9081 & TRN & \\
\hline CHEMBL1449386 & 688341 & 4.5 & 4.9221 & TRN & \\
\hline CHEMBL1466769 & 688341 & 4.7 & 4.9603 & TRN & \\
\hline CHEMBL1552985 & 688341 & 5.0 & 5.0566 & TRN & \\
\hline CHEMBL1472781 & 688341 & 4.4 & 5.2663 & TRN & \\
\hline CHEMBL1397558 & 688341 & 4.8 & 5.0303 & TRN & \\
\hline CHEMBL1542619 & 688341 & 4.7 & 4.8983 & TRN & \\
\hline CHEMBL1607327 & 688341 & 4.6 & 4.8154 & TRN & \\
\hline CHEMBL1488374 & 688341 & 4.6 & 4.8378 & TRN & \\
\hline CHEMBL1454201 & 688341 & 4.6 & 4.8683 & TRN & \\
\hline CHEMBL1500633 & 688341 & 5.0 & 4.8785 & TST & \\
\hline CHEMBL1551068 & 688341 & 5.4 & 4.98600 & 0000000001 & TRN \\
\hline CHEMBL1376959 & 688341 & 4.5 & 5.0434 & TRN & \\
\hline CHEMBL1418570 & 688341 & 4.6 & 4.9249 & TRN & \\
\hline CHEMBL1348233 & 688341 & 4.5 & 4.9106 & TST & \\
\hline CHEMBL1308944 & 688341 & 4.5 & 4.9745 & TRN & \\
\hline CHEMBL1457753 & 688341 & 4.5 & 4.9781 & TRN & \\
\hline CHEMBL1528118 & 688341 & 4.6 & 4.9276 & TRN & \\
\hline
\end{tabular}




\begin{tabular}{|c|c|c|c|c|}
\hline \multicolumn{5}{|c|}{ Supplemental Table S2.txt } \\
\hline CHEMBL1612686 & 688341 & 4.5 & 4.6216 & TRN \\
\hline CHEMBL1562133 & 688341 & 5.4 & 4.8444 & TRN \\
\hline CHEMBL1559033 & 688341 & 5.2 & 5.0166 & TST \\
\hline CHEMBL1529722 & 688341 & 4.7 & 4.7009 & TRN \\
\hline CHEMBL1548006 & 688341 & 4.4 & 5.0223 & TST \\
\hline CHEMBL1594527 & 688341 & 5.2 & 5.0884 & TST \\
\hline CHEMBL1461856 & 688341 & 4.4 & 4.9372 & TRN \\
\hline CHEMBL270299 & 688341 & 4.6 & 5.1507 & TST \\
\hline CHEMBL1541091 & 688341 & 6.8 & 4.8424 & TRN \\
\hline CHEMBL1492874 & 688341 & 5.1 & 5.1088 & TST \\
\hline CHEMBL1522900 & 688341 & 5.2 & 5.0226 & TST \\
\hline CHEMBL1560541 & 688341 & 5.1 & 5.073 & TRN \\
\hline CHEMBL1507262 & 688341 & 4.6 & 5.1015 & TST \\
\hline CHEMBL1376677 & 688341 & 5.3 & 5.2325 & TRN \\
\hline CHEMBL1579518 & 688341 & 4.6 & 4.8362 & TRN \\
\hline CHEMBL1544202 & 688341 & 5.4 & 5.0448 & TRN \\
\hline CHEMBL1328127 & 688341 & 4.8 & 4.96 & TRN \\
\hline CHEMBL1255747 & 688341 & 4.4 & 5.12 & TST \\
\hline CHEMBL1347061 & 688341 & 4.8 & 5.088 & TST \\
\hline CHEMBL1575570 & 688341 & 4.7 & 4.8043 & TRN \\
\hline CHEMBL1378208 & 688341 & 5.5 & 5.0244 & TRN \\
\hline CHEMBL1311108 & 688341 & 4.7 & 4.9699 & TRN \\
\hline CHEMBL1549529 & 688341 & 4.5 & 4.8435 & TRN \\
\hline CHEMBL1448752 & 688341 & 4.4 & 4.8743 & TRN \\
\hline CHEMBL1605496 & 688341 & 4.9 & 5.0146 & TRN \\
\hline CHEMBL1369631 & 688341 & 5.0 & 5.0327 & TST \\
\hline CHEMBL 1442580 & 688341 & 5.4 & 4.8538 & TRN \\
\hline CHEMBL3197105 & 688341 & 4.5 & 5.035 & TST \\
\hline CHEMBL1609896 & 688341 & 4.8 & 5.1198 & TRN \\
\hline CHEMBL1502354 & 688341 & 4.4 & 4.7514 & TST \\
\hline CHEMBL1329718 & 688341 & 7.4001 & 4.8099 & TST \\
\hline CHEMBL1360333 & 688341 & 4.5 & 4.9104 & TRN \\
\hline CHEMBL1357857 & 688341 & 4.5 & 5.0703 & TRN \\
\hline CHEMBL1549580 & 688341 & 4.8 & 4.8001 & TRN \\
\hline CHEMBL1310142 & 688341 & 4.4 & 4.9531 & TRN \\
\hline CHEMBL416657 & 688341 & 5.4 & 5.0295 & TST \\
\hline CHEMBL1352304 & 688341 & 4.8 & 4.8592 & TRN \\
\hline CHEMBL1354678 & 688341 & 6.0 & 5.0582 & TRN \\
\hline CHEMBL3145102 & 688341 & 4.6 & 5.0129 & TST \\
\hline CHEMBL3211966 & 688341 & 7.8996 & 4.8371 & TST \\
\hline CHEMBL1491563 & 688341 & 4.6 & 4.8667 & TRN \\
\hline CHEMBL1522650 & 688341 & 5.3 & 4.8485 & TRN \\
\hline CHEMBL1592041 & 688341 & 4.9 & 4.9268 & TRN \\
\hline CHEMBL1309379 & 688341 & 4.9 & 4.9425 & TRN \\
\hline CHEMBL1429074 & 688341 & 4.8 & 4.9453 & TRN \\
\hline CHEMBL1338439 & 688341 & 4.6 & 4.9008 & TRN \\
\hline CHEMBL903 & 688341 & 5.4 & 5.077 & TST \\
\hline CHEMBL1431235 & 688341 & 4.8 & 4.7678 & TRN \\
\hline
\end{tabular}




\begin{tabular}{|c|c|c|c|c|c|}
\hline & & & & & \\
\hline CHEMBL1300775 & 688341 & 4.5 & 5.0409 & TST & \\
\hline CHEMBL1384825 & 688341 & 4.6 & 4.9073 & TRN & \\
\hline CHEMBL1563840 & 688341 & 6.0 & 5.0058 & TST & \\
\hline CHEMBL1449581 & 688341 & 4.6 & 4.8595 & TRN & \\
\hline CHEMBL1374585 & 688341 & 4.8 & 5.0722 & TRN & \\
\hline CHEMBL1372627 & 688341 & 4.6 & 4.8437 & TRN & \\
\hline CHEMBL1397257 & 688341 & 4.6 & 5.0305 & TRN & \\
\hline CHEMBL1346186 & 688341 & 4.5 & 5.0759 & TRN & \\
\hline CHEMBL1602967 & 688341 & 4.4 & 4.8378 & TRN & \\
\hline CHEMBL1568579 & 688341 & 4.6 & 4.9454 & TRN & \\
\hline CHEMBL1583480 & 688341 & 4.6 & 4.9692 & TST & \\
\hline CHEMBL1417733 & 688341 & 4.7 & 4.9732 & TRN & \\
\hline CHEMBL1323648 & 688341 & 6.0 & 5.0286 & TRN & \\
\hline CHEMBL1437095 & 688341 & 4.5 & 5.0656 & TRN & \\
\hline CHEMBL1530061 & 688341 & 4.7 & 4.8641 & TRN & \\
\hline CHEMBL1526198 & 688341 & 4.7 & 5.0614 & TRN & \\
\hline CHEMBL1406820 & 688341 & 6.5 & 4.9509 & TRN & \\
\hline CHEMBL1311470 & 688341 & 4.7 & 5.0772 & TRN & \\
\hline CHEMBL1483908 & 688341 & 4.5 & 4.7935 & TRN & \\
\hline CHEMBL1445104 & 688341 & 4.7 & 4.9717 & TRN & \\
\hline CHEMBL1305038 & 688341 & 4.6 & 4.9518 & TRN & \\
\hline CHEMBL1476897 & 688341 & 5.1 & 4.9821 & TST & \\
\hline CHEMBL1527671 & 688341 & 4.7 & 4.9455 & TST & \\
\hline CHEMBL1395351 & 688341 & 4.9 & 5.0497 & TRN & \\
\hline CHEMBL1477411 & 688341 & 4.7 & $5.0710 e$ & 0000000001 & TRN \\
\hline CHEMBL1434801 & 688341 & 6.2 & 5.222 & TRN & \\
\hline CHEMBL1377555 & 688341 & 5.5 & 5.0933 & TST & \\
\hline CHEMBL1612292 & 688341 & 4.5 & 4.7873 & TRN & \\
\hline CHEMBL1311267 & 688341 & 4.5 & 4.9638 & TRN & \\
\hline CHEMBL1433055 & 688341 & 4.6 & 4.7312 & TRN & \\
\hline CHEMBL1527236 & 688341 & 4.8 & 5.1642 & TST & \\
\hline CHEMBL 1400050 & 688341 & 4.8 & 4.984 & TRN & \\
\hline CHEMBL1492029 & 688341 & 7.0 & 4.8985 & TRN & \\
\hline CHEMBL1370307 & 688341 & 4.4 & 4.7242 & TST & \\
\hline CHEMBL1503818 & 688341 & 4.6 & 4.8204 & TRN & \\
\hline CHEMBL1609957 & 688341 & 4.7 & 4.8966 & TST & \\
\hline CHEMBL1529087 & 688341 & 6.4 & 4.7433 & TRN & \\
\hline CHEMBL1537129 & 688341 & 4.6 & 4.8465 & TRN & \\
\hline CHEMBL1428792 & 688341 & 5.4 & 5.0788 & TRN & \\
\hline CHEMBL1532325 & 688341 & 5.2 & 4.9536 & TRN & \\
\hline CHEMBL1317626 & 688341 & 4.7 & 5.1054 & TRN & \\
\hline CHEMBL1406241 & 688341 & 4.6 & 4.6802 & TRN & \\
\hline CHEMBL16102 & 688341 & 7.0 & 5.17399 & 99999999995 & TRN \\
\hline CHEMBL1314434 & 688341 & 6.1 & 5.0061 & TRN & \\
\hline CHEMBL1320607 & 688341 & 4.9 & 4.8608 & TRN & \\
\hline CHEMBL7463 & 688341 & 4.8 & 5.0537 & TST & \\
\hline CHEMBL1577194 & 688341 & 4.4 & 4.8306 & TST & \\
\hline CHEMBL1347430 & 688341 & 4.4 & 4.8518 & TRN & \\
\hline & & & & 20585 & \\
\hline
\end{tabular}




\begin{tabular}{|c|c|c|c|c|c|}
\hline \multicolumn{6}{|c|}{ Supplemental Table s2.txt } \\
\hline CHEMBL1378255 & 688341 & 4.7 & 4.7755 & TRN & \\
\hline CHEMBL 3208888 & 688341 & 4.6 & 4.9903 & TRN & \\
\hline CHEMBL1479224 & 688341 & 4.7 & 4.8583 & TRN & \\
\hline CHEMBL1545054 & 688341 & 4.8 & 4.8791 & TRN & \\
\hline CHEMBL1437804 & 688341 & 4.8 & 5.0738 & TST & \\
\hline CHEMBL1565286 & 688341 & 4.5 & 4.754 & TRN & \\
\hline CHEMBL1515986 & 688341 & 5.4 & 4.9357 & TRN & \\
\hline CHEMBL1505290 & 688341 & 5.4 & 4.835 & TRN & \\
\hline CHEMBL1381609 & 688341 & 8.301 & 4.9351 & TST & \\
\hline CHEMBL1565292 & 688341 & 4.8 & 4.9036 & TRN & \\
\hline CHEMBL1419066 & 688341 & 4.8 & 4.7967 & TRN & \\
\hline CHEMBL1316081 & 688341 & 6.1 & 5.1824 & TRN & \\
\hline CHEMBL1548088 & 688341 & 4.6 & 4.8383 & TRN & \\
\hline CHEMBL1459294 & 688341 & 4.6 & 4.9636 & TST & \\
\hline CHEMBL1307361 & 688341 & 4.7 & 5.0426 & TRN & \\
\hline CHEMBL225257 & 688341 & 7.4001 & 4.9667 & TST & \\
\hline CHEMBL1440067 & 688341 & 4.4 & 4.8979 & TRN & \\
\hline CHEMBL1411204 & 688341 & 5.2 & 5.0627 & TST & \\
\hline CHEMBL1429456 & 688341 & 4.4 & 4.7879 & TRN & \\
\hline CHEMBL1311617 & 688341 & 4.8 & 4.9973 & TRN & \\
\hline CHEMBL1407106 & 688341 & 5.5 & 5.0048 & TST & \\
\hline CHEMBL1380020 & 688341 & 5.2 & 4.9448 & TST & \\
\hline CHEMBL1413869 & 688341 & 4.6 & 4.7995 & TRN & \\
\hline CHEMBL1599855 & 688341 & 5.2 & 4.8813 & TRN & \\
\hline CHEMBL1562623 & 688341 & 4.9 & 4.8515 & TRN & \\
\hline CHEMBL1551899 & 688341 & 4.8 & 5.0337 & TST & \\
\hline CHEMBL1589687 & 688341 & 4.4 & 4.9153 & TRN & \\
\hline CHEMBL1457503 & 688341 & 5.9 & 4.8665 & TRN & \\
\hline CHEMBL1418584 & 688341 & 5.1 & 4.9288 & TST & \\
\hline CHEMBL1459221 & 688341 & 5.1 & 4.9682 & TRN & \\
\hline CHEMBL1484912 & 688341 & 6.5 & 4.9522 & TRN & \\
\hline CHEMBL1566984 & 688341 & 5.2 & 5.0921 & TST & \\
\hline CHEMBL1306112 & 688341 & 4.4 & 4.8994 & TRN & \\
\hline CHEMBL1488813 & 688341 & 4.4 & 4.9439 & TST & \\
\hline CHEMBL1566318 & 688341 & 4.4 & 5.0308 & TRN & \\
\hline CHEMBL1381946 & 688341 & 4.8 & 4.8783 & TRN & \\
\hline CHEMBL1346825 & 688341 & 4.6 & 5.12200 & 0000000001 & TRN \\
\hline CHEMBL1517249 & 688341 & 4.8 & 4.916 & TRN & \\
\hline CHEMBL1371130 & 688341 & 4.5 & 4.9099 & TRN & \\
\hline CHEMBL1507992 & 688341 & 4.8 & 4.8637 & TST & \\
\hline CHEMBL1590980 & 688341 & 4.8 & 4.9822 & TRN & \\
\hline CHEMBL1443976 & 688341 & 4.6 & 4.9419 & TRN & \\
\hline CHEMBL1462945 & 688341 & 5.3 & 4.8647 & TRN & \\
\hline CHEMBL1486556 & 688341 & 4.6 & 4.7171 & TRN & \\
\hline CHEMBL1495792 & 688341 & 4.8 & 5.019 & TST & \\
\hline CHEMBL1598260 & 688341 & 4.8 & 5.0955 & TST & \\
\hline CHEMBL1521602 & 688341 & 4.4 & 4.8809 & TRN & \\
\hline CHEMBL1460019 & 688341 & 4.6 & 4.9944 & TRN & \\
\hline
\end{tabular}




\begin{tabular}{|c|c|c|c|c|}
\hline \multicolumn{5}{|c|}{ plemental T } \\
\hline CHEMBL1570885 & 688341 & 5.1 & 4.8073 & TRN \\
\hline CHEMBL1446651 & 688341 & 5.1 & 5.0796 & TRN \\
\hline CHEMBL1454473 & 688341 & 4.4 & 5.0203 & TRN \\
\hline CHEMBL1407005 & 688341 & 5.8 & 5.1753 & TST \\
\hline CHEMBL1513115 & 688341 & 5.9 & 5.0415 & TRN \\
\hline CHEMBL1528712 & 688341 & 5.7 & 4.9407 & TRN \\
\hline CHEMBL1353230 & 688341 & 4.5 & 4.9599 & TST \\
\hline CHEMBL1351643 & 688341 & 4.4 & 5.0553 & TST \\
\hline CHEMBL1469169 & 688341 & 4.8 & 4.7524 & TRN \\
\hline CHEMBL1499013 & 688341 & 4.7 & 4.9302 & TRN \\
\hline CHEMBL1305649 & 688341 & 4.7 & 4.9828 & TRN \\
\hline CHEMBL1600210 & 688341 & 5.2 & 5.0483 & TRN \\
\hline CHEMBL1402802 & 688341 & 4.8 & 5.1993 & TST \\
\hline CHEMBL1509520 & 688341 & 4.7 & 4.9024 & TRN \\
\hline CHEMBL1413172 & 688341 & 4.6 & 4.8527 & TRN \\
\hline CHEMBL1479248 & 688341 & 5.9 & 5.0351 & TRN \\
\hline CHEMBL1384822 & 688341 & 4.8 & 4.9412 & TRN \\
\hline CHEMBL1342999 & 688341 & 4.8 & 4.8751 & TRN \\
\hline CHEMBL1324051 & 688341 & 4.6 & 4.9078 & TST \\
\hline CHEMBL1517172 & 688341 & 4.4 & 5.1111 & TST \\
\hline CHEMBL1371975 & 688341 & 4.7 & 4.9412 & TST \\
\hline CHEMBL1335213 & 688341 & 5.0 & 4.9965 & TRN \\
\hline CHEMBL1301018 & 688341 & 4.7 & 4.8829 & TST \\
\hline CHEMBL1312719 & 688341 & 4.6 & 4.931 & TST \\
\hline CHEMBL1574160 & 688341 & 5.3 & 5.1033 & TRN \\
\hline CHEMBL1533209 & 688341 & 4.7 & 5.0134 & TRN \\
\hline CHEMBL1450197 & 688341 & 4.5 & 4.9685 & TRN \\
\hline CHEMBL1410702 & 688341 & 4.4 & 5.0784 & TST \\
\hline CHEMBL1561828 & 688341 & 5.0 & 4.857 & TRN \\
\hline CHEMBL1352278 & 688341 & 5.4 & 4.9315 & TST \\
\hline CHEMBL1425390 & 688341 & 4.8 & 5.0692 & TRN \\
\hline CHEMBL1718952 & 688341 & 5.8 & 5.1052 & TRN \\
\hline CHEMBL1543707 & 688341 & 4.7 & 4.8985 & TRN \\
\hline CHEMBL1451347 & 688341 & 4.6 & 4.9166 & TRN \\
\hline CHEMBL1428387 & 688341 & 5.9 & 4.921 & TRN \\
\hline CHEMBL1496009 & 688341 & 5.2 & 4.8073 & TST \\
\hline CHEMBL1564908 & 688341 & 4.7 & 5.0227 & TRN \\
\hline CHEMBL1338090 & 688341 & 4.4 & 4.8733 & TRN \\
\hline CHEMBL585481 & 688341 & 4.4 & 5.0454 & TRN \\
\hline CHEMBL1309451 & 688341 & 4.6 & 4.8218 & TST \\
\hline CHEMBL1345977 & 688341 & 4.4 & 4.8395 & TRN \\
\hline CHEMBL1370437 & 688341 & 4.9 & 4.7673 & TST \\
\hline CHEMBL 1457871 & 688341 & 5.4 & 4.8417 & TRN \\
\hline CHEMBL1393325 & 688341 & 5.3 & 5.025 & TRN \\
\hline CHEMBL1369528 & 688341 & 4.7 & 4.9541 & TRN \\
\hline CHEMBL1393097 & 688341 & 5.6 & 4.9445 & TRN \\
\hline CHEMBL1489993 & 688341 & 5.3 & 4.9529 & TST \\
\hline CHEMBL1598986 & 688341 & 5.5 & 5.143 & TRN \\
\hline
\end{tabular}




\begin{tabular}{|c|c|c|c|c|c|}
\hline \multicolumn{6}{|c|}{ Supplemental Table S2.txt } \\
\hline CHEMBL1452282 & 688341 & 4.6 & 4.7842 & TST & \\
\hline CHEMBL1609241 & 688341 & 4.5 & 5.0959 & TRN & \\
\hline CHEMBL1504797 & 688341 & 5.0 & 4.7541 & TRN & \\
\hline CHEMBL1515246 & 688341 & 4.7 & 5.2055 & TRN & \\
\hline CHEMBL1607167 & 688341 & 5.1 & 5.0177 & TST & \\
\hline CHEMBL1403608 & 688341 & 4.5 & 4.78 & TRN & \\
\hline CHEMBL1594750 & 688341 & 8.1024 & 4.909 & TRN & \\
\hline CHEMBL1600521 & 688341 & 5.5 & 5.0512 & TST & \\
\hline CHEMBL1316447 & 688341 & 4.6 & 5.2178 & TRN & \\
\hline CHEMBL1385946 & 688341 & 5.2 & 4.8909 & TRN & \\
\hline CHEMBL1576399 & 688341 & 4.5 & 4.8244 & TRN & \\
\hline CHEMBL1437047 & 688341 & 4.4 & 5.1629 & TST & \\
\hline CHEMBL1479015 & 688341 & 4.5 & 4.9061 & TRN & \\
\hline CHEMBL1327051 & 688341 & 5.2 & 5.0803 & TST & \\
\hline CHEMBL1504385 & 688341 & 5.1 & 4.9163 & TRN & \\
\hline CHEMBL1360455 & 688341 & 4.9 & $4.9110 e$ & 30000000005 & TRN \\
\hline CHEMBL 285819 & 688341 & 5.1 & 5.0902 & TRN & \\
\hline CHEMBL1421271 & 688341 & 4.5 & 4.8027 & TRN & \\
\hline CHEMBL1341211 & 688341 & 6.5 & 4.729 & TRN & \\
\hline CHEMBL1342346 & 688341 & 5.2 & 4.971 & TRN & \\
\hline CHEMBL1459571 & 688341 & 4.6 & 4.8643 & TST & \\
\hline CHEMBL1335634 & 688341 & 6.0 & 5.2156 & TRN & \\
\hline CHEMBL1332535 & 688341 & 5.2 & 4.8636 & TST & \\
\hline CHEMBL1597211 & 688341 & 4.5 & 5.0639 & TST & \\
\hline CHEMBL1299985 & 688341 & 4.5 & 5.1788 & TRN & \\
\hline CHEMBL1522688 & 688341 & 4.7 & 4.7356 & TRN & \\
\hline CHEMBL1411212 & 688341 & 4.5 & 4.8676 & TRN & \\
\hline CHEMBL1603624 & 688341 & 5.3 & 5.0412 & TST & \\
\hline CHEMBL1510400 & 688341 & 4.8 & 4.9066 & TST & \\
\hline CHEMBL1521325 & 688341 & 4.8 & 5.0519 & TST & \\
\hline CHEMBL1330922 & 688341 & 4.8 & 4.7617 & TRN & \\
\hline CHEMBL1348847 & 688341 & 4.8 & 4.9629 & TRN & \\
\hline CHEMBL1530492 & 688341 & 4.4 & 5.061 & TST & \\
\hline CHEMBL1392463 & 688341 & 4.6 & 4.812 & TST & \\
\hline CHEMBL1366185 & 688341 & 4.9 & 4.6412 & TRN & \\
\hline CHEMBL1385388 & 688341 & 4.4 & 5.0293 & TRN & \\
\hline CHEMBL1612279 & 688341 & 4.7 & 4.9859 & TST & \\
\hline CHEMBL1524064 & 688341 & 5.0 & 4.8469 & TRN & \\
\hline CHEMBL1084625 & 688341 & 4.5 & 5.0019 & TST & \\
\hline CHEMBL1585117 & 688341 & 4.5 & 4.8102 & TST & \\
\hline CHEMBL1451119 & 688341 & 5.0 & 5.1126 & TRN & \\
\hline CHEMBL1368995 & 688341 & 4.6 & 4.6697 & TRN & \\
\hline CHEMBL1378440 & 688341 & 4.6 & 5.1359 & TRN & \\
\hline CHEMBL1575759 & 688341 & 4.7 & 5.0121 & TRN & \\
\hline CHEMBL1599394 & 688341 & 4.4 & 4.9535 & TRN & \\
\hline CHEMBL1338979 & 688341 & 4.6 & 4.8796 & TST & \\
\hline CHEMBL1390311 & 688341 & 4.8 & 4.8865 & TST & \\
\hline CHEMBL1327185 & 688341 & 4.8 & 4.6983 & TRN & \\
\hline
\end{tabular}




\begin{tabular}{|c|c|c|c|c|}
\hline & & & 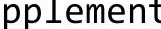 & \\
\hline CHEMBL1424620 & 688341 & 4.8 & 5.0062 & TRN \\
\hline CHEMBL1256480 & 688341 & 5.2 & 5.1551 & TST \\
\hline CHEMBL1457137 & 688341 & 4.5 & 4.9287 & TST \\
\hline CHEMBL1479082 & 688341 & 4.4 & 5.1535 & TRN \\
\hline CHEMBL1594479 & 688341 & 4.4 & 4.8379 & TRN \\
\hline CHEMBL1334758 & 688341 & 5.2 & 4.8834 & TRN \\
\hline CHEMBL1391062 & 688341 & 4.5 & 4.9135 & TRN \\
\hline CHEMBL1485710 & 688341 & 4.5 & 4.9398 & TRN \\
\hline CHEMBL1335332 & 688341 & 4.8 & 4.9407 & TRN \\
\hline CHEMBL1299659 & 688341 & 6.3 & 5.1849 & TST \\
\hline CHEMBL1371870 & 688341 & 4.8 & 4.9552 & TRN \\
\hline CHEMBL1538612 & 688341 & 4.4 & 4.9258 & TST \\
\hline CHEMBL1529629 & 688341 & 4.8 & 4.8708 & TRN \\
\hline CHEMBL1367977 & 688341 & 7.0 & 4.9325 & TRN \\
\hline CHEMBL1360179 & 688341 & 4.8 & 4.7673 & TRN \\
\hline CHEMBL1313167 & 688341 & 5.8 & 4.9583 & TRN \\
\hline CHEMBL1557048 & 688341 & 4.9 & 4.8604 & TRN \\
\hline CHEMBL171064 & 688341 & 4.5 & 5.0802 & TST \\
\hline CHEMBL1575123 & 688341 & 6.9 & 5.0307 & TRN \\
\hline CHEMBL77030 & 688341 & 5.1 & 5.0835 & TRN \\
\hline CHEMBL1530940 & 688341 & 4.6 & 4.8159 & TRN \\
\hline CHEMBL 338743 & 688341 & 5.2 & 5.0939 & TST \\
\hline CHEMBL1406204 & 688341 & 5.3 & 4.8098 & TST \\
\hline CHEMBL1256360 & 688341 & 6.0 & 5.2434 & TRN \\
\hline CHEMBL1363764 & 688341 & 5.6 & 4.9703 & TRN \\
\hline CHEMBL1404146 & 688341 & 4.6 & 4.8286 & TRN \\
\hline CHEMBL1396862 & 688341 & 5.0 & 4.9407 & TRN \\
\hline CHEMBL1465195 & 688341 & 4.6 & 4.8994 & TRN \\
\hline CHEMBL1400168 & 688341 & 5.0 & 4.7705 & TST \\
\hline CHEMBL1431783 & 688341 & 4.4 & 4.8741 & TRN \\
\hline CHEMBL1404123 & 688341 & 4.4 & 4.8103 & TRN \\
\hline CHEMBL1466777 & 688341 & 4.8 & 5.0532 & TRN \\
\hline CHEMBL1461435 & 688341 & 4.7 & 4.8259 & TST \\
\hline CHEMBL1477727 & 688341 & 4.8 & 4.8835 & TRN \\
\hline CHEMBL1554976 & 688341 & 4.6 & 5.1578 & TRN \\
\hline CHEMBL1364519 & 688341 & 4.5 & 4.86 & TRN \\
\hline CHEMBL1577238 & 688341 & 4.8 & 4.9802 & TRN \\
\hline CHEMBL1604159 & 688341 & 5.0 & 4.8451 & TRN \\
\hline CHEMBL1392862 & 688341 & 4.8 & 4.9344 & TRN \\
\hline CHEMBL1333501 & 688341 & 4.4 & 4.8893 & TRN \\
\hline CHEMBL1304045 & 688341 & 4.8 & 5.0671 & TRN \\
\hline CHEMBL1498944 & 688341 & 4.4 & 5.0223 & TRN \\
\hline CHEMBL1360723 & 688341 & 4.5 & 5.0634 & TRN \\
\hline CHEMBL1403656 & 688341 & 6.1 & 5.0082 & TST \\
\hline CHEMBL1493594 & 688341 & 5.6 & 4.8852 & TRN \\
\hline CHEMBL1375704 & 688341 & 4.9 & 4.9155 & TRN \\
\hline CHEMBL1369049 & 688341 & 4.6 & 4.9506 & TRN \\
\hline CHEMBL1333787 & 688341 & 4.4 & 5.1229 & TST \\
\hline
\end{tabular}




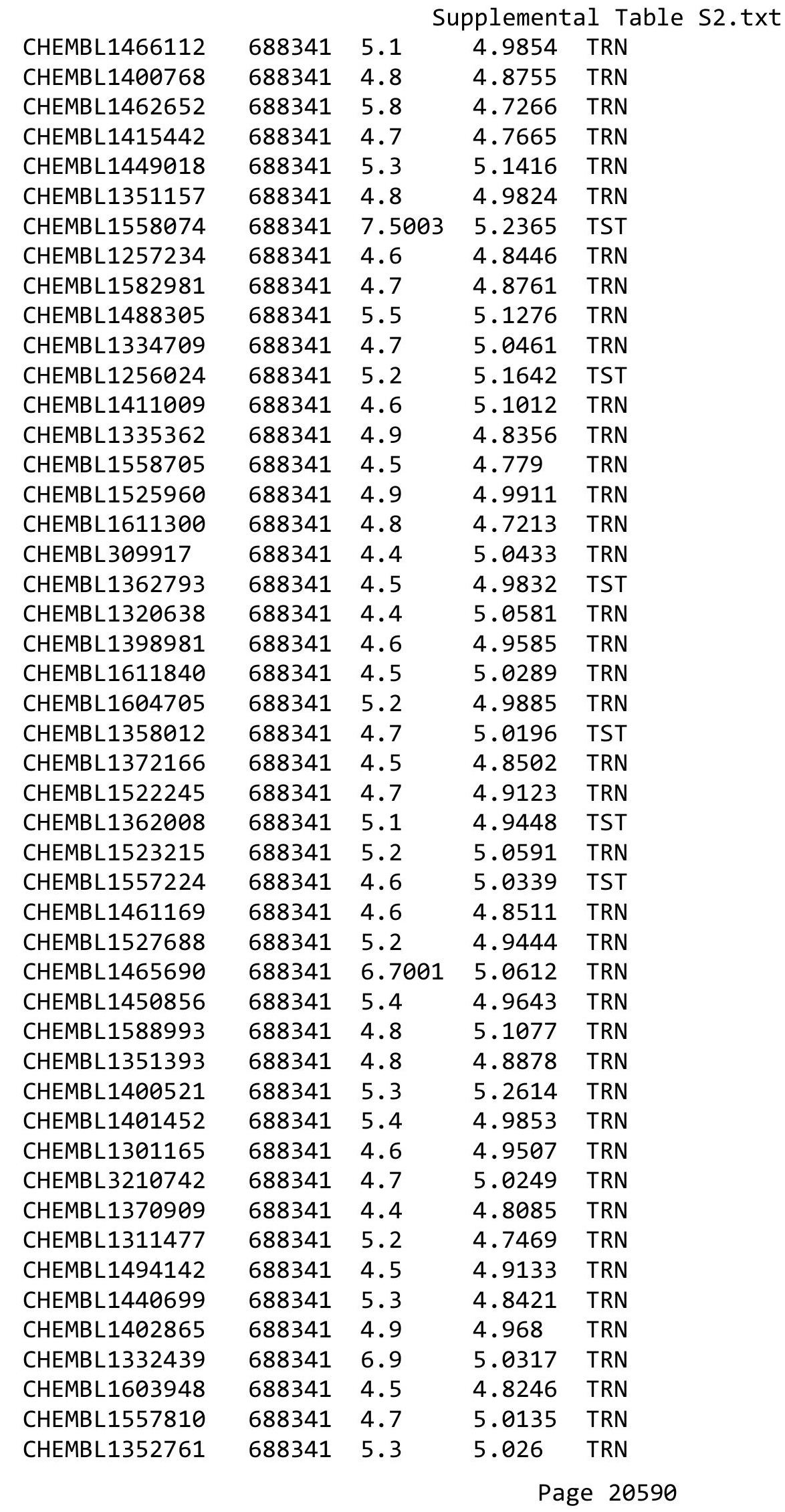




\begin{tabular}{|c|c|c|c|c|}
\hline \multicolumn{5}{|c|}{ Supplemental T } \\
\hline CHEMBL1478772 & 688341 & 4.5 & 5.0589 & TRN \\
\hline CHEMBL1316055 & 688341 & 5.5 & 5.033 & TRN \\
\hline CHEMBL1374415 & 688341 & 4.4 & 4.9806 & TRN \\
\hline CHEMBL1452253 & 688341 & 4.6 & 4.8207 & TRN \\
\hline CHEMBL1581061 & 688341 & 5.0 & 4.8253 & TRN \\
\hline CHEMBL1500242 & 688341 & 4.8 & 5.0323 & TST \\
\hline CHEMBL1302158 & 688341 & 4.8 & 4.857 & TRN \\
\hline CHEMBL1324769 & 688341 & 4.5 & 4.8969 & TRN \\
\hline CHEMBL1517925 & 688341 & 4.6 & 4.7757 & TRN \\
\hline CHEMBL1456811 & 688341 & 5.5 & 4.9729 & TRN \\
\hline CHEMBL1340364 & 688341 & 4.7 & 4.7652 & TRN \\
\hline CHEMBL1603868 & 688341 & 5.2 & 4.8885 & TRN \\
\hline CHEMBL1568484 & 688341 & 4.6 & 4.9175 & TRN \\
\hline CHEMBL 1605878 & 688341 & 5.0 & 4.8658 & TRN \\
\hline CHEMBL1613288 & 688341 & 4.6 & 4.9033 & TRN \\
\hline CHEMBL1449111 & 688341 & 4.6 & 4.8045 & TRN \\
\hline CHEMBL1322056 & 688341 & 4.5 & 4.8191 & TST \\
\hline CHEMBL1336509 & 688341 & 4.5 & 4.8896 & TRN \\
\hline CHEMBL1381887 & 688341 & 4.6 & 4.8989 & TST \\
\hline CHEMBL1352138 & 688341 & 4.5 & 5.1048 & TST \\
\hline CHEMBL1360047 & 688341 & 6.9 & 4.9695 & TRN \\
\hline CHEMBL1342585 & 688341 & 4.6 & 4.9646 & TST \\
\hline CHEMBL1409252 & 688341 & 4.4 & 5.0159 & TRN \\
\hline CHEMBL1477417 & 688341 & 5.0 & 5.073 & TRN \\
\hline CHEMBL1609459 & 688341 & 4.9 & 5.0678 & TST \\
\hline CHEMBL1537739 & 688341 & 4.4 & 4.9465 & TST \\
\hline CHEMBL1320931 & 688341 & 4.5 & 5.141 & TRN \\
\hline CHEMBL589439 & 688341 & 6.0 & 5.0609 & TRN \\
\hline CHEMBL1439741 & 688341 & 4.6 & 5.0222 & TST \\
\hline CHEMBL1552720 & 688341 & 4.7 & 4.9918 & TRN \\
\hline CHEMBL1603919 & 688341 & 5.4 & 4.896 & TRN \\
\hline CHEMBL1317620 & 688341 & 4.9 & 4.9647 & TRN \\
\hline CHEMBL1407616 & 688341 & 6.2 & 4.9906 & TRN \\
\hline CHEMBL1567257 & 688341 & 4.4 & 4.8039 & TRN \\
\hline CHEMBL1318056 & 688341 & 4.7 & 4.9993 & TRN \\
\hline CHEMBL1604551 & 688341 & 4.4 & 4.9044 & TST \\
\hline CHEMBL1479951 & 688341 & 4.6 & 4.8898 & TRN \\
\hline CHEMBL1606292 & 688341 & 5.4 & 5.2046 & TRN \\
\hline CHEMBL1488280 & 688341 & 6.1 & 4.8512 & TRN \\
\hline CHEMBL1561843 & 688341 & 6.0 & 4.9103 & TRN \\
\hline CHEMBL1430855 & 688341 & 6.0 & 4.7826 & TRN \\
\hline CHEMBL1377781 & 688341 & 4.6 & 5.0435 & TRN \\
\hline CHEMBL388054 & 688341 & 6.0 & 4.9478 & TST \\
\hline CHEMBL1485196 & 688341 & 4.8 & 4.9033 & TST \\
\hline CHEMBL1301017 & 688341 & 5.5 & 4.8555 & TRN \\
\hline CHEMBL1362301 & 688341 & 5.3 & 4.9492 & TRN \\
\hline CHEMBL1564386 & 688341 & 4.6 & 4.6646 & TRN \\
\hline CHEMBL1336243 & 688341 & 5.2 & 4.8976 & TRN \\
\hline
\end{tabular}




\begin{tabular}{|c|c|c|c|c|}
\hline \multicolumn{5}{|c|}{ ipplemental T } \\
\hline CHEMBL1350829 & 688341 & 4.6 & 4.9901 & TRN \\
\hline CHEMBL1583032 & 688341 & 4.4 & 4.7111 & TRN \\
\hline CHEMBL1421806 & 688341 & 4.4 & 4.9701 & TST \\
\hline CHEMBL1551981 & 688341 & 4.6 & 4.9498 & TRN \\
\hline CHEMBL1331148 & 688341 & 4.4 & 5.1186 & TRN \\
\hline CHEMBL1468280 & 688341 & 5.1 & 4.88 & TRN \\
\hline CHEMBL1323987 & 688341 & 5.2 & 4.7578 & TRN \\
\hline CHEMBL1457739 & 688341 & 4.8 & 4.9295 & TRN \\
\hline CHEMBL 1430570 & 688341 & 5.1 & 4.856 & TRN \\
\hline CHEMBL1422852 & 688341 & 5.6 & 4.9549 & TRN \\
\hline CHEMBL1601761 & 688341 & 5.1 & 4.9688 & TRN \\
\hline CHEMBL1565441 & 688341 & 4.5 & 5.1011 & TRN \\
\hline CHEMBL1597687 & 688341 & 4.6 & 4.8121 & TRN \\
\hline CHEMBL1339252 & 688341 & 4.5 & 5.016 & TRN \\
\hline CHEMBL1401324 & 688341 & 4.9 & 4.9176 & TST \\
\hline CHEMBL1401655 & 688341 & 4.5 & 4.8328 & TRN \\
\hline CHEMBL1501971 & 688341 & 4.8 & 4.6501 & TST \\
\hline CHEMBL1488436 & 688341 & 4.6 & 4.8568 & TRN \\
\hline CHEMBL1610955 & 688341 & 5.4 & 5.0309 & TRN \\
\hline CHEMBL 235260 & 688341 & 4.5 & 4.8215 & TST \\
\hline CHEMBL1563656 & 688341 & 5.4 & 5.0978 & TRN \\
\hline CHEMBL1512454 & 688341 & 5.5 & 5.1033 & TRN \\
\hline CHEMBL1337579 & 688341 & 4.5 & 4.8678 & TRN \\
\hline CHEMBL1389039 & 688341 & 5.5 & 4.9191 & TRN \\
\hline CHEMBL3198389 & 688341 & 5.2 & 4.8684 & TST \\
\hline CHEMBL1574231 & 688341 & 5.9 & 5.0993 & TRN \\
\hline CHEMBL1607113 & 688341 & 4.5 & 4.9291 & TRN \\
\hline CHEMBL1490042 & 688341 & 5.9 & 4.9538 & TRN \\
\hline CHEMBL1605585 & 688341 & 4.5 & 4.9373 & TRN \\
\hline CHEMBL1532417 & 688341 & 4.4 & 4.9287 & TRN \\
\hline CHEMBL1537552 & 688341 & 5.5 & 5.003 & TRN \\
\hline CHEMBL1325688 & 688341 & 4.5 & 5.0144 & TRN \\
\hline CHEMBL1335635 & 688341 & 5.2 & 4.9875 & TRN \\
\hline CHEMBL1365201 & 688341 & 4.5 & 4.9279 & TRN \\
\hline CHEMBL1529812 & 688341 & 4.8 & 4.9745 & TST \\
\hline CHEMBL1591731 & 688341 & 6.9 & 5.2548 & TST \\
\hline CHEMBL1485957 & 688341 & 4.8 & 4.8086 & TRN \\
\hline CHEMBL1475142 & 688341 & 4.9 & 4.9261 & TRN \\
\hline CHEMBL1414511 & 688341 & 4.4 & 5.0754 & TST \\
\hline CHEMBL1547078 & 688341 & 5.2 & 5.1619 & TST \\
\hline CHEMBL1383022 & 688341 & 5.3 & 4.9365 & TRN \\
\hline CHEMBL1411207 & 688341 & 4.4 & 4.9863 & TRN \\
\hline CHEMBL1572840 & 688341 & 5.2 & 4.8863 & TRN \\
\hline CHEMBL1506915 & 688341 & 4.4 & 4.9861 & TST \\
\hline CHEMBL1324148 & 688341 & 5.3 & 5.0697 & TST \\
\hline CHEMBL1494408 & 688341 & 6.5 & 5.1963 & TRN \\
\hline CHEMBL1567946 & 688341 & 5.5 & 5.047 & TST \\
\hline CHEMBL1508507 & 688341 & 4.9 & 4.9671 & TST \\
\hline
\end{tabular}




\begin{tabular}{|c|c|c|c|c|}
\hline \multicolumn{5}{|c|}{ plemental T } \\
\hline CHEMBL1611200 & 688341 & 5.0 & 4.9402 & TST \\
\hline CHEMBL1356721 & 688341 & 5.5 & 5.1462 & TRN \\
\hline CHEMBL1463041 & 688341 & 4.6 & 4.9395 & TST \\
\hline CHEMBL1456625 & 688341 & 5.1 & 4.9378 & TRN \\
\hline CHEMBL491748 & 688341 & 4.4 & 5.0771 & TRN \\
\hline CHEMBL1431961 & 688341 & 4.5 & 4.9025 & TST \\
\hline CHEMBL1549879 & 688341 & 5.0 & 4.8307 & TRN \\
\hline CHEMBL1572302 & 688341 & 5.5 & 5.0139 & TST \\
\hline CHEMBL1407269 & 688341 & 5.5 & 4.9185 & TST \\
\hline CHEMBL1569095 & 688341 & 4.8 & 4.9332 & TRN \\
\hline CHEMBL1572088 & 688341 & 4.5 & 5.0446 & TRN \\
\hline CHEMBL1578233 & 688341 & 4.6 & 4.8886 & TRN \\
\hline CHEMBL1528867 & 688341 & 4.8 & 4.9227 & TRN \\
\hline CHEMBL1481665 & 688341 & 7.0 & 4.842 & TRN \\
\hline CHEMBL1600077 & 688341 & 4.4 & 4.7919 & TRN \\
\hline CHEMBL 1527817 & 688341 & 4.4 & 4.8649 & TST \\
\hline CHEMBL1354864 & 688341 & 4.8 & 5.1738 & TRN \\
\hline CHEMBL1423918 & 688341 & 4.9 & 4.8577 & TRN \\
\hline CHEMBL1321745 & 688341 & 4.8 & 4.8245 & TRN \\
\hline CHEMBL1304290 & 688341 & 4.5 & 4.9062 & TRN \\
\hline CHEMBL 1492916 & 688341 & 4.5 & 5.0027 & TST \\
\hline CHEMBL1533903 & 688341 & 4.9 & 4.7991 & TST \\
\hline CHEMBL1426886 & 688341 & 4.7 & 4.8287 & TST \\
\hline CHEMBL1441762 & 688341 & 4.7 & 4.9688 & TRN \\
\hline CHEMBL1536690 & 688341 & 4.7 & 4.9293 & TST \\
\hline CHEMBL1427284 & 688341 & 4.6 & 4.9287 & TRN \\
\hline CHEMBL1529692 & 688341 & 5.2 & 4.9962 & TRN \\
\hline CHEMBL1388233 & 688341 & 4.8 & 4.8655 & TST \\
\hline CHEMBL3213925 & 688341 & 4.6 & 4.8534 & TRN \\
\hline CHEMBL1367995 & 688341 & 4.4 & 4.9658 & TRN \\
\hline CHEMBL1446372 & 688341 & 5.2 & 4.9917 & TRN \\
\hline CHEMBL1492580 & 688341 & 5.4 & 4.8928 & TRN \\
\hline CHEMBL1413787 & 688341 & 4.9 & 5.0777 & TRN \\
\hline CHEMBL1363235 & 688341 & 4.5 & 4.8574 & TRN \\
\hline CHEMBL1542361 & 688341 & 5.1 & 4.9909 & TRN \\
\hline CHEMBL1589435 & 688341 & 4.6 & 5.0456 & TRN \\
\hline CHEMBL1437172 & 688341 & 4.4 & 5.0373 & TRN \\
\hline CHEMBL1537751 & 688341 & 4.5 & 4.7471 & TRN \\
\hline CHEMBL1601483 & 688341 & 4.5 & 4.8583 & TST \\
\hline CHEMBL1436125 & 688341 & 4.7 & 4.8437 & TRN \\
\hline CHEMBL1454912 & 688341 & 4.4 & 5.0524 & TRN \\
\hline CHEMBL1353824 & 688341 & 5.0 & 4.927 & TST \\
\hline CHEMBL 1453103 & 688341 & 5.7 & 5.1552 & TST \\
\hline CHEMBL1585724 & 688341 & 4.5 & 4.918 & TST \\
\hline CHEMBL1581377 & 688341 & 5.0 & 4.8822 & TRN \\
\hline CHEMBL1519735 & 688341 & 4.5 & 5.0674 & TRN \\
\hline CHEMBL1585075 & 688341 & 4.8 & 5.019 & TRN \\
\hline CHEMBL1528564 & 688341 & 4.6 & 4.9408 & TST \\
\hline
\end{tabular}




\begin{tabular}{|c|c|c|c|c|}
\hline \multicolumn{5}{|c|}{ pplemental T } \\
\hline CHEMBL1299373 & 688341 & 4.4 & 4.9476 & TST \\
\hline CHEMBL1572198 & 688341 & 4.7 & 4.9769 & TRN \\
\hline CHEMBL1332244 & 688341 & 4.8 & 4.8019 & TRN \\
\hline CHEMBL1331619 & 688341 & 4.7 & 5.0505 & TST \\
\hline CHEMBL1488918 & 688341 & 5.3 & 5.1543 & TRN \\
\hline CHEMBL1483503 & 688341 & 4.7 & 4.7595 & TRN \\
\hline CHEMBL503470 & 688341 & 4.8 & 4.8354 & TST \\
\hline CHEMBL1389484 & 688341 & 4.9 & 4.931 & TRN \\
\hline CHEMBL1512701 & 688341 & 4.7 & 5.0311 & TRN \\
\hline CHEMBL1558130 & 688341 & 5.5 & 4.8594 & TRN \\
\hline CHEMBL1336813 & 688341 & 4.7 & 4.9113 & TRN \\
\hline CHEMBL1408083 & 688341 & 5.2 & 4.7573 & TST \\
\hline CHEMBL1489195 & 688341 & 4.5 & 4.9517 & TST \\
\hline CHEMBL1371755 & 688341 & 5.6 & 4.9488 & TRN \\
\hline CHEMBL1578187 & 688341 & 5.5 & 4.9202 & TRN \\
\hline CHEMBL1506982 & 688341 & 4.7 & 5.0349 & TST \\
\hline CHEMBL1369815 & 688341 & 4.8 & 4.9036 & TST \\
\hline CHEMBL1329612 & 688341 & 4.9 & 4.9465 & TRN \\
\hline CHEMBL 1607420 & 688341 & 5.0 & 4.8115 & TRN \\
\hline CHEMBL1428582 & 688341 & 4.9 & 4.6153 & TRN \\
\hline CHEMBL1425391 & 688341 & 4.4 & 4.8013 & TRN \\
\hline CHEMBL1364079 & 688341 & 4.7 & 4.7864 & TRN \\
\hline CHEMBL1519163 & 688341 & 6.0 & 5.0112 & TRN \\
\hline CHEMBL1320847 & 688341 & 4.5 & 5.0279 & TRN \\
\hline CHEMBL1446823 & 688341 & 4.9 & 4.9457 & TRN \\
\hline CHEMBL1421962 & 688341 & 4.7 & 5.0065 & TRN \\
\hline CHEMBL1566264 & 688341 & 4.8 & 4.9994 & TRN \\
\hline CHEMBL1566382 & 688341 & 4.4 & 4.9276 & TRN \\
\hline CHEMBL1365616 & 688341 & 6.3 & 5.1029 & TRN \\
\hline CHEMBL1329102 & 688341 & 5.2 & 5.091 & TST \\
\hline CHEMBL1602599 & 688341 & 4.4 & 4.982 & TRN \\
\hline CHEMBL1489766 & 688341 & 4.5 & 4.9121 & TRN \\
\hline CHEMBL1522462 & 688341 & 4.4 & 5.1039 & TST \\
\hline CHEMBL1491207 & 688341 & 5.2 & 4.8154 & TRN \\
\hline CHEMBL1445473 & 688341 & 4.5 & 5.2216 & TRN \\
\hline CHEMBL1323378 & 688341 & 4.6 & 4.9276 & TST \\
\hline CHEMBL1538485 & 688341 & 4.9 & 5.0797 & TRN \\
\hline CHEMBL1560982 & 688341 & 4.4 & 5.0021 & TST \\
\hline CHEMBL1319286 & 688341 & 5.0 & 4.9762 & TRN \\
\hline CHEMBL1305132 & 688341 & 4.7 & 4.8207 & TRN \\
\hline CHEMBL464859 & 688341 & 6.0 & 5.1038 & TRN \\
\hline CHEMBL1340774 & 688341 & 4.8 & 4.9664 & TRN \\
\hline CHEMBL1480648 & 688341 & 4.8 & 4.8628 & TRN \\
\hline CHEMBL1457733 & 688341 & 5.2 & 4.7408 & TST \\
\hline CHEMBL1337157 & 688341 & 4.7 & 4.8775 & TRN \\
\hline CHEMBL1452824 & 688341 & 4.7 & 4.9281 & TRN \\
\hline CHEMBL1348748 & 688341 & 4.5 & 4.828 & TRN \\
\hline CHEMBL1601397 & 688341 & 4.4 & 4.8412 & TRN \\
\hline
\end{tabular}




\begin{tabular}{|c|c|c|c|c|}
\hline & & & & \\
\hline CHEMBL1434272 & 688341 & 4.4 & 5.0954 & TRN \\
\hline CHEMBL1590181 & 688341 & 4.8 & 5.1928 & TRN \\
\hline CHEMBL1352844 & 688341 & 4.8 & 4.7471 & TRN \\
\hline CHEMBL1611449 & 688341 & 5.3 & 4.8956 & TRN \\
\hline CHEMBL1394533 & 688341 & 5.4 & 4.8617 & TRN \\
\hline CHEMBL1325975 & 688341 & 4.4 & 4.9354 & TRN \\
\hline CHEMBL1490835 & 688341 & 4.7 & 4.8947 & TRN \\
\hline CHEMBL1430829 & 688341 & 4.6 & 4.9462 & TRN \\
\hline CHEMBL1446297 & 688341 & 4.5 & 4.8176 & TRN \\
\hline CHEMBL1372348 & 688341 & 4.7 & 4.8302 & TST \\
\hline CHEMBL1577274 & 688341 & 4.8 & 4.9322 & TRN \\
\hline CHEMBL1369460 & 688341 & 4.8 & 4.8969 & TRN \\
\hline CHEMBL1609322 & 688341 & 4.7 & 4.7714 & TRN \\
\hline CHEMBL1512190 & 688341 & 4.5 & 4.9885 & TRN \\
\hline CHEMBL1360472 & 688341 & 4.4 & 4.7975 & TRN \\
\hline CHEMBL1350196 & 688341 & 5.2 & 4.9648 & TRN \\
\hline CHEMBL1351080 & 688341 & 5.7 & 4.971 & TRN \\
\hline CHEMBL1373183 & 688341 & 4.8 & 4.7436 & TRN \\
\hline CHEMBL1388603 & 688341 & 4.8 & 4.8561 & TRN \\
\hline CHEMBL1355089 & 688341 & 5.4 & 5.0865 & TRN \\
\hline CHEMBL1526622 & 688341 & 4.9 & 4.7856 & TRN \\
\hline CHEMBL1415385 & 688341 & 4.8 & 4.8746 & TST \\
\hline CHEMBL1482180 & 688341 & 4.6 & 4.8448 & TRN \\
\hline CHEMBL1472422 & 688341 & 4.9 & 4.9359 & TRN \\
\hline CHEMBL1448997 & 688341 & 5.1 & 4.9812 & TST \\
\hline CHEMBL1497927 & 688341 & 4.4 & 4.9945 & TST \\
\hline CHEMBL1399151 & 688341 & 5.8 & 5.1433 & TST \\
\hline CHEMBL1590855 & 688341 & 4.7 & 4.9539 & TRN \\
\hline CHEMBL1594961 & 688341 & 4.7 & 5.0198 & TST \\
\hline CHEMBL1313201 & 688341 & 4.4 & 4.9207 & TRN \\
\hline CHEMBL 183 & 688341 & 5.2 & 5.1071 & TST \\
\hline CHEMBL1446604 & 688341 & 5.4 & 4.9254 & TRN \\
\hline CHEMBL1390474 & 688341 & 4.7 & 4.9741 & TRN \\
\hline CHEMBL1428767 & 688341 & 4.6 & 4.7667 & TRN \\
\hline CHEMBL1467832 & 688341 & 4.7 & 4.8233 & TRN \\
\hline CHEMBL1562276 & 688341 & 4.8 & 4.9234 & TRN \\
\hline CHEMBL1311324 & 688341 & 4.5 & 4.8977 & TRN \\
\hline CHEMBL1340657 & 688341 & 4.4 & 4.8585 & TRN \\
\hline CHEMBL1516054 & 688341 & 5.1 & 4.952 & TRN \\
\hline CHEMBL 1448069 & 688341 & 4.8 & 4.9703 & TST \\
\hline CHEMBL1414753 & 688341 & 4.5 & 4.9359 & TRN \\
\hline CHEMBL1305160 & 688341 & 4.4 & 5.1332 & TST \\
\hline CHEMBL1586297 & 688341 & 5.9 & 5.1493 & TST \\
\hline CHEMBL1606798 & 688341 & 4.6 & 4.9963 & TRN \\
\hline CHEMBL1574475 & 688341 & 4.9 & 5.0102 & TST \\
\hline CHEMBL1326487 & 688341 & 5.9 & 4.9577 & TST \\
\hline CHEMBL1479618 & 688341 & 4.5 & 4.8494 & TST \\
\hline CHEMBL263116 & 688341 & 4.9 & 4.9551 & TRN \\
\hline
\end{tabular}




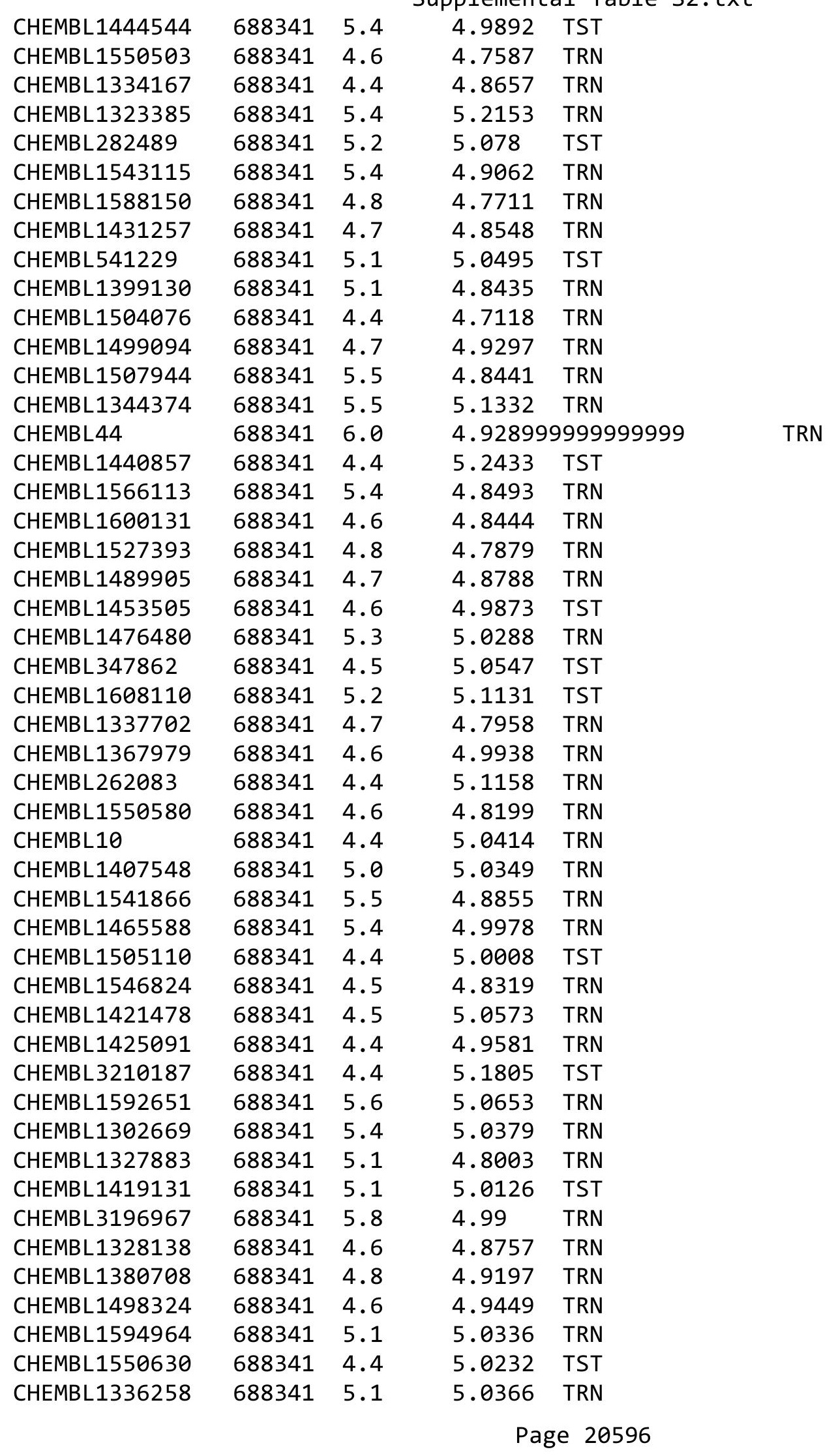




\begin{tabular}{|c|c|c|c|c|c|}
\hline \multicolumn{6}{|c|}{ Supplemental Table S2.txt } \\
\hline CHEMBL1558496 & 688341 & 4.6 & 4.9302 & TRN & \\
\hline CHEMBL1453955 & 688341 & 4.4 & 4.9192 & TRN & \\
\hline CHEMBL1407551 & 688341 & 4.6 & 5.0663 & TST & \\
\hline CHEMBL1373357 & 688341 & 4.5 & 4.8747 & TRN & \\
\hline CHEMBL1564653 & 688341 & 6.4 & 5.0239 & TRN & \\
\hline CHEMBL3213062 & 688341 & 5.5 & 5.0081 & TRN & \\
\hline CHEMBL1397177 & 688341 & 5.4 & 5.1097 & TRN & \\
\hline CHEMBL1569892 & 688341 & 4.9 & 4.9727 & TST & \\
\hline CHEMBL1334474 & 688341 & 4.4 & 4.9044 & TRN & \\
\hline CHEMBL1515024 & 688341 & 5.4 & 5.0638 & TRN & \\
\hline CHEMBL1385215 & 688341 & 4.5 & 4.8918 & TST & \\
\hline CHEMBL1411953 & 688341 & 5.5 & 5.0204 & TRN & \\
\hline CHEMBL1344981 & 688341 & 4.7 & 4.8582 & TRN & \\
\hline CHEMBL1466563 & 688341 & 4.5 & 4.769 & TRN & \\
\hline CHEMBL1581290 & 688341 & 4.9 & 4.8602 & TRN & \\
\hline CHEMBL1555592 & 688341 & 4.8 & 4.7301 & TST & \\
\hline CHEMBL1563066 & 688341 & 5.3 & 4.9999 & TRN & \\
\hline CHEMBL1370535 & 688341 & 4.9 & 5.0175 & TRN & \\
\hline CHEMBL1353575 & 688341 & 4.6 & 4.9751 & TRN & \\
\hline CHEMBL1556743 & 688341 & 5.4 & 4.9123 & TRN & \\
\hline CHEMBL1471105 & 688341 & 5.5 & 5.0035 & TST & \\
\hline CHEMBL1582295 & 688341 & 4.8 & 4.9741 & TST & \\
\hline CHEMBL1379445 & 688341 & 6.6 & 4.8773 & TST & \\
\hline CHEMBL1534825 & 688341 & 4.6 & 4.96399 & 99999999995 & TRN \\
\hline CHEMBL1467444 & 688341 & 4.9 & 4.745 & TRN & \\
\hline CHEMBL1365592 & 688341 & 6.0 & 5.0641 & TST & \\
\hline CHEMBL1333400 & 688341 & 5.2 & 5.1538 & TRN & \\
\hline CHEMBL1564425 & 688341 & 4.6 & 4.7635 & TRN & \\
\hline CHEMBL1331659 & 688341 & 5.5 & 4.8676 & TRN & \\
\hline CHEMBL1398538 & 688341 & 5.2 & 5.0096 & TST & \\
\hline CHEMBL1307179 & 688341 & 5.2 & 4.9187 & TRN & \\
\hline CHEMBL1469518 & 688341 & 4.6 & 4.9144 & TRN & \\
\hline CHEMBL1563657 & 688341 & 4.4 & 4.9501 & TRN & \\
\hline CHEMBL1353251 & 688341 & 4.9 & 4.8788 & TRN & \\
\hline CHEMBL365809 & 688341 & 5.4 & 5.0835 & TST & \\
\hline CHEMBL1307106 & 688341 & 6.5 & 5.0275 & TRN & \\
\hline CHEMBL1538360 & 688341 & 4.8 & 4.8258 & TST & \\
\hline CHEMBL1434646 & 688341 & 4.9 & 5.0054 & TRN & \\
\hline CHEMBL1342678 & 688341 & 4.7 & 4.9796 & TRN & \\
\hline CHEMBL1585260 & 688341 & 6.0 & 4.9367 & TRN & \\
\hline CHEMBL1439088 & 688341 & 4.8 & 5.0204 & TST & \\
\hline CHEMBL1321251 & 688341 & 4.4 & 5.0151 & TST & \\
\hline CHEMBL1345044 & 688341 & 4.9 & 4.9203 & TRN & \\
\hline CHEMBL1603811 & 688341 & 4.8 & 5.0076 & TRN & \\
\hline CHEMBL1568969 & 688341 & 4.5 & 4.8485 & TRN & \\
\hline CHEMBL1519978 & 688341 & 4.8 & 5.0859 & TRN & \\
\hline CHEMBL1336175 & 688341 & 4.6 & 4.9657 & TRN & \\
\hline CHEMBL1347363 & 688341 & 5.2 & 4.9354 & TST & \\
\hline
\end{tabular}




\begin{tabular}{|c|c|c|c|c|}
\hline & & & pplement & $\mathrm{a} \perp \mathrm{Ta}$ \\
\hline CHEMBL1483672 & 688341 & 6.0 & 5.1915 & TRN \\
\hline CHEMBL1431084 & 688341 & 4.5 & 4.9495 & TRN \\
\hline CHEMBL1584470 & 688341 & 5.2 & 4.9198 & TRN \\
\hline CHEMBL1543322 & 688341 & 6.0 & 4.8741 & TST \\
\hline CHEMBL1577295 & 688341 & 4.5 & 5.019 & TRN \\
\hline CHEMBL1479620 & 688341 & 4.9 & 4.9092 & TRN \\
\hline CHEMBL1482629 & 688341 & 5.0 & 5.0138 & TRN \\
\hline CHEMBL1556666 & 688341 & 4.8 & 4.7988 & TRN \\
\hline CHEMBL1364682 & 688341 & 4.5 & 4.8805 & TRN \\
\hline CHEMBL1484216 & 688341 & 4.7 & 4.9415 & TST \\
\hline CHEMBL1549342 & 688341 & 4.5 & 4.9876 & TRN \\
\hline CHEMBL578276 & 688341 & 5.7 & 4.7928 & TRN \\
\hline CHEMBL1366282 & 688341 & 5.7 & 4.9883 & TST \\
\hline CHEMBL1300336 & 688341 & 4.4 & 4.9285 & TRN \\
\hline CHEMBL1581280 & 688341 & 5.1 & 4.8746 & TST \\
\hline CHEMBL1553941 & 688341 & 4.7 & 4.9793 & TRN \\
\hline CHEMBL1422823 & 688341 & 4.6 & 5.0281 & TRN \\
\hline CHEMBL1597718 & 688341 & 4.5 & 5.0796 & TRN \\
\hline CHEMBL1511312 & 688341 & 5.0 & 4.8163 & TRN \\
\hline CHEMBL1459169 & 688341 & 5.2 & 5.0978 & TST \\
\hline CHEMBL1363204 & 688341 & 5.5 & 4.8792 & TRN \\
\hline CHEMBL1456076 & 688341 & 5.4 & 5.0532 & TRN \\
\hline CHEMBL325238 & 688341 & 5.4 & 5.018 & TRN \\
\hline CHEMBL1513568 & 688341 & 5.4 & 4.9679 & TRN \\
\hline CHEMBL1573292 & 688341 & 5.2 & 4.9448 & TST \\
\hline CHEMBL1201091 & 688341 & 4.6 & 4.99 & TST \\
\hline CHEMBL1491241 & 688341 & 4.7 & 4.8665 & TRN \\
\hline CHEMBL1421412 & 688341 & 5.5 & 4.9926 & TST \\
\hline CHEMBL2373626 & 688341 & 4.5 & 4.9988 & TST \\
\hline CHEMBL1480854 & 688341 & 5.1 & 5.0034 & TRN \\
\hline CHEMBL1303002 & 688341 & 4.6 & 4.8042 & TRN \\
\hline CHEMBL1498216 & 688341 & 4.6 & 4.9803 & TRN \\
\hline CHEMBL1438138 & 688341 & 5.7 & 5.019 & TRN \\
\hline CHEMBL1379798 & 688341 & 4.7 & 4.9196 & TRN \\
\hline CHEMBL1364404 & 688341 & 4.6 & 4.9877 & TST \\
\hline CHEMBL1358628 & 688341 & 4.4 & 5.0936 & TST \\
\hline CHEMBL1369089 & 688341 & 5.3 & 4.9609 & TST \\
\hline CHEMBL1340651 & 688341 & 5.2 & 5.1344 & TRN \\
\hline CHEMBL1503456 & 688341 & 5.0 & 5.0513 & TST \\
\hline CHEMBL3213950 & 688341 & 4.4 & 4.838 & TRN \\
\hline CHEMBL1387154 & 688341 & 4.6 & 4.8068 & TRN \\
\hline CHEMBL1482739 & 688341 & 5.5 & 4.9429 & TRN \\
\hline CHEMBL1454082 & 688341 & 4.5 & 4.7226 & TRN \\
\hline CHEMBL1377572 & 688341 & 4.8 & 5.0916 & TST \\
\hline CHEMBL1316760 & 688341 & 5.0 & 5.0239 & TRN \\
\hline CHEMBL1372808 & 688341 & 4.5 & 4.9649 & TST \\
\hline CHEMBL1420529 & 688341 & 4.4 & 4.9053 & TRN \\
\hline CHEMBL1440253 & 688341 & 4.6 & 5.0134 & TRN \\
\hline
\end{tabular}




\begin{tabular}{|c|c|c|c|c|}
\hline \multicolumn{5}{|c|}{ Supplemental Table S2.txt } \\
\hline CHEMBL516075 & 688341 & 4.9 & 5.0302 & TRN \\
\hline CHEMBL1335318 & 688341 & 4.8 & 4.9444 & TRN \\
\hline CHEMBL 20667 & 688341 & 5.2 & 5.1403 & TRN \\
\hline CHEMBL1341291 & 688341 & 4.6 & 4.9572 & TRN \\
\hline CHEMBL3208453 & 688341 & 5.4 & 5.0884 & TST \\
\hline CHEMBL1353259 & 688341 & 4.6 & 4.8936 & TRN \\
\hline CHEMBL1572590 & 688341 & 5.3 & 5.0007 & TRN \\
\hline CHEMBL1561561 & 688341 & 4.4 & 5.0791 & TRN \\
\hline CHEMBL1358629 & 688341 & 5.2 & 4.9461 & TST \\
\hline CHEMBL1448625 & 688341 & 5.2 & 4.9332 & TRN \\
\hline CHEMBL1387918 & 688341 & 4.5 & 4.8268 & TRN \\
\hline CHEMBL1484080 & 688341 & 4.5 & 4.9983 & TRN \\
\hline CHEMBL411085 & 688341 & 4.4 & 4.6568 & TRN \\
\hline CHEMBL1394899 & 688341 & 5.4 & 4.9983 & TRN \\
\hline CHEMBL1333962 & 688341 & 4.8 & 4.8755 & TRN \\
\hline CHEMBL1560035 & 688341 & 5.7 & 4.8261 & TRN \\
\hline CHEMBL1499405 & 688341 & 4.6 & 4.9324 & TRN \\
\hline CHEMBL1477461 & 688341 & 4.9 & 4.7688 & TRN \\
\hline CHEMBL1398960 & 688341 & 4.6 & 4.7429 & TRN \\
\hline CHEMBL1538915 & 688341 & 5.9 & 4.75 & TRN \\
\hline CHEMBL1480512 & 688341 & 4.4 & 4.9176 & TRN \\
\hline CHEMBL1319482 & 688341 & 4.8 & 4.7482 & TRN \\
\hline CHEMBL1447777 & 688341 & 4.7 & 4.8828 & TRN \\
\hline CHEMBL1598862 & 688341 & 4.5 & 4.9559 & TST \\
\hline CHEMBL1504299 & 688341 & 5.6 & 4.822 & TRN \\
\hline CHEMBL1563909 & 688341 & 4.4 & 4.8359 & TRN \\
\hline CHEMBL1308490 & 688341 & 6.5 & 4.9134 & TRN \\
\hline CHEMBL1256148 & 688341 & 5.2 & 5.1596 & TST \\
\hline CHEMBL1582310 & 688341 & 6.1 & 5.1827 & TST \\
\hline CHEMBL1540090 & 688341 & 4.5 & 4.8519 & TST \\
\hline CHEMBL1430632 & 688341 & 4.6 & 4.8676 & TST \\
\hline CHEMBL1369753 & 688341 & 6.0 & 5.1429 & TRN \\
\hline CHEMBL1507725 & 688341 & 4.4 & 4.9078 & TST \\
\hline CHEMBL1301390 & 688341 & 4.7 & 4.9852 & TST \\
\hline CHEMBL1519010 & 688341 & 4.7 & 5.0051 & TRN \\
\hline CHEMBL1516005 & 688341 & 5.4 & 5.0217 & TRN \\
\hline CHEMBL1305970 & 688341 & 4.7 & 4.8123 & TRN \\
\hline CHEMBL1476711 & 688341 & 4.8 & 5.0437 & TRN \\
\hline CHEMBL1270217 & 688341 & 5.5 & 4.7847 & TRN \\
\hline CHEMBL1479514 & 688341 & 4.6 & 4.8125 & TRN \\
\hline CHEMBL1508897 & 688341 & 4.8 & 4.8885 & TRN \\
\hline CHEMBL1493491 & 688341 & 5.2 & 5.0679 & TST \\
\hline CHEMBL1533694 & 688341 & 5.1 & 4.7901 & TRN \\
\hline CHEMBL45591 & 688341 & 8.7959 & 5.0188 & TRN \\
\hline CHEMBL1444078 & 688341 & 4.4 & 5.2421 & TST \\
\hline CHEMBL1346091 & 688341 & 4.4 & 4.8835 & TRN \\
\hline CHEMBL573214 & 688341 & 5.4 & 5.1348 & TRN \\
\hline CHEMBL1548680 & 688341 & 4.5 & 4.6887 & TRN \\
\hline
\end{tabular}




\begin{tabular}{|c|c|c|c|c|}
\hline & & & pplement & al $\mathrm{Ta}$ \\
\hline CHEMBL1524977 & 688341 & 6.0 & 4.8309 & TST \\
\hline CHEMBL1385896 & 688341 & 4.4 & 5.0941 & TST \\
\hline CHEMBL1391265 & 688341 & 4.6 & 4.853 & TRN \\
\hline CHEMBL1411907 & 688341 & 4.6 & 4.8415 & TST \\
\hline CHEMBL1299701 & 688341 & 4.6 & 4.8249 & TRN \\
\hline CHEMBL1373923 & 688341 & 5.6 & 4.9821 & TRN \\
\hline CHEMBL1594626 & 688341 & 4.6 & 5.2835 & TST \\
\hline CHEMBL1419548 & 688341 & 4.5 & 5.0205 & TRN \\
\hline CHEMBL1403626 & 688341 & 4.9 & 5.2127 & TRN \\
\hline CHEMBL1397825 & 688341 & 7.0 & 5.03 & TRN \\
\hline CHEMBL1502290 & 688341 & 4.4 & 4.8022 & TRN \\
\hline CHEMBL1529625 & 688341 & 5.3 & 5.3498 & TST \\
\hline CHEMBL1338249 & 688341 & 4.4 & 4.9117 & TRN \\
\hline CHEMBL1353987 & 688341 & 4.6 & 4.8812 & TRN \\
\hline CHEMBL1413584 & 688341 & 6.1 & 4.8017 & TST \\
\hline CHEMBL1518892 & 688341 & 4.5 & 5.0015 & TST \\
\hline CHEMBL1321899 & 688341 & 4.5 & 5.0656 & TRN \\
\hline CHEMBL1367330 & 688341 & 5.2 & 4.8638 & TST \\
\hline CHEMBL1407314 & 688341 & 4.6 & 4.9408 & TRN \\
\hline CHEMBL1568118 & 688341 & 5.2 & 4.8348 & TRN \\
\hline CHEMBL1365444 & 688341 & 4.4 & 4.8591 & TRN \\
\hline CHEMBL153 & 688341 & 4.8 & 5.0076 & TST \\
\hline CHEMBL1350474 & 688341 & 4.8 & 4.9596 & TST \\
\hline CHEMBL1436110 & 688341 & 5.3 & 4.8903 & TRN \\
\hline CHEMBL1390050 & 688341 & 4.6 & 4.828 & TRN \\
\hline CHEMBL1477600 & 688341 & 4.6 & 4.8056 & TRN \\
\hline CHEMBL1548266 & 688341 & 4.7 & 4.8175 & TRN \\
\hline CHEMBL1415957 & 688341 & 5.6 & 5.0525 & TRN \\
\hline CHEMBL1352410 & 688341 & 4.7 & 4.8813 & TRN \\
\hline CHEMBL1585127 & 688341 & 4.4 & 4.86 & TST \\
\hline CHEMBL48449 & 688341 & 4.5 & 5.1884 & TST \\
\hline CHEMBL1432701 & 688341 & 4.8 & 4.9399 & TRN \\
\hline CHEMBL1559999 & 688341 & 4.6 & 4.7865 & TRN \\
\hline CHEMBL1566137 & 688341 & 4.9 & 4.8948 & TRN \\
\hline CHEMBL1312478 & 688341 & 5.1 & 4.9843 & TRN \\
\hline CHEMBL342375 & 688341 & 5.5 & 5.0292 & TST \\
\hline CHEMBL1513278 & 688341 & 4.7 & 5.0606 & TRN \\
\hline CHEMBL1483857 & 688341 & 5.8 & 4.8621 & TRN \\
\hline CHEMBL1577785 & 688341 & 4.9 & 5.0858 & TST \\
\hline CHEMBL1423766 & 688341 & 5.2 & 4.8456 & TRN \\
\hline CHEMBL1472168 & 688341 & 6.1 & 4.7817 & TRN \\
\hline CHEMBL1592327 & 688341 & 4.8 & 4.9309 & TRN \\
\hline CHEMBL1540676 & 688341 & 5.2 & 4.9893 & TST \\
\hline CHEMBL1382384 & 688341 & 6.2 & 5.0143 & TST \\
\hline CHEMBL1454055 & 688341 & 4.6 & 4.8842 & TRN \\
\hline CHEMBL1526325 & 688341 & 4.8 & 4.7623 & TRN \\
\hline CHEMBL1445618 & 688341 & 5.9 & 4.9833 & TRN \\
\hline CHEMBL1410980 & 688341 & 4.7 & 4.9897 & TST \\
\hline
\end{tabular}




\begin{tabular}{|c|c|c|c|c|c|}
\hline \multirow[b]{2}{*}{ CHEMBL1421019 } & & \\
\hline & 688341 & 4.8 & 5.0075 & TRN & \\
\hline CHEMBL1564194 & 688341 & 4.9 & \multicolumn{2}{|c|}{4.9030000000000005} & TRN \\
\hline CHEMBL556024 & 688341 & 5.2 & 4.9888 & TRN & \\
\hline CHEMBL1449270 & 688341 & 4.9 & 4.9933 & TRN & \\
\hline CHEMBL1427685 & 688341 & 4.5 & 4.9282 & TRN & \\
\hline CHEMBL1490892 & 688341 & 4.7 & 5.0803 & TRN & \\
\hline CHEMBL1365850 & 688341 & 4.4 & 4.8584 & TRN & \\
\hline CHEMBL1544192 & 688341 & 4.5 & 5.0088 & TRN & \\
\hline CHEMBL1391275 & 688341 & 4.5 & 4.8929 & TRN & \\
\hline CHEMBL1568197 & 688341 & 5.3 & 4.915 & TRN & \\
\hline CHEMBL170365 & 688341 & 4.4 & \multicolumn{2}{|c|}{5.111000000000001} & TST \\
\hline CHEMBL1307946 & 688341 & 4.4 & 4.8601 & TRN & \\
\hline CHEMBL1385709 & 688341 & 4.4 & 4.9416 & TRN & \\
\hline CHEMBL1329067 & 688341 & 6.5 & 5.0731 & TRN & \\
\hline CHEMBL1549742 & 688341 & 4.5 & 5.0574 & TRN & \\
\hline CHEMBL1609038 & 688341 & 4.7 & 5.1068 & TRN & \\
\hline CHEMBL1341427 & 688341 & 4.7 & 4.9213 & TRN & \\
\hline CHEMBL1455219 & 688341 & 4.5 & 5.1569 & TST & \\
\hline CHEMBL1507626 & 688341 & 5.1 & 4.9596 & TRN & \\
\hline CHEMBL1405649 & 688341 & 4.8 & 4.9846 & TRN & \\
\hline CHEMBL1598058 & 688341 & 4.4 & 4.8505 & TRN & \\
\hline CHEMBL1415883 & 688341 & 4.5 & 4.7087 & TRN & \\
\hline CHEMBL1403254 & 688341 & 4.6 & 4.9078 & TRN & \\
\hline CHEMBL1304408 & 688341 & 4.6 & 4.862 & TRN & \\
\hline CHEMBL1343484 & 688341 & 4.7 & 5.0259 & TRN & \\
\hline CHEMBL1981833 & 688341 & 6.8 & 4.9785 & TRN & \\
\hline CHEMBL1458225 & 688341 & 4.9 & 4.9244 & TRN & \\
\hline CHEMBL1547956 & 688341 & 5.1 & 4.944 & TRN & \\
\hline CHEMBL588749 & 688341 & 4.5 & 4.9676 & TRN & \\
\hline CHEMBL1416812 & 688341 & 4.6 & 5.0597 & TST & \\
\hline CHEMBL1419020 & 688341 & 4.7 & 4.9738 & TRN & \\
\hline CHEMBL1318789 & 688341 & 6.0 & 5.3296 & TST & \\
\hline CHEMBL1516719 & 688341 & 5.0 & 4.828 & TST & \\
\hline CHEMBL1484422 & 688341 & 5.0 & 5.0647 & TRN & \\
\hline CHEMBL1488988 & 688341 & 4.5 & 5.0633 & TRN & \\
\hline CHEMBL1468425 & 688341 & 4.9 & 5.1672 & TST & \\
\hline CHEMBL3211146 & 688341 & 4.5 & 4.8649 & TRN & \\
\hline CHEMBL522600 & 688341 & 4.9 & 5.1043 & TRN & \\
\hline CHEMBL1400916 & 688341 & 4.4 & 4.8121 & TST & \\
\hline CHEMBL1503819 & 688341 & 4.6 & 4.919 & TRN & \\
\hline CHEMBL1324882 & 688341 & 5.6 & 5.1883 & TRN & \\
\hline CHEMBL1557396 & 688341 & 5.5 & 4.9378 & TRN & \\
\hline CHEMBL1200450 & 688341 & 6.0 & 4.82 & TST & \\
\hline CHEMBL1384347 & 688341 & 5.4 & 5.0645 & TST & \\
\hline CHEMBL1332346 & 688341 & 5.0 & 5.2431 & TRN & \\
\hline CHEMBL1595979 & 688341 & 4.6 & 4.8685 & TRN & \\
\hline CHEMBL1557653 & 688341 & 5.5 & 4.9759 & TRN & \\
\hline CHEMBL1550632 & 688341 & 5.8 & 5.2261 & TST & \\
\hline & & & & 20601 & \\
\hline
\end{tabular}




\begin{tabular}{|c|c|c|c|c|c|}
\hline \\
\hline CHEMBL1425045 & 688341 & 5.6 & 5.1319 & TST & \\
\hline CHEMBL1482262 & 688341 & 4.7 & 4.8536 & TRN & \\
\hline CHEMBL1401243 & 688341 & 4.6 & 5.0925 & TRN & \\
\hline CHEMBL489935 & 688341 & 4.8 & 5.1291 & TRN & \\
\hline CHEMBL1430099 & 688341 & 6.1 & 4.9223 & TRN & \\
\hline CHEMBL1308268 & 688341 & 4.8 & 4.8437 & TRN & \\
\hline CHEMBL1316828 & 688341 & 4.5 & 5.0893 & TRN & \\
\hline CHEMBL1526851 & 688341 & 4.4 & 4.8273 & TST & \\
\hline CHEMBL224214 & 688341 & 6.2 & 5.0907 & TST & \\
\hline CHEMBL45005 & 688341 & 4.9 & 4.9032 & TRN & \\
\hline CHEMBL1600559 & 688341 & 5.4 & 4.7981 & TRN & \\
\hline CHEMBL1300414 & 688341 & 5.3 & 4.8775 & TST & \\
\hline CHEMBL1435509 & 688341 & 4.6 & 5.0286 & TRN & \\
\hline CHEMBL1536811 & 688341 & 4.8 & 4.776 & TRN & \\
\hline CHEMBL1579823 & 688341 & 4.4 & 4.8711 & TRN & \\
\hline CHEMBL1337908 & 688341 & 4.8 & 4.7232 & TST & \\
\hline CHEMBL1474970 & 688341 & 6.0 & 5.0619 & TRN & \\
\hline CHEMBL1541747 & 688341 & 4.5 & 4.8668 & TRN & \\
\hline CHEMBL1597576 & 688341 & 4.6 & 4.8856 & TRN & \\
\hline CHEMBL1419868 & 688341 & 4.5 & 4.9721 & TRN & \\
\hline CHEMBL1605627 & 688341 & 4.7 & 4.9607 & TRN & \\
\hline CHEMBL1382508 & 688341 & 4.8 & 4.7356 & TST & \\
\hline CHEMBL1572988 & 688341 & 5.2 & 5.2622 & TRN & \\
\hline CHEMBL1430717 & 688341 & 4.4 & 5.1148 & TST & \\
\hline CHEMBL1566340 & 688341 & 4.7 & 4.8274 & TRN & \\
\hline CHEMBL1454785 & 688341 & 5.6 & 4.9963 & TRN & \\
\hline CHEMBL1437885 & 688341 & 4.8 & 4.9189 & TRN & \\
\hline CHEMBL1449082 & 688341 & 5.7 & 5.146 & TRN & \\
\hline CHEMBL1532056 & 688341 & 4.8 & $4.7780 e$ & 00000000005 & TRN \\
\hline CHEMBL1486577 & 688341 & 5.9 & 5.0911 & TST & \\
\hline CHEMBL1362135 & 688341 & 5.3 & 4.9336 & TRN & \\
\hline CHEMBL1483034 & 688341 & 5.5 & 4.8007 & TST & \\
\hline CHEMBL1430566 & 688341 & 4.9 & 4.9105 & TST & \\
\hline CHEMBL1510261 & 688341 & 5.1 & 4.9099 & TST & \\
\hline CHEMBL1377436 & 688341 & 4.4 & 4.8555 & TRN & \\
\hline CHEMBL1414037 & 688341 & 6.1 & 5.1086 & TST & \\
\hline CHEMBL1374501 & 688341 & 5.4 & 4.9554 & TRN & \\
\hline CHEMBL1420552 & 688341 & 4.4 & 4.8376 & TRN & \\
\hline CHEMBL1383919 & 688341 & 5.1 & 5.0188 & TRN & \\
\hline CHEMBL1330047 & 688341 & 5.1 & 4.8314 & TRN & \\
\hline CHEMBL1585938 & 688341 & 4.4 & 4.6763 & TST & \\
\hline CHEMBL1541906 & 688341 & 4.6 & 4.9784 & TRN & \\
\hline CHEMBL1423278 & 688341 & 4.8 & 5.0852 & TST & \\
\hline CHEMBL1502414 & 688341 & 4.5 & 4.9549 & TRN & \\
\hline CHEMBL1564665 & 688341 & 4.7 & 4.8504 & TRN & \\
\hline CHEMBL1478951 & 688341 & 4.5 & 5.0065 & TRN & \\
\hline CHEMBL1502184 & 688341 & 4.5 & 4.7771 & TRN & \\
\hline CHEMBL1428525 & 688341 & 4.5 & 4.7218 & TRN & \\
\hline
\end{tabular}




\begin{tabular}{|c|c|c|c|c|c|}
\hline \\
\hline CHEMBL1544046 & 688341 & 4.4 & 4.8126 & TRN & \\
\hline CHEMBL1594075 & 688341 & 7.0 & 5.276 & TRN & \\
\hline CHEMBL1407088 & 688341 & 4.4 & 4.8472 & TRN & \\
\hline CHEMBL1409496 & 688341 & 4.6 & 5.1724 & TRN & \\
\hline CHEMBL1524646 & 688341 & 4.6 & 4.8542 & TRN & \\
\hline CHEMBL1363029 & 688341 & 4.5 & 4.7019 & TRN & \\
\hline CHEMBL1493020 & 688341 & 4.7 & 4.9182 & TRN & \\
\hline CHEMBL1559659 & 688341 & 4.8 & 4.7723 & TRN & \\
\hline CHEMBL1304250 & 688341 & 5.3 & 4.8215 & TRN & \\
\hline CHEMBL1338147 & 688341 & 4.5 & 4.7475 & TRN & \\
\hline CHEMBL1603924 & 688341 & 4.4 & 5.1026 & TST & \\
\hline CHEMBL1333783 & 688341 & 5.2 & 4.987 & TRN & \\
\hline CHEMBL1490562 & 688341 & 4.6 & 4.9638 & TST & \\
\hline CHEMBL1440748 & 688341 & 4.4 & 4.8427 & TRN & \\
\hline CHEMBL1531439 & 688341 & 5.3 & 4.8941 & TRN & \\
\hline CHEMBL1484854 & 688341 & 4.4 & 4.9341 & TRN & \\
\hline CHEMBL1391567 & 688341 & 5.2 & 4.8851 & TRN & \\
\hline CHEMBL1344925 & 688341 & 6.9 & 5.0814 & TST & \\
\hline CHEMBL1407267 & 688341 & 4.7 & 4.8658 & TRN & \\
\hline CHEMBL169233 & 688341 & 4.4 & 5.0574 & TST & \\
\hline CHEMBL1304377 & 688341 & 4.6 & $4.8260 e$ & j0000000005 & TRN \\
\hline CHEMBL1311899 & 688341 & 4.8 & 4.9313 & TST & \\
\hline CHEMBL1456266 & 688341 & 4.5 & 5.0986 & TRN & \\
\hline CHEMBL1405470 & 688341 & 6.9 & 5.0111 & TST & \\
\hline CHEMBL1445150 & 688341 & 4.5 & 4.8725 & TRN & \\
\hline CHEMBL1537910 & 688341 & 5.5 & 5.0163 & TST & \\
\hline CHEMBL1555859 & 688341 & 5.3 & 5.1031 & TST & \\
\hline CHEMBL1308419 & 688341 & 4.6 & 4.9466 & TRN & \\
\hline CHEMBL1425932 & 688341 & 4.6 & 4.7899 & TRN & \\
\hline CHEMBL1483763 & 688341 & 4.6 & 5.0156 & TST & \\
\hline CHEMBL1300285 & 688341 & 5.1 & 4.9165 & TRN & \\
\hline CHEMBL1551445 & 688341 & 4.8 & 5.1512 & TRN & \\
\hline CHEMBL1418595 & 688341 & 4.8 & 5.0249 & TRN & \\
\hline CHEMBL1537383 & 688341 & 4.7 & 5.1054 & TRN & \\
\hline CHEMBL1381353 & 688341 & 4.6 & $4.7410 e$ & 00000000005 & TRN \\
\hline CHEMBL1571157 & 688341 & 4.8 & 5.1061 & TRN & \\
\hline CHEMBL1364867 & 688341 & 4.5 & 4.9472 & TRN & \\
\hline CHEMBL1545834 & 688341 & 4.4 & 4.93199 & 99999999995 & TST \\
\hline CHEMBL1338854 & 688341 & 5.5 & 4.8677 & TRN & \\
\hline CHEMBL1577908 & 688341 & 4.8 & 4.8599 & TRN & \\
\hline CHEMBL1309763 & 688341 & 5.5 & 4.9223 & TST & \\
\hline CHEMBL1394348 & 688341 & 6.0 & 5.2389 & TRN & \\
\hline CHEMBL1582033 & 688341 & 5.8 & 4.9739 & TST & \\
\hline CHEMBL1388322 & 688341 & 6.1 & 4.9101 & TST & \\
\hline CHEMBL1568825 & 688341 & 5.1 & 5.0918 & TRN & \\
\hline CHEMBL1471169 & 688341 & 5.4 & 4.8731 & TST & \\
\hline CHEMBL1353157 & 688341 & 4.8 & 4.7502 & TRN & \\
\hline CHEMBL1364372 & 688341 & 5.4 & 4.9901 & TST & \\
\hline & & & & 20603 & \\
\hline
\end{tabular}




\begin{tabular}{|c|c|c|c|c|c|}
\hline \\
\hline CHEMBL1458258 & 688341 & 4.4 & 5.0304 & TRN & \\
\hline CHEMBL1368887 & 688341 & 4.8 & 4.9503 & TRN & \\
\hline CHEMBL1568268 & 688341 & 4.7 & 4.7002 & TRN & \\
\hline CHEMBL3189575 & 688341 & 4.7 & 5.08899 & 99999999995 & TST \\
\hline CHEMBL1460779 & 688341 & 5.2 & 4.7736 & TRN & \\
\hline CHEMBL1399014 & 688341 & 5.4 & 5.0202 & TST & \\
\hline CHEMBL1370522 & 688341 & 4.8 & 5.0064 & TRN & \\
\hline CHEMBL1490807 & 688341 & 4.8 & 4.9047 & TRN & \\
\hline CHEMBL1501864 & 688341 & 4.4 & 4.8875 & TRN & \\
\hline CHEMBL1460392 & 688341 & 5.0 & 4.9713 & TRN & \\
\hline CHEMBL1420530 & 688341 & 4.7 & 4.9392 & TST & \\
\hline CHEMBL1563566 & 688341 & 5.9 & 5.07 & TRN & \\
\hline CHEMBL1522257 & 688341 & 4.8 & 4.9433 & TRN & \\
\hline CHEMBL1564471 & 688341 & 4.5 & 4.8104 & TRN & \\
\hline CHEMBL1579227 & 688341 & 4.6 & 4.9328 & TRN & \\
\hline CHEMBL1462977 & 688341 & 5.2 & 4.9212 & TRN & \\
\hline CHEMBL1542974 & 688341 & 4.7 & 5.05 & TRN & \\
\hline CHEMBL1532651 & 688341 & 4.7 & 4.8722 & TRN & \\
\hline CHEMBL1413105 & 688341 & 5.0 & 5.0151 & TRN & \\
\hline CHEMBL1417221 & 688341 & 4.7 & 4.8689 & TRN & \\
\hline CHEMBL1432468 & 688341 & 4.5 & 4.7808 & TRN & \\
\hline CHEMBL1454139 & 688341 & 4.6 & 4.8304 & TRN & \\
\hline CHEMBL1534533 & 688341 & 4.7 & 4.8403 & TST & \\
\hline CHEMBL1453168 & 688341 & 5.3 & 4.8871 & TST & \\
\hline CHEMBL1527157 & 688341 & 5.2 & 5.0263 & TST & \\
\hline CHEMBL1464187 & 688341 & 5.2 & 5.0135 & TRN & \\
\hline CHEMBL1471400 & 688341 & 6.0 & 4.9933 & TST & \\
\hline CHEMBL1363228 & 688341 & 4.9 & 4.9071 & TRN & \\
\hline CHEMBL1535635 & 688341 & 4.5 & 5.074 & TRN & \\
\hline CHEMBL1432458 & 688341 & 4.4 & 4.7295 & TRN & \\
\hline CHEMBL1324335 & 688341 & 5.9 & 4.9301 & TRN & \\
\hline CHEMBL1346720 & 688341 & 4.9 & 4.9961 & TRN & \\
\hline CHEMBL1429745 & 688341 & 4.5 & 4.9235 & TRN & \\
\hline CHEMBL1463575 & 688341 & 4.6 & 4.7505 & TRN & \\
\hline CHEMBL1574591 & 688341 & 5.9 & 4.86100 & 0000000001 & TRN \\
\hline CHEMBL1403437 & 688341 & 5.3 & 4.9205 & TRN & \\
\hline CHEMBL 257856 & 688341 & 4.6 & 4.7662 & TRN & \\
\hline CHEMBL1445335 & 688341 & 4.5 & 4.815 & TRN & \\
\hline CHEMBL1462547 & 688341 & 4.5 & 4.8311 & TRN & \\
\hline CHEMBL1468779 & 688341 & 4.5 & 4.7756 & TRN & \\
\hline CHEMBL1347350 & 688341 & 4.4 & 4.9082 & TRN & \\
\hline CHEMBL1450106 & 688341 & 5.2 & 5.154 & TRN & \\
\hline CHEMBL1485696 & 688341 & 4.5 & 5.0291 & TRN & \\
\hline CHEMBL1307002 & 688341 & 4.7 & 4.926 & TRN & \\
\hline CHEMBL1453019 & 688341 & 4.5 & 4.8402 & TRN & \\
\hline CHEMBL1384324 & 688341 & 5.3 & 4.7599 & TST & \\
\hline CHEMBL 267458 & 688341 & 4.8 & 4.9718 & TRN & \\
\hline CHEMBL1501783 & 688341 & 5.2 & 5.038 & TST & \\
\hline
\end{tabular}




\begin{tabular}{|c|c|c|c|c|c|}
\hline \multicolumn{6}{|c|}{ Supplemental Table S2.txt } \\
\hline CHEMBL1490722 & 688341 & 4.5 & 4.8154 & TRN & \\
\hline CHEMBL1553555 & 688341 & 4.5 & 5.0459 & TRN & \\
\hline CHEMBL1516882 & 688341 & 5.6 & 5.0106 & TRN & \\
\hline CHEMBL1540596 & 688341 & 4.8 & 4.9427 & TRN & \\
\hline CHEMBL1426369 & 688341 & 4.6 & 4.9305 & TRN & \\
\hline CHEMBL1426897 & 688341 & 6.9 & 4.814 & TRN & \\
\hline CHEMBL1509253 & 688341 & 4.4 & 4.8519 & TRN & \\
\hline CHEMBL1529114 & 688341 & 4.5 & 4.7169 & TRN & \\
\hline CHEMBL1580154 & 688341 & 4.4 & 4.9965 & TRN & \\
\hline CHEMBL1412893 & 688341 & 5.2 & 5.17 & TRN & \\
\hline CHEMBL1502681 & 688341 & 5.8 & 4.9021 & TRN & \\
\hline CHEMBL1587097 & 688341 & 4.4 & 4.9892 & TRN & \\
\hline CHEMBL1454658 & 688341 & 5.4 & 4.8331 & TRN & \\
\hline CHEMBL1469093 & 688341 & 6.2 & 4.9399 & TRN & \\
\hline CHEMBL1367075 & 688341 & 4.5 & 4.9014 & TRN & \\
\hline CHEMBL1612525 & 688341 & 4.8 & 4.8943 & TST & \\
\hline CHEMBL1389704 & 688341 & 6.2 & 4.995 & TST & \\
\hline CHEMBL1376371 & 688341 & 5.1 & 4.8939 & TST & \\
\hline CHEMBL1371093 & 688341 & 4.5 & 4.9023 & TRN & \\
\hline CHEMBL1585514 & 688341 & 5.1 & 5.0002 & TST & \\
\hline CHEMBL1449857 & 688341 & 4.6 & 4.7574 & TRN & \\
\hline CHEMBL1319284 & 688341 & 4.9 & 4.794 & TRN & \\
\hline CHEMBL1395402 & 688341 & 5.5 & 5.1013 & TRN & \\
\hline CHEMBL1375124 & 688341 & 5.0 & 5.1874 & TST & \\
\hline CHEMBL1557795 & 688341 & 5.6 & 5.0036 & TST & \\
\hline CHEMBL1378735 & 688341 & 4.8 & 4.8631 & TRN & \\
\hline CHEMBL1480481 & 688341 & 5.5 & 4.9761 & TRN & \\
\hline CHEMBL1508747 & 688341 & 4.9 & 5.0147 & TRN & \\
\hline CHEMBL1353786 & 688341 & 4.6 & 4.8733 & TRN & \\
\hline CHEMBL1516488 & 688341 & 4.8 & 4.7185 & TRN & \\
\hline CHEMBL1574575 & 688341 & 4.4 & 4.9184 & TRN & \\
\hline CHEMBL1487209 & 688341 & 5.2 & 4.86 & TRN & \\
\hline CHEMBL1587280 & 688341 & 5.2 & 4.7938 & TRN & \\
\hline CHEMBL1310014 & 688341 & 6.0 & 4.9433 & TRN & \\
\hline CHEMBL1323531 & 688341 & 4.8 & 4.95100 & 00000000005 & TRN \\
\hline CHEMBL1553114 & 688341 & 4.8 & 5.0799 & TRN & \\
\hline CHEMBL1459290 & 688341 & 4.8 & 4.8362 & TRN & \\
\hline CHEMBL1473753 & 688341 & 4.7 & 4.9851 & TRN & \\
\hline CHEMBL1517453 & 688341 & 5.6 & 4.9854 & TRN & \\
\hline CHEMBL1483422 & 688341 & 5.6 & 5.1136 & TRN & \\
\hline CHEMBL1606581 & 688341 & 4.4 & 4.78 & TRN & \\
\hline CHEMBL290426 & 688341 & 5.4 & 5.0419 & TRN & \\
\hline CHEMBL261836 & 688341 & 5.0 & 5.0553 & TST & \\
\hline CHEMBL1605116 & 688341 & 4.4 & 5.0605 & TST & \\
\hline CHEMBL1333882 & 688341 & 4.4 & 4.8516 & TST & \\
\hline CHEMBL1356115 & 688341 & 5.1 & 5.3807 & TST & \\
\hline CHEMBL1342109 & 688341 & 4.7 & 4.8154 & TRN & \\
\hline CHEMBL1493739 & 688341 & 4.5 & 4.8804 & TRN & \\
\hline
\end{tabular}




\begin{tabular}{|c|c|c|c|c|c|}
\hline \multicolumn{6}{|c|}{ Supplemental Table S2.txt } \\
\hline CHEMBL1458256 & 688341 & 5.0 & 4.9761 & TRN & \\
\hline CHEMBL1524448 & 688341 & 4.6 & 4.81 & TRN & \\
\hline CHEMBL1342502 & 688341 & 5.4 & 4.8892 & TST & \\
\hline CHEMBL1321919 & 688341 & 5.4 & 5.0603 & TST & \\
\hline CHEMBL1507611 & 688341 & 6.0 & 4.8779 & TST & \\
\hline CHEMBL447507 & 688341 & 4.8 & 5.0081 & TRN & \\
\hline CHEMBL1585845 & 688341 & 5.5 & 4.7135 & TRN & \\
\hline CHEMBL1456679 & 688341 & 4.4 & 4.9776 & TST & \\
\hline CHEMBL1319199 & 688341 & 4.4 & 4.8968 & TRN & \\
\hline CHEMBL1518481 & 688341 & 4.6 & 4.8574 & TRN & \\
\hline CHEMBL1386265 & 688341 & 4.4 & 4.7989 & TRN & \\
\hline CHEMBL1353590 & 688341 & 4.5 & 4.6469 & TRN & \\
\hline CHEMBL1610760 & 688341 & 4.6 & 4.9271 & TRN & \\
\hline CHEMBL1378869 & 688341 & 4.5 & 4.8724 & TRN & \\
\hline CHEMBL1543990 & 688341 & 4.4 & 5.0219 & TRN & \\
\hline CHEMBL1456116 & 688341 & 4.4 & 4.9157 & TST & \\
\hline CHEMBL1380354 & 688341 & 4.7 & 4.8558 & TRN & \\
\hline CHEMBL1412742 & 688341 & 5.1 & 5.0618 & TRN & \\
\hline CHEMBL1374765 & 688341 & 4.5 & 4.9034 & TRN & \\
\hline CHEMBL1451820 & 688341 & 4.7 & 4.9228 & TST & \\
\hline CHEMBL1343907 & 688341 & 4.6 & 4.8411 & TRN & \\
\hline CHEMBL1508446 & 688341 & 4.5 & 4.8524 & TST & \\
\hline CHEMBL1520633 & 688341 & 6.1 & 5.0751 & TRN & \\
\hline CHEMBL1566108 & 688341 & 4.7 & 4.9553 & TRN & \\
\hline CHEMBL1472395 & 688341 & 4.7 & 4.7522 & TRN & \\
\hline CHEMBL1381518 & 688341 & 4.7 & 4.94300 & 00000000005 & TRN \\
\hline CHEMBL1402225 & 688341 & 4.6 & 4.8059 & TRN & \\
\hline CHEMBL1088937 & 688341 & 5.7 & 5.0374 & TRN & \\
\hline CHEMBL1545045 & 688341 & 4.4 & 5.1006 & TST & \\
\hline CHEMBL1391859 & 688341 & 5.0 & 5.0695 & TRN & \\
\hline CHEMBL1476108 & 688341 & 4.4 & 5.0352 & TST & \\
\hline CHEMBL 222334 & 688341 & 5.4 & 5.0988 & TST & \\
\hline CHEMBL1405669 & 688341 & 4.4 & 4.9386 & TRN & \\
\hline CHEMBL1315716 & 688341 & 4.4 & 4.9503 & TRN & \\
\hline CHEMBL1304524 & 688341 & 4.6 & 5.1448 & TST & \\
\hline CHEMBL1392879 & 688341 & 4.9 & 4.7328 & TRN & \\
\hline CHEMBL1433289 & 688341 & 4.8 & 4.9484 & TST & \\
\hline CHEMBL1335130 & 688341 & 4.9 & 4.7473 & TRN & \\
\hline CHEMBL1562553 & 688341 & 4.4 & 5.1706 & TST & \\
\hline CHEMBL1366106 & 688341 & 5.5 & 5.0159 & TRN & \\
\hline CHEMBL475375 & 688341 & 4.4 & 5.1221 & TRN & \\
\hline CHEMBL1582763 & 688341 & 4.6 & 4.8655 & TRN & \\
\hline CHEMBL1507391 & 688341 & 4.6 & 4.8949 & TRN & \\
\hline CHEMBL1462316 & 688341 & 4.5 & 4.998 & TRN & \\
\hline CHEMBL1373679 & 688341 & 4.7 & 5.0728 & TST & \\
\hline CHEMBL492610 & 688341 & 4.5 & 5.0484 & TRN & \\
\hline CHEMBL1413782 & 688341 & 5.3 & 4.9701 & TST & \\
\hline CHEMBL1464641 & 688341 & 4.4 & 5.0184 & TST & \\
\hline
\end{tabular}




\begin{tabular}{|c|c|c|c|c|}
\hline \multicolumn{5}{|c|}{ Supplemental Table S2.txt } \\
\hline CHEMBL1343941 & 688341 & 4.8 & 4.7985 & TRN \\
\hline CHEMBL1554851 & 688341 & 4.6 & 5.0367 & TRN \\
\hline CHEMBL1502880 & 688341 & 6.3 & 4.8703 & TST \\
\hline CHEMBL1411871 & 688341 & 4.4 & 5.0916 & TRN \\
\hline CHEMBL1612117 & 688341 & 4.7 & 4.8577 & TRN \\
\hline CHEMBL1490232 & 688341 & 4.8 & 4.8445 & TRN \\
\hline CHEMBL1598623 & 688341 & 4.4 & 4.9655 & TRN \\
\hline CHEMBL1411686 & 688341 & 4.4 & 4.927 & TRN \\
\hline CHEMBL1381306 & 688341 & 4.6 & 5.0038 & TST \\
\hline CHEMBL1395049 & 688341 & 4.7 & 5.14 & TRN \\
\hline CHEMBL1358033 & 688341 & 4.4 & 5.1374 & TRN \\
\hline CHEMBL1376974 & 688341 & 6.7001 & 5.0642 & TST \\
\hline CHEMBL1417829 & 688341 & 4.7 & 4.8743 & TRN \\
\hline CHEMBL1555368 & 688341 & 5.1 & 5.0987 & TRN \\
\hline CHEMBL1369863 & 688341 & 4.6 & 4.9784 & TRN \\
\hline CHEMBL1491744 & 688341 & 5.6 & 5.1511 & TRN \\
\hline CHEMBL1494024 & 688341 & 4.6 & 4.9502 & TST \\
\hline CHEMBL1372773 & 688341 & 5.2 & 5.0013 & TRN \\
\hline CHEMBL1448655 & 688341 & 4.6 & 5.0691 & TST \\
\hline CHEMBL1372412 & 688341 & 5.3 & 4.9858 & TRN \\
\hline CHEMBL1324529 & 688341 & 6.3 & 5.1947 & TRN \\
\hline CHEMBL1383421 & 688341 & 4.7 & 5.0599 & TRN \\
\hline CHEMBL1383438 & 688341 & 5.2 & 4.9333 & TST \\
\hline CHEMBL1393471 & 688341 & 4.5 & 4.9199 & TST \\
\hline CHEMBL 299683 & 688341 & 5.4 & 5.0174 & TST \\
\hline CHEMBL1546751 & 688341 & 5.6 & 4.8931 & TRN \\
\hline CHEMBL1609044 & 688341 & 5.2 & 4.7699 & TRN \\
\hline CHEMBL1562288 & 688341 & 5.4 & 5.0072 & TST \\
\hline CHEMBL1387387 & 688341 & 4.5 & 4.8731 & TST \\
\hline CHEMBL1378722 & 688341 & 5.0 & 4.8057 & TRN \\
\hline CHEMBL1344621 & 688341 & 4.9 & 4.8758 & TRN \\
\hline CHEMBL1482751 & 688341 & 4.8 & 5.112 & TRN \\
\hline CHEMBL1301494 & 688341 & 6.1 & 5.0061 & TST \\
\hline CHEMBL1364367 & 688341 & 5.2 & 5.0398 & TST \\
\hline CHEMBL1581059 & 688341 & 4.5 & 4.8728 & TRN \\
\hline CHEMBL1470077 & 688341 & 4.4 & 5.1764 & TST \\
\hline CHEMBL1399701 & 688341 & 4.9 & 4.8079 & TRN \\
\hline CHEMBL1384522 & 688341 & 4.8 & 5.0358 & TRN \\
\hline CHEMBL546257 & 688341 & 4.5 & 5.1612 & TST \\
\hline CHEMBL1454183 & 688341 & 4.8 & 5.0369 & TST \\
\hline CHEMBL1608526 & 688341 & 4.6 & 4.8426 & TRN \\
\hline CHEMBL1571126 & 688341 & 4.4 & 4.8135 & TST \\
\hline CHEMBL1438777 & 688341 & 5.2 & 4.9533 & TRN \\
\hline CHEMBL1380867 & 688341 & 6.3 & 5.016 & TST \\
\hline CHEMBL1320934 & 688341 & 5.5 & 5.0157 & TRN \\
\hline CHEMBL1554577 & 688341 & 4.6 & 5.1605 & TRN \\
\hline CHEMBL30131 & 688341 & 4.8 & 4.9626 & TST \\
\hline CHEMBL1331312 & 688341 & 6.0 & 5.0424 & TRN \\
\hline
\end{tabular}




\begin{tabular}{|c|c|c|c|c|}
\hline \multicolumn{5}{|c|}{ Supplemental Table S2.txt } \\
\hline CHEMBL1505008 & 688341 & 6.6 & 4.9539 & TST \\
\hline CHEMBL1479486 & 688341 & 4.5 & 4.8947 & TRN \\
\hline CHEMBL1583614 & 688341 & 5.2 & 4.8928 & TRN \\
\hline CHEMBL1456906 & 688341 & 5.0 & 5.1611 & TRN \\
\hline CHEMBL1525033 & 688341 & 4.5 & 4.6126 & TRN \\
\hline CHEMBL429023 & 688341 & 6.0 & 5.1367 & TST \\
\hline CHEMBL1606513 & 688341 & 5.4 & 4.8906 & TRN \\
\hline CHEMBL1523894 & 688341 & 4.6 & 5.1523 & TST \\
\hline CHEMBL1380881 & 688341 & 4.8 & 4.7249 & TRN \\
\hline CHEMBL1343205 & 688341 & 4.5 & 4.9162 & TRN \\
\hline CHEMBL1343524 & 688341 & 4.4 & 4.9273 & TRN \\
\hline CHEMBL1605746 & 688341 & 4.5 & 4.9493 & TRN \\
\hline CHEMBL1351164 & 688341 & 4.5 & 4.7567 & TRN \\
\hline CHEMBL1549773 & 688341 & 4.4 & 4.8666 & TST \\
\hline CHEMBL1565215 & 688341 & 4.4 & 4.9081 & TRN \\
\hline CHEMBL1338220 & 688341 & 4.7 & 4.9249 & TRN \\
\hline CHEMBL16656 & 688341 & 7.6003 & 4.9957 & TRN \\
\hline CHEMBL1576755 & 688341 & 4.4 & 4.9349 & TRN \\
\hline CHEMBL1415594 & 688341 & 4.6 & 4.8515 & TRN \\
\hline CHEMBL 298461 & 688341 & 5.1 & 4.8953 & TRN \\
\hline CHEMBL1370078 & 688341 & 4.6 & 4.8418 & TRN \\
\hline CHEMBL1583398 & 688341 & 4.8 & 4.812 & TRN \\
\hline CHEMBL1483438 & 688341 & 5.3 & 5.1486 & TRN \\
\hline CHEMBL1463737 & 688341 & 4.5 & 4.8903 & TRN \\
\hline CHEMBL1345802 & 688341 & 4.8 & 4.9609 & TRN \\
\hline CHEMBL1320349 & 688341 & 4.6 & 4.8268 & TRN \\
\hline CHEMBL1413655 & 688341 & 5.3 & 4.8744 & TRN \\
\hline CHEMBL1435360 & 688341 & 4.9 & 4.8987 & TRN \\
\hline CHEMBL1415404 & 688341 & 4.6 & 4.962 & TRN \\
\hline CHEMBL1339573 & 688341 & 5.2 & 4.9203 & TST \\
\hline CHEMBL1336095 & 688341 & 5.0 & 4.877 & TRN \\
\hline CHEMBL1510023 & 688341 & 4.8 & 5.0109 & TRN \\
\hline CHEMBL1339504 & 688341 & 4.6 & 4.8146 & TRN \\
\hline CHEMBL1522857 & 688341 & 4.6 & 4.9959 & TRN \\
\hline CHEMBL1315292 & 688341 & 6.8 & 5.1167 & TRN \\
\hline CHEMBL3197066 & 688341 & 5.2 & 4.9024 & TST \\
\hline CHEMBL1451408 & 688341 & 4.8 & 4.9135 & TRN \\
\hline CHEMBL1388969 & 688341 & 5.0 & 4.8409 & TRN \\
\hline CHEMBL1478593 & 688341 & 4.6 & 4.8907 & TRN \\
\hline CHEMBL1407119 & 688341 & 5.1 & 4.9912 & TRN \\
\hline CHEMBL1345135 & 688341 & 5.3 & 4.7371 & TRN \\
\hline CHEMBL12014 & 688341 & 4.6 & 4.9912 & TST \\
\hline CHEMBL1440362 & 688341 & 7.5003 & 5.2076 & TRN \\
\hline CHEMBL1519529 & 688341 & 4.6 & 4.9772 & TST \\
\hline CHEMBL1584899 & 688341 & 4.5 & 4.7886 & TRN \\
\hline CHEMBL1466638 & 688341 & 4.6 & 4.9196 & TRN \\
\hline CHEMBL1333774 & 688341 & 4.7 & 4.9969 & TRN \\
\hline CHEMBL1370718 & 688341 & 5.3 & 4.9996 & TRN \\
\hline
\end{tabular}




\begin{tabular}{|c|c|c|c|c|}
\hline \multicolumn{5}{|c|}{ Supplemental Table S2.txt } \\
\hline CHEMBL1574468 & 688341 & 4.4 & 4.9321 & TRN \\
\hline CHEMBL1389115 & 688341 & 4.7 & 4.8809 & TST \\
\hline CHEMBL1368437 & 688341 & 5.2 & 4.9093 & TRN \\
\hline CHEMBL1320190 & 688341 & 4.7 & 5.0025 & TRN \\
\hline CHEMBL1597911 & 688341 & 6.5 & 5.0878 & TST \\
\hline CHEMBL1426347 & 688341 & 4.5 & 5.1228 & TRN \\
\hline CHEMBL1414483 & 688341 & 5.2 & 5.0508 & TRN \\
\hline CHEMBL1362615 & 688341 & 4.4 & 4.855 & TRN \\
\hline CHEMBL1384793 & 688341 & 4.5 & 4.797 & TRN \\
\hline CHEMBL1582286 & 688341 & 5.2 & 5.114 & TST \\
\hline CHEMBL1521689 & 688341 & 5.2 & 4.7571 & TRN \\
\hline CHEMBL1371686 & 688341 & 5.2 & 5.1834 & TRN \\
\hline CHEMBL1547916 & 688341 & 4.7 & 4.8698 & TRN \\
\hline CHEMBL1539450 & 688341 & 4.4 & 5.1178 & TRN \\
\hline CHEMBL1584001 & 688341 & 4.5 & 4.9099 & TRN \\
\hline CHEMBL1304672 & 688341 & 4.4 & 4.8149 & TRN \\
\hline CHEMBL1374755 & 688341 & 5.4 & 4.7911 & TRN \\
\hline CHEMBL1424345 & 688341 & 4.9 & 4.9425 & TST \\
\hline CHEMBL606474 & 688341 & 4.6 & 4.9626 & TRN \\
\hline CHEMBL1320203 & 688341 & 4.4 & 4.8914 & TRN \\
\hline CHEMBL1514016 & 688341 & 4.4 & 5.0445 & TRN \\
\hline CHEMBL86962 & 688341 & 4.4 & 4.8985 & TRN \\
\hline CHEMBL1533836 & 688341 & 4.4 & 4.7114 & TRN \\
\hline CHEMBL1462871 & 688341 & 5.8 & 4.8832 & TST \\
\hline CHEMBL1605730 & 688341 & 4.4 & 5.0665 & TST \\
\hline CHEMBL1390468 & 688341 & 4.6 & 4.8132 & TRN \\
\hline CHEMBL1379228 & 688341 & 5.0 & 4.8922 & TRN \\
\hline CHEMBL556489 & 688341 & 6.2 & 5.1068 & TRN \\
\hline CHEMBL1482064 & 688341 & 5.0 & 4.9476 & TRN \\
\hline CHEMBL1580616 & 688341 & 4.9 & 4.762 & TRN \\
\hline CHEMBL1424769 & 688341 & 4.7 & 4.9215 & TRN \\
\hline CHEMBL1309821 & 688341 & 4.4 & 4.9621 & TST \\
\hline CHEMBL1567849 & 688341 & 4.4 & 4.977 & TRN \\
\hline CHEMBL1607512 & 688341 & 4.4 & 4.8231 & TRN \\
\hline CHEMBL1437667 & 688341 & 4.5 & 5.2151 & TRN \\
\hline CHEMBL1493496 & 688341 & 5.5 & 5.1524 & TRN \\
\hline CHEMBL1504865 & 688341 & 4.8 & 4.8874 & TRN \\
\hline CHEMBL1588613 & 688341 & 5.0 & 4.8739 & TRN \\
\hline CHEMBL1326512 & 688341 & 5.0 & 4.9694 & TRN \\
\hline CHEMBL1566161 & 688341 & 4.8 & 4.7165 & TRN \\
\hline CHEMBL1523777 & 688341 & 4.6 & 4.814 & TST \\
\hline CHEMBL1465151 & 688341 & 4.8 & 4.7973 & TRN \\
\hline CHEMBL1554622 & 688341 & 4.6 & 4.9702 & TRN \\
\hline CHEMBL1337829 & 688341 & 8.1024 & 5.135 & TRN \\
\hline CHEMBL1463629 & 688341 & 4.6 & 4.9522 & TRN \\
\hline CHEMBL1412825 & 688341 & 4.7 & 4.9451 & TST \\
\hline CHEMBL1388545 & 688341 & 5.5 & 4.9392 & TRN \\
\hline CHEMBL1559875 & 688341 & 4.4 & 4.8841 & TRN \\
\hline
\end{tabular}




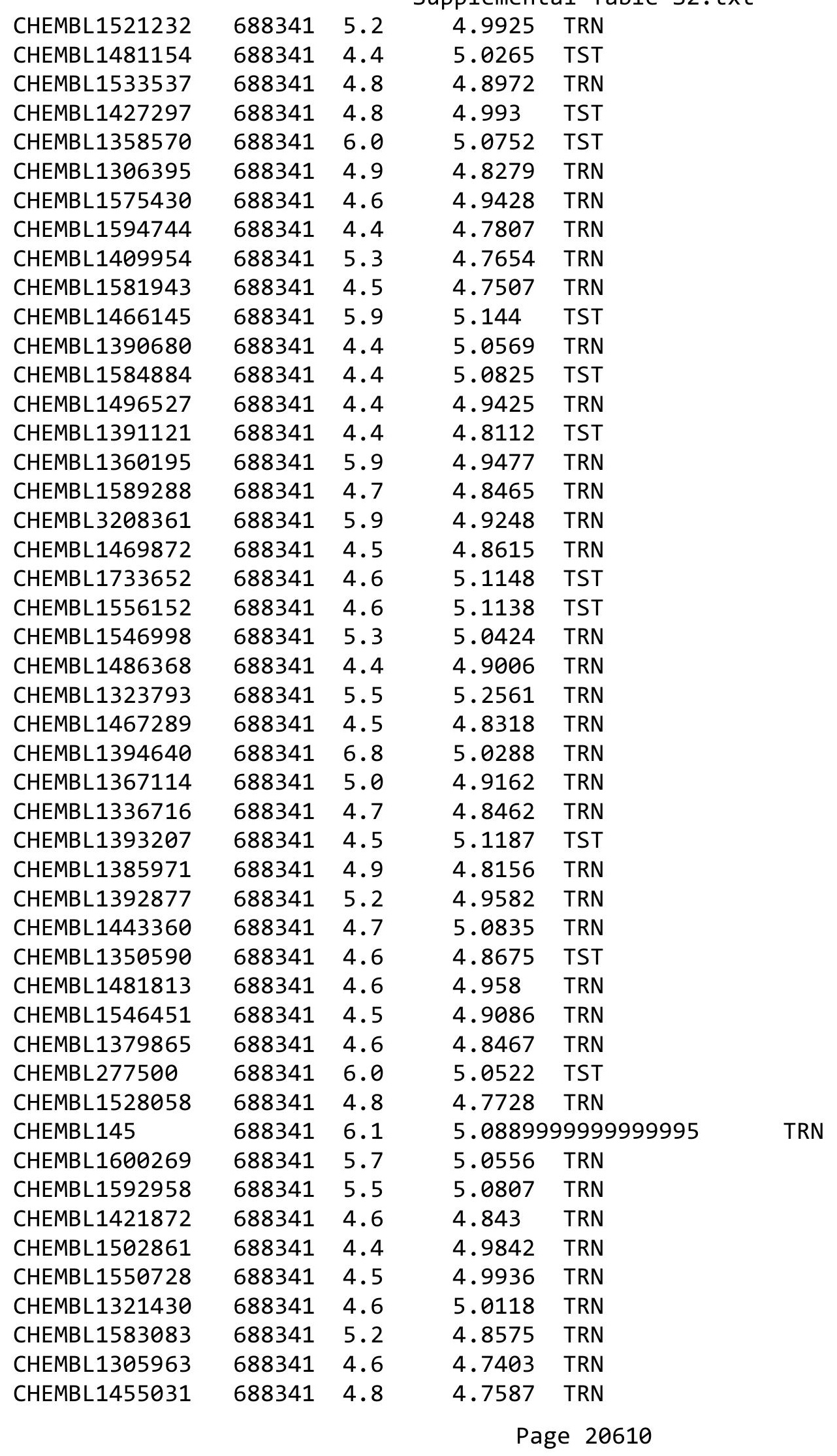




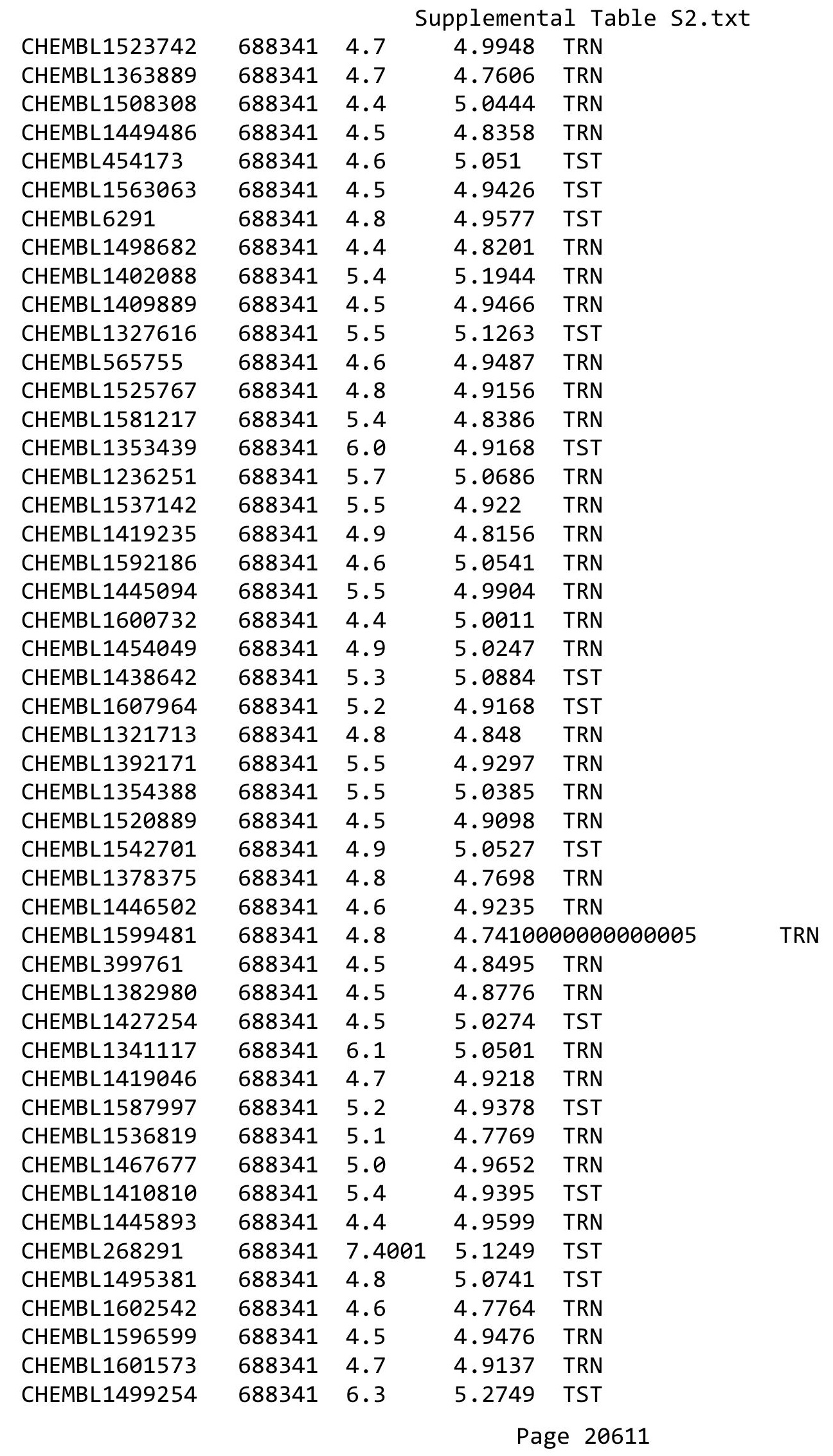




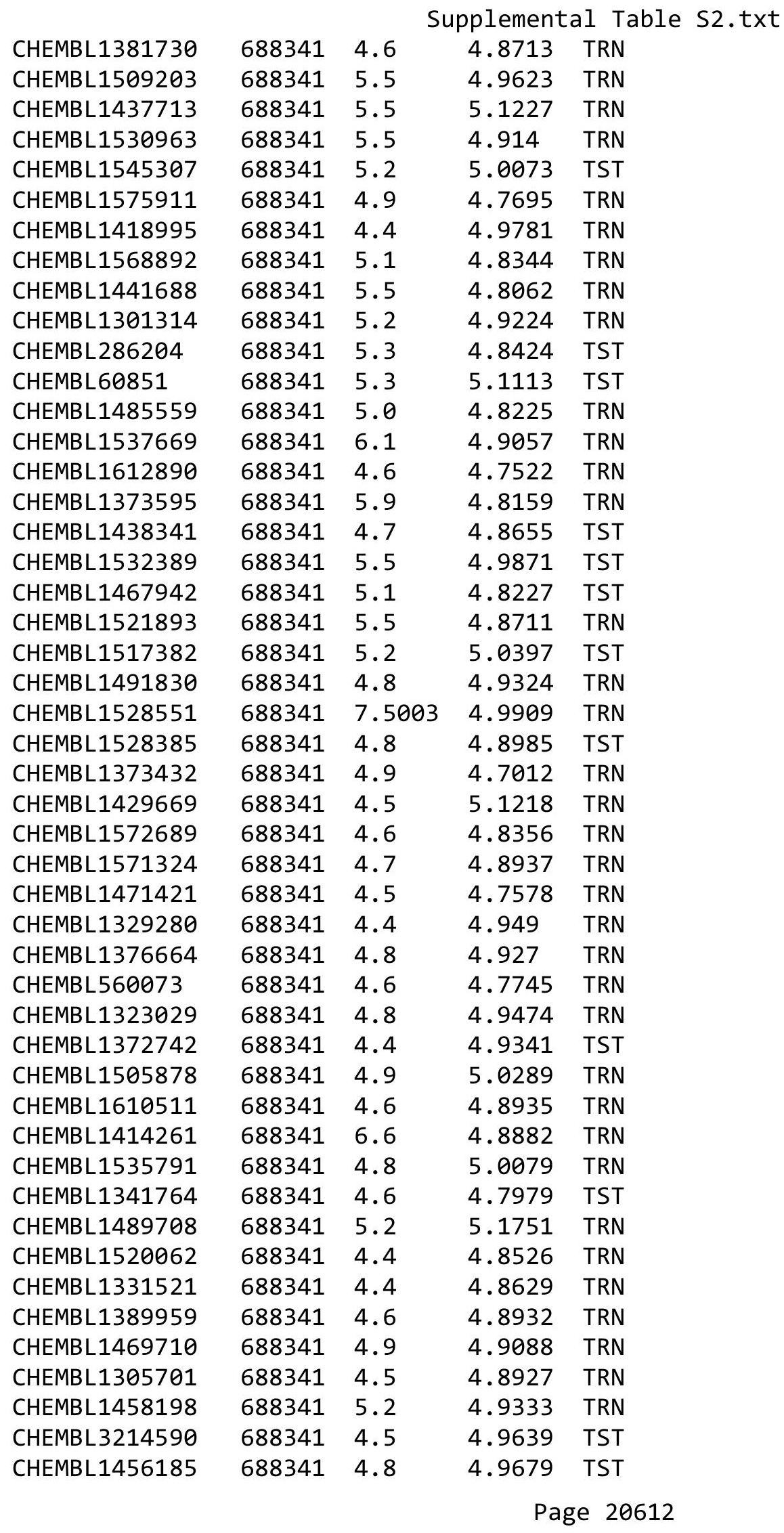




\begin{tabular}{|c|c|c|c|c|c|}
\hline CHEMBL1603373 & 688341 & 4.6 & 4.6836 & $\begin{array}{l}\text { TRN } \\
\text { TRN }\end{array}$ & \\
\hline CHEMBL1372415 & 688341 & 4.6 & 4.98300 & 20000000005 & TRN \\
\hline CHEMBL1500970 & 688341 & 5.2 & 4.871 & TRN & \\
\hline CHEMBL1272150 & 688341 & 4.6 & 4.7193 & TRN & \\
\hline CHEMBL1558569 & 688341 & 4.8 & 5.1191 & TRN & \\
\hline CHEMBL1502400 & 688341 & 4.4 & 4.9528 & TRN & \\
\hline CHEMBL1524813 & 688341 & 4.7 & 4.6922 & TRN & \\
\hline CHEMBL1482852 & 688341 & 4.8 & 4.6867 & TRN & \\
\hline CHEMBL1451255 & 688341 & 4.4 & 4.8405 & TRN & \\
\hline CHEMBL1349601 & 688341 & 4.5 & 4.793 & TRN & \\
\hline CHEMBL1483537 & 688341 & 4.5 & 4.8261 & TRN & \\
\hline CHEMBL1477559 & 688341 & 4.6 & 4.7683 & TRN & \\
\hline CHEMBL1300058 & 688341 & 4.4 & 5.0219 & TST & \\
\hline CHEMBL1481374 & 688341 & 4.5 & 4.7569 & TST & \\
\hline CHEMBL1389201 & 688341 & 4.5 & 4.7408 & TRN & \\
\hline CHEMBL1418088 & 688341 & 5.2 & 4.8817 & TRN & \\
\hline CHEMBL1369583 & 688341 & 4.7 & 4.829 & TRN & \\
\hline CHEMBL1373894 & 688341 & 5.5 & 4.8526 & TRN & \\
\hline CHEMBL1574426 & 688341 & 4.6 & 4.8063 & TRN & \\
\hline CHEMBL1536044 & 688341 & 4.7 & 4.8837 & TRN & \\
\hline CHEMBL1559160 & 688341 & 5.9 & 4.842 & TRN & \\
\hline CHEMBL1322376 & 688341 & 4.8 & 4.9693 & TST & \\
\hline CHEMBL1394258 & 688341 & 4.8 & 5.0289 & TRN & \\
\hline CHEMBL1539584 & 688341 & 4.5 & 4.9931 & TRN & \\
\hline CHEMBL1450576 & 688341 & 5.2 & 4.7276 & TRN & \\
\hline CHEMBL1605470 & 688341 & 5.0 & 5.0613 & TRN & \\
\hline CHEMBL1499961 & 688341 & 4.5 & 4.871 & TRN & \\
\hline CHEMBL1395162 & 688341 & 4.4 & 5.0148 & TRN & \\
\hline CHEMBL1508135 & 688341 & 4.4 & 4.7614 & TRN & \\
\hline CHEMBL1494745 & 688341 & 4.7 & 4.739 & TRN & \\
\hline CHEMBL1455653 & 688341 & 4.5 & 4.9685 & TST & \\
\hline CHEMBL1355139 & 688341 & 5.1 & 4.8936 & TRN & \\
\hline CHEMBL1313851 & 688341 & 4.7 & 4.8603 & TRN & \\
\hline CHEMBL320361 & 688341 & 4.4 & 5.0875 & TRN & \\
\hline CHEMBL1323764 & 688341 & 4.4 & 4.8108 & TRN & \\
\hline CHEMBL1568449 & 688341 & 5.9 & 4.9503 & TRN & \\
\hline CHEMBL1568019 & 688341 & 5.0 & 5.1057 & TRN & \\
\hline CHEMBL1374432 & 688341 & 4.5 & 4.9151 & TRN & \\
\hline CHEMBL497170 & 688341 & 4.4 & 4.8821 & TRN & \\
\hline CHEMBL1377293 & 688341 & 5.4 & 4.9121 & TST & \\
\hline CHEMBL1320442 & 688341 & 4.9 & 4.8662 & TRN & \\
\hline CHEMBL1327079 & 688341 & 4.7 & 4.8158 & TRN & \\
\hline CHEMBL1427121 & 688341 & 4.6 & 4.9657 & TST & \\
\hline CHEMBL1547931 & 688341 & 4.8 & 5.1192 & TRN & \\
\hline CHEMBL1440936 & 688341 & 4.6 & 4.8756 & TRN & \\
\hline CHEMBL1339050 & 688341 & 7.5003 & 4.8285 & TRN & \\
\hline CHEMBL1379948 & 688341 & 4.7 & 4.9369 & TRN & \\
\hline CHEMBL1494470 & 688341 & 5.4 & 5.0162 & TRN & \\
\hline
\end{tabular}




\begin{tabular}{|c|c|c|c|c|}
\hline & & & pplement & al $\mathrm{Ta}$ \\
\hline CHEMBL1529320 & 688341 & 6.0 & 5.0078 & TST \\
\hline CHEMBL1375859 & 688341 & 4.7 & 4.7574 & TST \\
\hline CHEMBL1369069 & 688341 & 4.8 & 4.8405 & TRN \\
\hline CHEMBL1330398 & 688341 & 5.1 & 5.0051 & TST \\
\hline CHEMBL1310238 & 688341 & 4.6 & 4.898 & TST \\
\hline CHEMBL1528820 & 688341 & 5.2 & 5.0617 & TRN \\
\hline CHEMBL1605370 & 688341 & 4.5 & 5.0122 & TRN \\
\hline CHEMBL1559098 & 688341 & 4.4 & 5.1596 & TRN \\
\hline CHEMBL1323134 & 688341 & 4.5 & 4.8585 & TRN \\
\hline CHEMBL1520347 & 688341 & 4.9 & 4.9532 & TRN \\
\hline CHEMBL1569346 & 688341 & 4.4 & 4.9686 & TRN \\
\hline CHEMBL1494373 & 688341 & 4.9 & 4.852 & TRN \\
\hline CHEMBL1311002 & 688341 & 4.7 & 4.9668 & TRN \\
\hline CHEMBL1303411 & 688341 & 4.5 & 4.8671 & TRN \\
\hline CHEMBL1599609 & 688341 & 4.8 & 4.8283 & TRN \\
\hline CHEMBL1334375 & 688341 & 6.9 & 5.0854 & TRN \\
\hline CHEMBL1355185 & 688341 & 5.5 & 5.1427 & TRN \\
\hline CHEMBL1349743 & 688341 & 4.8 & 4.9071 & TRN \\
\hline CHEMBL348856 & 688341 & 6.0 & 5.0737 & TST \\
\hline CHEMBL1347369 & 688341 & 4.8 & 4.9062 & TST \\
\hline CHEMBL260876 & 688341 & 6.4 & 5.0864 & TST \\
\hline CHEMBL1317275 & 688341 & 4.8 & 4.7824 & TRN \\
\hline CHEMBL1523404 & 688341 & 4.5 & 4.9472 & TST \\
\hline CHEMBL1543571 & 688341 & 4.4 & 4.7848 & TRN \\
\hline CHEMBL1598064 & 688341 & 4.5 & 5.0057 & TRN \\
\hline CHEMBL1313675 & 688341 & 5.5 & 5.0161 & TST \\
\hline CHEMBL1443810 & 688341 & 5.4 & 4.8597 & TRN \\
\hline CHEMBL1255662 & 688341 & 6.0 & 5.0169 & TST \\
\hline CHEMBL1305411 & 688341 & 6.0 & 4.8362 & TST \\
\hline CHEMBL1397860 & 688341 & 4.7 & 5.192 & TRN \\
\hline CHEMBL1471657 & 688341 & 4.9 & 4.8475 & TRN \\
\hline CHEMBL1489918 & 688341 & 4.8 & 5.1367 & TST \\
\hline CHEMBL1459751 & 688341 & 4.4 & 4.8705 & TST \\
\hline CHEMBL1418697 & 688341 & 4.6 & 4.8779 & TST \\
\hline CHEMBL1443614 & 688341 & 4.7 & 5.1366 & TRN \\
\hline CHEMBL1533636 & 688341 & 5.4 & 4.7606 & TST \\
\hline CHEMBL18840 & 688341 & 5.2 & 5.1096 & TRN \\
\hline CHEMBL1601181 & 688341 & 4.9 & 4.7873 & TST \\
\hline CHEMBL1332423 & 688341 & 4.8 & 4.7307 & TRN \\
\hline CHEMBL1401672 & 688341 & 5.5 & 4.9888 & TRN \\
\hline CHEMBL1321221 & 688341 & 4.6 & 4.9886 & TRN \\
\hline CHEMBL1587226 & 688341 & 4.8 & 5.0023 & TST \\
\hline CHEMBL1312517 & 688341 & 5.2 & 5.0578 & TST \\
\hline CHEMBL3209065 & 688341 & 4.5 & 4.9711 & TRN \\
\hline CHEMBL1348465 & 688341 & 4.6 & 4.8687 & TRN \\
\hline CHEMBL1568000 & 688341 & 5.6 & 4.9644 & TRN \\
\hline CHEMBL1358988 & 688341 & 4.6 & 4.8706 & TRN \\
\hline CHEMBL1566209 & 688341 & 5.4 & 5.0115 & TRN \\
\hline
\end{tabular}




\begin{tabular}{|c|c|c|c|c|c|}
\hline \multicolumn{6}{|c|}{ Supplemental Table S2.txt } \\
\hline CHEMBL1490334 & 688341 & 5.2 & 4.7314 & TRN & \\
\hline CHEMBL1530805 & 688341 & 4.7 & 5.0441 & TRN & \\
\hline CHEMBL1347816 & 688341 & 4.5 & 4.8779 & TRN & \\
\hline CHEMBL1370120 & 688341 & 5.1 & 4.8569 & TRN & \\
\hline CHEMBL1589006 & 688341 & 4.4 & 4.9072 & TST & \\
\hline CHEMBL1423146 & 688341 & 4.9 & 4.9383 & TRN & \\
\hline CHEMBL1566117 & 688341 & 4.4 & 4.9511 & TRN & \\
\hline CHEMBL1422320 & 688341 & 4.9 & 4.8776 & TRN & \\
\hline CHEMBL1485018 & 688341 & 4.8 & 5.1329 & TRN & \\
\hline CHEMBL1402457 & 688341 & 4.4 & 4.9484 & TST & \\
\hline CHEMBL1595761 & 688341 & 4.6 & 4.9615 & TRN & \\
\hline CHEMBL1307558 & 688341 & 5.5 & 4.9853 & TRN & \\
\hline CHEMBL1495571 & 688341 & 4.4 & 5.0277 & TRN & \\
\hline CHEMBL1365446 & 688341 & 5.2 & 4.9689 & TRN & \\
\hline CHEMBL1310944 & 688341 & 4.7 & 4.9155 & TRN & \\
\hline CHEMBL1411413 & 688341 & 4.8 & 4.7326 & TRN & \\
\hline CHEMBL1579263 & 688341 & 5.1 & 5.1247 & TST & \\
\hline CHEMBL1407308 & 688341 & 4.5 & 4.8701 & TRN & \\
\hline CHEMBL1377576 & 688341 & 4.7 & 4.9582 & TST & \\
\hline CHEMBL1478232 & 688341 & 4.6 & 5.0358 & TRN & \\
\hline CHEMBL1454746 & 688341 & 5.4 & 4.9136 & TRN & \\
\hline CHEMBL1584535 & 688341 & 4.8 & 4.9215 & TRN & \\
\hline CHEMBL1334895 & 688341 & 4.6 & 4.8803 & TST & \\
\hline CHEMBL1334872 & 688341 & 5.3 & 4.9255 & TRN & \\
\hline CHEMBL1406078 & 688341 & 4.4 & 5.0187 & TRN & \\
\hline CHEMBL1397913 & 688341 & 5.2 & 5.1422 & TRN & \\
\hline CHEMBL1595247 & 688341 & 4.7 & 4.9656 & TRN & \\
\hline CHEMBL1494650 & 688341 & 4.6 & 4.862 & TRN & \\
\hline CHEMBL1539715 & 688341 & 5.5 & 5.2064 & TST & \\
\hline CHEMBL1472085 & 688341 & 4.6 & 5.0099 & TST & \\
\hline CHEMBL1323622 & 688341 & 4.8 & 4.7443 & TRN & \\
\hline CHEMBL1411213 & 688341 & 4.4 & 4.9892 & TRN & \\
\hline CHEMBL1549356 & 688341 & 4.6 & 4.8767 & TRN & \\
\hline CHEMBL1425169 & 688341 & 4.6 & 4.9234 & TRN & \\
\hline CHEMBL1320632 & 688341 & 4.4 & 4.888 & TRN & \\
\hline CHEMBL1590974 & 688341 & 7.5003 & 5.1623 & TRN & \\
\hline CHEMBL1454052 & 688341 & 5.0 & 5.0754 & TRN & \\
\hline CHEMBL1420793 & 688341 & 4.6 & 4.8007 & TRN & \\
\hline CHEMBL1336201 & 688341 & 4.6 & 4.945 & TRN & \\
\hline CHEMBL1332117 & 688341 & 4.6 & 4.853 & TST & \\
\hline CHEMBL489934 & 688341 & 4.7 & 5.05699 & 99999999995 & TRN \\
\hline CHEMBL 3210620 & 688341 & 4.5 & 5.1453 & TRN & \\
\hline CHEMBL1468815 & 688341 & 5.3 & 4.8706 & TRN & \\
\hline CHEMBL1474695 & 688341 & 4.9 & 5.1239 & TRN & \\
\hline CHEMBL1500979 & 688341 & 4.9 & 4.7197 & TRN & \\
\hline CHEMBL1415139 & 688341 & 5.6 & 4.9914 & TRN & \\
\hline CHEMBL1449253 & 688341 & 4.6 & 4.828 & TRN & \\
\hline CHEMBL1546327 & 688341 & 4.5 & 4.9535 & TRN & \\
\hline
\end{tabular}




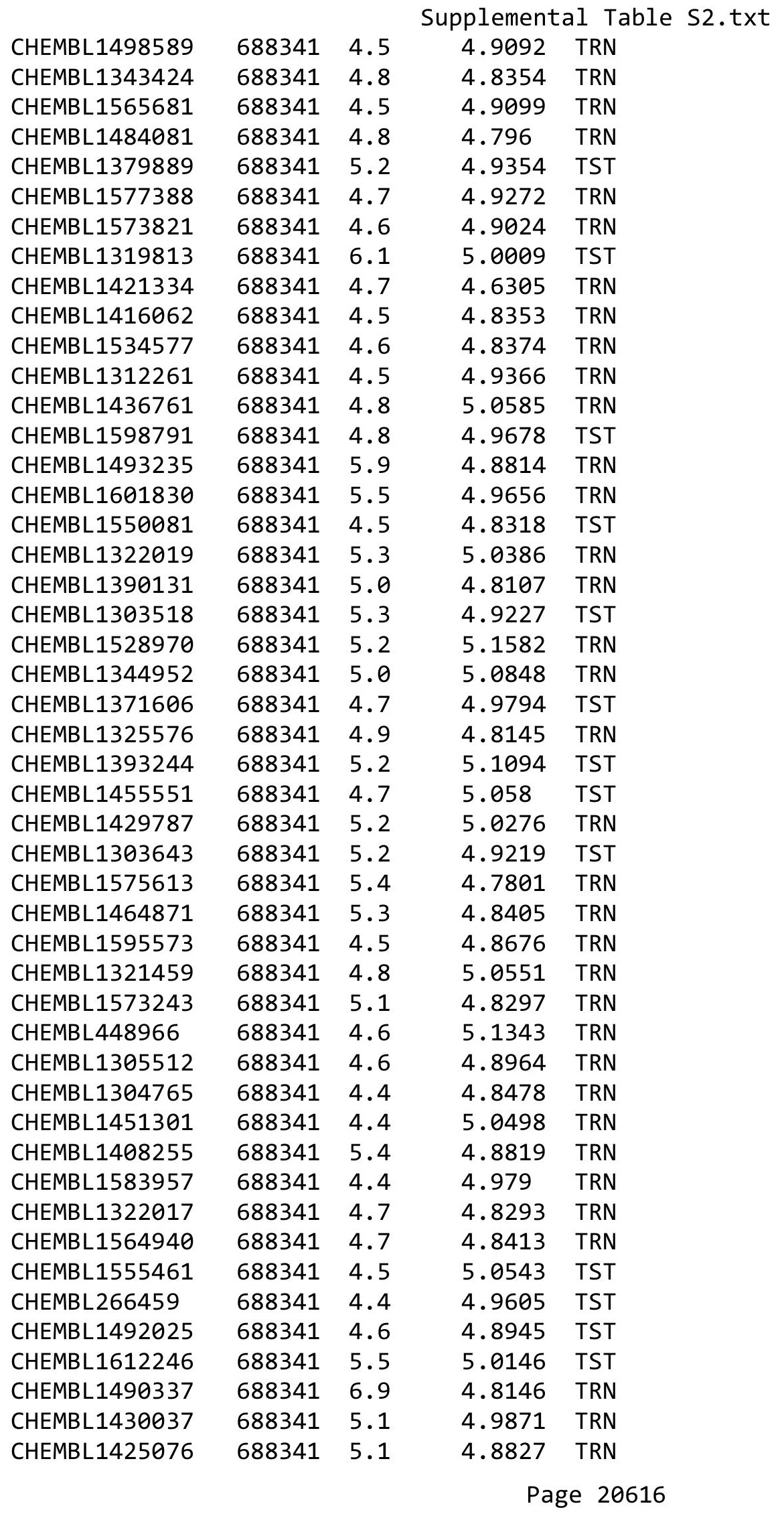




\begin{tabular}{|c|c|c|c|c|}
\hline & & & & al ta \\
\hline CHEMBL1513699 & 688341 & 4.4 & 4.9919 & TST \\
\hline CHEMBL1341254 & 688341 & 4.4 & 4.8159 & TRN \\
\hline CHEMBL1405325 & 688341 & 5.5 & 4.6281 & TRN \\
\hline CHEMBL1390863 & 688341 & 4.8 & 4.96399 & 99999999995 \\
\hline CHEMBL1345206 & 688341 & 4.7 & 4.9086 & TST \\
\hline CHEMBL1479807 & 688341 & 4.5 & 4.8729 & TRN \\
\hline CHEMBL1329440 & 688341 & 5.2 & 5.0636 & TST \\
\hline CHEMBL1515698 & 688341 & 5.3 & 5.2639 & TRN \\
\hline CHEMBL1526429 & 688341 & 6.0 & 5.0654 & TST \\
\hline CHEMBL1471765 & 688341 & 4.8 & 4.9173 & TRN \\
\hline CHEMBL1488183 & 688341 & 4.4 & 4.886 & TRN \\
\hline CHEMBL12252 & 688341 & 4.8 & 4.9094 & TRN \\
\hline CHEMBL1336432 & 688341 & 4.7 & 4.9969 & TST \\
\hline CHEMBL1438160 & 688341 & 5.2 & 5.0482 & TRN \\
\hline CHEMBL1440902 & 688341 & 4.8 & 4.8027 & TRN \\
\hline CHEMBL1377459 & 688341 & 5.0 & 4.7826 & TRN \\
\hline CHEMBL1414899 & 688341 & 4.7 & 4.9851 & TRN \\
\hline CHEMBL1336031 & 688341 & 4.7 & 4.9536 & TST \\
\hline CHEMBL1605035 & 688341 & 5.2 & 4.8459 & TST \\
\hline CHEMBL1469819 & 688341 & 4.5 & 4.8567 & TRN \\
\hline CHEMBL1510580 & 688341 & 4.6 & 4.956 & TRN \\
\hline CHEMBL1331442 & 688341 & 4.9 & 4.7228 & TST \\
\hline CHEMBL1316779 & 688341 & 5.9 & 5.2609 & TRN \\
\hline CHEMBL1346548 & 688341 & 4.5 & 5.043 & TRN \\
\hline CHEMBL1597988 & 688341 & 4.4 & 4.9734 & TRN \\
\hline CHEMBL1333917 & 688341 & 4.6 & 4.9376 & TRN \\
\hline CHEMBL1558310 & 688341 & 4.8 & 4.8983 & TST \\
\hline CHEMBL1425624 & 688341 & 4.5 & 4.8985 & TRN \\
\hline CHEMBL1602438 & 688341 & 4.5 & 5.0411 & TST \\
\hline CHEMBL1566946 & 688341 & 5.2 & 4.896 & TST \\
\hline CHEMBL1486808 & 688341 & 6.0 & 5.0185 & TRN \\
\hline CHEMBL1421004 & 688341 & 4.5 & 4.8983 & TRN \\
\hline CHEMBL1440908 & 688341 & 4.6 & 4.8131 & TRN \\
\hline CHEMBL1338028 & 688341 & 5.1 & 4.7474 & TRN \\
\hline CHEMBL1360272 & 688341 & 4.6 & 4.7201 & TRN \\
\hline CHEMBL348107 & 688341 & 4.4 & 5.1076 & TST \\
\hline CHEMBL1372090 & 688341 & 6.2 & 4.9205 & TST \\
\hline CHEMBL1511675 & 688341 & 4.6 & 4.9338 & TRN \\
\hline CHEMBL1574400 & 688341 & 4.9 & 4.9038 & TST \\
\hline CHEMBL1570135 & 688341 & 4.5 & 4.9943 & TRN \\
\hline CHEMBL1444917 & 688341 & 4.7 & 4.8079 & TRN \\
\hline CHEMBL170408 & 688341 & 4.2 & 5.0555 & TRN \\
\hline CHEMBL1565793 & 688341 & 4.5 & 4.8997 & TRN \\
\hline CHEMBL1256654 & 688341 & 4.5 & 5.1173 & TST \\
\hline CHEMBL1579130 & 688341 & 5.3 & 5.118 & TRN \\
\hline CHEMBL259507 & 688341 & 4.7 & 5.1353 & TRN \\
\hline CHEMBL1363951 & 688341 & 4.6 & 5.0048 & TRN \\
\hline CHEMBL1536946 & 688341 & 4.4 & 4.9064 & TRN \\
\hline
\end{tabular}




\begin{tabular}{|c|c|c|c|c|}
\hline \multicolumn{5}{|c|}{ Supplemental Table S2.txt } \\
\hline CHEMBL1328319 & 688341 & 5.2 & 5.2589 & TRN \\
\hline CHEMBL1312240 & 688341 & 5.5 & 5.0541 & TST \\
\hline CHEMBL1320619 & 688341 & 4.8 & 4.9253 & TRN \\
\hline CHEMBL1256746 & 688341 & 4.5 & 5.165 & TRN \\
\hline CHEMBL1492558 & 688341 & 4.8 & 5.0625 & TST \\
\hline CHEMBL1399977 & 688341 & 4.6 & 4.9477 & TRN \\
\hline CHEMBL1548243 & 688341 & 5.2 & 4.9824 & TST \\
\hline CHEMBL1325934 & 688341 & 4.5 & 4.8646 & TRN \\
\hline CHEMBL1372301 & 688341 & 4.4 & 4.9687 & TRN \\
\hline CHEMBL1463871 & 688341 & 4.5 & 4.9062 & TRN \\
\hline CHEMBL1493101 & 688341 & 4.6 & 5.0789 & TRN \\
\hline CHEMBL1380776 & 688341 & 5.4 & 5.0503 & TRN \\
\hline CHEMBL1318454 & 688341 & 5.2 & 5.1236 & TRN \\
\hline CHEMBL1611820 & 688341 & 6.0 & 5.1942 & TRN \\
\hline CHEMBL1520417 & 688341 & 4.8 & 4.9226 & TRN \\
\hline CHEMBL1359321 & 688341 & 4.6 & 4.8795 & TRN \\
\hline CHEMBL1305020 & 688341 & 4.8 & 5.0141 & TRN \\
\hline CHEMBL1546572 & 688341 & 4.7 & 4.9158 & TRN \\
\hline CHEMBL1431579 & 688341 & 4.5 & 4.8812 & TRN \\
\hline CHEMBL1499996 & 688341 & 5.1 & 4.918 & TST \\
\hline CHEMBL1581724 & 688341 & 5.2 & 5.1291 & TST \\
\hline CHEMBL1491064 & 688341 & 5.4 & 5.0358 & TST \\
\hline CHEMBL1402025 & 688341 & 4.6 & 4.9105 & TRN \\
\hline CHEMBL1334657 & 688341 & 4.9 & 5.0751 & TRN \\
\hline CHEMBL1367583 & 688341 & 4.5 & 4.8624 & TRN \\
\hline CHEMBL1580274 & 688341 & 4.5 & 4.8157 & TRN \\
\hline CHEMBL357625 & 688341 & 4.8 & 5.0485 & TST \\
\hline CHEMBL1402729 & 688341 & 5.5 & 4.7443 & TRN \\
\hline CHEMBL1344015 & 688341 & 4.4 & 4.9413 & TRN \\
\hline CHEMBL1531863 & 688341 & 4.4 & 4.9994 & TST \\
\hline CHEMBL1364693 & 688341 & 4.7 & 4.9119 & TST \\
\hline CHEMBL1610943 & 688341 & 4.7 & 4.9333 & TRN \\
\hline CHEMBL1366292 & 688341 & 4.5 & 5.0128 & TRN \\
\hline CHEMBL1322756 & 688341 & 4.8 & 4.9756 & TRN \\
\hline CHEMBL1479084 & 688341 & 4.5 & 4.9232 & TRN \\
\hline CHEMBL1332463 & 688341 & 4.8 & 4.9952 & TRN \\
\hline CHEMBL1377893 & 688341 & 4.8 & 5.0706 & TRN \\
\hline CHEMBL1324151 & 688341 & 7.5003 & 4.9772 & TRN \\
\hline CHEMBL1520711 & 688341 & 4.9 & 4.8834 & TRN \\
\hline CHEMBL1306623 & 688341 & 4.4 & 4.8729 & TST \\
\hline CHEMBL3211627 & 688341 & 4.4 & 5.1467 & TST \\
\hline CHEMBL1419718 & 688341 & 4.6 & 4.8843 & TRN \\
\hline CHEMBL1492122 & 688341 & 4.9 & 4.9436 & TRN \\
\hline CHEMBL1323665 & 688341 & 5.2 & 4.7567 & TRN \\
\hline CHEMBL1317884 & 688341 & 5.5 & 5.2105 & TRN \\
\hline CHEMBL1349348 & 688341 & 5.9 & 4.9802 & TRN \\
\hline CHEMBL1367929 & 688341 & 4.4 & 5.0332 & TRN \\
\hline CHEMBL1449197 & 688341 & 5.2 & 4.8859 & TRN \\
\hline
\end{tabular}




\begin{tabular}{|c|c|c|c|c|c|}
\hline & & & & & \\
\hline CHEMBL1548317 & 688341 & 5.4 & 4.9219 & TRN & \\
\hline CHEMBL602424 & 688341 & 5.2 & 4.8081 & TRN & \\
\hline CHEMBL1448614 & 688341 & 4.7 & 4.9762 & TRN & \\
\hline CHEMBL1511524 & 688341 & 4.4 & 4.8204 & TRN & \\
\hline CHEMBL 1468716 & 688341 & 5.2 & 5.0605 & TRN & \\
\hline CHEMBL1374649 & 688341 & 4.6 & 4.9632 & TRN & \\
\hline CHEMBL1442487 & 688341 & 4.8 & 4.7188 & TRN & \\
\hline CHEMBL1324936 & 688341 & 4.9 & 4.9553 & TRN & \\
\hline CHEMBL1597397 & 688341 & 4.9 & 4.9894 & TRN & \\
\hline CHEMBL1302967 & 688341 & 5.1 & 5.0209 & TRN & \\
\hline CHEMBL1501400 & 688341 & 4.6 & 4.9466 & TRN & \\
\hline CHEMBL1328248 & 688341 & 4.8 & 4.8742 & TST & \\
\hline CHEMBL1602505 & 688341 & 4.7 & 4.9864 & TRN & \\
\hline CHEMBL1418723 & 688341 & 4.5 & 4.9515 & TST & \\
\hline CHEMBL1506593 & 688341 & 4.6 & 4.9576 & TRN & \\
\hline CHEMBL3213714 & 688341 & 4.4 & 4.9365 & TRN & \\
\hline CHEMBL1524731 & 688341 & 4.8 & 4.7584 & TRN & \\
\hline CHEMBL1590492 & 688341 & 5.2 & 4.941 & TST & \\
\hline CHEMBL 72365 & 688341 & 4.9 & 5.1424 & TST & \\
\hline CHEMBL1499308 & 688341 & 4.7 & 4.7633 & TRN & \\
\hline CHEMBL1472880 & 688341 & 5.8 & 5.0903 & TRN & \\
\hline CHEMBL1544930 & 688341 & 4.7 & 5.0079 & TRN & \\
\hline CHEMBL1454479 & 688341 & 4.4 & 4.8813 & TST & \\
\hline CHEMBL1300798 & 688341 & 4.4 & 4.8683 & TRN & \\
\hline CHEMBL1512208 & 688341 & 5.4 & 4.8903 & TRN & \\
\hline CHEMBL1444673 & 688341 & 6.7001 & 4.9528 & TRN & \\
\hline CHEMBL1452503 & 688341 & 5.6 & 5.01399 & 9999999999 & TRN \\
\hline CHEMBL1568191 & 688341 & 4.5 & 4.9157 & TRN & \\
\hline CHEMBL1455083 & 688341 & 5.2 & 4.9334 & TRN & \\
\hline CHEMBL1544110 & 688341 & 4.7 & 4.8681 & TST & \\
\hline CHEMBL1465319 & 688341 & 4.6 & 4.816 & TRN & \\
\hline CHEMBL1318448 & 688341 & 4.7 & 5.1708 & TRN & \\
\hline CHEMBL1565927 & 688341 & 4.7 & 5.0097 & TRN & \\
\hline CHEMBL1501282 & 688341 & 4.8 & 4.7551 & TRN & \\
\hline CHEMBL1491130 & 688341 & 4.8 & 4.8634 & TRN & \\
\hline CHEMBL1475787 & 688341 & 4.5 & 4.9144 & TRN & \\
\hline CHEMBL1309339 & 688341 & 4.9 & 4.8647 & TRN & \\
\hline CHEMBL15897 & 688341 & 5.2 & 5.1264 & TRN & \\
\hline CHEMBL1611870 & 688341 & 4.7 & 4.7511 & TRN & \\
\hline CHEMBL1555098 & 688341 & 5.0 & 5.1206 & TRN & \\
\hline CHEMBL1256659 & 688341 & 5.1 & 5.0592 & TST & \\
\hline CHEMBL1372646 & 688341 & 4.6 & 4.7281 & TRN & \\
\hline CHEMBL1501851 & 688341 & 4.5 & 4.8878 & TRN & \\
\hline CHEMBL1480179 & 688341 & 5.4 & 4.8443 & TRN & \\
\hline CHEMBL1493423 & 688341 & 5.0 & 4.728 & TRN & \\
\hline CHEMBL1347645 & 688341 & 4.6 & 4.8744 & TRN & \\
\hline CHEMBL1491438 & 688341 & 5.0 & 4.8176 & TRN & \\
\hline CHEMBL1492395 & 688341 & 4.6 & 4.8388 & TRN & \\
\hline & & & & 20619 & \\
\hline
\end{tabular}




\begin{tabular}{|c|c|c|c|c|c|}
\hline \multirow[b]{2}{*}{ CHEMBL1321695 } & \multicolumn{5}{|c|}{ Supplemental Table S2.txt } \\
\hline & 688341 & 4.7 & 4.9259 & TRN & \\
\hline CHEMBL1515295 & 688341 & 5.0 & 4.96899 & 9999999999 & TRN \\
\hline CHEMBL1340701 & 688341 & 4.9 & 4.8278 & TST & \\
\hline CHEMBL1569176 & 688341 & 4.5 & 4.9736 & TST & \\
\hline CHEMBL1362854 & 688341 & 4.7 & 5.0146 & TRN & \\
\hline CHEMBL1548568 & 688341 & 5.2 & 4.8453 & TST & \\
\hline CHEMBL1510800 & 688341 & 4.8 & 4.9482 & TRN & \\
\hline CHEMBL1303668 & 688341 & 5.5 & 4.8463 & TRN & \\
\hline CHEMBL1426455 & 688341 & 4.6 & 4.7674 & TRN & \\
\hline CHEMBL1437325 & 688341 & 4.7 & 4.9743 & TRN & \\
\hline CHEMBL1302575 & 688341 & 5.2 & 4.8958 & TRN & \\
\hline CHEMBL1417871 & 688341 & 5.2 & 5.0499 & TST & \\
\hline CHEMBL1368100 & 688341 & 5.7 & 4.9612 & TST & \\
\hline CHEMBL1494574 & 688341 & 4.9 & 4.8557 & TRN & \\
\hline CHEMBL1381551 & 688341 & 4.5 & 4.9659 & TST & \\
\hline CHEMBL1442663 & 688341 & 5.6 & 4.8953 & TRN & \\
\hline CHEMBL1451198 & 688341 & 7.5003 & 4.8473 & TRN & \\
\hline CHEMBL1538217 & 688341 & 4.8 & 4.9621 & TRN & \\
\hline CHEMBL1452914 & 688341 & 4.8 & 4.735 & TRN & \\
\hline CHEMBL1505759 & 688341 & 4.7 & 4.9666 & TRN & \\
\hline CHEMBL1567924 & 688341 & 5.2 & 4.9823 & TST & \\
\hline CHEMBL1314255 & 688341 & 4.8 & 4.8522 & TRN & \\
\hline CHEMBL1308331 & 688341 & 4.4 & 4.8802 & TRN & \\
\hline CHEMBL1507891 & 688341 & 5.2 & 4.8403 & TRN & \\
\hline CHEMBL1514804 & 688341 & 4.7 & 5.0115 & TRN & \\
\hline CHEMBL1555538 & 688341 & 4.5 & 4.74 & TRN & \\
\hline CHEMBL1487093 & 688341 & 4.9 & 4.9316 & TRN & \\
\hline CHEMBL1430822 & 688341 & 4.4 & 4.6573 & TRN & \\
\hline CHEMBL1483130 & 688341 & 4.5 & 4.9261 & TRN & \\
\hline CHEMBL 8747 & 688341 & 4.7 & 5.0598 & TST & \\
\hline CHEMBL 273481 & 688341 & 4.5 & 5.0178 & TST & \\
\hline CHEMBL84685 & 688341 & 4.7 & 5.0433 & TST & \\
\hline CHEMBL1613659 & 688341 & 4.4 & 4.9578 & TRN & \\
\hline CHEMBL1444123 & 688341 & 4.8 & 4.9307 & TRN & \\
\hline CHEMBL1503094 & 688341 & 4.7 & 4.8603 & TRN & \\
\hline CHEMBL295337 & 688341 & 5.5 & 5.1296 & TRN & \\
\hline CHEMBL1368113 & 688341 & 5.3 & 5.012 & TST & \\
\hline CHEMBL1597310 & 688341 & 4.4 & 4.8177 & TST & \\
\hline CHEMBL1569631 & 688341 & 5.1 & 4.8942 & TRN & \\
\hline CHEMBL1481412 & 688341 & 4.5 & 5.0747 & TRN & \\
\hline CHEMBL1572414 & 688341 & 5.0 & 4.8171 & TST & \\
\hline CHEMBL1380219 & 688341 & 4.9 & 4.9686 & TST & \\
\hline CHEMBL1391856 & 688341 & 6.7001 & 5.1654 & TST & \\
\hline CHEMBL1330656 & 688341 & 4.7 & 4.8801 & TRN & \\
\hline CHEMBL1550750 & 688341 & 4.6 & 4.7934 & TRN & \\
\hline CHEMBL1587498 & 688341 & 4.9 & 4.959 & TRN & \\
\hline CHEMBL1557009 & 688341 & 4.5 & 4.915 & TRN & \\
\hline CHEMBL1542398 & 688341 & 4.4 & 4.7991 & TRN & \\
\hline
\end{tabular}




\begin{tabular}{|c|c|c|c|c|}
\hline \multicolumn{5}{|c|}{ Supplemental T } \\
\hline CHEMBL1601160 & 688341 & 4.7 & 5.0071 & TRN \\
\hline CHEMBL1334723 & 688341 & 5.2 & 4.9587 & TRN \\
\hline CHEMBL1583862 & 688341 & 4.5 & 5.0709 & TRN \\
\hline CHEMBL1486399 & 688341 & 4.8 & 5.0805 & TRN \\
\hline CHEMBL1428021 & 688341 & 4.9 & 4.8067 & TRN \\
\hline CHEMBL1346153 & 688341 & 5.2 & 5.0243 & TRN \\
\hline CHEMBL1307155 & 688341 & 4.7 & 4.9835 & TST \\
\hline CHEMBL1466720 & 688341 & 5.3 & 5.1389 & TRN \\
\hline CHEMBL1332033 & 688341 & 4.8 & 4.9249 & TRN \\
\hline CHEMBL1558955 & 688341 & 4.7 & 5.0619 & TRN \\
\hline CHEMBL1334461 & 688341 & 4.7 & 4.8574 & TRN \\
\hline CHEMBL1551139 & 688341 & 5.6 & 5.1354 & TRN \\
\hline CHEMBL1365652 & 688341 & 4.8 & 4.7274 & TRN \\
\hline CHEMBL1517935 & 688341 & 4.6 & 5.1306 & TRN \\
\hline CHEMBL1589619 & 688341 & 4.6 & 4.9458 & TRN \\
\hline CHEMBL1525663 & 688341 & 5.8 & 4.8095 & TRN \\
\hline CHEMBL1395355 & 688341 & 5.0 & 5.1497 & TRN \\
\hline CHEMBL1336840 & 688341 & 4.8 & 4.9847 & TST \\
\hline CHEMBL1358402 & 688341 & 6.0 & 5.1794 & TST \\
\hline CHEMBL 282433 & 688341 & 4.8 & 4.9159 & TRN \\
\hline CHEMBL1312118 & 688341 & 5.4 & 5.1317 & TST \\
\hline CHEMBL1477870 & 688341 & 4.8 & 4.9782 & TRN \\
\hline CHEMBL 1417025 & 688341 & 6.1 & 5.1071 & TRN \\
\hline CHEMBL1451617 & 688341 & 5.3 & 5.0351 & TRN \\
\hline CHEMBL567331 & 688341 & 4.9 & 4.8671 & TRN \\
\hline CHEMBL1561335 & 688341 & 4.6 & 4.7719 & TRN \\
\hline CHEMBL1473632 & 688341 & 5.5 & 5.1937 & TRN \\
\hline CHEMBL1564619 & 688341 & 4.5 & 4.9658 & TST \\
\hline CHEMBL1453357 & 688341 & 6.0 & 4.8545 & TRN \\
\hline CHEMBL 87285 & 688341 & 4.5 & 5.2101 & TRN \\
\hline CHEMBL1583506 & 688341 & 4.5 & 5.0566 & TST \\
\hline CHEMBL1365776 & 688341 & 4.8 & 5.1114 & TRN \\
\hline CHEMBL1581148 & 688341 & 4.4 & 4.9724 & TRN \\
\hline CHEMBL1577801 & 688341 & 4.9 & 4.9209 & TRN \\
\hline CHEMBL1426446 & 688341 & 4.9 & 4.7942 & TRN \\
\hline CHEMBL1330374 & 688341 & 4.8 & 4.8977 & TRN \\
\hline CHEMBL1360572 & 688341 & 4.4 & 4.8475 & TRN \\
\hline CHEMBL608714 & 688341 & 4.5 & 5.0211 & TST \\
\hline CHEMBL1583101 & 688341 & 4.4 & 5.0075 & TST \\
\hline CHEMBL1427751 & 688341 & 4.5 & 4.9929 & TRN \\
\hline CHEMBL1496947 & 688341 & 5.1 & 5.0172 & TRN \\
\hline CHEMBL1382628 & 688341 & 4.7 & 4.8891 & TRN \\
\hline CHEMBL1477042 & 688341 & 4.6 & 4.8846 & TRN \\
\hline CHEMBL1309292 & 688341 & 4.7 & 4.967 & TRN \\
\hline CHEMBL1354079 & 688341 & 4.6 & 5.0386 & TRN \\
\hline CHEMBL1421028 & 688341 & 4.9 & 4.9974 & TRN \\
\hline CHEMBL1381824 & 688341 & 4.7 & 4.7825 & TRN \\
\hline CHEMBL3192561 & 688341 & 5.5 & 5.0123 & TRN \\
\hline
\end{tabular}




\begin{tabular}{|c|c|c|c|c|c|}
\hline \multicolumn{6}{|c|}{ Supplemental Table S2.txt } \\
\hline CHEMBL1462403 & 688341 & 4.5 & 5.0227 & TRN & \\
\hline CHEMBL1335554 & 688341 & 4.4 & 4.7527 & TRN & \\
\hline CHEMBL1324334 & 688341 & 5.5 & 5.26200 & 00000000005 & TRN \\
\hline CHEMBL1488097 & 688341 & 4.6 & 4.8163 & TRN & \\
\hline CHEMBL1524703 & 688341 & 5.2 & 4.836 & TST & \\
\hline CHEMBL1605366 & 688341 & 4.4 & 5.062 & TRN & \\
\hline CHEMBL1430602 & 688341 & 4.8 & 4.8632 & TRN & \\
\hline CHEMBL1429539 & 688341 & 5.7 & 5.04 & TRN & \\
\hline CHEMBL1489876 & 688341 & 5.4 & 4.894 & TST & \\
\hline CHEMBL1255664 & 688341 & 5.2 & 4.9575 & TST & \\
\hline CHEMBL1503409 & 688341 & 5.3 & 4.9157 & TRN & \\
\hline CHEMBL1310906 & 688341 & 4.8 & 4.7479 & TST & \\
\hline CHEMBL1503228 & 688341 & 4.5 & 4.8591 & TST & \\
\hline CHEMBL1368672 & 688341 & 4.4 & 4.8345 & TRN & \\
\hline CHEMBL1540341 & 688341 & 5.8 & 4.663 & TRN & \\
\hline CHEMBL1236872 & 688341 & 4.6 & 5.1325 & TRN & \\
\hline CHEMBL1478134 & 688341 & 4.6 & 4.6823 & TRN & \\
\hline CHEMBL513678 & 688341 & 4.4 & 5.1387 & TST & \\
\hline CHEMBL1367488 & 688341 & 4.6 & 5.1653 & TRN & \\
\hline CHEMBL1406901 & 688341 & 7.5003 & 5.1485 & TRN & \\
\hline CHEMBL1574209 & 688341 & 4.5 & 4.8348 & TST & \\
\hline CHEMBL1332591 & 688341 & 5.8 & 5.0735 & TRN & \\
\hline CHEMBL1535324 & 688341 & 4.9 & 4.779 & TRN & \\
\hline CHEMBL1422889 & 688341 & 5.3 & 4.9658 & TRN & \\
\hline CHEMBL1326228 & 688341 & 5.3 & 5.0204 & TST & \\
\hline CHEMBL1583079 & 688341 & 4.6 & 4.8168 & TRN & \\
\hline CHEMBL1311673 & 688341 & 5.9 & 5.0908 & TRN & \\
\hline CHEMBL1381207 & 688341 & 5.4 & 5.0377 & TST & \\
\hline CHEMBL1306618 & 688341 & 4.4 & 4.8275 & TRN & \\
\hline CHEMBL1361446 & 688341 & 4.4 & 5.20299 & 9999999999 & TST \\
\hline CHEMBL1586957 & 688341 & 4.8 & 4.9103 & TST & \\
\hline CHEMBL1375169 & 688341 & 4.5 & 4.8414 & TRN & \\
\hline CHEMBL3193722 & 688341 & 4.6 & 5.0949 & TRN & \\
\hline CHEMBL1587527 & 688341 & 4.7 & 4.8391 & TRN & \\
\hline CHEMBL1585876 & 688341 & 5.9 & 5.0063 & TST & \\
\hline CHEMBL1484095 & 688341 & 5.0 & 4.8254 & TRN & \\
\hline CHEMBL1318419 & 688341 & 4.7 & 4.9162 & TRN & \\
\hline CHEMBL1418145 & 688341 & 4.8 & 4.75 & TST & \\
\hline CHEMBL1231330 & 688341 & 4.4 & 5.1704 & TRN & \\
\hline CHEMBL1521358 & 688341 & 5.4 & 4.9245 & TRN & \\
\hline CHEMBL1368810 & 688341 & 5.5 & 4.9051 & TST & \\
\hline CHEMBL1327355 & 688341 & 4.7 & 4.908 & TRN & \\
\hline CHEMBL1232474 & 688341 & 4.8 & 4.9998 & TRN & \\
\hline CHEMBL1371999 & 688341 & 4.5 & 4.8718 & TRN & \\
\hline CHEMBL1302877 & 688341 & 4.5 & 4.9535 & TRN & \\
\hline CHEMBL1487887 & 688341 & 5.5 & 4.8655 & TRN & \\
\hline CHEMBL1403666 & 688341 & 4.6 & 4.7465 & TRN & \\
\hline CHEMBL1538960 & 688341 & 5.2 & 5.0484 & TRN & \\
\hline
\end{tabular}




\begin{tabular}{|c|c|c|c|c|}
\hline \multicolumn{5}{|c|}{ Supplemental Tab } \\
\hline CHEMBL1442642 & 688341 & 4.8 & 4.7984 & TRN \\
\hline CHEMBL1518429 & 688341 & 6.1 & 4.989 & TRN \\
\hline CHEMBL1480503 & 688341 & 4.8 & 4.9239 & TRN \\
\hline CHEMBL1461249 & 688341 & 4.6 & 4.8698 & TRN \\
\hline CHEMBL1501050 & 688341 & 4.4 & 4.6632 & TRN \\
\hline CHEMBL1568508 & 688341 & 4.5 & 4.8182 & TRN \\
\hline CHEMBL539947 & 688341 & 5.5 & 5.1225 & TRN \\
\hline CHEMBL1355256 & 688341 & 4.7 & 5.0616 & TRN \\
\hline CHEMBL1493849 & 688341 & 4.4 & 4.922 & TRN \\
\hline CHEMBL1488038 & 688341 & 5.4 & 4.8754 & TRN \\
\hline CHEMBL1366874 & 688341 & 4.6 & 4.9721 & TST \\
\hline CHEMBL1419459 & 688341 & 5.7 & 4.9682 & TRN \\
\hline CHEMBL1407692 & 688341 & 4.4 & 4.7621 & TST \\
\hline CHEMBL3194730 & 688341 & 6.0 & 5.0779 & TST \\
\hline CHEMBL 1350850 & 688341 & 4.9 & 4.8301 & TRN \\
\hline CHEMBL 1517292 & 688341 & 5.1 & 4.8237 & TRN \\
\hline CHEMBL1503580 & 688341 & 4.9 & 4.9789 & TRN \\
\hline CHEMBL1411716 & 688341 & 4.7 & 4.9215 & TST \\
\hline CHEMBL1367376 & 688341 & 4.4 & 5.0697 & TRN \\
\hline CHEMBL1441799 & 688341 & 5.3 & 5.0262 & TRN \\
\hline CHEMBL 1365587 & 688341 & 5.5 & 4.8033 & TST \\
\hline CHEMBL1343779 & 688341 & 6.0 & 4.9232 & TRN \\
\hline CHEMBL1417190 & 688341 & 4.8 & 4.8218 & TRN \\
\hline CHEMBL1438073 & 688341 & 4.6 & 4.7482 & TRN \\
\hline CHEMBL1515508 & 688341 & 5.2 & 4.9314 & TRN \\
\hline CHEMBL1607473 & 688341 & 5.2 & 5.0919 & TRN \\
\hline CHEMBL1574849 & 688341 & 4.5 & 4.934 & TRN \\
\hline CHEMBL1538398 & 688341 & 4.6 & 4.7267 & TRN \\
\hline CHEMBL1542203 & 688341 & 4.8 & 4.876 & TST \\
\hline CHEMBL1448461 & 688341 & 5.1 & 4.8674 & TST \\
\hline CHEMBL1520427 & 688341 & 4.9 & 5.0091 & TRN \\
\hline CHEMBL3192733 & 688341 & 5.2 & 5.1405 & TRN \\
\hline CHEMBL1365367 & 688341 & 6.1 & 5.0792 & TRN \\
\hline CHEMBL1310329 & 688341 & 5.2 & 4.8566 & TST \\
\hline CHEMBL1376312 & 688341 & 4.7 & 4.9208 & TRN \\
\hline CHEMBL1507739 & 688341 & 4.9 & 4.8828 & TST \\
\hline CHEMBL1471467 & 688341 & 4.4 & 4.9387 & TRN \\
\hline CHEMBL1581345 & 688341 & 4.6 & 4.7258 & TRN \\
\hline CHEMBL1419647 & 688341 & 4.7 & 4.8946 & TRN \\
\hline CHEMBL1550293 & 688341 & 5.1 & 4.8738 & TRN \\
\hline CHEMBL1548028 & 688341 & 5.6 & 4.9992 & TST \\
\hline CHEMBL1379766 & 688341 & 4.7 & 5.0139 & TRN \\
\hline CHEMBL1544661 & 688341 & 4.6 & 4.9567 & TRN \\
\hline CHEMBL1411438 & 688341 & 5.6 & 5.0744 & TRN \\
\hline CHEMBL1571533 & 688341 & 4.7 & 5.0023 & TRN \\
\hline CHEMBL1319794 & 688341 & 4.8 & 4.9844 & TRN \\
\hline CHEMBL1509433 & 688341 & 4.9 & 5.0364 & TRN \\
\hline CHEMBL1502182 & 688341 & 5.1 & 5.0473 & TRN \\
\hline
\end{tabular}




\begin{tabular}{|c|c|c|c|c|}
\hline & & & & $a \perp 1 a$ \\
\hline CHEMBL1562130 & 688341 & 5.3 & 5.0086 & TRN \\
\hline CHEMBL1482767 & 688341 & 5.2 & 4.867 & TST \\
\hline CHEMBL1325376 & 688341 & 4.5 & 4.8096 & TRN \\
\hline CHEMBL1403535 & 688341 & 5.5 & 4.9937 & TRN \\
\hline CHEMBL1452690 & 688341 & 4.6 & 4.9618 & TRN \\
\hline CHEMBL1414605 & 688341 & 4.8 & 4.9516 & TRN \\
\hline CHEMBL1491602 & 688341 & 5.5 & 4.7754 & TRN \\
\hline CHEMBL1304063 & 688341 & 6.9 & 4.9092 & TRN \\
\hline CHEMBL1451788 & 688341 & 5.2 & 5.1896 & TRN \\
\hline CHEMBL1514517 & 688341 & 4.4 & 5.1122 & TRN \\
\hline CHEMBL1354112 & 688341 & 5.5 & 5.0132 & TST \\
\hline CHEMBL1380911 & 688341 & 4.6 & 4.8536 & TRN \\
\hline CHEMBL1575537 & 688341 & 4.7 & 4.8126 & TRN \\
\hline CHEMBL1326611 & 688341 & 4.6 & 4.8131 & TRN \\
\hline CHEMBL278751 & 688341 & 4.5 & 5.1484 & TST \\
\hline CHEMBL1417580 & 688341 & 4.9 & 4.8142 & TRN \\
\hline CHEMBL1596783 & 688341 & 4.4 & 5.0333 & TST \\
\hline CHEMBL1462693 & 688341 & 4.4 & 4.7727 & TRN \\
\hline CHEMBL1402708 & 688341 & 4.9 & 4.785 & TRN \\
\hline CHEMBL1507719 & 688341 & 4.5 & 4.7947 & TRN \\
\hline CHEMBL1361021 & 688341 & 5.3 & 4.9647 & TRN \\
\hline CHEMBL1543101 & 688341 & 5.4 & 4.9234 & TRN \\
\hline CHEMBL1517855 & 688341 & 4.5 & 4.8748 & TRN \\
\hline CHEMBL1492379 & 688341 & 5.5 & 5.1904 & TRN \\
\hline CHEMBL1589428 & 688341 & 4.6 & 4.997 & TST \\
\hline CHEMBL1468238 & 688341 & 4.6 & 4.868 & TRN \\
\hline CHEMBL1489325 & 688341 & 5.5 & 4.7777 & TRN \\
\hline CHEMBL1489926 & 688341 & 4.4 & 5.0799 & TST \\
\hline CHEMBL1451823 & 688341 & 6.0 & 5.1346 & TRN \\
\hline CHEMBL1444636 & 688341 & 5.0 & 5.1569 & TRN \\
\hline CHEMBL1584639 & 688341 & 4.4 & 4.8332 & TST \\
\hline CHEMBL1489704 & 688341 & 4.5 & 4.9258 & TRN \\
\hline CHEMBL1344156 & 688341 & 4.7 & 4.8684 & TST \\
\hline CHEMBL1407527 & 688341 & 4.7 & 5.0084 & TRN \\
\hline CHEMBL1389576 & 688341 & 5.2 & 5.1478 & TRN \\
\hline CHEMBL1468177 & 688341 & 4.6 & 5.1187 & TST \\
\hline CHEMBL1349492 & 688341 & 5.0 & 4.8695 & TST \\
\hline CHEMBL1477131 & 688341 & 4.6 & 4.8318 & TST \\
\hline CHEMBL1501962 & 688341 & 4.7 & 4.9435 & TRN \\
\hline CHEMBL1471973 & 688341 & 4.9 & 4.9943 & TST \\
\hline CHEMBL1495824 & 688341 & 4.8 & 4.8167 & TRN \\
\hline CHEMBL1431620 & 688341 & 4.5 & 4.8996 & TST \\
\hline CHEMBL1612744 & 688341 & 5.2 & 4.9646 & TST \\
\hline CHEMBL1386004 & 688341 & 4.6 & 4.829 & TST \\
\hline CHEMBL1558480 & 688341 & 5.1 & 5.1069 & TRN \\
\hline CHEMBL3196905 & 688341 & 5.1 & 4.9061 & TRN \\
\hline CHEMBL1373469 & 688341 & 4.7 & 4.9514 & TRN \\
\hline CHEMBL1337451 & 688341 & 4.7 & 4.8663 & TRN \\
\hline
\end{tabular}




\begin{tabular}{|c|c|c|c|c|c|}
\hline \multirow{2}{*}{ CHEMBL1376488 } & \\
\hline & 688341 & 4.6 & 4.8532 & TRN & \\
\hline CHEMBL603028 & 688341 & 4.8 & 4.7451 & TRN & \\
\hline CHEMBL3208554 & 688341 & 5.4 & 5.13399 & 99999999995 & TST \\
\hline CHEMBL1531515 & 688341 & 5.4 & 4.9356 & TRN & \\
\hline CHEMBL1425724 & 688341 & 4.6 & 4.8471 & TRN & \\
\hline CHEMBL1339656 & 688341 & 4.4 & 4.8924 & TRN & \\
\hline CHEMBL1317124 & 688341 & 6.0 & 5.0735 & TST & \\
\hline CHEMBL1460670 & 688341 & 4.9 & 4.8995 & TST & \\
\hline CHEMBL1570158 & 688341 & 5.5 & 4.9203 & TRN & \\
\hline CHEMBL1481127 & 688341 & 5.3 & 5.1217 & TRN & \\
\hline CHEMBL1308779 & 688341 & 4.6 & 4.9392 & TRN & \\
\hline CHEMBL1456016 & 688341 & 4.6 & 4.9901 & TRN & \\
\hline CHEMBL1432217 & 688341 & 5.2 & 4.9758 & TST & \\
\hline CHEMBL1432517 & 688341 & 7.699 & 4.9539 & TRN & \\
\hline CHEMBL1444530 & 688341 & 4.7 & 4.9709 & TRN & \\
\hline CHEMBL1501110 & 688341 & 5.0 & 4.8331 & TRN & \\
\hline CHEMBL1403882 & 688341 & 4.5 & 4.8901 & TRN & \\
\hline CHEMBL1362521 & 688341 & 5.1 & 4.9094 & TRN & \\
\hline CHEMBL1508376 & 688341 & 4.6 & 4.8023 & TRN & \\
\hline CHEMBL1424962 & 688341 & 4.6 & 4.86 & TRN & \\
\hline CHEMBL1385623 & 688341 & 4.6 & 5.0369 & TRN & \\
\hline CHEMBL1360484 & 688341 & 4.7 & 4.9374 & TRN & \\
\hline CHEMBL1352525 & 688341 & 4.6 & 4.8188 & TRN & \\
\hline CHEMBL1347536 & 688341 & 4.6 & 5.0255 & TST & \\
\hline CHEMBL1432786 & 688341 & 6.4 & 4.9181 & TRN & \\
\hline CHEMBL1575906 & 688341 & 4.6 & 4.8985 & TRN & \\
\hline CHEMBL1475990 & 688341 & 4.4 & 5.0759 & TRN & \\
\hline CHEMBL1442704 & 688341 & 5.3 & 4.9234 & TRN & \\
\hline CHEMBL1504303 & 688341 & 4.7 & 4.8783 & TRN & \\
\hline CHEMBL1343980 & 688341 & 4.6 & 4.9357 & TRN & \\
\hline CHEMBL1339659 & 688341 & 4.5 & 4.8015 & TRN & \\
\hline CHEMBL1605232 & 688341 & 4.8 & 4.8993 & TRN & \\
\hline CHEMBL1362232 & 688341 & 6.8 & 5.0894 & TRN & \\
\hline CHEMBL538965 & 688341 & 5.6 & 5.0302 & TRN & \\
\hline CHEMBL1481904 & 688341 & 6.4 & 5.0535 & TRN & \\
\hline CHEMBL1399767 & 688341 & 5.4 & 5.1329 & TST & \\
\hline CHEMBL1362418 & 688341 & 5.3 & 5.1209 & TST & \\
\hline CHEMBL1350844 & 688341 & 4.4 & 4.8716 & TRN & \\
\hline CHEMBL1324439 & 688341 & 5.1 & 5.1416 & TST & \\
\hline CHEMBL1539572 & 688341 & 4.5 & 4.9488 & TRN & \\
\hline CHEMBL1567336 & 688341 & 5.3 & 4.98300 & 00000000005 & TRN \\
\hline CHEMBL1454793 & 688341 & 5.0 & 5.2159 & TRN & \\
\hline CHEMBL289277 & 688341 & 6.0 & 4.9715 & TRN & \\
\hline CHEMBL267373 & 688341 & 5.9 & 4.9442 & TRN & \\
\hline CHEMBL428814 & 688341 & 6.2 & 5.0733 & TRN & \\
\hline CHEMBL1609686 & 688341 & 5.6 & 4.8142 & TST & \\
\hline CHEMBL1340876 & 688341 & 5.5 & 4.7004 & TRN & \\
\hline CHEMBL1394137 & 688341 & 4.9 & 5.0269 & TRN & \\
\hline & & & & 06 & \\
\hline
\end{tabular}




\begin{tabular}{|c|c|c|c|c|}
\hline \multicolumn{5}{|c|}{ Supplemental Table s2.txt } \\
\hline CHEMBL1315637 & 688341 & 5.5 & 4.9985 & TRN \\
\hline CHEMBL1447889 & 688341 & 4.9 & 4.8255 & TRN \\
\hline CHEMBL1606041 & 688341 & 5.6 & 5.0861 & TRN \\
\hline CHEMBL1528249 & 688341 & 4.4 & 4.8294 & TRN \\
\hline CHEMBL1423151 & 688341 & 5.4 & 5.0408 & TST \\
\hline CHEMBL1308867 & 688341 & 4.5 & 4.941 & TST \\
\hline CHEMBL1588088 & 688341 & 5.0 & 4.9948 & TST \\
\hline CHEMBL1362711 & 688341 & 4.8 & 4.83 & TRN \\
\hline CHEMBL1423336 & 688341 & 4.9 & 4.8743 & TRN \\
\hline CHEMBL1536892 & 688341 & 4.6 & 4.9457 & TRN \\
\hline CHEMBL1333376 & 688341 & 5.1 & 4.9503 & TST \\
\hline CHEMBL1331476 & 688341 & 7.1002 & 5.0415 & TST \\
\hline CHEMBL1311555 & 688341 & 4.6 & 4.9908 & TRN \\
\hline CHEMBL1499269 & 688341 & 5.2 & 5.0136 & TST \\
\hline CHEMBL1372763 & 688341 & 6.0 & 4.9534 & TRN \\
\hline CHEMBL1378030 & 688341 & 4.8 & 5.0645 & TST \\
\hline CHEMBL1312282 & 688341 & 8.0 & 4.7603 & TRN \\
\hline CHEMBL 1483700 & 688341 & 5.1 & 5.2645 & TRN \\
\hline CHEMBL89295 & 688341 & 5.3 & 5.1255 & TST \\
\hline CHEMBL1420320 & 688341 & 4.5 & 4.8141 & TST \\
\hline CHEMBL1611064 & 688341 & 4.5 & 4.8681 & TST \\
\hline CHEMBL1603213 & 688341 & 5.1 & 4.9769 & TST \\
\hline CHEMBL 1451315 & 688341 & 4.6 & 5.0814 & TRN \\
\hline CHEMBL1343083 & 688341 & 6.2 & 4.8076 & TST \\
\hline CHEMBL1545577 & 688341 & 4.6 & 4.9878 & TRN \\
\hline CHEMBL1539314 & 688341 & 5.1 & 5.1073 & TRN \\
\hline CHEMBL1519579 & 688341 & 4.9 & 4.9306 & TRN \\
\hline CHEMBL 1416282 & 688341 & 5.3 & 4.9229 & TRN \\
\hline CHEMBL1344858 & 688341 & 5.2 & 4.9164 & TRN \\
\hline CHEMBL1415180 & 688341 & 4.7 & 5.2315 & TRN \\
\hline CHEMBL1505553 & 688341 & 4.9 & 5.0298 & TRN \\
\hline CHEMBL1378258 & 688341 & 4.7 & 4.8654 & TRN \\
\hline CHEMBL1480494 & 688341 & 4.5 & 4.8182 & TST \\
\hline CHEMBL1592672 & 688341 & 4.7 & 4.9403 & TRN \\
\hline CHEMBL 1356256 & 688341 & 5.0 & 5.2406 & TRN \\
\hline CHEMBL1385395 & 688341 & 4.6 & 4.864 & TRN \\
\hline CHEMBL1567859 & 688341 & 4.4 & 4.887 & TRN \\
\hline CHEMBL1610931 & 688341 & 5.2 & 4.9346 & TRN \\
\hline CHEMBL1376345 & 688341 & 4.5 & 4.8575 & TRN \\
\hline CHEMBL1563743 & 688341 & 5.1 & 4.8379 & TRN \\
\hline CHEMBL1452066 & 688341 & 4.7 & 5.0033 & TRN \\
\hline CHEMBL1574497 & 688341 & 6.4 & 4.9399 & TRN \\
\hline CHEMBL 388676 & 688341 & 6.0 & 5.12799 & 9999999999 \\
\hline CHEMBL1415927 & 688341 & 4.6 & 5.0933 & TST \\
\hline CHEMBL1379345 & 688341 & 4.4 & 4.9109 & TRN \\
\hline CHEMBL1333952 & 688341 & 4.4 & 4.9958 & TRN \\
\hline CHEMBL1413465 & 688341 & 4.5 & 4.9048 & TRN \\
\hline CHEMBL 1443543 & 688341 & 5.2 & 5.0046 & TRN \\
\hline
\end{tabular}




\begin{tabular}{|c|c|c|c|c|c|}
\hline \multicolumn{6}{|c|}{ Supplemental Table S2.txt } \\
\hline CHEMBL1538120 & 688341 & 4.6 & 4.852 & TRN & \\
\hline CHEMBL1410321 & 688341 & 5.4 & 5.0748 & TRN & \\
\hline CHEMBL38934 & 688341 & 5.1 & 5.0058 & TRN & \\
\hline CHEMBL1411691 & 688341 & 4.6 & 4.9754 & TRN & \\
\hline CHEMBL1489212 & 688341 & 4.8 & 5.0333 & TST & \\
\hline CHEMBL1349169 & 688341 & 4.4 & 4.9766 & TRN & \\
\hline CHEMBL1314647 & 688341 & 6.6 & 5.2018 & TRN & \\
\hline CHEMBL1513324 & 688341 & 5.1 & 5.1034 & TRN & \\
\hline CHEMBL1604272 & 688341 & 4.4 & 4.9348 & TST & \\
\hline CHEMBL1463238 & 688341 & 5.6 & 4.8873 & TST & \\
\hline CHEMBL1400452 & 688341 & 4.6 & 4.9425 & TRN & \\
\hline CHEMBL1567251 & 688341 & 5.2 & 5.1706 & TRN & \\
\hline CHEMBL1319533 & 688341 & 4.5 & 4.9506 & TRN & \\
\hline CHEMBL1594058 & 688341 & 5.4 & 5.0877 & TRN & \\
\hline CHEMBL1452243 & 688341 & 5.2 & 4.8596 & TRN & \\
\hline CHEMBL1608857 & 688341 & 4.5 & 4.819 & TST & \\
\hline CHEMBL15712 & 688341 & 7.5003 & 5.2487 & TRN & \\
\hline CHEMBL1506963 & 688341 & 5.3 & 4.9553 & TRN & \\
\hline CHEMBL1301768 & 688341 & 4.5 & 4.9446 & TRN & \\
\hline CHEMBL1492136 & 688341 & 5.8 & 4.934 & TRN & \\
\hline CHEMBL1317913 & 688341 & 4.9 & 5.1863 & TRN & \\
\hline CHEMBL1504350 & 688341 & 4.9 & 4.9199 & TRN & \\
\hline CHEMBL3194743 & 688341 & 4.4 & 5.0848 & TST & \\
\hline CHEMBL1475036 & 688341 & 4.6 & 5.0461 & TRN & \\
\hline CHEMBL3208814 & 688341 & 5.5 & 4.93199 & 99999999995 & TRN \\
\hline CHEMBL1342209 & 688341 & 5.2 & 4.7817 & TST & \\
\hline CHEMBL1311841 & 688341 & 4.7 & 4.8138 & TRN & \\
\hline CHEMBL1431034 & 688341 & 5.1 & 4.8243 & TRN & \\
\hline CHEMBL1368942 & 688341 & 5.8 & 5.0366 & TRN & \\
\hline CHEMBL1322495 & 688341 & 4.4 & 5.1847 & TST & \\
\hline CHEMBL1430687 & 688341 & 5.0 & 4.9046 & TRN & \\
\hline CHEMBL1409297 & 688341 & 5.1 & 4.8733 & TRN & \\
\hline CHEMBL1567185 & 688341 & 4.6 & 4.86 & TST & \\
\hline CHEMBL1364357 & 688341 & 4.5 & 4.7936 & TRN & \\
\hline CHEMBL1399847 & 688341 & 4.5 & 4.7907 & TRN & \\
\hline CHEMBL1490263 & 688341 & 4.4 & 4.9994 & TRN & \\
\hline CHEMBL1611216 & 688341 & 4.4 & 4.9114 & TST & \\
\hline CHEMBL1566752 & 688341 & 4.6 & 4.8725 & TRN & \\
\hline CHEMBL1384652 & 688341 & 5.8 & 4.9849 & TRN & \\
\hline CHEMBL426123 & 688341 & 5.4 & 5.0483 & TST & \\
\hline CHEMBL362051 & 688341 & 4.4 & 5.0639 & TST & \\
\hline CHEMBL1494495 & 688341 & 4.4 & 4.6586 & TRN & \\
\hline CHEMBL1606727 & 688341 & 4.8 & 5.1928 & TRN & \\
\hline CHEMBL1606397 & 688341 & 5.4 & 4.9821 & TRN & \\
\hline CHEMBL1402233 & 688341 & 4.4 & 4.8207 & TST & \\
\hline CHEMBL1503585 & 688341 & 4.4 & 4.9519 & TRN & \\
\hline CHEMBL1340509 & 688341 & 4.4 & 4.8427 & TRN & \\
\hline CHEMBL1579377 & 688341 & 4.8 & 4.9975 & TRN & \\
\hline
\end{tabular}




\begin{tabular}{|c|c|c|c|c|}
\hline \multicolumn{5}{|c|}{ Supplemental Table S2.txt } \\
\hline CHEMBL1586286 & 688341 & 4.5 & 4.8924 & TRN \\
\hline CHEMBL1447959 & 688341 & 4.8 & 4.9992 & TRN \\
\hline CHEMBL1380507 & 688341 & 5.1 & 4.8177 & TRN \\
\hline CHEMBL1569522 & 688341 & 4.7 & 4.8974 & TRN \\
\hline CHEMBL1562706 & 688341 & 4.7 & 4.9106 & TRN \\
\hline CHEMBL1379438 & 688341 & 4.8 & 4.8664 & TRN \\
\hline CHEMBL323356 & 688341 & 4.4 & 4.8212 & TST \\
\hline CHEMBL1413213 & 688341 & 4.8 & 4.8326 & TRN \\
\hline CHEMBL1487809 & 688341 & 4.4 & 5.0587 & TRN \\
\hline CHEMBL1522681 & 688341 & 5.9 & 5.1669 & TRN \\
\hline CHEMBL1424438 & 688341 & 5.2 & 4.827 & TRN \\
\hline CHEMBL1608228 & 688341 & 4.5 & 4.9435 & TST \\
\hline CHEMBL1610780 & 688341 & 4.6 & 4.9643 & TRN \\
\hline CHEMBL1533733 & 688341 & 4.9 & 4.9804 & TRN \\
\hline CHEMBL1418959 & 688341 & 5.2 & 4.8446 & TRN \\
\hline CHEMBL1546117 & 688341 & 5.9 & 4.8336 & TRN \\
\hline CHEMBL466545 & 688341 & 5.1 & 5.2019 & TST \\
\hline CHEMBL1422370 & 688341 & 4.4 & 4.9489 & TST \\
\hline CHEMBL1348783 & 688341 & 7.0 & 4.947 & TST \\
\hline CHEMBL1499656 & 688341 & 4.8 & 4.9728 & TRN \\
\hline CHEMBL1578539 & 688341 & 4.9 & 4.8412 & TST \\
\hline CHEMBL1489100 & 688341 & 4.6 & 4.905 & TRN \\
\hline CHEMBL1506477 & 688341 & 4.4 & 4.8114 & TRN \\
\hline CHEMBL1334477 & 688341 & 5.4 & 4.9848 & TRN \\
\hline CHEMBL1611308 & 688341 & 5.9 & 5.157 & TRN \\
\hline CHEMBL1574187 & 688341 & 4.4 & 4.8362 & TRN \\
\hline CHEMBL1488418 & 688341 & 4.7 & 4.845 & TRN \\
\hline CHEMBL1430513 & 688341 & 4.4 & 4.9574 & TST \\
\hline CHEMBL1308898 & 688341 & 4.6 & 4.9098 & TRN \\
\hline CHEMBL1562316 & 688341 & 4.5 & 4.9822 & TRN \\
\hline CHEMBL1352906 & 688341 & 5.3 & 5.0057 & TRN \\
\hline CHEMBL1435744 & 688341 & 4.6 & 4.9492 & TRN \\
\hline CHEMBL1610464 & 688341 & 4.5 & 4.7848 & TRN \\
\hline CHEMBL1606723 & 688341 & 5.3 & 4.8931 & TRN \\
\hline CHEMBL1605298 & 688341 & 5.2 & 4.9489 & TST \\
\hline CHEMBL1332904 & 688341 & 4.5 & 4.8904 & TRN \\
\hline CHEMBL1331889 & 688341 & 5.9 & 4.8825 & TST \\
\hline CHEMBL1430669 & 688341 & 4.7 & 5.0261 & TST \\
\hline CHEMBL1561971 & 688341 & 5.0 & 5.1218 & TST \\
\hline CHEMBL1313927 & 688341 & 4.5 & 4.9957 & TST \\
\hline CHEMBL1540058 & 688341 & 4.7 & 5.0208 & TRN \\
\hline CHEMBL118752 & 688341 & 4.5 & 4.9211 & TRN \\
\hline CHEMBL1413972 & 688341 & 5.4 & 4.8322 & TRN \\
\hline CHEMBL1461995 & 688341 & 4.7 & 4.7787 & TRN \\
\hline CHEMBL1608558 & 688341 & 7.6003 & 5.1003 & TST \\
\hline CHEMBL1451711 & 688341 & 4.5 & 4.7854 & TRN \\
\hline CHEMBL1601019 & 688341 & 4.7 & 4.9893 & TRN \\
\hline CHEMBL1350073 & 688341 & 5.2 & 4.8206 & TRN \\
\hline
\end{tabular}




\begin{tabular}{|c|c|c|c|c|c|}
\hline \multicolumn{6}{|c|}{ Supplemental Table S2.txt } \\
\hline CHEMBL1580580 & 688341 & 4.9 & 4.9373 & TRN & \\
\hline CHEMBL1257081 & 688341 & 5.2 & 5.0751 & TST & \\
\hline CHEMBL1331128 & 688341 & 4.8 & 4.9595 & TST & \\
\hline CHEMBL1574269 & 688341 & 4.4 & 4.8408 & TRN & \\
\hline CHEMBL1609246 & 688341 & 5.4 & 4.9139 & TRN & \\
\hline CHEMBL1508186 & 688341 & 7.1002 & 4.7454 & TRN & \\
\hline CHEMBL1514458 & 688341 & 5.6 & 5.0329 & TRN & \\
\hline CHEMBL 269362 & 688341 & 5.4 & 5.0238 & TST & \\
\hline CHEMBL1371512 & 688341 & 4.4 & 4.8844 & TRN & \\
\hline CHEMBL1548931 & 688341 & 5.1 & 4.8508 & TRN & \\
\hline CHEMBL1483132 & 688341 & 4.6 & 4.7867 & TST & \\
\hline CHEMBL1450088 & 688341 & 4.7 & 4.8048 & TRN & \\
\hline CHEMBL1528542 & 688341 & 4.4 & 4.9776 & TRN & \\
\hline CHEMBL1600956 & 688341 & 4.6 & 4.842 & TRN & \\
\hline CHEMBL1311861 & 688341 & 5.3 & 5.0364 & TST & \\
\hline CHEMBL1380778 & 688341 & 4.5 & $5.1320 e$ & 0000000001 & TST \\
\hline CHEMBL1390886 & 688341 & 5.2 & 4.9562 & TST & \\
\hline CHEMBL1389139 & 688341 & 4.9 & 4.9004 & TRN & \\
\hline CHEMBL1533981 & 688341 & 5.5 & 4.9291 & TRN & \\
\hline CHEMBL1312088 & 688341 & 4.9 & 4.8995 & TST & \\
\hline CHEMBL1371768 & 688341 & 4.6 & 4.9181 & TRN & \\
\hline CHEMBL1530521 & 688341 & 4.9 & 4.9961 & TRN & \\
\hline CHEMBL 3207878 & 688341 & 5.5 & 4.9148 & TRN & \\
\hline CHEMBL1594970 & 688341 & 5.7 & 5.0157 & TRN & \\
\hline CHEMBL1454799 & 688341 & 5.2 & 4.7959 & TRN & \\
\hline CHEMBL1493369 & 688341 & 4.4 & 5.0748 & TST & \\
\hline CHEMBL249190 & 688341 & 4.8 & 4.8668 & TRN & \\
\hline CHEMBL1319881 & 688341 & 4.4 & 5.0063 & TRN & \\
\hline CHEMBL1480779 & 688341 & 5.1 & 4.96899 & 9999999999 & TRN \\
\hline CHEMBL3208298 & 688341 & 4.4 & 4.8723 & TST & \\
\hline CHEMBL1596183 & 688341 & 5.1 & 4.9397 & TRN & \\
\hline CHEMBL1328444 & 688341 & 4.6 & 4.9825 & TRN & \\
\hline CHEMBL1362370 & 688341 & 6.8 & 4.8668 & TRN & \\
\hline CHEMBL1427611 & 688341 & 4.6 & 5.0317 & TST & \\
\hline CHEMBL1319534 & 688341 & 4.7 & 4.9349 & TRN & \\
\hline CHEMBL1577187 & 688341 & 4.8 & 4.9251 & TRN & \\
\hline CHEMBL1490558 & 688341 & 5.2 & 4.9601 & TST & \\
\hline CHEMBL1419142 & 688341 & 4.6 & 4.7555 & TRN & \\
\hline CHEMBL1593153 & 688341 & 5.4 & 5.1564 & TRN & \\
\hline CHEMBL1451248 & 688341 & 5.1 & 4.9825 & TST & \\
\hline CHEMBL1382977 & 688341 & 4.5 & 4.7311 & TRN & \\
\hline CHEMBL1328466 & 688341 & 4.8 & 5.0275 & TRN & \\
\hline CHEMBL1427637 & 688341 & 4.8 & 5.1322 & TRN & \\
\hline CHEMBL1589519 & 688341 & 6.7001 & 4.9011 & TRN & \\
\hline CHEMBL1413178 & 688341 & 5.1 & 5.0858 & TST & \\
\hline CHEMBL1374810 & 688341 & 5.9 & 5.1456 & TRN & \\
\hline CHEMBL1352363 & 688341 & 4.4 & 4.9468 & TRN & \\
\hline CHEMBL1346650 & 688341 & 4.6 & 4.869 & TRN & \\
\hline
\end{tabular}




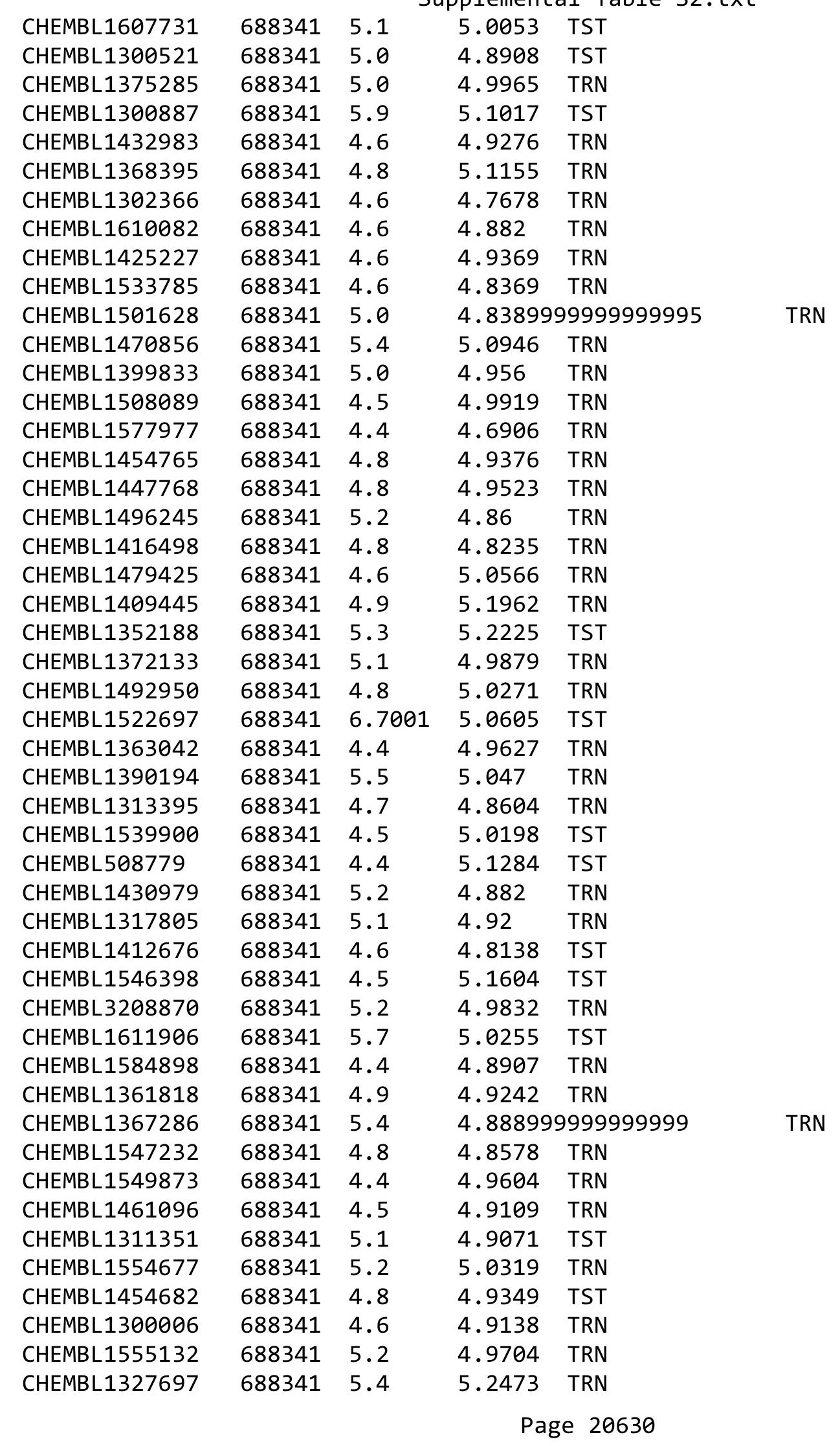




\begin{tabular}{|c|c|c|c|c|}
\hline \multicolumn{5}{|c|}{ Supplemental Table S2.txt } \\
\hline CHEMBL1352703 & 688341 & 4.4 & 4.7903 & TST \\
\hline CHEMBL1545113 & 688341 & 5.4 & 4.9763 & TRN \\
\hline CHEMBL1408032 & 688341 & 5.1 & 4.9244 & TRN \\
\hline CHEMBL1352639 & 688341 & 4.4 & 4.9002 & TRN \\
\hline CHEMBL1311993 & 688341 & 4.5 & 4.9616 & TRN \\
\hline CHEMBL1512470 & 688341 & 5.4 & 5.0191 & TRN \\
\hline CHEMBL1607105 & 688341 & 5.3 & 4.9362 & TRN \\
\hline CHEMBL1449586 & 688341 & 4.6 & 4.7984 & TRN \\
\hline CHEMBL1523346 & 688341 & 4.5 & 4.8403 & TRN \\
\hline CHEMBL1462804 & 688341 & 5.2 & 4.7168 & TRN \\
\hline CHEMBL 32307 & 688341 & 5.1 & 5.1476 & TRN \\
\hline CHEMBL3193107 & 688341 & 5.4 & 5.11 & TRN \\
\hline CHEMBL1356834 & 688341 & 4.8 & 5.0145 & TRN \\
\hline CHEMBL1600978 & 688341 & 4.7 & 5.1322 & TRN \\
\hline CHEMBL1379776 & 688341 & 4.6 & 4.8093 & TRN \\
\hline CHEMBL1547429 & 688341 & 4.6 & 4.7935 & TRN \\
\hline CHEMBL1441891 & 688341 & 4.6 & 4.9512 & TRN \\
\hline CHEMBL1412847 & 688341 & 4.9 & 5.1386 & TRN \\
\hline CHEMBL1378746 & 688341 & 4.6 & 4.7505 & TRN \\
\hline CHEMBL1472293 & 688341 & 4.4 & 4.7953 & TRN \\
\hline CHEMBL464135 & 688341 & 5.2 & 4.9925 & TST \\
\hline CHEMBL1570251 & 688341 & 4.7 & 4.9143 & TRN \\
\hline CHEMBL1535589 & 688341 & 5.4 & 5.0014 & TST \\
\hline CHEMBL1348591 & 688341 & 4.4 & 4.851 & TRN \\
\hline CHEMBL1322468 & 688341 & 5.5 & 5.0125 & TRN \\
\hline CHEMBL1477519 & 688341 & 4.6 & 4.8765 & TST \\
\hline CHEMBL1573862 & 688341 & 4.4 & 4.9506 & TRN \\
\hline CHEMBL1550510 & 688341 & 4.6 & 4.7721 & TRN \\
\hline CHEMBL1352741 & 688341 & 4.4 & 4.7297 & TRN \\
\hline CHEMBL1488204 & 688341 & 4.4 & 4.8169 & TRN \\
\hline CHEMBL1589269 & 688341 & 4.6 & 4.8304 & TRN \\
\hline CHEMBL1525780 & 688341 & 4.6 & 4.9067 & TST \\
\hline CHEMBL1570402 & 688341 & 4.8 & 4.845 & TRN \\
\hline CHEMBL1559347 & 688341 & 5.0 & 5.0456 & TRN \\
\hline CHEMBL1415465 & 688341 & 5.5 & 5.1804 & TRN \\
\hline CHEMBL1566562 & 688341 & 5.1 & 4.865 & TRN \\
\hline CHEMBL1500553 & 688341 & 5.4 & 5.0138 & TST \\
\hline CHEMBL1577516 & 688341 & 4.4 & 4.8671 & TRN \\
\hline CHEMBL1325008 & 688341 & 4.5 & 5.0043 & TST \\
\hline CHEMBL1474318 & 688341 & 4.4 & 5.1822 & TRN \\
\hline CHEMBL1568363 & 688341 & 4.6 & 4.6974 & TRN \\
\hline CHEMBL1548237 & 688341 & 5.9 & 4.9025 & TRN \\
\hline CHEMBL1506800 & 688341 & 5.2 & 4.8938 & TRN \\
\hline CHEMBL1473849 & 688341 & 4.8 & 4.9769 & TRN \\
\hline CHEMBL1443757 & 688341 & 5.5 & 5.0105 & TRN \\
\hline CHEMBL1318553 & 688341 & 4.5 & 5.0798 & TST \\
\hline CHEMBL1564190 & 688341 & 4.5 & 5.0793 & TST \\
\hline CHEMBL1430379 & 688341 & 6.5 & 4.7983 & TRN \\
\hline
\end{tabular}




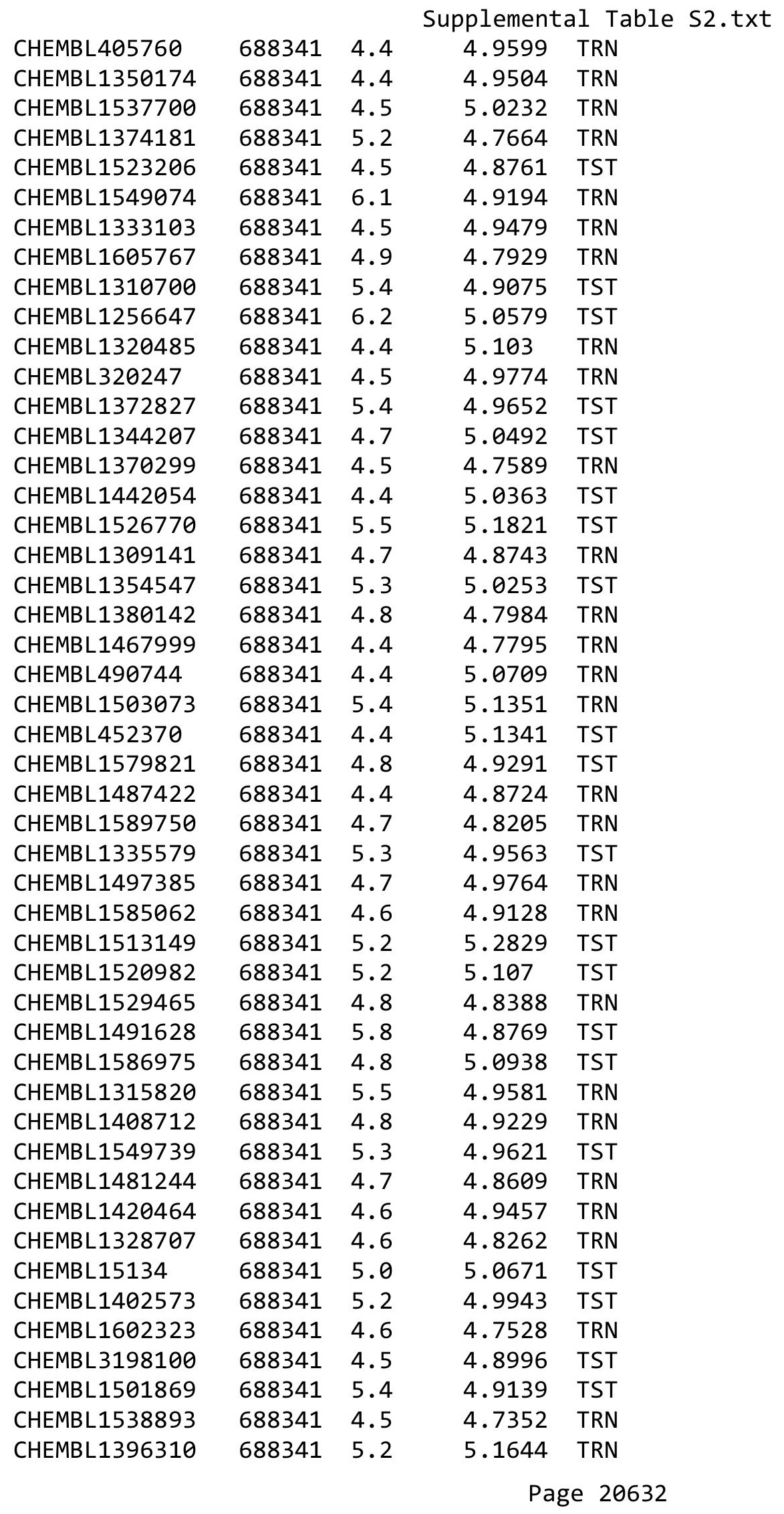




\begin{tabular}{|c|c|c|c|c|c|}
\hline & & & & & \\
\hline CHEMBL1498172 & 688341 & 4.6 & 4.8494 & TRN & \\
\hline CHEMBL1531535 & 688341 & 5.4 & 5.1219 & TST & \\
\hline CHEMBL1481585 & 688341 & 4.7 & 4.8228 & TRN & \\
\hline CHEMBL1500190 & 688341 & 4.9 & 4.8649 & TRN & \\
\hline CHEMBL1506356 & 688341 & 4.8 & 4.9182 & TST & \\
\hline CHEMBL1326251 & 688341 & 4.6 & 5.2379 & TRN & \\
\hline CHEMBL1376874 & 688341 & 4.4 & 4.8742 & TRN & \\
\hline CHEMBL1393731 & 688341 & 4.6 & 4.8977 & TRN & \\
\hline CHEMBL1430495 & 688341 & 5.4 & 4.7358 & TST & \\
\hline CHEMBL1606694 & 688341 & 5.2 & 5.078 & TRN & \\
\hline CHEMBL1445585 & 688341 & 4.8 & 5.1435 & TST & \\
\hline CHEMBL1375429 & 688341 & 4.5 & 4.9851 & TRN & \\
\hline CHEMBL1511506 & 688341 & 4.4 & 4.9975 & TST & \\
\hline CHEMBL1430166 & 688341 & 4.9 & 4.9245 & TRN & \\
\hline CHEMBL1375885 & 688341 & 4.6 & 4.9485 & TRN & \\
\hline CHEMBL584031 & 688341 & 4.6 & 4.9463 & TRN & \\
\hline CHEMBL1562090 & 688341 & 4.8 & 4.9642 & TRN & \\
\hline CHEMBL1364901 & 688341 & 4.6 & 4.8421 & TRN & \\
\hline CHEMBL1305880 & 688341 & 4.5 & 4.8801 & TST & \\
\hline CHEMBL448841 & 688341 & 4.5 & 4.80699 & 99999999995 & TRN \\
\hline CHEMBL1402397 & 688341 & 4.6 & 5.0219 & TST & \\
\hline CHEMBL1255578 & 688341 & 4.4 & 5.1054 & TST & \\
\hline CHEMBL1351093 & 688341 & 6.5 & 5.1251 & TRN & \\
\hline CHEMBL1566246 & 688341 & 5.0 & 4.8586 & TRN & \\
\hline CHEMBL1362517 & 688341 & 5.2 & 4.9529 & TRN & \\
\hline CHEMBL1477172 & 688341 & 5.0 & 4.62 & TRN & \\
\hline CHEMBL1353164 & 688341 & 4.8 & 4.9667 & TRN & \\
\hline CHEMBL310578 & 688341 & 5.3 & 5.0851 & TST & \\
\hline CHEMBL1473379 & 688341 & 6.5 & 5.2434 & TRN & \\
\hline CHEMBL1568261 & 688341 & 4.6 & 4.7941 & TRN & \\
\hline CHEMBL1374191 & 688341 & 6.9 & 5.0068 & TST & \\
\hline CHEMBL1317943 & 688341 & 5.0 & 5.0443 & TRN & \\
\hline CHEMBL1462113 & 688341 & 4.8 & 4.8942 & TRN & \\
\hline CHEMBL1409217 & 688341 & 5.1 & 4.837 & TRN & \\
\hline CHEMBL1499079 & 688341 & 4.4 & 4.8244 & TRN & \\
\hline CHEMBL1355387 & 688341 & 4.9 & 4.9931 & TRN & \\
\hline CHEMBL1429819 & 688341 & 4.5 & 4.7703 & TRN & \\
\hline CHEMBL1482532 & 688341 & 4.4 & 4.7662 & TRN & \\
\hline CHEMBL1572921 & 688341 & 4.4 & 4.9743 & TST & \\
\hline CHEMBL1462696 & 688341 & 4.5 & 4.7066 & TRN & \\
\hline CHEMBL 23832 & 688341 & 4.6 & 4.9567 & TRN & \\
\hline CHEMBL1413010 & 688341 & 5.3 & 5.0658 & TRN & \\
\hline CHEMBL1328639 & 688341 & 5.6 & 4.9122 & TRN & \\
\hline CHEMBL1459187 & 688341 & 4.6 & 4.8419 & TRN & \\
\hline CHEMBL1520880 & 688341 & 4.6 & 4.9237 & TST & \\
\hline CHEMBL1551308 & 688341 & 4.9 & 5.0108 & TRN & \\
\hline CHEMBL 1310750 & 688341 & 4.6 & 4.9864 & TST & \\
\hline CHEMBL1407650 & 688341 & 4.8 & 4.9227 & TST & \\
\hline & & & & 20633 & \\
\hline
\end{tabular}




\begin{tabular}{|c|c|c|c|c|c|}
\hline \multicolumn{6}{|c|}{ Supplemental Table S2.txt } \\
\hline CHEMBL1393365 & 688341 & 4.8 & 4.7156 & TRN & \\
\hline CHEMBL3207656 & 688341 & 6.0 & 4.9537 & TST & \\
\hline CHEMBL1491012 & 688341 & 4.5 & 5.0309 & TRN & \\
\hline CHEMBL1570390 & 688341 & 4.6 & 4.8941 & TRN & \\
\hline CHEMBL1572836 & 688341 & 5.0 & 4.8176 & TRN & \\
\hline CHEMBL1417443 & 688341 & 5.4 & 5.0749 & TST & \\
\hline CHEMBL1490957 & 688341 & 4.8 & 4.8417 & TRN & \\
\hline CHEMBL1388407 & 688341 & 4.6 & 4.8895 & TRN & \\
\hline CHEMBL1537605 & 688341 & 4.6 & 4.8919 & TST & \\
\hline CHEMBL1557431 & 688341 & 4.5 & 4.7573 & TRN & \\
\hline CHEMBL1526230 & 688341 & 5.2 & 4.6763 & TRN & \\
\hline CHEMBL1378783 & 688341 & 4.6 & 5.024 & TRN & \\
\hline CHEMBL1393881 & 688341 & 4.5 & 4.9582 & TRN & \\
\hline CHEMBL3209440 & 688341 & 4.9 & 4.9547 & TRN & \\
\hline CHEMBL1403448 & 688341 & 4.9 & 4.9656 & TRN & \\
\hline CHEMBL1596627 & 688341 & 5.2 & 5.1786 & TRN & \\
\hline CHEMBL1319844 & 688341 & 4.8 & 4.9627 & TRN & \\
\hline CHEMBL1399218 & 688341 & 4.8 & 4.9651 & TRN & \\
\hline CHEMBL1444396 & 688341 & 5.6 & 5.1036 & TRN & \\
\hline CHEMBL1539432 & 688341 & 4.6 & 4.896 & TRN & \\
\hline CHEMBL1530364 & 688341 & 4.5 & 4.905 & TRN & \\
\hline CHEMBL1601858 & 688341 & 4.5 & 4.8736 & TST & \\
\hline CHEMBL1522182 & 688341 & 4.4 & 4.9037 & TRN & \\
\hline CHEMBL1317234 & 688341 & 6.0 & 5.1219 & TST & \\
\hline CHEMBL1424574 & 688341 & 5.4 & 4.9957 & TRN & \\
\hline CHEMBL1448864 & 688341 & 5.3 & 4.95100 & 00000000005 & TRN \\
\hline CHEMBL1603246 & 688341 & 4.7 & 4.8386 & TST & \\
\hline CHEMBL1577538 & 688341 & 4.8 & 4.7724 & TRN & \\
\hline CHEMBL41092 & 688341 & 4.8 & 4.9386 & TRN & \\
\hline CHEMBL1582133 & 688341 & 4.5 & 4.9043 & TRN & \\
\hline CHEMBL1419836 & 688341 & 4.6 & 4.9631 & TRN & \\
\hline CHEMBL1465416 & 688341 & 4.6 & 5.0622 & TRN & \\
\hline CHEMBL1353393 & 688341 & 4.6 & 4.9511 & TST & \\
\hline CHEMBL1612517 & 688341 & 5.0 & 4.9815 & TRN & \\
\hline CHEMBL1523194 & 688341 & 4.5 & 4.968 & TRN & \\
\hline CHEMBL1520783 & 688341 & 5.4 & 5.0045 & TST & \\
\hline CHEMBL1352405 & 688341 & 5.2 & 4.8203 & TRN & \\
\hline CHEMBL1300946 & 688341 & 5.2 & 5.0737 & TST & \\
\hline CHEMBL1462234 & 688341 & 4.6 & 4.83899 & 99999999995 & TRN \\
\hline CHEMBL157427 & 688341 & 4.8 & 5.1646 & TST & \\
\hline CHEMBL1388759 & 688341 & 4.6 & 4.8936 & TRN & \\
\hline CHEMBL1439429 & 688341 & 4.4 & 4.9978 & TRN & \\
\hline CHEMBL1539080 & 688341 & 5.9 & 5.0277 & TST & \\
\hline CHEMBL1557369 & 688341 & 4.4 & 4.9491 & TRN & \\
\hline CHEMBL408653 & 688341 & 4.5 & 4.8555 & TRN & \\
\hline CHEMBL1371711 & 688341 & 5.8 & 4.9809 & TRN & \\
\hline CHEMBL1353297 & 688341 & 4.7 & 4.8358 & TST & \\
\hline CHEMBL1458777 & 688341 & 4.6 & 5.1067 & TRN & \\
\hline
\end{tabular}




\begin{tabular}{|c|c|c|c|c|}
\hline & & & IETIS & \\
\hline CHEMBL1563779 & 688341 & 4.8 & 4.9331 & TRN \\
\hline CHEMBL 289233 & 688341 & 6.1 & 5.14 & TRN \\
\hline CHEMBL1557211 & 688341 & 4.4 & 4.7787 & TRN \\
\hline CHEMBL1305209 & 688341 & 5.4 & 5.0346 & TRN \\
\hline CHEMBL1535147 & 688341 & 4.5 & 4.7631 & TRN \\
\hline CHEMBL1534361 & 688341 & 6.0 & 4.9928 & TRN \\
\hline CHEMBL1495172 & 688341 & 4.5 & 4.7762 & TRN \\
\hline CHEMBL1492779 & 688341 & 4.4 & 5.1272 & TRN \\
\hline CHEMBL1504007 & 688341 & 4.6 & 4.9195 & TRN \\
\hline CHEMBL1510421 & 688341 & 5.6 & 4.7547 & TRN \\
\hline CHEMBL1302088 & 688341 & 5.2 & 5.0724 & TRN \\
\hline CHEMBL1524954 & 688341 & 4.8 & 5.1406 & TRN \\
\hline CHEMBL1484572 & 688341 & 4.5 & 5.058 & TST \\
\hline CHEMBL1380395 & 688341 & 5.0 & 5.0155 & TRN \\
\hline CHEMBL1385148 & 688341 & 4.4 & 4.8242 & TRN \\
\hline CHEMBL1354408 & 688341 & 5.0 & 4.9365 & TRN \\
\hline CHEMBL1479088 & 688341 & 5.8 & 5.2281 & TRN \\
\hline CHEMBL1443198 & 688341 & 6.8 & 4.8686 & TRN \\
\hline CHEMBL1587585 & 688341 & 4.4 & 4.9609 & TRN \\
\hline CHEMBL1594329 & 688341 & 5.5 & 5.1116 & TRN \\
\hline CHEMBL1399466 & 688341 & 4.7 & 4.822 & TRN \\
\hline CHEMBL1374550 & 688341 & 4.5 & 5.0621 & TRN \\
\hline CHEMBL1574931 & 688341 & 4.7 & 5.0048 & TST \\
\hline CHEMBL1502260 & 688341 & 4.4 & 4.8416 & TRN \\
\hline CHEMBL1555389 & 688341 & 4.8 & 4.7867 & TRN \\
\hline CHEMBL 259849 & 688341 & 4.4 & 4.975 & TRN \\
\hline CHEMBL1428944 & 688341 & 4.6 & 4.9842 & TRN \\
\hline CHEMBL1338601 & 688341 & 4.5 & 5.2397 & TST \\
\hline CHEMBL1389608 & 688341 & 4.5 & 4.8268 & TRN \\
\hline CHEMBL1541166 & 688341 & 4.9 & 4.9993 & TST \\
\hline CHEMBL1535468 & 688341 & 4.5 & 4.8959 & TRN \\
\hline CHEMBL1517197 & 688341 & 6.4 & 4.88 & TRN \\
\hline CHEMBL1504386 & 688341 & 4.8 & 4.8665 & TRN \\
\hline CHEMBL1530586 & 688341 & 4.4 & 4.8443 & TST \\
\hline CHEMBL1419767 & 688341 & 5.1 & 5.0012 & TRN \\
\hline CHEMBL1599850 & 688341 & 4.8 & 4.7689 & TST \\
\hline CHEMBL1451739 & 688341 & 8.0 & 5.1315 & TST \\
\hline CHEMBL1533155 & 688341 & 4.6 & 4.7126 & TRN \\
\hline CHEMBL1558361 & 688341 & 4.5 & 4.9078 & TRN \\
\hline CHEMBL1453144 & 688341 & 5.4 & 5.0656 & TRN \\
\hline CHEMBL1359009 & 688341 & 4.8 & 4.811 & TRN \\
\hline CHEMBL538595 & 688341 & 4.4 & 5.1558 & TRN \\
\hline CHEMBL1393514 & 688341 & 5.3 & 4.8127 & TST \\
\hline CHEMBL1519116 & 688341 & 5.1 & 4.7349 & TRN \\
\hline CHEMBL1467595 & 688341 & 4.4 & 4.8559 & TRN \\
\hline CHEMBL1544612 & 688341 & 4.8 & 4.8458 & TRN \\
\hline CHEMBL1431956 & 688341 & 4.5 & 4.8459 & TRN \\
\hline CHEMBL618 & 688341 & 4.4 & 4.9566 & TRN \\
\hline
\end{tabular}




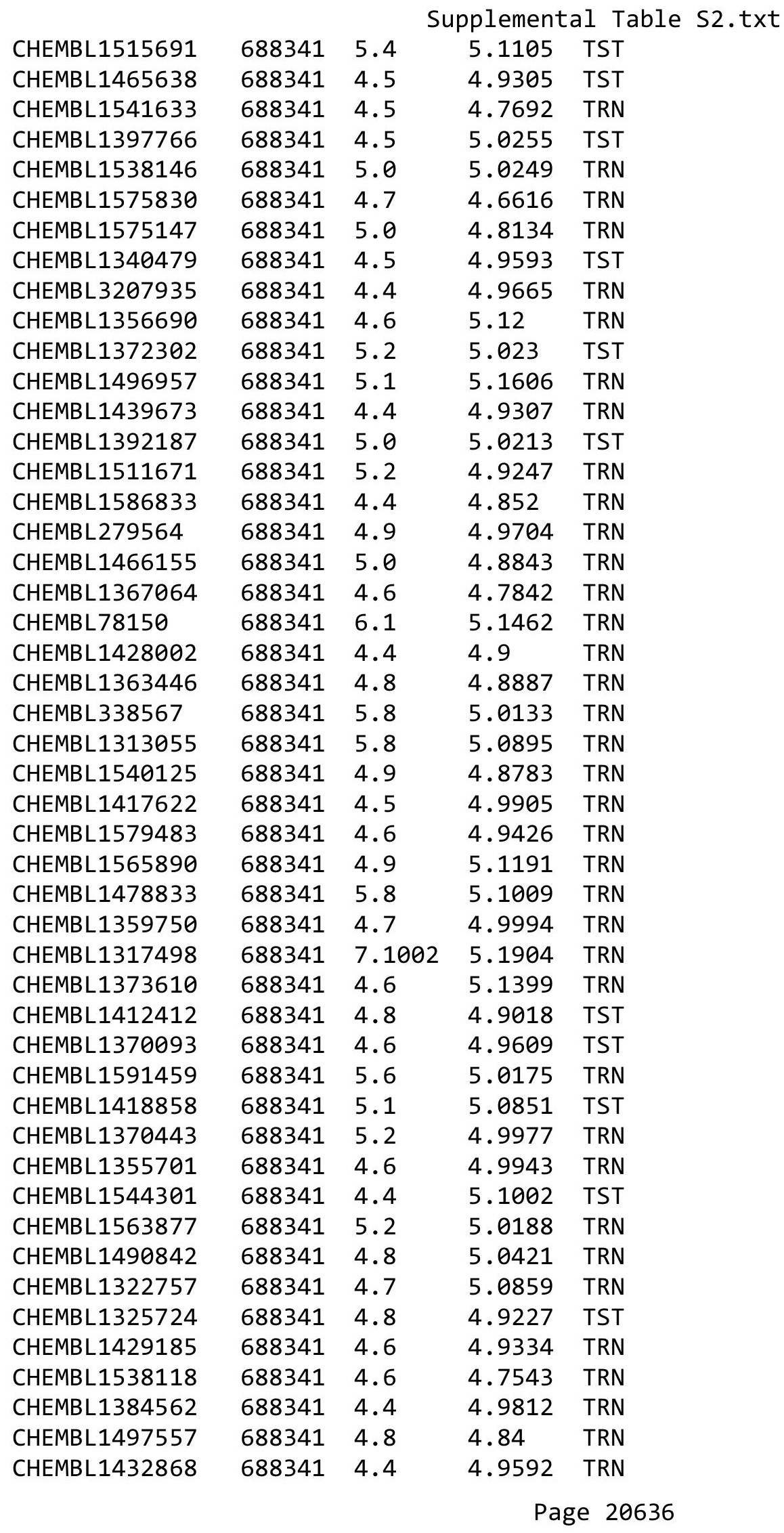




\begin{tabular}{|c|c|c|c|c|}
\hline \multicolumn{5}{|c|}{ Supplemental Table s2.txt } \\
\hline CHEMBL1528060 & 688341 & 4.4 & 5.0796 & TRN \\
\hline CHEMBL1485686 & 688341 & 5.1 & 5.239 & TRN \\
\hline CHEMBL1256693 & 688341 & 5.2 & 5.1627 & TST \\
\hline CHEMBL145725 & 688341 & 5.0 & 5.0551 & TST \\
\hline CHEMBL1527567 & 688341 & 7.2 & 5.1222 & TRN \\
\hline CHEMBL382541 & 688341 & 7.5003 & 4.8759 & TRN \\
\hline CHEMBL1335077 & 688341 & 5.3 & 4.9502 & TRN \\
\hline CHEMBL1548592 & 688341 & 4.4 & 5.189 & TRN \\
\hline CHEMBL1449457 & 688341 & 5.4 & 5.15600 & 0000000001 \\
\hline CHEMBL1610522 & 688341 & 4.4 & 5.1144 & TST \\
\hline CHEMBL1561370 & 688341 & 5.2 & 5.0028 & TST \\
\hline CHEMBL1508336 & 688341 & 5.5 & 5.0095 & TRN \\
\hline CHEMBL1487686 & 688341 & 4.7 & 4.7715 & TRN \\
\hline CHEMBL1406267 & 688341 & 4.8 & 4.8874 & TRN \\
\hline CHEMBL1371724 & 688341 & 5.8 & 4.9639 & TRN \\
\hline CHEMBL1336216 & 688341 & 4.5 & 4.8708 & TRN \\
\hline CHEMBL1342671 & 688341 & 4.4 & 5.032 & TST \\
\hline CHEMBL1306907 & 688341 & 4.4 & 5.0493 & TST \\
\hline CHEMBL1606549 & 688341 & 4.6 & 4.8358 & TRN \\
\hline CHEMBL1538593 & 688341 & 4.9 & 5.0515 & TST \\
\hline CHEMBL1567815 & 688341 & 4.5 & 4.817 & TST \\
\hline CHEMBL1440784 & 688341 & 4.4 & 5.0053 & TRN \\
\hline CHEMBL1605192 & 688341 & 5.0 & 4.9085 & TST \\
\hline CHEMBL1557377 & 688341 & 4.5 & 4.9806 & TRN \\
\hline CHEMBL1485781 & 688341 & 4.8 & 4.8196 & TRN \\
\hline CHEMBL1424106 & 688341 & 5.0 & 5.0505 & TRN \\
\hline CHEMBL1413056 & 688341 & 5.0 & 4.7649 & TRN \\
\hline CHEMBL1483992 & 688341 & 4.5 & 4.815 & TRN \\
\hline CHEMBL1333515 & 688341 & 4.5 & 4.8649 & TRN \\
\hline CHEMBL1597410 & 688341 & 4.8 & 5.26 & TRN \\
\hline CHEMBL1391424 & 688341 & 4.5 & 4.9495 & TST \\
\hline CHEMBL1370189 & 688341 & 4.7 & 4.9014 & TRN \\
\hline CHEMBL1471112 & 688341 & 4.6 & 5.1334 & TRN \\
\hline CHEMBL1417374 & 688341 & 4.8 & 4.9203 & TRN \\
\hline CHEMBL1547253 & 688341 & 4.7 & 4.9724 & TRN \\
\hline CHEMBL1462396 & 688341 & 5.7 & 5.0868 & TRN \\
\hline CHEMBL82949 & 688341 & 4.6 & 4.9605 & TRN \\
\hline CHEMBL1490863 & 688341 & 5.2 & 5.0441 & TRN \\
\hline CHEMBL1515975 & 688341 & 4.7 & 4.977 & TRN \\
\hline CHEMBL1334106 & 688341 & 5.2 & 5.0412 & TRN \\
\hline CHEMBL1549400 & 688341 & 5.2 & 5.0663 & TST \\
\hline CHEMBL1612145 & 688341 & 5.0 & 4.8425 & TRN \\
\hline CHEMBL1499165 & 688341 & 4.6 & 4.8778 & TRN \\
\hline CHEMBL1545068 & 688341 & 4.7 & 4.9154 & TRN \\
\hline CHEMBL1583268 & 688341 & 4.8 & 4.9168 & TRN \\
\hline CHEMBL1380671 & 688341 & 4.4 & 4.9958 & TRN \\
\hline CHEMBL1412569 & 688341 & 4.4 & 4.7415 & TRN \\
\hline CHEMBL1320287 & 688341 & 5.2 & 4.9433 & TRN \\
\hline
\end{tabular}




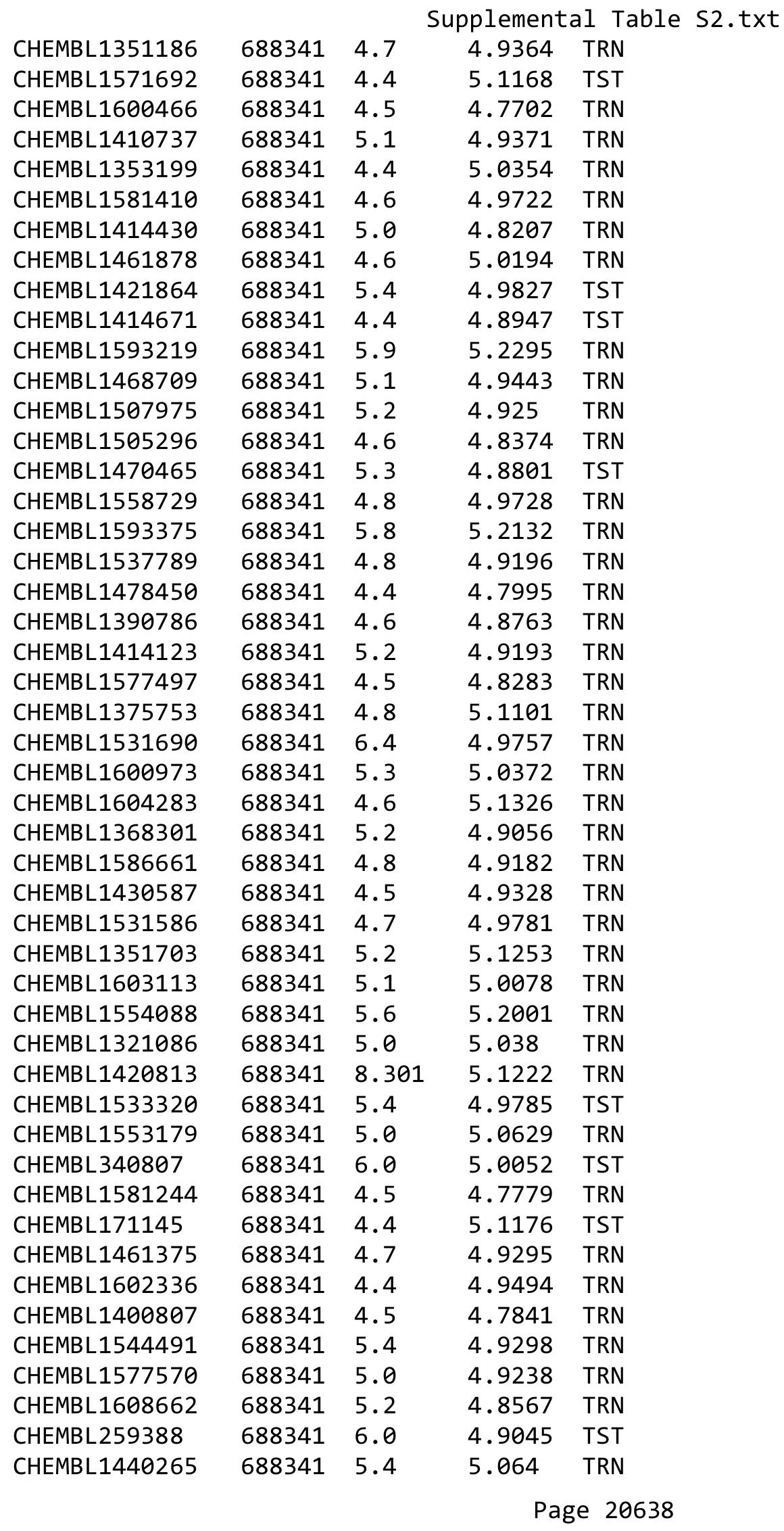




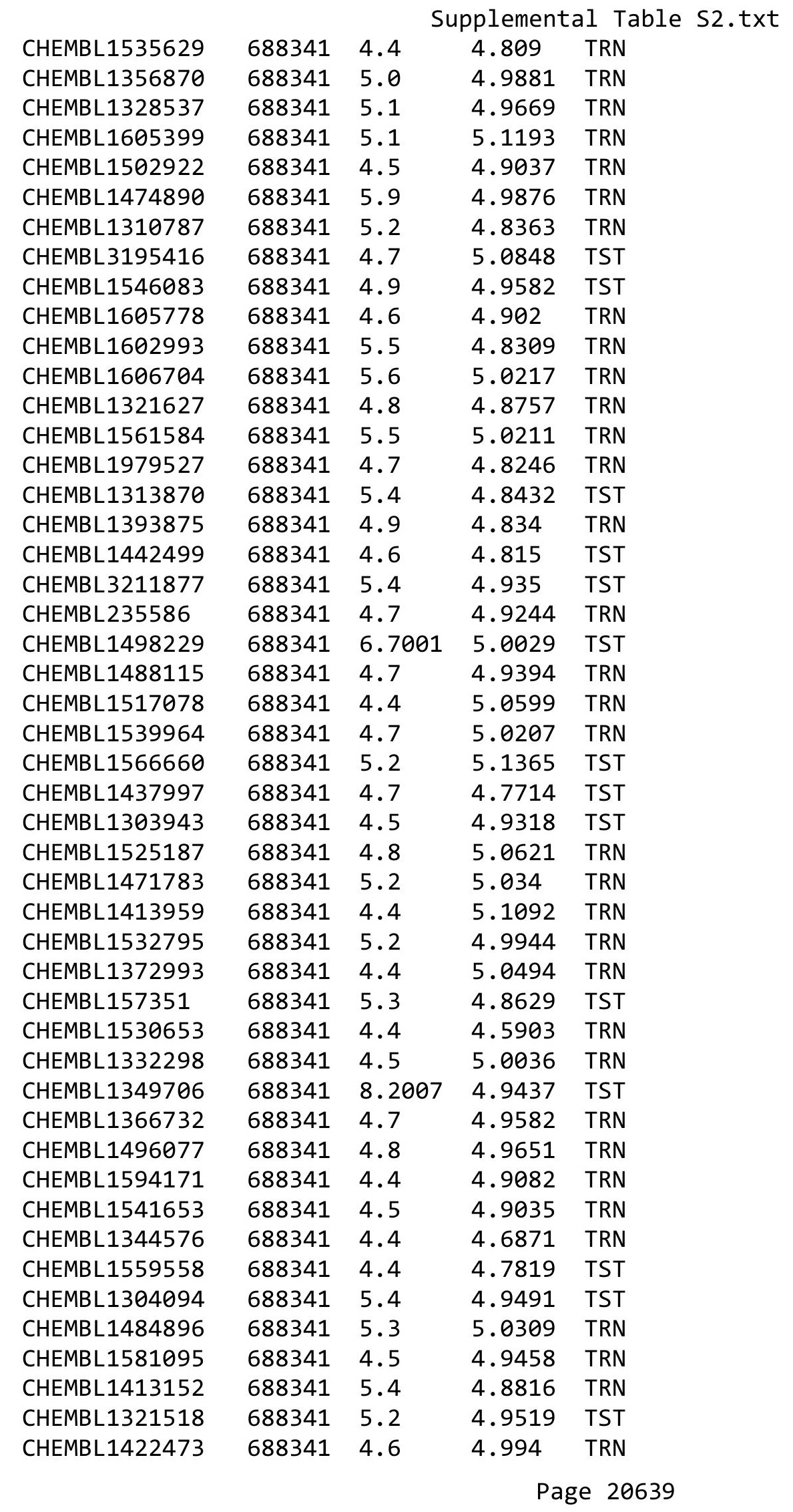




\begin{tabular}{|c|c|c|c|c|c|}
\hline CHEMBL1305990 & 688341 & 6.0 & 4.7855 & TRN & \\
\hline CHEMBL 258860 & 688341 & 4.6 & 5.0976 & TRN & \\
\hline CHEMBL1362219 & 688341 & 4.7 & 4.8627 & TRN & \\
\hline CHEMBL1582382 & 688341 & 5.1 & 4.9525 & TRN & \\
\hline CHEMBL1489568 & 688341 & 4.8 & 4.95100 & 00000000005 & TRN \\
\hline CHEMBL1595629 & 688341 & 4.6 & 4.9441 & TRN & \\
\hline CHEMBL1493096 & 688341 & 4.7 & 4.9606 & TRN & \\
\hline CHEMBL1488990 & 688341 & 4.6 & 5.0397 & TRN & \\
\hline CHEMBL1612347 & 688341 & 4.6 & 5.0374 & TRN & \\
\hline CHEMBL1533655 & 688341 & 4.6 & 4.7491 & TRN & \\
\hline CHEMBL1607565 & 688341 & 4.7 & 4.9332 & TRN & \\
\hline CHEMBL1596252 & 688341 & 4.4 & 5.0785 & TST & \\
\hline CHEMBL1360632 & 688341 & 4.7 & 4.8538 & TRN & \\
\hline CHEMBL1557696 & 688341 & 5.2 & 5.0615 & TRN & \\
\hline CHEMBL1407576 & 688341 & 6.1 & 5.232 & TST & \\
\hline CHEMBL1377714 & 688341 & 4.6 & 4.8388 & TRN & \\
\hline CHEMBL1320838 & 688341 & 4.6 & 4.9032 & TST & \\
\hline CHEMBL259358 & 688341 & 4.7 & 4.998 & TRN & \\
\hline CHEMBL1307208 & 688341 & 5.4 & 4.9733 & TRN & \\
\hline CHEMBL1433464 & 688341 & 5.6 & 4.888 & TRN & \\
\hline CHEMBL1336011 & 688341 & 4.5 & 4.9774 & TRN & \\
\hline CHEMBL1432647 & 688341 & 5.3 & 5.1481 & TRN & \\
\hline CHEMBL1425567 & 688341 & 4.7 & 4.8195 & TST & \\
\hline CHEMBL1404511 & 688341 & 4.6 & 4.9022 & TRN & \\
\hline CHEMBL1589670 & 688341 & 4.8 & 4.7216 & TRN & \\
\hline CHEMBL1448750 & 688341 & 5.2 & 4.8484 & TRN & \\
\hline CHEMBL142630 & 688341 & 4.9 & 4.989 & TRN & \\
\hline CHEMBL63154 & 688341 & 5.0 & 5.0196 & TST & \\
\hline CHEMBL1341760 & 688341 & 5.0 & 4.982 & TST & \\
\hline CHEMBL1593335 & 688341 & 4.8 & 5.0077 & TRN & \\
\hline CHEMBL1513614 & 688341 & 4.6 & 4.9718 & TRN & \\
\hline CHEMBL1509527 & 688341 & 6.1 & 4.9492 & TRN & \\
\hline CHEMBL1361725 & 688341 & 4.9 & 5.0236 & TRN & \\
\hline CHEMBL1336256 & 688341 & 4.5 & 4.9039 & TRN & \\
\hline CHEMBL1327614 & 688341 & 5.4 & 4.8699 & TRN & \\
\hline CHEMBL1401214 & 688341 & 4.8 & 5.1782 & TRN & \\
\hline CHEMBL1594502 & 688341 & 5.2 & 5.007 & TRN & \\
\hline CHEMBL1349063 & 688341 & 4.7 & 4.8835 & TRN & \\
\hline CHEMBL1537239 & 688341 & 5.9 & 4.7958 & TRN & \\
\hline CHEMBL1528639 & 688341 & 4.6 & 4.952 & TST & \\
\hline CHEMBL1305869 & 688341 & 4.8 & 4.9841 & TRN & \\
\hline CHEMBL1585499 & 688341 & 4.8 & 4.9999 & TRN & \\
\hline CHEMBL1587757 & 688341 & 4.6 & 4.9435 & TST & \\
\hline CHEMBL1543453 & 688341 & 4.8 & 4.868 & TRN & \\
\hline CHEMBL1537982 & 688341 & 5.2 & \multicolumn{2}{|c|}{4.928999999999999} & TRN \\
\hline CHEMBL1387744 & 688341 & 5.2 & 4.8676 & TRN & \\
\hline CHEMBL1322287 & 688341 & 5.2 & 4.8173 & TRN & \\
\hline CHEMBL1565664 & 688341 & 4.6 & 4.9863 & TRN & \\
\hline
\end{tabular}




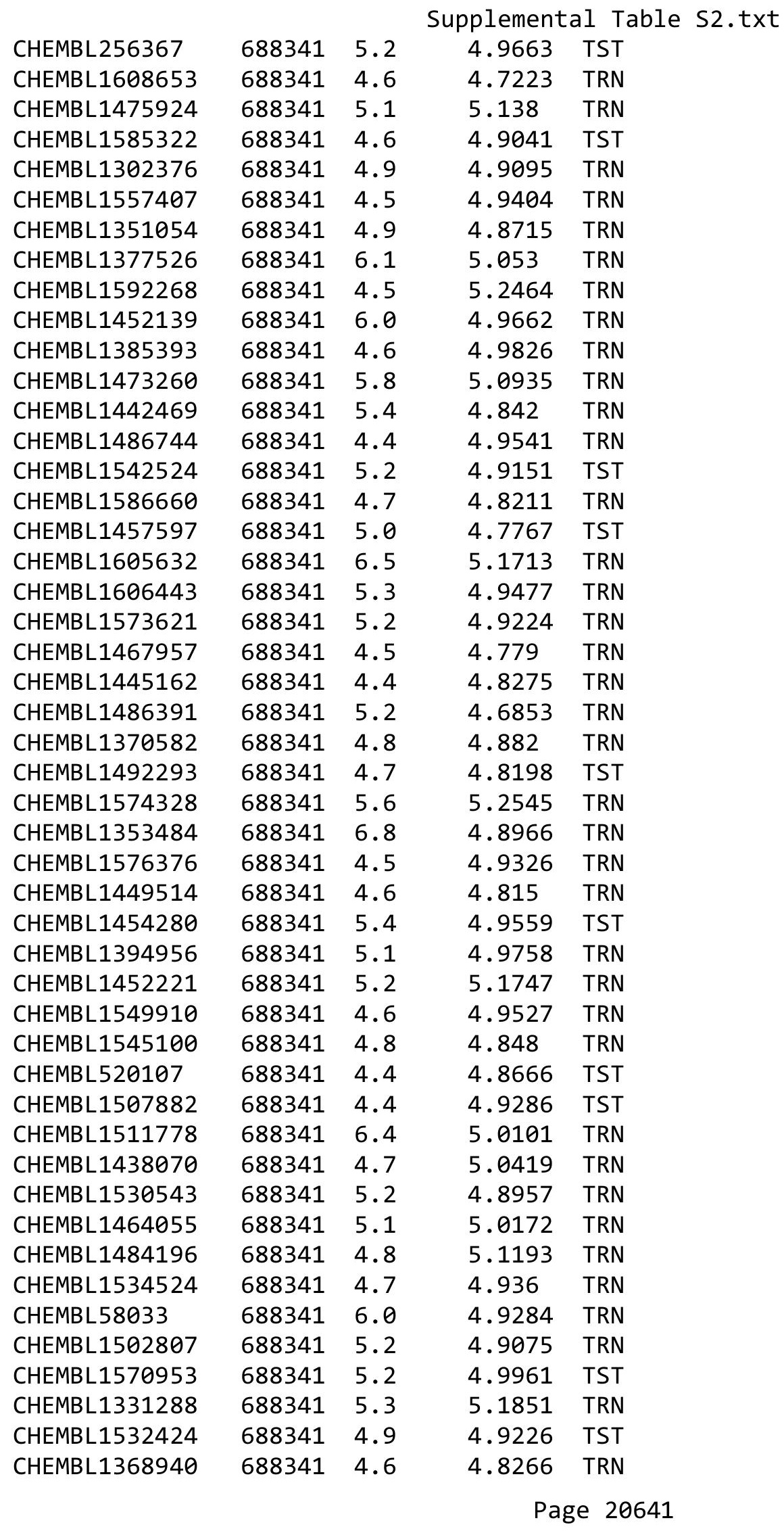




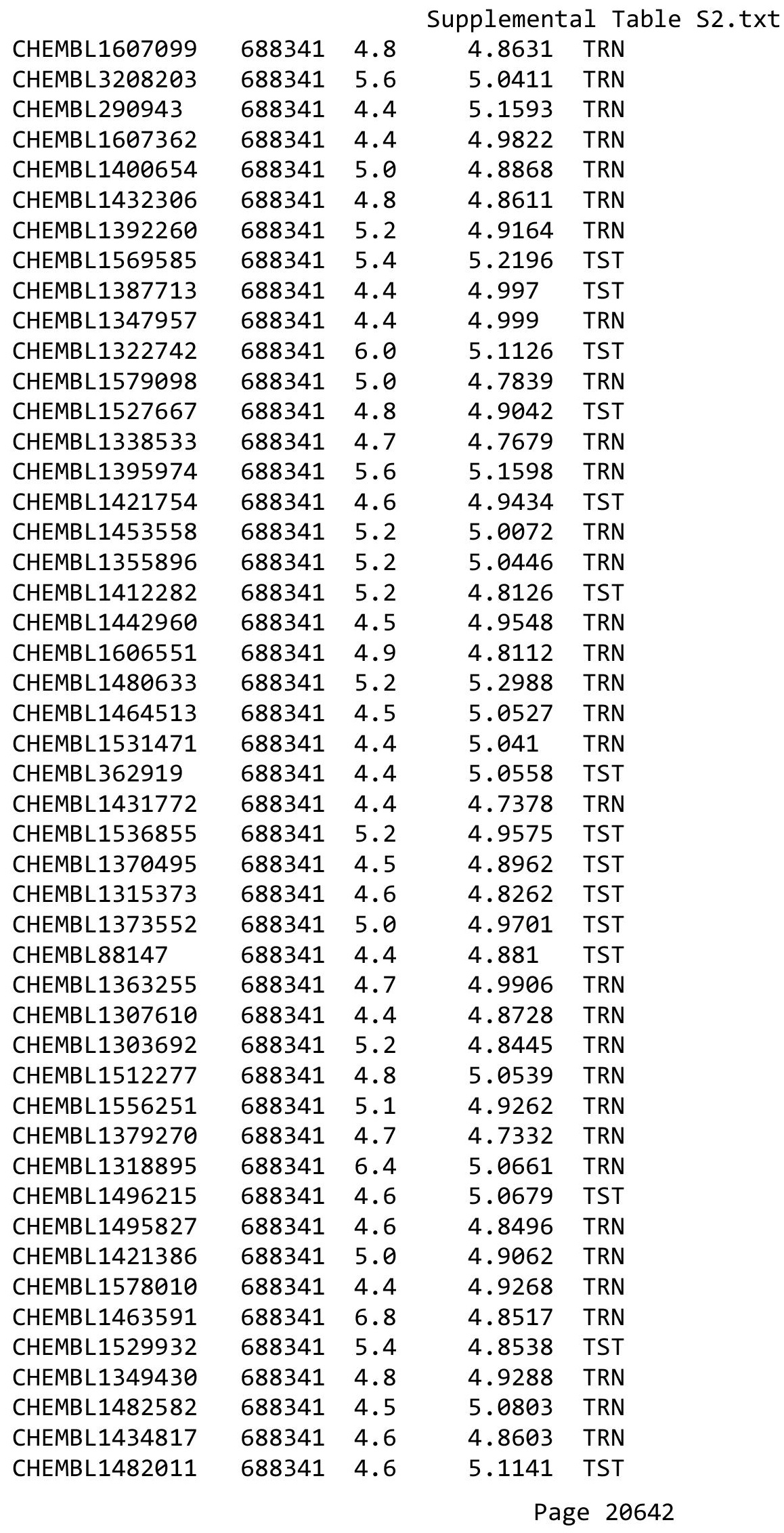




\begin{tabular}{|c|c|c|c|c|c|}
\hline \multirow{2}{*}{ CHEMBL1357016 } & \multirow[b]{2}{*}{688341} & \\
\hline & & 6.1 & 4.9318 & TRN & \\
\hline CHEMBL1443317 & 688341 & 4.6 & 4.8504 & TRN & \\
\hline CHEMBL1544119 & 688341 & 4.9 & 4.7352 & TRN & \\
\hline CHEMBL1528416 & 688341 & 4.5 & 4.8479 & TRN & \\
\hline CHEMBL1410508 & 688341 & 4.5 & 4.8539 & TRN & \\
\hline CHEMBL1520318 & 688341 & 5.7 & 4.8604 & TRN & \\
\hline CHEMBL1342845 & 688341 & 5.3 & 4.8969 & TRN & \\
\hline CHEMBL1497046 & 688341 & 5.2 & 5.0192 & TRN & \\
\hline CHEMBL1360891 & 688341 & 5.2 & 4.905 & TRN & \\
\hline CHEMBL1448538 & 688341 & 4.7 & 4.8029 & TRN & \\
\hline CHEMBL1411424 & 688341 & 4.4 & 5.1609 & TRN & \\
\hline CHEMBL1495025 & 688341 & 4.8 & \multicolumn{2}{|c|}{4.861000000000001} & TST \\
\hline CHEMBL1532206 & 688341 & 4.6 & 4.879 & TRN & \\
\hline CHEMBL1346330 & 688341 & 4.5 & 4.8944 & TST & \\
\hline CHEMBL1392604 & 688341 & 5.4 & 4.9925 & TST & \\
\hline CHEMBL1493859 & 688341 & 4.6 & 5.0173 & TRN & \\
\hline CHEMBL1493896 & 688341 & 5.2 & 4.7908 & TRN & \\
\hline CHEMBL1489774 & 688341 & 4.4 & 4.9541 & TRN & \\
\hline CHEMBL1311692 & 688341 & 4.9 & 4.9589 & TRN & \\
\hline CHEMBL1372547 & 688341 & 4.7 & 4.9001 & TRN & \\
\hline CHEMBL1576658 & 688341 & 4.5 & 5.0462 & TST & \\
\hline CHEMBL1452934 & 688341 & 4.8 & 4.8774 & TRN & \\
\hline CHEMBL271624 & 688341 & 4.6 & 4.8454 & TRN & \\
\hline CHEMBL1409985 & 688341 & 4.9 & 5.1242 & TST & \\
\hline CHEMBL 1371710 & 688341 & 6.1 & 5.1196 & TRN & \\
\hline CHEMBL1372584 & 688341 & 4.8 & 4.9946 & TRN & \\
\hline CHEMBL1483233 & 688341 & 4.6 & 4.9031 & TRN & \\
\hline CHEMBL1560193 & 688341 & 5.9 & 4.9784 & TRN & \\
\hline CHEMBL1351991 & 688341 & 5.3 & 4.8184 & TRN & \\
\hline CHEMBL1559924 & 688341 & 5.2 & 4.9624 & TRN & \\
\hline CHEMBL1484000 & 688341 & 4.4 & 4.7959 & TRN & \\
\hline CHEMBL1488200 & 688341 & 4.6 & 4.8602 & TRN & \\
\hline CHEMBL1368934 & 688341 & 4.5 & 5.0191 & TRN & \\
\hline CHEMBL1468300 & 688341 & 5.2 & 4.9216 & TRN & \\
\hline CHEMBL491578 & 688341 & 4.5 & 5.0952 & TRN & \\
\hline CHEMBL1407869 & 688341 & 4.9 & 5.0191 & TRN & \\
\hline CHEMBL1480417 & 688341 & 4.8 & 4.8592 & TRN & \\
\hline CHEMBL1541506 & 688341 & 4.4 & 5.05699 & 99999999995 & TST \\
\hline CHEMBL1595282 & 688341 & 5.4 & 5.0784 & TRN & \\
\hline CHEMBL1581719 & 688341 & 4.5 & 4.8419 & TRN & \\
\hline CHEMBL1471921 & 688341 & 5.0 & 5.0177 & TRN & \\
\hline CHEMBL1609357 & 688341 & 5.1 & 4.9675 & TRN & \\
\hline CHEMBL1509066 & 688341 & 4.6 & 4.9756 & TRN & \\
\hline CHEMBL1307028 & 688341 & 4.5 & 4.8891 & TRN & \\
\hline CHEMBL1509562 & 688341 & 4.5 & 4.7383 & TRN & \\
\hline CHEMBL1387442 & 688341 & 4.5 & 4.9194 & TRN & \\
\hline CHEMBL1452812 & 688341 & 5.8 & 4.9012 & TRN & \\
\hline \multirow[t]{2}{*}{ CHEMBL1578323 } & 688341 & 5.2 & 4.9305 & TRN & \\
\hline & & \multicolumn{4}{|c|}{ Page 20643} \\
\hline
\end{tabular}




\begin{tabular}{|c|c|c|c|c|}
\hline \multicolumn{5}{|c|}{ Supplemental Tab } \\
\hline CHEMBL1437064 & 688341 & 5.4 & 4.8952 & TRN \\
\hline CHEMBL1488583 & 688341 & 4.4 & 4.7453 & TST \\
\hline CHEMBL1524127 & 688341 & 5.3 & 4.8227 & TRN \\
\hline CHEMBL1346709 & 688341 & 4.4 & 4.922 & TRN \\
\hline CHEMBL1304477 & 688341 & 4.6 & 4.9869 & TRN \\
\hline CHEMBL1589639 & 688341 & 5.4 & 4.8289 & TST \\
\hline CHEMBL1446323 & 688341 & 5.3 & 5.0483 & TRN \\
\hline CHEMBL1478879 & 688341 & 6.0 & 4.8478 & TRN \\
\hline CHEMBL365739 & 688341 & 4.7 & 5.0064 & TST \\
\hline CHEMBL1369152 & 688341 & 5.0 & 4.8864 & TRN \\
\hline CHEMBL 1343722 & 688341 & 4.8 & 4.9751 & TRN \\
\hline CHEMBL1307897 & 688341 & 4.7 & 5.246 & TST \\
\hline CHEMBL1592470 & 688341 & 5.3 & 5.0403 & TRN \\
\hline CHEMBL1348248 & 688341 & 4.7 & 5.0801 & TRN \\
\hline CHEMBL1612668 & 688341 & 5.4 & 4.9966 & TRN \\
\hline CHEMBL 605747 & 688341 & 4.7 & 4.8475 & TRN \\
\hline CHEMBL1416040 & 688341 & 4.7 & 5.0049 & TRN \\
\hline CHEMBL1454735 & 688341 & 4.6 & 5.0358 & TST \\
\hline CHEMBL1548487 & 688341 & 4.4 & 4.9801 & TRN \\
\hline CHEMBL1443948 & 688341 & 4.5 & 4.9781 & TRN \\
\hline CHEMBL1365142 & 688341 & 4.4 & 4.9252 & TRN \\
\hline CHEMBL1526809 & 688341 & 5.1 & 4.7633 & TRN \\
\hline CHEMBL1580694 & 688341 & 4.7 & 4.8138 & TRN \\
\hline CHEMBL1444583 & 688341 & 4.9 & 4.9192 & TRN \\
\hline CHEMBL1429139 & 688341 & 4.5 & 5.1151 & TRN \\
\hline CHEMBL1408469 & 688341 & 6.6 & 5.0824 & TST \\
\hline CHEMBL1601591 & 688341 & 4.5 & 4.9445 & TRN \\
\hline CHEMBL1549053 & 688341 & 4.6 & 4.87 & TRN \\
\hline CHEMBL1565576 & 688341 & 4.8 & 4.7713 & TRN \\
\hline CHEMBL1505797 & 688341 & 4.4 & 4.898 & TRN \\
\hline CHEMBL1567080 & 688341 & 4.5 & 4.7161 & TRN \\
\hline CHEMBL1455570 & 688341 & 5.0 & 5.1614 & TRN \\
\hline CHEMBL1605688 & 688341 & 4.8 & 4.9211 & TRN \\
\hline CHEMBL1480952 & 688341 & 4.6 & 4.788 & TRN \\
\hline CHEMBL1550860 & 688341 & 5.0 & 4.8415 & TRN \\
\hline CHEMBL1417006 & 688341 & 5.4 & 4.9291 & TST \\
\hline CHEMBL1309269 & 688341 & 5.2 & 4.7998 & TST \\
\hline CHEMBL1559507 & 688341 & 5.3 & 4.871 & TRN \\
\hline CHEMBL1588802 & 688341 & 4.4 & 4.7936 & TRN \\
\hline CHEMBL1451594 & 688341 & 5.2 & 4.9685 & TRN \\
\hline CHEMBL1457043 & 688341 & 4.4 & 5.3305 & TRN \\
\hline CHEMBL1497427 & 688341 & 5.0 & 4.9553 & TRN \\
\hline CHEMBL1366061 & 688341 & 5.4 & 5.1752 & TRN \\
\hline CHEMBL1410995 & 688341 & 5.9 & 4.8141 & TRN \\
\hline CHEMBL1445123 & 688341 & 5.1 & 4.7644 & TRN \\
\hline CHEMBL1373561 & 688341 & 4.8 & 5.1383 & TRN \\
\hline CHEMBL1352833 & 688341 & 4.4 & 4.9189 & TRN \\
\hline CHEMBL1448520 & 688341 & 4.7 & 4.8805 & TRN \\
\hline
\end{tabular}




\begin{tabular}{|c|c|c|c|c|}
\hline & & & ient & al Ta \\
\hline CHEMBL1501813 & 688341 & 5.0 & 4.9955 & TST \\
\hline CHEMBL8918 & 688341 & 5.4 & 4.9049 & TRN \\
\hline CHEMBL1602975 & 688341 & 4.8 & 4.8731 & TRN \\
\hline CHEMBL1407298 & 688341 & 4.6 & 4.8234 & TRN \\
\hline CHEMBL1460497 & 688341 & 4.5 & 4.8711 & TRN \\
\hline CHEMBL1330587 & 688341 & 5.4 & 5.1173 & TRN \\
\hline CHEMBL1317921 & 688341 & 5.1 & 5.1047 & TST \\
\hline CHEMBL1479046 & 688341 & 5.2 & 4.8961 & TRN \\
\hline CHEMBL1455586 & 688341 & 5.1 & 4.8826 & TRN \\
\hline CHEMBL1598747 & 688341 & 4.8 & 4.8259 & TRN \\
\hline CHEMBL1594372 & 688341 & 5.0 & 5.1277 & TRN \\
\hline CHEMBL1478761 & 688341 & 5.2 & 4.9431 & TRN \\
\hline CHEMBL1322883 & 688341 & 4.6 & 4.9433 & TRN \\
\hline CHEMBL1302365 & 688341 & 4.6 & 5.0939 & TST \\
\hline CHEMBL1580759 & 688341 & 4.8 & 5.0612 & TST \\
\hline CHEMBL1515305 & 688341 & 4.8 & 5.1046 & TRN \\
\hline CHEMBL1441415 & 688341 & 4.5 & 4.9511 & TRN \\
\hline CHEMBL1346165 & 688341 & 5.2 & 4.9251 & TRN \\
\hline CHEMBL3436365 & 688341 & 4.8 & 5.1581 & TST \\
\hline CHEMBL1345903 & 688341 & 5.3 & 4.8416 & TRN \\
\hline CHEMBL1352398 & 688341 & 4.7 & 4.8357 & TRN \\
\hline CHEMBL1461192 & 688341 & 4.6 & 4.7518 & TRN \\
\hline CHEMBL1404394 & 688341 & 4.5 & 5.0215 & TST \\
\hline CHEMBL1338900 & 688341 & 6.1 & 5.0702 & TST \\
\hline CHEMBL1572253 & 688341 & 4.4 & 4.9424 & TRN \\
\hline CHEMBL1572007 & 688341 & 4.5 & 4.9508 & TST \\
\hline CHEMBL1403786 & 688341 & 4.6 & 5.1727 & TST \\
\hline CHEMBL1485770 & 688341 & 5.0 & 4.8321 & TRN \\
\hline CHEMBL1606245 & 688341 & 5.2 & 5.0559 & TST \\
\hline CHEMBL609030 & 688341 & 4.6 & 5.0878 & TST \\
\hline CHEMBL1380191 & 688341 & 4.4 & 4.8705 & TRN \\
\hline CHEMBL1375205 & 688341 & 4.6 & 4.937 & TRN \\
\hline CHEMBL1457928 & 688341 & 5.9 & 5.1303 & TST \\
\hline CHEMBL1440508 & 688341 & 5.6 & 4.7442 & TRN \\
\hline CHEMBL1489351 & 688341 & 4.4 & 4.9447 & TRN \\
\hline CHEMBL1482744 & 688341 & 4.4 & 5.0063 & TRN \\
\hline CHEMBL1606249 & 688341 & 4.7 & 4.9735 & TST \\
\hline CHEMBL1390465 & 688341 & 4.5 & 4.7878 & TRN \\
\hline CHEMBL1346609 & 688341 & 4.6 & 4.9044 & TRN \\
\hline CHEMBL1563998 & 688341 & 5.3 & 4.8885 & TRN \\
\hline CHEMBL1305671 & 688341 & 4.6 & 4.8333 & TRN \\
\hline CHEMBL1566336 & 688341 & 4.6 & 4.8006 & TRN \\
\hline CHEMBL1514634 & 688341 & 5.0 & 5.1801 & TST \\
\hline CHEMBL1571573 & 688341 & 4.4 & 4.7746 & TRN \\
\hline CHEMBL611207 & 688341 & 5.3 & 4.9151 & TST \\
\hline CHEMBL1256191 & 688341 & 4.5 & 5.0867 & TST \\
\hline CHEMBL1517264 & 688341 & 4.4 & 4.9273 & TRN \\
\hline CHEMBL1344249 & 688341 & 4.4 & 4.753 & TRN \\
\hline
\end{tabular}




\begin{tabular}{|c|c|c|c|c|c|}
\hline \multicolumn{6}{|c|}{ Supplemental Table S2.txt } \\
\hline CHEMBL1411270 & 688341 & 4.8 & 4.96 & TRN & \\
\hline CHEMBL1566704 & 688341 & 4.6 & 4.8093 & TRN & \\
\hline CHEMBL1404169 & 688341 & 4.4 & 5.0364 & TST & \\
\hline CHEMBL1317056 & 688341 & 5.3 & 5.1117 & TRN & \\
\hline CHEMBL1352121 & 688341 & 4.4 & 4.8807 & TRN & \\
\hline CHEMBL1360650 & 688341 & 4.8 & 5.1819 & TRN & \\
\hline CHEMBL1505947 & 688341 & 4.6 & 4.7994 & TRN & \\
\hline CHEMBL1442106 & 688341 & 5.8 & 5.1406 & TRN & \\
\hline CHEMBL1390658 & 688341 & 4.7 & 4.8517 & TRN & \\
\hline CHEMBL1560871 & 688341 & 4.8 & 4.9025 & TRN & \\
\hline CHEMBL1346739 & 688341 & 5.1 & 4.9017 & TST & \\
\hline CHEMBL1556888 & 688341 & 4.6 & 4.8032 & TRN & \\
\hline CHEMBL1403333 & 688341 & 4.7 & 4.9508 & TRN & \\
\hline CHEMBL1464550 & 688341 & 4.6 & 4.916 & TRN & \\
\hline CHEMBL1423482 & 688341 & 4.5 & 4.8917 & TST & \\
\hline CHEMBL1305086 & 688341 & 5.5 & 4.9121 & TRN & \\
\hline CHEMBL1471008 & 688341 & 4.4 & 4.8679 & TST & \\
\hline CHEMBL1358955 & 688341 & 5.1 & 4.9076 & TRN & \\
\hline CHEMBL1338241 & 688341 & 5.2 & 4.9355 & TRN & \\
\hline CHEMBL1595916 & 688341 & 7.4001 & 4.9769 & TRN & \\
\hline CHEMBL1419530 & 688341 & 4.9 & 4.9013 & TRN & \\
\hline CHEMBL1519955 & 688341 & 4.7 & 4.9366 & TRN & \\
\hline CHEMBL1495071 & 688341 & 4.4 & 5.0029 & TST & \\
\hline CHEMBL1367702 & 688341 & 4.6 & 4.9298 & TRN & \\
\hline CHEMBL1357812 & 688341 & 5.4 & 4.9417 & TRN & \\
\hline CHEMBL1330712 & 688341 & 4.6 & 5.0233 & TST & \\
\hline CHEMBL1523614 & 688341 & 4.5 & 4.8961 & TRN & \\
\hline CHEMBL1488720 & 688341 & 4.4 & $4.8580 €$ & 00000000005 & TRN \\
\hline CHEMBL1592160 & 688341 & 4.5 & 5.0748 & TRN & \\
\hline CHEMBL1362562 & 688341 & 5.4 & 5.0731 & TST & \\
\hline CHEMBL1377250 & 688341 & 4.8 & 4.7322 & TRN & \\
\hline CHEMBL1528265 & 688341 & 4.6 & 5.0688 & TRN & \\
\hline CHEMBL1510100 & 688341 & 4.6 & 4.8738 & TRN & \\
\hline CHEMBL1478904 & 688341 & 4.6 & 4.8901 & TRN & \\
\hline CHEMBL1571264 & 688341 & 5.9 & 5.0003 & TRN & \\
\hline CHEMBL1362994 & 688341 & 5.1 & 4.8056 & TST & \\
\hline CHEMBL1444534 & 688341 & 4.8 & 4.8488 & TRN & \\
\hline CHEMBL1411094 & 688341 & 6.2 & 5.1486 & TRN & \\
\hline CHEMBL1317041 & 688341 & 5.3 & 4.9703 & TRN & \\
\hline CHEMBL1563352 & 688341 & 4.4 & 5.1785 & TRN & \\
\hline CHEMBL1586442 & 688341 & 4.4 & 4.7153 & TRN & \\
\hline CHEMBL1609391 & 688341 & 4.8 & 4.8189 & TRN & \\
\hline CHEMBL1554745 & 688341 & 5.5 & 5.0038 & TRN & \\
\hline CHEMBL1399619 & 688341 & 5.8 & 4.8544 & TST & \\
\hline CHEMBL1441920 & 688341 & 6.0 & 5.0787 & TST & \\
\hline CHEMBL1318963 & 688341 & 4.6 & 4.6355 & TRN & \\
\hline CHEMBL1524355 & 688341 & 4.7 & 4.9138 & TRN & \\
\hline CHEMBL1609915 & 688341 & 4.9 & 5.0839 & TST & \\
\hline
\end{tabular}




\begin{tabular}{|c|c|c|c|c|c|}
\hline \multicolumn{6}{|c|}{ Supplemental Table S2.txt } \\
\hline CHEMBL1451720 & 688341 & 4.5 & 5.0622 & TRN & \\
\hline CHEMBL1421763 & 688341 & 4.7 & 4.9167 & TRN & \\
\hline CHEMBL1598424 & 688341 & 4.9 & 5.002 & TRN & \\
\hline CHEMBL1450744 & 688341 & 4.8 & 4.8654 & TRN & \\
\hline CHEMBL1515287 & 688341 & 5.2 & 5.1656 & TRN & \\
\hline CHEMBL1313479 & 688341 & 5.2 & 5.041 & TRN & \\
\hline CHEMBL1602407 & 688341 & 4.6 & 4.952 & TRN & \\
\hline CHEMBL1488689 & 688341 & 5.2 & 4.9208 & TRN & \\
\hline CHEMBL1561170 & 688341 & 4.8 & 4.8657 & TRN & \\
\hline CHEMBL1428838 & 688341 & 4.9 & 4.966 & TRN & \\
\hline CHEMBL1320865 & 688341 & 4.4 & 4.8817 & TRN & \\
\hline CHEMBL1605922 & 688341 & 4.6 & 4.8473 & TST & \\
\hline CHEMBL1525732 & 688341 & 4.5 & 4.9143 & TRN & \\
\hline CHEMBL1496206 & 688341 & 5.2 & 4.9602 & TRN & \\
\hline CHEMBL1462823 & 688341 & 4.5 & 4.8967 & TRN & \\
\hline CHEMBL1457788 & 688341 & 4.5 & 5.0101 & TRN & \\
\hline CHEMBL1607095 & 688341 & 4.8 & 5.1171 & TRN & \\
\hline CHEMBL1579827 & 688341 & 4.5 & 5.087 & TRN & \\
\hline CHEMBL462314 & 688341 & 4.4 & 5.1048 & TST & \\
\hline CHEMBL1446896 & 688341 & 4.5 & 4.8709 & TRN & \\
\hline CHEMBL1421762 & 688341 & 4.8 & 4.9961 & TRN & \\
\hline CHEMBL1516762 & 688341 & 5.5 & 4.8847 & TST & \\
\hline CHEMBL1471888 & 688341 & 4.4 & 4.8077 & TRN & \\
\hline CHEMBL1454751 & 688341 & 4.8 & 5.1455 & TRN & \\
\hline CHEMBL1379012 & 688341 & 5.2 & 5.0393 & TST & \\
\hline CHEMBL1526042 & 688341 & 5.2 & 4.7908 & TRN & \\
\hline CHEMBL1324667 & 688341 & 4.6 & 5.2082 & TRN & \\
\hline CHEMBL1406513 & 688341 & 4.4 & 5.0175 & TRN & \\
\hline CHEMBL1487898 & 688341 & 5.5 & 5.1143 & TRN & \\
\hline CHEMBL1591460 & 688341 & 5.1 & 4.9802 & TRN & \\
\hline CHEMBL1306711 & 688341 & 4.5 & 4.8575 & TST & \\
\hline CHEMBL1565666 & 688341 & 4.6 & 4.8852 & TRN & \\
\hline CHEMBL1602620 & 688341 & 7.8996 & 4.8849 & TRN & \\
\hline CHEMBL1381076 & 688341 & 5.5 & 4.9156 & TRN & \\
\hline CHEMBL1344791 & 688341 & 4.6 & 4.9756 & TRN & \\
\hline CHEMBL1441145 & 688341 & 4.4 & 5.05699 & 99999999995 & TST \\
\hline CHEMBL1407952 & 688341 & 4.8 & 4.9988 & TRN & \\
\hline CHEMBL1469431 & 688341 & 4.6 & 4.8182 & TRN & \\
\hline CHEMBL1528816 & 688341 & 5.2 & 5.1106 & TRN & \\
\hline CHEMBL1454922 & 688341 & 6.0 & 4.9791 & TRN & \\
\hline CHEMBL1317148 & 688341 & 5.5 & 5.2869 & TRN & \\
\hline CHEMBL1480019 & 688341 & 4.6 & 4.7668 & TRN & \\
\hline CHEMBL1509566 & 688341 & 5.4 & 4.9517 & TRN & \\
\hline CHEMBL1497278 & 688341 & 4.7 & 4.9689 & TRN & \\
\hline CHEMBL1611341 & 688341 & 4.6 & 5.0222 & TRN & \\
\hline CHEMBL1362638 & 688341 & 5.0 & 4.9042 & TRN & \\
\hline CHEMBL1304640 & 688341 & 4.4 & 4.9579 & TRN & \\
\hline CHEMBL18602 & 688341 & 4.4 & 5.2028 & TRN & \\
\hline
\end{tabular}




\begin{tabular}{|c|c|c|c|c|}
\hline & & & upplement & \\
\hline CHEMBL1308012 & 688341 & 4.5 & 5.0242 & TRN \\
\hline CHEMBL1353601 & 688341 & 4.8 & 4.9879 & TST \\
\hline CHEMBL1452923 & 688341 & 5.2 & 4.8531 & TRN \\
\hline CHEMBL1441750 & 688341 & 4.5 & 4.9407 & TRN \\
\hline CHEMBL1579942 & 688341 & 4.9 & 4.8045 & TRN \\
\hline CHEMBL1488663 & 688341 & 4.8 & 4.9485 & TRN \\
\hline CHEMBL1255583 & 688341 & 4.6 & 5.0771 & TRN \\
\hline CHEMBL1483983 & 688341 & 5.4 & 4.9782 & TRN \\
\hline CHEMBL1528006 & 688341 & 5.1 & 4.8497 & TRN \\
\hline CHEMBL114070 & 688341 & 5.2 & 5.0439 & TRN \\
\hline CHEMBL1488462 & 688341 & 5.2 & 4.9407 & TRN \\
\hline CHEMBL1575923 & 688341 & 6.0 & 4.9558 & TRN \\
\hline CHEMBL1377242 & 688341 & 4.8 & 4.8161 & TRN \\
\hline CHEMBL1332074 & 688341 & 4.4 & 5.0535 & TRN \\
\hline CHEMBL1502259 & 688341 & 4.6 & 4.8997 & TRN \\
\hline CHEMBL1484774 & 688341 & 4.5 & 5.1019 & TST \\
\hline CHEMBL1611683 & 688341 & 4.7 & 4.8193 & TRN \\
\hline CHEMBL1340054 & 688341 & 5.4 & 4.9652 & TRN \\
\hline CHEMBL1510755 & 688341 & 5.2 & 4.9191 & TRN \\
\hline CHEMBL1408183 & 688341 & 4.6 & 5.0545 & TRN \\
\hline CHEMBL1433135 & 688341 & 4.4 & 5.0073 & TRN \\
\hline CHEMBL1530577 & 688341 & 4.6 & 4.9243 & TRN \\
\hline CHEMBL1600224 & 688341 & 4.8 & 5.1097 & TST \\
\hline CHEMBL1470305 & 688341 & 4.4 & 4.9565 & TRN \\
\hline CHEMBL1480413 & 688341 & 4.4 & 5.0139 & TRN \\
\hline CHEMBL1350280 & 688341 & 4.4 & 4.9412 & TRN \\
\hline CHEMBL208484 & 688341 & 4.4 & 4.8948 & TRN \\
\hline CHEMBL1486659 & 688341 & 5.5 & 5.0044 & TST \\
\hline CHEMBL1451905 & 688341 & 6.2 & 4.9593 & TST \\
\hline CHEMBL1572056 & 688341 & 4.5 & 4.7638 & TRN \\
\hline CHEMBL1376143 & 688341 & 4.7 & 4.9206 & TRN \\
\hline CHEMBL1545058 & 688341 & 4.7 & 4.8226 & TRN \\
\hline CHEMBL1438188 & 688341 & 4.7 & 4.8338 & TRN \\
\hline CHEMBL1326826 & 688341 & 5.2 & 5.025 & TRN \\
\hline CHEMBL1594554 & 688341 & 4.7 & 4.885 & TRN \\
\hline CHEMBL1409056 & 688341 & 4.7 & 4.9254 & TRN \\
\hline CHEMBL1607413 & 688341 & 5.7 & 4.8859 & TST \\
\hline CHEMBL1428889 & 688341 & 5.1 & 4.9716 & TST \\
\hline CHEMBL1522067 & 688341 & 4.4 & 4.9868 & TRN \\
\hline CHEMBL1367089 & 688341 & 4.5 & 4.9263 & TRN \\
\hline CHEMBL1589243 & 688341 & 4.5 & 4.9254 & TRN \\
\hline CHEMBL1491397 & 688341 & 5.1 & 4.9465 & TRN \\
\hline CHEMBL1485835 & 688341 & 4.6 & 4.9467 & TST \\
\hline CHEMBL1578407 & 688341 & 4.9 & 4.8326 & TST \\
\hline CHEMBL1318752 & 688341 & 5.5 & 5.0584 & TRN \\
\hline CHEMBL1412276 & 688341 & 5.1 & 5.0516 & TRN \\
\hline CHEMBL1363615 & 688341 & 4.5 & 5.0006 & TRN \\
\hline CHEMBL1464595 & 688341 & 4.6 & 4.9723 & TST \\
\hline
\end{tabular}




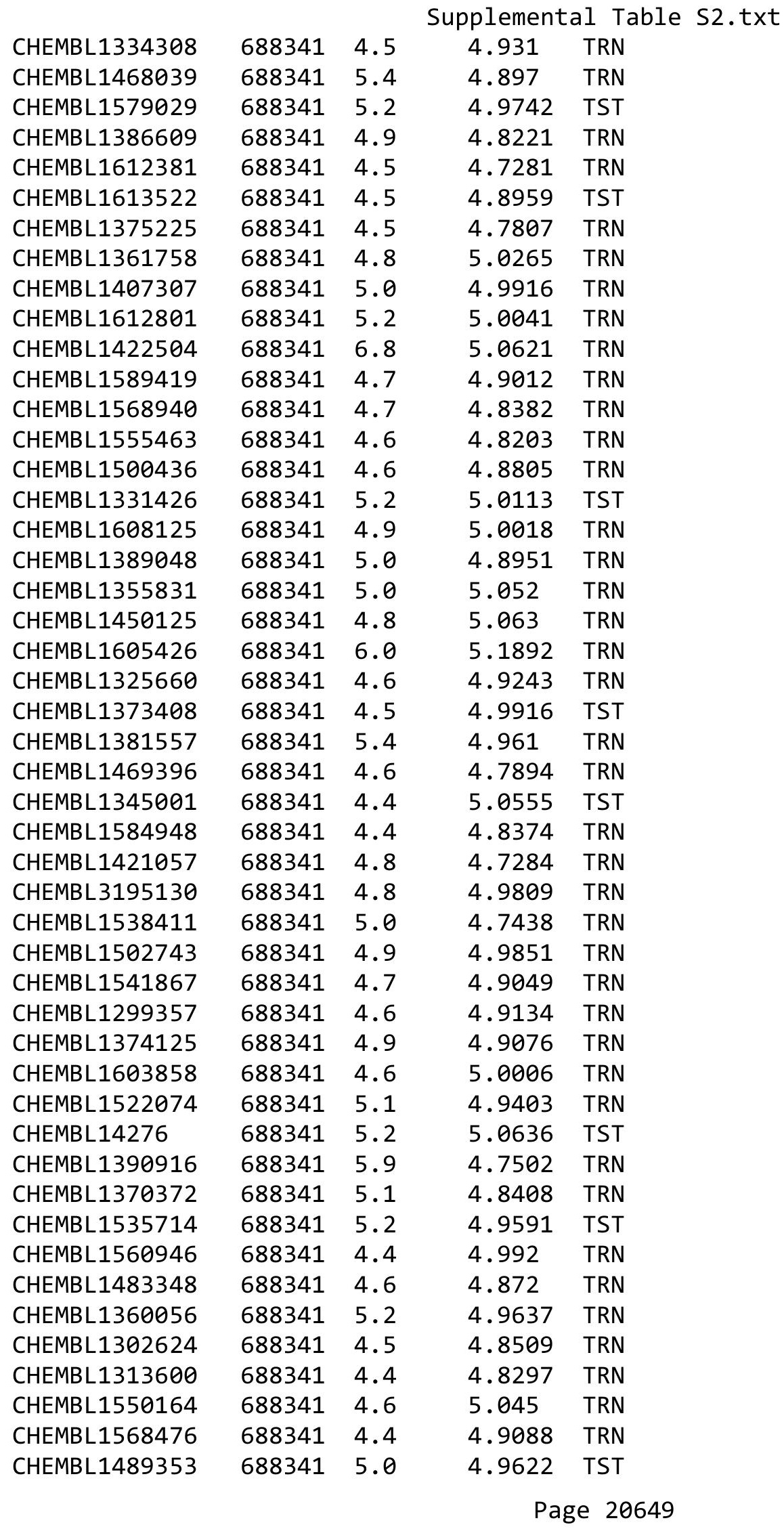




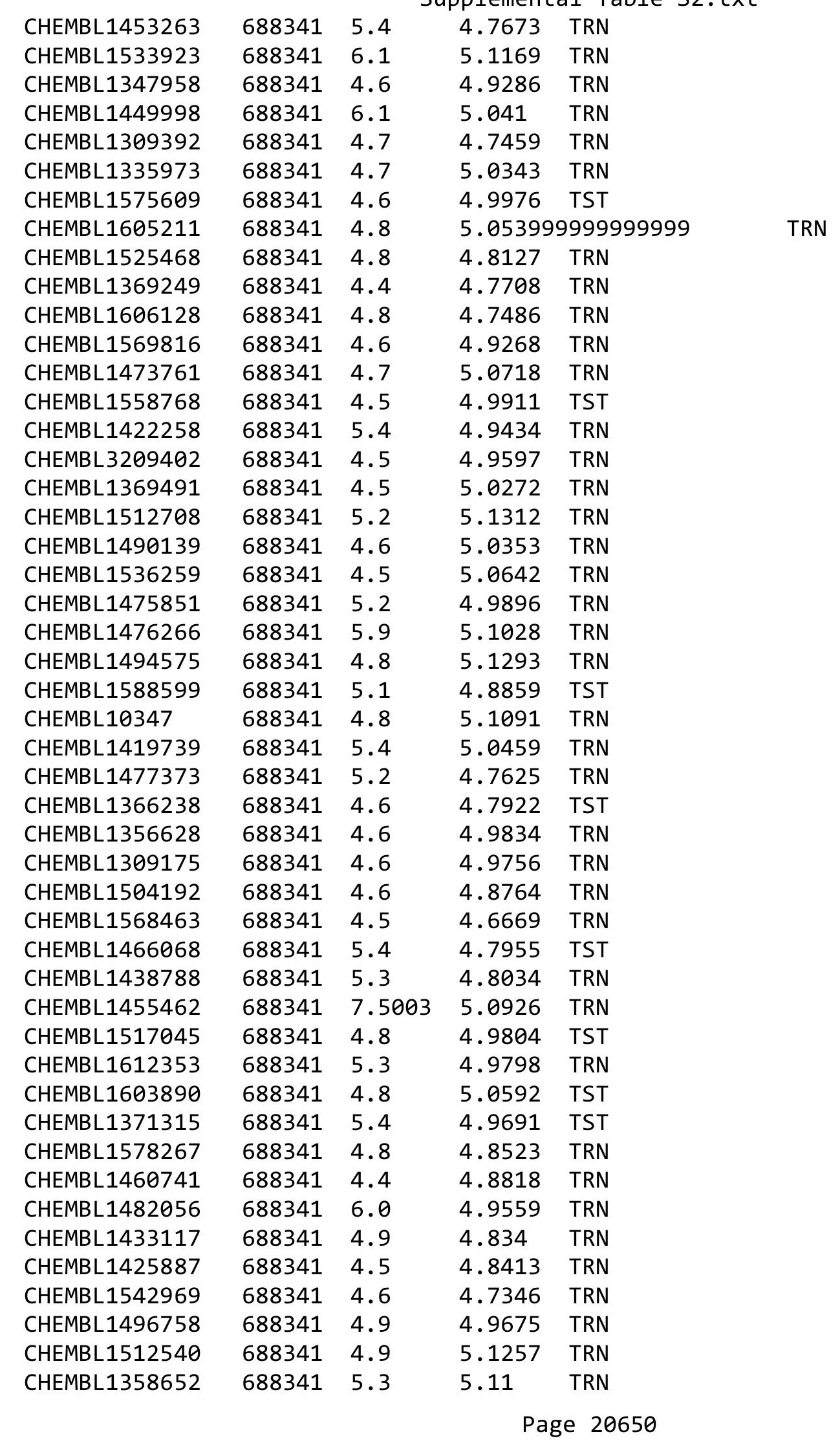




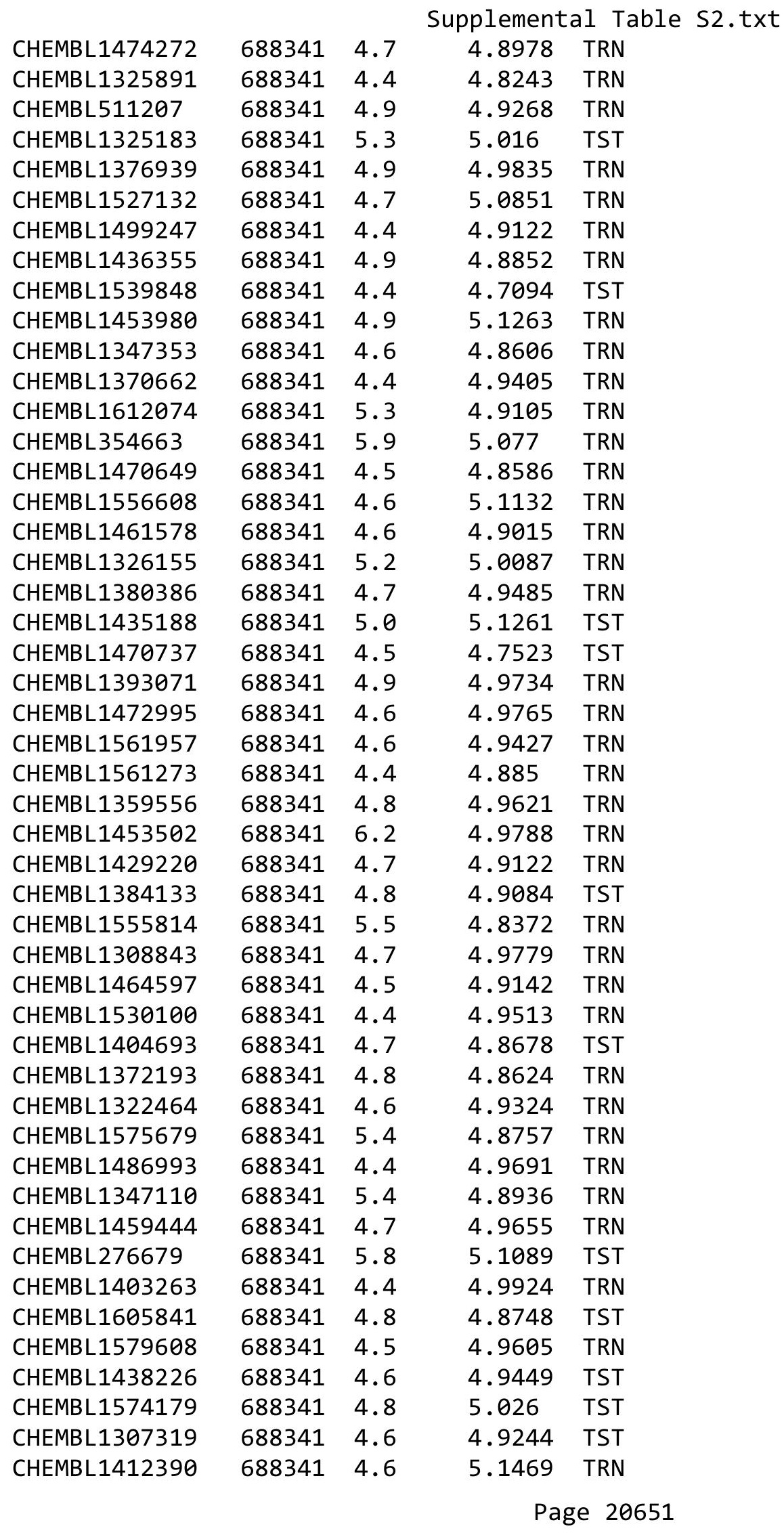




\begin{tabular}{|c|c|c|c|c|}
\hline \multicolumn{5}{|c|}{ Supplemental Table S2.txt } \\
\hline CHEMBL1386306 & 688341 & 5.2 & 4.8816 & TRN \\
\hline CHEMBL1491746 & 688341 & 4.5 & 4.8703 & TRN \\
\hline CHEMBL1565222 & 688341 & 5.9 & 4.9859 & TST \\
\hline CHEMBL1579937 & 688341 & 6.7001 & 4.9547 & TRN \\
\hline CHEMBL1523911 & 688341 & 4.7 & 4.9731 & TRN \\
\hline CHEMBL7162 & 688341 & 4.4 & 5.0929 & TST \\
\hline CHEMBL 287045 & 688341 & 6.4 & 4.999 & TST \\
\hline CHEMBL1400541 & 688341 & 5.2 & 4.9738 & TRN \\
\hline CHEMBL1346439 & 688341 & 4.4 & 4.894 & TRN \\
\hline CHEMBL1409672 & 688341 & 4.6 & 4.897 & TRN \\
\hline CHEMBL1460654 & 688341 & 4.8 & 4.9786 & TRN \\
\hline CHEMBL1564920 & 688341 & 4.7 & 4.9919 & TST \\
\hline CHEMBL1570047 & 688341 & 5.4 & 4.8309 & TST \\
\hline CHEMBL1372895 & 688341 & 4.5 & 5.0447 & TRN \\
\hline CHEMBL1489067 & 688341 & 4.6 & 5.1283 & TRN \\
\hline CHEMBL1494768 & 688341 & 4.5 & 5.0088 & TST \\
\hline CHEMBL1503554 & 688341 & 4.6 & 4.801 & TRN \\
\hline CHEMBL1552953 & 688341 & 5.7 & 4.958 & TST \\
\hline CHEMBL1358985 & 688341 & 4.6 & 5.0236 & TRN \\
\hline CHEMBL1601416 & 688341 & 4.8 & 4.9845 & TRN \\
\hline CHEMBL1366168 & 688341 & 4.4 & 4.8917 & TRN \\
\hline CHEMBL1582649 & 688341 & 4.4 & 5.0112 & TST \\
\hline CHEMBL1503110 & 688341 & 4.6 & 4.727 & TRN \\
\hline CHEMBL1348916 & 688341 & 4.9 & 4.9725 & TRN \\
\hline CHEMBL1405991 & 688341 & 4.9 & 5.0915 & TRN \\
\hline CHEMBL1382086 & 688341 & 4.7 & 5.0123 & TRN \\
\hline CHEMBL1459280 & 688341 & 4.4 & 4.9182 & TST \\
\hline CHEMBL1559024 & 688341 & 4.5 & 4.8467 & TRN \\
\hline CHEMBL1406319 & 688341 & 4.6 & 4.9656 & TRN \\
\hline CHEMBL1452952 & 688341 & 4.5 & 4.6601 & TRN \\
\hline CHEMBL1572010 & 688341 & 5.4 & 4.8699 & TST \\
\hline CHEMBL1368007 & 688341 & 5.4 & 4.8948 & TRN \\
\hline CHEMBL1339485 & 688341 & 4.4 & 4.9235 & TRN \\
\hline CHEMBL1605152 & 688341 & 5.4 & 4.9971 & TST \\
\hline CHEMBL1605795 & 688341 & 4.9 & 4.9322 & TRN \\
\hline CHEMBL1362198 & 688341 & 4.6 & 5.1346 & TST \\
\hline CHEMBL 2374027 & 688341 & 4.5 & 5.1245 & TRN \\
\hline CHEMBL1409369 & 688341 & 6.3 & 5.023 & TRN \\
\hline CHEMBL1314279 & 688341 & 5.7 & 4.8786 & TRN \\
\hline CHEMBL1368545 & 688341 & 4.8 & 5.1101 & TRN \\
\hline CHEMBL 25048 & 688341 & 6.3 & 5.0418 & TRN \\
\hline CHEMBL1507969 & 688341 & 5.2 & 4.9719 & TRN \\
\hline CHEMBL1317055 & 688341 & 6.0 & 5.1009 & TRN \\
\hline CHEMBL1425134 & 688341 & 4.6 & 4.9158 & TRN \\
\hline CHEMBL1312247 & 688341 & 5.3 & 4.9456 & TRN \\
\hline CHEMBL1411054 & 688341 & 4.6 & 4.7561 & TRN \\
\hline CHEMBL1387247 & 688341 & 4.7 & 5.1099 & TRN \\
\hline CHEMBL1499888 & 688341 & 6.5 & 4.8725 & TST \\
\hline
\end{tabular}




\begin{tabular}{|c|c|c|c|c|c|}
\hline \multicolumn{6}{|c|}{ Supplemental Table S2.txt } \\
\hline CHEMBL1446769 & 688341 & 4.8 & 4.938 & TRN & \\
\hline CHEMBL1390986 & 688341 & 5.4 & 4.8408 & TRN & \\
\hline CHEMBL1595645 & 688341 & 4.8 & 4.9795 & TRN & \\
\hline CHEMBL1411401 & 688341 & 4.5 & 4.7992 & TRN & \\
\hline CHEMBL1388493 & 688341 & 6.1 & 4.8467 & TRN & \\
\hline CHEMBL1346140 & 688341 & 4.5 & 4.9251 & TRN & \\
\hline CHEMBL1497143 & 688341 & 6.5 & 5.0192 & TST & \\
\hline CHEMBL1307365 & 688341 & 5.2 & 5.0401 & TST & \\
\hline CHEMBL1518249 & 688341 & 4.5 & 5.0979 & TRN & \\
\hline CHEMBL1565435 & 688341 & 4.5 & 5.0756 & TST & \\
\hline CHEMBL1550298 & 688341 & 4.9 & 4.8034 & TRN & \\
\hline CHEMBL1519428 & 688341 & 4.7 & 4.978 & TRN & \\
\hline CHEMBL1332732 & 688341 & 5.3 & 4.7016 & TRN & \\
\hline CHEMBL1477833 & 688341 & 6.0 & 5.0817 & TRN & \\
\hline CHEMBL1333517 & 688341 & 5.1 & 4.6218 & TST & \\
\hline CHEMBL1328533 & 688341 & 6.1 & 5.2373 & TRN & \\
\hline CHEMBL14090 & 688341 & 4.5 & 5.0879 & TST & \\
\hline CHEMBL1313190 & 688341 & 4.8 & 4.9095 & TRN & \\
\hline CHEMBL1585481 & 688341 & 4.5 & 4.9162 & TRN & \\
\hline CHEMBL1309802 & 688341 & 4.6 & 5.0245 & TST & \\
\hline CHEMBL1539072 & 688341 & 4.7 & 4.8091 & TRN & \\
\hline CHEMBL1608942 & 688341 & 5.0 & 5.0514 & TST & \\
\hline CHEMBL1436925 & 688341 & 5.2 & 4.7482 & TRN & \\
\hline CHEMBL1327823 & 688341 & 5.1 & 5.0803 & TST & \\
\hline CHEMBL1447799 & 688341 & 4.5 & 4.9094 & TRN & \\
\hline CHEMBL1533059 & 688341 & 4.4 & 4.9812 & TRN & \\
\hline CHEMBL1462097 & 688341 & 4.6 & 4.7338 & TRN & \\
\hline CHEMBL1378036 & 688341 & 4.6 & 4.9291 & TST & \\
\hline CHEMBL1388110 & 688341 & 5.5 & 4.8252 & TST & \\
\hline CHEMBL1599007 & 688341 & 4.6 & 4.8895 & TST & \\
\hline CHEMBL1492780 & 688341 & 5.6 & 4.9687 & TRN & \\
\hline CHEMBL1448775 & 688341 & 5.5 & 4.8928 & TRN & \\
\hline CHEMBL1323790 & 688341 & 4.6 & 4.7628 & TRN & \\
\hline CHEMBL1479470 & 688341 & 5.2 & 4.8761 & TRN & \\
\hline CHEMBL1331935 & 688341 & 7.5003 & 4.8849 & TST & \\
\hline CHEMBL1323628 & 688341 & 4.7 & 4.9422 & TRN & \\
\hline CHEMBL1605029 & 688341 & 4.6 & 4.9754 & TST & \\
\hline CHEMBL1612228 & 688341 & 5.2 & 4.9874 & TRN & \\
\hline CHEMBL1558175 & 688341 & 4.4 & 5.0001 & TRN & \\
\hline CHEMBL492127 & 688341 & 4.6 & 5.1376 & TRN & \\
\hline CHEMBL 222409 & 688341 & 4.5 & 5.05699 & 99999999995 & TRN \\
\hline CHEMBL1504033 & 688341 & 4.4 & 4.8903 & TST & \\
\hline CHEMBL3199301 & 688341 & 4.8 & 4.7196 & TRN & \\
\hline CHEMBL1305315 & 688341 & 4.7 & 4.9492 & TRN & \\
\hline CHEMBL1405678 & 688341 & 4.4 & 4.606 & TST & \\
\hline CHEMBL1512210 & 688341 & 5.4 & 5.0523 & TRN & \\
\hline CHEMBL1497021 & 688341 & 4.6 & 4.976 & TRN & \\
\hline CHEMBL3197797 & 688341 & 5.3 & 4.9786 & TST & \\
\hline
\end{tabular}




\begin{tabular}{|c|c|c|c|c|}
\hline & & & & \\
\hline CHEMBL1508328 & 688341 & 5.2 & 4.9746 & TRN \\
\hline CHEMBL1419613 & 688341 & 4.5 & 4.9614 & TRN \\
\hline CHEMBL1448725 & 688341 & 4.7 & 4.894 & TRN \\
\hline CHEMBL1441375 & 688341 & 4.7 & 4.8894 & TRN \\
\hline CHEMBL1599469 & 688341 & 4.6 & 5.2111 & TRN \\
\hline CHEMBL1401280 & 688341 & 4.5 & 5.1239 & TRN \\
\hline CHEMBL1424677 & 688341 & 5.1 & 4.8597 & TRN \\
\hline CHEMBL1594779 & 688341 & 5.3 & 4.8424 & TRN \\
\hline CHEMBL1361543 & 688341 & 4.5 & 4.9547 & TST \\
\hline CHEMBL1462474 & 688341 & 5.1 & 5.062 & TST \\
\hline CHEMBL1416452 & 688341 & 4.8 & 5.0818 & TRN \\
\hline CHEMBL1341604 & 688341 & 4.4 & 4.9164 & TRN \\
\hline CHEMBL1455814 & 688341 & 4.6 & 4.9785 & TRN \\
\hline CHEMBL457504 & 688341 & 6.2 & 5.1753 & TST \\
\hline CHEMBL1554360 & 688341 & 4.4 & 5.1056 & TRN \\
\hline CHEMBL1350068 & 688341 & 5.2 & 4.7641 & TRN \\
\hline CHEMBL1376987 & 688341 & 4.4 & 5.0614 & TRN \\
\hline CHEMBL1377138 & 688341 & 4.7 & 4.9152 & TRN \\
\hline CHEMBL1597856 & 688341 & 5.3 & 4.9186 & TST \\
\hline CHEMBL1583517 & 688341 & 4.6 & 4.9921 & TST \\
\hline CHEMBL1604529 & 688341 & 4.5 & 4.9185 & TRN \\
\hline CHEMBL1601662 & 688341 & 5.0 & 4.9885 & TRN \\
\hline CHEMBL1510629 & 688341 & 5.1 & 4.8817 & TRN \\
\hline CHEMBL1581147 & 688341 & 4.7 & 4.8397 & TST \\
\hline CHEMBL1469467 & 688341 & 5.0 & 4.7527 & TRN \\
\hline CHEMBL1353458 & 688341 & 4.4 & 4.9835 & TRN \\
\hline CHEMBL1405692 & 688341 & 5.2 & 4.9816 & TRN \\
\hline CHEMBL1371868 & 688341 & 5.5 & 4.9388 & TRN \\
\hline CHEMBL1586234 & 688341 & 4.5 & 4.738 & TRN \\
\hline CHEMBL1325463 & 688341 & 4.4 & 4.9714 & TRN \\
\hline CHEMBL1580319 & 688341 & 4.9 & 4.8646 & TST \\
\hline CHEMBL1497983 & 688341 & 5.3 & 4.9347 & TST \\
\hline CHEMBL1400519 & 688341 & 5.0 & 4.9608 & TRN \\
\hline CHEMBL1578570 & 688341 & 4.6 & 4.8768 & TRN \\
\hline CHEMBL1335205 & 688341 & 5.4 & 4.8323 & TST \\
\hline CHEMBL1371652 & 688341 & 5.2 & 4.9009 & TRN \\
\hline CHEMBL1531716 & 688341 & 4.4 & 5.0438 & TST \\
\hline CHEMBL1396778 & 688341 & 4.7 & 4.9441 & TRN \\
\hline CHEMBL589207 & 688341 & 4.8 & 4.897 & TST \\
\hline CHEMBL1303576 & 688341 & 4.4 & 4.9633 & TRN \\
\hline CHEMBL1422128 & 688341 & 4.6 & 5.0617 & TRN \\
\hline CHEMBL1546387 & 688341 & 4.8 & 4.9497 & TRN \\
\hline CHEMBL3207598 & 688341 & 5.2 & 5.0133 & TRN \\
\hline CHEMBL1336932 & 688341 & 5.5 & 5.0884 & TRN \\
\hline CHEMBL1335460 & 688341 & 4.7 & 5.0653 & TRN \\
\hline CHEMBL1604588 & 688341 & 4.9 & 5.0449 & TRN \\
\hline CHEMBL1342298 & 688341 & 5.2 & 4.7418 & TRN \\
\hline CHEMBL1488238 & 688341 & 5.3 & 4.8924 & TST \\
\hline
\end{tabular}




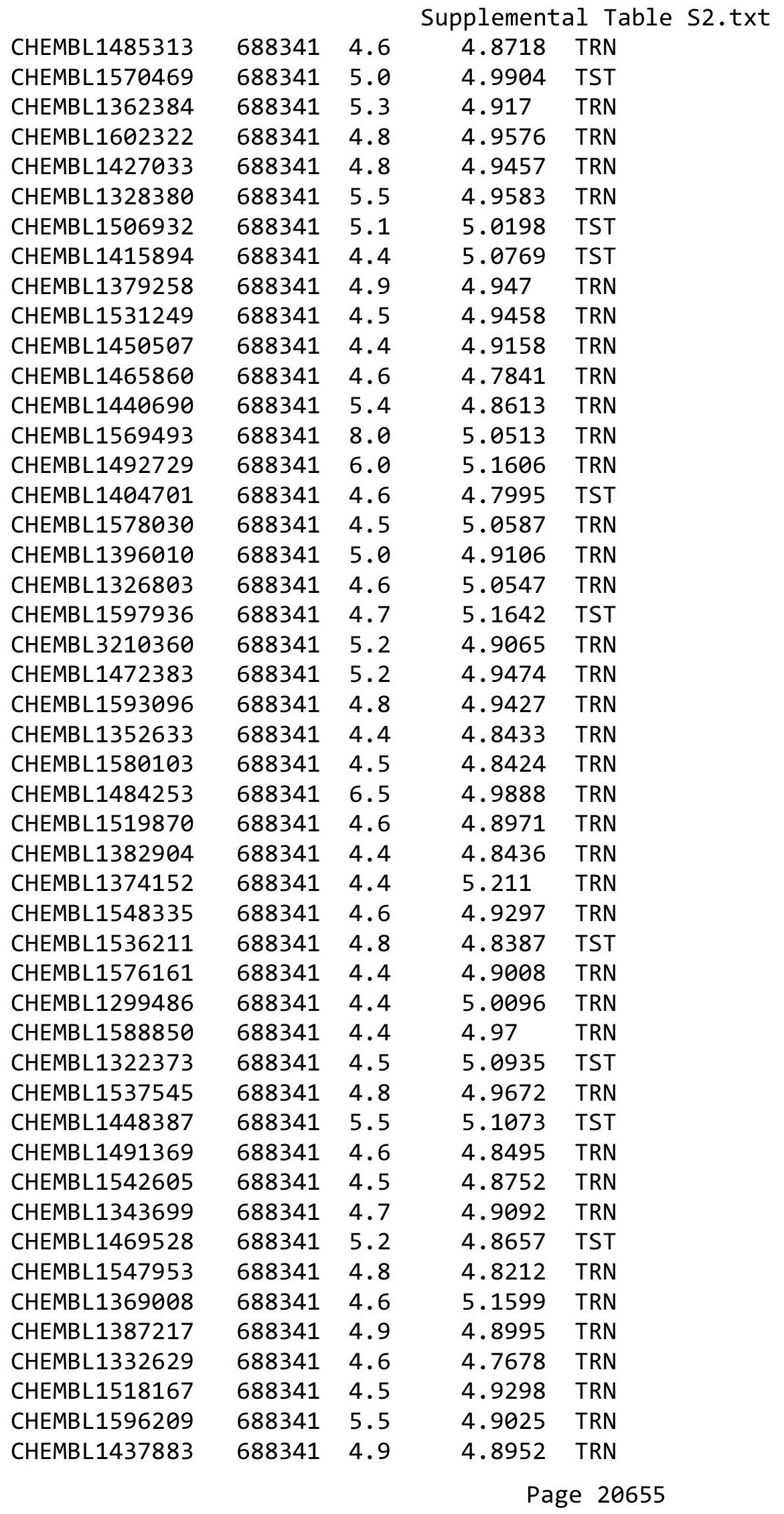




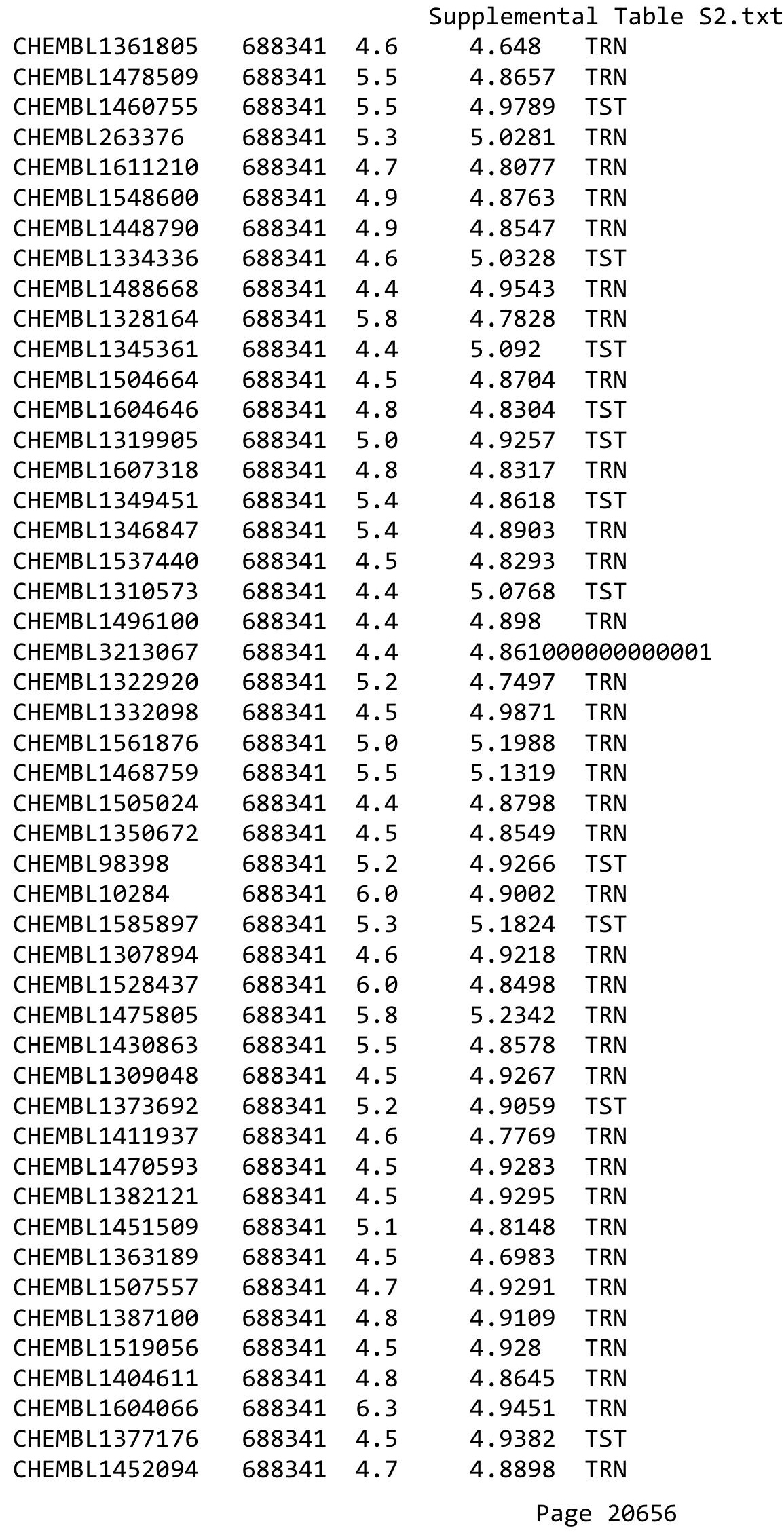

TRN 


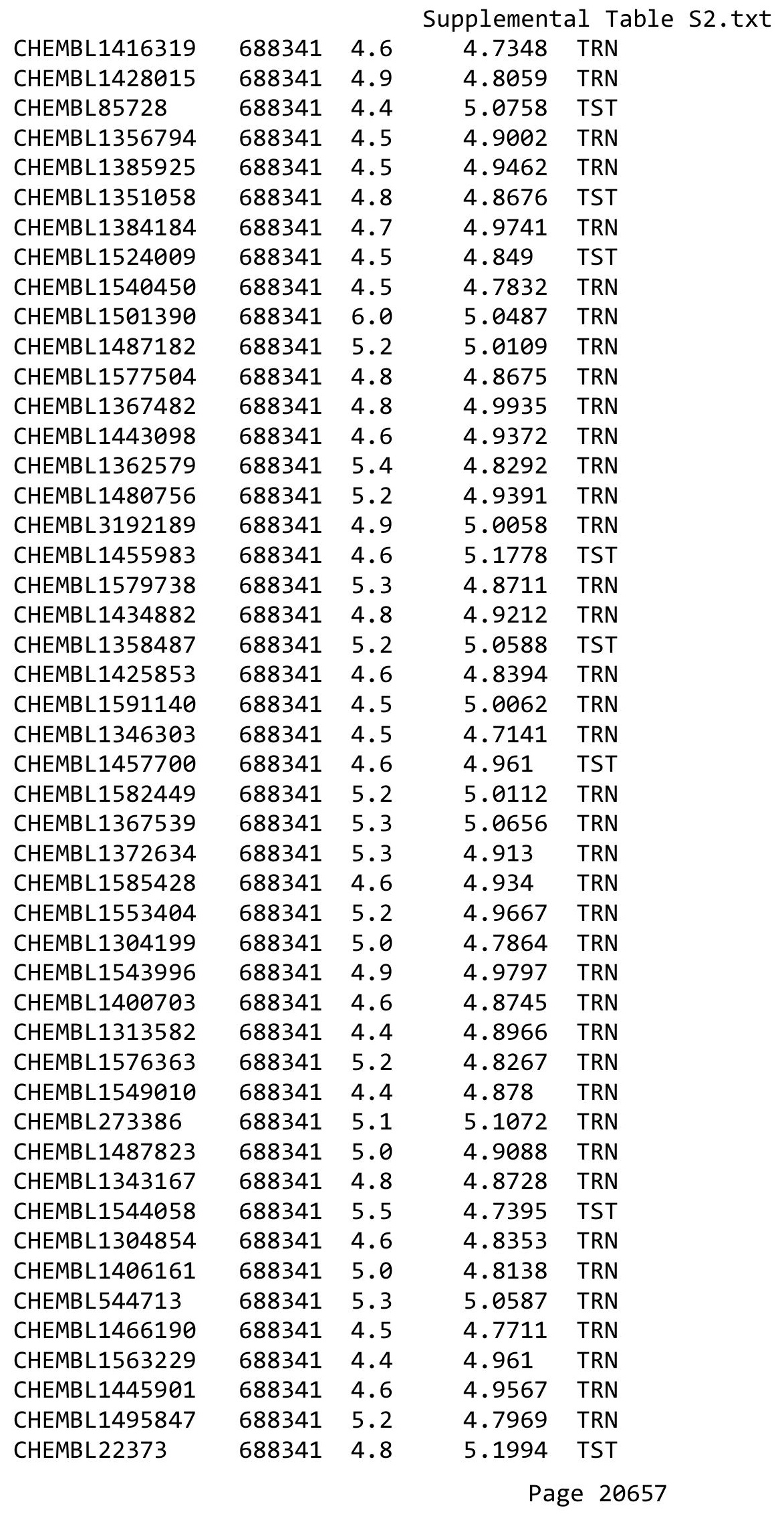




\begin{tabular}{|c|c|c|c|c|c|}
\hline \\
\hline CHEMBL1527466 & 688341 & 5.2 & 5.1138 & TRN & \\
\hline CHEMBL1369340 & 688341 & 4.4 & 4.955 & TRN & \\
\hline CHEMBL1557024 & 688341 & 4.8 & 4.9508 & TRN & \\
\hline CHEMBL1501336 & 688341 & 4.5 & 4.8298 & TRN & \\
\hline CHEMBL1303068 & 688341 & 5.1 & 5.0182 & TRN & \\
\hline CHEMBL1342878 & 688341 & 4.5 & 4.8445 & TRN & \\
\hline CHEMBL1338613 & 688341 & 4.8 & 5.0069 & TRN & \\
\hline CHEMBL1348876 & 688341 & 4.5 & 4.7371 & TRN & \\
\hline CHEMBL1568539 & 688341 & 4.8 & 5.0712 & TRN & \\
\hline CHEMBL1449017 & 688341 & 4.6 & 4.9183 & TRN & \\
\hline CHEMBL1570378 & 688341 & 6.1 & 4.9038 & TST & \\
\hline CHEMBL467085 & 688341 & 4.5 & 4.9665 & TST & \\
\hline CHEMBL498770 & 688341 & 4.4 & 5.1221 & TST & \\
\hline CHEMBL1305755 & 688341 & 5.0 & 4.9843 & TST & \\
\hline CHEMBL1341417 & 688341 & 4.9 & 4.9663 & TRN & \\
\hline CHEMBL1591294 & 688341 & 5.7 & 5.221 & TST & \\
\hline CHEMBL319244 & 688341 & 5.3 & 5.0705 & TRN & \\
\hline CHEMBL1312094 & 688341 & 5.2 & 4.9709 & TST & \\
\hline CHEMBL1389657 & 688341 & 4.6 & 4.8091 & TRN & \\
\hline CHEMBL1318118 & 688341 & 4.4 & 4.9447 & TRN & \\
\hline CHEMBL1476831 & 688341 & 6.2 & 5.0981 & TST & \\
\hline CHEMBL1607196 & 688341 & 4.5 & 4.9914 & TRN & \\
\hline CHEMBL1335771 & 688341 & 5.2 & 4.7388 & TRN & \\
\hline CHEMBL1385628 & 688341 & 6.9 & 4.9107 & TRN & \\
\hline CHEMBL1447658 & 688341 & 4.7 & 5.1104 & TRN & \\
\hline CHEMBL1543543 & 688341 & 4.5 & 4.79899 & 99999999995 & TRN \\
\hline CHEMBL3208184 & 688341 & 5.2 & 4.8832 & TRN & \\
\hline CHEMBL 375107 & 688341 & 4.4 & 5.2408 & TST & \\
\hline CHEMBL1440590 & 688341 & 6.0 & 5.0721 & TRN & \\
\hline CHEMBL1409798 & 688341 & 4.5 & 4.8134 & TRN & \\
\hline CHEMBL1488337 & 688341 & 5.1 & 4.7805 & TST & \\
\hline CHEMBL1506415 & 688341 & 4.8 & $4.9030 e$ & 30000000005 & TRN \\
\hline CHEMBL1419926 & 688341 & 4.6 & 4.9294 & TST & \\
\hline CHEMBL1447866 & 688341 & 5.2 & 4.7927 & TRN & \\
\hline CHEMBL1540342 & 688341 & 4.4 & 4.7396 & TRN & \\
\hline CHEMBL1337775 & 688341 & 5.5 & $4.9910 e$ & 20000000005 & TST \\
\hline CHEMBL1337997 & 688341 & 5.7 & 4.819 & TRN & \\
\hline CHEMBL 372227 & 688341 & 4.5 & 4.9561 & TST & \\
\hline CHEMBL1360349 & 688341 & 5.2 & 4.9459 & TST & \\
\hline CHEMBL1472090 & 688341 & 4.7 & 4.8507 & TRN & \\
\hline CHEMBL1448702 & 688341 & 4.6 & 4.7316 & TRN & \\
\hline CHEMBL1446084 & 688341 & 4.8 & 4.9313 & TST & \\
\hline CHEMBL1496265 & 688341 & 4.4 & 5.0206 & TRN & \\
\hline CHEMBL1213406 & 688341 & 4.6 & 4.9132 & TST & \\
\hline CHEMBL1341221 & 688341 & 4.7 & 4.84 & TST & \\
\hline CHEMBL1461818 & 688341 & 4.4 & 4.794 & TRN & \\
\hline CHEMBL1344963 & 688341 & 6.8 & 5.1139 & TRN & \\
\hline CHEMBL520992 & 688341 & 6.0 & 4.9675 & TRN & \\
\hline
\end{tabular}




\begin{tabular}{|c|c|c|c|c|}
\hline & & & ipplemen & \\
\hline CHEMBL1332851 & 688341 & 4.5 & 4.8435 & TRN \\
\hline CHEMBL1582160 & 688341 & 4.5 & 4.8737 & TRN \\
\hline CHEMBL1530033 & 688341 & 5.5 & 4.9201 & TRN \\
\hline CHEMBL1401366 & 688341 & 4.6 & 4.9324 & TRN \\
\hline CHEMBL1338177 & 688341 & 5.4 & 4.8792 & TST \\
\hline CHEMBL1464207 & 688341 & 4.8 & 4.9705 & TRN \\
\hline CHEMBL1595842 & 688341 & 4.8 & 4.994 & TRN \\
\hline CHEMBL1501559 & 688341 & 5.1 & 5.0451 & TRN \\
\hline CHEMBL1440757 & 688341 & 5.3 & 4.9744 & TRN \\
\hline CHEMBL1550403 & 688341 & 4.5 & 4.8609 & TRN \\
\hline CHEMBL1509305 & 688341 & 5.1 & 4.9117 & TST \\
\hline CHEMBL1372697 & 688341 & 5.9 & 4.987 & TRN \\
\hline CHEMBL1548451 & 688341 & 5.1 & 4.8161 & TRN \\
\hline CHEMBL1549782 & 688341 & 5.6 & 5.0531 & TST \\
\hline CHEMBL1494079 & 688341 & 5.0 & 4.8126 & TRN \\
\hline CHEMBL591836 & 688341 & 4.7 & 5.0283 & TRN \\
\hline CHEMBL1524501 & 688341 & 6.3 & 5.0707 & TRN \\
\hline CHEMBL1483755 & 688341 & 4.4 & 4.8791 & TST \\
\hline CHEMBL1551133 & 688341 & 5.4 & 5.0451 & TRN \\
\hline CHEMBL1371785 & 688341 & 4.7 & 4.7823 & TST \\
\hline CHEMBL1585445 & 688341 & 5.2 & 4.8745 & TRN \\
\hline CHEMBL1446112 & 688341 & 5.1 & 4.8918 & TRN \\
\hline CHEMBL1349278 & 688341 & 5.3 & 4.9012 & TRN \\
\hline CHEMBL1533755 & 688341 & 4.4 & 5.0082 & TRN \\
\hline CHEMBL1561763 & 688341 & 4.5 & 4.8464 & TRN \\
\hline CHEMBL1424299 & 688341 & 4.5 & 4.8051 & TRN \\
\hline CHEMBL1521352 & 688341 & 5.5 & 4.9215 & TRN \\
\hline CHEMBL1332918 & 688341 & 4.5 & 4.8872 & TST \\
\hline CHEMBL1430992 & 688341 & 4.7 & 4.8539 & TRN \\
\hline CHEMBL1574552 & 688341 & 5.3 & 5.2614 & TRN \\
\hline CHEMBL1423425 & 688341 & 4.5 & 4.9429 & TRN \\
\hline CHEMBL1322512 & 688341 & 4.5 & 5.0698 & TRN \\
\hline CHEMBL1412483 & 688341 & 4.8 & 4.773 & TRN \\
\hline CHEMBL1422641 & 688341 & 4.4 & 4.9314 & TRN \\
\hline CHEMBL1589780 & 688341 & 4.6 & 4.9097 & TST \\
\hline CHEMBL1462601 & 688341 & 4.5 & 4.8251 & TST \\
\hline CHEMBL1341609 & 688341 & 4.4 & 5.042 & TRN \\
\hline CHEMBL1599647 & 688341 & 5.4 & 5.0724 & TST \\
\hline CHEMBL1389382 & 688341 & 5.2 & 5.0807 & TRN \\
\hline CHEMBL1351793 & 688341 & 4.6 & 4.8487 & TRN \\
\hline CHEMBL1413002 & 688341 & 4.8 & 5.0279 & TRN \\
\hline CHEMBL1484899 & 688341 & 5.5 & 4.882 & TRN \\
\hline CHEMBL1540677 & 688341 & 4.6 & 5.0872 & TST \\
\hline CHEMBL1524617 & 688341 & 4.9 & 5.1103 & TST \\
\hline CHEMBL1372884 & 688341 & 4.8 & 5.0164 & TST \\
\hline CHEMBL1412427 & 688341 & 4.6 & 5.0239 & TRN \\
\hline CHEMBL1341119 & 688341 & 4.6 & 4.7192 & TRN \\
\hline CHEMBL1316492 & 688341 & 6.0 & 5.2067 & TRN \\
\hline
\end{tabular}




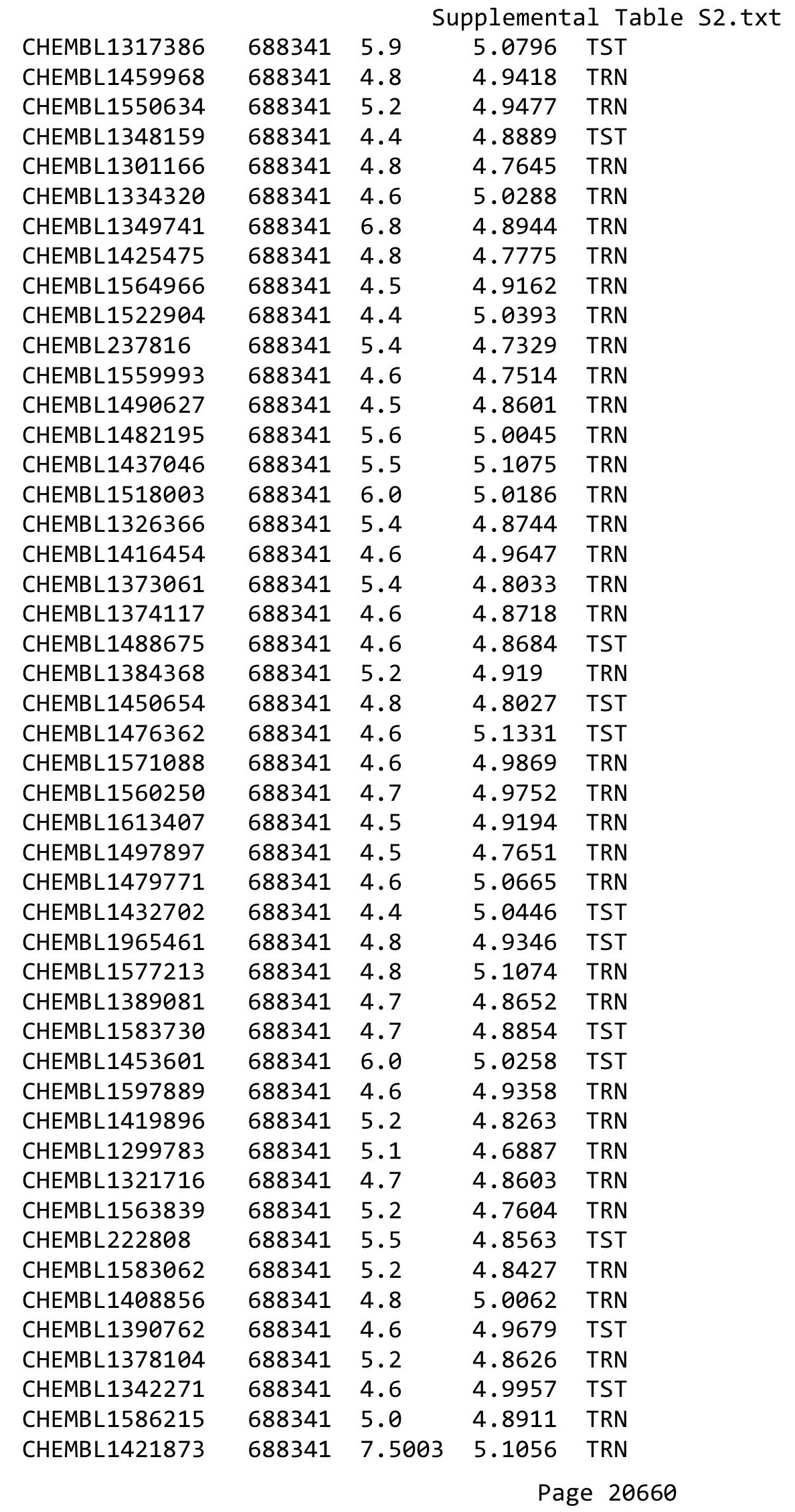




\begin{tabular}{|c|c|c|c|c|}
\hline \multicolumn{5}{|c|}{ olemental labıe s } \\
\hline CHEMBL1399222 & 688341 & 5.1 & 4.7556 & TRN \\
\hline CHEMBL1408603 & 688341 & 5.2 & 5.0873 & TST \\
\hline CHEMBL1355002 & 688341 & 5.4 & 5.0193 & TRN \\
\hline CHEMBL1567490 & 688341 & 4.5 & 4.9198 & TRN \\
\hline CHEMBL1328884 & 688341 & 4.6 & 4.8553 & TRN \\
\hline CHEMBL1583911 & 688341 & 4.9 & \multicolumn{2}{|c|}{4.843999999999999} \\
\hline CHEMBL41172 & 688341 & 5.8 & 5.0019 & TST \\
\hline CHEMBL1551479 & 688341 & 5.7 & 5.1162 & TRN \\
\hline CHEMBL1367222 & 688341 & 5.5 & 5.035 & TRN \\
\hline CHEMBL1464180 & 688341 & 4.6 & 4.8567 & TRN \\
\hline CHEMBL1494654 & 688341 & 4.6 & 4.8044 & TRN \\
\hline CHEMBL1457512 & 688341 & 6.1 & 5.0191 & TRN \\
\hline CHEMBL1595336 & 688341 & 4.7 & 4.7876 & TRN \\
\hline CHEMBL1563741 & 688341 & 4.8 & 5.0285 & TST \\
\hline CHEMBL1313066 & 688341 & 4.5 & 4.8258 & TRN \\
\hline CHEMBL1344490 & 688341 & 5.3 & 4.9346 & TRN \\
\hline CHEMBL1448422 & 688341 & 6.9 & 4.9003 & TRN \\
\hline CHEMBL1394181 & 688341 & 5.2 & 5.1995 & TRN \\
\hline CHEMBL1574722 & 688341 & 4.5 & 4.8942 & TRN \\
\hline CHEMBL3192631 & 688341 & 4.6 & 4.9838 & TRN \\
\hline CHEMBL1419017 & 688341 & 4.5 & 4.8335 & TRN \\
\hline CHEMBL1328437 & 688341 & 4.5 & 4.9134 & TRN \\
\hline CHEMBL 1453530 & 688341 & 5.9 & 5.0041 & TRN \\
\hline CHEMBL1575766 & 688341 & 4.6 & 4.9086 & TRN \\
\hline CHEMBL1409436 & 688341 & 5.1 & 4.9278 & TST \\
\hline CHEMBL1313754 & 688341 & 4.6 & 4.7626 & TRN \\
\hline CHEMBL1561366 & 688341 & 4.6 & 4.8452 & TRN \\
\hline CHEMBL1545534 & 688341 & 4.5 & 4.6531 & TRN \\
\hline CHEMBL1469299 & 688341 & 4.6 & 4.8926 & TRN \\
\hline CHEMBL280065 & 688341 & 6.0 & 5.2961 & TRN \\
\hline CHEMBL1594612 & 688341 & 4.5 & 5.0314 & TST \\
\hline CHEMBL3196534 & 688341 & 4.6 & 5.0186 & TST \\
\hline CHEMBL1608034 & 688341 & 5.1 & 4.9385 & TRN \\
\hline CHEMBL1440653 & 688341 & 4.6 & 5.1061 & TRN \\
\hline CHEMBL1519872 & 688341 & 4.6 & 4.9308 & TRN \\
\hline CHEMBL1477394 & 688341 & 4.6 & 5.0355 & TRN \\
\hline CHEMBL1487475 & 688341 & 5.1 & 4.7953 & TRN \\
\hline CHEMBL1605980 & 688341 & 5.1 & 4.8763 & TRN \\
\hline CHEMBL261123 & 688341 & 4.5 & 4.7422 & TRN \\
\hline CHEMBL1306028 & 688341 & 4.4 & 4.9262 & TRN \\
\hline CHEMBL1362221 & 688341 & 5.3 & 5.0879 & TRN \\
\hline CHEMBL1353034 & 688341 & 5.4 & 4.8657 & TRN \\
\hline CHEMBL1540079 & 688341 & 4.4 & 4.8288 & TRN \\
\hline CHEMBL1356842 & 688341 & 5.0 & 5.0647 & TRN \\
\hline CHEMBL1335639 & 688341 & 6.0 & 4.8239 & TRN \\
\hline CHEMBL1482227 & 688341 & 4.4 & 4.9871 & TST \\
\hline CHEMBL1546137 & 688341 & 4.7 & 4.9785 & TRN \\
\hline CHEMBL1377338 & 688341 & 4.4 & 5.0031 & TRN \\
\hline
\end{tabular}




\begin{tabular}{|c|c|c|c|c|c|}
\hline \multicolumn{6}{|c|}{ Supplemental Table S2.txt } \\
\hline CHEMBL1377095 & 688341 & 4.6 & 4.7599 & TRN & \\
\hline CHEMBL1526875 & 688341 & 4.6 & 5.1109 & TST & \\
\hline CHEMBL1566790 & 688341 & 4.8 & 5.0156 & TRN & \\
\hline CHEMBL1570558 & 688341 & 7.1002 & 5.0492 & TRN & \\
\hline CHEMBL1561943 & 688341 & 6.2 & 4.9611 & TRN & \\
\hline CHEMBL1567313 & 688341 & 7.1002 & 5.04899 & 99999999995 & TST \\
\hline CHEMBL1431735 & 688341 & 4.7 & 4.9836 & TRN & \\
\hline CHEMBL1351197 & 688341 & 5.5 & 5.0729 & TST & \\
\hline CHEMBL1412094 & 688341 & 4.5 & 4.853 & TRN & \\
\hline CHEMBL1358272 & 688341 & 4.5 & 5.0004 & TRN & \\
\hline CHEMBL1475151 & 688341 & 5.2 & 4.95 & TRN & \\
\hline CHEMBL1450253 & 688341 & 4.6 & 4.8119 & TRN & \\
\hline CHEMBL1307226 & 688341 & 4.7 & 4.8066 & TRN & \\
\hline CHEMBL1412889 & 688341 & 7.5003 & 4.9203 & TST & \\
\hline CHEMBL1395137 & 688341 & 4.4 & 5.1577 & TRN & \\
\hline CHEMBL1464163 & 688341 & 4.9 & 4.8457 & TRN & \\
\hline CHEMBL1480497 & 688341 & 5.5 & 4.9344 & TRN & \\
\hline CHEMBL1584211 & 688341 & 5.0 & 4.8718 & TRN & \\
\hline CHEMBL1516524 & 688341 & 4.5 & 4.9125 & TST & \\
\hline CHEMBL1447188 & 688341 & 4.8 & 4.7328 & TRN & \\
\hline CHEMBL1380357 & 688341 & 4.4 & 4.9103 & TRN & \\
\hline CHEMBL1532701 & 688341 & 5.0 & 4.9094 & TST & \\
\hline CHEMBL152299 & 688341 & 4.4 & 4.9799 & TRN & \\
\hline CHEMBL1403558 & 688341 & 4.7 & 4.9588 & TST & \\
\hline CHEMBL1407572 & 688341 & 4.8 & 5.0421 & TRN & \\
\hline CHEMBL1441111 & 688341 & 4.6 & 4.984 & TST & \\
\hline CHEMBL1525493 & 688341 & 4.7 & 4.8991 & TRN & \\
\hline CHEMBL1388179 & 688341 & 4.5 & 4.9114 & TRN & \\
\hline CHEMBL1394840 & 688341 & 5.1 & 5.0592 & TRN & \\
\hline CHEMBL1569029 & 688341 & 6.0 & 4.7976 & TRN & \\
\hline CHEMBL1466728 & 688341 & 6.1 & 4.9635 & TRN & \\
\hline CHEMBL1404076 & 688341 & 4.6 & 4.7553 & TRN & \\
\hline CHEMBL1366586 & 688341 & 4.8 & 5.1448 & TRN & \\
\hline CHEMBL1318045 & 688341 & 7.8013 & 5.0072 & TRN & \\
\hline CHEMBL1445749 & 688341 & 4.8 & 4.8064 & TRN & \\
\hline CHEMBL1328850 & 688341 & 5.6 & 4.8244 & TRN & \\
\hline CHEMBL1510576 & 688341 & 4.6 & 4.9517 & TRN & \\
\hline CHEMBL1374323 & 688341 & 5.2 & 5.0113 & TRN & \\
\hline CHEMBL1408730 & 688341 & 4.8 & 4.8859 & TRN & \\
\hline CHEMBL1391623 & 688341 & 4.8 & 4.8019 & TRN & \\
\hline CHEMBL1352687 & 688341 & 4.8 & 4.9274 & TST & \\
\hline CHEMBL1575246 & 688341 & 6.5 & 4.8933 & TRN & \\
\hline CHEMBL1584777 & 688341 & 4.4 & 4.756 & TRN & \\
\hline CHEMBL1413006 & 688341 & 4.9 & 4.9511 & TRN & \\
\hline CHEMBL1374352 & 688341 & 4.5 & 4.8101 & TRN & \\
\hline CHEMBL1380225 & 688341 & 4.5 & 5.0203 & TRN & \\
\hline CHEMBL1540323 & 688341 & 4.5 & 4.8966 & TST & \\
\hline CHEMBL1549993 & 688341 & 4.8 & 5.0582 & TST & \\
\hline
\end{tabular}




\begin{tabular}{|c|c|c|c|c|}
\hline & & & ient & al Ta \\
\hline CHEMBL1353661 & 688341 & 6.0 & 4.7672 & TRN \\
\hline CHEMBL1598164 & 688341 & 5.1 & 4.902 & TRN \\
\hline CHEMBL1314165 & 688341 & 4.7 & 4.7995 & TRN \\
\hline CHEMBL1389606 & 688341 & 4.6 & 4.89 & TRN \\
\hline CHEMBL1525199 & 688341 & 5.2 & 4.8425 & TST \\
\hline CHEMBL1444259 & 688341 & 5.2 & 4.9332 & TRN \\
\hline CHEMBL1308659 & 688341 & 4.4 & 5.0604 & TRN \\
\hline CHEMBL1496744 & 688341 & 5.5 & 5.1629 & TRN \\
\hline CHEMBL1415932 & 688341 & 4.5 & 4.8192 & TRN \\
\hline CHEMBL1428621 & 688341 & 4.8 & 4.9758 & TRN \\
\hline CHEMBL69367 & 688341 & 5.1 & 5.0577 & TST \\
\hline CHEMBL 20730 & 688341 & 4.5 & 5.0634 & TST \\
\hline CHEMBL1397088 & 688341 & 5.3 & 5.1125 & TRN \\
\hline CHEMBL1613092 & 688341 & 4.6 & 4.9027 & TRN \\
\hline CHEMBL1384647 & 688341 & 4.6 & 4.913 & TRN \\
\hline CHEMBL1490993 & 688341 & 4.6 & 4.8797 & TRN \\
\hline CHEMBL1603026 & 688341 & 4.4 & 4.9314 & TST \\
\hline CHEMBL1543167 & 688341 & 5.2 & 5.1304 & TRN \\
\hline CHEMBL1358950 & 688341 & 4.9 & 4.6369 & TRN \\
\hline CHEMBL1465487 & 688341 & 6.1 & 5.0842 & TRN \\
\hline CHEMBL1597696 & 688341 & 5.3 & 4.8424 & TRN \\
\hline CHEMBL1486681 & 688341 & 4.5 & 5.0734 & TRN \\
\hline CHEMBL1317998 & 688341 & 4.9 & 5.0969 & TRN \\
\hline CHEMBL1500292 & 688341 & 4.9 & 4.9005 & TRN \\
\hline CHEMBL1334564 & 688341 & 5.3 & 4.7711 & TRN \\
\hline CHEMBL1408858 & 688341 & 4.6 & 4.9615 & TST \\
\hline CHEMBL1550093 & 688341 & 4.5 & 4.8324 & TRN \\
\hline CHEMBL442565 & 688341 & 5.2 & 5.0637 & TST \\
\hline CHEMBL1522115 & 688341 & 4.4 & 4.8521 & TRN \\
\hline CHEMBL1521545 & 688341 & 4.7 & 4.8715 & TRN \\
\hline CHEMBL1422166 & 688341 & 6.8 & 4.9159 & TRN \\
\hline CHEMBL1463712 & 688341 & 4.4 & 4.9125 & TRN \\
\hline CHEMBL1478458 & 688341 & 4.4 & 4.9741 & TRN \\
\hline CHEMBL1328068 & 688341 & 4.5 & 4.8708 & TRN \\
\hline CHEMBL1421883 & 688341 & 5.4 & 4.9292 & TRN \\
\hline CHEMBL1371510 & 688341 & 5.3 & 5.1902 & TST \\
\hline CHEMBL1409199 & 688341 & 5.9 & 5.0492 & TRN \\
\hline CHEMBL1612219 & 688341 & 4.4 & 4.7092 & TRN \\
\hline CHEMBL1542820 & 688341 & 4.6 & 4.7945 & TRN \\
\hline CHEMBL1369517 & 688341 & 5.2 & 4.9074 & TRN \\
\hline CHEMBL1519571 & 688341 & 4.7 & 4.9897 & TST \\
\hline CHEMBL1333156 & 688341 & 5.1 & 5.0293 & TRN \\
\hline CHEMBL1346206 & 688341 & 4.4 & 4.9474 & TRN \\
\hline CHEMBL1441101 & 688341 & 5.1 & 4.8362 & TRN \\
\hline CHEMBL1330422 & 688341 & 4.7 & 5.1541 & TRN \\
\hline CHEMBL1467730 & 688341 & 4.6 & 4.9697 & TRN \\
\hline CHEMBL1379250 & 688341 & 4.5 & 5.0661 & TRN \\
\hline CHEMBL1313778 & 688341 & 4.6 & 4.8385 & TRN \\
\hline
\end{tabular}




\begin{tabular}{|c|c|c|c|c|c|}
\hline & & & & & \\
\hline CHEMBL1468477 & 688341 & 4.6 & 5.1269 & TRN & \\
\hline CHEMBL1383379 & 688341 & 6.8 & 4.8495 & TRN & \\
\hline CHEMBL1482304 & 688341 & 5.0 & 4.8407 & TRN & \\
\hline CHEMBL1429011 & 688341 & 4.4 & 4.7297 & TRN & \\
\hline CHEMBL1550363 & 688341 & 4.9 & 4.822 & TRN & \\
\hline CHEMBL1519798 & 688341 & 4.6 & 4.8719 & TRN & \\
\hline CHEMBL1417381 & 688341 & 4.5 & 4.9071 & TRN & \\
\hline CHEMBL1314453 & 688341 & 5.3 & 4.9494 & TRN & \\
\hline CHEMBL1408036 & 688341 & 4.8 & 4.7955 & TST & \\
\hline CHEMBL1371247 & 688341 & 4.8 & 4.7091 & TRN & \\
\hline CHEMBL1467582 & 688341 & 4.4 & 4.6655 & TRN & \\
\hline CHEMBL467423 & 688341 & 6.5 & 5.1389 & TRN & \\
\hline CHEMBL1546857 & 688341 & 4.8 & 4.7065 & TRN & \\
\hline CHEMBL1465230 & 688341 & 4.4 & 5.1197 & TST & \\
\hline CHEMBL1521970 & 688341 & 4.4 & 4.8805 & TST & \\
\hline CHEMBL1524508 & 688341 & 4.7 & 4.8972 & TRN & \\
\hline CHEMBL1457783 & 688341 & 4.7 & 4.8962 & TRN & \\
\hline CHEMBL1487225 & 688341 & 5.0 & 4.9705 & TRN & \\
\hline CHEMBL1200462 & 688341 & 8.699 & 5.0201 & TST & \\
\hline CHEMBL1508182 & 688341 & 5.2 & 5.0718 & TRN & \\
\hline CHEMBL1610143 & 688341 & 4.7 & 5.0119 & TST & \\
\hline CHEMBL1553990 & 688341 & 5.6 & 5.1487 & TRN & \\
\hline CHEMBL1422108 & 688341 & 5.1 & 5.2223 & TRN & \\
\hline CHEMBL1560726 & 688341 & 5.2 & 4.999 & TRN & \\
\hline CHEMBL1532900 & 688341 & 5.2 & 4.8765 & TRN & \\
\hline CHEMBL1499595 & 688341 & 4.5 & 4.7298 & TRN & \\
\hline CHEMBL1404206 & 688341 & 4.6 & 4.7843 & TRN & \\
\hline CHEMBL1309081 & 688341 & 5.0 & 4.9256 & TRN & \\
\hline CHEMBL1256740 & 688341 & 4.7 & 5.1585 & TST & \\
\hline CHEMBL1497999 & 688341 & 5.0 & 4.7716 & TRN & \\
\hline CHEMBL1402481 & 688341 & 4.5 & 4.965 & TRN & \\
\hline CHEMBL1463231 & 688341 & 4.8 & 4.8219 & TRN & \\
\hline CHEMBL1408055 & 688341 & 5.2 & 4.8464 & TRN & \\
\hline CHEMBL1329054 & 688341 & 4.9 & 4.7826 & TRN & \\
\hline CHEMBL1396611 & 688341 & 7.0 & 4.8697 & TRN & \\
\hline CHEMBL1330207 & 688341 & 4.9 & 4.8648 & TRN & \\
\hline CHEMBL1552154 & 688341 & 5.2 & 5.041 & TRN & \\
\hline CHEMBL1383057 & 688341 & 4.5 & 4.8331 & TRN & \\
\hline CHEMBL1317885 & 688341 & 4.7 & 5.0791 & TRN & \\
\hline CHEMBL1494934 & 688341 & 4.6 & 4.9145 & TRN & \\
\hline CHEMBL1418483 & 688341 & 4.6 & 4.88 & TST & \\
\hline CHEMBL1565908 & 688341 & 4.4 & 4.8411 & TRN & \\
\hline CHEMBL1369033 & 688341 & 4.9 & 5.0258 & TRN & \\
\hline CHEMBL1586056 & 688341 & 4.5 & 4.83899 & 99999999995 & TRN \\
\hline CHEMBL1302494 & 688341 & 5.4 & 4.7903 & TRN & \\
\hline CHEMBL1392033 & 688341 & 4.9 & 5.0444 & TRN & \\
\hline CHEMBL1441404 & 688341 & 4.9 & 4.8085 & TRN & \\
\hline CHEMBL1404781 & 688341 & 4.7 & 4.8804 & TRN & \\
\hline
\end{tabular}




\begin{tabular}{|c|c|c|c|c|}
\hline \multicolumn{5}{|c|}{ le s2.txt } \\
\hline CHEMBL1334230 & 688341 & 4.4 & 5.1071 & TRN \\
\hline CHEMBL1323474 & 688341 & 5.4 & 5.0076 & TRN \\
\hline CHEMBL1540363 & 688341 & 4.6 & 5.0987 & TRN \\
\hline CHEMBL1374388 & 688341 & 4.6 & 4.8174 & TRN \\
\hline CHEMBL1548198 & 688341 & 5.3 & 4.8166 & TST \\
\hline CHEMBL1339753 & 688341 & 5.4 & 5.0429 & TRN \\
\hline CHEMBL1568601 & 688341 & 4.6 & 4.9513 & TRN \\
\hline CHEMBL1569541 & 688341 & 4.5 & 4.8559 & TRN \\
\hline CHEMBL1600993 & 688341 & 4.6 & 4.8866 & TRN \\
\hline CHEMBL1348071 & 688341 & 4.6 & 5.0495 & TST \\
\hline CHEMBL1379936 & 688341 & 4.4 & 4.9375 & TRN \\
\hline CHEMBL1504816 & 688341 & 4.6 & 5.0133 & TRN \\
\hline CHEMBL1568782 & 688341 & 4.4 & 4.8432 & TRN \\
\hline CHEMBL1463139 & 688341 & 4.4 & 4.8949 & TST \\
\hline CHEMBL1599783 & 688341 & 5.2 & 4.9095 & TRN \\
\hline CHEMBL1538344 & 688341 & 6.0 & 5.0339 & TST \\
\hline CHEMBL1435544 & 688341 & 4.7 & 4.9378 & TRN \\
\hline CHEMBL1389412 & 688341 & 4.5 & 5.0401 & TST \\
\hline CHEMBL1478570 & 688341 & 4.8 & 4.8798 & TRN \\
\hline CHEMBL1593754 & 688341 & 6.0 & 5.2376 & TST \\
\hline CHEMBL1345542 & 688341 & 5.2 & 5.0722 & TST \\
\hline CHEMBL1435276 & 688341 & 5.0 & 5.0173 & TRN \\
\hline CHEMBL1583671 & 688341 & 5.2 & 4.7111 & TRN \\
\hline CHEMBL1358983 & 688341 & 4.6 & 4.9136 & TST \\
\hline CHEMBL1549367 & 688341 & 4.6 & 4.7023 & TRN \\
\hline CHEMBL1557091 & 688341 & 6.0 & 4.8901 & TST \\
\hline CHEMBL1598873 & 688341 & 4.8 & 4.7461 & TRN \\
\hline CHEMBL546597 & 688341 & 5.4 & 4.9356 & TRN \\
\hline CHEMBL1371726 & 688341 & 4.9 & 5.0852 & TRN \\
\hline CHEMBL1497019 & 688341 & 4.6 & 4.8018 & TST \\
\hline CHEMBL1304227 & 688341 & 4.6 & 4.8339 & TRN \\
\hline CHEMBL1603235 & 688341 & 4.4 & 4.8417 & TRN \\
\hline CHEMBL1337547 & 688341 & 4.5 & 5.0475 & TRN \\
\hline CHEMBL1299387 & 688341 & 5.2 & 5.0528 & TRN \\
\hline CHEMBL1335023 & 688341 & 5.2 & 4.8455 & TRN \\
\hline CHEMBL1396949 & 688341 & 5.5 & 5.0847 & TRN \\
\hline CHEMBL1508997 & 688341 & 4.8 & 4.8143 & TRN \\
\hline CHEMBL1464645 & 688341 & 4.7 & 4.7763 & TRN \\
\hline CHEMBL1487085 & 688341 & 5.2 & 4.8355 & TRN \\
\hline CHEMBL1566928 & 688341 & 4.6 & 5.0371 & TST \\
\hline CHEMBL1450525 & 688341 & 5.4 & 5.0715 & TST \\
\hline CHEMBL1391435 & 688341 & 6.7001 & 5.0048 & TRN \\
\hline CHEMBL1490113 & 688341 & 5.5 & 5.0433 & TST \\
\hline CHEMBL1535565 & 688341 & 5.8 & 4.9231 & TRN \\
\hline CHEMBL1395567 & 688341 & 4.6 & 5.1653 & TRN \\
\hline CHEMBL1411418 & 688341 & 4.5 & 4.7494 & TRN \\
\hline CHEMBL1458134 & 688341 & 4.4 & 4.7946 & TRN \\
\hline CHEMBL1438621 & 688341 & 5.4 & 4.8753 & TST \\
\hline
\end{tabular}




\begin{tabular}{|c|c|c|c|c|c|}
\hline \multicolumn{6}{|c|}{ Supplemental Table S2.txt } \\
\hline CHEMBL1530565 & 688341 & 5.0 & 5.0034 & TRN & \\
\hline CHEMBL1347524 & 688341 & 6.7001 & 5.1008 & TRN & \\
\hline CHEMBL1509861 & 688341 & 4.5 & 4.8611 & TRN & \\
\hline CHEMBL1421382 & 688341 & 4.7 & 4.8584 & TRN & \\
\hline CHEMBL1423124 & 688341 & 4.9 & 5.1921 & TRN & \\
\hline CHEMBL1540158 & 688341 & 5.1 & 5.0499 & TRN & \\
\hline CHEMBL184450 & 688341 & 6.0 & 5.1742 & TRN & \\
\hline CHEMBL1284 & 688341 & 4.4 & 5.0581 & TRN & \\
\hline CHEMBL1385434 & 688341 & 4.4 & 4.8967 & TRN & \\
\hline CHEMBL1444431 & 688341 & 4.5 & 4.8025 & TRN & \\
\hline CHEMBL1599620 & 688341 & 4.5 & 4.9023 & TRN & \\
\hline CHEMBL1495677 & 688341 & 4.5 & 4.9347 & TST & \\
\hline CHEMBL1542303 & 688341 & 5.9 & 4.9859 & TRN & \\
\hline CHEMBL1341815 & 688341 & 4.5 & 4.8372 & TRN & \\
\hline CHEMBL1596096 & 688341 & 5.4 & 4.9336 & TST & \\
\hline CHEMBL1452758 & 688341 & 5.5 & 5.1024 & TST & \\
\hline CHEMBL1529534 & 688341 & 4.9 & 4.9589 & TRN & \\
\hline CHEMBL1568408 & 688341 & 4.8 & 4.8177 & TRN & \\
\hline CHEMBL1554170 & 688341 & 4.8 & 5.218 & TRN & \\
\hline CHEMBL1432629 & 688341 & 4.7 & 4.9051 & TST & \\
\hline CHEMBL1561421 & 688341 & 4.6 & 4.7425 & TST & \\
\hline CHEMBL1352501 & 688341 & 4.7 & 4.854 & TRN & \\
\hline CHEMBL1369831 & 688341 & 4.4 & 4.9738 & TRN & \\
\hline CHEMBL1600998 & 688341 & 5.1 & 5.1145 & TRN & \\
\hline CHEMBL1458107 & 688341 & 5.2 & 4.9131 & TST & \\
\hline CHEMBL1537905 & 688341 & 4.6 & 4.857 & TRN & \\
\hline CHEMBL1356113 & 688341 & 5.4 & 5.08899 & 99999999995 & TRN \\
\hline CHEMBL1446935 & 688341 & 4.4 & 4.7462 & TRN & \\
\hline CHEMBL2136498 & 688341 & 4.8 & 4.8845 & TRN & \\
\hline CHEMBL1378110 & 688341 & 4.4 & 4.7015 & TRN & \\
\hline CHEMBL1332611 & 688341 & 5.3 & 4.9885 & TRN & \\
\hline CHEMBL1508109 & 688341 & 4.4 & 4.93 & TST & \\
\hline CHEMBL1537764 & 688341 & 4.7 & 5.0047 & TRN & \\
\hline CHEMBL1491104 & 688341 & 4.8 & 5.0703 & TRN & \\
\hline CHEMBL1587325 & 688341 & 4.7 & 5.1786 & TST & \\
\hline CHEMBL1444802 & 688341 & 5.0 & 4.9034 & TRN & \\
\hline CHEMBL1493770 & 688341 & 4.9 & 4.8487 & TST & \\
\hline CHEMBL1388003 & 688341 & 5.9 & 4.8773 & TRN & \\
\hline CHEMBL1321561 & 688341 & 5.5 & 4.9067 & TRN & \\
\hline CHEMBL1335128 & 688341 & 4.6 & 4.9282 & TST & \\
\hline CHEMBL3212119 & 688341 & 4.4 & 4.9933 & TST & \\
\hline CHEMBL1420563 & 688341 & 4.5 & 5.0671 & TRN & \\
\hline CHEMBL1373217 & 688341 & 4.6 & 4.8101 & TRN & \\
\hline CHEMBL1352443 & 688341 & 4.6 & 4.7607 & TRN & \\
\hline CHEMBL1412804 & 688341 & 4.4 & 4.7911 & TST & \\
\hline CHEMBL1514923 & 688341 & 5.0 & 5.1108 & TRN & \\
\hline CHEMBL1589751 & 688341 & 4.7 & 4.7067 & TST & \\
\hline CHEMBL1587587 & 688341 & 5.0 & 4.9677 & TRN & \\
\hline
\end{tabular}




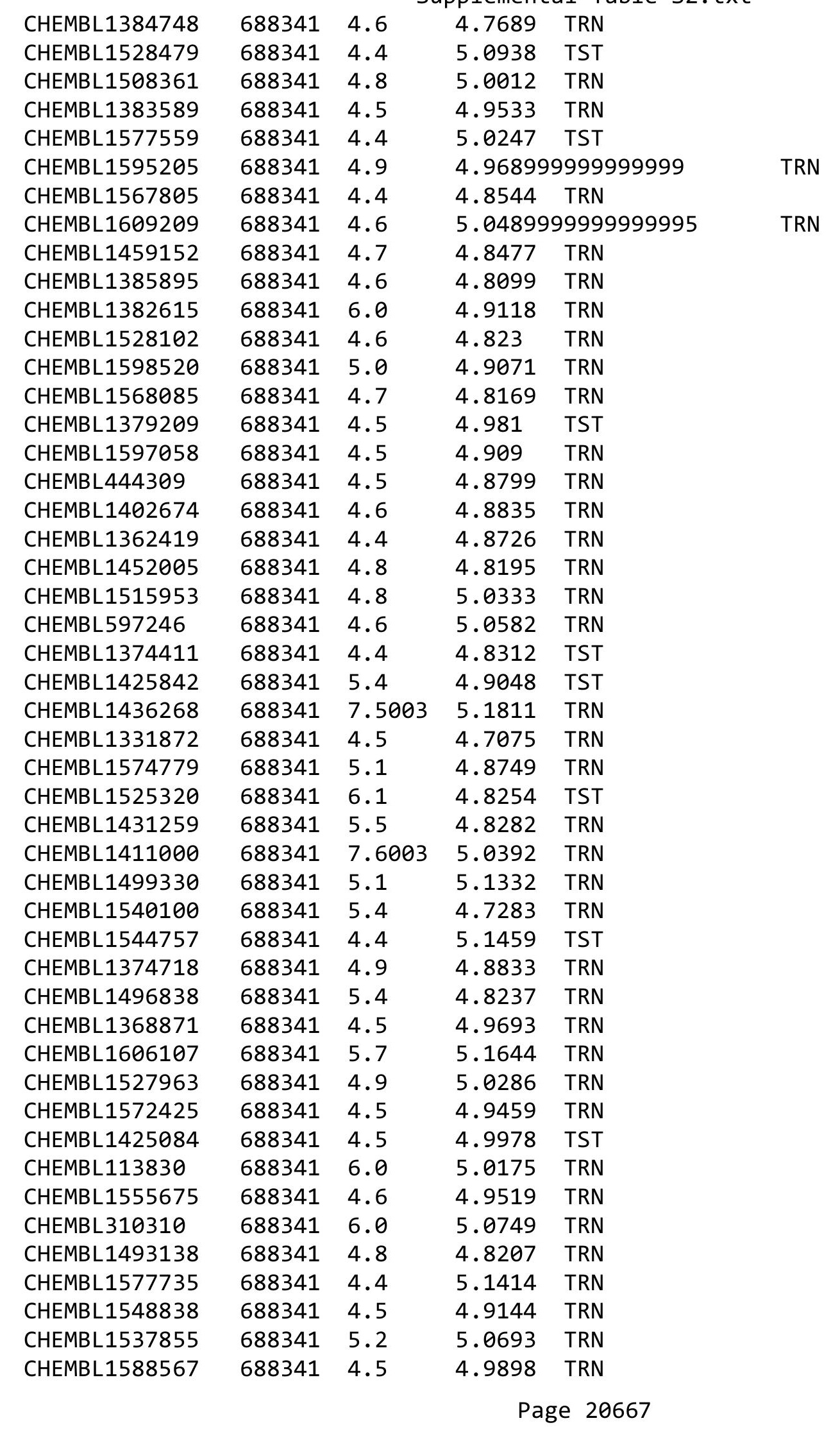




\begin{tabular}{|c|c|c|c|c|}
\hline & & & & $a \perp 1 a$ \\
\hline CHEMBL1323050 & 688341 & 5.3 & 5.0147 & TRN \\
\hline CHEMBL1410865 & 688341 & 4.5 & 5.0373 & TRN \\
\hline CHEMBL1591238 & 688341 & 4.9 & 5.1527 & TRN \\
\hline CHEMBL1554131 & 688341 & 4.8 & 5.1477 & TRN \\
\hline CHEMBL1330853 & 688341 & 5.6 & 4.88 & TRN \\
\hline CHEMBL1605078 & 688341 & 4.5 & 4.9211 & TRN \\
\hline CHEMBL1392745 & 688341 & 4.8 & 4.9361 & TST \\
\hline CHEMBL1541819 & 688341 & 4.4 & 4.7394 & TRN \\
\hline CHEMBL1388319 & 688341 & 4.4 & 4.8901 & TRN \\
\hline CHEMBL1431485 & 688341 & 4.4 & 4.9213 & TRN \\
\hline CHEMBL182786 & 688341 & 5.5 & 4.8962 & TST \\
\hline CHEMBL1509510 & 688341 & 5.2 & 4.9489 & TRN \\
\hline CHEMBL1527029 & 688341 & 6.8 & 4.988 & TRN \\
\hline CHEMBL1389701 & 688341 & 4.5 & 4.8344 & TST \\
\hline CHEMBL1550356 & 688341 & 4.8 & 4.9546 & TRN \\
\hline CHEMBL1574934 & 688341 & 4.9 & 4.934 & TRN \\
\hline CHEMBL3214326 & 688341 & 4.7 & 4.9319 & TST \\
\hline CHEMBL1540230 & 688341 & 4.7 & 4.9907 & TRN \\
\hline CHEMBL1391644 & 688341 & 5.3 & 4.9228 & TRN \\
\hline CHEMBL1587360 & 688341 & 5.3 & 4.8893 & TST \\
\hline CHEMBL1526767 & 688341 & 4.7 & 4.8362 & TRN \\
\hline CHEMBL1427182 & 688341 & 5.1 & 5.0495 & TRN \\
\hline CHEMBL1548388 & 688341 & 4.5 & 5.069 & TST \\
\hline CHEMBL1436174 & 688341 & 4.5 & 4.9559 & TRN \\
\hline CHEMBL1368282 & 688341 & 5.4 & 4.9457 & TST \\
\hline CHEMBL1595251 & 688341 & 4.9 & 4.8697 & TRN \\
\hline CHEMBL1454271 & 688341 & 6.0 & 4.8985 & TRN \\
\hline CHEMBL1389851 & 688341 & 4.7 & 4.9022 & TRN \\
\hline CHEMBL1326090 & 688341 & 4.6 & 4.7186 & TRN \\
\hline CHEMBL1467490 & 688341 & 4.7 & 4.7515 & TRN \\
\hline CHEMBL1415382 & 688341 & 4.4 & 5.0314 & TRN \\
\hline CHEMBL1377727 & 688341 & 5.2 & 5.06 & TRN \\
\hline CHEMBL1368596 & 688341 & 4.6 & 4.8728 & TRN \\
\hline CHEMBL1420119 & 688341 & 5.1 & 4.8844 & TST \\
\hline CHEMBL1402096 & 688341 & 5.0 & 5.1154 & TRN \\
\hline CHEMBL1482713 & 688341 & 4.5 & 4.8408 & TRN \\
\hline CHEMBL1303712 & 688341 & 4.4 & 4.9029 & TRN \\
\hline CHEMBL1497581 & 688341 & 5.0 & 4.8249 & TRN \\
\hline CHEMBL1597881 & 688341 & 4.4 & 4.7924 & TRN \\
\hline CHEMBL1439866 & 688341 & 4.8 & 5.2227 & TRN \\
\hline CHEMBL1586127 & 688341 & 4.5 & 4.7328 & TRN \\
\hline CHEMBL1587683 & 688341 & 5.8 & 4.8589 & TRN \\
\hline CHEMBL1415706 & 688341 & 4.4 & 5.0097 & TRN \\
\hline CHEMBL1374478 & 688341 & 5.2 & 4.7059 & TRN \\
\hline CHEMBL1386368 & 688341 & 5.4 & 4.9333 & TST \\
\hline CHEMBL1459569 & 688341 & 5.0 & 4.9689 & TRN \\
\hline CHEMBL1623028 & 688341 & 4.6 & 5.078 & TST \\
\hline CHEMBL45068 & 688341 & 4.8 & 5.0203 & TST \\
\hline
\end{tabular}




\begin{tabular}{|c|c|c|c|c|c|}
\hline & & & & & \\
\hline CHEMBL1489374 & 688341 & 4.4 & 4.9473 & TRN & \\
\hline CHEMBL1525668 & 688341 & 5.1 & 4.9365 & TRN & \\
\hline CHEMBL1395737 & 688341 & 5.9 & 5.0973 & TRN & \\
\hline CHEMBL1563397 & 688341 & 4.8 & 4.9749 & TRN & \\
\hline CHEMBL3192909 & 688341 & 5.2 & 5.0053 & TRN & \\
\hline CHEMBL1392276 & 688341 & 5.2 & 4.8758 & TRN & \\
\hline CHEMBL1443347 & 688341 & 4.5 & 4.8956 & TRN & \\
\hline CHEMBL1584048 & 688341 & 5.1 & 4.9526 & TRN & \\
\hline CHEMBL1311756 & 688341 & 4.5 & 4.8796 & TRN & \\
\hline CHEMBL1579239 & 688341 & 4.6 & 4.9347 & TRN & \\
\hline CHEMBL1452199 & 688341 & 5.5 & 5.0756 & TRN & \\
\hline CHEMBL1535127 & 688341 & 4.6 & 5.0046 & TRN & \\
\hline CHEMBL1587071 & 688341 & 4.9 & 5.032 & TRN & \\
\hline CHEMBL1518275 & 688341 & 4.5 & 4.885 & TRN & \\
\hline CHEMBL1487087 & 688341 & 4.6 & 4.8956 & TST & \\
\hline CHEMBL66105 & 688341 & 4.6 & 5.0674 & TST & \\
\hline CHEMBL1490804 & 688341 & 4.6 & 4.7698 & TRN & \\
\hline CHEMBL1508989 & 688341 & 4.6 & 4.7884 & TRN & \\
\hline CHEMBL1589502 & 688341 & 4.6 & 5.1285 & TRN & \\
\hline CHEMBL1438166 & 688341 & 5.5 & 5.0404 & TRN & \\
\hline CHEMBL1488590 & 688341 & 4.5 & 4.8549 & TRN & \\
\hline CHEMBL1552588 & 688341 & 5.3 & 5.17899 & 9999999999 & TRN \\
\hline CHEMBL1300721 & 688341 & 4.7 & 4.9944 & TRN & \\
\hline CHEMBL1321624 & 688341 & 5.4 & 5.28799 & 9999999999 & TRN \\
\hline CHEMBL1362068 & 688341 & 5.4 & 5.1808 & TRN & \\
\hline CHEMBL1389757 & 688341 & 5.0 & 4.8035 & TRN & \\
\hline CHEMBL1311973 & 688341 & 4.6 & 4.9971 & TRN & \\
\hline CHEMBL1303331 & 688341 & 6.8 & 4.9271 & TRN & \\
\hline CHEMBL1303383 & 688341 & 5.4 & 5.0308 & TRN & \\
\hline CHEMBL1557460 & 688341 & 5.2 & 4.9369 & TST & \\
\hline CHEMBL1401209 & 688341 & 4.7 & 4.9189 & TRN & \\
\hline CHEMBL1329708 & 688341 & 4.5 & 4.7807 & TRN & \\
\hline CHEMBL3207451 & 688341 & 4.4 & 5.1061 & TST & \\
\hline CHEMBL1589098 & 688341 & 4.4 & 4.9312 & TRN & \\
\hline CHEMBL18104 & 688341 & 5.1 & 5.2409 & TRN & \\
\hline CHEMBL1423568 & 688341 & 4.5 & 4.9611 & TST & \\
\hline CHEMBL1413443 & 688341 & 5.1 & 4.872 & TRN & \\
\hline CHEMBL1328092 & 688341 & 5.3 & 4.9904 & TRN & \\
\hline CHEMBL1595866 & 688341 & 5.0 & 4.9413 & TST & \\
\hline CHEMBL1486250 & 688341 & 4.5 & 4.9811 & TRN & \\
\hline CHEMBL1590213 & 688341 & 4.6 & 5.0459 & TRN & \\
\hline CHEMBL1401442 & 688341 & 4.6 & 4.9522 & TRN & \\
\hline CHEMBL1540962 & 688341 & 4.6 & 4.8758 & TRN & \\
\hline CHEMBL1446523 & 688341 & 4.6 & 4.8839 & TRN & \\
\hline CHEMBL1397238 & 688341 & 5.2 & 5.1369 & TRN & \\
\hline CHEMBL1442912 & 688341 & 6.2 & 5.0278 & TRN & \\
\hline CHEMBL1339537 & 688341 & 4.4 & 4.8602 & TRN & \\
\hline CHEMBL1558599 & 688341 & 5.8 & 5.1612 & TST & \\
\hline & & & & 20669 & \\
\hline
\end{tabular}




\begin{tabular}{|c|c|c|c|c|c|}
\hline \multicolumn{6}{|c|}{ Supplemental Table S2.txt } \\
\hline CHEMBL1495845 & 688341 & 5.5 & 4.8405 & TRN & \\
\hline CHEMBL1405342 & 688341 & 5.3 & 4.7004 & TRN & \\
\hline CHEMBL1432721 & 688341 & 4.9 & 4.879 & TRN & \\
\hline CHEMBL1305287 & 688341 & 4.9 & 4.86600 & 00000000005 & TRN \\
\hline CHEMBL1377212 & 688341 & 5.3 & 4.8644 & TRN & \\
\hline CHEMBL443949 & 688341 & 4.4 & 5.2513 & TST & \\
\hline CHEMBL1481561 & 688341 & 4.7 & 4.8463 & TRN & \\
\hline CHEMBL1432753 & 688341 & 5.9 & 5.0237 & TST & \\
\hline CHEMBL1482431 & 688341 & 4.5 & 4.8198 & TRN & \\
\hline CHEMBL1367737 & 688341 & 5.7 & 4.9033 & TST & \\
\hline CHEMBL1606519 & 688341 & 4.5 & 4.6427 & TRN & \\
\hline CHEMBL1444183 & 688341 & 5.1 & 4.9716 & TRN & \\
\hline CHEMBL1435296 & 688341 & 4.8 & 5.1299 & TRN & \\
\hline CHEMBL1538675 & 688341 & 6.0 & 4.9831 & TRN & \\
\hline CHEMBL1520775 & 688341 & 5.6 & 4.9253 & TRN & \\
\hline CHEMBL1312087 & 688341 & 4.6 & 4.9425 & TRN & \\
\hline CHEMBL1388874 & 688341 & 5.5 & 4.9055 & TST & \\
\hline CHEMBL1509221 & 688341 & 6.0 & 5.0788 & TRN & \\
\hline CHEMBL1502097 & 688341 & 7.1002 & 5.1806 & TRN & \\
\hline CHEMBL1444271 & 688341 & 4.6 & 4.8247 & TST & \\
\hline CHEMBL1567897 & 688341 & 4.4 & 4.7335 & TRN & \\
\hline CHEMBL1381205 & 688341 & 4.8 & 4.7414 & TRN & \\
\hline CHEMBL474415 & 688341 & 4.4 & 5.1065 & TRN & \\
\hline CHEMBL1483555 & 688341 & 4.7 & 4.8586 & TRN & \\
\hline CHEMBL1487702 & 688341 & 5.3 & 4.9786 & TST & \\
\hline CHEMBL1406919 & 688341 & 4.9 & 4.9644 & TRN & \\
\hline CHEMBL1402258 & 688341 & 5.7 & 4.9692 & TRN & \\
\hline CHEMBL1471463 & 688341 & 7.0 & 5.0801 & TST & \\
\hline CHEMBL1357724 & 688341 & 5.0 & 5.1007 & TRN & \\
\hline CHEMBL1418716 & 688341 & 4.7 & 4.9626 & TRN & \\
\hline CHEMBL1310359 & 688341 & 4.9 & 4.8508 & TRN & \\
\hline CHEMBL1463703 & 688341 & 4.7 & 4.9344 & TST & \\
\hline CHEMBL1312038 & 688341 & 4.5 & 4.7467 & TRN & \\
\hline CHEMBL1367593 & 688341 & 4.7 & 4.8984 & TST & \\
\hline CHEMBL1605780 & 688341 & 5.2 & 4.7414 & TRN & \\
\hline CHEMBL1421600 & 688341 & 5.2 & 4.9414 & TST & \\
\hline CHEMBL3212480 & 688341 & 4.8 & 4.9954 & TRN & \\
\hline CHEMBL1372997 & 688341 & 7.0 & 5.0366 & TST & \\
\hline CHEMBL1389202 & 688341 & 4.4 & 4.8593 & TRN & \\
\hline CHEMBL1309238 & 688341 & 4.5 & 5.0589 & TST & \\
\hline CHEMBL3196987 & 688341 & 4.6 & 4.8557 & TRN & \\
\hline CHEMBL1366393 & 688341 & 4.5 & 4.9729 & TRN & \\
\hline CHEMBL1532659 & 688341 & 4.6 & 4.965 & TRN & \\
\hline CHEMBL1474534 & 688341 & 5.4 & 4.9848 & TST & \\
\hline CHEMBL1450001 & 688341 & 4.6 & 4.944 & TRN & \\
\hline CHEMBL1359452 & 688341 & 4.5 & 5.0098 & TRN & \\
\hline CHEMBL1529663 & 688341 & 5.2 & 4.9419 & TRN & \\
\hline CHEMBL1331931 & 688341 & 5.7 & 4.8773 & TST & \\
\hline
\end{tabular}




\begin{tabular}{|c|c|c|c|c|c|}
\hline CHEMBL1470796 & 688341 & 5.0 & 4.8725 & TST & \\
\hline CHEMBL1430754 & 688341 & 5.0 & 4.9428 & TRN & \\
\hline CHEMBL1428087 & 688341 & 4.8 & 4.8932 & TRN & \\
\hline CHEMBL1302808 & 688341 & 4.8 & 5.0227 & TST & \\
\hline CHEMBL1520645 & 688341 & 5.4 & 4.9999 & TRN & \\
\hline CHEMBL1496747 & 688341 & 4.8 & 4.8067 & TRN & \\
\hline CHEMBL1576757 & 688341 & 4.9 & 4.7853 & TRN & \\
\hline CHEMBL1601159 & 688341 & 4.4 & 5.1054 & TRN & \\
\hline CHEMBL1506315 & 688341 & 4.4 & 5.0856 & TST & \\
\hline CHEMBL1481844 & 688341 & 4.8 & 4.9265 & TRN & \\
\hline CHEMBL1472056 & 688341 & 4.6 & 4.9538 & TST & \\
\hline CHEMBL1465461 & 688341 & 4.8 & 4.8748 & TRN & \\
\hline CHEMBL1613268 & 688341 & 4.8 & 4.9732 & TRN & \\
\hline CHEMBL1455212 & 688341 & 5.2 & 4.9561 & TRN & \\
\hline CHEMBL1405376 & 688341 & 4.5 & 4.8318 & TRN & \\
\hline CHEMBL1353986 & 688341 & 4.5 & 4.9239 & TRN & \\
\hline CHEMBL437450 & 688341 & 4.7 & 5.0932 & TRN & \\
\hline CHEMBL1371286 & 688341 & 4.6 & 4.8825 & TRN & \\
\hline CHEMBL1349712 & 688341 & 5.0 & 4.8546 & TST & \\
\hline CHEMBL1576122 & 688341 & 4.8 & 5.0218 & TRN & \\
\hline CHEMBL1444064 & 688341 & 4.9 & 4.8261 & TRN & \\
\hline CHEMBL1488216 & 688341 & 5.2 & 4.7289 & TRN & \\
\hline CHEMBL1459960 & 688341 & 5.3 & 5.0183 & TST & \\
\hline CHEMBL1571364 & 688341 & 4.8 & 4.7663 & TRN & \\
\hline CHEMBL1478609 & 688341 & 4.6 & 4.8774 & TRN & \\
\hline CHEMBL1403178 & 688341 & 5.3 & 4.8797 & TRN & \\
\hline CHEMBL1373505 & 688341 & 4.6 & 4.9036 & TRN & \\
\hline CHEMBL1424372 & 688341 & 4.9 & 4.8969 & TRN & \\
\hline CHEMBL1456452 & 688341 & 7.0 & 4.9312 & TRN & \\
\hline CHEMBL1538288 & 688341 & 6.1 & 5.0886 & TST & \\
\hline CHEMBL1367129 & 688341 & 5.2 & 4.831 & TRN & \\
\hline CHEMBL1490740 & 688341 & 4.9 & 5.0866 & TRN & \\
\hline CHEMBL1590081 & 688341 & 6.1 & 5.1836 & TRN & \\
\hline CHEMBL1323451 & 688341 & 4.4 & 4.7787 & TST & \\
\hline CHEMBL57394 & 688341 & 4.4 & 4.9616 & TRN & \\
\hline CHEMBL1538993 & 688341 & 4.8 & 4.9046 & TRN & \\
\hline CHEMBL1610228 & 688341 & 4.4 & 4.973 & TRN & \\
\hline CHEMBL1459729 & 688341 & 4.4 & 4.8536 & TRN & \\
\hline CHEMBL1322199 & 688341 & 4.7 & 4.8272 & TRN & \\
\hline CHEMBL1589279 & 688341 & 4.8 & 4.837 & TRN & \\
\hline CHEMBL1471355 & 688341 & 4.7 & 5.0783 & TRN & \\
\hline CHEMBL1529543 & 688341 & 5.4 & 5.1218 & TRN & \\
\hline CHEMBL1405306 & 688341 & 4.7 & 4.7777 & TRN & \\
\hline CHEMBL1496055 & 688341 & 4.6 & 4.8367 & TRN & \\
\hline CHEMBL1340087 & 688341 & 5.2 & \multicolumn{2}{|c|}{4.986000000000001} & TRN \\
\hline CHEMBL1549988 & 688341 & 5.2 & 4.8714 & TST & \\
\hline CHEMBL1333556 & 688341 & 4.5 & 4.8883 & TST & \\
\hline CHEMBL1524567 & 688341 & 4.5 & 5.0221 & TRN & \\
\hline
\end{tabular}




\begin{tabular}{|c|c|c|c|c|}
\hline \multicolumn{5}{|c|}{ Supplemental Table S2.txt } \\
\hline CHEMBL1352160 & 688341 & 4.5 & 4.7884 & TRN \\
\hline CHEMBL1561433 & 688341 & 5.3 & 4.7225 & TRN \\
\hline CHEMBL1454920 & 688341 & 6.1 & 4.9928 & TRN \\
\hline CHEMBL1443380 & 688341 & 4.5 & 4.9771 & TRN \\
\hline CHEMBL1331292 & 688341 & 4.4 & 5.0805 & TST \\
\hline CHEMBL1516381 & 688341 & 5.3 & 4.7686 & TRN \\
\hline CHEMBL489943 & 688341 & 4.5 & 5.2972 & TRN \\
\hline CHEMBL1423574 & 688341 & 7.5003 & 4.8664 & TRN \\
\hline CHEMBL1562104 & 688341 & 5.1 & 5.0603 & TST \\
\hline CHEMBL1600726 & 688341 & 4.7 & 4.7275 & TRN \\
\hline CHEMBL1603515 & 688341 & 4.5 & 4.9096 & TRN \\
\hline CHEMBL1594935 & 688341 & 5.2 & 5.1706 & TST \\
\hline CHEMBL1478935 & 688341 & 5.3 & 4.9913 & TST \\
\hline CHEMBL1336489 & 688341 & 4.4 & 4.8385 & TRN \\
\hline CHEMBL1589156 & 688341 & 4.6 & 4.8638 & TST \\
\hline CHEMBL1406011 & 688341 & 7.0 & 4.897 & TRN \\
\hline CHEMBL1436763 & 688341 & 5.2 & 5.0421 & TRN \\
\hline CHEMBL1347871 & 688341 & 4.8 & 4.8245 & TRN \\
\hline CHEMBL1574279 & 688341 & 4.4 & 4.8505 & TST \\
\hline CHEMBL1525470 & 688341 & 4.8 & 4.8422 & TST \\
\hline CHEMBL1418470 & 688341 & 6.0 & 4.916 & TRN \\
\hline CHEMBL1430092 & 688341 & 4.5 & 4.8724 & TRN \\
\hline CHEMBL1583709 & 688341 & 4.5 & 5.1614 & TRN \\
\hline CHEMBL1525939 & 688341 & 4.4 & 4.8289 & TRN \\
\hline CHEMBL1358631 & 688341 & 4.8 & 5.2 & TRN \\
\hline CHEMBL1328097 & 688341 & 5.2 & 4.9855 & TST \\
\hline CHEMBL1420677 & 688341 & 4.6 & 4.9699 & TRN \\
\hline CHEMBL1427147 & 688341 & 4.6 & 4.8252 & TRN \\
\hline CHEMBL1368175 & 688341 & 4.8 & 4.9213 & TRN \\
\hline CHEMBL1359108 & 688341 & 6.7001 & 5.2346 & TRN \\
\hline CHEMBL1414912 & 688341 & 5.2 & 4.9876 & TRN \\
\hline CHEMBL1323215 & 688341 & 5.4 & 5.043 & TRN \\
\hline CHEMBL1574881 & 688341 & 4.5 & 4.9948 & TRN \\
\hline CHEMBL1327908 & 688341 & 4.6 & 4.7975 & TST \\
\hline CHEMBL1562750 & 688341 & 4.8 & 4.9374 & TRN \\
\hline CHEMBL1430852 & 688341 & 4.6 & 4.8081 & TRN \\
\hline CHEMBL1490516 & 688341 & 5.0 & 4.9061 & TRN \\
\hline CHEMBL1455133 & 688341 & 4.8 & 4.9395 & TRN \\
\hline CHEMBL1322959 & 688341 & 5.6 & 5.2164 & TST \\
\hline CHEMBL1339329 & 688341 & 4.6 & 5.0712 & TRN \\
\hline CHEMBL1371834 & 688341 & 4.6 & 4.879 & TRN \\
\hline CHEMBL1596996 & 688341 & 4.5 & 4.9909 & TRN \\
\hline CHEMBL1403484 & 688341 & 5.8 & 5.0873 & TST \\
\hline CHEMBL1612795 & 688341 & 4.4 & 4.9312 & TRN \\
\hline CHEMBL1441618 & 688341 & 4.5 & 4.8824 & TRN \\
\hline CHEMBL1415937 & 688341 & 5.1 & 4.6433 & TRN \\
\hline CHEMBL1591876 & 688341 & 5.3 & 4.8917 & TRN \\
\hline CHEMBL3211124 & 688341 & 4.4 & 5.0679 & TST \\
\hline
\end{tabular}




\begin{tabular}{|c|c|c|c|c|}
\hline \multicolumn{5}{|c|}{ Supplemental Table S2.txt } \\
\hline CHEMBL1396773 & 688341 & 4.9 & 5.086 & TRN \\
\hline CHEMBL1430160 & 688341 & 4.4 & 4.8884 & TRN \\
\hline CHEMBL1591779 & 688341 & 5.3 & 4.9346 & TRN \\
\hline CHEMBL1329790 & 688341 & 4.4 & 5.0672 & TST \\
\hline CHEMBL1550528 & 688341 & 4.6 & 4.8331 & TRN \\
\hline CHEMBL1307167 & 688341 & 5.2 & 4.8777 & TRN \\
\hline CHEMBL1330096 & 688341 & 5.1 & 4.9142 & TRN \\
\hline CHEMBL1373190 & 688341 & 5.0 & 4.9801 & TRN \\
\hline CHEMBL1305863 & 688341 & 4.4 & 4.8192 & TST \\
\hline CHEMBL1578595 & 688341 & 7.2 & 4.8148 & TRN \\
\hline CHEMBL1441216 & 688341 & 4.7 & 5.1004 & TRN \\
\hline CHEMBL1382377 & 688341 & 5.4 & 5.1083 & TRN \\
\hline CHEMBL1345867 & 688341 & 4.4 & 4.9724 & TRN \\
\hline CHEMBL1386667 & 688341 & 5.1 & 5.0573 & TST \\
\hline CHEMBL1545766 & 688341 & 6.0 & 4.9721 & TST \\
\hline CHEMBL1595774 & 688341 & 4.6 & 4.8732 & TRN \\
\hline CHEMBL1348426 & 688341 & 5.2 & 5.1041 & TST \\
\hline CHEMBL1441711 & 688341 & 4.4 & 4.8821 & TRN \\
\hline CHEMBL1497762 & 688341 & 4.4 & 5.0122 & TRN \\
\hline CHEMBL1613658 & 688341 & 6.1 & 4.948 & TST \\
\hline CHEMBL1601116 & 688341 & 4.4 & 4.8835 & TRN \\
\hline CHEMBL1447625 & 688341 & 4.4 & 4.8355 & TRN \\
\hline CHEMBL1601135 & 688341 & 4.8 & 4.8005 & TRN \\
\hline CHEMBL1403311 & 688341 & 4.5 & 4.9489 & TST \\
\hline CHEMBL1488467 & 688341 & 4.8 & 5.0953 & TST \\
\hline CHEMBL37708 & 688341 & 5.4 & 4.8952 & TST \\
\hline CHEMBL1613110 & 688341 & 4.6 & 4.9793 & TST \\
\hline CHEMBL3207743 & 688341 & 4.5 & 5.2257 & TST \\
\hline CHEMBL1387820 & 688341 & 4.4 & 4.9498 & TRN \\
\hline CHEMBL1341157 & 688341 & 4.4 & 4.8 & TRN \\
\hline CHEMBL1560725 & 688341 & 5.0 & 4.9332 & TRN \\
\hline CHEMBL1574587 & 688341 & 4.7 & 4.859 & TST \\
\hline CHEMBL1406408 & 688341 & 5.0 & 5.1086 & TRN \\
\hline CHEMBL1404783 & 688341 & 5.2 & 5.0081 & TST \\
\hline CHEMBL1311707 & 688341 & 4.7 & 4.8565 & TST \\
\hline CHEMBL1537788 & 688341 & 4.5 & 4.9596 & TST \\
\hline CHEMBL1333484 & 688341 & 5.1 & 4.8069 & TRN \\
\hline CHEMBL1448288 & 688341 & 4.7 & 5.1259 & TRN \\
\hline CHEMBL1467967 & 688341 & 5.3 & 5.0087 & TRN \\
\hline CHEMBL1370957 & 688341 & 4.6 & 4.8365 & TRN \\
\hline CHEMBL1328413 & 688341 & 4.6 & 4.9303 & TRN \\
\hline CHEMBL1332958 & 688341 & 4.4 & 4.7796 & TRN \\
\hline CHEMBL1320937 & 688341 & 5.2 & 4.8248 & TRN \\
\hline CHEMBL1592464 & 688341 & 4.4 & 5.1611 & TRN \\
\hline CHEMBL1458268 & 688341 & 4.9 & 5.0301 & TRN \\
\hline CHEMBL1563783 & 688341 & 4.7 & 5.1152 & TRN \\
\hline CHEMBL1525504 & 688341 & 4.7 & 5.0617 & TST \\
\hline CHEMBL1328745 & 688341 & 4.5 & 4.8675 & TRN \\
\hline
\end{tabular}




\begin{tabular}{|c|c|c|c|c|c|}
\hline \multicolumn{6}{|c|}{ Supplemental Table S2.txt } \\
\hline CHEMBL1543716 & 688341 & 4.8 & 5.0271 & TRN & \\
\hline CHEMBL1408947 & 688341 & 4.7 & 4.8865 & TST & \\
\hline CHEMBL1336496 & 688341 & 4.6 & 4.832 & TRN & \\
\hline CHEMBL1450313 & 688341 & 5.2 & 5.0528 & TRN & \\
\hline CHEMBL1326553 & 688341 & 4.8 & 5.1074 & TRN & \\
\hline CHEMBL1571445 & 688341 & 5.5 & 4.9824 & TST & \\
\hline CHEMBL1595337 & 688341 & 5.8 & 4.9892 & TST & \\
\hline CHEMBL1530269 & 688341 & 4.8 & 4.9505 & TST & \\
\hline CHEMBL1584686 & 688341 & 4.4 & 4.8237 & TST & \\
\hline CHEMBL1603676 & 688341 & 4.5 & 4.7852 & TRN & \\
\hline CHEMBL1393509 & 688341 & 4.8 & 4.8947 & TRN & \\
\hline CHEMBL1529842 & 688341 & 4.4 & 4.82 & TRN & \\
\hline CHEMBL1539477 & 688341 & 4.5 & 4.9594 & TRN & \\
\hline CHEMBL1311095 & 688341 & 5.0 & 4.9644 & TRN & \\
\hline CHEMBL1418677 & 688341 & 4.6 & 4.90606 & 0000000001 & TST \\
\hline CHEMBL1329237 & 688341 & 4.5 & 4.7633 & TRN & \\
\hline CHEMBL1571568 & 688341 & 6.8 & 5.0316 & TRN & \\
\hline CHEMBL1335360 & 688341 & 4.4 & 4.9175 & TST & \\
\hline CHEMBL1498510 & 688341 & 5.2 & 4.8757 & TRN & \\
\hline CHEMBL1424395 & 688341 & 4.6 & 4.9051 & TRN & \\
\hline CHEMBL1312521 & 688341 & 4.8 & 4.9066 & TRN & \\
\hline CHEMBL1430700 & 688341 & 6.7001 & 4.8965 & TRN & \\
\hline CHEMBL1370553 & 688341 & 4.8 & 5.0244 & TRN & \\
\hline CHEMBL1308630 & 688341 & 5.2 & 5.1898 & TRN & \\
\hline CHEMBL551883 & 688341 & 5.8 & 5.053 & TRN & \\
\hline CHEMBL1351353 & 688341 & 4.8 & 4.9442 & TST & \\
\hline CHEMBL1452728 & 688341 & 5.3 & 4.731 & TST & \\
\hline CHEMBL1313855 & 688341 & 6.0 & 5.0151 & TRN & \\
\hline CHEMBL1452251 & 688341 & 5.6 & 5.0064 & TRN & \\
\hline CHEMBL1603782 & 688341 & 4.4 & 4.968 & TST & \\
\hline CHEMBL1415693 & 688341 & 4.6 & 5.0078 & TRN & \\
\hline CHEMBL1581955 & 688341 & 5.2 & 4.9458 & TRN & \\
\hline CHEMBL1543903 & 688341 & 4.6 & 4.9821 & TRN & \\
\hline CHEMBL1558777 & 688341 & 5.2 & 5.0621 & TRN & \\
\hline CHEMBL1235226 & 688341 & 5.0 & 5.13206 & 2000000001 & TRN \\
\hline CHEMBL1370174 & 688341 & 5.3 & 4.9261 & TRN & \\
\hline CHEMBL1517593 & 688341 & 4.4 & 4.8857 & TST & \\
\hline CHEMBL1338891 & 688341 & 5.1 & 4.8836 & TRN & \\
\hline CHEMBL1540738 & 688341 & 4.6 & 4.988 & TRN & \\
\hline CHEMBL1590197 & 688341 & 4.8 & 4.8145 & TRN & \\
\hline CHEMBL1550057 & 688341 & 6.0 & 4.9141 & TRN & \\
\hline CHEMBL1488678 & 688341 & 4.5 & 4.8852 & TRN & \\
\hline CHEMBL1402518 & 688341 & 5.4 & 4.9521 & TRN & \\
\hline CHEMBL1257003 & 688341 & 5.1 & 5.0999 & TST & \\
\hline CHEMBL1520172 & 688341 & 4.8 & 4.9984 & TRN & \\
\hline CHEMBL1349038 & 688341 & 5.1 & 4.9522 & TRN & \\
\hline CHEMBL1483691 & 688341 & 4.7 & 5.1102 & TST & \\
\hline CHEMBL1492840 & 688341 & 4.6 & 4.9878 & TST & \\
\hline
\end{tabular}




\begin{tabular}{|c|c|c|c|c|}
\hline \multicolumn{5}{|c|}{ Supplemental Table S2.txt } \\
\hline CHEMBL1393143 & 688341 & 4.7 & 4.7301 & TRN \\
\hline CHEMBL1602606 & 688341 & 4.6 & 4.8567 & TRN \\
\hline CHEMBL1461412 & 688341 & 4.8 & 4.8145 & TRN \\
\hline CHEMBL1474483 & 688341 & 6.7001 & 4.9598 & TRN \\
\hline CHEMBL1310661 & 688341 & 5.2 & 4.8245 & TRN \\
\hline CHEMBL1394499 & 688341 & 5.4 & 5.0837 & TRN \\
\hline CHEMBL481537 & 688341 & 4.5 & 4.9336 & TST \\
\hline CHEMBL1586626 & 688341 & 5.2 & 5.0913 & TRN \\
\hline CHEMBL1473707 & 688341 & 5.4 & 5.1424 & TRN \\
\hline CHEMBL1329528 & 688341 & 4.6 & 4.8624 & TRN \\
\hline CHEMBL1408257 & 688341 & 4.6 & 4.9068 & TRN \\
\hline CHEMBL119556 & 688341 & 4.5 & 4.9271 & TST \\
\hline CHEMBL1589018 & 688341 & 4.4 & 4.9557 & TST \\
\hline CHEMBL1477117 & 688341 & 5.4 & 4.9667 & TRN \\
\hline CHEMBL1532948 & 688341 & 5.2 & 5.0196 & TST \\
\hline CHEMBL1601477 & 688341 & 4.4 & 5.0387 & TRN \\
\hline CHEMBL1363561 & 688341 & 4.6 & 4.965 & TRN \\
\hline CHEMBL1511411 & 688341 & 4.7 & 5.2182 & TST \\
\hline CHEMBL1593071 & 688341 & 4.5 & 5.0602 & TRN \\
\hline CHEMBL1467168 & 688341 & 4.7 & 5.015 & TRN \\
\hline CHEMBL1588426 & 688341 & 4.6 & 4.8496 & TRN \\
\hline CHEMBL1422602 & 688341 & 4.6 & 4.8205 & TRN \\
\hline CHEMBL1440157 & 688341 & 4.8 & 4.9409 & TRN \\
\hline CHEMBL1306761 & 688341 & 4.9 & 5.006 & TRN \\
\hline CHEMBL1381499 & 688341 & 5.2 & 4.9956 & TRN \\
\hline CHEMBL1535689 & 688341 & 5.0 & 5.1482 & TRN \\
\hline CHEMBL1334204 & 688341 & 4.8 & 5.0052 & TRN \\
\hline CHEMBL1358591 & 688341 & 4.7 & 4.9863 & TRN \\
\hline CHEMBL3198071 & 688341 & 4.4 & 4.8577 & TRN \\
\hline CHEMBL1309441 & 688341 & 4.4 & 4.9634 & TRN \\
\hline CHEMBL1475484 & 688341 & 5.1 & 5.1376 & TRN \\
\hline CHEMBL1448249 & 688341 & 5.2 & 4.977 & TRN \\
\hline CHEMBL1366334 & 688341 & 4.6 & 4.9058 & TRN \\
\hline CHEMBL1569309 & 688341 & 5.9 & 4.9761 & TRN \\
\hline CHEMBL1487016 & 688341 & 4.6 & 4.8777 & TRN \\
\hline CHEMBL1383992 & 688341 & 4.4 & 5.1817 & TRN \\
\hline CHEMBL1441883 & 688341 & 4.6 & 4.7832 & TRN \\
\hline CHEMBL1320946 & 688341 & 5.0 & 4.8446 & TRN \\
\hline CHEMBL1490654 & 688341 & 5.5 & 4.9532 & TST \\
\hline CHEMBL579219 & 688341 & 4.4 & 4.8657 & TRN \\
\hline CHEMBL1312013 & 688341 & 4.8 & 4.9295 & TRN \\
\hline CHEMBL1576215 & 688341 & 4.5 & 4.8515 & TST \\
\hline CHEMBL1496189 & 688341 & 4.8 & 4.8766 & TST \\
\hline CHEMBL1333531 & 688341 & 5.4 & 5.0675 & TRN \\
\hline CHEMBL1373766 & 688341 & 4.6 & 4.9244 & TRN \\
\hline CHEMBL1357157 & 688341 & 5.9 & 5.0608 & TST \\
\hline CHEMBL1470214 & 688341 & 4.6 & 4.9925 & TRN \\
\hline CHEMBL1412443 & 688341 & 5.1 & 4.9847 & TRN \\
\hline
\end{tabular}




\begin{tabular}{|c|c|c|c|c|c|}
\hline & & & & & \\
\hline CHEMBL1525434 & 688341 & 4.6 & 4.8497 & TRN & \\
\hline CHEMBL1548726 & 688341 & 4.6 & 5.1931 & TRN & \\
\hline CHEMBL1471303 & 688341 & 4.7 & 4.8065 & TRN & \\
\hline CHEMBL1256911 & 688341 & 4.8 & 5.1838 & TST & \\
\hline CHEMBL1402717 & 688341 & 5.1 & 4.9392 & TRN & \\
\hline CHEMBL1382882 & 688341 & 5.3 & 4.9055 & TST & \\
\hline CHEMBL1487937 & 688341 & 5.4 & 5.0359 & TRN & \\
\hline CHEMBL1599748 & 688341 & 4.7 & 4.987 & TRN & \\
\hline CHEMBL1305544 & 688341 & 6.4 & 5.0288 & TRN & \\
\hline CHEMBL1300731 & 688341 & 4.8 & 4.8215 & TRN & \\
\hline CHEMBL1407762 & 688341 & 4.6 & 5.0415 & TRN & \\
\hline CHEMBL1411381 & 688341 & 4.5 & 4.9704 & TRN & \\
\hline CHEMBL1562510 & 688341 & 4.4 & 5.1766 & TRN & \\
\hline CHEMBL1443192 & 688341 & 4.6 & 5.119 & TST & \\
\hline CHEMBL1561554 & 688341 & 4.9 & 4.9174 & TRN & \\
\hline CHEMBL1485898 & 688341 & 4.7 & 4.772 & TRN & \\
\hline CHEMBL1432954 & 688341 & 5.2 & 5.0665 & TST & \\
\hline CHEMBL1458707 & 688341 & 4.8 & $5.0760 e$ & 20000000005 & TRN \\
\hline CHEMBL1543331 & 688341 & 4.4 & 4.9757 & TST & \\
\hline CHEMBL1420834 & 688341 & 4.4 & 4.9585 & TRN & \\
\hline CHEMBL1470063 & 688341 & 4.8 & 4.6952 & TRN & \\
\hline CHEMBL1413521 & 688341 & 4.7 & 4.8425 & TRN & \\
\hline CHEMBL1372780 & 688341 & 4.6 & 4.7498 & TRN & \\
\hline CHEMBL1312797 & 688341 & 5.8 & 5.0607 & TRN & \\
\hline CHEMBL1391474 & 688341 & 4.5 & 4.9553 & TST & \\
\hline CHEMBL1445084 & 688341 & 4.6 & 4.9847 & TRN & \\
\hline CHEMBL1556175 & 688341 & 4.8 & 4.8818 & TRN & \\
\hline CHEMBL1400901 & 688341 & 4.5 & 4.9028 & TRN & \\
\hline CHEMBL1325194 & 688341 & 5.5 & 5.0711 & TST & \\
\hline CHEMBL1463915 & 688341 & 6.0 & 5.0114 & TST & \\
\hline CHEMBL3212799 & 688341 & 4.6 & 5.0585 & TRN & \\
\hline CHEMBL1318616 & 688341 & 4.7 & 5.0979 & TRN & \\
\hline CHEMBL1567516 & 688341 & 5.9 & 5.1508 & TST & \\
\hline CHEMBL1256943 & 688341 & 4.4 & 4.9395 & TRN & \\
\hline CHEMBL1303167 & 688341 & 5.2 & 4.9309 & TST & \\
\hline CHEMBL1311124 & 688341 & 4.4 & 4.7675 & TRN & \\
\hline CHEMBL1349095 & 688341 & 4.6 & 5.0288 & TST & \\
\hline CHEMBL1255659 & 688341 & 5.2 & 4.8997 & TST & \\
\hline CHEMBL1349329 & 688341 & 5.4 & 4.8204 & TRN & \\
\hline CHEMBL1459254 & 688341 & 4.6 & 4.9755 & TST & \\
\hline CHEMBL1315268 & 688341 & 5.6 & 5.0625 & TRN & \\
\hline CHEMBL1521440 & 688341 & 4.6 & 5.1361 & TRN & \\
\hline CHEMBL1500452 & 688341 & 4.5 & 4.9952 & TRN & \\
\hline CHEMBL1446178 & 688341 & 4.9 & 4.8534 & TRN & \\
\hline CHEMBL1412878 & 688341 & 4.4 & 4.948 & TRN & \\
\hline CHEMBL1407488 & 688341 & 4.8 & 5.0169 & TRN & \\
\hline CHEMBL1369940 & 688341 & 4.8 & 5.1341 & TRN & \\
\hline CHEMBL1333370 & 688341 & 6.3 & 4.8819 & TRN & \\
\hline & & & & 20676 & \\
\hline
\end{tabular}




\begin{tabular}{|c|c|c|c|c|c|}
\hline & & & & & \\
\hline CHEMBL1473331 & 688341 & 4.6 & 5.2453 & TRN & \\
\hline CHEMBL1592371 & 688341 & 4.9 & 5.0107 & TRN & \\
\hline CHEMBL1599755 & 688341 & 4.5 & 4.8477 & TRN & \\
\hline CHEMBL1381404 & 688341 & 5.6 & 4.9385 & TRN & \\
\hline CHEMBL1581477 & 688341 & 4.6 & 4.8967 & TRN & \\
\hline CHEMBL1409553 & 688341 & 5.0 & 4.9427 & TRN & \\
\hline CHEMBL1442216 & 688341 & 4.4 & 4.9316 & TRN & \\
\hline CHEMBL1497202 & 688341 & 4.6 & 5.0306 & TST & \\
\hline CHEMBL1534287 & 688341 & 5.5 & 4.8541 & TRN & \\
\hline CHEMBL1470847 & 688341 & 4.4 & 4.8365 & TRN & \\
\hline CHEMBL1453119 & 688341 & 4.9 & 4.7543 & TST & \\
\hline CHEMBL1488030 & 688341 & 4.6 & 4.9749 & TST & \\
\hline CHEMBL1597208 & 688341 & 4.6 & 4.9507 & TRN & \\
\hline CHEMBL1567201 & 688341 & 4.4 & 5.0383 & TRN & \\
\hline CHEMBL1447825 & 688341 & 4.6 & 4.88 & TRN & \\
\hline CHEMBL1388809 & 688341 & 5.0 & 4.90300 & 00000000005 & TRN \\
\hline CHEMBL152557 & 688341 & 4.6 & 5.2258 & TST & \\
\hline CHEMBL1449668 & 688341 & 4.9 & 5.145 & TRN & \\
\hline CHEMBL1510642 & 688341 & 5.0 & 4.8709 & TRN & \\
\hline CHEMBL1410121 & 688341 & 4.5 & 4.8447 & TRN & \\
\hline CHEMBL1358122 & 688341 & 5.9 & 5.0548 & TRN & \\
\hline CHEMBL1336328 & 688341 & 5.5 & 5.0779 & TRN & \\
\hline CHEMBL1468909 & 688341 & 4.6 & 4.8214 & TRN & \\
\hline CHEMBL1445178 & 688341 & 4.5 & 4.9673 & TRN & \\
\hline CHEMBL1498283 & 688341 & 4.4 & 4.8694 & TRN & \\
\hline CHEMBL1609093 & 688341 & 4.8 & 5.0628 & TRN & \\
\hline CHEMBL1468529 & 688341 & 4.8 & 5.0395 & TRN & \\
\hline CHEMBL1408077 & 688341 & 5.4 & 5.0524 & TRN & \\
\hline CHEMBL1458690 & 688341 & 5.1 & 4.7387 & TRN & \\
\hline CHEMBL1580880 & 688341 & 4.7 & 4.9043 & TRN & \\
\hline CHEMBL20866 & 688341 & 5.2 & 5.0638 & TST & \\
\hline CHEMBL1595845 & 688341 & 4.4 & 5.0979 & TST & \\
\hline CHEMBL1537596 & 688341 & 4.4 & 5.1046 & TRN & \\
\hline CHEMBL1599370 & 688341 & 4.6 & 4.9687 & TST & \\
\hline CHEMBL1470726 & 688341 & 4.7 & 4.8894 & TRN & \\
\hline CHEMBL1590270 & 688341 & 5.0 & 5.1949 & TRN & \\
\hline CHEMBL1391187 & 688341 & 4.7 & 4.923 & TRN & \\
\hline CHEMBL1345275 & 688341 & 5.3 & 5.0707 & TRN & \\
\hline CHEMBL1444568 & 688341 & 4.8 & 5.0445 & TRN & \\
\hline CHEMBL1529151 & 688341 & 4.8 & 5.0261 & TRN & \\
\hline CHEMBL1500078 & 688341 & 5.8 & 4.8465 & TRN & \\
\hline CHEMBL1586450 & 688341 & 4.4 & 5.0071 & TRN & \\
\hline CHEMBL1420172 & 688341 & 4.8 & 4.7017 & TRN & \\
\hline CHEMBL1335008 & 688341 & 5.2 & 5.0134 & TRN & \\
\hline CHEMBL1318943 & 688341 & 4.6 & 5.1221 & TRN & \\
\hline CHEMBL1200471 & 688341 & 5.2 & 5.0372 & TST & \\
\hline CHEMBL1362467 & 688341 & 4.4 & 4.9576 & TRN & \\
\hline CHEMBL1507590 & 688341 & 5.1 & 4.9386 & TRN & \\
\hline
\end{tabular}




\begin{tabular}{|c|c|c|c|c|c|}
\hline \multicolumn{6}{|c|}{ Supplemental Table S2.txt } \\
\hline CHEMBL1505375 & 688341 & 5.0 & 5.0108 & TRN & \\
\hline CHEMBL1418307 & 688341 & 4.6 & 5.1487 & TST & \\
\hline CHEMBL1531499 & 688341 & 6.0 & 5.1702 & TST & \\
\hline CHEMBL1608226 & 688341 & 4.4 & 4.8067 & TST & \\
\hline CHEMBL1595964 & 688341 & 4.9 & 4.8306 & TST & \\
\hline CHEMBL21015 & 688341 & 4.9 & 4.9494 & TRN & \\
\hline CHEMBL1381853 & 688341 & 4.5 & 5.112 & TST & \\
\hline CHEMBL1451329 & 688341 & 4.6 & 4.9853 & TRN & \\
\hline CHEMBL1594078 & 688341 & 4.8 & 5.1132 & TRN & \\
\hline CHEMBL1490638 & 688341 & 5.0 & 4.8405 & TRN & \\
\hline CHEMBL1577505 & 688341 & 5.5 & 4.9789 & TRN & \\
\hline CHEMBL41680 & 688341 & 6.1 & 5.1485 & TST & \\
\hline CHEMBL1387717 & 688341 & 5.0 & 4.9942 & TRN & \\
\hline CHEMBL1332292 & 688341 & 4.4 & 5.0042 & TRN & \\
\hline CHEMBL1476049 & 688341 & 4.8 & 4.8625 & TRN & \\
\hline CHEMBL1547865 & 688341 & 4.4 & 4.9703 & TST & \\
\hline CHEMBL1457471 & 688341 & 4.8 & 4.9346 & TRN & \\
\hline CHEMBL1609757 & 688341 & 4.6 & 4.8248 & TRN & \\
\hline CHEMBL3145067 & 688341 & 4.6 & 4.9293 & TST & \\
\hline CHEMBL1367173 & 688341 & 4.9 & 4.864 & TRN & \\
\hline CHEMBL1312427 & 688341 & 4.4 & 4.8875 & TST & \\
\hline CHEMBL1411746 & 688341 & 6.0 & 4.9338 & TST & \\
\hline CHEMBL1386243 & 688341 & 4.6 & 4.9086 & TRN & \\
\hline CHEMBL1324618 & 688341 & 5.4 & 4.84399 & 9999999999 & TRN \\
\hline CHEMBL1330463 & 688341 & 4.6 & 4.9015 & TRN & \\
\hline CHEMBL1569640 & 688341 & 4.7 & 4.7911 & TRN & \\
\hline CHEMBL1303125 & 688341 & 5.0 & 4.9531 & TRN & \\
\hline CHEMBL1610232 & 688341 & 4.4 & 4.7808 & TRN & \\
\hline CHEMBL1577245 & 688341 & 5.1 & 5.0343 & TST & \\
\hline CHEMBL1518814 & 688341 & 4.5 & 4.8724 & TRN & \\
\hline CHEMBL1466198 & 688341 & 4.6 & 4.9232 & TST & \\
\hline CHEMBL1341351 & 688341 & 5.4 & 4.8818 & TRN & \\
\hline CHEMBL1375046 & 688341 & 6.0 & 5.15 & TRN & \\
\hline CHEMBL1499261 & 688341 & 7.8996 & 4.9616 & TRN & \\
\hline CHEMBL1401872 & 688341 & 5.2 & 4.7514 & TST & \\
\hline CHEMBL1447920 & 688341 & 5.8 & 5.1333 & TST & \\
\hline CHEMBL1504227 & 688341 & 4.4 & 4.7701 & TRN & \\
\hline CHEMBL1496752 & 688341 & 5.5 & 5.1823 & TRN & \\
\hline CHEMBL1577646 & 688341 & 4.7 & 4.8195 & TST & \\
\hline CHEMBL321691 & 688341 & 5.1 & 5.0746 & TRN & \\
\hline CHEMBL1452869 & 688341 & 5.2 & 4.9128 & TRN & \\
\hline CHEMBL1542786 & 688341 & 4.4 & 4.8758 & TRN & \\
\hline CHEMBL 278041 & 688341 & 6.0 & 4.9725 & TRN & \\
\hline CHEMBL1410920 & 688341 & 5.0 & 4.8556 & TRN & \\
\hline CHEMBL1465199 & 688341 & 4.4 & 5.16799 & 9999999999 & TST \\
\hline CHEMBL1312236 & 688341 & 5.4 & 4.6437 & TRN & \\
\hline CHEMBL1570509 & 688341 & 4.7 & 4.9351 & TRN & \\
\hline CHEMBL1387289 & 688341 & 6.0 & 5.1395 & TST & \\
\hline
\end{tabular}




\begin{tabular}{|c|c|c|c|c|}
\hline \multicolumn{5}{|c|}{ Supplemental Table S2.txt } \\
\hline CHEMBL1506872 & 688341 & 5.3 & 4.9686 & TRN \\
\hline CHEMBL1488055 & 688341 & 7.0 & 4.8097 & TRN \\
\hline CHEMBL1511986 & 688341 & 4.6 & 5.1105 & TRN \\
\hline CHEMBL1595565 & 688341 & 4.4 & 4.7723 & TRN \\
\hline CHEMBL1481551 & 688341 & 6.0 & 5.1175 & TRN \\
\hline CHEMBL1464984 & 688341 & 4.8 & 4.9873 & TRN \\
\hline CHEMBL1469018 & 688341 & 4.7 & 5.0236 & TRN \\
\hline CHEMBL1396997 & 688341 & 5.0 & 5.0279 & TRN \\
\hline CHEMBL1422775 & 688341 & 4.5 & 5.0337 & TST \\
\hline CHEMBL1582044 & 688341 & 4.6 & 4.9433 & TST \\
\hline CHEMBL1426512 & 688341 & 4.5 & 4.7624 & TRN \\
\hline CHEMBL1423070 & 688341 & 4.6 & 4.7582 & TRN \\
\hline CHEMBL1576436 & 688341 & 4.7 & 5.1111 & TRN \\
\hline CHEMBL1417852 & 688341 & 6.6 & 5.0958 & TRN \\
\hline CHEMBL1490005 & 688341 & 4.5 & 4.9732 & TRN \\
\hline CHEMBL1574741 & 688341 & 4.7 & 4.8626 & TRN \\
\hline CHEMBL1408486 & 688341 & 5.3 & 4.8064 & TRN \\
\hline CHEMBL1305634 & 688341 & 5.2 & 4.9105 & TRN \\
\hline CHEMBL1327559 & 688341 & 4.5 & 4.8027 & TRN \\
\hline CHEMBL1452111 & 688341 & 4.6 & 5.1019 & TRN \\
\hline CHEMBL1333797 & 688341 & 4.8 & 5.0098 & TRN \\
\hline CHEMBL1414426 & 688341 & 4.4 & 4.9679 & TRN \\
\hline CHEMBL1401584 & 688341 & 4.5 & 4.9019 & TRN \\
\hline CHEMBL1413962 & 688341 & 4.6 & 5.1868 & TRN \\
\hline CHEMBL1439610 & 688341 & 6.7001 & 4.9643 & TRN \\
\hline CHEMBL1354273 & 688341 & 5.0 & 4.9886 & TRN \\
\hline CHEMBL1415734 & 688341 & 4.6 & 4.9082 & TRN \\
\hline CHEMBL450493 & 688341 & 7.6003 & 5.0748 & TRN \\
\hline CHEMBL1374544 & 688341 & 4.8 & 4.8636 & TRN \\
\hline CHEMBL1510847 & 688341 & 5.2 & 4.8827 & TRN \\
\hline CHEMBL1496007 & 688341 & 4.8 & 5.0412 & TRN \\
\hline CHEMBL1535402 & 688341 & 4.8 & 5.0837 & TST \\
\hline CHEMBL1421681 & 688341 & 4.6 & 4.9018 & TRN \\
\hline CHEMBL1323038 & 688341 & 4.6 & 5.043 & TST \\
\hline CHEMBL1524095 & 688341 & 4.6 & 4.8615 & TRN \\
\hline CHEMBL1451986 & 688341 & 5.9 & 5.1321 & TST \\
\hline CHEMBL1321338 & 688341 & 4.9 & 5.077 & TRN \\
\hline CHEMBL220087 & 688341 & 4.5 & 5.0404 & TRN \\
\hline CHEMBL1479324 & 688341 & 4.7 & 5.0622 & TRN \\
\hline CHEMBL1561581 & 688341 & 6.4 & 5.1670 & 0000000001 \\
\hline CHEMBL1594951 & 688341 & 5.2 & 4.7959 & TRN \\
\hline CHEMBL1525524 & 688341 & 4.8 & 4.8279 & TRN \\
\hline CHEMBL1394223 & 688341 & 4.8 & 5.0882 & TRN \\
\hline CHEMBL1478751 & 688341 & 5.4 & 4.9552 & TRN \\
\hline CHEMBL1306998 & 688341 & 6.2 & 4.9094 & TRN \\
\hline CHEMBL1503397 & 688341 & 4.4 & 4.9039 & TRN \\
\hline CHEMBL1568625 & 688341 & 4.5 & 4.856 & TST \\
\hline CHEMBL1594557 & 688341 & 4.7 & 4.9376 & TRN \\
\hline
\end{tabular}




\begin{tabular}{|c|c|c|c|c|}
\hline \multicolumn{5}{|c|}{ Supplemental Table S2.txt } \\
\hline CHEMBL1596825 & 688341 & 5.5 & 4.9628 & TRN \\
\hline CHEMBL1332371 & 688341 & 4.4 & 4.7719 & TRN \\
\hline CHEMBL1484237 & 688341 & 4.7 & 5.0225 & TST \\
\hline CHEMBL1407220 & 688341 & 4.5 & 4.9425 & TST \\
\hline CHEMBL1609951 & 688341 & 4.4 & 4.8554 & TRN \\
\hline CHEMBL1448969 & 688341 & 4.6 & 4.8691 & TRN \\
\hline CHEMBL1495197 & 688341 & 5.2 & 5.0624 & TST \\
\hline CHEMBL1373711 & 688341 & 4.8 & 4.8926 & TRN \\
\hline CHEMBL1567128 & 688341 & 4.5 & 4.7708 & TRN \\
\hline CHEMBL1303731 & 688341 & 5.2 & 4.8741 & TST \\
\hline CHEMBL1314022 & 688341 & 4.5 & 4.9639 & TST \\
\hline CHEMBL1339054 & 688341 & 4.9 & 4.8168 & TRN \\
\hline CHEMBL1603966 & 688341 & 4.6 & 4.9007 & TRN \\
\hline CHEMBL1406119 & 688341 & 4.4 & 4.7067 & TRN \\
\hline CHEMBL1571980 & 688341 & 4.8 & 4.8815 & TRN \\
\hline CHEMBL1301207 & 688341 & 6.0 & 4.9285 & TRN \\
\hline CHEMBL1406630 & 688341 & 5.2 & 4.6914 & TRN \\
\hline CHEMBL1376526 & 688341 & 4.7 & 4.8289 & TRN \\
\hline CHEMBL454761 & 688341 & 5.3 & 5.1195 & TRN \\
\hline CHEMBL3207738 & 688341 & 4.6 & 4.9045 & TST \\
\hline CHEMBL3193695 & 688341 & 4.5 & 4.7697 & TST \\
\hline CHEMBL1334256 & 688341 & 5.2 & 4.8945 & TST \\
\hline CHEMBL1534227 & 688341 & 5.1 & 4.9486 & TRN \\
\hline CHEMBL1463381 & 688341 & 4.6 & 4.9167 & TST \\
\hline CHEMBL1369828 & 688341 & 4.6 & 5.098 & TRN \\
\hline CHEMBL3195734 & 688341 & 6.2 & 5.0551 & TRN \\
\hline CHEMBL1307517 & 688341 & 5.2 & 4.8966 & TRN \\
\hline CHEMBL1612133 & 688341 & 5.3 & 4.8144 & TST \\
\hline CHEMBL1403905 & 688341 & 5.9 & 5.2968 & TRN \\
\hline CHEMBL1435293 & 688341 & 5.7 & 5.1215 & TRN \\
\hline CHEMBL475198 & 688341 & 4.8 & 5.0526 & TRN \\
\hline CHEMBL1396374 & 688341 & 5.5 & 4.7705 & TRN \\
\hline CHEMBL3194566 & 688341 & 4.4 & 5.0542 & TRN \\
\hline CHEMBL142592 & 688341 & 8.2007 & 4.9998 & TST \\
\hline CHEMBL1380503 & 688341 & 4.6 & 4.8367 & TST \\
\hline CHEMBL1464918 & 688341 & 4.6 & 4.9286 & TRN \\
\hline CHEMBL1321018 & 688341 & 4.6 & 4.7768 & TRN \\
\hline CHEMBL1418247 & 688341 & 4.6 & 4.9325 & TRN \\
\hline CHEMBL1311716 & 688341 & 4.6 & 4.6947 & TRN \\
\hline CHEMBL1325506 & 688341 & 4.7 & 4.7829 & TST \\
\hline CHEMBL1562870 & 688341 & 5.3 & 4.7295 & TRN \\
\hline CHEMBL1416650 & 688341 & 4.7 & 4.8625 & TRN \\
\hline CHEMBL1372813 & 688341 & 4.5 & 4.6805 & TRN \\
\hline CHEMBL1600468 & 688341 & 5.0 & 4.9246 & TRN \\
\hline CHEMBL1491587 & 688341 & 5.4 & 4.825 & TRN \\
\hline CHEMBL1349765 & 688341 & 5.0 & 5.0378 & TRN \\
\hline CHEMBL2001481 & 688341 & 4.6 & 4.8504 & TST \\
\hline CHEMBL1452123 & 688341 & 4.6 & 4.9448 & TRN \\
\hline
\end{tabular}




\begin{tabular}{|c|c|c|c|c|}
\hline \multicolumn{5}{|c|}{ Supplemental Table S2.txt } \\
\hline CHEMBL1324163 & 688341 & 4.7 & 4.8639 & TRN \\
\hline CHEMBL1352701 & 688341 & 4.4 & 4.9418 & TRN \\
\hline CHEMBL1450521 & 688341 & 4.6 & 5.3381 & TRN \\
\hline CHEMBL1503929 & 688341 & 4.4 & 4.8482 & TRN \\
\hline CHEMBL1460147 & 688341 & 5.0 & 4.8886 & TRN \\
\hline CHEMBL1529181 & 688341 & 4.5 & 4.8193 & TRN \\
\hline CHEMBL1607228 & 688341 & 6.0 & 5.1703 & TRN \\
\hline CHEMBL1481119 & 688341 & 4.4 & 4.9957 & TST \\
\hline CHEMBL1343806 & 688341 & 4.5 & 4.8376 & TRN \\
\hline CHEMBL1368965 & 688341 & 4.9 & 5.1299 & TRN \\
\hline CHEMBL1479610 & 688341 & 4.5 & 5.0147 & TRN \\
\hline CHEMBL1553034 & 688341 & 5.2 & 5.1338 & TRN \\
\hline CHEMBL1583205 & 688341 & 4.5 & 4.7475 & TRN \\
\hline CHEMBL1581643 & 688341 & 4.6 & 5.0226 & TRN \\
\hline CHEMBL1607076 & 688341 & 5.2 & 5.0298 & TRN \\
\hline CHEMBL1386806 & 688341 & 4.6 & 5.1122 & TRN \\
\hline CHEMBL1484944 & 688341 & 4.7 & 5.1948 & TRN \\
\hline CHEMBL1549877 & 688341 & 4.8 & 4.7607 & TRN \\
\hline CHEMBL1574707 & 688341 & 4.4 & 4.8008 & TST \\
\hline CHEMBL1568293 & 688341 & 4.7 & 4.9562 & TRN \\
\hline CHEMBL1528383 & 688341 & 4.8 & 4.6828 & TRN \\
\hline CHEMBL1366423 & 688341 & 4.6 & 5.0642 & TRN \\
\hline CHEMBL1459858 & 688341 & 4.8 & 5.0396 & TRN \\
\hline CHEMBL1406976 & 688341 & 4.6 & 5.0398 & TRN \\
\hline CHEMBL1470953 & 688341 & 4.6 & 4.8325 & TRN \\
\hline CHEMBL1365281 & 688341 & 4.4 & 5.0823 & TST \\
\hline CHEMBL1545129 & 688341 & 4.5 & 4.6368 & TST \\
\hline CHEMBL1409032 & 688341 & 5.2 & 5.0225 & TRN \\
\hline CHEMBL1312114 & 688341 & 4.7 & 5.0508 & TRN \\
\hline CHEMBL1539035 & 688341 & 4.4 & 4.8286 & TST \\
\hline CHEMBL1342384 & 688341 & 7.4001 & 4.9888 & TRN \\
\hline CHEMBL1482442 & 688341 & 4.9 & 4.9999 & TST \\
\hline CHEMBL1525622 & 688341 & 4.7 & 4.9364 & TRN \\
\hline CHEMBL1360448 & 688341 & 5.0 & 4.9501 & TRN \\
\hline CHEMBL1384832 & 688341 & 5.2 & 4.8788 & TST \\
\hline CHEMBL1394964 & 688341 & 5.1 & 5.1894 & TRN \\
\hline CHEMBL3194605 & 688341 & 5.7 & 4.9104 & TST \\
\hline CHEMBL1408259 & 688341 & 4.4 & 5.0375 & TRN \\
\hline CHEMBL1340617 & 688341 & 5.4 & 4.7515 & TRN \\
\hline CHEMBL1488197 & 688341 & 6.0 & 5.0341 & TRN \\
\hline CHEMBL266158 & 688341 & 4.8 & 4.9933 & TST \\
\hline CHEMBL1459889 & 688341 & 4.6 & 4.9026 & TRN \\
\hline CHEMBL1325336 & 688341 & 5.0 & 4.6559 & TRN \\
\hline CHEMBL1576851 & 688341 & 4.4 & 4.8656 & TRN \\
\hline CHEMBL1333421 & 688341 & 5.9 & 4.9244 & TRN \\
\hline CHEMBL1404605 & 688341 & 4.5 & 4.9166 & TST \\
\hline CHEMBL1591107 & 688341 & 4.8 & 4.9027 & TRN \\
\hline CHEMBL1566731 & 688341 & 4.9 & 4.8202 & TRN \\
\hline
\end{tabular}




\begin{tabular}{|c|c|c|c|c|c|}
\hline \multicolumn{6}{|c|}{ Supplemental Table S2.txt } \\
\hline CHEMBL1613481 & 688341 & 4.6 & 4.9585 & TRN & \\
\hline CHEMBL1315083 & 688341 & 5.4 & 5.0703 & TRN & \\
\hline CHEMBL1587996 & 688341 & 5.2 & 4.987 & TST & \\
\hline CHEMBL1338829 & 688341 & 4.9 & 4.8845 & TRN & \\
\hline CHEMBL1583976 & 688341 & 4.7 & 4.9342 & TRN & \\
\hline CHEMBL1489771 & 688341 & 5.2 & 4.9739 & TRN & \\
\hline CHEMBL1417433 & 688341 & 4.6 & 4.8802 & TRN & \\
\hline CHEMBL1413340 & 688341 & 4.6 & 4.9864 & TRN & \\
\hline CHEMBL1365324 & 688341 & 4.7 & 4.8965 & TRN & \\
\hline CHEMBL1342513 & 688341 & 4.6 & 4.8382 & TRN & \\
\hline CHEMBL1548183 & 688341 & 5.3 & 4.8514 & TRN & \\
\hline CHEMBL1368776 & 688341 & 4.4 & 4.9638 & TST & \\
\hline CHEMBL42485 & 688341 & 4.8 & 4.9786 & TST & \\
\hline CHEMBL1483679 & 688341 & 4.8 & 4.7955 & TRN & \\
\hline CHEMBL1346648 & 688341 & 4.6 & 4.73300 & 00000000005 & TRN \\
\hline CHEMBL1500636 & 688341 & 4.8 & 4.7262 & TRN & \\
\hline CHEMBL1559368 & 688341 & 5.4 & 4.8683 & TRN & \\
\hline CHEMBL1507299 & 688341 & 4.8 & 4.8958 & TRN & \\
\hline CHEMBL1333253 & 688341 & 5.9 & 5.0677 & TST & \\
\hline CHEMBL453019 & 688341 & 4.9 & 4.9292 & TST & \\
\hline CHEMBL1575967 & 688341 & 4.5 & 4.8941 & TRN & \\
\hline CHEMBL1547047 & 688341 & 4.4 & 4.8757 & TRN & \\
\hline CHEMBL1370155 & 688341 & 4.6 & 4.8836 & TRN & \\
\hline CHEMBL1354355 & 688341 & 5.4 & 5.1857 & TRN & \\
\hline CHEMBL1497693 & 688341 & 4.5 & 4.9081 & TST & \\
\hline CHEMBL1541257 & 688341 & 4.7 & 4.8761 & TST & \\
\hline CHEMBL1542493 & 688341 & 4.9 & 4.9734 & TST & \\
\hline CHEMBL1543721 & 688341 & 4.7 & 4.9435 & TRN & \\
\hline CHEMBL1442979 & 688341 & 4.8 & 4.8394 & TRN & \\
\hline CHEMBL1438512 & 688341 & 4.5 & 4.6391 & TRN & \\
\hline CHEMBL1391166 & 688341 & 4.6 & 4.887 & TRN & \\
\hline CHEMBL1494695 & 688341 & 4.5 & 5.0226 & TRN & \\
\hline CHEMBL1585470 & 688341 & 4.4 & 4.9865 & TRN & \\
\hline CHEMBL1371160 & 688341 & 5.1 & 4.8216 & TST & \\
\hline CHEMBL1524817 & 688341 & 4.6 & 4.8704 & TST & \\
\hline CHEMBL1472222 & 688341 & 5.4 & 4.958 & TRN & \\
\hline CHEMBL1498811 & 688341 & 4.7 & 5.0843 & TRN & \\
\hline CHEMBL1538493 & 688341 & 4.7 & 4.9069 & TRN & \\
\hline CHEMBL1574220 & 688341 & 4.5 & 4.985 & TRN & \\
\hline CHEMBL1566037 & 688341 & 4.5 & 5.0036 & TRN & \\
\hline CHEMBL1608373 & 688341 & 4.6 & 4.9361 & TRN & \\
\hline CHEMBL1355351 & 688341 & 5.4 & 5.16100 & 00000000005 & TRN \\
\hline CHEMBL1611841 & 688341 & 5.7 & 4.9872 & TRN & \\
\hline CHEMBL327919 & 688341 & 4.4 & 4.9982 & TST & \\
\hline CHEMBL1562810 & 688341 & 4.9 & 5.0854 & TRN & \\
\hline CHEMBL1363440 & 688341 & 5.2 & 5.023 & TRN & \\
\hline CHEMBL1337941 & 688341 & 4.9 & 4.8872 & TRN & \\
\hline CHEMBL1424628 & 688341 & 4.8 & 4.9356 & TRN & \\
\hline
\end{tabular}




\begin{tabular}{|c|c|c|c|c|c|}
\hline & & \multicolumn{4}{|c|}{ Supplemental Table S2.txt } \\
\hline CHEMBL1416476 & 688341 & 5.4 & 5.0394 & TRN & \\
\hline CHEMBL1352262 & 688341 & 7.699 & 5.0212 & TRN & \\
\hline CHEMBL1412651 & 688341 & 5.2 & 4.9199 & TRN & \\
\hline CHEMBL1609879 & 688341 & 5.2 & 4.941 & TRN & \\
\hline CHEMBL1482072 & 688341 & 4.5 & 4.7836 & TST & \\
\hline CHEMBL1556511 & 688341 & 5.2 & 4.9029 & TRN & \\
\hline CHEMBL1511490 & 688341 & 4.6 & 4.9366 & TRN & \\
\hline CHEMBL3190774 & 688341 & 4.8 & 4.8843 & TRN & \\
\hline CHEMBL1560517 & 688341 & 4.7 & 4.9542 & TRN & \\
\hline CHEMBL1328465 & 688341 & 4.8 & 4.9824 & TRN & \\
\hline CHEMBL1447561 & 688341 & 5.1 & 4.9012 & TRN & \\
\hline CHEMBL1565645 & 688341 & 4.6 & 4.9117 & TST & \\
\hline CHEMBL1446564 & 688341 & 4.8 & 4.7447 & TRN & \\
\hline CHEMBL1494405 & 688341 & 4.6 & 4.9296 & TRN & \\
\hline CHEMBL399121 & 688341 & 5.6 & 5.1169 & TST & \\
\hline CHEMBL 250053 & 688341 & 4.4 & 4.9576 & TST & \\
\hline CHEMBL1320408 & 688341 & 5.4 & 4.9154 & TST & \\
\hline CHEMBL1427201 & 688341 & 4.5 & 4.9832 & TRN & \\
\hline CHEMBL1585074 & 688341 & 4.4 & 4.8683 & TRN & \\
\hline CHEMBL1564549 & 688341 & 4.4 & 5.13899 & 9999999999 & TST \\
\hline CHEMBL1371340 & 688341 & 4.5 & 5.0433 & TST & \\
\hline CHEMBL1392054 & 688341 & 4.6 & 4.7395 & TRN & \\
\hline CHEMBL1460072 & 688341 & 4.9 & 4.8408 & TRN & \\
\hline CHEMBL1518866 & 688341 & 4.9 & 5.0548 & TRN & \\
\hline CHEMBL1344053 & 688341 & 4.9 & 4.6177 & TRN & \\
\hline CHEMBL1369588 & 688341 & 4.4 & 4.8496 & TST & \\
\hline CHEMBL1575066 & 688341 & 4.6 & 4.8288 & TRN & \\
\hline CHEMBL1469929 & 688341 & 5.2 & 5.1463 & TRN & \\
\hline CHEMBL1427982 & 688341 & 4.6 & 4.9836 & TST & \\
\hline CHEMBL1511760 & 688341 & 4.5 & 4.9475 & TRN & \\
\hline CHEMBL1495011 & 688341 & 5.4 & 4.9047 & TRN & \\
\hline CHEMBL1486734 & 688341 & 4.8 & 4.9891 & TRN & \\
\hline CHEMBL1428659 & 688341 & 4.5 & 4.7865 & TRN & \\
\hline CHEMBL1608220 & 688341 & 4.6 & 4.7676 & TRN & \\
\hline CHEMBL1431939 & 688341 & 4.6 & 4.8811 & TRN & \\
\hline CHEMBL1452984 & 688341 & 4.6 & 4.8818 & TRN & \\
\hline CHEMBL1302174 & 688341 & 5.4 & 5.0071 & TRN & \\
\hline CHEMBL1551557 & 688341 & 4.8 & 5.1176 & TRN & \\
\hline CHEMBL1552677 & 688341 & 4.7 & 5.2164 & TRN & \\
\hline CHEMBL1467437 & 688341 & 5.3 & 4.7853 & TRN & \\
\hline CHEMBL1473430 & 688341 & 6.1 & 4.97 & TRN & \\
\hline CHEMBL9113 & 688341 & 4.9 & 4.859 & TRN & \\
\hline CHEMBL1565310 & 688341 & 5.2 & 4.8684 & TRN & \\
\hline CHEMBL1585404 & 688341 & 4.8 & 4.7793 & TRN & \\
\hline CHEMBL1508573 & 688341 & 5.4 & 4.7656 & TRN & \\
\hline CHEMBL1411875 & 688341 & 4.6 & 4.9029 & TRN & \\
\hline CHEMBL1514149 & 688341 & 4.8 & 5.0851 & TRN & \\
\hline CHEMBL1497343 & 688341 & 4.7 & 5.0852 & TST & \\
\hline
\end{tabular}




\begin{tabular}{|c|c|c|c|c|c|}
\hline \\
\hline CHEMBL1420570 & 688341 & 4.7 & 4.7874 & TRN & \\
\hline CHEMBL1590397 & 688341 & 6.4 & 5.0616 & TRN & \\
\hline CHEMBL1466737 & 688341 & 4.5 & 4.745 & TRN & \\
\hline CHEMBL1570057 & 688341 & 4.5 & 4.85800 & 00000000005 & TRN \\
\hline CHEMBL1309088 & 688341 & 4.8 & 4.7314 & TRN & \\
\hline CHEMBL1460534 & 688341 & 4.6 & 4.9145 & TRN & \\
\hline CHEMBL1350771 & 688341 & 5.4 & 4.8122 & TRN & \\
\hline CHEMBL1521069 & 688341 & 4.7 & 4.8435 & TRN & \\
\hline CHEMBL1517889 & 688341 & 4.5 & 4.8863 & TRN & \\
\hline CHEMBL1598091 & 688341 & 4.5 & 4.7715 & TRN & \\
\hline CHEMBL1435235 & 688341 & 4.8 & 5.0023 & TRN & \\
\hline CHEMBL559612 & 688341 & 5.2 & 5.315 & TST & \\
\hline CHEMBL1537051 & 688341 & 4.6 & 4.9058 & TRN & \\
\hline CHEMBL1532447 & 688341 & 4.6 & 4.9769 & TST & \\
\hline CHEMBL1535796 & 688341 & 4.5 & 5.0483 & TRN & \\
\hline CHEMBL1465620 & 688341 & 4.8 & 4.9801 & TRN & \\
\hline CHEMBL1370530 & 688341 & 4.6 & 4.897 & TRN & \\
\hline CHEMBL1436507 & 688341 & 4.7 & 5.1433 & TRN & \\
\hline CHEMBL1432540 & 688341 & 4.7 & 4.9172 & TRN & \\
\hline CHEMBL1333055 & 688341 & 4.6 & 4.7582 & TRN & \\
\hline CHEMBL1612035 & 688341 & 5.2 & 4.8561 & TRN & \\
\hline CHEMBL1306607 & 688341 & 4.6 & 4.8586 & TRN & \\
\hline CHEMBL1347450 & 688341 & 5.0 & 4.8575 & TRN & \\
\hline CHEMBL1527275 & 688341 & 4.4 & 5.035 & TST & \\
\hline CHEMBL1572973 & 688341 & 4.4 & 4.8365 & TST & \\
\hline CHEMBL1342974 & 688341 & 4.8 & 4.6499 & TRN & \\
\hline CHEMBL1393189 & 688341 & 4.8 & 4.8401 & TST & \\
\hline CHEMBL1511045 & 688341 & 4.6 & 4.8515 & TRN & \\
\hline CHEMBL1351580 & 688341 & 4.6 & 4.8221 & TRN & \\
\hline CHEMBL1351942 & 688341 & 4.6 & 4.7411 & TRN & \\
\hline CHEMBL1486341 & 688341 & 5.4 & 4.7496 & TRN & \\
\hline CHEMBL1500235 & 688341 & 6.2 & 4.8532 & TRN & \\
\hline CHEMBL1558891 & 688341 & 4.4 & 4.863 & TST & \\
\hline CHEMBL1498956 & 688341 & 5.7 & 4.792 & TRN & \\
\hline CHEMBL1331105 & 688341 & 4.9 & 5.06800 & 00000000005 & TST \\
\hline CHEMBL1466279 & 688341 & 4.8 & 4.9043 & TRN & \\
\hline CHEMBL1465737 & 688341 & 4.9 & 4.8564 & TRN & \\
\hline CHEMBL1313158 & 688341 & 5.2 & 5.0132 & TST & \\
\hline CHEMBL1518244 & 688341 & 4.6 & 4.96 & TRN & \\
\hline CHEMBL1461667 & 688341 & 4.7 & 4.7874 & TRN & \\
\hline CHEMBL1418832 & 688341 & 4.4 & 4.9473 & TRN & \\
\hline CHEMBL1523854 & 688341 & 5.4 & 4.9521 & TRN & \\
\hline CHEMBL1351261 & 688341 & 4.4 & 4.8908 & TRN & \\
\hline CHEMBL1398837 & 688341 & 4.4 & 4.9296 & TRN & \\
\hline CHEMBL1487795 & 688341 & 4.5 & 4.8757 & TRN & \\
\hline CHEMBL1525007 & 688341 & 5.0 & 4.9103 & TRN & \\
\hline CHEMBL1480119 & 688341 & 5.0 & 4.8783 & TRN & \\
\hline CHEMBL1570641 & 688341 & 4.5 & 4.9128 & TST & \\
\hline
\end{tabular}




\begin{tabular}{|c|c|c|c|c|c|}
\hline \multicolumn{6}{|c|}{ Supplemental Table S2.txt } \\
\hline CHEMBL1339942 & 688341 & 4.7 & 4.751 & TRN & \\
\hline CHEMBL1381863 & 688341 & 4.9 & 4.6711 & TRN & \\
\hline CHEMBL1373177 & 688341 & 5.2 & 5.0032 & TST & \\
\hline CHEMBL1441780 & 688341 & 6.5 & 5.01699 & 99999999995 & TRN \\
\hline CHEMBL1538259 & 688341 & 4.8 & 4.9447 & TRN & \\
\hline CHEMBL1453592 & 688341 & 5.0 & 4.7495 & TRN & \\
\hline CHEMBL1459795 & 688341 & 5.0 & 4.9752 & TRN & \\
\hline CHEMBL1401490 & 688341 & 4.5 & 4.8136 & TRN & \\
\hline CHEMBL1448138 & 688341 & 4.8 & 5.1459 & TRN & \\
\hline CHEMBL1527407 & 688341 & 5.6 & 4.9324 & TRN & \\
\hline CHEMBL1361935 & 688341 & 4.6 & 4.9293 & TRN & \\
\hline CHEMBL1454327 & 688341 & 4.6 & 4.9178 & TRN & \\
\hline CHEMBL1489084 & 688341 & 4.4 & 4.891 & TRN & \\
\hline CHEMBL1576580 & 688341 & 4.5 & 4.9131 & TRN & \\
\hline CHEMBL1370907 & 688341 & 4.7 & 4.8103 & TRN & \\
\hline CHEMBL1389438 & 688341 & 4.6 & 4.9081 & TST & \\
\hline CHEMBL1605916 & 688341 & 6.8 & 5.2667 & TST & \\
\hline CHEMBL1560093 & 688341 & 5.1 & 4.9218 & TRN & \\
\hline CHEMBL1523699 & 688341 & 4.7 & 5.0752 & TRN & \\
\hline CHEMBL1539788 & 688341 & 5.5 & 4.8092 & TRN & \\
\hline CHEMBL1544761 & 688341 & 4.5 & 4.8765 & TRN & \\
\hline CHEMBL1547762 & 688341 & 5.4 & 4.8968 & TST & \\
\hline CHEMBL1604109 & 688341 & 4.4 & 4.7378 & TRN & \\
\hline CHEMBL1378771 & 688341 & 4.5 & 4.843 & TRN & \\
\hline CHEMBL1465671 & 688341 & 5.4 & 5.0384 & TST & \\
\hline CHEMBL1469840 & 688341 & 5.4 & 5.0622 & TST & \\
\hline CHEMBL1303178 & 688341 & 5.2 & 4.9925 & TRN & \\
\hline CHEMBL1544055 & 688341 & 4.6 & 4.90300 & 00000000005 & TRN \\
\hline CHEMBL1402455 & 688341 & 4.6 & 5.0518 & TST & \\
\hline CHEMBL1310517 & 688341 & 4.8 & 4.9461 & TRN & \\
\hline CHEMBL377642 & 688341 & 5.4 & 4.9822 & TRN & \\
\hline CHEMBL1345052 & 688341 & 5.5 & 5.0442 & TST & \\
\hline CHEMBL1331031 & 688341 & 5.6 & 5.1377 & TRN & \\
\hline CHEMBL1499501 & 688341 & 5.5 & 5.0298 & TRN & \\
\hline CHEMBL1312163 & 688341 & 6.2 & 4.9349 & TRN & \\
\hline CHEMBL1578311 & 688341 & 5.2 & 4.9349 & TRN & \\
\hline CHEMBL1337381 & 688341 & 4.5 & 4.8637 & TRN & \\
\hline CHEMBL1580189 & 688341 & 5.2 & 4.7819 & TRN & \\
\hline CHEMBL1585598 & 688341 & 4.9 & 5.0322 & TST & \\
\hline CHEMBL1608250 & 688341 & 4.5 & 5.1033 & TST & \\
\hline CHEMBL1407918 & 688341 & 5.2 & 4.9497 & TRN & \\
\hline CHEMBL1356497 & 688341 & 5.9 & 5.079 & TRN & \\
\hline CHEMBL1579416 & 688341 & 4.5 & 4.7009 & TRN & \\
\hline CHEMBL1604968 & 688341 & 4.4 & 4.7543 & TRN & \\
\hline CHEMBL1552272 & 688341 & 5.3 & 5.0713 & TRN & \\
\hline CHEMBL189438 & 688341 & 4.8 & 5.1055 & TRN & \\
\hline CHEMBL1422470 & 688341 & 4.5 & 4.8693 & TRN & \\
\hline CHEMBL1562171 & 688341 & 6.0 & 4.9039 & TRN & \\
\hline
\end{tabular}




\begin{tabular}{|c|c|c|c|c|}
\hline & & & pplement & al Ta \\
\hline CHEMBL529939 & 688341 & 4.5 & 4.8128 & TRN \\
\hline CHEMBL1377449 & 688341 & 4.4 & 5.0074 & TRN \\
\hline CHEMBL1452870 & 688341 & 4.8 & 4.9992 & TRN \\
\hline CHEMBL1340214 & 688341 & 5.2 & 4.9963 & TST \\
\hline CHEMBL1563812 & 688341 & 5.3 & 4.9745 & TST \\
\hline CHEMBL1326360 & 688341 & 5.9 & 5.2501 & TRN \\
\hline CHEMBL1335497 & 688341 & 4.5 & 4.8653 & TRN \\
\hline CHEMBL1344905 & 688341 & 5.4 & 5.0799 & TRN \\
\hline CHEMBL1417789 & 688341 & 4.9 & 5.0488 & TRN \\
\hline CHEMBL 1459570 & 688341 & 4.7 & 4.9688 & TRN \\
\hline CHEMBL87310 & 688341 & 8.301 & 5.2505 & TST \\
\hline CHEMBL1428601 & 688341 & 5.5 & 4.925 & TRN \\
\hline CHEMBL1609614 & 688341 & 4.7 & 5.0681 & TRN \\
\hline CHEMBL1540554 & 688341 & 4.5 & 5.0499 & TRN \\
\hline CHEMBL88621 & 688341 & 4.4 & 5.1694 & TRN \\
\hline CHEMBL1565563 & 688341 & 5.4 & 4.7758 & TRN \\
\hline CHEMBL1533904 & 688341 & 4.8 & 4.8162 & TRN \\
\hline CHEMBL1567369 & 688341 & 4.9 & 5.0623 & TRN \\
\hline CHEMBL1481930 & 688341 & 5.4 & 4.8155 & TST \\
\hline CHEMBL1388566 & 688341 & 4.5 & 4.8562 & TRN \\
\hline CHEMBL1437943 & 688341 & 4.4 & 4.775 & TRN \\
\hline CHEMBL1476762 & 688341 & 6.2 & 5.251 & TRN \\
\hline CHEMBL1382656 & 688341 & 5.0 & 4.7703 & TRN \\
\hline CHEMBL1447120 & 688341 & 5.1 & 4.9144 & TRN \\
\hline CHEMBL1331618 & 688341 & 5.2 & 5.1752 & TRN \\
\hline CHEMBL1489659 & 688341 & 4.9 & 5.1795 & TRN \\
\hline CHEMBL1412531 & 688341 & 4.5 & 4.8857 & TRN \\
\hline CHEMBL1437650 & 688341 & 5.2 & 5.0822 & TRN \\
\hline CHEMBL1376094 & 688341 & 5.4 & 4.9179 & TRN \\
\hline CHEMBL1380091 & 688341 & 4.9 & 4.8744 & TRN \\
\hline CHEMBL1328281 & 688341 & 4.9 & 4.9504 & TST \\
\hline CHEMBL3196509 & 688341 & 4.4 & 4.9182 & TST \\
\hline CHEMBL1476670 & 688341 & 5.5 & 5.1874 & TRN \\
\hline CHEMBL1539112 & 688341 & 4.7 & 4.8792 & TST \\
\hline CHEMBL1458209 & 688341 & 4.8 & 4.9365 & TRN \\
\hline CHEMBL1462482 & 688341 & 4.5 & 4.8143 & TRN \\
\hline CHEMBL1322702 & 688341 & 6.1 & 5.0077 & TST \\
\hline CHEMBL527271 & 688341 & 4.5 & 4.7659 & TRN \\
\hline CHEMBL1456346 & 688341 & 4.5 & 5.2722 & TRN \\
\hline CHEMBL1523594 & 688341 & 5.9 & 5.2388 & TRN \\
\hline CHEMBL1332316 & 688341 & 5.2 & 5.018 & TST \\
\hline CHEMBL1325833 & 688341 & 5.3 & 5.1814 & TRN \\
\hline CHEMBL1567725 & 688341 & 4.4 & 5.0384 & TRN \\
\hline CHEMBL1464858 & 688341 & 6.2 & 4.9731 & TST \\
\hline CHEMBL1379558 & 688341 & 4.7 & 5.1661 & TRN \\
\hline CHEMBL1399652 & 688341 & 5.9 & 5.0286 & TRN \\
\hline CHEMBL1394113 & 688341 & 6.1 & 4.8874 & TRN \\
\hline CHEMBL1455972 & 688341 & 5.7 & 5.2256 & TRN \\
\hline
\end{tabular}




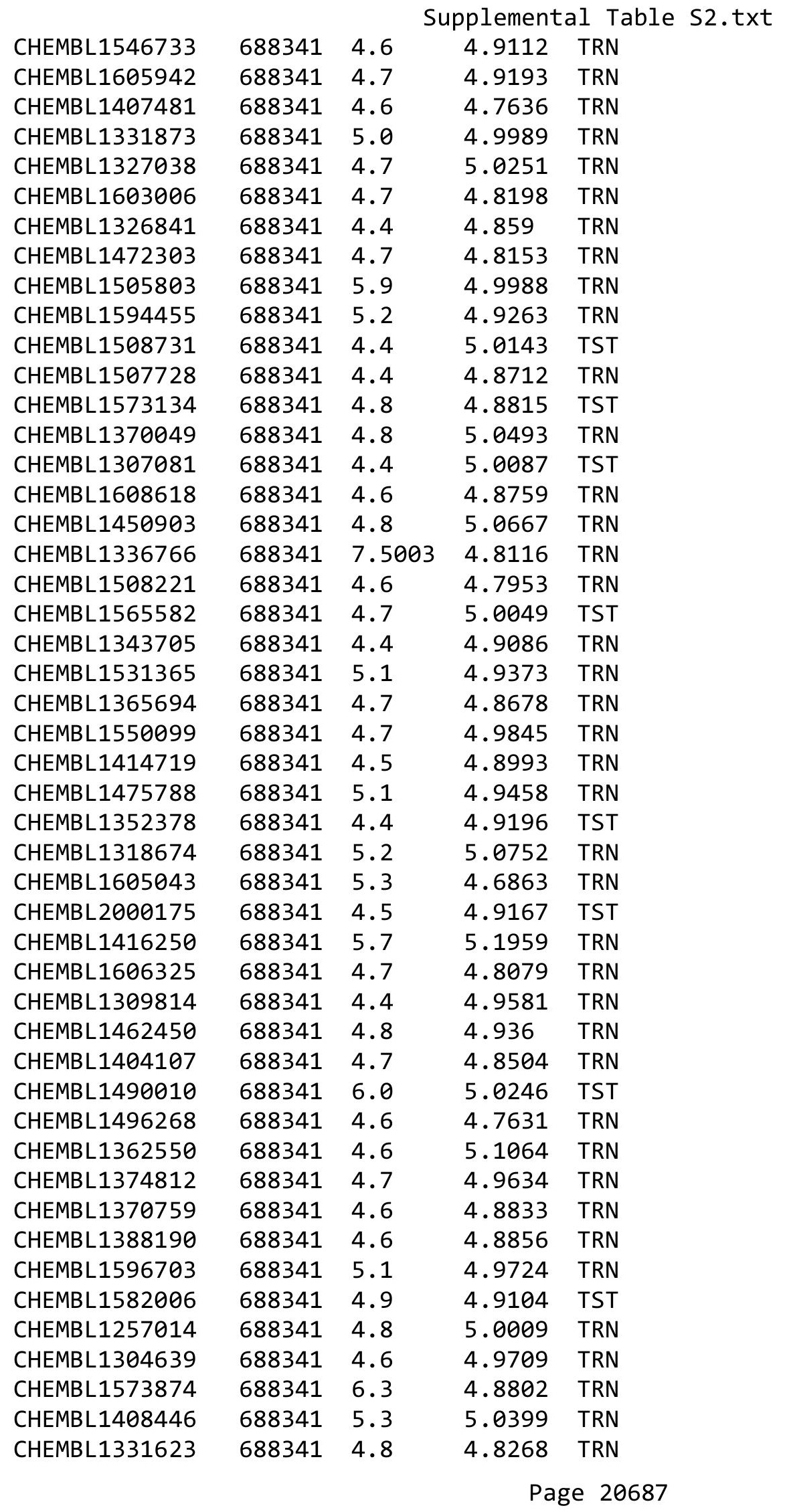




\begin{tabular}{|c|c|c|c|c|}
\hline & & & & \\
\hline CHEMBL1568767 & 688341 & 5.1 & 5.0039 & TRN \\
\hline CHEMBL1539370 & 688341 & 4.5 & 4.8185 & TST \\
\hline CHEMBL1608360 & 688341 & 4.8 & 5.044 & TST \\
\hline CHEMBL1351195 & 688341 & 6.8 & 4.8275 & TRN \\
\hline CHEMBL1401024 & 688341 & 4.8 & 5.0174 & TRN \\
\hline CHEMBL1353486 & 688341 & 6.5 & 5.0062 & TRN \\
\hline CHEMBL1428019 & 688341 & 4.8 & 5.043 & TRN \\
\hline CHEMBL1339588 & 688341 & 4.6 & 4.8 & TRN \\
\hline CHEMBL1567912 & 688341 & 4.4 & 5.0462 & TST \\
\hline CHEMBL1490602 & 688341 & 5.3 & 4.9881 & TRN \\
\hline CHEMBL1385108 & 688341 & 5.2 & 4.9003 & TST \\
\hline CHEMBL1349820 & 688341 & 5.5 & 4.8625 & TRN \\
\hline CHEMBL1458387 & 688341 & 5.1 & 4.9096 & TRN \\
\hline CHEMBL1331184 & 688341 & 4.8 & 4.8431 & TST \\
\hline CHEMBL1584016 & 688341 & 5.0 & 4.9576 & TRN \\
\hline CHEMBL1412475 & 688341 & 5.3 & 4.9097 & TRN \\
\hline CHEMBL1587001 & 688341 & 4.5 & 4.8279 & TRN \\
\hline CHEMBL1410075 & 688341 & 5.0 & 4.9708 & TRN \\
\hline CHEMBL1370583 & 688341 & 4.8 & 4.8309 & TRN \\
\hline CHEMBL1417302 & 688341 & 4.7 & 4.9582 & TRN \\
\hline CHEMBL1491454 & 688341 & 5.2 & 5.1135 & TST \\
\hline CHEMBL1595870 & 688341 & 4.4 & 4.7574 & TRN \\
\hline CHEMBL1372088 & 688341 & 6.0 & 5.1195 & TRN \\
\hline CHEMBL523283 & 688341 & 4.9 & 5.0312 & TRN \\
\hline CHEMBL1576325 & 688341 & 5.1 & 4.8486 & TRN \\
\hline CHEMBL1342791 & 688341 & 4.6 & 4.888 & TRN \\
\hline CHEMBL1488286 & 688341 & 4.6 & 4.9518 & TRN \\
\hline CHEMBL1354294 & 688341 & 5.9 & 5.1395 & TRN \\
\hline CHEMBL1317039 & 688341 & 5.1 & 5.1249 & TRN \\
\hline CHEMBL1530572 & 688341 & 4.4 & 4.997 & TST \\
\hline CHEMBL1612265 & 688341 & 4.8 & 4.976 & TRN \\
\hline CHEMBL1529618 & 688341 & 5.4 & 4.9548 & TST \\
\hline CHEMBL1447431 & 688341 & 4.8 & 4.9094 & TRN \\
\hline CHEMBL1379255 & 688341 & 5.5 & 4.942 & TRN \\
\hline CHEMBL1384685 & 688341 & 4.7 & 4.9442 & TRN \\
\hline CHEMBL1548458 & 688341 & 4.4 & 4.8081 & TRN \\
\hline CHEMBL1469378 & 688341 & 4.5 & 4.8544 & TRN \\
\hline CHEMBL1391395 & 688341 & 4.7 & 4.7653 & TRN \\
\hline CHEMBL1426154 & 688341 & 4.6 & 5.101 & TRN \\
\hline CHEMBL 1490452 & 688341 & 4.6 & 4.8808 & TRN \\
\hline CHEMBL1334907 & 688341 & 5.5 & 4.8823 & TRN \\
\hline CHEMBL1347516 & 688341 & 4.9 & 5.053 & TRN \\
\hline CHEMBL1577745 & 688341 & 5.2 & 4.8374 & TRN \\
\hline CHEMBL1330913 & 688341 & 6.2 & 5.0964 & TRN \\
\hline CHEMBL1359923 & 688341 & 4.6 & 4.8451 & TRN \\
\hline CHEMBL1543554 & 688341 & 4.6 & 4.8703 & TRN \\
\hline CHEMBL1464213 & 688341 & 5.3 & 5.1029 & TST \\
\hline CHEMBL1329341 & 688341 & 5.0 & 4.9318 & TRN \\
\hline
\end{tabular}




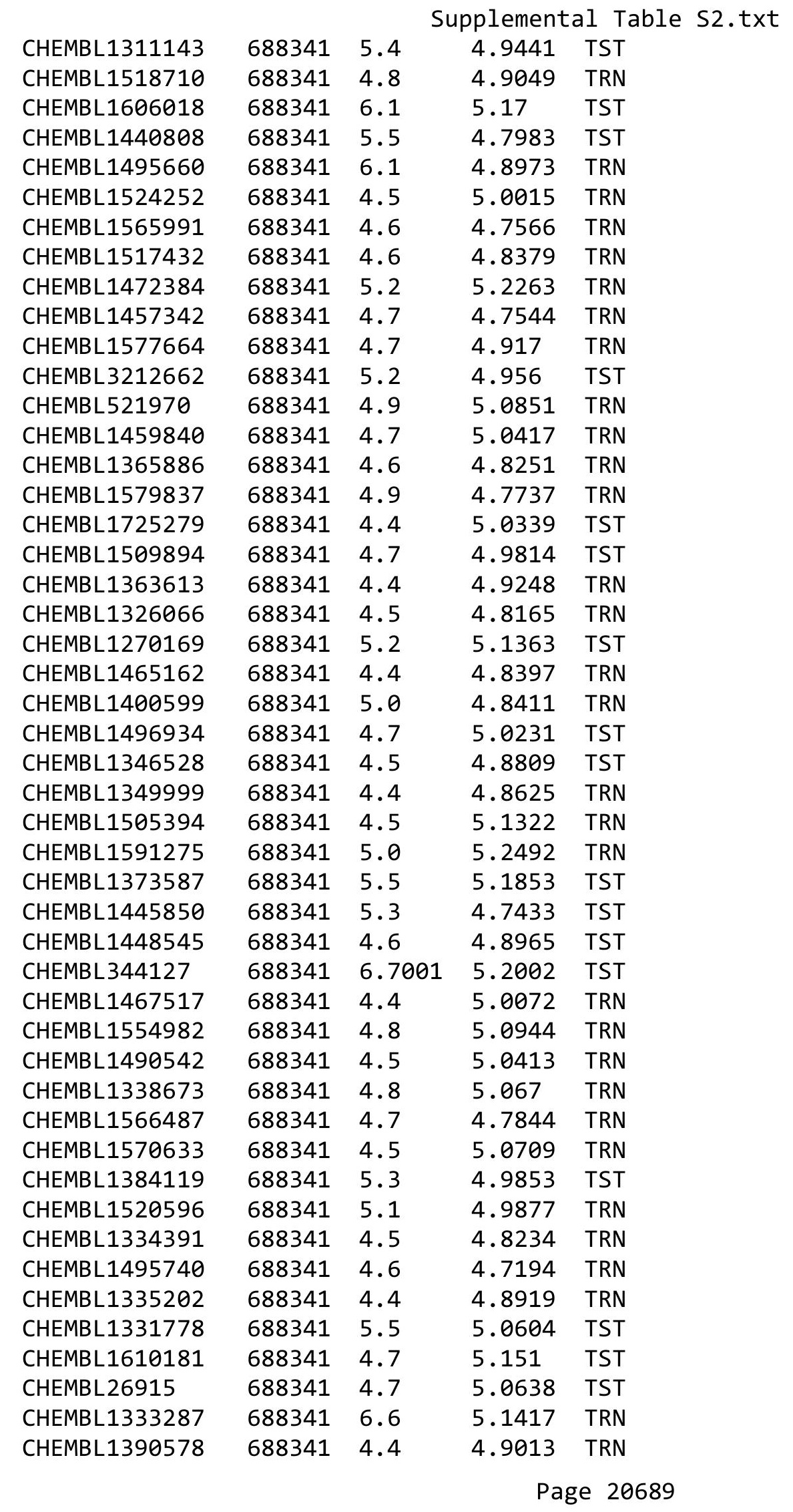




\begin{tabular}{|c|c|c|c|c|c|}
\hline \multicolumn{6}{|c|}{ Supplemental Table s2.txt } \\
\hline CHEMBL1594560 & 688341 & 4.4 & 4.8424 & TRN & \\
\hline CHEMBL 87026 & 2432 & 7.88 & 8.4173 & TRN & \\
\hline CHEMBL155486 & 2432 & 8.57 & 7.1766 & TST & \\
\hline CHEMBL111352 & 2432 & 8.17 & 7.2952 & TST & \\
\hline CHEMBL310153 & 2432 & 6.29 & 6.4897 & TRN & \\
\hline CHEMBL163012 & 2432 & 8.37 & 6.8677 & TST & \\
\hline CHEMBL95112 & 2432 & 7.37 & 6.9905 & TRN & \\
\hline CHEMBL163180 & 2432 & 6.76 & 6.6685 & TRN & \\
\hline CHEMBL109548 & 2432 & 7.58 & 8.137 & TRN & \\
\hline CHEMBL109528 & 2432 & 5.82 & 6.3286 & TRN & \\
\hline CHEMBL 263790 & 2432 & 8.76 & 7.2861 & TST & \\
\hline CHEMBL142316 & 2432 & 5.9 & 6.2562 & TRN & \\
\hline CHEMBL 87458 & 2432 & 8.42 & 8.2677 & TRN & \\
\hline CHEMBL110847 & 2432 & 6.84 & 6.7923 & TRN & \\
\hline CHEMBL358895 & 2432 & 6.0 & 6.0166 & TRN & \\
\hline CHEMBL121744 & 2432 & 6.2 & 6.3164 & TST & \\
\hline CHEMBL325253 & 2432 & 6.97 & 6.575 & TRN & \\
\hline CHEMBL160907 & 2432 & 7.27 & 7.0769 & TRN & \\
\hline CHEMBL164471 & 2432 & 8.97 & 7.107 & TST & \\
\hline CHEMBL87717 & 2432 & 8.6 & 8.4411 & TRN & \\
\hline CHEMBL109673 & 2432 & 8.84 & 8.1929 & TRN & \\
\hline CHEMBL159969 & 2432 & 8.15 & 8.1751 & TRN & \\
\hline CHEMBL141600 & 2432 & 7.66 & 6.3443 & TRN & \\
\hline CHEMBL142668 & 2432 & 6.02 & $6.2360 e$ & 0000000001 & TRN \\
\hline CHEMBL143022 & 2432 & 7.29 & 7.435 & TRN & \\
\hline CHEMBL161423 & 2432 & 6.71 & 6.8204 & TRN & \\
\hline CHEMBL92145 & 2432 & 7.39 & 6.9729 & TRN & \\
\hline CHEMBL357517 & 2432 & 6.0 & 5.8843 & TRN & \\
\hline CHEMBL160019 & 2432 & 6.72 & 6.5483 & TRN & \\
\hline CHEMBL159917 & 2432 & 6.45 & 6.391 & TRN & \\
\hline CHEMBL110948 & 2432 & 8.56 & 7.2979 & TST & \\
\hline CHEMBL310734 & 2432 & 7.75 & 6.829 & TRN & \\
\hline CHEMBL111393 & 2432 & 7.24 & 7.7939 & TRN & \\
\hline CHEMBL444269 & 2432 & 6.05 & 6.5487 & TRN & \\
\hline CHEMBL159771 & 2432 & 6.0 & 6.4087 & TST & \\
\hline CHEMBL159929 & 2432 & 7.71 & 7.9067 & TRN & \\
\hline CHEMBL120903 & 2432 & 8.04 & 7.8403 & TRN & \\
\hline CHEMBL111509 & 2432 & 7.34 & 6.8896 & TRN & \\
\hline CHEMBL321682 & 2432 & 7.95 & 8.1629 & TRN & \\
\hline CHEMBL333174 & 2432 & 8.8 & 7.0249 & TST & \\
\hline CHEMBL143027 & 2432 & 7.97 & 6.6594 & TST & \\
\hline CHEMBL155006 & 2432 & 7.04 & 6.7354 & TST & \\
\hline CHEMBL143937 & 2432 & 5.08 & 5.8499 & TRN & \\
\hline CHEMBL87943 & 2432 & 8.11 & 8.4758 & TRN & \\
\hline CHEMBL111189 & 2432 & 6.54 & $7.1160 e$ & 00000000005 & TRN \\
\hline CHEMBL95098 & 2432 & 6.91 & 7.2381 & TRN & \\
\hline CHEMBL163605 & 2432 & 6.04 & 6.4656 & TRN & \\
\hline CHEMBL96781 & 2432 & 7.14 & 7.38700 & 00000000005 & TRN \\
\hline & & & & 20690 & \\
\hline
\end{tabular}




\begin{tabular}{|c|c|c|c|c|c|}
\hline \multicolumn{6}{|c|}{ Supplemental Table S2.txt } \\
\hline CHEMBL349832 & 2432 & 6.55 & 6.3211 & TST & \\
\hline CHEMBL162901 & 2432 & 8.06 & 7.6525 & TRN & \\
\hline CHEMBL159466 & 2432 & 5.75 & 6.1936 & TST & \\
\hline CHEMBL 308480 & 2432 & 8.8 & 8.0764 & TRN & \\
\hline CHEMBL1915439 & 788036 & 7.6778 & 7.8789 & TST & \\
\hline CHEMBL1915432 & 788036 & 6.7122 & 7.5068 & TST & \\
\hline CHEMBL1915647 & 788036 & 7.7959 & 7.7864 & TRN & \\
\hline CHEMBL1915436 & 788036 & 7.5528 & 7.5338 & TRN & \\
\hline CHEMBL1915435 & 788036 & 7.3872 & 7.3486 & TRN & \\
\hline CHEMBL1649762 & 788036 & 4.6021 & 5.7860 & 00000000005 & TST \\
\hline CHEMBL1915447 & 788036 & 7.3468 & 7.3412 & TRN & \\
\hline CHEMBL1915649 & 788036 & 7.3872 & 7.3539 & TRN & \\
\hline CHEMBL1649586 & 788036 & 6.2388 & 6.0527 & TST & \\
\hline CHEMBL1915449 & 788036 & 8.699 & 8.6802 & TRN & \\
\hline CHEMBL1915438 & 788036 & 8.301 & 8.2699 & TRN & \\
\hline CHEMBL1915429 & 788036 & 7.6021 & 7.5729 & 99999999995 & TRN \\
\hline CHEMBL1915424 & 788036 & 6.9706 & 6.9692 & TRN & \\
\hline CHEMBL1915633 & 788036 & 8.0969 & 8.1678 & TRN & \\
\hline CHEMBL1915444 & 788036 & 7.585 & 7.6268 & TRN & \\
\hline CHEMBL1649765 & 788036 & 6.466 & 6.4747 & TRN & \\
\hline CHEMBL1915642 & 788036 & 8.1549 & 8.122 & TRN & \\
\hline CHEMBL1915648 & 788036 & 7.6778 & 7.6813 & TRN & \\
\hline CHEMBL1915431 & 788036 & 7.284 & 7.6668 & TST & \\
\hline CHEMBL1649759 & 788036 & 4.6021 & 5.8018 & TST & \\
\hline CHEMBL1915644 & 788036 & 8.0458 & 8.0818 & TRN & \\
\hline CHEMBL1915440 & 788036 & 7.1308 & 7.1558 & TRN & \\
\hline CHEMBL1915636 & 788036 & 8.699 & 8.6383 & TRN & \\
\hline CHEMBL1915638 & 788036 & 7.7959 & 7.8537 & TRN & \\
\hline CHEMBL1915634 & 788036 & 8.1549 & 8.1295 & TRN & \\
\hline CHEMBL1915637 & 788036 & 7.8861 & 7.8777 & TRN & \\
\hline CHEMBL1915645 & 788036 & 8.0 & 7.932 & TRN & \\
\hline CHEMBL1915425 & 788036 & 6.9431 & 6.9646 & TRN & \\
\hline CHEMBL1915442 & 788036 & 8.301 & 8.3068 & TRN & \\
\hline CHEMBL1915446 & 788036 & 7.585 & 7.6114 & TRN & \\
\hline CHEMBL1915650 & 788036 & 7.6198 & 7.624 & TRN & \\
\hline CHEMBL1649761 & 788036 & 6.098 & 6.1386 & TST & \\
\hline CHEMBL1915646 & 788036 & 8.0969 & 8.1046 & TRN & \\
\hline CHEMBL1915443 & 788036 & 8.1549 & 8.1819 & TRN & \\
\hline CHEMBL1915434 & 788036 & 7.6383 & 7.6612 & TRN & \\
\hline CHEMBL1915426 & 788036 & 7.5686 & 7.6077 & TRN & \\
\hline CHEMBL1915639 & 788036 & 8.0 & 7.9783 & TRN & \\
\hline CHEMBL1915427 & 788036 & 6.6421 & 6.9192 & TST & \\
\hline CHEMBL1915651 & 788036 & 7.6021 & 7.6977 & TRN & \\
\hline CHEMBL1915419 & 788036 & 4.6021 & 5.7324 & TST & \\
\hline CHEMBL1915635 & 788036 & 8.2218 & 8.2497 & TRN & \\
\hline CHEMBL1915421 & 788036 & 7.0 & 6.9361 & TRN & \\
\hline CHEMBL1915423 & 788036 & 4.6021 & 6.0311 & TST & \\
\hline CHEMBL1915643 & 788036 & 7.7959 & 7.6901 & TST & \\
\hline
\end{tabular}




\begin{tabular}{|c|c|c|c|c|c|}
\hline \\
\hline CHEMBL1915445 & 788036 & 8.301 & 8.2784 & TRN & \\
\hline CHEMBL1915428 & 788036 & 7.8861 & 7.8881 & TRN & \\
\hline CHEMBL1915448 & 788036 & 8.699 & 8.6981 & TRN & \\
\hline CHEMBL1915641 & 788036 & 8.3979 & 8.4281 & TRN & \\
\hline CHEMBL1915433 & 788036 & 7.7696 & 7.7788 & TRN & \\
\hline CHEMBL1915441 & 788036 & 7.7447 & 7.74799 & 9999999999 & TRN \\
\hline CHEMBL 1915640 & 788036 & 8.1549 & 8.1437 & TRN & \\
\hline CHEMBL1915420 & 788036 & 5.6536 & 6.3339 & TST & \\
\hline CHEMBL1915430 & 788036 & 7.4089 & 7.41100 & 00000000005 & TRN \\
\hline CHEMBL1915437 & 788036 & 7.5528 & 7.4863 & TRN & \\
\hline CHEMBL1914471 & 788036 & 7.8861 & 7.9252 & TST & \\
\hline CHEMBL1915422 & 788036 & 7.2596 & 7.1468 & TST & \\
\hline CHEMBL3657273 & 1528893 & 6.0 & 6.763 & TRN & \\
\hline CHEMBL 3657364 & 1528893 & 6.0 & 8.3347 & TST & \\
\hline CHEMBL3657350 & 1528893 & 7.1427 & 8.2834 & TST & \\
\hline CHEMBL 3657266 & 1528893 & 8.0 & 8.2433 & TRN & \\
\hline CHEMBL3661425 & 1528893 & 9.0 & 8.8276 & TRN & \\
\hline CHEMBL 3657373 & 1528893 & 9.0 & 8.7378 & TRN & \\
\hline CHEMBL 3657326 & 1528893 & 7.2757 & 7.1697 & TST & \\
\hline CHEMBL3657383 & 1528893 & 9.0 & 9.1418 & TRN & \\
\hline CHEMBL3657321 & 1528893 & 6.3979 & 6.7734 & TST & \\
\hline CHEMBL 3661438 & 1528893 & 8.5229 & 8.3237 & TRN & \\
\hline CHEMBL 3661423 & 1528893 & 6.3979 & 6.1337 & TRN & \\
\hline CHEMBL 3657274 & 1528893 & 8.5229 & 8.3968 & TRN & \\
\hline CHEMBL3929423 & 1528893 & 9.0 & 8.8668 & TRN & \\
\hline CHEMBL 3657268 & 1528893 & 8.3979 & 7.9749 & TRN & \\
\hline CHEMBL3661435 & 1528893 & 9.0 & 9.1559 & TRN & \\
\hline CHEMBL 3657347 & 1528893 & 6.3979 & 7.2456 & TST & \\
\hline CHEMBL 3657392 & 1528893 & 9.0 & 9.317 & TRN & \\
\hline CHEMBL 3657403 & 1528893 & 9.0 & 8.9811 & TRN & \\
\hline CHEMBL 3657380 & 1528893 & 8.5229 & 8.2549 & TRN & \\
\hline CHEMBL 3661419 & 1528893 & 8.0 & 8.0222 & TRN & \\
\hline CHEMBL 3657293 & 1528893 & 7.9586 & 7.584 & TST & \\
\hline CHEMBL 3657291 & 1528893 & 8.1549 & 8.3974 & TRN & \\
\hline CHEMBL3661454 & 1528893 & 9.0 & 8.9267 & TRN & \\
\hline CHEMBL3661433 & 1528893 & 7.9586 & 8.1934 & TRN & \\
\hline CHEMBL 3661430 & 1528893 & 9.0 & 8.9005 & TRN & \\
\hline CHEMBL 3657340 & 1528893 & 7.9586 & 8.5551 & TST & \\
\hline CHEMBL 3661444 & 1528893 & 9.0 & 9.2594 & TST & \\
\hline CHEMBL 3657344 & 1528893 & 9.0 & 8.8537 & TRN & \\
\hline CHEMBL 3661446 & 1528893 & 8.699 & 8.6847 & TST & \\
\hline CHEMBL3917375 & 1528893 & 9.0 & 8.8602 & TST & \\
\hline CHEMBL 3944161 & 1528893 & 9.0 & 8.7384 & TRN & \\
\hline CHEMBL3657262 & 1528893 & 8.301 & 8.3452 & TRN & \\
\hline CHEMBL3661450 & 1528893 & 8.699 & 8.808 & TRN & \\
\hline CHEMBL 3657292 & 1528893 & 8.301 & 8.104 & TRN & \\
\hline CHEMBL 3657246 & 1528893 & 9.0 & 8.9717 & TRN & \\
\hline CHEMBL 3661447 & 1528893 & 8.699 & 8.8308 & TST & \\
\hline
\end{tabular}




\begin{tabular}{|c|c|c|c|c|c|}
\hline \multicolumn{6}{|c|}{ Supplemental Table S2.txt } \\
\hline CHEMBL 3971784 & 1528893 & 9.0 & 9.3995 & TRN & \\
\hline CHEMBL3661431 & 1528893 & 8.699 & 8.4029 & TRN & \\
\hline CHEMBL 3657381 & 1528893 & 9.0 & 8.9791 & TRN & \\
\hline CHEMBL 3657341 & 1528893 & 9.0 & 9.7326 & TST & \\
\hline CHEMBL 3944357 & 1528893 & 8.5229 & 8.7975 & TST & \\
\hline CHEMBL3657336 & 1528893 & 7.5376 & 8.6405 & TST & \\
\hline CHEMBL 3922574 & 1528893 & 9.0 & 8.8643 & TRN & \\
\hline CHEMBL 3980610 & 1528893 & 9.0 & 9.71600 & 0000000001 & TST \\
\hline CHEMBL 3657352 & 1528893 & 9.0 & 9.7517 & TST & \\
\hline CHEMBL 3657362 & 1528893 & 8.699 & 8.9381 & TRN & \\
\hline CHEMBL3657391 & 1528893 & 8.699 & 8.3497 & TRN & \\
\hline CHEMBL 3949294 & 1528893 & 9.0 & 8.4854 & TRN & \\
\hline CHEMBL 3657248 & 1528893 & 8.3979 & 8.3987 & TRN & \\
\hline CHEMBL 3657339 & 1528893 & 7.4437 & 8.2133 & TST & \\
\hline CHEMBL3657335 & 1528893 & 6.3979 & 7.5624 & TST & \\
\hline CHEMBL3957949 & 1528893 & 9.0 & 8.8844 & TRN & \\
\hline CHEMBL3661457 & 1528893 & 9.0 & 8.7991 & TRN & \\
\hline CHEMBL 3657331 & 1528893 & 9.0 & 10.0937 & TST & \\
\hline CHEMBL 3657346 & 1528893 & 7.4559 & 8.7501 & TST & \\
\hline CHEMBL3661420 & 1528893 & 6.9914 & 7.2122 & TST & \\
\hline CHEMBL3657353 & 1528893 & 8.699 & 9.1543 & TRN & \\
\hline CHEMBL 3657314 & 1528893 & 7.585 & 7.7404 & TRN & \\
\hline CHEMBL 3657363 & 1528893 & 8.5229 & 8.6097 & TRN & \\
\hline CHEMBL 3661422 & 1528893 & 6.3979 & 6.2876 & TRN & \\
\hline CHEMBL3657319 & 1528893 & 8.699 & 8.5815 & TRN & \\
\hline CHEMBL 3657384 & 1528893 & 8.5229 & 8.5658 & TRN & \\
\hline CHEMBL 3899428 & 1528893 & 9.0 & 9.2304 & TRN & \\
\hline CHEMBL3657295 & 1528893 & 8.0458 & 8.277006 & 0000000001 & TRN \\
\hline CHEMBL 3661458 & 1528893 & 8.3979 & 8.3672 & TRN & \\
\hline CHEMBL 3940100 & 1528893 & 9.0 & 8.7458 & TRN & \\
\hline CHEMBL3903771 & 1528893 & 9.0 & 8.7004 & TRN & \\
\hline CHEMBL 3661428 & 1528893 & 9.0 & 8.8991 & TRN & \\
\hline CHEMBL 3657405 & 1528893 & 9.0 & 8.3635 & TRN & \\
\hline CHEMBL3657365 & 1528893 & 9.0 & 9.0592 & TRN & \\
\hline CHEMBL3935497 & 1528893 & 9.0 & 8.7404 & TRN & \\
\hline CHEMBL 3657285 & 1528893 & 6.51 & 6.2336 & TRN & \\
\hline CHEMBL 3657308 & 1528893 & 6.0 & 6.9985 & TRN & \\
\hline CHEMBL3657395 & 1528893 & 8.699 & 8.2278 & TRN & \\
\hline CHEMBL 3657271 & 1528893 & 7.9586 & 7.1483 & TST & \\
\hline CHEMBL3657369 & 1528893 & 8.699 & 8.6968 & TRN & \\
\hline CHEMBL 3657264 & 1528893 & 6.0 & 6.5408 & TRN & \\
\hline CHEMBL 3657404 & 1528893 & 8.699 & 8.6887 & TRN & \\
\hline CHEMBL3927660 & 1528893 & 9.0 & 9.1022 & TRN & \\
\hline CHEMBL 3897808 & 1528893 & 9.0 & 8.4404 & TST & \\
\hline CHEMBL 3657355 & 1528893 & 9.0 & 8.7518 & TRN & \\
\hline CHEMBL3657265 & 1528893 & 8.699 & 8.0866 & TRN & \\
\hline CHEMBL 3657368 & 1528893 & 9.0 & 9.1874 & TRN & \\
\hline CHEMBL 3657290 & 1528893 & 8.301 & 8.5305 & TRN & \\
\hline
\end{tabular}




\begin{tabular}{|c|c|c|c|c|c|}
\hline \multirow[b]{2}{*}{ CHEMBL 3986531} & \multicolumn{5}{|c|}{ Supplemental Table S2.txt } \\
\hline & 1528893 & 9.0 & 8.9259 & TST & \\
\hline CHEMBL 3657325 & 1528893 & 8.699 & 9.3423 & TST & \\
\hline CHEMBL 3661441 & 1528893 & 8.699 & 8.9863 & TRN & \\
\hline CHEMBL 3657370 & 1528893 & 9.0 & 8.7161 & TRN & \\
\hline CHEMBL 3657305 & 1528893 & 6.0 & 7.2741 & TRN & \\
\hline CHEMBL 3661427 & 1528893 & 8.699 & 8.5933 & TRN & \\
\hline CHEMBL 3657375 & 1528893 & 7.5528 & 7.9789 & TST & \\
\hline CHEMBL 3657333 & 1528893 & 9.0 & 8.94 & TRN & \\
\hline CHEMBL 3661445 & 1528893 & 9.0 & 8.8439 & TST & \\
\hline CHEMBL 3657302 & 1528893 & 8.699 & 8.8275 & TRN & \\
\hline CHEMBL 3657400 & 1528893 & 9.0 & 9.5507 & TRN & \\
\hline CHEMBL 3657316 & 1528893 & 6.7077 & 7.6683 & TST & \\
\hline CHEMBL 3657287 & 1528893 & 8.0458 & 7.9895 & TRN & \\
\hline CHEMBL 3657337 & 1528893 & 8.3979 & 8.4551 & TST & \\
\hline CHEMBL3657322 & 1528893 & 6.3979 & 7.3702 & TST & \\
\hline CHEMBL 3657247 & 1528893 & 8.5229 & 8.4461 & TRN & \\
\hline CHEMBL 3657366 & 1528893 & 8.699 & 8.7947 & TRN & \\
\hline CHEMBL3661426 & 1528893 & 8.5229 & 8.5001 & TRN & \\
\hline CHEMBL 3661453 & 1528893 & 9.0 & 8.467 & TRN & \\
\hline CHEMBL 3657329 & 1528893 & 6.644 & 7.9451 & TST & \\
\hline CHEMBL3657311 & 1528893 & 9.0 & 8.7661 & TRN & \\
\hline CHEMBL 3657317 & 1528893 & 6.3979 & 7.3336 & TST & \\
\hline CHEMBL3661459 & 1528893 & 8.5229 & 8.6393 & TRN & \\
\hline CHEMBL 3657324 & 1528893 & 8.5229 & 8.257 & TRN & \\
\hline CHEMBL 3657351 & 1528893 & 9.0 & 8.9083 & TRN & \\
\hline CHEMBL 3657313 & 1528893 & 7.1249 & 7.0876 & TRN & \\
\hline CHEMBL 3657272 & 1528893 & 7.9208 & 7.9444 & TST & \\
\hline CHEMBL 3657413 & 1528893 & 8.0458 & 8.0486 & TRN & \\
\hline CHEMBL 3657279 & 1528893 & 8.3979 & 7.0511 & TRN & \\
\hline CHEMBL 3657390 & 1528893 & 8.699 & 8.8095 & TRN & \\
\hline CHEMBL 3657385 & 1528893 & 9.0 & 9.2271 & TRN & \\
\hline CHEMBL 3657284 & 1528893 & 8.5229 & 8.53399 & 9999999999 & TRN \\
\hline CHEMBL 3657320 & 1528893 & 9.0 & 9.0636 & TRN & \\
\hline CHEMBL 3657323 & 1528893 & 9.0 & 9.4058 & TRN & \\
\hline CHEMBL 3657328 & 1528893 & 7.4685 & 8.2052 & TST & \\
\hline CHEMBL 3661455 & 1528893 & 9.0 & 9.1378 & TRN & \\
\hline CHEMBL 3657315 & 1528893 & 7.2218 & 8.2862 & TST & \\
\hline CHEMBL3661432 & 1528893 & 8.699 & 8.8325 & TRN & \\
\hline CHEMBL 3657270 & 1528893 & 8.0458 & 7.524 & TST & \\
\hline CHEMBL 3657306 & 1528893 & 9.0 & 7.4997 & TRN & \\
\hline CHEMBL 3657281 & 1528893 & 9.0 & 8.991 & TRN & \\
\hline CHEMBL 3657300 & 1528893 & 8.301 & 8.0805 & TRN & \\
\hline CHEMBL3661443 & 1528893 & 9.0 & 9.2571 & TRN & \\
\hline CHEMBL 3661439 & 1528893 & 9.0 & 9.0666 & TRN & \\
\hline CHEMBL 3657318 & 1528893 & 8.699 & 8.754 & TRN & \\
\hline CHEMBL 3657245 & 1528893 & 6.0 & 6.9073 & TRN & \\
\hline CHEMBL 3661440 & 1528893 & 8.5229 & 8.5393 & TRN & \\
\hline CHEMBL3657282 & 1528893 & 8.699 & 8.8941 & TRN & \\
\hline
\end{tabular}


Supplemental Table S2.txt

\begin{tabular}{|c|c|c|c|c|}
\hline 67 & & 9 & & \\
\hline CHEMRI 3657283 & 528893 & 8.699 & 8.5944 & \\
\hline IEMBL & 528893 & 9.0 & 901 & \\
\hline IEMBL3 & 528893 & 9.0 & 4983 & \\
\hline AEMBL3661421 & 528893 & 7.0362 & 6325 & \\
\hline HEMBL: & 528893 & 229 & & \\
\hline 27 & 528893 & 376 & & \\
\hline IEMBL & 528893 & 7.7959 & & \\
\hline AEMBL3657250 & 528893 & 6.0 & 5009 & \\
\hline AEMBL36 & 528893 & & 7769 & \\
\hline IEMBL: & 528893 & 979 & 23 & \\
\hline IEMBL & 528893 & & & \\
\hline AEMBL & 1528893 & 9.0 & & \\
\hline AEMBL3 & .528893 & & & \\
\hline 257 & 528893 & & 99 & \\
\hline 37 & 528893 & 9 . & & \\
\hline & 93 & & & \\
\hline IEMBL & 1528893 & 58 & & \\
\hline 94 & 528893 & & & \\
\hline 79 & 528893 & 9.6 & 66 & \\
\hline & 528893 & & & \\
\hline & 3 & & & \\
\hline 42 & 152 & & & \\
\hline 34 & 93 & & & \\
\hline 78 & 528893 & 6. & & \\
\hline & 28893 & & & \\
\hline & 93 & 0 & & \\
\hline & 93 & & & \\
\hline & 93 & & & \\
\hline 82 & 528893 & 9. & 381 & \\
\hline & 528893 & 8 . & & \\
\hline & 3 & & & \\
\hline & & & & \\
\hline & 528893 & & & \\
\hline 18 & 528893 & & 16 & \\
\hline & 528893 & & 72 & \\
\hline & & & & \\
\hline & & 7.9586 & & \\
\hline 1 & 528893 & 6. & & \\
\hline & 893 & & & \\
\hline & 528893 & 9. & 94 & \\
\hline & & & & \\
\hline 36 & 393 & 7.9208 & & \\
\hline 99 & 1528893 & 9. & 661 & \\
\hline & 152 & 8. & & \\
\hline 289 & 1528893 & 9.0 & 8.3543 & \\
\hline & 1528893 & 9.0 & 9.0991 & \\
\hline CHEMBL3657298 & 1528893 & 7.7696 & 7.6109 & \\
\hline
\end{tabular}

Page 20695 


\begin{tabular}{|c|c|c|c|c|}
\hline \multicolumn{5}{|c|}{ Supplemental Table S2.txt } \\
\hline CHEMBL 3657358 & 1528893 & 9.0 & 9.0168 & TRN \\
\hline CHEMBL3657410 & 1528893 & 8.3979 & 8.3382 & TRN \\
\hline CHEMBL3657367 & 1528893 & 8.699 & 8.8732 & TRN \\
\hline CHEMBL3661436 & 1528893 & 9.0 & 8.6132 & TST \\
\hline CHEMBL3661429 & 1528893 & 8.2218 & 7.9721 & TST \\
\hline CHEMBL3769412 & 1556481 & 3.301 & 3.2 & TRN \\
\hline CHEMBL3769423 & 1556481 & 3.301 & 3.2263 & TRN \\
\hline CHEMBL3770089 & 1556481 & 3.301 & 3.0495 & TRN \\
\hline CHEMBL3769642 & 1556481 & 3.301 & 3.7466 & TRN \\
\hline CHEMBL3770494 & 1556481 & 3.301 & 3.3684 & TRN \\
\hline CHEMBL3769468 & 1556481 & 4.5129 & 4.3551 & TRN \\
\hline CHEMBL3770937 & 1556481 & 4.9066 & 4.5254 & TRN \\
\hline CHEMBL3771126 & 1556481 & 3.301 & 3.7945 & TRN \\
\hline CHEMBL3769726 & 1556481 & 3.301 & 3.2738 & TRN \\
\hline CHEMBL3770552 & 1556481 & 4.5406 & 4.4 & TRN \\
\hline CHEMBL3769894 & 1556481 & 3.301 & 4.2043 & TRN \\
\hline CHEMBL3769882 & 1556481 & 3.301 & 3.426 & TRN \\
\hline CHEMBL 3771301 & 1556481 & 3.301 & 3.1345 & TRN \\
\hline CHEMBL 3770007 & 1556481 & 4.5406 & 4.1299 & TRN \\
\hline CHEMBL3770658 & 1556481 & 4.5017 & 4.0717 & TRN \\
\hline CHEMBL3769627 & 1556481 & 3.301 & 3.2476 & TST \\
\hline CHEMBL3770052 & 1556481 & 3.301 & 3.1126 & TRN \\
\hline CHEMBL 3770814 & 1556481 & 4.5391 & 4.3955 & TRN \\
\hline CHEMBL 3770280 & 1556481 & 4.449 & 4.1622 & TRN \\
\hline CHEMBL3771097 & 1556481 & 3.301 & 3.7813 & TRN \\
\hline CHEMBL3769969 & 1556481 & 3.301 & 3.09 & TRN \\
\hline CHEMBL3770881 & 1556481 & 3.301 & 3.1733 & TRN \\
\hline CHEMBL 3770085 & 1556481 & 3.301 & 3.4618 & TRN \\
\hline CHEMBL3769625 & 1556481 & 3.301 & 3.7224 & TST \\
\hline CHEMBL3771107 & 1556481 & 4.5686 & 4.1811 & TRN \\
\hline CHEMBL 3771257 & 1556481 & 5.4202 & 5.4962 & TRN \\
\hline CHEMBL3769955 & 1556481 & 3.301 & 4.2564 & TRN \\
\hline CHEMBL3771262 & 1556481 & 3.301 & 3.5101 & TRN \\
\hline CHEMBL 3770742 & 1556481 & 3.301 & 3.2735 & TRN \\
\hline CHEMBL3771236 & 1556481 & 4.6459 & 4.6776 & TRN \\
\hline CHEMBL3770932 & 1556481 & 4.4179 & 3.7976 & TRN \\
\hline CHEMBL3770781 & 1556481 & 3.301 & 3.6544 & TRN \\
\hline CHEMBL 3770172 & 1556481 & 5.1024 & 5.2938 & TRN \\
\hline CHEMBL 3769549 & 1556481 & 3.301 & 3.2889 & TRN \\
\hline CHEMBL3771318 & 1556481 & 4.3188 & 3.9695 & TRN \\
\hline CHEMBL 3769884 & 1556481 & 3.301 & 3.7724 & TST \\
\hline CHEMBL 3770373 & 1556481 & 5.2549 & 4.6955 & TRN \\
\hline CHEMBL3771114 & 1556481 & 3.301 & 3.3037 & TRN \\
\hline CHEMBL 3770376 & 1556481 & 5.0292 & 4.9132 & TRN \\
\hline CHEMBL3771214 & 1556481 & 3.301 & 3.8034 & TRN \\
\hline CHEMBL3769967 & 1556481 & 3.301 & 3.5166 & TRN \\
\hline CHEMBL3769809 & 1556481 & 3.301 & 3.2589 & TRN \\
\hline CHEMBL 3771040 & 1556481 & 6.3098 & 4.8709 & TST \\
\hline
\end{tabular}


Supplemental Table S2.txt

\begin{tabular}{|c|c|c|c|c|}
\hline CHEMBL377e & 1556481 & 3.301 & 3.194 & TST \\
\hline CHEMBL3769608 & 1556481 & 3.301 & 3.7474 & TST \\
\hline HEMBL3771121 & 556481 & 5.4989 & 5.4346 & \\
\hline HEMBL3769467 & 556481 & 5.2076 & 4.4874 & \\
\hline HEMBL3770069 & 556481 & 3.301 & 4.487 & \\
\hline HEMBL 3770386 & 556481 & 3.301 & 3.6323 & \\
\hline HEMBL3769886 & 556481 & 3.301 & 3.0117 & \\
\hline HEMBL 3770970 & 556481 & 3.301 & 3.7062 & \\
\hline HEMBL 3769738 & 556481 & 3.301 & .8801 & \\
\hline HEMBL3770296 & 1556481 & 3.301 & 3.3758 & ST \\
\hline HEMBL319514 & 3364 & 6.699 & 6.7415 & $\mathrm{RN}$ \\
\hline HEMBL148025 & 3364 & 3.6635 & 4.0352 & RN \\
\hline CHEMBL 383705 & 3364 & 5.3979 & 5.334 & \\
\hline HEMBL145862 & 3364 & 4.7423 & 4.7799 & RN \\
\hline HEMBL 278393 & 3364 & 4.7696 & 4.0352 & RN \\
\hline HEMBL148461 & 3364 & 2.0 & 1.8369 & RN \\
\hline CHEMBL146509 & 3364 & 2.0 & 2.2056 & RN \\
\hline CHEMBL359211 & 3364 & 2.301 & 2.3603 & \\
\hline HEMBL460886 & 3364 & 5.4559 & 5.6783 & RN \\
\hline HEMBL145855 & 3364 & 2.0 & 1.7067 & RN \\
\hline HEMBL 348246 & 3364 & 3.301 & 3.5269 & $\mathrm{RN}$ \\
\hline CHEMBL97025 & 3364 & 2.0 & 3.1749 & II \\
\hline CHEMBL146437 & 53364 & 2.301 & 3.6652 & ST \\
\hline HEMBL148285 & 3364 & 3.6021 & 3.5716 & RN \\
\hline CHEMBL461913 & 3364 & 4.2924 & 4.4192 & RN \\
\hline CHEMBL149498 & 3364 & 2.0 & 2.6798 & RN \\
\hline CHEMBL147314 & 3364 & 3.6021 & 3.4794 & RN \\
\hline CHEMBL 97180 & 53364 & 3.6716 & 4.1516 & TRN \\
\hline CHEMBL14 & 53364 & 2.301 & 2.5453 & TRN \\
\hline CHEMBL461911 & 53364 & 3.301 & 3.2183 & TRN \\
\hline CHEMBL403882 & 3364 & 4.8239 & 5.381 & ST \\
\hline CHEMBL356207 & 3364 & 3.5391 & 3.4675 & TRN \\
\hline CHEMBL46 & 53364 & 3.9706 & 3.8952 & TRN \\
\hline CHEMBL 35 & 53364 & 2 . & 2.1002 & TRN \\
\hline CHEMBL503274 & 53364 & 5.3979 & 4.5651 & TRN \\
\hline CHEMBL343616 & 53364 & 2.0 & 2.2341 & TRN \\
\hline CHEMBL452470 & 53364 & 4.284 & 3.8798 & TRN \\
\hline CHEMBL446007 & 53364 & 3.4271 & 3.9816 & TRN \\
\hline CHEMBL461496 & 53364 & 4.2976 & 4.8 & TRN \\
\hline CHEMBL461912 & 53364 & 6.4949 & 6.231 & TRN \\
\hline CHEMBL148954 & 3364 & 4.0915 & 3.7172 & TRN \\
\hline CHEMBL455298 & 53364 & 3.4976 & 3.8259 & TRN \\
\hline CHEMBL456298 & 53364 & 2.0 & 1.7393 & TRN \\
\hline CHEMBL 83418 & 53364 & 4.1739 & 3.9816 & TRN \\
\hline CHEMBL146995 & 53364 & 4.1739 & 3.8568 & TRN \\
\hline CHEMBL501126 & 53364 & 4.4089 & 3.4522 & TRN \\
\hline CHEMBL148392 & 53364 & 2.0 & 1.9875 & I KIV \\
\hline CHEMBL501521 & 53364 & 4.6364 & 4.5324 & \\
\hline
\end{tabular}

Page 20697 


\begin{tabular}{|c|c|c|c|c|c|}
\hline CHEMBL146190 & 53364 & 3.6402 & \multicolumn{2}{|c|}{ 3.2910000000000004 } & \multirow[t]{2}{*}{ TRN } \\
\hline CHEMBL343907 & 53364 & 2.301 & 5.4759 & TST & \\
\hline CHEMBL343650 & 53364 & 3.4237 & 3.2568 & TST & \\
\hline CHEMBL148002 & 53364 & 3.4437 & 3.7166 & TST & \\
\hline CHEMBL459641 & 53364 & 3.7212 & 4.2941 & TRN & \\
\hline CHEMBL443622 & 53364 & 4.3872 & 4.5703 & TRN & \\
\hline CHEMBL146877 & 53364 & 3.821 & 3.9788 & TRN & \\
\hline CHEMBL329171 & 53364 & 2.301 & 2.6571 & TRN & \\
\hline CHEMBL453918 & 53364 & 4.6778 & 4.7572 & TRN & \\
\hline CHEMBL499101 & 53364 & 3.9136 & 3.8544 & TRN & \\
\hline CHEMBL511346 & 53364 & 4.8539 & 4.7326 & TST & \\
\hline CHEMBL344507 & 53364 & 2.9031 & 4.0963 & TST & \\
\hline CHEMBL503809 & 53364 & 4.0315 & 4.73 & TST & \\
\hline CHEMBL443373 & 53364 & 3.7258 & 4.2466 & TST & \\
\hline CHEMBL457550 & 53364 & 2.0 & 3.1156 & TST & \\
\hline CHEMBL434886 & 53364 & 3.7773 & 3.6729 & TST & \\
\hline CHEMBL98408 & 53364 & 5.7696 & 5.8619 & TST & \\
\hline CHEMBL147583 & 53364 & 2.0 & 3.5478 & TST & \\
\hline CHEMBL3894732 & 1637979 & 9.0458 & 9.5765 & TRN & \\
\hline CHEMBL3930485 & 1637979 & 9.6198 & 9.3558 & TRN & \\
\hline CHEMBL3968859 & 1637979 & 8.8539 & 9.4933 & TST & \\
\hline CHEMBL3952496 & 1637979 & 9.0969 & 9.426 & TRN & \\
\hline CHEMBL3899067 & 1637979 & 6.699 & 7.5189 & TRN & \\
\hline CHEMBL3938388 & 1637979 & 8.0969 & 7.803 & TST & \\
\hline CHEMBL 3949835 & 1637979 & 5.5229 & 6.1381 & TRN & \\
\hline CHEMBL3904228 & 1637979 & 7.0 & 7.8996 & TRN & \\
\hline CHEMBL3938361 & 1637979 & 9.0969 & 9.6222 & TST & \\
\hline CHEMBL3983004 & 1637979 & 7.3565 & 7.4263 & TRN & \\
\hline CHEMBL3945525 & 1637979 & 7.0458 & 6.7584 & TRN & \\
\hline CHEMBL 3899200 & 1637979 & 9.8239 & 9.19700 & 3000000001 & TRN \\
\hline CHEMBL3953227 & 1637979 & 8.8861 & 9.421 & TRN & \\
\hline CHEMBL3896103 & 1637979 & 8.0915 & 8.0814 & TRN & \\
\hline CHEMBL3974881 & 1637979 & 8.699 & 9.1957 & TRN & \\
\hline CHEMBL3935733 & 1637979 & 5.0 & 6.1893 & TST & \\
\hline CHEMBL 3898428 & 1637979 & 5.0 & 6.7244 & TST & \\
\hline CHEMBL3963146 & 1637979 & 9.7447 & 8.8698 & TST & \\
\hline CHEMBL3915562 & 1637979 & 6.5528 & 5.7777 & TRN & \\
\hline CHEMBL3892583 & 1637979 & 8.0706 & 8.1209 & TRN & \\
\hline CHEMBL 3984623 & 1637979 & 8.3098 & 7.9099 & TRN & \\
\hline CHEMBL 3914057 & 1637979 & 7.9208 & 7.8573 & TRN & \\
\hline CHEMBL3927752 & 1637979 & 8.0223 & 7.7494 & TRN & \\
\hline CHEMBL3956618 & 1637979 & 8.699 & 7.6818 & TRN & \\
\hline CHEMBL3961315 & 1637979 & 8.5229 & 8.2754 & TRN & \\
\hline CHEMBL3956824 & 1637979 & 8.6383 & 8.4566 & TRN & \\
\hline CHEMBL 3915607 & 1637979 & 9.3188 & 9.3179 & TRN & \\
\hline CHEMBL3930504 & 1637979 & 5.1549 & 5.007 & TRN & \\
\hline CHEMBL3891979 & 1637979 & 9.3979 & 9.106 & TRN & \\
\hline CHEMBL3966821 & 1637979 & 8.3468 & 8.4557 & TST & \\
\hline
\end{tabular}


Supplemental Table S2.txt

\begin{tabular}{|c|c|c|c|c|c|}
\hline CHEMBL 3981871 & 1637979 & 8.7212 & 8.4338 & TRN & \\
\hline CHEMBL 3923888 & 1637979 & 7.2676 & 5.8775 & TST & \\
\hline CHEMBL 3931953 & 1637979 & 9.9586 & 9.3007 & TST & \\
\hline CHEMBL 3975092 & 1637979 & 5.0 & 5.5764 & TRN & \\
\hline CHEMBL 3897763 & 1637979 & 6.2218 & 6.8041 & TRN & \\
\hline CHEMBL 3915043 & 1637979 & 8.3188 & 8.1267 & TRN & \\
\hline CHEMBL 3948411 & 1637979 & 8.1675 & 7.577999 & 9999999999 & TRN \\
\hline CHEMBL 3947822 & 1637979 & 7.4202 & 7.6506 & TRN & \\
\hline CHEMBL 3889841 & 1637979 & 8.3468 & 8.6326 & TRN & \\
\hline CHEMBL 3906996 & 1637979 & 7.9586 & 8.2088 & TRN & \\
\hline CHEMBL 3898789 & 1637979 & 7.9208 & 8.0141 & TRN & \\
\hline CHEMBL 3899609 & 1637979 & 9.6021 & 9.6742 & TRN & \\
\hline CHEMBL 3960830 & 1637979 & 9.4437 & 8.9021 & TST & \\
\hline CHEMBL 3969393 & 1637979 & 5.1549 & 4.9416 & TRN & \\
\hline CHEMBL 3935569 & 1637979 & 8.585 & 8.6066 & TRN & \\
\hline CHEMBL 3907574 & 1637979 & 8.6021 & 8.8046 & TRN & \\
\hline CHEMBL 3897567 & 1637979 & 6.5229 & 7.3624 & TRN & \\
\hline CHEMBL 3891135 & 1637979 & 9.0458 & 9.1243 & TRN & \\
\hline CHEMBL 3978730 & 1637979 & 9.3468 & 9.2166 & TRN & \\
\hline CHEMBL 3895850 & 1637979 & 7.1024 & 8.4089 & TST & \\
\hline CHEMBL 3959310 & 1637979 & 9.0 & 9.3216 & TRN & \\
\hline CHEMBL 3953791 & 1637979 & 8.2218 & 8.1533 & TRN & \\
\hline CHEMBL 3941907 & 1637979 & 8.5376 & 7.9117 & TRN & \\
\hline CHEMBL 3908857 & 1637979 & 8.8861 & 9.0191 & TRN & \\
\hline CHEMBL 3965277 & 1637979 & \multicolumn{2}{|c|}{10.300999999999998} & 9.0585 & TST \\
\hline CHEMBL 3960801 & 1637979 & 8.0862 & 7.9792 & TRN & \\
\hline CHEMBL 3891392 & 1637979 & 6.3468 & 5.9766 & TST & \\
\hline CHEMBL 3945318 & 1637979 & 8.4685 & 8.1654 & TRN & \\
\hline CHEMBL 3944638 & 1637979 & 7.7696 & \multicolumn{2}{|c|}{7.468999999999999} & $1 \mathrm{~K}$ \\
\hline CHEMBL 3901866 & 1637979 & 5.1549 & 5.841 & TRN & \\
\hline CHEMBL 3951790 & 1637979 & 8.3279 & 7.8721 & TRN & \\
\hline CHEMBL 3891895 & 1637979 & 9.5686 & 9.2302 & TRN & \\
\hline CHEMBL 3921873 & 1637979 & 9.1549 & 9.4893 & TRN & \\
\hline CHEMBL 3912858 & 1637979 & 6.0605 & 5.7676 & TRN & \\
\hline CHEMBL 3954085 & 1637979 & 8.6778 & 8.1937 & TST & \\
\hline CHEMBL 3942288 & 1637979 & 8.4318 & 8.1289 & TRN & \\
\hline CHEMBL 3985867 & 1637979 & 8.4089 & 8.3736 & TRN & \\
\hline CHEMBL 3944307 & 1637979 & 8.3188 & 8.0424 & TRN & \\
\hline CHEMBL 3922509 & 1637979 & 8.6576 & 8.3656 & TRN & \\
\hline CHEMBL 3900345 & 1637979 & 5.5229 & 5.8671 & TRN & \\
\hline CHEMBL 3895731 & 1637979 & 5.0 & 5.794 & TST & \\
\hline CHEMBL 3907423 & 1637979 & 9.3372 & 9.0691 & TST & \\
\hline CHEMBL 3984370 & 1637979 & 8.5086 & 8.3991 & TST & \\
\hline CHEMBL 3959522 & 1637979 & 8.7959 & 8.372 & TST & \\
\hline CHEMBL 3959357 & 1637979 & 9.7959 & 9.4324 & TST & \\
\hline CHEMBL 2023521 & 816545 & 8.9208 & 8.8642 & TRN & \\
\hline CHEMBL 2023517 & 816545 & \multicolumn{3}{|c|}{9.283999999999999} & KI \\
\hline CHEMBL 2023400 & 816545 & 8.585 & 8.6497 & TRN & \\
\hline
\end{tabular}




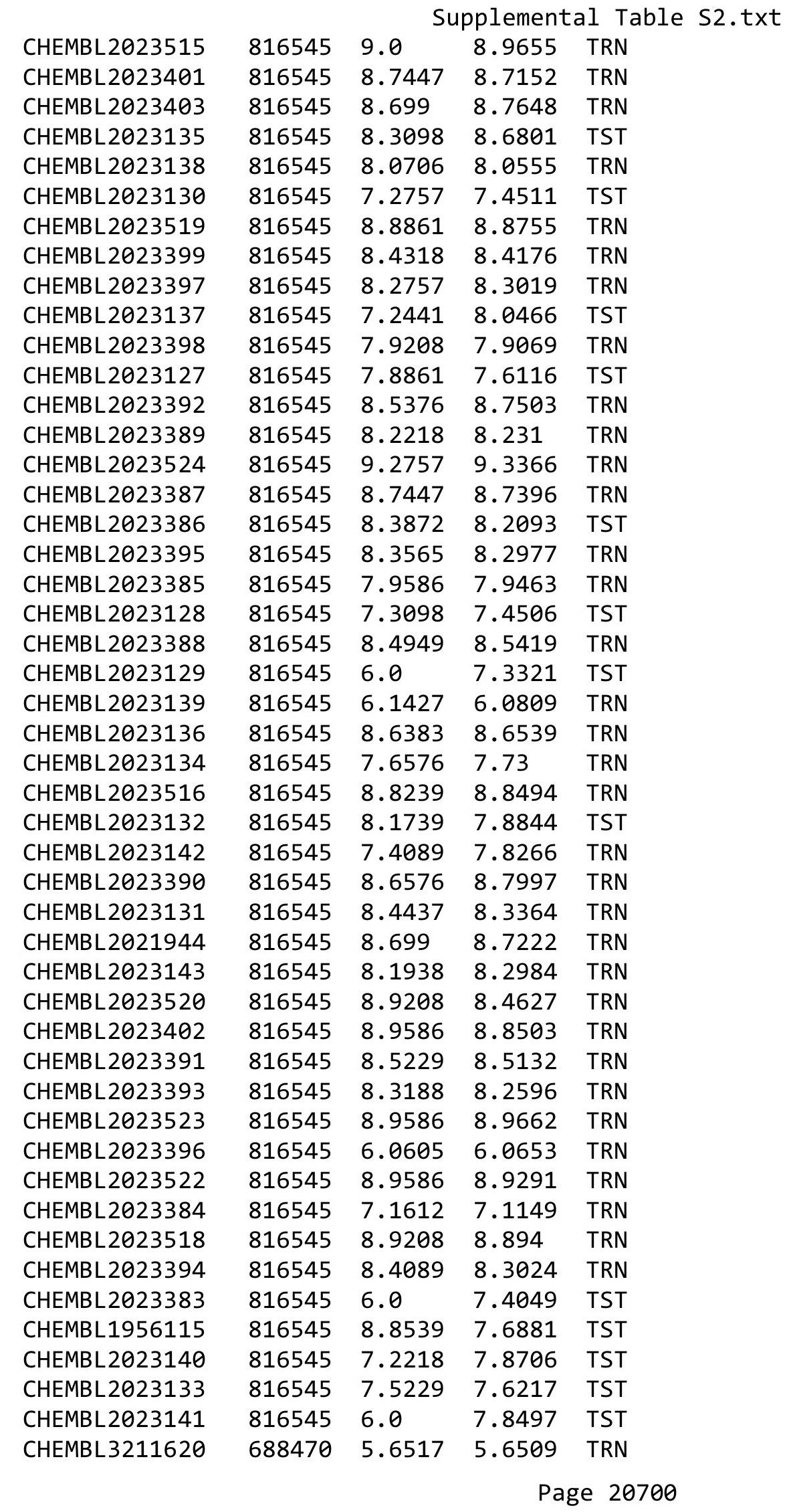




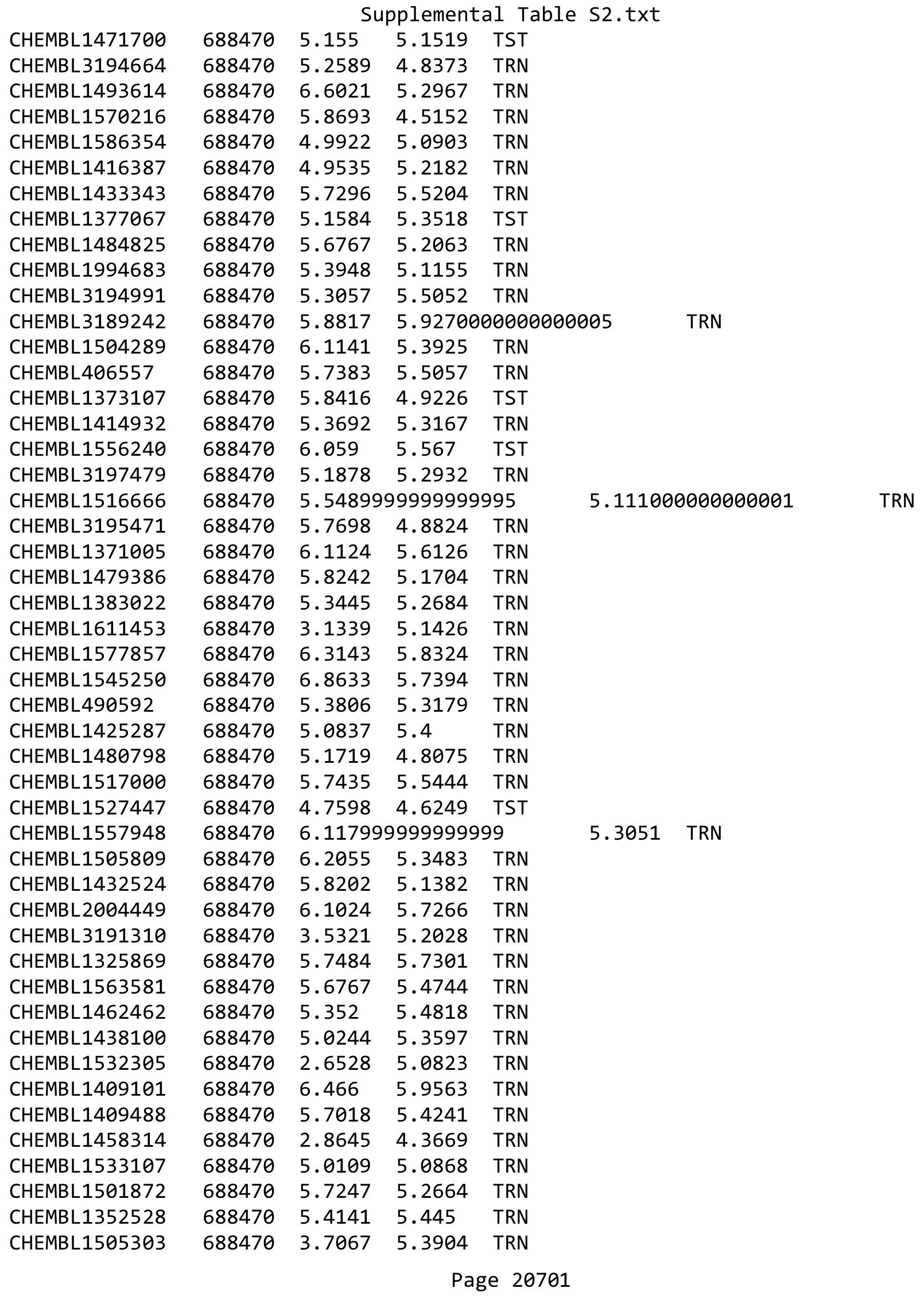




\begin{tabular}{|c|c|c|c|c|c|c|}
\hline \multirow[b]{2}{*}{ CHEMBL1361452 } & \multicolumn{6}{|c|}{ Supplemental Table S2.txt } \\
\hline & 688470 & 5.8265 & 5.5493 & TRN & & \\
\hline CHEMBL1339521 & 688470 & 5.0226 & 4.9297 & TRN & & \\
\hline CHEMBL1491210 & 688470 & 5.95700 & 00000000 & & 5.5516 & TRN \\
\hline CHEMBL1527757 & 688470 & 6.1007 & 5.6216 & TRN & & \\
\hline CHEMBL1465434 & 688470 & 4.4026 & 5.3462 & TRN & & \\
\hline CHEMBL408850 & 688470 & 5.3994 & 5.7763 & TRN & & \\
\hline CHEMBL1601032 & 688470 & 4.2596 & 5.2234 & TST & & \\
\hline CHEMBL1458622 & 688470 & 5.7615 & 4.8865 & TRN & & \\
\hline CHEMBL1340530 & 688470 & 4.8139 & 5.0348 & TRN & & \\
\hline CHEMBL1412987 & 688470 & 5.9122 & 5.5903 & TRN & & \\
\hline CHEMBL1489184 & 688470 & 5.9055 & 5.4787 & TRN & & \\
\hline CHEMBL1543804 & 688470 & 5.7364 & 5.4997 & TRN & & \\
\hline CHEMBL1322308 & 688470 & 7.2291 & 5.6101 & TRN & & \\
\hline CHEMBL1469904 & 688470 & 3.2151 & 4.9879 & TRN & & \\
\hline CHEMBL1518606 & 688470 & 4.3435 & 5.2719 & TRN & & \\
\hline CHEMBL3195881 & 688470 & 5.1985 & 4.8965 & TRN & & \\
\hline CHEMBL1501255 & 688470 & 4.8626 & 5.1003 & TRN & & \\
\hline CHEMBL201325 & 688470 & 6.0615 & 5.5062 & TRN & & \\
\hline CHEMBL1427004 & 688470 & 5.1163 & 4.3698 & TST & & \\
\hline CHEMBL1532623 & 688470 & 6.0872 & 5.2432 & TRN & & \\
\hline CHEMBL1380683 & 688470 & 6.1713 & 5.3461 & TST & & \\
\hline CHEMBL1541584 & 688470 & 5.0947 & 5.3433 & TRN & & \\
\hline CHEMBL1398171 & 688470 & 5.7602 & 5.3539 & TRN & & \\
\hline CHEMBL1534174 & 688470 & 3.4274 & 5.1034 & TRN & & \\
\hline CHEMBL1414624 & 688470 & 5.8914 & 5.636 & TRN & & \\
\hline CHEMBL1328072 & 688470 & 5.9512 & 5.1578 & TRN & & \\
\hline CHEMBL1536118 & 688470 & 5.7406 & 5.0175 & TRN & & \\
\hline CHEMBL1542576 & 688470 & 5.8884 & 5.6243 & TRN & & \\
\hline CHEMBL1401717 & 688470 & 5.2297 & 4.8691 & TST & & \\
\hline CHEMBL1381226 & 688470 & 5.2439 & 5.3585 & TRN & & \\
\hline CHEMBL1596486 & 688470 & 5.9735 & 5.2985 & TRN & & \\
\hline CHEMBL1490017 & 688470 & 6.0429 & 5.4039 & TRN & & \\
\hline CHEMBL1390388 & 688470 & 5.2022 & 5.3085 & TRN & & \\
\hline CHEMBL1561248 & 688470 & 5.7962 & 5.5303 & TRN & & \\
\hline CHEMBL1331509 & 688470 & 6.1343 & 5.4411 & TRN & & \\
\hline CHEMBL1438507 & 688470 & 3.5011 & 5.1624 & TRN & & \\
\hline CHEMBL1595804 & 688470 & 5.6515 & 5.5109 & TRN & & \\
\hline CHEMBL 78010 & 688470 & 5.6402 & 5.28100 & 0000000001 & & TRN \\
\hline CHEMBL1462803 & 688470 & 5.7053 & 5.1029 & TRN & & \\
\hline CHEMBL464433 & 688470 & 5.7632 & 5.2519 & TRN & & \\
\hline CHEMBL1339927 & 688470 & 5.1555 & 5.3689 & TRN & & \\
\hline CHEMBL 1458023 & 688470 & 5.4774 & 5.2904 & TST & & \\
\hline CHEMBL1329367 & 688470 & 5.9133 & 5.4442 & TST & & \\
\hline CHEMBL505057 & 688470 & 5.0593 & 4.6307 & TRN & & \\
\hline CHEMBL1372396 & 688470 & 5.5682 & 5.1851 & TRN & & \\
\hline CHEMBL1518550 & 688470 & 5.9678 & 5.676 & TRN & & \\
\hline CHEMBL1490104 & 688470 & 5.5926 & 5.4062 & TRN & & \\
\hline CHEMBL502774 & 688470 & 4.7762 & 5.3807 & TRN & & \\
\hline
\end{tabular}

Page 20702 


\begin{tabular}{|c|c|c|c|c|c|}
\hline \multicolumn{6}{|c|}{ Supplemental Table S2.txt } \\
\hline CHEMBL1464550 & 688470 & 5.95 & 5.1212 & TRN & \\
\hline CHEMBL1714915 & 688470 & 5.6788 & 4.5203 & TST & \\
\hline CHEMBL1568340 & 688470 & 5.8419 & 5.5068 & TRN & \\
\hline CHEMBL1565955 & 688470 & 2.1617 & 5.091 & TRN & \\
\hline CHEMBL1523538 & 688470 & 5.2517 & 5.1317 & TST & \\
\hline CHEMBL1412555 & 688470 & 4.901 & 4.4849 & TRN & \\
\hline CHEMBL1452208 & 688470 & 5.3742 & 5.5694 & TRN & \\
\hline CHEMBL1348675 & 688470 & 6.2161 & 5.88299 & 9999999999 & TRN \\
\hline CHEMBL1443965 & 688470 & 5.4103 & 5.341 & TRN & \\
\hline CHEMBL3209263 & 688470 & 5.3065 & 5.0578 & TST & \\
\hline CHEMBL1503238 & 688470 & 5.8389 & 5.4502 & TRN & \\
\hline CHEMBL1341938 & 688470 & 5.4961 & 5.2985 & TRN & \\
\hline CHEMBL1387024 & 688470 & 3.375 & 5.0097 & TRN & \\
\hline CHEMBL3191258 & 688470 & 4.0775 & 4.6758 & TST & \\
\hline CHEMBL1606862 & 688470 & 5.7174 & 4.8561 & TRN & \\
\hline CHEMBL1522438 & 688470 & 4.1926 & 5.3624 & TRN & \\
\hline CHEMBL118009 & 688470 & 6.1959 & 5.4955 & TRN & \\
\hline CHEMBL1410536 & 688470 & 5.7066 & 4.5227 & TRN & \\
\hline CHEMBL1442927 & 688470 & 5.3353 & 5.0905 & TRN & \\
\hline CHEMBL1313648 & 688470 & 5.7402 & 5.0419 & TRN & \\
\hline CHEMBL1334342 & 688470 & 5.5465 & 4.8125 & TRN & \\
\hline CHEMBL1594554 & 688470 & 5.7319 & 5.3672 & TRN & \\
\hline CHEMBL1409043 & 688470 & 5.2166 & 5.5426 & TST & \\
\hline CHEMBL1516925 & 688470 & 5.5442 & 5.1383 & TRN & \\
\hline CHEMBL1096706 & 688470 & 5.4047 & 5.5089 & TRN & \\
\hline CHEMBL1528493 & 688470 & 2.9426 & 4.5643 & TST & \\
\hline CHEMBL1371507 & 688470 & 5.3921 & 5.3545 & TRN & \\
\hline CHEMBL1978594 & 688470 & 5.7647 & 5.6613 & TST & \\
\hline CHEMBL1405071 & 688470 & 5.5812 & 4.6108 & TRN & \\
\hline CHEMBL3191171 & 688470 & 4.9473 & 5.6995 & TRN & \\
\hline CHEMBL1440238 & 688470 & 5.6176 & 5.0992 & TST & \\
\hline CHEMBL1428897 & 688470 & 5.4423 & 4.9191 & TRN & \\
\hline CHEMBL1571160 & 688470 & 3.6641 & 5.2318 & TRN & \\
\hline CHEMBL1547029 & 688470 & 6.1186 & 5.0087 & TRN & \\
\hline CHEMBL1564403 & 688470 & 5.6005 & 4.4239 & TST & \\
\hline CHEMBL1415311 & 688470 & 2.1653 & 5.2899 & TRN & \\
\hline CHEMBL1601781 & 688470 & 2.5398 & 4.3913 & TRN & \\
\hline CHEMBL1466554 & 688470 & 3.8199 & 5.1138 & TRN & \\
\hline CHEMBL1438451 & 688470 & 5.5812 & 5.3502 & TRN & \\
\hline CHEMBL1359529 & 688470 & 5.3595 & 5.1596 & TRN & \\
\hline CHEMBL1419794 & 688470 & 4.8667 & 5.374 & TRN & \\
\hline CHEMBL1464144 & 688470 & 3.0633 & 5.3924 & TRN & \\
\hline CHEMBL1603509 & 688470 & 5.2152 & 5.5079 & TRN & \\
\hline CHEMBL1418018 & 688470 & 5.6629 & 5.6574 & TRN & \\
\hline CHEMBL1550664 & 688470 & 6.8601 & 5.4268 & TRN & \\
\hline CHEMBL1411343 & 688470 & 3.9434 & 5.2947 & TRN & \\
\hline CHEMBL84010 & 688470 & 5.8703 & 5.169 & TST & \\
\hline CHEMBL1526653 & 688470 & 6.015 & 5.4155 & TRN & \\
\hline
\end{tabular}




\begin{tabular}{|c|c|c|c|c|c|}
\hline \multicolumn{6}{|c|}{ Supplemental Table S2.txt } \\
\hline CHEMBL1400658 & 688470 & 5.4594 & 4.6584 & TRN & \\
\hline CHEMBL1411327 & 688470 & 6.041 & 5.315 & TST & \\
\hline CHEMBL1327715 & 688470 & 5.9586 & 5.3797 & TRN & \\
\hline CHEMBL3208732 & 688470 & 6.0545 & 5.296 & TRN & \\
\hline CHEMBL1562314 & 688470 & 2.0553 & 4.9815 & TRN & \\
\hline CHEMBL1606065 & 688470 & 5.8904 & 5.5026 & TRN & \\
\hline CHEMBL1347057 & 688470 & 4.3334 & 5.2389 & TRN & \\
\hline CHEMBL3195763 & 688470 & 5.2599 & 5.1885 & TRN & \\
\hline CHEMBL1492763 & 688470 & 3.1783 & 5.3464 & TRN & \\
\hline CHEMBL1577071 & 688470 & 6.8013 & 5.3641 & TRN & \\
\hline CHEMBL3196042 & 688470 & 5.902 & 5.7352 & TRN & \\
\hline CHEMBL472929 & 688470 & 5.8413 & 5.4692 & TRN & \\
\hline CHEMBL1600381 & 688470 & 5.6498 & 5.0583 & TRN & \\
\hline CHEMBL1529092 & 688470 & 4.7398 & 5.351 & TRN & \\
\hline CHEMBL1469517 & 688470 & 5.4086 & 5.1383 & TRN & \\
\hline CHEMBL1343389 & 688470 & 6.9031 & 5.9019 & TRN & \\
\hline CHEMBL1342798 & 688470 & 5.7222 & 5.5977 & TRN & \\
\hline CHEMBL1601364 & 688470 & 5.2807 & 5.42 & TRN & \\
\hline CHEMBL1302493 & 688470 & 5.0421 & 4.6743 & TRN & \\
\hline CHEMBL1419082 & 688470 & 6.1439 & 4.6451 & TST & \\
\hline CHEMBL1373256 & 688470 & 2.5374 & 5.4807 & TRN & \\
\hline CHEMBL1532568 & 688470 & 3.7636 & 5.4364 & TRN & \\
\hline CHEMBL1333630 & 688470 & 5.8706 & 5.4868 & TRN & \\
\hline CHEMBL3199860 & 688470 & 5.2237 & 4.6452 & TRN & \\
\hline CHEMBL3145382 & 688470 & 2.2162 & 5.0716 & TST & \\
\hline CHEMBL1420610 & 688470 & 6.0438 & 5.4057 & TRN & \\
\hline CHEMBL1384832 & 688470 & 4.7637 & 5.6595 & TRN & \\
\hline CHEMBL1347491 & 688470 & 5.6908 & 5.58 & TRN & \\
\hline CHEMBL3194606 & 688470 & 5.4133 & 4.71899 & 9999999999 & TRN \\
\hline CHEMBL1385532 & 688470 & 5.6899 & 5.1276 & TRN & \\
\hline CHEMBL1425019 & 688470 & 3.0334 & 5.3174 & TRN & \\
\hline CHEMBL1495154 & 688470 & 5.9658 & 5.4751 & TRN & \\
\hline CHEMBL1488090 & 688470 & 3.3814 & 5.0931 & TRN & \\
\hline CHEMBL1352555 & 688470 & 2.406 & 4.3421 & TRN & \\
\hline CHEMBL1426754 & 688470 & 5.7069 & 5.1346 & TRN & \\
\hline CHEMBL1366712 & 688470 & 6.3706 & 5.2391 & TRN & \\
\hline CHEMBL1367191 & 688470 & 5.6043 & 5.32 & TRN & \\
\hline CHEMBL1342156 & 688470 & 5.115 & 4.5271 & TRN & \\
\hline CHEMBL1359029 & 688470 & 6.4486 & 5.4326 & TRN & \\
\hline CHEMBL1548093 & 688470 & 6.1163 & 5.5942 & TRN & \\
\hline CHEMBL1492524 & 688470 & 5.7331 & 5.6543 & TRN & \\
\hline CHEMBL1548899 & 688470 & 4.5298 & 5.3909 & TRN & \\
\hline CHEMBL3195897 & 688470 & 5.1695 & 4.9277 & TST & \\
\hline CHEMBL1537857 & 688470 & 5.4884 & 5.2093 & TRN & \\
\hline CHEMBL1503780 & 688470 & 5.9718 & 5.5746 & TRN & \\
\hline CHEMBL1302906 & 688470 & 5.2356 & 5.062 & TRN & \\
\hline CHEMBL1343311 & 688470 & 4.4981 & 5.5243 & TRN & \\
\hline CHEMBL1507129 & 688470 & 5.6568 & 5.407 & TRN & \\
\hline
\end{tabular}


Supplemental Table S2.txt

\begin{tabular}{|c|c|c|c|c|c|}
\hline CHEMBL1488614 & 688470 & 6.1884 & 5.4731 & TRN & \\
\hline CHEMBL1495072 & 688470 & 4.9577 & 4.6412 & TST & \\
\hline CHEMBL1429821 & 688470 & 6.4647 & 5.9636 & TRN & \\
\hline CHEMBL1502047 & 688470 & 4.4097 & 5.1083 & TRN & \\
\hline CHEMBL1534441 & 688470 & 6.0585 & 5.6121 & TRN & \\
\hline CHEMBL1541933 & 688470 & 3.8043 & 5.2692 & TRN & \\
\hline CHEMBL1311605 & 688470 & 5.6084 & 5.072 & TRN & \\
\hline CHEMBL1323791 & 688470 & 5.5899 & 5.1563 & TRN & \\
\hline CHEMBL1421980 & 688470 & 5.5688 & 5.2769 & TRN & \\
\hline CHEMBL 3192901 & 688470 & 4.7394 & 5.1759 & TRN & \\
\hline CHEMBL 3191023 & 688470 & 5.8359 & 5.0665 & TST & \\
\hline CHEMBL1559624 & 688470 & 5.4412 & 5.0663 & TRN & \\
\hline CHEMBL1358788 & 688470 & 5.57299 & 9999999 & 995 & 5.1782 \\
\hline CHEMBL1606307 & 688470 & 4.7237 & 4.9686 & TRN & \\
\hline CHEMBL1450536 & 688470 & 6.0 & 5.2343 & TRN & \\
\hline CHEMBL 2001831 & 688470 & 4.0135 & 4.7018 & TST & \\
\hline CHEMBL3212802 & 688470 & 4.6598 & 5.1095 & TRN & \\
\hline CHEMBL1578093 & 688470 & 5.6156 & 5.2293 & TRN & \\
\hline CHEMBL1496401 & 688470 & 5.9867 & 5.5635 & TRN & \\
\hline CHEMBL1610066 & 688470 & 6.0017 & 4.9608 & TRN & \\
\hline CHEMBL1495910 & 688470 & 3.4324 & 4.6886 & TRN & \\
\hline CHEMBL1407587 & 688470 & 2.2515 & 5.0523 & TRN & \\
\hline CHEMBL1988666 & 688470 & 5.7036 & 4.5893 & TRN & \\
\hline CHEMBL1363829 & 688470 & 4.3351 & 5.0266 & TRN & \\
\hline CHEMBL1525546 & 688470 & 4.4482 & 4.6423 & TST & \\
\hline CHEMBL 3194568 & 688470 & 4.8926 & 5.6028 & TRN & \\
\hline CHEMBL1309011 & 688470 & 5.0313 & 5.314 & TRN & \\
\hline CHEMBL1307312 & 688470 & 4.0291 & 5.0008 & TST & \\
\hline CHEMBL1341169 & 688470 & 4.81 & 4.8514 & TRN & \\
\hline CHEMBL1367297 & 688470 & 5.0772 & 4.3579 & TST & \\
\hline CHEMBL1520399 & 688470 & 5.7095 & 4.8182 & TRN & \\
\hline CHEMBL1558211 & 688470 & 4.6304 & 5.0541 & TRN & \\
\hline CHEMBL3197533 & 688470 & 4.1601 & 5.8548 & TRN & \\
\hline CHEMBL1979295 & 688470 & 5.2286 & 5.5605 & TRN & \\
\hline CHEMBL1368212 & 688470 & 4.6624 & 5.3393 & TRN & \\
\hline CHEMBL1364646 & 688470 & 5.1413 & 5.1559 & TRN & \\
\hline CHEMBL 3193763 & 688470 & 5.1876 & 5.0696 & TRN & \\
\hline CHEMBL1353909 & 688470 & 4.2684 & 5.0993 & TRN & \\
\hline CHEMBL1597276 & 688470 & 6.6162 & 5.6837 & TRN & \\
\hline CHEMBL 3189848 & 688470 & 5.4118 & 4.9081 & TRN & \\
\hline CHEMBL518575 & 688470 & 5.0638 & 5.0053 & TRN & \\
\hline CHEMBL1534496 & 688470 & 4.8119 & 5.6745 & TRN & \\
\hline CHEMBL1549548 & 688470 & 5.5124 & 4.6307 & TST & \\
\hline CHEMBL1477419 & 688470 & 5.0567 & 5.4211 & TRN & \\
\hline CHEMBL1559110 & 688470 & 5.6949 & 4.9159 & TRN & \\
\hline CHEMBL1444768 & 688470 & 4.8209 & 5.0287 & TRN & \\
\hline CHEMBL1332600 & 688470 & 5.3524 & 4.9558 & TRN & \\
\hline CHEMBL1393105 & 688470 & 5.8551 & 5.3873 & TRN & \\
\hline
\end{tabular}

Page 20705 


\begin{tabular}{|c|c|c|c|c|c|c|}
\hline \multirow{3}{*}{$\begin{array}{l}\text { CHEMBL1497617 } \\
\text { CHEMBL3189872 }\end{array}$} & & \multicolumn{5}{|c|}{ Supplemental Table S2.txt } \\
\hline & 688470 & 6.0424 & \multicolumn{3}{|c|}{5.4270000000000005} & TST \\
\hline & 688470 & 5.6694 & 5.3123 & TRN & & \\
\hline CHEMBL1300383 & 688470 & 6.065 & 5.5905 & TRN & & \\
\hline CHEMBL 3194052 & 688470 & 6.8894 & 5.4672 & TRN & & \\
\hline CHEMBL1350513 & 688470 & 5.4942 & 4.9208 & TST & & \\
\hline CHEMBL1543847 & 688470 & 5.3849 & 4.7476 & TRN & & \\
\hline CHEMBL1428108 & 688470 & 5.6503 & 5.3979 & TRN & & \\
\hline CHEMBL1469032 & 688470 & 5.4908 & 4.8786 & TRN & & \\
\hline CHEMBL1374200 & 688470 & 6.2233 & 5.6134 & TRN & & \\
\hline CHEMBL460601 & 688470 & 6.6556 & 4.7128 & TRN & & \\
\hline CHEMBL1537810 & 688470 & 5.63399 & 99999999 & 995 & 4.8146 & TRN \\
\hline CHEMBL1439006 & 688470 & 5.6749 & 5.5789 & TRN & & \\
\hline CHEMBL1486253 & 688470 & 5.7978 & 4.6937 & TST & & \\
\hline CHEMBL3196832 & 688470 & 5.8703 & 4.8593 & TRN & & \\
\hline CHEMBL1586732 & 688470 & 5.9767 & 5.8112 & TRN & & \\
\hline CHEMBL1353561 & 688470 & 4.3257 & 5.4698 & TRN & & \\
\hline CHEMBL3190837 & 688470 & 2.3087 & 5.0407 & TST & & \\
\hline CHEMBL1569541 & 688470 & 4.9004 & 4.6681 & TRN & & \\
\hline CHEMBL1400505 & 688470 & 5.7238 & 5.3795 & TRN & & \\
\hline CHEMBL1407077 & 688470 & 4.7614 & 5.1712 & TRN & & \\
\hline CHEMBL1527869 & 688470 & 4.6053 & 5.6666 & TRN & & \\
\hline CHEMBL1573511 & 688470 & 4.9603 & 5.0765 & TRN & & \\
\hline CHEMBL1575228 & 688470 & 4.5425 & 5.2988 & TRN & & \\
\hline CHEMBL1406081 & 688470 & 4.533 & 5.1779 & TRN & & \\
\hline CHEMBL1338750 & 688470 & 5.4865 & 5.19799 & 99999 & 995 & TST \\
\hline CHEMBL2369298 & 688470 & 4.419 & 5.0541 & TRN & & \\
\hline CHEMBL1309377 & 688470 & 3.3031 & 5.3858 & TRN & & \\
\hline CHEMBL1494058 & 688470 & 3.5733 & 4.989 & TST & & \\
\hline CHEMBL1304398 & 688470 & 5.7755 & 5.4971 & TRN & & \\
\hline CHEMBL1496441 & 688470 & 5.5058 & 5.3756 & TRN & & \\
\hline CHEMBL1544831 & 688470 & 5.6173 & 5.5244 & TRN & & \\
\hline CHEMBL1606047 & 688470 & 4.4355 & 4.9704 & TRN & & \\
\hline CHEMBL1368519 & 688470 & 5.3157 & 5.5499 & TRN & & \\
\hline CHEMBL1550895 & 688470 & 5.5107 & 5.5413 & TRN & & \\
\hline CHEMBL1381126 & 688470 & 5.4733 & 5.2757 & TST & & \\
\hline CHEMBL3193795 & 688470 & 6.1871 & 5.8314 & TRN & & \\
\hline CHEMBL1371289 & 688470 & 6.2255 & 5.5844 & TRN & & \\
\hline CHEMBL1600668 & 688470 & 5.9094 & 5.4459 & TRN & & \\
\hline CHEMBL1309268 & 688470 & 4.7112 & 4.953 & TST & & \\
\hline CHEMBL1347354 & 688470 & 5.8122 & 4.5809 & TST & & \\
\hline CHEMBL1345306 & 688470 & 5.38200 & 000000006 & 01 & 4.5813 & TRN \\
\hline CHEMBL1445850 & 688470 & 6.1057 & 5.6921 & TRN & & \\
\hline CHEMBL1377231 & 688470 & 5.6007 & 5.4824 & TRN & & \\
\hline CHEMBL1492461 & 688470 & 4.8059 & 5.3229 & TRN & & \\
\hline CHEMBL1371815 & 688470 & 5.7447 & 5.5835 & TRN & & \\
\hline CHEMBL1336860 & 688470 & 5.5103 & 5.1347 & TRN & & \\
\hline CHEMBL1422346 & 688470 & 6.6635 & 5.5888 & TRN & & \\
\hline CHEMBL1424024 & 688470 & 4.4537 & 5.0477 & TST & & \\
\hline
\end{tabular}




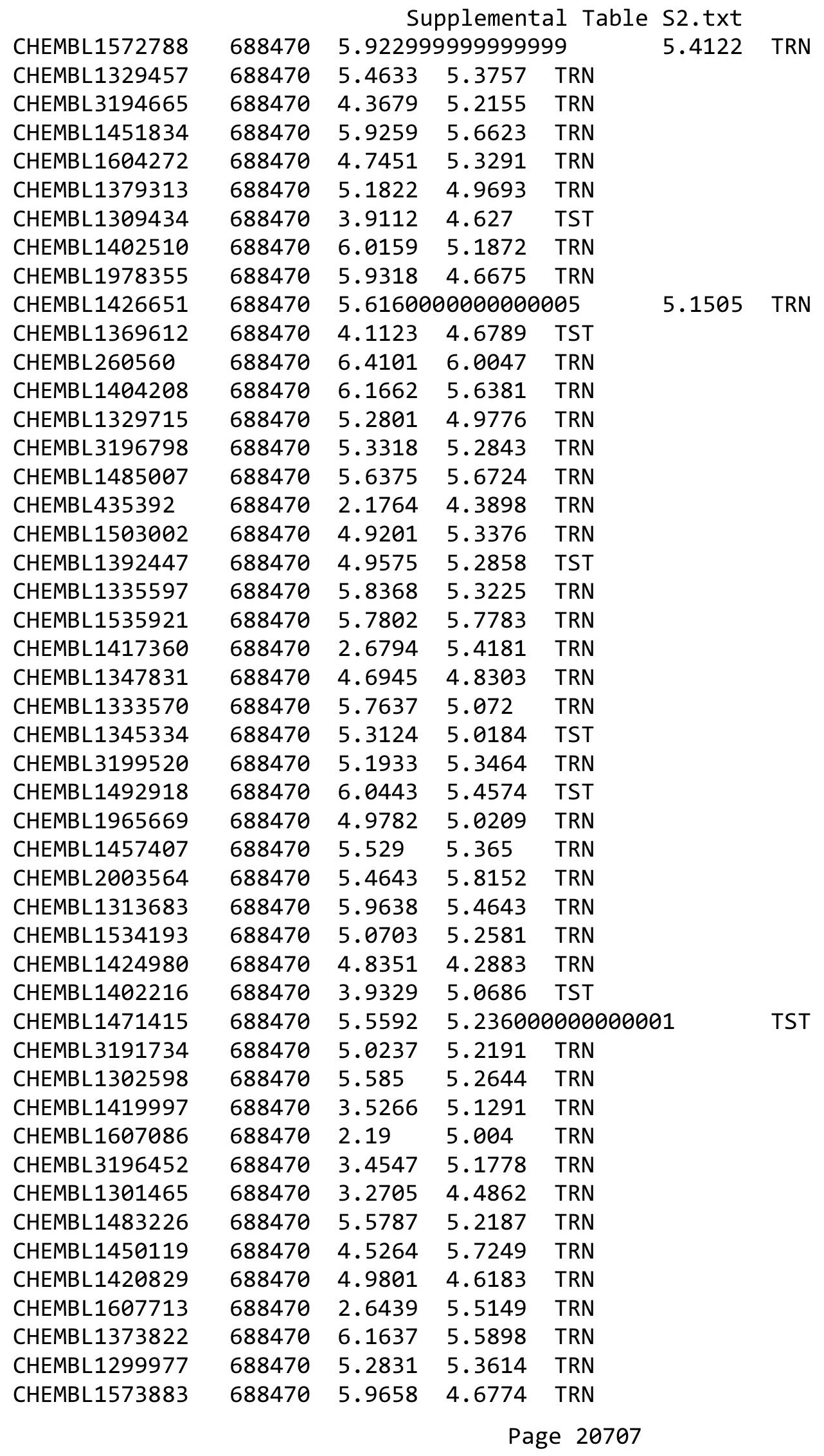


Supplemental Table S2.txt

\begin{tabular}{|c|c|c|c|c|c|}
\hline CHEMBL3191307 & 688470 & 4.9337 & 5.7604 & TST & \\
\hline CHEMBL1410800 & 688470 & 5.3212 & 4.7955 & TRN & \\
\hline CHEMBL1477057 & 688470 & 5.7296 & 5.417999 & 999999999 & TR \\
\hline CHEMBL1467350 & 688470 & 5.9404 & 5.178 & TRN & \\
\hline CHEMBL1607304 & 688470 & 5.8471 & 5.3726 & TRN & \\
\hline CHEMBL1309607 & 688470 & 4.963 & 5.3051 & TRN & \\
\hline CHEMBL1422637 & 688470 & 4.9829 & 5.1831 & TRN & \\
\hline CHEMBL1419880 & 688470 & 5.563 & 5.2726 & TRN & \\
\hline CHEMBL112597 & 688470 & 5.6929 & 5.1623 & TRN & \\
\hline CHEMBL1489045 & 688470 & 5.8781 & 5.4491 & TRN & \\
\hline CHEMBL1344555 & 688470 & 5.6503 & 5.7534 & TRN & \\
\hline CHEMBL1561797 & 688470 & 5.8002 & 5.6003 & TRN & \\
\hline CHEMBL1360012 & 688470 & 4.0046 & 5.2119 & TRN & \\
\hline CHEMBL 2004950 & 688470 & 5.8539 & 5.2104 & TRN & \\
\hline CHEMBL1492961 & 688470 & 4.0075 & 4.7656 & TRN & \\
\hline CHEMBL1387710 & 688470 & 6.0721 & 5.3444 & TST & \\
\hline CHEMBL1477550 & 688470 & 5.9055 & 5.5533 & TRN & \\
\hline CHEMBL1548929 & 688470 & 4.3052 & 4.7995 & TRN & \\
\hline CHEMBL1508377 & 688470 & 5.6857 & 5.3912 & TRN & \\
\hline CHEMBL1496329 & 688470 & 3.6369 & 4.8074 & TRN & \\
\hline CHEMBL1603053 & 688470 & 5.2659 & 5.2016 & TST & \\
\hline CHEMBL1350120 & 688470 & 6.1993 & 5.521 & TRN & \\
\hline CHEMBL1520849 & 688470 & 5.1458 & 5.4056 & TRN & \\
\hline CHEMBL3193405 & 688470 & 5.3599 & 5.9988 & TRN & \\
\hline CHEMBL1450266 & 688470 & 4.3809 & 4.516999 & 9999999995 & \\
\hline CHEMBL1431377 & 688470 & 5.5134 & 5.3727 & TRN & \\
\hline CHEMBL1540914 & 688470 & 4.4348 & 5.1183 & TRN & \\
\hline CHEMBL1539876 & 688470 & 5.2548 & 5.2533 & TRN & \\
\hline CHEMBL1389236 & 688470 & 5.3917 & 5.405 & TRN & \\
\hline CHEMBL1308210 & 688470 & 5.6535 & 5.3194 & TRN & \\
\hline CHEMBL 2007190 & 688470 & 5.4796 & 4.7981 & TRN & \\
\hline CHEMBL1532931 & 688470 & 4.8379 & 5.7422 & TRN & \\
\hline CHEMBL1605430 & 688470 & 6.4609 & 5.3253 & TST & \\
\hline CHEMBL1602538 & 688470 & 5.0 & 5.4627 & TRN & \\
\hline CHEMBL1403136 & 688470 & 4.5522 & 4.6716 & TST & \\
\hline CHEMBL1605613 & 688470 & 4.7614 & 5.3961 & TRN & \\
\hline CHEMBL1534488 & 688470 & 5.4336 & 5.0929 & TRN & \\
\hline CHEMBL1494181 & 688470 & 6.0615 & 5.5518 & TRN & \\
\hline CHEMBL1384689 & 688470 & 5.5226 & 4.7459 & TRN & \\
\hline CHEMBL 246957 & 688470 & \multicolumn{2}{|c|}{5.632999999999999} & 4.6523 & TST \\
\hline CHEMBL1519352 & 688470 & 5.6114 & 4.7944 & TRN & \\
\hline CHEMBL1610659 & 688470 & 5.3988 & 5.346 & TRN & \\
\hline CHEMBL1442502 & 688470 & 4.7612 & 5.3754 & TRN & \\
\hline CHEMBL1365162 & 688470 & 5.0561 & 5.2807 & TRN & \\
\hline CHEMBL1441265 & 688470 & 5.9706 & 5.6242 & TRN & \\
\hline CHEMBL1516879 & 688470 & 6.0097 & 5.5698 & TRN & \\
\hline CHEMBL1495119 & 688470 & 4.4737 & 5.6927 & TRN & \\
\hline CHEMBL1520939 & 688470 & 2.0439 & 5.2217 & TRN & \\
\hline
\end{tabular}

Page 20708 
Supplemental Table S2.txt

\begin{tabular}{|c|c|c|c|c|c|c|}
\hline CHEMBL1504368 & 688470 & 5.595 & 4.7881 & TST & & \\
\hline CHEMBL1324559 & 688470 & 6.1561 & 5.8673 & TRN & & \\
\hline CHEMBL 2369285 & 688470 & 5.5272 & 5.5731 & TST & & \\
\hline CHEMBL1555930 & 688470 & 5.4679 & 5.4089 & TRN & & \\
\hline CHEMBL1584073 & 688470 & 5.8742 & 5.5142 & TRN & & \\
\hline CHEMBL1498364 & 688470 & 5.1468 & 5.0253 & TRN & & \\
\hline CHEMBL1339830 & 688470 & 5.3727 & 4.7366 & TRN & & \\
\hline CHEMBL1386658 & 688470 & 6.983 & 5.189 & TRN & & \\
\hline CHEMBL1354075 & 688470 & 5.2388 & 4.6824 & TST & & \\
\hline CHEMBL1610972 & 688470 & 5.9423 & 5.2254 & TST & & \\
\hline CHEMBL1339303 & 688470 & 3.9106 & 4.423 & TRN & & \\
\hline CHEMBL1598581 & 688470 & 6.1537 & 5.6601 & TRN & & \\
\hline CHEMBL1492459 & 688470 & 3.6301 & 5.1902 & TRN & & \\
\hline CHEMBL1595014 & 688470 & 4.5984 & 5.5238 & TRN & & \\
\hline CHEMBL1521312 & 688470 & 6.4855 & 5.3182 & TRN & & \\
\hline CHEMBL1579060 & 688470 & 2.1953 & 4.4969 & TRN & & \\
\hline CHEMBL1597921 & 688470 & 3.7988 & 5.4241 & TST & & \\
\hline CHEMBL1343689 & 688470 & 5.8601 & 5.5073 & TRN & & \\
\hline CHEMBL1569170 & 688470 & 5.4951 & 5.3603 & TRN & & \\
\hline CHEMBL1421125 & 688470 & 4.88399 & 99999999 & 995 & 5.3616 & TRN \\
\hline CHEMBL1384734 & 688470 & 5.0985 & 5.2473 & TRN & & \\
\hline CHEMBL1444150 & 688470 & 5.7683 & 5.0232 & TRN & & \\
\hline CHEMBL1478934 & 688470 & 2.305 & 5.2706 & TRN & & \\
\hline CHEMBL3194357 & 688470 & 5.7945 & 5.8139 & TRN & & \\
\hline CHEMBL1431340 & 688470 & 6.4056 & 5.9513 & TRN & & \\
\hline CHEMBL1365104 & 688470 & 3.4123 & 4.7267 & TST & & \\
\hline CHEMBL1330558 & 688470 & 5.1001 & 4.4325 & TST & & \\
\hline CHEMBL1468662 & 688470 & 6.0969 & 5.6054 & TRN & & \\
\hline CHEMBL1605478 & 688470 & 5.4318 & 5.3999 & TRN & & \\
\hline CHEMBL1534577 & 688470 & 3.8453 & 5.3761 & TRN & & \\
\hline CHEMBL1559996 & 688470 & 5.074 & 4.9524 & TRN & & \\
\hline CHEMBL1598743 & 688470 & 6.2154 & 5.7827 & TRN & & \\
\hline CHEMBL1501547 & 688470 & 5.9234 & 5.6081 & TST & & \\
\hline CHEMBL1499152 & 688470 & 5.9772 & 5.6789 & TRN & & \\
\hline CHEMBL1438472 & 688470 & 5.7277 & 5.3468 & TRN & & \\
\hline CHEMBL1393874 & 688470 & 6.2958 & 5.5595 & TRN & & \\
\hline CHEMBL1458453 & 688470 & 5.4593 & 5.0825 & TRN & & \\
\hline CHEMBL1376360 & 688470 & 5.2465 & 5.5825 & TRN & & \\
\hline CHEMBL3211119 & 688470 & 5.9948 & 5.3419 & TRN & & \\
\hline CHEMBL1380405 & 688470 & 4.9202 & 5.1111 & TST & & \\
\hline CHEMBL1422678 & 688470 & 6.0814 & 5.2981 & TRN & & \\
\hline CHEMBL1372017 & 688470 & 4.4496 & 5.0697 & TRN & & \\
\hline CHEMBL1478628 & 688470 & \multicolumn{3}{|c|}{4.8069999999999995} & 4.9889 & TRN \\
\hline CHEMBL1532190 & 688470 & 5.862 & 5.8431 & TRN & & \\
\hline CHEMBL1481284 & 688470 & 5.9931 & 4.6253 & TRN & & \\
\hline CHEMBL1347533 & 688470 & 4.3461 & 5.1077 & TRN & & \\
\hline CHEMBL1596709 & 688470 & 4.7298 & 5.0793 & TRN & & \\
\hline CHEMBL1468011 & 688470 & 6.8356 & 5.6092 & TRN & & \\
\hline
\end{tabular}

Page 20709 


\begin{tabular}{|c|c|c|c|c|c|}
\hline & & \multicolumn{4}{|c|}{ Supplemental Table s2.txt } \\
\hline CHEMBL1372863 & 688470 & 5.6743 & 5.6517 & TRN & \\
\hline CHEMBL1519338 & 688470 & 4.2696 & 4.4223 & TST & \\
\hline CHEMBL1501717 & 688470 & 2.7536 & 5.0086 & TRN & \\
\hline CHEMBL1381136 & 688470 & 5.9252 & 5.1339 & TRN & \\
\hline CHEMBL1381918 & 688470 & 5.575 & 5.1776 & TRN & \\
\hline CHEMBL1404393 & 688470 & 5.1752 & 5.2174 & TST & \\
\hline CHEMBL1502635 & 688470 & 5.9252 & 5.2998 & TRN & \\
\hline CHEMBL1330781 & 688470 & 5.2237 & 4.769 & TST & \\
\hline CHEMBL1531806 & 688470 & 5.1901 & 5.2418 & TRN & \\
\hline CHEMBL3192307 & 688470 & 6.2916 & 5.6396 & TRN & \\
\hline CHEMBL1300249 & 688470 & 5.1099 & 5.6354 & TST & \\
\hline CHEMBL1501859 & 688470 & 5.9014 & 4.7912 & TRN & \\
\hline CHEMBL1965298 & 688470 & 6.0953 & 5.6071 & TRN & \\
\hline CHEMBL1987798 & 688470 & 6.0035 & \multicolumn{2}{|c|}{5.071000000000001} & TRN \\
\hline CHEMBL1569816 & 688470 & 5.9876 & 5.5005 & TRN & \\
\hline CHEMBL1461991 & 688470 & 5.6536 & 5.3429 & TRN & \\
\hline CHEMBL1361994 & 688470 & 6.2741 & 5.5989 & TST & \\
\hline CHEMBL1334327 & 688470 & 5.2319 & 4.8972 & TRN & \\
\hline CHEMBL1382028 & 688470 & 5.87 & 5.727 & TRN & \\
\hline CHEMBL1351929 & 688470 & 6.1261 & 5.5292 & TRN & \\
\hline CHEMBL149322 & 688470 & 5.3868 & 5.0935 & TRN & \\
\hline CHEMBL1516542 & 688470 & 6.2916 & \multicolumn{2}{|c|}{5.638999999999999} & TRN \\
\hline CHEMBL1387395 & 688470 & 5.4083 & 5.1761 & TRN & \\
\hline CHEMBL1983530 & 688470 & 5.4397 & 4.7132 & TST & \\
\hline CHEMBL1313940 & 688470 & 5.5746 & 5.2959 & TRN & \\
\hline CHEMBL1523268 & 688470 & 5.3612 & 5.4137 & TRN & \\
\hline CHEMBL1510925 & 688470 & 5.1711 & 4.9532 & TRN & \\
\hline CHEMBL1491393 & 688470 & 6.0246 & 5.1169 & TRN & \\
\hline CHEMBL602718 & 688470 & 5.0762 & 4.7421 & TST & \\
\hline CHEMBL3199742 & 688470 & 5.3985 & 5.4191 & TRN & \\
\hline CHEMBL1372333 & 688470 & 6.0141 & 5.6434 & TRN & \\
\hline CHEMBL1386636 & 688470 & 6.3363 & 5.7953 & TRN & \\
\hline CHEMBL3198067 & 688470 & 6.0477 & 5.058 & TRN & \\
\hline CHEMBL1420838 & 688470 & 5.7711 & 5.2089 & TRN & \\
\hline CHEMBL1432434 & 688470 & \multicolumn{3}{|c|}{5.382000000000001} & TST \\
\hline CHEMBL1306439 & 688470 & 4.7897 & 5.131 & TRN & \\
\hline CHEMBL3194739 & 688470 & 5.7481 & 5.77 & TRN & \\
\hline CHEMBL1326533 & 688470 & 4.9543 & 5.2397 & TRN & \\
\hline CHEMBL1451347 & 688470 & 5.0781 & 5.015 & TST & \\
\hline CHEMBL1603941 & 688470 & 4.7852 & 5.2135 & TRN & \\
\hline CHEMBL1398633 & 688470 & 5.0318 & 5.23600 & 0000000001 & TRN \\
\hline CHEMBL1341284 & 688470 & 5.4639 & 5.3906 & TST & \\
\hline CHEMBL1581270 & 688470 & 5.7729 & 5.3626 & TRN & \\
\hline CHEMBL1509671 & 688470 & 5.0866 & 5.0644 & TST & \\
\hline CHEMBL1455894 & 688470 & 5.7867 & 5.5262 & TRN & \\
\hline CHEMBL1461857 & 688470 & 5.9523 & 5.6749 & TRN & \\
\hline CHEMBL1443435 & 688470 & 3.9511 & 5.1394 & TRN & \\
\hline CHEMBL1601122 & 688470 & 5.6868 & 5.6364 & TRN & \\
\hline
\end{tabular}




\begin{tabular}{|c|c|c|c|c|c|c|}
\hline & & \multicolumn{5}{|c|}{ Supplemental Table S2.txt } \\
\hline CHEMBL1336496 & 688470 & 5.9481 & 5.5484 & TRN & & \\
\hline CHEMBL1605528 & 688470 & 4.6291 & 4.9201 & TST & & \\
\hline CHEMBL1504973 & 688470 & 2.9829 & 4.9519 & TRN & & \\
\hline CHEMBL1549037 & 688470 & 4.5852 & 5.3432 & TST & & \\
\hline CHEMBL3194248 & 688470 & 5.9796 & 6.1208 & TRN & & \\
\hline CHEMBL476513 & 688470 & 5.3047 & 5.3558 & TRN & & \\
\hline CHEMBL1333621 & 688470 & 6.0292 & 5.8127 & TRN & & \\
\hline CHEMBL1477846 & 688470 & 6.1463 & 5.5595 & TRN & & \\
\hline CHEMBL1477920 & 688470 & 5.5539 & 4.3866 & TST & & \\
\hline CHEMBL3199298 & 688470 & 6.0061 & 5.0719 & TRN & & \\
\hline CHEMBL1455814 & 688470 & 5.8788 & 5.4574 & TRN & & \\
\hline CHEMBL1352575 & 688470 & 5.0557 & 5.026 & TST & & \\
\hline CHEMBL1457311 & 688470 & 5.0017 & 4.8462 & TRN & & \\
\hline CHEMBL1440781 & 688470 & \multicolumn{3}{|c|}{6.3420000000000005} & 5.6641 & TRN \\
\hline CHEMBL1557083 & 688470 & 5.8245 & 5.434 & TRN & & \\
\hline CHEMBL1416655 & 688470 & 6.0195 & 5.4813 & TRN & & \\
\hline CHEMBL144626 & 688470 & 3.0304 & 4.8815 & TRN & & \\
\hline CHEMBL1422230 & 688470 & 5.5714 & 5.2015 & TST & & \\
\hline CHEMBL1572597 & 688470 & 2.0116 & 5.2145 & TST & & \\
\hline CHEMBL1368578 & 688470 & 6.0255 & 5.0369 & TST & & \\
\hline CHEMBL1583879 & 688470 & 5.5262 & 5.2217 & TRN & & \\
\hline CHEMBL579102 & 688470 & 2.8687 & 4.9439 & TRN & & \\
\hline CHEMBL1375600 & 688470 & 5.5607 & 4.5257 & TRN & & \\
\hline CHEMBL3190958 & 688470 & 5.3814 & 5.3284 & TRN & & \\
\hline CHEMBL1465522 & 688470 & 2.7579 & 5.5484 & TRN & & \\
\hline CHEMBL1392842 & 688470 & 4.3801 & 5.5493 & TRN & & \\
\hline CHEMBL 2369311 & 688470 & 5.7846 & 5.2327 & TST & & \\
\hline CHEMBL1372199 & 688470 & 5.5186 & 4.5009 & TRN & & \\
\hline CHEMBL1375958 & 688470 & 4.0476 & 4.8821 & TST & & \\
\hline CHEMBL1497197 & 688470 & 6.1707 & 5.7161 & TST & & \\
\hline CHEMBL1505267 & 688470 & 6.1232 & 4.9047 & TRN & & \\
\hline CHEMBL1382374 & 688470 & 4.7225 & 5.0766 & TRN & & \\
\hline CHEMBL1302862 & 688470 & 6.2541 & 5.6155 & TRN & & \\
\hline CHEMBL1519655 & 688470 & 3.9852 & 4.3477 & TST & & \\
\hline CHEMBL3208479 & 688470 & 5.6872 & 4.7822 & TRN & & \\
\hline CHEMBL3209746 & 688470 & 5.6747 & 5.8051 & TRN & & \\
\hline CHEMBL1402732 & 688470 & 5.8586 & 5.4231 & TRN & & \\
\hline CHEMBL1575926 & 688470 & 6.4597 & 5.6047 & TRN & & \\
\hline CHEMBL3198736 & 688470 & 6.2526 & 4.8321 & TRN & & \\
\hline CHEMBL1341073 & 688470 & 5.4397 & 4.4759 & TST & & \\
\hline CHEMBL1577902 & 688470 & 5.2856 & 5.4371 & TRN & & \\
\hline CHEMBL1326813 & 688470 & 4.9127 & 5.0525 & TST & & \\
\hline CHEMBL1333515 & 688470 & 5.3838 & 5.4614 & TRN & & \\
\hline CHEMBL1384554 & 688470 & 7.2291 & 4.6019 & TST & & \\
\hline CHEMBL1572507 & 688470 & 3.3461 & 5.1976 & TRN & & \\
\hline CHEMBL1303553 & 688470 & 6.6576 & 5.2286 & TRN & & \\
\hline CHEMBL1561456 & 688470 & 5.4844 & 5.2715 & TRN & & \\
\hline CHEMBL1520121 & 688470 & 4.6012 & 5.4421 & TRN & & \\
\hline
\end{tabular}




\begin{tabular}{|c|c|c|c|c|c|}
\hline & & \multicolumn{4}{|c|}{ Supplemental Table S2.txt } \\
\hline CHEMBL1362188 & 688470 & 4.739 & 5.3078 & TRN & \\
\hline CHEMBL1335489 & 688470 & 5.9686 & 5.8245 & TRN & \\
\hline CHEMBL1458741 & 688470 & 3.0641 & 5.4145 & TRN & \\
\hline CHEMBL452409 & 688470 & 5.7846 & 5.6547 & TRN & \\
\hline CHEMBL3209857 & 688470 & 5.5522 & 5.2482 & TRN & \\
\hline CHEMBL1389366 & 688470 & 6.1175 & 5.5172 & TRN & \\
\hline CHEMBL1524276 & 688470 & 3.7702 & 5.3537 & TRN & \\
\hline CHEMBL 3212446 & 688470 & 2.7636 & 5.0577 & TRN & \\
\hline CHEMBL1596248 & 688470 & 5.3984 & 5.2391 & TRN & \\
\hline CHEMBL1444771 & 688470 & 5.4632 & 5.3866 & TRN & \\
\hline CHEMBL1610566 & 688470 & 4.5653 & 5.5376 & TRN & \\
\hline CHEMBL 2369186 & 688470 & 5.1586 & 5.3303 & TST & \\
\hline CHEMBL3198870 & 688470 & 5.475 & 5.2935 & TRN & \\
\hline CHEMBL1329650 & 688470 & 6.3575 & 5.9314 & TRN & \\
\hline CHEMBL1567097 & 688470 & 6.1945 & 5.9368 & TRN & \\
\hline CHEMBL1586581 & 688470 & 5.3516 & 4.6306 & TST & \\
\hline CHEMBL1306267 & 688470 & 5.9355 & 4.8287 & TST & \\
\hline CHEMBL1546332 & 688470 & 5.75799 & 99999999 & 5.362 & TRN \\
\hline CHEMBL1398925 & 688470 & 5.9755 & 5.4866 & TRN & \\
\hline CHEMBL1579104 & 688470 & 6.1073 & 5.7634 & TST & \\
\hline CHEMBL3198939 & 688470 & 2.3719 & 5.8714 & TRN & \\
\hline CHEMBL1418920 & 688470 & 4.4074 & 5.44600 & 0000000001 & TRN \\
\hline CHEMBL1399035 & 688470 & 3.9913 & 4.8002 & TRN & \\
\hline CHEMBL1541090 & 688470 & 5.572 & 5.0896 & TST & \\
\hline CHEMBL3197208 & 688470 & 4.6522 & 5.0172 & TST & \\
\hline CHEMBL1335557 & 688470 & 5.3628 & 5.3171 & TRN & \\
\hline CHEMBL1497391 & 688470 & 6.0205 & 5.4022 & TRN & \\
\hline CHEMBL261777 & 688470 & 5.6341 & 5.3639 & TRN & \\
\hline CHEMBL1437965 & 688470 & 5.5339 & 4.9381 & TRN & \\
\hline CHEMBL1439730 & 688470 & 4.6848 & 5.4141 & TRN & \\
\hline CHEMBL1587583 & 688470 & 5.7496 & 5.6385 & TRN & \\
\hline CHEMBL1594218 & 688470 & 6.1759 & 5.705 & TRN & \\
\hline CHEMBL1585105 & 688470 & 5.9788 & 5.4508 & TRN & \\
\hline CHEMBL1527857 & 688470 & 5.4118 & 5.6382 & TRN & \\
\hline CHEMBL1417994 & 688470 & 5.2784 & 5.1193 & TRN & \\
\hline CHEMBL3195058 & 688470 & 5.5246 & 4.6505 & TST & \\
\hline CHEMBL1490918 & 688470 & 5.7547 & 5.6791 & TRN & \\
\hline CHEMBL1521476 & 688470 & 5.7951 & 5.3096 & TRN & \\
\hline CHEMBL1366369 & 688470 & 5.7567 & 5.1676 & TRN & \\
\hline CHEMBL1499328 & 688470 & 5.2101 & 5.4939 & TRN & \\
\hline CHEMBL1430941 & 688470 & 5.0897 & 4.9933 & TRN & \\
\hline CHEMBL1451492 & 688470 & 2.3607 & 5.2879 & TRN & \\
\hline CHEMBL3212830 & 688470 & 5.6362 & 5.1923 & TRN & \\
\hline CHEMBL1462302 & 688470 & 5.9838 & 5.2534 & TRN & \\
\hline CHEMBL1365850 & 688470 & 4.644 & 5.401 & TRN & \\
\hline CHEMBL1427621 & 688470 & 6.1805 & 5.6703 & TRN & \\
\hline CHEMBL1549911 & 688470 & 5.4151 & 4.8772 & TRN & \\
\hline CHEMBL1439000 & 688470 & 5.6936 & 5.3795 & TRN & \\
\hline
\end{tabular}




\begin{tabular}{|c|c|c|c|c|c|c|}
\hline & & & & & & \\
\hline CHEMBL1521797 & 688470 & 6.7033 & 5.5742 & TRN & & \\
\hline CHEMBL1499934 & 688470 & 5.1906 & 5.0734 & TRN & & \\
\hline CHEMBL3192131 & 688470 & 6.6968 & 5.983 & TRN & & \\
\hline CHEMBL1503034 & 688470 & 5.0933 & 4.2981 & TRN & & \\
\hline CHEMBL1377303 & 688470 & 5.8336 & 5.3078 & TRN & & \\
\hline CHEMBL3196123 & 688470 & 4.80699 & 79999999 & 995 & 5.0917 & TRN \\
\hline CHEMBL1466652 & 688470 & 5.1085 & 5.0713 & TRN & & \\
\hline CHEMBL3189729 & 688470 & 5.9961 & 5.0424 & TRN & & \\
\hline CHEMBL1597076 & 688470 & 5.1864 & 5.4227 & TRN & & \\
\hline CHEMBL3197012 & 688470 & 5.769 & 5.3458 & TRN & & \\
\hline CHEMBL428789 & 688470 & 5.7739 & 5.5923 & TRN & & \\
\hline CHEMBL1483638 & 688470 & 3.8825 & 5.1399 & TST & & \\
\hline CHEMBL1438614 & 688470 & 4.9404 & 5.8912 & TST & & \\
\hline CHEMBL131921 & 688470 & 4.2523 & 5.1818 & TRN & & \\
\hline CHEMBL1462944 & 688470 & 6.8097 & 5.8679 & TRN & & \\
\hline CHEMBL1569074 & 688470 & 5.4811 & 5.5687 & TRN & & \\
\hline CHEMBL1485549 & 688470 & 5.9735 & 5.6202 & TRN & & \\
\hline CHEMBL1596719 & 688470 & 6.38399 & 99999999 & 995 & 5.8237 & TRN \\
\hline CHEMBL1583414 & 688470 & 5.7878 & 5.1026 & TRN & & \\
\hline CHEMBL1461080 & 688470 & 4.6196 & 5.0754 & TRN & & \\
\hline CHEMBL1429106 & 688470 & 5.8713 & 5.7196 & TRN & & \\
\hline CHEMBL1564471 & 688470 & 5.8784 & 5.4701 & TST & & \\
\hline CHEMBL1540130 & 688470 & 5.1726 & 5.3148 & TRN & & \\
\hline CHEMBL1518672 & 688470 & 6.4101 & 5.12299 & 9999999999 & & TRN \\
\hline CHEMBL1538689 & 688470 & 5.1312 & 5.36700 & 0000000001 & & TRN \\
\hline CHEMBL1525161 & 688470 & 5.4957 & 5.1503 & TST & & \\
\hline CHEMBL1574671 & 688470 & 4.7518 & 4.926 & TST & & \\
\hline CHEMBL1488450 & 688470 & 4.6603 & 4.9164 & TRN & & \\
\hline CHEMBL1457941 & 688470 & 5.3641 & 5.4765 & TRN & & \\
\hline CHEMBL1523375 & 688470 & 5.6128 & 5.3829 & TRN & & \\
\hline CHEMBL1380514 & 688470 & 5.4903 & 5.3683 & TRN & & \\
\hline CHEMBL1381473 & 688470 & 5.755 & 5.3763 & TRN & & \\
\hline CHEMBL 3212000 & 688470 & 2.4764 & 4.9463 & TRN & & \\
\hline CHEMBL1400093 & 688470 & 4.262 & 4.9859 & TRN & & \\
\hline CHEMBL1491944 & 688470 & 4.508 & 5.4266 & TRN & & \\
\hline CHEMBL1526511 & 688470 & 5.1025 & 4.8868 & TRN & & \\
\hline CHEMBL1460868 & 688470 & 5.1802 & 4.6838 & TRN & & \\
\hline CHEMBL1557437 & 688470 & 5.0605 & 5.077 & TRN & & \\
\hline CHEMBL1412393 & 688470 & 5.2584 & 4.6047 & TRN & & \\
\hline CHEMBL 2369252 & 688470 & 5.7319 & 5.539 & TST & & \\
\hline CHEMBL1509605 & 688470 & 5.9245 & 5.7017 & TRN & & \\
\hline CHEMBL1605722 & 688470 & 5.8088 & 4.5358 & TST & & \\
\hline CHEMBL1608540 & 688470 & 5.7307 & 5.2901 & TRN & & \\
\hline CHEMBL1463825 & 688470 & 3.031 & 5.1925 & TRN & & \\
\hline CHEMBL1965415 & 688470 & 5.2572 & 5.0151 & TRN & & \\
\hline CHEMBL1570213 & 688470 & 5.6022 & 5.4684 & TRN & & \\
\hline CHEMBL 2369217 & 688470 & 5.6631 & 5.5731 & TST & & \\
\hline CHEMBL1214525 & 688470 & 5.0574 & 5.2342 & TRN & & \\
\hline
\end{tabular}




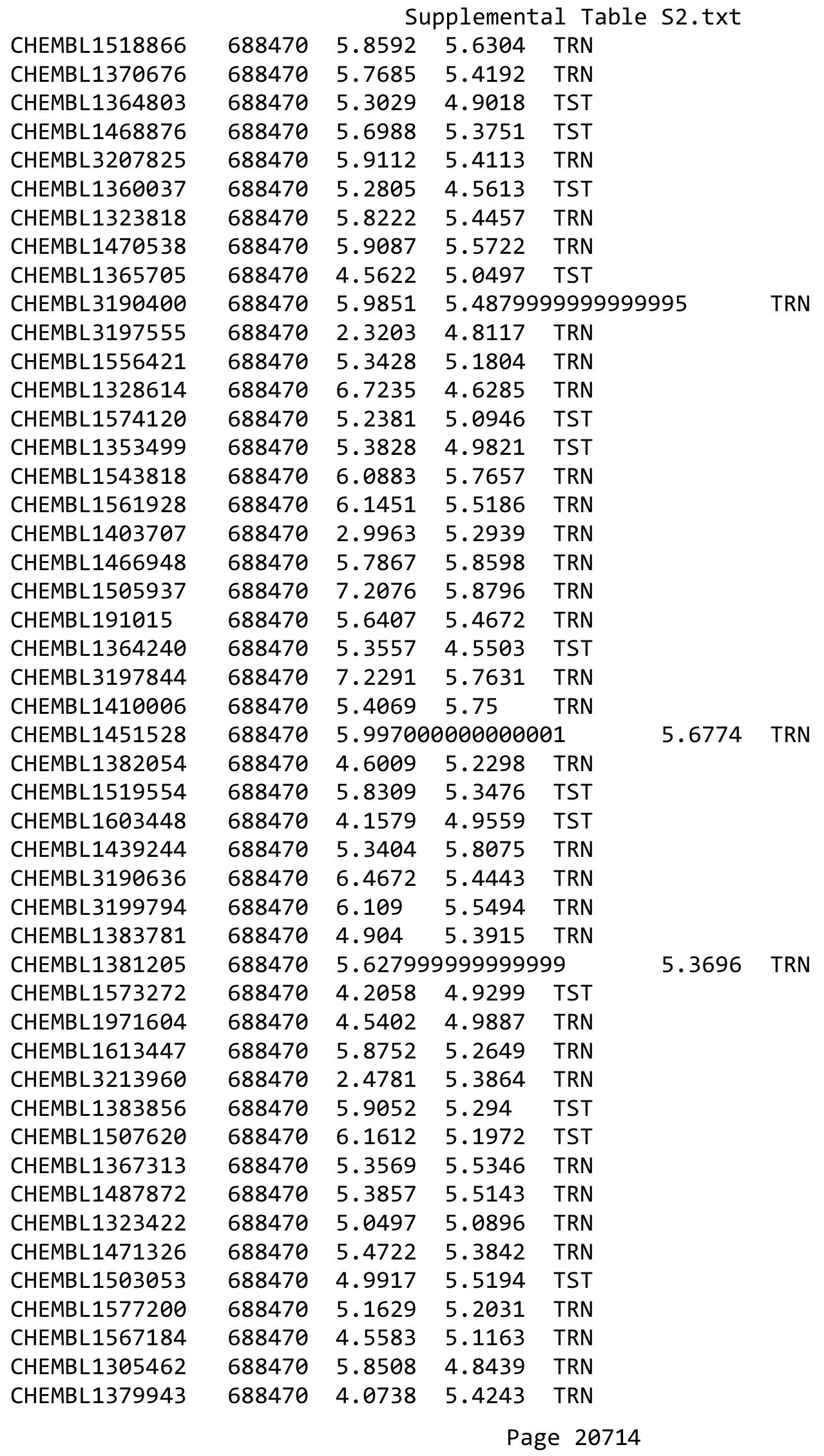




\begin{tabular}{|c|c|c|c|c|}
\hline \multirow[b]{2}{*}{ CHEMBL1518753 } & \multicolumn{4}{|c|}{ Supplemental Tabl } \\
\hline & 688470 & 3.9218 & 4.994 & TST \\
\hline CHEMBL1600851 & 688470 & 6.06 & 4.9823 & TRN \\
\hline CHEMBL1537619 & 688470 & 5.5959 & 5.4528 & TRN \\
\hline CHEMBL1426911 & 688470 & 4.3409 & 5.3623 & TRN \\
\hline CHEMBL1330307 & 688470 & 5.3986 & 4.8468 & TST \\
\hline CHEMBL3191763 & 688470 & 5.1193 & 5.5166 & TRN \\
\hline CHEMBL1470588 & 688470 & 2.5903 & 5.1592 & TRN \\
\hline CHEMBL1509112 & 688470 & 4.673 & 5.0367 & TRN \\
\hline CHEMBL472839 & 688470 & 3.9802 & 4.9469 & TRN \\
\hline CHEMBL504598 & 688470 & 5.9682 & 5.6426 & TRN \\
\hline CHEMBL1335571 & 688470 & 5.2069 & 5.0946 & TRN \\
\hline CHEMBL1506506 & 688470 & 5.9031 & 5.3272 & TRN \\
\hline CHEMBL1585747 & 688470 & 5.2886 & 5.0148 & TST \\
\hline CHEMBL3209853 & 688470 & 3.9693 & 4.9719 & TRN \\
\hline CHEMBL1483160 & 688470 & 5.6325 & 5.1684 & TRN \\
\hline CHEMBL1400143 & 688470 & 5.7667 & 5.4622 & TRN \\
\hline CHEMBL1328930 & 688470 & 5.3345 & 5.3325 & TRN \\
\hline CHEMBL1372204 & 688470 & 6.1238 & 5.603 & TRN \\
\hline CHEMBL1406726 & 688470 & 4.438 & 5.3881 & TRN \\
\hline CHEMBL1559414 & 688470 & 6.0214 & 5.4022 & TRN \\
\hline CHEMBL1547559 & 688470 & 3.0793 & 5.6664 & TRN \\
\hline CHEMBL1399607 & 688470 & 4.2487 & 5.269 & TST \\
\hline CHEMBL 2001100 & 688470 & 4.3677 & 4.6067 & TRN \\
\hline CHEMBL1534136 & 688470 & 4.7032 & 5.3159 & TST \\
\hline CHEMBL1404788 & 688470 & 6.3028 & 4.8325 & TRN \\
\hline CHEMBL1990057 & 688470 & 5.8486 & 4.997 & TRN \\
\hline CHEMBL1376212 & 688470 & 4.255 & 4.7568 & TRN \\
\hline CHEMBL1461285 & 688470 & 4.2996 & 5.0059 & TRN \\
\hline CHEMBL1336246 & 688470 & 4.3205 & 5.4426 & TRN \\
\hline CHEMBL1605300 & 688470 & 5.7825 & 5.3373 & TRN \\
\hline CHEMBL1527175 & 688470 & 5.1653 & 5.2187 & TRN \\
\hline CHEMBL1470626 & 688470 & 5.3009 & 4.5494 & TRN \\
\hline CHEMBL1564062 & 688470 & 5.5538 & 5.2618 & TRN \\
\hline CHEMBL3199849 & 688470 & 5.5834 & 5.3929 & TST \\
\hline CHEMBL1445676 & 688470 & 5.3231 & 5.4221 & TST \\
\hline CHEMBL1360431 & 688470 & 5.0889 & 5.1103 & TRN \\
\hline CHEMBL3189975 & 688470 & 5.7729 & 4.9086 & TRN \\
\hline CHEMBL1427426 & 688470 & 5.7924 & 5.1484 & TST \\
\hline CHEMBL1338533 & 688470 & 5.7089 & 5.2956 & TST \\
\hline CHEMBL1516303 & 688470 & 4.9739 & 5.1544 & TRN \\
\hline CHEMBL1453212 & 688470 & 2.2158 & 4.6244 & TST \\
\hline CHEMBL1452108 & 688470 & 5.2753 & 5.0868 & TRN \\
\hline CHEMBL1492533 & 688470 & 6.0878 & 5.5763 & TRN \\
\hline CHEMBL1480605 & 688470 & 5.6276 & 5.3071 & TST \\
\hline CHEMBL1526182 & 688470 & 5.2338 & 4.7821 & TST \\
\hline CHEMBL1585720 & 688470 & 5.8395 & 5.437 & TRN \\
\hline CHEMBL1982575 & 688470 & 5.942 & 5.3519 & TRN \\
\hline CHEMBL1369639 & 688470 & 5.6811 & 5.4881 & TRN \\
\hline
\end{tabular}


Supplemental Table S2.txt

\begin{tabular}{|c|c|c|c|c|}
\hline 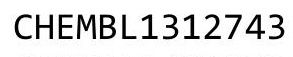 & & & & \\
\hline HEMBL1420639 & 38470 & 655 & 2356 & \\
\hline AEMBL1340489 & 70 & $\partial 91$ & 2586 & \\
\hline AEMBL14 & & & 813 & \\
\hline EMBL15 & & & 136 & \\
\hline AEMBL1390081 & 88470 & 101 & 5517 & \\
\hline AEMBL1344529 & 88470 & 741 & 5417 & \\
\hline HEMBL1454222 & & & 083 & \\
\hline EMBL15 & & 083 & 158 & \\
\hline EMBL31 & & & 261 & \\
\hline AEMBL3190812 & 88470 & 881 & 9901 & \\
\hline AEMBL1426922 & & 409 & 3429 & \\
\hline HEMBL1322828 & & 44 & 4727 & \\
\hline AEMBL13 & & & 33 & \\
\hline AEMBL20 & & & & \\
\hline AEMBL1351643 & & 854 & 458 & \\
\hline JEMBL15 & & 778 & & \\
\hline IEMBL14 & & 67 & 23 & \\
\hline AEMBL14 & & & & \\
\hline AEMBL14 & & & & \\
\hline JEMBL15 & & 357 & 72 & \\
\hline JEMBL13. & & & & \\
\hline AEMBL14 & & 13 & & \\
\hline AEMBL 14 & & & & \\
\hline 51 & & & & \\
\hline 535 & & & 044 & \\
\hline IEMBL15 & & & & \\
\hline EMBL15 & & & & \\
\hline AFMR 11 & & & & \\
\hline JEMPI 27 & & & & \\
\hline JEMBL16 & & & & \\
\hline AEMBL3191021 & & & 789 & \\
\hline & & & & \\
\hline 9 & & & 26 & \\
\hline 979 & & & 212 & $a^{2}+2$ \\
\hline AEMBL1370879 & & & 628 & F \\
\hline AEMBL1539502 & & & 545 & 1 \\
\hline & & & 02 & \\
\hline 76 & & & & mo \\
\hline HEMBL1529656 & & & & $\mathrm{RI}$ \\
\hline AEMBL1517284 & & 37 & 742 & $\Gamma R$ \\
\hline HEMBL14C & & & 87 & Ts \\
\hline & & & 476 & \\
\hline CHEMBL15e & & & 942 & RN \\
\hline AEMBL3198294 & & 4.7399 & .2706 & $\mathrm{R}$ \\
\hline IEMBL13 & 70 & 723 & 2467 & TS \\
\hline & & & 271 & \\
\hline רברחת & & 0171 & & \\
\hline
\end{tabular}

Page 20716 


\begin{tabular}{|c|c|c|c|c|c|c|}
\hline & & & s.tim & & & \\
\hline CHEMBL1964998 & 688470 & 4.3422 & 4.6377 & TRN & & \\
\hline CHEMBL1449424 & 688470 & 5.7607 & 5.11 & TRN & & \\
\hline CHEMBL1490423 & 688470 & 4.8012 & 5.2208 & TRN & & \\
\hline CHEMBL1214519 & 688470 & 5.20799 & 99999999 & 99 & 5.355 & TRN \\
\hline CHEMBL3199125 & 688470 & 5.5297 & 5.0037 & TRN & & \\
\hline CHEMBL1370490 & 688470 & 7.0177 & 5.7796 & TRN & & \\
\hline CHEMBL1449707 & 688470 & 3.695 & 4.9556 & TRN & & \\
\hline CHEMBL85826 & 688470 & 6.7328 & 5.7308 & TRN & & \\
\hline CHEMBL1447448 & 688470 & 5.2547 & 5.3243 & TRN & & \\
\hline CHEMBL1326034 & 688470 & 5.2398 & 5.48600 & 0000000001 & & TRN \\
\hline CHEMBL3213690 & 688470 & 5.6353 & 5.6327 & TRN & & \\
\hline CHEMBL1561625 & 688470 & 5.2379 & 4.8486 & TRN & & \\
\hline CHEMBL1338695 & 688470 & 4.9567 & 5.4181 & TRN & & \\
\hline CHEMBL1571426 & 688470 & 4.3686 & 5.2152 & TRN & & \\
\hline CHEMBL1991234 & 688470 & 5.1874 & 4.8245 & TST & & \\
\hline CHEMBL1564238 & 688470 & 5.2392 & 4.8968 & TST & & \\
\hline CHEMBL159895 & 688470 & 5.7836 & 5.5597 & TRN & & \\
\hline CHEMBL1432324 & 688470 & 5.7402 & 5.499 & TST & & \\
\hline CHEMBL1411784 & 688470 & 2.4674 & 5.7016 & TRN & & \\
\hline CHEMBL1540848 & 688470 & 5.7678 & 5.3448 & TRN & & \\
\hline CHEMBL1535810 & 688470 & 4.335 & 5.4062 & TRN & & \\
\hline CHEMBL1427981 & 688470 & 5.5569 & 5.3524 & TRN & & \\
\hline CHEMBL104728 & 688470 & 4.6031 & 4.8182 & TRN & & \\
\hline CHEMBL1610124 & 688470 & 3.4974 & 5.2968 & TRN & & \\
\hline CHEMBL1320357 & 688470 & 5.5769 & 5.3036 & TST & & \\
\hline CHEMBL1453222 & 688470 & 2.42 & 4.4383 & TST & & \\
\hline CHEMBL1466028 & 688470 & 6.0009 & 5.4442 & TRN & & \\
\hline CHEMBL1464608 & 688470 & 3.3562 & 5.1635 & TRN & & \\
\hline CHEMBL1507347 & 688470 & 6.9706 & 4.6426 & TRN & & \\
\hline CHEMBL1368351 & 688470 & 3.29600 & 30000000 & 203 & 5.4189 & TST \\
\hline CHEMBL1321836 & 688470 & 2.0424 & 5.3523 & TRN & & \\
\hline CHEMBL1444061 & 688470 & 5.414 & 4.755 & TRN & & \\
\hline CHEMBL1269508 & 688470 & 3.8048 & 5.3503 & TRN & & \\
\hline CHEMBL1587117 & 688470 & 5.7326 & 5.2341 & TRN & & \\
\hline CHEMBL1390551 & 688470 & 6.8416 & 5.608 & TRN & & \\
\hline CHEMBL1557514 & 688470 & 5.2361 & 5.1288 & TRN & & \\
\hline CHEMBL1417112 & 688470 & 5.9512 & 5.6511 & TRN & & \\
\hline CHEMBL1531925 & 688470 & 5.2486 & 5.1527 & TRN & & \\
\hline CHEMBL1323490 & 688470 & 6.0241 & 5.5276 & TRN & & \\
\hline CHEMBL1302779 & 688470 & 5.9237 & 5.6619 & TRN & & \\
\hline CHEMBL1534683 & 688470 & 4.1593 & 5.2956 & TRN & & \\
\hline CHEMBL1499860 & 688470 & 4.6185 & 4.3682 & TRN & & \\
\hline CHEMBL1587862 & 688470 & 4.9832 & 5.8935 & TRN & & \\
\hline CHEMBL1567692 & 688470 & 5.4656 & 5.1961 & TRN & & \\
\hline CHEMBL1417800 & 688470 & 4.1556 & 5.0461 & TST & & \\
\hline CHEMBL1331097 & 688470 & 4.6217 & 5.2699 & TRN & & \\
\hline CHEMBL1385176 & 688470 & 5.9727 & 5.5084 & TRN & & \\
\hline CHEMBL2006757 & 688470 & 5.6509 & 5.1486 & TRN & & \\
\hline
\end{tabular}




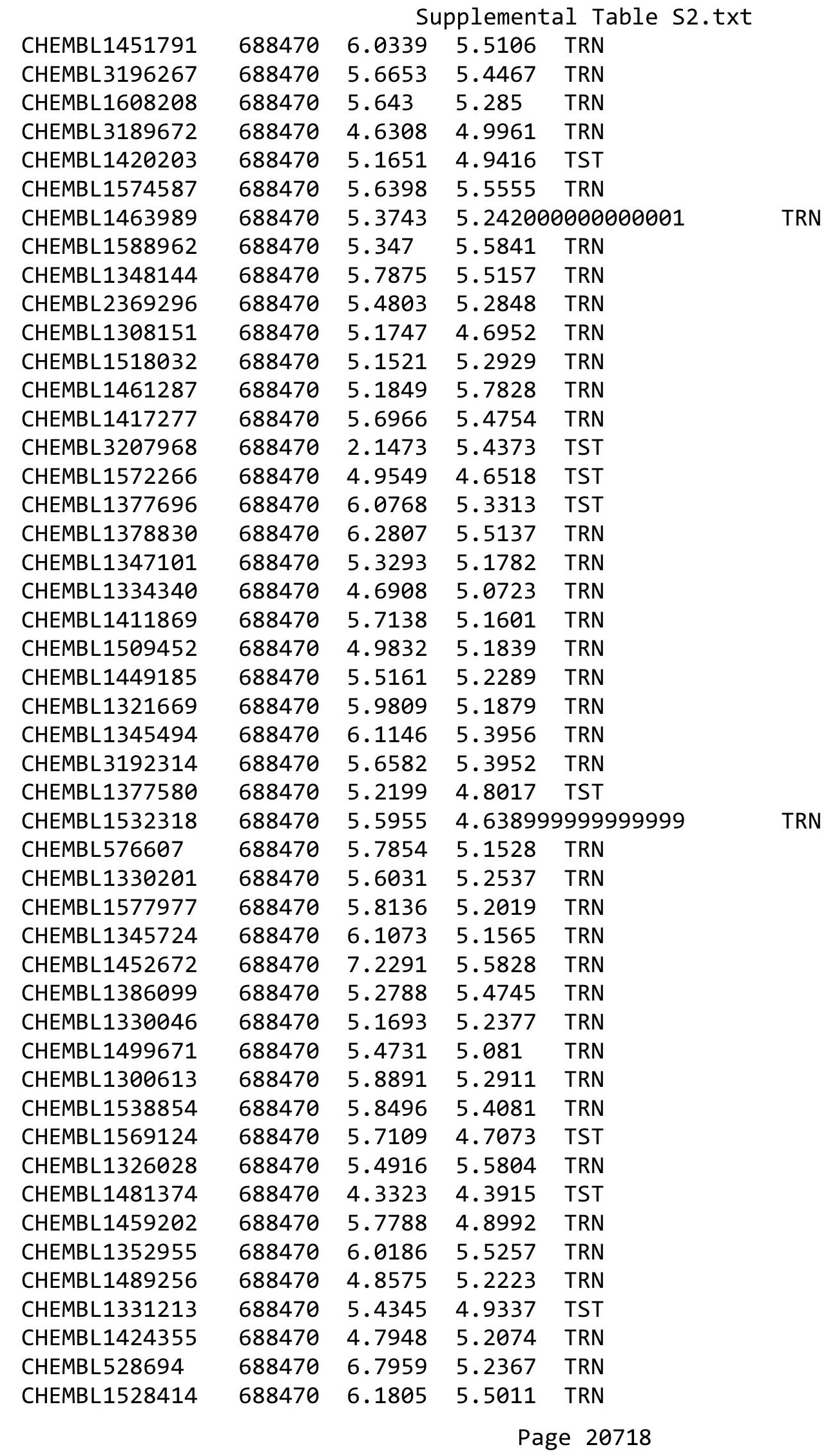


Supplemental Table S2.txt

\begin{tabular}{|c|c|c|c|c|c|}
\hline CHEMBL1329465 & 688470 & 5.8768 & 5.0014 & TRN & \\
\hline CHEMBL1371479 & 688470 & 5.7149 & 5.6497 & TRN & \\
\hline CHEMBL1307028 & 688470 & 5.6767 & 5.3398 & TRN & \\
\hline CHEMBL1360792 & 688470 & 5.9259 & 4.6316 & TRN & \\
\hline CHEMBL1348198 & 688470 & 6.0841 & 5.1743 & TST & \\
\hline CHEMBL1607129 & 688470 & 4.0962 & 5.2109 & TRN & \\
\hline CHEMBL1492108 & 688470 & 5.0052 & 5.2844 & TST & \\
\hline CHEMBL1606956 & 688470 & 5.8027 & 5.1787 & TST & \\
\hline CHEMBL1451245 & 688470 & 4.4541 & 5.5727 & TRN & \\
\hline CHEMBL1563513 & 688470 & 4.5681 & 5.0529 & TST & \\
\hline CHEMBL1471578 & 688470 & 4.3986 & 5.0793 & TRN & \\
\hline CHEMBL1353759 & 688470 & 6.3595 & 5.7187 & TRN & \\
\hline CHEMBL1313936 & 688470 & 6.5302 & 5.789 & TRN & \\
\hline CHEMBL1503172 & 688470 & 6.0164 & 5.4861 & TRN & \\
\hline CHEMBL1609270 & 688470 & 2.4957 & 4.253 & TRN & \\
\hline CHEMBL1549430 & 688470 & 5.7765 & 5.2987 & TRN & \\
\hline CHEMBL1485228 & 688470 & 5.1941 & 5.0198 & TRN & \\
\hline CHEMBL1334210 & 688470 & 5.4821 & 5.4031 & TRN & \\
\hline CHEMBL1306548 & 688470 & 2.5052 & 5.4359 & TRN & \\
\hline CHEMBL1321305 & 688470 & 5.4108 & 5.1423 & TRN & \\
\hline CHEMBL1496008 & 688470 & 5.5959 & 4.6122 & TST & \\
\hline CHEMBL1980667 & 688470 & 5.8142 & 5.3768 & TRN & \\
\hline CHEMBL1489071 & 688470 & 4.82 & 4.9871 & TRN & \\
\hline CHEMBL1378442 & 688470 & 5.5613 & 5.5403 & TRN & \\
\hline CHEMBL1334132 & 688470 & 5.3679 & 5.25799 & 9999999999 & TRN \\
\hline CHEMBL1213769 & 688470 & 2.9552 & 5.1453 & TRN & \\
\hline CHEMBL1309678 & 688470 & 6.3947 & 5.8239 & TRN & \\
\hline CHEMBL1489087 & 688470 & 5.7783 & 5.4361 & TRN & \\
\hline CHEMBL1563323 & 688470 & 4.8818 & 4.4849 & TST & \\
\hline CHEMBL1533198 & 688470 & 4.8737 & 5.1342 & TRN & \\
\hline CHEMBL1415585 & 688470 & 5.3405 & 5.0665 & TST & \\
\hline CHEMBL1387929 & 688470 & 5.9965 & 5.7003 & TRN & \\
\hline CHEMBL1418032 & 688470 & 5.3831 & 4.8891 & TRN & \\
\hline CHEMBL1989372 & 688470 & 5.763 & 5.2331 & TRN & \\
\hline CHEMBL305469 & 688470 & 5.1619 & 4.4338 & TRN & \\
\hline CHEMBL1604679 & 688470 & 5.2852 & 4.9874 & TST & \\
\hline CHEMBL1558563 & 688470 & 5.3025 & 4.89 & TST & \\
\hline CHEMBL1561348 & 688470 & 4.354 & 5.2283 & TRN & \\
\hline CHEMBL 3194422 & 688470 & 5.678 & 4.8535 & TRN & \\
\hline CHEMBL1504089 & 688470 & 5.6609 & 5.3513 & TRN & \\
\hline CHEMBL3194361 & 688470 & 6.0511 & 5.3318 & TRN & \\
\hline CHEMBL1499770 & 688470 & 6.0195 & 5.4401 & TRN & \\
\hline CHEMBL1415253 & 688470 & 5.4722 & 5.1589 & TRN & \\
\hline CHEMBL1417999 & 688470 & 5.0139 & 5.2389 & TST & \\
\hline CHEMBL1413316 & 688470 & 5.4814 & 4.7993 & TST & \\
\hline CHEMBL1493052 & 688470 & 5.8847 & 4.9821 & TST & \\
\hline CHEMBL1496611 & 688470 & 5.4334 & 5.2984 & TST & \\
\hline CHEMBL1568835 & 688470 & 5.4616 & 5.4414 & TST & \\
\hline
\end{tabular}


Supplemental Table S2.txt

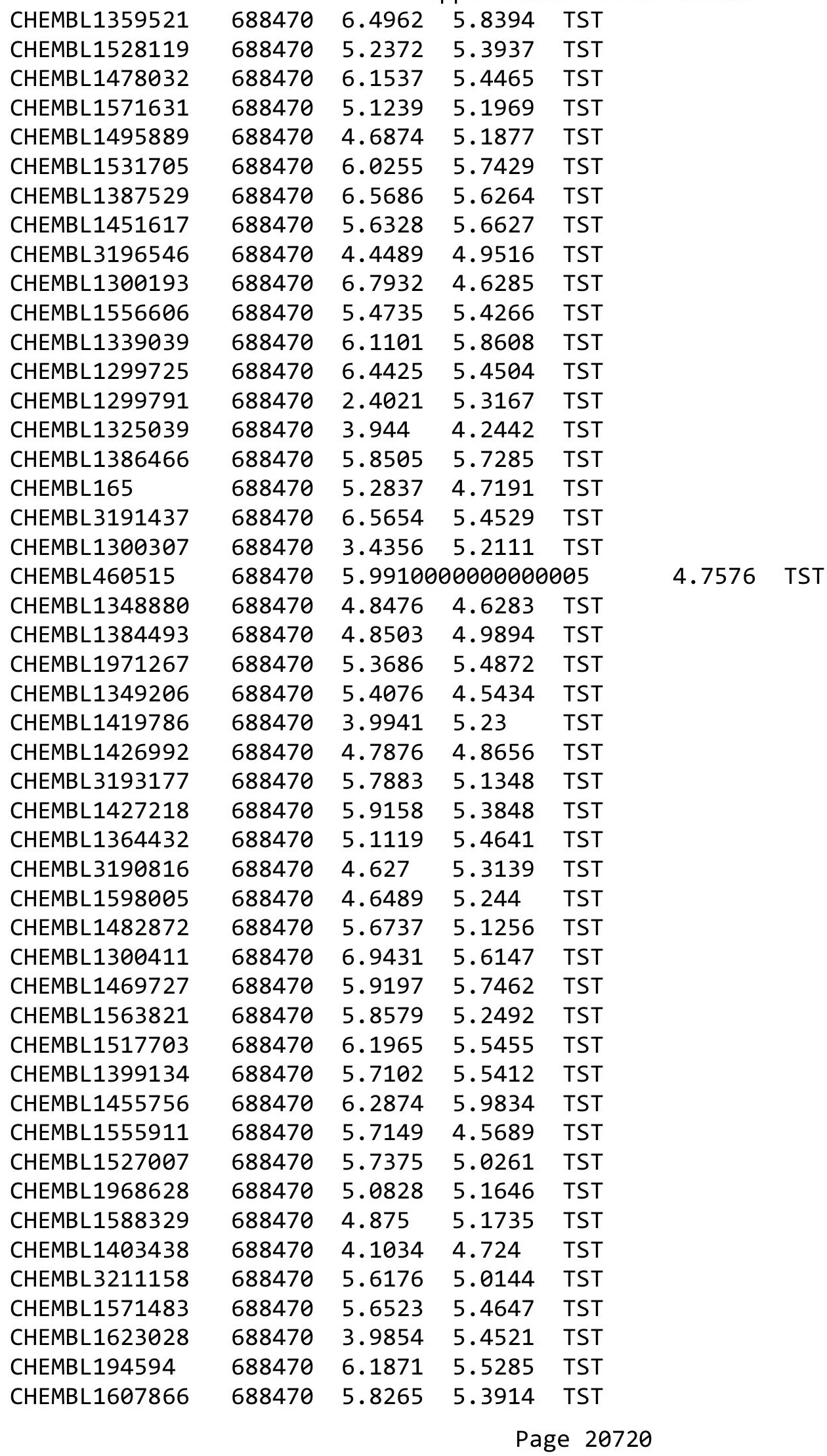




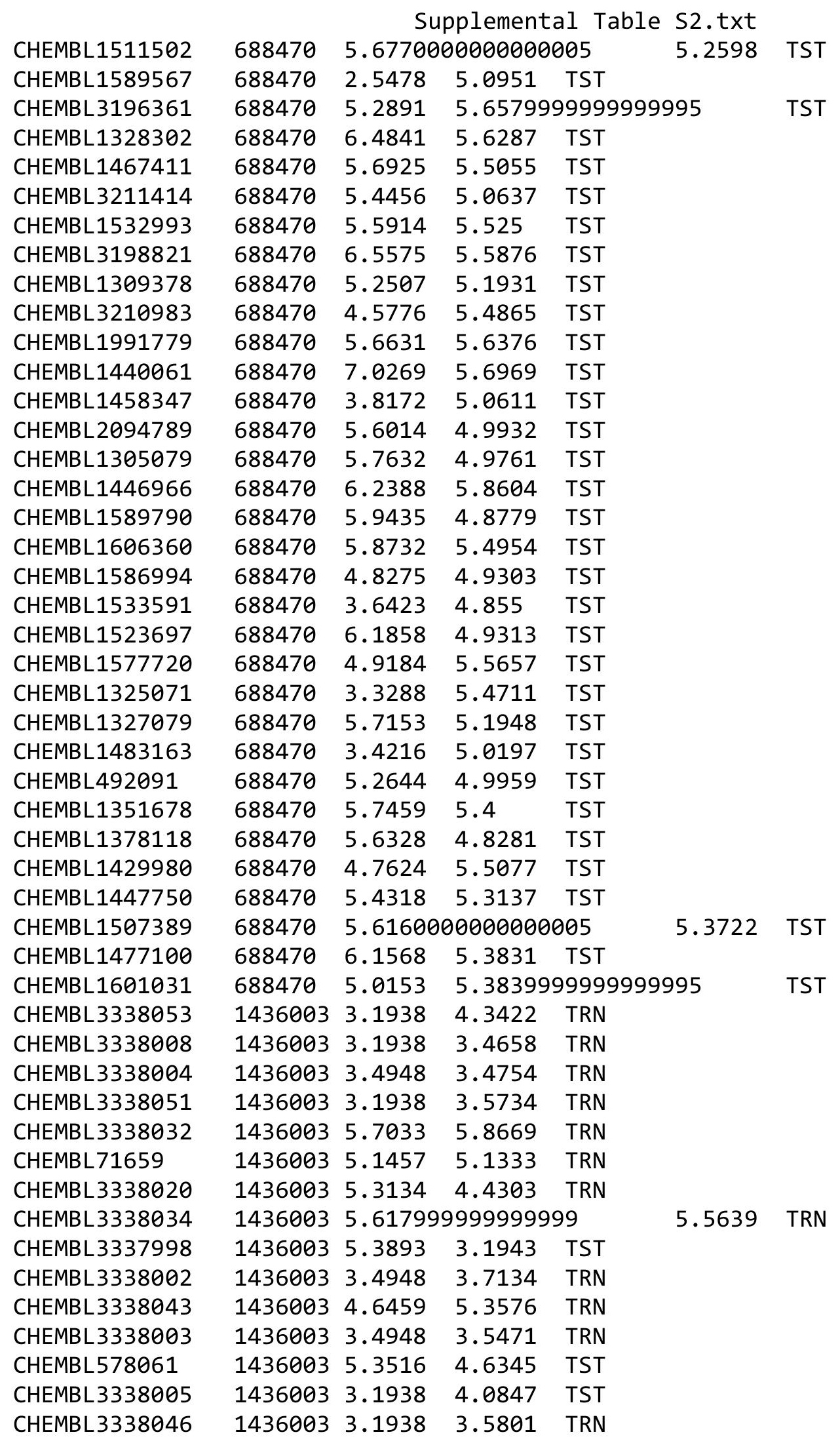

Page 20721 
Supplemental Table S2.txt

\begin{tabular}{|c|c|c|c|c|}
\hline 2 & & & & TRN \\
\hline HЕMP 179925 & & 5.1772 & 4.6667 & \\
\hline IEMBL & & 0625 & & \\
\hline IEMBL3 & 5003 & 0747 & & \\
\hline HEMBL3338028 & 436003 & 5.2503 & & \\
\hline 38001 & 203 & 3.4948 & & \\
\hline FMRI & & & & \\
\hline 38021 & 6003 & 3.1938 & & \\
\hline HEMBL3338047 & 436003 & 5.0915 & 8889 & \\
\hline 37461 & 6003 & 3.4948 & & \\
\hline 8042 & 003 & 938 & & \\
\hline IEMBL & & & & \\
\hline 38045 & 6003 & 5.2832 & & \\
\hline AEMBL3 & 6003 & 3.4948 & & \\
\hline AEMBL: & 6003 & 96 & 06 & \\
\hline IEMBL & & 5 & & \\
\hline AEMBL & & & & \\
\hline 8039 & 003 & 3.1938 & & \\
\hline IEMBL: & 5003 & 1675 & & \\
\hline AEMBL: & 5003 & 5 . & & \\
\hline IEMBL & & & & $\mathrm{RN}$ \\
\hline AEMBL & & & & \\
\hline AEMBL. & 5003 & 78 & & \\
\hline IEMBL & 003 & & & \\
\hline AEMBL & 33 & כ. & & \\
\hline IEMBL & & & & 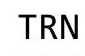 \\
\hline EME & & & & \\
\hline 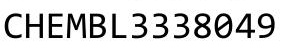 & & & & \\
\hline IEMBL3 & & & & \\
\hline AEMBL & 5003 & 37 & & RI \\
\hline AEMB & & & & \\
\hline EM & & & & \\
\hline IEMBL & & & & \\
\hline AEMBL & & & & \\
\hline AEMBL & 003 & 3 & & $\mathrm{R}$ \\
\hline IFMPI $>$ & & 8 & & \\
\hline AEMRI & & & & \\
\hline AEMBL & & & & $\Gamma R I$ \\
\hline AEMBL & 003 & & & \\
\hline ILTIL & & & & \\
\hline HEMBL & & & & \\
\hline HEMBL & & & & \\
\hline IEMBL & 36003 & 3.1938 & & TRI \\
\hline HEMBL & 600 & 39 & & $\pi \sigma^{-1}$ \\
\hline CHEMBI & & & & \\
\hline CHEMBL3 & ( & & 4269 & \\
\hline CHEMBL3 & 4360 & 4.9555 & 5.4065 & \\
\hline CHEMBL3338012 & 1436003 & 4.3211 & 3.5854 & \\
\hline
\end{tabular}

Page 20722 
Supplemental Table S2.txt

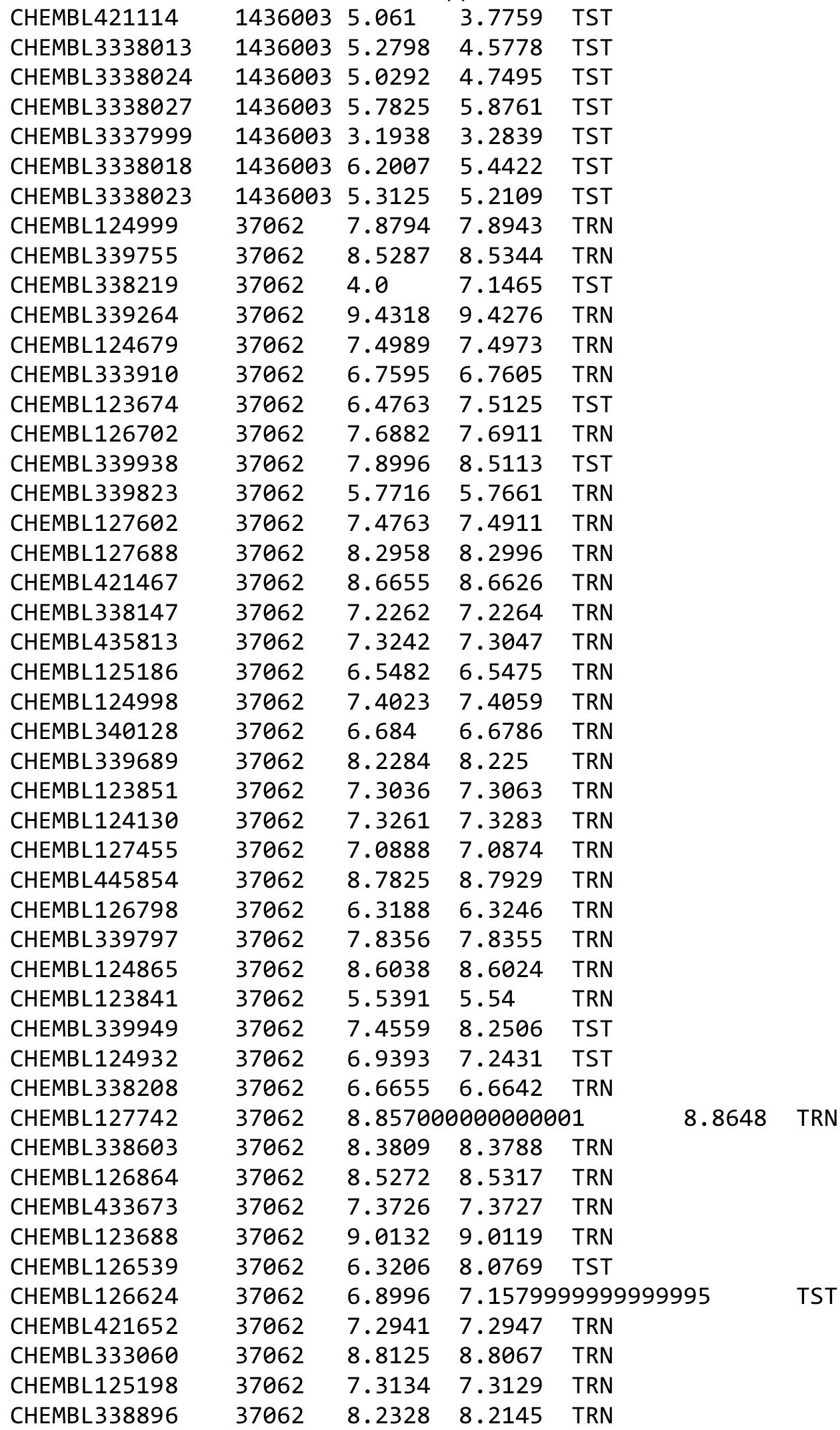

Page 20723 

Supplemental Table S2.txt

\begin{tabular}{|c|c|c|c|c|}
\hline HEMBL2 & & & 76 & TR \\
\hline HFMRI 1189770 & 301779 & & 0138 & \\
\hline HEMBL1396619 & 1779 & & 0777 & \\
\hline AEMBL2355165 & 301779 & & 1206 & \\
\hline HEMBL 2355430 & 301779 & 6.0 & 9899 & \\
\hline HEMBL2361659 & 301779 & 4. & 3312 & \\
\hline AEMBL 2 & 779 & & & \\
\hline HEMBL2358156 & 779 & 561 & 9364 & \\
\hline HEMBL2355771 & 301779 & 195 & 1304 & \\
\hline HEMBL2359863 & 301779 & 4.6319 & 4544 & \\
\hline AEMBL16 & 779 & 5 . & 886 & \\
\hline AEMBL 2 & & & & \\
\hline HEMBL1559741 & 779 & & 9332 & \\
\hline HEMBL 236 & 779 & & & \\
\hline HEMBL2354800 & 79 & 4.7585 & & \\
\hline AEMBL2: & 79 & 6 & 35 & \\
\hline AEMBL1 & & & & \\
\hline HEMBL1 & 79 & 22 & 35 & \\
\hline AEMBL1\& & & & & \\
\hline AEMBL 2360055 & 79 & 4. & 25 & \\
\hline AEMBL1 & 9 & 84 & 45 & \\
\hline AEMBL 2 & & & & NIV \\
\hline HEMBL2 & & 92 & 747 & \\
\hline AEMBL2 & & & & \\
\hline AEMBL 2360811 & 79 & 5 & 042 & IRN \\
\hline AEMBL 2 & 9 & 6 & 326 & RN \\
\hline AEMBL2 2 & & & 16 & RN \\
\hline - & & & & \\
\hline AEMBL2 & & & & IRN \\
\hline HEMBL 235 & 79 & & 99 & RN \\
\hline IEMBL 2 & & & 34 & RN \\
\hline 0 & & & & RN \\
\hline & & & & TST \\
\hline HEMBL 236 & & & 596 & RN \\
\hline HEMBL 235 & 79 & 94 & 3612 & RN \\
\hline AEMBL13 & 9 & 4 & 182 & \\
\hline - & & & & RN \\
\hline HEMBL 23 & & 4.7038 & 058 & RN \\
\hline AEMBL2355724 & & 6. & 978 & 「RN \\
\hline IEMBL31 & & & 197 & RN \\
\hline HEMBL21 & & & 162 & \\
\hline HEMBL14 & & & 4.9126 & ST \\
\hline HEMBL2356746 & & 4. & 5.3525 & RN \\
\hline AEMBL2: & 79 & 4. & 85 & $\mathrm{R}$ \\
\hline MBL2 & & & & \\
\hline HEMBL 2359438 & & 4.3408 & & \\
\hline CHEMBL1379675 & & 4.7557 & 4.6049 & \\
\hline CHEMBL1420472 & 1301779 & 4.5797 & 5.004 & IST \\
\hline
\end{tabular}

Page 20725 
Supplemental Table S2.txt

\begin{tabular}{|c|c|c|c|c|}
\hline 2 & 01779 & & & \\
\hline & 301779 & 4.6588 & 4.7403 & \\
\hline HFMRI & 01779 & 6.0 & & \\
\hline IEMBL & 79 & 767 & & \\
\hline AEMBL2359895 & 301779 & 1278 & 1341 & \\
\hline HEMBL 2361832 & 301779 & 4.7442 & 06 & \\
\hline & 01779 & 486 & & \\
\hline IEMBL23 & 779 & 6.0 & & (M \\
\hline HEMBL2354712 & 301779 & 4.6221 & 4.8066 & \\
\hline HEMBL2360567 & 301779 & 4.7739 & 765 & \\
\hline HEMBL1378851 & 79 & 4.5256 & & \\
\hline EM & 79 & 697 & & ST \\
\hline AEMBL13 & & 43 & & \\
\hline HEMBL1451348 & 301779 & 5.0947 & 4.7059 & - \\
\hline AEMBL2358823 & 79 & 5.2226 & & \\
\hline AEMBL1 & 79 & 59 & & וס \\
\hline HEMBL2 & 9 & 481 & & RN \\
\hline AEMBL2 & 79 & & & RN \\
\hline AEMBL2361365 & 79 & 302 & & \\
\hline AEMBL 235 & & & & I KIV \\
\hline HEMBL 2 & 30 & & 63 & RN \\
\hline HEM & 9 & & & RN \\
\hline HEMBL 2 & 79 & 38 & & RN \\
\hline HEMP 236 & & & & \\
\hline AEMBL 2357 & 99 & 4.659 & 52 & I RN \\
\hline HEMBL2 & 30 & 6 & & 「RN \\
\hline HFM & & & & I \\
\hline 56 & & 6. & & \\
\hline IEMBL1 & & 4 & & IRN \\
\hline HEMBL3182400 & 30 & 6. & & TRN \\
\hline AEMBL 2 & 79 & 95 & & TRN \\
\hline 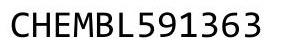 & & 4 & & \\
\hline 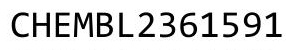 & & & & 「RN \\
\hline HEMBL155 & & & & ГST \\
\hline AEMBL 23562 & 30 & & & RN \\
\hline JCMPI 2 & $30 \div-2>3$ & 32 & & TRN \\
\hline 1 & & & & ST \\
\hline HEMBL 2354 & & & & TRN \\
\hline HEMBL2 & 9 & & & $\Gamma R$ \\
\hline כ) & & & & RN \\
\hline HEMBL 2 & & 4. & & TRN \\
\hline HEMBL 2 & & & & 「RN \\
\hline HEMBL2358924 & & 4.8948 & & $\mathrm{R}$ \\
\hline HEMBL 2136 & 79 & 4.2507 & & TR \\
\hline CHEMPI 23612 & & 636 & & $\mathrm{~N}$ \\
\hline HEMBL2358490 & 301779 & 0.0 & & \\
\hline HEMBL1544797 & 301779 & 4.902 & 5.471 & \\
\hline CHEMBL3186447 & 1301779 & 4.2618 & 4.7775 & TRN \\
\hline
\end{tabular}

Page 20726 
Supplemental Table S2.txt

\begin{tabular}{|c|c|c|c|c|c|}
\hline CHEMBL 3182041 & 1301779 & 4.494 & 5.2187 & TST & \\
\hline CHEMBL2358923 & 1301779 & 4.901 & 5.1398 & TRN & \\
\hline CHEMBL2355923 & 1301779 & 4.8052 & 5.5394 & TRN & \\
\hline CHEMBL 2355664 & 1301779 & 7.585 & 5.4113 & TRN & \\
\hline CHEMBL1568022 & 1301779 & 4.9884 & 4.5462 & TST & \\
\hline CHEMBL 2360014 & 1301779 & 4.7126 & 4.7573 & TRN & \\
\hline CHEMBL2361921 & 1301779 & 4.4592 & 4.794 & TRN & \\
\hline CHEMBL 2362273 & 1301779 & 4.4708 & 5.193 & TRN & \\
\hline CHEMBL 2362144 & 1301779 & 5.0434 & 4.9007 & TRN & \\
\hline CHEMBL 2362547 & 1301779 & 4.3562 & 4.8465 & TST & \\
\hline CHEMBL 3184551 & 1301779 & 4.9226 & 4.6914 & TST & \\
\hline CHEMBL1321427 & 1301779 & 5.301 & 5.3076 & TST & \\
\hline CHEMBL 2357811 & 1301779 & 4.1963 & 5.152 & TST & \\
\hline CHEMBL 2358709 & 1301779 & 4.7791 & 4.5056 & TST & \\
\hline CHEMBL 2361807 & 1301779 & 6.0 & 5.1422 & TST & \\
\hline CHEMBL3184193 & 1301779 & 6.5017 & 4.8715 & TST & \\
\hline CHEMBL1483562 & 1301779 & 4.82100 & 00000000 & 5.1676 & TST \\
\hline CHEMBL 2359612 & 1301779 & 6.0 & 4.9267 & TST & \\
\hline CHEMBL 2361274 & 1301779 & 4.7525 & 5.0754 & TST & \\
\hline CHEMBL3184290 & 1301806 & 4.7719 & 4.7804 & TRN & \\
\hline CHEMBL3184993 & 1301806 & 4.4394 & 4.6367 & TRN & \\
\hline CHEMBL1352168 & 1301806 & 5.1904 & 5.2675 & TRN & \\
\hline CHEMBL1543387 & 1301806 & 4.513 & 4.4778 & TRN & \\
\hline CHEMBL 2138714 & 1301806 & 6.6021 & 6.3715 & TRN & \\
\hline CHEMBL599924 & 1301806 & 5.5421 & 5.5545 & TRN & \\
\hline CHEMBL3186478 & 1301806 & 4.5248 & 4.3779 & TRN & \\
\hline CHEMBL3186528 & 1301806 & 4.9129 & 4.7083 & TRN & \\
\hline CHEMBL1326557 & 1301806 & 4.5284 & 4.6023 & TST & \\
\hline CHEMBL1383774 & 1301806 & 4.8925 & 5.016 & TRN & \\
\hline CHEMBL1734503 & 1301806 & 6.1215 & 5.9903 & TRN & \\
\hline CHEMBL1363219 & 1301806 & 5.4179 & 5.3821 & TRN & \\
\hline CHEMBL 2140821 & 1301806 & 4.4599 & 4.6055 & TRN & \\
\hline CHEMBL1437635 & 1301806 & 4.4921 & 4.5226 & TRN & \\
\hline CHEMBL1369655 & 1301806 & 5.2865 & 5.539 & TRN & \\
\hline CHEMBL1585742 & 1301806 & 4.6635 & 4.4595 & TRN & \\
\hline CHEMBL1401942 & 1301806 & 4.5136 & 4.7252 & TST & \\
\hline CHEMBL1497597 & 1301806 & 5.1586 & 4.9544 & TRN & \\
\hline CHEMBL 3193204 & 1301806 & 4.4988 & 4.5872 & TRN & \\
\hline CHEMBL1401040 & 1301806 & 5.1385 & 5.0066 & TRN & \\
\hline CHEMBL1727324 & 1301806 & 4.96899 & 99999999 & 5.165 & TRN \\
\hline CHEMBL1314866 & 1301806 & 4.6024 & 4.9048 & TST & \\
\hline CHEMBL1523206 & 1301806 & 5.2832 & 5.3585 & TRN & \\
\hline CHEMBL1522827 & 1301806 & 5.3625 & 5.3176 & TRN & \\
\hline CHEMBL1507345 & 1301806 & 4.8857 & 5.0599 & TRN & \\
\hline CHEMBL 2132619 & 1301806 & 4.4217 & \multicolumn{2}{|c|}{4.7219999999999995} & TRN \\
\hline CHEMBL3184689 & 1301806 & 4.5879 & 4.9094 & TRN & \\
\hline CHEMBL 3186044 & 1301806 & 5.1238 & 4.8938 & TRN & \\
\hline CHEMBL 3186208 & 1301806 & 4.7533 & 4.9913 & TRN & \\
\hline
\end{tabular}

Page 20727 
Supplemental Table S2.txt

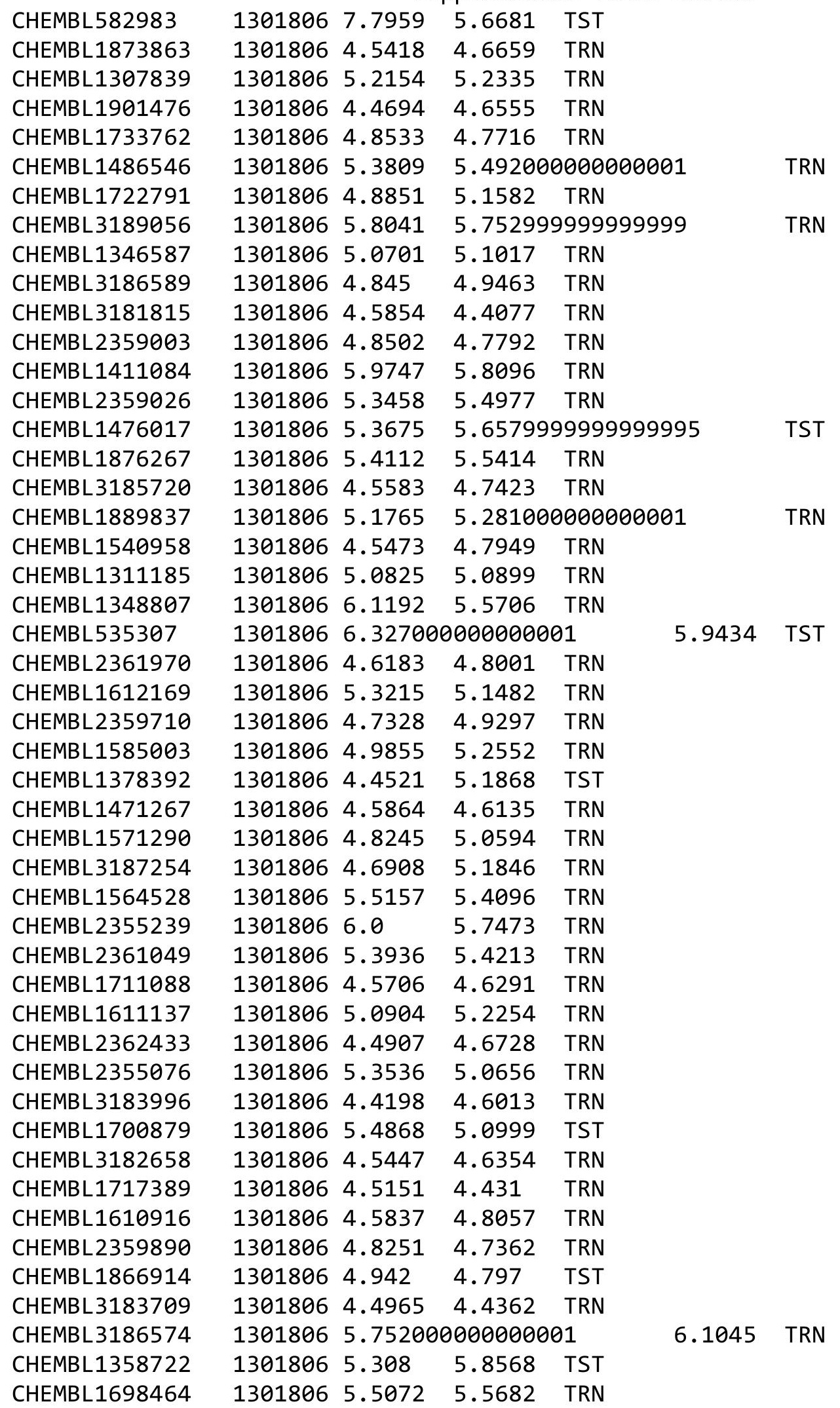


Supplemental Table S2.txt

\begin{tabular}{|c|c|c|c|c|c|}
\hline CHEMBL1549204 & 1301806 & 5.4498 & 5.0753 & TST & \\
\hline CHEMBL1704703 & 1301806 & 5.9788 & \multicolumn{2}{|c|}{5.9079999999999995} & TRN \\
\hline CHEMBL1432798 & 1301806 & 4.5924 & 4.6693 & TRN & \\
\hline CHEMBL1335658 & 1301806 & 4.5011 & 4.3978 & TRN & \\
\hline CHEMBL1353194 & 1301806 & 4.8164 & 4.8883 & TRN & \\
\hline CHEMBL1882125 & 1301806 & 5.2612 & \multicolumn{2}{|c|}{5.4110000000000005} & TRN \\
\hline CHEMBL1323000 & 1301806 & 5.2457 & 5.3444 & TRN & \\
\hline CHEMBL1548253 & 1301806 & 5.0241 & 5.3819 & TST & \\
\hline CHEMBL1306420 & 1301806 & 4.5995 & 4.5372 & TRN & \\
\hline CHEMBL3184582 & 1301806 & 4.4429 & 4.3588 & TRN & \\
\hline CHEMBL1335844 & 1301806 & 5.0052 & 4.9157 & TRN & \\
\hline CHEMBL 3182767 & 1301806 & 5.1007 & 4.8679 & TRN & \\
\hline CHEMBL 3186036 & 1301806 & 4.6662 & 4.9814 & TRN & \\
\hline CHEMBL 2357399 & 1301806 & 6.0 & 5.5164 & TRN & \\
\hline CHEMBL1423597 & 1301806 & 5.4535 & 5.2924 & TRN & \\
\hline CHEMBL1571058 & 1301806 & 4.5081 & 4.4939 & TRN & \\
\hline CHEMBL 3182246 & 1301806 & 5.9666 & 6.1513 & TRN & \\
\hline CHEMBL 3183232 & 1301806 & 4.5346 & 4.4983 & TRN & \\
\hline CHEMBL1391334 & 1301806 & 4.7781 & 4.7285 & TRN & \\
\hline CHEMBL 3183583 & 1301806 & 4.588 & 4.4764 & TRN & \\
\hline CHEMBL1308821 & 1301806 & 4.763 & 5.0924 & TRN & \\
\hline CHEMBL1359655 & 1301806 & 4.9646 & 5.0261 & TRN & \\
\hline CHEMBL1439384 & 1301806 & 5.0883 & 5.2236 & TRN & \\
\hline CHEMBL1485214 & 1301806 & 4.5255 & 5.126 & TST & \\
\hline CHEMBL1605667 & 1301806 & 4.551 & 4.6816 & TRN & \\
\hline CHEMBL 3182088 & 1301806 & 4.8911 & 4.9889 & TRN & \\
\hline CHEMBL 2359934 & 1301806 & 5.8097 & 5.7021 & TRN & \\
\hline CHEMBL1417430 & 1301806 & 5.1701 & 4.9607 & TRN & \\
\hline CHEMBL1582045 & 1301806 & 4.6295 & 4.5424 & TRN & \\
\hline CHEMBL1346713 & 1301806 & 4.5408 & 4.5962 & TRN & \\
\hline CHEMBL1384167 & 1301806 & 5.3716 & 5.446006 & 0000000001 & TRN \\
\hline CHEMBL1409883 & 1301806 & 4.8911 & 4.9354 & TRN & \\
\hline CHEMBL 3183821 & 1301806 & 4.4608 & 4.6986 & TRN & \\
\hline CHEMBL1888056 & 1301806 & 4.6178 & 4.5704 & TRN & \\
\hline CHEMBL1875746 & 1301806 & 5.3116 & 5.2829 & TRN & \\
\hline CHEMBL 3187937 & 1301806 & 4.5768 & 4.8462 & TRN & \\
\hline CHEMBL 2360285 & 1301806 & 5.8041 & 5.2396 & TRN & \\
\hline CHEMBL 2137286 & 1301806 & 4.7719 & 4.5483 & TRN & \\
\hline CHEMBL 86464 & 1301806 & 5.7055 & 5.7275 & TRN & \\
\hline CHEMBL1458479 & 1301806 & 5.4976 & 5.4676 & TRN & \\
\hline CHEMBL 3184473 & 1301806 & 4.6899 & 4.9324 & TRN & \\
\hline CHEMBL1879338 & 1301806 & 5.4123 & 5.3812 & TRN & \\
\hline CHEMBL 2362650 & 1301806 & 6.5258 & 6.436 & TRN & \\
\hline CHEMBL1428003 & 1301806 & 5.3565 & 5.3174 & TRN & \\
\hline CHEMBL 3183585 & 1301806 & 4.7852 & 5.0649 & TRN & \\
\hline CHEMBL 3181958 & 1301806 & 4.797 & 5.1527 & TRN & \\
\hline CHEMBL1299745 & 1301806 & 4.76399 & 99999999 & 4.8144 & TRN \\
\hline CHEMBL 3186808 & 1301806 & 4.567 & 4.5121 & TRN & \\
\hline
\end{tabular}


Supplemental Table S2.txt

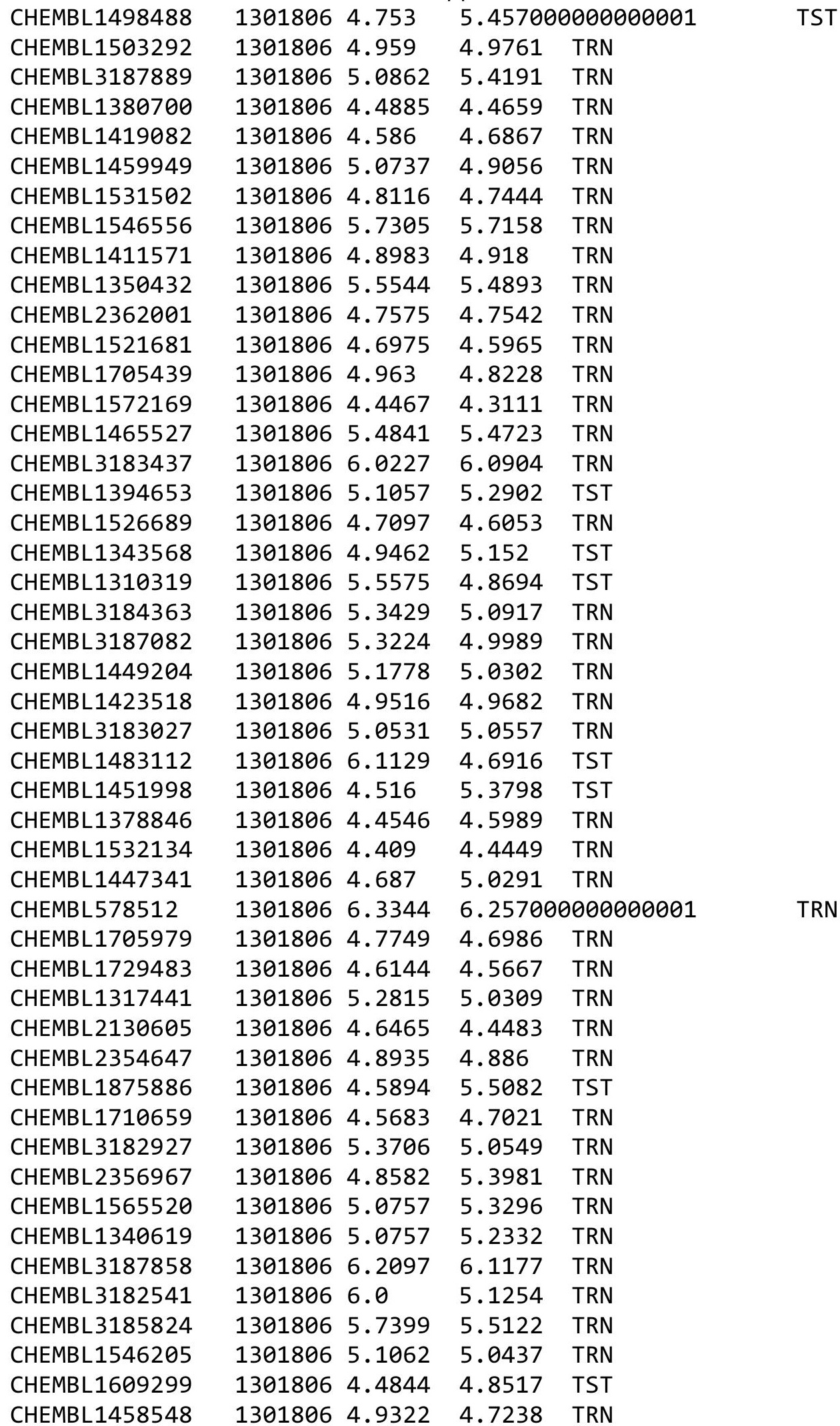

Page 20730 
Supplemental Table S2.txt

\begin{tabular}{|c|c|c|c|c|}
\hline HEM & & & & \\
\hline & & & 5.1458 & \\
\hline & & & & \\
\hline AEMBL & 806 & 23 & 3503 & \\
\hline AEMBL3 & 301806 & 719 & 3451 & \\
\hline HEMBL3185450 & 301806 & 4.553 & 8613 & \\
\hline 36 & 06 & & 945 & \\
\hline |FMRI & 806 & & 658 & \\
\hline HEMBL3188797 & 301806 & & 4654 & \\
\hline HEMBL1528714 & 301806 & 5 . & 4027 & \\
\hline HEMBL2359185 & 806 & 5 . & 9498 & \\
\hline AEMBL5 & 06 & & 105 & \\
\hline AEMBL1 & & & & \\
\hline HEMBL 31 & 306 & & 5454 & \\
\hline AEMBL31 & 06 & 5 . & 545 & \\
\hline AEMBL1722002 & 30 & 5. & 4478 & \\
\hline HEMBL1: & 50 & & 306 & KIV \\
\hline HEMBL1: & 66 & & 628 & \\
\hline HEMBL17 & 06 & & 9334 & \\
\hline AEMBL1; & $\partial 6$ & & 1879 & \\
\hline AEMBLI & 30 & & 3702 & Niv \\
\hline HEMBLI & 36 & & 424 & וזנה \\
\hline HEMBLI & 66 & & 563 & \\
\hline HFMBI 31 & & & 695 & \\
\hline HEMBL 318 & & & & I RIV \\
\hline HEMBL1 & 30 & & 199 & RN \\
\hline HEMBL; & 36 & & 987 & Niv \\
\hline HFMBI $\epsilon$ & 16 & & 523 & \\
\hline HEMBL1 & & & 484 & 15 15 \\
\hline HEMBL605 & & & 3075 & IK \\
\hline HEMBL1 & & & 694 & RN \\
\hline HEMBL & 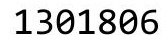 & & 312 & RN \\
\hline HEMBL2 & 6 & 6 & 705 & 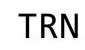 \\
\hline HEMBL1563561 & & & 2693 & is \\
\hline HEMBL1580852 & 30 & & 7045 & TRN \\
\hline HEMBL2: & 36 & & 6532 & \\
\hline HFMRI & & & & RN \\
\hline HEMBL3: & & & 5283 & IRN \\
\hline HEMBL1864760 & 30 & & 3574 & TRN \\
\hline IEMBL14 & 30 & & 329 & TRN \\
\hline HEMBL23 & 20 & & 172 & \\
\hline CHEMBL 31 & & & 1.4843 & RIN \\
\hline HEMBL1588339 & $\partial 6$ & & 6773 & TRN \\
\hline HEMBL1373255 & 30180 & 5.3 & 28 & TRN \\
\hline MBL1 & מב & & 5695 & 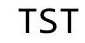 \\
\hline HEMBL19 & & & 5994 & \\
\hline CHEMBL1903021 & & & .5405 & \\
\hline CHEMBL146290e & 13018 & 5.4078 & 5.5312 & RN \\
\hline
\end{tabular}

Page 20731 
Supplemental Table S2.txt

\begin{tabular}{|c|c|c|c|c|c|c|}
\hline CHEMBL3184084 & 1301806 & 4.9427 & 5.1801 & TRN & & \\
\hline CHEMBL1481342 & 1301806 & 4.5488 & 4.7725 & TRN & & \\
\hline CHEMBL1574572 & 1301806 & 4.4859 & 4.732 & TST & & \\
\hline CHEMBL1575588 & 1301806 & 5.1831 & 5.0849 & TRN & & \\
\hline CHEMBL3186710 & 1301806 & 5.0921 & 5.1554 & TRN & & \\
\hline CHEMBL1413724 & 1301806 & 4.7111 & 5.2028 & TST & & \\
\hline CHEMBL3186119 & 1301806 & 6.0 & 5.7029 & TRN & & \\
\hline CHEMBL1463659 & 1301806 & 5.5017 & 5.6516 & TRN & & \\
\hline CHEMBL1468847 & 1301806 & 5.4698 & 5.1971 & TRN & & \\
\hline CHEMBL1418972 & 1301806 & 4.5322 & 4.3298 & TRN & & \\
\hline CHEMBL1574879 & 1301806 & 5.7825 & 5.7722 & TRN & & \\
\hline CHEMBL 2136465 & 1301806 & 6.0 & 5.3862 & TRN & & \\
\hline CHEMBL1587078 & 1301806 & 5.6459 & 5.4182 & TRN & & \\
\hline CHEMBL1371915 & 1301806 & 4.5737 & 4.6461 & TRN & & \\
\hline CHEMBL1353015 & 1301806 & 5.4012 & 5.2942 & TRN & & \\
\hline CHEMBL3182185 & 1301806 & 4.5768 & 4.637 & TRN & & \\
\hline CHEMBL1369865 & 1301806 & 4.4293 & 4.9178 & TST & & \\
\hline CHEMBL1451470 & 1301806 & 5.4535 & 5.2688 & TRN & & \\
\hline CHEMBL1985044 & 1301806 & 4.9755 & 4.8876 & TRN & & \\
\hline CHEMBL1530189 & 1301806 & 4.7147 & 4.6114 & TRN & & \\
\hline CHEMBL 2356209 & 1301806 & 4.9776 & 5.1601 & TRN & & \\
\hline CHEMBL1341399 & 1301806 & 5.0472 & 5.0706 & TST & & \\
\hline CHEMBL1895744 & 1301806 & 4.6696 & 5.6677 & TST & & \\
\hline CHEMBL1431489 & 1301806 & 4.5761 & 4.9583 & TST & & \\
\hline CHEMBL1538205 & 1301806 & 5.8013 & 4.828 & TST & & \\
\hline CHEMBL3181937 & 1301806 & 4.8857 & 5.0771 & TST & & \\
\hline CHEMBL1399925 & 1301806 & 4.4451 & 5.1359 & TST & & \\
\hline CHEMBL1424562 & 1301806 & 4.9859 & 5.301 & TST & & \\
\hline CHEMBL1418848 & 1301806 & \multicolumn{3}{|c|}{4.593999999999999} & 4.9118 & TST \\
\hline CHEMBL1378118 & 1301806 & 5.1046 & 5.2048 & TST & & \\
\hline CHEMBL1447796 & 1301806 & 4.9527 & 5.1267 & TST & & \\
\hline CHEMBL 2354467 & 1301806 & 4.8884 & 5.1916 & TST & & \\
\hline CHEMBL1388353 & 1301806 & 4.5262 & 5.1532 & TST & & \\
\hline CHEMBL 2143788 & 1301806 & 4.4358 & 5.4153 & TST & & \\
\hline CHEMBL3184471 & 1301806 & 4.7605 & 5.1015 & TST & & \\
\hline CHEMBL528791 & 1301806 & 5.1752 & 5.0011 & TST & & \\
\hline CHEMBL1441254 & 1301806 & 4.7058 & 5.1972 & TST & & \\
\hline CHEMBL1512375 & 1301806 & 5.1662 & 4.6492 & TST & & \\
\hline CHEMBL 2136180 & 1301806 & 6.0 & 4.6258 & TST & & \\
\hline CHEMBL1481849 & 1301806 & 5.4895 & 5.4528 & TST & & \\
\hline CHEMBL1331419 & 1301806 & 4.6857 & 5.1925 & TST & & \\
\hline CHEMBL1341981 & 1301806 & 4.797 & 4.8923 & TST & & \\
\hline CHEMBL 2362415 & 1301806 & 6.0 & 5.3715 & TST & & \\
\hline CHEMBL1325945 & 1301806 & 5.5302 & 5.8812 & TST & & \\
\hline CHEMBL1399757 & 1301806 & \multicolumn{3}{|c|}{5.327000000000001} & 5.2539 & TST \\
\hline CHEMBL1497909 & 1301806 & 5.0975 & 4.3564 & TST & & \\
\hline CHEMBL1440703 & 1301806 & 5.3107 & 5.0115 & TST & & \\
\hline CHEMBL1609270 & 1301806 & 4.8471 & 4.681 & TST & & \\
\hline
\end{tabular}




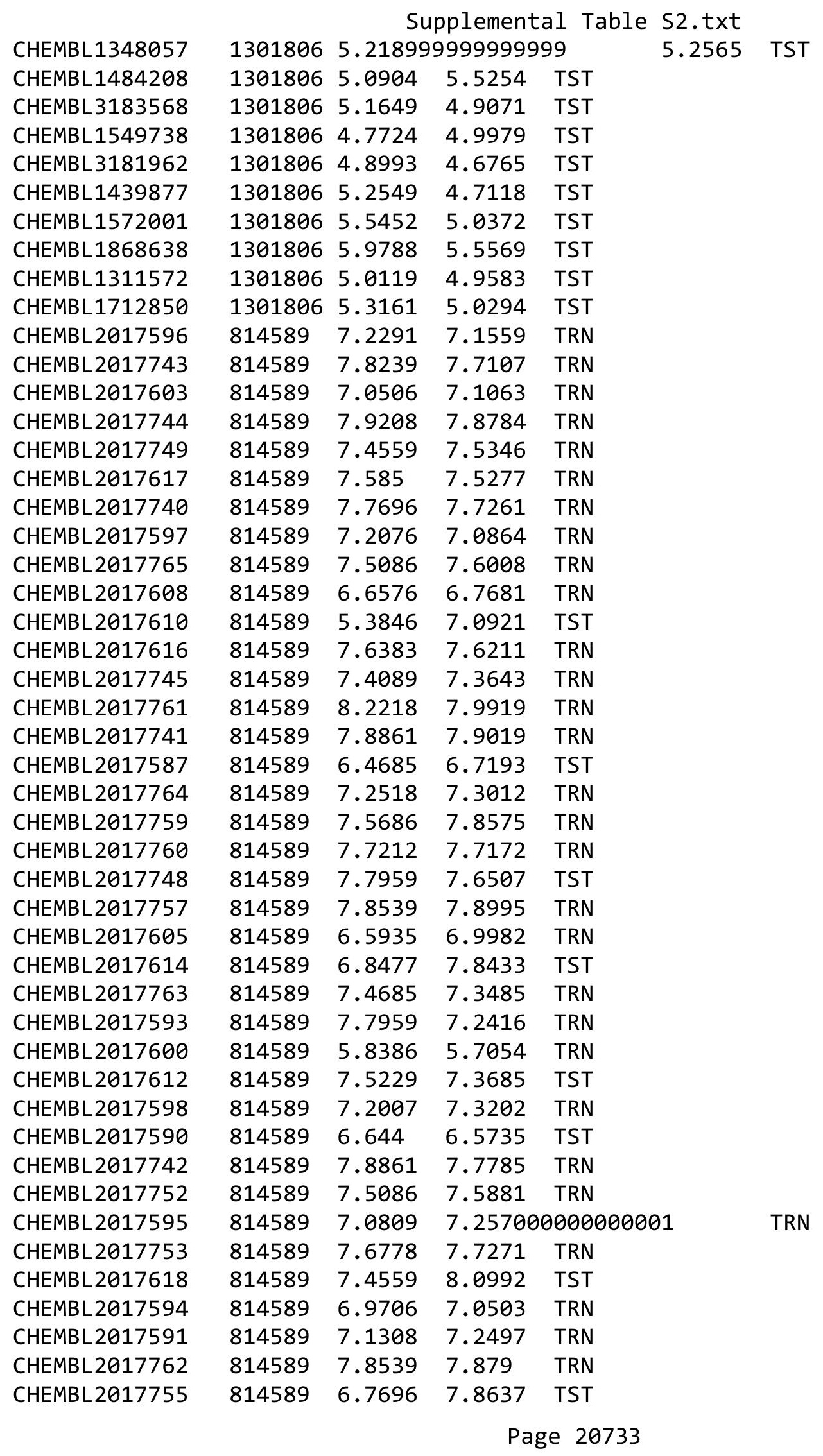


Supplemental Table S2.txt

\begin{tabular}{|c|c|c|c|c|}
\hline CHEMBL 2017609 & 814589 & 7.2441 & 7.4054 & TST \\
\hline CHEMBL 2017592 & 814589 & 6.7077 & 6.8454 & TST \\
\hline CHEMBL 2017758 & 814589 & 7.4685 & 7.3419 & TST \\
\hline CHEMBL 2017599 & 814589 & 6.2403 & 6.3865 & TRN \\
\hline CHEMBL 2017606 & 814589 & 7.6198 & 7.3481 & TRN \\
\hline CHEMBL 2017750 & 814589 & 7.5086 & 7.6356 & TRN \\
\hline CHEMBL 2017751 & 814589 & 7.7447 & 7.9098 & TRN \\
\hline CHEMBL 2017589 & 814589 & 7.1367 & 7.1366 & TRN \\
\hline CHEMBL 2017607 & 814589 & 6.6383 & 6.7682 & TRN \\
\hline CHEMBL 2017611 & 814589 & 6.7399 & 7.0822 & TST \\
\hline CHEMBL 2017604 & 814589 & 7.041 & 7.0251 & TRN \\
\hline CHEMBL 2017754 & 814589 & 7.585 & 7.3767 & TST \\
\hline CHEMBL 2017615 & 814589 & 7.4949 & 7.8244 & TST \\
\hline CHEMBL 2017613 & 814589 & 6.5935 & 6.9929 & TST \\
\hline CHEMBL 2017601 & 814589 & 7.0655 & 7.0251 & TRN \\
\hline CHEMBL 2017588 & 814589 & 7.3979 & 7.2891 & TRN \\
\hline CHEMBL 2017602 & 814589 & 7.2676 & 7.2195 & TRN \\
\hline CHEMBL 2017756 & 814589 & 7.3468 & 7.2572 & TRN \\
\hline CHEMBL 2017746 & 814589 & 7.699 & 7.7143 & TRN \\
\hline CHEMBL 2017747 & 814589 & 7.3665 & 7.2299 & TRN \\
\hline CHEMBL 9470 & 955067 & 6.4143 & 6.3228 & TST \\
\hline CHEMBL92309 & 955067 & 3.3202 & 3.3511 & TST \\
\hline CHEMBL483849 & 955067 & 2.6475 & 2.273 & TST \\
\hline CHEMBL135561 & 955067 & 4.6507 & 4.6528 & TRN \\
\hline CHEMBL217354 & 955067 & 6.6728 & 6.6713 & TRN \\
\hline CHEMBL 2005886 & 955067 & 5.3184 & 5.3172 & TRN \\
\hline CHEMBL3186408 & 955067 & 3.639 & 4.0242 & TST \\
\hline CHEMBL573107 & 955067 & 4.9722 & 4.9714 & TRN \\
\hline CHEMBL210618 & 955067 & 3.3498 & 3.3487 & TRN \\
\hline CHEMBL1242367 & 955067 & 4.1086 & 4.1066 & TRN \\
\hline CHEMBL1788116 & 955067 & 4.619 & 4.6149 & TRN \\
\hline CHEMBL1909414 & 955067 & 3.6654 & 3.6689 & TRN \\
\hline CHEMBL515416 & 955067 & 4.8445 & 4.8421 & TRN \\
\hline CHEMBL1590308 & 955067 & 3.0663 & 3.7504 & TST \\
\hline CHEMBL558642 & 955067 & 5.1796 & 5.182 & TRN \\
\hline CHEMBL379300 & 955067 & 5.6777 & 5.6771 & TRN \\
\hline CHEMBL483847 & 955067 & 4.4324 & 4.4333 & TRN \\
\hline CHEMBL512504 & 955067 & 4.3467 & 4.3429 & TRN \\
\hline CHEMBL3349342 & 955067 & 6.4955 & 6.4969 & TRN \\
\hline CHEMBL188678 & 955067 & 4.8493 & 4.8386 & TRN \\
\hline CHEMBL258844 & 955067 & 4.2756 & 4.2765 & TRN \\
\hline CHEMBL221137 & 955067 & 5.1988 & 5.0088 & TST \\
\hline CHEMBL65 & 955067 & 7.8505 & 7.8503 & TRN \\
\hline CHEMBL1190711 & 955067 & 5.4588 & 5.4584 & TRN \\
\hline CHEMBL 2144069 & 955067 & 6.1004 & 6.0969 & TRN \\
\hline CHEMBL449158 & 955067 & 6.9485 & \multicolumn{2}{|c|}{6.992999999999999} \\
\hline CHEMBL399530 & 955067 & 4.6233 & 4.625 & TRN \\
\hline CHEMBL1230020 & 955067 & 4.7941 & 4.7942 & TRN \\
\hline
\end{tabular}

\section{TST}

Page 20734 


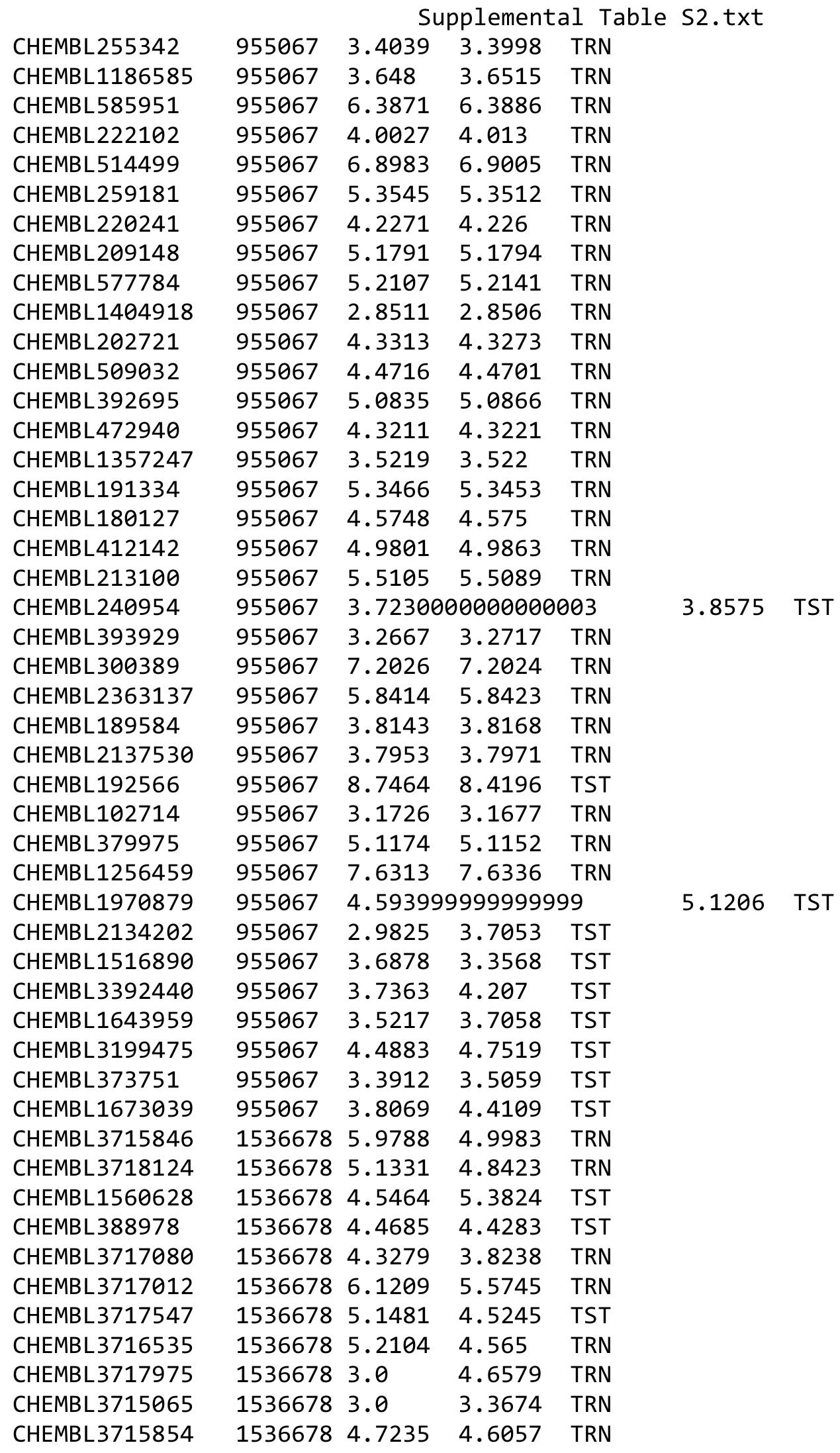

Page 20735 


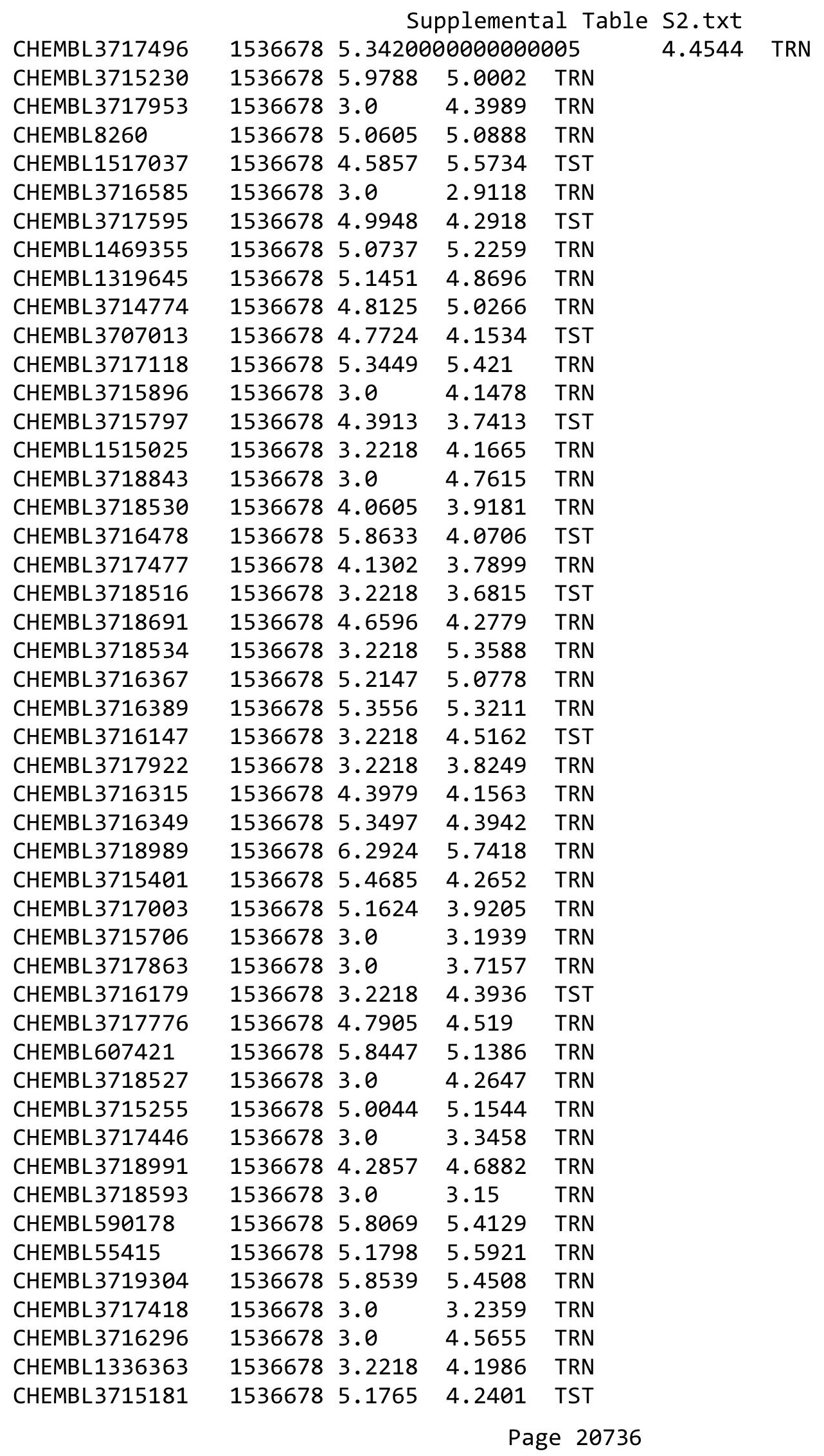


Supplemental Table S2.txt

\begin{tabular}{|c|c|c|c|c|c|}
\hline CHEMBL 3719088 & 1536678 & 5.5935 & 3.9955 & TRN & \\
\hline CHEMBL3718739 & 1536678 & 6.3706 & 5.8754 & TRN & \\
\hline CHEMBL3717247 & 1536678 & 4.4473 & 4.4979 & TRN & \\
\hline CHEMBL1387051 & 1536678 & 3.2218 & 4.6673 & TST & \\
\hline CHEMBL3715687 & 1536678 & 3.0 & 4.4752 & TRN & \\
\hline CHEMBL3717096 & 1536678 & 5.2993 & 5.287000 & 3000000001 & TRN \\
\hline CHEMBL 3716327 & 1536678 & 5.1884 & 7.1542 & TST & \\
\hline CHEMBL3718518 & 1536678 & 6.3799 & 5.4973 & TRN & \\
\hline CHEMBL3716387 & 1536678 & 5.1325 & 4.8655 & TRN & \\
\hline CHEMBL3715640 & 1536678 & 3.0 & 4.0798 & TRN & \\
\hline CHEMBL3717179 & 1536678 & 4.8979 & 3.9155 & TRN & \\
\hline CHEMBL3719063 & 1536678 & 4.4584 & 4.6439 & TRN & \\
\hline CHEMBL3717649 & 1536678 & 5.3862 & 4.9599 & TRN & \\
\hline CHEMBL3718452 & 1536678 & 5.0535 & 4.7216 & TRN & \\
\hline CHEMBL511583 & 1536678 & 3.2218 & 4.5089 & TST & \\
\hline CHEMBL3715051 & 1536678 & 4.9355 & 4.33 & TRN & \\
\hline CHEMBL3718611 & 1536678 & 4.5884 & 4.3397 & TRN & \\
\hline CHEMBL3716382 & 1536678 & 5.05399 & 999999999 & 5.1045 & TRN \\
\hline CHEMBL3718375 & 1536678 & 5.1278 & 4.8471 & TRN & \\
\hline CHEMBL3716909 & 1536678 & 3.0 & 3.6757 & TRN & \\
\hline CHEMBL3718044 & 1536678 & 4.4522 & 5.1099 & TRN & \\
\hline CHEMBL3715971 & 1536678 & 4.7986 & 5.1836 & TRN & \\
\hline CHEMBL3719246 & 1536678 & 3.0 & 2.2325 & TRN & \\
\hline CHEMBL3714864 & 1536678 & 4.6799 & 4.2424 & TRN & \\
\hline CHEMBL3716868 & 1536678 & 5.3279 & 5.2822 & TRN & \\
\hline CHEMBL3715521 & 1536678 & 5.1707 & 3.68 & TRN & \\
\hline CHEMBL3715149 & 1536678 & 3.1308 & 4.8434 & TRN & \\
\hline CHEMBL3715689 & 1536678 & 4.3979 & 4.4398 & TRN & \\
\hline CHEMBL3716299 & 1536678 & 4.9889 & 3.7937 & TRN & \\
\hline CHEMBL3715524 & 1536678 & 5.058 & 4.5985 & TRN & \\
\hline CHEMBL3718283 & 1536678 & 3.0 & 4.6675 & TRN & \\
\hline CHEMBL3718376 & 1536678 & 5.1675 & 5.5152 & TRN & \\
\hline CHEMBL3719184 & 1536678 & 4.4145 & 4.6191 & TRN & \\
\hline CHEMBL3716532 & 1536678 & 4.0878 & 4.784 & TRN & \\
\hline CHEMBL3715663 & 1536678 & 5.4815 & 5.4021 & TRN & \\
\hline CHEMBL 3714961 & 1536678 & 5.3487 & 3.9997 & TRN & \\
\hline CHEMBL3716337 & 1536678 & 5.3019 & 4.6875 & TRN & \\
\hline CHEMBL3715856 & 1536678 & 4.7375 & 4.7807 & TRN & \\
\hline CHEMBL3718841 & 1536678 & 5.0031 & 4.258 & TRN & \\
\hline CHEMBL3717262 & 1536678 & 3.0 & 4.3589 & TRN & \\
\hline CHEMBL1573309 & 1536678 & 4.727 & 4.7673 & TRN & \\
\hline CHEMBL6291 & 1536678 & 3.4559 & 4.2189 & TST & \\
\hline CHEMBL3715884 & 1536678 & 4.6253 & 4.3641 & TRN & \\
\hline CHEMBL3715390 & 1536678 & 4.9292 & 6.3007 & TST & \\
\hline CHEMBL3715045 & 1536678 & 5.05399 & 999999999 & 5.1714 & TRN \\
\hline CHEMBL3716148 & 1536678 & 4.8508 & 5.5413 & TRN & \\
\hline CHEMBL3715383 & 1536678 & 4.8761 & 4.9576 & TRN & \\
\hline CHEMBL3715400 & 1536678 & 3.2218 & 4.4665 & TST & \\
\hline
\end{tabular}


Supplemental Table S2.txt

\begin{tabular}{|c|c|c|c|c|c|}
\hline CHEMBL3716228 & 1536678 & 3.0 & 3.4919 & TRN & \\
\hline CHEMBL1313485 & 1536678 & 5.1518 & 4.5814 & TRN & \\
\hline CHEMBL3717219 & 1536678 & 3.0 & 3.2423 & TRN & \\
\hline CHEMBL 3717241 & 1536678 & 6.0119 & 4.9133 & TRN & \\
\hline CHEMBL3716736 & 1536678 & 6.1244 & 5.2207 & TRN & \\
\hline CHEMBL3716466 & 1536678 & 5.1965 & 4.375 & TRN & \\
\hline CHEMBL3716832 & 1536678 & 3.0 & 4.2176 & TRN & \\
\hline CHEMBL3717328 & 1536678 & 5.6364 & 5.4372 & TRN & \\
\hline CHEMBL3718269 & 1536678 & 5.5482 & 4.9338 & TRN & \\
\hline CHEMBL3717146 & 1536678 & 5.0846 & 4.4762 & TRN & \\
\hline CHEMBL3716833 & 1536678 & 3.0 & 2.6576 & TRN & \\
\hline CHEMBL3715220 & 1536678 & 5.1871 & 4.8097 & TRN & \\
\hline CHEMBL3715525 & 1536678 & 4.9813 & 5.0973 & TRN & \\
\hline CHEMBL3717243 & 1536678 & 3.1549 & 4.5121 & TRN & \\
\hline CHEMBL3716413 & 1536678 & 6.0367 & 5.5939 & TRN & \\
\hline CHEMBL3716051 & 1536678 & 5.8416 & 4.4224 & TRN & \\
\hline CHEMBL1571373 & 1536678 & 5.2328 & 5.527 & TRN & \\
\hline CHEMBL3716214 & 1536678 & 5.0195 & 4.8989 & TRN & \\
\hline CHEMBL3718727 & 1536678 & 3.0 & 3.5695 & TRN & \\
\hline CHEMBL3718480 & 1536678 & 5.5834 & 5.42700 & 00000000005 & TRN \\
\hline CHEMBL3717092 & 1536678 & 4.7493 & 4.6617 & TST & \\
\hline CHEMBL3718517 & 1536678 & 3.0 & 4.5823 & TRN & \\
\hline CHEMBL3717135 & 1536678 & 5.52 & 5.5569 & TRN & \\
\hline CHEMBL3716984 & 1536678 & 5.1844 & 5.0715 & TRN & \\
\hline CHEMBL3715130 & 1536678 & 5.4461 & 5.0565 & TRN & \\
\hline CHEMBL3717807 & 1536678 & 3.0 & 3.9413 & TRN & \\
\hline CHEMBL3718129 & 1536678 & 3.0 & 3.3294 & TRN & \\
\hline CHEMBL3717611 & 1536678 & 3.0 & 3.2224 & TRN & \\
\hline CHEMBL3715967 & 1536678 & 3.2218 & 4.5441 & TST & \\
\hline CHEMBL3717039 & 1536678 & 5.2277 & 4.8797 & TRN & \\
\hline CHEMBL3716418 & 1536678 & 5.567 & 4.1215 & TRN & \\
\hline CHEMBL3715432 & 1536678 & 4.1107 & 4.3074 & TST & \\
\hline CHEMBL3715789 & 1536678 & 5.4737 & 5.9165 & TST & \\
\hline CHEMBL3717069 & 1536678 & 4.9226 & 4.8932 & TST & \\
\hline CHEMBL3717362 & 1536678 & 4.684 & 4.7099 & TST & \\
\hline CHEMBL3715704 & 1536678 & 3.0 & 4.4494 & TST & \\
\hline CHEMBL3716062 & 1536678 & 4.3979 & 5.1818 & TST & \\
\hline CHEMBL3716275 & 1536678 & 3.0 & 4.3751 & TST & \\
\hline CHEMBL3718560 & 1536678 & 3.0 & 3.9828 & TST & \\
\hline CHEMBL1402572 & 1536678 & 5.1904 & 4.2697 & TST & \\
\hline CHEMBL3714870 & 1536678 & 3.0 & 3.04399 & 99999999996 & TST \\
\hline CHEMBL3718378 & 1536678 & 4.3439 & 3.7629 & TST & \\
\hline CHEMBL3718494 & 1536678 & 4.9706 & 4.2797 & TST & \\
\hline CHEMBL3718607 & 1536678 & 3.2218 & 4.617 & TST & \\
\hline CHEMBL104264 & 1536678 & 2.1549 & 4.4165 & TST & \\
\hline CHEMBL3718128 & 1536678 & 5.1791 & 5.6593 & TST & \\
\hline CHEMBL 2159845 & 1536678 & 5.3372 & 4.9333 & TST & \\
\hline CHEMBL3717833 & 1536678 & 4.9017 & 4.8373 & TST & \\
\hline
\end{tabular}


Supplemental Table S2.txt

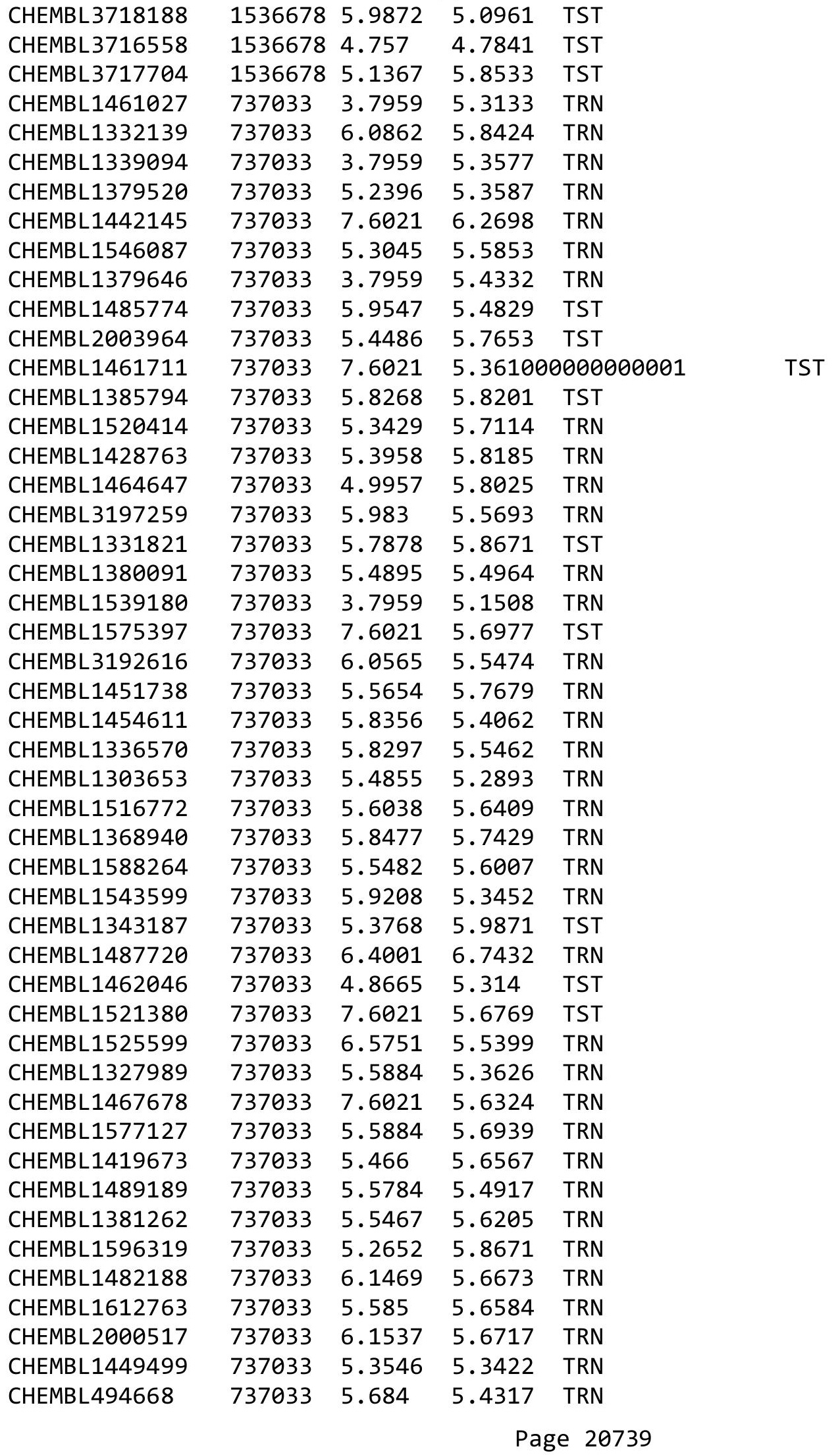


Supplemental Table S2.txt

\begin{tabular}{|c|c|c|c|c|}
\hline CHEMBL1490339 & 737033 & 7.6021 & 5.8313 & TRN \\
\hline CHEMBL590927 & 737033 & 5.8182 & 6.2655 & TRN \\
\hline CHEMBL1453809 & 737033 & 5.5129 & 5.5596 & TST \\
\hline CHEMBL1547229 & 737033 & 5.8477 & 5.7131 & TRN \\
\hline CHEMBL1562136 & 737033 & 5.1451 & 5.5671 & TRN \\
\hline CHEMBL1549500 & 737033 & 6.1938 & \multicolumn{2}{|c|}{6.117000000000001} \\
\hline CHEMBL1502771 & 737033 & 5.5003 & 5.53 & TRN \\
\hline CHEMBL1574540 & 737033 & 5.7799 & 5.5192 & TRN \\
\hline CHEMBL579380 & 737033 & 5.9914 & 5.6827 & TRN \\
\hline CHEMBL1588513 & 737033 & 6.0477 & 5.9973 & TRN \\
\hline CHEMBL1369200 & 737033 & 5.6615 & 5.4627 & TRN \\
\hline CHEMBL1492961 & 737033 & 5.8697 & 5.4887 & TRN \\
\hline CHEMBL1518085 & 737033 & 5.9172 & 5.9294 & TRN \\
\hline CHEMBL1430669 & 737033 & 5.5513 & 5.8008 & TRN \\
\hline CHEMBL1300625 & 737033 & 5.7545 & 5.7899 & TRN \\
\hline CHEMBL3213394 & 737033 & 6.0381 & 5.6536 & TRN \\
\hline CHEMBL1313121 & 737033 & 5.8069 & 5.5323 & TST \\
\hline CHEMBL1597211 & 737033 & 5.9355 & 5.9367 & TST \\
\hline CHEMBL1549450 & 737033 & 5.5969 & 5.6085 & TRN \\
\hline CHEMBL578294 & 737033 & 6.1555 & 6.0835 & TRN \\
\hline CHEMBL1605536 & 737033 & 6.5317 & 5.8622 & TRN \\
\hline CHEMBL1501102 & 737033 & 5.9469 & 5.5326 & TRN \\
\hline CHEMBL1979574 & 737033 & 5.5129 & 5.3487 & TRN \\
\hline CHEMBL1302109 & 737033 & 5.9469 & 5.7752 & TRN \\
\hline CHEMBL1789998 & 737033 & 5.4377 & 5.829 & TRN \\
\hline CHEMBL1334148 & 737033 & 5.251 & 5.5894 & TRN \\
\hline CHEMBL1597195 & 737033 & 5.6108 & 5.6464 & TRN \\
\hline CHEMBL1381242 & 737033 & 5.1029 & 5.7148 & TRN \\
\hline CHEMBL1522066 & 737033 & 6.0701 & 5.7723 & TRN \\
\hline CHEMBL1402428 & 737033 & 5.7282 & 5.609 & TRN \\
\hline CHEMBL1432711 & 737033 & 5.3655 & 5.3856 & TRN \\
\hline CHEMBL1496993 & 737033 & 5.7305 & 6.1432 & TRN \\
\hline CHEMBL1391839 & 737033 & 5.7852 & 5.5419 & TRN \\
\hline CHEMBL1373334 & 737033 & 5.4935 & 5.2969 & TRN \\
\hline CHEMBL3199665 & 737033 & 5.6819 & 5.6553 & TRN \\
\hline CHEMBL1363127 & 737033 & 5.7773 & 5.4657 & TRN \\
\hline CHEMBL1605299 & 737033 & 6.0325 & 5.2532 & TRN \\
\hline CHEMBL1495725 & 737033 & 5.8729 & 6.2157 & TRN \\
\hline CHEMBL1467705 & 737033 & 5.5086 & 5.6529 & TRN \\
\hline CHEMBL1447872 & 737033 & 5.5045 & 5.2823 & TRN \\
\hline CHEMBL1424253 & 737033 & 5.1662 & 5.6289 & TRN \\
\hline CHEMBL1523610 & 737033 & 5.4868 & 5.5397 & TRN \\
\hline CHEMBL1344934 & 737033 & 4.8239 & 5.7483 & TRN \\
\hline CHEMBL592068 & 737033 & 6.2684 & 5.9367 & TRN \\
\hline CHEMBL1482663 & 737033 & 5.9136 & 5.5775 & TST \\
\hline CHEMBL1457902 & 737033 & 6.1085 & 6.1011 & TRN \\
\hline CHEMBL1469032 & 737033 & 5.3904 & 5.7213 & TRN \\
\hline CHEMBL1562926 & 737033 & 6.2457 & 6.1373 & TRN \\
\hline
\end{tabular}




\begin{tabular}{|c|c|c|c|c|c|c|}
\hline \multicolumn{7}{|c|}{ Supplemental Table S2.txt } \\
\hline CHEMBL1506049 & 737033 & 4.8239 & 5.3634 & TRN & & \\
\hline CHEMBL1980322 & 737033 & 5.7011 & 5.8103 & TRN & & \\
\hline CHEMBL1443900 & 737033 & 6.26200 & 30000000 & 005 & 0000000001 & TRN \\
\hline CHEMBL1587780 & 737033 & 5.3325 & 5.7734 & TRN & & \\
\hline CHEMBL1313249 & 737033 & 3.7959 & 5.5146 & TRN & & \\
\hline CHEMBL1308223 & 737033 & 6.2581 & 5.9035 & TRN & & \\
\hline CHEMBL1491079 & 737033 & 6.3768 & 5.9347 & TST & & \\
\hline CHEMBL1383333 & 737033 & 5.4342 & 5.7518 & TRN & & \\
\hline CHEMBL1490799 & 737033 & 5.5591 & 5.3902 & TRN & & \\
\hline CHEMBL1507404 & 737033 & 3.7959 & 5.4463 & TST & & \\
\hline CHEMBL1523841 & 737033 & 6.2716 & 5.61799 & 9999999999 & TST & \\
\hline CHEMBL1374476 & 737033 & 3.7959 & 5.5694 & TST & & \\
\hline CHEMBL1607674 & 737033 & 5.9136 & 5.4304 & TRN & & \\
\hline CHEMBL1572672 & 737033 & 5.7011 & 5.4378 & TRN & & \\
\hline CHEMBL3145137 & 737033 & 5.6576 & 5.6769 & TRN & & \\
\hline CHEMBL1448584 & 737033 & 5.4776 & 5.4355 & TRN & & \\
\hline CHEMBL1537553 & 737033 & 5.4306 & 5.4264 & TST & & \\
\hline CHEMBL1370977 & 737033 & 5.9788 & 5.3372 & TRN & & \\
\hline CHEMBL1308879 & 737033 & 5.9666 & 5.6097 & TRN & & \\
\hline CHEMBL1313542 & 737033 & 5.3449 & 5.5059 & TRN & & \\
\hline CHEMBL1390785 & 737033 & 5.8539 & 5.5927 & TRN & & \\
\hline CHEMBL3210428 & 737033 & 5.3279 & 5.3486 & TRN & & \\
\hline CHEMBL1580434 & 737033 & 5.51 & 5.7274 & TRN & & \\
\hline CHEMBL1595690 & 737033 & 5.3904 & 5.6807 & TRN & & \\
\hline CHEMBL1423457 & 737033 & 5.7167 & 5.7115 & TST & & \\
\hline CHEMBL1377902 & 737033 & 5.8928 & 5.9556 & TRN & & \\
\hline CHEMBL584269 & 737033 & 5.7144 & 5.5838 & TRN & & \\
\hline CHEMBL1445752 & 737033 & 5.2857 & 5.3856 & TRN & & \\
\hline CHEMBL1574187 & 737033 & 6.0026 & 5.6386 & TRN & & \\
\hline CHEMBL1367786 & 737033 & 5.2933 & 5.3733 & TST & & \\
\hline CHEMBL1339659 & 737033 & 6.1146 & 5.7556 & TRN & & \\
\hline CHEMBL1462064 & 737033 & 5.7055 & 5.6798 & TRN & & \\
\hline CHEMBL1303799 & 737033 & 5.3958 & 5.3797 & TRN & & \\
\hline CHEMBL1503034 & 737033 & 5.3536 & 5.683 & TST & & \\
\hline CHEMBL1501632 & 737033 & 5.8297 & 5.8292 & TRN & & \\
\hline CHEMBL1979957 & 737033 & 3.7959 & 5.5812 & TST & & \\
\hline CHEMBL1369945 & 737033 & 6.2147 & 5.5931 & TRN & & \\
\hline CHEMBL 89445 & 737033 & 6.1451 & 6.0469 & TRN & & \\
\hline CHEMBL3198723 & 737033 & 5.7055 & 5.6367 & TRN & & \\
\hline CHEMBL3199467 & 737033 & 5.8665 & 5.7801 & TRN & & \\
\hline CHEMBL1500255 & 737033 & 5.6596 & 5.8105 & TST & & \\
\hline CHEMBL1564670 & 737033 & 3.7959 & 5.2953 & TRN & & \\
\hline CHEMBL1428284 & 737033 & 5.6596 & 5.4723 & TRN & & \\
\hline CHEMBL1500265 & 737033 & 5.4377 & 6.0997 & TRN & & \\
\hline CHEMBL1419104 & 737033 & 7.6021 & 5.7192 & TRN & & \\
\hline CHEMBL3190293 & 737033 & 5.6536 & 5.5467 & TRN & & \\
\hline CHEMBL1544175 & 737033 & 5.7011 & 5.6222 & TRN & & \\
\hline CHEMBL1465542 & 737033 & 3.7959 & 5.4771 & TRN & & \\
\hline
\end{tabular}


Supplemental Table S2.txt

\begin{tabular}{|c|c|c|c|c|c|}
\hline CHEMBL 3198447 & 737033 & 5.5031 & 5.4082 & TRN & \\
\hline CHEMBL1465706 & 737033 & 6.2396 & 5.9375 & TRN & \\
\hline CHEMBL1432841 & 737033 & 5.4672 & 5.5827 & TRN & \\
\hline CHEMBL1450526 & 737033 & 5.7496 & 5.7875 & TRN & \\
\hline CHEMBL1418247 & 737033 & 5.4486 & 5.6269 & TRN & \\
\hline CHEMBL1375155 & 737033 & 5.8928 & 5.577999 & 9999999999 & TRA \\
\hline CHEMBL1600678 & 737033 & 7.6021 & 5.6701 & TST & \\
\hline CHEMBL1608247 & 737033 & 5.6757 & 5.7763 & TRN & \\
\hline CHEMBL363535 & 737033 & 5.5528 & 5.7808 & TST & \\
\hline CHEMBL1421976 & 737033 & 6.3125 & 5.8314 & TRN & \\
\hline CHEMBL595700 & 737033 & 6.2434 & 5.9595 & TRN & \\
\hline CHEMBL528181 & 737033 & 6.0565 & 6.0094 & TRN & \\
\hline CHEMBL1585527 & 737033 & 5.3382 & 5.7519 & TRN & \\
\hline CHEMBL1585672 & 737033 & 5.4498 & 5.5508 & TRN & \\
\hline CHEMBL1503312 & 737033 & 5.9957 & 5.6848 & TST & \\
\hline CHEMBL1378724 & 737033 & 5.7447 & 5.7039 & TRN & \\
\hline CHEMBL1612169 & 737033 & 5.7696 & 5.5202 & TRN & \\
\hline CHEMBL146525 & 737033 & 5.3098 & 5.6608 & TRN & \\
\hline CHEMBL1439575 & 737033 & 5.6925 & 5.7437 & TRN & \\
\hline CHEMBL1565212 & 737033 & 5.4498 & 5.3824 & TRN & \\
\hline CHEMBL1375373 & 737033 & 5.7799 & 6.1434 & TRN & \\
\hline CHEMBL1540377 & 737033 & 5.9245 & 5.9135 & TRN & \\
\hline CHEMBL1563861 & 737033 & 5.0223 & 5.7484 & TRN & \\
\hline CHEMBL1406945 & 737033 & 4.8508 & 5.5528 & TRN & \\
\hline CHEMBL591412 & 737033 & 5.71899 & 99999999 & 6.0316 & \\
\hline CHEMBL3199278 & 737033 & 5.6271 & 5.7598 & TRN & \\
\hline CHEMBL1458178 & 737033 & 5.8928 & 5.7172 & TST & \\
\hline CHEMBL1496007 & 737033 & 5.6778 & 5.3082 & TRN & \\
\hline CHEMBL1463257 & 737033 & 7.6021 & 5.8145 & TST & \\
\hline CHEMBL1384702 & 737033 & 5.6216 & 5.5754 & TRN & \\
\hline CHEMBL1523952 & 737033 & 5.8761 & 5.704 & TRN & \\
\hline CHEMBL1523792 & 737033 & 5.4949 & 5.7212 & TRN & \\
\hline CHEMBL1351037 & 737033 & 7.6021 & 5.6993 & TRN & \\
\hline CHEMBL1492096 & 737033 & 6.5003 & 5.9839 & TRN & \\
\hline CHEMBL1438200 & 737033 & 5.4908 & 6.0743 & TRN & \\
\hline CHEMBL1455191 & 737033 & 5.5918 & 5.5681 & TRN & \\
\hline CHEMBL1343952 & 737033 & 6.3429 & 5.7439 & TRN & \\
\hline CHEMBL1607899 & 737033 & 5.8153 & 5.6951 & TRN & \\
\hline CHEMBL1401987 & 737033 & 5.9788 & 5.6996 & TRN & \\
\hline CHEMBL3199744 & 737033 & 5.4597 & 5.8313 & TRN & \\
\hline CHEMBL1342693 & 737033 & 5.58 & 5.6373 & TRN & \\
\hline CHEMBL3199204 & 737033 & 5.1844 & 5.4423 & TRN & \\
\hline CHEMBL1413155 & 737033 & 5.7447 & 5.8112 & TRN & \\
\hline CHEMBL65374 & 737033 & 5.5654 & 5.5012 & TRN & \\
\hline CHEMBL1422155 & 737033 & 5.6253 & 5.5951 & TRN & \\
\hline CHEMBL1347890 & 737033 & 5.7328 & 5.3673 & TRN & \\
\hline CHEMBL1497373 & 737033 & 5.1938 & 5.6401 & TRN & \\
\hline CHEMBL1589036 & 737033 & 5.1537 & 5.62700 & 0000000001 & \\
\hline
\end{tabular}


Supplemental Table S2.txt

\begin{tabular}{|c|c|c|c|c|c|c|}
\hline CHEMBL1407945 & 737033 & 5.3605 & \multicolumn{3}{|c|}{5.888999999999999} & RN \\
\hline CHEMBL1607862 & 737033 & 5.7645 & 5.6743 & TRN & & \\
\hline CHEMBL1331541 & 737033 & 6.4698 & \multicolumn{3}{|c|}{6.2620000000000005} & \\
\hline CHEMBL530049 & 737033 & 5.6289 & 5.981 & TRN & & \\
\hline CHEMBL1350693 & 737033 & 5.9281 & 5.6884 & TRN & & \\
\hline CHEMBL1424564 & 737033 & 5.6737 & 5.4898 & TRN & & \\
\hline CHEMBL581449 & 737033 & 5.4012 & 5.6538 & TRN & & \\
\hline CHEMBL1550290 & 737033 & 5.5157 & 5.8308 & TRN & & \\
\hline CHEMBL1450615 & 737033 & 5.71 & \multicolumn{3}{|c|}{5.632000000000001} & \\
\hline CHEMBL1319643 & 737033 & 5.6091 & 5.6394 & TRN & & \\
\hline CHEMBL1507537 & 737033 & 5.9547 & 5.7442 & TRN & & \\
\hline CHEMBL1458849 & 737033 & 5.4855 & 5.1867 & TRN & & \\
\hline CHEMBL1496734 & 737033 & 5.2336 & 5.6161 & TRN & & \\
\hline CHEMBL1428866 & 737033 & 4.9706 & 5.7267 & TST & & \\
\hline CHEMBL1568190 & 737033 & 5.3737 & \multicolumn{3}{|c|}{5.422000000000001} & \\
\hline CHEMBL1597655 & 737033 & 5.7721 & 6.2665 & TRN & & \\
\hline CHEMBL1422434 & 737033 & 5.4145 & 5.6584 & TRN & & \\
\hline CHEMBL1495602 & 737033 & 5.6716 & 5.6693 & TST & & \\
\hline CHEMBL1545677 & 737033 & 6.2967 & 5.8384 & TRN & & \\
\hline CHEMBL3194921 & 737033 & 4.9508 & 5.4898 & TRN & & \\
\hline CHEMBL3192181 & 737033 & 5.6003 & 5.5758 & TRN & & \\
\hline CHEMBL1599863 & 737033 & 5.2832 & 5.2967 & TRN & & \\
\hline CHEMBL1480798 & 737033 & 5.4145 & 5.6958 & TRN & & \\
\hline CHEMBL3193878 & 737033 & 5.251 & 5.8513 & TRN & & \\
\hline CHEMBL1549738 & 737033 & 5.7033 & 5.6784 & TST & & \\
\hline CHEMBL3193664 & 737033 & 5.2083 & 6.0032 & TRN & & \\
\hline CHEMBL3192659 & 737033 & 5.4295 & 5.437 & TRN & & \\
\hline CHEMBL1465355 & 737033 & 5.1938 & 5.4112 & TST & & \\
\hline CHEMBL1369099 & 737033 & 5.8665 & 5.3599 & TRN & & \\
\hline CHEMBL1439624 & 737033 & \multicolumn{3}{|c|}{5.752000000000001} & 5.9768 & \\
\hline CHEMBL1359940 & 737033 & 5.6271 & 5.5958 & TRN & & \\
\hline CHEMBL1374582 & 737033 & 4.857 & 5.3862 & TRN & & \\
\hline CHEMBL1426831 & 737033 & 7.6021 & 5.8506 & TST & & \\
\hline CHEMBL1326768 & 737033 & 5.3372 & 5.3666 & TRN & & \\
\hline CHEMBL1864040 & 737033 & 5.5467 & 5.6597 & TRN & & \\
\hline CHEMBL1556555 & 737033 & 5.3655 & 5.2506 & TRN & & \\
\hline CHEMBL1414483 & 737033 & 5.6364 & 5.5737 & TRN & & \\
\hline CHEMBL1373255 & 737033 & 5.5591 & 5.7772 & TRN & & \\
\hline CHEMBL2001794 & 737033 & 5.4609 & 5.4834 & TRN & & \\
\hline CHEMBL1534358 & 737033 & 7.6021 & 5.6905 & TRN & & \\
\hline CHEMBL581225 & 737033 & 5.7011 & 5.596 & TST & & \\
\hline CHEMBL1575686 & 737033 & 5.5243 & 5.3922 & TRN & & \\
\hline CHEMBL1993522 & 737033 & 5.7011 & 5.5378 & TRN & & \\
\hline CHEMBL1500169 & 737033 & 5.5406 & 5.6019 & TRN & & \\
\hline CHEMBL1458840 & 737033 & 5.4023 & 5.4808 & TRN & & \\
\hline CHEMBL1319541 & 737033 & 5.1898 & 5.6559 & TRN & & \\
\hline CHEMBL1369547 & 737033 & 5.3179 & 5.5454 & TRN & & \\
\hline CHEMBL1493661 & 737033 & 5.2612 & 5.7378 & TRN & & \\
\hline
\end{tabular}

Page 20743 


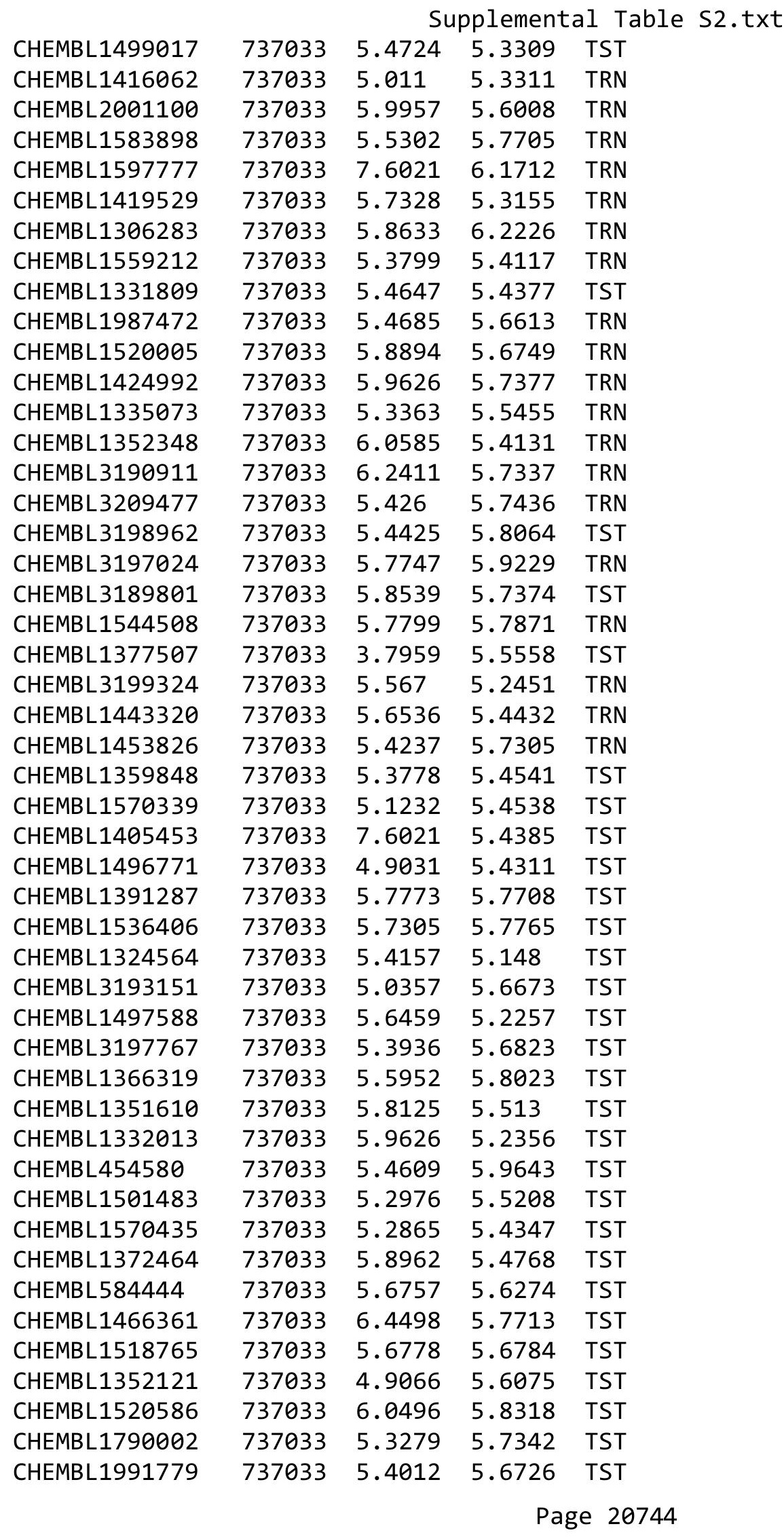


Supplemental Table S2.txt

\begin{tabular}{|c|c|c|c|c|}
\hline HEl & & .7959 & & \\
\hline & & 6.2668 & 5.8859 & \\
\hline & & & & \\
\hline HEMBL13ऽ & & 686 & & \\
\hline HEMBL1349832 & 37033 & 55 & 5776 & \\
\hline HEMBL1349485 & 37033 & .0287 & 8808 & \\
\hline HEMBL1967436 & 33 & 996 & & \\
\hline HEMBL132 & & & & \\
\hline HEMBL1558021 & 33 & & & \\
\hline HEMBL1499914 & 33 & 01 & 5686 & \\
\hline HEMBL1308186 & 33 & 47 & 9777 & \\
\hline AEMBL3427712 & 59 & & 319 & \\
\hline AEMBL3604044 & & & & \\
\hline HEMBL3604046 & 59 & & & \\
\hline AEMBL3603843 & & 7. & & \\
\hline AEMBL3604054 & & 7. & 02 & \\
\hline HEMBL3604056 & & & & \\
\hline HEMBL3604062 & & & & \\
\hline HEMBL3604055 & & & & \\
\hline AEMBL3288362 & & & & \\
\hline HEMBL3604 & & 6 & 27 & \\
\hline AEMBL: & & & & \\
\hline HEMBL; & & & & \\
\hline HEMBL3604042 & & & & \\
\hline AEMBL3427 & & & & \\
\hline HEMBL3 & & 7. & & \\
\hline HEMBL; & & & & \\
\hline $\mathrm{AFMBI}=$ & & & & RN \\
\hline HEMBL3427711 & & & & \\
\hline HEMBL 3604035 & & & & \\
\hline HEMBL 3286 & & & & RN \\
\hline AFMB : & & & & Niv \\
\hline 1 & & & & RN \\
\hline HEMBL3604037 & & & & RN \\
\hline HEMBL3604038 & & & & TRN \\
\hline HEMBL 3604049 & & & & \\
\hline HCMP - & & & & RN \\
\hline HEMBL3 & & & & RN \\
\hline HEMBL3427707 & 59 & 7. & & TRN \\
\hline IEMBL & & & & IST \\
\hline HEMBL3604065 & & 8 . & & וד \\
\hline CHEMBL 3604045 & & & & RN \\
\hline HEMBL3604063 & & 7.8861 & 7.7666 & TST \\
\hline HEMBL3604067 & 159 & 7.699 & 5066 & TST \\
\hline EMBL3 & & & & \\
\hline CHEMBL3288363 & & & & \\
\hline CHEMBL 3604031 & & & .7731 & \\
\hline THEMBL3604068 & 1511159 & 7.4437 & 7.4398 & 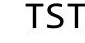 \\
\hline
\end{tabular}

Page 20745 
Supplemental Table S2.txt

\begin{tabular}{|c|c|c|c|c|}
\hline CHEMBL 3604060 & 1511159 & 6.9208 & 6.6464 & TST \\
\hline CHEMBL 3604052 & 1511159 & 7.8861 & 7.4754 & TRN \\
\hline CHEMBL 3604059 & 1511159 & 5.2518 & 6.5323 & TST \\
\hline CHEMBL 3604033 & 1511159 & 7.5686 & 7.2666 & TRN \\
\hline CHEMBL 3604043 & 1511159 & 7.0 & 7.2407 & TRN \\
\hline CHEMBL 3427709 & 1511159 & 7.5376 & 7.4404 & TST \\
\hline CHEMBL 3604057 & 1511159 & 7.8861 & 7.6183 & TRN \\
\hline CHEMBL3604058 & 1511159 & 8.1249 & 8.0742 & TRN \\
\hline CHEMBL 3604061 & 1511159 & 7.9208 & 7.6663 & TST \\
\hline CHEMBL 3604041 & 1511159 & 7.7212 & 8.1804 & TRN \\
\hline CHEMBL 3604032 & 1511159 & 5.7959 & 6.7679 & TST \\
\hline CHEMBL 3604066 & 1511159 & 7.6778 & 8.1485 & TST \\
\hline CHEMBL 3604050 & 1511159 & 5.6778 & 5.8079 & TRN \\
\hline CHEMBL100510 & 633769 & 7.0 & 7.211 & TRN \\
\hline CHEMBL74922 & 633769 & 7.5376 & 7.5834 & TRN \\
\hline CHEMBL124933 & 633769 & 8.8539 & 8.6171 & TRN \\
\hline CHEMBL1083066 & 633769 & 6.9431 & 7.4324 & TRN \\
\hline CHEMBL1084775 & 633769 & 7.9957 & 7.8045 & TRN \\
\hline CHEMBL105874 & 633769 & 7.9031 & 7.6473 & TRN \\
\hline CHEMBL1082435 & 633769 & 8.3665 & 8.4735 & TRN \\
\hline CHEMBL1085758 & 633769 & 4.8996 & 5.0268 & TRN \\
\hline CHEMBL331637 & 633769 & 3.9586 & 5.7488 & TST \\
\hline CHEMBL 75274 & 633769 & 8.7959 & 8.5937 & TRN \\
\hline CHEMBL1083661 & 633769 & 7.2676 & 7.0797 & TRN \\
\hline CHEMBL1082741 & 633769 & 3.5686 & 6.0997 & TST \\
\hline CHEMBL125578 & 633769 & 6.1805 & 6.17899 & 9999999999 \\
\hline CHEMBL1083054 & 633769 & 5.0 & 5.7678 & TST \\
\hline CHEMBL1083065 & 633769 & 8.0969 & 6.0067 & TST \\
\hline CHEMBL 345124 & 633769 & 5.1463 & 5.789 & TST \\
\hline CHEMBL92955 & 633769 & 7.8539 & 7.70299 & э999999999 \\
\hline CHEMBL62084 & 633769 & 6.2596 & 6.2412 & TRN \\
\hline CHEMBL433678 & 633769 & 8.5528 & 8.7185 & TRN \\
\hline CHEMBL1084367 & 633769 & 7.3468 & 7.0679 & TRN \\
\hline CHEMBL330004 & 633769 & 7.301 & 7.1378 & TRN \\
\hline CHEMBL186896 & 633769 & 5.0969 & 6.0505 & TST \\
\hline CHEMBL1085279 & 633769 & 4.8996 & 4.739 & TRN \\
\hline CHEMBL1084774 & 633769 & 6.5834 & 7.2366 & TRN \\
\hline CHEMBL140948 & 633769 & 5.1675 & 5.2897 & TRN \\
\hline CHEMBL1086248 & 633769 & 7.0991 & 7.3059 & TRN \\
\hline CHEMBL333909 & 633769 & 7.0088 & 6.8972 & TRN \\
\hline CHEMBL1084776 & 633769 & 6.1249 & 5.8354 & TRN \\
\hline CHEMBL1085022 & 633769 & 5.7959 & 5.9517 & TRN \\
\hline CHEMBL 332454 & 633769 & 3.7796 & 5.2419 & TST \\
\hline CHEMBL 72967 & 633769 & 6.0721 & 5.5294 & TRN \\
\hline CHEMBL1083367 & 633769 & 4.2518 & 5.8181 & TST \\
\hline CHEMBL 73160 & 633769 & 9.2218 & 9.6602 & TRN \\
\hline CHEMBL1084255 & 633769 & 4.4559 & 5.2434 & TST \\
\hline CHEMBL95020 & 633769 & 8.4437 & 8.412 & TRN \\
\hline
\end{tabular}




\begin{tabular}{|c|c|c|c|c|c|}
\hline & & & & & \\
\hline CHEMBL119389 & 633769 & 4.6021 & 6.4451 & TST & \\
\hline CHEMBL1084093 & 633769 & 6.7447 & 6.8859 & TRN & \\
\hline CHEMBL1084882 & 633769 & 6.2958 & 6.3038 & TRN & \\
\hline CHEMBL61986 & 633769 & 6.3372 & 6.4295 & TRN & \\
\hline CHEMBL151417 & 633769 & 3.0 & 5.4675 & TST & \\
\hline CHEMBL426015 & 633769 & 7.9626 & 7.8593 & TRN & \\
\hline CHEMBL1085939 & 633769 & 8.0083 & 8.0551 & TRN & \\
\hline CHEMBL1084254 & 633769 & 5.8268 & 5.942 & TRN & \\
\hline CHEMBL431058 & 633769 & 7.585 & 7.3098 & TRN & \\
\hline CHEMBL185896 & 633769 & 6.2076 & 5.8906 & TST & \\
\hline CHEMBL118968 & 633769 & 5.041 & 6.7611 & TRN & \\
\hline CHEMBL1084542 & 633769 & 4.8861 & 4.2634 & TST & \\
\hline CHEMBL340228 & 633769 & 7.6757 & 7.58200 & 0000000001 & TRN \\
\hline CHEMBL1082750 & 633769 & 4.6882 & 4.8256 & TRN & \\
\hline CHEMBL142014 & 633769 & 6.0 & 6.0226 & TRN & \\
\hline CHEMBL420827 & 633769 & 5.0 & 5.1076 & TRN & \\
\hline CHEMBL1083070 & 633769 & 7.0 & 6.8111 & TRN & \\
\hline CHEMBL91774 & 633769 & 6.3565 & 6.148 & TST & \\
\hline CHEMBL129753 & 633769 & 7.4318 & 8.2851 & TRN & \\
\hline CHEMBL388615 & 633769 & 7.0223 & 7.0245 & TRN & \\
\hline CHEMBL128863 & 633769 & 7.8861 & 7.8645 & TRN & \\
\hline CHEMBL189875 & 633769 & 4.8539 & 5.5209 & TST & \\
\hline CHEMBL190060 & 633769 & 8.1637 & 8.3951 & TRN & \\
\hline CHEMBL25264 & 633769 & 4.8239 & 5.1003 & TST & \\
\hline CHEMBL62085 & 633769 & 5.0915 & 5.365 & TRN & \\
\hline CHEMBL1084275 & 633769 & 8.1675 & 8.1292 & TRN & \\
\hline CHEMBL1085018 & 633769 & 5.3188 & 5.6796 & TRN & \\
\hline CHEMBL1084785 & 633769 & 5.0 & 5.1211 & TRN & \\
\hline CHEMBL 74962 & 633769 & 5.5031 & 5.6107 & TRN & \\
\hline CHEMBL117826 & 633769 & 3.0 & 7.7575 & TST & \\
\hline CHEMBL1085277 & 633769 & 5.3565 & 6.2245 & TST & \\
\hline CHEMBL141001 & 633769 & 8.0458 & 8.0762 & TRN & \\
\hline CHEMBL1084531 & 633769 & 6.7545 & 7.27 & TRN & \\
\hline CHEMBL150985 & 633769 & 4.4685 & 5.3586 & TST & \\
\hline CHEMBL76173 & 633769 & 8.8861 & 8.60799 & 9999999999 & TRN \\
\hline CHEMBL1085527 & 633769 & 7.6615 & 8.6171 & TRN & \\
\hline CHEMBL1084789 & 633769 & 4.3279 & 4.5192 & TST & \\
\hline CHEMBL1085026 & 633769 & 5.0915 & 5.1414 & TRN & \\
\hline CHEMBL1085281 & 633769 & 4.301 & 5.76399 & 9999999999 & TST \\
\hline CHEMBL188019 & 633769 & 5.3872 & 6.7731 & TST & \\
\hline CHEMBL340427 & 633769 & 9.5229 & 8.68700 & 0000000001 & TRN \\
\hline CHEMBL128551 & 633769 & 7.8539 & 7.75899 & 99999999995 & TRN \\
\hline CHEMBL1083488 & 633769 & 8.6021 & 8.4779 & TRN & \\
\hline CHEMBL89012 & 633769 & 4.4318 & 5.6845 & TST & \\
\hline CHEMBL1084787 & 633769 & 4.2676 & 5.7092 & TST & \\
\hline CHEMBL 302842 & 633769 & 6.4559 & 6.2282 & TRN & \\
\hline CHEMBL1085386 & 633769 & 5.6592 & 5.9404 & TRN & \\
\hline CHEMBL1085938 & 633769 & 8.7447 & 8.9272 & TRN & \\
\hline
\end{tabular}

Page 20747 


\begin{tabular}{|c|c|c|c|c|c|}
\hline & & \multicolumn{4}{|c|}{ Supplemental Table S2.txt } \\
\hline CHEMBL75649 & 633769 & 5.1965 & 5.6003 & TRN & \\
\hline CHEMBL1083977 & 633769 & 6.7696 & 7.1502 & TRN & \\
\hline CHEMBL101809 & 633769 & 6.6383 & 6.7682 & TRN & \\
\hline CHEMBL74359 & 633769 & 6.9469 & 6.9526 & TRN & \\
\hline CHEMBL141042 & 633769 & 7.6383 & 7.6222 & TRN & \\
\hline CHEMBL1084784 & 633769 & 4.76699 & 99999999 & 5.011 & TRN \\
\hline CHEMBL131579 & 633769 & 9.1549 & 8.7674 & TRN & \\
\hline CHEMBL1083067 & 633769 & 8.0 & 7.4324 & TRN & \\
\hline CHEMBL1082428 & 633769 & 5.3979 & 5.4537 & TRN & \\
\hline CHEMBL292314 & 633769 & 8.0044 & 8.0151 & TRN & \\
\hline CHEMBL1084096 & 633769 & 7.8665 & 7.27 & TRN & \\
\hline CHEMBL140770 & 633769 & 8.0969 & 8.1528 & TRN & \\
\hline CHEMBL1084543 & 633769 & 4.0 & 3.8968 & TST & \\
\hline CHEMBL 330883 & 633769 & 7.4089 & 6.7611 & TRN & \\
\hline CHEMBL92463 & 633769 & 7.585 & 7.5691 & TRN & \\
\hline CHEMBL115697 & 633769 & 4.1586 & 6.0127 & TST & \\
\hline CHEMBL91240 & 633769 & 7.6778 & 6.5581 & TST & \\
\hline CHEMBL1086246 & 633769 & 7.6073 & 7.6813 & TRN & \\
\hline CHEMBL1084709 & 633769 & 4.5686 & 5.6916 & TST & \\
\hline CHEMBL427082 & 633769 & 9.301 & 9.3229 & TRN & \\
\hline CHEMBL131411 & 633769 & 7.0 & 7.3096 & TRN & \\
\hline CHEMBL421501 & 633769 & 6.9393 & 7.8247 & TRN & \\
\hline CHEMBL93241 & 633769 & 6.0458 & 6.1584 & TRN & \\
\hline CHEMBL141801 & 633769 & 6.1549 & 6.0475 & TRN & \\
\hline CHEMBL1083374 & 633769 & 8.5243 & 8.85799 & 9999999999 & TRN \\
\hline CHEMBL1083057 & 633769 & 6.1308 & 5.6549 & TST & \\
\hline CHEMBL1082433 & 633769 & 6.5157 & 6.6768 & TRN & \\
\hline CHEMBL141167 & 633769 & 7.1871 & 7.3493 & TRN & \\
\hline CHEMBL281588 & 633769 & 4.8861 & 4.5678 & TST & \\
\hline CHEMBL191314 & 633769 & 7.1018 & 7.4736 & TRN & \\
\hline CHEMBL1085128 & 633769 & 5.8761 & 5.7461 & TRN & \\
\hline CHEMBL1082419 & 633769 & 6.7959 & 7.6698 & TRN & \\
\hline CHEMBL364545 & 633769 & 8.6799 & 8.4495 & TRN & \\
\hline CHEMBL189764 & 633769 & 5.0706 & 4.0948 & TST & \\
\hline CHEMBL1085933 & 633769 & 8.6799 & 8.5533 & TRN & \\
\hline CHEMBL340672 & 633769 & 7.284 & 7.0526 & TRN & \\
\hline CHEMBL1085526 & 633769 & 7.9318 & 8.6171 & TRN & \\
\hline CHEMBL340171 & 633769 & 7.5817 & 7.582006 & 0000000001 & TRN \\
\hline CHEMBL61930 & 633769 & 6.3279 & 6.3234 & TRN & \\
\hline CHEMBL76108 & 633769 & 4.8761 & 4.7477 & TRN & \\
\hline CHEMBL 306179 & 633769 & 7.301 & 7.1195 & TRN & \\
\hline CHEMBL127465 & 633769 & 7.5622 & 7.582006 & 0000000001 & TRN \\
\hline CHEMBL 74827 & 633769 & 7.6576 & 7.8247 & TRN & \\
\hline CHEMBL1085278 & 633769 & 8.1675 & 8.6171 & TRN & \\
\hline CHEMBL307908 & 633769 & 8.5686 & 8.4917 & TRN & \\
\hline CHEMBL55312 & 633769 & 7.4559 & 7.30399 & 9999999999 & TRN \\
\hline CHEMBL1083982 & 633769 & 8.2441 & 6.9583 & TST & \\
\hline CHEMBL1082748 & 633769 & 4.6198 & 5.0719 & TRN & \\
\hline
\end{tabular}




\begin{tabular}{|c|c|c|c|c|c|c|}
\hline & & \multicolumn{5}{|c|}{ Supplemental Table S2.txt } \\
\hline CHEMBL1086358 & 633769 & 5.1739 & 5.7522 & TST & & \\
\hline CHEMBL1085759 & 633769 & 5.8861 & 5.3249 & TRN & & \\
\hline CHEMBL389192 & 633769 & 9.301 & 8.7788 & TRN & & \\
\hline CHEMBL55014 & 633769 & 6.2518 & 6.2719 & TRN & & \\
\hline CHEMBL388575 & 633769 & 6.7447 & 7.2964 & TRN & & \\
\hline CHEMBL1083379 & 633769 & 7.0 & 6.8111 & TRN & & \\
\hline CHEMBL189797 & 633769 & 5.7932 & 5.6336 & TRN & & \\
\hline CHEMBL102142 & 633769 & 7.1135 & 6.9194 & TST & & \\
\hline CHEMBL1084368 & 633769 & 6.5784 & 7.0679 & TRN & & \\
\hline CHEMBL534319 & 633769 & 8.8539 & 8.5937 & TRN & & \\
\hline CHEMBL1085629 & 633769 & 6.5969 & 6.3836 & TRN & & \\
\hline CHEMBL1085932 & 633769 & 9.28399 & 99999999 & 99 & 8.9349 & TRN \\
\hline CHEMBL224998 & 633769 & 7.4815 & 7.2964 & TRN & & \\
\hline CHEMBL1085703 & 633769 & 6.0487 & 5.4791 & TST & & \\
\hline CHEMBL1084544 & 633769 & 9.1549 & 8.7619 & TRN & & \\
\hline CHEMBL223443 & 633769 & 9.699 & 9.2246 & TRN & & \\
\hline CHEMBL1084262 & 633769 & 8.3565 & 8.7788 & TRN & & \\
\hline CHEMBL101988 & 633769 & 5.7447 & 4.4249 & TST & & \\
\hline CHEMBL1083678 & 633769 & 4.8239 & 5.5464 & TST & & \\
\hline CHEMBL90264 & 633769 & 7.5686 & 6.3377 & TST & & \\
\hline CHEMBL128618 & 633769 & 8.0506 & 8.2634 & TRN & & \\
\hline CHEMBL307004 & 633769 & 10.1549 & 9.6602 & TRN & & \\
\hline CHEMBL310918 & 633769 & 7.1938 & 7.1105 & TRN & & \\
\hline CHEMBL138552 & 633769 & 8.3468 & 7.6125 & TST & & \\
\hline CHEMBL1085019 & 633769 & 5.2676 & 5.106 & TST & & \\
\hline CHEMBL225326 & 633769 & 9.2218 & 9.324 & TRN & & \\
\hline CHEMBL372710 & 633769 & 8.0969 & 7.8831 & TRN & & \\
\hline CHEMBL1083064 & 633769 & 6.4559 & 5.5799 & TRN & & \\
\hline CHEMBL325203 & 633769 & 3.4077 & 6.0136 & TST & & \\
\hline CHEMBL91291 & 633769 & 8.2366 & 8.2505 & TRN & & \\
\hline CHEMBL141622 & 633769 & 6.4685 & 6.5062 & TRN & & \\
\hline CHEMBL329518 & 633769 & 5.8239 & 6.096 & TST & & \\
\hline CHEMBL306175 & 633769 & 7.1192 & 7.1983 & TRN & & \\
\hline CHEMBL1084257 & 633769 & 4.9586 & 5.2201 & TST & & \\
\hline CHEMBL189957 & 633769 & 9.4949 & 8.6171 & TRN & & \\
\hline CHEMBL1085030 & 633769 & 7.5229 & 7.3313 & TST & & \\
\hline CHEMBL1085630 & 633769 & 6.2013 & 6.2468 & TRN & & \\
\hline CHEMBL1084786 & 633769 & 4.2441 & 4.4315 & TST & & \\
\hline CHEMBL140769 & 633769 & 5.0269 & 4.7538 & TRN & & \\
\hline CHEMBL431844 & 633769 & 6.6198 & 6.4439 & TST & & \\
\hline CHEMBL224336 & 633769 & 6.8327 & 7.6355 & TRN & & \\
\hline CHEMBL61929 & 633769 & 5.284 & 5.0114 & TRN & & \\
\hline CHEMBL419184 & 633769 & 4.5686 & 4.5298 & TRN & & \\
\hline CHEMBL1085031 & 633769 & 8.2218 & 7.5501 & TST & & \\
\hline CHEMBL60167 & 633769 & 6.4559 & 5.8901 & TST & & \\
\hline CHEMBL1083063 & 633769 & 5.6021 & 5.57 & TRN & & \\
\hline CHEMBL 308093 & 633769 & 6.8386 & 7.0675 & TRN & & \\
\hline CHEMBL141873 & 633769 & 6.2291 & 6.6776 & TRN & & \\
\hline
\end{tabular}




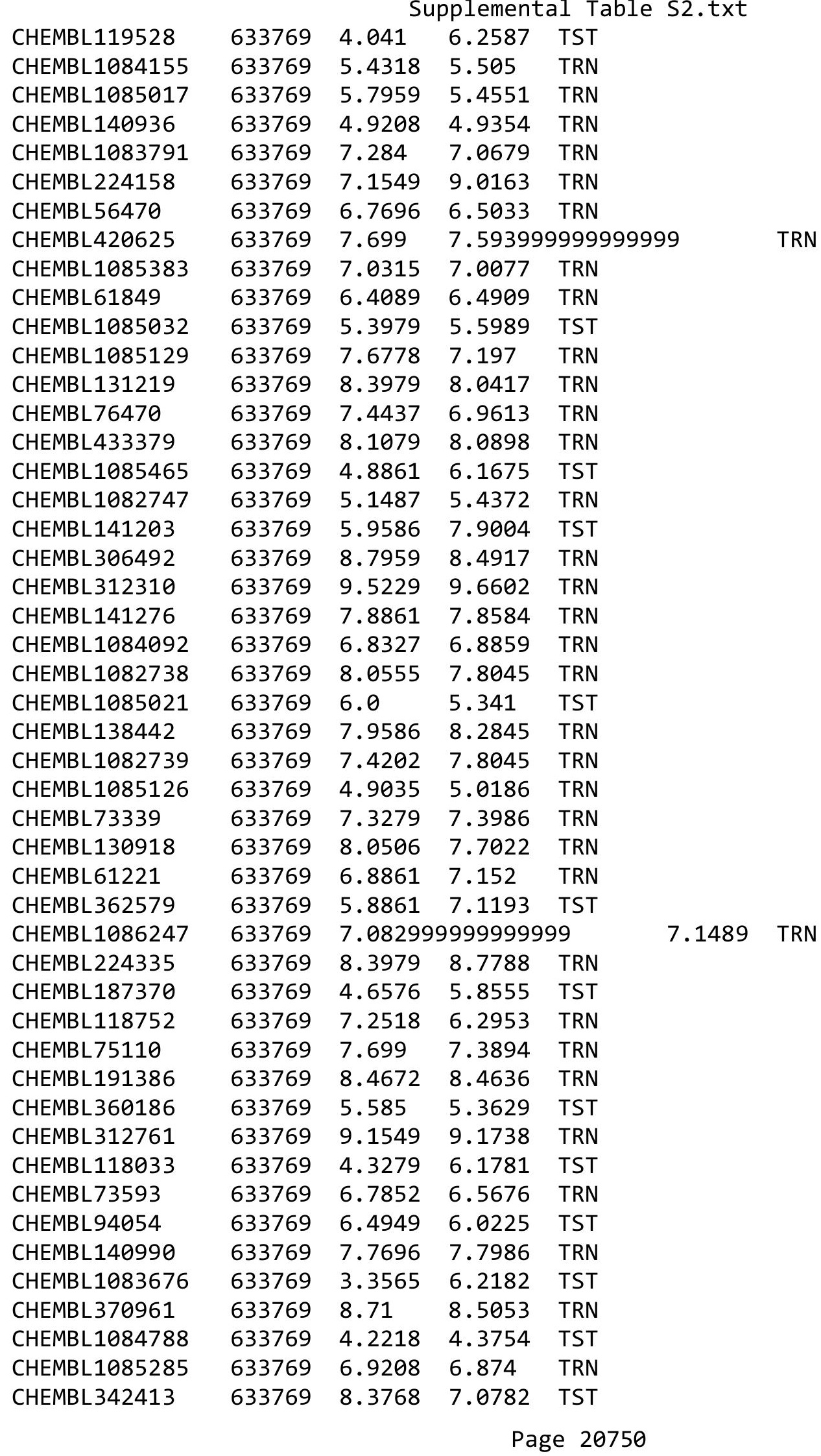


Supplemental Table S2.txt

\begin{tabular}{|c|c|c|c|c|c|}
\hline CHEMBL1086245 & 633769 & 8.2676 & 8.0745 & TRN & \\
\hline CHEMBL1085127 & 633769 & 6.8125 & 6.8296 & TRN & \\
\hline CHEMBL329231 & 633769 & 9.2441 & 9.0534 & TRN & \\
\hline CHEMBL1083056 & 633769 & 6.5229 & 6.5682 & TST & \\
\hline CHEMBL1085027 & 633769 & 5.9208 & 6.1777 & TRN & \\
\hline CHEMBL128471 & 633769 & 8.2441 & 8.3517 & TRN & \\
\hline CHEMBL420378 & 633769 & 6.4776 & 6.584 & TRN & \\
\hline CHEMBL1084167 & 633769 & 6.1549 & 5.8836 & TRN & \\
\hline CHEMBL413765 & 633769 & 7.3468 & 7.2609 & TRN & \\
\hline CHEMBL1084635 & 633769 & 7.4202 & 7.2577 & TRN & \\
\hline CHEMBL1085274 & 633769 & 4.2076 & 4.4649 & TST & \\
\hline CHEMBL1084442 & 633769 & 4.71 & 5.1209 & TRN & \\
\hline CHEMBL1085020 & 633769 & 5.8861 & 4.369 & TST & \\
\hline CHEMBL1084790 & 633769 & 7.9208 & 8.0255 & TRN & \\
\hline CHEMBL308807 & 633769 & 7.7959 & 7.5234 & TRN & \\
\hline CHEMBL1083660 & 633769 & 7.6198 & 7.6779 & TRN & \\
\hline CHEMBL90241 & 633769 & 6.3665 & 5.9467 & TST & \\
\hline CHEMBL1085702 & 633769 & 8.8268 & 7.7425 & TST & \\
\hline CHEMBL1086090 & 633769 & 6.4191 & 6.3521 & TRN & \\
\hline CHEMBL 74927 & 633769 & 9.2218 & 9.1738 & TRN & \\
\hline CHEMBL75985 & 633769 & 8.7212 & 8.60799 & э999999999 & TRN \\
\hline CHEMBL1083069 & 633769 & 9.3188 & 9.3546 & TRN & \\
\hline CHEMBL141810 & 633769 & 6.0969 & 6.0089 & TRN & \\
\hline CHEMBL 74940 & 633769 & 9.0458 & 9.1738 & TRN & \\
\hline CHEMBL328468 & 633769 & 9.0223 & 9.1476 & TRN & \\
\hline CHEMBL1082434 & 633769 & 7.5229 & 7.4476 & TRN & \\
\hline CHEMBL101028 & 633769 & 6.0 & 5.8497 & TST & \\
\hline CHEMBL92460 & 633769 & 7.2596 & 7.1487 & TRN & \\
\hline CHEMBL1084095 & 633769 & 7.1487 & 7.0679 & TRN & \\
\hline CHEMBL329531 & 633769 & 6.4685 & 6.3692 & TRN & \\
\hline CHEMBL388627 & 633769 & 7.4437 & 7.2964 & TRN & \\
\hline CHEMBL32823 & 633769 & 9.699 & 8.5937 & TRN & \\
\hline CHEMBL128452 & 633769 & 7.1549 & 7.0378 & TRN & \\
\hline CHEMBL126354 & 633769 & 8.2676 & 8.0365 & TRN & \\
\hline CHEMBL430679 & 633769 & 7.8239 & 7.626 & TST & \\
\hline CHEMBL128043 & 633769 & 7.5086 & 7.268 & TRN & \\
\hline CHEMBL101155 & 633769 & 5.9586 & 7.0383 & TST & \\
\hline CHEMBL1084703 & 633769 & 7.0044 & 6.8209 & TRN & \\
\hline CHEMBL130847 & 633769 & 7.4437 & 7.24 & TRN & \\
\hline CHEMBL128260 & 633769 & 8.5528 & 8.2229 & TRN & \\
\hline CHEMBL1083789 & 633769 & 6.4962 & 6.8859 & TRN & \\
\hline CHEMBL 75157 & 633769 & 6.9031 & 7.4204 & TRN & \\
\hline CHEMBL59782 & 633769 & 7.8861 & 7.8702 & TRN & \\
\hline CHEMBL 75305 & 633769 & 8.3188 & \multicolumn{2}{|c|}{8.607999999999999} & TRN \\
\hline CHEMBL1084545 & 633769 & 8.5229 & 8.7619 & TRN & \\
\hline CHEMBL1083790 & 633769 & 6.8827 & 6.8859 & TRN & \\
\hline CHEMBL1083662 & 633769 & 7.2676 & 6.9906 & TRN & \\
\hline CHEMBL339039 & 633769 & 8.0655 & 7.8569 & TRN & \\
\hline
\end{tabular}

Page 20751 


\begin{tabular}{|c|c|c|c|c|c|}
\hline & & \multicolumn{4}{|c|}{ Supplemental Table s2.txt } \\
\hline CHEMBL140106 & 633769 & 7.8861 & 7.9278 & TRN & \\
\hline CHEMBL1085382 & 633769 & 7.1612 & 7.1629 & TRN & \\
\hline CHEMBL186349 & 633769 & 4.7959 & 6.4311 & TST & \\
\hline CHEMBL93123 & 633769 & 8.0269 & 8.1405 & TRN & \\
\hline CHEMBL119390 & 633769 & 5.4559 & 6.4422 & TST & \\
\hline CHEMBL94186 & 633769 & 8.1427 & 8.2591 & TRN & \\
\hline CHEMBL140328 & 633769 & 5.9208 & 7.435 & TST & \\
\hline CHEMBL93936 & 633769 & 9.0969 & 9.6338 & TRN & \\
\hline CHEMBL93619 & 633769 & 8.1487 & 8.0912 & TRN & \\
\hline CHEMBL336686 & 633769 & 6.3565 & 6.1849 & TRN & \\
\hline CHEMBL1085029 & 633769 & 5.8697 & 5.7719 & TRN & \\
\hline CHEMBL131827 & 633769 & 8.9586 & 9.0921 & TRN & \\
\hline CHEMBL1084952 & 633769 & 3.8413 & 6.318 & TST & \\
\hline CHEMBL1082436 & 633769 & 7.4815 & 7.4626 & TRN & \\
\hline CHEMBL119634 & 633769 & 4.1624 & 5.5812 & TST & \\
\hline CHEMBL74747 & 633769 & 7.0915 & 7.0925 & TRN & \\
\hline CHEMBL1083976 & 633769 & 6.3979 & 6.8638 & TRN & \\
\hline CHEMBL 75127 & 633769 & 6.4802 & 6.6162 & TRN & \\
\hline CHEMBL186400 & 633769 & 4.5686 & 4.0043 & TST & \\
\hline CHEMBL309173 & 633769 & 5.5764 & 5.6142 & TRN & \\
\hline CHEMBL189870 & 633769 & 5.6021 & 5.862 & TST & \\
\hline CHEMBL1084094 & 633769 & 7.3279 & 7.0679 & TRN & \\
\hline CHEMBL340609 & 633769 & 6.6882 & 6.7186 & TRN & \\
\hline CHEMBL356224 & 633769 & 3.585 & 5.5808 & TST & \\
\hline CHEMBL1085276 & 633769 & 6.8239 & 6.3421 & TST & \\
\hline CHEMBL 307513 & 633769 & 5.8761 & 5.7945 & TRN & \\
\hline CHEMBL1085284 & 633769 & 5.9586 & 5.7602 & TRN & \\
\hline CHEMBL 364678 & 633769 & 7.3507 & 7.3972 & TRN & \\
\hline CHEMBL337999 & 633769 & 9.0862 & 8.6171 & TRN & \\
\hline CHEMBL1084369 & 633769 & 7.8928 & 7.27 & TRN & \\
\hline CHEMBL115580 & 633769 & 3.8729 & 5.6552 & TST & \\
\hline CHEMBL139353 & 633769 & 8.0555 & 8.1745 & TRN & \\
\hline CHEMBL 294525 & 633769 & 6.5376 & 6.57100 & 0000000001 & TRN \\
\hline CHEMBL61561 & 633769 & 7.3468 & 7.4323 & TRN & \\
\hline CHEMBL1083058 & 633769 & 4.1871 & 5.7242 & TST & \\
\hline CHEMBL1084880 & 633769 & 6.7545 & 6.8728 & TRN & \\
\hline CHEMBL1084091 & 633769 & 6.6021 & 7.1502 & TRN & \\
\hline CHEMBL1085937 & 633769 & 3.3872 & 6.1987 & TST & \\
\hline CHEMBL1085280 & 633769 & 5.0223 & 5.5344 & TST & \\
\hline CHEMBL140737 & 633769 & 7.7447 & 7.79299 & 9999999999 & TRN \\
\hline CHEMBL1085385 & 633769 & 5.9682 & 6.2618 & TRN & \\
\hline CHEMBL311017 & 633769 & 8.0 & 7.9939 & TRN & \\
\hline CHEMBL76384 & 633769 & 6.4056 & 6.4083 & TRN & \\
\hline CHEMBL127857 & 633769 & 7.5331 & 7.58200 & 0000000001 & TRN \\
\hline CHEMBL 307832 & 633769 & 6.4089 & 6.6953 & TRN & \\
\hline CHEMBL73974 & 633769 & 7.3665 & 7.2936 & TRN & \\
\hline CHEMBL1086185 & 633769 & 3.7696 & 4.9354 & TST & \\
\hline CHEMBL187017 & 633769 & 4.8239 & 5.4225 & TST & \\
\hline
\end{tabular}




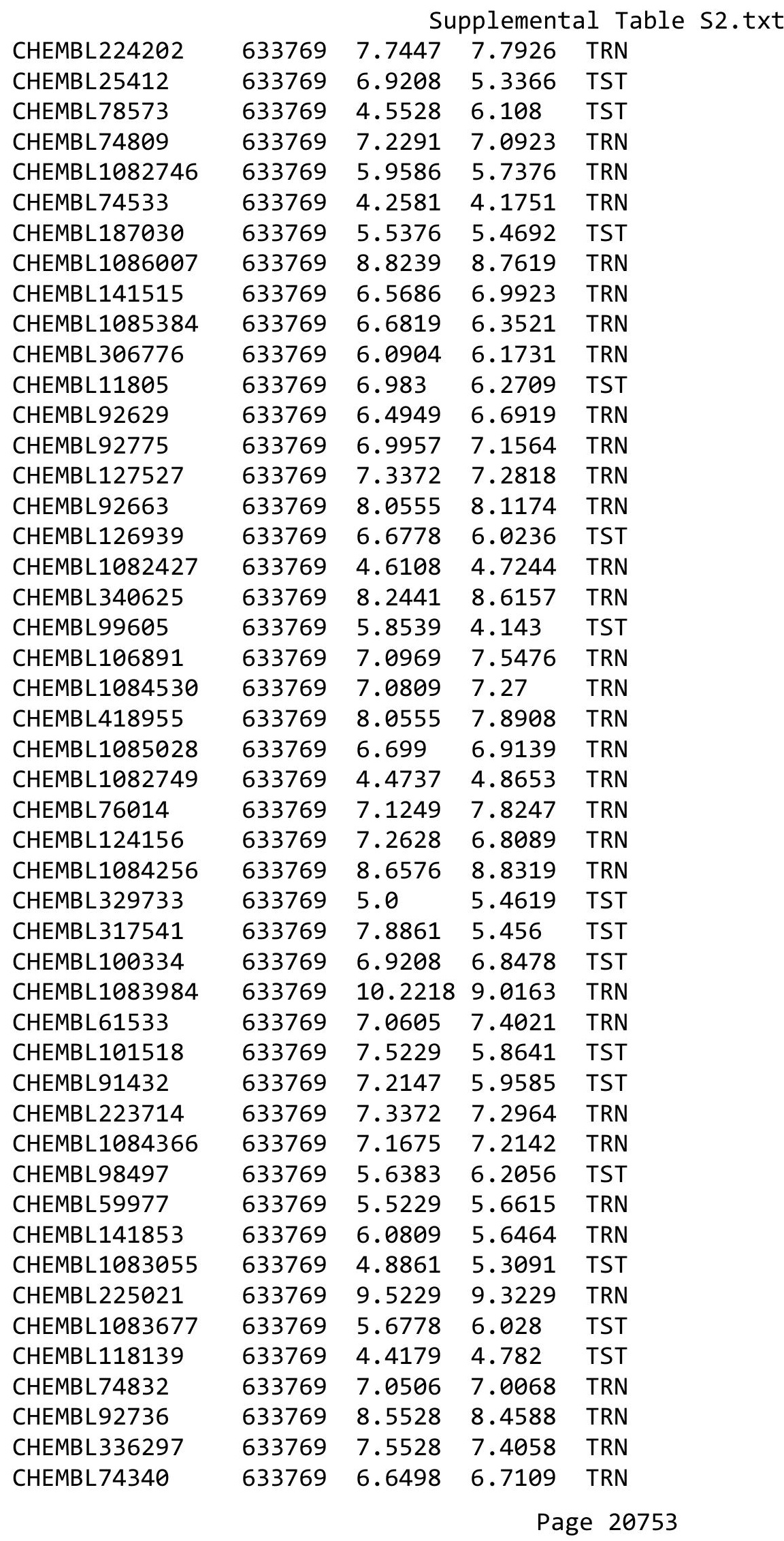




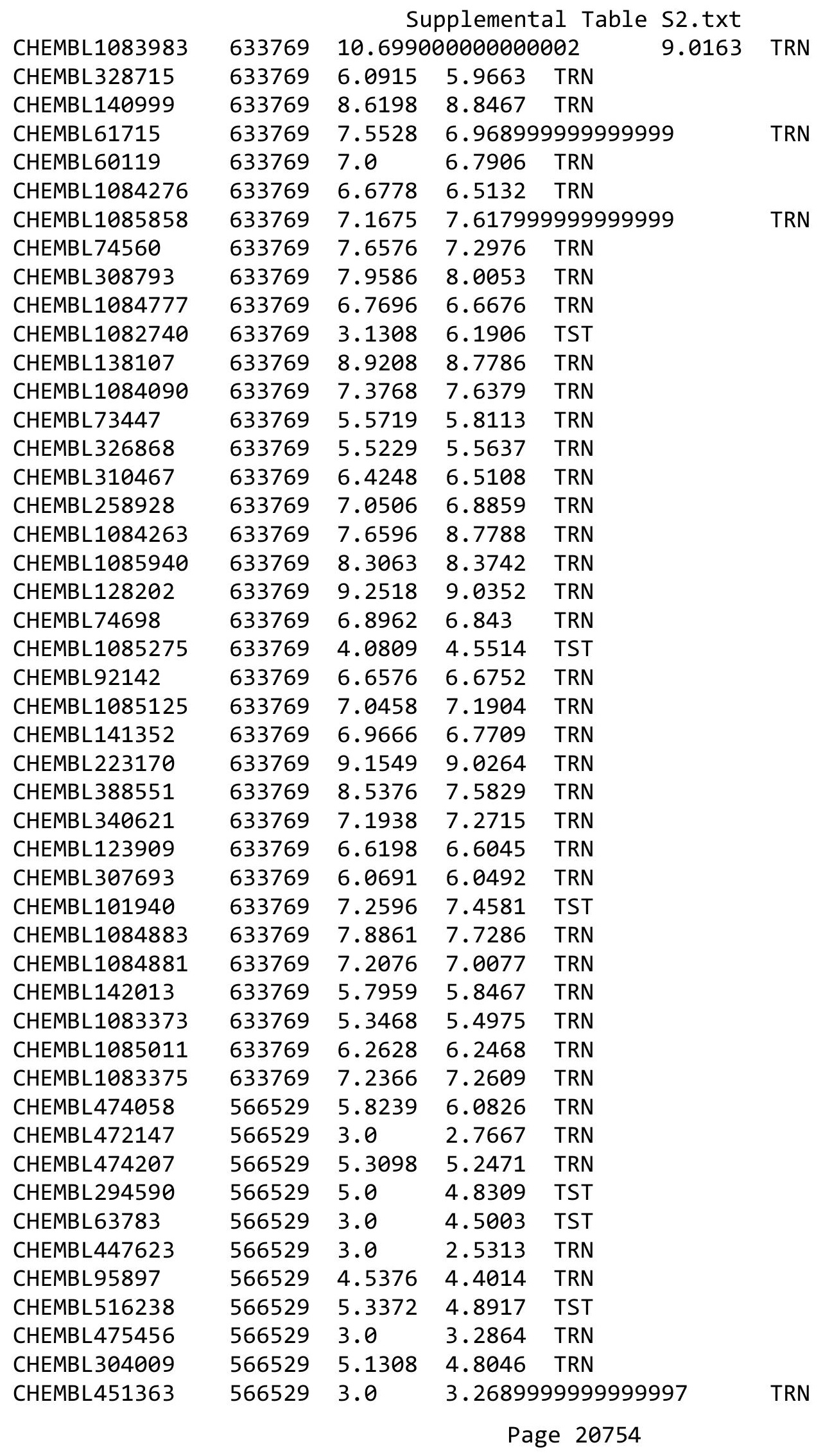




\begin{tabular}{|c|c|c|c|c|c|}
\hline \multicolumn{6}{|c|}{ Supplemental Table S2.txt } \\
\hline CHEMBL466850 & 566529 & 3.0 & 3.3967 & TRN & \\
\hline CHEMBL266094 & 566529 & 3.0 & 2.8963 & TRN & \\
\hline CHEMBL504495 & 566529 & 4.5376 & 4.1465 & TRN & \\
\hline CHEMBL474623 & 566529 & 3.0 & 2.4856 & TRN & \\
\hline CHEMBL475030 & 566529 & 3.0 & 2.9478 & TRN & \\
\hline CHEMBL475455 & 566529 & 6.0 & 5.9963 & TRN & \\
\hline CHEMBL445974 & 566529 & 3.0 & 3.5885 & TRN & \\
\hline CHEMBL505633 & 566529 & 4.7959 & 4.6143 & TRN & \\
\hline CHEMBL151071 & 566529 & 5.1739 & 5.0511 & TRN & \\
\hline CHEMBL455493 & 566529 & 5.0605 & 4.9554 & TST & \\
\hline CHEMBL503376 & 566529 & 4.9208 & 4.9528 & TRN & \\
\hline CHEMBL508561 & 566529 & 5.3098 & 5.3221 & TRN & \\
\hline CHEMBL446264 & 566529 & 6.0809 & 5.996 & TRN & \\
\hline CHEMBL505089 & 566529 & 5.4949 & 5.3695 & TRN & \\
\hline CHEMBL475617 & 566529 & 5.5376 & 5.5562 & TRN & \\
\hline CHEMBL449628 & 566529 & 3.0 & 3.1429 & TRN & \\
\hline CHEMBL65747 & 566529 & 4.4815 & 4.4606 & TST & \\
\hline CHEMBL65976 & 566529 & 4.9208 & 4.8397 & TRN & \\
\hline CHEMBL469409 & 566529 & 3.0 & 4.8122 & TST & \\
\hline CHEMBL494759 & 566529 & 3.0 & 3.18300 & 00000000003 & TRN \\
\hline CHEMBL62835 & 566529 & 3.0 & 4.5003 & TST & \\
\hline CHEMBL449108 & 566529 & 3.0 & 3.3739 & TRN & \\
\hline CHEMBL468633 & 566529 & 6.5528 & 6.4971 & TRN & \\
\hline CHEMBL503566 & 566529 & 3.0 & 3.3266 & TRN & \\
\hline CHEMBL475023 & 566529 & 5.0269 & 4.5832 & TRN & \\
\hline CHEMBL506450 & 566529 & 5.9586 & 6.1573 & TRN & \\
\hline CHEMBL67199 & 566529 & 5.3665 & 5.5742 & TRN & \\
\hline CHEMBL449924 & 566529 & 6.0 & 5.4308 & TST & \\
\hline CHEMBL474396 & 566529 & 3.0 & 4.8917 & TST & \\
\hline CHEMBL506888 & 566529 & 5.0757 & 5.1484 & TRN & \\
\hline CHEMBL510907 & 566529 & 3.0 & 3.2139 & TRN & \\
\hline CHEMBL449346 & 566529 & 3.0 & 3.0612 & TRN & \\
\hline CHEMBL509367 & 566529 & 5.5086 & 5.2096 & TST & \\
\hline CHEMBL515419 & 566529 & 5.6576 & 5.5496 & TST & \\
\hline CHEMBL445696 & 566529 & 3.0 & 2.9385 & TRN & \\
\hline CHEMBL510288 & 566529 & 6.2441 & 5.939 & TST & \\
\hline CHEMBL466044 & 566529 & 4.4685 & 4.4202 & TRN & \\
\hline CHEMBL183 & 566529 & 8.3979 & 4.9914 & TST & \\
\hline CHEMBL448396 & 566529 & 4.699 & 4.5532 & TRN & \\
\hline CHEMBL534283 & 1369321 & 6.0 & 5.8089 & TST & \\
\hline CHEMBL535730 & 1369321 & 4.7744 & 5.1112 & TST & \\
\hline CHEMBL596652 & 1369321 & 3.6021 & 4.652 & TRN & \\
\hline CHEMBL537071 & 1369321 & 5.983 & 5.2351 & TRN & \\
\hline CHEMBL 206540 & 1369321 & 4.757 & 4.5503 & TRN & \\
\hline CHEMBL525692 & 1369321 & 4.7959 & 4.8719 & TRN & \\
\hline CHEMBL579105 & 1369321 & 7.0315 & 5.2916 & TRN & \\
\hline CHEMBL587825 & 1369321 & 6.0 & 5.3207 & TRN & \\
\hline CHEMBL530978 & 1369321 & 5.0 & 5.0023 & TRN & \\
\hline
\end{tabular}


Supplemental Table S2.txt

\begin{tabular}{|c|c|c|c|c|}
\hline CHEMBL546531 & 1369321 & 7.0969 & 5.7224 & TRN \\
\hline CHEMBL600374 & 1369321 & 4.7457 & 5.4586 & TRN \\
\hline CHEMBL589922 & 1369321 & 5.1163 & 5.0348 & TRN \\
\hline CHEMBL577445 & 1369321 & 4.9226 & 5.41299 & 9999999999 \\
\hline CHEMBL605281 & 1369321 & 4.7627 & 5.1049 & TRN \\
\hline CHEMBL588732 & 1369321 & 5.0 & 5.2676 & TRN \\
\hline CHEMBL592344 & 1369321 & 7.0 & 5.6457 & TRN \\
\hline CHEMBL582420 & 1369321 & 5.2487 & 5.1037 & TRN \\
\hline CHEMBL591641 & 1369321 & 6.0605 & 5.1623 & TRN \\
\hline CHEMBL590212 & 1369321 & 4.7627 & 5.6433 & TRN \\
\hline CHEMBL602764 & 1369321 & 4.6021 & 5.1096 & TRN \\
\hline CHEMBL582070 & 1369321 & 4.9952 & 5.6992 & TRN \\
\hline CHEMBL585966 & 1369321 & 4.9034 & 4.9944 & TRN \\
\hline CHEMBL527131 & 1369321 & 4.8861 & 4.3029 & TRN \\
\hline CHEMBL587485 & 1369321 & 5.3089 & 5.1422 & TRN \\
\hline CHEMBL532597 & 1369321 & 6.3872 & 6.3888 & TRN \\
\hline CHEMBL590675 & 1369321 & 7.0 & 5.6259 & TRN \\
\hline CHEMBL 2028063 & 1369321 & 6.4949 & 6.1194 & TRN \\
\hline CHEMBL602234 & 1369321 & 7.0 & 6.5527 & TRN \\
\hline CHEMBL578933 & 1369321 & 4.782 & 5.2514 & TRN \\
\hline CHEMBL591128 & 1369321 & 5.5186 & 5.5209 & TRN \\
\hline CHEMBL10835 & 1369321 & 5.5302 & 5.7512 & TRN \\
\hline CHEMBL537087 & 1369321 & 4.7635 & 5.4138 & TRN \\
\hline CHEMBL533598 & 1369321 & 5.5157 & 5.8796 & TRN \\
\hline CHEMBL596852 & 1369321 & 5.1249 & 5.4134 & TRN \\
\hline CHEMBL459199 & 1369321 & 4.8925 & 5.225 & TRN \\
\hline CHEMBL532141 & 1369321 & 5.857 & 6.2299 & TRN \\
\hline CHEMBL601743 & 1369321 & 5.0057 & 5.4331 & TRN \\
\hline CHEMBL586704 & 1369321 & 5.5901 & 5.1266 & TRN \\
\hline CHEMBL597262 & 1369321 & 4.8891 & 5.7962 & TRN \\
\hline CHEMBL589951 & 1369321 & 6.1427 & 5.295 & TRN \\
\hline CHEMBL599885 & 1369321 & 4.6021 & 5.0227 & TRN \\
\hline CHEMBL534589 & 1369321 & 4.8511 & 5.0089 & TRN \\
\hline CHEMBL600906 & 1369321 & 5.5287 & 5.0039 & TRN \\
\hline CHEMBL605751 & 1369321 & 5.4815 & 5.5263 & TRN \\
\hline CHEMBL 2028061 & 1369321 & 5.1152 & 5.2062 & TRN \\
\hline CHEMBL601580 & 1369321 & 5.3883 & 5.2581 & TRN \\
\hline CHEMBL591147 & 1369321 & 4.7212 & 5.2853 & TRN \\
\hline CHEMBL532079 & 1369321 & 4.7688 & 4.9871 & TRN \\
\hline CHEMBL601122 & 1369321 & 6.2218 & 5.7681 & TRN \\
\hline CHEMBL1623897 & 1369321 & 4.7235 & 5.294 & TRN \\
\hline CHEMBL261095 & 1369321 & 5.5436 & 5.2262 & TRN \\
\hline CHEMBL587104 & 1369321 & 5.4763 & 5.1891 & TRN \\
\hline CHEMBL584015 & 1369321 & 5.5302 & 5.8893 & TRN \\
\hline CHEMBL527541 & 1369321 & 4.9702 & 5.2598 & TRN \\
\hline CHEMBL584240 & 1369321 & 5.0 & 5.5607 & TRN \\
\hline CHEMBL580388 & 1369321 & 5.3778 & 5.0947 & TST \\
\hline CHEMBL607688 & 1369321 & 6.0 & 6.1844 & TRN \\
\hline
\end{tabular}


Supplemental Table S2.txt

\begin{tabular}{|c|c|c|c|c|c|}
\hline CHEMBL589946 & 1369321 & 3.6021 & 5.0362 & TRN & \\
\hline CHEMBL584655 & 1369321 & 6.6576 & 5.1996 & TRN & \\
\hline CHEMBL547269 & 1369321 & 5.1013 & 5.2482 & TRN & \\
\hline CHEMBL580381 & 1369321 & 4.8242 & 5.1628 & TRN & \\
\hline CHEMBL585431 & 1369321 & 4.757 & 4.9701 & TRN & \\
\hline CHEMBL1740701 & 1369321 & 4.8147 & 4.88899 & 9999999999 & TRN \\
\hline CHEMBL604982 & 1369321 & 4.8775 & 5.3787 & TRN & \\
\hline CHEMBL2028066 & 1369321 & 5.0 & 5.0256 & TST & \\
\hline CHEMBL 2028041 & 1369321 & 6.0 & 5.7246 & TRN & \\
\hline CHEMBL578030 & 1369321 & 7.1871 & 6.4486 & TRN & \\
\hline CHEMBL528245 & 1369321 & 5.1152 & 5.0447 & TRN & \\
\hline CHEMBL585983 & 1369321 & 5.8861 & 5.5078 & TRN & \\
\hline CHEMBL606252 & 1369321 & 5.9172 & 5.7305 & TRN & \\
\hline CHEMBL528533 & 1369321 & 5.0888 & 5.44 & TRN & \\
\hline CHEMBL 2028048 & 1369321 & 4.8996 & 5.0744 & TRN & \\
\hline CHEMBL525826 & 1369321 & 6.0 & 5.4492 & TRN & \\
\hline CHEMBL587022 & 1369321 & 4.7986 & 5.044 & TST & \\
\hline CHEMBL526800 & 1369321 & 4.8511 & 4.9486 & TRN & \\
\hline CHEMBL546168 & 1369321 & 4.8283 & 5.0227 & TRN & \\
\hline CHEMBL581475 & 1369321 & 5.2933 & 5.0025 & TRN & \\
\hline CHEMBL583555 & 1369321 & 5.3696 & 5.4556 & TST & \\
\hline CHEMBL579459 & 1369321 & 4.8033 & 4.2412 & TST & \\
\hline CHEMBL588516 & 1369321 & 5.4789 & 4.97 & TRN & \\
\hline CHEMBL546994 & 1369321 & 4.6992 & 4.4085 & TRN & \\
\hline CHEMBL582072 & 1369321 & 4.7245 & 5.2082 & TRN & \\
\hline CHEMBL584841 & 1369321 & 7.1079 & 5.0025 & TRN & \\
\hline CHEMBL578952 & 1369321 & 5.5986 & 5.3541 & TRN & \\
\hline CHEMBL588155 & 1369321 & 4.751 & 5.1193 & TRN & \\
\hline CHEMBL547266 & 1369321 & 4.8617 & 5.5751 & TRN & \\
\hline CHEMBL602946 & 1369321 & 5.4089 & 6.0884 & TRN & \\
\hline CHEMBL547193 & 1369321 & 5.3487 & 5.3413 & TRN & \\
\hline CHEMBL590435 & 1369321 & 4.8834 & 5.1523 & TRN & \\
\hline CHEMBL319952 & 1369321 & 5.2449 & 5.4745 & TRN & \\
\hline CHEMBL531611 & 1369321 & 4.8821 & 5.1808 & TRN & \\
\hline CHEMBL578294 & 1369321 & 7.1739 & 6.4756 & TRN & \\
\hline CHEMBL529874 & 1369321 & 7.1871 & 6.3268 & TST & \\
\hline CHEMBL1619026 & 1369321 & 6.041 & 6.2808 & TRN & \\
\hline CHEMBL524930 & 1369321 & 6.1367 & 5.0889 & TRN & \\
\hline CHEMBL586026 & 1369321 & 5.3449 & 5.1914 & TST & \\
\hline CHEMBL1594640 & 1369321 & 4.9991 & 5.2376 & TRN & \\
\hline CHEMBL581194 & 1369321 & 4.9412 & 5.16 & TRN & \\
\hline CHEMBL1616787 & 1369321 & 7.1805 & 6.226 & TRN & \\
\hline CHEMBL601786 & 1369321 & 5.0942 & 6.3076 & TRN & \\
\hline CHEMBL589422 & 1369321 & 4.7997 & 5.0662 & TST & \\
\hline CHEMBL582547 & 1369321 & 7.2218 & 6.3145 & TRN & \\
\hline CHEMBL580188 & 1369321 & 5.383999 & 79999999ऽ & 5.0054 & TRN \\
\hline CHEMBL597444 & 1369321 & 7.1675 & 6.3231 & TRN & \\
\hline CHEMBL2028056 & 1369321 & 5.0685 & 5.1711 & TRN & \\
\hline
\end{tabular}


Supplemental Table S2.txt

\begin{tabular}{|c|c|c|c|c|c|c|}
\hline CHEMBL609036 & 1369321 & 4.9901 & 5.1532 & TRN & & \\
\hline CHEMBL579294 & 1369321 & 6.0706 & 5.317 & TRN & & \\
\hline CHEMBL600904 & 1369321 & 3.6021 & 5.216 & TRN & & \\
\hline CHEMBL 2028054 & 1369321 & 5.05399 & 99999999 & 99 & 5.0241 & TST \\
\hline CHEMBL600030 & 1369321 & 4.8179 & 5.2185 & TRN & & \\
\hline CHEMBL531222 & 1369321 & 4.8289 & 5.2204 & TRN & & \\
\hline CHEMBL533999 & 1369321 & 5.0 & 5.6311 & TRN & & \\
\hline CHEMBL527620 & 1369321 & 6.3372 & 5.0767 & TRN & & \\
\hline CHEMBL591393 & 1369321 & 5.4698 & 5.4956 & TRN & & \\
\hline CHEMBL601534 & 1369321 & 5.0 & 6.2343 & TST & & \\
\hline CHEMBL587410 & 1369321 & 4.7627 & 4.4715 & TST & & \\
\hline CHEMBL581240 & 1369321 & 4.6955 & 4.9391 & TRN & & \\
\hline CHEMBL548209 & 1369321 & 5.0438 & 6.0945 & TRN & & \\
\hline CHEMBL582486 & 1369321 & 6.0 & 4.995 & TST & & \\
\hline CHEMBL586933 & 1369321 & 6.1612 & 6.0255 & TRN & & \\
\hline CHEMBL1738986 & 1369321 & 6.1024 & 5.0497 & TRN & & \\
\hline CHEMBL2028068 & 1369321 & 5.38399 & 99999999 & 995 & 5.8513 & T \\
\hline CHEMBL1623028 & 1369321 & 5.1163 & 5.8435 & TRN & & \\
\hline CHEMBL583682 & 1369321 & 4.7038 & 4.908 & TRN & & \\
\hline CHEMBL536393 & 1369321 & 6.2757 & 5.1546 & TRN & & \\
\hline CHEMBL525106 & 1369321 & 6.0 & 5.5212 & TRN & & \\
\hline CHEMBL587923 & 1369321 & 5.4425 & 5.3516 & TRN & & \\
\hline CHEMBL536421 & 1369321 & 4.6021 & 5.0485 & TRN & & \\
\hline CHEMBL592550 & 1369321 & 3.6021 & 5.0668 & TRN & & \\
\hline CHEMBL529773 & 1369321 & 5.466 & 5.1856 & TRN & & \\
\hline CHEMBL582180 & 1369321 & 7.0 & 5.9504 & TRN & & \\
\hline CHEMBL528437 & 1369321 & 5.4622 & 6.0244 & TRN & & \\
\hline CHEMBL548334 & 1369321 & 5.0 & 5.0991 & TST & & \\
\hline CHEMBL591887 & 1369321 & 4.8791 & 5.5522 & TRN & & \\
\hline CHEMBL533563 & 1369321 & 4.7913 & 4.4299 & TST & & \\
\hline CHEMBL592808 & 1369321 & 7.0 & 5.2906 & TRN & & \\
\hline CHEMBL546799 & 1369321 & 7.1135 & 6.2346 & TRN & & \\
\hline CHEMBL529984 & 1369321 & 4.6021 & 5.0743 & TRN & & \\
\hline CHEMBL547825 & 1369321 & 5.6198 & 5.4433 & TRN & & \\
\hline CHEMBL600305 & 1369321 & 4.8111 & 4.9991 & TRN & & \\
\hline CHEMBL577440 & 1369321 & 4.7174 & 5.106 & TRN & & \\
\hline CHEMBL584237 & 1369321 & 6.5406 & 4.9924 & TRN & & \\
\hline CHEMBL579760 & 1369321 & 5.0052 & 5.1627 & TST & & \\
\hline CHEMBL601567 & 1369321 & 5.1361 & 5.8342 & TRN & & \\
\hline CHEMBL582286 & 1369321 & 5.2933 & 5.3252 & TRN & & \\
\hline CHEMBL 2028055 & 1369321 & 4.7913 & 5.1306 & TRN & & \\
\hline CHEMBL601492 & 1369321 & 6.2596 & 5.8784 & TRN & & \\
\hline CHEMBL591623 & 1369321 & 6.5376 & 5.5083 & TRN & & \\
\hline CHEMBL585686 & 1369321 & 7.0809 & 6.239 & TRN & & \\
\hline CHEMBL577014 & 1369321 & 5.4622 & 6.2478 & TRN & & \\
\hline CHEMBL601566 & 1369321 & 4.7652 & 4.9765 & TST & & \\
\hline CHEMBL582079 & 1369321 & 5.5186 & 5.6121 & TRN & & \\
\hline CHEMBL529385 & 1369321 & 7.2441 & 6.2356 & TRN & & \\
\hline
\end{tabular}

Page 20758 
Supplemental Table S2.txt

\begin{tabular}{|c|c|c|c|c|}
\hline 86468 & 369321 & 5.0685 & 5.935 & TR \\
\hline HEMBL548399 & 369321 & 4.7153 & 4.6132 & חת \\
\hline 44 & 69321 & 5.0 & 9554 & CRN \\
\hline HEMBL1744512 & 369321 & 6.0 & 2939 & \\
\hline HEMBL 580353 & 369321 & 4.8413 & 2405 & \\
\hline HEMBL2028053 & 369321 & 4.7796 & .6884 & \\
\hline HEMBL526587 & 321 & 5.6108 & 3384 & \\
\hline HEMBL 584829 & 321 & 5.2588 & 5.8957 & RN \\
\hline HEMBL 584235 & 369321 & 6.1192 & 6.159 & RN \\
\hline HEMBL1437888 & 369321 & 7.4815 & .3372 & \\
\hline HEMBL1615697 & 321 & 4.7683 & .1157 & \\
\hline HEMBL590686 & 21 & 5.0462 & .1052 & \\
\hline HEMBL 582552 & & & 3581 & RN \\
\hline HEMBL579300 & 21 & 5.0 & 5.0625 & \\
\hline HEMBL 586962 & 21 & 5.0 & 5498 & \\
\hline HEMBL2028059 & 21 & 4.6021 & .984 & \\
\hline HEMBL597248 & 21 & 5 . & 412 & RN \\
\hline HEMBL 591890 & & 4. & 1012 & \\
\hline HEMBL 586442 & 21 & 5.0862 & 5.169 & N \\
\hline HEMBL 548374 & & 5.0 & 9417 & TRN \\
\hline HEMBL 589060 & 21 & 4.7062 & 486 & RN \\
\hline HEMBL 607975 & 1 & 73 & 129 & $\mathrm{RN}$ \\
\hline HEMBL 600235 & & 5.3372 & 283 & RN \\
\hline HEMBL602940 & 21 & 6.0 & 5.3841 & 1 \\
\hline HEMBL585622 & & 5.9872 & 7449 & TRN \\
\hline HEMBL532510 & 21 & 4. & 866 & RN \\
\hline HEMBL602127 & & 89 & 168 & $\mathrm{RN}$ \\
\hline HEMBL 532155 & & 5.0953 & 1881 & $\Gamma R N$ \\
\hline HEMBL534319 & & 5.6635 & 7414 & TRN \\
\hline HEMBL589205 & & 4.7169 & 5318 & TRN \\
\hline HEMBL 52 & & 6. & 1232 & RN \\
\hline HEMBL5 & & 215 & 699 & TRN \\
\hline HEMBL 5 & & 4. & 906 & 「RN \\
\hline HEMBL533399 & & 5.3675 & 5.8373 & TST \\
\hline HEMBL582767 & 21 & 5.3778 & 5.8641 & TST \\
\hline HEMBL589733 & 1 & 5.4306 & 5.6385 & TRN \\
\hline SHEMBL $\epsilon$ & & 33 & 244 & TRN \\
\hline CHEMBL529348 & & 5 & 5.1986 & TRN \\
\hline HEMBL 2028056 & 369321 & 4.8735 & 1147 & TRN \\
\hline HEMBL533855 & r & 6.8861 & 4162 & TRN \\
\hline HEMBL547443 & 36 & 7.284 & 3299 & RN \\
\hline CHEMBL580819 & & 5.1675 & 5.4307 & TRN \\
\hline CHEMBL545880 & 21 & 5.7282 & 5.2812 & TRN \\
\hline HEMBL49055 & 369321 & 5.5186 & 5.4062 & TRN \\
\hline HEMBL6 & & 7.1675 & 6.4321 & TST \\
\hline CHEMBL 2028058 & 28 & .2007 & 5.3183 & \\
\hline CHEMBL 2028060 & 136932 & 4.7038 & 5.0503 & \\
\hline CHEMBL537505 & 1369321 & 5.1367 & 4.7664 & ГRN \\
\hline
\end{tabular}

Page 20759 
Supplemental Table S2.txt

\begin{tabular}{|c|c|c|c|c|}
\hline CHEMBL599886 & 369321 & 4.9255 & 5.5408 & TST \\
\hline HEMBL590919 & 369321 & 6.2218 & 5.3942 & TRN \\
\hline HEMBI 592786 & 69321 & 5.2358 & 356 & N \\
\hline HEMBL546162 & 369321 & 4.7627 & 158 & \\
\hline HEMBL597855 & 369321 & 4.8511 & 4482 & \\
\hline HEMBL 582119 & 369321 & 4.9714 & 5.0835 & \\
\hline HEMBL602580 & 369321 & 5.6737 & .9417 & ST \\
\hline HEMBL601825 & 321 & 3.6021 & .9837 & PN \\
\hline HEMBL598881 & 369321 & 4.7491 & 5.1551 & \\
\hline HEMBL603945 & 369321 & 6.0 & 5.8021 & \\
\hline HEMBL577012 & 321 & 4.9212 & 3484 & \\
\hline HEMBL 547488 & 321 & 4.7683 & .0476 & $\mathrm{RN}$ \\
\hline HEMBL589723 & & 4.757 & 2911 & \\
\hline HEMBL535556 & 369321 & 4.6021 & 5.278 & \\
\hline HEMBL 2028044 & 369321 & 5.0057 & 5.02 & \\
\hline HEMBL592123 & 1 & 5 . & 5031 & RIV \\
\hline HEMBL6 & 21 & 5 . & 65 & RN \\
\hline HEMBL6 & & 269 & 971 & \\
\hline HEMBL588481 & 21 & 4.782 & 5.5633 & \\
\hline HEMBL531290 & & 4.7862 & 23 & 131 \\
\hline HEMBL5 & 1 & 5 . & 27 & ST \\
\hline HEMBL5 & & 6. & 45 & $\mathrm{RN}$ \\
\hline HEMBL533921 & & 6. & 03 & TRN \\
\hline HEMBL581874 & & $5 . \varepsilon$ & 6.1406 & TRN \\
\hline HEMBL529968 & & 4.7038 & 5.9661 & IRN \\
\hline HEMBL5 & & 4.7862 & 194 & ST \\
\hline HEMBL5 & & 4. & 21 & RN \\
\hline HEMBL5 & & 5. & 56 & TRN \\
\hline HEMBL526981 & & 4.7688 & 42 & IRIN \\
\hline HEMBL603686 & 36 & 5.0 & 0607 & TST \\
\hline HEMBL 5 & $2 \perp$ & 4. & 1703 & TRN \\
\hline HEMBL & & 5 . & 56 & TRN \\
\hline HEMBL5 & & & & TRN \\
\hline HEMBL584676 & & 4.7567 & 9943 & TRN \\
\hline HEMBL548469 & 21 & 7.0915 & 6.2747 & TRN \\
\hline HEMBL 5 & \pm & 4. & 79 & TRN \\
\hline CHEMBL5 & & 5 . & 21 & TRN \\
\hline CHEMBL531060 & & 4.8063 & 5.2484 & TRN \\
\hline HEMBL338094 & & 6.1135 & 906 & TRN \\
\hline HEMBL 5 & & 53 & 3092 & TRN \\
\hline CHEMBL581187 & + & 4.8579 & 4.6256 & TRN \\
\hline CHEMBL1545915 & 21 & 4.8474 & 4.9991 & TRN \\
\hline CHEMBL602552 & 369321 & 4.9255 & 5.1869 & TRN \\
\hline CHEMBL2028045 & 369321 & 7.1871 & 774 & $\mathrm{TR}$ \\
\hline CHEMBL5 & & 5.0996 & 905 & \\
\hline CHEMBL582478 & 1369321 & 6.0 & 6.29 & \\
\hline CHEMBL600439 & 1369321 & 5.6655 & 5.7732 & ST \\
\hline CHEMBL602312 & 1369321 & 5.6655 & 5.7878 & TRN \\
\hline
\end{tabular}

Page 20760 
Supplemental Table S2.txt

\begin{tabular}{|c|c|c|c|c|c|c|}
\hline CHEMBL590683 & 1369321 & 5.8539 & 5.4276 & TRN & & \\
\hline CHEMBL527234 & 1369321 & 6.0 & 5.0304 & TRN & & \\
\hline CHEMBL599100 & 1369321 & 4.7997 & 6.097 & TRN & & \\
\hline CHEMBL 2028057 & 1369321 & 4.9987 & 5.0023 & TRN & & \\
\hline CHEMBL581860 & 1369321 & 5.4763 & 5.7948 & TRN & & \\
\hline CHEMBL587371 & 1369321 & 5.0721 & 5.506 & TRN & & \\
\hline CHEMBL602211 & 1369321 & 7.0 & 5.7212 & TRN & & \\
\hline CHEMBL 2028049 & 1369321 & 5.0947 & 5.3699 & TRN & & \\
\hline CHEMBL529640 & 1369321 & 5.7212 & 4.8902 & TRN & & \\
\hline CHEMBL596643 & 1369321 & 3.6021 & 4.9928 & TRN & & \\
\hline CHEMBL 2028052 & 1369321 & 4.7683 & 4.412 & TRN & & \\
\hline CHEMBL 2028043 & 1369321 & 5.1029 & 5.2692 & TRN & & \\
\hline CHEMBL590182 & 1369321 & 5.0 & 5.2423 & TRN & & \\
\hline CHEMBL537778 & 1369321 & 5.4283 & 5.5551 & TRN & & \\
\hline CHEMBL 2021322 & 1369321 & 5.0 & 5.064 & TRN & & \\
\hline CHEMBL587892 & 1369321 & 5.0057 & 5.4359 & TRN & & \\
\hline CHEMBL577011 & 1369321 & 4.8196 & 5.2705 & TRN & & \\
\hline CHEMBL586078 & 1369321 & 6.585 & 5.6951 & TRN & & \\
\hline CHEMBL549208 & 1369321 & 4.8794 & 5.0118 & TRN & & \\
\hline CHEMBL580249 & 1369321 & 5.3778 & 4.3401 & TRN & & \\
\hline CHEMBL580159 & 1369321 & 5.2958 & 5.2175 & TRN & & \\
\hline CHEMBL600132 & 1369321 & 4.8894 & 5.2559 & TST & & \\
\hline CHEMBL609628 & 1369321 & 7.2291 & 6.1563 & TRN & & \\
\hline CHEMBL601325 & 1369321 & 6.0315 & 5.5429 & TST & & \\
\hline CHEMBL586888 & 1369321 & 7.0969 & 5.9883 & TRN & & \\
\hline CHEMBL591395 & 1369321 & 3.6021 & 4.9656 & TRN & & \\
\hline CHEMBL586178 & 1369321 & 3.6021 & 5.0625 & TRN & & \\
\hline CHEMBL581225 & 1369321 & 5.4763 & 5.7667 & TST & & \\
\hline CHEMBL2028042 & 1369321 & 4.8655 & 4.9576 & TRN & & \\
\hline CHEMBL578508 & 1369321 & 4.7183 & 5.0739 & TRN & & \\
\hline CHEMBL592125 & 1369321 & 4.8821 & 5.6653 & TRN & & \\
\hline CHEMBL528734 & 1369321 & 5.1439 & 5.1754 & TRN & & \\
\hline CHEMBL 600488 & 1369321 & 4.9255 & 4.9468 & TRN & & \\
\hline CHEMBL529919 & 1369321 & 5.1319 & 4.4911 & TRN & & \\
\hline CHEMBL588501 & 1369321 & 5.4078 & 5.4888 & TRN & & \\
\hline CHEMBL530149 & 1369321 & 4.6755 & 5.7462 & TRN & & \\
\hline CHEMBL2028046 & 1369321 & 6.1675 & 5.8158 & TRN & & \\
\hline CHEMBL580140 & 1369321 & 6.4437 & 5.0857 & TRN & & \\
\hline CHEMBL547614 & 1369321 & 4.9431 & 4.3641 & TST & & \\
\hline CHEMBL601806 & 1369321 & 6.7212 & 5.6379 & TST & & \\
\hline CHEMBL532525 & 1369321 & 7.0915 & 6.2143 & TRN & & \\
\hline CHEMBL600706 & 1369321 & $4.9910 e$ & 000000000 & 305 & 5.0635 TRN & \\
\hline CHEMBL608855 & 1369321 & 4.9226 & 5.2208 & TST & & \\
\hline CHEMBL585839 & 1369321 & $4.9830 e$ & 000000000 & 305 & 5.122000000000001 & TRN \\
\hline CHEMBL590933 & 1369321 & 5.5302 & 6.5457 & TRN & & \\
\hline CHEMBL601612 & 1369321 & 4.6021 & 4.4284 & TST & & \\
\hline CHEMBL527730 & 1369321 & 5.7282 & 4.6898 & TRN & & \\
\hline CHEMBL601348 & 1369321 & 4.8283 & 4.3499 & TST & & \\
\hline
\end{tabular}

Page 20761 


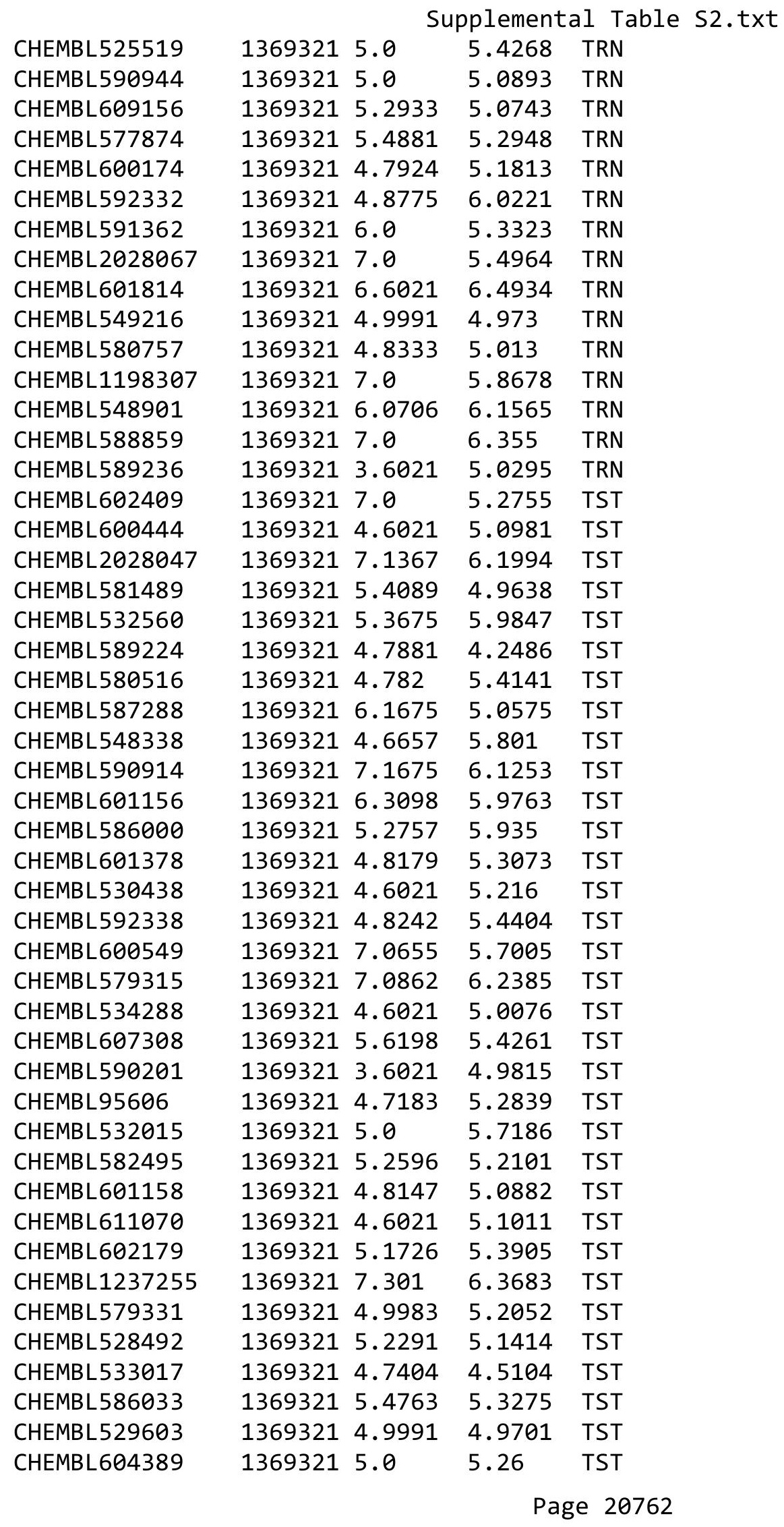


Supplemental Table S2.txt

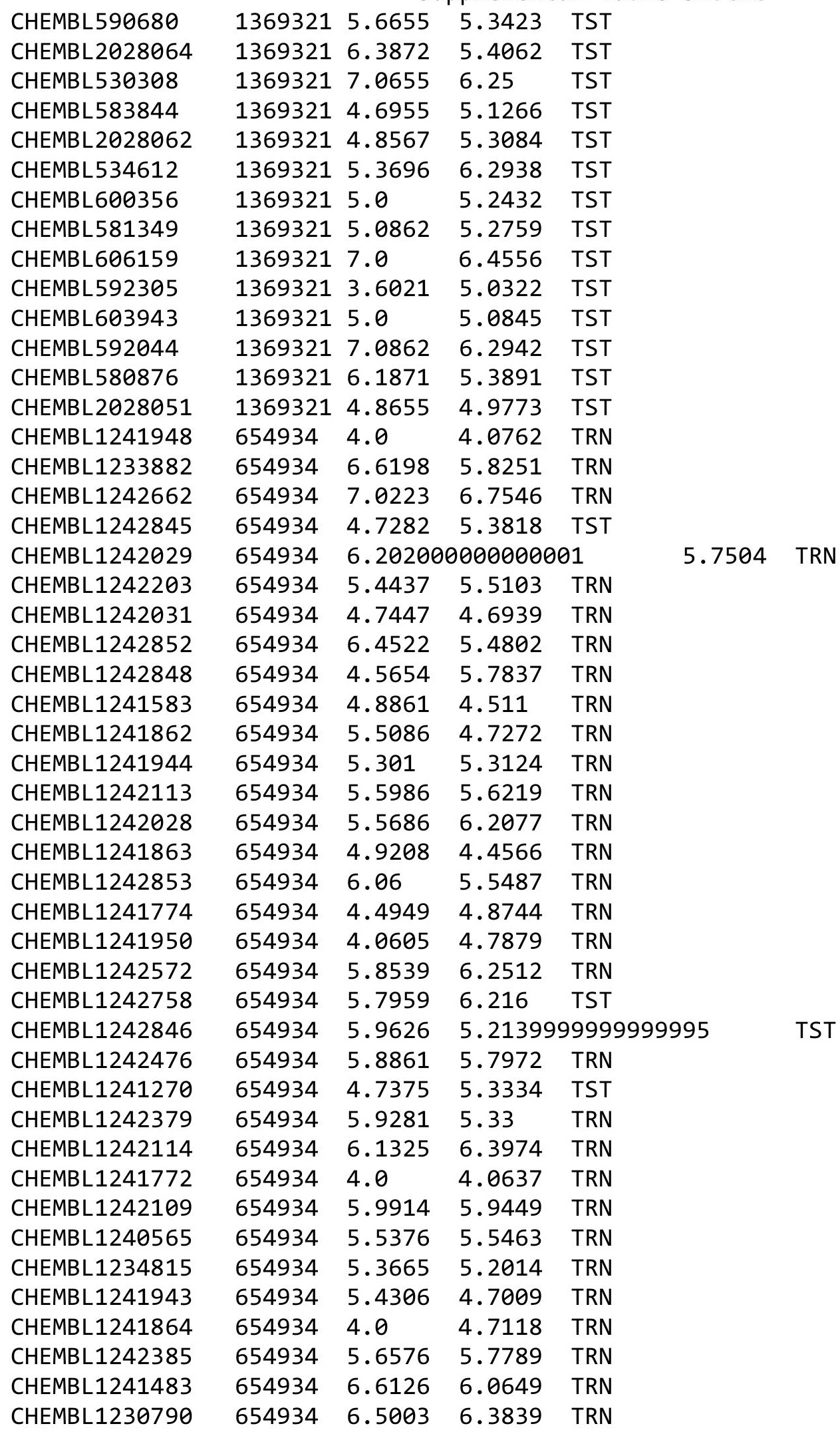

Page 20763 


\begin{tabular}{|c|c|c|c|c|c|}
\hline & & & & & \\
\hline CHEMBL1241770 & 654934 & 6.4535 & 5.1491 & TRN & \\
\hline CHEMBL1241860 & 654934 & 4.8239 & 5.1522 & TRN & \\
\hline CHEMBL1241679 & 654934 & 5.0 & 4.3988 & TRN & \\
\hline CHEMBL1242290 & 654934 & 5.4559 & 5.6121 & TRN & \\
\hline CHEMBL1241484 & 654934 & 6.9747 & 6.6755 & TRN & \\
\hline CHEMBL1241486 & 654934 & 4.9586 & 5.2372 & TRN & \\
\hline CHEMBL1241588 & 654934 & 5.1701 & 5.01699 & 99999999995 & TST \\
\hline CHEMBL1242117 & 654934 & 4.0 & 3.9236 & TRN & \\
\hline CHEMBL1241485 & 654934 & 5.58 & 5.822 & TRN & \\
\hline CHEMBL1242757 & 654934 & 5.5376 & 5.8384 & TST & \\
\hline CHEMBL1242659 & 654934 & 4.0 & 5.3992 & TRN & \\
\hline CHEMBL1242470 & 654934 & 4.0 & 5.2043 & TST & \\
\hline CHEMBL1242209 & 654934 & 5.4202 & 4.9617 & TRN & \\
\hline CHEMBL1242110 & 654934 & 6.2472 & 6.2639 & TRN & \\
\hline CHEMBL1242202 & 654934 & 6.7799 & 6.7319 & TRN & \\
\hline CHEMBL1241439 & 654934 & 4.7696 & 4.6772 & TST & \\
\hline CHEMBL1242295 & 654934 & 6.9788 & 6.7542 & TRN & \\
\hline CHEMBL1242656 & 654934 & 7.2676 & 6.9005 & TRN & \\
\hline CHEMBL1242754 & 654934 & 5.7696 & 5.7841 & TRN & \\
\hline CHEMBL1241581 & 654934 & 7.3468 & 6.5874 & TRN & \\
\hline CHEMBL1233881 & 654934 & 5.8539 & 6.2709 & TRN & \\
\hline CHEMBL1241767 & 654934 & 3.301 & 4.836 & TST & \\
\hline CHEMBL1242294 & 654934 & 6.6383 & 6.4676 & TRN & \\
\hline CHEMBL1242293 & 654934 & 6.4685 & 6.5691 & TRN & \\
\hline CHEMBL1242752 & 654934 & 4.8327 & 5.0462 & TRN & \\
\hline CHEMBL1242027 & 654934 & 5.7545 & 6.0069 & TRN & \\
\hline CHEMBL1241946 & 654934 & 5.4202 & 4.771 & TRN & \\
\hline CHEMBL1242198 & 654934 & 6.6003 & 6.7254 & TRN & \\
\hline CHEMBL1240566 & 654934 & 5.301 & 5.2398 & TRN & \\
\hline CHEMBL1241682 & 654934 & 5.5686 & 5.0954 & TRN & \\
\hline CHEMBL1241487 & 654934 & 6.1169 & 6.3016 & TRN & \\
\hline CHEMBL1241681 & 654934 & 5.5686 & 5.7223 & TRN & \\
\hline CHEMBL1242381 & 654934 & 6.0 & 5.4471 & TRN & \\
\hline CHEMBL1241776 & 654934 & 4.8539 & 5.1998 & TRN & \\
\hline CHEMBL1241949 & 654934 & 4.7447 & 5.2119 & TRN & \\
\hline CHEMBL1242285 & 654934 & 7.7696 & 6.5329 & TRN & \\
\hline CHEMBL1242753 & 654934 & 4.0 & 4.3069 & TRN & \\
\hline CHEMBL1241586 & 654934 & 4.7696 & 4.9471 & TRN & \\
\hline CHEMBL1242472 & 654934 & 5.3516 & 5.1532 & TRN & \\
\hline CHEMBL1241271 & 654934 & 5.0491 & 5.2884 & TRN & \\
\hline CHEMBL1242755 & 654934 & 6.1805 & 6.221 & TRN & \\
\hline CHEMBL1242847 & 654934 & 5.5258 & 5.7029 & TRN & \\
\hline CHEMBL1242199 & 654934 & 7.0177 & 7.0713 & TRN & \\
\hline CHEMBL1242115 & 654934 & 5.5361 & 4.875 & TST & \\
\hline CHEMBL1241683 & 654934 & 5.4949 & 5.3612 & TRN & \\
\hline CHEMBL1242378 & 654934 & 6.0 & 5.837006 & 0000000001 & TRN \\
\hline CHEMBL1242748 & 654934 & 6.0 & 5.8679 & TRN & \\
\hline CHEMBL1242471 & 654934 & 4.0 & 4.4101 & TST & \\
\hline & & & & 20764 & \\
\hline
\end{tabular}




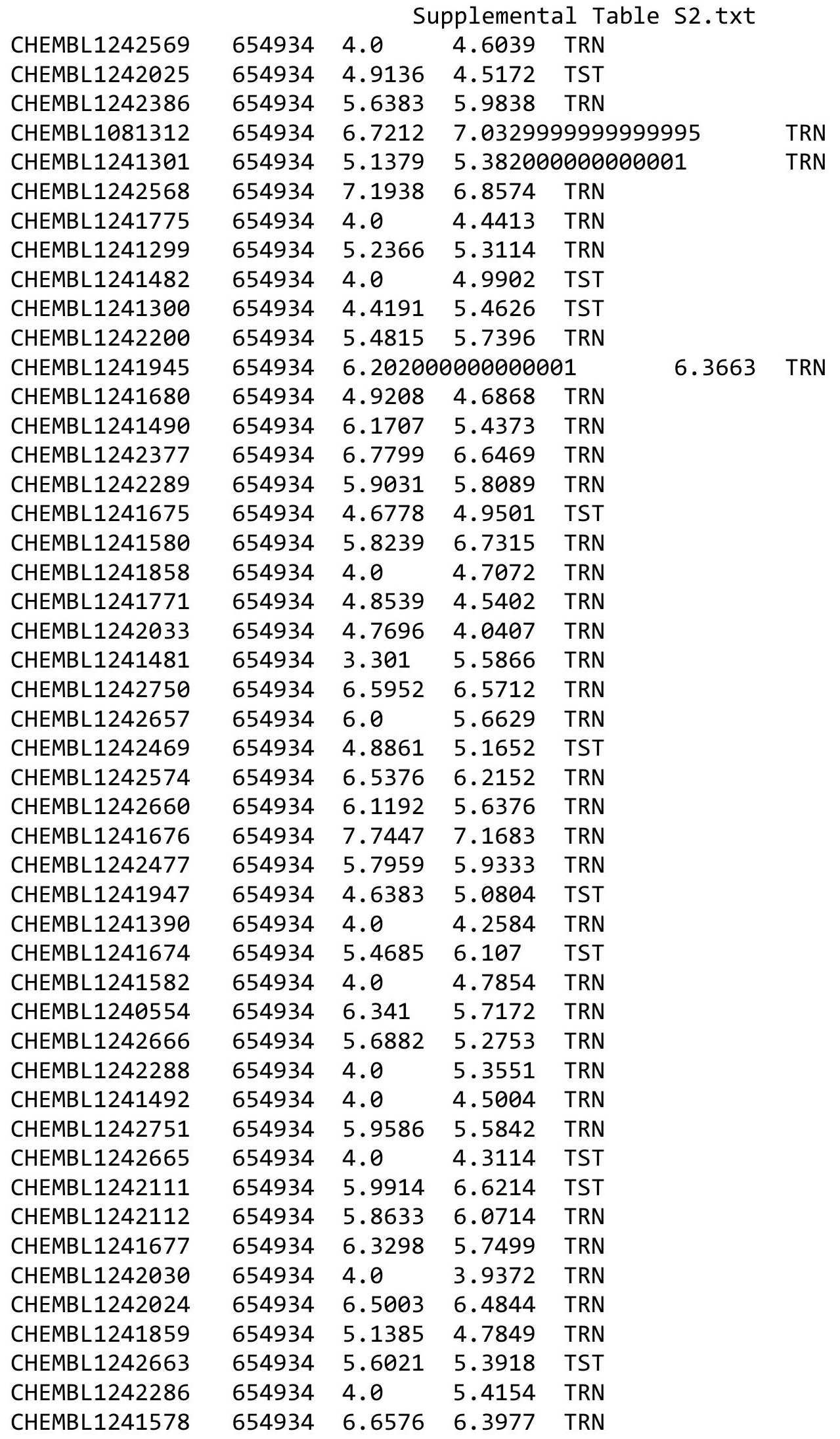

Page 20765 
Supplemental Table S2.txt

\begin{tabular}{|c|c|c|c|c|c|}
\hline CHEMBL1241684 & 654934 & 4.6576 & 4.7902 & TST & \\
\hline CHEMBL1241861 & 654934 & 5.1487 & 5.1834 & TRN & \\
\hline CHEMBL1242032 & 654934 & 4.8239 & 4.1455 & TRN & \\
\hline CHEMBL1242034 & 654934 & 4.8539 & 4.4969 & TRN & \\
\hline CHEMBL1242026 & 654934 & 6.6038 & 6.3597 & TRN & \\
\hline CHEMBL1240553 & 654934 & 5.8239 & 6.2315 & TRN & \\
\hline CHEMBL1242287 & 654934 & 6.4921 & 6.5437 & TRN & \\
\hline CHEMBL1242376 & 654934 & 6.4597 & 6.5908 & TRN & \\
\hline CHEMBL1242118 & 654934 & 5.0655 & 4.6842 & TRN & \\
\hline CHEMBL1242384 & 654934 & 4.0 & 5.5011 & TRN & \\
\hline CHEMBL1241773 & 654934 & 4.0 & 4.4846 & TST & \\
\hline CHEMBL1242475 & 654934 & 5.699 & 6.2569 & TST & \\
\hline CHEMBL1241391 & 654934 & 4.0 & 4.0948 & TST & \\
\hline CHEMBL1242201 & 654934 & 6.5884 & 6.6881 & TST & \\
\hline CHEMBL1241491 & 654934 & 6.4202 & 5.8468 & TST & \\
\hline CHEMBL1242119 & 654934 & 4.7447 & 5.2923 & TST & \\
\hline CHEMBL1242661 & 654934 & 5.9586 & 4.5553 & TST & \\
\hline CHEMBL1242664 & 654934 & 6.7696 & 6.5929 & TST & \\
\hline CHEMBL1242208 & 654934 & 4.9208 & 4.7389 & TST & \\
\hline CHEMBL1242566 & 654934 & 5.699 & 6.457999 & 7999999999 & TST \\
\hline CHEMBL1241769 & 654934 & 5.0942 & 5.062 & TST & \\
\hline CHEMBL1242573 & 654934 & 5.3468 & 6.1186 & TST & \\
\hline CHEMBL1240545 & 654934 & 4.0 & 4.4509 & TST & \\
\hline CHEMBL1242207 & 654934 & 4.9208 & 4.5086 & TST & \\
\hline CHEMBL1241587 & 654934 & 5.5229 & 4.9446 & TST & \\
\hline CHEMBL1242844 & 654934 & 4.0 & 4.6773 & TST & \\
\hline CHEMBL1242756 & 654934 & 5.0 & 4.6445 & TST & \\
\hline CHEMBL1241241 & 654934 & 5.9101 & 5.9772 & TST & \\
\hline CHEMBL259181 & 954703 & 4.5846 & 4.5154 & TRN & \\
\hline CHEMBL472940 & 954703 & 4.2587 & 3.6836 & TRN & \\
\hline CHEMBL 210618 & 954703 & 3.324 & 3.4643 & TRN & \\
\hline CHEMBL135561 & 954703 & 4.9621 & 4.447 & TRN & \\
\hline CHEMBL509032 & 954703 & 5.9534 & 5.6016 & TRN & \\
\hline CHEMBL1643959 & 954703 & 3.95399 & 999999999 & 3.7943 & TRN \\
\hline CHEMBL1230020 & 954703 & 3.4025 & 4.0229 & TRN & \\
\hline CHEMBL 2363137 & 954703 & 5.57100 & 000000000 & 4.7885 & TRN \\
\hline CHEMBL 2144069 & 954703 & 5.1924 & 4.9845 & TRN & \\
\hline CHEMBL393929 & 954703 & 3.8256 & 3.9221 & TRN & \\
\hline CHEMBL399530 & 954703 & 5.125 & 4.5741 & TRN & \\
\hline CHEMBL 221137 & 954703 & 5.0706 & 4.6927 & TST & \\
\hline CHEMBL3199475 & 954703 & 3.9856 & 4.3971 & TRN & \\
\hline CHEMBL1516890 & 954703 & 4.7084 & 4.0457 & TRN & \\
\hline CHEMBL1256459 & 954703 & 6.5378 & 7.1022 & TRN & \\
\hline CHEMBL 3392440 & 954703 & 3.5731 & 3.8989 & TRN & \\
\hline CHEMBL1404918 & 954703 & 2.8579 & 2.9355 & TRN & \\
\hline CHEMBL573107 & 954703 & 5.6628 & 5.0884 & TRN & \\
\hline CHEMBL102714 & 954703 & 3.0973 & 3.5599 & TRN & \\
\hline CHEMBL240954 & 954703 & 3.5477 & 3.7246 & TST & \\
\hline
\end{tabular}




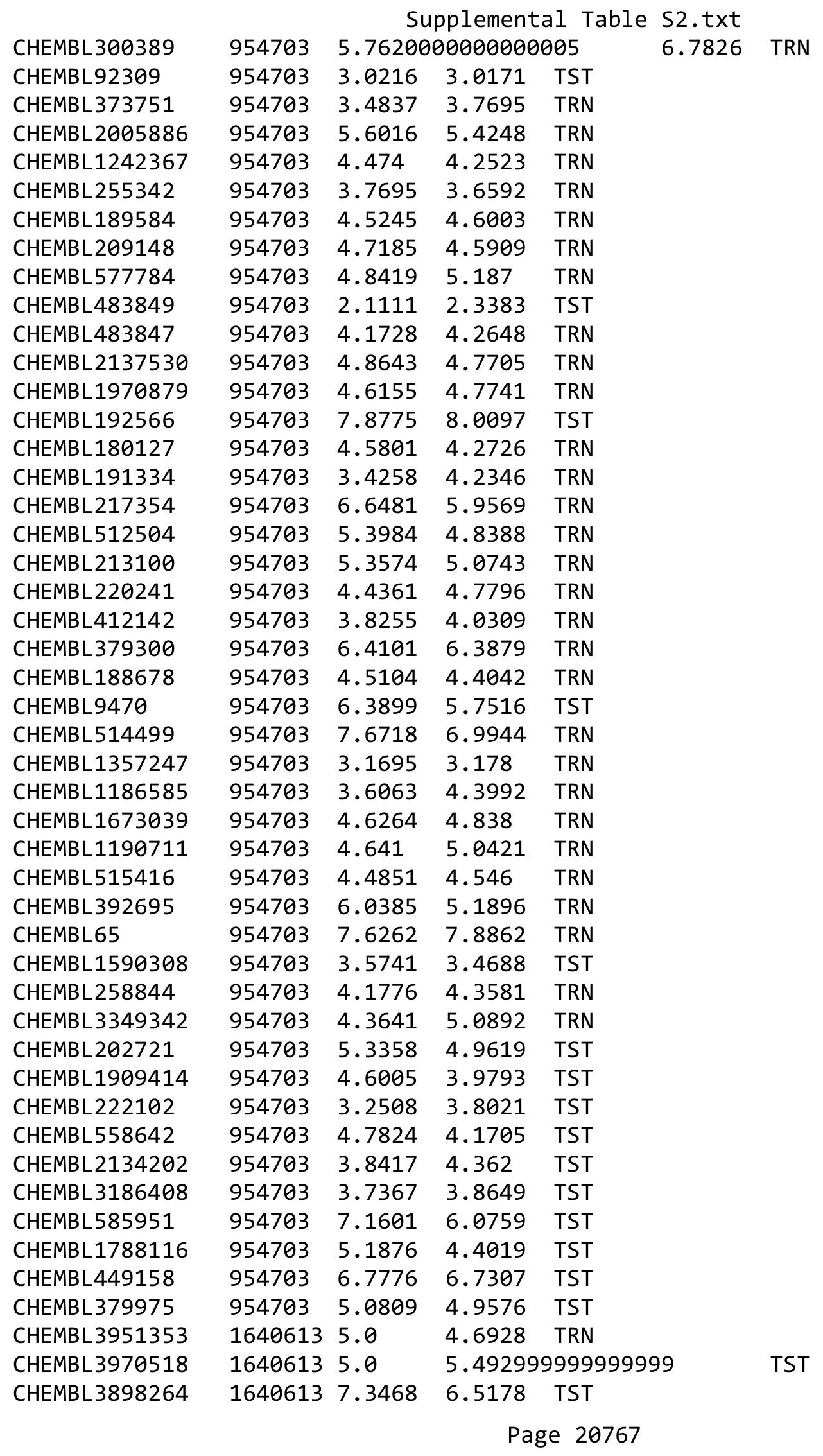




$$
\text { Supplemental Table S2.txt }
$$

\begin{tabular}{|c|c|c|c|c|}
\hline CHEMBL3954455 & 1640613 & 8.5229 & 8.2862 & TRN \\
\hline CHEMBL3913730 & 1640613 & 8.301 & 7.2567 & TRN \\
\hline CHEMBL3901961 & 1640613 & 6.4202 & 5.5512 & TRN \\
\hline CHEMBL 3933420 & 1640613 & 6.7959 & 7.1989 & TRN \\
\hline CHEMBL3892644 & 1640613 & 7.4559 & 7.0699 & TRN \\
\hline CHEMBL3894086 & 1640613 & 8.301 & 8.4842 & TRN \\
\hline CHEMBL3905924 & 1640613 & 5.8539 & 5.9859 & TRN \\
\hline CHEMBL3971847 & 1640613 & 7.6198 & 7.9902 & TRN \\
\hline CHEMBL 3908305 & 1640613 & 7.3979 & \multicolumn{2}{|c|}{7.388999999999999} \\
\hline CHEMBL3932225 & 1640613 & 7.1135 & 6.7927 & TRN \\
\hline CHEMBL3969027 & 1640613 & 5.0 & 5.3175 & TRN \\
\hline CHEMBL3899382 & 1640613 & 9.0 & 8.7652 & TRN \\
\hline CHEMBL3959131 & 1640613 & 7.585 & 7.4155 & TRN \\
\hline CHEMBL 3925688 & 1640613 & 8.301 & 7.9965 & TRN \\
\hline CHEMBL3937436 & 1640613 & 6.1726 & 6.7396 & TST \\
\hline CHEMBL3358119 & 1640613 & 9.0 & 8.8795 & TRN \\
\hline CHEMBL3941157 & 1640613 & 7.9586 & 7.8535 & TRN \\
\hline CHEMBL3917083 & 1640613 & 5.0 & 5.038 & TRN \\
\hline CHEMBL 3937813 & 1640613 & 8.301 & 7.654 & TST \\
\hline CHEMBL3936245 & 1640613 & 7.5528 & 7.1308 & TRN \\
\hline CHEMBL3937674 & 1640613 & 7.3188 & 7.7402 & TRN \\
\hline CHEMBL3950436 & 1640613 & 7.3468 & 7.4711 & TST \\
\hline CHEMBL 3980267 & 1640613 & 5.7986 & 5.7277 & TST \\
\hline CHEMBL3938432 & 1640613 & 6.6757 & 7.0644 & TRN \\
\hline CHEMBL3935642 & 1640613 & 6.3279 & 6.4953 & TRN \\
\hline CHEMBL3949901 & 1640613 & 8.301 & 8.5377 & TRN \\
\hline CHEMBL 3942893 & 1640613 & 6.8861 & 7.0985 & TST \\
\hline CHEMBL3959734 & 1640613 & 5.0 & 5.261 & TRN \\
\hline CHEMBL 3896484 & 1640613 & 6.8861 & 7.2696 & TST \\
\hline CHEMBL3911487 & 1640613 & 7.3565 & 7.3544 & TRN \\
\hline CHEMBL3889829 & 1640613 & 5.0 & 4.7039 & TRN \\
\hline CHEMBL3918165 & 1640613 & 7.3468 & 7.347 & TRN \\
\hline CHEMBL3961881 & 1640613 & 7.9586 & 7.7295 & TST \\
\hline CHEMBL3931957 & 1640613 & 6.109 & 6.9318 & TST \\
\hline CHEMBL3944899 & 1640613 & 7.2291 & 7.7414 & TRN \\
\hline CHEMBL3965395 & 1640613 & 6.7959 & 7.8671 & TST \\
\hline CHEMBL3974330 & 1640613 & 5.0 & 4.8764 & TRN \\
\hline CHEMBL3898675 & 1640613 & 5.0 & 5.5024 & TRN \\
\hline CHEMBL3358120 & 1640613 & 9.0 & 8.9887 & TRN \\
\hline CHEMBL3958400 & 1640613 & 8.301 & 8.0762 & TST \\
\hline CHEMBL3979069 & 1640613 & 7.4559 & 7.9564 & TRN \\
\hline CHEMBL3944999 & 1640613 & 7.041 & 7.1737 & TRN \\
\hline CHEMBL3964038 & 1640613 & 7.1308 & 7.4766 & TRN \\
\hline CHEMBL 3958873 & 1640613 & 8.301 & 8.1621 & TRN \\
\hline CHEMBL3933932 & 1640613 & 6.6383 & 6.7582 & TRN \\
\hline CHEMBL3929504 & 1640613 & 6.6498 & 6.5258 & TRN \\
\hline CHEMBL3930636 & 1640613 & 8.3979 & 8.0873 & TRN \\
\hline CHEMBL3913151 & 1640613 & 7.1367 & 7.1421 & TRN \\
\hline
\end{tabular}


Supplemental Table S2.txt

\begin{tabular}{|c|c|c|c|c|}
\hline CHEMBL3942889 & 1640613 & 6.4559 & 6.432 & TRN \\
\hline CHEMBL3953146 & 1640613 & 8.0458 & 8.1832 & TRN \\
\hline CHEMBL3893679 & 1640613 & 7.7212 & 6.9294 & TRN \\
\hline CHEMBL3982330 & 1640613 & 5.0 & 3.827 & TST \\
\hline CHEMBL 3896984 & 1640613 & 8.699 & 8.4225 & TRN \\
\hline CHEMBL3985307 & 1640613 & 7.4089 & 6.8232 & TST \\
\hline CHEMBL3922714 & 1640613 & 7.3565 & 7.3235 & TRN \\
\hline CHEMBL3908101 & 1640613 & 5.7212 & 5.9547 & TRN \\
\hline CHEMBL3898749 & 1640613 & 5.0 & 5.499 & TST \\
\hline CHEMBL3959452 & 1640613 & 5.0 & 5.5678 & TRN \\
\hline CHEMBL3358121 & 1640613 & 9.0 & 8.6884 & TRN \\
\hline CHEMBL3969455 & 1640613 & 5.9208 & 4.4093 & TST \\
\hline CHEMBL 3945163 & 1640613 & 6.2596 & 6.952999 & 9999999999 \\
\hline CHEMBL 3924504 & 1640613 & 7.301 & 7.4472 & TRN \\
\hline CHEMBL 3904140 & 1640613 & 7.6021 & 8.0323 & TRN \\
\hline CHEMBL3926712 & 1640613 & 6.5686 & 6.7311 & TRN \\
\hline CHEMBL3939644 & 1640613 & 7.2676 & 7.5247 & TRN \\
\hline CHEMBL3935150 & 1640613 & 7.9208 & 7.3575 & TST \\
\hline CHEMBL75295 & 139462 & 8.2441 & 8.0909 & TRN \\
\hline CHEMBL306825 & 139462 & 8.4949 & 8.6078 & TRN \\
\hline CHEMBL75358 & 139462 & 8.3768 & 8.3079 & TRN \\
\hline CHEMBL 74792 & 139462 & 8.0506 & 8.5983 & TST \\
\hline CHEMBL48269 & 139462 & 8.1487 & 8.1984 & TRN \\
\hline CHEMBL 77348 & 139462 & 7.7212 & 7.909 & TRN \\
\hline CHEMBL 76647 & 139462 & 6.8601 & 6.947999 & 99999999995 \\
\hline CHEMBL 307600 & 139462 & 8.0223 & 7.9317 & TRN \\
\hline CHEMBL309054 & 139462 & 6.5638 & 6.4659 & TRN \\
\hline CHEMBL11081 & 139462 & 9.0362 & 9.5133 & TRN \\
\hline CHEMBL307265 & 139462 & 4.0 & 4.0713 & TRN \\
\hline CHEMBL 74426 & 139462 & 7.8861 & 7.7377 & TRN \\
\hline CHEMBL307512 & 139462 & 8.1487 & 8.0383 & TST \\
\hline CHEMBL 309000 & 139462 & 7.0862 & 7.0544 & TRN \\
\hline CHEMBL76059 & 139462 & 7.8356 & 7.6797 & TRN \\
\hline CHEMBL 307051 & 139462 & 7.6383 & 8.1394 & TRN \\
\hline CHEMBL 78304 & 139462 & 7.7959 & 7.6001 & TRN \\
\hline CHEMBL306366 & 139462 & 8.8861 & 8.4717 & TRN \\
\hline CHEMBL 77432 & 139462 & 7.9872 & 8.0754 & TRN \\
\hline CHEMBL77218 & 139462 & 6.6716 & 6.2284 & TRN \\
\hline CHEMBL 75144 & 139462 & 7.5361 & 7.3963 & TRN \\
\hline CHEMBL 75805 & 139462 & 8.4425 & 8.494 & TRN \\
\hline CHEMBL41779 & 139462 & 8.9586 & 8.7197 & TRN \\
\hline CHEMBL 77793 & 139462 & 9.5229 & 9.1826 & TRN \\
\hline CHEMBL310852 & 139462 & 9.0655 & 9.05 & TST \\
\hline CHEMBL74265 & 139462 & 7.4559 & 7.4134 & TST \\
\hline CHEMBL 77763 & 139462 & 4.0 & 4.1374 & TRN \\
\hline CHEMBL 77886 & 139462 & 7.3665 & 7.62 & TST \\
\hline CHEMBL 7634 & 139462 & 9.301 & 9.3081 & TRN \\
\hline CHEMBL 78262 & 139462 & 8.0 & 7.881 & TRN \\
\hline
\end{tabular}




\begin{tabular}{|c|c|c|c|c|c|c|}
\hline & & \multicolumn{5}{|c|}{ Supplemental Table S2.txt } \\
\hline CHEMBL 74917 & 139462 & 8.4437 & \multicolumn{3}{|c|}{8.857999999999999} & TST \\
\hline CHEMBL 74424 & 139462 & 7.7447 & 8.0423 & TRN & & \\
\hline CHEMBL77160 & 139462 & 7.9208 & 8.2346 & TRN & & \\
\hline CHEMBL421127 & 139462 & 8.3468 & 8.9487 & TST & & \\
\hline CHEMBL76995 & 139462 & 4.0 & 5.8062 & TST & & \\
\hline CHEMBL 73404 & 139462 & 7.9914 & 8.026 & TRN & & \\
\hline CHEMBL308605 & 139462 & 8.6778 & 8.4966 & TRN & & \\
\hline CHEMBL306376 & 139462 & 8.7959 & 8.4274 & TRN & & \\
\hline CHEMBL74425 & 139462 & 6.9208 & 6.9733 & TRN & & \\
\hline CHEMBL 307014 & 139462 & 7.2076 & 7.3193 & TRN & & \\
\hline CHEMBL309829 & 139462 & 7.4437 & 7.9588 & TRN & & \\
\hline CHEMBL51682 & 139462 & 8.9586 & 8.6815 & TRN & & \\
\hline CHEMBL73909 & 139462 & 6.8069 & 6.4518 & TRN & & \\
\hline CHEMBL 73848 & 139462 & 8.0655 & 8.1855 & TRN & & \\
\hline CHEMBL51405 & 139462 & 8.8239 & 8.7927 & TRN & & \\
\hline CHEMBL73871 & 139462 & 7.7959 & 7.5141 & TST & & \\
\hline CHEMBL77636 & 139462 & 8.7167 & 8.3742 & TRN & & \\
\hline CHEMBL 74264 & 139462 & 7.4318 & 7.2208 & TST & & \\
\hline CHEMBL307612 & 139462 & 8.2823 & 8.0427 & TRN & & \\
\hline CHEMBL 75417 & 139462 & 6.7282 & 6.9734 & TRN & & \\
\hline CHEMBL307955 & 139462 & 6.71899 & 999999999 & 99 & 6.5433 & TRN \\
\hline CHEMBL76067 & 139462 & 8.8239 & 8.9387 & TST & & \\
\hline CHEMBL 76385 & 139462 & 7.8861 & 8.2233 & TST & & \\
\hline CHEMBL77079 & 139462 & 8.5686 & 9.2088 & TST & & \\
\hline CHEMBL311856 & 139462 & 7.475 & 7.9393 & TRN & & \\
\hline CHEMBL310020 & 139462 & 6.6861 & 6.7678 & TRN & & \\
\hline CHEMBL 309080 & 139462 & 7.8861 & 8.2279 & TRN & & \\
\hline CHEMBL 75086 & 139462 & 7.1675 & 7.3198 & TRN & & \\
\hline CHEMBL 77870 & 139462 & 7.5784 & 8.0103 & TRN & & \\
\hline CHEMBL 75033 & 139462 & 7.4089 & 7.6273 & TST & & \\
\hline CHEMBL 75026 & 139462 & 7.6576 & 7.5948 & TST & & \\
\hline CHEMBL 73257 & 139462 & 8.585 & 9.104 & TST & & \\
\hline CHEMBL 75111 & 139462 & 8.7747 & 8.1501 & TRN & & \\
\hline CHEMBL 75027 & 139462 & 6.8069 & 6.7762 & TRN & & \\
\hline CHEMBL 77533 & 139462 & 7.1871 & 7.6347 & TST & & \\
\hline CHEMBL 78046 & 139462 & 7.2757 & 7.6055 & TRN & & \\
\hline CHEMBL1336883 & 688741 & 5.4462 & 5.2251 & TRN & & \\
\hline CHEMBL1545187 & 688741 & 3.301 & 3.3258 & TRN & & \\
\hline CHEMBL1610467 & 688741 & 3.301 & 4.5976 & TST & & \\
\hline CHEMBL 1413502 & 688741 & 3.301 & 3.3924 & TRN & & \\
\hline CHEMBL1579001 & 688741 & 3.301 & 3.0832 & TRN & & \\
\hline CHEMBL1550700 & 688741 & 3.301 & 3.2047 & TRN & & \\
\hline CHEMBL1575426 & 688741 & 6.3133 & 6.7702 & TRN & & \\
\hline CHEMBL1524061 & 688741 & 5.8436 & 6.1516 & TRN & & \\
\hline CHEMBL1604088 & 688741 & 7.62799 & 9999999 & 99 & 7.2734 & TRN \\
\hline CHEMBL 3195524 & 688741 & 3.301 & 2.681 & TST & & \\
\hline CHEMBL1600315 & 688741 & 7.0 & 6.6138 & TRN & & \\
\hline CHEMBL1540513 & 688741 & 5.5785 & 5.2813 & TRN & & \\
\hline
\end{tabular}




\begin{tabular}{|c|c|c|c|c|}
\hline & & & oplement & al $\mathrm{T}$ \\
\hline CHEMBL1457821 & 688741 & 3.301 & 3.2713 & TRN \\
\hline CHEMBL1374228 & 688741 & 4.8962 & 4.7652 & TRN \\
\hline CHEMBL1526570 & 688741 & 3.301 & 3.0151 & TRN \\
\hline CHEMBL1386734 & 688741 & 3.301 & 3.4837 & TRN \\
\hline CHEMBL1542095 & 688741 & 3.301 & 3.3526 & TRN \\
\hline CHEMBL1377749 & 688741 & 5.8582 & 4.9024 & TRN \\
\hline CHEMBL491908 & 688741 & 4.8554 & 5.3627 & TRN \\
\hline CHEMBL1253382 & 688741 & 5.5076 & 5.376 & TRN \\
\hline CHEMBL1462875 & 688741 & 3.301 & 3.7109 & TST \\
\hline CHEMBL1495621 & 688741 & 3.301 & 3.645 & TRN \\
\hline CHEMBL1428491 & 688741 & 3.301 & 3.3635 & TRN \\
\hline CHEMBL1570552 & 688741 & 3.301 & 3.1721 & TRN \\
\hline CHEMBL1363803 & 688741 & 5.4704 & 6.1852 & TRN \\
\hline CHEMBL1570270 & 688741 & 3.301 & 2.9143 & TRN \\
\hline CHEMBL1518851 & 688741 & 5.6712 & 5.3171 & TRN \\
\hline CHEMBL1427169 & 688741 & 3.301 & 4.1786 & TST \\
\hline CHEMBL396324 & 688741 & 3.301 & 3.1499 & TRN \\
\hline CHEMBL1335616 & 688741 & 3.301 & 3.847 & TRN \\
\hline CHEMBL1530879 & 688741 & 3.301 & 3.5038 & TRN \\
\hline CHEMBL1319503 & 688741 & 3.301 & 2.8436 & TST \\
\hline CHEMBL1520357 & 688741 & 3.301 & 3.3854 & TRN \\
\hline CHEMBL1969001 & 688741 & 3.301 & 4.2491 & TST \\
\hline CHEMBL1378054 & 688741 & 3.301 & 3.6617 & TRN \\
\hline CHEMBL 240332 & 688741 & 3.301 & 4.8831 & TST \\
\hline CHEMBL1447386 & 688741 & 5.7105 & 5.2737 & TRN \\
\hline CHEMBL1452006 & 688741 & 8.2464 & 8.2448 & TRN \\
\hline CHEMBL1338147 & 688741 & 3.301 & 3.2664 & TRN \\
\hline CHEMBL1562618 & 688741 & 3.301 & 3.7554 & TRN \\
\hline CHEMBL1478850 & 688741 & 3.301 & 3.2494 & TRN \\
\hline CHEMBL1538071 & 688741 & 3.301 & 3.4659 & TRN \\
\hline CHEMBL1583954 & 688741 & 3.301 & 3.3363 & TRN \\
\hline CHEMBL1461489 & 688741 & 6.0291 & 6.1128 & TRN \\
\hline CHEMBL1525709 & 688741 & 3.301 & 3.2225 & TRN \\
\hline CHEMBL544752 & 688741 & 3.301 & 2.7514 & TRN \\
\hline CHEMBL1362905 & 688741 & 5.7437 & 5.7008 & TRN \\
\hline CHEMBL1370953 & 688741 & 3.301 & 4.953 & TST \\
\hline CHEMBL1457954 & 688741 & 4.758 & 5.4582 & TRN \\
\hline CHEMBL1405770 & 688741 & 5.6691 & 5.8059 & TRN \\
\hline CHEMBL1467395 & 688741 & 3.301 & 3.3915 & TRN \\
\hline CHEMBL1505829 & 688741 & 3.301 & 4.3436 & TST \\
\hline CHEMBL1348430 & 688741 & 3.301 & 3.0168 & TRN \\
\hline CHEMBL3190185 & 688741 & 3.301 & 3.615 & TRN \\
\hline CHEMBL491716 & 688741 & 6.0819 & 5.6468 & TRN \\
\hline CHEMBL1428918 & 688741 & 3.301 & 3.5191 & TRN \\
\hline CHEMBL1537629 & 688741 & 5.7646 & 6.053 & TRN \\
\hline CHEMBL1386363 & 688741 & 6.0695 & 5.8569 & TRN \\
\hline CHEMBL1466749 & 688741 & 5.9413 & 5.4572 & TRN \\
\hline CHEMBL1607381 & 688741 & 3.301 & 4.7147 & TST \\
\hline
\end{tabular}




\begin{tabular}{|c|c|c|c|c|c|}
\hline & & \multicolumn{4}{|c|}{ Supplemental Table S2.txt } \\
\hline CHEMBL1588131 & 688741 & 3.301 & 3.4416 & TRN & \\
\hline CHEMBL1416285 & 688741 & 5.7393 & 6.1202 & TRN & \\
\hline CHEMBL1325913 & 688741 & 3.301 & 3.824 & TST & \\
\hline CHEMBL1548600 & 688741 & 6.9876 & 7.0701 & TRN & \\
\hline CHEMBL1309142 & 688741 & 5.0191 & 4.8246 & TRN & \\
\hline CHEMBL1428752 & 688741 & 5.5165 & 5.7468 & TRN & \\
\hline CHEMBL1332800 & 688741 & 5.7389 & 5.8447 & TRN & \\
\hline CHEMBL1526573 & 688741 & 7.0157 & 7.09200 & 00000000005 & TRN \\
\hline CHEMBL1429488 & 688741 & 6.3335 & 6.9539 & TRN & \\
\hline CHEMBL1561555 & 688741 & 5.3828 & 5.9976 & TST & \\
\hline CHEMBL1518232 & 688741 & 3.301 & 3.0352 & TRN & \\
\hline CHEMBL1565514 & 688741 & 5.1176 & 5.3089 & TRN & \\
\hline CHEMBL1378972 & 688741 & 5.3665 & 4.9026 & TRN & \\
\hline CHEMBL3197943 & 688741 & 3.301 & 2.9458 & TRN & \\
\hline CHEMBL1301129 & 688741 & 3.301 & 3.3363 & TRN & \\
\hline CHEMBL1454408 & 688741 & 3.301 & 3.5713 & TRN & \\
\hline CHEMBL1342209 & 688741 & 6.273 & 5.6413 & TRN & \\
\hline CHEMBL1415617 & 688741 & 3.301 & 3.6595 & TRN & \\
\hline CHEMBL1491958 & 688741 & 3.301 & 3.6785 & TST & \\
\hline CHEMBL1533178 & 688741 & 3.301 & 3.5465 & TRN & \\
\hline CHEMBL1393137 & 688741 & 3.301 & 3.4883 & TRN & \\
\hline CHEMBL1418178 & 688741 & 3.301 & 3.384 & TRN & \\
\hline CHEMBL1609347 & 688741 & 5.2427 & 4.8948 & TRN & \\
\hline CHEMBL1308938 & 688741 & 3.301 & 3.0349 & TRN & \\
\hline CHEMBL1335897 & 688741 & 3.301 & 3.4388 & TRN & \\
\hline CHEMBL1422019 & 688741 & 6.2996 & 5.8168 & TRN & \\
\hline CHEMBL1504481 & 688741 & 3.301 & 4.0507 & TST & \\
\hline CHEMBL1574979 & 688741 & 3.301 & 3.795 & TST & \\
\hline CHEMBL1568601 & 688741 & 6.5718 & 6.6073 & TRN & \\
\hline CHEMBL1571717 & 688741 & 3.301 & 3.6256 & TST & \\
\hline CHEMBL1444918 & 688741 & 7.3857 & 7.0527 & TRN & \\
\hline CHEMBL1525396 & 688741 & 3.301 & 3.7029 & TRN & \\
\hline CHEMBL1472412 & 688741 & 7.0803 & 6.0837 & TRN & \\
\hline CHEMBL1497640 & 688741 & 3.301 & 4.0225 & TST & \\
\hline CHEMBL1463644 & 688741 & 3.301 & 3.9896 & TRN & \\
\hline CHEMBL1545633 & 688741 & 3.301 & 2.91300 & 00000000003 & TRN \\
\hline CHEMBL1542550 & 688741 & 3.301 & 3.1191 & TRN & \\
\hline CHEMBL1522758 & 688741 & 3.301 & 3.3244 & TRN & \\
\hline CHEMBL1326182 & 688741 & 4.9627 & 5.0169 & TRN & \\
\hline CHEMBL1388274 & 688741 & 5.7699 & 6.0646 & TRN & \\
\hline CHEMBL1450585 & 688741 & 6.2799 & 6.5525 & TRN & \\
\hline CHEMBL1581685 & 688741 & 3.301 & 3.2285 & TRN & \\
\hline CHEMBL1588059 & 688741 & 6.0199 & 6.6074 & TRN & \\
\hline CHEMBL1320797 & 688741 & 3.301 & 3.3861 & TRN & \\
\hline CHEMBL1324566 & 688741 & 5.0471 & 4.9367 & TRN & \\
\hline CHEMBL1576589 & 688741 & 3.301 & 4.4937 & TST & \\
\hline CHEMBL1319698 & 688741 & 3.301 & 3.318 & TRN & \\
\hline CHEMBL1570863 & 688741 & 3.301 & 3.3116 & TRN & \\
\hline
\end{tabular}




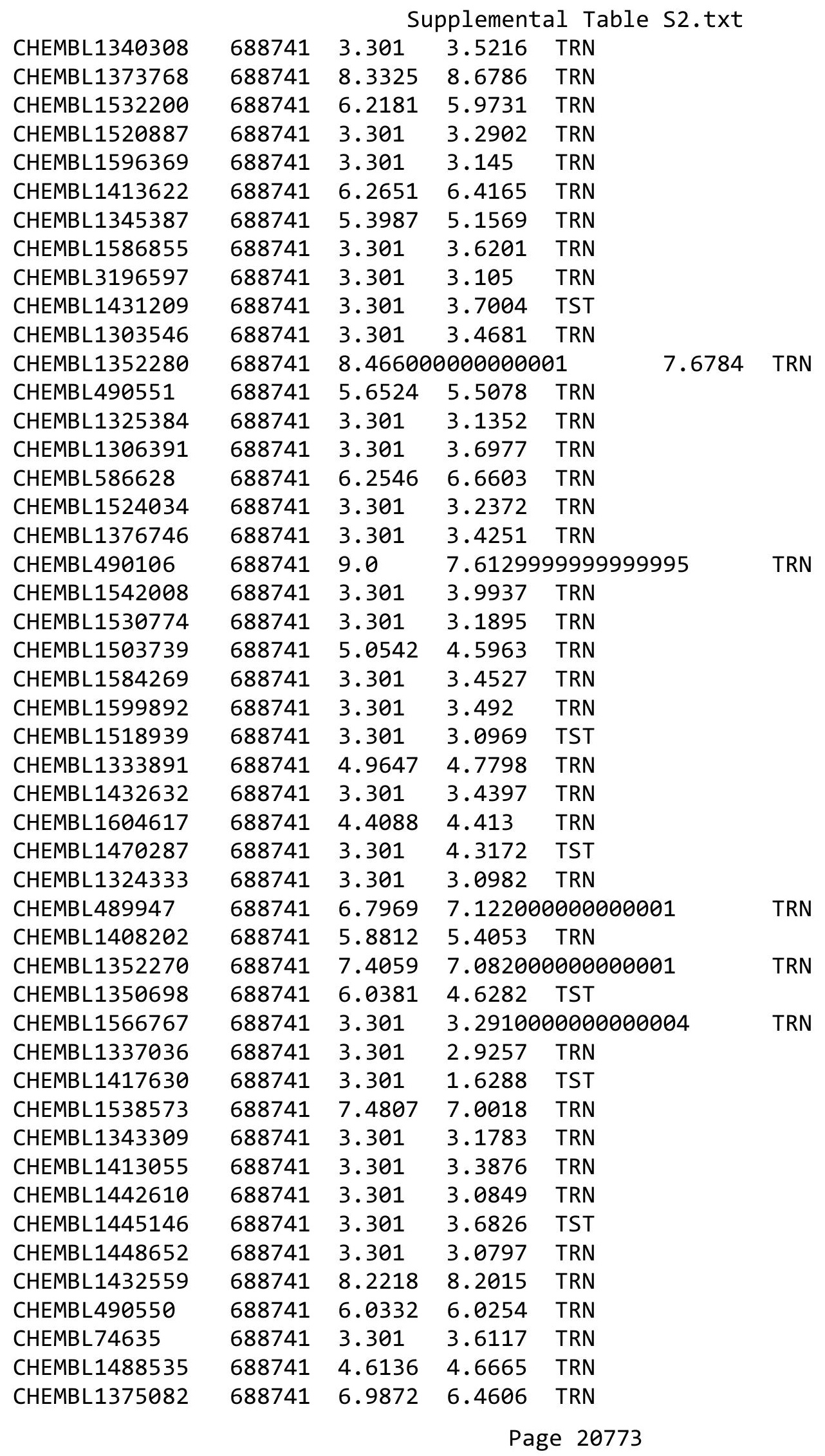


Supplemental Table S2.txt

\begin{tabular}{|c|c|c|c|c|c|}
\hline CHEMBL1392028 & 688741 & 5.5579 & 5.3938 & TRN & \\
\hline CHEMBL1557178 & 688741 & 3.301 & 3.58100 & 00000000004 & TRN \\
\hline CHEMBL1457041 & 688741 & 3.301 & 2.8249 & TRN & \\
\hline CHEMBL1423163 & 688741 & 3.301 & 2.7412 & TST & \\
\hline CHEMBL1387205 & 688741 & 3.301 & 4.9692 & TST & \\
\hline CHEMBL1382397 & 688741 & 3.301 & 3.3992 & TRN & \\
\hline CHEMBL1400795 & 688741 & 5.664 & 5.8133 & TRN & \\
\hline CHEMBL1437866 & 688741 & 5.037 & 4.9957 & TRN & \\
\hline CHEMBL3195008 & 688741 & 3.301 & 3.2821 & TRN & \\
\hline CHEMBL1325551 & 688741 & 3.301 & 3.7274 & TRN & \\
\hline CHEMBL1458569 & 688741 & 3.301 & 3.6861 & TRN & \\
\hline CHEMBL1560937 & 688741 & 9.0 & 8.6009 & TRN & \\
\hline CHEMBL1608232 & 688741 & 6.1608 & 6.4595 & TRN & \\
\hline CHEMBL1419428 & 688741 & 5.2335 & 5.1642 & TRN & \\
\hline CHEMBL1327312 & 688741 & 5.3338 & 5.0721 & TRN & \\
\hline CHEMBL1386617 & 688741 & 3.301 & 3.3243 & TRN & \\
\hline CHEMBL1489748 & 688741 & 4.9802 & 5.1461 & TRN & \\
\hline CHEMBL1559958 & 688741 & 3.301 & 3.451 & TRN & \\
\hline CHEMBL1415374 & 688741 & 3.301 & 3.1765 & TRN & \\
\hline CHEMBL1320375 & 688741 & 3.301 & 4.6983 & TST & \\
\hline CHEMBL1528258 & 688741 & 3.301 & 3.2323 & TRN & \\
\hline CHEMBL3208838 & 688741 & 3.301 & 3.2677 & TRN & \\
\hline CHEMBL1467139 & 688741 & 3.301 & 3.6224 & TST & \\
\hline CHEMBL1313606 & 688741 & 3.301 & 2.9223 & TRN & \\
\hline CHEMBL1997717 & 688741 & 3.301 & 3.0961 & TRN & \\
\hline CHEMBL1561382 & 688741 & 3.301 & 3.1759 & TRN & \\
\hline CHEMBL1487973 & 688741 & 3.301 & 3.4423 & TRN & \\
\hline CHEMBL1565647 & 688741 & 4.502 & 4.4961 & TRN & \\
\hline CHEMBL1424840 & 688741 & 3.301 & 2.7714 & TRN & \\
\hline CHEMBL1431277 & 688741 & 3.301 & 3.8736 & TRN & \\
\hline CHEMBL1486150 & 688741 & 7.4264 & 7.4069 & TRN & \\
\hline CHEMBL1382933 & 688741 & 3.301 & 3.12100 & 20000000004 & TRN \\
\hline CHEMBL1361896 & 688741 & 3.301 & 3.2989 & TRN & \\
\hline CHEMBL1363160 & 688741 & 5.1593 & 5.0588 & TRN & \\
\hline CHEMBL1485997 & 688741 & 3.301 & 3.0969 & TRN & \\
\hline CHEMBL1329234 & 688741 & 7.1234 & 7.3071 & TRN & \\
\hline CHEMBL1404682 & 688741 & 3.301 & 3.495 & TRN & \\
\hline CHEMBL1606874 & 688741 & 6.6573 & 6.8461 & TRN & \\
\hline CHEMBL1517064 & 688741 & 5.9114 & 5.3538 & TRN & \\
\hline CHEMBL1437991 & 688741 & 6.0475 & 6.8558 & TRN & \\
\hline CHEMBL1451242 & 688741 & 3.301 & 4.0153 & TST & \\
\hline CHEMBL1604924 & 688741 & 6.0062 & 6.4624 & TRN & \\
\hline CHEMBL1378678 & 688741 & 3.301 & 3.0957 & TRN & \\
\hline CHEMBL3190040 & 688741 & 3.301 & 2.7628 & TRN & \\
\hline CHEMBL1525769 & 688741 & 5.4473 & 5.5244 & TRN & \\
\hline CHEMBL1375832 & 688741 & 5.1672 & 4.4978 & TST & \\
\hline CHEMBL1288725 & 688741 & \multicolumn{3}{|c|}{6.3660000000000005} & TRN \\
\hline CHEMBL1423724 & 688741 & 3.301 & 3.237 & TRN & \\
\hline
\end{tabular}




\begin{tabular}{|c|c|c|c|c|c|}
\hline \multicolumn{6}{|c|}{ Supplemental Table S2.txt } \\
\hline CHEMBL1488483 & 688741 & 9.0 & 8.2976 & TRN & \\
\hline CHEMBL1405535 & 688741 & 6.2634 & 6.0533 & TRN & \\
\hline CHEMBL1325703 & 688741 & 5.772 & 5.9809 & TST & \\
\hline CHEMBL1601636 & 688741 & 4.9558 & 5.4165 & TRN & \\
\hline CHEMBL1468862 & 688741 & 6.6967 & 6.5927 & TRN & \\
\hline CHEMBL1538801 & 688741 & 6.0725 & 5.9113 & TRN & \\
\hline CHEMBL1606242 & 688741 & 3.301 & 3.3286 & TRN & \\
\hline CHEMBL1578052 & 688741 & 3.301 & 3.3966 & TRN & \\
\hline CHEMBL1509951 & 688741 & 3.301 & 3.14300 & 00000000002 & TRN \\
\hline CHEMBL1382403 & 688741 & 3.301 & 4.1146 & TRN & \\
\hline CHEMBL1502276 & 688741 & 3.301 & 3.3644 & TRN & \\
\hline CHEMBL1411089 & 688741 & 5.5894 & 6.0471 & TRN & \\
\hline CHEMBL1380485 & 688741 & 3.301 & 3.153 & TRN & \\
\hline CHEMBL3192668 & 688741 & 3.301 & 3.6042 & TRN & \\
\hline CHEMBL1427183 & 688741 & 3.301 & 3.3969 & TRN & \\
\hline CHEMBL1540022 & 688741 & 6.7763 & 6.9789 & TRN & \\
\hline CHEMBL1310664 & 688741 & 3.301 & 4.13899 & 9999999999 & TST \\
\hline CHEMBL1414657 & 688741 & 3.301 & 3.5626 & TRN & \\
\hline CHEMBL1464494 & 688741 & 3.301 & 3.4305 & TRN & \\
\hline CHEMBL490107 & 688741 & 7.0862 & 7.4758 & TRN & \\
\hline CHEMBL1340347 & 688741 & 3.301 & 3.5808 & TRN & \\
\hline CHEMBL1540908 & 688741 & 3.301 & 3.1107 & TRN & \\
\hline CHEMBL 2006590 & 688741 & 5.881 & 6.0845 & TRN & \\
\hline CHEMBL522809 & 688741 & 6.13 & 5.9138 & TRN & \\
\hline CHEMBL1486909 & 688741 & 5.3922 & 6.2371 & TRN & \\
\hline CHEMBL1491043 & 688741 & 5.9123 & 5.5301 & TRN & \\
\hline CHEMBL3189192 & 688741 & 3.301 & 2.853 & TRN & \\
\hline CHEMBL3194191 & 688741 & 5.2968 & 5.3832 & TRN & \\
\hline CHEMBL1402375 & 688741 & 6.0557 & 6.2559 & TRN & \\
\hline CHEMBL1588046 & 688741 & 3.301 & 2.9901 & TRN & \\
\hline CHEMBL1382245 & 688741 & 3.301 & 2.986 & TRN & \\
\hline CHEMBL1310401 & 688741 & 3.301 & 3.833 & TRN & \\
\hline CHEMBL1360370 & 688741 & 3.301 & 5.4878 & TST & \\
\hline CHEMBL1545624 & 688741 & 3.301 & 3.0502 & TRN & \\
\hline CHEMBL41920 & 688741 & 3.301 & 3.4684 & TRN & \\
\hline CHEMBL1566235 & 688741 & 3.301 & 4.5773 & TST & \\
\hline CHEMBL490552 & 688741 & 5.1591 & 6.1709 & TRN & \\
\hline CHEMBL1463190 & 688741 & 5.472 & 4.4633 & TST & \\
\hline CHEMBL1412092 & 688741 & 3.301 & 3.1132 & TRN & \\
\hline CHEMBL1522434 & 688741 & 6.2298 & 6.3805 & TRN & \\
\hline CHEMBL1306933 & 688741 & 3.301 & 3.5512 & TRN & \\
\hline CHEMBL1413020 & 688741 & 7.7196 & 6.8488 & TRN & \\
\hline CHEMBL1376280 & 688741 & 4.822 & 5.0262 & TRN & \\
\hline CHEMBL1457764 & 688741 & 8.2588 & 7.6865 & TRN & \\
\hline CHEMBL1501332 & 688741 & 3.301 & 3.6175 & TRN & \\
\hline CHEMBL1418134 & 688741 & 5.5169 & 4.9875 & TRN & \\
\hline CHEMBL1583918 & 688741 & 3.301 & 3.0896 & TRN & \\
\hline CHEMBL1613190 & 688741 & 5.3935 & 5.3644 & TRN & \\
\hline
\end{tabular}




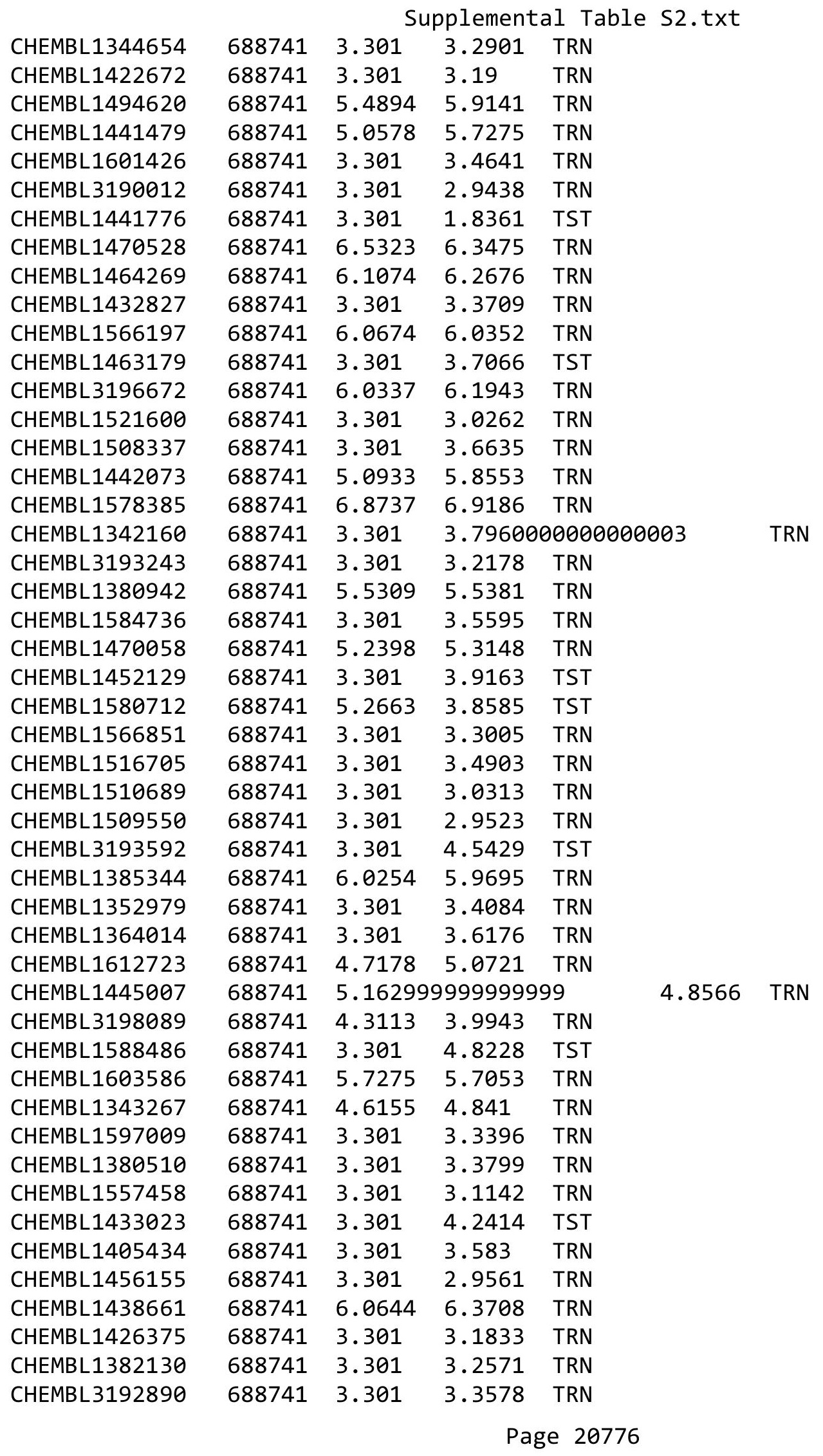




\begin{tabular}{|c|c|c|c|c|c|}
\hline & & \multicolumn{4}{|c|}{ Supplemental Table S2.txt } \\
\hline CHEMBL1313583 & 688741 & 3.301 & 3.6046 & TST & \\
\hline CHEMBL1381951 & 688741 & 3.301 & 3.0961 & TST & \\
\hline CHEMBL1439239 & 688741 & 3.301 & 3.2702 & TRN & \\
\hline CHEMBL1523444 & 688741 & 3.301 & 3.7309 & TRN & \\
\hline CHEMBL1509479 & 688741 & 6.3307 & 6.7448 & TRN & \\
\hline CHEMBL1575674 & 688741 & 6.0682 & 5.3674 & TRN & \\
\hline CHEMBL1441690 & 688741 & 3.301 & 3.2454 & TRN & \\
\hline CHEMBL1370430 & 688741 & 4.744 & 4.5622 & TRN & \\
\hline CHEMBL1483514 & 688741 & 3.301 & 3.4332 & TRN & \\
\hline CHEMBL1424726 & 688741 & 6.3893 & 5.7668 & TRN & \\
\hline CHEMBL1557824 & 688741 & 3.301 & 3.449 & TRN & \\
\hline CHEMBL1426908 & 688741 & 8.6271 & 8.5525 & TRN & \\
\hline CHEMBL1338480 & 688741 & 3.301 & 3.41899 & 99999999996 & TRN \\
\hline CHEMBL1531524 & 688741 & 5.9759 & 5.2909 & TRN & \\
\hline CHEMBL1595024 & 688741 & 3.301 & 3.0756 & TRN & \\
\hline CHEMBL1562266 & 688741 & 3.301 & 3.2758 & TRN & \\
\hline CHEMBL1364339 & 688741 & 5.1584 & 5.033 & TRN & \\
\hline CHEMBL1524669 & 688741 & 3.301 & 3.0026 & TRN & \\
\hline CHEMBL1612574 & 688741 & 3.301 & 3.6205 & TRN & \\
\hline CHEMBL1324794 & 688741 & 3.301 & 3.3101 & TRN & \\
\hline CHEMBL521762 & 688741 & 6.6904 & 6.6649 & TRN & \\
\hline CHEMBL1390632 & 688741 & 6.0396 & 6.1947 & TRN & \\
\hline CHEMBL1376769 & 688741 & 3.301 & 3.5852 & TRN & \\
\hline CHEMBL1449026 & 688741 & 3.301 & 2.8629 & TRN & \\
\hline CHEMBL1501618 & 688741 & 5.6042 & 5.8509 & TRN & \\
\hline CHEMBL1528294 & 688741 & 5.8097 & 5.8453 & TRN & \\
\hline CHEMBL1424053 & 688741 & 5.5089 & 5.3647 & TRN & \\
\hline CHEMBL1543608 & 688741 & 5.6623 & 4.8348 & TRN & \\
\hline CHEMBL1559457 & 688741 & 5.1442 & 5.25299 & 9999999999 & TRN \\
\hline CHEMBL1462956 & 688741 & 6.0262 & 6.1333 & TRN & \\
\hline CHEMBL1511534 & 688741 & 3.301 & 3.2687 & TST & \\
\hline CHEMBL149322 & 688741 & 3.301 & 3.2702 & TRN & \\
\hline CHEMBL1334489 & 688741 & 3.301 & 3.0035 & TRN & \\
\hline CHEMBL1300684 & 688741 & 8.2907 & 6.8861 & TRN & \\
\hline CHEMBL1359714 & 688741 & 3.301 & 3.1936 & TRN & \\
\hline CHEMBL1464085 & 688741 & 3.301 & 3.4106 & TRN & \\
\hline CHEMBL1463842 & 688741 & 3.301 & 3.2796 & TRN & \\
\hline CHEMBL1401761 & 688741 & 6.6089 & 6.4368 & TRN & \\
\hline CHEMBL1477307 & 688741 & 7.2635 & 7.109 & TRN & \\
\hline CHEMBL1607247 & 688741 & 6.5874 & 6.2621 & TRN & \\
\hline CHEMBL1404183 & 688741 & 3.301 & 3.3655 & TRN & \\
\hline CHEMBL1492722 & 688741 & 6.015 & 5.8308 & TRN & \\
\hline CHEMBL1339683 & 688741 & 5.9561 & 5.5888 & TRN & \\
\hline CHEMBL1563342 & 688741 & 5.8407 & 5.6092 & TRN & \\
\hline CHEMBL1389735 & 688741 & 3.301 & 4.1807 & TST & \\
\hline CHEMBL1421353 & 688741 & 3.301 & 3.2015 & TRN & \\
\hline CHEMBL1565992 & 688741 & 3.301 & 3.6128 & TRN & \\
\hline CHEMBL1545407 & 688741 & 7.53299 & 99999999 & 6.9818 & TRN \\
\hline
\end{tabular}


Supplemental Table S2.txt

\begin{tabular}{|c|c|c|c|c|c|c|}
\hline CHEMBL1327635 & 688741 & 6.0229 & 5.8532 & TRN & & \\
\hline CHEMBL1381230 & 688741 & 3.301 & 4.4152 & TST & & \\
\hline CHEMBL1432504 & 688741 & 5.8937 & 5.8369 & TRN & & \\
\hline CHEMBL1572848 & 688741 & \multicolumn{3}{|c|}{5.922999999999999} & 6.6601 & TRN \\
\hline CHEMBL1518483 & 688741 & 5.7569 & 6.2558 & TRN & & \\
\hline CHEMBL1596980 & 688741 & 7.0 & 6.2874 & TRN & & \\
\hline CHEMBL1386277 & 688741 & \multicolumn{3}{|c|}{6.287999999999999} & 6.109 & TRN \\
\hline CHEMBL1493461 & 688741 & 5.1461 & 5.9103 & TRN & & \\
\hline CHEMBL1496726 & 688741 & 3.301 & 4.4308 & TST & & \\
\hline CHEMBL1388917 & 688741 & 3.301 & 4.0993 & TRN & & \\
\hline CHEMBL1549541 & 688741 & 3.301 & 3.3469 & TRN & & \\
\hline CHEMBL1595658 & 688741 & 3.301 & 3.2838 & TRN & & \\
\hline CHEMBL1505828 & 688741 & \multicolumn{3}{|c|}{7.8629999999999995} & 7.4071 & TRN \\
\hline CHEMBL1331881 & 688741 & 3.301 & 3.1849 & TRN & & \\
\hline CHEMBL1598852 & 688741 & 6.1484 & 6.6847 & TRN & & \\
\hline CHEMBL1540738 & 688741 & 3.301 & 3.0872 & TST & & \\
\hline CHEMBL1587519 & 688741 & 6.2318 & 5.9772 & TRN & & \\
\hline CHEMBL1549247 & 688741 & 3.301 & 3.0303 & TRN & & \\
\hline CHEMBL1420705 & 688741 & 3.301 & 2.7014 & TRN & & \\
\hline CHEMBL1383720 & 688741 & 5.5301 & 5.6209 & TRN & & \\
\hline CHEMBL1459868 & 688741 & 3.301 & 3.557 & TRN & & \\
\hline CHEMBL1363049 & 688741 & 3.301 & 3.1933 & TRN & & \\
\hline CHEMBL3192274 & 688741 & 3.301 & 3.3552 & TRN & & \\
\hline CHEMBL1485928 & 688741 & 5.2517 & 5.3389 & TRN & & \\
\hline CHEMBL1574223 & 688741 & 4.5108 & 4.8298 & TRN & & \\
\hline CHEMBL1971698 & 688741 & 6.2787 & 6.0735 & TRN & & \\
\hline CHEMBL1527420 & 688741 & 3.301 & 4.8371 & TST & & \\
\hline CHEMBL1467264 & 688741 & 8.5376 & 8.5201 & TRN & & \\
\hline CHEMBL1569786 & 688741 & 3.301 & 3.489 & TRN & & \\
\hline CHEMBL1382315 & 688741 & 3.301 & 3.2661 & TRN & & \\
\hline CHEMBL1539146 & 688741 & 4.833 & 5.4484 & TRN & & \\
\hline CHEMBL1432912 & 688741 & 3.301 & 3.1251 & TRN & & \\
\hline CHEMBL1229545 & 688741 & 3.301 & 3.7708 & TRN & & \\
\hline CHEMBL1611680 & 688741 & 6.4942 & 6.5011 & TRN & & \\
\hline CHEMBL3208908 & 688741 & 5.6314 & 5.6476 & TRN & & \\
\hline CHEMBL1413795 & 688741 & 3.301 & 3.0526 & TRN & & \\
\hline CHEMBL1539581 & 688741 & 6.5278 & 6.7806 & TRN & & \\
\hline CHEMBL1452900 & 688741 & 7.5533 & 6.6753 & TRN & & \\
\hline CHEMBL1399479 & 688741 & 3.301 & 2.8407 & TRN & & \\
\hline CHEMBL1331413 & 688741 & 3.301 & 3.0984 & TRN & & \\
\hline CHEMBL1525906 & 688741 & 3.301 & 3.3225 & TRN & & \\
\hline CHEMBL1319242 & 688741 & 6.27 & 6.0371 & TRN & & \\
\hline CHEMBL1468965 & 688741 & 6.1578 & 6.1294 & TRN & & \\
\hline CHEMBL1299195 & 688741 & 3.301 & 3.7341 & TRN & & \\
\hline CHEMBL1523693 & 688741 & 3.301 & 3.4337 & TRN & & \\
\hline CHEMBL1393121 & 688741 & 3.301 & 3.6862 & TRN & & \\
\hline CHEMBL3208151 & 688741 & 3.301 & 3.7675 & TRN & & \\
\hline CHEMBL1431619 & 688741 & 6.1362 & 5.7978 & TRN & & \\
\hline
\end{tabular}

Page 20778 


\begin{tabular}{|c|c|c|c|c|c|c|}
\hline & & \multicolumn{5}{|c|}{ Supplemental Table S2.txt } \\
\hline CHEMBL1342581 & 688741 & 3.301 & 5.0551 & TST & & \\
\hline CHEMBL1307718 & 688741 & 3.301 & 3.3343 & TRN & & \\
\hline CHEMBL1350849 & 688741 & 5.0951 & 5.2672 & TRN & & \\
\hline CHEMBL1427565 & 688741 & 6.4285 & 6.4523 & TRN & & \\
\hline CHEMBL1486556 & 688741 & 3.301 & 3.1539 & TRN & & \\
\hline CHEMBL1564100 & 688741 & 3.301 & 3.984 & TRN & & \\
\hline CHEMBL1606361 & 688741 & 5.0643 & 4.7819 & TRN & & \\
\hline CHEMBL1606465 & 688741 & 3.301 & 3.5136 & TRN & & \\
\hline CHEMBL1563725 & 688741 & 3.301 & 3.0253 & TRN & & \\
\hline CHEMBL1477032 & 688741 & 3.301 & 2.7919 & TRN & & \\
\hline CHEMBL1365565 & 688741 & 5.5099 & 5.6768 & TRN & & \\
\hline CHEMBL1544530 & 688741 & 5.1111 & 4.6808 & TRN & & \\
\hline CHEMBL1427579 & 688741 & 5.9899 & 5.9684 & TRN & & \\
\hline CHEMBL1526168 & 688741 & 3.301 & 4.2548 & TRN & & \\
\hline CHEMBL1594934 & 688741 & 6.07299 & 99999999 & 995 & 6.2598 & TRN \\
\hline CHEMBL1384791 & 688741 & 5.4747 & 5.482 & TRN & & \\
\hline CHEMBL1556136 & 688741 & 6.0903 & 5.8467 & TRN & & \\
\hline CHEMBL1346756 & 688741 & 3.301 & 5.7185 & TST & & \\
\hline CHEMBL1537125 & 688741 & 3.301 & 3.2732 & TST & & \\
\hline CHEMBL1491401 & 688741 & 3.301 & 3.7283 & TRN & & \\
\hline CHEMBL1604527 & 688741 & 5.8041 & 5.9038 & TRN & & \\
\hline CHEMBL1365696 & 688741 & 5.4906 & 3.9187 & TST & & \\
\hline CHEMBL1561302 & 688741 & 3.301 & 3.5847 & TRN & & \\
\hline CHEMBL1326677 & 688741 & 5.6388 & 6.2255 & TRN & & \\
\hline CHEMBL1367213 & 688741 & 3.301 & 3.4476 & TST & & \\
\hline CHEMBL 3195677 & 688741 & 3.301 & 2.676 & TRN & & \\
\hline CHEMBL1504045 & 688741 & 3.301 & 3.4929 & TRN & & \\
\hline CHEMBL1304990 & 688741 & 6.0772 & 6.59399 & 9999999999 & & TRN \\
\hline CHEMBL1566310 & 688741 & 3.301 & 3.1417 & TST & & \\
\hline CHEMBL1414346 & 688741 & 3.301 & 2.7578 & TST & & \\
\hline CHEMBL1579278 & 688741 & 5.83 & 6.755 & TRN & & \\
\hline CHEMBL1567380 & 688741 & 3.301 & 3.8531 & TRN & & \\
\hline CHEMBL1478481 & 688741 & 5.8639 & 5.587006 & 0000000001 & & TRN \\
\hline CHEMBL1416199 & 688741 & 3.301 & 3.3067 & TRN & & \\
\hline CHEMBL1303664 & 688741 & 6.6515 & 6.5619 & TRN & & \\
\hline CHEMBL1310681 & 688741 & 4.5988 & 4.618 & TRN & & \\
\hline CHEMBL1427661 & 688741 & 3.301 & 3.1503 & TRN & & \\
\hline CHEMBL1602458 & 688741 & 3.301 & 3.4577 & TRN & & \\
\hline CHEMBL1546904 & 688741 & 5.4406 & 5.5085 & TRN & & \\
\hline CHEMBL1589800 & 688741 & 3.301 & 4.6737 & TST & & \\
\hline CHEMBL1374067 & 688741 & 7.05399 & 99999999 & 99 & 6.7757 & TRN \\
\hline CHEMBL1308515 & 688741 & 5.6971 & 6.6059 & TRN & & \\
\hline CHEMBL1603432 & 688741 & 3.301 & 2.1519 & TST & & \\
\hline CHEMBL1577592 & 688741 & 5.2253 & 5.7177 & TRN & & \\
\hline CHEMBL1580283 & 688741 & 7.5984 & 7.2469 & TRN & & \\
\hline CHEMBL1445348 & 688741 & 7.7812 & 7.1381 & TRN & & \\
\hline CHEMBL1568760 & 688741 & 3.301 & 3.213 & TRN & & \\
\hline CHEMBL1310323 & 688741 & 3.301 & 3.2161 & TRN & & \\
\hline
\end{tabular}


Supplemental Table S2.txt

\begin{tabular}{|c|c|c|c|c|c|}
\hline CHEMBL1499711 & 688741 & 5.3472 & 5.574 & TRN & \\
\hline CHEMBL1498734 & 688741 & 3.301 & 3.3164 & TRN & \\
\hline CHEMBL1429174 & 688741 & 3.301 & 2.7345 & TST & \\
\hline CHEMBL1421826 & 688741 & 3.301 & 3.6674 & TRN & \\
\hline CHEMBL1595992 & 688741 & 5.6213 & 6.2195 & TRN & \\
\hline CHEMBL1426558 & 688741 & 6.5224 & 6.3285 & TRN & \\
\hline CHEMBL1510337 & 688741 & 3.301 & \multicolumn{2}{|c|}{3.4160000000000004} & TRN \\
\hline CHEMBL1333538 & 688741 & 3.301 & 3.3257 & TRN & \\
\hline CHEMBL3194435 & 688741 & 3.301 & 4.5906 & TST & \\
\hline CHEMBL1376624 & 688741 & 3.301 & 3.6106 & TST & \\
\hline CHEMBL1576702 & 688741 & 3.301 & 5.2991 & TST & \\
\hline CHEMBL1339563 & 688741 & 6.2251 & 5.5343 & TRN & \\
\hline CHEMBL47875 & 688741 & 3.301 & 3.3116 & TRN & \\
\hline CHEMBL1557736 & 688741 & 4.3886 & 4.3617 & TRN & \\
\hline CHEMBL1392770 & 688741 & 6.2828 & 5.9971 & TRN & \\
\hline CHEMBL1517443 & 688741 & 3.301 & 3.5731 & TST & \\
\hline CHEMBL1535147 & 688741 & 3.301 & 3.6377 & TST & \\
\hline CHEMBL1482799 & 688741 & 7.6351 & 7.0608 & TST & \\
\hline CHEMBL1325081 & 688741 & 3.301 & 4.8816 & TST & \\
\hline CHEMBL1492668 & 688741 & 5.6359 & 5.8105 & TST & \\
\hline CHEMBL1457958 & 688741 & 3.301 & 3.4325 & TST & \\
\hline CHEMBL1547749 & 688741 & 3.301 & 3.8678 & TST & \\
\hline CHEMBL1405760 & 688741 & 6.8765 & 7.7085 & TST & \\
\hline CHEMBL1327537 & 688741 & 3.301 & 4.8181 & TST & \\
\hline CHEMBL1402372 & 688741 & 3.301 & 3.3945 & TST & \\
\hline CHEMBL1522472 & 688741 & 3.301 & 2.3437 & TST & \\
\hline CHEMBL1437999 & 688741 & 8.2692 & 8.0629 & TST & \\
\hline CHEMBL1490338 & 688741 & 6.8023 & 6.2819 & TST & \\
\hline CHEMBL1493513 & 688741 & 3.301 & 2.5385 & TST & \\
\hline CHEMBL1341839 & 688741 & 3.301 & 3.515 & TST & \\
\hline CHEMBL1364178 & 688741 & 3.301 & 2.8066 & TST & \\
\hline CHEMBL1511680 & 688741 & 3.301 & 2.9593 & TST & \\
\hline CHEMBL1409627 & 688741 & 3.301 & 3.7309 & TST & \\
\hline CHEMBL1490799 & 688741 & 3.301 & 3.0787 & TST & \\
\hline CHEMBL1377383 & 688741 & 3.301 & 4.1885 & TST & \\
\hline CHEMBL1533811 & 688741 & 3.301 & 3.83699 & 99999999997 & TST \\
\hline CHEMBL1338804 & 688741 & 3.301 & 2.7798 & TST & \\
\hline CHEMBL1305524 & 688741 & 4.5956 & 5.2327 & TST & \\
\hline CHEMBL1390074 & 688741 & 3.301 & 5.2175 & TST & \\
\hline CHEMBL1495018 & 688741 & 3.301 & 3.7631 & TST & \\
\hline CHEMBL1433218 & 688741 & 3.301 & 3.4814 & TST & \\
\hline CHEMBL1377018 & 688741 & 3.301 & 5.1134 & TST & \\
\hline CHEMBL1458171 & 688741 & 3.301 & 2.8064 & TST & \\
\hline CHEMBL1577413 & 688741 & 3.301 & 2.6466 & TST & \\
\hline CHEMBL1509376 & 688741 & 3.301 & 3.9472 & TST & \\
\hline CHEMBL1411706 & 688741 & 3.301 & 5.0019 & TST & \\
\hline CHEMBL1333358 & 688741 & 4.6381 & 2.9784 & TST & \\
\hline CHEMBL504911 & 688741 & 5.8351 & 5.984 & TST & \\
\hline
\end{tabular}




\begin{tabular}{|c|c|c|c|c|c|}
\hline \multicolumn{6}{|c|}{ Supplemental Table S2.txt } \\
\hline CHEMBL1549907 & 688741 & 6.4736 & 6.5047 & TST & \\
\hline CHEMBL1583288 & 688741 & 3.301 & 3.548 & TST & \\
\hline CHEMBL1580892 & 688741 & 3.301 & 2.7697 & TST & \\
\hline CHEMBL1538168 & 688741 & 3.301 & 3.6457 & TST & \\
\hline CHEMBL1343809 & 688741 & 4.8602 & 4.1056 & TST & \\
\hline CHEMBL 3211104 & 688741 & 3.301 & 3.7579 & TST & \\
\hline CHEMBL1525224 & 688741 & 3.301 & 3.1299 & TST & \\
\hline CHEMBL1602879 & 688741 & 3.301 & 4.0225 & TST & \\
\hline CHEMBL1442702 & 688741 & 6.1395 & 6.4915 & TST & \\
\hline CHEMBL1385929 & 688741 & 5.0193 & 3.2471 & TST & \\
\hline CHEMBL1535020 & 688741 & 7.4226 & 7.1557 & TST & \\
\hline CHEMBL1597921 & 688741 & 3.301 & 3.7661 & TST & \\
\hline CHEMBL1489027 & 688741 & 3.301 & 3.4529 & TST & \\
\hline CHEMBL1976489 & 688741 & 5.8633 & 5.6312 & TST & \\
\hline CHEMBL1568832 & 688741 & 5.8308 & 6.1113 & TST & \\
\hline CHEMBL1521682 & 688741 & 5.4876 & 4.315 & TST & \\
\hline CHEMBL1495985 & 688741 & 3.301 & 3.3622 & TST & \\
\hline CHEMBL1607970 & 688741 & 6.0386 & 3.843 & TST & \\
\hline CHEMBL1457850 & 688741 & 3.301 & 2.9256 & TST & \\
\hline CHEMBL1588542 & 688741 & 3.301 & 2.485 & TST & \\
\hline CHEMBL1492709 & 688741 & 3.301 & 4.4759 & TST & \\
\hline CHEMBL1363686 & 688741 & 3.301 & 5.10800 & 20000000005 & TST \\
\hline CHEMBL1307184 & 688741 & 3.301 & 4.0306 & TST & \\
\hline CHEMBL1565398 & 688741 & 3.301 & 4.6616 & TST & \\
\hline CHEMBL1353615 & 688741 & 5.8204 & 6.315 & TST & \\
\hline CHEMBL1461522 & 688741 & 3.301 & 3.8516 & TST & \\
\hline CHEMBL1464819 & 688741 & 3.301 & 3.2698 & TST & \\
\hline CHEMBL1369239 & 688741 & 3.301 & 4.7736 & TST & \\
\hline CHEMBL1561767 & 688741 & 7.0474 & 5.9488 & TST & \\
\hline CHEMBL3199030 & 688741 & 5.204 & 3.8645 & TST & \\
\hline CHEMBL1492412 & 688741 & 3.301 & 5.4249 & TST & \\
\hline CHEMBL1549529 & 688741 & 5.9441 & 5.1783 & TST & \\
\hline CHEMBL1350952 & 688741 & 8.3706 & 7.9796 & TST & \\
\hline CHEMBL1338774 & 688741 & 5.5494 & 4.8407 & TST & \\
\hline CHEMBL161254 & 688741 & 6.9364 & 4.6836 & TST & \\
\hline CHEMBL1344636 & 688741 & 3.301 & 2.0832 & TST & \\
\hline CHEMBL1543050 & 688741 & 7.0859 & 7.1689 & TST & \\
\hline CHEMBL 306529 & 570539 & 8.538 & 8.6805 & TRN & \\
\hline CHEMBL306764 & 570539 & 7.86 & 7.46700 & 00000000005 & TRN \\
\hline CHEMBL561013 & 570539 & 8.538 & 8.5096 & TRN & \\
\hline CHEMBL558801 & 570539 & 7.796 & 7.6058 & TRN & \\
\hline CHEMBL564066 & 570539 & 9.31 & 8.9486 & TRN & \\
\hline CHEMBL563390 & 570539 & 6.77 & 6.9289 & TRN & \\
\hline CHEMBL551833 & 570539 & 6.975 & 7.5047 & TRN & \\
\hline CHEMBL561349 & 570539 & 7.495 & 7.5319 & TST & \\
\hline CHEMBL565042 & 570539 & 7.907 & 8.9771 & TST & \\
\hline CHEMBL550949 & 570539 & 7.013 & 7.0987 & TRN & \\
\hline CHEMBL564888 & 570539 & 8.721 & 8.5693 & TRN & \\
\hline
\end{tabular}

Page 20781 


\begin{tabular}{|c|c|c|c|c|c|c|c|}
\hline \multicolumn{8}{|c|}{ PPमеmет } \\
\hline CHEMBL497811 & 570539 & 8.215 & 7.7727 & TRN & & & \\
\hline CHEMBL557004 & 570539 & 8.921 & 9.8954 & TST & & & \\
\hline CHEMBL561089 & 570539 & 7.854 & 8.1529 & TRN & & & \\
\hline CHEMBL561090 & 570539 & 9.137 & 9.4607 & TRN & & & \\
\hline CHEMBL562895 & 570539 & 7.959 & 8.1395 & TRN & & & \\
\hline CHEMBL551351 & 570539 & 7.983 & 7.8947 & TRN & & & \\
\hline CHEMBL563670 & 570539 & 6.356 & 6.6106 & TRN & & & \\
\hline CHEMBL552087 & 570539 & 6.86 & 6.9722 & TRN & & & \\
\hline CHEMBL552088 & 570539 & 8.161 & 8.3241 & TRN & & & \\
\hline CHEMBL564407 & 570539 & 7.149 & 6.9642 & TRN & & & \\
\hline CHEMBL563929 & 570539 & 8.721 & 8.3321 & TRN & & & \\
\hline CHEMBL539479 & 570539 & 8.0179 & 999999999 & & 8.0304 & TST & \\
\hline CHEMBL564901 & 570539 & 9.208 & 9.2373 & TRN & & & \\
\hline CHEMBL564302 & 570539 & 8.959 & 9.4895 & TST & & & \\
\hline CHEMBL565194 & 570539 & 7.921 & 7.9085 & TRN & & & \\
\hline CHEMBL549603 & 570539 & 9.161 & 9.5663 & TST & & & \\
\hline CHEMBL562350 & 570539 & 7.921 & 7.9324 & TRN & & & \\
\hline CHEMBL557627 & 570539 & 8.0 & 8.057 & TST & & & \\
\hline CHEMBL564622 & 570539 & 9.377 & 9.3547 & TRN & & & \\
\hline CHEMBL539994 & 570539 & 8.42 & 8.3661 & TRN & & & \\
\hline CHEMBL561894 & 570539 & 6.91 & 6.9699 & TRN & & & \\
\hline CHEMBL564623 & 570539 & 6.62 & 6.8653 & TRN & & & \\
\hline CHEMBL552499 & 570539 & 7.284 & 7.2482 & TST & & & \\
\hline CHEMBL558474 & 570539 & 8.1429 & 999999995 & & 8.5051 & TST & \\
\hline CHEMBL552150 & 570539 & 7.31 & 7.3425 & TRN & & & \\
\hline CHEMBL540248 & 570539 & 8.1870 & 000000006 & & 8.1522 & TRN & \\
\hline CHEMBL540759 & 570539 & 7.979 & 8.2521 & TST & & & \\
\hline CHEMBL562704 & 570539 & 7.131 & 6.7525 & TST & & & \\
\hline CHEMBL562549 & 570539 & 7.602 & 7.6981 & TRN & & & \\
\hline CHEMBL550419 & 570539 & 6.6560 & 000000006 & & 6.4006 & TRN & \\
\hline CHEMBL562489 & 570539 & 8.252 & 8.1712 & TRN & & & \\
\hline CHEMBL556101 & 570539 & 7.097 & 6.5594 & TST & & & \\
\hline CHEMBL564543 & 570539 & 8.1429 & 999999999 & & 7.5372 & TST & \\
\hline CHEMBL524822 & 570539 & 7.398 & 7.3187 & TRN & & & \\
\hline CHEMBL 365878 & 570539 & 6.7989 & 999999995 & 995 & 6.76399 & 9999999999 & TRN \\
\hline CHEMBL188940 & 570539 & 6.352 & 6.2571 & TRN & & & \\
\hline CHEMBL364111 & 570539 & 6.19 & 6.0954 & TRN & & & \\
\hline CHEMBL189035 & 570539 & 8.154 & 7.831 & TST & & & \\
\hline CHEMBL361032 & 570539 & 7.602 & 7.6447 & TRN & & & \\
\hline CHEMBL186525 & 570539 & 6.744 & 6.6883 & TRN & & & \\
\hline CHEMBL188819 & 570539 & 6.3020 & 000000006 & 305 & 5.9576 & TRN & \\
\hline CHEMBL187813 & 570539 & 5.4289 & 999999999 & & 5.591 & TRN & \\
\hline CHEMBL187354 & 570539 & 6.244 & 6.2387 & TRN & & & \\
\hline CHEMBL187771 & 570539 & 5.8679 & 999999995 & & 5.8499 & TRN & \\
\hline CHEMBL188822 & 570539 & 6.974 & 7.0779 & TRN & & & \\
\hline CHEMBL190305 & 570539 & 6.182 & 6.2577 & TRN & & & \\
\hline CHEMBL363471 & 570539 & 7.6979 & 999999995 & 995 & 7.7222 & TST & \\
\hline CHEMBL188031 & 570539 & 7.481 & 7.5401 & TST & & & \\
\hline
\end{tabular}




\begin{tabular}{|c|c|c|c|c|c|c|}
\hline \multirow[b]{2}{*}{ CHEMBL364820 } & & \multicolumn{5}{|c|}{ Supplemental Table S2.txt } \\
\hline & 570539 & 6.835 & 7.6721 & TST & & \\
\hline CHEMBL188494 & 570539 & 7.721 & 7.6342 & TRN & & \\
\hline CHEMBL188887 & 570539 & 7.075 & 6.9724 & TRN & & \\
\hline CHEMBL186674 & 570539 & 7.05 & 7.2517 & TRN & & \\
\hline CHEMBL188910 & 570539 & 6.86 & 6.8928 & TRN & & \\
\hline CHEMBL187559 & 570539 & 7.5370 & 00000000 & & 7.5204 & TRN \\
\hline CHEMBL361088 & 570539 & 7.086 & 7.18 & TRN & & \\
\hline CHEMBL187883 & 570539 & 7.4079 & 99999999 & 995 & 7.1937 & TST \\
\hline CHEMBL189545 & 570539 & 7.04 & 7.0963 & TRN & & \\
\hline CHEMBL187412 & 570539 & 6.437 & 6.5015 & TRN & & \\
\hline CHEMBL190469 & 570539 & 7.119 & 7.1009 & TRN & & \\
\hline CHEMBL427524 & 570539 & 6.739 & 6.8213 & TRN & & \\
\hline CHEMBL262083 & 688722 & 5.05 & 5.1207 & TRN & & \\
\hline CHEMBL546257 & 688722 & 4.85 & 4.6728 & TRN & & \\
\hline CHEMBL1554098 & 688722 & 4.8 & 5.3734 & TRN & & \\
\hline CHEMBL501701 & 688722 & 4.95 & 5.0979 & TRN & & \\
\hline CHEMBL1256878 & 688722 & 4.85 & 5.081 & TRN & & \\
\hline CHEMBL1256775 & 688722 & 5.6 & 5.7482 & TRN & & \\
\hline CHEMBL168276 & 688722 & 5.35 & 5.3438 & TRN & & \\
\hline CHEMBL66654 & 688722 & 5.8 & 5.5237 & TRN & & \\
\hline CHEMBL1316314 & 688722 & 5.1 & 4.9129 & TRN & & \\
\hline CHEMBL 293749 & 688722 & 5.05 & 5.5284 & TRN & & \\
\hline CHEMBL299613 & 688722 & 5.1 & 5.1405 & TRN & & \\
\hline CHEMBL405358 & 688722 & 6.3 & 6.2183 & TRN & & \\
\hline CHEMBL1256180 & 688722 & 4.5 & 5.0771 & TRN & & \\
\hline CHEMBL1255733 & 688722 & 5.8 & 5.3796 & TST & & \\
\hline CHEMBL1257013 & 688722 & 4.85 & 4.7816 & TRN & & \\
\hline CHEMBL1520976 & 688722 & 6.45 & 5.5266 & TST & & \\
\hline CHEMBL1255837 & 688722 & 4.5 & 4.7888 & TRN & & \\
\hline CHEMBL297784 & 688722 & 5.5 & 5.5925 & TRN & & \\
\hline CHEMBL1435120 & 688722 & 4.95 & 4.7096 & TRN & & \\
\hline CHEMBL441282 & 688722 & 5.7 & 4.9959 & TRN & & \\
\hline CHEMBL445102 & 688722 & 5.55 & 5.0449 & TRN & & \\
\hline CHEMBL1336727 & 688722 & 4.45 & 4.4954 & TRN & & \\
\hline CHEMBL20730 & 688722 & 4.6 & 5.3886 & TRN & & \\
\hline CHEMBL 2373602 & 688722 & 5.1 & 5.1055 & TRN & & \\
\hline CHEMBL595227 & 688722 & 5.1 & 4.8823 & TRN & & \\
\hline CHEMBL1284 & 688722 & 5.05 & 5.6549 & TRN & & \\
\hline CHEMBL536950 & 688722 & 4.8 & 5.4445 & TRN & & \\
\hline CHEMBL1256720 & 688722 & 8.0 & 6.3068 & TRN & & \\
\hline CHEMBL402468 & 688722 & 4.95 & 5.4216 & TRN & & \\
\hline CHEMBL1528565 & 688722 & 5.0 & 4.8426 & TRN & & \\
\hline CHEMBL539947 & 688722 & 5.1 & 5.4614 & TRN & & \\
\hline CHEMBL 282489 & 688722 & 5.0 & 5.1643 & TRN & & \\
\hline CHEMBL1256914 & 688722 & 4.95 & 4.5999 & TRN & & \\
\hline CHEMBL1255758 & 688722 & 4.85 & 5.2466 & TST & & \\
\hline CHEMBL587714 & 688722 & 4.65 & 4.9982 & TRN & & \\
\hline CHEMBL429023 & 688722 & 5.25 & 5.9747 & TRN & & \\
\hline
\end{tabular}




\begin{tabular}{|c|c|c|c|c|c|}
\hline \multicolumn{6}{|c|}{ Supplemental Table S2.txt } \\
\hline CHEMBL78150 & 688722 & 5.6 & 5.5119 & TRN & \\
\hline CHEMBL1255659 & 688722 & 4.85 & 5.4956 & TRN & \\
\hline CHEMBL1256737 & 688722 & 4.8 & 4.7866 & TRN & \\
\hline CHEMBL278041 & 688722 & 4.9 & 5.0186 & TRN & \\
\hline CHEMBL1515001 & 688722 & 5.0 & 4.9578 & TRN & \\
\hline CHEMBL1593815 & 688722 & 5.15 & 5.0882 & TRN & \\
\hline CHEMBL1256839 & 688722 & 4.9 & 4.7565 & TRN & \\
\hline CHEMBL270299 & 688722 & 4.95 & 5.3571 & TRN & \\
\hline CHEMBL1559663 & 688722 & 5.95 & 5.7759 & TST & \\
\hline CHEMBL85139 & 688722 & 6.35 & 6.5777 & TRN & \\
\hline CHEMBL1408519 & 688722 & 5.0 & 4.82100 & 0000000001 & TRN \\
\hline CHEMBL28626 & 688722 & 4.9 & 5.63700 & 00000000005 & TRN \\
\hline CHEMBL1594626 & 688722 & 5.05 & 4.9429 & TST & \\
\hline CHEMBL1554486 & 688722 & 4.7 & 4.8974 & TRN & \\
\hline CHEMBL576349 & 688722 & 5.15 & 5.2395 & TRN & \\
\hline CHEMBL1200938 & 688722 & 5.05 & 5.1159 & TRN & \\
\hline CHEMBL1255936 & 688722 & 5.0 & 5.6087 & TRN & \\
\hline CHEMBL1316222 & 688722 & 4.45 & 5.2497 & TRN & \\
\hline CHEMBL330129 & 688722 & 4.75 & 5.8051 & TRN & \\
\hline CHEMBL371811 & 688722 & 5.0 & 5.2013 & TRN & \\
\hline CHEMBL 8211 & 688722 & 4.8 & 5.5911 & TST & \\
\hline CHEMBL14276 & 688722 & 5.05 & 4.6842 & TRN & \\
\hline CHEMBL1357894 & 688722 & 6.6 & 5.6256 & TRN & \\
\hline CHEMBL126077 & 688722 & 6.7501 & 6.5045 & TRN & \\
\hline CHEMBL605003 & 688722 & 6.5501 & 5.4876 & TRN & \\
\hline CHEMBL1554131 & 688722 & 5.05 & 4.9328 & TRN & \\
\hline CHEMBL407232 & 688722 & 5.6 & 5.4449 & TRN & \\
\hline CHEMBL604119 & 688722 & 4.45 & 5.059 & TST & \\
\hline CHEMBL1367076 & 688722 & 5.9 & 5.7407 & TRN & \\
\hline CHEMBL1255866 & 688722 & 4.95 & 5.4015 & TRN & \\
\hline CHEMBL1595524 & 688722 & 5.0 & 4.6895 & TRN & \\
\hline CHEMBL35482 & 688722 & 5.7 & 5.5626 & TRN & \\
\hline CHEMBL164 & 688722 & 4.45 & 5.4888 & TRN & \\
\hline CHEMBL1336166 & 688722 & 5.65 & 5.7485 & TRN & \\
\hline CHEMBL1256647 & 688722 & 4.95 & 4.6623 & TRN & \\
\hline CHEMBL 2374259 & 688722 & 6.05 & 5.6462 & TRN & \\
\hline CHEMBL 2374027 & 688722 & 4.7 & 4.9389 & TRN & \\
\hline CHEMBL66105 & 688722 & 7.1002 & 5.8406 & TRN & \\
\hline CHEMBL 323356 & 688722 & 6.5 & 5.7661 & TRN & \\
\hline CHEMBL429095 & 688722 & 5.3 & 5.5142 & TRN & \\
\hline CHEMBL3216928 & 688722 & 5.0 & 4.6466 & TRN & \\
\hline CHEMBL596674 & 688722 & 4.7 & 5.1347 & TRN & \\
\hline CHEMBL280563 & 688722 & 7.9508 & 6.1723 & TRN & \\
\hline CHEMBL1449651 & 688722 & 5.6 & 5.5296 & TST & \\
\hline CHEMBL1256290 & 688722 & 5.25 & 5.1008 & TRN & \\
\hline CHEMBL28 & 688722 & 5.35 & 5.9035 & TRN & \\
\hline CHEMBL1256727 & 688722 & 4.6 & 5.2593 & TRN & \\
\hline CHEMBL328710 & 688722 & 5.1 & 5.8586 & TRN & \\
\hline
\end{tabular}




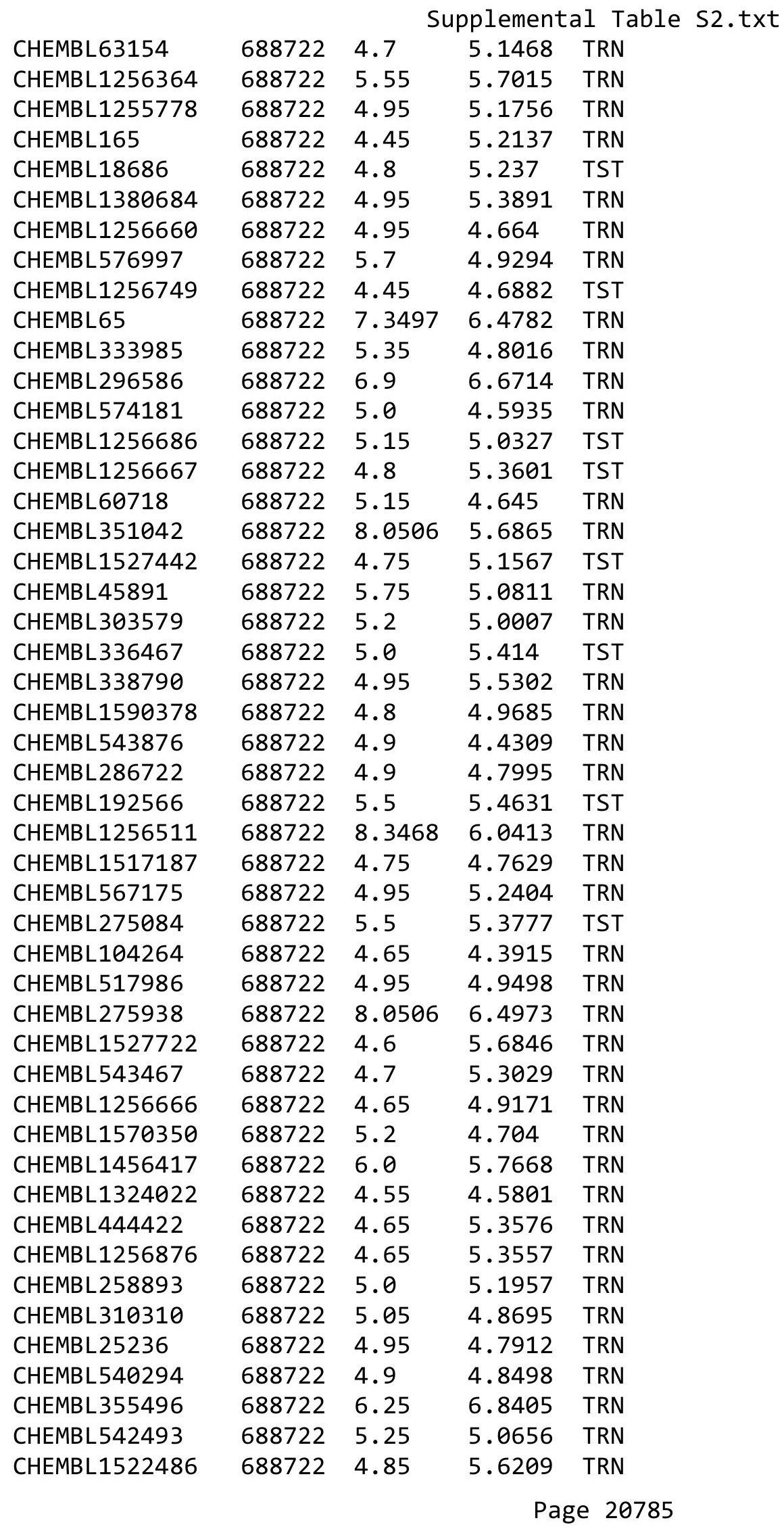




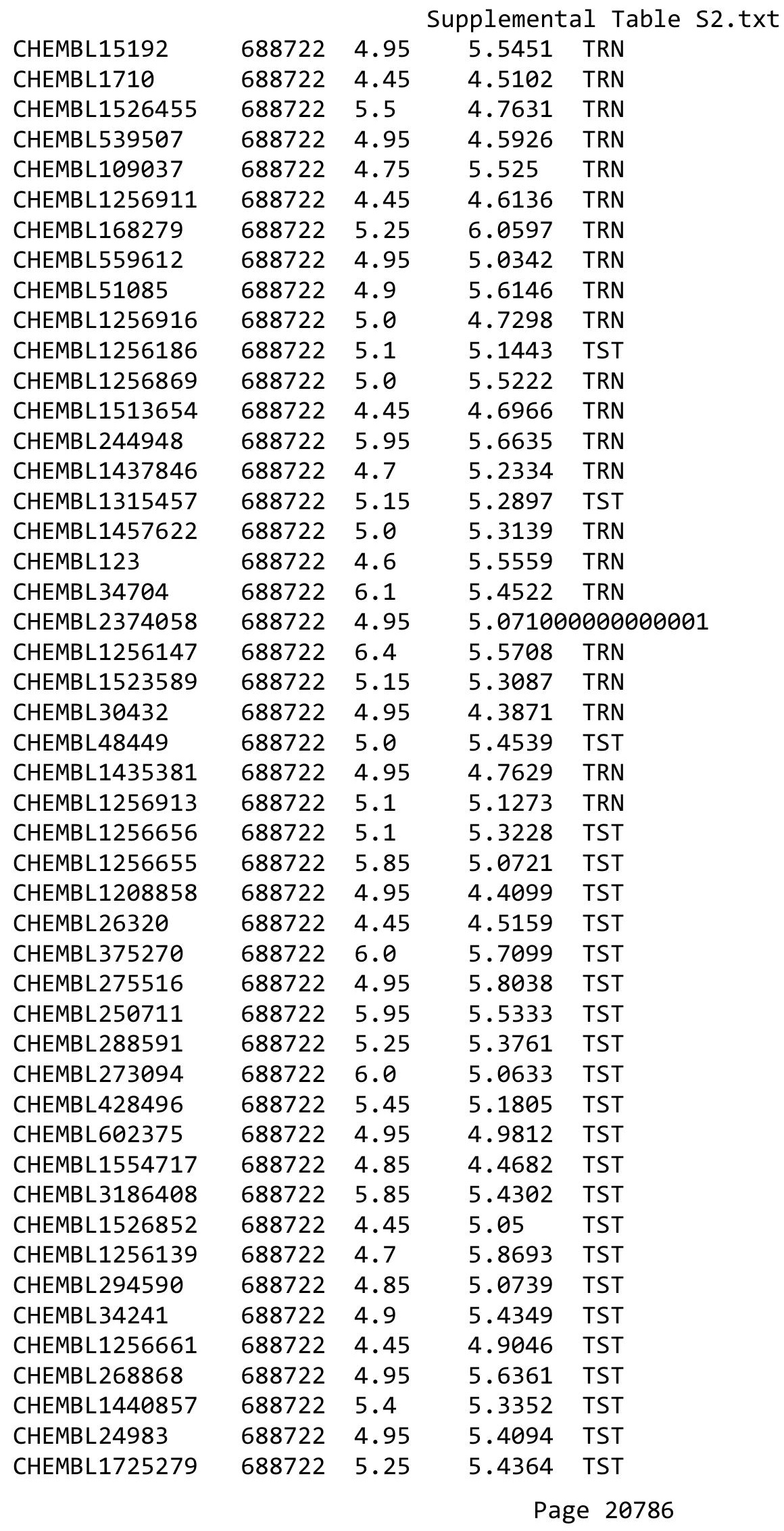




\begin{tabular}{|c|c|c|c|c|c|c|}
\hline \multirow[b]{2}{*}{ CHEMBL316966 } & \multicolumn{6}{|c|}{ Supplemental Table S2.txt } \\
\hline & 688722 & 7.5003 & 5.5827 & TST & & \\
\hline CHEMBL 1256740 & 688722 & 4.95 & 4.625 & TST & & \\
\hline CHEMBL1256995 & 688722 & 4.85 & 4.5982 & TST & & \\
\hline CHEMBL1322702 & 688722 & 5.3 & 4.6727 & TST & & \\
\hline CHEMBL3561520 & 1495300 & 4.6108 & 3.3875 & TST & & \\
\hline CHEMBL3560554 & 1495300 & 4.5336 & 4.039 & TST & & \\
\hline CHEMBL3561310 & 1495300 & 3.4089 & 4.2644 & TRN & & \\
\hline CHEMBL3186589 & 1495300 & 5.05399 & 99999999 & 99 & 5.4079 & TRN \\
\hline CHEMBL3560036 & 1495300 & 6.0 & 4.2676 & TRN & & \\
\hline CHEMBL3561830 & 1495300 & 6.0 & 4.0156 & TRN & & \\
\hline CHEMBL3560008 & 1495300 & 4.5941 & 4.4305 & TRN & & \\
\hline CHEMBL3560196 & 1495300 & 3.4089 & 4.0222 & TRN & & \\
\hline CHEMBL3561485 & 1495300 & 4.6008 & 4.3326 & TST & & \\
\hline CHEMBL 2359515 & 1495300 & 6.0 & 5.4249 & TRN & & \\
\hline CHEMBL3560110 & 1495300 & 4.8649 & 4.8858 & TRN & & \\
\hline CHEMBL3560521 & 1495300 & 5.0273 & 4.96899 & 9999999999 & & TRN \\
\hline CHEMBL3561942 & 1495300 & 4.7951 & 4.5054 & TRN & & \\
\hline CHEMBL3561914 & 1495300 & 3.3768 & 3.7448 & TST & & \\
\hline CHEMBL 2138809 & 1495300 & 6.0 & 5.3472 & TRN & & \\
\hline CHEMBL3561653 & 1495300 & 3.4089 & 3.3868 & TRN & & \\
\hline CHEMBL3559741 & 1495300 & 4.7897 & 4.3446 & TRN & & \\
\hline CHEMBL3561727 & 1495300 & 3.4089 & 4.0215 & TST & & \\
\hline CHEMBL 2357075 & 1495300 & 3.4089 & 3.9213 & TRN & & \\
\hline CHEMBL3561278 & 1495300 & 4.7655 & 4.2426 & TRN & & \\
\hline CHEMBL3560410 & 1495300 & 5.0004 & 5.2578 & TRN & & \\
\hline CHEMBL 2144022 & 1495300 & 3.4089 & 3.799 & TRN & & \\
\hline CHEMBL3561080 & 1495300 & 4.8128 & 4.8981 & TRN & & \\
\hline CHEMBL3560049 & 1495300 & 5.104 & 4.7517 & TRN & & \\
\hline CHEMBL3560665 & 1495300 & 6.0 & 5.2033 & TRN & & \\
\hline CHEMBL3560160 & 1495300 & 3.4089 & 4.494 & TST & & \\
\hline CHEMBL3559898 & 1495300 & 4.5153 & 4.6776 & TST & & \\
\hline CHEMBL3182316 & 1495300 & 5.1249 & 4.9947 & TRN & & \\
\hline CHEMBL3560671 & 1495300 & 3.4089 & 4.4794 & TST & & \\
\hline CHEMBL3561745 & 1495300 & 4.8011 & 4.2963 & TRN & & \\
\hline CHEMBL3561012 & 1495300 & 3.4089 & 3.4753 & TRN & & \\
\hline CHEMBL3561552 & 1495300 & 4.6694 & 3.6197 & TST & & \\
\hline CHEMBL3561607 & 1495300 & 3.4089 & 4.7114 & TRN & & \\
\hline CHEMBL3561034 & 1495300 & 4.4899 & 3.9676 & TRN & & \\
\hline CHEMBL3561339 & 1495300 & 3.4089 & 4.7879 & TRN & & \\
\hline CHEMBL 2359034 & 1495300 & 3.4089 & 3.7969 & TRN & & \\
\hline CHEMBL3561763 & 1495300 & 3.4089 & 4.4114 & TST & & \\
\hline CHEMBL3561300 & 1495300 & 4.5809 & 4.1965 & TST & & \\
\hline CHEMBL3560038 & 1495300 & 6.0 & 3.6946 & TST & & \\
\hline CHEMBL3183027 & 1495300 & 3.4089 & 4.6809 & TRN & & \\
\hline CHEMBL3188238 & 1495300 & 4.5455 & 5.3061 & TRN & & \\
\hline CHEMBL3561112 & 1495300 & 6.0 & 5.3543 & TRN & & \\
\hline CHEMBL 2362298 & 1495300 & 3.4089 & 4.1559 & TST & & \\
\hline CHEMBL3186592 & 1495300 & 4.937 & 5.109 & TRN & & \\
\hline
\end{tabular}


Supplemental Table S2.txt

\begin{tabular}{|c|c|c|c|c|c|}
\hline CHEMBL3561297 & 1495300 & 3.3768 & 4.225 & TRN & \\
\hline CHEMBL 2356002 & 1495300 & 5.1192 & 5.3749 & TRN & \\
\hline CHEMBL3560879 & 1495300 & 4.7326 & 4.2526 & TRN & \\
\hline CHEMBL3561218 & 1495300 & 5.1062 & 4.9253 & TRN & \\
\hline CHEMBL2361127 & 1495300 & 3.4089 & 4.4816 & TRN & \\
\hline CHEMBL3560428 & 1495300 & 4.6698 & 4.5822 & TRN & \\
\hline CHEMBL3561876 & 1495300 & 4.4487 & 4.1441 & TST & \\
\hline CHEMBL3561675 & 1495300 & 3.3768 & 3.6803 & TRN & \\
\hline CHEMBL3560580 & 1495300 & 6.0 & 4.7399 & TRN & \\
\hline CHEMBL3560387 & 1495300 & 4.5581 & 3.7619 & TST & \\
\hline CHEMBL3182236 & 1495300 & 4.7031 & 4.275 & TRN & \\
\hline CHEMBL2358640 & 1495300 & 4.8901 & 4.2659 & TRN & \\
\hline CHEMBL3188797 & 1495300 & 5.0545 & 5.1203 & TRN & \\
\hline CHEMBL3183012 & 1495300 & 4.9863 & \multicolumn{2}{|c|}{5.2379999999999995} & TRN \\
\hline CHEMBL3561438 & 1495300 & 4.4378 & 5.3285 & TRN & \\
\hline CHEMBL3560706 & 1495300 & 3.4089 & 3.8306 & TST & \\
\hline CHEMBL2135917 & 1495300 & 4.7607 & 5.2073 & TRN & \\
\hline CHEMBL3560625 & 1495300 & 3.3768 & 3.9325 & TRN & \\
\hline CHEMBL2359591 & 1495300 & 6.0 & 4.2742 & TST & \\
\hline CHEMBL3560749 & 1495300 & 4.9594 & 4.8769 & TRN & \\
\hline CHEMBL3560421 & 1495300 & 3.4089 & 3.8262 & TST & \\
\hline CHEMBL3187467 & 1495300 & 4.4639 & 3.986 & TRN & \\
\hline CHEMBL 2360631 & 1495300 & 6.0 & 4.8925 & TRN & \\
\hline CHEMBL3559959 & 1495300 & 4.9682 & 3.9089 & TST & \\
\hline CHEMBL3559906 & 1495300 & 3.4437 & 3.5646 & TRN & \\
\hline CHEMBL3561746 & 1495300 & 3.4089 & 3.9918 & TRN & \\
\hline CHEMBL3560162 & 1495300 & 3.4089 & 4.0277 & TST & \\
\hline CHEMBL3561674 & 1495300 & 3.4089 & 3.5803 & TRN & \\
\hline CHEMBL2357418 & 1495300 & 3.4089 & 3.9293 & TST & \\
\hline CHEMBL3561291 & 1495300 & 4.5408 & 3.4974 & TST & \\
\hline CHEMBL3560842 & 1495300 & 6.0 & 4.8423 & TRN & \\
\hline CHEMBL3561188 & 1495300 & 3.3768 & 3.6755 & TRN & \\
\hline CHEMBL3561336 & 1495300 & 3.4089 & 3.4325 & TST & \\
\hline CHEMBL2354467 & 1495300 & 5.1096 & 4.4845 & TRN & \\
\hline CHEMBL3561637 & 1495300 & 3.4089 & 4.3183 & TRN & \\
\hline CHEMBL2355572 & 1495300 & 6.0 & 4.5974 & TRN & \\
\hline CHEMBL3561767 & 1495300 & 3.4089 & 4.8696 & TST & \\
\hline CHEMBL3560452 & 1495300 & 3.3768 & 4.7143 & TRN & \\
\hline CHEMBL3188803 & 1495300 & 4.7937 & 4.9033 & TST & \\
\hline CHEMBL3559925 & 1495300 & 4.4761 & 3.279 & TST & \\
\hline CHEMBL2361049 & 1495300 & 5.4535 & 5.3146 & TRN & \\
\hline CHEMBL3561556 & 1495300 & 4.4438 & 3.8978 & TRN & \\
\hline CHEMBL3560460 & 1495300 & 4.8193 & 4.2368 & TST & \\
\hline CHEMBL3561315 & 1495300 & 3.4089 & 3.918 & TST & \\
\hline CHEMBL3560469 & 1495300 & 6.0 & 4.6267 & TRN & \\
\hline CHEMBL3561361 & 1495300 & 4.5597 & 4.0916 & TST & \\
\hline CHEMBL3561738 & 1495300 & 4.6921 & 4.348 & TRN & \\
\hline CHEMBL3561621 & 1495300 & 4.978 & 5.024 & TRN & \\
\hline
\end{tabular}


Supplemental Table S2.txt

\begin{tabular}{|c|c|c|c|c|}
\hline HEMBL3559754 & 495300 & 3.4089 & & \\
\hline & 495300 & 3.4089 & & \\
\hline & & & & \\
\hline IEMBL1 & 495300 & & & \\
\hline AEMBL2 & 300 & 172 & & \\
\hline HEMBL3560408 & 495300 & 4.4514 & 747 & \\
\hline HEMBL & 300 & & & \\
\hline EMBL & & & & \\
\hline AEMBL2356106 & 300 & 4.3835 & & \\
\hline AEMBL3561 & 300 & 3.4089 & 243 & Rा \\
\hline AEMBL3559752 & 300 & 089 & & \\
\hline IEMBL: & 300 & 537 & & \\
\hline IEMBL: & 300 & & & \\
\hline IEMBL356 & 300 & 202 & & \\
\hline AEMBL35 & 300 & & & \\
\hline AEMBL3 & 00 & 45 & & \\
\hline AEMBL & 300 & & & \\
\hline AEMBL & 300 & & & \\
\hline AEMBL2 & 300 & & & \\
\hline EMBL & 00 & & & $\mathrm{R}$ \\
\hline AEMBL & 4 & 39 & & \\
\hline EMBL & 96 & & & \\
\hline EMB & 300 & & & \\
\hline IFMPI & 300 & & & \\
\hline IEMBL3 & & & & RIN \\
\hline AEMBL & 14 & 89 & & RI \\
\hline IEMBL & & & & 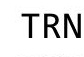 \\
\hline EMB & $\theta 0$ & & & ST \\
\hline IEMBL & & & & RN \\
\hline AEMBL 356 & & & & SI \\
\hline AEMBL: & 300 & 21 & & st \\
\hline EMB & 300 & & & . \\
\hline AEMBL & 30 & 89 & & ST \\
\hline AEMBL3 & & & & RN \\
\hline AEMBL23598 & $\theta t$ & 78 & & $\mathrm{RN}$ \\
\hline AEMBL; & $30 e$ & & & ות \\
\hline JCM I & & & & RN \\
\hline HEMBL & & & & ST \\
\hline AEMBL1891222 & & 089 & & RA \\
\hline IEMBL: & & 089 & & RN \\
\hline HEMBL & & 89 & & TST \\
\hline HEMBL2 & & & & RN \\
\hline HEMBL2 & & 6. & & RN \\
\hline AEMBL 2361477 & 306 & 4.6444 & 63 & $\mathrm{c}$ \\
\hline ME & & & & RIN \\
\hline CHEMBL 3560275 & & & & TRN \\
\hline CHEMBL3559897 & & 5.1118 & & \\
\hline CHEMBL3559869 & 1495300 & 3.4089 & 3.4855 & TR \\
\hline
\end{tabular}

Page 20789 
Supplemental Table S2.txt

\begin{tabular}{|c|c|c|c|c|}
\hline HEM & & & & \\
\hline & & 3.4089 & 3.8674 & \\
\hline & 300 & 6 & & \\
\hline HEMBL & 300 & & 0255 & \\
\hline AEMBL3 & 495300 & 089 & 8029 & \\
\hline HEMBL3560943 & 495300 & 5445 & 564 & \\
\hline & 300 & 059 & 472 & \\
\hline |FMRI & 300 & & 3362 & \\
\hline HEMBL356 & 300 & 089 & 2884 & \\
\hline HEMBL3560819 & 495300 & 4.7282 & 1873 & \\
\hline HEMBL356 & 300 & 3.4089 & 3669 & \\
\hline IEMBL & 300 & 089 & 067 & \\
\hline AEMBL & & & & \\
\hline HEMBL35 & 300 & 977 & 4.1689 & \\
\hline AEMBL35 & 300 & 297 & 2745 & \\
\hline AEMBL356 & 00 & 794 & 1658 & \\
\hline AEMBL3: & 00 & 99 & 313 & \\
\hline HEMBL2: & & 6 . & 659 & \\
\hline HEMBL23 & 300 & & 5342 & \\
\hline AEMBL35 & & 89 & & \\
\hline HEMBLS & $\partial 0$ & 58 & & 1SI \\
\hline AEMBL & 30 & 45 & 64 & RN \\
\hline HEMBL; & & 89 & & \\
\hline 73 & 300 & 315 & 242 & \\
\hline AEMBL35 & & & & I RIV \\
\hline HEMBL 35 & $\partial 0$ & 3. & 221 & RN \\
\hline HEMBL 2 & & & 307 & Niv \\
\hline HFMBI 3 & $\partial 0$ & 6. & 827 & \\
\hline HEMBL356 & & 4.7247 & 5772 & I \\
\hline HEMBL 356 & & & 793 & I RN \\
\hline HEMBL 35 & & & 423 & RN \\
\hline HEMBL; & & 1 & 238 & RN \\
\hline 1 & & 39 & 734 & 3 \\
\hline HEMBL 236 & & & 734 & R \\
\hline HEMBL 3559927 & $\partial 0$ & 3.3768 & 104 & TRN \\
\hline HEMBL3 & & 39 & 996 & RN \\
\hline HFMRI & & & 09 & IRIV \\
\hline HEMBL 2 & & & 277 & IRN \\
\hline HEMBL3560816 & 300 & 089 & 372 & TST \\
\hline AEMBL35 & & & 125 & TRN \\
\hline HEMBL35 & 00 & 089 & 794 & \\
\hline CHEMBL 35 & & & & RN \\
\hline HEMBL35 & 300 & 4.4763 & 562 & ST \\
\hline HEMBL3560759 & 495300 & 4.9634 & 418 & TRN \\
\hline 12 & & & 019 & ב \\
\hline HEMBL 35 & & & & \\
\hline HEMBL 35 & & 4.9446 & 4.8172 & \\
\hline CHEMBL3561632 & 1495306 & 4.9397 & 4.6657 & \\
\hline
\end{tabular}

Page 20790 
Supplemental Table S2.txt

\begin{tabular}{|c|c|c|c|c|}
\hline$\theta$ & & & & \\
\hline & 300 & 6.0 & & \\
\hline $123+2+3$ & 300 & 1 & & \\
\hline IEMBL & 300 & 598 & & \\
\hline AEMBL3561772 & 495300 & 1089 & 1011 & \\
\hline HEMBL3560482 & 300 & 3.4089 & 2871 & \\
\hline 207 & 300 & 86 & & \\
\hline AEMBL2 & & & & \\
\hline HEMBL3561402 & 495300 & 3.4089 & 9784 & \\
\hline HEMBL3181937 & 495300 & 6.0 & & \\
\hline HEMBL3561818 & & 3.4089 & & \\
\hline EM & & 89 & & \\
\hline AEMBL3 & & 116 & & \\
\hline HEMBL3560313 & 300 & 4.8871 & 561 & \\
\hline AEMBL3559938 & 300 & 3.4089 & & \\
\hline AEMBL3 & & 4. & 18 & RIN \\
\hline HEMBL2 & & 5 . & & (1) \\
\hline HEMBL 2 & 00 & 3. & & \\
\hline HEMBI 3 & 300 & 4 . & & \\
\hline AEMBL3182522 & & & & I KIV \\
\hline HEMBL; & & & & RN \\
\hline HEM & & & & MIV \\
\hline AEMBL & 00 & 4. & & BN \\
\hline 899 & & 5. & & \\
\hline AEMBL3 & 00 & 3. & 23 & I RN \\
\hline AEMBL3 & & 4 & & RN \\
\hline HFM & & & & KIV \\
\hline 3 & & & & CRN \\
\hline AEMBL2 & & & & IRN \\
\hline HEMBL3560884 & 00 & 4. & & TRN \\
\hline AEMBL: & 00 & 3. & & $\mathrm{RN}$ \\
\hline 1 & & & & 「RN \\
\hline & & & & RN \\
\hline HEMBL3 & & & & ГST \\
\hline HEMBL3560731 & 00 & 4. & & RN \\
\hline - גיםנזו & & & & TRN \\
\hline 5 & & & & TRN \\
\hline HEMBL 3561797 & & & & 「RN \\
\hline HEMBL2 & & & & Th \\
\hline כ & & & & 11 \\
\hline HEMBL3 & & & & TRN \\
\hline & & & & 「RN \\
\hline HEMBL356052 & 300 & & & RN \\
\hline HEMBL 356 & & & & TR \\
\hline CHEMPI 21860 & & & & ST \\
\hline HEMBL3559887 & & 4.9842 & .3224 & \\
\hline CHEMBL 3560846 & & 5.0311 & 675 & \\
\hline LHEMBL 3559848 & 1495300 & 3.4089 & 3.8463 & \\
\hline
\end{tabular}

Page 20791 
Supplemental Table S2.txt

\begin{tabular}{|c|c|c|c|c|}
\hline 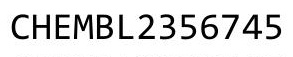 & & & & \\
\hline HEMBL2136465 & 5300 & 4.9412 & 3765 & \\
\hline HEMBL3560269 & & 4089 & 7813 & \\
\hline IEM & 300 & 513 & 118 & \\
\hline IEMBL & 300 & 778 & & \\
\hline HEMBL2355072 & 495300 & 4.7575 & .9683 & \\
\hline HEMBL 2356472 & 495300 & 4.9412 & 4.2835 & \\
\hline HEMBL3560996 & 300 & 004 & 5471 & \\
\hline 729 & 300 & 114 & 5.1652 & \\
\hline IEMBL: & 300 & 258 & .5726 & \\
\hline HEMBL3560563 & 300 & 5.0496 & 4.4563 & \\
\hline HEMBL3561264 & 300 & 4.965 & 81 & \\
\hline HEMBL3561044 & 300 & 768 & 4.2201 & \\
\hline 1604 & 300 & 36 & 89 & \\
\hline HEMBL2359303 & & 924 & 03 & \\
\hline HEMBL2361210 & 300 & 4.8202 & 6372 & \\
\hline HEMBL3560250 & 300 & 3. & & \\
\hline HEMBL356 & 30 & 4. & 322 & \\
\hline HEMBL35 & & 58 & 51 & \\
\hline HEMBL & & & & \\
\hline HEMBL3560687 & & 89 & & \\
\hline HEMBL3560886 & & & & ST \\
\hline HEMBL3560 & $\partial \theta$ & 4 & & RN \\
\hline HEMBL2 & & & & \\
\hline 54 & 00 & & & RN \\
\hline AEMBL2134576 & & & & ST \\
\hline AEMBL3188435 & & & & \\
\hline HEMBL3: & $\partial \theta$ & & & \\
\hline HEMBL 3 & & & & ST \\
\hline HEMBL3 & 00 & 4 & 46 & RN \\
\hline HEMBL3561328 & & & & RN \\
\hline HEMBL3560890 & 300 & 5. & 331 & RN \\
\hline HEMBL & 300 & 63 & 579 & RN \\
\hline 3 & & & & ST \\
\hline HEMBL3561244 & & 4 & & RN \\
\hline HEMBL2357399 & 300 & & & RN \\
\hline HEMBL 2139690 & 300 & & & ST \\
\hline 625 & 00 & & & Niv \\
\hline 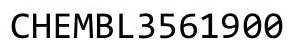 & & & & I \\
\hline HEMBL1213691 & & & & RN \\
\hline HEMBL1213693 & & & 58 & RN \\
\hline HEMBL1214 & & & & RN \\
\hline HEMBL1214197 & & & & \\
\hline HEMBL1214136 & & & & RN \\
\hline HEMBL1214324 & & 6.9957 & 7.2734 & RN \\
\hline HEMBL1214618 & & 1559 & & ST \\
\hline EM & & & & \\
\hline 1001919 & & & & \\
\hline
\end{tabular}

Page 20792 


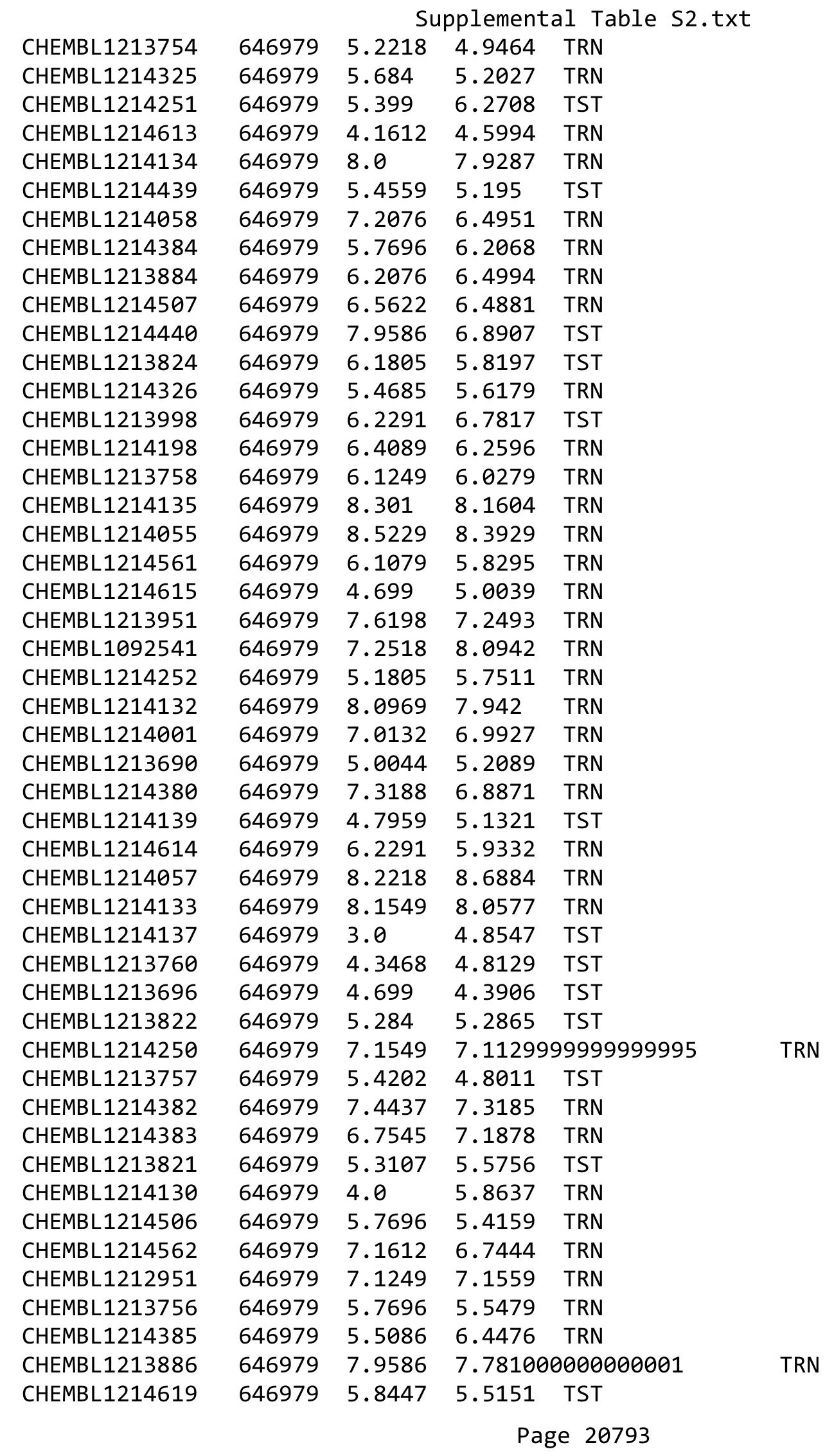


Supplemental Table S2.txt

\begin{tabular}{|c|c|c|c|c|}
\hline CHEMBL1214616 & 646979 & 5.1805 & 4.7359 & TST \\
\hline CHEMBL1213885 & 646979 & 6.5638 & 6.7004 & TRN \\
\hline CHEMBL1213692 & 646979 & 4.6198 & 4.5522 & TRN \\
\hline CHEMBL1091849 & 646979 & 7.3979 & 6.9527 & TRN \\
\hline CHEMBL1212949 & 646979 & 4.8861 & 5.0334 & TRN \\
\hline CHEMBL1213952 & 646979 & 6.7282 & 6.9764 & TST \\
\hline CHEMBL1214056 & 646979 & 8.301 & 8.4371 & TRN \\
\hline CHEMBL1214617 & 646979 & 6.0706 & 5.09699 & 99999999995 \\
\hline CHEMBL1214381 & 646979 & 6.8508 & 6.9802 & TRN \\
\hline CHEMBL1213694 & 646979 & 4.7959 & 5.0019 & TST \\
\hline CHEMBL1214000 & 646979 & 6.2596 & 6.5101 & TRN \\
\hline CHEMBL1214196 & 646979 & 6.1979 & 6.4772 & TRN \\
\hline CHEMBL1214563 & 646979 & 5.3979 & 4.5572 & TST \\
\hline CHEMBL1213753 & 646979 & 5.0706 & 4.7946 & TRN \\
\hline CHEMBL1214438 & 646979 & 7.2596 & 6.9699 & TRN \\
\hline CHEMBL1213823 & 646979 & 7.0177 & 7.2124 & TRN \\
\hline CHEMBL1214504 & 646979 & 3.0 & 4.0151 & TRN \\
\hline CHEMBL1214129 & 646979 & 7.3098 & 6.553 & TRN \\
\hline CHEMBL1214441 & 646979 & 5.0 & 4.6089 & TRN \\
\hline CHEMBL1213689 & 646979 & 5.8097 & 5.9377 & TRN \\
\hline CHEMBL1213999 & 646979 & 6.71 & 6.523 & TRN \\
\hline CHEMBL1213755 & 646979 & 4.0 & 4.7572 & TRN \\
\hline CHEMBL1213695 & 646979 & 6.1249 & 6.1386 & TRN \\
\hline CHEMBL1214379 & 646979 & 5.0706 & 5.1765 & TST \\
\hline CHEMBL1213759 & 646979 & 6.5528 & 6.4103 & TRN \\
\hline CHEMBL1214564 & 646979 & 4.4318 & 3.9145 & TST \\
\hline CHEMBL1214505 & 646979 & 6.5528 & 6.0534 & TRN \\
\hline CHEMBL1214612 & 646979 & 6.1079 & 5.3414 & TST \\
\hline CHEMBL2418186 & 978480 & 3.6021 & 3.5892 & TRN \\
\hline CHEMBL 2418156 & 978480 & 3.6021 & 3.9457 & TST \\
\hline CHEMBL 2418165 & 978480 & 3.6021 & 3.6661 & TRN \\
\hline CHEMBL 2418180 & 978480 & 5.5376 & 5.3133 & TRN \\
\hline CHEMBL 2418194 & 978480 & 3.6021 & 3.5871 & TRN \\
\hline CHEMBL 2418191 & 978480 & 3.6021 & 3.5497 & TRN \\
\hline CHEMBL 236232 & 978480 & 3.301 & 3.2222 & TRN \\
\hline CHEMBL2418145 & 978480 & 3.6021 & 3.5816 & TRN \\
\hline CHEMBL 2418192 & 978480 & 3.6021 & 3.7864 & TRN \\
\hline CHEMBL 2418161 & 978480 & 3.6021 & 4.1103 & TST \\
\hline CHEMBL 2418155 & 978480 & 5.3872 & 5.3045 & TST \\
\hline CHEMBL 2418140 & 978480 & 3.301 & 3.093 & TST \\
\hline CHEMBL 2418144 & 978480 & 3.6021 & 3.3359 & TST \\
\hline CHEMBL 2418162 & 978480 & 3.6021 & 3.5625 & TRN \\
\hline CHEMBL2418187 & 978480 & 3.6021 & 3.4828 & TRN \\
\hline CHEMBL 2418170 & 978480 & 3.6021 & 3.5965 & TRN \\
\hline CHEMBL2418160 & 978480 & 3.6021 & 3.5873 & TRN \\
\hline CHEMBL 2418182 & 978480 & 5.4815 & 5.3711 & TRN \\
\hline CHEMBL2418175 & 978480 & 5.0809 & 5.0537 & TRN \\
\hline CHEMBL2418181 & 978480 & 5.7696 & 5.8382 & TST \\
\hline
\end{tabular}


Supplemental Table S2.txt

\begin{tabular}{|c|c|c|c|c|}
\hline CHEMBL 2418169 & 978480 & 3.6021 & 3.5953 & TRN \\
\hline CHEMBL 2418159 & 978480 & 3.6021 & 3.6362 & TRN \\
\hline CHEMBL 2418179 & 978480 & 5.5229 & 5.5499 & TRN \\
\hline CHEMBL 2418178 & 978480 & 5.9586 & 5.8646 & TRN \\
\hline CHEMBL 2418149 & 978480 & 5.3372 & 5.944 & TST \\
\hline CHEMBL 2418139 & 978480 & 5.6576 & \multicolumn{2}{|c|}{5.593999999999999} \\
\hline CHEMBL 2418171 & 978480 & 3.6021 & 3.7071 & TRN \\
\hline CHEMBL 2418154 & 978480 & 3.6021 & 3.6525 & TRN \\
\hline CHEMBL 2418174 & 978480 & 6.0223 & 5.9863 & TRN \\
\hline CHEMBL 2418166 & 978480 & 3.6021 & \multicolumn{2}{|c|}{ 3.6519999999999997 } \\
\hline CHEMBL2418189 & 978480 & 3.6021 & 3.5886 & TRN \\
\hline CHEMBL 2418188 & 978480 & 3.6021 & 3.6004 & TRN \\
\hline CHEMBL 2418152 & 978480 & 3.6021 & 3.7903 & TST \\
\hline CHEMBL 2418173 & 978480 & 6.2007 & 6.4044 & TRN \\
\hline CHEMBL 2418172 & 978480 & 5.9208 & 5.8885 & TRN \\
\hline CHEMBL 2418142 & 978480 & 3.6021 & 3.5763 & TRN \\
\hline CHEMBL2418183 & 978480 & 3.6021 & 3.5814 & TRN \\
\hline CHEMBL 2418157 & 978480 & 3.6021 & 3.7446 & TST \\
\hline CHEMBL 2418167 & 978480 & 3.6021 & 3.6064 & TRN \\
\hline CHEMBL2418148 & 978480 & 4.7212 & 5.4788 & TST \\
\hline CHEMBL2418184 & 978480 & 3.6021 & 3.5642 & TRN \\
\hline CHEMBL 2418141 & 978480 & 3.6021 & 3.5148 & TRN \\
\hline CHEMBL 2418163 & 978480 & 3.6021 & 3.4812 & TRN \\
\hline CHEMBL2418164 & 978480 & 3.6021 & 3.5636 & TRN \\
\hline CHEMBL 2418146 & 978480 & 3.6021 & 3.1765 & TST \\
\hline CHEMBL2418151 & 978480 & 3.6021 & 4.0664 & TST \\
\hline CHEMBL 2418147 & 978480 & 3.6021 & 3.7044 & TST \\
\hline CHEMBL 2418176 & 978480 & 5.8539 & 5.9673 & TRN \\
\hline CHEMBL2418153 & 978480 & 3.6021 & \multicolumn{2}{|c|}{3.5980000000000003} \\
\hline CHEMBL 2418185 & 978480 & 3.6021 & 3.6289 & TRN \\
\hline CHEMBL2418168 & 978480 & 3.6021 & 3.6645 & TRN \\
\hline CHEMBL 2418143 & 978480 & 3.6021 & 3.4744 & TST \\
\hline CHEMBL 2418150 & 978480 & 3.6021 & 3.786 & TST \\
\hline CHEMBL2418193 & 978480 & 3.6021 & 3.6332 & TRN \\
\hline CHEMBL 2418190 & 978480 & 3.6021 & 3.6358 & TRN \\
\hline CHEMBL2418177 & 978480 & 3.6021 & 3.8972 & TRN \\
\hline CHEMBL 2418158 & 978480 & 3.6021 & 3.6193 & TRN \\
\hline CHEMBL 220241 & 955042 & 3.7013 & 3.7224 & TRN \\
\hline CHEMBL 213100 & 955042 & 3.1469 & 3.0679 & TRN \\
\hline CHEMBL577784 & 955042 & 5.0181 & 5.0085 & TRN \\
\hline CHEMBL585951 & 955042 & 5.2281 & 5.0774 & TRN \\
\hline CHEMBL 2005886 & 955042 & 3.082 & 2.9938 & TRN \\
\hline CHEMBL65 & 955042 & 5.2781 & 5.2001 & TRN \\
\hline CHEMBL412142 & 955042 & 3.6955 & 3.38 & TRN \\
\hline CHEMBL 217354 & 955042 & 6.0722 & 6.0406 & TRN \\
\hline CHEMBL188678 & 955042 & 3.6317 & 4.1475 & TRN \\
\hline CHEMBL 222102 & 955042 & 4.4974 & 4.0382 & TRN \\
\hline CHEMBL 258844 & 955042 & 3.1614 & 3.1161 & TRN \\
\hline
\end{tabular}

Page 20795 


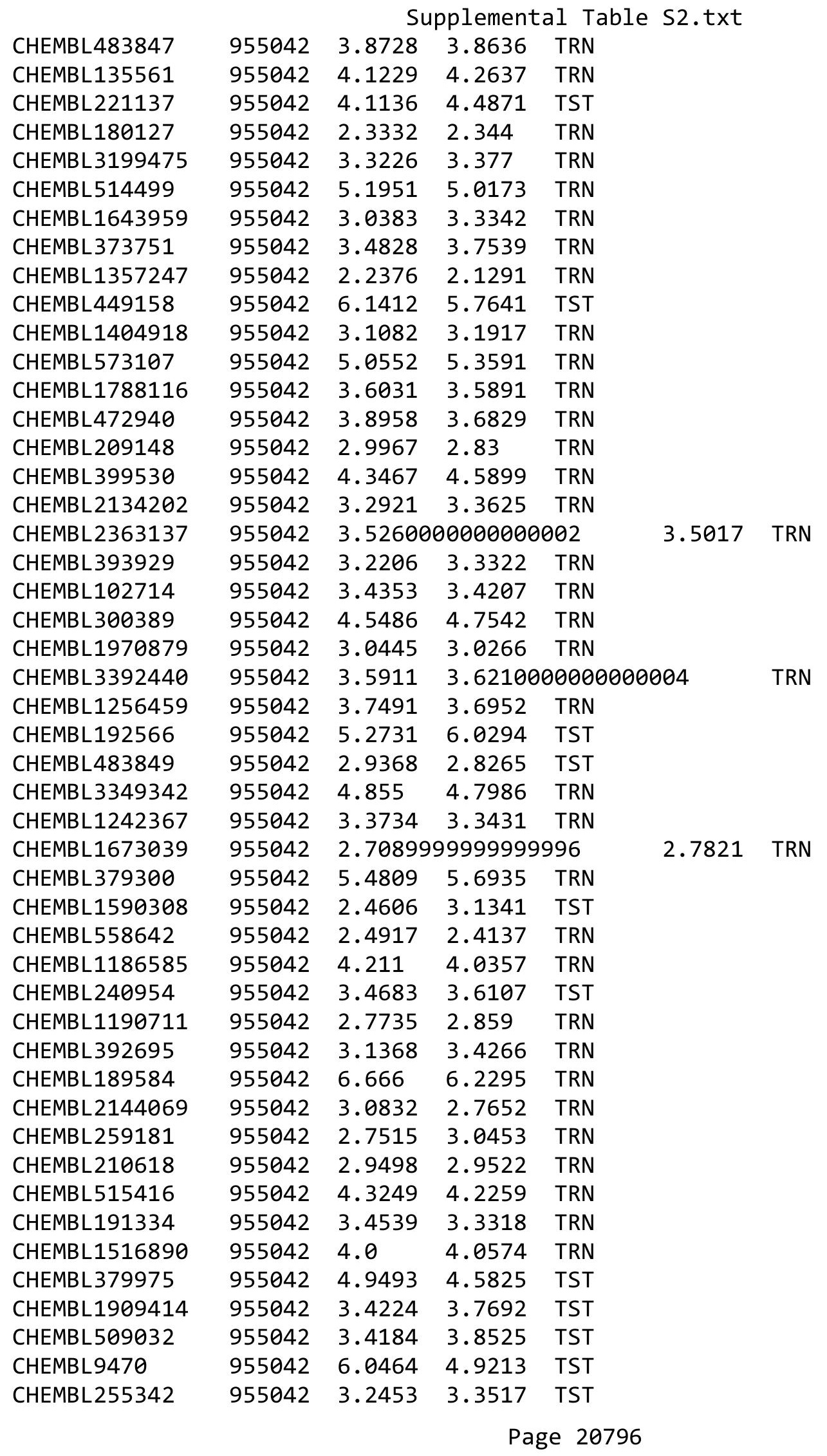




\begin{tabular}{|c|c|c|c|c|c|c|}
\hline \multirow[b]{2}{*}{ CHEMBL92309 } & & \multicolumn{5}{|c|}{ Supplemental Table s2.txt } \\
\hline & 955042 & 1.4085 & 2.9384 & TST & & \\
\hline CHEMBL1230020 & 955042 & 3.69 & 3.5907 & TST & & \\
\hline CHEMBL2137530 & 955042 & 3.3709 & 4.5496 & TST & & \\
\hline CHEMBL512504 & 955042 & 3.7227 & 4.3759 & TST & & \\
\hline CHEMBL 3186408 & 955042 & \multicolumn{3}{|c|}{2.8569999999999998} & 3.2645 & TST \\
\hline CHEMBL202721 & 955042 & 3.6946 & 4.3168 & TST & & \\
\hline CHEMBL333247 & 47858 & 6.0 & \multicolumn{3}{|c|}{6.247999999999999} & TRN \\
\hline CHEMBL412379 & 47858 & 7.131 & 7.6104 & TRN & & \\
\hline CHEMBL433026 & 47858 & \multicolumn{3}{|c|}{6.7139999999999995} & 6.6975 & TRN \\
\hline CHEMBL 263230 & 47858 & \multicolumn{3}{|c|}{5.3420000000000005} & 5.5775 & TRN \\
\hline CHEMBL385749 & 47858 & 5.501 & 5.8857 & TRN & & \\
\hline CHEMBL438981 & 47858 & 6.176 & 6.5406 & TRN & & \\
\hline CHEMBL331863 & 47858 & 6.301 & 7.0602 & TRN & & \\
\hline CHEMBL412786 & 47858 & 6.484 & 5.8705 & TRN & & \\
\hline CHEMBL333138 & 47858 & 7.0 & 6.6069 & TRN & & \\
\hline CHEMBL118986 & 47858 & 7.398 & 7.0436 & TRN & & \\
\hline CHEMBL269504 & 47858 & 6.335 & 6.5382 & TRN & & \\
\hline CHEMBL403514 & 47858 & 7.066 & 7.1243 & TRN & & \\
\hline CHEMBL116822 & 47858 & \multicolumn{3}{|c|}{7.1739999999999995} & 6.475 & TRN \\
\hline CHEMBL405580 & 47858 & 7.886 & 7.772 & TRN & & \\
\hline CHEMBL410648 & 47858 & 8.658 & 8.0946 & TRN & & \\
\hline CHEMBL432031 & 47858 & 6.58 & 5.9699 & TRN & & \\
\hline CHEMBL407429 & 47858 & 8.051 & 8.0842 & TRN & & \\
\hline CHEMBL331895 & 47858 & 5.447 & \multicolumn{3}{|c|}{6.202999999999999} & TRN \\
\hline CHEMBL414923 & 47858 & 7.921 & 7.349 & TRN & & \\
\hline CHEMBL 263173 & 47858 & 7.939 & 7.7432 & TRN & & \\
\hline CHEMBL110989 & 47858 & \multicolumn{3}{|c|}{8.347000000000001} & 6.9069 & TRN \\
\hline CHEMBL330761 & 47858 & 5.869 & \multicolumn{3}{|c|}{7.287999999999999} & TRN \\
\hline CHEMBL 330841 & 47858 & 6.419 & 6.4192 & TRN & & \\
\hline CHEMBL384323 & 47858 & 7.398 & 7.4119 & TRN & & \\
\hline CHEMBL119133 & 47858 & 6.38 & 6.0064 & TRN & & \\
\hline CHEMBL339197 & 47858 & 6.511 & 6.6356 & TRN & & \\
\hline CHEMBL267539 & 47858 & 6.796 & 6.9759 & TST & & \\
\hline CHEMBL217741 & 47858 & 7.585 & 7.188 & TRN & & \\
\hline CHEMBL411527 & 47858 & 7.845 & 7.42899 & 9999999999 & & TRN \\
\hline CHEMBL386178 & 47858 & 8.495 & 8.0036 & TRN & & \\
\hline CHEMBL122183 & 47858 & 8.367 & 7.9731 & TRN & & \\
\hline CHEMBL408630 & 47858 & 6.556 & 7.0638 & TST & & \\
\hline CHEMBL405797 & 47858 & \multicolumn{3}{|c|}{6.662999999999999} & 6.9977 & TST \\
\hline CHEMBL425984 & 47858 & 6.983 & 6.8068 & TRN & & \\
\hline CHEMBL331761 & 47858 & 7.301 & \multicolumn{3}{|c|}{6.757000000000001} & TRN \\
\hline CHEMBL279112 & 47858 & 7.398 & 7.0381 & TRN & & \\
\hline CHEMBL385884 & 47858 & 7.796 & 7.5368 & TRN & & \\
\hline CHEMBL402482 & 47858 & 8.77 & 8.1868 & TRN & & \\
\hline CHEMBL120219 & 47858 & 6.398 & 6.3478 & TRN & & \\
\hline CHEMBL415514 & 47858 & 7.532 & 8.0129 & TRN & & \\
\hline CHEMBL409031 & 47858 & \multicolumn{3}{|c|}{6.638999999999999} & 6.9694 & TRN \\
\hline CHEMBL413017 & 47858 & 6.025 & 6.8437 & TRN & & \\
\hline
\end{tabular}




\begin{tabular}{|c|c|c|c|c|c|c|}
\hline \multirow{4}{*}{$\begin{array}{l}\text { CHEMBL415381 } \\
\text { CHEMBL386201 }\end{array}$} & & \multicolumn{5}{|c|}{ Supplemental Table S2.txt } \\
\hline & 47858 & \multicolumn{4}{|c|}{7.127000000000001} & TRN \\
\hline & 47858 & \multicolumn{3}{|c|}{7.3420000000000005} & 7.7149 & TST \\
\hline & 47858 & 7.114 & 7.3342 & TST & & \\
\hline CHEMBL265220 & 47858 & \multicolumn{3}{|c|}{7.763999999999999} & 6.8498 & TST \\
\hline CHEMBL263791 & 47858 & \multicolumn{3}{|c|}{5.8420000000000005} & 5.8627 & TRN \\
\hline CHEMBL402703 & 47858 & 6.947 & 6.9886 & TRN & & \\
\hline CHEMBL 385441 & 47858 & 7.955 & 6.4393 & TST & & \\
\hline CHEMBL415611 & 47858 & 8.638 & 8.2741 & TRN & & \\
\hline CHEMBL118138 & 47858 & 7.845 & 7.5775 & TRN & & \\
\hline CHEMBL407044 & 47858 & 6.17 & 7.1642 & TRN & & \\
\hline CHEMBL333403 & 47858 & 5.301 & 5.3855 & TRN & & \\
\hline CHEMBL413934 & 47858 & 6.886 & 6.8871 & TRN & & \\
\hline CHEMBL415345 & 47858 & 5.869 & 6.5494 & TRN & & \\
\hline CHEMBL263009 & 47858 & 6.38 & 6.476 & TST & & \\
\hline CHEMBL413423 & 47858 & 7.0 & 5.9204 & TST & & \\
\hline CHEMBL437514 & 47858 & 8.125 & 8.5571 & TRN & & \\
\hline CHEMBL119851 & 47858 & 6.815 & 6.5619 & TRN & & \\
\hline CHEMBL261959 & 47858 & 6.996 & 7.4998 & TRN & & \\
\hline CHEMBL415397 & 47858 & 5.881 & 6.7554 & TRN & & \\
\hline CHEMBL324537 & 47858 & 7.159 & 6.023 & TST & & \\
\hline CHEMBL 263600 & 47858 & 7.699 & 8.3594 & TRN & & \\
\hline CHEMBL385981 & 47858 & \multicolumn{3}{|c|}{6.832000000000001} & 6.8019 & TRN \\
\hline CHEMBL 267444 & 47858 & 6.845 & 6.9808 & TRN & & \\
\hline CHEMBL216809 & 47858 & 6.886 & 6.461 & TST & & \\
\hline CHEMBL408312 & 47858 & \multicolumn{3}{|c|}{ 7.327999999999999 } & 6.6592 & TRN \\
\hline CHEMBL402481 & 47858 & 8.398 & 7.9032 & TRN & & \\
\hline CHEMBL405014 & 47858 & 6.072 & 6.4678 & TRN & & \\
\hline CHEMBL261936 & 47858 & 6.581 & 6.603 & TRN & & \\
\hline CHEMBL408388 & 47858 & 7.31 & 7.3042 & TRN & & \\
\hline CHEMBL 216627 & 47858 & 8.048 & 8.5088 & TRN & & \\
\hline CHEMBL118773 & 47858 & 7.02 & 6.9146 & TRN & & \\
\hline CHEMBL266179 & 47858 & 7.48 & 7.4036 & TRN & & \\
\hline CHEMBL412034 & 47858 & 8.699 & 8.3594 & TRN & & \\
\hline CHEMBL118556 & 47858 & 5.58 & 6.4802 & TRN & & \\
\hline CHEMBL 325020 & 47858 & 6.176 & 6.2322 & TRN & & \\
\hline CHEMBL402668 & 47858 & 6.477 & 7.5182 & TST & & \\
\hline CHEMBL386566 & 47858 & \multicolumn{3}{|c|}{7.212000000000001} & 6.9024 & TRN \\
\hline CHEMBL 386200 & 47858 & 7.478 & 6.6534 & TRN & & \\
\hline CHEMBL402667 & 47858 & 7.058 & 7.1381 & TRN & & \\
\hline CHEMBL 268344 & 47858 & \multicolumn{3}{|c|}{7.247999999999999} & 6.5087 & TST \\
\hline CHEMBL 216628 & 47858 & 7.347 & 7.8451 & TRN & & \\
\hline CHEMBL 386067 & 47858 & 7.444 & 6.8332 & TRN & & \\
\hline CHEMBL 334030 & 47858 & \multicolumn{3}{|c|}{6.792999999999999} & 6.1465 & TRN \\
\hline CHEMBL 385599 & 47858 & \multicolumn{3}{|c|}{6.622999999999999} & 5.7573 & TRN \\
\hline CHEMBL432249 & 47858 & 5.146 & 6.2423 & TRN & & \\
\hline CHEMBL120256 & 47858 & 6.495 & 6.1971 & TRN & & \\
\hline CHEMBL406562 & 47858 & 7.921 & 8.2595 & TST & & \\
\hline \multirow[t]{2}{*}{ CHEMBL386299 } & 47858 & 8.495 & 7.6828 & TRN & & \\
\hline & & \multicolumn{5}{|c|}{ Page 207} \\
\hline
\end{tabular}




\begin{tabular}{|c|c|c|c|c|c|c|}
\hline \multirow[b]{2}{*}{ CHEMBL407345 } & \multirow[b]{2}{*}{47858} & \multicolumn{5}{|c|}{ Supplemental Table S2.txt } \\
\hline & & 6.682 & 6.5618 & TRN & & \\
\hline CHEMBL331109 & 47858 & 8.0 & 7.3317 & TRN & & \\
\hline CHEMBL264902 & 47858 & 6.682 & 6.7874 & TRN & & \\
\hline CHEMBL429894 & 47858 & 7.772 & 7.8503 & TRN & & \\
\hline CHEMBL438282 & 47858 & \multicolumn{3}{|c|}{6.3420000000000005} & 6.4807 & TRN \\
\hline CHEMBL408536 & 47858 & \multicolumn{3}{|c|}{7.178999999999999} & 7.1732 & TRN \\
\hline CHEMBL 2111780 & 47858 & 6.419 & 7.15 & TRN & & \\
\hline CHEMBL214420 & 47858 & 7.585 & 7.1027 & TRN & & \\
\hline CHEMBL263599 & 47858 & 7.682 & 6.8069 & TRN & & \\
\hline CHEMBL384056 & 47858 & 6.145 & 6.7581 & TRN & & \\
\hline CHEMBL262132 & 47858 & 7.398 & 6.9193 & TRN & & \\
\hline CHEMBL407614 & 47858 & 8.149 & 7.2295 & TST & & \\
\hline CHEMBL415513 & 47858 & \multicolumn{3}{|c|}{6.196000000000001} & 7.1732 & TRN \\
\hline CHEMBL118985 & 47858 & 6.954 & 6.9951 & TRN & & \\
\hline CHEMBL118223 & 47858 & \multicolumn{3}{|c|}{6.667999999999999} & 7.3352 & TRN \\
\hline CHEMBL415603 & 47858 & \multicolumn{3}{|c|}{6.792999999999999} & 6.5035 & TRN \\
\hline CHEMBL333457 & 47858 & 6.211 & 6.7677 & TRN & & \\
\hline CHEMBL431673 & 47858 & \multicolumn{3}{|c|}{7.6579999999999995} & 7.5615 & TRN \\
\hline CHEMBL120035 & 47858 & 8.032 & 8.0364 & TRN & & \\
\hline CHEMBL324787 & 47858 & 5.38 & 5.303 & TST & & \\
\hline CHEMBL119267 & 47858 & 6.477 & 6.4933 & TRN & & \\
\hline CHEMBL325531 & 47858 & 6.898 & 6.9648 & TRN & & \\
\hline CHEMBL331323 & 47858 & 7.642 & 7.9698 & TRN & & \\
\hline CHEMBL 263228 & 47858 & \multicolumn{3}{|c|}{8.097000000000001} & 7.3009 & TRN \\
\hline CHEMBL424714 & 47858 & 5.301 & 7.1895 & TST & & \\
\hline CHEMBL407741 & 47858 & 6.0 & 5.982 & TRN & & \\
\hline CHEMBL264021 & 47858 & \multicolumn{3}{|c|}{6.082000000000001} & 6.6336 & TRN \\
\hline CHEMBL 263440 & 47858 & 7.187 & 7.2948 & TRN & & \\
\hline CHEMBL118999 & 47858 & \multirow{2}{*}{\multicolumn{3}{|c|}{5.3420000000000005}} & & \\
\hline CHEMBL431472 & 47858 & & & & 6.0509 & TRN \\
\hline CHEMBL120232 & 47858 & 7.119 & 6.3214 & TRN & & \\
\hline CHEMBL428098 & 47858 & 8.237 & 8.2372 & TRN & & \\
\hline CHEMBL420704 & 47858 & 5.146 & 6.3435 & TRN & & \\
\hline CHEMBL119275 & 47858 & 6.415 & 5.7686 & TRN & & \\
\hline CHEMBL447477 & 47858 & 6.785 & 7.1233 & TRN & & \\
\hline CHEMBL 266756 & 47858 & 6.875 & 7.0516 & TST & & \\
\hline CHEMBL333017 & 47858 & 5.58 & 6.5837 & TRN & & \\
\hline CHEMBL269257 & 47858 & 5.74 & 6.489 & TST & & \\
\hline CHEMBL333432 & 47858 & \multicolumn{3}{|c|}{6.832000000000001} & 6.7269 & TRN \\
\hline CHEMBL 266418 & 47858 & 7.644 & 6.4771 & TST & & \\
\hline CHEMBL428270 & 47858 & 6.726 & 7.1841 & TST & & \\
\hline CHEMBL 323837 & 47858 & 7.585 & 6.5363 & TST & & \\
\hline CHEMBL216217 & 47858 & \multicolumn{3}{|c|}{7.462999999999999} & 7.2018 & TST \\
\hline CHEMBL439360 & 47858 & 7.77 & 7.3843 & TST & & \\
\hline CHEMBL332016 & 47858 & \multicolumn{3}{|c|}{6.622999999999999} & 7.5413 & TST \\
\hline CHEMBL 269268 & 47858 & \multicolumn{3}{|c|}{6.622999999999999} & 7.4397 & TST \\
\hline CHEMBL405270 & 47858 & 8.125 & 7.9 & TST & & \\
\hline CHEMBL214423 & 47858 & 7.824 & 7.9338 & TST & & \\
\hline
\end{tabular}




\begin{tabular}{|c|c|c|c|c|c|c|}
\hline & & \multicolumn{5}{|c|}{ Supplemental Table S2.txt } \\
\hline CHEMBL121646 & 47858 & 7.932 & 8.1969 & TST & & \\
\hline CHEMBL334056 & 47858 & 7.818 & 8.0574 & TST & & \\
\hline CHEMBL263685 & 47858 & 7.939 & 8.0813 & TST & & \\
\hline CHEMBL430065 & 47858 & 8.05299 & 99999999 & & 7.3719 & TST \\
\hline CHEMBL333289 & 47858 & 7.38299 & 99999999 & 99 & 7.7164 & TST \\
\hline CHEMBL325914 & 47858 & 8.237 & 6.4802 & TST & & \\
\hline CHEMBL440266 & 47858 & 8.31 & 8.5497 & TST & & \\
\hline CHEMBL426344 & 47858 & 8.481 & 7.8817 & TST & & \\
\hline CHEMBL215223 & 47858 & 6.947 & 6.7006 & TST & & \\
\hline CHEMBL483453 & 535054 & 4.5086 & 4.8625 & TST & & \\
\hline CHEMBL490803 & 535054 & 2.8356 & 2.8354 & TRN & & \\
\hline CHEMBL489605 & 535054 & 4.2441 & 4.2473 & TRN & & \\
\hline CHEMBL521620 & 535054 & 2.4522 & 2.4399 & TRN & & \\
\hline CHEMBL448179 & 535054 & 4.2291 & 4.2309 & TRN & & \\
\hline CHEMBL492044 & 535054 & 3.6882 & 4.5495 & TST & & \\
\hline CHEMBL137048 & 535054 & 3.7595 & 3.7682 & TRN & & \\
\hline CHEMBL489573 & 535054 & 4.0044 & 3.9966 & TRN & & \\
\hline CHEMBL505028 & 535054 & 3.9747 & 3.9723 & TRN & & \\
\hline CHEMBL489160 & 535054 & 5.4318 & 5.4299 & TRN & & \\
\hline CHEMBL343131 & 535054 & 5.1871 & 5.1875 & TRN & & \\
\hline CHEMBL490392 & 535054 & 4.9586 & 4.9584 & TRN & & \\
\hline CHEMBL504636 & 535054 & 2.475 & 2.4797 & TRN & & \\
\hline CHEMBL337564 & 535054 & 5.2076 & 5.2047 & TRN & & \\
\hline CHEMBL137710 & 535054 & 5.1612 & 5.1568 & TRN & & \\
\hline CHEMBL490802 & 535054 & 5.0 & 4.0251 & TST & & \\
\hline CHEMBL491414 & 535054 & 2.4711 & 2.4733 & TRN & & \\
\hline CHEMBL 335144 & 535054 & 4.8861 & 4.8997 & TRN & & \\
\hline CHEMBL489572 & 535054 & 5.2076 & 5.2019 & TRN & & \\
\hline CHEMBL488934 & 535054 & 3.2757 & 3.2804 & TRN & & \\
\hline CHEMBL137345 & 535054 & 5.0605 & 5.0609 & TRN & & \\
\hline CHEMBL342263 & 535054 & 4.0315 & 4.0446 & TRN & & \\
\hline CHEMBL447605 & 535054 & 5.699 & 5.7017 & TRN & & \\
\hline CHEMBL488957 & 535054 & 4.9586 & 4.9555 & TRN & & \\
\hline CHEMBL484875 & 535054 & 5.1308 & 5.1259 & TRN & & \\
\hline CHEMBL133137 & 535054 & 4.2676 & 4.2707 & TRN & & \\
\hline CHEMBL522452 & 535054 & 2.4895 & 2.4884 & TRN & & \\
\hline CHEMBL492043 & 535054 & 3.6308 & 3.6317 & TRN & & \\
\hline CHEMBL342663 & 535054 & 3.0915 & 3.0903 & TRN & & \\
\hline CHEMBL506352 & 535054 & 5.2441 & 5.2384 & TRN & & \\
\hline CHEMBL484874 & 535054 & 4.9586 & 4.958 & TRN & & \\
\hline CHEMBL482620 & 535054 & 2.4535 & 2.4455 & TRN & & \\
\hline CHEMBL137761 & 535054 & 5.3872 & 5.3981 & TRN & & \\
\hline CHEMBL490391 & 535054 & 5.1739 & 5.1773 & TRN & & \\
\hline CHEMBL135319 & 535054 & 5.3098 & 5.3131 & TRN & & \\
\hline CHEMBL335123 & 535054 & 4.4559 & 4.4687 & TRN & & \\
\hline CHEMBL483240 & 535054 & 5.301 & 5.3093 & TRN & & \\
\hline CHEMBL490393 & 535054 & 2.4815 & 4.6283 & TST & & \\
\hline CHEMBL444158 & 535054 & 2.4535 & 2.4588 & TRN & & \\
\hline
\end{tabular}


Supplemental Table S2.txt

\begin{tabular}{|c|c|c|c|c|c|c|}
\hline CHEMBL335547 & 535054 & 4.9208 & 4.9159 & TRN & & \\
\hline CHEMBL422450 & 535054 & 5.4202 & 5.4064 & TRN & & \\
\hline CHEMBL345072 & 535054 & 5.3098 & 5.3149 & TRN & & \\
\hline CHEMBL336203 & 535054 & 5.301 & 5.2985 & TRN & & \\
\hline CHEMBL137439 & 535054 & 4.3372 & 4.329 & TRN & & \\
\hline CHEMBL484064 & 535054 & 4.2441 & 4.2401 & TRN & & \\
\hline CHEMBL489161 & 535054 & 5.1367 & 5.1262 & TRN & & \\
\hline CHEMBL136778 & 535054 & 2.8447 & 2.8448 & TRN & & \\
\hline CHEMBL491415 & 535054 & 3.9172 & 3.9151 & TRN & & \\
\hline CHEMBL491838 & 535054 & 5.2441 & 5.2437 & TRN & & \\
\hline CHEMBL489606 & 535054 & 5.1938 & 4.5029 & TST & & \\
\hline CHEMBL489780 & 535054 & 5.585 & 4.2608 & TST & & \\
\hline CHEMBL483044 & 535054 & 2.4737 & 3.0598 & TST & & \\
\hline CHEMBL483452 & 535054 & 4.3979 & 4.4102 & TST & & \\
\hline CHEMBL482836 & 535054 & 5.4815 & 4.8195 & TST & & \\
\hline CHEMBL502106 & 535054 & 5.4318 & 4.5777 & TST & & \\
\hline CHEMBL338493 & 535054 & 5.2441 & 5.949 & TST & & \\
\hline CHEMBL482417 & 535054 & \multicolumn{3}{|c|}{3.6180000000000003} & 3.6954 & TST \\
\hline CHEMBL490804 & 535054 & 4.1427 & 3.8576 & TST & & \\
\hline CHEMBL490587 & 535054 & 4.4089 & 4.3233 & TST & & \\
\hline CHEMBL482837 & 535054 & 3.9172 & 3.3361 & TST & & \\
\hline CHEMBL447163 & 535054 & 4.4202 & 4.874 & TST & & \\
\hline CHEMBL333127 & 69119 & 4.0 & 4.1779 & TRN & & \\
\hline CHEMBL126187 & 69119 & 5.2757 & 5.4066 & TRN & & \\
\hline CHEMBL339940 & 69119 & 4.0 & 5.3354 & TRN & & \\
\hline CHEMBL125526 & 69119 & 5.301 & 5.5017 & TRN & & \\
\hline CHEMBL341010 & 69119 & 4.0 & 4.0333 & TRN & & \\
\hline CHEMBL126653 & 69119 & 5.3979 & 5.4933 & TST & & \\
\hline CHEMBL126890 & 69119 & 4.0 & 3.6993 & TRN & & \\
\hline CHEMBL126456 & 69119 & 6.1938 & 5.5546 & TRN & & \\
\hline CHEMBL420347 & 69119 & 4.0 & 4.1313 & TRN & & \\
\hline CHEMBL340378 & 69119 & 4.0 & 3.8874 & TRN & & \\
\hline CHEMBL338103 & 69119 & 6.0044 & 5.9796 & TRN & & \\
\hline CHEMBL339084 & 69119 & 4.0 & 4.0355 & TRN & & \\
\hline CHEMBL434240 & 69119 & 4.0 & 4.2163 & TRN & & \\
\hline CHEMBL125515 & 69119 & 5.3468 & 5.6108 & TRN & & \\
\hline CHEMBL338472 & 69119 & 6.3188 & 6.0286 & TRN & & \\
\hline CHEMBL340257 & 69119 & 5.2147 & 5.4671 & TRN & & \\
\hline CHEMBL127647 & 69119 & 6.1135 & 5.7646 & TRN & & \\
\hline CHEMBL129592 & 69119 & 6.1871 & 6.2178 & TRN & & \\
\hline CHEMBL338218 & 69119 & 6.3768 & 6.2686 & TRN & & \\
\hline CHEMBL340617 & 69119 & 4.0 & 4.112 & TST & & \\
\hline CHEMBL129591 & 69119 & 6.301 & 6.2434 & TRN & & \\
\hline CHEMBL340114 & 69119 & 4.0 & 4.4281 & TRN & & \\
\hline CHEMBL125527 & 69119 & 5.8539 & 5.9304 & TRN & & \\
\hline CHEMBL126668 & 69119 & 6.0809 & 6.0663 & TRN & & \\
\hline CHEMBL65250 & 69119 & 6.6021 & 6.0828 & TST & & \\
\hline CHEMBL341121 & 69119 & 6.0177 & 5.6825 & TRN & & \\
\hline
\end{tabular}




\begin{tabular}{|c|c|c|c|c|}
\hline & & & oplement & al $\mathrm{T}$ \\
\hline CHEMBL126974 & 69119 & 5.9208 & 5.5672 & TRN \\
\hline CHEMBL125861 & 69119 & 6.4089 & 6.0127 & TRN \\
\hline CHEMBL127893 & 69119 & 5.9208 & 5.893 & TRN \\
\hline CHEMBL129713 & 69119 & 5.8539 & 5.8491 & TRN \\
\hline CHEMBL127970 & 69119 & 5.2218 & 5.4443 & TRN \\
\hline CHEMBL340622 & 69119 & 4.0 & 4.0771 & TRN \\
\hline CHEMBL340714 & 69119 & 6.2147 & 6.1848 & TRN \\
\hline CHEMBL125086 & 69119 & 5.8539 & 5.9312 & TST \\
\hline CHEMBL63451 & 69119 & 4.0 & 3.552 & TST \\
\hline CHEMBL127926 & 69119 & 5.1367 & 5.1838 & TRN \\
\hline CHEMBL420520 & 69119 & 4.0 & 4.9147 & TRN \\
\hline CHEMBL338673 & 69119 & 5.2147 & 5.2732 & TRN \\
\hline CHEMBL126588 & 69119 & 4.0 & 4.2226 & TST \\
\hline CHEMBL127159 & 69119 & 5.7447 & 5.769 & TRN \\
\hline CHEMBL434636 & 69119 & 4.0 & 3.938 & TRN \\
\hline CHEMBL126310 & 69119 & 5.7447 & 5.6433 & TRN \\
\hline CHEMBL127367 & 69119 & 6.1938 & 6.1178 & TST \\
\hline CHEMBL341075 & 69119 & 5.585 & 5.5233 & TRN \\
\hline CHEMBL340862 & 69119 & 6.0088 & 5.9195 & TST \\
\hline CHEMBL443033 & 69119 & 6.0969 & 6.0107 & TRN \\
\hline CHEMBL338427 & 69119 & 4.0 & 3.8633 & TRN \\
\hline CHEMBL338375 & 69119 & 6.6576 & 6.766 & TRN \\
\hline CHEMBL123918 & 69119 & 4.0 & 4.6166 & TRN \\
\hline CHEMBL127542 & 69119 & 5.6383 & 4.9147 & TRN \\
\hline CHEMBL338691 & 69119 & 4.0 & 4.0499 & TST \\
\hline CHEMBL339339 & 69119 & 4.0 & 4.2335 & TRN \\
\hline CHEMBL434253 & 69119 & 5.3872 & 5.6138 & TRN \\
\hline CHEMBL421091 & 69119 & 5.6198 & 5.4561 & TRN \\
\hline CHEMBL125920 & 69119 & 6.1367 & 6.1325 & TRN \\
\hline CHEMBL129424 & 69119 & 5.6778 & 5.8136 & TRN \\
\hline CHEMBL338533 & 69119 & 6.0 & 5.8155 & TRN \\
\hline CHEMBL127424 & 69119 & 4.0 & 4.0689 & TRN \\
\hline CHEMBL127178 & 69119 & 4.0 & 4.0227 & TRN \\
\hline CHEMBL127458 & 69119 & 6.0809 & 5.8489 & TRN \\
\hline CHEMBL128027 & 69119 & 6.0 & 5.9278 & TRN \\
\hline CHEMBL177671 & 69119 & 5.6778 & 5.7227 & TRN \\
\hline CHEMBL338164 & 69119 & 5.0969 & 5.2253 & TRN \\
\hline CHEMBL126466 & 69119 & 6.0605 & 6.0465 & TRN \\
\hline CHEMBL340660 & 69119 & 5.4559 & 5.806 & TRN \\
\hline CHEMBL124816 & 69119 & 5.2518 & 4.3221 & TRN \\
\hline CHEMBL126233 & 69119 & 4.0 & 3.8302 & TRN \\
\hline CHEMBL126360 & 69119 & 5.699 & 5.5975 & TRN \\
\hline CHEMBL340357 & 69119 & 4.0 & 4.1812 & TRN \\
\hline CHEMBL63787 & 69119 & 4.0 & 3.4429 & TST \\
\hline CHEMBL126996 & 69119 & 5.4437 & 5.5232 & TST \\
\hline CHEMBL339328 & 69119 & 6.0 & 6.0199 & TRN \\
\hline CHEMBL125577 & 69119 & 5.8539 & 5.6311 & TRN \\
\hline CHEMBL126192 & 69119 & 6.4202 & 6.3567 & TST \\
\hline
\end{tabular}




\begin{tabular}{|c|c|c|c|c|c|}
\hline \multicolumn{6}{|c|}{ Supplemental Table S2.txt } \\
\hline CHEMBL126769 & 69119 & 5.7696 & 5.6089 & TRN & \\
\hline CHEMBL414241 & 69119 & 4.0 & 5.1168 & TRN & \\
\hline CHEMBL126483 & 69119 & 5.8239 & 5.9278 & TRN & \\
\hline CHEMBL127694 & 69119 & 5.8861 & 4.4583 & TRN & \\
\hline CHEMBL127935 & 69119 & 5.3565 & 5.2879 & TRN & \\
\hline CHEMBL127835 & 69119 & 4.0 & 3.9521 & TRN & \\
\hline CHEMBL127223 & 69119 & 6.4089 & 6.1534 & TST & \\
\hline CHEMBL67906 & 69119 & 4.0 & 3.4977 & TST & \\
\hline CHEMBL127673 & 69119 & 6.1079 & 6.2108 & TST & \\
\hline CHEMBL419776 & 69119 & 6.0315 & 5.8438 & TST & \\
\hline CHEMBL127249 & 69119 & 4.0 & 4.1779 & TST & \\
\hline CHEMBL127793 & 69119 & 4.0 & 4.6166 & TST & \\
\hline CHEMBL127292 & 69119 & 5.4685 & 5.893 & TST & \\
\hline CHEMBL126645 & 69119 & 4.0 & 3.6819 & TST & \\
\hline CHEMBL127354 & 69119 & 5.8239 & 5.9377 & TST & \\
\hline CHEMBL123678 & 69119 & 6.0809 & 6.0246 & TST & \\
\hline CHEMBL127948 & 69119 & 5.7696 & 5.8818 & TST & \\
\hline CHEMBL2152992 & 852361 & 5.9066 & 5.6761 & TRN & \\
\hline CHEMBL2153139 & 852361 & 5.4342 & 5.2026 & TRN & \\
\hline CHEMBL 2153133 & 852361 & 6.8861 & 6.5972 & TRN & \\
\hline CHEMBL 2152977 & 852361 & 4.0 & 3.7547 & TRN & \\
\hline CHEMBL2153149 & 852361 & 5.3089 & 5.3973 & TRN & \\
\hline CHEMBL2153130 & 852361 & 5.059 & 4.9662 & TRN & \\
\hline CHEMBL2153145 & 852361 & 5.3288 & 5.3422 & TRN & \\
\hline CHEMBL 2153152 & 852361 & 4.0 & 4.53600 & 00000000005 & TRN \\
\hline CHEMBL 2153135 & 852361 & 7.0 & 7.5392 & TRN & \\
\hline CHEMBL2153142 & 852361 & 5.0482 & 4.7512 & TRN & \\
\hline CHEMBL2153151 & 852361 & 5.8633 & 5.4571 & TRN & \\
\hline CHEMBL2153156 & 852361 & 5.5719 & 5.694 & TST & \\
\hline CHEMBL 2153143 & 852361 & 5.2104 & 5.0408 & TRN & \\
\hline CHEMBL 2152993 & 852361 & 4.0 & 4.4995 & TST & \\
\hline CHEMBL2152979 & 852361 & 5.0615 & 5.1314 & TRN & \\
\hline CHEMBL 2152978 & 852361 & 5.5702 & 5.2924 & TRN & \\
\hline CHEMBL2153154 & 852361 & 6.301 & 6.0213 & TRN & \\
\hline CHEMBL 2153150 & 852361 & 4.0 & 4.1978 & TRN & \\
\hline CHEMBL2152986 & 852361 & 5.1733 & 4.3769 & TST & \\
\hline CHEMBL 2152976 & 852361 & 4.0 & 4.2847 & TRN & \\
\hline CHEMBL 2153129 & 852361 & 5.7545 & 5.8433 & TRN & \\
\hline CHEMBL2153125 & 852361 & 5.9031 & 6.0865 & TRN & \\
\hline CHEMBL2152997 & 852361 & 5.1739 & 5.0962 & TRN & \\
\hline CHEMBL2153132 & 852361 & 5.1249 & 4.8131 & TRN & \\
\hline CHEMBL 2153137 & 852361 & 5.4935 & 5.6893 & TRN & \\
\hline CHEMBL 2152988 & 852361 & 4.0 & 4.5293 & TRN & \\
\hline CHEMBL2153127 & 852361 & 5.6676 & 5.9447 & TST & \\
\hline CHEMBL 2152975 & 852361 & 5.4461 & 5.50899 & 99999999995 & TRN \\
\hline CHEMBL 2153122 & 852361 & 5.6517 & 6.0668 & TRN & \\
\hline CHEMBL2153123 & 852361 & 5.6345 & 5.831 & TRN & \\
\hline CHEMBL2153155 & 852361 & 6.2924 & 6.3337 & TRN & \\
\hline
\end{tabular}

Page 20803 
Supplemental Table S2.txt

\begin{tabular}{|c|c|c|c|c|c|c|}
\hline CHEMBL2152983 & 852361 & 5.2388 & 5.0013 & TST & & \\
\hline CHEMBL 2152987 & 852361 & 5.0097 & 4.6707 & TRN & & \\
\hline CHEMBL2153146 & 852361 & 5.6289 & 5.3752 & TST & & \\
\hline CHEMBL 2152982 & 852361 & 5.1238 & 5.0594 & TRN & & \\
\hline CHEMBL 2152991 & 852361 & 5.2464 & 5.5261 & TRN & & \\
\hline CHEMBL2152985 & 852361 & 4.0 & 3.928 & TRN & & \\
\hline CHEMBL2153126 & 852361 & 5.7696 & 6.0292 & TST & & \\
\hline CHEMBL2152998 & 852361 & 5.9469 & 6.0641 & TRN & & \\
\hline CHEMBL 2152995 & 852361 & 6.0655 & 6.291 & TRN & & \\
\hline CHEMBL2152990 & 852361 & 5.6737 & 5.3621 & TST & & \\
\hline CHEMBL 2153147 & 852361 & 4.0 & 4.6034 & TST & & \\
\hline CHEMBL2152984 & 852361 & 5.1463 & 4.7997 & TST & & \\
\hline CHEMBL2152994 & 852361 & 6.3279 & 6.0904 & TRN & & \\
\hline CHEMBL2152989 & 852361 & 4.0 & 4.0261 & TST & & \\
\hline CHEMBL2153131 & 852361 & 6.4949 & 5.7716 & TRN & & \\
\hline CHEMBL 2153148 & 852361 & 4.0 & 4.2982 & TRN & & \\
\hline CHEMBL67 & 852361 & 9.0 & 7.0877 & TST & & \\
\hline CHEMBL2152981 & 852361 & 5.1675 & 4.6338 & TST & & \\
\hline CHEMBL2153141 & 852361 & 5.4895 & 5.6041 & TRN & & \\
\hline CHEMBL 2153134 & 852361 & 6.8239 & 6.565 & TRN & & \\
\hline CHEMBL 2153140 & 852361 & 4.0 & 4.0449 & TRN & & \\
\hline CHEMBL2153136 & 852361 & 5.7747 & 6.1033 & TST & & \\
\hline CHEMBL 2153153 & 852361 & 5.8794 & 5.9878 & TRN & & \\
\hline CHEMBL2153144 & 852361 & 4.0 & 4.2991 & TRN & & \\
\hline CHEMBL2153124 & 852361 & 5.5317 & 5.4643 & TRN & & \\
\hline CHEMBL 2152974 & 852361 & 4.0 & 5.1836 & TST & & \\
\hline CHEMBL 2153128 & 852361 & 5.5986 & 5.3253 & TRN & & \\
\hline CHEMBL 2152996 & 852361 & 5.5918 & 5.6679 & TRN & & \\
\hline CHEMBL2152980 & 852361 & 5.2692 & 4.7354 & TST & & \\
\hline CHEMBL2153138 & 852361 & \multicolumn{3}{|c|}{5.718999999999999} & 5.6574 & TRN \\
\hline CHEMBL357338 & 210045 & 3.301 & 3.2826 & TST & & \\
\hline CHEMBL345932 & 210045 & 3.301 & 3.1462 & TRN & & \\
\hline CHEMBL135287 & 210045 & 3.301 & 3.3625 & TRN & & \\
\hline CHEMBL356232 & 210045 & 5.2291 & 3.7342 & TST & & \\
\hline CHEMBL152700 & 210045 & 3.301 & 3.1645 & TRN & & \\
\hline CHEMBL152712 & 210045 & 4.4949 & 4.6641 & TRN & & \\
\hline CHEMBL153356 & 210045 & 4.3768 & 3.3614 & TST & & \\
\hline CHEMBL152142 & 210045 & 5.6021 & 5.9034 & TRN & & \\
\hline CHEMBL152313 & 210045 & 3.2441 & 5.2394 & TST & & \\
\hline CHEMBL135504 & 210045 & 3.301 & 3.4229 & TRN & & \\
\hline CHEMBL153583 & 210045 & 5.585 & 5.4064 & TRN & & \\
\hline CHEMBL152868 & 210045 & 3.301 & 3.2874 & TRN & & \\
\hline CHEMBL155143 & 210045 & 5.301 & 5.1692 & TRN & & \\
\hline CHEMBL152394 & 210045 & 5.2218 & 5.0205 & TRN & & \\
\hline CHEMBL152422 & 210045 & 5.7696 & 6.004 & TRN & & \\
\hline CHEMBL152558 & 210045 & 3.2441 & 3.891 & TST & & \\
\hline CHEMBL358636 & 210045 & 6.3468 & 5.8368 & TRN & & \\
\hline CHEMBL152954 & 210045 & 5.2076 & 5.1122 & TRN & & \\
\hline
\end{tabular}

Page 20804 


\begin{tabular}{|c|c|c|c|c|c|}
\hline \multicolumn{6}{|c|}{ Supplemental Table S2.txt } \\
\hline CHEMBL152191 & 210045 & 3.301 & 3.4253 & TRN & \\
\hline CHEMBL134615 & 210045 & 3.301 & 3.3847 & TRN & \\
\hline CHEMBL153789 & 210045 & 3.2441 & 4.9875 & TST & \\
\hline CHEMBL152532 & 210045 & 3.6021 & 3.6536 & TRN & \\
\hline CHEMBL152822 & 210045 & 3.301 & 3.1322 & TRN & \\
\hline CHEMBL346422 & 210045 & 5.5086 & 5.7939 & TRN & \\
\hline CHEMBL152150 & 210045 & 5.0458 & 4.9712 & TST & \\
\hline CHEMBL152627 & 210045 & 4.5528 & 4.6193 & TRN & \\
\hline CHEMBL154224 & 210045 & 3.6021 & 3.5434 & TRN & \\
\hline CHEMBL153191 & 210045 & 3.301 & 3.4107 & TRN & \\
\hline CHEMBL155515 & 210045 & 5.699 & 5.8357 & TRN & \\
\hline CHEMBL153447 & 210045 & 3.301 & 3.2492 & TRN & \\
\hline CHEMBL152177 & 210045 & 5.5686 & 5.3626 & TRN & \\
\hline CHEMBL153039 & 210045 & 4.9208 & 4.7378 & TRN & \\
\hline CHEMBL153197 & 210045 & 3.301 & 3.2901 & TST & \\
\hline CHEMBL443557 & 210045 & 4.3565 & 4.4532 & TRN & \\
\hline CHEMBL151680 & 210045 & 3.6021 & 3.4496 & TST & \\
\hline CHEMBL152353 & 210045 & 4.301 & 3.34899 & و9999999998 & TST \\
\hline CHEMBL153337 & 210045 & 4.5528 & 4.8941 & TRN & \\
\hline CHEMBL152312 & 210045 & 3.2441 & 3.9572 & TST & \\
\hline CHEMBL358688 & 210045 & 3.2441 & 2.9424 & TRN & \\
\hline CHEMBL345281 & 210045 & 5.5376 & 5.6194 & TRN & \\
\hline CHEMBL153287 & 210045 & 3.6021 & 3.5195 & TST & \\
\hline CHEMBL152629 & 210045 & 5.7959 & 5.9834 & TRN & \\
\hline CHEMBL355938 & 210045 & 5.9508 & 5.7127 & TRN & \\
\hline CHEMBL153450 & 210045 & 3.2441 & 3.6432 & TST & \\
\hline CHEMBL152234 & 210045 & 5.6383 & 5.6839 & TRN & \\
\hline CHEMBL152807 & 210045 & 5.8539 & 5.6556 & TRN & \\
\hline CHEMBL153399 & 210045 & 5.5376 & 3.7666 & TST & \\
\hline CHEMBL152768 & 210045 & 5.0 & 5.0636 & TRN & \\
\hline CHEMBL351108 & 210045 & 5.3468 & 5.3859 & TRN & \\
\hline CHEMBL152794 & 210045 & 3.301 & 3.5423 & TST & \\
\hline CHEMBL153514 & 210045 & 5.7212 & 5.4503 & TRN & \\
\hline CHEMBL152787 & 210045 & 6.0969 & 5.2112 & TRN & \\
\hline CHEMBL151798 & 210045 & 3.301 & 3.4164 & TRN & \\
\hline CHEMBL152345 & 210045 & 4.2441 & 4.46399 & 99999999995 & TRN \\
\hline CHEMBL152874 & 210045 & 4.4202 & 4.3383 & TRN & \\
\hline CHEMBL348457 & 210045 & 5.7696 & 5.6564 & TRN & \\
\hline CHEMBL152308 & 210045 & 5.1871 & 5.0054 & TRN & \\
\hline CHEMBL152395 & 210045 & 3.2441 & 3.238 & TRN & \\
\hline CHEMBL152178 & 210045 & 3.301 & 4.4709 & TRN & \\
\hline CHEMBL152753 & 210045 & 3.6021 & 3.6588 & TST & \\
\hline CHEMBL153804 & 210045 & 5.3979 & 5.3436 & TRN & \\
\hline CHEMBL152263 & 210045 & 3.301 & 3.2783 & TRN & \\
\hline CHEMBL152285 & 210045 & 4.757 & 3.3772 & TST & \\
\hline CHEMBL152534 & 210045 & 5.699 & 5.5176 & TRN & \\
\hline CHEMBL153574 & 210045 & 5.6383 & 5.5717 & TRN & \\
\hline CHEMBL153554 & 210045 & 5.6021 & 5.49 & TRN & \\
\hline
\end{tabular}




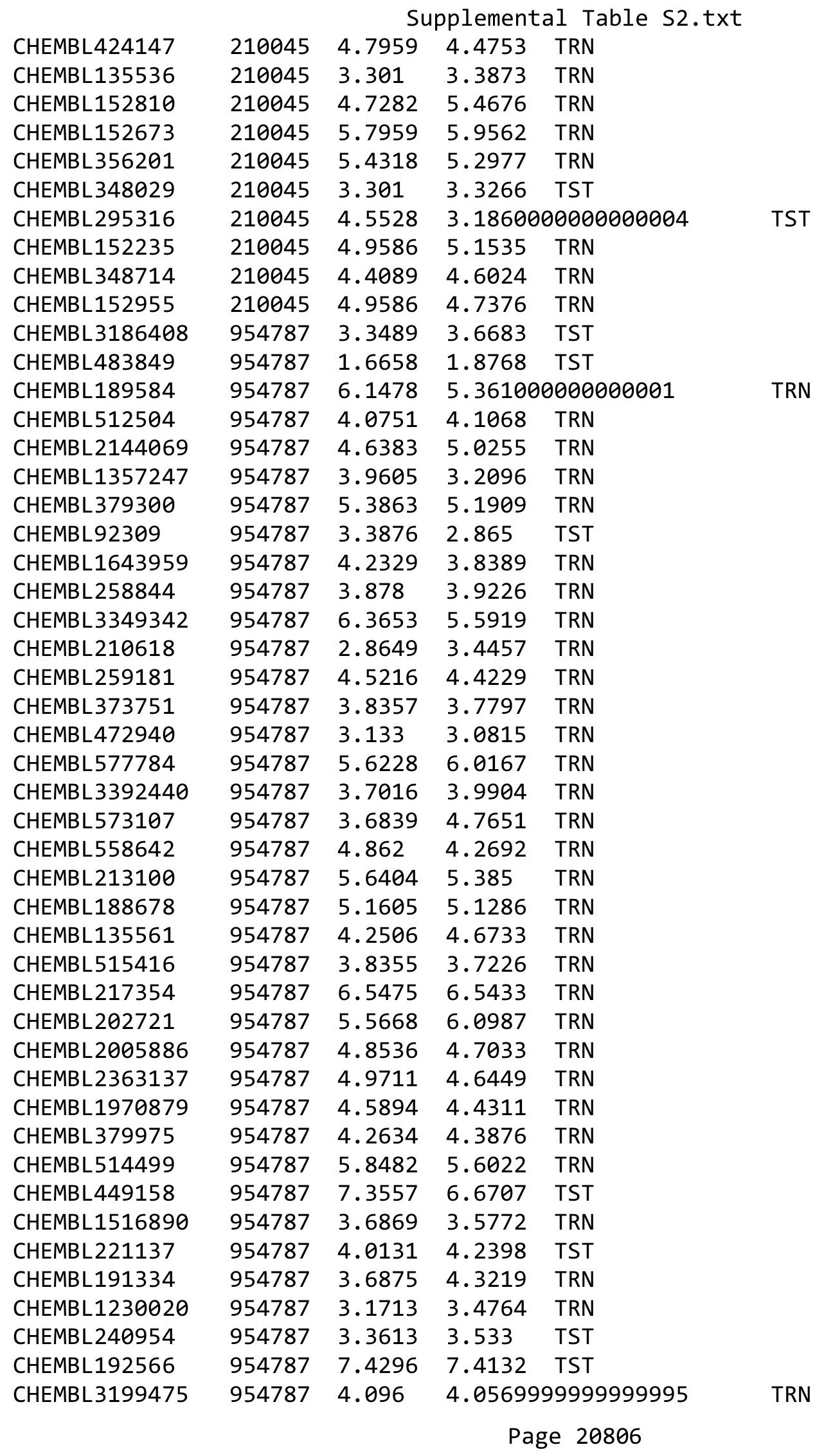




\begin{tabular}{|c|c|c|c|c|c|}
\hline \multirow[b]{2}{*}{ CHEMBL1186585 } & \multirow[b]{2}{*}{954787} & \multicolumn{4}{|c|}{ Supplemental Table s2.txt } \\
\hline & & 3.7311 & 4.0354 & TRN & \\
\hline CHEMBL 209148 & 954787 & 3.7972 & 4.1916 & TRN & \\
\hline CHEMBL1242367 & 954787 & 3.6149 & 3.6869 & TRN & \\
\hline CHEMBL1788116 & 954787 & 3.2796 & 3.6143 & TRN & \\
\hline CHEMBL220241 & 954787 & 7.0701 & 6.7824 & TRN & \\
\hline CHEMBL1909414 & 954787 & 3.242 & 3.4008 & TRN & \\
\hline CHEMBL1590308 & 954787 & 2.8856 & 3.0903 & TST & \\
\hline CHEMBL2137530 & 954787 & 4.4399 & 4.0899 & TRN & \\
\hline CHEMBL 222102 & 954787 & 4.5325 & 4.4336 & TRN & \\
\hline CHEMBL412142 & 954787 & 3.9627 & 3.7418 & TRN & \\
\hline CHEMBL1256459 & 954787 & 6.1798 & 5.7539 & TRN & \\
\hline CHEMBL9470 & 954787 & 5.6517 & 5.1442 & TST & \\
\hline CHEMBL 2134202 & 954787 & 3.7561 & 3.4357 & TRN & \\
\hline CHEMBL65 & 954787 & 8.0403 & 8.3453 & TRN & \\
\hline CHEMBL180127 & 954787 & 3.8044 & 3.7006 & TRN & \\
\hline CHEMBL399530 & 954787 & 3.4525 & 3.9566 & TRN & \\
\hline CHEMBL393929 & 954787 & 3.6983 & 3.7821 & TRN & \\
\hline CHEMBL392695 & 954787 & 3.9213 & 3.7693 & TRN & \\
\hline CHEMBL509032 & 954787 & 5.0678 & 5.1768 & TRN & \\
\hline CHEMBL255342 & 954787 & 3.7629 & 3.2873 & TST & \\
\hline CHEMBL483847 & 954787 & 3.9041 & 4.4465 & TST & \\
\hline CHEMBL1190711 & 954787 & 3.6415 & 4.8407 & TST & \\
\hline CHEMBL300389 & 954787 & 5.8086 & 5.73600 & $\partial 000000001$ & TST \\
\hline CHEMBL585951 & 954787 & 6.1394 & 5.9119 & TST & \\
\hline CHEMBL102714 & 954787 & 4.0458 & 3.3418 & TST & \\
\hline CHEMBL1404918 & 954787 & 2.8754 & 2.9864 & TST & \\
\hline CHEMBL1673039 & 954787 & 4.9438 & 4.5069 & TST & \\
\hline CHEMBL 2028179 & 737371 & 3.0 & 3.5176 & TRN & \\
\hline CHEMBL1519111 & 737371 & 4.58 & 4.4267 & TRN & \\
\hline CHEMBL1470091 & 737371 & 4.3098 & 4.1182 & TRN & \\
\hline CHEMBL1559307 & 737371 & 4.2182 & 3.9977 & TST & \\
\hline CHEMBL1486697 & 737371 & 3.0 & 3.5067 & TRN & \\
\hline CHEMBL1731833 & 737371 & 4.0506 & 4.216 & TRN & \\
\hline CHEMBL1325366 & 737371 & 4.6459 & 4.3625 & TRN & \\
\hline CHEMBL1408276 & 737371 & 4.3391 & 4.198 & TRN & \\
\hline CHEMBL1470268 & 737371 & 4.2373 & 3.4892 & TST & \\
\hline CHEMBL1519162 & 737371 & 4.2596 & 4.5228 & TRN & \\
\hline CHEMBL1378661 & 737371 & 4.8827 & 4.6503 & TRN & \\
\hline CHEMBL1412423 & 737371 & 4.2013 & 4.1838 & TRN & \\
\hline CHEMBL56393 & 737371 & 5.0953 & 4.6446 & TRN & \\
\hline CHEMBL1564638 & 737371 & 4.21399 & 99999999 & 4.1525 & TRN \\
\hline CHEMBL3190268 & 737371 & 3.0 & 4.1372 & TRN & \\
\hline CHEMBL1318350 & 737371 & 4.1851 & 4.1427 & TST & \\
\hline CHEMBL1310972 & 737371 & 3.0 & 3.8352 & TRN & \\
\hline CHEMBL1968928 & 737371 & 4.1675 & 4.3882 & TRN & \\
\hline CHEMBL1284 & 737371 & 3.0 & 3.5161 & TRN & \\
\hline CHEMBL1993780 & 737371 & 4.3036 & 4.1918 & TRN & \\
\hline CHEMBL164 & 737371 & 4.4908 & 3.50100 & 20000000003 & TRN \\
\hline & & & & 20807 & \\
\hline
\end{tabular}




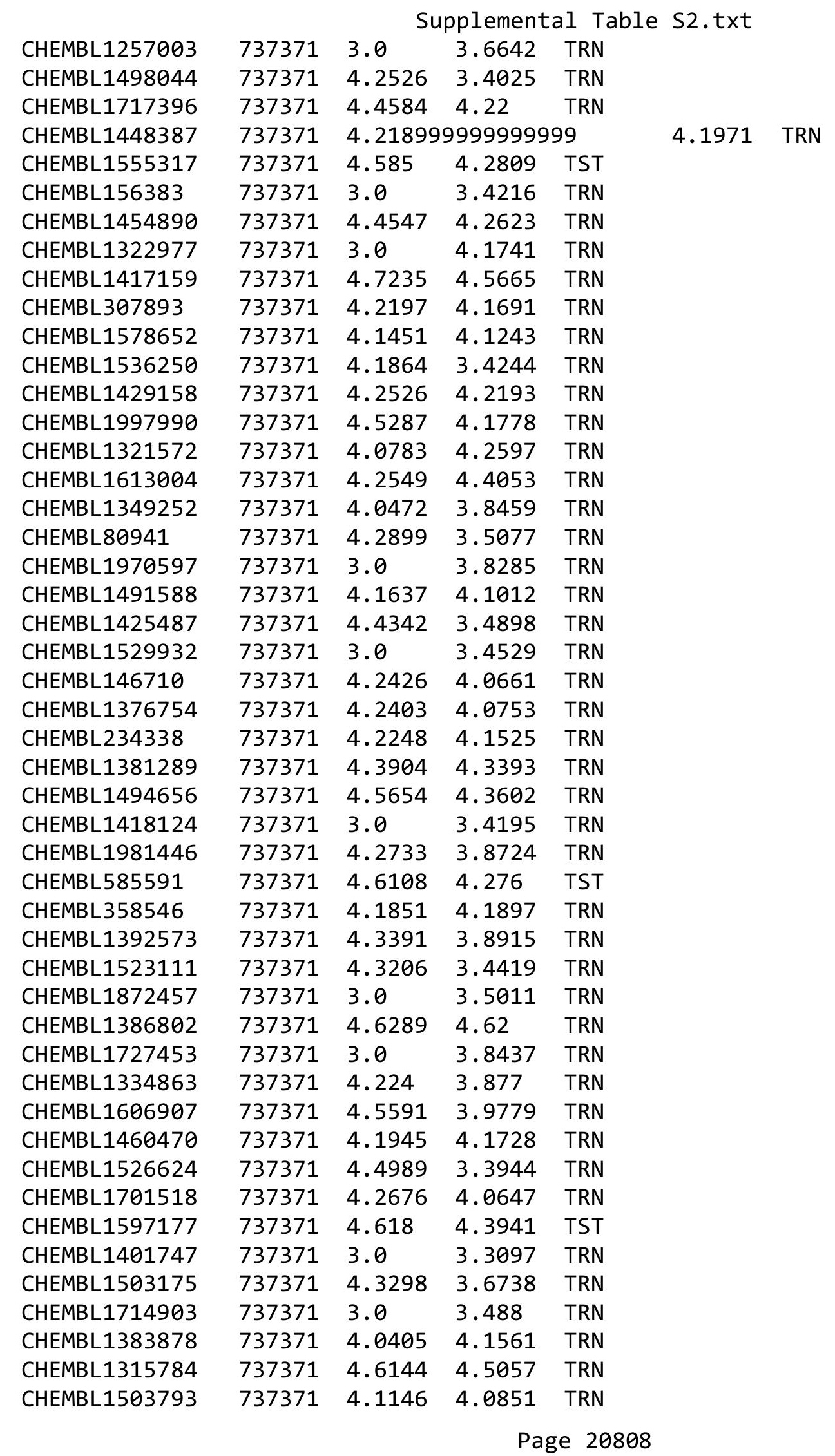


Supplemental Table S2.txt

\begin{tabular}{|c|c|c|c|c|c|}
\hline CHEMBL1982107 & 737371 & 4.1707 & 4.1929 & TRN & \\
\hline CHEMBL1493191 & 737371 & 4.209 & 3.8585 & TRN & \\
\hline CHEMBL1497387 & 737371 & 3.0 & 4.0664 & TRN & \\
\hline CHEMBL1363730 & 737371 & 3.0 & 3.8871 & TRN & \\
\hline CHEMBL1543835 & 737371 & 4.1079 & 4.2363 & TRN & \\
\hline CHEMBL1556531 & 737371 & 3.0 & 3.4508 & TRN & \\
\hline CHEMBL1407474 & 737371 & 4.1367 & 4.1329 & TRN & \\
\hline CHEMBL1380128 & 737371 & 3.0 & 3.4979 & TRN & \\
\hline CHEMBL3192693 & 737371 & 4.1824 & 4.1807 & TRN & \\
\hline CHEMBL1539157 & 737371 & 4.1561 & 4.0744 & TRN & \\
\hline CHEMBL1465511 & 737371 & 4.2248 & 4.1174 & TRN & \\
\hline CHEMBL1471932 & 737371 & 4.7545 & 4.2887 & TRN & \\
\hline CHEMBL1546048 & 737371 & 4.2161 & 3.4696 & TST & \\
\hline CHEMBL1608149 & 737371 & 3.0 & 3.333 & TST & \\
\hline CHEMBL3209801 & 737371 & 4.5834 & 4.0437 & TST & \\
\hline CHEMBL1383312 & 737371 & 4.3161 & 3.4679 & TST & \\
\hline CHEMBL1345538 & 737371 & 4.1898 & 4.1301 & TST & \\
\hline CHEMBL1307459 & 737371 & 4.0716 & 4.0142 & TST & \\
\hline CHEMBL463175 & 737371 & 4.6757 & 4.3192 & TST & \\
\hline CHEMBL1609128 & 737371 & 4.2403 & 4.1534 & TST & \\
\hline CHEMBL1588052 & 737371 & 4.3497 & 3.8491 & TST & \\
\hline CHEMBL1446234 & 737371 & 3.0 & 3.691006 & 00000000003 & TST \\
\hline CHEMBL1574218 & 737371 & 3.0 & 4.0238 & TST & \\
\hline CHEMBL224916 & 737371 & 3.0 & 4.1655 & TST & \\
\hline CHEMBL1986342 & 737371 & 3.0 & 3.4426 & TST & \\
\hline CHEMBL1333659 & 737371 & 3.0 & 4.0887 & TST & \\
\hline CHEMBL1976638 & 737371 & 4.1785 & 4.1618 & TST & \\
\hline CHEMBL1390521 & 737371 & 4.1593 & 4.0255 & TST & \\
\hline CHEMBL1609006 & 737371 & 5.0074 & 4.752 & TST & \\
\hline CHEMBL1385899 & 737371 & 3.0 & 3.388 & TST & \\
\hline CHEMBL1416439 & 737371 & 3.0 & 3.4502 & TST & \\
\hline CHEMBL3652472 & 1536365 & 5.7794 & 5.85 & TRN & \\
\hline CHEMBL3649106 & 1536365 & 7.1549 & 6.4228 & TST & \\
\hline CHEMBL 3646160 & 1536365 & 6.1605 & 6.1953 & TRN & \\
\hline CHEMBL3649155 & 1536365 & 6.1898 & 6.0356 & TRN & \\
\hline CHEMBL3649180 & 1536365 & 5.0 & 5.1102 & TRN & \\
\hline CHEMBL3649075 & 1536365 & 5.5141 & 5.87799 & 9999999999 & TRN \\
\hline CHEMBL3649191 & 1536365 & 5.0 & 5.08899 & 99999999995 & TRN \\
\hline CHEMBL3646153 & 1536365 & 6.7235 & 6.7139 & TRN & \\
\hline CHEMBL3646155 & 1536365 & 6.3497 & 6.319 & TRN & \\
\hline CHEMBL3649117 & 1536365 & 5.301 & 5.4902 & TRN & \\
\hline CHEMBL3652465 & 1536365 & 7.0506 & 6.9143 & TRN & \\
\hline CHEMBL3652452 & 1536365 & 6.1107 & 6.1789 & TRN & \\
\hline CHEMBL3646187 & 1536365 & 5.8359 & 5.7345 & TST & \\
\hline CHEMBL3649201 & 1536365 & 6.433 & 5.9032 & TST & \\
\hline CHEMBL3652443 & 1536365 & 6.6289 & 6.2166 & TRN & \\
\hline CHEMBL3652529 & 1536365 & 5.0 & 5.2153 & TRN & \\
\hline CHEMBL3652476 & 1536365 & 5.0 & 4.9492 & TRN & \\
\hline
\end{tabular}




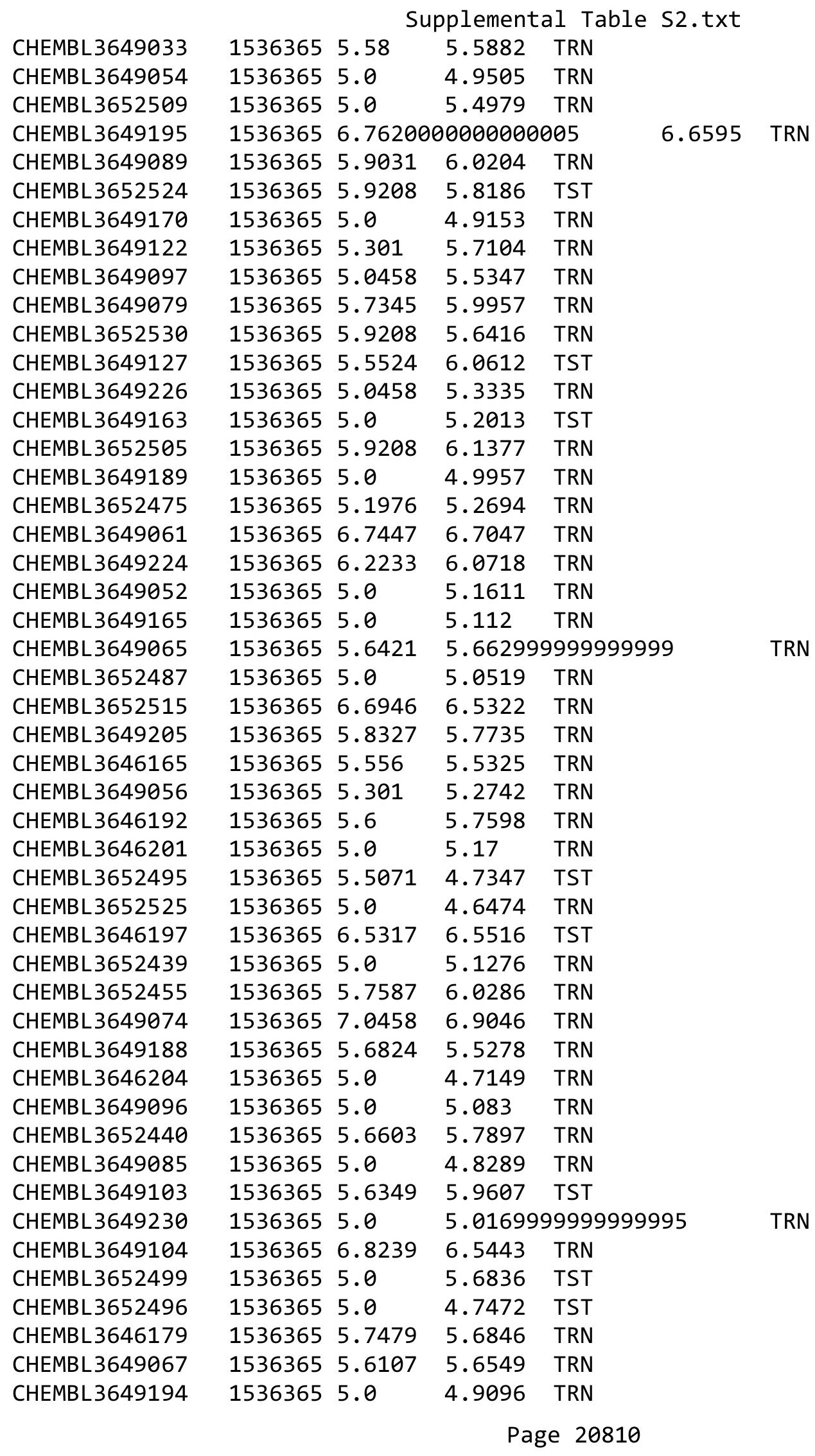




$$
\text { Supplemental Table S2.txt }
$$

\begin{tabular}{|c|c|c|c|c|c|c|}
\hline CHEMBL 3649026 & 1536365 & 5.6633 & 5.529 & TRN & & \\
\hline CHEMBL 3649229 & 1536365 & 5.0 & 4.9401 & TRN & & \\
\hline CHEMBL3649109 & 1536365 & 6.0237 & 6.0391 & TRN & & \\
\hline CHEMBL3649166 & 1536365 & 5.0 & 4.9583 & TRN & & \\
\hline CHEMBL3649040 & 1536365 & \multicolumn{3}{|c|}{6.2620000000000005} & 6.0809 & TRN \\
\hline CHEMBL3652463 & 1536365 & 6.5143 & 6.1649 & TRN & & \\
\hline CHEMBL3649051 & 1536365 & 5.0458 & 5.0785 & TRN & & \\
\hline CHEMBL3646175 & 1536365 & 5.8114 & 6.135 & TRN & & \\
\hline CHEMBL3652480 & 1536365 & 5.0 & 4.9286 & TRN & & \\
\hline CHEMBL3649069 & 1536365 & 7.0969 & 7.0634 & TRN & & \\
\hline CHEMBL3649078 & 1536365 & 7.3768 & 7.26 & TRN & & \\
\hline CHEMBL3649032 & 1536365 & 5.5112 & 5.62299 & 9999999999 & & TRN \\
\hline CHEMBL3649240 & 1536365 & 5.7943 & 6.0039 & TRN & & \\
\hline CHEMBL3646193 & 1536365 & 5.301 & 5.5507 & TRN & & \\
\hline CHEMBL3652493 & 1536365 & 5.0 & 4.9761 & TST & & \\
\hline CHEMBL3652444 & 1536365 & 6.5834 & 6.4207 & TRN & & \\
\hline CHEMBL3652491 & 1536365 & 5.7447 & 5.8353 & TRN & & \\
\hline CHEMBL3649049 & 1536365 & 5.5845 & 5.619 & TST & & \\
\hline CHEMBL3652516 & 1536365 & 5.6906 & 5.9006 & TRN & & \\
\hline CHEMBL3649029 & 1536365 & \multicolumn{3}{|c|}{6.382000000000001} & 6.1657 & TRN \\
\hline CHEMBL3646174 & 1536365 & 6.1694 & 6.1968 & TRN & & \\
\hline CHEMBL3646159 & 1536365 & 5.0 & 4.985 & TST & & \\
\hline CHEMBL3652485 & 1536365 & 5.0 & 4.992 & TRN & & \\
\hline CHEMBL3649135 & 1536365 & 5.8567 & 5.8667 & TRN & & \\
\hline CHEMBL3649196 & 1536365 & 6.3372 & 6.2963 & TRN & & \\
\hline CHEMBL3649232 & 1536365 & 7.1487 & 6.6731 & TRN & & \\
\hline CHEMBL3652459 & 1536365 & 5.4594 & 5.8615 & TRN & & \\
\hline CHEMBL3652523 & 1536365 & 5.0 & 5.4268 & TST & & \\
\hline CHEMBL3649187 & 1536365 & 5.7924 & 6.1911 & TRN & & \\
\hline CHEMBL3649207 & 1536365 & 5.0 & 4.6276 & TST & & \\
\hline CHEMBL3649184 & 1536365 & 5.0 & 4.7753 & TRN & & \\
\hline CHEMBL3916080 & 1536365 & \multicolumn{3}{|c|}{6.4510000000000005} & 6.4856 & TRN \\
\hline CHEMBL3646157 & 1536365 & 6.8125 & 6.7691 & TRN & & \\
\hline CHEMBL3649102 & 1536365 & \multicolumn{3}{|c|}{6.382000000000001} & 6.165 & TRN \\
\hline CHEMBL3649168 & 1536365 & 5.0 & 4.9461 & TRN & & \\
\hline CHEMBL3649059 & 1536365 & 5.6146 & 6.1048 & TRN & & \\
\hline CHEMBL3652512 & 1536365 & 5.7983 & 5.896 & TRN & & \\
\hline CHEMBL3649084 & 1536365 & 5.0 & 5.1755 & TRN & & \\
\hline CHEMBL3649129 & 1536365 & 5.7486 & 5.8273 & TST & & \\
\hline CHEMBL3649023 & 1536365 & 5.5777 & 5.6969 & TRN & & \\
\hline CHEMBL3652442 & 1536365 & 5.9586 & 5.8626 & TRN & & \\
\hline CHEMBL3649095 & 1536365 & 5.5651 & 5.5868 & TRN & & \\
\hline CHEMBL3649077 & 1536365 & 7.2147 & 7.5523 & TRN & & \\
\hline CHEMBL3649237 & 1536365 & 5.0 & 5.2217 & TRN & & \\
\hline CHEMBL3649185 & 1536365 & 5.0 & 5.1676 & TRN & & \\
\hline CHEMBL3646194 & 1536365 & 6.3747 & 6.4046 & TRN & & \\
\hline CHEMBL3652511 & 1536365 & 5.4968 & 5.3896 & TRN & & \\
\hline CHEMBL3649228 & 1536365 & 5.0 & 5.0797 & TRN & & \\
\hline
\end{tabular}




\begin{tabular}{|c|c|c|c|c|c|c|}
\hline \multicolumn{7}{|c|}{ Supplemental Table S2.txt } \\
\hline CHEMBL 3649238 & 1536365 & 5.0 & 4.9778 & TRN & & \\
\hline CHEMBL3646196 & 1536365 & 6.1409 & 6.0383 & TRN & & \\
\hline CHEMBL3649024 & 1536365 & 5.6436 & 5.5782 & TRN & & \\
\hline CHEMBL 3649045 & 1536365 & 5.0 & 4.8813 & TRN & & \\
\hline CHEMBL3649212 & 1536365 & 6.475 & 6.0722 & TRN & & \\
\hline CHEMBL3649215 & 1536365 & 5.0 & 5.4177 & TST & & \\
\hline CHEMBL 3652510 & 1536365 & 5.9792 & 5.8846 & TRN & & \\
\hline CHEMBL3646208 & 1536365 & 5.63399 & 99999999 & 995 & 5.4495 & TRN \\
\hline CHEMBL3649158 & 1536365 & 5.6964 & 5.8051 & TRN & & \\
\hline CHEMBL3652457 & 1536365 & 5.3014 & 5.4396 & TRN & & \\
\hline CHEMBL3646172 & 1536365 & 5.9622 & 6.0075 & TRN & & \\
\hline CHEMBL3652462 & 1536365 & 5.5471 & 5.8273 & TRN & & \\
\hline CHEMBL3649022 & 1536365 & 5.0458 & 4.7562 & TRN & & \\
\hline CHEMBL3652508 & 1536365 & 5.0969 & 5.3485 & TRN & & \\
\hline CHEMBL3652489 & 1536365 & 5.5376 & 5.6941 & TRN & & \\
\hline CHEMBL3652507 & 1536365 & 5.0 & 4.8986 & TRN & & \\
\hline CHEMBL3646190 & 1536365 & 5.0 & 4.859 & TRN & & \\
\hline CHEMBL3652467 & 1536365 & 7.2676 & 7.2504 & TRN & & \\
\hline CHEMBL3649177 & 1536365 & 5.0 & 4.8604 & TRN & & \\
\hline CHEMBL3649213 & 1536365 & 5.0458 & 5.216 & TRN & & \\
\hline CHEMBL 3649114 & 1536365 & 5.5776 & 5.9472 & TRN & & \\
\hline CHEMBL3649174 & 1536365 & 5.9678 & 5.9717 & TRN & & \\
\hline CHEMBL 3652494 & 1536365 & 5.0 & 5.209 & TRN & & \\
\hline CHEMBL3639513 & 1536365 & 5.0 & 4.7144 & TST & & \\
\hline CHEMBL 3652450 & 1536365 & 5.0 & 4.9663 & TRN & & \\
\hline CHEMBL 3646188 & 1536365 & 6.8633 & 6.4178 & TRN & & \\
\hline CHEMBL3649099 & 1536365 & 6.6364 & 6.4353 & TRN & & \\
\hline CHEMBL 3649070 & 1536365 & 7.1871 & 6.8252 & TRN & & \\
\hline CHEMBL3646163 & 1536365 & 5.3587 & 5.8299 & TST & & \\
\hline CHEMBL3649080 & 1536365 & 5.4476 & 5.6601 & TRN & & \\
\hline CHEMBL 3649136 & 1536365 & 6.0348 & 5.9917 & TST & & \\
\hline CHEMBL 3652458 & 1536365 & 6.5058 & 6.6363 & TRN & & \\
\hline CHEMBL 3649090 & 1536365 & 5.813 & 5.6932 & TRN & & \\
\hline CHEMBL3649225 & 1536365 & 5.0 & 4.893 & TRN & & \\
\hline CHEMBL3652473 & 1536365 & 6.82100 & 00000000 & $\partial 1$ & 6.4559 & TRN \\
\hline CHEMBL 3649167 & 1536365 & 5.0 & 4.9287 & TRN & & \\
\hline CHEMBL3649217 & 1536365 & 5.0 & 4.9751 & TRN & & \\
\hline CHEMBL3649162 & 1536365 & 5.0 & 4.8263 & TRN & & \\
\hline CHEMBL3646198 & 1536365 & 5.9492 & 5.7198 & TRN & & \\
\hline CHEMBL3652517 & 1536365 & 5.0 & 4.6013 & TST & & \\
\hline CHEMBL 3649064 & 1536365 & 6.3344 & 6.1643 & TRN & & \\
\hline CHEMBL3646183 & 1536365 & 5.0458 & 5.7052 & TRN & & \\
\hline CHEMBL3649179 & 1536365 & 5.0 & 5.0785 & TRN & & \\
\hline CHEMBL3649058 & 1536365 & 6.1113 & 6.1304 & TRN & & \\
\hline CHEMBL3646202 & 1536365 & 5.0 & 4.9513 & TRN & & \\
\hline CHEMBL 3652504 & 1536365 & 6.0762 & 5.8245 & TRN & & \\
\hline CHEMBL3649204 & 1536365 & 5.8539 & 5.8716 & TRN & & \\
\hline CHEMBL 3652514 & 1536365 & 6.2941 & 6.2931 & TRN & & \\
\hline
\end{tabular}

Page 20812 


\begin{tabular}{|c|c|c|c|c|c|}
\hline \multicolumn{6}{|c|}{ Supplemental Table S2.txt } \\
\hline CHEMBL3652501 & 1536365 & 5.0 & 5.4302 & TST & \\
\hline CHEMBL3646158 & 1536365 & 6.857 & 6.8758 & TRN & \\
\hline CHEMBL3649112 & 1536365 & 6.2976 & 6.2378 & TRN & \\
\hline CHEMBL3649138 & 1536365 & \multicolumn{3}{|c|}{6.117999999999999} & TRN \\
\hline CHEMBL3652460 & 1536365 & 6.8928 & 6.6235 & TRN & \\
\hline CHEMBL 3652454 & 1536365 & 5.0 & 4.6936 & TRN & \\
\hline CHEMBL 3646200 & 1536365 & 5.7716 & 5.5562 & TRN & \\
\hline CHEMBL3646191 & 1536365 & 5.8438 & 6.0581 & TRN & \\
\hline CHEMBL3652453 & 1536365 & 5.6383 & 5.6447 & TRN & \\
\hline CHEMBL3652490 & 1536365 & 5.0 & 4.7852 & TST & \\
\hline CHEMBL3649041 & 1536365 & 5.0 & 5.3459 & TRN & \\
\hline CHEMBL3646207 & 1536365 & 6.0969 & 5.9446 & TRN & \\
\hline CHEMBL3649110 & 1536365 & 6.8477 & 6.1313 & TST & \\
\hline CHEMBL3649239 & 1536365 & 5.0 & 5.1179 & TRN & \\
\hline CHEMBL3649076 & 1536365 & 5.0 & 4.4952 & TRN & \\
\hline CHEMBL 3649028 & 1536365 & 6.684 & 6.7652 & TRN & \\
\hline CHEMBL3646169 & 1536365 & 5.8983 & 5.8001 & TST & \\
\hline CHEMBL3649105 & 1536365 & 6.27 & 6.1668 & TST & \\
\hline CHEMBL3652502 & 1536365 & 5.5686 & 5.9573 & TST & \\
\hline CHEMBL3646164 & 1536365 & 5.0 & 5.7048 & TST & \\
\hline CHEMBL3649055 & 1536365 & 5.0458 & 4.9943 & TRN & \\
\hline CHEMBL3646167 & 1536365 & 5.0 & 5.6905 & TST & \\
\hline CHEMBL3652436 & 1536365 & 5.0 & 5.25299 & 9999999999 & TRN \\
\hline CHEMBL 3652484 & 1536365 & 5.0 & 5.0625 & TRN & \\
\hline CHEMBL3649234 & 1536365 & 5.8428 & 6.0493 & TRN & \\
\hline CHEMBL 3652448 & 1536365 & 6.9431 & 6.6554 & TRN & \\
\hline CHEMBL3646206 & 1536365 & 5.0458 & 4.9108 & TRN & \\
\hline CHEMBL3649182 & 1536365 & 5.0 & 4.7337 & TRN & \\
\hline CHEMBL3652466 & 1536365 & 6.27 & 6.1778 & TRN & \\
\hline CHEMBL3649031 & 1536365 & 6.6478 & 6.731 & TRN & \\
\hline CHEMBL3649050 & 1536365 & 5.0 & 4.7601 & TRN & \\
\hline CHEMBL3649150 & 1536365 & 5.301 & 5.61700 & 0000000001 & TST \\
\hline CHEMBL3649101 & 1536365 & 5.813 & 6.0793 & TST & \\
\hline CHEMBL3652526 & 1536365 & 5.0 & 4.8136 & TRN & \\
\hline CHEMBL3649092 & 1536365 & 6.8827 & 6.6211 & TRN & \\
\hline CHEMBL3652527 & 1536365 & 5.0 & 5.1093 & TRN & \\
\hline CHEMBL3649021 & 1536365 & 5.301 & 5.0746 & TRN & \\
\hline CHEMBL3649176 & 1536365 & 5.0 & 4.9121 & TRN & \\
\hline CHEMBL3646152 & 1536365 & 7.0 & 6.8503 & TRN & \\
\hline CHEMBL3649171 & 1536365 & 5.0 & 5.1892 & TRN & \\
\hline CHEMBL3649202 & 1536365 & 6.6819 & 6.4718 & TST & \\
\hline CHEMBL 3652528 & 1536365 & 5.0 & 5.1249 & TRN & \\
\hline CHEMBL3649128 & 1536365 & 6.0701 & 6.1428 & TRN & \\
\hline CHEMBL3646182 & 1536365 & 6.1864 & 6.1072 & TRN & \\
\hline CHEMBL3649082 & 1536365 & 7.3768 & 7.056 & TRN & \\
\hline CHEMBL3649120 & 1536365 & 6.1811 & 6.0796 & TRN & \\
\hline CHEMBL3652486 & 1536365 & 5.0 & 5.1147 & TRN & \\
\hline CHEMBL3646166 & 1536365 & 5.739 & 5.76200 & 0000000005 & TRN \\
\hline & & & & 20813 & \\
\hline
\end{tabular}


Supplemental Table S2.txt

\begin{tabular}{|c|c|c|c|c|c|}
\hline CHEMBL 3649088 & 1536365 & 7.3979 & 6.8707 & TRN & \\
\hline CHEMBL 3652445 & 1536365 & 6.7959 & 6.6087 & TRN & \\
\hline CHEMBL3649091 & 1536365 & 5.4637 & 5.6472 & TRN & \\
\hline CHEMBL 3649236 & 1536365 & 6.2314 & 5.9548 & TRN & \\
\hline CHEMBL 3646180 & 1536365 & 5.9961 & 5.9914 & TRN & \\
\hline CHEMBL3649121 & 1536365 & 5.2743 & 5.4316 & TRN & \\
\hline CHEMBL 3652506 & 1536365 & 5.1038 & 5.2571 & TRN & \\
\hline CHEMBL 3649220 & 1536365 & 5.0 & 5.0795 & TRN & \\
\hline CHEMBL 3649098 & 1536365 & 6.0501 & 6.1378 & TRN & \\
\hline CHEMBL 3649231 & 1536365 & 5.7951 & 6.0099 & TRN & \\
\hline CHEMBL3649190 & 1536365 & 5.0 & 4.5022 & TRN & \\
\hline CHEMBL3649111 & 1536365 & 5.301 & 5.5071 & TRN & \\
\hline CHEMBL 3652438 & 1536365 & 5.0 & 5.7155 & TST & \\
\hline CHEMBL 3649116 & 1536365 & 5.301 & 5.5401 & TRN & \\
\hline CHEMBL 3649115 & 1536365 & 5.0458 & 5.048 & TRN & \\
\hline CHEMBL3649108 & 1536365 & 5.5308 & 5.4044 & TRN & \\
\hline CHEMBL3652519 & 1536365 & 5.0 & 5.103 & TRN & \\
\hline CHEMBL 3646171 & 1536365 & 6.58 & 6.0737 & TST & \\
\hline CHEMBL 3646170 & 1536365 & 7.1135 & 6.8372 & TRN & \\
\hline CHEMBL 3652470 & 1536365 & 5.6066 & 5.8008 & TRN & \\
\hline CHEMBL 3649118 & 1536365 & 5.301 & 5.5401 & TRN & \\
\hline CHEMBL3652461 & 1536365 & 6.0186 & 5.6757 & TRN & \\
\hline CHEMBL 3649072 & 1536365 & 6.8153 & 7.1636 & TRN & \\
\hline CHEMBL3649192 & 1536365 & 5.0 & 4.9735 & TST & \\
\hline CHEMBL 3646154 & 1536365 & 6.8962 & 6.8162 & TRN & \\
\hline CHEMBL 3652518 & 1536365 & 5.4332 & 5.5044 & TRN & \\
\hline CHEMBL3646199 & 1536365 & 5.0 & 4.6452 & TRN & \\
\hline CHEMBL 3646173 & 1536365 & 6.5186 & 7.0152 & TRN & \\
\hline CHEMBL 3646162 & 1536365 & 5.0 & 4.6495 & TRN & \\
\hline CHEMBL 3652456 & 1536365 & 6.38299 & 999999999 & 6.2971 & TRN \\
\hline CHEMBL 3649144 & 1536365 & 6.056 & 5.6418 & TST & \\
\hline CHEMBL 3652477 & 1536365 & 5.0 & 5.4446 & TRN & \\
\hline CHEMBL 3652498 & 1536365 & 5.0 & 5.307 & TST & \\
\hline CHEMBL3649047 & 1536365 & 5.8788 & 5.957999 & э999999999 & TRN \\
\hline CHEMBL 3649178 & 1536365 & 5.0 & 5.0139 & TRN & \\
\hline CHEMBL 3649087 & 1536365 & 7.1249 & 6.9216 & TRN & \\
\hline CHEMBL3646195 & 1536365 & 5.0 & 5.4748 & TRN & \\
\hline CHEMBL 3649210 & 1536365 & 5.0 & 4.9004 & TST & \\
\hline CHEMBL 3646203 & 1536365 & 5.0458 & 5.3005 & TRN & \\
\hline CHEMBL 3649173 & 1536365 & 5.0 & 4.905 & TRN & \\
\hline CHEMBL 3646184 & 1536365 & 6.3116 & 6.4533 & TRN & \\
\hline CHEMBL 3649100 & 1536365 & 7.0809 & 6.5309 & TST & \\
\hline CHEMBL 3649200 & 1536365 & 6.1805 & 6.0725 & TRN & \\
\hline CHEMBL 3649209 & 1536365 & 5.0 & 4.6898 & TST & \\
\hline CHEMBL 3652474 & 1536365 & 5.2596 & 5.6249 & TST & \\
\hline CHEMBL 3646185 & 1536365 & 6.8447 & 6.8342 & TRN & \\
\hline CHEMBL 3649227 & 1536365 & 5.0 & 4.8985 & TRN & \\
\hline CHEMBL3649216 & 1536365 & 5.0 & 4.7653 & TRN & \\
\hline
\end{tabular}




\begin{tabular}{|c|c|c|c|c|c|c|}
\hline \multicolumn{7}{|c|}{ Supplemental Table S2.txt } \\
\hline CHEMBL 3652483 & 1536365 & 5.0 & 5.0298 & TRN & & \\
\hline CHEMBL 3649172 & 1536365 & 5.301 & 5.3448 & TRN & & \\
\hline CHEMBL3649126 & 1536365 & 6.1238 & 6.3374 & TST & & \\
\hline CHEMBL 3649062 & 1536365 & 5.0 & 5.1926 & TRN & & \\
\hline CHEMBL 3649048 & 1536365 & 5.9348 & 6.0311 & TRN & & \\
\hline CHEMBL 3652468 & 1536365 & 6.0883 & 5.9988 & TST & & \\
\hline CHEMBL 3652488 & 1536365 & 5.0 & 5.0916 & TRN & & \\
\hline CHEMBL 3652481 & 1536365 & 5.4949 & 5.4686 & TRN & & \\
\hline CHEMBL 3649124 & 1536365 & 6.1415 & 6.0678 & TRN & & \\
\hline CHEMBL 3649086 & 1536365 & 5.0458 & 4.9698 & TRN & & \\
\hline CHEMBL3649214 & 1536365 & 5.0 & 5.6839 & TST & & \\
\hline CHEMBL 3649175 & 1536365 & 5.0 & 4.683 & TRN & & \\
\hline CHEMBL 3649221 & 1536365 & 5.0 & 4.9336 & TST & & \\
\hline CHEMBL 3652464 & 1536365 & 7.4685 & 7.2249 & TRN & & \\
\hline CHEMBL 3652520 & 1536365 & 6.3595 & 6.6504 & TST & & \\
\hline CHEMBL3652478 & 1536365 & 5.4212 & 5.4237 & TRN & & \\
\hline CHEMBL3649066 & 1536365 & 5.4432 & 5.3462 & TRN & & \\
\hline CHEMBL3652497 & 1536365 & 5.0 & 5.3634 & TST & & \\
\hline CHEMBL 3649113 & 1536365 & 5.0 & 5.0188 & TST & & \\
\hline CHEMBL 3649044 & 1536365 & 5.1734 & 5.3849 & TRN & & \\
\hline CHEMBL3652446 & 1536365 & 6.4101 & 6.2644 & TRN & & \\
\hline CHEMBL 3649222 & 1536365 & 5.0 & 4.9514 & TRN & & \\
\hline CHEMBL3652441 & 1536365 & 6.9031 & 6.6392 & TRN & & \\
\hline CHEMBL 3649198 & 1536365 & 6.1986 & 5.9959 & TRN & & \\
\hline CHEMBL3646176 & 1536365 & 6.7905 & 6.6351 & TRN & & \\
\hline CHEMBL 3652447 & 1536365 & 5.5528 & 5.62200 & 0000000001 & & TRN \\
\hline CHEMBL 3649094 & 1536365 & 6.4089 & 6.2774 & TRN & & \\
\hline CHEMBL3649030 & 1536365 & 5.0 & 5.2738 & TRN & & \\
\hline CHEMBL 3649161 & 1536365 & 5.0 & 5.1291 & TRN & & \\
\hline CHEMBL 3639480 & 1536365 & 5.0 & 4.8406 & TRN & & \\
\hline CHEMBL 3652449 & 1536365 & 6.76200 & 00000000 & 205 & 6.5691 & TRN \\
\hline CHEMBL 3652471 & 1536365 & 6.4112 & 6.4655 & TRN & & \\
\hline CHEMBL3649186 & 1536365 & 5.0 & 5.3027 & TRN & & \\
\hline CHEMBL 3649034 & 1536365 & 5.0 & 5.4753 & TRN & & \\
\hline CHEMBL 3649036 & 1536365 & 7.1612 & 6.7329 & TRN & & \\
\hline CHEMBL3649142 & 1536365 & 5.0 & 4.7579 & TRN & & \\
\hline CHEMBL3649119 & 1536365 & 5.6114 & 5.7988 & TRN & & \\
\hline CHEMBL3649037 & 1536365 & 5.3691 & 5.7732 & TRN & & \\
\hline CHEMBL 3649046 & 1536365 & 5.75299 & 99999999 & 99 & 5.8553 & TRN \\
\hline CHEMBL 3649183 & 1536365 & 5.0 & 5.0776 & TRN & & \\
\hline CHEMBL 3652437 & 1536365 & 5.6676 & 5.6096 & TRN & & \\
\hline CHEMBL 3646186 & 1536365 & 5.3595 & 5.2941 & TRN & & \\
\hline CHEMBL3646156 & 1536365 & 7.2007 & 6.8584 & TRN & & \\
\hline CHEMBL 3649071 & 1536365 & 6.4559 & 6.6398 & TRN & & \\
\hline CHEMBL3652492 & 1536365 & 5.0 & 5.3194 & TST & & \\
\hline CHEMBL3649208 & 1536365 & 5.0 & 4.8191 & TST & & \\
\hline CHEMBL 3649193 & 1536365 & 5.0837 & 5.1659 & TRN & & \\
\hline CHEMBL 3649211 & 1536365 & 6.0329 & 6.1962 & TRN & & \\
\hline
\end{tabular}

Page 20815 
Supplemental Table S2.txt

\begin{tabular}{|c|c|c|c|c|c|}
\hline CHEMBL3649035 & 1536365 & 5.0458 & 5.2173 & TRN & \\
\hline CHEMBL 3649181 & 1536365 & 5.0 & 5.0782 & TRN & \\
\hline CHEMBL3649053 & 1536365 & 5.761 & 5.6136 & TRN & \\
\hline CHEMBL3646189 & 1536365 & 6.0521 & 6.2298 & TRN & \\
\hline CHEMBL 3649025 & 1536365 & 6.1618 & 6.3734 & TRN & \\
\hline CHEMBL3649039 & 1536365 & 5.0 & 4.9922 & TRN & \\
\hline CHEMBL 3649068 & 1536365 & 6.6737 & 7.0937 & TRN & \\
\hline CHEMBL3649107 & 1536365 & 6.8633 & 6.6731 & TST & \\
\hline CHEMBL3649169 & 1536365 & 5.0 & 4.8947 & TRN & \\
\hline CHEMBL3649160 & 1536365 & 5.0 & 4.4734 & TRN & \\
\hline CHEMBL 3649218 & 1536365 & 5.0458 & 5.2925 & TST & \\
\hline CHEMBL 3652479 & 1536365 & 5.0 & 5.2018 & TST & \\
\hline CHEMBL 3649164 & 1536365 & 6.7721 & 6.332006 & 2000000001 & TST \\
\hline CHEMBL3649060 & 1536365 & 6.5607 & 6.6576 & TST & \\
\hline CHEMBL3649219 & 1536365 & 5.0 & 4.643 & TST & \\
\hline CHEMBL3652521 & 1536365 & 6.1586 & 6.0488 & TST & \\
\hline CHEMBL3652451 & 1536365 & 5.0 & 5.4429 & TST & \\
\hline CHEMBL 3649073 & 1536365 & 6.9136 & 6.6388 & TST & \\
\hline CHEMBL3649083 & 1536365 & 5.0 & 4.9903 & TST & \\
\hline CHEMBL3652503 & 1536365 & 5.7212 & 5.9935 & TST & \\
\hline CHEMBL3649199 & 1536365 & 6.4461 & 6.5705 & TST & \\
\hline CHEMBL3649043 & 1536365 & 5.0458 & 5.4243 & TST & \\
\hline CHEMBL 3652482 & 1536365 & 5.0 & 4.9688 & TST & \\
\hline CHEMBL3649233 & 1536365 & 5.0 & 4.8479 & TST & \\
\hline CHEMBL3649038 & 1536365 & 5.035 & 5.0659 & TST & \\
\hline CHEMBL3646161 & 1536365 & 5.1734 & 5.8846 & TST & \\
\hline CHEMBL3652513 & 1536365 & 5.6603 & 5.9042 & TST & \\
\hline CHEMBL 3649081 & 1536365 & 5.5426 & 6.1035 & TST & \\
\hline CHEMBL3646205 & 1536365 & 5.301 & 5.1077 & TST & \\
\hline CHEMBL3649093 & 1536365 & 5.1505 & 5.7713 & TST & \\
\hline CHEMBL3649153 & 1536365 & 6.0894 & 5.7124 & TST & \\
\hline CHEMBL3649235 & 1536365 & 6.0097 & 6.2546 & TST & \\
\hline CHEMBL 3649042 & 1536365 & 5.0458 & 5.4096 & TST & \\
\hline CHEMBL3649197 & 1536365 & 6.0097 & 6.0301 & TST & \\
\hline CHEMBL3649206 & 1536365 & 5.0 & 4.9285 & TST & \\
\hline CHEMBL3649203 & 1536365 & 5.3566 & 5.335 & TST & \\
\hline CHEMBL3652469 & 1536365 & 6.4225 & 6.3764 & TST & \\
\hline CHEMBL 3649027 & 1536365 & 5.0 & 4.8582 & TST & \\
\hline CHEMBL3649223 & 1536365 & 5.0 & 4.6522 & TST & \\
\hline CHEMBL 3649125 & 1536365 & 5.3338 & 5.7755 & TST & \\
\hline CHEMBL3649057 & 1536365 & 6.0721 & 6.3539 & TST & \\
\hline CHEMBL3639479 & 1536365 & 5.0153 & 5.1198 & TST & \\
\hline CHEMBL3652522 & 1536365 & 6.308 & 6.2584 & TST & \\
\hline CHEMBL 3652500 & 1536365 & 5.0 & 5.8092 & TST & \\
\hline CHEMBL 3649063 & 1536365 & 5.3732 & 5.2431 & TST & \\
\hline CHEMBL3649141 & 1536365 & 5.0458 & 5.7537 & TST & \\
\hline CHEMBL 286959 & 29456 & 4.9574 & 4.9767 & TRN & \\
\hline CHEMBL282993 & 29456 & 6.1844 & 6.1983 & TRN & \\
\hline
\end{tabular}

Page 20816 


\begin{tabular}{|c|c|c|c|c|c|c|}
\hline & & \multicolumn{5}{|c|}{ Supplemental Table s2.txt } \\
\hline CHEMBL 27215 & 29456 & 5.58 & 5.7027 & TRN & & \\
\hline CHEMBL 281885 & 29456 & 5.5654 & 5.5117 & TRN & & \\
\hline CHEMBL25914 & 29456 & 5.2013 & 5.1646 & TRN & & \\
\hline CHEMBL 281811 & 29456 & 4.5528 & 5.43 & TST & & \\
\hline CHEMBL 280982 & 29456 & 4.8604 & 4.8104 & TRN & & \\
\hline CHEMBL 283937 & 29456 & 6.4214 & 6.4408 & TRN & & \\
\hline CHEMBL 285589 & 29456 & 5.2725 & 5.3529 & TRN & & \\
\hline CHEMBL25859 & 29456 & 5.0237 & 5.0594 & TRN & & \\
\hline CHEMBL 283939 & 29456 & 7.4949 & 7.4964 & TRN & & \\
\hline CHEMBL 26698 & 29456 & 5.6326 & 5.6491 & TRN & & \\
\hline CHEMBL 281468 & 29456 & 4.8312 & 4.8888 & TRN & & \\
\hline CHEMBL 27032 & 29456 & 5.7375 & 5.8469 & TRN & & \\
\hline CHEMBL26138 & 29456 & 4.5498 & 4.582 & TRN & & \\
\hline CHEMBL25976 & 29456 & 4.4547 & 4.4959 & TRN & & \\
\hline CHEMBL26938 & 29456 & 6.5654 & 6.6686 & TRN & & \\
\hline CHEMBL 28267 & 29456 & 5.4776 & 5.472 & TRN & & \\
\hline CHEMBL 283184 & 29456 & 6.1537 & 6.1129 & TRN & & \\
\hline CHEMBL26668 & 29456 & 5.7721 & 5.7619 & TRN & & \\
\hline CHEMBL 26963 & 29456 & 4.8477 & 4.9565 & TRN & & \\
\hline CHEMBL25799 & 29456 & 5.5166 & 5.4895 & TRN & & \\
\hline CHEMBL 281958 & 29456 & 6.0665 & 5.9797 & TRN & & \\
\hline CHEMBL 26979 & 29456 & 4.6421 & 4.6141 & TRN & & \\
\hline CHEMBL 284571 & 29456 & 7.1079 & 6.7271 & TST & & \\
\hline CHEMBL 27883 & 29456 & 4.6271 & 4.6233 & TRN & & \\
\hline CHEMBL27203 & 29456 & 4.0362 & 3.9895 & TRN & & \\
\hline CHEMBL27496 & 29456 & 7.1487 & 6.5004 & TST & & \\
\hline CHEMBL28395 & 29456 & 6.7773 & 6.3853 & TST & & \\
\hline CHEMBL26899 & 29456 & 5.5186 & 5.5169 & TRN & & \\
\hline CHEMBL 283906 & 29456 & 4.8019 & 4.9086 & TRN & & \\
\hline CHEMBL25906 & 29456 & 6.9469 & 7.0218 & TRN & & \\
\hline CHEMBL 25964 & 29456 & 6.0585 & 5.9798 & TRN & & \\
\hline CHEMBL 285339 & 29456 & 5.9747 & 6.0057 & TRN & & \\
\hline CHEMBL 281305 & 29456 & 5.7959 & 5.8931 & TST & & \\
\hline CHEMBL 282599 & 29456 & 5.6596 & 6.5883 & TST & & \\
\hline CHEMBL26070 & 29456 & 5.6696 & 5.5674 & TRN & & \\
\hline CHEMBL 283908 & 29456 & 7.2596 & 7.32700 & $0000 t$ & & TST \\
\hline CHEMBL 27508 & 29456 & 6.2388 & 6.1655 & TRN & & \\
\hline CHEMBL28046 & 29456 & 5.76200 & 30000000 & 205 & 6.0055 & TST \\
\hline CHEMBL 281657 & 29456 & 5.2652 & 5.1399 & TRN & & \\
\hline CHEMBL26837 & 29456 & 6.8447 & 6.6587 & TST & & \\
\hline CHEMBL 26897 & 29456 & 5.4101 & 5.404 & TRN & & \\
\hline CHEMBL 283406 & 29456 & 5.20200 & 30000000 & $\partial 1$ & 5.2043 & TRN \\
\hline CHEMBL 280839 & 29456 & 6.0696 & 5.9029 & TST & & \\
\hline CHEMBL 27140 & 29456 & 7.0132 & 6.8499 & TST & & \\
\hline CHEMBL28346 & 29456 & 5.75200 & 00000000 & $\partial 1$ & 5.8137 & TST \\
\hline CHEMBL 283258 & 29456 & 6.055 & 5.8843 & TST & & \\
\hline CHEMBL418196 & 29456 & 4.9666 & 5.0944 & TST & & \\
\hline CHEMBL 26792 & 29456 & 5.3936 & 5.4176 & TRN & & \\
\hline
\end{tabular}




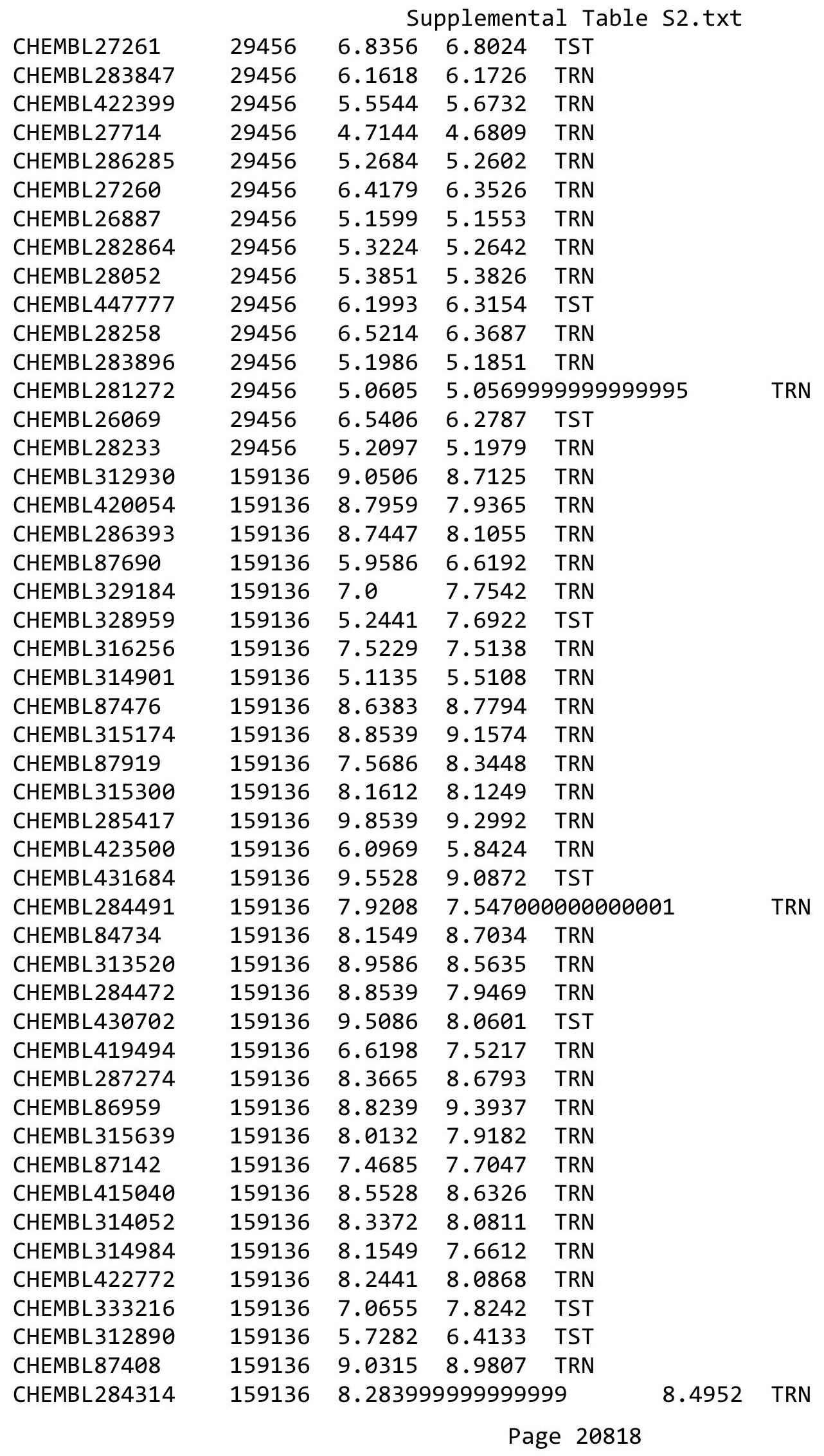


Supplemental Table S2.txt

\begin{tabular}{|c|c|c|c|c|c|}
\hline CHEMBL332212 & 159136 & 5.3979 & 7.9313 & TST & \\
\hline CHEMBL32733 & 159136 & 8.0969 & 7.814 & TRN & \\
\hline CHEMBL412810 & 159136 & 9.4815 & 10.1559 & TRN & \\
\hline CHEMBL315306 & 159136 & 8.4437 & 8.2998 & TRN & \\
\hline CHEMBL86874 & 159136 & 7.3098 & 7.5784 & TRN & \\
\hline CHEMBL85294 & 159136 & 9.3768 & 9.0102 & TRN & \\
\hline CHEMBL35860 & 159136 & 9.9208 & 9.5046 & TRN & \\
\hline CHEMBL284136 & 159136 & 9.9208 & 10.15299 & & TRN \\
\hline CHEMBL431306 & 159136 & 8.6778 & 8.7771 & TRN & \\
\hline CHEMBL85915 & 159136 & 9.2218 & 8.6274 & TRN & \\
\hline CHEMBL87592 & 159136 & 9.0 & 9.2723 & TRN & \\
\hline CHEMBL313289 & 159136 & 8.7959 & 7.6763 & TRN & \\
\hline CHEMBL89794 & 159136 & 6.8041 & 6.917000 & 0000000001 & TRN \\
\hline CHEMBL315439 & 159136 & 6.8386 & 7.436 & TRN & \\
\hline CHEMBL313599 & 159136 & 7.2218 & 6.9281 & TRN & \\
\hline CHEMBL287355 & 159136 & 8.8861 & 8.7376 & TRN & \\
\hline CHEMBL313008 & 159136 & 7.6576 & 7.7546 & TRN & \\
\hline CHEMBL432993 & 159136 & 7.4437 & 7.4177 & TRN & \\
\hline CHEMBL334180 & 159136 & 9.5528 & 8.7418 & TST & \\
\hline CHEMBL316433 & 159136 & 7.2924 & 7.6145 & TRN & \\
\hline CHEMBL315177 & 159136 & 7.0458 & 7.5614 & TRN & \\
\hline CHEMBL87991 & 159136 & 8.28399 & 999999999 & 8.0108 & \\
\hline CHEMBL 290576 & 159136 & 8.5229 & 8.2351 & TST & \\
\hline CHEMBL432190 & 159136 & 6.585 & 8.0811 & TST & \\
\hline CHEMBL85771 & 159136 & 8.8539 & 7.8137 & TST & \\
\hline CHEMBL 313732 & 159136 & 8.8539 & 9.1817 & TST & \\
\hline CHEMBL32828 & 159136 & 7.4318 & 8.6512 & TST & \\
\hline CHEMBL418939 & 159136 & 8.5229 & 8.5676 & TST & \\
\hline CHEMBL420042 & 159136 & 6.9586 & 7.6313 & TST & \\
\hline CHEMBL314944 & 159136 & 7.6576 & 8.4978 & TST & \\
\hline CHEMBL313188 & 159136 & 8.1367 & 7.9525 & TST & \\
\hline CHEMBL314709 & 159136 & 8.28399 & 999999999 & 8.4138 & \\
\hline CHEMBL 307626 & 535 & 7.301 & 7.2825 & TRN & \\
\hline CHEMBL 76260 & 535 & 8.0809 & 8.0633 & TRN & \\
\hline CHEMBL76536 & 535 & 5.9586 & 5.9632 & TRN & \\
\hline CHEMBL311577 & 535 & 7.9586 & 7.9393 & TRN & \\
\hline CHEMBL 2298601 & 535 & 7.699 & 8.0168 & TST & \\
\hline CHEMBL308258 & 535 & 7.0 & 7.0104 & TRN & \\
\hline CHEMBL421696 & 535 & 4.9586 & 6.6222 & TST & \\
\hline CHEMBL 76671 & 535 & 4.7959 & 7.131 & TST & \\
\hline CHEMBL 3706584 & 535 & 6.0 & 5.9355 & TRN & \\
\hline CHEMBL 78275 & 535 & 8.0362 & 7.9881 & TRN & \\
\hline CHEMBL75320 & 535 & 7.6383 & 7.6602 & TRN & \\
\hline CHEMBL 76648 & 535 & 7.2218 & 7.2529 & TRN & \\
\hline CHEMBL77328 & 535 & 5.3979 & 5.4085 & TRN & \\
\hline CHEMBL3706586 & 535 & 5.6576 & 5.7363 & TRN & \\
\hline CHEMBL 306554 & 535 & 7.9586 & 7.9264 & TRN & \\
\hline CHEMBL77024 & 535 & 7.1079 & 7.1187 & TRN & \\
\hline
\end{tabular}




\begin{tabular}{|c|c|c|c|c|c|}
\hline & & \multicolumn{4}{|c|}{ Supplemental Table S2.txt } \\
\hline CHEMBL76693 & 535 & 7.0223 & 5.9644 & TST & \\
\hline CHEMBL311818 & 535 & 5.9208 & 5.9289 & TRN & \\
\hline CHEMBL305855 & 535 & 7.8861 & 7.9222 & TRN & \\
\hline CHEMBL 78064 & 535 & 7.2076 & 7.2139 & TRN & \\
\hline CHEMBL 297524 & 535 & 7.9208 & 7.9195 & TRN & \\
\hline CHEMBL80669 & 535 & 8.0 & 7.4399 & TST & \\
\hline CHEMBL75982 & 535 & 6.2924 & 6.2915 & TRN & \\
\hline CHEMBL80163 & 535 & 6.284 & 6.9914 & TST & \\
\hline CHEMBL1159458 & 535 & 8.9208 & 6.3253 & TST & \\
\hline CHEMBL76803 & 535 & 7.8239 & 7.8352 & TRN & \\
\hline CHEMBL442747 & 535 & 4.4685 & 6.8615 & TST & \\
\hline CHEMBL77144 & 535 & 7.9586 & 7.6798 & TST & \\
\hline CHEMBL311874 & 535 & 6.5229 & 5.2754 & TST & \\
\hline CHEMBL306507 & 535 & 7.2076 & 7.15799 & 99999999995 & TRN \\
\hline CHEMBL 310710 & 535 & 6.6576 & 6.6553 & TRN & \\
\hline CHEMBL 305932 & 535 & 5.8239 & 6.9144 & TST & \\
\hline CHEMBL24291 & 535 & 6.7212 & 6.7223 & TRN & \\
\hline CHEMBL420020 & 535 & 8.0 & 7.9891 & TRN & \\
\hline CHEMBL77378 & 535 & 5.4437 & 6.7061 & TST & \\
\hline CHEMBL311045 & 535 & 8.6383 & 8.6392 & TRN & \\
\hline CHEMBL77765 & 535 & 7.7447 & 7.7446 & TRN & \\
\hline CHEMBL76892 & 535 & 8.4437 & 8.304 & TST & \\
\hline CHEMBL3706581 & 535 & 6.0044 & 5.999 & TRN & \\
\hline CHEMBL77129 & 535 & 6.9586 & 6.9572 & TRN & \\
\hline CHEMBL3706583 & 535 & 7.0969 & 7.0799 & TRN & \\
\hline CHEMBL76637 & 535 & 8.1079 & 8.1137 & TRN & \\
\hline CHEMBL312531 & 535 & 6.7959 & 6.7942 & TRN & \\
\hline CHEMBL 308532 & 535 & 7.3098 & 7.1516 & TST & \\
\hline CHEMBL310711 & 535 & 8.5686 & 8.5546 & TRN & \\
\hline CHEMBL 307745 & 535 & 8.1249 & 8.1232 & TRN & \\
\hline CHEMBL 307181 & 535 & 7.8861 & 7.8613 & TRN & \\
\hline CHEMBL430617 & 535 & 7.7959 & 7.8185 & TRN & \\
\hline CHEMBL 306781 & 535 & 7.9586 & 7.9687 & TRN & \\
\hline CHEMBL312143 & 535 & 8.1805 & 8.2402 & TRN & \\
\hline CHEMBL 309585 & 535 & 6.7447 & 6.0845 & TST & \\
\hline CHEMBL311783 & 535 & 6.7447 & 6.6848 & TST & \\
\hline CHEMBL432729 & 535 & 7.5686 & 7.5738 & TRN & \\
\hline CHEMBL412425 & 535 & 6.2924 & 6.2922 & TRN & \\
\hline CHEMBL308107 & 535 & 7.2076 & 7.2483 & TRN & \\
\hline CHEMBL 78161 & 535 & 5.8239 & 5.8168 & TRN & \\
\hline CHEMBL80160 & 535 & 8.9586 & 9.1837 & TST & \\
\hline CHEMBL309261 & 535 & 7.6576 & 7.9144 & TST & \\
\hline CHEMBL 77290 & 535 & 7.7447 & 7.7614 & TRN & \\
\hline CHEMBL307398 & 535 & 7.7447 & 7.7291 & TRN & \\
\hline CHEMBL 306289 & 535 & 8.0458 & 8.0628 & TRN & \\
\hline CHEMBL 306722 & 535 & 6.4949 & 6.50299 & 9999999999 & TRN \\
\hline CHEMBL 24088 & 535 & 6.8239 & 6.8309 & TRN & \\
\hline CHEMBL 3085538 & 535 & 6.7447 & 6.7427 & TRN & \\
\hline
\end{tabular}

Page 20820 


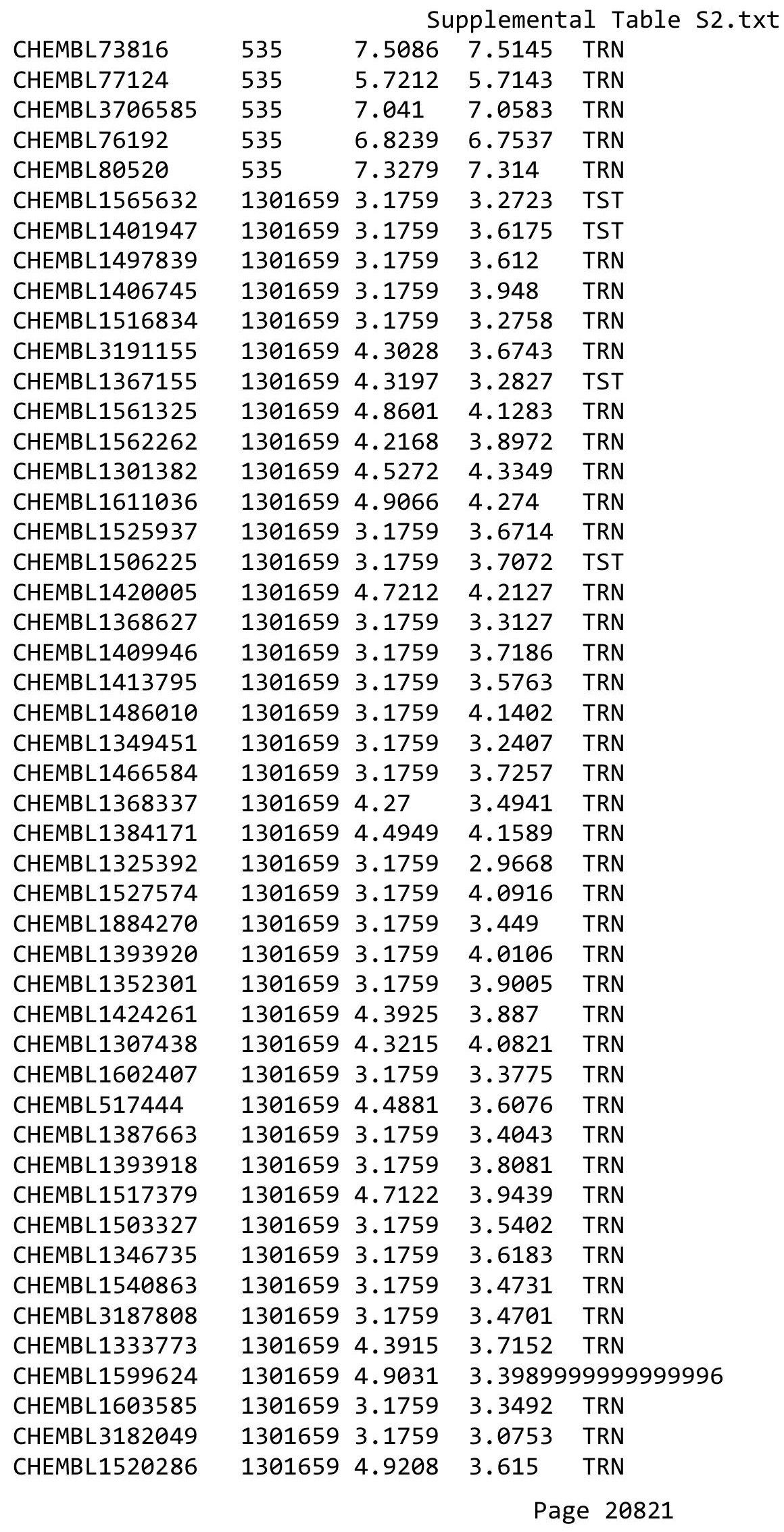


Supplemental Table S2.txt

\begin{tabular}{|c|c|c|c|c|}
\hline W & & & & \\
\hline & & & & \\
\hline & & & & \\
\hline IEMBL1 & & & 302 & \\
\hline AEMBL1549010 & 59 & & 349 & \\
\hline HEMBL1430943 & 301659 & 759 & 6836 & \\
\hline 440 & 59 & & & \\
\hline JEMBL1546060 & & & & \\
\hline HEMBL1585547 & 59 & & 1115 & \\
\hline HEMBL1422672 & 59 & & 3565 & \\
\hline HEMBL1322376 & 59 & & 401 & \\
\hline AEMBL1499830 & 99 & & 78 & \\
\hline AEMBL1564655 & & & & \\
\hline HEMBL1443953 & 59 & & 7843 & \\
\hline AEMBL1351384 & $20 \div \div$ & & 908 & \\
\hline AEMBL1465358 & 30 & & 95 & \\
\hline AEMBL1588313 & 59 & & 19 & \\
\hline HEMBL1447863 & & & & \\
\hline HEMBL3185931 & 59 & & 2922 & \\
\hline AEMBL1509433 & & & & \\
\hline AEIMBL $1889 / 15$ & y & & 27 & ונד \\
\hline HEMBL147 & 9 & & 344 & 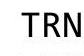 \\
\hline HEMBL133 & 9 & & & \\
\hline AEMBL1604645 & & & 394 & \\
\hline AEMBL1342327 & & & & To \\
\hline HEMBL136 & 36 & & 943 & $\cdots$ \\
\hline HEMBL1 & & & 45 & RN \\
\hline HEMBL1534581 & & & & \\
\hline HEMBL1723342 & & & 817 & I RाV \\
\hline HEMBL1501475 & & & & INIV \\
\hline HEMBL1351200 & 36 & & & SI \\
\hline HEMBL3 & & & & RN \\
\hline 313 & & & & RN \\
\hline HEMBL1498167 & & & & RIV \\
\hline HEMBL1304985 & - & & 331 & TRN \\
\hline HEMBL1537448 & 36 & & 343 & RN \\
\hline HFMRI 132 & & & & RN \\
\hline HEMBL1320109 & & & 547 & RN \\
\hline HEMBL1490452 & 9 & & 576 & TRN \\
\hline IEMBL1517647 & 30 & & 373 & $\mathrm{RN}$ \\
\hline HEMBL1366745 & $20+2>$ & & 622 & \\
\hline HEMBL1731167 & & & & RN \\
\hline HEMBL1560619 & & & 579 & $\Gamma \mathrm{RN}$ \\
\hline AEMBL1345083 & 30 & & 5105 & TRN \\
\hline MBL13 & (2) & & 008 & $T$ \\
\hline HEMBL1529812 & & & 7597 & \\
\hline CHEMBL1469246 & & 3.17 & .5221 & \\
\hline HEMBL1323117 & 1301659 & 4.3696 & 4.1442 & \\
\hline
\end{tabular}

Page 20822 
Supplemental Table S2.txt

\begin{tabular}{|c|c|c|c|c|}
\hline CHEMBL1566689 & 1301659 & 3.1759 & 4.1854 & TRN \\
\hline CHEMBL1342311 & 1301659 & 4.5287 & 4.1 & TRN \\
\hline CHEMBL1563599 & 1301659 & 3.1759 & 3.3757 & TRN \\
\hline CHEMBL1406161 & 1301659 & 3.1759 & 3.1951 & TRN \\
\hline CHEMBL1427520 & 1301659 & 3.1759 & 3.5175 & TRN \\
\hline CHEMBL1477639 & 1301659 & 3.1759 & 2.872 & TRN \\
\hline CHEMBL1327566 & 1301659 & 4.4535 & 4.1492 & TRN \\
\hline CHEMBL1425169 & 1301659 & 3.1759 & 3.4792 & TRN \\
\hline CHEMBL1487404 & 1301659 & 4.9393 & 3.4629 & TST \\
\hline CHEMBL1508547 & 1301659 & 3.1759 & 3.4021 & TRN \\
\hline CHEMBL1521564 & 1301659 & 4.4342 & 3.5841 & TRN \\
\hline CHEMBL1498055 & 1301659 & 3.1759 & 3.713 & TRN \\
\hline CHEMBL572203 & 1301659 & 3.1759 & 3.127 & TRN \\
\hline CHEMBL1374226 & 1301659 & 3.1759 & 3.5309 & TRN \\
\hline CHEMBL1993145 & 1301659 & 3.1759 & 3.4633 & TST \\
\hline CHEMBL1545295 & 1301659 & 3.1759 & 3.4238 & TRN \\
\hline CHEMBL1309064 & 1301659 & 4.1986 & 3.9258 & TRN \\
\hline CHEMBL1496459 & 1301659 & 4.2388 & 4.0801 & TRN \\
\hline CHEMBL1389556 & 1301659 & 3.1759 & 3.5046 & TRN \\
\hline CHEMBL1302847 & 1301659 & 3.1759 & 3.5412 & TRN \\
\hline CHEMBL1463571 & 1301659 & 3.1759 & 3.2048 & TRN \\
\hline CHEMBL1422976 & 1301659 & 3.1759 & 3.2541 & TRN \\
\hline CHEMBL1537279 & 1301659 & 3.1759 & 3.1288 & TST \\
\hline CHEMBL1467704 & 1301659 & 3.1759 & 3.4773 & TRN \\
\hline CHEMBL1565471 & 1301659 & 3.1759 & 3.7909 & TRN \\
\hline CHEMBL1424316 & 1301659 & 3.1759 & 3.7697 & TRN \\
\hline CHEMBL1419835 & 1301659 & 3.1759 & 3.3729 & TST \\
\hline CHEMBL1299357 & 1301659 & 4.6162 & 3.7001 & TRN \\
\hline CHEMBL1602770 & 1301659 & 4.7055 & 4.0285 & TRN \\
\hline CHEMBL392515 & 1301659 & 3.1759 & 4.0853 & TRN \\
\hline CHEMBL1557544 & 1301659 & 3.1759 & 3.475 & TRN \\
\hline CHEMBL1401945 & 1301659 & 3.1759 & 3.4748 & TST \\
\hline CHEMBL1426583 & 1301659 & 3.1759 & 3.1775 & TRN \\
\hline CHEMBL1460252 & 1301659 & 3.1759 & 3.2723 & TRN \\
\hline CHEMBL1304907 & 1301659 & 4.6635 & 3.534 & TRN \\
\hline CHEMBL1574274 & 1301659 & 3.1759 & 3.1308 & TRN \\
\hline CHEMBL1392525 & 1301659 & 3.1759 & 3.8024 & TRN \\
\hline CHEMBL1599466 & 1301659 & 3.1759 & 3.4289 & TRN \\
\hline CHEMBL1400122 & 1301659 & 3.1759 & 3.5572 & TRN \\
\hline CHEMBL1538337 & 1301659 & 4.301 & 3.7918 & TRN \\
\hline CHEMBL1543781 & 1301659 & 3.1759 & 3.1676 & TRN \\
\hline CHEMBL1550467 & 1301659 & 3.1759 & 3.5976 & TRN \\
\hline CHEMBL1543129 & 1301659 & 3.1759 & 3.466 & TRN \\
\hline CHEMBL1306550 & 1301659 & 3.1759 & 4.2294 & TRN \\
\hline CHEMBL1568452 & 1301659 & 4.301 & 3.6054 & TST \\
\hline CHEMBL1466140 & 1301659 & 4.6757 & 3.9336 & TRN \\
\hline CHEMBL1343699 & 1301659 & 3.1759 & \multicolumn{2}{|c|}{3.5860000000000003} \\
\hline CHEMBL1741640 & 1301659 & 4.3883 & 3.8116 & TRN \\
\hline
\end{tabular}


Supplemental Table S2.txt

\begin{tabular}{|c|c|c|c|c|c|}
\hline CHEMBL1309430 & 1301659 & 4.4672 & 3.5955 & TRN & \\
\hline CHEMBL1539091 & 1301659 & 4.433 & 4.3065 & TRN & \\
\hline CHEMBL1364022 & 1301659 & 3.1759 & 3.3089 & TRN & \\
\hline CHEMBL1334790 & 1301659 & 4.5186 & 3.51899 & 99999999997 & TST \\
\hline CHEMBL1612493 & 1301659 & 3.1759 & 3.3317 & TRN & \\
\hline CHEMBL1541286 & 1301659 & 3.1759 & 4.1959 & TRN & \\
\hline CHEMBL1407375 & 1301659 & 4.4498 & 3.6217 & TRN & \\
\hline CHEMBL1607212 & 1301659 & 4.3045 & 3.4403 & TRN & \\
\hline CHEMBL1507725 & 1301659 & 3.1759 & 3.7143 & TRN & \\
\hline CHEMBL1343705 & 1301659 & 3.1759 & 3.3077 & TST & \\
\hline CHEMBL1311143 & 1301659 & 3.1759 & 3.7344 & TRN & \\
\hline CHEMBL1431501 & 1301659 & 3.1759 & 3.6698 & TRN & \\
\hline CHEMBL1609248 & 1301659 & 3.1759 & 4.3125 & TRN & \\
\hline CHEMBL1528253 & 1301659 & 5.0132 & 3.97 & TRN & \\
\hline CHEMBL1995336 & 1301659 & 3.1759 & 3.3716 & TST & \\
\hline CHEMBL1483985 & 1301659 & 4.8665 & 4.2248 & TRN & \\
\hline CHEMBL1303183 & 1301659 & 4.21399 & 99999999 & 3.5664 & TRN \\
\hline CHEMBL1578334 & 1301659 & 3.1759 & 4.069 & TRN & \\
\hline CHEMBL1569039 & 1301659 & 4.382 & 3.5163 & TRN & \\
\hline CHEMBL1367025 & 1301659 & 4.8386 & 4.4081 & TRN & \\
\hline CHEMBL1330578 & 1301659 & 3.1759 & 3.3362 & TRN & \\
\hline CHEMBL1597827 & 1301659 & 3.1759 & 3.1198 & TRN & \\
\hline CHEMBL1417363 & 1301659 & 4.7212 & 3.2907 & TRN & \\
\hline CHEMBL1345141 & 1301659 & 3.1759 & 3.4214 & TRN & \\
\hline CHEMBL1557619 & 1301659 & 3.1759 & 3.0552 & TRN & \\
\hline CHEMBL1541719 & 1301659 & 4.7055 & 4.1462 & TRN & \\
\hline CHEMBL1498529 & 1301659 & 3.1759 & 3.85 & TRN & \\
\hline CHEMBL1518089 & 1301659 & 3.1759 & 3.5533 & TST & \\
\hline CHEMBL1389122 & 1301659 & 4.2403 & 4.0169 & TRN & \\
\hline CHEMBL1459454 & 1301659 & 4.6904 & 3.3468 & TRN & \\
\hline CHEMBL1585310 & 1301659 & 3.1759 & 3.687 & TRN & \\
\hline CHEMBL1568248 & 1301659 & 3.1759 & 3.4973 & TST & \\
\hline CHEMBL1452966 & 1301659 & 3.1759 & 3.2371 & TRN & \\
\hline CHEMBL1566214 & 1301659 & 3.1759 & 3.3238 & TRN & \\
\hline CHEMBL1547376 & 1301659 & 3.1759 & 3.5 & TST & \\
\hline CHEMBL1410774 & 1301659 & 3.1759 & 4.2278 & TRN & \\
\hline CHEMBL 3191861 & 1301659 & 3.1759 & 3.5873 & TRN & \\
\hline CHEMBL1329406 & 1301659 & 3.1759 & 3.5481 & TRN & \\
\hline CHEMBL 2140184 & 1301659 & 4.4389 & 3.8116 & TRN & \\
\hline CHEMBL1382210 & 1301659 & 3.1759 & 3.5111 & TRN & \\
\hline CHEMBL1487270 & 1301659 & 5.0706 & 3.7501 & TRN & \\
\hline CHEMBL 3193785 & 1301659 & 3.1759 & 3.2325 & TST & \\
\hline CHEMBL1612072 & 1301659 & 3.1759 & 3.5047 & TRN & \\
\hline CHEMBL1501418 & 1301659 & 3.1759 & 3.3679 & TRN & \\
\hline CHEMBL1471631 & 1301659 & 3.1759 & 3.6249 & TRN & \\
\hline CHEMBL1441874 & 1301659 & 4.7055 & 3.7436 & TST & \\
\hline CHEMBL1454239 & 1301659 & 3.1759 & 3.4746 & TST & \\
\hline CHEMBL1548838 & 1301659 & 4.8153 & 4.3524 & TRN & \\
\hline
\end{tabular}


Supplemental Table S2.txt

\begin{tabular}{|c|c|c|c|c|c|}
\hline CHEMBL1584898 & 1301659 & 3.1759 & 3.4619 & TST & \\
\hline CHEMBL1351651 & 1301659 & 3.1759 & 3.0337 & TRN & \\
\hline CHEMBL3186149 & 1301659 & 3.1759 & 3.713 & TST & \\
\hline CHEMBL1535358 & 1301659 & 4.2612 & 4.2263 & TRN & \\
\hline CHEMBL1326246 & 1301659 & 3.1759 & \multicolumn{2}{|c|}{ 3.7539999999999996 } & TRN \\
\hline CHEMBL1529049 & 1301659 & 3.1759 & 4.4363 & TRN & \\
\hline CHEMBL1411390 & 1301659 & 4.6091 & 4.0478 & TRN & \\
\hline CHEMBL1486477 & 1301659 & 3.1759 & 3.3806 & TRN & \\
\hline CHEMBL1526212 & 1301659 & 5.4685 & 4.2253 & TRN & \\
\hline CHEMBL1335290 & 1301659 & 3.1759 & 3.3489 & TRN & \\
\hline CHEMBL1519083 & 1301659 & 4.5622 & 3.767 & TRN & \\
\hline CHEMBL1497016 & 1301659 & 3.1759 & 3.8406 & TRN & \\
\hline CHEMBL1532408 & 1301659 & 3.1759 & \multicolumn{2}{|c|}{3.3110000000000004} & TRN \\
\hline CHEMBL1374204 & 1301659 & 3.1759 & 4.1018 & TRN & \\
\hline CHEMBL1563387 & 1301659 & 4.7375 & 3.4897 & TRN & \\
\hline CHEMBL1595687 & 1301659 & 3.1759 & 3.3933 & TST & \\
\hline CHEMBL1456551 & 1301659 & 3.1759 & 3.3408 & TST & \\
\hline CHEMBL1388022 & 1301659 & 5.0458 & \multicolumn{2}{|c|}{3.8960000000000004} & TRN \\
\hline CHEMBL1707147 & 1301659 & 3.1759 & 3.4565 & TRN & \\
\hline CHEMBL1320528 & 1301659 & 4.6819 & 3.9107 & TRN & \\
\hline CHEMBL1367446 & 1301659 & 3.1759 & 3.2962 & TST & \\
\hline CHEMBL1336641 & 1301659 & 3.1759 & 3.6214 & TRN & \\
\hline CHEMBL1393932 & 1301659 & 3.1759 & 4.0517 & TRN & \\
\hline CHEMBL1529795 & 1301659 & 4.5686 & 4.1598 & TRN & \\
\hline CHEMBL1587683 & 1301659 & 4.4365 & \multicolumn{2}{|c|}{3.8510000000000004} & TRN \\
\hline CHEMBL3197060 & 1301659 & 3.1759 & 3.3719 & TST & \\
\hline CHEMBL1302322 & 1301659 & 3.1759 & 3.3363 & TST & \\
\hline CHEMBL1417897 & 1301659 & 3.1759 & 3.8898 & TRN & \\
\hline CHEMBL1446025 & 1301659 & 3.1759 & 3.6968 & TRN & \\
\hline CHEMBL1380856 & 1301659 & 3.1759 & 3.6568 & TRN & \\
\hline CHEMBL1344524 & 1301659 & 5.0044 & 4.4206 & TRN & \\
\hline CHEMBL1352096 & 1301659 & 3.1759 & 3.5576 & TRN & \\
\hline CHEMBL1540596 & 1301659 & 4.8327 & \multicolumn{2}{|c|}{3.7089999999999996} & TRN \\
\hline CHEMBL1380975 & 1301659 & 3.1759 & 3.7725 & TRN & \\
\hline CHEMBL1426787 & 1301659 & 3.1759 & 3.4 & TST & \\
\hline CHEMBL1370753 & 1301659 & 4.5058 & 4.2362 & TRN & \\
\hline CHEMBL1510139 & 1301659 & 3.1759 & 3.0415 & TRN & \\
\hline CHEMBL1501898 & 1301659 & 3.1759 & 3.6515 & TST & \\
\hline CHEMBL1449589 & 1301659 & 3.1759 & \multicolumn{2}{|c|}{ 3.3489999999999998 } & TRN \\
\hline CHEMBL1430202 & 1301659 & 3.1759 & 3.4651 & TRN & \\
\hline CHEMBL1537196 & 1301659 & 3.1759 & 3.5255 & TST & \\
\hline CHEMBL1573313 & 1301659 & 3.1759 & 3.5072 & TRN & \\
\hline CHEMBL1522845 & 1301659 & 3.1759 & 3.3931 & TRN & \\
\hline CHEMBL1300796 & 1301659 & 4.6402 & 3.7221 & TRN & \\
\hline CHEMBL1345939 & 1301659 & 3.1759 & 3.2565 & TST & \\
\hline CHEMBL1603724 & 1301659 & 4.4134 & 4.0307 & TST & \\
\hline CHEMBL1487207 & 1301659 & 3.1759 & 4.3131 & TST & \\
\hline CHEMBL3194619 & 1301659 & 4.6421 & 3.3451 & TST & \\
\hline
\end{tabular}


Supplemental Table S2.txt

\begin{tabular}{|c|c|c|c|c|c|}
\hline CHEMBL1613090 & 1301659 & 3.1759 & 3.2979 & TST & \\
\hline CHEMBL1438893 & 1301659 & 4.8697 & 3.9551 & TST & \\
\hline CHEMBL1520147 & 1301659 & 3.1759 & 3.413999 & 79999999997 & TST \\
\hline CHEMBL1530090 & 1301659 & 3.1759 & 3.2468 & TST & \\
\hline CHEMBL1904795 & 1301659 & 3.1759 & 3.3783 & TST & \\
\hline CHEMBL1573989 & 1301659 & 3.1759 & 3.6749 & TST & \\
\hline CHEMBL1493716 & 1301659 & 3.1759 & 3.0396 & TST & \\
\hline CHEMBL1536688 & 1301659 & 3.1759 & 4.0979 & TST & \\
\hline CHEMBL1600466 & 1301659 & 3.1759 & 3.2508 & TST & \\
\hline CHEMBL1547272 & 1301659 & 3.1759 & 3.7059 & TST & \\
\hline CHEMBL1368947 & 1301659 & 3.1759 & 3.6546 & TST & \\
\hline CHEMBL1453327 & 1301659 & 4.3851 & 3.2478 & TST & \\
\hline CHEMBL1371060 & 1301659 & 4.9355 & 3.6799 & TST & \\
\hline CHEMBL1450917 & 1301659 & 4.8327 & 4.2515 & TST & \\
\hline CHEMBL1528083 & 1301659 & 3.1759 & 3.2517 & TST & \\
\hline CHEMBL1392442 & 1301659 & 4.8508 & 3.0654 & TST & \\
\hline CHEMBL1560268 & 1301659 & 3.1759 & 3.6821 & TST & \\
\hline CHEMBL1536363 & 1301659 & 3.1759 & 3.9611 & TST & \\
\hline CHEMBL1313648 & 1301659 & 4.3655 & 3.0 & TST & \\
\hline CHEMBL1313466 & 1301659 & 3.1759 & 3.293 & TST & \\
\hline CHEMBL1612968 & 1301659 & 3.1759 & 3.8194 & TST & \\
\hline CHEMBL1566536 & 1301659 & 3.1759 & 3.3117 & TST & \\
\hline CHEMBL1376581 & 1301659 & 3.1759 & 3.2897 & TST & \\
\hline CHEMBL1312768 & 1301659 & 4.3401 & 3.6622 & TST & \\
\hline CHEMBL1487874 & 1301659 & 4.4318 & 3.4942 & TST & \\
\hline CHEMBL1339330 & 1301659 & 5.301 & 3.9052 & TST & \\
\hline CHEMBL1326700 & 1301659 & 3.1759 & 3.228999 & 99999999996 & \\
\hline CHEMBL1386047 & 1301659 & 3.1759 & 3.1754 & TST & \\
\hline CHEMBL1530728 & 1301659 & 4.5171 & 4.1299 & TST & \\
\hline CHEMBL522345 & 629376 & 10.2218 & 10.1836 & TRN & \\
\hline CHEMBL493941 & 629376 & 6.4034 & 6.3805 & TRN & \\
\hline CHEMBL522372 & 629376 & 8.1367 & 8.0977 & TRN & \\
\hline CHEMBL495031 & 629376 & 7.7595 & 7.7864 & TRN & \\
\hline CHEMBL523372 & 629376 & 8.1805 & 8.1938 & TRN & \\
\hline CHEMBL524048 & 629376 & 8.0862 & 8.0995 & TRN & \\
\hline CHEMBL494349 & 629376 & 7.6162 & 7.6242 & TRN & \\
\hline CHEMBL492951 & 629376 & 4.6045 & 4.5805 & TRN & \\
\hline CHEMBL522665 & 629376 & 6.5768 & 6.5587 & TST & \\
\hline CHEMBL524010 & 629376 & 7.6757 & 7.6712 & TRN & \\
\hline CHEMBL523717 & 629376 & 9.1487 & 9.1379 & TRN & \\
\hline CHEMBL523864 & 629376 & 9.283999 & 999999999 & 9.3061 & T \\
\hline CHEMBL492345 & 629376 & 3.9189 & 6.3385 & TST & \\
\hline CHEMBL522666 & 629376 & 4.333 & 4.3347 & TRN & \\
\hline CHEMBL493535 & 629376 & 5.4202 & 5.2589 & TST & \\
\hline CHEMBL493838 & 629376 & 7.3686 & 7.3777 & TRN & \\
\hline CHEMBL494547 & 629376 & 9.8539 & 9.8379 & TRN & \\
\hline CHEMBL135339 & 629376 & 8.5867 & 8.5966 & TRN & \\
\hline CHEMBL494134 & 629376 & 5.8101 & 5.8017 & TRN & \\
\hline
\end{tabular}




\begin{tabular}{|c|c|c|c|c|c|}
\hline \multirow[b]{2}{*}{ CHEMBL494225 } & \multicolumn{5}{|c|}{ Supplemental Table s2.txt } \\
\hline & 629376 & 9.4559 & 9.4599 & TRN & \\
\hline CHEMBL492938 & 629376 & 6.8245 & 6.8394 & TRN & \\
\hline CHEMBL492586 & 629376 & 10.1549 & 10.1398 & TRN & \\
\hline CHEMBL493011 & 629376 & 5.8386 & 6.8089 & TST & \\
\hline CHEMBL493184 & 629376 & 5.5768 & 6.7402 & TST & \\
\hline CHEMBL1096109 & 629376 & 5.1701 & 7.3983 & TST & \\
\hline CHEMBL494358 & 629376 & 8.3098 & 8.297 & TRN & \\
\hline CHEMBL522322 & 629376 & 9.6383 & 9.6421 & TRN & \\
\hline CHEMBL494002 & 629376 & 9.8861 & 9.8751 & TRN & \\
\hline CHEMBL492948 & 629376 & 6.4831 & 6.4855 & TRN & \\
\hline CHEMBL445522 & 629376 & 9.301 & 9.3013 & TRN & \\
\hline CHEMBL492946 & 629376 & 6.0213 & 6.0104 & TRN & \\
\hline CHEMBL495019 & 629376 & 9.3768 & 9.3807 & TRN & \\
\hline CHEMBL492937 & 629376 & 8.3468 & 8.3109 & TRN & \\
\hline CHEMBL494164 & 629376 & 7.6364 & 8.6663 & TST & \\
\hline CHEMBL495032 & 629376 & 7.0482 & 7.0443 & TRN & \\
\hline CHEMBL493172 & 629376 & 4.8617 & 7.2944 & TST & \\
\hline CHEMBL493338 & 629376 & 4.6757 & 4.6895 & TRN & \\
\hline CHEMBL493000 & 629376 & 8.7696 & 8.7844 & TRN & \\
\hline CHEMBL523702 & 629376 & 6.301 & 6.292006 & 0000000001 & TRN \\
\hline CHEMBL522687 & 629376 & 8.3565 & 8.3763 & TRN & \\
\hline CHEMBL493934 & 629376 & 6.0766 & 6.0762 & TRN & \\
\hline CHEMBL522175 & 629376 & 9.2518 & 9.2736 & TRN & \\
\hline CHEMBL492947 & 629376 & 6.6819 & 6.7104 & TRN & \\
\hline CHEMBL523842 & 629376 & 8.3665 & 8.357006 & 0000000001 & TRN \\
\hline CHEMBL493738 & 629376 & 9.3468 & 9.3642 & TRN & \\
\hline CHEMBL336293 & 629376 & 6.8154 & 6.8254 & TRN & \\
\hline CHEMBL523362 & 629376 & 10.2218 & 10.2344 & TRN & \\
\hline CHEMBL495004 & 629376 & 8.7212 & 10.5497 & TST & \\
\hline CHEMBL493942 & 629376 & 5.9625 & 5.9162 & TST & \\
\hline CHEMBL522022 & 629376 & 9.8861 & 9.7246 & TST & \\
\hline CHEMBL522010 & 629376 & 4.696000 & 0000000 & 8.2614 & TST \\
\hline CHEMBL523369 & 629376 & 7.1361 & 7.671 & TST & \\
\hline CHEMBL202721 & 954456 & 4.6817 & 4.4155 & TRN & \\
\hline CHEMBL1404918 & 954456 & 2.983 & 3.194 & TRN & \\
\hline CHEMBL210618 & 954456 & 3.8491 & 3.9748 & TRN & \\
\hline CHEMBL180127 & 954456 & 4.6339 & 4.6694 & TRN & \\
\hline CHEMBL1357247 & 954456 & 3.1157 & 3.0716 & TRN & \\
\hline CHEMBL515416 & 954456 & 4.5014 & 4.5229 & TRN & \\
\hline CHEMBL3392440 & 954456 & 3.359 & 3.3883 & TRN & \\
\hline CHEMBL221137 & 954456 & 4.3048 & 4.1565 & TST & \\
\hline CHEMBL1590308 & 954456 & 3.9548 & 3.8881 & TST & \\
\hline CHEMBL3186408 & 954456 & 3.1223 & 3.7581 & TST & \\
\hline CHEMBL189584 & 954456 & 4.8723 & 4.9144 & TRN & \\
\hline CHEMBL 379300 & 954456 & 6.7846 & 7.1365 & TRN & \\
\hline CHEMBL577784 & 954456 & 4.7116 & 4.3994 & TRN & \\
\hline CHEMBL 240954 & 954456 & 5.2957 & 4.2315 & TST & \\
\hline CHEMBL573107 & 954456 & 4.7058 & 4.5473 & TRN & \\
\hline
\end{tabular}




\begin{tabular}{|c|c|c|c|c|c|c|}
\hline & & \multicolumn{5}{|c|}{ Supplemental Table S2.txt } \\
\hline CHEMBL509032 & 954456 & 3.7259 & 3.4323 & TRN & & \\
\hline CHEMBL449158 & 954456 & 6.0185 & 5.381 & TST & & \\
\hline CHEMBL259181 & 954456 & 3.0431 & 3.4956 & TRN & & \\
\hline CHEMBL192566 & 954456 & 7.5074 & 6.1062 & TST & & \\
\hline CHEMBL1242367 & 954456 & 4.0163 & 3.7319 & TRN & & \\
\hline CHEMBL392695 & 954456 & 5.9204 & 5.7344 & TRN & & \\
\hline CHEMBL 2005886 & 954456 & 3.7111 & 3.5924 & TRN & & \\
\hline CHEMBL558642 & 954456 & 4.2932 & 3.8911 & TRN & & \\
\hline CHEMBL585951 & 954456 & 4.1876 & 4.6777 & TRN & & \\
\hline CHEMBL1909414 & 954456 & 4.6118 & 4.435 & TRN & & \\
\hline CHEMBL483847 & 954456 & \multicolumn{3}{|c|}{3.6439999999999997} & 4.3079 & TRN \\
\hline CHEMBL3349342 & 954456 & 3.447 & 3.6035 & TRN & & \\
\hline CHEMBL379975 & 954456 & 4.9773 & 5.1439 & TRN & & \\
\hline CHEMBL65 & 954456 & 6.2304 & 5.9308 & TRN & & \\
\hline CHEMBL300389 & 954456 & \multicolumn{3}{|c|}{6.082000000000001} & 6.0235 & TRN \\
\hline CHEMBL512504 & 954456 & 4.383 & 4.5483 & TRN & & \\
\hline CHEMBL213100 & 954456 & 4.1513 & 4.098 & TRN & & \\
\hline CHEMBL 2144069 & 954456 & 3.4783 & 3.54 & TRN & & \\
\hline CHEMBL472940 & 954456 & 2.8455 & 3.1674 & TRN & & \\
\hline CHEMBL412142 & 954456 & 4.8764 & 4.1619 & TRN & & \\
\hline CHEMBL1643959 & 954456 & 3.0102 & 3.2039 & TRN & & \\
\hline CHEMBL393929 & 954456 & 4.3168 & 4.4362 & TRN & & \\
\hline CHEMBL135561 & 954456 & 3.7704 & 4.005 & TRN & & \\
\hline CHEMBL9470 & 954456 & 3.39 & 4.3235 & TST & & \\
\hline CHEMBL209148 & 954456 & 4.1364 & 4.0408 & TRN & & \\
\hline CHEMBL1788116 & 954456 & 3.31 & 3.7814 & TRN & & \\
\hline CHEMBL1673039 & 954456 & 3.6507 & 3.985 & TRN & & \\
\hline CHEMBL1190711 & 954456 & 4.811 & 4.4647 & TRN & & \\
\hline CHEMBL 1256459 & 954456 & 6.8507 & 7.1124 & TRN & & \\
\hline CHEMBL 2363137 & 954456 & 4.7449 & 4.3946 & TRN & & \\
\hline CHEMBL222102 & 954456 & 4.758 & 4.4015 & TRN & & \\
\hline CHEMBL1230020 & 954456 & 4.5861 & 4.6889 & TRN & & \\
\hline CHEMBL92309 & 954456 & 2.3629 & 3.2891 & TST & & \\
\hline CHEMBL1970879 & 954456 & 3.242 & 3.4216 & TRN & & \\
\hline CHEMBL514499 & 954456 & 7.8196 & 7.8624 & TRN & & \\
\hline CHEMBL188678 & 954456 & 5.1387 & 4.7397 & TRN & & \\
\hline CHEMBL191334 & 954456 & 4.4793 & 4.1592 & TRN & & \\
\hline CHEMBL3199475 & 954456 & 3.3785 & 3.9458 & TST & & \\
\hline CHEMBL1516890 & 954456 & 4.0871 & 3.947 & TST & & \\
\hline CHEMBL258844 & 954456 & 3.5102 & 3.8027 & TST & & \\
\hline CHEMBL483849 & 954456 & 3.003 & 3.2802 & TST & & \\
\hline CHEMBL373751 & 954456 & 2.9963 & 4.1185 & TST & & \\
\hline CHEMBL220241 & 954456 & 4.1296 & 4.4172 & TST & & \\
\hline CHEMBL102714 & 954456 & 4.2848 & 4.2011 & TST & & \\
\hline CHEMBL456295 & 688792 & 3.1225 & 3.1902 & TRN & & \\
\hline CHEMBL1469144 & 688792 & 4.996 & 5.0679 & TRN & & \\
\hline CHEMBL1381318 & 688792 & 3.1225 & 3.2805 & TRN & & \\
\hline CHEMBL1362550 & 688792 & 3.1226 & 3.9354 & TST & & \\
\hline
\end{tabular}




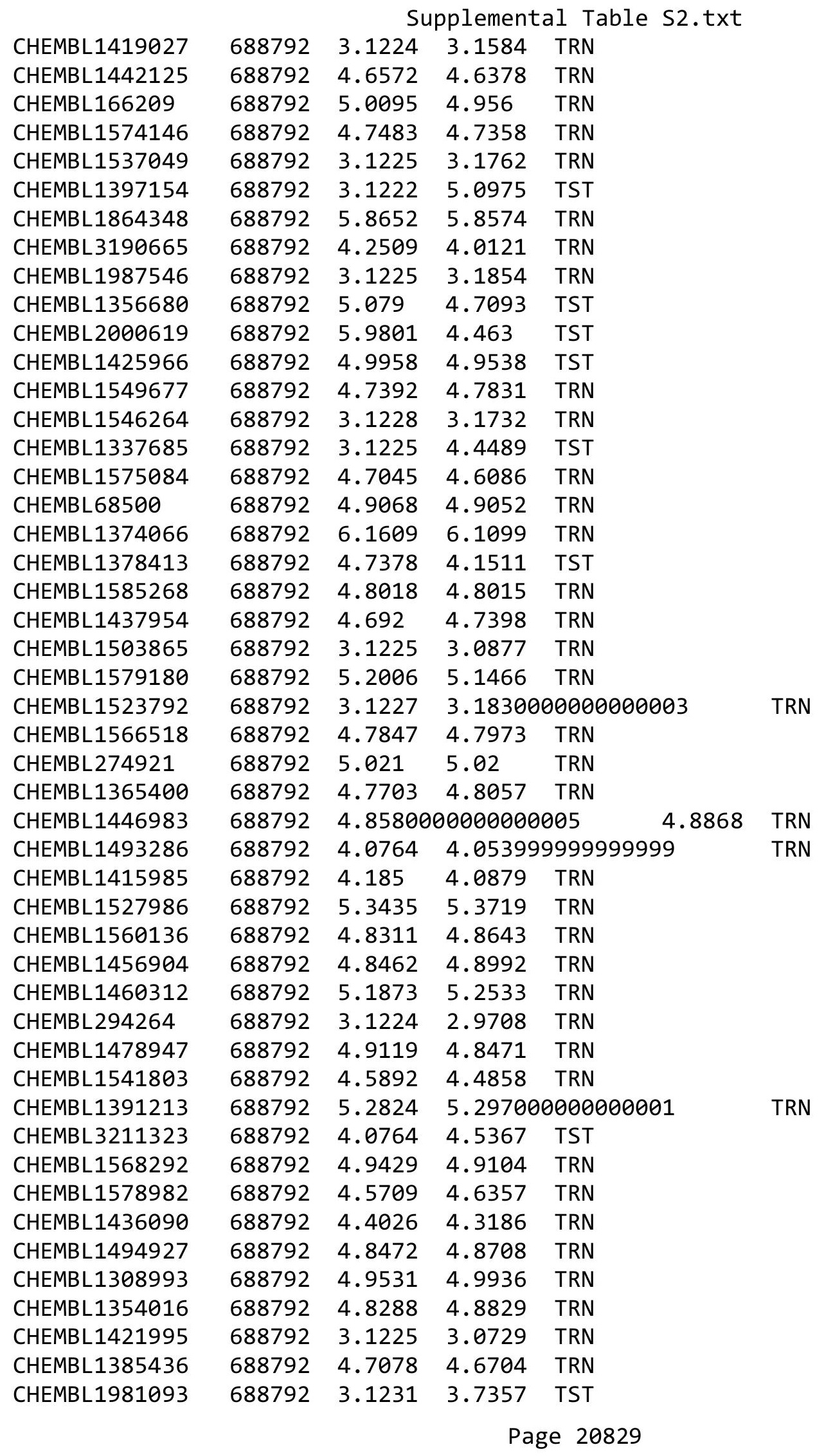




\begin{tabular}{|c|c|c|c|c|c|}
\hline \multirow[b]{2}{*}{ CHEMBL1332240 } & \multicolumn{5}{|c|}{ Supplemental Table S2.txt } \\
\hline & 688792 & 4.7128 & 4.7637 & TRN & \\
\hline CHEMBL1495503 & 688792 & 3.1226 & 3.0164 & TRN & \\
\hline CHEMBL88326 & 688792 & 3.1225 & 3.109 & TRN & \\
\hline CHEMBL1601851 & 688792 & 3.1226 & 3.1374 & TRN & \\
\hline CHEMBL1312914 & 688792 & 3.122 & 3.1042 & TRN & \\
\hline CHEMBL1573564 & 688792 & 3.1227 & 4.9282 & TST & \\
\hline CHEMBL1502839 & 688792 & 3.1223 & 3.1633 & TRN & \\
\hline CHEMBL1411766 & 688792 & 5.13899 & 99999999 & 5.1677 & TRN \\
\hline CHEMBL1469407 & 688792 & 3.1221 & 3.1237 & TRN & \\
\hline CHEMBL1391235 & 688792 & 4.7894 & 4.8544 & TRN & \\
\hline CHEMBL11475 & 688792 & 3.1225 & 3.1346 & TRN & \\
\hline CHEMBL1549136 & 688792 & 3.5991 & 3.6122 & TRN & \\
\hline CHEMBL1378107 & 688792 & 4.981 & 4.6946 & TST & \\
\hline CHEMBL1357473 & 688792 & 4.0768 & 4.08899 & 99999999995 & TRN \\
\hline CHEMBL1517523 & 688792 & 5.5178 & 5.4731 & TRN & \\
\hline CHEMBL1442453 & 688792 & 3.1226 & 3.1716 & TRN & \\
\hline CHEMBL1470560 & 688792 & 4.5342 & 4.7461 & TST & \\
\hline CHEMBL 269410 & 688792 & 5.1044 & 4.944 & TST & \\
\hline CHEMBL282433 & 688792 & 5.0803 & 4.1096 & TST & \\
\hline CHEMBL1445765 & 688792 & 4.1702 & 4.6765 & TST & \\
\hline CHEMBL1553837 & 688792 & 5.0737 & 3.9514 & TST & \\
\hline CHEMBL1376371 & 688792 & 3.1225 & 4.8149 & TST & \\
\hline CHEMBL1587496 & 688792 & 3.1225 & 2.423 & TST & \\
\hline CHEMBL1998429 & 688792 & 3.6002 & 4.6343 & TST & \\
\hline CHEMBL3919338 & 1642293 & 8.8239 & 8.635 & TRN & \\
\hline CHEMBL3970737 & 1642293 & 7.0 & 7.8775 & TRN & \\
\hline CHEMBL3952708 & 1642293 & 8.5229 & 8.2881 & TRN & \\
\hline CHEMBL 3952082 & 1642293 & 8.5229 & 8.3436 & TRN & \\
\hline CHEMBL3915896 & 1642293 & 8.0 & 8.4917 & TRN & \\
\hline CHEMBL3977034 & 1642293 & 8.0 & 8.5269 & TST & \\
\hline CHEMBL3984412 & 1642293 & 8.0 & 7.8283 & TRN & \\
\hline CHEMBL3943824 & 1642293 & 8.0 & 8.3793 & TRN & \\
\hline CHEMBL 3928858 & 1642293 & 8.5229 & 8.526 & TRN & \\
\hline CHEMBL3940846 & 1642293 & 8.5229 & 8.4226 & TRN & \\
\hline CHEMBL3957230 & 1642293 & 8.5229 & 8.4634 & TRN & \\
\hline CHEMBL3943961 & 1642293 & 8.0 & 8.2312 & TRN & \\
\hline CHEMBL3934205 & 1642293 & 8.5229 & 8.7101 & TRN & \\
\hline CHEMBL3892819 & 1642293 & 8.5229 & 7.9829 & TRN & \\
\hline CHEMBL 3942227 & 1642293 & 8.0 & 8.5221 & TRN & \\
\hline CHEMBL3956706 & 1642293 & 8.0 & 8.3323 & TRN & \\
\hline CHEMBL 3985241 & 1642293 & 8.8239 & 8.3131 & TRN & \\
\hline CHEMBL3975437 & 1642293 & 8.0 & 8.3219 & TRN & \\
\hline CHEMBL 3904420 & 1642293 & 8.8239 & 8.87 & TRN & \\
\hline CHEMBL3927043 & 1642293 & 8.5229 & 8.3392 & TST & \\
\hline CHEMBL3904190 & 1642293 & 8.8239 & 8.8777 & TST & \\
\hline CHEMBL 3972720 & 1642293 & 7.0 & 7.1342 & TST & \\
\hline CHEMBL 3890843 & 1642293 & 8.8239 & 8.9371 & TRN & \\
\hline CHEMBL 3918874 & 1642293 & 8.5229 & 8.4737 & TRN & \\
\hline
\end{tabular}

Page 20830 
Supplemental Table S2.txt

\begin{tabular}{|c|c|c|c|c|}
\hline IEMBL & 542293 & 8.0 & 8.3054 & TR \\
\hline HEMBL 3957288 & 642293 & 8.0 & 8.474 & TON \\
\hline 527 & 2293 & 7.0 & 5139 & $2 \mathrm{~N}$ \\
\hline 158 & 542293 & 8.8239 & 843 & DN \\
\hline |EMBL 3984327 & 542293 & 8.8239 & 7859 & RIN \\
\hline AEMBL3943539 & 642293 & 7.0 & .0294 & $m$ \\
\hline HEMBL 398 & 642293 & 8.5229 & .1748 & \\
\hline EMB & 542293 & 7.0 & .195 & ST \\
\hline EMBL39 & 642293 & 8.0 & .0308 & ST \\
\hline AEMBL3921247 & 642293 & 7.0 & .4053 & RI \\
\hline IEMBL395 & 642293 & 8.0 & 0302 & KIN \\
\hline HEMBL 389 & 542293 & 8.8239 & .65 & $\mathrm{RN}$ \\
\hline IEME & 293 & 8.52 & 1018 & RN \\
\hline HEMBL3 & 293 & 8.8239 & 7891 & DN \\
\hline IEMBL3943995 & 642293 & 6.0458 & 7.0828 & $m$ \\
\hline EMBL391 & 93 & 8.8239 & 7308 & WT \\
\hline AEMBL3 & 293 & .5229 & 938 & RN \\
\hline AEMBL3 & 293 & 8.0 & 83 & $\mathrm{RN}$ \\
\hline AEMBL3S & 293 & 8.5229 & 561 & r \\
\hline AEMBL397 & 293 & 8.5229 & 7783 & $\mathrm{nI}$ \\
\hline EMIBL 396 & 93 & 8.0 & 1545 & IRI \\
\hline IEMBL & 93 & 8.82 & $8.1 / 3$ & TST \\
\hline AEMBL & 93 & 7.0 & 179 & \\
\hline 62 & 93 & 7.0 & 6.7973 & TST \\
\hline AEMBL39 & 293 & 8.8239 & 528 & TRI \\
\hline EMBL3 & 93 & 8.52 & 33 & TRN \\
\hline AEMB 3 & 93 & 3 . & 18 & TRN \\
\hline AEMBL 3 & & $\theta$ & 718 & TRN \\
\hline 69 & 93 & 8.52 & 58 & S \\
\hline EMBL39 & 93 & 7.0 & & $\mathrm{TS}$ \\
\hline EMBL39 & 64 & 8.82 & 7929 & TRN \\
\hline AEMB 3 & 293 & .52 & 676 & TRN \\
\hline 54 & & 0 & 11 & $\mathrm{RN}$ \\
\hline & 3 & 7.0 & 1519 & TRN \\
\hline EMBL 390 & 64 & 8.52 & & TRI \\
\hline EMBL3 & 93 & 8.52 & 744 & TRN \\
\hline AEMBL3 & 64 & 3.8239 & 291 & TRN \\
\hline & & & & RN \\
\hline 564 & 93 & 8.0 & 5812 & TRI \\
\hline EMBL 398 & 3 & 8.52 & 356 & TRI \\
\hline EMBL3 & 93 & 8.82 & 811 & TRN \\
\hline HEMBL3S & & .5229 & 5055 & TRN \\
\hline HEMBL3 & & 8.8239 & & TST \\
\hline HEMBL396 & 293 & 8.5229 & .4038 & TRI \\
\hline IEMBL 392 & 64 & 7.0 & .0286 & $\mathrm{TS}$ \\
\hline MBL3 & & 3.52 & & RIV \\
\hline 94 & & & 7.9968 & RI \\
\hline & & & .1307 & 「RI \\
\hline
\end{tabular}

Page 20831 


\begin{tabular}{|c|c|c|c|c|}
\hline \multicolumn{5}{|c|}{ Supplemental Table S2.txt } \\
\hline CHEMBL3895616 & 1642293 & 8.0 & 7.6441 & TRN \\
\hline CHEMBL3907890 & 1642293 & 8.5229 & 8.2628 & TRN \\
\hline CHEMBL3928378 & 1642293 & 8.0 & 8.2701 & TRN \\
\hline CHEMBL3955566 & 1642293 & 8.5229 & 8.8936 & TRN \\
\hline CHEMBL 3919044 & 1642293 & 8.5229 & 8.1677 & TRN \\
\hline CHEMBL3971527 & 1642293 & 8.0 & 7.237 & TRN \\
\hline CHEMBL3891771 & 1642293 & 8.0 & 8.2269 & TRN \\
\hline CHEMBL3895278 & 1642293 & 8.0 & 8.5725 & TRN \\
\hline CHEMBL3955989 & 1642293 & 8.0 & 8.022 & TST \\
\hline CHEMBL3931115 & 1642293 & 8.0 & 8.5645 & TST \\
\hline CHEMBL3971959 & 1642293 & 8.8239 & 8.6669 & TRN \\
\hline CHEMBL 3896740 & 1642293 & 8.0 & 8.3405 & TRN \\
\hline CHEMBL3909236 & 1642293 & 8.5229 & 7.8595 & TRN \\
\hline CHEMBL3939994 & 1642293 & 7.0 & 6.9055 & TRN \\
\hline CHEMBL 3932700 & 1642293 & 8.8239 & 8.7263 & TRN \\
\hline CHEMBL3911737 & 1642293 & 7.0 & 7.1516 & TRN \\
\hline CHEMBL3973089 & 1642293 & 7.0 & 6.8619 & TRN \\
\hline CHEMBL3949617 & 1642293 & 8.5229 & 8.5439 & TRN \\
\hline CHEMBL3966321 & 1642293 & 7.0 & 7.7934 & TST \\
\hline CHEMBL3968958 & 1642293 & 8.5229 & 8.3802 & TRN \\
\hline CHEMBL3924783 & 1642293 & 8.5229 & 8.3787 & TRN \\
\hline CHEMBL3931468 & 1642293 & 8.0 & 7.5439 & TRN \\
\hline CHEMBL3953508 & 1642293 & 8.0 & 7.5365 & TRN \\
\hline CHEMBL3968490 & 1642293 & 7.0 & 7.5586 & TRN \\
\hline CHEMBL 3896086 & 1642293 & 8.0 & 7.7669 & TRN \\
\hline CHEMBL3985372 & 1642293 & 8.5229 & 8.0899 & TRN \\
\hline CHEMBL3916574 & 1642293 & 8.0 & 7.803 & TRN \\
\hline CHEMBL3889505 & 1642293 & 8.0 & 7.5931 & TRN \\
\hline CHEMBL3931338 & 1642293 & 8.5229 & 8.7297 & TRN \\
\hline CHEMBL3940936 & 1642293 & 8.0 & 8.0806 & TRN \\
\hline CHEMBL3904385 & 1642293 & 8.8239 & 8.7352 & TRN \\
\hline CHEMBL3921622 & 1642293 & 8.5229 & 8.6044 & TST \\
\hline CHEMBL3946601 & 1642293 & 8.0 & 8.6706 & TST \\
\hline CHEMBL3943587 & 1642293 & 8.8239 & 8.6207 & TRN \\
\hline CHEMBL3967101 & 1642293 & 7.0 & 8.0976 & TST \\
\hline CHEMBL3912853 & 1642293 & 8.0 & 7.8998 & TRN \\
\hline CHEMBL3916897 & 1642293 & 8.8239 & 8.1364 & TRN \\
\hline CHEMBL3919184 & 1642293 & 8.8239 & 8.5652 & TRN \\
\hline CHEMBL3934438 & 1642293 & 8.5229 & 8.3669 & TRN \\
\hline CHEMBL3914507 & 1642293 & 7.0 & 7.553 & TST \\
\hline CHEMBL3896079 & 1642293 & 7.0 & 7.5089 & TRN \\
\hline CHEMBL3915999 & 1642293 & 8.0 & 8.1204 & TRN \\
\hline CHEMBL3921294 & 1642293 & 7.0 & 7.3304 & TRN \\
\hline CHEMBL3947539 & 1642293 & 8.0 & 8.4444 & TRN \\
\hline CHEMBL3910276 & 1642293 & 8.8239 & 8.6764 & TRN \\
\hline CHEMBL3938197 & 1642293 & 8.5229 & 8.3132 & TRN \\
\hline CHEMBL3946780 & 1642293 & 8.5229 & 8.5179 & TRN \\
\hline CHEMBL3960782 & 1642293 & 8.0 & 8.1036 & TRN \\
\hline
\end{tabular}




\begin{tabular}{|c|c|c|c|c|}
\hline \multicolumn{5}{|c|}{ Supplemental Table S2.txt } \\
\hline CHEMBL3927596 & 1642293 & 8.0 & 7.831 & TRN \\
\hline CHEMBL3904581 & 1642293 & 8.0 & 7.5993 & TST \\
\hline CHEMBL3891126 & 1642293 & 8.5229 & 8.5218 & TRN \\
\hline CHEMBL3985702 & 1642293 & 7.0 & 7.8626 & TST \\
\hline CHEMBL3929670 & 1642293 & 8.5229 & 8.238 & TRN \\
\hline CHEMBL3968667 & 1642293 & 8.5229 & 8.4897 & TRN \\
\hline CHEMBL3902062 & 1642293 & 8.5229 & 7.91 & TRN \\
\hline CHEMBL3959400 & 1642293 & 8.5229 & 8.3551 & TRN \\
\hline CHEMBL3929435 & 1642293 & 8.0 & 8.2719 & TRN \\
\hline CHEMBL3908778 & 1642293 & 7.0 & 7.6847 & TRN \\
\hline CHEMBL3901065 & 1642293 & 8.5229 & 8.7225 & TRN \\
\hline CHEMBL3935860 & 1642293 & 8.8239 & 8.5511 & TRN \\
\hline CHEMBL3901208 & 1642293 & 8.0 & 7.4695 & TST \\
\hline CHEMBL3932195 & 1642293 & 8.5229 & 8.4798 & TST \\
\hline CHEMBL 3928470 & 1642293 & 8.0 & 8.3741 & TRN \\
\hline CHEMBL3984119 & 1642293 & 8.0 & 8.4161 & TRN \\
\hline CHEMBL3961080 & 1642293 & 7.0 & 7.6825 & TST \\
\hline CHEMBL3889803 & 1642293 & 8.8239 & 8.6194 & TRN \\
\hline CHEMBL3950524 & 1642293 & 8.5229 & 8.029 & TRN \\
\hline CHEMBL3918912 & 1642293 & 8.0 & 8.0253 & TST \\
\hline CHEMBL3927876 & 1642293 & 7.0 & 7.8228 & TST \\
\hline CHEMBL3903354 & 1642293 & 7.0 & 7.7161 & TST \\
\hline CHEMBL3954664 & 1642293 & 7.0 & 7.3128 & TRN \\
\hline CHEMBL3985538 & 1642293 & 8.8239 & 8.7846 & TRN \\
\hline CHEMBL3984323 & 1642293 & 8.0 & 7.8579 & TRN \\
\hline CHEMBL3900993 & 1642293 & 7.0 & 7.6431 & TRN \\
\hline CHEMBL3930440 & 1642293 & 8.8239 & 8.6246 & TRN \\
\hline CHEMBL3913990 & 1642293 & 8.0 & 8.0982 & TRN \\
\hline CHEMBL3978449 & 1642293 & 8.5229 & 8.3926 & TST \\
\hline CHEMBL3941055 & 1642293 & 7.0 & 7.3182 & TST \\
\hline CHEMBL3916744 & 1642293 & 8.5229 & 8.7011 & TST \\
\hline CHEMBL3971833 & 1642293 & 8.5229 & 8.5367 & TST \\
\hline CHEMBL3961831 & 1642293 & 8.0 & 7.9965 & TST \\
\hline CHEMBL3898354 & 1642293 & 8.8239 & 8.5321 & TST \\
\hline CHEMBL3975272 & 1642293 & 8.8239 & 8.6613 & TST \\
\hline CHEMBL3923611 & 1642293 & 8.0 & 7.7866 & TST \\
\hline CHEMBL 3920382 & 1642293 & 8.0 & 8.5997 & TST \\
\hline CHEMBL3974819 & 1642293 & 8.5229 & 7.8586 & TST \\
\hline CHEMBL3933243 & 1642293 & 8.5229 & 7.9543 & TST \\
\hline CHEMBL3892095 & 1642293 & 8.0 & 7.9243 & TST \\
\hline CHEMBL541988 & 200079 & 4.4472 & 5.5282 & TST \\
\hline CHEMBL109259 & 200079 & 4.558 & 4.8755 & TRN \\
\hline CHEMBL110577 & 200079 & 6.0223 & 5.3836 & TRN \\
\hline CHEMBL112096 & 200079 & 4.7926 & 5.6047 & TST \\
\hline CHEMBL109515 & 200079 & 6.2518 & 6.0776 & TRN \\
\hline CHEMBL323900 & 200079 & 5.8327 & 6.0227 & TRN \\
\hline CHEMBL1203088 & 200079 & 6.284 & 5.9648 & TRN \\
\hline CHEMBL110055 & 200079 & 5.8601 & 6.0538 & TRN \\
\hline
\end{tabular}




\begin{tabular}{|c|c|c|c|c|c|}
\hline \multirow[b]{2}{*}{ CHEMBL109355 } & & \multicolumn{4}{|c|}{ Supplemental Table s2.txt } \\
\hline & 200079 & 6.0269 & 6.08899 & 99999999995 & TRN \\
\hline CHEMBL83228 & 200079 & 4.8807 & 5.6285 & TRN & \\
\hline CHEMBL111033 & 200079 & 4.5855 & 5.2374 & TRN & \\
\hline CHEMBL325981 & 200079 & 5.295 & 5.9306 & TST & \\
\hline CHEMBL1203047 & 200079 & 4.6028 & 5.0133 & TRN & \\
\hline CHEMBL109428 & 200079 & 5.7545 & 5.607 & TRN & \\
\hline CHEMBL109575 & 200079 & 6.0969 & 5.6138 & TST & \\
\hline CHEMBL111443 & 200079 & 7.2218 & 6.3199 & TRN & \\
\hline CHEMBL432396 & 200079 & 6.1308 & 5.8536 & TRN & \\
\hline CHEMBL114446 & 200079 & 5.109 & 5.4914 & TST & \\
\hline CHEMBL324045 & 200079 & 6.3098 & 7.0312 & TRN & \\
\hline CHEMBL110945 & 200079 & 5.8894 & 5.9957 & TRN & \\
\hline CHEMBL324399 & 200079 & 5.8097 & 5.2997 & TRN & \\
\hline CHEMBL419185 & 200079 & 5.6953 & 5.9593 & TRN & \\
\hline CHEMBL323970 & 200079 & 5.0737 & 5.2284 & TRN & \\
\hline CHEMBL111038 & 200079 & 6.3188 & 5.7414 & TRN & \\
\hline CHEMBL111664 & 200079 & 6.2676 & 6.1231 & TRN & \\
\hline CHEMBL1203059 & 200079 & 5.7721 & 6.1094 & TRN & \\
\hline CHEMBL110036 & 200079 & 5.6108 & 5.3061 & TRN & \\
\hline CHEMBL109476 & 200079 & 6.1938 & 5.8378 & TRN & \\
\hline CHEMBL29197 & 200079 & 6.0862 & 5.505 & TST & \\
\hline CHEMBL109332 & 200079 & 5.5272 & 5.605 & TST & \\
\hline CHEMBL1203037 & 200079 & 6.4437 & 5.6316 & TRN & \\
\hline CHEMBL109625 & 200079 & 5.1713 & 5.3514 & TRN & \\
\hline CHEMBL443277 & 200079 & 5.2069 & 5.9217 & TST & \\
\hline CHEMBL1203026 & 200079 & 5.8125 & 5.5336 & TRN & \\
\hline CHEMBL109503 & 200079 & 4.8722 & 5.3117 & TRN & \\
\hline CHEMBL323424 & 200079 & 5.5361 & 5.8291 & TRN & \\
\hline CHEMBL110065 & 200079 & 6.1938 & 6.3199 & TRN & \\
\hline CHEMBL109212 & 200079 & 7.0458 & 6.5814 & TRN & \\
\hline CHEMBL110062 & 200079 & 5.7122 & 5.91 & TST & \\
\hline CHEMBL111222 & 200079 & 4.8477 & 5.9249 & TRN & \\
\hline CHEMBL439596 & 200079 & 4.8136 & 5.6878 & TST & \\
\hline CHEMBL111307 & 200079 & 6.2596 & 6.0711 & TRN & \\
\hline CHEMBL111520 & 200079 & 5.699 & 5.2462 & TRN & \\
\hline CHEMBL113535 & 200079 & 5.9355 & 5.5368 & TRN & \\
\hline CHEMBL111442 & 200079 & 6.5686 & 5.9275 & TST & \\
\hline CHEMBL109372 & 200079 & 6.3279 & 6.3009 & TRN & \\
\hline CHEMBL112225 & 200079 & 6.4089 & 5.7333 & TST & \\
\hline CHEMBL325760 & 200079 & 5.2907 & 5.2868 & TRN & \\
\hline CHEMBL320479 & 200079 & 5.0814 & 5.4862 & TRN & \\
\hline CHEMBL111586 & 200079 & 5.5622 & 5.8621 & TRN & \\
\hline CHEMBL326445 & 200079 & 5.9245 & 6.0365 & TST & \\
\hline CHEMBL 2407780 & 973093 & 3.5229 & 3.5242 & TRN & \\
\hline CHEMBL 2407764 & 973093 & 5.8539 & 5.7219 & TST & \\
\hline CHEMBL 2407790 & 973093 & 5.7447 & 5.7505 & TRN & \\
\hline CHEMBL 2407755 & 973093 & 5.5528 & 5.5465 & TRN & \\
\hline CHEMBL 2407779 & 973093 & 6.3665 & 6.3667 & TRN & \\
\hline
\end{tabular}




\begin{tabular}{|c|c|c|c|c|c|}
\hline \multicolumn{6}{|c|}{ Supplemental Table S2.txt } \\
\hline CHEMBL 2407777 & 973093 & 6.5686 & 6.5592 & TRN & \\
\hline CHEMBL 2407962 & 973093 & 6.1871 & 5.6149 & TST & \\
\hline CHEMBL 2407757 & 973093 & 7.6383 & 7.6474 & TRN & \\
\hline CHEMBL 2407791 & 973093 & 5.8539 & 5.8601 & TRN & \\
\hline CHEMBL 2407753 & 973093 & 5.6021 & 5.6068 & TRN & \\
\hline CHEMBL 2407756 & 973093 & 5.8239 & 5.8287 & TRN & \\
\hline CHEMBL 2407769 & 973093 & 5.5528 & 5.5597 & TRN & \\
\hline CHEMBL 2407783 & 973093 & 5.2676 & 5.274 & TRN & \\
\hline CHEMBL 2407796 & 973093 & 5.7447 & 5.7441 & TRN & \\
\hline CHEMBL 2407782 & 973093 & 3.5229 & 3.52699 & 99999999997 & TRN \\
\hline CHEMBL 2407771 & 973093 & 6.1024 & 6.1041 & TRN & \\
\hline CHEMBL 2407761 & 973093 & 7.7447 & 6.3241 & TST & \\
\hline CHEMBL 2407778 & 973093 & 6.0555 & 6.0469 & TRN & \\
\hline CHEMBL 2407957 & 973093 & 5.4559 & 5.4703 & TRN & \\
\hline CHEMBL 2407760 & 973093 & 7.5229 & 7.5299 & TRN & \\
\hline CHEMBL 2407774 & 973093 & 4.5901 & 4.6017 & TRN & \\
\hline CHEMBL 2407788 & 973093 & 5.3665 & 5.3589 & TRN & \\
\hline CHEMBL 2407759 & 973093 & 8.3979 & 8.3969 & TRN & \\
\hline CHEMBL 2407958 & 973093 & 5.9586 & 5.9614 & TRN & \\
\hline CHEMBL 2407770 & 973093 & 6.2757 & 6.2664 & TRN & \\
\hline CHEMBL 2407786 & 973093 & 5.8539 & 5.8646 & TRN & \\
\hline CHEMBL 2407795 & 973093 & 7.2147 & 7.2271 & TRN & \\
\hline CHEMBL 2407965 & 973093 & 6.3188 & 6.3171 & TRN & \\
\hline CHEMBL 2407792 & 973093 & 7.0506 & 7.0527 & TRN & \\
\hline CHEMBL 2407768 & 973093 & 5.5528 & 5.5412 & TRN & \\
\hline CHEMBL 2407787 & 973093 & 6.6021 & 6.5955 & TRN & \\
\hline CHEMBL 2407794 & 973093 & 5.4949 & 5.4945 & TRN & \\
\hline CHEMBL 2407968 & 973093 & 5.9208 & 5.9207 & TRN & \\
\hline CHEMBL 2407961 & 973093 & 6.3372 & 5.8859 & TST & \\
\hline CHEMBL 2407098 & 973093 & 5.6198 & 5.6165 & TRN & \\
\hline CHEMBL 2407772 & 973093 & 6.0706 & 6.0723 & TRN & \\
\hline CHEMBL 2407754 & 973093 & 3.5229 & 3.5226 & TRN & \\
\hline CHEMBL 2407762 & 973093 & 6.0 & 5.9965 & TRN & \\
\hline CHEMBL 2407763 & 973093 & 6.4685 & 6.4661 & TRN & \\
\hline CHEMBL 2407776 & 973093 & 5.3098 & 5.3142 & TRN & \\
\hline CHEMBL 2407775 & 973093 & 5.7447 & 5.7421 & TRN & \\
\hline CHEMBL 2407967 & 973093 & 5.7959 & 5.7967 & TRN & \\
\hline CHEMBL 2407781 & 973093 & 6.2518 & 6.2505 & TRN & \\
\hline CHEMBL 2407956 & 973093 & 5.4949 & 5.4984 & TRN & \\
\hline CHEMBL 2407765 & 973093 & 5.5686 & 6.9536 & TST & \\
\hline CHEMBL 2407964 & 973093 & 5.6778 & 5.6156 & TST & \\
\hline CHEMBL 2407966 & 973093 & 6.8861 & 6.8838 & TRN & \\
\hline CHEMBL 2407963 & 973093 & 5.9208 & 6.0376 & TST & \\
\hline CHEMBL 2407959 & 973093 & 6.1487 & 6.1305 & TRN & \\
\hline CHEMBL 2407752 & 973093 & 5.4559 & 5.4514 & TRN & \\
\hline CHEMBL 2407789 & 973093 & 5.3098 & 5.2885 & TRN & \\
\hline CHEMBL 2407758 & 973093 & 7.8861 & 7.6065 & TST & \\
\hline CHEMBL 2407793 & 973093 & 6.1135 & 6.2597 & TST & \\
\hline
\end{tabular}




\begin{tabular}{|c|c|c|c|c|c|}
\hline \multicolumn{6}{|c|}{ Supplemental Table S2.txt } \\
\hline CHEMBL 2407766 & 973093 & 5.9208 & 8.3486 & TST & \\
\hline CHEMBL 2407785 & 973093 & 6.1249 & 5.8755 & TST & \\
\hline CHEMBL 2407784 & 973093 & 5.2218 & 5.6451 & TST & \\
\hline CHEMBL 2407767 & 973093 & 6.6021 & 6.3525 & TST & \\
\hline CHEMBL 2407960 & 973093 & 6.0969 & 6.3417 & TST & \\
\hline CHEMBL 2407773 & 973093 & 4.757 & 5.1096 & TST & \\
\hline CHEMBL584321 & 596088 & 4.0 & 4.7597 & TRN & \\
\hline CHEMBL579240 & 596088 & 4.0 & 4.1041 & TRN & \\
\hline CHEMBL 3085420 & 596088 & 7.2076 & 7.841 & TRN & \\
\hline CHEMBL583472 & 596088 & 4.0 & 3.9017 & TRN & \\
\hline CHEMBL 262865 & 596088 & 6.0246 & 5.1297 & TRN & \\
\hline CHEMBL569992 & 596088 & 6.2692 & 7.0078 & TST & \\
\hline CHEMBL571999 & 596088 & 7.1367 & 7.157 & TST & \\
\hline CHEMBL570875 & 596088 & 4.0 & 4.6755 & TRN & \\
\hline CHEMBL570876 & 596088 & 6.2549 & 5.8565 & TRN & \\
\hline CHEMBL579241 & 596088 & 5.3665 & 5.8041 & TRN & \\
\hline CHEMBL570659 & 596088 & 6.4413 & 6.1887 & TRN & \\
\hline CHEMBL568755 & 596088 & 4.0 & 4.2223 & TRN & \\
\hline CHEMBL584742 & 596088 & 6.4559 & 6.0753 & TRN & \\
\hline CHEMBL584534 & 596088 & 4.0 & 5.2069 & TRN & \\
\hline CHEMBL570877 & 596088 & 5.7375 & 5.2335 & TRN & \\
\hline CHEMBL578179 & 596088 & 4.0 & 4.71899 & 9999999999 & TRN \\
\hline CHEMBL569301 & 596088 & 7.4089 & 6.4569 & TRN & \\
\hline CHEMBL571776 & 596088 & 4.0 & 3.7234 & TRN & \\
\hline CHEMBL 3085421 & 596088 & 5.5147 & 5.6868 & TRN & \\
\hline CHEMBL584528 & 596088 & 5.8386 & 6.3469 & TRN & \\
\hline CHEMBL569082 & 596088 & 7.8239 & 6.8367 & TRN & \\
\hline CHEMBL584105 & 596088 & 6.4202 & 6.0868 & TRN & \\
\hline CHEMBL576706 & 596088 & 4.2518 & 5.8236 & TRN & \\
\hline CHEMBL571773 & 596088 & 6.8239 & 6.8016 & TRN & \\
\hline CHEMBL569993 & 596088 & 4.0 & 5.3942 & TRN & \\
\hline CHEMBL583473 & 596088 & 4.0 & 5.0456 & TST & \\
\hline CHEMBL582810 & 596088 & 5.7212 & 4.6786 & TRN & \\
\hline CHEMBL571559 & 596088 & 6.1024 & 5.8565 & TRN & \\
\hline CHEMBL576485 & 596088 & 4.0 & 3.7614 & TRN & \\
\hline CHEMBL571549 & 596088 & 4.0 & 4.0967 & TRN & \\
\hline CHEMBL578178 & 596088 & 5.6925 & 5.2261 & TRN & \\
\hline CHEMBL188 & 596088 & 7.8761 & 6.0732 & TST & \\
\hline CHEMBL570198 & 596088 & 6.5086 & 5.67899 & 9999999999 & TRN \\
\hline CHEMBL570874 & 596088 & 5.7878 & 6.1887 & TRN & \\
\hline CHEMBL569524 & 596088 & 5.6576 & 5.1908 & TRN & \\
\hline CHEMBL570650 & 596088 & 4.0 & 4.3502 & TRN & \\
\hline CHEMBL569300 & 596088 & 6.1549 & 5.8473 & TRN & \\
\hline CHEMBL572000 & 596088 & 6.1805 & 6.2367 & TRN & \\
\hline CHEMBL576920 & 596088 & 4.0 & 4.8707 & TRN & \\
\hline CHEMBL568796 & 596088 & 5.3768 & 5.7329 & TST & \\
\hline CHEMBL570909 & 596088 & 5.6676 & 4.096 & TRN & \\
\hline CHEMBL584738 & 596088 & 6.2104 & 5.8741 & TRN & \\
\hline
\end{tabular}




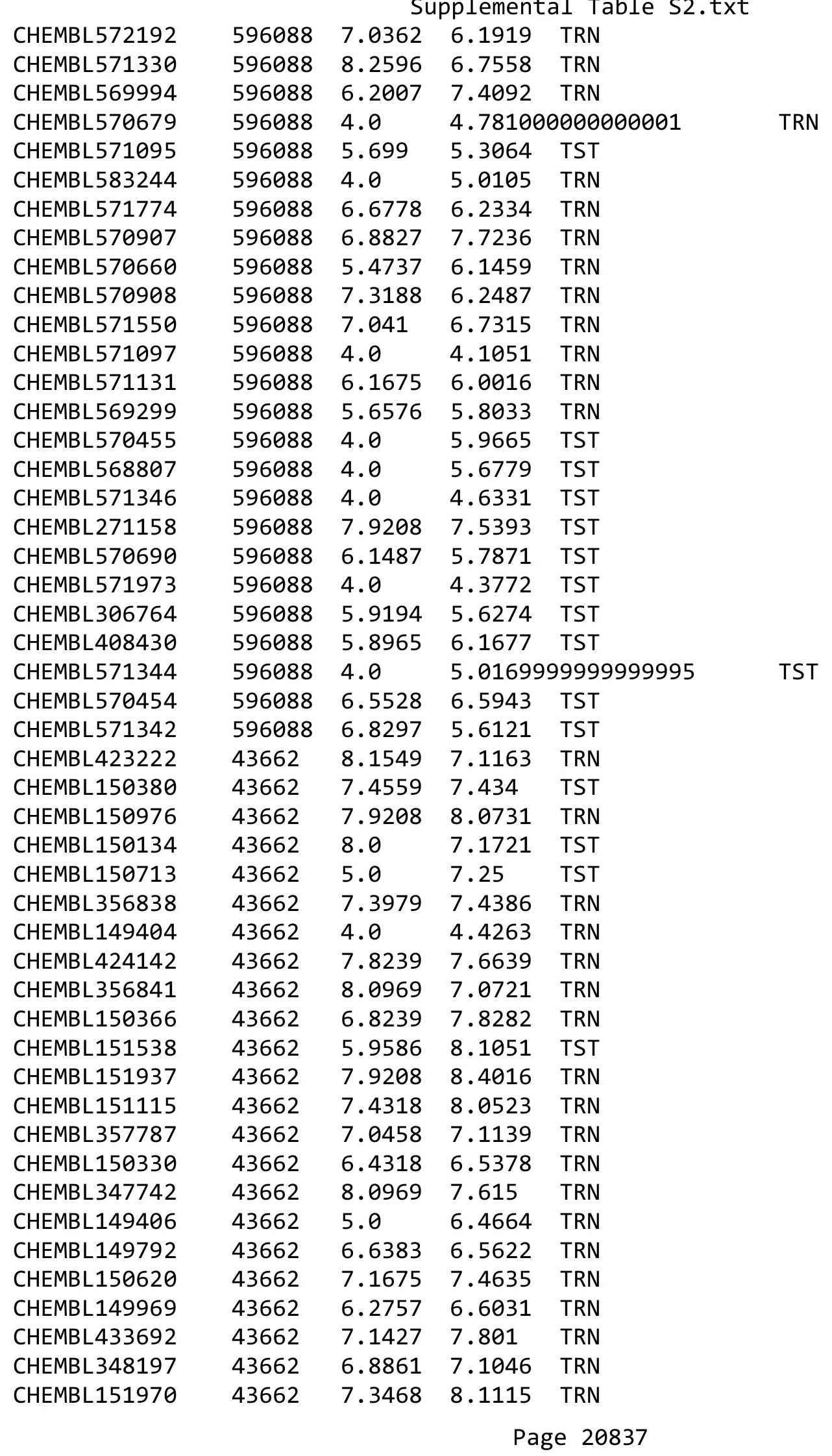




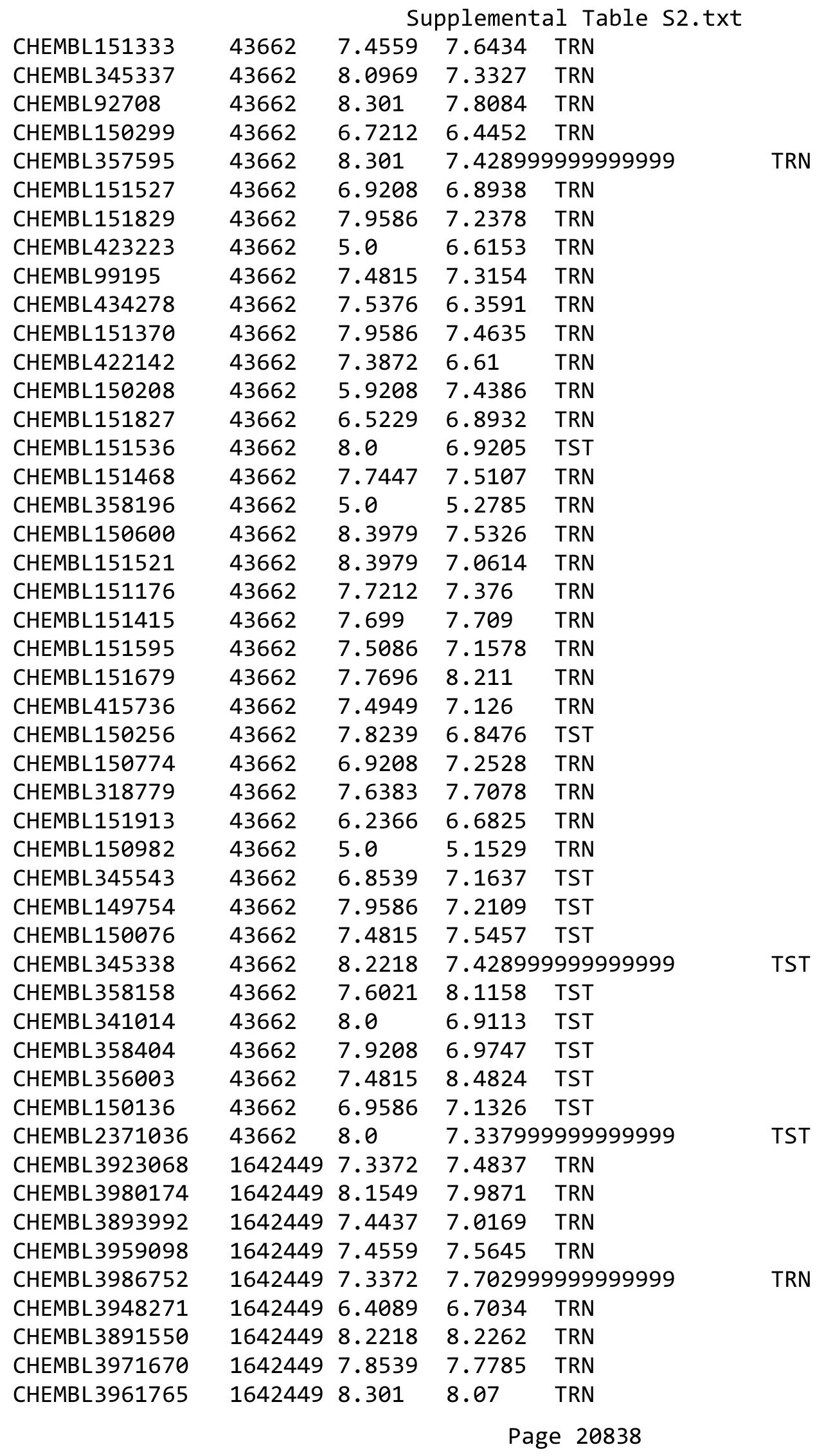


Supplemental Table S2.txt

\begin{tabular}{|c|c|c|c|c|}
\hline CHEMBL 3907299 & 1642449 & 6.2676 & 6.2988 & TRN \\
\hline CHEMBL 3900867 & 1642449 & 7.5686 & 7.4304 & TRN \\
\hline CHEMBL 3933337 & 1642449 & 7.5376 & 7.5055 & TRN \\
\hline CHEMBL 3892760 & 1642449 & 8.1549 & 8.1969 & TRN \\
\hline CHEMBL 3967394 & 1642449 & 7.5229 & 7.4588 & TRN \\
\hline CHEMBL 3966386 & 1642449 & 6.7959 & 7.0546 & TRN \\
\hline CHEMBL 3948456 & 1642449 & 7.3098 & 7.0786 & TRN \\
\hline CHEMBL 3942894 & 1642449 & 7.9586 & 8.1289 & TRN \\
\hline CHEMBL 3911962 & 1642449 & 7.6576 & 7.8327 & TRN \\
\hline CHEMBL 3909531 & 1642449 & 7.6021 & 7.3606 & TRN \\
\hline CHEMBL 3924401 & 1642449 & 7.3279 & 7.2272 & TRN \\
\hline CHEMBL3915509 & 1642449 & 7.5086 & 7.6801 & TRN \\
\hline CHEMBL 3911605 & 1642449 & 8.699 & 8.5822 & TRN \\
\hline CHEMBL 3910049 & 1642449 & 8.1549 & 8.0394 & TRN \\
\hline CHEMBL 3942192 & 1642449 & 7.9208 & 7.9353 & TRN \\
\hline CHEMBL 3972525 & 1642449 & 7.0655 & 7.0926 & TRN \\
\hline CHEMBL 3963944 & 1642449 & 7.4685 & 7.4273 & TRN \\
\hline CHEMBL 3987061 & 1642449 & 8.0458 & 8.2579 & TRN \\
\hline CHEMBL 3942927 & 1642449 & 6.8861 & 6.7204 & TRN \\
\hline CHEMBL 3945517 & 1642449 & 8.3979 & 8.2951 & TRN \\
\hline CHEMBL 3901720 & 1642449 & 8.3979 & 8.3171 & TRN \\
\hline CHEMBL 3908908 & 1642449 & 7.7696 & 8.0534 & TST \\
\hline CHEMBL 3935056 & 1642449 & 6.7447 & 6.7117 & TRN \\
\hline CHEMBL 3985179 & 1642449 & 7.9208 & 7.9157 & TRN \\
\hline CHEMBL 3900559 & 1642449 & 8.3979 & 8.567 & TRN \\
\hline CHEMBL 3943469 & 1642449 & 7.3979 & 7.2903 & TRN \\
\hline CHEMBL 3920849 & 1642449 & 8.301 & 8.3579 & TST \\
\hline CHEMBL 3897650 & 1642449 & 6.7696 & 6.7933 & TRN \\
\hline CHEMBL3920547 & 1642449 & 7.7212 & 7.8626 & TRN \\
\hline CHEMBL 3980736 & 1642449 & 9.0 & 8.1912 & TST \\
\hline CHEMBL 3985727 & 1642449 & 6.9586 & 7.1939 & TRN \\
\hline CHEMBL 3943133 & 1642449 & 9.3979 & 9.2837 & TRN \\
\hline CHEMBL 3936755 & 1642449 & 8.699 & 9.4275 & TST \\
\hline CHEMBL3942946 & 1642449 & 7.1249 & 6.8613 & TST \\
\hline CHEMBL 3921376 & 1642449 & 7.0269 & 7.2124 & TST \\
\hline CHEMBL3918970 & 1642449 & 7.8861 & 7.5794 & TST \\
\hline CHEMBL 3908939 & 1642449 & 6.9208 & 6.3406 & TST \\
\hline CHEMBL3979729 & 1642449 & 7.6198 & 7.7879 & TST \\
\hline CHEMBL 3975980 & 1642449 & 7.4815 & 7.209 & TST \\
\hline CHEMBL 3896384 & 1642449 & 7.2291 & 7.3167 & TST \\
\hline CHEMBL 3890476 & 1642449 & 7.3372 & 7.3037 & TST \\
\hline CHEMBL3966526 & 1642449 & 9.5229 & 9.55299 & 9999999999 \\
\hline CHEMBL341336 & 201510 & 7.8097 & 8.0633 & TRN \\
\hline CHEMBL125574 & 201510 & 5.3451 & 5.2609 & TRN \\
\hline CHEMBL421651 & 201510 & 5.9197 & 4.9855 & TRN \\
\hline CHEMBL340760 & 201510 & 4.3595 & 4.8307 & TRN \\
\hline CHEMBL 3085512 & 201510 & 4.9066 & 5.7087 & TST \\
\hline CHEMBL127447 & 201510 & 3.9741 & 4.3012 & TRN \\
\hline
\end{tabular}

Page 20839 


\begin{tabular}{|c|c|c|c|c|c|c|}
\hline & & \multicolumn{5}{|c|}{ Supplemental Table s2.txt } \\
\hline CHEMBL338093 & 201510 & 6.4271 & 6.4922 & TRN & & \\
\hline CHEMBL125524 & 201510 & 4.6269 & 4.9958 & TRN & & \\
\hline CHEMBL339149 & 201510 & 7.0097 & 6.8364 & TRN & & \\
\hline CHEMBL14144 & 201510 & 5.6315 & 5.4535 & TRN & & \\
\hline CHEMBL127700 & 201510 & 4.3487 & 4.4339 & TRN & & \\
\hline CHEMBL125400 & 201510 & 4.636 & 4.3277 & TRN & & \\
\hline CHEMBL126682 & 201510 & \multicolumn{3}{|c|}{5.9670000000000005} & .6268 & TRN \\
\hline CHEMBL340761 & 201510 & 6.7352 & 6.4696 & TRN & & \\
\hline CHEMBL126660 & 201510 & 4.7971 & 4.5322 & TRN & & \\
\hline CHEMBL127981 & 201510 & 6.52 & 6.3112 & TRN & & \\
\hline CHEMBL127533 & 201510 & 5.7902 & 5.6657 & TRN & & \\
\hline CHEMBL130531 & 201510 & 6.4342 & 4.5967 & TST & & \\
\hline CHEMBL127040 & 201510 & 5.8526 & 5.8924 & TRN & & \\
\hline CHEMBL446357 & 201510 & 5.9112 & 6.2545 & TRN & & \\
\hline CHEMBL125974 & 201510 & \multicolumn{3}{|c|}{5.667000000000001} & .7308 & TRN \\
\hline CHEMBL127472 & 201510 & 5.4234 & 5.3642 & TRN & & \\
\hline CHEMBL126410 & 201510 & 5.6949 & 5.9964 & TRN & & \\
\hline CHEMBL126887 & 201510 & 4.0845 & 4.0669 & TRN & & \\
\hline CHEMBL 306208 & 201510 & 7.3516 & 7.191 & TRN & & \\
\hline CHEMBL82027 & 201510 & 6.6198 & 6.8612 & TRN & & \\
\hline CHEMBL126261 & 201510 & 6.9208 & 7.2258 & TST & & \\
\hline CHEMBL127011 & 201510 & 6.7747 & 6.7739 & TRN & & \\
\hline CHEMBL87031 & 201510 & 8.5045 & 8.4085 & TRN & & \\
\hline CHEMBL127146 & 201510 & 3.0 & 4.8675 & TST & & \\
\hline CHEMBL338220 & 201510 & 6.0894 & 5.6721 & TST & & \\
\hline CHEMBL321806 & 201510 & 5.2154 & 5.3331 & TRN & & \\
\hline CHEMBL126336 & 201510 & 7.1314 & 7.0777 & TST & & \\
\hline CHEMBL339763 & 201510 & 6.8861 & 7.431 & TST & & \\
\hline CHEMBL 339809 & 201510 & 6.2111 & 6.1952 & TRN & & \\
\hline CHEMBL340912 & 201510 & 4.6113 & 5.0414 & TRN & & \\
\hline CHEMBL126610 & 201510 & 5.4683 & 5.5336 & TST & & \\
\hline CHEMBL126229 & 201510 & 5.0254 & 5.718 & TST & & \\
\hline CHEMBL125678 & 201510 & 3.8425 & 4.1565 & TRN & & \\
\hline CHEMBL127546 & 201510 & 7.1752 & 7.313 & TRN & & \\
\hline CHEMBL127479 & 201510 & 5.1958 & 5.2863 & TRN & & \\
\hline CHEMBL127260 & 201510 & 5.6073 & 6.42399 & 99999999995 & & TST \\
\hline CHEMBL126503 & 201510 & 5.2809 & 5.4738 & TRN & & \\
\hline CHEMBL1643896 & 201510 & 5.7625 & 7.0962 & TST & & \\
\hline CHEMBL126772 & 201510 & 5.9722 & 6.2968 & TRN & & \\
\hline CHEMBL14391 & 201510 & 8.3757 & 8.218 & TRN & & \\
\hline CHEMBL127457 & 201510 & 5.2365 & 5.1354 & TRN & & \\
\hline CHEMBL420343 & 201510 & 4.7718 & 4.7918 & TRN & & \\
\hline CHEMBL340372 & 201510 & 4.8625 & 4.6584 & TRN & & \\
\hline CHEMBL126271 & 201510 & 4.0517 & 5.54899 & 99999999995 & & TST \\
\hline CHEMBL97887 & 201510 & 7.9747 & 7.8999 & TRN & & \\
\hline CHEMBL 2079586 & 201510 & 6.1599 & 5.943 & TRN & & \\
\hline CHEMBL126538 & 201510 & 6.1403 & 5.931 & TST & & \\
\hline CHEMBL127026 & 201510 & 4.4728 & 4.3273 & TST & & \\
\hline
\end{tabular}




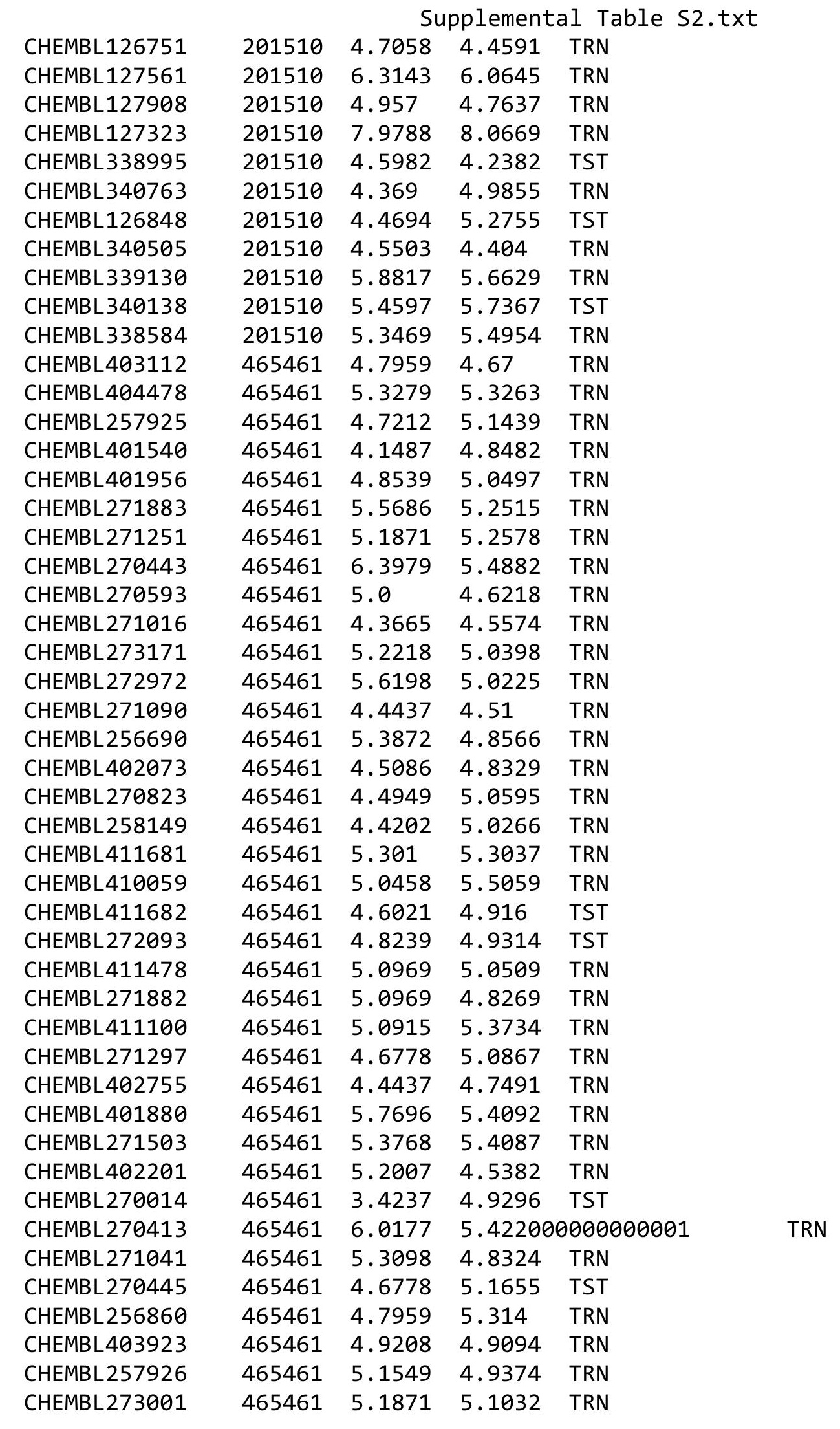

Page 20841 


\begin{tabular}{|c|c|c|c|c|c|}
\hline \multicolumn{6}{|c|}{ Supplemental Table S2.txt } \\
\hline CHEMBL402961 & 465461 & 5.0969 & 5.3273 & TRN & \\
\hline CHEMBL257924 & 465461 & 5.0458 & 5.0816 & TRN & \\
\hline CHEMBL257497 & 465461 & 4.3565 & 4.7371 & TRN & \\
\hline CHEMBL271089 & 465461 & 5.1938 & 4.8041 & TRN & \\
\hline CHEMBL272094 & 465461 & 4.3098 & 4.7281 & TRN & \\
\hline CHEMBL402581 & 465461 & 4.7212 & 4.9171 & TST & \\
\hline CHEMBL313155 & 465461 & 4.9586 & 4.9164 & TRN & \\
\hline CHEMBL256859 & 465461 & 4.4089 & 4.773 & TRN & \\
\hline CHEMBL271897 & 465461 & 5.3665 & 5.3276 & TRN & \\
\hline CHEMBL273172 & 465461 & 5.1549 & 4.814 & TRN & \\
\hline CHEMBL270825 & 465461 & 5.3372 & 5.12799 & 9999999999 & TST \\
\hline CHEMBL403289 & 465461 & 4.4089 & 4.586 & TST & \\
\hline CHEMBL257496 & 465461 & 4.4949 & 4.9413 & TST & \\
\hline CHEMBL273159 & 465461 & 5.3565 & 5.2627 & TST & \\
\hline CHEMBL404862 & 465461 & 3.0 & 4.9734 & TST & \\
\hline CHEMBL257686 & 465461 & 4.7212 & 5.0937 & TST & \\
\hline CHEMBL3856120 & 465461 & 5.8861 & 4.9076 & TST & \\
\hline CHEMBL402850 & 465461 & 4.4318 & 5.3409 & TST & \\
\hline CHEMBL272268 & 465461 & 4.7959 & 5.2044 & TST & \\
\hline CHEMBL333125 & 139631 & 5.6651 & 5.7303 & TRN & \\
\hline CHEMBL122354 & 139631 & 6.644 & 7.278 & TRN & \\
\hline CHEMBL332335 & 139631 & 6.4036 & 6.4071 & TRN & \\
\hline CHEMBL120581 & 139631 & 6.3691 & 6.351 & TRN & \\
\hline CHEMBL 338280 & 139631 & 6.0203 & 6.0343 & TRN & \\
\hline CHEMBL543890 & 139631 & 5.985 & 5.8824 & TRN & \\
\hline CHEMBL330885 & 139631 & 4.5488 & 4.5525 & TRN & \\
\hline CHEMBL121385 & 139631 & 6.3298 & 6.37700 & 0000000001 & тाт \\
\hline CHEMBL120135 & 139631 & 6.0 & 5.7178 & TST & \\
\hline CHEMBL120472 & 139631 & 6.6231 & 6.6306 & TRN & \\
\hline CHEMBL121059 & 139631 & 7.6536 & 7.278 & TRN & \\
\hline CHEMBL334093 & 139631 & 6.1797 & 6.1063 & TRN & \\
\hline CHEMBL324712 & 139631 & 5.7293 & 5.7906 & TRN & \\
\hline CHEMBL330892 & 139631 & 5.8295 & 5.8008 & TRN & \\
\hline CHEMBL330999 & 139631 & 6.1763 & 6.1843 & TRN & \\
\hline CHEMBL332405 & 139631 & 4.967 & 3.8201 & TST & \\
\hline CHEMBL333940 & 139631 & 5.93 & 6.0747 & TRN & \\
\hline CHEMBL331516 & 139631 & 6.9183 & 6.9565 & TRN & \\
\hline CHEMBL123099 & 139631 & 4.4147 & 4.4178 & TRN & \\
\hline CHEMBL118241 & 139631 & 6.1115 & 6.0747 & TRN & \\
\hline CHEMBL540316 & 139631 & 5.6549 & 5.7353 & TRN & \\
\hline CHEMBL121476 & 139631 & 6.1258 & 6.0747 & TRN & \\
\hline CHEMBL332181 & 139631 & 6.3273 & 6.2378 & TRN & \\
\hline CHEMBL122353 & 139631 & 5.7777 & 5.8755 & TRN & \\
\hline CHEMBL334245 & 139631 & 7.1349 & 7.278 & TRN & \\
\hline CHEMBL120963 & 139631 & 5.5895 & 5.607 & TRN & \\
\hline CHEMBL120329 & 139631 & 6.2658 & 6.1725 & TRN & \\
\hline CHEMBL332320 & 139631 & 7.6882 & 7.278 & TRN & \\
\hline CHEMBL 332980 & 139631 & 6.5931 & 6.58 & TRN & \\
\hline
\end{tabular}


Supplemental Table S2.txt

\begin{tabular}{|c|c|c|c|c|}
\hline CHEMBL543177 & 139631 & 6.3462 & 6.3596 & TRN \\
\hline CHEMBL332645 & 139631 & 4.8357 & 4.8182 & TRN \\
\hline CHEMBL120080 & 139631 & 7.2798 & 7.278 & TRN \\
\hline CHEMBL541584 & 139631 & 6.6174 & 6.6132 & TRN \\
\hline CHEMBL120539 & 139631 & 5.5585 & 5.565 & TRN \\
\hline CHEMBL121520 & 139631 & 6.24799 & 999999999 & 6.2371 \\
\hline CHEMBL120109 & 139631 & 5.7625 & 5.7655 & TRN \\
\hline CHEMBL 340780 & 139631 & 6.3925 & 6.8172 & TST \\
\hline CHEMBL118553 & 139631 & 4.9608 & 4.9146 & TRN \\
\hline CHEMBL431688 & 139631 & 5.9129 & 4.4753 & TST \\
\hline CHEMBL340561 & 139631 & 6.2213 & 6.1912 & TRN \\
\hline CHEMBL116601 & 139631 & 5.8237 & 5.7062 & TST \\
\hline CHEMBL120972 & 139631 & 6.3133 & 6.0747 & TST \\
\hline CHEMBL262198 & 139631 & 6.6133 & 6.6197 & TRN \\
\hline CHEMBL121552 & 139631 & 5.9037 & 6.1158 & TST \\
\hline CHEMBL124173 & 139631 & 6.0194 & 5.9719 & TST \\
\hline CHEMBL324936 & 139631 & 6.563 & 5.6295 & TST \\
\hline CHEMBL120119 & 139631 & 6.8665 & 6.8715 & TRN \\
\hline CHEMBL121298 & 139631 & 5.4785 & 5.1614 & TST \\
\hline CHEMBL120599 & 139631 & 5.7113 & 5.5737 & TST \\
\hline CHEMBL121299 & 139631 & 6.1339 & 5.375 & TST \\
\hline CHEMBL123198 & 139631 & 6.3233 & 5.8781 & TST \\
\hline CHEMBL 7033 & 30535 & 4.3768 & 5.4254 & TST \\
\hline CHEMBL306351 & 30535 & 4.2218 & 4.6367 & TRN \\
\hline CHEMBL312449 & 30535 & 7.6383 & 7.2812 & TRN \\
\hline CHEMBL16687 & 30535 & 8.5528 & 6.2381 & TST \\
\hline CHEMBL431376 & 30535 & 7.4437 & 7.3379 & TRN \\
\hline CHEMBL 73006 & 30535 & 5.4089 & 4.7743 & TRN \\
\hline CHEMBL73056 & 30535 & 3.0 & 4.3664 & TRN \\
\hline CHEMBL 74681 & 30535 & 5.3468 & 5.525 & TRN \\
\hline CHEMBL73596 & 30535 & 5.1871 & 4.8466 & TRN \\
\hline CHEMBL71106 & 30535 & 6.7696 & 7.0095 & TRN \\
\hline CHEMBL 70422 & 30535 & 4.7696 & 4.917 & TRN \\
\hline CHEMBL70585 & 30535 & 5.4815 & 4.834 & TRN \\
\hline CHEMBL311616 & 30535 & 5.6383 & 4.7079 & TRN \\
\hline CHEMBL72367 & 30535 & 6.6778 & 6.9598 & TRN \\
\hline CHEMBL69722 & 30535 & 4.585 & 4.951000 & 20000000005 \\
\hline CHEMBL72953 & 30535 & 5.1938 & 5.0274 & TRN \\
\hline CHEMBL 73163 & 30535 & 3.0 & 4.5666 & TRN \\
\hline CHEMBL 269318 & 30535 & 4.7696 & 4.5388 & TRN \\
\hline CHEMBL304769 & 30535 & 4.3188 & 4.874 & TRN \\
\hline CHEMBL 72177 & 30535 & 5.7696 & 4.9305 & TRN \\
\hline CHEMBL302511 & 30535 & 3.0 & 4.3731 & TRN \\
\hline CHEMBL 72052 & 30535 & 7.2076 & 6.8438 & TRN \\
\hline CHEMBL73210 & 30535 & 5.0223 & 5.0533 & TRN \\
\hline CHEMBL6958 & 30535 & 5.1938 & 4.6918 & TRN \\
\hline CHEMBL 74403 & 30535 & 6.2518 & 6.7897 & TRN \\
\hline CHEMBL421117 & 30535 & 4.8539 & 4.8744 & TRN \\
\hline
\end{tabular}




\begin{tabular}{|c|c|c|c|c|}
\hline \multicolumn{5}{|c|}{ Supplemental Table S2.txt } \\
\hline CHEMBL312744 & 30535 & 7.0 & 7.044 & TRN \\
\hline CHEMBL311481 & 30535 & 7.0 & 6.7453 & TRN \\
\hline CHEMBL303198 & 30535 & 7.6778 & 6.5641 & TRN \\
\hline CHEMBL420368 & 30535 & 5.5086 & 4.7919 & TRN \\
\hline CHEMBL70359 & 30535 & 5.4559 & 4.7657 & TRN \\
\hline CHEMBL73696 & 30535 & 5.0 & 6.9687 & TRN \\
\hline CHEMBL73682 & 30535 & 6.1549 & 6.9312 & TRN \\
\hline CHEMBL307187 & 30535 & 7.3565 & 6.8942 & TRN \\
\hline CHEMBL73181 & 30535 & 7.5376 & 7.1893 & TRN \\
\hline CHEMBL72398 & 30535 & 4.8861 & 4.7279 & TRN \\
\hline CHEMBL72577 & 30535 & 6.2757 & 5.782 & TST \\
\hline CHEMBL310177 & 30535 & 5.4949 & 5.0965 & TRN \\
\hline CHEMBL73478 & 30535 & 3.0 & 4.7262 & TRN \\
\hline CHEMBL 72903 & 30535 & 6.3979 & 6.6093 & TRN \\
\hline CHEMBL72669 & 30535 & 5.6778 & 4.7954 & TRN \\
\hline CHEMBL72051 & 30535 & 7.5528 & 7.1168 & TRN \\
\hline CHEMBL306850 & 30535 & 5.3872 & 4.4646 & TRN \\
\hline CHEMBL73132 & 30535 & 3.9586 & 4.7396 & TRN \\
\hline CHEMBL464859 & 30535 & 7.7696 & 6.1607 & TST \\
\hline CHEMBL72517 & 30535 & 6.0506 & 4.9652 & TRN \\
\hline CHEMBL73039 & 30535 & 6.0 & 6.7526 & TST \\
\hline CHEMBL45891 & 30535 & 6.1938 & 4.9743 & TST \\
\hline CHEMBL73595 & 30535 & 3.0 & 4.4799 & TST \\
\hline CHEMBL308592 & 30535 & 3.0 & 4.9102 & TST \\
\hline CHEMBL442176 & 30535 & 5.4089 & 4.5923 & TST \\
\hline CHEMBL73747 & 30535 & 5.3872 & 4.8938 & TST \\
\hline CHEMBL73095 & 30535 & 7.4815 & 7.1069 & TST \\
\hline CHEMBL275084 & 30535 & 4.8861 & 5.6483 & TST \\
\hline CHEMBL308834 & 30535 & 5.1612 & 4.6853 & TST \\
\hline CHEMBL303884 & 30535 & 3.0 & 5.4883 & TST \\
\hline CHEMBL3752648 & 1547124 & 7.7696 & 7.8448 & TRN \\
\hline CHEMBL3752861 & 1547124 & 5.301 & 7.0096 & TST \\
\hline CHEMBL3753611 & 1547124 & 7.7932 & 7.851 & TRN \\
\hline CHEMBL3753582 & 1547124 & 5.301 & 6.9993 & TST \\
\hline CHEMBL3754168 & 1547124 & 8.0458 & 8.0822 & TRN \\
\hline CHEMBL3754183 & 1547124 & 7.3372 & 7.4643 & TRN \\
\hline CHEMBL 3754184 & 1547124 & 6.0 & 5.9798 & TRN \\
\hline CHEMBL3753034 & 1547124 & 6.0 & 7.1064 & TST \\
\hline CHEMBL 3752480 & 1547124 & 7.7696 & 7.6197 & TRN \\
\hline CHEMBL3752994 & 1547124 & 7.7696 & 7.6626 & TRN \\
\hline CHEMBL3623223 & 1547124 & 7.3468 & 7.9823 & TST \\
\hline CHEMBL3752341 & 1547124 & 8.6021 & 8.3494 & TRN \\
\hline CHEMBL3752402 & 1547124 & 6.0 & 7.8677 & TST \\
\hline CHEMBL1630274 & 1547124 & 8.4685 & 8.5369 & TRN \\
\hline CHEMBL3751881 & 1547124 & 6.0 & 6.29 & TRN \\
\hline CHEMBL3752405 & 1547124 & 7.7696 & 7.9922 & TRN \\
\hline CHEMBL3752440 & 1547124 & 7.7959 & 7.1624 & TRN \\
\hline CHEMBL1630263 & 1547124 & 7.1549 & 7.6263 & TST \\
\hline
\end{tabular}


Supplemental Table S2.txt

\begin{tabular}{|c|c|c|c|c|c|}
\hline CHEMBL 3753000 & 1547124 & 5.301 & 7.1622 & TST & \\
\hline CHEMBL3754729 & 1547124 & 6.0 & 6.3762 & TRN & \\
\hline CHEMBL3752618 & 1547124 & 5.301 & 7.0714 & TST & \\
\hline CHEMBL3754305 & 1547124 & 7.0 & 7.319 & TRN & \\
\hline CHEMBL1627334 & 1547124 & 7.0 & 7.2212 & TRN & \\
\hline CHEMBL3754603 & 1547124 & 7.4089 & 7.5583 & TRN & \\
\hline CHEMBL 3754538 & 1547124 & 7.0132 & 6.9268 & TRN & \\
\hline CHEMBL3349864 & 1547124 & 7.6021 & 7.6737 & TRN & \\
\hline CHEMBL 3752155 & 1547124 & 8.0706 & 8.8019 & TRN & \\
\hline CHEMBL 3752278 & 1547124 & 7.2366 & 7.1585 & TRN & \\
\hline CHEMBL 3623221 & 1547124 & 5.8153 & 5.5734 & TRN & \\
\hline CHEMBL 3754787 & 1547124 & 7.2518 & 7.3885 & TRN & \\
\hline CHEMBL 3753505 & 1547124 & 7.2366 & 7.3842 & TRN & \\
\hline CHEMBL3752556 & 1547124 & 6.0 & 7.7479 & TST & \\
\hline CHEMBL189051 & 1547124 & 7.0 & 7.121 & TRN & \\
\hline CHEMBL3754473 & 1547124 & 7.7696 & 7.5518 & TRN & \\
\hline CHEMBL1630264 & 1547124 & 7.2218 & 7.2273 & TST & \\
\hline CHEMBL 3753279 & 1547124 & 5.301 & 7.0663 & TST & \\
\hline CHEMBL 3753352 & 1547124 & 7.0915 & 6.7389 & TRN & \\
\hline CHEMBL 2311178 & 1547124 & 8.6021 & 8.4887 & TRN & \\
\hline CHEMBL3753971 & 1547124 & 6.0 & 7.7612 & TST & \\
\hline CHEMBL1079595 & 1547124 & 7.0 & 7.3186 & TRN & \\
\hline CHEMBL 3754425 & 1547124 & 6.9208 & 7.1825 & TRN & \\
\hline CHEMBL1628064 & 1547124 & 7.0 & 7.1375 & TRN & \\
\hline CHEMBL 3753803 & 1547124 & 8.6021 & 8.7114 & TRN & \\
\hline CHEMBL3752315 & 1547124 & 8.6021 & 8.3494 & TRN & \\
\hline CHEMBL 241993 & 1547124 & 7.0 & 7.3414 & TRN & \\
\hline CHEMBL 3754186 & 1547124 & 7.7696 & 7.6197 & TRN & \\
\hline CHEMBL3752619 & 1547124 & 8.6021 & 8.5753 & TRN & \\
\hline CHEMBL 2112739 & 1547124 & 7.0458 & 6.9785 & TRN & \\
\hline CHEMBL3752011 & 1547124 & 8.6021 & 8.6531 & TRN & \\
\hline CHEMBL 3752788 & 1547124 & 8.0 & 8.1661 & TRN & \\
\hline CHEMBL3752099 & 1547124 & 7.1249 & 7.3704 & TRN & \\
\hline CHEMBL3752506 & 1547124 & 7.7696 & 7.9216 & TRN & \\
\hline CHEMBL 3752038 & 1547124 & 8.1549 & 8.1097 & TRN & \\
\hline CHEMBL1629804 & 1547124 & 8.1675 & 7.2626 & TRN & \\
\hline CHEMBL 3753425 & 1547124 & 7.0 & 7.4662 & TST & \\
\hline CHEMBL3754546 & 1547124 & 8.6021 & 8.573 & TRN & \\
\hline CHEMBL3752939 & 1547124 & 7.6383 & 7.24700 & 0000000001 & TRN \\
\hline CHEMBL 3754285 & 1547124 & 6.0 & 6.2923 & TRN & \\
\hline CHEMBL3752063 & 1547124 & 6.0 & 6.194 & TRN & \\
\hline CHEMBL 3753084 & 1547124 & 7.9208 & 7.0371 & TRN & \\
\hline CHEMBL3753928 & 1547124 & 7.0 & 7.221 & TST & \\
\hline CHEMBL 3752998 & 1547124 & 8.1549 & 7.9585 & TRN & \\
\hline CHEMBL3754366 & 1547124 & 6.0 & 6.2923 & TRN & \\
\hline CHEMBL3752704 & 1547124 & 7.5686 & 7.6055 & TRN & \\
\hline CHEMBL 3752252 & 1547124 & 7.7959 & 7.4038 & TRN & \\
\hline CHEMBL 3754547 & 1547124 & 5.301 & 7.9839 & TST & \\
\hline
\end{tabular}


Supplemental Table S2.txt

\begin{tabular}{|c|c|c|c|c|}
\hline HEMBL & 124 & & & \\
\hline UГMDI & 547124 & 7.7696 & 7.8551 & \\
\hline 573 & & & & \\
\hline AEMBL3753272 & & $\partial 223$ & & \\
\hline AEMBL3752165 & 24 & 6021 & 4016 & \\
\hline HEMBL3752366 & 124 & .2366 & .0708 & \\
\hline HEMBL36 & & 5.6576 & 7028 & \\
\hline 112 & & & 0557 & \\
\hline AEMBL3753258 & 24 & 6.0 & 7.7989 & \\
\hline HEMBL3623220 & 24 & 5778 & .0175 & \\
\hline AEMBL3752650 & $=4$ & 6.0 & .5336 & \\
\hline IEMBL1 & & 99 & .8002 & \\
\hline IEMBL1 & & & & \\
\hline HEMBL12 & & 3979 & . 6605 & \\
\hline AEMBL12 & $5<$ & 62 & 803 & \\
\hline AEMBL1 & 54 & 52 & 799 & \\
\hline AEMBL12 & & 75 & 718 & \\
\hline HEMBL1 & & & 86 & \\
\hline HEMBL12 & & 69 & 6.1549 & \\
\hline AEMBL12 & & & & \\
\hline AEMBL1 & & & 1868 & \\
\hline AEMBL1 & & 49 & 74 & \\
\hline HEMBL1 & & 26 & 5768 & \\
\hline HEMBL12 & & 447 & 5852 & \\
\hline AEMBL12 & & 3 & 64 & \\
\hline HEMBL1 & & 1 & 136 & RN \\
\hline HEMBL1 & & 92 & 53 & \\
\hline AFMBI 1 & & 27 & 636 & \\
\hline HEMBL12 & & & 4.9598 & " \\
\hline HEMBL12 & & & 5.6745 & r \\
\hline HEMBL1 & & 962 & & RN \\
\hline AFMBI 1 & & 36 & 20 & Niv \\
\hline HEMBL1 & & 37 & 88 & $\mathrm{~N}$ \\
\hline HEMBL12 & & & 13 & Is \\
\hline HEMBL1242294 & & & 6.4544 & TRN \\
\hline HEMBL1 & & & 5.5947 & \\
\hline HFMRI 1 & & & 5.2228 & RN \\
\hline HEMBL1 & & & 5.2456 & RN \\
\hline HEMBL1242032 & & & 5.2425 & TRN \\
\hline AEMBL12 & & & .2618 & RN \\
\hline HEMBL1 & & & .6748 & \\
\hline CHEMBL12 & & & 6.0794 & RIV \\
\hline HEMBL 124 & & & 5.0223 & RN \\
\hline HEMBL 12 & 5 & 37 & .3829 & TRN \\
\hline MRI 1 & & & .9856 & \\
\hline HEMBL1 & & & 4.0061 & \\
\hline CHEMBL12 & & 6.0794 & 5.5385 & \\
\hline CHEMBL1242657 & 654925 & 6.0 & 5.5126 & 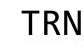 \\
\hline
\end{tabular}

Page 20846 
Supplemental Table S2.txt

\begin{tabular}{|c|c|c|c|c|c|c|}
\hline CHEMBL1242024 & 654925 & 5.6778 & 6.2211 & TRN & & \\
\hline CHEMBL1241773 & 654925 & 4.0 & 4.6417 & TRN & & \\
\hline CHEMBL1241948 & 654925 & 5.301 & 4.9983 & TRN & & \\
\hline CHEMBL1242477 & 654925 & 5.9208 & 6.4789 & TRN & & \\
\hline CHEMBL1242664 & 654925 & 6.3072 & 6.36 & TRN & & \\
\hline CHEMBL1233882 & 654925 & 6.8539 & 7.1021 & TRN & & \\
\hline CHEMBL1241485 & 654925 & 4.0 & 5.2092 & TRN & & \\
\hline CHEMBL1241271 & 654925 & 6.065 & 6.3681 & TRN & & \\
\hline CHEMBL1241862 & 654925 & 5.0 & 5.0723 & TRN & & \\
\hline CHEMBL1242755 & 654925 & 6.6144 & 5.7973 & TRN & & \\
\hline CHEMBL1242666 & 654925 & 6.6576 & 6.4563 & TRN & & \\
\hline CHEMBL1241772 & 654925 & 5.2366 & 4.3545 & TRN & & \\
\hline CHEMBL1242110 & 654925 & 6.7167 & 5.4885 & TRN & & \\
\hline CHEMBL1242665 & 654925 & 5.1192 & 4.6684 & TST & & \\
\hline CHEMBL1241487 & 654925 & 6.0405 & 5.2317 & TRN & & \\
\hline CHEMBL1242572 & 654925 & 6.2248 & 6.5967 & TRN & & \\
\hline CHEMBL1242289 & 654925 & 6.9586 & 6.3146 & TRN & & \\
\hline CHEMBL1241484 & 654925 & 6.8861 & 6.9174 & TRN & & \\
\hline CHEMBL1242033 & 654925 & 5.4949 & 4.825 & TRN & & \\
\hline CHEMBL1241588 & 654925 & 5.7212 & 4.849 & TST & & \\
\hline CHEMBL1242756 & 654925 & 5.5229 & 6.8753 & TRN & & \\
\hline CHEMBL1242109 & 654925 & 7.7959 & 6.4371 & TRN & & \\
\hline CHEMBL1241677 & 654925 & 5.6198 & 6.3602 & TRN & & \\
\hline CHEMBL1233881 & 654925 & 5.7696 & 6.4348 & TRN & & \\
\hline CHEMBL1242026 & 654925 & 7.4815 & 6.6738 & TRN & & \\
\hline CHEMBL1241679 & 654925 & 4.3979 & 4.8613 & TRN & & \\
\hline CHEMBL1241769 & 654925 & 4.8239 & 5.2394 & TRN & & \\
\hline CHEMBL1241684 & 654925 & 5.3468 & 6.0828 & TST & & \\
\hline CHEMBL1242030 & 654925 & 5.4202 & 4.9658 & TRN & & \\
\hline CHEMBL1241860 & 654925 & 5.6198 & 5.8604 & TRN & & \\
\hline CHEMBL1242384 & 654925 & 6.3401 & 6.0514 & TRN & & \\
\hline CHEMBL1242113 & 654925 & 7.699 & 6.2048 & TRN & & \\
\hline CHEMBL1242209 & 654925 & 5.9586 & 5.2326 & TRN & & \\
\hline CHEMBL1241300 & 654925 & 6.1487 & 5.5583 & TST & & \\
\hline CHEMBL1241682 & 654925 & \multicolumn{3}{|c|}{6.247999999999999} & 6.3175 & TRN \\
\hline CHEMBL1242376 & 654925 & 6.8069 & 6.9747 & TRN & & \\
\hline CHEMBL1242663 & 654925 & 5.6576 & 4.907 & TST & & \\
\hline CHEMBL1242207 & 654925 & 5.6576 & 4.9371 & TRN & & \\
\hline CHEMBL1241299 & 654925 & 6.2612 & 6.5789 & TRN & & \\
\hline CHEMBL1242386 & 654925 & 6.1824 & 6.437 & TRN & & \\
\hline CHEMBL1242293 & 654925 & 7.2218 & 6.8469 & TRN & & \\
\hline CHEMBL1242753 & 654925 & 4.0 & 5.284 & TRN & & \\
\hline CHEMBL1234815 & 654925 & 4.0 & 6.0436 & TRN & & \\
\hline CHEMBL1240554 & 654925 & 5.1871 & 5.8724 & TRN & & \\
\hline CHEMBL1242844 & 654925 & 4.0 & 5.0039 & TRN & & \\
\hline CHEMBL1241861 & 654925 & 4.5229 & 4.7387 & TRN & & \\
\hline CHEMBL1242853 & 654925 & 6.2396 & 5.2663 & TRN & & \\
\hline CHEMBL1242285 & 654925 & 4.5229 & 6.0483 & TRN & & \\
\hline
\end{tabular}

Page 20847 


\begin{tabular}{|c|c|c|c|c|c|}
\hline & & \multicolumn{4}{|c|}{ Supplemental Table S2.txt } \\
\hline CHEMBL1242198 & 654925 & 4.8539 & 6.0858 & TRN & \\
\hline CHEMBL1242758 & 654925 & 5.2676 & 5.4493 & TST & \\
\hline CHEMBL1240553 & 654925 & 5.6021 & 5.95799 & 9999999999 & TRN \\
\hline CHEMBL1242748 & 654925 & 6.0 & 5.5764 & TRN & \\
\hline CHEMBL1241864 & 654925 & 4.0 & 3.96199 & 99999999997 & TRN \\
\hline CHEMBL1242114 & 654925 & 8.5229 & 6.4029 & TRN & \\
\hline CHEMBL1242029 & 654925 & 5.0969 & 4.8168 & TRN & \\
\hline CHEMBL1241676 & 654925 & 6.3575 & 7.0626 & TRN & \\
\hline CHEMBL1242200 & 654925 & 5.0 & 5.3437 & TRN & \\
\hline CHEMBL1241859 & 654925 & 5.5229 & 5.528 & TRN & \\
\hline CHEMBL1242201 & 654925 & 7.3979 & 6.5563 & TRN & \\
\hline CHEMBL1242569 & 654925 & 5.3188 & 5.0147 & TRN & \\
\hline CHEMBL1242295 & 654925 & 6.3904 & 6.8457 & TRN & \\
\hline CHEMBL1242031 & 654925 & 5.3665 & 5.5014 & TRN & \\
\hline CHEMBL1242751 & 654925 & 5.2596 & 4.6918 & TRN & \\
\hline CHEMBL1241680 & 654925 & 4.0 & 4.638 & TRN & \\
\hline CHEMBL1241771 & 654925 & 4.0 & 4.875 & TRN & \\
\hline CHEMBL1230790 & 654925 & 5.6778 & 6.0571 & TRN & \\
\hline CHEMBL1242469 & 654925 & 5.6576 & 5.5999 & TST & \\
\hline CHEMBL1241946 & 654925 & 4.7959 & 4.8841 & TRN & \\
\hline CHEMBL1242379 & 654925 & 4.0 & 4.8898 & TRN & \\
\hline CHEMBL1242288 & 654925 & 5.4089 & 5.6509 & TRN & \\
\hline CHEMBL1242377 & 654925 & 7.4318 & 6.4226 & TRN & \\
\hline CHEMBL1242656 & 654925 & 6.0888 & 6.3432 & TRN & \\
\hline CHEMBL1242199 & 654925 & 5.0 & 6.0897 & TRN & \\
\hline CHEMBL1242754 & 654925 & 5.7212 & 5.5713 & TRN & \\
\hline CHEMBL1241241 & 654925 & 5.2218 & 5.7772 & TRN & \\
\hline CHEMBL1240545 & 654925 & 5.4559 & 4.9213 & TRN & \\
\hline CHEMBL1241683 & 654925 & 6.9469 & 6.2519 & TRN & \\
\hline CHEMBL1242852 & 654925 & 6.5229 & 5.5987 & TRN & \\
\hline CHEMBL1242659 & 654925 & 6.2104 & 5.2413 & TRN & \\
\hline CHEMBL1242381 & 654925 & 6.0 & 5.4914 & TRN & \\
\hline CHEMBL1241681 & 654925 & 6.2596 & 6.5934 & TRN & \\
\hline CHEMBL1242847 & 654925 & 5.3665 & 5.4098 & TRN & \\
\hline CHEMBL1242568 & 654925 & 5.7447 & 6.14 & TRN & \\
\hline CHEMBL1241863 & 654925 & 5.0605 & 3.8305 & TRN & \\
\hline CHEMBL1241492 & 654925 & 4.0 & 4.6564 & TRN & \\
\hline CHEMBL1242750 & 654925 & 5.9586 & 6.4425 & TRN & \\
\hline CHEMBL1241439 & 654925 & 6.1158 & 5.711 & TST & \\
\hline CHEMBL1242208 & 654925 & 5.8239 & 5.5695 & TRN & \\
\hline CHEMBL1241949 & 654925 & 7.4815 & 6.4073 & TRN & \\
\hline CHEMBL1241947 & 654925 & 6.0297 & 6.23799 & 99999999995 & TST \\
\hline CHEMBL1081312 & 654925 & 9.0 & 7.2044 & TRN & \\
\hline CHEMBL1241587 & 654925 & 5.3468 & 4.93 & TST & \\
\hline CHEMBL1242119 & 654925 & 6.3706 & 5.8482 & TRN & \\
\hline CHEMBL1242661 & 654925 & 4.0 & 5.4381 & TRN & \\
\hline CHEMBL1241776 & 654925 & 7.699 & 6.4551 & TRN & \\
\hline CHEMBL1242202 & 654925 & 6.7696 & 6.6693 & TRN & \\
\hline
\end{tabular}




\begin{tabular}{|c|c|c|c|c|}
\hline & & & pplement & al $\mathrm{T}$ \\
\hline CHEMBL1242845 & 654925 & 4.301 & 5.0716 & TST \\
\hline CHEMBL1241581 & 654925 & 5.7212 & 5.6869 & TRN \\
\hline CHEMBL1241301 & 654925 & 7.0088 & 6.1199 & TRN \\
\hline CHEMBL1242752 & 654925 & 5.6198 & 5.1445 & TRN \\
\hline CHEMBL1242471 & 654925 & 4.0 & 4.5005 & TST \\
\hline CHEMBL1242117 & 654925 & 4.0 & 5.0889 & TRN \\
\hline CHEMBL1242203 & 654925 & 5.2924 & 5.7804 & TST \\
\hline CHEMBL1241490 & 654925 & 5.4685 & 5.6316 & TST \\
\hline CHEMBL1242566 & 654925 & 5.8239 & 5.9722 & TST \\
\hline CHEMBL1242378 & 654925 & 6.0 & 5.7051 & TST \\
\hline CHEMBL1241770 & 654925 & 5.3188 & 5.51 & TST \\
\hline CHEMBL1241483 & 654925 & 5.0862 & 4.8481 & TST \\
\hline CHEMBL1241945 & 654925 & 8.5229 & 6.4258 & TST \\
\hline CHEMBL1242475 & 654925 & 5.9586 & 6.5174 & TST \\
\hline CHEMBL1241944 & 654925 & 6.2248 & 6.5066 & TST \\
\hline CHEMBL1242472 & 654925 & 5.4815 & 5.4214 & TST \\
\hline CHEMBL1241675 & 654925 & 5.3188 & 5.2256 & TST \\
\hline CHEMBL1242385 & 654925 & 6.6882 & 6.3842 & TST \\
\hline CHEMBL1241582 & 654925 & 5.2676 & 4.6639 & TST \\
\hline CHEMBL1241767 & 654925 & 4.301 & 4.0023 & TST \\
\hline CHEMBL1241390 & 654925 & 5.2596 & 4.6428 & TST \\
\hline CHEMBL1242034 & 654925 & 5.0 & 5.1235 & TST \\
\hline CHEMBL1242290 & 654925 & 5.5086 & 5.271 & TST \\
\hline CHEMBL1241482 & 654925 & 4.0 & 4.2307 & TST \\
\hline CHEMBL1242112 & 654925 & 5.9208 & 5.4205 & TST \\
\hline CHEMBL1241858 & 654925 & 5.4949 & 4.9418 & TST \\
\hline CHEMBL1385004 & 688889 & 4.65 & 4.7616 & TRN \\
\hline CHEMBL1439488 & 688889 & 4.5 & 4.7346 & TRN \\
\hline CHEMBL 3211554 & 688889 & 4.3 & 4.7393 & TST \\
\hline CHEMBL1489888 & 688889 & 4.45 & 4.7396 & TRN \\
\hline CHEMBL1557558 & 688889 & 4.3 & 4.9826 & TRN \\
\hline CHEMBL1401851 & 688889 & 6.7501 & 4.8946 & TRN \\
\hline CHEMBL1431760 & 688889 & 5.3 & 4.9701 & TRN \\
\hline CHEMBL1455119 & 688889 & 5.2 & 4.7346 & TRN \\
\hline CHEMBL1398618 & 688889 & 5.7 & 4.6479 & TST \\
\hline CHEMBL1364430 & 688889 & 4.95 & 4.7934 & TRN \\
\hline CHEMBL1543646 & 688889 & 6.15 & 4.8545 & TST \\
\hline CHEMBL 3190641 & 688889 & 4.25 & 4.9264 & TRN \\
\hline CHEMBL1363121 & 688889 & 4.25 & 4.6846 & TRN \\
\hline CHEMBL1399519 & 688889 & 4.45 & 4.7258 & TRN \\
\hline CHEMBL1402794 & 688889 & 4.25 & 4.8125 & TST \\
\hline CHEMBL1303180 & 688889 & 5.5 & 4.6748 & TRN \\
\hline CHEMBL1471570 & 688889 & 4.25 & 4.8393 & TRN \\
\hline CHEMBL1898074 & 688889 & 5.1 & 4.7037 & TRN \\
\hline CHEMBL1312470 & 688889 & 4.65 & 4.8894 & TRN \\
\hline CHEMBL1598432 & 688889 & 5.35 & 4.7279 & TRN \\
\hline CHEMBL1375894 & 688889 & 4.9 & 4.6267 & TST \\
\hline CHEMBL1422097 & 688889 & 4.95 & 4.6455 & TRN \\
\hline
\end{tabular}




\begin{tabular}{|c|c|c|c|c|c|}
\hline \multicolumn{6}{|c|}{ Supplemental Table S2.txt } \\
\hline CHEMBL1586031 & 688889 & 4.4 & 4.8929 & TRN & \\
\hline CHEMBL1486698 & 688889 & 4.6 & 4.6664 & TRN & \\
\hline CHEMBL1561699 & 688889 & 4.25 & 4.8337 & TST & \\
\hline CHEMBL1584294 & 688889 & 5.4 & 4.7476 & TST & \\
\hline CHEMBL1545060 & 688889 & 6.7501 & 4.8538 & TRN & \\
\hline CHEMBL3197774 & 688889 & 5.15 & 4.6858 & TRN & \\
\hline CHEMBL1411571 & 688889 & 4.55 & 4.7167 & TRN & \\
\hline CHEMBL1566534 & 688889 & 4.55 & 4.7225 & TRN & \\
\hline CHEMBL1309506 & 688889 & 5.55 & 4.8495 & TRN & \\
\hline CHEMBL1422360 & 688889 & 4.6 & 4.7637 & TRN & \\
\hline CHEMBL1327804 & 688889 & 5.3 & 4.6619 & TST & \\
\hline CHEMBL1596587 & 688889 & 4.55 & 4.7164 & TRN & \\
\hline CHEMBL1420632 & 688889 & 4.7 & 4.7525 & TST & \\
\hline CHEMBL1328705 & 688889 & 4.5 & 4.7733 & TST & \\
\hline CHEMBL1560735 & 688889 & 4.3 & 4.9858 & TST & \\
\hline CHEMBL1531706 & 688889 & 4.95 & 4.8871 & TRN & \\
\hline CHEMBL1463728 & 688889 & 4.45 & 4.845 & TRN & \\
\hline CHEMBL1460905 & 688889 & 4.25 & 4.7701 & TST & \\
\hline CHEMBL1460692 & 688889 & 5.45 & 4.7562 & TST & \\
\hline CHEMBL1375616 & 688889 & 5.45 & 4.8748 & TRN & \\
\hline CHEMBL1541977 & 688889 & 4.9 & 4.6297 & TST & \\
\hline CHEMBL1503974 & 688889 & 4.95 & 4.765 & TRN & \\
\hline CHEMBL1589194 & 688889 & 4.35 & 4.68 & TRN & \\
\hline CHEMBL1491751 & 688889 & 4.3 & 4.9473 & TRN & \\
\hline CHEMBL1531179 & 688889 & 4.95 & 4.7597 & TRN & \\
\hline CHEMBL1345676 & 688889 & 5.35 & 5.0048 & TST & \\
\hline CHEMBL1328297 & 688889 & 4.55 & 5.0031 & TRN & \\
\hline CHEMBL1326478 & 688889 & 6.7501 & 4.8662 & TST & \\
\hline CHEMBL1299871 & 688889 & 4.45 & 4.6559 & TRN & \\
\hline CHEMBL1348105 & 688889 & 5.4 & 4.9238 & TST & \\
\hline CHEMBL1539644 & 688889 & 5.9 & 4.8922 & TRN & \\
\hline CHEMBL1472031 & 688889 & 4.3 & 4.7434 & TST & \\
\hline CHEMBL1457108 & 688889 & 4.75 & $4.9860 e$ & 3000000001 & TRN \\
\hline CHEMBL1499149 & 688889 & 4.25 & 4.8813 & TST & \\
\hline CHEMBL1574187 & 688889 & 6.7501 & 4.8178 & TST & \\
\hline CHEMBL1458730 & 688889 & 4.3 & 4.7486 & TRN & \\
\hline CHEMBL1477152 & 688889 & 4.9 & 4.9574 & TST & \\
\hline CHEMBL1309123 & 688889 & 4.95 & 4.8988 & TRN & \\
\hline CHEMBL1424106 & 688889 & 4.4 & 4.782 & TRN & \\
\hline CHEMBL1303203 & 688889 & 5.8 & 4.6117 & TRN & \\
\hline CHEMBL1610603 & 688889 & 5.35 & $4.6530 e$ & 00000000005 & TRN \\
\hline CHEMBL1469193 & 688889 & 4.35 & 4.8818 & TRN & \\
\hline CHEMBL1309643 & 688889 & 4.3 & 4.6667 & TST & \\
\hline CHEMBL1433084 & 688889 & 4.6 & 4.6971 & TRN & \\
\hline CHEMBL1299609 & 688889 & 4.3 & 4.7498 & TST & \\
\hline CHEMBL1377641 & 688889 & 4.25 & 4.7824 & TST & \\
\hline CHEMBL3194991 & 688889 & 4.35 & 4.8417 & TST & \\
\hline CHEMBL3195599 & 688889 & 4.4 & 4.763 & TRN & \\
\hline
\end{tabular}




\begin{tabular}{|c|c|c|c|c|c|}
\hline \multicolumn{6}{|c|}{ Supplemental Table S2.txt } \\
\hline CHEMBL1347514 & 688889 & 4.5 & 4.6474 & TST & \\
\hline CHEMBL1461019 & 688889 & 4.4 & 4.7558 & TRN & \\
\hline CHEMBL1300141 & 688889 & 5.15 & 4.749 & TST & \\
\hline CHEMBL 3197372 & 688889 & 4.45 & 4.85800 & 00000000005 & TRN \\
\hline CHEMBL1321074 & 688889 & 4.95 & 4.7787 & TST & \\
\hline CHEMBL1400969 & 688889 & 5.1 & 4.9298 & TST & \\
\hline CHEMBL1408085 & 688889 & 4.5 & 4.7998 & TRN & \\
\hline CHEMBL1426722 & 688889 & 4.55 & 4.8423 & TRN & \\
\hline CHEMBL1589110 & 688889 & 4.45 & 4.5625 & TRN & \\
\hline CHEMBL1608513 & 688889 & 4.25 & 4.8345 & TRN & \\
\hline CHEMBL1542804 & 688889 & 4.4 & 4.6667 & TRN & \\
\hline CHEMBL1522654 & 688889 & 5.45 & 4.8466 & TRN & \\
\hline CHEMBL1531637 & 688889 & 4.3 & 4.6861 & TRN & \\
\hline CHEMBL1352516 & 688889 & 4.25 & 4.6951 & TRN & \\
\hline CHEMBL1533123 & 688889 & 4.3 & 4.6264 & TRN & \\
\hline CHEMBL1599872 & 688889 & 6.0 & 4.8511 & TST & \\
\hline CHEMBL3209791 & 688889 & 4.5 & 4.7171 & TRN & \\
\hline CHEMBL1485053 & 688889 & 4.3 & 4.8562 & TRN & \\
\hline CHEMBL1385973 & 688889 & 4.45 & 4.6027 & TRN & \\
\hline CHEMBL1611632 & 688889 & 4.45 & 4.6892 & TRN & \\
\hline CHEMBL1309355 & 688889 & 4.3 & 4.8391 & TST & \\
\hline CHEMBL1349936 & 688889 & 6.35 & 4.9381 & TRN & \\
\hline CHEMBL1544333 & 688889 & 4.25 & 4.9003 & TRN & \\
\hline CHEMBL1366184 & 688889 & 5.15 & 4.9292 & TRN & \\
\hline CHEMBL1571146 & 688889 & 4.3 & 4.7727 & TRN & \\
\hline CHEMBL1601337 & 688889 & 4.25 & 4.7606 & TRN & \\
\hline CHEMBL3194410 & 688889 & 5.75 & 4.78100 & 0000000001 & TRN \\
\hline CHEMBL1583505 & 688889 & 4.6 & 4.8434 & TRN & \\
\hline CHEMBL1406444 & 688889 & 4.5 & 4.9292 & TST & \\
\hline CHEMBL3208660 & 688889 & 4.6 & 4.9088 & TRN & \\
\hline CHEMBL1376774 & 688889 & 4.45 & 4.6844 & TRN & \\
\hline CHEMBL 275000 & 688889 & 4.45 & 4.7833 & TRN & \\
\hline CHEMBL1538327 & 688889 & 4.45 & 4.8864 & TRN & \\
\hline CHEMBL1587264 & 688889 & 4.35 & 4.659 & TRN & \\
\hline CHEMBL1605311 & 688889 & 4.35 & 4.7275 & TRN & \\
\hline CHEMBL1462817 & 688889 & 4.3 & 4.8283 & TRN & \\
\hline CHEMBL1565888 & 688889 & 4.55 & 4.7247 & TRN & \\
\hline CHEMBL1441983 & 688889 & 4.95 & 4.7737 & TRN & \\
\hline CHEMBL1420584 & 688889 & 4.25 & 4.9194 & TRN & \\
\hline CHEMBL1420007 & 688889 & 6.7501 & 4.9627 & TST & \\
\hline CHEMBL1465475 & 688889 & 4.5 & 4.766 & TRN & \\
\hline CHEMBL1606763 & 688889 & 4.3 & 4.7217 & TRN & \\
\hline CHEMBL1523550 & 688889 & 4.25 & 4.7462 & TST & \\
\hline CHEMBL1301611 & 688889 & 4.55 & 4.7805 & TRN & \\
\hline CHEMBL 3191643 & 688889 & 4.55 & 4.6012 & TST & \\
\hline CHEMBL1467194 & 688889 & 4.25 & 4.7169 & TST & \\
\hline CHEMBL3210653 & 688889 & 5.1 & 4.8067 & TST & \\
\hline CHEMBL3209685 & 688889 & 4.3 & 4.774 & TRN & \\
\hline
\end{tabular}




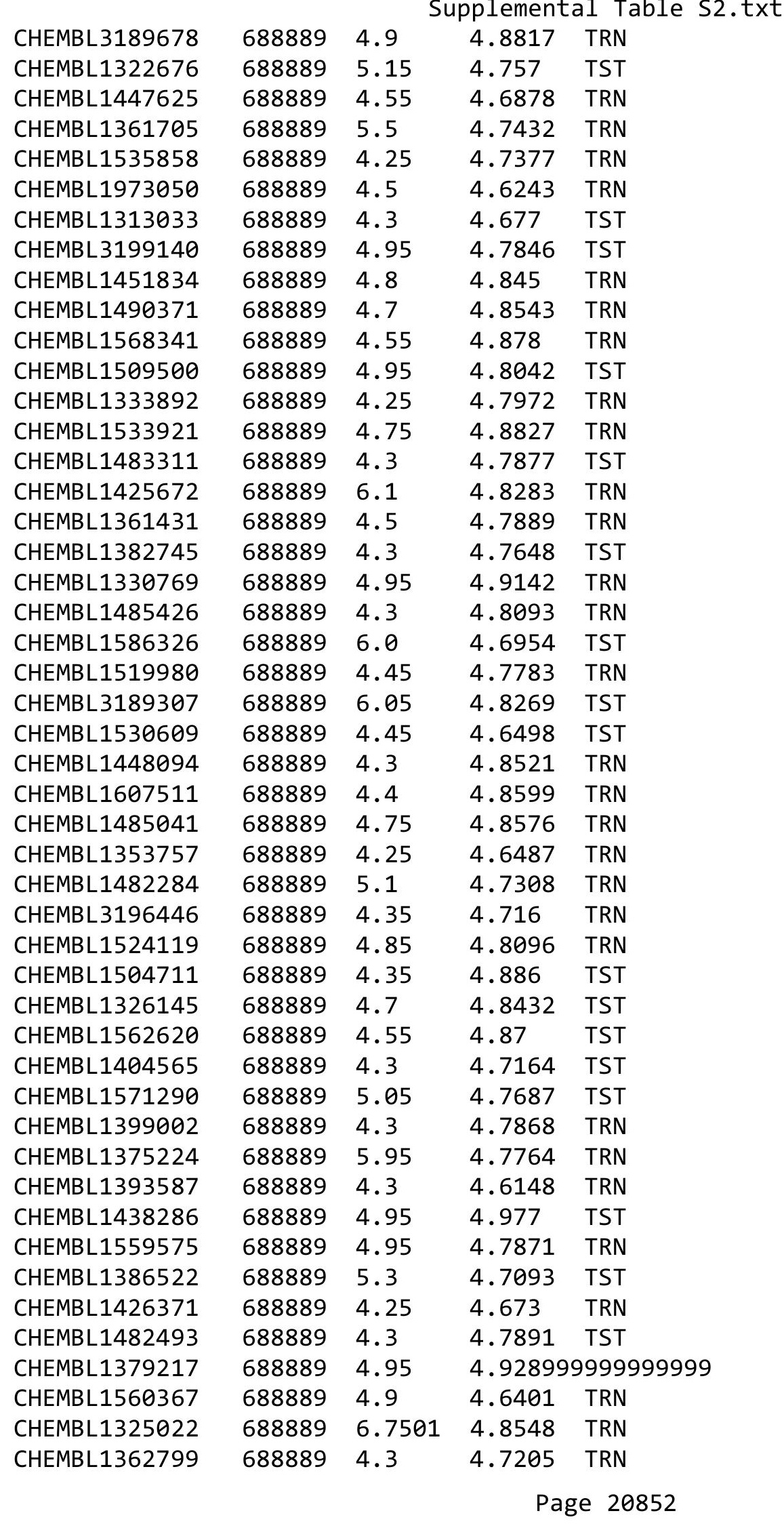




\begin{tabular}{|c|c|c|c|c|c|}
\hline \multicolumn{6}{|c|}{ Supplemental Table s2.txt } \\
\hline CHEMBL3209943 & 688889 & 4.25 & 4.7672 & TRN & \\
\hline CHEMBL1517045 & 688889 & 4.3 & 4.6872 & TST & \\
\hline CHEMBL1964475 & 688889 & 4.35 & 4.6547 & TST & \\
\hline CHEMBL1490158 & 688889 & 5.15 & 4.6951 & TRN & \\
\hline CHEMBL1347191 & 688889 & 4.4 & 4.7212 & TRN & \\
\hline CHEMBL1556020 & 688889 & 4.45 & 4.7013 & TRN & \\
\hline CHEMBL1425378 & 688889 & 5.2 & 4.9187 & TRN & \\
\hline CHEMBL1544989 & 688889 & 5.75 & 4.7755 & TRN & \\
\hline CHEMBL1526816 & 688889 & 5.05 & 4.9137 & TRN & \\
\hline CHEMBL581574 & 688889 & 4.4 & 4.899 & TRN & \\
\hline CHEMBL1335161 & 688889 & 4.65 & 4.6776 & TRN & \\
\hline CHEMBL 3199854 & 688889 & 4.95 & 4.63899 & 9999999999 & TRN \\
\hline CHEMBL1478885 & 688889 & 4.25 & 4.8421 & TST & \\
\hline CHEMBL1389608 & 688889 & 4.3 & 4.6546 & TRN & \\
\hline CHEMBL1410737 & 688889 & 4.55 & 4.7193 & TRN & \\
\hline CHEMBL1335507 & 688889 & 6.7501 & 4.7724 & TRN & \\
\hline CHEMBL1560035 & 688889 & 4.25 & 4.7085 & TST & \\
\hline CHEMBL1430643 & 688889 & 4.4 & 4.7505 & TRN & \\
\hline CHEMBL1321518 & 688889 & 4.55 & 4.8016 & TRN & \\
\hline CHEMBL1969713 & 688889 & 4.7 & 4.641 & TST & \\
\hline CHEMBL1504230 & 688889 & 4.3 & 4.7905 & TRN & \\
\hline CHEMBL1602486 & 688889 & 6.7501 & 4.8559 & TRN & \\
\hline CHEMBL1462143 & 688889 & 4.25 & 4.67899 & 9999999999 & TST \\
\hline CHEMBL1454487 & 688889 & 6.8 & 4.8736 & TST & \\
\hline CHEMBL1460871 & 688889 & 4.6 & 4.9401 & TRN & \\
\hline CHEMBL1478223 & 688889 & 5.9 & 4.8691 & TRN & \\
\hline CHEMBL1517918 & 688889 & 4.25 & 4.6761 & TRN & \\
\hline CHEMBL1413521 & 688889 & 4.8 & 4.6558 & TRN & \\
\hline CHEMBL1432762 & 688889 & 4.5 & 4.6654 & TRN & \\
\hline CHEMBL1492181 & 688889 & 6.05 & 4.8645 & TRN & \\
\hline CHEMBL1546474 & 688889 & 4.3 & 4.7942 & TRN & \\
\hline CHEMBL1369559 & 688889 & 4.5 & 4.7467 & TRN & \\
\hline CHEMBL1549758 & 688889 & 4.25 & 4.9364 & TST & \\
\hline CHEMBL1389470 & 688889 & 4.95 & 4.7946 & TST & \\
\hline CHEMBL1598299 & 688889 & 4.3 & 4.7885 & TST & \\
\hline CHEMBL1404206 & 688889 & 4.3 & 4.6721 & TRN & \\
\hline CHEMBL1550068 & 688889 & 4.6 & 4.9145 & TRN & \\
\hline CHEMBL1468386 & 688889 & 4.35 & 4.8656 & TST & \\
\hline CHEMBL1462854 & 688889 & 5.05 & 4.8903 & TRN & \\
\hline CHEMBL1482010 & 688889 & 5.25 & 4.6301 & TST & \\
\hline CHEMBL1299531 & 688889 & 6.05 & 4.6986 & TRN & \\
\hline CHEMBL1543330 & 688889 & 4.5 & 4.9079 & TST & \\
\hline CHEMBL1605986 & 688889 & 6.7501 & 4.9001 & TRN & \\
\hline CHEMBL1300662 & 688889 & 4.45 & 4.6459 & TRN & \\
\hline CHEMBL1437980 & 688889 & 6.8 & 4.8213 & TRN & \\
\hline CHEMBL1478088 & 688889 & 4.3 & 4.6671 & TRN & \\
\hline CHEMBL1345017 & 688889 & 4.6 & 4.6752 & TRN & \\
\hline CHEMBL1346929 & 688889 & 4.45 & 4.6927 & TRN & \\
\hline
\end{tabular}




\begin{tabular}{|c|c|c|c|c|c|}
\hline \multicolumn{6}{|c|}{ Supplemental Table S2.txt } \\
\hline CHEMBL 3214232 & 688889 & 4.25 & 4.8778 & TRN & \\
\hline CHEMBL1487712 & 688889 & 4.3 & 4.7975 & TRN & \\
\hline CHEMBL1597104 & 688889 & 4.75 & 4.6893 & TRN & \\
\hline CHEMBL1528789 & 688889 & 4.4 & 4.8144 & TST & \\
\hline CHEMBL1549801 & 688889 & 4.45 & 4.6897 & TST & \\
\hline CHEMBL1601537 & 688889 & 5.35 & 4.77800 & 00000000005 & TST \\
\hline CHEMBL1465434 & 688889 & 4.75 & 4.7565 & TRN & \\
\hline CHEMBL1596792 & 688889 & 5.15 & 4.7612 & TRN & \\
\hline CHEMBL1352733 & 688889 & 4.5 & 4.7257 & TRN & \\
\hline CHEMBL1338066 & 688889 & 5.35 & 4.7199 & TRN & \\
\hline CHEMBL 3196362 & 688889 & 4.5 & 4.6729 & TST & \\
\hline CHEMBL1532309 & 688889 & 4.25 & 4.8797 & TRN & \\
\hline CHEMBL1299245 & 688889 & 4.25 & 4.8133 & TRN & \\
\hline CHEMBL1428880 & 688889 & 4.55 & 4.6893 & TRN & \\
\hline CHEMBL117447 & 688889 & 5.75 & 4.7774 & TST & \\
\hline CHEMBL1504041 & 688889 & 4.35 & 4.7667 & TST & \\
\hline CHEMBL3197171 & 688889 & 4.65 & 4.7682 & TST & \\
\hline CHEMBL1347163 & 688889 & 4.25 & 4.7796 & TST & \\
\hline CHEMBL1462550 & 688889 & 4.35 & 4.8198 & TRN & \\
\hline CHEMBL3191372 & 688889 & 4.45 & 4.8928 & TRN & \\
\hline CHEMBL1588727 & 688889 & 4.55 & 4.7494 & TRN & \\
\hline CHEMBL1324861 & 688889 & 4.55 & 4.72199 & 99999999995 & TRN \\
\hline CHEMBL1352669 & 688889 & 4.25 & 4.8598 & TRN & \\
\hline CHEMBL1440954 & 688889 & 5.95 & 4.8765 & TRN & \\
\hline CHEMBL1342412 & 688889 & 4.3 & 4.8718 & TRN & \\
\hline CHEMBL1443408 & 688889 & 4.35 & 4.7517 & TRN & \\
\hline CHEMBL1364272 & 688889 & 5.1 & 4.7732 & TRN & \\
\hline CHEMBL1373722 & 688889 & 4.55 & 4.7269 & TRN & \\
\hline CHEMBL1477127 & 688889 & 6.7501 & 4.8954 & TRN & \\
\hline CHEMBL1402793 & 688889 & 4.95 & 4.7138 & TRN & \\
\hline CHEMBL507369 & 688889 & 4.95 & 4.7081 & TST & \\
\hline CHEMBL1547388 & 688889 & 4.95 & 4.6866 & TST & \\
\hline CHEMBL1599755 & 688889 & 4.4 & 4.7778 & TRN & \\
\hline CHEMBL1392490 & 688889 & 4.5 & 4.7454 & TRN & \\
\hline CHEMBL1549334 & 688889 & 4.3 & 4.9021 & TRN & \\
\hline CHEMBL1556395 & 688889 & 4.45 & 4.8496 & TRN & \\
\hline CHEMBL1301573 & 688889 & 4.6 & 4.6757 & TRN & \\
\hline CHEMBL1388848 & 688889 & 4.5 & 4.7055 & TRN & \\
\hline CHEMBL1601977 & 688889 & 4.8 & 4.8143 & TRN & \\
\hline CHEMBL3199314 & 688889 & 4.3 & 4.7932 & TST & \\
\hline CHEMBL1404669 & 688889 & 5.25 & 4.8425 & TST & \\
\hline CHEMBL 3214250 & 688889 & 4.3 & 4.8723 & TRN & \\
\hline CHEMBL1381167 & 688889 & 6.4 & 4.9277 & TST & \\
\hline CHEMBL1991441 & 688889 & 4.5 & 4.7816 & TRN & \\
\hline CHEMBL1458862 & 688889 & 4.9 & 4.797 & TRN & \\
\hline CHEMBL1478399 & 688889 & 4.95 & 4.9506 & TRN & \\
\hline CHEMBL1547683 & 688889 & 4.6 & 4.9306 & TRN & \\
\hline CHEMBL1537216 & 688889 & 4.4 & 4.662 & TRN & \\
\hline
\end{tabular}




\begin{tabular}{|c|c|c|c|c|c|}
\hline \multicolumn{6}{|c|}{ Supplemental Table S2.txt } \\
\hline CHEMBL1416288 & 688889 & 4.4 & 4.6668 & TRN & \\
\hline CHEMBL1306100 & 688889 & 5.95 & 4.7821 & TST & \\
\hline CHEMBL1479334 & 688889 & 4.9 & 4.7302 & TRN & \\
\hline CHEMBL1363764 & 688889 & 4.55 & 4.7322 & TRN & \\
\hline CHEMBL1497617 & 688889 & 4.35 & 4.7606 & TRN & \\
\hline CHEMBL1382501 & 688889 & 4.45 & 4.751 & TRN & \\
\hline CHEMBL1556644 & 688889 & 4.65 & 4.5998 & TRN & \\
\hline CHEMBL1528219 & 688889 & 4.95 & 4.6935 & TRN & \\
\hline CHEMBL1382126 & 688889 & 4.95 & 4.845 & TRN & \\
\hline CHEMBL1418278 & 688889 & 4.25 & 4.8108 & TRN & \\
\hline CHEMBL1299833 & 688889 & 5.4 & 4.8821 & TRN & \\
\hline CHEMBL1570727 & 688889 & 6.7501 & 4.8951 & TRN & \\
\hline CHEMBL1365856 & 688889 & 5.2 & 4.7844 & TRN & \\
\hline CHEMBL1343075 & 688889 & 4.35 & 4.8164 & TRN & \\
\hline CHEMBL1302511 & 688889 & 5.5 & 4.9937 & TRN & \\
\hline CHEMBL1575891 & 688889 & 6.4 & 4.8047 & TRN & \\
\hline CHEMBL1449066 & 688889 & 4.45 & 4.7812 & TRN & \\
\hline CHEMBL1459962 & 688889 & 4.75 & 4.683 & TRN & \\
\hline CHEMBL1610284 & 688889 & 5.7 & 4.8683 & TRN & \\
\hline CHEMBL1495047 & 688889 & 4.95 & 4.8757 & TRN & \\
\hline CHEMBL3191131 & 688889 & 5.1 & 4.8043 & TRN & \\
\hline CHEMBL1336141 & 688889 & 5.5 & 4.9064 & TRN & \\
\hline CHEMBL1577997 & 688889 & 5.7 & 4.9434 & TRN & \\
\hline CHEMBL1529785 & 688889 & 4.85 & 4.8508 & TRN & \\
\hline CHEMBL1504065 & 688889 & 4.4 & 4.8105 & TRN & \\
\hline CHEMBL1468796 & 688889 & 4.4 & 4.6741 & TRN & \\
\hline CHEMBL1588910 & 688889 & 4.25 & 4.9141 & TRN & \\
\hline CHEMBL1507975 & 688889 & 4.25 & 4.83899 & 99999999995 & TRN \\
\hline CHEMBL1406880 & 688889 & 5.45 & 4.6587 & TRN & \\
\hline CHEMBL1305264 & 688889 & 4.3 & 4.7792 & TST & \\
\hline CHEMBL1561391 & 688889 & 6.05 & 4.71399 & 99999999995 & TRN \\
\hline CHEMBL1575548 & 688889 & 4.3 & 4.9238 & TRN & \\
\hline CHEMBL3199373 & 688889 & 4.4 & 4.9484 & TST & \\
\hline CHEMBL1342609 & 688889 & 4.95 & 4.7631 & TST & \\
\hline CHEMBL1541223 & 688889 & 4.9 & 4.9513 & TRN & \\
\hline CHEMBL1528598 & 688889 & 4.25 & 4.7846 & TST & \\
\hline CHEMBL1329965 & 688889 & 4.55 & 4.7559 & TRN & \\
\hline CHEMBL1371368 & 688889 & 4.25 & 4.9271 & TRN & \\
\hline CHEMBL1532017 & 688889 & 4.45 & 4.6944 & TRN & \\
\hline CHEMBL1601479 & 688889 & 4.4 & 4.7863 & TRN & \\
\hline CHEMBL1477064 & 688889 & 5.05 & 4.8433 & TRN & \\
\hline CHEMBL1371790 & 688889 & 4.45 & 4.6296 & TST & \\
\hline CHEMBL1491994 & 688889 & 4.25 & 4.7282 & TRN & \\
\hline CHEMBL1444202 & 688889 & 4.9 & 4.7548 & TRN & \\
\hline CHEMBL1383226 & 688889 & 4.3 & 4.8126 & TRN & \\
\hline CHEMBL1428560 & 688889 & 4.4 & 4.8615 & TRN & \\
\hline CHEMBL1577550 & 688889 & 6.7501 & 4.8713 & TRN & \\
\hline CHEMBL1523916 & 688889 & 5.0 & 4.8184 & TST & \\
\hline
\end{tabular}




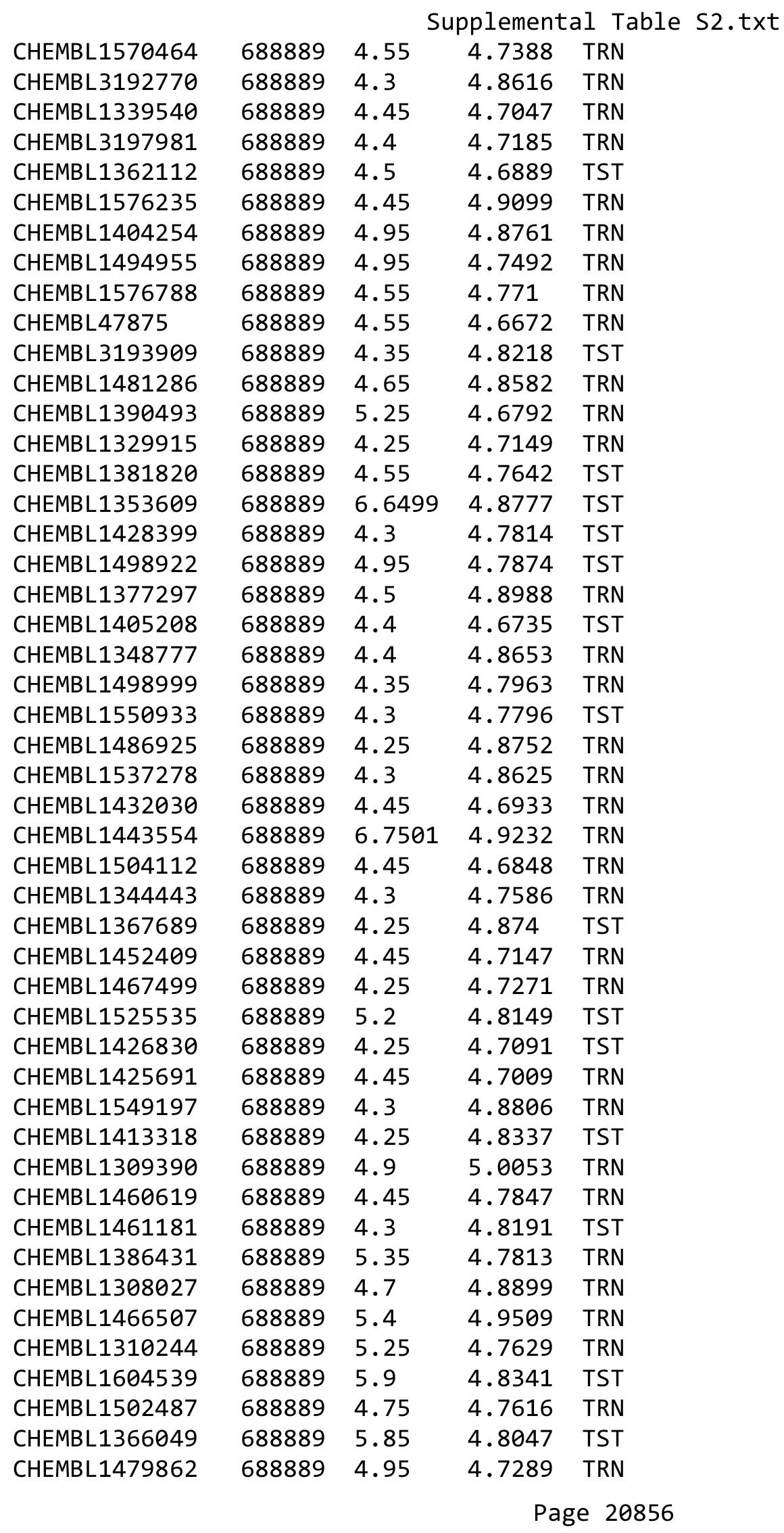




\begin{tabular}{|c|c|c|c|c|c|}
\hline & & \multicolumn{4}{|c|}{ Supplemental Table S2.txt } \\
\hline CHEMBL1359105 & 688889 & 4.7 & 4.8137 & TRN & \\
\hline CHEMBL1550093 & 688889 & 4.7 & 4.8052 & TRN & \\
\hline CHEMBL1463376 & 688889 & 5.2 & 4.6885 & TRN & \\
\hline CHEMBL1372312 & 688889 & 4.95 & 4.9729 & TRN & \\
\hline CHEMBL1585157 & 688889 & 4.45 & 4.8686 & TRN & \\
\hline CHEMBL1490225 & 688889 & 4.9 & 4.7913 & TRN & \\
\hline CHEMBL1491136 & 688889 & 4.9 & 4.9464 & TRN & \\
\hline CHEMBL1407524 & 688889 & 4.5 & 4.8573 & TRN & \\
\hline CHEMBL1363429 & 688889 & 4.55 & 4.9209 & TRN & \\
\hline CHEMBL1600462 & 688889 & 4.9 & 4.9623 & TRN & \\
\hline CHEMBL1331859 & 688889 & 5.45 & 4.8172 & TST & \\
\hline CHEMBL1417341 & 688889 & 4.6 & 4.7321 & TRN & \\
\hline CHEMBL541521 & 688889 & 4.25 & 5.02800 & 00000000005 & TRN \\
\hline CHEMBL1547282 & 688889 & 5.0 & 4.7936 & TRN & \\
\hline CHEMBL1487031 & 688889 & 5.8 & 4.80399 & 9999999999 & TRN \\
\hline CHEMBL1605856 & 688889 & 4.45 & 4.8331 & TRN & \\
\hline CHEMBL1322428 & 688889 & 4.9 & 4.7884 & TRN & \\
\hline CHEMBL1375143 & 688889 & 5.95 & 4.9913 & TRN & \\
\hline CHEMBL1562294 & 688889 & 4.55 & 4.8924 & TST & \\
\hline CHEMBL1541441 & 688889 & 6.5 & 4.8249 & TST & \\
\hline CHEMBL1350990 & 688889 & 4.85 & 4.8378 & TRN & \\
\hline CHEMBL1452484 & 688889 & 5.3 & 4.762 & TRN & \\
\hline CHEMBL1348312 & 688889 & 6.15 & 4.9137 & TRN & \\
\hline CHEMBL1418677 & 688889 & 4.3 & 4.8448 & TST & \\
\hline CHEMBL1600800 & 688889 & 4.5 & 4.676 & TRN & \\
\hline CHEMBL1608168 & 688889 & 4.55 & 4.7349 & TRN & \\
\hline CHEMBL1519945 & 688889 & 4.4 & 4.7779 & TRN & \\
\hline CHEMBL1508375 & 688889 & 6.7501 & 4.8109 & TRN & \\
\hline CHEMBL 3198540 & 688889 & 4.4 & 4.7775 & TST & \\
\hline CHEMBL1401085 & 688889 & 4.3 & 4.8478 & TRN & \\
\hline CHEMBL 3191786 & 688889 & 5.4 & 4.6801 & TST & \\
\hline CHEMBL1423688 & 688889 & 4.95 & 4.7315 & TST & \\
\hline CHEMBL1498767 & 688889 & 4.7 & 4.899 & TRN & \\
\hline CHEMBL1414002 & 688889 & 4.25 & 4.883 & TRN & \\
\hline CHEMBL1425785 & 688889 & 5.9 & 4.7198 & TRN & \\
\hline CHEMBL1579906 & 688889 & 4.65 & 4.7662 & TRN & \\
\hline CHEMBL1399721 & 688889 & 4.9 & 4.7385 & TRN & \\
\hline CHEMBL3192946 & 688889 & 4.45 & 4.6527 & TRN & \\
\hline CHEMBL1518192 & 688889 & 4.25 & 4.7978 & TST & \\
\hline CHEMBL 3212442 & 688889 & 4.25 & 4.7476 & TST & \\
\hline CHEMBL1350463 & 688889 & 6.7501 & 4.8313 & TST & \\
\hline CHEMBL1502470 & 688889 & 4.95 & 4.7635 & TRN & \\
\hline CHEMBL1505000 & 688889 & 4.6 & 4.6741 & TRN & \\
\hline CHEMBL3191686 & 688889 & 4.25 & 4.8345 & TRN & \\
\hline CHEMBL1427815 & 688889 & 4.3 & 4.8405 & TRN & \\
\hline CHEMBL1451779 & 688889 & 4.45 & 4.6998 & TRN & \\
\hline CHEMBL1378551 & 688889 & 4.55 & 4.8176 & TST & \\
\hline CHEMBL1575536 & 688889 & 4.65 & 4.7954 & TRN & \\
\hline
\end{tabular}




\begin{tabular}{|c|c|c|c|c|c|}
\hline & & \multicolumn{4}{|c|}{ Supplemental Table s2.txt } \\
\hline CHEMBL1445205 & 688889 & 6.1 & 4.7819 & TRN & \\
\hline CHEMBL1299296 & 688889 & 4.25 & 4.9131 & TRN & \\
\hline CHEMBL1529581 & 688889 & 4.45 & 4.7778 & TRN & \\
\hline CHEMBL1385654 & 688889 & 4.55 & 4.6478 & TRN & \\
\hline CHEMBL1561066 & 688889 & 4.35 & 4.6085 & TRN & \\
\hline CHEMBL1360241 & 688889 & 4.35 & 4.7256 & TRN & \\
\hline CHEMBL1451267 & 688889 & 4.55 & 4.8352 & TST & \\
\hline CHEMBL3194397 & 688889 & 4.45 & 4.5955 & TRN & \\
\hline CHEMBL1567737 & 688889 & 4.5 & 4.8671 & TRN & \\
\hline CHEMBL1487402 & 688889 & 4.4 & 4.7622 & TRN & \\
\hline CHEMBL1534628 & 688889 & 5.6 & 4.8034 & TRN & \\
\hline CHEMBL1352549 & 688889 & 4.9 & 4.9366 & TRN & \\
\hline CHEMBL1415108 & 688889 & 4.3 & 4.6637 & TRN & \\
\hline CHEMBL1351722 & 688889 & 5.65 & 4.6616 & TRN & \\
\hline CHEMBL1405682 & 688889 & 4.25 & 4.9569 & TRN & \\
\hline CHEMBL1583632 & 688889 & 5.15 & 4.886 & TRN & \\
\hline CHEMBL1596327 & 688889 & 5.0 & 4.7099 & TRN & \\
\hline CHEMBL1314084 & 688889 & 4.35 & 4.9219 & TRN & \\
\hline CHEMBL1455361 & 688889 & 4.4 & 4.729 & TST & \\
\hline CHEMBL1363711 & 688889 & 4.95 & 4.7404 & TRN & \\
\hline CHEMBL1540618 & 688889 & 4.8 & 4.6805 & TRN & \\
\hline CHEMBL609606 & 688889 & 4.3 & 4.7251 & TST & \\
\hline CHEMBL3190321 & 688889 & 4.5 & 4.7484 & TRN & \\
\hline CHEMBL1453979 & 688889 & 4.25 & 4.8088 & TRN & \\
\hline CHEMBL1425085 & 688889 & 4.45 & 4.7518 & TRN & \\
\hline CHEMBL3191763 & 688889 & 4.45 & 4.7315 & TRN & \\
\hline CHEMBL1382085 & 688889 & 4.9 & 4.8414 & TRN & \\
\hline CHEMBL1479406 & 688889 & 4.45 & 4.7713 & TRN & \\
\hline CHEMBL1531859 & 688889 & 4.7 & 4.8932 & TST & \\
\hline CHEMBL1449739 & 688889 & 4.9 & 4.8579 & TRN & \\
\hline CHEMBL1422725 & 688889 & 4.95 & 4.9073 & TRN & \\
\hline CHEMBL1412351 & 688889 & 5.25 & 4.7346 & TST & \\
\hline CHEMBL1453844 & 688889 & 5.2 & 4.7801 & TST & \\
\hline CHEMBL1598952 & 688889 & 4.45 & 4.7415 & TRN & \\
\hline CHEMBL1578446 & 688889 & 4.5 & 4.8595 & TRN & \\
\hline CHEMBL1500570 & 688889 & 4.45 & 4.6296 & TRN & \\
\hline CHEMBL1363982 & 688889 & 5.1 & 4.7948 & TST & \\
\hline CHEMBL1405965 & 688889 & 4.8 & 4.9419 & TRN & \\
\hline CHEMBL1404515 & 688889 & 6.8 & 4.7622 & TST & \\
\hline CHEMBL1353229 & 688889 & 4.3 & 4.6946 & TST & \\
\hline CHEMBL1501839 & 688889 & 4.45 & $4.6560 e$ & 0000000001 & TRN \\
\hline CHEMBL1331190 & 688889 & 4.95 & 4.7638 & TST & \\
\hline CHEMBL473314 & 688889 & 5.45 & 4.67899 & 9999999999 & TRN \\
\hline CHEMBL1531336 & 688889 & 4.4 & 4.8088 & TRN & \\
\hline CHEMBL1503344 & 688889 & 4.35 & 4.9674 & TST & \\
\hline CHEMBL 2142883 & 688889 & 5.8 & 4.7852 & TST & \\
\hline CHEMBL3195281 & 688889 & 4.6 & 4.7234 & TRN & \\
\hline CHEMBL1462181 & 688889 & 5.3 & 4.8393 & TRN & \\
\hline
\end{tabular}




\begin{tabular}{|c|c|c|c|c|}
\hline \multicolumn{5}{|c|}{ Supplemental Table S2.txt } \\
\hline CHEMBL1365788 & 688889 & 4.25 & 4.8254 & TRN \\
\hline CHEMBL1338205 & 688889 & 4.5 & 4.7675 & TRN \\
\hline CHEMBL1573524 & 688889 & 4.3 & 4.8231 & TRN \\
\hline CHEMBL1385745 & 688889 & 5.25 & 4.6478 & TRN \\
\hline CHEMBL1534198 & 688889 & 6.35 & 4.921 & TST \\
\hline CHEMBL1453050 & 688889 & 4.45 & 4.7794 & TRN \\
\hline CHEMBL1529049 & 688889 & 4.25 & 4.7262 & TRN \\
\hline CHEMBL1351988 & 688889 & 6.7001 & 4.8153 & TRN \\
\hline CHEMBL1506661 & 688889 & 6.05 & 4.8848 & TST \\
\hline CHEMBL1540662 & 688889 & 4.7 & 4.8393 & TRN \\
\hline CHEMBL240332 & 688889 & 4.45 & 4.6954 & TST \\
\hline CHEMBL1311145 & 688889 & 4.25 & 4.834 & TST \\
\hline CHEMBL1309529 & 688889 & 5.1 & 4.8684 & TST \\
\hline CHEMBL1604992 & 688889 & 5.85 & 4.8449 & TST \\
\hline CHEMBL1429185 & 688889 & 4.95 & 4.6773 & TRN \\
\hline CHEMBL1579595 & 688889 & 6.35 & 4.7699 & TST \\
\hline CHEMBL1528549 & 688889 & 5.35 & 4.7729 & TRN \\
\hline CHEMBL1359483 & 688889 & 4.45 & 4.8302 & TRN \\
\hline CHEMBL3210723 & 688889 & 4.5 & 4.6678 & TRN \\
\hline CHEMBL1493374 & 688889 & 4.25 & 4.7579 & TST \\
\hline CHEMBL1481813 & 688889 & 4.5 & 4.7277 & TRN \\
\hline CHEMBL1559235 & 688889 & 4.95 & 4.7745 & TRN \\
\hline CHEMBL1458017 & 688889 & 6.7501 & 4.8835 & TST \\
\hline CHEMBL1409587 & 688889 & 4.4 & 4.7691 & TRN \\
\hline CHEMBL1482849 & 688889 & 5.1 & 4.7598 & TRN \\
\hline CHEMBL1409460 & 688889 & 5.85 & 4.7474 & TST \\
\hline CHEMBL1398704 & 688889 & 4.25 & 4.8158 & TRN \\
\hline CHEMBL1399059 & 688889 & 5.3 & 4.6982 & TST \\
\hline CHEMBL1319124 & 688889 & 6.0 & 4.7199 & TRN \\
\hline CHEMBL1349780 & 688889 & 4.55 & 4.6049 & TRN \\
\hline CHEMBL1578363 & 688889 & 4.35 & 4.8078 & TRN \\
\hline CHEMBL1491104 & 688889 & 4.3 & 4.9472 & TST \\
\hline CHEMBL1321445 & 688889 & 4.5 & 4.7453 & TRN \\
\hline CHEMBL1520296 & 688889 & 4.4 & 4.7762 & TRN \\
\hline CHEMBL1423146 & 688889 & 4.25 & 4.8533 & TST \\
\hline CHEMBL1543207 & 688889 & 4.4 & 4.8388 & TRN \\
\hline CHEMBL1418998 & 688889 & 6.2 & 4.7003 & TST \\
\hline CHEMBL1462695 & 688889 & 4.45 & 4.7442 & TRN \\
\hline CHEMBL1374320 & 688889 & 4.6 & 4.7925 & TRN \\
\hline CHEMBL1504168 & 688889 & 4.55 & 4.9262 & TST \\
\hline CHEMBL1503686 & 688889 & 4.9 & 4.7411 & TRN \\
\hline CHEMBL1490683 & 688889 & 6.35 & 4.8065 & TRN \\
\hline CHEMBL1604383 & 688889 & 4.25 & 4.6722 & TRN \\
\hline CHEMBL1326442 & 688889 & 5.2 & 4.6998 & TST \\
\hline CHEMBL1492497 & 688889 & 4.25 & 4.8128 & TRN \\
\hline CHEMBL1379013 & 688889 & 4.85 & 4.8608 & TST \\
\hline CHEMBL1988679 & 688889 & 5.3 & 4.8542 & TST \\
\hline CHEMBL1433286 & 688889 & 4.55 & 4.8431 & TST \\
\hline
\end{tabular}




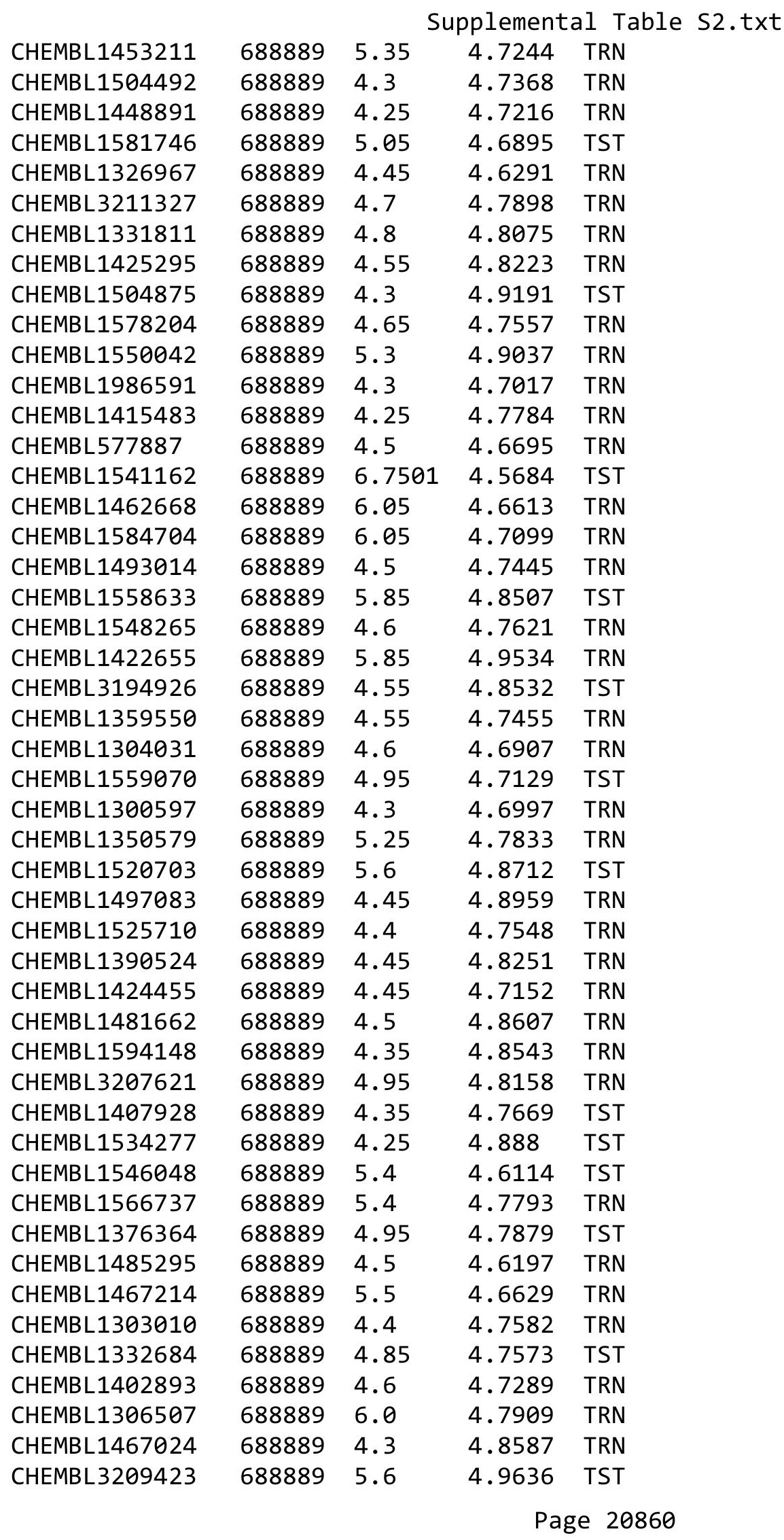




\begin{tabular}{|c|c|c|c|c|}
\hline \multirow[b]{2}{*}{ CHEMBL1485570 } & \multicolumn{4}{|c|}{ Supplemental Table Sa } \\
\hline & 688889 & 4.5 & 4.8938 & TRN \\
\hline CHEMBL1484230 & 688889 & 4.45 & 4.7289 & TRN \\
\hline CHEMBL1320004 & 688889 & 4.35 & 4.6175 & TRN \\
\hline CHEMBL1338131 & 688889 & 4.4 & 4.9367 & TRN \\
\hline CHEMBL1500269 & 688889 & 4.3 & 4.8774 & TST \\
\hline CHEMBL1610369 & 688889 & 6.05 & 4.8955 & TRN \\
\hline CHEMBL536375 & 688889 & 4.3 & 4.8939 & TST \\
\hline CHEMBL1586254 & 688889 & 5.55 & 4.9611 & TST \\
\hline CHEMBL1496384 & 688889 & 4.3 & 4.7666 & TRN \\
\hline CHEMBL1559138 & 688889 & 4.3 & 4.811 & TRN \\
\hline CHEMBL1402205 & 688889 & 4.45 & 4.7934 & TRN \\
\hline CHEMBL1359315 & 688889 & 4.25 & 4.9491 & TRN \\
\hline CHEMBL1524467 & 688889 & 5.85 & 4.7959 & TRN \\
\hline CHEMBL1547074 & 688889 & 4.45 & 4.7391 & TRN \\
\hline CHEMBL1419558 & 688889 & 4.3 & 4.7414 & TRN \\
\hline CHEMBL1368500 & 688889 & 4.9 & 4.8184 & TRN \\
\hline CHEMBL1441612 & 688889 & 4.9 & 4.828 & TST \\
\hline CHEMBL1500928 & 688889 & 4.45 & 4.9708 & TRN \\
\hline CHEMBL1344751 & 688889 & 5.1 & 4.7608 & TRN \\
\hline CHEMBL1548936 & 688889 & 4.55 & 4.6732 & TRN \\
\hline CHEMBL1536252 & 688889 & 4.45 & 4.7504 & TRN \\
\hline CHEMBL1373342 & 688889 & 5.5 & 4.9538 & TRN \\
\hline CHEMBL1521107 & 688889 & 4.4 & 4.7775 & TRN \\
\hline CHEMBL1353320 & 688889 & 5.2 & 4.8992 & TRN \\
\hline CHEMBL1576025 & 688889 & 5.95 & 4.7158 & TST \\
\hline CHEMBL1533127 & 688889 & 4.3 & 4.854 & TRN \\
\hline CHEMBL1390589 & 688889 & 4.45 & 4.6784 & TST \\
\hline CHEMBL1490169 & 688889 & 4.55 & 4.6007 & TRN \\
\hline CHEMBL1403407 & 688889 & 5.25 & 4.7977 & TRN \\
\hline CHEMBL1495883 & 688889 & 4.9 & 4.7721 & TST \\
\hline CHEMBL1310700 & 688889 & 4.95 & 4.8532 & TST \\
\hline CHEMBL1378822 & 688889 & 4.6 & 4.7265 & TRN \\
\hline CHEMBL1302215 & 688889 & 4.95 & 4.789 & TRN \\
\hline CHEMBL1479489 & 688889 & 6.7501 & 4.7299 & TST \\
\hline CHEMBL1417696 & 688889 & 4.45 & 4.6593 & TRN \\
\hline CHEMBL286346 & 688889 & 4.5 & 4.7924 & TST \\
\hline CHEMBL1378553 & 688889 & 4.25 & 4.8902 & TRN \\
\hline CHEMBL1470935 & 688889 & 4.45 & 4.7624 & TRN \\
\hline CHEMBL 3211767 & 688889 & 5.35 & 4.8356 & TST \\
\hline CHEMBL1430785 & 688889 & 4.4 & 4.7476 & TRN \\
\hline CHEMBL1582730 & 688889 & 4.95 & 4.8194 & TRN \\
\hline CHEMBL1466441 & 688889 & 6.05 & 4.7847 & TST \\
\hline CHEMBL3199608 & 688889 & 4.35 & 4.7601 & TRN \\
\hline CHEMBL1570730 & 688889 & 4.45 & 4.6815 & TRN \\
\hline CHEMBL1346462 & 688889 & 5.85 & 5.0121 & TRN \\
\hline CHEMBL1520140 & 688889 & 4.3 & 4.9323 & TST \\
\hline CHEMBL1369042 & 688889 & 4.9 & 4.8886 & TRN \\
\hline CHEMBL1508340 & 688889 & 6.7501 & 4.7742 & TRN \\
\hline
\end{tabular}




\begin{tabular}{|c|c|c|c|c|}
\hline \multicolumn{5}{|c|}{ Supplemental Table } \\
\hline CHEMBL1533625 & 688889 & 6.5501 & 4.7985 & TRN \\
\hline CHEMBL1391307 & 688889 & 5.85 & 4.7912 & TST \\
\hline CHEMBL1560139 & 688889 & 4.55 & 4.8328 & TRN \\
\hline CHEMBL1480398 & 688889 & 5.05 & 4.7963 & TST \\
\hline CHEMBL1381988 & 688889 & 4.5 & 4.8151 & TST \\
\hline CHEMBL1371062 & 688889 & 4.3 & 4.8783 & TRN \\
\hline CHEMBL1563269 & 688889 & 5.5 & 4.8053 & TRN \\
\hline CHEMBL1588029 & 688889 & 4.3 & 4.8457 & TRN \\
\hline CHEMBL1495362 & 688889 & 4.25 & 4.8351 & TST \\
\hline CHEMBL1545106 & 688889 & 4.45 & 4.6465 & TST \\
\hline CHEMBL1379178 & 688889 & 4.45 & 4.7008 & TRN \\
\hline CHEMBL1566762 & 688889 & 4.3 & 4.7046 & TST \\
\hline CHEMBL1444438 & 688889 & 4.5 & 4.7873 & TRN \\
\hline CHEMBL1365539 & 688889 & 4.3 & 4.7206 & TRN \\
\hline CHEMBL1494025 & 688889 & 4.25 & 4.8716 & TRN \\
\hline CHEMBL3196541 & 688889 & 4.45 & 4.6519 & TRN \\
\hline CHEMBL1523728 & 688889 & 6.0 & 5.0222 & TRN \\
\hline CHEMBL1589450 & 688889 & 6.4 & 4.8725 & TRN \\
\hline CHEMBL1299778 & 688889 & 4.55 & 4.7955 & TRN \\
\hline CHEMBL1576775 & 688889 & 5.05 & 4.6869 & TRN \\
\hline CHEMBL1576244 & 688889 & 4.55 & 4.7445 & TRN \\
\hline CHEMBL1401165 & 688889 & 4.45 & 4.7118 & TRN \\
\hline CHEMBL1299343 & 688889 & 4.75 & 4.7461 & TRN \\
\hline CHEMBL1301917 & 688889 & 4.85 & 4.6997 & TRN \\
\hline CHEMBL1507103 & 688889 & 4.3 & 4.916 & TST \\
\hline CHEMBL1393502 & 688889 & 6.3 & 4.9117 & TRN \\
\hline CHEMBL1497871 & 688889 & 4.3 & 4.87 & TRN \\
\hline CHEMBL1374206 & 688889 & 4.25 & 4.8343 & TST \\
\hline CHEMBL1598587 & 688889 & 4.25 & 4.907 & TRN \\
\hline CHEMBL1543294 & 688889 & 4.95 & 4.8214 & TRN \\
\hline CHEMBL1312924 & 688889 & 4.4 & 4.8406 & TST \\
\hline CHEMBL1336661 & 688889 & 4.95 & 4.7409 & TRN \\
\hline CHEMBL1561200 & 688889 & 5.15 & 4.9028 & TRN \\
\hline CHEMBL1390734 & 688889 & 4.65 & 4.7535 & TRN \\
\hline CHEMBL 224286 & 688889 & 4.5 & 4.7483 & TRN \\
\hline CHEMBL1413543 & 688889 & 4.45 & 4.6991 & TRN \\
\hline CHEMBL1543241 & 688889 & 4.45 & 4.7815 & TST \\
\hline CHEMBL1611844 & 688889 & 5.15 & 4.7759 & TST \\
\hline CHEMBL1563719 & 688889 & 4.45 & 4.6597 & TST \\
\hline CHEMBL1426675 & 688889 & 4.7 & 4.6678 & TRN \\
\hline CHEMBL1459399 & 688889 & 4.3 & 4.9686 & TRN \\
\hline CHEMBL1596678 & 688889 & 4.25 & 4.9201 & TST \\
\hline CHEMBL1529613 & 688889 & 5.95 & 4.6041 & TRN \\
\hline CHEMBL1351217 & 688889 & 4.95 & 4.6389 & TRN \\
\hline CHEMBL3189581 & 688889 & 4.45 & 4.723 & TRN \\
\hline CHEMBL1506301 & 688889 & 4.45 & 4.7292 & TRN \\
\hline CHEMBL1422079 & 688889 & 4.5 & 4.6478 & TRN \\
\hline CHEMBL1390338 & 688889 & 4.35 & 4.8484 & TRN \\
\hline
\end{tabular}




\begin{tabular}{|c|c|c|c|c|}
\hline \multicolumn{5}{|c|}{ Supplemental Table S2.txt } \\
\hline CHEMBL1471064 & 688889 & 4.4 & 4.9138 & TRN \\
\hline CHEMBL1374693 & 688889 & 4.3 & 4.872 & TST \\
\hline CHEMBL1365230 & 688889 & 4.25 & 4.7005 & TRN \\
\hline CHEMBL 3351142 & 688889 & 6.5501 & 4.9581 & TST \\
\hline CHEMBL1478252 & 688889 & 4.5 & 4.7662 & TST \\
\hline CHEMBL1537548 & 688889 & 4.45 & 4.6602 & TRN \\
\hline CHEMBL1538130 & 688889 & 6.7501 & 4.8421 & TST \\
\hline CHEMBL1381002 & 688889 & 4.5 & 4.7947 & TRN \\
\hline CHEMBL1401665 & 688889 & 4.3 & 4.6846 & TRN \\
\hline CHEMBL3208443 & 688889 & 5.0 & 4.8142 & TRN \\
\hline CHEMBL1389013 & 688889 & 4.45 & 4.7982 & TST \\
\hline CHEMBL571295 & 688889 & 6.8 & 4.7687 & TST \\
\hline CHEMBL1413782 & 688889 & 5.15 & 4.6976 & TST \\
\hline CHEMBL1448930 & 688889 & 4.25 & 5.0381 & TRN \\
\hline CHEMBL1373082 & 688889 & 4.25 & 4.6345 & TRN \\
\hline CHEMBL1574147 & 688889 & 5.45 & 4.8249 & TRN \\
\hline CHEMBL1467840 & 688889 & 4.35 & 4.6444 & TRN \\
\hline CHEMBL1499297 & 688889 & 4.25 & 4.8261 & TST \\
\hline CHEMBL1608742 & 688889 & 4.55 & 4.8788 & TST \\
\hline CHEMBL1508752 & 688889 & 5.6 & 4.9524 & TRN \\
\hline CHEMBL1332208 & 688889 & 5.85 & 4.7961 & TRN \\
\hline CHEMBL1299399 & 688889 & 4.3 & 4.7984 & TRN \\
\hline CHEMBL1505198 & 688889 & 4.8 & 4.774 & TST \\
\hline CHEMBL1596298 & 688889 & 4.3 & 4.7881 & TRN \\
\hline CHEMBL1334983 & 688889 & 5.55 & 4.8101 & TRN \\
\hline CHEMBL1455685 & 688889 & 4.4 & 4.7669 & TST \\
\hline CHEMBL1501461 & 688889 & 4.5 & 4.6997 & TRN \\
\hline CHEMBL1469431 & 688889 & 4.5 & 4.7942 & TRN \\
\hline CHEMBL1344357 & 688889 & 4.55 & 4.7178 & TST \\
\hline CHEMBL1415036 & 688889 & 4.55 & 4.8509 & TRN \\
\hline CHEMBL1557823 & 688889 & 5.2 & 4.742 & TRN \\
\hline CHEMBL1351160 & 688889 & 4.6 & 5.0098 & TST \\
\hline CHEMBL1501533 & 688889 & 5.1 & 4.8889 & TRN \\
\hline CHEMBL1311119 & 688889 & 4.4 & 4.7296 & TRN \\
\hline CHEMBL1461207 & 688889 & 4.25 & 4.7985 & TST \\
\hline CHEMBL1555875 & 688889 & 5.4 & 4.916 & TRN \\
\hline CHEMBL1458225 & 688889 & 4.65 & 4.7993 & TST \\
\hline CHEMBL1336368 & 688889 & 4.3 & 4.8792 & TRN \\
\hline CHEMBL1444530 & 688889 & 4.9 & 4.9378 & TRN \\
\hline CHEMBL1548672 & 688889 & 6.45 & 4.7544 & TRN \\
\hline CHEMBL1528112 & 688889 & 4.5 & 4.6669 & TRN \\
\hline CHEMBL1488357 & 688889 & 5.85 & 4.81 & TRN \\
\hline CHEMBL1501426 & 688889 & 4.3 & 4.8943 & TRN \\
\hline CHEMBL1431644 & 688889 & 4.5 & 4.7788 & TRN \\
\hline CHEMBL1549060 & 688889 & 4.3 & 4.667 & TST \\
\hline CHEMBL1538552 & 688889 & 4.3 & 4.7999 & TRN \\
\hline CHEMBL1600492 & 688889 & 4.95 & 4.7756 & TST \\
\hline CHEMBL1372242 & 688889 & 4.45 & 4.7025 & TRN \\
\hline
\end{tabular}




\begin{tabular}{|c|c|c|c|c|}
\hline \multicolumn{5}{|c|}{ Supplemental Table S2.txt } \\
\hline CHEMBL1326887 & 688889 & 4.3 & 4.8681 & TST \\
\hline CHEMBL1506021 & 688889 & 4.5 & 4.775 & TST \\
\hline CHEMBL1409131 & 688889 & 4.9 & 4.8992 & TRN \\
\hline CHEMBL1498756 & 688889 & 4.65 & 4.8086 & TRN \\
\hline CHEMBL1559102 & 688889 & 6.45 & 4.7165 & TRN \\
\hline CHEMBL3193697 & 688889 & 6.4 & 4.8129 & TST \\
\hline CHEMBL494668 & 688889 & 5.0 & 4.6487 & TST \\
\hline CHEMBL1458940 & 688889 & 4.45 & 4.9242 & TRN \\
\hline CHEMBL1491218 & 688889 & 6.6 & 4.7971 & TRN \\
\hline CHEMBL6703 & 688889 & 4.45 & 4.7038 & TRN \\
\hline CHEMBL1595155 & 688889 & 4.45 & 4.6954 & TRN \\
\hline CHEMBL3208753 & 688889 & 4.7 & 4.7074 & TRN \\
\hline CHEMBL1456225 & 688889 & 4.45 & 4.6692 & TRN \\
\hline CHEMBL1364298 & 688889 & 5.8 & 5.0032 & TRN \\
\hline CHEMBL3195572 & 688889 & 4.3 & 4.7885 & TRN \\
\hline CHEMBL1504138 & 688889 & 4.55 & 4.7802 & TST \\
\hline CHEMBL1431312 & 688889 & 4.25 & 4.7671 & TRN \\
\hline CHEMBL1506604 & 688889 & 4.85 & 4.8864 & TST \\
\hline CHEMBL1541250 & 688889 & 5.9 & 4.9344 & TRN \\
\hline CHEMBL1320407 & 688889 & 4.55 & 4.9766 & TRN \\
\hline CHEMBL1465781 & 688889 & 5.45 & 4.8526 & TRN \\
\hline CHEMBL1322593 & 688889 & 4.35 & 4.6532 & TRN \\
\hline CHEMBL1564569 & 688889 & 5.0 & 4.7621 & TST \\
\hline CHEMBL1438437 & 688889 & 5.35 & 4.7387 & TST \\
\hline CHEMBL1319440 & 688889 & 4.5 & 4.7172 & TRN \\
\hline CHEMBL1585126 & 688889 & 4.45 & 4.7158 & TRN \\
\hline CHEMBL1428586 & 688889 & 4.3 & 4.7509 & TRN \\
\hline CHEMBL1375730 & 688889 & 4.85 & 4.8819 & TRN \\
\hline CHEMBL1348648 & 688889 & 4.5 & 4.7281 & TRN \\
\hline CHEMBL1575811 & 688889 & 5.0 & 4.9115 & TST \\
\hline CHEMBL3196731 & 688889 & 4.3 & 4.7558 & TRN \\
\hline CHEMBL1466887 & 688889 & 4.65 & 4.7434 & TRN \\
\hline CHEMBL3211638 & 688889 & 4.3 & 4.7634 & TRN \\
\hline CHEMBL1558251 & 688889 & 4.6 & 4.78 & TST \\
\hline CHEMBL1409927 & 688889 & 4.5 & 4.7587 & TRN \\
\hline CHEMBL1414335 & 688889 & 4.45 & 4.6518 & TRN \\
\hline CHEMBL1365022 & 688889 & 5.5 & 4.8518 & TST \\
\hline CHEMBL1360869 & 688889 & 4.85 & 4.8277 & TRN \\
\hline CHEMBL1532324 & 688889 & 4.95 & 4.8797 & TRN \\
\hline CHEMBL1503851 & 688889 & 4.9 & 4.9052 & TRN \\
\hline CHEMBL1428961 & 688889 & 4.5 & 4.796 & TRN \\
\hline CHEMBL1485942 & 688889 & 4.55 & 4.8552 & TRN \\
\hline CHEMBL1415214 & 688889 & 6.4 & 4.753 & TRN \\
\hline CHEMBL1403890 & 688889 & 5.0 & 4.7655 & TRN \\
\hline CHEMBL3211540 & 688889 & 6.7501 & 4.6463 & TRN \\
\hline CHEMBL1412201 & 688889 & 4.25 & 4.9146 & TRN \\
\hline CHEMBL1338005 & 688889 & 4.3 & 4.9052 & TST \\
\hline CHEMBL3190178 & 688889 & 4.25 & 4.7513 & TST \\
\hline
\end{tabular}




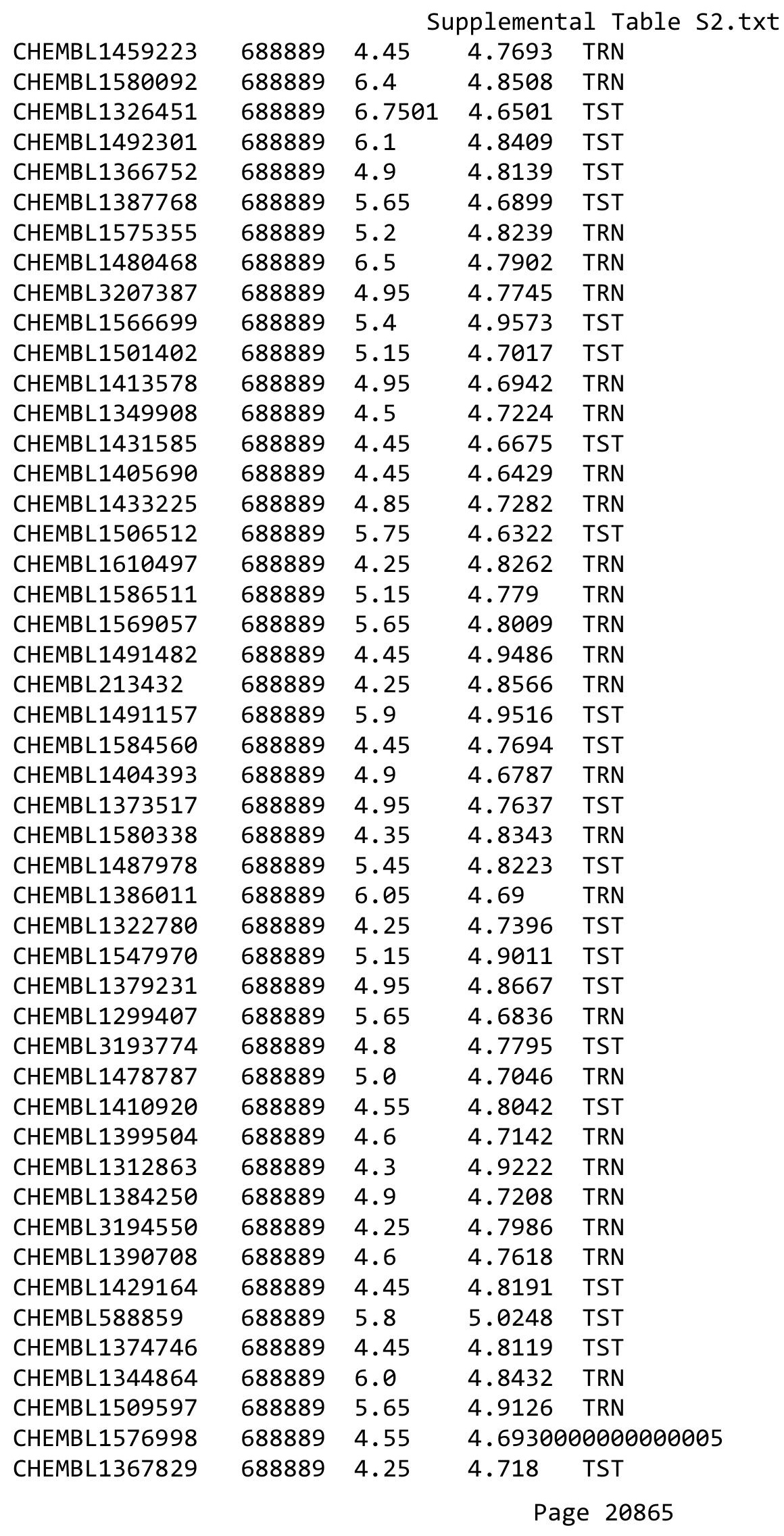

TRN 


\begin{tabular}{|c|c|c|c|c|}
\hline \multicolumn{5}{|c|}{ Supplemental Table S2.txt } \\
\hline CHEMBL1561308 & 688889 & 5.2 & 4.8684 & TST \\
\hline CHEMBL1505497 & 688889 & 4.5 & 4.7746 & TRN \\
\hline CHEMBL1432136 & 688889 & 4.7 & 4.7491 & TRN \\
\hline CHEMBL1369386 & 688889 & 4.3 & 4.8799 & TRN \\
\hline CHEMBL1401502 & 688889 & 4.3 & 4.7645 & TRN \\
\hline CHEMBL1427931 & 688889 & 4.3 & 4.7302 & TRN \\
\hline CHEMBL1453144 & 688889 & 4.45 & 4.873 & TRN \\
\hline CHEMBL1586127 & 688889 & 4.3 & 4.8958 & TRN \\
\hline CHEMBL1461215 & 688889 & 4.9 & 4.7693 & TRN \\
\hline CHEMBL1303533 & 688889 & 5.3 & 4.9249 & TRN \\
\hline CHEMBL3213517 & 688889 & 4.5 & 4.7661 & TRN \\
\hline CHEMBL1531007 & 688889 & 4.3 & 4.8254 & TRN \\
\hline CHEMBL1399653 & 688889 & 4.55 & 4.6696 & TRN \\
\hline CHEMBL1386231 & 688889 & 4.5 & 4.8264 & TRN \\
\hline CHEMBL1353448 & 688889 & 4.45 & 4.8691 & TRN \\
\hline CHEMBL1601300 & 688889 & 4.65 & 4.7328 & TRN \\
\hline CHEMBL1568010 & 688889 & 5.0 & 4.895 & TRN \\
\hline CHEMBL1990646 & 688889 & 4.4 & 4.8209 & TST \\
\hline CHEMBL1308386 & 688889 & 4.75 & 4.7131 & TRN \\
\hline CHEMBL1463703 & 688889 & 4.5 & 4.7902 & TRN \\
\hline CHEMBL1578905 & 688889 & 5.3 & 4.8627 & TST \\
\hline CHEMBL1469299 & 688889 & 4.95 & 4.755 & TST \\
\hline CHEMBL1517577 & 688889 & 4.85 & 4.8295 & TRN \\
\hline CHEMBL1340176 & 688889 & 5.15 & 4.7541 & TST \\
\hline CHEMBL1545510 & 688889 & 4.25 & 4.8266 & TST \\
\hline CHEMBL1312190 & 688889 & 4.55 & 4.7673 & TRN \\
\hline CHEMBL1502451 & 688889 & 4.5 & 4.7823 & TST \\
\hline CHEMBL1476084 & 688889 & 4.6 & 4.6297 & TRN \\
\hline CHEMBL1341626 & 688889 & 4.45 & 4.8303 & TRN \\
\hline CHEMBL1405472 & 688889 & 6.1 & 4.9411 & TRN \\
\hline CHEMBL1333143 & 688889 & 4.4 & 4.8106 & TRN \\
\hline CHEMBL1433128 & 688889 & 4.35 & 4.7246 & TRN \\
\hline CHEMBL1379505 & 688889 & 4.45 & 4.6132 & TRN \\
\hline CHEMBL1594604 & 688889 & 4.45 & 4.8124 & TRN \\
\hline CHEMBL1321354 & 688889 & 4.25 & 4.8332 & TRN \\
\hline CHEMBL1342683 & 688889 & 4.4 & 4.9366 & TRN \\
\hline CHEMBL1506270 & 688889 & 5.1 & 4.7598 & TRN \\
\hline CHEMBL1383269 & 688889 & 4.45 & 4.7422 & TRN \\
\hline CHEMBL1578704 & 688889 & 4.3 & 4.9046 & TST \\
\hline CHEMBL1418009 & 688889 & 6.05 & 4.7112 & TRN \\
\hline CHEMBL1369812 & 688889 & 4.3 & 4.7484 & TST \\
\hline CHEMBL1334994 & 688889 & 4.95 & 4.815 & TST \\
\hline CHEMBL1567699 & 688889 & 6.05 & 4.9801 & TRN \\
\hline CHEMBL1446254 & 688889 & 6.0 & 4.817 & TRN \\
\hline CHEMBL1359620 & 688889 & 4.45 & 4.6251 & TRN \\
\hline CHEMBL3194665 & 688889 & 4.5 & 4.7183 & TST \\
\hline CHEMBL1607561 & 688889 & 4.3 & 4.9754 & TRN \\
\hline CHEMBL1388380 & 688889 & 4.95 & 4.8967 & TRN \\
\hline
\end{tabular}




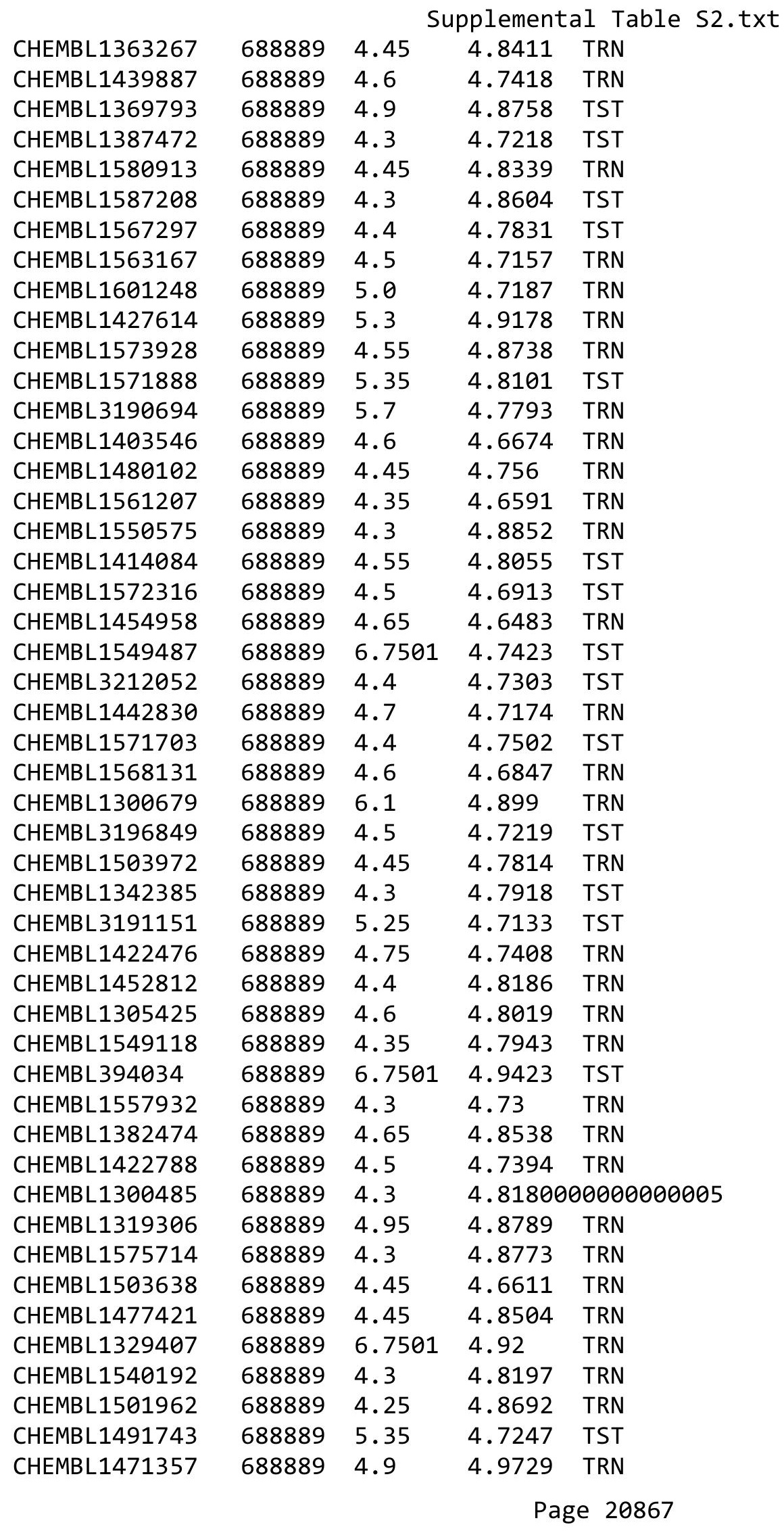




\begin{tabular}{|c|c|c|c|c|c|}
\hline & & & & & \\
\hline CHEMBL1467404 & 688889 & 4.5 & 4.7956 & TRN & \\
\hline CHEMBL1319343 & 688889 & 4.3 & 4.7973 & TRN & \\
\hline CHEMBL1523148 & 688889 & 4.25 & 5.0234 & TRN & \\
\hline CHEMBL3210329 & 688889 & 4.8 & 4.802 & TST & \\
\hline CHEMBL1451865 & 688889 & 4.55 & 4.91 & TRN & \\
\hline CHEMBL1530521 & 688889 & 5.35 & 4.7163 & TRN & \\
\hline CHEMBL1457597 & 688889 & 4.55 & 4.7522 & TRN & \\
\hline CHEMBL1566078 & 688889 & 4.7 & 4.7336 & TRN & \\
\hline CHEMBL3212750 & 688889 & 6.1 & 4.6445 & TRN & \\
\hline CHEMBL1550065 & 688889 & 6.1 & 4.758 & TST & \\
\hline CHEMBL1507988 & 688889 & 4.55 & 4.7639 & TRN & \\
\hline CHEMBL1344411 & 688889 & 4.25 & 4.9178 & TRN & \\
\hline CHEMBL1450574 & 688889 & 4.25 & 4.8519 & TRN & \\
\hline CHEMBL1557849 & 688889 & 6.7501 & 4.6879 & TRN & \\
\hline CHEMBL1448232 & 688889 & 4.55 & 4.8696 & TRN & \\
\hline CHEMBL1424689 & 688889 & 4.85 & 4.8989 & TST & \\
\hline CHEMBL1527363 & 688889 & 4.45 & 4.9945 & TRN & \\
\hline CHEMBL1387744 & 688889 & 4.45 & 4.6752 & TRN & \\
\hline CHEMBL1538928 & 688889 & 4.5 & 4.6323 & TRN & \\
\hline CHEMBL1535578 & 688889 & 4.8 & 4.7396 & TRN & \\
\hline CHEMBL1461530 & 688889 & 6.8 & 4.7669 & TRN & \\
\hline CHEMBL 3190449 & 688889 & 4.35 & 4.644 & TRN & \\
\hline CHEMBL1573763 & 688889 & 4.6 & 4.7986 & TRN & \\
\hline CHEMBL1488663 & 688889 & 4.45 & 4.6987 & TRN & \\
\hline CHEMBL1509917 & 688889 & 5.25 & 4.896 & TST & \\
\hline CHEMBL1306181 & 688889 & 4.25 & 4.9087 & TRN & \\
\hline CHEMBL1352412 & 688889 & 4.6 & 4.8681 & TRN & \\
\hline CHEMBL1432368 & 688889 & 4.25 & 4.7232 & TRN & \\
\hline CHEMBL324852 & 688889 & 6.7501 & 4.89 & TST & \\
\hline CHEMBL1540343 & 688889 & 4.3 & 4.758 & TRN & \\
\hline CHEMBL1469680 & 688889 & 4.9 & 4.73 & TRN & \\
\hline CHEMBL1330661 & 688889 & 4.45 & 4.7153 & TRN & \\
\hline CHEMBL1305254 & 688889 & 4.55 & 4.6846 & TST & \\
\hline CHEMBL1531456 & 688889 & 4.4 & 4.7942 & TRN & \\
\hline CHEMBL 23081 & 688889 & 6.45 & 4.9142 & TST & \\
\hline CHEMBL1307280 & 688889 & 4.9 & 4.67399 & 99999999995 & TST \\
\hline CHEMBL1484167 & 688889 & 4.5 & 4.7496 & TRN & \\
\hline CHEMBL1595442 & 688889 & 4.45 & 4.7973 & TST & \\
\hline CHEMBL1301644 & 688889 & 4.6 & 4.9203 & TRN & \\
\hline CHEMBL1587654 & 688889 & 4.5 & 4.57600 & 00000000005 & TRN \\
\hline CHEMBL1350526 & 688889 & 4.3 & 4.8291 & TST & \\
\hline CHEMBL1570820 & 688889 & 4.45 & 4.7109 & TST & \\
\hline CHEMBL1611920 & 688889 & 4.55 & 4.8085 & TRN & \\
\hline CHEMBL1563060 & 688889 & 4.6 & 4.7456 & TRN & \\
\hline CHEMBL1588967 & 688889 & 4.6 & 4.8076 & TRN & \\
\hline CHEMBL1481141 & 688889 & 4.3 & 4.8167 & TRN & \\
\hline CHEMBL1350151 & 688889 & 4.45 & 4.9606 & TRN & \\
\hline CHEMBL1362560 & 688889 & 4.4 & 4.8288 & TRN & \\
\hline
\end{tabular}




\begin{tabular}{|c|c|c|c|c|}
\hline \multicolumn{5}{|c|}{ Supplemental Table S2.txt } \\
\hline CHEMBL1405730 & 688889 & 6.0 & 4.7196 & TRN \\
\hline CHEMBL1587380 & 688889 & 4.3 & 4.806 & TRN \\
\hline CHEMBL1540534 & 688889 & 4.55 & 4.8068 & TRN \\
\hline CHEMBL1462728 & 688889 & 4.45 & 4.8279 & TRN \\
\hline CHEMBL1468159 & 688889 & 4.4 & 4.8817 & TRN \\
\hline CHEMBL3209403 & 688889 & 4.7 & 4.8432 & TRN \\
\hline CHEMBL1536006 & 688889 & 6.7501 & 4.898 & TRN \\
\hline CHEMBL1310863 & 688889 & 4.3 & 4.6741 & TST \\
\hline CHEMBL1447565 & 688889 & 5.15 & 4.7624 & TRN \\
\hline CHEMBL1518949 & 688889 & 4.5 & 4.7129 & TST \\
\hline CHEMBL1563034 & 688889 & 4.3 & 4.8708 & TRN \\
\hline CHEMBL1549775 & 688889 & 4.9 & 4.8197 & TRN \\
\hline CHEMBL1603278 & 688889 & 4.3 & 4.7024 & TRN \\
\hline CHEMBL1431241 & 688889 & 6.35 & 4.6447 & TST \\
\hline CHEMBL1429471 & 688889 & 4.5 & 4.7379 & TRN \\
\hline CHEMBL1386945 & 688889 & 4.45 & 4.803 & TRN \\
\hline CHEMBL1404655 & 688889 & 5.2 & 4.7689 & TRN \\
\hline CHEMBL1389713 & 688889 & 4.45 & 4.6907 & TRN \\
\hline CHEMBL1330376 & 688889 & 4.3 & 4.9869 & TST \\
\hline CHEMBL1452189 & 688889 & 4.55 & 4.8829 & TRN \\
\hline CHEMBL1429367 & 688889 & 4.3 & 4.7301 & TST \\
\hline CHEMBL1361923 & 688889 & 4.75 & 5.0057 & TRN \\
\hline CHEMBL1462905 & 688889 & 4.4 & 4.912 & TRN \\
\hline CHEMBL1582521 & 688889 & 4.55 & 4.8653 & TST \\
\hline CHEMBL1480238 & 688889 & 5.2 & 4.7847 & TRN \\
\hline CHEMBL1365184 & 688889 & 4.35 & 4.7138 & TRN \\
\hline CHEMBL1451243 & 688889 & 4.25 & 4.8057 & TRN \\
\hline CHEMBL1340227 & 688889 & 4.35 & 4.7395 & TRN \\
\hline CHEMBL1386068 & 688889 & 4.25 & 4.7075 & TST \\
\hline CHEMBL1408103 & 688889 & 5.4 & 4.8273 & TRN \\
\hline CHEMBL1369411 & 688889 & 4.4 & 4.7217 & TRN \\
\hline CHEMBL564661 & 688889 & 4.25 & 4.8688 & TRN \\
\hline CHEMBL1583639 & 688889 & 5.0 & 4.7997 & TRN \\
\hline CHEMBL1425132 & 688889 & 5.9 & 4.8756 & TST \\
\hline CHEMBL1569749 & 688889 & 4.6 & 4.7269 & TRN \\
\hline CHEMBL1409653 & 688889 & 6.7501 & 4.7526 & TRN \\
\hline CHEMBL3195241 & 688889 & 4.4 & 4.7166 & TRN \\
\hline CHEMBL1526463 & 688889 & 4.5 & 4.9987 & TRN \\
\hline CHEMBL1328703 & 688889 & 4.3 & 4.9072 & TRN \\
\hline CHEMBL1602489 & 688889 & 5.2 & 4.8793 & TST \\
\hline CHEMBL3191771 & 688889 & 4.8 & 4.6873 & TRN \\
\hline CHEMBL3208357 & 688889 & 4.3 & 4.713 & TRN \\
\hline CHEMBL1349978 & 688889 & 4.5 & 4.7254 & TRN \\
\hline CHEMBL1568229 & 688889 & 4.3 & 4.6688 & TRN \\
\hline CHEMBL1511869 & 688889 & 4.4 & 4.8827 & TRN \\
\hline CHEMBL1492897 & 688889 & 4.25 & 4.7417 & TRN \\
\hline CHEMBL1517292 & 688889 & 4.45 & 4.7417 & TRN \\
\hline CHEMBL1311577 & 688889 & 4.3 & 4.7917 & TRN \\
\hline
\end{tabular}




\begin{tabular}{|c|c|c|c|c|c|}
\hline \multirow{3}{*}{ CHEMBL 1305429} & \multirow{2}{*}{688889} & & & & \\
\hline & & 6.1 & 4.974 & TRN & \\
\hline & 688889 & 4.95 & 4.7857 & TRN & \\
\hline CHEMBL1549739 & 688889 & 4.5 & 4.8741 & TRN & \\
\hline CHEMBL3191919 & 688889 & 5.05 & 4.8472 & TRN & \\
\hline CHEMBL220009 & 688889 & 4.25 & 4.8716 & TRN & \\
\hline CHEMBL3214058 & 688889 & 4.55 & 4.6971 & TRN & \\
\hline CHEMBL1414120 & 688889 & 6.15 & 5.0619 & TST & \\
\hline CHEMBL1508579 & 688889 & 4.45 & 4.7184 & TRN & \\
\hline CHEMBL1587406 & 688889 & 4.25 & 4.7414 & TRN & \\
\hline CHEMBL1546391 & 688889 & 4.3 & 4.8762 & TST & \\
\hline CHEMBL1382662 & 688889 & 5.05 & 4.8147 & TST & \\
\hline CHEMBL1312956 & 688889 & 4.5 & 4.8384 & TRN & \\
\hline CHEMBL1456098 & 688889 & 6.7501 & 4.8699 & TRN & \\
\hline CHEMBL1494191 & 688889 & 4.25 & 4.689 & TRN & \\
\hline CHEMBL1541733 & 688889 & 4.45 & 4.626 & TRN & \\
\hline CHEMBL1462259 & 688889 & 4.35 & 4.735 & TRN & \\
\hline CHEMBL1353472 & 688889 & 5.75 & 4.8261 & TRN & \\
\hline CHEMBL1427688 & 688889 & 4.35 & 4.8518 & TST & \\
\hline CHEMBL1402852 & 688889 & 4.45 & 4.6316 & TRN & \\
\hline CHEMBL1529180 & 688889 & 5.15 & 4.7833 & TRN & \\
\hline CHEMBL1532953 & 688889 & 4.3 & 4.5839 & TRN & \\
\hline CHEMBL1597293 & 688889 & 4.9 & 4.8264 & TRN & \\
\hline CHEMBL1299577 & 688889 & 5.35 & 4.6508 & TST & \\
\hline CHEMBL3209715 & 688889 & 4.55 & 4.7655 & TRN & \\
\hline CHEMBL1568059 & 688889 & 4.55 & 4.6676 & TRN & \\
\hline CHEMBL1369154 & 688889 & 4.3 & 4.7326 & TRN & \\
\hline CHEMBL1559326 & 688889 & 4.45 & 4.8341 & TRN & \\
\hline CHEMBL3193207 & 688889 & 5.2 & 4.7425 & TRN & \\
\hline CHEMBL1471516 & 688889 & 4.6 & 4.8481 & TST & \\
\hline CHEMBL1547632 & 688889 & 4.45 & 4.8135 & TST & \\
\hline CHEMBL1438063 & 688889 & 5.05 & 4.8326 & TRN & \\
\hline CHEMBL3197281 & 688889 & 4.35 & 4.6958 & TRN & \\
\hline CHEMBL1994048 & 688889 & 4.95 & 4.8419 & TRN & \\
\hline CHEMBL1465727 & 688889 & 4.25 & 4.8025 & TRN & \\
\hline CHEMBL1493842 & 688889 & 5.45 & 4.8409 & TRN & \\
\hline CHEMBL1502936 & 688889 & 4.6 & 4.7559 & TRN & \\
\hline CHEMBL1449992 & 688889 & 4.3 & 4.8419 & TRN & \\
\hline CHEMBL1378045 & 688889 & 4.6 & 4.7889 & TRN & \\
\hline CHEMBL1330791 & 688889 & 4.9 & 4.9073 & TRN & \\
\hline CHEMBL1459762 & 688889 & 4.5 & 4.6782 & TRN & \\
\hline CHEMBL1393417 & 688889 & 4.55 & 4.8152 & TRN & \\
\hline CHEMBL1382344 & 688889 & 5.6 & 4.8397 & TRN & \\
\hline CHEMBL1428212 & 688889 & 4.3 & 4.6576 & TRN & \\
\hline CHEMBL1303040 & 688889 & 5.35 & 4.8467 & TST & \\
\hline CHEMBL1350727 & 688889 & 4.55 & 4.8288 & TRN & \\
\hline CHEMBL1391672 & 688889 & 4.4 & 4.8003 & TRN & \\
\hline CHEMBL1491901 & 688889 & 5.5 & 4.98300 & 00000000005 & TRN \\
\hline \multirow[t]{2}{*}{ CHEMBL1573815 } & 688889 & 5.6 & 4.8092 & TRN & \\
\hline & & \multicolumn{4}{|c|}{ Page 20870} \\
\hline
\end{tabular}




\begin{tabular}{|c|c|c|c|c|}
\hline \multicolumn{5}{|c|}{ Supplemental Table S2.txt } \\
\hline CHEMBL1452101 & 688889 & 5.0 & 4.7368 & TRN \\
\hline CHEMBL1378244 & 688889 & 4.4 & 4.7638 & TRN \\
\hline CHEMBL1585619 & 688889 & 5.3 & 4.9066 & TRN \\
\hline CHEMBL1996858 & 688889 & 4.25 & 4.7904 & TRN \\
\hline CHEMBL1320019 & 688889 & 4.25 & 4.8504 & TRN \\
\hline CHEMBL1375904 & 688889 & 4.6 & 4.6759 & TRN \\
\hline CHEMBL3191519 & 688889 & 4.5 & 4.686 & TRN \\
\hline CHEMBL1535617 & 688889 & 4.55 & 4.7985 & TST \\
\hline CHEMBL3198607 & 688889 & 4.6 & 4.8744 & TRN \\
\hline CHEMBL1543839 & 688889 & 4.3 & 4.8275 & TST \\
\hline CHEMBL1449689 & 688889 & 4.3 & 4.9389 & TRN \\
\hline CHEMBL1503812 & 688889 & 4.25 & 4.8537 & TST \\
\hline CHEMBL56654 & 688889 & 6.8 & 4.9072 & TST \\
\hline CHEMBL1520679 & 688889 & 4.25 & 4.6715 & TRN \\
\hline CHEMBL1986921 & 688889 & 5.8 & 4.875 & TRN \\
\hline CHEMBL104916 & 688889 & 6.7501 & 4.7569 & TST \\
\hline CHEMBL1561553 & 688889 & 4.6 & 4.7659 & TRN \\
\hline CHEMBL1527365 & 688889 & 4.25 & 4.8112 & TRN \\
\hline CHEMBL1495592 & 688889 & 4.25 & 4.6044 & TST \\
\hline CHEMBL1411318 & 688889 & 5.85 & 4.6353 & TRN \\
\hline CHEMBL1466178 & 688889 & 4.5 & 4.8816 & TRN \\
\hline CHEMBL1387057 & 688889 & 4.95 & 4.8707 & TRN \\
\hline CHEMBL1440538 & 688889 & 5.05 & 4.8456 & TRN \\
\hline CHEMBL1311526 & 688889 & 4.3 & 4.6857 & TST \\
\hline CHEMBL1380346 & 688889 & 5.55 & 4.8473 & TST \\
\hline CHEMBL3214483 & 688889 & 4.6 & 4.6896 & TST \\
\hline CHEMBL1380970 & 688889 & 4.3 & 4.8115 & TRN \\
\hline CHEMBL1325171 & 688889 & 4.55 & 4.8068 & TST \\
\hline CHEMBL1543280 & 688889 & 4.25 & 4.9057 & TRN \\
\hline CHEMBL1389953 & 688889 & 4.25 & 4.6626 & TRN \\
\hline CHEMBL3193282 & 688889 & 4.3 & 4.7808 & TRN \\
\hline CHEMBL1559107 & 688889 & 4.5 & 4.6726 & TRN \\
\hline CHEMBL1575196 & 688889 & 4.55 & 4.842 & TRN \\
\hline CHEMBL1508826 & 688889 & 4.45 & 4.7195 & TRN \\
\hline CHEMBL1557432 & 688889 & 4.65 & 4.9056 & TRN \\
\hline CHEMBL1425405 & 688889 & 4.35 & 4.7825 & TST \\
\hline CHEMBL1386270 & 688889 & 5.8 & 4.8597 & TRN \\
\hline CHEMBL1581133 & 688889 & 6.8 & 4.8036 & TRN \\
\hline CHEMBL1543084 & 688889 & 5.0 & 4.7483 & TRN \\
\hline CHEMBL1497597 & 688889 & 6.15 & 4.8142 & TRN \\
\hline CHEMBL1308694 & 688889 & 4.45 & 4.7208 & TRN \\
\hline CHEMBL1429110 & 688889 & 5.3 & 4.7708 & TRN \\
\hline CHEMBL1393898 & 688889 & 4.95 & 4.677 & TST \\
\hline CHEMBL1563513 & 688889 & 4.45 & 4.6975 & TRN \\
\hline CHEMBL1520818 & 688889 & 6.7501 & 4.8888 & TRN \\
\hline CHEMBL1384784 & 688889 & 4.4 & 4.7316 & TRN \\
\hline CHEMBL1511653 & 688889 & 5.4 & 4.8915 & TRN \\
\hline CHEMBL1569241 & 688889 & 4.7 & 4.6961 & TRN \\
\hline
\end{tabular}




\begin{tabular}{|c|c|c|c|c|c|}
\hline \\
\hline CHEMBL1977602 & 688889 & 4.3 & 4.8043 & TST & \\
\hline CHEMBL1528177 & 688889 & 4.5 & 4.7317 & TRN & \\
\hline CHEMBL1489074 & 688889 & 4.4 & 4.6441 & TRN & \\
\hline CHEMBL1928490 & 688889 & 4.5 & 4.5965 & TRN & \\
\hline CHEMBL1467236 & 688889 & 4.3 & 4.8496 & TRN & \\
\hline CHEMBL1419029 & 688889 & 4.25 & 4.6905 & TRN & \\
\hline CHEMBL1610051 & 688889 & 5.05 & 4.7014 & TRN & \\
\hline CHEMBL1598995 & 688889 & 4.95 & 4.8361 & TRN & \\
\hline CHEMBL1507013 & 688889 & 4.45 & 4.7884 & TRN & \\
\hline CHEMBL1390862 & 688889 & 4.6 & 4.8116 & TRN & \\
\hline CHEMBL1322170 & 688889 & 5.95 & 4.9481 & TST & \\
\hline CHEMBL1347053 & 688889 & 4.35 & 4.8785 & TRN & \\
\hline CHEMBL1543635 & 688889 & 4.85 & 4.7564 & TRN & \\
\hline CHEMBL1555491 & 688889 & 5.2 & 4.9 & TRN & \\
\hline CHEMBL 3207803 & 688889 & 4.55 & 4.6748 & TST & \\
\hline CHEMBL1447076 & 688889 & 4.5 & 4.743 & TRN & \\
\hline CHEMBL1319983 & 688889 & 4.3 & 4.8573 & TRN & \\
\hline CHEMBL3193298 & 688889 & 4.4 & 4.68 & TRN & \\
\hline CHEMBL3199697 & 688889 & 4.25 & 4.8298 & TRN & \\
\hline CHEMBL1482075 & 688889 & 4.5 & 4.7521 & TRN & \\
\hline CHEMBL1607135 & 688889 & 4.45 & 4.71899 & 9999999999 & TRN \\
\hline CHEMBL1445153 & 688889 & 4.5 & 4.7294 & TRN & \\
\hline CHEMBL1564444 & 688889 & 4.8 & 4.8056 & TRN & \\
\hline CHEMBL1398965 & 688889 & 4.55 & 4.773 & TRN & \\
\hline CHEMBL1388790 & 688889 & 5.45 & 4.6689 & TRN & \\
\hline CHEMBL1573630 & 688889 & 4.85 & 4.8416 & TST & \\
\hline CHEMBL1529825 & 688889 & 5.05 & 4.7644 & TST & \\
\hline CHEMBL1387044 & 688889 & 4.3 & 4.7974 & TRN & \\
\hline CHEMBL1573221 & 688889 & 4.9 & 4.728 & TRN & \\
\hline CHEMBL1412915 & 688889 & 4.3 & 4.9224 & TRN & \\
\hline CHEMBL1463256 & 688889 & 4.55 & 4.742 & TST & \\
\hline CHEMBL1603717 & 688889 & 5.55 & 4.63399 & 99999999995 & TRN \\
\hline CHEMBL1613589 & 688889 & 5.9 & 4.8666 & TST & \\
\hline CHEMBL1452457 & 688889 & 6.8 & 4.7737 & TST & \\
\hline CHEMBL3196716 & 688889 & 6.7501 & 4.8038 & TST & \\
\hline CHEMBL1585913 & 688889 & 5.45 & 4.7475 & TRN & \\
\hline CHEMBL1388075 & 688889 & 4.5 & 4.9097 & TRN & \\
\hline CHEMBL1544113 & 688889 & 5.3 & 4.8883 & TRN & \\
\hline CHEMBL1538191 & 688889 & 4.95 & 4.8943 & TST & \\
\hline CHEMBL 1458610 & 688889 & 5.55 & 4.8197 & TST & \\
\hline CHEMBL1446183 & 688889 & 4.25 & 4.9525 & TRN & \\
\hline CHEMBL1478458 & 688889 & 4.55 & 4.7834 & TRN & \\
\hline CHEMBL1544692 & 688889 & 4.25 & 4.8905 & TRN & \\
\hline CHEMBL1577483 & 688889 & 4.6 & 4.89199 & 99999999995 & TRN \\
\hline CHEMBL1301214 & 688889 & 6.7501 & 4.8457 & TRN & \\
\hline CHEMBL1479927 & 688889 & 5.35 & 4.7392 & TST & \\
\hline CHEMBL1452334 & 688889 & 4.45 & 4.7386 & TRN & \\
\hline CHEMBL1309006 & 688889 & 4.45 & 4.7888 & TRN & \\
\hline
\end{tabular}




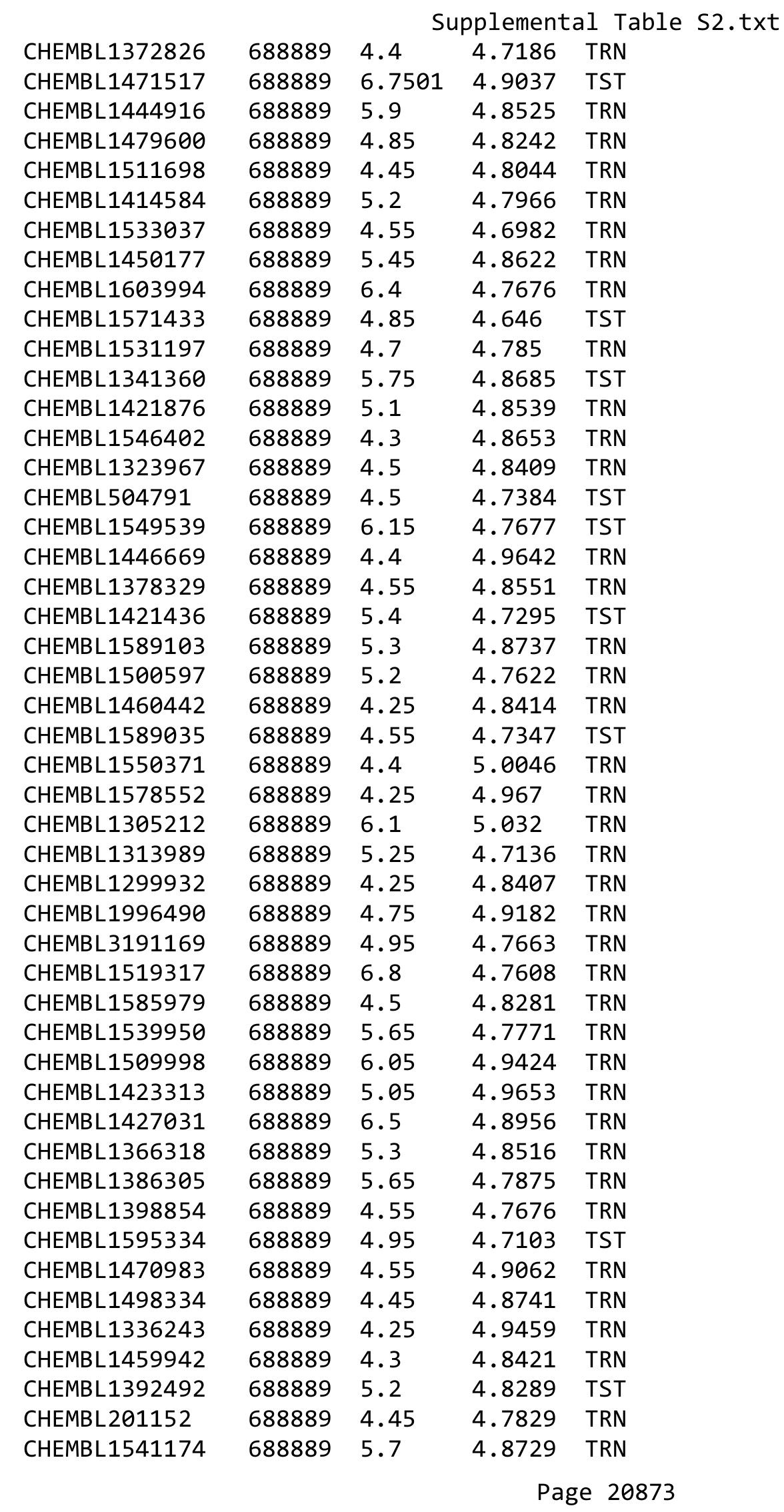




\begin{tabular}{|c|c|c|c|c|}
\hline \multicolumn{5}{|c|}{ Supplemental Table s2.txt } \\
\hline CHEMBL3189906 & 688889 & 4.3 & 4.8426 & TRN \\
\hline CHEMBL1427486 & 688889 & 5.4 & 4.6668 & TRN \\
\hline CHEMBL1458090 & 688889 & 5.35 & 4.9107 & TRN \\
\hline CHEMBL1580712 & 688889 & 4.35 & 4.6498 & TST \\
\hline CHEMBL1502857 & 688889 & 4.25 & 4.7401 & TST \\
\hline CHEMBL1534520 & 688889 & 4.45 & 4.8451 & TRN \\
\hline CHEMBL1520132 & 688889 & 4.95 & 4.7352 & TRN \\
\hline CHEMBL1505849 & 688889 & 4.45 & 4.669 & TRN \\
\hline CHEMBL1380321 & 688889 & 5.95 & 4.7168 & TRN \\
\hline CHEMBL1534109 & 688889 & 4.5 & 4.7613 & TRN \\
\hline CHEMBL1442642 & 688889 & 4.3 & 4.9222 & TRN \\
\hline CHEMBL1378352 & 688889 & 4.4 & 4.7828 & TST \\
\hline CHEMBL1595623 & 688889 & 4.9 & 4.8797 & TRN \\
\hline CHEMBL1387086 & 688889 & 4.3 & 4.9204 & TST \\
\hline CHEMBL1344025 & 688889 & 4.85 & 4.6952 & TRN \\
\hline CHEMBL1461010 & 688889 & 4.25 & 4.8483 & TRN \\
\hline CHEMBL1480521 & 688889 & 4.3 & 4.8201 & TST \\
\hline CHEMBL1575084 & 688889 & 4.55 & 4.7627 & TRN \\
\hline CHEMBL1312903 & 688889 & 5.25 & 4.7314 & TRN \\
\hline CHEMBL1360250 & 688889 & 4.25 & 4.7135 & TRN \\
\hline CHEMBL3197516 & 688889 & 4.55 & 4.7185 & TRN \\
\hline CHEMBL1607501 & 688889 & 4.95 & 4.7276 & TST \\
\hline CHEMBL1364128 & 688889 & 4.3 & 5.044 & TRN \\
\hline CHEMBL1332999 & 688889 & 4.3 & 4.8043 & TRN \\
\hline CHEMBL1563861 & 688889 & 6.7501 & 4.6818 & TRN \\
\hline CHEMBL1350496 & 688889 & 4.3 & 4.7397 & TRN \\
\hline CHEMBL1324802 & 688889 & 4.9 & 4.9072 & TRN \\
\hline CHEMBL1567366 & 688889 & 5.85 & 4.757 & TRN \\
\hline CHEMBL1557877 & 688889 & 5.35 & 4.8137 & TRN \\
\hline CHEMBL1321933 & 688889 & 6.05 & 4.916 & TRN \\
\hline CHEMBL 3210045 & 688889 & 4.5 & 4.7874 & TRN \\
\hline CHEMBL3210994 & 688889 & 5.4 & 4.8833 & TRN \\
\hline CHEMBL1385443 & 688889 & 5.75 & 4.7765 & TRN \\
\hline CHEMBL1588981 & 688889 & 4.3 & 4.8392 & TRN \\
\hline CHEMBL1387780 & 688889 & 6.7501 & 4.8189 & TRN \\
\hline CHEMBL1559029 & 688889 & 6.7501 & 4.7709 & TRN \\
\hline CHEMBL3197010 & 688889 & 5.15 & 4.7673 & TST \\
\hline CHEMBL1997195 & 688889 & 4.9 & 4.6761 & TRN \\
\hline CHEMBL1304190 & 688889 & 4.6 & 4.8404 & TRN \\
\hline CHEMBL1447306 & 688889 & 6.3 & 4.6653 & TST \\
\hline CHEMBL1494923 & 688889 & 5.4 & 4.9643 & TRN \\
\hline CHEMBL1338958 & 688889 & 4.25 & 4.8099 & TST \\
\hline CHEMBL1417524 & 688889 & 4.95 & 4.9873 & TRN \\
\hline CHEMBL1336152 & 688889 & 4.65 & 4.6566 & TRN \\
\hline CHEMBL1385971 & 688889 & 5.1 & 4.9137 & TRN \\
\hline CHEMBL1345125 & 688889 & 6.7501 & 4.8144 & TST \\
\hline CHEMBL1540240 & 688889 & 4.95 & 4.7894 & TRN \\
\hline CHEMBL1526884 & 688889 & 4.25 & 4.9111 & TRN \\
\hline
\end{tabular}




\begin{tabular}{|c|c|c|c|c|}
\hline \multicolumn{5}{|c|}{ Supplemental Table S2.txt } \\
\hline CHEMBL1333833 & 688889 & 4.5 & 4.6712 & TRN \\
\hline CHEMBL1380710 & 688889 & 6.1 & 4.8008 & TST \\
\hline CHEMBL1546972 & 688889 & 5.3 & 4.817 & TRN \\
\hline CHEMBL1604679 & 688889 & 4.25 & 4.82 & TST \\
\hline CHEMBL3197900 & 688889 & 4.3 & 4.6792 & TRN \\
\hline CHEMBL1536467 & 688889 & 5.05 & 4.7669 & TRN \\
\hline CHEMBL1360802 & 688889 & 4.5 & 4.8105 & TRN \\
\hline CHEMBL1560369 & 688889 & 4.95 & 4.8624 & TRN \\
\hline CHEMBL1996766 & 688889 & 4.95 & 4.8896 & TST \\
\hline CHEMBL1544574 & 688889 & 5.2 & 4.8487 & TRN \\
\hline CHEMBL1600445 & 688889 & 4.25 & 4.6466 & TST \\
\hline CHEMBL1428768 & 688889 & 4.25 & 4.8161 & TRN \\
\hline CHEMBL1570765 & 688889 & 4.3 & 4.7074 & TST \\
\hline CHEMBL 2000619 & 688889 & 4.95 & 4.7157 & TRN \\
\hline CHEMBL1375060 & 688889 & 4.7 & 4.8673 & TRN \\
\hline CHEMBL1428278 & 688889 & 4.3 & 4.7241 & TRN \\
\hline CHEMBL3209588 & 688889 & 4.3 & 4.7716 & TRN \\
\hline CHEMBL1495681 & 688889 & 4.95 & 4.7725 & TRN \\
\hline CHEMBL1428482 & 688889 & 4.75 & 4.7358 & TST \\
\hline CHEMBL3207462 & 688889 & 4.45 & 4.8466 & TST \\
\hline CHEMBL1534866 & 688889 & 4.4 & 4.6608 & TRN \\
\hline CHEMBL1341212 & 688889 & 6.2 & 4.9417 & TRN \\
\hline CHEMBL1419585 & 688889 & 4.25 & 4.8374 & TST \\
\hline CHEMBL1312376 & 688889 & 4.3 & 4.8322 & TRN \\
\hline CHEMBL1352223 & 688889 & 4.5 & 4.803 & TST \\
\hline CHEMBL1353101 & 688889 & 6.8 & 4.9977 & TRN \\
\hline CHEMBL1424254 & 688889 & 4.25 & 4.806 & TST \\
\hline CHEMBL1405985 & 688889 & 4.9 & 4.8789 & TST \\
\hline CHEMBL1585982 & 688889 & 4.5 & 4.7268 & TRN \\
\hline CHEMBL1344249 & 688889 & 4.5 & 4.812 & TRN \\
\hline CHEMBL1367951 & 688889 & 5.25 & 4.7815 & TRN \\
\hline CHEMBL1493906 & 688889 & 4.25 & 4.6796 & TRN \\
\hline CHEMBL1373654 & 688889 & 4.4 & 4.8777 & TST \\
\hline CHEMBL1589378 & 688889 & 5.05 & 4.6597 & TRN \\
\hline CHEMBL1459287 & 688889 & 4.95 & 4.8455 & TST \\
\hline CHEMBL 3208253 & 688889 & 4.25 & 4.6577 & TRN \\
\hline CHEMBL1347531 & 688889 & 4.35 & 4.8486 & TRN \\
\hline CHEMBL1373195 & 688889 & 4.9 & 4.9337 & TST \\
\hline CHEMBL1567802 & 688889 & 4.95 & 4.7545 & TRN \\
\hline CHEMBL1548245 & 688889 & 4.45 & 4.7807 & TST \\
\hline CHEMBL1570915 & 688889 & 4.25 & 4.7422 & TST \\
\hline CHEMBL1415305 & 688889 & 4.4 & 4.798 & TST \\
\hline CHEMBL1569780 & 688889 & 4.35 & 4.8355 & TRN \\
\hline CHEMBL1309786 & 688889 & 6.35 & 4.9374 & TRN \\
\hline CHEMBL1446261 & 688889 & 6.5501 & 4.902 & TRN \\
\hline CHEMBL1304444 & 688889 & 4.85 & 4.8163 & TRN \\
\hline CHEMBL1453858 & 688889 & 4.45 & 4.6811 & TRN \\
\hline CHEMBL1376713 & 688889 & 5.0 & 4.8472 & TST \\
\hline
\end{tabular}




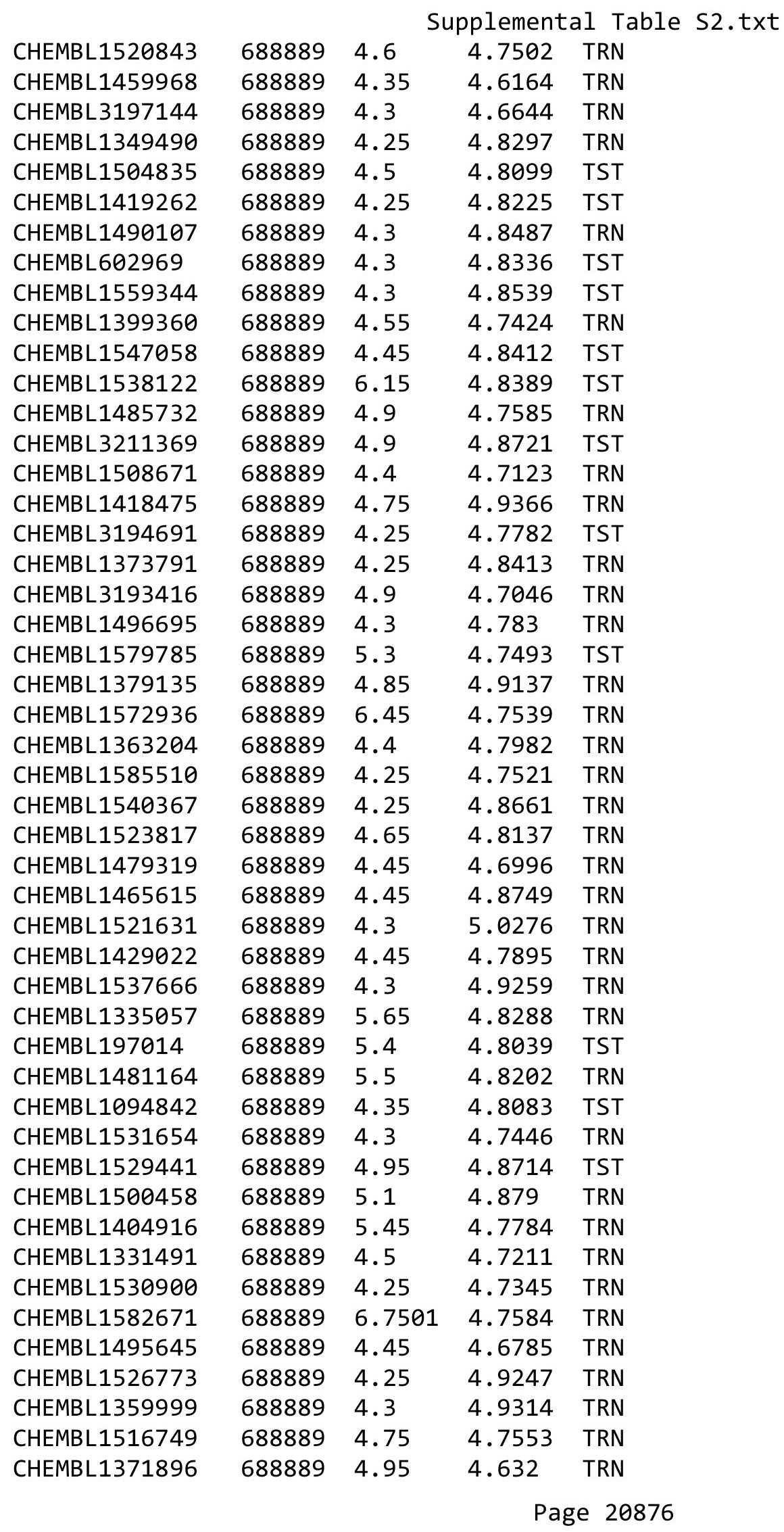




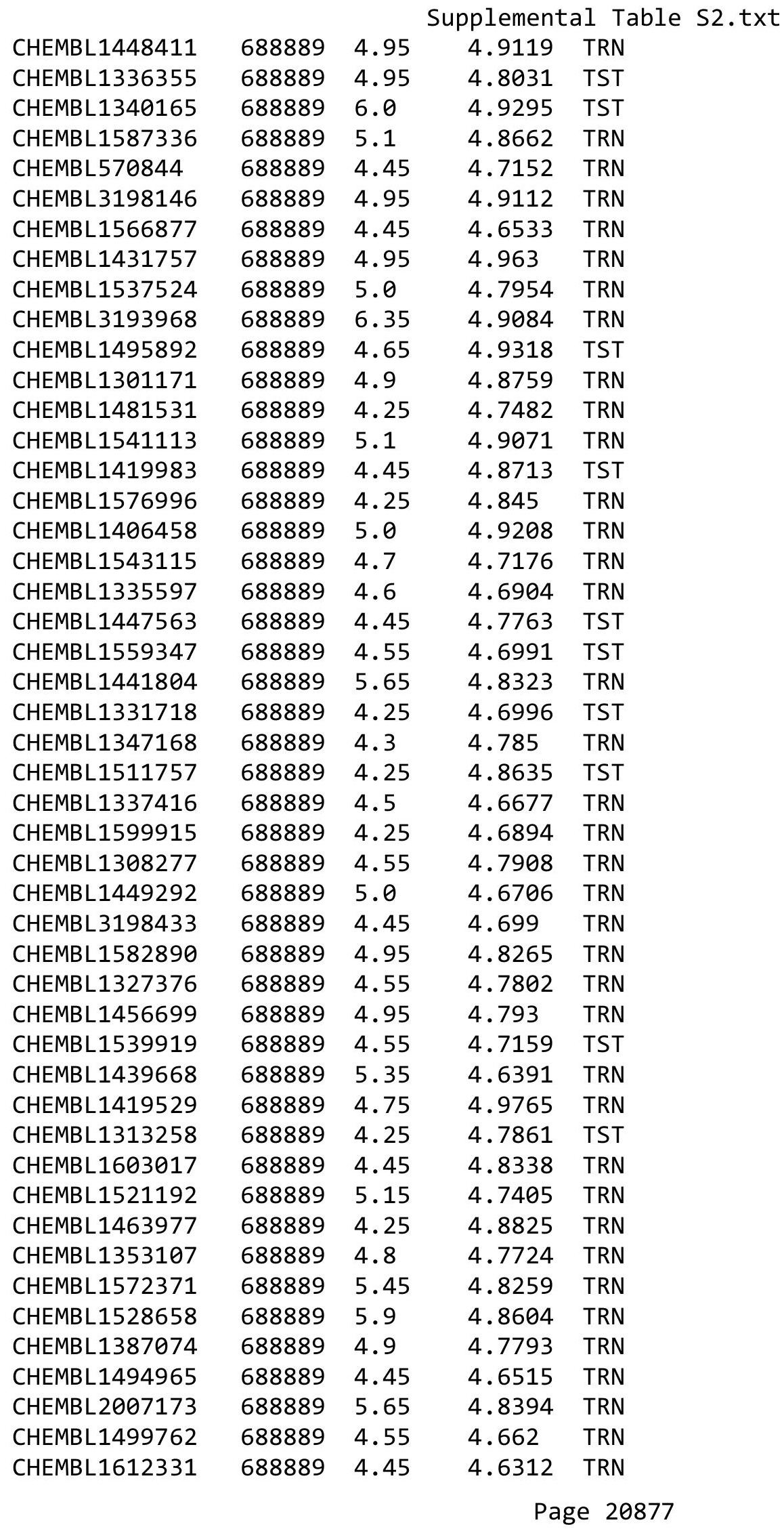




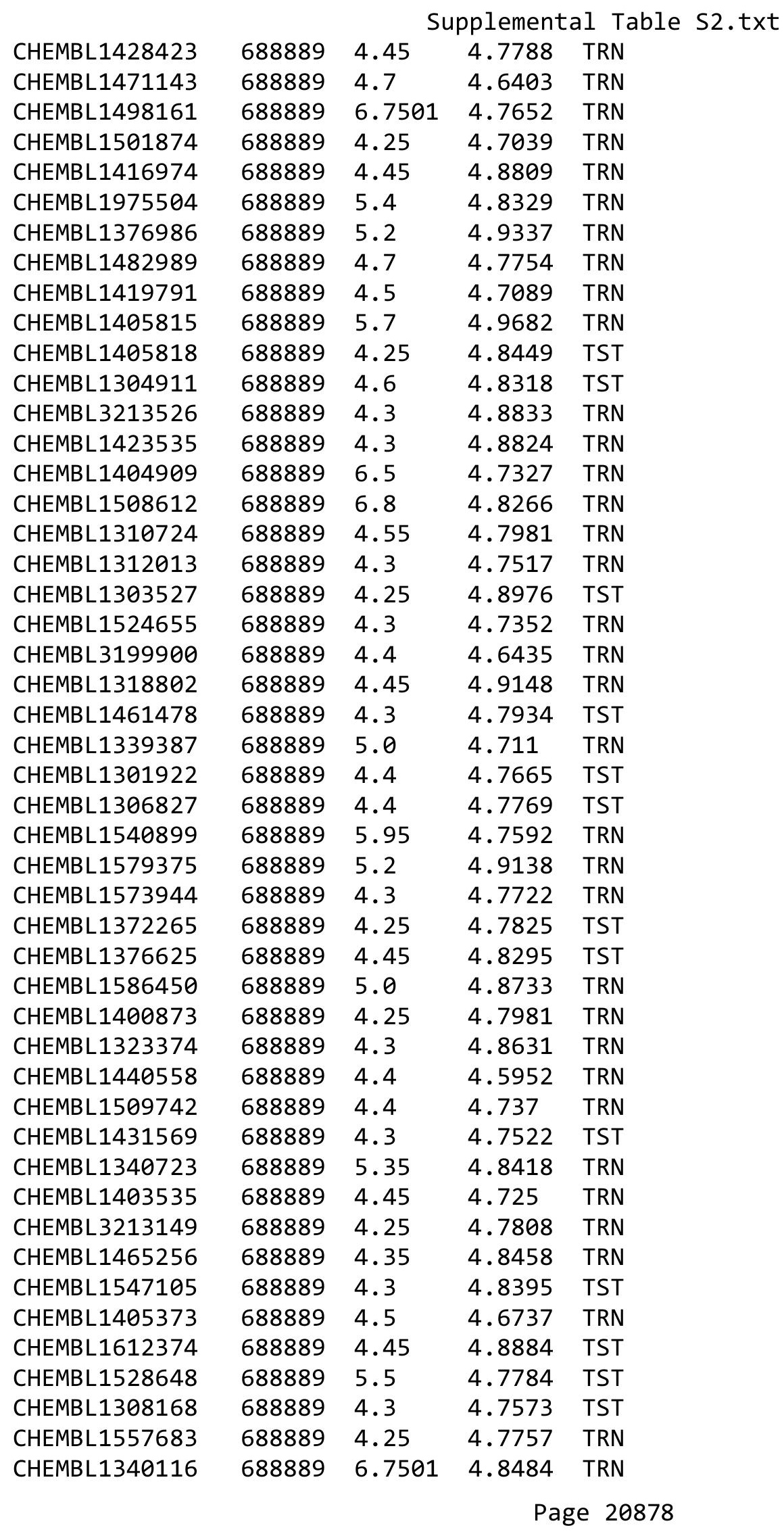




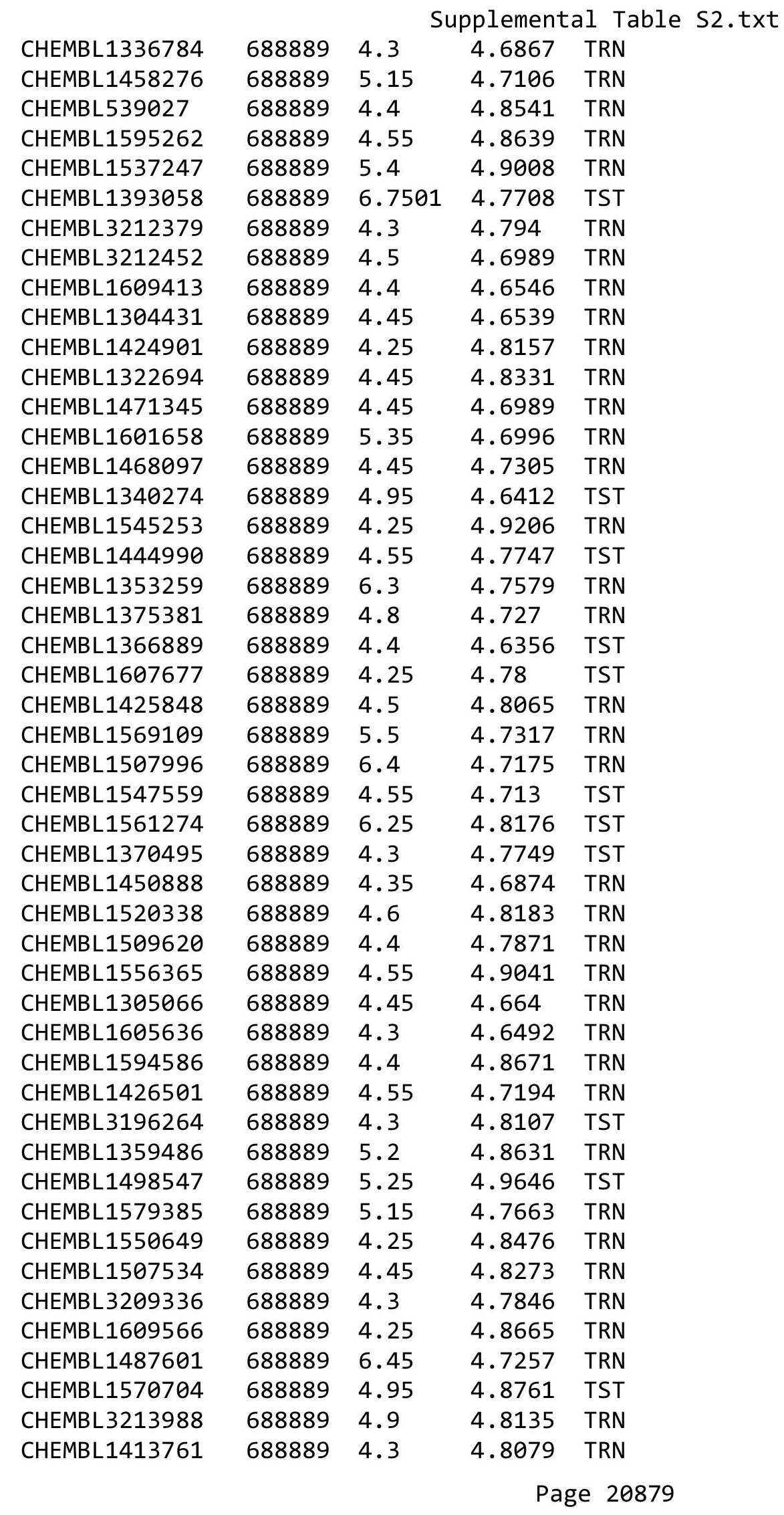




\begin{tabular}{|c|c|c|c|c|c|}
\hline \multicolumn{6}{|c|}{ Supplemental Table S2.txt } \\
\hline CHEMBL1385759 & 688889 & 4.85 & 4.9884 & TST & \\
\hline CHEMBL1427963 & 688889 & 6.0 & 4.7235 & TRN & \\
\hline CHEMBL1587747 & 688889 & 4.6 & 4.7084 & TRN & \\
\hline CHEMBL1549130 & 688889 & 4.3 & 4.9023 & TRN & \\
\hline CHEMBL1368900 & 688889 & 4.95 & 4.7611 & TRN & \\
\hline CHEMBL1421580 & 688889 & 4.45 & 4.9333 & TRN & \\
\hline CHEMBL1464622 & 688889 & 4.25 & 4.7528 & TRN & \\
\hline CHEMBL1334674 & 688889 & 4.35 & 4.7811 & TRN & \\
\hline CHEMBL1545657 & 688889 & 5.85 & 4.63899 & 9999999999 & TRN \\
\hline CHEMBL1588028 & 688889 & 4.3 & 4.7716 & TRN & \\
\hline CHEMBL1403830 & 688889 & 4.25 & 4.7702 & TRN & \\
\hline CHEMBL 3214139 & 688889 & 4.3 & 4.7854 & TST & \\
\hline CHEMBL1492821 & 688889 & 4.5 & 4.7428 & TRN & \\
\hline CHEMBL1384596 & 688889 & 5.9 & 4.9044 & TRN & \\
\hline CHEMBL1371632 & 688889 & 4.25 & 4.8708 & TRN & \\
\hline CHEMBL1510208 & 688889 & 4.3 & 4.7062 & TRN & \\
\hline CHEMBL1415631 & 688889 & 4.4 & 4.7581 & TRN & \\
\hline CHEMBL1534196 & 688889 & 4.95 & 4.9155 & TRN & \\
\hline CHEMBL1383570 & 688889 & 4.9 & 4.8545 & TST & \\
\hline CHEMBL3199452 & 688889 & 4.4 & 4.7888 & TRN & \\
\hline CHEMBL3194148 & 688889 & 4.25 & 4.8307 & TRN & \\
\hline CHEMBL1471353 & 688889 & 4.3 & 4.7497 & TRN & \\
\hline CHEMBL1343400 & 688889 & 4.45 & 4.7455 & TST & \\
\hline CHEMBL 3197869 & 688889 & 5.3 & 4.8477 & TRN & \\
\hline CHEMBL1362146 & 688889 & 4.65 & 4.704 & TST & \\
\hline CHEMBL1482916 & 688889 & 4.25 & 4.6397 & TRN & \\
\hline CHEMBL1449353 & 688889 & 5.5 & 4.7993 & TRN & \\
\hline CHEMBL568385 & 688889 & 4.5 & 4.6853 & TRN & \\
\hline CHEMBL1370512 & 688889 & 4.3 & 4.7599 & TRN & \\
\hline CHEMBL1509810 & 688889 & 4.45 & 4.7832 & TRN & \\
\hline CHEMBL1506815 & 688889 & 4.25 & 4.8063 & TRN & \\
\hline CHEMBL1428984 & 688889 & 4.55 & 4.7395 & TRN & \\
\hline CHEMBL1393181 & 688889 & 4.6 & 4.9064 & TRN & \\
\hline CHEMBL1497297 & 688889 & 6.25 & 4.8881 & TRN & \\
\hline CHEMBL1400648 & 688889 & 4.25 & 4.7668 & TRN & \\
\hline CHEMBL1547220 & 688889 & 4.45 & 4.7387 & TST & \\
\hline CHEMBL1345435 & 688889 & 5.6 & 4.8531 & TRN & \\
\hline CHEMBL1466068 & 688889 & 4.35 & 4.7846 & TRN & \\
\hline CHEMBL1365001 & 688889 & 4.55 & 4.7985 & TRN & \\
\hline CHEMBL1447396 & 688889 & 5.15 & 4.9497 & TRN & \\
\hline CHEMBL1503262 & 688889 & 4.45 & 4.7753 & TRN & \\
\hline CHEMBL 1465877 & 688889 & 4.35 & 4.8184 & TRN & \\
\hline CHEMBL3199767 & 688889 & 4.45 & 4.8322 & TRN & \\
\hline CHEMBL1365898 & 688889 & 4.4 & 4.6918 & TRN & \\
\hline CHEMBL1343216 & 688889 & 4.35 & 4.686 & TRN & \\
\hline CHEMBL3195213 & 688889 & 5.7 & 4.7782 & TST & \\
\hline CHEMBL 1366120 & 688889 & 4.25 & 4.716 & TRN & \\
\hline CHEMBL1305403 & 688889 & 5.9 & 4.8074 & TRN & \\
\hline
\end{tabular}




\begin{tabular}{|c|c|c|c|c|c|}
\hline \multicolumn{6}{|c|}{ Supplemental Table S2.txt } \\
\hline CHEMBL1401824 & 688889 & 5.35 & 4.8855 & TRN & \\
\hline CHEMBL1518870 & 688889 & 5.45 & 4.6435 & TRN & \\
\hline CHEMBL1550962 & 688889 & 4.55 & 4.8328 & TRN & \\
\hline CHEMBL1381020 & 688889 & 5.15 & 4.8758 & TRN & \\
\hline CHEMBL1368361 & 688889 & 4.55 & 4.7705 & TRN & \\
\hline CHEMBL1502287 & 688889 & 5.7 & 4.7614 & TRN & \\
\hline CHEMBL1578638 & 688889 & 5.4 & 4.7957 & TST & \\
\hline CHEMBL1584221 & 688889 & 4.9 & 4.7273 & TRN & \\
\hline CHEMBL1480549 & 688889 & 6.4 & 4.7487 & TRN & \\
\hline CHEMBL1456914 & 688889 & 5.5 & 4.8372 & TST & \\
\hline CHEMBL1421895 & 688889 & 4.65 & 4.7036 & TRN & \\
\hline CHEMBL1393146 & 688889 & 4.4 & 4.8508 & TRN & \\
\hline CHEMBL3211728 & 688889 & 4.3 & 4.8546 & TRN & \\
\hline CHEMBL1533529 & 688889 & 5.15 & 4.83899 & 99999999995 & TRN \\
\hline CHEMBL1982203 & 688889 & 4.45 & 4.8475 & TRN & \\
\hline CHEMBL1322929 & 688889 & 4.45 & 4.7231 & TRN & \\
\hline CHEMBL1360699 & 688889 & 6.7501 & 4.7457 & TST & \\
\hline CHEMBL1566655 & 688889 & 4.3 & 4.7734 & TRN & \\
\hline CHEMBL1545901 & 688889 & 5.05 & 4.6781 & TRN & \\
\hline CHEMBL1419348 & 688889 & 4.95 & 4.7912 & TST & \\
\hline CHEMBL1579119 & 688889 & 5.75 & 4.8493 & TRN & \\
\hline CHEMBL1336785 & 688889 & 4.65 & 4.8913 & TST & \\
\hline CHEMBL1562264 & 688889 & 6.8 & 4.8057 & TST & \\
\hline CHEMBL3198187 & 688889 & 5.0 & 4.8435 & TRN & \\
\hline CHEMBL1441897 & 688889 & 4.5 & 4.7043 & TRN & \\
\hline CHEMBL1337559 & 688889 & 4.35 & 4.7214 & TRN & \\
\hline CHEMBL1408430 & 688889 & 4.4 & 4.9269 & TRN & \\
\hline CHEMBL1342534 & 688889 & 4.9 & 4.8274 & TRN & \\
\hline CHEMBL1338069 & 688889 & 4.3 & 4.8224 & TRN & \\
\hline CHEMBL1457908 & 688889 & 4.55 & 4.6964 & TRN & \\
\hline CHEMBL1428685 & 688889 & 4.7 & 4.6945 & TST & \\
\hline CHEMBL1584581 & 688889 & 4.55 & 4.7932 & TRN & \\
\hline CHEMBL1471021 & 688889 & 4.85 & 4.6365 & TST & \\
\hline CHEMBL1342409 & 688889 & 4.25 & 4.8133 & TRN & \\
\hline CHEMBL1714669 & 688889 & 4.4 & 4.7764 & TRN & \\
\hline CHEMBL1990057 & 688889 & 4.4 & 4.7052 & TRN & \\
\hline CHEMBL1539859 & 688889 & 4.95 & 4.9201 & TST & \\
\hline CHEMBL1457595 & 688889 & 5.1 & 4.8157 & TRN & \\
\hline CHEMBL1413799 & 688889 & 4.9 & 4.8283 & TRN & \\
\hline CHEMBL1426409 & 688889 & 4.45 & 4.8186 & TRN & \\
\hline CHEMBL1565081 & 688889 & 4.45 & 4.6445 & TRN & \\
\hline CHEMBL1501755 & 688889 & 4.3 & 4.7709 & TRN & \\
\hline CHEMBL1463398 & 688889 & 4.45 & 4.7235 & TRN & \\
\hline CHEMBL1484625 & 688889 & 4.6 & 4.7731 & TRN & \\
\hline CHEMBL1464193 & 688889 & 5.25 & 4.6537 & TRN & \\
\hline CHEMBL1323495 & 688889 & 6.05 & 4.9534 & TST & \\
\hline CHEMBL1375394 & 688889 & 4.3 & 4.8619 & TRN & \\
\hline CHEMBL1415885 & 688889 & 4.25 & 4.7213 & TRN & \\
\hline
\end{tabular}




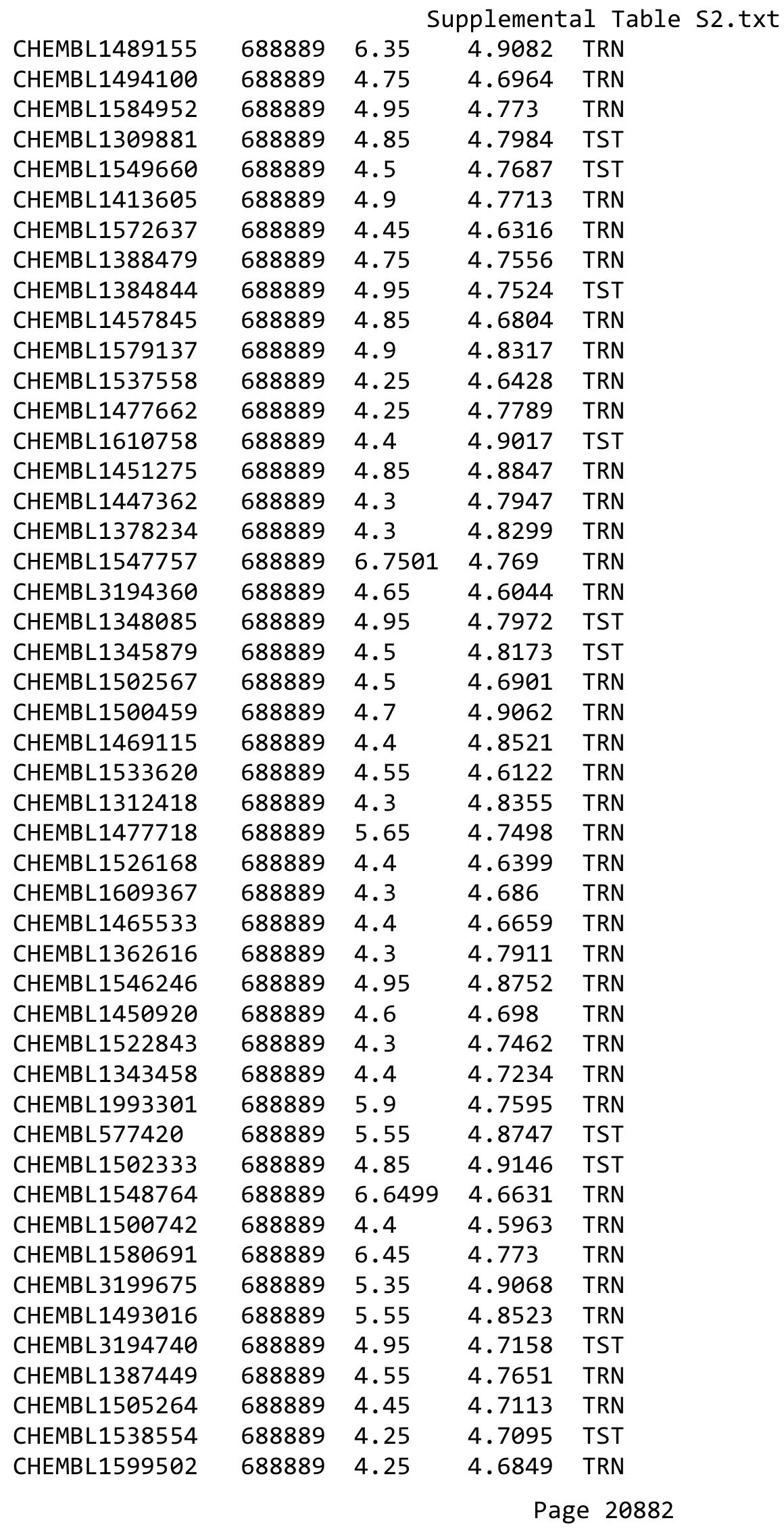




\begin{tabular}{|c|c|c|c|c|c|}
\hline \\
\hline CHEMBL1450035 & 688889 & 4.5 & 4.6894 & TRN & \\
\hline CHEMBL1380304 & 688889 & 4.9 & 4.8985 & TRN & \\
\hline CHEMBL1995878 & 688889 & 4.3 & 4.73 & TRN & \\
\hline CHEMBL1322390 & 688889 & 5.0 & 4.7973 & TRN & \\
\hline CHEMBL1565222 & 688889 & 5.9 & 4.8648 & TRN & \\
\hline CHEMBL3193814 & 688889 & 6.7501 & 4.7057 & TST & \\
\hline CHEMBL3210177 & 688889 & 5.45 & 4.7508 & TST & \\
\hline CHEMBL3208831 & 688889 & 4.35 & 4.6091 & TRN & \\
\hline CHEMBL3197304 & 688889 & 4.9 & 4.7882 & TST & \\
\hline CHEMBL1562936 & 688889 & 5.35 & 4.6909 & TRN & \\
\hline CHEMBL1544269 & 688889 & 5.4 & 4.7227 & TST & \\
\hline CHEMBL1581146 & 688889 & 5.15 & 4.6243 & TRN & \\
\hline CHEMBL1373078 & 688889 & 5.1 & 4.9451 & TST & \\
\hline CHEMBL3194833 & 688889 & 4.4 & 4.8749 & TRN & \\
\hline CHEMBL1550941 & 688889 & 4.3 & 4.7619 & TRN & \\
\hline CHEMBL1308435 & 688889 & 4.45 & 4.7897 & TRN & \\
\hline CHEMBL3192067 & 688889 & 6.5501 & 4.9007 & TRN & \\
\hline CHEMBL1403940 & 688889 & 4.55 & 4.7091 & TRN & \\
\hline CHEMBL1612500 & 688889 & 5.65 & 4.8827 & TST & \\
\hline CHEMBL1420787 & 688889 & 4.95 & 4.8523 & TRN & \\
\hline CHEMBL1517046 & 688889 & 4.45 & 4.7539 & TRN & \\
\hline CHEMBL3211505 & 688889 & 4.55 & 4.6944 & TRN & \\
\hline CHEMBL1490974 & 688889 & 4.35 & 4.973 & TRN & \\
\hline CHEMBL1351920 & 688889 & 4.6 & 4.7173 & TRN & \\
\hline CHEMBL1336672 & 688889 & 6.1 & 4.8979 & TRN & \\
\hline CHEMBL1491807 & 688889 & 4.6 & 4.8149 & TRN & \\
\hline CHEMBL1307165 & 688889 & 4.5 & 4.78100 & 3000000001 & TRN \\
\hline CHEMBL1569740 & 688889 & 5.2 & 4.708 & TRN & \\
\hline CHEMBL1482002 & 688889 & 4.55 & 4.6803 & TRN & \\
\hline CHEMBL1439300 & 688889 & 6.8 & 4.7763 & TRN & \\
\hline CHEMBL1579546 & 688889 & 4.55 & 4.728 & TRN & \\
\hline CHEMBL1382077 & 688889 & 4.3 & 4.8071 & TRN & \\
\hline CHEMBL1439778 & 688889 & 5.15 & 4.7723 & TRN & \\
\hline CHEMBL1461508 & 688889 & 4.55 & 4.6715 & TRN & \\
\hline CHEMBL1429302 & 688889 & 6.05 & 4.7541 & TRN & \\
\hline CHEMBL1327105 & 688889 & 4.25 & 4.8697 & TRN & \\
\hline CHEMBL1385846 & 688889 & 5.9 & 4.7963 & TRN & \\
\hline CHEMBL1371666 & 688889 & 5.55 & 4.8464 & TRN & \\
\hline CHEMBL1526133 & 688889 & 4.25 & 4.8154 & TRN & \\
\hline CHEMBL1509985 & 688889 & 4.45 & 4.7421 & TRN & \\
\hline CHEMBL3214169 & 688889 & 4.35 & 4.8788 & TRN & \\
\hline CHEMBL1558696 & 688889 & 4.95 & 4.8761 & TST & \\
\hline CHEMBL1312251 & 688889 & 4.3 & 4.7496 & TST & \\
\hline CHEMBL1405532 & 688889 & 4.45 & 4.822 & TRN & \\
\hline CHEMBL311226 & 688889 & 4.95 & 4.909 & TST & \\
\hline CHEMBL1440186 & 688889 & 4.5 & 4.8836 & TRN & \\
\hline CHEMBL1347686 & 688889 & 4.6 & 4.7848 & TRN & \\
\hline CHEMBL1400326 & 688889 & 4.9 & 4.8972 & TST & \\
\hline
\end{tabular}




\begin{tabular}{|c|c|c|c|c|c|}
\hline \multirow{3}{*}{$\begin{array}{l}\text { CHEMBL1368626 } \\
\text { CHEMBL1470210 }\end{array}$} & \multirow{3}{*}{$\begin{array}{l}688889 \\
688889\end{array}$} & \multicolumn{4}{|c|}{ Supplemental Table S2.txt } \\
\hline & & 4.5 & 4.83899 & 99999999995 & TRN \\
\hline & & 4.45 & 4.751 & TST & \\
\hline CHEMBL1578210 & 688889 & 5.5 & 4.8075 & TRN & \\
\hline CHEMBL1301741 & 688889 & 5.55 & 4.7813 & TRN & \\
\hline CHEMBL1330229 & 688889 & 4.5 & 5.0133 & TRN & \\
\hline CHEMBL1393096 & 688889 & 4.4 & 4.7588 & TRN & \\
\hline CHEMBL1441182 & 688889 & 4.9 & 4.9584 & TRN & \\
\hline CHEMBL1365177 & 688889 & 5.4 & 4.869 & TST & \\
\hline CHEMBL1384248 & 688889 & 4.55 & 4.9332 & TRN & \\
\hline CHEMBL1372596 & 688889 & 6.1 & 4.8426 & TRN & \\
\hline CHEMBL1547024 & 688889 & 6.2 & 4.9735 & TRN & \\
\hline CHEMBL1604300 & 688889 & 4.55 & 4.7704 & TRN & \\
\hline CHEMBL1608590 & 688889 & 5.2 & 4.8746 & TRN & \\
\hline CHEMBL1333835 & 688889 & 5.15 & 4.8215 & TRN & \\
\hline CHEMBL1601128 & 688889 & 4.5 & 4.6847 & TRN & \\
\hline CHEMBL1445901 & 688889 & 4.35 & 4.8076 & TRN & \\
\hline CHEMBL1538985 & 688889 & 6.1 & 4.9598 & TST & \\
\hline CHEMBL1468119 & 688889 & 6.0 & 4.8751 & TRN & \\
\hline CHEMBL1525213 & 688889 & 4.4 & 4.6792 & TRN & \\
\hline CHEMBL1421731 & 688889 & 4.25 & 4.7649 & TRN & \\
\hline CHEMBL1555417 & 688889 & 4.25 & 4.7833 & TRN & \\
\hline CHEMBL1458744 & 688889 & 4.45 & 4.6954 & TRN & \\
\hline CHEMBL1418931 & 688889 & 4.5 & 4.9707 & TRN & \\
\hline CHEMBL1533022 & 688889 & 4.3 & 4.7828 & TRN & \\
\hline CHEMBL1330520 & 688889 & 4.85 & 5.0437 & TRN & \\
\hline CHEMBL1312081 & 688889 & 4.25 & 4.8101 & TST & \\
\hline CHEMBL1421645 & 688889 & 4.3 & 4.9701 & TRN & \\
\hline CHEMBL1308013 & 688889 & 5.65 & 4.6484 & TST & \\
\hline CHEMBL1499508 & 688889 & 4.7 & 4.6984 & TRN & \\
\hline CHEMBL 2005119 & 688889 & 4.45 & 4.7546 & TRN & \\
\hline CHEMBL1390484 & 688889 & 5.15 & 5.0117 & TST & \\
\hline CHEMBL1305402 & 688889 & 6.05 & 4.6924 & TRN & \\
\hline CHEMBL1543114 & 688889 & 4.3 & 4.7099 & TRN & \\
\hline CHEMBL1484933 & 688889 & 4.4 & 4.9217 & TRN & \\
\hline CHEMBL1496581 & 688889 & 4.4 & 4.8121 & TRN & \\
\hline CHEMBL1569912 & 688889 & 4.95 & 4.9442 & TRN & \\
\hline CHEMBL1576114 & 688889 & 4.3 & 4.8865 & TRN & \\
\hline CHEMBL1505868 & 688889 & 4.45 & 4.7872 & TRN & \\
\hline CHEMBL1594783 & 688889 & 6.7501 & 4.9451 & TRN & \\
\hline CHEMBL1418907 & 688889 & 4.45 & 4.6125 & TRN & \\
\hline CHEMBL1305606 & 688889 & 4.5 & 4.688 & TST & \\
\hline CHEMBL1528594 & 688889 & 4.9 & 4.8159 & TRN & \\
\hline CHEMBL1451911 & 688889 & 5.35 & 4.6265 & TRN & \\
\hline CHEMBL1310777 & 688889 & 4.3 & 4.7722 & TRN & \\
\hline CHEMBL3190520 & 688889 & 4.95 & 4.8959 & TST & \\
\hline CHEMBL1564390 & 688889 & 4.6 & 4.7958 & TRN & \\
\hline CHEMBL1303812 & 688889 & 4.3 & 4.63 & TRN & \\
\hline CHEMBL1495663 & 688889 & 5.1 & 4.7385 & TRN & \\
\hline
\end{tabular}




\begin{tabular}{|c|c|c|c|c|}
\hline \multicolumn{5}{|c|}{ Supplemental Table S2.txt } \\
\hline CHEMBL1302144 & 688889 & 5.5 & 4.8121 & TRN \\
\hline CHEMBL1598877 & 688889 & 5.2 & 4.8907 & TRN \\
\hline CHEMBL1488453 & 688889 & 6.7501 & 4.8171 & TRN \\
\hline CHEMBL1346204 & 688889 & 4.65 & 4.5775 & TST \\
\hline CHEMBL1359009 & 688889 & 4.3 & 4.8888 & TRN \\
\hline CHEMBL1536585 & 688889 & 6.45 & 4.6941 & TST \\
\hline CHEMBL1565531 & 688889 & 4.45 & 4.6498 & TRN \\
\hline CHEMBL1538629 & 688889 & 4.25 & 4.7384 & TRN \\
\hline CHEMBL3210871 & 688889 & 4.5 & 4.8547 & TST \\
\hline CHEMBL1580329 & 688889 & 5.55 & 4.8341 & TRN \\
\hline CHEMBL1464288 & 688889 & 4.45 & 4.687 & TRN \\
\hline CHEMBL1586798 & 688889 & 4.3 & 4.7021 & TRN \\
\hline CHEMBL1450203 & 688889 & 4.3 & 4.7894 & TRN \\
\hline CHEMBL1582965 & 688889 & 6.4 & 4.7334 & TRN \\
\hline CHEMBL1442946 & 688889 & 4.25 & 4.7978 & TRN \\
\hline CHEMBL1517958 & 688889 & 5.15 & 4.918 & TRN \\
\hline CHEMBL3197937 & 688889 & 4.95 & 4.6858 & TRN \\
\hline CHEMBL1352493 & 688889 & 6.2 & 4.8433 & TST \\
\hline CHEMBL1540836 & 688889 & 5.2 & 4.7103 & TRN \\
\hline CHEMBL1351486 & 688889 & 4.9 & 4.8288 & TRN \\
\hline CHEMBL1442570 & 688889 & 4.55 & 4.7726 & TRN \\
\hline CHEMBL1380684 & 688889 & 4.25 & 4.756 & TST \\
\hline CHEMBL1359427 & 688889 & 5.45 & 4.7517 & TRN \\
\hline CHEMBL1339232 & 688889 & 5.2 & 4.9458 & TRN \\
\hline CHEMBL1319647 & 688889 & 4.6 & 4.7763 & TRN \\
\hline CHEMBL1305136 & 688889 & 4.25 & 4.8158 & TRN \\
\hline CHEMBL583378 & 688889 & 4.25 & 4.7766 & TST \\
\hline CHEMBL1559155 & 688889 & 4.3 & 4.7286 & TRN \\
\hline CHEMBL1309782 & 688889 & 4.3 & 4.7612 & TRN \\
\hline CHEMBL1511819 & 688889 & 6.7501 & 4.9296 & TRN \\
\hline CHEMBL1404450 & 688889 & 4.65 & 4.7135 & TRN \\
\hline CHEMBL1597766 & 688889 & 4.4 & 4.8189 & TST \\
\hline CHEMBL1509744 & 688889 & 5.15 & 4.8585 & TRN \\
\hline CHEMBL1361543 & 688889 & 4.95 & 4.93 & TRN \\
\hline CHEMBL1329398 & 688889 & 4.75 & 4.7885 & TST \\
\hline CHEMBL1345518 & 688889 & 4.8 & 4.779 & TST \\
\hline CHEMBL1361928 & 688889 & 6.1 & 4.7793 & TST \\
\hline CHEMBL1350409 & 688889 & 4.6 & 4.9622 & TST \\
\hline CHEMBL1511618 & 688889 & 5.3 & 4.8169 & TRN \\
\hline CHEMBL1520767 & 688889 & 4.95 & 5.0 & TRN \\
\hline CHEMBL1323660 & 688889 & 4.9 & 4.7102 & TRN \\
\hline CHEMBL1570669 & 688889 & 5.8 & 4.713 & TST \\
\hline CHEMBL3209363 & 688889 & 4.95 & 4.7985 & TST \\
\hline CHEMBL1527372 & 688889 & 4.3 & 4.8924 & TST \\
\hline CHEMBL3191789 & 688889 & 4.3 & 4.9104 & TST \\
\hline CHEMBL592184 & 688889 & 4.35 & 4.8223 & TRN \\
\hline CHEMBL1364297 & 688889 & 5.6 & 4.7275 & TRN \\
\hline CHEMBL1578927 & 688889 & 4.25 & 4.8647 & TRN \\
\hline
\end{tabular}




\begin{tabular}{|c|c|c|c|c|c|}
\hline \multicolumn{6}{|c|}{ Supplemental Table S2.txt } \\
\hline CHEMBL1577537 & 688889 & 4.5 & 4.8149 & TST & \\
\hline CHEMBL1463982 & 688889 & 5.35 & 4.6735 & TRN & \\
\hline CHEMBL3199523 & 688889 & 4.65 & 4.7597 & TST & \\
\hline CHEMBL1326097 & 688889 & 4.3 & 4.8076 & TRN & \\
\hline CHEMBL1516997 & 688889 & 4.55 & 4.9461 & TRN & \\
\hline CHEMBL1488555 & 688889 & 5.55 & 4.726 & TST & \\
\hline CHEMBL1423949 & 688889 & 4.3 & 4.8148 & TRN & \\
\hline CHEMBL1330994 & 688889 & 4.65 & 4.5866 & TST & \\
\hline CHEMBL1438925 & 688889 & 4.65 & 4.8524 & TRN & \\
\hline CHEMBL1375921 & 688889 & 4.4 & 4.8971 & TRN & \\
\hline CHEMBL1441977 & 688889 & 4.3 & 4.6483 & TRN & \\
\hline CHEMBL1385800 & 688889 & 5.25 & 4.8344 & TRN & \\
\hline CHEMBL1481083 & 688889 & 4.4 & 4.8589 & TRN & \\
\hline CHEMBL1401417 & 688889 & 5.8 & 4.749 & TRN & \\
\hline CHEMBL1363095 & 688889 & 4.3 & 4.706 & TRN & \\
\hline CHEMBL1447774 & 688889 & 4.45 & 4.6468 & TRN & \\
\hline CHEMBL1596356 & 688889 & 4.7 & 4.7542 & TST & \\
\hline CHEMBL1483108 & 688889 & 4.25 & 4.82 & TRN & \\
\hline CHEMBL1497440 & 688889 & 4.25 & 4.7998 & TRN & \\
\hline CHEMBL1454853 & 688889 & 4.4 & 4.6914 & TRN & \\
\hline CHEMBL1466303 & 688889 & 4.7 & 4.7763 & TRN & \\
\hline CHEMBL1346991 & 688889 & 4.25 & 4.73 & TST & \\
\hline CHEMBL1429516 & 688889 & 4.4 & 4.8569 & TRN & \\
\hline CHEMBL1344123 & 688889 & 4.45 & 4.8674 & TRN & \\
\hline CHEMBL1594360 & 688889 & 4.5 & 4.9377 & TRN & \\
\hline CHEMBL1518102 & 688889 & 4.95 & 4.907 & TRN & \\
\hline CHEMBL1613064 & 688889 & 4.35 & 4.7805 & TRN & \\
\hline CHEMBL1400974 & 688889 & 5.2 & 4.8508 & TST & \\
\hline CHEMBL1549236 & 688889 & 4.9 & 4.7377 & TRN & \\
\hline CHEMBL1559168 & 688889 & 4.35 & 4.9448 & TST & \\
\hline CHEMBL1425061 & 688889 & 6.1 & 4.8212 & TST & \\
\hline CHEMBL1341152 & 688889 & 4.25 & 4.6703 & TST & \\
\hline CHEMBL1490992 & 688889 & 5.7 & 4.7524 & TST & \\
\hline CHEMBL1306388 & 688889 & 4.3 & 4.9112 & TST & \\
\hline CHEMBL1524954 & 688889 & 6.1 & 4.8285 & TRN & \\
\hline CHEMBL1471287 & 688889 & 4.3 & 4.8948 & TST & \\
\hline CHEMBL1438836 & 688889 & 4.8 & 4.7145 & TRN & \\
\hline CHEMBL3207466 & 688889 & 4.25 & 4.68199 & 99999999995 & TRN \\
\hline CHEMBL1522181 & 688889 & 4.95 & 4.8913 & TST & \\
\hline CHEMBL1429056 & 688889 & 4.75 & 4.8659 & TST & \\
\hline CHEMBL1578790 & 688889 & 4.4 & 4.703 & TST & \\
\hline CHEMBL1305292 & 688889 & 4.75 & 4.7725 & TRN & \\
\hline CHEMBL1422094 & 688889 & 4.5 & 4.7629 & TRN & \\
\hline CHEMBL1351046 & 688889 & 4.55 & 4.8636 & TRN & \\
\hline CHEMBL1332220 & 688889 & 4.5 & 4.706 & TRN & \\
\hline CHEMBL1331747 & 688889 & 4.95 & 4.7122 & TST & \\
\hline CHEMBL1574408 & 688889 & 5.9 & 4.8218 & TST & \\
\hline CHEMBL1335039 & 688889 & 4.3 & 4.7722 & TRN & \\
\hline
\end{tabular}




\begin{tabular}{|c|c|c|c|c|c|}
\hline \multicolumn{6}{|c|}{ Supplemental Table S2.txt } \\
\hline CHEMBL1557483 & 688889 & 4.25 & 4.904 & TST & \\
\hline CHEMBL1536625 & 688889 & 4.55 & 4.7208 & TRN & \\
\hline CHEMBL1470605 & 688889 & 4.25 & 5.0768 & TRN & \\
\hline CHEMBL1539620 & 688889 & 4.7 & 4.6993 & TRN & \\
\hline CHEMBL1470294 & 688889 & 5.3 & 4.8786 & TRN & \\
\hline CHEMBL1976563 & 688889 & 4.9 & 4.7153 & TRN & \\
\hline CHEMBL1534720 & 688889 & 4.3 & 4.6235 & TRN & \\
\hline CHEMBL1542605 & 688889 & 4.3 & 4.8306 & TRN & \\
\hline CHEMBL1340461 & 688889 & 5.15 & 4.9676 & TRN & \\
\hline CHEMBL1500294 & 688889 & 6.05 & 4.8481 & TRN & \\
\hline CHEMBL1464203 & 688889 & 4.55 & 4.791 & TST & \\
\hline CHEMBL1345384 & 688889 & 4.35 & 4.7633 & TRN & \\
\hline CHEMBL1426849 & 688889 & 5.15 & 4.8344 & TST & \\
\hline CHEMBL3196153 & 688889 & 4.45 & 4.8034 & TRN & \\
\hline CHEMBL1527984 & 688889 & 4.9 & 4.8225 & TST & \\
\hline CHEMBL1485414 & 688889 & 4.95 & 5.0115 & TST & \\
\hline CHEMBL1341887 & 688889 & 6.7501 & 4.7806 & TRN & \\
\hline CHEMBL 3207407 & 688889 & 4.45 & 4.9586 & TRN & \\
\hline CHEMBL1531919 & 688889 & 4.5 & 4.7393 & TRN & \\
\hline CHEMBL1600001 & 688889 & 4.25 & 4.8254 & TST & \\
\hline CHEMBL1510797 & 688889 & 4.55 & 4.7715 & TRN & \\
\hline CHEMBL1365847 & 688889 & 4.25 & 4.6748 & TRN & \\
\hline CHEMBL1326263 & 688889 & 4.6 & 4.8097 & TRN & \\
\hline CHEMBL1313114 & 688889 & 5.15 & 4.8201 & TST & \\
\hline CHEMBL1604389 & 688889 & 4.25 & 4.6474 & TRN & \\
\hline CHEMBL3209643 & 688889 & 4.3 & 4.7959 & TRN & \\
\hline CHEMBL1402246 & 688889 & 6.35 & 4.9232 & TRN & \\
\hline CHEMBL1443136 & 688889 & 4.3 & 4.9759 & TRN & \\
\hline CHEMBL1597425 & 688889 & 4.45 & 4.7448 & TRN & \\
\hline CHEMBL1415571 & 688889 & 4.3 & 4.7996 & TRN & \\
\hline CHEMBL1549232 & 688889 & 4.25 & 4.70100 & 00000000005 & TRN \\
\hline CHEMBL1329351 & 688889 & 6.4 & 4.7441 & TST & \\
\hline CHEMBL1609481 & 688889 & 4.45 & 4.8208 & TRN & \\
\hline CHEMBL1466564 & 688889 & 4.45 & 4.7599 & TRN & \\
\hline CHEMBL1362310 & 688889 & 4.3 & 4.836 & TRN & \\
\hline CHEMBL1321187 & 688889 & 4.5 & 4.8101 & TRN & \\
\hline CHEMBL1423548 & 688889 & 4.3 & 4.6277 & TRN & \\
\hline CHEMBL1544704 & 688889 & 4.45 & 4.8162 & TRN & \\
\hline CHEMBL1583215 & 688889 & 4.8 & 4.8338 & TRN & \\
\hline CHEMBL1422370 & 688889 & 6.7501 & 4.8082 & TST & \\
\hline CHEMBL1424030 & 688889 & 4.35 & 4.8256 & TRN & \\
\hline CHEMBL1570306 & 688889 & 4.3 & 4.9035 & TRN & \\
\hline CHEMBL1329690 & 688889 & 5.2 & 4.8423 & TST & \\
\hline CHEMBL3210359 & 688889 & 4.25 & 4.6957 & TRN & \\
\hline CHEMBL1497405 & 688889 & 4.4 & 4.8788 & TRN & \\
\hline CHEMBL1341609 & 688889 & 4.25 & 4.8396 & TRN & \\
\hline CHEMBL1429013 & 688889 & 4.3 & 4.7531 & TST & \\
\hline CHEMBL1566817 & 688889 & 4.25 & 4.8943 & TRN & \\
\hline
\end{tabular}




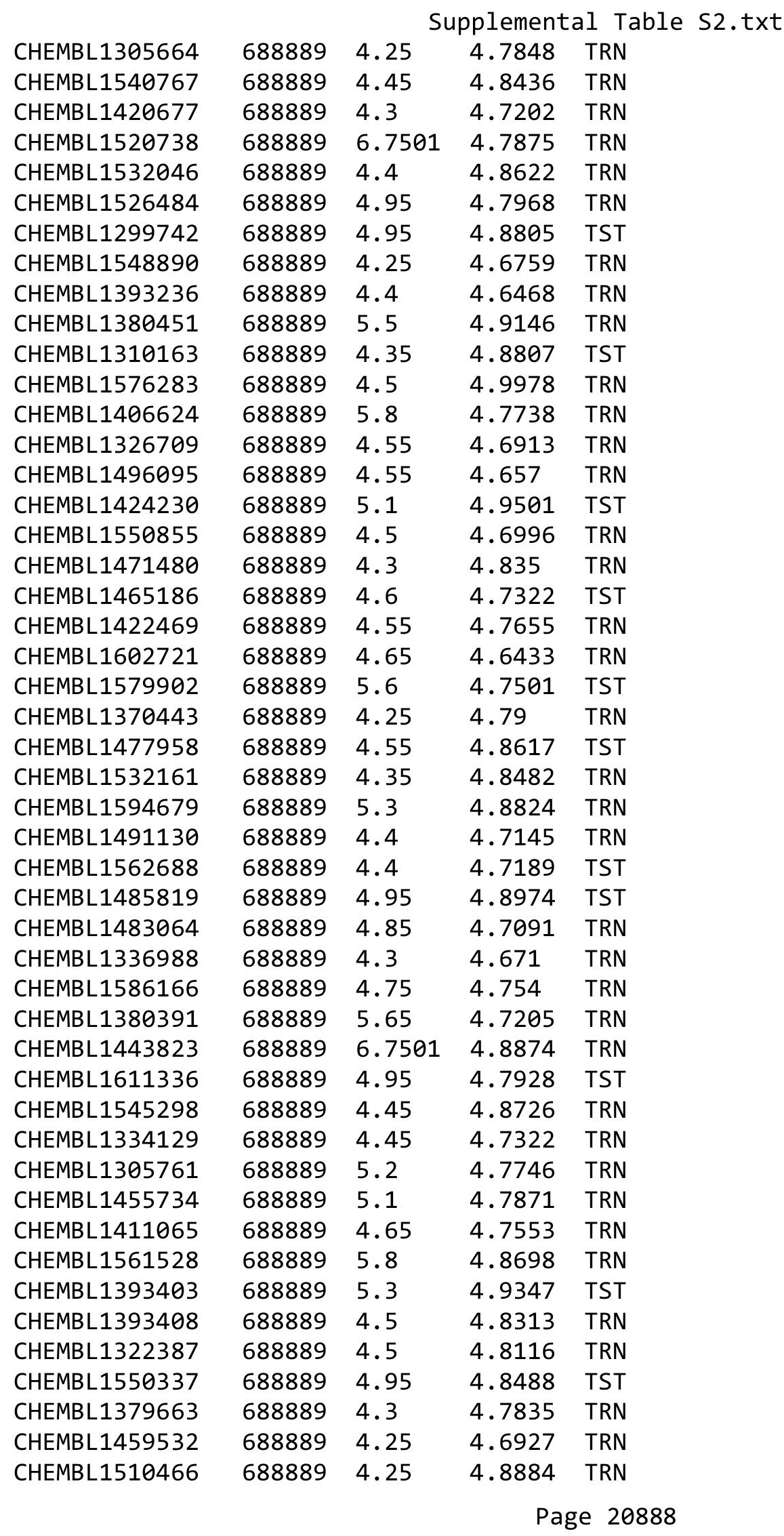




\begin{tabular}{|c|c|c|c|c|c|}
\hline \multicolumn{6}{|c|}{ Supplemental Table S2.txt } \\
\hline CHEMBL1352845 & 688889 & 4.45 & 4.7929 & TRN & \\
\hline CHEMBL1460513 & 688889 & 4.75 & 4.7326 & TRN & \\
\hline CHEMBL1491750 & 688889 & 5.85 & 4.76 & TST & \\
\hline CHEMBL1491940 & 688889 & 4.8 & 4.90300 & 00000000005 & TRN \\
\hline CHEMBL1511325 & 688889 & 4.35 & 4.7945 & TST & \\
\hline CHEMBL1495510 & 688889 & 4.35 & 4.7143 & TRN & \\
\hline CHEMBL1415753 & 688889 & 4.35 & 4.8471 & TST & \\
\hline CHEMBL1533972 & 688889 & 4.4 & 4.8138 & TRN & \\
\hline CHEMBL1319597 & 688889 & 4.45 & 4.6118 & TRN & \\
\hline CHEMBL1507509 & 688889 & 6.05 & 4.6242 & TRN & \\
\hline CHEMBL50175 & 688889 & 4.55 & 4.7204 & TRN & \\
\hline CHEMBL1497836 & 688889 & 4.3 & 4.6722 & TRN & \\
\hline CHEMBL3209241 & 688889 & 4.55 & 4.8411 & TRN & \\
\hline CHEMBL1510853 & 688889 & 4.4 & 4.8452 & TST & \\
\hline CHEMBL1561835 & 688889 & 4.5 & 4.6827 & TST & \\
\hline CHEMBL1550445 & 688889 & 4.3 & 4.6478 & TST & \\
\hline CHEMBL1350911 & 688889 & 4.95 & 4.7612 & TST & \\
\hline CHEMBL1383981 & 688889 & 4.25 & 4.7893 & TRN & \\
\hline CHEMBL1563947 & 688889 & 4.45 & 4.673 & TRN & \\
\hline CHEMBL1458516 & 688889 & 4.45 & 4.8478 & TRN & \\
\hline CHEMBL1384659 & 688889 & 4.9 & 4.6903 & TRN & \\
\hline CHEMBL1478612 & 688889 & 4.45 & 4.7213 & TRN & \\
\hline CHEMBL1391705 & 688889 & 5.3 & 4.7768 & TST & \\
\hline CHEMBL1304258 & 688889 & 4.45 & 4.6558 & TRN & \\
\hline CHEMBL1322401 & 688889 & 4.75 & 4.6863 & TRN & \\
\hline CHEMBL1560264 & 688889 & 4.3 & 4.9546 & TRN & \\
\hline CHEMBL1543163 & 688889 & 4.95 & 4.6756 & TST & \\
\hline CHEMBL1438192 & 688889 & 4.3 & 4.9586 & TST & \\
\hline CHEMBL1583721 & 688889 & 4.3 & 4.8062 & TST & \\
\hline CHEMBL1404262 & 688889 & 6.7501 & 4.9099 & TRN & \\
\hline CHEMBL1442764 & 688889 & 4.95 & 4.7521 & TST & \\
\hline CHEMBL1319663 & 688889 & 4.25 & 4.8956 & TRN & \\
\hline CHEMBL1561918 & 688889 & 4.3 & 4.84 & TRN & \\
\hline CHEMBL1362157 & 688889 & 4.5 & 4.69300 & 00000000005 & TRN \\
\hline CHEMBL1417861 & 688889 & 4.9 & 4.8258 & TST & \\
\hline CHEMBL1416184 & 688889 & 6.7001 & 4.726 & TRN & \\
\hline CHEMBL1363809 & 688889 & 4.45 & 4.7434 & TRN & \\
\hline CHEMBL1539414 & 688889 & 4.3 & 4.8499 & TRN & \\
\hline CHEMBL1454924 & 688889 & 6.7501 & 4.6814 & TRN & \\
\hline CHEMBL1343473 & 688889 & 4.45 & 4.753 & TRN & \\
\hline CHEMBL1533401 & 688889 & 4.45 & 4.7776 & TRN & \\
\hline CHEMBL1347326 & 688889 & 4.25 & 4.7191 & TRN & \\
\hline CHEMBL1525562 & 688889 & 4.95 & 4.9742 & TRN & \\
\hline CHEMBL1375449 & 688889 & 6.7501 & 4.7546 & TRN & \\
\hline CHEMBL1386781 & 688889 & 6.8 & 4.7875 & TRN & \\
\hline CHEMBL329872 & 688889 & 4.3 & 4.8793 & TRN & \\
\hline CHEMBL3210818 & 688889 & 4.95 & 4.8247 & TST & \\
\hline CHEMBL1326844 & 688889 & 4.25 & 4.7675 & TRN & \\
\hline
\end{tabular}




\begin{tabular}{|c|c|c|c|c|}
\hline \multicolumn{5}{|c|}{ Supplemental Table S2.txt } \\
\hline CHEMBL1611957 & 688889 & 4.35 & 4.7993 & TRN \\
\hline CHEMBL3192081 & 688889 & 4.5 & 4.8191 & TRN \\
\hline CHEMBL1497813 & 688889 & 4.65 & 4.772 & TST \\
\hline CHEMBL1460359 & 688889 & 4.3 & 4.82100 & 0000000001 \\
\hline CHEMBL1481929 & 688889 & 4.9 & 4.9774 & TST \\
\hline CHEMBL1405964 & 688889 & 4.45 & 4.5839 & TRN \\
\hline CHEMBL1368832 & 688889 & 4.65 & 4.7745 & TST \\
\hline CHEMBL1389371 & 688889 & 4.6 & 4.7384 & TRN \\
\hline CHEMBL1492178 & 688889 & 4.35 & 4.727 & TRN \\
\hline CHEMBL1391098 & 688889 & 5.9 & 4.9022 & TRN \\
\hline CHEMBL1470706 & 688889 & 5.05 & 4.9095 & TRN \\
\hline CHEMBL1378414 & 688889 & 4.65 & 4.8188 & TRN \\
\hline CHEMBL1375741 & 688889 & 4.3 & 4.8525 & TST \\
\hline CHEMBL1588709 & 688889 & 4.7 & 4.8411 & TRN \\
\hline CHEMBL1362279 & 688889 & 4.55 & 4.7321 & TST \\
\hline CHEMBL1562125 & 688889 & 4.6 & 4.7389 & TRN \\
\hline CHEMBL1365495 & 688889 & 4.8 & 4.7655 & TRN \\
\hline CHEMBL1526257 & 688889 & 4.6 & 4.6987 & TRN \\
\hline CHEMBL1341971 & 688889 & 5.15 & 4.8024 & TST \\
\hline CHEMBL1429833 & 688889 & 4.9 & 4.9583 & TST \\
\hline CHEMBL3214611 & 688889 & 4.4 & 4.8332 & TRN \\
\hline CHEMBL1353312 & 688889 & 4.35 & 4.7889 & TRN \\
\hline CHEMBL1580948 & 688889 & 4.55 & 4.8056 & TST \\
\hline CHEMBL1387725 & 688889 & 5.05 & 4.6614 & TRN \\
\hline CHEMBL1607909 & 688889 & 4.3 & 4.9825 & TST \\
\hline CHEMBL1570750 & 688889 & 4.55 & 4.7338 & TRN \\
\hline CHEMBL1581575 & 688889 & 4.95 & 4.8632 & TST \\
\hline CHEMBL1574574 & 688889 & 4.45 & 4.7055 & TRN \\
\hline CHEMBL1490263 & 688889 & 4.25 & 4.9761 & TRN \\
\hline CHEMBL1564133 & 688889 & 4.4 & 4.8757 & TRN \\
\hline CHEMBL1504349 & 688889 & 4.5 & 4.7072 & TST \\
\hline CHEMBL1433195 & 688889 & 4.35 & 4.7539 & TRN \\
\hline CHEMBL1413452 & 688889 & 4.95 & 4.9182 & TRN \\
\hline CHEMBL1462721 & 688889 & 4.4 & 4.8345 & TRN \\
\hline CHEMBL1328085 & 688889 & 4.45 & 4.7251 & TRN \\
\hline CHEMBL1399650 & 688889 & 4.4 & 4.7223 & TRN \\
\hline CHEMBL1611681 & 688889 & 4.45 & 4.766 & TRN \\
\hline CHEMBL1451657 & 688889 & 4.65 & 4.8556 & TRN \\
\hline CHEMBL1506360 & 688889 & 4.3 & 4.7267 & TRN \\
\hline CHEMBL1559146 & 688889 & 4.25 & 4.8282 & TRN \\
\hline CHEMBL1607116 & 688889 & 5.45 & 4.75 & TRN \\
\hline CHEMBL1563647 & 688889 & 4.5 & 4.7839 & TRN \\
\hline CHEMBL1431889 & 688889 & 5.25 & 4.8751 & TRN \\
\hline CHEMBL1309830 & 688889 & 4.35 & 4.9234 & TRN \\
\hline CHEMBL1577399 & 688889 & 4.25 & 4.6675 & TRN \\
\hline CHEMBL1540563 & 688889 & 5.25 & 4.993 & TRN \\
\hline CHEMBL1578828 & 688889 & 5.05 & 4.8743 & TRN \\
\hline CHEMBL1565685 & 688889 & 4.55 & 4.7543 & TRN \\
\hline
\end{tabular}




\begin{tabular}{|c|c|c|c|c|}
\hline \multicolumn{5}{|c|}{ Supplemental Table S2.txt } \\
\hline CHEMBL1488485 & 688889 & 5.05 & 4.6664 & TRN \\
\hline CHEMBL1507666 & 688889 & 4.3 & 4.9277 & TST \\
\hline CHEMBL1362210 & 688889 & 4.25 & 4.8679 & TRN \\
\hline CHEMBL1374563 & 688889 & 4.3 & 4.728 & TRN \\
\hline CHEMBL1406316 & 688889 & 4.6 & 4.743 & TRN \\
\hline CHEMBL1602059 & 688889 & 4.9 & 4.81 & TRN \\
\hline CHEMBL1455256 & 688889 & 4.4 & 4.7199 & TRN \\
\hline CHEMBL3195002 & 688889 & 4.55 & 4.6893 & TRN \\
\hline CHEMBL1391377 & 688889 & 4.25 & 4.8336 & TRN \\
\hline CHEMBL1440643 & 688889 & 4.4 & 4.8083 & TRN \\
\hline CHEMBL1307244 & 688889 & 4.45 & 4.6828 & TRN \\
\hline CHEMBL1578119 & 688889 & 4.25 & 4.8169 & TST \\
\hline CHEMBL1303501 & 688889 & 4.95 & 4.9381 & TRN \\
\hline CHEMBL 3211694 & 688889 & 4.95 & 4.7088 & TRN \\
\hline CHEMBL1383237 & 688889 & 5.3 & 4.8432 & TRN \\
\hline CHEMBL1360790 & 688889 & 4.4 & 4.81 & TRN \\
\hline CHEMBL1464696 & 688889 & 5.45 & 4.8149 & TST \\
\hline CHEMBL1366734 & 688889 & 4.4 & 4.9054 & TST \\
\hline CHEMBL1613285 & 688889 & 4.6 & 4.8171 & TRN \\
\hline CHEMBL1326303 & 688889 & 5.5 & 4.9335 & TRN \\
\hline CHEMBL1339433 & 688889 & 4.75 & 4.9053 & TRN \\
\hline CHEMBL1501855 & 688889 & 5.25 & 4.7438 & TRN \\
\hline CHEMBL1572758 & 688889 & 4.8 & 4.6286 & TRN \\
\hline CHEMBL1452610 & 688889 & 4.25 & 4.7203 & TRN \\
\hline CHEMBL1599269 & 688889 & 4.25 & 4.7612 & TRN \\
\hline CHEMBL1348338 & 688889 & 4.95 & 4.8018 & TRN \\
\hline CHEMBL1362961 & 688889 & 4.4 & 4.8916 & TRN \\
\hline CHEMBL1609742 & 688889 & 5.85 & 4.8561 & TRN \\
\hline CHEMBL1388564 & 688889 & 5.35 & 4.7091 & TST \\
\hline CHEMBL1528741 & 688889 & 4.5 & 4.9604 & TRN \\
\hline CHEMBL1403563 & 688889 & 4.25 & 4.8421 & TRN \\
\hline CHEMBL1307549 & 688889 & 5.5 & 4.7472 & TRN \\
\hline CHEMBL3392060 & 688889 & 6.05 & 4.823 & TST \\
\hline CHEMBL1472274 & 688889 & 4.6 & 4.8299 & TRN \\
\hline CHEMBL1371837 & 688889 & 5.6 & 4.9224 & TST \\
\hline CHEMBL1439877 & 688889 & 5.4 & 4.8416 & TST \\
\hline CHEMBL1386395 & 688889 & 4.95 & 4.9016 & TRN \\
\hline CHEMBL1577846 & 688889 & 4.9 & 4.7258 & TRN \\
\hline CHEMBL1489263 & 688889 & 4.9 & 4.9296 & TST \\
\hline CHEMBL1540526 & 688889 & 4.25 & 4.8882 & TRN \\
\hline CHEMBL1464698 & 688889 & 4.55 & 4.7823 & TRN \\
\hline CHEMBL1490352 & 688889 & 4.6 & 4.8208 & TRN \\
\hline CHEMBL1367677 & 688889 & 4.4 & 4.7035 & TRN \\
\hline CHEMBL1387667 & 688889 & 5.85 & 4.9158 & TRN \\
\hline CHEMBL1562277 & 688889 & 4.25 & 4.8287 & TRN \\
\hline CHEMBL1444280 & 688889 & 4.4 & 4.8243 & TRN \\
\hline CHEMBL1402555 & 688889 & 4.25 & 4.8051 & TRN \\
\hline CHEMBL1415559 & 688889 & 4.85 & 4.8475 & TRN \\
\hline
\end{tabular}




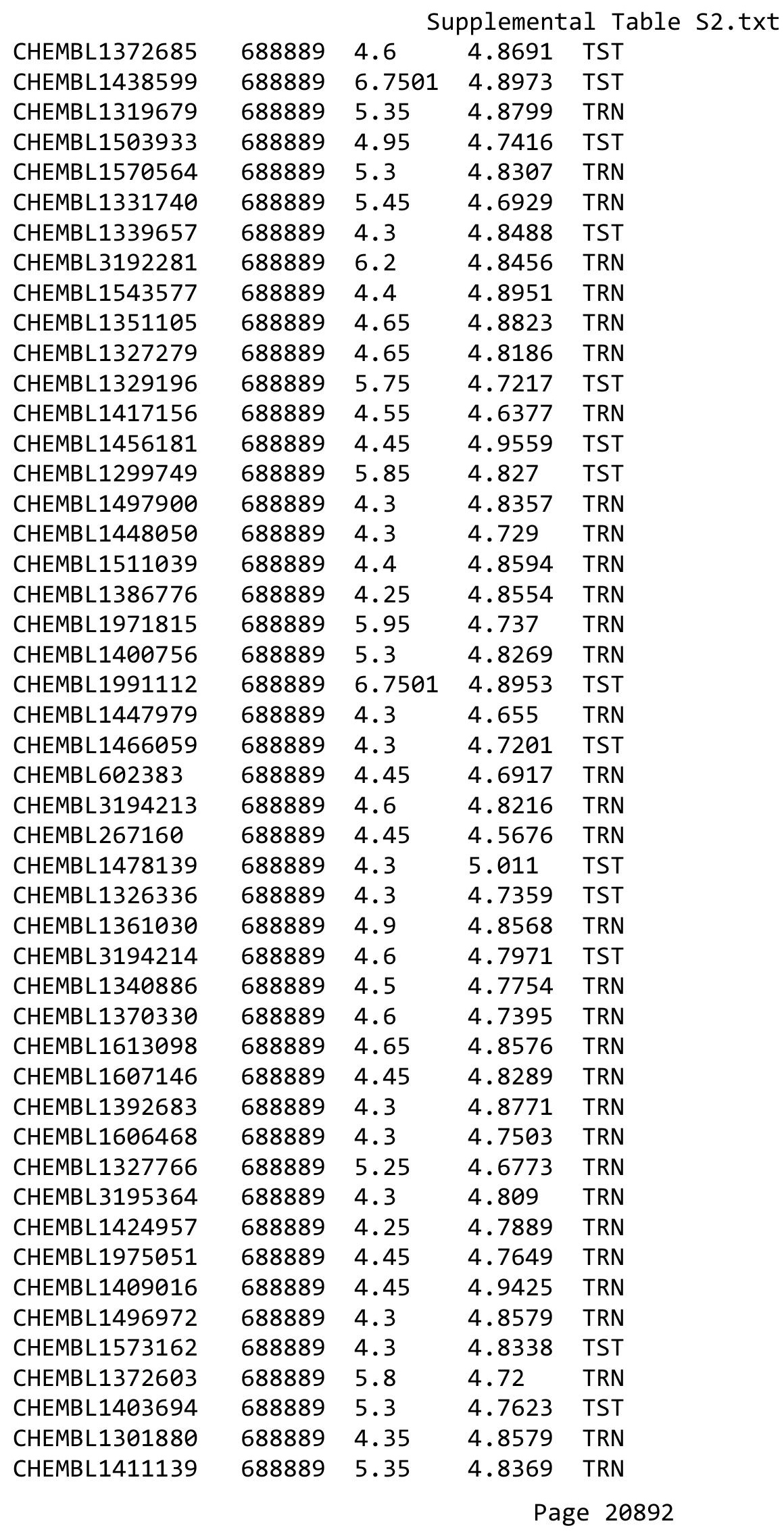




\begin{tabular}{|c|c|c|c|c|c|}
\hline \\
\hline CHEMBL1414789 & 688889 & 4.9 & 4.7492 & TRN & \\
\hline CHEMBL1497403 & 688889 & 5.3 & 4.793 & TST & \\
\hline CHEMBL1430609 & 688889 & 4.3 & 4.8425 & TRN & \\
\hline CHEMBL1495404 & 688889 & 5.2 & 4.7185 & TRN & \\
\hline CHEMBL1403739 & 688889 & 4.25 & 4.8892 & TST & \\
\hline CHEMBL1578074 & 688889 & 4.25 & 4.9241 & TRN & \\
\hline CHEMBL1326832 & 688889 & 4.25 & 4.7242 & TRN & \\
\hline CHEMBL1432443 & 688889 & 4.4 & 4.6733 & TRN & \\
\hline CHEMBL1449298 & 688889 & 4.25 & 4.7522 & TRN & \\
\hline CHEMBL1461852 & 688889 & 4.6 & 4.8583 & TRN & \\
\hline CHEMBL1564272 & 688889 & 4.4 & 4.9014 & TRN & \\
\hline CHEMBL1381712 & 688889 & 4.3 & 4.7342 & TST & \\
\hline CHEMBL1348637 & 688889 & 4.3 & 4.9401 & TRN & \\
\hline CHEMBL1511134 & 688889 & 5.35 & 4.8536 & TRN & \\
\hline CHEMBL1598241 & 688889 & 4.9 & 4.80399 & 9999999999 & TRN \\
\hline CHEMBL1426603 & 688889 & 4.3 & 4.7757 & TST & \\
\hline CHEMBL1537574 & 688889 & 4.85 & 4.8458 & TRN & \\
\hline CHEMBL1509434 & 688889 & 4.45 & 4.79899 & 99999999995 & TST \\
\hline CHEMBL1368775 & 688889 & 4.35 & 4.7934 & TRN & \\
\hline CHEMBL1483995 & 688889 & 4.25 & 4.8413 & TRN & \\
\hline CHEMBL1313927 & 688889 & 4.45 & 4.6867 & TRN & \\
\hline CHEMBL1534569 & 688889 & 4.25 & 4.7355 & TRN & \\
\hline CHEMBL1549694 & 688889 & 5.35 & 4.9158 & TRN & \\
\hline CHEMBL1340672 & 688889 & 4.45 & 4.8377 & TRN & \\
\hline CHEMBL1583769 & 688889 & 4.35 & 4.8719 & TRN & \\
\hline CHEMBL1445247 & 688889 & 6.7001 & 4.7285 & TRN & \\
\hline CHEMBL1545749 & 688889 & 4.3 & 4.7806 & TRN & \\
\hline CHEMBL1443775 & 688889 & 5.55 & 4.8995 & TRN & \\
\hline CHEMBL1350552 & 688889 & 4.35 & 4.8079 & TRN & \\
\hline CHEMBL1578843 & 688889 & 4.35 & 4.7675 & TST & \\
\hline CHEMBL1972915 & 688889 & 4.4 & 4.6934 & TRN & \\
\hline CHEMBL1358783 & 688889 & 4.9 & 4.8887 & TRN & \\
\hline CHEMBL1569236 & 688889 & 4.45 & 4.7741 & TST & \\
\hline CHEMBL1567818 & 688889 & 4.25 & 4.8044 & TRN & \\
\hline CHEMBL1604505 & 688889 & 4.3 & 4.69 & TRN & \\
\hline CHEMBL1588350 & 688889 & 6.05 & 4.8118 & TST & \\
\hline CHEMBL1508938 & 688889 & 5.0 & 4.9107 & TRN & \\
\hline CHEMBL1524044 & 688889 & 4.3 & 4.7897 & TRN & \\
\hline CHEMBL1424362 & 688889 & 4.4 & 4.7895 & TRN & \\
\hline CHEMBL1588367 & 688889 & 4.25 & 4.6617 & TST & \\
\hline CHEMBL1440373 & 688889 & 4.25 & 4.8928 & TRN & \\
\hline CHEMBL1575996 & 688889 & 5.9 & 4.8772 & TRN & \\
\hline CHEMBL1419081 & 688889 & 4.5 & 4.7851 & TST & \\
\hline CHEMBL1566919 & 688889 & 4.95 & 4.8052 & TST & \\
\hline CHEMBL1423759 & 688889 & 5.35 & 4.8003 & TRN & \\
\hline CHEMBL1505053 & 688889 & 4.55 & 4.851 & TRN & \\
\hline CHEMBL1345989 & 688889 & 4.45 & 4.7971 & TRN & \\
\hline CHEMBL1340125 & 688889 & 4.55 & 4.6459 & TRN & \\
\hline
\end{tabular}




\begin{tabular}{|c|c|c|c|c|c|}
\hline \multicolumn{6}{|c|}{ Supplemental Table S2.txt } \\
\hline CHEMBL1333249 & 688889 & 4.5 & 4.59 & TRN & \\
\hline CHEMBL1603658 & 688889 & 4.95 & 4.8214 & TST & \\
\hline CHEMBL1309148 & 688889 & 4.8 & 4.6504 & TRN & \\
\hline CHEMBL1524910 & 688889 & 4.75 & 4.9089 & TRN & \\
\hline CHEMBL1438721 & 688889 & 4.45 & 4.7138 & TRN & \\
\hline CHEMBL1319746 & 688889 & 5.7 & 4.859 & TRN & \\
\hline CHEMBL3193318 & 688889 & 4.65 & 4.8892 & TRN & \\
\hline CHEMBL1393739 & 688889 & 4.9 & 4.7347 & TRN & \\
\hline CHEMBL1603093 & 688889 & 4.7 & 4.8918 & TST & \\
\hline CHEMBL1340843 & 688889 & 4.3 & 4.8165 & TST & \\
\hline CHEMBL1567154 & 688889 & 5.0 & 4.6919 & TRN & \\
\hline CHEMBL1405152 & 688889 & 6.7501 & 4.8029 & TST & \\
\hline CHEMBL1594218 & 688889 & 5.8 & 4.7459 & TST & \\
\hline CHEMBL1565423 & 688889 & 4.45 & 4.9242 & TST & \\
\hline CHEMBL1530948 & 688889 & 4.55 & 4.8032 & TRN & \\
\hline CHEMBL1301301 & 688889 & 4.3 & 4.8123 & TRN & \\
\hline CHEMBL3194674 & 688889 & 6.15 & 4.8162 & TRN & \\
\hline CHEMBL1534873 & 688889 & 4.25 & 4.8347 & TRN & \\
\hline CHEMBL1535921 & 688889 & 4.9 & 4.6039 & TRN & \\
\hline CHEMBL1339979 & 688889 & 4.25 & 4.8988 & TST & \\
\hline CHEMBL1388206 & 688889 & 4.5 & 4.7335 & TRN & \\
\hline CHEMBL1896972 & 688889 & 4.75 & 4.7011 & TRN & \\
\hline CHEMBL1596975 & 688889 & 5.35 & 4.8167 & TRN & \\
\hline CHEMBL1524735 & 688889 & 4.25 & 4.8443 & TST & \\
\hline CHEMBL1438221 & 688889 & 4.3 & 4.8618 & TRN & \\
\hline CHEMBL1462912 & 688889 & 4.3 & 4.9501 & TRN & \\
\hline CHEMBL1588805 & 688889 & 4.95 & 4.7073 & TRN & \\
\hline CHEMBL1536016 & 688889 & 4.45 & 4.6323 & TRN & \\
\hline CHEMBL1389627 & 688889 & 4.95 & 4.6835 & TRN & \\
\hline CHEMBL1507595 & 688889 & 5.4 & 4.7823 & TRN & \\
\hline CHEMBL1585962 & 688889 & 4.65 & 4.8335 & TST & \\
\hline CHEMBL1441898 & 688889 & 4.3 & 4.7611 & TRN & \\
\hline CHEMBL1515681 & 688889 & 4.4 & 4.7418 & TRN & \\
\hline CHEMBL1329107 & 688889 & 6.7501 & 4.8973 & TRN & \\
\hline CHEMBL1360170 & 688889 & 4.25 & 4.7376 & TRN & \\
\hline CHEMBL1489148 & 688889 & 5.6 & 4.7826 & TRN & \\
\hline CHEMBL1426108 & 688889 & 5.7 & 4.6584 & TST & \\
\hline CHEMBL3196877 & 688889 & 4.95 & 4.6994 & TRN & \\
\hline CHEMBL1385359 & 688889 & 4.3 & 4.7847 & TRN & \\
\hline CHEMBL1460216 & 688889 & 5.25 & 4.9449 & TRN & \\
\hline CHEMBL1432893 & 688889 & 4.3 & 4.8118 & TRN & \\
\hline CHEMBL1320414 & 688889 & 4.25 & 4.9251 & TRN & \\
\hline CHEMBL3192288 & 688889 & 4.25 & 4.7996 & TRN & \\
\hline CHEMBL1431724 & 688889 & 6.5501 & 4.7364 & TST & \\
\hline CHEMBL1582072 & 688889 & 4.95 & 4.8281 & TST & \\
\hline CHEMBL1305091 & 688889 & 4.45 & 4.6148 & TRN & \\
\hline CHEMBL1534459 & 688889 & 4.9 & 4.8087 & TST & \\
\hline CHEMBL1326246 & 688889 & 4.3 & 4.63399 & 99999999995 & TRN \\
\hline & & & & 2089 & \\
\hline
\end{tabular}




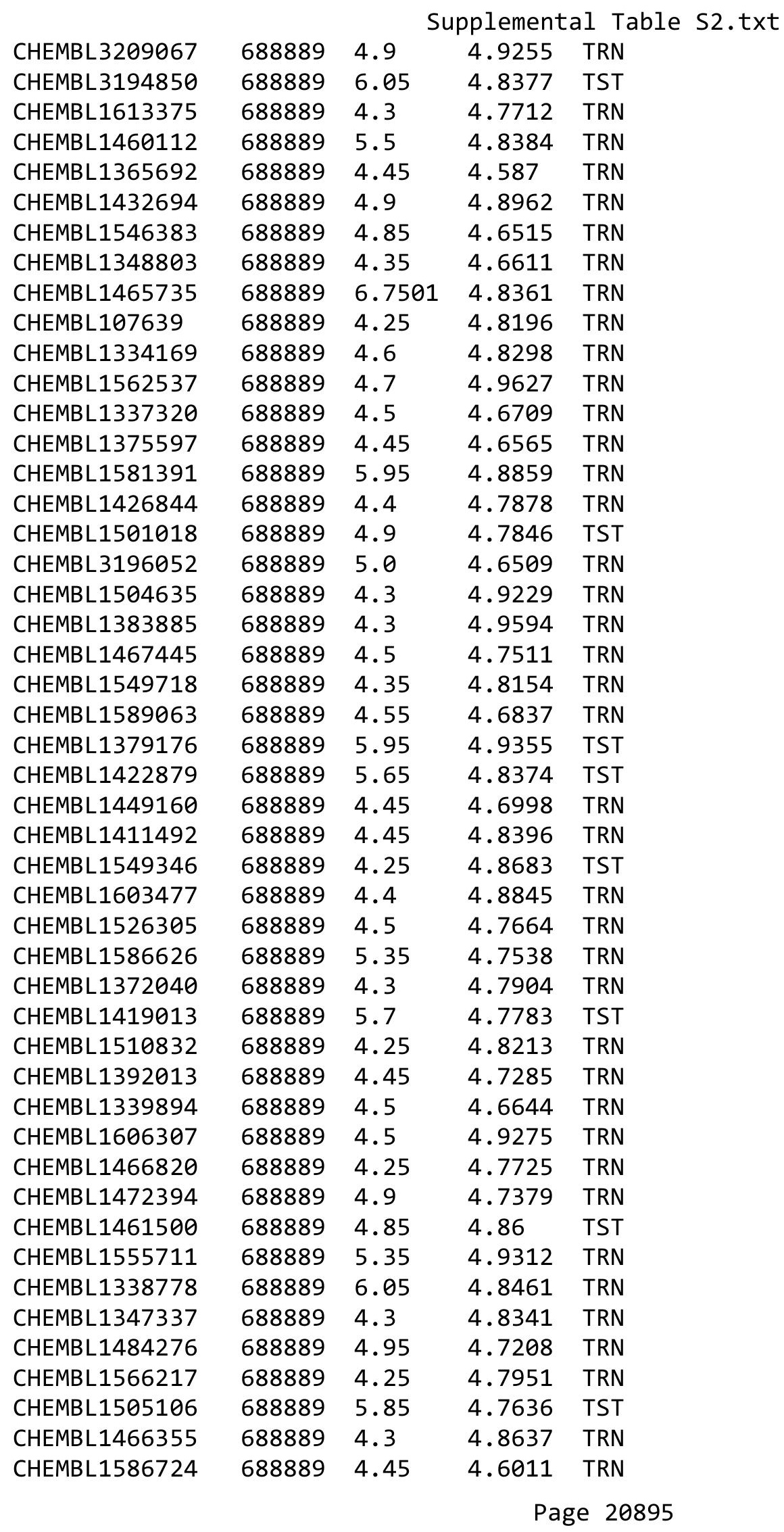




\begin{tabular}{|c|c|c|c|c|}
\hline \multicolumn{5}{|c|}{ Supplemental Table S2.txt } \\
\hline CHEMBL 2007056 & 688889 & 6.0 & 4.7546 & TST \\
\hline CHEMBL1589093 & 688889 & 4.25 & 4.7277 & TST \\
\hline CHEMBL1419878 & 688889 & 4.95 & 4.8977 & TST \\
\hline CHEMBL1472368 & 688889 & 6.7501 & 4.7017 & TST \\
\hline CHEMBL1323994 & 688889 & 4.45 & 4.6945 & TRN \\
\hline CHEMBL1399477 & 688889 & 4.3 & 4.715 & TRN \\
\hline CHEMBL1444947 & 688889 & 6.0 & 4.7719 & TRN \\
\hline CHEMBL1334789 & 688889 & 4.7 & 4.8855 & TST \\
\hline CHEMBL1517909 & 688889 & 4.5 & 4.6903 & TRN \\
\hline CHEMBL1609759 & 688889 & 5.35 & 4.6673 & TST \\
\hline CHEMBL1597783 & 688889 & 5.6 & 4.7517 & TRN \\
\hline CHEMBL1359087 & 688889 & 4.6 & 4.7815 & TRN \\
\hline CHEMBL1312419 & 688889 & 4.35 & 4.7369 & TRN \\
\hline CHEMBL1485346 & 688889 & 4.3 & 4.829 & TRN \\
\hline CHEMBL1548888 & 688889 & 5.45 & 4.7894 & TST \\
\hline CHEMBL1342564 & 688889 & 5.55 & 4.7877 & TRN \\
\hline CHEMBL1479660 & 688889 & 5.35 & 4.7681 & TRN \\
\hline CHEMBL1426998 & 688889 & 5.65 & 4.9002 & TRN \\
\hline CHEMBL1321038 & 688889 & 4.4 & 4.8189 & TRN \\
\hline CHEMBL1346710 & 688889 & 4.95 & 4.913 & TRN \\
\hline CHEMBL1605537 & 688889 & 4.95 & 4.8639 & TRN \\
\hline CHEMBL1569154 & 688889 & 4.75 & 4.7819 & TRN \\
\hline CHEMBL1484830 & 688889 & 6.8 & 5.0071 & TST \\
\hline CHEMBL1519904 & 688889 & 4.45 & 4.7321 & TRN \\
\hline CHEMBL1349645 & 688889 & 5.85 & 4.8935 & TRN \\
\hline CHEMBL1399755 & 688889 & 4.25 & 4.832 & TRN \\
\hline CHEMBL1573945 & 688889 & 4.3 & 4.8646 & TST \\
\hline CHEMBL1336039 & 688889 & 4.45 & 4.6729 & TRN \\
\hline CHEMBL1466660 & 688889 & 5.45 & 4.95 & TRN \\
\hline CHEMBL1359995 & 688889 & 4.25 & 4.8936 & TRN \\
\hline CHEMBL 2143754 & 688889 & 6.05 & 4.7718 & TRN \\
\hline CHEMBL1480978 & 688889 & 4.8 & 4.713 & TRN \\
\hline CHEMBL1442986 & 688889 & 4.5 & 4.8195 & TRN \\
\hline CHEMBL1501053 & 688889 & 4.7 & 4.7565 & TRN \\
\hline CHEMBL 3198558 & 688889 & 5.55 & 4.8625 & TRN \\
\hline CHEMBL1539483 & 688889 & 4.7 & 4.6859 & TRN \\
\hline CHEMBL1447938 & 688889 & 5.3 & 4.7635 & TRN \\
\hline CHEMBL1582324 & 688889 & 4.25 & 4.7628 & TRN \\
\hline CHEMBL1408527 & 688889 & 4.9 & 4.9545 & TRN \\
\hline CHEMBL1611423 & 688889 & 6.0 & 4.7603 & TRN \\
\hline CHEMBL1569472 & 688889 & 4.4 & 4.7893 & TRN \\
\hline CHEMBL1600213 & 688889 & 4.25 & 4.7004 & TST \\
\hline CHEMBL1588679 & 688889 & 4.25 & 4.8425 & TRN \\
\hline CHEMBL1489726 & 688889 & 5.85 & 4.9979 & TRN \\
\hline CHEMBL1385293 & 688889 & 5.8 & 4.8472 & TRN \\
\hline CHEMBL1604596 & 688889 & 4.95 & 4.7831 & TST \\
\hline CHEMBL1334936 & 688889 & 4.35 & 4.7611 & TRN \\
\hline CHEMBL1408447 & 688889 & 4.45 & 4.8436 & TRN \\
\hline
\end{tabular}




\begin{tabular}{|c|c|c|c|c|c|}
\hline \multicolumn{6}{|c|}{ Supplemental Table S2.txt } \\
\hline CHEMBL1304688 & 688889 & 5.95 & 4.8058 & TST & \\
\hline CHEMBL1549986 & 688889 & 4.4 & 4.6876 & TRN & \\
\hline CHEMBL1303512 & 688889 & 5.25 & 4.8797 & TRN & \\
\hline CHEMBL1387582 & 688889 & 4.4 & 4.77800 & 00000000005 & TRN \\
\hline CHEMBL1382947 & 688889 & 4.5 & 4.9283 & TRN & \\
\hline CHEMBL1508882 & 688889 & 4.3 & 4.7844 & TRN & \\
\hline CHEMBL1313486 & 688889 & 4.45 & 4.8403 & TRN & \\
\hline CHEMBL1499148 & 688889 & 4.25 & 4.8308 & TRN & \\
\hline CHEMBL1604736 & 688889 & 4.3 & 4.7807 & TRN & \\
\hline CHEMBL1360534 & 688889 & 4.7 & 4.8112 & TRN & \\
\hline CHEMBL1576947 & 688889 & 4.45 & 4.8244 & TRN & \\
\hline CHEMBL1467599 & 688889 & 6.15 & 4.7896 & TRN & \\
\hline CHEMBL1579456 & 688889 & 4.25 & 4.755 & TRN & \\
\hline CHEMBL1543165 & 688889 & 4.95 & 4.8178 & TRN & \\
\hline CHEMBL1484697 & 688889 & 5.15 & 4.8041 & TRN & \\
\hline CHEMBL1467503 & 688889 & 4.3 & 4.8202 & TRN & \\
\hline CHEMBL1565940 & 688889 & 5.35 & 4.8439 & TRN & \\
\hline CHEMBL1606346 & 688889 & 4.65 & 4.8031 & TRN & \\
\hline CHEMBL1450879 & 688889 & 5.65 & 4.6959 & TRN & \\
\hline CHEMBL1612842 & 688889 & 4.6 & 4.9025 & TRN & \\
\hline CHEMBL3193648 & 688889 & 4.45 & 4.8101 & TRN & \\
\hline CHEMBL1534430 & 688889 & 4.4 & 4.8074 & TRN & \\
\hline CHEMBL1548347 & 688889 & 4.35 & 4.7888 & TST & \\
\hline CHEMBL 3193274 & 688889 & 4.9 & 4.6417 & TRN & \\
\hline CHEMBL1337115 & 688889 & 6.8 & 4.8606 & TRN & \\
\hline CHEMBL1443903 & 688889 & 4.5 & 4.8091 & TRN & \\
\hline CHEMBL1478967 & 688889 & 5.0 & 4.70100 & 00000000005 & TRN \\
\hline CHEMBL1566900 & 688889 & 4.9 & 4.9278 & TRN & \\
\hline CHEMBL1498488 & 688889 & 5.25 & 4.646 & TST & \\
\hline CHEMBL1455399 & 688889 & 4.5 & 4.9898 & TRN & \\
\hline CHEMBL1518110 & 688889 & 4.25 & 4.7765 & TRN & \\
\hline CHEMBL1568373 & 688889 & 4.65 & 4.721 & TRN & \\
\hline CHEMBL1469476 & 688889 & 5.15 & 4.7947 & TRN & \\
\hline CHEMBL1531155 & 688889 & 5.3 & 4.8141 & TRN & \\
\hline CHEMBL1559722 & 688889 & 4.45 & 4.9838 & TRN & \\
\hline CHEMBL1570282 & 688889 & 5.5 & 4.7329 & TRN & \\
\hline CHEMBL1468011 & 688889 & 4.45 & 4.6882 & TRN & \\
\hline CHEMBL1413933 & 688889 & 4.95 & 4.8021 & TST & \\
\hline CHEMBL1323468 & 688889 & 4.3 & 4.9008 & TRN & \\
\hline CHEMBL1299710 & 688889 & 4.45 & 4.9003 & TST & \\
\hline CHEMBL1598440 & 688889 & 4.55 & 4.8225 & TST & \\
\hline CHEMBL 1410021 & 688889 & 5.4 & 4.7686 & TRN & \\
\hline CHEMBL1331702 & 688889 & 4.8 & 4.6315 & TST & \\
\hline CHEMBL1542359 & 688889 & 4.85 & 4.9747 & TRN & \\
\hline CHEMBL1400512 & 688889 & 5.45 & 4.7568 & TST & \\
\hline CHEMBL1307271 & 688889 & 6.25 & 4.7129 & TST & \\
\hline CHEMBL1529197 & 688889 & 4.45 & 4.6062 & TRN & \\
\hline CHEMBL1325533 & 688889 & 4.25 & 4.7758 & TRN & \\
\hline
\end{tabular}




\begin{tabular}{|c|c|c|c|c|}
\hline \multicolumn{5}{|c|}{ Supplemental Table S2.txt } \\
\hline CHEMBL1565243 & 688889 & 6.7501 & 4.8693 & TST \\
\hline CHEMBL1584632 & 688889 & 4.3 & 4.8737 & TRN \\
\hline CHEMBL1589470 & 688889 & 5.1 & 4.8218 & TST \\
\hline CHEMBL1309167 & 688889 & 4.25 & 4.7454 & TST \\
\hline CHEMBL1325942 & 688889 & 4.3 & 4.8021 & TST \\
\hline CHEMBL1564638 & 688889 & 4.3 & 4.7482 & TRN \\
\hline CHEMBL1388270 & 688889 & 6.7501 & 4.7944 & TST \\
\hline CHEMBL1531066 & 688889 & 4.3 & 4.8883 & TRN \\
\hline CHEMBL544348 & 688889 & 4.35 & 4.6762 & TRN \\
\hline CHEMBL3194485 & 688889 & 4.55 & 4.8991 & TRN \\
\hline CHEMBL1604546 & 688889 & 4.35 & 4.7293 & TRN \\
\hline CHEMBL1362761 & 688889 & 4.35 & 4.7439 & TST \\
\hline CHEMBL1419125 & 688889 & 4.45 & 4.8891 & TRN \\
\hline CHEMBL1424918 & 688889 & 4.3 & 4.7505 & TST \\
\hline CHEMBL1340302 & 688889 & 4.4 & 4.8373 & TRN \\
\hline CHEMBL1387811 & 688889 & 4.35 & 4.9857 & TRN \\
\hline CHEMBL1598981 & 688889 & 4.5 & 4.7075 & TRN \\
\hline CHEMBL1601115 & 688889 & 4.85 & 4.7135 & TRN \\
\hline CHEMBL1563723 & 688889 & 4.25 & 4.7799 & TRN \\
\hline CHEMBL1403128 & 688889 & 4.45 & 4.8716 & TRN \\
\hline CHEMBL1374841 & 688889 & 4.35 & 4.606 & TRN \\
\hline CHEMBL3212159 & 688889 & 4.35 & 4.6964 & TRN \\
\hline CHEMBL1518909 & 688889 & 4.55 & 4.7946 & TRN \\
\hline CHEMBL1311827 & 688889 & 4.55 & 4.8531 & TRN \\
\hline CHEMBL1563582 & 688889 & 4.5 & 4.6786 & TRN \\
\hline CHEMBL1441020 & 688889 & 4.9 & 4.7549 & TRN \\
\hline CHEMBL1582262 & 688889 & 4.3 & 4.6867 & TRN \\
\hline CHEMBL3207829 & 688889 & 4.6 & 4.8948 & TRN \\
\hline CHEMBL1322374 & 688889 & 4.25 & 4.9089 & TRN \\
\hline CHEMBL1603365 & 688889 & 4.45 & 4.825 & TRN \\
\hline CHEMBL1557003 & 688889 & 4.5 & 4.7719 & TRN \\
\hline CHEMBL1364458 & 688889 & 4.45 & 4.7252 & TRN \\
\hline CHEMBL1495820 & 688889 & 4.25 & 4.8309 & TRN \\
\hline CHEMBL1471119 & 688889 & 4.25 & 4.854 & TRN \\
\hline CHEMBL1572134 & 688889 & 5.0 & 4.9437 & TRN \\
\hline CHEMBL1608504 & 688889 & 4.3 & 4.8074 & TRN \\
\hline CHEMBL1546502 & 688889 & 4.9 & 4.8295 & TRN \\
\hline CHEMBL1425073 & 688889 & 4.5 & 4.7122 & TRN \\
\hline CHEMBL1425249 & 688889 & 5.3 & 4.9419 & TRN \\
\hline CHEMBL1428977 & 688889 & 4.55 & 4.7276 & TRN \\
\hline CHEMBL3214344 & 688889 & 4.55 & 4.7726 & TRN \\
\hline CHEMBL1321438 & 688889 & 4.3 & 4.7872 & TRN \\
\hline CHEMBL1533322 & 688889 & 4.4 & 4.7764 & TRN \\
\hline CHEMBL1569573 & 688889 & 5.2 & 4.8758 & TRN \\
\hline CHEMBL1445726 & 688889 & 4.3 & 4.7966 & TST \\
\hline CHEMBL1487077 & 688889 & 4.95 & 4.9173 & TRN \\
\hline CHEMBL1424065 & 688889 & 4.3 & 4.6617 & TRN \\
\hline CHEMBL1328373 & 688889 & 5.1 & 4.5749 & TST \\
\hline
\end{tabular}




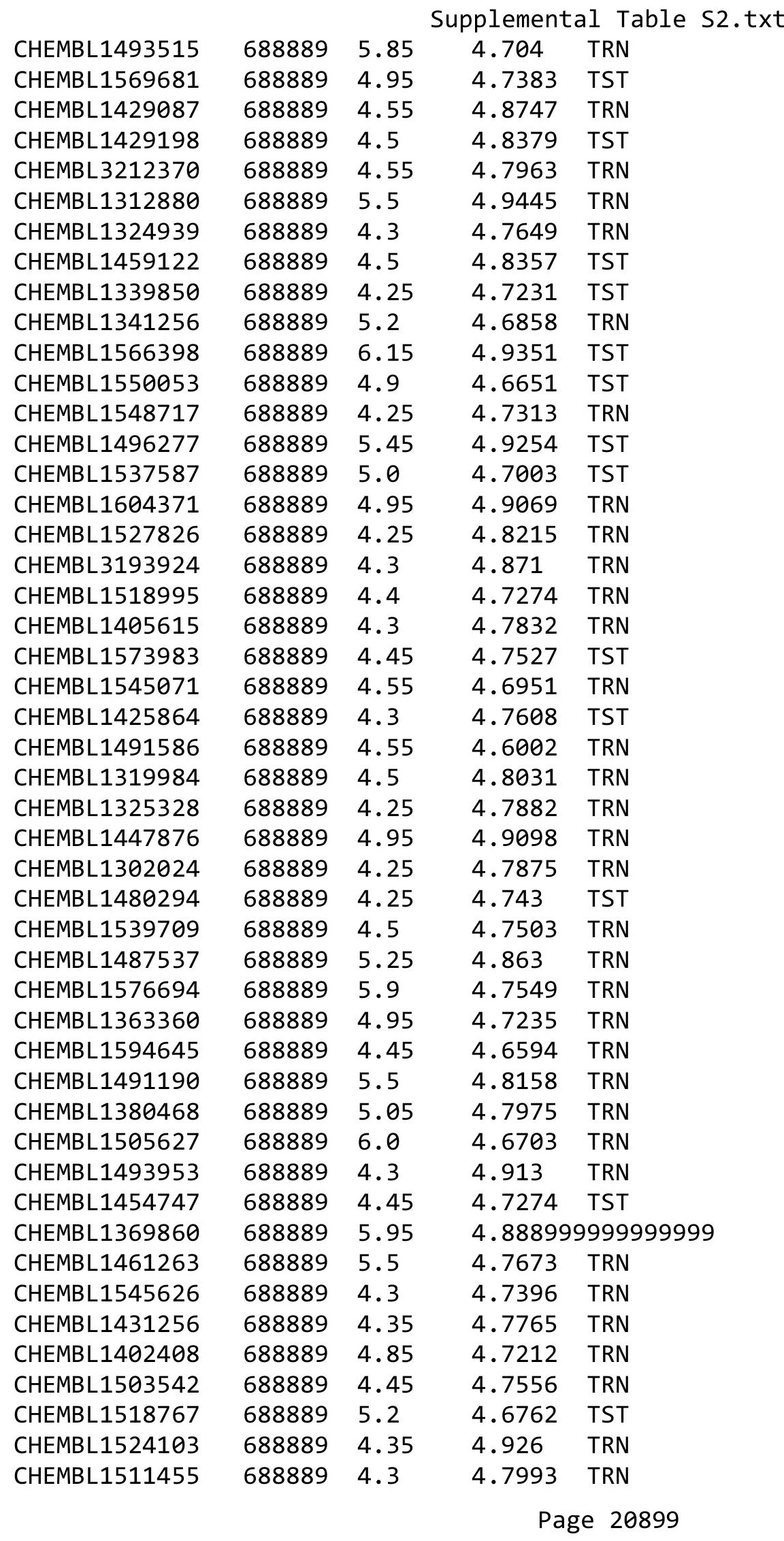




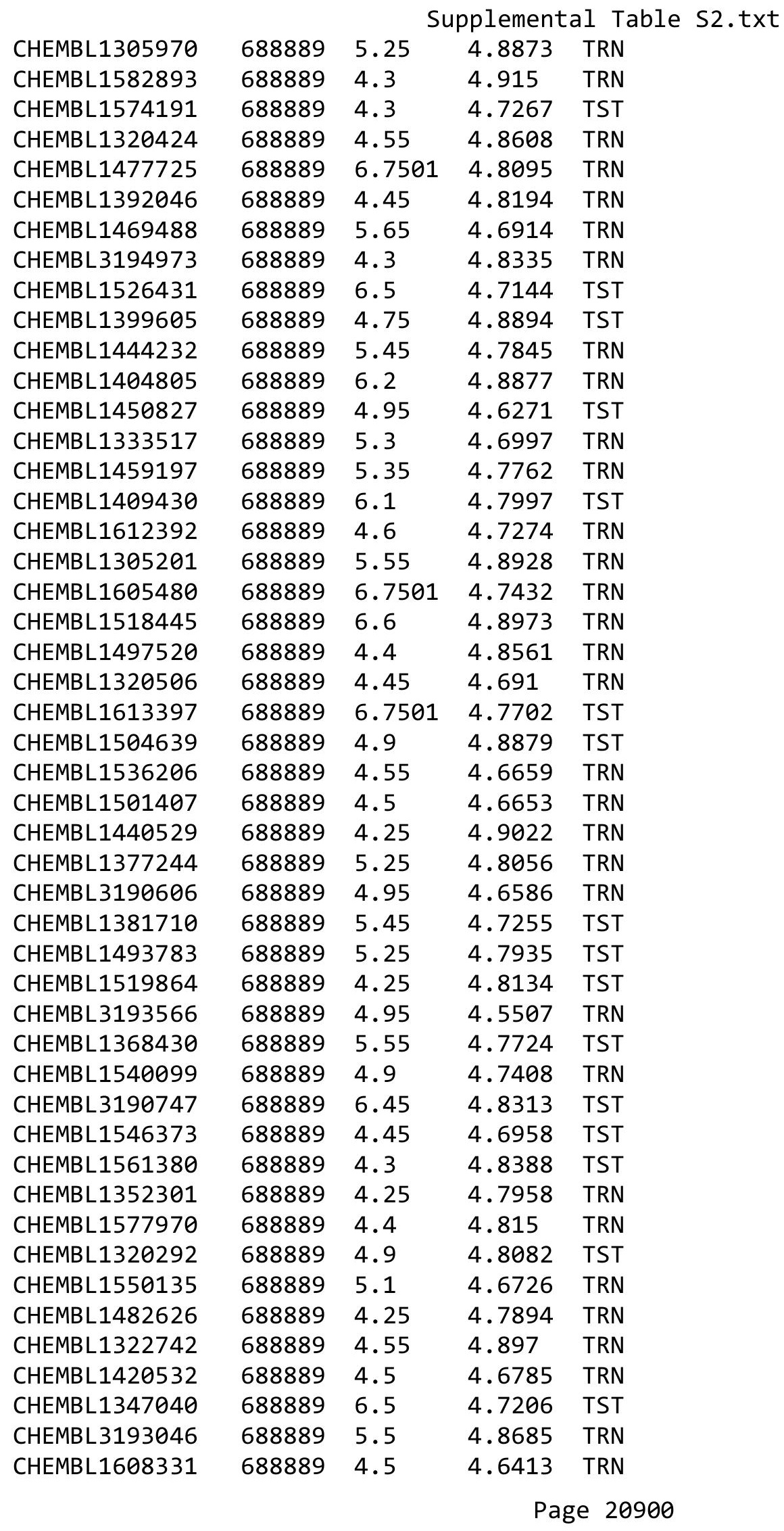




\begin{tabular}{|c|c|c|c|c|c|}
\hline \multicolumn{6}{|c|}{ Supplemental Table S2.txt } \\
\hline CHEMBL3199209 & 688889 & 4.25 & 4.7965 & TST & \\
\hline CHEMBL1374995 & 688889 & 5.4 & 4.8864 & TST & \\
\hline CHEMBL1499052 & 688889 & 5.15 & 4.7971 & TRN & \\
\hline CHEMBL1322778 & 688889 & 4.7 & 4.9549 & TRN & \\
\hline CHEMBL1578027 & 688889 & 4.55 & 4.8463 & TRN & \\
\hline CHEMBL1487525 & 688889 & 5.3 & 4.7294 & TRN & \\
\hline CHEMBL3213807 & 688889 & 4.95 & 4.7995 & TST & \\
\hline CHEMBL1425962 & 688889 & 4.7 & 4.8788 & TRN & \\
\hline CHEMBL1598694 & 688889 & 4.95 & 4.8166 & TST & \\
\hline CHEMBL1479290 & 688889 & 4.9 & 4.91 & TRN & \\
\hline CHEMBL1300763 & 688889 & 4.55 & 4.8447 & TRN & \\
\hline CHEMBL1966853 & 688889 & 4.4 & 4.6091 & TST & \\
\hline CHEMBL1510934 & 688889 & 4.45 & 4.9028 & TRN & \\
\hline CHEMBL1336922 & 688889 & 5.35 & 4.6286 & TRN & \\
\hline CHEMBL1558294 & 688889 & 4.25 & 4.8025 & TRN & \\
\hline CHEMBL1501742 & 688889 & 4.45 & 4.7172 & TRN & \\
\hline CHEMBL1303361 & 688889 & 5.45 & 4.88399 & 99999999995 & TRN \\
\hline CHEMBL1497205 & 688889 & 4.3 & 4.7936 & TRN & \\
\hline CHEMBL1567996 & 688889 & 4.25 & 4.7107 & TRN & \\
\hline CHEMBL1402673 & 688889 & 4.25 & 4.8595 & TRN & \\
\hline CHEMBL1582101 & 688889 & 6.25 & 4.9373 & TRN & \\
\hline CHEMBL1307748 & 688889 & 4.45 & 4.8539 & TRN & \\
\hline CHEMBL1432151 & 688889 & 4.7 & 4.7241 & TRN & \\
\hline CHEMBL1327979 & 688889 & 4.55 & 4.685 & TRN & \\
\hline CHEMBL3208983 & 688889 & 4.35 & 4.7698 & TST & \\
\hline CHEMBL1380946 & 688889 & 4.4 & 4.7334 & TRN & \\
\hline CHEMBL1399358 & 688889 & 4.45 & 4.747 & TRN & \\
\hline CHEMBL399761 & 688889 & 4.3 & 4.6715 & TRN & \\
\hline CHEMBL1466387 & 688889 & 4.25 & 4.8949 & TRN & \\
\hline CHEMBL1373244 & 688889 & 4.55 & 4.8855 & TST & \\
\hline CHEMBL1304737 & 688889 & 5.5 & 4.8578 & TST & \\
\hline CHEMBL3212644 & 688889 & 5.4 & 4.851 & TST & \\
\hline CHEMBL1543010 & 688889 & 4.95 & 4.8226 & TRN & \\
\hline CHEMBL1611363 & 688889 & 4.3 & 4.7792 & TRN & \\
\hline CHEMBL1369357 & 688889 & 4.6 & 4.6909 & TRN & \\
\hline CHEMBL1332298 & 688889 & 4.3 & 4.8503 & TST & \\
\hline CHEMBL1306311 & 688889 & 4.5 & 4.7433 & TRN & \\
\hline CHEMBL1375830 & 688889 & 4.3 & 4.7159 & TRN & \\
\hline CHEMBL3208024 & 688889 & 4.55 & 4.7718 & TRN & \\
\hline CHEMBL1556637 & 688889 & 4.25 & 4.7435 & TST & \\
\hline CHEMBL1528533 & 688889 & 5.05 & 4.8499 & TRN & \\
\hline CHEMBL 1445566 & 688889 & 4.5 & 4.7541 & TRN & \\
\hline CHEMBL1391203 & 688889 & 6.7501 & 4.8708 & TRN & \\
\hline CHEMBL1589443 & 688889 & 5.25 & 4.9305 & TRN & \\
\hline CHEMBL1423037 & 688889 & 4.6 & 4.7311 & TRN & \\
\hline CHEMBL1543757 & 688889 & 4.95 & 4.7788 & TRN & \\
\hline CHEMBL1973265 & 688889 & 4.75 & 4.7202 & TRN & \\
\hline CHEMBL3192311 & 688889 & 4.35 & 4.8111 & TRN & \\
\hline
\end{tabular}




\begin{tabular}{|c|c|c|c|c|}
\hline \multicolumn{5}{|c|}{ Supplemental Table S2.txt } \\
\hline CHEMBL1518743 & 688889 & 4.3 & 4.8382 & TST \\
\hline CHEMBL 3214129 & 688889 & 4.95 & 4.7606 & TST \\
\hline CHEMBL1384201 & 688889 & 4.3 & 4.7891 & TRN \\
\hline CHEMBL1604488 & 688889 & 4.9 & 4.8369 & TRN \\
\hline CHEMBL1393357 & 688889 & 4.4 & 4.643 & TRN \\
\hline CHEMBL1432689 & 688889 & 6.8 & 4.7049 & TST \\
\hline CHEMBL1452794 & 688889 & 4.3 & 4.9042 & TST \\
\hline CHEMBL1427160 & 688889 & 6.15 & 4.7498 & TRN \\
\hline CHEMBL3190537 & 688889 & 4.9 & 4.851 & TRN \\
\hline CHEMBL1383164 & 688889 & 5.4 & 4.9172 & TRN \\
\hline CHEMBL1426432 & 688889 & 4.9 & 4.7748 & TRN \\
\hline CHEMBL1491571 & 688889 & 6.0 & 4.9452 & TST \\
\hline CHEMBL1531309 & 688889 & 5.95 & 4.6719 & TST \\
\hline CHEMBL1578723 & 688889 & 5.4 & 5.0431 & TRN \\
\hline CHEMBL1305525 & 688889 & 4.3 & 4.6842 & TRN \\
\hline CHEMBL1457250 & 688889 & 4.9 & 4.7743 & TRN \\
\hline CHEMBL1574911 & 688889 & 4.25 & 4.6608 & TRN \\
\hline CHEMBL1342131 & 688889 & 5.5 & 4.7258 & TST \\
\hline CHEMBL1428024 & 688889 & 4.4 & 4.7669 & TRN \\
\hline CHEMBL1548595 & 688889 & 4.35 & 4.9204 & TST \\
\hline CHEMBL1567574 & 688889 & 4.9 & 4.9331 & TRN \\
\hline CHEMBL1390276 & 688889 & 4.4 & 4.8182 & TST \\
\hline CHEMBL1329736 & 688889 & 4.95 & 4.8227 & TST \\
\hline CHEMBL1522737 & 688889 & 5.45 & 4.8261 & TST \\
\hline CHEMBL3191927 & 688889 & 4.95 & 4.7486 & TST \\
\hline CHEMBL1463870 & 688889 & 6.7501 & 4.8806 & TRN \\
\hline CHEMBL1414490 & 688889 & 4.25 & 4.8517 & TST \\
\hline CHEMBL1502976 & 688889 & 5.05 & 4.8356 & TRN \\
\hline CHEMBL1445085 & 688889 & 5.15 & 4.80399 & 9999999999 \\
\hline CHEMBL1450241 & 688889 & 5.9 & 4.7888 & TST \\
\hline CHEMBL1464078 & 688889 & 5.8 & 4.846 & TRN \\
\hline CHEMBL1347188 & 688889 & 5.85 & 4.7529 & TST \\
\hline CHEMBL1374456 & 688889 & 4.95 & 4.8262 & TRN \\
\hline CHEMBL1386612 & 688889 & 4.65 & 5.0252 & TRN \\
\hline CHEMBL1530759 & 688889 & 4.9 & 4.5637 & TST \\
\hline CHEMBL1323855 & 688889 & 4.3 & 4.897 & TRN \\
\hline CHEMBL1603332 & 688889 & 5.0 & 4.8552 & TRN \\
\hline CHEMBL1419686 & 688889 & 4.75 & 4.6158 & TRN \\
\hline CHEMBL1404456 & 688889 & 4.25 & 4.6642 & TST \\
\hline CHEMBL1327715 & 688889 & 5.55 & 4.6642 & TRN \\
\hline CHEMBL1413080 & 688889 & 4.9 & 4.7358 & TST \\
\hline CHEMBL3209384 & 688889 & 4.25 & 4.8069 & TST \\
\hline CHEMBL1579392 & 688889 & 4.35 & 4.9117 & TRN \\
\hline CHEMBL3191540 & 688889 & 6.7501 & 4.8277 & TST \\
\hline CHEMBL1528317 & 688889 & 4.85 & 4.9207 & TRN \\
\hline CHEMBL1462788 & 688889 & 4.85 & 4.7847 & TRN \\
\hline CHEMBL1440588 & 688889 & 4.6 & 4.872 & TRN \\
\hline CHEMBL1523133 & 688889 & 4.65 & 4.6551 & TST \\
\hline
\end{tabular}




\begin{tabular}{|c|c|c|c|c|c|}
\hline & & \multicolumn{4}{|c|}{ Supplemental Table S2.txt } \\
\hline CHEMBL1384662 & 688889 & 6.7001 & 4.9395 & TRN & \\
\hline CHEMBL1338125 & 688889 & 4.5 & 4.9121 & TRN & \\
\hline CHEMBL1496692 & 688889 & 4.85 & 4.8938 & TRN & \\
\hline CHEMBL1577589 & 688889 & 4.95 & 4.7882 & TRN & \\
\hline CHEMBL1547734 & 688889 & 4.3 & 4.8288 & TRN & \\
\hline CHEMBL1339385 & 688889 & 4.3 & 4.8713 & TRN & \\
\hline CHEMBL1387683 & 688889 & 4.35 & 4.8033 & TST & \\
\hline CHEMBL1409366 & 688889 & 4.55 & 4.75899 & 99999999995 & TRN \\
\hline CHEMBL1588421 & 688889 & 4.9 & 4.8562 & TST & \\
\hline CHEMBL531709 & 688889 & 6.05 & 4.756 & TST & \\
\hline CHEMBL1439049 & 688889 & 5.95 & 4.9919 & TRN & \\
\hline CHEMBL1452593 & 688889 & 5.2 & 4.8527 & TRN & \\
\hline CHEMBL1414524 & 688889 & 4.65 & 4.6922 & TRN & \\
\hline CHEMBL1329073 & 688889 & 5.35 & 4.6948 & TRN & \\
\hline CHEMBL1532962 & 688889 & 4.55 & 4.8346 & TRN & \\
\hline CHEMBL1336047 & 688889 & 4.65 & 4.84699 & 99999999995 & TRN \\
\hline CHEMBL1304521 & 688889 & 4.25 & 4.9226 & TRN & \\
\hline CHEMBL1413923 & 688889 & 4.35 & 4.8324 & TRN & \\
\hline CHEMBL1362169 & 688889 & 4.25 & 4.9451 & TRN & \\
\hline CHEMBL1578017 & 688889 & 4.25 & 4.6972 & TRN & \\
\hline CHEMBL1570334 & 688889 & 5.2 & 4.6792 & TRN & \\
\hline CHEMBL1605919 & 688889 & 6.7501 & 4.7762 & TST & \\
\hline CHEMBL1546760 & 688889 & 4.3 & 4.8078 & TST & \\
\hline CHEMBL1326299 & 688889 & 4.7 & 4.775 & TRN & \\
\hline CHEMBL1490270 & 688889 & 5.7 & 4.8871 & TST & \\
\hline CHEMBL1580133 & 688889 & 4.25 & 4.8479 & TRN & \\
\hline CHEMBL1399239 & 688889 & 4.4 & 4.6954 & TRN & \\
\hline CHEMBL3199206 & 688889 & 5.25 & 4.7708 & TRN & \\
\hline CHEMBL1507621 & 688889 & 5.6 & 4.7847 & TRN & \\
\hline CHEMBL1488267 & 688889 & 4.7 & 4.91100 & 00000000005 & TRN \\
\hline CHEMBL1422539 & 688889 & 4.95 & 4.8192 & TST & \\
\hline CHEMBL1313247 & 688889 & 4.25 & 4.8976 & TST & \\
\hline CHEMBL1485606 & 688889 & 4.35 & 4.67399 & 99999999995 & TST \\
\hline CHEMBL1324948 & 688889 & 4.9 & 4.7608 & TST & \\
\hline CHEMBL1310165 & 688889 & 4.3 & 4.8885 & TST & \\
\hline CHEMBL3197933 & 688889 & 5.4 & 4.6921 & TRN & \\
\hline CHEMBL3199774 & 688889 & 4.35 & 4.6747 & TRN & \\
\hline CHEMBL1344535 & 688889 & 4.3 & 4.6394 & TRN & \\
\hline CHEMBL1320460 & 688889 & 4.45 & 4.7453 & TRN & \\
\hline CHEMBL1581676 & 688889 & 4.55 & 4.7917 & TRN & \\
\hline CHEMBL1438080 & 688889 & 4.95 & 4.791 & TRN & \\
\hline CHEMBL1439470 & 688889 & 4.5 & 4.8034 & TRN & \\
\hline CHEMBL1370527 & 688889 & 4.35 & 4.7699 & TRN & \\
\hline CHEMBL1420746 & 688889 & 4.55 & 4.9537 & TRN & \\
\hline CHEMBL1375298 & 688889 & 4.25 & 4.7603 & TRN & \\
\hline CHEMBL1521859 & 688889 & 4.35 & 4.7382 & TST & \\
\hline CHEMBL1596110 & 688889 & 6.7501 & 4.8495 & TRN & \\
\hline CHEMBL1493025 & 688889 & 4.95 & 4.7846 & TRN & \\
\hline
\end{tabular}




\begin{tabular}{|c|c|c|c|c|c|}
\hline \multicolumn{6}{|c|}{ Supplemental Table S2.txt } \\
\hline CHEMBL1400811 & 688889 & 4.5 & 4.9025 & TRN & \\
\hline CHEMBL1339896 & 688889 & 4.25 & 4.8068 & TRN & \\
\hline CHEMBL1545132 & 688889 & 4.4 & 4.8941 & TRN & \\
\hline CHEMBL1493664 & 688889 & 4.55 & 4.71399 & 99999999995 & TST \\
\hline CHEMBL1341873 & 688889 & 4.25 & 4.7696 & TST & \\
\hline CHEMBL1391612 & 688889 & 4.9 & 4.6349 & TRN & \\
\hline CHEMBL1313666 & 688889 & 4.6 & 4.8101 & TRN & \\
\hline CHEMBL1525868 & 688889 & 4.25 & 4.8503 & TRN & \\
\hline CHEMBL1508439 & 688889 & 4.5 & 4.7528 & TRN & \\
\hline CHEMBL1402586 & 688889 & 5.15 & 4.6976 & TST & \\
\hline CHEMBL1363029 & 688889 & 5.6 & 4.7358 & TST & \\
\hline CHEMBL1386022 & 688889 & 6.15 & 4.8632 & TRN & \\
\hline CHEMBL1448724 & 688889 & 4.45 & 4.7756 & TST & \\
\hline CHEMBL1432419 & 688889 & 4.25 & 4.724 & TRN & \\
\hline CHEMBL1369340 & 688889 & 4.4 & 4.9144 & TRN & \\
\hline CHEMBL1521233 & 688889 & 4.3 & 4.7606 & TRN & \\
\hline CHEMBL1604895 & 688889 & 5.2 & 4.8988 & TRN & \\
\hline CHEMBL1516947 & 688889 & 4.55 & 4.6776 & TRN & \\
\hline CHEMBL1534939 & 688889 & 4.3 & 4.8257 & TRN & \\
\hline CHEMBL1594989 & 688889 & 4.5 & 4.7384 & TRN & \\
\hline CHEMBL1570624 & 688889 & 5.2 & 4.7379 & TST & \\
\hline CHEMBL1368760 & 688889 & 5.85 & 4.8576 & TRN & \\
\hline CHEMBL1519218 & 688889 & 5.2 & 4.6986 & TRN & \\
\hline CHEMBL1403955 & 688889 & 4.85 & 4.6485 & TRN & \\
\hline CHEMBL1444247 & 688889 & 5.9 & 4.8532 & TST & \\
\hline CHEMBL1410617 & 688889 & 4.4 & 4.9434 & TRN & \\
\hline CHEMBL1527774 & 688889 & 5.6 & 4.8149 & TST & \\
\hline CHEMBL1467005 & 688889 & 4.4 & 4.7913 & TST & \\
\hline CHEMBL1500643 & 688889 & 4.6 & 4.9463 & TRN & \\
\hline CHEMBL1331563 & 688889 & 4.5 & 4.7575 & TRN & \\
\hline CHEMBL1439549 & 688889 & 4.4 & 4.7277 & TRN & \\
\hline CHEMBL1522130 & 688889 & 5.65 & 4.7306 & TRN & \\
\hline CHEMBL1563441 & 688889 & 4.95 & 4.8864 & TRN & \\
\hline CHEMBL1350637 & 688889 & 4.45 & 4.7104 & TRN & \\
\hline CHEMBL1389519 & 688889 & 4.95 & 4.7574 & TRN & \\
\hline CHEMBL1303249 & 688889 & 5.45 & 4.8015 & TRN & \\
\hline CHEMBL1466973 & 688889 & 5.5 & 4.8077 & TST & \\
\hline CHEMBL1423913 & 688889 & 4.45 & 4.8233 & TRN & \\
\hline CHEMBL1365455 & 688889 & 4.3 & 4.8403 & TST & \\
\hline CHEMBL1338422 & 688889 & 5.65 & 4.8396 & TRN & \\
\hline CHEMBL1364466 & 688889 & 5.4 & 4.9939 & TST & \\
\hline CHEMBL1414246 & 688889 & 4.75 & 4.7991 & TRN & \\
\hline CHEMBL1369052 & 688889 & 4.65 & 4.5909 & TRN & \\
\hline CHEMBL1463101 & 688889 & 4.25 & 4.8355 & TST & \\
\hline CHEMBL1388510 & 688889 & 6.2 & 4.7877 & TRN & \\
\hline CHEMBL1378242 & 688889 & 6.7501 & 4.9111 & TRN & \\
\hline CHEMBL1517593 & 688889 & 5.45 & 4.76 & TST & \\
\hline CHEMBL1484902 & 688889 & 4.3 & 4.8668 & TRN & \\
\hline
\end{tabular}




\begin{tabular}{|c|c|c|c|c|}
\hline \multicolumn{5}{|c|}{ Supplemental Table S2.txt } \\
\hline CHEMBL1330133 & 688889 & 4.4 & 4.8482 & TRN \\
\hline CHEMBL1438102 & 688889 & 4.5 & 4.8182 & TRN \\
\hline CHEMBL1393753 & 688889 & 6.1 & 4.7964 & TRN \\
\hline CHEMBL1384738 & 688889 & 6.8 & 4.8323 & TST \\
\hline CHEMBL 1438785 & 688889 & 6.7501 & 4.8023 & TRN \\
\hline CHEMBL1377647 & 688889 & 6.15 & 4.8762 & TRN \\
\hline CHEMBL1582564 & 688889 & 5.15 & 4.745 & TRN \\
\hline CHEMBL1461169 & 688889 & 5.1 & 4.7867 & TRN \\
\hline CHEMBL1388290 & 688889 & 4.35 & 4.6016 & TRN \\
\hline CHEMBL1495661 & 688889 & 6.7501 & 4.7022 & TST \\
\hline CHEMBL1443317 & 688889 & 4.95 & 4.7233 & TRN \\
\hline CHEMBL1307513 & 688889 & 4.3 & 4.7794 & TST \\
\hline CHEMBL3211445 & 688889 & 4.25 & 4.5608 & TRN \\
\hline CHEMBL1377449 & 688889 & 4.95 & 4.7201 & TRN \\
\hline CHEMBL3195143 & 688889 & 5.95 & 4.7337 & TRN \\
\hline CHEMBL1333807 & 688889 & 4.5 & 4.6469 & TRN \\
\hline CHEMBL1534592 & 688889 & 4.4 & 4.8945 & TRN \\
\hline CHEMBL1465163 & 688889 & 5.95 & 4.9636 & TST \\
\hline CHEMBL 3207648 & 688889 & 4.55 & 4.8295 & TRN \\
\hline CHEMBL1489587 & 688889 & 4.65 & 4.6948 & TST \\
\hline CHEMBL1573961 & 688889 & 4.45 & 4.7295 & TRN \\
\hline CHEMBL1572913 & 688889 & 5.95 & 4.8109 & TST \\
\hline CHEMBL1426233 & 688889 & 4.9 & 4.6299 & TRN \\
\hline CHEMBL1383903 & 688889 & 5.25 & 4.7974 & TRN \\
\hline CHEMBL1594486 & 688889 & 4.5 & 4.7009 & TRN \\
\hline CHEMBL1428644 & 688889 & 5.15 & 4.9642 & TRN \\
\hline CHEMBL1511224 & 688889 & 4.3 & 4.7524 & TRN \\
\hline CHEMBL1429613 & 688889 & 4.25 & 4.6788 & TRN \\
\hline CHEMBL1308136 & 688889 & 6.5 & 4.9194 & TRN \\
\hline CHEMBL1559212 & 688889 & 4.35 & 4.8319 & TRN \\
\hline CHEMBL1586589 & 688889 & 4.35 & 4.8353 & TRN \\
\hline CHEMBL13670 & 688889 & 4.3 & 4.8035 & TST \\
\hline CHEMBL3208607 & 688889 & 5.65 & 4.8286 & TST \\
\hline CHEMBL1460295 & 688889 & 4.6 & 4.7294 & TRN \\
\hline CHEMBL1578722 & 688889 & 4.3 & 4.8557 & TRN \\
\hline CHEMBL1469884 & 688889 & 4.45 & 4.9193 & TRN \\
\hline CHEMBL3191307 & 688889 & 5.2 & 4.7631 & TRN \\
\hline CHEMBL1496696 & 688889 & 4.7 & 4.8652 & TRN \\
\hline CHEMBL3214406 & 688889 & 4.4 & 4.6892 & TRN \\
\hline CHEMBL3199328 & 688889 & 4.25 & 4.735 & TST \\
\hline CHEMBL1442915 & 688889 & 4.45 & 4.7146 & TRN \\
\hline CHEMBL1587149 & 688889 & 4.95 & 4.7694 & TRN \\
\hline CHEMBL1540355 & 688889 & 4.25 & 4.8799 & TRN \\
\hline CHEMBL1467672 & 688889 & 4.65 & 4.7566 & TRN \\
\hline CHEMBL1444769 & 688889 & 4.45 & 4.7031 & TRN \\
\hline CHEMBL1736377 & 688889 & 4.45 & 4.6765 & TRN \\
\hline CHEMBL1458939 & 688889 & 4.6 & 4.7122 & TRN \\
\hline CHEMBL1383439 & 688889 & 4.95 & 4.5578 & TRN \\
\hline
\end{tabular}




\begin{tabular}{|c|c|c|c|c|c|}
\hline \multicolumn{6}{|c|}{ Supplemental Table S2.txt } \\
\hline CHEMBL1572194 & 688889 & 4.4 & 4.865 & TRN & \\
\hline CHEMBL1335256 & 688889 & 4.3 & 4.9391 & TST & \\
\hline CHEMBL1417936 & 688889 & 4.3 & 4.9074 & TRN & \\
\hline CHEMBL1309010 & 688889 & 5.6 & 4.8068 & TST & \\
\hline CHEMBL1429397 & 688889 & 5.15 & 4.8559 & TRN & \\
\hline CHEMBL1461246 & 688889 & 5.15 & 4.7529 & TRN & \\
\hline CHEMBL1548739 & 688889 & 4.5 & 4.9094 & TRN & \\
\hline CHEMBL1368995 & 688889 & 4.5 & 4.8283 & TRN & \\
\hline CHEMBL1458844 & 688889 & 4.4 & 4.7332 & TST & \\
\hline CHEMBL1402593 & 688889 & 4.25 & 4.8035 & TRN & \\
\hline CHEMBL1595160 & 688889 & 5.95 & 4.8528 & TRN & \\
\hline CHEMBL1444688 & 688889 & 4.3 & 4.8195 & TST & \\
\hline CHEMBL1415503 & 688889 & 4.6 & 4.7549 & TRN & \\
\hline CHEMBL1451792 & 688889 & 4.35 & 4.7247 & TRN & \\
\hline CHEMBL1420871 & 688889 & 4.25 & 4.8359 & TRN & \\
\hline CHEMBL1420839 & 688889 & 4.95 & 4.822 & TST & \\
\hline CHEMBL1570625 & 688889 & 5.3 & 4.7221 & TRN & \\
\hline CHEMBL1518120 & 688889 & 5.05 & 4.8654 & TST & \\
\hline CHEMBL1431768 & 688889 & 4.35 & 4.8814 & TRN & \\
\hline CHEMBL1493909 & 688889 & 4.4 & 4.7721 & TRN & \\
\hline CHEMBL1581259 & 688889 & 4.45 & 4.9373 & TRN & \\
\hline CHEMBL1346163 & 688889 & 4.55 & 4.935 & TRN & \\
\hline CHEMBL1456345 & 688889 & 4.3 & 4.7484 & TST & \\
\hline CHEMBL1373286 & 688889 & 4.35 & 4.8889 & TRN & \\
\hline CHEMBL1337832 & 688889 & 4.25 & 4.7893 & TST & \\
\hline CHEMBL1439981 & 688889 & 4.95 & 4.6845 & TRN & \\
\hline CHEMBL1368785 & 688889 & 6.8 & 5.0498 & TRN & \\
\hline CHEMBL1307272 & 688889 & 5.95 & 4.796 & TST & \\
\hline CHEMBL1463789 & 688889 & 5.05 & 4.8457 & TRN & \\
\hline CHEMBL1531439 & 688889 & 5.25 & 4.756 & TRN & \\
\hline CHEMBL1335284 & 688889 & 4.95 & 4.9673 & TRN & \\
\hline CHEMBL1562263 & 688889 & 5.1 & 4.7758 & TRN & \\
\hline CHEMBL1339987 & 688889 & 4.95 & 4.58899 & 99999999995 & TRN \\
\hline CHEMBL1459165 & 688889 & 4.35 & 4.6956 & TRN & \\
\hline CHEMBL1388477 & 688889 & 5.45 & 4.816 & TST & \\
\hline CHEMBL1341789 & 688889 & 4.3 & 4.7885 & TRN & \\
\hline CHEMBL1468458 & 688889 & 4.3 & 4.6197 & TRN & \\
\hline CHEMBL1546594 & 688889 & 4.3 & 4.704 & TRN & \\
\hline CHEMBL1417090 & 688889 & 4.6 & 4.8935 & TST & \\
\hline CHEMBL1463899 & 688889 & 6.2 & 4.859 & TST & \\
\hline CHEMBL1324865 & 688889 & 5.95 & 4.92899 & 9999999999 & TRN \\
\hline CHEMBL1507525 & 688889 & 4.25 & 4.9761 & TRN & \\
\hline CHEMBL1575994 & 688889 & 5.4 & 4.7628 & TRN & \\
\hline CHEMBL 3213874 & 688889 & 4.4 & 4.6578 & TRN & \\
\hline CHEMBL1454734 & 688889 & 5.95 & 4.7445 & TST & \\
\hline CHEMBL1534629 & 688889 & 4.5 & 4.7009 & TRN & \\
\hline CHEMBL1321992 & 688889 & 4.95 & 4.9824 & TRN & \\
\hline CHEMBL1422940 & 688889 & 5.25 & 4.8674 & TST & \\
\hline
\end{tabular}




\begin{tabular}{|c|c|c|c|c|c|}
\hline \\
\hline CHEMBL1448557 & 688889 & 4.6 & 4.7916 & TST & \\
\hline CHEMBL1431003 & 688889 & 4.6 & 4.7506 & TRN & \\
\hline CHEMBL1549907 & 688889 & 5.9 & 4.7728 & TRN & \\
\hline CHEMBL3192085 & 688889 & 4.8 & 4.715 & TST & \\
\hline CHEMBL1340951 & 688889 & 4.6 & 4.8037 & TST & \\
\hline CHEMBL1569648 & 688889 & 5.95 & 4.8059 & TRN & \\
\hline CHEMBL1322755 & 688889 & 6.7501 & 4.7254 & TST & \\
\hline CHEMBL1335331 & 688889 & 4.6 & 4.6883 & TRN & \\
\hline CHEMBL1542186 & 688889 & 5.7 & 4.7911 & TRN & \\
\hline CHEMBL1572056 & 688889 & 4.25 & 4.7086 & TRN & \\
\hline CHEMBL1380257 & 688889 & 5.8 & 4.7603 & TST & \\
\hline CHEMBL1383785 & 688889 & 4.3 & 4.8589 & TRN & \\
\hline CHEMBL1507968 & 688889 & 4.25 & 4.8398 & TST & \\
\hline CHEMBL3207604 & 688889 & 4.75 & 4.7324 & TRN & \\
\hline CHEMBL1332883 & 688889 & 6.45 & 4.7212 & TRN & \\
\hline CHEMBL1333873 & 688889 & 4.95 & 4.9174 & TST & \\
\hline CHEMBL1350089 & 688889 & 6.8 & 4.8476 & TRN & \\
\hline CHEMBL1549006 & 688889 & 4.75 & 4.7334 & TRN & \\
\hline CHEMBL1605612 & 688889 & 4.25 & 4.9131 & TST & \\
\hline CHEMBL1600585 & 688889 & 5.9 & 4.6797 & TRN & \\
\hline CHEMBL1488708 & 688889 & 4.6 & 4.7219 & TRN & \\
\hline CHEMBL1425191 & 688889 & 4.95 & 4.9685 & TRN & \\
\hline CHEMBL3195471 & 688889 & 5.35 & 4.7012 & TRN & \\
\hline CHEMBL 2003886 & 688889 & 4.55 & 4.6767 & TRN & \\
\hline CHEMBL1440120 & 688889 & 4.25 & 4.6943 & TRN & \\
\hline CHEMBL1353678 & 688889 & 5.6 & 4.8729 & TRN & \\
\hline CHEMBL1524130 & 688889 & 5.65 & 4.734 & TST & \\
\hline CHEMBL1451002 & 688889 & 4.25 & 4.8749 & TRN & \\
\hline CHEMBL1304204 & 688889 & 6.7501 & 4.8046 & TRN & \\
\hline CHEMBL1485618 & 688889 & 4.25 & 4.8232 & TRN & \\
\hline CHEMBL1481166 & 688889 & 4.7 & 4.7384 & TRN & \\
\hline CHEMBL1536238 & 688889 & 4.95 & 4.8843 & TRN & \\
\hline CHEMBL1542149 & 688889 & 4.3 & 4.8044 & TRN & \\
\hline CHEMBL1370297 & 688889 & 6.6499 & 4.7884 & TRN & \\
\hline CHEMBL1548536 & 688889 & 4.3 & 4.8454 & TRN & \\
\hline CHEMBL1589643 & 688889 & 4.9 & 4.8141 & TRN & \\
\hline CHEMBL1577799 & 688889 & 5.45 & 4.83899 & 99999999995 & TRN \\
\hline CHEMBL1440525 & 688889 & 6.7501 & 4.8337 & TRN & \\
\hline CHEMBL1401134 & 688889 & 4.85 & 4.6127 & TRN & \\
\hline CHEMBL1313926 & 688889 & 4.5 & 4.7046 & TRN & \\
\hline CHEMBL1375326 & 688889 & 4.4 & 4.8129 & TST & \\
\hline CHEMBL1601720 & 688889 & 5.55 & 4.89 & TST & \\
\hline CHEMBL1320693 & 688889 & 6.7501 & 4.8854 & TRN & \\
\hline CHEMBL1416068 & 688889 & 5.6 & 4.8479 & TST & \\
\hline CHEMBL1450788 & 688889 & 4.6 & 4.8631 & TST & \\
\hline CHEMBL1995314 & 688889 & 4.5 & 4.7633 & TRN & \\
\hline CHEMBL1454022 & 688889 & 5.35 & 4.8258 & TRN & \\
\hline CHEMBL1411072 & 688889 & 6.5 & 4.731 & TRN & \\
\hline
\end{tabular}




\begin{tabular}{|c|c|c|c|c|c|}
\hline \\
\hline CHEMBL1376210 & 688889 & 5.2 & 4.9671 & TST & \\
\hline CHEMBL1530503 & 688889 & 4.95 & 4.9482 & TST & \\
\hline CHEMBL1603352 & 688889 & 4.6 & 5.0054 & TRN & \\
\hline CHEMBL1448530 & 688889 & 4.45 & 4.9141 & TRN & \\
\hline CHEMBL1329427 & 688889 & 4.45 & 4.7397 & TRN & \\
\hline CHEMBL1463737 & 688889 & 4.45 & 4.6522 & TRN & \\
\hline CHEMBL3190111 & 688889 & 4.4 & 4.6546 & TRN & \\
\hline CHEMBL1984894 & 688889 & 4.95 & 4.8667 & TST & \\
\hline CHEMBL1438264 & 688889 & 4.9 & 4.6991 & TRN & \\
\hline CHEMBL1386472 & 688889 & 6.15 & 4.8615 & TST & \\
\hline CHEMBL1485670 & 688889 & 4.45 & 4.868 & TRN & \\
\hline CHEMBL1548049 & 688889 & 6.8 & 4.8056 & TRN & \\
\hline CHEMBL1585438 & 688889 & 4.25 & 4.8972 & TRN & \\
\hline CHEMBL1441099 & 688889 & 4.4 & 4.6943 & TRN & \\
\hline CHEMBL1389090 & 688889 & 4.25 & 4.8291 & TRN & \\
\hline CHEMBL1419846 & 688889 & 5.45 & 4.881 & TRN & \\
\hline CHEMBL1565290 & 688889 & 4.5 & 4.76699 & 99999999995 & TRN \\
\hline CHEMBL3198411 & 688889 & 4.25 & 4.7847 & TRN & \\
\hline CHEMBL1478577 & 688889 & 4.75 & 4.7096 & TRN & \\
\hline CHEMBL1372089 & 688889 & 4.35 & 4.8022 & TRN & \\
\hline CHEMBL1378282 & 688889 & 5.3 & 4.6967 & TRN & \\
\hline CHEMBL1602697 & 688889 & 5.4 & 4.7302 & TRN & \\
\hline CHEMBL1492274 & 688889 & 5.9 & 4.7366 & TST & \\
\hline CHEMBL 241898 & 688889 & 4.95 & 4.7758 & TRN & \\
\hline CHEMBL1504205 & 688889 & 4.85 & 4.7509 & TRN & \\
\hline CHEMBL1306433 & 688889 & 4.3 & 4.6993 & TRN & \\
\hline CHEMBL3214566 & 688889 & 4.3 & 4.7114 & TRN & \\
\hline CHEMBL3192226 & 688889 & 4.95 & 4.9077 & TRN & \\
\hline CHEMBL1320908 & 688889 & 4.4 & 4.7148 & TST & \\
\hline CHEMBL1586657 & 688889 & 4.6 & 4.9269 & TST & \\
\hline CHEMBL1503133 & 688889 & 4.3 & 4.7947 & TRN & \\
\hline CHEMBL1425166 & 688889 & 4.25 & 4.8716 & TRN & \\
\hline CHEMBL1349602 & 688889 & 4.25 & 5.021 & TRN & \\
\hline CHEMBL1560965 & 688889 & 5.6 & 4.9444 & TST & \\
\hline CHEMBL1463302 & 688889 & 4.7 & 4.6959 & TRN & \\
\hline CHEMBL1382110 & 688889 & 4.4 & 4.7549 & TRN & \\
\hline CHEMBL1384088 & 688889 & 4.3 & 4.7769 & TRN & \\
\hline CHEMBL1540762 & 688889 & 4.45 & 4.7936 & TRN & \\
\hline CHEMBL 270672 & 688889 & 4.45 & 4.7436 & TRN & \\
\hline CHEMBL1497764 & 688889 & 4.9 & 4.7994 & TRN & \\
\hline CHEMBL1498222 & 688889 & 5.35 & 4.8126 & TRN & \\
\hline CHEMBL1570526 & 688889 & 4.3 & 4.7136 & TRN & \\
\hline CHEMBL1451748 & 688889 & 4.95 & 4.8912 & TRN & \\
\hline CHEMBL1507367 & 688889 & 4.55 & 4.7551 & TST & \\
\hline CHEMBL1538023 & 688889 & 4.85 & 4.7035 & TST & \\
\hline CHEMBL3197839 & 688889 & 4.45 & 4.6986 & TRN & \\
\hline CHEMBL3210654 & 688889 & 4.3 & 4.7887 & TRN & \\
\hline CHEMBL1424986 & 688889 & 4.3 & 4.801 & TRN & \\
\hline
\end{tabular}




\begin{tabular}{|c|c|c|c|c|c|}
\hline & & \multicolumn{4}{|c|}{ Supplemental Table s2.txt } \\
\hline CHEMBL1516601 & 688889 & 4.7 & 4.7157 & TRN & \\
\hline CHEMBL1422503 & 688889 & 5.15 & 4.9544 & TRN & \\
\hline CHEMBL1492798 & 688889 & 4.4 & 4.8518 & TRN & \\
\hline CHEMBL1538451 & 688889 & 4.3 & 4.8497 & TRN & \\
\hline CHEMBL3197602 & 688889 & 4.35 & 4.6942 & TRN & \\
\hline CHEMBL1365306 & 688889 & 4.4 & 4.7848 & TRN & \\
\hline CHEMBL3194628 & 688889 & 4.25 & 4.8568 & TRN & \\
\hline CHEMBL1608962 & 688889 & 4.8 & 4.7245 & TRN & \\
\hline CHEMBL1349046 & 688889 & 6.4 & 4.801 & TST & \\
\hline CHEMBL1546737 & 688889 & 5.1 & 4.9225 & TRN & \\
\hline CHEMBL1374854 & 688889 & 4.5 & 4.6927 & TRN & \\
\hline CHEMBL1570695 & 688889 & 4.75 & 4.7755 & TRN & \\
\hline CHEMBL1541946 & 688889 & 5.15 & 4.8094 & TST & \\
\hline CHEMBL1426096 & 688889 & 4.25 & 4.792 & TST & \\
\hline CHEMBL1447441 & 688889 & 4.45 & 4.6455 & TRN & \\
\hline CHEMBL1398991 & 688889 & 4.55 & 4.6411 & TRN & \\
\hline CHEMBL1544110 & 688889 & 4.7 & 4.6649 & TRN & \\
\hline CHEMBL1299805 & 688889 & 4.9 & 4.9581 & TRN & \\
\hline CHEMBL1383360 & 688889 & 4.3 & 4.8618 & TRN & \\
\hline CHEMBL1564097 & 688889 & 5.15 & 4.7636 & TST & \\
\hline CHEMBL1507694 & 688889 & 6.05 & 4.9034 & TST & \\
\hline CHEMBL3213752 & 688889 & 4.5 & 4.8846 & TRN & \\
\hline CHEMBL1373359 & 688889 & 4.8 & 4.8229 & TST & \\
\hline CHEMBL1486972 & 688889 & 5.05 & 4.6904 & TRN & \\
\hline CHEMBL1500128 & 688889 & 4.95 & 4.7529 & TST & \\
\hline CHEMBL1537647 & 688889 & 4.45 & 4.7767 & TRN & \\
\hline CHEMBL1587685 & 688889 & 4.5 & 4.7231 & TRN & \\
\hline CHEMBL1574815 & 688889 & 4.5 & 4.9503 & TRN & \\
\hline CHEMBL1444944 & 688889 & 4.25 & 4.8565 & TRN & \\
\hline CHEMBL3190876 & 688889 & 5.3 & 4.8607 & TRN & \\
\hline CHEMBL1525221 & 688889 & 4.45 & 4.6409 & TRN & \\
\hline CHEMBL1367721 & 688889 & 4.25 & $4.9060 e$ & 0000000001 & TRN \\
\hline CHEMBL1359066 & 688889 & 4.3 & 4.873 & TRN & \\
\hline CHEMBL1350075 & 688889 & 5.1 & 4.894 & TRN & \\
\hline CHEMBL1380716 & 688889 & 5.9 & 4.8001 & TRN & \\
\hline CHEMBL1537596 & 688889 & 4.3 & 4.8341 & TRN & \\
\hline CHEMBL1419141 & 688889 & 4.3 & 4.7838 & TST & \\
\hline CHEMBL1488323 & 688889 & 4.45 & 4.6555 & TRN & \\
\hline CHEMBL1564778 & 688889 & 5.0 & 4.6672 & TRN & \\
\hline CHEMBL1490943 & 688889 & 5.45 & 4.9402 & TRN & \\
\hline CHEMBL1321938 & 688889 & 5.25 & 4.8319 & TRN & \\
\hline CHEMBL1484561 & 688889 & 4.3 & 4.744 & TST & \\
\hline CHEMBL1579827 & 688889 & 4.35 & 4.7644 & TRN & \\
\hline CHEMBL1495491 & 688889 & 4.5 & 4.7855 & TRN & \\
\hline CHEMBL1376847 & 688889 & 4.95 & 4.8368 & TST & \\
\hline CHEMBL1307622 & 688889 & 4.4 & 4.7165 & TRN & \\
\hline CHEMBL 225012 & 688889 & 4.5 & 4.7453 & TRN & \\
\hline CHEMBL1537204 & 688889 & 4.5 & 4.7466 & TRN & \\
\hline
\end{tabular}




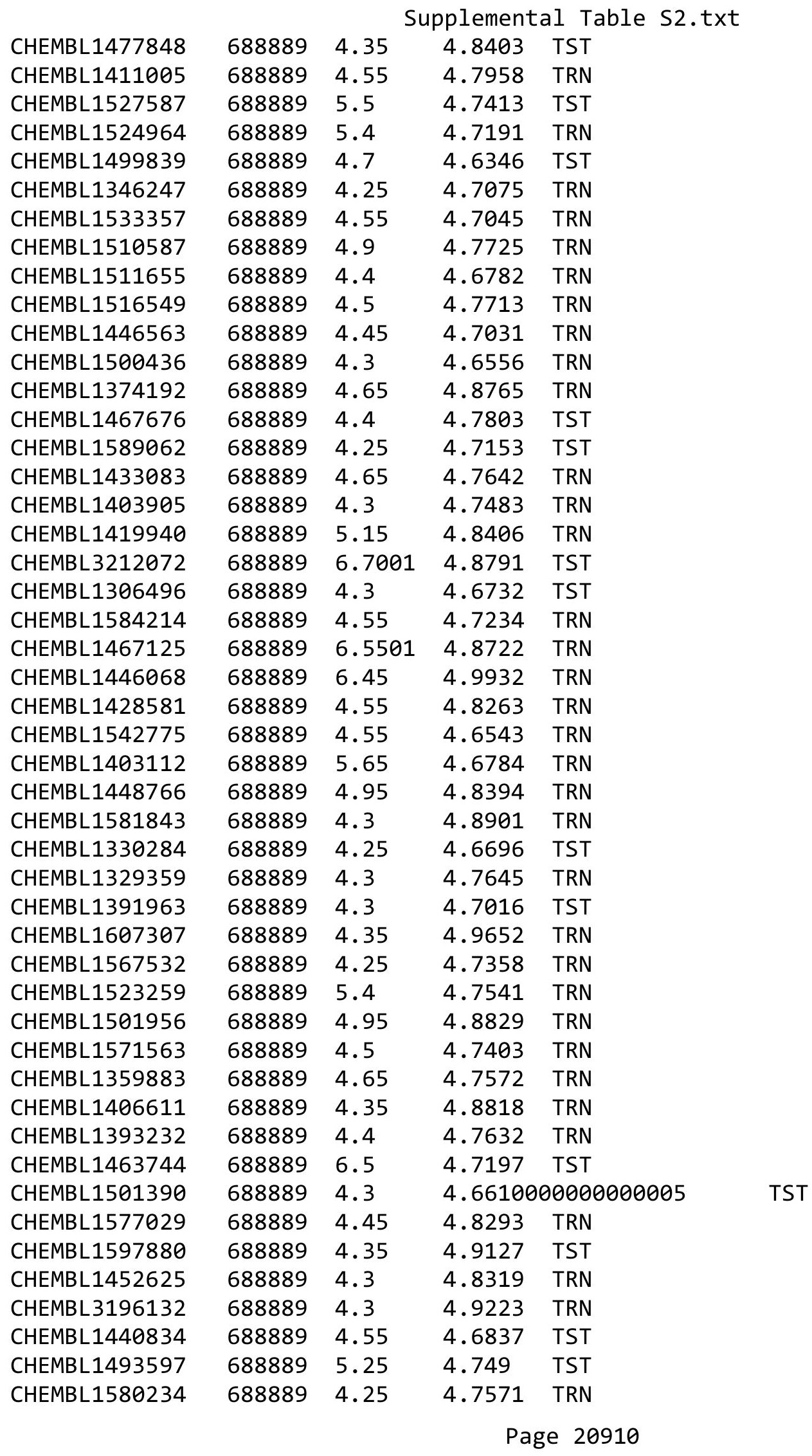




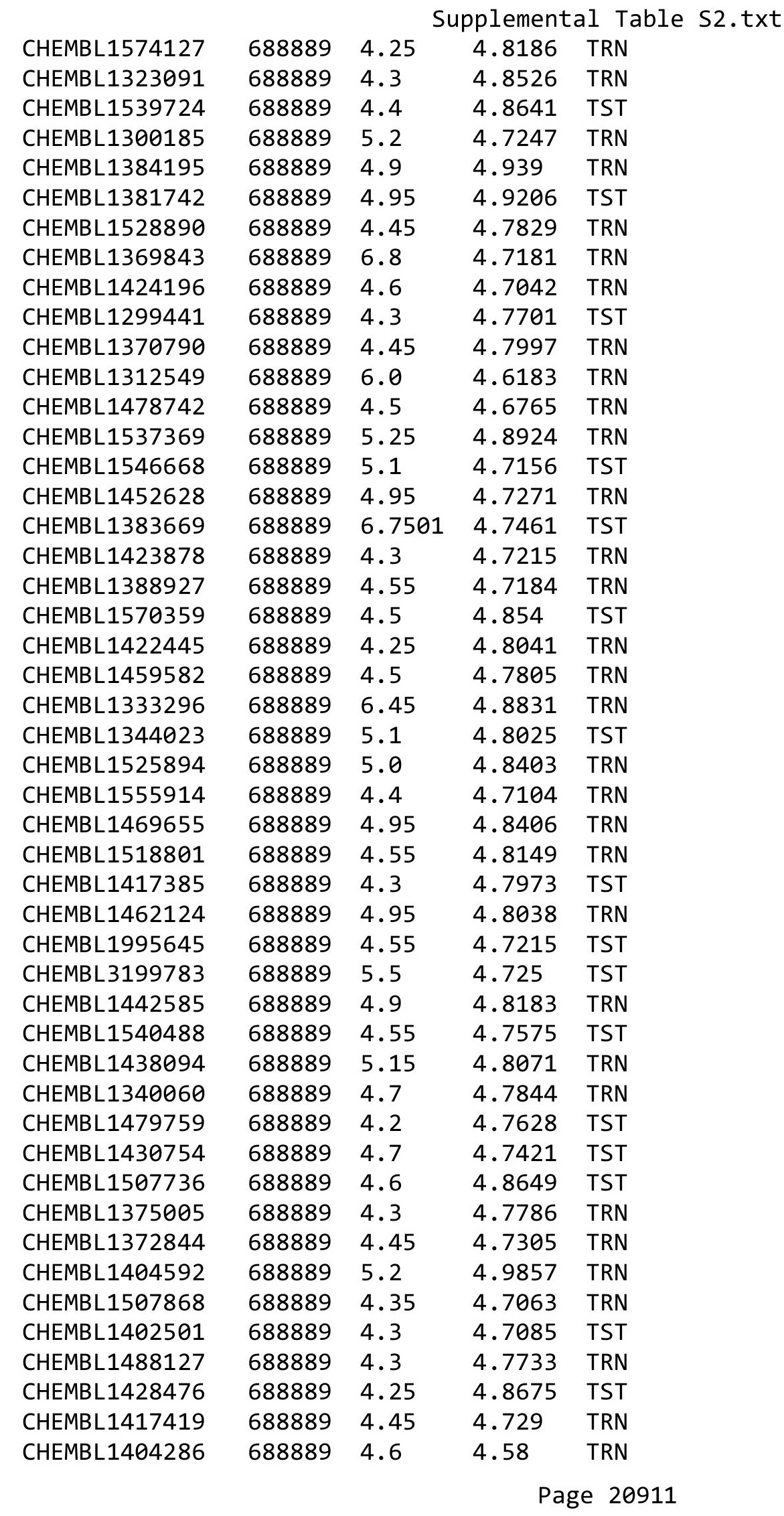




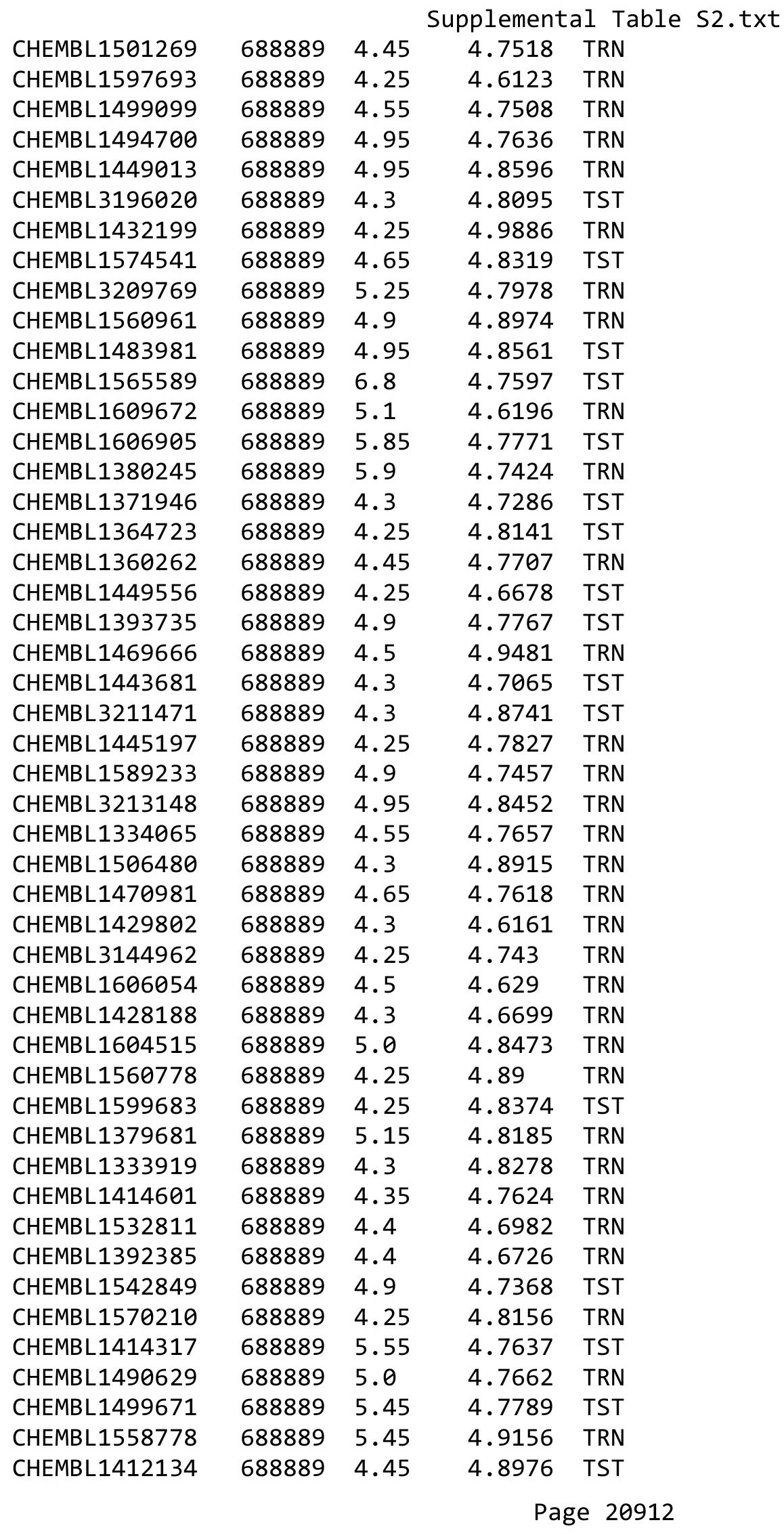




\begin{tabular}{|c|c|c|c|c|}
\hline \multicolumn{5}{|c|}{ Supplemental Table s2.txt } \\
\hline CHEMBL1524363 & 688889 & 4.55 & 4.6217 & TRN \\
\hline CHEMBL1328024 & 688889 & 4.35 & 5.0519 & TRN \\
\hline CHEMBL1579333 & 688889 & 4.45 & 4.7523 & TRN \\
\hline CHEMBL1489522 & 688889 & 4.3 & 4.8247 & TRN \\
\hline CHEMBL1306667 & 688889 & 5.75 & 4.8377 & TRN \\
\hline CHEMBL1399522 & 688889 & 4.5 & 4.8428 & TST \\
\hline CHEMBL3192938 & 688889 & 4.5 & 4.7618 & TST \\
\hline CHEMBL3191438 & 688889 & 5.05 & 4.8643 & TRN \\
\hline CHEMBL1607249 & 688889 & 4.5 & 4.7251 & TRN \\
\hline CHEMBL1594286 & 688889 & 4.3 & 4.8696 & TST \\
\hline CHEMBL 3193284 & 688889 & 4.7 & 4.6212 & TRN \\
\hline CHEMBL1566982 & 688889 & 4.55 & 4.7737 & TST \\
\hline CHEMBL3191276 & 688889 & 4.5 & 4.8155 & TRN \\
\hline CHEMBL1439184 & 688889 & 5.15 & 4.7238 & TRN \\
\hline CHEMBL1443990 & 688889 & 4.9 & 4.7923 & TRN \\
\hline CHEMBL1496641 & 688889 & 4.95 & 4.8952 & TRN \\
\hline CHEMBL1450847 & 688889 & 5.4 & 4.9629 & TRN \\
\hline CHEMBL1418678 & 688889 & 4.5 & 4.7592 & TST \\
\hline CHEMBL3193075 & 688889 & 5.5 & 4.789 & TRN \\
\hline CHEMBL1442207 & 688889 & 4.4 & 4.7581 & TRN \\
\hline CHEMBL1401434 & 688889 & 5.1 & 4.9209 & TRN \\
\hline CHEMBL1409049 & 688889 & 4.3 & 4.8442 & TRN \\
\hline CHEMBL1347586 & 688889 & 6.05 & 4.9021 & TST \\
\hline CHEMBL1300902 & 688889 & 4.3 & 4.7099 & TRN \\
\hline CHEMBL1583513 & 688889 & 4.6 & 4.8078 & TRN \\
\hline CHEMBL1350952 & 688889 & 4.35 & 4.7834 & TRN \\
\hline CHEMBL1299238 & 688889 & 4.85 & 4.8707 & TRN \\
\hline CHEMBL1479679 & 688889 & 4.5 & 4.7706 & TRN \\
\hline CHEMBL3198912 & 688889 & 4.4 & 4.7196 & TST \\
\hline CHEMBL1576690 & 688889 & 4.9 & 4.8963 & TRN \\
\hline CHEMBL1608022 & 688889 & 5.4 & 4.8717 & TST \\
\hline CHEMBL1344647 & 688889 & 4.3 & 4.681 & TRN \\
\hline CHEMBL1340834 & 688889 & 4.7 & 4.7692 & TRN \\
\hline CHEMBL3208964 & 688889 & 5.4 & 4.7385 & TRN \\
\hline CHEMBL1450583 & 688889 & 5.4 & 4.8737 & TRN \\
\hline CHEMBL3199022 & 688889 & 5.65 & 4.6488 & TRN \\
\hline CHEMBL1508357 & 688889 & 4.45 & 4.7974 & TRN \\
\hline CHEMBL1533157 & 688889 & 5.1 & 4.9004 & TRN \\
\hline CHEMBL1391179 & 688889 & 5.0 & 4.7758 & TST \\
\hline CHEMBL1337080 & 688889 & 4.25 & 4.69600 & 0000000001 \\
\hline CHEMBL1413105 & 688889 & 4.4 & 4.7948 & TST \\
\hline CHEMBL1503165 & 688889 & 4.4 & 4.6921 & TRN \\
\hline CHEMBL1602857 & 688889 & 4.3 & 4.7757 & TRN \\
\hline CHEMBL1564877 & 688889 & 4.45 & 4.7227 & TRN \\
\hline CHEMBL1347734 & 688889 & 4.55 & 4.6392 & TRN \\
\hline CHEMBL1324487 & 688889 & 4.4 & 4.6744 & TRN \\
\hline CHEMBL1507032 & 688889 & 5.15 & 4.7194 & TRN \\
\hline CHEMBL1334928 & 688889 & 5.25 & 4.6561 & TRN \\
\hline
\end{tabular}




\begin{tabular}{|c|c|c|c|c|c|}
\hline \multicolumn{6}{|c|}{ Supplemental Table S2.txt } \\
\hline CHEMBL1557744 & 688889 & 5.0 & 4.7789 & TRN & \\
\hline CHEMBL1306327 & 688889 & 4.25 & 4.7682 & TST & \\
\hline CHEMBL1494470 & 688889 & 5.8 & 4.831 & TST & \\
\hline CHEMBL1605598 & 688889 & 4.95 & 5.1269 & TRN & \\
\hline CHEMBL1302019 & 688889 & 4.5 & 4.7294 & TRN & \\
\hline CHEMBL1493573 & 688889 & 4.5 & 4.9128 & TST & \\
\hline CHEMBL1334790 & 688889 & 5.15 & 4.7266 & TST & \\
\hline CHEMBL1447442 & 688889 & 4.4 & 4.8618 & TRN & \\
\hline CHEMBL1444888 & 688889 & 4.55 & 4.8643 & TRN & \\
\hline CHEMBL3213348 & 688889 & 4.3 & 4.9218 & TST & \\
\hline CHEMBL1447632 & 688889 & 4.75 & 4.7638 & TRN & \\
\hline CHEMBL1523991 & 688889 & 4.9 & 4.7727 & TRN & \\
\hline CHEMBL1528880 & 688889 & 4.65 & 4.5926 & TST & \\
\hline CHEMBL1328395 & 688889 & 4.5 & 4.7302 & TRN & \\
\hline CHEMBL1539830 & 688889 & 4.95 & 4.5874 & TST & \\
\hline CHEMBL1392636 & 688889 & 4.45 & 4.8257 & TRN & \\
\hline CHEMBL 373940 & 688889 & 4.4 & 4.8184 & TST & \\
\hline CHEMBL1498327 & 688889 & 4.35 & 4.8025 & TST & \\
\hline CHEMBL1348845 & 688889 & 4.6 & 4.8895 & TST & \\
\hline CHEMBL1572629 & 688889 & 4.95 & 4.7485 & TRN & \\
\hline CHEMBL3195662 & 688889 & 4.5 & 4.8105 & TST & \\
\hline CHEMBL1337068 & 688889 & 4.95 & 4.7246 & TRN & \\
\hline CHEMBL1439060 & 688889 & 6.25 & 4.7666 & TRN & \\
\hline CHEMBL1449723 & 688889 & 5.25 & 4.9444 & TST & \\
\hline CHEMBL1308512 & 688889 & 5.25 & 4.9444 & TST & \\
\hline CHEMBL1541593 & 688889 & 4.4 & 4.8267 & TRN & \\
\hline CHEMBL1374531 & 688889 & 4.25 & 4.8424 & TST & \\
\hline CHEMBL1580091 & 688889 & 4.9 & 4.8396 & TST & \\
\hline CHEMBL1352887 & 688889 & 4.5 & 4.7854 & TRN & \\
\hline CHEMBL1378612 & 688889 & 4.35 & 4.8586 & TRN & \\
\hline CHEMBL1372976 & 688889 & 4.55 & 4.7698 & TRN & \\
\hline CHEMBL1336445 & 688889 & 4.3 & 4.7908 & TST & \\
\hline CHEMBL1454462 & 688889 & 5.25 & 4.9137 & TST & \\
\hline CHEMBL1502798 & 688889 & 7.1002 & 4.7876 & TST & \\
\hline CHEMBL1544614 & 688889 & 4.25 & 4.7286 & TRN & \\
\hline CHEMBL1483687 & 688889 & 4.95 & 4.709 & TRN & \\
\hline CHEMBL1537481 & 688889 & 4.45 & 4.6047 & TRN & \\
\hline CHEMBL1334117 & 688889 & 5.85 & 4.9142 & TST & \\
\hline CHEMBL1407139 & 688889 & 5.45 & 4.89199 & 99999999995 & TST \\
\hline CHEMBL1407552 & 688889 & 4.3 & 4.6373 & TRN & \\
\hline CHEMBL1583050 & 688889 & 5.55 & 4.7589 & TRN & \\
\hline CHEMBL1524707 & 688889 & 4.25 & 4.7707 & TST & \\
\hline CHEMBL1505044 & 688889 & 4.65 & 4.7506 & TST & \\
\hline CHEMBL1547165 & 688889 & 4.3 & 4.8584 & TRN & \\
\hline CHEMBL1466809 & 688889 & 5.15 & 4.8591 & TST & \\
\hline CHEMBL1379103 & 688889 & 4.7 & 4.8023 & TST & \\
\hline CHEMBL1481836 & 688889 & 5.85 & 4.6632 & TRN & \\
\hline CHEMBL1567008 & 688889 & 4.55 & 4.7837 & TRN & \\
\hline
\end{tabular}




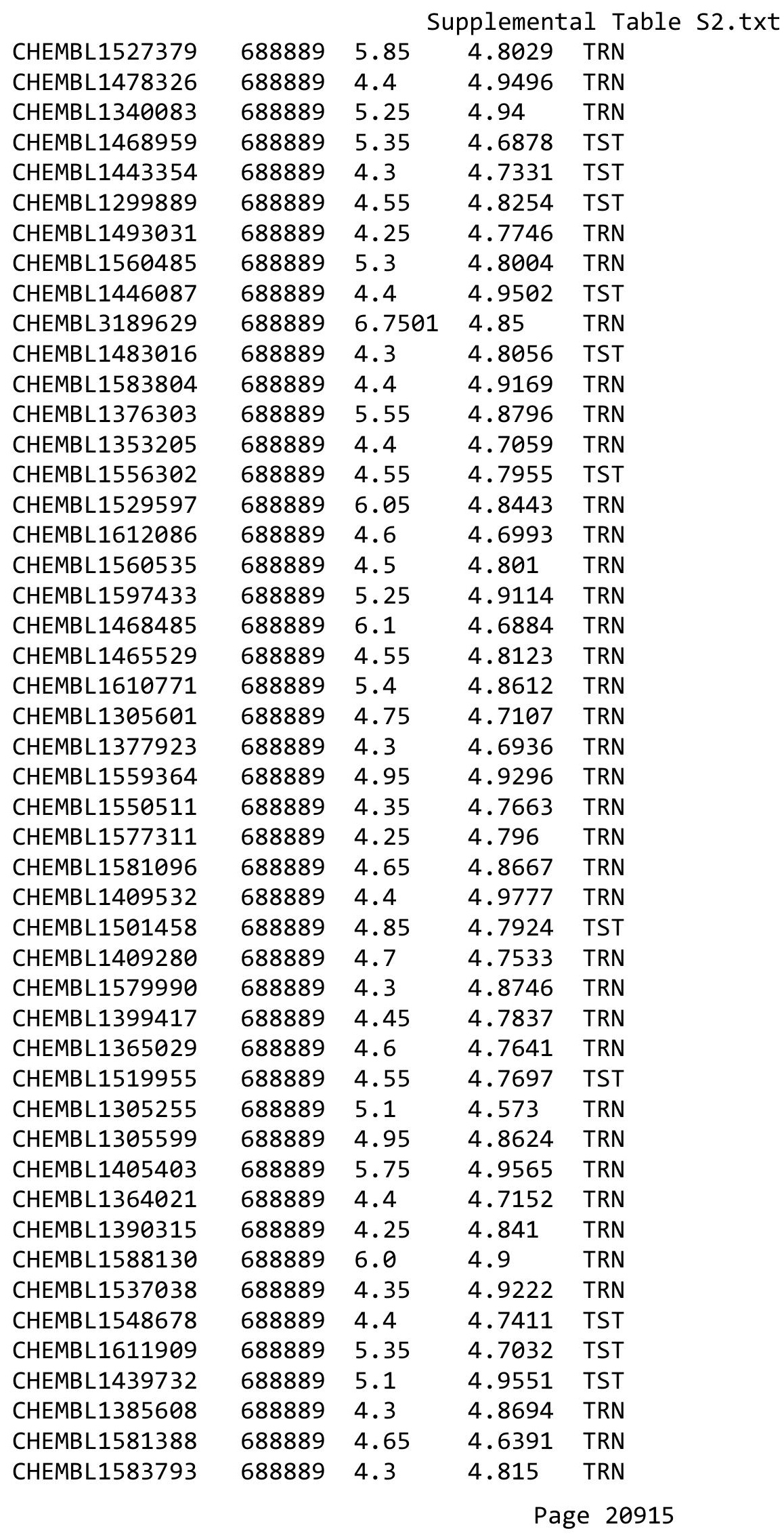




\begin{tabular}{|c|c|c|c|c|c|}
\hline \\
\hline CHEMBL1453023 & 688889 & 5.3 & 4.6336 & TRN & \\
\hline CHEMBL1322162 & 688889 & 5.45 & 4.9495 & TRN & \\
\hline CHEMBL1345190 & 688889 & 4.9 & 4.7178 & TRN & \\
\hline CHEMBL1542155 & 688889 & 4.95 & 4.7515 & TRN & \\
\hline CHEMBL1565300 & 688889 & 4.55 & 4.8069 & TST & \\
\hline CHEMBL1574058 & 688889 & 5.45 & 4.8749 & TRN & \\
\hline CHEMBL1577289 & 688889 & 6.6 & 4.9249 & TRN & \\
\hline CHEMBL1530084 & 688889 & 4.25 & 4.8099 & TRN & \\
\hline CHEMBL1392 & 688889 & 5.85 & 4.7679 & TST & \\
\hline CHEMBL1365822 & 688889 & 4.65 & 4.7981 & TRN & \\
\hline CHEMBL1416843 & 688889 & 4.45 & 4.6683 & TRN & \\
\hline CHEMBL1491283 & 688889 & 4.25 & 4.9535 & TRN & \\
\hline CHEMBL1412286 & 688889 & 4.95 & 4.8918 & TST & \\
\hline CHEMBL1307668 & 688889 & 4.6 & 4.7127 & TST & \\
\hline CHEMBL1538162 & 688889 & 4.9 & 4.8495 & TRN & \\
\hline CHEMBL1589629 & 688889 & 4.55 & 4.8447 & TRN & \\
\hline CHEMBL1388178 & 688889 & 5.5 & 4.7474 & TST & \\
\hline CHEMBL1468124 & 688889 & 4.55 & 4.7299 & TRN & \\
\hline CHEMBL1464631 & 688889 & 5.15 & 4.8332 & TRN & \\
\hline CHEMBL1328430 & 688889 & 4.25 & 4.8649 & TST & \\
\hline CHEMBL1565944 & 688889 & 4.95 & 4.9031 & TRN & \\
\hline CHEMBL1555825 & 688889 & 6.7501 & 4.8614 & TST & \\
\hline CHEMBL1333004 & 688889 & 4.75 & 4.7651 & TRN & \\
\hline CHEMBL1580849 & 688889 & 4.5 & 4.9143 & TRN & \\
\hline CHEMBL1594896 & 688889 & 4.95 & 4.8463 & TRN & \\
\hline CHEMBL1584285 & 688889 & 4.45 & 4.6398 & TRN & \\
\hline CHEMBL1300306 & 688889 & 4.3 & 4.6829 & TST & \\
\hline CHEMBL1411343 & 688889 & 5.4 & 4.8607 & TST & \\
\hline CHEMBL1505530 & 688889 & 5.75 & 4.8568 & TRN & \\
\hline CHEMBL1452139 & 688889 & 4.25 & 4.7777 & TST & \\
\hline CHEMBL1389904 & 688889 & 4.25 & 4.9875 & TRN & \\
\hline CHEMBL1389120 & 688889 & 4.95 & 4.92899 & 9999999999 & TRN \\
\hline CHEMBL1586061 & 688889 & 4.6 & 4.7984 & TST & \\
\hline CHEMBL1483509 & 688889 & 4.95 & 4.8223 & TST & \\
\hline CHEMBL1352286 & 688889 & 4.25 & 4.8625 & TRN & \\
\hline CHEMBL1607633 & 688889 & 6.8 & 4.9764 & TRN & \\
\hline CHEMBL1339161 & 688889 & 4.6 & 4.8826 & TRN & \\
\hline CHEMBL 3192632 & 688889 & 5.05 & 4.5822 & TRN & \\
\hline CHEMBL1331177 & 688889 & 5.8 & 4.8122 & TST & \\
\hline CHEMBL1332499 & 688889 & 4.6 & 4.8664 & TRN & \\
\hline CHEMBL1339327 & 688889 & 4.4 & 4.8427 & TRN & \\
\hline CHEMBL1377335 & 688889 & 4.3 & 4.7845 & TRN & \\
\hline CHEMBL1571139 & 688889 & 4.95 & 4.8349 & TRN & \\
\hline CHEMBL1440856 & 688889 & 5.1 & 4.9315 & TRN & \\
\hline CHEMBL1441399 & 688889 & 4.45 & 4.8218 & TRN & \\
\hline CHEMBL1560785 & 688889 & 4.3 & 4.8976 & TRN & \\
\hline CHEMBL1572558 & 688889 & 4.9 & 4.5926 & TST & \\
\hline CHEMBL3209606 & 688889 & 5.2 & 4.8496 & TRN & \\
\hline
\end{tabular}




\begin{tabular}{|c|c|c|c|c|c|}
\hline \multicolumn{6}{|c|}{ Supplemental Table S2.txt } \\
\hline CHEMBL1401987 & 688889 & 4.25 & 4.8164 & TST & \\
\hline CHEMBL1312790 & 688889 & 4.25 & 4.8337 & TRN & \\
\hline CHEMBL1381437 & 688889 & 4.25 & 4.7463 & TRN & \\
\hline CHEMBL1338871 & 688889 & 6.1 & 4.6694 & TRN & \\
\hline CHEMBL1518099 & 688889 & 4.6 & 4.9479 & TRN & \\
\hline CHEMBL1427746 & 688889 & 4.6 & 4.9361 & TST & \\
\hline CHEMBL1370299 & 688889 & 5.2 & 4.5782 & TRN & \\
\hline CHEMBL1333797 & 688889 & 4.45 & 4.7908 & TRN & \\
\hline CHEMBL584442 & 688889 & 4.25 & 4.7214 & TRN & \\
\hline CHEMBL1345437 & 688889 & 4.95 & 4.6905 & TRN & \\
\hline CHEMBL1307208 & 688889 & 4.65 & 4.9245 & TRN & \\
\hline CHEMBL3197882 & 688889 & 4.4 & 4.8981 & TRN & \\
\hline CHEMBL1588086 & 688889 & 4.45 & 4.752 & TRN & \\
\hline CHEMBL1470868 & 688889 & 4.25 & 4.7305 & TRN & \\
\hline CHEMBL1378682 & 688889 & 4.7 & 4.7091 & TRN & \\
\hline CHEMBL1416442 & 688889 & 4.4 & 4.7394 & TST & \\
\hline CHEMBL1447121 & 688889 & 4.25 & 4.9642 & TRN & \\
\hline CHEMBL235929 & 688889 & 4.5 & 4.8144 & TRN & \\
\hline CHEMBL1408386 & 688889 & 4.3 & 4.8648 & TRN & \\
\hline CHEMBL1573147 & 688889 & 4.5 & 4.8332 & TRN & \\
\hline CHEMBL1507659 & 688889 & 4.9 & 4.7862 & TRN & \\
\hline CHEMBL1575785 & 688889 & 6.7501 & 4.9366 & TRN & \\
\hline CHEMBL1545727 & 688889 & 4.5 & 4.9055 & TST & \\
\hline CHEMBL1465814 & 688889 & 5.4 & 4.7215 & TRN & \\
\hline CHEMBL1522912 & 688889 & 4.95 & 4.6893 & TST & \\
\hline CHEMBL1372108 & 688889 & 4.45 & 4.7457 & TRN & \\
\hline CHEMBL1511586 & 688889 & 4.9 & 4.8963 & TRN & \\
\hline CHEMBL1454088 & 688889 & 4.3 & 4.8697 & TRN & \\
\hline CHEMBL1390636 & 688889 & 4.85 & 4.8167 & TRN & \\
\hline CHEMBL1371785 & 688889 & 4.3 & 4.8484 & TRN & \\
\hline CHEMBL1377744 & 688889 & 4.3 & 4.8152 & TST & \\
\hline CHEMBL1520555 & 688889 & 4.7 & 4.775 & TRN & \\
\hline CHEMBL1438939 & 688889 & 6.15 & 4.8305 & TRN & \\
\hline CHEMBL3189223 & 688889 & 4.35 & 4.785 & TRN & \\
\hline CHEMBL1564558 & 688889 & 5.8 & 4.9294 & TST & \\
\hline CHEMBL1422694 & 688889 & 5.05 & 4.7073 & TRN & \\
\hline CHEMBL1313073 & 688889 & 6.2 & 4.7562 & TRN & \\
\hline CHEMBL1570580 & 688889 & 4.25 & 4.9119 & TRN & \\
\hline CHEMBL600230 & 688889 & 5.0 & 4.9416 & TRN & \\
\hline CHEMBL1531691 & 688889 & 6.1 & 4.7798 & TRN & \\
\hline CHEMBL1571743 & 688889 & 4.4 & 4.9523 & TRN & \\
\hline CHEMBL1492834 & 688889 & 4.5 & 4.8011 & TRN & \\
\hline CHEMBL3193272 & 688889 & 4.55 & 4.5618 & TRN & \\
\hline CHEMBL1544781 & 688889 & 4.5 & $4.9510 e$ & 00000000005 & TRN \\
\hline CHEMBL1409868 & 688889 & 4.7 & 4.7145 & TRN & \\
\hline CHEMBL1342368 & 688889 & 4.7 & 4.7828 & TRN & \\
\hline CHEMBL1323119 & 688889 & 4.45 & 4.813 & TRN & \\
\hline CHEMBL1370200 & 688889 & 4.45 & 4.81 & TRN & \\
\hline
\end{tabular}




\begin{tabular}{|c|c|c|c|c|}
\hline \multicolumn{5}{|c|}{ Supplemental Table S2.txt } \\
\hline CHEMBL1541800 & 688889 & 4.75 & 4.7877 & TRN \\
\hline CHEMBL1393963 & 688889 & 5.05 & 4.9325 & TRN \\
\hline CHEMBL1533439 & 688889 & 4.25 & 4.7854 & TST \\
\hline CHEMBL1579051 & 688889 & 4.95 & 4.8739 & TRN \\
\hline CHEMBL1467204 & 688889 & 5.95 & 4.7029 & TRN \\
\hline CHEMBL1488196 & 688889 & 4.3 & 4.7723 & TRN \\
\hline CHEMBL1540964 & 688889 & 4.95 & 4.8793 & TRN \\
\hline CHEMBL1538959 & 688889 & 4.5 & 4.7369 & TRN \\
\hline CHEMBL1540739 & 688889 & 4.4 & 4.7607 & TST \\
\hline CHEMBL1605219 & 688889 & 4.25 & 4.7057 & TRN \\
\hline CHEMBL1332775 & 688889 & 4.9 & 4.7222 & TRN \\
\hline CHEMBL1321361 & 688889 & 4.5 & 4.67 & TRN \\
\hline CHEMBL1519554 & 688889 & 6.05 & 4.795 & TRN \\
\hline CHEMBL1572103 & 688889 & 4.3 & 4.7339 & TRN \\
\hline CHEMBL1363109 & 688889 & 4.95 & 4.8202 & TST \\
\hline CHEMBL1586630 & 688889 & 5.0 & 4.8482 & TRN \\
\hline CHEMBL1336444 & 688889 & 4.45 & 4.71 & TRN \\
\hline CHEMBL1392086 & 688889 & 5.4 & 4.6242 & TRN \\
\hline CHEMBL1569531 & 688889 & 5.1 & 4.9975 & TRN \\
\hline CHEMBL1573071 & 688889 & 4.3 & 4.7026 & TRN \\
\hline CHEMBL1411809 & 688889 & 4.25 & 4.8717 & TRN \\
\hline CHEMBL 3192224 & 688889 & 6.7501 & 4.7164 & TST \\
\hline CHEMBL1385292 & 688889 & 4.45 & 4.8411 & TRN \\
\hline CHEMBL1558321 & 688889 & 4.25 & 4.8793 & TRN \\
\hline CHEMBL1550513 & 688889 & 5.8 & 4.8594 & TST \\
\hline CHEMBL1350762 & 688889 & 4.3 & 4.8264 & TRN \\
\hline CHEMBL1312176 & 688889 & 4.95 & 4.8048 & TRN \\
\hline CHEMBL1318735 & 688889 & 4.3 & 4.7086 & TST \\
\hline CHEMBL1600163 & 688889 & 4.4 & 4.7626 & TRN \\
\hline CHEMBL1478511 & 688889 & 4.9 & 4.8712 & TST \\
\hline CHEMBL1304169 & 688889 & 4.25 & 4.6297 & TST \\
\hline CHEMBL1505266 & 688889 & 4.4 & 4.7909 & TRN \\
\hline CHEMBL1388415 & 688889 & 5.15 & 4.836 & TST \\
\hline CHEMBL1549266 & 688889 & 4.35 & 4.7842 & TRN \\
\hline CHEMBL1370011 & 688889 & 4.45 & 4.684 & TRN \\
\hline CHEMBL1329337 & 688889 & 4.3 & 4.8889 & TRN \\
\hline CHEMBL1432973 & 688889 & 4.5 & 4.6868 & TRN \\
\hline CHEMBL1462247 & 688889 & 6.0 & 4.8289 & TRN \\
\hline CHEMBL1557520 & 688889 & 4.25 & 4.6904 & TRN \\
\hline CHEMBL1378709 & 688889 & 4.6 & 4.7418 & TST \\
\hline CHEMBL1386794 & 688889 & 4.6 & 4.9085 & TRN \\
\hline CHEMBL1471636 & 688889 & 4.25 & 4.8695 & TRN \\
\hline CHEMBL3199077 & 688889 & 4.25 & 4.8816 & TRN \\
\hline CHEMBL1321274 & 688889 & 4.9 & 4.7818 & TRN \\
\hline CHEMBL1587837 & 688889 & 4.55 & 4.6826 & TST \\
\hline CHEMBL1578185 & 688889 & 5.1 & 4.8384 & TST \\
\hline CHEMBL1353131 & 688889 & 5.2 & 4.8876 & TRN \\
\hline CHEMBL1445321 & 688889 & 5.05 & 4.8471 & TRN \\
\hline
\end{tabular}




\begin{tabular}{|c|c|c|c|c|c|}
\hline \multicolumn{6}{|c|}{ Supplemental Table S2.txt } \\
\hline CHEMBL1573091 & 688889 & 4.5 & 4.6635 & TRN & \\
\hline CHEMBL1400965 & 688889 & 4.4 & 4.6677 & TRN & \\
\hline CHEMBL1353936 & 688889 & 5.45 & 4.8211 & TST & \\
\hline CHEMBL1450082 & 688889 & 4.25 & 4.7909 & TRN & \\
\hline CHEMBL1443662 & 688889 & 4.25 & 4.8501 & TRN & \\
\hline CHEMBL1372755 & 688889 & 4.95 & 4.7218 & TRN & \\
\hline CHEMBL1311478 & 688889 & 4.45 & 4.8178 & TRN & \\
\hline CHEMBL1578175 & 688889 & 4.25 & 4.7624 & TST & \\
\hline CHEMBL1534155 & 688889 & 4.45 & 4.802 & TRN & \\
\hline CHEMBL1344865 & 688889 & 4.55 & 4.8979 & TRN & \\
\hline CHEMBL1504833 & 688889 & 4.4 & 4.8173 & TRN & \\
\hline CHEMBL1480661 & 688889 & 4.25 & 4.8986 & TRN & \\
\hline CHEMBL1339448 & 688889 & 4.4 & 4.8061 & TRN & \\
\hline CHEMBL1571392 & 688889 & 4.35 & 4.8182 & TST & \\
\hline CHEMBL1457810 & 688889 & 6.7501 & 4.8469 & TRN & \\
\hline CHEMBL1383181 & 688889 & 4.95 & 4.7392 & TST & \\
\hline CHEMBL1529818 & 688889 & 5.15 & 4.8871 & TRN & \\
\hline CHEMBL1334311 & 688889 & 6.7501 & 4.806 & TRN & \\
\hline CHEMBL1323711 & 688889 & 6.7501 & 4.7191 & TRN & \\
\hline CHEMBL1380272 & 688889 & 4.25 & 4.9095 & TRN & \\
\hline CHEMBL1412679 & 688889 & 5.95 & 4.8307 & TST & \\
\hline CHEMBL1430080 & 688889 & 4.45 & 4.7498 & TST & \\
\hline CHEMBL1399201 & 688889 & 4.3 & 4.7042 & TRN & \\
\hline CHEMBL1546216 & 688889 & 4.95 & 4.801 & TST & \\
\hline CHEMBL1517167 & 688889 & 4.3 & 4.7102 & TRN & \\
\hline CHEMBL1339887 & 688889 & 4.9 & 4.7937 & TRN & \\
\hline CHEMBL1507893 & 688889 & 6.45 & 4.7852 & TST & \\
\hline CHEMBL1484867 & 688889 & 5.95 & 4.9104 & TRN & \\
\hline CHEMBL1383879 & 688889 & 6.25 & 4.7994 & TRN & \\
\hline CHEMBL1469206 & 688889 & 4.3 & 4.8298 & TRN & \\
\hline CHEMBL1410321 & 688889 & 4.45 & 4.8263 & TRN & \\
\hline CHEMBL1508405 & 688889 & 4.45 & 4.8245 & TRN & \\
\hline CHEMBL1530025 & 688889 & 4.45 & 4.6781 & TRN & \\
\hline CHEMBL1545267 & 688889 & 6.0 & 4.8554 & TST & \\
\hline CHEMBL1409002 & 688889 & 4.3 & 4.9406 & TRN & \\
\hline CHEMBL1491480 & 688889 & 6.7501 & 4.7812 & TST & \\
\hline CHEMBL1332467 & 688889 & 5.0 & 4.8003 & TRN & \\
\hline CHEMBL1427577 & 688889 & 4.25 & 4.8625 & TST & \\
\hline CHEMBL1531101 & 688889 & 4.5 & 4.75899 & 99999999995 & TST \\
\hline CHEMBL1379462 & 688889 & 5.35 & 4.9097 & TRN & \\
\hline CHEMBL1369369 & 688889 & 5.35 & 4.6721 & TST & \\
\hline CHEMBL1335445 & 688889 & 4.5 & 4.6992 & TST & \\
\hline CHEMBL3190211 & 688889 & 4.25 & 4.8659 & TRN & \\
\hline CHEMBL1388588 & 688889 & 4.55 & 4.7521 & TRN & \\
\hline CHEMBL1353018 & 688889 & 4.3 & 4.7331 & TRN & \\
\hline CHEMBL1440729 & 688889 & 4.35 & 4.8479 & TRN & \\
\hline CHEMBL1547000 & 688889 & 6.05 & 4.88899 & 9999999999 & TRN \\
\hline CHEMBL3199380 & 688889 & 5.45 & 4.7565 & TST & \\
\hline
\end{tabular}




\begin{tabular}{|c|c|c|c|c|}
\hline & & & pplement & al $\mathrm{Ta}$ \\
\hline CHEMBL1501184 & 688889 & 4.3 & 4.6676 & TRN \\
\hline CHEMBL1328050 & 688889 & 4.5 & 4.819 & TST \\
\hline CHEMBL1585091 & 688889 & 4.45 & 4.8895 & TRN \\
\hline CHEMBL3212985 & 688889 & 4.4 & 4.7483 & TRN \\
\hline CHEMBL1531812 & 688889 & 4.3 & 4.8826 & TRN \\
\hline CHEMBL1412093 & 688889 & 4.25 & 4.6756 & TRN \\
\hline CHEMBL1465695 & 688889 & 4.55 & 4.7483 & TRN \\
\hline CHEMBL1573166 & 688889 & 5.35 & 4.8135 & TRN \\
\hline CHEMBL1403895 & 688889 & 4.4 & 4.8921 & TRN \\
\hline CHEMBL1492859 & 688889 & 4.9 & 4.792 & TST \\
\hline CHEMBL1503672 & 688889 & 4.5 & 4.6893 & TRN \\
\hline CHEMBL1419576 & 688889 & 4.9 & 4.8651 & TST \\
\hline CHEMBL1557704 & 688889 & 4.3 & 4.6642 & TRN \\
\hline CHEMBL1423038 & 688889 & 4.7 & 4.7794 & TRN \\
\hline CHEMBL1305966 & 688889 & 4.25 & 4.8531 & TST \\
\hline CHEMBL1422421 & 688889 & 4.25 & 4.885 & TRN \\
\hline CHEMBL1409607 & 688889 & 4.3 & 4.9403 & TRN \\
\hline CHEMBL1582902 & 688889 & 4.5 & 4.7168 & TST \\
\hline CHEMBL1454710 & 688889 & 4.9 & 4.9425 & TRN \\
\hline CHEMBL1373945 & 688889 & 4.3 & 4.6793 & TRN \\
\hline CHEMBL1516829 & 688889 & 4.3 & 4.6971 & TST \\
\hline CHEMBL1359737 & 688889 & 4.5 & 4.6629 & TRN \\
\hline CHEMBL1425367 & 688889 & 5.5 & 4.7728 & TRN \\
\hline CHEMBL1431905 & 688889 & 4.5 & 4.8479 & TRN \\
\hline CHEMBL 3208918 & 688889 & 4.3 & 4.7466 & TST \\
\hline CHEMBL1310637 & 688889 & 4.35 & 4.865 & TRN \\
\hline CHEMBL1546693 & 688889 & 4.95 & 4.7598 & TRN \\
\hline CHEMBL1418995 & 688889 & 4.35 & 4.6967 & TST \\
\hline CHEMBL1313370 & 688889 & 4.75 & 4.8994 & TRN \\
\hline CHEMBL1465729 & 688889 & 4.25 & 4.9737 & TRN \\
\hline CHEMBL1541883 & 688889 & 4.25 & 4.7666 & TRN \\
\hline CHEMBL1472355 & 688889 & 4.65 & 4.7305 & TST \\
\hline CHEMBL1522697 & 688889 & 5.05 & 4.7204 & TST \\
\hline CHEMBL1608713 & 688889 & 4.3 & 4.9543 & TRN \\
\hline CHEMBL1387164 & 688889 & 4.35 & 4.8717 & TST \\
\hline CHEMBL1388120 & 688889 & 6.45 & 4.8138 & TRN \\
\hline CHEMBL1584624 & 688889 & 4.5 & 4.7729 & TRN \\
\hline CHEMBL1301324 & 688889 & 4.3 & 4.8373 & TRN \\
\hline CHEMBL1460071 & 688889 & 4.95 & 4.8658 & TST \\
\hline CHEMBL1547164 & 688889 & 4.55 & 4.9663 & TST \\
\hline CHEMBL1391267 & 688889 & 4.4 & 4.9097 & TRN \\
\hline CHEMBL1363133 & 688889 & 4.35 & 4.815 & TRN \\
\hline CHEMBL1305366 & 688889 & 5.25 & 4.738 & TRN \\
\hline CHEMBL1330356 & 688889 & 4.25 & 4.7896 & TRN \\
\hline CHEMBL1405953 & 688889 & 4.5 & 4.8983 & TRN \\
\hline CHEMBL1341432 & 688889 & 4.45 & 4.7883 & TRN \\
\hline CHEMBL1419043 & 688889 & 6.15 & 4.8862 & TRN \\
\hline CHEMBL1501114 & 688889 & 4.9 & 4.9757 & TRN \\
\hline
\end{tabular}




\begin{tabular}{|c|c|c|c|c|}
\hline \multicolumn{5}{|c|}{ Supplemental Ta } \\
\hline CHEMBL1469859 & 688889 & 5.2 & 4.8771 & TRN \\
\hline CHEMBL1500158 & 688889 & 5.6 & 4.5954 & TRN \\
\hline CHEMBL1423861 & 688889 & 5.15 & 4.787 & TST \\
\hline CHEMBL1311518 & 688889 & 5.45 & 4.8209 & TST \\
\hline CHEMBL1312197 & 688889 & 5.25 & 4.8031 & TRN \\
\hline CHEMBL3211392 & 688889 & 4.45 & 4.8046 & TST \\
\hline CHEMBL3211666 & 688889 & 4.45 & 4.8994 & TST \\
\hline CHEMBL1339108 & 688889 & 5.15 & 4.7987 & TST \\
\hline CHEMBL1442150 & 688889 & 4.25 & 4.8381 & TRN \\
\hline CHEMBL1343257 & 688889 & 4.85 & 4.8677 & TST \\
\hline CHEMBL1314104 & 688889 & 4.3 & 4.9092 & TRN \\
\hline CHEMBL1564028 & 688889 & 4.4 & 4.7146 & TRN \\
\hline CHEMBL1471453 & 688889 & 5.8 & 4.8736 & TRN \\
\hline CHEMBL1518175 & 688889 & 5.1 & 4.7399 & TRN \\
\hline CHEMBL1511175 & 688889 & 4.25 & 4.7244 & TRN \\
\hline CHEMBL1367116 & 688889 & 6.5501 & 4.9062 & TRN \\
\hline CHEMBL1602410 & 688889 & 4.55 & 4.8062 & TRN \\
\hline CHEMBL1481564 & 688889 & 4.35 & 4.9942 & TST \\
\hline CHEMBL1510330 & 688889 & 4.55 & 4.5724 & TRN \\
\hline CHEMBL1470911 & 688889 & 4.25 & 4.8434 & TST \\
\hline CHEMBL1569690 & 688889 & 4.8 & 4.7719 & TST \\
\hline CHEMBL1366220 & 688889 & 4.5 & 4.7431 & TRN \\
\hline CHEMBL1366745 & 688889 & 4.85 & 4.773 & TRN \\
\hline CHEMBL1507744 & 688889 & 5.25 & 4.8622 & TST \\
\hline CHEMBL1538818 & 688889 & 4.95 & 4.8503 & TST \\
\hline CHEMBL1588119 & 688889 & 5.85 & 4.8341 & TST \\
\hline CHEMBL1363853 & 688889 & 4.25 & 4.8542 & TRN \\
\hline CHEMBL1470795 & 688889 & 4.45 & 4.8292 & TRN \\
\hline CHEMBL1488429 & 688889 & 4.6 & 4.7278 & TRN \\
\hline CHEMBL1602972 & 688889 & 4.3 & 4.8724 & TST \\
\hline CHEMBL1466037 & 688889 & 5.15 & 4.8071 & TST \\
\hline CHEMBL1414747 & 688889 & 4.65 & 4.8342 & TRN \\
\hline CHEMBL3197489 & 688889 & 4.3 & 4.771 & TRN \\
\hline CHEMBL1519723 & 688889 & 4.45 & 4.648 & TRN \\
\hline CHEMBL1569856 & 688889 & 4.4 & 4.758 & TST \\
\hline CHEMBL1345212 & 688889 & 4.45 & 4.7879 & TRN \\
\hline CHEMBL1503118 & 688889 & 4.95 & 4.9232 & TRN \\
\hline CHEMBL1379606 & 688889 & 6.1 & 4.8527 & TRN \\
\hline CHEMBL1990573 & 688889 & 5.95 & 4.8452 & TST \\
\hline CHEMBL1464647 & 688889 & 4.95 & 4.8269 & TRN \\
\hline CHEMBL3192183 & 688889 & 5.5 & 4.8646 & TRN \\
\hline CHEMBL1485394 & 688889 & 4.3 & 5.0258 & TRN \\
\hline CHEMBL1464036 & 688889 & 4.45 & 4.6092 & TRN \\
\hline CHEMBL1306019 & 688889 & 5.5 & 4.9527 & TST \\
\hline CHEMBL1326513 & 688889 & 4.3 & 4.7774 & TRN \\
\hline CHEMBL1558757 & 688889 & 6.5501 & 4.9242 & TRN \\
\hline CHEMBL1426086 & 688889 & 6.7501 & 4.9365 & TRN \\
\hline CHEMBL1331615 & 688889 & 4.5 & 4.7375 & TRN \\
\hline
\end{tabular}




\begin{tabular}{|c|c|c|c|c|c|}
\hline \multicolumn{6}{|c|}{ Supplemental Table S2.txt } \\
\hline CHEMBL1421603 & 688889 & 5.95 & 4.6781 & TST & \\
\hline CHEMBL1500938 & 688889 & 4.7 & 4.913 & TST & \\
\hline CHEMBL1525626 & 688889 & 4.25 & 4.8051 & TRN & \\
\hline CHEMBL1464775 & 688889 & 4.3 & 4.7887 & TRN & \\
\hline CHEMBL1335367 & 688889 & 4.4 & 4.6671 & TRN & \\
\hline CHEMBL1360573 & 688889 & 4.75 & 4.7959 & TRN & \\
\hline CHEMBL1359606 & 688889 & 4.25 & 4.7971 & TRN & \\
\hline CHEMBL1502853 & 688889 & 4.4 & 4.762 & TRN & \\
\hline CHEMBL1365595 & 688889 & 4.25 & 4.76 & TRN & \\
\hline CHEMBL1584248 & 688889 & 6.05 & 4.8731 & TST & \\
\hline CHEMBL1481526 & 688889 & 5.85 & 4.9216 & TRN & \\
\hline CHEMBL1428621 & 688889 & 4.9 & 4.8618 & TRN & \\
\hline CHEMBL1393659 & 688889 & 5.3 & 4.8546 & TRN & \\
\hline CHEMBL1468336 & 688889 & 6.7501 & 4.8416 & TST & \\
\hline CHEMBL1457646 & 688889 & 4.4 & 4.709 & TRN & \\
\hline CHEMBL1324646 & 688889 & 4.5 & 4.8896 & TST & \\
\hline CHEMBL3196011 & 688889 & 4.5 & 4.8574 & TRN & \\
\hline CHEMBL1494473 & 688889 & 5.55 & 4.8579 & TRN & \\
\hline CHEMBL1596434 & 688889 & 5.75 & 4.8618 & TRN & \\
\hline CHEMBL1408530 & 688889 & 4.95 & 4.6799 & TRN & \\
\hline CHEMBL1542386 & 688889 & 5.0 & 4.6348 & TRN & \\
\hline CHEMBL1402614 & 688889 & 6.0 & 4.7155 & TST & \\
\hline CHEMBL1380657 & 688889 & 5.25 & 4.9347 & TRN & \\
\hline CHEMBL1500574 & 688889 & 5.8 & 4.7488 & TST & \\
\hline CHEMBL1379191 & 688889 & 4.4 & 4.7609 & TST & \\
\hline CHEMBL1485726 & 688889 & 4.45 & 4.8241 & TRN & \\
\hline CHEMBL1457918 & 688889 & 4.55 & 4.7753 & TRN & \\
\hline CHEMBL1421799 & 688889 & 4.3 & 4.8051 & TRN & \\
\hline CHEMBL1611518 & 688889 & 5.1 & 4.827 & TRN & \\
\hline CHEMBL1423046 & 688889 & 4.3 & 4.7609 & TRN & \\
\hline CHEMBL1326161 & 688889 & 4.9 & 4.895 & TRN & \\
\hline CHEMBL1324564 & 688889 & 4.25 & 4.773 & TRN & \\
\hline CHEMBL1502154 & 688889 & 4.45 & $4.7780 e$ & 00000000005 & TRN \\
\hline CHEMBL1498476 & 688889 & 4.3 & 4.9016 & TRN & \\
\hline CHEMBL1495787 & 688889 & 4.95 & 4.8044 & TST & \\
\hline CHEMBL3213540 & 688889 & 6.7501 & 4.8589 & TST & \\
\hline CHEMBL1364417 & 688889 & 6.0 & 4.8618 & TST & \\
\hline CHEMBL1565594 & 688889 & 5.3 & 4.6223 & TRN & \\
\hline CHEMBL1541260 & 688889 & 4.5 & $4.7410 e$ & 00000000005 & TRN \\
\hline CHEMBL1353890 & 688889 & 6.7501 & 4.77 & TST & \\
\hline CHEMBL1428636 & 688889 & 4.5 & 4.813 & TRN & \\
\hline CHEMBL1495014 & 688889 & 5.85 & 4.9593 & TRN & \\
\hline CHEMBL1326748 & 688889 & 5.25 & 4.689 & TRN & \\
\hline CHEMBL1349723 & 688889 & 4.3 & 4.7938 & TST & \\
\hline CHEMBL1479962 & 688889 & 4.6 & 4.7852 & TRN & \\
\hline CHEMBL1303623 & 688889 & 4.3 & 4.8133 & TRN & \\
\hline CHEMBL1504198 & 688889 & 5.4 & 4.8566 & TRN & \\
\hline CHEMBL1348609 & 688889 & 4.95 & 4.9045 & TST & \\
\hline
\end{tabular}




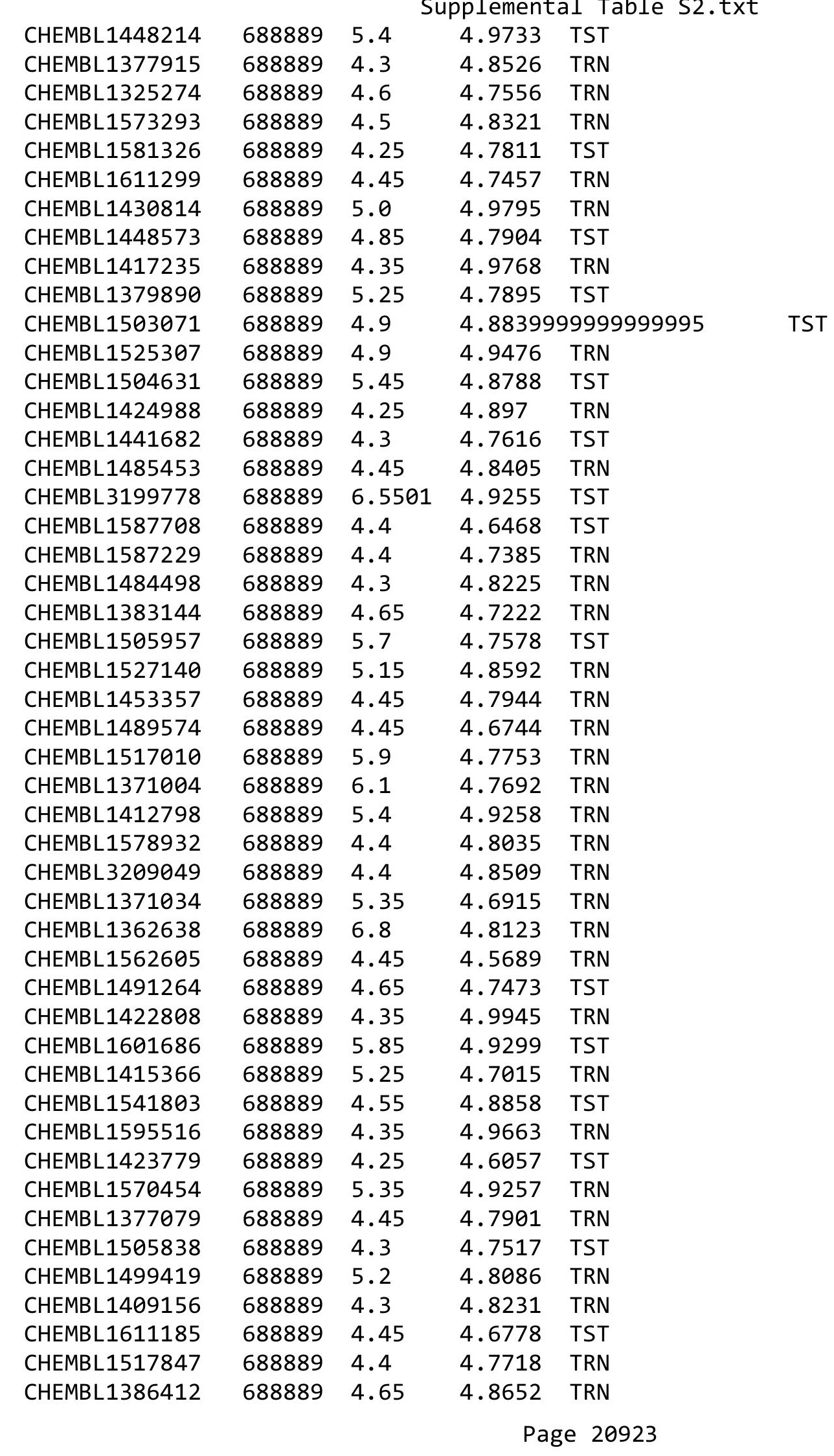




\begin{tabular}{|c|c|c|c|c|c|}
\hline & & \multicolumn{4}{|c|}{ Supplemental Table S2.txt } \\
\hline CHEMBL1486272 & 688889 & 4.3 & 4.746 & TRN & \\
\hline CHEMBL1488625 & 688889 & 4.3 & 4.6001 & TRN & \\
\hline CHEMBL1531162 & 688889 & 4.25 & 4.7437 & TRN & \\
\hline CHEMBL1462520 & 688889 & 4.3 & 4.6571 & TRN & \\
\hline CHEMBL1519295 & 688889 & 4.25 & 4.8396 & TST & \\
\hline CHEMBL1359661 & 688889 & 5.2 & 4.7123 & TRN & \\
\hline CHEMBL1339873 & 688889 & 4.55 & 4.671 & TRN & \\
\hline CHEMBL1448265 & 688889 & 4.25 & 4.7237 & TRN & \\
\hline CHEMBL1556061 & 688889 & 4.4 & 4.8513 & TRN & \\
\hline CHEMBL1361855 & 688889 & 5.95 & 4.6437 & TST & \\
\hline CHEMBL1333066 & 688889 & 4.95 & 4.8176 & TST & \\
\hline CHEMBL1560174 & 688889 & 5.15 & 4.8965 & TRN & \\
\hline CHEMBL1606494 & 688889 & 6.05 & 4.7783 & TRN & \\
\hline CHEMBL1597153 & 688889 & 4.3 & 4.7947 & TRN & \\
\hline CHEMBL1302597 & 688889 & 5.65 & 4.7583 & TRN & \\
\hline CHEMBL 3213214 & 688889 & 4.25 & 4.8064 & TST & \\
\hline CHEMBL1366367 & 688889 & 4.35 & 4.6281 & TRN & \\
\hline CHEMBL1570530 & 688889 & 4.45 & 4.6806 & TRN & \\
\hline CHEMBL1602587 & 688889 & 4.25 & 4.7993 & TRN & \\
\hline CHEMBL1374235 & 688889 & 4.95 & 4.86 & TRN & \\
\hline CHEMBL1453712 & 688889 & 4.6 & 4.7602 & TRN & \\
\hline CHEMBL1611749 & 688889 & 5.45 & 4.9285 & TRN & \\
\hline CHEMBL1446100 & 688889 & 6.05 & 4.9004 & TST & \\
\hline CHEMBL1408812 & 688889 & 4.3 & 4.7207 & TST & \\
\hline CHEMBL1566565 & 688889 & 4.4 & 4.8242 & TST & \\
\hline CHEMBL1517388 & 688889 & 4.55 & 4.7549 & TST & \\
\hline CHEMBL1565285 & 688889 & 4.3 & 4.7812 & TRN & \\
\hline CHEMBL1428995 & 688889 & 4.3 & 4.6903 & TRN & \\
\hline CHEMBL1388977 & 688889 & 4.55 & 4.8074 & TRN & \\
\hline CHEMBL1427701 & 688889 & 5.1 & 4.7275 & TRN & \\
\hline CHEMBL236899 & 688889 & 6.0 & 4.6913 & TRN & \\
\hline CHEMBL1309755 & 688889 & 4.25 & 4.9253 & TRN & \\
\hline CHEMBL1320124 & 688889 & 5.95 & 4.7639 & TRN & \\
\hline CHEMBL1374718 & 688889 & 4.3 & 4.6839 & TRN & \\
\hline CHEMBL1530496 & 688889 & 5.6 & 4.8269 & TST & \\
\hline CHEMBL1382530 & 688889 & 4.55 & 4.8006 & TST & \\
\hline CHEMBL1534144 & 688889 & 4.85 & 4.7503 & TRN & \\
\hline CHEMBL1547670 & 688889 & 5.3 & 4.8515 & TRN & \\
\hline CHEMBL1566483 & 688889 & 4.95 & 4.86 & TRN & \\
\hline CHEMBL1413796 & 688889 & 4.3 & 4.8468 & TRN & \\
\hline CHEMBL1521512 & 688889 & 4.3 & 4.712 & TRN & \\
\hline CHEMBL1560647 & 688889 & 4.3 & 4.8157 & TRN & \\
\hline CHEMBL1485573 & 688889 & 4.5 & 4.72199 & 99999999995 & TRN \\
\hline CHEMBL1530482 & 688889 & 5.15 & 4.8103 & TRN & \\
\hline CHEMBL1322330 & 688889 & 4.3 & 4.8708 & TRN & \\
\hline CHEMBL1441505 & 688889 & 4.95 & 4.873 & TST & \\
\hline CHEMBL1371629 & 688889 & 4.85 & 4.8957 & TRN & \\
\hline CHEMBL1525029 & 688889 & 6.1 & 4.6419 & TRN & \\
\hline
\end{tabular}




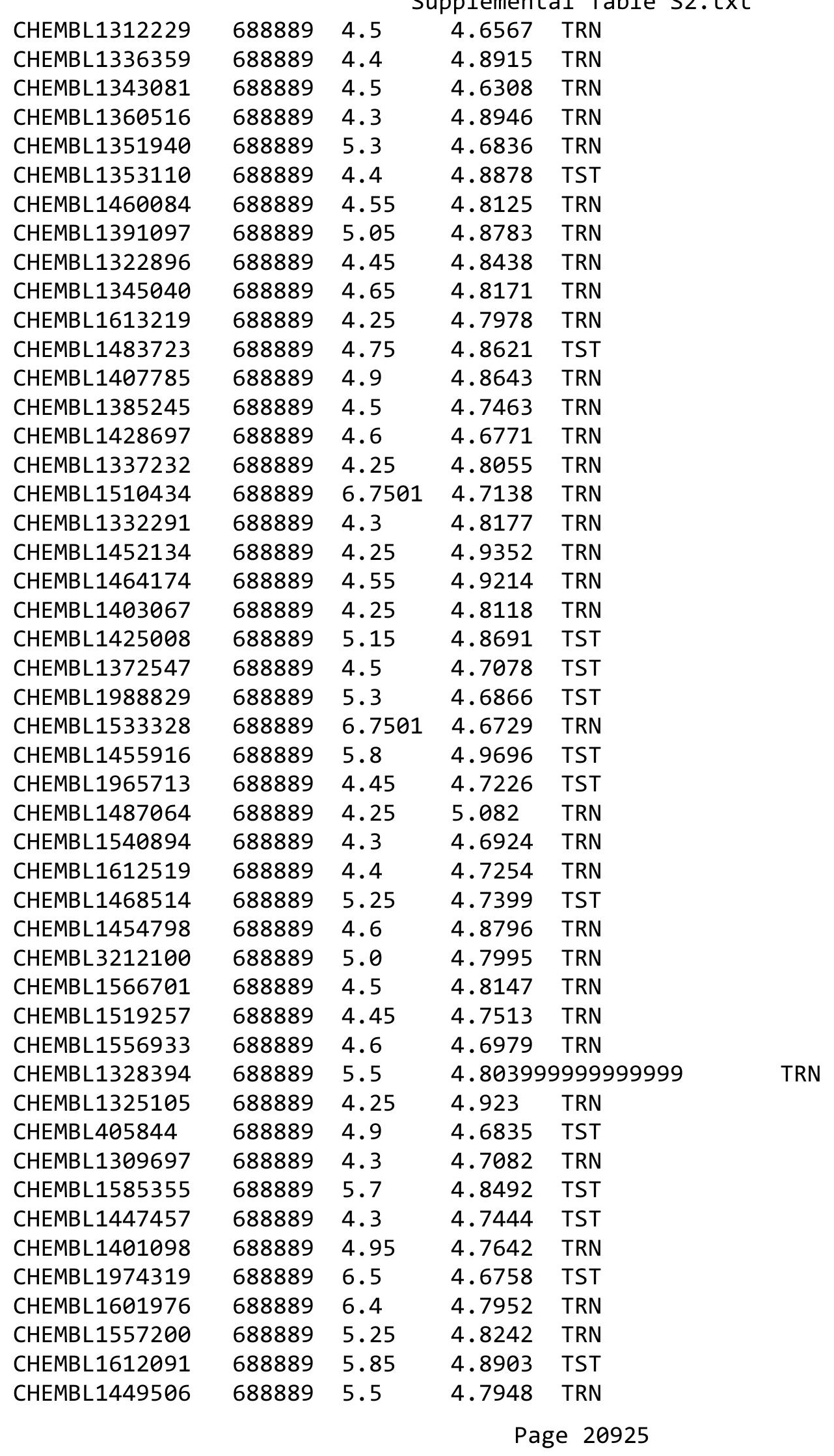




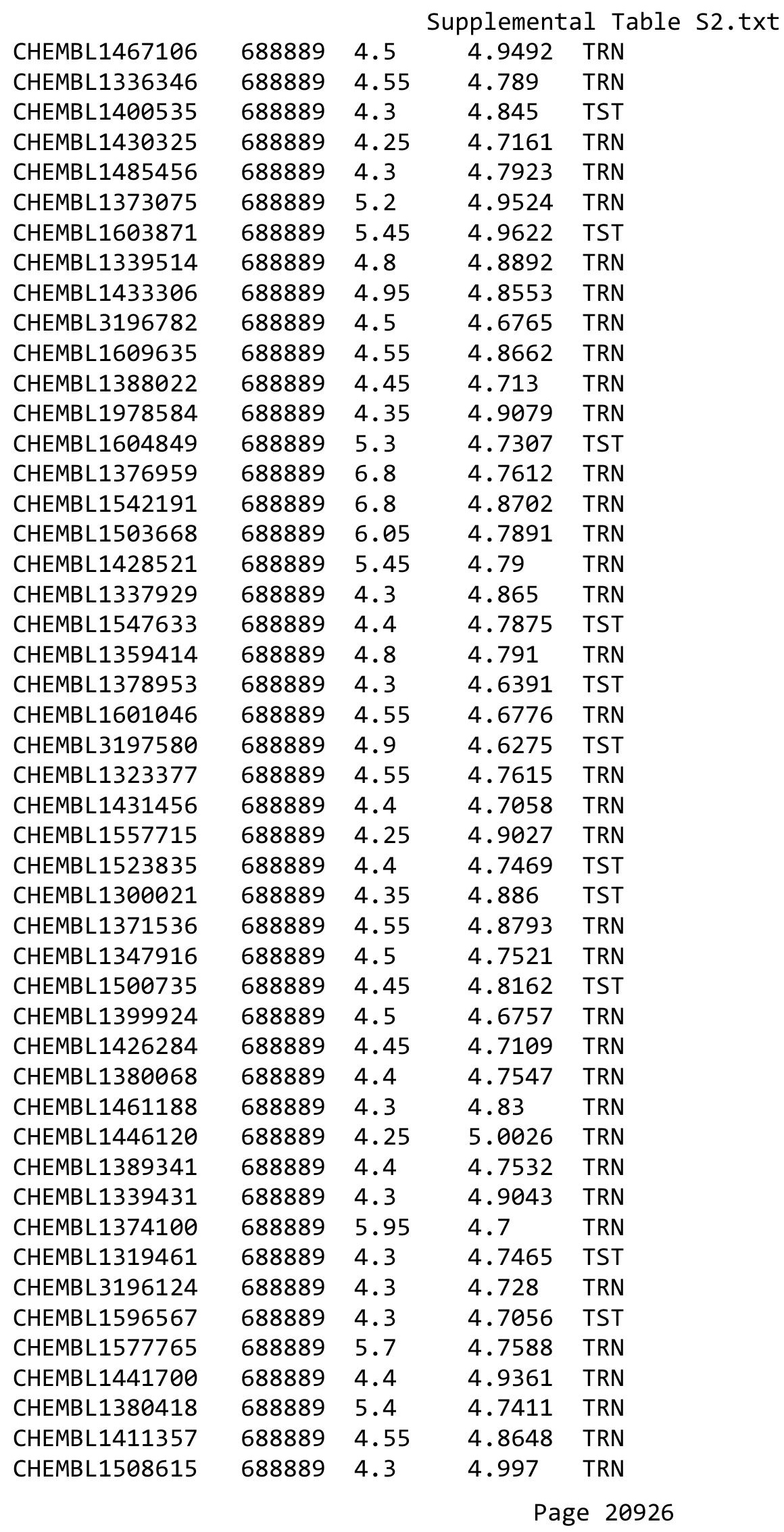




\begin{tabular}{|c|c|c|c|c|c|}
\hline \multirow{2}{*}{ CHEMBL1511154 } & \multirow{2}{*}{688889} & \\
\hline & & 4.3 & 4.7331 & TRN & \\
\hline CHEMBL1586513 & 688889 & 4.65 & 4.7293 & TST & \\
\hline CHEMBL1577741 & 688889 & 4.5 & 4.8106 & TRN & \\
\hline CHEMBL1503693 & 688889 & 4.25 & 4.7461 & TRN & \\
\hline CHEMBL1491385 & 688889 & 4.9 & 4.7708 & TRN & \\
\hline CHEMBL1340219 & 688889 & 4.4 & 4.6847 & TRN & \\
\hline CHEMBL1339928 & 688889 & 4.55 & 4.67899 & 9999999999 & TRN \\
\hline CHEMBL596271 & 688889 & 5.5 & 4.7455 & TRN & \\
\hline CHEMBL1506985 & 688889 & 4.3 & 4.7939 & TRN & \\
\hline CHEMBL1584508 & 688889 & 5.5 & 4.8524 & TRN & \\
\hline CHEMBL3198757 & 688889 & 4.4 & 4.8923 & TST & \\
\hline CHEMBL3208664 & 688889 & 4.55 & 4.9164 & TST & \\
\hline CHEMBL1582442 & 688889 & 5.75 & 4.8733 & TST & \\
\hline CHEMBL1500973 & 688889 & 4.25 & 4.7905 & TST & \\
\hline CHEMBL585828 & 688889 & 4.5 & 4.8183 & TRN & \\
\hline CHEMBL1372404 & 688889 & 4.25 & 4.7722 & TRN & \\
\hline CHEMBL1349012 & 688889 & 4.9 & 4.6949 & TST & \\
\hline CHEMBL1321034 & 688889 & 4.25 & 4.6722 & TRN & \\
\hline CHEMBL1534539 & 688889 & 4.25 & 4.8715 & TRN & \\
\hline CHEMBL1508743 & 688889 & 4.45 & 4.7229 & TRN & \\
\hline CHEMBL1497833 & 688889 & 4.95 & 4.8376 & TRN & \\
\hline CHEMBL1606920 & 688889 & 5.7 & 4.7425 & TRN & \\
\hline CHEMBL1583076 & 688889 & 4.45 & 4.6793 & TRN & \\
\hline CHEMBL1467088 & 688889 & 4.95 & 4.7621 & TRN & \\
\hline CHEMBL1303632 & 688889 & 4.45 & 4.7212 & TRN & \\
\hline CHEMBL1364187 & 688889 & 4.3 & 4.8749 & TRN & \\
\hline CHEMBL3196792 & 688889 & 4.45 & 4.8004 & TRN & \\
\hline CHEMBL1572662 & 688889 & 4.6 & 4.6553 & TRN & \\
\hline CHEMBL1478454 & 688889 & 4.4 & 4.742 & TST & \\
\hline CHEMBL1383390 & 688889 & 4.45 & 4.8233 & TRN & \\
\hline CHEMBL1458549 & 688889 & 4.95 & 4.7952 & TRN & \\
\hline CHEMBL3189857 & 688889 & 4.75 & 4.6581 & TST & \\
\hline CHEMBL1549897 & 688889 & 4.5 & 4.8772 & TRN & \\
\hline CHEMBL1485174 & 688889 & 4.35 & 4.7638 & TST & \\
\hline CHEMBL1419754 & 688889 & 4.55 & 4.8787 & TST & \\
\hline CHEMBL1503201 & 688889 & 4.25 & 4.76699 & 99999999995 & TRN \\
\hline CHEMBL1362373 & 688889 & 6.1 & 4.8654 & TRN & \\
\hline CHEMBL1539194 & 688889 & 4.65 & 4.7434 & TST & \\
\hline CHEMBL1522247 & 688889 & 4.25 & 4.8601 & TRN & \\
\hline CHEMBL1559901 & 688889 & 5.9 & 4.6372 & TRN & \\
\hline CHEMBL3209391 & 688889 & 4.35 & 4.8032 & TRN & \\
\hline CHEMBL1531462 & 688889 & 6.25 & 4.7732 & TRN & \\
\hline CHEMBL1575194 & 688889 & 4.25 & 4.7596 & TST & \\
\hline CHEMBL1544277 & 688889 & 4.95 & 4.824 & TRN & \\
\hline CHEMBL1301468 & 688889 & 4.25 & 4.7799 & TST & \\
\hline CHEMBL1503026 & 688889 & 4.4 & 4.9195 & TST & \\
\hline CHEMBL571139 & 688889 & 5.0 & 4.8921 & TRN & \\
\hline CHEMBL1566415 & 688889 & 4.8 & 4.6174 & TRN & \\
\hline & & & & 20927 & \\
\hline
\end{tabular}




\begin{tabular}{|c|c|c|c|c|c|}
\hline \multicolumn{6}{|c|}{ Supplemental Table S2.txt } \\
\hline CHEMBL1478970 & 688889 & 4.45 & 4.7597 & TRN & \\
\hline CHEMBL1530190 & 688889 & 4.5 & 4.9425 & TRN & \\
\hline CHEMBL1382780 & 688889 & 4.8 & 4.8823 & TST & \\
\hline CHEMBL1337673 & 688889 & 4.25 & 4.7936 & TRN & \\
\hline CHEMBL1527122 & 688889 & 4.3 & 4.8233 & TRN & \\
\hline CHEMBL1465989 & 688889 & 5.5 & 4.9383 & TRN & \\
\hline CHEMBL1463286 & 688889 & 6.05 & 4.8656 & TRN & \\
\hline CHEMBL1504193 & 688889 & 5.1 & 4.9473 & TRN & \\
\hline CHEMBL1313453 & 688889 & 4.5 & 4.7866 & TRN & \\
\hline CHEMBL1585432 & 688889 & 5.2 & 4.72199 & 99999999995 & TST \\
\hline CHEMBL1345682 & 688889 & 6.8 & 4.7547 & TRN & \\
\hline CHEMBL1424278 & 688889 & 4.3 & 4.8419 & TST & \\
\hline CHEMBL1460887 & 688889 & 6.4 & 4.8773 & TST & \\
\hline CHEMBL1583145 & 688889 & 5.35 & 4.7565 & TST & \\
\hline CHEMBL1455378 & 688889 & 4.95 & 4.8287 & TRN & \\
\hline CHEMBL1387767 & 688889 & 4.35 & 4.8849 & TST & \\
\hline CHEMBL1538312 & 688889 & 5.25 & 4.7728 & TRN & \\
\hline CHEMBL1574727 & 688889 & 4.5 & 4.8227 & TST & \\
\hline CHEMBL1597123 & 688889 & 4.7 & 4.7573 & TRN & \\
\hline CHEMBL1483803 & 688889 & 6.0 & 4.88 & TRN & \\
\hline CHEMBL1346498 & 688889 & 4.25 & 4.782 & TRN & \\
\hline CHEMBL1411619 & 688889 & 4.4 & 4.7033 & TRN & \\
\hline CHEMBL1377282 & 688889 & 4.45 & 4.819 & TRN & \\
\hline CHEMBL1598965 & 688889 & 4.4 & 4.8688 & TRN & \\
\hline CHEMBL1379424 & 688889 & 4.9 & 4.8079 & TRN & \\
\hline CHEMBL1585267 & 688889 & 4.5 & 4.7873 & TRN & \\
\hline CHEMBL1414576 & 688889 & 4.3 & 4.9325 & TRN & \\
\hline CHEMBL1545168 & 688889 & 4.3 & 4.8367 & TRN & \\
\hline CHEMBL1607695 & 688889 & 4.3 & 4.8591 & TST & \\
\hline CHEMBL1332902 & 688889 & 6.8 & 4.812 & TST & \\
\hline CHEMBL1502300 & 688889 & 4.4 & 4.8156 & TRN & \\
\hline CHEMBL1989858 & 688889 & 4.9 & 4.762 & TST & \\
\hline CHEMBL1451957 & 688889 & 5.75 & 4.9128 & TRN & \\
\hline CHEMBL 3213754 & 688889 & 5.35 & 4.735 & TST & \\
\hline CHEMBL1409968 & 688889 & 5.1 & 4.8878 & TRN & \\
\hline CHEMBL1568026 & 688889 & 4.25 & 4.7444 & TST & \\
\hline CHEMBL1574002 & 688889 & 4.9 & 4.7892 & TST & \\
\hline CHEMBL1527980 & 688889 & 4.55 & 4.6848 & TRN & \\
\hline CHEMBL1410782 & 688889 & 4.3 & 4.8884 & TRN & \\
\hline CHEMBL1348201 & 688889 & 4.25 & 4.8029 & TST & \\
\hline CHEMBL1502098 & 688889 & 4.5 & 4.6892 & TRN & \\
\hline CHEMBL1381306 & 688889 & 4.8 & 4.6876 & TRN & \\
\hline CHEMBL1404438 & 688889 & 4.45 & 4.92899 & 9999999999 & TRN \\
\hline CHEMBL1560945 & 688889 & 4.65 & 4.6983 & TRN & \\
\hline CHEMBL1417357 & 688889 & 4.95 & 4.9532 & TRN & \\
\hline CHEMBL1445562 & 688889 & 4.95 & 4.8177 & TRN & \\
\hline CHEMBL1560827 & 688889 & 4.3 & 4.8655 & TRN & \\
\hline CHEMBL1505141 & 688889 & 4.25 & 4.9076 & TRN & \\
\hline
\end{tabular}




\begin{tabular}{|c|c|c|c|c|c|}
\hline & & & & & \\
\hline CHEMBL1426402 & 688889 & 4.6 & 4.5843 & TRN & \\
\hline CHEMBL1393485 & 688889 & 4.4 & 4.7317 & TST & \\
\hline CHEMBL1524168 & 688889 & 5.35 & 4.8053 & TRN & \\
\hline CHEMBL1364051 & 688889 & 4.3 & 4.8294 & TRN & \\
\hline CHEMBL1479346 & 688889 & 4.95 & 4.7011 & TST & \\
\hline CHEMBL1341601 & 688889 & 4.3 & 4.7792 & TST & \\
\hline CHEMBL1574359 & 688889 & 5.05 & $4.8210 e$ & 0000000001 & TST \\
\hline CHEMBL1520404 & 688889 & 5.2 & 4.7576 & TST & \\
\hline CHEMBL1535974 & 688889 & 4.3 & 4.8389 & TRN & \\
\hline CHEMBL1305678 & 688889 & 4.25 & 4.6957 & TRN & \\
\hline CHEMBL1462538 & 688889 & 5.25 & 4.9837 & TST & \\
\hline CHEMBL1091787 & 688889 & 4.25 & 4.7745 & TRN & \\
\hline CHEMBL3198057 & 688889 & 4.65 & 4.6713 & TRN & \\
\hline CHEMBL1407650 & 688889 & 4.85 & 4.6629 & TRN & \\
\hline CHEMBL1579765 & 688889 & 4.4 & 4.8883 & TRN & \\
\hline CHEMBL1311703 & 688889 & 4.5 & 4.8585 & TRN & \\
\hline CHEMBL1544951 & 688889 & 4.45 & 4.7477 & TST & \\
\hline CHEMBL1609726 & 688889 & 4.3 & 4.8004 & TRN & \\
\hline CHEMBL1502352 & 688889 & 4.4 & 4.78 & TST & \\
\hline CHEMBL1452239 & 688889 & 5.2 & 4.7128 & TRN & \\
\hline CHEMBL1454778 & 688889 & 5.1 & 4.7907 & TRN & \\
\hline CHEMBL1520823 & 688889 & 4.4 & 4.8658 & TST & \\
\hline CHEMBL1583216 & 688889 & 5.15 & 4.8535 & TRN & \\
\hline CHEMBL3191907 & 688889 & 5.5 & 4.7107 & TST & \\
\hline CHEMBL1337556 & 688889 & 5.9 & 4.8436 & TST & \\
\hline CHEMBL1560238 & 688889 & 4.25 & 4.8234 & TRN & \\
\hline CHEMBL1368095 & 688889 & 4.25 & 4.7491 & TST & \\
\hline CHEMBL1477620 & 688889 & 4.6 & 4.7242 & TRN & \\
\hline CHEMBL1451004 & 688889 & 4.55 & 4.7415 & TST & \\
\hline CHEMBL1426956 & 688889 & 5.15 & 4.7721 & TST & \\
\hline CHEMBL1385824 & 688889 & 4.25 & 4.6508 & TRN & \\
\hline CHEMBL1302262 & 688889 & 4.3 & 4.7587 & TRN & \\
\hline CHEMBL1505788 & 688889 & 6.45 & 4.7823 & TRN & \\
\hline CHEMBL1453508 & 688889 & 4.65 & 4.6666 & TRN & \\
\hline CHEMBL1378513 & 688889 & 4.9 & 4.7692 & TRN & \\
\hline CHEMBL3207519 & 688889 & 4.3 & 4.9145 & TST & \\
\hline CHEMBL1429949 & 688889 & 4.4 & 4.6789 & TRN & \\
\hline CHEMBL1327137 & 688889 & 4.45 & 4.738 & TRN & \\
\hline CHEMBL1337587 & 688889 & 4.3 & 4.71399 & 99999999995 & TRN \\
\hline CHEMBL3191189 & 688889 & 4.25 & 4.8483 & TST & \\
\hline CHEMBL3196840 & 688889 & 4.3 & 4.8925 & TST & \\
\hline CHEMBL1501724 & 688889 & 4.3 & 4.7753 & TRN & \\
\hline CHEMBL1565478 & 688889 & 4.6 & 4.7877 & TRN & \\
\hline CHEMBL1406554 & 688889 & 4.45 & 4.731 & TRN & \\
\hline CHEMBL1464502 & 688889 & 4.35 & 4.8294 & TRN & \\
\hline CHEMBL1583585 & 688889 & 4.3 & 4.7392 & TRN & \\
\hline CHEMBL 1458490 & 688889 & 5.55 & 4.7532 & TRN & \\
\hline CHEMBL1403368 & 688889 & 4.45 & 4.7554 & TRN & \\
\hline & & & & 20929 & \\
\hline
\end{tabular}




\begin{tabular}{|c|c|c|c|c|c|}
\hline \multicolumn{6}{|c|}{ Supplemental Table S2.txt } \\
\hline CHEMBL1538539 & 688889 & 4.7 & 4.8022 & TRN & \\
\hline CHEMBL1560303 & 688889 & 4.6 & 4.7409 & TRN & \\
\hline CHEMBL1370710 & 688889 & 4.25 & 4.7626 & TST & \\
\hline CHEMBL1343674 & 688889 & 5.05 & 4.8102 & TST & \\
\hline CHEMBL1576913 & 688889 & 4.5 & 4.8015 & TRN & \\
\hline CHEMBL1462253 & 688889 & 4.45 & 4.8472 & TST & \\
\hline CHEMBL1544326 & 688889 & 4.95 & 4.828 & TRN & \\
\hline CHEMBL1567420 & 688889 & 4.3 & 4.9201 & TRN & \\
\hline CHEMBL1410455 & 688889 & 6.7501 & 4.8977 & TST & \\
\hline CHEMBL1388684 & 688889 & 5.9 & 4.7762 & TRN & \\
\hline CHEMBL1599481 & 688889 & 4.6 & 4.8271 & TRN & \\
\hline CHEMBL1465383 & 688889 & 4.9 & 4.8882 & TST & \\
\hline CHEMBL1538814 & 688889 & 4.45 & 4.734 & TRN & \\
\hline CHEMBL1408369 & 688889 & 4.3 & 4.7726 & TRN & \\
\hline CHEMBL1385519 & 688889 & 4.95 & 4.7011 & TST & \\
\hline CHEMBL1610232 & 688889 & 4.25 & 4.8273 & TRN & \\
\hline CHEMBL1536290 & 688889 & 4.85 & 4.8504 & TRN & \\
\hline CHEMBL1568074 & 688889 & 5.1 & 4.7687 & TRN & \\
\hline CHEMBL1303864 & 688889 & 4.35 & 4.9176 & TRN & \\
\hline CHEMBL1350491 & 688889 & 4.45 & 4.6731 & TRN & \\
\hline CHEMBL1361859 & 688889 & 4.45 & 4.8912 & TST & \\
\hline CHEMBL1468969 & 688889 & 4.5 & 4.8535 & TST & \\
\hline CHEMBL1545220 & 688889 & 4.3 & 4.7245 & TST & \\
\hline CHEMBL1341197 & 688889 & 4.35 & 4.9342 & TRN & \\
\hline CHEMBL1540200 & 688889 & 4.45 & 5.0233 & TRN & \\
\hline CHEMBL1451411 & 688889 & 4.5 & 4.80399 & 9999999999 & TRN \\
\hline CHEMBL1463541 & 688889 & 4.8 & 4.8045 & TRN & \\
\hline CHEMBL1326868 & 688889 & 4.3 & 4.7823 & TRN & \\
\hline CHEMBL1364788 & 688889 & 4.65 & 4.8756 & TST & \\
\hline CHEMBL1323268 & 688889 & 4.25 & 4.7965 & TRN & \\
\hline CHEMBL3212981 & 688889 & 4.4 & 4.8268 & TRN & \\
\hline CHEMBL1338855 & 688889 & 4.45 & 4.8003 & TRN & \\
\hline CHEMBL1405700 & 688889 & 4.55 & 4.7433 & TRN & \\
\hline CHEMBL1380312 & 688889 & 4.6 & 4.774 & TRN & \\
\hline CHEMBL1351153 & 688889 & 5.8 & 4.8456 & TST & \\
\hline CHEMBL 2002332 & 688889 & 5.4 & 4.7696 & TRN & \\
\hline CHEMBL1387923 & 688889 & 4.55 & 4.9155 & TRN & \\
\hline CHEMBL1586319 & 688889 & 5.2 & 4.6745 & TRN & \\
\hline CHEMBL1454025 & 688889 & 4.55 & 4.7509 & TRN & \\
\hline CHEMBL1438305 & 688889 & 4.25 & 4.899 & TRN & \\
\hline CHEMBL1312121 & 688889 & 5.15 & 4.8278 & TRN & \\
\hline CHEMBL1450032 & 688889 & 5.5 & 4.7985 & TRN & \\
\hline CHEMBL1543454 & 688889 & 4.6 & 4.8137 & TST & \\
\hline CHEMBL3207510 & 688889 & 4.45 & 4.7783 & TRN & \\
\hline CHEMBL1390643 & 688889 & 4.75 & 4.8431 & TRN & \\
\hline CHEMBL1457871 & 688889 & 4.3 & 4.7227 & TRN & \\
\hline CHEMBL1303488 & 688889 & 4.3 & 4.7566 & TST & \\
\hline CHEMBL145557 & 688889 & 4.3 & 4.8438 & TST & \\
\hline
\end{tabular}




\begin{tabular}{|c|c|c|c|c|c|}
\hline \multicolumn{6}{|c|}{ Supplemental Table S2.txt } \\
\hline CHEMBL1371271 & 688889 & 5.1 & 4.8381 & TRN & \\
\hline CHEMBL1558802 & 688889 & 5.2 & 4.7498 & TST & \\
\hline CHEMBL1484980 & 688889 & 4.3 & 4.7256 & TRN & \\
\hline CHEMBL1545560 & 688889 & 4.3 & 4.8304 & TRN & \\
\hline CHEMBL1511135 & 688889 & 4.3 & 4.9815 & TRN & \\
\hline CHEMBL1336208 & 688889 & 5.25 & 4.7171 & TRN & \\
\hline CHEMBL1455829 & 688889 & 4.3 & 4.896 & TRN & \\
\hline CHEMBL1485338 & 688889 & 4.45 & 4.8039 & TRN & \\
\hline CHEMBL1399021 & 688889 & 4.25 & 4.97199 & 99999999995 & TST \\
\hline CHEMBL1323969 & 688889 & 4.3 & 4.8824 & TRN & \\
\hline CHEMBL1309461 & 688889 & 4.55 & 4.8152 & TRN & \\
\hline CHEMBL3192852 & 688889 & 4.3 & 4.7334 & TRN & \\
\hline CHEMBL3209844 & 688889 & 5.6 & 4.774 & TST & \\
\hline CHEMBL1572491 & 688889 & 4.4 & 4.6146 & TST & \\
\hline CHEMBL1548917 & 688889 & 4.9 & 4.8222 & TST & \\
\hline CHEMBL1571407 & 688889 & 4.7 & 4.73300 & 00000000005 & TRN \\
\hline CHEMBL1576994 & 688889 & 4.35 & 4.8101 & TRN & \\
\hline CHEMBL1567878 & 688889 & 4.6 & 4.6247 & TRN & \\
\hline CHEMBL1505922 & 688889 & 4.85 & 4.8242 & TRN & \\
\hline CHEMBL1493038 & 688889 & 5.65 & 4.8265 & TST & \\
\hline CHEMBL1371360 & 688889 & 5.0 & 4.971 & TST & \\
\hline CHEMBL1410019 & 688889 & 5.0 & 4.8594 & TRN & \\
\hline CHEMBL1320042 & 688889 & 4.35 & 4.7616 & TST & \\
\hline CHEMBL3207950 & 688889 & 6.0 & 4.8808 & TRN & \\
\hline CHEMBL1561535 & 688889 & 4.5 & 4.6405 & TRN & \\
\hline CHEMBL1369522 & 688889 & 4.3 & 4.8264 & TRN & \\
\hline CHEMBL1525269 & 688889 & 5.4 & 4.8428 & TST & \\
\hline CHEMBL1982071 & 688889 & 4.55 & 4.6693 & TRN & \\
\hline CHEMBL1531999 & 688889 & 4.4 & 4.7807 & TRN & \\
\hline CHEMBL1485656 & 688889 & 4.45 & 4.8643 & TST & \\
\hline CHEMBL3198896 & 688889 & 4.5 & 4.7574 & TRN & \\
\hline CHEMBL1530298 & 688889 & 5.5 & 4.8679 & TST & \\
\hline CHEMBL1313757 & 688889 & 4.4 & 4.6881 & TRN & \\
\hline CHEMBL1312593 & 688889 & 5.15 & 4.896 & TRN & \\
\hline CHEMBL1596589 & 688889 & 4.55 & 4.8351 & TRN & \\
\hline CHEMBL1502289 & 688889 & 4.85 & 4.7252 & TST & \\
\hline CHEMBL1323789 & 688889 & 4.25 & 4.7518 & TRN & \\
\hline CHEMBL3144995 & 688889 & 4.9 & 4.739 & TST & \\
\hline CHEMBL1545403 & 688889 & 5.55 & 4.7854 & TRN & \\
\hline CHEMBL1496126 & 688889 & 4.4 & 4.864 & TRN & \\
\hline CHEMBL1324853 & 688889 & 4.25 & 4.6753 & TRN & \\
\hline CHEMBL1451819 & 688889 & 4.45 & 4.7913 & TRN & \\
\hline CHEMBL1449459 & 688889 & 4.25 & 4.8658 & TRN & \\
\hline CHEMBL1306736 & 688889 & 4.55 & 4.7255 & TRN & \\
\hline CHEMBL1430936 & 688889 & 4.35 & 4.6945 & TRN & \\
\hline CHEMBL1583953 & 688889 & 4.95 & 4.8292 & TST & \\
\hline CHEMBL1393700 & 688889 & 4.5 & 4.7717 & TRN & \\
\hline CHEMBL1323469 & 688889 & 6.7501 & 4.9126 & TRN & \\
\hline
\end{tabular}




\begin{tabular}{|c|c|c|c|c|c|}
\hline & & \multicolumn{4}{|c|}{ Supplemental Table S2.txt } \\
\hline CHEMBL1332662 & 688889 & 5.05 & 4.8725 & TRN & \\
\hline CHEMBL1362529 & 688889 & 4.3 & 4.8256 & TRN & \\
\hline CHEMBL1424852 & 688889 & 4.85 & 4.7084 & TRN & \\
\hline CHEMBL 3209148 & 688889 & 5.15 & 4.6574 & TRN & \\
\hline CHEMBL1531707 & 688889 & 5.5 & 4.8965 & TRN & \\
\hline CHEMBL1461734 & 688889 & 4.95 & 4.8086 & TRN & \\
\hline CHEMBL1341533 & 688889 & 6.1 & $4.9030 e$ & 00000000005 & TRN \\
\hline CHEMBL1451622 & 688889 & 4.6 & 4.7285 & TRN & \\
\hline CHEMBL1419232 & 688889 & 4.4 & 4.841 & TST & \\
\hline CHEMBL1471126 & 688889 & 4.25 & 4.6718 & TRN & \\
\hline CHEMBL1587636 & 688889 & 5.15 & 4.6449 & TST & \\
\hline CHEMBL1444536 & 688889 & 4.45 & 4.8385 & TST & \\
\hline CHEMBL 2004351 & 688889 & 5.1 & 4.7864 & TST & \\
\hline CHEMBL1300832 & 688889 & 4.7 & 4.7248 & TRN & \\
\hline CHEMBL1364805 & 688889 & 4.3 & 4.8608 & TRN & \\
\hline CHEMBL1564965 & 688889 & 4.25 & 4.7982 & TST & \\
\hline CHEMBL1460719 & 688889 & 4.45 & 4.7883 & TRN & \\
\hline CHEMBL1426183 & 688889 & 4.85 & 4.8277 & TRN & \\
\hline CHEMBL1386050 & 688889 & 6.8 & 4.904 & TST & \\
\hline CHEMBL1556983 & 688889 & 4.9 & 4.8279 & TRN & \\
\hline CHEMBL1560398 & 688889 & 4.4 & 4.7245 & TRN & \\
\hline CHEMBL1576747 & 688889 & 4.25 & 4.6983 & TRN & \\
\hline CHEMBL1432904 & 688889 & 5.1 & 4.7715 & TRN & \\
\hline CHEMBL1348020 & 688889 & 5.15 & 4.7737 & TST & \\
\hline CHEMBL1601731 & 688889 & 5.2 & 4.9424 & TRN & \\
\hline CHEMBL3191114 & 688889 & 6.7501 & 4.7781 & TST & \\
\hline CHEMBL1611306 & 688889 & 4.4 & 4.7751 & TRN & \\
\hline CHEMBL531451 & 688889 & 4.45 & 4.689 & TRN & \\
\hline CHEMBL1429794 & 688889 & 4.55 & 4.6796 & TRN & \\
\hline CHEMBL1525045 & 688889 & 5.4 & 4.7409 & TST & \\
\hline CHEMBL1313077 & 688889 & 6.7001 & 4.9354 & TRN & \\
\hline CHEMBL1310133 & 688889 & 4.5 & 4.5911 & TST & \\
\hline CHEMBL1359892 & 688889 & 4.8 & 4.8577 & TRN & \\
\hline CHEMBL1524719 & 688889 & 5.45 & 4.9057 & TST & \\
\hline CHEMBL1530592 & 688889 & 4.55 & 4.9957 & TRN & \\
\hline CHEMBL1602370 & 688889 & 4.8 & 4.8007 & TST & \\
\hline CHEMBL1585189 & 688889 & 4.25 & 4.7622 & TST & \\
\hline CHEMBL1420058 & 688889 & 4.85 & 4.8656 & TRN & \\
\hline CHEMBL1492009 & 688889 & 4.3 & 4.8891 & TRN & \\
\hline CHEMBL1313282 & 688889 & 4.95 & 4.7321 & TST & \\
\hline CHEMBL3190622 & 688889 & 4.75 & 4.8773 & TRN & \\
\hline CHEMBL1582655 & 688889 & 5.5 & 4.8315 & TRN & \\
\hline CHEMBL1379567 & 688889 & 4.3 & 4.8748 & TRN & \\
\hline CHEMBL1362684 & 688889 & 4.95 & 4.938 & TRN & \\
\hline CHEMBL1463701 & 688889 & 4.25 & 4.8986 & TST & \\
\hline CHEMBL1337308 & 688889 & 4.25 & 4.9128 & TRN & \\
\hline CHEMBL1455904 & 688889 & 4.35 & 4.6108 & TRN & \\
\hline CHEMBL1430344 & 688889 & 4.5 & 4.9297 & TRN & \\
\hline
\end{tabular}




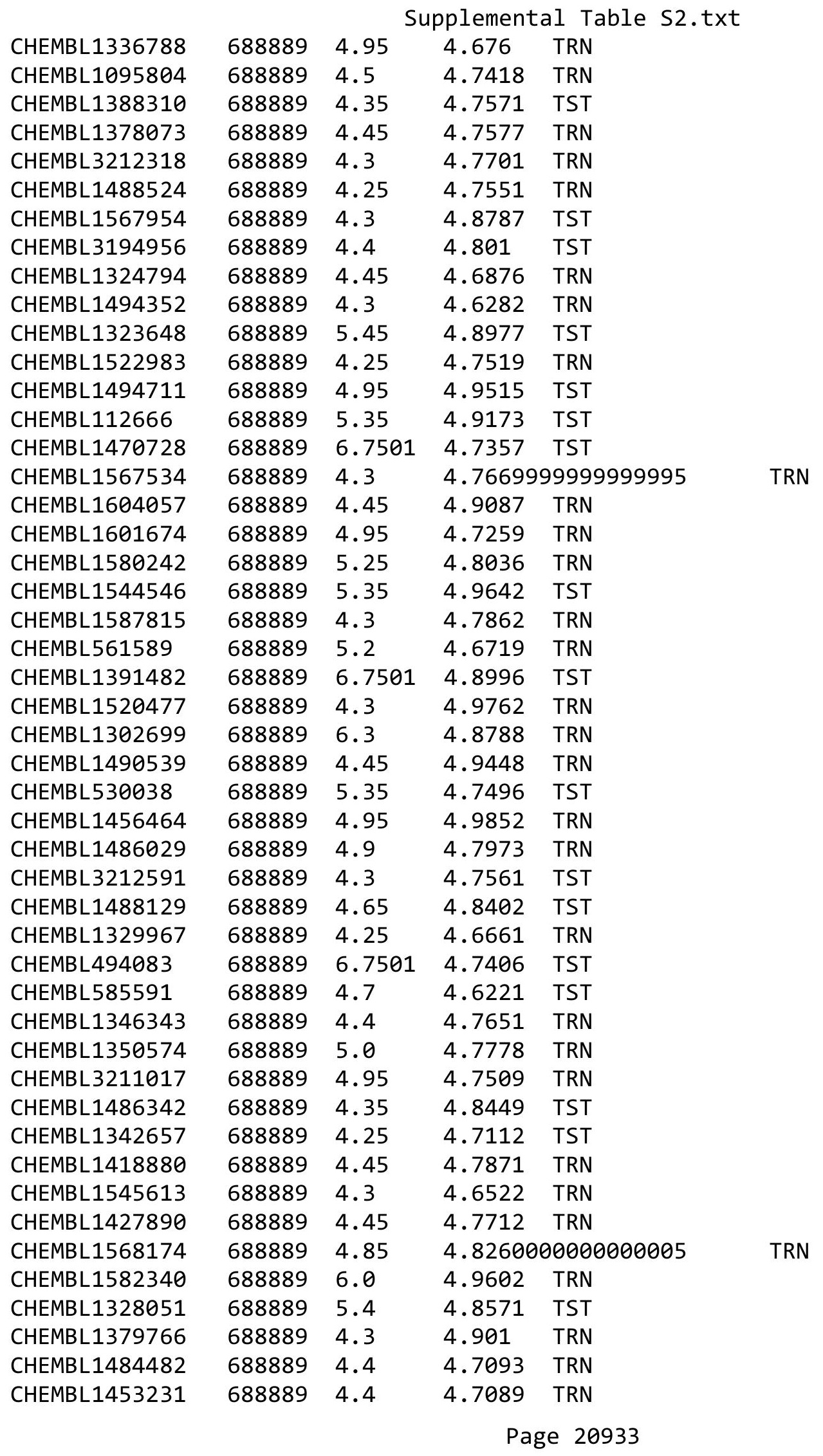




\begin{tabular}{|c|c|c|c|c|}
\hline \multicolumn{5}{|c|}{ Supplemental Table } \\
\hline CHEMBL1460897 & 688889 & 4.95 & 4.8558 & TRN \\
\hline CHEMBL1330219 & 688889 & 4.3 & 4.7593 & TRN \\
\hline CHEMBL1327961 & 688889 & 6.1 & 4.8154 & TRN \\
\hline CHEMBL1498173 & 688889 & 4.55 & 4.7359 & TRN \\
\hline CHEMBL1377309 & 688889 & 4.3 & 4.838 & TRN \\
\hline CHEMBL1500690 & 688889 & 4.5 & 4.7172 & TST \\
\hline CHEMBL1335491 & 688889 & 5.5 & 4.6902 & TRN \\
\hline CHEMBL1335750 & 688889 & 4.7 & 4.9098 & TRN \\
\hline CHEMBL1387047 & 688889 & 4.3 & 4.9578 & TRN \\
\hline CHEMBL1572356 & 688889 & 6.15 & 4.8734 & TST \\
\hline CHEMBL1557238 & 688889 & 5.6 & 4.8391 & TRN \\
\hline CHEMBL1532617 & 688889 & 6.05 & 4.8221 & TST \\
\hline CHEMBL1595628 & 688889 & 5.5 & 4.9426 & TRN \\
\hline CHEMBL1577030 & 688889 & 4.6 & 4.85 & TRN \\
\hline CHEMBL1565528 & 688889 & 4.35 & 4.6195 & TST \\
\hline CHEMBL1419836 & 688889 & 4.65 & 4.8047 & TRN \\
\hline CHEMBL1461862 & 688889 & 5.35 & 4.8 & TRN \\
\hline CHEMBL1511032 & 688889 & 6.35 & 4.7636 & TST \\
\hline CHEMBL1586097 & 688889 & 4.4 & 4.7932 & TRN \\
\hline CHEMBL1460452 & 688889 & 4.25 & 4.652 & TRN \\
\hline CHEMBL1445076 & 688889 & 5.45 & 4.814 & TST \\
\hline CHEMBL1560080 & 688889 & 4.55 & 4.7734 & TRN \\
\hline CHEMBL1338650 & 688889 & 5.95 & 4.8246 & TST \\
\hline CHEMBL 3198774 & 688889 & 4.95 & 4.8451 & TRN \\
\hline CHEMBL1451711 & 688889 & 4.6 & 4.7946 & TRN \\
\hline CHEMBL1299587 & 688889 & 5.0 & 4.688 & TRN \\
\hline CHEMBL1537571 & 688889 & 5.25 & 4.9118 & TRN \\
\hline CHEMBL1582935 & 688889 & 4.55 & 4.7003 & TRN \\
\hline CHEMBL1335945 & 688889 & 4.35 & 4.669 & TST \\
\hline CHEMBL1338469 & 688889 & 4.95 & 4.7753 & TRN \\
\hline CHEMBL1332784 & 688889 & 4.4 & 4.7265 & TRN \\
\hline CHEMBL1323587 & 688889 & 4.9 & 4.749 & TRN \\
\hline CHEMBL 3194845 & 688889 & 5.5 & 4.6135 & TRN \\
\hline CHEMBL1313183 & 688889 & 4.25 & 4.945 & TRN \\
\hline CHEMBL1482478 & 688889 & 4.25 & 4.8939 & TST \\
\hline CHEMBL1413009 & 688889 & 4.95 & 4.7777 & TRN \\
\hline CHEMBL1361867 & 688889 & 4.4 & 4.8113 & TRN \\
\hline CHEMBL1095796 & 688889 & 5.1 & 4.7831 & TST \\
\hline CHEMBL1531219 & 688889 & 4.3 & 4.6984 & TRN \\
\hline CHEMBL1501410 & 688889 & 4.5 & 4.7863 & TRN \\
\hline CHEMBL1561893 & 688889 & 4.5 & 4.758 & TST \\
\hline CHEMBL1561349 & 688889 & 4.55 & 4.816 & TRN \\
\hline CHEMBL1570862 & 688889 & 6.0 & 4.7503 & TRN \\
\hline CHEMBL1538147 & 688889 & 5.25 & 4.8431 & TRN \\
\hline CHEMBL1372169 & 688889 & 5.75 & 4.8672 & TRN \\
\hline CHEMBL1540780 & 688889 & 5.7 & 4.7004 & TRN \\
\hline CHEMBL1336866 & 688889 & 4.5 & 4.6918 & TRN \\
\hline CHEMBL1351837 & 688889 & 5.6 & 4.8766 & TST \\
\hline
\end{tabular}




\begin{tabular}{|c|c|c|c|c|c|}
\hline \multicolumn{6}{|c|}{ Supplemental Table S2.txt } \\
\hline CHEMBL1517523 & 688889 & 4.25 & 4.7564 & TST & \\
\hline CHEMBL1604772 & 688889 & 4.45 & 4.8077 & TRN & \\
\hline CHEMBL1413683 & 688889 & 5.4 & 4.8831 & TRN & \\
\hline CHEMBL1426477 & 688889 & 4.45 & 4.9112 & TRN & \\
\hline CHEMBL1439954 & 688889 & 4.5 & 4.61 & TRN & \\
\hline CHEMBL3209160 & 688889 & 4.55 & 4.7713 & TRN & \\
\hline CHEMBL1334619 & 688889 & 4.45 & 4.62 & TRN & \\
\hline CHEMBL1486536 & 688889 & 4.5 & 4.6642 & TST & \\
\hline CHEMBL1417811 & 688889 & 5.15 & 4.8942 & TRN & \\
\hline CHEMBL1528677 & 688889 & 4.25 & 4.9376 & TRN & \\
\hline CHEMBL 3213770 & 688889 & 4.3 & 4.75899 & 99999999995 & TST \\
\hline CHEMBL1588121 & 688889 & 4.95 & 4.8612 & TRN & \\
\hline CHEMBL1556150 & 688889 & 4.3 & 4.838 & TRN & \\
\hline CHEMBL1301008 & 688889 & 4.5 & 4.8083 & TRN & \\
\hline CHEMBL1574586 & 688889 & 5.05 & 4.7128 & TRN & \\
\hline CHEMBL1417815 & 688889 & 4.55 & $4.7010 e$ & 00000000005 & TRN \\
\hline CHEMBL1336418 & 688889 & 5.05 & 4.7849 & TRN & \\
\hline CHEMBL1538190 & 688889 & 5.75 & 4.8543 & TST & \\
\hline CHEMBL1547658 & 688889 & 4.35 & 4.6256 & TRN & \\
\hline CHEMBL1568695 & 688889 & 4.45 & 4.7965 & TRN & \\
\hline CHEMBL1987092 & 688889 & 4.9 & 4.69 & TRN & \\
\hline CHEMBL1466841 & 688889 & 5.35 & 4.8547 & TRN & \\
\hline CHEMBL1581165 & 688889 & 4.45 & 4.7751 & TRN & \\
\hline CHEMBL1491697 & 688889 & 4.75 & 4.8788 & TRN & \\
\hline CHEMBL1359753 & 688889 & 4.3 & 4.8564 & TRN & \\
\hline CHEMBL1566583 & 688889 & 4.3 & 4.7916 & TRN & \\
\hline CHEMBL1430336 & 688889 & 4.25 & 4.8938 & TRN & \\
\hline CHEMBL1333083 & 688889 & 4.45 & 4.8415 & TST & \\
\hline CHEMBL1479696 & 688889 & 4.35 & 4.7961 & TRN & \\
\hline CHEMBL1097687 & 688889 & 4.4 & 4.7495 & TRN & \\
\hline CHEMBL1586803 & 688889 & 4.4 & 4.8221 & TRN & \\
\hline CHEMBL1545979 & 688889 & 4.55 & 4.5872 & TRN & \\
\hline CHEMBL1511403 & 688889 & 4.4 & 4.7411 & TRN & \\
\hline CHEMBL1089894 & 688889 & 4.95 & 4.7007 & TRN & \\
\hline CHEMBL3212862 & 688889 & 4.35 & 4.7492 & TST & \\
\hline CHEMBL1500410 & 688889 & 4.45 & 4.8903 & TRN & \\
\hline CHEMBL1539835 & 688889 & 4.5 & 4.6241 & TRN & \\
\hline CHEMBL1349705 & 688889 & 4.45 & 4.8555 & TRN & \\
\hline CHEMBL1472572 & 688889 & 4.35 & 4.6305 & TRN & \\
\hline CHEMBL1404944 & 688889 & 4.55 & 4.6672 & TRN & \\
\hline CHEMBL3196338 & 688889 & 4.45 & 4.6982 & TRN & \\
\hline CHEMBL1403256 & 688889 & 4.25 & 4.6941 & TRN & \\
\hline CHEMBL1499870 & 688889 & 6.8 & 4.8831 & TRN & \\
\hline CHEMBL1313206 & 688889 & 4.3 & 4.9521 & TRN & \\
\hline CHEMBL1407348 & 688889 & 4.45 & 4.7707 & TST & \\
\hline CHEMBL1330870 & 688889 & 5.95 & 4.92399 & 99999999995 & TRN \\
\hline CHEMBL1341823 & 688889 & 4.45 & 4.9521 & TST & \\
\hline CHEMBL1489629 & 688889 & 4.6 & 4.9283 & TST & \\
\hline
\end{tabular}




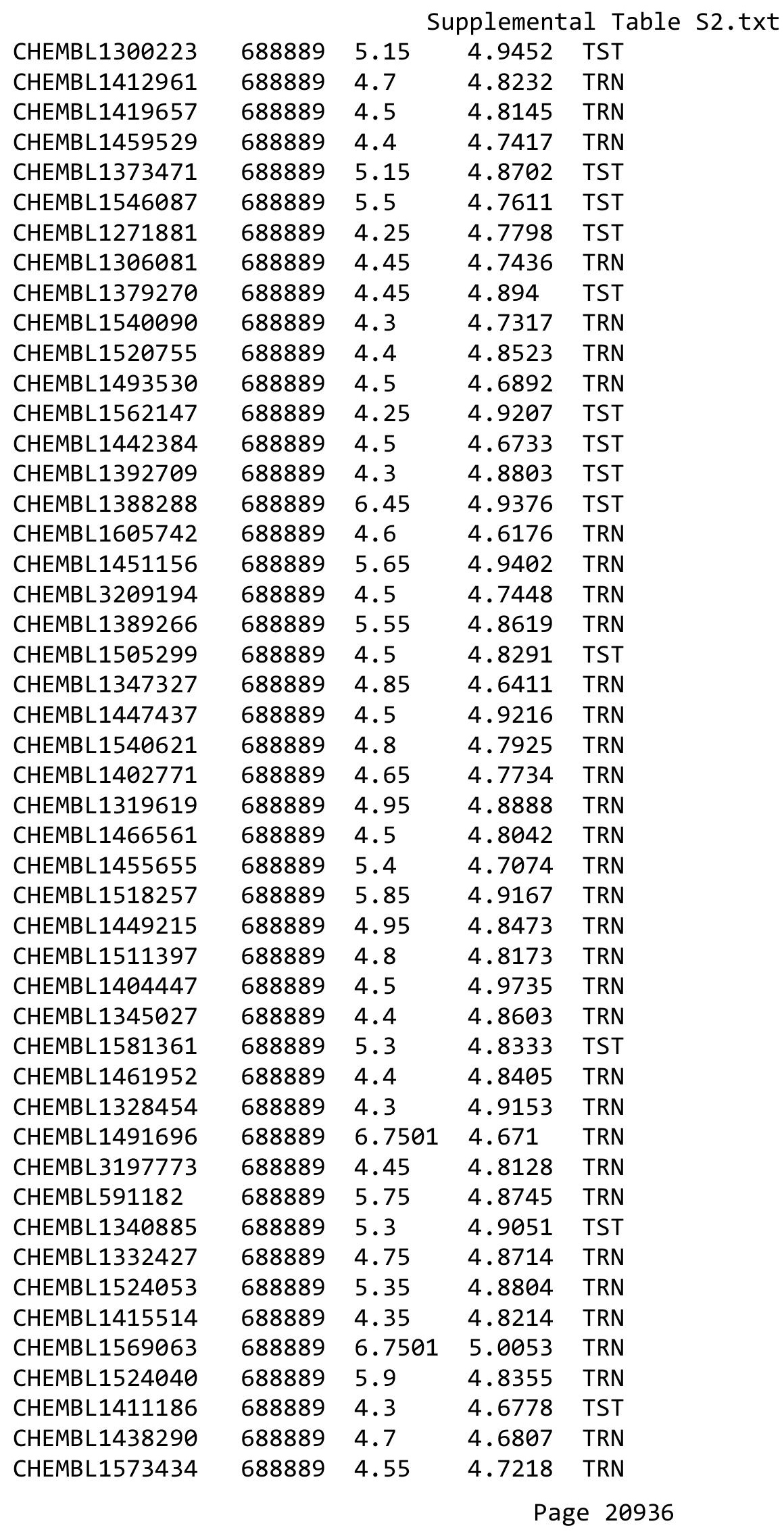




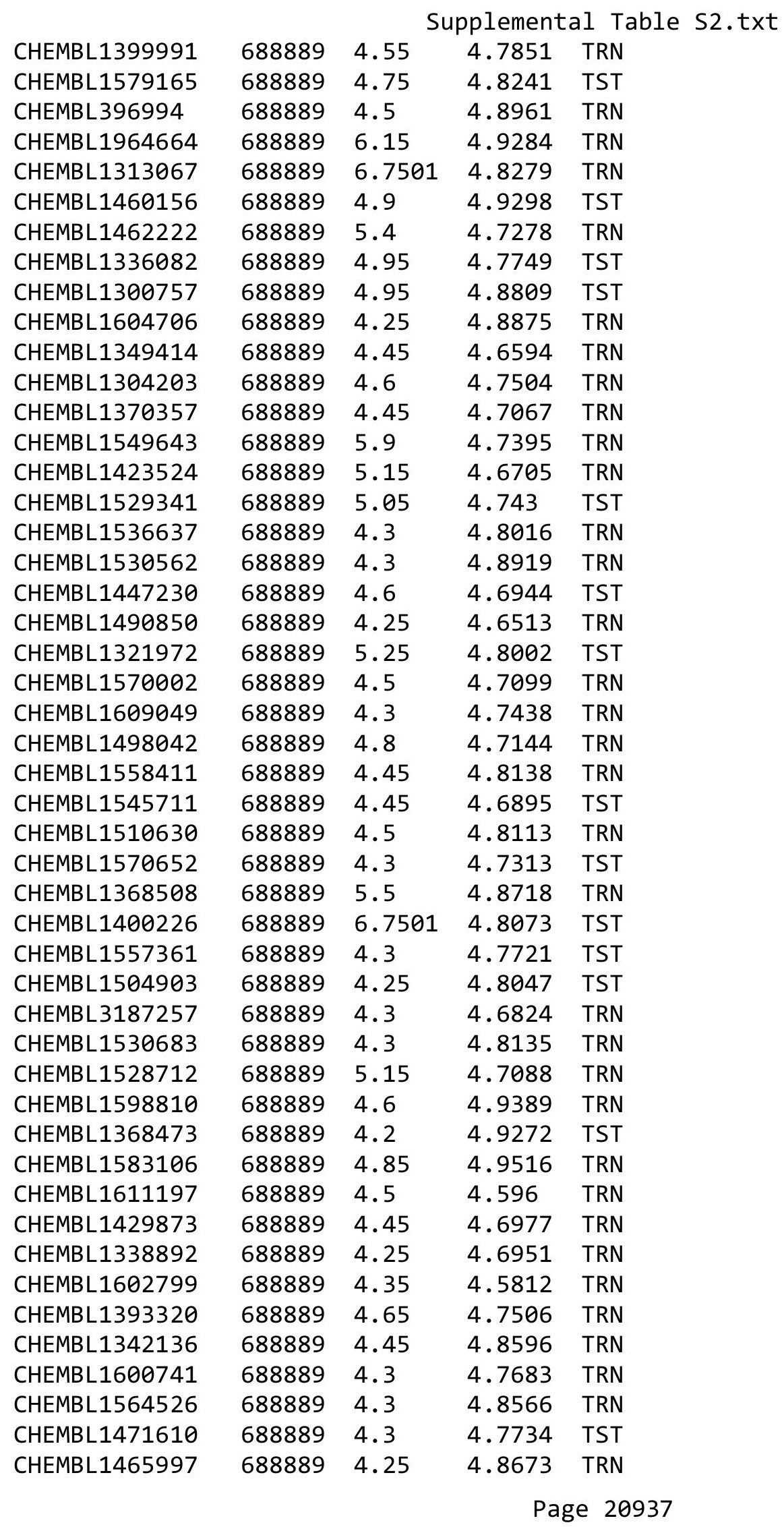




\begin{tabular}{|c|c|c|c|c|}
\hline \multicolumn{5}{|c|}{ Supplemental Table S2.txt } \\
\hline CHEMBL1438503 & 688889 & 4.55 & 4.8248 & TRN \\
\hline CHEMBL1583907 & 688889 & 4.5 & 4.8152 & TRN \\
\hline CHEMBL1597200 & 688889 & 4.55 & 4.789 & TST \\
\hline CHEMBL1524152 & 688889 & 6.1 & 4.88899 & 9999999999 \\
\hline CHEMBL1517908 & 688889 & 4.6 & 4.8729 & TRN \\
\hline CHEMBL1556072 & 688889 & 4.9 & 4.8474 & TRN \\
\hline CHEMBL1345971 & 688889 & 4.55 & 4.8999 & TRN \\
\hline CHEMBL1430314 & 688889 & 4.35 & 4.5621 & TST \\
\hline CHEMBL1540918 & 688889 & 6.8 & 4.7978 & TRN \\
\hline CHEMBL1522883 & 688889 & 4.25 & 4.8061 & TST \\
\hline CHEMBL1456083 & 688889 & 4.5 & 4.8771 & TRN \\
\hline CHEMBL1546338 & 688889 & 4.9 & 4.8275 & TRN \\
\hline CHEMBL1480728 & 688889 & 5.85 & 4.6187 & TST \\
\hline CHEMBL1602119 & 688889 & 4.3 & 4.9901 & TRN \\
\hline CHEMBL1339798 & 688889 & 4.85 & 4.7586 & TRN \\
\hline CHEMBL1439591 & 688889 & 4.3 & 4.6741 & TRN \\
\hline CHEMBL3209646 & 688889 & 4.95 & 4.928 & TRN \\
\hline CHEMBL1565991 & 688889 & 4.6 & 4.7793 & TST \\
\hline CHEMBL1302347 & 688889 & 5.2 & 4.6717 & TRN \\
\hline CHEMBL3208585 & 688889 & 4.85 & 4.7328 & TRN \\
\hline CHEMBL1404777 & 688889 & 4.4 & 4.9507 & TRN \\
\hline CHEMBL1347950 & 688889 & 6.7501 & 4.8119 & TST \\
\hline CHEMBL1560446 & 688889 & 5.5 & 4.7696 & TST \\
\hline CHEMBL1559194 & 688889 & 4.25 & 4.8526 & TST \\
\hline CHEMBL1451306 & 688889 & 4.8 & 4.7999 & TRN \\
\hline CHEMBL1585097 & 688889 & 4.55 & 4.6621 & TRN \\
\hline CHEMBL1420982 & 688889 & 5.45 & 4.8079 & TST \\
\hline CHEMBL1445916 & 688889 & 4.45 & 4.8383 & TRN \\
\hline CHEMBL1502646 & 688889 & 4.35 & 4.8572 & TRN \\
\hline CHEMBL1307089 & 688889 & 6.6 & 4.8561 & TST \\
\hline CHEMBL1330339 & 688889 & 4.6 & 4.9011 & TRN \\
\hline CHEMBL1352433 & 688889 & 4.3 & 4.922 & TRN \\
\hline CHEMBL3194039 & 688889 & 6.7501 & 4.7375 & TRN \\
\hline CHEMBL1427525 & 688889 & 4.4 & 4.8502 & TRN \\
\hline CHEMBL1329111 & 688889 & 4.4 & 4.6507 & TRN \\
\hline CHEMBL1310563 & 688889 & 4.55 & 4.817 & TRN \\
\hline CHEMBL 3193787 & 688889 & 5.4 & 4.6989 & TRN \\
\hline CHEMBL1996555 & 688889 & 5.35 & 4.7315 & TRN \\
\hline CHEMBL1561455 & 688889 & 4.3 & 4.708 & TRN \\
\hline CHEMBL1416972 & 688889 & 4.3 & 4.8656 & TRN \\
\hline CHEMBL1324640 & 688889 & 4.45 & 4.664 & TRN \\
\hline CHEMBL1966867 & 688889 & 5.2 & 4.765 & TST \\
\hline CHEMBL1530441 & 688889 & 4.25 & 4.7997 & TRN \\
\hline CHEMBL1599750 & 688889 & 4.25 & 4.814 & TST \\
\hline CHEMBL1542001 & 688889 & 5.0 & 4.8953 & TST \\
\hline CHEMBL1481169 & 688889 & 4.3 & 4.757 & TRN \\
\hline CHEMBL1523058 & 688889 & 4.4 & 4.8764 & TST \\
\hline CHEMBL1503702 & 688889 & 4.25 & 4.8473 & TRN \\
\hline
\end{tabular}




\begin{tabular}{|c|c|c|c|c|c|}
\hline \multicolumn{6}{|c|}{ Supplemental Table S2.txt } \\
\hline CHEMBL1447496 & 688889 & 5.0 & 4.8321 & TRN & \\
\hline CHEMBL1584656 & 688889 & 4.55 & 4.7548 & TST & \\
\hline CHEMBL3199850 & 688889 & 4.45 & 4.6201 & TRN & \\
\hline CHEMBL1519001 & 688889 & 5.15 & 4.8852 & TRN & \\
\hline CHEMBL1373172 & 688889 & 4.55 & 4.8144 & TST & \\
\hline CHEMBL3211198 & 688889 & 4.65 & 4.6805 & TRN & \\
\hline CHEMBL1313512 & 688889 & 4.3 & 4.6152 & TRN & \\
\hline CHEMBL1379798 & 688889 & 4.65 & 4.834 & TRN & \\
\hline CHEMBL1376342 & 688889 & 4.45 & 4.8839 & TST & \\
\hline CHEMBL1342989 & 688889 & 4.3 & 4.7572 & TRN & \\
\hline CHEMBL1529108 & 688889 & 5.6 & 4.8574 & TRN & \\
\hline CHEMBL1338442 & 688889 & 5.35 & 4.6364 & TRN & \\
\hline CHEMBL1346258 & 688889 & 4.3 & 4.801 & TRN & \\
\hline CHEMBL1525732 & 688889 & 4.3 & 4.6588 & TRN & \\
\hline CHEMBL1402047 & 688889 & 4.35 & 4.7137 & TRN & \\
\hline CHEMBL1308526 & 688889 & 4.25 & 4.84399 & 9999999999 & TRN \\
\hline CHEMBL1581955 & 688889 & 5.55 & 4.7534 & TRN & \\
\hline CHEMBL1379666 & 688889 & 4.4 & 4.7695 & TST & \\
\hline CHEMBL1537365 & 688889 & 4.95 & 4.8624 & TST & \\
\hline CHEMBL1485362 & 688889 & 4.55 & 4.8484 & TRN & \\
\hline CHEMBL1392213 & 688889 & 4.7 & 4.8706 & TST & \\
\hline CHEMBL1509556 & 688889 & 5.2 & 4.8561 & TRN & \\
\hline CHEMBL507756 & 688889 & 4.45 & 4.7486 & TRN & \\
\hline CHEMBL1507019 & 688889 & 4.9 & 4.7126 & TRN & \\
\hline CHEMBL3210497 & 688889 & 5.7 & 4.8766 & TRN & \\
\hline CHEMBL1420996 & 688889 & 4.95 & 4.7341 & TST & \\
\hline CHEMBL1393861 & 688889 & 4.45 & 4.7818 & TRN & \\
\hline CHEMBL 3207448 & 688889 & 4.25 & 4.6298 & TRN & \\
\hline CHEMBL1309655 & 688889 & 4.55 & 4.8198 & TRN & \\
\hline CHEMBL1510447 & 688889 & 4.25 & 4.6611 & TRN & \\
\hline CHEMBL1531244 & 688889 & 5.1 & 4.753 & TRN & \\
\hline CHEMBL1429836 & 688889 & 4.5 & 4.8227 & TRN & \\
\hline CHEMBL1323577 & 688889 & 4.25 & 4.7801 & TRN & \\
\hline CHEMBL1501519 & 688889 & 4.35 & 4.8079 & TRN & \\
\hline CHEMBL1428728 & 688889 & 4.4 & 4.663 & TST & \\
\hline CHEMBL1428534 & 688889 & 4.9 & 4.8812 & TST & \\
\hline CHEMBL1323402 & 688889 & 4.3 & 4.8499 & TRN & \\
\hline CHEMBL1520098 & 688889 & 4.95 & 4.9341 & TST & \\
\hline CHEMBL1483415 & 688889 & 4.3 & 4.6987 & TST & \\
\hline CHEMBL1309014 & 688889 & 4.9 & 4.7182 & TRN & \\
\hline CHEMBL1368367 & 688889 & 4.5 & 4.776 & TRN & \\
\hline CHEMBL1498333 & 688889 & 4.5 & 4.8354 & TRN & \\
\hline CHEMBL1345483 & 688889 & 4.45 & 4.6819 & TRN & \\
\hline CHEMBL1444613 & 688889 & 4.5 & 4.7736 & TRN & \\
\hline CHEMBL1374931 & 688889 & 4.4 & 4.7811 & TRN & \\
\hline CHEMBL1613003 & 688889 & 5.95 & 4.7674 & TRN & \\
\hline CHEMBL1576436 & 688889 & 4.3 & 4.8492 & TRN & \\
\hline CHEMBL1509722 & 688889 & 4.25 & 4.883 & TRN & \\
\hline
\end{tabular}




\begin{tabular}{|c|c|c|c|c|c|}
\hline \multicolumn{6}{|c|}{ Supplemental Table s2.txt } \\
\hline CHEMBL1540038 & 688889 & 4.45 & 4.5225 & TST & \\
\hline CHEMBL1585309 & 688889 & 4.3 & 4.7531 & TRN & \\
\hline CHEMBL1369939 & 688889 & 4.25 & 4.7128 & TST & \\
\hline CHEMBL1538344 & 688889 & 4.45 & 4.8321 & TRN & \\
\hline CHEMBL3189262 & 688889 & 4.25 & 4.8051 & TRN & \\
\hline CHEMBL1343685 & 688889 & 4.3 & 4.6689 & TRN & \\
\hline CHEMBL1599655 & 688889 & 4.3 & 4.8529 & TST & \\
\hline CHEMBL1443258 & 688889 & 6.05 & 4.6995 & TST & \\
\hline CHEMBL1588929 & 688889 & 4.45 & 4.6236 & TRN & \\
\hline CHEMBL1329368 & 688889 & 4.5 & 4.7787 & TST & \\
\hline CHEMBL1426934 & 688889 & 5.3 & 4.7612 & TRN & \\
\hline CHEMBL3208514 & 688889 & 4.7 & 4.7533 & TRN & \\
\hline CHEMBL1611515 & 688889 & 5.0 & 4.6698 & TRN & \\
\hline CHEMBL1362962 & 688889 & 6.8 & 4.9024 & TST & \\
\hline CHEMBL1574416 & 688889 & 5.45 & 4.7709 & TRN & \\
\hline CHEMBL1461004 & 688889 & 4.4 & 4.8115 & TRN & \\
\hline CHEMBL1468635 & 688889 & 4.6 & 4.6217 & TRN & \\
\hline CHEMBL1420710 & 688889 & 4.25 & 4.8611 & TST & \\
\hline CHEMBL1508677 & 688889 & 4.75 & 4.8786 & TRN & \\
\hline CHEMBL1329224 & 688889 & 4.45 & 4.7607 & TST & \\
\hline CHEMBL1601788 & 688889 & 4.55 & 4.8268 & TST & \\
\hline CHEMBL1465462 & 688889 & 5.0 & 4.8596 & TRN & \\
\hline CHEMBL353764 & 688889 & 4.6 & 4.7199 & TST & \\
\hline CHEMBL1380604 & 688889 & 4.6 & 4.7986 & TRN & \\
\hline CHEMBL1575663 & 688889 & 5.45 & 4.7673 & TRN & \\
\hline CHEMBL1571704 & 688889 & 5.05 & 4.71399 & 99999999995 & TST \\
\hline CHEMBL1311206 & 688889 & 6.0 & 4.758 & TRN & \\
\hline CHEMBL1335505 & 688889 & 4.6 & 4.718 & TRN & \\
\hline CHEMBL1409611 & 688889 & 4.25 & 4.9869 & TRN & \\
\hline CHEMBL1507211 & 688889 & 5.45 & 4.8076 & TST & \\
\hline CHEMBL1319544 & 688889 & 4.3 & 4.7943 & TRN & \\
\hline CHEMBL1373941 & 688889 & 4.95 & 4.6444 & TRN & \\
\hline CHEMBL1595593 & 688889 & 4.25 & 4.7597 & TRN & \\
\hline CHEMBL1432698 & 688889 & 4.25 & 4.8568 & TST & \\
\hline CHEMBL1499180 & 688889 & 4.35 & 4.7109 & TRN & \\
\hline CHEMBL1402888 & 688889 & 4.55 & 4.8341 & TRN & \\
\hline CHEMBL1501540 & 688889 & 5.0 & 4.7124 & TRN & \\
\hline CHEMBL1331925 & 688889 & 4.55 & 4.6936 & TRN & \\
\hline CHEMBL1439163 & 688889 & 4.9 & 4.8533 & TRN & \\
\hline CHEMBL1447537 & 688889 & 5.2 & 4.8922 & TRN & \\
\hline CHEMBL1306004 & 688889 & 4.95 & 4.7051 & TST & \\
\hline CHEMBL1414425 & 688889 & 4.3 & 4.7617 & TRN & \\
\hline CHEMBL1490388 & 688889 & 4.5 & 4.7247 & TRN & \\
\hline CHEMBL1542779 & 688889 & 4.9 & 4.805 & TRN & \\
\hline CHEMBL1441756 & 688889 & 4.95 & 4.7583 & TST & \\
\hline CHEMBL1578700 & 688889 & 4.35 & 4.819 & TRN & \\
\hline CHEMBL3195735 & 688889 & 5.25 & 4.9295 & TST & \\
\hline CHEMBL1301938 & 688889 & 4.5 & 4.7945 & TRN & \\
\hline
\end{tabular}




\begin{tabular}{|c|c|c|c|c|}
\hline \multicolumn{5}{|c|}{ Supplemental Table S2.txt } \\
\hline CHEMBL1390860 & 688889 & 4.55 & 4.6154 & TRN \\
\hline CHEMBL1438878 & 688889 & 4.25 & 4.7318 & TRN \\
\hline CHEMBL1462862 & 688889 & 4.85 & 4.6863 & TRN \\
\hline CHEMBL1545873 & 688889 & 4.3 & 4.6565 & TST \\
\hline CHEMBL1541840 & 688889 & 4.5 & 4.7319 & TRN \\
\hline CHEMBL1608247 & 688889 & 4.25 & 4.9162 & TRN \\
\hline CHEMBL1308506 & 688889 & 4.6 & 4.9532 & TRN \\
\hline CHEMBL1478366 & 688889 & 5.1 & 4.5677 & TST \\
\hline CHEMBL1583975 & 688889 & 6.7501 & 4.881 & TST \\
\hline CHEMBL1438751 & 688889 & 4.5 & 4.7416 & TST \\
\hline CHEMBL1453521 & 688889 & 4.45 & 4.7457 & TRN \\
\hline CHEMBL1382038 & 688889 & 4.55 & 4.9077 & TRN \\
\hline CHEMBL1489871 & 688889 & 4.25 & 4.6535 & TRN \\
\hline CHEMBL1429423 & 688889 & 4.25 & 4.7573 & TRN \\
\hline CHEMBL1347710 & 688889 & 4.25 & 4.7552 & TRN \\
\hline CHEMBL1542820 & 688889 & 4.25 & 4.9941 & TRN \\
\hline CHEMBL1453131 & 688889 & 4.4 & 4.6439 & TRN \\
\hline CHEMBL1557909 & 688889 & 5.15 & 4.7339 & TRN \\
\hline CHEMBL3211179 & 688889 & 4.45 & 4.5917 & TRN \\
\hline CHEMBL3196682 & 688889 & 6.7501 & 4.8251 & TST \\
\hline CHEMBL1332181 & 688889 & 4.25 & 4.7147 & TRN \\
\hline CHEMBL499028 & 688889 & 5.4 & 4.7604 & TST \\
\hline CHEMBL1470805 & 688889 & 4.95 & 4.8613 & TRN \\
\hline CHEMBL1975892 & 688889 & 4.9 & 4.6446 & TRN \\
\hline CHEMBL1426240 & 688889 & 4.4 & 4.8068 & TRN \\
\hline CHEMBL1444201 & 688889 & 4.55 & 4.8144 & TRN \\
\hline CHEMBL1486067 & 688889 & 4.95 & 4.7533 & TST \\
\hline CHEMBL1331860 & 688889 & 4.25 & 4.9181 & TRN \\
\hline CHEMBL1599029 & 688889 & 5.3 & 4.7149 & TRN \\
\hline CHEMBL1385618 & 688889 & 4.25 & 4.8138 & TRN \\
\hline CHEMBL1431906 & 688889 & 5.25 & 4.7693 & TRN \\
\hline CHEMBL1607099 & 688889 & 4.3 & 4.8761 & TRN \\
\hline CHEMBL1305660 & 688889 & 4.3 & 4.6654 & TRN \\
\hline CHEMBL1345906 & 688889 & 4.25 & 4.7799 & TRN \\
\hline CHEMBL1309126 & 688889 & 4.5 & 4.6922 & TST \\
\hline CHEMBL1467156 & 688889 & 4.4 & 4.82 & TRN \\
\hline CHEMBL1366128 & 688889 & 4.9 & 4.7632 & TRN \\
\hline CHEMBL1440038 & 688889 & 4.95 & 4.7503 & TRN \\
\hline CHEMBL1366112 & 688889 & 4.3 & 4.7064 & TRN \\
\hline CHEMBL1311566 & 688889 & 4.25 & 4.8241 & TRN \\
\hline CHEMBL3192812 & 688889 & 4.55 & 4.7389 & TRN \\
\hline CHEMBL1334335 & 688889 & 4.3 & 4.782 & TRN \\
\hline CHEMBL1605874 & 688889 & 5.25 & 4.8441 & TST \\
\hline CHEMBL1540997 & 688889 & 5.65 & 4.7488 & TST \\
\hline CHEMBL3195474 & 688889 & 4.25 & 4.8732 & TRN \\
\hline CHEMBL1404747 & 688889 & 4.55 & 4.8329 & TRN \\
\hline CHEMBL1525956 & 688889 & 4.25 & 4.6699 & TRN \\
\hline CHEMBL1465414 & 688889 & 5.45 & 4.8766 & TRN \\
\hline
\end{tabular}




\begin{tabular}{|c|c|c|c|c|}
\hline \multicolumn{5}{|c|}{ Supplemental Table S2.txt } \\
\hline CHEMBL1588672 & 688889 & 4.5 & 4.676 & TRN \\
\hline CHEMBL1348651 & 688889 & 4.3 & 4.8658 & TRN \\
\hline CHEMBL1602081 & 688889 & 4.65 & 4.7483 & TST \\
\hline CHEMBL3194314 & 688889 & 4.25 & 4.6675 & TST \\
\hline CHEMBL1392200 & 688889 & 4.5 & 4.7179 & TRN \\
\hline CHEMBL1398737 & 688889 & 6.7501 & 4.9469 & TRN \\
\hline CHEMBL1388769 & 688889 & 4.5 & 4.7469 & TRN \\
\hline CHEMBL1550026 & 688889 & 4.55 & 4.6949 & TRN \\
\hline CHEMBL1350685 & 688889 & 4.45 & 4.6376 & TRN \\
\hline CHEMBL1485515 & 688889 & 4.45 & 4.748 & TRN \\
\hline CHEMBL1523556 & 688889 & 4.45 & 4.6959 & TRN \\
\hline CHEMBL1964480 & 688889 & 4.3 & 4.814 & TRN \\
\hline CHEMBL1585171 & 688889 & 4.45 & 4.715 & TRN \\
\hline CHEMBL1323170 & 688889 & 4.9 & 4.7907 & TRN \\
\hline CHEMBL1604728 & 688889 & 4.25 & 4.7999 & TRN \\
\hline CHEMBL1367630 & 688889 & 4.45 & 4.8241 & TRN \\
\hline CHEMBL1570860 & 688889 & 4.95 & 4.9394 & TRN \\
\hline CHEMBL1613583 & 688889 & 4.25 & 4.9292 & TRN \\
\hline CHEMBL1444063 & 688889 & 4.9 & 4.6779 & TRN \\
\hline CHEMBL1403344 & 688889 & 5.25 & 4.8044 & TRN \\
\hline CHEMBL3196015 & 688889 & 4.25 & 4.7467 & TRN \\
\hline CHEMBL1335123 & 688889 & 4.45 & 4.7601 & TRN \\
\hline CHEMBL1470773 & 688889 & 5.55 & 4.9506 & TRN \\
\hline CHEMBL1421389 & 688889 & 6.4 & 4.8256 & TRN \\
\hline CHEMBL1327266 & 688889 & 4.25 & 4.9174 & TST \\
\hline CHEMBL1424034 & 688889 & 4.55 & 4.6954 & TRN \\
\hline CHEMBL1346090 & 688889 & 4.5 & 4.7997 & TRN \\
\hline CHEMBL1303147 & 688889 & 6.5 & 4.9147 & TRN \\
\hline CHEMBL1390703 & 688889 & 5.45 & 4.7475 & TRN \\
\hline CHEMBL1345997 & 688889 & 4.25 & 4.8594 & TRN \\
\hline CHEMBL1471392 & 688889 & 5.4 & 4.8147 & TRN \\
\hline CHEMBL1523123 & 688889 & 4.25 & 4.9292 & TRN \\
\hline CHEMBL1581284 & 688889 & 4.4 & 4.744 & TRN \\
\hline CHEMBL1373338 & 688889 & 6.3 & 4.879 & TRN \\
\hline CHEMBL1452075 & 688889 & 6.05 & 4.7984 & TRN \\
\hline CHEMBL1366259 & 688889 & 4.9 & 4.7653 & TRN \\
\hline CHEMBL1611969 & 688889 & 4.4 & 4.9281 & TRN \\
\hline CHEMBL1557132 & 688889 & 4.25 & 4.9597 & TRN \\
\hline CHEMBL1370068 & 688889 & 4.25 & 4.7796 & TRN \\
\hline CHEMBL1583049 & 688889 & 4.6 & 4.6511 & TRN \\
\hline CHEMBL1609610 & 688889 & 4.3 & 4.6321 & TRN \\
\hline CHEMBL1568993 & 688889 & 5.4 & 4.688 & TRN \\
\hline CHEMBL1311011 & 688889 & 4.4 & 4.6827 & TST \\
\hline CHEMBL1346825 & 688889 & 4.25 & 4.8128 & TRN \\
\hline CHEMBL1606433 & 688889 & 4.4 & 4.7509 & TST \\
\hline CHEMBL1492381 & 688889 & 4.95 & 4.7664 & TST \\
\hline CHEMBL1499859 & 688889 & 5.85 & 4.9637 & TRN \\
\hline CHEMBL1583455 & 688889 & 6.05 & 4.8074 & TST \\
\hline
\end{tabular}




\begin{tabular}{|c|c|c|c|c|c|}
\hline \multicolumn{6}{|c|}{ Supplemental Table S2.txt } \\
\hline CHEMBL1606856 & 688889 & 5.0 & 4.9956 & TRN & \\
\hline CHEMBL1522803 & 688889 & 4.3 & 4.7167 & TRN & \\
\hline CHEMBL1329015 & 688889 & 4.25 & 4.9502 & TRN & \\
\hline CHEMBL1429291 & 688889 & 5.2 & 4.7842 & TRN & \\
\hline CHEMBL1547414 & 688889 & 4.45 & 4.8392 & TRN & \\
\hline CHEMBL1422949 & 688889 & 4.95 & 4.7706 & TRN & \\
\hline CHEMBL1352062 & 688889 & 4.6 & 4.7756 & TRN & \\
\hline CHEMBL1545244 & 688889 & 4.5 & 4.7226 & TRN & \\
\hline CHEMBL1377714 & 688889 & 4.5 & 4.6951 & TRN & \\
\hline CHEMBL1471443 & 688889 & 4.35 & 4.8501 & TRN & \\
\hline CHEMBL3196108 & 688889 & 4.3 & 4.6576 & TST & \\
\hline CHEMBL1483667 & 688889 & 4.9 & 4.8408 & TRN & \\
\hline CHEMBL1391297 & 688889 & 4.6 & 4.84399 & 9999999999 & TRN \\
\hline CHEMBL1453006 & 688889 & 4.95 & 4.6575 & TRN & \\
\hline CHEMBL1579415 & 688889 & 4.25 & 4.9657 & TRN & \\
\hline CHEMBL1585321 & 688889 & 6.1 & 4.8978 & TRN & \\
\hline CHEMBL3193818 & 688889 & 4.65 & 4.7714 & TRN & \\
\hline CHEMBL1579296 & 688889 & 4.6 & 4.8167 & TRN & \\
\hline CHEMBL1449038 & 688889 & 5.05 & 4.8589 & TRN & \\
\hline CHEMBL3196530 & 688889 & 5.3 & 4.7097 & TRN & \\
\hline CHEMBL1597166 & 688889 & 5.1 & 4.936 & TRN & \\
\hline CHEMBL1351192 & 688889 & 4.3 & 4.7628 & TRN & \\
\hline CHEMBL1484119 & 688889 & 4.9 & 4.7929 & TST & \\
\hline CHEMBL1392033 & 688889 & 4.55 & 4.8619 & TRN & \\
\hline CHEMBL1548148 & 688889 & 6.5 & 4.8786 & TST & \\
\hline CHEMBL1472246 & 688889 & 5.85 & 4.9003 & TRN & \\
\hline CHEMBL3192521 & 688889 & 4.55 & 4.833 & TRN & \\
\hline CHEMBL1305253 & 688889 & 6.7501 & 4.7064 & TRN & \\
\hline CHEMBL1564995 & 688889 & 4.6 & 4.84699 & 99999999995 & TRN \\
\hline CHEMBL1545474 & 688889 & 4.6 & 4.7689 & TRN & \\
\hline CHEMBL1408661 & 688889 & 4.9 & 4.7904 & TRN & \\
\hline CHEMBL1597860 & 688889 & 4.45 & 4.7424 & TRN & \\
\hline CHEMBL1323743 & 688889 & 4.5 & 4.9159 & TRN & \\
\hline CHEMBL1542811 & 688889 & 4.25 & 4.748 & TRN & \\
\hline CHEMBL1417197 & 688889 & 4.4 & 4.8696 & TRN & \\
\hline CHEMBL1368871 & 688889 & 4.3 & 4.7558 & TST & \\
\hline CHEMBL1347539 & 688889 & 4.5 & 4.8741 & TRN & \\
\hline CHEMBL1306292 & 688889 & 5.5 & 4.8513 & TST & \\
\hline CHEMBL1588315 & 688889 & 6.0 & 4.8055 & TST & \\
\hline CHEMBL1304416 & 688889 & 6.8 & 4.81800 & 00000000005 & TRN \\
\hline CHEMBL1416237 & 688889 & 4.45 & 4.8489 & TRN & \\
\hline CHEMBL1428477 & 688889 & 6.6499 & 4.8176 & TRN & \\
\hline CHEMBL 2000420 & 688889 & 4.3 & 4.7954 & TST & \\
\hline CHEMBL1410162 & 688889 & 4.45 & 4.9058 & TRN & \\
\hline CHEMBL1510332 & 688889 & 4.25 & 4.7262 & TST & \\
\hline CHEMBL1307745 & 688889 & 4.25 & 4.8311 & TST & \\
\hline CHEMBL1301771 & 688889 & 4.45 & 4.7849 & TST & \\
\hline CHEMBL1423062 & 688889 & 6.8 & 4.9624 & TRN & \\
\hline
\end{tabular}




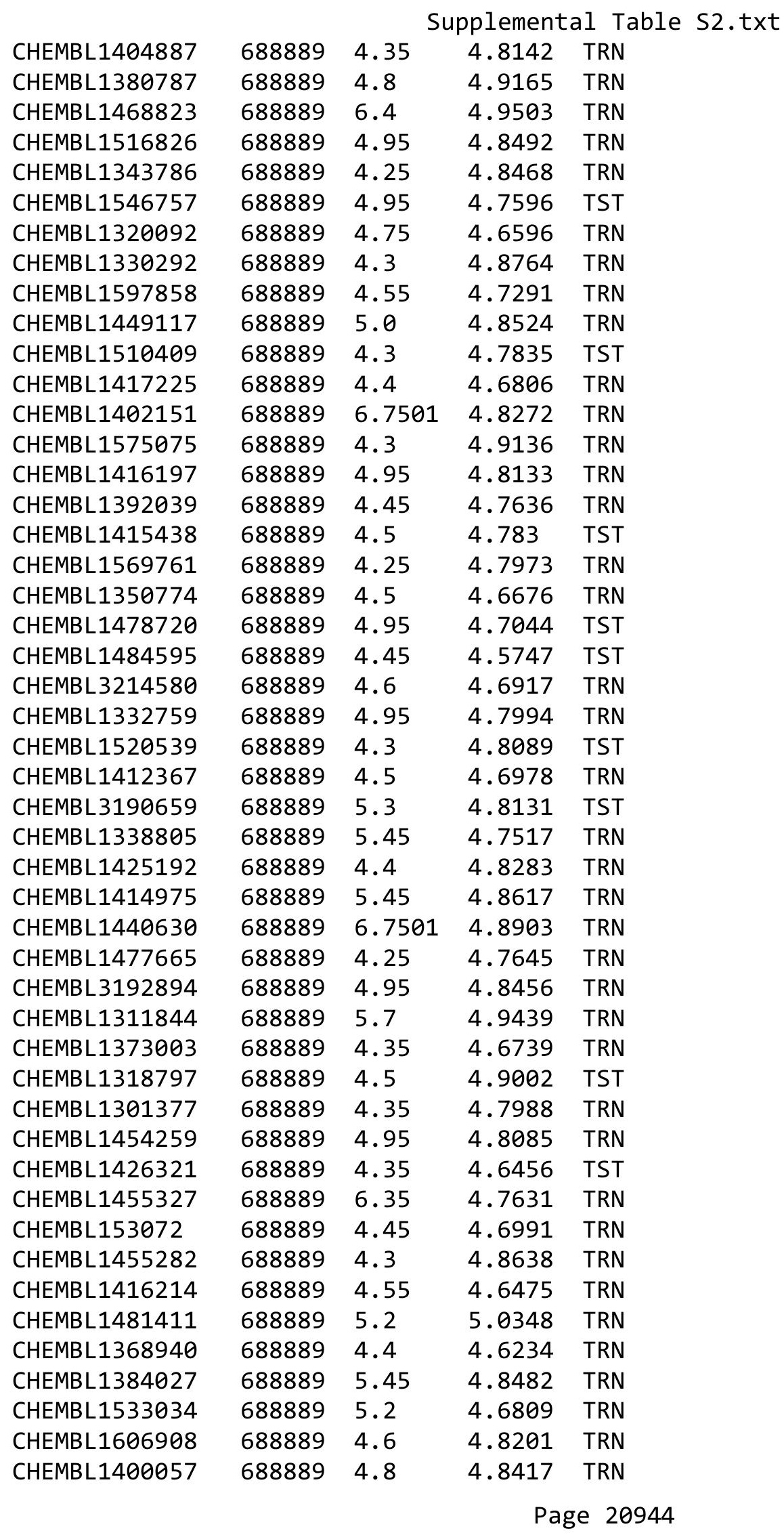




\begin{tabular}{|c|c|c|c|c|}
\hline \multicolumn{5}{|c|}{ Supplemental Table S2.txt } \\
\hline CHEMBL1563197 & 688889 & 4.4 & 4.8705 & TRN \\
\hline CHEMBL1579211 & 688889 & 6.0 & 4.7867 & TST \\
\hline CHEMBL1549887 & 688889 & 4.25 & 4.9563 & TRN \\
\hline CHEMBL1409489 & 688889 & 5.4 & 4.8277 & TRN \\
\hline CHEMBL3199931 & 688889 & 4.4 & 4.8935 & TRN \\
\hline CHEMBL1599566 & 688889 & 4.3 & 4.7338 & TRN \\
\hline CHEMBL1484105 & 688889 & 4.25 & 4.6379 & TST \\
\hline CHEMBL1410915 & 688889 & 4.35 & 4.8067 & TRN \\
\hline CHEMBL1332445 & 688889 & 4.25 & 4.7753 & TST \\
\hline CHEMBL1449380 & 688889 & 4.95 & 4.8741 & TRN \\
\hline CHEMBL1532107 & 688889 & 4.45 & 4.8165 & TRN \\
\hline CHEMBL1466527 & 688889 & 4.4 & 4.8402 & TRN \\
\hline CHEMBL1320561 & 688889 & 4.3 & 4.8306 & TST \\
\hline CHEMBL1465363 & 688889 & 4.45 & 4.8018 & TRN \\
\hline CHEMBL1602732 & 688889 & 6.3 & 4.6585 & TST \\
\hline CHEMBL1563450 & 688889 & 4.3 & 4.8157 & TRN \\
\hline CHEMBL1320195 & 688889 & 4.55 & 4.6939 & TRN \\
\hline CHEMBL1388497 & 688889 & 5.65 & 4.8179 & TRN \\
\hline CHEMBL1362414 & 688889 & 5.5 & 4.7854 & TRN \\
\hline CHEMBL1984804 & 688889 & 5.4 & 4.6877 & TRN \\
\hline CHEMBL1419665 & 688889 & 4.5 & 4.7067 & TST \\
\hline CHEMBL1548535 & 688889 & 4.35 & 4.7616 & TRN \\
\hline CHEMBL1440818 & 688889 & 4.25 & 4.8583 & TRN \\
\hline CHEMBL1601129 & 688889 & 4.5 & 4.933 & TRN \\
\hline CHEMBL1550270 & 688889 & 6.1 & 4.7652 & TST \\
\hline CHEMBL1462836 & 688889 & 4.9 & 4.7385 & TRN \\
\hline CHEMBL1566246 & 688889 & 6.7501 & 4.8981 & TRN \\
\hline CHEMBL1582162 & 688889 & 4.65 & 4.7626 & TRN \\
\hline CHEMBL1491378 & 688889 & 5.25 & 4.9123 & TRN \\
\hline CHEMBL1321952 & 688889 & 4.25 & 4.7952 & TRN \\
\hline CHEMBL1388461 & 688889 & 4.95 & 4.6959 & TRN \\
\hline CHEMBL3195113 & 688889 & 4.45 & 4.7712 & TRN \\
\hline CHEMBL1345554 & 688889 & 4.4 & 4.7837 & TRN \\
\hline CHEMBL1411975 & 688889 & 4.6 & 4.6509 & TRN \\
\hline CHEMBL1611229 & 688889 & 5.2 & 4.8739 & TST \\
\hline CHEMBL1445431 & 688889 & 4.45 & 4.6571 & TST \\
\hline CHEMBL1463234 & 688889 & 4.3 & 4.7754 & TRN \\
\hline CHEMBL3207587 & 688889 & 4.3 & 4.798 & TRN \\
\hline CHEMBL1415654 & 688889 & 4.3 & 4.6842 & TRN \\
\hline CHEMBL1522478 & 688889 & 4.25 & 4.8218 & TRN \\
\hline CHEMBL1304743 & 688889 & 4.45 & 4.6554 & TRN \\
\hline CHEMBL1339724 & 688889 & 4.65 & 4.7535 & TRN \\
\hline CHEMBL1559624 & 688889 & 5.45 & 4.7083 & TRN \\
\hline CHEMBL1465069 & 688889 & 4.35 & 4.7909 & TRN \\
\hline CHEMBL1300713 & 688889 & 4.25 & 4.8828 & TRN \\
\hline CHEMBL3193898 & 688889 & 6.35 & 4.9038 & TRN \\
\hline CHEMBL1488143 & 688889 & 4.25 & 4.9774 & TST \\
\hline CHEMBL1596915 & 688889 & 4.25 & 4.9347 & TST \\
\hline
\end{tabular}




\begin{tabular}{|c|c|c|c|c|c|}
\hline \multicolumn{6}{|c|}{ Supplemental Table S2.txt } \\
\hline CHEMBL1490693 & 688889 & 5.3 & 4.8696 & TRN & \\
\hline CHEMBL1310214 & 688889 & 6.6 & 5.0199 & TRN & \\
\hline CHEMBL1549592 & 688889 & 5.85 & 4.8865 & TRN & \\
\hline CHEMBL1605490 & 688889 & 5.3 & 4.9069 & TRN & \\
\hline CHEMBL1429117 & 688889 & 4.55 & 4.7433 & TRN & \\
\hline CHEMBL1423407 & 688889 & 4.5 & 4.8233 & TRN & \\
\hline CHEMBL1322582 & 688889 & 4.7 & 4.6941 & TRN & \\
\hline CHEMBL1448548 & 688889 & 5.85 & 4.7894 & TRN & \\
\hline CHEMBL1381541 & 688889 & 4.3 & 4.6433 & TRN & \\
\hline CHEMBL1482280 & 688889 & 5.25 & 4.773 & TST & \\
\hline CHEMBL1503776 & 688889 & 4.3 & 4.6966 & TST & \\
\hline CHEMBL1601646 & 688889 & 5.25 & 4.7367 & TRN & \\
\hline CHEMBL1582127 & 688889 & 4.45 & 4.85 & TST & \\
\hline CHEMBL1455721 & 688889 & 5.15 & 4.8109 & TRN & \\
\hline CHEMBL3213016 & 688889 & 5.6 & 4.7848 & TST & \\
\hline CHEMBL162783 & 688889 & 4.5 & $4.7010 e$ & 00000000005 & TST \\
\hline CHEMBL3199282 & 688889 & 5.2 & 4.7002 & TST & \\
\hline CHEMBL1578075 & 688889 & 4.25 & 4.7334 & TST & \\
\hline CHEMBL1299658 & 688889 & 5.1 & 4.8343 & TRN & \\
\hline CHEMBL1460668 & 688889 & 4.25 & 4.7837 & TRN & \\
\hline CHEMBL1373011 & 688889 & 4.6 & 4.7393 & TRN & \\
\hline CHEMBL1603107 & 688889 & 4.45 & 4.654 & TRN & \\
\hline CHEMBL1078384 & 688889 & 4.9 & 4.7462 & TST & \\
\hline CHEMBL1432540 & 688889 & 4.3 & 4.7559 & TST & \\
\hline CHEMBL1506402 & 688889 & 4.3 & 4.8514 & TRN & \\
\hline CHEMBL1299351 & 688889 & 4.25 & 4.9311 & TRN & \\
\hline CHEMBL1442950 & 688889 & 4.45 & 4.67 & TRN & \\
\hline CHEMBL1330547 & 688889 & 4.25 & 4.8157 & TRN & \\
\hline CHEMBL1441619 & 688889 & 4.45 & 4.5317 & TRN & \\
\hline CHEMBL1421882 & 688889 & 6.05 & 4.8305 & TST & \\
\hline CHEMBL1600869 & 688889 & 5.1 & 4.8629 & TRN & \\
\hline CHEMBL1470903 & 688889 & 4.95 & 4.7139 & TST & \\
\hline CHEMBL1446616 & 688889 & 4.95 & 4.883 & TST & \\
\hline CHEMBL1608435 & 688889 & 4.3 & 4.9081 & TST & \\
\hline CHEMBL3207535 & 688889 & 4.95 & 4.8341 & TRN & \\
\hline CHEMBL1415670 & 688889 & 4.75 & 4.7473 & TRN & \\
\hline CHEMBL1464394 & 688889 & 4.4 & 4.7989 & TRN & \\
\hline CHEMBL1505799 & 688889 & 4.35 & 4.8452 & TRN & \\
\hline CHEMBL1373528 & 688889 & 6.1 & 4.7073 & TRN & \\
\hline CHEMBL1505014 & 688889 & 4.95 & 4.8641 & TST & \\
\hline CHEMBL1400980 & 688889 & 4.4 & 4.8497 & TRN & \\
\hline CHEMBL1409284 & 688889 & 5.25 & 4.7592 & TST & \\
\hline CHEMBL1438798 & 688889 & 5.2 & 4.8358 & TRN & \\
\hline CHEMBL1544295 & 688889 & 4.4 & 4.7462 & TRN & \\
\hline CHEMBL1407267 & 688889 & 4.3 & 4.6829 & TRN & \\
\hline CHEMBL3213398 & 688889 & 6.1 & 4.8053 & TRN & \\
\hline CHEMBL1457829 & 688889 & 6.5501 & 4.8241 & TRN & \\
\hline CHEMBL1576519 & 688889 & 4.45 & 4.8441 & TST & \\
\hline
\end{tabular}




\begin{tabular}{|c|c|c|c|c|}
\hline \multicolumn{5}{|c|}{ Supplemental Table S2.txt } \\
\hline CHEMBL1568727 & 688889 & 4.3 & 4.8212 & TRN \\
\hline CHEMBL 249032 & 688889 & 4.55 & 4.8039 & TRN \\
\hline CHEMBL1417039 & 688889 & 4.5 & 4.9772 & TRN \\
\hline CHEMBL 3210706 & 688889 & 4.35 & 4.8088 & TRN \\
\hline CHEMBL 1558357 & 688889 & 4.3 & 4.7978 & TRN \\
\hline CHEMBL1422562 & 688889 & 4.55 & 4.7677 & TRN \\
\hline CHEMBL1333507 & 688889 & 4.6 & 4.7501 & TRN \\
\hline CHEMBL1524613 & 688889 & 4.45 & 4.659 & TRN \\
\hline CHEMBL1331047 & 688889 & 4.35 & 4.7977 & TRN \\
\hline CHEMBL1375992 & 688889 & 5.0 & 4.6943 & TRN \\
\hline CHEMBL1597429 & 688889 & 4.95 & 4.8552 & TRN \\
\hline CHEMBL 3197571 & 688889 & 4.9 & 4.703 & TRN \\
\hline CHEMBL1510809 & 688889 & 4.35 & 4.8566 & TST \\
\hline CHEMBL1549706 & 688889 & 5.3 & 4.8514 & TST \\
\hline CHEMBL1523299 & 688889 & 4.55 & 4.8059 & TRN \\
\hline CHEMBL1312802 & 688889 & 4.4 & 4.7242 & TRN \\
\hline CHEMBL1303217 & 688889 & 4.7 & 4.75 & TST \\
\hline CHEMBL1570431 & 688889 & 4.8 & 4.7829 & TRN \\
\hline CHEMBL1455161 & 688889 & 4.4 & 4.7786 & TRN \\
\hline CHEMBL1305491 & 688889 & 5.25 & 4.8766 & TRN \\
\hline CHEMBL1601617 & 688889 & 4.4 & 4.6837 & TST \\
\hline CHEMBL1501998 & 688889 & 6.05 & 4.7232 & TRN \\
\hline CHEMBL1550441 & 688889 & 4.4 & 4.5822 & TRN \\
\hline CHEMBL1300082 & 688889 & 4.3 & 4.6825 & TST \\
\hline CHEMBL1385353 & 688889 & 4.45 & 4.745 & TRN \\
\hline CHEMBL1517319 & 688889 & 4.9 & 4.9652 & TRN \\
\hline CHEMBL1581710 & 688889 & 4.75 & 4.7218 & TRN \\
\hline CHEMBL1460969 & 688889 & 5.15 & 4.8456 & TRN \\
\hline CHEMBL1483228 & 688889 & 4.95 & 4.791 & TRN \\
\hline CHEMBL1388072 & 688889 & 4.55 & 4.8719 & TST \\
\hline CHEMBL1346079 & 688889 & 4.4 & 4.9043 & TRN \\
\hline CHEMBL1480884 & 688889 & 4.95 & 4.9396 & TRN \\
\hline CHEMBL1603051 & 688889 & 4.3 & 4.7692 & TRN \\
\hline CHEMBL1570263 & 688889 & 5.35 & 4.8926 & TST \\
\hline CHEMBL1519788 & 688889 & 4.95 & 4.7497 & TST \\
\hline CHEMBL1523376 & 688889 & 5.3 & 4.8017 & TST \\
\hline CHEMBL1544731 & 688889 & 4.45 & 4.646 & TRN \\
\hline CHEMBL1571299 & 688889 & 4.6 & 4.7916 & TRN \\
\hline CHEMBL1440622 & 688889 & 6.7501 & 4.7858 & TST \\
\hline CHEMBL1421654 & 688889 & 4.35 & 4.8209 & TRN \\
\hline CHEMBL1444460 & 688889 & 4.3 & 4.8125 & TRN \\
\hline CHEMBL3194108 & 688889 & 4.35 & 4.7735 & TST \\
\hline CHEMBL1409133 & 688889 & 4.85 & 4.8298 & TRN \\
\hline CHEMBL1366118 & 688889 & 4.45 & 4.7061 & TRN \\
\hline CHEMBL1483652 & 688889 & 5.65 & 4.6596 & TST \\
\hline CHEMBL1505943 & 688889 & 6.8 & 4.8177 & TRN \\
\hline CHEMBL1565229 & 688889 & 5.0 & 4.6539 & TRN \\
\hline CHEMBL1351610 & 688889 & 4.55 & 4.7183 & TST \\
\hline
\end{tabular}




\begin{tabular}{|c|c|c|c|c|c|}
\hline \multicolumn{6}{|c|}{ Supplemental Table S2.txt } \\
\hline CHEMBL1309831 & 688889 & 5.3 & 4.7664 & TRN & \\
\hline CHEMBL1489122 & 688889 & 4.5 & 4.8186 & TST & \\
\hline CHEMBL1366216 & 688889 & 4.5 & 4.9278 & TRN & \\
\hline CHEMBL3210451 & 688889 & 4.6 & 4.6823 & TRN & \\
\hline CHEMBL1573529 & 688889 & 5.15 & 4.7787 & TRN & \\
\hline CHEMBL1446286 & 688889 & 4.35 & 4.8029 & TRN & \\
\hline CHEMBL1526092 & 688889 & 4.25 & 4.8469 & TST & \\
\hline CHEMBL1443561 & 688889 & 4.3 & 4.832 & TRN & \\
\hline CHEMBL1443853 & 688889 & 4.7 & 4.7163 & TRN & \\
\hline CHEMBL1563013 & 688889 & 4.65 & 4.7695 & TRN & \\
\hline CHEMBL1525055 & 688889 & 6.6 & 4.7345 & TRN & \\
\hline CHEMBL1312570 & 688889 & 4.3 & 4.7795 & TRN & \\
\hline CHEMBL1531619 & 688889 & 4.3 & 4.96399 & 99999999995 & TRN \\
\hline CHEMBL1379812 & 688889 & 4.6 & 4.7293 & TST & \\
\hline CHEMBL358644 & 688889 & 4.55 & 4.6737 & TRN & \\
\hline CHEMBL1362247 & 688889 & 4.7 & 4.7541 & TRN & \\
\hline CHEMBL1414565 & 688889 & 5.05 & 4.8707 & TST & \\
\hline CHEMBL1488076 & 688889 & 6.8 & 4.8476 & TRN & \\
\hline CHEMBL1575339 & 688889 & 4.25 & 4.9012 & TRN & \\
\hline CHEMBL1444224 & 688889 & 4.95 & 4.8626 & TST & \\
\hline CHEMBL1440880 & 688889 & 4.3 & 4.8196 & TRN & \\
\hline CHEMBL1480371 & 688889 & 4.25 & 4.67 & TRN & \\
\hline CHEMBL1542856 & 688889 & 4.95 & 4.845 & TRN & \\
\hline CHEMBL1427973 & 688889 & 4.3 & 5.0064 & TRN & \\
\hline CHEMBL1400681 & 688889 & 4.45 & 4.8813 & TRN & \\
\hline CHEMBL527584 & 688889 & 4.6 & 4.828 & TRN & \\
\hline CHEMBL3211490 & 688889 & 5.95 & 4.8118 & TRN & \\
\hline CHEMBL1461546 & 688889 & 4.6 & 4.8596 & TRN & \\
\hline CHEMBL1305649 & 688889 & 4.4 & 4.672 & TRN & \\
\hline CHEMBL1382737 & 688889 & 4.45 & 4.9586 & TST & \\
\hline CHEMBL1344335 & 688889 & 4.35 & 4.76399 & 9999999999 & TRN \\
\hline CHEMBL1576763 & 688889 & 5.5 & 4.8511 & TRN & \\
\hline CHEMBL1471584 & 688889 & 4.55 & 4.6913 & TRN & \\
\hline CHEMBL1505234 & 688889 & 4.65 & 4.8446 & TRN & \\
\hline CHEMBL1341278 & 688889 & 4.25 & 4.7543 & TRN & \\
\hline CHEMBL1455404 & 688889 & 4.55 & 4.709 & TRN & \\
\hline CHEMBL1425462 & 688889 & 4.4 & 4.7661 & TRN & \\
\hline CHEMBL1402084 & 688889 & 4.4 & 4.8941 & TST & \\
\hline CHEMBL1446343 & 688889 & 5.0 & 5.0083 & TRN & \\
\hline CHEMBL1543886 & 688889 & 4.35 & 4.8124 & TRN & \\
\hline CHEMBL1991187 & 688889 & 5.0 & 4.6602 & TRN & \\
\hline CHEMBL1455352 & 688889 & 6.8 & 4.8489 & TST & \\
\hline CHEMBL1565101 & 688889 & 4.5 & 4.7675 & TRN & \\
\hline CHEMBL1414858 & 688889 & 5.45 & 4.7971 & TST & \\
\hline CHEMBL1352127 & 688889 & 4.5 & 4.7547 & TRN & \\
\hline CHEMBL1312995 & 688889 & 4.35 & 4.9232 & TST & \\
\hline CHEMBL1502298 & 688889 & 4.3 & 4.8995 & TST & \\
\hline CHEMBL1410770 & 688889 & 4.65 & 4.817 & TRN & \\
\hline
\end{tabular}




\begin{tabular}{|c|c|c|c|c|}
\hline \multicolumn{5}{|c|}{ Supplemental Table S2.txt } \\
\hline CHEMBL1451118 & 688889 & 6.7501 & 4.776 & TST \\
\hline CHEMBL3191059 & 688889 & 4.55 & 4.8296 & TRN \\
\hline CHEMBL1527843 & 688889 & 5.4 & 4.9279 & TRN \\
\hline CHEMBL1510511 & 688889 & 4.5 & 4.6237 & TST \\
\hline CHEMBL3195915 & 688889 & 4.85 & 4.9902 & TST \\
\hline CHEMBL1343739 & 688889 & 4.5 & 5.0299 & TRN \\
\hline CHEMBL1581251 & 688889 & 4.6 & 4.9174 & TST \\
\hline CHEMBL1577139 & 688889 & 4.95 & 4.6689 & TRN \\
\hline CHEMBL1350226 & 688889 & 4.95 & 4.7215 & TRN \\
\hline CHEMBL1333224 & 688889 & 4.25 & 4.8467 & TRN \\
\hline CHEMBL 1559230 & 688889 & 4.55 & 4.8987 & TRN \\
\hline CHEMBL1460416 & 688889 & 5.2 & 4.9912 & TRN \\
\hline CHEMBL1301164 & 688889 & 4.3 & 4.7496 & TST \\
\hline CHEMBL1389473 & 688889 & 4.4 & 4.7345 & TRN \\
\hline CHEMBL1343610 & 688889 & 4.3 & 4.9136 & TRN \\
\hline CHEMBL1331278 & 688889 & 4.5 & 4.6607 & TRN \\
\hline CHEMBL1611022 & 688889 & 4.9 & 4.852 & TST \\
\hline CHEMBL1372948 & 688889 & 4.9 & 4.8949 & TST \\
\hline CHEMBL1393762 & 688889 & 4.4 & 4.894 & TRN \\
\hline CHEMBL1470580 & 688889 & 4.8 & 4.8431 & TST \\
\hline CHEMBL1373130 & 688889 & 4.3 & 4.8068 & TRN \\
\hline CHEMBL1343101 & 688889 & 5.7 & 4.8543 & TST \\
\hline CHEMBL1608732 & 688889 & 4.3 & 4.6972 & TST \\
\hline CHEMBL1442635 & 688889 & 4.5 & 4.854 & TRN \\
\hline CHEMBL1519338 & 688889 & 4.3 & 4.7784 & TRN \\
\hline CHEMBL 1428470 & 688889 & 5.45 & 4.7812 & TST \\
\hline CHEMBL1544505 & 688889 & 4.3 & 4.7383 & TRN \\
\hline CHEMBL3213159 & 688889 & 5.9 & 4.8732 & TST \\
\hline CHEMBL1468634 & 688889 & 5.2 & 4.8164 & TST \\
\hline CHEMBL1538640 & 688889 & 4.25 & 4.7124 & TST \\
\hline CHEMBL1347131 & 688889 & 4.5 & 4.7132 & TRN \\
\hline CHEMBL1362842 & 688889 & 4.5 & 4.8291 & TRN \\
\hline CHEMBL1419900 & 688889 & 4.4 & 4.7415 & TRN \\
\hline CHEMBL1563194 & 688889 & 4.45 & 4.9124 & TST \\
\hline CHEMBL1429114 & 688889 & 4.55 & 4.792 & TRN \\
\hline CHEMBL1417422 & 688889 & 4.95 & 4.6976 & TST \\
\hline CHEMBL1472312 & 688889 & 4.5 & 4.8139 & TRN \\
\hline CHEMBL1561209 & 688889 & 4.3 & 4.9353 & TST \\
\hline CHEMBL1374673 & 688889 & 5.25 & 4.7987 & TST \\
\hline CHEMBL3209215 & 688889 & 4.95 & 4.7067 & TRN \\
\hline CHEMBL1381114 & 688889 & 5.25 & 4.8948 & TRN \\
\hline CHEMBL1359455 & 688889 & 4.5 & 4.6256 & TRN \\
\hline CHEMBL1529631 & 688889 & 4.95 & 4.7338 & TRN \\
\hline CHEMBL1580903 & 688889 & 4.3 & 4.83 & TRN \\
\hline CHEMBL1389219 & 688889 & 4.75 & 4.7716 & TRN \\
\hline CHEMBL 1487259 & 688889 & 5.15 & 4.8233 & TST \\
\hline CHEMBL1313219 & 688889 & 6.3 & 4.8328 & TRN \\
\hline CHEMBL1595489 & 688889 & 6.7501 & 4.8324 & TST \\
\hline
\end{tabular}




\begin{tabular}{|c|c|c|c|c|c|}
\hline \multicolumn{6}{|c|}{ Supplemental Table S2.txt } \\
\hline CHEMBL1577210 & 688889 & 4.4 & 4.8841 & TST & \\
\hline CHEMBL1365800 & 688889 & 4.5 & 4.8772 & TRN & \\
\hline CHEMBL1391280 & 688889 & 4.95 & 4.7477 & TRN & \\
\hline CHEMBL1502516 & 688889 & 4.45 & 4.7125 & TRN & \\
\hline CHEMBL1446836 & 688889 & 5.9 & 4.7074 & TRN & \\
\hline CHEMBL1453680 & 688889 & 6.35 & 4.7776 & TRN & \\
\hline CHEMBL1354059 & 688889 & 5.45 & 4.7882 & TRN & \\
\hline CHEMBL1348630 & 688889 & 4.5 & 4.8046 & TRN & \\
\hline CHEMBL1518880 & 688889 & 4.95 & 4.8736 & TRN & \\
\hline CHEMBL1428815 & 688889 & 4.3 & 4.8632 & TRN & \\
\hline CHEMBL 876 & 688889 & 4.95 & 4.8898 & TST & \\
\hline CHEMBL1506413 & 688889 & 4.95 & 4.7779 & TRN & \\
\hline CHEMBL1996519 & 688889 & 4.7 & 4.6583 & TRN & \\
\hline CHEMBL1345509 & 688889 & 4.25 & 4.9382 & TRN & \\
\hline CHEMBL1345078 & 688889 & 4.5 & 4.7853 & TRN & \\
\hline CHEMBL1341050 & 688889 & 4.45 & 4.8585 & TRN & \\
\hline CHEMBL1532909 & 688889 & 4.25 & $4.8610 e$ & 0000000001 & TST \\
\hline CHEMBL1337499 & 688889 & 4.25 & 4.7315 & TRN & \\
\hline CHEMBL1494471 & 688889 & 4.45 & 4.7027 & TRN & \\
\hline CHEMBL1339759 & 688889 & 4.4 & 4.8613 & TRN & \\
\hline CHEMBL1548712 & 688889 & 4.25 & 4.7858 & TST & \\
\hline CHEMBL1458159 & 688889 & 4.4 & 4.604 & TRN & \\
\hline CHEMBL1347463 & 688889 & 4.85 & 4.7415 & TRN & \\
\hline CHEMBL1483707 & 688889 & 5.1 & 4.8692 & TRN & \\
\hline CHEMBL1367222 & 688889 & 4.3 & 4.6457 & TRN & \\
\hline CHEMBL1333482 & 688889 & 4.4 & 4.8272 & TRN & \\
\hline CHEMBL3198329 & 688889 & 4.45 & 4.7251 & TRN & \\
\hline CHEMBL1481598 & 688889 & 5.0 & 4.9062 & TRN & \\
\hline CHEMBL1495208 & 688889 & 5.05 & 4.6843 & TRN & \\
\hline CHEMBL1603798 & 688889 & 4.3 & 4.8873 & TRN & \\
\hline CHEMBL1609705 & 688889 & 5.1 & 4.8033 & TRN & \\
\hline CHEMBL1541204 & 688889 & 4.4 & 4.7542 & TRN & \\
\hline CHEMBL1320909 & 688889 & 4.55 & 4.8283 & TST & \\
\hline CHEMBL1312300 & 688889 & 4.25 & 4.7045 & TRN & \\
\hline CHEMBL1338061 & 688889 & 4.4 & 4.9063 & TRN & \\
\hline CHEMBL1401094 & 688889 & 4.3 & 4.854 & TST & \\
\hline CHEMBL1304620 & 688889 & 4.3 & 4.8201 & TRN & \\
\hline CHEMBL1438360 & 688889 & 5.25 & 4.762 & TRN & \\
\hline CHEMBL1390314 & 688889 & 4.9 & 4.9178 & TRN & \\
\hline CHEMBL1382617 & 688889 & 5.35 & 4.631 & TST & \\
\hline CHEMBL1484690 & 688889 & 5.55 & 4.753 & TRN & \\
\hline CHEMBL1302400 & 688889 & 4.5 & 4.8463 & TRN & \\
\hline CHEMBL3197899 & 688889 & 4.3 & 4.7863 & TRN & \\
\hline CHEMBL1430358 & 688889 & 4.45 & 4.7907 & TRN & \\
\hline CHEMBL1487386 & 688889 & 6.5 & 4.7446 & TST & \\
\hline CHEMBL1459370 & 688889 & 4.65 & 4.7712 & TST & \\
\hline CHEMBL1312087 & 688889 & 4.75 & 4.7383 & TST & \\
\hline CHEMBL1324441 & 688889 & 6.7501 & 4.8613 & TRN & \\
\hline
\end{tabular}




\begin{tabular}{|c|c|c|c|c|c|}
\hline \multicolumn{6}{|c|}{ Supplemental Table S2.txt } \\
\hline CHEMBL1343517 & 688889 & 4.3 & 4.6219 & TRN & \\
\hline CHEMBL1380482 & 688889 & 4.25 & 4.8126 & TRN & \\
\hline CHEMBL1425724 & 688889 & 4.35 & 4.69600 & 2000000001 & TRN \\
\hline CHEMBL1385555 & 688889 & 4.3 & 4.7879 & TRN & \\
\hline CHEMBL1412026 & 688889 & 5.45 & 4.9163 & TST & \\
\hline CHEMBL1966852 & 688889 & 4.4 & 4.6827 & TRN & \\
\hline CHEMBL1574743 & 688889 & 4.8 & 4.933 & TRN & \\
\hline CHEMBL1557054 & 688889 & 5.4 & 4.6767 & TRN & \\
\hline CHEMBL1463716 & 688889 & 4.3 & 4.9806 & TRN & \\
\hline CHEMBL1457571 & 688889 & 4.55 & 4.75899 & 99999999995 & TRN \\
\hline CHEMBL1305069 & 688889 & 4.45 & 4.6086 & TRN & \\
\hline CHEMBL1576041 & 688889 & 4.4 & 4.7375 & TRN & \\
\hline CHEMBL1448451 & 688889 & 4.3 & 4.8062 & TRN & \\
\hline CHEMBL1328195 & 688889 & 4.65 & 4.619 & TRN & \\
\hline CHEMBL1372231 & 688889 & 4.45 & 4.627 & TRN & \\
\hline CHEMBL3190332 & 688889 & 4.65 & 4.8011 & TRN & \\
\hline CHEMBL1313899 & 688889 & 5.3 & 4.9055 & TRN & \\
\hline CHEMBL1541559 & 688889 & 4.25 & 4.9781 & TST & \\
\hline CHEMBL1519109 & 688889 & 4.35 & 4.7739 & TRN & \\
\hline CHEMBL452002 & 688889 & 4.35 & 4.9413 & TRN & \\
\hline CHEMBL1604344 & 688889 & 6.7501 & 4.8918 & TRN & \\
\hline CHEMBL1558084 & 688889 & 4.5 & 4.768 & TRN & \\
\hline CHEMBL1324139 & 688889 & 4.5 & 4.8963 & TRN & \\
\hline CHEMBL1300931 & 688889 & 4.25 & 4.8609 & TRN & \\
\hline CHEMBL1503568 & 688889 & 5.85 & 4.9069 & TRN & \\
\hline CHEMBL1417451 & 688889 & 4.25 & 4.7438 & TRN & \\
\hline CHEMBL1530148 & 688889 & 4.5 & 4.7248 & TRN & \\
\hline CHEMBL1536634 & 688889 & 4.45 & 4.6495 & TRN & \\
\hline CHEMBL1444532 & 688889 & 4.45 & 4.6717 & TRN & \\
\hline CHEMBL1539325 & 688889 & 4.5 & 4.8313 & TRN & \\
\hline CHEMBL3196934 & 688889 & 4.3 & 4.6579 & TRN & \\
\hline CHEMBL1612006 & 688889 & 5.0 & 4.6969 & TST & \\
\hline CHEMBL1519112 & 688889 & 4.4 & 4.71 & TRN & \\
\hline CHEMBL1415864 & 688889 & 4.4 & 4.7772 & TST & \\
\hline CHEMBL1526615 & 688889 & 4.4 & 4.809 & TRN & \\
\hline CHEMBL1380822 & 688889 & 4.3 & 4.6886 & TST & \\
\hline CHEMBL1576093 & 688889 & 5.75 & 4.7185 & TRN & \\
\hline CHEMBL1302175 & 688889 & 4.7 & 4.6771 & TRN & \\
\hline CHEMBL12019 & 688889 & 4.45 & 4.7754 & TRN & \\
\hline CHEMBL1479046 & 688889 & 4.3 & 4.9105 & TRN & \\
\hline CHEMBL3198298 & 688889 & 5.35 & 4.6986 & TRN & \\
\hline CHEMBL1608913 & 688889 & 4.3 & 4.7918 & TRN & \\
\hline CHEMBL1521584 & 688889 & 4.35 & 4.7636 & TRN & \\
\hline CHEMBL1399767 & 688889 & 4.3 & 4.9816 & TRN & \\
\hline CHEMBL1604971 & 688889 & 4.5 & 4.7918 & TST & \\
\hline CHEMBL1497759 & 688889 & 4.9 & 4.8222 & TST & \\
\hline CHEMBL1508343 & 688889 & 4.6 & 4.7805 & TRN & \\
\hline CHEMBL1446463 & 688889 & 4.55 & 4.675 & TST & \\
\hline
\end{tabular}




\begin{tabular}{|c|c|c|c|c|c|}
\hline \multicolumn{6}{|c|}{ Supplemental Table S2.txt } \\
\hline CHEMBL1429057 & 688889 & 5.45 & 4.8571 & TRN & \\
\hline CHEMBL1594279 & 688889 & 4.3 & 4.8049 & TRN & \\
\hline CHEMBL1540887 & 688889 & 6.7501 & 4.8679 & TST & \\
\hline CHEMBL1409610 & 688889 & 6.7501 & 4.8217 & TRN & \\
\hline CHEMBL1367355 & 688889 & 5.85 & 4.9593 & TRN & \\
\hline CHEMBL1489981 & 688889 & 4.3 & 4.7937 & TRN & \\
\hline CHEMBL1583148 & 688889 & 5.1 & 4.7664 & TST & \\
\hline CHEMBL1519336 & 688889 & 5.4 & 4.9805 & TRN & \\
\hline CHEMBL1423454 & 688889 & 4.4 & 4.8425 & TRN & \\
\hline CHEMBL1469460 & 688889 & 4.25 & 4.8048 & TST & \\
\hline CHEMBL1360872 & 688889 & 4.5 & 4.7587 & TST & \\
\hline CHEMBL1526221 & 688889 & 4.55 & 4.8227 & TRN & \\
\hline CHEMBL1489771 & 688889 & 4.5 & 4.6803 & TRN & \\
\hline CHEMBL1301189 & 688889 & 4.35 & 4.8854 & TRN & \\
\hline CHEMBL1606373 & 688889 & 4.5 & 4.7572 & TRN & \\
\hline CHEMBL1340288 & 688889 & 4.8 & 4.8139 & TRN & \\
\hline CHEMBL1411141 & 688889 & 4.95 & 4.7735 & TRN & \\
\hline CHEMBL1572018 & 688889 & 4.65 & 4.7097 & TRN & \\
\hline CHEMBL1373759 & 688889 & 4.55 & 4.944 & TRN & \\
\hline CHEMBL1481614 & 688889 & 6.7501 & 4.8377 & TRN & \\
\hline CHEMBL1415470 & 688889 & 4.4 & 4.7669 & TRN & \\
\hline CHEMBL1535257 & 688889 & 5.05 & 4.7258 & TRN & \\
\hline CHEMBL1408140 & 688889 & 4.25 & 4.8935 & TRN & \\
\hline CHEMBL1432875 & 688889 & 6.7501 & 4.9621 & TRN & \\
\hline CHEMBL1499293 & 688889 & 6.0 & 4.9447 & TRN & \\
\hline CHEMBL3189694 & 688889 & 4.35 & 4.739 & TST & \\
\hline CHEMBL1306800 & 688889 & 4.4 & 4.756 & TRN & \\
\hline CHEMBL1448151 & 688889 & 4.95 & 4.9307 & TRN & \\
\hline CHEMBL1713905 & 688889 & 4.95 & 4.7322 & TRN & \\
\hline CHEMBL1601273 & 688889 & 5.4 & 4.8865 & TST & \\
\hline CHEMBL1478435 & 688889 & 4.6 & 4.6219 & TST & \\
\hline CHEMBL1976676 & 688889 & 5.45 & 4.6777 & TST & \\
\hline CHEMBL1602715 & 688889 & 4.55 & 4.6848 & TRN & \\
\hline CHEMBL1402578 & 688889 & 5.65 & 4.8329 & TST & \\
\hline CHEMBL1707911 & 688889 & 4.25 & 4.7932 & TRN & \\
\hline CHEMBL3214508 & 688889 & 5.35 & 4.7984 & TST & \\
\hline CHEMBL1451519 & 688889 & 5.25 & 4.9044 & TST & \\
\hline CHEMBL1477515 & 688889 & 5.8 & 4.7718 & TRN & \\
\hline CHEMBL1323672 & 688889 & 4.35 & 4.7108 & TRN & \\
\hline CHEMBL1543963 & 688889 & 5.25 & 4.91100 & 00000000005 & TRN \\
\hline CHEMBL1471939 & 688889 & 4.35 & 4.9674 & TST & \\
\hline CHEMBL1504336 & 688889 & 4.4 & 4.8239 & TRN & \\
\hline CHEMBL1327707 & 688889 & 4.45 & 4.7314 & TRN & \\
\hline CHEMBL3192269 & 688889 & 4.95 & 4.8408 & TRN & \\
\hline CHEMBL1964556 & 688889 & 4.7 & 4.7795 & TRN & \\
\hline CHEMBL1528132 & 688889 & 4.5 & 4.8823 & TST & \\
\hline CHEMBL1492641 & 688889 & 4.5 & 4.7475 & TRN & \\
\hline CHEMBL1565313 & 688889 & 4.35 & 4.7177 & TRN & \\
\hline
\end{tabular}




\begin{tabular}{|c|c|c|c|c|c|}
\hline \multicolumn{6}{|c|}{ Supplemental Table S2.txt } \\
\hline CHEMBL1464946 & 688889 & 5.35 & 4.8311 & TST & \\
\hline CHEMBL1371988 & 688889 & 5.55 & 4.7863 & TRN & \\
\hline CHEMBL1611989 & 688889 & 4.7 & 4.801 & TRN & \\
\hline CHEMBL1448697 & 688889 & 5.1 & 4.6953 & TRN & \\
\hline CHEMBL1569825 & 688889 & 6.15 & 4.7972 & TRN & \\
\hline CHEMBL1595948 & 688889 & 4.45 & 4.6919 & TRN & \\
\hline CHEMBL1455427 & 688889 & 4.55 & 4.6232 & TRN & \\
\hline CHEMBL1541623 & 688889 & 5.8 & 4.8042 & TST & \\
\hline CHEMBL1518052 & 688889 & 4.95 & 4.7542 & TRN & \\
\hline CHEMBL1306624 & 688889 & 4.25 & 4.7267 & TST & \\
\hline CHEMBL1478707 & 688889 & 4.45 & 4.8423 & TRN & \\
\hline CHEMBL1561738 & 688889 & 5.3 & 4.6665 & TRN & \\
\hline CHEMBL1468741 & 688889 & 4.45 & 4.7212 & TRN & \\
\hline CHEMBL1490175 & 688889 & 4.45 & 4.7961 & TST & \\
\hline CHEMBL1469237 & 688889 & 4.95 & 4.8638 & TRN & \\
\hline CHEMBL1470627 & 688889 & 4.5 & 4.7927 & TST & \\
\hline CHEMBL1609075 & 688889 & 6.0 & 4.8134 & TST & \\
\hline CHEMBL1392327 & 688889 & 4.35 & 4.7712 & TST & \\
\hline CHEMBL1390669 & 688889 & 4.45 & 4.6921 & TRN & \\
\hline CHEMBL1413675 & 688889 & 5.0 & 4.7611 & TRN & \\
\hline CHEMBL1546283 & 688889 & 4.3 & 4.6233 & TRN & \\
\hline CHEMBL1300612 & 688889 & 4.5 & 4.7907 & TRN & \\
\hline CHEMBL1598252 & 688889 & 4.95 & 4.6341 & TRN & \\
\hline CHEMBL1607932 & 688889 & 4.6 & 4.6014 & TRN & \\
\hline CHEMBL1524972 & 688889 & 4.55 & 4.7094 & TRN & \\
\hline CHEMBL1383949 & 688889 & 4.6 & 4.6127 & TST & \\
\hline CHEMBL1462686 & 688889 & 4.3 & 4.796 & TST & \\
\hline CHEMBL1576927 & 688889 & 4.25 & 4.8433 & TST & \\
\hline CHEMBL1549290 & 688889 & 4.35 & 4.6947 & TST & \\
\hline CHEMBL1387559 & 688889 & 5.25 & 4.8195 & TRN & \\
\hline CHEMBL1344289 & 688889 & 4.65 & 4.803 & TRN & \\
\hline CHEMBL1485891 & 688889 & 5.85 & 5.1498 & TRN & \\
\hline CHEMBL1557859 & 688889 & 4.65 & 4.7131 & TRN & \\
\hline CHEMBL1501637 & 688889 & 4.8 & 4.7838 & TRN & \\
\hline CHEMBL1429627 & 688889 & 4.3 & 4.66100 & 00000000005 & TRN \\
\hline CHEMBL1549435 & 688889 & 4.55 & 4.8334 & TST & \\
\hline CHEMBL1574110 & 688889 & 4.3 & 4.708 & TST & \\
\hline CHEMBL1439372 & 688889 & 4.3 & 4.8259 & TRN & \\
\hline CHEMBL1578854 & 688889 & 4.65 & 4.776 & TRN & \\
\hline CHEMBL1510072 & 688889 & 4.55 & 4.7956 & TRN & \\
\hline CHEMBL1466462 & 688889 & 4.45 & 4.7468 & TRN & \\
\hline CHEMBL1371958 & 688889 & 4.5 & 4.7503 & TRN & \\
\hline CHEMBL1384283 & 688889 & 4.3 & 4.7593 & TRN & \\
\hline CHEMBL1422754 & 688889 & 4.3 & 4.7311 & TST & \\
\hline CHEMBL1423582 & 688889 & 6.05 & 4.9694 & TRN & \\
\hline CHEMBL1547612 & 688889 & 5.15 & 4.808 & TST & \\
\hline CHEMBL1607386 & 688889 & 4.3 & 4.8194 & TST & \\
\hline CHEMBL1455036 & 688889 & 4.5 & 4.8226 & TRN & \\
\hline
\end{tabular}




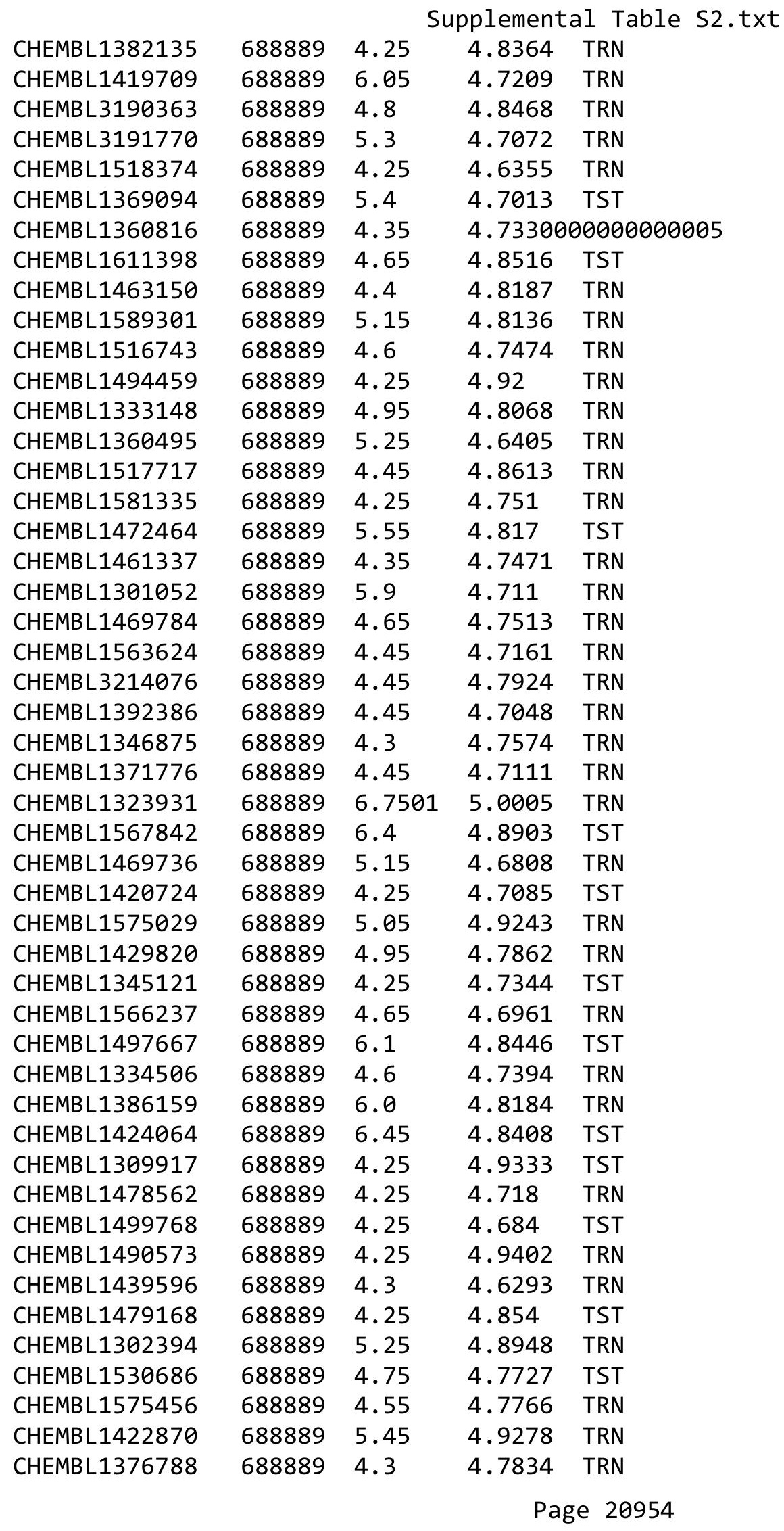




\begin{tabular}{|c|c|c|c|c|c|}
\hline \multicolumn{6}{|c|}{ Supplemental Table S2.txt } \\
\hline CHEMBL1421681 & 688889 & 5.8 & 4.726 & TRN & \\
\hline CHEMBL1603257 & 688889 & 4.3 & 4.8092 & TRN & \\
\hline CHEMBL1452094 & 688889 & 4.9 & 4.9995 & TRN & \\
\hline CHEMBL1324224 & 688889 & 4.65 & 4.8663 & TRN & \\
\hline CHEMBL1502906 & 688889 & 4.45 & 4.8479 & TST & \\
\hline CHEMBL1536619 & 688889 & 5.15 & 4.8811 & TRN & \\
\hline CHEMBL1565636 & 688889 & 4.95 & 4.8867 & TRN & \\
\hline CHEMBL3210377 & 688889 & 4.7 & 4.8072 & TST & \\
\hline CHEMBL1456109 & 688889 & 4.4 & 4.6928 & TRN & \\
\hline CHEMBL1560276 & 688889 & 4.5 & 4.7417 & TRN & \\
\hline CHEMBL1588060 & 688889 & 6.3 & 4.8487 & TRN & \\
\hline CHEMBL1601816 & 688889 & 4.45 & 4.7757 & TRN & \\
\hline CHEMBL1544424 & 688889 & 4.55 & 4.7215 & TRN & \\
\hline CHEMBL1480154 & 688889 & 4.85 & 4.7171 & TST & \\
\hline CHEMBL1369590 & 688889 & 4.4 & 4.7183 & TRN & \\
\hline CHEMBL1330243 & 688889 & 4.3 & 4.8994 & TRN & \\
\hline CHEMBL1452118 & 688889 & 4.9 & 4.6709 & TRN & \\
\hline CHEMBL1341676 & 688889 & 4.35 & 4.8898 & TST & \\
\hline CHEMBL1986425 & 688889 & 4.45 & 4.6847 & TRN & \\
\hline CHEMBL1346909 & 688889 & 5.7 & 4.7186 & TST & \\
\hline CHEMBL1454428 & 688889 & 6.7501 & 4.75899 & 99999999995 & TST \\
\hline CHEMBL1374259 & 688889 & 5.9 & 4.9315 & TRN & \\
\hline CHEMBL1444636 & 688889 & 4.4 & 4.782 & TRN & \\
\hline CHEMBL1485804 & 688889 & 6.15 & 4.8108 & TRN & \\
\hline CHEMBL577752 & 688889 & 4.4 & 4.7452 & TST & \\
\hline CHEMBL1565765 & 688889 & 4.45 & 4.6231 & TRN & \\
\hline CHEMBL3190558 & 688889 & 4.45 & 4.6503 & TST & \\
\hline CHEMBL1463939 & 688889 & 4.3 & 4.8142 & TRN & \\
\hline CHEMBL1604606 & 688889 & 5.15 & 4.7693 & TST & \\
\hline CHEMBL1371238 & 688889 & 4.4 & 4.7703 & TST & \\
\hline CHEMBL1300650 & 688889 & 4.25 & 4.9263 & TRN & \\
\hline CHEMBL1416598 & 688889 & 5.55 & 4.9392 & TRN & \\
\hline CHEMBL1302857 & 688889 & 4.25 & 4.6045 & TRN & \\
\hline CHEMBL1320222 & 688889 & 4.5 & 4.698 & TRN & \\
\hline CHEMBL1393059 & 688889 & 4.35 & 4.9102 & TST & \\
\hline CHEMBL1518948 & 688889 & 4.45 & 4.703 & TRN & \\
\hline CHEMBL1573235 & 688889 & 5.5 & 4.918 & TRN & \\
\hline CHEMBL1546375 & 688889 & 4.5 & 4.8127 & TRN & \\
\hline CHEMBL1609489 & 688889 & 5.1 & 4.7428 & TST & \\
\hline CHEMBL1327168 & 688889 & 5.85 & 4.7721 & TRN & \\
\hline CHEMBL1492868 & 688889 & 4.4 & 4.8614 & TRN & \\
\hline CHEMBL1365168 & 688889 & 4.45 & 4.8908 & TRN & \\
\hline CHEMBL3192542 & 688889 & 4.55 & 4.7336 & TST & \\
\hline CHEMBL1400518 & 688889 & 4.4 & 4.8199 & TST & \\
\hline CHEMBL1342840 & 688889 & 4.4 & 4.8701 & TRN & \\
\hline CHEMBL1502585 & 688889 & 4.35 & 4.8956 & TRN & \\
\hline CHEMBL1516388 & 688889 & 4.35 & 4.7672 & TST & \\
\hline CHEMBL1381513 & 688889 & 4.4 & 4.6844 & TRN & \\
\hline
\end{tabular}




\begin{tabular}{|c|c|c|c|c|}
\hline \multicolumn{5}{|c|}{ Supplemental Table S2.txt } \\
\hline CHEMBL1449915 & 688889 & 5.6 & 4.9346 & TRN \\
\hline CHEMBL1569473 & 688889 & 4.55 & 4.6913 & TST \\
\hline CHEMBL1322862 & 688889 & 4.35 & 4.8979 & TRN \\
\hline CHEMBL1580529 & 688889 & 4.4 & 4.6146 & TRN \\
\hline CHEMBL 1458457 & 688889 & 4.25 & 4.9119 & TRN \\
\hline CHEMBL1563068 & 688889 & 4.9 & 4.7407 & TRN \\
\hline CHEMBL1301851 & 688889 & 4.5 & 4.7821 & TST \\
\hline CHEMBL1501828 & 688889 & 4.3 & 4.9961 & TRN \\
\hline CHEMBL1327850 & 688889 & 4.45 & 4.7502 & TRN \\
\hline CHEMBL1568354 & 688889 & 5.25 & 4.8535 & TRN \\
\hline CHEMBL1521086 & 688889 & 5.75 & 4.8249 & TST \\
\hline CHEMBL1450386 & 688889 & 4.5 & 4.8901 & TRN \\
\hline CHEMBL1379587 & 688889 & 4.45 & 4.7967 & TRN \\
\hline CHEMBL1579464 & 688889 & 4.95 & 4.8517 & TRN \\
\hline CHEMBL291083 & 688889 & 4.45 & 4.8131 & TRN \\
\hline CHEMBL1350689 & 688889 & 4.55 & 4.6801 & TRN \\
\hline CHEMBL1338380 & 688889 & 4.9 & 4.9443 & TRN \\
\hline CHEMBL1534011 & 688889 & 6.7501 & 4.7508 & TRN \\
\hline CHEMBL1509756 & 688889 & 4.25 & 4.9644 & TRN \\
\hline CHEMBL1485374 & 688889 & 5.0 & 4.7583 & TRN \\
\hline CHEMBL1387929 & 688889 & 4.95 & 4.7914 & TRN \\
\hline CHEMBL1583408 & 688889 & 6.8 & 4.8089 & TRN \\
\hline CHEMBL1467776 & 688889 & 4.25 & 4.7853 & TST \\
\hline CHEMBL1366859 & 688889 & 6.15 & 4.8169 & TRN \\
\hline CHEMBL1374720 & 688889 & 4.6 & 4.6643 & TRN \\
\hline CHEMBL1326453 & 688889 & 4.55 & 4.7094 & TRN \\
\hline CHEMBL1407135 & 688889 & 4.95 & 4.8347 & TRN \\
\hline CHEMBL1429289 & 688889 & 4.3 & 4.7146 & TRN \\
\hline CHEMBL1517339 & 688889 & 4.25 & 4.7066 & TRN \\
\hline CHEMBL1511604 & 688889 & 6.15 & 4.817 & TRN \\
\hline CHEMBL1574788 & 688889 & 4.5 & 4.8181 & TST \\
\hline CHEMBL1339565 & 688889 & 4.65 & 4.7481 & TRN \\
\hline CHEMBL1545131 & 688889 & 6.1 & 4.9007 & TRN \\
\hline CHEMBL1345904 & 688889 & 5.95 & 4.9485 & TRN \\
\hline CHEMBL1547945 & 688889 & 6.7501 & 4.8282 & TRN \\
\hline CHEMBL1382225 & 688889 & 4.95 & 4.732 & TRN \\
\hline CHEMBL1387555 & 688889 & 5.1 & 4.8668 & TRN \\
\hline CHEMBL1482449 & 688889 & 6.1 & 4.7813 & TRN \\
\hline CHEMBL1565919 & 688889 & 4.55 & 4.8292 & TRN \\
\hline CHEMBL3197141 & 688889 & 6.8 & 4.7194 & TRN \\
\hline CHEMBL584225 & 688889 & 4.35 & 4.7997 & TST \\
\hline CHEMBL 1605847 & 688889 & 4.5 & 4.7948 & TRN \\
\hline CHEMBL1351349 & 688889 & 4.85 & 4.9662 & TRN \\
\hline CHEMBL1485296 & 688889 & 4.85 & 4.7655 & TST \\
\hline CHEMBL1323298 & 688889 & 6.8 & 4.9151 & TRN \\
\hline CHEMBL1467484 & 688889 & 4.3 & 4.8032 & TRN \\
\hline CHEMBL1464507 & 688889 & 4.5 & 4.6962 & TRN \\
\hline CHEMBL3190145 & 688889 & 4.9 & 4.7822 & TRN \\
\hline
\end{tabular}




\begin{tabular}{|c|c|c|c|c|}
\hline \multicolumn{5}{|c|}{ Supplemental Table S2.txt } \\
\hline CHEMBL1404014 & 688889 & 6.1 & 4.9158 & TRN \\
\hline CHEMBL1527659 & 688889 & 4.25 & 4.9582 & TRN \\
\hline CHEMBL1452259 & 688889 & 4.95 & 4.8251 & TRN \\
\hline CHEMBL1528548 & 688889 & 4.6 & 4.8122 & TRN \\
\hline CHEMBL1346794 & 688889 & 4.4 & 4.652 & TRN \\
\hline CHEMBL1581816 & 688889 & 5.0 & 4.8169 & TST \\
\hline CHEMBL1976049 & 688889 & 4.35 & 4.7322 & TRN \\
\hline CHEMBL1540968 & 688889 & 4.6 & 4.848 & TRN \\
\hline CHEMBL1305168 & 688889 & 4.3 & 4.9058 & TST \\
\hline CHEMBL1415300 & 688889 & 4.4 & 4.7168 & TRN \\
\hline CHEMBL1425386 & 688889 & 4.45 & 4.8646 & TRN \\
\hline CHEMBL1546967 & 688889 & 5.15 & 4.7222 & TRN \\
\hline CHEMBL518575 & 688889 & 4.25 & 4.776 & TRN \\
\hline CHEMBL1307379 & 688889 & 4.95 & 4.9793 & TRN \\
\hline CHEMBL1579407 & 688889 & 5.55 & 4.8922 & TRN \\
\hline CHEMBL1463487 & 688889 & 4.45 & 4.7469 & TRN \\
\hline CHEMBL1550662 & 688889 & 4.7 & 4.702 & TRN \\
\hline CHEMBL1432283 & 688889 & 5.8 & 4.702 & TST \\
\hline CHEMBL 3197626 & 688889 & 4.45 & 4.7326 & TRN \\
\hline CHEMBL1402803 & 688889 & 5.3 & 4.758 & TRN \\
\hline CHEMBL1442358 & 688889 & 5.1 & 4.8098 & TST \\
\hline CHEMBL1359176 & 688889 & 5.3 & 4.7391 & TST \\
\hline CHEMBL1454307 & 688889 & 4.3 & 4.78 & TST \\
\hline CHEMBL1466625 & 688889 & 4.6 & 4.6658 & TRN \\
\hline CHEMBL1603635 & 688889 & 4.55 & 4.6622 & TRN \\
\hline CHEMBL1497613 & 688889 & 4.25 & 4.8004 & TRN \\
\hline CHEMBL1610368 & 688889 & 4.75 & 4.8532 & TRN \\
\hline CHEMBL1606672 & 688889 & 4.75 & 4.7594 & TRN \\
\hline CHEMBL1328986 & 688889 & 5.6 & 4.7844 & TST \\
\hline CHEMBL1496298 & 688889 & 4.45 & 4.6825 & TRN \\
\hline CHEMBL1330772 & 688889 & 5.45 & 4.8573 & TRN \\
\hline CHEMBL1584471 & 688889 & 4.4 & 4.7974 & TRN \\
\hline CHEMBL1385539 & 688889 & 4.3 & 4.9122 & TRN \\
\hline CHEMBL1409506 & 688889 & 4.85 & 4.7923 & TST \\
\hline CHEMBL1408924 & 688889 & 4.5 & 4.8631 & TRN \\
\hline CHEMBL1471215 & 688889 & 5.05 & 4.7292 & TRN \\
\hline CHEMBL1489772 & 688889 & 4.9 & 4.8952 & TRN \\
\hline CHEMBL1519987 & 688889 & 5.0 & 4.727 & TST \\
\hline CHEMBL1312801 & 688889 & 5.1 & 4.8384 & TRN \\
\hline CHEMBL3211398 & 688889 & 4.95 & 4.5713 & TRN \\
\hline CHEMBL1545155 & 688889 & 4.7 & 4.823 & TRN \\
\hline CHEMBL1550087 & 688889 & 4.45 & 4.6095 & TST \\
\hline CHEMBL1362154 & 688889 & 4.4 & 4.7008 & TRN \\
\hline CHEMBL1542752 & 688889 & 4.45 & 4.7397 & TRN \\
\hline CHEMBL1418843 & 688889 & 4.8 & 4.7994 & TRN \\
\hline CHEMBL1379987 & 688889 & 4.6 & 4.9194 & TRN \\
\hline CHEMBL1393118 & 688889 & 4.45 & 4.773 & TST \\
\hline CHEMBL1339269 & 688889 & 4.85 & 4.837 & TST \\
\hline
\end{tabular}




\begin{tabular}{|c|c|c|c|c|c|}
\hline & & \multicolumn{4}{|c|}{ Supplemental Table s2.txt } \\
\hline CHEMBL1385426 & 688889 & 4.45 & 4.8821 & TRN & \\
\hline CHEMBL1481841 & 688889 & 4.3 & 4.8874 & TRN & \\
\hline CHEMBL1608065 & 688889 & 4.95 & 4.8072 & TST & \\
\hline CHEMBL1413275 & 688889 & 5.95 & 4.8589 & TST & \\
\hline CHEMBL1464850 & 688889 & 4.25 & 4.8245 & TST & \\
\hline CHEMBL1612354 & 688889 & 4.3 & 4.6713 & TRN & \\
\hline CHEMBL1470092 & 688889 & 4.7 & 4.9851 & TRN & \\
\hline CHEMBL1501351 & 688889 & 4.25 & 4.9288 & TRN & \\
\hline CHEMBL1536117 & 688889 & 5.65 & 4.7195 & TRN & \\
\hline CHEMBL1350888 & 688889 & 4.95 & 4.6844 & TRN & \\
\hline CHEMBL1586800 & 688889 & 4.5 & 4.6348 & TRN & \\
\hline CHEMBL3208763 & 688889 & 4.3 & 4.7553 & TRN & \\
\hline CHEMBL1375166 & 688889 & 5.4 & 4.5112 & TRN & \\
\hline CHEMBL1426399 & 688889 & 5.3 & 4.83 & TRN & \\
\hline CHEMBL3209112 & 688889 & 4.5 & 4.6978 & TRN & \\
\hline CHEMBL1377992 & 688889 & 4.4 & 4.62 & TRN & \\
\hline CHEMBL1527837 & 688889 & 4.25 & 4.9713 & TRN & \\
\hline CHEMBL1301407 & 688889 & 5.25 & 4.8242 & TRN & \\
\hline CHEMBL1456662 & 688889 & 4.45 & 4.9507 & TRN & \\
\hline CHEMBL1575560 & 688889 & 5.75 & 4.8838 & TRN & \\
\hline CHEMBL1438957 & 688889 & 4.45 & 4.7067 & TRN & \\
\hline CHEMBL1374546 & 688889 & 5.8 & 4.90600 & 0000000001 & TRN \\
\hline CHEMBL1352565 & 688889 & 4.95 & 4.7973 & TRN & \\
\hline CHEMBL1337529 & 688889 & 4.45 & 4.7657 & TRN & \\
\hline CHEMBL1377388 & 688889 & 4.45 & 4.7534 & TRN & \\
\hline CHEMBL1337035 & 688889 & 4.45 & 4.6471 & TRN & \\
\hline CHEMBL1330886 & 688889 & 5.15 & 4.80699 & 99999999995 & TST \\
\hline CHEMBL1311420 & 688889 & 5.45 & 4.8314 & TRN & \\
\hline CHEMBL1595935 & 688889 & 4.5 & 4.8478 & TRN & \\
\hline CHEMBL1460775 & 688889 & 4.35 & 4.7993 & TRN & \\
\hline CHEMBL1505400 & 688889 & 4.85 & 4.8326 & TRN & \\
\hline CHEMBL1343210 & 688889 & 4.45 & 4.7141 & TST & \\
\hline CHEMBL1576918 & 688889 & 4.25 & 4.7471 & TRN & \\
\hline CHEMBL1406185 & 688889 & 4.85 & 4.7398 & TRN & \\
\hline CHEMBL1308710 & 688889 & 6.25 & 4.8164 & TRN & \\
\hline CHEMBL3197274 & 688889 & 6.8 & 4.8809 & TRN & \\
\hline CHEMBL1568312 & 688889 & 4.25 & 4.6781 & TST & \\
\hline CHEMBL1421866 & 688889 & 5.5 & 4.8599 & TRN & \\
\hline CHEMBL1983886 & 688889 & 4.3 & 4.7158 & TRN & \\
\hline CHEMBL1609223 & 688889 & 4.35 & 4.8193 & TRN & \\
\hline CHEMBL1469167 & 688889 & 6.8 & 4.9108 & TRN & \\
\hline CHEMBL3207879 & 688889 & 5.2 & 4.8639 & TRN & \\
\hline CHEMBL1449403 & 688889 & 4.55 & 4.8586 & TRN & \\
\hline CHEMBL1595086 & 688889 & 4.75 & 4.7192 & TRN & \\
\hline CHEMBL1373698 & 688889 & 4.45 & 4.8514 & TST & \\
\hline CHEMBL1477154 & 688889 & 4.25 & 4.7748 & TRN & \\
\hline CHEMBL1478590 & 688889 & 4.75 & 4.9062 & TRN & \\
\hline CHEMBL1319831 & 688889 & 4.95 & 4.8162 & TRN & \\
\hline
\end{tabular}




\begin{tabular}{|c|c|c|c|c|c|}
\hline \multicolumn{6}{|c|}{ Supplemental Table S2.txt } \\
\hline CHEMBL1589171 & 688889 & 4.45 & 4.6502 & TRN & \\
\hline CHEMBL1610512 & 688889 & 4.3 & 4.7702 & TRN & \\
\hline CHEMBL1449473 & 688889 & 4.45 & 4.6649 & TST & \\
\hline CHEMBL1492945 & 688889 & 4.25 & 4.9626 & TRN & \\
\hline CHEMBL1968356 & 688889 & 4.6 & 4.7834 & TRN & \\
\hline CHEMBL1359037 & 688889 & 4.5 & 4.6882 & TRN & \\
\hline CHEMBL1584578 & 688889 & 4.65 & 4.694 & TRN & \\
\hline CHEMBL1539409 & 688889 & 4.55 & 4.5156 & TST & \\
\hline CHEMBL1421710 & 688889 & 4.3 & 4.7084 & TRN & \\
\hline CHEMBL1548783 & 688889 & 4.3 & 4.7342 & TRN & \\
\hline CHEMBL1306263 & 688889 & 4.4 & 4.8708 & TST & \\
\hline CHEMBL1458051 & 688889 & 4.25 & 4.8598 & TRN & \\
\hline CHEMBL1419681 & 688889 & 5.45 & 4.8916 & TST & \\
\hline CHEMBL1417782 & 688889 & 4.55 & 4.7854 & TRN & \\
\hline CHEMBL1479259 & 688889 & 4.45 & 4.7247 & TRN & \\
\hline CHEMBL1485580 & 688889 & 4.75 & 4.6958 & TRN & \\
\hline CHEMBL 246448 & 688889 & 4.35 & 4.7505 & TRN & \\
\hline CHEMBL1431252 & 688889 & 4.45 & 4.6557 & TRN & \\
\hline CHEMBL1557869 & 688889 & 4.85 & 4.749 & TRN & \\
\hline CHEMBL1565338 & 688889 & 4.45 & 4.8102 & TRN & \\
\hline CHEMBL3208898 & 688889 & 4.25 & 4.8794 & TRN & \\
\hline CHEMBL1575086 & 688889 & 4.5 & 4.7972 & TST & \\
\hline CHEMBL1540688 & 688889 & 5.9 & 4.8275 & TST & \\
\hline CHEMBL1391933 & 688889 & 4.25 & 4.9102 & TRN & \\
\hline CHEMBL1506540 & 688889 & 5.05 & 4.8157 & TRN & \\
\hline CHEMBL1577831 & 688889 & 5.6 & 4.7538 & TRN & \\
\hline CHEMBL1463529 & 688889 & 4.3 & 4.7464 & TRN & \\
\hline CHEMBL1391158 & 688889 & 5.4 & 4.75899 & 99999999995 & TRN \\
\hline CHEMBL1507692 & 688889 & 4.3 & 4.9529 & TRN & \\
\hline CHEMBL1450744 & 688889 & 6.7501 & 4.875 & TRN & \\
\hline CHEMBL1481986 & 688889 & 4.65 & 4.7283 & TRN & \\
\hline CHEMBL 3212922 & 688889 & 4.25 & 4.6706 & TRN & \\
\hline CHEMBL1419157 & 688889 & 4.3 & 4.8082 & TRN & \\
\hline CHEMBL1516976 & 688889 & 4.6 & 4.567 & TRN & \\
\hline CHEMBL1569028 & 688889 & 4.75 & 4.7327 & TRN & \\
\hline CHEMBL1523759 & 688889 & 5.25 & 4.8894 & TRN & \\
\hline CHEMBL3211176 & 688889 & 4.3 & 4.7234 & TRN & \\
\hline CHEMBL1308381 & 688889 & 4.25 & 4.707 & TRN & \\
\hline CHEMBL1371167 & 688889 & 4.45 & 4.7415 & TRN & \\
\hline CHEMBL1354020 & 688889 & 4.25 & 4.8245 & TRN & \\
\hline CHEMBL1382277 & 688889 & 4.25 & 4.6863 & TRN & \\
\hline CHEMBL1501332 & 688889 & 4.45 & 4.7683 & TRN & \\
\hline CHEMBL1408894 & 688889 & 4.45 & 4.754 & TST & \\
\hline CHEMBL1392769 & 688889 & 4.5 & 4.7932 & TST & \\
\hline CHEMBL1610801 & 688889 & 4.25 & 4.7384 & TST & \\
\hline CHEMBL1320026 & 688889 & 4.7 & 4.6577 & TRN & \\
\hline CHEMBL1503785 & 688889 & 5.75 & 4.9312 & TRN & \\
\hline CHEMBL1580003 & 688889 & 4.25 & 4.8219 & TST & \\
\hline
\end{tabular}




\begin{tabular}{|c|c|c|c|c|c|}
\hline & & & & & \\
\hline CHEMBL1586594 & 688889 & 5.6 & 4.7573 & TRN & \\
\hline CHEMBL1411635 & 688889 & 4.9 & 4.7637 & TRN & \\
\hline CHEMBL1519309 & 688889 & 4.25 & 4.9061 & TRN & \\
\hline CHEMBL1401802 & 688889 & 6.35 & 4.8717 & TRN & \\
\hline CHEMBL1509139 & 688889 & 4.5 & 4.7267 & TRN & \\
\hline CHEMBL1345039 & 688889 & 5.15 & 4.8129 & TST & \\
\hline CHEMBL1570620 & 688889 & 4.4 & 4.8555 & TST & \\
\hline CHEMBL1452342 & 688889 & 5.45 & 4.9613 & TRN & \\
\hline CHEMBL1544126 & 688889 & 4.4 & 4.9363 & TST & \\
\hline CHEMBL1489843 & 688889 & 4.95 & 4.7746 & TRN & \\
\hline CHEMBL1421837 & 688889 & 4.55 & 4.7829 & TST & \\
\hline CHEMBL1570896 & 688889 & 5.05 & 4.8056 & TST & \\
\hline CHEMBL1416540 & 688889 & 4.25 & 4.7843 & TRN & \\
\hline CHEMBL1542241 & 688889 & 4.85 & 4.8417 & TRN & \\
\hline CHEMBL1409778 & 688889 & 6.1 & 4.8881 & TRN & \\
\hline CHEMBL1393104 & 688889 & 4.35 & 4.9163 & TRN & \\
\hline CHEMBL1428813 & 688889 & 6.8 & 4.9055 & TRN & \\
\hline CHEMBL1352605 & 688889 & 4.25 & 4.8773 & TRN & \\
\hline CHEMBL3213592 & 688889 & 6.7501 & 4.9975 & TRN & \\
\hline CHEMBL1572082 & 688889 & 5.75 & 4.94300 & 00000000005 & TRN \\
\hline CHEMBL3194805 & 688889 & 5.95 & 4.6515 & TST & \\
\hline CHEMBL1501468 & 688889 & 4.6 & 4.7339 & TRN & \\
\hline CHEMBL1320128 & 688889 & 5.95 & 4.7776 & TRN & \\
\hline CHEMBL1425457 & 688889 & 4.45 & 4.9703 & TRN & \\
\hline CHEMBL1574044 & 688889 & 6.1 & 4.9133 & TST & \\
\hline CHEMBL1359688 & 688889 & 4.4 & 4.8566 & TRN & \\
\hline CHEMBL1415440 & 688889 & 4.4 & 4.8491 & TRN & \\
\hline CHEMBL1385920 & 688889 & 4.5 & 4.8 & TST & \\
\hline CHEMBL1588707 & 688889 & 4.6 & 4.666 & TRN & \\
\hline CHEMBL1542430 & 688889 & 5.35 & 4.8641 & TST & \\
\hline CHEMBL 3192997 & 688889 & 4.4 & 4.9518 & TRN & \\
\hline CHEMBL1537860 & 688889 & 4.3 & 4.75 & TRN & \\
\hline CHEMBL1601544 & 688889 & 4.35 & 4.7191 & TRN & \\
\hline CHEMBL1604884 & 688889 & 5.6 & 4.8439 & TRN & \\
\hline CHEMBL3195032 & 688889 & 4.95 & 4.7804 & TST & \\
\hline CHEMBL1534290 & 688889 & 6.45 & 4.9075 & TST & \\
\hline CHEMBL1350540 & 688889 & 4.95 & 4.9231 & TST & \\
\hline CHEMBL1369724 & 688889 & 4.4 & 4.8259 & TRN & \\
\hline CHEMBL1612383 & 688889 & 5.15 & 4.8027 & TRN & \\
\hline CHEMBL1519432 & 688889 & 4.5 & 4.8097 & TRN & \\
\hline CHEMBL1348159 & 688889 & 4.9 & 4.7717 & TST & \\
\hline CHEMBL1432203 & 688889 & 4.4 & 4.7357 & TRN & \\
\hline CHEMBL1587593 & 688889 & 4.3 & 4.7594 & TST & \\
\hline CHEMBL1313669 & 688889 & 4.9 & 4.7428 & TRN & \\
\hline CHEMBL1504991 & 688889 & 4.45 & 4.7939 & TRN & \\
\hline CHEMBL1504312 & 688889 & 5.95 & 4.7411 & TRN & \\
\hline CHEMBL1528934 & 688889 & 4.35 & 4.7314 & TRN & \\
\hline CHEMBL1302354 & 688889 & 4.45 & 4.8473 & TRN & \\
\hline
\end{tabular}




\begin{tabular}{|c|c|c|c|c|}
\hline \multicolumn{5}{|c|}{ Supplemental Table S2.txt } \\
\hline CHEMBL1390365 & 688889 & 4.55 & 4.7593 & TRN \\
\hline CHEMBL1502129 & 688889 & 4.4 & 4.7469 & TRN \\
\hline CHEMBL1537567 & 688889 & 4.9 & 4.6813 & TRN \\
\hline CHEMBL1411399 & 688889 & 4.45 & 4.7504 & TRN \\
\hline CHEMBL1452402 & 688889 & 4.45 & 4.6732 & TRN \\
\hline CHEMBL1586815 & 688889 & 5.35 & 4.7607 & TST \\
\hline CHEMBL3194359 & 688889 & 4.55 & 4.7469 & TRN \\
\hline CHEMBL1492391 & 688889 & 5.95 & 4.8248 & TRN \\
\hline CHEMBL1520244 & 688889 & 6.7501 & 4.9241 & TRN \\
\hline CHEMBL1344800 & 688889 & 4.55 & 4.7162 & TRN \\
\hline CHEMBL1446210 & 688889 & 5.3 & 4.8004 & TRN \\
\hline CHEMBL1465224 & 688889 & 4.3 & 4.7244 & TST \\
\hline CHEMBL1409480 & 688889 & 4.45 & 4.7455 & TRN \\
\hline CHEMBL1311887 & 688889 & 4.8 & 4.8354 & TRN \\
\hline CHEMBL1481790 & 688889 & 4.3 & 4.7057 & TST \\
\hline CHEMBL1326272 & 688889 & 6.1 & 4.7728 & TRN \\
\hline CHEMBL1325084 & 688889 & 4.25 & 4.785 & TRN \\
\hline CHEMBL1305766 & 688889 & 6.0 & 4.7158 & TST \\
\hline CHEMBL 1322482 & 688889 & 4.6 & 4.7887 & TST \\
\hline CHEMBL1569099 & 688889 & 6.2 & 4.7932 & TRN \\
\hline CHEMBL1443114 & 688889 & 4.4 & 4.7033 & TRN \\
\hline CHEMBL1489352 & 688889 & 4.7 & 4.8956 & TST \\
\hline CHEMBL1449354 & 688889 & 4.6 & 4.7508 & TRN \\
\hline CHEMBL1416381 & 688889 & 6.3 & 4.8335 & TRN \\
\hline CHEMBL1508632 & 688889 & 4.4 & 4.813 & TRN \\
\hline CHEMBL1562276 & 688889 & 5.0 & 4.794 & TRN \\
\hline CHEMBL1523920 & 688889 & 4.3 & 4.7615 & TST \\
\hline CHEMBL1485923 & 688889 & 4.45 & 4.7202 & TRN \\
\hline CHEMBL1462028 & 688889 & 6.2 & 4.9743 & TRN \\
\hline CHEMBL1360033 & 688889 & 4.3 & 4.808 & TRN \\
\hline CHEMBL1582589 & 688889 & 4.7 & 4.6581 & TRN \\
\hline CHEMBL1460431 & 688889 & 4.5 & 4.8602 & TRN \\
\hline CHEMBL1516894 & 688889 & 4.9 & 4.7691 & TST \\
\hline CHEMBL1327864 & 688889 & 4.4 & 4.6886 & TRN \\
\hline CHEMBL1429741 & 688889 & 4.45 & 4.7467 & TRN \\
\hline CHEMBL1503627 & 688889 & 4.55 & 4.7702 & TST \\
\hline CHEMBL1338376 & 688889 & 4.5 & 4.7055 & TRN \\
\hline CHEMBL1439907 & 688889 & 4.25 & 4.7362 & TRN \\
\hline CHEMBL 1482782 & 688889 & 5.0 & 4.6553 & TRN \\
\hline CHEMBL1471749 & 688889 & 4.6 & 4.7833 & TRN \\
\hline CHEMBL1539591 & 688889 & 4.3 & 4.8412 & TST \\
\hline CHEMBL1403292 & 688889 & 4.65 & 4.9102 & TRN \\
\hline CHEMBL1306426 & 688889 & 5.95 & 4.8894 & TRN \\
\hline CHEMBL1557929 & 688889 & 4.4 & 4.666 & TRN \\
\hline CHEMBL1342132 & 688889 & 5.65 & 4.8293 & TRN \\
\hline CHEMBL1422429 & 688889 & 4.3 & 4.6363 & TST \\
\hline CHEMBL1585706 & 688889 & 5.85 & 4.8068 & TRN \\
\hline CHEMBL1579682 & 688889 & 4.4 & 4.6754 & TRN \\
\hline
\end{tabular}




\begin{tabular}{|c|c|c|c|c|}
\hline \multicolumn{5}{|c|}{ Supplemental Table S2.txt } \\
\hline CHEMBL1386608 & 688889 & 6.25 & 4.7987 & TRN \\
\hline CHEMBL1530671 & 688889 & 4.45 & 4.7778 & TRN \\
\hline CHEMBL1558926 & 688889 & 5.2 & 4.7591 & TRN \\
\hline CHEMBL1447967 & 688889 & 4.95 & 4.7822 & TRN \\
\hline CHEMBL1347453 & 688889 & 5.35 & 4.9503 & TRN \\
\hline CHEMBL1314144 & 688889 & 5.25 & 4.5939 & TRN \\
\hline CHEMBL1564273 & 688889 & 4.9 & 4.803 & TRN \\
\hline CHEMBL1464916 & 688889 & 4.6 & 4.8389 & TRN \\
\hline CHEMBL1323451 & 688889 & 6.1 & 4.824 & TRN \\
\hline CHEMBL1422873 & 688889 & 4.5 & 4.8197 & TRN \\
\hline CHEMBL1373317 & 688889 & 5.9 & 4.7274 & TRN \\
\hline CHEMBL 3199262 & 688889 & 4.5 & 4.7057 & TST \\
\hline CHEMBL1576869 & 688889 & 5.3 & 4.8086 & TRN \\
\hline CHEMBL1574560 & 688889 & 4.3 & 4.8679 & TRN \\
\hline CHEMBL1312375 & 688889 & 4.3 & 4.9211 & TST \\
\hline CHEMBL1375889 & 688889 & 5.4 & 4.7553 & TST \\
\hline CHEMBL1363833 & 688889 & 4.4 & 4.8745 & TRN \\
\hline CHEMBL1521599 & 688889 & 4.3 & 4.7911 & TRN \\
\hline CHEMBL3214016 & 688889 & 5.35 & 4.7754 & TRN \\
\hline CHEMBL1457500 & 688889 & 4.5 & 4.6961 & TST \\
\hline CHEMBL1369277 & 688889 & 4.5 & 4.7245 & TRN \\
\hline CHEMBL1410968 & 688889 & 6.2 & 4.7671 & TRN \\
\hline CHEMBL1546548 & 688889 & 4.35 & 4.6685 & TRN \\
\hline CHEMBL1489523 & 688889 & 4.5 & 4.7247 & TRN \\
\hline CHEMBL1352633 & 688889 & 4.55 & 4.6271 & TRN \\
\hline CHEMBL1472162 & 688889 & 4.25 & 4.8562 & TST \\
\hline CHEMBL1599468 & 688889 & 4.25 & 4.6905 & TRN \\
\hline CHEMBL3212245 & 688889 & 4.9 & 4.9177 & TRN \\
\hline CHEMBL1528266 & 688889 & 5.3 & 4.8137 & TRN \\
\hline CHEMBL1477072 & 688889 & 4.5 & 4.8961 & TRN \\
\hline CHEMBL1488014 & 688889 & 4.95 & 4.8509 & TRN \\
\hline CHEMBL1363830 & 688889 & 4.3 & 4.7413 & TRN \\
\hline CHEMBL1486039 & 688889 & 5.2 & 4.8176 & TST \\
\hline CHEMBL1414115 & 688889 & 6.7501 & 4.6992 & TRN \\
\hline CHEMBL1345768 & 688889 & 4.3 & 4.7272 & TRN \\
\hline CHEMBL3194657 & 688889 & 5.6 & 4.6806 & TRN \\
\hline CHEMBL1517769 & 688889 & 5.7 & 4.8464 & TRN \\
\hline CHEMBL1320603 & 688889 & 4.25 & 4.8169 & TRN \\
\hline CHEMBL1559245 & 688889 & 4.55 & 4.8034 & TRN \\
\hline CHEMBL1470081 & 688889 & 4.3 & 4.8289 & TRN \\
\hline CHEMBL1386716 & 688889 & 4.5 & 4.7467 & TRN \\
\hline CHEMBL1535265 & 688889 & 4.25 & 4.6925 & TRN \\
\hline CHEMBL1477470 & 688889 & 6.7501 & 4.6523 & TST \\
\hline CHEMBL1299332 & 688889 & 6.15 & 4.8113 & TST \\
\hline CHEMBL1580874 & 688889 & 4.45 & 4.6694 & TRN \\
\hline CHEMBL1408969 & 688889 & 5.1 & 4.6681 & TRN \\
\hline CHEMBL1403248 & 688889 & 5.4 & 4.7838 & TRN \\
\hline CHEMBL1310142 & 688889 & 5.4 & 4.7441 & TRN \\
\hline
\end{tabular}




\begin{tabular}{|c|c|c|c|c|c|}
\hline \multirow{2}{*}{ CHEMBL1563667 } & \multirow{2}{*}{688889} & \\
\hline & & 4.3 & 4.8956 & TRN & \\
\hline CHEMBL1458410 & 688889 & 4.6 & 4.8348 & TRN & \\
\hline CHEMBL1582281 & 688889 & 4.25 & 4.8529 & TRN & \\
\hline CHEMBL1305218 & 688889 & 4.3 & 4.8164 & TRN & \\
\hline CHEMBL1420777 & 688889 & 4.95 & 4.8704 & TST & \\
\hline CHEMBL1300405 & 688889 & 4.45 & 4.6065 & TRN & \\
\hline CHEMBL1300877 & 688889 & 6.2 & 4.7993 & TST & \\
\hline CHEMBL1536955 & 688889 & 4.9 & 4.8698 & TST & \\
\hline CHEMBL1333755 & 688889 & 4.35 & 4.692 & TRN & \\
\hline CHEMBL1441603 & 688889 & 6.05 & \multicolumn{2}{|c|}{4.678999999999999} & TRN \\
\hline CHEMBL1570999 & 688889 & 5.4 & 4.7466 & TRN & \\
\hline CHEMBL1569532 & 688889 & 4.95 & 4.6678 & TRN & \\
\hline CHEMBL1383323 & 688889 & 4.45 & 4.757 & TRN & \\
\hline CHEMBL1572979 & 688889 & 4.25 & 4.8307 & TRN & \\
\hline CHEMBL1303926 & 688889 & 4.85 & 4.8818 & TRN & \\
\hline CHEMBL1507312 & 688889 & 4.4 & 4.7964 & TRN & \\
\hline CHEMBL1490788 & 688889 & 4.65 & 4.7453 & TRN & \\
\hline CHEMBL1369438 & 688889 & 5.85 & 4.6752 & TRN & \\
\hline CHEMBL1303097 & 688889 & 4.3 & 4.9224 & TRN & \\
\hline CHEMBL1545418 & 688889 & 4.3 & 4.7709 & TRN & \\
\hline CHEMBL1502099 & 688889 & 4.45 & 4.9493 & TRN & \\
\hline CHEMBL1465705 & 688889 & 4.6 & 4.7287 & TRN & \\
\hline CHEMBL1451444 & 688889 & 5.55 & 4.7219 & TRN & \\
\hline CHEMBL1565415 & 688889 & 4.75 & 4.6749 & TRN & \\
\hline CHEMBL1328627 & 688889 & 6.5501 & 4.9626 & TRN & \\
\hline CHEMBL1349260 & 688889 & 4.35 & 4.8071 & TRN & \\
\hline CHEMBL1453625 & 688889 & 4.3 & 4.9557 & TRN & \\
\hline CHEMBL3191109 & 688889 & 4.25 & 4.7633 & TRN & \\
\hline CHEMBL1462945 & 688889 & 4.5 & 4.7411 & TRN & \\
\hline CHEMBL1502446 & 688889 & 4.8 & \multicolumn{2}{|c|}{4.7669999999999995} & TRN \\
\hline CHEMBL1613250 & 688889 & 4.7 & 4.926 & TRN & \\
\hline CHEMBL1532605 & 688889 & 4.25 & 4.9433 & TRN & \\
\hline CHEMBL1420778 & 688889 & 4.5 & 4.6843 & TRN & \\
\hline CHEMBL1517463 & 688889 & 4.65 & 4.8689 & TST & \\
\hline CHEMBL1486701 & 688889 & 5.4 & 4.8036 & TRN & \\
\hline CHEMBL1419982 & 688889 & 4.25 & 4.806 & TRN & \\
\hline CHEMBL1427790 & 688889 & 4.35 & 4.7079 & TRN & \\
\hline CHEMBL1387948 & 688889 & 4.25 & 4.6556 & TRN & \\
\hline CHEMBL1430251 & 688889 & 4.3 & 4.8356 & TRN & \\
\hline CHEMBL1372941 & 688889 & 4.3 & 4.8032 & TST & \\
\hline CHEMBL1304692 & 688889 & 4.45 & 4.7968 & TRN & \\
\hline CHEMBL1376164 & 688889 & 4.95 & 4.7134 & TRN & \\
\hline CHEMBL1578388 & 688889 & 4.3 & 4.8406 & TRN & \\
\hline CHEMBL1602785 & 688889 & 6.4 & 4.8859 & TRN & \\
\hline CHEMBL1376489 & 688889 & 4.3 & 4.7649 & TRN & \\
\hline CHEMBL3211660 & 688889 & 5.0 & 4.8308 & TRN & \\
\hline CHEMBL 1497260 & 688889 & 5.7 & 4.9507 & TRN & \\
\hline \multirow[t]{2}{*}{ CHEMBL1456043 } & 688889 & 6.8 & 4.7589 & TST & \\
\hline & & \multicolumn{4}{|c|}{ Page 20963} \\
\hline
\end{tabular}




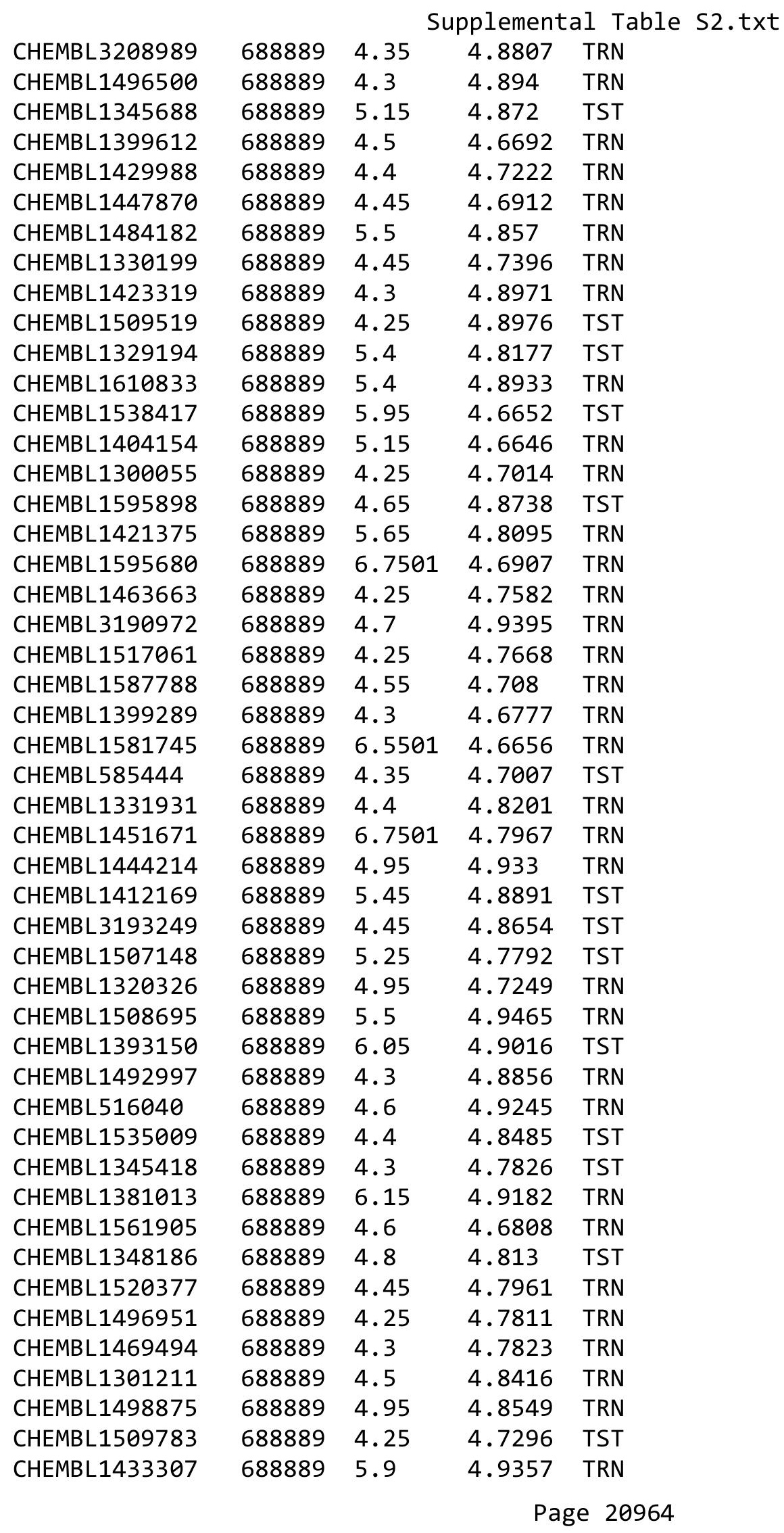




\begin{tabular}{|c|c|c|c|c|c|}
\hline \multicolumn{6}{|c|}{ plemental } \\
\hline CHEMBL1430800 & 688889 & 4.3 & 4.8868 & TRN & \\
\hline CHEMBL1463284 & 688889 & 5.35 & 4.9005 & TRN & \\
\hline CHEMBL1495050 & 688889 & 4.5 & 4.934 & TRN & \\
\hline CHEMBL1482177 & 688889 & 4.45 & 4.7518 & TRN & \\
\hline CHEMBL1336557 & 688889 & 6.8 & 4.8162 & TST & \\
\hline CHEMBL1561240 & 688889 & 4.45 & 4.6203 & TRN & \\
\hline CHEMBL1299326 & 688889 & 5.5 & 4.9158 & TRN & \\
\hline CHEMBL1402071 & 688889 & 5.9 & 4.7943 & TRN & \\
\hline CHEMBL1585104 & 688889 & 4.3 & 4.7827 & TST & \\
\hline CHEMBL1336449 & 688889 & 4.25 & 4.9087 & TST & \\
\hline CHEMBL1584867 & 688889 & 4.25 & 4.7789 & TRN & \\
\hline CHEMBL1364799 & 688889 & 6.25 & $4.9110 e$ & 00000000005 & TST \\
\hline CHEMBL1509427 & 688889 & 4.45 & 4.7676 & TRN & \\
\hline CHEMBL1589181 & 688889 & 4.85 & 4.687 & TRN & \\
\hline CHEMBL1349386 & 688889 & 4.25 & 4.7577 & TRN & \\
\hline CHEMBL1324543 & 688889 & 6.6 & 4.9902 & TST & \\
\hline CHEMBL1529960 & 688889 & 5.95 & 4.6756 & TST & \\
\hline CHEMBL1472091 & 688889 & 4.65 & 4.7845 & TRN & \\
\hline CHEMBL1580755 & 688889 & 5.45 & 4.7189 & TST & \\
\hline CHEMBL1546690 & 688889 & 5.45 & 4.8594 & TRN & \\
\hline CHEMBL1310478 & 688889 & 4.3 & 4.8303 & TRN & \\
\hline CHEMBL1606270 & 688889 & 5.9 & 4.937 & TRN & \\
\hline CHEMBL1427862 & 688889 & 4.95 & 4.7095 & TRN & \\
\hline CHEMBL1541349 & 688889 & 4.45 & 4.8569 & TRN & \\
\hline CHEMBL 3213881 & 688889 & 4.3 & 4.8458 & TRN & \\
\hline CHEMBL1599335 & 688889 & 5.9 & 4.8653 & TRN & \\
\hline CHEMBL1339787 & 688889 & 4.4 & 4.9194 & TRN & \\
\hline CHEMBL1429805 & 688889 & 6.35 & 4.8326 & TRN & \\
\hline CHEMBL1380918 & 688889 & 4.95 & 4.8746 & TRN & \\
\hline CHEMBL1421754 & 688889 & 4.45 & 4.6362 & TRN & \\
\hline CHEMBL1548047 & 688889 & 6.4 & 4.6325 & TST & \\
\hline CHEMBL1558484 & 688889 & 4.85 & 4.6889 & TRN & \\
\hline CHEMBL1542470 & 688889 & 4.95 & 4.8801 & TRN & \\
\hline CHEMBL1542971 & 688889 & 5.35 & 4.8425 & TRN & \\
\hline CHEMBL1534129 & 688889 & 4.25 & 4.7285 & TRN & \\
\hline CHEMBL1521607 & 688889 & 4.4 & 4.6864 & TRN & \\
\hline CHEMBL1425387 & 688889 & 6.3 & 4.9447 & TRN & \\
\hline CHEMBL1543877 & 688889 & 4.45 & 4.9192 & TRN & \\
\hline CHEMBL1331817 & 688889 & 4.55 & 4.8437 & TRN & \\
\hline CHEMBL1359796 & 688889 & 4.5 & 4.7951 & TRN & \\
\hline CHEMBL1485577 & 688889 & 4.45 & 4.6442 & TRN & \\
\hline CHEMBL1544882 & 688889 & 4.3 & 4.5891 & TST & \\
\hline CHEMBL1604376 & 688889 & 4.95 & 4.8778 & TRN & \\
\hline CHEMBL1505285 & 688889 & 4.45 & 4.6923 & TST & \\
\hline CHEMBL1518889 & 688889 & 4.95 & 4.8926 & TRN & \\
\hline CHEMBL1300164 & 688889 & 4.25 & 4.7457 & TST & \\
\hline CHEMBL1444491 & 688889 & 6.8 & 4.9659 & TRN & \\
\hline CHEMBL1531053 & 688889 & 4.3 & 4.8943 & TRN & \\
\hline
\end{tabular}




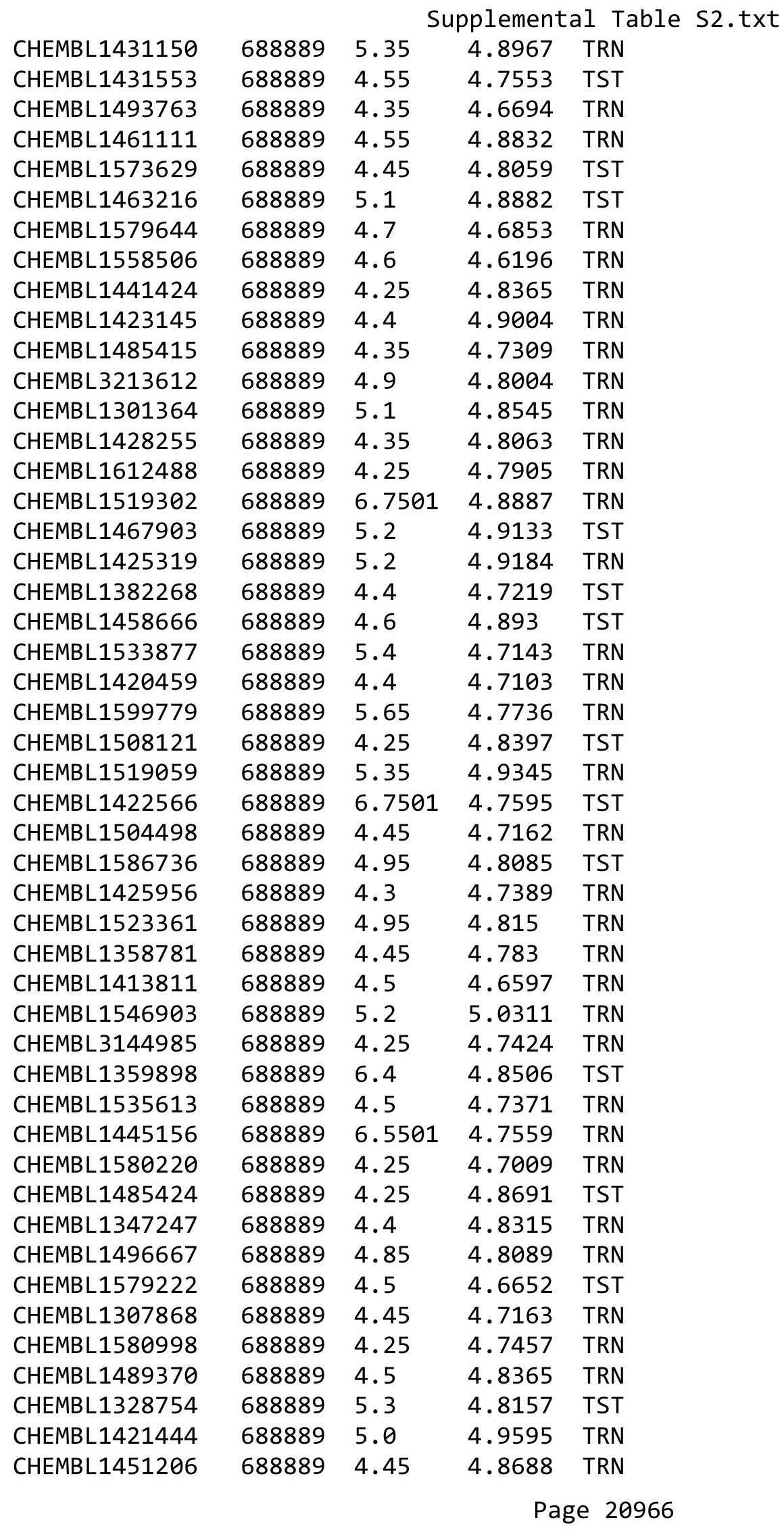




\begin{tabular}{|c|c|c|c|c|c|}
\hline \multicolumn{6}{|c|}{ Supplemental Table S2.txt } \\
\hline CHEMBL1312250 & 688889 & 4.85 & 4.6934 & TRN & \\
\hline CHEMBL1576220 & 688889 & 4.3 & 4.8716 & TRN & \\
\hline CHEMBL1485423 & 688889 & 4.3 & 4.9072 & TRN & \\
\hline CHEMBL1558739 & 688889 & 5.45 & 4.8613 & TST & \\
\hline CHEMBL1570008 & 688889 & 4.85 & 4.8177 & TRN & \\
\hline CHEMBL1466194 & 688889 & 5.1 & 4.827 & TST & \\
\hline CHEMBL1563285 & 688889 & 5.85 & 4.8521 & TRN & \\
\hline CHEMBL 3213021 & 688889 & 4.3 & 4.7928 & TST & \\
\hline CHEMBL1446313 & 688889 & 4.9 & 4.6923 & TST & \\
\hline CHEMBL1321711 & 688889 & 4.6 & 4.8764 & TRN & \\
\hline CHEMBL1464409 & 688889 & 4.35 & 4.7218 & TRN & \\
\hline CHEMBL1564376 & 688889 & 6.5 & 4.7416 & TRN & \\
\hline CHEMBL1368842 & 688889 & 4.3 & 4.8427 & TRN & \\
\hline CHEMBL1486834 & 688889 & 4.4 & 4.8097 & TRN & \\
\hline CHEMBL1471738 & 688889 & 4.55 & 4.7765 & TRN & \\
\hline CHEMBL1375301 & 688889 & 6.7501 & 4.9517 & TST & \\
\hline CHEMBL1485609 & 688889 & 4.9 & 4.7314 & TRN & \\
\hline CHEMBL1500438 & 688889 & 4.45 & 4.7598 & TRN & \\
\hline CHEMBL1603812 & 688889 & 4.25 & 4.7864 & TRN & \\
\hline CHEMBL1537315 & 688889 & 4.65 & 4.8651 & TRN & \\
\hline CHEMBL1360375 & 688889 & 4.95 & 4.8398 & TRN & \\
\hline CHEMBL1471103 & 688889 & 6.8 & 4.8225 & TST & \\
\hline CHEMBL1352311 & 688889 & 4.45 & 4.727 & TRN & \\
\hline CHEMBL1310858 & 688889 & 4.3 & 4.8504 & TRN & \\
\hline CHEMBL1509111 & 688889 & 4.5 & 4.8038 & TRN & \\
\hline CHEMBL1472109 & 688889 & 4.4 & 4.8865 & TRN & \\
\hline CHEMBL1586988 & 688889 & 5.45 & 4.9416 & TRN & \\
\hline CHEMBL1401828 & 688889 & 4.25 & 4.7982 & TRN & \\
\hline CHEMBL1386372 & 688889 & 4.4 & 4.8219 & TRN & \\
\hline CHEMBL1319533 & 688889 & 6.5 & 4.85 & TST & \\
\hline CHEMBL1348672 & 688889 & 6.5501 & 4.6021 & TRN & \\
\hline CHEMBL1330936 & 688889 & 4.25 & 4.8202 & TST & \\
\hline CHEMBL1502038 & 688889 & 4.9 & 4.7043 & TST & \\
\hline CHEMBL1343964 & 688889 & 4.3 & 4.872 & TST & \\
\hline CHEMBL1492912 & 688889 & 4.3 & 4.7693 & TST & \\
\hline CHEMBL1547911 & 688889 & 4.3 & 4.63399 & 99999999995 & TRN \\
\hline CHEMBL1529091 & 688889 & 4.9 & 4.9056 & TRN & \\
\hline CHEMBL1589101 & 688889 & 4.3 & 4.6047 & TRN & \\
\hline CHEMBL1603287 & 688889 & 4.9 & 4.7469 & TRN & \\
\hline CHEMBL1577754 & 688889 & 4.25 & 4.8495 & TRN & \\
\hline CHEMBL1446630 & 688889 & 4.45 & 4.7386 & TRN & \\
\hline CHEMBL1538617 & 688889 & 4.7 & 4.6979 & TRN & \\
\hline CHEMBL1550074 & 688889 & 4.4 & 4.763 & TRN & \\
\hline CHEMBL3194088 & 688889 & 4.45 & 4.75899 & 99999999995 & TRN \\
\hline CHEMBL1600734 & 688889 & 4.45 & 4.9745 & TRN & \\
\hline CHEMBL1452011 & 688889 & 6.7501 & 4.9863 & TRN & \\
\hline CHEMBL459825 & 688889 & 4.45 & 4.6906 & TRN & \\
\hline CHEMBL1312711 & 688889 & 4.4 & 4.7677 & TRN & \\
\hline
\end{tabular}




\begin{tabular}{|c|c|c|c|c|}
\hline \multicolumn{5}{|c|}{ Supplemental Table S2.txt } \\
\hline CHEMBL1399189 & 688889 & 4.3 & 4.8173 & TRN \\
\hline CHEMBL1466984 & 688889 & 4.45 & 4.6599 & TRN \\
\hline CHEMBL1541151 & 688889 & 4.95 & 4.8023 & TST \\
\hline CHEMBL1335679 & 688889 & 5.35 & 4.8135 & TRN \\
\hline CHEMBL1366274 & 688889 & 4.9 & 4.9287 & TRN \\
\hline CHEMBL1511786 & 688889 & 6.6 & 4.6797 & TRN \\
\hline CHEMBL1492263 & 688889 & 6.5501 & 4.8929 & TRN \\
\hline CHEMBL1411779 & 688889 & 4.45 & 4.793 & TST \\
\hline CHEMBL3145201 & 688889 & 5.15 & 4.752 & TRN \\
\hline CHEMBL1601285 & 688889 & 4.3 & 4.8695 & TRN \\
\hline CHEMBL1384458 & 688889 & 4.95 & 4.7418 & TRN \\
\hline CHEMBL1401976 & 688889 & 5.25 & 4.8547 & TRN \\
\hline CHEMBL1405099 & 688889 & 4.55 & 4.7543 & TST \\
\hline CHEMBL1535982 & 688889 & 4.95 & 4.9424 & TRN \\
\hline CHEMBL3209239 & 688889 & 4.7 & 4.8113 & TRN \\
\hline CHEMBL1522565 & 688889 & 5.95 & 4.8396 & TRN \\
\hline CHEMBL1388607 & 688889 & 4.3 & 4.7883 & TST \\
\hline CHEMBL 3214145 & 688889 & 4.6 & 4.8097 & TRN \\
\hline CHEMBL1456820 & 688889 & 4.3 & 4.8309 & TRN \\
\hline CHEMBL 3193041 & 688889 & 4.3 & 4.7443 & TRN \\
\hline CHEMBL1539028 & 688889 & 4.95 & 4.7632 & TST \\
\hline CHEMBL1529561 & 688889 & 5.9 & 4.8624 & TST \\
\hline CHEMBL1463492 & 688889 & 4.55 & 4.768 & TST \\
\hline CHEMBL1519311 & 688889 & 4.45 & 4.8147 & TRN \\
\hline CHEMBL1522939 & 688889 & 5.3 & 5.0075 & TST \\
\hline CHEMBL1483140 & 688889 & 5.2 & 4.7976 & TRN \\
\hline CHEMBL1541529 & 688889 & 6.5 & 4.7966 & TRN \\
\hline CHEMBL1589538 & 688889 & 4.3 & 4.8977 & TRN \\
\hline CHEMBL1378839 & 688889 & 4.55 & 4.7919 & TRN \\
\hline CHEMBL1569449 & 688889 & 5.0 & 4.8861 & TRN \\
\hline CHEMBL1319860 & 688889 & 5.15 & 4.7421 & TRN \\
\hline CHEMBL1360092 & 688889 & 4.25 & 4.8374 & TRN \\
\hline CHEMBL1336106 & 688889 & 4.4 & 4.7664 & TRN \\
\hline CHEMBL1422426 & 688889 & 4.55 & 4.7731 & TRN \\
\hline CHEMBL1332130 & 688889 & 4.7 & 4.8297 & TST \\
\hline CHEMBL1538789 & 688889 & 4.55 & 4.7067 & TRN \\
\hline CHEMBL3198665 & 688889 & 5.25 & 4.8319 & TRN \\
\hline CHEMBL1441339 & 688889 & 5.15 & 4.9062 & TRN \\
\hline CHEMBL1438793 & 688889 & 4.7 & 4.798 & TRN \\
\hline CHEMBL1389042 & 688889 & 4.35 & 4.8165 & TRN \\
\hline CHEMBL1360932 & 688889 & 5.4 & 4.7847 & TRN \\
\hline CHEMBL1510998 & 688889 & 5.0 & 4.8394 & TST \\
\hline CHEMBL1458956 & 688889 & 4.25 & 4.86 & TRN \\
\hline CHEMBL1543648 & 688889 & 4.75 & 4.7023 & TST \\
\hline CHEMBL1505809 & 688889 & 4.25 & 4.8835 & TRN \\
\hline CHEMBL1467492 & 688889 & 6.7501 & 4.8327 & TRN \\
\hline CHEMBL1547225 & 688889 & 4.3 & 4.855 & TRN \\
\hline CHEMBL1324498 & 688889 & 5.2 & 4.6045 & TRN \\
\hline
\end{tabular}




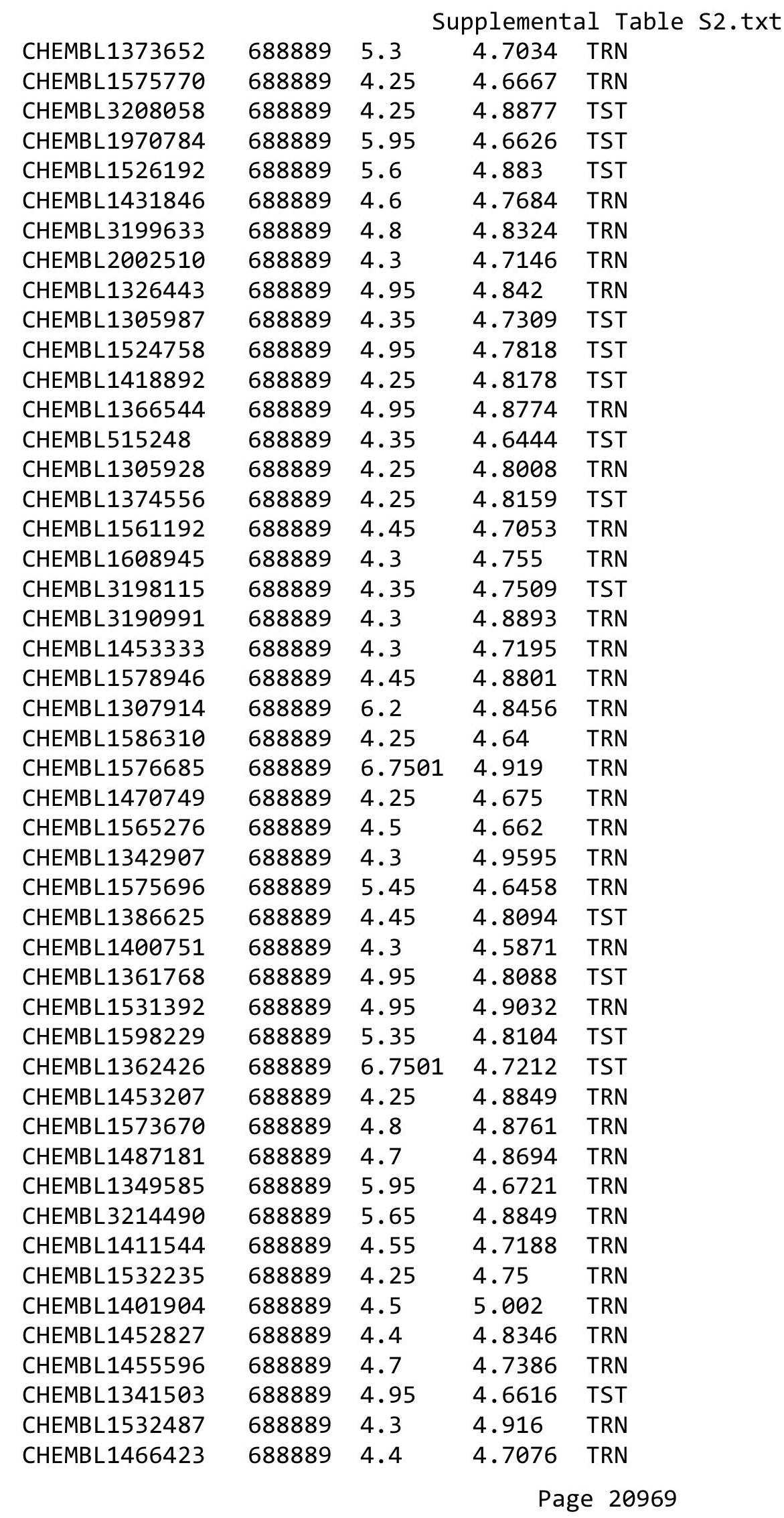




\begin{tabular}{|c|c|c|c|c|c|}
\hline \multicolumn{6}{|c|}{ Supplemental Table s2.txt } \\
\hline CHEMBL1990571 & 688889 & 4.9 & 4.68 & TST & \\
\hline CHEMBL1527732 & 688889 & 5.35 & 4.9137 & TRN & \\
\hline CHEMBL1489806 & 688889 & 4.25 & 4.8177 & TST & \\
\hline CHEMBL1569804 & 688889 & 4.4 & 4.6532 & TST & \\
\hline CHEMBL1544518 & 688889 & 5.5 & 4.7651 & TRN & \\
\hline CHEMBL1341408 & 688889 & 6.7501 & 4.9905 & TRN & \\
\hline CHEMBL1613552 & 688889 & 4.25 & 4.7934 & TRN & \\
\hline CHEMBL1324614 & 688889 & 4.4 & 4.9342 & TRN & \\
\hline CHEMBL1528808 & 688889 & 6.7501 & 4.8156 & TST & \\
\hline CHEMBL1509788 & 688889 & 4.8 & 4.9094 & TRN & \\
\hline CHEMBL1550045 & 688889 & 4.6 & 4.7292 & TRN & \\
\hline CHEMBL1517081 & 688889 & 4.3 & 4.9017 & TRN & \\
\hline CHEMBL1402072 & 688889 & 4.25 & 4.8171 & TRN & \\
\hline CHEMBL1481576 & 688889 & 4.4 & 4.7443 & TRN & \\
\hline CHEMBL1541347 & 688889 & 4.4 & 4.6506 & TRN & \\
\hline CHEMBL1504310 & 688889 & 4.65 & 4.7644 & TST & \\
\hline CHEMBL1579845 & 688889 & 5.0 & 4.8706 & TST & \\
\hline CHEMBL1380212 & 688889 & 5.0 & 4.7585 & TST & \\
\hline CHEMBL2369296 & 688889 & 4.25 & 4.7996 & TST & \\
\hline CHEMBL1305451 & 688889 & 4.25 & 4.7078 & TRN & \\
\hline CHEMBL1538115 & 688889 & 4.3 & 4.7129 & TST & \\
\hline CHEMBL1385048 & 688889 & 4.65 & 4.7178 & TRN & \\
\hline CHEMBL1339618 & 688889 & 4.45 & 4.817 & TRN & \\
\hline CHEMBL1450557 & 688889 & 4.65 & 4.8193 & TST & \\
\hline CHEMBL1500482 & 688889 & 6.7501 & 4.854 & TST & \\
\hline CHEMBL1335276 & 688889 & 4.55 & 4.6653 & TRN & \\
\hline CHEMBL1500811 & 688889 & 4.85 & 4.7839 & TST & \\
\hline CHEMBL1329027 & 688889 & 4.35 & 4.7897 & TRN & \\
\hline CHEMBL1504231 & 688889 & 4.65 & 4.7558 & TRN & \\
\hline CHEMBL1393866 & 688889 & 6.0 & 4.73300 & 00000000005 & TRN \\
\hline CHEMBL1326812 & 688889 & 4.3 & 4.6356 & TRN & \\
\hline CHEMBL1361677 & 688889 & 6.15 & 4.9339 & TST & \\
\hline CHEMBL1409299 & 688889 & 4.85 & 4.9132 & TRN & \\
\hline CHEMBL1305567 & 688889 & 5.9 & 4.9077 & TRN & \\
\hline CHEMBL1589879 & 688889 & 4.4 & 4.6003 & TST & \\
\hline CHEMBL1503677 & 688889 & 5.55 & 4.7171 & TRN & \\
\hline CHEMBL1374900 & 688889 & 4.95 & 4.7459 & TST & \\
\hline CHEMBL1599948 & 688889 & 5.25 & 4.7989 & TRN & \\
\hline CHEMBL1557038 & 688889 & 4.5 & 4.913 & TST & \\
\hline CHEMBL1365587 & 688889 & 4.25 & 4.7695 & TST & \\
\hline CHEMBL1463911 & 688889 & 4.3 & 4.8476 & TST & \\
\hline CHEMBL1511162 & 688889 & 4.45 & 4.7539 & TRN & \\
\hline CHEMBL1331857 & 688889 & 4.45 & 4.8373 & TRN & \\
\hline CHEMBL1352109 & 688889 & 5.85 & 4.8541 & TST & \\
\hline CHEMBL1559867 & 688889 & 4.45 & 4.6677 & TRN & \\
\hline CHEMBL1366604 & 688889 & 4.25 & 4.6761 & TRN & \\
\hline CHEMBL1586983 & 688889 & 4.95 & 4.7126 & TST & \\
\hline CHEMBL1594599 & 688889 & 4.9 & 4.7929 & TST & \\
\hline
\end{tabular}




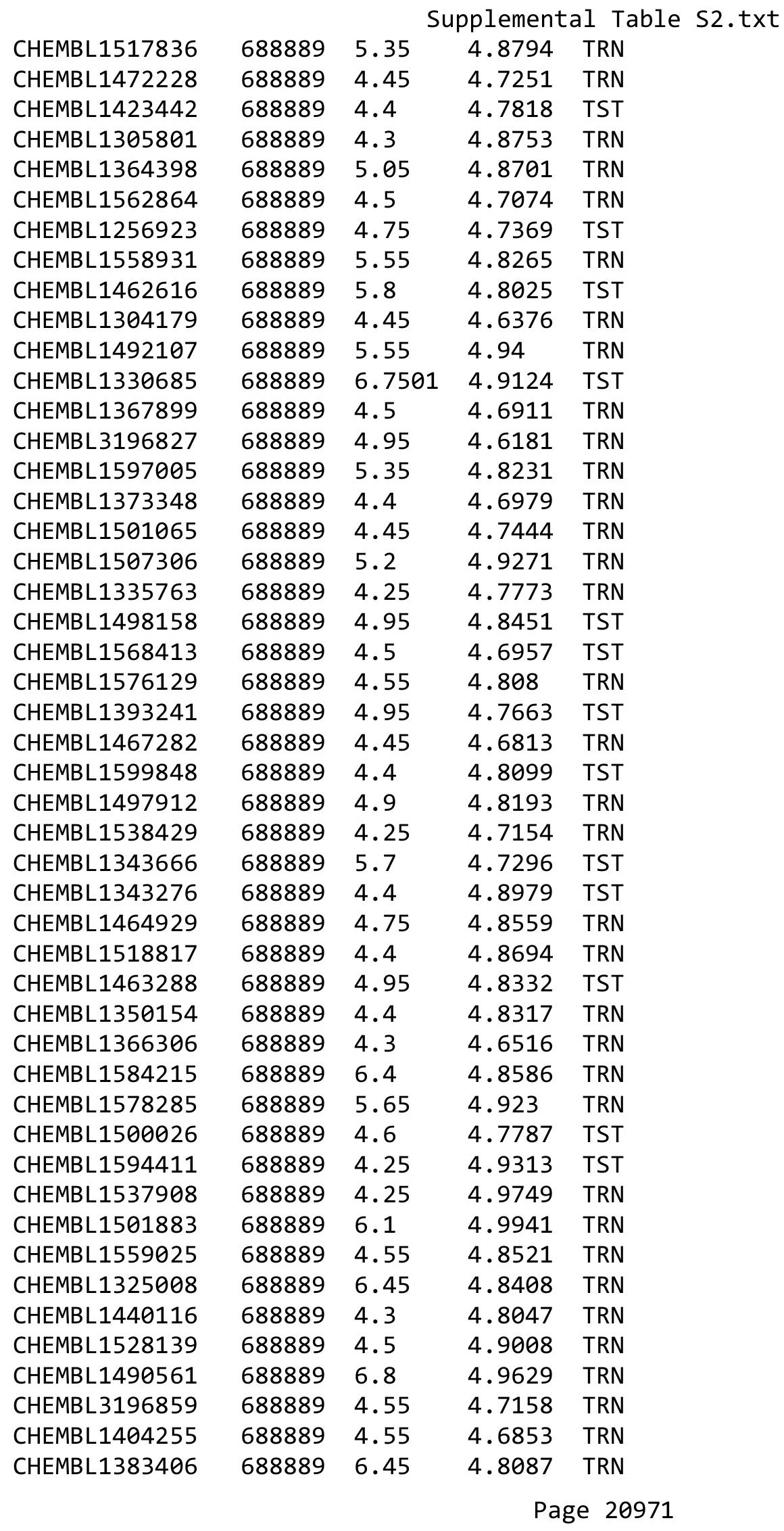




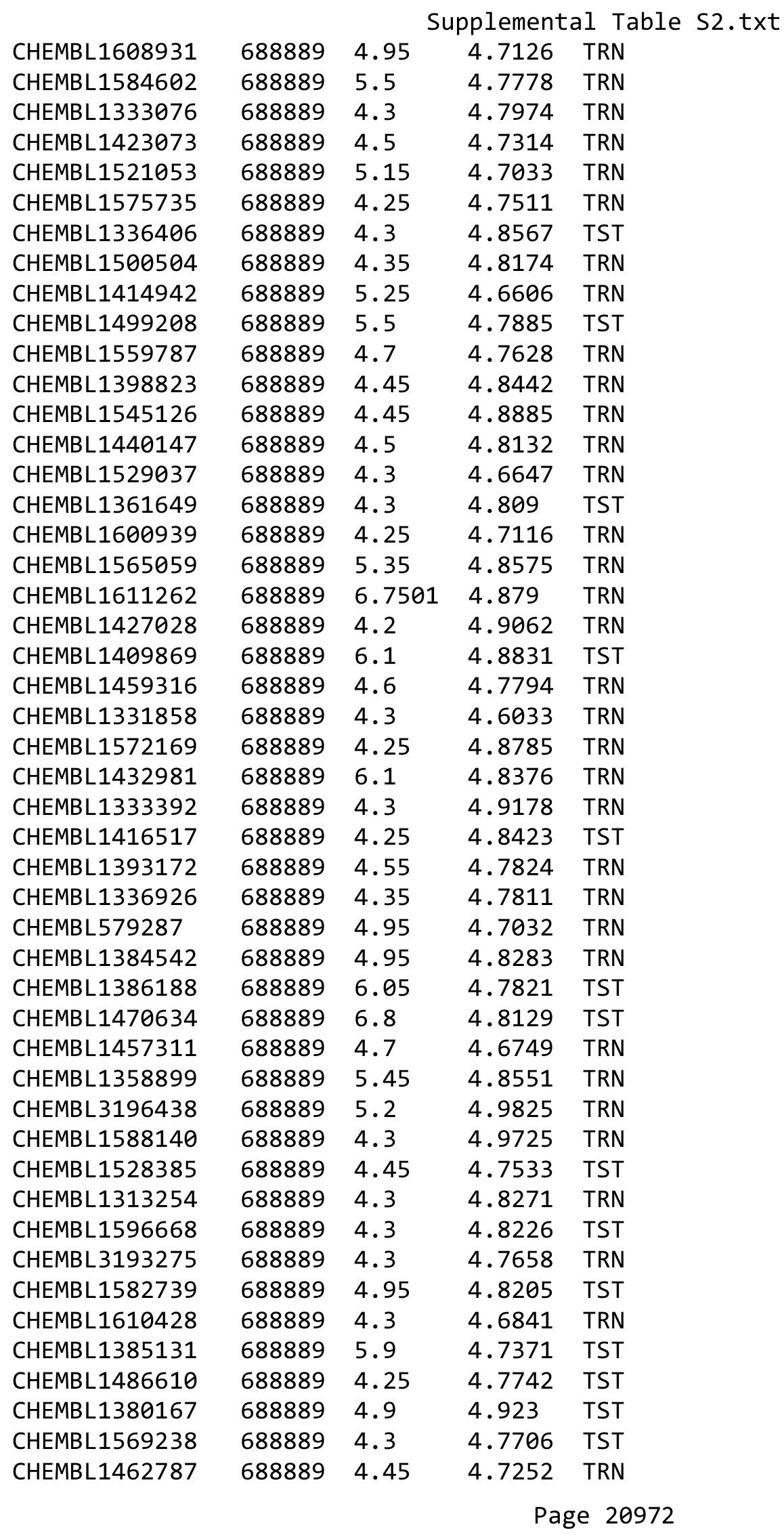




\begin{tabular}{|c|c|c|c|c|c|}
\hline \multicolumn{6}{|c|}{ Supplemental Table S2.txt } \\
\hline CHEMBL1369597 & 688889 & 4.3 & 4.7064 & TRN & \\
\hline CHEMBL1530697 & 688889 & 4.3 & 4.8085 & TST & \\
\hline CHEMBL1490834 & 688889 & 4.75 & 4.7997 & TST & \\
\hline CHEMBL1587552 & 688889 & 6.5 & 4.8056 & TST & \\
\hline CHEMBL1564469 & 688889 & 4.45 & 5.0311 & TRN & \\
\hline CHEMBL1732967 & 688889 & 5.35 & 4.6376 & TRN & \\
\hline CHEMBL1479769 & 688889 & 4.4 & 4.7914 & TRN & \\
\hline CHEMBL1308625 & 688889 & 4.3 & 5.0756 & TRN & \\
\hline CHEMBL3213472 & 688889 & 4.8 & 4.7226 & TST & \\
\hline CHEMBL1504444 & 688889 & 5.8 & 4.727 & TRN & \\
\hline CHEMBL1399917 & 688889 & 4.3 & 4.9155 & TRN & \\
\hline CHEMBL1517906 & 688889 & 4.9 & 4.885 & TST & \\
\hline CHEMBL 36641 & 688889 & 4.45 & 4.8897 & TRN & \\
\hline CHEMBL1509007 & 688889 & 4.95 & 4.7304 & TRN & \\
\hline CHEMBL1546597 & 688889 & 4.45 & 4.71899 & 9999999999 & TRN \\
\hline CHEMBL1352890 & 688889 & 4.3 & 4.8133 & TRN & \\
\hline CHEMBL1484092 & 688889 & 4.6 & 4.7942 & TRN & \\
\hline CHEMBL1508189 & 688889 & 4.45 & 4.7623 & TRN & \\
\hline CHEMBL1331266 & 688889 & 4.95 & 4.942 & TST & \\
\hline CHEMBL1608566 & 688889 & 5.55 & 4.698 & TST & \\
\hline CHEMBL1493077 & 688889 & 4.25 & 4.8821 & TRN & \\
\hline CHEMBL1565177 & 688889 & 4.95 & 4.7662 & TRN & \\
\hline CHEMBL1362220 & 688889 & 4.6 & 4.9201 & TRN & \\
\hline CHEMBL3211612 & 688889 & 6.7501 & 4.8345 & TST & \\
\hline CHEMBL1344746 & 688889 & 5.05 & 4.7291 & TRN & \\
\hline CHEMBL1490374 & 688889 & 5.5 & 4.9022 & TST & \\
\hline CHEMBL1516834 & 688889 & 5.4 & 4.7428 & TRN & \\
\hline CHEMBL1338416 & 688889 & 4.35 & 4.7531 & TRN & \\
\hline CHEMBL1492715 & 688889 & 4.25 & 4.7542 & TST & \\
\hline CHEMBL1500934 & 688889 & 4.4 & 4.95 & TST & \\
\hline CHEMBL3197460 & 688889 & 4.45 & 4.7785 & TRN & \\
\hline CHEMBL1589386 & 688889 & 5.05 & 4.9258 & TRN & \\
\hline CHEMBL1363140 & 688889 & 4.3 & 4.8945 & TRN & \\
\hline CHEMBL1470373 & 688889 & 4.45 & 4.9198 & TST & \\
\hline CHEMBL1561936 & 688889 & 4.25 & 4.8558 & TRN & \\
\hline CHEMBL1384130 & 688889 & 4.35 & 4.8881 & TST & \\
\hline CHEMBL1559688 & 688889 & 5.3 & 4.9053 & TRN & \\
\hline CHEMBL1334764 & 688889 & 4.9 & 4.5895 & TRN & \\
\hline CHEMBL1300844 & 688889 & 4.95 & 4.9044 & TST & \\
\hline CHEMBL1305166 & 688889 & 4.3 & 4.6305 & TRN & \\
\hline CHEMBL1566115 & 688889 & 4.25 & 4.7905 & TRN & \\
\hline CHEMBL1425345 & 688889 & 4.25 & 4.8409 & TRN & \\
\hline CHEMBL1376714 & 688889 & 4.75 & 4.8382 & TRN & \\
\hline CHEMBL3208060 & 688889 & 4.45 & 4.6629 & TRN & \\
\hline CHEMBL1503616 & 688889 & 6.7501 & 4.5298 & TRN & \\
\hline CHEMBL1986893 & 688889 & 5.85 & 4.8874 & TST & \\
\hline CHEMBL1345118 & 688889 & 5.9 & 4.90600 & 2000000001 & TST \\
\hline CHEMBL1538446 & 688889 & 4.75 & 4.706 & TRN & \\
\hline
\end{tabular}




\begin{tabular}{|c|c|c|c|c|c|}
\hline \multicolumn{6}{|c|}{ Supplemental Table S2.txt } \\
\hline CHEMBL1499569 & 688889 & 4.55 & 4.8265 & TST & \\
\hline CHEMBL1492322 & 688889 & 4.5 & 4.7098 & TST & \\
\hline CHEMBL 2358966 & 688889 & 5.35 & 4.7752 & TRN & \\
\hline CHEMBL1598771 & 688889 & 6.35 & 4.7394 & TST & \\
\hline CHEMBL1329350 & 688889 & 6.7501 & 4.6305 & TRN & \\
\hline CHEMBL1541027 & 688889 & 4.5 & 4.6631 & TRN & \\
\hline CHEMBL1308352 & 688889 & 5.0 & 4.8641 & TRN & \\
\hline CHEMBL1328056 & 688889 & 5.2 & 4.7216 & TRN & \\
\hline CHEMBL1502732 & 688889 & 4.5 & 4.8408 & TRN & \\
\hline CHEMBL1503644 & 688889 & 4.55 & 4.6595 & TRN & \\
\hline CHEMBL1414367 & 688889 & 4.5 & 4.9139 & TRN & \\
\hline CHEMBL1573473 & 688889 & 4.25 & 4.9115 & TST & \\
\hline CHEMBL1344329 & 688889 & 4.3 & 4.8313 & TRN & \\
\hline CHEMBL1420596 & 688889 & 4.95 & 4.5764 & TST & \\
\hline CHEMBL3195470 & 688889 & 4.3 & 4.7826 & TRN & \\
\hline CHEMBL1405129 & 688889 & 6.5 & 4.7437 & TRN & \\
\hline CHEMBL1351716 & 688889 & 4.45 & 4.6696 & TRN & \\
\hline CHEMBL1504621 & 688889 & 4.3 & 4.7788 & TST & \\
\hline CHEMBL1596996 & 688889 & 4.25 & 4.7285 & TRN & \\
\hline CHEMBL1605062 & 688889 & 5.75 & 4.8481 & TRN & \\
\hline CHEMBL1375375 & 688889 & 4.8 & 4.6447 & TRN & \\
\hline CHEMBL525103 & 688889 & 4.3 & 4.6242 & TRN & \\
\hline CHEMBL1518328 & 688889 & 4.3 & 4.9799 & TST & \\
\hline CHEMBL1440690 & 688889 & 4.3 & 4.7547 & TRN & \\
\hline CHEMBL1502969 & 688889 & 6.8 & 4.9328 & TST & \\
\hline CHEMBL1425563 & 688889 & 5.25 & 4.8768 & TRN & \\
\hline CHEMBL1306148 & 688889 & 4.9 & 4.8501 & TST & \\
\hline CHEMBL1500533 & 688889 & 4.4 & 4.7575 & TRN & \\
\hline CHEMBL1526929 & 688889 & 5.75 & 4.6765 & TRN & \\
\hline CHEMBL3198280 & 688889 & 4.5 & 4.6539 & TRN & \\
\hline CHEMBL1429914 & 688889 & 4.3 & 4.9298 & TRN & \\
\hline CHEMBL1331054 & 688889 & 4.5 & $4.7780 e$ & 00000000005 & TRN \\
\hline CHEMBL1511093 & 688889 & 4.3 & 4.7563 & TRN & \\
\hline CHEMBL1490879 & 688889 & 4.9 & 4.8323 & TST & \\
\hline CHEMBL1419889 & 688889 & 4.3 & 4.748 & TRN & \\
\hline CHEMBL1558735 & 688889 & 4.35 & 4.6704 & TRN & \\
\hline CHEMBL1517410 & 688889 & 5.6 & 4.6846 & TRN & \\
\hline CHEMBL1464047 & 688889 & 4.25 & 4.9478 & TST & \\
\hline CHEMBL1491376 & 688889 & 4.25 & 4.8888 & TRN & \\
\hline CHEMBL1596944 & 688889 & 6.15 & 4.7107 & TRN & \\
\hline CHEMBL3195889 & 688889 & 4.9 & 4.8598 & TST & \\
\hline CHEMBL1580584 & 688889 & 4.4 & 4.773 & TRN & \\
\hline CHEMBL1546132 & 688889 & 4.55 & 4.9673 & TST & \\
\hline CHEMBL1313330 & 688889 & 4.45 & 4.7967 & TST & \\
\hline CHEMBL1444775 & 688889 & 5.3 & 4.6796 & TST & \\
\hline CHEMBL1589573 & 688889 & 6.7501 & 4.9037 & TST & \\
\hline CHEMBL3211721 & 688889 & 4.25 & 4.8818 & TRN & \\
\hline CHEMBL1350710 & 688889 & 5.3 & 4.8311 & TRN & \\
\hline
\end{tabular}




\begin{tabular}{|c|c|c|c|c|c|}
\hline \multicolumn{6}{|c|}{ Supplemental Table S2.txt } \\
\hline CHEMBL1588599 & 688889 & 6.15 & 4.8217 & TST & \\
\hline CHEMBL1597359 & 688889 & 4.65 & 4.7135 & TRN & \\
\hline CHEMBL1533840 & 688889 & 4.95 & 4.8389 & TST & \\
\hline CHEMBL1523224 & 688889 & 4.5 & 4.7125 & TRN & \\
\hline CHEMBL1497513 & 688889 & 4.45 & 4.6427 & TST & \\
\hline CHEMBL3193491 & 688889 & 4.5 & 4.75 & TST & \\
\hline CHEMBL1603958 & 688889 & 4.7 & 4.7625 & TRN & \\
\hline CHEMBL1414034 & 688889 & 5.35 & 4.88399 & 99999999995 & TRN \\
\hline CHEMBL1481025 & 688889 & 5.55 & 4.7592 & TRN & \\
\hline CHEMBL1406520 & 688889 & 4.35 & 4.8211 & TRN & \\
\hline CHEMBL1603266 & 688889 & 4.8 & 4.7402 & TST & \\
\hline CHEMBL1390706 & 688889 & 4.45 & 4.8178 & TRN & \\
\hline CHEMBL1525889 & 688889 & 4.5 & 4.7751 & TST & \\
\hline CHEMBL1546837 & 688889 & 4.45 & 4.72199 & 99999999995 & TST \\
\hline CHEMBL1529977 & 688889 & 6.5501 & 4.8019 & TRN & \\
\hline CHEMBL1607654 & 688889 & 4.4 & 4.8426 & TRN & \\
\hline CHEMBL1502731 & 688889 & 5.8 & 4.8511 & TRN & \\
\hline CHEMBL1347915 & 688889 & 4.5 & 4.8129 & TRN & \\
\hline CHEMBL1454166 & 688889 & 4.5 & 4.8697 & TRN & \\
\hline CHEMBL1575115 & 688889 & 4.5 & 4.7722 & TRN & \\
\hline CHEMBL1306912 & 688889 & 4.9 & 4.7811 & TST & \\
\hline CHEMBL1380905 & 688889 & 4.3 & 5.0034 & TRN & \\
\hline CHEMBL1346577 & 688889 & 4.25 & 4.7771 & TRN & \\
\hline CHEMBL3196072 & 688889 & 6.2 & 4.7468 & TRN & \\
\hline CHEMBL1548324 & 688889 & 5.2 & 4.914 & TRN & \\
\hline CHEMBL1460145 & 688889 & 4.4 & 4.6129 & TST & \\
\hline CHEMBL1387502 & 688889 & 5.4 & 4.8329 & TRN & \\
\hline CHEMBL1560834 & 688889 & 4.25 & 4.8308 & TST & \\
\hline CHEMBL1322331 & 688889 & 4.6 & 4.6951 & TRN & \\
\hline CHEMBL1085765 & 688889 & 4.3 & 4.8573 & TST & \\
\hline CHEMBL1408982 & 688889 & 4.3 & 4.8292 & TRN & \\
\hline CHEMBL1486034 & 688889 & 4.25 & 4.8013 & TST & \\
\hline CHEMBL1351280 & 688889 & 6.8 & 4.9497 & TRN & \\
\hline CHEMBL1363553 & 688889 & 5.05 & 4.9042 & TRN & \\
\hline CHEMBL1506341 & 688889 & 4.95 & 4.8542 & TST & \\
\hline CHEMBL1416151 & 688889 & 4.45 & 4.5996 & TRN & \\
\hline CHEMBL1339184 & 688889 & 4.95 & 4.8468 & TST & \\
\hline CHEMBL1550009 & 688889 & 4.7 & 4.8872 & TST & \\
\hline CHEMBL1595889 & 688889 & 6.4 & 4.751 & TRN & \\
\hline CHEMBL1517379 & 688889 & 4.45 & 4.7268 & TRN & \\
\hline CHEMBL3194348 & 688889 & 5.55 & 4.7258 & TRN & \\
\hline CHEMBL1507728 & 688889 & 4.45 & 4.8932 & TRN & \\
\hline CHEMBL63273 & 688889 & 4.6 & 4.7989 & TRN & \\
\hline CHEMBL1503067 & 688889 & 4.3 & 4.8772 & TST & \\
\hline CHEMBL 3210597 & 688889 & 4.45 & 4.7395 & TRN & \\
\hline CHEMBL1486858 & 688889 & 6.7501 & 4.9206 & TST & \\
\hline CHEMBL538430 & 688889 & 5.25 & 4.9954 & TRN & \\
\hline CHEMBL1511290 & 688889 & 4.95 & 4.7166 & TRN & \\
\hline
\end{tabular}




\begin{tabular}{|c|c|c|c|c|c|}
\hline & & & & & \\
\hline CHEMBL1432870 & 688889 & 4.3 & 4.7913 & TRN & \\
\hline CHEMBL1561694 & 688889 & 4.5 & 4.6636 & TST & \\
\hline CHEMBL1587463 & 688889 & 4.4 & 4.6493 & TRN & \\
\hline CHEMBL1330131 & 688889 & 4.45 & 4.7564 & TRN & \\
\hline CHEMBL1370081 & 688889 & 4.45 & 4.7853 & TRN & \\
\hline CHEMBL1489177 & 688889 & 4.4 & 4.9502 & TST & \\
\hline CHEMBL1562517 & 688889 & 6.8 & 4.7437 & TRN & \\
\hline CHEMBL3199657 & 688889 & 4.25 & 4.8151 & TST & \\
\hline CHEMBL1470666 & 688889 & 5.0 & 4.775 & TRN & \\
\hline CHEMBL1347736 & 688889 & 4.25 & 4.8688 & TRN & \\
\hline CHEMBL1430338 & 688889 & 5.85 & 4.8068 & TRN & \\
\hline CHEMBL1561313 & 688889 & 5.1 & 4.8788 & TRN & \\
\hline CHEMBL1336972 & 688889 & 4.45 & 4.816 & TRN & \\
\hline CHEMBL1985381 & 688889 & 4.3 & 4.7967 & TRN & \\
\hline CHEMBL1390628 & 688889 & 5.15 & 4.75 & TRN & \\
\hline CHEMBL1401657 & 688889 & 4.75 & 4.8191 & TST & \\
\hline CHEMBL1568453 & 688889 & 5.25 & 4.921 & TRN & \\
\hline CHEMBL1605054 & 688889 & 4.95 & 4.7928 & TRN & \\
\hline CHEMBL1391649 & 688889 & 4.5 & 4.7276 & TRN & \\
\hline CHEMBL1455859 & 688889 & 5.7 & 4.7896 & TST & \\
\hline CHEMBL1393208 & 688889 & 4.25 & 4.7234 & TRN & \\
\hline CHEMBL1320156 & 688889 & 4.95 & 4.9041 & TST & \\
\hline CHEMBL1416484 & 688889 & 4.55 & 4.6531 & TRN & \\
\hline CHEMBL1445964 & 688889 & 4.4 & 4.7872 & TST & \\
\hline CHEMBL1540231 & 688889 & 4.7 & 4.7867 & TRN & \\
\hline CHEMBL1344704 & 688889 & 4.3 & 4.7827 & TRN & \\
\hline CHEMBL1324955 & 688889 & 4.5 & 4.8695 & TRN & \\
\hline CHEMBL1363268 & 688889 & 4.45 & 4.6003 & TRN & \\
\hline CHEMBL1555882 & 688889 & 4.25 & 4.776 & TRN & \\
\hline CHEMBL1490177 & 688889 & 4.4 & 4.8468 & TRN & \\
\hline CHEMBL1311403 & 688889 & 5.5 & 4.887 & TRN & \\
\hline CHEMBL1498341 & 688889 & 4.9 & 4.8912 & TRN & \\
\hline CHEMBL1380910 & 688889 & 4.45 & 4.8324 & TRN & \\
\hline CHEMBL1312194 & 688889 & 4.95 & 4.8972 & TRN & \\
\hline CHEMBL3195990 & 688889 & 4.45 & 4.6433 & TRN & \\
\hline CHEMBL 244743 & 688889 & 4.45 & 4.7388 & TST & \\
\hline CHEMBL1332010 & 688889 & 5.9 & 4.9098 & TRN & \\
\hline CHEMBL1605039 & 688889 & 4.5 & 4.8269 & TRN & \\
\hline CHEMBL1344907 & 688889 & 5.6 & 4.7682 & TRN & \\
\hline CHEMBL1606495 & 688889 & 4.5 & 4.7375 & TRN & \\
\hline CHEMBL1379478 & 688889 & 4.4 & 4.8692 & TRN & \\
\hline CHEMBL1345292 & 688889 & 4.95 & 4.9456 & TST & \\
\hline CHEMBL1428652 & 688889 & 4.95 & 4.8038 & TRN & \\
\hline CHEMBL1432431 & 688889 & 4.95 & 4.8699 & TRN & \\
\hline CHEMBL1600412 & 688889 & 4.7 & 4.7751 & TRN & \\
\hline CHEMBL1441412 & 688889 & 4.85 & 4.7646 & TRN & \\
\hline CHEMBL1384111 & 688889 & 4.35 & 4.8357 & TRN & \\
\hline CHEMBL3198066 & 688889 & 4.25 & $4.7010 e$ & 20000000005 & TRN \\
\hline & & & & 20976 & \\
\hline
\end{tabular}




\begin{tabular}{|c|c|c|c|c|c|}
\hline & & & & & \\
\hline CHEMBL1454079 & 688889 & 4.3 & 4.6793 & TRN & \\
\hline CHEMBL1599210 & 688889 & 5.2 & 4.5818 & TRN & \\
\hline CHEMBL1596813 & 688889 & 4.55 & 4.672 & TRN & \\
\hline CHEMBL1481988 & 688889 & 4.25 & 4.9765 & TRN & \\
\hline CHEMBL1599700 & 688889 & 4.3 & 4.6504 & TRN & \\
\hline CHEMBL1568736 & 688889 & 5.5 & 4.7886 & TST & \\
\hline CHEMBL1509782 & 688889 & 5.25 & 4.7904 & TST & \\
\hline CHEMBL1608965 & 688889 & 4.3 & 4.88399 & 99999999995 & TRN \\
\hline CHEMBL1542908 & 688889 & 4.95 & 4.6732 & TST & \\
\hline CHEMBL1606430 & 688889 & 5.15 & 4.7293 & TRN & \\
\hline CHEMBL1324744 & 688889 & 4.5 & 4.9325 & TRN & \\
\hline CHEMBL1402437 & 688889 & 6.8 & 4.9235 & TRN & \\
\hline CHEMBL1539672 & 688889 & 4.5 & 4.8351 & TRN & \\
\hline CHEMBL1471369 & 688889 & 5.25 & 4.8319 & TRN & \\
\hline CHEMBL1300500 & 688889 & 4.5 & 4.7931 & TRN & \\
\hline CHEMBL1548850 & 688889 & 4.4 & 4.9184 & TST & \\
\hline CHEMBL1586400 & 688889 & 4.45 & 4.8127 & TST & \\
\hline CHEMBL1376929 & 688889 & 5.4 & 4.6817 & TRN & \\
\hline CHEMBL1372966 & 688889 & 6.35 & 4.9567 & TRN & \\
\hline CHEMBL3197322 & 688889 & 4.5 & 4.6516 & TRN & \\
\hline CHEMBL1326295 & 688889 & 4.4 & 4.7485 & TRN & \\
\hline CHEMBL1531427 & 688889 & 5.9 & 4.7125 & TRN & \\
\hline CHEMBL1579071 & 688889 & 5.0 & 4.8618 & TRN & \\
\hline CHEMBL1322111 & 688889 & 4.4 & 4.8344 & TRN & \\
\hline CHEMBL3194118 & 688889 & 4.75 & 4.7884 & TRN & \\
\hline CHEMBL1361808 & 688889 & 5.5 & 4.8355 & TRN & \\
\hline CHEMBL3198553 & 688889 & 4.95 & 4.8122 & TRN & \\
\hline CHEMBL1367453 & 688889 & 4.45 & 4.7997 & TRN & \\
\hline CHEMBL1545398 & 688889 & 4.4 & 4.9033 & TRN & \\
\hline CHEMBL1488740 & 688889 & 4.3 & 4.9355 & TRN & \\
\hline CHEMBL1581652 & 688889 & 6.05 & 4.7714 & TRN & \\
\hline CHEMBL1565468 & 688889 & 5.45 & 4.7033 & TRN & \\
\hline CHEMBL1387945 & 688889 & 4.6 & 4.6989 & TRN & \\
\hline CHEMBL1532991 & 688889 & 6.7501 & 4.90600 & 3000000001 & TST \\
\hline CHEMBL3199132 & 688889 & 4.7 & 4.8428 & TST & \\
\hline CHEMBL1401452 & 688889 & 4.5 & 4.7815 & TRN & \\
\hline CHEMBL1465236 & 688889 & 4.95 & 4.8512 & TRN & \\
\hline CHEMBL1563734 & 688889 & 4.25 & 4.9399 & TRN & \\
\hline CHEMBL1500548 & 688889 & 6.2 & 4.9981 & TRN & \\
\hline CHEMBL1323694 & 688889 & 5.45 & 4.7647 & TST & \\
\hline CHEMBL1587148 & 688889 & 4.95 & 4.9263 & TRN & \\
\hline CHEMBL1336722 & 688889 & 4.3 & 4.7737 & TRN & \\
\hline CHEMBL1538188 & 688889 & 4.65 & 4.7387 & TRN & \\
\hline CHEMBL1472362 & 688889 & 5.0 & 4.7687 & TRN & \\
\hline CHEMBL1364883 & 688889 & 4.45 & 4.8199 & TRN & \\
\hline CHEMBL1556140 & 688889 & 4.3 & 4.8563 & TRN & \\
\hline CHEMBL1508548 & 688889 & 4.65 & 4.9236 & TST & \\
\hline CHEMBL1542303 & 688889 & 4.45 & 4.6684 & TRN & \\
\hline & & & & 20977 & \\
\hline
\end{tabular}




\begin{tabular}{|c|c|c|c|c|}
\hline \multicolumn{5}{|c|}{ Supplemental Table S2.txt } \\
\hline CHEMBL1331499 & 688889 & 4.5 & 4.8182 & TRN \\
\hline CHEMBL1611718 & 688889 & 4.9 & 4.8314 & TST \\
\hline CHEMBL1369392 & 688889 & 4.45 & 4.6719 & TRN \\
\hline CHEMBL1455253 & 688889 & 4.95 & 4.6588 & TRN \\
\hline CHEMBL1505076 & 688889 & 4.45 & 4.831 & TRN \\
\hline CHEMBL1340541 & 688889 & 6.1 & 4.8099 & TRN \\
\hline CHEMBL1464984 & 688889 & 4.65 & 4.8757 & TRN \\
\hline CHEMBL1461362 & 688889 & 5.1 & 4.7804 & TRN \\
\hline CHEMBL1386834 & 688889 & 5.0 & 4.6743 & TRN \\
\hline CHEMBL1607379 & 688889 & 5.6 & 4.8266 & TST \\
\hline CHEMBL1382557 & 688889 & 5.9 & 4.7125 & TST \\
\hline CHEMBL 3213527 & 688889 & 4.95 & 4.7907 & TRN \\
\hline CHEMBL1378922 & 688889 & 4.35 & 4.7954 & TRN \\
\hline CHEMBL1599414 & 688889 & 4.75 & 4.8118 & TRN \\
\hline CHEMBL3209625 & 688889 & 4.3 & 4.8572 & TRN \\
\hline CHEMBL1538149 & 688889 & 4.25 & 4.9068 & TRN \\
\hline CHEMBL1382991 & 688889 & 5.2 & 4.9334 & TST \\
\hline CHEMBL1589520 & 688889 & 5.15 & 4.9002 & TRN \\
\hline CHEMBL1344953 & 688889 & 4.5 & 4.9028 & TST \\
\hline CHEMBL1598989 & 688889 & 5.35 & 4.9043 & TRN \\
\hline CHEMBL1508046 & 688889 & 6.2 & 4.6685 & TRN \\
\hline CHEMBL1560925 & 688889 & 5.05 & 4.8237 & TRN \\
\hline CHEMBL1488994 & 688889 & 4.6 & 4.8309 & TST \\
\hline CHEMBL1503105 & 688889 & 4.45 & 4.6009 & TRN \\
\hline CHEMBL1492033 & 688889 & 4.55 & 4.8226 & TRN \\
\hline CHEMBL1346471 & 688889 & 4.25 & 4.7485 & TRN \\
\hline CHEMBL3212829 & 688889 & 4.55 & 4.7191 & TST \\
\hline CHEMBL1532305 & 688889 & 4.3 & 4.8121 & TST \\
\hline CHEMBL3195833 & 688889 & 4.45 & 4.6482 & TRN \\
\hline CHEMBL1493082 & 688889 & 4.25 & 4.76699 & 99999999995 \\
\hline CHEMBL1982539 & 688889 & 5.0 & 4.6822 & TST \\
\hline CHEMBL1566329 & 688889 & 4.3 & 4.7493 & TRN \\
\hline CHEMBL1970554 & 688889 & 4.4 & 4.8099 & TRN \\
\hline CHEMBL1580383 & 688889 & 4.7 & 4.7363 & TST \\
\hline CHEMBL1492522 & 688889 & 4.3 & 4.9415 & TST \\
\hline CHEMBL1574774 & 688889 & 4.3 & 4.7656 & TRN \\
\hline CHEMBL1340537 & 688889 & 6.8 & 4.9081 & TRN \\
\hline CHEMBL3194579 & 688889 & 5.45 & 4.7918 & TST \\
\hline CHEMBL1567974 & 688889 & 4.6 & 4.7951 & TST \\
\hline CHEMBL1463481 & 688889 & 4.8 & 4.8405 & TRN \\
\hline CHEMBL1387915 & 688889 & 4.45 & 4.7021 & TRN \\
\hline CHEMBL1566394 & 688889 & 4.45 & 4.7266 & TST \\
\hline CHEMBL1526475 & 688889 & 6.6 & 4.8063 & TRN \\
\hline CHEMBL1413404 & 688889 & 5.45 & 4.6872 & TRN \\
\hline CHEMBL1548616 & 688889 & 4.95 & 4.7608 & TST \\
\hline CHEMBL1319227 & 688889 & 4.45 & 4.6946 & TRN \\
\hline CHEMBL1535537 & 688889 & 4.25 & 4.8415 & TRN \\
\hline CHEMBL1426813 & 688889 & 4.95 & 4.7587 & TST \\
\hline
\end{tabular}




\begin{tabular}{|c|c|c|c|c|}
\hline \multicolumn{5}{|c|}{ Supplemental Table S2.txt } \\
\hline CHEMBL1482951 & 688889 & 4.3 & 4.7541 & TRN \\
\hline CHEMBL1490530 & 688889 & 6.15 & 4.9041 & TST \\
\hline CHEMBL1527394 & 688889 & 4.25 & 4.7384 & TRN \\
\hline CHEMBL1332758 & 688889 & 4.9 & 4.6586 & TRN \\
\hline CHEMBL1570199 & 688889 & 4.9 & 4.9298 & TRN \\
\hline CHEMBL3195594 & 688889 & 4.35 & 4.6677 & TRN \\
\hline CHEMBL1304601 & 688889 & 4.25 & 4.689 & TRN \\
\hline CHEMBL1388501 & 688889 & 5.45 & 4.9004 & TRN \\
\hline CHEMBL1409517 & 688889 & 4.3 & 4.9078 & TRN \\
\hline CHEMBL1368718 & 688889 & 4.95 & 4.8214 & TRN \\
\hline CHEMBL1381299 & 688889 & 4.3 & 4.8134 & TRN \\
\hline CHEMBL1324815 & 688889 & 4.55 & 4.8464 & TRN \\
\hline CHEMBL1325981 & 688889 & 4.25 & 4.8115 & TRN \\
\hline CHEMBL1470281 & 688889 & 4.45 & 4.8247 & TST \\
\hline CHEMBL1365806 & 688889 & 4.25 & 4.6872 & TRN \\
\hline CHEMBL1570554 & 688889 & 4.65 & 4.8405 & TRN \\
\hline CHEMBL1531153 & 688889 & 5.0 & 4.8406 & TRN \\
\hline CHEMBL1384684 & 688889 & 4.45 & 4.9596 & TRN \\
\hline CHEMBL1585947 & 688889 & 4.5 & 4.7559 & TRN \\
\hline CHEMBL1393465 & 688889 & 4.3 & 4.9048 & TRN \\
\hline CHEMBL1530955 & 688889 & 4.45 & 4.7044 & TRN \\
\hline CHEMBL1538375 & 688889 & 4.3 & 4.6536 & TRN \\
\hline CHEMBL408982 & 688889 & 4.95 & 4.7376 & TST \\
\hline CHEMBL1578960 & 688889 & 4.95 & 4.8301 & TST \\
\hline CHEMBL1348006 & 688889 & 4.4 & 4.9358 & TST \\
\hline CHEMBL1442453 & 688889 & 4.3 & 4.7319 & TRN \\
\hline CHEMBL1324566 & 688889 & 4.4 & 4.737 & TST \\
\hline CHEMBL475742 & 688889 & 4.95 & 4.8574 & TST \\
\hline CHEMBL1389253 & 688889 & 4.9 & 4.8745 & TST \\
\hline CHEMBL1335111 & 688889 & 5.25 & 4.9031 & TST \\
\hline CHEMBL1428510 & 688889 & 4.3 & 4.8227 & TRN \\
\hline CHEMBL1400435 & 688889 & 4.45 & 4.8672 & TRN \\
\hline CHEMBL1369398 & 688889 & 5.85 & 4.9412 & TST \\
\hline CHEMBL1392302 & 688889 & 4.45 & 4.9388 & TRN \\
\hline CHEMBL1542452 & 688889 & 6.6 & 4.9831 & TRN \\
\hline CHEMBL1523946 & 688889 & 4.95 & 4.8429 & TST \\
\hline CHEMBL1310090 & 688889 & 5.6 & 4.7042 & TRN \\
\hline CHEMBL1602667 & 688889 & 4.3 & 4.8577 & TRN \\
\hline CHEMBL1577827 & 688889 & 6.5 & 4.8441 & TRN \\
\hline CHEMBL1339881 & 688889 & 4.9 & 4.6842 & TRN \\
\hline CHEMBL1386430 & 688889 & 4.3 & 4.8055 & TRN \\
\hline CHEMBL1566068 & 688889 & 5.2 & 4.8729 & TRN \\
\hline CHEMBL3208751 & 688889 & 4.4 & 4.7897 & TRN \\
\hline CHEMBL1580668 & 688889 & 4.55 & 4.8217 & TRN \\
\hline CHEMBL1452766 & 688889 & 4.55 & 4.8185 & TST \\
\hline CHEMBL1385431 & 688889 & 4.25 & 4.8889 & TST \\
\hline CHEMBL1558736 & 688889 & 4.7 & 4.7213 & TRN \\
\hline CHEMBL1362217 & 688889 & 4.95 & 4.6691 & TRN \\
\hline
\end{tabular}




\begin{tabular}{|c|c|c|c|c|}
\hline \multicolumn{5}{|c|}{ Supplemental Table S2.txt } \\
\hline CHEMBL1566005 & 688889 & 4.5 & 4.7916 & TRN \\
\hline CHEMBL1524381 & 688889 & 4.25 & 4.7795 & TRN \\
\hline CHEMBL1402358 & 688889 & 4.35 & 4.7521 & TRN \\
\hline CHEMBL1383727 & 688889 & 4.9 & 4.9406 & TRN \\
\hline CHEMBL1384760 & 688889 & 5.05 & 4.6628 & TRN \\
\hline CHEMBL1611565 & 688889 & 4.35 & 4.6287 & TRN \\
\hline CHEMBL1484282 & 688889 & 4.3 & 4.709 & TRN \\
\hline CHEMBL1313467 & 688889 & 4.55 & 4.6813 & TRN \\
\hline CHEMBL1530650 & 688889 & 4.5 & 4.8071 & TST \\
\hline CHEMBL1598640 & 688889 & 4.25 & 4.873 & TST \\
\hline CHEMBL1518855 & 688889 & 4.45 & 4.8552 & TRN \\
\hline CHEMBL1521414 & 688889 & 4.7 & 4.6936 & TRN \\
\hline CHEMBL1370720 & 688889 & 4.25 & 4.9163 & TST \\
\hline CHEMBL1365920 & 688889 & 4.4 & 4.8354 & TST \\
\hline CHEMBL1607436 & 688889 & 5.95 & 4.955 & TRN \\
\hline CHEMBL1596765 & 688889 & 4.6 & 4.7318 & TST \\
\hline CHEMBL1546051 & 688889 & 4.65 & 4.8225 & TRN \\
\hline CHEMBL 71271 & 688889 & 4.95 & 4.6124 & TRN \\
\hline CHEMBL1534352 & 688889 & 6.5 & 4.935 & TRN \\
\hline CHEMBL3191098 & 688889 & 4.45 & 4.7009 & TRN \\
\hline CHEMBL1350636 & 688889 & 4.95 & 4.6355 & TST \\
\hline CHEMBL1522711 & 688889 & 4.95 & 4.9048 & TST \\
\hline CHEMBL1416187 & 688889 & 4.45 & 4.64 & TRN \\
\hline CHEMBL1481142 & 688889 & 4.25 & 4.7834 & TRN \\
\hline CHEMBL1376998 & 688889 & 6.05 & 4.6476 & TST \\
\hline CHEMBL1577967 & 688889 & 4.35 & 4.7834 & TST \\
\hline CHEMBL1535892 & 688889 & 4.45 & 4.7354 & TRN \\
\hline CHEMBL1461175 & 688889 & 5.4 & 4.7916 & TRN \\
\hline CHEMBL1467268 & 688889 & 4.4 & 4.8626 & TST \\
\hline CHEMBL1494773 & 688889 & 4.25 & 4.7547 & TRN \\
\hline CHEMBL1422475 & 688889 & 6.05 & 4.8246 & TRN \\
\hline CHEMBL1488661 & 688889 & 4.8 & 4.6554 & TRN \\
\hline CHEMBL1507271 & 688889 & 4.25 & 4.7855 & TRN \\
\hline CHEMBL1568758 & 688889 & 6.7501 & 4.8045 & TRN \\
\hline CHEMBL1389242 & 688889 & 5.25 & 4.7838 & TRN \\
\hline CHEMBL1301373 & 688889 & 4.95 & 4.8344 & TST \\
\hline CHEMBL1602206 & 688889 & 4.3 & 4.6464 & TRN \\
\hline CHEMBL473107 & 688889 & 4.45 & 4.704 & TRN \\
\hline CHEMBL1333177 & 688889 & 4.5 & 4.6105 & TST \\
\hline CHEMBL 74930 & 688889 & 4.95 & 4.8421 & TRN \\
\hline CHEMBL1597951 & 688889 & 5.4 & 4.7251 & TRN \\
\hline CHEMBL1588135 & 688889 & 4.55 & 4.9874 & TRN \\
\hline CHEMBL1401142 & 688889 & 5.0 & 4.9816 & TRN \\
\hline CHEMBL1432104 & 688889 & 6.7501 & 4.6503 & TRN \\
\hline CHEMBL1561044 & 688889 & 5.3 & 4.9164 & TRN \\
\hline CHEMBL1471904 & 688889 & 4.35 & 4.8886 & TRN \\
\hline CHEMBL1461430 & 688889 & 4.25 & 4.9843 & TRN \\
\hline CHEMBL1327936 & 688889 & 4.25 & 4.8402 & TST \\
\hline
\end{tabular}




\begin{tabular}{|c|c|c|c|c|c|}
\hline \multicolumn{6}{|c|}{ Supplemental Table S2.txt } \\
\hline CHEMBL1538972 & 688889 & 4.5 & 4.633 & TRN & \\
\hline CHEMBL1429377 & 688889 & 4.45 & 4.7651 & TRN & \\
\hline CHEMBL1571893 & 688889 & 4.4 & 4.6741 & TRN & \\
\hline CHEMBL1994007 & 688889 & 4.25 & 4.7049 & TRN & \\
\hline CHEMBL1549672 & 688889 & 5.8 & 4.7683 & TRN & \\
\hline CHEMBL1304729 & 688889 & 6.0 & 4.5932 & TRN & \\
\hline CHEMBL1306582 & 688889 & 5.4 & 4.659 & TST & \\
\hline CHEMBL1426502 & 688889 & 5.4 & 4.8348 & TST & \\
\hline CHEMBL1408346 & 688889 & 4.25 & 4.9572 & TRN & \\
\hline CHEMBL1595937 & 688889 & 4.5 & 4.9903 & TRN & \\
\hline CHEMBL3190352 & 688889 & 5.3 & 4.8369 & TRN & \\
\hline CHEMBL1549099 & 688889 & 4.95 & 4.6377 & TRN & \\
\hline CHEMBL1541868 & 688889 & 4.3 & 4.8206 & TRN & \\
\hline CHEMBL1344042 & 688889 & 5.15 & 4.63399 & 99999999995 & TRN \\
\hline CHEMBL1540464 & 688889 & 4.45 & 4.7148 & TRN & \\
\hline CHEMBL1521608 & 688889 & 4.4 & 4.7084 & TST & \\
\hline CHEMBL1505634 & 688889 & 4.45 & 4.7248 & TRN & \\
\hline CHEMBL1539755 & 688889 & 4.3 & 4.7174 & TRN & \\
\hline CHEMBL1477373 & 688889 & 4.45 & 4.7573 & TRN & \\
\hline CHEMBL1368039 & 688889 & 4.7 & 4.8924 & TRN & \\
\hline CHEMBL1494071 & 688889 & 6.8 & 4.79 & TST & \\
\hline CHEMBL1605728 & 688889 & 4.25 & 4.8803 & TRN & \\
\hline CHEMBL1341450 & 688889 & 4.45 & 4.6013 & TRN & \\
\hline CHEMBL1449260 & 688889 & 4.3 & 4.7627 & TRN & \\
\hline CHEMBL1402286 & 688889 & 4.3 & 4.6286 & TRN & \\
\hline CHEMBL1464411 & 688889 & 5.95 & 4.6855 & TRN & \\
\hline CHEMBL3196167 & 688889 & 5.25 & 4.7791 & TRN & \\
\hline CHEMBL1465680 & 688889 & 4.25 & 4.768 & TRN & \\
\hline CHEMBL2369160 & 688889 & 4.55 & 4.7992 & TRN & \\
\hline CHEMBL1452926 & 688889 & 4.7 & 4.8238 & TRN & \\
\hline CHEMBL1567538 & 688889 & 4.9 & 4.7251 & TST & \\
\hline CHEMBL1588737 & 688889 & 6.3 & 4.9745 & TRN & \\
\hline CHEMBL1576250 & 688889 & 5.1 & 4.8588 & TST & \\
\hline CHEMBL1529039 & 688889 & 4.25 & 4.7903 & TRN & \\
\hline CHEMBL3189634 & 688889 & 4.7 & 4.7375 & TRN & \\
\hline CHEMBL1547783 & 688889 & 4.45 & 4.8787 & TRN & \\
\hline CHEMBL1965471 & 688889 & 5.2 & 4.7149 & TRN & \\
\hline CHEMBL1547422 & 688889 & 4.3 & 4.8078 & TST & \\
\hline CHEMBL3199136 & 688889 & 4.25 & 4.7853 & TRN & \\
\hline CHEMBL1430809 & 688889 & 4.95 & 4.7933 & TST & \\
\hline CHEMBL1498688 & 688889 & 4.5 & 4.852 & TST & \\
\hline CHEMBL1531251 & 688889 & 4.3 & 4.6834 & TRN & \\
\hline CHEMBL1564079 & 688889 & 4.55 & 4.7858 & TRN & \\
\hline CHEMBL1570237 & 688889 & 4.5 & 4.8288 & TRN & \\
\hline CHEMBL1365917 & 688889 & 6.0 & 4.8294 & TST & \\
\hline CHEMBL1449762 & 688889 & 5.8 & 4.8486 & TST & \\
\hline CHEMBL1385505 & 688889 & 4.25 & 4.7602 & TRN & \\
\hline CHEMBL1550789 & 688889 & 4.25 & 4.7969 & TRN & \\
\hline
\end{tabular}




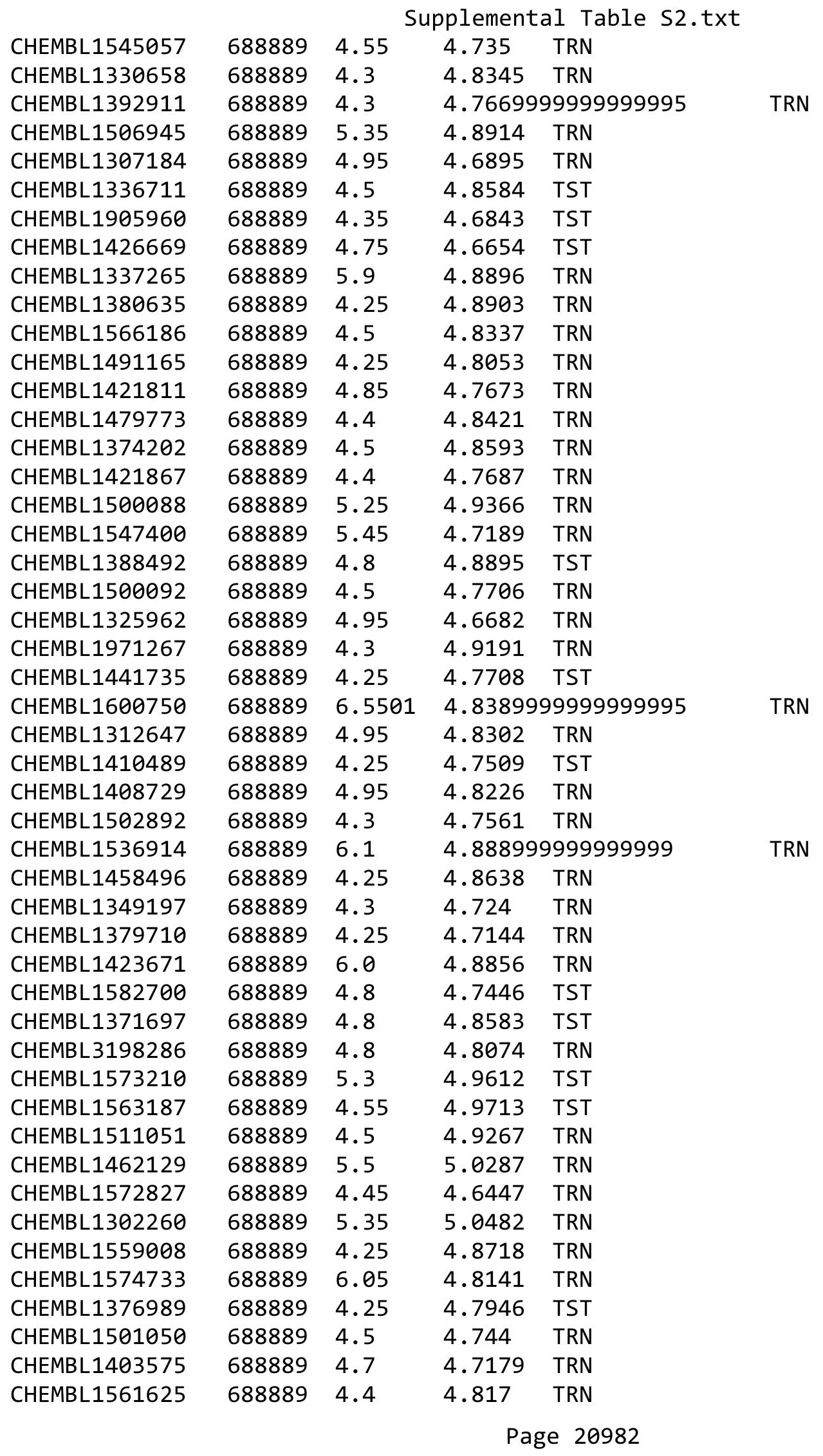




\begin{tabular}{|c|c|c|c|c|c|}
\hline \multicolumn{6}{|c|}{ Supplemental Table S2.txt } \\
\hline CHEMBL1601209 & 688889 & 5.4 & 4.7946 & TST & \\
\hline CHEMBL1365545 & 688889 & 4.5 & 4.6917 & TRN & \\
\hline CHEMBL1542501 & 688889 & 4.9 & 4.7853 & TRN & \\
\hline CHEMBL1439595 & 688889 & 4.35 & 4.7863 & TRN & \\
\hline CHEMBL1300197 & 688889 & 5.9 & 4.8951 & TST & \\
\hline CHEMBL1381382 & 688889 & 5.3 & 4.676 & TST & \\
\hline CHEMBL1453075 & 688889 & 4.25 & 4.7728 & TRN & \\
\hline CHEMBL1569078 & 688889 & 4.7 & 4.8884 & TRN & \\
\hline CHEMBL 3212077 & 688889 & 4.7 & 4.8072 & TRN & \\
\hline CHEMBL1322296 & 688889 & 4.6 & 4.857 & TST & \\
\hline CHEMBL1486181 & 688889 & 4.45 & 4.7128 & TRN & \\
\hline CHEMBL1587369 & 688889 & 4.5 & 4.7186 & TRN & \\
\hline CHEMBL 3212548 & 688889 & 4.55 & 4.825 & TST & \\
\hline CHEMBL1487305 & 688889 & 4.9 & 4.8298 & TST & \\
\hline CHEMBL1410781 & 688889 & 4.45 & 4.7988 & TST & \\
\hline CHEMBL1483960 & 688889 & 4.3 & 4.8953 & TST & \\
\hline CHEMBL1523800 & 688889 & 5.35 & 4.825 & TRN & \\
\hline CHEMBL1420247 & 688889 & 4.7 & 4.8161 & TST & \\
\hline CHEMBL1549862 & 688889 & 4.25 & 4.8145 & TRN & \\
\hline CHEMBL1578618 & 688889 & 4.4 & 4.6985 & TRN & \\
\hline CHEMBL1549402 & 688889 & 5.05 & 4.6512 & TST & \\
\hline CHEMBL1559144 & 688889 & 6.7501 & 4.922 & TRN & \\
\hline CHEMBL1418276 & 688889 & 5.85 & 4.8368 & TRN & \\
\hline CHEMBL1576457 & 688889 & 4.5 & 4.7791 & TRN & \\
\hline CHEMBL1325890 & 688889 & 4.9 & 4.7486 & TRN & \\
\hline CHEMBL1574469 & 688889 & 4.25 & 4.70100 & 00000000005 & TST \\
\hline CHEMBL1359612 & 688889 & 4.45 & 4.7987 & TRN & \\
\hline CHEMBL3199758 & 688889 & 4.25 & 4.8462 & TST & \\
\hline CHEMBL1588560 & 688889 & 4.5 & 4.80699 & 99999999995 & TRN \\
\hline CHEMBL1572925 & 688889 & 4.85 & 4.7633 & TRN & \\
\hline CHEMBL1583880 & 688889 & 4.45 & 4.8298 & TRN & \\
\hline CHEMBL1433183 & 688889 & 4.9 & 4.9207 & TRN & \\
\hline CHEMBL1404915 & 688889 & 5.3 & 4.6877 & TRN & \\
\hline CHEMBL1511149 & 688889 & 4.7 & 4.6494 & TRN & \\
\hline CHEMBL1399158 & 688889 & 5.0 & 4.8278 & TRN & \\
\hline CHEMBL1531457 & 688889 & 6.45 & 4.8699 & TST & \\
\hline CHEMBL1542049 & 688889 & 4.35 & 4.7496 & TRN & \\
\hline CHEMBL1537194 & 688889 & 4.3 & 4.874 & TRN & \\
\hline CHEMBL1410906 & 688889 & 5.2 & 4.9805 & TRN & \\
\hline CHEMBL1460227 & 688889 & 5.2 & 4.9149 & TRN & \\
\hline CHEMBL1594449 & 688889 & 5.4 & 4.806 & TRN & \\
\hline CHEMBL1460595 & 688889 & 4.65 & 4.7648 & TRN & \\
\hline CHEMBL1561127 & 688889 & 5.6 & 4.8856 & TST & \\
\hline CHEMBL3212568 & 688889 & 4.75 & 4.7479 & TRN & \\
\hline CHEMBL1311054 & 688889 & 4.6 & 4.7153 & TRN & \\
\hline CHEMBL1448837 & 688889 & 5.45 & 4.8171 & TRN & \\
\hline CHEMBL1375433 & 688889 & 4.45 & 4.7337 & TRN & \\
\hline CHEMBL1548075 & 688889 & 4.5 & 4.6315 & TST & \\
\hline
\end{tabular}




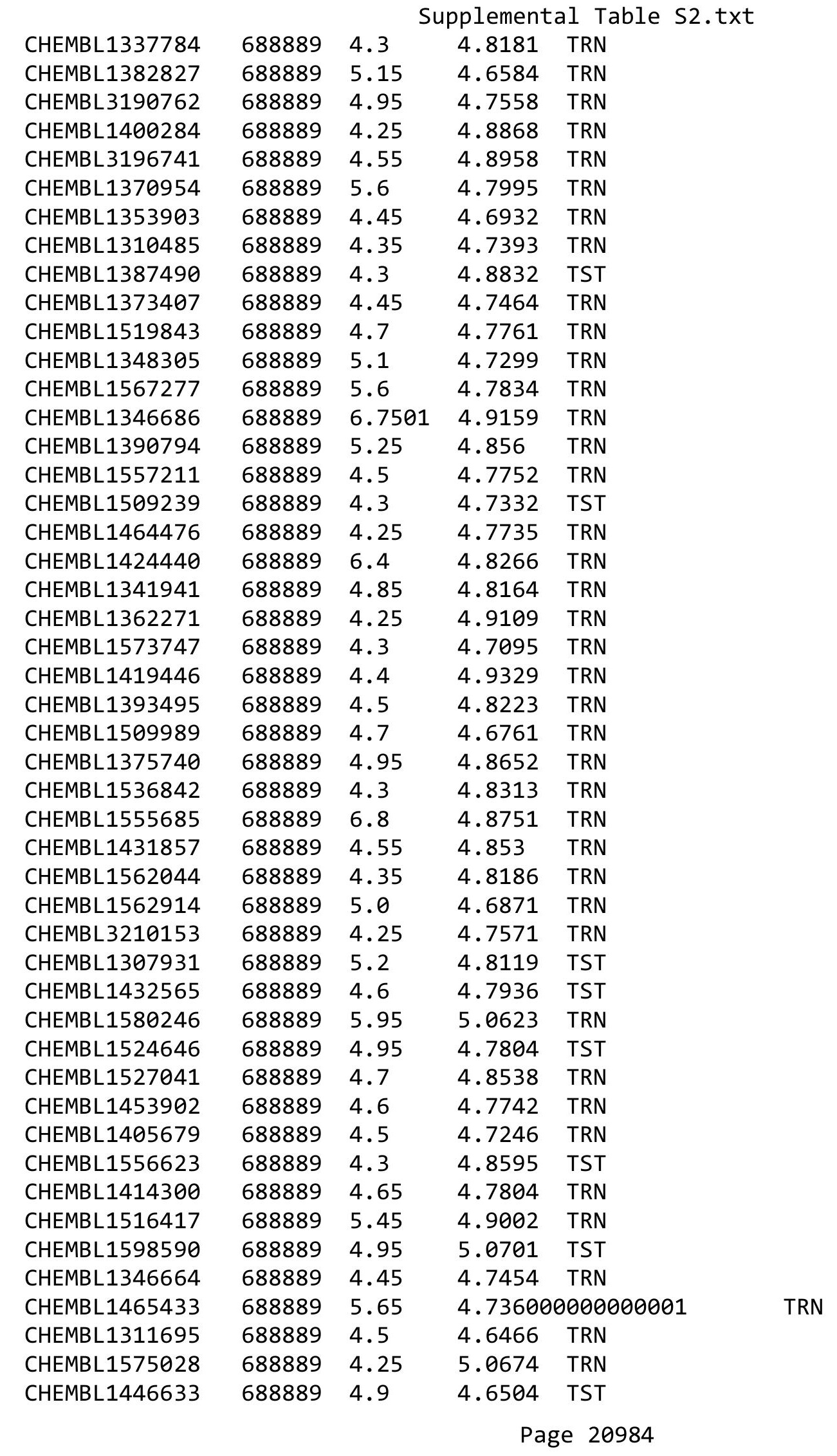




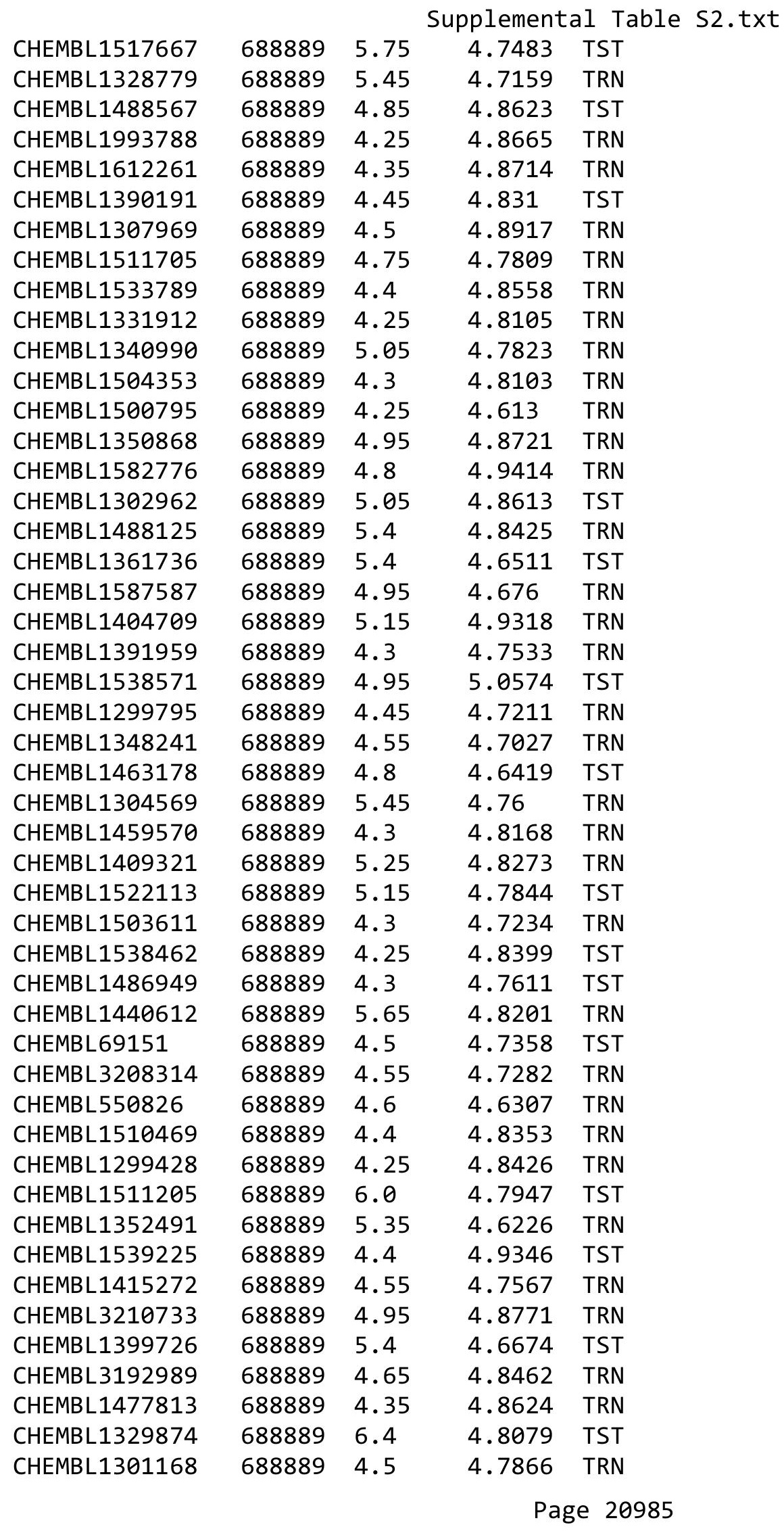




\begin{tabular}{|c|c|c|c|c|}
\hline \multicolumn{5}{|c|}{ Supplemental Table S2.txt } \\
\hline CHEMBL3198633 & 688889 & 4.95 & 4.7334 & TST \\
\hline CHEMBL1484160 & 688889 & 4.85 & 4.8102 & TST \\
\hline CHEMBL1468264 & 688889 & 5.25 & 4.6247 & TRN \\
\hline CHEMBL1472522 & 688889 & 4.3 & 4.9419 & TST \\
\hline CHEMBL1378685 & 688889 & 4.55 & 4.8755 & TRN \\
\hline CHEMBL1367965 & 688889 & 4.3 & 4.6807 & TRN \\
\hline CHEMBL1429171 & 688889 & 4.95 & 4.8318 & TRN \\
\hline CHEMBL1307532 & 688889 & 5.05 & 4.8088 & TST \\
\hline CHEMBL1376444 & 688889 & 4.35 & 4.6741 & TRN \\
\hline CHEMBL1594502 & 688889 & 4.95 & 4.8502 & TRN \\
\hline CHEMBL1324817 & 688889 & 4.85 & 4.6645 & TRN \\
\hline CHEMBL1448879 & 688889 & 5.0 & 4.7818 & TRN \\
\hline CHEMBL1469198 & 688889 & 4.4 & 4.7052 & TRN \\
\hline CHEMBL1547946 & 688889 & 6.05 & 4.8937 & TRN \\
\hline CHEMBL1484820 & 688889 & 4.75 & 4.7875 & TST \\
\hline CHEMBL1568200 & 688889 & 4.25 & 4.7218 & TST \\
\hline CHEMBL1604041 & 688889 & 4.3 & 4.9417 & TST \\
\hline CHEMBL1420549 & 688889 & 4.3 & 4.7879 & TRN \\
\hline CHEMBL1599337 & 688889 & 4.9 & 4.7253 & TRN \\
\hline CHEMBL1349952 & 688889 & 4.45 & 4.7216 & TRN \\
\hline CHEMBL1340938 & 688889 & 4.4 & 4.6592 & TST \\
\hline CHEMBL1506640 & 688889 & 5.3 & 4.703 & TRN \\
\hline CHEMBL1317300 & 688889 & 4.25 & 4.7245 & TST \\
\hline CHEMBL1456810 & 688889 & 4.65 & 4.7717 & TRN \\
\hline CHEMBL1337737 & 688889 & 4.25 & 4.7807 & TRN \\
\hline CHEMBL1496326 & 688889 & 4.25 & 4.7727 & TST \\
\hline CHEMBL1486619 & 688889 & 4.4 & 4.8083 & TRN \\
\hline CHEMBL1573282 & 688889 & 6.7501 & 4.8074 & TRN \\
\hline CHEMBL1384289 & 688889 & 5.15 & 4.97 & TRN \\
\hline CHEMBL3214487 & 688889 & 4.3 & 4.7308 & TST \\
\hline CHEMBL1384429 & 688889 & 4.9 & 4.8871 & TRN \\
\hline CHEMBL1411667 & 688889 & 5.2 & 4.7756 & TST \\
\hline CHEMBL1441372 & 688889 & 4.3 & 4.8903 & TRN \\
\hline CHEMBL1560101 & 688889 & 4.55 & 4.5359 & TRN \\
\hline CHEMBL3214364 & 688889 & 4.55 & 4.7544 & TRN \\
\hline CHEMBL1577518 & 688889 & 4.4 & 4.7825 & TST \\
\hline CHEMBL3192357 & 688889 & 5.1 & 4.6556 & TRN \\
\hline CHEMBL1537016 & 688889 & 4.55 & 4.6767 & TRN \\
\hline CHEMBL1529211 & 688889 & 4.45 & 4.731 & TRN \\
\hline CHEMBL1451184 & 688889 & 6.3 & 4.871 & TRN \\
\hline CHEMBL1319113 & 688889 & 4.35 & 4.8476 & TST \\
\hline CHEMBL1470205 & 688889 & 4.3 & 4.7715 & TRN \\
\hline CHEMBL1455956 & 688889 & 4.95 & 4.6498 & TRN \\
\hline CHEMBL1510837 & 688889 & 4.4 & 4.8067 & TRN \\
\hline CHEMBL1406688 & 688889 & 4.45 & 4.8405 & TRN \\
\hline CHEMBL1363562 & 688889 & 4.45 & 4.8568 & TRN \\
\hline CHEMBL1304747 & 688889 & 6.8 & 4.7259 & TST \\
\hline CHEMBL1331705 & 688889 & 5.7 & 4.6709 & TST \\
\hline
\end{tabular}




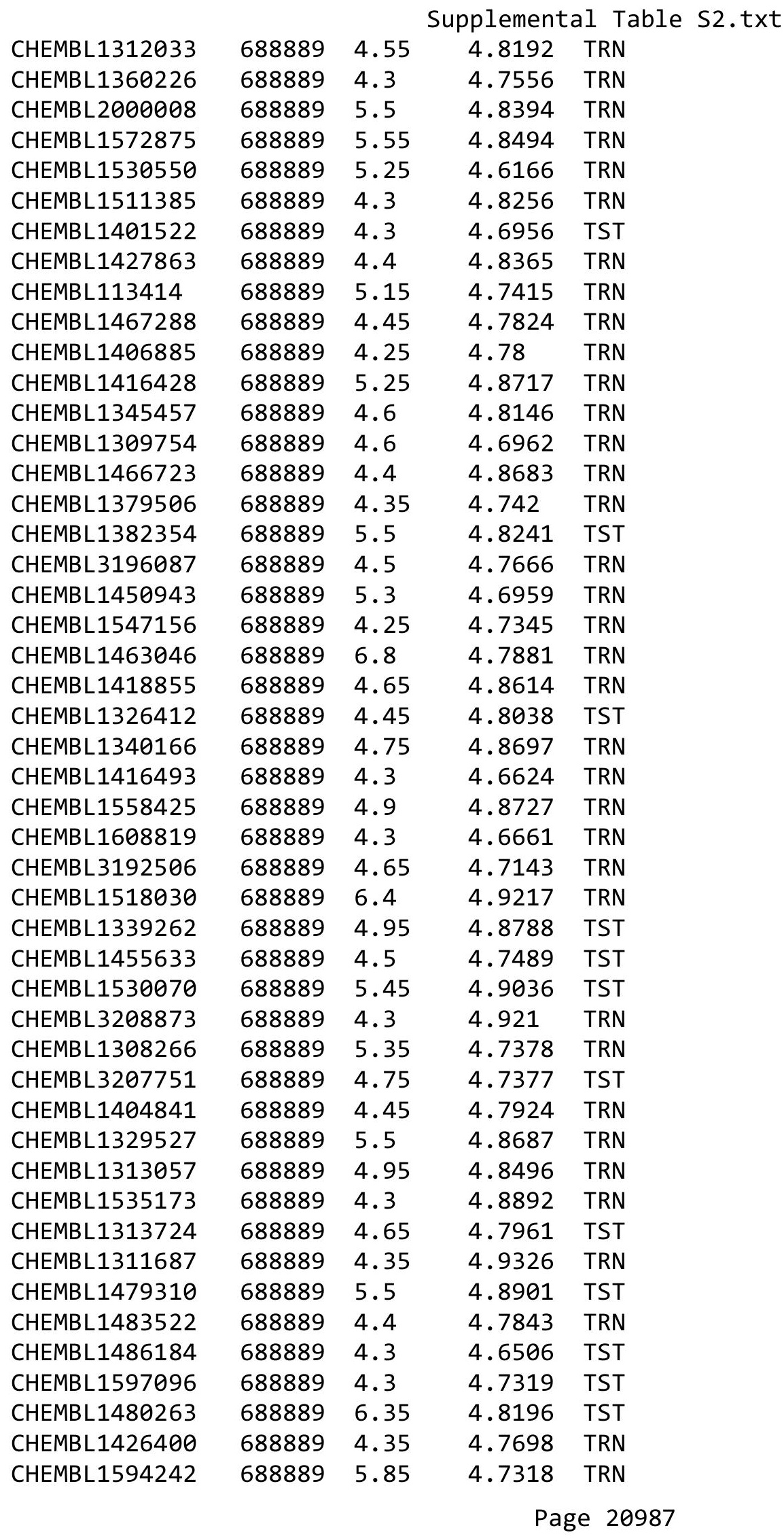




\begin{tabular}{|c|c|c|c|c|c|}
\hline CHEMBL1376343 & 688889 & 4.4 & \multicolumn{2}{|c|}{ 4.7139999999999995 } & TRN \\
\hline CHEMBL1526157 & 688889 & 4.3 & 4.7639 & TRN & \\
\hline CHEMBL1497485 & 688889 & 4.25 & 4.8249 & TRN & \\
\hline CHEMBL1413068 & 688889 & 4.95 & 4.9095 & TRN & \\
\hline CHEMBL1531658 & 688889 & 5.85 & 4.6916 & TST & \\
\hline CHEMBL1586077 & 688889 & 5.3 & 4.796 & TRN & \\
\hline CHEMBL1535546 & 688889 & 4.35 & 4.7519 & TRN & \\
\hline CHEMBL1322578 & 688889 & 5.25 & 4.8456 & TRN & \\
\hline CHEMBL1533776 & 688889 & 4.35 & 4.6047 & TRN & \\
\hline CHEMBL1526000 & 688889 & 4.55 & 4.7214 & TRN & \\
\hline CHEMBL3193582 & 688889 & 4.55 & 4.8293 & TST & \\
\hline CHEMBL1575721 & 688889 & 4.45 & 4.7451 & TRN & \\
\hline CHEMBL1573102 & 688889 & 4.25 & 4.6522 & TRN & \\
\hline CHEMBL1408665 & 688889 & 5.6 & 4.8722 & TST & \\
\hline CHEMBL3210974 & 688889 & 4.5 & 4.9087 & TRN & \\
\hline CHEMBL1520286 & 688889 & 4.4 & 4.7781 & TST & \\
\hline CHEMBL1491648 & 688889 & 4.95 & 4.7981 & TRN & \\
\hline CHEMBL3211304 & 688889 & 4.25 & 4.7296 & TRN & \\
\hline CHEMBL1523350 & 688889 & 5.25 & 4.9213 & TST & \\
\hline CHEMBL1606864 & 688889 & 4.25 & 4.8201 & TRN & \\
\hline CHEMBL3192691 & 688889 & 4.5 & 4.5834 & TRN & \\
\hline CHEMBL1412077 & 688889 & 5.8 & 4.779 & TRN & \\
\hline CHEMBL1417270 & 688889 & 4.95 & 4.7716 & TRN & \\
\hline CHEMBL1566365 & 688889 & 4.4 & 4.6353 & TRN & \\
\hline CHEMBL1600293 & 688889 & 4.3 & 4.8324 & TRN & \\
\hline CHEMBL1525130 & 688889 & 4.45 & 4.7615 & TST & \\
\hline CHEMBL1408390 & 688889 & 5.2 & 4.8686 & TST & \\
\hline CHEMBL3208655 & 688889 & 5.3 & 4.8474 & TST & \\
\hline CHEMBL1310746 & 688889 & 5.7 & 4.7576 & TRN & \\
\hline CHEMBL1499110 & 688889 & 4.5 & 4.8094 & TRN & \\
\hline CHEMBL1451950 & 688889 & 4.35 & 4.8418 & TST & \\
\hline CHEMBL1440215 & 688889 & 4.25 & 4.8009 & TRN & \\
\hline CHEMBL1460694 & 688889 & 5.9 & 4.9006 & TRN & \\
\hline CHEMBL1990866 & 688889 & 4.4 & 4.7968 & TST & \\
\hline CHEMBL1516993 & 688889 & 4.3 & 4.9897 & TRN & \\
\hline CHEMBL1580923 & 688889 & 4.95 & 4.878 & TST & \\
\hline CHEMBL1367063 & 688889 & 4.9 & 4.7781 & TRN & \\
\hline CHEMBL1595998 & 688889 & 5.2 & 4.9221 & TRN & \\
\hline CHEMBL1341687 & 688889 & 4.45 & 4.6831 & TST & \\
\hline CHEMBL1587977 & 688889 & 4.25 & 4.7829 & TST & \\
\hline CHEMBL1402718 & 688889 & 5.4 & 4.9189 & TRN & \\
\hline CHEMBL1564202 & 688889 & 5.3 & 4.8258 & TRN & \\
\hline CHEMBL1493063 & 688889 & 5.3 & 4.6885 & TRN & \\
\hline CHEMBL1545718 & 688889 & 4.95 & 4.8661 & TRN & \\
\hline CHEMBL1328660 & 688889 & 4.5 & 4.8477 & TRN & \\
\hline CHEMBL1439500 & 688889 & 4.25 & 4.7581 & TST & \\
\hline CHEMBL1406768 & 688889 & 4.35 & 4.8426 & TRN & \\
\hline CHEMBL1575408 & 688889 & 5.45 & 4.7152 & TRN & \\
\hline
\end{tabular}




\begin{tabular}{|c|c|c|c|c|c|}
\hline \multicolumn{6}{|c|}{ Supplemental Table S2.txt } \\
\hline CHEMBL1536814 & 688889 & 4.7 & 4.7545 & TRN & \\
\hline CHEMBL1522691 & 688889 & 4.9 & 4.7566 & TRN & \\
\hline CHEMBL1572295 & 688889 & 4.35 & 4.8138 & TRN & \\
\hline CHEMBL1369737 & 688889 & 5.35 & 4.8288 & TRN & \\
\hline CHEMBL1438733 & 688889 & 4.35 & 4.765 & TRN & \\
\hline CHEMBL1351896 & 688889 & 4.5 & 4.6508 & TRN & \\
\hline CHEMBL1299567 & 688889 & 4.9 & 4.8162 & TRN & \\
\hline CHEMBL1498009 & 688889 & 4.3 & 4.8222 & TST & \\
\hline CHEMBL1328291 & 688889 & 6.6 & 4.9194 & TRN & \\
\hline CHEMBL473106 & 688889 & 4.65 & 4.8113 & TRN & \\
\hline CHEMBL1381997 & 688889 & 4.3 & 4.9683 & TRN & \\
\hline CHEMBL1557568 & 688889 & 4.55 & 4.7081 & TRN & \\
\hline CHEMBL1568723 & 688889 & 4.3 & 4.6778 & TRN & \\
\hline CHEMBL1455168 & 688889 & 4.5 & 4.686 & TRN & \\
\hline CHEMBL1339665 & 688889 & 4.95 & $4.7780 e$ & 00000000005 & TST \\
\hline CHEMBL1372527 & 688889 & 4.9 & 4.878 & TRN & \\
\hline CHEMBL1352812 & 688889 & 4.9 & 4.9774 & TRN & \\
\hline CHEMBL1535337 & 688889 & 4.9 & 4.8482 & TRN & \\
\hline CHEMBL3212521 & 688889 & 5.15 & 4.8102 & TST & \\
\hline CHEMBL1498628 & 688889 & 4.95 & 4.9023 & TRN & \\
\hline CHEMBL1306287 & 688889 & 4.65 & 4.7937 & TST & \\
\hline CHEMBL1537168 & 688889 & 4.3 & 4.7856 & TST & \\
\hline CHEMBL1308918 & 688889 & 4.35 & 4.9735 & TRN & \\
\hline CHEMBL1542046 & 688889 & 4.45 & 4.7566 & TRN & \\
\hline CHEMBL1332739 & 688889 & 4.3 & 4.8589 & TRN & \\
\hline CHEMBL1540428 & 688889 & 4.3 & 4.888 & TRN & \\
\hline CHEMBL1385740 & 688889 & 5.8 & 4.8042 & TRN & \\
\hline CHEMBL1560906 & 688889 & 4.3 & 4.8733 & TST & \\
\hline CHEMBL1348491 & 688889 & 4.25 & 4.7751 & TST & \\
\hline CHEMBL1493998 & 688889 & 5.95 & 4.7897 & TST & \\
\hline CHEMBL1363984 & 688889 & 4.25 & 4.7834 & TRN & \\
\hline CHEMBL540851 & 688889 & 4.55 & 4.8851 & TST & \\
\hline CHEMBL1337136 & 688889 & 4.95 & 4.8494 & TRN & \\
\hline CHEMBL1500207 & 688889 & 5.1 & 4.9001 & TRN & \\
\hline CHEMBL1538322 & 688889 & 4.45 & 4.6684 & TRN & \\
\hline CHEMBL1334134 & 688889 & 4.5 & 4.6733 & TRN & \\
\hline CHEMBL1502227 & 688889 & 4.3 & 4.8213 & TRN & \\
\hline CHEMBL1304805 & 688889 & 4.65 & 4.7469 & TST & \\
\hline CHEMBL3196068 & 688889 & 4.3 & 4.8796 & TRN & \\
\hline CHEMBL1468854 & 688889 & 4.25 & 4.8827 & TRN & \\
\hline CHEMBL1477642 & 688889 & 4.55 & 4.7315 & TRN & \\
\hline CHEMBL1326778 & 688889 & 4.6 & 4.6439 & TST & \\
\hline CHEMBL1344732 & 688889 & 4.9 & 4.684 & TST & \\
\hline CHEMBL1402400 & 688889 & 5.45 & 4.6535 & TRN & \\
\hline CHEMBL1429476 & 688889 & 4.55 & 4.649 & TRN & \\
\hline CHEMBL1414665 & 688889 & 4.3 & 4.7826 & TST & \\
\hline CHEMBL588907 & 688889 & 6.8 & 4.769 & TST & \\
\hline CHEMBL1407387 & 688889 & 4.45 & 4.6914 & TRN & \\
\hline
\end{tabular}




\begin{tabular}{|c|c|c|c|c|c|}
\hline \\
\hline CHEMBL1541966 & 688889 & 4.9 & 4.8374 & TRN & \\
\hline CHEMBL1392624 & 688889 & 4.55 & 4.7173 & TRN & \\
\hline CHEMBL1463244 & 688889 & 5.4 & 4.7991 & TST & \\
\hline CHEMBL1565573 & 688889 & 4.7 & 4.7506 & TRN & \\
\hline CHEMBL1348730 & 688889 & 4.5 & 4.7484 & TRN & \\
\hline CHEMBL1391513 & 688889 & 4.5 & 4.6005 & TRN & \\
\hline CHEMBL1407281 & 688889 & 4.9 & 5.0042 & TRN & \\
\hline CHEMBL1373255 & 688889 & 4.45 & 4.5438 & TRN & \\
\hline CHEMBL1500231 & 688889 & 4.3 & 4.6996 & TST & \\
\hline CHEMBL460571 & 688889 & 4.3 & 4.6408 & TRN & \\
\hline CHEMBL1327319 & 688889 & 6.5 & 4.9961 & TRN & \\
\hline CHEMBL1505823 & 688889 & 4.55 & 4.7065 & TRN & \\
\hline CHEMBL1420551 & 688889 & 4.65 & 4.7759 & TRN & \\
\hline CHEMBL1340409 & 688889 & 4.25 & 4.9589 & TRN & \\
\hline CHEMBL3196447 & 688889 & 4.3 & 4.8479 & TRN & \\
\hline CHEMBL1575559 & 688889 & 4.8 & 4.8535 & TRN & \\
\hline CHEMBL1299462 & 688889 & 5.25 & 4.8606 & TRN & \\
\hline CHEMBL3145369 & 688889 & 4.5 & 4.7877 & TRN & \\
\hline CHEMBL1314828 & 688889 & 4.95 & 4.8246 & TST & \\
\hline CHEMBL1559539 & 688889 & 4.5 & 4.8971 & TRN & \\
\hline CHEMBL1338196 & 688889 & 4.85 & 4.6805 & TRN & \\
\hline CHEMBL1364856 & 688889 & 4.45 & 4.6476 & TRN & \\
\hline CHEMBL 3212712 & 688889 & 4.9 & 4.8413 & TST & \\
\hline CHEMBL1438641 & 688889 & 6.4 & 4.6962 & TRN & \\
\hline CHEMBL1499910 & 688889 & 4.9 & 4.6822 & TRN & \\
\hline CHEMBL1388368 & 688889 & 4.55 & 4.8591 & TRN & \\
\hline CHEMBL1549345 & 688889 & 4.3 & 4.8719 & TRN & \\
\hline CHEMBL1334131 & 688889 & 5.0 & 4.9259 & TRN & \\
\hline CHEMBL1446309 & 688889 & 4.4 & 4.8216 & TST & \\
\hline CHEMBL1369370 & 688889 & 5.45 & 4.8388 & TRN & \\
\hline CHEMBL1330714 & 688889 & 4.65 & 4.72199 & 99999999995 & TRN \\
\hline CHEMBL1582594 & 688889 & 4.35 & 4.9027 & TRN & \\
\hline CHEMBL1568753 & 688889 & 5.1 & 4.9169 & TRN & \\
\hline CHEMBL1076559 & 688889 & 4.55 & 4.641 & TST & \\
\hline CHEMBL1575653 & 688889 & 6.8 & 4.8347 & TRN & \\
\hline CHEMBL1416042 & 688889 & 4.3 & 5.0017 & TRN & \\
\hline CHEMBL1577601 & 688889 & 4.4 & 4.6548 & TRN & \\
\hline CHEMBL1500150 & 688889 & 4.3 & 4.8376 & TRN & \\
\hline CHEMBL3195890 & 688889 & 5.3 & 4.746 & TRN & \\
\hline CHEMBL1413588 & 688889 & 5.4 & 4.6963 & TRN & \\
\hline CHEMBL1430500 & 688889 & 5.1 & 4.8739 & TRN & \\
\hline CHEMBL1331503 & 688889 & 5.15 & 4.7585 & TRN & \\
\hline CHEMBL1342766 & 688889 & 4.8 & 4.6955 & TRN & \\
\hline CHEMBL1538676 & 688889 & 4.45 & 4.6988 & TRN & \\
\hline CHEMBL3192061 & 688889 & 6.8 & 4.7514 & TST & \\
\hline CHEMBL1386700 & 688889 & 5.3 & 4.8098 & TRN & \\
\hline CHEMBL1511722 & 688889 & 6.25 & 4.7206 & TRN & \\
\hline CHEMBL1454703 & 688889 & 6.7501 & 4.7939 & TST & \\
\hline
\end{tabular}




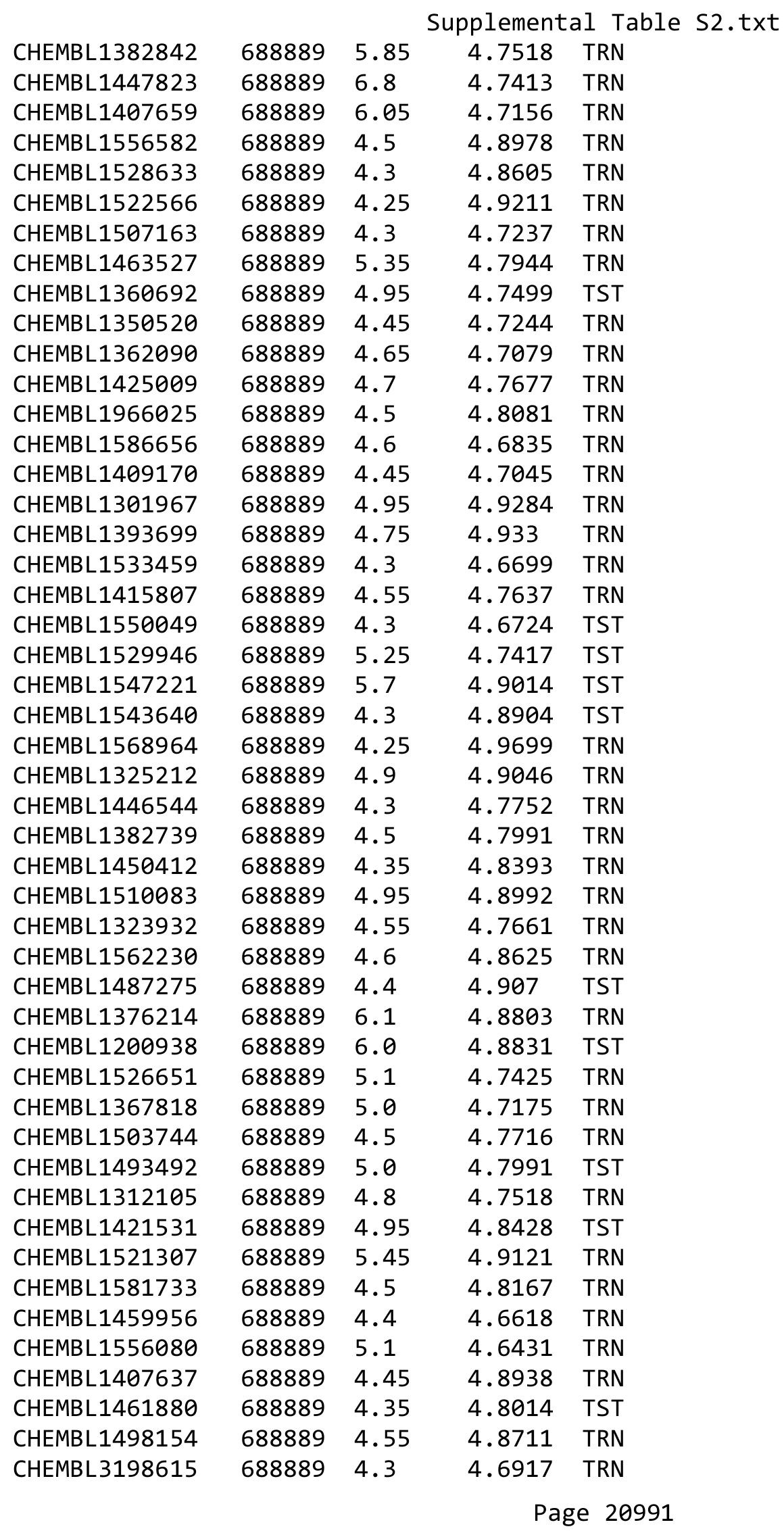




\begin{tabular}{|c|c|c|c|c|c|}
\hline \multicolumn{6}{|c|}{ Supplemental Table S2.txt } \\
\hline CHEMBL1337907 & 688889 & 5.7 & 4.6966 & TRN & \\
\hline CHEMBL606167 & 688889 & 4.6 & 4.7863 & TST & \\
\hline CHEMBL1560511 & 688889 & 4.45 & 4.7662 & TST & \\
\hline CHEMBL1401653 & 688889 & 4.35 & 4.7062 & TST & \\
\hline CHEMBL1518776 & 688889 & 5.0 & 4.921 & TRN & \\
\hline CHEMBL1310175 & 688889 & 4.3 & 4.9165 & TRN & \\
\hline CHEMBL1586636 & 688889 & 5.9 & 4.7269 & TST & \\
\hline CHEMBL1335492 & 688889 & 4.55 & 4.7259 & TRN & \\
\hline CHEMBL1500235 & 688889 & 4.25 & 4.9203 & TRN & \\
\hline CHEMBL1449317 & 688889 & 6.4 & 4.9566 & TRN & \\
\hline CHEMBL1350359 & 688889 & 5.1 & 4.8403 & TST & \\
\hline CHEMBL1581950 & 688889 & 4.6 & 4.7302 & TRN & \\
\hline CHEMBL 3212840 & 688889 & 4.7 & 4.7611 & TRN & \\
\hline CHEMBL1304580 & 688889 & 5.3 & 4.8932 & TST & \\
\hline CHEMBL1300408 & 688889 & 4.4 & 4.6064 & TRN & \\
\hline CHEMBL3192400 & 688889 & 4.25 & 4.7846 & TRN & \\
\hline CHEMBL1531300 & 688889 & 4.9 & 4.7827 & TRN & \\
\hline CHEMBL 3210053 & 688889 & 4.95 & 4.805 & TRN & \\
\hline CHEMBL1411576 & 688889 & 4.65 & 4.7507 & TST & \\
\hline CHEMBL1489145 & 688889 & 4.4 & 4.7038 & TRN & \\
\hline CHEMBL1598444 & 688889 & 4.25 & 4.9181 & TRN & \\
\hline CHEMBL1363626 & 688889 & 5.5 & 4.9277 & TRN & \\
\hline CHEMBL3207353 & 688889 & 5.3 & 4.84399 & 9999999999 & TRN \\
\hline CHEMBL1429470 & 688889 & 4.25 & 4.8771 & TRN & \\
\hline CHEMBL1533501 & 688889 & 4.6 & 4.8818 & TST & \\
\hline CHEMBL1985321 & 688889 & 4.45 & 4.6623 & TRN & \\
\hline CHEMBL1374654 & 688889 & 4.95 & 4.6334 & TRN & \\
\hline CHEMBL1334615 & 688889 & 4.25 & 4.7951 & TRN & \\
\hline CHEMBL1451241 & 688889 & 5.0 & 4.9306 & TRN & \\
\hline CHEMBL1538295 & 688889 & 4.4 & 4.8837 & TRN & \\
\hline CHEMBL1479331 & 688889 & 5.0 & 4.8702 & TRN & \\
\hline CHEMBL1556258 & 688889 & 4.35 & 4.8678 & TRN & \\
\hline CHEMBL1368674 & 688889 & 4.3 & 4.7793 & TRN & \\
\hline CHEMBL1431276 & 688889 & 4.35 & 4.8052 & TRN & \\
\hline CHEMBL1490424 & 688889 & 4.25 & 4.8268 & TST & \\
\hline CHEMBL1500639 & 688889 & 6.8 & 4.9978 & TRN & \\
\hline CHEMBL1421698 & 688889 & 4.45 & 4.7661 & TRN & \\
\hline CHEMBL1460317 & 688889 & 5.5 & 4.7721 & TST & \\
\hline CHEMBL1496289 & 688889 & 4.3 & 4.79899 & 99999999995 & TRN \\
\hline CHEMBL1303482 & 688889 & 4.25 & 4.8561 & TST & \\
\hline CHEMBL3194067 & 688889 & 5.55 & 4.8121 & TRN & \\
\hline CHEMBL1580511 & 688889 & 4.35 & 4.6103 & TRN & \\
\hline CHEMBL1529824 & 688889 & 4.8 & 4.7957 & TST & \\
\hline CHEMBL1443319 & 688889 & 4.55 & 4.6902 & TRN & \\
\hline CHEMBL1501393 & 688889 & 4.25 & 4.8501 & TST & \\
\hline CHEMBL1985350 & 688889 & 5.1 & 4.6499 & TRN & \\
\hline CHEMBL1392688 & 688889 & 4.25 & 4.7823 & TRN & \\
\hline CHEMBL1498657 & 688889 & 5.75 & 4.8069 & TST & \\
\hline
\end{tabular}




\begin{tabular}{|c|c|c|c|c|c|}
\hline \multicolumn{6}{|c|}{ Supplemental Table S2.txt } \\
\hline CHEMBL1566405 & 688889 & 4.45 & 4.8395 & TRN & \\
\hline CHEMBL 1446348 & 688889 & 4.25 & 4.8003 & TST & \\
\hline CHEMBL1526936 & 688889 & 4.55 & 4.8511 & TRN & \\
\hline CHEMBL1329868 & 688889 & 4.3 & 4.7407 & TRN & \\
\hline CHEMBL1371657 & 688889 & 4.3 & 4.6782 & TRN & \\
\hline CHEMBL1305674 & 688889 & 4.5 & 4.8303 & TST & \\
\hline CHEMBL1426674 & 688889 & 5.3 & 5.0167 & TRN & \\
\hline CHEMBL1570452 & 688889 & 4.95 & 4.9012 & TST & \\
\hline CHEMBL1451424 & 688889 & 4.25 & 4.97199 & 99999999995 & TST \\
\hline CHEMBL1321896 & 688889 & 4.75 & 4.7055 & TRN & \\
\hline CHEMBL1346112 & 688889 & 4.45 & 4.7562 & TRN & \\
\hline CHEMBL1348218 & 688889 & 4.25 & 4.9236 & TRN & \\
\hline CHEMBL1601517 & 688889 & 5.4 & 4.748 & TST & \\
\hline CHEMBL3192179 & 688889 & 4.85 & 4.7353 & TRN & \\
\hline CHEMBL1333153 & 688889 & 5.55 & 4.84 & TST & \\
\hline CHEMBL1597025 & 688889 & 5.9 & 4.8584 & TRN & \\
\hline CHEMBL1368060 & 688889 & 4.65 & 4.8508 & TRN & \\
\hline CHEMBL1404385 & 688889 & 6.15 & 4.7947 & TRN & \\
\hline CHEMBL1501538 & 688889 & 4.3 & 4.6511 & TRN & \\
\hline CHEMBL1576777 & 688889 & 4.25 & 4.8892 & TRN & \\
\hline CHEMBL1423621 & 688889 & 4.55 & 4.7726 & TRN & \\
\hline CHEMBL1346410 & 688889 & 4.45 & 4.6308 & TRN & \\
\hline CHEMBL1377177 & 688889 & 4.45 & 4.7445 & TRN & \\
\hline CHEMBL1429387 & 688889 & 4.5 & 4.6719 & TRN & \\
\hline CHEMBL1338931 & 688889 & 4.3 & 4.9463 & TRN & \\
\hline CHEMBL3213492 & 688889 & 4.45 & 4.7845 & TRN & \\
\hline CHEMBL1606443 & 688889 & 4.25 & 4.7315 & TRN & \\
\hline CHEMBL1374247 & 688889 & 4.45 & 4.6705 & TRN & \\
\hline CHEMBL1864436 & 688889 & 4.3 & 4.6746 & TST & \\
\hline CHEMBL 1450446 & 688889 & 4.3 & 4.7098 & TRN & \\
\hline CHEMBL151252 & 688889 & 4.3 & 4.6997 & TRN & \\
\hline CHEMBL1516503 & 688889 & 4.35 & 4.8229 & TRN & \\
\hline CHEMBL1570188 & 688889 & 6.05 & 4.8983 & TST & \\
\hline CHEMBL581452 & 688889 & 4.95 & 4.8802 & TRN & \\
\hline CHEMBL1430726 & 688889 & 4.95 & 4.7373 & TRN & \\
\hline CHEMBL1437869 & 688889 & 4.4 & 4.7651 & TRN & \\
\hline CHEMBL1346923 & 688889 & 4.65 & 4.8263 & TRN & \\
\hline CHEMBL1314100 & 688889 & 4.4 & 4.6004 & TRN & \\
\hline CHEMBL454173 & 688889 & 4.3 & 4.7146 & TST & \\
\hline CHEMBL1411761 & 688889 & 4.4 & 4.7967 & TRN & \\
\hline CHEMBL3196379 & 688889 & 4.55 & 4.7713 & TST & \\
\hline CHEMBL1467442 & 688889 & 4.95 & 4.7878 & TRN & \\
\hline CHEMBL1561229 & 688889 & 4.3 & 4.7305 & TRN & \\
\hline CHEMBL1337470 & 688889 & 4.3 & 4.7215 & TRN & \\
\hline CHEMBL1331016 & 688889 & 4.45 & 4.7763 & TRN & \\
\hline CHEMBL1580589 & 688889 & 4.25 & 4.7083 & TRN & \\
\hline CHEMBL1560630 & 688889 & 4.55 & 4.7947 & TRN & \\
\hline CHEMBL1412271 & 688889 & 4.9 & 4.7996 & TRN & \\
\hline
\end{tabular}




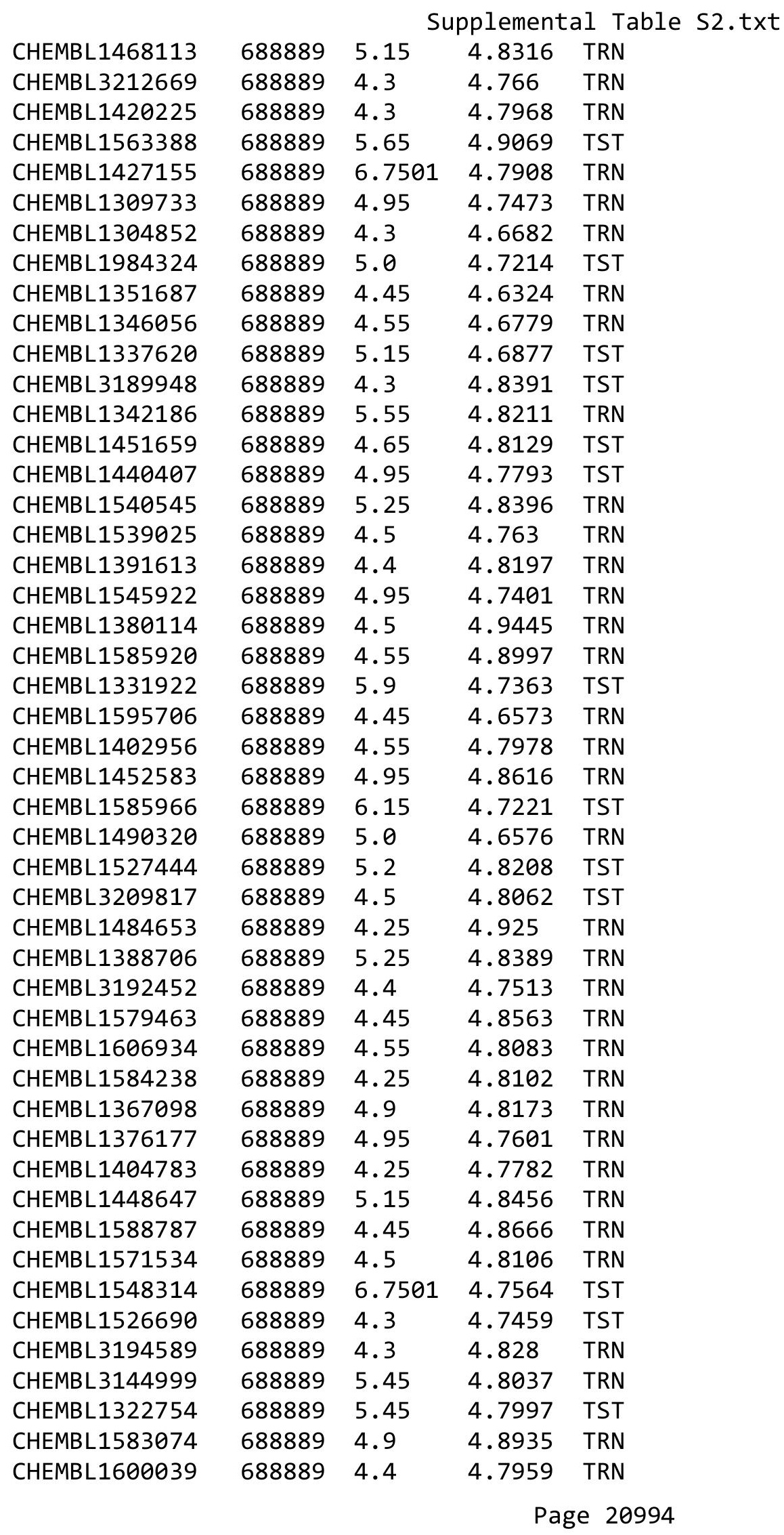




\begin{tabular}{|c|c|c|c|c|c|}
\hline \multicolumn{6}{|c|}{ Supplemental Table S2.txt } \\
\hline CHEMBL1480533 & 688889 & 6.1 & 4.7907 & TRN & \\
\hline CHEMBL1537572 & 688889 & 4.35 & 4.8365 & TRN & \\
\hline CHEMBL3208402 & 688889 & 5.85 & 4.7515 & TRN & \\
\hline CHEMBL1326776 & 688889 & 5.05 & 4.8699 & TRN & \\
\hline CHEMBL1490333 & 688889 & 6.7501 & 4.9387 & TRN & \\
\hline CHEMBL1583303 & 688889 & 4.4 & 4.9331 & TRN & \\
\hline CHEMBL1366700 & 688889 & 5.25 & 4.883 & TST & \\
\hline CHEMBL1425058 & 688889 & 4.4 & 4.8108 & TRN & \\
\hline CHEMBL1362901 & 688889 & 4.4 & 4.7807 & TST & \\
\hline CHEMBL1426239 & 688889 & 4.3 & 4.7252 & TRN & \\
\hline CHEMBL1416473 & 688889 & 5.05 & 4.758 & TRN & \\
\hline CHEMBL1312201 & 688889 & 4.3 & 4.7187 & TRN & \\
\hline CHEMBL1312737 & 688889 & 4.5 & 4.6429 & TRN & \\
\hline CHEMBL1504367 & 688889 & 5.45 & 4.9771 & TRN & \\
\hline CHEMBL1441637 & 688889 & 5.65 & $4.9460 e$ & 0000000001 & TRN \\
\hline CHEMBL1503314 & 688889 & 4.4 & 4.8734 & TRN & \\
\hline CHEMBL1524104 & 688889 & 4.35 & 4.8221 & TRN & \\
\hline CHEMBL1608804 & 688889 & 4.95 & 4.8814 & TST & \\
\hline CHEMBL1510865 & 688889 & 4.25 & 4.7752 & TST & \\
\hline CHEMBL3194028 & 688889 & 4.4 & 4.7578 & TRN & \\
\hline CHEMBL1391954 & 688889 & 5.3 & 4.9104 & TRN & \\
\hline CHEMBL1420885 & 688889 & 4.3 & 4.765 & TST & \\
\hline CHEMBL1420421 & 688889 & 4.95 & 4.9643 & TST & \\
\hline CHEMBL 3208367 & 688889 & 4.4 & 4.7894 & TRN & \\
\hline CHEMBL1418211 & 688889 & 4.3 & 4.8254 & TRN & \\
\hline CHEMBL1334164 & 688889 & 6.25 & 4.7927 & TST & \\
\hline CHEMBL1420119 & 688889 & 5.55 & 4.7553 & TST & \\
\hline CHEMBL1586058 & 688889 & 4.55 & 4.7554 & TRN & \\
\hline CHEMBL1381674 & 688889 & 4.9 & 4.7941 & TRN & \\
\hline CHEMBL1407017 & 688889 & 4.6 & 4.7289 & TRN & \\
\hline CHEMBL1536287 & 688889 & 5.1 & 4.9379 & TST & \\
\hline CHEMBL1338140 & 688889 & 4.75 & 4.6592 & TRN & \\
\hline CHEMBL1423113 & 688889 & 4.95 & 4.7389 & TST & \\
\hline CHEMBL1387731 & 688889 & 6.1 & 4.79 & TRN & \\
\hline CHEMBL1574631 & 688889 & 4.45 & 4.8588 & TRN & \\
\hline CHEMBL1977983 & 688889 & 4.5 & 4.7919 & TRN & \\
\hline CHEMBL1345153 & 688889 & 4.95 & 4.8972 & TRN & \\
\hline CHEMBL1520131 & 688889 & 4.5 & 4.6262 & TRN & \\
\hline CHEMBL1485007 & 688889 & 4.55 & 4.7606 & TRN & \\
\hline CHEMBL1527615 & 688889 & 4.5 & 4.7954 & TRN & \\
\hline CHEMBL1383872 & 688889 & 4.55 & 4.6395 & TRN & \\
\hline CHEMBL1588183 & 688889 & 6.4 & 4.9056 & TRN & \\
\hline CHEMBL3195373 & 688889 & 5.65 & 4.8209 & TRN & \\
\hline CHEMBL1595148 & 688889 & 5.15 & 4.6913 & TST & \\
\hline CHEMBL1339885 & 688889 & 5.45 & 4.9769 & TST & \\
\hline CHEMBL1363597 & 688889 & 4.85 & 4.7644 & TRN & \\
\hline CHEMBL1492194 & 688889 & 5.6 & 4.8122 & TRN & \\
\hline CHEMBL1299674 & 688889 & 4.25 & 4.7538 & TRN & \\
\hline
\end{tabular}




\begin{tabular}{|c|c|c|c|c|}
\hline \multicolumn{5}{|c|}{ Supplemental Table S2.txt } \\
\hline CHEMBL1518421 & 688889 & 4.5 & 4.6891 & TRN \\
\hline CHEMBL1543218 & 688889 & 5.5 & 4.9516 & TRN \\
\hline CHEMBL1547692 & 688889 & 4.45 & 4.8784 & TRN \\
\hline CHEMBL1380722 & 688889 & 4.55 & 4.7745 & TRN \\
\hline CHEMBL3198769 & 688889 & 4.5 & 4.7167 & TRN \\
\hline CHEMBL1465103 & 688889 & 5.55 & 4.6886 & TST \\
\hline CHEMBL1402965 & 688889 & 6.8 & 4.9601 & TST \\
\hline CHEMBL1385366 & 688889 & 4.45 & 4.6902 & TST \\
\hline CHEMBL1611907 & 688889 & 4.95 & 4.8116 & TST \\
\hline CHEMBL1308408 & 688889 & 5.0 & 4.7127 & TRN \\
\hline CHEMBL1446921 & 688889 & 4.3 & 4.6255 & TRN \\
\hline CHEMBL1301239 & 688889 & 5.35 & 4.6569 & TRN \\
\hline CHEMBL1585325 & 688889 & 4.95 & 4.8556 & TST \\
\hline CHEMBL1546727 & 688889 & 6.7001 & 4.8266 & TST \\
\hline CHEMBL1602496 & 688889 & 4.35 & 5.0393 & TRN \\
\hline CHEMBL1414984 & 688889 & 5.0 & 4.7936 & TRN \\
\hline CHEMBL1373134 & 688889 & 5.9 & 4.8619 & TRN \\
\hline CHEMBL1542873 & 688889 & 6.0 & 4.8639 & TRN \\
\hline CHEMBL1463795 & 688889 & 4.5 & 4.7663 & TST \\
\hline CHEMBL1611753 & 688889 & 4.5 & 4.6062 & TRN \\
\hline CHEMBL1423831 & 688889 & 4.45 & 4.7499 & TRN \\
\hline CHEMBL1382927 & 688889 & 5.3 & 4.6831 & TRN \\
\hline CHEMBL1461936 & 688889 & 4.3 & 4.8191 & TRN \\
\hline CHEMBL1486911 & 688889 & 4.3 & 4.7966 & TST \\
\hline CHEMBL1472260 & 688889 & 4.45 & 4.7061 & TRN \\
\hline CHEMBL1596957 & 688889 & 4.3 & 4.8564 & TRN \\
\hline CHEMBL1522750 & 688889 & 5.0 & 4.7133 & TRN \\
\hline CHEMBL1544132 & 688889 & 4.45 & 4.7466 & TRN \\
\hline CHEMBL1439900 & 688889 & 4.5 & 4.8507 & TRN \\
\hline CHEMBL1571914 & 688889 & 4.4 & 4.6492 & TRN \\
\hline CHEMBL1563531 & 688889 & 5.7 & 4.7925 & TRN \\
\hline CHEMBL1411788 & 688889 & 4.3 & 4.7815 & TST \\
\hline CHEMBL1546352 & 688889 & 6.5 & 4.7385 & TRN \\
\hline CHEMBL1370991 & 688889 & 5.35 & 4.8616 & TRN \\
\hline CHEMBL1609860 & 688889 & 4.5 & 4.8427 & TRN \\
\hline CHEMBL1319815 & 688889 & 5.2 & 4.7888 & TST \\
\hline CHEMBL1570746 & 688889 & 4.9 & 4.5906 & TRN \\
\hline CHEMBL1478091 & 688889 & 4.45 & 4.9149 & TST \\
\hline CHEMBL1383481 & 688889 & 5.75 & 5.0254 & TRN \\
\hline CHEMBL1418822 & 688889 & 4.3 & 4.6418 & TRN \\
\hline CHEMBL1504156 & 688889 & 4.95 & 4.7346 & TRN \\
\hline CHEMBL1527685 & 688889 & 4.45 & 4.966 & TST \\
\hline CHEMBL1459536 & 688889 & 4.45 & 4.6858 & TRN \\
\hline CHEMBL1401196 & 688889 & 5.0 & 4.817 & TST \\
\hline CHEMBL1341002 & 688889 & 4.75 & 4.8887 & TRN \\
\hline CHEMBL1559143 & 688889 & 5.05 & 4.7943 & TRN \\
\hline CHEMBL1520147 & 688889 & 4.65 & 4.8669 & TRN \\
\hline CHEMBL1312058 & 688889 & 4.45 & 4.8025 & TST \\
\hline
\end{tabular}




\begin{tabular}{|c|c|c|c|c|}
\hline & & & pplement & al $\mathrm{Ta}$ \\
\hline CHEMBL1404428 & 688889 & 4.3 & 4.7852 & TST \\
\hline CHEMBL3195531 & 688889 & 4.9 & 4.5703 & TRN \\
\hline CHEMBL1307172 & 688889 & 5.5 & 4.6487 & TRN \\
\hline CHEMBL1533370 & 688889 & 4.3 & 4.9049 & TRN \\
\hline CHEMBL1556010 & 688889 & 6.25 & 4.9441 & TST \\
\hline CHEMBL 3195553 & 688889 & 4.95 & 4.6348 & TRN \\
\hline CHEMBL1523465 & 688889 & 4.3 & 4.755 & TRN \\
\hline CHEMBL1339022 & 688889 & 4.25 & 4.8977 & TRN \\
\hline CHEMBL1463801 & 688889 & 4.4 & 4.7428 & TRN \\
\hline CHEMBL1613161 & 688889 & 6.05 & 4.9192 & TST \\
\hline CHEMBL1467510 & 688889 & 4.55 & 4.7851 & TRN \\
\hline CHEMBL39878 & 688889 & 4.25 & 4.9179 & TRN \\
\hline CHEMBL1422741 & 688889 & 4.6 & 4.8623 & TRN \\
\hline CHEMBL1406589 & 688889 & 4.75 & 4.761 & TRN \\
\hline CHEMBL1306680 & 688889 & 4.3 & 4.8236 & TRN \\
\hline CHEMBL1419076 & 688889 & 4.3 & 4.9618 & TRN \\
\hline CHEMBL1326823 & 688889 & 4.45 & 4.7509 & TRN \\
\hline CHEMBL1583762 & 688889 & 5.55 & 4.8378 & TST \\
\hline CHEMBL246447 & 688889 & 4.45 & 4.7216 & TRN \\
\hline CHEMBL1493475 & 688889 & 6.05 & 4.7153 & TST \\
\hline CHEMBL1354019 & 688889 & 4.45 & 4.7153 & TRN \\
\hline CHEMBL1425464 & 688889 & 4.85 & 4.8766 & TRN \\
\hline CHEMBL1423992 & 688889 & 4.25 & 4.8675 & TRN \\
\hline CHEMBL1391341 & 688889 & 4.25 & 4.7774 & TRN \\
\hline CHEMBL1303056 & 688889 & 4.5 & 4.8361 & TRN \\
\hline CHEMBL1375239 & 688889 & 5.25 & 4.7556 & TRN \\
\hline CHEMBL1455542 & 688889 & 4.55 & 4.6083 & TRN \\
\hline CHEMBL1519926 & 688889 & 4.95 & 4.9554 & TST \\
\hline CHEMBL1322525 & 688889 & 4.3 & 4.7938 & TST \\
\hline CHEMBL1521154 & 688889 & 4.3 & 4.8594 & TRN \\
\hline CHEMBL1570113 & 688889 & 5.2 & 4.6468 & TRN \\
\hline CHEMBL1498324 & 688889 & 4.25 & 4.8521 & TRN \\
\hline CHEMBL1579268 & 688889 & 4.25 & 4.9164 & TRN \\
\hline CHEMBL1526217 & 688889 & 4.9 & 4.8372 & TRN \\
\hline CHEMBL1605590 & 688889 & 5.0 & 4.8523 & TRN \\
\hline CHEMBL1559494 & 688889 & 4.95 & 4.8828 & TRN \\
\hline CHEMBL1572788 & 688889 & 4.3 & 4.7097 & TRN \\
\hline CHEMBL1601427 & 688889 & 4.35 & 4.6083 & TRN \\
\hline CHEMBL1384220 & 688889 & 4.7 & 4.864 & TST \\
\hline CHEMBL1346666 & 688889 & 4.25 & 4.8538 & TRN \\
\hline CHEMBL1303002 & 688889 & 6.2 & 4.8701 & TRN \\
\hline CHEMBL1483780 & 688889 & 4.5 & 4.836 & TRN \\
\hline CHEMBL1425311 & 688889 & 6.7501 & 4.9196 & TRN \\
\hline CHEMBL1305679 & 688889 & 4.3 & 4.8086 & TRN \\
\hline CHEMBL1608660 & 688889 & 4.3 & 4.8035 & TRN \\
\hline CHEMBL1411720 & 688889 & 4.95 & 4.7781 & TRN \\
\hline CHEMBL1511914 & 688889 & 4.4 & 4.7843 & TST \\
\hline CHEMBL1340617 & 688889 & 5.5 & 4.6436 & TRN \\
\hline
\end{tabular}




\begin{tabular}{|c|c|c|c|c|}
\hline \multicolumn{5}{|c|}{ Supplemental Table S2.txt } \\
\hline CHEMBL1381571 & 688889 & 4.3 & 4.8671 & TRN \\
\hline CHEMBL1339641 & 688889 & 4.45 & 4.6345 & TRN \\
\hline CHEMBL1415227 & 688889 & 4.45 & 4.7335 & TRN \\
\hline CHEMBL1390293 & 688889 & 5.45 & 4.6731 & TRN \\
\hline CHEMBL1484458 & 688889 & 4.6 & 4.8092 & TST \\
\hline CHEMBL1548506 & 688889 & 4.55 & 4.8164 & TRN \\
\hline CHEMBL1391127 & 688889 & 5.85 & 4.9515 & TST \\
\hline CHEMBL1544588 & 688889 & 5.4 & 4.8548 & TRN \\
\hline CHEMBL1454640 & 688889 & 4.7 & 4.769 & TST \\
\hline CHEMBL1495845 & 688889 & 4.6 & 4.7195 & TRN \\
\hline CHEMBL1544586 & 688889 & 6.7501 & 4.7267 & TRN \\
\hline CHEMBL1463204 & 688889 & 4.95 & 4.8155 & TRN \\
\hline CHEMBL1352458 & 688889 & 4.4 & 4.76 & TRN \\
\hline CHEMBL1549698 & 688889 & 4.3 & 4.7608 & TRN \\
\hline CHEMBL1975147 & 688889 & 5.1 & 4.7206 & TST \\
\hline CHEMBL1600772 & 688889 & 4.3 & 4.8742 & TST \\
\hline CHEMBL1472101 & 688889 & 4.25 & 4.6727 & TRN \\
\hline CHEMBL1352440 & 688889 & 4.3 & 4.7127 & TRN \\
\hline CHEMBL1457285 & 688889 & 4.45 & 4.8434 & TRN \\
\hline CHEMBL1424467 & 688889 & 5.05 & 4.9013 & TRN \\
\hline CHEMBL1472350 & 688889 & 4.3 & 4.7278 & TRN \\
\hline CHEMBL1345563 & 688889 & 4.6 & 4.8761 & TRN \\
\hline CHEMBL1498682 & 688889 & 4.25 & 4.7711 & TRN \\
\hline CHEMBL1556453 & 688889 & 5.0 & 4.7202 & TST \\
\hline CHEMBL1308004 & 688889 & 4.6 & 4.8735 & TRN \\
\hline CHEMBL1981008 & 688889 & 4.25 & 4.7821 & TST \\
\hline CHEMBL1388192 & 688889 & 4.3 & 4.9844 & TRN \\
\hline CHEMBL1345725 & 688889 & 4.95 & 4.7968 & TRN \\
\hline CHEMBL1352710 & 688889 & 4.25 & 4.8162 & TRN \\
\hline CHEMBL1369782 & 688889 & 5.25 & 4.8154 & TRN \\
\hline CHEMBL1533487 & 688889 & 6.1 & 4.945 & TRN \\
\hline CHEMBL1424581 & 688889 & 6.6499 & 4.8326 & TRN \\
\hline CHEMBL1344308 & 688889 & 5.5 & 4.9342 & TST \\
\hline CHEMBL1342521 & 688889 & 4.5 & 4.748 & TRN \\
\hline CHEMBL1555208 & 688889 & 5.3 & 4.8816 & TST \\
\hline CHEMBL1346466 & 688889 & 4.9 & 4.7283 & TRN \\
\hline CHEMBL3191300 & 688889 & 5.15 & 4.8296 & TRN \\
\hline CHEMBL1342967 & 688889 & 5.7 & 4.6946 & TST \\
\hline CHEMBL1562246 & 688889 & 5.2 & 4.7747 & TRN \\
\hline CHEMBL 3192170 & 688889 & 4.6 & 4.7233 & TRN \\
\hline CHEMBL 2001996 & 688889 & 4.25 & 4.8883 & TRN \\
\hline CHEMBL1366729 & 688889 & 4.8 & 4.8543 & TRN \\
\hline CHEMBL1402154 & 688889 & 4.4 & 5.0063 & TRN \\
\hline CHEMBL1569981 & 688889 & 4.25 & 4.7327 & TRN \\
\hline CHEMBL1345183 & 688889 & 5.7 & 4.7421 & TRN \\
\hline CHEMBL1539030 & 688889 & 4.95 & 4.8877 & TRN \\
\hline CHEMBL1526590 & 688889 & 4.3 & 4.926 & TST \\
\hline CHEMBL1464588 & 688889 & 4.95 & 4.7913 & TRN \\
\hline
\end{tabular}




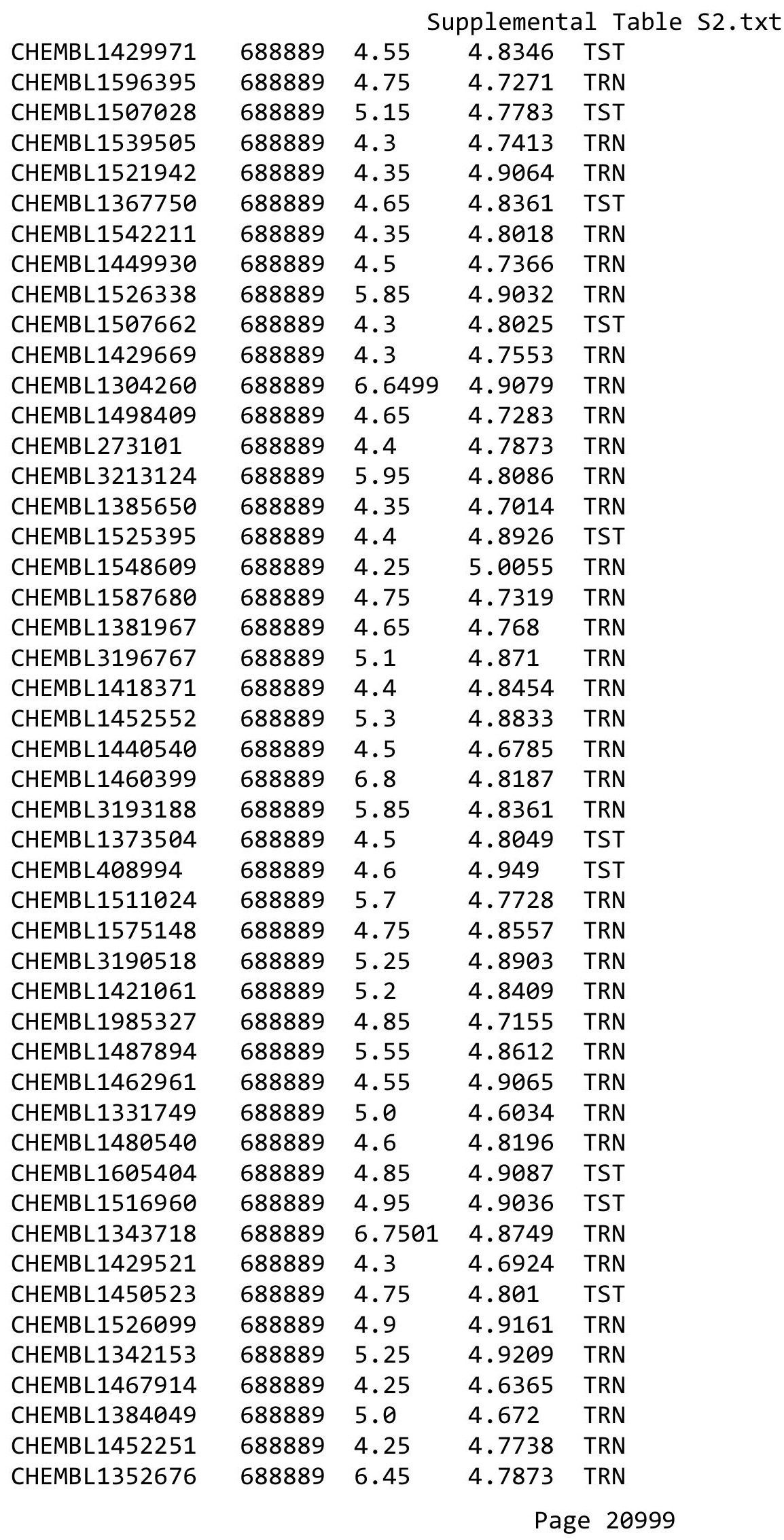




\begin{tabular}{|c|c|c|c|c|c|}
\hline \multicolumn{6}{|c|}{ Supplemental Table S2.txt } \\
\hline CHEMBL1524023 & 688889 & 5.4 & 4.8752 & TRN & \\
\hline CHEMBL1313801 & 688889 & 5.35 & 4.8692 & TRN & \\
\hline CHEMBL1424517 & 688889 & 4.35 & 4.8714 & TST & \\
\hline CHEMBL1456108 & 688889 & 4.25 & 4.8249 & TRN & \\
\hline CHEMBL 392680 & 688889 & 4.55 & 4.8292 & TRN & \\
\hline CHEMBL1310596 & 688889 & 4.55 & 4.8195 & TRN & \\
\hline CHEMBL1496956 & 688889 & 5.15 & 4.896 & TRN & \\
\hline CHEMBL1976549 & 688889 & 4.45 & 4.8703 & TST & \\
\hline CHEMBL1443784 & 688889 & 4.95 & 4.9093 & TRN & \\
\hline CHEMBL1556970 & 688889 & 4.25 & 4.7562 & TRN & \\
\hline CHEMBL1981242 & 688889 & 4.5 & 4.7538 & TRN & \\
\hline CHEMBL1599815 & 688889 & 4.95 & 4.8214 & TST & \\
\hline CHEMBL1581264 & 688889 & 4.25 & 4.8214 & TRN & \\
\hline CHEMBL1477099 & 688889 & 4.45 & 4.897 & TST & \\
\hline CHEMBL1338839 & 688889 & 4.45 & 4.779 & TRN & \\
\hline CHEMBL1311514 & 688889 & 5.25 & 4.8741 & TRN & \\
\hline CHEMBL1568689 & 688889 & 4.4 & 4.927 & TRN & \\
\hline CHEMBL1344205 & 688889 & 4.45 & 4.6216 & TRN & \\
\hline CHEMBL1442687 & 688889 & 4.25 & 4.7565 & TRN & \\
\hline CHEMBL3213622 & 688889 & 4.3 & 4.5883 & TRN & \\
\hline CHEMBL 224343 & 688889 & 4.4 & 4.7191 & TRN & \\
\hline CHEMBL1605727 & 688889 & 6.05 & 4.7742 & TST & \\
\hline CHEMBL1564394 & 688889 & 4.95 & 4.8533 & TRN & \\
\hline CHEMBL1971712 & 688889 & 4.25 & 4.704 & TRN & \\
\hline CHEMBL1463576 & 688889 & 4.45 & 4.6651 & TRN & \\
\hline CHEMBL1509807 & 688889 & 4.95 & 4.8307 & TST & \\
\hline CHEMBL3199860 & 688889 & 4.45 & 4.7181 & TRN & \\
\hline CHEMBL1369057 & 688889 & 5.25 & 5.0134 & TRN & \\
\hline CHEMBL1586510 & 688889 & 4.95 & 4.8596 & TST & \\
\hline CHEMBL1499346 & 688889 & 4.8 & 4.7391 & TRN & \\
\hline CHEMBL1601765 & 688889 & 4.3 & 4.69600 & 0000000001 & TRN \\
\hline CHEMBL1378360 & 688889 & 4.6 & 4.8118 & TRN & \\
\hline CHEMBL1488423 & 688889 & 4.3 & 4.834 & TST & \\
\hline CHEMBL1375570 & 688889 & 4.65 & 4.8895 & TST & \\
\hline CHEMBL3198939 & 688889 & 4.95 & 4.8081 & TST & \\
\hline CHEMBL1612645 & 688889 & 6.7001 & 4.7127 & TRN & \\
\hline CHEMBL1500669 & 688889 & 4.3 & 4.6801 & TRN & \\
\hline CHEMBL1497391 & 688889 & 4.5 & 4.5849 & TST & \\
\hline CHEMBL1299248 & 688889 & 4.7 & 4.8185 & TRN & \\
\hline CHEMBL1557037 & 688889 & 5.0 & 4.8073 & TRN & \\
\hline CHEMBL1493829 & 688889 & 4.45 & 4.8972 & TST & \\
\hline CHEMBL1510830 & 688889 & 4.3 & 4.7762 & TST & \\
\hline CHEMBL1388427 & 688889 & 4.3 & 4.8158 & TST & \\
\hline CHEMBL1464085 & 688889 & 6.2 & 4.8982 & TRN & \\
\hline CHEMBL1322914 & 688889 & 4.45 & 4.7559 & TRN & \\
\hline CHEMBL3190609 & 688889 & 4.9 & 4.7623 & TST & \\
\hline CHEMBL1308829 & 688889 & 4.95 & 4.8791 & TRN & \\
\hline CHEMBL3190528 & 688889 & 5.85 & 4.7371 & TRN & \\
\hline
\end{tabular}




\begin{tabular}{|c|c|c|c|c|c|}
\hline \multicolumn{6}{|c|}{ Supplemental Table S2.txt } \\
\hline CHEMBL1706577 & 688889 & 4.25 & 4.6971 & TRN & \\
\hline CHEMBL1977078 & 688889 & 4.85 & 4.835 & TRN & \\
\hline CHEMBL1532480 & 688889 & 4.25 & 4.7729 & TRN & \\
\hline CHEMBL1094105 & 688889 & 4.95 & 4.8197 & TRN & \\
\hline CHEMBL1455929 & 688889 & 4.25 & 4.6258 & TRN & \\
\hline CHEMBL1094844 & 688889 & 4.4 & 4.7876 & TRN & \\
\hline CHEMBL1511140 & 688889 & 4.25 & 4.8813 & TST & \\
\hline CHEMBL1385980 & 688889 & 4.5 & 4.8865 & TST & \\
\hline CHEMBL1375606 & 688889 & 5.15 & 5.0511 & TRN & \\
\hline CHEMBL1324452 & 688889 & 6.45 & 4.7909 & TRN & \\
\hline CHEMBL1402171 & 688889 & 4.45 & 4.6571 & TRN & \\
\hline CHEMBL1499134 & 688889 & 4.35 & 4.8881 & TST & \\
\hline CHEMBL1480991 & 688889 & 4.3 & 4.8932 & TRN & \\
\hline CHEMBL1441918 & 688889 & 4.25 & 4.7242 & TST & \\
\hline CHEMBL1482109 & 688889 & 4.45 & 4.7501 & TRN & \\
\hline CHEMBL1538262 & 688889 & 5.2 & 4.8038 & TST & \\
\hline CHEMBL1329612 & 688889 & 6.1 & 4.8055 & TRN & \\
\hline CHEMBL1339432 & 688889 & 4.45 & 4.8648 & TRN & \\
\hline CHEMBL1381668 & 688889 & 4.25 & 4.8414 & TRN & \\
\hline CHEMBL1302133 & 688889 & 4.25 & 4.8812 & TRN & \\
\hline CHEMBL1363953 & 688889 & 4.65 & 4.6841 & TRN & \\
\hline CHEMBL1455683 & 688889 & 4.55 & 4.8739 & TST & \\
\hline CHEMBL1311634 & 688889 & 4.3 & 4.867 & TRN & \\
\hline CHEMBL1365957 & 688889 & 5.0 & 4.8433 & TRN & \\
\hline CHEMBL1586301 & 688889 & 4.5 & 4.8499 & TRN & \\
\hline CHEMBL1306926 & 688889 & 4.95 & 4.8133 & TRN & \\
\hline CHEMBL1504350 & 688889 & 4.25 & 4.7166 & TRN & \\
\hline CHEMBL1300857 & 688889 & 5.45 & 4.7014 & TRN & \\
\hline CHEMBL1457199 & 688889 & 4.45 & 4.5999 & TST & \\
\hline CHEMBL1413554 & 688889 & 4.95 & 4.6662 & TRN & \\
\hline CHEMBL1450810 & 688889 & 4.25 & 4.7836 & TRN & \\
\hline CHEMBL1520901 & 688889 & 4.25 & 5.0045 & TRN & \\
\hline CHEMBL1311422 & 688889 & 4.55 & 4.7966 & TRN & \\
\hline CHEMBL3196432 & 688889 & 4.95 & 4.7828 & TST & \\
\hline CHEMBL 258881 & 688889 & 4.3 & 4.80399 & 9999999999 & TRN \\
\hline CHEMBL1431112 & 688889 & 4.6 & 4.8157 & TST & \\
\hline CHEMBL 3214013 & 688889 & 4.65 & 4.7765 & TRN & \\
\hline CHEMBL1336255 & 688889 & 5.1 & 4.7918 & TRN & \\
\hline CHEMBL1488759 & 688889 & 4.3 & 4.8421 & TST & \\
\hline CHEMBL1350607 & 688889 & 6.4 & 4.813 & TRN & \\
\hline CHEMBL1420806 & 688889 & 4.9 & 4.7392 & TRN & \\
\hline CHEMBL1567844 & 688889 & 4.9 & 4.704 & TRN & \\
\hline CHEMBL1312186 & 688889 & 5.15 & 4.8002 & TST & \\
\hline CHEMBL1361779 & 688889 & 4.5 & 4.9327 & TRN & \\
\hline CHEMBL1534470 & 688889 & 4.45 & 4.7342 & TST & \\
\hline CHEMBL1594527 & 688889 & 4.45 & 4.8245 & TST & \\
\hline CHEMBL1351283 & 688889 & 4.6 & 4.9131 & TST & \\
\hline CHEMBL1479360 & 688889 & 5.85 & 4.768 & TST & \\
\hline
\end{tabular}




\begin{tabular}{|c|c|c|c|c|}
\hline \multicolumn{5}{|c|}{ Supplemental Table S2.txt } \\
\hline CHEMBL1411491 & 688889 & 4.3 & 4.8179 & TRN \\
\hline CHEMBL1372061 & 688889 & 5.45 & 4.7449 & TRN \\
\hline CHEMBL1302433 & 688889 & 4.6 & 4.6707 & TST \\
\hline CHEMBL1457400 & 688889 & 4.55 & 4.7726 & TRN \\
\hline CHEMBL1523218 & 688889 & 5.4 & 4.8588 & TRN \\
\hline CHEMBL1453739 & 688889 & 4.45 & 4.7862 & TRN \\
\hline CHEMBL1380558 & 688889 & 4.3 & 4.7716 & TRN \\
\hline CHEMBL1432961 & 688889 & 4.3 & 4.8724 & TRN \\
\hline CHEMBL1566820 & 688889 & 4.25 & 4.9168 & TRN \\
\hline CHEMBL3195193 & 688889 & 4.25 & 4.7748 & TRN \\
\hline CHEMBL1535388 & 688889 & 4.25 & 4.7455 & TRN \\
\hline CHEMBL1447019 & 688889 & 4.95 & 4.7205 & TRN \\
\hline CHEMBL1530757 & 688889 & 4.5 & 4.8225 & TRN \\
\hline CHEMBL1341323 & 688889 & 4.75 & 4.74 & TRN \\
\hline CHEMBL1448080 & 688889 & 5.25 & 4.8243 & TRN \\
\hline CHEMBL1438826 & 688889 & 5.3 & 4.6776 & TST \\
\hline CHEMBL1588098 & 688889 & 5.45 & 4.8082 & TRN \\
\hline CHEMBL1380165 & 688889 & 5.05 & 4.7513 & TRN \\
\hline CHEMBL1303271 & 688889 & 6.8 & 4.6685 & TRN \\
\hline CHEMBL1587477 & 688889 & 4.3 & 4.7893 & TRN \\
\hline CHEMBL1458041 & 688889 & 5.15 & 4.7828 & TRN \\
\hline CHEMBL1522277 & 688889 & 6.7501 & 4.763 & TRN \\
\hline CHEMBL1586297 & 688889 & 4.25 & 4.7544 & TST \\
\hline CHEMBL1464318 & 688889 & 4.3 & 4.9294 & TRN \\
\hline CHEMBL1312941 & 688889 & 4.3 & 4.9802 & TRN \\
\hline CHEMBL1307406 & 688889 & 4.5 & 4.7443 & TRN \\
\hline CHEMBL1351808 & 688889 & 4.55 & 4.8021 & TRN \\
\hline CHEMBL1442450 & 688889 & 5.6 & 4.8801 & TRN \\
\hline CHEMBL1388342 & 688889 & 4.9 & 4.7309 & TRN \\
\hline CHEMBL1424075 & 688889 & 4.45 & 4.8353 & TRN \\
\hline CHEMBL1493891 & 688889 & 4.55 & 4.7001 & TRN \\
\hline CHEMBL1500696 & 688889 & 4.25 & 4.7655 & TRN \\
\hline CHEMBL3194961 & 688889 & 5.15 & 5.0088 & TRN \\
\hline CHEMBL1398824 & 688889 & 4.55 & 4.7118 & TST \\
\hline CHEMBL1565085 & 688889 & 4.25 & 4.7597 & TRN \\
\hline CHEMBL1467168 & 688889 & 4.5 & 4.721 & TRN \\
\hline CHEMBL1490887 & 688889 & 4.5 & 4.78 & TST \\
\hline CHEMBL3212931 & 688889 & 6.05 & 4.7668 & TRN \\
\hline CHEMBL1404134 & 688889 & 4.25 & 4.8415 & TRN \\
\hline CHEMBL1310454 & 688889 & 6.1 & 4.7561 & TST \\
\hline CHEMBL1422817 & 688889 & 4.25 & 4.6708 & TST \\
\hline CHEMBL1569601 & 688889 & 4.25 & 4.8069 & TRN \\
\hline CHEMBL3193195 & 688889 & 5.4 & 4.8449 & TRN \\
\hline CHEMBL1507628 & 688889 & 4.35 & 4.7476 & TRN \\
\hline CHEMBL1418186 & 688889 & 5.8 & 4.8749 & TST \\
\hline CHEMBL1588666 & 688889 & 4.4 & 4.8967 & TST \\
\hline CHEMBL1452978 & 688889 & 4.55 & 4.9311 & TRN \\
\hline CHEMBL1334583 & 688889 & 6.5 & 4.9119 & TRN \\
\hline
\end{tabular}




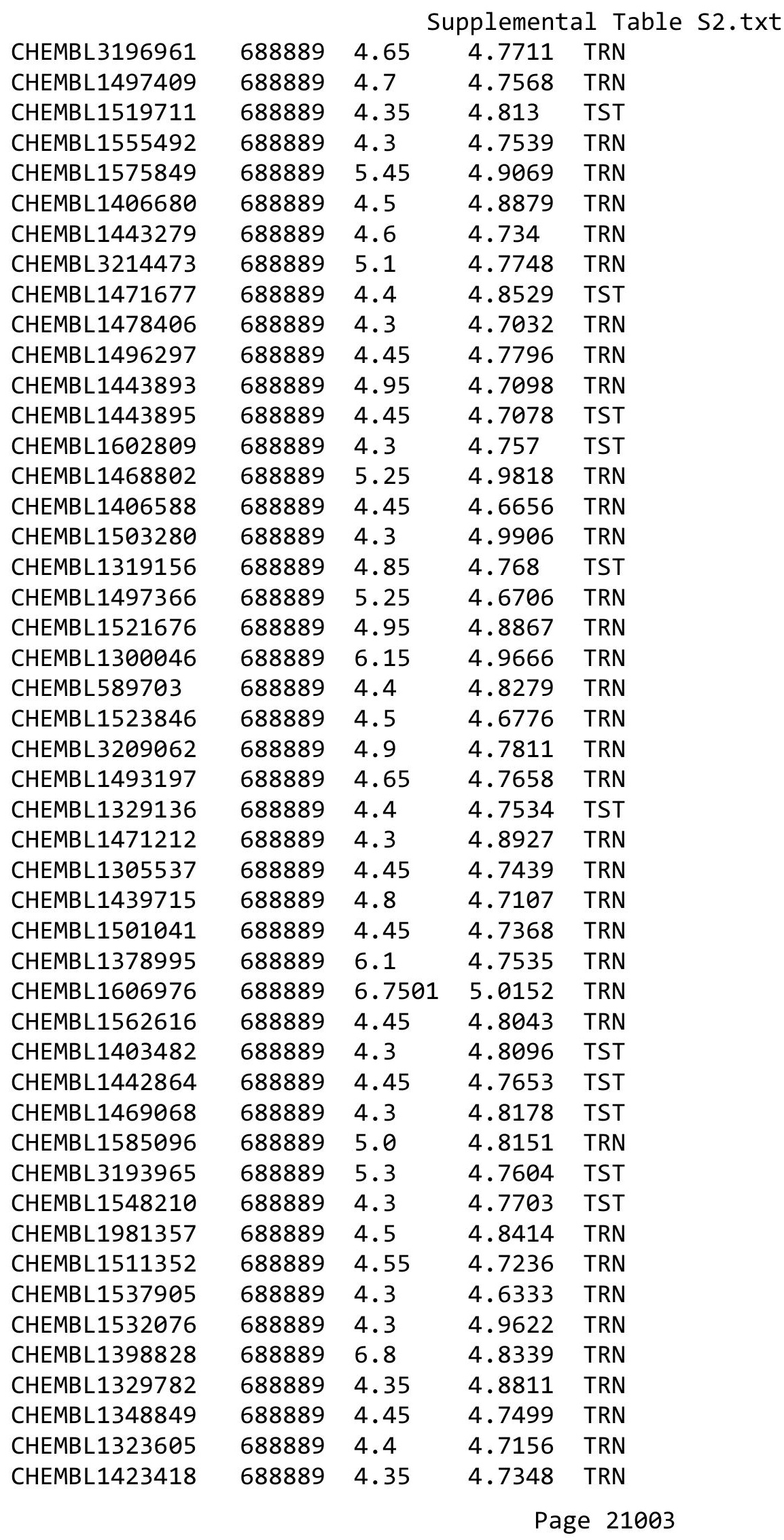




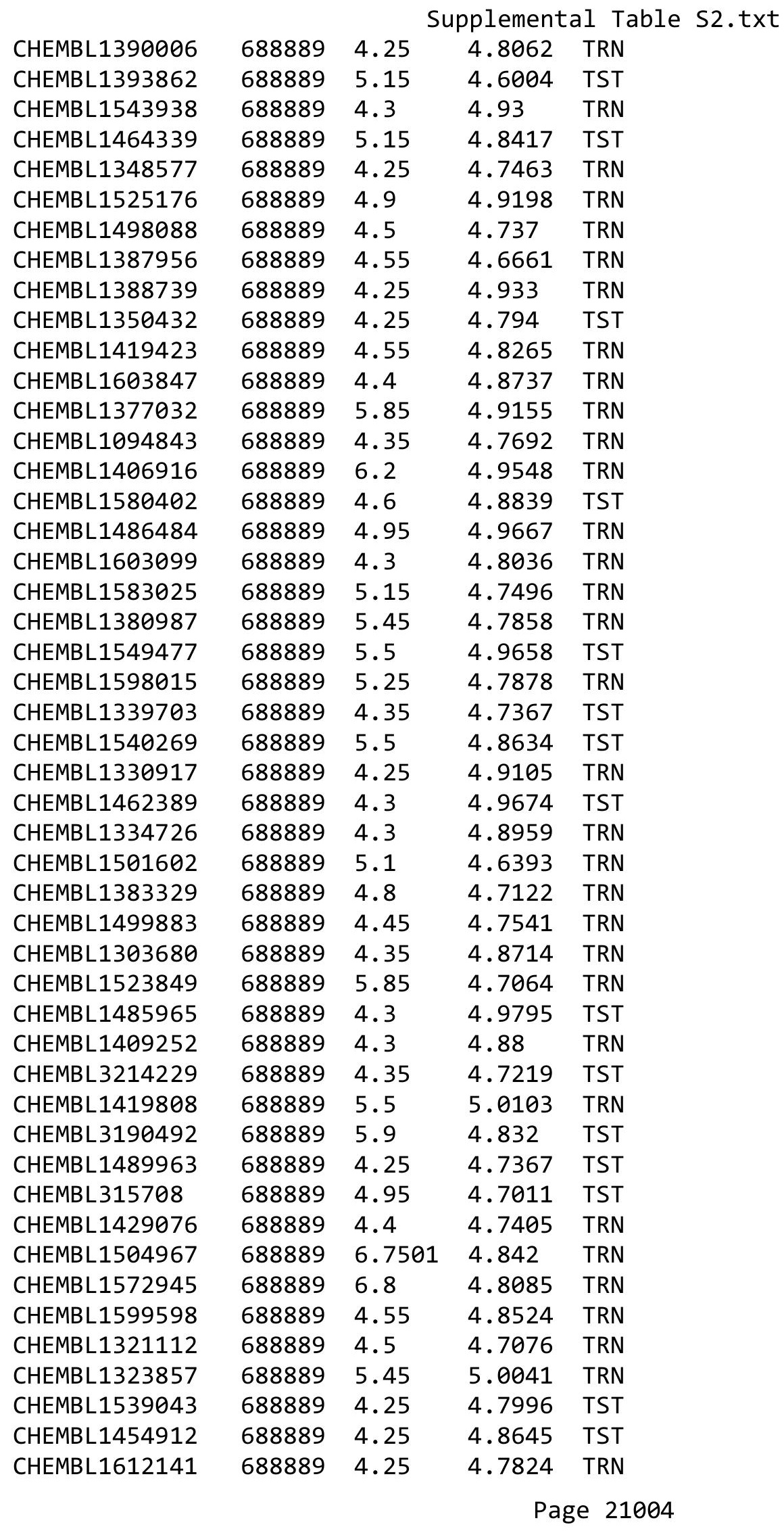




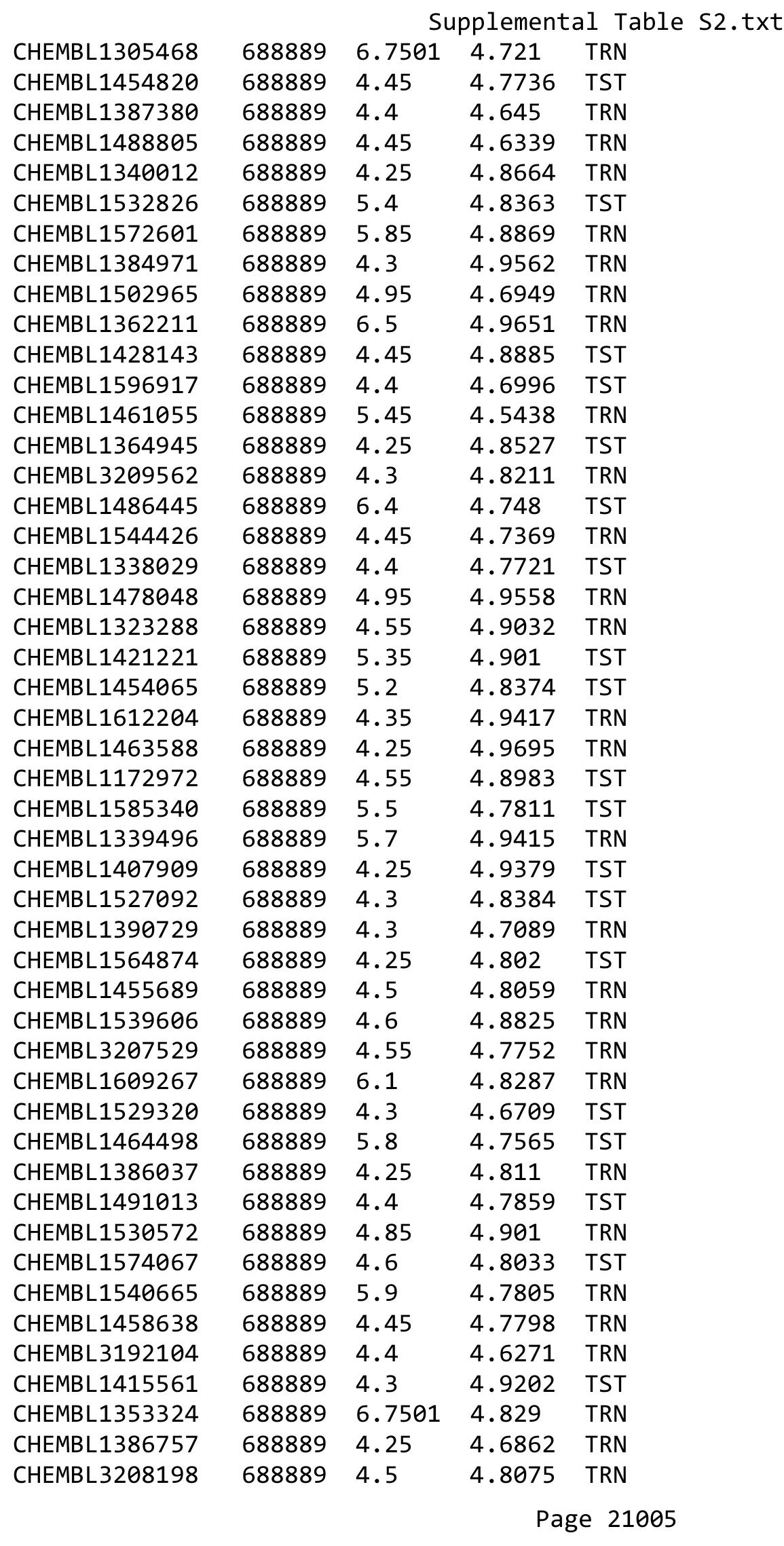




\begin{tabular}{|c|c|c|c|c|}
\hline \multicolumn{5}{|c|}{ Supplemental Table S2.txt } \\
\hline CHEMBL1606284 & 688889 & 5.1 & 4.7137 & TRN \\
\hline CHEMBL1370627 & 688889 & 4.45 & 4.9803 & TRN \\
\hline CHEMBL1323674 & 688889 & 4.3 & 4.8856 & TRN \\
\hline CHEMBL1302143 & 688889 & 5.85 & 4.987 & TRN \\
\hline CHEMBL486706 & 688889 & 4.65 & 4.7567 & TST \\
\hline CHEMBL1437820 & 688889 & 4.3 & 4.6943 & TRN \\
\hline CHEMBL1349263 & 688889 & 4.95 & 4.7541 & TRN \\
\hline CHEMBL1586062 & 688889 & 4.25 & 4.7836 & TST \\
\hline CHEMBL3208639 & 688889 & 4.3 & 4.7496 & TST \\
\hline CHEMBL1391811 & 688889 & 5.6 & 4.8102 & TST \\
\hline CHEMBL1430373 & 688889 & 4.95 & 4.7925 & TST \\
\hline CHEMBL1381249 & 688889 & 4.35 & 4.7649 & TRN \\
\hline CHEMBL1414472 & 688889 & 4.95 & 4.6996 & TRN \\
\hline CHEMBL1557772 & 688889 & 4.95 & 4.7388 & TRN \\
\hline CHEMBL1360892 & 688889 & 4.3 & 4.6768 & TRN \\
\hline CHEMBL1516673 & 688889 & 4.55 & 4.6592 & TRN \\
\hline CHEMBL3198357 & 688889 & 4.9 & 4.7757 & TRN \\
\hline CHEMBL1468863 & 688889 & 6.0 & 4.876 & TRN \\
\hline CHEMBL3213891 & 688889 & 5.2 & 4.9258 & TST \\
\hline CHEMBL1490119 & 688889 & 4.3 & 4.8363 & TRN \\
\hline CHEMBL1447058 & 688889 & 4.45 & 4.942 & TRN \\
\hline CHEMBL1392415 & 688889 & 6.5501 & 4.7803 & TST \\
\hline CHEMBL1362758 & 688889 & 4.5 & 4.8901 & TST \\
\hline CHEMBL1468640 & 688889 & 4.6 & 4.8423 & TST \\
\hline CHEMBL1300244 & 688889 & 4.35 & 4.7905 & TST \\
\hline CHEMBL1332142 & 688889 & 6.8 & 5.0101 & TRN \\
\hline CHEMBL1439020 & 688889 & 4.35 & 4.859 & TRN \\
\hline CHEMBL1342669 & 688889 & 4.95 & 4.9506 & TRN \\
\hline CHEMBL1511895 & 688889 & 4.45 & 4.7088 & TRN \\
\hline CHEMBL1344791 & 688889 & 4.25 & 4.8304 & TRN \\
\hline CHEMBL1361938 & 688889 & 4.3 & 4.7935 & TRN \\
\hline CHEMBL1312038 & 688889 & 4.25 & 4.6014 & TRN \\
\hline CHEMBL1402750 & 688889 & 5.35 & 4.8083 & TST \\
\hline CHEMBL1517491 & 688889 & 4.25 & 4.7014 & TRN \\
\hline CHEMBL1305098 & 688889 & 4.3 & 4.7111 & TRN \\
\hline CHEMBL1543541 & 688889 & 4.3 & 4.8586 & TST \\
\hline CHEMBL1367008 & 688889 & 4.45 & 4.8322 & TRN \\
\hline CHEMBL1584411 & 688889 & 4.3 & 4.8076 & TRN \\
\hline CHEMBL1530054 & 688889 & 4.6 & 4.794 & TRN \\
\hline CHEMBL1347538 & 688889 & 5.4 & 4.8264 & TRN \\
\hline CHEMBL1477120 & 688889 & 4.65 & 4.8538 & TRN \\
\hline CHEMBL1430824 & 688889 & 4.5 & 5.0129 & TRN \\
\hline CHEMBL1446858 & 688889 & 6.25 & 4.8212 & TRN \\
\hline CHEMBL1350941 & 688889 & 4.25 & 4.6471 & TST \\
\hline CHEMBL1518602 & 688889 & 4.45 & 4.6718 & TRN \\
\hline CHEMBL3191777 & 688889 & 4.9 & 4.8264 & TRN \\
\hline CHEMBL1350203 & 688889 & 4.6 & 4.7614 & TST \\
\hline CHEMBL1583817 & 688889 & 4.25 & 4.7105 & TRN \\
\hline
\end{tabular}




\begin{tabular}{|c|c|c|c|c|}
\hline \multicolumn{5}{|c|}{ Supplemental Table S2.txt } \\
\hline CHEMBL1390969 & 688889 & 5.1 & 4.813 & TRN \\
\hline CHEMBL1454135 & 688889 & 4.25 & 4.8506 & TRN \\
\hline CHEMBL3145067 & 688889 & 4.8 & 4.6223 & TRN \\
\hline CHEMBL1418225 & 688889 & 4.4 & 4.6348 & TST \\
\hline CHEMBL1602936 & 688889 & 4.5 & 4.7075 & TRN \\
\hline CHEMBL1594198 & 688889 & 4.95 & 4.7944 & TST \\
\hline CHEMBL3195499 & 688889 & 4.25 & 4.7671 & TRN \\
\hline CHEMBL1444315 & 688889 & 6.7501 & 4.6168 & TST \\
\hline CHEMBL1430279 & 688889 & 6.5 & 4.9161 & TRN \\
\hline CHEMBL1421153 & 688889 & 4.9 & 4.7787 & TST \\
\hline CHEMBL1571682 & 688889 & 4.5 & 4.9203 & TST \\
\hline CHEMBL1334940 & 688889 & 4.45 & 4.7141 & TRN \\
\hline CHEMBL1367859 & 688889 & 5.35 & 4.8635 & TST \\
\hline CHEMBL1581148 & 688889 & 4.3 & 4.6903 & TRN \\
\hline CHEMBL1468427 & 688889 & 4.6 & 4.6655 & TRN \\
\hline CHEMBL1455016 & 688889 & 4.45 & 4.8123 & TRN \\
\hline CHEMBL3191057 & 688889 & 4.35 & 4.7058 & TRN \\
\hline CHEMBL1561914 & 688889 & 5.2 & 4.7991 & TRN \\
\hline CHEMBL 3189194 & 688889 & 4.45 & 4.7106 & TRN \\
\hline CHEMBL1543744 & 688889 & 4.25 & 4.7101 & TRN \\
\hline CHEMBL1506179 & 688889 & 4.4 & 4.7078 & TRN \\
\hline CHEMBL1507207 & 688889 & 4.55 & 4.7068 & TRN \\
\hline CHEMBL1425059 & 688889 & 4.55 & 4.7799 & TRN \\
\hline CHEMBL1372518 & 688889 & 5.9 & 4.9669 & TRN \\
\hline CHEMBL 3192410 & 688889 & 4.65 & 4.7999 & TRN \\
\hline CHEMBL1341955 & 688889 & 4.25 & 4.8576 & TST \\
\hline CHEMBL1460425 & 688889 & 4.65 & 4.7526 & TRN \\
\hline CHEMBL1332281 & 688889 & 6.5501 & 4.8153 & TRN \\
\hline CHEMBL1343954 & 688889 & 4.95 & 4.8675 & TST \\
\hline CHEMBL1564857 & 688889 & 4.3 & 4.783 & TRN \\
\hline CHEMBL1411681 & 688889 & 5.05 & 4.8402 & TRN \\
\hline CHEMBL1337129 & 688889 & 4.3 & 4.7686 & TRN \\
\hline CHEMBL1401112 & 688889 & 4.3 & 4.8731 & TRN \\
\hline CHEMBL1384307 & 688889 & 4.25 & 4.7412 & TRN \\
\hline CHEMBL1555421 & 688889 & 4.45 & 4.6792 & TRN \\
\hline CHEMBL1491555 & 688889 & 4.25 & 4.8545 & TST \\
\hline CHEMBL1379304 & 688889 & 4.25 & 4.8082 & TRN \\
\hline CHEMBL3211419 & 688889 & 4.25 & 4.7674 & TRN \\
\hline CHEMBL1430602 & 688889 & 4.55 & 4.6218 & TRN \\
\hline CHEMBL1414133 & 688889 & 4.6 & 4.921 & TRN \\
\hline CHEMBL1594745 & 688889 & 4.4 & 4.8457 & TRN \\
\hline CHEMBL1539146 & 688889 & 4.55 & 4.7397 & TRN \\
\hline CHEMBL1346567 & 688889 & 5.15 & 4.6197 & TRN \\
\hline CHEMBL3213757 & 688889 & 4.3 & 4.8271 & TRN \\
\hline CHEMBL1561376 & 688889 & 5.1 & 4.9653 & TRN \\
\hline CHEMBL1301060 & 688889 & 4.45 & 4.785 & TRN \\
\hline CHEMBL1387192 & 688889 & 4.6 & 4.7139 & TRN \\
\hline CHEMBL1376741 & 688889 & 4.5 & 4.7257 & TRN \\
\hline
\end{tabular}




\begin{tabular}{|c|c|c|c|c|c|}
\hline & & \multicolumn{4}{|c|}{ Supplemental Table S2.txt } \\
\hline CHEMBL1441092 & 688889 & 4.85 & 4.745 & TST & \\
\hline CHEMBL1449447 & 688889 & 4.9 & 4.8605 & TST & \\
\hline CHEMBL1398711 & 688889 & 4.95 & 4.7053 & TRN & \\
\hline CHEMBL1405174 & 688889 & 4.25 & 4.8212 & TST & \\
\hline CHEMBL1424584 & 688889 & 4.95 & 4.8865 & TRN & \\
\hline CHEMBL1370411 & 688889 & 5.25 & 4.8943 & TST & \\
\hline CHEMBL1458176 & 688889 & 6.0 & 4.8079 & TST & \\
\hline CHEMBL1381480 & 688889 & 6.1 & 4.9038 & TST & \\
\hline CHEMBL1611438 & 688889 & 4.3 & 4.8884 & TST & \\
\hline CHEMBL1478554 & 688889 & 5.0 & 4.7304 & TST & \\
\hline CHEMBL1431373 & 688889 & 4.9 & 4.7545 & TRN & \\
\hline CHEMBL1596744 & 688889 & 4.7 & 4.8098 & TRN & \\
\hline CHEMBL1511934 & 688889 & 4.25 & 4.8483 & TST & \\
\hline CHEMBL1369155 & 688889 & 5.2 & 4.8758 & TST & \\
\hline CHEMBL1377448 & 688889 & 5.0 & 4.7787 & TRN & \\
\hline CHEMBL1518556 & 688889 & 4.65 & 4.8509 & TRN & \\
\hline CHEMBL1403824 & 688889 & 4.55 & 4.8435 & TRN & \\
\hline CHEMBL1333983 & 688889 & 4.3 & 4.7311 & TST & \\
\hline CHEMBL1606298 & 688889 & 4.5 & 4.7418 & TST & \\
\hline CHEMBL490106 & 688889 & 4.45 & 4.8179 & TST & \\
\hline CHEMBL1422807 & 688889 & 4.55 & 4.6393 & TRN & \\
\hline CHEMBL1311490 & 688889 & 4.55 & 4.8877 & TRN & \\
\hline CHEMBL1419872 & 688889 & 4.5 & 4.8459 & TRN & \\
\hline CHEMBL1464925 & 688889 & 5.25 & 4.7817 & TRN & \\
\hline CHEMBL1532179 & 688889 & 4.6 & 4.7069 & TRN & \\
\hline CHEMBL1443473 & 688889 & 4.25 & 4.725 & TRN & \\
\hline CHEMBL1532714 & 688889 & 4.25 & 4.8717 & TST & \\
\hline CHEMBL1541880 & 688889 & 4.45 & 4.805 & TRN & \\
\hline CHEMBL1499777 & 688889 & 4.3 & 4.77800 & 00000000005 & TRN \\
\hline CHEMBL1560342 & 688889 & 6.8 & 4.7723 & TRN & \\
\hline CHEMBL1595788 & 688889 & 5.3 & 4.729 & TRN & \\
\hline CHEMBL1565861 & 688889 & 5.1 & 4.7665 & TST & \\
\hline CHEMBL1487109 & 688889 & 4.45 & 4.7681 & TRN & \\
\hline CHEMBL1469815 & 688889 & 4.3 & 4.8507 & TRN & \\
\hline CHEMBL1401912 & 688889 & 5.65 & 4.9301 & TRN & \\
\hline CHEMBL1444402 & 688889 & 4.25 & 4.8082 & TRN & \\
\hline CHEMBL1573409 & 688889 & 4.95 & 4.8201 & TST & \\
\hline CHEMBL1340677 & 688889 & 4.55 & 4.9034 & TRN & \\
\hline CHEMBL1347221 & 688889 & 4.5 & 4.8478 & TRN & \\
\hline CHEMBL1404748 & 688889 & 4.25 & 4.7893 & TST & \\
\hline CHEMBL1481361 & 688889 & 5.85 & 4.8192 & TST & \\
\hline CHEMBL1371159 & 688889 & 4.45 & 4.8871 & TRN & \\
\hline CHEMBL1367035 & 688889 & 4.45 & 4.7915 & TRN & \\
\hline CHEMBL1482040 & 688889 & 4.25 & 4.888 & TRN & \\
\hline CHEMBL3198914 & 688889 & 4.4 & 4.9747 & TRN & \\
\hline CHEMBL1517201 & 688889 & 5.95 & 4.89 & TRN & \\
\hline CHEMBL1992164 & 688889 & 4.8 & 4.6878 & TRN & \\
\hline CHEMBL1365623 & 688889 & 4.25 & 4.8532 & TRN & \\
\hline
\end{tabular}




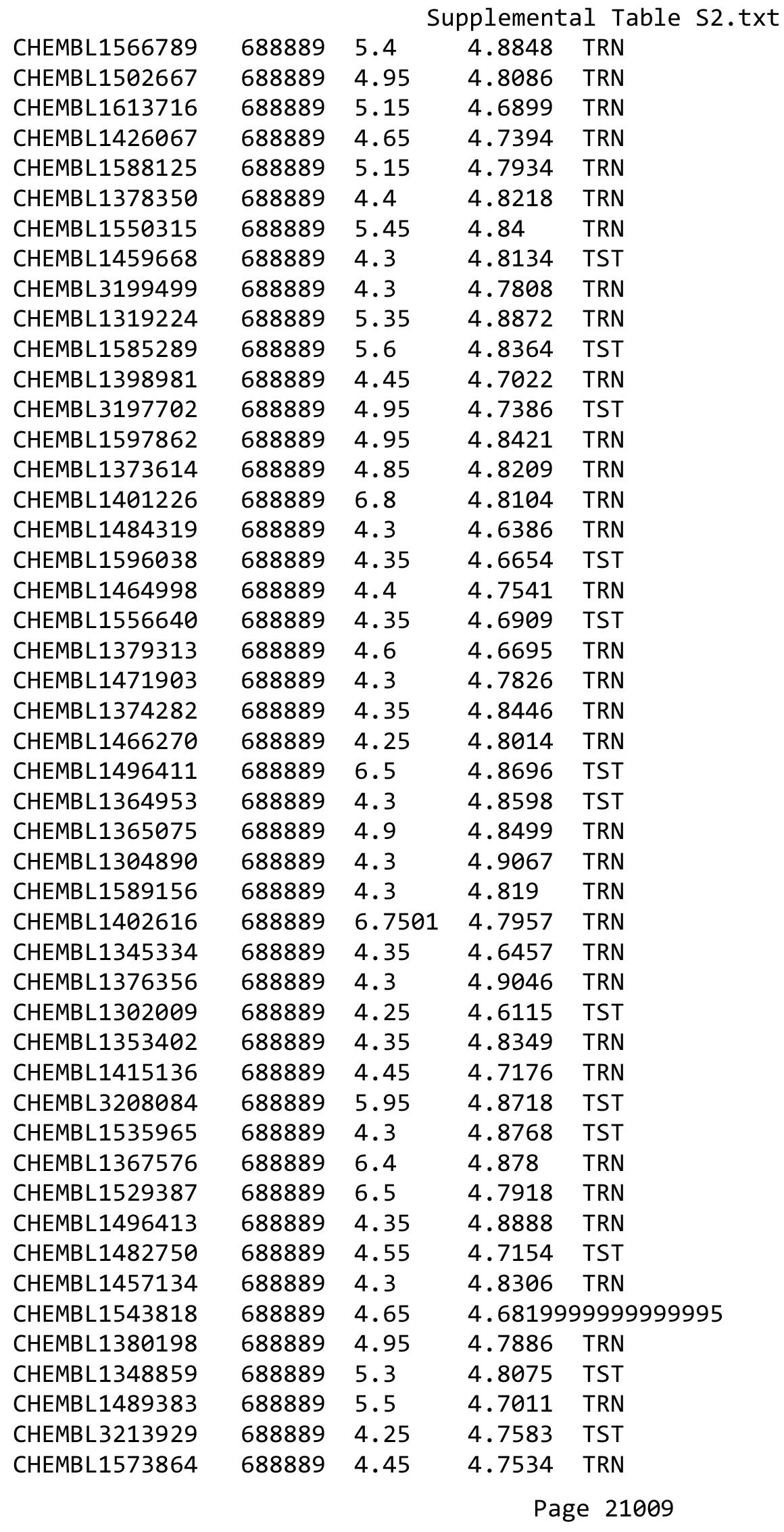




\begin{tabular}{|c|c|c|c|c|c|}
\hline \multicolumn{6}{|c|}{ Supplemental Table S2.txt } \\
\hline CHEMBL 2002776 & 688889 & 4.55 & 4.7013 & TRN & \\
\hline CHEMBL1561590 & 688889 & 5.4 & 4.687 & TRN & \\
\hline CHEMBL1596460 & 688889 & 5.1 & 4.6586 & TRN & \\
\hline CHEMBL1376683 & 688889 & 4.55 & 4.6927 & TST & \\
\hline CHEMBL 3212246 & 688889 & 4.8 & 4.715 & TRN & \\
\hline CHEMBL1453234 & 688889 & 4.55 & 4.8546 & TRN & \\
\hline CHEMBL1352209 & 688889 & 4.35 & 4.8898 & TRN & \\
\hline CHEMBL1380940 & 688889 & 4.3 & 4.7694 & TRN & \\
\hline CHEMBL1427888 & 688889 & 4.5 & 4.7295 & TRN & \\
\hline CHEMBL1503085 & 688889 & 4.25 & 4.9267 & TRN & \\
\hline CHEMBL3197111 & 688889 & 4.95 & 4.8121 & TRN & \\
\hline CHEMBL1351442 & 688889 & 6.7501 & 4.902 & TRN & \\
\hline CHEMBL1569891 & 688889 & 4.4 & 4.744 & TRN & \\
\hline CHEMBL1594433 & 688889 & 4.95 & 4.848 & TRN & \\
\hline CHEMBL1523179 & 688889 & 4.3 & 4.71899 & 9999999999 & TST \\
\hline CHEMBL1340293 & 688889 & 4.55 & 4.7976 & TST & \\
\hline CHEMBL1359511 & 688889 & 4.6 & 4.6869 & TRN & \\
\hline CHEMBL1373740 & 688889 & 4.45 & 4.7399 & TST & \\
\hline CHEMBL1393887 & 688889 & 6.7501 & 4.7735 & TRN & \\
\hline CHEMBL1563821 & 688889 & 4.3 & 4.5738 & TRN & \\
\hline CHEMBL1306308 & 688889 & 5.25 & 4.8178 & TRN & \\
\hline CHEMBL1405193 & 688889 & 4.3 & 4.7288 & TRN & \\
\hline CHEMBL1449461 & 688889 & 4.3 & 4.7841 & TST & \\
\hline CHEMBL1521851 & 688889 & 5.3 & 4.8277 & TST & \\
\hline CHEMBL1480000 & 688889 & 4.45 & 4.7407 & TRN & \\
\hline CHEMBL1342457 & 688889 & 4.7 & 4.8646 & TRN & \\
\hline CHEMBL1484765 & 688889 & 4.95 & 4.74 & TST & \\
\hline CHEMBL1564327 & 688889 & 6.8 & 4.9601 & TRN & \\
\hline CHEMBL1410698 & 688889 & 5.5 & 4.6934 & TRN & \\
\hline CHEMBL1595976 & 688889 & 5.6 & 4.7281 & TRN & \\
\hline CHEMBL1401676 & 688889 & 5.5 & 4.7532 & TRN & \\
\hline CHEMBL1549174 & 688889 & 4.65 & 4.6922 & TRN & \\
\hline CHEMBL 3214385 & 688889 & 5.45 & 4.812 & TRN & \\
\hline CHEMBL1482064 & 688889 & 4.5 & 4.6969 & TRN & \\
\hline CHEMBL1467182 & 688889 & 6.8 & 4.7825 & TRN & \\
\hline CHEMBL1344731 & 688889 & 4.65 & 4.6951 & TRN & \\
\hline CHEMBL1585666 & 688889 & 4.55 & 4.8365 & TRN & \\
\hline CHEMBL1601845 & 688889 & 4.4 & 4.7856 & TRN & \\
\hline CHEMBL1321437 & 688889 & 4.45 & 4.7588 & TRN & \\
\hline CHEMBL3192459 & 688889 & 4.55 & 4.7244 & TRN & \\
\hline CHEMBL1300133 & 688889 & 4.4 & 4.816 & TRN & \\
\hline CHEMBL1540905 & 688889 & 4.65 & 4.7771 & TST & \\
\hline CHEMBL1518586 & 688889 & 4.3 & 4.6299 & TRN & \\
\hline CHEMBL1602028 & 688889 & 6.5501 & 4.956 & TRN & \\
\hline CHEMBL1417160 & 688889 & 5.1 & 4.6719 & TST & \\
\hline CHEMBL1519818 & 688889 & 4.3 & 4.7105 & TRN & \\
\hline CHEMBL1326063 & 688889 & 4.55 & 4.7103 & TRN & \\
\hline CHEMBL1451183 & 688889 & 5.6 & 4.8825 & TST & \\
\hline
\end{tabular}




\begin{tabular}{|c|c|c|c|c|c|}
\hline \multicolumn{6}{|c|}{ Supplemental Table S2.txt } \\
\hline CHEMBL1596689 & 688889 & 5.45 & 4.8729 & TRN & \\
\hline CHEMBL1424904 & 688889 & 6.15 & 4.7828 & TRN & \\
\hline CHEMBL1455516 & 688889 & 4.65 & 4.7384 & TRN & \\
\hline CHEMBL1308256 & 688889 & 4.25 & 4.9288 & TRN & \\
\hline CHEMBL1422075 & 688889 & 5.2 & 4.9335 & TRN & \\
\hline CHEMBL1490036 & 688889 & 4.3 & 4.726 & TRN & \\
\hline CHEMBL1500830 & 688889 & 4.3 & 4.7083 & TRN & \\
\hline CHEMBL1346202 & 688889 & 4.25 & 4.7695 & TST & \\
\hline CHEMBL1507239 & 688889 & 4.45 & 4.7048 & TRN & \\
\hline CHEMBL1419176 & 688889 & 5.35 & 4.7693 & TST & \\
\hline CHEMBL1501439 & 688889 & 4.3 & 4.7348 & TRN & \\
\hline CHEMBL3193130 & 688889 & 5.55 & 4.8185 & TRN & \\
\hline CHEMBL1546187 & 688889 & 4.75 & 4.742 & TRN & \\
\hline CHEMBL1307196 & 688889 & 4.75 & 4.8919 & TRN & \\
\hline CHEMBL1503731 & 688889 & 4.3 & 4.5945 & TRN & \\
\hline CHEMBL1422762 & 688889 & 5.85 & 4.8426 & TRN & \\
\hline CHEMBL1447188 & 688889 & 4.4 & 4.7025 & TRN & \\
\hline CHEMBL1312437 & 688889 & 4.9 & 4.8861 & TRN & \\
\hline CHEMBL1429456 & 688889 & 4.35 & 4.672 & TRN & \\
\hline CHEMBL1469332 & 688889 & 5.4 & 4.725 & TRN & \\
\hline CHEMBL 2004428 & 688889 & 4.25 & 4.7699 & TRN & \\
\hline CHEMBL1444182 & 688889 & 4.25 & 4.7891 & TRN & \\
\hline CHEMBL1584515 & 688889 & 6.8 & 4.7518 & TST & \\
\hline CHEMBL1545869 & 688889 & 4.25 & 4.8154 & TRN & \\
\hline CHEMBL1407969 & 688889 & 4.9 & 4.982 & TRN & \\
\hline CHEMBL1469044 & 688889 & 4.6 & 4.7947 & TRN & \\
\hline CHEMBL1313982 & 688889 & 4.35 & 4.7147 & TST & \\
\hline CHEMBL1334917 & 688889 & 4.4 & 4.766 & TRN & \\
\hline CHEMBL1443617 & 688889 & 5.85 & 4.8981 & TRN & \\
\hline CHEMBL1330854 & 688889 & 5.25 & 4.7949 & TRN & \\
\hline CHEMBL1457031 & 688889 & 4.5 & 4.71399 & 99999999995 & TRN \\
\hline CHEMBL1500538 & 688889 & 5.4 & 4.8802 & TRN & \\
\hline CHEMBL3189551 & 688889 & 4.4 & 4.5719 & TRN & \\
\hline CHEMBL1539660 & 688889 & 4.25 & 4.6782 & TRN & \\
\hline CHEMBL1373715 & 688889 & 5.25 & 4.7132 & TRN & \\
\hline CHEMBL1548517 & 688889 & 4.3 & 4.77800 & 00000000005 & TRN \\
\hline CHEMBL253989 & 688889 & 4.95 & 4.7038 & TST & \\
\hline CHEMBL3207370 & 688889 & 4.95 & 4.7919 & TST & \\
\hline CHEMBL3197919 & 688889 & 5.95 & 4.8672 & TRN & \\
\hline CHEMBL1541831 & 688889 & 4.4 & 4.8384 & TRN & \\
\hline CHEMBL1342444 & 688889 & 4.45 & 4.8637 & TRN & \\
\hline CHEMBL1520408 & 688889 & 4.25 & 4.9322 & TST & \\
\hline CHEMBL1378722 & 688889 & 4.25 & 4.9065 & TRN & \\
\hline CHEMBL1421382 & 688889 & 4.45 & 4.8359 & TRN & \\
\hline CHEMBL1453793 & 688889 & 4.95 & 4.6839 & TRN & \\
\hline CHEMBL1492915 & 688889 & 4.45 & 4.8312 & TRN & \\
\hline CHEMBL1414362 & 688889 & 5.35 & 4.7025 & TRN & \\
\hline CHEMBL3210370 & 688889 & 6.8 & 4.6624 & TST & \\
\hline
\end{tabular}




\begin{tabular}{|c|c|c|c|c|c|}
\hline \multicolumn{6}{|c|}{ Supplemental Table S2.txt } \\
\hline CHEMBL1328213 & 688889 & 4.45 & 4.7529 & TRN & \\
\hline CHEMBL1582278 & 688889 & 4.95 & 4.8185 & TRN & \\
\hline CHEMBL1520779 & 688889 & 4.45 & 4.8345 & TRN & \\
\hline CHEMBL1336641 & 688889 & 6.7501 & 4.8888 & TRN & \\
\hline CHEMBL1420949 & 688889 & 4.95 & 4.6943 & TRN & \\
\hline CHEMBL1376388 & 688889 & 4.45 & 4.784 & TRN & \\
\hline CHEMBL1362270 & 688889 & 4.45 & 4.7888 & TRN & \\
\hline CHEMBL1346518 & 688889 & 4.3 & 4.753 & TRN & \\
\hline CHEMBL1562954 & 688889 & 4.4 & 4.7874 & TST & \\
\hline CHEMBL1521240 & 688889 & 4.5 & 4.6846 & TRN & \\
\hline CHEMBL1546512 & 688889 & 4.5 & 4.9114 & TST & \\
\hline CHEMBL1464593 & 688889 & 4.95 & 4.6995 & TST & \\
\hline CHEMBL1308037 & 688889 & 4.75 & 4.7111 & TRN & \\
\hline CHEMBL1516870 & 688889 & 4.45 & 4.8603 & TRN & \\
\hline CHEMBL 2105246 & 688889 & 6.8 & 4.938 & TST & \\
\hline CHEMBL1454037 & 688889 & 4.3 & 4.6966 & TST & \\
\hline CHEMBL155563 & 688889 & 4.95 & 4.8306 & TRN & \\
\hline CHEMBL1373321 & 688889 & 5.0 & 4.8066 & TST & \\
\hline CHEMBL1489104 & 688889 & 4.25 & 4.8218 & TRN & \\
\hline CHEMBL3207400 & 688889 & 4.55 & 4.7709 & TRN & \\
\hline CHEMBL1338317 & 688889 & 4.45 & 4.6372 & TRN & \\
\hline CHEMBL1348969 & 688889 & 4.75 & 4.6019 & TRN & \\
\hline CHEMBL1569910 & 688889 & 5.85 & 4.6591 & TRN & \\
\hline CHEMBL1509530 & 688889 & 6.1 & 4.6251 & TST & \\
\hline CHEMBL3210786 & 688889 & 4.9 & 4.7551 & TRN & \\
\hline CHEMBL1541194 & 688889 & 4.55 & 4.6928 & TRN & \\
\hline CHEMBL1432137 & 688889 & 5.3 & 4.7556 & TRN & \\
\hline CHEMBL1333938 & 688889 & 4.2 & $4.7860 €$ & 00000000005 & TRN \\
\hline CHEMBL 1334710 & 688889 & 5.0 & 4.7701 & TRN & \\
\hline CHEMBL1608662 & 688889 & 4.7 & 4.9262 & TRN & \\
\hline CHEMBL1529652 & 688889 & 4.55 & 4.6031 & TRN & \\
\hline CHEMBL1303053 & 688889 & 4.25 & 4.8435 & TRN & \\
\hline CHEMBL1310065 & 688889 & 6.6499 & 4.8366 & TRN & \\
\hline CHEMBL1484484 & 688889 & 4.65 & 4.8009 & TRN & \\
\hline CHEMBL1464732 & 688889 & 5.1 & 4.8305 & TRN & \\
\hline CHEMBL1425822 & 688889 & 4.4 & 4.707 & TRN & \\
\hline CHEMBL1601868 & 688889 & 4.55 & 4.7876 & TRN & \\
\hline CHEMBL1578641 & 688889 & 5.95 & 4.796 & TRN & \\
\hline CHEMBL1483453 & 688889 & 4.65 & 4.7905 & TST & \\
\hline CHEMBL1458541 & 688889 & 4.5 & 4.6978 & TST & \\
\hline CHEMBL1560020 & 688889 & 4.3 & 4.8935 & TRN & \\
\hline CHEMBL1536957 & 688889 & 4.45 & 4.6362 & TRN & \\
\hline CHEMBL1391901 & 688889 & 4.95 & 4.7267 & TRN & \\
\hline CHEMBL1541348 & 688889 & 6.3 & 4.7892 & TRN & \\
\hline CHEMBL1454548 & 688889 & 6.05 & 4.7209 & TRN & \\
\hline CHEMBL1461660 & 688889 & 5.7 & 4.967 & TST & \\
\hline CHEMBL1321811 & 688889 & 4.5 & 4.8303 & TRN & \\
\hline CHEMBL3210059 & 688889 & 4.25 & 4.8585 & TRN & \\
\hline
\end{tabular}




\begin{tabular}{|c|c|c|c|c|}
\hline & & & pplement & $d \pm$ \\
\hline CHEMBL1457955 & 688889 & 4.3 & 4.8379 & TRN \\
\hline CHEMBL1577430 & 688889 & 4.4 & 4.7338 & TRN \\
\hline CHEMBL3192119 & 688889 & 6.7501 & 4.7507 & TST \\
\hline CHEMBL1604203 & 688889 & 5.25 & 4.8784 & TRN \\
\hline CHEMBL1202929 & 688889 & 6.8 & 4.735 & TST \\
\hline CHEMBL3213363 & 688889 & 4.85 & 4.8912 & TRN \\
\hline CHEMBL3191892 & 688889 & 4.5 & 4.7894 & TST \\
\hline CHEMBL1400275 & 688889 & 4.3 & 4.8093 & TST \\
\hline CHEMBL1483332 & 688889 & 5.2 & 4.7576 & TRN \\
\hline CHEMBL1307468 & 688889 & 5.45 & 4.83 & TST \\
\hline CHEMBL1426618 & 688889 & 6.7501 & 4.7864 & TRN \\
\hline CHEMBL1333837 & 688889 & 4.65 & 4.7409 & TRN \\
\hline CHEMBL1352979 & 688889 & 4.85 & 4.7331 & TRN \\
\hline CHEMBL1376734 & 688889 & 6.15 & 4.8253 & TRN \\
\hline CHEMBL1493628 & 688889 & 4.75 & 4.7063 & TRN \\
\hline CHEMBL1568920 & 688889 & 4.3 & 4.7211 & TRN \\
\hline CHEMBL3192727 & 688889 & 4.3 & 4.7905 & TRN \\
\hline CHEMBL1415657 & 688889 & 4.35 & 4.7481 & TRN \\
\hline CHEMBL1548848 & 688889 & 4.9 & 4.8435 & TST \\
\hline CHEMBL1533027 & 688889 & 5.1 & 4.8744 & TRN \\
\hline CHEMBL3211937 & 688889 & 4.5 & 4.7049 & TRN \\
\hline CHEMBL1490602 & 688889 & 4.45 & 4.7351 & TRN \\
\hline CHEMBL1597496 & 688889 & 4.9 & 4.694 & TRN \\
\hline CHEMBL1562329 & 688889 & 4.65 & 4.8186 & TRN \\
\hline CHEMBL1401610 & 688889 & 4.4 & 4.6892 & TRN \\
\hline CHEMBL1585529 & 688889 & 5.4 & 4.8033 & TST \\
\hline CHEMBL1559552 & 688889 & 4.55 & 4.7418 & TRN \\
\hline CHEMBL1522815 & 688889 & 5.1 & 4.756 & TST \\
\hline CHEMBL1581482 & 688889 & 6.8 & 4.9283 & TST \\
\hline CHEMBL1508388 & 688889 & 5.45 & 4.8994 & TRN \\
\hline CHEMBL1586901 & 688889 & 5.65 & 4.6501 & TRN \\
\hline CHEMBL1460631 & 688889 & 4.9 & 4.7547 & TST \\
\hline CHEMBL1517768 & 688889 & 4.25 & 4.6861 & TRN \\
\hline CHEMBL1485809 & 688889 & 5.25 & 4.7709 & TST \\
\hline CHEMBL1385886 & 688889 & 4.35 & 4.8413 & TST \\
\hline CHEMBL1610634 & 688889 & 4.9 & 4.8873 & TST \\
\hline CHEMBL3190070 & 688889 & 4.45 & 4.5603 & TRN \\
\hline CHEMBL1399315 & 688889 & 5.55 & 4.8807 & TRN \\
\hline CHEMBL1403276 & 688889 & 5.9 & 4.6571 & TRN \\
\hline CHEMBL1319353 & 688889 & 4.9 & 4.9185 & TRN \\
\hline CHEMBL1492427 & 688889 & 4.95 & 4.8262 & TST \\
\hline CHEMBL1414318 & 688889 & 4.95 & 4.782 & TRN \\
\hline CHEMBL1415613 & 688889 & 5.5 & 4.9512 & TRN \\
\hline CHEMBL1566863 & 688889 & 4.9 & 4.7947 & TRN \\
\hline CHEMBL1587216 & 688889 & 4.5 & 4.9135 & TRN \\
\hline CHEMBL1338596 & 688889 & 4.3 & 4.8095 & TST \\
\hline CHEMBL1489978 & 688889 & 4.5 & 4.8722 & TRN \\
\hline CHEMBL1376269 & 688889 & 4.95 & 4.8289 & TST \\
\hline
\end{tabular}




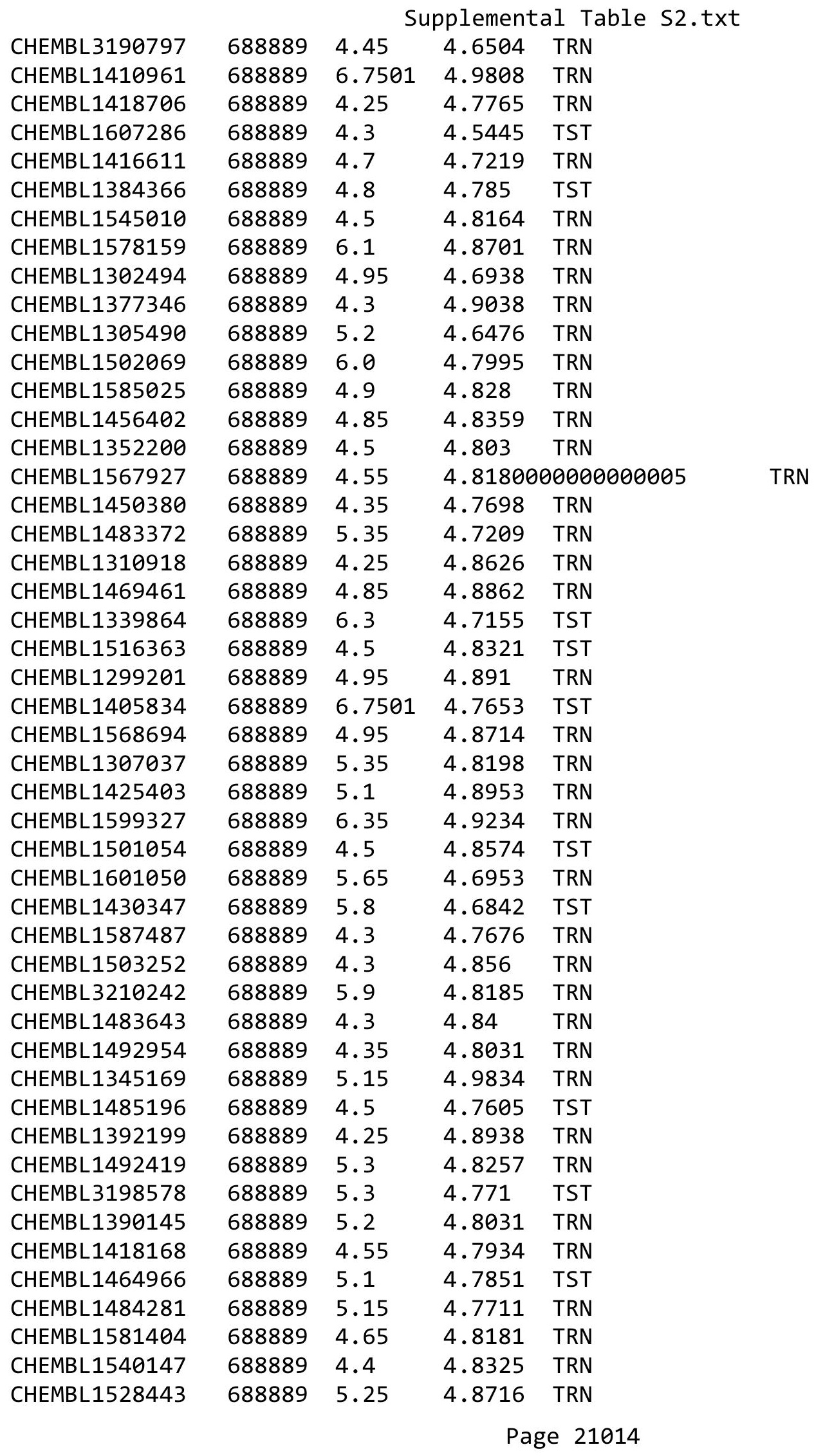




\begin{tabular}{|c|c|c|c|c|c|}
\hline \multicolumn{6}{|c|}{ Supplemental Table S2.txt } \\
\hline CHEMBL1425652 & 688889 & 4.65 & 4.8872 & TST & \\
\hline CHEMBL1384236 & 688889 & 4.25 & 4.8303 & TRN & \\
\hline CHEMBL1522146 & 688889 & 6.0 & 4.7003 & TRN & \\
\hline CHEMBL1455659 & 688889 & 6.7501 & 4.958 & TRN & \\
\hline CHEMBL1526538 & 688889 & 4.25 & 4.8404 & TRN & \\
\hline CHEMBL1469789 & 688889 & 4.45 & 4.7696 & TST & \\
\hline CHEMBL1574065 & 688889 & 5.1 & 4.6732 & TRN & \\
\hline CHEMBL1547539 & 688889 & 4.25 & 4.7647 & TRN & \\
\hline CHEMBL1545967 & 688889 & 4.5 & 4.9562 & TRN & \\
\hline CHEMBL1500336 & 688889 & 4.45 & 4.7998 & TRN & \\
\hline CHEMBL1530272 & 688889 & 4.45 & 4.6791 & TRN & \\
\hline CHEMBL528086 & 688889 & 4.9 & 4.8609 & TRN & \\
\hline CHEMBL1611371 & 688889 & 6.7001 & 4.7971 & TST & \\
\hline CHEMBL1390254 & 688889 & 4.4 & 4.6363 & TRN & \\
\hline CHEMBL1479478 & 688889 & 4.25 & 4.7691 & TST & \\
\hline CHEMBL1455463 & 688889 & 4.95 & 4.8538 & TRN & \\
\hline CHEMBL1449923 & 688889 & 4.55 & 4.6193 & TRN & \\
\hline CHEMBL1415758 & 688889 & 4.25 & 4.7489 & TRN & \\
\hline CHEMBL1163763 & 688889 & 4.5 & 4.7586 & TST & \\
\hline CHEMBL1372947 & 688889 & 5.4 & 4.787 & TRN & \\
\hline CHEMBL1383487 & 688889 & 5.15 & 4.837 & TST & \\
\hline CHEMBL1391059 & 688889 & 4.7 & 4.7535 & TST & \\
\hline CHEMBL1602892 & 688889 & 6.45 & 4.7201 & TRN & \\
\hline CHEMBL1509314 & 688889 & 4.4 & 4.8018 & TRN & \\
\hline CHEMBL1330689 & 688889 & 4.45 & 4.8925 & TRN & \\
\hline CHEMBL1497169 & 688889 & 6.1 & 4.83899 & 99999999995 & TRN \\
\hline CHEMBL1382392 & 688889 & 4.45 & 4.7077 & TRN & \\
\hline CHEMBL1560359 & 688889 & 4.55 & 4.8378 & TRN & \\
\hline CHEMBL1348194 & 688889 & 4.25 & 4.855 & TST & \\
\hline CHEMBL1581046 & 688889 & 5.85 & 4.9014 & TRN & \\
\hline CHEMBL1314107 & 688889 & 4.55 & 4.7351 & TRN & \\
\hline CHEMBL1559717 & 688889 & 6.0 & 4.8019 & TRN & \\
\hline CHEMBL1537242 & 688889 & 5.0 & 4.8875 & TST & \\
\hline CHEMBL1447372 & 688889 & 6.0 & 4.9006 & TRN & \\
\hline CHEMBL1588604 & 688889 & 5.3 & 4.6865 & TRN & \\
\hline CHEMBL1420768 & 688889 & 4.25 & 4.9811 & TRN & \\
\hline CHEMBL3189435 & 688889 & 4.45 & 4.886 & TRN & \\
\hline CHEMBL1300755 & 688889 & 4.3 & 4.8404 & TST & \\
\hline CHEMBL1334088 & 688889 & 5.35 & 4.9889 & TST & \\
\hline CHEMBL1326584 & 688889 & 4.55 & 4.6166 & TRN & \\
\hline CHEMBL1568210 & 688889 & 6.6499 & 4.7162 & TST & \\
\hline CHEMBL3196798 & 688889 & 4.25 & 4.8787 & TRN & \\
\hline CHEMBL1338784 & 688889 & 4.9 & 4.7368 & TST & \\
\hline CHEMBL1407854 & 688889 & 4.5 & 4.7317 & TRN & \\
\hline CHEMBL1456011 & 688889 & 5.4 & 4.8323 & TRN & \\
\hline CHEMBL572774 & 688889 & 4.95 & 4.7834 & TRN & \\
\hline CHEMBL1604171 & 688889 & 4.9 & 4.8719 & TST & \\
\hline CHEMBL1464799 & 688889 & 4.5 & 4.8238 & TRN & \\
\hline
\end{tabular}




\begin{tabular}{|c|c|c|c|c|c|}
\hline \multicolumn{6}{|c|}{ Supplemental Table s2.txt } \\
\hline CHEMBL1432231 & 688889 & 4.25 & 4.8637 & TRN & \\
\hline CHEMBL1520364 & 688889 & 4.25 & 4.7135 & TRN & \\
\hline CHEMBL1413717 & 688889 & 4.25 & 4.7353 & TRN & \\
\hline CHEMBL1405426 & 688889 & 4.25 & 4.8999 & TRN & \\
\hline CHEMBL1482574 & 688889 & 4.4 & 4.7738 & TRN & \\
\hline CHEMBL1391038 & 688889 & 4.3 & 4.855 & TRN & \\
\hline CHEMBL1459159 & 688889 & 5.55 & 4.6791 & TST & \\
\hline CHEMBL1527522 & 688889 & 5.4 & 4.9726 & TST & \\
\hline CHEMBL1533744 & 688889 & 4.45 & 4.7653 & TRN & \\
\hline CHEMBL1505672 & 688889 & 4.45 & 4.6568 & TST & \\
\hline CHEMBL1362163 & 688889 & 6.8 & 4.877 & TRN & \\
\hline CHEMBL1536497 & 688889 & 4.25 & 4.6424 & TRN & \\
\hline CHEMBL1407884 & 688889 & 6.7501 & 4.9611 & TST & \\
\hline CHEMBL1385054 & 688889 & 4.3 & 4.9364 & TRN & \\
\hline CHEMBL1305740 & 688889 & 4.25 & 4.8238 & TRN & \\
\hline CHEMBL1470657 & 688889 & 5.7 & 4.9572 & TRN & \\
\hline CHEMBL1581386 & 688889 & 4.6 & 4.8099 & TRN & \\
\hline CHEMBL3199601 & 688889 & 4.3 & 4.61 & TRN & \\
\hline CHEMBL1538691 & 688889 & 4.6 & 4.98300 & 00000000005 & TRN \\
\hline CHEMBL1459240 & 688889 & 4.6 & 4.6772 & TRN & \\
\hline CHEMBL1346882 & 688889 & 5.6 & 4.9606 & TRN & \\
\hline CHEMBL1607629 & 688889 & 5.45 & 4.8056 & TRN & \\
\hline CHEMBL1374386 & 688889 & 4.35 & 4.7805 & TRN & \\
\hline CHEMBL1544164 & 688889 & 4.9 & 4.9265 & TRN & \\
\hline CHEMBL1347151 & 688889 & 4.3 & 4.9695 & TRN & \\
\hline CHEMBL1340929 & 688889 & 5.15 & 4.9621 & TST & \\
\hline CHEMBL3211667 & 688889 & 4.45 & 4.8218 & TRN & \\
\hline CHEMBL1308749 & 688889 & 4.3 & 4.7962 & TRN & \\
\hline CHEMBL1493394 & 688889 & 4.4 & 4.6786 & TRN & \\
\hline CHEMBL1460405 & 688889 & 5.45 & 4.8621 & TRN & \\
\hline CHEMBL1327507 & 688889 & 5.25 & 5.0196 & TRN & \\
\hline CHEMBL1545009 & 688889 & 4.55 & 4.7742 & TRN & \\
\hline CHEMBL1327130 & 688889 & 4.35 & 4.7936 & TRN & \\
\hline CHEMBL1371779 & 688889 & 4.25 & 4.8252 & TST & \\
\hline CHEMBL1417218 & 688889 & 4.5 & 4.7319 & TRN & \\
\hline CHEMBL1348895 & 688889 & 4.3 & 4.6825 & TRN & \\
\hline CHEMBL1432924 & 688889 & 4.5 & 4.7536 & TRN & \\
\hline CHEMBL1557567 & 688889 & 4.25 & 4.8681 & TST & \\
\hline CHEMBL1301315 & 688889 & 4.3 & 4.7795 & TRN & \\
\hline CHEMBL1487657 & 688889 & 4.45 & 4.7013 & TRN & \\
\hline CHEMBL1403564 & 688889 & 4.45 & 4.6998 & TRN & \\
\hline CHEMBL1588097 & 688889 & 5.7 & 4.789 & TRN & \\
\hline CHEMBL1375134 & 688889 & 4.55 & 4.8564 & TRN & \\
\hline CHEMBL1350254 & 688889 & 4.65 & 4.641 & TRN & \\
\hline CHEMBL1441379 & 688889 & 4.7 & 4.8298 & TST & \\
\hline CHEMBL1605347 & 688889 & 4.25 & 4.8552 & TRN & \\
\hline CHEMBL1989636 & 688889 & 4.6 & 4.8613 & TRN & \\
\hline CHEMBL1549886 & 688889 & 4.25 & 4.7783 & TRN & \\
\hline
\end{tabular}




\begin{tabular}{|c|c|c|c|c|c|}
\hline \\
\hline CHEMBL1481481 & 688889 & 5.9 & 4.8224 & TRN & \\
\hline CHEMBL1537419 & 688889 & 5.0 & 4.9483 & TRN & \\
\hline CHEMBL1527164 & 688889 & 4.55 & 4.7445 & TRN & \\
\hline CHEMBL1327527 & 688889 & 4.95 & 4.9648 & TRN & \\
\hline CHEMBL1598638 & 688889 & 5.65 & $4.7810 e$ & 0000000001 & TRN \\
\hline CHEMBL1352863 & 688889 & 4.25 & 4.7984 & TRN & \\
\hline CHEMBL1313516 & 688889 & 4.3 & 4.9364 & TRN & \\
\hline CHEMBL1406097 & 688889 & 4.25 & 4.7258 & TRN & \\
\hline CHEMBL1580104 & 688889 & 5.3 & 4.9538 & TRN & \\
\hline CHEMBL3198667 & 688889 & 4.4 & 4.8577 & TRN & \\
\hline CHEMBL1406951 & 688889 & 4.5 & 4.8205 & TST & \\
\hline CHEMBL1573697 & 688889 & 4.45 & 4.6769 & TST & \\
\hline CHEMBL1456547 & 688889 & 4.9 & 4.7526 & TRN & \\
\hline CHEMBL1342471 & 688889 & 5.9 & 4.8577 & TRN & \\
\hline CHEMBL1386804 & 688889 & 4.25 & 4.8585 & TRN & \\
\hline CHEMBL1587254 & 688889 & 5.3 & 4.749 & TST & \\
\hline CHEMBL1583930 & 688889 & 4.5 & 4.7691 & TST & \\
\hline CHEMBL1360805 & 688889 & 4.5 & 4.7989 & TRN & \\
\hline CHEMBL1377010 & 688889 & 4.3 & 4.7678 & TRN & \\
\hline CHEMBL1550694 & 688889 & 4.95 & 4.6886 & TST & \\
\hline CHEMBL1511361 & 688889 & 5.7 & 4.681 & TRN & \\
\hline CHEMBL1445742 & 688889 & 4.25 & 4.8805 & TRN & \\
\hline CHEMBL1501453 & 688889 & 4.55 & 4.8193 & TST & \\
\hline CHEMBL1402262 & 688889 & 4.3 & 4.7921 & TST & \\
\hline CHEMBL1409965 & 688889 & 4.3 & 4.8498 & TST & \\
\hline CHEMBL1313855 & 688889 & 6.05 & 4.8133 & TST & \\
\hline CHEMBL1579818 & 688889 & 6.45 & 4.8002 & TRN & \\
\hline CHEMBL1550253 & 688889 & 4.45 & 4.8603 & TRN & \\
\hline CHEMBL1302992 & 688889 & 4.55 & 4.873 & TRN & \\
\hline CHEMBL3213982 & 688889 & 4.3 & 4.8115 & TRN & \\
\hline CHEMBL1321625 & 688889 & 5.5 & 4.7757 & TST & \\
\hline CHEMBL1537679 & 688889 & 4.3 & 4.7616 & TRN & \\
\hline CHEMBL1383558 & 688889 & 4.45 & 4.7054 & TRN & \\
\hline CHEMBL1424982 & 688889 & 4.25 & 4.8731 & TRN & \\
\hline CHEMBL1399930 & 688889 & 6.15 & 4.8465 & TRN & \\
\hline CHEMBL1426370 & 688889 & 5.2 & 4.8424 & TRN & \\
\hline CHEMBL1523656 & 688889 & 5.0 & 4.8338 & TST & \\
\hline CHEMBL1351626 & 688889 & 4.45 & 4.7961 & TRN & \\
\hline CHEMBL1363933 & 688889 & 4.6 & 4.7404 & TRN & \\
\hline CHEMBL1299499 & 688889 & 4.45 & 4.8185 & TRN & \\
\hline CHEMBL1489281 & 688889 & 4.25 & 4.8505 & TST & \\
\hline CHEMBL581459 & 688889 & 4.3 & 4.823 & TRN & \\
\hline CHEMBL1585194 & 688889 & 4.25 & 4.7785 & TST & \\
\hline CHEMBL1531512 & 688889 & 5.9 & 4.588 & TRN & \\
\hline CHEMBL1568261 & 688889 & 4.25 & 4.7232 & TST & \\
\hline CHEMBL1346401 & 688889 & 5.3 & 4.8269 & TRN & \\
\hline CHEMBL1415439 & 688889 & 4.3 & 4.9388 & TRN & \\
\hline CHEMBL1445500 & 688889 & 5.5 & 4.6883 & TRN & \\
\hline
\end{tabular}




\begin{tabular}{|c|c|c|c|c|c|}
\hline \\
\hline CHEMBL1570481 & 688889 & 5.1 & 4.7919 & TRN & \\
\hline CHEMBL1573929 & 688889 & 4.25 & 4.7828 & TST & \\
\hline CHEMBL1428211 & 688889 & 4.4 & 4.7838 & TST & \\
\hline CHEMBL1581520 & 688889 & 4.9 & 4.8574 & TRN & \\
\hline CHEMBL1524208 & 688889 & 4.35 & 4.7895 & TRN & \\
\hline CHEMBL1462046 & 688889 & 4.4 & 4.7037 & TRN & \\
\hline CHEMBL1601296 & 688889 & 4.45 & 4.7558 & TRN & \\
\hline CHEMBL1300482 & 688889 & 5.0 & 4.8603 & TRN & \\
\hline CHEMBL1586023 & 688889 & 6.15 & 4.8177 & TST & \\
\hline CHEMBL1303031 & 688889 & 4.3 & 4.6763 & TRN & \\
\hline CHEMBL1498371 & 688889 & 4.85 & 4.8408 & TRN & \\
\hline CHEMBL1447026 & 688889 & 4.85 & 4.7748 & TRN & \\
\hline CHEMBL1310338 & 688889 & 4.55 & 4.7852 & TRN & \\
\hline CHEMBL1464566 & 688889 & 5.25 & 4.7302 & TST & \\
\hline CHEMBL1498043 & 688889 & 5.25 & 4.808 & TRN & \\
\hline CHEMBL175003 & 688889 & 4.35 & 4.8249 & TRN & \\
\hline CHEMBL1365303 & 688889 & 4.95 & 4.7295 & TST & \\
\hline CHEMBL1347024 & 688889 & 4.65 & 4.8511 & TRN & \\
\hline CHEMBL1345297 & 688889 & 4.4 & 4.9198 & TRN & \\
\hline CHEMBL1349610 & 688889 & 4.45 & 4.7241 & TRN & \\
\hline CHEMBL1445764 & 688889 & 4.45 & 4.88899 & 9999999999 & TRN \\
\hline CHEMBL1598860 & 688889 & 6.05 & 4.9052 & TRN & \\
\hline CHEMBL1520621 & 688889 & 4.3 & 4.7597 & TST & \\
\hline CHEMBL1340666 & 688889 & 6.7501 & 4.8118 & TRN & \\
\hline CHEMBL1385575 & 688889 & 4.5 & 4.716 & TRN & \\
\hline CHEMBL1486767 & 688889 & 4.75 & 4.9482 & TRN & \\
\hline CHEMBL1978186 & 688889 & 4.25 & 4.8659 & TRN & \\
\hline CHEMBL1401425 & 688889 & 5.2 & 4.9565 & TRN & \\
\hline CHEMBL1383337 & 688889 & 5.7 & 4.7507 & TRN & \\
\hline CHEMBL1322746 & 688889 & 4.95 & 4.9356 & TRN & \\
\hline CHEMBL1584572 & 688889 & 4.45 & 4.8139 & TRN & \\
\hline CHEMBL1510772 & 688889 & 4.45 & 4.8935 & TRN & \\
\hline CHEMBL1477649 & 688889 & 4.9 & 4.8861 & TRN & \\
\hline CHEMBL1391081 & 688889 & 4.95 & 4.8521 & TST & \\
\hline CHEMBL1380938 & 688889 & 5.9 & 4.7672 & TRN & \\
\hline CHEMBL1423692 & 688889 & 4.95 & 4.8185 & TRN & \\
\hline CHEMBL1451029 & 688889 & 4.25 & 4.9463 & TRN & \\
\hline CHEMBL1343115 & 688889 & 4.65 & 4.7309 & TRN & \\
\hline CHEMBL1510698 & 688889 & 4.4 & 4.6985 & TRN & \\
\hline CHEMBL1612009 & 688889 & 4.95 & 4.9704 & TRN & \\
\hline CHEMBL1563993 & 688889 & 4.45 & 4.8497 & TRN & \\
\hline CHEMBL1427602 & 688889 & 4.6 & 4.6862 & TRN & \\
\hline CHEMBL1425645 & 688889 & 4.3 & 4.8824 & TRN & \\
\hline CHEMBL1342030 & 688889 & 4.95 & 4.7898 & TRN & \\
\hline CHEMBL1348591 & 688889 & 4.3 & 4.76399 & 9999999999 & TRN \\
\hline CHEMBL1370701 & 688889 & 5.25 & 4.8686 & TST & \\
\hline CHEMBL1450838 & 688889 & 4.55 & 4.6284 & TRN & \\
\hline CHEMBL1610645 & 688889 & 4.4 & 4.7992 & TRN & \\
\hline
\end{tabular}




\begin{tabular}{|c|c|c|c|c|}
\hline \multicolumn{5}{|c|}{ Supplemental Table S2.txt } \\
\hline CHEMBL1499778 & 688889 & 4.45 & 4.7611 & TRN \\
\hline CHEMBL1327995 & 688889 & 4.35 & 4.8395 & TST \\
\hline CHEMBL1582227 & 688889 & 4.85 & 4.9561 & TRN \\
\hline CHEMBL1451435 & 688889 & 4.25 & 4.7462 & TRN \\
\hline CHEMBL1319407 & 688889 & 4.55 & 4.8283 & TRN \\
\hline CHEMBL1451984 & 688889 & 4.25 & 4.8717 & TRN \\
\hline CHEMBL1424180 & 688889 & 4.95 & 4.7984 & TRN \\
\hline CHEMBL1354108 & 688889 & 4.25 & 4.8661 & TST \\
\hline CHEMBL568556 & 688889 & 6.8 & 4.8768 & TRN \\
\hline CHEMBL1348608 & 688889 & 4.4 & 4.8026 & TRN \\
\hline CHEMBL1432279 & 688889 & 4.3 & 4.8051 & TRN \\
\hline CHEMBL1557946 & 688889 & 4.3 & 4.9122 & TST \\
\hline CHEMBL1327701 & 688889 & 4.45 & 4.7448 & TRN \\
\hline CHEMBL1542005 & 688889 & 4.3 & 4.8367 & TRN \\
\hline CHEMBL1332721 & 688889 & 4.4 & 4.9038 & TRN \\
\hline CHEMBL1506234 & 688889 & 5.5 & 4.7351 & TRN \\
\hline CHEMBL1363090 & 688889 & 4.45 & 4.7129 & TRN \\
\hline CHEMBL1311630 & 688889 & 4.4 & 4.7485 & TRN \\
\hline CHEMBL3208130 & 688889 & 4.6 & 4.8356 & TRN \\
\hline CHEMBL1467655 & 688889 & 4.4 & 4.762 & TRN \\
\hline CHEMBL1448568 & 688889 & 5.65 & 4.6942 & TST \\
\hline CHEMBL1309013 & 688889 & 4.3 & 4.6716 & TRN \\
\hline CHEMBL1460907 & 688889 & 5.3 & 4.7713 & TRN \\
\hline CHEMBL1481980 & 688889 & 4.55 & 4.8204 & TST \\
\hline CHEMBL1312134 & 688889 & 4.55 & 4.8644 & TRN \\
\hline CHEMBL1548546 & 688889 & 4.55 & 4.7227 & TST \\
\hline CHEMBL1536427 & 688889 & 4.4 & 4.9562 & TRN \\
\hline CHEMBL1373002 & 688889 & 4.45 & 4.7765 & TRN \\
\hline CHEMBL1483791 & 688889 & 4.9 & 4.7414 & TRN \\
\hline CHEMBL1487479 & 688889 & 4.45 & 4.7275 & TRN \\
\hline CHEMBL1299731 & 688889 & 6.5 & 4.9589 & TRN \\
\hline CHEMBL1325135 & 688889 & 5.2 & 4.8232 & TRN \\
\hline CHEMBL1522968 & 688889 & 4.45 & 4.8578 & TRN \\
\hline CHEMBL1471737 & 688889 & 4.35 & 4.787 & TRN \\
\hline CHEMBL1459525 & 688889 & 4.3 & 4.79 & TRN \\
\hline CHEMBL1453813 & 688889 & 4.5 & 4.7694 & TRN \\
\hline CHEMBL1582117 & 688889 & 4.3 & 4.9078 & TRN \\
\hline CHEMBL1540498 & 688889 & 4.3 & 4.6713 & TRN \\
\hline CHEMBL1353457 & 688889 & 4.55 & 4.6777 & TST \\
\hline CHEMBL1510711 & 688889 & 4.6 & 4.7372 & TST \\
\hline CHEMBL1339237 & 688889 & 4.3 & 4.7288 & TRN \\
\hline CHEMBL1352294 & 688889 & 4.55 & 4.6582 & TRN \\
\hline CHEMBL1382352 & 688889 & 5.85 & 4.8044 & TRN \\
\hline CHEMBL1389321 & 688889 & 4.25 & 4.8392 & TRN \\
\hline CHEMBL1508359 & 688889 & 4.3 & 4.6844 & TRN \\
\hline CHEMBL1997098 & 688889 & 4.95 & 4.8681 & TRN \\
\hline CHEMBL1441914 & 688889 & 4.25 & 4.7134 & TRN \\
\hline CHEMBL1422960 & 688889 & 4.8 & 4.6232 & TRN \\
\hline
\end{tabular}




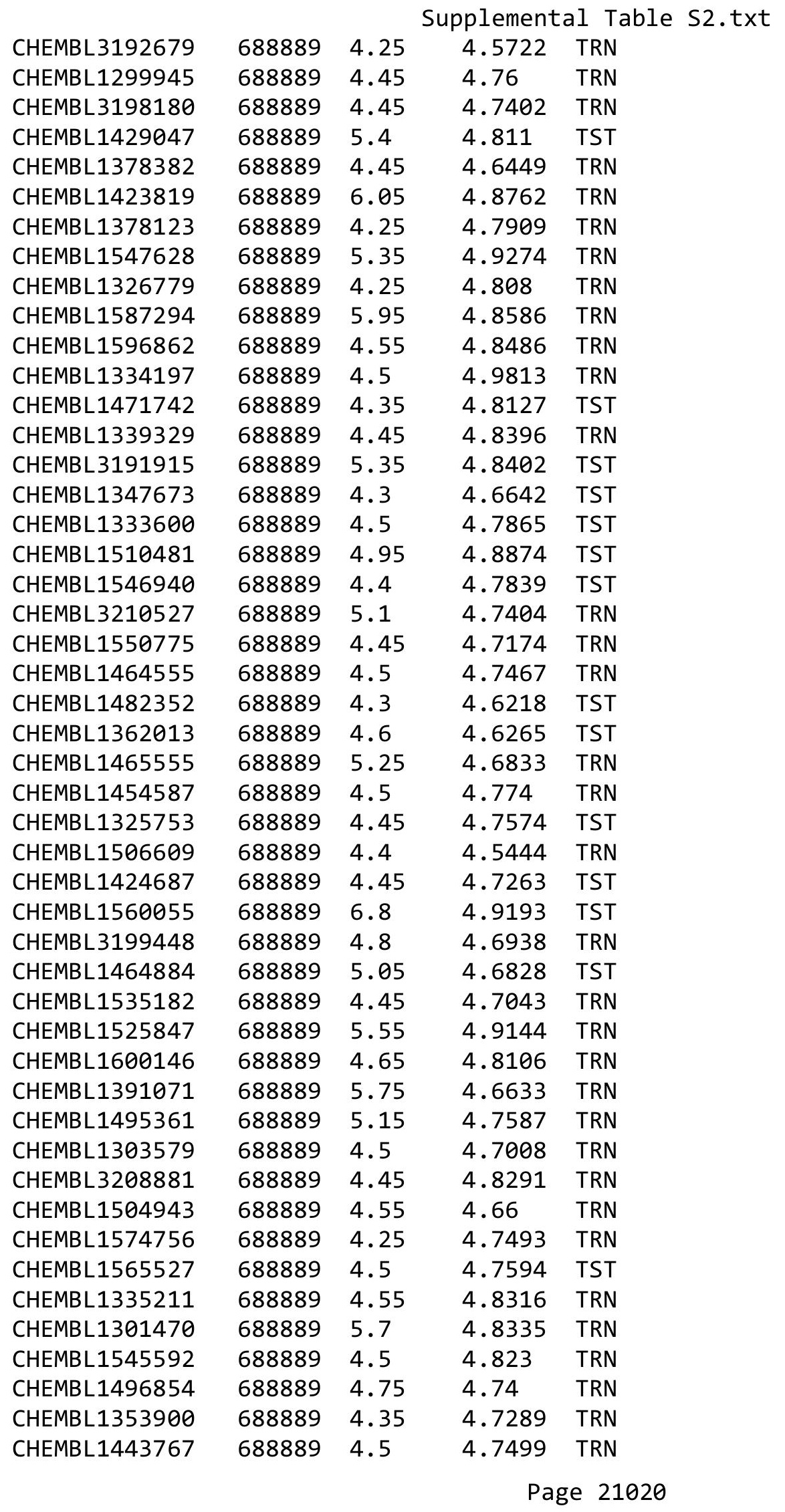




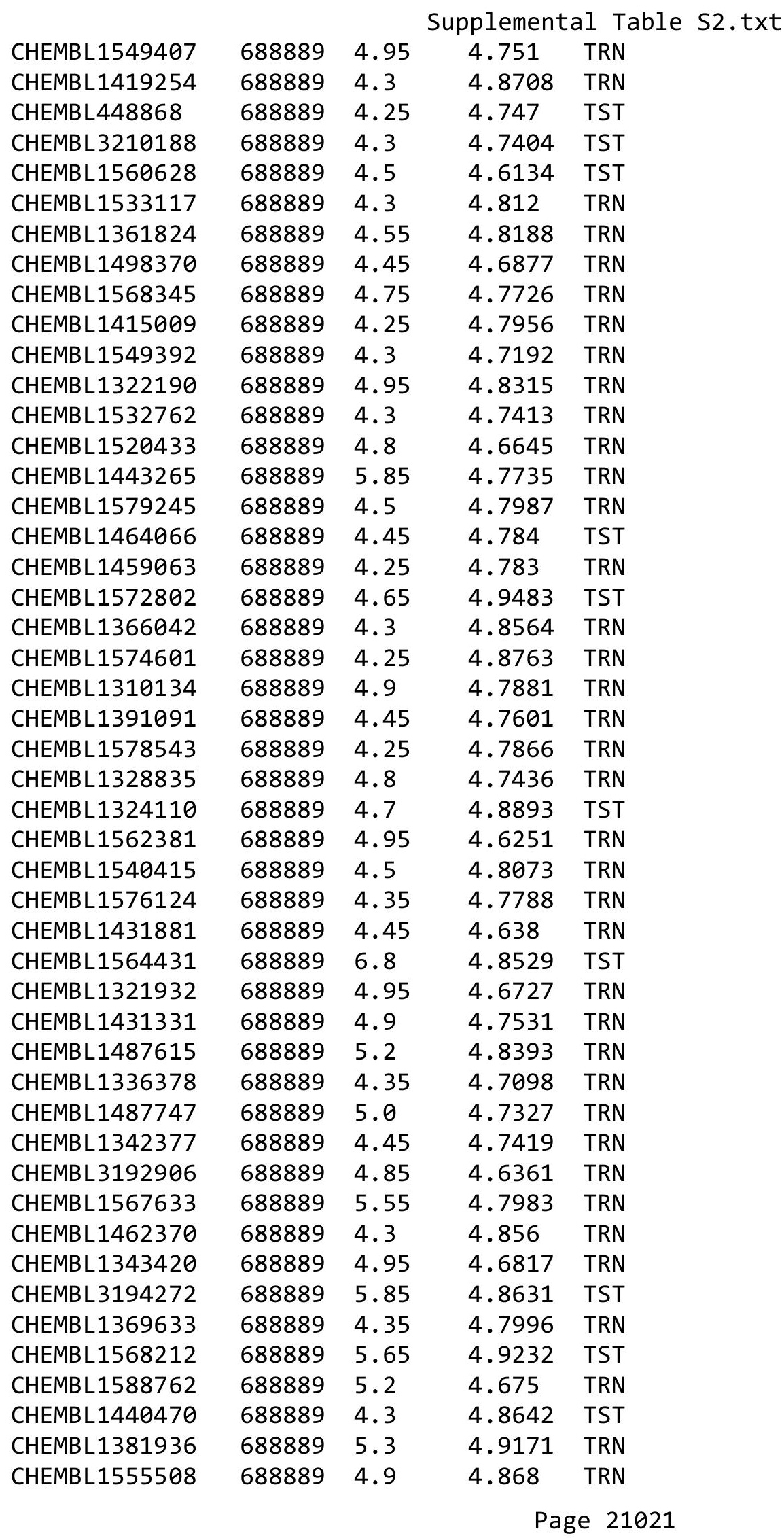




\begin{tabular}{|c|c|c|c|c|c|}
\hline & & \multicolumn{4}{|c|}{ Supplemental Table S2.txt } \\
\hline CHEMBL1537441 & 688889 & 4.35 & 4.7211 & TRN & \\
\hline CHEMBL1385735 & 688889 & 6.8 & 4.8611 & TST & \\
\hline CHEMBL1364365 & 688889 & 4.45 & 4.7924 & TRN & \\
\hline CHEMBL1497821 & 688889 & 5.2 & 4.8753 & TRN & \\
\hline CHEMBL1447163 & 688889 & 5.2 & 4.808 & TRN & \\
\hline CHEMBL1528346 & 688889 & 4.5 & 4.7678 & TRN & \\
\hline CHEMBL1330141 & 688889 & 6.5501 & 4.8528 & TRN & \\
\hline CHEMBL1345080 & 688889 & 5.05 & 4.7182 & TST & \\
\hline CHEMBL1330213 & 688889 & 5.0 & 4.8548 & TRN & \\
\hline CHEMBL1565275 & 688889 & 4.3 & 4.8632 & TRN & \\
\hline CHEMBL1550746 & 688889 & 4.5 & 4.7492 & TRN & \\
\hline CHEMBL1401669 & 688889 & 4.55 & 4.7689 & TRN & \\
\hline CHEMBL3213239 & 688889 & 4.25 & 4.7614 & TRN & \\
\hline CHEMBL1497662 & 688889 & 5.4 & 4.9213 & TST & \\
\hline CHEMBL1450704 & 688889 & 5.05 & 4.793 & TRN & \\
\hline CHEMBL1457013 & 688889 & 4.15 & 4.8196 & TST & \\
\hline CHEMBL1605397 & 688889 & 5.45 & 4.80699 & 99999999995 & TST \\
\hline CHEMBL1577674 & 688889 & 5.2 & 4.837 & TRN & \\
\hline CHEMBL1510183 & 688889 & 6.8 & 4.7034 & TRN & \\
\hline CHEMBL1457363 & 688889 & 4.25 & 4.8545 & TRN & \\
\hline CHEMBL1574031 & 688889 & 6.15 & 4.8427 & TRN & \\
\hline CHEMBL1564364 & 688889 & 5.95 & 4.9276 & TST & \\
\hline CHEMBL1466077 & 688889 & 6.0 & 4.8777 & TRN & \\
\hline CHEMBL1550883 & 688889 & 4.6 & 4.7413 & TRN & \\
\hline CHEMBL1522391 & 688889 & 4.4 & 4.9511 & TRN & \\
\hline CHEMBL3190778 & 688889 & 4.5 & 4.7497 & TRN & \\
\hline CHEMBL1393097 & 688889 & 4.25 & 4.7048 & TST & \\
\hline CHEMBL3199070 & 688889 & 4.45 & 4.9041 & TRN & \\
\hline CHEMBL1607659 & 688889 & 5.65 & 4.7505 & TRN & \\
\hline CHEMBL1518714 & 688889 & 4.25 & 4.8582 & TST & \\
\hline CHEMBL1598520 & 688889 & 4.25 & 4.7714 & TRN & \\
\hline CHEMBL 3213014 & 688889 & 4.25 & 4.8526 & TRN & \\
\hline CHEMBL1555772 & 688889 & 4.7 & 4.7075 & TRN & \\
\hline CHEMBL1390701 & 688889 & 4.7 & 4.7752 & TRN & \\
\hline CHEMBL1469581 & 688889 & 4.5 & 4.7055 & TRN & \\
\hline CHEMBL1468908 & 688889 & 4.85 & 4.7299 & TST & \\
\hline CHEMBL1506464 & 688889 & 5.1 & 4.8488 & TST & \\
\hline CHEMBL1505358 & 688889 & 5.75 & 4.7974 & TST & \\
\hline CHEMBL1382184 & 688889 & 4.25 & 4.7735 & TRN & \\
\hline CHEMBL1578288 & 688889 & 4.3 & 4.9739 & TRN & \\
\hline CHEMBL1609320 & 688889 & 4.45 & 4.8389 & TRN & \\
\hline CHEMBL1431810 & 688889 & 4.4 & 4.7312 & TST & \\
\hline CHEMBL1388127 & 688889 & 4.4 & 4.743 & TRN & \\
\hline CHEMBL1502370 & 688889 & 4.3 & 4.7884 & TRN & \\
\hline CHEMBL1335121 & 688889 & 4.3 & 4.7303 & TRN & \\
\hline CHEMBL1461518 & 688889 & 5.45 & 4.7977 & TRN & \\
\hline CHEMBL1299711 & 688889 & 4.6 & 4.9287 & TRN & \\
\hline CHEMBL1578962 & 688889 & 4.3 & 4.8472 & TRN & \\
\hline
\end{tabular}




\begin{tabular}{|c|c|c|c|c|}
\hline \multicolumn{5}{|c|}{ Supplemental Table S2.txt } \\
\hline CHEMBL1444745 & 688889 & 4.75 & 4.7601 & TRN \\
\hline CHEMBL1328054 & 688889 & 4.3 & 4.6808 & TRN \\
\hline CHEMBL1983345 & 688889 & 4.3 & 4.6729 & TRN \\
\hline CHEMBL1445388 & 688889 & 4.25 & 4.8799 & TRN \\
\hline CHEMBL1379538 & 688889 & 4.3 & 4.8146 & TRN \\
\hline CHEMBL1307025 & 688889 & 4.9 & 4.8763 & TRN \\
\hline CHEMBL1459075 & 688889 & 4.3 & 4.7082 & TRN \\
\hline CHEMBL1563669 & 688889 & 4.45 & 4.8004 & TRN \\
\hline CHEMBL1332221 & 688889 & 4.45 & 4.7103 & TRN \\
\hline CHEMBL1477353 & 688889 & 5.05 & 4.7918 & TRN \\
\hline CHEMBL1372426 & 688889 & 5.45 & 4.8789 & TRN \\
\hline CHEMBL3199473 & 688889 & 4.25 & 4.7794 & TST \\
\hline CHEMBL1497238 & 688889 & 4.5 & 4.816 & TRN \\
\hline CHEMBL1467138 & 688889 & 4.65 & 4.7259 & TRN \\
\hline CHEMBL1520561 & 688889 & 5.15 & 4.9148 & TST \\
\hline CHEMBL1588880 & 688889 & 4.8 & 4.7737 & TRN \\
\hline CHEMBL1384886 & 688889 & 4.25 & 4.7685 & TRN \\
\hline CHEMBL1404961 & 688889 & 4.95 & 4.8891 & TRN \\
\hline CHEMBL1401316 & 688889 & 5.2 & 4.9089 & TRN \\
\hline CHEMBL1336339 & 688889 & 5.05 & 4.7681 & TRN \\
\hline CHEMBL1602017 & 688889 & 5.5 & 4.8743 & TRN \\
\hline CHEMBL1608350 & 688889 & 4.25 & 4.8611 & TST \\
\hline CHEMBL1605768 & 688889 & 4.45 & 4.8969 & TRN \\
\hline CHEMBL1528583 & 688889 & 5.4 & 4.857 & TRN \\
\hline CHEMBL1322661 & 688889 & 4.45 & 4.8071 & TRN \\
\hline CHEMBL1493526 & 688889 & 4.9 & 4.8379 & TST \\
\hline CHEMBL1344571 & 688889 & 4.3 & 4.7569 & TRN \\
\hline CHEMBL1359670 & 688889 & 4.7 & 4.7554 & TRN \\
\hline CHEMBL1520591 & 688889 & 6.7501 & 4.7694 & TRN \\
\hline CHEMBL1505833 & 688889 & 5.4 & 4.6815 & TRN \\
\hline CHEMBL1367147 & 688889 & 5.0 & 4.6516 & TST \\
\hline CHEMBL1327428 & 688889 & 4.5 & 4.7883 & TRN \\
\hline CHEMBL 3210154 & 688889 & 4.95 & 4.6163 & TRN \\
\hline CHEMBL1342975 & 688889 & 4.4 & 4.8726 & TRN \\
\hline CHEMBL3210668 & 688889 & 4.35 & 4.8059 & TST \\
\hline CHEMBL1318377 & 688889 & 4.5 & 4.73 & TRN \\
\hline CHEMBL1535919 & 688889 & 4.45 & 4.7334 & TRN \\
\hline CHEMBL1371091 & 688889 & 5.85 & 4.8987 & TRN \\
\hline CHEMBL1459094 & 688889 & 4.45 & 4.7976 & TRN \\
\hline CHEMBL1419663 & 688889 & 4.4 & 4.7466 & TRN \\
\hline CHEMBL1497299 & 688889 & 6.2 & 4.7605 & TRN \\
\hline CHEMBL3194622 & 688889 & 4.25 & 4.7404 & TST \\
\hline CHEMBL1371239 & 688889 & 4.5 & 4.8359 & TRN \\
\hline CHEMBL1537410 & 688889 & 4.65 & 4.8012 & TST \\
\hline CHEMBL1506429 & 688889 & 6.4 & 4.8045 & TST \\
\hline CHEMBL1384452 & 688889 & 5.25 & 4.8391 & TST \\
\hline CHEMBL1989414 & 688889 & 4.6 & 4.6029 & TRN \\
\hline CHEMBL1610672 & 688889 & 5.3 & 4.9244 & TRN \\
\hline
\end{tabular}




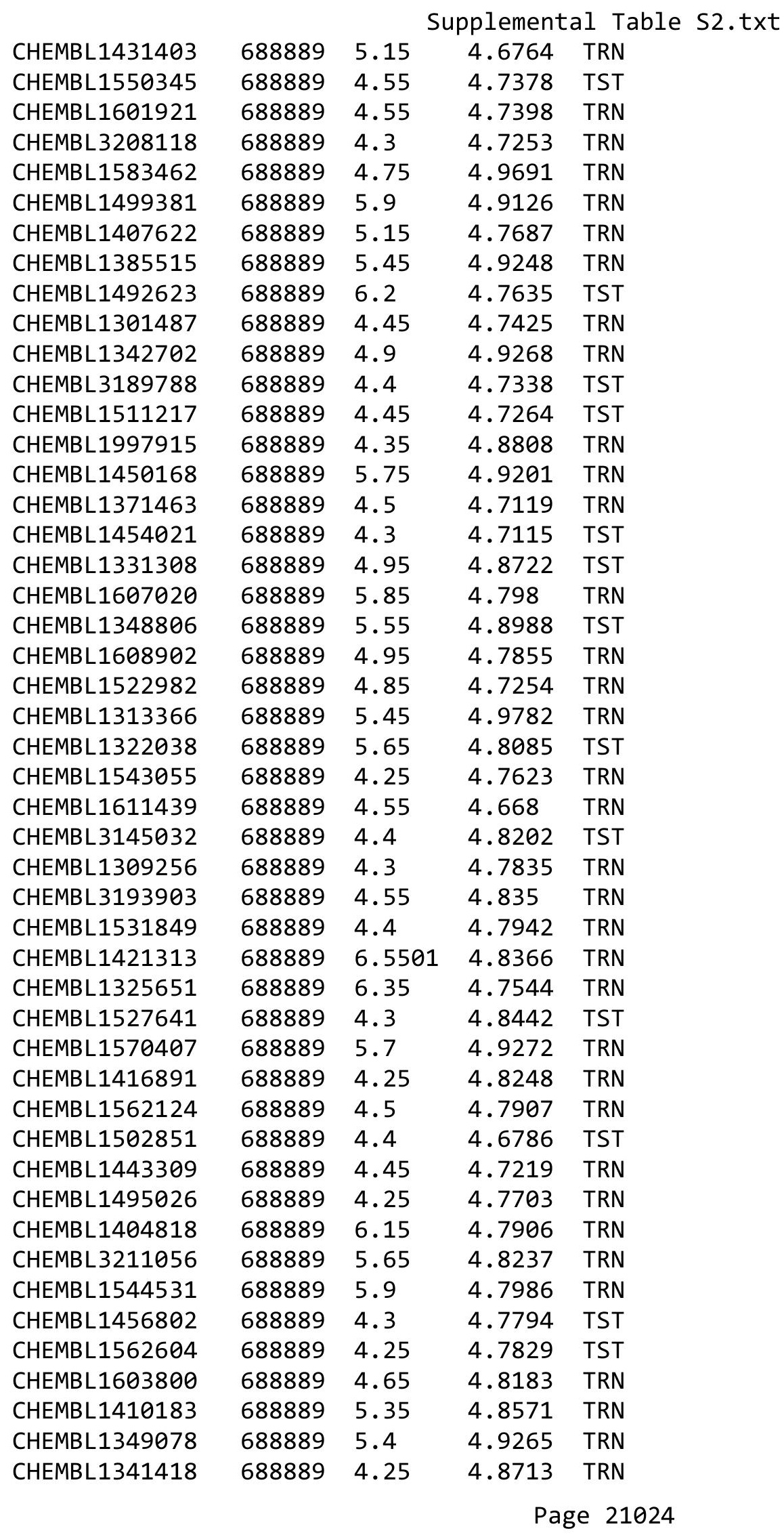




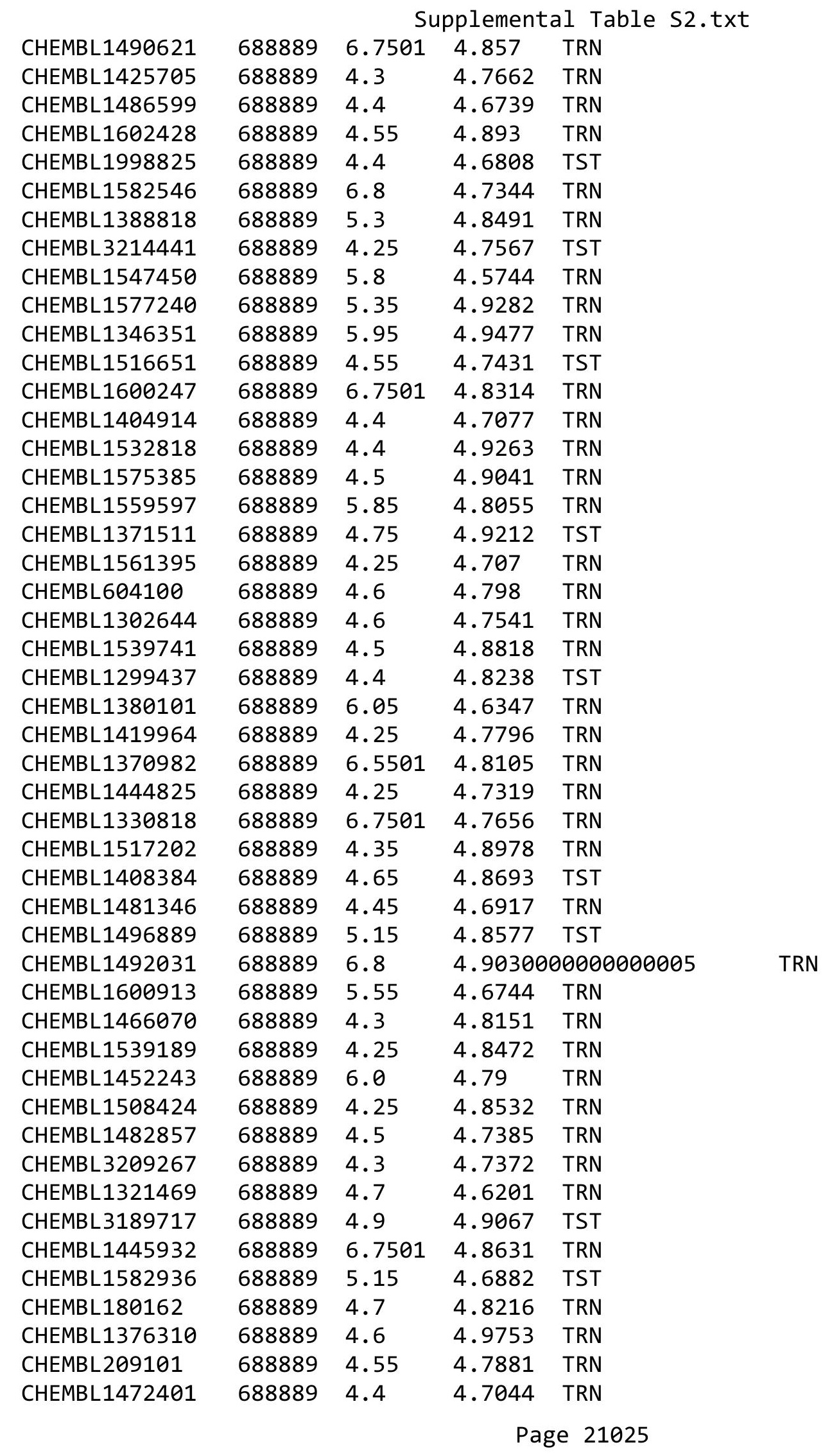




\begin{tabular}{|c|c|c|c|c|}
\hline \multicolumn{5}{|c|}{ Supplemental Table } \\
\hline CHEMBL1339538 & 688889 & 4.6 & 4.7919 & TRN \\
\hline CHEMBL3199797 & 688889 & 4.3 & 4.7917 & TST \\
\hline CHEMBL1533106 & 688889 & 4.25 & 4.8609 & TRN \\
\hline CHEMBL1507997 & 688889 & 4.45 & 4.7208 & TRN \\
\hline CHEMBL1431090 & 688889 & 5.15 & 4.8914 & TST \\
\hline CHEMBL1456659 & 688889 & 4.65 & 4.7199 & TRN \\
\hline CHEMBL1535449 & 688889 & 4.95 & 4.7284 & TRN \\
\hline CHEMBL182786 & 688889 & 4.45 & 4.7088 & TST \\
\hline CHEMBL1522379 & 688889 & 4.5 & 4.7955 & TRN \\
\hline CHEMBL1485796 & 688889 & 4.55 & 4.8316 & TRN \\
\hline CHEMBL1497915 & 688889 & 4.4 & 4.5743 & TRN \\
\hline CHEMBL1497463 & 688889 & 4.5 & 4.9569 & TRN \\
\hline CHEMBL1333792 & 688889 & 5.2 & 4.7402 & TST \\
\hline CHEMBL1413172 & 688889 & 4.95 & 4.7514 & TRN \\
\hline CHEMBL1561119 & 688889 & 4.55 & 4.7687 & TST \\
\hline CHEMBL1490206 & 688889 & 4.25 & 4.8279 & TST \\
\hline CHEMBL1533057 & 688889 & 4.55 & 4.75 & TRN \\
\hline CHEMBL1336678 & 688889 & 5.3 & 4.7604 & TST \\
\hline CHEMBL1347000 & 688889 & 5.4 & 4.808 & TRN \\
\hline CHEMBL1500285 & 688889 & 4.45 & 4.7842 & TST \\
\hline CHEMBL590457 & 688889 & 5.95 & 4.6502 & TST \\
\hline CHEMBL1559485 & 688889 & 4.6 & 4.8928 & TRN \\
\hline CHEMBL1506962 & 688889 & 4.4 & 4.7505 & TRN \\
\hline CHEMBL1500874 & 688889 & 4.75 & 4.6409 & TST \\
\hline CHEMBL1499125 & 688889 & 4.7 & 4.809 & TRN \\
\hline CHEMBL1561923 & 688889 & 5.15 & 4.8382 & TST \\
\hline CHEMBL1527485 & 688889 & 4.55 & 4.6542 & TRN \\
\hline CHEMBL1368196 & 688889 & 5.15 & 4.7061 & TST \\
\hline CHEMBL1575033 & 688889 & 4.95 & 4.6717 & TRN \\
\hline CHEMBL1491624 & 688889 & 5.6 & 4.9247 & TRN \\
\hline CHEMBL1467904 & 688889 & 4.95 & 4.8998 & TRN \\
\hline CHEMBL1536362 & 688889 & 4.3 & 4.85 & TRN \\
\hline CHEMBL1511401 & 688889 & 4.85 & 4.8287 & TRN \\
\hline CHEMBL1549805 & 688889 & 4.45 & 4.7593 & TRN \\
\hline CHEMBL1521019 & 688889 & 4.4 & 4.8366 & TRN \\
\hline CHEMBL1373425 & 688889 & 4.25 & 4.7779 & TST \\
\hline CHEMBL1566730 & 688889 & 6.8 & 4.7406 & TRN \\
\hline CHEMBL1503406 & 688889 & 4.9 & 4.8181 & TRN \\
\hline CHEMBL1604484 & 688889 & 5.1 & 4.8548 & TRN \\
\hline CHEMBL1353713 & 688889 & 5.9 & 4.7575 & TRN \\
\hline CHEMBL1546063 & 688889 & 4.6 & 4.6993 & TRN \\
\hline CHEMBL1608615 & 688889 & 5.0 & 4.7253 & TRN \\
\hline CHEMBL1470269 & 688889 & 4.3 & 4.8398 & TRN \\
\hline CHEMBL1489077 & 688889 & 4.5 & 4.7704 & TRN \\
\hline CHEMBL1427758 & 688889 & 4.9 & 4.824 & TRN \\
\hline CHEMBL1586249 & 688889 & 4.5 & 4.7106 & TRN \\
\hline CHEMBL1490639 & 688889 & 4.65 & 4.766 & TRN \\
\hline CHEMBL1517647 & 688889 & 4.9 & 4.7507 & TRN \\
\hline
\end{tabular}




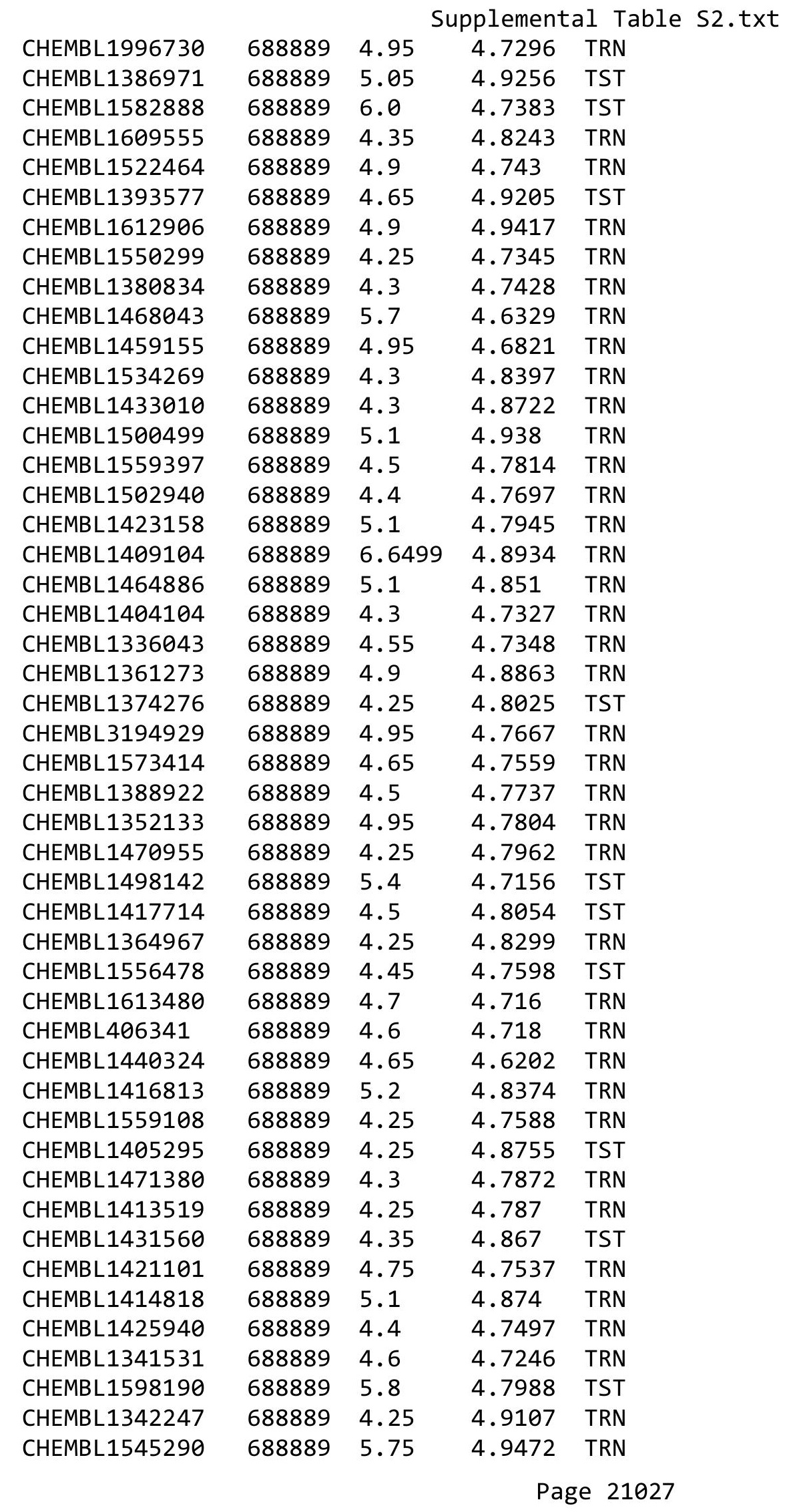




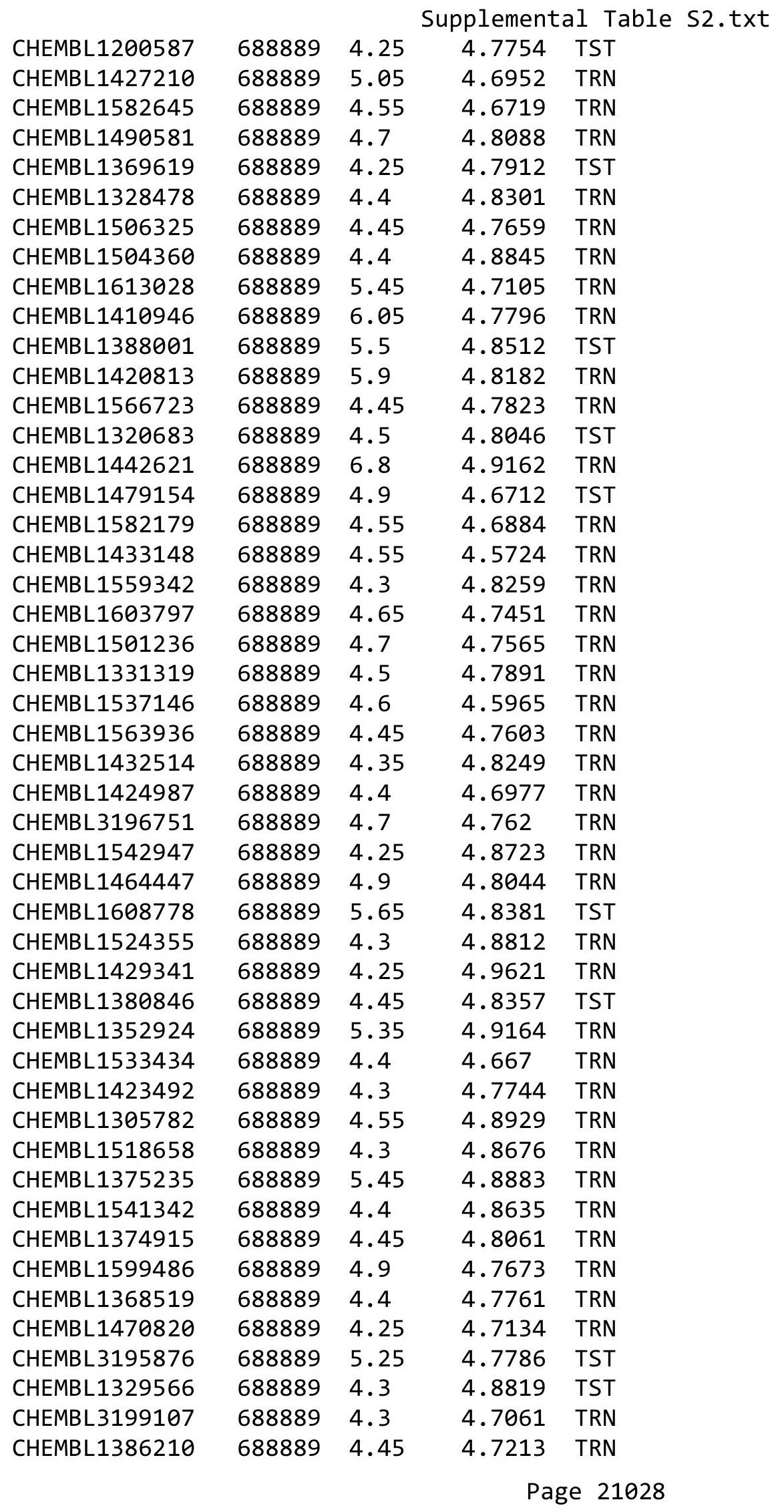




\begin{tabular}{|c|c|c|c|c|c|}
\hline \multicolumn{6}{|c|}{ Supplemental Table S2.txt } \\
\hline CHEMBL1340667 & 688889 & 4.4 & 4.9169 & TRN & \\
\hline CHEMBL1505041 & 688889 & 4.3 & 4.7014 & TRN & \\
\hline CHEMBL1380228 & 688889 & 4.95 & 4.6694 & TRN & \\
\hline CHEMBL227925 & 688889 & 4.5 & 4.7308 & TRN & \\
\hline CHEMBL1312404 & 688889 & 4.3 & 4.8128 & TST & \\
\hline CHEMBL1367710 & 688889 & 4.3 & 4.7029 & TRN & \\
\hline CHEMBL1523812 & 688889 & 4.4 & 4.8815 & TST & \\
\hline CHEMBL1567873 & 688889 & 4.25 & 4.7942 & TST & \\
\hline CHEMBL1300081 & 688889 & 5.05 & 4.8069 & TRN & \\
\hline CHEMBL1304510 & 688889 & 5.2 & 4.9199 & TST & \\
\hline CHEMBL1603613 & 688889 & 4.3 & 4.8036 & TRN & \\
\hline CHEMBL1500113 & 688889 & 4.4 & 4.7797 & TRN & \\
\hline CHEMBL1568009 & 688889 & 4.95 & 4.668 & TRN & \\
\hline CHEMBL1359188 & 688889 & 5.95 & 4.8229 & TRN & \\
\hline CHEMBL1361783 & 688889 & 5.6 & 4.9003 & TST & \\
\hline CHEMBL1485887 & 688889 & 4.25 & 4.7773 & TRN & \\
\hline CHEMBL1608782 & 688889 & 4.65 & 4.6592 & TRN & \\
\hline CHEMBL1526946 & 688889 & 4.25 & 4.7749 & TRN & \\
\hline CHEMBL1304982 & 688889 & 5.3 & 4.8593 & TST & \\
\hline CHEMBL1365012 & 688889 & 4.45 & 4.9021 & TRN & \\
\hline CHEMBL1537043 & 688889 & 4.9 & 4.9247 & TRN & \\
\hline CHEMBL1431332 & 688889 & 5.15 & 4.7544 & TST & \\
\hline CHEMBL1414155 & 688889 & 4.55 & 4.8169 & TST & \\
\hline CHEMBL1494889 & 688889 & 4.6 & 4.7931 & TST & \\
\hline CHEMBL1480317 & 688889 & 4.3 & 4.803 & TRN & \\
\hline CHEMBL1561757 & 688889 & 4.55 & 4.6513 & TRN & \\
\hline CHEMBL1535395 & 688889 & 4.5 & 4.7528 & TRN & \\
\hline CHEMBL1569608 & 688889 & 5.55 & 4.80699 & 99999999995 & TRN \\
\hline CHEMBL1344260 & 688889 & 5.15 & 4.6357 & TST & \\
\hline CHEMBL1309334 & 688889 & 4.9 & 4.6727 & TST & \\
\hline CHEMBL1613468 & 688889 & 4.25 & 4.8331 & TRN & \\
\hline CHEMBL1576162 & 688889 & 5.1 & 4.7666 & TRN & \\
\hline CHEMBL 3210829 & 688889 & 4.95 & 4.92899 & 9999999999 & TST \\
\hline CHEMBL1423870 & 688889 & 4.4 & 4.7186 & TRN & \\
\hline CHEMBL3211974 & 688889 & 5.15 & 4.773 & TST & \\
\hline CHEMBL1309714 & 688889 & 6.7501 & 4.7981 & TST & \\
\hline CHEMBL1361817 & 688889 & 4.45 & 4.8565 & TRN & \\
\hline CHEMBL1448393 & 688889 & 5.25 & 4.729 & TST & \\
\hline CHEMBL1557024 & 688889 & 4.25 & 4.9424 & TRN & \\
\hline CHEMBL1438534 & 688889 & 4.55 & 4.7817 & TST & \\
\hline CHEMBL1300912 & 688889 & 4.6 & 4.7503 & TST & \\
\hline CHEMBL1966691 & 688889 & 5.3 & 4.6672 & TRN & \\
\hline CHEMBL1562564 & 688889 & 4.9 & 4.9086 & TRN & \\
\hline CHEMBL1555495 & 688889 & 5.6 & 4.9769 & TST & \\
\hline CHEMBL1487976 & 688889 & 4.45 & 4.9545 & TRN & \\
\hline CHEMBL1401334 & 688889 & 4.3 & 4.9735 & TRN & \\
\hline CHEMBL1575914 & 688889 & 6.2 & 4.6821 & TRN & \\
\hline CHEMBL1589153 & 688889 & 4.3 & 4.771 & TRN & \\
\hline
\end{tabular}




\begin{tabular}{|c|c|c|c|c|c|}
\hline \multicolumn{6}{|c|}{ Supplemental Table s2.txt } \\
\hline CHEMBL1461017 & 688889 & 4.25 & 4.7025 & TRN & \\
\hline CHEMBL 1404400 & 688889 & 6.7501 & 4.8702 & TRN & \\
\hline CHEMBL3209052 & 688889 & 4.95 & 4.7571 & TRN & \\
\hline CHEMBL1411083 & 688889 & 4.45 & 4.7369 & TRN & \\
\hline CHEMBL592106 & 688889 & 4.3 & 4.9284 & TRN & \\
\hline CHEMBL1505837 & 688889 & 4.9 & 4.8458 & TRN & \\
\hline CHEMBL1328766 & 688889 & 5.8 & 4.7866 & TRN & \\
\hline CHEMBL1509941 & 688889 & 5.05 & 4.828 & TRN & \\
\hline CHEMBL1402345 & 688889 & 4.25 & 4.9562 & TST & \\
\hline CHEMBL3195995 & 688889 & 4.3 & 4.6522 & TRN & \\
\hline CHEMBL1427261 & 688889 & 5.95 & 4.7307 & TRN & \\
\hline CHEMBL1313145 & 688889 & 6.0 & 4.8506 & TRN & \\
\hline CHEMBL1545150 & 688889 & 5.95 & 4.6989 & TRN & \\
\hline CHEMBL1606956 & 688889 & 6.3 & 4.6924 & TRN & \\
\hline CHEMBL1497049 & 688889 & 5.05 & 4.7001 & TST & \\
\hline CHEMBL1401643 & 688889 & 4.4 & 4.7673 & TRN & \\
\hline CHEMBL1303347 & 688889 & 4.55 & 4.7085 & TRN & \\
\hline CHEMBL1432020 & 688889 & 4.6 & 4.8083 & TRN & \\
\hline CHEMBL3198029 & 688889 & 6.7501 & 4.8574 & TRN & \\
\hline CHEMBL1372400 & 688889 & 6.7501 & 4.652 & TST & \\
\hline CHEMBL1401558 & 688889 & 4.25 & 4.71399 & 99999999995 & TRN \\
\hline CHEMBL1371038 & 688889 & 4.55 & 4.8166 & TST & \\
\hline CHEMBL1546282 & 688889 & 4.3 & 4.795 & TST & \\
\hline CHEMBL3193847 & 688889 & 5.3 & 4.8013 & TRN & \\
\hline CHEMBL1417899 & 688889 & 4.55 & 4.6317 & TST & \\
\hline CHEMBL1393235 & 688889 & 4.9 & 4.9656 & TRN & \\
\hline CHEMBL1572586 & 688889 & 5.45 & 4.7326 & TST & \\
\hline CHEMBL1401498 & 688889 & 4.4 & 4.9063 & TRN & \\
\hline CHEMBL1549316 & 688889 & 4.9 & 4.8641 & TST & \\
\hline CHEMBL1545173 & 688889 & 4.45 & 4.7551 & TRN & \\
\hline CHEMBL1558140 & 688889 & 5.95 & 4.8333 & TRN & \\
\hline CHEMBL1566961 & 688889 & 5.45 & 4.8149 & TRN & \\
\hline CHEMBL3211830 & 688889 & 5.15 & 4.7028 & TRN & \\
\hline CHEMBL1332909 & 688889 & 4.45 & 4.8675 & TST & \\
\hline CHEMBL1612476 & 688889 & 4.45 & 4.6325 & TRN & \\
\hline CHEMBL1490864 & 688889 & 4.55 & 4.7305 & TRN & \\
\hline CHEMBL1381551 & 688889 & 4.25 & 4.7758 & TST & \\
\hline CHEMBL1311245 & 688889 & 5.4 & 4.7994 & TRN & \\
\hline CHEMBL1421454 & 688889 & 4.5 & 4.9109 & TST & \\
\hline CHEMBL1449194 & 688889 & 5.2 & 4.7796 & TRN & \\
\hline CHEMBL1460880 & 688889 & 4.95 & 4.7363 & TRN & \\
\hline CHEMBL1471180 & 688889 & 5.8 & 4.6681 & TRN & \\
\hline CHEMBL3191738 & 688889 & 4.9 & 4.8405 & TRN & \\
\hline CHEMBL1423325 & 688889 & 4.65 & 4.7758 & TRN & \\
\hline CHEMBL1439561 & 688889 & 6.7501 & 4.7206 & TST & \\
\hline CHEMBL1392284 & 688889 & 4.3 & 4.8965 & TRN & \\
\hline CHEMBL1573851 & 688889 & 5.45 & 4.7014 & TRN & \\
\hline CHEMBL1539981 & 688889 & 4.3 & 4.7092 & TST & \\
\hline
\end{tabular}




\begin{tabular}{|c|c|c|c|c|c|}
\hline \multicolumn{6}{|c|}{ Supplemental Table S2.txt } \\
\hline CHEMBL1538555 & 688889 & 4.65 & 4.6951 & TRN & \\
\hline CHEMBL1608482 & 688889 & 4.95 & 4.9157 & TRN & \\
\hline CHEMBL1431997 & 688889 & 4.35 & 4.945 & TST & \\
\hline CHEMBL1504661 & 688889 & 4.25 & 4.792 & TRN & \\
\hline CHEMBL1612700 & 688889 & 4.45 & 4.845 & TRN & \\
\hline CHEMBL1508808 & 688889 & 4.95 & 4.7682 & TRN & \\
\hline CHEMBL1400666 & 688889 & 4.6 & 4.8483 & TRN & \\
\hline CHEMBL1525001 & 688889 & 4.95 & 4.7121 & TST & \\
\hline CHEMBL1507703 & 688889 & 4.85 & 4.8733 & TRN & \\
\hline CHEMBL1375602 & 688889 & 4.3 & 4.8210 & 0000000001 & TRN \\
\hline CHEMBL1562373 & 688889 & 6.7501 & 4.81 & TRN & \\
\hline CHEMBL1533082 & 688889 & 4.25 & 4.7131 & TRN & \\
\hline CHEMBL1345842 & 688889 & 4.25 & 4.8445 & TRN & \\
\hline CHEMBL1380182 & 688889 & 4.3 & 4.6616 & TST & \\
\hline CHEMBL1413788 & 688889 & 4.3 & 4.8307 & TRN & \\
\hline CHEMBL1468990 & 688889 & 4.5 & 4.7014 & TRN & \\
\hline CHEMBL1511777 & 688889 & 5.8 & 4.8449 & TRN & \\
\hline CHEMBL1366034 & 688889 & 4.3 & 4.6518 & TRN & \\
\hline CHEMBL474749 & 688889 & 4.5 & 4.9115 & TRN & \\
\hline CHEMBL1582605 & 688889 & 4.25 & 4.8474 & TST & \\
\hline CHEMBL1399801 & 688889 & 5.15 & 4.9766 & TST & \\
\hline CHEMBL3213062 & 688889 & 4.55 & 4.7567 & TRN & \\
\hline CHEMBL1601105 & 688889 & 5.5 & 4.8917 & TST & \\
\hline CHEMBL1471791 & 688889 & 4.35 & 4.7421 & TRN & \\
\hline CHEMBL1300646 & 688889 & 6.35 & 4.9057 & TRN & \\
\hline CHEMBL3209164 & 688889 & 4.3 & 4.8403 & TRN & \\
\hline CHEMBL1380881 & 688889 & 5.2 & 4.7515 & TRN & \\
\hline CHEMBL1422167 & 688889 & 5.9 & 4.8588 & TRN & \\
\hline CHEMBL1391423 & 688889 & 4.25 & 4.928 & TRN & \\
\hline CHEMBL1409853 & 688889 & 4.55 & 4.6934 & TST & \\
\hline CHEMBL1544677 & 688889 & 4.3 & 4.8077 & TRN & \\
\hline CHEMBL1339735 & 688889 & 4.35 & 4.913 & TRN & \\
\hline CHEMBL1453179 & 688889 & 4.35 & 4.7994 & TRN & \\
\hline CHEMBL1605218 & 688889 & 4.45 & 4.7353 & TRN & \\
\hline CHEMBL3214088 & 688889 & 4.3 & 4.8791 & TRN & \\
\hline CHEMBL1403529 & 688889 & 5.75 & 5.0371 & TRN & \\
\hline CHEMBL1377024 & 688889 & 4.6 & 4.9418 & TRN & \\
\hline CHEMBL1492388 & 688889 & 4.4 & 4.7292 & TRN & \\
\hline CHEMBL1363272 & 688889 & 5.8 & 4.8425 & TST & \\
\hline CHEMBL1460018 & 688889 & 4.6 & 4.768 & TRN & \\
\hline CHEMBL1405863 & 688889 & 4.4 & 4.6695 & TRN & \\
\hline CHEMBL1508965 & 688889 & 4.25 & 4.8582 & TRN & \\
\hline CHEMBL1383950 & 688889 & 5.15 & 4.8244 & TRN & \\
\hline CHEMBL3209935 & 688889 & 6.4 & 4.8881 & TST & \\
\hline CHEMBL1501190 & 688889 & 4.6 & 4.6476 & TRN & \\
\hline CHEMBL1595127 & 688889 & 4.4 & 4.8425 & TRN & \\
\hline CHEMBL1326919 & 688889 & 4.3 & 4.895 & TRN & \\
\hline CHEMBL1608664 & 688889 & 6.6499 & 4.8806 & TRN & \\
\hline
\end{tabular}




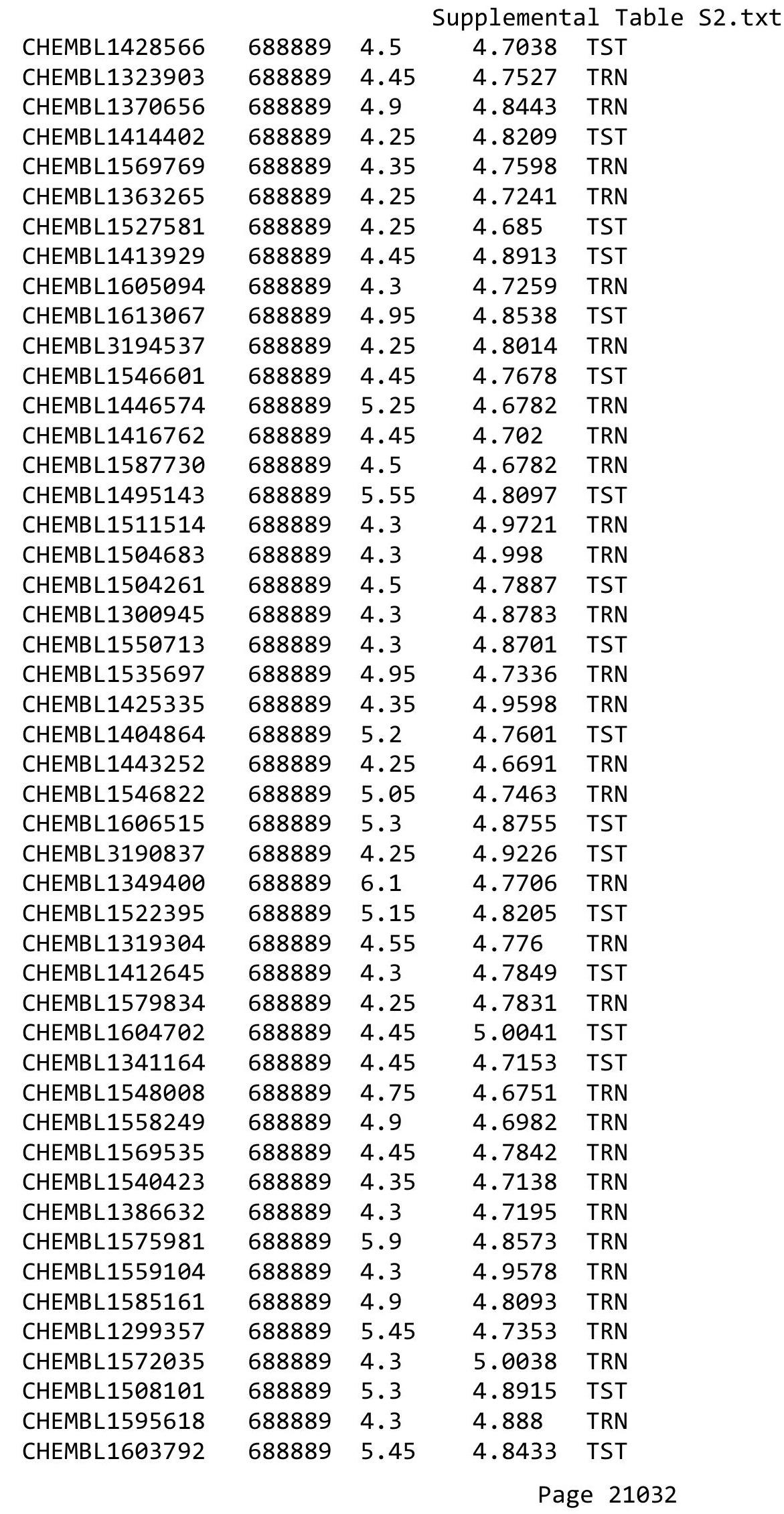




\begin{tabular}{|c|c|c|c|c|c|}
\hline \multicolumn{6}{|c|}{ Supplemental Table S2.txt } \\
\hline CHEMBL1335319 & 688889 & 4.45 & 4.7048 & TRN & \\
\hline CHEMBL1386900 & 688889 & 5.15 & 4.7747 & TRN & \\
\hline CHEMBL1414895 & 688889 & 4.4 & 4.9283 & TRN & \\
\hline CHEMBL1510396 & 688889 & 4.3 & 4.8088 & TRN & \\
\hline CHEMBL1594911 & 688889 & 4.95 & 4.8099 & TRN & \\
\hline CHEMBL3208614 & 688889 & 6.1 & 4.7313 & TRN & \\
\hline CHEMBL1489875 & 688889 & 4.5 & 4.7844 & TST & \\
\hline CHEMBL3210917 & 688889 & 4.35 & 4.7325 & TRN & \\
\hline CHEMBL1456986 & 688889 & 6.7501 & 4.7977 & TRN & \\
\hline CHEMBL1490027 & 688889 & 5.2 & 4.8135 & TRN & \\
\hline CHEMBL1422030 & 688889 & 4.55 & 4.6479 & TRN & \\
\hline CHEMBL1341471 & 688889 & 4.3 & 4.8245 & TRN & \\
\hline CHEMBL1527794 & 688889 & 4.65 & 4.6113 & TRN & \\
\hline CHEMBL1390126 & 688889 & 4.45 & 4.7566 & TST & \\
\hline CHEMBL 3196453 & 688889 & 4.4 & 4.814 & TST & \\
\hline CHEMBL1467928 & 688889 & 4.95 & 4.8378 & TST & \\
\hline CHEMBL1521675 & 688889 & 4.55 & 4.7534 & TRN & \\
\hline CHEMBL1545480 & 688889 & 5.55 & 4.9751 & TRN & \\
\hline CHEMBL1479864 & 688889 & 4.35 & 4.7615 & TRN & \\
\hline CHEMBL1341464 & 688889 & 4.25 & 4.91100 & 00000000005 & TRN \\
\hline CHEMBL1603834 & 688889 & 4.6 & 4.8165 & TRN & \\
\hline CHEMBL1487610 & 688889 & 4.95 & 4.7741 & TRN & \\
\hline CHEMBL1603938 & 688889 & 5.3 & 4.6628 & TRN & \\
\hline CHEMBL1491951 & 688889 & 4.55 & 4.6178 & TRN & \\
\hline CHEMBL1466111 & 688889 & 4.25 & 4.9537 & TRN & \\
\hline CHEMBL1502681 & 688889 & 4.4 & 4.7011 & TRN & \\
\hline CHEMBL1445796 & 688889 & 4.45 & 4.7081 & TRN & \\
\hline CHEMBL1558971 & 688889 & 4.45 & 4.9212 & TST & \\
\hline CHEMBL1348841 & 688889 & 5.1 & 4.7669 & TRN & \\
\hline CHEMBL1562134 & 688889 & 4.5 & 4.8305 & TST & \\
\hline CHEMBL1331677 & 688889 & 4.6 & 4.8228 & TRN & \\
\hline CHEMBL1421217 & 688889 & 4.55 & 4.7062 & TRN & \\
\hline CHEMBL1541244 & 688889 & 4.25 & 4.8026 & TRN & \\
\hline CHEMBL 2001887 & 688889 & 4.95 & 4.8429 & TRN & \\
\hline CHEMBL1528460 & 688889 & 5.65 & 4.7354 & TST & \\
\hline CHEMBL1546390 & 688889 & 6.7501 & 4.8568 & TST & \\
\hline CHEMBL1346734 & 688889 & 4.6 & 4.6647 & TRN & \\
\hline CHEMBL1562342 & 688889 & 4.45 & 4.8664 & TRN & \\
\hline CHEMBL1489092 & 688889 & 4.35 & 4.94300 & 20000000005 & TRN \\
\hline CHEMBL1506951 & 688889 & 4.4 & 4.7419 & TST & \\
\hline CHEMBL1564382 & 688889 & 4.9 & 4.7424 & TRN & \\
\hline CHEMBL1483742 & 688889 & 4.3 & 4.9425 & TRN & \\
\hline CHEMBL1502661 & 688889 & 4.45 & 4.7181 & TRN & \\
\hline CHEMBL1370245 & 688889 & 4.25 & 4.6976 & TRN & \\
\hline CHEMBL1302603 & 688889 & 5.1 & 4.7737 & TRN & \\
\hline CHEMBL1535408 & 688889 & 4.3 & 4.9291 & TST & \\
\hline CHEMBL1302885 & 688889 & 4.4 & 4.6766 & TRN & \\
\hline CHEMBL1538265 & 688889 & 6.0 & 4.966 & TST & \\
\hline
\end{tabular}




\begin{tabular}{|c|c|c|c|c|}
\hline \multicolumn{5}{|c|}{ Supplemental Table S2.txt } \\
\hline CHEMBL1531297 & 688889 & 5.25 & 4.8094 & TRN \\
\hline CHEMBL1586981 & 688889 & 4.5 & 4.7798 & TRN \\
\hline CHEMBL1387894 & 688889 & 5.05 & 4.785 & TRN \\
\hline CHEMBL1491886 & 688889 & 5.5 & 4.8962 & TRN \\
\hline CHEMBL1387067 & 688889 & 4.3 & 4.834 & TST \\
\hline CHEMBL1524073 & 688889 & 4.25 & 4.8061 & TST \\
\hline CHEMBL1548353 & 688889 & 4.5 & 4.7238 & TRN \\
\hline CHEMBL1494672 & 688889 & 4.25 & 4.7764 & TST \\
\hline CHEMBL1607661 & 688889 & 5.05 & 4.8002 & TRN \\
\hline CHEMBL3194588 & 688889 & 4.5 & 4.8813 & TST \\
\hline CHEMBL3209862 & 688889 & 5.0 & 4.8004 & TRN \\
\hline CHEMBL1498239 & 688889 & 6.6499 & 4.8595 & TRN \\
\hline CHEMBL1320458 & 688889 & 4.3 & 4.9444 & TST \\
\hline CHEMBL1559312 & 688889 & 5.9 & 4.837 & TRN \\
\hline CHEMBL1575024 & 688889 & 4.9 & 4.9317 & TRN \\
\hline CHEMBL1463800 & 688889 & 4.3 & 4.6753 & TRN \\
\hline CHEMBL1571016 & 688889 & 5.35 & 4.9237 & TRN \\
\hline CHEMBL1389573 & 688889 & 4.3 & 4.6757 & TST \\
\hline CHEMBL1537970 & 688889 & 4.45 & 4.7053 & TRN \\
\hline CHEMBL1472385 & 688889 & 6.0 & 4.8163 & TRN \\
\hline CHEMBL1416333 & 688889 & 4.65 & 4.8755 & TRN \\
\hline CHEMBL1605409 & 688889 & 4.95 & 4.9817 & TRN \\
\hline CHEMBL1507375 & 688889 & 4.9 & 4.7721 & TRN \\
\hline CHEMBL1414302 & 688889 & 5.35 & 4.6993 & TRN \\
\hline CHEMBL1418734 & 688889 & 4.95 & 4.707 & TRN \\
\hline CHEMBL1487526 & 688889 & 4.3 & 4.9376 & TRN \\
\hline CHEMBL1511009 & 688889 & 4.9 & 4.877 & TRN \\
\hline CHEMBL1489215 & 688889 & 4.4 & 4.8351 & TRN \\
\hline CHEMBL1557309 & 688889 & 4.35 & 4.76 & TST \\
\hline CHEMBL 3212804 & 688889 & 4.25 & 4.8541 & TRN \\
\hline CHEMBL1333340 & 688889 & 5.1 & 4.6936 & TST \\
\hline CHEMBL1603973 & 688889 & 5.05 & 4.8482 & TST \\
\hline CHEMBL1602224 & 688889 & 4.25 & 4.7877 & TRN \\
\hline CHEMBL1526650 & 688889 & 4.75 & 4.8185 & TRN \\
\hline CHEMBL1406660 & 688889 & 4.45 & 4.669 & TRN \\
\hline CHEMBL1547715 & 688889 & 5.4 & 4.6721 & TST \\
\hline CHEMBL1547247 & 688889 & 4.9 & 4.7723 & TST \\
\hline CHEMBL1360393 & 688889 & 5.15 & 4.6842 & TST \\
\hline CHEMBL1529055 & 688889 & 4.25 & 5.0106 & TST \\
\hline CHEMBL1369781 & 688889 & 4.35 & 4.6859 & TRN \\
\hline CHEMBL1400479 & 688889 & 4.25 & 4.838 & TST \\
\hline CHEMBL3191473 & 688889 & 5.2 & 4.9533 & TST \\
\hline CHEMBL1500135 & 688889 & 4.55 & 4.7229 & TRN \\
\hline CHEMBL1542131 & 688889 & 5.3 & 4.806 & TST \\
\hline CHEMBL1348248 & 688889 & 4.4 & 4.881 & TST \\
\hline CHEMBL1526219 & 688889 & 4.3 & 4.7661 & TRN \\
\hline CHEMBL1535094 & 688889 & 5.65 & 4.8424 & TST \\
\hline CHEMBL1301231 & 688889 & 4.45 & 4.8252 & TRN \\
\hline
\end{tabular}




\begin{tabular}{|c|c|c|c|c|c|}
\hline \\
\hline CHEMBL1409741 & 688889 & 6.8 & 4.9193 & TRN & \\
\hline CHEMBL1323586 & 688889 & 6.15 & 4.7164 & TST & \\
\hline CHEMBL1469957 & 688889 & 4.45 & 4.7506 & TRN & \\
\hline CHEMBL3192593 & 688889 & 4.3 & 4.7953 & TRN & \\
\hline CHEMBL1424253 & 688889 & 4.45 & 4.8779 & TRN & \\
\hline CHEMBL1348666 & 688889 & 4.65 & 4.8431 & TRN & \\
\hline CHEMBL1385808 & 688889 & 4.25 & 4.7418 & TST & \\
\hline CHEMBL1423747 & 688889 & 4.45 & 4.7924 & TRN & \\
\hline CHEMBL1454195 & 688889 & 4.85 & 4.6375 & TRN & \\
\hline CHEMBL1504370 & 688889 & 4.3 & 4.6942 & TRN & \\
\hline CHEMBL1354125 & 688889 & 5.25 & 4.58899 & 99999999995 & TRN \\
\hline CHEMBL1600490 & 688889 & 4.55 & 4.7127 & TRN & \\
\hline CHEMBL1601588 & 688889 & 5.5 & 4.7947 & TRN & \\
\hline CHEMBL1426578 & 688889 & 4.25 & 4.8666 & TST & \\
\hline CHEMBL1575087 & 688889 & 4.3 & 4.8199 & TRN & \\
\hline CHEMBL1320514 & 688889 & 4.6 & 5.0303 & TST & \\
\hline CHEMBL1563574 & 688889 & 4.7 & 4.7886 & TRN & \\
\hline CHEMBL1440269 & 688889 & 4.6 & 4.9254 & TRN & \\
\hline CHEMBL1343987 & 688889 & 5.95 & 4.7396 & TST & \\
\hline CHEMBL3189951 & 688889 & 4.35 & 4.5329 & TRN & \\
\hline CHEMBL1606800 & 688889 & 4.5 & 4.6444 & TRN & \\
\hline CHEMBL1586419 & 688889 & 5.3 & 4.7594 & TRN & \\
\hline CHEMBL1403032 & 688889 & 4.45 & 4.7749 & TRN & \\
\hline CHEMBL1320417 & 688889 & 4.4 & 4.9318 & TRN & \\
\hline CHEMBL1444568 & 688889 & 4.15 & 4.7165 & TRN & \\
\hline CHEMBL577938 & 688889 & 4.8 & 4.6548 & TRN & \\
\hline CHEMBL1581930 & 688889 & 4.85 & 4.7248 & TRN & \\
\hline CHEMBL1490441 & 688889 & 4.95 & 4.8139 & TRN & \\
\hline CHEMBL1448115 & 688889 & 4.4 & 4.7481 & TRN & \\
\hline CHEMBL1427838 & 688889 & 4.75 & 4.6586 & TRN & \\
\hline CHEMBL1468983 & 688889 & 4.25 & 4.9777 & TRN & \\
\hline CHEMBL1361315 & 688889 & 6.8 & 4.829 & TRN & \\
\hline CHEMBL1417717 & 688889 & 4.45 & 4.6272 & TRN & \\
\hline CHEMBL1348308 & 688889 & 4.3 & 4.724 & TRN & \\
\hline CHEMBL3192719 & 688889 & 4.45 & 4.7718 & TRN & \\
\hline CHEMBL1525594 & 688889 & 4.95 & 5.0056 & TRN & \\
\hline CHEMBL3212224 & 688889 & 4.7 & 4.7664 & TST & \\
\hline CHEMBL1375855 & 688889 & 4.3 & 4.9006 & TRN & \\
\hline CHEMBL1566749 & 688889 & 4.45 & 4.80699 & 99999999995 & TRN \\
\hline CHEMBL1508361 & 688889 & 4.95 & 4.6464 & TRN & \\
\hline CHEMBL1408794 & 688889 & 4.45 & 4.8264 & TRN & \\
\hline CHEMBL1413573 & 688889 & 4.65 & 4.8778 & TST & \\
\hline CHEMBL1484553 & 688889 & 5.45 & 4.9344 & TRN & \\
\hline CHEMBL1454277 & 688889 & 4.95 & 4.8557 & TST & \\
\hline CHEMBL1371339 & 688889 & 4.45 & 4.6818 & TRN & \\
\hline CHEMBL3209163 & 688889 & 5.1 & 4.8812 & TRN & \\
\hline CHEMBL3198835 & 688889 & 4.3 & 4.8301 & TRN & \\
\hline CHEMBL1550200 & 688889 & 4.3 & 4.7411 & TRN & \\
\hline
\end{tabular}




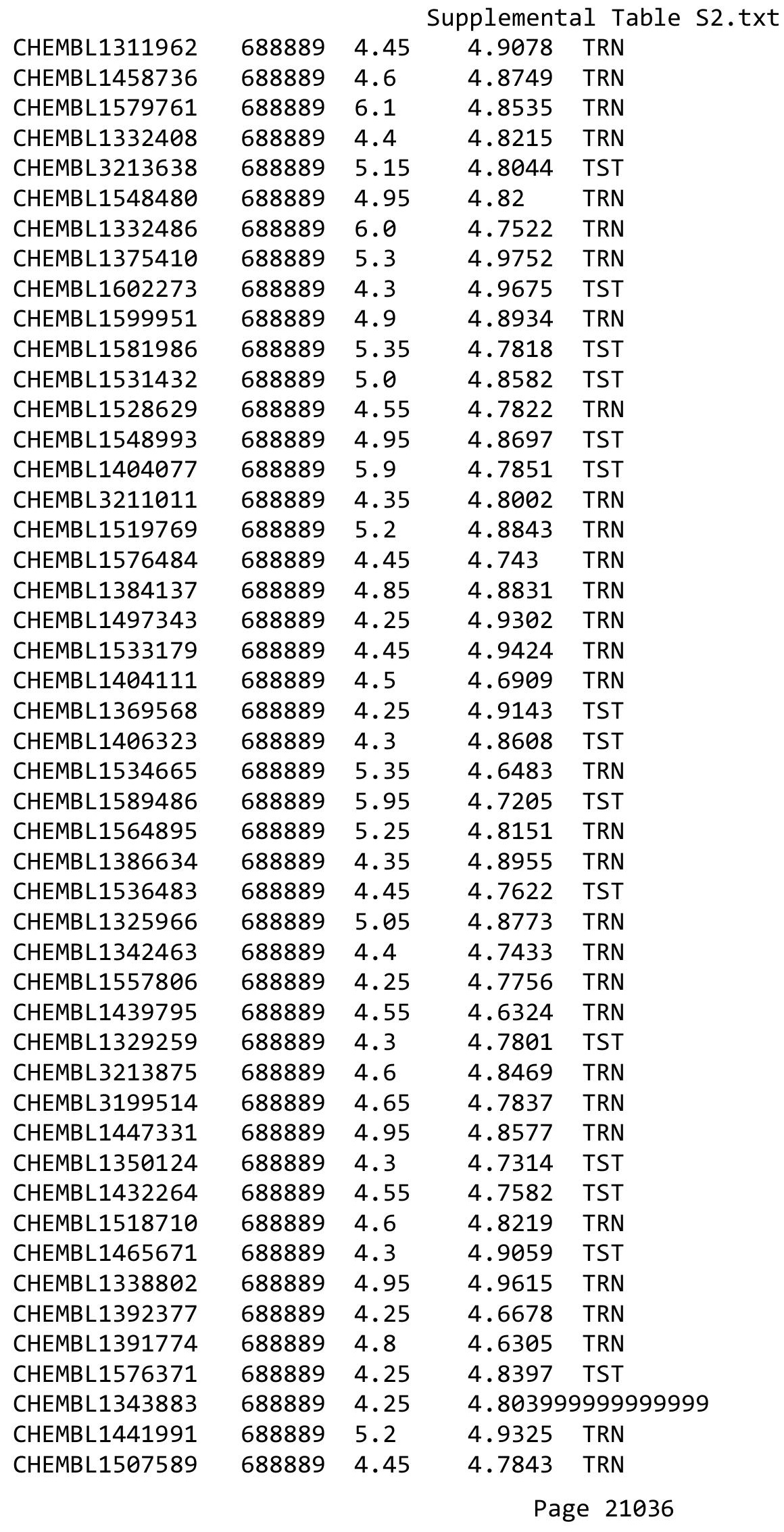

TRN 


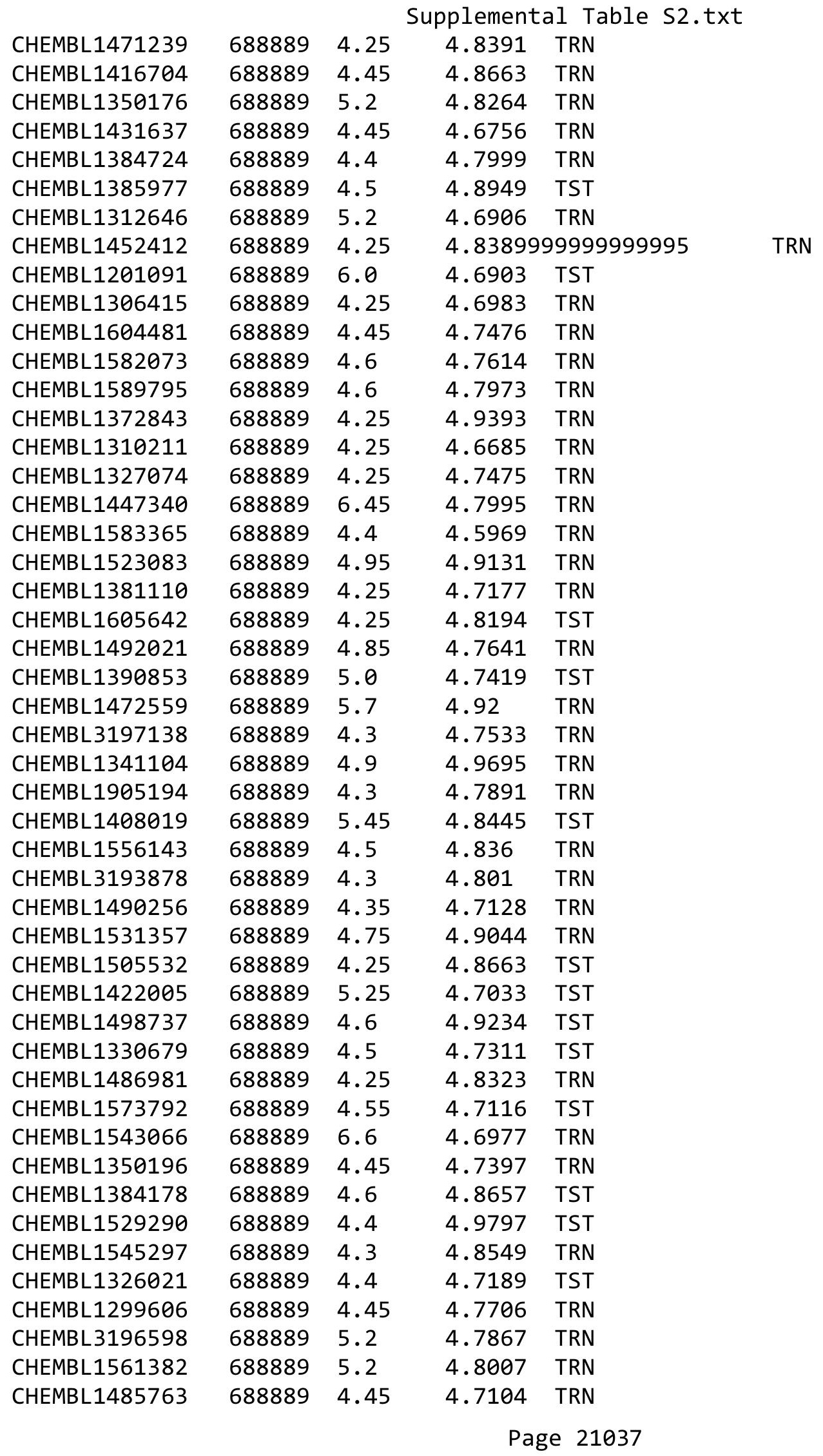




\begin{tabular}{|c|c|c|c|c|c|}
\hline \multicolumn{6}{|c|}{ Supplemental Table S2.txt } \\
\hline CHEMBL1319396 & 688889 & 5.35 & 4.8434 & TST & \\
\hline CHEMBL1595607 & 688889 & 4.4 & 4.8313 & TRN & \\
\hline CHEMBL1323189 & 688889 & 5.3 & 4.8372 & TST & \\
\hline CHEMBL1428935 & 688889 & 4.95 & 4.8115 & TRN & \\
\hline CHEMBL1324523 & 688889 & 4.35 & 4.9093 & TRN & \\
\hline CHEMBL1348104 & 688889 & 4.4 & 4.6589 & TRN & \\
\hline CHEMBL1543001 & 688889 & 4.35 & 4.7359 & TRN & \\
\hline CHEMBL1499086 & 688889 & 4.3 & 4.8027 & TST & \\
\hline CHEMBL1392986 & 688889 & 5.9 & 4.801 & TST & \\
\hline CHEMBL1495995 & 688889 & 4.3 & 4.7237 & TRN & \\
\hline CHEMBL1413699 & 688889 & 5.15 & 4.9782 & TST & \\
\hline CHEMBL1534280 & 688889 & 4.25 & 4.8825 & TRN & \\
\hline CHEMBL3208091 & 688889 & 4.55 & 4.8853 & TRN & \\
\hline CHEMBL1498823 & 688889 & 4.9 & 4.7648 & TRN & \\
\hline CHEMBL1598227 & 688889 & 6.7501 & 4.7973 & TRN & \\
\hline CHEMBL1567631 & 688889 & 4.45 & 4.6962 & TRN & \\
\hline CHEMBL1302218 & 688889 & 6.45 & 4.9361 & TST & \\
\hline CHEMBL1495977 & 688889 & 4.9 & 4.8077 & TRN & \\
\hline CHEMBL1376258 & 688889 & 4.45 & 4.6729 & TRN & \\
\hline CHEMBL1470480 & 688889 & 4.35 & 4.5857 & TRN & \\
\hline CHEMBL3193196 & 688889 & 5.15 & 4.64199 & 99999999995 & TST \\
\hline CHEMBL1303917 & 688889 & 4.25 & 4.8974 & TRN & \\
\hline CHEMBL1318743 & 688889 & 4.3 & 4.721 & TST & \\
\hline CHEMBL1604761 & 688889 & 4.85 & 4.8038 & TRN & \\
\hline CHEMBL1304841 & 688889 & 4.35 & 4.63899 & 9999999999 & TRN \\
\hline CHEMBL1446024 & 688889 & 6.7501 & 4.9135 & TRN & \\
\hline CHEMBL1304634 & 688889 & 4.35 & 4.6849 & TRN & \\
\hline CHEMBL1561030 & 688889 & 4.4 & 4.5555 & TRN & \\
\hline CHEMBL 3144902 & 688889 & 4.25 & 4.7167 & TRN & \\
\hline CHEMBL1607424 & 688889 & 5.3 & 4.9169 & TRN & \\
\hline CHEMBL1440459 & 688889 & 4.25 & 4.7309 & TRN & \\
\hline CHEMBL1495349 & 688889 & 6.6 & 4.8261 & TRN & \\
\hline CHEMBL1583224 & 688889 & 5.75 & 4.8751 & TST & \\
\hline CHEMBL1447291 & 688889 & 4.55 & 4.7759 & TRN & \\
\hline CHEMBL1386503 & 688889 & 4.3 & 4.7246 & TRN & \\
\hline CHEMBL1429202 & 688889 & 4.25 & 4.7411 & TST & \\
\hline CHEMBL1571651 & 688889 & 4.6 & 4.7414 & TRN & \\
\hline CHEMBL1499444 & 688889 & 4.3 & 4.6341 & TST & \\
\hline CHEMBL1606807 & 688889 & 5.25 & 4.8779 & TRN & \\
\hline CHEMBL1373221 & 688889 & 4.7 & 4.9039 & TST & \\
\hline CHEMBL1580063 & 688889 & 5.25 & 4.7832 & TST & \\
\hline CHEMBL1558356 & 688889 & 5.95 & 4.96899 & 9999999999 & TRN \\
\hline CHEMBL1333189 & 688889 & 4.4 & 4.8761 & TRN & \\
\hline CHEMBL1527872 & 688889 & 4.45 & 4.8443 & TST & \\
\hline CHEMBL1541406 & 688889 & 6.8 & 4.9654 & TRN & \\
\hline CHEMBL3196812 & 688889 & 4.3 & 4.7036 & TRN & \\
\hline CHEMBL1409462 & 688889 & 4.9 & 4.8271 & TRN & \\
\hline CHEMBL1335410 & 688889 & 4.45 & 4.7859 & TST & \\
\hline
\end{tabular}




\begin{tabular}{|c|c|c|c|c|}
\hline \multicolumn{5}{|c|}{ Supplemental Table S2.txt } \\
\hline CHEMBL 3145372 & 688889 & 4.3 & 4.7224 & TRN \\
\hline CHEMBL1558479 & 688889 & 5.1 & 4.9335 & TRN \\
\hline CHEMBL1510669 & 688889 & 5.55 & 4.8743 & TRN \\
\hline CHEMBL1318805 & 688889 & 4.9 & 4.8913 & TST \\
\hline CHEMBL1522371 & 688889 & 4.25 & 4.9137 & TST \\
\hline CHEMBL1311539 & 688889 & 4.6 & 4.7334 & TST \\
\hline CHEMBL 3194087 & 688889 & 4.45 & 4.7321 & TRN \\
\hline CHEMBL1424121 & 688889 & 4.45 & 4.7853 & TRN \\
\hline CHEMBL1418488 & 688889 & 5.3 & 4.8353 & TRN \\
\hline CHEMBL1520904 & 688889 & 4.45 & 4.8571 & TRN \\
\hline CHEMBL1353056 & 688889 & 4.45 & 4.7464 & TRN \\
\hline CHEMBL1574262 & 688889 & 4.55 & 4.6693 & TRN \\
\hline CHEMBL1613363 & 688889 & 4.5 & 4.8635 & TRN \\
\hline CHEMBL 3212082 & 688889 & 5.3 & 4.958 & TRN \\
\hline CHEMBL1501156 & 688889 & 5.2 & 4.8659 & TST \\
\hline CHEMBL3209959 & 688889 & 4.75 & 4.9282 & TRN \\
\hline CHEMBL1446133 & 688889 & 4.45 & 4.8786 & TRN \\
\hline CHEMBL1386646 & 688889 & 5.9 & 4.7505 & TST \\
\hline CHEMBL1438241 & 688889 & 4.35 & 4.81 & TRN \\
\hline CHEMBL3193873 & 688889 & 4.9 & 4.6484 & TST \\
\hline CHEMBL1585428 & 688889 & 4.25 & 4.7499 & TRN \\
\hline CHEMBL1448703 & 688889 & 4.35 & 4.8895 & TRN \\
\hline CHEMBL1500777 & 688889 & 4.55 & 4.8625 & TRN \\
\hline CHEMBL1503523 & 688889 & 4.8 & 4.7263 & TRN \\
\hline CHEMBL1368688 & 688889 & 6.5501 & 4.8714 & TRN \\
\hline CHEMBL576607 & 688889 & 4.25 & 4.8488 & TRN \\
\hline CHEMBL1378837 & 688889 & 5.45 & 4.8573 & TRN \\
\hline CHEMBL1343384 & 688889 & 5.45 & 4.9605 & TST \\
\hline CHEMBL1490148 & 688889 & 4.55 & 4.7042 & TRN \\
\hline CHEMBL1326825 & 688889 & 5.15 & 4.8035 & TRN \\
\hline CHEMBL1557369 & 688889 & 4.9 & 4.7907 & TRN \\
\hline CHEMBL1490289 & 688889 & 4.25 & 4.7645 & TST \\
\hline CHEMBL1401588 & 688889 & 5.6 & 4.8493 & TRN \\
\hline CHEMBL1388686 & 688889 & 4.25 & 4.8508 & TST \\
\hline CHEMBL3190899 & 688889 & 4.55 & 4.8251 & TST \\
\hline CHEMBL1523890 & 688889 & 5.9 & 4.728 & TRN \\
\hline CHEMBL401743 & 688889 & 5.0 & 4.8026 & TRN \\
\hline CHEMBL1456523 & 688889 & 4.9 & 4.5346 & TRN \\
\hline CHEMBL1537864 & 688889 & 4.75 & 4.9396 & TST \\
\hline CHEMBL1319701 & 688889 & 4.8 & 4.7221 & TRN \\
\hline CHEMBL1505728 & 688889 & 4.3 & 4.8642 & TRN \\
\hline CHEMBL1545870 & 688889 & 4.9 & 4.7607 & TRN \\
\hline CHEMBL1333182 & 688889 & 4.35 & 4.8329 & TRN \\
\hline CHEMBL1532496 & 688889 & 4.25 & 4.8709 & TRN \\
\hline CHEMBL1430621 & 688889 & 4.45 & 4.7477 & TRN \\
\hline CHEMBL1429245 & 688889 & 5.2 & 4.7112 & TRN \\
\hline CHEMBL1519057 & 688889 & 4.5 & 4.7573 & TRN \\
\hline CHEMBL1485204 & 688889 & 4.65 & 4.8368 & TST \\
\hline
\end{tabular}




\begin{tabular}{|c|c|c|c|c|c|}
\hline & & \multicolumn{4}{|c|}{ Supplemental Table S2.txt } \\
\hline CHEMBL1363179 & 688889 & 4.45 & 4.7703 & TRN & \\
\hline CHEMBL 3211621 & 688889 & 4.25 & 4.8732 & TST & \\
\hline CHEMBL1354233 & 688889 & 4.9 & 4.8244 & TRN & \\
\hline CHEMBL1380037 & 688889 & 5.15 & 4.7528 & TRN & \\
\hline CHEMBL1603204 & 688889 & 4.3 & 4.8359 & TST & \\
\hline CHEMBL1485497 & 688889 & 4.25 & 4.7557 & TRN & \\
\hline CHEMBL1370905 & 688889 & 4.65 & 4.9704 & TRN & \\
\hline CHEMBL1484168 & 688889 & 4.3 & 4.9268 & TRN & \\
\hline CHEMBL 3213898 & 688889 & 4.9 & 4.664 & TRN & \\
\hline CHEMBL1350599 & 688889 & 5.7 & 4.7667 & TST & \\
\hline CHEMBL1546353 & 688889 & 5.3 & 4.8993 & TRN & \\
\hline CHEMBL1346733 & 688889 & 4.45 & 4.8043 & TST & \\
\hline CHEMBL3145060 & 688889 & 4.9 & 4.7466 & TRN & \\
\hline CHEMBL1559256 & 688889 & 4.5 & 4.6408 & TRN & \\
\hline CHEMBL1379889 & 688889 & 4.25 & 4.7627 & TRN & \\
\hline CHEMBL1462151 & 688889 & 4.9 & 4.9108 & TST & \\
\hline CHEMBL1556751 & 688889 & 5.2 & 4.9063 & TRN & \\
\hline CHEMBL1550190 & 688889 & 4.4 & 4.8045 & TRN & \\
\hline CHEMBL1307705 & 688889 & 4.95 & 4.8307 & TST & \\
\hline CHEMBL3195218 & 688889 & 4.35 & 4.8213 & TRN & \\
\hline CHEMBL1483733 & 688889 & 4.3 & 4.7422 & TRN & \\
\hline CHEMBL1989234 & 688889 & 5.55 & 4.6703 & TRN & \\
\hline CHEMBL1427096 & 688889 & 4.3 & 4.8815 & TST & \\
\hline CHEMBL 3195651 & 688889 & 4.45 & 4.7591 & TRN & \\
\hline CHEMBL1413869 & 688889 & 4.5 & 4.7613 & TRN & \\
\hline CHEMBL1325000 & 688889 & 5.15 & 5.004 & TRN & \\
\hline CHEMBL1532729 & 688889 & 4.55 & 4.919 & TRN & \\
\hline CHEMBL1600378 & 688889 & 4.45 & 4.9738 & TRN & \\
\hline CHEMBL1402713 & 688889 & 4.25 & 4.9302 & TRN & \\
\hline CHEMBL1400473 & 688889 & 4.6 & 4.7072 & TRN & \\
\hline CHEMBL1377048 & 688889 & 4.4 & 4.6965 & TRN & \\
\hline CHEMBL1344500 & 688889 & 5.0 & 4.8048 & TRN & \\
\hline CHEMBL1363231 & 688889 & 5.3 & 4.7688 & TRN & \\
\hline CHEMBL1463823 & 688889 & 5.65 & 4.8485 & TRN & \\
\hline CHEMBL1389840 & 688889 & 6.6 & 4.825 & TRN & \\
\hline CHEMBL 3192701 & 688889 & 4.65 & 4.6297 & TST & \\
\hline CHEMBL1304471 & 688889 & 4.25 & 4.7657 & TST & \\
\hline CHEMBL1444290 & 688889 & 4.3 & 4.9448 & TST & \\
\hline CHEMBL1606360 & 688889 & 4.55 & 4.9664 & TRN & \\
\hline CHEMBL1527772 & 688889 & 4.55 & 4.82600 & 00000000005 & TRN \\
\hline CHEMBL1381538 & 688889 & 4.35 & 4.8924 & TST & \\
\hline CHEMBL1420887 & 688889 & 4.95 & 4.7849 & TRN & \\
\hline CHEMBL142634 & 688889 & 5.3 & 4.8535 & TRN & \\
\hline CHEMBL1324718 & 688889 & 4.75 & 4.8393 & TRN & \\
\hline CHEMBL1359485 & 688889 & 5.1 & 4.891 & TRN & \\
\hline CHEMBL1370884 & 688889 & 5.25 & 4.6853 & TST & \\
\hline CHEMBL1567234 & 688889 & 4.3 & 4.7985 & TRN & \\
\hline CHEMBL1609167 & 688889 & 4.45 & 4.8997 & TRN & \\
\hline
\end{tabular}




\begin{tabular}{|c|c|c|c|c|}
\hline \multicolumn{5}{|c|}{ Supplemental Table S2.txt } \\
\hline CHEMBL1377163 & 688889 & 4.45 & 4.8943 & TRN \\
\hline CHEMBL1379860 & 688889 & 4.35 & 4.8267 & TRN \\
\hline CHEMBL1483038 & 688889 & 5.2 & 4.8037 & TST \\
\hline CHEMBL1457301 & 688889 & 4.9 & 4.7601 & TST \\
\hline CHEMBL1582478 & 688889 & 6.8 & 4.9076 & TRN \\
\hline CHEMBL1445873 & 688889 & 5.4 & 4.7646 & TRN \\
\hline CHEMBL1547311 & 688889 & 4.45 & 4.7778 & TRN \\
\hline CHEMBL1508426 & 688889 & 4.95 & 4.7592 & TRN \\
\hline CHEMBL1326644 & 688889 & 4.4 & 4.8324 & TRN \\
\hline CHEMBL1401079 & 688889 & 5.0 & 4.6972 & TRN \\
\hline CHEMBL1463942 & 688889 & 5.45 & 4.8014 & TST \\
\hline CHEMBL1352648 & 688889 & 4.3 & 4.8237 & TRN \\
\hline CHEMBL1450635 & 688889 & 4.4 & 4.6567 & TRN \\
\hline CHEMBL1601623 & 688889 & 4.4 & 4.7464 & TRN \\
\hline CHEMBL1477193 & 688889 & 4.95 & 4.7361 & TST \\
\hline CHEMBL1367155 & 688889 & 5.85 & 4.7093 & TRN \\
\hline CHEMBL1563461 & 688889 & 6.0 & 4.8411 & TRN \\
\hline CHEMBL1306622 & 688889 & 4.3 & 4.8738 & TST \\
\hline CHEMBL1444967 & 688889 & 4.3 & 5.0598 & TRN \\
\hline CHEMBL1388753 & 688889 & 4.35 & 4.7652 & TST \\
\hline CHEMBL1493236 & 688889 & 6.7501 & 4.8481 & TRN \\
\hline CHEMBL340807 & 688889 & 4.65 & 4.6815 & TST \\
\hline CHEMBL1420161 & 688889 & 4.5 & 4.819 & TST \\
\hline CHEMBL1458448 & 688889 & 4.7 & 4.7461 & TRN \\
\hline CHEMBL1448394 & 688889 & 5.95 & 4.6617 & TRN \\
\hline CHEMBL1493695 & 688889 & 5.75 & 4.8323 & TRN \\
\hline CHEMBL1483593 & 688889 & 4.5 & 4.7443 & TRN \\
\hline CHEMBL1478607 & 688889 & 4.9 & 4.8428 & TST \\
\hline CHEMBL1563296 & 688889 & 5.85 & 4.9269 & TRN \\
\hline CHEMBL1537243 & 688889 & 4.3 & 4.8653 & TRN \\
\hline CHEMBL1449127 & 688889 & 5.2 & 4.7899 & TRN \\
\hline CHEMBL3196968 & 688889 & 4.3 & 4.865 & TRN \\
\hline CHEMBL1488104 & 688889 & 4.95 & 4.9019 & TRN \\
\hline CHEMBL1526993 & 688889 & 5.4 & 4.9275 & TRN \\
\hline CHEMBL1983243 & 688889 & 4.4 & 4.8144 & TRN \\
\hline CHEMBL1562854 & 688889 & 4.5 & 4.8383 & TST \\
\hline CHEMBL1532824 & 688889 & 6.7501 & 4.7943 & TST \\
\hline CHEMBL1304570 & 688889 & 4.3 & 4.7441 & TRN \\
\hline CHEMBL1380080 & 688889 & 4.35 & 4.8685 & TRN \\
\hline CHEMBL1381683 & 688889 & 4.6 & 4.9941 & TRN \\
\hline CHEMBL1381547 & 688889 & 4.25 & 4.6374 & TRN \\
\hline CHEMBL3194566 & 688889 & 4.35 & 4.7728 & TST \\
\hline CHEMBL1326616 & 688889 & 6.1 & 4.7627 & TRN \\
\hline CHEMBL1488931 & 688889 & 4.5 & 4.6982 & TRN \\
\hline CHEMBL578177 & 688889 & 5.3 & 4.6341 & TRN \\
\hline CHEMBL1595862 & 688889 & 4.3 & 4.6599 & TRN \\
\hline CHEMBL1969300 & 688889 & 4.5 & 4.8388 & TRN \\
\hline CHEMBL1310710 & 688889 & 4.6 & 4.8764 & TRN \\
\hline
\end{tabular}




\begin{tabular}{|c|c|c|c|c|c|}
\hline \multicolumn{6}{|c|}{ Supplemental Table S2.txt } \\
\hline CHEMBL3209375 & 688889 & 4.3 & 4.8071 & TRN & \\
\hline CHEMBL1597565 & 688889 & 4.35 & 4.7772 & TRN & \\
\hline CHEMBL1335743 & 688889 & 4.9 & 4.8954 & TST & \\
\hline CHEMBL1213966 & 688889 & 4.95 & 4.8611 & TRN & \\
\hline CHEMBL1413413 & 688889 & 4.5 & 4.6745 & TRN & \\
\hline CHEMBL1300884 & 688889 & 4.25 & 4.7896 & TRN & \\
\hline CHEMBL3190592 & 688889 & 4.95 & 4.8081 & TRN & \\
\hline CHEMBL1429395 & 688889 & 4.4 & 4.8761 & TST & \\
\hline CHEMBL3189974 & 688889 & 4.7 & 4.899 & TRN & \\
\hline CHEMBL1463672 & 688889 & 4.45 & 4.7125 & TRN & \\
\hline CHEMBL3195697 & 688889 & 5.45 & 4.8174 & TRN & \\
\hline CHEMBL1336838 & 688889 & 4.45 & 4.6813 & TRN & \\
\hline CHEMBL1549668 & 688889 & 4.4 & 4.8494 & TST & \\
\hline CHEMBL1571529 & 688889 & 4.25 & 4.9308 & TST & \\
\hline CHEMBL1497835 & 688889 & 4.95 & 4.8402 & TRN & \\
\hline CHEMBL3208116 & 688889 & 4.7 & 4.9492 & TRN & \\
\hline CHEMBL1427035 & 688889 & 5.95 & 4.948 & TRN & \\
\hline CHEMBL1534834 & 688889 & 4.25 & 4.7774 & TRN & \\
\hline CHEMBL1999182 & 688889 & 4.9 & 4.7817 & TST & \\
\hline CHEMBL1582769 & 688889 & 5.45 & 4.8382 & TRN & \\
\hline CHEMBL1326843 & 688889 & 4.7 & 4.8128 & TRN & \\
\hline CHEMBL1301795 & 688889 & 5.05 & 4.8718 & TRN & \\
\hline CHEMBL1432793 & 688889 & 5.45 & 4.705 & TRN & \\
\hline CHEMBL1359336 & 688889 & 4.35 & 4.7783 & TRN & \\
\hline CHEMBL1399332 & 688889 & 4.45 & 4.7289 & TST & \\
\hline CHEMBL1561483 & 688889 & 4.25 & 4.8148 & TRN & \\
\hline CHEMBL1333631 & 688889 & 4.25 & 4.7836 & TST & \\
\hline CHEMBL1455416 & 688889 & 4.9 & 4.7255 & TST & \\
\hline CHEMBL1567716 & 688889 & 4.35 & 4.851 & TRN & \\
\hline CHEMBL1508821 & 688889 & 4.3 & $4.6530 e$ & 00000000005 & TRN \\
\hline CHEMBL1560841 & 688889 & 4.4 & 4.7147 & TST & \\
\hline CHEMBL1505563 & 688889 & 4.45 & 4.7481 & TRN & \\
\hline CHEMBL1506121 & 688889 & 4.3 & 4.7785 & TRN & \\
\hline CHEMBL1573013 & 688889 & 4.3 & 4.5701 & TRN & \\
\hline CHEMBL1468801 & 688889 & 4.25 & 4.8028 & TRN & \\
\hline CHEMBL1467832 & 688889 & 6.35 & 4.78 & TRN & \\
\hline CHEMBL1336950 & 688889 & 4.55 & 4.7538 & TST & \\
\hline CHEMBL1405119 & 688889 & 6.05 & 4.7708 & TRN & \\
\hline CHEMBL1332118 & 688889 & 4.25 & 4.8578 & TRN & \\
\hline CHEMBL1533694 & 688889 & 4.4 & 4.7074 & TRN & \\
\hline CHEMBL1457794 & 688889 & 4.95 & 4.6759 & TST & \\
\hline CHEMBL3193949 & 688889 & 4.5 & 4.7419 & TST & \\
\hline CHEMBL3192742 & 688889 & 4.55 & 4.7661 & TRN & \\
\hline CHEMBL1455179 & 688889 & 4.7 & 4.7516 & TRN & \\
\hline CHEMBL1544060 & 688889 & 4.45 & 4.77 & TRN & \\
\hline CHEMBL1481106 & 688889 & 4.6 & 4.793 & TRN & \\
\hline CHEMBL1600298 & 688889 & 4.3 & 4.7601 & TRN & \\
\hline CHEMBL1366654 & 688889 & 4.5 & 4.9511 & TRN & \\
\hline
\end{tabular}




\begin{tabular}{|c|c|c|c|c|c|}
\hline \multicolumn{6}{|c|}{ Supplemental Table S2.txt } \\
\hline CHEMBL1459860 & 688889 & 4.75 & 4.8434 & TST & \\
\hline CHEMBL1400100 & 688889 & 6.8 & 4.8308 & TRN & \\
\hline CHEMBL1510154 & 688889 & 4.35 & 4.8175 & TRN & \\
\hline CHEMBL587856 & 688889 & 4.3 & 4.6123 & TST & \\
\hline CHEMBL485636 & 688889 & 5.15 & 4.763 & TRN & \\
\hline CHEMBL1607006 & 688889 & 4.55 & 4.7623 & TST & \\
\hline CHEMBL300685 & 688889 & 6.5 & 4.76699 & 99999999995 & TRN \\
\hline CHEMBL3210630 & 688889 & 4.6 & 4.6359 & TRN & \\
\hline CHEMBL1448911 & 688889 & 4.45 & 4.6447 & TRN & \\
\hline CHEMBL1327720 & 688889 & 4.3 & 4.5735 & TRN & \\
\hline CHEMBL1547574 & 688889 & 4.45 & 4.8447 & TST & \\
\hline CHEMBL1369316 & 688889 & 4.25 & 4.7699 & TRN & \\
\hline CHEMBL1384793 & 688889 & 5.35 & 4.6881 & TRN & \\
\hline CHEMBL1372925 & 688889 & 4.3 & 4.6668 & TRN & \\
\hline CHEMBL3199273 & 688889 & 4.95 & 4.8295 & TRN & \\
\hline CHEMBL1558081 & 688889 & 5.85 & 4.628 & TRN & \\
\hline CHEMBL1422076 & 688889 & 4.3 & 4.8269 & TRN & \\
\hline CHEMBL1347158 & 688889 & 5.1 & 4.7183 & TRN & \\
\hline CHEMBL1339597 & 688889 & 4.45 & 4.7335 & TRN & \\
\hline CHEMBL1423866 & 688889 & 4.35 & 4.9072 & TST & \\
\hline CHEMBL588919 & 688889 & 4.7 & 4.7543 & TRN & \\
\hline CHEMBL1564110 & 688889 & 4.35 & 4.7225 & TRN & \\
\hline CHEMBL1427787 & 688889 & 4.25 & 4.7281 & TRN & \\
\hline CHEMBL1370974 & 688889 & 4.4 & 4.7493 & TRN & \\
\hline CHEMBL1348391 & 688889 & 4.35 & 4.646 & TST & \\
\hline CHEMBL1430437 & 688889 & 4.35 & 4.6787 & TRN & \\
\hline CHEMBL1490818 & 688889 & 4.6 & 4.6176 & TRN & \\
\hline CHEMBL1444236 & 688889 & 4.5 & 4.6985 & TST & \\
\hline CHEMBL1499932 & 688889 & 4.45 & 4.8031 & TST & \\
\hline CHEMBL 3212711 & 688889 & 4.9 & 4.9635 & TRN & \\
\hline CHEMBL1479499 & 688889 & 4.3 & 4.8407 & TRN & \\
\hline CHEMBL1545119 & 688889 & 5.3 & 4.9373 & TRN & \\
\hline CHEMBL1373890 & 688889 & 6.1 & 4.7032 & TRN & \\
\hline CHEMBL1336857 & 688889 & 4.55 & 4.871 & TRN & \\
\hline CHEMBL1535633 & 688889 & 4.95 & 4.7264 & TST & \\
\hline CHEMBL1478644 & 688889 & 4.75 & 4.6564 & TRN & \\
\hline CHEMBL533954 & 688889 & 4.25 & 4.7797 & TRN & \\
\hline CHEMBL1386501 & 688889 & 6.1 & 5.0102 & TRN & \\
\hline CHEMBL1364803 & 688889 & 4.6 & 4.6755 & TRN & \\
\hline CHEMBL1540533 & 688889 & 4.3 & 4.749 & TRN & \\
\hline CHEMBL1405304 & 688889 & 4.25 & 4.8352 & TRN & \\
\hline CHEMBL1455087 & 688889 & 5.4 & 4.9778 & TRN & \\
\hline CHEMBL1486574 & 688889 & 4.95 & 4.7394 & TRN & \\
\hline CHEMBL1490988 & 688889 & 4.5 & 4.8954 & TRN & \\
\hline CHEMBL1585488 & 688889 & 4.65 & 4.9375 & TRN & \\
\hline CHEMBL1521409 & 688889 & 4.25 & 4.8406 & TRN & \\
\hline CHEMBL1428063 & 688889 & 4.25 & 4.9244 & TST & \\
\hline CHEMBL1538098 & 688889 & 4.4 & 4.7093 & TRN & \\
\hline
\end{tabular}




\begin{tabular}{|c|c|c|c|c|c|}
\hline & & & & & \\
\hline CHEMBL1377382 & 688889 & 5.5 & 4.697 & TRN & \\
\hline CHEMBL1612974 & 688889 & 5.35 & 4.7721 & TRN & \\
\hline CHEMBL1541767 & 688889 & 4.7 & 4.7309 & TRN & \\
\hline CHEMBL 3194631 & 688889 & 5.65 & 4.7085 & TRN & \\
\hline CHEMBL1523886 & 688889 & 4.95 & 4.8776 & TST & \\
\hline CHEMBL1423452 & 688889 & 4.4 & 4.6628 & TRN & \\
\hline CHEMBL1605571 & 688889 & 4.5 & 4.7674 & TRN & \\
\hline CHEMBL3211472 & 688889 & 4.85 & 4.7794 & TRN & \\
\hline CHEMBL1519771 & 688889 & 4.3 & $4.7860 e$ & 30000000005 & TRN \\
\hline CHEMBL1497139 & 688889 & 4.3 & 4.8023 & TRN & \\
\hline CHEMBL3195467 & 688889 & 4.6 & 4.7868 & TRN & \\
\hline CHEMBL1549766 & 688889 & 4.25 & 4.9273 & TRN & \\
\hline CHEMBL1415287 & 688889 & 4.25 & 4.9424 & TRN & \\
\hline CHEMBL1441135 & 688889 & 4.5 & 4.689 & TRN & \\
\hline CHEMBL1451924 & 688889 & 4.5 & 4.9221 & TRN & \\
\hline CHEMBL1575147 & 688889 & 4.7 & 4.7479 & TRN & \\
\hline CHEMBL1324798 & 688889 & 4.3 & 4.8799 & TRN & \\
\hline CHEMBL1318895 & 688889 & 5.85 & 4.8167 & TRN & \\
\hline CHEMBL1492365 & 688889 & 5.2 & 4.7854 & TRN & \\
\hline CHEMBL1408061 & 688889 & 4.35 & 4.896 & TRN & \\
\hline CHEMBL1371716 & 688889 & 4.45 & 4.7022 & TRN & \\
\hline CHEMBL1563559 & 688889 & 4.65 & 4.9765 & TRN & \\
\hline CHEMBL1544652 & 688889 & 4.45 & 4.753 & TST & \\
\hline CHEMBL1438929 & 688889 & 5.0 & 4.9516 & TRN & \\
\hline CHEMBL1594167 & 688889 & 4.4 & 4.6331 & TRN & \\
\hline CHEMBL1510937 & 688889 & 6.6 & 4.8273 & TST & \\
\hline CHEMBL3192149 & 688889 & 5.4 & 4.7444 & TRN & \\
\hline CHEMBL81115 & 688889 & 6.8 & 4.8464 & TST & \\
\hline CHEMBL1612963 & 688889 & 6.3 & 4.6584 & TST & \\
\hline CHEMBL1524496 & 688889 & 5.15 & 4.7913 & TRN & \\
\hline CHEMBL1425080 & 688889 & 4.45 & 4.6488 & TST & \\
\hline CHEMBL1462038 & 688889 & 4.45 & 4.8706 & TRN & \\
\hline CHEMBL1533984 & 688889 & 4.5 & 4.8605 & TRN & \\
\hline CHEMBL 3208263 & 688889 & 5.2 & 4.806 & TRN & \\
\hline CHEMBL1323718 & 688889 & 5.15 & 5.0149 & TRN & \\
\hline CHEMBL3192462 & 688889 & 4.6 & 4.7424 & TST & \\
\hline CHEMBL3195557 & 688889 & 4.45 & 4.846 & TRN & \\
\hline CHEMBL1542028 & 688889 & 4.75 & 4.7985 & TRN & \\
\hline CHEMBL1583405 & 688889 & 5.15 & 4.7565 & TST & \\
\hline CHEMBL1425252 & 688889 & 4.9 & 4.7818 & TRN & \\
\hline CHEMBL1363482 & 688889 & 4.6 & 4.6538 & TST & \\
\hline CHEMBL1449702 & 688889 & 4.45 & 4.9328 & TRN & \\
\hline CHEMBL1536158 & 688889 & 5.2 & 4.8555 & TRN & \\
\hline CHEMBL1549217 & 688889 & 4.4 & 4.8478 & TRN & \\
\hline CHEMBL1442817 & 688889 & 4.25 & 4.8771 & TRN & \\
\hline CHEMBL1342852 & 688889 & 6.1 & 4.836 & TRN & \\
\hline CHEMBL1387124 & 688889 & 5.3 & 4.8075 & TRN & \\
\hline CHEMBL1565942 & 688889 & 4.25 & 4.8088 & TRN & \\
\hline
\end{tabular}




\begin{tabular}{|c|c|c|c|c|c|}
\hline \multicolumn{6}{|c|}{ Supplemental Table S2.txt } \\
\hline CHEMBL1492455 & 688889 & 5.85 & 4.8191 & TRN & \\
\hline CHEMBL1577972 & 688889 & 4.65 & 4.6619 & TRN & \\
\hline CHEMBL 3214548 & 688889 & 5.1 & 4.8822 & TRN & \\
\hline CHEMBL1582268 & 688889 & 6.5501 & 4.8073 & TRN & \\
\hline CHEMBL1447469 & 688889 & 5.5 & 4.7897 & TST & \\
\hline CHEMBL1334640 & 688889 & 4.5 & 5.0575 & TRN & \\
\hline CHEMBL1611013 & 688889 & 4.45 & 4.9867 & TST & \\
\hline CHEMBL1366730 & 688889 & 4.5 & 4.7819 & TRN & \\
\hline CHEMBL1323939 & 688889 & 4.5 & 4.8227 & TRN & \\
\hline CHEMBL1579586 & 688889 & 4.35 & 4.6956 & TRN & \\
\hline CHEMBL1408800 & 688889 & 5.2 & 4.837 & TST & \\
\hline CHEMBL1428542 & 688889 & 5.5 & 4.7387 & TRN & \\
\hline CHEMBL1411636 & 688889 & 4.9 & 5.0068 & TRN & \\
\hline CHEMBL1594237 & 688889 & 4.4 & 4.7372 & TRN & \\
\hline CHEMBL1589094 & 688889 & 4.7 & 4.7723 & TST & \\
\hline CHEMBL1485470 & 688889 & 4.3 & 4.7901 & TST & \\
\hline CHEMBL512749 & 688889 & 4.95 & 4.7411 & TRN & \\
\hline CHEMBL1366059 & 688889 & 4.5 & 4.8242 & TST & \\
\hline CHEMBL1490620 & 688889 & 4.3 & 4.7939 & TRN & \\
\hline CHEMBL1438459 & 688889 & 6.8 & 4.8756 & TRN & \\
\hline CHEMBL1529689 & 688889 & 6.3 & 4.7322 & TRN & \\
\hline CHEMBL1340934 & 688889 & 4.25 & 4.7653 & TRN & \\
\hline CHEMBL1996451 & 688889 & 5.9 & 4.6309 & TRN & \\
\hline CHEMBL1546218 & 688889 & 4.95 & 5.0902 & TRN & \\
\hline CHEMBL1343088 & 688889 & 6.3 & 4.7878 & TRN & \\
\hline CHEMBL1576547 & 688889 & 5.15 & 4.7204 & TRN & \\
\hline CHEMBL1525715 & 688889 & 4.45 & 4.70100 & 00000000005 & TRN \\
\hline CHEMBL1464707 & 688889 & 4.5 & 4.9439 & TST & \\
\hline CHEMBL 600495 & 688889 & 4.6 & 4.708 & TST & \\
\hline CHEMBL1508508 & 688889 & 4.45 & 4.7024 & TRN & \\
\hline CHEMBL1964836 & 688889 & 4.9 & 4.7423 & TST & \\
\hline CHEMBL1471465 & 688889 & 4.25 & 4.7791 & TRN & \\
\hline CHEMBL1363308 & 688889 & 4.4 & 4.623 & TRN & \\
\hline CHEMBL1610037 & 688889 & 5.1 & 4.773 & TRN & \\
\hline CHEMBL1487346 & 688889 & 4.55 & 4.7741 & TRN & \\
\hline CHEMBL1346035 & 688889 & 4.45 & 4.6151 & TRN & \\
\hline CHEMBL1468154 & 688889 & 5.3 & 4.8643 & TST & \\
\hline CHEMBL1319425 & 688889 & 5.85 & 4.6775 & TST & \\
\hline CHEMBL1338663 & 688889 & 4.35 & 4.646 & TST & \\
\hline CHEMBL1456620 & 688889 & 4.45 & 4.69300 & 00000000005 & TRN \\
\hline CHEMBL1438859 & 688889 & 4.6 & 4.8568 & TRN & \\
\hline CHEMBL1375402 & 688889 & 4.25 & 4.7079 & TST & \\
\hline CHEMBL1547342 & 688889 & 4.4 & 4.9567 & TRN & \\
\hline CHEMBL1383884 & 688889 & 4.6 & 4.8008 & TRN & \\
\hline CHEMBL1425006 & 688889 & 4.95 & 4.8036 & TST & \\
\hline CHEMBL1385483 & 688889 & 4.3 & 4.9818 & TRN & \\
\hline CHEMBL1583282 & 688889 & 4.75 & 4.9548 & TRN & \\
\hline CHEMBL1496866 & 688889 & 4.95 & 4.6302 & TRN & \\
\hline
\end{tabular}




\begin{tabular}{|c|c|c|c|c|}
\hline \multicolumn{5}{|c|}{ Supplemental Table S2.txt } \\
\hline CHEMBL1382785 & 688889 & 4.45 & 4.7361 & TRN \\
\hline CHEMBL1307363 & 688889 & 5.45 & 4.8667 & TST \\
\hline CHEMBL1384476 & 688889 & 4.55 & 4.9889 & TRN \\
\hline CHEMBL1410471 & 688889 & 4.55 & 4.7893 & TST \\
\hline CHEMBL1533809 & 688889 & 4.25 & 4.7975 & TRN \\
\hline CHEMBL1386584 & 688889 & 4.4 & 4.7423 & TRN \\
\hline CHEMBL1329888 & 688889 & 5.25 & 4.8945 & TRN \\
\hline CHEMBL1381212 & 688889 & 4.35 & 4.8391 & TRN \\
\hline CHEMBL1309240 & 688889 & 5.1 & 4.8599 & TRN \\
\hline CHEMBL1549079 & 688889 & 4.45 & 4.6105 & TRN \\
\hline CHEMBL1366712 & 688889 & 4.25 & 4.8179 & TRN \\
\hline CHEMBL1326561 & 688889 & 4.4 & 4.8054 & TST \\
\hline CHEMBL1385967 & 688889 & 4.3 & 4.8397 & TRN \\
\hline CHEMBL1329225 & 688889 & 4.55 & 4.7768 & TRN \\
\hline CHEMBL1393846 & 688889 & 6.8 & 4.6177 & TRN \\
\hline CHEMBL1477689 & 688889 & 4.55 & 4.8554 & TRN \\
\hline CHEMBL1327880 & 688889 & 6.8 & 4.7256 & TST \\
\hline CHEMBL1463157 & 688889 & 5.9 & 4.8367 & TRN \\
\hline CHEMBL1602233 & 688889 & 4.25 & 4.8731 & TST \\
\hline CHEMBL1310690 & 688889 & 5.15 & 4.6545 & TRN \\
\hline CHEMBL1545521 & 688889 & 4.3 & 4.9528 & TRN \\
\hline CHEMBL1507422 & 688889 & 5.1 & 4.8136 & TRN \\
\hline CHEMBL1556059 & 688889 & 4.95 & 4.7259 & TRN \\
\hline CHEMBL1417848 & 688889 & 5.4 & 4.6949 & TRN \\
\hline CHEMBL1526609 & 688889 & 4.25 & 4.7767 & TRN \\
\hline CHEMBL1574536 & 688889 & 4.4 & 4.9259 & TST \\
\hline CHEMBL1387421 & 688889 & 5.45 & 4.6678 & TRN \\
\hline CHEMBL1307436 & 688889 & 6.7501 & 5.0187 & TST \\
\hline CHEMBL1562203 & 688889 & 4.8 & 4.7482 & TRN \\
\hline CHEMBL3196727 & 688889 & 4.5 & 4.6743 & TRN \\
\hline CHEMBL1452292 & 688889 & 4.3 & 4.8173 & TRN \\
\hline CHEMBL1597956 & 688889 & 4.45 & 4.6072 & TRN \\
\hline CHEMBL1588205 & 688889 & 4.6 & 4.8648 & TRN \\
\hline CHEMBL1572143 & 688889 & 6.35 & 4.8614 & TRN \\
\hline CHEMBL1456255 & 688889 & 4.4 & 4.5715 & TRN \\
\hline CHEMBL1438435 & 688889 & 4.5 & 4.8036 & TRN \\
\hline CHEMBL1530970 & 688889 & 5.6 & 4.6863 & TRN \\
\hline CHEMBL1480715 & 688889 & 4.3 & 4.8184 & TST \\
\hline CHEMBL3212415 & 688889 & 4.25 & 4.7132 & TRN \\
\hline CHEMBL1563597 & 688889 & 4.3 & 4.7627 & TST \\
\hline CHEMBL1479196 & 688889 & 4.7 & 4.7988 & TST \\
\hline CHEMBL1547955 & 688889 & 6.6499 & 4.9632 & TRN \\
\hline CHEMBL1342296 & 688889 & 5.2 & 4.7722 & TST \\
\hline CHEMBL1341000 & 688889 & 5.25 & 4.7428 & TRN \\
\hline CHEMBL1518050 & 688889 & 4.45 & 4.8262 & TRN \\
\hline CHEMBL1511350 & 688889 & 4.7 & 4.6919 & TST \\
\hline CHEMBL1381122 & 688889 & 4.45 & 4.8307 & TRN \\
\hline CHEMBL1351356 & 688889 & 4.45 & 4.8021 & TST \\
\hline
\end{tabular}




\begin{tabular}{|c|c|c|c|c|c|}
\hline \multicolumn{6}{|c|}{ Supplemental Table S2.txt } \\
\hline CHEMBL1369045 & 688889 & 4.5 & 4.771 & TRN & \\
\hline CHEMBL1415151 & 688889 & 4.35 & 4.9777 & TRN & \\
\hline CHEMBL1328861 & 688889 & 4.3 & 4.8525 & TRN & \\
\hline CHEMBL1344204 & 688889 & 4.75 & 4.7603 & TRN & \\
\hline CHEMBL1422066 & 688889 & 5.4 & 4.902 & TST & \\
\hline CHEMBL1611594 & 688889 & 4.25 & 4.8378 & TRN & \\
\hline CHEMBL1530677 & 688889 & 6.7501 & 4.9269 & TST & \\
\hline CHEMBL1450836 & 688889 & 5.2 & 4.7577 & TRN & \\
\hline CHEMBL1450271 & 688889 & 5.45 & 4.7794 & TST & \\
\hline CHEMBL1392922 & 688889 & 6.0 & 4.962 & TRN & \\
\hline CHEMBL1432633 & 688889 & 6.3 & 4.7139 & TST & \\
\hline CHEMBL1300297 & 688889 & 4.5 & 4.6705 & TRN & \\
\hline CHEMBL1611726 & 688889 & 4.9 & 4.823 & TRN & \\
\hline CHEMBL1391851 & 688889 & 5.4 & 4.9062 & TRN & \\
\hline CHEMBL1333500 & 688889 & 4.5 & 4.8682 & TRN & \\
\hline CHEMBL1429590 & 688889 & 4.3 & 4.6709 & TRN & \\
\hline CHEMBL1487660 & 688889 & 4.5 & 4.6241 & TRN & \\
\hline CHEMBL3190799 & 688889 & 4.5 & 4.8226 & TRN & \\
\hline CHEMBL1375071 & 688889 & 4.45 & 4.7998 & TRN & \\
\hline CHEMBL1545324 & 688889 & 6.7501 & 4.63899 & 9999999999 & TRN \\
\hline CHEMBL1349187 & 688889 & 4.45 & 4.9779 & TRN & \\
\hline CHEMBL1454682 & 688889 & 4.55 & 4.7646 & TRN & \\
\hline CHEMBL1305469 & 688889 & 5.45 & 4.6708 & TRN & \\
\hline CHEMBL1445506 & 688889 & 4.3 & 4.8398 & TRN & \\
\hline CHEMBL1471716 & 688889 & 4.3 & 4.748 & TRN & \\
\hline CHEMBL1560698 & 688889 & 5.15 & 4.8745 & TRN & \\
\hline CHEMBL1547901 & 688889 & 4.3 & 4.7294 & TRN & \\
\hline CHEMBL1414641 & 688889 & 4.6 & 4.7836 & TRN & \\
\hline CHEMBL1500607 & 688889 & 5.2 & 4.7232 & TRN & \\
\hline CHEMBL1387519 & 688889 & 5.75 & 4.7282 & TRN & \\
\hline CHEMBL1366156 & 688889 & 4.7 & 4.8496 & TST & \\
\hline CHEMBL1581473 & 688889 & 4.4 & 4.6999 & TRN & \\
\hline CHEMBL1583388 & 688889 & 4.3 & 4.8173 & TRN & \\
\hline CHEMBL1372751 & 688889 & 4.9 & 4.7239 & TRN & \\
\hline CHEMBL1526547 & 688889 & 5.3 & 4.8464 & TST & \\
\hline CHEMBL1480245 & 688889 & 6.8 & 4.8457 & TRN & \\
\hline CHEMBL1526585 & 688889 & 4.95 & 4.8885 & TRN & \\
\hline CHEMBL1427708 & 688889 & 4.4 & 4.7917 & TRN & \\
\hline CHEMBL1333109 & 688889 & 4.35 & 4.8948 & TST & \\
\hline CHEMBL1542969 & 688889 & 4.85 & 4.7527 & TRN & \\
\hline CHEMBL1323753 & 688889 & 4.95 & 4.7655 & TRN & \\
\hline CHEMBL1516616 & 688889 & 5.45 & 4.7171 & TRN & \\
\hline CHEMBL3209908 & 688889 & 4.3 & 4.6222 & TST & \\
\hline CHEMBL1558283 & 688889 & 4.3 & 4.8715 & TRN & \\
\hline CHEMBL1360530 & 688889 & 6.0 & 4.9154 & TST & \\
\hline CHEMBL1548226 & 688889 & 4.6 & 4.7806 & TRN & \\
\hline CHEMBL1507631 & 688889 & 4.7 & 4.7246 & TRN & \\
\hline CHEMBL1333696 & 688889 & 4.25 & 4.7482 & TRN & \\
\hline
\end{tabular}




\begin{tabular}{|c|c|c|c|c|c|}
\hline \multicolumn{6}{|c|}{ Supplemental Table S2.txt } \\
\hline CHEMBL3212869 & 688889 & 4.4 & 4.8894 & TRN & \\
\hline CHEMBL1439292 & 688889 & 4.3 & 4.7718 & TST & \\
\hline CHEMBL1350000 & 688889 & 4.3 & 4.7253 & TRN & \\
\hline CHEMBL1429646 & 688889 & 5.4 & 4.6807 & TRN & \\
\hline CHEMBL1425445 & 688889 & 6.5501 & 4.9446 & TRN & \\
\hline CHEMBL1598510 & 688889 & 4.25 & 4.8024 & TRN & \\
\hline CHEMBL1479799 & 688889 & 5.55 & 4.8959 & TRN & \\
\hline CHEMBL1527648 & 688889 & 4.55 & 4.8982 & TRN & \\
\hline CHEMBL1506932 & 688889 & 4.45 & 4.761 & TST & \\
\hline CHEMBL1532663 & 688889 & 5.3 & 4.7104 & TRN & \\
\hline CHEMBL1466513 & 688889 & 4.55 & 4.9559 & TRN & \\
\hline CHEMBL1597315 & 688889 & 4.5 & 4.9962 & TRN & \\
\hline CHEMBL1387905 & 688889 & 6.8 & 4.9015 & TRN & \\
\hline CHEMBL1353389 & 688889 & 4.4 & 4.6837 & TRN & \\
\hline CHEMBL1504183 & 688889 & 4.3 & 4.7198 & TRN & \\
\hline CHEMBL1386131 & 688889 & 4.95 & $4.9030 e$ & 00000000005 & TST \\
\hline CHEMBL1371863 & 688889 & 5.05 & 4.7348 & TRN & \\
\hline CHEMBL1576177 & 688889 & 4.25 & 4.7951 & TST & \\
\hline CHEMBL1423795 & 688889 & 4.45 & 4.6333 & TRN & \\
\hline CHEMBL1417212 & 688889 & 4.55 & 4.7538 & TRN & \\
\hline CHEMBL1449590 & 688889 & 4.45 & 4.7898 & TRN & \\
\hline CHEMBL1380923 & 688889 & 5.55 & 4.7966 & TRN & \\
\hline CHEMBL1328967 & 688889 & 4.55 & 4.7728 & TRN & \\
\hline CHEMBL1557120 & 688889 & 4.95 & 4.8294 & TRN & \\
\hline CHEMBL1731995 & 688889 & 4.3 & 4.7031 & TST & \\
\hline CHEMBL1991215 & 688889 & 4.5 & 4.6455 & TRN & \\
\hline CHEMBL1578880 & 688889 & 6.7501 & 4.6875 & TRN & \\
\hline CHEMBL1530556 & 688889 & 4.4 & 4.7461 & TRN & \\
\hline CHEMBL3145108 & 688889 & 4.25 & 4.5686 & TRN & \\
\hline CHEMBL1604325 & 688889 & 4.45 & 4.8992 & TRN & \\
\hline CHEMBL1375149 & 688889 & 4.4 & 4.8138 & TRN & \\
\hline CHEMBL1362660 & 688889 & 4.3 & 4.7493 & TST & \\
\hline CHEMBL1542101 & 688889 & 4.6 & 4.7856 & TRN & \\
\hline CHEMBL1499111 & 688889 & 4.25 & 4.7553 & TRN & \\
\hline CHEMBL3212435 & 688889 & 4.3 & 4.7381 & TST & \\
\hline CHEMBL1586126 & 688889 & 6.1 & $4.7860 e$ & 20000000005 & TRN \\
\hline CHEMBL3208342 & 688889 & 5.2 & 4.7958 & TRN & \\
\hline CHEMBL1505255 & 688889 & 4.45 & 4.7155 & TRN & \\
\hline CHEMBL1346240 & 688889 & 4.45 & 4.6446 & TRN & \\
\hline CHEMBL1449034 & 688889 & 5.95 & 4.756 & TST & \\
\hline CHEMBL1373817 & 688889 & 4.25 & 4.8022 & TST & \\
\hline CHEMBL1470241 & 688889 & 4.4 & 4.7255 & TRN & \\
\hline CHEMBL1349102 & 688889 & 5.95 & 4.8466 & TRN & \\
\hline CHEMBL1313895 & 688889 & 5.55 & 4.8442 & TST & \\
\hline CHEMBL1385989 & 688889 & 5.45 & 4.7731 & TST & \\
\hline CHEMBL1324559 & 688889 & 4.7 & 4.7427 & TST & \\
\hline CHEMBL1543610 & 688889 & 4.3 & 4.825 & TST & \\
\hline CHEMBL1492841 & 688889 & 4.3 & 4.7047 & TST & \\
\hline
\end{tabular}




\begin{tabular}{|c|c|c|c|c|}
\hline \multicolumn{5}{|c|}{ Supplemental Table S2.txt } \\
\hline CHEMBL1319389 & 688889 & 4.5 & 4.7368 & TRN \\
\hline CHEMBL1568569 & 688889 & 5.25 & 4.8763 & TRN \\
\hline CHEMBL1422352 & 688889 & 4.5 & 4.6805 & TRN \\
\hline CHEMBL1611633 & 688889 & 4.25 & 4.831 & TRN \\
\hline CHEMBL1327062 & 688889 & 5.5 & 4.8992 & TRN \\
\hline CHEMBL1384163 & 688889 & 6.7501 & 4.8912 & TRN \\
\hline CHEMBL1365598 & 688889 & 4.4 & 4.8952 & TRN \\
\hline CHEMBL1586333 & 688889 & 6.7501 & 4.8259 & TRN \\
\hline CHEMBL1457947 & 688889 & 4.4 & 4.7781 & TST \\
\hline CHEMBL1600898 & 688889 & 4.3 & 4.7541 & TRN \\
\hline CHEMBL1363937 & 688889 & 4.25 & 4.9158 & TRN \\
\hline CHEMBL1327637 & 688889 & 5.95 & 4.9021 & TRN \\
\hline CHEMBL1325519 & 688889 & 5.4 & 4.7084 & TRN \\
\hline CHEMBL1324079 & 688889 & 4.25 & 4.8004 & TRN \\
\hline CHEMBL1440539 & 688889 & 4.4 & 4.8139 & TRN \\
\hline CHEMBL1584771 & 688889 & 4.75 & 4.7568 & TST \\
\hline CHEMBL1460158 & 688889 & 4.5 & 4.9325 & TRN \\
\hline CHEMBL1490765 & 688889 & 4.5 & 4.9199 & TRN \\
\hline CHEMBL1399104 & 688889 & 4.25 & 4.711 & TRN \\
\hline CHEMBL1608110 & 688889 & 5.3 & 4.7918 & TRN \\
\hline CHEMBL1347490 & 688889 & 4.5 & 4.6306 & TRN \\
\hline CHEMBL1462313 & 688889 & 4.95 & 4.8912 & TRN \\
\hline CHEMBL3194167 & 688889 & 5.25 & 4.7875 & TST \\
\hline CHEMBL1499181 & 688889 & 5.7 & 4.8142 & TRN \\
\hline CHEMBL1600986 & 688889 & 4.75 & 4.785 & TRN \\
\hline CHEMBL1326486 & 688889 & 4.3 & 4.7812 & TRN \\
\hline CHEMBL1339326 & 688889 & 4.35 & 4.6768 & TRN \\
\hline CHEMBL1388399 & 688889 & 6.8 & 4.8642 & TRN \\
\hline CHEMBL1308993 & 688889 & 4.3 & 4.8263 & TRN \\
\hline CHEMBL1527360 & 688889 & 4.35 & 4.7049 & TRN \\
\hline CHEMBL1562060 & 688889 & 4.3 & 4.8216 & TST \\
\hline CHEMBL1412370 & 688889 & 4.55 & 4.7784 & TRN \\
\hline CHEMBL1605539 & 688889 & 6.0 & 4.6928 & TRN \\
\hline CHEMBL1329008 & 688889 & 4.35 & 4.6036 & TRN \\
\hline CHEMBL1562697 & 688889 & 4.55 & 4.8172 & TRN \\
\hline CHEMBL1492601 & 688889 & 4.95 & 4.7612 & TRN \\
\hline CHEMBL 1351880 & 688889 & 5.3 & 4.9483 & TRN \\
\hline CHEMBL1605616 & 688889 & 4.55 & 4.8325 & TRN \\
\hline CHEMBL1373741 & 688889 & 4.4 & 4.8906 & TRN \\
\hline CHEMBL1403486 & 688889 & 4.35 & 4.8218 & TRN \\
\hline CHEMBL1519906 & 688889 & 6.35 & 4.7387 & TST \\
\hline CHEMBL1347071 & 688889 & 4.5 & 4.6677 & TRN \\
\hline CHEMBL1300592 & 688889 & 4.85 & 4.7197 & TST \\
\hline CHEMBL1409431 & 688889 & 4.3 & 4.9948 & TRN \\
\hline CHEMBL2005947 & 688889 & 4.65 & 4.7935 & TST \\
\hline CHEMBL1338147 & 688889 & 5.2 & 4.8668 & TRN \\
\hline CHEMBL1505878 & 688889 & 4.5 & 4.7592 & TRN \\
\hline CHEMBL1569887 & 688889 & 4.55 & 4.8463 & TST \\
\hline
\end{tabular}




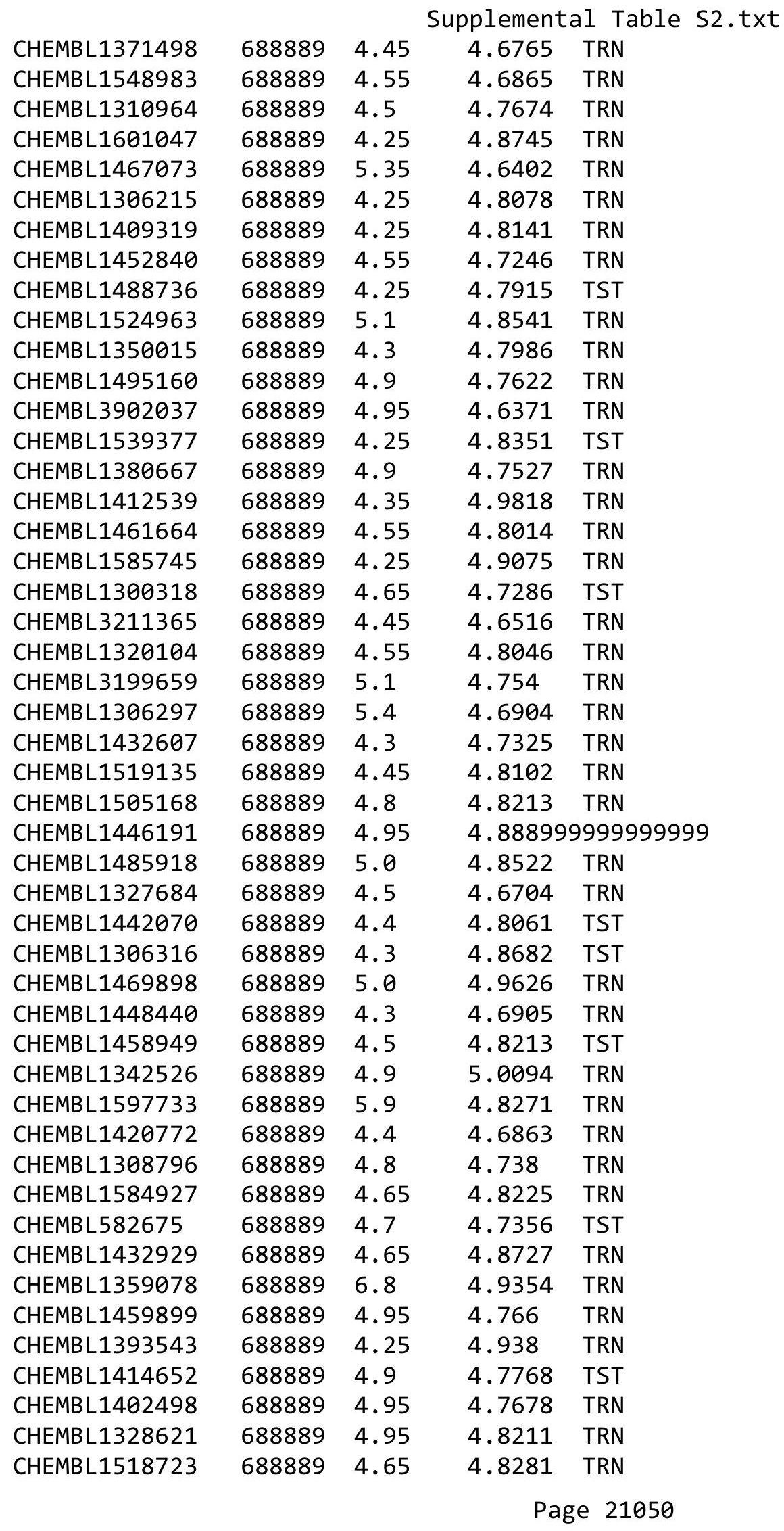

TRN 


\begin{tabular}{|c|c|c|c|c|c|}
\hline \multicolumn{6}{|c|}{ Supplemental Table S2.txt } \\
\hline CHEMBL1339535 & 688889 & 4.25 & 4.7603 & TRN & \\
\hline CHEMBL1594888 & 688889 & 5.25 & 4.9221 & TRN & \\
\hline CHEMBL 3208858 & 688889 & 4.95 & 4.8298 & TST & \\
\hline CHEMBL1971154 & 688889 & 4.65 & 4.6684 & TRN & \\
\hline CHEMBL1391388 & 688889 & 4.8 & 4.89199 & 99999999995 & TST \\
\hline CHEMBL1349988 & 688889 & 6.8 & 4.9566 & TRN & \\
\hline CHEMBL1378085 & 688889 & 4.75 & 4.7075 & TRN & \\
\hline CHEMBL1308105 & 688889 & 6.7501 & 4.7656 & TRN & \\
\hline CHEMBL1336142 & 688889 & 4.4 & 4.7337 & TRN & \\
\hline CHEMBL1537863 & 688889 & 4.6 & 4.8999 & TRN & \\
\hline CHEMBL1364212 & 688889 & 5.5 & 4.769 & TRN & \\
\hline CHEMBL1344555 & 688889 & 4.55 & 4.7614 & TRN & \\
\hline CHEMBL1522200 & 688889 & 4.25 & 4.8826 & TRN & \\
\hline CHEMBL1364841 & 688889 & 4.3 & 4.6845 & TRN & \\
\hline CHEMBL1413321 & 688889 & 4.3 & 4.8958 & TRN & \\
\hline CHEMBL1502662 & 688889 & 4.95 & 4.8715 & TRN & \\
\hline CHEMBL1438084 & 688889 & 4.6 & 4.785 & TRN & \\
\hline CHEMBL1578292 & 688889 & 4.35 & 4.8399 & TST & \\
\hline CHEMBL1322396 & 688889 & 6.15 & 4.7889 & TRN & \\
\hline CHEMBL1300626 & 688889 & 5.85 & 4.9015 & TST & \\
\hline CHEMBL1351388 & 688889 & 5.2 & 4.8686 & TRN & \\
\hline CHEMBL1516897 & 688889 & 4.3 & 4.7487 & TRN & \\
\hline CHEMBL1347805 & 688889 & 4.3 & 4.8749 & TRN & \\
\hline CHEMBL1440321 & 688889 & 4.35 & 4.9363 & TRN & \\
\hline CHEMBL1595724 & 688889 & 6.3 & 4.7813 & TRN & \\
\hline CHEMBL1490023 & 688889 & 6.35 & 4.8355 & TST & \\
\hline CHEMBL1346451 & 688889 & 5.2 & 4.7775 & TST & \\
\hline CHEMBL1529937 & 688889 & 4.25 & 4.8602 & TRN & \\
\hline CHEMBL1543490 & 688889 & 4.5 & 4.9151 & TST & \\
\hline CHEMBL 3193730 & 688889 & 4.45 & 4.9068 & TRN & \\
\hline CHEMBL 3199243 & 688889 & 4.25 & 4.8424 & TRN & \\
\hline CHEMBL1460606 & 688889 & 4.55 & 4.7312 & TRN & \\
\hline CHEMBL1351320 & 688889 & 4.25 & 4.6516 & TRN & \\
\hline CHEMBL1579781 & 688889 & 4.3 & 4.8228 & TST & \\
\hline CHEMBL1495401 & 688889 & 5.1 & 4.8815 & TRN & \\
\hline CHEMBL1559076 & 688889 & 5.4 & 4.83899 & 99999999995 & TRN \\
\hline CHEMBL1489342 & 688889 & 5.9 & 4.7901 & TST & \\
\hline CHEMBL1450429 & 688889 & 4.45 & 4.7522 & TRN & \\
\hline CHEMBL 3208047 & 688889 & 4.3 & 4.6674 & TRN & \\
\hline CHEMBL1532613 & 688889 & 4.75 & 4.6218 & TRN & \\
\hline CHEMBL1601762 & 688889 & 4.95 & 4.9086 & TRN & \\
\hline CHEMBL1303054 & 688889 & 4.4 & 4.8181 & TRN & \\
\hline CHEMBL1560731 & 688889 & 4.45 & 4.7949 & TRN & \\
\hline CHEMBL1562024 & 688889 & 5.3 & 4.8538 & TST & \\
\hline CHEMBL1582982 & 688889 & 4.7 & 4.7886 & TRN & \\
\hline CHEMBL1331901 & 688889 & 4.55 & 4.7586 & TRN & \\
\hline CHEMBL1447562 & 688889 & 4.25 & 4.8709 & TRN & \\
\hline CHEMBL1610005 & 688889 & 4.4 & 4.8361 & TST & \\
\hline
\end{tabular}




\begin{tabular}{|c|c|c|c|c|c|}
\hline \multicolumn{6}{|c|}{ Supplemental Table S2.txt } \\
\hline CHEMBL1403919 & 688889 & 4.95 & 4.6519 & TRN & \\
\hline CHEMBL1610379 & 688889 & 6.5501 & 4.8304 & TRN & \\
\hline CHEMBL1449434 & 688889 & 4.25 & 4.7711 & TRN & \\
\hline CHEMBL1307998 & 688889 & 4.35 & 4.853 & TST & \\
\hline CHEMBL1360224 & 688889 & 5.2 & 4.7922 & TRN & \\
\hline CHEMBL1581582 & 688889 & 4.3 & 4.7954 & TRN & \\
\hline CHEMBL1557372 & 688889 & 4.45 & 4.8702 & TRN & \\
\hline CHEMBL1509760 & 688889 & 4.25 & 4.9288 & TRN & \\
\hline CHEMBL1612222 & 688889 & 4.7 & 4.7708 & TRN & \\
\hline CHEMBL1445101 & 688889 & 4.95 & 4.8262 & TRN & \\
\hline CHEMBL1525792 & 688889 & 5.35 & 4.7319 & TST & \\
\hline CHEMBL1331894 & 688889 & 4.5 & 4.7021 & TRN & \\
\hline CHEMBL1523984 & 688889 & 4.35 & 4.7463 & TRN & \\
\hline CHEMBL1546225 & 688889 & 4.45 & 4.8444 & TRN & \\
\hline CHEMBL1555907 & 688889 & 5.5 & 4.8872 & TRN & \\
\hline CHEMBL1363577 & 688889 & 4.4 & 4.8927 & TRN & \\
\hline CHEMBL1585792 & 688889 & 5.95 & 4.6621 & TRN & \\
\hline CHEMBL1599458 & 688889 & 4.55 & 4.6641 & TRN & \\
\hline CHEMBL 1575892 & 688889 & 4.8 & 4.6485 & TST & \\
\hline CHEMBL1309869 & 688889 & 4.5 & 4.6914 & TRN & \\
\hline CHEMBL1570309 & 688889 & 5.1 & 4.8331 & TST & \\
\hline CHEMBL1563022 & 688889 & 5.55 & 4.8174 & TRN & \\
\hline CHEMBL1328353 & 688889 & 5.65 & 4.8346 & TST & \\
\hline CHEMBL1582229 & 688889 & 4.5 & 4.6111 & TRN & \\
\hline CHEMBL1498499 & 688889 & 4.9 & 4.9154 & TRN & \\
\hline CHEMBL1299309 & 688889 & 5.45 & 4.8982 & TRN & \\
\hline CHEMBL1550647 & 688889 & 5.2 & 4.7133 & TRN & \\
\hline CHEMBL1367444 & 688889 & 4.6 & 4.8252 & TRN & \\
\hline CHEMBL1517728 & 688889 & 4.3 & 4.6403 & TRN & \\
\hline CHEMBL 1445542 & 688889 & 5.25 & 4.734 & TRN & \\
\hline CHEMBL1420167 & 688889 & 4.25 & 4.8879 & TRN & \\
\hline CHEMBL1500481 & 688889 & 4.55 & 4.7338 & TRN & \\
\hline CHEMBL1352345 & 688889 & 4.45 & 4.7443 & TRN & \\
\hline CHEMBL1337605 & 688889 & 4.65 & 4.6798 & TRN & \\
\hline CHEMBL1520425 & 688889 & 4.65 & 4.8288 & TRN & \\
\hline CHEMBL3207545 & 688889 & 4.7 & 4.8548 & TRN & \\
\hline CHEMBL1482581 & 688889 & 5.25 & 4.8048 & TRN & \\
\hline CHEMBL1549292 & 688889 & 4.5 & 4.744 & TRN & \\
\hline CHEMBL3192567 & 688889 & 4.7 & 4.7448 & TRN & \\
\hline CHEMBL1498351 & 688889 & 5.25 & 4.7151 & TRN & \\
\hline CHEMBL1573807 & 688889 & 4.45 & 4.6335 & TRN & \\
\hline CHEMBL1425112 & 688889 & 4.5 & 4.71399 & 99999999995 & TRN \\
\hline CHEMBL1350647 & 688889 & 4.95 & 4.9046 & TRN & \\
\hline CHEMBL1424158 & 688889 & 4.85 & 4.9377 & TRN & \\
\hline CHEMBL1420222 & 688889 & 6.15 & 4.8057 & TRN & \\
\hline CHEMBL1450551 & 688889 & 4.25 & 5.0055 & TRN & \\
\hline CHEMBL1600522 & 688889 & 4.9 & 4.7354 & TRN & \\
\hline CHEMBL1307432 & 688889 & 4.65 & 4.6277 & TRN & \\
\hline
\end{tabular}




\begin{tabular}{|c|c|c|c|c|c|}
\hline \multicolumn{6}{|c|}{ Supplemental Table S2.txt } \\
\hline CHEMBL1345969 & 688889 & 4.25 & 4.715 & TST & \\
\hline CHEMBL1332007 & 688889 & 5.45 & 4.8096 & TST & \\
\hline CHEMBL1368803 & 688889 & 5.2 & 4.9259 & TRN & \\
\hline CHEMBL1548380 & 688889 & 4.3 & 4.7783 & TST & \\
\hline CHEMBL1309678 & 688889 & 4.45 & 4.7612 & TRN & \\
\hline CHEMBL1599620 & 688889 & 4.7 & 4.7813 & TRN & \\
\hline CHEMBL3197612 & 688889 & 5.1 & 4.8176 & TRN & \\
\hline CHEMBL1305327 & 688889 & 5.0 & 4.8414 & TRN & \\
\hline CHEMBL1522915 & 688889 & 5.45 & 4.9554 & TRN & \\
\hline CHEMBL1351573 & 688889 & 4.8 & 4.8509 & TST & \\
\hline CHEMBL1511456 & 688889 & 4.95 & 4.6812 & TRN & \\
\hline CHEMBL1561885 & 688889 & 4.75 & 4.7342 & TRN & \\
\hline CHEMBL600760 & 688889 & 5.2 & 4.7982 & TST & \\
\hline CHEMBL1516957 & 688889 & 4.55 & 4.7064 & TRN & \\
\hline CHEMBL1380570 & 688889 & 4.45 & 4.698 & TRN & \\
\hline CHEMBL1510612 & 688889 & 4.25 & 4.6532 & TRN & \\
\hline CHEMBL1413341 & 688889 & 4.45 & 4.7358 & TRN & \\
\hline CHEMBL1364645 & 688889 & 4.6 & 4.8592 & TRN & \\
\hline CHEMBL1538067 & 688889 & 5.8 & 4.7079 & TST & \\
\hline CHEMBL1509159 & 688889 & 4.3 & 4.7746 & TRN & \\
\hline CHEMBL1368935 & 688889 & 4.75 & 4.8269 & TRN & \\
\hline CHEMBL1342903 & 688889 & 6.6499 & 4.7269 & TST & \\
\hline CHEMBL1382272 & 688889 & 4.25 & 4.9 & TST & \\
\hline CHEMBL1497991 & 688889 & 4.5 & 4.6701 & TRN & \\
\hline CHEMBL1428290 & 688889 & 4.95 & 4.881 & TRN & \\
\hline CHEMBL1519530 & 688889 & 5.15 & 4.7168 & TRN & \\
\hline CHEMBL1338744 & 688889 & 4.25 & 4.7498 & TRN & \\
\hline CHEMBL1345369 & 688889 & 4.85 & 4.86100 & 0000000001 & TRN \\
\hline CHEMBL1307875 & 688889 & 5.45 & 4.9123 & TRN & \\
\hline CHEMBL1410686 & 688889 & 4.5 & 4.7085 & TRN & \\
\hline CHEMBL1586801 & 688889 & 4.3 & 4.7837 & TST & \\
\hline CHEMBL1425788 & 688889 & 4.25 & 4.8679 & TRN & \\
\hline CHEMBL1574108 & 688889 & 4.45 & 4.7902 & TRN & \\
\hline CHEMBL1413235 & 688889 & 4.25 & 4.886 & TRN & \\
\hline CHEMBL1488241 & 688889 & 4.3 & 4.9213 & TRN & \\
\hline CHEMBL1327069 & 688889 & 6.5 & 4.6827 & TRN & \\
\hline CHEMBL1566122 & 688889 & 4.8 & 5.0067 & TRN & \\
\hline CHEMBL1612810 & 688889 & 4.25 & 4.8142 & TST & \\
\hline CHEMBL1478344 & 688889 & 4.3 & 4.8286 & TRN & \\
\hline CHEMBL1556807 & 688889 & 5.3 & 4.7792 & TRN & \\
\hline CHEMBL1344730 & 688889 & 4.45 & 4.7008 & TRN & \\
\hline CHEMBL1589235 & 688889 & 4.9 & 4.6968 & TRN & \\
\hline CHEMBL1496007 & 688889 & 4.55 & 4.7398 & TRN & \\
\hline CHEMBL1468255 & 688889 & 4.25 & 4.8441 & TRN & \\
\hline CHEMBL1337038 & 688889 & 4.3 & 4.8568 & TST & \\
\hline CHEMBL1530274 & 688889 & 4.3 & 4.9433 & TRN & \\
\hline CHEMBL1519177 & 688889 & 4.25 & 4.8805 & TRN & \\
\hline CHEMBL3196137 & 688889 & 4.3 & 4.8757 & TRN & \\
\hline
\end{tabular}




\begin{tabular}{|c|c|c|c|c|}
\hline \multicolumn{5}{|c|}{ Supplemental Table S2.txt } \\
\hline CHEMBL1548081 & 688889 & 5.6 & 5.0712 & TRN \\
\hline CHEMBL 3208884 & 688889 & 4.95 & 4.8082 & TRN \\
\hline CHEMBL1544136 & 688889 & 4.25 & 4.6951 & TRN \\
\hline CHEMBL1381717 & 688889 & 5.95 & 4.9397 & TRN \\
\hline CHEMBL1388162 & 688889 & 4.65 & 4.6446 & TRN \\
\hline CHEMBL1305046 & 688889 & 4.45 & 4.9713 & TRN \\
\hline CHEMBL1420749 & 688889 & 6.8 & 4.887 & TRN \\
\hline CHEMBL1335787 & 688889 & 4.25 & 4.7473 & TRN \\
\hline CHEMBL1539183 & 688889 & 4.3 & 4.7735 & TRN \\
\hline CHEMBL1429413 & 688889 & 4.5 & 4.8426 & TRN \\
\hline CHEMBL346323 & 688889 & 4.6 & 4.7481 & TST \\
\hline CHEMBL1540161 & 688889 & 4.6 & 4.8339 & TRN \\
\hline CHEMBL1560337 & 688889 & 4.3 & 4.6811 & TRN \\
\hline CHEMBL1567205 & 688889 & 6.7501 & 4.923 & TRN \\
\hline CHEMBL1446972 & 688889 & 4.9 & 4.8787 & TRN \\
\hline CHEMBL1453005 & 688889 & 4.3 & 4.7767 & TRN \\
\hline CHEMBL1529995 & 688889 & 4.3 & 4.7531 & TRN \\
\hline CHEMBL1451554 & 688889 & 4.9 & 4.851 & TRN \\
\hline CHEMBL552272 & 688889 & 4.25 & 4.78 & TRN \\
\hline CHEMBL1415933 & 688889 & 4.95 & 4.8486 & TRN \\
\hline CHEMBL1543535 & 688889 & 4.6 & 4.7254 & TRN \\
\hline CHEMBL1568974 & 688889 & 5.2 & 4.6868 & TRN \\
\hline CHEMBL1465841 & 688889 & 4.6 & 4.8591 & TRN \\
\hline CHEMBL1410963 & 688889 & 4.6 & 4.8474 & TRN \\
\hline CHEMBL1344537 & 688889 & 4.25 & 4.8068 & TRN \\
\hline CHEMBL1439966 & 688889 & 5.6 & 4.8461 & TRN \\
\hline CHEMBL1382246 & 688889 & 5.05 & 4.8636 & TRN \\
\hline CHEMBL1507613 & 688889 & 4.45 & 4.7735 & TRN \\
\hline CHEMBL1442927 & 688889 & 6.35 & 4.8886 & TRN \\
\hline CHEMBL1537318 & 688889 & 5.3 & 4.9717 & TRN \\
\hline CHEMBL1422437 & 688889 & 5.75 & 4.8654 & TRN \\
\hline CHEMBL1530819 & 688889 & 4.45 & 4.6681 & TRN \\
\hline CHEMBL1595579 & 688889 & 6.4 & 4.9336 & TST \\
\hline CHEMBL1531609 & 688889 & 4.35 & 4.8082 & TST \\
\hline CHEMBL1341644 & 688889 & 5.05 & 4.8762 & TRN \\
\hline CHEMBL3193170 & 688889 & 4.25 & 4.7316 & TRN \\
\hline CHEMBL1410260 & 688889 & 6.05 & 4.6618 & TRN \\
\hline CHEMBL42529 & 688889 & 4.95 & 4.802 & TRN \\
\hline CHEMBL1402230 & 688889 & 4.4 & 4.7703 & TST \\
\hline CHEMBL1303548 & 688889 & 5.65 & 4.8163 & TRN \\
\hline CHEMBL1307772 & 688889 & 6.7001 & 4.8763 & TRN \\
\hline CHEMBL1374437 & 688889 & 4.55 & 4.6957 & TRN \\
\hline CHEMBL1606122 & 688889 & 4.25 & 4.7808 & TRN \\
\hline CHEMBL1572790 & 688889 & 4.7 & 4.6922 & TRN \\
\hline CHEMBL1611034 & 688889 & 4.95 & 4.8381 & TRN \\
\hline CHEMBL1368068 & 688889 & 4.5 & 4.7547 & TRN \\
\hline CHEMBL1300493 & 688889 & 4.95 & 4.9413 & TRN \\
\hline CHEMBL 3192408 & 688889 & 4.3 & 4.7525 & TST \\
\hline
\end{tabular}




\begin{tabular}{|c|c|c|c|c|}
\hline & & & ıpplemen & \\
\hline CHEMBL 3198203 & 688889 & 4.55 & 4.6862 & TRN \\
\hline CHEMBL1501730 & 688889 & 4.3 & 4.8443 & TRN \\
\hline CHEMBL1789996 & 688889 & 5.15 & 4.816 & TST \\
\hline CHEMBL1606614 & 688889 & 4.35 & 4.8193 & TRN \\
\hline CHEMBL1309199 & 688889 & 4.5 & 4.9081 & TRN \\
\hline CHEMBL1530311 & 688889 & 4.95 & 4.7674 & TST \\
\hline CHEMBL1405015 & 688889 & 4.95 & 4.777 & TRN \\
\hline CHEMBL1537907 & 688889 & 4.45 & 4.8018 & TRN \\
\hline CHEMBL1595462 & 688889 & 5.2 & 4.7869 & TST \\
\hline CHEMBL1464355 & 688889 & 4.25 & 4.7939 & TRN \\
\hline CHEMBL1381308 & 688889 & 4.45 & 4.8393 & TRN \\
\hline CHEMBL1540341 & 688889 & 4.25 & 4.9043 & TRN \\
\hline CHEMBL1527703 & 688889 & 4.45 & 4.7201 & TRN \\
\hline CHEMBL1470342 & 688889 & 4.8 & 4.6434 & TRN \\
\hline CHEMBL1448455 & 688889 & 4.25 & 4.8865 & TRN \\
\hline CHEMBL1301246 & 688889 & 4.7 & 4.7562 & TST \\
\hline CHEMBL1352156 & 688889 & 5.25 & 4.6386 & TRN \\
\hline CHEMBL1601126 & 688889 & 6.0 & 4.867 & TRN \\
\hline CHEMBL1328266 & 688889 & 4.4 & 4.8419 & TRN \\
\hline CHEMBL1349689 & 688889 & 4.9 & 4.8352 & TRN \\
\hline CHEMBL1520067 & 688889 & 4.6 & 4.8427 & TRN \\
\hline CHEMBL1572857 & 688889 & 4.55 & 4.7617 & TRN \\
\hline CHEMBL1606450 & 688889 & 4.25 & 4.8195 & TRN \\
\hline CHEMBL1368075 & 688889 & 4.95 & 4.8402 & TRN \\
\hline CHEMBL1342139 & 688889 & 6.05 & 4.848 & TST \\
\hline CHEMBL1601862 & 688889 & 5.6 & 4.7799 & TRN \\
\hline CHEMBL1575442 & 688889 & 5.4 & 4.6118 & TRN \\
\hline CHEMBL1462897 & 688889 & 4.95 & 4.9361 & TRN \\
\hline CHEMBL1441300 & 688889 & 4.3 & 4.9458 & TRN \\
\hline CHEMBL 3189836 & 688889 & 4.4 & 4.7278 & TRN \\
\hline CHEMBL1607322 & 688889 & 4.25 & 4.8078 & TRN \\
\hline CHEMBL1333974 & 688889 & 4.95 & 4.8295 & TST \\
\hline CHEMBL1477983 & 688889 & 4.45 & 4.7523 & TRN \\
\hline CHEMBL1411034 & 688889 & 4.6 & 4.7952 & TRN \\
\hline CHEMBL1501331 & 688889 & 5.5 & 4.8732 & TRN \\
\hline CHEMBL1310601 & 688889 & 4.45 & 4.7633 & TRN \\
\hline CHEMBL1529463 & 688889 & 5.9 & 4.8996 & TRN \\
\hline CHEMBL1309947 & 688889 & 4.9 & 4.8757 & TST \\
\hline CHEMBL1530666 & 688889 & 4.5 & 4.7176 & TRN \\
\hline CHEMBL1581590 & 688889 & 4.3 & 4.7032 & TRN \\
\hline CHEMBL1300154 & 688889 & 4.65 & 4.6647 & TRN \\
\hline CHEMBL1403262 & 688889 & 6.5 & 4.8145 & TST \\
\hline CHEMBL3191251 & 688889 & 4.4 & 4.6166 & TRN \\
\hline CHEMBL1563359 & 688889 & 4.45 & 4.7524 & TRN \\
\hline CHEMBL1425599 & 688889 & 4.25 & 4.8591 & TRN \\
\hline CHEMBL1456276 & 688889 & 4.35 & 4.6344 & TRN \\
\hline CHEMBL1430567 & 688889 & 5.55 & 4.8732 & TRN \\
\hline CHEMBL1377287 & 688889 & 4.55 & 4.8099 & TRN \\
\hline
\end{tabular}




\begin{tabular}{|c|c|c|c|c|}
\hline \multicolumn{5}{|c|}{ Supplemental Table S2.txt } \\
\hline CHEMBL 3214149 & 688889 & 4.45 & 4.7916 & TRN \\
\hline CHEMBL1577959 & 688889 & 4.25 & 4.7795 & TST \\
\hline CHEMBL1412437 & 688889 & 4.5 & 4.793 & TRN \\
\hline CHEMBL1493900 & 688889 & 6.05 & 4.7705 & TST \\
\hline CHEMBL1301617 & 688889 & 4.45 & 4.7879 & TRN \\
\hline CHEMBL1517069 & 688889 & 6.7501 & 4.8659 & TST \\
\hline CHEMBL1568977 & 688889 & 4.95 & 4.7525 & TST \\
\hline CHEMBL1547139 & 688889 & 6.7001 & 4.8012 & TST \\
\hline CHEMBL3193562 & 688889 & 4.55 & 4.8682 & TRN \\
\hline CHEMBL1477131 & 688889 & 4.25 & 4.896 & TRN \\
\hline CHEMBL1574561 & 688889 & 4.35 & 4.7475 & TRN \\
\hline CHEMBL1371258 & 688889 & 4.6 & 4.6351 & TRN \\
\hline CHEMBL1447493 & 688889 & 4.8 & 4.7214 & TRN \\
\hline CHEMBL1341696 & 688889 & 5.5 & 4.8633 & TRN \\
\hline CHEMBL1462701 & 688889 & 4.9 & 4.8813 & TRN \\
\hline CHEMBL1550615 & 688889 & 5.3 & 4.9116 & TRN \\
\hline CHEMBL1505589 & 688889 & 4.55 & 4.8745 & TRN \\
\hline CHEMBL1587306 & 688889 & 4.25 & 4.716 & TRN \\
\hline CHEMBL1584343 & 688889 & 4.4 & 4.834 & TRN \\
\hline CHEMBL1422500 & 688889 & 4.3 & 4.7761 & TRN \\
\hline CHEMBL1454685 & 688889 & 4.55 & 4.77 & TRN \\
\hline CHEMBL150924 & 688889 & 4.4 & 4.6774 & TRN \\
\hline CHEMBL1596357 & 688889 & 5.15 & 4.6799 & TRN \\
\hline CHEMBL30953 & 688889 & 4.45 & 4.6498 & TRN \\
\hline CHEMBL1318780 & 688889 & 4.45 & 4.715 & TRN \\
\hline CHEMBL1440414 & 688889 & 4.4 & 4.8822 & TRN \\
\hline CHEMBL1347692 & 688889 & 4.3 & 4.8356 & TRN \\
\hline CHEMBL1465184 & 688889 & 4.9 & 4.6575 & TRN \\
\hline CHEMBL 3212782 & 688889 & 4.35 & 4.7775 & TST \\
\hline CHEMBL1435313 & 688889 & 5.25 & 4.8023 & TST \\
\hline CHEMBL3211904 & 688889 & 4.55 & 4.7754 & TST \\
\hline CHEMBL1388418 & 688889 & 4.7 & 4.8046 & TRN \\
\hline CHEMBL1508555 & 688889 & 6.7501 & 4.8549 & TRN \\
\hline CHEMBL1456689 & 688889 & 4.3 & 4.8564 & TRN \\
\hline CHEMBL1458966 & 688889 & 4.3 & 4.8023 & TRN \\
\hline CHEMBL1505091 & 688889 & 4.25 & 4.7087 & TRN \\
\hline CHEMBL1381435 & 688889 & 4.25 & 4.796 & TRN \\
\hline CHEMBL1557589 & 688889 & 4.25 & 4.898 & TRN \\
\hline CHEMBL1418934 & 688889 & 4.75 & 4.8751 & TRN \\
\hline CHEMBL1510055 & 688889 & 4.4 & 4.8455 & TRN \\
\hline CHEMBL1468829 & 688889 & 4.55 & 4.8683 & TRN \\
\hline CHEMBL1509725 & 688889 & 4.3 & 4.8404 & TRN \\
\hline CHEMBL3214223 & 688889 & 4.3 & 4.6777 & TRN \\
\hline CHEMBL1546182 & 688889 & 5.4 & 4.7438 & TRN \\
\hline CHEMBL1596939 & 688889 & 4.55 & 4.8457 & TRN \\
\hline CHEMBL1269508 & 688889 & 4.9 & 4.7401 & TRN \\
\hline CHEMBL1570792 & 688889 & 4.45 & 4.7858 & TRN \\
\hline CHEMBL3197343 & 688889 & 4.65 & 4.7388 & TRN \\
\hline
\end{tabular}




\begin{tabular}{|c|c|c|c|c|c|}
\hline & & & & & \\
\hline CHEMBL1420834 & 688889 & 4.5 & 4.9042 & TRN & \\
\hline CHEMBL1380279 & 688889 & 5.45 & 4.8933 & TRN & \\
\hline CHEMBL1532390 & 688889 & 4.6 & 4.7174 & TRN & \\
\hline CHEMBL1359333 & 688889 & 4.25 & 4.6609 & TST & \\
\hline CHEMBL600971 & 688889 & 4.3 & 4.8094 & TRN & \\
\hline CHEMBL1541769 & 688889 & 4.45 & 4.5959 & TRN & \\
\hline CHEMBL1392137 & 688889 & 4.75 & 4.6778 & TRN & \\
\hline CHEMBL1586371 & 688889 & 4.3 & 4.8774 & TRN & \\
\hline CHEMBL1609330 & 688889 & 4.4 & 4.7406 & TRN & \\
\hline CHEMBL3195981 & 688889 & 5.25 & 4.7075 & TRN & \\
\hline CHEMBL1466471 & 688889 & 4.55 & 4.82600 & 00000000005 & TRN \\
\hline CHEMBL3191454 & 688889 & 4.25 & 4.8776 & TRN & \\
\hline CHEMBL1352602 & 688889 & 4.45 & 4.6538 & TRN & \\
\hline CHEMBL1569101 & 688889 & 5.25 & 4.9162 & TRN & \\
\hline CHEMBL1549661 & 688889 & 4.45 & 4.8143 & TRN & \\
\hline CHEMBL1579414 & 688889 & 4.55 & 4.612 & TRN & \\
\hline CHEMBL1518765 & 688889 & 4.55 & 4.6684 & TST & \\
\hline CHEMBL1460801 & 688889 & 4.95 & 5.0757 & TRN & \\
\hline CHEMBL1405908 & 688889 & 5.25 & 4.8696 & TST & \\
\hline CHEMBL1491372 & 688889 & 5.05 & 4.8731 & TRN & \\
\hline CHEMBL1576513 & 688889 & 4.6 & 4.7205 & TRN & \\
\hline CHEMBL1493896 & 688889 & 4.3 & 4.8678 & TRN & \\
\hline CHEMBL1407234 & 688889 & 4.3 & 4.8294 & TST & \\
\hline CHEMBL3209059 & 688889 & 5.25 & 4.9421 & TRN & \\
\hline CHEMBL1529532 & 688889 & 5.1 & 4.8198 & TRN & \\
\hline CHEMBL1546266 & 688889 & 6.3 & 4.9075 & TRN & \\
\hline CHEMBL1517137 & 688889 & 4.3 & 4.8469 & TRN & \\
\hline CHEMBL1482321 & 688889 & 4.3 & 4.9389 & TRN & \\
\hline CHEMBL1340530 & 688889 & 4.45 & 4.9153 & TRN & \\
\hline CHEMBL 3193647 & 688889 & 5.05 & 4.7887 & TST & \\
\hline CHEMBL1426634 & 688889 & 4.25 & 4.7027 & TRN & \\
\hline CHEMBL1511388 & 688889 & 6.7501 & 4.8955 & TRN & \\
\hline CHEMBL1410774 & 688889 & 4.65 & 4.7834 & TRN & \\
\hline CHEMBL1583619 & 688889 & 5.1 & 4.6714 & TRN & \\
\hline CHEMBL1520817 & 688889 & 4.45 & 4.6495 & TST & \\
\hline CHEMBL1543129 & 688889 & 4.85 & 4.8108 & TRN & \\
\hline CHEMBL1372543 & 688889 & 4.7 & 4.6911 & TRN & \\
\hline CHEMBL1532758 & 688889 & 4.25 & 4.7757 & TST & \\
\hline CHEMBL1400599 & 688889 & 4.3 & 4.5918 & TRN & \\
\hline CHEMBL1445192 & 688889 & 4.3 & 4.6348 & TRN & \\
\hline CHEMBL1507749 & 688889 & 4.6 & 4.7375 & TRN & \\
\hline CHEMBL1531276 & 688889 & 5.35 & 4.7931 & TRN & \\
\hline CHEMBL1415534 & 688889 & 4.3 & 4.7779 & TRN & \\
\hline CHEMBL3191353 & 688889 & 5.75 & 4.8847 & TST & \\
\hline CHEMBL1556186 & 688889 & 4.95 & 4.8543 & TRN & \\
\hline CHEMBL1454898 & 688889 & 5.15 & 4.6684 & TRN & \\
\hline CHEMBL1469851 & 688889 & 4.45 & 4.8342 & TST & \\
\hline CHEMBL1498044 & 688889 & 4.6 & 4.9166 & TST & \\
\hline & & & & 21057 & \\
\hline
\end{tabular}




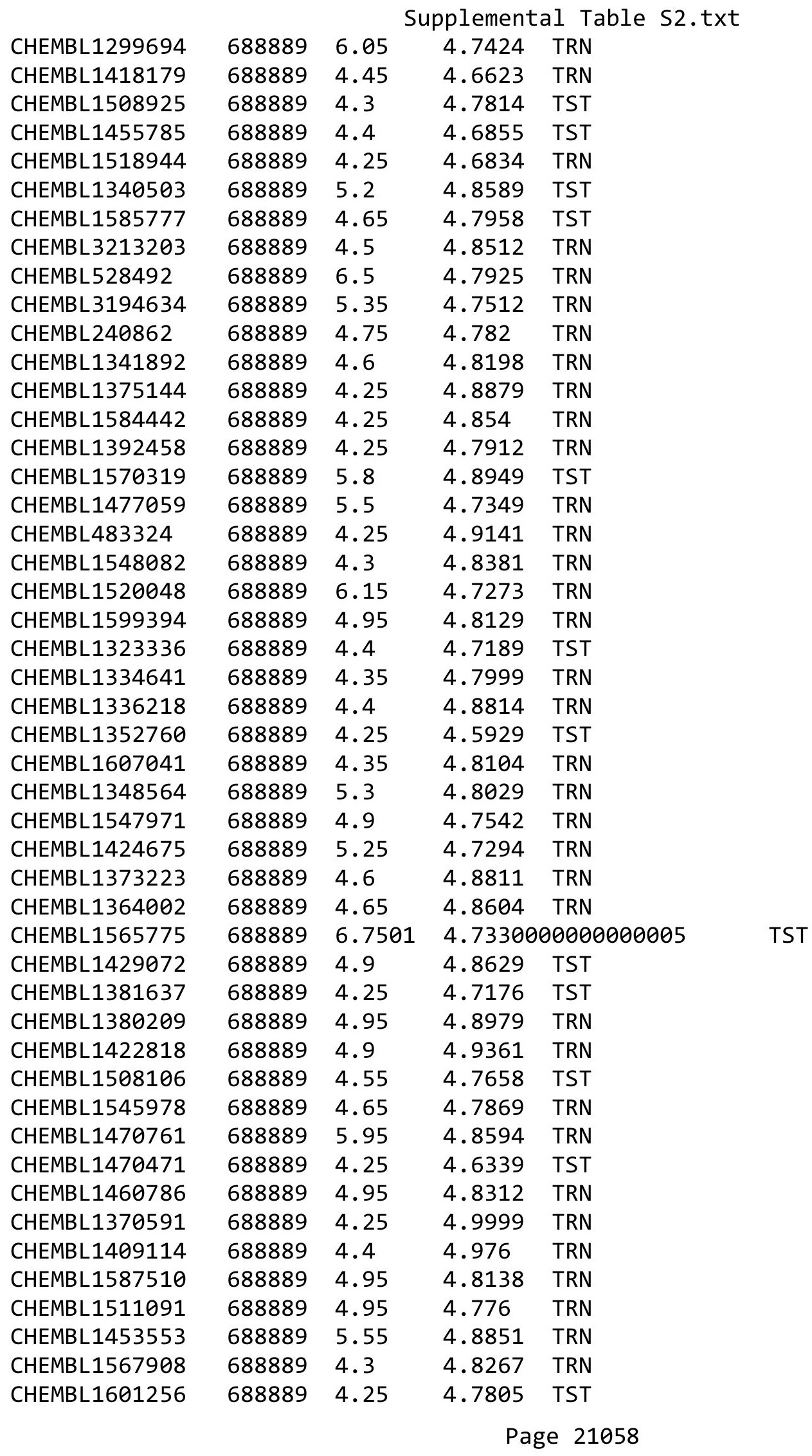




\begin{tabular}{|c|c|c|c|c|}
\hline \multicolumn{5}{|c|}{ Supplemental Table S2.txt } \\
\hline CHEMBL1536734 & 688889 & 5.5 & 4.88 & TRN \\
\hline CHEMBL1383270 & 688889 & 4.45 & 4.7093 & TRN \\
\hline CHEMBL1565278 & 688889 & 5.0 & 4.7593 & TST \\
\hline CHEMBL1464449 & 688889 & 4.95 & 4.8154 & TRN \\
\hline CHEMBL3211634 & 688889 & 4.35 & 4.7837 & TRN \\
\hline CHEMBL1441242 & 688889 & 5.05 & 4.8538 & TRN \\
\hline CHEMBL1401612 & 688889 & 4.35 & 4.8419 & TRN \\
\hline CHEMBL1492122 & 688889 & 4.3 & 4.7766 & TST \\
\hline CHEMBL1497317 & 688889 & 4.4 & 4.6892 & TRN \\
\hline CHEMBL1460537 & 688889 & 6.25 & 4.8529 & TRN \\
\hline CHEMBL1449968 & 688889 & 4.45 & 4.7251 & TRN \\
\hline CHEMBL1342058 & 688889 & 5.5 & 4.9392 & TRN \\
\hline CHEMBL1400777 & 688889 & 5.95 & 4.6825 & TRN \\
\hline CHEMBL 3192974 & 688889 & 5.25 & 4.7979 & TRN \\
\hline CHEMBL1583894 & 688889 & 4.3 & 4.8894 & TRN \\
\hline CHEMBL1418821 & 688889 & 4.3 & 4.8072 & TRN \\
\hline CHEMBL1485132 & 688889 & 4.3 & 4.6577 & TRN \\
\hline CHEMBL1499553 & 688889 & 4.25 & 4.8096 & TRN \\
\hline CHEMBL1579823 & 688889 & 5.15 & 4.7457 & TST \\
\hline CHEMBL1453248 & 688889 & 4.25 & 4.957 & TRN \\
\hline CHEMBL1443166 & 688889 & 4.95 & 4.9067 & TRN \\
\hline CHEMBL1405631 & 688889 & 4.7 & 4.742 & TRN \\
\hline CHEMBL1998824 & 688889 & 4.3 & 4.7808 & TRN \\
\hline CHEMBL1404822 & 688889 & 4.25 & 4.7403 & TRN \\
\hline CHEMBL1369941 & 688889 & 4.95 & 4.8117 & TRN \\
\hline CHEMBL1488110 & 688889 & 4.25 & 4.773 & TRN \\
\hline CHEMBL1477655 & 688889 & 4.5 & 4.8746 & TRN \\
\hline CHEMBL1384674 & 688889 & 4.6 & 4.8661 & TRN \\
\hline CHEMBL1311692 & 688889 & 4.8 & 4.7609 & TRN \\
\hline CHEMBL3194446 & 688889 & 4.9 & 4.8528 & TST \\
\hline CHEMBL1549599 & 688889 & 5.2 & 4.8026 & TRN \\
\hline CHEMBL1464684 & 688889 & 4.3 & 4.8115 & TRN \\
\hline CHEMBL1527315 & 688889 & 4.95 & 4.9074 & TRN \\
\hline CHEMBL1579264 & 688889 & 4.25 & 4.7207 & TRN \\
\hline CHEMBL1366602 & 688889 & 6.8 & 4.8663 & TRN \\
\hline CHEMBL1341114 & 688889 & 4.25 & 4.8852 & TRN \\
\hline CHEMBL 1457366 & 688889 & 5.25 & 4.75 & TST \\
\hline CHEMBL1301291 & 688889 & 4.35 & 4.8003 & TST \\
\hline CHEMBL1345182 & 688889 & 4.7 & 4.8877 & TST \\
\hline CHEMBL1424297 & 688889 & 4.3 & 4.7813 & TRN \\
\hline CHEMBL1308183 & 688889 & 5.0 & 4.8221 & TRN \\
\hline CHEMBL1523826 & 688889 & 5.3 & 4.662 & TRN \\
\hline CHEMBL1341548 & 688889 & 4.6 & 4.8852 & TRN \\
\hline CHEMBL1393398 & 688889 & 4.3 & 4.7788 & TRN \\
\hline CHEMBL1527578 & 688889 & 4.7 & 4.7739 & TRN \\
\hline CHEMBL1600531 & 688889 & 4.6 & 4.7789 & TRN \\
\hline CHEMBL1393996 & 688889 & 4.3 & 4.8623 & TRN \\
\hline CHEMBL1498176 & 688889 & 5.5 & 4.8398 & TRN \\
\hline
\end{tabular}




\begin{tabular}{|c|c|c|c|c|c|}
\hline \\
\hline CHEMBL1300065 & 688889 & 5.3 & 4.6299 & TRN & \\
\hline CHEMBL1380444 & 688889 & 5.5 & 4.7857 & TRN & \\
\hline CHEMBL1567373 & 688889 & 4.25 & 4.835 & TRN & \\
\hline CHEMBL1360443 & 688889 & 4.3 & 5.0423 & TRN & \\
\hline CHEMBL1309448 & 688889 & 4.3 & 4.7394 & TRN & \\
\hline CHEMBL1576368 & 688889 & 5.7 & 4.7523 & TRN & \\
\hline CHEMBL1300104 & 688889 & 4.35 & 4.8212 & TRN & \\
\hline CHEMBL1470077 & 688889 & 4.55 & 4.7388 & TRN & \\
\hline CHEMBL1458896 & 688889 & 6.7501 & 4.878 & TRN & \\
\hline CHEMBL1550899 & 688889 & 5.0 & 4.8003 & TRN & \\
\hline CHEMBL1427111 & 688889 & 4.95 & 4.793 & TRN & \\
\hline CHEMBL3193616 & 688889 & 4.25 & 4.7935 & TRN & \\
\hline CHEMBL1382746 & 688889 & 4.3 & 4.9419 & TRN & \\
\hline CHEMBL1543528 & 688889 & 5.9 & 4.9469 & TST & \\
\hline CHEMBL1600878 & 688889 & 4.4 & 4.7829 & TST & \\
\hline CHEMBL1887938 & 688889 & 4.6 & 4.6909 & TRN & \\
\hline CHEMBL1611814 & 688889 & 6.45 & 4.7596 & TRN & \\
\hline CHEMBL1461513 & 688889 & 4.4 & 4.8601 & TST & \\
\hline CHEMBL1543384 & 688889 & 4.55 & 4.7808 & TRN & \\
\hline CHEMBL1390216 & 688889 & 4.4 & 4.76699 & 99999999995 & TRN \\
\hline CHEMBL1393142 & 688889 & 4.3 & 4.8142 & TRN & \\
\hline CHEMBL1303715 & 688889 & 4.6 & 4.7501 & TRN & \\
\hline CHEMBL3190658 & 688889 & 4.45 & 4.6285 & TRN & \\
\hline CHEMBL1415525 & 688889 & 4.25 & 4.8103 & TRN & \\
\hline CHEMBL 3192232 & 688889 & 4.6 & 4.8268 & TRN & \\
\hline CHEMBL1541369 & 688889 & 4.25 & 4.919 & TRN & \\
\hline CHEMBL1390550 & 688889 & 4.9 & 4.9588 & TRN & \\
\hline CHEMBL1312044 & 688889 & 4.45 & 4.6911 & TRN & \\
\hline CHEMBL1585612 & 688889 & 5.0 & 4.8138 & TST & \\
\hline CHEMBL1550128 & 688889 & 4.35 & 4.7085 & TRN & \\
\hline CHEMBL3198521 & 688889 & 4.45 & 4.7533 & TRN & \\
\hline CHEMBL1539803 & 688889 & 4.25 & 4.9549 & TRN & \\
\hline CHEMBL1373149 & 688889 & 4.25 & 4.7462 & TST & \\
\hline CHEMBL1479880 & 688889 & 5.65 & 4.7034 & TRN & \\
\hline CHEMBL1589183 & 688889 & 5.15 & 4.758 & TRN & \\
\hline CHEMBL1489214 & 688889 & 4.95 & 4.9262 & TRN & \\
\hline CHEMBL3207860 & 688889 & 4.4 & 4.8205 & TST & \\
\hline CHEMBL1320247 & 688889 & 4.5 & 4.8249 & TRN & \\
\hline CHEMBL1582368 & 688889 & 5.55 & 4.9229 & TST & \\
\hline CHEMBL1443804 & 688889 & 4.3 & 4.6356 & TRN & \\
\hline CHEMBL1391033 & 688889 & 4.65 & 4.785 & TRN & \\
\hline CHEMBL1469344 & 688889 & 4.25 & 4.8238 & TRN & \\
\hline CHEMBL1421112 & 688889 & 4.75 & 4.6841 & TRN & \\
\hline CHEMBL1518952 & 688889 & 4.8 & 4.8092 & TST & \\
\hline CHEMBL3194351 & 688889 & 4.3 & 4.9135 & TST & \\
\hline CHEMBL1546992 & 688889 & 4.45 & 4.6766 & TRN & \\
\hline CHEMBL1499308 & 688889 & 4.45 & 4.8776 & TRN & \\
\hline CHEMBL1403047 & 688889 & 5.75 & 4.9654 & TRN & \\
\hline
\end{tabular}




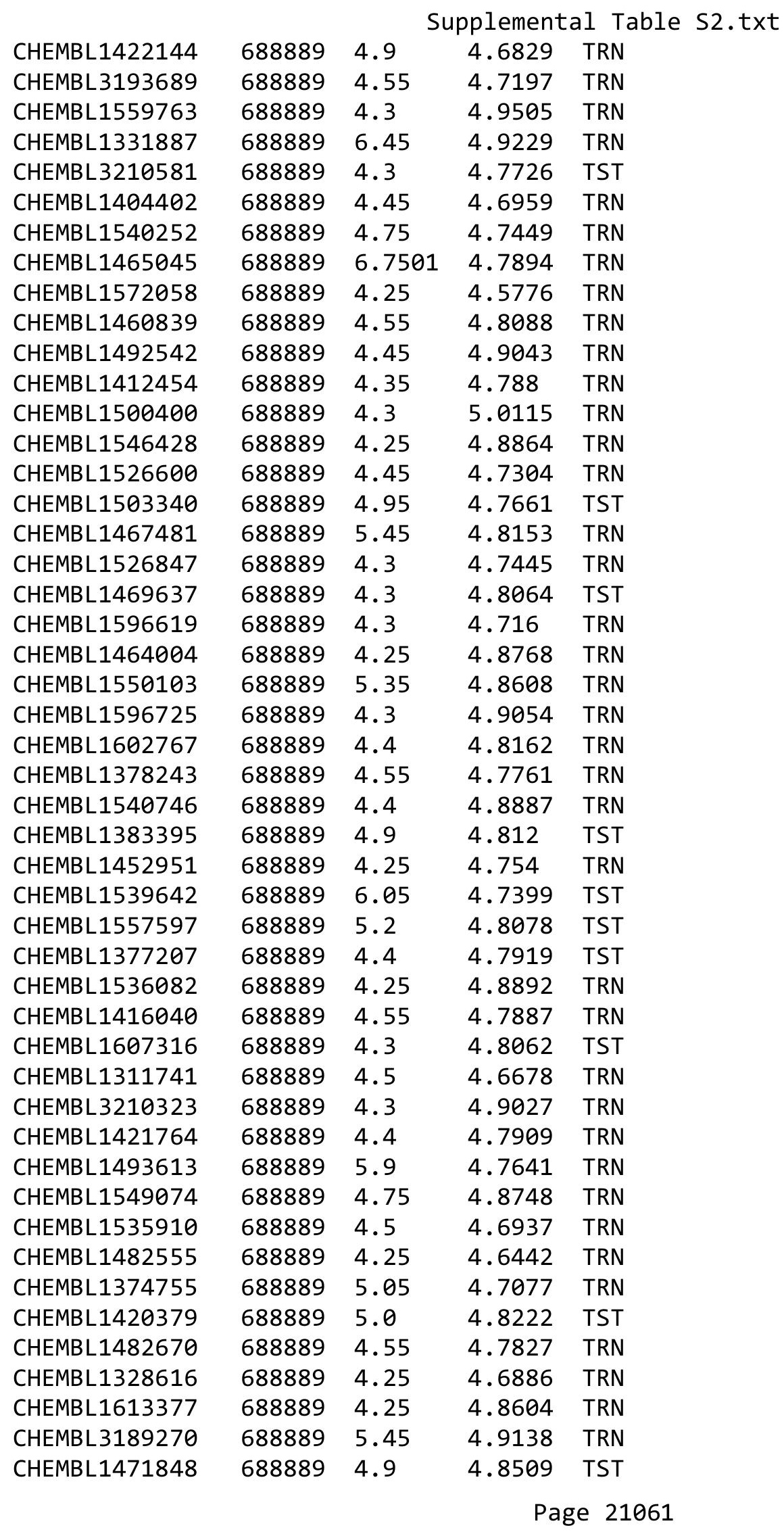




\begin{tabular}{|c|c|c|c|c|c|}
\hline \multicolumn{6}{|c|}{ Supplemental Table S2.txt } \\
\hline CHEMBL1488025 & 688889 & 4.55 & 4.7126 & TRN & \\
\hline CHEMBL1362740 & 688889 & 4.8 & 4.7857 & TST & \\
\hline CHEMBL1401428 & 688889 & 5.8 & 4.777 & TRN & \\
\hline CHEMBL1486813 & 688889 & 4.55 & 4.6557 & TRN & \\
\hline CHEMBL1415037 & 688889 & 4.45 & 4.7862 & TRN & \\
\hline CHEMBL1583954 & 688889 & 4.95 & 4.8506 & TRN & \\
\hline CHEMBL1504738 & 688889 & 4.75 & 4.7076 & TRN & \\
\hline CHEMBL1401790 & 688889 & 4.65 & 4.7923 & TRN & \\
\hline CHEMBL1466326 & 688889 & 5.3 & 4.802 & TST & \\
\hline CHEMBL1421540 & 688889 & 6.7501 & 4.7109 & TST & \\
\hline CHEMBL1613437 & 688889 & 4.9 & 4.8912 & TRN & \\
\hline CHEMBL 3210072 & 688889 & 4.35 & 4.8218 & TST & \\
\hline CHEMBL1424753 & 688889 & 4.3 & 4.7741 & TRN & \\
\hline CHEMBL1500069 & 688889 & 4.5 & 4.7583 & TRN & \\
\hline CHEMBL1384050 & 688889 & 6.8 & 4.9527 & TRN & \\
\hline CHEMBL1610952 & 688889 & 5.5 & 4.7822 & TRN & \\
\hline CHEMBL1386985 & 688889 & 4.5 & 4.8016 & TRN & \\
\hline CHEMBL1595173 & 688889 & 4.45 & 4.8132 & TRN & \\
\hline CHEMBL1601781 & 688889 & 4.3 & 4.7795 & TST & \\
\hline CHEMBL1430904 & 688889 & 5.55 & 4.8059 & TST & \\
\hline CHEMBL1604110 & 688889 & 4.25 & 4.7213 & TST & \\
\hline CHEMBL1313888 & 688889 & 4.75 & 4.8355 & TRN & \\
\hline CHEMBL1337938 & 688889 & 4.6 & 4.7392 & TRN & \\
\hline CHEMBL1332838 & 688889 & 5.15 & 4.7144 & TRN & \\
\hline CHEMBL1520120 & 688889 & 4.45 & 4.8288 & TRN & \\
\hline CHEMBL1456463 & 688889 & 5.15 & 4.7818 & TRN & \\
\hline CHEMBL1338363 & 688889 & 4.6 & 4.8552 & TRN & \\
\hline CHEMBL1329914 & 688889 & 4.55 & 4.6531 & TRN & \\
\hline CHEMBL1382103 & 688889 & 4.5 & 4.7688 & TRN & \\
\hline CHEMBL1503618 & 688889 & 4.25 & 4.7691 & TRN & \\
\hline CHEMBL1995112 & 688889 & 4.3 & 4.6861 & TRN & \\
\hline CHEMBL1482009 & 688889 & 4.5 & 4.69 & TRN & \\
\hline CHEMBL1598654 & 688889 & 4.65 & 4.7265 & TRN & \\
\hline CHEMBL592068 & 688889 & 4.3 & 4.7286 & TRN & \\
\hline CHEMBL3189428 & 688889 & 6.05 & 4.7138 & TRN & \\
\hline CHEMBL399962 & 688889 & 4.55 & 4.79899 & 99999999995 & TRN \\
\hline CHEMBL1511792 & 688889 & 4.25 & 4.7814 & TRN & \\
\hline CHEMBL1411234 & 688889 & 4.6 & 4.8149 & TRN & \\
\hline CHEMBL1427151 & 688889 & 4.9 & 4.7411 & TRN & \\
\hline CHEMBL1391505 & 688889 & 4.25 & 4.9362 & TRN & \\
\hline CHEMBL1353351 & 688889 & 4.45 & 4.7898 & TRN & \\
\hline CHEMBL1333720 & 688889 & 4.25 & 4.8909 & TRN & \\
\hline CHEMBL3193798 & 688889 & 5.3 & 4.9281 & TRN & \\
\hline CHEMBL1460350 & 688889 & 4.3 & 4.7746 & TST & \\
\hline CHEMBL1364445 & 688889 & 4.4 & 4.756 & TRN & \\
\hline CHEMBL1389793 & 688889 & 4.4 & 4.7829 & TRN & \\
\hline CHEMBL1550592 & 688889 & 4.35 & 4.8576 & TST & \\
\hline CHEMBL1402031 & 688889 & 4.25 & 4.6938 & TRN & \\
\hline
\end{tabular}




\begin{tabular}{|c|c|c|c|c|}
\hline \multicolumn{5}{|c|}{ Supplemental Table S2.txt } \\
\hline CHEMBL3196100 & 688889 & 4.3 & 4.6203 & TRN \\
\hline CHEMBL1408226 & 688889 & 4.95 & 4.6748 & TRN \\
\hline CHEMBL1557006 & 688889 & 4.95 & 4.7561 & TRN \\
\hline CHEMBL1326965 & 688889 & 6.5 & 4.7883 & TRN \\
\hline CHEMBL1594637 & 688889 & 4.65 & 4.8004 & TRN \\
\hline CHEMBL1540684 & 688889 & 4.45 & 4.8033 & TRN \\
\hline CHEMBL1507288 & 688889 & 5.25 & 4.9888 & TRN \\
\hline CHEMBL1567012 & 688889 & 5.25 & 4.8944 & TRN \\
\hline CHEMBL1453583 & 688889 & 6.7501 & 4.672 & TRN \\
\hline CHEMBL1571970 & 688889 & 6.05 & 4.7712 & TRN \\
\hline CHEMBL1506017 & 688889 & 4.25 & 4.7343 & TRN \\
\hline CHEMBL1559806 & 688889 & 4.3 & 4.8527 & TRN \\
\hline CHEMBL1389300 & 688889 & 6.8 & 4.5839 & TST \\
\hline CHEMBL1536012 & 688889 & 4.4 & 4.8441 & TST \\
\hline CHEMBL1575661 & 688889 & 4.55 & 4.8343 & TRN \\
\hline CHEMBL1484796 & 688889 & 4.25 & 4.7919 & TST \\
\hline CHEMBL1299256 & 688889 & 5.2 & 4.813 & TRN \\
\hline CHEMBL1584407 & 688889 & 4.55 & 4.811 & TRN \\
\hline CHEMBL1608832 & 688889 & 4.3 & 4.8128 & TRN \\
\hline CHEMBL1420404 & 688889 & 5.95 & 4.8386 & TRN \\
\hline CHEMBL1506603 & 688889 & 4.3 & 4.8283 & TST \\
\hline CHEMBL1580399 & 688889 & 4.3 & 4.8372 & TRN \\
\hline CHEMBL1481152 & 688889 & 4.9 & 4.8821 & TST \\
\hline CHEMBL1516447 & 688889 & 4.3 & 4.8988 & TST \\
\hline CHEMBL1609969 & 688889 & 4.5 & 4.7918 & TRN \\
\hline CHEMBL1431776 & 688889 & 4.45 & 4.8001 & TST \\
\hline CHEMBL3193923 & 688889 & 4.95 & 4.8426 & TRN \\
\hline CHEMBL1383050 & 688889 & 4.6 & 4.7342 & TRN \\
\hline CHEMBL3208649 & 688889 & 6.7501 & 4.8964 & TRN \\
\hline CHEMBL3198017 & 688889 & 4.65 & 4.7112 & TST \\
\hline CHEMBL1375278 & 688889 & 4.25 & 4.9525 & TRN \\
\hline CHEMBL1346502 & 688889 & 4.25 & 4.9116 & TST \\
\hline CHEMBL1523271 & 688889 & 4.5 & 4.6012 & TRN \\
\hline CHEMBL1567341 & 688889 & 4.25 & 4.6949 & TRN \\
\hline CHEMBL1511108 & 688889 & 4.3 & 4.6876 & TRN \\
\hline CHEMBL1589415 & 688889 & 4.4 & 4.8284 & TRN \\
\hline CHEMBL1384357 & 688889 & 4.8 & 4.8545 & TRN \\
\hline CHEMBL1334127 & 688889 & 5.45 & 4.9531 & TRN \\
\hline CHEMBL1467839 & 688889 & 4.35 & 4.7927 & TRN \\
\hline CHEMBL1534536 & 688889 & 5.75 & 4.6614 & TRN \\
\hline CHEMBL1535152 & 688889 & 5.75 & 4.8797 & TRN \\
\hline CHEMBL1463198 & 688889 & 5.8 & 4.8484 & TRN \\
\hline CHEMBL1497681 & 688889 & 5.6 & 4.7652 & TST \\
\hline CHEMBL1500849 & 688889 & 6.8 & 4.7816 & TRN \\
\hline CHEMBL1383587 & 688889 & 4.25 & 4.954 & TST \\
\hline CHEMBL1530814 & 688889 & 5.65 & 4.6998 & TRN \\
\hline CHEMBL1401594 & 688889 & 4.55 & 4.8978 & TRN \\
\hline CHEMBL1448296 & 688889 & 4.4 & 4.8482 & TRN \\
\hline
\end{tabular}




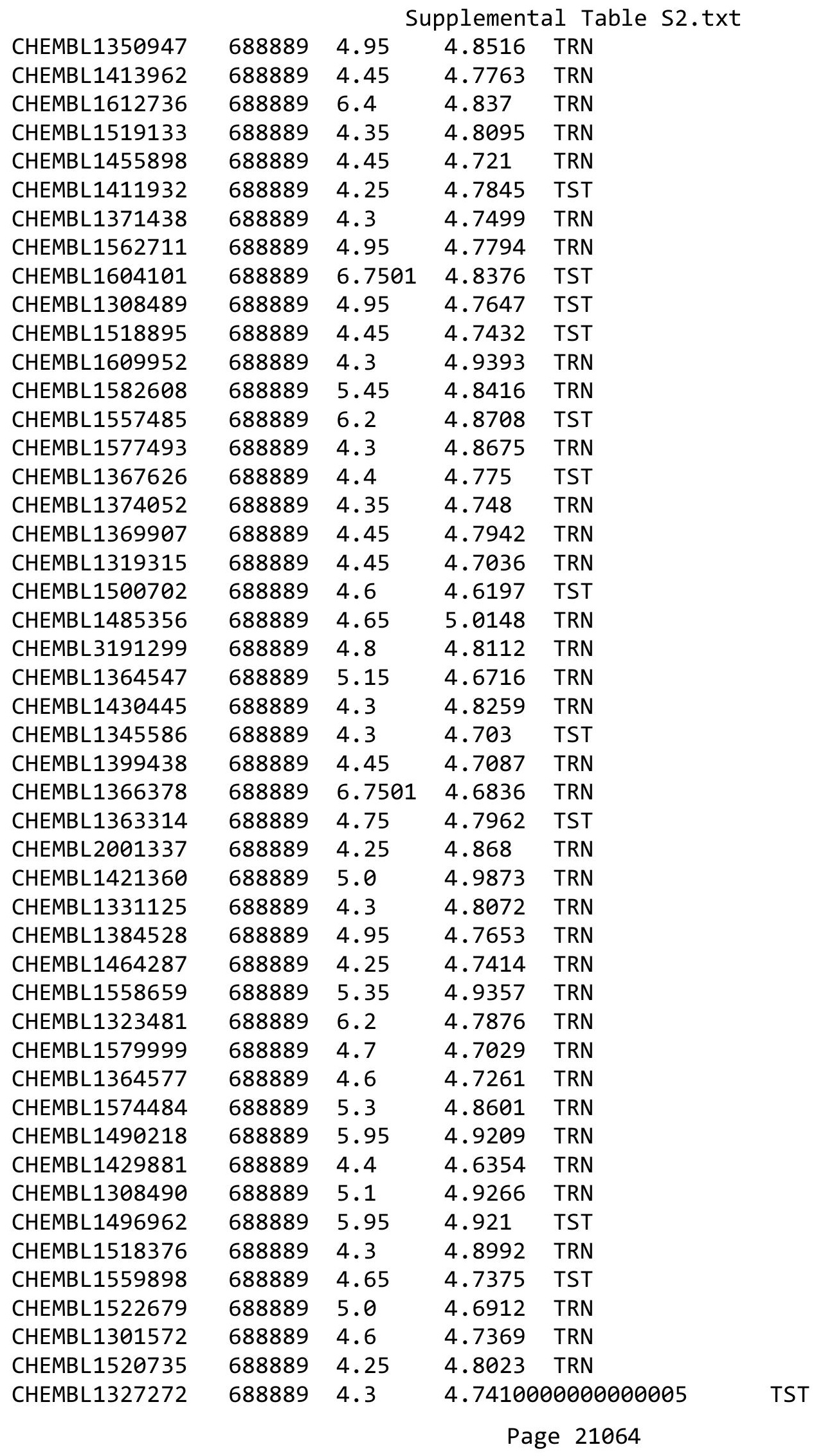




\begin{tabular}{|c|c|c|c|c|}
\hline \multicolumn{5}{|c|}{ Supplemental Table S2.txt } \\
\hline CHEMBL1544483 & 688889 & 4.5 & 4.8052 & TRN \\
\hline CHEMBL1324850 & 688889 & 4.25 & 4.9039 & TRN \\
\hline CHEMBL1420162 & 688889 & 4.45 & 4.7662 & TRN \\
\hline CHEMBL1307854 & 688889 & 4.9 & 4.8486 & TRN \\
\hline CHEMBL1455526 & 688889 & 4.5 & 4.9558 & TST \\
\hline CHEMBL1464390 & 688889 & 4.5 & 4.747 & TRN \\
\hline CHEMBL1529294 & 688889 & 4.55 & 4.7855 & TRN \\
\hline CHEMBL1571483 & 688889 & 4.95 & 4.8399 & TRN \\
\hline CHEMBL 3213817 & 688889 & 4.45 & 4.9169 & TRN \\
\hline CHEMBL1462470 & 688889 & 6.15 & 4.6846 & TRN \\
\hline CHEMBL1376836 & 688889 & 5.5 & 4.7113 & TRN \\
\hline CHEMBL1610566 & 688889 & 7.0 & 4.8309 & TRN \\
\hline CHEMBL1541802 & 688889 & 4.75 & 4.7196 & TRN \\
\hline CHEMBL1599914 & 688889 & 4.6 & 4.7743 & TRN \\
\hline CHEMBL1375455 & 688889 & 4.45 & 4.7197 & TRN \\
\hline CHEMBL1581595 & 688889 & 4.3 & 4.8266 & TST \\
\hline CHEMBL1346580 & 688889 & 4.8 & 4.796 & TRN \\
\hline CHEMBL1457753 & 688889 & 4.85 & 4.7291 & TRN \\
\hline CHEMBL1359725 & 688889 & 4.3 & 4.8755 & TRN \\
\hline CHEMBL1313035 & 688889 & 6.05 & 4.9883 & TRN \\
\hline CHEMBL1494764 & 688889 & 4.45 & 4.8074 & TRN \\
\hline CHEMBL1372609 & 688889 & 4.25 & 4.7732 & TRN \\
\hline CHEMBL1573799 & 688889 & 4.5 & 4.7299 & TST \\
\hline CHEMBL1348773 & 688889 & 5.2 & 4.8286 & TST \\
\hline CHEMBL1333742 & 688889 & 4.3 & 4.6581 & TRN \\
\hline CHEMBL1581145 & 688889 & 4.4 & 4.8876 & TRN \\
\hline CHEMBL1978388 & 688889 & 5.2 & 4.7177 & TRN \\
\hline CHEMBL1415371 & 688889 & 4.55 & 4.6908 & TRN \\
\hline CHEMBL1566542 & 688889 & 4.75 & 4.9026 & TRN \\
\hline CHEMBL1374761 & 688889 & 4.95 & 4.7988 & TRN \\
\hline CHEMBL1580363 & 688889 & 4.3 & 4.7376 & TRN \\
\hline CHEMBL1491601 & 688889 & 4.3 & 4.6883 & TRN \\
\hline CHEMBL1456850 & 688889 & 4.3 & 4.746 & TRN \\
\hline CHEMBL1508557 & 688889 & 4.95 & 4.8211 & TRN \\
\hline CHEMBL3198506 & 688889 & 5.3 & 4.7499 & TRN \\
\hline CHEMBL1478570 & 688889 & 4.45 & 4.7307 & TRN \\
\hline CHEMBL1365687 & 688889 & 4.95 & 4.9247 & TRN \\
\hline CHEMBL1323202 & 688889 & 5.5 & 4.8036 & TRN \\
\hline CHEMBL1604658 & 688889 & 5.65 & 4.8148 & TST \\
\hline CHEMBL1439734 & 688889 & 6.5 & 4.9438 & TRN \\
\hline CHEMBL1585431 & 688889 & 4.35 & 4.8819 & TRN \\
\hline CHEMBL1524422 & 688889 & 5.95 & 4.8299 & TRN \\
\hline CHEMBL1502409 & 688889 & 4.3 & 4.7128 & TRN \\
\hline CHEMBL1331723 & 688889 & 4.4 & 4.6898 & TRN \\
\hline CHEMBL1569612 & 688889 & 5.35 & 4.8444 & TRN \\
\hline CHEMBL1307291 & 688889 & 5.9 & 4.9619 & TRN \\
\hline CHEMBL3194053 & 688889 & 4.75 & 4.7574 & TRN \\
\hline CHEMBL1583261 & 688889 & 6.7501 & 4.8317 & TRN \\
\hline
\end{tabular}




\begin{tabular}{|c|c|c|c|c|}
\hline \multicolumn{5}{|c|}{ Supplemental Table S2.txt } \\
\hline CHEMBL1303580 & 688889 & 4.25 & 4.5891 & TRN \\
\hline CHEMBL1306078 & 688889 & 4.45 & 4.8359 & TRN \\
\hline CHEMBL1384636 & 688889 & 4.6 & 4.8175 & TRN \\
\hline CHEMBL1407056 & 688889 & 4.5 & 4.7062 & TRN \\
\hline CHEMBL1343053 & 688889 & 5.3 & 4.8202 & TRN \\
\hline CHEMBL1582177 & 688889 & 6.25 & 4.8315 & TRN \\
\hline CHEMBL1559425 & 688889 & 4.3 & 4.7773 & TST \\
\hline CHEMBL1556503 & 688889 & 4.55 & 4.7379 & TST \\
\hline CHEMBL1501007 & 688889 & 6.5501 & 4.9568 & TRN \\
\hline CHEMBL1521944 & 688889 & 4.55 & 4.7693 & TRN \\
\hline CHEMBL1501361 & 688889 & 5.4 & 4.863 & TRN \\
\hline CHEMBL1427208 & 688889 & 4.3 & 4.6863 & TRN \\
\hline CHEMBL1508325 & 688889 & 6.05 & 4.8673 & TRN \\
\hline CHEMBL1581543 & 688889 & 4.95 & 4.6501 & TRN \\
\hline CHEMBL1307536 & 688889 & 4.4 & 4.7998 & TRN \\
\hline CHEMBL1611722 & 688889 & 5.1 & 4.6364 & TRN \\
\hline CHEMBL1451524 & 688889 & 4.3 & 4.9252 & TRN \\
\hline CHEMBL1548753 & 688889 & 4.35 & 4.849 & TRN \\
\hline CHEMBL1311812 & 688889 & 4.3 & 4.7478 & TST \\
\hline CHEMBL1601397 & 688889 & 4.4 & 4.6377 & TRN \\
\hline CHEMBL1383919 & 688889 & 4.55 & 4.7055 & TRN \\
\hline CHEMBL1570320 & 688889 & 4.9 & 4.8486 & TST \\
\hline CHEMBL1404772 & 688889 & 5.4 & 4.6713 & TRN \\
\hline CHEMBL1406211 & 688889 & 5.4 & 4.708 & TST \\
\hline CHEMBL1576100 & 688889 & 6.7501 & 4.8366 & TST \\
\hline CHEMBL1389272 & 688889 & 5.1 & 4.7972 & TRN \\
\hline CHEMBL1413715 & 688889 & 4.4 & 4.9196 & TRN \\
\hline CHEMBL1571803 & 688889 & 4.3 & 4.6301 & TRN \\
\hline CHEMBL1532342 & 688889 & 4.6 & 4.8118 & TST \\
\hline CHEMBL1483076 & 688889 & 5.2 & 4.9269 & TRN \\
\hline CHEMBL1386332 & 688889 & 4.6 & 4.7857 & TRN \\
\hline CHEMBL1409281 & 688889 & 6.3 & 4.8392 & TRN \\
\hline CHEMBL1530938 & 688889 & 5.25 & 4.6875 & TRN \\
\hline CHEMBL1324682 & 688889 & 5.35 & 4.8692 & TRN \\
\hline CHEMBL1530797 & 688889 & 4.45 & 4.7614 & TRN \\
\hline CHEMBL1321861 & 688889 & 4.6 & 4.7919 & TRN \\
\hline CHEMBL1337742 & 688889 & 4.3 & 4.6062 & TST \\
\hline CHEMBL1342066 & 688889 & 4.9 & 5.0146 & TRN \\
\hline CHEMBL1535681 & 688889 & 5.25 & 4.7564 & TST \\
\hline CHEMBL3208026 & 688889 & 4.6 & 4.8645 & TRN \\
\hline CHEMBL1454468 & 688889 & 4.35 & 4.6193 & TRN \\
\hline CHEMBL1311558 & 688889 & 5.75 & 4.7921 & TRN \\
\hline CHEMBL1547806 & 688889 & 4.45 & 4.8003 & TRN \\
\hline CHEMBL1556354 & 688889 & 4.95 & 4.8542 & TRN \\
\hline CHEMBL1333585 & 688889 & 4.5 & 4.7711 & TRN \\
\hline CHEMBL1341521 & 688889 & 4.55 & 4.7977 & TRN \\
\hline CHEMBL1311108 & 688889 & 6.45 & 4.8323 & TRN \\
\hline CHEMBL1372067 & 688889 & 4.55 & 4.8922 & TRN \\
\hline
\end{tabular}




\begin{tabular}{|c|c|c|c|c|c|}
\hline \multicolumn{6}{|c|}{ Supplemental Table S2.txt } \\
\hline CHEMBL1443790 & 688889 & 4.35 & 4.7003 & TRN & \\
\hline CHEMBL1472479 & 688889 & 4.9 & 4.8034 & TST & \\
\hline CHEMBL1976036 & 688889 & 4.45 & 4.8147 & TST & \\
\hline CHEMBL1429445 & 688889 & 5.65 & 4.7887 & TST & \\
\hline CHEMBL1489240 & 688889 & 4.35 & 4.7603 & TRN & \\
\hline CHEMBL1403650 & 688889 & 4.25 & 4.7652 & TRN & \\
\hline CHEMBL1322501 & 688889 & 4.4 & 4.9047 & TRN & \\
\hline CHEMBL1574441 & 688889 & 4.25 & 4.7773 & TST & \\
\hline CHEMBL1468698 & 688889 & 4.6 & 4.7011 & TST & \\
\hline CHEMBL1375804 & 688889 & 4.65 & 4.7411 & TRN & \\
\hline CHEMBL1607631 & 688889 & 4.5 & 4.8293 & TRN & \\
\hline CHEMBL1558928 & 688889 & 4.65 & 4.6488 & TRN & \\
\hline CHEMBL1483692 & 688889 & 4.4 & 4.8493 & TRN & \\
\hline CHEMBL1299703 & 688889 & 4.8 & 4.7965 & TRN & \\
\hline CHEMBL1332634 & 688889 & 4.25 & 4.8954 & TRN & \\
\hline CHEMBL1547481 & 688889 & 4.25 & 4.7706 & TRN & \\
\hline CHEMBL1469864 & 688889 & 4.95 & 4.7584 & TRN & \\
\hline CHEMBL1442610 & 688889 & 4.6 & 4.8759 & TRN & \\
\hline CHEMBL1587367 & 688889 & 5.45 & 4.7804 & TST & \\
\hline CHEMBL1577755 & 688889 & 4.3 & 4.6245 & TRN & \\
\hline CHEMBL1398798 & 688889 & 4.25 & 4.8219 & TRN & \\
\hline CHEMBL1561977 & 688889 & 4.25 & 4.6789 & TRN & \\
\hline CHEMBL1453132 & 688889 & 4.4 & 4.8024 & TRN & \\
\hline CHEMBL1363724 & 688889 & 5.65 & 4.7747 & TRN & \\
\hline CHEMBL1541527 & 688889 & 5.1 & 4.8052 & TRN & \\
\hline CHEMBL1459555 & 688889 & 6.5501 & 4.8104 & TRN & \\
\hline CHEMBL1370346 & 688889 & 6.1 & 4.8373 & TST & \\
\hline CHEMBL1560300 & 688889 & 4.3 & 4.8175 & TRN & \\
\hline CHEMBL1303774 & 688889 & 4.3 & 4.8733 & TST & \\
\hline CHEMBL1440331 & 688889 & 4.3 & 4.9143 & TRN & \\
\hline CHEMBL1444893 & 688889 & 4.45 & 4.8075 & TRN & \\
\hline CHEMBL1341813 & 688889 & 4.6 & 4.7874 & TRN & \\
\hline CHEMBL 30707 & 688889 & 4.5 & 4.6994 & TRN & \\
\hline CHEMBL1470923 & 688889 & 4.95 & 4.9338 & TST & \\
\hline CHEMBL3194460 & 688889 & 4.3 & 4.8809 & TRN & \\
\hline CHEMBL1348753 & 688889 & 4.45 & 4.6938 & TRN & \\
\hline CHEMBL1326866 & 688889 & 4.6 & 4.8499 & TRN & \\
\hline CHEMBL1329331 & 688889 & 4.65 & 4.9055 & TST & \\
\hline CHEMBL1444715 & 688889 & 4.5 & 4.9291 & TRN & \\
\hline CHEMBL1379879 & 688889 & 4.4 & 4.9073 & TRN & \\
\hline CHEMBL1988042 & 688889 & 4.85 & 4.6863 & TRN & \\
\hline CHEMBL1409353 & 688889 & 4.95 & 4.8069 & TST & \\
\hline CHEMBL1468987 & 688889 & 4.25 & 4.9561 & TRN & \\
\hline CHEMBL1559467 & 688889 & 4.5 & $4.7860 e$ & 00000000005 & TRN \\
\hline CHEMBL1533998 & 688889 & 4.4 & 4.7974 & TRN & \\
\hline CHEMBL1573791 & 688889 & 4.35 & 4.7957 & TRN & \\
\hline CHEMBL287193 & 688889 & 4.6 & 4.6631 & TRN & \\
\hline CHEMBL1335362 & 688889 & 4.7 & 4.7906 & TRN & \\
\hline
\end{tabular}




\begin{tabular}{|c|c|c|c|c|c|}
\hline \multicolumn{6}{|c|}{ Supplemental Table S2.txt } \\
\hline CHEMBL1369683 & 688889 & 4.25 & 4.7767 & TRN & \\
\hline CHEMBL1579833 & 688889 & 4.3 & 4.615 & TST & \\
\hline CHEMBL1408407 & 688889 & 4.25 & 4.9528 & TRN & \\
\hline CHEMBL1452433 & 688889 & 4.95 & 4.8477 & TRN & \\
\hline CHEMBL1580795 & 688889 & 4.65 & 4.7784 & TST & \\
\hline CHEMBL1324475 & 688889 & 6.2 & 4.8029 & TST & \\
\hline CHEMBL1599624 & 688889 & 4.6 & 4.7309 & TRN & \\
\hline CHEMBL1467728 & 688889 & 4.5 & 4.8199 & TRN & \\
\hline CHEMBL1486331 & 688889 & 4.3 & 4.7073 & TRN & \\
\hline CHEMBL1303541 & 688889 & 6.7501 & 4.6438 & TRN & \\
\hline CHEMBL3198037 & 688889 & 4.45 & 4.6989 & TRN & \\
\hline CHEMBL1454457 & 688889 & 4.6 & 4.8555 & TST & \\
\hline CHEMBL3213103 & 688889 & 6.05 & 4.7439 & TST & \\
\hline CHEMBL1463293 & 688889 & 4.25 & 4.8331 & TRN & \\
\hline CHEMBL1503521 & 688889 & 5.75 & 4.7904 & TST & \\
\hline CHEMBL1385135 & 688889 & 4.25 & 4.7352 & TRN & \\
\hline CHEMBL1532886 & 688889 & 5.7 & 4.9305 & TRN & \\
\hline CHEMBL1366674 & 688889 & 5.0 & 4.8016 & TRN & \\
\hline CHEMBL1461691 & 688889 & 4.95 & 4.9971 & TRN & \\
\hline CHEMBL1575461 & 688889 & 4.85 & 4.7608 & TRN & \\
\hline CHEMBL1338065 & 688889 & 5.4 & 4.8918 & TRN & \\
\hline CHEMBL1390965 & 688889 & 5.2 & 4.8321 & TST & \\
\hline CHEMBL3189658 & 688889 & 4.25 & 4.8961 & TST & \\
\hline CHEMBL1336757 & 688889 & 4.5 & 4.8343 & TRN & \\
\hline CHEMBL1561150 & 688889 & 4.4 & 4.8943 & TRN & \\
\hline CHEMBL1304170 & 688889 & 5.55 & 4.8584 & TRN & \\
\hline CHEMBL1370535 & 688889 & 6.8 & 4.8951 & TRN & \\
\hline CHEMBL1472521 & 688889 & 4.5 & 4.6407 & TRN & \\
\hline CHEMBL1377959 & 688889 & 4.25 & 4.7201 & TRN & \\
\hline CHEMBL1535412 & 688889 & 4.95 & 4.7238 & TRN & \\
\hline CHEMBL1525149 & 688889 & 4.85 & 4.791 & TRN & \\
\hline CHEMBL1440021 & 688889 & 4.9 & 4.6784 & TRN & \\
\hline CHEMBL1479833 & 688889 & 4.9 & 4.7268 & TRN & \\
\hline CHEMBL1401357 & 688889 & 4.55 & 4.8065 & TRN & \\
\hline CHEMBL1307186 & 688889 & 4.25 & 4.6057 & TRN & \\
\hline CHEMBL1565376 & 688889 & 4.55 & 4.9441 & TRN & \\
\hline CHEMBL1563284 & 688889 & 4.25 & 4.7953 & TRN & \\
\hline CHEMBL1486592 & 688889 & 4.45 & 4.7491 & TRN & \\
\hline CHEMBL1361119 & 688889 & 4.25 & 4.7802 & TRN & \\
\hline CHEMBL1587804 & 688889 & 4.3 & 4.8562 & TST & \\
\hline CHEMBL1325724 & 688889 & 5.9 & 4.8129 & TST & \\
\hline CHEMBL1383279 & 688889 & 4.45 & 4.8257 & TRN & \\
\hline CHEMBL1382670 & 688889 & 4.4 & 4.7726 & TRN & \\
\hline CHEMBL3197548 & 688889 & 4.5 & 4.6868 & TRN & \\
\hline CHEMBL1334684 & 688889 & 4.35 & 4.7822 & TST & \\
\hline CHEMBL1493660 & 688889 & 4.25 & 4.8863 & TST & \\
\hline CHEMBL1570903 & 688889 & 4.2 & 4.69600 & 0000000001 & TRN \\
\hline CHEMBL1579720 & 688889 & 4.9 & 4.8267 & TRN & \\
\hline & & & & 21068 & \\
\hline
\end{tabular}




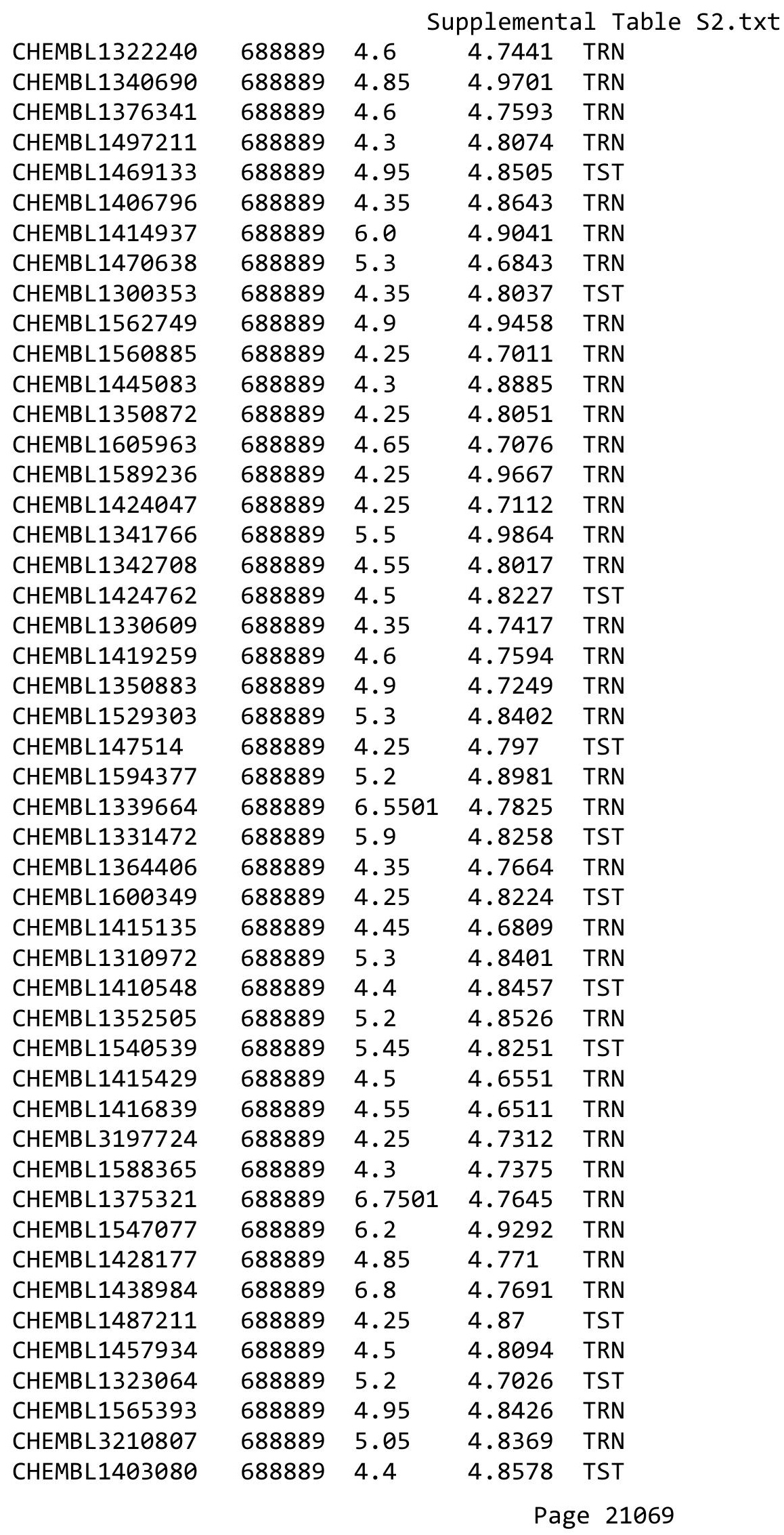




\begin{tabular}{|c|c|c|c|c|}
\hline \multicolumn{5}{|c|}{ Supplemental Table S2.txt } \\
\hline CHEMBL1405590 & 688889 & 7.0501 & 4.9515 & TRN \\
\hline CHEMBL1511787 & 688889 & 5.85 & 4.7992 & TST \\
\hline CHEMBL1529376 & 688889 & 4.95 & 5.0048 & TRN \\
\hline CHEMBL1382301 & 688889 & 4.7 & 4.7197 & TRN \\
\hline CHEMBL1364986 & 688889 & 4.95 & 4.6301 & TRN \\
\hline CHEMBL1489960 & 688889 & 4.3 & 4.8695 & TRN \\
\hline CHEMBL1424346 & 688889 & 4.25 & 4.7832 & TST \\
\hline CHEMBL1419217 & 688889 & 4.3 & 4.7098 & TRN \\
\hline CHEMBL578164 & 688889 & 6.05 & 4.948 & TRN \\
\hline CHEMBL1469748 & 688889 & 4.6 & 4.6938 & TRN \\
\hline CHEMBL1576161 & 688889 & 5.45 & 4.8718 & TRN \\
\hline CHEMBL1307682 & 688889 & 5.3 & 4.669 & TRN \\
\hline CHEMBL1409605 & 688889 & 4.25 & 4.9699 & TRN \\
\hline CHEMBL1342689 & 688889 & 4.85 & 4.8025 & TRN \\
\hline CHEMBL405914 & 688889 & 4.45 & 4.8436 & TRN \\
\hline CHEMBL1544442 & 688889 & 4.6 & 4.8997 & TRN \\
\hline CHEMBL1572449 & 688889 & 4.95 & 4.8528 & TRN \\
\hline CHEMBL1321915 & 688889 & 4.5 & 4.7344 & TRN \\
\hline CHEMBL3194094 & 688889 & 4.95 & 4.7864 & TST \\
\hline CHEMBL1542121 & 688889 & 4.3 & 4.8234 & TRN \\
\hline CHEMBL1494966 & 688889 & 4.25 & 4.75 & TRN \\
\hline CHEMBL3212889 & 688889 & 4.6 & 4.9049 & TRN \\
\hline CHEMBL1477756 & 688889 & 4.25 & 4.6466 & TRN \\
\hline CHEMBL1457075 & 688889 & 4.3 & 4.6675 & TRN \\
\hline CHEMBL1578109 & 688889 & 5.85 & 4.7803 & TRN \\
\hline CHEMBL1429696 & 688889 & 4.3 & 4.8291 & TRN \\
\hline CHEMBL1447970 & 688889 & 4.7 & 4.7265 & TRN \\
\hline CHEMBL1427909 & 688889 & 4.95 & 4.9621 & TRN \\
\hline CHEMBL1504080 & 688889 & 4.5 & 4.7552 & TST \\
\hline CHEMBL1504768 & 688889 & 4.45 & 4.797 & TRN \\
\hline CHEMBL1350255 & 688889 & 4.4 & 4.8262 & TST \\
\hline CHEMBL1498705 & 688889 & 6.7501 & 4.9325 & TRN \\
\hline CHEMBL3208378 & 688889 & 4.55 & 4.7376 & TRN \\
\hline CHEMBL1362308 & 688889 & 5.3 & 4.7088 & TRN \\
\hline CHEMBL3190134 & 688889 & 4.35 & 4.879 & TST \\
\hline CHEMBL1393837 & 688889 & 4.3 & 4.7439 & TRN \\
\hline CHEMBL1564091 & 688889 & 6.2 & 4.8277 & TRN \\
\hline CHEMBL1599400 & 688889 & 4.45 & 4.7915 & TRN \\
\hline CHEMBL1306540 & 688889 & 4.5 & 4.7239 & TST \\
\hline CHEMBL3211165 & 688889 & 4.9 & 4.9016 & TST \\
\hline CHEMBL1301515 & 688889 & 5.0 & 4.8312 & TRN \\
\hline CHEMBL1308585 & 688889 & 4.6 & 4.6178 & TRN \\
\hline CHEMBL1417030 & 688889 & 4.35 & 4.7705 & TRN \\
\hline CHEMBL1468369 & 688889 & 5.1 & 4.6936 & TST \\
\hline CHEMBL1343650 & 688889 & 6.05 & 4.8767 & TST \\
\hline CHEMBL1568730 & 688889 & 4.5 & 4.738 & TRN \\
\hline CHEMBL1341575 & 688889 & 4.6 & 4.7106 & TRN \\
\hline CHEMBL1413221 & 688889 & 5.5 & 4.9978 & TRN \\
\hline
\end{tabular}




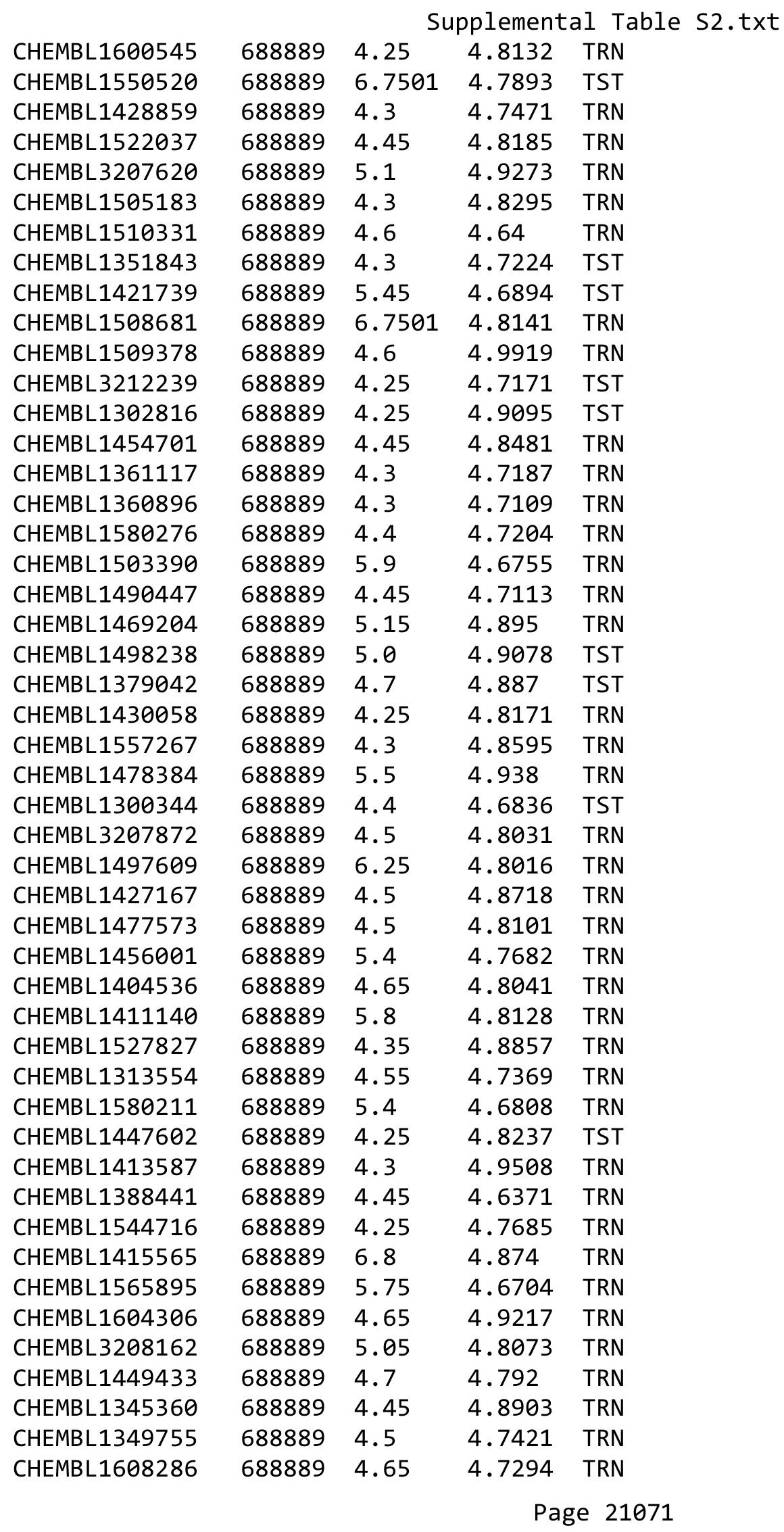




\begin{tabular}{|c|c|c|c|c|}
\hline \multicolumn{5}{|c|}{ Supplemental Table S2.txt } \\
\hline CHEMBL1327670 & 688889 & 5.9 & 4.7995 & TRN \\
\hline CHEMBL1381559 & 688889 & 4.95 & 4.7153 & TRN \\
\hline CHEMBL1991439 & 688889 & 4.3 & 4.7178 & TST \\
\hline CHEMBL1610525 & 688889 & 6.8 & 4.6898 & TRN \\
\hline CHEMBL3196475 & 688889 & 5.7 & 4.8371 & TRN \\
\hline CHEMBL1577099 & 688889 & 6.5 & 4.8924 & TRN \\
\hline CHEMBL1518807 & 688889 & 4.4 & 4.6345 & TST \\
\hline CHEMBL1608784 & 688889 & 5.5 & 4.7899 & TST \\
\hline CHEMBL1305639 & 688889 & 4.3 & 4.8263 & TRN \\
\hline CHEMBL1368876 & 688889 & 4.6 & 4.6295 & TRN \\
\hline CHEMBL1504600 & 688889 & 4.9 & 4.6497 & TRN \\
\hline CHEMBL1507767 & 688889 & 4.35 & 4.9955 & TRN \\
\hline CHEMBL1345642 & 688889 & 4.25 & 4.9811 & TRN \\
\hline CHEMBL1579035 & 688889 & 4.95 & 4.9035 & TRN \\
\hline CHEMBL1340756 & 688889 & 6.7501 & 4.7836 & TRN \\
\hline CHEMBL1363818 & 688889 & 4.45 & 4.7649 & TRN \\
\hline CHEMBL1606612 & 688889 & 4.25 & 4.8637 & TRN \\
\hline CHEMBL1382813 & 688889 & 4.45 & 4.7382 & TRN \\
\hline CHEMBL1549245 & 688889 & 4.55 & 4.7824 & TRN \\
\hline CHEMBL3189567 & 688889 & 5.25 & 4.6149 & TRN \\
\hline CHEMBL1538032 & 688889 & 4.5 & 4.708 & TRN \\
\hline CHEMBL1518412 & 688889 & 5.05 & 4.6557 & TRN \\
\hline CHEMBL1507680 & 688889 & 5.2 & 4.8573 & TRN \\
\hline CHEMBL1338979 & 688889 & 4.3 & 4.9204 & TRN \\
\hline CHEMBL1510059 & 688889 & 4.8 & 4.8307 & TST \\
\hline CHEMBL1312016 & 688889 & 4.3 & 4.9393 & TRN \\
\hline CHEMBL1429003 & 688889 & 5.1 & 4.7456 & TRN \\
\hline CHEMBL1522386 & 688889 & 4.4 & 4.9267 & TST \\
\hline CHEMBL1611779 & 688889 & 4.3 & 4.7766 & TRN \\
\hline CHEMBL3213618 & 688889 & 5.35 & 4.846 & TST \\
\hline CHEMBL1581250 & 688889 & 4.5 & 4.6773 & TRN \\
\hline CHEMBL1605895 & 688889 & 4.55 & 4.8399 & TRN \\
\hline CHEMBL1522492 & 688889 & 4.6 & 4.7493 & TRN \\
\hline CHEMBL1349526 & 688889 & 4.75 & 4.7694 & TST \\
\hline CHEMBL1470406 & 688889 & 4.55 & 4.8287 & TST \\
\hline CHEMBL1309410 & 688889 & 5.3 & 4.8998 & TRN \\
\hline CHEMBL1440454 & 688889 & 5.5 & 4.7096 & TST \\
\hline CHEMBL3197738 & 688889 & 5.0 & 4.7269 & TST \\
\hline CHEMBL1460175 & 688889 & 5.6 & 4.8966 & TRN \\
\hline CHEMBL1600853 & 688889 & 4.45 & 4.6642 & TRN \\
\hline CHEMBL1534475 & 688889 & 4.95 & 4.905 & TRN \\
\hline CHEMBL1539968 & 688889 & 4.5 & 4.7387 & TRN \\
\hline CHEMBL1565712 & 688889 & 6.0 & 4.8725 & TRN \\
\hline CHEMBL3196713 & 688889 & 4.25 & 4.8823 & TRN \\
\hline CHEMBL1583334 & 688889 & 4.3 & 4.9097 & TRN \\
\hline CHEMBL1345903 & 688889 & 4.8 & 4.7461 & TRN \\
\hline CHEMBL1578720 & 688889 & 4.4 & 4.7628 & TRN \\
\hline CHEMBL1582335 & 688889 & 6.35 & 4.8536 & TRN \\
\hline
\end{tabular}




\begin{tabular}{|c|c|c|c|c|c|}
\hline \\
\hline CHEMBL1584380 & 688889 & 4.9 & 4.8388 & TST & \\
\hline CHEMBL1329237 & 688889 & 4.75 & 4.7796 & TRN & \\
\hline CHEMBL1589651 & 688889 & 6.7501 & 4.8193 & TRN & \\
\hline CHEMBL1507243 & 688889 & 4.25 & 4.6873 & TRN & \\
\hline CHEMBL1439189 & 688889 & 4.5 & 4.7231 & TST & \\
\hline CHEMBL1358942 & 688889 & 4.3 & 4.6779 & TRN & \\
\hline CHEMBL1373492 & 688889 & 4.85 & 4.6494 & TRN & \\
\hline CHEMBL1481908 & 688889 & 4.45 & 4.7735 & TRN & \\
\hline CHEMBL1603615 & 688889 & 5.35 & 4.9289 & TST & \\
\hline CHEMBL1348726 & 688889 & 4.25 & 4.7771 & TRN & \\
\hline CHEMBL1378151 & 688889 & 4.25 & 4.9121 & TRN & \\
\hline CHEMBL1578187 & 688889 & 4.85 & 4.8172 & TRN & \\
\hline CHEMBL1417067 & 688889 & 4.7 & 4.6676 & TRN & \\
\hline CHEMBL1499289 & 688889 & 4.75 & 4.8749 & TRN & \\
\hline CHEMBL1610053 & 688889 & 4.95 & 4.7213 & TRN & \\
\hline CHEMBL1534405 & 688889 & 4.6 & 4.933 & TRN & \\
\hline CHEMBL1311900 & 688889 & 6.0 & 4.7903 & TST & \\
\hline CHEMBL1380096 & 688889 & 4.25 & 4.82600 & 00000000005 & TRN \\
\hline CHEMBL1543510 & 688889 & 4.3 & 4.8177 & TRN & \\
\hline CHEMBL1500056 & 688889 & 4.95 & 4.7848 & TST & \\
\hline CHEMBL1333898 & 688889 & 4.4 & 4.7819 & TRN & \\
\hline CHEMBL1977563 & 688889 & 4.5 & 4.8159 & TRN & \\
\hline CHEMBL1469974 & 688889 & 5.5 & 4.7897 & TRN & \\
\hline CHEMBL3191524 & 688889 & 4.55 & 4.8477 & TRN & \\
\hline CHEMBL1581055 & 688889 & 4.3 & 4.8745 & TST & \\
\hline CHEMBL368655 & 688889 & 6.05 & 4.8381 & TST & \\
\hline CHEMBL1566448 & 688889 & 5.35 & 4.928 & TRN & \\
\hline CHEMBL1329300 & 688889 & 4.25 & 4.6975 & TRN & \\
\hline CHEMBL1386936 & 688889 & 4.8 & 4.8956 & TRN & \\
\hline CHEMBL1525941 & 688889 & 5.0 & 4.81 & TST & \\
\hline CHEMBL1348197 & 688889 & 4.45 & 4.6802 & TRN & \\
\hline CHEMBL1470502 & 688889 & 5.15 & 4.7911 & TST & \\
\hline CHEMBL1504791 & 688889 & 4.25 & 4.8156 & TRN & \\
\hline CHEMBL1597480 & 688889 & 4.3 & 4.7611 & TRN & \\
\hline CHEMBL1540177 & 688889 & 4.5 & 4.8768 & TRN & \\
\hline CHEMBL1414830 & 688889 & 4.3 & 4.7087 & TRN & \\
\hline CHEMBL1325782 & 688889 & 4.3 & 4.7154 & TRN & \\
\hline CHEMBL1583956 & 688889 & 4.45 & 4.7152 & TRN & \\
\hline CHEMBL1424528 & 688889 & 5.9 & 4.7826 & TRN & \\
\hline CHEMBL1322658 & 688889 & 5.3 & 4.7759 & TRN & \\
\hline CHEMBL1345654 & 688889 & 4.55 & 4.7774 & TST & \\
\hline CHEMBL1308991 & 688889 & 5.45 & 4.7235 & TST & \\
\hline CHEMBL1501643 & 688889 & 4.9 & 4.9306 & TRN & \\
\hline CHEMBL1578988 & 688889 & 4.5 & 4.7177 & TRN & \\
\hline CHEMBL1442518 & 688889 & 5.35 & 4.9573 & TRN & \\
\hline CHEMBL1338757 & 688889 & 4.25 & 4.7922 & TRN & \\
\hline CHEMBL1338673 & 688889 & 4.35 & 4.7491 & TST & \\
\hline CHEMBL1404449 & 688889 & 4.25 & 4.9627 & TRN & \\
\hline
\end{tabular}




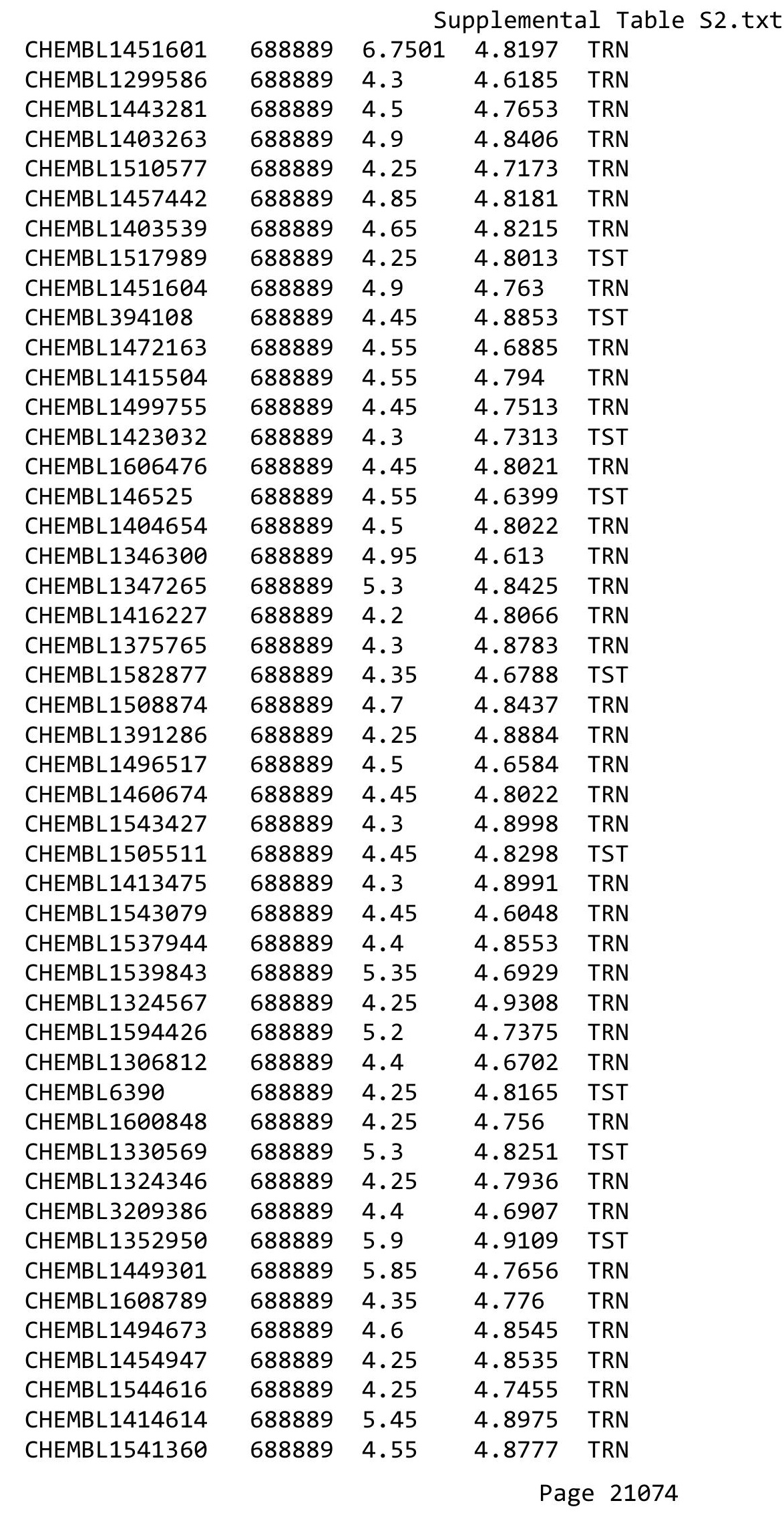




\begin{tabular}{|c|c|c|c|c|c|}
\hline \multicolumn{6}{|c|}{ Supplemental Table S2.txt } \\
\hline CHEMBL1446426 & 688889 & 4.45 & 4.9048 & TRN & \\
\hline CHEMBL1336709 & 688889 & 4.25 & 4.7384 & TRN & \\
\hline CHEMBL1468594 & 688889 & 4.5 & 4.8213 & TRN & \\
\hline CHEMBL1342074 & 688889 & 4.5 & 4.758 & TRN & \\
\hline CHEMBL1419119 & 688889 & 4.95 & 4.8064 & TRN & \\
\hline CHEMBL1306836 & 688889 & 4.4 & 4.9284 & TRN & \\
\hline CHEMBL1472420 & 688889 & 5.2 & 4.82 & TRN & \\
\hline CHEMBL1307638 & 688889 & 6.0 & 4.6977 & TST & \\
\hline CHEMBL1347266 & 688889 & 4.95 & 4.8466 & TRN & \\
\hline CHEMBL1304449 & 688889 & 4.65 & 4.7477 & TRN & \\
\hline CHEMBL1577699 & 688889 & 4.25 & 4.7158 & TRN & \\
\hline CHEMBL1414022 & 688889 & 5.25 & 4.9377 & TRN & \\
\hline CHEMBL1567948 & 688889 & 5.1 & 4.8946 & TRN & \\
\hline CHEMBL1579587 & 688889 & 5.0 & 4.6733 & TRN & \\
\hline CHEMBL1312136 & 688889 & 4.45 & 4.9747 & TRN & \\
\hline CHEMBL1588593 & 688889 & 5.65 & 4.8922 & TST & \\
\hline CHEMBL1332626 & 688889 & 4.65 & 4.7602 & TRN & \\
\hline CHEMBL1414249 & 688889 & 5.0 & 4.8406 & TRN & \\
\hline CHEMBL1544754 & 688889 & 4.4 & 4.5954 & TRN & \\
\hline CHEMBL1372147 & 688889 & 6.7501 & 4.9214 & TRN & \\
\hline CHEMBL3210087 & 688889 & 5.05 & 4.7272 & TRN & \\
\hline CHEMBL3195236 & 688889 & 4.85 & 4.7412 & TRN & \\
\hline CHEMBL1344939 & 688889 & 4.3 & 4.8798 & TRN & \\
\hline CHEMBL1491566 & 688889 & 4.5 & 4.9494 & TRN & \\
\hline CHEMBL1442711 & 688889 & 4.25 & 4.7445 & TRN & \\
\hline CHEMBL1319600 & 688889 & 4.25 & 4.9088 & TRN & \\
\hline CHEMBL1572850 & 688889 & 4.45 & 4.7952 & TRN & \\
\hline CHEMBL1461939 & 688889 & 4.75 & 4.762 & TRN & \\
\hline CHEMBL1311710 & 688889 & 4.3 & 4.7614 & TRN & \\
\hline CHEMBL1555850 & 688889 & 4.25 & 4.9165 & TRN & \\
\hline CHEMBL1497278 & 688889 & 4.4 & 4.8354 & TRN & \\
\hline CHEMBL1451425 & 688889 & 4.4 & 5.0019 & TRN & \\
\hline CHEMBL1556313 & 688889 & 4.9 & 4.6576 & TST & \\
\hline CHEMBL1324785 & 688889 & 5.45 & 4.9859 & TRN & \\
\hline CHEMBL1390607 & 688889 & 4.5 & 4.8197 & TRN & \\
\hline CHEMBL1576064 & 688889 & 5.8 & 4.7179 & TRN & \\
\hline CHEMBL1429816 & 688889 & 5.5 & 4.7957 & TRN & \\
\hline CHEMBL1363032 & 688889 & 4.7 & 4.603 & TRN & \\
\hline CHEMBL1480923 & 688889 & 4.3 & 4.8829 & TRN & \\
\hline CHEMBL1349134 & 688889 & 4.8 & 4.66100 & 00000000005 & TRN \\
\hline CHEMBL1487897 & 688889 & 4.95 & 4.6629 & TRN & \\
\hline CHEMBL1323818 & 688889 & 4.45 & 4.9441 & TRN & \\
\hline CHEMBL1555510 & 688889 & 4.25 & 4.8769 & TRN & \\
\hline CHEMBL1342468 & 688889 & 4.55 & 4.6295 & TRN & \\
\hline CHEMBL1582713 & 688889 & 6.2 & 4.7824 & TRN & \\
\hline CHEMBL1328686 & 688889 & 4.35 & 4.6645 & TRN & \\
\hline CHEMBL1568366 & 688889 & 4.9 & 4.8604 & TRN & \\
\hline CHEMBL1378927 & 688889 & 6.7501 & 4.7493 & TST & \\
\hline
\end{tabular}

Page 21075 


\begin{tabular}{|c|c|c|c|c|}
\hline \multirow[b]{2}{*}{ CHEMBL1444347 } & \multicolumn{4}{|c|}{ Supplemental Table S2.txt } \\
\hline & 688889 & 4.3 & 4.8526 & TRN \\
\hline CHEMBL1338163 & 688889 & 4.3 & 4.8871 & TST \\
\hline CHEMBL1391518 & 688889 & 4.5 & 4.7523 & TRN \\
\hline CHEMBL121291 & 688889 & 4.4 & 4.6833 & TRN \\
\hline CHEMBL1439577 & 688889 & 4.4 & 4.7713 & TRN \\
\hline CHEMBL1409828 & 688889 & 4.45 & 4.6934 & TRN \\
\hline CHEMBL1460807 & 688889 & 4.5 & 4.742 & TST \\
\hline CHEMBL1488096 & 688889 & 6.8 & 4.8584 & TST \\
\hline CHEMBL1586813 & 688889 & 5.2 & 4.8345 & TRN \\
\hline CHEMBL1330989 & 688889 & 4.3 & 4.6071 & TRN \\
\hline CHEMBL1390325 & 688889 & 4.25 & 4.7052 & TRN \\
\hline CHEMBL1500972 & 688889 & 4.5 & 4.9131 & TRN \\
\hline CHEMBL1494710 & 688889 & 4.3 & 4.8086 & TRN \\
\hline CHEMBL1445309 & 688889 & 5.9 & 4.8697 & TRN \\
\hline CHEMBL1543804 & 688889 & 4.45 & 4.9151 & TRN \\
\hline CHEMBL 3210383 & 688889 & 4.5 & 4.8358 & TRN \\
\hline CHEMBL1501900 & 688889 & 5.4 & 4.6937 & TRN \\
\hline CHEMBL1526575 & 688889 & 4.45 & 4.8315 & TST \\
\hline CHEMBL1388976 & 688889 & 4.65 & 4.8603 & TRN \\
\hline CHEMBL1350167 & 688889 & 4.55 & 4.7381 & TRN \\
\hline CHEMBL1390759 & 688889 & 4.45 & 4.6809 & TRN \\
\hline CHEMBL3191022 & 688889 & 4.5 & 4.7295 & TRN \\
\hline CHEMBL1343324 & 688889 & 4.3 & 4.9305 & TST \\
\hline CHEMBL1378572 & 688889 & 4.3 & 4.8009 & TST \\
\hline CHEMBL1529887 & 688889 & 4.45 & 4.9011 & TRN \\
\hline CHEMBL1384706 & 688889 & 4.5 & 4.7272 & TRN \\
\hline CHEMBL1324705 & 688889 & 4.3 & 4.8032 & TRN \\
\hline CHEMBL1455218 & 688889 & 5.2 & 4.8802 & TRN \\
\hline CHEMBL1502739 & 688889 & 6.15 & 4.7187 & TRN \\
\hline CHEMBL1373035 & 688889 & 4.3 & 4.8367 & TRN \\
\hline CHEMBL1543969 & 688889 & 4.95 & 4.7951 & TRN \\
\hline CHEMBL1572473 & 688889 & 4.75 & 4.8671 & TRN \\
\hline CHEMBL1570444 & 688889 & 4.5 & 4.8986 & TRN \\
\hline CHEMBL1499465 & 688889 & 4.3 & 4.7345 & TRN \\
\hline CHEMBL1577227 & 688889 & 4.3 & 4.8911 & TRN \\
\hline CHEMBL1380108 & 688889 & 6.7501 & 4.7096 & TRN \\
\hline CHEMBL1471888 & 688889 & 5.45 & 4.7591 & TRN \\
\hline CHEMBL1505859 & 688889 & 4.25 & 4.9004 & TRN \\
\hline CHEMBL3198121 & 688889 & 4.45 & 4.6461 & TRN \\
\hline CHEMBL1425688 & 688889 & 4.4 & 4.7574 & TRN \\
\hline CHEMBL1542813 & 688889 & 4.55 & 4.851 & TRN \\
\hline CHEMBL1508137 & 688889 & 4.3 & 4.7107 & TRN \\
\hline CHEMBL1571616 & 688889 & 4.3 & 4.8502 & TRN \\
\hline CHEMBL1515671 & 688889 & 5.2 & 4.9152 & TRN \\
\hline CHEMBL1418264 & 688889 & 5.1 & 4.8022 & TST \\
\hline CHEMBL1571413 & 688889 & 4.55 & 4.7718 & TRN \\
\hline CHEMBL1325255 & 688889 & 4.55 & 4.8782 & TRN \\
\hline CHEMBL1587630 & 688889 & 4.3 & 4.784 & TRN \\
\hline
\end{tabular}




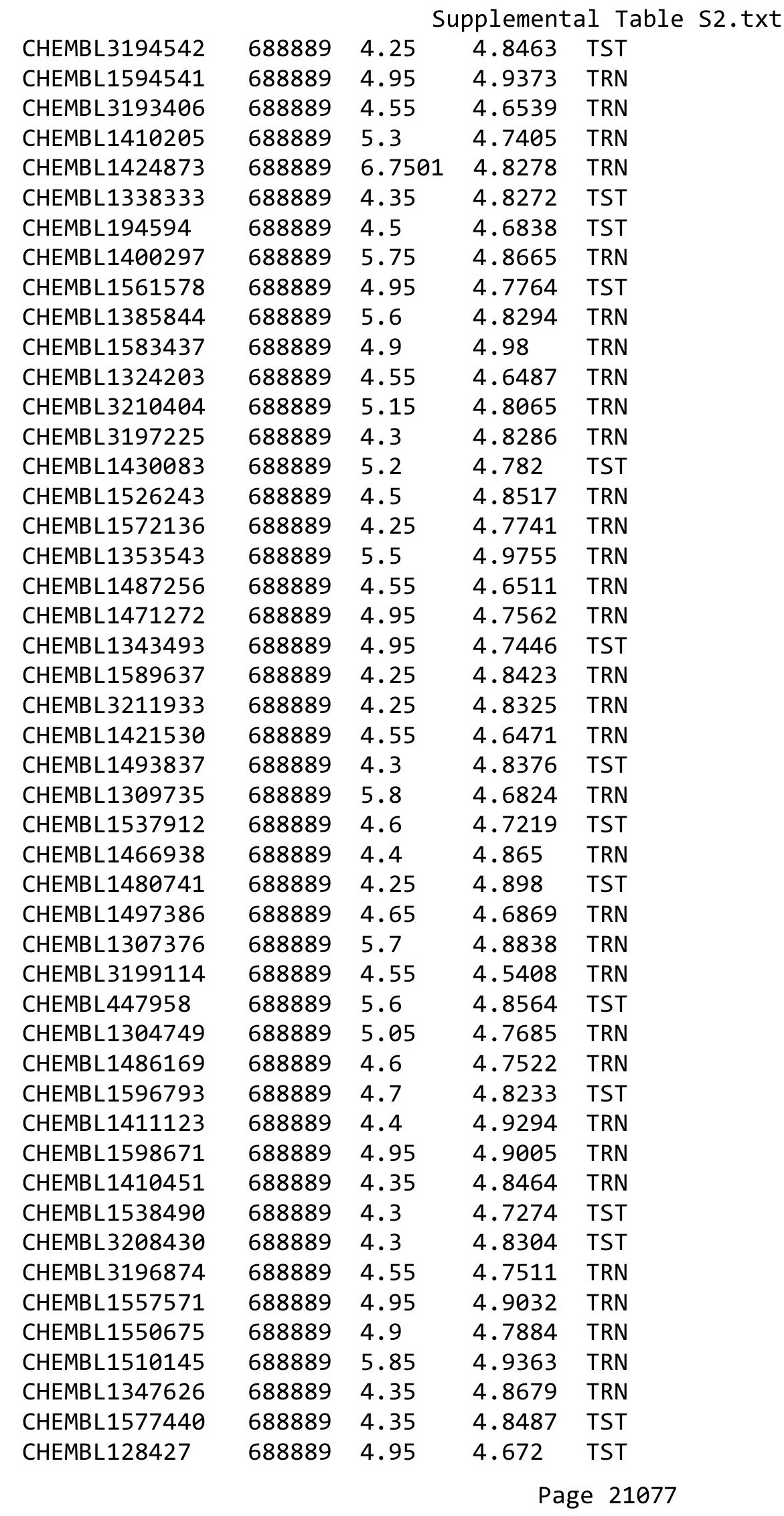




\begin{tabular}{|c|c|c|c|c|}
\hline \multicolumn{5}{|c|}{ Supplemental Table S2.txt } \\
\hline CHEMBL1583255 & 688889 & 4.9 & 4.8358 & TRN \\
\hline CHEMBL1330163 & 688889 & 4.45 & 4.8263 & TST \\
\hline CHEMBL1546422 & 688889 & 4.4 & 4.8007 & TST \\
\hline CHEMBL1439895 & 688889 & 5.0 & 4.729 & TRN \\
\hline CHEMBL1381618 & 688889 & 4.5 & 4.8296 & TRN \\
\hline CHEMBL1517860 & 688889 & 4.45 & 4.694 & TRN \\
\hline CHEMBL1605578 & 688889 & 4.65 & 4.7201 & TRN \\
\hline CHEMBL1468649 & 688889 & 6.7501 & 4.8986 & TST \\
\hline CHEMBL1410641 & 688889 & 4.95 & 4.7173 & TST \\
\hline CHEMBL1536465 & 688889 & 5.15 & 4.7368 & TRN \\
\hline CHEMBL 2005423 & 688889 & 4.35 & 4.8895 & TRN \\
\hline CHEMBL1503144 & 688889 & 5.0 & 4.7664 & TRN \\
\hline CHEMBL1557795 & 688889 & 5.45 & 4.7521 & TRN \\
\hline CHEMBL1587447 & 688889 & 4.55 & 4.7609 & TRN \\
\hline CHEMBL1556465 & 688889 & 4.9 & 4.8093 & TRN \\
\hline CHEMBL1428304 & 688889 & 6.05 & 4.8591 & TRN \\
\hline CHEMBL1607458 & 688889 & 4.25 & 4.9443 & TRN \\
\hline CHEMBL 3197978 & 688889 & 4.3 & 4.7354 & TRN \\
\hline CHEMBL1487839 & 688889 & 4.45 & 4.744 & TRN \\
\hline CHEMBL1319479 & 688889 & 4.95 & 4.7613 & TRN \\
\hline CHEMBL1488694 & 688889 & 6.3 & 4.8525 & TRN \\
\hline CHEMBL1528893 & 688889 & 4.7 & 4.7404 & TRN \\
\hline CHEMBL 3194573 & 688889 & 4.75 & 4.7132 & TRN \\
\hline CHEMBL1346307 & 688889 & 5.0 & 4.8151 & TRN \\
\hline CHEMBL1425903 & 688889 & 6.05 & 4.8824 & TRN \\
\hline CHEMBL1340641 & 688889 & 5.75 & 4.7243 & TRN \\
\hline CHEMBL1321500 & 688889 & 4.5 & 4.8828 & TRN \\
\hline CHEMBL1607132 & 688889 & 4.45 & 4.7349 & TRN \\
\hline CHEMBL1578661 & 688889 & 4.25 & 4.7453 & TRN \\
\hline CHEMBL1374920 & 688889 & 4.55 & 4.8664 & TRN \\
\hline CHEMBL1497637 & 688889 & 4.25 & 4.6996 & TST \\
\hline CHEMBL3211842 & 688889 & 4.9 & 4.8357 & TST \\
\hline CHEMBL1369249 & 688889 & 4.25 & 4.9016 & TRN \\
\hline CHEMBL3189399 & 688889 & 4.65 & 4.8659 & TRN \\
\hline CHEMBL1479591 & 688889 & 4.45 & 4.813 & TRN \\
\hline CHEMBL1555752 & 688889 & 4.5 & 4.7979 & TST \\
\hline CHEMBL1311787 & 688889 & 4.95 & 4.77 & TRN \\
\hline CHEMBL1488350 & 688889 & 4.4 & 4.7768 & TRN \\
\hline CHEMBL 3192884 & 688889 & 5.5 & 4.8372 & TRN \\
\hline CHEMBL1362307 & 688889 & 4.45 & 4.6207 & TRN \\
\hline CHEMBL1498811 & 688889 & 4.55 & 4.7191 & TRN \\
\hline CHEMBL1305869 & 688889 & 4.3 & 4.8103 & TRN \\
\hline CHEMBL1545999 & 688889 & 4.9 & 4.8442 & TRN \\
\hline CHEMBL1322690 & 688889 & 4.45 & 4.7838 & TST \\
\hline CHEMBL1429558 & 688889 & 4.95 & 4.9579 & TRN \\
\hline CHEMBL1422308 & 688889 & 4.4 & 4.7576 & TST \\
\hline CHEMBL1471622 & 688889 & 4.6 & 4.8638 & TRN \\
\hline CHEMBL1970711 & 688889 & 4.35 & 4.6937 & TST \\
\hline
\end{tabular}




\begin{tabular}{|c|c|c|c|c|c|}
\hline \multicolumn{6}{|c|}{ b1e S2. } \\
\hline CHEMBL1558040 & 688889 & 4.3 & 4.7951 & TST & \\
\hline CHEMBL1497731 & 688889 & 4.25 & 4.8177 & TRN & \\
\hline CHEMBL1361869 & 688889 & 4.5 & 4.69600 & 0000000001 & TRN \\
\hline CHEMBL1478244 & 688889 & 4.85 & 4.9015 & TRN & \\
\hline CHEMBL3198295 & 688889 & 4.4 & 4.7827 & TRN & \\
\hline CHEMBL1340571 & 688889 & 4.35 & 4.7893 & TRN & \\
\hline CHEMBL1518247 & 688889 & 4.65 & 4.8242 & TRN & \\
\hline CHEMBL1403474 & 688889 & 4.35 & 4.7665 & TRN & \\
\hline CHEMBL1489687 & 688889 & 4.5 & 4.6983 & TRN & \\
\hline CHEMBL1560765 & 688889 & 6.3 & 4.9314 & TRN & \\
\hline CHEMBL1416048 & 688889 & 4.3 & 4.9227 & TRN & \\
\hline CHEMBL1504724 & 688889 & 6.7501 & 4.638 & TST & \\
\hline CHEMBL1308177 & 688889 & 4.45 & 4.8157 & TRN & \\
\hline CHEMBL1497964 & 688889 & 6.7501 & 4.7633 & TRN & \\
\hline CHEMBL1432927 & 688889 & 4.45 & 4.6959 & TRN & \\
\hline CHEMBL1445106 & 688889 & 4.95 & 4.9813 & TRN & \\
\hline CHEMBL1347600 & 688889 & 4.9 & 4.7632 & TRN & \\
\hline CHEMBL1380290 & 688889 & 4.25 & 4.8265 & TST & \\
\hline CHEMBL1500298 & 688889 & 4.5 & 5.0025 & TST & \\
\hline CHEMBL1484931 & 688889 & 5.35 & 4.7967 & TRN & \\
\hline CHEMBL1386137 & 688889 & 4.3 & 4.8192 & TST & \\
\hline CHEMBL1526530 & 688889 & 4.3 & 4.812 & TRN & \\
\hline CHEMBL3194115 & 688889 & 5.2 & 4.815 & TRN & \\
\hline CHEMBL1460766 & 688889 & 5.25 & 4.8156 & TRN & \\
\hline CHEMBL1403079 & 688889 & 5.3 & 4.9321 & TRN & \\
\hline CHEMBL1427554 & 688889 & 4.9 & 4.7713 & TRN & \\
\hline CHEMBL1562796 & 688889 & 4.95 & 4.7905 & TST & \\
\hline CHEMBL1492306 & 688889 & 4.5 & 4.7962 & TRN & \\
\hline CHEMBL1485378 & 688889 & 4.5 & 4.6439 & TRN & \\
\hline CHEMBL1361416 & 688889 & 5.15 & 4.9597 & TRN & \\
\hline CHEMBL1370012 & 688889 & 5.55 & 4.9082 & TRN & \\
\hline CHEMBL1373161 & 688889 & 4.25 & 5.0254 & TST & \\
\hline CHEMBL1335718 & 688889 & 4.4 & 4.6843 & TRN & \\
\hline CHEMBL1545438 & 688889 & 4.6 & 4.6673 & TRN & \\
\hline CHEMBL1536399 & 688889 & 4.35 & 4.718 & TRN & \\
\hline CHEMBL1536801 & 688889 & 4.35 & 4.8012 & TST & \\
\hline CHEMBL1612163 & 688889 & 4.9 & 4.7763 & TRN & \\
\hline CHEMBL1573798 & 688889 & 4.25 & 4.8541 & TRN & \\
\hline CHEMBL1330736 & 688889 & 5.3 & 4.8358 & TST & \\
\hline CHEMBL1491910 & 688889 & 4.4 & 4.7972 & TRN & \\
\hline CHEMBL1521379 & 688889 & 4.5 & 4.9754 & TRN & \\
\hline CHEMBL3199360 & 688889 & 4.3 & 4.8152 & TRN & \\
\hline CHEMBL1384025 & 688889 & 4.45 & 4.687 & TRN & \\
\hline CHEMBL1604403 & 688889 & 4.55 & 4.8166 & TST & \\
\hline CHEMBL1516629 & 688889 & 4.25 & 4.72199 & 99999999995 & TRN \\
\hline CHEMBL1977384 & 688889 & 4.55 & 4.7302 & TRN & \\
\hline CHEMBL1440843 & 688889 & 4.3 & 4.7985 & TRN & \\
\hline CHEMBL1371864 & 688889 & 6.7501 & 4.6994 & TRN & \\
\hline
\end{tabular}




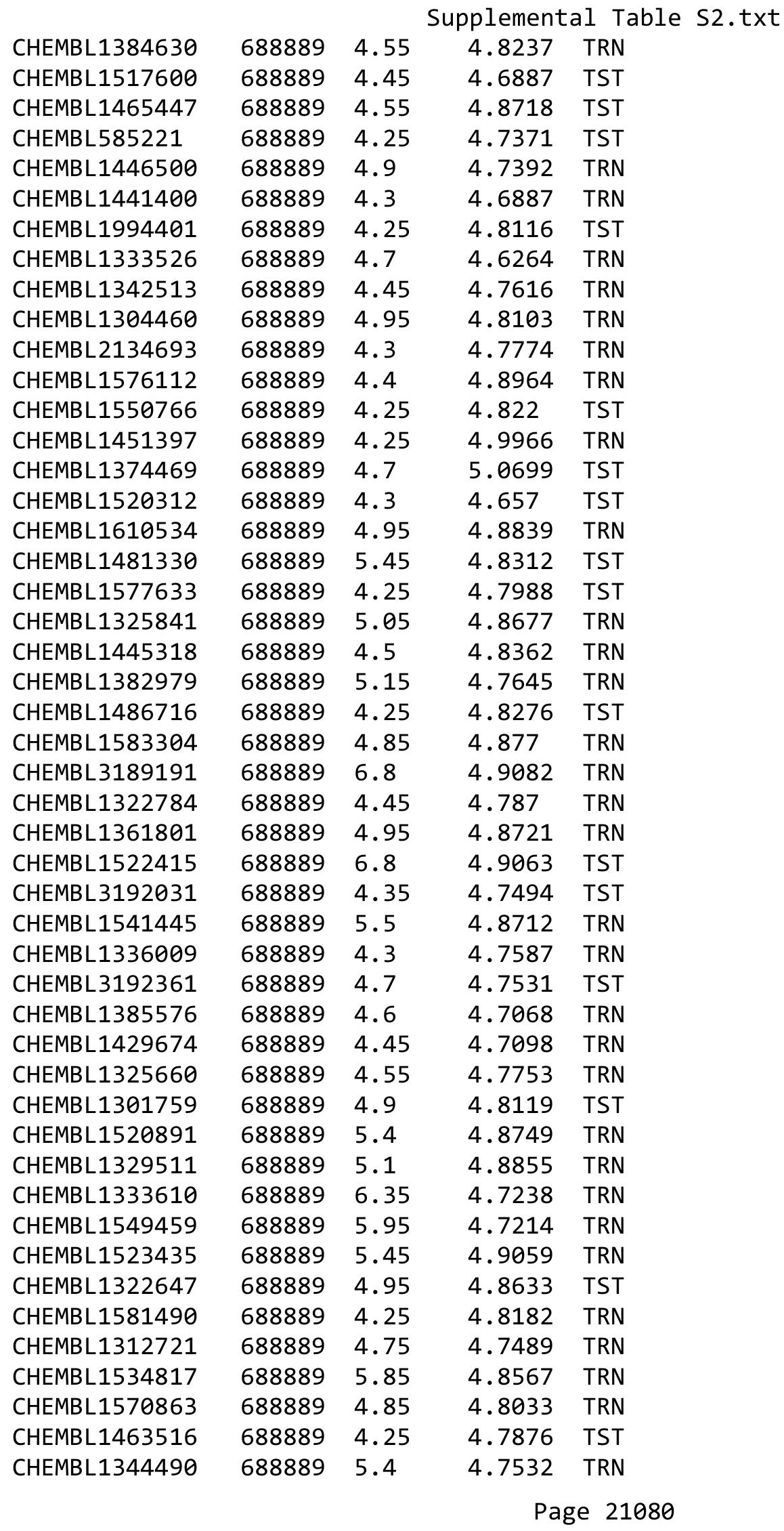




\begin{tabular}{|c|c|c|c|c|c|}
\hline \multicolumn{6}{|c|}{ Supplemental Table S2.txt } \\
\hline CHEMBL1384638 & 688889 & 4.25 & 4.7525 & TRN & \\
\hline CHEMBL1538564 & 688889 & 4.95 & 4.8978 & TST & \\
\hline CHEMBL1612311 & 688889 & 4.4 & 4.7123 & TRN & \\
\hline CHEMBL 3192065 & 688889 & 4.3 & 4.8293 & TST & \\
\hline CHEMBL1348381 & 688889 & 5.3 & 5.0066 & TRN & \\
\hline CHEMBL1389174 & 688889 & 4.6 & 4.6609 & TRN & \\
\hline CHEMBL1328544 & 688889 & 5.9 & 4.7825 & TRN & \\
\hline CHEMBL1342332 & 688889 & 4.45 & 4.6589 & TRN & \\
\hline CHEMBL1596462 & 688889 & 5.15 & 4.9156 & TRN & \\
\hline CHEMBL1486533 & 688889 & 4.7 & 4.7886 & TRN & \\
\hline CHEMBL1502014 & 688889 & 4.25 & 4.6674 & TST & \\
\hline CHEMBL1372362 & 688889 & 5.65 & 4.697 & TRN & \\
\hline CHEMBL1419489 & 688889 & 4.35 & 4.73300 & 00000000005 & TRN \\
\hline CHEMBL1334319 & 688889 & 4.25 & 4.7861 & TRN & \\
\hline CHEMBL1309939 & 688889 & 4.25 & 4.7635 & TRN & \\
\hline CHEMBL1373402 & 688889 & 4.95 & 4.8924 & TRN & \\
\hline CHEMBL1393441 & 688889 & 5.65 & 4.7553 & TRN & \\
\hline CHEMBL1550359 & 688889 & 5.0 & 4.7244 & TST & \\
\hline CHEMBL1374073 & 688889 & 6.1 & 4.789 & TST & \\
\hline CHEMBL1497147 & 688889 & 4.4 & 4.8162 & TRN & \\
\hline CHEMBL1599808 & 688889 & 4.5 & 4.8167 & TST & \\
\hline CHEMBL1340342 & 688889 & 4.9 & 4.7895 & TRN & \\
\hline CHEMBL1304458 & 688889 & 5.1 & 4.802 & TST & \\
\hline CHEMBL1579841 & 688889 & 4.4 & 4.7541 & TST & \\
\hline CHEMBL1389315 & 688889 & 4.4 & 4.6358 & TRN & \\
\hline CHEMBL1557709 & 688889 & 4.3 & 4.8008 & TRN & \\
\hline CHEMBL1419154 & 688889 & 6.8 & 4.8989 & TRN & \\
\hline CHEMBL1478659 & 688889 & 4.55 & 4.7748 & TRN & \\
\hline CHEMBL1564945 & 688889 & 4.65 & 4.7141 & TST & \\
\hline CHEMBL1508596 & 688889 & 4.5 & 4.7709 & TRN & \\
\hline CHEMBL1599063 & 688889 & 6.8 & 4.8468 & TRN & \\
\hline CHEMBL1546017 & 688889 & 6.7501 & 4.8593 & TRN & \\
\hline CHEMBL1335639 & 688889 & 5.4 & 4.8402 & TRN & \\
\hline CHEMBL1497079 & 688889 & 5.55 & 4.9392 & TRN & \\
\hline CHEMBL1320164 & 688889 & 4.35 & 4.6263 & TST & \\
\hline CHEMBL1470686 & 688889 & 4.25 & 4.8921 & TRN & \\
\hline CHEMBL1400555 & 688889 & 6.6 & 4.9072 & TST & \\
\hline CHEMBL1546975 & 688889 & 4.95 & 4.7387 & TRN & \\
\hline CHEMBL1493775 & 688889 & 4.65 & 4.6915 & TRN & \\
\hline CHEMBL1390321 & 688889 & 4.3 & 4.7765 & TRN & \\
\hline CHEMBL1323772 & 688889 & 4.45 & 4.7744 & TRN & \\
\hline CHEMBL1610342 & 688889 & 4.95 & 4.8916 & TRN & \\
\hline CHEMBL1537784 & 688889 & 4.35 & 4.662 & TRN & \\
\hline CHEMBL1413647 & 688889 & 4.25 & 4.865 & TRN & \\
\hline CHEMBL1334866 & 688889 & 4.25 & 4.8993 & TRN & \\
\hline CHEMBL1579747 & 688889 & 4.5 & 4.7021 & TRN & \\
\hline CHEMBL1340705 & 688889 & 4.65 & 4.7321 & TRN & \\
\hline CHEMBL1565596 & 688889 & 4.6 & 4.7441 & TRN & \\
\hline
\end{tabular}




\begin{tabular}{|c|c|c|c|c|}
\hline & & & oplement & \\
\hline CHEMBL1310774 & 688889 & 4.5 & 4.8593 & TRN \\
\hline CHEMBL1328071 & 688889 & 4.25 & 4.7505 & TRN \\
\hline CHEMBL1479036 & 688889 & 5.55 & 4.918 & TRN \\
\hline CHEMBL1462769 & 688889 & 4.55 & 4.8671 & TRN \\
\hline CHEMBL1446084 & 688889 & 4.3 & 4.8074 & TRN \\
\hline CHEMBL1613195 & 688889 & 4.25 & 4.8809 & TRN \\
\hline CHEMBL1498954 & 688889 & 5.3 & 4.8065 & TRN \\
\hline CHEMBL1564886 & 688889 & 5.9 & 4.8374 & TST \\
\hline CHEMBL1374444 & 688889 & 4.3 & 4.8621 & TRN \\
\hline CHEMBL3196818 & 688889 & 5.2 & 4.7691 & TRN \\
\hline CHEMBL1425701 & 688889 & 4.3 & 4.7007 & TRN \\
\hline CHEMBL 3199258 & 688889 & 6.15 & 4.8827 & TRN \\
\hline CHEMBL1421005 & 688889 & 4.45 & 4.8664 & TRN \\
\hline CHEMBL1504447 & 688889 & 7.0 & 4.706 & TST \\
\hline CHEMBL1479018 & 688889 & 4.6 & 4.9068 & TST \\
\hline CHEMBL1433082 & 688889 & 4.3 & 4.7468 & TRN \\
\hline CHEMBL1577478 & 688889 & 4.25 & 4.9676 & TRN \\
\hline CHEMBL 282003 & 688889 & 4.9 & 4.7545 & TST \\
\hline CHEMBL1466448 & 688889 & 4.45 & 4.8441 & TRN \\
\hline CHEMBL1340579 & 688889 & 4.55 & 4.7647 & TRN \\
\hline CHEMBL1447843 & 688889 & 4.55 & 4.8315 & TRN \\
\hline CHEMBL3211338 & 688889 & 4.7 & 4.6575 & TRN \\
\hline CHEMBL1310680 & 688889 & 4.75 & 4.7269 & TRN \\
\hline CHEMBL1404728 & 688889 & 5.25 & 4.9031 & TRN \\
\hline CHEMBL1600641 & 688889 & 4.9 & 4.8918 & TRN \\
\hline CHEMBL3211406 & 688889 & 4.3 & 4.6709 & TRN \\
\hline CHEMBL1451902 & 688889 & 4.5 & 4.9157 & TRN \\
\hline CHEMBL1425890 & 688889 & 4.55 & 4.9544 & TRN \\
\hline CHEMBL1520914 & 688889 & 5.95 & 4.7228 & TRN \\
\hline CHEMBL 2006431 & 688889 & 5.15 & 4.6877 & TRN \\
\hline CHEMBL1543746 & 688889 & 4.95 & 4.8905 & TST \\
\hline CHEMBL1558398 & 688889 & 5.85 & 4.7819 & TRN \\
\hline CHEMBL1534378 & 688889 & 4.3 & 4.9586 & TRN \\
\hline CHEMBL1558465 & 688889 & 6.8 & 5.0236 & TRN \\
\hline CHEMBL1439666 & 688889 & 5.4 & 4.6643 & TRN \\
\hline CHEMBL1486119 & 688889 & 4.45 & 4.7814 & TRN \\
\hline CHEMBL1490375 & 688889 & 4.5 & 4.7653 & TRN \\
\hline CHEMBL1419867 & 688889 & 5.75 & 4.8202 & TST \\
\hline CHEMBL1385413 & 688889 & 6.2 & 4.7748 & TRN \\
\hline CHEMBL1559370 & 688889 & 4.45 & 4.7297 & TRN \\
\hline CHEMBL1492684 & 688889 & 4.45 & 4.8216 & TRN \\
\hline CHEMBL1444984 & 688889 & 4.85 & 4.7533 & TRN \\
\hline CHEMBL1384905 & 688889 & 4.25 & 4.6302 & TST \\
\hline CHEMBL1570753 & 688889 & 4.45 & 4.6946 & TRN \\
\hline CHEMBL436589 & 688889 & 4.4 & 4.8133 & TRN \\
\hline CHEMBL1321982 & 688889 & 4.65 & 4.9266 & TST \\
\hline CHEMBL 1430540 & 688889 & 4.55 & 4.8553 & TRN \\
\hline CHEMBL1609121 & 688889 & 4.35 & 4.7383 & TRN \\
\hline
\end{tabular}




\begin{tabular}{|c|c|c|c|c|c|}
\hline & & \multicolumn{4}{|c|}{ Supplemental Table S2.txt } \\
\hline CHEMBL1360050 & 688889 & 6.8499 & 4.8063 & TRN & \\
\hline CHEMBL1538891 & 688889 & 4.7 & 4.6761 & TRN & \\
\hline CHEMBL1307897 & 688889 & 4.95 & 4.7114 & TRN & \\
\hline CHEMBL1362051 & 688889 & 4.3 & 4.7283 & TRN & \\
\hline CHEMBL1535732 & 688889 & 5.5 & 4.8066 & TST & \\
\hline CHEMBL1525836 & 688889 & 4.3 & 4.9539 & TST & \\
\hline CHEMBL1449862 & 688889 & 4.5 & 4.8114 & TRN & \\
\hline CHEMBL1534132 & 688889 & 4.85 & 4.8322 & TRN & \\
\hline CHEMBL1537193 & 688889 & 4.5 & 4.6969 & TRN & \\
\hline CHEMBL1446312 & 688889 & 5.85 & 4.83899 & 99999999995 & TST \\
\hline CHEMBL1549514 & 688889 & 4.9 & 4.7214 & TRN & \\
\hline CHEMBL3211199 & 688889 & 5.45 & 4.8166 & TST & \\
\hline CHEMBL1527737 & 688889 & 4.4 & 4.8385 & TRN & \\
\hline CHEMBL1461292 & 688889 & 4.5 & 4.8 & TRN & \\
\hline CHEMBL1441676 & 688889 & 6.8 & 4.8576 & TRN & \\
\hline CHEMBL1600765 & 688889 & 4.9 & 4.7762 & TST & \\
\hline CHEMBL1368962 & 688889 & 5.4 & 4.8654 & TRN & \\
\hline CHEMBL1328017 & 688889 & 5.15 & 4.8663 & TST & \\
\hline CHEMBL1587712 & 688889 & 6.4 & 4.9396 & TRN & \\
\hline CHEMBL 3210893 & 688889 & 4.25 & 4.7032 & TST & \\
\hline CHEMBL1407580 & 688889 & 6.7501 & 4.9333 & TRN & \\
\hline CHEMBL25280 & 688889 & 4.95 & 4.8999 & TST & \\
\hline CHEMBL1536919 & 688889 & 4.6 & 4.8857 & TRN & \\
\hline CHEMBL1469033 & 688889 & 4.4 & 4.8193 & TRN & \\
\hline CHEMBL1574450 & 688889 & 4.3 & 4.7864 & TRN & \\
\hline CHEMBL3189419 & 688889 & 6.3 & 4.8653 & TRN & \\
\hline CHEMBL1608848 & 688889 & 4.25 & 4.7609 & TRN & \\
\hline CHEMBL1612393 & 688889 & 5.25 & 4.7153 & TRN & \\
\hline CHEMBL1524622 & 688889 & 4.45 & 4.8101 & TRN & \\
\hline CHEMBL1501809 & 688889 & 4.3 & 4.8146 & TST & \\
\hline CHEMBL1370548 & 688889 & 4.3 & 4.9386 & TRN & \\
\hline CHEMBL1429804 & 688889 & 4.9 & 4.8654 & TRN & \\
\hline CHEMBL1544761 & 688889 & 4.25 & 4.9278 & TRN & \\
\hline CHEMBL1450406 & 688889 & 4.35 & 4.6766 & TRN & \\
\hline CHEMBL3189964 & 688889 & 4.75 & 4.805 & TRN & \\
\hline CHEMBL3199536 & 688889 & 4.4 & 4.717 & TRN & \\
\hline CHEMBL1529063 & 688889 & 5.3 & 4.8388 & TST & \\
\hline CHEMBL1493266 & 688889 & 4.55 & 4.9273 & TST & \\
\hline CHEMBL1510705 & 688889 & 4.25 & 4.8883 & TRN & \\
\hline CHEMBL1698217 & 688889 & 4.45 & 4.6443 & TRN & \\
\hline CHEMBL1398633 & 688889 & 4.25 & 4.8731 & TRN & \\
\hline CHEMBL1374465 & 688889 & 5.3 & 4.6883 & TST & \\
\hline CHEMBL1612706 & 688889 & 5.15 & 4.7159 & TRN & \\
\hline CHEMBL1335538 & 688889 & 4.9 & 4.7692 & TRN & \\
\hline CHEMBL1548350 & 688889 & 4.3 & 4.649 & TRN & \\
\hline CHEMBL1533490 & 688889 & 4.25 & 4.7983 & TST & \\
\hline CHEMBL1578635 & 688889 & 5.4 & 4.7315 & TRN & \\
\hline CHEMBL1330907 & 688889 & 4.25 & 4.6568 & TRN & \\
\hline
\end{tabular}




\begin{tabular}{|c|c|c|c|c|c|}
\hline \multicolumn{6}{|c|}{ Supplemental Table S2.txt } \\
\hline CHEMBL1339856 & 688889 & 4.9 & 4.8488 & TRN & \\
\hline CHEMBL1536856 & 688889 & 4.25 & 4.8021 & TRN & \\
\hline CHEMBL3213945 & 688889 & 5.55 & 4.7013 & TRN & \\
\hline CHEMBL1382622 & 688889 & 4.3 & 4.7952 & TRN & \\
\hline CHEMBL1366311 & 688889 & 4.7 & 4.6615 & TRN & \\
\hline CHEMBL1337039 & 688889 & 4.25 & 4.6662 & TST & \\
\hline CHEMBL1361240 & 688889 & 4.3 & 4.73300 & 00000000005 & TRN \\
\hline CHEMBL1488840 & 688889 & 4.3 & 4.8888 & TST & \\
\hline CHEMBL1325947 & 688889 & 4.3 & 4.7856 & TRN & \\
\hline CHEMBL1560195 & 688889 & 4.3 & 4.7888 & TRN & \\
\hline CHEMBL1607940 & 688889 & 4.4 & 4.8464 & TRN & \\
\hline CHEMBL1307366 & 688889 & 5.9 & 4.7643 & TST & \\
\hline CHEMBL1601501 & 688889 & 6.05 & 4.8113 & TRN & \\
\hline CHEMBL1523229 & 688889 & 5.2 & 4.8986 & TRN & \\
\hline CHEMBL1579314 & 688889 & 6.45 & 4.8734 & TRN & \\
\hline CHEMBL1417747 & 688889 & 6.15 & 4.8157 & TST & \\
\hline CHEMBL1485002 & 688889 & 4.5 & 4.7239 & TRN & \\
\hline CHEMBL1530389 & 688889 & 4.95 & 4.806 & TRN & \\
\hline CHEMBL1407509 & 688889 & 4.3 & 4.7161 & TRN & \\
\hline CHEMBL1525212 & 688889 & 4.5 & 4.7265 & TRN & \\
\hline CHEMBL1408240 & 688889 & 4.3 & 4.949 & TRN & \\
\hline CHEMBL1583690 & 688889 & 4.5 & 4.7723 & TRN & \\
\hline CHEMBL1326489 & 688889 & 4.4 & 4.7049 & TRN & \\
\hline CHEMBL 1410757 & 688889 & 4.4 & 4.7313 & TRN & \\
\hline CHEMBL1529636 & 688889 & 5.7 & 4.9526 & TRN & \\
\hline CHEMBL1423832 & 688889 & 4.65 & 4.6361 & TRN & \\
\hline CHEMBL1323790 & 688889 & 4.3 & 4.7431 & TRN & \\
\hline CHEMBL1426380 & 688889 & 4.4 & 4.981 & TRN & \\
\hline CHEMBL1333187 & 688889 & 4.8 & 4.8039 & TRN & \\
\hline CHEMBL1319491 & 688889 & 4.25 & 4.8471 & TRN & \\
\hline CHEMBL1345424 & 688889 & 4.3 & 4.8661 & TRN & \\
\hline CHEMBL1381755 & 688889 & 5.25 & 4.9994 & TRN & \\
\hline CHEMBL1371013 & 688889 & 4.4 & 4.7393 & TRN & \\
\hline CHEMBL1495239 & 688889 & 4.55 & 4.7898 & TRN & \\
\hline CHEMBL1569994 & 688889 & 4.3 & 4.9603 & TST & \\
\hline CHEMBL1333055 & 688889 & 4.8 & 4.9058 & TRN & \\
\hline CHEMBL1528062 & 688889 & 4.5 & 4.732 & TRN & \\
\hline CHEMBL1589046 & 688889 & 4.3 & 4.8141 & TRN & \\
\hline CHEMBL1504189 & 688889 & 4.45 & 4.8336 & TRN & \\
\hline CHEMBL1538189 & 688889 & 4.95 & 4.8905 & TRN & \\
\hline CHEMBL1422678 & 688889 & 6.0 & 4.6349 & TRN & \\
\hline CHEMBL1517194 & 688889 & 5.25 & 4.907 & TST & \\
\hline CHEMBL1572195 & 688889 & 4.9 & 4.739 & TRN & \\
\hline CHEMBL1401961 & 688889 & 4.25 & 4.7707 & TRN & \\
\hline CHEMBL1483533 & 688889 & 4.35 & 4.8027 & TRN & \\
\hline CHEMBL1366718 & 688889 & 4.25 & 4.7825 & TRN & \\
\hline CHEMBL1612897 & 688889 & 5.2 & 4.6774 & TRN & \\
\hline CHEMBL1584196 & 688889 & 4.45 & 4.7061 & TRN & \\
\hline
\end{tabular}




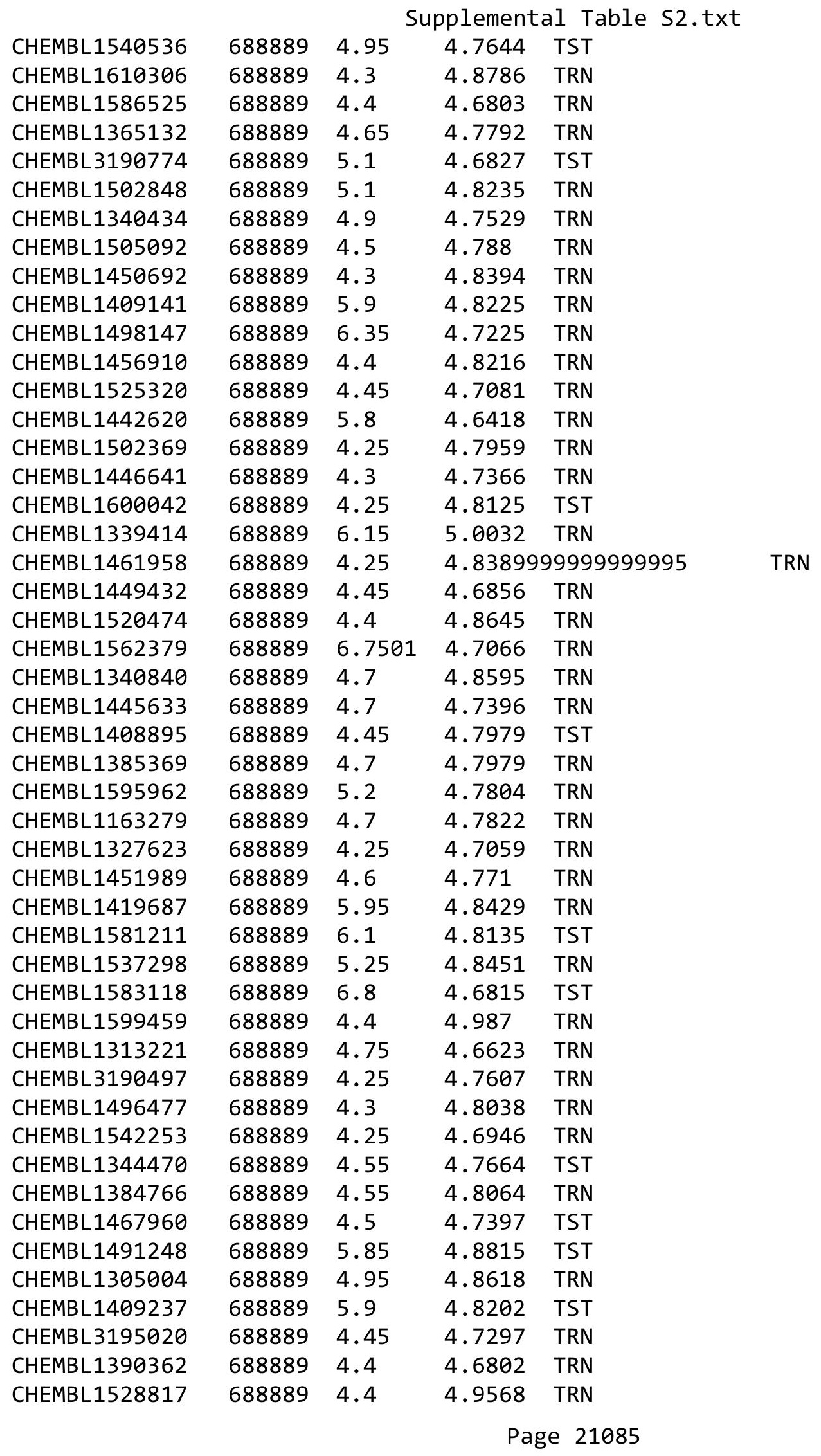




\begin{tabular}{|c|c|c|c|c|}
\hline \multicolumn{5}{|c|}{ Supplemental Table S2.txt } \\
\hline CHEMBL1557476 & 688889 & 6.15 & 4.7236 & TRN \\
\hline CHEMBL1583492 & 688889 & 4.55 & 4.8485 & TRN \\
\hline CHEMBL1605082 & 688889 & 4.25 & 4.9726 & TRN \\
\hline CHEMBL1380859 & 688889 & 4.55 & 4.8839 & TRN \\
\hline CHEMBL1594871 & 688889 & 5.55 & 4.7223 & TRN \\
\hline CHEMBL1306967 & 688889 & 4.6 & 4.6708 & TRN \\
\hline CHEMBL1544365 & 688889 & 4.6 & 4.9265 & TRN \\
\hline CHEMBL1421413 & 688889 & 5.6 & 4.8463 & TRN \\
\hline CHEMBL1470021 & 688889 & 4.25 & 4.9033 & TRN \\
\hline CHEMBL1601075 & 688889 & 5.3 & 4.8301 & TRN \\
\hline CHEMBL1383025 & 688889 & 4.6 & 4.732 & TST \\
\hline CHEMBL1463134 & 688889 & 4.5 & 4.6605 & TRN \\
\hline CHEMBL1504660 & 688889 & 4.4 & 4.6944 & TRN \\
\hline CHEMBL1585886 & 688889 & 4.25 & 4.8423 & TRN \\
\hline CHEMBL1471220 & 688889 & 5.1 & 4.9337 & TST \\
\hline CHEMBL1342815 & 688889 & 5.0 & 4.7651 & TRN \\
\hline CHEMBL1310515 & 688889 & 4.4 & 4.8512 & TRN \\
\hline CHEMBL1486929 & 688889 & 4.35 & 4.6246 & TRN \\
\hline CHEMBL1567768 & 688889 & 5.25 & 4.6971 & TRN \\
\hline CHEMBL1352931 & 688889 & 4.25 & 5.0002 & TRN \\
\hline CHEMBL1408630 & 688889 & 4.35 & 4.6965 & TRN \\
\hline CHEMBL1602965 & 688889 & 4.95 & 4.9099 & TRN \\
\hline CHEMBL1416602 & 688889 & 4.95 & 4.7298 & TRN \\
\hline CHEMBL1563349 & 688889 & 6.2 & 4.8487 & TRN \\
\hline CHEMBL1595562 & 688889 & 5.2 & 4.7562 & TRN \\
\hline CHEMBL3191629 & 688889 & 4.4 & 4.9076 & TRN \\
\hline CHEMBL1583743 & 688889 & 5.0 & 4.9529 & TRN \\
\hline CHEMBL1347685 & 688889 & 4.5 & 4.791 & TRN \\
\hline CHEMBL1314143 & 688889 & 5.65 & 4.6858 & TRN \\
\hline CHEMBL1539124 & 688889 & 4.95 & 4.7778 & TRN \\
\hline CHEMBL3199381 & 688889 & 4.4 & 4.822 & TRN \\
\hline CHEMBL 1384345 & 688889 & 4.9 & 4.7674 & TRN \\
\hline CHEMBL1415040 & 688889 & 4.25 & 4.8953 & TRN \\
\hline CHEMBL1457187 & 688889 & 4.4 & 4.7632 & TRN \\
\hline CHEMBL1479042 & 688889 & 4.55 & 4.9188 & TRN \\
\hline CHEMBL1506533 & 688889 & 4.55 & 4.8647 & TRN \\
\hline CHEMBL1523881 & 688889 & 4.55 & 4.8341 & TRN \\
\hline CHEMBL1574446 & 688889 & 4.25 & 4.8301 & TRN \\
\hline CHEMBL1510840 & 688889 & 4.25 & 4.7824 & TRN \\
\hline CHEMBL1543536 & 688889 & 4.6 & 4.7299 & TRN \\
\hline CHEMBL1403707 & 688889 & 4.4 & 4.6579 & TRN \\
\hline CHEMBL1493129 & 688889 & 4.95 & 4.8465 & TRN \\
\hline CHEMBL1392256 & 688889 & 4.5 & 4.8046 & TRN \\
\hline CHEMBL 2000815 & 688889 & 5.55 & 4.7846 & TST \\
\hline CHEMBL1379627 & 688889 & 4.25 & 4.8509 & TRN \\
\hline CHEMBL1309724 & 688889 & 4.3 & 4.8688 & TST \\
\hline CHEMBL1371959 & 688889 & 4.4 & 4.7628 & TRN \\
\hline CHEMBL1608403 & 688889 & 4.55 & 4.842 & TRN \\
\hline
\end{tabular}




\begin{tabular}{|c|c|c|c|c|}
\hline \multirow[b]{2}{*}{ CHEMBL1516762 } & \multicolumn{4}{|c|}{ Supplemental Table S2.txt } \\
\hline & 688889 & 4.3 & 4.794 & TST \\
\hline CHEMBL1597644 & 688889 & 4.95 & 4.9878 & TRN \\
\hline CHEMBL1545987 & 688889 & 4.95 & 4.7902 & TST \\
\hline CHEMBL3216654 & 688889 & 5.45 & 4.7033 & TST \\
\hline CHEMBL1569742 & 688889 & 4.3 & 4.897 & TRN \\
\hline CHEMBL1492361 & 688889 & 4.3 & 4.8099 & TRN \\
\hline CHEMBL1584784 & 688889 & 4.75 & 4.7106 & TRN \\
\hline CHEMBL1306875 & 688889 & 4.25 & 4.8423 & TRN \\
\hline CHEMBL1522874 & 688889 & 4.35 & 4.9012 & TRN \\
\hline CHEMBL1511690 & 688889 & 4.45 & 4.7829 & TST \\
\hline CHEMBL1539688 & 688889 & 5.95 & 4.7809 & TRN \\
\hline CHEMBL1446469 & 688889 & 4.65 & 4.7597 & TRN \\
\hline CHEMBL1527275 & 688889 & 4.65 & 4.633 & TST \\
\hline CHEMBL1505326 & 688889 & 4.45 & 4.8929 & TRN \\
\hline CHEMBL1598484 & 688889 & 4.4 & 4.7025 & TRN \\
\hline CHEMBL1534984 & 688889 & 4.55 & 4.9356 & TRN \\
\hline CHEMBL1405774 & 688889 & 4.5 & 4.9241 & TST \\
\hline CHEMBL1345709 & 688889 & 4.25 & 4.7984 & TRN \\
\hline CHEMBL1527784 & 688889 & 4.55 & 4.888 & TRN \\
\hline CHEMBL1523016 & 688889 & 4.55 & 4.9144 & TRN \\
\hline CHEMBL1489118 & 688889 & 4.25 & 4.7247 & TRN \\
\hline CHEMBL1527775 & 688889 & 5.5 & 4.8715 & TRN \\
\hline CHEMBL1598630 & 688889 & 4.3 & 4.919 & TST \\
\hline CHEMBL3189659 & 688889 & 6.7501 & 4.8057 & TRN \\
\hline CHEMBL1388984 & 688889 & 5.4 & 4.9244 & TRN \\
\hline CHEMBL1324324 & 688889 & 4.3 & 4.9168 & TST \\
\hline CHEMBL1432042 & 688889 & 4.35 & 4.7824 & TRN \\
\hline CHEMBL1482050 & 688889 & 5.45 & 4.75 & TRN \\
\hline CHEMBL1324616 & 688889 & 6.7501 & 4.881 & TST \\
\hline CHEMBL1984166 & 688889 & 4.3 & 4.6867 & TRN \\
\hline CHEMBL1328498 & 688889 & 4.3 & 4.8321 & TRN \\
\hline CHEMBL3208179 & 688889 & 4.3 & 4.8585 & TRN \\
\hline CHEMBL 3209847 & 688889 & 4.3 & 4.7198 & TST \\
\hline CHEMBL1342278 & 688889 & 4.3 & 4.6624 & TRN \\
\hline CHEMBL1531169 & 688889 & 4.25 & 4.9193 & TST \\
\hline CHEMBL1598445 & 688889 & 4.5 & 4.8177 & TRN \\
\hline CHEMBL1544907 & 688889 & 4.8 & 4.7305 & TRN \\
\hline CHEMBL1425657 & 688889 & 5.05 & 4.8753 & TRN \\
\hline CHEMBL1612604 & 688889 & 6.8 & 5.0272 & TRN \\
\hline CHEMBL1390049 & 688889 & 4.55 & 4.6907 & TRN \\
\hline CHEMBL3212692 & 688889 & 4.3 & 4.8304 & TST \\
\hline CHEMBL1440249 & 688889 & 4.6 & 4.7761 & TST \\
\hline CHEMBL1340956 & 688889 & 4.45 & 4.7922 & TRN \\
\hline CHEMBL1378821 & 688889 & 6.7501 & 4.856 & TST \\
\hline CHEMBL1605917 & 688889 & 5.35 & 4.5667 & TRN \\
\hline CHEMBL1440475 & 688889 & 4.35 & 4.9163 & TST \\
\hline CHEMBL1336949 & 688889 & 4.4 & 4.7136 & TST \\
\hline CHEMBL3209231 & 688889 & 4.25 & 4.7196 & TST \\
\hline
\end{tabular}




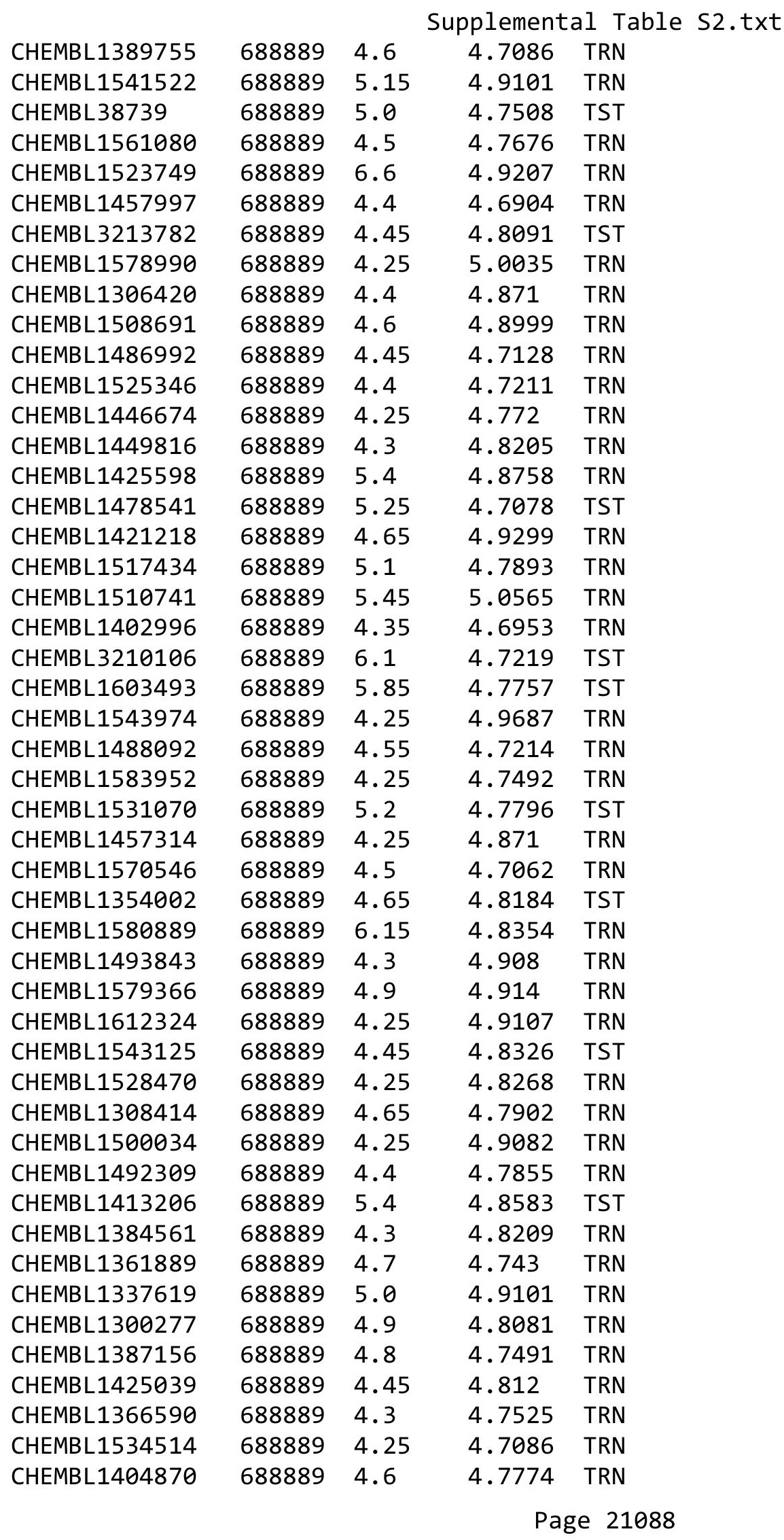




\begin{tabular}{|c|c|c|c|c|}
\hline \multicolumn{5}{|c|}{ Supplemental Table S2.txt } \\
\hline CHEMBL1607976 & 688889 & 4.25 & 4.7496 & TRN \\
\hline CHEMBL1385774 & 688889 & 6.5 & 4.9033 & TST \\
\hline CHEMBL1341570 & 688889 & 4.3 & 4.7867 & TRN \\
\hline CHEMBL1572348 & 688889 & 4.45 & 4.8202 & TRN \\
\hline CHEMBL1415361 & 688889 & 4.25 & 4.8629 & TRN \\
\hline CHEMBL1307769 & 688889 & 4.55 & 4.7641 & TRN \\
\hline CHEMBL1536626 & 688889 & 4.3 & 4.8133 & TST \\
\hline CHEMBL1561688 & 688889 & 5.15 & 4.7766 & TRN \\
\hline CHEMBL1352800 & 688889 & 4.45 & 4.8237 & TRN \\
\hline CHEMBL1336347 & 688889 & 4.6 & 4.7644 & TRN \\
\hline CHEMBL1467895 & 688889 & 5.5 & 4.8547 & TST \\
\hline CHEMBL595438 & 688889 & 5.35 & 4.7551 & TST \\
\hline CHEMBL1492711 & 688889 & 4.3 & 4.6589 & TRN \\
\hline CHEMBL1536251 & 688889 & 5.8 & 4.8565 & TRN \\
\hline CHEMBL1363427 & 688889 & 4.3 & 4.9096 & TRN \\
\hline CHEMBL1483864 & 688889 & 4.7 & 4.6966 & TRN \\
\hline CHEMBL1320946 & 688889 & 4.45 & 4.6982 & TST \\
\hline CHEMBL1447673 & 688889 & 4.3 & 4.7538 & TST \\
\hline CHEMBL1382568 & 688889 & 4.25 & 4.8924 & TRN \\
\hline CHEMBL1525169 & 688889 & 4.95 & 4.8012 & TRN \\
\hline CHEMBL1321330 & 688889 & 4.3 & 4.8193 & TRN \\
\hline CHEMBL1319256 & 688889 & 4.3 & 4.7961 & TRN \\
\hline CHEMBL1444255 & 688889 & 5.2 & 4.8133 & TST \\
\hline CHEMBL1565088 & 688889 & 4.4 & 4.8283 & TRN \\
\hline CHEMBL1517903 & 688889 & 5.1 & 4.8503 & TRN \\
\hline CHEMBL 2005411 & 688889 & 4.7 & 4.7281 & TRN \\
\hline CHEMBL1534549 & 688889 & 4.95 & 4.86 & TRN \\
\hline CHEMBL1536273 & 688889 & 4.5 & 4.7328 & TRN \\
\hline CHEMBL1470952 & 688889 & 4.25 & 4.7778 & TRN \\
\hline CHEMBL1377480 & 688889 & 4.5 & 4.7275 & TST \\
\hline CHEMBL1583297 & 688889 & 4.3 & 4.6996 & TRN \\
\hline CHEMBL1326862 & 688889 & 4.3 & 4.8442 & TRN \\
\hline CHEMBL1341062 & 688889 & 4.25 & 4.8244 & TST \\
\hline CHEMBL1382648 & 688889 & 4.65 & 4.8133 & TRN \\
\hline CHEMBL1405380 & 688889 & 4.25 & 4.7585 & TRN \\
\hline CHEMBL1974856 & 688889 & 4.25 & 4.6847 & TST \\
\hline CHEMBL1523635 & 688889 & 5.05 & 4.885 & TRN \\
\hline CHEMBL1488279 & 688889 & 4.45 & 4.7123 & TRN \\
\hline CHEMBL1300335 & 688889 & 4.3 & 4.87 & TST \\
\hline CHEMBL1338665 & 688889 & 5.0 & 4.6553 & TRN \\
\hline CHEMBL1536614 & 688889 & 6.1 & 4.7572 & TST \\
\hline CHEMBL1338457 & 688889 & 6.0 & 4.9928 & TRN \\
\hline CHEMBL1535157 & 688889 & 4.5 & 4.8713 & TRN \\
\hline CHEMBL1584523 & 688889 & 4.4 & 4.6822 & TRN \\
\hline CHEMBL1490221 & 688889 & 4.25 & 4.7435 & TRN \\
\hline CHEMBL1319465 & 688889 & 4.25 & 4.7632 & TRN \\
\hline CHEMBL1172995 & 688889 & 6.7501 & 4.8758 & TST \\
\hline CHEMBL1380386 & 688889 & 4.6 & 4.8157 & TRN \\
\hline
\end{tabular}




\begin{tabular}{|c|c|c|c|c|c|}
\hline & & \multicolumn{4}{|c|}{ Supplemental Table s2.txt } \\
\hline CHEMBL3195033 & 688889 & 4.45 & 4.6761 & TRN & \\
\hline CHEMBL3209281 & 688889 & 5.2 & 4.5733 & TRN & \\
\hline CHEMBL1425096 & 688889 & 4.35 & 4.7051 & TRN & \\
\hline CHEMBL1468865 & 688889 & 5.1 & 4.8288 & TRN & \\
\hline CHEMBL1563287 & 688889 & 5.8 & 4.7564 & TRN & \\
\hline CHEMBL1527117 & 688889 & 4.6 & 4.7733 & TRN & \\
\hline CHEMBL1587526 & 688889 & 4.45 & 4.883 & TST & \\
\hline CHEMBL1497467 & 688889 & 4.45 & 4.9049 & TRN & \\
\hline CHEMBL1419251 & 688889 & 5.05 & 4.6963 & TRN & \\
\hline CHEMBL1444360 & 688889 & 5.1 & 4.8731 & TRN & \\
\hline CHEMBL1390274 & 688889 & 4.55 & 4.7223 & TRN & \\
\hline CHEMBL1494548 & 688889 & 4.3 & 4.8724 & TRN & \\
\hline CHEMBL1485381 & 688889 & 4.55 & 4.6422 & TRN & \\
\hline CHEMBL1606539 & 688889 & 4.2 & 4.854 & TRN & \\
\hline CHEMBL1491086 & 688889 & 6.8 & 4.6967 & TST & \\
\hline CHEMBL1337683 & 688889 & 4.25 & 4.7605 & TRN & \\
\hline CHEMBL1580252 & 688889 & 4.55 & 4.90600 & 0000000001 & TST \\
\hline CHEMBL1522657 & 688889 & 4.4 & 4.6598 & TRN & \\
\hline CHEMBL1412113 & 688889 & 5.0 & 4.8092 & TRN & \\
\hline CHEMBL1510838 & 688889 & 4.25 & 4.7858 & TRN & \\
\hline CHEMBL1505008 & 688889 & 4.95 & 4.83899 & 99999999995 & TST \\
\hline CHEMBL1415114 & 688889 & 4.4 & 4.6223 & TRN & \\
\hline CHEMBL1415316 & 688889 & 5.3 & 4.9552 & TRN & \\
\hline CHEMBL1304384 & 688889 & 4.4 & 4.8345 & TST & \\
\hline CHEMBL3190541 & 688889 & 4.6 & 4.7459 & TRN & \\
\hline CHEMBL1564619 & 688889 & 4.25 & 4.7212 & TRN & \\
\hline CHEMBL1444207 & 688889 & 4.95 & 4.8676 & TRN & \\
\hline CHEMBL1547006 & 688889 & 4.5 & 4.7298 & TRN & \\
\hline CHEMBL1477093 & 688889 & 4.45 & 4.6452 & TRN & \\
\hline CHEMBL1301692 & 688889 & 4.3 & 4.8055 & TST & \\
\hline CHEMBL1384311 & 688889 & 4.45 & 4.7618 & TRN & \\
\hline CHEMBL1426482 & 688889 & 4.5 & 4.7613 & TRN & \\
\hline CHEMBL1965162 & 688889 & 4.5 & 4.6525 & TRN & \\
\hline CHEMBL1353182 & 688889 & 5.25 & 4.6775 & TST & \\
\hline CHEMBL1607290 & 688889 & 4.25 & 4.7873 & TRN & \\
\hline CHEMBL1998118 & 688889 & 4.8 & 4.6816 & TRN & \\
\hline CHEMBL1423608 & 688889 & 4.3 & 4.9547 & TRN & \\
\hline CHEMBL1611081 & 688889 & 4.4 & 4.7648 & TST & \\
\hline CHEMBL1528046 & 688889 & 4.45 & 4.9058 & TRN & \\
\hline CHEMBL1412617 & 688889 & 4.25 & 4.7645 & TRN & \\
\hline CHEMBL1562873 & 688889 & 4.55 & 4.632 & TRN & \\
\hline CHEMBL1603132 & 688889 & 4.35 & 4.7892 & TRN & \\
\hline CHEMBL1470076 & 688889 & 4.3 & 4.7949 & TRN & \\
\hline CHEMBL1581558 & 688889 & 5.2 & 4.8696 & TRN & \\
\hline CHEMBL1583696 & 688889 & 4.3 & 4.8763 & TRN & \\
\hline CHEMBL1406945 & 688889 & 4.6 & 4.6562 & TRN & \\
\hline CHEMBL1423657 & 688889 & 4.25 & 4.7445 & TRN & \\
\hline CHEMBL1371148 & 688889 & 4.45 & 4.8063 & TRN & \\
\hline
\end{tabular}




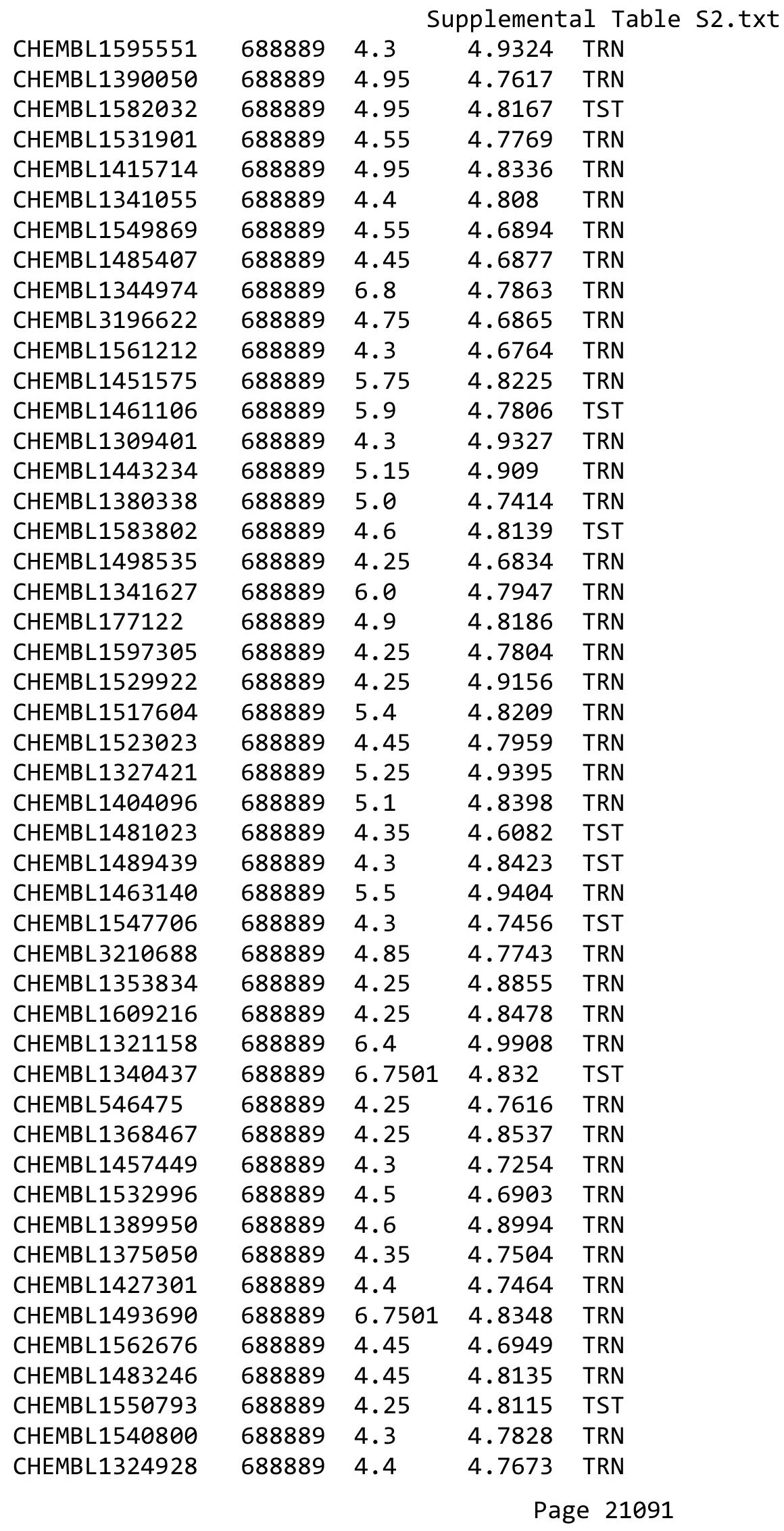




\begin{tabular}{|c|c|c|c|c|}
\hline \multirow[b]{2}{*}{ CHEMBL1566698 } & \multicolumn{4}{|c|}{ Supplemental Table S2.txt } \\
\hline & 688889 & 4.3 & 4.7824 & TRN \\
\hline CHEMBL1537583 & 688889 & 4.35 & 4.7782 & TRN \\
\hline CHEMBL1451107 & 688889 & 4.95 & 4.8097 & TRN \\
\hline CHEMBL1457324 & 688889 & 4.95 & 4.8574 & TRN \\
\hline CHEMBL1589491 & 688889 & 5.15 & 4.8276 & TRN \\
\hline CHEMBL1312203 & 688889 & 4.45 & 4.5889 & TRN \\
\hline CHEMBL1483907 & 688889 & 4.7 & 4.8051 & TRN \\
\hline CHEMBL1602312 & 688889 & 4.95 & 4.8753 & TRN \\
\hline CHEMBL1462142 & 688889 & 4.35 & 4.7464 & TRN \\
\hline CHEMBL1301731 & 688889 & 4.8 & 4.7262 & TRN \\
\hline CHEMBL1480388 & 688889 & 6.05 & 4.7398 & TRN \\
\hline CHEMBL1537894 & 688889 & 4.35 & 4.8536 & TRN \\
\hline CHEMBL 3207782 & 688889 & 4.3 & 4.6565 & TRN \\
\hline CHEMBL1346069 & 688889 & 4.4 & 4.7657 & TRN \\
\hline CHEMBL1340264 & 688889 & 5.0 & 4.7966 & TRN \\
\hline CHEMBL1577461 & 688889 & 5.0 & 4.7839 & TRN \\
\hline CHEMBL1575166 & 688889 & 4.55 & 4.7371 & TRN \\
\hline CHEMBL1488609 & 688889 & 6.1 & 4.9223 & TRN \\
\hline CHEMBL1522917 & 688889 & 4.95 & 4.8423 & TST \\
\hline CHEMBL1482175 & 688889 & 4.45 & 4.7634 & TRN \\
\hline CHEMBL1466078 & 688889 & 4.5 & 4.9135 & TRN \\
\hline CHEMBL203606 & 688889 & 4.3 & 4.8933 & TST \\
\hline CHEMBL 3193716 & 688889 & 6.8 & 4.8215 & TRN \\
\hline CHEMBL1501601 & 688889 & 4.9 & 4.8164 & TRN \\
\hline CHEMBL1325473 & 688889 & 4.95 & 4.8412 & TRN \\
\hline CHEMBL1465239 & 688889 & 4.25 & 4.8247 & TRN \\
\hline CHEMBL1543095 & 688889 & 4.75 & 4.9724 & TST \\
\hline CHEMBL1466411 & 688889 & 6.5501 & 4.7434 & TRN \\
\hline CHEMBL1517049 & 688889 & 4.95 & 4.769 & TRN \\
\hline CHEMBL1579934 & 688889 & 6.7501 & 4.8422 & TRN \\
\hline CHEMBL1305505 & 688889 & 5.15 & 4.7392 & TST \\
\hline CHEMBL1521067 & 688889 & 6.8 & 4.6675 & TST \\
\hline CHEMBL1386030 & 688889 & 4.3 & 4.822 & TST \\
\hline CHEMBL1369848 & 688889 & 5.75 & 4.7392 & TRN \\
\hline CHEMBL1360767 & 688889 & 4.55 & 4.7308 & TRN \\
\hline CHEMBL1492253 & 688889 & 6.0 & 4.8773 & TRN \\
\hline CHEMBL1573600 & 688889 & 4.4 & 4.8072 & TRN \\
\hline CHEMBL1379718 & 688889 & 4.55 & 4.7075 & TST \\
\hline CHEMBL1518920 & 688889 & 4.5 & 4.8209 & TST \\
\hline CHEMBL 3190368 & 688889 & 4.4 & 4.7799 & TST \\
\hline CHEMBL1498973 & 688889 & 4.85 & 4.7095 & TRN \\
\hline CHEMBL1319307 & 688889 & 5.85 & 4.8422 & TRN \\
\hline CHEMBL1324796 & 688889 & 4.45 & 4.7158 & TRN \\
\hline CHEMBL1449075 & 688889 & 4.25 & 4.7525 & TST \\
\hline CHEMBL1302077 & 688889 & 5.25 & 4.8189 & TRN \\
\hline CHEMBL1594442 & 688889 & 4.9 & 4.8528 & TRN \\
\hline CHEMBL165188 & 688889 & 4.9 & 4.8996 & TRN \\
\hline CHEMBL1563440 & 688889 & 5.2 & 4.7396 & TRN \\
\hline
\end{tabular}




\begin{tabular}{|c|c|c|c|c|c|}
\hline \multicolumn{6}{|c|}{ Supplemental Table S2.txt } \\
\hline CHEMBL1430660 & 688889 & 4.4 & 4.6579 & TRN & \\
\hline CHEMBL1485593 & 688889 & 4.3 & 4.7305 & TST & \\
\hline CHEMBL3209094 & 688889 & 4.3 & 4.761 & TRN & \\
\hline CHEMBL 3214401 & 688889 & 5.2 & 4.9274 & TRN & \\
\hline CHEMBL1336602 & 688889 & 4.3 & 4.6761 & TST & \\
\hline CHEMBL3210407 & 688889 & 4.35 & 4.8623 & TRN & \\
\hline CHEMBL1521983 & 688889 & 5.25 & 4.8746 & TRN & \\
\hline CHEMBL1601545 & 688889 & 4.4 & 4.6628 & TRN & \\
\hline CHEMBL1568497 & 688889 & 4.3 & 4.8056 & TRN & \\
\hline CHEMBL1544712 & 688889 & 4.45 & 4.84699 & 99999999995 & TST \\
\hline CHEMBL1505150 & 688889 & 4.45 & 4.788 & TRN & \\
\hline CHEMBL3196768 & 688889 & 6.1 & 4.7905 & TST & \\
\hline CHEMBL1524805 & 688889 & 4.4 & 4.7528 & TRN & \\
\hline CHEMBL1330425 & 688889 & 4.45 & 4.6983 & TRN & \\
\hline CHEMBL1570236 & 688889 & 6.8 & 4.9203 & TRN & \\
\hline CHEMBL1425630 & 688889 & 5.2 & 4.8832 & TRN & \\
\hline CHEMBL1492663 & 688889 & 4.3 & 4.8746 & TRN & \\
\hline CHEMBL1567088 & 688889 & 4.9 & 4.9304 & TRN & \\
\hline CHEMBL1546364 & 688889 & 4.45 & 4.7881 & TRN & \\
\hline CHEMBL1546916 & 688889 & 4.9 & 4.7676 & TRN & \\
\hline CHEMBL1387007 & 688889 & 5.2 & 4.8041 & TST & \\
\hline CHEMBL1412368 & 688889 & 4.25 & 4.8559 & TRN & \\
\hline CHEMBL1451016 & 688889 & 4.3 & 4.7143 & TRN & \\
\hline CHEMBL1363964 & 688889 & 5.7 & 4.8546 & TRN & \\
\hline CHEMBL1365949 & 688889 & 4.4 & 4.7388 & TRN & \\
\hline CHEMBL1408872 & 688889 & 4.25 & 4.6857 & TST & \\
\hline CHEMBL1309369 & 688889 & 4.25 & 4.8695 & TRN & \\
\hline CHEMBL1456826 & 688889 & 4.7 & 4.8247 & TRN & \\
\hline CHEMBL1506655 & 688889 & 5.5 & 4.8327 & TST & \\
\hline CHEMBL1530512 & 688889 & 4.45 & 4.8505 & TRN & \\
\hline CHEMBL1306326 & 688889 & 4.95 & 4.793 & TST & \\
\hline CHEMBL1494974 & 688889 & 4.55 & 4.8418 & TRN & \\
\hline CHEMBL1603490 & 688889 & 4.3 & 4.8388 & TRN & \\
\hline CHEMBL1509904 & 688889 & 6.7001 & 4.7363 & TST & \\
\hline CHEMBL1385634 & 688889 & 4.5 & 4.7369 & TRN & \\
\hline CHEMBL1543063 & 688889 & 4.5 & 4.7716 & TST & \\
\hline CHEMBL1409588 & 688889 & 4.55 & 4.9253 & TRN & \\
\hline CHEMBL1393186 & 688889 & 4.3 & 4.7559 & TST & \\
\hline CHEMBL1470579 & 688889 & 4.35 & 4.864 & TST & \\
\hline CHEMBL1983549 & 688889 & 4.95 & 4.698 & TRN & \\
\hline CHEMBL1393494 & 688889 & 4.45 & 4.8889 & TST & \\
\hline CHEMBL1448835 & 688889 & 6.2 & 4.7193 & TRN & \\
\hline CHEMBL1345733 & 688889 & 5.3 & 4.6747 & TST & \\
\hline CHEMBL3197677 & 688889 & 4.75 & 4.8123 & TST & \\
\hline CHEMBL1549448 & 688889 & 4.45 & 4.8022 & TST & \\
\hline CHEMBL1409507 & 688889 & 4.45 & 4.7585 & TST & \\
\hline CHEMBL1369107 & 688889 & 4.3 & 4.9433 & TRN & \\
\hline CHEMBL1439754 & 688889 & 4.4 & 4.7252 & TRN & \\
\hline
\end{tabular}




\begin{tabular}{|c|c|c|c|c|c|}
\hline \multicolumn{6}{|c|}{ Supplemental Table s2.txt } \\
\hline CHEMBL1587017 & 688889 & 4.75 & 4.8744 & TRN & \\
\hline CHEMBL1329764 & 688889 & 4.25 & 4.7368 & TRN & \\
\hline CHEMBL1427979 & 688889 & 4.4 & 4.7519 & TRN & \\
\hline CHEMBL1349049 & 688889 & 4.25 & 4.8644 & TRN & \\
\hline CHEMBL1402442 & 688889 & 4.45 & 4.7031 & TRN & \\
\hline CHEMBL560832 & 688889 & 6.35 & 4.7557 & TRN & \\
\hline CHEMBL1587396 & 688889 & 5.15 & 4.6969 & TST & \\
\hline CHEMBL1417530 & 688889 & 5.35 & 4.7623 & TRN & \\
\hline CHEMBL1566072 & 688889 & 4.45 & 4.8732 & TRN & \\
\hline CHEMBL1429039 & 688889 & 4.3 & 4.7468 & TRN & \\
\hline CHEMBL1519852 & 688889 & 4.3 & 4.7106 & TRN & \\
\hline CHEMBL1603191 & 688889 & 4.8 & 4.7199 & TRN & \\
\hline CHEMBL1342093 & 688889 & 4.3 & 4.8506 & TST & \\
\hline CHEMBL1538502 & 688889 & 4.95 & 4.8239 & TST & \\
\hline CHEMBL1311672 & 688889 & 4.55 & 4.7645 & TRN & \\
\hline CHEMBL1439402 & 688889 & 5.6 & 4.7897 & TST & \\
\hline CHEMBL1594182 & 688889 & 5.15 & 4.6382 & TST & \\
\hline CHEMBL3192659 & 688889 & 6.15 & 4.7418 & TRN & \\
\hline CHEMBL1400197 & 688889 & 4.3 & 4.8247 & TST & \\
\hline CHEMBL1603787 & 688889 & 4.45 & 4.9447 & TST & \\
\hline CHEMBL1419398 & 688889 & 4.25 & 4.8439 & TRN & \\
\hline CHEMBL1555675 & 688889 & 4.3 & 4.816 & TRN & \\
\hline CHEMBL1465481 & 688889 & 4.6 & 4.953 & TRN & \\
\hline CHEMBL1382476 & 688889 & 4.3 & 4.7732 & TST & \\
\hline CHEMBL1432243 & 688889 & 4.55 & 4.765 & TRN & \\
\hline CHEMBL1444392 & 688889 & 5.3 & 4.7043 & TRN & \\
\hline CHEMBL 3193943 & 688889 & 4.35 & 4.8051 & TRN & \\
\hline CHEMBL1313343 & 688889 & 5.2 & 4.845 & TRN & \\
\hline CHEMBL1451345 & 688889 & 4.3 & 4.8711 & TRN & \\
\hline CHEMBL1529671 & 688889 & 4.55 & 4.6836 & TRN & \\
\hline CHEMBL1521551 & 688889 & 4.55 & 4.8492 & TRN & \\
\hline CHEMBL1601060 & 688889 & 4.4 & 4.6677 & TRN & \\
\hline CHEMBL1586318 & 688889 & 4.95 & 4.81800 & 00000000005 & TRN \\
\hline CHEMBL1445336 & 688889 & 6.7501 & 4.7503 & TRN & \\
\hline CHEMBL1412625 & 688889 & 5.25 & 4.878 & TST & \\
\hline CHEMBL1578587 & 688889 & 5.45 & 4.854 & TRN & \\
\hline CHEMBL1362030 & 688889 & 4.95 & 4.7497 & TST & \\
\hline CHEMBL1429882 & 688889 & 4.6 & 4.7603 & TRN & \\
\hline CHEMBL1517079 & 688889 & 6.7501 & 4.9449 & TRN & \\
\hline CHEMBL1507438 & 688889 & 4.4 & 4.7078 & TRN & \\
\hline CHEMBL532412 & 688889 & 4.35 & 4.7902 & TST & \\
\hline CHEMBL1538514 & 688889 & 4.6 & 4.9621 & TRN & \\
\hline CHEMBL1571456 & 688889 & 4.9 & 4.7071 & TRN & \\
\hline CHEMBL1588488 & 688889 & 4.45 & 4.626 & TRN & \\
\hline CHEMBL1307871 & 688889 & 4.3 & 4.7749 & TST & \\
\hline CHEMBL 3197226 & 688889 & 4.45 & 4.7069 & TST & \\
\hline CHEMBL1584754 & 688889 & 4.75 & 4.6833 & TST & \\
\hline CHEMBL1604563 & 688889 & 4.25 & 4.8815 & TRN & \\
\hline
\end{tabular}




\begin{tabular}{|c|c|c|c|c|c|}
\hline & & \\
\hline CHEMBL1334472 & 688889 & 4.3 & 4.7375 & TRN & \\
\hline CHEMBL1402288 & 688889 & 4.5 & 4.7937 & TRN & \\
\hline CHEMBL1602985 & 688889 & 4.4 & 4.7254 & TRN & \\
\hline CHEMBL1544693 & 688889 & 4.55 & 4.7223 & TRN & \\
\hline CHEMBL3199579 & 688889 & 4.5 & 4.7787 & TRN & \\
\hline CHEMBL1372378 & 688889 & 5.0 & 4.7429 & TRN & \\
\hline CHEMBL1321674 & 688889 & 4.35 & 4.8132 & TRN & \\
\hline CHEMBL1376894 & 688889 & 4.8 & 4.7375 & TRN & \\
\hline CHEMBL1482413 & 688889 & 5.15 & 4.7952 & TST & \\
\hline CHEMBL1565749 & 688889 & 4.75 & 4.7926 & TST & \\
\hline CHEMBL1500500 & 688889 & 4.95 & 4.7155 & TRN & \\
\hline CHEMBL1311277 & 688889 & 4.3 & 4.9326 & TRN & \\
\hline CHEMBL 1448030 & 688889 & 5.0 & 4.7793 & TRN & \\
\hline CHEMBL1391573 & 688889 & 4.5 & 4.8938 & TRN & \\
\hline CHEMBL1365867 & 688889 & 4.95 & 4.8271 & TRN & \\
\hline CHEMBL1423108 & 688889 & 4.3 & 4.9378 & TRN & \\
\hline CHEMBL1516850 & 688889 & 4.45 & 4.6772 & TRN & \\
\hline CHEMBL1539237 & 688889 & 4.25 & 4.7962 & TRN & \\
\hline CHEMBL1999648 & 688889 & 4.55 & 4.70100 & 00000000005 & TST \\
\hline CHEMBL1576921 & 688889 & 5.3 & 5.0187 & TRN & \\
\hline CHEMBL1609428 & 688889 & 4.55 & 4.64199 & 99999999995 & TRN \\
\hline CHEMBL1303674 & 688889 & 5.4 & 4.8598 & TST & \\
\hline CHEMBL1570997 & 688889 & 6.8 & 4.8643 & TRN & \\
\hline CHEMBL1466624 & 688889 & 4.4 & 4.9372 & TRN & \\
\hline CHEMBL1538427 & 688889 & 4.55 & 4.7966 & TRN & \\
\hline CHEMBL1577130 & 688889 & 4.45 & 4.8687 & TRN & \\
\hline CHEMBL605753 & 688889 & 4.3 & 4.649 & TRN & \\
\hline CHEMBL1448053 & 688889 & 5.05 & 4.7939 & TRN & \\
\hline CHEMBL1498759 & 688889 & 5.05 & 4.8017 & TRN & \\
\hline CHEMBL1407197 & 688889 & 4.95 & 4.6097 & TST & \\
\hline CHEMBL1325487 & 688889 & 5.85 & 4.7702 & TST & \\
\hline CHEMBL1464184 & 688889 & 5.35 & 4.9751 & TRN & \\
\hline CHEMBL1517459 & 688889 & 4.45 & 4.8507 & TRN & \\
\hline CHEMBL1439427 & 688889 & 5.5 & 4.7595 & TRN & \\
\hline CHEMBL1371394 & 688889 & 4.9 & 4.7569 & TRN & \\
\hline CHEMBL1558716 & 688889 & 5.0 & 4.8818 & TRN & \\
\hline CHEMBL1405081 & 688889 & 4.45 & 4.7446 & TRN & \\
\hline CHEMBL1504802 & 688889 & 4.3 & 4.8111 & TST & \\
\hline CHEMBL1375191 & 688889 & 4.25 & 4.8888 & TST & \\
\hline CHEMBL3211851 & 688889 & 4.3 & 4.7358 & TST & \\
\hline CHEMBL3189467 & 688889 & 4.25 & 4.7688 & TST & \\
\hline CHEMBL1562898 & 688889 & 5.6 & 4.8397 & TRN & \\
\hline CHEMBL1569562 & 688889 & 4.35 & 4.9172 & TRN & \\
\hline CHEMBL3927931 & 1620781 & 4.2457 & 3.82 & TRN & \\
\hline CHEMBL3927428 & 1620781 & 4.8861 & 4.5586 & TRN & \\
\hline CHEMBL3889910 & 1620781 & 4.8928 & 4.2113 & TST & \\
\hline CHEMBL3917925 & 1620781 & 4.2823 & 4.7558 & TRN & \\
\hline CHEMBL 3896200 & 1620781 & 3.2218 & 3.2357 & TRN & \\
\hline
\end{tabular}

Page 21095 
Supplemental Table S2.txt

\begin{tabular}{|c|c|c|c|c|c|}
\hline CHEMBL 3942565 & 1620781 & 4.4895 & \multicolumn{2}{|c|}{4.946000000000001} & TRN \\
\hline CHEMBL3919019 & 1620781 & 3.2218 & 3.8227 & TRN & \\
\hline CHEMBL 3896287 & 1620781 & 4.4763 & 4.3489 & TRN & \\
\hline CHEMBL 3942151 & 1620781 & 3.2218 & 3.2078 & TRN & \\
\hline CHEMBL 3977013 & 1620781 & 4.2933 & 3.8537 & TRN & \\
\hline CHEMBL3968509 & 1620781 & 4.3665 & 3.8484 & TRN & \\
\hline CHEMBL3982285 & 1620781 & 4.8182 & 4.5873 & TRN & \\
\hline CHEMBL 3923140 & 1620781 & 3.2218 & 3.1261 & TRN & \\
\hline CHEMBL 3898833 & 1620781 & 4.3883 & 4.4807 & TRN & \\
\hline CHEMBL 3976940 & 1620781 & 3.2218 & 3.2694 & TST & \\
\hline CHEMBL 3906327 & 1620781 & 3.2218 & 4.0095 & TRN & \\
\hline CHEMBL3942219 & 1620781 & 4.5686 & 4.4744 & TRN & \\
\hline CHEMBL 3929010 & 1620781 & 4.2233 & 3.6056 & TRN & \\
\hline CHEMBL 3892752 & 1620781 & 4.433 & 3.2126 & TST & \\
\hline CHEMBL 3908735 & 1620781 & 5.1135 & \multicolumn{2}{|c|}{4.236000000000001} & TST \\
\hline CHEMBL 3950874 & 1620781 & 3.2218 & 3.2036 & TRN & \\
\hline CHEMBL3924215 & 1620781 & 4.4498 & 3.1309 & TST & \\
\hline CHEMBL3910092 & 1620781 & 3.2218 & 3.5708 & TRN & \\
\hline CHEMBL 3979294 & 1620781 & 4.2882 & 4.3504 & TRN & \\
\hline CHEMBL 3975455 & 1620781 & 5.2291 & 4.5991 & TRN & \\
\hline CHEMBL3935984 & 1620781 & 3.2218 & 3.0253 & TRN & \\
\hline CHEMBL3964849 & 1620781 & 3.2218 & \multicolumn{2}{|c|}{ 3.4419999999999997 } & TRN \\
\hline CHEMBL 3893304 & 1620781 & 5.301 & 4.7104 & TRN & \\
\hline CHEMBL 3902292 & 1620781 & 4.3242 & 4.6447 & TRN & \\
\hline CHEMBL 3914150 & 1620781 & 3.2495 & 3.0692 & TRN & \\
\hline CHEMBL3967787 & 1620781 & 3.2218 & 3.6011 & TRN & \\
\hline CHEMBL3907853 & 1620781 & 4.4283 & \multicolumn{2}{|c|}{4.4510000000000005} & TST \\
\hline CHEMBL3897361 & 1620781 & 3.2218 & 3.8722 & TRN & \\
\hline CHEMBL3956454 & 1620781 & 4.2388 & 4.5026 & TRN & \\
\hline CHEMBL 3966677 & 1620781 & 4.2464 & 3.8458 & TRN & \\
\hline CHEMBL3946588 & 1620781 & 4.6925 & 4.8629 & TRN & \\
\hline CHEMBL3936929 & 1620781 & 5.2757 & 4.3091 & TRN & \\
\hline CHEMBL3930268 & 1620781 & 3.2218 & \multicolumn{2}{|c|}{3.9819999999999998} & TRIV \\
\hline CHEMBL 3901044 & 1620781 & 3.2218 & 3.6668 & TRN & \\
\hline CHEMBL 3926885 & 1620781 & 4.8041 & 4.5135 & TRN & \\
\hline CHEMBL 3921300 & 1620781 & 4.5086 & 4.6255 & TST & \\
\hline CHEMBL 3940635 & 1620781 & 4.8125 & 4.2784 & TST & \\
\hline CHEMBL3946976 & 1620781 & 4.5918 & 4.2595 & TST & \\
\hline CHEMBL 3928972 & 1620781 & 4.8239 & 4.5504 & TST & \\
\hline CHEMBL3935815 & 1620781 & 4.6003 & 4.4874 & TST & \\
\hline CHEMBL 3933164 & 1620781 & 3.2218 & 3.0351 & TRN & \\
\hline CHEMBL3939259 & 1620781 & 3.2218 & 4.3763 & TST & \\
\hline CHEMBL 3946833 & 1620781 & 4.5331 & 4.1122 & TRN & \\
\hline CHEMBL 3955540 & 1620781 & 3.2218 & 3.9485 & TRN & \\
\hline CHEMBL 3946922 & 1620781 & 4.2757 & 4.5433 & TST & \\
\hline CHEMBL 3967808 & 1641299 & 6.0 & 6.0553 & TRN & \\
\hline CHEMBL 3946017 & 1641299 & 8.6576 & 8.8377 & TRN & \\
\hline CHEMBL 3979841 & 1641299 & 8.6383 & 8.5916 & TRN & \\
\hline
\end{tabular}

Page 21096 
Supplemental Table S2.txt

\begin{tabular}{|c|c|c|c|c|}
\hline CHEMBL3899967 & 1641299 & 8.3098 & 8.4742 & TRN \\
\hline CHEMBL3954661 & 1641299 & 8.585 & 8.5034 & TRN \\
\hline CHEMBL 3938321 & 1641299 & 8.3565 & 8.2329 & TST \\
\hline CHEMBL3906025 & 1641299 & 8.7696 & 8.6301 & TRN \\
\hline CHEMBL 3890390 & 1641299 & 8.301 & 8.5259 & TST \\
\hline CHEMBL 3935682 & 1641299 & 7.5086 & 7.5379 & TRN \\
\hline CHEMBL 3945962 & 1641299 & 7.4437 & 7.4038 & TRN \\
\hline CHEMBL 3962512 & 1641299 & 8.1308 & 8.06200 & 0000000001 \\
\hline CHEMBL3923738 & 1641299 & 7.4318 & 7.3535 & TST \\
\hline CHEMBL 3958205 & 1641299 & 6.0 & 6.0168 & TRN \\
\hline CHEMBL 3980227 & 1641299 & 7.6576 & 7.6749 & TRN \\
\hline CHEMBL 3946180 & 1641299 & 8.1612 & 8.0339 & TST \\
\hline CHEMBL 3913819 & 1641299 & 8.2007 & 8.0022 & TRN \\
\hline CHEMBL 3967681 & 1641299 & 8.0969 & 8.0033 & TRN \\
\hline CHEMBL 3922467 & 1641299 & 7.8539 & 7.8423 & TST \\
\hline CHEMBL 3945106 & 1641299 & 7.5229 & 7.3178 & TRN \\
\hline CHEMBL 3906694 & 1641299 & 7.6198 & 7.5172 & TRN \\
\hline CHEMBL 3952955 & 1641299 & 8.3188 & 8.4511 & TRN \\
\hline CHEMBL 3903413 & 1641299 & 8.4318 & 8.3846 & TRN \\
\hline CHEMBL3896646 & 1641299 & 7.5376 & 7.4607 & TRN \\
\hline CHEMBL3941534 & 1641299 & 8.3279 & 8.4532 & TRN \\
\hline CHEMBL 3905576 & 1641299 & 8.6576 & 8.8881 & TST \\
\hline CHEMBL 3934010 & 1641299 & 8.0458 & 7.9794 & TRN \\
\hline CHEMBL 3941558 & 1641299 & 8.5376 & 8.4895 & TRN \\
\hline CHEMBL 3929278 & 1641299 & 6.0 & 5.997006 & 000000001 \\
\hline CHEMBL3940680 & 1641299 & 7.6383 & 7.6427 & TRN \\
\hline CHEMBL 3901053 & 1641299 & 7.8861 & 7.8632 & TRN \\
\hline CHEMBL 3903608 & 1641299 & 8.4559 & 8.2573 & TRN \\
\hline CHEMBL 3907098 & 1641299 & 8.3468 & 8.4745 & TRN \\
\hline CHEMBL 3940667 & 1641299 & 8.4815 & 8.5228 & TRN \\
\hline CHEMBL 3915462 & 1641299 & 8.9208 & 8.9582 & TRN \\
\hline CHEMBL3970132 & 1641299 & 8.2291 & 8.2384 & TRN \\
\hline CHEMBL 3911144 & 1641299 & 8.1249 & 8.2514 & TRN \\
\hline CHEMBL 3948086 & 1641299 & 7.301 & 7.3821 & TST \\
\hline CHEMBL3978992 & 1641299 & 7.3098 & 7.4074 & TRN \\
\hline CHEMBL 3935279 & 1641299 & 8.2924 & 8.3029 & TRN \\
\hline CHEMBL 3929280 & 1641299 & 8.3188 & 8.4736 & TST \\
\hline CHEMBL 3889552 & 1641299 & 8.1024 & 7.7227 & TST \\
\hline CHEMBL 3963660 & 1641299 & 8.2924 & 8.2982 & TRN \\
\hline CHEMBL 3926257 & 1641299 & 8.3768 & 8.3391 & TRN \\
\hline CHEMBL 3981505 & 1641299 & 8.2596 & 8.3232 & TRN \\
\hline CHEMBL 3960183 & 1641299 & 8.2291 & 8.2417 & TRN \\
\hline CHEMBL 3897778 & 1641299 & 8.1612 & 8.174 & TRN \\
\hline CHEMBL 3951818 & 1641299 & 8.6198 & 8.5353 & TRN \\
\hline CHEMBL3939179 & 1641299 & 7.7696 & 7.8144 & TRN \\
\hline CHEMBL 3909662 & 1641299 & 8.3468 & 8.2039 & TRN \\
\hline CHEMBL 3902852 & 1641299 & 6.0 & 5.9966 & TRN \\
\hline CHEMBL 3949178 & 1641299 & 6.0 & 5.9837 & TRN \\
\hline
\end{tabular}


Supplemental Table S2.txt

\begin{tabular}{|c|c|c|c|c|}
\hline 962 & 541299 & & & \\
\hline & 641299 & 8.3872 & 8.4183 & \\
\hline & 541299 & 6.0 & & \\
\hline IEMBL: & 541299 & 4949 & & \\
\hline AEMBL3 & 541299 & 6198 & & \\
\hline AEMBL3914699 & 641299 & 7.9208 & 429 & \\
\hline IEMBL & 299 & 383 & & \\
\hline EMBL & 299 & & & \\
\hline HEMBL397 & 641299 & 7.8239 & & \\
\hline AEMBL3968720 & 641299 & 8.5376 & & \\
\hline AEMBL 3971534 & 299 & 3565 & & \\
\hline IEMBL395 & 299 & & & \\
\hline EMBL & & & & \\
\hline AEMBL396 & 299 & & 388 & \\
\hline HEMBL394 & 299 & 55 & & \\
\hline AEMBL394 & 64 & 586 & & \\
\hline IEMBL395 & 99 & 89 & & \\
\hline IEMBL 389 & 99 & & & \\
\hline IEMBL393 & 299 & & & \\
\hline IEMBL & 99 & 86 & & \\
\hline IEMBL & 6 & 8 & & \\
\hline EMB & 9 & 47 & & \\
\hline EMB & 99 & 12 & & \\
\hline 57 & & 372 & & \\
\hline IEMBL3 & & & & \\
\hline IEMBL & 6 & 47 & & S \\
\hline EMBL & 99 & & & \\
\hline EMB & 99 & 37 & & \\
\hline IEMBL & 16 & & & \\
\hline IEMBL 397 & 62 & 778 & & 1 \\
\hline AEMBL & 16 & & & \\
\hline 8 & 16 & 86 & & \\
\hline AEMBL394 & 99 & 08 & & \\
\hline AEMBL 3930640 & 16 & 269 & & \\
\hline AEMBL3981158 & 64 & 979 & & RI \\
\hline IEMBL & 16 & 202 & & \\
\hline 36 & & & & \\
\hline & & & & \\
\hline AEMBL 3956927 & 62 & 605 & & \\
\hline IEMBL3 & t. & 665 & & \\
\hline AEMBL: & 9 & & & \\
\hline HEMBL & & 576 & & \\
\hline HEMBL3895806 & 299 & 7.6383 & & \\
\hline AEMBL3929078 & 29 & 8.4685 & & \\
\hline 17 & & 132 & & $=$ \\
\hline CHEMBL3978542 & & & & \\
\hline CHEMBL3962111 & a & & 7.1686 & \\
\hline CHEMBL3965623 & 164129 & 8.3768 & 8.3668 & \\
\hline
\end{tabular}

Page 21098 
Supplemental Table S2.txt

\begin{tabular}{|c|c|c|c|c|}
\hline - & 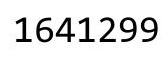 & & & \\
\hline HEMBL3892547 & 641299 & 8.2757 & 8.1876 & \\
\hline & 299 & & & \\
\hline 333 & 299 & 7447 & & \\
\hline AEMBL3908021 & 541299 & 8.3979 & 5346 & \\
\hline HEMBL3985657 & 641299 & 8.585 & 5402 & \\
\hline HEMBL397 & 641299 & 5778 & 7604 & \\
\hline AFMBI: & 299 & 383 & 384 & \\
\hline AEMBL39 & 299 & 8.9208 & 8777 & \\
\hline AEMBL3939023 & 299 & 8.8861 & 8105 & \\
\hline HEMBL3960437 & 299 & 7.2291 & 0958 & \\
\hline AEMBL3980692 & 299 & 8.7212 & 3619 & \\
\hline AEMBL39 & & & & \\
\hline HEMBL3S & 299 & 861 & 09 & \\
\hline AEMBL3979654 & 299 & 15 & 4857 & \\
\hline AEMBL3964596 & 299 & 36 & .06 & \\
\hline HEMBL39 & 299 & 78 & 3423 & \\
\hline HEMBL39 & 299 & & & \\
\hline HEMBL 39 & 299 & & 8919 & \\
\hline HEMBL 397 & 299 & & & ST \\
\hline AEMBL395903/ & 299 & 55 & 08 & $|\mathrm{R}|$ \\
\hline HEMBL39 & 299 & & 668 & \\
\hline HEMBL3S & & & & \\
\hline 53 & & 6 & & RN \\
\hline AEMBL3S & 99 & & 67 & ГRN \\
\hline L3s & & & 39 & ST \\
\hline 13898 & 9 & & 48 & RN \\
\hline 3 & & & & RN \\
\hline AEMBL3S & & & & RN \\
\hline AEMBL3S & 99 & & 06 & SI \\
\hline AEMBL3S & & 7 & 339 & RN \\
\hline 23 & & & & KIV \\
\hline HEN & & & & RN \\
\hline HEMBL3930550 & 99 & & & RN \\
\hline HEMBL3925209 & 99 & 565 & 374 & RN \\
\hline HEMBL393. & 99 & 09 & & \\
\hline HEMRI 38 & 99 & & & RN \\
\hline HEMBL3913474 & & & & TST \\
\hline HEMBL3953262 & 299 & 7.9586 & 3525 & TST \\
\hline AEMBL39626 & 99 & 208 & 163 & RN \\
\hline HEMBL 3940626 & 299 & 586 & 238 & -3 \\
\hline HEMBL3947402 & & & & RN \\
\hline HEMBL3901790 & 299 & 7.7212 & 7265 & TRN \\
\hline HEMBL3902656 & 299 & 18 & 1374 & $\Gamma R$ \\
\hline IEMBL3948 & & & & \\
\hline HEMBL 3985971 & 16 & & & \\
\hline CHEMBL3915250 & 299 & & 785 & \\
\hline CHEMBL3920850 & 1641299 & 7.7212 & 7.8542 & ГRN \\
\hline
\end{tabular}

Page 21099 
Supplemental Table S2.txt

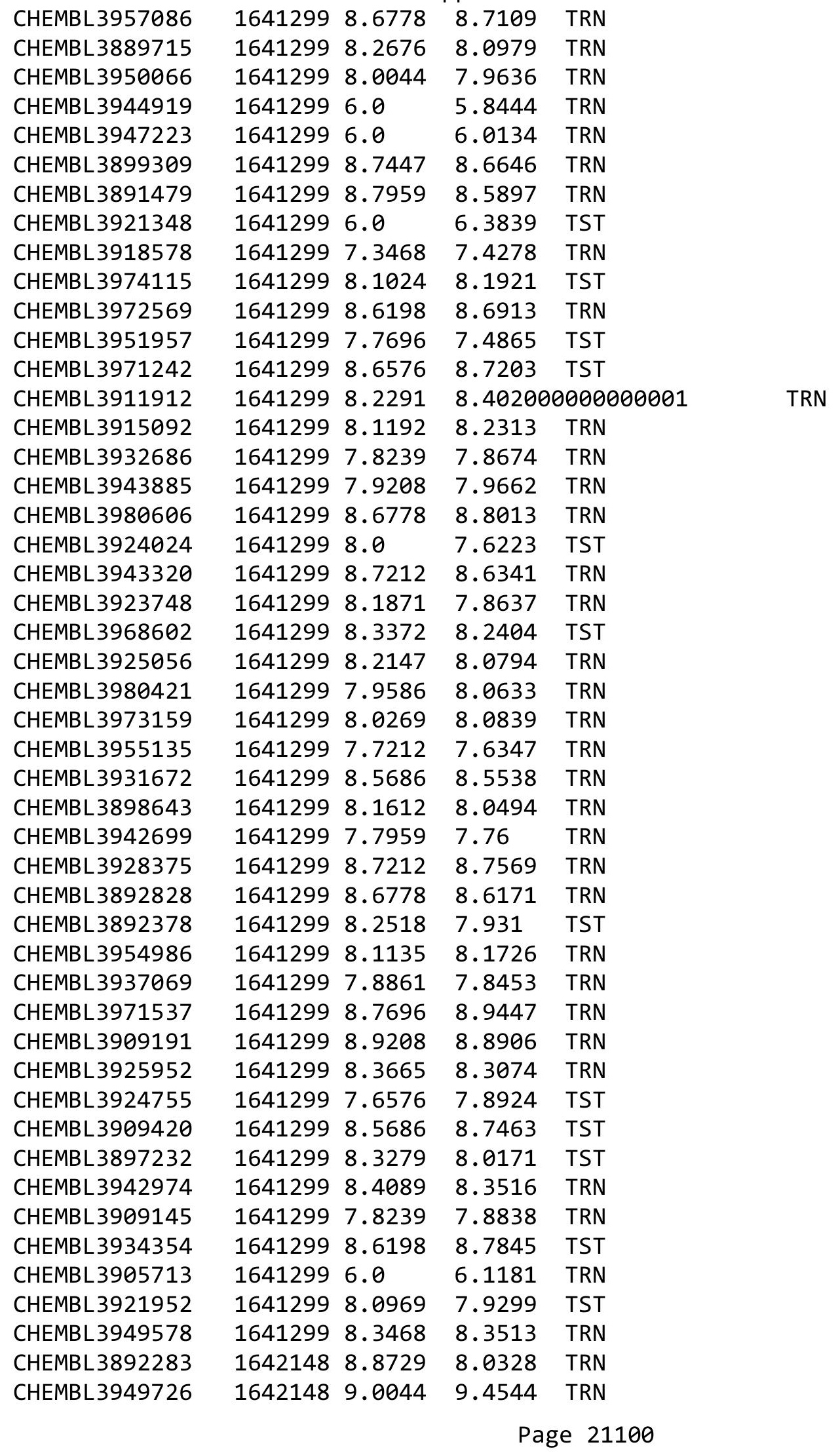


Supplemental Table S2.txt

\begin{tabular}{|c|c|c|c|c|c|c|}
\hline CHEMBL3931229 & 1642148 & 7.4417 & 7.8935 & TRN & & \\
\hline CHEMBL3953049 & 1642148 & 8.0675 & 8.1369 & TRN & & \\
\hline CHEMBL3962892 & 1642148 & 9.4202 & 9.3477 & TRN & & \\
\hline CHEMBL3907945 & 1642148 & 6.9197 & 6.6067 & TRN & & \\
\hline CHEMBL3950860 & 1642148 & 8.2125 & 9.0894 & TRN & & \\
\hline CHEMBL3931867 & 1642148 & 8.5918 & 7.5516 & TRN & & \\
\hline CHEMBL3956686 & 1642148 & 5.3898 & 6.6815 & TST & & \\
\hline CHEMBL3961705 & 1642148 & 8.9747 & 9.1999 & TRN & & \\
\hline CHEMBL3945328 & 1642148 & 6.8002 & 6.9682 & TRN & & \\
\hline CHEMBL3941651 & 1642148 & 7.5222 & 7.2393 & TST & & \\
\hline CHEMBL3935214 & 1642148 & 8.5607 & 8.9242 & TRN & & \\
\hline CHEMBL3908247 & 1642148 & 7.7828 & 7.1772 & TRN & & \\
\hline CHEMBL3978591 & 1642148 & 8.2328 & 8.5753 & TRN & & \\
\hline CHEMBL3967943 & 1642148 & 8.451 & 8.9885 & TRN & & \\
\hline CHEMBL3897054 & 1642148 & 7.7298 & 8.1253 & TRN & & \\
\hline CHEMBL3986929 & 1642148 & 8.3215 & 7.6957 & TRN & & \\
\hline CHEMBL3944483 & 1642148 & 7.1244 & 7.1129 & TRN & & \\
\hline CHEMBL3922030 & 1642148 & \multicolumn{3}{|c|}{11.300999999999998} & 9.3902 & TRN \\
\hline CHEMBL3972269 & 1642148 & 9.2518 & 9.3022 & TST & & \\
\hline CHEMBL3959324 & 1642148 & 9.6383 & 9.106 & TRN & & \\
\hline CHEMBL3957192 & 1642148 & 8.7799 & 8.3268 & TRN & & \\
\hline CHEMBL3903266 & 1642148 & 5.3893 & 5.5423 & TRN & & \\
\hline CHEMBL 3930228 & 1642148 & 5.3839 & 5.2045 & TRN & & \\
\hline CHEMBL3983517 & 1642148 & 7.1253 & 7.0385 & TRN & & \\
\hline CHEMBL3907069 & 1642148 & 10.1549 & 9.2507 & TRN & & \\
\hline CHEMBL3964855 & 1642148 & 8.3799 & 8.1973 & TRN & & \\
\hline CHEMBL3976704 & 1642148 & 9.8239 & 9.355 & TST & & \\
\hline CHEMBL 3890260 & 1642148 & 10.5229 & 9.9135 & TRN & & \\
\hline CHEMBL3895836 & 1642148 & 9.0362 & \multicolumn{3}{|c|}{9.597000000000001} & TRN \\
\hline CHEMBL 3925857 & 1642148 & 8.5918 & \multicolumn{3}{|c|}{8.312000000000001} & TST \\
\hline CHEMBL3982389 & 1642148 & 6.9817 & 8.0119 & TRN & & \\
\hline CHEMBL3916853 & 1642148 & 7.4742 & 7.2261 & TST & & \\
\hline CHEMBL3905352 & 1642148 & 6.5262 & 7.0676 & TST & & \\
\hline CHEMBL 3894288 & 1642148 & 8.3215 & 8.5189 & TST & & \\
\hline CHEMBL 3948120 & 1642148 & 10.0458 & 9.1127 & TRN & & \\
\hline CHEMBL 3898485 & 1642148 & 8.0376 & 7.9721 & TRN & & \\
\hline CHEMBL3958053 & 1642148 & 7.0641 & 7.5526 & TRN & & \\
\hline CHEMBL 3973665 & 1642148 & \multicolumn{3}{|c|}{6.9670000000000005} & 7.1207 & TRN \\
\hline CHEMBL3978709 & 1642148 & 7.7131 & 7.9003 & TRN & & \\
\hline CHEMBL3963118 & 1642148 & 6.0 & 6.7403 & TRN & & \\
\hline CHEMBL3977845 & 1642148 & 7.0453 & 7.4083 & TRN & & \\
\hline CHEMBL3900349 & 1642148 & 8.1319 & 7.6817 & TRN & & \\
\hline CHEMBL3960611 & 1642148 & 5.466 & 6.3006 & TRN & & \\
\hline CHEMBL3892932 & 1642148 & 9.1612 & 9.7184 & TRN & & \\
\hline CHEMBL3929758 & 1642148 & 5.3533 & 6.9556 & TRN & & \\
\hline CHEMBL3906434 & 1642148 & 5.3802 & 6.3241 & TST & & \\
\hline CHEMBL3910869 & 1642148 & 9.5086 & 9.6136 & TRN & & \\
\hline CHEMBL3897184 & 1642148 & 10.0969 & 9.8254 & TRN & & \\
\hline
\end{tabular}

Page 21101 
Supplemental Table S2.txt

\begin{tabular}{|c|c|c|c|c|c|c|}
\hline CHEMBL3928483 & 1642148 & 9.0605 & 9.8833 & TST & & \\
\hline CHEMBL3946381 & 1642148 & 8.8477 & 9.1963 & TRN & & \\
\hline CHEMBL3978860 & 1642148 & 8.982999 & 999999999 & & 9.1968 & TRN \\
\hline CHEMBL3942702 & 1642148 & 8.8539 & 9.227 & TRN & & \\
\hline CHEMBL3922172 & 1642148 & 8.1046 & 8.2029 & TRN & & \\
\hline CHEMBL3940340 & 1642148 & 8.5575 & 8.9014 & TRN & & \\
\hline CHEMBL3909421 & 1642148 & 7.8202 & 7.0941 & TRN & & \\
\hline CHEMBL3973209 & 1642148 & 8.5258 & 8.2305 & TRN & & \\
\hline CHEMBL3901809 & 1642148 & 8.4449 & 8.7941 & TRN & & \\
\hline CHEMBL3955015 & 1642148 & 7.8088 & 7.8366 & TRN & & \\
\hline CHEMBL3958265 & 1642148 & 8.9031 & 8.7685 & TRN & & \\
\hline CHEMBL3957815 & 1642148 & 7.0047 & 7.4218 & TRN & & \\
\hline CHEMBL3906303 & 1642148 & 6.0 & 6.7313 & TRN & & \\
\hline CHEMBL3917345 & 1642148 & 7.8681 & 7.5966 & TRN & & \\
\hline CHEMBL3931901 & 1642148 & 9.7447 & 9.079 & TRN & & \\
\hline CHEMBL3984533 & 1642148 & 5.388 & 6.3828 & TRN & & \\
\hline CHEMBL3928432 & 1642148 & 9.3372 & 9.9366 & TRN & & \\
\hline CHEMBL3986369 & 1642148 & 8.7747 & 7.5126 & TST & & \\
\hline CHEMBL3973668 & 1642148 & 9.1739 & 9.7372 & TRN & & \\
\hline CHEMBL3920143 & 1642148 & 8.0958 & 8.6517 & TST & & \\
\hline CHEMBL3929340 & 1642148 & 8.1029 & 8.3064 & TRN & & \\
\hline CHEMBL3931085 & 1642148 & 7.1014 & 7.1757 & TRN & & \\
\hline CHEMBL3969517 & 1642148 & 8.6421 & 7.8378 & TST & & \\
\hline CHEMBL 3904844 & 1642148 & 8.3116 & 6.902 & TST & & \\
\hline CHEMBL3947813 & 1642148 & 7.0411 & 7.5442 & TRN & & \\
\hline CHEMBL3959898 & 1642148 & 9.5686 & 9.6183 & TRN & & \\
\hline CHEMBL3929617 & 1642148 & 7.758999 & 999999999 & 995 & 7.63899 & 9999999999 \\
\hline CHEMBL3922589 & 1642148 & 5.3623 & 6.8596 & TST & & \\
\hline CHEMBL3958586 & 1642148 & 10.30099 & 999999999 & 998 & 9.2837 & TRN \\
\hline CHEMBL3930953 & 1642148 & 7.2371 & 7.4812 & TRN & & \\
\hline CHEMBL3890976 & 1642148 & 6.574 & 6.2858 & TRN & & \\
\hline CHEMBL3916545 & 1642148 & 9.9586 & 8.6369 & TRN & & \\
\hline CHEMBL3908281 & 1642148 & 7.627999 & 999999999 & 99 & 6.9088 & TRN \\
\hline CHEMBL3973762 & 1642148 & 8.5784 & 9.6735 & TRN & & \\
\hline CHEMBL3957332 & 1642148 & 8.5406 & 8.9637 & TRN & & \\
\hline CHEMBL3958750 & 1642148 & 7.3316 & 8.0954 & TST & & \\
\hline CHEMBL3927413 & 1642148 & 7.5914 & 7.732 & TRN & & \\
\hline CHEMBL3913707 & 1642148 & 5.3503 & 5.4832 & TRN & & \\
\hline CHEMBL3968405 & 1642148 & 9.1427 & 9.4852 & TRN & & \\
\hline CHEMBL3924765 & 1642148 & 10.0969 & 9.3494 & TRN & & \\
\hline CHEMBL3960524 & 1642148 & 9.2291 & 8.414 & TRN & & \\
\hline CHEMBL3899207 & 1642148 & 8.699 & 9.2902 & TRN & & \\
\hline CHEMBL3912555 & 1642148 & 8.0701 & 8.2343 & TST & & \\
\hline CHEMBL3958935 & 1642148 & 10.2218 & 8.9846 & TRN & & \\
\hline CHEMBL3960366 & 1642148 & 7.5355 & 7.7676 & TRN & & \\
\hline CHEMBL3986853 & 1642148 & 5.3933 & 5.9938 & TRN & & \\
\hline CHEMBL3973727 & 1642148 & 9.8861 & 8.1928 & TRN & & \\
\hline CHEMBL3944060 & 1642148 & 10.0 & 8.675 & TRN & & \\
\hline
\end{tabular}


Supplemental Table S2.txt

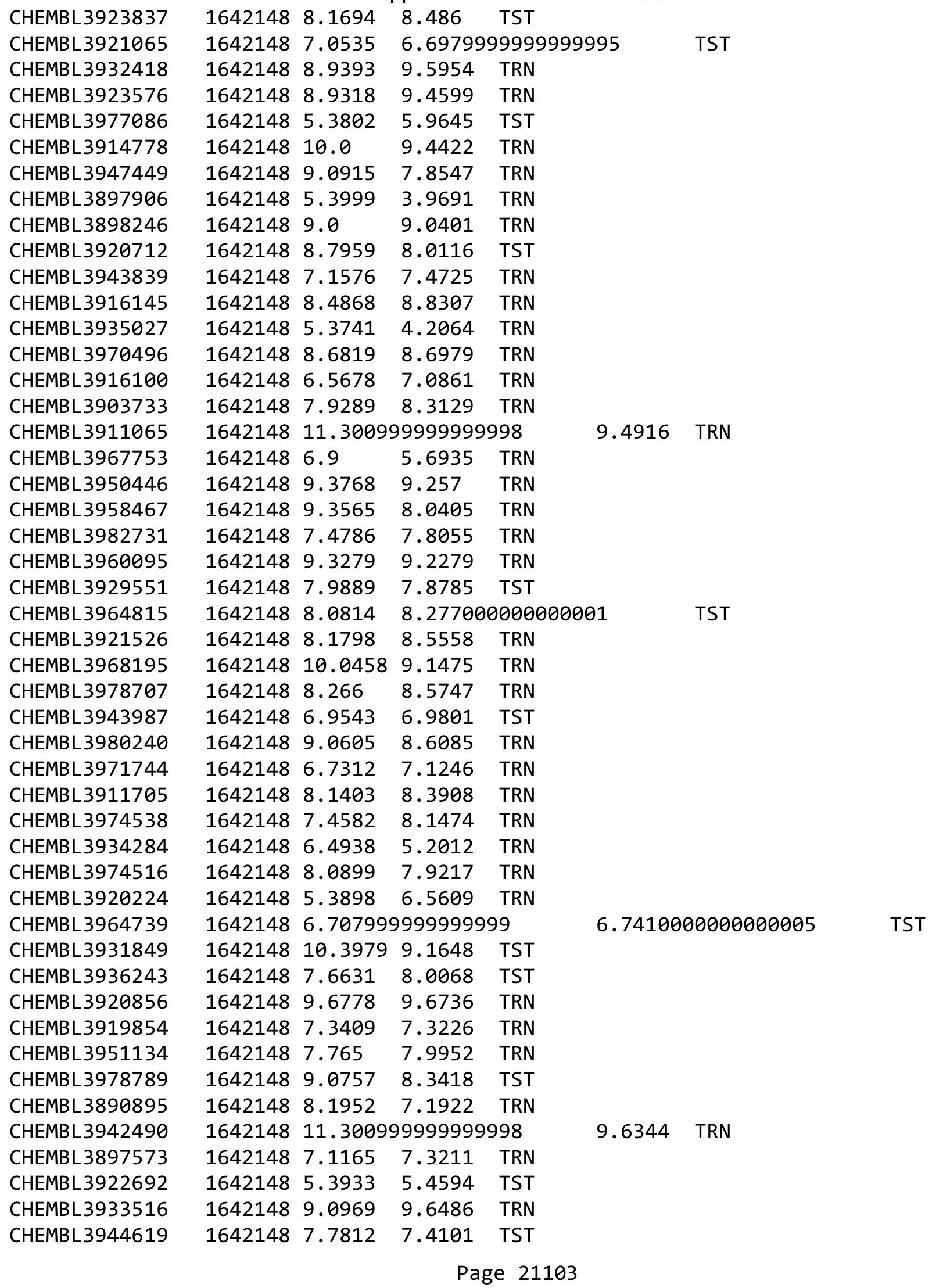




\begin{tabular}{|c|c|c|c|c|c|}
\hline \multicolumn{6}{|c|}{ Supplemental Table S2.txt } \\
\hline CHEMBL3938635 & 1642148 & 5.466 & 5.8099 & TRN & \\
\hline CHEMBL3914929 & 1642148 & 8.7423 & 9.1551 & TRN & \\
\hline CHEMBL3905504 & 1642148 & 8.3429 & 9.001 & TST & \\
\hline CHEMBL3955069 & 1642148 & 10.2218 & 8.3494 & TST & \\
\hline CHEMBL3963203 & 1642148 & 6.3218 & 6.2011 & TST & \\
\hline CHEMBL3899364 & 1642148 & 6.0 & 6.3269 & TST & \\
\hline CHEMBL3935215 & 1642148 & 10.0458 & 9.8504 & TRN & \\
\hline CHEMBL3939516 & 1642148 & 8.6946 & 9.2343 & TRN & \\
\hline CHEMBL 3972874 & 1642148 & 8.6108 & 7.5073 & TRN & \\
\hline CHEMBL3941032 & 1642148 & 7.7617 & 7.855 & TRN & \\
\hline CHEMBL3901782 & 1642148 & 9.699 & 9.4915 & TST & \\
\hline CHEMBL 3904738 & 1642148 & 5.3802 & 6.2681 & TST & \\
\hline CHEMBL3964476 & 1642148 & 10.0458 & 8.6259 & TRN & \\
\hline CHEMBL 3938387 & 1642148 & 7.3963 & 7.0816 & TST & \\
\hline CHEMBL3950625 & 1642148 & 5.3397 & 7.3979 & TRN & \\
\hline CHEMBL3939754 & 1642148 & 9.2076 & 8.6763 & TRN & \\
\hline CHEMBL3893940 & 1642148 & 9.3468 & 9.6304 & TRN & \\
\hline CHEMBL3940739 & 1642148 & 7.1596 & 7.8693 & TST & \\
\hline CHEMBL3920016 & 1642148 & 8.9914 & 9.2251 & TST & \\
\hline CHEMBL3949751 & 1642148 & 7.3436 & 7.2563 & TRN & \\
\hline CHEMBL3986590 & 1642148 & 10.30099 & 79999999 & 9.846 & TST \\
\hline CHEMBL3923005 & 1642148 & 8.5719 & 8.4781 & TRN & \\
\hline CHEMBL3914701 & 1642148 & 9.2518 & 9.3115 & TST & \\
\hline CHEMBL3984222 & 1642148 & 7.3007 & 7.4262 & TRN & \\
\hline CHEMBL3985285 & 1642148 & 5.3752 & 7.0652 & TRN & \\
\hline CHEMBL3914403 & 1642148 & 7.7433 & 7.9278 & TST & \\
\hline CHEMBL 3964200 & 1642148 & 9.2596 & 9.4406 & TST & \\
\hline CHEMBL3980772 & 1642148 & 7.7567 & 8.0612 & TRN & \\
\hline CHEMBL 3912747 & 1642148 & 8.3507 & 8.3688 & TRN & \\
\hline CHEMBL3917115 & 1642148 & 5.3724 & 5.7953 & TRN & \\
\hline CHEMBL3936195 & 1642148 & 7.8639 & 8.344 & TRN & \\
\hline CHEMBL 3957981 & 1642148 & 6.5782 & 6.9699 & TRN & \\
\hline CHEMBL3898613 & 1642148 & 7.1765 & 8.0115 & TRN & \\
\hline CHEMBL3969958 & 1642148 & 7.3443 & 7.6564 & TRN & \\
\hline CHEMBL3985650 & 1642148 & 6.8342 & 6.8716 & TRN & \\
\hline CHEMBL3916367 & 1642148 & 9.0088 & 8.8993 & TST & \\
\hline CHEMBL 3893241 & 1642148 & 9.7696 & 8.5973 & TRN & \\
\hline CHEMBL3978918 & 1642148 & 9.6383 & 8.5427 & TRN & \\
\hline CHEMBL3938650 & 1642148 & 7.3604 & 8.8958 & TRN & \\
\hline CHEMBL3976326 & 1642148 & 6.8545 & 6.656006 & 0000000001 & TST \\
\hline CHEMBL3917085 & 1642148 & 8.4802 & 7.3353 & TRN & \\
\hline CHEMBL3952811 & 1642148 & 6.0 & 8.058 & TRN & \\
\hline CHEMBL3985861 & 1642148 & 8.8827 & 9.2535 & TST & \\
\hline CHEMBL3948880 & 1642148 & 6.5201 & 7.137006 & 00000000005 & TST \\
\hline CHEMBL3936185 & 1642148 & 7.449 & 6.8367 & TRN & \\
\hline CHEMBL3950501 & 1642148 & 6.4883 & 6.5393 & TRN & \\
\hline CHEMBL 3943647 & 1642148 & 7.6087 & 8.7911 & TST & \\
\hline CHEMBL3948542 & 1642148 & 7.1185 & 7.7524 & TRN & \\
\hline
\end{tabular}


Supplemental Table S2.txt

\begin{tabular}{|c|c|c|c|c|c|}
\hline CHEMBL3933933 & 1642148 & 7.0062 & 7.3366 & TRN & \\
\hline CHEMBL3983718 & 1642148 & 8.0191 & 7.9244 & TST & \\
\hline CHEMBL3928560 & 1642148 & 5.359 & 7.1886 & TRN & \\
\hline CHEMBL3946379 & 1642148 & 8.6144 & 9.1877 & TRN & \\
\hline CHEMBL3916701 & 1642148 & 7.3223 & 7.535 & TST & \\
\hline CHEMBL3966036 & 1642148 & 8.8239 & 9.4241 & TRN & \\
\hline CHEMBL3920775 & 1642148 & 8.4425 & 8.5693 & TST & \\
\hline CHEMBL3931467 & 1642148 & 8.5638 & 8.005 & TRN & \\
\hline CHEMBL3955175 & 1642148 & 6.9927 & 7.1885 & TRN & \\
\hline CHEMBL3902693 & 1642148 & 6.8908 & 7.0092 & TRN & \\
\hline CHEMBL3937047 & 1642468 & 9.0969 & 8.9944 & TRN & \\
\hline CHEMBL3936013 & 1642468 & 9.585 & 8.9489 & TRN & \\
\hline CHEMBL3965173 & 1642468 & 8.9208 & 9.0342 & TRN & \\
\hline CHEMBL3936282 & 1642468 & 9.3098 & 8.8985 & TRN & \\
\hline CHEMBL3911610 & 1642468 & 8.9208 & 9.008 & TRN & \\
\hline CHEMBL3928656 & 1642468 & 8.9586 & 8.7069 & TRN & \\
\hline CHEMBL3920691 & 1642468 & 8.9586 & 8.8234 & TRN & \\
\hline CHEMBL3944954 & 1642468 & 9.3188 & 9.2011 & TRN & \\
\hline CHEMBL3910433 & 1642468 & 6.0 & 9.0045 & TRN & \\
\hline CHEMBL3945070 & 1642468 & 9.0706 & 8.8376 & TRN & \\
\hline CHEMBL3954687 & 1642468 & 9.0362 & 8.2781 & TST & \\
\hline CHEMBL3897827 & 1642468 & 8.7447 & 8.9461 & TRN & \\
\hline CHEMBL 3984448 & 1642468 & 8.1079 & 7.962006 & 0000000001 & TRN \\
\hline CHEMBL3902536 & 1642468 & 9.2676 & 8.8087 & TRN & \\
\hline CHEMBL3952711 & 1642468 & 7.7959 & 8.1754 & TRN & \\
\hline CHEMBL3969138 & 1642468 & 9.5086 & 9.1702 & TRN & \\
\hline CHEMBL3973207 & 1642468 & 9.301 & 9.0264 & TRN & \\
\hline CHEMBL3893536 & 1642468 & 7.9208 & 8.9323 & TRN & \\
\hline CHEMBL3930964 & 1642468 & 9.1308 & 8.7097 & TRN & \\
\hline CHEMBL3905678 & 1642468 & 9.3279 & 8.1223 & TST & \\
\hline CHEMBL3896029 & 1642468 & 7.6021 & 8.1231 & TST & \\
\hline CHEMBL3940463 & 1642468 & 6.0 & 8.9345 & TRN & \\
\hline CHEMBL3949233 & 1642468 & 9.0458 & 8.4831 & TRN & \\
\hline CHEMBL3967656 & 1642468 & 8.6383 & 8.4575 & TST & \\
\hline CHEMBL3949698 & 1642468 & 9.0362 & 8.8883 & TST & \\
\hline CHEMBL3941342 & 1642468 & 8.9208 & 8.6516 & TRN & \\
\hline CHEMBL3918847 & 1642468 & 9.5086 & 8.874 & TRN & \\
\hline CHEMBL3972165 & 1642468 & 9.9208 & 8.7998 & TRN & \\
\hline CHEMBL3912247 & 1642468 & 8.699 & 8.2177 & TRN & \\
\hline CHEMBL3921648 & 1642468 & 9.9586 & 9.1159 & TRN & \\
\hline CHEMBL3917899 & 1642468 & 8.041 & 8.0458 & TRN & \\
\hline CHEMBL3891260 & 1642468 & 8.0 & 8.0626 & TST & \\
\hline CHEMBL3917898 & 1642468 & 9.2757 & 8.6388 & TRN & \\
\hline CHEMBL3944660 & 1642468 & 8.3188 & 8.1484 & TST & \\
\hline CHEMBL3918118 & 1642468 & 9.1249 & 8.8619 & TRN & \\
\hline CHEMBL3959122 & 1642468 & 8.6576 & 8.4763 & TST & \\
\hline CHEMBL3966796 & 1642468 & 8.5376 & 8.916 & TRN & \\
\hline CHEMBL3979787 & 1642468 & 8.3565 & 8.5468 & TST & \\
\hline
\end{tabular}




\begin{tabular}{|c|c|c|c|c|c|}
\hline \multirow[b]{2}{*}{ CHEMBL3983206 } & \multicolumn{5}{|c|}{ Supplemental Table S2.txt } \\
\hline & 1642468 & 9.041 & 8.9337 & TRN & \\
\hline CHEMBL3915791 & 1642468 & 9.0 & 8.1755 & TST & \\
\hline CHEMBL3938164 & 1642468 & 8.6778 & 8.6204 & TRN & \\
\hline CHEMBL 3909923 & 1642468 & 7.7447 & 8.7209 & TST & \\
\hline CHEMBL 3958084 & 1642468 & 9.6778 & 9.155 & TRN & \\
\hline CHEMBL3937839 & 1642468 & 7.9208 & 8.1709 & TST & \\
\hline CHEMBL3913649 & 1642468 & 9.0506 & 8.9944 & TST & \\
\hline CHEMBL3937512 & 1642468 & 8.301 & 8.0839 & TRN & \\
\hline CHEMBL3938733 & 1642468 & 9.0655 & 8.8392 & TRN & \\
\hline CHEMBL3958357 & 1642468 & 8.6778 & 9.0247 & TRN & \\
\hline CHEMBL3965717 & 1642468 & 8.0 & 8.0664 & TST & \\
\hline CHEMBL3927333 & 1642468 & 9.301 & 8.9689 & TRN & \\
\hline CHEMBL3984139 & 1642468 & 8.9586 & 8.8923 & TRN & \\
\hline CHEMBL3965651 & 1642468 & 6.0 & 8.7946 & TRN & \\
\hline CHEMBL3986517 & 1642468 & 8.5229 & 8.56 & TRN & \\
\hline CHEMBL3966724 & 1642468 & 8.7959 & 8.5492 & TST & \\
\hline CHEMBL3918232 & 1642468 & 8.3979 & 8.3468 & TST & \\
\hline CHEMBL3966121 & 1642468 & 9.3565 & 9.0145 & TRN & \\
\hline CHEMBL3961394 & 1642468 & 8.5229 & 8.293 & TRN & \\
\hline CHEMBL3978397 & 1642468 & 7.9586 & 8.2331 & TRN & \\
\hline CHEMBL3912474 & 1642468 & 9.0269 & 8.7012 & TST & \\
\hline CHEMBL3921921 & 1642468 & 8.2076 & 9.0157 & TRN & \\
\hline CHEMBL 3981670 & 1642468 & 8.7959 & 8.8525 & TRN & \\
\hline CHEMBL 3890078 & 1642468 & 8.7959 & 8.8583 & TRN & \\
\hline CHEMBL 3934797 & 1642468 & 9.4089 & 8.9757 & TRN & \\
\hline CHEMBL3978401 & 1642468 & 8.699 & 8.7875 & TRN & \\
\hline CHEMBL3951578 & 1642468 & 10.2676 & 8.6816 & TST & \\
\hline CHEMBL3957415 & 1642468 & 8.9586 & 8.7453 & TRN & \\
\hline CHEMBL3916208 & 1642468 & 9.2218 & 9.0369 & TRN & \\
\hline CHEMBL3965190 & 1642468 & 8.8861 & 9.1035 & TRN & \\
\hline CHEMBL3957161 & 1642468 & 8.585 & 8.9793 & TRN & \\
\hline CHEMBL3929861 & 1642468 & 8.1487 & 8.5621 & TRN & \\
\hline CHEMBL3973823 & 1642468 & 8.585 & 8.1197 & TRN & \\
\hline CHEMBL 3890079 & 1642468 & 7.699 & 8.0445 & TRN & \\
\hline CHEMBL3958918 & 1642468 & 8.7959 & 8.8406 & TRN & \\
\hline CHEMBL3974107 & 1642468 & 8.585 & 8.0955 & TST & \\
\hline CHEMBL3930590 & 1642468 & 9.9586 & 9.1606 & TRN & \\
\hline CHEMBL3935706 & 1642468 & 9.0506 & 8.4797 & TST & \\
\hline CHEMBL 3974376 & 1642468 & 8.9208 & 9.1048 & TRN & \\
\hline CHEMBL3957024 & 1642468 & 9.9586 & 8.98299 & 9999999999 & TRN \\
\hline CHEMBL3904358 & 1642468 & 9.3468 & 8.7968 & TST & \\
\hline CHEMBL3894275 & 1642468 & 9.1739 & 8.3383 & TST & \\
\hline CHEMBL3901356 & 1642468 & 8.7447 & 8.3854 & TRN & \\
\hline CHEMBL 3922429 & 1642468 & 9.4559 & 8.9679 & TRN & \\
\hline CHEMBL3946008 & 1642468 & 9.3768 & 8.9822 & TRN & \\
\hline CHEMBL3929600 & 1642468 & 8.8239 & 8.6947 & TRN & \\
\hline CHEMBL3946680 & 1642468 & 10.0706 & 8.8453 & TRN & \\
\hline CHEMBL3908135 & 1642468 & 9.6383 & 8.9565 & TRN & \\
\hline
\end{tabular}

Page 21106 


\begin{tabular}{|c|c|c|c|c|c|}
\hline \multicolumn{6}{|c|}{ Supplemental Table S2.txt } \\
\hline CHEMBL 3899426 & 1642468 & 6.0 & 8.6043 & TRN & \\
\hline CHEMBL 2046475 & 826558 & 5.1675 & 5.1608 & TRN & \\
\hline CHEMBL 2046664 & 826558 & 4.0 & 3.9506 & TRN & \\
\hline CHEMBL 2046679 & 826558 & 6.5686 & 6.5929 & TRN & \\
\hline CHEMBL 2046673 & 826558 & 6.4089 & 6.1724 & TRN & \\
\hline CHEMBL 2047524 & 826558 & 6.3872 & 6.3303 & TRN & \\
\hline CHEMBL 2047505 & 826558 & 4.0 & 6.3747 & TST & \\
\hline CHEMBL 2047504 & 826558 & 4.0 & 3.9676 & TRN & \\
\hline CHEMBL 2047518 & 826558 & 6.585 & 6.6246 & TST & \\
\hline CHEMBL 2047516 & 826558 & 6.9586 & 6.942 & TRN & \\
\hline CHEMBL 2046665 & 826558 & 4.0 & 3.9906 & TRN & \\
\hline CHEMBL 2046672 & 826558 & 5.9586 & 5.8313 & TRN & \\
\hline CHEMBL1454208 & 826558 & 6.0088 & 6.1931 & TRN & \\
\hline CHEMBL 2046670 & 826558 & 5.7959 & 5.8088 & TRN & \\
\hline CHEMBL 2046680 & 826558 & 7.0969 & 6.9304 & TRN & \\
\hline CHEMBL 2047510 & 826558 & 6.7696 & 6.7637 & TRN & \\
\hline CHEMBL 2046685 & 826558 & 6.5528 & 6.6766 & TRN & \\
\hline CHEMBL 2046667 & 826558 & 6.3188 & 5.1394 & TST & \\
\hline CHEMBL 2046677 & 826558 & 6.1612 & 6.1582 & TRN & \\
\hline CHEMBL 2046668 & 826558 & 5.1079 & 4.6359 & TST & \\
\hline CHEMBL 2046682 & 826558 & 4.0 & 4.0792 & TRN & \\
\hline CHEMBL 2047517 & 826558 & 6.8539 & 6.8463 & TRN & \\
\hline CHEMBL 2047509 & 826558 & 6.2441 & 6.2169 & TRN & \\
\hline CHEMBL 2046678 & 826558 & 6.1739 & 6.3057 & TRN & \\
\hline CHEMBL 2046684 & 826558 & 6.7212 & 6.8078 & TRN & \\
\hline CHEMBL 2046666 & 826558 & 5.5686 & 5.1976 & TST & \\
\hline CHEMBL 2047508 & 826558 & 5.4949 & 5.442 & TRN & \\
\hline CHEMBL 2046681 & 826558 & 6.3768 & 6.36600 & 00000000005 & TRN \\
\hline CHEMBL 2046671 & 826558 & 4.0 & 6.2488 & TST & \\
\hline CHEMBL 2047519 & 826558 & 6.7447 & 7.8897 & TST & \\
\hline CHEMBL 2046663 & 826558 & 5.0 & 4.9848 & TRN & \\
\hline CHEMBL 2047515 & 826558 & 6.7959 & 6.6519 & TST & \\
\hline CHEMBL402146 & 826558 & 6.4202 & 6.5397 & TRN & \\
\hline CHEMBL 2047523 & 826558 & 5.3665 & 5.6061 & TRN & \\
\hline CHEMBL 2047511 & 826558 & 7.5229 & 7.5501 & TRN & \\
\hline CHEMBL 2046474 & 826558 & 5.3188 & 5.3805 & TRN & \\
\hline CHEMBL 2047520 & 826558 & 5.1427 & 5.1573 & TRN & \\
\hline CHEMBL 2046675 & 826558 & 6.585 & 6.6365 & TRN & \\
\hline CHEMBL 2046674 & 826558 & 6.4949 & 6.4345 & TRN & \\
\hline CHEMBL 2047513 & 826558 & 7.1549 & 6.2312 & TST & \\
\hline CHEMBL 2047846 & 826558 & 6.2218 & 6.0487 & TRN & \\
\hline CHEMBL 2046472 & 826558 & 4.0 & 4.0282 & TRN & \\
\hline CHEMBL 2046676 & 826558 & 5.2596 & 5.2382 & TRN & \\
\hline CHEMBL 2047512 & 826558 & 7.0969 & 7.0659 & TRN & \\
\hline CHEMBL 2046683 & 826558 & 6.4318 & 6.4977 & TRN & \\
\hline CHEMBL 2047522 & 826558 & 5.9586 & 5.9149 & TRN & \\
\hline CHEMBL 2047507 & 826558 & 5.9586 & 5.9251 & TRN & \\
\hline CHEMBL 2046669 & 826558 & 6.4202 & 6.3567 & TRN & \\
\hline
\end{tabular}

Page 21107 
Supplemental Table S2.txt

\begin{tabular}{|c|c|c|c|c|}
\hline 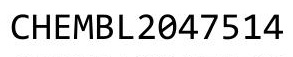 & & 9 & 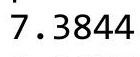 & \\
\hline HEMBL2047506 & 6558 & 8.0 & 8807 & \\
\hline HEMBL2046662 & 26558 & & & \\
\hline IEMBL 204 & & 1612 & 9292 & \\
\hline EMBL 239 & & 7696 & 1469 & \\
\hline AEMBL2391664 & 54081 & 3872 & 9008 & \\
\hline HEMBL 2391813 & 64081 & .5229 & 4479 & \\
\hline HEMBL2391668 & 54081 & .5229 & 5802 & \\
\hline 315 & 81 & 9101 & 994 & \\
\hline IEMBL23 & 881 & .9208 & & \\
\hline HEMBL2391828 & 64081 & .7696 & 7626 & \\
\hline HEMBL 2391821 & 081 & 7.4815 & 5686 & \\
\hline HEMBL179 & 081 & 86 & 642 & \\
\hline HEMBL 23S & & 84 & & \\
\hline HEMBL 23 & & & & \\
\hline HEMBL 239 & 081 & 872 & & \\
\hline HEMBL2391673 & 64081 & 8.585 & 378 & \\
\hline HEMBL 23 & 081 & 45 & 46 & \\
\hline HEMBL 23 & & & & \\
\hline HEMBL 23 & & & & \\
\hline HEMBL 23 & 081 & 12 & & \\
\hline HEMBL 239 & 64081 & 78 & 89 & \\
\hline HEMBL 23 & $\partial 81$ & 47 & 62 & \\
\hline HEMBL 23 & & & & \\
\hline 75 & & 29 & & RN \\
\hline AEMBL 23 & 81 & & & \\
\hline HEMBL132 & 54081 & 72 & 3092 & RN \\
\hline HEMBL 235 & 81 & 31 & 852 & \\
\hline 60 & & 38 & 37 & RN \\
\hline HEMBL23 & & 39 & & RN \\
\hline HEMBL 239 & & & & RN \\
\hline HEMBL2391685 & 54081 & 7.4318 & 384 & RN \\
\hline HEMBL239 & 081 & 539 & 61 & 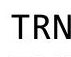 \\
\hline 2 & & & & RN \\
\hline HEMBL 23S & & & & RN \\
\hline HEMBL2391656 & & 39 & 57 & RN \\
\hline HEMBL 239 & 54081 & 7.7696 & 3546 & RN \\
\hline JEMBL239 & 81 & 98 & 944 & RN \\
\hline 2 & & & & RN \\
\hline HEMBL 239 & & & 3971 & RN \\
\hline HEMBL 239 & 881 & 872 & 336 & RN \\
\hline HEMBL 239 & & 12 & 703 & RN \\
\hline HEMBL 239 & & & & \\
\hline & & & 5845 & ST \\
\hline HEMBL2. & & & 6386 & ST \\
\hline HEMBL 239 & $\partial 81$ & 318 & 477 & RN \\
\hline 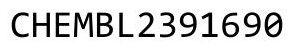 & & & & \\
\hline & & 3979 & & \\
\hline
\end{tabular}

Page 21108 
Supplemental Table S2.txt

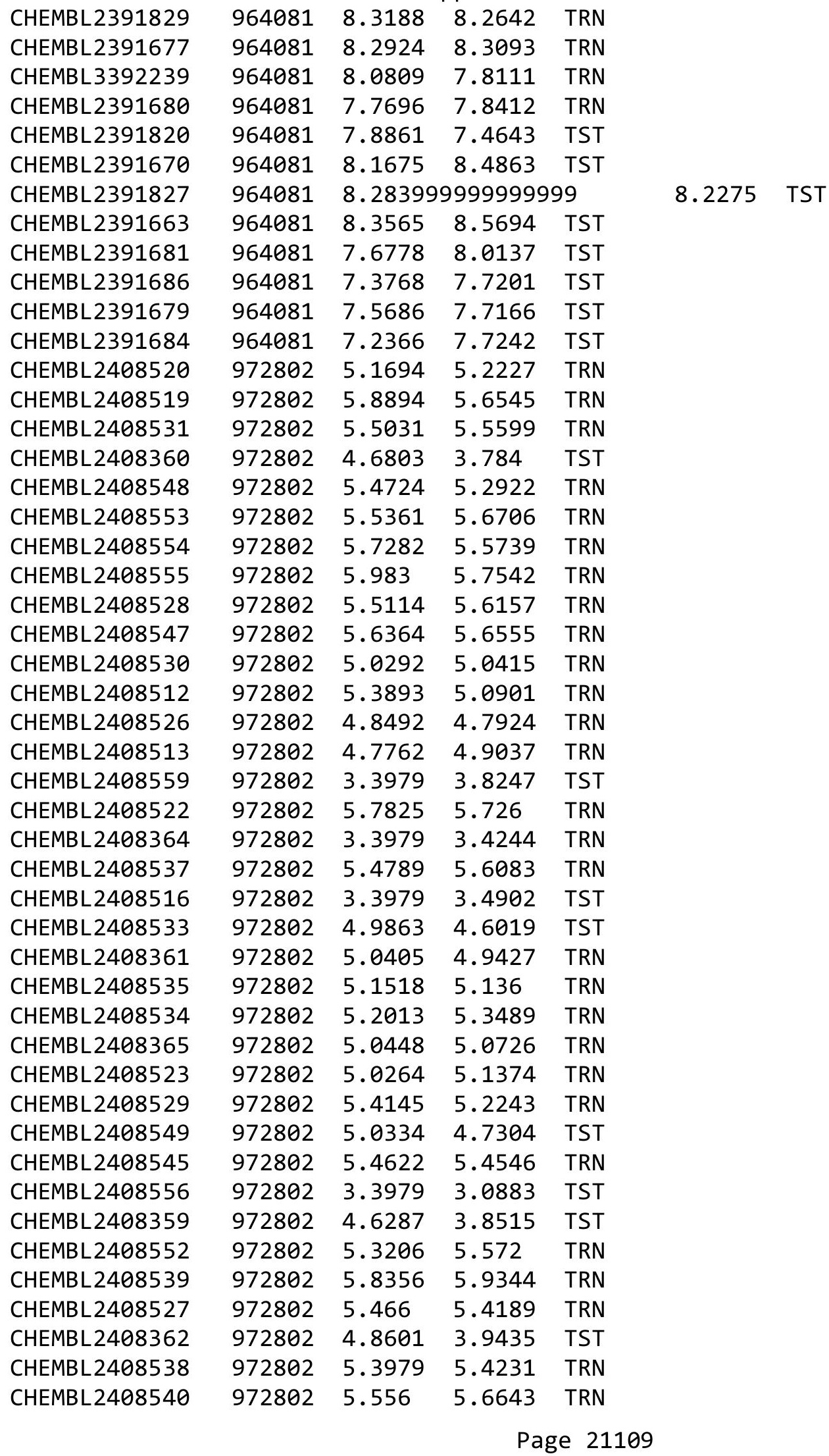


Supplemental Table S2.txt

\begin{tabular}{|c|c|c|c|c|}
\hline CHEMBL 2408543 & 972802 & 4.9296 & 4.8825 & TRN \\
\hline CHEMBL 2408517 & 972802 & 5.3478 & 5.1152 & TRN \\
\hline CHEMBL2408525 & 972802 & 4.9027 & 5.0653 & TRN \\
\hline CHEMBL 2408363 & 972802 & 4.8511 & 4.9397 & TRN \\
\hline CHEMBL 2408532 & 972802 & 5.2197 & 5.255 & TRN \\
\hline CHEMBL 2408550 & 972802 & 5.6021 & 5.4341 & TRN \\
\hline CHEMBL 2408542 & 972802 & 4.8153 & 4.0512 & TST \\
\hline CHEMBL 2408544 & 972802 & 5.6162 & 5.6887 & TRN \\
\hline CHEMBL 2408514 & 972802 & 5.4559 & 5.353 & TRN \\
\hline CHEMBL 2408541 & 972802 & 4.9248 & 4.6786 & TST \\
\hline CHEMBL 2408546 & 972802 & 5.4908 & 5.4419 & TRN \\
\hline CHEMBL 2408515 & 972802 & 5.1805 & 4.8034 & TST \\
\hline CHEMBL 2408551 & 972802 & 5.0386 & 5.1155 & TRN \\
\hline CHEMBL 2408557 & 972802 & 4.7272 & 3.8831 & TST \\
\hline CHEMBL 2408518 & 972802 & 4.5781 & 4.5598 & TRN \\
\hline CHEMBL 2408536 & 972802 & 5.3851 & 5.3929 & TRN \\
\hline CHEMBL 2408524 & 972802 & 4.8617 & 4.3821 & TST \\
\hline CHEMBL 2408521 & 972802 & 4.7894 & 5.0992 & TRN \\
\hline CHEMBL 2408558 & 972802 & 3.3979 & 2.9898 & TST \\
\hline CHEMBL591044 & 609122 & 6.4202 & 6.4244 & TRN \\
\hline CHEMBL589814 & 609122 & 8.5086 & 8.1306 & TRN \\
\hline CHEMBL600456 & 609122 & 7.3979 & 7.4987 & TRN \\
\hline CHEMBL598127 & 609122 & 8.4559 & 8.5413 & TRN \\
\hline CHEMBL597536 & 609122 & 6.2291 & 6.8247 & TRN \\
\hline CHEMBL589815 & 609122 & 8.5086 & 8.3083 & TRN \\
\hline CHEMBL606389 & 609122 & 8.4089 & 8.3968 & TRN \\
\hline CHEMBL602528 & 609122 & 6.3565 & 6.7358 & TST \\
\hline CHEMBL597323 & 609122 & 7.699 & 7.5579 & TRN \\
\hline CHEMBL597333 & 609122 & 5.8239 & 5.5237 & TRN \\
\hline CHEMBL592699 & 609122 & 7.5376 & 7.8921 & TRN \\
\hline CHEMBL598143 & 609122 & 7.2147 & 7.1136 & TRN \\
\hline CHEMBL592484 & 609122 & 7.7959 & 7.4788 & TRN \\
\hline CHEMBL607084 & 609122 & 6.4437 & 6.4444 & TRN \\
\hline CHEMBL590633 & 609122 & 7.7447 & 7.7208 & TRN \\
\hline CHEMBL597943 & 609122 & 6.0915 & 6.3765 & TRN \\
\hline CHEMBL591751 & 609122 & 5.5376 & 5.3414 & TST \\
\hline CHEMBL605763 & 609122 & 7.2441 & 7.4035 & TRN \\
\hline CHEMBL589406 & 609122 & 7.7696 & 8.16 & TRN \\
\hline CHEMBL591749 & 609122 & 6.6576 & 7.0071 & TRN \\
\hline CHEMBL605403 & 609122 & 7.2518 & 7.0152 & TRN \\
\hline CHEMBL599773 & 609122 & 8.0 & 8.3238 & TRN \\
\hline CHEMBL597942 & 609122 & 8.0757 & 7.7851 & TRN \\
\hline CHEMBL589106 & 609122 & 6.301 & 6.6674 & TST \\
\hline CHEMBL600649 & 609122 & 6.4685 & 6.1222 & TRN \\
\hline CHEMBL589576 & 609122 & 8.2676 & \multicolumn{2}{|c|}{7.917000000000001} \\
\hline CHEMBL597542 & 609122 & 5.4949 & 5.546 & TRN \\
\hline CHEMBL600845 & 609122 & 9.3188 & 8.7294 & TRN \\
\hline CHEMBL608976 & 609122 & 7.1675 & 7.5879 & TRN \\
\hline
\end{tabular}

Page 21110 


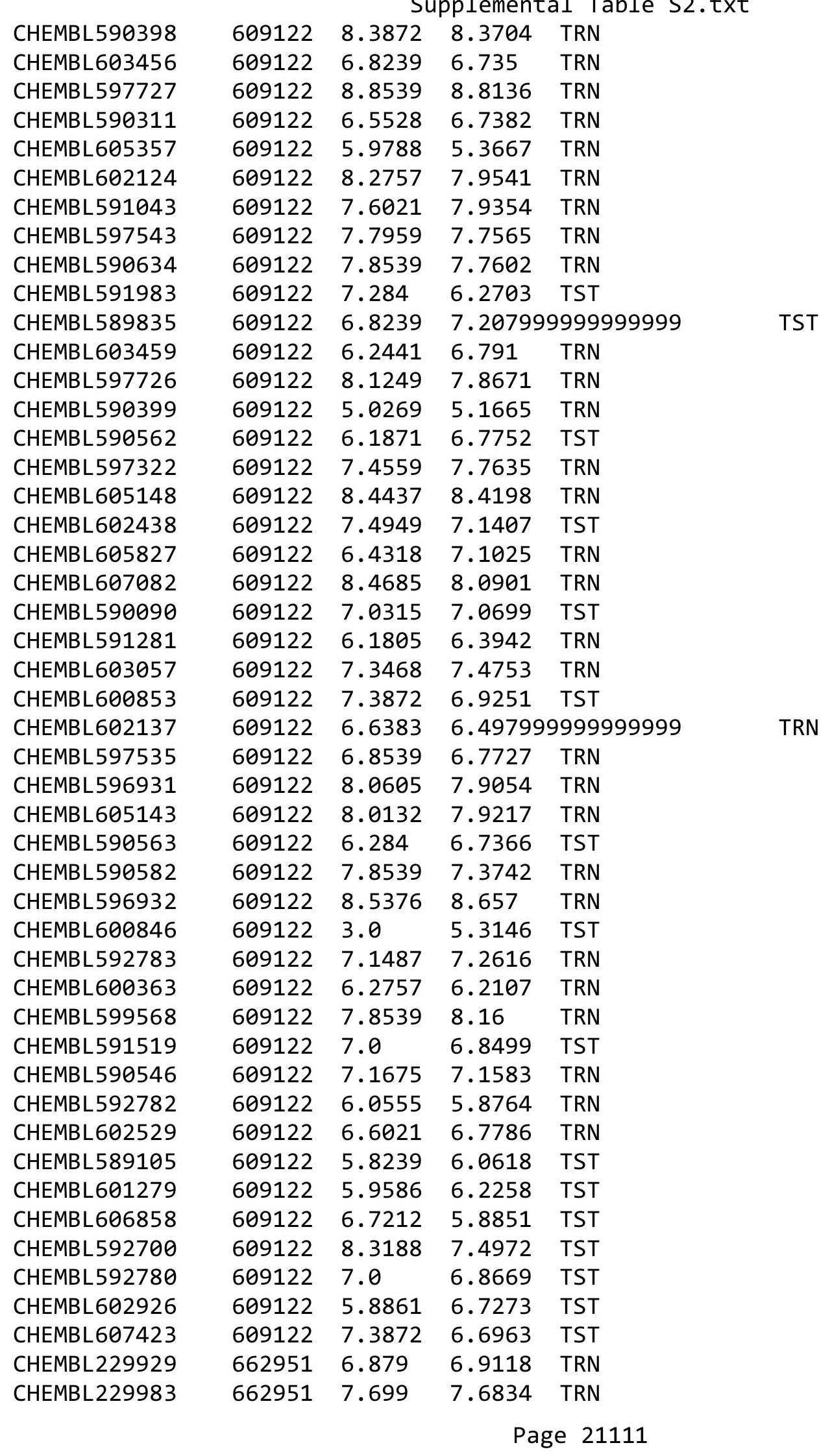




\begin{tabular}{|c|c|c|c|c|c|c|}
\hline \multirow[b]{2}{*}{ CHEMBL 389483} & \multicolumn{6}{|c|}{ Supplemental Table S2.txt } \\
\hline & 662951 & 6.428 & 6.4332 & TRN & & \\
\hline CHEMBL229504 & 662951 & 7.268 & 7.2718 & TRN & & \\
\hline CHEMBL229505 & 662951 & 7.824 & 7.7901 & TRN & & \\
\hline CHEMBL426364 & 662951 & 7.699 & 7.7639 & TRN & & \\
\hline CHEMBL389484 & 662951 & 7.319 & 7.3026 & TRN & & \\
\hline CHEMBL1253628 & 662951 & \multicolumn{3}{|c|}{6.872999999999999} & 6.874 & $\mathrm{TR}$ \\
\hline CHEMBL389517 & 662951 & 7.222 & 7.239 & TRN & & \\
\hline CHEMBL229824 & 662951 & \multicolumn{3}{|c|}{7.468999999999999} & 7.4007 & \\
\hline CHEMBL229875 & 662951 & 7.569 & 7.5348 & TRN & & \\
\hline CHEMBL229876 & 662951 & \multicolumn{3}{|c|}{7.0360000000000005} & 7.0844 & \\
\hline CHEMBL229715 & 662951 & \multicolumn{3}{|c|}{8.302999999999999} & 8.3363 & \\
\hline CHEMBL229716 & 662951 & \multicolumn{3}{|c|}{8.568999999999999} & 8.5175 & \\
\hline CHEMBL387961 & 662951 & 8.244 & 8.2884 & TRN & & \\
\hline CHEMBL426369 & 662951 & \multicolumn{3}{|c|}{8.677999999999999} & 8.5819 & TRN \\
\hline CHEMBL229767 & 662951 & \multicolumn{3}{|c|}{8.222000000000001} & 8.298 & \\
\hline CHEMBL229768 & 662951 & 8.119 & 8.0584 & TRN & & \\
\hline CHEMBL387962 & 662951 & \multicolumn{3}{|c|}{8.347000000000001} & 8.3868 & \\
\hline CHEMBL229769 & 662951 & \multicolumn{3}{|c|}{8.552999999999999} & 8.5705 & \\
\hline CHEMBL229822 & 662951 & 7.983 & 8.0036 & TRN & & \\
\hline CHEMBL1254560 & 662951 & 7.638 & 7.6608 & TRN & & \\
\hline CHEMBL1253196 & 662951 & 7.824 & 7.801 & TRN & & \\
\hline CHEMBL 1254713 & 662951 & \multicolumn{3}{|c|}{7.6579999999999995} & 7.6593 & \\
\hline CHEMBL1254714 & 662951 & 7.824 & 7.8402 & TRN & & \\
\hline CHEMBL 229665 & 662951 & 7.959 & 7.9587 & TRN & & \\
\hline CHEMBL229877 & 662951 & 8.11 & 8.1335 & TRN & & \\
\hline CHEMBL229930 & 662951 & \multicolumn{3}{|c|}{7.468999999999999} & 7.4652 & \\
\hline CHEMBL229931 & 662951 & 7.319 & 7.3083 & TRN & & \\
\hline CHEMBL434747 & 662951 & \multirow{2}{*}{\multicolumn{3}{|c|}{$\begin{array}{ll}8.387 & 7.4938 \\
7.537999999999999\end{array}$}} & & \\
\hline CHEMBL229986 & 662951 & & & & 7.2775 & \\
\hline CHEMBL375465 & 662951 & 7.745 & 7.7417 & TRN & & \\
\hline CHEMBL229178 & 662951 & \multicolumn{3}{|c|}{7.5089999999999995} & 7.5264 & \\
\hline CHEMBL229229 & 662951 & 7.678 & 7.6935 & TRN & & \\
\hline CHEMBL229981 & 662951 & \multirow{2}{*}{\multicolumn{3}{|c|}{$\begin{array}{ll}7.268 & 7.2572 \\
7.337000000000001\end{array}$}} & & \\
\hline CHEMBL375466 & 662951 & & & & 7.3315 & TP \\
\hline CHEMBL229230 & 662951 & \multicolumn{3}{|c|}{$\begin{array}{l}7.337000000000001 \\
7.886 \quad 7.8568\end{array}$} & & \\
\hline CHEMBL229988 & 662951 & 8.06 & 8.0501 & TRN & & \\
\hline CHEMBL 374843 & 662951 & 7.921 & 7.9774 & TST & & \\
\hline CHEMBL1254329 & 662951 & 8.62 & 9.2652 & TST & & \\
\hline CHEMBL 229113 & 662951 & 8.796 & 9.0183 & TST & & \\
\hline CHEMBL229171 & 662951 & 8.796 & 8.809 & TST & & \\
\hline CHEMBL374844 & 662951 & 8.721 & 8.5718 & TST & & \\
\hline CHEMBL441726 & 662951 & \multicolumn{3}{|c|}{8.357000000000001} & 8.4506 & TS \\
\hline CHEMBL 229223 & 662951 & 7.959 & 7.9503 & TRN & & \\
\hline CHEMBL425654 & 662951 & 8.921 & 8.9356 & TRN & & \\
\hline CHEMBL229285 & 662951 & 8.06 & 8.0236 & TRN & & \\
\hline CHEMBL229339 & 662951 & \multicolumn{3}{|c|}{6.742000000000001} & 6.7279 & T \\
\hline CHEMBL229870 & 662951 & 6.506 & 6.5159 & TRN & & \\
\hline \multirow[t]{2}{*}{ CHEMBL229871 } & 662951 & \multicolumn{3}{|c|}{8.142999999999999} & 8.1521 & \\
\hline & & & & & & \\
\hline
\end{tabular}




\begin{tabular}{|c|c|c|c|c|c|c|}
\hline & & \multicolumn{4}{|c|}{ Supplemental Table S2.txt } & \multirow[b]{2}{*}{ TRN } \\
\hline CHEMBL229925 & 662951 & 8.26799 & 99999999 & & 8.2352 & \\
\hline CHEMBL229926 & 662951 & 7.678 & 7.6598 & TRN & & \\
\hline CHEMBL 229979 & 662951 & 7.585 & 7.6076 & TRN & & \\
\hline CHEMBL389058 & 662951 & 8.013 & 8.0735 & TRN & & \\
\hline CHEMBL228289 & 662951 & 7.097 & 7.0666 & TRN & & \\
\hline CHEMBL 229980 & 662951 & 6.676 & 6.7032 & TRN & & \\
\hline CHEMBL389059 & 662951 & 6.53 & 6.5084 & TRN & & \\
\hline CHEMBL 388723 & 662951 & 7.824 & 7.8072 & TRN & & \\
\hline CHEMBL229291 & 662951 & 8.481 & 8.4892 & TRN & & \\
\hline CHEMBL388972 & 662951 & 8.051 & 8.0495 & TRN & & \\
\hline CHEMBL 229348 & 662951 & \multicolumn{3}{|c|}{6.832999999999999} & 7.2451 & TST \\
\hline CHEMBL 229406 & 662951 & 6.932 & 6.5909 & TST & & \\
\hline CHEMBL 229407 & 662951 & 6.5 & 6.7696 & TST & & \\
\hline CHEMBL1254402 & 662951 & \multicolumn{3}{|c|}{7.071000000000001} & 6.5369 & TST \\
\hline CHEMBL1254403 & 662951 & \multicolumn{3}{|c|}{7.5089999999999995} & 6.5799 & TST \\
\hline CHEMBL229463 & 662951 & 7.244 & 7.2989 & TST & & \\
\hline CHEMBL388524 & 662951 & 7.886 & 7.0257 & TST & & \\
\hline CHEMBL441886 & 662951 & 7.77 & 7.1574 & TST & & \\
\hline CHEMBL1254564 & 662951 & 7.796 & 7.5244 & TST & & \\
\hline CHEMBL1254636 & 662951 & 7.824 & 7.3992 & TST & & \\
\hline CHEMBL3596452 & 1506611 & 6.699 & 6.7036 & TRN & & \\
\hline CHEMBL3596458 & 1506611 & 7.1549 & 7.439 & TST & & \\
\hline CHEMBL3596479 & 1506611 & 8.4202 & 8.3616 & TRN & & \\
\hline CHEMBL3596487 & 1506611 & 8.3188 & 8.3059 & TRN & & \\
\hline CHEMBL3596459 & 1506611 & 6.9208 & 6.9532 & TRN & & \\
\hline CHEMBL3596473 & 1506611 & 7.5229 & 7.5004 & TRN & & \\
\hline CHEMBL3596489 & 1506611 & 8.9208 & 8.8993 & TRN & & \\
\hline CHEMBL3596200 & 1506611 & 7.3872 & 7.3807 & TRN & & \\
\hline CHEMBL3596460 & 1506611 & 6.2676 & 6.2662 & TRN & & \\
\hline CHEMBL3596470 & 1506611 & \multicolumn{3}{|c|}{8.283999999999999} & 8.2924 & TRN \\
\hline CHEMBL3596461 & 1506611 & 7.1675 & 7.1889 & TRN & & \\
\hline CHEMBL3596494 & 1506611 & 9.4089 & 9.3949 & TRN & & \\
\hline CHEMBL3596449 & 1506611 & 7.0605 & 8.4259 & TST & & \\
\hline CHEMBL3596455 & 1506611 & 8.2007 & 8.2115 & TRN & & \\
\hline CHEMBL3596480 & 1506611 & 8.4685 & 8.4773 & TRN & & \\
\hline CHEMBL3596491 & 1506611 & 8.7212 & 8.7243 & TRN & & \\
\hline CHEMBL3596465 & 1506611 & 7.2676 & 7.2678 & TRN & & \\
\hline CHEMBL3596493 & 1506611 & 9.6021 & 9.5939 & TRN & & \\
\hline CHEMBL3596481 & 1506611 & 8.4437 & 8.4311 & TRN & & \\
\hline CHEMBL3596447 & 1506611 & \multicolumn{3}{|c|}{10.300999999999998} & 8.9671 & TST \\
\hline CHEMBL3596484 & 1506611 & 8.9586 & 9.0304 & TRN & & \\
\hline CHEMBL3596485 & 1506611 & 9.4949 & 9.4874 & TRN & & \\
\hline CHEMBL3596476 & 1506611 & 8.6576 & 8.6655 & TRN & & \\
\hline CHEMBL3596446 & 1506611 & \multicolumn{3}{|c|}{10.300999999999998} & 8.5811 & TST \\
\hline CHEMBL3596468 & 1506611 & 8.301 & 8.339 & TRN & & \\
\hline CHEMBL 3596482 & 1506611 & 9.0315 & 9.0179 & TRN & & \\
\hline CHEMBL3596475 & 1506611 & 7.7696 & 7.7636 & TRN & & \\
\hline CHEMBL3596453 & 1506611 & 7.1871 & 7.5786 & TST & & \\
\hline
\end{tabular}


Supplemental Table S2.txt

\begin{tabular}{|c|c|c|c|c|}
\hline CHEMBL3596488 & 1506611 & 8.9586 & 8.9483 & TRN \\
\hline CHEMBL3596483 & 1506611 & 9.3468 & 9.3562 & TRN \\
\hline CHEMBL3596474 & 1506611 & 8.5528 & 8.5769 & TRN \\
\hline CHEMBL3596495 & 1506611 & 8.7447 & 8.7476 & TRN \\
\hline CHEMBL3596478 & 1506611 & 7.7447 & 7.7332 & TRN \\
\hline CHEMBL3596462 & 1506611 & 7.6383 & 7.5843 & TRN \\
\hline CHEMBL3596466 & 1506611 & 7.6198 & 7.6174 & TRN \\
\hline CHEMBL3596469 & 1506611 & 7.6021 & 7.597 & TRN \\
\hline CHEMBL3596467 & 1506611 & 7.3098 & 7.303 & TRN \\
\hline CHEMBL3596463 & 1506611 & 6.8861 & 6.8844 & TRN \\
\hline CHEMBL3596490 & 1506611 & 8.0915 & 8.1137 & TRN \\
\hline CHEMBL3596448 & 1506611 & 10.5229 & 8.2917 & TST \\
\hline CHEMBL3596486 & 1506611 & 9.041 & 9.0197 & TRN \\
\hline CHEMBL3596471 & 1506611 & 7.8861 & 7.8998 & TRN \\
\hline CHEMBL3596472 & 1506611 & 8.1487 & 8.1515 & TRN \\
\hline CHEMBL3596477 & 1506611 & 8.0757 & 8.08 & TRN \\
\hline CHEMBL3596454 & 1506611 & 7.4437 & 7.5753 & TST \\
\hline CHEMBL3596496 & 1506611 & 8.699 & 8.7102 & TRN \\
\hline CHEMBL3596464 & 1506611 & 8.1871 & 7.7358 & TST \\
\hline CHEMBL3596457 & 1506611 & 7.3279 & 8.4082 & TST \\
\hline CHEMBL3596492 & 1506611 & 9.5376 & 9.36 & TST \\
\hline CHEMBL3596451 & 1506611 & 6.1549 & 7.17899 & 9999999999 \\
\hline CHEMBL3596456 & 1506611 & 8.7959 & 7.2289 & TST \\
\hline CHEMBL3596450 & 1506611 & 6.7447 & 7.7566 & TST \\
\hline CHEMBL1565949 & 737256 & 3.0969 & 3.3285 & TST \\
\hline CHEMBL1519454 & 737256 & 4.8268 & 5.4681 & TST \\
\hline CHEMBL1433138 & 737256 & 4.2197 & 4.1385 & TRN \\
\hline CHEMBL1352270 & 737256 & 5.4437 & 5.9975 & TRN \\
\hline CHEMBL1503607 & 737256 & 3.0969 & 3.7621 & TRN \\
\hline CHEMBL1575808 & 737256 & 5.71 & 4.3544 & TRN \\
\hline CHEMBL1546693 & 737256 & 4.7878 & 4.4816 & TST \\
\hline CHEMBL1723778 & 737256 & 4.2076 & 4.4282 & TRN \\
\hline CHEMBL1706065 & 737256 & 4.9172 & 3.6465 & TST \\
\hline CHEMBL1496657 & 737256 & 3.0969 & 3.4371 & TRN \\
\hline CHEMBL1704298 & 737256 & 4.9136 & 3.5332 & TRN \\
\hline CHEMBL1422720 & 737256 & 6.1024 & 4.7573 & TRN \\
\hline CHEMBL1356345 & 737256 & 4.8962 & 3.677 & TRN \\
\hline CHEMBL3209192 & 737256 & 3.0969 & 3.6576 & TRN \\
\hline CHEMBL3195661 & 737256 & 4.7471 & 5.269 & TRN \\
\hline CHEMBL1570747 & 737256 & 4.3546 & 4.5754 & TRN \\
\hline CHEMBL1353474 & 737256 & 3.0969 & 3.6935 & TRN \\
\hline CHEMBL1305294 & 737256 & 3.0969 & 3.5654 & TRN \\
\hline CHEMBL1428877 & 737256 & 3.0969 & 3.3623 & TRN \\
\hline CHEMBL1455409 & 737256 & 4.4647 & 5.6766 & TRN \\
\hline CHEMBL1383331 & 737256 & 3.0969 & 3.5743 & TRN \\
\hline CHEMBL3208118 & 737256 & 4.6345 & 4.8543 & TRN \\
\hline CHEMBL1379472 & 737256 & 3.0969 & 4.0823 & TRN \\
\hline CHEMBL1461080 & 737256 & 3.0969 & 3.7117 & TRN \\
\hline
\end{tabular}




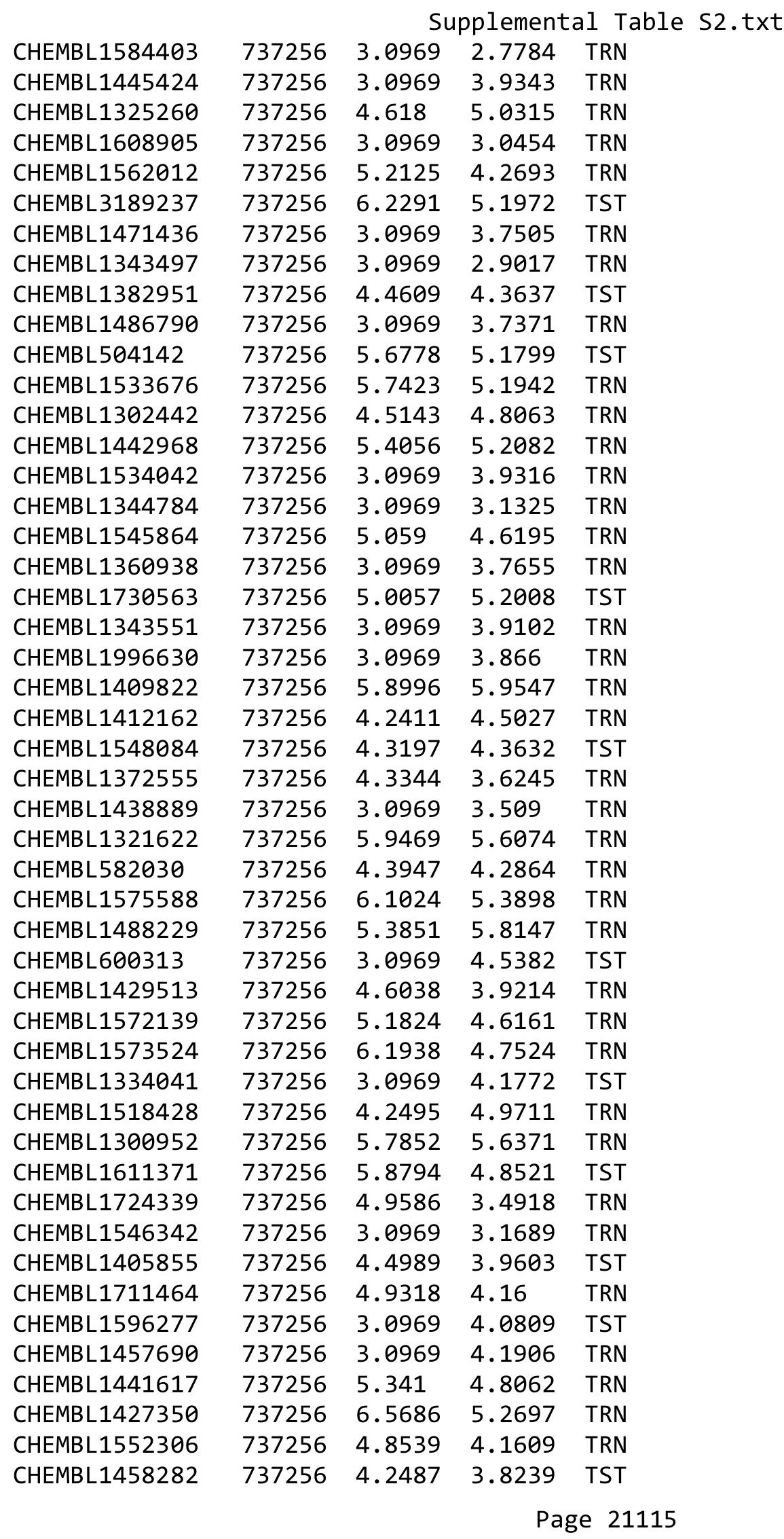


Supplemental Table S2.txt

\begin{tabular}{|c|c|c|c|c|}
\hline CHEMBL1559811 & 737256 & 6.6778 & 6.8583 & TRN \\
\hline CHEMBL3199485 & 737256 & 5.0424 & 5.5102 & TRN \\
\hline CHEMBL3197177 & 737256 & 7.7959 & 5.5288 & TRN \\
\hline CHEMBL1521044 & 737256 & 4.9872 & 4.9079 & TRN \\
\hline CHEMBL1343711 & 737256 & 4.3809 & 4.1359 & TRN \\
\hline CHEMBL1523428 & 737256 & 3.0969 & 3.4997 & TRN \\
\hline CHEMBL1403324 & 737256 & 5.9066 & 5.3833 & TRN \\
\hline CHEMBL1404247 & 737256 & 3.0969 & 3.2627 & TRN \\
\hline CHEMBL1483537 & 737256 & 3.0969 & 3.3187 & TRN \\
\hline CHEMBL1485571 & 737256 & 4.3936 & 4.4547 & TRN \\
\hline CHEMBL1553841 & 737256 & 3.0969 & 3.6495 & TRN \\
\hline CHEMBL587856 & 737256 & 3.0969 & 3.9789 & TRN \\
\hline CHEMBL1352723 & 737256 & 3.0969 & 3.9631 & TRN \\
\hline CHEMBL1388599 & 737256 & 4.6253 & 4.6254 & TRN \\
\hline CHEMBL1447724 & 737256 & 4.5287 & 4.1676 & TRN \\
\hline CHEMBL1727813 & 737256 & 3.0969 & 3.8605 & TST \\
\hline CHEMBL1386431 & 737256 & 4.3161 & 4.8684 & TRN \\
\hline CHEMBL1419363 & 737256 & 3.0969 & 3.3076 & TRN \\
\hline CHEMBL1469670 & 737256 & 5.9469 & 5.8752 & TRN \\
\hline CHEMBL1351128 & 737256 & 3.0969 & 3.6784 & TRN \\
\hline CHEMBL1496891 & 737256 & 7.7959 & 5.7109 & TRN \\
\hline CHEMBL1348010 & 737256 & 3.0969 & 3.6822 & TRN \\
\hline CHEMBL1392896 & 737256 & 3.0969 & 3.5745 & TRN \\
\hline CHEMBL1306343 & 737256 & 3.0969 & 3.4013 & TRN \\
\hline CHEMBL1467489 & 737256 & 3.0969 & 3.2512 & TRN \\
\hline CHEMBL3190354 & 737256 & 3.0969 & 3.9446 & TST \\
\hline CHEMBL1724352 & 737256 & 4.3152 & 4.4172 & TRN \\
\hline CHEMBL1313238 & 737256 & 4.7696 & 6.1045 & TRN \\
\hline CHEMBL1719312 & 737256 & 4.6716 & 4.5865 & TST \\
\hline CHEMBL1381600 & 737256 & 4.2464 & 4.7413 & TRN \\
\hline CHEMBL1438842 & 737256 & 6.5528 & 5.7885 & TRN \\
\hline CHEMBL1541771 & 737256 & 3.0969 & 3.8581 & TRN \\
\hline CHEMBL1454683 & 737256 & 4.1445 & 3.4352 & TRN \\
\hline CHEMBL3209594 & 737256 & 4.2526 & 3.5564 & TRN \\
\hline CHEMBL1528979 & 737256 & 4.1186 & 4.1007 & TST \\
\hline CHEMBL1461141 & 737256 & 5.06 & 5.1126 & TRN \\
\hline CHEMBL 2297588 & 737256 & 4.1506 & 3.6857 & TRN \\
\hline CHEMBL1331700 & 737256 & 4.8601 & 4.0054 & TRN \\
\hline CHEMBL1485824 & 737256 & 4.5003 & 4.8684 & TRN \\
\hline CHEMBL1377607 & 737256 & 3.0969 & 3.3872 & TST \\
\hline CHEMBL1357675 & 737256 & 4.8041 & 4.0847 & TRN \\
\hline CHEMBL1405953 & 737256 & 4.5361 & 3.9812 & TRN \\
\hline CHEMBL1428362 & 737256 & 4.4711 & 4.3334 & TRN \\
\hline CHEMBL1730475 & 737256 & 3.0969 & 3.6657 & TST \\
\hline CHEMBL1310877 & 737256 & 4.0991 & 3.93899 & 99999999996 \\
\hline CHEMBL1423463 & 737256 & 4.7399 & 4.9787 & TST \\
\hline CHEMBL1519480 & 737256 & 4.2874 & 4.7094 & TRN \\
\hline CHEMBL1494188 & 737256 & 4.1373 & 4.3554 & TRN \\
\hline
\end{tabular}




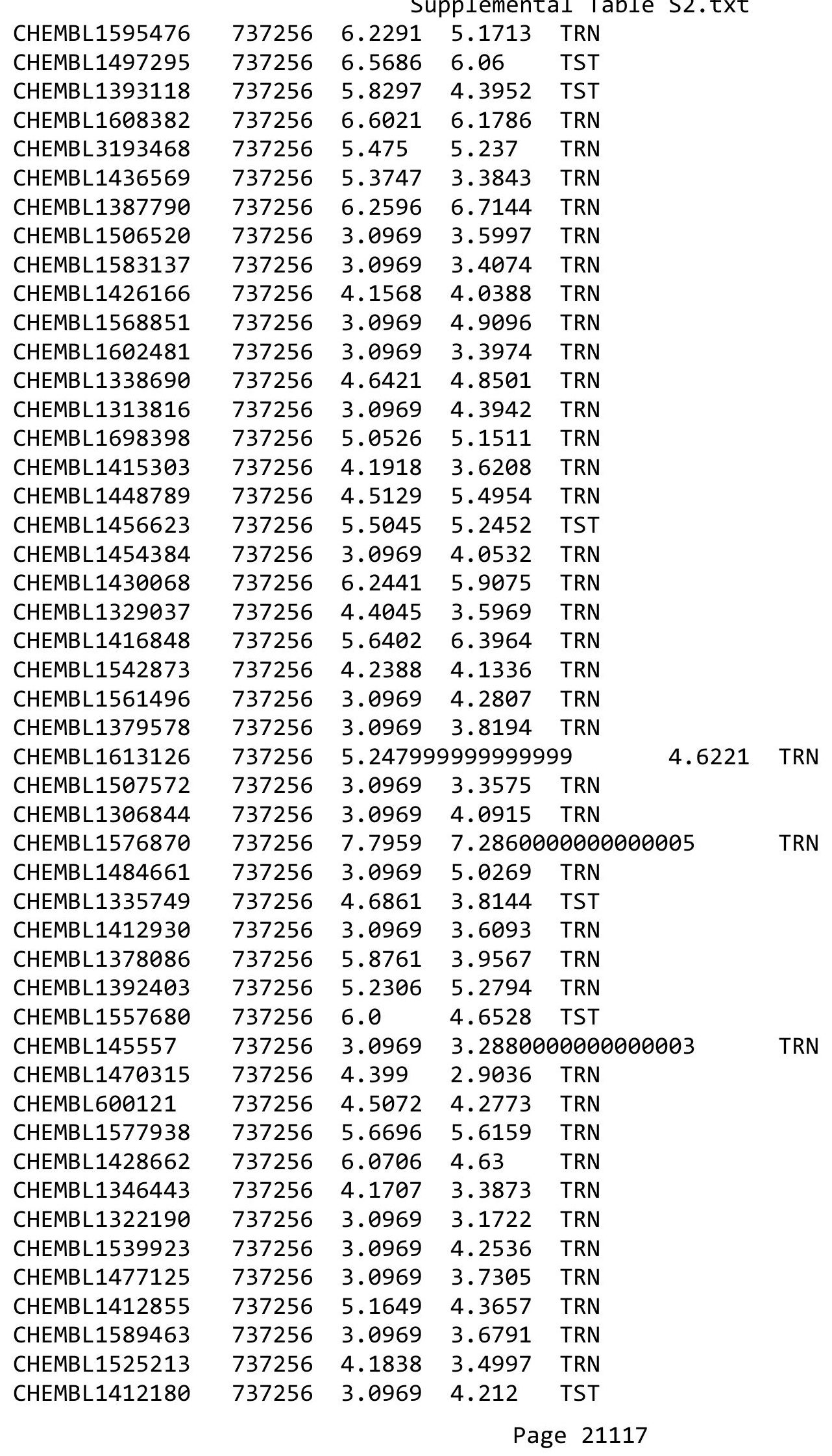




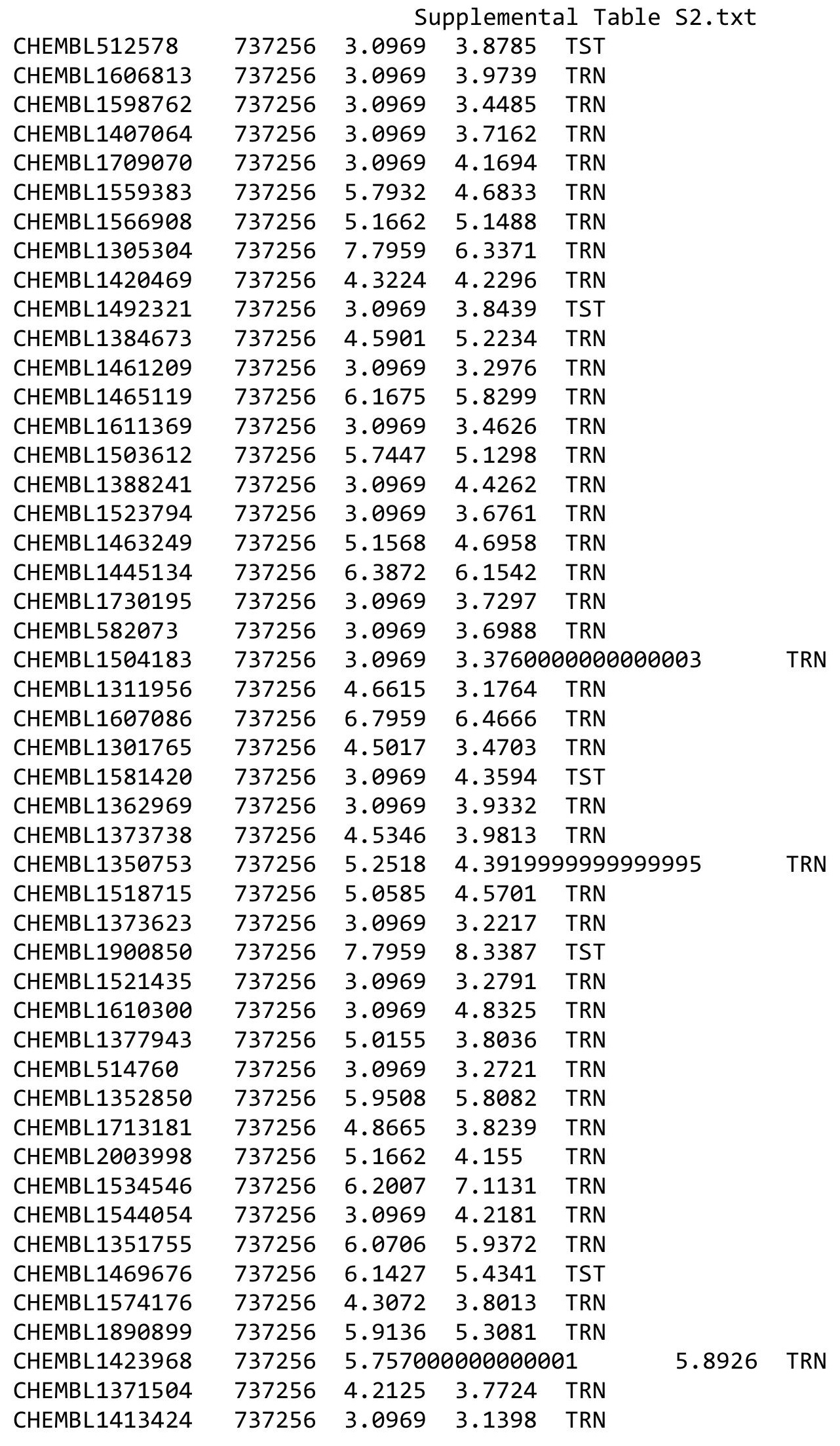

Page 21118 
Supplemental Table S2.txt

\begin{tabular}{|c|c|c|c|c|}
\hline CHEMBL1353529 & 737256 & 4.6737 & 4.5342 & TST \\
\hline CHEMBL3211093 & 737256 & 5.2358 & 5.4991 & TRN \\
\hline CHEMBL1699107 & 737256 & 5.3936 & 3.5602 & TRN \\
\hline CHEMBL1446437 & 737256 & 5.6757 & 5.3608 & TRN \\
\hline CHEMBL1610614 & 737256 & 4.8962 & 4.7957 & TRN \\
\hline CHEMBL3210100 & 737256 & 3.0969 & 4.1468 & TRN \\
\hline CHEMBL1704636 & 737256 & 3.0969 & 3.5526 & TRN \\
\hline CHEMBL431525 & 737256 & 4.1451 & 4.3281 & TST \\
\hline CHEMBL1450096 & 737256 & 5.0655 & 4.6087 & TRN \\
\hline CHEMBL1527929 & 737256 & 5.0675 & \multicolumn{2}{|c|}{5.212000000000001} \\
\hline CHEMBL1371372 & 737256 & 3.0969 & 3.3126 & TRN \\
\hline CHEMBL1498710 & 737256 & 3.0969 & 4.0142 & TST \\
\hline CHEMBL 3197567 & 737256 & 3.0969 & 4.0275 & TRN \\
\hline CHEMBL1418371 & 737256 & 5.3215 & 5.1365 & TRN \\
\hline CHEMBL1734009 & 737256 & 4.4168 & 4.2079 & TRN \\
\hline CHEMBL1490048 & 737256 & 5.0841 & 5.5499 & TRN \\
\hline CHEMBL1424292 & 737256 & 3.0969 & 3.5144 & TRN \\
\hline CHEMBL1385332 & 737256 & 4.9393 & 4.8093 & TRN \\
\hline CHEMBL1507548 & 737256 & 4.9626 & 3.4529 & TRN \\
\hline CHEMBL1568892 & 737256 & 5.2628 & 5.0338 & TRN \\
\hline CHEMBL1572914 & 737256 & 5.2426 & 5.0157 & TRN \\
\hline CHEMBL1443643 & 737256 & 3.0969 & 3.4693 & TRN \\
\hline CHEMBL1472889 & 737256 & 3.0969 & 3.2725 & TRN \\
\hline CHEMBL1431035 & 737256 & 4.4634 & 4.0259 & TRN \\
\hline CHEMBL77705 & 737256 & 3.0969 & 3.2222 & TST \\
\hline CHEMBL1536689 & 737256 & 5.4012 & 5.8965 & TRN \\
\hline CHEMBL1896972 & 737256 & 5.5243 & 4.7399 & TRN \\
\hline CHEMBL1554602 & 737256 & 4.5171 & 5.0476 & TRN \\
\hline CHEMBL1598445 & 737256 & 6.7959 & 5.5151 & TRN \\
\hline CHEMBL3210191 & 737256 & 3.0969 & 3.7361 & TRN \\
\hline CHEMBL1399076 & 737256 & 3.0969 & 3.1483 & TRN \\
\hline CHEMBL1533857 & 737256 & 4.4921 & 4.8066 & TRN \\
\hline CHEMBL1387015 & 737256 & 4.5086 & 3.6307 & TRN \\
\hline CHEMBL1487080 & 737256 & 3.0969 & 4.0697 & TRN \\
\hline CHEMBL1348837 & 737256 & 4.7986 & 5.1359 & TRN \\
\hline CHEMBL1345991 & 737256 & 5.4112 & 4.5108 & TRN \\
\hline CHEMBL1453819 & 737256 & 4.7144 & 3.4117 & TRN \\
\hline CHEMBL1370849 & 737256 & 4.8794 & 4.8909 & TRN \\
\hline CHEMBL1705677 & 737256 & 4.4921 & 4.3667 & TRN \\
\hline CHEMBL1377924 & 737256 & 5.3737 & 5.688 & TRN \\
\hline CHEMBL1413514 & 737256 & 3.0969 & 3.4396 & TRN \\
\hline CHEMBL1327993 & 737256 & 3.0969 & 3.3084 & TRN \\
\hline CHEMBL1503666 & 737256 & 4.8477 & 3.4796 & TRN \\
\hline CHEMBL1486981 & 737256 & 4.9031 & 5.3432 & TRN \\
\hline CHEMBL1484158 & 737256 & 5.6144 & 5.7112 & TRN \\
\hline CHEMBL1310132 & 737256 & 3.0969 & 4.6092 & TRN \\
\hline CHEMBL583351 & 737256 & 3.0969 & 3.603 & TRN \\
\hline CHEMBL 3207905 & 737256 & 5.2874 & 4.3112 & TRN \\
\hline
\end{tabular}

Page 21119 


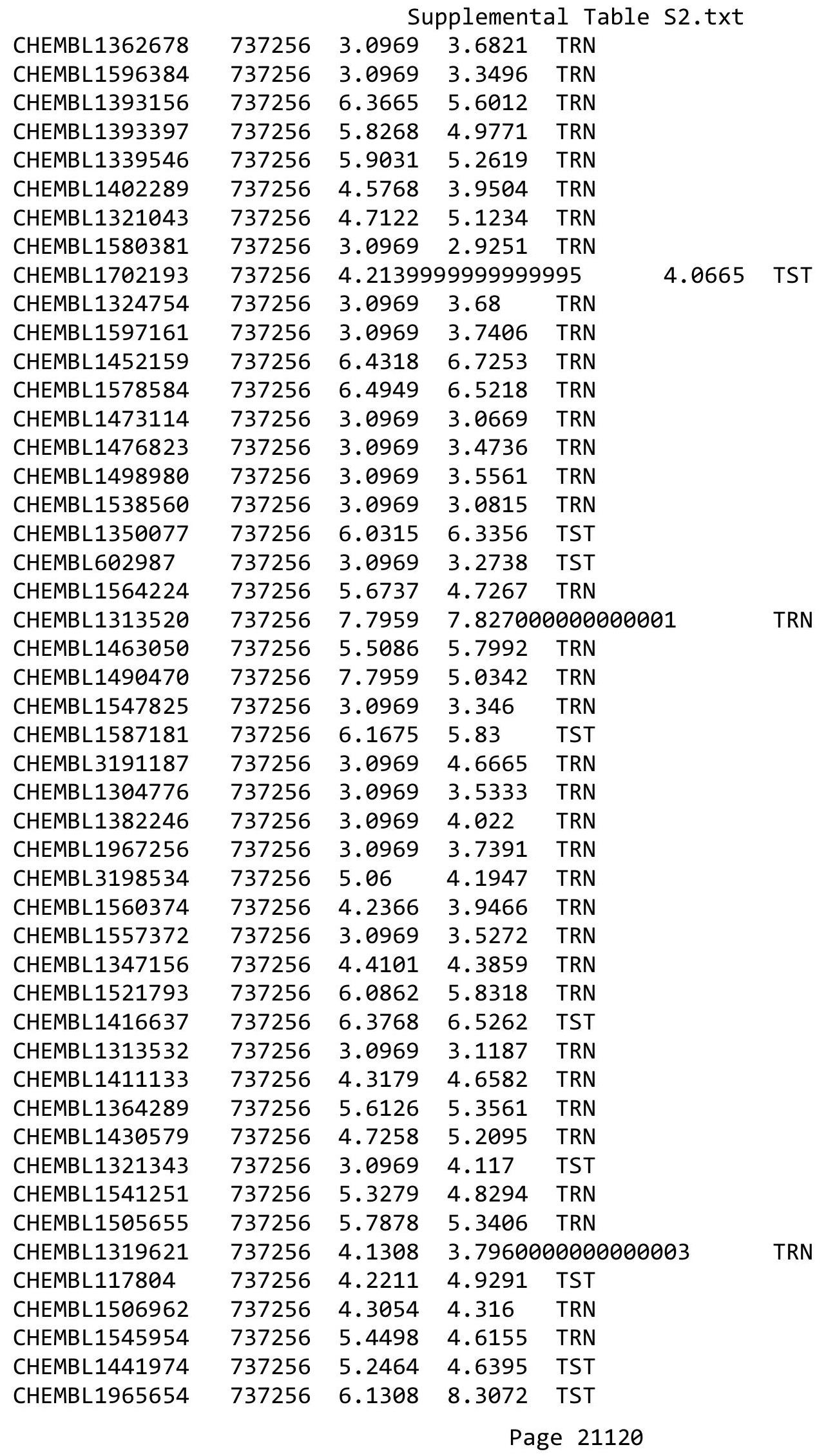




\begin{tabular}{|c|c|c|c|c|c|}
\hline \multicolumn{6}{|c|}{ Supplemental Table S2.txt } \\
\hline CHEMBL1348824 & 737256 & 3.0969 & 3.2038 & TRN & \\
\hline CHEMBL1419673 & 737256 & 3.0969 & 3.2992 & TST & \\
\hline CHEMBL1456075 & 737256 & 4.8508 & 3.6219 & TRN & \\
\hline CHEMBL1379416 & 737256 & 5.0237 & 6.1303 & TRN & \\
\hline CHEMBL1385709 & 737256 & 3.0969 & 3.2341 & TRN & \\
\hline CHEMBL1436389 & 737256 & 6.1739 & 5.1973 & TST & \\
\hline CHEMBL3198224 & 737256 & 4.466 & 3.4818 & TRN & \\
\hline CHEMBL1447345 & 737256 & 3.0969 & 3.4122 & TRN & \\
\hline CHEMBL1377807 & 737256 & 4.2218 & 4.4824 & TRN & \\
\hline CHEMBL1472681 & 737256 & 6.3565 & 5.754 & TRN & \\
\hline CHEMBL1455877 & 737256 & 3.0969 & 4.4105 & TRN & \\
\hline CHEMBL1363955 & 737256 & 4.8601 & 4.9273 & TRN & \\
\hline CHEMBL1533110 & 737256 & 3.0969 & 3.091 & TRN & \\
\hline CHEMBL1430446 & 737256 & 3.0969 & 3.1563 & TRN & \\
\hline CHEMBL1578168 & 737256 & 3.0969 & 3.93300 & 00000000003 & TST \\
\hline CHEMBL1604602 & 737256 & 3.0969 & 3.46199 & 99999999997 & TRN \\
\hline CHEMBL1431151 & 737256 & 6.5229 & 4.5271 & TRN & \\
\hline CHEMBL1471715 & 737256 & 5.8697 & 4.0311 & TRN & \\
\hline CHEMBL1612757 & 737256 & 3.0969 & 4.0188 & TRN & \\
\hline CHEMBL1440051 & 737256 & 5.7375 & 5.8775 & TRN & \\
\hline CHEMBL1333858 & 737256 & 5.3904 & 4.2597 & TRN & \\
\hline CHEMBL1326942 & 737256 & 5.5243 & 4.7726 & TRN & \\
\hline CHEMBL3194942 & 737256 & 4.308 & 4.0332 & TRN & \\
\hline CHEMBL607309 & 737256 & 4.1343 & 4.05399 & 9999999999 & TRN \\
\hline CHEMBL191750 & 737256 & 4.9957 & 6.1299 & TRN & \\
\hline CHEMBL1529883 & 737256 & 3.0969 & 3.8741 & TRN & \\
\hline CHEMBL1529440 & 737256 & 3.0969 & 3.69 & TRN & \\
\hline CHEMBL1397386 & 737256 & 4.4535 & 4.2507 & TST & \\
\hline CHEMBL1480464 & 737256 & 5.3251 & 5.2061 & TRN & \\
\hline CHEMBL369142 & 737256 & 3.0969 & 3.3523 & TRN & \\
\hline CHEMBL1432867 & 737256 & 3.0969 & 3.90199 & 99999999997 & TRN \\
\hline CHEMBL1541316 & 737256 & 5.2299 & 4.5017 & TRN & \\
\hline CHEMBL1542780 & 737256 & 3.0969 & 3.5558 & TRN & \\
\hline CHEMBL1608402 & 737256 & 5.2426 & 4.2746 & TRN & \\
\hline CHEMBL1497909 & 737256 & 5.4389 & 4.3766 & TRN & \\
\hline CHEMBL1389966 & 737256 & 3.0969 & 4.8321 & TRN & \\
\hline CHEMBL 2369258 & 737256 & 3.0969 & 3.7169 & TST & \\
\hline CHEMBL1513846 & 737256 & 3.0969 & 3.6998 & TRN & \\
\hline CHEMBL1401568 & 737256 & 3.0969 & 3.4109 & TRN & \\
\hline CHEMBL3197039 & 737256 & 5.5072 & 4.8931 & TRN & \\
\hline CHEMBL1472194 & 737256 & 4.7645 & 3.6905 & TRN & \\
\hline CHEMBL1733981 & 737256 & 3.0969 & 3.1958 & TRN & \\
\hline CHEMBL1446542 & 737256 & 4.4535 & 3.7728 & TRN & \\
\hline CHEMBL1507520 & 737256 & 5.1986 & 4.9626 & TRN & \\
\hline CHEMBL1342974 & 737256 & 3.0969 & 3.2906 & TRN & \\
\hline CHEMBL1409494 & 737256 & 3.0969 & 4.1254 & TRN & \\
\hline CHEMBL1366006 & 737256 & 4.9208 & 4.7062 & TRN & \\
\hline CHEMBL1601749 & 737256 & 3.0969 & 3.4765 & TRN & \\
\hline
\end{tabular}




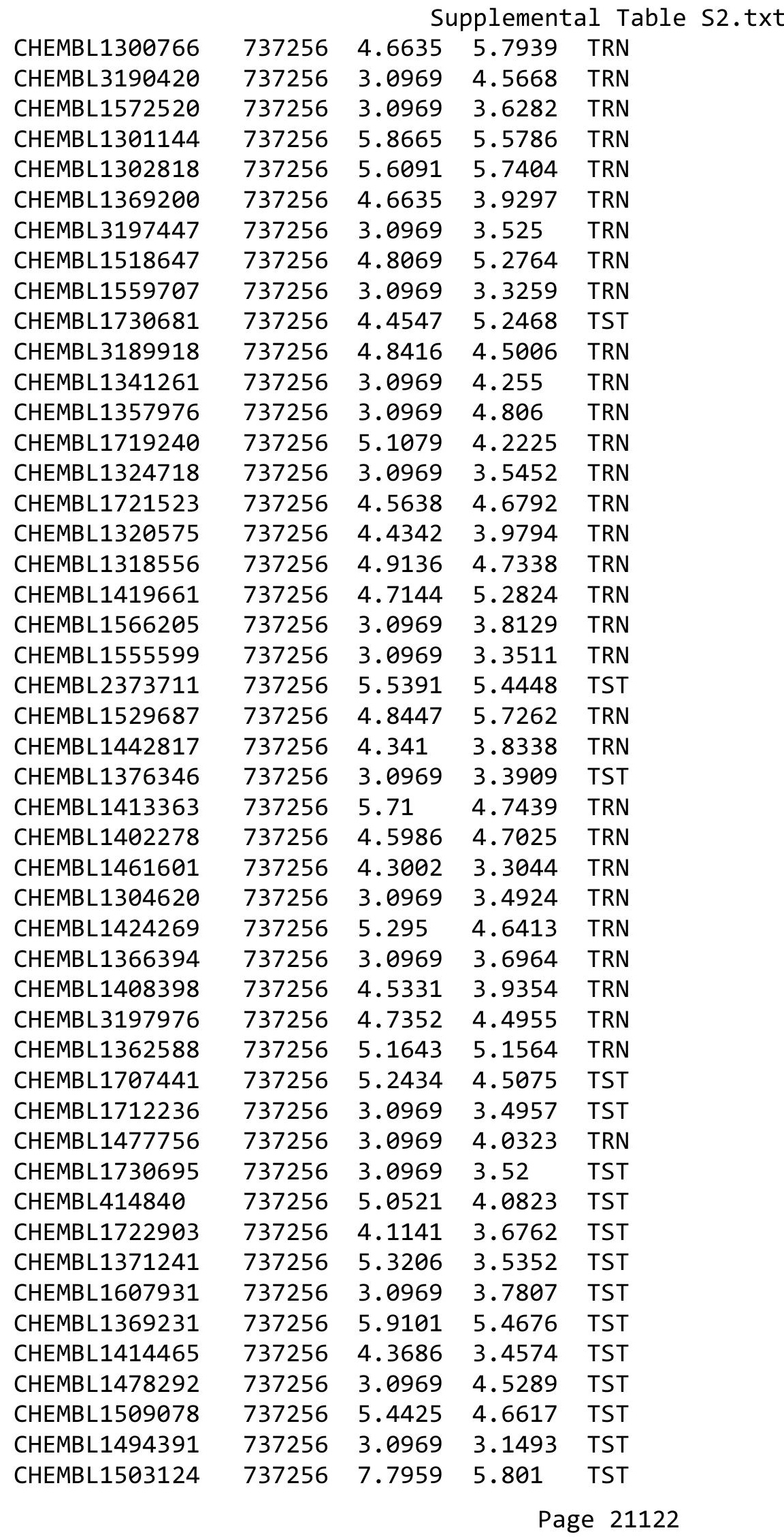


Supplemental Table S2.txt

\begin{tabular}{|c|c|c|c|c|}
\hline CHEMBL1478054 & 737256 & 4.1593 & 4.9565 & TST \\
\hline CHEMBL1328214 & 737256 & 3.0969 & 4.1304 & TST \\
\hline CHEMBL1349387 & 737256 & 4.6576 & 5.1899 & TST \\
\hline CHEMBL1582024 & 737256 & 4.4401 & 3.4194 & TST \\
\hline CHEMBL1484886 & 737256 & 3.0969 & 4.1488 & TST \\
\hline CHEMBL1403102 & 737256 & 5.3063 & 3.9802 & TST \\
\hline CHEMBL1464197 & 737256 & 4.7825 & 3.8118 & TST \\
\hline CHEMBL1703455 & 737256 & 3.0969 & 4.6502 & TST \\
\hline CHEMBL1423158 & 737256 & 3.0969 & 3.8368 & TST \\
\hline CHEMBL1305438 & 737256 & 4.7959 & 4.4578 & TST \\
\hline CHEMBL1580495 & 737256 & 4.7799 & 4.7756 & TST \\
\hline CHEMBL1712805 & 737256 & 3.0969 & 3.2585 & TST \\
\hline CHEMBL1517893 & 737256 & 3.0969 & 3.0185 & TST \\
\hline CHEMBL580609 & 737256 & 4.2226 & 4.2554 & TST \\
\hline CHEMBL1527862 & 737256 & 3.0969 & 4.4345 & TST \\
\hline CHEMBL1717272 & 737256 & 3.0969 & 3.27100 & 20000000004 \\
\hline CHEMBL1384841 & 737256 & 5.308 & 5.0157 & TST \\
\hline CHEMBL3192670 & 737256 & 3.0969 & 4.3022 & TST \\
\hline CHEMBL1598116 & 737256 & 3.0969 & 3.6843 & TST \\
\hline CHEMBL1320514 & 737256 & 5.6799 & 6.183 & TST \\
\hline CHEMBL1705775 & 737256 & 5.1062 & 4.3618 & TST \\
\hline CHEMBL1549107 & 737256 & 3.0969 & 2.9393 & TST \\
\hline CHEMBL1470695 & 737256 & 3.0969 & 2.842 & TST \\
\hline CHEMBL1328161 & 737256 & 5.8894 & 3.8955 & TST \\
\hline CHEMBL1716010 & 737256 & 4.1314 & 4.3161 & TST \\
\hline CHEMBL 3212183 & 737256 & 3.0969 & 3.9709 & TST \\
\hline CHEMBL1552506 & 737256 & 4.8928 & 4.7577 & TST \\
\hline CHEMBL1528660 & 737256 & 6.4089 & 5.8643 & TST \\
\hline CHEMBL1372952 & 737256 & 4.7399 & 4.2462 & TST \\
\hline CHEMBL1347158 & 737256 & 3.0969 & 4.7201 & TST \\
\hline CHEMBL1520650 & 737256 & 4.9066 & 5.4117 & TST \\
\hline CHEMBL1497097 & 737256 & 3.0969 & 3.5688 & TST \\
\hline CHEMBL1299637 & 737256 & 7.7959 & 6.4872 & TST \\
\hline CHEMBL1429636 & 737256 & 4.4389 & 4.5538 & TST \\
\hline CHEMBL1478067 & 737256 & 3.0969 & 4.5496 & TST \\
\hline CHEMBL1335746 & 737256 & 3.0969 & 3.2532 & TST \\
\hline CHEMBL1480380 & 737256 & 3.0969 & 3.3511 & TST \\
\hline CHEMBL1589649 & 737256 & 4.3605 & 3.5176 & TST \\
\hline CHEMBL1526910 & 737256 & 5.0405 & 5.3087 & TST \\
\hline CHEMBL1700017 & 737256 & 5.4486 & 3.6957 & TST \\
\hline CHEMBL1305586 & 737256 & 3.0969 & 3.6968 & TST \\
\hline CHEMBL1711360 & 737256 & 4.2782 & 4.3729 & TST \\
\hline CHEMBL1705361 & 737256 & 3.0969 & 3.5614 & TST \\
\hline CHEMBL1479442 & 737256 & 3.0969 & 3.1661 & TST \\
\hline CHEMBL1732297 & 737256 & 4.8416 & 3.5968 & TST \\
\hline CHEMBL1364853 & 737256 & 3.0969 & 4.93199 & 99999999995 \\
\hline CHEMBL3189935 & 737256 & 5.9031 & 4.3657 & TST \\
\hline CHEMBL481323 & 515687 & 5.5086 & 5.0824 & TRN \\
\hline
\end{tabular}




\begin{tabular}{|c|c|c|c|c|c|}
\hline \multicolumn{6}{|c|}{ supplemental } \\
\hline CHEMBL480236 & 515687 & 6.8239 & 6.9522 & TRN & \\
\hline CHEMBL479273 & 515687 & 3.1938 & 3.1946 & TRN & \\
\hline CHEMBL481777 & 515687 & 4.9586 & 5.0067 & TRN & \\
\hline CHEMBL452186 & 515687 & 5.1805 & 5.2676 & TRN & \\
\hline CHEMBL521097 & 515687 & 4.6576 & 4.3092 & TRN & \\
\hline CHEMBL480631 & 515687 & 5.7212 & 5.9564 & TRN & \\
\hline CHEMBL518771 & 515687 & 3.1938 & 3.3182 & TRN & \\
\hline CHEMBL480636 & 515687 & 7.4685 & 7.8807 & TRN & \\
\hline CHEMBL519771 & 515687 & 5.6383 & 5.41700 & 0000000001 & TRN \\
\hline CHEMBL480448 & 515687 & 5.8861 & 5.3008 & TRN & \\
\hline CHEMBL480225 & 515687 & 3.1938 & 3.5035 & TRN & \\
\hline CHEMBL481610 & 515687 & 5.8239 & 5.3303 & TRN & \\
\hline CHEMBL517223 & 515687 & 3.1938 & 4.1888 & TRN & \\
\hline CHEMBL480441 & 515687 & 5.7212 & 4.822 & TST & \\
\hline CHEMBL479261 & 515687 & 4.5376 & 4.3981 & TRN & \\
\hline CHEMBL454289 & 515687 & 5.5086 & 5.8799 & TRN & \\
\hline CHEMBL480235 & 515687 & 6.5528 & 6.1435 & TRN & \\
\hline CHEMBL474066 & 515687 & 4.2441 & 3.9415 & TRN & \\
\hline CHEMBL479276 & 515687 & 5.5686 & 5.3139 & TST & \\
\hline CHEMBL520115 & 515687 & 5.6778 & 4.9309 & TST & \\
\hline CHEMBL481419 & 515687 & 5.0969 & 4.6786 & TRN & \\
\hline CHEMBL480050 & 515687 & 5.4559 & 5.9121 & TRN & \\
\hline CHEMBL480842 & 515687 & 6.0757 & 5.8481 & TRN & \\
\hline CHEMBL519940 & 515687 & 4.6198 & 4.9934 & TRN & \\
\hline CHEMBL480226 & 515687 & 7.1739 & 7.2664 & TRN & \\
\hline CHEMBL480431 & 515687 & 6.4437 & 5.9204 & TRN & \\
\hline CHEMBL481201 & 515687 & 3.1938 & 3.8207 & TRN & \\
\hline CHEMBL480432 & 515687 & 3.1938 & 4.7682 & TST & \\
\hline CHEMBL479726 & 515687 & 7.7696 & 7.5598 & TRN & \\
\hline CHEMBL480843 & 515687 & 3.1938 & 5.0289 & TST & \\
\hline CHEMBL482139 & 515687 & 5.2596 & 5.3801 & TST & \\
\hline CHEMBL481216 & 515687 & 4.8539 & 4.3878 & TRN & \\
\hline CHEMBL481215 & 515687 & 4.7959 & 4.8992 & TRN & \\
\hline CHEMBL520771 & 515687 & 6.6198 & 6.9203 & TST & \\
\hline CHEMBL479277 & 515687 & 5.7696 & 5.0468 & TST & \\
\hline CHEMBL480832 & 515687 & 8.0605 & 8.4287 & TRN & \\
\hline CHEMBL443899 & 515687 & 4.9586 & 5.1697 & TST & \\
\hline CHEMBL479451 & 515687 & 5.3372 & 5.1312 & TRN & \\
\hline CHEMBL479862 & 515687 & 6.8239 & 6.8814 & TRN & \\
\hline CHEMBL480051 & 515687 & 6.7696 & 6.2037 & TRN & \\
\hline CHEMBL506548 & 515687 & 4.9208 & 5.0721 & TST & \\
\hline CHEMBL480844 & 515687 & 7.4202 & 6.7033 & TRN & \\
\hline CHEMBL482400 & 515687 & 4.2441 & 4.4549 & TRN & \\
\hline CHEMBL479272 & 515687 & 3.1938 & 3.8242 & TRN & \\
\hline CHEMBL480831 & 515687 & 7.5229 & 8.2783 & TRN & \\
\hline CHEMBL479468 & 515687 & 5.585 & 5.2691 & TST & \\
\hline CHEMBL479466 & 515687 & 4.9586 & 5.1389 & TST & \\
\hline CHEMBL479274 & 515687 & 6.8861 & 6.7506 & TRN & \\
\hline
\end{tabular}




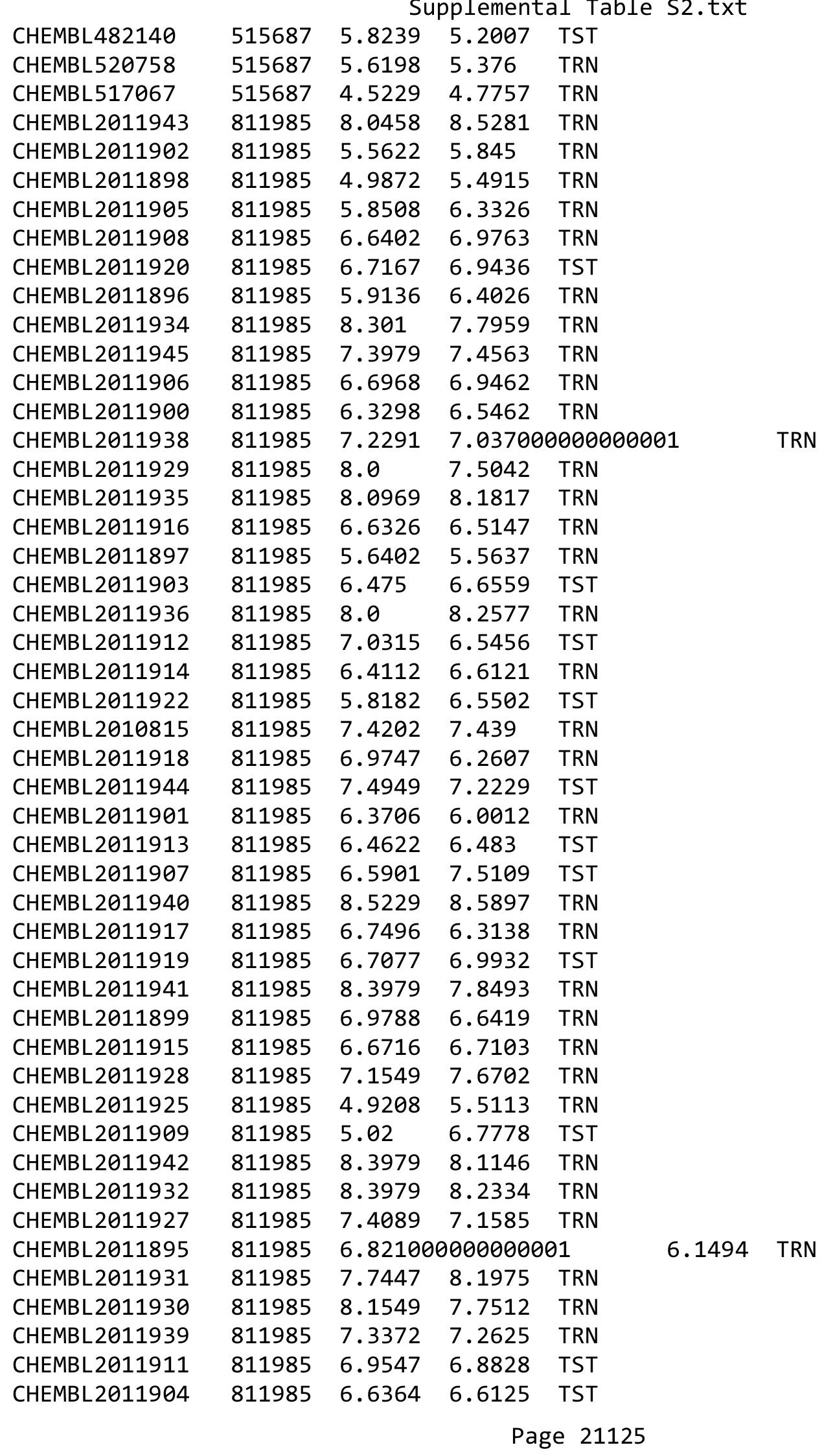


Supplemental Table S2.txt

\begin{tabular}{|c|c|c|c|c|}
\hline CHEMBL 2011937 & 811985 & 6.9747 & 6.9069 & TRN \\
\hline CHEMBL2011923 & 811985 & 6.7905 & 7.4281 & TRN \\
\hline CHEMBL 2011924 & 811985 & 6.4168 & 6.1224 & TRN \\
\hline CHEMBL 2011926 & 811985 & 7.2441 & 7.2807 & TRN \\
\hline CHEMBL 2011910 & 811985 & 7.1871 & 6.7895 & TST \\
\hline CHEMBL 2011933 & 811985 & 8.3979 & 8.3997 & TRN \\
\hline CHEMBL 2011921 & 811985 & 6.5406 & 6.6137 & TST \\
\hline CHEMBL 3677612 & 1528566 & 8.4089 & 8.6538 & TRN \\
\hline CHEMBL 3672660 & 1528566 & 9.0 & 9.2625 & TRN \\
\hline CHEMBL 3682481 & 1528566 & 7.8013 & 7.3035 & TRN \\
\hline CHEMBL 3677520 & 1528566 & 9.0 & 8.576 & TST \\
\hline CHEMBL 3677607 & 1528566 & 7.8069 & 8.1372 & TST \\
\hline CHEMBL 3677562 & 1528566 & 7.3382 & 8.3955 & TST \\
\hline CHEMBL 3677429 & 1528566 & 7.1135 & 7.9928 & TST \\
\hline CHEMBL 3672623 & 1528566 & 7.8539 & 8.5627 & TRN \\
\hline CHEMBL 3672650 & 1528566 & 9.0 & 8.9976 & TRN \\
\hline CHEMBL 3677583 & 1528566 & 6.6474 & 6.9642 & TRN \\
\hline CHEMBL 3677609 & 1528566 & 7.7471 & 8.7374 & TRN \\
\hline CHEMBL 3677502 & 1528566 & 9.0 & 8.9559 & TRN \\
\hline CHEMBL 3677433 & 1528566 & 9.301 & 9.2302 & TRN \\
\hline CHEMBL 3677621 & 1528566 & 7.6799 & 7.9681 & TRN \\
\hline CHEMBL 3677544 & 1528566 & 8.7959 & 8.5584 & TRN \\
\hline CHEMBL 3677593 & 1528566 & 7.2291 & 7.12299 & 9999999999 \\
\hline CHEMBL 3677595 & 1528566 & 7.3516 & 8.1777 & TRN \\
\hline CHEMBL3672589 & 1528566 & 3.2076 & 8.51 & TST \\
\hline CHEMBL 3672641 & 1528566 & 9.0 & 9.0014 & TRN \\
\hline CHEMBL 3682473 & 1528566 & 8.3279 & 8.6742 & TRN \\
\hline CHEMBL 3677564 & 1528566 & 8.3098 & 8.27 & TST \\
\hline CHEMBL 3677493 & 1528566 & 9.0 & 8.9358 & TRN \\
\hline CHEMBL 3672655 & 1528566 & 9.0 & 8.65899 & \\
\hline CHEMBL 3677534 & 1528566 & 7.6383 & 7.3712 & TRN \\
\hline CHEMBL 3677604 & 1528566 & 8.9586 & 8.809 & TRN \\
\hline CHEMBL 3677452 & 1528566 & 9.0 & 8.7715 & TRN \\
\hline CHEMBL 3677457 & 1528566 & 6.0 & 7.7708 & TRN \\
\hline CHEMBL 3677640 & 1528566 & 7.2549 & 8.1482 & TST \\
\hline CHEMBL 3682475 & 1528566 & 6.9169 & 7.8016 & TRN \\
\hline CHEMBL 3672595 & 1528566 & 9.0 & 8.9114 & TRN \\
\hline CHEMBL 3677567 & 1528566 & 8.0269 & 8.5783 & TRN \\
\hline CHEMBL 3677498 & 1528566 & 9.0 & 8.513 & TRN \\
\hline CHEMBL 3677561 & 1528566 & 6.5363 & 8.0133 & TST \\
\hline CHEMBL 3677466 & 1528566 & 7.3565 & 8.2551 & TRN \\
\hline CHEMBL 3682439 & 1528566 & 8.9208 & 8.3412 & TRN \\
\hline CHEMBL3677489 & 1528566 & 9.0 & 7.8362 & TRN \\
\hline CHEMBL 3672637 & 1528566 & 9.0 & 9.0309 & TRN \\
\hline CHEMBL 3672657 & 1528566 & 9.0 & 8.4677 & TRN \\
\hline CHEMBL 3677508 & 1528566 & 9.0 & 8.5748 & TRN \\
\hline CHEMBL 3682453 & 1528566 & 8.0132 & 8.4252 & TRN \\
\hline CHEMBL 3677524 & 1528566 & 9.0 & 8.3702 & TRN \\
\hline
\end{tabular}




\begin{tabular}{|c|c|c|c|c|}
\hline \multicolumn{5}{|c|}{ Supplemental Table S2.txt } \\
\hline CHEMBL 3677490 & 1528566 & 9.0 & 8.0053 & TRN \\
\hline CHEMBL3677443 & 1528566 & 7.6198 & 7.5443 & TRN \\
\hline CHEMBL3677633 & 1528566 & 8.8861 & 8.9056 & TRN \\
\hline CHEMBL3682501 & 1528566 & 8.4559 & 8.0334 & TST \\
\hline CHEMBL3677439 & 1528566 & 9.301 & 9.0321 & TRN \\
\hline CHEMBL3677436 & 1528566 & 9.0 & 8.297 & TST \\
\hline CHEMBL3672621 & 1528566 & 6.8827 & 7.6724 & TST \\
\hline CHEMBL3682440 & 1528566 & 8.7959 & 8.6231 & TRN \\
\hline CHEMBL3672618 & 1528566 & 6.9586 & 8.228 & TRN \\
\hline CHEMBL3677601 & 1528566 & 8.8539 & 8.7156 & TRN \\
\hline CHEMBL 3677614 & 1528566 & 9.0969 & 8.7905 & TRN \\
\hline CHEMBL3672639 & 1528566 & 9.0 & 8.3271 & TRN \\
\hline CHEMBL3677616 & 1528566 & 7.9172 & 8.5937 & TRN \\
\hline CHEMBL3677589 & 1528566 & 6.994 & 7.2142 & TRN \\
\hline CHEMBL3677531 & 1528566 & 6.8297 & 7.62 & TST \\
\hline CHEMBL3677545 & 1528566 & 8.3565 & 8.6588 & TRN \\
\hline CHEMBL3677611 & 1528566 & 8.2676 & 7.8996 & TRN \\
\hline CHEMBL3682490 & 1528566 & 9.1549 & 9.0153 & TRN \\
\hline CHEMBL3672624 & 1528566 & 9.0 & 8.6841 & TRN \\
\hline CHEMBL3677536 & 1528566 & 6.6882 & 7.3987 & TRN \\
\hline CHEMBL3677456 & 1528566 & 9.0 & 8.0333 & TRN \\
\hline CHEMBL3682500 & 1528566 & 8.699 & 7.8751 & TST \\
\hline CHEMBL3677549 & 1528566 & 8.6576 & 8.2018 & TRN \\
\hline CHEMBL3677632 & 1528566 & 8.5229 & 8.5886 & TRN \\
\hline CHEMBL3672640 & 1528566 & 9.0 & 8.9772 & TRN \\
\hline CHEMBL3677579 & 1528566 & 8.585 & 8.333 & TST \\
\hline CHEMBL3677582 & 1528566 & 6.5322 & 7.1987 & TRN \\
\hline CHEMBL3682441 & 1528566 & 8.5229 & 8.2118 & TRN \\
\hline CHEMBL3677491 & 1528566 & 9.0 & 9.2431 & TRN \\
\hline CHEMBL3672656 & 1528566 & 9.0 & 8.6813 & TRN \\
\hline CHEMBL3677528 & 1528566 & 9.301 & 8.7409 & TRN \\
\hline CHEMBL3677622 & 1528566 & 8.5376 & 8.4678 & TRN \\
\hline CHEMBL3677460 & 1528566 & 9.0 & 8.5295 & TRN \\
\hline CHEMBL3672601 & 1528566 & 9.0 & 8.8323 & TRN \\
\hline CHEMBL3677447 & 1528566 & 9.0 & 9.1453 & TRN \\
\hline CHEMBL3682437 & 1528566 & 8.585 & 7.9909 & TRN \\
\hline CHEMBL3639813 & 1528566 & 7.5482 & 7.7494 & TRN \\
\hline CHEMBL3677585 & 1528566 & 7.4949 & 7.4419 & TRN \\
\hline CHEMBL3677440 & 1528566 & 9.0 & 9.1676 & TRN \\
\hline CHEMBL3672644 & 1528566 & 9.0 & 9.3064 & TRN \\
\hline CHEMBL3672600 & 1528566 & 9.0 & 8.7187 & TRN \\
\hline CHEMBL3677461 & 1528566 & 9.0 & 8.5773 & TRN \\
\hline CHEMBL3677521 & 1528566 & 9.0 & 8.805 & TRN \\
\hline CHEMBL3682496 & 1528566 & 8.0862 & 8.4799 & TST \\
\hline CHEMBL3677590 & 1528566 & 6.9935 & 7.4535 & TRN \\
\hline CHEMBL3672592 & 1528566 & 9.0 & 9.0021 & TST \\
\hline CHEMBL3677606 & 1528566 & 6.8019 & 6.8465 & TST \\
\hline CHEMBL3672599 & 1528566 & 7.8861 & 8.3417 & TST \\
\hline
\end{tabular}


Supplemental Table S2.txt

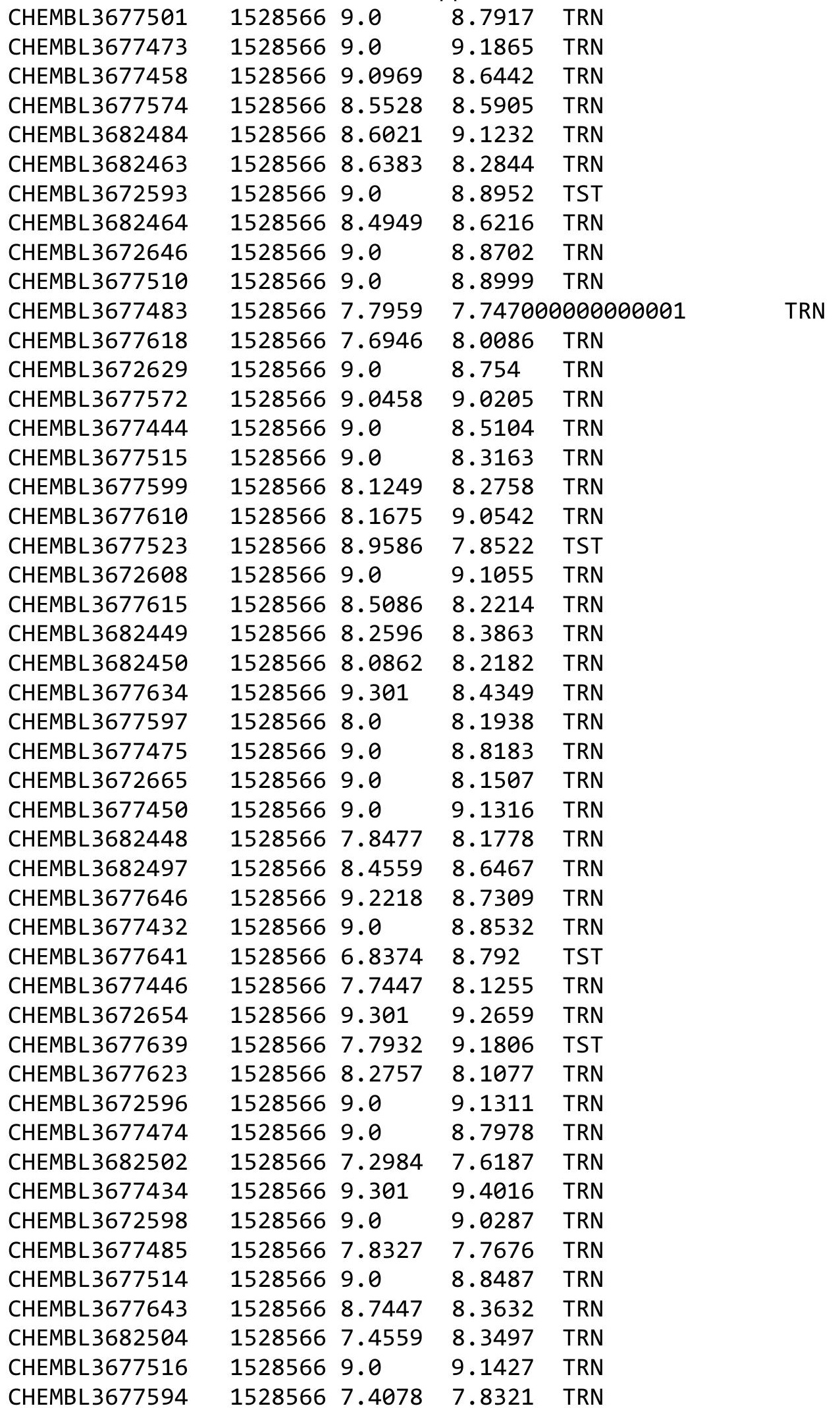

Page 21128 
Supplemental Table S2.txt

\begin{tabular}{|c|c|c|c|c|}
\hline CHEMBL 3682452 & 1528566 & 7.5702 & 7.9384 & TRN \\
\hline CHEMBL3677496 & 1528566 & 9.0 & 8.317 & TRN \\
\hline CHEMBL3682487 & 1528566 & 7.8539 & 8.4503 & TRN \\
\hline CHEMBL3672594 & 1528566 & 9.0 & 8.8362 & TRN \\
\hline CHEMBL3677568 & 1528566 & 7.5901 & 8.7283 & TRN \\
\hline CHEMBL3672622 & 1528566 & 9.0 & 8.1155 & TRN \\
\hline CHEMBL3677565 & 1528566 & 8.2924 & 8.2191 & TST \\
\hline CHEMBL3677468 & 1528566 & 7.585 & 7.29299 & 999999999 \\
\hline CHEMBL3677431 & 1528566 & 7.9586 & 7.468 & TST \\
\hline CHEMBL3677506 & 1528566 & 9.0 & 7.8656 & TST \\
\hline CHEMBL3672604 & 1528566 & 9.0 & 8.9157 & TRN \\
\hline CHEMBL 3672597 & 1528566 & 9.0 & 7.6482 & TST \\
\hline CHEMBL3682477 & 1528566 & 7.9355 & 7.5156 & TST \\
\hline CHEMBL3677511 & 1528566 & 9.0 & 8.7771 & TRN \\
\hline CHEMBL3682460 & 1528566 & 8.2757 & 8.2231 & TRN \\
\hline CHEMBL3672611 & 1528566 & 7.3979 & 8.746 & TRN \\
\hline CHEMBL3677596 & 1528566 & 8.0362 & 8.3743 & TRN \\
\hline CHEMBL 3677553 & 1528566 & 8.9208 & 8.934 & TRN \\
\hline CHEMBL3672625 & 1528566 & 9.0 & 8.6872 & TRN \\
\hline CHEMBL3672615 & 1528566 & 9.0 & 9.1415 & TRN \\
\hline CHEMBL3677645 & 1528566 & 8.7212 & 8.2529 & TRN \\
\hline CHEMBL3677484 & 1528566 & 7.8633 & 7.4397 & TRN \\
\hline CHEMBL 3682474 & 1528566 & 8.2076 & 8.5584 & TRN \\
\hline CHEMBL3677482 & 1528566 & 9.0 & 8.6037 & TST \\
\hline CHEMBL3677459 & 1528566 & 8.9208 & 8.5576 & TRN \\
\hline CHEMBL3672643 & 1528566 & 9.0 & 8.7878 & TRN \\
\hline CHEMBL 3677584 & 1528566 & 6.7219 & 7.7952 & TRN \\
\hline CHEMBL 3677522 & 1528566 & 9.0 & 8.8378 & TRN \\
\hline CHEMBL3677437 & 1528566 & 9.0 & 8.7872 & TRN \\
\hline CHEMBL3677507 & 1528566 & 7.4318 & 8.0208 & TRN \\
\hline CHEMBL3682445 & 1528566 & 7.1397 & 8.0676 & TRN \\
\hline CHEMBL3672590 & 1528566 & 3.2076 & 8.32 & TST \\
\hline CHEMBL 3677541 & 1528566 & 9.1549 & 9.0566 & TRN \\
\hline CHEMBL3677533 & 1528566 & 7.585 & 7.2962 & TRN \\
\hline CHEMBL3682493 & 1528566 & 8.9586 & 9.0306 & TRN \\
\hline CHEMBL3677495 & 1528566 & 9.0 & 8.3944 & TRN \\
\hline CHEMBL3672607 & 1528566 & 9.0 & 8.4911 & TRN \\
\hline CHEMBL 3677505 & 1528566 & 7.5528 & 7.5678 & TRN \\
\hline CHEMBL3677577 & 1528566 & 8.0809 & 8.1077 & TRN \\
\hline CHEMBL3677454 & 1528566 & 9.0 & 8.4008 & TRN \\
\hline CHEMBL3682442 & 1528566 & 6.0 & 8.1508 & TRN \\
\hline CHEMBL3672652 & 1528566 & 8.9208 & 8.8741 & TST \\
\hline CHEMBL3682457 & 1528566 & 7.8697 & 8.3701 & TRN \\
\hline CHEMBL3677526 & 1528566 & 9.0 & 8.7498 & TRN \\
\hline CHEMBL3639762 & 1528566 & 7.0706 & 7.8262 & TRN \\
\hline CHEMBL3677529 & 1528566 & 8.699 & 9.1585 & TRN \\
\hline CHEMBL3677617 & 1528566 & 9.1549 & 8.8722 & TRN \\
\hline CHEMBL3677587 & 1528566 & 6.9161 & 7.3045 & TRN \\
\hline
\end{tabular}

Page 21129 
Supplemental Table S2.txt

\begin{tabular}{|c|c|c|c|c|}
\hline AEMBL 3677620 & 528566 & & 8.1002 & \\
\hline HEMBL3672619 & & 7.0315 & 8.6554 & \\
\hline 7470 & 528566 & 9.0 & & \\
\hline IEMBL3677488 & 528566 & 9.0 & 3035 & \\
\hline AEMBL 3682478 & 528566 & 7.7645 & 319 & \\
\hline AEMBL3677465 & 528566 & 7.0969 & 809 & \\
\hline 546 & 528566 & 8.6778 & 863 & \\
\hline EMBL3672605 & 528566 & 9.0 & & \\
\hline AEMBL3672666 & 528566 & 9.0 & 3224 & \\
\hline HEMBL3672661 & 528566 & 9.0 & 464 & \\
\hline HEMBL3677600 & 5285 & 7.4522 & 192 & \\
\hline IEMBL & 528566 & .3747 & 579 & \\
\hline 2447 & 528566 & 8.0088 & & \\
\hline IEMBL 3677530 & 528566 & 9.0 & 628 & \\
\hline HEMBL3672642 & 528566 & & & \\
\hline HEMBL; & 5285 & 8.21 & & \\
\hline AEMBL & 528 & & 752 & 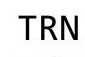 \\
\hline 603 & 528566 & 6.7612 & 341 & \\
\hline 577462 & 528566 & 9.0 & 804 & \\
\hline 672616 & 56 & & & \\
\hline AEMBL & 528 & 0. & & ונד \\
\hline 659 & 6 & & & RN \\
\hline 494 & 528566 & 8.5086 & 233 & CT \\
\hline 77494 & 528566 & 9.0 & & $\mathrm{RN}$ \\
\hline AEMBL 3682459 & 56 & & & रा \\
\hline 577638 & 528 & 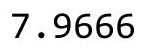 & & וס \\
\hline 486 & 0 & & 79 & RN \\
\hline 554 & 56 & 807 & 493 & \\
\hline IEMBL & $=0$ & 201 & & RN \\
\hline 82476 & 026 & 6.80 & & RN \\
\hline 09 & 528 & & & RN \\
\hline 51 & 56 & & & RN \\
\hline 91 & 56 & 5 & & 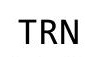 \\
\hline 39764 & 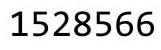 & 8.1079 & & rRN \\
\hline 77635 & 528566 & & 904 & $n$ \\
\hline 612 & 528 & 9. & 38 & $\Gamma R$ \\
\hline 6 & 56 & & & ГRN \\
\hline 582451 & & 8.1675 & & $\mathrm{RI}$ \\
\hline IEMBL: & 528 & 7.00 & 007 & $\Gamma R$ \\
\hline 477 & 528 & 9. & 93 & ST 1 \\
\hline 578 & 5201 & 8 . & & $\Gamma R$ \\
\hline 77580 & 6 & 7.6676 & 364 & IST \\
\hline AEMBL3672664 & 528566 & & 8.8099 & RN \\
\hline AEMBL & 52 & 9.0969 & 532 & R \\
\hline 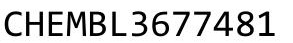 & & & & $\mathbf{k}$ \\
\hline CHEMBL3639763 & 528 & & 8.1865 & $\Gamma R$ \\
\hline CHEMBL 3677445 & 528 & 9.0 & 8.7715 & \\
\hline CHEMBL3677517 & 1528566 & 7.6198 & 8.1627 & TR \\
\hline
\end{tabular}

Page 21130 


\begin{tabular}{|c|c|c|c|c|}
\hline \multicolumn{5}{|c|}{ Supplemental Table s2.txt } \\
\hline CHEMBL 3672606 & 1528566 & 9.0 & 8.7286 & TRN \\
\hline CHEMBL 3677480 & 1528566 & 9.0 & 9.3657 & TRN \\
\hline CHEMBL3682455 & 1528566 & 8.2218 & 8.4451 & TRN \\
\hline CHEMBL 3677497 & 1528566 & 9.0 & 8.1388 & TRN \\
\hline CHEMBL3677628 & 1528566 & 8.6021 & 8.0215 & TST \\
\hline CHEMBL 3677644 & 1528566 & 8.3188 & 8.5695 & TRN \\
\hline CHEMBL 3672630 & 1528566 & 9.0 & 9.0414 & TRN \\
\hline CHEMBL3682436 & 1528566 & 8.6198 & 8.6785 & TRN \\
\hline CHEMBL 3677527 & 1528566 & 9.0 & 8.6974 & TRN \\
\hline CHEMBL3682471 & 1528566 & 7.8239 & 8.6217 & TRN \\
\hline CHEMBL 3677547 & 1528566 & 8.6383 & 8.3599 & TST \\
\hline CHEMBL 3672631 & 1528566 & 9.0 & 9.0089 & TRN \\
\hline CHEMBL3672591 & 1528566 & 9.0 & 9.0684 & TST \\
\hline CHEMBL 3677560 & 1528566 & 8.3372 & 8.1201 & TRN \\
\hline CHEMBL3677563 & 1528566 & 7.5003 & 8.212 & TST \\
\hline CHEMBL 3677513 & 1528566 & 9.0 & 8.5938 & TRN \\
\hline CHEMBL3677492 & 1528566 & 9.0 & 8.8906 & TRN \\
\hline CHEMBL 3672610 & 1528566 & 9.0 & 9.0919 & TRN \\
\hline CHEMBL3677637 & 1528566 & 8.2076 & 8.6852 & TRN \\
\hline CHEMBL3677476 & 1528566 & 9.0 & 8.4399 & TRN \\
\hline CHEMBL 3677631 & 1528566 & 8.4202 & 8.5084 & TRN \\
\hline CHEMBL 3672662 & 1528566 & 9.0 & 8.8288 & TRN \\
\hline CHEMBL 3677428 & 1528566 & 7.8539 & 7.6371 & TRN \\
\hline CHEMBL3677592 & 1528566 & 7.0315 & 7.2694 & TRN \\
\hline CHEMBL 3677427 & 1528566 & 9.0 & 8.3476 & TRN \\
\hline CHEMBL 3672633 & 1528566 & 9.0 & 8.9821 & TRN \\
\hline CHEMBL 3677540 & 1528566 & 9.2218 & 9.135 & TRN \\
\hline CHEMBL 3677539 & 1528566 & 8.0969 & 8.5413 & TRN \\
\hline CHEMBL 3677438 & 1528566 & 9.0 & 9.4776 & TRN \\
\hline CHEMBL 3677588 & 1528566 & 7.1739 & 7.5814 & TRN \\
\hline CHEMBL 3672603 & 1528566 & 9.0 & 9.1461 & TRN \\
\hline CHEMBL3682461 & 1528566 & 8.4685 & 8.0638 & TRN \\
\hline CHEMBL 3677542 & 1528566 & 8.9208 & 8.2749 & TRN \\
\hline CHEMBL3677627 & 1528566 & 8.1427 & 8.4389 & TRN \\
\hline CHEMBL 3677500 & 1528566 & 9.0 & 9.1037 & TRN \\
\hline CHEMBL3677512 & 1528566 & 9.0 & 8.8612 & TRN \\
\hline CHEMBL3677629 & 1528566 & 9.1549 & 8.623 & TRN \\
\hline CHEMBL 3677608 & 1528566 & 8.3188 & 8.6751 & TST \\
\hline CHEMBL 3682444 & 1528566 & 9.1549 & 8.602 & TRN \\
\hline CHEMBL 3677448 & 1528566 & 9.0 & 8.8883 & TRN \\
\hline CHEMBL 3677430 & 1528566 & 7.4685 & 7.9326 & TST \\
\hline CHEMBL 3677537 & 1528566 & 8.8539 & 8.8105 & TRN \\
\hline CHEMBL3672635 & 1528566 & 9.0 & 8.8151 & TRN \\
\hline CHEMBL3672609 & 1528566 & 9.0 & 8.9174 & TRN \\
\hline CHEMBL3672636 & 1528566 & 9.0 & 8.711 & TRN \\
\hline CHEMBL 3682485 & 1528566 & 8.4815 & 8.7125 & TRN \\
\hline CHEMBL 3672638 & 1528566 & 9.0 & 9.0488 & TRN \\
\hline CHEMBL 3672634 & 1528566 & 9.0 & 8.3761 & TRN \\
\hline
\end{tabular}


Supplemental Table S2.txt

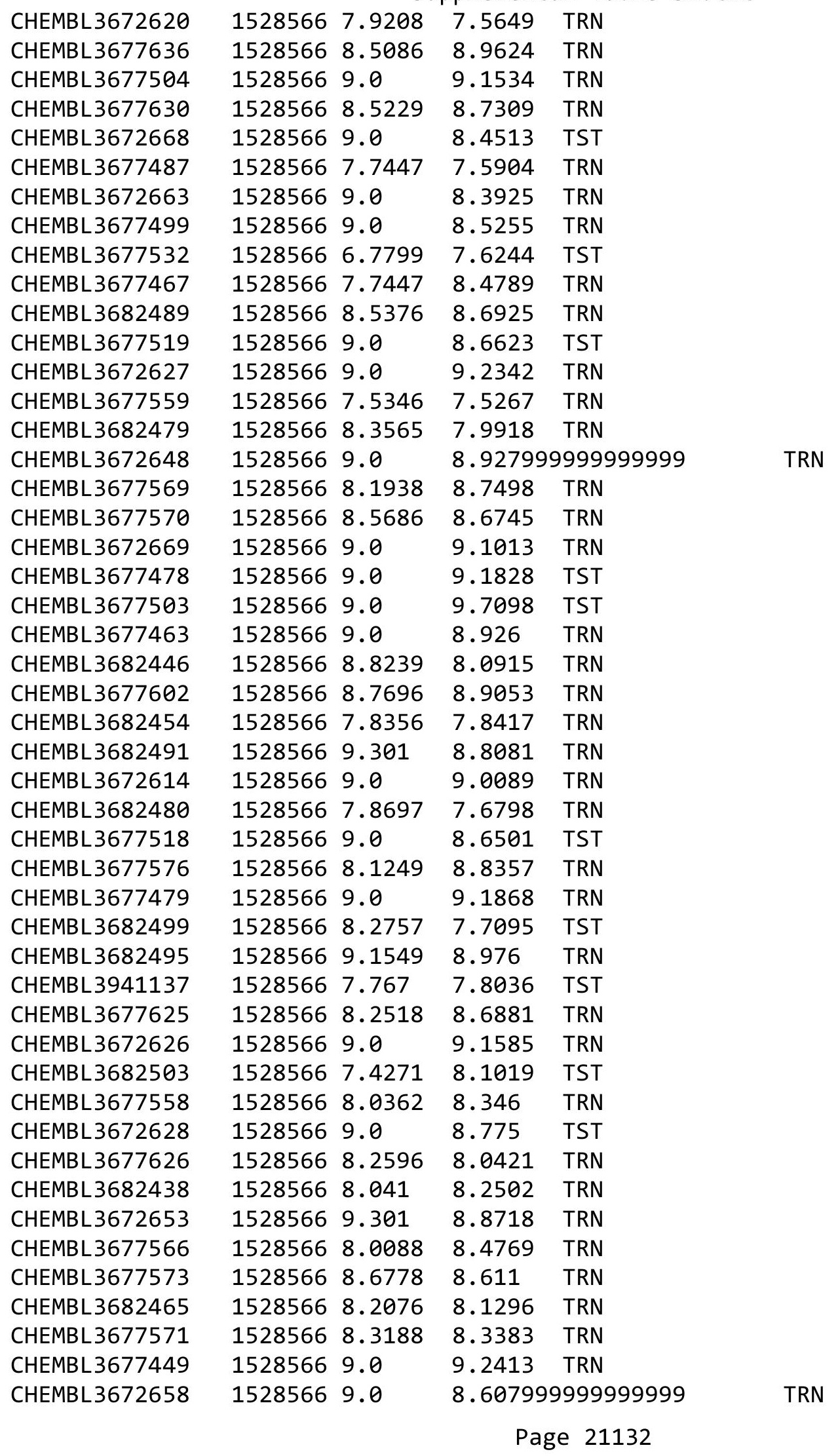


Supplemental Table S2.txt

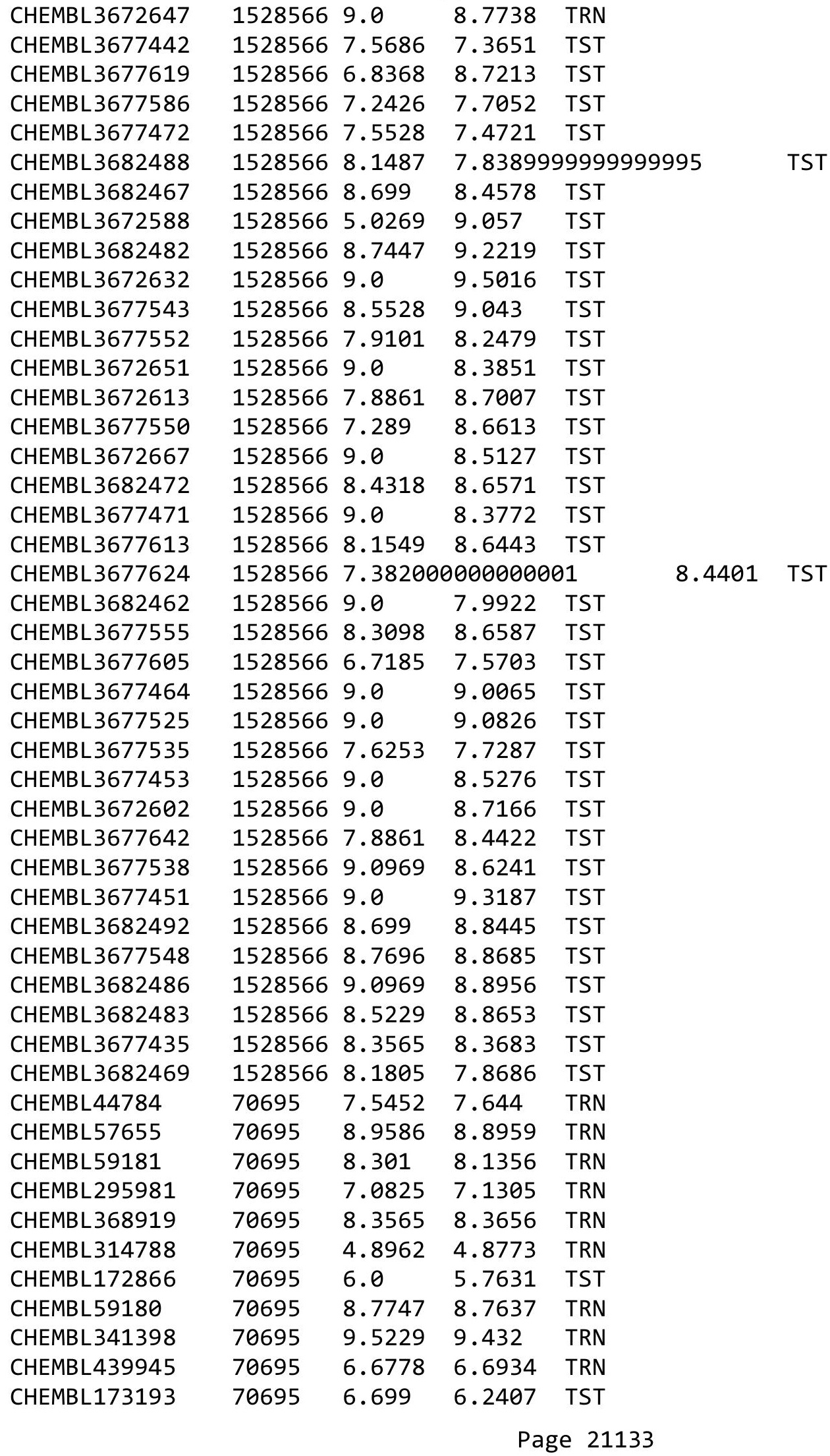




\begin{tabular}{|c|c|c|c|c|c|c|}
\hline & & \multicolumn{5}{|c|}{ Supplemental Table S2.txt } \\
\hline CHEMBL335960 & 70695 & 7.6383 & 7.3201 & TRN & & \\
\hline CHEMBL43718 & 70695 & 6.7399 & 6.7753 & TRN & & \\
\hline CHEMBL173339 & 70695 & 7.9393 & 7.9576 & TRN & & \\
\hline CHEMBL10195 & 70695 & 7.7328 & 7.7299 & TRN & & \\
\hline CHEMBL53651 & 70695 & 4.5229 & 4.5083 & TRN & & \\
\hline CHEMBL335555 & 70695 & \multicolumn{3}{|c|}{6.3420000000000005} & 6.4762 & TRN \\
\hline CHEMBL6597 & 70695 & 9.5229 & 9.6322 & TRN & & \\
\hline CHEMBL19732 & 70695 & 9.6021 & 8.2851 & TST & & \\
\hline CHEMBL299250 & 70695 & \multicolumn{3}{|c|}{6.082999999999999} & 6.1185 & TRN \\
\hline CHEMBL3144841 & 70695 & 9.699 & 10.1009 & TST & & \\
\hline CHEMBL3144698 & 70695 & 8.8861 & 8.9652 & TST & & \\
\hline CHEMBL 336728 & 70695 & 9.4318 & 9.4412 & TRN & & \\
\hline CHEMBL66902 & 70695 & 6.0 & 6.0543 & TRN & & \\
\hline CHEMBL173938 & 70695 & 6.6198 & 6.5516 & TST & & \\
\hline CHEMBL131977 & 70695 & 8.0339 & 8.1632 & TRN & & \\
\hline CHEMBL133049 & 70695 & 9.5376 & 9.557 & TRN & & \\
\hline CHEMBL298561 & 70695 & 6.0 & 5.9953 & TRN & & \\
\hline CHEMBL83581 & 70695 & 6.4789 & 6.4256 & TRN & & \\
\hline CHEMBL295277 & 70695 & 5.5229 & 5.4217 & TRN & & \\
\hline CHEMBL13458 & 70695 & 6.8539 & 6.735 & TST & & \\
\hline CHEMBL177076 & 70695 & 6.5003 & 6.5321 & TRN & & \\
\hline CHEMBL435550 & 70695 & 6.5686 & 6.572999 & 9999999999 & 95 & TRN \\
\hline CHEMBL58385 & 70695 & 8.8239 & 8.7167 & TRN & & \\
\hline CHEMBL 307202 & 70695 & 8.8125 & 8.899 & TST & & \\
\hline CHEMBL368130 & 70695 & 6.8239 & 6.8972 & TRN & & \\
\hline CHEMBL 3144615 & 70695 & 9.3565 & 9.7896 & TST & & \\
\hline CHEMBL1269093 & 70695 & 6.0 & 6.6142 & TST & & \\
\hline CHEMBL 309267 & 70695 & 4.5229 & 4.5333 & TRN & & \\
\hline CHEMBL335888 & 70695 & 8.3188 & 8.2806 & TRN & & \\
\hline CHEMBL 6655 & 70695 & 9.3279 & 9.5009 & TRN & & \\
\hline CHEMBL3144696 & 70695 & 10.0969 & 10.3931 & TST & & \\
\hline CHEMBL 174535 & 70695 & 8.1675 & 8.0487 & TRN & & \\
\hline CHEMBL133705 & 70695 & 8.0706 & 8.0551 & TRN & & \\
\hline CHEMBL 7290 & 70695 & 8.4559 & 8.5066 & TRN & & \\
\hline CHEMBL1518572 & 70695 & 8.3468 & 8.316 & TRN & & \\
\hline CHEMBL133272 & 70695 & 9.3979 & 9.4327 & TRN & & \\
\hline CHEMBL45174 & 70695 & 6.433 & 6.3804 & TRN & & \\
\hline CHEMBL 268262 & 70695 & 6.3233 & 6.3429 & TRN & & \\
\hline CHEMBL 3144849 & 70695 & 9.7696 & 9.559 & TST & & \\
\hline CHEMBL366789 & 70695 & 4.0 & 4.5572 & TST & & \\
\hline CHEMBL52030 & 70695 & 9.3468 & 9.282 & TRN & & \\
\hline CHEMBL58570 & 70695 & 8.7645 & 8.9208 & TRN & & \\
\hline CHEMBL368768 & 70695 & 8.1135 & 8.1123 & TRN & & \\
\hline CHEMBL173325 & 70695 & 6.5031 & 6.0003 & TST & & \\
\hline CHEMBL314804 & 70695 & 5.5229 & 5.5859 & TRN & & \\
\hline CHEMBL368179 & 70695 & 6.9666 & 6.7592 & TST & & \\
\hline CHEMBL43725 & 70695 & 5.5834 & 5.5215 & TRN & & \\
\hline CHEMBL6814 & 70695 & 8.6021 & 8.6624 & TRN & & \\
\hline
\end{tabular}




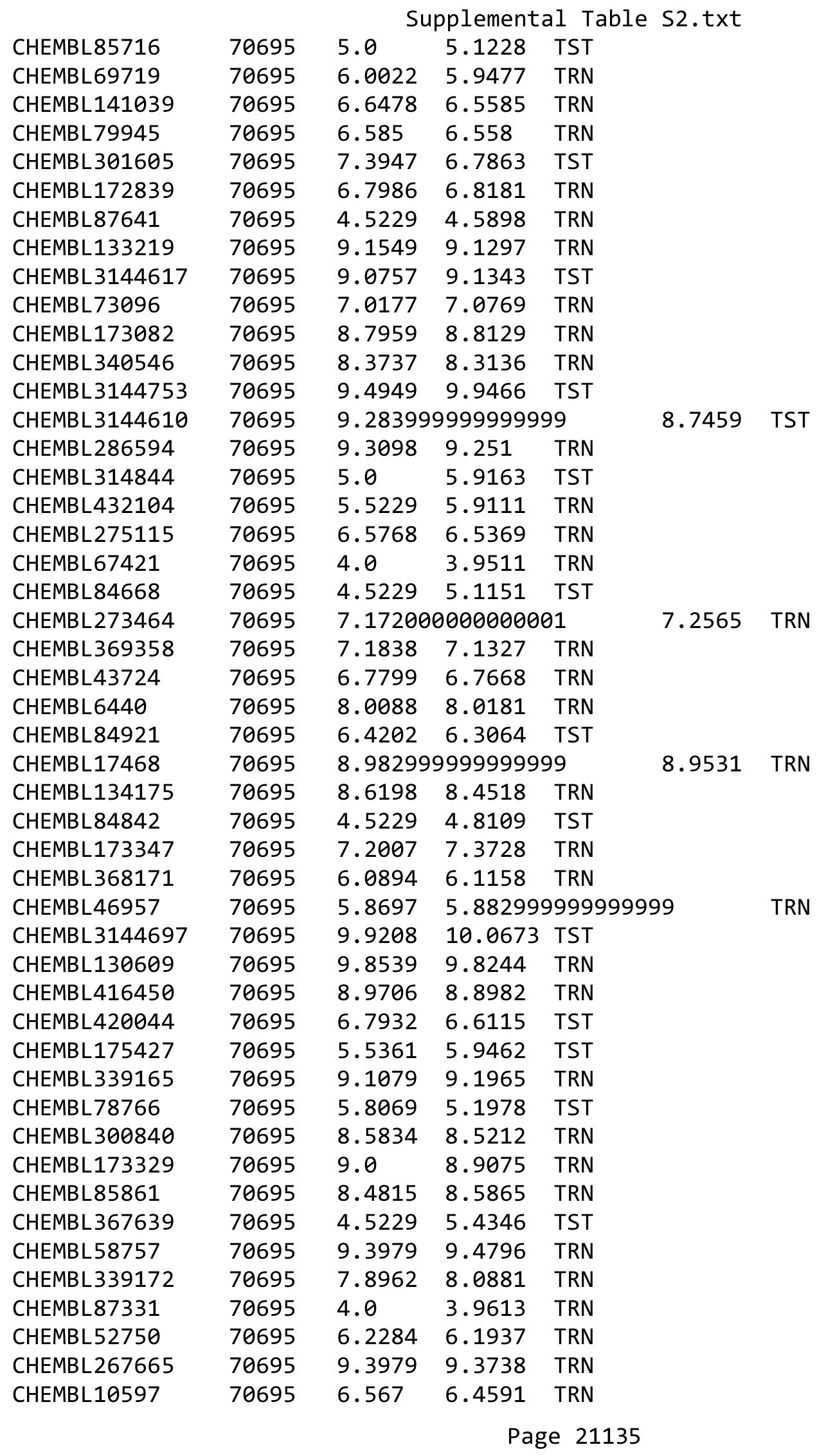




\begin{tabular}{|c|c|c|c|c|c|c|}
\hline & & \multicolumn{5}{|c|}{ Supplemental Table s2.txt } \\
\hline CHEMBL170808 & 70695 & 8.1135 & 8.1055 & TRN & & \\
\hline CHEMBL173219 & 70695 & 6.8508 & 6.8183 & TRN & & \\
\hline CHEMBL10483 & 70695 & 8.3979 & 8.5044 & TRN & & \\
\hline CHEMBL173087 & 70695 & 7.0386 & 7.0781 & TRN & & \\
\hline CHEMBL49141 & 70695 & 8.6216 & 8.1278 & TST & & \\
\hline CHEMBL47853 & 70695 & 5.5884 & 5.5522 & TRN & & \\
\hline CHEMBL408797 & 70695 & 6.7011 & 7.9694 & TST & & \\
\hline CHEMBL6659 & 70695 & 9.4202 & 9.3285 & TRN & & \\
\hline CHEMBL415293 & 70695 & 9.1871 & 9.1134 & TRN & & \\
\hline CHEMBL337166 & 70695 & 8.1427 & 8.1111 & TRN & & \\
\hline CHEMBL431973 & 70695 & 4.0 & 4.0781 & TRN & & \\
\hline CHEMBL3144795 & 70695 & 7.6198 & 8.3193 & TST & & \\
\hline CHEMBL10534 & 70695 & 7.983 & 7.9446 & TRN & & \\
\hline CHEMBL133914 & 70695 & 6.4271 & 6.3621 & TRN & & \\
\hline CHEMBL132529 & 70695 & 8.2218 & 8.211 & TRN & & \\
\hline CHEMBL415290 & 70695 & 9.0706 & 9.1144 & TRN & & \\
\hline CHEMBL 307783 & 70695 & 6.9547 & 6.9006 & TRN & & \\
\hline CHEMBL176457 & 70695 & 6.4908 & 6.4834 & TRN & & \\
\hline CHEMBL130416 & 70695 & 8.585 & 8.6497 & TRN & & \\
\hline CHEMBL6421 & 70695 & 9.5229 & 9.4395 & TRN & & \\
\hline CHEMBL171302 & 70695 & 5.7852 & 6.9731 & TST & & \\
\hline CHEMBL 367051 & 70695 & 5.5229 & 5.4791 & TRN & & \\
\hline CHEMBL45346 & 70695 & 7.4112 & 7.4768 & TRN & & \\
\hline CHEMBL11709 & 70695 & 7.5719 & 7.61799 & 9999999999 & & TRN \\
\hline CHEMBL176307 & 70695 & 5.5229 & 5.4812 & TRN & & \\
\hline CHEMBL13662 & 70695 & 6.251 & 4.9535 & TST & & \\
\hline CHEMBL85539 & 70695 & 5.5229 & 5.441 & TRN & & \\
\hline CHEMBL1076466 & 619936 & 6.4365 & 6.8788 & TRN & & \\
\hline CHEMBL1087128 & 619936 & 7.7959 & 7.8729 & TRN & & \\
\hline CHEMBL1087638 & 619936 & 6.6402 & 6.7732 & TRN & & \\
\hline CHEMBL1076437 & 619936 & 8.3979 & 8.9834 & TRN & & \\
\hline CHEMBL1076471 & 619936 & 7.3979 & 7.0052 & TRN & & \\
\hline CHEMBL1076198 & 619936 & 7.4202 & 7.3836 & TRN & & \\
\hline CHEMBL1080930 & 619936 & 4.0 & 4.4928 & TRN & & \\
\hline CHEMBL1079422 & 619936 & 7.0757 & 6.6132 & TRN & & \\
\hline CHEMBL1087127 & 619936 & 8.1549 & 7.9194 & TRN & & \\
\hline CHEMBL1076199 & 619936 & 7.284 & 7.4469 & TRN & & \\
\hline CHEMBL1087649 & 619936 & 7.1192 & 6.2174 & TRN & & \\
\hline CHEMBL1076433 & 619936 & 8.301 & 8.1528 & TST & & \\
\hline CHEMBL1076533 & 619936 & 5.6421 & 5.7388 & TRN & & \\
\hline CHEMBL1079946 & 619936 & 5.96899 & 99999999 & 99 & 6.1186 & TRN \\
\hline CHEMBL1076195 & 619936 & 6.3915 & 6.6247 & TRN & & \\
\hline CHEMBL1076201 & 619936 & 7.6383 & 7.7499 & TRN & & \\
\hline CHEMBL1088028 & 619936 & 7.284 & 6.69600 & 0000000001 & & TRN \\
\hline CHEMBL1081090 & 619936 & 6.8041 & 6.772 & TRN & & \\
\hline CHEMBL1076194 & 619936 & 6.2749 & 6.5494 & TRN & & \\
\hline CHEMBL1076196 & 619936 & 6.11799 & 79999999 & 99 & 6.5217 & TRN \\
\hline CHEMBL1076202 & 619936 & 6.5607 & 6.7871 & TRN & & \\
\hline
\end{tabular}




\begin{tabular}{|c|c|c|c|c|}
\hline \multicolumn{5}{|c|}{ Supplemental } \\
\hline HEMBL1076468 & 519936 & 6.3788 & מכשי & \\
\hline HEMBL1088153 & 19936 & 6.6498 & 406 & \\
\hline HEMBL10 & & & & \\
\hline EMBL1076477 & 36 & & & \\
\hline HEMBL1076474 & 19936 & & 272 & \\
\hline HEMBL1076200 & 19936 & 7.3468 & .5693 & \\
\hline AEMBL1 & & & & \\
\hline 30 & 36 & & & \\
\hline AEMBL10 & & & & \\
\hline HEMBL1076478 & 19936 & 7.6021 & 7.2817 & \\
\hline HEMBL107 & 19936 & & 6.7524 & \\
\hline AEME & 6 & & & \\
\hline 6 & & & & \\
\hline HEMBL1 & & & 7.9 & \\
\hline HEMBL1 & 36 & & & \\
\hline 24 & & & & \\
\hline 7EIMIDL & & & & \\
\hline HEMB & 36 & & 65 & \\
\hline 27 & & & & \\
\hline 9 & & & & \\
\hline 9 & & & & \\
\hline HEME & & & & \\
\hline 3 & 36 & & & \\
\hline & & & & \\
\hline 75 & & & & \\
\hline 22 & & & & \\
\hline HEMBL] & 36 & & & \\
\hline & & & & \\
\hline & & & & \\
\hline ل > סמת. & & & & \\
\hline 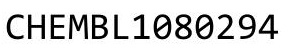 & & & & \\
\hline 3 & & & & \\
\hline & 6 & & & \\
\hline 3 & & & 83 & \\
\hline & 36 & & & \\
\hline & 641908 & & & \\
\hline & & & & \\
\hline 4 & 08 & 5 & 52 & \\
\hline 1 & & 72 & & $\mathrm{R}$ \\
\hline HEMBL 39 & 1641908 & & & \\
\hline HEMBL3 & 1908 & & & \\
\hline & & & & $R^{2}$ \\
\hline CHEMBL3 & 08 & 8. & & \\
\hline CHEMBL3 & 1908 & 48 & 94 & $\mathrm{~S}$ \\
\hline Сигм口 20 & 41908 & 7.4881 & 584 & TR \\
\hline CHEMBL3 & 1908 & 6.2877 & & \\
\hline & 08 & & & \\
\hline CHEMBL 3944853 & 1641908 & 7.3261 & 7.4259 & \\
\hline
\end{tabular}

Page 21137 
Supplemental Table S2.txt

\begin{tabular}{|c|c|c|c|c|}
\hline CHEMBL3908713 & 1641908 & 9.0969 & 9.4495 & TRN \\
\hline CHEMBL3946902 & 1641908 & 8.2441 & 8.2644 & TRN \\
\hline CHEMBL3945556 & 1641908 & 8.2366 & 8.0293 & TRN \\
\hline CHEMBL3938178 & 1641908 & 6.7852 & 6.6745 & TRN \\
\hline CHEMBL3894902 & 1641908 & 7.9957 & 8.2775 & TRN \\
\hline CHEMBL3900215 & 1641908 & 7.4001 & 7.4508 & TRN \\
\hline CHEMBL3963879 & 1641908 & 6.0 & 6.6793 & TRN \\
\hline CHEMBL 3960904 & 1641908 & 8.0915 & 7.5549 & TRN \\
\hline CHEMBL3912938 & 1641908 & 8.2757 & 7.7084 & TRN \\
\hline CHEMBL 3943143 & 1641908 & 7.3526 & 7.1718 & TRN \\
\hline CHEMBL3895787 & 1641908 & 6.0 & 6.0549 & TRN \\
\hline CHEMBL3962190 & 1641908 & 7.5638 & 7.6952 & TRN \\
\hline CHEMBL3945164 & 1641908 & 7.6498 & 7.6796 & TRN \\
\hline CHEMBL3903526 & 1641908 & 6.6174 & 6.9417 & TST \\
\hline CHEMBL 3671849 & 1641908 & 6.8125 & 7.3072 & TST \\
\hline CHEMBL3931187 & 1641908 & 6.3307 & 6.0436 & TRN \\
\hline CHEMBL3909245 & 1641908 & 6.233 & 6.0414 & TRN \\
\hline CHEMBL3901246 & 1641908 & 7.2226 & 7.3928 & TRN \\
\hline CHEMBL 3978370 & 1641908 & 7.7852 & 7.5655 & TST \\
\hline CHEMBL3914597 & 1641908 & 6.6062 & 6.5076 & TRN \\
\hline CHEMBL3971175 & 1641908 & 7.0799 & 6.8657 & TST \\
\hline CHEMBL3949473 & 1641908 & 6.0 & 6.5001 & TST \\
\hline CHEMBL3909165 & 1641908 & 7.066 & 7.2937 & TRN \\
\hline CHEMBL3911228 & 1641908 & 8.2076 & 7.45799 & 9999999999 \\
\hline CHEMBL3906626 & 1641908 & 7.9469 & 7.9421 & TRN \\
\hline CHEMBL3940355 & 1641908 & 6.2291 & 7.2761 & TST \\
\hline CHEMBL3970965 & 1641908 & 7.3799 & 7.1646 & TRN \\
\hline CHEMBL3915442 & 1641908 & 6.4418 & 6.1414 & TRN \\
\hline CHEMBL3894583 & 1641908 & 7.2652 & 7.0304 & TRN \\
\hline CHEMBL 3982583 & 1641908 & 7.3788 & 7.9119 & TRN \\
\hline CHEMBL3911313 & 1641908 & 8.0362 & 8.1958 & TRN \\
\hline CHEMBL 3972373 & 1641908 & 7.091 & 7.2007 & TRN \\
\hline CHEMBL3985435 & 1641908 & 7.6925 & 7.2459 & TRN \\
\hline CHEMBL 3933640 & 1641908 & 8.0458 & 7.5143 & TST \\
\hline CHEMBL3954601 & 1641908 & 7.2013 & 7.1787 & TRN \\
\hline CHEMBL3984423 & 1641908 & 6.5093 & 6.8049 & TRN \\
\hline CHEMBL3962224 & 1641908 & 6.0 & 7.1608 & TRN \\
\hline CHEMBL3911135 & 1641908 & 8.0458 & 7.1906 & TST \\
\hline CHEMBL 3945903 & 1641908 & 7.8827 & 7.5723 & TRN \\
\hline CHEMBL3894534 & 1641908 & 6.0 & 6.8455 & TRN \\
\hline CHEMBL3923627 & 1641908 & 7.8697 & 7.5862 & TRN \\
\hline CHEMBL3923626 & 1641908 & 6.9747 & 6.7331 & TST \\
\hline CHEMBL3939832 & 1641908 & 7.7258 & 7.5817 & TRN \\
\hline CHEMBL3920273 & 1641908 & 7.7447 & 7.4288 & TRN \\
\hline CHEMBL3923451 & 1641908 & 7.0716 & 7.04700 & 0000000001 \\
\hline CHEMBL3962528 & 1641908 & 7.7447 & 7.8449 & TRN \\
\hline CHEMBL 3932404 & 1641908 & 7.3768 & 7.2112 & TRN \\
\hline CHEMBL 3898905 & 1641908 & 8.9586 & 8.4041 & TRN \\
\hline
\end{tabular}


Supplemental Table S2.txt

\begin{tabular}{|c|c|c|c|c|c|}
\hline CHEMBL3969918 & 1641908 & 7.2907 & 7.7168 & TST & \\
\hline CHEMBL 3975771 & 1641908 & 6.9296 & 6.7868 & TRN & \\
\hline CHEMBL3931726 & 1641908 & 6.0 & 6.7369 & TRN & \\
\hline CHEMBL 3671845 & 1641908 & 6.7328 & 7.0309 & TRN & \\
\hline CHEMBL3910652 & 1641908 & 6.9646 & 7.1374 & TST & \\
\hline CHEMBL3953894 & 1641908 & 7.3925 & 7.3976 & TRN & \\
\hline CHEMBL 3947925 & 1641908 & 7.8894 & 7.7949 & TST & \\
\hline CHEMBL 3926234 & 1641908 & 6.0 & 6.9818 & TST & \\
\hline CHEMBL 3969387 & 1641908 & 7.8697 & 7.9699 & TRN & \\
\hline CHEMBL3910306 & 1641908 & 6.0 & 6.5757 & TST & \\
\hline CHEMBL 3982250 & 1641908 & 7.8239 & 7.7608 & TST & \\
\hline CHEMBL3971361 & 1641908 & 6.8508 & 6.9478 & TRN & \\
\hline CHEMBL 3895752 & 1641908 & 7.8327 & 7.5095 & TRN & \\
\hline CHEMBL3913616 & 1641908 & 7.3045 & 7.6537 & TRN & \\
\hline CHEMBL3958827 & 1641908 & 7.7258 & 7.6689 & TRN & \\
\hline CHEMBL3924855 & 1641908 & 7.7305 & 7.0207 & TST & \\
\hline CHEMBL3699930 & 1528667 & 8.7696 & 8.7963 & TRN & \\
\hline CHEMBL 3699873 & 1528667 & 8.5686 & 7.773 & TST & \\
\hline CHEMBL 3699904 & 1528667 & 7.3565 & 7.4726 & TRN & \\
\hline CHEMBL3699826 & 1528667 & 7.6778 & 7.8676 & TRN & \\
\hline CHEMBL3699905 & 1528667 & 7.5086 & 7.5537 & TRN & \\
\hline CHEMBL 2419600 & 1528667 & 8.9586 & 8.985 & TRN & \\
\hline CHEMBL 3699857 & 1528667 & 7.0177 & 6.6805 & TST & \\
\hline CHEMBL 3699874 & 1528667 & 8.0362 & 8.2061 & TRN & \\
\hline CHEMBL 3699861 & 1528667 & 7.041 & 6.3681 & TST & \\
\hline CHEMBL 3699859 & 1528667 & 6.9666 & 6.5297 & TST & \\
\hline CHEMBL 3699832 & 1528667 & 6.7595 & 6.7543 & TRN & \\
\hline CHEMBL3699916 & 1528667 & 9.0 & 8.9464 & TRN & \\
\hline CHEMBL 3699907 & 1528667 & 7.2596 & $7.57700 e$ & 0000000001 & TRN \\
\hline CHEMBL 3699871 & 1528667 & 8.6778 & 8.3326 & TST & \\
\hline CHEMBL 3699885 & 1528667 & 7.8861 & 7.8498 & TRN & \\
\hline CHEMBL3699896 & 1528667 & 8.4949 & 8.4133 & TRN & \\
\hline CHEMBL 2419589 & 1528667 & 8.8239 & 8.824 & TRN & \\
\hline CHEMBL 3699894 & 1528667 & 8.2291 & 8.3265 & TRN & \\
\hline CHEMBL3699844 & 1528667 & 6.1433 & 6.1616 & TRN & \\
\hline CHEMBL2419593 & 1528667 & 8.3872 & 8.3579 & TRN & \\
\hline CHEMBL3699842 & 1528667 & 7.0458 & 6.6861 & TST & \\
\hline CHEMBL 3699898 & 1528667 & 8.0757 & 7.9419 & TRN & \\
\hline CHEMBL3699836 & 1528667 & 6.3028 & 6.4148 & TST & \\
\hline CHEMBL 3699924 & 1528667 & 8.5686 & 8.5453 & TRN & \\
\hline CHEMBL3699856 & 1528667 & 7.5229 & 7.5485 & TRN & \\
\hline CHEMBL3699870 & 1528667 & 8.0 & 7.9053 & TST & \\
\hline CHEMBL 3699827 & 1528667 & 7.585 & 7.3503 & TRN & \\
\hline CHEMBL 2419596 & 1528667 & 8.28399 & 999999999 & 8.2555 & TRN \\
\hline CHEMBL3699846 & 1528667 & 6.5243 & 6.4989 & TRN & \\
\hline CHEMBL 3699876 & 1528667 & 8.1249 & 8.0383 & TRN & \\
\hline CHEMBL3699893 & 1528667 & 8.6198 & 8.7202 & TRN & \\
\hline CHEMBL3699823 & 1528667 & 6.5058 & 6.7055 & TRN & \\
\hline
\end{tabular}

Page 21139 
Supplemental Table S2.txt

\begin{tabular}{|c|c|c|c|c|c|}
\hline CHEMBL 2419609 & 1528667 & 7.7212 & 7.9224 & TRN & \\
\hline CHEMBL3699903 & 1528667 & 8.6778 & 8.5668 & TRN & \\
\hline CHEMBL3699852 & 1528667 & 7.2218 & 7.1585 & TRN & \\
\hline CHEMBL3699866 & 1528667 & $6.7520 e$ & 30000000 & 6.4503 & TST \\
\hline CHEMBL 3699877 & 1528667 & 8.3565 & 8.2456 & TRN & \\
\hline CHEMBL3699879 & 1528667 & 7.8861 & 7.8528 & TRN & \\
\hline CHEMBL3699839 & 1528667 & 5.8097 & 6.0105 & TST & \\
\hline CHEMBL3699831 & 1528667 & 7.4202 & 7.4318 & TRN & \\
\hline CHEMBL3699899 & 1528667 & 7.4685 & 7.5487 & TRN & \\
\hline CHEMBL3699901 & 1528667 & 8.2757 & 8.1856 & TRN & \\
\hline CHEMBL3699840 & 1528667 & 7.041 & 7.0324 & TST & \\
\hline CHEMBL3699929 & 1528667 & 8.7645 & 8.7775 & TRN & \\
\hline CHEMBL3699915 & 1528667 & 8.6198 & 8.5242 & TRN & \\
\hline CHEMBL 2419606 & 1528667 & 7.8861 & 7.9197 & TST & \\
\hline CHEMBL3699923 & 1528667 & 7.2676 & 7.3212 & TRN & \\
\hline CHEMBL3699925 & 1528667 & 8.6021 & 8.5989 & TRN & \\
\hline CHEMBL 2419595 & 1528667 & 7.9208 & 7.8391 & TRN & \\
\hline CHEMBL3699902 & 1528667 & 7.4815 & 7.2686 & TRN & \\
\hline CHEMBL3699886 & 1528667 & 8.6778 & 8.665 & TRN & \\
\hline CHEMBL3699837 & 1528667 & 7.1427 & 7.023 & TST & \\
\hline CHEMBL3699928 & 1528667 & 7.1135 & 7.0695 & TRN & \\
\hline CHEMBL 3639987 & 1528667 & 7.7212 & 7.5312 & TRN & \\
\hline CHEMBL3699855 & 1528667 & 8.0362 & 7.7361 & TRN & \\
\hline CHEMBL 3699847 & 1528667 & 6.4672 & \multicolumn{2}{|c|}{6.3629999999999995} & I \\
\hline CHEMBL 3699878 & 1528667 & 7.7696 & 7.8364 & TRN & \\
\hline CHEMBL3699834 & 1528667 & 7.3279 & 7.3071 & TRN & \\
\hline CHEMBL3699884 & 1528667 & 7.8539 & 7.8658 & TRN & \\
\hline CHEMBL 2419590 & 1528667 & 7.6778 & 7.8161 & TRN & \\
\hline CHEMBL3699849 & 1528667 & 6.284 & 6.2766 & TRN & \\
\hline CHEMBL3699828 & 1528667 & 8.0506 & 7.9335 & TRN & \\
\hline CHEMBL3699912 & 1528667 & 7.3468 & 7.3264 & TRN & \\
\hline CHEMBL3699883 & 1528667 & 7.8539 & 7.8165 & TRN & \\
\hline CHEMBL3699908 & 1528667 & 8.0655 & 7.9507 & TRN & \\
\hline CHEMBL3699850 & 1528667 & 6.4949 & 6.3918 & TRN & \\
\hline CHEMBL3699825 & 1528667 & 8.2518 & 8.2727 & TRN & \\
\hline CHEMBL3699860 & 1528667 & 7.301 & 6.775 & TST & \\
\hline CHEMBL3699888 & 1528667 & 7.2518 & 7.435 & TRN & \\
\hline CHEMBL3699830 & 1528667 & 8.2007 & 8.0978 & TRN & \\
\hline CHEMBL 2419594 & 1528667 & 8.3768 & 8.3431 & TRN & \\
\hline CHEMBL3699917 & 1528667 & 8.4815 & 8.4426 & TRN & \\
\hline CHEMBL 3699880 & 1528667 & 8.2924 & 8.3788 & TRN & \\
\hline CHEMBL3699862 & 1528667 & 7.5528 & 7.5846 & TRN & \\
\hline CHEMBL3699833 & 1528667 & 6.5157 & 6.6093 & TRN & \\
\hline CHEMBL 2419592 & 1528667 & 8.2291 & 8.2577 & TRN & \\
\hline CHEMBL3699854 & 1528667 & 7.2518 & 7.2093 & TRN & \\
\hline CHEMBL3699875 & 1528667 & 8.4202 & 8.5478 & TRN & \\
\hline CHEMBL3699909 & 1528667 & 7.6383 & 7.69799 & 99999999995 & RI \\
\hline CHEMBL 3699843 & 1528667 & 7.5086 & 7.6582 & TST & \\
\hline
\end{tabular}


Supplemental Table S2.txt

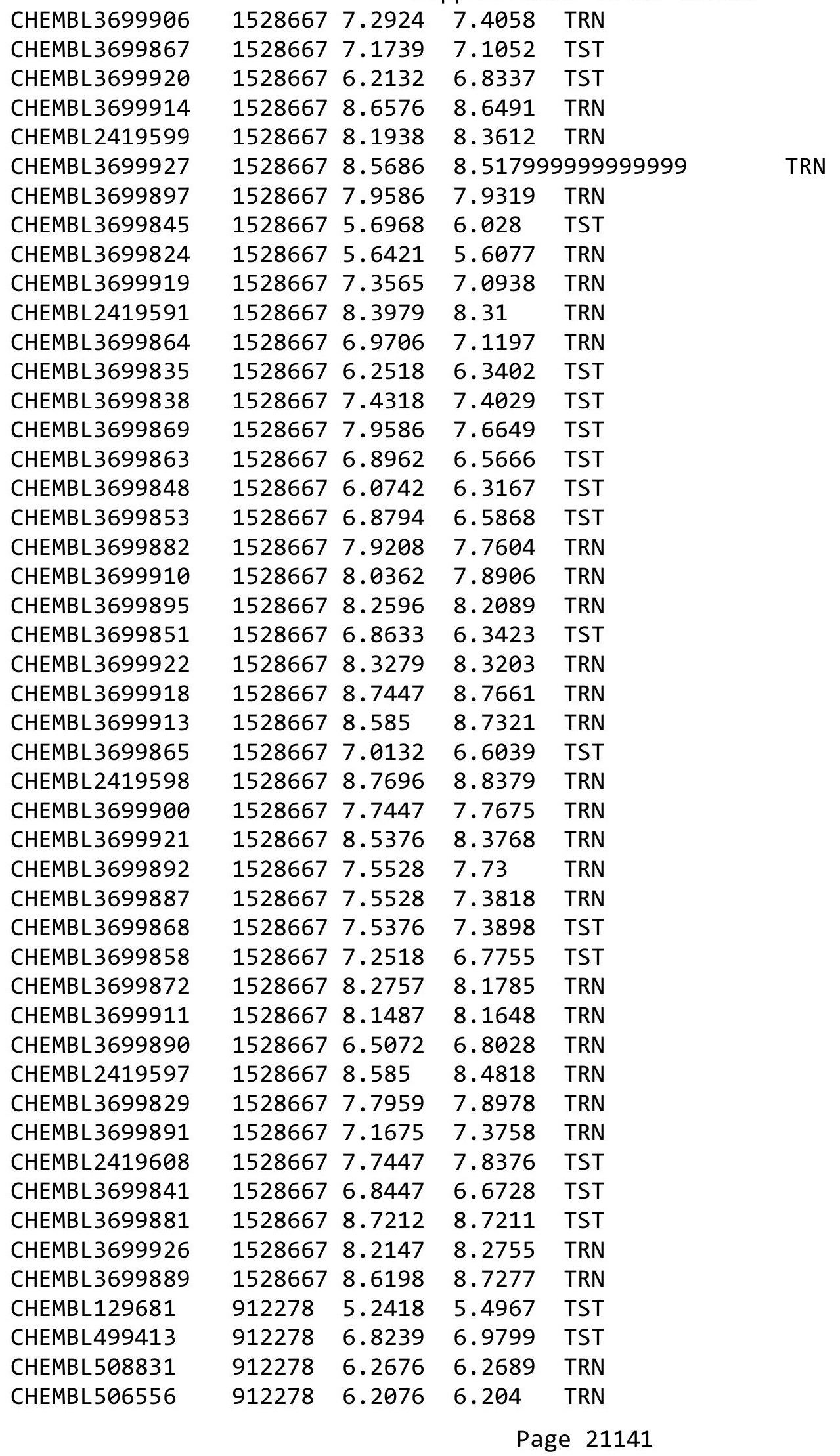




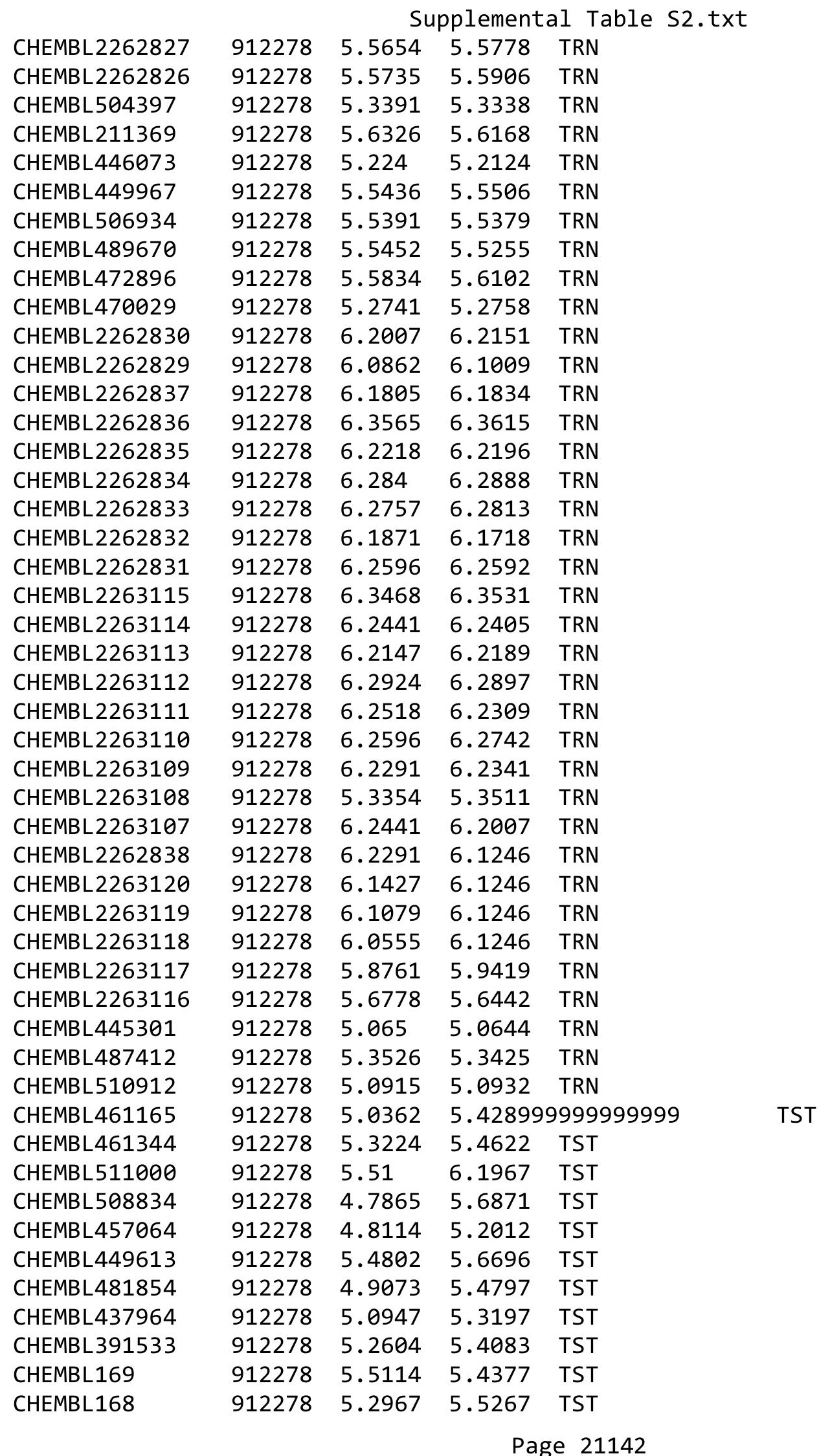


Supplemental Table S2.txt

\begin{tabular}{|c|c|c|c|c|}
\hline CHEMBL3770376 & 1556482 & 4.301 & \multicolumn{2}{|c|}{4.5280000000000005} \\
\hline CHEMBL3771318 & 1556482 & 3.301 & 3.344 & TRN \\
\hline CHEMBL3769884 & 1556482 & 3.301 & 3.6491 & TST \\
\hline CHEMBL3771257 & 1556482 & 5.6021 & 5.5844 & TRN \\
\hline CHEMBL3769738 & 1556482 & 4.301 & 4.1616 & TRN \\
\hline CHEMBL3769467 & 1556482 & 5.2757 & 5.4625 & TRN \\
\hline CHEMBL3771107 & 1556482 & 4.7721 & 4.4797 & TRN \\
\hline CHEMBL3770069 & 1556482 & 5.2076 & 5.3343 & TRN \\
\hline CHEMBL3769967 & 1556482 & 3.301 & 3.3153 & TRN \\
\hline CHEMBL3769468 & 1556482 & 4.9747 & 4.8925 & TRN \\
\hline CHEMBL3769882 & 1556482 & 3.301 & 3.12899 & 99999999996 \\
\hline CHEMBL3769726 & 1556482 & 3.301 & 3.3919 & TRN \\
\hline CHEMBL3771262 & 1556482 & 3.301 & 3.4795 & TRN \\
\hline CHEMBL3770373 & 1556482 & 5.6021 & 5.5001 & TRN \\
\hline CHEMBL3770494 & 1556482 & 3.301 & 3.548 & TRN \\
\hline CHEMBL3770386 & 1556482 & 3.301 & 4.6778 & TST \\
\hline CHEMBL3771301 & 1556482 & 3.301 & 3.1373 & TRN \\
\hline CHEMBL3770052 & 1556482 & 3.301 & 3.3415 & TRN \\
\hline CHEMBL3769642 & 1556482 & 3.301 & 3.4542 & TRN \\
\hline CHEMBL3770814 & 1556482 & 4.9706 & 4.8621 & TRN \\
\hline CHEMBL3770937 & 1556482 & 4.6162 & 4.7905 & TRN \\
\hline CHEMBL3770658 & 1556482 & 4.5114 & 4.5182 & TRN \\
\hline CHEMBL3769886 & 1556482 & 3.0 & 3.0906 & TRN \\
\hline CHEMBL3771126 & 1556482 & 3.301 & 3.4439 & TRN \\
\hline CHEMBL3769608 & 1556482 & 3.301 & 3.3668 & TRN \\
\hline CHEMBL3770085 & 1556482 & 3.301 & 3.3997 & TRN \\
\hline CHEMBL3770172 & 1556482 & 4.9872 & 4.9714 & TRN \\
\hline CHEMBL3771236 & 1556482 & 3.301 & 3.2149 & TRN \\
\hline CHEMBL3770335 & 1556482 & 3.301 & 3.1851 & TRN \\
\hline CHEMBL3769549 & 1556482 & 3.301 & 3.4429 & TRN \\
\hline CHEMBL 3770742 & 1556482 & 3.301 & 3.0901 & TRN \\
\hline CHEMBL3771114 & 1556482 & 3.301 & 3.4389 & TRN \\
\hline CHEMBL3770296 & 1556482 & 3.301 & 3.1778 & TRN \\
\hline CHEMBL3770552 & 1556482 & 4.6925 & 4.6969 & TRN \\
\hline CHEMBL3770932 & 1556482 & 3.301 & 3.3605 & TRN \\
\hline CHEMBL3769955 & 1556482 & 4.7033 & 4.4793 & TRN \\
\hline CHEMBL3770007 & 1556482 & 4.5214 & 4.3218 & TRN \\
\hline CHEMBL3770089 & 1556482 & 3.301 & 3.2063 & TRN \\
\hline CHEMBL3770280 & 1556482 & 4.6289 & 4.6096 & TRN \\
\hline CHEMBL3769412 & 1556482 & 3.301 & 3.2893 & TRN \\
\hline CHEMBL3769627 & 1556482 & 3.301 & 3.25 & TRN \\
\hline CHEMBL3771040 & 1556482 & 6.1549 & 5.8869 & TST \\
\hline CHEMBL3770970 & 1556482 & 3.301 & 3.9799 & TST \\
\hline CHEMBL3769809 & 1556482 & 3.301 & 2.8748 & TST \\
\hline CHEMBL3769423 & 1556482 & 3.301 & 3.3585 & TST \\
\hline CHEMBL3769894 & 1556482 & 4.3778 & 3.7259 & TST \\
\hline CHEMBL3771097 & 1556482 & 4.301 & 4.6037 & TST \\
\hline CHEMBL3771121 & 1556482 & 5.3872 & 5.6313 & TST \\
\hline
\end{tabular}


Supplemental Table S2.txt

\begin{tabular}{|c|c|c|c|c|}
\hline HEMBL & & & 3.7917 & 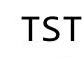 \\
\hline & & 3.301 & 3.7539 & \\
\hline & & & & \\
\hline HEMBL3769625 & & 301 & & \\
\hline HEMBL3769969 & 556482 & 3.301 & 0137 & \\
\hline HEMBL 241427 & 592868 & 5.4237 & 4266 & \\
\hline HEMBL 2 & 368 & 5.3851 & 883 & \\
\hline AEMBL12 & & & & \\
\hline HEMBL472854 & 592868 & 4948 & 4969 & \\
\hline HEMBL46 & 592868 & 4.5812 & 367 & \\
\hline HEMBL 34 & 592868 & 6.9586 & 9507 & \\
\hline AEMBL3 & 68 & 539 & 509 & \\
\hline HEMBL4 & & 289 & & \\
\hline HEMBL1 & 68 & 5407 & 2046 & \\
\hline HEMBL3 & 58 & 6.8861 & 3915 & \\
\hline AEMBL3 & ס & 3372 & 3279 & \\
\hline HEMBL4 & 8 & 503 & 531 & \\
\hline HEMBL3 & & 948 & & \\
\hline HEMBL1 & & 7.8861 & 8878 & \\
\hline AEMBL4 & & 948 & & \\
\hline HEMBL & 68 & 861 & 942 & \\
\hline HEMBL & 8 & 525 & 528 & RIV \\
\hline HEMBL; & 58 & 827 & 836 & \\
\hline HEMBL3 & & 4.6003 & 5061 & \\
\hline HEMBL36 & & 7. & & IST \\
\hline HEMBL3 & 68 & 214 & 248 & RN \\
\hline HEMBL & & 979 & 46 & (1) \\
\hline HFMRI & 58 & 878 & 61 & \\
\hline HEMBL1 & & 295 & & 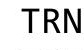 \\
\hline HEMBL1 & & 072 & & ISI \\
\hline HEMBL 2 & & 29 & 247 & RN \\
\hline HEMBL & & 861 & 901 & RIV \\
\hline HEMBL. & 58 & 5 . & 754 & $\mathrm{RN}$ \\
\hline HEMBL36 & & 129 & 34 & IR \\
\hline HEMBL 22 & 368 & 4.6912 & 5888 & TRN \\
\hline HEMBL & & 696 & 684 & ГRN \\
\hline HFMRI & & 33 & 353 & RN \\
\hline HEMBL: & & 5 . & 293 & $\Gamma \mathrm{RN}$ \\
\hline HEMBL45 & 592868 & 6.6383 & 1767 & TST \\
\hline AEMBL3 & 68 & 824 & 3803 & TRN \\
\hline HEMBL1 & 58 & 959 & 061 & \\
\hline CHEMBL 3 & & 7.8861 & 7.8784 & RN \\
\hline HEMBL1 & 592868 & 6.3665 & 6.3994 & TST \\
\hline HEMBL3 & 592868 & 6.1871 & 7751 & S \\
\hline$M B L$ & & 7857 & $\partial 562$ & TS \\
\hline HEMBL3 & & 686 & .5672 & \\
\hline CHEMBL 2 & 592868 & 5.0132 & 6.0207 & \\
\hline HEMBL130822 & 1592868 & 6.3188 & 6.3167 & ГRN \\
\hline
\end{tabular}

Page 21144 
Supplemental Table S2.txt

\begin{tabular}{|c|c|c|c|c|c|}
\hline CHEMBL241634 & 1592868 & 5.8894 & 5.8687 & TRN & \\
\hline CHEMBL3431007 & 1592868 & 6.3979 & 6.3944 & TRN & \\
\hline CHEMBL3637899 & 1592868 & 4.5824 & 4.5894 & TRN & \\
\hline CHEMBL 3637895 & 1592868 & 6.0177 & 6.0146 & TRN & \\
\hline CHEMBL520654 & 1592868 & 6.1079 & 6.1143 & TRN & \\
\hline CHEMBL393580 & 1592868 & 6.6198 & 6.6223 & TRN & \\
\hline CHEMBL 3431323 & 1592868 & 6.9208 & 6.9227 & TRN & \\
\hline CHEMBL519040 & 1592868 & 3.4948 & 3.4776 & TST & \\
\hline CHEMBL413331 & 1592868 & 6.699 & 6.3516 & TST & \\
\hline CHEMBL1683016 & 1592868 & 3.4948 & 4.8016 & TST & \\
\hline CHEMBL511692 & 1592868 & 4.5658 & 4.4035 & TST & \\
\hline CHEMBL 3431063 & 1592868 & 6.4202 & 6.0054 & TST & \\
\hline CHEMBL 227240 & 1592868 & 5.9666 & 6.3123 & TST & \\
\hline CHEMBL 3431322 & 1592868 & 6.3979 & 6.6986 & TST & \\
\hline CHEMBL592281 & 603744 & 7.8539 & 7.8532 & TRN & \\
\hline CHEMBL589885 & 603744 & 8.6576 & 7.4347 & TST & \\
\hline CHEMBL602705 & 603744 & 8.585 & 8.5848 & TRN & \\
\hline CHEMBL589651 & 603744 & 8.2366 & 8.2314 & TRN & \\
\hline CHEMBL589893 & 603744 & 8.7959 & 8.7992 & TRN & \\
\hline CHEMBL589884 & 603744 & 9.3098 & 9.0204 & TRN & \\
\hline CHEMBL590136 & 603744 & 8.9208 & 8.9159 & TRN & \\
\hline CHEMBL592283 & 603744 & 7.7959 & 7.7951 & TRN & \\
\hline CHEMBL589398 & 603744 & 9.3872 & 7.2304 & TST & \\
\hline CHEMBL606249 & 603744 & 8.6576 & 8.6597 & TRN & \\
\hline CHEMBL592282 & 603744 & 7.2596 & 7.2714 & TRN & \\
\hline CHEMBL590132 & 603744 & 8.9208 & 8.9225 & TRN & \\
\hline CHEMBL606242 & 603744 & 9.28399 & 999999999 & 99 & 8.7016 \\
\hline CHEMBL594655 & 603744 & 8.6778 & 8.6772 & TRN & \\
\hline CHEMBL608861 & 603744 & 7.5086 & 7.5068 & TRN & \\
\hline CHEMBL590137 & 603744 & 8.1549 & 8.1508 & TRN & \\
\hline CHEMBL589161 & 603744 & 8.1367 & 8.1297 & TRN & \\
\hline CHEMBL607031 & 603744 & 9.2924 & 9.3013 & TRN & \\
\hline CHEMBL592770 & 603744 & 8.2518 & 8.2449 & TRN & \\
\hline CHEMBL592767 & 603744 & 8.2441 & 8.4987 & TST & \\
\hline CHEMBL590382 & 603744 & 8.4202 & 8.4166 & TRN & \\
\hline CHEMBL589162 & 603744 & 9.6576 & 8.149 & TST & \\
\hline CHEMBL603741 & 603744 & 7.2441 & 7.24 & TRN & \\
\hline CHEMBL595367 & 603744 & 5.5513 & 5.5468 & TRN & \\
\hline CHEMBL590616 & 603744 & 8.0362 & 8.0431 & TRN & \\
\hline CHEMBL604138 & 603744 & 7.8861 & 7.8959 & TRN & \\
\hline CHEMBL604061 & 603744 & 7.1487 & 7.1444 & TRN & \\
\hline CHEMBL591098 & 603744 & 5.3516 & 5.3558 & TRN & \\
\hline CHEMBL589159 & 603744 & 5.9547 & 5.9552 & TRN & \\
\hline CHEMBL590133 & 603744 & 5.2041 & 5.2103 & TRN & \\
\hline CHEMBL589643 & 603744 & 8.2366 & 8.2371 & TRN & \\
\hline CHEMBL589397 & 603744 & 7.8239 & 7.8204 & TRN & \\
\hline CHEMBL599963 & 603744 & 7.7447 & 8.1028 & TST & \\
\hline CHEMBL589400 & 603744 & 7.6383 & 7.6316 & TRN & \\
\hline
\end{tabular}


Supplemental Table S2.txt

\begin{tabular}{|c|c|c|c|c|c|}
\hline CHEMBL596377 & 603744 & 8.5229 & 8.5242 & TRN & \\
\hline CHEMBL589652 & 603744 & 8.3872 & 8.3892 & TRN & \\
\hline CHEMBL602106 & 603744 & 8.3768 & 8.3734 & TRN & \\
\hline CHEMBL601289 & 603744 & 7.7696 & 8.1698 & TST & \\
\hline CHEMBL599964 & 603744 & 8.7959 & 8.7922 & TRN & \\
\hline CHEMBL604456 & 603744 & 7.699 & 7.763 & TST & \\
\hline CHEMBL590387 & 603744 & 9.1549 & 9.1606 & TRN & \\
\hline CHEMBL602506 & 603744 & 8.7212 & 9.0204 & TRN & \\
\hline CHEMBL592287 & 603744 & 7.5686 & 7.5269 & TST & \\
\hline CHEMBL605914 & 603744 & 7.9586 & 7.9573 & TRN & \\
\hline CHEMBL604688 & 603744 & 6.7011 & 8.3741 & TST & \\
\hline CHEMBL590380 & 603744 & 9.0 & 7.8149 & TST & \\
\hline CHEMBL602507 & 603744 & 8.2441 & 7.5028 & TST & \\
\hline CHEMBL592051 & 603744 & 8.4685 & 7.6521 & TST & \\
\hline CHEMBL589157 & 603744 & 7.7212 & 7.7194 & TRN & \\
\hline CHEMBL596163 & 603744 & 8.1249 & 8.7016 & TRN & \\
\hline CHEMBL589649 & 603744 & 8.6778 & 7.5938 & TST & \\
\hline CHEMBL1713955 & 737310 & 5.251 & 5.2603 & TST & \\
\hline CHEMBL1736405 & 737310 & 5.5608 & 4.3744 & TRN & \\
\hline CHEMBL1538234 & 737310 & 4.8957 & 4.8855 & TRN & \\
\hline CHEMBL1326235 & 737310 & 4.6011 & 4.9682 & TRN & \\
\hline CHEMBL1487646 & 737310 & 5.6264 & 5.3228 & TST & \\
\hline CHEMBL1411719 & 737310 & 4.6265 & 5.0685 & TRN & \\
\hline CHEMBL1579173 & 737310 & 4.7723 & 5.6667 & TST & \\
\hline CHEMBL1457068 & 737310 & 5.6099 & 5.3232 & TRN & \\
\hline CHEMBL1360923 & 737310 & 6.9626 & 5.1715 & TRN & \\
\hline CHEMBL1541552 & 737310 & 4.9346 & 5.0494 & TRN & \\
\hline CHEMBL1334837 & 737310 & 5.5637 & 5.5809 & TRN & \\
\hline CHEMBL1590115 & 737310 & 4.9554 & 4.9179 & TRN & \\
\hline CHEMBL1597288 & 737310 & 4.3108 & 4.3723 & TRN & \\
\hline CHEMBL1372844 & 737310 & 4.9299 & 5.5974 & TRN & \\
\hline CHEMBL1498627 & 737310 & 5.2401 & 5.6845 & TRN & \\
\hline CHEMBL1735201 & 737310 & 4.3241 & 5.49 & TRN & \\
\hline CHEMBL1586200 & 737310 & 6.1986 & 5.4737 & TST & \\
\hline CHEMBL1498873 & 737310 & 5.1367 & 5.6087 & TRN & \\
\hline CHEMBL1592938 & 737310 & 7.0362 & 5.3179 & TRN & \\
\hline CHEMBL1510344 & 737310 & 4.4685 & 5.011 & TRN & \\
\hline CHEMBL1448017 & 737310 & 3.6311 & 4.9756 & TRN & \\
\hline CHEMBL1583870 & 737310 & 4.8898 & 5.4297 & TRN & \\
\hline CHEMBL1441579 & 737310 & 7.301 & 6.1206 & TRN & \\
\hline CHEMBL1612880 & 737310 & 4.3355 & 4.6719 & TRN & \\
\hline CHEMBL1705548 & 737310 & 4.7619 & 5.2429 & TRN & \\
\hline CHEMBL1527552 & 737310 & 4.6906 & 5.6106 & TRN & \\
\hline CHEMBL1328771 & 737310 & 4.7437 & 4.9646 & TRN & \\
\hline CHEMBL1487352 & 737310 & 5.8063 & 5.1263 & TRN & \\
\hline CHEMBL1599355 & 737310 & 6.7352 & 5.6813 & TRN & \\
\hline CHEMBL1347715 & 737310 & \multicolumn{3}{|c|}{4.2989999999999995} & 4.7113 \\
\hline CHEMBL487356 & 737310 & 4.8728 & 4.8314 & TRN & \\
\hline
\end{tabular}


Supplemental Table S2.txt

\begin{tabular}{|c|c|c|c|c|c|}
\hline CHEMBL1446531 & 737310 & 5.6499 & 5.5634 & TRN & \\
\hline CHEMBL1388771 & 737310 & 4.7494 & 4.4685 & TRN & \\
\hline CHEMBL1540099 & 737310 & 4.4779 & 4.8822 & TRN & \\
\hline CHEMBL1718478 & 737310 & 3.8678 & 4.8464 & TRN & \\
\hline CHEMBL1721472 & 737310 & 4.3382 & 4.8359 & TRN & \\
\hline CHEMBL1582537 & 737310 & 4.7432 & 4.3775 & TRN & \\
\hline CHEMBL1384209 & 737310 & 6.4597 & 4.8526 & TRN & \\
\hline CHEMBL1539180 & 737310 & 4.6288 & 5.1936 & TRN & \\
\hline CHEMBL1425675 & 737310 & 4.8638 & 5.2598 & TRN & \\
\hline CHEMBL1332465 & 737310 & 7.3665 & 6.4326 & TRN & \\
\hline CHEMBL1510164 & 737310 & 4.9643 & 5.2123 & TRN & \\
\hline CHEMBL1528413 & 737310 & 4.7942 & 5.256 & TRN & \\
\hline CHEMBL1349430 & 737310 & 5.185 & 5.4428 & TRN & \\
\hline CHEMBL1502744 & 737310 & 5.7706 & 5.742999 & 9999999999 & TRN \\
\hline CHEMBL1597028 & 737310 & 5.9834 & 5.888 & TRN & \\
\hline CHEMBL1328776 & 737310 & 4.0424 & 4.8309 & TRN & \\
\hline CHEMBL1567379 & 737310 & 4.5602 & 5.3246 & TRN & \\
\hline CHEMBL1496289 & 737310 & 4.7044 & 4.7802 & TRN & \\
\hline CHEMBL1331475 & 737310 & 4.6375 & 5.122000 & 0000000001 & TRN \\
\hline CHEMBL1327316 & 737310 & 6.38299 & 999999999 & 5.1707 & TRN \\
\hline CHEMBL1366279 & 737310 & 6.4365 & 4.5599 & TRN & \\
\hline CHEMBL1386522 & 737310 & 4.7121 & 5.2124 & TST & \\
\hline CHEMBL1548302 & 737310 & 5.4833 & 5.8657 & TST & \\
\hline CHEMBL1533166 & 737310 & 6.5884 & 4.9044 & TST & \\
\hline CHEMBL1481558 & 737310 & 4.6229 & 4.7806 & TST & \\
\hline CHEMBL1431009 & 737310 & 5.9983 & 4.8695 & TST & \\
\hline CHEMBL1526531 & 737310 & 4.4953 & 4.8819 & TST & \\
\hline CHEMBL1578757 & 737310 & 6.1972 & 5.281000 & 0000000001 & TST \\
\hline CHEMBL1578303 & 737310 & 5.0872 & 5.7837 & TST & \\
\hline CHEMBL1552929 & 737310 & 4.6945 & 4.8122 & TST & \\
\hline CHEMBL1715968 & 737310 & 5.1629 & 5.08 & TST & \\
\hline CHEMBL1500583 & 737310 & 6.0867 & 5.7012 & TST & \\
\hline CHEMBL1301520 & 737310 & \multicolumn{3}{|c|}{5.0760000000000005} & TST \\
\hline CHEMBL1427125 & 737310 & 4.7212 & 4.9421 & TST & \\
\hline CHEMBL 3984839 & 1642378 & 7.8041 & 7.9395 & TRN & \\
\hline CHEMBL 3953849 & 1642378 & 8.4271 & 8.5933 & TRN & \\
\hline CHEMBL 3922549 & 1642378 & 10.2596 & 10.0631 & TRN & \\
\hline CHEMBL 3942446 & 1642378 & 10.0223 & 9.9429 & TRN & \\
\hline CHEMBL 3939262 & 1642378 & 9.3958 & 8.9024 & TRN & \\
\hline CHEMBL 3935018 & 1642378 & 10.1308 & 10.1401 & TRN & \\
\hline CHEMBL3958253 & 1642378 & 9.2976 & 9.2351 & TRN & \\
\hline CHEMBL 3953990 & 1642378 & 9.3224 & 9.4762 & TRN & \\
\hline CHEMBL 3946464 & 1642378 & 10.585 & 10.8441 & TRN & \\
\hline CHEMBL 3901533 & 1642378 & 6.0 & 5.8535 & TRN & \\
\hline CHEMBL 3926007 & 1642378 & 6.0 & 6.2502 & TST & \\
\hline CHEMBL 3892509 & 1642378 & 9.8125 & 9.6518 & TRN & \\
\hline CHEMBL 3959091 & 1642378 & 10.9208 & 10.7554 & TRN & \\
\hline CHEMBL3906421 & 1642378 & 6.0 & 6.1641 & TRN & \\
\hline
\end{tabular}


Supplemental Table S2.txt

\begin{tabular}{|c|c|c|c|c|}
\hline & 378 & 10 & & \\
\hline & & 9.9066 & 9.6796 & \\
\hline & 378 & & & \\
\hline 85 & 378 & L8 & & \\
\hline 519 & 378 & 685 & & \\
\hline 46970 & 642378 & .2366 & 301 & \\
\hline 111 & 378 & 76 & & \\
\hline 78 & 78 & & & \\
\hline EMBL & & 565 & & \\
\hline IEMBL 3917077 & 378 & 469 & & \\
\hline IEMBL 3909947 & 378 & & & \\
\hline 176 & 378 & 382 & & \\
\hline 760 & & & & \\
\hline 417 & 16 & & & \\
\hline L3953482 & 378 & 413 & & \\
\hline 795 & 88 & 97 & & \\
\hline 35 & 78 & 18 & & \\
\hline 48 & & & & \\
\hline 262 & & 223 & & \\
\hline 0453 & & & & \\
\hline 705 & 78 & 5778 & & \\
\hline 02 & 78 & 09 & & \\
\hline & & & & \\
\hline 40 & & & & \\
\hline 38 & 8 & 78 & & \\
\hline 13 & & & & \\
\hline 90 & 78 & 97 & & \\
\hline & & & & \\
\hline & & 2506 & & \\
\hline & 78 & 17 & & \\
\hline 19 & & 05 & & \\
\hline 25 & & 78 & & \\
\hline & & & & \\
\hline & & 685 & & \\
\hline 017 & 78 & 56 & & \\
\hline & 78 & 78 & & \\
\hline & & 88 & & \\
\hline & & & & \\
\hline L3975766 & 378 & 586 & & 11 \\
\hline 04 & 78 & 376 & & \\
\hline & 78 & 352 & & \\
\hline & & & & \\
\hline 26614 & 164 & 8.9101 & & \\
\hline 3L3934315 & 1642378 & 9.3635 & 9. & $R$ \\
\hline & 164 & 1612 & & \\
\hline & 164 & 10.2007 & & \\
\hline & 164 & 9.6144 & 9.2017 & \\
\hline HEMBL3970183 & 1642378 & 7.2487 & 7.0093 & \\
\hline
\end{tabular}

Page 21148 


\begin{tabular}{|c|c|c|c|c|}
\hline & & & oplement & 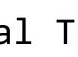 \\
\hline CHEMBL3927952 & 1642378 & 6.0 & 5.8108 & TRN \\
\hline CHEMBL3900796 & 1642378 & 8.821 & 8.7506 & TST \\
\hline CHEMBL3947370 & 1642378 & 8.7825 & 9.1594 & TRN \\
\hline CHEMBL3891387 & 1642378 & 10.3565 & 10.2951 & TRN \\
\hline CHEMBL3919378 & 1642378 & 9.1057 & 9.047 & TRN \\
\hline CHEMBL3945513 & 1642378 & 6.3125 & 5.7909 & TST \\
\hline CHEMBL3892536 & 1642378 & 9.2055 & 9.3673 & TRN \\
\hline CHEMBL3898989 & 1642378 & 10.1675 & 10.5828 & TRN \\
\hline CHEMBL3893598 & 1642378 & 9.7399 & 9.7127 & TRN \\
\hline CHEMBL3924152 & 1642378 & 6.0 & 5.909 & TRN \\
\hline CHEMBL3961360 & 1642378 & 9.7878 & 10.2133 & TRN \\
\hline CHEMBL3915323 & 1642378 & 9.3706 & 9.3322 & TRN \\
\hline CHEMBL3908853 & 1642378 & 9.5317 & 8.7814 & TRN \\
\hline CHEMBL3907493 & 1642378 & 10.2924 & 9.8304 & TRN \\
\hline CHEMBL3976267 & 1642378 & 6.0 & 5.7857 & TRN \\
\hline CHEMBL3922364 & 1642378 & 7.2993 & 8.0043 & TST \\
\hline CHEMBL3950820 & 1642378 & 6.0 & 6.6114 & TRN \\
\hline CHEMBL3906798 & 1642378 & 10.3468 & 10.6534 & TRN \\
\hline CHEMBL3982539 & 1642378 & 10.7447 & 10.5395 & TRN \\
\hline CHEMBL3968206 & 1642378 & 9.4572 & 9.3146 & TRN \\
\hline CHEMBL 3973175 & 1642378 & 8.9318 & 8.6748 & TST \\
\hline CHEMBL3947309 & 1642378 & 9.8761 & 10.0281 & TRN \\
\hline CHEMBL3970981 & 1642378 & 9.8416 & 9.5968 & TRN \\
\hline CHEMBL3933868 & 1642378 & 9.6498 & 9.9166 & TRN \\
\hline CHEMBL3969289 & 1642378 & 8.4522 & 8.7696 & TRN \\
\hline CHEMBL3915913 & 1642378 & 9.9208 & 9.6903 & TST \\
\hline CHEMBL3931274 & 1642378 & 9.3665 & 9.2461 & TST \\
\hline CHEMBL3956440 & 1642378 & 10.0605 & 9.9376 & TRN \\
\hline CHEMBL 3940227 & 1642378 & 9.5482 & 9.6459 & TRN \\
\hline CHEMBL3953164 & 1642378 & 10.3188 & 10.8472 & TRN \\
\hline CHEMBL3897351 & 1642378 & 6.2774 & 6.3038 & TRN \\
\hline CHEMBL 3924903 & 1642378 & 6.0 & 6.0324 & TST \\
\hline CHEMBL3975198 & 1642378 & 6.0 & 6.1882 & TRN \\
\hline CHEMBL3968140 & 1642378 & 8.8069 & 8.5377 & TRN \\
\hline CHEMBL3901481 & 1642378 & 9.9245 & 9.9718 & TRN \\
\hline CHEMBL3952989 & 1642378 & 8.251 & 8.3472 & TRN \\
\hline CHEMBL3926146 & 1642378 & 6.8861 & 6.1332 & TST \\
\hline CHEMBL3914639 & 1642378 & 10.6737 & 10.6152 & TRN \\
\hline CHEMBL 3900425 & 1642378 & 10.3979 & 9.5379 & TST \\
\hline CHEMBL3963170 & 1642378 & 10.0269 & 9.709 & TST \\
\hline CHEMBL3960554 & 1642378 & 10.6904 & 10.6066 & TRN \\
\hline CHEMBL3925403 & 1642378 & 6.0 & 5.8628 & TRN \\
\hline CHEMBL3963946 & 1642378 & 6.0 & 5.9216 & TRN \\
\hline CHEMBL3936808 & 1642378 & 9.8097 & 8.8744 & TRN \\
\hline CHEMBL3961692 & 1642378 & 10.6383 & 10.4485 & TRN \\
\hline CHEMBL3907320 & 1642378 & 9.4145 & 9.4713 & TRN \\
\hline CHEMBL 3900258 & 1642378 & 10.2218 & 10.2645 & TST \\
\hline CHEMBL3930816 & 1642378 & 10.4815 & 10.3728 & TRN \\
\hline
\end{tabular}

Page 21149 


$$
\text { Supplemental Table S2.txt }
$$

\begin{tabular}{|c|c|c|c|c|c|c|}
\hline CHEMBL 3932475 & 1642378 & 10.8539 & 10.6512 & TRN & & \\
\hline CHEMBL3985665 & 1642378 & 9.5544 & 9.417 & TST & & \\
\hline CHEMBL3935096 & 1642378 & 9.7986 & 9.9315 & TRN & & \\
\hline CHEMBL 3983224 & 1642378 & 10.2147 & 9.5708 & TRN & & \\
\hline CHEMBL3951387 & 1642378 & 6.0 & 6.1485 & TRN & & \\
\hline CHEMBL3970953 & 1642378 & 10.1367 & 10.3582 & TRN & & \\
\hline CHEMBL3937209 & 1642378 & 10.1549 & 9.8721 & TRN & & \\
\hline CHEMBL3931279 & 1642378 & 9.2865 & 9.3415 & TRN & & \\
\hline CHEMBL3959083 & 1642378 & 8.2967 & 8.2308 & TST & & \\
\hline CHEMBL3951088 & 1642378 & 10.4202 & 9.9897 & TRN & & \\
\hline CHEMBL3986159 & 1642378 & 8.8097 & 8.9519 & TRN & & \\
\hline CHEMBL3938583 & 1642378 & 9.2366 & 9.103 & TRN & & \\
\hline CHEMBL3975764 & 1642378 & 10.4949 & 9.9947 & TRN & & \\
\hline CHEMBL3965741 & 1642378 & 9.3197 & 9.282 & TRN & & \\
\hline CHEMBL3949274 & 1642378 & 6.0 & 6.2625 & TRN & & \\
\hline CHEMBL3984232 & 1642378 & 9.1385 & 8.8178 & TST & & \\
\hline CHEMBL3968789 & 1642378 & 9.9136 & 10.0 & TRN & & \\
\hline CHEMBL3956717 & 1642378 & 9.1451 & 9.3253 & TRN & & \\
\hline CHEMBL3890745 & 1642378 & 9.9706 & 9.3987 & TRN & & \\
\hline CHEMBL3965243 & 1642378 & 9.1911 & 8.5883 & TRN & & \\
\hline CHEMBL3983351 & 1642378 & 10.1675 & 10.3381 & TRN & & \\
\hline CHEMBL3958302 & 1642378 & 8.982999 & 999999999 & 99 & 8.6089 & TRN \\
\hline CHEMBL3897912 & 1642378 & 9.9031 & 10.0063 & TRN & & \\
\hline CHEMBL 3974800 & 1642378 & 9.0372 & 8.9654 & TST & & \\
\hline CHEMBL3959634 & 1642378 & 8.9666 & 9.2609 & TRN & & \\
\hline CHEMBL3929332 & 1642378 & 7.5143 & 7.6985 & TRN & & \\
\hline CHEMBL3981915 & 1642378 & 9.6517 & 9.8294 & TRN & & \\
\hline CHEMBL3929264 & 1642378 & 9.2741 & 8.8634 & TRN & & \\
\hline CHEMBL3900834 & 1642378 & 9.4134 & 9.0359 & TRN & & \\
\hline CHEMBL3937096 & 1642378 & 6.0 & 6.6342 & TRN & & \\
\hline CHEMBL3957997 & 1642378 & 9.6402 & 9.7931 & TRN & & \\
\hline CHEMBL3952845 & 1642378 & 6.0 & 6.7519 & TRN & & \\
\hline CHEMBL3920778 & 1642378 & 10.585 & 10.2625 & TRN & & \\
\hline CHEMBL3975199 & 1642378 & 8.982999 & 999999999 & 99 & 9.5455 & TRN \\
\hline CHEMBL3920503 & 1642378 & 8.6253 & 8.7609 & TRN & & \\
\hline CHEMBL3909280 & 1642378 & 6.0 & 6.0633 & TRN & & \\
\hline CHEMBL3939101 & 1642378 & 10.0969 & 9.7967 & TRN & & \\
\hline CHEMBL3908350 & 1642378 & 9.8508 & 10.2754 & TRN & & \\
\hline CHEMBL3973544 & 1642378 & 9.1487 & 9.3804 & TRN & & \\
\hline CHEMBL3968874 & 1642378 & 8.5986 & 8.1786 & TRN & & \\
\hline CHEMBL3981104 & 1642378 & 8.9172 & 8.8173 & TRN & & \\
\hline CHEMBL3942104 & 1642378 & 6.0 & 5.7029 & TRN & & \\
\hline CHEMBL3919520 & 1642378 & 9.9318 & 10.5133 & TRN & & \\
\hline CHEMBL3970681 & 1642378 & 7.9393 & 8.2541 & TRN & & \\
\hline CHEMBL3918384 & 1642378 & 6.0 & 5.9499 & TST & & \\
\hline CHEMBL3892308 & 1642378 & 8.2464 & 7.9689 & TST & & \\
\hline CHEMBL3975787 & 1642378 & 9.1457 & 9.0831 & TST & & \\
\hline CHEMBL3896312 & 1642378 & 10.3279 & 10.7314 & TRN & & \\
\hline
\end{tabular}


Supplemental Table S2.txt

\begin{tabular}{|c|c|c|c|c|c|}
\hline CHEMBL3972050 & 1642378 & 10.0915 & 9.8078 & TRN & \\
\hline CHEMBL3947770 & 1642378 & 9.7423 & 10.1189 & TST & \\
\hline CHEMBL3906850 & 1642378 & 9.0575 & 8.624 & TST & \\
\hline CHEMBL 3894381 & 1642378 & 7.8097 & 6.3776 & TST & \\
\hline CHEMBL3951741 & 1642378 & 10.69900 & 000000000 & 10.5153 & TST \\
\hline CHEMBL 3944757 & 1642378 & 9.6716 & 9.6369 & TST & \\
\hline CHEMBL3961823 & 1642378 & 10.4685 & 11.39599 & 99999999999 & TST \\
\hline CHEMBL 3916844 & 1642378 & 6.8928 & 7.5147 & TST & \\
\hline CHEMBL 3899519 & 1642378 & 8.4191 & 8.2402 & TST & \\
\hline CHEMBL3906127 & 1642378 & 8.4101 & 8.9937 & TST & \\
\hline CHEMBL 3937034 & 1642378 & 6.0 & 6.2608 & TST & \\
\hline CHEMBL 3972453 & 1642378 & 9.3063 & 9.4522 & TST & \\
\hline CHEMBL3952360 & 1642378 & 9.0878 & 9.005 & TST & \\
\hline CHEMBL 3891851 & 1642378 & 10.1367 & 10.4618 & TST & \\
\hline CHEMBL3960858 & 1642378 & 7.9469 & 8.2373 & TST & \\
\hline CHEMBL3955604 & 1642378 & 9.5918 & 9.51 & TST & \\
\hline CHEMBL3982105 & 1642378 & 8.9172 & 9.4136 & TST & \\
\hline CHEMBL 3900423 & 1642378 & 9.1561 & 9.465 & TST & \\
\hline CHEMBL3934298 & 1642378 & 8.9245 & 8.8735 & TST & \\
\hline CHEMBL3913945 & 1642378 & 8.2534 & 8.6555 & TST & \\
\hline CHEMBL3895094 & 1642378 & 9.0264 & 9.2511 & TST & \\
\hline CHEMBL3940744 & 1642378 & 10.4437 & 10.6666 & TST & \\
\hline CHEMBL53068 & 560809 & 6.7696 & 6.787999 & 9999999999 & TRN \\
\hline CHEMBL54803 & 560809 & 6.4559 & 6.4393 & TRN & \\
\hline CHEMBL351167 & 560809 & 5.9586 & 6.0432 & TRN & \\
\hline CHEMBL209731 & 560809 & 7.1612 & 7.0842 & TRN & \\
\hline CHEMBL522733 & 560809 & 7.2596 & 7.297999 & & TRN \\
\hline CHEMBL375046 & 560809 & 6.7747 & 6.8335 & TRN & \\
\hline CHEMBL495567 & 560809 & 7.1192 & 6.0631 & TST & \\
\hline CHEMBL293122 & 560809 & 6.301 & 6.3239 & TRN & \\
\hline CHEMBL224786 & 560809 & 5.2899 & 5.3868 & TRN & \\
\hline CHEMBL376371 & 560809 & 5.3979 & 4.6597 & TST & \\
\hline CHEMBL495574 & 560809 & 4.4248 & 4.1255 & TST & \\
\hline CHEMBL421149 & 560809 & 7.3665 & 7.4557 & TRN & \\
\hline CHEMBL350922 & 560809 & 6.4089 & 6.3481 & TRN & \\
\hline CHEMBL225447 & 560809 & 5.5452 & 5.8832 & TST & \\
\hline CHEMBL224787 & 560809 & 6.9747 & 7.0367 & TRN & \\
\hline CHEMBL362906 & 560809 & 3.0 & 3.0635 & TRN & \\
\hline CHEMBL213587 & 560809 & 7.1487 & 7.0224 & TRN & \\
\hline CHEMBL184051 & 560809 & 5.5229 & 5.4618 & TRN & \\
\hline CHEMBL387518 & 560809 & 4.5751 & 4.5525 & TRN & \\
\hline CHEMBL185819 & 560809 & 5.0362 & 5.0962 & TRN & \\
\hline CHEMBL448463 & 560809 & 4.7696 & 4.471999 & 79999999995 & TST \\
\hline CHEMBL161530 & 560809 & 5.6778 & 5.7319 & TRN & \\
\hline CHEMBL364326 & 560809 & 5.4437 & 5.3915 & TRN & \\
\hline CHEMBL387892 & 560809 & 5.5498 & 5.5344 & TRN & \\
\hline CHEMBL495777 & 560809 & 5.8539 & 5.1155 & TST & \\
\hline CHEMBL57513 & 560809 & 6.0 & 6.0138 & TRN & \\
\hline
\end{tabular}




\begin{tabular}{|c|c|c|c|c|c|}
\hline \multicolumn{6}{|c|}{ Supplemental Table S2.txt } \\
\hline CHEMBL223874 & 560809 & 7.1308 & 5.6382 & TST & \\
\hline CHEMBL53290 & 560809 & 6.6576 & 6.6369 & TRN & \\
\hline CHEMBL459503 & 560809 & 7.6038 & 7.6475 & TRN & \\
\hline CHEMBL189472 & 560809 & 5.699 & 5.8512 & TRN & \\
\hline CHEMBL377766 & 560809 & 6.3565 & 6.3743 & TRN & \\
\hline CHEMBL 213588 & 560809 & 7.3468 & 7.405 & TRN & \\
\hline CHEMBL 307160 & 560809 & 6.0132 & 6.0429 & TRN & \\
\hline CHEMBL56059 & 560809 & 5.6198 & 5.6404 & TRN & \\
\hline CHEMBL189274 & 560809 & 5.3279 & 5.4857 & TRN & \\
\hline CHEMBL442373 & 560809 & 5.6383 & 5.61600 & 00000000005 & TRN \\
\hline CHEMBL 225178 & 560809 & 6.1192 & 6.1397 & TRN & \\
\hline CHEMBL184749 & 560809 & 6.2147 & 6.1836 & TRN & \\
\hline CHEMBL388604 & 560809 & 5.4437 & 5.4832 & TRN & \\
\hline CHEMBL185809 & 560809 & 5.7959 & 5.9445 & TRN & \\
\hline CHEMBL495565 & 560809 & 7.0177 & 6.9236 & TRN & \\
\hline CHEMBL161230 & 560809 & 6.6198 & 6.4621 & TRN & \\
\hline CHEMBL224228 & 560809 & 6.0 & 6.0405 & TRN & \\
\hline CHEMBL158635 & 560809 & 6.2596 & 6.3581 & TRN & \\
\hline CHEMBL192306 & 560809 & 6.1135 & 5.9808 & TRN & \\
\hline CHEMBL523231 & 560809 & 4.5258 & 5.561 & TST & \\
\hline CHEMBL437731 & 560809 & 7.2924 & 7.2803 & TRN & \\
\hline CHEMBL 78322 & 560809 & 6.0269 & 5.9101 & TRN & \\
\hline CHEMBL159073 & 560809 & 7.3979 & 7.4053 & TRN & \\
\hline CHEMBL523232 & 560809 & 5.6778 & 5.4621 & TST & \\
\hline CHEMBL190099 & 560809 & 4.7447 & 4.6905 & TRN & \\
\hline CHEMBL427247 & 560809 & 5.6778 & 5.8004 & TRN & \\
\hline CHEMBL 298720 & 560809 & 5.8601 & 5.8997 & TRN & \\
\hline CHEMBL495563 & 560809 & 5.5086 & 4.1033 & TST & \\
\hline CHEMBL377626 & 560809 & 5.7447 & 5.824 & TRN & \\
\hline CHEMBL496375 & 560809 & 6.6576 & 6.6273 & TRN & \\
\hline CHEMBL212168 & 560809 & 6.3279 & 6.2296 & TRN & \\
\hline CHEMBL 224665 & 560809 & 6.0 & 6.0172 & TRN & \\
\hline CHEMBL191488 & 560809 & 3.301 & 3.2185 & TRN & \\
\hline CHEMBL497614 & 560809 & 5.2518 & 4.2426 & TST & \\
\hline CHEMBL157925 & 560809 & 5.4318 & 5.4116 & TRN & \\
\hline CHEMBL185950 & 560809 & 6.5528 & 6.6075 & TRN & \\
\hline CHEMBL509750 & 560809 & 7.3215 & 6.2574 & TST & \\
\hline CHEMBL188664 & 560809 & 6.6778 & 6.7575 & TRN & \\
\hline CHEMBL513615 & 560809 & 8.2757 & 8.2234 & TRN & \\
\hline CHEMBL186079 & 560809 & 6.2757 & 6.0235 & TRN & \\
\hline CHEMBL 225472 & 560809 & 6.5528 & 6.3072 & TRN & \\
\hline CHEMBL158984 & 560809 & 7.0 & 7.0985 & TRN & \\
\hline CHEMBL212473 & 560809 & 7.0969 & 7.0824 & TRN & \\
\hline CHEMBL421829 & 560809 & 7.0506 & 7.0236 & TRN & \\
\hline CHEMBL 363493 & 560809 & 6.284 & 6.2682 & TRN & \\
\hline CHEMBL460382 & 560809 & 5.4486 & 5.3722 & TRN & \\
\hline CHEMBL 299066 & 560809 & 5.5143 & 6.2281 & TST & \\
\hline CHEMBL224649 & 560809 & 6.1675 & 6.0343 & TST & \\
\hline
\end{tabular}




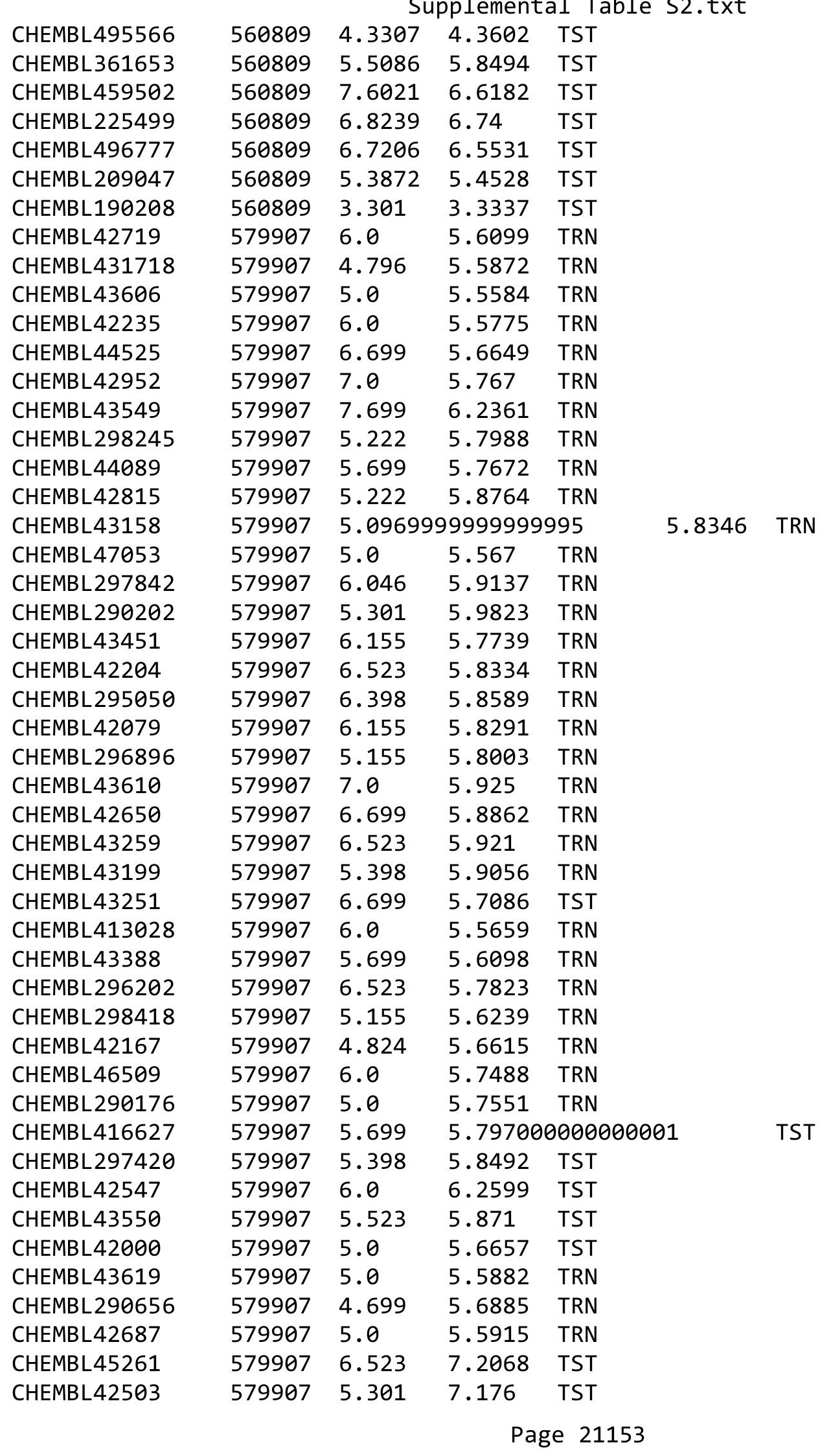


Supplemental Table S2.txt

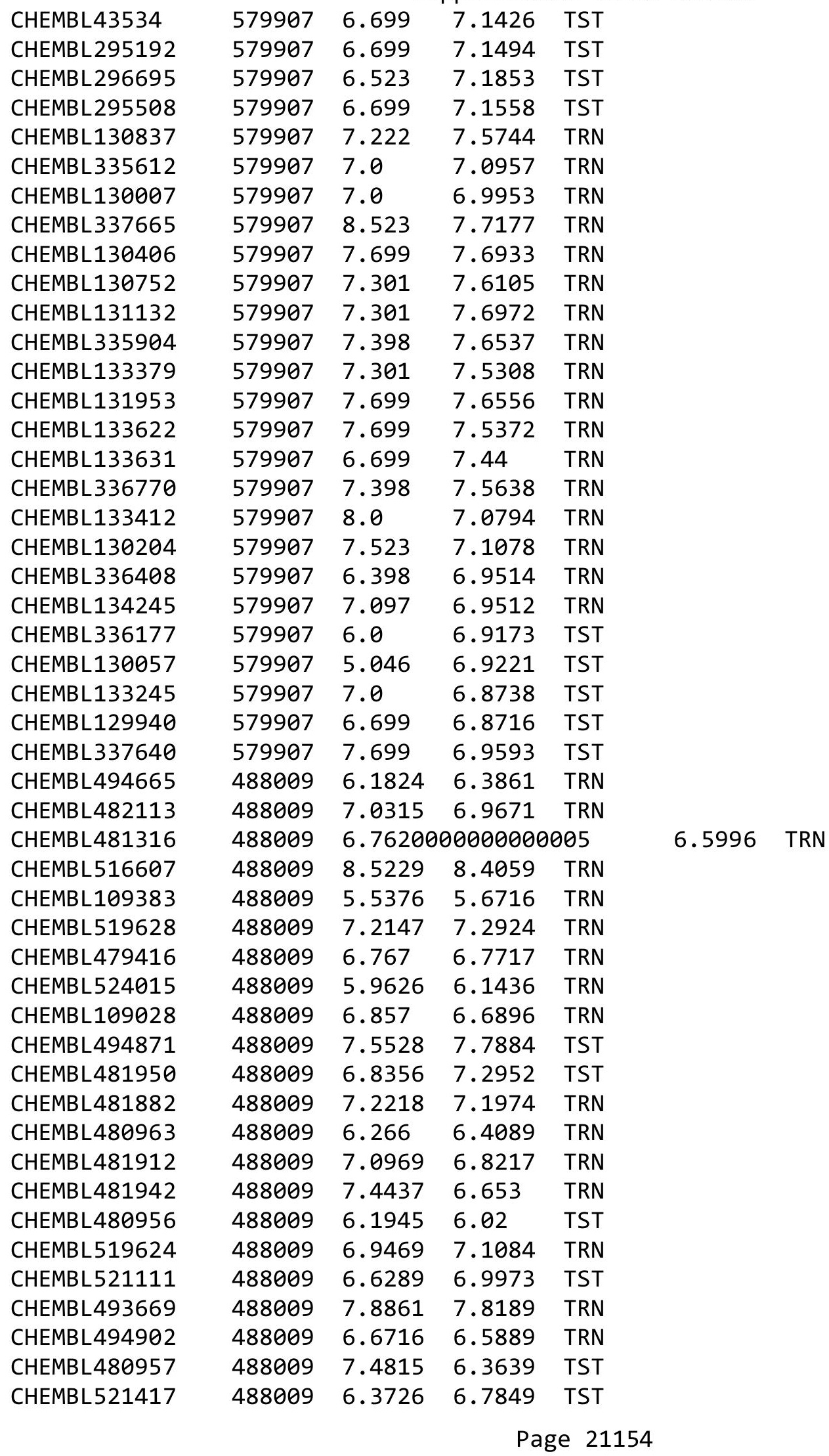




\begin{tabular}{|c|c|c|c|c|c|}
\hline & & & & & \\
\hline CHEMBL506001 & 488009 & 6.0 & 6.7754 & TRN & \\
\hline CHEMBL481926 & 488009 & 6.8996 & 6.8724 & TRN & \\
\hline CHEMBL523880 & 488009 & 7.7696 & 7.4524 & TRN & \\
\hline CHEMBL482112 & 488009 & 7.0088 & 7.1381 & TRN & \\
\hline CHEMBL521091 & 488009 & 7.6778 & 7.8206 & TRN & \\
\hline CHEMBL521250 & 488009 & 8.2218 & 7.8419 & TRN & \\
\hline CHEMBL452471 & 488009 & 7.3372 & 7.4951 & TRN & \\
\hline CHEMBL481705 & 488009 & 6.7011 & 6.6693 & TRN & \\
\hline CHEMBL481749 & 488009 & 7.9586 & 8.0837 & TRN & \\
\hline CHEMBL111403 & 488009 & 6.2526 & 6.1561 & TRN & \\
\hline CHEMBL113060 & 488009 & 5.983 & 5.9121 & TRN & \\
\hline CHEMBL519621 & 488009 & 6.6383 & 7.0545 & TRN & \\
\hline CHEMBL494879 & 488009 & 7.3279 & 7.8818 & TST & \\
\hline CHEMBL493870 & 488009 & 6.4584 & 6.1962 & TRN & \\
\hline CHEMBL520280 & 488009 & 6.71899 & 799999999 & 6.8189 & TRN \\
\hline CHEMBL481706 & 488009 & 6.6055 & 7.417999 & э999999999 & TST \\
\hline CHEMBL519791 & 488009 & 6.6757 & 7.5995 & TST & \\
\hline CHEMBL480952 & 488009 & 7.4559 & 7.3584 & TRN & \\
\hline CHEMBL110262 & 488009 & 6.5884 & 6.0111 & TRN & \\
\hline CHEMBL494901 & 488009 & 6.3862 & 6.3044 & TST & \\
\hline CHEMBL494666 & 488009 & 7.1675 & 7.4033 & TRN & \\
\hline CHEMBL480951 & 488009 & 7.3468 & 7.572999 & 99999999995 & TRN \\
\hline CHEMBL481100 & 488009 & 7.8239 & 7.7705 & TRN & \\
\hline CHEMBL516761 & 488009 & 7.0605 & 6.8048 & TRN & \\
\hline CHEMBL481943 & 488009 & 7.3768 & 7.3489 & TST & \\
\hline CHEMBL482111 & 488009 & 7.4685 & 7.0393 & TRN & \\
\hline CHEMBL481944 & 488009 & 7.4202 & 7.7634 & TST & \\
\hline CHEMBL481116 & 488009 & 7.4685 & 7.6082 & TRN & \\
\hline CHEMBL481919 & 488009 & 7.6383 & 7.9355 & TRN & \\
\hline CHEMBL521692 & 488009 & 6.4295 & 6.2437 & TRN & \\
\hline CHEMBL481952 & 488009 & 8.5229 & 8.0449 & TST & \\
\hline CHEMBL519617 & 488009 & 7.6383 & 7.6163 & TRN & \\
\hline CHEMBL481315 & 488009 & 5.8729 & 5.9928 & TRN & \\
\hline CHEMBL518964 & 488009 & 7.699 & 7.5353 & TRN & \\
\hline CHEMBL506320 & 488009 & 6.9245 & 6.8619 & TRN & \\
\hline CHEMBL482279 & 488009 & 7.3098 & 7.3454 & TRN & \\
\hline CHEMBL454698 & 488009 & 6.1931 & 6.5199 & TST & \\
\hline CHEMBL481698 & 488009 & 6.5031 & 6.7829 & TRN & \\
\hline CHEMBL482086 & 488009 & 7.699 & 7.7088 & TRN & \\
\hline CHEMBL10 & 488009 & 7.2076 & 6.7553 & TST & \\
\hline CHEMBL481766 & 488009 & 7.585 & 7.6809 & TRN & \\
\hline CHEMBL481965 & 488009 & 7.0862 & 6.966 & TRN & \\
\hline CHEMBL482087 & 488009 & 7.8861 & 7.7371 & TRN & \\
\hline CHEMBL480981 & 488009 & 6.0 & 7.2103 & TST & \\
\hline CHEMBL479810 & 488009 & 7.0458 & 7.2965 & TRN & \\
\hline CHEMBL480962 & 488009 & 8.301 & 8.1826 & TRN & \\
\hline CHEMBL480958 & 488009 & 8.0 & 7.9802 & TRN & \\
\hline CHEMBL518962 & 488009 & 5.6676 & 6.0201 & TRN & \\
\hline
\end{tabular}




\begin{tabular}{|c|c|c|c|c|}
\hline & & & splemen & \\
\hline CHEMBL479985 & 488009 & 6.3605 & 5.9776 & TST \\
\hline CHEMBL516460 & 488009 & 6.0 & 7.3614 & TST \\
\hline CHEMBL481951 & 488009 & 6.4449 & 6.4336 & TST \\
\hline CHEMBL521265 & 488009 & 6.5498 & 6.4658 & TRN \\
\hline CHEMBL522362 & 488009 & 5.71 & 5.9759 & TRN \\
\hline CHEMBL481911 & 488009 & 6.6216 & 7.0617 & TRN \\
\hline CHEMBL481883 & 488009 & 7.1549 & 7.2812 & TRN \\
\hline CHEMBL521435 & 488009 & 7.2924 & 7.2627 & TST \\
\hline CHEMBL481765 & 488009 & 7.9586 & 7.6062 & TRN \\
\hline CHEMBL494279 & 539400 & 5.9393 & 5.9389 & TRN \\
\hline CHEMBL478004 & 539400 & 3.93 & 3.9281 & TRN \\
\hline CHEMBL416301 & 539400 & 5.5702 & 5.556 & TRN \\
\hline CHEMBL492621 & 539400 & 6.1192 & 6.1189 & TRN \\
\hline CHEMBL494898 & 539400 & 6.3979 & 6.3997 & TRN \\
\hline CHEMBL492471 & 539400 & 5.3401 & 5.3205 & TRN \\
\hline CHEMBL56073 & 539400 & 5.3799 & 5.0728 & TST \\
\hline CHEMBL495315 & 539400 & 4.56 & 3.5746 & TST \\
\hline CHEMBL493706 & 539400 & 5.6696 & 6.1114 & TRN \\
\hline CHEMBL494317 & 539400 & 5.3002 & 5.3205 & TRN \\
\hline CHEMBL277580 & 539400 & 4.18 & 4.1789 & TRN \\
\hline CHEMBL235059 & 539400 & 4.18 & 4.181 & TRN \\
\hline CHEMBL522167 & 539400 & 5.6003 & 5.5996 & TRN \\
\hline CHEMBL191634 & 539400 & 3.85 & 3.8489 & TRN \\
\hline CHEMBL213343 & 539400 & 4.27 & 4.2701 & TRN \\
\hline CHEMBL524189 & 539400 & 5.6308 & 5.6266 & TRN \\
\hline CHEMBL405865 & 539400 & 5.0501 & 5.05 & TRN \\
\hline CHEMBL492622 & 539400 & 6.0506 & 6.5261 & TRN \\
\hline CHEMBL55264 & 539400 & 4.95 & 5.556 & TRN \\
\hline CHEMBL258994 & 539400 & 6.0088 & 4.7596 & TST \\
\hline CHEMBL494897 & 539400 & 6.5528 & 6.551 & TRN \\
\hline CHEMBL494876 & 539400 & 5.7595 & 5.7577 & TRN \\
\hline CHEMBL495079 & 539400 & 5.8996 & 5.8989 & TRN \\
\hline CHEMBL192017 & 539400 & 4.95 & 4.9511 & TRN \\
\hline CHEMBL493443 & 539400 & 6.2291 & 6.2331 & TRN \\
\hline CHEMBL522337 & 539400 & 6.2924 & 6.2928 & TRN \\
\hline CHEMBL392884 & 539400 & 5.06 & 5.0634 & TRN \\
\hline CHEMBL213470 & 539400 & 3.97 & 3.9696 & TRN \\
\hline CHEMBL260880 & 539400 & 5.3904 & 5.3901 & TRN \\
\hline CHEMBL238046 & 539400 & 5.9101 & 5.7416 & TRN \\
\hline CHEMBL54004 & 539400 & 6.1487 & 5.556 & TRN \\
\hline CHEMBL494694 & 539400 & 6.5528 & 6.1114 & TRN \\
\hline CHEMBL213490 & 539400 & 5.6696 & 5.6702 & TRN \\
\hline CHEMBL411274 & 539400 & 5.4001 & 5.4002 & TRN \\
\hline CHEMBL262616 & 539400 & 6.1427 & 6.14 & TRN \\
\hline CHEMBL523845 & 539400 & 4.03 & 4.0321 & TRN \\
\hline CHEMBL495485 & 539400 & 6.1805 & 6.1815 & TRN \\
\hline CHEMBL237808 & 539400 & 5.8297 & 5.7416 & TRN \\
\hline CHEMBL493906 & 539400 & 5.6003 & 5.6022 & TRN \\
\hline
\end{tabular}




\begin{tabular}{|c|c|c|c|c|c|}
\hline \multicolumn{6}{|c|}{ Supplemental Table S2.txt } \\
\hline CHEMBL1162303 & 539400 & 4.13 & 3.6665 & TST & \\
\hline CHEMBL192342 & 539400 & 4.8499 & 4.8523 & TRN & \\
\hline CHEMBL 291314 & 539400 & 7.0 & 6.5261 & TRN & \\
\hline CHEMBL494896 & 539400 & 6.4559 & 6.4562 & TRN & \\
\hline CHEMBL 235690 & 539400 & 5.4895 & 5.7416 & TRN & \\
\hline CHEMBL441692 & 539400 & 5.0 & 4.9986 & TST & \\
\hline CHEMBL 384308 & 539400 & 3.77 & 4.2097 & TST & \\
\hline CHEMBL98110 & 539400 & 3.48 & 3.4011 & TST & \\
\hline CHEMBL495127 & 539400 & 5.52 & 6.551 & TST & \\
\hline CHEMBL 259026 & 539400 & 5.5702 & 5.6712 & TST & \\
\hline CHEMBL495126 & 539400 & 5.6003 & 5.8422 & TST & \\
\hline CHEMBL522861 & 539400 & 5.2 & 6.3997 & TST & \\
\hline CHEMBL494708 & 539400 & 5.7305 & 5.5055 & TST & \\
\hline CHEMBL442917 & 539400 & 4.1 & 4.9696 & TST & \\
\hline CHEMBL493910 & 539400 & 3.5 & 3.9985 & TST & \\
\hline CHEMBL 398450 & 459970 & 4.1739 & 4.2237 & TRN & \\
\hline CHEMBL254039 & 459970 & 4.1549 & 3.8035 & TST & \\
\hline CHEMBL 252965 & 459970 & 4.0555 & 4.4753 & TRN & \\
\hline CHEMBL 251937 & 459970 & 4.2076 & 3.9253 & TST & \\
\hline CHEMBL 253372 & 459970 & 4.0269 & 4.0806 & TRN & \\
\hline CHEMBL399998 & 459970 & 2.8239 & 3.3891 & TST & \\
\hline CHEMBL 253374 & 459970 & 5.5229 & 4.34699 & 99999999995 & TRN \\
\hline CHEMBL 253820 & 459970 & 4.1612 & 4.2889 & TRN & \\
\hline CHEMBL 254838 & 459970 & 4.0269 & 3.9308 & TST & \\
\hline CHEMBL400357 & 459970 & 2.8239 & 3.1613 & TST & \\
\hline CHEMBL399908 & 459970 & 4.0223 & 3.8572 & TRN & \\
\hline CHEMBL 254610 & 459970 & 4.0809 & 3.7564 & TRN & \\
\hline CHEMBL 251423 & 459970 & 2.8239 & 3.428 & TRN & \\
\hline CHEMBL 249861 & 459970 & 2.8239 & 2.3977 & TRN & \\
\hline CHEMBL254657 & 459970 & 4.1367 & 4.1335 & TRN & \\
\hline CHEMBL398892 & 459970 & 4.301 & 4.6183 & TRN & \\
\hline CHEMBL 399684 & 459970 & 4.1487 & 4.4462 & TRN & \\
\hline CHEMBL 251465 & 459970 & 2.8239 & 3.1898 & TST & \\
\hline CHEMBL400449 & 459970 & 3.8539 & 4.0021 & TRN & \\
\hline CHEMBL399504 & 459970 & 3.9626 & 3.7809 & TST & \\
\hline CHEMBL 250070 & 459970 & 3.9586 & 4.1728 & TRN & \\
\hline CHEMBL 252522 & 459970 & 3.9706 & 3.8221 & TRN & \\
\hline CHEMBL399997 & 459970 & 2.8239 & 3.51800 & 00000000002 & TRN \\
\hline CHEMBL 254837 & 459970 & 4.1675 & 4.0396 & TRN & \\
\hline CHEMBL253189 & 459970 & 3.9431 & 4.0356 & TRN & \\
\hline CHEMBL 252327 & 459970 & 3.8633 & 3.364 & TST & \\
\hline CHEMBL 249860 & 459970 & 2.8239 & 2.5976 & TST & \\
\hline CHEMBL399685 & 459970 & 4.0915 & 4.0168 & TRN & \\
\hline CHEMBL 254627 & 459970 & 4.1612 & 4.0873 & TRN & \\
\hline CHEMBL249859 & 459970 & 3.9626 & 3.6192 & TRN & \\
\hline CHEMBL1162966 & 459970 & 3.9957 & 4.3933 & TRN & \\
\hline CHEMBL 251424 & 459970 & 3.9245 & 3.8077 & TRN & \\
\hline CHEMBL 254406 & 459970 & 4.0315 & 4.1841 & TRN & \\
\hline
\end{tabular}




\begin{tabular}{|c|c|c|c|c|}
\hline & & & ol€ & \\
\hline CHEMBL438519 & 459970 & 3.8962 & 4.2953 & TRN \\
\hline CHEMBL 250057 & 459970 & 3.9208 & 4.0516 & TRN \\
\hline CHEMBL 255051 & 459970 & 4.0915 & 4.1839 & TRN \\
\hline CHEMBL 254448 & 459970 & 3.9431 & 4.0579 & TRN \\
\hline CHEMBL398838 & 459970 & 4.1739 & 4.0826 & TST \\
\hline CHEMBL253172 & 459970 & 4.0 & 4.0866 & TRN \\
\hline CHEMBL 250059 & 459970 & 3.9788 & 3.9321 & TRN \\
\hline CHEMBL445939 & 459970 & 4.1739 & 3.8547 & TST \\
\hline CHEMBL 253373 & 459970 & 4.1192 & 4.1069 & TRN \\
\hline CHEMBL250069 & 459970 & 4.1249 & 4.5342 & TRN \\
\hline CHEMBL 252326 & 459970 & 4.1805 & 3.9193 & TRN \\
\hline CHEMBL 251081 & 459970 & 3.9508 & 3.9363 & TRN \\
\hline CHEMBL254240 & 459970 & 4.1739 & 4.3846 & TRN \\
\hline CHEMBL 249863 & 459970 & 2.8239 & 2.6186 & TRN \\
\hline CHEMBL 249862 & 459970 & 2.8239 & 2.6924 & TRN \\
\hline CHEMBL253823 & 459970 & 4.1739 & 4.7421 & TRN \\
\hline CHEMBL 254404 & 459970 & 3.9245 & 3.9685 & TRN \\
\hline CHEMBL253188 & 459970 & 3.9872 & 4.0974 & TST \\
\hline CHEMBL442286 & 459970 & 4.041 & 3.5564 & TST \\
\hline CHEMBL400851 & 459970 & 2.8239 & 2.6533 & TST \\
\hline CHEMBL254239 & 459970 & 4.2291 & 3.9518 & TRN \\
\hline CHEMBL 253835 & 459970 & 5.8239 & 4.8256 & TRN \\
\hline CHEMBL252523 & 459970 & 3.9508 & 3.822 & TRN \\
\hline CHEMBL 398662 & 459970 & 3.8508 & 4.0466 & TRN \\
\hline CHEMBL 254403 & 459970 & 5.1549 & 4.4349 & TRN \\
\hline CHEMBL 254821 & 459970 & 4.0458 & 3.8405 & TST \\
\hline CHEMBL 254238 & 459970 & 4.1675 & 4.28 & TRN \\
\hline CHEMBL 251425 & 459970 & 3.8239 & 4.1186 & TRN \\
\hline CHEMBL 251426 & 459970 & 4.301 & 4.4958 & TRN \\
\hline CHEMBL 399070 & 459970 & 4.1612 & 4.4084 & TRN \\
\hline CHEMBL399304 & 459970 & 4.0706 & 4.2707 & TRN \\
\hline CHEMBL 254006 & 459970 & 5.8239 & 5.0292 & TRN \\
\hline CHEMBL 253375 & 459970 & 4.2218 & 4.2318 & TRN \\
\hline CHEMBL 254611 & 459970 & 3.9706 & 4.2139 & TRN \\
\hline CHEMBL 254405 & 459970 & 3.8996 & 4.4349 & TRN \\
\hline CHEMBL400358 & 459970 & 2.8239 & 3.1701 & TST \\
\hline CHEMBL399999 & 459970 & 4.0458 & 3.7401 & TRN \\
\hline CHEMBL 249249 & 459970 & 2.8239 & 2.8886 & TST \\
\hline CHEMBL 254038 & 459970 & 5.8239 & 5.0257 & TRN \\
\hline CHEMBL400850 & 459970 & 2.8239 & 2.3977 & TST \\
\hline CHEMBL402720 & 459970 & 4.0555 & 4.0759 & TRN \\
\hline CHEMBL253605 & 459970 & 4.4815 & 4.4247 & TRN \\
\hline CHEMBL404205 & 459970 & 3.8794 & 3.3589 & TST \\
\hline CHEMBL 250058 & 459970 & 3.9957 & 3.9242 & TRN \\
\hline CHEMBL253801 & 459970 & 4.1675 & 4.2913 & TRN \\
\hline CHEMBL 428762 & 459970 & 2.8239 & 3.2504 & TST \\
\hline CHEMBL1242289 & 654929 & 7.0862 & 7.0758 & TRN \\
\hline CHEMBL1234815 & 654929 & 6.585 & 6.1042 & TRN \\
\hline
\end{tabular}




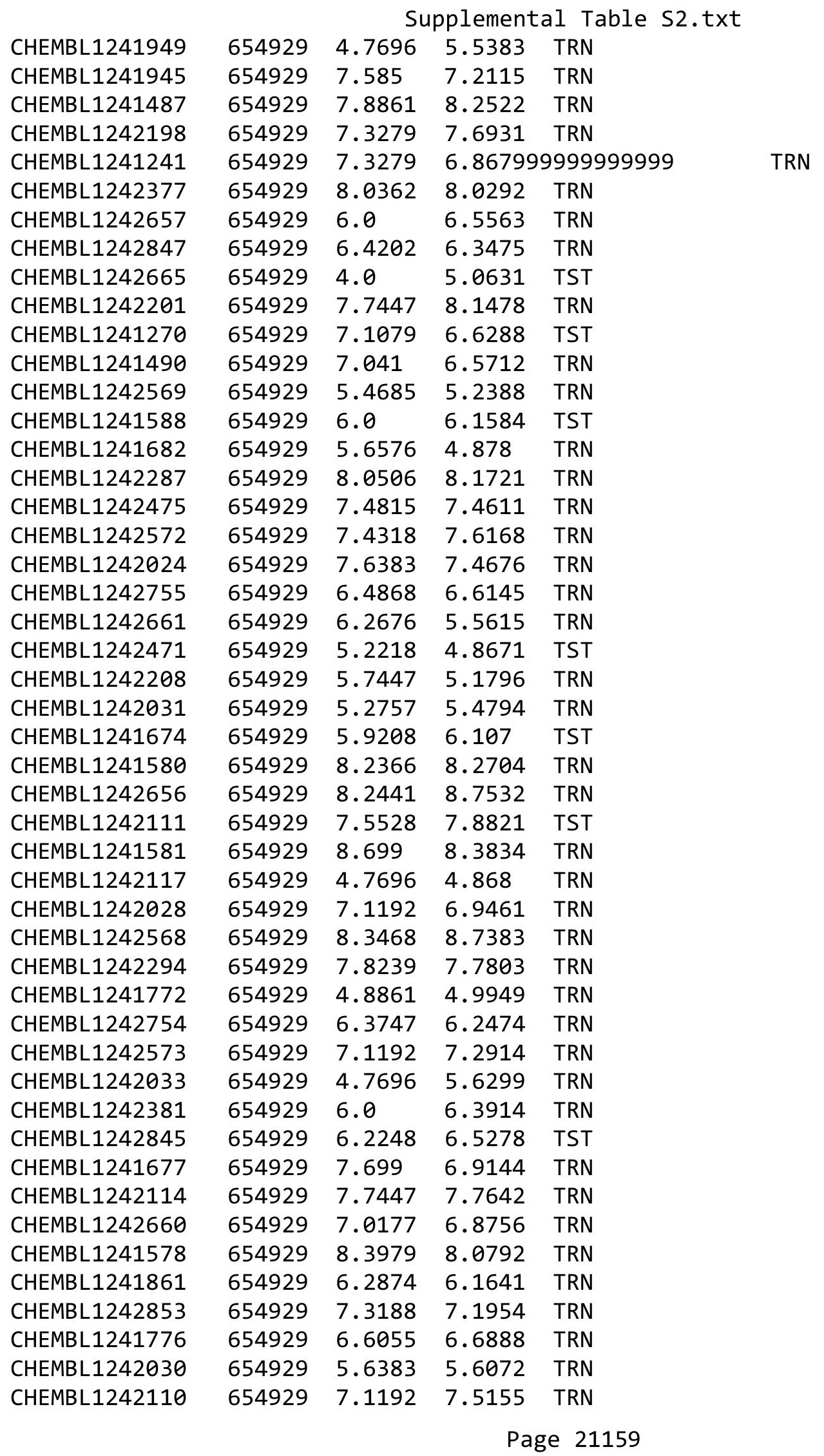


Supplemental Table S2.txt

\begin{tabular}{|c|c|c|c|c|}
\hline 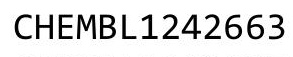 & & & & \\
\hline HEMBL1242027 & 54929 & 469 & 3108 & \\
\hline HEMBL1242846 & 29 & & 9097 & \\
\hline EMBL12 & 29 & & 378 & \\
\hline AEMBL124 & 29 & 959 & & \\
\hline AEMBL1242034 & 54929 & 685 & 1735 & \\
\hline AEMBL1241679 & 654929 & & 1486 & \\
\hline HEMBL124 & & & & \\
\hline EMBL12 & 29 & & & \\
\hline IEMBL12 & & 8. & & \\
\hline AEMBL1242378 & 654929 & 6.0 & 5761 & \\
\hline AEMBL1242757 & 654 & & 1625 & \\
\hline HEMBL124 & 9 & & & \\
\hline AEMBL12 & & & & \\
\hline HEMBL12 & & & & \\
\hline HEMBL124 & 29 & & 71 & \\
\hline HEMBL124 & 29 & & & \\
\hline IEMBL12 & 9 & & & \\
\hline HEMBL12 & & & & \\
\hline JEMBL12 & & & & \\
\hline AEMBL12 & & & & \\
\hline HEMBL124 & & & & \\
\hline HEMBL12 & & & & \\
\hline AEMBL 12 & & & & \\
\hline AFMBI 12 & & & & \\
\hline AEMBL12 & & & & \\
\hline IEMBL124 & & & & \\
\hline EMBL12 & & & & \\
\hline AFMBI 12 & & & & \\
\hline 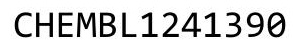 & & & & \\
\hline HEMBL108 & & & & \\
\hline HEMBL124 & & & & \\
\hline & & & & \\
\hline 9 & & & & \\
\hline HEMBL124 & & & & 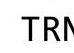 \\
\hline HEMBL124 & & & & $S$ \\
\hline HEMBL124 & & & & \\
\hline 8 & & & & \\
\hline (2MO & & & & \\
\hline HEMBL 124 & & & & RN \\
\hline HEMBL124 & & & 877 & R \\
\hline HEMBL124 & & & & \\
\hline 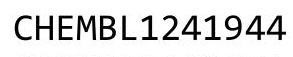 & & & & \\
\hline CHEMBL124 & & & & 1 \\
\hline HEMBL124 & & & & RI \\
\hline AEMBL12 & & & 48 & TR \\
\hline 124 & & & & \\
\hline HEMBI 124 & & & & \\
\hline
\end{tabular}

Page 21160 
Supplemental Table S2.txt

\begin{tabular}{|c|c|c|c|c|}
\hline HEMBL12 & 54929 & .1024 & & \\
\hline & 54929 & .4685 & 6.9906 & \\
\hline 26 & & & & \\
\hline AEMBL12 & & & & \\
\hline AEMBL1241484 & 4929 & & & \\
\hline HEMBL1241771 & 54929 & 3665 & 4635 & \\
\hline HEMBL124 & & & & \\
\hline IEMBL12 & & & & \\
\hline HEMBL124 & & 208 & 8598 & \\
\hline HEMBL124 & 29 & & 4874 & \\
\hline AEMBL124 & 29 & 576 & 65 & \\
\hline AEMBL12 & & & 361 & \\
\hline JEMBL12 & & & & \\
\hline HEMBL12 12 & & 58 & 7.4611 & \\
\hline AEMBL124 & 29 & & 3203 & \\
\hline AEMBL124 & 29 & & 7.0773 & \\
\hline HEMBL12 & & 48 & 162 & \\
\hline HEMBL12 & & & & \\
\hline HEMBL124 & & & 8.0013 & \\
\hline HEMBL124 & & & & \\
\hline AEMBLIL & & & 401 & Niv \\
\hline HEMBL12 & & & & RN \\
\hline HEMBL 12 & & 229 & & \\
\hline HEMBL12L & & & & \\
\hline HEMBL124 & & & & ISI \\
\hline HEMBL12 & & & 31 & RN \\
\hline HEMBL12 & & & & RN \\
\hline HFMBI 12 & & & 535 & \\
\hline HEMBL 12 & & & & IS \\
\hline HEMBL124 & & & & I RN \\
\hline HEMBL12 & & & 912 & RIV \\
\hline HEMBL1 & & & 6 & RN \\
\hline HFMRI 1 & & & 315 & \\
\hline HEMBL124 & & & & IR \\
\hline HEMBL 124 & & 605 & 6.66 & 「RN \\
\hline HEMBL12 & & & 648 & RN \\
\hline HFMRI 1 & & & 49 & TRN \\
\hline HEMBL 124 & & 153 & & TRN \\
\hline HEMBL124 & & & 5.4598 & $\mathrm{TR}$ \\
\hline HEMBL 124 & & & 28 & $T$ \\
\hline HEMBL12 & & & 6.4706 & ונד \\
\hline CHEMBL124 & & .9208 & 5.2591 & ГST \\
\hline HEMBL12 & & 2676 & 7.895 & TST \\
\hline HEMBL124 & & 1024 & 5.0839 & TST \\
\hline HEMBL124 & & .6198 & 6. & TS \\
\hline CHEMBL 12 & & & 5.8362 & \\
\hline CHEMBL124 & & 6.0241 & 5.7779 & \\
\hline CHEMBL1241582 & 654929 & 5.6198 & 6.0916 & - \\
\hline
\end{tabular}

Page 21161 
Supplemental Table S2.txt

\begin{tabular}{|c|c|c|c|c|}
\hline-1 & 929 & & 17 & \\
\hline HEMBL1241482 & 54929 & .1463 & 6.4733 & \\
\hline EMBL12 & & & 581 & \\
\hline EMBI 124 & 29 & & 401 & \\
\hline AEMBL1242664 & 54929 & 301 & 0119 & \\
\hline AEMBL1242477 & 54929 & 7.5229 & 4109 & \\
\hline HEMBL1241486 & 54929 & & .5774 & \\
\hline IEMBL12 & & & 5373 & \\
\hline IEMBL12 & & & 5459 & \\
\hline HEMBL1242288 & 54929 & & .3302 & \\
\hline HEMBL1233881 & 54929 & 61 & 0879 & \\
\hline AEMBL 12 & 54929 & 86 & 7564 & \\
\hline AEMBL12 & & & 7737 & \\
\hline HEMBL15 & 769 & & 7655 & \\
\hline AEMBL318 & .769 & & 8798 & \\
\hline AEMBL136 & 769 & & 7953 & \\
\hline HEMBL15 & 769 & & 428 & \\
\hline HEMBL14 & & & & \\
\hline HEMBL1: & & & 357 & \\
\hline HEMBL13 & 769 & & 199 & \\
\hline UEMBLI48 & 769 & 71 & 1525 & \\
\hline HEMBL 21 & 769 & 5 & 793 & \\
\hline HEMBL 15 & & & 11 & \\
\hline HFMBI 13 & 769 & & & \\
\hline AEMBL13e & & & & RI \\
\hline HEMBL13] & 69 & 5 . & 42 & \\
\hline HEMBL31S & 769 & 5 & 512 & \\
\hline HEMBL13 & & & 39 & \\
\hline HEM & & & & \\
\hline IEMBL19 & 69 & & & II \\
\hline AEMBL142 & 59 & & 619 & \\
\hline HEMBL 22 & 69 & & 4824 & \\
\hline HFMBI 15 & & & & \\
\hline & & & 194 & RN \\
\hline HEMBL136 & 769 & & 467 & RN \\
\hline EMBL13. & 769 & & 788 & \\
\hline HEMBL31C & 769 & & 38 & Niv \\
\hline & & & & RN \\
\hline HEMBL1353474 & .769 & & 3098 & RN \\
\hline HEMBL134 & 769 & & 3629 & RI \\
\hline IEMBL14 & 69 & & 006 & \\
\hline HEMBL133 & & & 5.3711 & \\
\hline 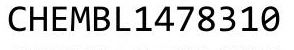 & & & 4.8465 & RN \\
\hline HEMBL17 & 769 & 6.2 & 916 & RN \\
\hline HEMBL14 & 769 & 4 . & 172 & \\
\hline & & & & \\
\hline HEMBL31 & & 5.0053 & & \\
\hline 40620 & - & 5.4713 & 5.5 & \\
\hline
\end{tabular}

Page 21162 
Supplemental Table S2.txt

\begin{tabular}{|c|c|c|c|c|c|}
\hline CHEMBL1306281 & 1301769 & 5.0332 & 5.1551 & TRN & \\
\hline CHEMBL1323872 & 1301769 & 6.2098 & \multicolumn{2}{|c|}{5.7010000000000005} & TRN \\
\hline CHEMBL1725453 & 1301769 & 5.3562 & 5.0843 & TRN & \\
\hline CHEMBL 2140354 & 1301769 & 5.1894 & 5.3798 & TRN & \\
\hline CHEMBL1566205 & 1301769 & 5.3753 & 5.2548 & TRN & \\
\hline CHEMBL95431 & 1301769 & 5.0359 & 4.9917 & TRN & \\
\hline CHEMBL1472925 & 1301769 & 4.0223 & 4.1013 & TRN & \\
\hline CHEMBL1489149 & 1301769 & 5.3649 & 5.3812 & TRN & \\
\hline CHEMBL 3194760 & 1301769 & 5.5746 & 5.0343 & TRN & \\
\hline CHEMBL1579602 & 1301769 & 5.0235 & \multicolumn{2}{|c|}{4.7410000000000005} & TRN \\
\hline CHEMBL1519955 & 1301769 & 5.9454 & 5.4986 & TRN & \\
\hline CHEMBL1596496 & 1301769 & 4.8528 & 5.1162 & TST & \\
\hline CHEMBL530291 & 1301769 & 5.4536 & 5.1406 & TRN & \\
\hline CHEMBL1469224 & 1301769 & 5.0385 & 4.7271 & TRN & \\
\hline CHEMBL1461631 & 1301769 & 5.902 & 5.3941 & TST & \\
\hline CHEMBL1420007 & 1301769 & 4.9472 & 5.0097 & TST & \\
\hline CHEMBL1734142 & 1301769 & 5.2478 & 4.6984 & TST & \\
\hline CHEMBL1388241 & 1301769 & 5.5719 & 5.2841 & TRN & \\
\hline CHEMBL1723919 & 1301769 & 4.8087 & 5.105 & TST & \\
\hline CHEMBL1415184 & 1301769 & 6.2019 & 5.4141 & TST & \\
\hline CHEMBL1348555 & 1301769 & 5.0337 & \multicolumn{2}{|c|}{5.0280000000000005} & TRN \\
\hline CHEMBL1732861 & 1301769 & 4.6759 & 5.0566 & TRN & \\
\hline CHEMBL1449336 & 1301769 & 5.2925 & 4.7116 & TRN & \\
\hline CHEMBL1382917 & 1301769 & 5.5607 & 5.9053 & TRN & \\
\hline CHEMBL1573112 & 1301769 & 5.1221 & 4.9053 & TRN & \\
\hline CHEMBL1315391 & 1301769 & 5.1646 & 5.0503 & TRN & \\
\hline CHEMBL 2362703 & 1301769 & 4.9957 & 5.0394 & TRN & \\
\hline CHEMBL1314867 & 1301769 & 5.154 & 5.1518 & TRN & \\
\hline CHEMBL262627 & 1301769 & 4.9501 & 4.93 & TRN & \\
\hline CHEMBL1713335 & 1301769 & 6.8867 & 5.5918 & TST & \\
\hline CHEMBL1496004 & 1301769 & 5.1755 & 5.5923 & TRN & \\
\hline CHEMBL1401965 & 1301769 & 5.5837 & 5.3738 & TRN & \\
\hline CHEMBL1543258 & 1301769 & 3.0686 & 5.2727 & TST & \\
\hline CHEMBL272945 & 1301769 & 5.0841 & 5.4337 & TRN & \\
\hline CHEMBL1893675 & 1301769 & 5.3803 & 5.1074 & TRN & \\
\hline CHEMBL1519558 & 1301769 & 4.9917 & 4.9512 & TRN & \\
\hline CHEMBL1418720 & 1301769 & 5.0691 & 5.0718 & TRN & \\
\hline CHEMBL1575397 & 1301769 & 4.773 & 5.2263 & TST & \\
\hline CHEMBL1702665 & 1301769 & 7.6509 & 5.4592 & TST & \\
\hline CHEMBL1525599 & 1301769 & 5.1718 & 5.2543 & TRN & \\
\hline CHEMBL1734839 & 1301769 & 7.3696 & 5.631 & TST & \\
\hline CHEMBL1428488 & 1301769 & 5.2844 & 5.2927 & TRN & \\
\hline CHEMBL1310479 & 1301769 & 5.2473 & \multicolumn{2}{|c|}{5.247000000000001} & TRN \\
\hline CHEMBL1611369 & 1301769 & 5.2331 & 5.4131 & TRN & \\
\hline CHEMBL1569724 & 1301769 & 5.6955 & 5.3561 & TRN & \\
\hline CHEMBL1708045 & 1301769 & 5.4117 & 5.2146 & TST & \\
\hline CHEMBL1485417 & 1301769 & 5.2837 & 5.2151 & TST & \\
\hline CHEMBL1533321 & 1301769 & 5.1746 & 5.1618 & TRN & \\
\hline
\end{tabular}

Page 21163 
Supplemental Table S2.txt

\begin{tabular}{|c|c|c|c|c|}
\hline CHEMBL1429289 & 1301769 & 5.1018 & 5.3846 & TRN \\
\hline CHEMBL3187992 & 1301769 & 5.197 & 5.1222 & TST \\
\hline CHEMBL1306343 & 1301769 & 5.0609 & 5.3183 & TRN \\
\hline CHEMBL1704996 & 1301769 & 5.0577 & 4.9314 & TRN \\
\hline CHEMBL1334003 & 1301769 & 5.1758 & 5.4314 & TRN \\
\hline CHEMBL1734534 & 1301769 & 5.125 & 5.1545 & TST \\
\hline CHEMBL1497024 & 1301769 & 5.3777 & 5.3743 & TRN \\
\hline CHEMBL1357535 & 1301769 & 5.0822 & 5.4206 & TRN \\
\hline CHEMBL1366727 & 1301769 & 5.4772 & 5.4198 & TRN \\
\hline CHEMBL1528781 & 1301769 & 5.1034 & 5.3565 & TRN \\
\hline CHEMBL1380507 & 1301769 & 5.2159 & 5.037 & TRN \\
\hline CHEMBL1531328 & 1301769 & 5.8222 & 5.4206 & TST \\
\hline CHEMBL1727678 & 1301769 & 5.3107 & 5.3705 & TST \\
\hline CHEMBL1470979 & 1301769 & 5.2474 & 5.0022 & TRN \\
\hline CHEMBL1500847 & 1301769 & 4.8667 & 5.0582 & TRN \\
\hline CHEMBL1374425 & 1301769 & 5.1789 & 5.1568 & TRN \\
\hline CHEMBL1605536 & 1301769 & 5.3506 & 5.3303 & TRN \\
\hline CHEMBL584442 & 1301769 & 5.3458 & 5.3807 & TRN \\
\hline CHEMBL1338085 & 1301769 & 4.6552 & 4.8169 & TRN \\
\hline CHEMBL1610504 & 1301769 & 4.9202 & 5.091 & TST \\
\hline CHEMBL1404493 & 1301769 & 5.7481 & 5.7668 & TRN \\
\hline CHEMBL1437030 & 1301769 & 5.6887 & 5.8962 & TRN \\
\hline CHEMBL1358722 & 1301769 & 5.9863 & 5.3339 & TST \\
\hline CHEMBL1547232 & 1301769 & 5.3122 & 5.4218 & TRN \\
\hline CHEMBL1561171 & 1301769 & 3.0686 & 4.4377 & TRN \\
\hline CHEMBL1716010 & 1301769 & 5.0877 & 4.9983 & TST \\
\hline CHEMBL1603001 & 1301769 & 5.6552 & 5.952999 & 9999999999 \\
\hline CHEMBL1567331 & 1301769 & 5.3736 & 5.463999 & \\
\hline CHEMBL1604200 & 1301769 & 4.881 & 5.0994 & TRN \\
\hline CHEMBL1443900 & 1301769 & 4.9624 & 4.7209 & TRN \\
\hline CHEMBL1466305 & 1301769 & 5.0556 & 4.9457 & TRN \\
\hline CHEMBL1446412 & 1301769 & 5.2884 & 5.0074 & TRN \\
\hline CHEMBL1869738 & 1301769 & 4.0228 & 5.1405 & TST \\
\hline CHEMBL509617 & 1301769 & 6.4437 & 5.4834 & TST \\
\hline CHEMBL1576078 & 1301769 & 4.8549 & 5.0462 & TST \\
\hline CHEMBL1567944 & 1301769 & 6.6808 & 5.4036 & TST \\
\hline CHEMBL1341031 & 1301769 & 5.024 & 5.2024 & TRN \\
\hline CHEMBL1444822 & 1301769 & 3.0686 & 3.9445 & TRN \\
\hline CHEMBL1308547 & 1301769 & 5.3036 & 5.5927 & TRN \\
\hline CHEMBL1720343 & 1301769 & 5.2435 & 5.0222 & TRN \\
\hline CHEMBL1482468 & 1301769 & 5.2734 & 5.4162 & TRN \\
\hline CHEMBL1323442 & 1301769 & 5.0684 & 5.143 & TRN \\
\hline CHEMBL1442515 & 1301769 & 5.1642 & 5.2947 & TRN \\
\hline CHEMBL1333600 & 1301769 & 5.1122 & 5.5168 & TST \\
\hline CHEMBL1699691 & 1301769 & 8.1169 & 5.6033 & TST \\
\hline CHEMBL1711093 & 1301769 & 4.9321 & 4.9869 & TRN \\
\hline CHEMBL1402539 & 1301769 & 5.085 & 4.8011 & TRN \\
\hline CHEMBL1462064 & 1301769 & 4.7191 & 5.1385 & TRN \\
\hline
\end{tabular}

Page 21164 
Supplemental Table S2.txt

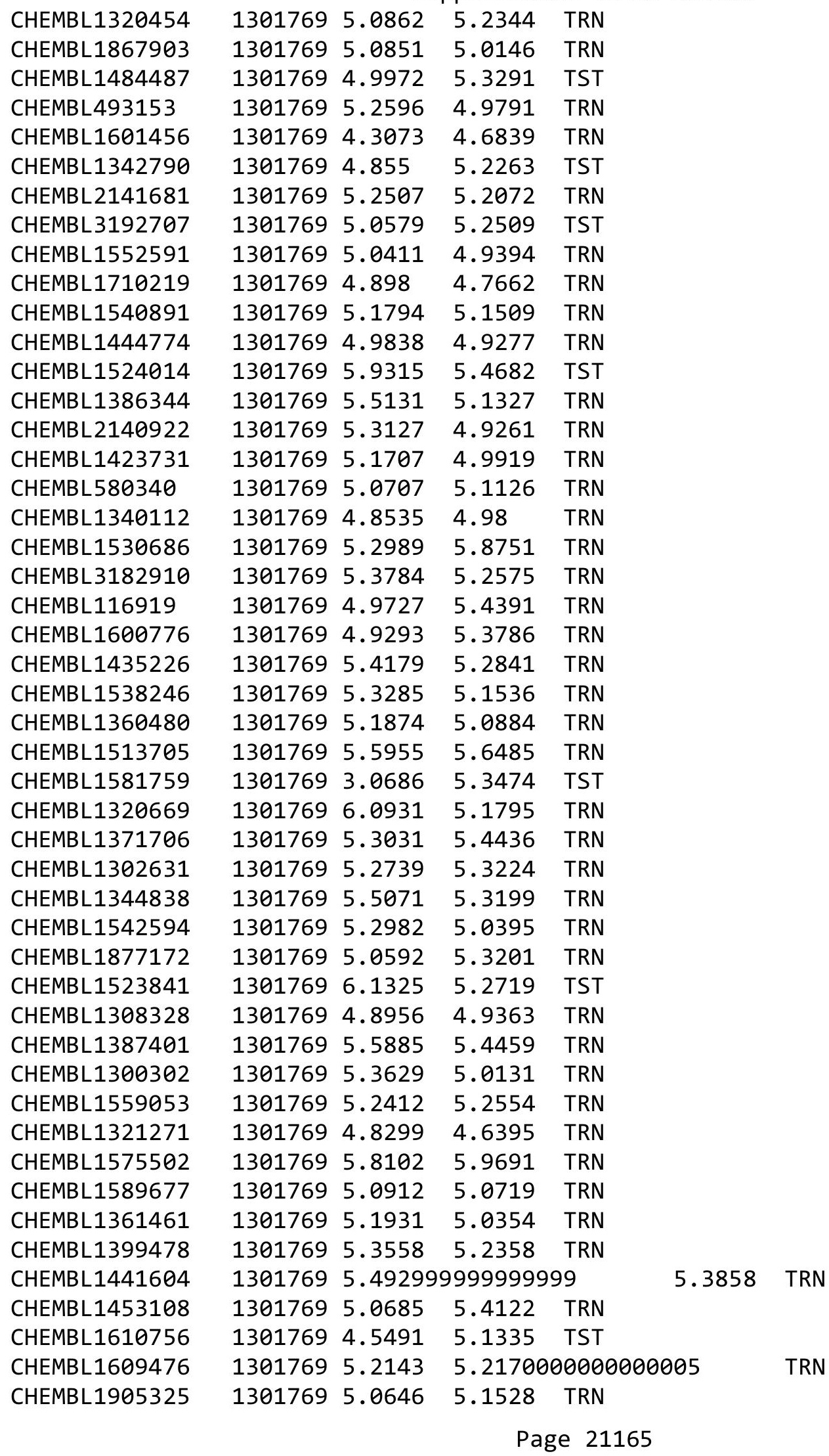


Supplemental Table S2.txt

\begin{tabular}{|c|c|c|c|c|c|}
\hline CHEMBL3197447 & 1301769 & 5.2934 & 5.3788 & TRN & \\
\hline CHEMBL1878609 & 1301769 & 5.8342 & 5.6639 & TRN & \\
\hline CHEMBL1528668 & 1301769 & 4.9191 & 5.1027 & TST & \\
\hline CHEMBL1717082 & 1301769 & 5.2223 & 5.2703 & TRN & \\
\hline CHEMBL 2136643 & 1301769 & 4.9979 & 5.4322 & TST & \\
\hline CHEMBL1903414 & 1301769 & 5.2023 & 5.1456 & TRN & \\
\hline CHEMBL1457961 & 1301769 & 4.3965 & 4.8587 & TRN & \\
\hline CHEMBL1312690 & 1301769 & 5.0697 & 5.1703 & TRN & \\
\hline CHEMBL1902024 & 1301769 & 5.1939 & 5.4071 & TRN & \\
\hline CHEMBL1446827 & 1301769 & 4.6269 & 4.9929 & TRN & \\
\hline CHEMBL 2355112 & 1301769 & 5.2719 & 5.1886 & TRN & \\
\hline CHEMBL1420175 & 1301769 & 4.8924 & 4.7941 & TST & \\
\hline CHEMBL1582710 & 1301769 & 4.8614 & 5.2048 & TRN & \\
\hline CHEMBL1434450 & 1301769 & 5.4837 & 5.3911 & TRN & \\
\hline CHEMBL1973921 & 1301769 & 4.0228 & 4.6278 & TRN & \\
\hline CHEMBL1902767 & 1301769 & 5.007 & 5.1771 & TRN & \\
\hline CHEMBL1500404 & 1301769 & 5.2566 & 5.2548 & TRN & \\
\hline CHEMBL1538692 & 1301769 & 5.2804 & 5.0982 & TRN & \\
\hline CHEMBL1734361 & 1301769 & 5.0218 & 4.9155 & TRN & \\
\hline CHEMBL1586284 & 1301769 & 5.1441 & 5.3801 & TRN & \\
\hline CHEMBL1487136 & 1301769 & 5.9315 & 5.3871 & TST & \\
\hline CHEMBL1428181 & 1301769 & 5.075 & 4.8506 & TRN & \\
\hline CHEMBL1490503 & 1301769 & 5.6407 & 5.8265 & TRN & \\
\hline CHEMBL1377607 & 1301769 & 5.4883 & 5.4182 & TRN & \\
\hline CHEMBL582073 & 1301769 & 4.7594 & 4.9118 & TRN & \\
\hline CHEMBL1445198 & 1301769 & 5.0495 & 5.2547 & TST & \\
\hline CHEMBL1503651 & 1301769 & 5.4363 & 5.2256 & TST & \\
\hline CHEMBL1508914 & 1301769 & 4.9737 & 4.8991 & TRN & \\
\hline CHEMBL1544743 & 1301769 & 5.3229 & 5.4465 & TRN & \\
\hline CHEMBL1423004 & 1301769 & 6.2457 & 6.1465 & TRN & \\
\hline CHEMBL3184181 & 1301769 & 5.7515 & 5.2787 & TRN & \\
\hline CHEMBL1468672 & 1301769 & 5.1016 & 5.138999 & & TRN \\
\hline CHEMBL1495977 & 1301769 & 4.4684 & 4.5536 & TRN & \\
\hline CHEMBL1423660 & 1301769 & 5.7058 & 6.0231 & TST & \\
\hline CHEMBL1491079 & 1301769 & 5.0088 & 4.8456 & TST & \\
\hline CHEMBL1349075 & 1301769 & 5.1961 & 5.0272 & TST & \\
\hline CHEMBL1547430 & 1301769 & 4.9088 & 5.0912 & TST & \\
\hline CHEMBL1369262 & 1301769 & 5.1285 & 5.3242 & TST & \\
\hline CHEMBL584883 & 1301769 & 4.8605 & 5.0939 & TST & \\
\hline CHEMBL1575768 & 1301769 & 3.0685 & 5.3442 & TST & \\
\hline CHEMBL1376162 & 1301769 & 4.9726 & 4.9256 & TST & \\
\hline CHEMBL 2137984 & 1301769 & 4.9701 & 4.9389 & TST & \\
\hline CHEMBL1448690 & 1301769 & 5.0823 & 5.0241 & TST & \\
\hline CHEMBL1877083 & 1301769 & 4.9991 & 5.1353 & TST & \\
\hline CHEMBL1544190 & 1301769 & 5.1345 & 5.5666 & TST & \\
\hline CHEMBL1336211 & 1301769 & 3.3295 & 5.3678 & TST & \\
\hline CHEMBL1511029 & 1301769 & 5.1166 & 5.1184 & TST & \\
\hline CHEMBL1407955 & 1301769 & 5.2804 & 5.3644 & TST & \\
\hline
\end{tabular}


Supplemental Table S2.txt

\begin{tabular}{|c|c|c|c|c|}
\hline 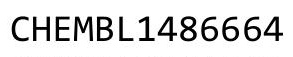 & & & 5.5093 & \\
\hline HEMBL2144069 & 55018 & 3489 & 3489 & \\
\hline 11 & & & 553 & \\
\hline EMBL1970879 & 5018 & & & \\
\hline AEMBL300389 & 55018 & 6.784 & .784 & \\
\hline HEMBL1186585 & 55018 & 3.4841 & .4841 & \\
\hline HEMBL180127 & 55018 & .9525 & .9525 & \\
\hline IEMBL 3186408 & 8 & 302 & .9771 & \\
\hline IEMBL515416 & 550 & 4.8671 & 4.8671 & \\
\hline HEMBL483849 & 55018 & 0.6961 & 0.6961 & \\
\hline AEMBL189584 & 55018 & 8833 & 8833 & \\
\hline AEMBL509032 & 55018 & 868 & .9868 & \\
\hline HEMBL 319 & & & & \\
\hline HEMBL 210618 & 556 & 682 & 4.0682 & \\
\hline AEMBL1643959 & 55018 & 889 & 3.6889 & \\
\hline AEMBL 221137 & 55018 & & 39 & \\
\hline HEMBL135 & 5018 & 09 & 509 & RIV \\
\hline HEMBL $22 €$ & 8 & & 86 & \\
\hline HEMBL 379300 & 8 & & 6.7462 & \\
\hline HEMBL2363137 & 556 & & 2709 & \\
\hline HEMBL1256459 & 55018 & 18 & 7.5418 & RIN \\
\hline HEMBL393 & 8 & 49 & 49 & RN \\
\hline HEMBL 24 & & & & \\
\hline 918 & 8 & & 2.7436 & \\
\hline AEMBL392695 & 18 & & 6.01 & $I R I N$ \\
\hline AEMBL1242367 & 8 & 56 & 56 & RN \\
\hline HEMBL 2137530 & 8 & 52 & 52 & RN \\
\hline HEMBL 255 & 8 & & 67 & \\
\hline JEMBL472940 & & & 139 & RN \\
\hline AEMBL123 & & & 05 & I RN \\
\hline JEMBL 65 & 8 & 16 & 516 & ГRN \\
\hline HEMBL178811 & 8 & 248 & 248 & RN \\
\hline HEMBL192566 & 8 & 778 & 248 & ST \\
\hline 21 & & & 945 & RN \\
\hline AEMBL512504 & 50 & 61 & 794 & ГST \\
\hline AEMBL483847 & 8 & 26 & 4.1426 & RN \\
\hline HEMBL558642 & 8 & 34 & 534 & NIV \\
\hline & & & & RN \\
\hline HEMBL1590308 & 55018 & & 3.6633 & ST \\
\hline HEMBL412142 & 5018 & 57 & 4.2557 & TRN \\
\hline HEMBL 577784 & 50 & 325 & 6.1825 & RN \\
\hline HEMBL135561 & & 683 & 4.4683 & RN \\
\hline HEMBL373751 & & & & RN \\
\hline HEMBL585951 & 55018 & 84 & 6.0984 & RN \\
\hline AEMBL 222102 & 556 & 885 & 4.7885 & RN \\
\hline MBL44 & 5 & & 6.5263 & \\
\hline-19094 & 55018 & 3425 & 425 & \\
\hline 191334 & 955018 & 4.625 & 5 & \\
\hline
\end{tabular}

Page 21167 
Supplemental Table S2.txt

\begin{tabular}{|c|c|c|c|c|}
\hline AEMBL 2005886 & 5018 & 5.8092 & 5.8092 & .1 \\
\hline & 55018 & 5.4511 & & \\
\hline IEMRI & 18 & 899 & & \\
\hline IEMBL573107 & & 563 & & \\
\hline HEMBL9470 & 5018 & 852 & & 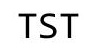 \\
\hline HEMBL1516890 & 18 & .2376 & 376 & \\
\hline IEMBL188678 & & 4078 & & \\
\hline IEMBL3392440 & & .702 & & \\
\hline AEMBL2134202 & 55018 & .4202 & 202 & \\
\hline HEMBL 217354 & 55018 & .1376 & 6.6224 & \\
\hline AEMBL: & 8 & 3.95 & & \\
\hline EMBL & & 3953 & & 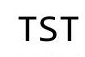 \\
\hline AEMBL & & 851 & & \\
\hline HEMBL399530 & 55018 & .9982 & & \\
\hline HEMBL 209148 & & 401 & & \\
\hline AEMBL & 8 & 184 & & \\
\hline EMBL & & 543 & & \\
\hline 15831 & 77 & 198 & & \\
\hline 16068 & & 1308 & & \\
\hline 16060 & & 861 & & \\
\hline 6071 & $8 \varepsilon$ & 362 & & \\
\hline IEMB & & 021 & & \\
\hline 840 & 77 & 4.0 & 722 & P \\
\hline 5065 & & 086 & & ? \\
\hline 15833 & & & & \\
\hline 15845 & 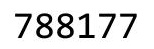 & & & 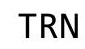 \\
\hline 54 & & & & 更 \\
\hline 966 & & 098 & & 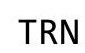 \\
\hline 839 & & & & ST \\
\hline 15843 & 7 & & & $\mathrm{R} \mid$ \\
\hline 355 & & & & $1 \mathrm{~T}$ \\
\hline 30 & 7 & & & \\
\hline 4473 & & 7 & & $\mathrm{O}_{2}$ \\
\hline 5837 & & & & $\Gamma \mathrm{R}$ \\
\hline AEMBL] & 7 & 7. & & $n$ \\
\hline & & & & $\Gamma R$ \\
\hline 72 & 7 & 5 & 15 & ГRN \\
\hline HEMBL67 & & & & $S$ \\
\hline IEMBL: & 7 & 605 & & IRI \\
\hline IEMBL & 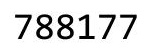 & & & $n$ \\
\hline HEMBL & & 7. & & $\Gamma R$ \\
\hline HEMBL & 77 & 7.7212 & & - \\
\hline 15846 & & & & $S$ \\
\hline 5849 & 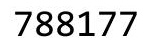 & 870 & & TS \\
\hline HEMBL & & & & IS \\
\hline HEMBL & & 6.0132 & 272 & \\
\hline CHEMBL1916075 & 88177 & 7.7212 & 7.4211 & \\
\hline CHEMBL1916073 & 788177 & 7.3979 & 7.6603 & TR \\
\hline
\end{tabular}

Page 21168 


\begin{tabular}{|c|c|c|c|c|}
\hline \multicolumn{5}{|c|}{ Supplemental Table S2.txt } \\
\hline CHEMBL1916074 & 788177 & 4.0 & 6.6783 & TRN \\
\hline CHEMBL1916062 & 788177 & 7.8239 & 7.7594 & TRN \\
\hline CHEMBL1915828 & 788177 & 6.8539 & 6.4338 & TRN \\
\hline CHEMBL1915835 & 788177 & 6.0132 & 5.8902 & TRN \\
\hline CHEMBL1916064 & 788177 & 7.2596 & 7.325 & TRN \\
\hline CHEMBL1916077 & 788177 & 7.6576 & 7.4319 & TRN \\
\hline CHEMBL1916059 & 788177 & 6.3468 & 6.9363 & TRN \\
\hline CHEMBL1916069 & 788177 & 7.4202 & 6.6792 & TRN \\
\hline CHEMBL1915832 & 788177 & 6.5086 & 6.3101 & TRN \\
\hline CHEMBL1915844 & 788177 & 6.3188 & 5.0249 & TRN \\
\hline CHEMBL1915842 & 788177 & 4.0 & 3.6949 & TRN \\
\hline CHEMBL1916070 & 788177 & 6.9586 & 6.1969 & TRN \\
\hline CHEMBL1915834 & 788177 & 8.9208 & 6.9131 & TRN \\
\hline CHEMBL1915838 & 788177 & 8.7447 & 7.1866 & TST \\
\hline CHEMBL1916076 & 788177 & 7.7696 & 7.4637 & TST \\
\hline CHEMBL1915848 & 788177 & 4.0 & 5.3991 & TST \\
\hline CHEMBL1915853 & 788177 & 7.4685 & 7.3182 & TST \\
\hline CHEMBL1915847 & 788177 & 4.0 & 4.7747 & TST \\
\hline CHEMBL1915841 & 788177 & 4.0 & 4.8429 & TST \\
\hline CHEMBL 3951544 & 1642465 & 8.2291 & 8.4462 & TST \\
\hline CHEMBL 3960842 & 1642465 & 8.1656 & 8.1505 & TST \\
\hline CHEMBL 3947873 & 1642465 & 7.2161 & 7.4563 & TRN \\
\hline CHEMBL3925923 & 1642465 & 7.8861 & 7.8049 & TRN \\
\hline CHEMBL 3929667 & 1642465 & 8.1079 & 7.8479 & TRN \\
\hline CHEMBL 3978204 & 1642465 & 7.556 & 7.2083 & TRN \\
\hline CHEMBL 3947635 & 1642465 & 8.2807 & 7.319 & TRN \\
\hline CHEMBL 3956339 & 1642465 & 7.1308 & 6.6839 & TRN \\
\hline CHEMBL3964328 & 1642465 & 6.8729 & 7.7176 & TRN \\
\hline CHEMBL 3924358 & 1642465 & 8.5528 & 8.4167 & TRN \\
\hline CHEMBL 3985920 & 1642465 & 7.1209 & 7.1235 & TST \\
\hline CHEMBL 3910042 & 1642465 & 7.1367 & 7.143 & TRN \\
\hline CHEMBL 3394734 & 1642465 & 8.2518 & 7.8379 & TRN \\
\hline CHEMBL3959602 & 1642465 & 8.2147 & 8.329 & TRN \\
\hline CHEMBL 3893514 & 1642465 & 7.4001 & 7.8122 & TRN \\
\hline CHEMBL 3968358 & 1642465 & 8.5086 & 7.9257 & TRN \\
\hline CHEMBL 3978701 & 1642465 & 7.6882 & 7.7626 & TRN \\
\hline CHEMBL 3394740 & 1642465 & 8.1427 & 7.7313 & TRN \\
\hline CHEMBL3960596 & 1642465 & 7.3089 & 7.8468 & TRN \\
\hline CHEMBL 3394731 & 1642465 & 7.3363 & 6.9572 & TRN \\
\hline CHEMBL3394735 & 1642465 & 7.7011 & 7.3119 & TST \\
\hline CHEMBL 3973866 & 1642465 & 8.5528 & 8.2581 & TRN \\
\hline CHEMBL3904947 & 1642465 & 7.5638 & 7.4417 & TRN \\
\hline CHEMBL3953179 & 1642465 & 6.6498 & 6.7555 & TRN \\
\hline CHEMBL 3949539 & 1642465 & 7.2495 & 7.0295 & TRN \\
\hline CHEMBL3916926 & 1642465 & 6.3449 & 6.2349 & TRN \\
\hline CHEMBL 3913140 & 1642465 & 7.5575 & 7.3785 & TST \\
\hline CHEMBL3907168 & 1642465 & 7.7545 & 7.4831 & TRN \\
\hline CHEMBL3930254 & 1642465 & 6.2083 & 6.3456 & TST \\
\hline
\end{tabular}


Supplemental Table S2.txt

\begin{tabular}{|c|c|c|c|c|c|}
\hline CHEMBL3977371 & 1642465 & 8.1805 & 8.1 & TST & \\
\hline CHEMBL3945598 & 1642465 & 6.9957 & 7.2187 & TRN & \\
\hline CHEMBL3937961 & 1642465 & 7.8962 & 7.6629 & TRN & \\
\hline CHEMBL3958067 & 1642465 & 6.9031 & 7.1114 & TRN & \\
\hline CHEMBL3939434 & 1642465 & 7.4855 & \multicolumn{2}{|c|}{7.247000000000001} & TST \\
\hline CHEMBL3959092 & 1642465 & 6.2426 & 6.159 & TRN & \\
\hline CHEMBL3891406 & 1642465 & 7.2076 & 7.3979 & TST & \\
\hline CHEMBL3933613 & 1642465 & 8.3098 & 8.1835 & TRN & \\
\hline CHEMBL3981498 & 1642465 & 7.3242 & 7.1067 & TRN & \\
\hline CHEMBL3932091 & 1642465 & 7.7144 & 7.6859 & TRN & \\
\hline CHEMBL3946249 & 1642465 & 6.2503 & 7.0528 & TST & \\
\hline CHEMBL3910097 & 1642465 & 6.6576 & 7.3925 & TST & \\
\hline CHEMBL3959047 & 1642465 & 7.9318 & 7.6698 & TRN & \\
\hline CHEMBL3973696 & 1642465 & 8.585 & 8.0786 & TRN & \\
\hline CHEMBL 3909722 & 1642465 & 7.1778 & 7.3854 & TRN & \\
\hline CHEMBL3939351 & 1642465 & 7.4237 & 7.6724 & TRN & \\
\hline CHEMBL3935129 & 1642465 & 8.4685 & 8.6249 & TRN & \\
\hline CHEMBL3957389 & 1642465 & 8.1675 & 7.7997 & TRN & \\
\hline CHEMBL3954293 & 1642465 & 8.6778 & 8.753 & TRN & \\
\hline CHEMBL3981478 & 1642465 & 7.4949 & 7.7899 & TRN & \\
\hline CHEMBL3976797 & 1642465 & 8.1487 & 7.4763 & TRN & \\
\hline CHEMBL3970656 & 1642465 & 7.2226 & 7.5054 & TRN & \\
\hline CHEMBL3972826 & 1642465 & 6.5969 & 6.8096 & TRN & \\
\hline CHEMBL3908255 & 1642465 & 7.9281 & 7.6674 & TST & \\
\hline CHEMBL3930794 & 1642465 & 7.9547 & 7.87 & TRN & \\
\hline CHEMBL 3946784 & 1642465 & 7.8539 & 8.3675 & TST & \\
\hline CHEMBL3394733 & 1642465 & 8.1805 & 8.046 & TRN & \\
\hline CHEMBL3930160 & 1642465 & 7.27 & 7.4135 & TRN & \\
\hline CHEMBL3937366 & 1642465 & 5.699 & 6.5343 & TST & \\
\hline CHEMBL 3952743 & 1642465 & 7.266 & 7.8441 & TRN & \\
\hline CHEMBL3945117 & 1642465 & 8.2147 & 8.1878 & TRN & \\
\hline CHEMBL3962595 & 1642465 & 6.3635 & 6.9399 & TRN & \\
\hline CHEMBL3932483 & 1642465 & 7.1662 & 7.5624 & TST & \\
\hline CHEMBL3914395 & 1642465 & 8.699 & 8.2896 & TRN & \\
\hline CHEMBL3923144 & 1642465 & 8.4559 & 8.3874 & TRN & \\
\hline CHEMBL3908273 & 1642465 & 7.2262 & 7.7508 & TRN & \\
\hline CHEMBL3944220 & 1642465 & 8.2676 & 8.5143 & TRN & \\
\hline CHEMBL3922747 & 1642465 & 8.6383 & 8.6744 & TRN & \\
\hline CHEMBL3951542 & 1642465 & 9.0044 & 8.3322 & TRN & \\
\hline CHEMBL3964015 & 1642465 & 8.0969 & 7.8369 & TRN & \\
\hline CHEMBL3922669 & 1642465 & 6.6904 & 6.518 & TRN & \\
\hline CHEMBL3922833 & 1642465 & 6.6635 & 7.03700 & 0000000001 & TRN \\
\hline CHEMBL3902278 & 1642465 & 7.0035 & 7.3577 & TST & \\
\hline CHEMBL3892908 & 1642465 & 7.3054 & 7.8309 & TRN & \\
\hline CHEMBL3917703 & 1642465 & 8.0655 & 7.8523 & TRN & \\
\hline CHEMBL3925078 & 1642465 & 8.4685 & 8.2346 & TST & \\
\hline CHEMBL3977128 & 1642465 & 7.6383 & 7.6961 & TRN & \\
\hline CHEMBL3935060 & 1642465 & 7.426 & 7.2972 & TST & \\
\hline
\end{tabular}


Supplemental Table S2.txt

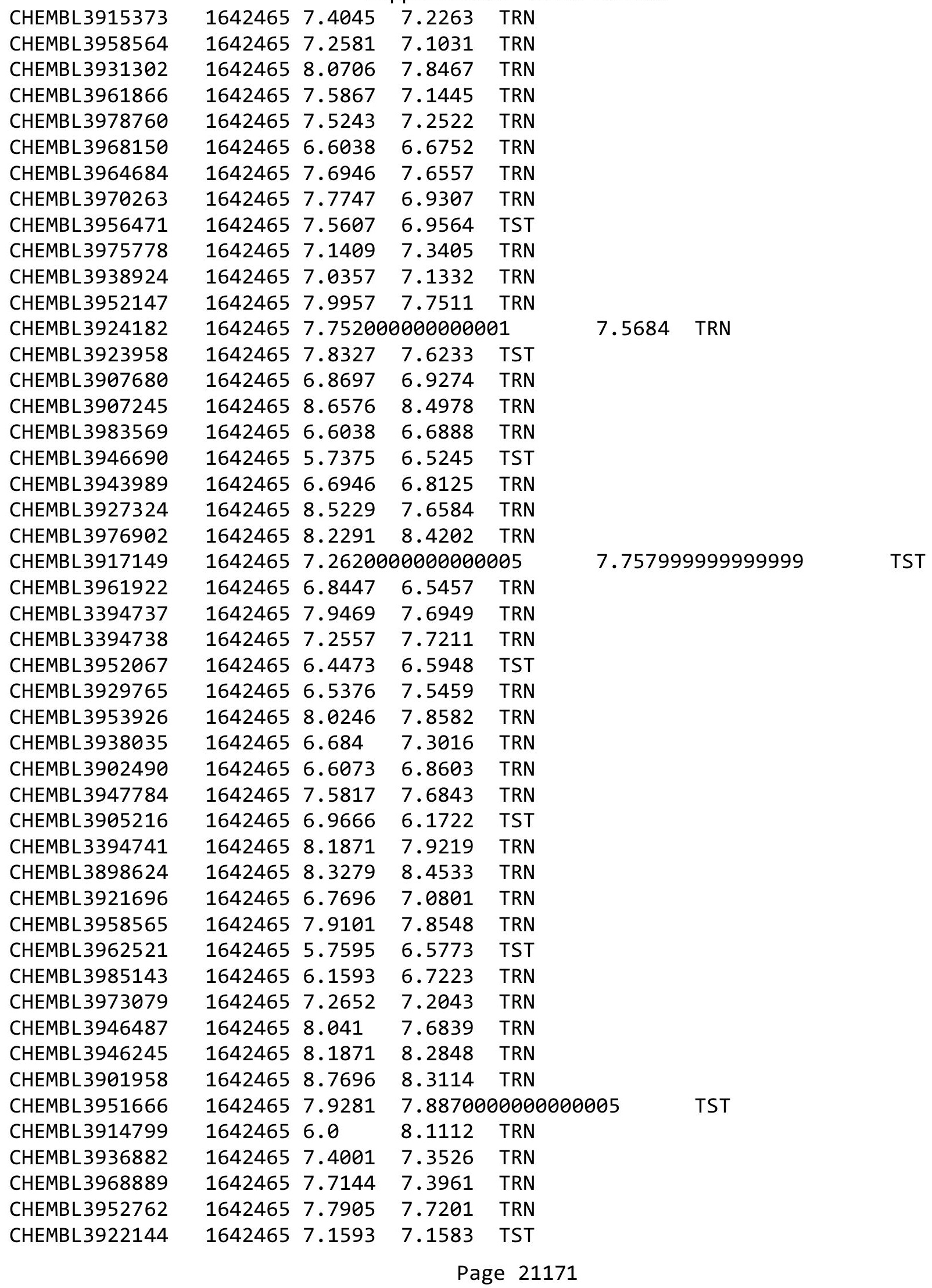


Supplemental Table S2.txt

\begin{tabular}{|c|c|c|c|c|c|c|c|}
\hline CHEMBL3944555 & 1642465 & 8.3372 & 8.7466 & TRN & & & \\
\hline CHEMBL3931704 & 1642465 & 8.1612 & 7.6989 & TRN & & & \\
\hline CHEMBL3983814 & 1642465 & 7.644 & 7.6998 & TST & & & \\
\hline CHEMBL 3942797 & 1642465 & 8.6737 & 7.8158 & TST & & & \\
\hline CHEMBL3937982 & 1642465 & 7.308 & 7.3041 & TRN & & & \\
\hline CHEMBL3900992 & 1642465 & 6.9872 & 7.5139 & TRN & & & \\
\hline CHEMBL3952015 & 1642465 & 7.3143 & 7.3953 & TRN & & & \\
\hline CHEMBL3901715 & 1642465 & 8.6576 & 8.1573 & TRN & & & \\
\hline CHEMBL 3934558 & 1642465 & 7.1681 & 7.188 & TST & & & \\
\hline CHEMBL3900964 & 1642465 & \multicolumn{3}{|c|}{7.718999999999999} & 7.4678 & TRN & \\
\hline CHEMBL3927864 & 1642465 & 6.0 & 6.9907 & TRN & & & \\
\hline CHEMBL 3922484 & 1642465 & 7.1649 & 7.3834 & TST & & & \\
\hline CHEMBL3917299 & 1642465 & 7.7212 & 7.6096 & TRN & & & \\
\hline CHEMBL 3900480 & 1642465 & 8.1427 & 7.9509 & TRN & & & \\
\hline CHEMBL3922746 & 1642465 & 7.2457 & 7.3952 & TRN & & & \\
\hline CHEMBL3913684 & 1642465 & 7.7905 & 7.772 & TRN & & & \\
\hline CHEMBL3975563 & 1642465 & 7.6003 & 7.638 & TRN & & & \\
\hline CHEMBL3956301 & 1642465 & \multicolumn{3}{|c|}{7.7620000000000005} & 7.9117 & TST & \\
\hline CHEMBL 3957999 & 1642465 & 7.4698 & 7.2874 & TRN & & & \\
\hline CHEMBL3975449 & 1642465 & 7.0035 & 6.8389 & TRN & & & \\
\hline CHEMBL 3926658 & 1642465 & \multicolumn{3}{|c|}{ 7.718999999999999 } & \multicolumn{2}{|c|}{7.502000000000001} & TST \\
\hline CHEMBL3929825 & 1642465 & 7.8761 & 7.3514 & TRN & & & \\
\hline CHEMBL3924459 & 1642465 & 8.248 & 7.7477 & TST & & & \\
\hline CHEMBL3985198 & 1642465 & 6.6635 & 6.9925 & TRN & & & \\
\hline CHEMBL3947807 & 1642465 & 7.5129 & 7.8451 & TRN & & & \\
\hline CHEMBL 3894770 & 1642465 & 8.4318 & 8.086 & TST & & & \\
\hline CHEMBL3967407 & 1642465 & 7.4828 & 7.7916 & TRN & & & \\
\hline CHEMBL3915169 & 1642465 & \multicolumn{3}{|c|}{6.4510000000000005} & 7.482 & TST & \\
\hline CHEMBL 3906407 & 1642465 & 7.2573 & 6.9136 & TST & & & \\
\hline CHEMBL3900739 & 1642465 & 6.8239 & 6.3955 & TST & & & \\
\hline CHEMBL 3961282 & 1642465 & 5.8601 & 7.2062 & TST & & & \\
\hline CHEMBL3907935 & 1642465 & 6.8069 & 7.1306 & TST & & & \\
\hline CHEMBL3394739 & 1642465 & 6.9031 & 7.2329 & TST & & & \\
\hline CHEMBL 3944593 & 1642465 & 6.1361 & 6.8866 & TRN & & & \\
\hline CHEMBL3970103 & 1642465 & 7.2581 & 7.1001 & TRN & & & \\
\hline CHEMBL3927689 & 1642465 & 7.6615 & 8.2263 & TRN & & & \\
\hline CHEMBL3949891 & 1642465 & 7.5017 & 7.4006 & TRN & & & \\
\hline CHEMBL3394732 & 1642465 & 7.4191 & 7.1656 & TRN & & & \\
\hline CHEMBL3895737 & 1642465 & 6.4535 & 6.6496 & TRN & & & \\
\hline CHEMBL3946838 & 1642465 & 6.9547 & 7.3729 & TST & & & \\
\hline CHEMBL3961561 & 1640355 & 9.7077 & 9.2583 & TRN & & & \\
\hline CHEMBL3979200 & 1640355 & 9.5086 & 8.2877 & TRN & & & \\
\hline CHEMBL3948700 & 1640355 & 7.4597 & 7.768 & TRN & & & \\
\hline CHEMBL3986541 & 1640355 & 7.1798 & 7.2143 & TRN & & & \\
\hline CHEMBL3978317 & 1640355 & 7.5157 & 7.778 & TRN & & & \\
\hline CHEMBL 3895592 & 1640355 & 6.0 & 7.6359 & TST & & & \\
\hline CHEMBL3970519 & 1640355 & 9.1249 & 8.4224 & TRN & & & \\
\hline CHEMBL 3900871 & 1640355 & 8.0969 & 7.3371 & TRN & & & \\
\hline
\end{tabular}

Page 21172 
Supplemental Table S2.txt

\begin{tabular}{|c|c|c|c|c|}
\hline CHEMBL3947910 & 1640355 & 7.1337 & 7.5001 & TRN \\
\hline CHEMBL3975262 & 1640355 & 7.6635 & 7.6041 & TRN \\
\hline CHEMBL3928841 & 1640355 & 7.2757 & 7.2699 & TRN \\
\hline CHEMBL3913551 & 1640355 & 8.4559 & 8.6921 & TRN \\
\hline CHEMBL3978658 & 1640355 & 7.6799 & 7.5727 & TRN \\
\hline CHEMBL3943362 & 1640355 & 6.0 & 8.3942 & TRN \\
\hline CHEMBL3958569 & 1640355 & 7.5867 & 7.2091 & TRN \\
\hline CHEMBL3961461 & 1640355 & 6.0 & 6.5155 & TRN \\
\hline CHEMBL3903365 & 1640355 & 9.3565 & 9.4951 & TRN \\
\hline CHEMBL3898902 & 1640355 & 9.3279 & 9.0414 & TRN \\
\hline CHEMBL3906310 & 1640355 & 6.3883 & 7.4914 & TRN \\
\hline CHEMBL3984264 & 1640355 & 8.3747 & 8.7087 & TST \\
\hline CHEMBL3931311 & 1640355 & 9.3468 & 8.9778 & TRN \\
\hline CHEMBL3951988 & 1640355 & 6.0214 & 6.603 & TRN \\
\hline CHEMBL3908887 & 1640355 & 7.1765 & 7.3452 & TRN \\
\hline CHEMBL3943784 & 1640355 & 7.3585 & 8.2851 & TST \\
\hline CHEMBL3955109 & 1640355 & 7.9245 & 7.0995 & TRN \\
\hline CHEMBL3915697 & 1640355 & 8.2007 & 7.3142 & TRN \\
\hline CHEMBL3939579 & 1640355 & 6.9586 & 7.4114 & TST \\
\hline CHEMBL3893969 & 1640355 & 6.7122 & 7.9805 & TST \\
\hline CHEMBL3917790 & 1640355 & 8.1805 & 7.3991 & TST \\
\hline CHEMBL3923038 & 1640355 & 7.5607 & 7.8036 & TRN \\
\hline CHEMBL3935809 & 1640355 & 8.9101 & 9.061 & TRN \\
\hline CHEMBL3892466 & 1640355 & 7.2048 & 6.4292 & TRN \\
\hline CHEMBL3976221 & 1640355 & 8.8794 & 9.0746 & TRN \\
\hline CHEMBL3982172 & 1640355 & 6.0 & 6.4909 & TRN \\
\hline CHEMBL3977485 & 1640355 & 9.2676 & 8.8133 & TRN \\
\hline CHEMBL3914981 & 1640355 & 9.0706 & 9.0987 & TRN \\
\hline CHEMBL3924005 & 1640355 & 7.5017 & 7.3474 & TRN \\
\hline CHEMBL3895888 & 1640355 & 8.585 & 7.6511 & TRN \\
\hline CHEMBL3933982 & 1640355 & 8.1778 & 8.0416 & TST \\
\hline CHEMBL3913004 & 1640355 & 9.7447 & 8.2196 & TRN \\
\hline CHEMBL3982475 & 1640355 & 8.4449 & 8.1435 & TST \\
\hline CHEMBL3974165 & 1640355 & 7.8665 & 6.6973 & TST \\
\hline CHEMBL3945241 & 1640355 & 9.1135 & 8.2276 & TRN \\
\hline CHEMBL3942202 & 1640355 & 8.3224 & 8.117 & TRN \\
\hline CHEMBL3960407 & 1640355 & 8.0259 & 8.0257 & TRN \\
\hline CHEMBL3985675 & 1640355 & 6.0 & 7.466 & TRN \\
\hline CHEMBL3952606 & 1640355 & 8.451 & 8.5956 & TRN \\
\hline CHEMBL3953925 & 1640355 & 8.2899 & 6.6416 & TST \\
\hline CHEMBL3934562 & 1640355 & 9.3565 & 6.87200 & 0000000001 \\
\hline CHEMBL3942344 & 1640355 & 9.0458 & 9.1098 & TRN \\
\hline CHEMBL3982283 & 1640355 & 7.9172 & 7.6416 & TRN \\
\hline CHEMBL3970100 & 1640355 & 8.6144 & 8.0494 & TST \\
\hline CHEMBL3908392 & 1640355 & 7.7144 & 6.944 & TRN \\
\hline CHEMBL3926418 & 1640355 & 9.4815 & 9.2678 & TRN \\
\hline CHEMBL3977507 & 1640355 & 7.5086 & 6.9552 & TRN \\
\hline CHEMBL3915855 & 1640355 & 6.0 & 6.5168 & TRN \\
\hline
\end{tabular}


Supplemental Table S2.txt

\begin{tabular}{|c|c|c|c|c|c|}
\hline CHEMBL 3981877 & 1640355 & 7.0339 & 7.4388 & TRN & \\
\hline CHEMBL3928022 & 1640355 & 7.5702 & 6.9753 & TST & \\
\hline CHEMBL 3965045 & 1640355 & 8.158 & 7.5458 & TST & \\
\hline CHEMBL 3946434 & 1640355 & 8.752 & 9.0281 & TRN & \\
\hline CHEMBL3938041 & 1640355 & 9.5086 & 9.5829 & TRN & \\
\hline CHEMBL3960939 & 1640355 & 8.699 & 8.6084 & TRN & \\
\hline CHEMBL3939124 & 1640355 & 8.6198 & 7.0328 & TST & \\
\hline CHEMBL 3954054 & 1640355 & 8.585 & 9.3774 & TRN & \\
\hline CHEMBL 3915830 & 1640355 & 8.055 & 7.8782 & TRN & \\
\hline CHEMBL 3917826 & 1640355 & 10.0458 & 8.7712 & TRN & \\
\hline CHEMBL3908390 & 1640355 & 9.5229 & 9.0614 & TRN & \\
\hline CHEMBL3968213 & 1640355 & 6.0 & 7.9626 & TRN & \\
\hline CHEMBL3896229 & 1640355 & 7.3696 & 7.7109 & TST & \\
\hline CHEMBL 3915289 & 1640355 & 7.1024 & 6.8705 & TRN & \\
\hline CHEMBL 3955230 & 1640355 & 8.4001 & 8.3057 & TRN & \\
\hline CHEMBL3933318 & 1640355 & 7.6308 & 7.1295 & TRN & \\
\hline CHEMBL3943515 & 1640355 & 8.4023 & 8.2912 & TRN & \\
\hline CHEMBL3916803 & 1640355 & 7.9031 & 7.587006 & 2000000001 & TRN \\
\hline CHEMBL 3941286 & 1640355 & 6.0 & 8.0336 & TST & \\
\hline CHEMBL 3894242 & 1640355 & 7.9281 & $8.40200 t$ & 0000000001 & TRN \\
\hline CHEMBL 3952236 & 1640355 & 8.567 & 8.4094 & TRN & \\
\hline CHEMBL 3941881 & 1640355 & 8.5376 & 8.3152 & TRN & \\
\hline CHEMBL3936928 & 1640355 & 8.4089 & 8.1023 & TRN & \\
\hline CHEMBL 3913631 & 1640355 & 7.857 & 7.6651 & TST & \\
\hline CHEMBL3961476 & 1640355 & 8.5003 & 8.4878 & TRN & \\
\hline CHEMBL 3931825 & 1640355 & 9.4685 & 9.1704 & TRN & \\
\hline CHEMBL3930264 & 1640355 & 7.1379 & 8.2752 & TST & \\
\hline CHEMBL3920378 & 1640355 & 9.2007 & 9.6625 & TRN & \\
\hline CHEMBL 3921297 & 1640355 & 6.6021 & 7.3018 & TRN & \\
\hline CHEMBL3891216 & 1640355 & 8.054 & 7.3042 & TST & \\
\hline CHEMBL3965718 & 1640355 & 8.71 & 8.249 & TRN & \\
\hline CHEMBL 3927784 & 1640355 & 8.1549 & 7.5425 & TRN & \\
\hline CHEMBL3914343 & 1640355 & 9.0757 & 8.9715 & TRN & \\
\hline CHEMBL 3924004 & 1640355 & 6.7345 & 6.5626 & TRN & \\
\hline CHEMBL3953435 & 1640355 & 6.0 & 8.0893 & TRN & \\
\hline CHEMBL3969905 & 1640355 & 8.6925 & 8.9822 & TRN & \\
\hline CHEMBL3983753 & 1640355 & 8.0472 & 6.9486 & TST & \\
\hline CHEMBL3900913 & 1640355 & 7.3391 & 8.2992 & TST & \\
\hline CHEMBL 3957362 & 1640355 & 8.0269 & 8.208 & TRN & \\
\hline CHEMBL3937869 & 1640355 & 8.3979 & 7.9358 & TRN & \\
\hline CHEMBL 3937851 & 1640355 & 6.9172 & 7.3556 & TRN & \\
\hline CHEMBL3946928 & 1640355 & 7.2262 & 8.1357 & TRN & \\
\hline CHEMBL3959034 & 1640355 & \multicolumn{2}{|c|}{6.757000000000001} & 7.3772 & TST \\
\hline CHEMBL 3912046 & 1640355 & 8.2976 & 7.6154 & TST & \\
\hline CHEMBL3943252 & 1640355 & 6.6655 & 6.9956 & TRN & \\
\hline CHEMBL 3964215 & 1640355 & 7.9788 & 7.3185 & TRN & \\
\hline CHEMBL3958819 & 1640355 & 8.1029 & 8.3136 & TRN & \\
\hline CHEMBL 3904274 & 1640355 & 7.8182 & 7.8124 & TRN & \\
\hline
\end{tabular}


Supplemental Table S2.txt

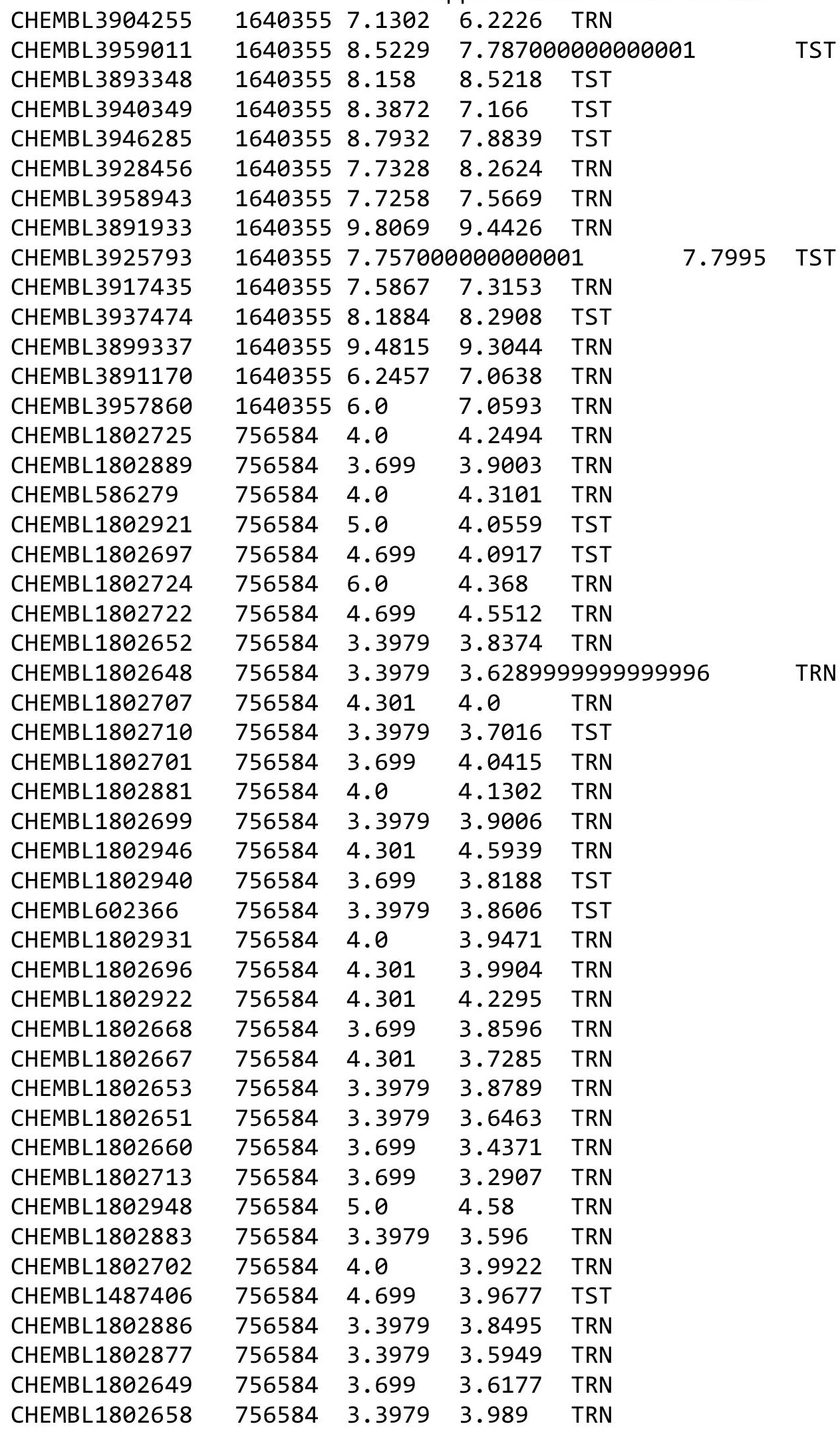

Page 21175 


\begin{tabular}{|c|c|c|c|c|c|}
\hline & & & & & \\
\hline CHEMBL1802708 & 756584 & 4.301 & 3.9617 & TST & \\
\hline CHEMBL1802947 & 756584 & 4.699 & 4.5983 & TRN & \\
\hline CHEMBL1802939 & 756584 & 4.0 & 4.0683 & TRN & \\
\hline CHEMBL1802655 & 756584 & 3.699 & 3.84800 & 00000000003 & TRN \\
\hline CHEMBL1802705 & 756584 & 3.699 & 4.006 & TRN & \\
\hline CHEMBL1802714 & 756584 & 3.699 & 3.3506 & TRN & \\
\hline CHEMBL1802719 & 756584 & 5.0 & 4.7072 & TRN & \\
\hline CHEMBL1802694 & 756584 & 5.0 & 4.2379 & TRN & \\
\hline CHEMBL1802925 & 756584 & 3.3979 & 3.9958 & TST & \\
\hline CHEMBL1802876 & 756584 & 3.699 & 3.5949 & TRN & \\
\hline CHEMBL1802718 & 756584 & 4.0 & 4.7683 & TRN & \\
\hline CHEMBL1802949 & 756584 & 6.0 & 4.6798 & TRN & \\
\hline CHEMBL1802926 & 756584 & 3.3979 & 4.0439 & TST & \\
\hline CHEMBL1802712 & 756584 & 4.301 & 3.636 & TRN & \\
\hline CHEMBL1800102 & 756584 & 3.699 & 3.8176 & TRN & \\
\hline CHEMBL1802943 & 756584 & 3.699 & 3.9579 & TRN & \\
\hline CHEMBL1802919 & 756584 & 3.699 & 3.5851 & TRN & \\
\hline CHEMBL1802647 & 756584 & 3.3979 & 3.4253 & TRN & \\
\hline CHEMBL1802885 & 756584 & 3.3979 & 3.6233 & TRN & \\
\hline CHEMBL1802661 & 756584 & 3.3979 & 3.6364 & TRN & \\
\hline CHEMBL1802665 & 756584 & 4.0 & 3.8514 & TRN & \\
\hline CHEMBL1802941 & 756584 & 4.301 & 4.2215 & TRN & \\
\hline CHEMBL1802663 & 756584 & 3.699 & 3.5479 & TRN & \\
\hline CHEMBL1802700 & 756584 & 3.699 & 4.1378 & TRN & \\
\hline CHEMBL1802884 & 756584 & 3.699 & 3.4859 & TRN & \\
\hline CHEMBL1802875 & 756584 & 3.3979 & 3.5809 & TRN & \\
\hline CHEMBL1802721 & 756584 & 4.0 & 4.64199 & 99999999995 & TRN \\
\hline CHEMBL1802933 & 756584 & 4.0 & 4.082 & TRN & \\
\hline CHEMBL1802929 & 756584 & 4.0 & 4.133 & TRN & \\
\hline CHEMBL1802945 & 756584 & 3.699 & 4.4533 & TRN & \\
\hline CHEMBL1802928 & 756584 & 3.3979 & 4.0456 & TRN & \\
\hline CHEMBL1802879 & 756584 & 3.699 & 4.1642 & TRN & \\
\hline CHEMBL1802666 & 756584 & 4.699 & 3.9106 & TRN & \\
\hline CHEMBL1802878 & 756584 & 3.3979 & 4.1253 & TRN & \\
\hline CHEMBL1802720 & 756584 & 5.0 & 4.6832 & TRN & \\
\hline CHEMBL1802650 & 756584 & 3.699 & 3.5406 & TRN & \\
\hline CHEMBL1802935 & 756584 & 4.699 & 4.5173 & TRN & \\
\hline CHEMBL1802938 & 756584 & 4.0 & 3.7447 & TRN & \\
\hline CHEMBL1802887 & 756584 & 3.3979 & 3.8857 & TRN & \\
\hline CHEMBL1802698 & 756584 & 4.301 & 4.1257 & TST & \\
\hline CHEMBL1802706 & 756584 & 3.3979 & 3.9996 & TRN & \\
\hline CHEMBL1802924 & 756584 & 5.0 & 4.1684 & TRN & \\
\hline CHEMBL1802930 & 756584 & 3.699 & 3.9289 & TRN & \\
\hline CHEMBL1802715 & 756584 & 3.3979 & 3.4877 & TRN & \\
\hline CHEMBL1802709 & 756584 & 3.699 & 3.6805 & TST & \\
\hline CHEMBL1802882 & 756584 & 3.699 & 3.3555 & TRN & \\
\hline CHEMBL1802932 & 756584 & 6.0 & 4.1774 & TRN & \\
\hline CHEMBL1802656 & 756584 & 3.3979 & 4.225 & TRN & \\
\hline
\end{tabular}




\begin{tabular}{|c|c|c|c|c|}
\hline \multicolumn{5}{|c|}{ Supplemental Table S2.txt } \\
\hline CHEMBL1802936 & 756584 & 4.0 & 3.7696 & TRN \\
\hline CHEMBL1802645 & 756584 & 4.301 & 4.055 & TRN \\
\hline CHEMBL1802923 & 756584 & 3.699 & 3.9711 & TRN \\
\hline CHEMBL1802657 & 756584 & 3.3979 & 4.2657 & TRN \\
\hline CHEMBL1802704 & 756584 & 4.301 & 4.0755 & TRN \\
\hline CHEMBL1802716 & 756584 & 3.699 & 3.3478 & TRN \\
\hline CHEMBL1802695 & 756584 & 5.0 & 4.2873 & TRN \\
\hline CHEMBL1802920 & 756584 & 3.699 & 3.9426 & TST \\
\hline CHEMBL1802937 & 756584 & 3.699 & 3.6142 & TRN \\
\hline CHEMBL1802874 & 756584 & 3.3979 & 3.5382 & TRN \\
\hline CHEMBL1802654 & 756584 & 3.3979 & 3.7355 & TRN \\
\hline CHEMBL1802934 & 756584 & 4.0 & 4.1256 & TST \\
\hline CHEMBL1802717 & 756584 & 4.301 & 4.484 & TST \\
\hline CHEMBL1802726 & 756584 & 6.0 & 4.5054 & TST \\
\hline CHEMBL1802644 & 756584 & 4.699 & 4.3495 & TST \\
\hline CHEMBL1802659 & 756584 & 3.3979 & 3.8194 & TST \\
\hline CHEMBL1802942 & 756584 & 3.3979 & 4.0013 & TST \\
\hline CHEMBL1802664 & 756584 & 3.3979 & 3.6591 & TST \\
\hline CHEMBL1802880 & 756584 & 4.0 & 4.1302 & TST \\
\hline CHEMBL1802723 & 756584 & 4.699 & 4.519 & TST \\
\hline CHEMBL1802646 & 756584 & 3.699 & 3.8057 & TST \\
\hline CHEMBL1802944 & 756584 & 3.699 & 4.4523 & TST \\
\hline CHEMBL1802888 & 756584 & 3.699 & 3.7296 & TST \\
\hline CHEMBL1802703 & 756584 & 4.0 & 3.8023 & TST \\
\hline CHEMBL1802662 & 756584 & 4.301 & 3.6291 & TST \\
\hline CHEMBL1802927 & 756584 & 4.699 & 4.151 & TST \\
\hline CHEMBL1716469 & 736954 & 3.0 & 2.5729 & TRN \\
\hline CHEMBL1324267 & 736954 & 4.3224 & 4.0169 & TRN \\
\hline CHEMBL1492305 & 736954 & 6.2161 & 6.4443 & TRN \\
\hline CHEMBL1443268 & 736954 & 6.3179 & 6.0215 & TRN \\
\hline CHEMBL1716207 & 736954 & 5.1007 & 4.5461 & TRN \\
\hline CHEMBL1730304 & 736954 & 5.567 & 6.0164 & TRN \\
\hline CHEMBL601167 & 736954 & 5.8013 & 5.6153 & TRN \\
\hline CHEMBL1713107 & 736954 & 3.0 & 2.7626 & TRN \\
\hline CHEMBL3209371 & 736954 & 3.0 & 3.3886 & TRN \\
\hline CHEMBL1574614 & 736954 & 3.0 & 3.498 & TRN \\
\hline CHEMBL1487870 & 736954 & 5.8928 & 6.1682 & TRN \\
\hline CHEMBL1343331 & 736954 & 5.4881 & 5.6734 & TRN \\
\hline CHEMBL1719458 & 736954 & 3.0 & 3.6224 & TRN \\
\hline CHEMBL1322542 & 736954 & 3.0 & 3.1965 & TRN \\
\hline CHEMBL1732016 & 736954 & 6.3316 & 6.5142 & TRN \\
\hline CHEMBL1708168 & 736954 & 3.0 & 4.1323 & TST \\
\hline CHEMBL1727280 & 736954 & 3.0 & 3.3374 & TRN \\
\hline CHEMBL1390354 & 736954 & 6.4647 & 6.4334 & TRN \\
\hline CHEMBL 1709810 & 736954 & 5.9136 & 5.8372 & TRN \\
\hline CHEMBL1550429 & 736954 & 6.2541 & 6.2608 & TRN \\
\hline CHEMBL1715912 & 736954 & 3.0 & 3.1115 & TRN \\
\hline CHEMBL1562411 & 736954 & 5.6946 & 5.9776 & TRN \\
\hline
\end{tabular}




\begin{tabular}{|c|c|c|c|c|c|}
\hline & & \multicolumn{4}{|c|}{ Supplemental Table s2.txt } \\
\hline CHEMBL1724547 & 736954 & 5.7645 & 6.0222 & TRN & \\
\hline CHEMBL1704989 & 736954 & 3.0 & 4.5672 & TST & \\
\hline CHEMBL 2000167 & 736954 & 5.71899 & 99999999 & 5.7146 & TRN \\
\hline CHEMBL1444708 & 736954 & 5.6946 & 5.7096 & TRN & \\
\hline CHEMBL1729772 & 736954 & 3.0 & 3.4144 & TRN & \\
\hline CHEMBL1327648 & 736954 & 6.4802 & 6.5879 & TRN & \\
\hline CHEMBL1488869 & 736954 & 6.3325 & 5.1222 & TRN & \\
\hline CHEMBL1714966 & 736954 & 5.4377 & 5.2642 & TRN & \\
\hline CHEMBL1725265 & 736954 & 3.0 & 3.8359 & TST & \\
\hline CHEMBL1735637 & 736954 & 4.3979 & 3.6551 & TST & \\
\hline CHEMBL1333032 & 736954 & 5.7235 & 5.9363 & TRN & \\
\hline CHEMBL1701224 & 736954 & 6.7144 & 6.3497 & TRN & \\
\hline CHEMBL1439815 & 736954 & 5.5346 & 5.8987 & TST & \\
\hline CHEMBL1589711 & 736954 & 5.058 & 4.7315 & TRN & \\
\hline CHEMBL1708751 & 736954 & 3.0 & 3.0431 & TRN & \\
\hline CHEMBL1304580 & 736954 & 4.06 & 4.4335 & TST & \\
\hline CHEMBL1724311 & 736954 & 5.6326 & 6.0009 & TRN & \\
\hline CHEMBL1572439 & 736954 & 5.6925 & 6.4118 & TRN & \\
\hline CHEMBL1478943 & 736954 & 3.0 & 3.1112 & TRN & \\
\hline CHEMBL1672291 & 736954 & 6.5171 & 6.6586 & TRN & \\
\hline CHEMBL1732186 & 736954 & 3.0 & 3.4155 & TRN & \\
\hline CHEMBL1438889 & 736954 & 6.5058 & 6.4525 & TRN & \\
\hline CHEMBL1719149 & 736954 & 6.0752 & 6.3208 & TRN & \\
\hline CHEMBL1715328 & 736954 & 6.3468 & 5.1729 & TST & \\
\hline CHEMBL1729688 & 736954 & 5.8041 & 5.7177 & TRN & \\
\hline CHEMBL1717637 & 736954 & 4.6021 & 4.4565 & TST & \\
\hline CHEMBL1721448 & 736954 & 3.0 & 3.8759 & TST & \\
\hline CHEMBL3193786 & 736954 & 6.1649 & 6.1938 & TRN & \\
\hline CHEMBL 1417070 & 736954 & 5.4056 & 5.9169 & TST & \\
\hline CHEMBL1721258 & 736954 & 5.015 & 4.4971 & TRN & \\
\hline CHEMBL1672292 & 736954 & 6.3778 & 6.0624 & TRN & \\
\hline CHEMBL1715316 & 736954 & 3.0 & 4.7503 & TST & \\
\hline CHEMBL1710376 & 736954 & 4.618 & 4.4213 & TRN & \\
\hline CHEMBL1718018 & 736954 & 5.6478 & 5.7799 & TRN & \\
\hline CHEMBL408702 & 736954 & 4.9431 & 3.38100 & 00000000002 & TS \\
\hline CHEMBL1373210 & 736954 & 6.2248 & 5.7405 & TRN & \\
\hline CHEMBL1569076 & 736954 & 3.0 & 3.4636 & TST & \\
\hline CHEMBL3210218 & 736954 & 3.0 & 2.9777 & TRN & \\
\hline CHEMBL1367928 & 736954 & 5.0675 & 5.4445 & TRN & \\
\hline CHEMBL1447397 & 736954 & 3.0 & 4.0347 & TST & \\
\hline CHEMBL1704862 & 736954 & 6.4045 & 5.984 & TRN & \\
\hline CHEMBL1413629 & 736954 & 6.2358 & 5.8667 & TRN & \\
\hline CHEMBL1700415 & 736954 & 5.3206 & 4.7472 & TRN & \\
\hline CHEMBL1560901 & 736954 & 5.6073 & 5.2657 & TRN & \\
\hline CHEMBL1552304 & 736954 & 5.0114 & 5.0221 & TRN & \\
\hline CHEMBL1425801 & 736954 & 3.0 & 2.8758 & TRN & \\
\hline CHEMBL1719800 & 736954 & 3.0 & 4.2265 & TST & \\
\hline CHEMBL1736901 & 736954 & 3.0 & 4.1334 & TST & \\
\hline
\end{tabular}


Supplemental Table S2.txt

\begin{tabular}{|c|c|c|c|c|}
\hline CHEMBL1700998 & 736954 & 3.0 & 4.6504 & TST \\
\hline CHEMBL1723383 & 736954 & 4.1772 & 4.4694 & TST \\
\hline CHEMBL1532025 & 736954 & 5.7011 & 5.7502 & TRN \\
\hline CHEMBL1589694 & 736954 & 3.0 & 3.1197 & TRN \\
\hline CHEMBL1373132 & 736954 & 6.2604 & 6.3857 & TRN \\
\hline CHEMBL1387413 & 736954 & 5.5544 & 5.3339 & TRN \\
\hline CHEMBL1425844 & 736954 & 4.5528 & 3.3068 & TST \\
\hline CHEMBL1721618 & 736954 & 5.4425 & 5.9001 & TRN \\
\hline CHEMBL1714384 & 736954 & 3.0 & 4.4273 & TST \\
\hline CHEMBL1713374 & 736954 & 4.4908 & 3.1084 & TST \\
\hline CHEMBL1371816 & 736954 & 6.1864 & 6.0717 & TRN \\
\hline CHEMBL1732934 & 736954 & 4.2161 & 4.2763 & TRN \\
\hline CHEMBL1718472 & 736954 & 5.8539 & 5.494 & TRN \\
\hline CHEMBL1724482 & 736954 & 5.8665 & 5.8146 & TRN \\
\hline CHEMBL1722719 & 736954 & 5.4191 & 5.2922 & TRN \\
\hline CHEMBL1571536 & 736954 & 4.2967 & 3.9851 & TST \\
\hline CHEMBL1706168 & 736954 & 5.1543 & 5.5504 & TRN \\
\hline CHEMBL3183001 & 1301559 & 4.1968 & 4.349 & TRN \\
\hline CHEMBL 2359406 & 1301559 & 5.289 & 4.7602 & TRN \\
\hline CHEMBL1551808 & 1301559 & 4.497 & 4.2725 & TRN \\
\hline CHEMBL 2356442 & 1301559 & 4.6902 & 4.4573 & TRN \\
\hline CHEMBL 2354788 & 1301559 & 4.5051 & 4.1798 & TRN \\
\hline CHEMBL257286 & 1301559 & 4.6702 & 4.6856 & TRN \\
\hline CHEMBL1543417 & 1301559 & 4.3169 & 4.2352 & TRN \\
\hline CHEMBL1321754 & 1301559 & 4.6747 & 4.7051 & TRN \\
\hline CHEMBL 2356002 & 1301559 & 4.507 & 4.5611 & TRN \\
\hline CHEMBL1559741 & 1301559 & 4.5547 & 4.9166 & TRN \\
\hline CHEMBL1420472 & 1301559 & 4.3664 & 4.1239 & TRN \\
\hline CHEMBL1711200 & 1301559 & 4.7744 & 4.4584 & TRN \\
\hline CHEMBL1396619 & 1301559 & 4.5717 & 4.8491 & TST \\
\hline CHEMBL1375884 & 1301559 & 4.9792 & 4.7097 & TRN \\
\hline CHEMBL1622981 & 1301559 & 4.5064 & 4.6523 & TRN \\
\hline CHEMBL1428095 & 1301559 & 4.586 & 4.5468 & TRN \\
\hline CHEMBL1418341 & 1301559 & 4.4579 & 4.6284 & TRN \\
\hline CHEMBL 2354497 & 1301559 & 4.3407 & 4.5078 & TRN \\
\hline CHEMBL 2360014 & 1301559 & 4.7258 & 4.4776 & TRN \\
\hline CHEMBL591363 & 1301559 & 4.7423 & 5.0531 & TRN \\
\hline CHEMBL 2358729 & 1301559 & 5.2168 & 4.7565 & TRN \\
\hline CHEMBL1379675 & 1301559 & 4.8626 & 4.8526 & TRN \\
\hline CHEMBL 2354539 & 1301559 & 4.7908 & 4.7966 & TRN \\
\hline CHEMBL3182148 & 1301559 & 4.8292 & 4.1045 & TRN \\
\hline CHEMBL1445297 & 1301559 & 6.7011 & 6.5138 & TRN \\
\hline CHEMBL1321427 & 1301559 & 6.1898 & 6.26399 & э999999999 \\
\hline CHEMBL1544186 & 1301559 & 4.6536 & 4.4747 & TRN \\
\hline CHEMBL 2358863 & 1301559 & 4.5177 & 4.4781 & TRN \\
\hline CHEMBL 2359612 & 1301559 & 4.4738 & 4.599 & TRN \\
\hline CHEMBL1459394 & 1301559 & 4.518 & 4.2438 & TRN \\
\hline CHEMBL 2355378 & 1301559 & 4.6269 & 4.6586 & TRN \\
\hline
\end{tabular}

Page 21179 
Supplemental Table S2.txt

\begin{tabular}{|c|c|c|c|c|c|}
\hline CHEMBL1392527 & 1301559 & 5.9355 & 5.6642 & TST & \\
\hline CHEMBL1487099 & 1301559 & 5.4698 & 5.5124 & TST & \\
\hline CHEMBL1602637 & 1301559 & 5.7375 & 5.6806 & TRN & \\
\hline CHEMBL1530866 & 1301559 & 4.2905 & 4.4571 & TRN & \\
\hline CHEMBL1375289 & 1301559 & 4.093 & 4.6298 & TRN & \\
\hline CHEMBL1500469 & 1301559 & 4.3627 & 4.7057 & TRN & \\
\hline CHEMBL 2359110 & 1301559 & 4.965 & \multicolumn{2}{|c|}{4.6739999999999995} & TRN \\
\hline CHEMBL 2356872 & 1301559 & 4.2237 & 4.5832 & TRN & \\
\hline CHEMBL 2359502 & 1301559 & 4.3925 & 4.4573 & TRN & \\
\hline CHEMBL585827 & 1301559 & 5.0353 & 5.1065 & TRN & \\
\hline CHEMBL 2357026 & 1301559 & 4.716 & 4.555 & TRN & \\
\hline CHEMBL 3182522 & 1301559 & 5.5214 & 4.3891 & TRN & \\
\hline CHEMBL 2356728 & 1301559 & 4.4216 & 4.7124 & TRN & \\
\hline CHEMBL1568022 & 1301559 & 4.6821 & 4.4438 & TRN & \\
\hline CHEMBL1452421 & 1301559 & 4.7883 & 4.9707 & TRN & \\
\hline CHEMBL1560870 & 1301559 & 4.9876 & 4.4106 & TST & \\
\hline CHEMBL2355506 & 1301559 & 5.1118 & 4.7386 & TRN & \\
\hline CHEMBL1579170 & 1301559 & 4.7978 & 4.4487 & TRN & \\
\hline CHEMBL1306900 & 1301559 & 4.6554 & \multicolumn{2}{|c|}{4.6339999999999995} & TRN \\
\hline CHEMBL3185444 & 1301559 & 3.1549 & 4.4252 & TRN & \\
\hline CHEMBL 2357535 & 1301559 & 4.9397 & 5.1369 & TRN & \\
\hline CHEMBL1405749 & 1301559 & 6.4365 & 6.5221 & TRN & \\
\hline CHEMBL1347023 & 1301559 & 4.3523 & 4.5299 & TRN & \\
\hline CHEMBL 3182281 & 1301559 & 4.3699 & 4.1825 & TRN & \\
\hline CHEMBL1489779 & 1301559 & 6.4389 & 6.2124 & TRN & \\
\hline CHEMBL 3188673 & 1301559 & 3.1549 & 4.4993 & TRN & \\
\hline CHEMBL1617452 & 1301559 & 4.6428 & 4.7077 & TRN & \\
\hline CHEMBL2358940 & 1301559 & 4.3542 & 4.5732 & TRN & \\
\hline CHEMBL 2362650 & 1301559 & 5.8633 & 4.9603 & TRN & \\
\hline CHEMBL1473633 & 1301559 & 3.0 & 4.305 & TRN & \\
\hline CHEMBL1390112 & 1301559 & 4.5067 & 4.6837 & TST & \\
\hline CHEMBL1582221 & 1301559 & 5.3747 & 4.1818 & TST & \\
\hline CHEMBL1544797 & 1301559 & 5.3072 & 5.131 & TST & \\
\hline CHEMBL1345220 & 1301559 & 5.767 & 5.227 & TST & \\
\hline CHEMBL2138714 & 1301559 & 5.8041 & 4.8829 & TST & \\
\hline CHEMBL1578386 & 1301559 & 4.5575 & 4.5247 & TST & \\
\hline CHEMBL3187821 & 1301559 & 4.3535 & 4.382 & TST & \\
\hline CHEMBL1488060 & 1301559 & 4.2125 & 4.4484 & TST & \\
\hline CHEMBL1704298 & 1301559 & 4.2296 & 4.4712 & TST & \\
\hline CHEMBL1483562 & 1301559 & 4.8633 & 4.6343 & TST & \\
\hline CHEMBL2354712 & 1301559 & 4.6426 & 4.7152 & TST & \\
\hline CHEMBL1378851 & 1301559 & 4.4014 & 4.5804 & TST & \\
\hline CHEMBL1584985 & 1301559 & 6.0531 & 5.6687 & TST & \\
\hline CHEMBL1337726 & 1301559 & 5.2299 & 5.325 & TST & \\
\hline CHEMBL1574530 & 1301559 & 4.7615 & 4.7922 & TST & \\
\hline CHEMBL3663618 & 1528728 & 5.7959 & 5.7694 & TRN & \\
\hline CHEMBL3659453 & 1528728 & 6.0 & 5.6338 & TST & \\
\hline CHEMBL3663598 & 1528728 & 5.0177 & 5.4245 & TST & \\
\hline
\end{tabular}


Supplemental Table S2.txt

\begin{tabular}{|c|c|c|c|c|c|}
\hline CHEMBL 3659411 & 1528728 & 4.6778 & 5.3777 & TST & \\
\hline CHEMBL3659459 & 1528728 & 5.4949 & 5.3237 & TRN & \\
\hline CHEMBL3659463 & 1528728 & 5.7212 & 5.444 & TRN & \\
\hline CHEMBL3659405 & 1528728 & 3.0969 & \multicolumn{2}{|c|}{5.5360000000000005} & TST \\
\hline CHEMBL 3659388 & 1528728 & 4.8539 & 4.5882 & TRN & \\
\hline CHEMBL3659365 & 1528728 & 5.0809 & 5.2828 & TRN & \\
\hline CHEMBL3663604 & 1528728 & 5.5229 & 6.0396 & TRN & \\
\hline CHEMBL3659384 & 1528728 & 5.5229 & 4.9066 & TRN & \\
\hline CHEMBL3659436 & 1528728 & 6.0132 & 5.4606 & TST & \\
\hline CHEMBL3659441 & 1528728 & 5.0132 & 5.2715 & TST & \\
\hline CHEMBL3659381 & 1528728 & 4.699 & 5.0371 & TRN & \\
\hline CHEMBL3659386 & 1528728 & 5.4949 & 5.4163 & TST & \\
\hline CHEMBL 3659423 & 1528728 & 5.0177 & 4.703 & TRN & \\
\hline CHEMBL3659383 & 1528728 & 5.3565 & 4.776 & TRN & \\
\hline CHEMBL 3659431 & 1528728 & 5.6021 & 5.6416 & TRN & \\
\hline CHEMBL3659415 & 1528728 & 3.0969 & 5.4048 & TST & \\
\hline CHEMBL3659368 & 1528728 & 5.2291 & 5.2731 & TRN & \\
\hline CHEMBL3659439 & 1528728 & 4.8539 & 5.2518 & TRN & \\
\hline CHEMBL3659461 & 1528728 & 4.5229 & 5.2824 & TRN & \\
\hline CHEMBL 3659464 & 1528728 & 5.1135 & 5.1829 & TRN & \\
\hline CHEMBL 3659437 & 1528728 & 6.0 & 5.3461 & TRN & \\
\hline CHEMBL3663605 & 1528728 & 5.5528 & 5.7462 & TRN & \\
\hline CHEMBL 3659418 & 1528728 & 5.2596 & 5.5012 & TST & \\
\hline CHEMBL3659387 & 1528728 & 4.7212 & 4.8684 & TRN & \\
\hline CHEMBL3659417 & 1528728 & 5.0506 & 5.4622 & TST & \\
\hline CHEMBL 3659380 & 1528728 & 4.9586 & 4.8406 & TRN & \\
\hline CHEMBL3659379 & 1528728 & 4.8539 & 4.8338 & TRN & \\
\hline CHEMBL 3659399 & 1528728 & 4.8861 & 4.6179 & TRN & \\
\hline CHEMBL3659428 & 1528728 & 5.4949 & 5.9666 & TRN & \\
\hline CHEMBL3659434 & 1528728 & 5.8861 & 4.9553 & TRN & \\
\hline CHEMBL3659401 & 1528728 & 4.585 & 4.5527 & TRN & \\
\hline CHEMBL 3659421 & 1528728 & 5.699 & 5.5179 & TRN & \\
\hline CHEMBL3923596 & 1528728 & 5.0706 & \multicolumn{2}{|c|}{ 4.8469999999999995 } & TRN \\
\hline CHEMBL3663619 & 1528728 & 6.1549 & 5.6147 & TRN & \\
\hline CHEMBL3659430 & 1528728 & 5.6778 & 5.6632 & TRN & \\
\hline CHEMBL3659455 & 1528728 & 5.2676 & \multicolumn{2}{|c|}{5.1770000000000005} & TRN \\
\hline CHEMBL 3663625 & 1528728 & 5.7696 & 5.591 & TRN & \\
\hline CHEMBL3659366 & 1528728 & 5.6198 & 5.1873 & TRN & \\
\hline CHEMBL 3659426 & 1528728 & 5.1487 & 5.006 & TRN & \\
\hline CHEMBL3659419 & 1528728 & 5.1135 & 5.4975 & TST & \\
\hline CHEMBL3933746 & 1528728 & 5.4318 & 5.4882 & TRN & \\
\hline CHEMBL 3659440 & 1528728 & 5.9208 & 5.3214 & TRN & \\
\hline CHEMBL3663622 & 1528728 & 5.9586 & 5.4747 & TRN & \\
\hline CHEMBL3663596 & 1528728 & 5.1135 & 5.2976 & TRN & \\
\hline CHEMBL3659397 & 1528728 & 3.0969 & 4.0777 & TRN & \\
\hline CHEMBL 3659425 & 1528728 & 4.9586 & 4.6924 & TRN & \\
\hline CHEMBL 3659402 & 1528728 & 4.9208 & 4.5918 & TRN & \\
\hline CHEMBL 3659367 & 1528728 & 5.6021 & 5.1606 & TRN & \\
\hline
\end{tabular}

Page 21181 
Supplemental Table S2.txt

\begin{tabular}{|c|c|c|c|c|c|}
\hline CHEMBL3659406 & 1528728 & 3.0969 & 5.4642 & TST & \\
\hline CHEMBL3639582 & 1528728 & 3.0969 & 5.3842 & TST & \\
\hline CHEMBL3659407 & 1528728 & 3.0969 & 5.4555 & TST & \\
\hline CHEMBL3659396 & 1528728 & 3.0969 & 3.7862 & TRN & \\
\hline CHEMBL3948745 & 1528728 & 4.9208 & 4.7803 & TRN & \\
\hline CHEMBL3659445 & 1528728 & 5.699 & 5.4424 & TST & \\
\hline CHEMBL3663608 & 1528728 & 5.585 & 5.5988 & TRN & \\
\hline CHEMBL3663628 & 1528728 & 5.8539 & 5.6517 & TRN & \\
\hline CHEMBL3659360 & 1528728 & 4.7212 & 4.8592 & TRN & \\
\hline CHEMBL3659408 & 1528728 & 5.1079 & 5.3182 & TST & \\
\hline CHEMBL3659394 & 1528728 & 4.5229 & 4.5969 & TRN & \\
\hline CHEMBL3663602 & 1528728 & 5.2596 & 5.301 & TRN & \\
\hline CHEMBL3663597 & 1528728 & 5.8239 & 5.3613 & TRN & \\
\hline CHEMBL 3663617 & 1528728 & 5.7212 & 5.58 & TRN & \\
\hline CHEMBL 3659447 & 1528728 & 5.301 & 5.2266 & TST & \\
\hline CHEMBL3659373 & 1528728 & 5.8861 & 5.6911 & TRN & \\
\hline CHEMBL3659427 & 1528728 & 5.7696 & 5.4747 & TRN & \\
\hline CHEMBL3663627 & 1528728 & 3.0969 & 5.4766 & TRN & \\
\hline CHEMBL3659374 & 1528728 & 6.0 & 5.3101 & TRN & \\
\hline CHEMBL3659382 & 1528728 & 5.585 & 4.9401 & TRN & \\
\hline CHEMBL3663603 & 1528728 & 6.0969 & 5.9508 & TRN & \\
\hline CHEMBL3659452 & 1528728 & 4.9586 & 5.1519 & TST & \\
\hline CHEMBL3659432 & 1528728 & 5.5086 & 5.3655 & TRN & \\
\hline CHEMBL3659462 & 1528728 & 5.7696 & 5.4287 & TRN & \\
\hline CHEMBL3659395 & 1528728 & 3.0969 & 4.1365 & TRN & \\
\hline CHEMBL3659424 & 1528728 & 5.5376 & 5.4036 & TRN & \\
\hline CHEMBL3663623 & 1528728 & 5.6576 & 5.4434 & TRN & \\
\hline CHEMBL3659449 & 1528728 & 5.5229 & 5.3956 & TST & \\
\hline CHEMBL3659413 & 1528728 & 4.8239 & 5.3252 & TST & \\
\hline CHEMBL 3659363 & 1528728 & 5.699 & 6.0432 & TRN & \\
\hline CHEMBL3663631 & 1528728 & 5.4559 & 5.55399 & э999999999 & TST \\
\hline CHEMBL3659398 & 1528728 & 5.3768 & 4.7072 & TRN & \\
\hline CHEMBL3963073 & 1528728 & 5.2291 & 5.3061 & TRN & \\
\hline CHEMBL 3663621 & 1528728 & 4.9586 & 5.4712 & TRN & \\
\hline CHEMBL3975265 & 1528728 & 5.3979 & 4.8813 & TRN & \\
\hline CHEMBL3659370 & 1528728 & 4.9208 & 5.1656 & TRN & \\
\hline CHEMBL3659385 & 1528728 & 5.3979 & 4.8587 & TRN & \\
\hline CHEMBL3659377 & 1528728 & 4.8861 & 4.9436 & TRN & \\
\hline CHEMBL 3659448 & 1528728 & 5.3188 & 5.2605 & TST & \\
\hline CHEMBL3659458 & 1528728 & 5.1192 & 5.3641 & TRN & \\
\hline CHEMBL3659376 & 1528728 & 5.301 & 5.5121 & TRN & \\
\hline CHEMBL3663626 & 1528728 & 5.7696 & 5.6786 & TRN & \\
\hline CHEMBL3663612 & 1528728 & 5.7959 & 5.7395 & TRN & \\
\hline CHEMBL3659361 & 1528728 & 5.585 & 5.1197 & TRN & \\
\hline CHEMBL 3659410 & 1528728 & 5.0 & 5.4549 & TST & \\
\hline CHEMBL3659391 & 1528728 & 3.0969 & 4.374 & TRN & \\
\hline CHEMBL3659460 & 1528728 & 6.0 & \multicolumn{2}{|c|}{5.622000000000001} & TRN \\
\hline CHEMBL3659364 & 1528728 & 4.6383 & 5.0384 & TRN & \\
\hline
\end{tabular}


Supplemental Table S2.txt

\begin{tabular}{|c|c|c|c|c|}
\hline TLTILL & & 36 & 1 & \\
\hline HEMPI 3663612 & 528728 & 5.8539 & 5.6557 & \\
\hline HEMBL & & & & \\
\hline AEMBL: & 528728 & 815 & 6666 & \\
\hline HEMBL3659416 & 528728 & 3.0969 & 4156 & \\
\hline HEMBL3659450 & 528728 & 5.8239 & 3711 & \\
\hline$A F M B$ & 3728 & 3861 & 3359 & \\
\hline HEMBL; & 3728 & 5778 & 3655 & \\
\hline HEMBL366. & 528728 & 5.6576 & 3443 & \\
\hline HEMBL3663614 & 528728 & 4.2596 & .7283 & \\
\hline AEMBL36 & 528728 & 5.3768 & 419 & \\
\hline AEMBL: & & & & \\
\hline HEMBL & 3728 & 239 & & \\
\hline AEMBL3 & 728 & 7447 & 123 & \\
\hline HEMBL365 & 528728 & 229 & 45 & \\
\hline IEMBL & 28 & 83 & 41 & \\
\hline AEMBL & & & & RN \\
\hline HEMBL: & 728 & & 198 & \\
\hline AEMBL3 & 28 & 59 & & \\
\hline AEMBL36 & 728 & 5 . & 348 & $\mid$ \\
\hline EMBL & 28 & & 71 & RN \\
\hline EM & & & & NIV \\
\hline HEMBL & 28 & & 998 & \\
\hline HEMBL & & $\partial 8$ & & \\
\hline AEMBL3 & 28 & 91 & 558 & $R N$ \\
\hline IEMBL: & 28 & 5 & 99 & $R N_{-}$ \\
\hline IFM & 28 & & & ST \\
\hline 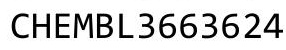 & & 96 & & RN \\
\hline IEMBL: & & & & IRN \\
\hline AEMBL36 & 728 & 4. & 346 & RN \\
\hline IEMBL & 28 & 69 & 22 & $\mathrm{RN}$ \\
\hline 2 & 8 & & & RN \\
\hline & & & & ST \\
\hline AEMBL36 & 728 & & & TST \\
\hline AEMBL 3936 & 728 & 4. & 143 & ГRN \\
\hline$A F M B$ & 28 & & & 「RN \\
\hline & & & & 「RN \\
\hline HEMBL & & & & RN \\
\hline AEMBL 365 & 528728 & 372 & & 「RN \\
\hline EMBL: & 728 & & & RN \\
\hline HEMBL36 & 728 & 86 & 411 & Not \\
\hline & & & & RN \\
\hline HEMBL36 & .528728 & & & RN \\
\hline AEMBL36 & 728 & 861 & & TR \\
\hline 3 & & & & \\
\hline HEMBL3659375 & $52872 \varepsilon$ & & & \\
\hline HEMBL3663600 & .528728 & .2147 & 5.6842 & \\
\hline CHEMBL3659443 & 1528728 & 5.8861 & 5.782 & - \\
\hline
\end{tabular}

Page 21183 
Supplemental Table S2.txt

\begin{tabular}{|c|c|c|c|c|c|}
\hline CHEMBL3659420 & 1528728 & 5.2441 & 5.4529 & TST & \\
\hline CHEMBL 2385281 & 1335495 & 7.9872 & 6.483 & TRN & \\
\hline CHEMBL3233544 & 1335495 & 3.9031 & 3.4478 & TRN & \\
\hline CHEMBL3233538 & 1335495 & 5.2218 & 5.1398 & TRN & \\
\hline CHEMBL3233836 & 1335495 & 7.1549 & 7.0693 & TRN & \\
\hline CHEMBL3233549 & 1335495 & 4.5528 & 2.953999 & 99999999997 & TST \\
\hline CHEMBL 2333026 & 1335495 & 7.6021 & 5.6666 & TST & \\
\hline CHEMBL3233561 & 1335495 & 5.4815 & 5.5342 & TRN & \\
\hline CHEMBL3233845 & 1335495 & 5.1427 & 6.8704 & TRN & \\
\hline CHEMBL3233542 & 1335495 & 4.4318 & 3.9191 & TRN & \\
\hline CHEMBL3233843 & 1335495 & 8.0706 & 8.0014 & TRN & \\
\hline CHEMBL3233575 & 1335495 & 5.4949 & 5.9747 & TRN & \\
\hline CHEMBL3233551 & 1335495 & 4.7144 & 4.0126 & TST & \\
\hline CHEMBL 2385300 & 1335495 & 7.9586 & 6.8638 & TRN & \\
\hline CHEMBL1243153 & 1335495 & 7.7696 & 4.0337 & TST & \\
\hline CHEMBL3233569 & 1335495 & 4.9914 & 5.4751 & TRN & \\
\hline CHEMBL3233573 & 1335495 & 7.699 & 6.8614 & TRN & \\
\hline CHEMBL3233564 & 1335495 & 5.8633 & 5.3811 & TRN & \\
\hline CHEMBL3233548 & 1335495 & 4.5513 & 3.4145 & TRN & \\
\hline CHEMBL3233550 & 1335495 & 4.5528 & 3.7858 & TST & \\
\hline CHEMBL3233562 & 1335495 & 6.1249 & 4.9503 & TST & \\
\hline CHEMBL3233554 & 1335495 & 7.2007 & 5.9745 & TRN & \\
\hline CHEMBL3233837 & 1335495 & 7.2291 & 7.5661 & TRN & \\
\hline CHEMBL3233541 & 1335495 & 3.0 & 5.0261 & TRN & \\
\hline CHEMBL3233571 & 1335495 & 5.1487 & 5.1825 & TRN & \\
\hline CHEMBL3233572 & 1335495 & 7.3979 & 7.2907 & TRN & \\
\hline CHEMBL 3233834 & 1335495 & 8.1612 & 7.87 & TRN & \\
\hline CHEMBL3233545 & 1335495 & 3.0 & 3.9394 & TRN & \\
\hline CHEMBL3233844 & 1335495 & 5.0458 & 7.1938 & TRN & \\
\hline CHEMBL3233842 & 1335495 & 8.4949 & 6.7695 & TRN & \\
\hline CHEMBL3233570 & 1335495 & 4.9872 & 5.1517 & TRN & \\
\hline CHEMBL 3233547 & 1335495 & 4.8097 & 3.6779 & TRN & \\
\hline CHEMBL3233833 & 1335495 & 7.5528 & 7.5468 & TRN & \\
\hline CHEMBL3233555 & 1335495 & 6.1192 & 6.4428 & TRN & \\
\hline CHEMBL3233546 & 1335495 & 3.0 & 3.3425 & TRN & \\
\hline CHEMBL3233558 & 1335495 & 6.5376 & 6.4543 & TRN & \\
\hline CHEMBL3233557 & 1335495 & 6.8601 & 6.5078 & TRN & \\
\hline CHEMBL3233568 & 1335495 & 5.6021 & 5.5608 & TRN & \\
\hline CHEMBL3233846 & 1335495 & 5.2924 & 6.7769 & TRN & \\
\hline CHEMBL3233848 & 1335495 & \multicolumn{3}{|c|}{6.752000000000001} & TRN \\
\hline CHEMBL3233835 & 1335495 & 8.3665 & 7.126 & TRN & \\
\hline CHEMBL3233543 & 1335495 & 3.0 & 3.7487 & TRN & \\
\hline CHEMBL3233552 & 1335495 & 3.0 & 3.7753 & TST & \\
\hline CHEMBL3233566 & 1335495 & 4.6498 & 5.107 & TRN & \\
\hline CHEMBL3233847 & 1335495 & 8.4318 & 7.2743 & TRN & \\
\hline CHEMBL3233839 & 1335495 & 4.7799 & 6.5733 & TRN & \\
\hline CHEMBL3233565 & 1335495 & 5.2441 & 5.388999 & 9999999999 & TRN \\
\hline CHEMBL 3233556 & 1335495 & 6.8996 & 6.5959 & TRN & \\
\hline
\end{tabular}


Supplemental Table S2.txt

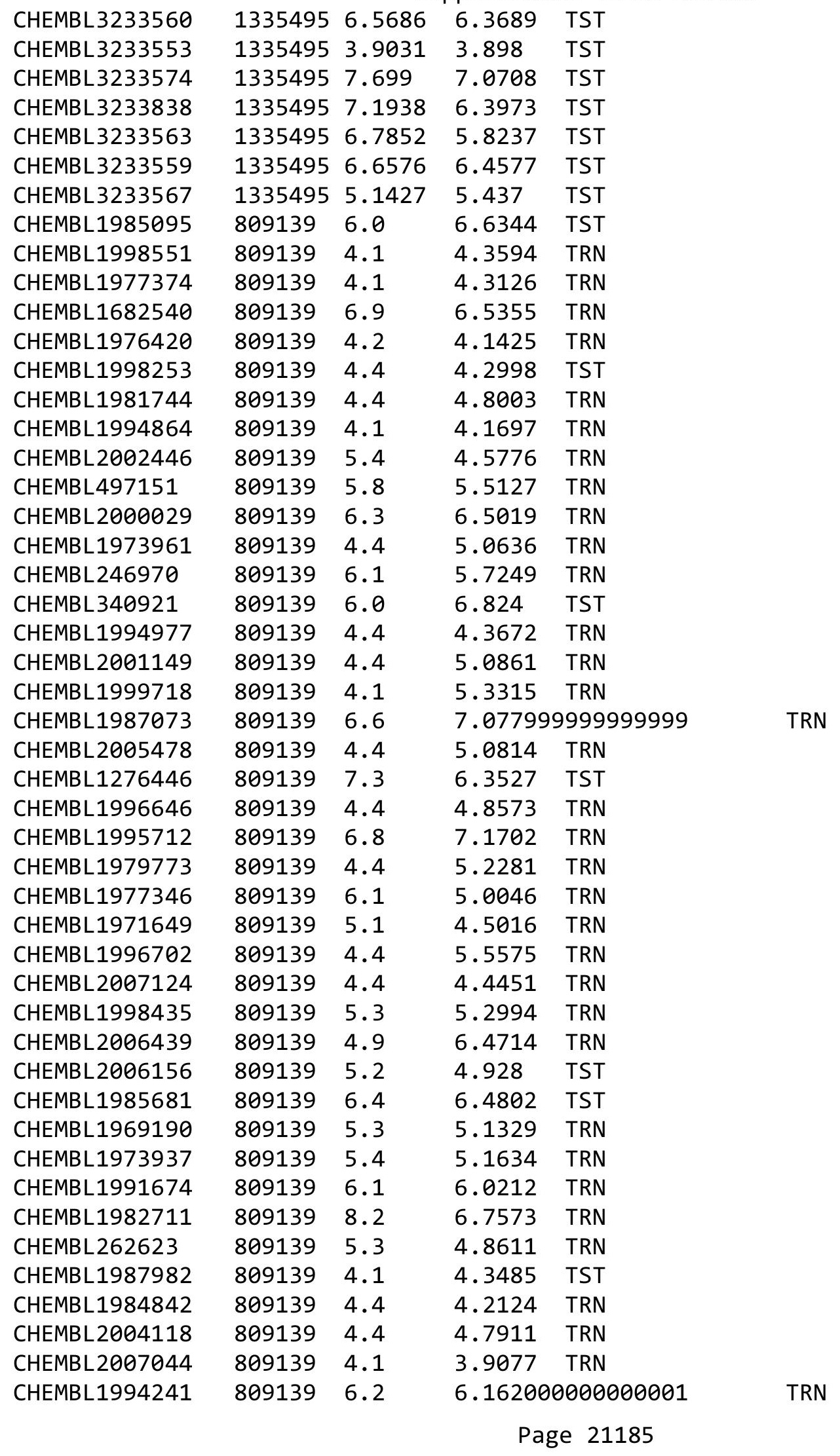




\begin{tabular}{|c|c|c|c|c|c|}
\hline \multicolumn{6}{|c|}{ Supplemental Table S2.txt } \\
\hline CHEMBL223460 & 809139 & 4.1 & 4.2672 & TST & \\
\hline CHEMBL1998829 & 809139 & 5.3 & 5.3616 & TRN & \\
\hline CHEMBL50894 & 809139 & 4.2 & 4.2178 & TST & \\
\hline CHEMBL1995211 & 809139 & 6.2 & 6.3049 & TRN & \\
\hline CHEMBL1988838 & 809139 & 6.4 & 6.7564 & TRN & \\
\hline CHEMBL1981725 & 809139 & 4.1 & 4.7313 & TRN & \\
\hline CHEMBL1982753 & 809139 & 5.5 & 5.2986 & TRN & \\
\hline CHEMBL2006299 & 809139 & 4.4 & 4.7752 & TRN & \\
\hline CHEMBL1972346 & 809139 & 6.3 & 5.9383 & TST & \\
\hline CHEMBL1980562 & 809139 & 7.5 & 7.6092 & TRN & \\
\hline CHEMBL1965169 & 809139 & 4.4 & 5.138 & TRN & \\
\hline CHEMBL1081312 & 809139 & 6.0 & 5.4841 & TRN & \\
\hline CHEMBL1965170 & 809139 & 4.4 & 4.1772 & TRN & \\
\hline CHEMBL1982866 & 809139 & 4.1 & 3.9551 & TRN & \\
\hline CHEMBL 2005792 & 809139 & 4.4 & 4.3654 & TRN & \\
\hline CHEMBL1968926 & 809139 & 4.1 & 4.0843 & TRN & \\
\hline CHEMBL462120 & 809139 & 5.8 & 4.5125 & TST & \\
\hline CHEMBL1991867 & 809139 & 4.4 & 4.6179 & TST & \\
\hline CHEMBL1979933 & 809139 & 4.4 & 5.3415 & TRN & \\
\hline CHEMBL1986503 & 809139 & 4.4 & 4.4482 & TST & \\
\hline CHEMBL1965570 & 809139 & 5.1 & 5.6221 & TRN & \\
\hline CHEMBL2007592 & 809139 & 4.1 & 4.2525 & TST & \\
\hline CHEMBL1972355 & 809139 & 4.4 & 5.4861 & TRN & \\
\hline CHEMBL1997892 & 809139 & 4.4 & 4.2842 & TRN & \\
\hline CHEMBL 2001641 & 809139 & 5.2 & 5.4906 & TRN & \\
\hline CHEMBL1976936 & 809139 & 6.1 & 6.0451 & TRN & \\
\hline CHEMBL1997193 & 809139 & 4.4 & 4.2907 & TST & \\
\hline CHEMBL210963 & 809139 & 4.1 & 3.9069 & TRN & \\
\hline CHEMBL1964902 & 809139 & 4.4 & 4.0166 & TRN & \\
\hline CHEMBL1082440 & 809139 & 5.6 & 5.1665 & TST & \\
\hline CHEMBL1614705 & 809139 & 4.1 & 4.0069 & TST & \\
\hline CHEMBL1984633 & 809139 & 5.7 & 4.8058 & TRN & \\
\hline CHEMBL1972988 & 809139 & 6.2 & 6.1528 & TRN & \\
\hline CHEMBL1965845 & 809139 & 6.6 & 6.1064 & TRN & \\
\hline CHEMBL 2007372 & 809139 & 4.1 & 3.7817 & TRN & \\
\hline CHEMBL1983715 & 809139 & 6.6 & 7.115 & TRN & \\
\hline CHEMBL 2006715 & 809139 & 4.1 & 4.051 & TRN & \\
\hline CHEMBL1986597 & 809139 & 5.3 & 5.1464 & TRN & \\
\hline CHEMBL1990482 & 809139 & 5.5 & 5.6689 & TRN & \\
\hline CHEMBL1990904 & 809139 & 4.1 & 5.2821 & TRN & \\
\hline CHEMBL2005475 & 809139 & 5.2 & 5.3693 & TRN & \\
\hline CHEMBL1987448 & 809139 & 8.4 & 7.9655 & TRN & \\
\hline CHEMBL402846 & 809139 & 5.2 & 6.2152 & TRN & \\
\hline CHEMBL1997349 & 809139 & 5.1 & 5.3791 & TST & \\
\hline CHEMBL183844 & 809139 & 4.1 & 3.6998 & TRN & \\
\hline CHEMBL220057 & 809139 & 5.7 & 6.25799 & 9999999999 & TRN \\
\hline CHEMBL1682545 & 809139 & 6.5 & 5.5958 & TRN & \\
\hline CHEMBL383541 & 809139 & 7.6 & 7.2032 & TRN & \\
\hline
\end{tabular}




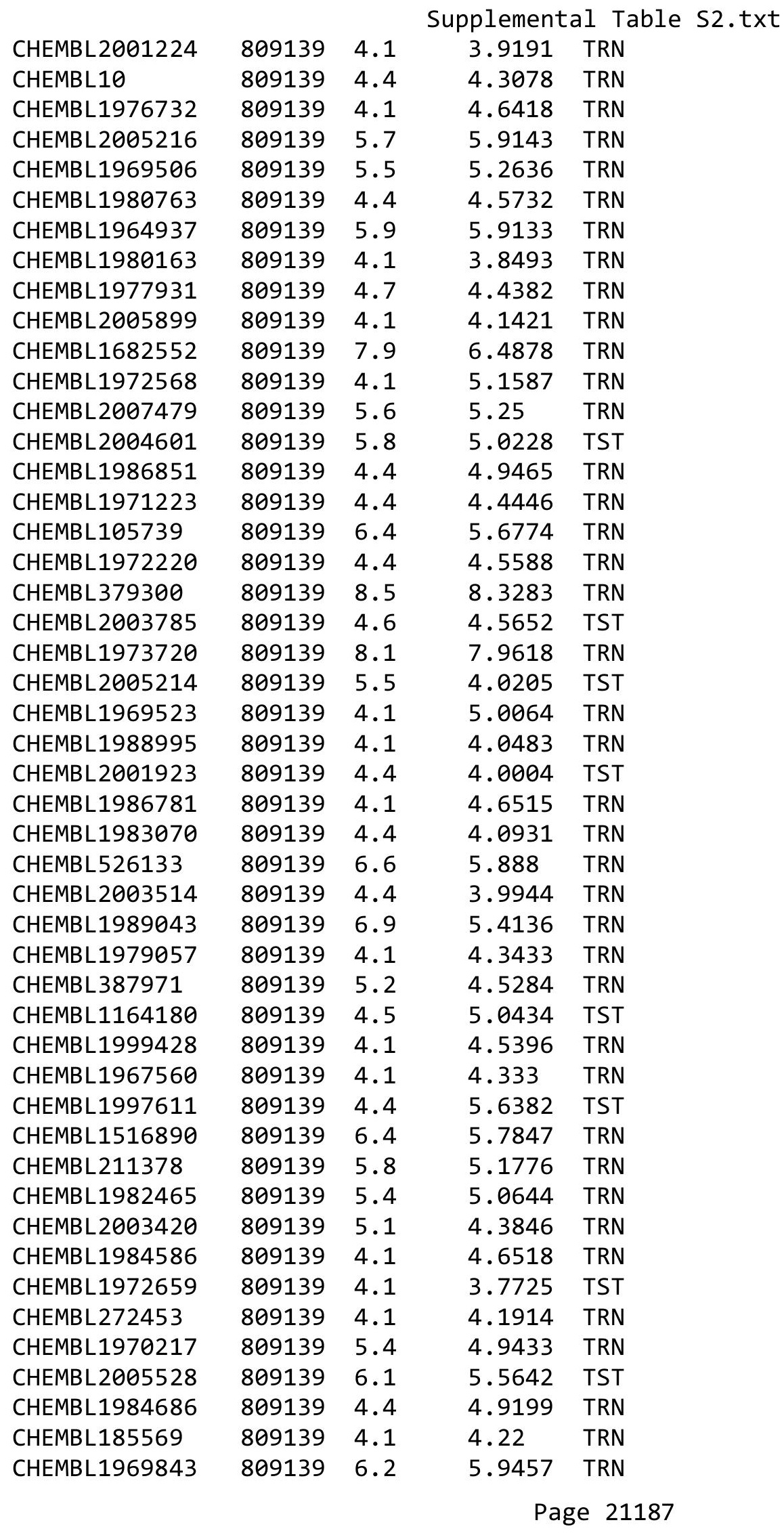




\begin{tabular}{|c|c|c|c|c|}
\hline & & & pplement & $\mathrm{a} \perp \mathrm{Ta}$ \\
\hline CHEMBL2007002 & 809139 & 6.8 & 6.4097 & TRN \\
\hline CHEMBL1987007 & 809139 & 4.1 & 4.9828 & TRN \\
\hline CHEMBL1990288 & 809139 & 4.1 & 4.0795 & TRN \\
\hline CHEMBL1973793 & 809139 & 4.4 & 4.3443 & TST \\
\hline CHEMBL1969588 & 809139 & 8.4 & 7.7573 & TRN \\
\hline CHEMBL1984711 & 809139 & 5.5 & 4.9944 & TRN \\
\hline CHEMBL1992073 & 809139 & 4.4 & 4.5583 & TRN \\
\hline CHEMBL484390 & 809139 & 6.4 & 6.0472 & TRN \\
\hline CHEMBL1979252 & 809139 & 5.3 & 4.4685 & TRN \\
\hline CHEMBL1986143 & 809139 & 4.4 & 4.735 & TRN \\
\hline CHEMBL1972934 & 809139 & 4.3 & 4.9111 & TRN \\
\hline CHEMBL2007559 & 809139 & 4.4 & 5.1904 & TRN \\
\hline CHEMBL1992581 & 809139 & 5.6 & 5.5708 & TRN \\
\hline CHEMBL 2004290 & 809139 & 4.2 & 4.0679 & TRN \\
\hline CHEMBL1986499 & 809139 & 6.6 & 6.5163 & TRN \\
\hline CHEMBL1972937 & 809139 & 4.1 & 4.7949 & TRN \\
\hline CHEMBL 2000393 & 809139 & 6.0 & 6.0172 & TST \\
\hline CHEMBL1089101 & 809139 & 5.1 & 4.8212 & TRN \\
\hline CHEMBL 2004311 & 809139 & 4.1 & 3.799 & TRN \\
\hline CHEMBL1992634 & 809139 & 6.4 & 6.5568 & TRN \\
\hline CHEMBL1242373 & 809139 & 6.0 & 6.3733 & TRN \\
\hline CHEMBL56543 & 809139 & 4.1 & 3.7999 & TRN \\
\hline CHEMBL1984847 & 809139 & 4.4 & 4.4905 & TST \\
\hline CHEMBL316264 & 809139 & 4.1 & 4.4889 & TRN \\
\hline CHEMBL1988075 & 809139 & 5.2 & 4.334 & TRN \\
\hline CHEMBL1996576 & 809139 & 4.4 & 4.2669 & TST \\
\hline CHEMBL1991678 & 809139 & 4.4 & 4.1931 & TRN \\
\hline CHEMBL 2001239 & 809139 & 5.1 & 5.149 & TRN \\
\hline CHEMBL1988594 & 809139 & 5.2 & 5.0415 & TRN \\
\hline CHEMBL 2001288 & 809139 & 6.1 & 6.0084 & TRN \\
\hline CHEMBL1992363 & 809139 & 7.1 & 6.8243 & TRN \\
\hline CHEMBL1999811 & 809139 & 7.2 & 6.2834 & TRN \\
\hline CHEMBL235157 & 809139 & 4.4 & 4.8507 & TST \\
\hline CHEMBL1985074 & 809139 & 5.6 & 4.5961 & TST \\
\hline CHEMBL 2000481 & 809139 & 5.4 & 5.275 & TRN \\
\hline CHEMBL1982874 & 809139 & 4.1 & 4.9614 & TRN \\
\hline CHEMBL1991725 & 809139 & 6.9 & 6.4372 & TRN \\
\hline CHEMBL1992242 & 809139 & 4.1 & 3.9224 & TRN \\
\hline CHEMBL1982271 & 809139 & 8.0 & 7.8844 & TRN \\
\hline CHEMBL 2007296 & 809139 & 4.1 & 5.0565 & TRN \\
\hline CHEMBL 208637 & 809139 & 4.1 & 3.8506 & TRN \\
\hline CHEMBL 2004159 & 809139 & 4.4 & 4.0273 & TRN \\
\hline CHEMBL396523 & 809139 & 6.8 & 7.2683 & TRN \\
\hline CHEMBL1978371 & 809139 & 4.4 & 4.544 & TST \\
\hline CHEMBL1970203 & 809139 & 4.1 & 4.0559 & TRN \\
\hline CHEMBL1986530 & 809139 & 6.3 & 5.0226 & TST \\
\hline CHEMBL440084 & 809139 & 4.4 & 4.1855 & TRN \\
\hline CHEMBL1999321 & 809139 & 4.1 & 3.5187 & TRN \\
\hline
\end{tabular}




\begin{tabular}{|c|c|c|c|c|}
\hline & & & ipplemen & al $\mathrm{T}$ \\
\hline CHEMBL1968590 & 809139 & 4.1 & 4.4286 & TRN \\
\hline CHEMBL 2005375 & 809139 & 5.7 & 4.8236 & TRN \\
\hline CHEMBL1984191 & 809139 & 4.1 & 4.5031 & TRN \\
\hline CHEMBL1972183 & 809139 & 4.1 & 3.8122 & TST \\
\hline CHEMBL1971029 & 809139 & 7.7 & 7.0704 & TRN \\
\hline CHEMBL394790 & 809139 & 6.2 & 5.27 & TRN \\
\hline CHEMBL226471 & 809139 & 5.9 & 6.3151 & TRN \\
\hline CHEMBL1974702 & 809139 & 5.1 & 5.1441 & TRN \\
\hline CHEMBL1996111 & 809139 & 5.5 & 5.3148 & TRN \\
\hline CHEMBL1966175 & 809139 & 4.4 & 4.3346 & TRN \\
\hline CHEMBL1965589 & 809139 & 4.2 & 4.8147 & TRN \\
\hline CHEMBL 2007375 & 809139 & 5.6 & 5.2437 & TRN \\
\hline CHEMBL1998193 & 809139 & 4.1 & 4.0571 & TRN \\
\hline CHEMBL379975 & 809139 & 4.7 & 4.7473 & TST \\
\hline CHEMBL474432 & 809139 & 6.2 & 5.3295 & TST \\
\hline CHEMBL1973016 & 809139 & 5.7 & 5.2134 & TRN \\
\hline CHEMBL1965387 & 809139 & 4.4 & 4.5813 & TRN \\
\hline CHEMBL2001539 & 809139 & 4.0 & 4.4393 & TST \\
\hline CHEMBL1997041 & 809139 & 5.7 & 5.3777 & TRN \\
\hline CHEMBL1988153 & 809139 & 4.2 & 5.7225 & TRN \\
\hline CHEMBL550418 & 809139 & 4.4 & 4.9498 & TRN \\
\hline CHEMBL1986666 & 809139 & 5.5 & 5.9562 & TRN \\
\hline CHEMBL1972584 & 809139 & 4.1 & 4.7413 & TRN \\
\hline CHEMBL1971289 & 809139 & 6.4 & 6.0536 & TRN \\
\hline CHEMBL1988437 & 809139 & 4.4 & 4.8453 & TST \\
\hline CHEMBL1979577 & 809139 & 6.4 & 5.6639 & TRN \\
\hline CHEMBL1998121 & 809139 & 7.7 & 7.1675 & TRN \\
\hline CHEMBL1233887 & 809139 & 4.4 & 4.4013 & TRN \\
\hline CHEMBL1991800 & 809139 & 4.1 & 4.8401 & TRN \\
\hline CHEMBL52387 & 809139 & 6.3 & 5.6039 & TST \\
\hline CHEMBL 2003689 & 809139 & 4.4 & 4.1587 & TRN \\
\hline CHEMBL379835 & 809139 & 4.1 & 4.0841 & TST \\
\hline CHEMBL1979357 & 809139 & 4.1 & 5.0342 & TRN \\
\hline CHEMBL1996649 & 809139 & 4.4 & 5.0329 & TRN \\
\hline CHEMBL1996817 & 809139 & 7.9 & 6.4209 & TRN \\
\hline CHEMBL1986756 & 809139 & 4.4 & 5.2467 & TRN \\
\hline CHEMBL 3197315 & 809139 & 4.1 & 3.9595 & TST \\
\hline CHEMBL468280 & 809139 & 4.1 & 3.8574 & TST \\
\hline CHEMBL1990884 & 809139 & 4.1 & 4.5767 & TRN \\
\hline CHEMBL 3109278 & 809139 & 4.6 & 5.6878 & TRN \\
\hline CHEMBL256835 & 809139 & 4.1 & 4.3556 & TRN \\
\hline CHEMBL1970006 & 809139 & 5.5 & 5.1534 & TST \\
\hline CHEMBL1974998 & 809139 & 4.4 & 4.5837 & TRN \\
\hline CHEMBL1980142 & 809139 & 4.1 & 4.1998 & TRN \\
\hline CHEMBL41783 & 809139 & 6.5 & 5.8252 & TRN \\
\hline CHEMBL 2004438 & 809139 & 4.4 & 4.4273 & TRN \\
\hline CHEMBL 2006276 & 809139 & 4.1 & 3.3188 & TRN \\
\hline CHEMBL191003 & 809139 & 6.2 & 5.9817 & TRN \\
\hline
\end{tabular}




\begin{tabular}{|c|c|c|c|c|c|}
\hline \multicolumn{6}{|c|}{ Supplemental Table S2.txt } \\
\hline CHEMBL271381 & 809139 & 6.1 & 5.0262 & TRN & \\
\hline CHEMBL 2006785 & 809139 & 4.1 & 5.0829 & TRN & \\
\hline CHEMBL1982466 & 809139 & 4.1 & 4.0241 & TRN & \\
\hline CHEMBL1973359 & 809139 & 6.7 & 6.4983 & TST & \\
\hline CHEMBL1995740 & 809139 & 4.1 & 3.9079 & TRN & \\
\hline CHEMBL1990162 & 809139 & 7.4 & 7.4234 & TRN & \\
\hline CHEMBL1992220 & 809139 & 7.8 & 8.1493 & TRN & \\
\hline CHEMBL1986943 & 809139 & 8.1 & 7.6852 & TRN & \\
\hline CHEMBL1979690 & 809139 & 6.6 & 6.95100 & 00000000005 & TRN \\
\hline CHEMBL234085 & 809139 & 4.7 & 4.3866 & TRN & \\
\hline CHEMBL1998414 & 809139 & 5.6 & 5.2146 & TRN & \\
\hline CHEMBL1995832 & 809139 & 4.1 & 4.2484 & TRN & \\
\hline CHEMBL1969042 & 809139 & 4.1 & 5.7956 & TRN & \\
\hline CHEMBL 2000345 & 809139 & 6.1 & 6.1987 & TRN & \\
\hline CHEMBL1999931 & 809139 & 8.0 & 7.835 & TRN & \\
\hline CHEMBL1976376 & 809139 & 4.4 & 4.074 & TRN & \\
\hline CHEMBL1983575 & 809139 & 7.8 & 6.5059 & TRN & \\
\hline CHEMBL1968868 & 809139 & 6.5 & 5.1858 & TRN & \\
\hline CHEMBL1375418 & 809139 & 4.1 & 3.8169 & TRN & \\
\hline CHEMBL 2007064 & 809139 & 6.0 & 5.6 & TRN & \\
\hline CHEMBL1981047 & 809139 & 5.9 & 5.6238 & TRN & \\
\hline CHEMBL1976196 & 809139 & 4.4 & 4.1472 & TST & \\
\hline CHEMBL1976240 & 809139 & 4.1 & 5.3255 & TRN & \\
\hline CHEMBL1987948 & 809139 & 7.8 & 7.0923 & TRN & \\
\hline CHEMBL1997197 & 809139 & 5.5 & 5.1186 & TRN & \\
\hline CHEMBL1979093 & 809139 & 5.8 & 5.2657 & TRN & \\
\hline CHEMBL1968151 & 809139 & 4.1 & 4.4629 & TST & \\
\hline CHEMBL1987009 & 809139 & 5.6 & 5.5163 & TRN & \\
\hline CHEMBL 2003817 & 809139 & 6.2 & 6.1686 & TRN & \\
\hline CHEMBL1994830 & 809139 & 6.3 & 6.2482 & TRN & \\
\hline CHEMBL 226403 & 809139 & 5.9 & 6.6173 & TRN & \\
\hline CHEMBL 2005631 & 809139 & 5.7 & 5.2484 & TRN & \\
\hline CHEMBL1994938 & 809139 & 4.1 & 4.7831 & TRN & \\
\hline CHEMBL1977223 & 809139 & 7.2 & 7.3844 & TRN & \\
\hline CHEMBL1995765 & 809139 & 4.3 & 4.8983 & TST & \\
\hline CHEMBL1966279 & 809139 & 4.1 & 4.7442 & TRN & \\
\hline CHEMBL1236126 & 809139 & 5.5 & 5.6618 & TRN & \\
\hline CHEMBL1997846 & 809139 & 4.5 & 5.0882 & TRN & \\
\hline CHEMBL1984760 & 809139 & 5.8 & 5.1637 & TRN & \\
\hline CHEMBL 2004419 & 809139 & 4.1 & 4.46399 & 99999999995 & TRN \\
\hline CHEMBL360847 & 809139 & 6.8 & 5.051 & TST & \\
\hline CHEMBL1995811 & 809139 & 6.9 & 7.195 & TRN & \\
\hline CHEMBL1972489 & 809139 & 5.3 & 5.2312 & TRN & \\
\hline CHEMBL1994074 & 809139 & 5.2 & 5.0036 & TRN & \\
\hline CHEMBL1992937 & 809139 & 6.6 & 6.499 & TRN & \\
\hline CHEMBL1968930 & 809139 & 7.3 & 7.3935 & TRN & \\
\hline CHEMBL1972119 & 809139 & 5.1 & 4.5828 & TRN & \\
\hline CHEMBL1986328 & 809139 & 5.2 & 5.2149 & TST & \\
\hline
\end{tabular}




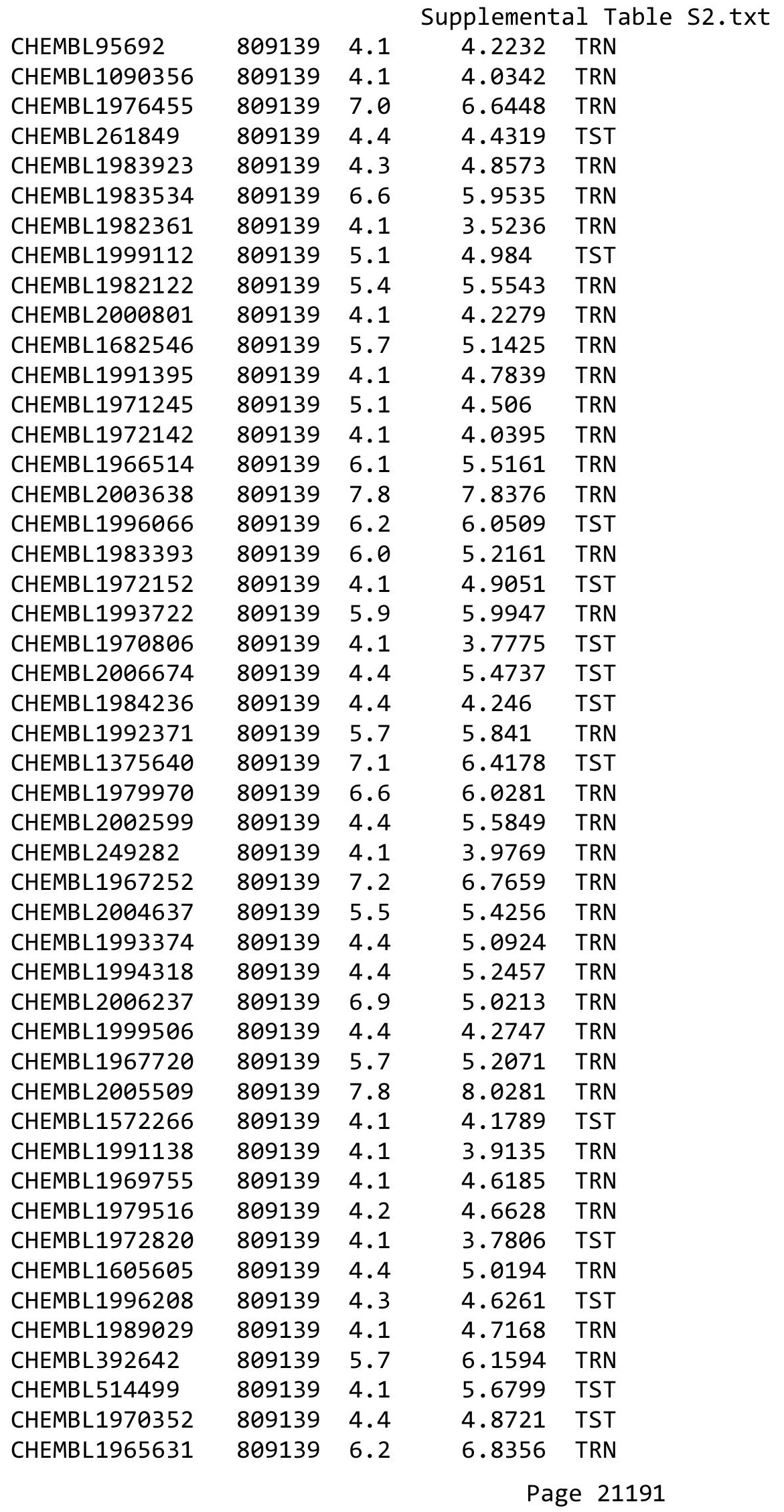




\begin{tabular}{|c|c|c|c|c|}
\hline & & & ipplemen & al $\mathrm{T}$ \\
\hline CHEMBL1980144 & 809139 & 4.1 & 4.4801 & TRN \\
\hline CHEMBL1991188 & 809139 & 5.2 & 5.3136 & TRN \\
\hline CHEMBL1980167 & 809139 & 4.4 & 4.3956 & TST \\
\hline CHEMBL1972849 & 809139 & 4.1 & 4.1514 & TRN \\
\hline CHEMBL377408 & 809139 & 4.4 & 4.0302 & TRN \\
\hline CHEMBL1986855 & 809139 & 7.8 & 7.2368 & TRN \\
\hline CHEMBL 215152 & 809139 & 4.6 & 4.4927 & TRN \\
\hline CHEMBL231209 & 809139 & 6.1 & 5.6174 & TRN \\
\hline CHEMBL1975357 & 809139 & 4.1 & 3.8358 & TST \\
\hline CHEMBL1976220 & 809139 & 6.5 & 5.7595 & TRN \\
\hline CHEMBL 2006765 & 809139 & 7.0 & 6.3231 & TRN \\
\hline CHEMBL259922 & 809139 & 4.1 & 4.2313 & TST \\
\hline CHEMBL1997617 & 809139 & 4.2 & 4.1462 & TRN \\
\hline CHEMBL1969301 & 809139 & 6.4 & 6.0507 & TRN \\
\hline CHEMBL1982383 & 809139 & 4.1 & 4.2311 & TRN \\
\hline CHEMBL17370 & 809139 & 4.1 & 4.3436 & TRN \\
\hline CHEMBL1980246 & 809139 & 4.4 & 4.378 & TRN \\
\hline CHEMBL1987910 & 809139 & 4.1 & 4.3367 & TRN \\
\hline CHEMBL1983932 & 809139 & 6.1 & 6.4392 & TRN \\
\hline CHEMBL1983980 & 809139 & 4.4 & 5.2649 & TRN \\
\hline CHEMBL1999484 & 809139 & 7.3 & 7.2717 & TRN \\
\hline CHEMBL1986899 & 809139 & 4.4 & 4.1111 & TRN \\
\hline CHEMBL1991285 & 809139 & 5.5 & 4.5602 & TRN \\
\hline CHEMBL1997822 & 809139 & 5.7 & 5.0937 & TRN \\
\hline CHEMBL 243088 & 809139 & 6.0 & 6.3805 & TRN \\
\hline CHEMBL1984038 & 809139 & 4.3 & 3.9579 & TRN \\
\hline CHEMBL1974416 & 809139 & 5.8 & 6.1318 & TRN \\
\hline CHEMBL1993661 & 809139 & 6.6 & 6.3596 & TRN \\
\hline CHEMBL 2004615 & 809139 & 5.7 & 5.3861 & TST \\
\hline CHEMBL1984039 & 809139 & 4.1 & 3.7384 & TST \\
\hline CHEMBL1997872 & 809139 & 5.2 & 4.3425 & TRN \\
\hline CHEMBL2003768 & 809139 & 4.1 & 3.6844 & TRN \\
\hline CHEMBL 213505 & 809139 & 5.9 & 5.7018 & TRN \\
\hline CHEMBL 202721 & 809139 & 4.6 & 4.1883 & TRN \\
\hline CHEMBL1987034 & 809139 & 7.8 & 7.4326 & TRN \\
\hline CHEMBL1993941 & 809139 & 4.1 & 4.4473 & TRN \\
\hline CHEMBL1980435 & 809139 & 7.5 & 7.2244 & TRN \\
\hline CHEMBL377383 & 809139 & 4.1 & 3.9862 & TRN \\
\hline CHEMBL 2005886 & 809139 & 6.5 & 6.0202 & TRN \\
\hline CHEMBL481491 & 809139 & 4.1 & 5.4702 & TST \\
\hline CHEMBL1973142 & 809139 & 6.4 & 6.4146 & TRN \\
\hline CHEMBL388311 & 809139 & 9.1 & 8.9677 & TRN \\
\hline CHEMBL1973145 & 809139 & 4.1 & 4.8515 & TRN \\
\hline CHEMBL1982924 & 809139 & 6.0 & 6.6323 & TRN \\
\hline CHEMBL2005936 & 809139 & 6.9 & 6.978 & TRN \\
\hline CHEMBL1807515 & 809139 & 8.3 & 8.2869 & TRN \\
\hline CHEMBL1964948 & 809139 & 4.4 & 4.4485 & TRN \\
\hline CHEMBL1971141 & 809139 & 4.1 & 4.0032 & TRN \\
\hline
\end{tabular}




\begin{tabular}{|c|c|c|c|c|c|}
\hline \multicolumn{6}{|c|}{ Supplemental Table S2.txt } \\
\hline CHEMBL1995813 & 809139 & 7.4 & 7.7346 & TRN & \\
\hline CHEMBL206236 & 809139 & 5.8 & 5.2291 & TRN & \\
\hline CHEMBL1987430 & 809139 & 4.4 & 5.1491 & TRN & \\
\hline CHEMBL244378 & 809139 & 6.2 & 6.8752 & TRN & \\
\hline CHEMBL 2001957 & 809139 & 4.1 & 4.102 & TRN & \\
\hline CHEMBL1969372 & 809139 & 6.3 & 5.4281 & TRN & \\
\hline CHEMBL1993413 & 809139 & 4.5 & 5.6642 & TRN & \\
\hline CHEMBL 2006263 & 809139 & 4.1 & 4.867 & TST & \\
\hline CHEMBL1993584 & 809139 & 6.3 & 5.8421 & TRN & \\
\hline CHEMBL1986263 & 809139 & 8.3 & 6.8826 & TRN & \\
\hline CHEMBL 2000114 & 809139 & 6.5 & 6.3267 & TRN & \\
\hline CHEMBL210618 & 809139 & 4.1 & 3.8786 & TRN & \\
\hline CHEMBL1986265 & 809139 & 4.4 & 4.1153 & TRN & \\
\hline CHEMBL1971172 & 809139 & 7.5 & 7.2507 & TRN & \\
\hline CHEMBL1975647 & 809139 & 6.2 & 5.8833 & TRN & \\
\hline CHEMBL1968380 & 809139 & 6.3 & 5.3117 & TRN & \\
\hline CHEMBL1964644 & 809139 & 4.1 & 4.5956 & TRN & \\
\hline CHEMBL1991734 & 809139 & 4.4 & 5.6916 & TST & \\
\hline CHEMBL1981782 & 809139 & 6.1 & 5.732 & TRN & \\
\hline CHEMBL1977681 & 809139 & 6.4 & 5.5536 & TRN & \\
\hline CHEMBL1970142 & 809139 & 4.1 & 4.1878 & TRN & \\
\hline CHEMBL1990912 & 809139 & 7.0 & 6.7211 & TRN & \\
\hline CHEMBL1991782 & 809139 & 3.1 & 3.865 & TRN & \\
\hline CHEMBL 2002105 & 809139 & 4.5 & 4.5314 & TRN & \\
\hline CHEMBL1983348 & 809139 & 6.4 & 6.2616 & TRN & \\
\hline CHEMBL1988163 & 809139 & 7.3 & 7.5766 & TRN & \\
\hline CHEMBL 2000934 & 809139 & 4.4 & 5.2131 & TRN & \\
\hline CHEMBL 2006493 & 809139 & 4.1 & 3.7145 & TST & \\
\hline CHEMBL1986177 & 809139 & 4.4 & 4.3563 & TRN & \\
\hline CHEMBL1996923 & 809139 & 4.1 & 4.1599 & TST & \\
\hline CHEMBL1983449 & 809139 & 4.1 & 3.9479 & TRN & \\
\hline CHEMBL1992323 & 809139 & 5.3 & 4.72 & TRN & \\
\hline CHEMBL1969735 & 809139 & 4.1 & 4.0738 & TRN & \\
\hline CHEMBL 2002649 & 809139 & 6.2 & 6.00200 & 0000000001 & TRN \\
\hline CHEMBL1983589 & 809139 & 6.6 & 6.2565 & TRN & \\
\hline CHEMBL1985367 & 809139 & 5.8 & 4.9395 & TST & \\
\hline CHEMBL1996510 & 809139 & 4.6 & 4.6747 & TRN & \\
\hline CHEMBL 2005718 & 809139 & 7.4 & 7.5149 & TRN & \\
\hline CHEMBL1995172 & 809139 & 4.2 & 3.7692 & TST & \\
\hline CHEMBL 2001584 & 809139 & 6.2 & 4.2657 & TRN & \\
\hline CHEMBL1967998 & 809139 & 6.4 & 7.0472 & TRN & \\
\hline CHEMBL1994321 & 809139 & 5.5 & 5.0677 & TRN & \\
\hline CHEMBL1978562 & 809139 & 4.4 & 4.5042 & TRN & \\
\hline CHEMBL1997129 & 809139 & 7.6 & 6.7813 & TRN & \\
\hline CHEMBL1984788 & 809139 & 5.1 & 4.603 & TRN & \\
\hline CHEMBL1974875 & 809139 & 4.7 & 4.3959 & TST & \\
\hline CHEMBL1989471 & 809139 & 5.8 & 5.6383 & TST & \\
\hline CHEMBL2000508 & 809139 & 4.1 & 4.2309 & TRN & \\
\hline
\end{tabular}




\begin{tabular}{|c|c|c|c|c|c|}
\hline \multicolumn{6}{|c|}{ Supplemental Table S2.txt } \\
\hline CHEMBL1971694 & 809139 & 5.7 & 4.2453 & TST & \\
\hline CHEMBL 2001547 & 809139 & 4.1 & 3.9858 & TRN & \\
\hline CHEMBL210928 & 809139 & 4.1 & 3.9061 & TRN & \\
\hline CHEMBL1978195 & 809139 & 5.9 & 5.8386 & TRN & \\
\hline CHEMBL1986603 & 809139 & 6.0 & 5.8225 & TST & \\
\hline CHEMBL1977148 & 809139 & 4.1 & 3.9778 & TRN & \\
\hline CHEMBL 2003286 & 809139 & 6.6 & 6.1177 & TRN & \\
\hline CHEMBL1992306 & 809139 & 4.1 & 4.2372 & TRN & \\
\hline CHEMBL2002165 & 809139 & 5.7 & 5.1474 & TRN & \\
\hline CHEMBL 2001668 & 809139 & 6.0 & 4.3775 & TST & \\
\hline CHEMBL1979318 & 809139 & 5.3 & 3.715 & TST & \\
\hline CHEMBL206382 & 809139 & 5.5 & 5.7928 & TRN & \\
\hline CHEMBL1998585 & 809139 & 5.4 & 6.3266 & TRN & \\
\hline CHEMBL127898 & 809139 & 4.1 & 4.7488 & TST & \\
\hline CHEMBL519697 & 809139 & 6.9 & 6.1871 & TRN & \\
\hline CHEMBL 2004934 & 809139 & 4.1 & 4.6412 & TRN & \\
\hline CHEMBL1987261 & 809139 & 7.6 & 7.2307 & TRN & \\
\hline CHEMBL1996345 & 809139 & 4.4 & 5.0511 & TST & \\
\hline CHEMBL1975128 & 809139 & 6.5 & 6.6393 & TRN & \\
\hline CHEMBL 2004025 & 809139 & 4.4 & 5.1317 & TRN & \\
\hline CHEMBL1996048 & 809139 & 4.4 & 4.4121 & TST & \\
\hline CHEMBL1970369 & 809139 & 5.2 & 4.8223 & TRN & \\
\hline CHEMBL461876 & 809139 & 7.5 & 6.397 & TRN & \\
\hline CHEMBL1965033 & 809139 & 4.4 & 4.5514 & TRN & \\
\hline CHEMBL 2001485 & 809139 & 4.1 & 4.27 & TRN & \\
\hline CHEMBL1971519 & 809139 & 5.7 & 5.2416 & TRN & \\
\hline CHEMBL1997335 & 809139 & 6.5 & 6.1238 & TRN & \\
\hline CHEMBL1966425 & 809139 & 4.1 & 4.9957 & TRN & \\
\hline CHEMBL1984363 & 809139 & 6.0 & 5.9574 & TRN & \\
\hline CHEMBL1978099 & 809139 & 5.7 & 6.5089 & TRN & \\
\hline CHEMBL1988608 & 809139 & 6.1 & 5.7469 & TRN & \\
\hline CHEMBL184847 & 809139 & 4.1 & 3.7209 & TRN & \\
\hline CHEMBL1971132 & 809139 & 4.4 & 4.298 & TRN & \\
\hline CHEMBL1984367 & 809139 & 4.1 & 4.7142 & TRN & \\
\hline CHEMBL1985723 & 809139 & 7.5 & 7.3723 & TRN & \\
\hline CHEMBL178737 & 809139 & 6.1 & 5.1674 & TST & \\
\hline CHEMBL1982563 & 809139 & 4.1 & 4.3308 & TRN & \\
\hline CHEMBL539474 & 809139 & 4.1 & 4.7501 & TST & \\
\hline CHEMBL575824 & 809139 & 8.3 & 8.0971 & TRN & \\
\hline CHEMBL1988387 & 809139 & 4.1 & 4.4169 & TRN & \\
\hline CHEMBL1973868 & 809139 & 5.7 & 5.8463 & TRN & \\
\hline CHEMBL1972462 & 809139 & 4.4 & 4.493 & TRN & \\
\hline CHEMBL1977128 & 809139 & 7.1 & 7.305 & TRN & \\
\hline CHEMBL1974803 & 809139 & 5.2 & 4.9521 & TST & \\
\hline CHEMBL1970074 & 809139 & 5.6 & 5.1247 & TRN & \\
\hline CHEMBL1965702 & 809139 & 7.0 & 6.90799 & 99999999995 & TRN \\
\hline CHEMBL1984500 & 809139 & 3.1 & 3.7457 & TRN & \\
\hline CHEMBL1986970 & 809139 & 5.4 & 5.4483 & TRN & \\
\hline
\end{tabular}




\begin{tabular}{|c|c|c|c|c|}
\hline & & & pplement & al $\mathrm{T}$ \\
\hline CHEMBL2005112 & 809139 & 5.3 & 4.8126 & TST \\
\hline CHEMBL1958401 & 809139 & 6.3 & 5.5981 & TRN \\
\hline CHEMBL1984044 & 809139 & 6.0 & 4.6136 & TRN \\
\hline CHEMBL 2003456 & 809139 & 4.1 & 4.172 & TRN \\
\hline CHEMBL1966816 & 809139 & 7.4 & 5.8682 & TRN \\
\hline CHEMBL2002992 & 809139 & 5.9 & 5.8508 & TRN \\
\hline CHEMBL560813 & 809139 & 5.3 & 4.7913 & TRN \\
\hline CHEMBL 207253 & 809139 & 5.1 & 4.3617 & TST \\
\hline CHEMBL1982700 & 809139 & 4.4 & 4.7087 & TST \\
\hline CHEMBL1990635 & 809139 & 5.2 & 5.2438 & TST \\
\hline CHEMBL1968791 & 809139 & 4.1 & 4.2466 & TRN \\
\hline CHEMBL 2002682 & 809139 & 5.6 & 4.3902 & TST \\
\hline CHEMBL1977634 & 809139 & 4.4 & 4.3032 & TRN \\
\hline CHEMBL1971186 & 809139 & 5.1 & 4.3819 & TRN \\
\hline CHEMBL 2003482 & 809139 & 4.1 & 4.1191 & TRN \\
\hline CHEMBL 2006456 & 809139 & 7.4 & 7.5767 & TRN \\
\hline CHEMBL1973211 & 809139 & 5.5 & 5.6293 & TRN \\
\hline CHEMBL1984700 & 809139 & 4.1 & 4.0993 & TRN \\
\hline CHEMBL1998953 & 809139 & 4.4 & 5.3759 & TRN \\
\hline CHEMBL1971606 & 809139 & 4.4 & 5.1717 & TRN \\
\hline CHEMBL1972125 & 809139 & 5.9 & 5.6993 & TRN \\
\hline CHEMBL1461728 & 809139 & 5.8 & 5.3567 & TRN \\
\hline CHEMBL1999120 & 809139 & 4.3 & 4.3298 & TST \\
\hline CHEMBL1976134 & 809139 & 5.9 & 6.1878 & TRN \\
\hline CHEMBL1965131 & 809139 & 6.2 & 6.2997 & TRN \\
\hline CHEMBL1972158 & 809139 & 7.0 & 6.7858 & TRN \\
\hline CHEMBL1981215 & 809139 & 4.4 & 5.3989 & TRN \\
\hline CHEMBL 2006580 & 809139 & 5.3 & 5.2009 & TRN \\
\hline CHEMBL1999414 & 809139 & 4.5 & 5.3296 & TRN \\
\hline CHEMBL1967336 & 809139 & 4.4 & 4.7761 & TRN \\
\hline CHEMBL 2006481 & 809139 & 4.1 & 4.8195 & TRN \\
\hline CHEMBL1979855 & 809139 & 4.1 & 4.0734 & TRN \\
\hline CHEMBL1970340 & 809139 & 3.7 & 4.5021 & TRN \\
\hline CHEMBL1967992 & 809139 & 5.5 & 5.4938 & TRN \\
\hline CHEMBL 2005186 & 809139 & 5.3 & 4.9351 & TRN \\
\hline CHEMBL1995927 & 809139 & 4.1 & 3.9321 & TRN \\
\hline CHEMBL1981671 & 809139 & 4.4 & 4.3854 & TRN \\
\hline CHEMBL 2006450 & 809139 & 5.8 & 6.4031 & TRN \\
\hline CHEMBL1975534 & 809139 & 6.6 & 6.2153 & TRN \\
\hline CHEMBL1993424 & 809139 & 6.7 & 7.2951 & TRN \\
\hline CHEMBL1966703 & 809139 & 4.1 & 4.1927 & TST \\
\hline CHEMBL 2001987 & 809139 & 4.4 & 4.6333 & TRN \\
\hline CHEMBL1969561 & 809139 & 4.1 & 5.1943 & TRN \\
\hline CHEMBL1994555 & 809139 & 4.4 & 5.12 & TRN \\
\hline CHEMBL1983640 & 809139 & 4.4 & 5.047 & TRN \\
\hline CHEMBL1997023 & 809139 & 4.1 & 4.167 & TST \\
\hline CHEMBL1964687 & 809139 & 5.2 & 5.9317 & TRN \\
\hline CHEMBL1971943 & 809139 & 4.7 & 5.4004 & TRN \\
\hline
\end{tabular}




\begin{tabular}{|c|c|c|c|c|c|}
\hline \\
\hline CHEMBL1974254 & 809139 & 4.1 & 4.0194 & TRN & \\
\hline CHEMBL1988537 & 809139 & 5.7 & 6.278 & TST & \\
\hline CHEMBL1969049 & 809139 & 4.1 & 4.3966 & TRN & \\
\hline CHEMBL 2005828 & 809139 & 5.3 & 5.0025 & TRN & \\
\hline CHEMBL 2002240 & 809139 & 4.1 & 4.5301 & TRN & \\
\hline CHEMBL1991143 & 809139 & 4.1 & 3.9815 & TST & \\
\hline CHEMBL1980178 & 809139 & 7.3 & 7.04206 & 0000000001 & TRN \\
\hline CHEMBL1998611 & 809139 & 6.3 & 6.1456 & TRN & \\
\hline CHEMBL1975900 & 809139 & 5.3 & 4.7684 & TRN & \\
\hline CHEMBL255822 & 809139 & 6.9 & 6.8433 & TRN & \\
\hline CHEMBL1972221 & 809139 & 5.7 & 5.8311 & TRN & \\
\hline CHEMBL 2006778 & 809139 & 5.9 & 5.7354 & TRN & \\
\hline CHEMBL378627 & 809139 & 4.1 & 4.1329 & TRN & \\
\hline CHEMBL1996979 & 809139 & 5.8 & 5.9033 & TRN & \\
\hline CHEMBL1997025 & 809139 & 5.9 & 5.0514 & TRN & \\
\hline CHEMBL1968406 & 809139 & 6.0 & 6.5838 & TRN & \\
\hline CHEMBL1975921 & 809139 & 4.6 & 4.6869 & TRN & \\
\hline CHEMBL1984274 & 809139 & 4.1 & 4.1121 & TST & \\
\hline CHEMBL1998545 & 809139 & 4.1 & 4.5634 & TRN & \\
\hline CHEMBL1986869 & 809139 & 4.1 & 4.6608 & TRN & \\
\hline CHEMBL1975923 & 809139 & 4.7 & 4.2782 & TST & \\
\hline CHEMBL 2005449 & 809139 & 4.4 & 4.775 & TRN & \\
\hline CHEMBL1987998 & 809139 & 4.4 & 4.0157 & TRN & \\
\hline CHEMBL 2006010 & 809139 & 4.1 & 4.2312 & TRN & \\
\hline CHEMBL1682558 & 809139 & 4.1 & 4.4358 & TRN & \\
\hline CHEMBL1971534 & 809139 & 4.8 & 5.2995 & TRN & \\
\hline CHEMBL1990496 & 809139 & 4.3 & 4.1934 & TRN & \\
\hline CHEMBL 242865 & 809139 & 6.0 & 6.0833 & TRN & \\
\hline CHEMBL 2002479 & 809139 & 6.7 & 5.4057 & TRN & \\
\hline CHEMBL1983884 & 809139 & 4.4 & 4.1154 & TST & \\
\hline CHEMBL1967094 & 809139 & 5.6 & 5.2285 & TRN & \\
\hline CHEMBL1966035 & 809139 & 4.1 & 4.0867 & TRN & \\
\hline CHEMBL 2003341 & 809139 & 4.1 & 4.9865 & TRN & \\
\hline CHEMBL1982992 & 809139 & 6.1 & 5.7293 & TRN & \\
\hline CHEMBL1998110 & 809139 & 4.4 & 3.8883 & TRN & \\
\hline CHEMBL1999590 & 809139 & 4.1 & 3.9658 & TST & \\
\hline CHEMBL1978166 & 809139 & 5.5 & 6.1052 & TRN & \\
\hline CHEMBL1972276 & 809139 & 4.1 & 4.7061 & TRN & \\
\hline CHEMBL1980489 & 809139 & 4.1 & 4.2986 & TRN & \\
\hline CHEMBL 2000832 & 809139 & 5.3 & 5.5203 & TRN & \\
\hline CHEMBL1967116 & 809139 & 5.6 & 4.4384 & TRN & \\
\hline CHEMBL1990590 & 809139 & 4.4 & 4.1249 & TRN & \\
\hline CHEMBL1977814 & 809139 & 4.4 & 4.445 & TST & \\
\hline CHEMBL513846 & 809139 & 4.1 & 4.8489 & TRN & \\
\hline CHEMBL 86755 & 809139 & 4.4 & $5.1610 €$ & 00000000005 & TRN \\
\hline CHEMBL1970709 & 809139 & 4.2 & 4.8248 & TRN & \\
\hline CHEMBL1974617 & 809139 & 6.0 & 5.9737 & TRN & \\
\hline CHEMBL1992125 & 809139 & 5.4 & 5.308 & TRN & \\
\hline
\end{tabular}




\begin{tabular}{|c|c|c|c|c|c|}
\hline \multicolumn{6}{|c|}{ Supplemental Table S2.txt } \\
\hline CHEMBL1998112 & 809139 & 4.1 & 4.6439 & TRN & \\
\hline CHEMBL1972290 & 809139 & 7.7 & 7.6535 & TRN & \\
\hline CHEMBL1969126 & 809139 & 4.1 & 4.17 & TRN & \\
\hline CHEMBL1980896 & 809139 & 5.6 & 5.4553 & TRN & \\
\hline CHEMBL1975208 & 809139 & 4.1 & 3.8901 & TST & \\
\hline CHEMBL1970104 & 809139 & 6.5 & 6.1031 & TRN & \\
\hline CHEMBL1991429 & 809139 & 4.1 & 3.8228 & TRN & \\
\hline CHEMBL1964777 & 809139 & 5.5 & 5.9128 & TRN & \\
\hline CHEMBL1971149 & 809139 & 4.1 & 3.8698 & TRN & \\
\hline CHEMBL1999714 & 809139 & 4.1 & 3.1967 & TRN & \\
\hline CHEMBL1987533 & 809139 & 5.4 & 4.8601 & TRN & \\
\hline CHEMBL1994040 & 809139 & 4.1 & 4.2677 & TRN & \\
\hline CHEMBL 388978 & 809139 & 7.7 & 6.7493 & TST & \\
\hline CHEMBL1984548 & 809139 & 8.0 & 7.584 & TRN & \\
\hline CHEMBL579246 & 809139 & 8.3 & 7.9889 & TRN & \\
\hline CHEMBL398951 & 809139 & 4.3 & 4.17899 & 9999999999 & TRN \\
\hline CHEMBL1982506 & 809139 & 5.3 & 5.2417 & TST & \\
\hline CHEMBL 2004716 & 809139 & 4.5 & 4.7998 & TRN & \\
\hline CHEMBL1968127 & 809139 & 4.1 & 4.123 & TRN & \\
\hline CHEMBL1975233 & 809139 & 5.1 & 4.1843 & TRN & \\
\hline CHEMBL1985406 & 809139 & 7.0 & 6.6567 & TRN & \\
\hline CHEMBL2007603 & 809139 & 5.5 & 5.3166 & TRN & \\
\hline CHEMBL 207400 & 809139 & 4.1 & 4.705 & TST & \\
\hline CHEMBL2000894 & 809139 & 6.2 & 6.4804 & TST & \\
\hline CHEMBL1421720 & 809139 & 4.4 & 5.1803 & TRN & \\
\hline CHEMBL1968130 & 809139 & 4.5 & 4.8385 & TST & \\
\hline CHEMBL2002553 & 809139 & 4.1 & 4.5024 & TST & \\
\hline CHEMBL1982135 & 809139 & 5.7 & 5.9522 & TRN & \\
\hline CHEMBL1976090 & 809139 & 6.7 & 6.7561 & TRN & \\
\hline CHEMBL1993243 & 809139 & 4.1 & 4.5877 & TRN & \\
\hline CHEMBL 2004771 & 809139 & 4.1 & 4.5674 & TRN & \\
\hline CHEMBL1992922 & 809139 & 7.3 & 6.6917 & TRN & \\
\hline CHEMBL1997597 & 809139 & 5.5 & 5.7075 & TRN & \\
\hline CHEMBL1969537 & 809139 & 4.1 & 4.7722 & TST & \\
\hline CHEMBL1976093 & 809139 & 4.1 & 4.5544 & TRN & \\
\hline CHEMBL 210032 & 809139 & 5.5 & 4.4751 & TRN & \\
\hline CHEMBL1975256 & 809139 & 4.1 & 4.3022 & TST & \\
\hline CHEMBL508928 & 809139 & 4.1 & $5.4510 e$ & 00000000005 & TRN \\
\hline CHEMBL1991356 & 809139 & 4.1 & 4.4576 & TRN & \\
\hline CHEMBL1983309 & 809139 & 4.1 & 4.4558 & TRN & \\
\hline CHEMBL2004892 & 809139 & 5.5 & 5.9853 & TRN & \\
\hline CHEMBL1949855 & 809139 & 5.1 & 4.9859 & TRN & \\
\hline CHEMBL1999126 & 809139 & 4.1 & 4.5676 & TST & \\
\hline CHEMBL1997503 & 809139 & 4.1 & 4.2663 & TST & \\
\hline CHEMBL1972339 & 809139 & 6.7 & 6.857 & TRN & \\
\hline CHEMBL116070 & 809139 & 5.8 & 5.8336 & TRN & \\
\hline CHEMBL1990821 & 809139 & 4.1 & 3.5786 & TST & \\
\hline CHEMBL1970314 & 809139 & 4.1 & 3.8331 & TRN & \\
\hline
\end{tabular}




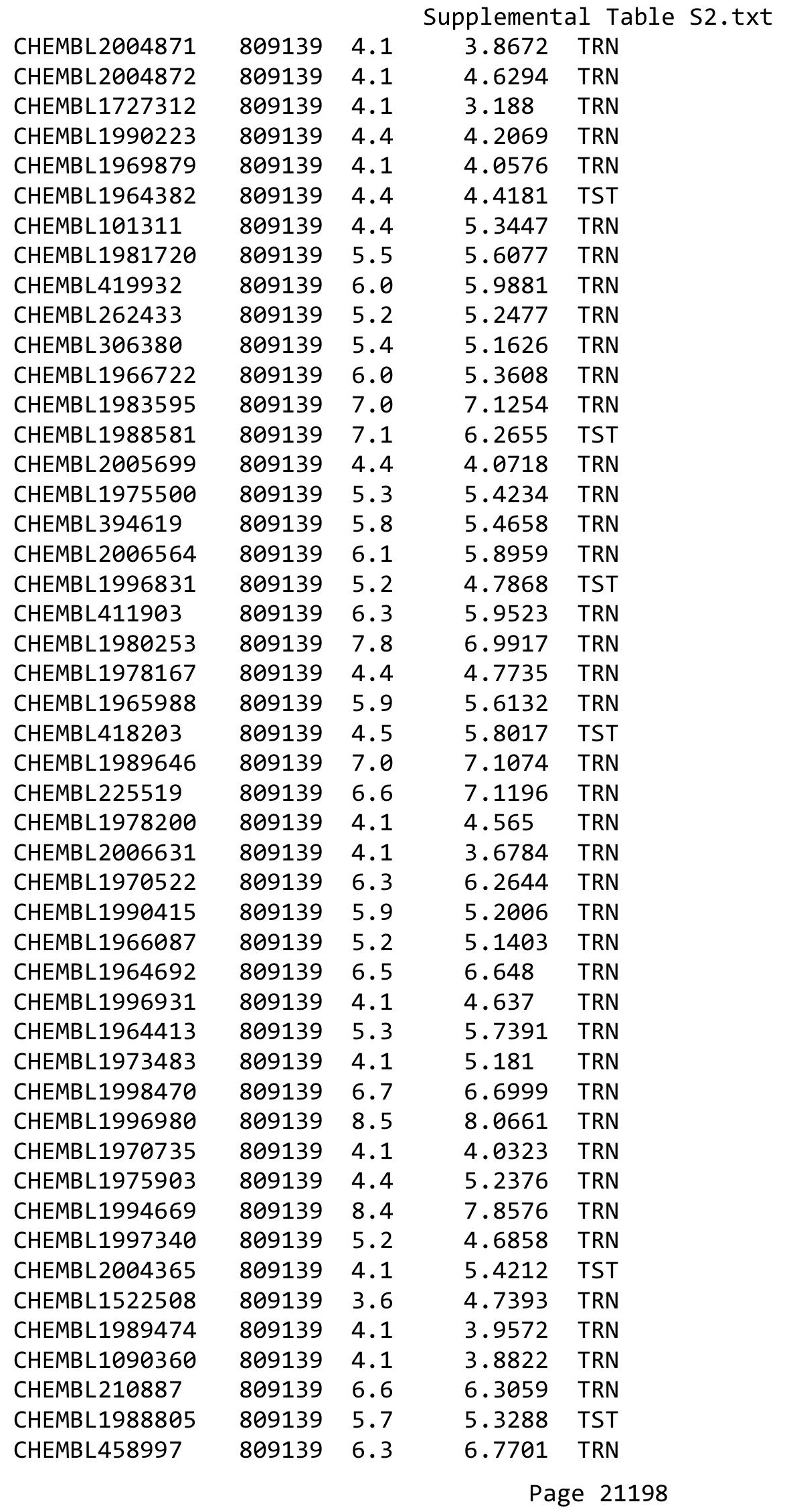




\begin{tabular}{|c|c|c|c|c|c|}
\hline & & \multicolumn{4}{|c|}{ Supplemental Table S2.txt } \\
\hline CHEMBL1971021 & 809139 & 4.1 & 3.7852 & TRN & \\
\hline CHEMBL583144 & 809139 & 6.0 & 5.7088 & TRN & \\
\hline CHEMBL1974310 & 809139 & 6.3 & 6.03 & TRN & \\
\hline CHEMBL1969942 & 809139 & 4.4 & 4.6549 & TRN & \\
\hline CHEMBL1978567 & 809139 & 4.4 & 3.8883 & TRN & \\
\hline CHEMBL1982660 & 809139 & 7.0 & 6.2757 & TRN & \\
\hline CHEMBL1994693 & 809139 & 6.4 & 6.282 & TRN & \\
\hline CHEMBL1982957 & 809139 & 7.4 & 7.2045 & TRN & \\
\hline CHEMBL1725279 & 809139 & 6.2 & 6.1497 & TST & \\
\hline CHEMBL1975138 & 809139 & 5.5 & 4.7202 & TRN & \\
\hline CHEMBL424872 & 809139 & 4.3 & 4.1116 & TRN & \\
\hline CHEMBL 2006836 & 809139 & 4.1 & 4.5119 & TST & \\
\hline CHEMBL412142 & 809139 & 4.1 & 4.7834 & TST & \\
\hline CHEMBL1988000 & 809139 & 5.2 & 5.01 & TST & \\
\hline CHEMBL1980704 & 809139 & 4.1 & 4.3993 & TST & \\
\hline CHEMBL 2003271 & 809139 & 6.4 & 6.5686 & TRN & \\
\hline CHEMBL1966808 & 809139 & 4.1 & 4.4936 & TST & \\
\hline CHEMBL 2004447 & 809139 & 4.1 & 3.6295 & TST & \\
\hline CHEMBL1992231 & 809139 & 4.4 & 4.3088 & TRN & \\
\hline CHEMBL1983111 & 809139 & 6.2 & 6.4479 & TRN & \\
\hline CHEMBL1973860 & 809139 & 5.3 & 5.4514 & TRN & \\
\hline CHEMBL1977713 & 809139 & 4.1 & 5.17 & TRN & \\
\hline CHEMBL260135 & 809139 & 6.3 & 4.5932 & TRN & \\
\hline CHEMBL220241 & 809139 & 4.1 & 5.0237 & TRN & \\
\hline CHEMBL 2004544 & 809139 & 5.2 & 5.3483 & TST & \\
\hline CHEMBL1988141 & 809139 & 4.4 & 5.8692 & TST & \\
\hline CHEMBL1982610 & 809139 & 7.0 & 5.2477 & TST & \\
\hline CHEMBL1977134 & 809139 & 4.4 & 4.55699 & 99999999995 & TRN \\
\hline CHEMBL1999496 & 809139 & 4.1 & 3.9958 & TRN & \\
\hline CHEMBL1985206 & 809139 & 4.4 & 4.4461 & TRN & \\
\hline CHEMBL1988300 & 809139 & 4.1 & 4.6198 & TRN & \\
\hline CHEMBL1991078 & 809139 & 7.2 & 7.6251 & TRN & \\
\hline CHEMBL1987359 & 809139 & 4.1 & 3.9847 & TST & \\
\hline CHEMBL1977749 & 809139 & 6.1 & 5.1334 & TST & \\
\hline CHEMBL1975212 & 809139 & 4.4 & 4.9029 & TRN & \\
\hline CHEMBL2001613 & 809139 & 4.8 & 4.8365 & TRN & \\
\hline CHEMBL1997275 & 809139 & 4.4 & 5.3205 & TRN & \\
\hline CHEMBL1993904 & 809139 & 4.4 & 5.9758 & TRN & \\
\hline CHEMBL1994438 & 809139 & 6.4 & 6.8672 & TRN & \\
\hline CHEMBL1967513 & 809139 & 5.5 & 5.16 & TRN & \\
\hline CHEMBL2000724 & 809139 & 4.4 & 4.2118 & TRN & \\
\hline CHEMBL1989265 & 809139 & 4.1 & 4.3119 & TST & \\
\hline CHEMBL1965660 & 809139 & 7.6 & 8.1343 & TST & \\
\hline CHEMBL1982413 & 809139 & 4.4 & 4.7982 & TRN & \\
\hline CHEMBL 2004647 & 809139 & 4.1 & 4.0126 & TST & \\
\hline CHEMBL1969502 & 809139 & 5.3 & 5.5032 & TRN & \\
\hline CHEMBL1682553 & 809139 & 7.1 & 6.4677 & TRN & \\
\hline CHEMBL1971430 & 809139 & 4.3 & 3.886 & TRN & \\
\hline
\end{tabular}




\begin{tabular}{|c|c|c|c|c|}
\hline \multicolumn{5}{|c|}{ Supplemental T } \\
\hline CHEMBL1983963 & 809139 & 5.2 & 5.3519 & TRN \\
\hline CHEMBL1997764 & 809139 & 5.9 & 6.0855 & TRN \\
\hline CHEMBL1981792 & 809139 & 4.4 & 4.6975 & TRN \\
\hline CHEMBL1987535 & 809139 & 6.3 & 6.2299 & TRN \\
\hline CHEMBL1985092 & 809139 & 5.4 & 5.7822 & TRN \\
\hline CHEMBL 2004692 & 809139 & 4.1 & 4.0557 & TST \\
\hline CHEMBL1981410 & 809139 & 5.3 & 4.671 & TRN \\
\hline CHEMBL 2002586 & 809139 & 4.4 & 4.9396 & TRN \\
\hline CHEMBL1996234 & 809139 & 4.1 & 3.5381 & TRN \\
\hline CHEMBL 383264 & 809139 & 8.6 & 8.0432 & TRN \\
\hline CHEMBL 2007421 & 809139 & 5.6 & 5.2757 & TRN \\
\hline CHEMBL1991434 & 809139 & 4.1 & 4.4061 & TRN \\
\hline CHEMBL1967544 & 809139 & 5.8 & 6.044 & TRN \\
\hline CHEMBL1973138 & 809139 & 4.4 & 4.204 & TRN \\
\hline CHEMBL 223367 & 809139 & 4.1 & 4.1358 & TST \\
\hline CHEMBL340384 & 809139 & 7.1 & 7.4051 & TST \\
\hline CHEMBL1969151 & 809139 & 7.4 & 7.4581 & TRN \\
\hline CHEMBL1996587 & 809139 & 6.3 & 4.9892 & TRN \\
\hline CHEMBL1981492 & 809139 & 4.2 & 4.3595 & TRN \\
\hline CHEMBL1993335 & 809139 & 5.5 & 5.0016 & TRN \\
\hline CHEMBL1988692 & 809139 & 4.4 & 4.2654 & TRN \\
\hline CHEMBL 2007574 & 809139 & 7.8 & 7.7205 & TRN \\
\hline CHEMBL1964804 & 809139 & 7.3 & 6.9853 & TRN \\
\hline CHEMBL443962 & 809139 & 5.8 & 5.3233 & TRN \\
\hline CHEMBL 2000354 & 809139 & 6.7 & 6.3365 & TRN \\
\hline CHEMBL1965507 & 809139 & 4.5 & 4.9991 & TRN \\
\hline CHEMBL 274064 & 809139 & 5.9 & 4.9493 & TRN \\
\hline CHEMBL1998680 & 809139 & 4.4 & 4.1705 & TRN \\
\hline CHEMBL1967564 & 809139 & 4.1 & 5.1465 & TRN \\
\hline CHEMBL592030 & 809139 & 4.6 & 6.3226 & TST \\
\hline CHEMBL 2000071 & 809139 & 6.7 & 6.7676 & TRN \\
\hline CHEMBL1979176 & 809139 & 5.7 & 5.4668 & TRN \\
\hline CHEMBL1970317 & 809139 & 4.4 & 4.5834 & TRN \\
\hline CHEMBL 2002613 & 809139 & 7.5 & 6.9693 & TRN \\
\hline CHEMBL 2000408 & 809139 & 4.1 & 4.3756 & TRN \\
\hline CHEMBL248757 & 809139 & 4.1 & 4.2192 & TST \\
\hline CHEMBL1978014 & 809139 & 5.4 & 5.6202 & TRN \\
\hline CHEMBL1997007 & 809139 & 5.5 & 5.3346 & TRN \\
\hline CHEMBL1994538 & 809139 & 6.1 & 5.8965 & TRN \\
\hline CHEMBL1983195 & 809139 & 5.2 & 5.1992 & TST \\
\hline CHEMBL1975490 & 809139 & 4.1 & 5.2152 & TRN \\
\hline CHEMBL1964444 & 809139 & 4.7 & 5.4304 & TRN \\
\hline CHEMBL1989957 & 809139 & 4.1 & 4.9378 & TRN \\
\hline CHEMBL 2002690 & 809139 & 4.4 & 4.1084 & TRN \\
\hline CHEMBL1986139 & 809139 & 5.3 & 4.7224 & TRN \\
\hline CHEMBL1980540 & 809139 & 4.1 & 4.69 & TRN \\
\hline CHEMBL 278041 & 809139 & 4.4 & 4.6306 & TRN \\
\hline CHEMBL1979883 & 809139 & 5.5 & 5.5055 & TRN \\
\hline
\end{tabular}




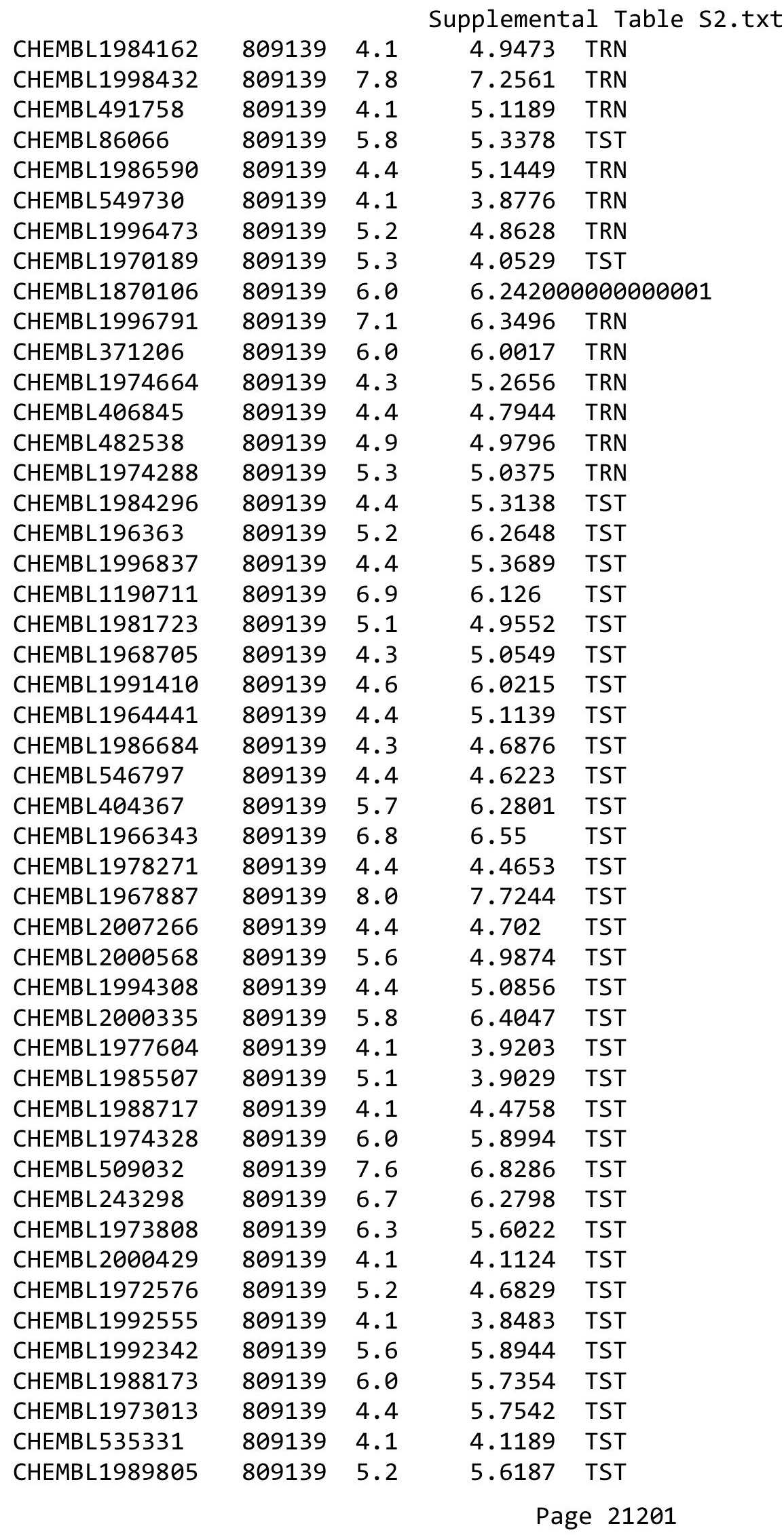

TRN 


\begin{tabular}{|c|c|c|c|c|c|}
\hline \multicolumn{6}{|c|}{ Supplemental Table S2.txt } \\
\hline CHEMBL1966204 & 809139 & 7.6 & 7.5296 & TST & \\
\hline CHEMBL1982980 & 809139 & 4.1 & 3.8543 & TST & \\
\hline CHEMBL1965423 & 809139 & 4.1 & 4.9815 & TST & \\
\hline CHEMBL1983025 & 809139 & 5.7 & 5.5226 & TST & \\
\hline CHEMBL1975927 & 809139 & 6.1 & 5.5844 & TST & \\
\hline CHEMBL205415 & 809139 & 5.8 & 5.9074 & TST & \\
\hline CHEMBL1977135 & 809139 & 4.1 & 4.6883 & TST & \\
\hline CHEMBL 2001920 & 809139 & 5.1 & 5.1942 & TST & \\
\hline CHEMBL1977138 & 809139 & 8.3 & 6.9857 & TST & \\
\hline CHEMBL1241473 & 809139 & 7.5 & 7.28700 & 2000000001 & TST \\
\hline CHEMBL2000879 & 809139 & 4.1 & 4.0946 & TST & \\
\hline CHEMBL1978448 & 809139 & 4.2 & 4.0774 & TST & \\
\hline CHEMBL 2004513 & 809139 & 4.1 & 3.8525 & TST & \\
\hline CHEMBL1972258 & 809139 & 5.4 & 5.6381 & TST & \\
\hline CHEMBL1980329 & 809139 & 4.4 & 5.2332 & TST & \\
\hline CHEMBL 2004515 & 809139 & 6.6 & 5.5056 & TST & \\
\hline CHEMBL2001257 & 809139 & 4.2 & 4.8843 & TST & \\
\hline CHEMBL1992042 & 809139 & 4.4 & 4.6394 & TST & \\
\hline CHEMBL1987793 & 809139 & 4.1 & 3.9412 & TST & \\
\hline CHEMBL1992536 & 809139 & 4.1 & 5.1587 & TST & \\
\hline CHEMBL21156 & 809139 & 4.4 & 5.0657 & TST & \\
\hline CHEMBL1992740 & 809139 & 6.6 & 5.7568 & TST & \\
\hline CHEMBL1994724 & 809139 & 4.4 & 4.6604 & TST & \\
\hline CHEMBL1989267 & 809139 & 4.4 & 4.7625 & TST & \\
\hline CHEMBL 2002373 & 809139 & 4.1 & 3.8484 & TST & \\
\hline CHEMBL439340 & 809139 & 4.1 & 4.7215 & TST & \\
\hline CHEMBL1974574 & 809139 & 4.4 & 4.9043 & TST & \\
\hline CHEMBL 2006188 & 809139 & 4.1 & 4.8526 & TST & \\
\hline CHEMBL1970290 & 809139 & 5.5 & 4.9022 & TST & \\
\hline CHEMBL1967531 & 809139 & 5.4 & 6.0306 & TST & \\
\hline CHEMBL1970913 & 809139 & 4.1 & 4.9858 & TST & \\
\hline CHEMBL1973893 & 809139 & 5.8 & 5.7913 & TST & \\
\hline CHEMBL1995736 & 809139 & 5.1 & 5.0285 & TST & \\
\hline CHEMBL1997534 & 809139 & 5.5 & 5.5159 & TST & \\
\hline CHEMBL1993877 & 809139 & 6.9 & 6.2689 & TST & \\
\hline CHEMBL1996500 & 809139 & 4.3 & 4.0139 & TST & \\
\hline CHEMBL63031 & 89731 & 6.1675 & 6.2548 & TRN & \\
\hline CHEMBL 293214 & 89731 & 6.0 & 6.0613 & TRN & \\
\hline CHEMBL292743 & 89731 & 5.3372 & 5.6665 & TRN & \\
\hline CHEMBL 302682 & 89731 & 6.3098 & 6.19799 & 99999999995 & TRN \\
\hline CHEMBL444306 & 89731 & 6.0 & 5.9087 & TRN & \\
\hline CHEMBL1790446 & 89731 & 6.0 & 6.2486 & TRN & \\
\hline CHEMBL64299 & 89731 & 4.699 & 5.195 & TST & \\
\hline CHEMBL66530 & 89731 & 6.0 & 6.1407 & TRN & \\
\hline CHEMBL65517 & 89731 & 6.0 & 6.0138 & TRN & \\
\hline CHEMBL65138 & 89731 & 4.4647 & 4.555 & TRN & \\
\hline CHEMBL1790445 & 89731 & 6.0 & 5.9885 & TST & \\
\hline CHEMBL 304228 & 89731 & 4.699 & 5.6618 & TST & \\
\hline
\end{tabular}




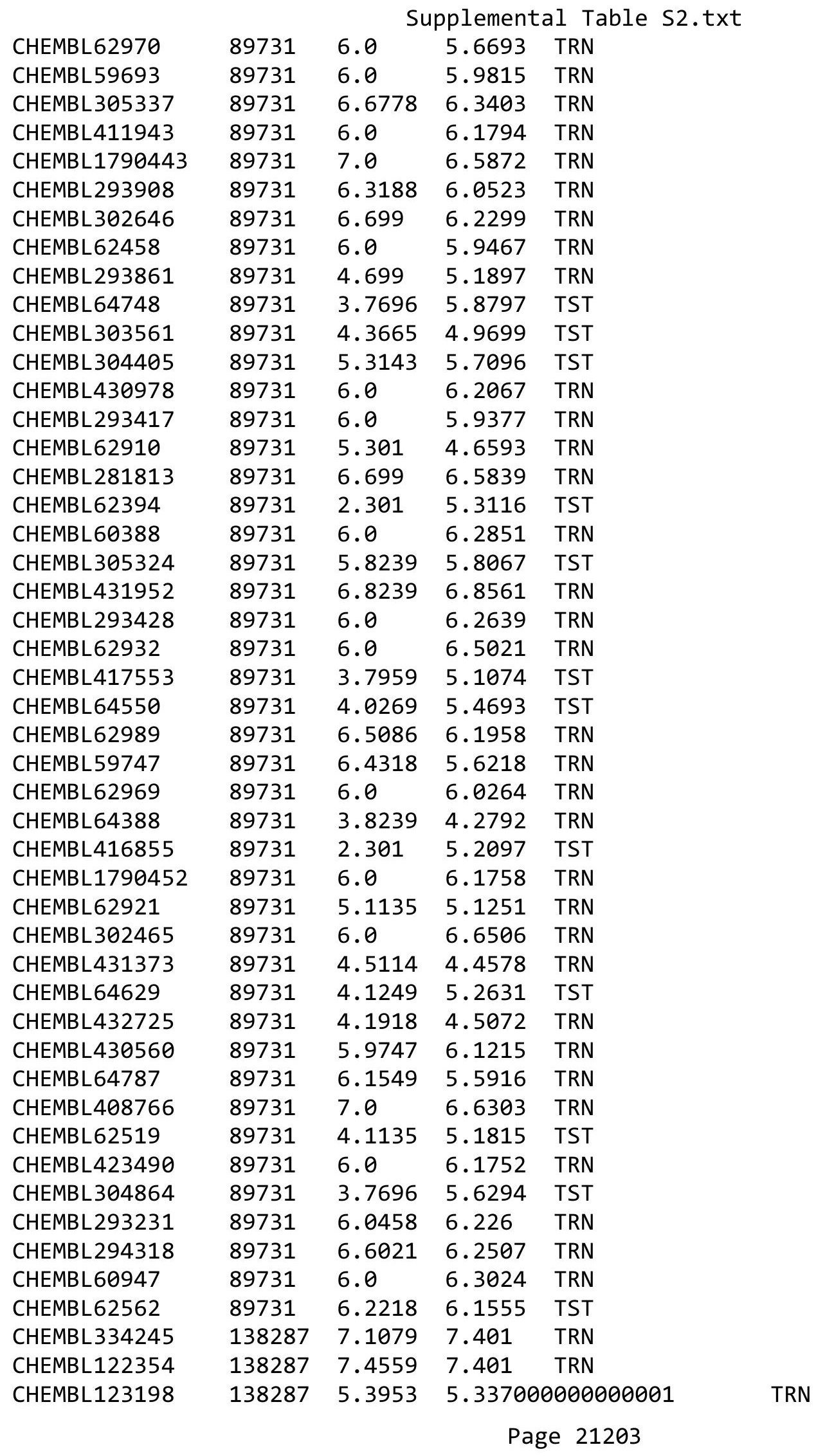




\begin{tabular}{|c|c|c|c|c|c|}
\hline \multicolumn{6}{|c|}{ Supplemental Table S2.txt } \\
\hline CHEMBL123099 & 138287 & $5.7120 e$ & 00000000 & 5.7024 & TRN \\
\hline CHEMBL340561 & 138287 & 7.1959 & 7.3634 & TRN & \\
\hline CHEMBL121385 & 138287 & 6.2142 & 6.4082 & TRN & \\
\hline CHEMBL116601 & 138287 & 7.0716 & 7.2463 & TRN & \\
\hline CHEMBL543177 & 138287 & 7.1844 & 7.233 & TRN & \\
\hline CHEMBL541584 & 138287 & 7.8729 & 7.8222 & TRN & \\
\hline CHEMBL332645 & 138287 & 4.7206 & 4.7854 & TRN & \\
\hline CHEMBL120963 & 138287 & 5.5483 & 5.5675 & TRN & \\
\hline CHEMBL120472 & 138287 & 7.4123 & 7.50899 & 99999999995 & TRN \\
\hline CHEMBL120080 & 138287 & 7.6576 & 7.401 & TRN & \\
\hline CHEMBL120972 & 138287 & 7.5171 & 6.8627 & TRN & \\
\hline CHEMBL332335 & 138287 & 6.0515 & 6.0605 & TRN & \\
\hline CHEMBL121520 & 138287 & 7.8386 & 7.6732 & TRN & \\
\hline CHEMBL333125 & 138287 & 7.1586 & 6.7092 & TRN & \\
\hline CHEMBL431688 & 138287 & 5.9635 & 5.7993 & TST & \\
\hline CHEMBL121552 & 138287 & 6.8928 & 6.88399 & 99999999995 & TRN \\
\hline CHEMBL332405 & 138287 & 6.0513 & 5.75899 & 99999999995 & TST \\
\hline CHEMBL118553 & 138287 & 6.0163 & 5.7744 & TRN & \\
\hline CHEMBL331516 & 138287 & 6.4994 & 6.6942 & TRN & \\
\hline CHEMBL120135 & 138287 & 6.0 & 6.7966 & TST & \\
\hline CHEMBL120581 & 138287 & 6.919 & 6.9281 & TRN & \\
\hline CHEMBL324936 & 138287 & 7.7721 & 7.8141 & TRN & \\
\hline CHEMBL262198 & 138287 & 8.0177 & 7.7153 & TRN & \\
\hline CHEMBL333940 & 138287 & 6.315 & 6.8627 & TRN & \\
\hline CHEMBL334093 & 138287 & 6.1739 & 6.1718 & TRN & \\
\hline CHEMBL120329 & 138287 & 6.556 & 6.67200 & 0000000001 & TRN \\
\hline CHEMBL120539 & 138287 & 5.6536 & 5.5823 & TRN & \\
\hline CHEMBL332980 & 138287 & 7.7423 & 7.7411 & TRN & \\
\hline CHEMBL 324712 & 138287 & 7.1681 & 7.2359 & TRN & \\
\hline CHEMBL330892 & 138287 & 6.6315 & 6.8474 & TRN & \\
\hline CHEMBL330999 & 138287 & 7.266 & 7.375 & TRN & \\
\hline CHEMBL332181 & 138287 & 7.1146 & 7.1344 & TRN & \\
\hline CHEMBL118241 & 138287 & 7.1118 & 6.8627 & TST & \\
\hline CHEMBL340780 & 138287 & 7.2118 & 7.2327 & TST & \\
\hline CHEMBL540316 & 138287 & 7.2277 & 7.0302 & TST & \\
\hline CHEMBL120599 & 138287 & 6.978 & 7.2268 & TST & \\
\hline CHEMBL122353 & 138287 & 6.5358 & 6.3395 & TST & \\
\hline CHEMBL120119 & 138287 & 8.0555 & 8.0254 & TRN & \\
\hline CHEMBL121059 & 138287 & 7.9393 & 7.401 & TRN & \\
\hline CHEMBL121298 & 138287 & 6.129 & 5.9907 & TST & \\
\hline CHEMBL124173 & 138287 & 7.0292 & 7.108 & TST & \\
\hline CHEMBL332320 & 138287 & 6.9743 & 7.401 & TRN & \\
\hline CHEMBL121299 & 138287 & 6.7986 & 5.9646 & TST & \\
\hline CHEMBL330885 & 138287 & 4.4799 & 5.0825 & TST & \\
\hline CHEMBL543890 & 138287 & 6.9136 & 6.9673 & TRN & \\
\hline CHEMBL120109 & 138287 & 5.6367 & 5.7055 & TRN & \\
\hline CHEMBL121476 & 138287 & 6.7921 & 6.8627 & TST & \\
\hline CHEMBL338280 & 138287 & 5.74 & 5.6969 & TRN & \\
\hline
\end{tabular}


Supplemental Table S2.txt

\begin{tabular}{|c|c|c|c|c|}
\hline CHEMBL 3589443 & 1503510 & 7.0655 & 7.1198 & TRN \\
\hline CHEMBL 3589444 & 1503510 & 6.3872 & 7.1323 & TRN \\
\hline CHEMBL3589433 & 1503510 & 3.7959 & 7.0693 & TRN \\
\hline CHEMBL 2347538 & 1503510 & 7.5686 & 7.1324 & TRN \\
\hline CHEMBL 3589045 & 1503510 & 7.0 & 7.2409 & TST \\
\hline CHEMBL3590285 & 1503510 & 6.0655 & 6.3967 & TST \\
\hline CHEMBL 3589429 & 1503510 & 7.4559 & 6.294 & TRN \\
\hline CHEMBL3589456 & 1503510 & 6.8861 & 7.1419 & TRN \\
\hline CHEMBL3589436 & 1503510 & 7.0269 & 7.2647 & TRN \\
\hline CHEMBL 3589440 & 1503510 & 5.4685 & 6.4382 & TRN \\
\hline CHEMBL 3590280 & 1503510 & 6.5528 & 6.5248 & TRN \\
\hline CHEMBL 2347539 & 1503510 & 7.3372 & 7.2225 & TRN \\
\hline CHEMBL3589453 & 1503510 & 6.6198 & 6.3898 & TRN \\
\hline CHEMBL 3589044 & 1503510 & 7.3665 & 7.1752 & TST \\
\hline CHEMBL 3590279 & 1503510 & 6.7959 & 6.6957 & TRN \\
\hline CHEMBL3590286 & 1503510 & 6.284 & 6.4345 & TST \\
\hline CHEMBL3589445 & 1503510 & 6.2676 & 6.362999 & 99999999995 \\
\hline CHEMBL 3590276 & 1503510 & 7.5376 & 7.2911 & TRN \\
\hline CHEMBL 3589450 & 1503510 & 7.8539 & 7.2985 & TRN \\
\hline CHEMBL3590282 & 1503510 & 6.6778 & 6.8774 & TRN \\
\hline CHEMBL3589435 & 1503510 & 7.0655 & 7.1544 & TRN \\
\hline CHEMBL 3589046 & 1503510 & 7.0 & 7.2447 & TST \\
\hline CHEMBL 3590283 & 1503510 & 7.3279 & 7.1819 & TRN \\
\hline CHEMBL 3589448 & 1503510 & 6.8239 & 6.6855 & TRN \\
\hline CHEMBL 3590288 & 1503510 & 6.6576 & 6.6008 & TST \\
\hline CHEMBL 3589454 & 1503510 & 6.2676 & 6.5734 & TRN \\
\hline CHEMBL 3589455 & 1503510 & 6.9586 & 6.5821 & TRN \\
\hline CHEMBL 3589449 & 1503510 & 6.8861 & 7.1577 & TRN \\
\hline CHEMBL3589442 & 1503510 & 6.9586 & 7.027 & TRN \\
\hline CHEMBL3590289 & 1503510 & 7.6778 & 7.1743 & TST \\
\hline CHEMBL 3589431 & 1503510 & 7.4949 & 6.4833 & TST \\
\hline CHEMBL 3590284 & 1503510 & 7.2366 & 6.9931 & TRN \\
\hline CHEMBL 3590277 & 1503510 & 6.3188 & 6.3292 & TRN \\
\hline CHEMBL 3589432 & 1503510 & 7.7959 & 6.588999 & \\
\hline CHEMBL3589452 & 1503510 & 6.9586 & 6.375 & TRN \\
\hline CHEMBL 3589434 & 1503510 & 7.7212 & 7.1908 & TRN \\
\hline CHEMBL 3590287 & 1503510 & 6.2076 & 6.5904 & TST \\
\hline CHEMBL 3589457 & 1503510 & 7.3468 & 7.1911 & TRN \\
\hline CHEMBL 3589441 & 1503510 & 7.3979 & 6.9965 & TRN \\
\hline CHEMBL 2347559 & 1503510 & 6.585 & 6.5307 & TST \\
\hline CHEMBL 3589430 & 1503510 & 7.2147 & 6.4051 & TRN \\
\hline CHEMBL 3589437 & 1503510 & 5.585 & 6.2277 & TRN \\
\hline CHEMBL3590275 & 1503510 & 7.0269 & 7.2362 & TRN \\
\hline CHEMBL 3589447 & 1503510 & 6.0862 & 6.5635 & TST \\
\hline CHEMBL 3589446 & 1503510 & 6.699 & 6.4853 & TRN \\
\hline CHEMBL 3588866 & 1503510 & 7.5686 & 7.2622 & TRN \\
\hline CHEMBL 3589438 & 1503510 & 5.5528 & 6.2467 & TRN \\
\hline CHEMBL 3590278 & 1503510 & 6.0132 & 6.1635 & TRN \\
\hline
\end{tabular}

Page 21205 
Supplemental Table S2.txt

\begin{tabular}{|c|c|c|c|c|c|c|}
\hline CHEMBL 2347404 & 1503510 & 6.6383 & 6.3458 & TRN & & \\
\hline CHEMBL3590281 & 1503510 & 7.0862 & 7.0428 & TRN & & \\
\hline CHEMBL3589451 & 1503510 & 8.5229 & 7.3645 & TRN & & \\
\hline CHEMBL3589439 & 1503510 & 6.0605 & 6.4199 & TST & & \\
\hline CHEMBL577784 & 954540 & 5.4268 & 5.4269 & TRN & & \\
\hline CHEMBL189584 & 954540 & 3.9813 & 3.9813 & TRN & & \\
\hline CHEMBL 2363137 & 954540 & 4.6776 & 4.6776 & TRN & & \\
\hline CHEMBL188678 & 954540 & 4.2548 & 4.2547 & TRN & & \\
\hline CHEMBL135561 & 954540 & \multicolumn{3}{|c|}{3.8110000000000004} & 3.8110000000000004 & TRN \\
\hline CHEMBL65 & 954540 & 8.0453 & 8.0453 & TRN & & \\
\hline CHEMBL1256459 & 954540 & \multicolumn{3}{|c|}{6.007000000000001} & 6.007000000000001 & TRN \\
\hline CHEMBL1516890 & 954540 & 3.9015 & 3.9014 & TRN & & \\
\hline CHEMBL3186408 & 954540 & 5.6068 & 3.9268 & TST & & \\
\hline CHEMBL222102 & 954540 & 3.384 & 3.384 & TRN & & \\
\hline CHEMBL1788116 & 954540 & 4.7637 & 4.7637 & TRN & & \\
\hline CHEMBL379300 & 954540 & 5.421 & 5.421 & TRN & & \\
\hline CHEMBL202721 & 954540 & 5.023 & 5.023 & TRN & & \\
\hline CHEMBL220241 & 954540 & 5.8906 & 5.8906 & TRN & & \\
\hline CHEMBL399530 & 954540 & 4.1605 & 4.1605 & TRN & & \\
\hline CHEMBL 258844 & 954540 & 3.9778 & 3.9778 & TRN & & \\
\hline CHEMBL509032 & 954540 & 9.2485 & 9.2485 & TRN & & \\
\hline CHEMBL393929 & 954540 & 5.1219 & 5.1219 & TRN & & \\
\hline CHEMBL9470 & 954540 & 6.0671 & 6.0622 & TST & & \\
\hline CHEMBL472940 & 954540 & 3.9181 & 3.9181 & TRN & & \\
\hline CHEMBL3349342 & 954540 & 5.6555 & 5.6555 & TRN & & \\
\hline CHEMBL373751 & 954540 & 3.7443 & 3.7443 & TRN & & \\
\hline CHEMBL1590308 & 954540 & 3.2406 & 2.8299 & TST & & \\
\hline CHEMBL1190711 & 954540 & 5.0559 & 5.0559 & TRN & & \\
\hline CHEMBL217354 & 954540 & 6.3278 & 6.3278 & TRN & & \\
\hline CHEMBL483849 & 954540 & 1.5952 & 1.0602 & TST & & \\
\hline CHEMBL191334 & 954540 & 3.3826 & 3.3826 & TRN & & \\
\hline CHEMBL1230020 & 954540 & 2.9524 & 2.9524 & TRN & & \\
\hline CHEMBL 2005886 & 954540 & \multicolumn{3}{|c|}{ 4.718999999999999 } & 4.718999999999999 & TRN \\
\hline CHEMBL585951 & 954540 & \multicolumn{3}{|c|}{6.172000000000001} & 6.1721 TRN & \\
\hline CHEMBL 213100 & 954540 & 3.6508 & 3.6508 & TRN & & \\
\hline CHEMBL512504 & 954540 & 4.5436 & 4.5436 & TRN & & \\
\hline CHEMBL1404918 & 954540 & 2.7063 & 2.7063 & TRN & & \\
\hline CHEMBL 2134202 & 954540 & 3.8582 & 3.8582 & TRN & & \\
\hline CHEMBL1970879 & 954540 & 3.6868 & 3.6867 & TRN & & \\
\hline CHEMBL 255342 & 954540 & 3.6231 & 3.6231 & TRN & & \\
\hline CHEMBL210618 & 954540 & 3.9351 & 3.9351 & TRN & & \\
\hline CHEMBL412142 & 954540 & 4.8535 & 4.8535 & TRN & & \\
\hline CHEMBL192566 & 954540 & 8.7111 & 8.8659 & TST & & \\
\hline CHEMBL300389 & 954540 & 6.4952 & 6.4952 & TRN & & \\
\hline CHEMBL483847 & 954540 & 3.6209 & 3.6209 & TRN & & \\
\hline CHEMBL102714 & 954540 & 4.6572 & 4.6572 & TRN & & \\
\hline CHEMBL1643959 & 954540 & 2.9501 & 2.9501 & TRN & & \\
\hline CHEMBL449158 & 954540 & 6.1267 & 6.5702 & TST & & \\
\hline
\end{tabular}


Supplemental Table S2.txt

\begin{tabular}{|c|c|c|c|c|}
\hline LHEMBL 392695 & 54540 & 5.6857 & 5.6857 & TRN \\
\hline HEMBL 221137 & 54540 & 4.8111 & 4.1629 & \\
\hline HEMBI 514 & 540 & 731 & 6.4731 & CRN \\
\hline HEMBL 209148 & 54540 & 2.9877 & 9877 & PN \\
\hline HEMBL1186585 & 54540 & 3.7963 & .7964 & $\mathrm{RN}$ \\
\hline HEMBL573107 & 54540 & 4.9699 & 4.9699 & \\
\hline HEMBL 240954 & 54540 & 3.1645 & 3.4668 & \\
\hline HEMBL 515416 & 54540 & 4.8645 & & RN \\
\hline HEMBL 3392440 & 954540 & 4.2987 & 4.2987 & PN \\
\hline HEMBL 92309 & 54540 & 3.5092 & 2.4804 & IST \\
\hline HEMBL180127 & 54540 & 2.6363 & 2.6363 & \\
\hline HEMBL1909414 & 40 & 3.2322 & 3.2322 & \\
\hline HEMBL 558642 & & 3.1678 & 3.1678 & \\
\hline HEMBL379975 & 40 & 5.9037 & 5.1043 & \\
\hline HEMBL 259181 & 40 & 4.587 & 316 & \\
\hline HEMBL3199475 & 954 & 4.8827 & 3.8321 & DI \\
\hline HEMBL2144069 & 40 & 4.748 & 3.4825 & 31 \\
\hline HEMBL1357247 & & 3.3049 & 3.5827 & \\
\hline HEMBL1242367 & 40 & 4.3739 & 2.85 & \\
\hline HEMBL1673039 & 10 & 33 & & TST \\
\hline HEMBL2137530 & 40 & 4.9874 & 738 & |S1 \\
\hline HEMBL173721 & 54 & 1 & 64 & ST \\
\hline HEMBL 369362 & 6 & 47 & 35 & RN \\
\hline HEMBL 367317 & 6 & 98 & 6.5696 & 「RN \\
\hline HEMBL170401 & 6 & 51 & & TRN \\
\hline HEMBL176482 & & 8 & 68 & $\mathrm{RN}$ \\
\hline HEMBL 368828 & & 59 & 25 & RN \\
\hline HEMBL 275897 & 6 & 39 & 7.8765 & RN \\
\hline HEMBL173689 & 65486 & 6.857 & & TRN \\
\hline HEMBL176741 & - & 778 & 7.6752 & TRN \\
\hline HEMBL368117 & & 05 & 532 & TST \\
\hline HEMBL172184 & 36 & 77 & 85 & TRN \\
\hline HEMBL177111 & 65486 & 49 & 83 & TRN \\
\hline HEMBL174094 & 54 & 7545 & 5553 & TRN \\
\hline HEMBL 366797 & 5486 & .0757 & 3839 & TST \\
\hline HEMBL 264 & & 861 & 81 & TRN \\
\hline HEMBL176 & 51 & 1 & 23 & TRN \\
\hline HEMBL177203 & 6 & 97 & 7.8703 & TST \\
\hline HEMBL425682 & 5486 & 7.2757 & 7.2804 & TRN \\
\hline LHEMBL 368929 & 6 & 172 & 7.5073 & TST \\
\hline CHEMBL176698 & 652 & 98 & 6.4628 & TRN \\
\hline CHEMBL367036 & 5 & .4559 & 7.4615 & TRN \\
\hline CHEMBL174607 & 65486 & 7.0706 & 7.0904 & TRN \\
\hline CHEMBL139734 & 65486 & 5.8928 & 5.8627 & TRN \\
\hline CHEMBL163638 & $G 5$ & 7.7447 & 7.4664 & TST \\
\hline CHEMBL176999 & & 7.5686 & 7.4906 & \\
\hline CHEMBL177143 & 5486 & 6.9031 & 6.9006 & \\
\hline CHEMBL368383 & 65486 & 6.8041 & 6.7944 & ГRN \\
\hline
\end{tabular}

Page 21207 


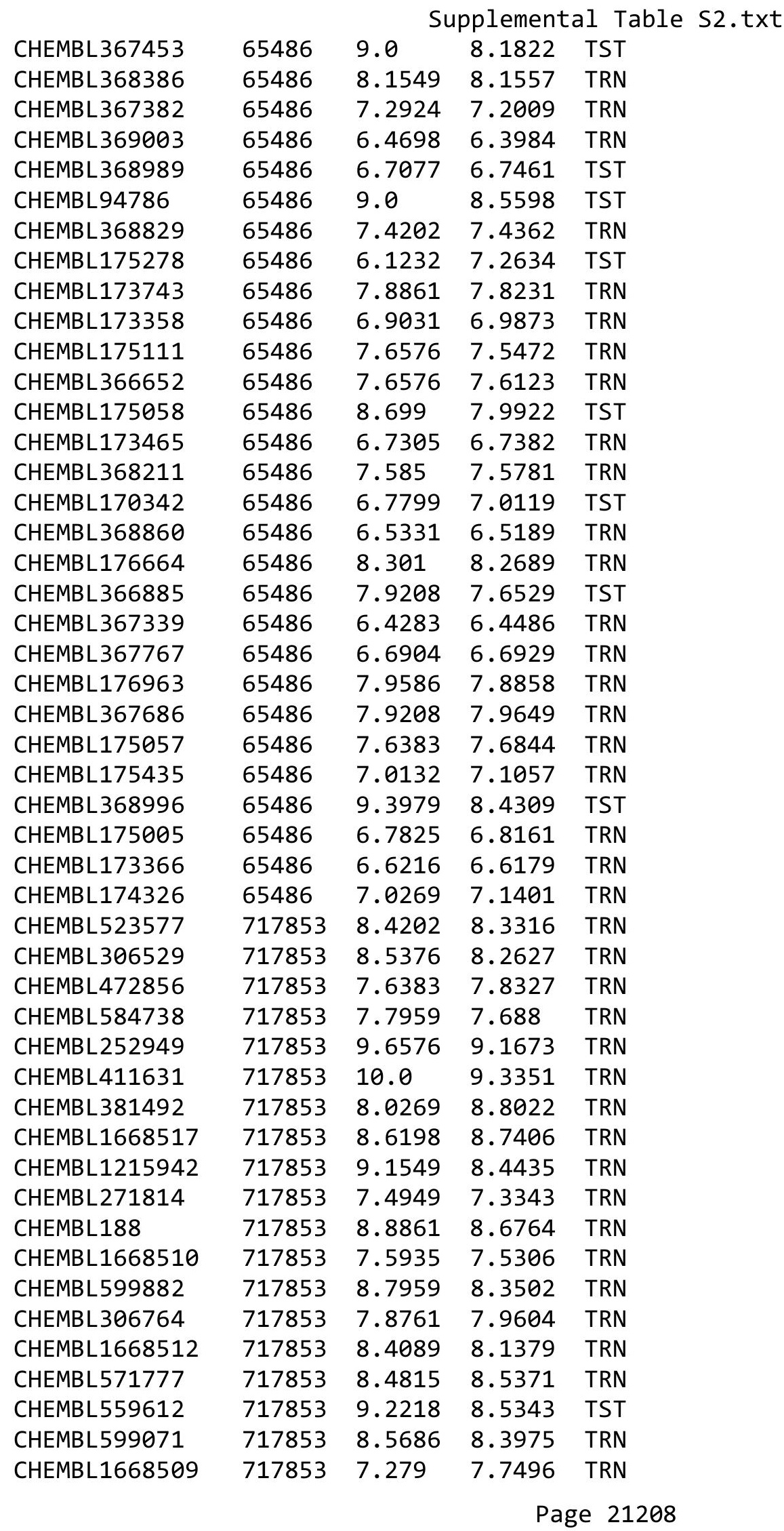




\begin{tabular}{|c|c|c|c|c|c|c|}
\hline \multirow[b]{2}{*}{ CHEMBL1668514 } & \multicolumn{6}{|c|}{ Supplemental Table S2.txt } \\
\hline & 717853 & 8.5686 & 7.5567 & TST & & \\
\hline CHEMBL262865 & 717853 & 8.3565 & 7.9574 & TRN & & \\
\hline CHEMBL258242 & 717853 & 7.4685 & 7.7566 & TRN & & \\
\hline CHEMBL1215944 & 717853 & 7.6861 & 7.8184 & TRN & & \\
\hline CHEMBL270546 & 717853 & 9.0458 & 8.94399 & 99999 & & TRN \\
\hline CHEMBL474897 & 717853 & 8.28399 & 99999999 & 99 & 8.1652 & TRN \\
\hline CHEMBL1215888 & 717853 & 8.0555 & 7.521 & TRN & & \\
\hline CHEMBL264521 & 717853 & 7.8729 & 8.1213 & TRN & & \\
\hline CHEMBL19847 & 717853 & 9.0458 & 9.048 & TRN & & \\
\hline CHEMBL593434 & 717853 & 8.0969 & 7.9203 & TST & & \\
\hline CHEMBL272203 & 717853 & 8.7696 & 8.1418 & TST & & \\
\hline CHEMBL1668513 & 717853 & 8.0458 & 7.5567 & TST & & \\
\hline CHEMBL1668521 & 717853 & 8.0969 & 8.0682 & TRN & & \\
\hline CHEMBL 303479 & 717853 & 8.2676 & 8.6574 & TRN & & \\
\hline CHEMBL495528 & 717853 & 6.3747 & 7.7912 & TST & & \\
\hline CHEMBL570690 & 717853 & 8.5086 & 8.2953 & TRN & & \\
\hline CHEMBL498297 & 717853 & 7.8447 & 7.8456 & TRN & & \\
\hline CHEMBL1215978 & 717853 & 7.3028 & 7.3534 & TRN & & \\
\hline CHEMBL1668395 & 717853 & 8.1871 & 8.6385 & TRN & & \\
\hline CHEMBL205888 & 717853 & 8.4089 & 8.6664 & TRN & & \\
\hline CHEMBL57367 & 717853 & 8.1938 & 8.7708 & TRN & & \\
\hline CHEMBL519575 & 717853 & 9.041 & 8.9809 & TST & & \\
\hline CHEMBL1215963 & 717853 & 8.0969 & 8.0217 & TRN & & \\
\hline CHEMBL1354658 & 717853 & 7.34200 & 30000000 & 005 & 7.7322 & TST \\
\hline CHEMBL1215916 & 717853 & 7.7959 & 7.9917 & TRN & & \\
\hline CHEMBL381689 & 717853 & 8.2676 & 8.4553 & TRN & & \\
\hline CHEMBL502276 & 717853 & 8.2007 & 7.9319 & TRN & & \\
\hline CHEMBL261381 & 717853 & 7.699 & 7.8995 & TST & & \\
\hline CHEMBL294013 & 717853 & 7.9281 & 8.455 & TST & & \\
\hline CHEMBL511150 & 717853 & 7.6383 & 7.7564 & TRN & & \\
\hline CHEMBL117033 & 717853 & 8.9788 & 8.9485 & TST & & \\
\hline CHEMBL408430 & 717853 & 7.9393 & 7.6975 & TRN & & \\
\hline CHEMBL474896 & 717853 & 7.6383 & 8.1831 & TRN & & \\
\hline CHEMBL1216000 & 717853 & 8.3565 & 8.2242 & TRN & & \\
\hline CHEMBL1215919 & 717853 & 8.0809 & 8.031 & TRN & & \\
\hline CHEMBL409491 & 717853 & 8.0809 & 8.4065 & TRN & & \\
\hline CHEMBL181633 & 717853 & 7.5058 & 7.3307 & TRN & & \\
\hline CHEMBL524884 & 717853 & 7.9355 & 7.9868 & TRN & & \\
\hline CHEMBL596579 & 717853 & 8.7696 & 7.8108 & TST & & \\
\hline CHEMBL271824 & 717853 & 8.8861 & 8.0637 & TST & & \\
\hline CHEMBL1215918 & 717853 & 8.3768 & 8.0603 & TRN & & \\
\hline CHEMBL1668515 & 717853 & 8.0132 & 8.5437 & TRN & & \\
\hline CHEMBL201571 & 717853 & 8.3279 & 8.2554 & TRN & & \\
\hline CHEMBL73711 & 717853 & 7.9208 & 7.4363 & TRN & & \\
\hline CHEMBL385508 & 717853 & 7.301 & 7.4855 & TRN & & \\
\hline CHEMBL 2179724 & 717853 & 7.644 & 8.3931 & TST & & \\
\hline CHEMBL1215900 & 717853 & 7.3778 & 7.4239 & TRN & & \\
\hline CHEMBL 259462 & 717853 & 8.0458 & 8.0778 & TRN & & \\
\hline
\end{tabular}




\begin{tabular}{|c|c|c|c|c|c|}
\hline \multirow[b]{2}{*}{ CHEMBL524456 } & \multicolumn{5}{|c|}{ Supplemental Table S } \\
\hline & 717853 & 8.4685 & 8.2776 & TRN & \\
\hline CHEMBL566248 & 717853 & 7.6198 & \multicolumn{2}{|c|}{7.587000000000001} & TST \\
\hline CHEMBL1668504 & 717853 & 8.4559 & 8.3269 & TRN & \\
\hline CHEMBL120669 & 717853 & 8.8861 & 8.8793 & TST & \\
\hline CHEMBL406399 & 717853 & 7.6021 & 7.892 & TRN & \\
\hline CHEMBL597438 & 717853 & 8.0088 & 8.3481 & TRN & \\
\hline CHEMBL1668505 & 717853 & 8.9208 & 8.0392 & TST & \\
\hline CHEMBL564901 & 717853 & 9.2218 & 8.4363 & TRN & \\
\hline CHEMBL1215917 & 717853 & 7.9586 & 7.8192 & TRN & \\
\hline CHEMBL1215908 & 717853 & 7.3487 & 8.1077 & TRN & \\
\hline CHEMBL 272876 & 717853 & 8.8861 & 8.689 & TRN & \\
\hline CHEMBL1668396 & 717853 & 8.5229 & 8.9889 & TRN & \\
\hline CHEMBL570907 & 717853 & 7.9586 & 8.4055 & TRN & \\
\hline CHEMBL409647 & 717853 & 7.5229 & 7.5176 & TRN & \\
\hline CHEMBL1668507 & 717853 & 8.0 & 7.9234 & TST & \\
\hline CHEMBL1215977 & 717853 & 7.2472 & 7.7495 & TRN & \\
\hline CHEMBL474692 & 717853 & 7.9586 & 8.0475 & TRN & \\
\hline CHEMBL 272882 & 717853 & 8.3372 & 8.4051 & TRN & \\
\hline CHEMBL411244 & 717853 & 9.3979 & 9.2987 & TRN & \\
\hline CHEMBL1215898 & 717853 & 7.6676 & 8.2555 & TRN & \\
\hline CHEMBL1668518 & 717853 & 8.3098 & 8.2258 & TRN & \\
\hline CHEMBL1215976 & 717853 & 7.7721 & 7.6833 & TRN & \\
\hline CHEMBL108085 & 717853 & 9.699 & 9.0762 & TST & \\
\hline CHEMBL1668520 & 717853 & 7.7959 & 8.125 & TST & \\
\hline CHEMBL1668519 & 717853 & 9.1938 & 8.1306 & TST & \\
\hline CHEMBL1215941 & 717853 & 8.6383 & 8.2492 & TRN & \\
\hline CHEMBL1215964 & 717853 & 8.1367 & 7.8064 & TRN & \\
\hline CHEMBL 216276 & 717853 & 10.3979 & 7.925 & TST & \\
\hline CHEMBL1668506 & 717853 & 8.2441 & 8.1202 & TST & \\
\hline CHEMBL271839 & 717853 & 9.699 & 9.3189 & TRN & \\
\hline CHEMBL371214 & 717853 & 8.4685 & 8.4388 & TST & \\
\hline CHEMBL 270125 & 717853 & 9.1549 & 8.9818 & TRN & \\
\hline CHEMBL1668516 & 717853 & 8.0969 & 8.0894 & TST & \\
\hline CHEMBL178372 & 717853 & 7.4449 & 7.9955 & TST & \\
\hline CHEMBL 286838 & 27577 & 5.0 & 5.0079 & TRN & \\
\hline CHEMBL33653 & 27577 & 7.3098 & 7.3384 & TRN & \\
\hline CHEMBL33491 & 27577 & 6.1549 & 6.1412 & TRN & \\
\hline CHEMBL 289903 & 27577 & 7.1871 & 7.2438 & TRN & \\
\hline CHEMBL32118 & 27577 & 5.9978 & 6.0067 & TRN & \\
\hline CHEMBL32388 & 27577 & 6.0915 & 6.0861 & TRN & \\
\hline CHEMBL 32755 & 27577 & 5.0 & 5.0134 & TRN & \\
\hline CHEMBL32098 & 27577 & 5.0 & 6.8089 & TST & \\
\hline CHEMBL32591 & 27577 & 6.2472 & 6.26399 & 9999999999 & TRN \\
\hline CHEMBL 286102 & 27577 & 5.8416 & 5.8459 & TRN & \\
\hline CHEMBL 32150 & 27577 & 6.0706 & 6.0692 & TRN & \\
\hline CHEMBL32697 & 27577 & 6.3307 & 6.3342 & TRN & \\
\hline CHEMBL408186 & 27577 & 5.0 & 4.974 & TRN & \\
\hline CHEMBL 32581 & 27577 & 5.93 & 5.9499 & TRN & \\
\hline & & & & 21210 & \\
\hline
\end{tabular}




\begin{tabular}{|c|c|c|c|c|c|c|}
\hline \multicolumn{7}{|c|}{ Supplemental Table S2.txt } \\
\hline CHEMBL32447 & 27577 & 5.0 & 4.9949 & TRN & & \\
\hline CHEMBL32311 & 27577 & 5.61799 & 99999999 & 99 & 5.6119 & TRN \\
\hline CHEMBL444787 & 27577 & 5.0 & 5.0339 & TST & & \\
\hline CHEMBL 32757 & 27577 & 5.0 & 5.0244 & TRN & & \\
\hline CHEMBL 32205 & 27577 & 5.0 & 4.1799 & TST & & \\
\hline CHEMBL 284789 & 27577 & 5.0 & 4.9774 & TRN & & \\
\hline CHEMBL32534 & 27577 & 5.6149 & 5.6682 & TRN & & \\
\hline CHEMBL 32552 & 27577 & 6.3487 & 6.3323 & TRN & & \\
\hline CHEMBL34097 & 27577 & 6.7878 & 6.7711 & TRN & & \\
\hline CHEMBL32225 & 27577 & 6.284 & 6.2997 & TRN & & \\
\hline CHEMBL33591 & 27577 & 7.1427 & 7.0518 & TRN & & \\
\hline CHEMBL32289 & 27577 & 6.699 & 6.7101 & TRN & & \\
\hline CHEMBL 32229 & 27577 & 7.2518 & 7.2471 & TRN & & \\
\hline CHEMBL 285900 & 27577 & 5.0 & 4.9978 & TRN & & \\
\hline CHEMBL34281 & 27577 & 5.0 & 5.0096 & TRN & & \\
\hline CHEMBL32507 & 27577 & 5.0 & 4.7605 & TST & & \\
\hline CHEMBL445056 & 27577 & 5.0 & 4.9831 & TRN & & \\
\hline CHEMBL 286420 & 27577 & 6.02 & 6.0341 & TRN & & \\
\hline CHEMBL431703 & 27577 & 5.0 & 4.9886 & TRN & & \\
\hline CHEMBL432273 & 27577 & 5.7632 & 5.7671 & TRN & & \\
\hline CHEMBL33695 & 27577 & 7.1024 & 7.0824 & TRN & & \\
\hline CHEMBL32952 & 27577 & 5.0 & 4.9846 & TRN & & \\
\hline CHEMBL 289002 & 27577 & 5.0 & 5.0207 & TRN & & \\
\hline CHEMBL2112067 & 27577 & 6.7747 & 6.7965 & TRN & & \\
\hline CHEMBL32814 & 27577 & 5.0 & 5.8522 & TST & & \\
\hline CHEMBL 2112066 & 27577 & 6.7423 & 6.7811 & TRN & & \\
\hline CHEMBL 284615 & 27577 & 5.0 & 5.0004 & TRN & & \\
\hline CHEMBL32770 & 27577 & 5.4912 & 5.4894 & TRN & & \\
\hline CHEMBL287529 & 27577 & 6.8239 & 6.7412 & TRN & & \\
\hline CHEMBL 286212 & 27577 & 7.0 & 7.0138 & TRN & & \\
\hline CHEMBL32802 & 27577 & 6.5229 & 6.5284 & TRN & & \\
\hline CHEMBL 32750 & 27577 & 5.0 & 5.0166 & TRN & & \\
\hline CHEMBL32288 & 27577 & 5.0 & 5.0057 & TRN & & \\
\hline CHEMBL417312 & 27577 & 5.0 & 4.9924 & TRN & & \\
\hline CHEMBL32582 & 27577 & 5.0 & 4.9861 & TRN & & \\
\hline CHEMBL555577 & 27577 & 6.2612 & 6.2385 & TRN & & \\
\hline CHEMBL433235 & 27577 & 5.0 & 5.0054 & TRN & & \\
\hline CHEMBL32425 & 27577 & 5.3486 & 5.3606 & TRN & & \\
\hline CHEMBL 32359 & 27577 & 5.0 & 4.9943 & TRN & & \\
\hline CHEMBL32751 & 27577 & 5.8661 & 5.8575 & TRN & & \\
\hline CHEMBL 260331 & 27577 & 6.699 & 6.0692 & TST & & \\
\hline CHEMBL 285151 & 27577 & 5.0 & 4.9934 & TRN & & \\
\hline CHEMBL33602 & 27577 & 6.6968 & 7.1031 & TST & & \\
\hline CHEMBL 33930 & 27577 & 5.0 & 4.9914 & TRN & & \\
\hline CHEMBL287493 & 27577 & 5.0 & 7.3375 & TST & & \\
\hline CHEMBL 290105 & 27577 & 5.7005 & 5.9753 & TST & & \\
\hline CHEMBL32281 & 27577 & 7.2596 & 5.2525 & TST & & \\
\hline CHEMBL32481 & 27577 & 6.0458 & 5.48 & TST & & \\
\hline
\end{tabular}




\begin{tabular}{|c|c|c|c|c|c|c|}
\hline \multicolumn{7}{|c|}{ Supplemental Table S2.txt } \\
\hline CHEMBL33305 & 27577 & 5.0 & 6.8835 & TST & & \\
\hline CHEMBL 2113342 & 27577 & 5.0 & 3.6996 & TST & & \\
\hline CHEMBL36352 & 27577 & 5.0 & 4.5211 & TST & & \\
\hline CHEMBL32950 & 27577 & 5.7217 & 6.0477 & TST & & \\
\hline CHEMBL32478 & 27577 & 6.1273 & 7.1857 & TST & & \\
\hline CHEMBL32598 & 27577 & 7.1871 & 6.5352 & TST & & \\
\hline CHEMBL33709 & 27577 & 6.8539 & 6.7865 & TST & & \\
\hline CHEMBL1724744 & 954312 & 2.9255 & 3.9169 & TRN & & \\
\hline CHEMBL1325945 & 954312 & 2.9264 & 2.8588 & TST & & \\
\hline CHEMBL187263 & 954312 & 4.2601 & 4.2108 & TRN & & \\
\hline CHEMBL1496329 & 954312 & 2.9261 & 3.4239 & TRN & & \\
\hline CHEMBL1863802 & 954312 & 2.9261 & 2.7233 & TST & & \\
\hline CHEMBL1543433 & 954312 & 4.0712 & 3.7793 & TRN & & \\
\hline CHEMBL1527358 & 954312 & 2.9263 & 2.9868 & TRN & & \\
\hline CHEMBL187866 & 954312 & 4.6651 & 4.6265 & TRN & & \\
\hline CHEMBL1889525 & 954312 & 2.9253 & 2.7995 & TRN & & \\
\hline CHEMBL364837 & 954312 & 2.9257 & 3.0908 & TRN & & \\
\hline CHEMBL1901922 & 954312 & 2.9259 & 2.7957 & TST & & \\
\hline CHEMBL1979662 & 954312 & 3.4035 & 3.682 & TRN & & \\
\hline CHEMBL580130 & 954312 & 2.9262 & 2.9818 & TRN & & \\
\hline CHEMBL1463647 & 954312 & 2.9265 & 2.8605 & TST & & \\
\hline CHEMBL1503864 & 954312 & 2.9264 & 2.8675 & TRN & & \\
\hline CHEMBL1362047 & 954312 & 4.5147 & 4.2294 & TRN & & \\
\hline CHEMBL2143139 & 954312 & 2.926 & 2.8908 & TRN & & \\
\hline CHEMBL1454391 & 954312 & 4.333 & 4.2981 & TRN & & \\
\hline CHEMBL1310196 & 954312 & 4.0712 & 3.4571 & TRN & & \\
\hline CHEMBL316589 & 954312 & 4.5432 & 4.0514 & TRN & & \\
\hline CHEMBL1422429 & 954312 & 4.3545 & 4.1325 & TRN & & \\
\hline CHEMBL1702547 & 954312 & 2.9252 & 2.9187 & TST & & \\
\hline CHEMBL23970 & 954312 & 4.2247 & 3.8134 & TST & & \\
\hline CHEMBL1527664 & 954312 & 2.926 & 2.8673 & TST & & \\
\hline CHEMBL1564468 & 954312 & 2.926 & 2.8927 & TST & & \\
\hline CHEMBL1724529 & 954312 & 2.9263 & 2.9178 & TRN & & \\
\hline CHEMBL1878003 & 954312 & 2.9265 & 2.9734 & TRN & & \\
\hline CHEMBL1969543 & 954312 & 4.7011 & 4.4031 & TRN & & \\
\hline CHEMBL1571122 & 954312 & 4.1912 & 3.873 & TST & & \\
\hline CHEMBL1560341 & 954312 & 4.0082 & 3.4157 & TRN & & \\
\hline CHEMBL1865566 & 954312 & 2.9263 & 2.7962 & TRN & & \\
\hline CHEMBL 3195045 & 954312 & 4.0987 & 3.2397 & TRN & & \\
\hline CHEMBL1718436 & 954312 & 2.926 & 2.9965 & TRN & & \\
\hline CHEMBL1410679 & 954312 & 2.9258 & 2.8596 & TRN & & \\
\hline CHEMBL1596605 & 954312 & 4.43199 & 99999999 & 995 & 4.5446 & TRN \\
\hline CHEMBL1971965 & 954312 & 4.1789 & 4.1409 & TRN & & \\
\hline CHEMBL3198269 & 954312 & 2.926 & 3.1966 & TRN & & \\
\hline CHEMBL1985082 & 954312 & 4.2676 & 4.119 & TRN & & \\
\hline CHEMBL3199665 & 954312 & 2.926 & 2.8352 & TRN & & \\
\hline CHEMBL 301808 & 954312 & 2.9263 & 3.0011 & TST & & \\
\hline CHEMBL1576260 & 954312 & 2.9256 & 2.8602 & TRN & & \\
\hline
\end{tabular}

Page 21212 


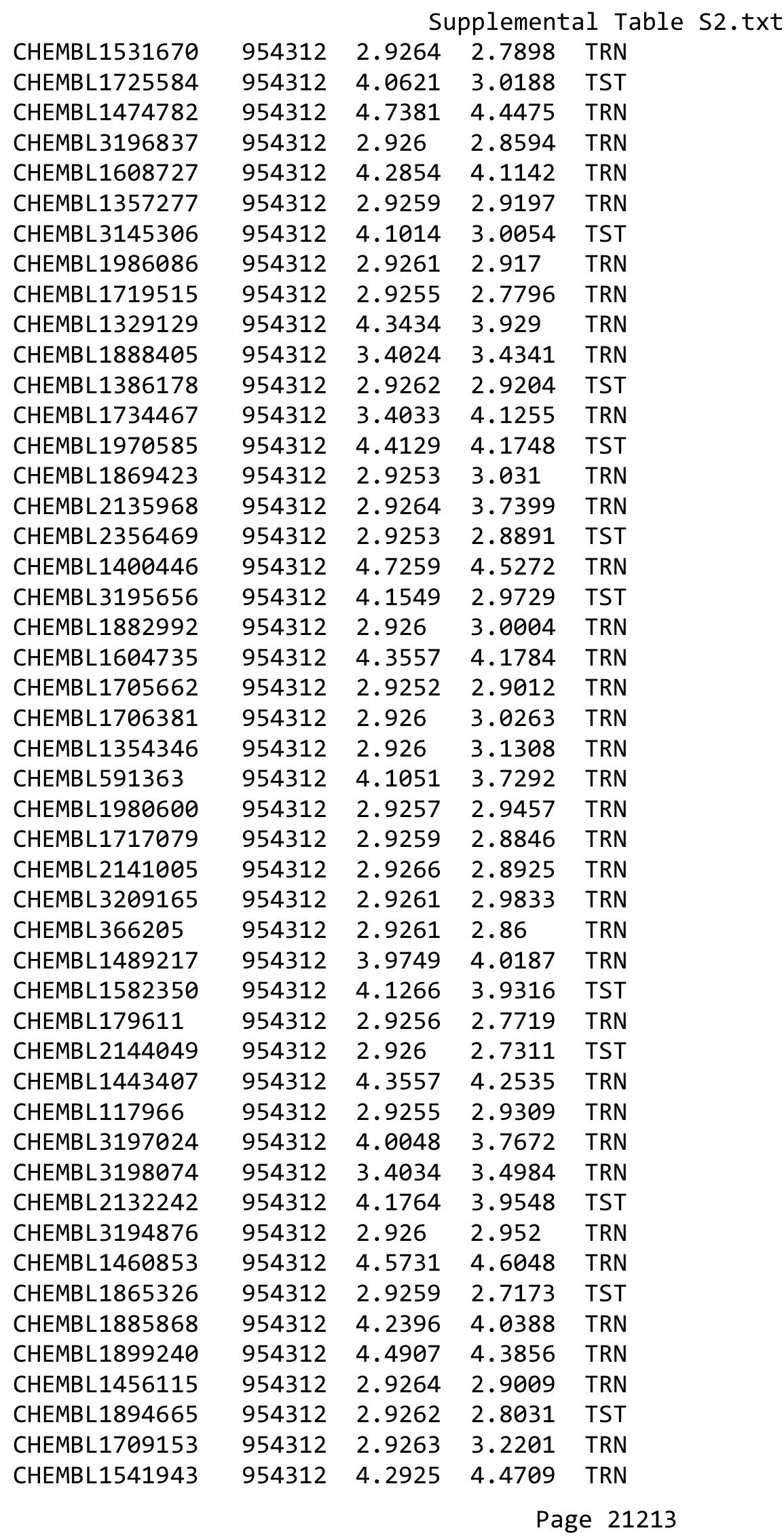


Supplemental Table S2.txt

\begin{tabular}{|c|c|c|c|c|}
\hline CHEMBL1344875 & 954312 & 2.926 & 2.8135 & TRN \\
\hline CHEMBL1427717 & 954312 & 4.8325 & 4.4545 & TRN \\
\hline CHEMBL 2143575 & 954312 & 2.9257 & 3.8474 & TRN \\
\hline CHEMBL1982308 & 954312 & 2.9261 & 2.9839 & TRN \\
\hline CHEMBL1905996 & 954312 & 3.4032 & 3.9635 & TRN \\
\hline CHEMBL1735962 & 954312 & 4.3466 & 4.3909 & TRN \\
\hline CHEMBL3145315 & 954312 & 4.1193 & 3.7924 & TST \\
\hline CHEMBL1404493 & 954312 & 4.1407 & 3.3437 & TST \\
\hline CHEMBL 3198603 & 954312 & 3.403 & 3.9383 & TRN \\
\hline CHEMBL1729277 & 954312 & 2.9265 & 2.97399 & 99999999998 \\
\hline CHEMBL 2130806 & 954312 & 3.4044 & 3.3758 & TRN \\
\hline CHEMBL2359471 & 954312 & 2.9264 & 2.8254 & TRN \\
\hline CHEMBL1509550 & 954312 & 2.926 & 3.3268 & TRN \\
\hline CHEMBL1982539 & 954312 & 2.926 & 2.9532 & TRN \\
\hline CHEMBL1348654 & 954312 & 2.9258 & 3.3691 & TRN \\
\hline CHEMBL1455137 & 954312 & 2.926 & 2.9595 & TRN \\
\hline CHEMBL1374694 & 954312 & 2.926 & 2.843 & TRN \\
\hline CHEMBL1457229 & 954312 & 4.216 & 3.8519 & TST \\
\hline CHEMBL1528479 & 954312 & 4.0849 & 3.8187 & TST \\
\hline CHEMBL1867000 & 954312 & 4.3796 & 3.9323 & TST \\
\hline CHEMBL1530766 & 954312 & 4.0335 & 4.1782 & TRN \\
\hline CHEMBL1490222 & 954312 & 2.9259 & 2.9154 & TRN \\
\hline CHEMBL586000 & 954312 & 2.9261 & 2.8776 & TST \\
\hline CHEMBL1466490 & 954312 & 4.0004 & 3.7318 & TRN \\
\hline CHEMBL572994 & 954312 & 4.3858 & 4.3478 & TST \\
\hline CHEMBL3214537 & 954312 & 3.4031 & 3.3434 & TRN \\
\hline CHEMBL1351695 & 954312 & 2.9261 & 2.8955 & TST \\
\hline CHEMBL1606613 & 688167 & 4.4977 & 4.4809 & TRN \\
\hline CHEMBL1518821 & 688167 & 3.2541 & 3.5913 & TST \\
\hline CHEMBL1326850 & 688167 & 3.2541 & 3.258 & TRN \\
\hline CHEMBL1574403 & 688167 & 3.2541 & 3.2429 & TRN \\
\hline CHEMBL1607286 & 688167 & 4.308 & 4.3113 & TRN \\
\hline CHEMBL1465899 & 688167 & 4.4868 & 4.5133 & TRN \\
\hline CHEMBL1601512 & 688167 & 3.2541 & 3.7769 & TST \\
\hline CHEMBL1462729 & 688167 & 3.2541 & 3.2503 & TRN \\
\hline CHEMBL1299470 & 688167 & 4.7916 & 4.7958 & TRN \\
\hline CHEMBL1574527 & 688167 & 3.2541 & 3.7561 & TST \\
\hline CHEMBL1518620 & 688167 & 3.2541 & 4.3455 & TST \\
\hline CHEMBL1370681 & 688167 & 4.5933 & 4.6085 & TRN \\
\hline CHEMBL1375338 & 688167 & 4.624 & 4.6391 & TRN \\
\hline CHEMBL1299252 & 688167 & 3.2541 & 3.2549 & TRN \\
\hline CHEMBL1308733 & 688167 & 3.2541 & 3.7637 & TST \\
\hline CHEMBL1545160 & 688167 & 4.5913 & 4.5742 & TRN \\
\hline CHEMBL1525358 & 688167 & 3.2541 & 3.2513 & TRN \\
\hline CHEMBL3195771 & 688167 & 3.2541 & 3.2559 & TRN \\
\hline CHEMBL1502512 & 688167 & 4.9136 & 3.2982 & TST \\
\hline CHEMBL1340469 & 688167 & 3.2541 & 3.2504 & TRN \\
\hline CHEMBL1352434 & 688167 & 5.0118 & 5.0186 & TRN \\
\hline
\end{tabular}




\begin{tabular}{|c|c|c|c|c|c|}
\hline \multicolumn{6}{|c|}{ Supplemental Table S2.txt } \\
\hline CHEMBL1374466 & 688167 & 3.2541 & 3.2535 & TRN & \\
\hline CHEMBL1314042 & 688167 & 4.5103 & 4.4971 & TRN & \\
\hline CHEMBL1539189 & 688167 & 3.2541 & 3.2668 & TRN & \\
\hline CHEMBL1487321 & 688167 & 3.2541 & 3.2581 & TRN & \\
\hline CHEMBL1541307 & 688167 & 3.2541 & 3.2522 & TRN & \\
\hline CHEMBL1304647 & 688167 & 4.6923 & 4.7028 & TRN & \\
\hline CHEMBL1578386 & 688167 & 4.6059 & 4.609 & TRN & \\
\hline CHEMBL1324820 & 688167 & 3.2541 & 3.2493 & TRN & \\
\hline CHEMBL1385084 & 688167 & 3.2541 & 3.27399 & 99999999996 & TRN \\
\hline CHEMBL1329658 & 688167 & 4.7989 & 4.8024 & TRN & \\
\hline CHEMBL1378851 & 688167 & 4.6467 & 3.6148 & TST & \\
\hline CHEMBL1354211 & 688167 & 4.5423 & 4.5498 & TRN & \\
\hline CHEMBL1444859 & 688167 & 4.4196 & 4.4214 & TRN & \\
\hline CHEMBL1516617 & 688167 & 4.8365 & 4.8474 & TRN & \\
\hline CHEMBL1371761 & 688167 & 3.2541 & 3.2632 & TRN & \\
\hline CHEMBL1328462 & 688167 & 4.5088 & 4.4936 & TRN & \\
\hline CHEMBL1447780 & 688167 & 3.2541 & 3.2532 & TRN & \\
\hline CHEMBL1424535 & 688167 & 3.2541 & 3.2704 & TRN & \\
\hline CHEMBL1492648 & 688167 & 4.6819 & 4.6565 & TRN & \\
\hline CHEMBL1389279 & 688167 & 3.7305 & 3.7081 & TRN & \\
\hline CHEMBL1382249 & 688167 & 3.2541 & 3.2424 & TRN & \\
\hline CHEMBL1492504 & 688167 & 3.2541 & 3.2513 & TRN & \\
\hline CHEMBL1479604 & 688167 & 4.4302 & 4.4284 & TRN & \\
\hline CHEMBL1986725 & 688167 & 4.6236 & 4.6119 & TRN & \\
\hline CHEMBL1335610 & 688167 & 4.4612 & 4.4527 & TRN & \\
\hline CHEMBL1444667 & 688167 & 3.2541 & 3.6666 & TST & \\
\hline CHEMBL1461002 & 688167 & 3.2541 & 3.1989 & TST & \\
\hline CHEMBL1429929 & 688167 & 4.6165 & 4.2692 & TST & \\
\hline CHEMBL1447505 & 688167 & 4.783 & 3.3033 & TST & \\
\hline CHEMBL1420733 & 688167 & 3.2541 & 3.8047 & TST & \\
\hline CHEMBL1360505 & 688167 & 4.6572 & 3.73100 & 00000000003 & TST \\
\hline CHEMBL1568022 & 688167 & 3.2541 & 4.4002 & TST & \\
\hline CHEMBL3983076 & 1528549 & 9.699 & 9.7264 & TRN & \\
\hline CHEMBL 3653751 & 1528549 & 6.3983 & 6.0731 & TRN & \\
\hline CHEMBL3952041 & 1528549 & 9.3979 & 9.3233 & TRN & \\
\hline CHEMBL 3653812 & 1528549 & 7.9318 & 8.0487 & TRN & \\
\hline CHEMBL3979515 & 1528549 & 8.8539 & 8.5586 & TRN & \\
\hline CHEMBL3933282 & 1528549 & 9.2218 & 9.1234 & TRN & \\
\hline CHEMBL 3653831 & 1528549 & 7.6757 & 7.7182 & TRN & \\
\hline CHEMBL 3653753 & 1528549 & 8.5686 & 8.4741 & TRN & \\
\hline CHEMBL3929239 & 1528549 & 8.3468 & 8.6437 & TRN & \\
\hline CHEMBL3890656 & 1528549 & 9.301 & 9.009 & TRN & \\
\hline CHEMBL3903291 & 1528549 & 9.5229 & 9.0407 & TRN & \\
\hline CHEMBL 3943363 & 1528549 & 9.5229 & 9.2549 & TRN & \\
\hline CHEMBL3986938 & 1528549 & 6.965 & 7.3591 & TST & \\
\hline CHEMBL 3653761 & 1528549 & 7.8097 & 7.8717 & TRN & \\
\hline CHEMBL3918916 & 1528549 & 8.0757 & 8.4757 & TST & \\
\hline CHEMBL3945711 & 1528549 & 9.2218 & 8.988 & TRN & \\
\hline
\end{tabular}


Supplemental Table S2.txt

\begin{tabular}{|c|c|c|c|c|c|}
\hline CHEMBL 3650444 & 1528549 & 5.9602 & 7.7154 & TST & \\
\hline CHEMBL3653802 & 1528549 & 7.3344 & 7.6008 & TRN & \\
\hline CHEMBL 3895126 & 1528549 & 9.3979 & 9.4149 & TRN & \\
\hline CHEMBL3903595 & 1528549 & 9.0458 & 8.7925 & TRN & \\
\hline CHEMBL3927755 & 1528549 & 8.1024 & 7.7489 & TRN & \\
\hline CHEMBL 3908100 & 1528549 & 9.3979 & 9.2858 & TRN & \\
\hline CHEMBL 3650443 & 1528549 & 5.9169 & 7.1949 & TST & \\
\hline CHEMBL 3653826 & 1528549 & 7.7773 & 7.5932 & TRN & \\
\hline CHEMBL 3653808 & 1528549 & 7.1993 & 7.4191 & TRN & \\
\hline CHEMBL3931938 & 1528549 & 8.699 & 8.4473 & TST & \\
\hline CHEMBL 3899838 & 1528549 & 7.4962 & 7.8017 & TRN & \\
\hline CHEMBL 3653774 & 1528549 & 8.699 & 8.5686 & TRN & \\
\hline CHEMBL3913337 & 1528549 & 8.4437 & 8.3145 & TRN & \\
\hline CHEMBL 3977793 & 1528549 & 7.7986 & 8.1225 & TRN & \\
\hline CHEMBL3653810 & 1528549 & 8.0915 & 7.576000 & 00000000005 & TRN \\
\hline CHEMBL 3924808 & 1528549 & 9.2218 & 9.2842 & TRN & \\
\hline CHEMBL3901287 & 1528549 & 9.3979 & 9.3717 & TRN & \\
\hline CHEMBL3653778 & 1528549 & 8.7959 & 8.6409 & TRN & \\
\hline CHEMBL 3894646 & 1528549 & 7.6819 & 8.2915 & TST & \\
\hline CHEMBL3965064 & 1528549 & 8.7447 & 8.6826 & TRN & \\
\hline CHEMBL3899435 & 1528549 & 7.2588 & 7.3493 & TRN & \\
\hline CHEMBL3917184 & 1528549 & 8.6021 & 9.0874 & TST & \\
\hline CHEMBL 3948903 & 1528549 & 8.6021 & 8.5525 & TRN & \\
\hline CHEMBL3955915 & 1528549 & 8.9586 & 9.1915 & TRN & \\
\hline CHEMBL 3653765 & 1528549 & 7.9281 & 7.9579 & TRN & \\
\hline CHEMBL3927268 & 1528549 & 8.2757 & 8.4343 & TRN & \\
\hline CHEMBL3911176 & 1528549 & 7.7905 & 7.355 & TST & \\
\hline CHEMBL3912378 & 1528549 & 9.0 & 8.2731 & TST & \\
\hline CHEMBL3972909 & 1528549 & 9.699 & 9.6824 & TRN & \\
\hline CHEMBL3920618 & 1528549 & 8.7212 & 8.8168 & TRN & \\
\hline CHEMBL3959932 & 1528549 & 9.0458 & 9.9424 & TRN & \\
\hline CHEMBL3911041 & 1528549 & 9.2218 & 8.9551 & TRN & \\
\hline CHEMBL3981061 & 1528549 & 10.0 & 10.3178 & TRN & \\
\hline CHEMBL 3925917 & 1528549 & 8.4685 & 8.4459 & TRN & \\
\hline CHEMBL 3653755 & 1528549 & 7.8477 & 7.7378 & TRN & \\
\hline CHEMBL3912186 & 1528549 & 9.0458 & 9.0775 & TRN & \\
\hline CHEMBL 3890763 & 1528549 & 9.699 & 8.8268 & TST & \\
\hline CHEMBL3985546 & 1528549 & 9.1549 & 9.3195 & TRN & \\
\hline CHEMBL 3986022 & 1528549 & 9.3979 & 9.5983 & TRN & \\
\hline CHEMBL 3653767 & 1528549 & 6.2983 & 7.6994 & TST & \\
\hline CHEMBL3967956 & 1528549 & 9.0458 & 8.0846 & TST & \\
\hline CHEMBL3918225 & 1528549 & 10.0 & 9.3363 & TST & \\
\hline CHEMBL 3653764 & 1528549 & 8.7696 & 8.4642 & TRN & \\
\hline CHEMBL 3653786 & 1528549 & 8.7959 & 8.6724 & TRN & \\
\hline CHEMBL3903021 & 1528549 & 10.0 & 10.252 & TRN & \\
\hline CHEMBL 3890726 & 1528549 & 10.0 & 9.8222 & TRN & \\
\hline CHEMBL3947353 & 1528549 & 8.8239 & 8.4823 & TRN & \\
\hline CHEMBL 3639526 & 1528549 & 8.3979 & 8.3309 & TRN & \\
\hline
\end{tabular}

Page 21216 
Supplemental Table S2.txt

\begin{tabular}{|c|c|c|c|c|c|}
\hline CHEMBL 3653782 & 1528549 & 8.6576 & 8.1907 & TST & \\
\hline CHEMBL 3922954 & 1528549 & 8.5086 & 8.5841 & TRN & \\
\hline CHEMBL3916801 & 1528549 & 9.5229 & 9.4307 & TRN & \\
\hline CHEMBL3653792 & 1528549 & 8.6198 & 8.2933 & TST & \\
\hline CHEMBL 3906735 & 1528549 & 7.5622 & 7.8749 & TRN & \\
\hline CHEMBL 3929498 & 1528549 & 8.7959 & 8.7443 & TRN & \\
\hline CHEMBL 3653773 & 1528549 & 8.7959 & 8.7932 & TRN & \\
\hline CHEMBL3926175 & 1528549 & 8.2218 & 7.8597 & TST & \\
\hline CHEMBL 3653772 & 1528549 & 9.0 & 8.6346 & TRN & \\
\hline CHEMBL 3653838 & 1528549 & 7.104 & 7.0466 & TRN & \\
\hline CHEMBL 3947013 & 1528549 & 7.9101 & \multicolumn{2}{|c|}{7.9670000000000005} & TST \\
\hline CHEMBL 3653825 & 1528549 & 7.1543 & 7.8396 & TRN & \\
\hline CHEMBL 3653752 & 1528549 & 6.3979 & 7.735 & TST & \\
\hline CHEMBL3914518 & 1528549 & 7.5072 & 7.8868 & TST & \\
\hline CHEMBL 3948667 & 1528549 & 8.9208 & 8.9591 & TRN & \\
\hline CHEMBL 3653845 & 1528549 & 8.8239 & 9.0451 & TRN & \\
\hline CHEMBL 3927754 & 1528549 & 8.8539 & 9.1766 & TRN & \\
\hline CHEMBL 3975072 & 1528549 & 8.585 & 8.5865 & TRN & \\
\hline CHEMBL3653841 & 1528549 & 9.301 & 9.1937 & TRN & \\
\hline CHEMBL 3653780 & 1528549 & 8.1135 & 8.1904 & TST & \\
\hline CHEMBL 3653785 & 1528549 & 7.6517 & 7.5233 & TRN & \\
\hline CHEMBL 3653836 & 1528549 & 8.6021 & 8.4233 & TRN & \\
\hline CHEMBL3978136 & 1528549 & 8.6021 & 8.1258 & TRN & \\
\hline CHEMBL 3653757 & 1528549 & 6.3887 & 7.6749 & TST & \\
\hline CHEMBL 3653799 & 1528549 & 7.0996 & 7.4191 & TRN & \\
\hline CHEMBL3924338 & 1528549 & 9.5229 & 8.8132 & TRN & \\
\hline CHEMBL 3910090 & 1528549 & 7.3325 & 7.9024 & TRN & \\
\hline CHEMBL 3653820 & 1528549 & 6.9792 & 7.1495 & TRN & \\
\hline CHEMBL3961865 & 1528549 & 8.3098 & 8.6444 & TRN & \\
\hline CHEMBL 3918833 & 1528549 & 9.699 & 9.172 & TRN & \\
\hline CHEMBL 3653790 & 1528549 & 9.3979 & 7.7008 & TST & \\
\hline CHEMBL 3653807 & 1528549 & 5.5796 & 6.2867 & TRN & \\
\hline CHEMBL 3653787 & 1528549 & 7.4078 & 7.3806 & TRN & \\
\hline CHEMBL3983268 & 1528549 & 9.5229 & 9.5602 & TRN & \\
\hline CHEMBL 3894422 & 1528549 & 9.5229 & 9.8021 & TRN & \\
\hline CHEMBL 3653754 & 1528549 & 9.2218 & 7.9813 & TST & \\
\hline CHEMBL3951965 & 1528549 & 9.0 & 8.8098 & TRN & \\
\hline CHEMBL 3901381 & 1528549 & 9.699 & 10.2144 & TRN & \\
\hline CHEMBL 3972880 & 1528549 & 9.699 & 9.4076 & TRN & \\
\hline CHEMBL 3653803 & 1528549 & \multicolumn{3}{|c|}{7.821000000000001} & TST \\
\hline CHEMBL3975660 & 1528549 & 8.7696 & 8.9186 & TRN & \\
\hline CHEMBL 3653824 & 1528549 & 7.4647 & 7.9749 & TST & \\
\hline CHEMBL 3928941 & 1528549 & 8.8861 & 9.0545 & TRN & \\
\hline CHEMBL 3653798 & 1528549 & 7.4498 & 8.0225 & TST & \\
\hline CHEMBL3653805 & 1528549 & 9.0 & 8.8226 & TST & \\
\hline CHEMBL3916817 & 1528549 & 8.2676 & 8.597999 & 9999999999 & $\mathrm{IKI}$ \\
\hline CHEMBL3921140 & 1528549 & 9.5229 & 9.3298 & TRN & \\
\hline CHEMBL 3653788 & 1528549 & 7.1898 & 7.7544 & TST & \\
\hline
\end{tabular}


Supplemental Table S2.txt

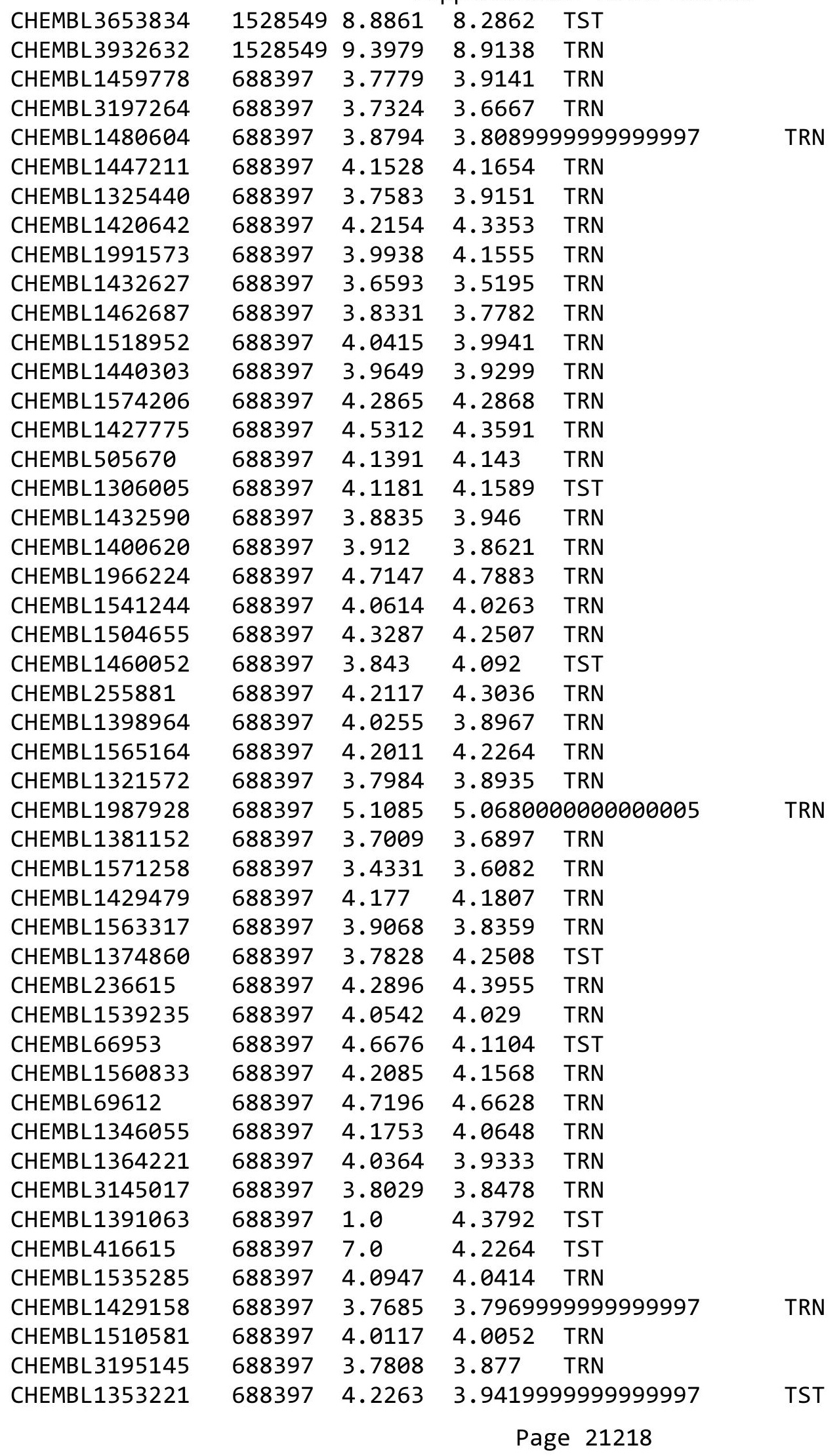




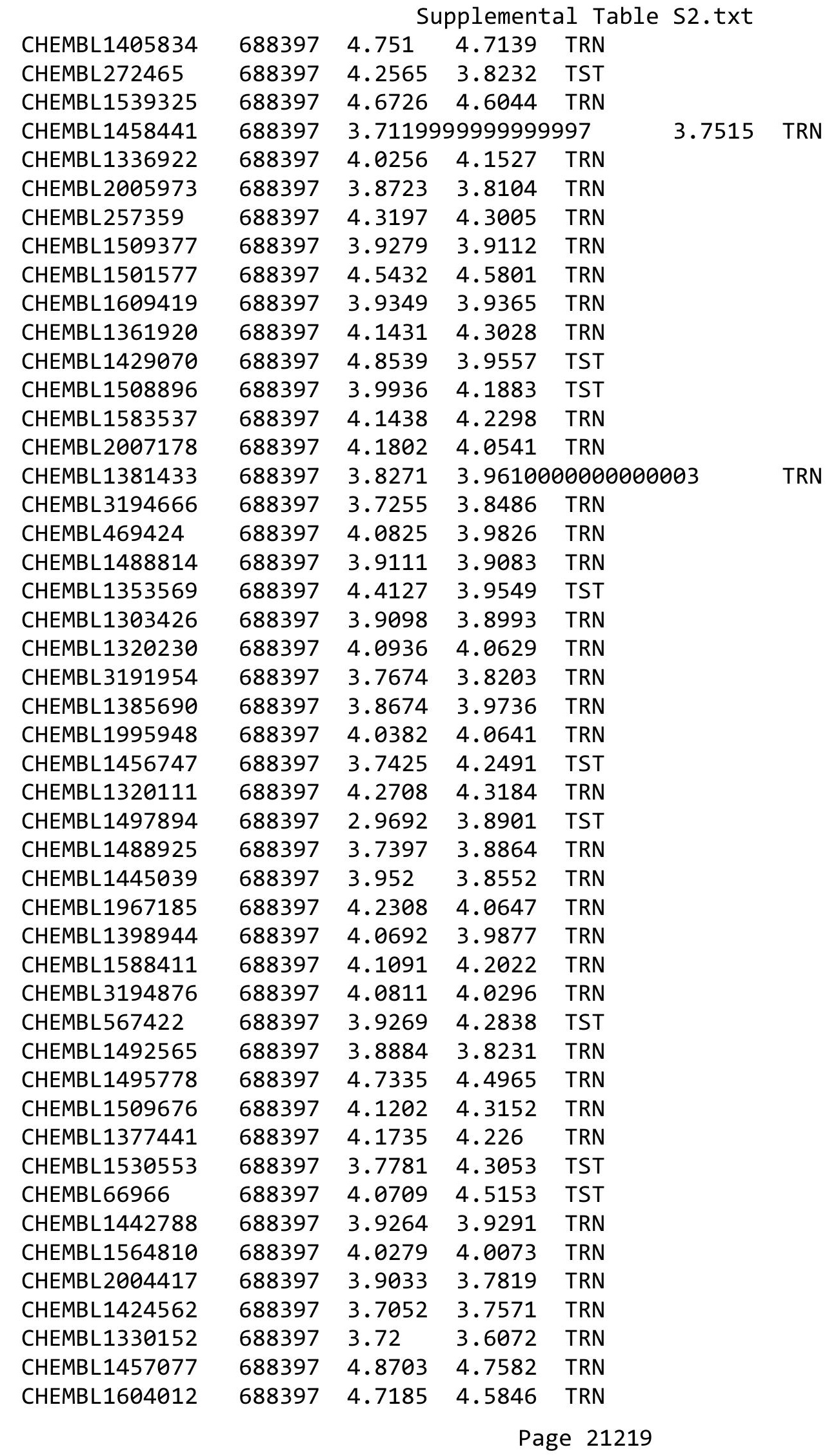


Supplemental Table S2.txt

\begin{tabular}{|c|c|c|c|c|}
\hline CHEMBL1327783 & 688397 & 3.7422 & 3.7235 & TRN \\
\hline CHEMBL1530127 & 688397 & 4.2288 & 4.2458 & TRN \\
\hline CHEMBL1409883 & 688397 & 3.9877 & 3.9096 & TRN \\
\hline CHEMBL1393131 & 688397 & 4.0869 & 4.2158 & TRN \\
\hline CHEMBL1381264 & 688397 & 4.3063 & 4.5135 & TRN \\
\hline CHEMBL1546656 & 688397 & 4.0654 & 4.0009 & TRN \\
\hline CHEMBL1571824 & 688397 & 3.9431 & 4.0975 & TST \\
\hline CHEMBL1416439 & 688397 & 4.3047 & \multicolumn{2}{|c|}{ 4.2989999999999995 } \\
\hline CHEMBL1567396 & 688397 & 3.9603 & 4.09 & TST \\
\hline CHEMBL1388689 & 688397 & 5.7471 & 5.7136 & TRN \\
\hline CHEMBL1371132 & 688397 & 3.6755 & 3.679 & TRN \\
\hline CHEMBL3197798 & 688397 & 3.8644 & 3.872 & TRN \\
\hline CHEMBL212414 & 688397 & 3.989 & 4.1388 & TRN \\
\hline CHEMBL1393256 & 688397 & 3.9077 & 4.147 & TST \\
\hline CHEMBL1456386 & 688397 & 3.8171 & 3.9987 & TST \\
\hline CHEMBL2001396 & 688397 & 4.467 & 4.3562 & TRN \\
\hline CHEMBL1452185 & 688397 & 3.9206 & 4.0085 & TST \\
\hline CHEMBL1981657 & 688397 & 4.5465 & 4.3601 & TST \\
\hline CHEMBL1532491 & 688397 & 3.9311 & 3.9171 & TST \\
\hline CHEMBL1492995 & 688397 & 4.0048 & 3.8543 & TST \\
\hline CHEMBL1304345 & 688397 & 4.4178 & 3.7328 & TST \\
\hline CHEMBL81935 & 688397 & 3.9123 & 4.2036 & TST \\
\hline CHEMBL1492926 & 688397 & 4.0265 & 3.8948 & TST \\
\hline CHEMBL3193405 & 688397 & 3.8635 & 3.5889 & TST \\
\hline CHEMBL 3192541 & 688397 & 4.1649 & 4.371 & TST \\
\hline CHEMBL1571704 & 688397 & 3.8146 & 4.2522 & TST \\
\hline CHEMBL3186408 & 955074 & 3.6042 & 4.4894 & TST \\
\hline CHEMBL 210618 & 955074 & 2.9684 & 2.9684 & TRN \\
\hline CHEMBL1186585 & 955074 & 5.0443 & 5.044 & TRN \\
\hline CHEMBL259181 & 955074 & 3.7512 & 3.7509 & TRN \\
\hline CHEMBL65 & 955074 & 7.3563 & 7.3563 & TRN \\
\hline CHEMBL135561 & 955074 & 4.3272 & 4.3269 & TRN \\
\hline CHEMBL1516890 & 955074 & 3.7963 & 3.7961 & TRN \\
\hline CHEMBL1590308 & 955074 & 3.2895 & 3.8132 & TST \\
\hline CHEMBL472940 & 955074 & 2.6763 & 2.6757 & TRN \\
\hline CHEMBL220241 & 955074 & 4.7808 & 4.7808 & TRN \\
\hline CHEMBL202721 & 955074 & 4.415 & 4.4151 & TRN \\
\hline CHEMBL221137 & 955074 & 5.0845 & 5.0847 & TRN \\
\hline CHEMBL258844 & 955074 & 4.7486 & 4.7486 & TRN \\
\hline CHEMBL1230020 & 955074 & 3.3888 & 3.3886 & TRN \\
\hline CHEMBL1909414 & 955074 & 3.5005 & 3.5 & TRN \\
\hline CHEMBL3199475 & 955074 & 3.7437 & 3.7437 & TRN \\
\hline CHEMBL1788116 & 955074 & 4.0023 & 4.0028 & TRN \\
\hline CHEMBL373751 & 955074 & 3.4864 & 3.4863 & TRN \\
\hline CHEMBL217354 & 955074 & 6.865 & 6.8648 & TRN \\
\hline CHEMBL3349342 & 955074 & 3.9178 & 3.9178 & TRN \\
\hline CHEMBL102714 & 955074 & 4.0279 & 4.0283 & TRN \\
\hline CHEMBL 2363137 & 955074 & 4.9548 & 4.9546 & TRN \\
\hline
\end{tabular}

Page 21220 


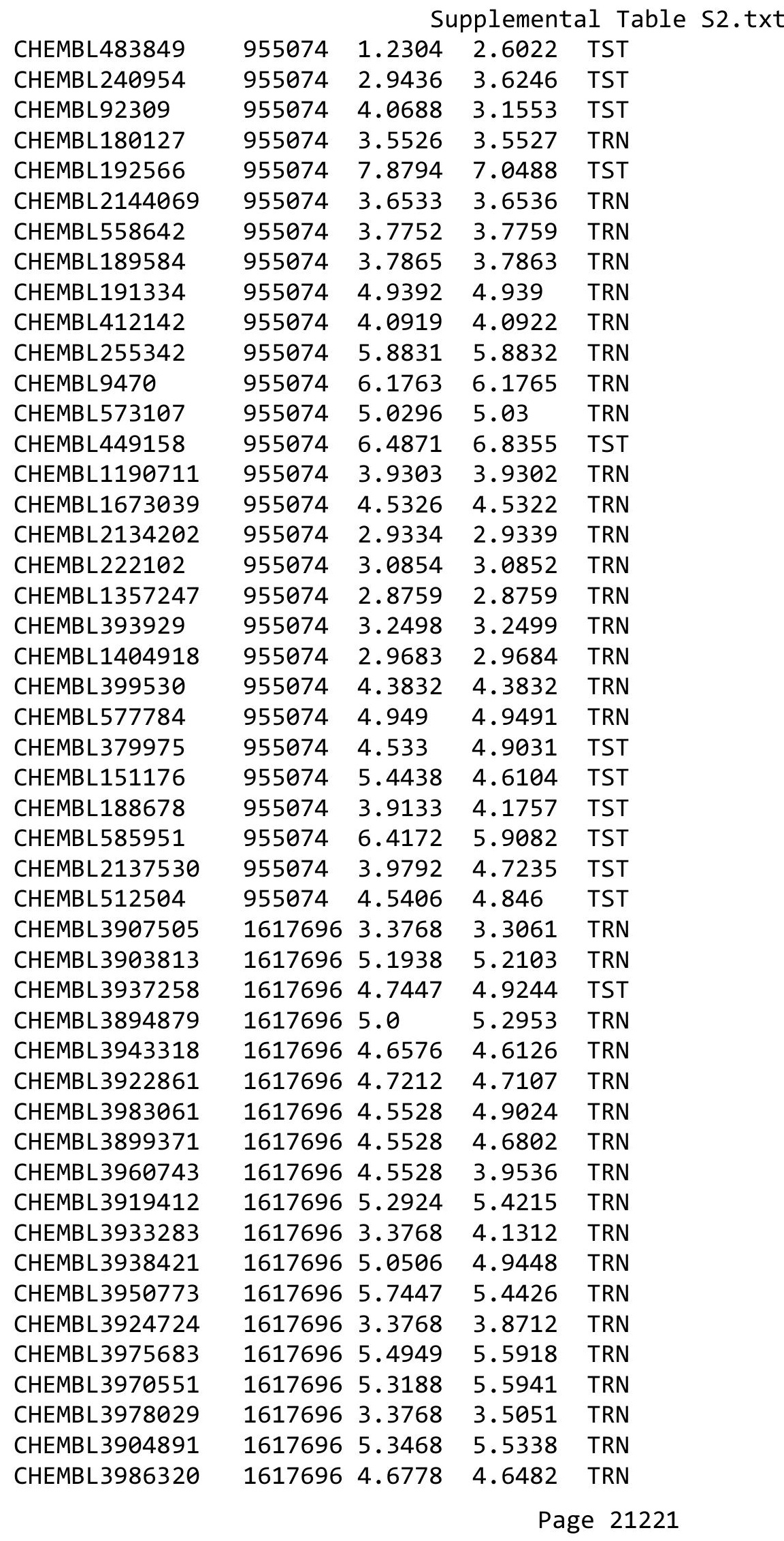


Supplemental Table S2.txt

\begin{tabular}{|c|c|c|c|c|}
\hline CHEMBL 3924343 & 1617696 & 3.3768 & 3.5328 & TRN \\
\hline CHEMBL 3952406 & 1617696 & 5.4318 & 4.603 & TST \\
\hline CHEMBL 3980253 & 1617696 & 3.3768 & 3.5989 & TRN \\
\hline CHEMBL 3942054 & 1617696 & 5.0969 & 5.1593 & TRN \\
\hline CHEMBL 3890411 & 1617696 & 5.3098 & 5.4395 & TRN \\
\hline CHEMBL 3908434 & 1617696 & 5.3872 & 5.5595 & TRN \\
\hline CHEMBL 3115908 & 1617696 & 5.5086 & 5.3336 & TST \\
\hline CHEMBL 3928317 & 1617696 & 4.9586 & 4.4976 & TRN \\
\hline CHEMBL 3979736 & 1617696 & 5.6198 & 5.4159 & TRN \\
\hline CHEMBL 3947198 & 1617696 & 5.4815 & 5.4043 & TRN \\
\hline CHEMBL 3983712 & 1617696 & 5.2291 & 5.3427 & TRN \\
\hline CHEMBL 3952045 & 1617696 & 4.6383 & 4.3375 & TRN \\
\hline CHEMBL 3951335 & 1617696 & 4.6021 & 4.29 & TRN \\
\hline CHEMBL 3955935 & 1617696 & 4.8239 & 4.5854 & TRN \\
\hline CHEMBL 3906378 & 1617696 & 4.7959 & 4.8435 & TRN \\
\hline CHEMBL3919336 & 1617696 & 4.8861 & 4.8097 & TST \\
\hline CHEMBL 3967047 & 1617696 & 3.3768 & 3.6417 & TRN \\
\hline CHEMBL 3912547 & 1617696 & 3.3768 & 2.9986 & TRN \\
\hline CHEMBL 3894125 & 1617696 & 3.3768 & 4.5446 & TST \\
\hline CHEMBL 3953543 & 1617696 & 3.3768 & 4.6263 & TST \\
\hline CHEMBL 3978830 & 1617696 & 5.5686 & 5.1537 & TRN \\
\hline CHEMBL 3915348 & 1617696 & 4.6383 & 4.3595 & TRN \\
\hline CHEMBL 3934460 & 1617696 & 5.6778 & 5.2436 & TRN \\
\hline CHEMBL 3040216 & 1617696 & 6.9208 & 3.1392 & TST \\
\hline CHEMBL 3947125 & 1617696 & 3.3768 & 3.616 & TRN \\
\hline CHEMBL 3910488 & 1617696 & 5.301 & 4.5367 & TST \\
\hline CHEMBL 3954893 & 1617696 & 5.4815 & 4.5176 & TST \\
\hline CHEMBL 3966262 & 1617696 & 4.8239 & 4.7296 & TST \\
\hline CHEMBL 3913878 & 1617696 & 5.3665 & 5.2166 & TST \\
\hline CHEMBL 3975456 & 1617696 & 4.7696 & 4.5945 & TST \\
\hline CHEMBL 3934352 & 1617696 & 4.4089 & 4.7591 & TST \\
\hline CHEMBL85692 & 36483 & 7.7212 & 7.6566 & TRN \\
\hline CHEMBL 86292 & 36483 & 4.4559 & 5.676 & TRN \\
\hline CHEMBL82799 & 36483 & 6.4089 & 5.7811 & TRN \\
\hline CHEMBL 82445 & 36483 & 6.3872 & 7.3691 & TST \\
\hline CHEMBL313715 & 36483 & 7.699 & 7.6002 & TRN \\
\hline CHEMBL 86120 & 36483 & 6.5686 & 6.5119 & TST \\
\hline CHEMBL 88017 & 36483 & 6.8239 & 6.4127 & TRN \\
\hline CHEMBL84995 & 36483 & 4.0 & 4.5461 & TRN \\
\hline CHEMBL 85028 & 36483 & 5.3098 & 5.5598 & TRN \\
\hline CHEMBL84111 & 36483 & 5.5376 & 5.4245 & TRN \\
\hline CHEMBL87315 & 36483 & 7.0458 & 7.0604 & TRN \\
\hline CHEMBL312950 & 36483 & 6.5229 & 7.0956 & TST \\
\hline CHEMBL315724 & 36483 & 6.585 & 6.751 & TRN \\
\hline CHEMBL315711 & 36483 & 6.1549 & \multicolumn{2}{|c|}{6.627000000000001} \\
\hline CHEMBL82791 & 36483 & 6.1805 & 6.7051 & TRN \\
\hline CHEMBL446095 & 36483 & 6.6198 & 6.279 & TRN \\
\hline CHEMBL83409 & 36483 & 6.6021 & 6.2868 & TRN \\
\hline
\end{tabular}




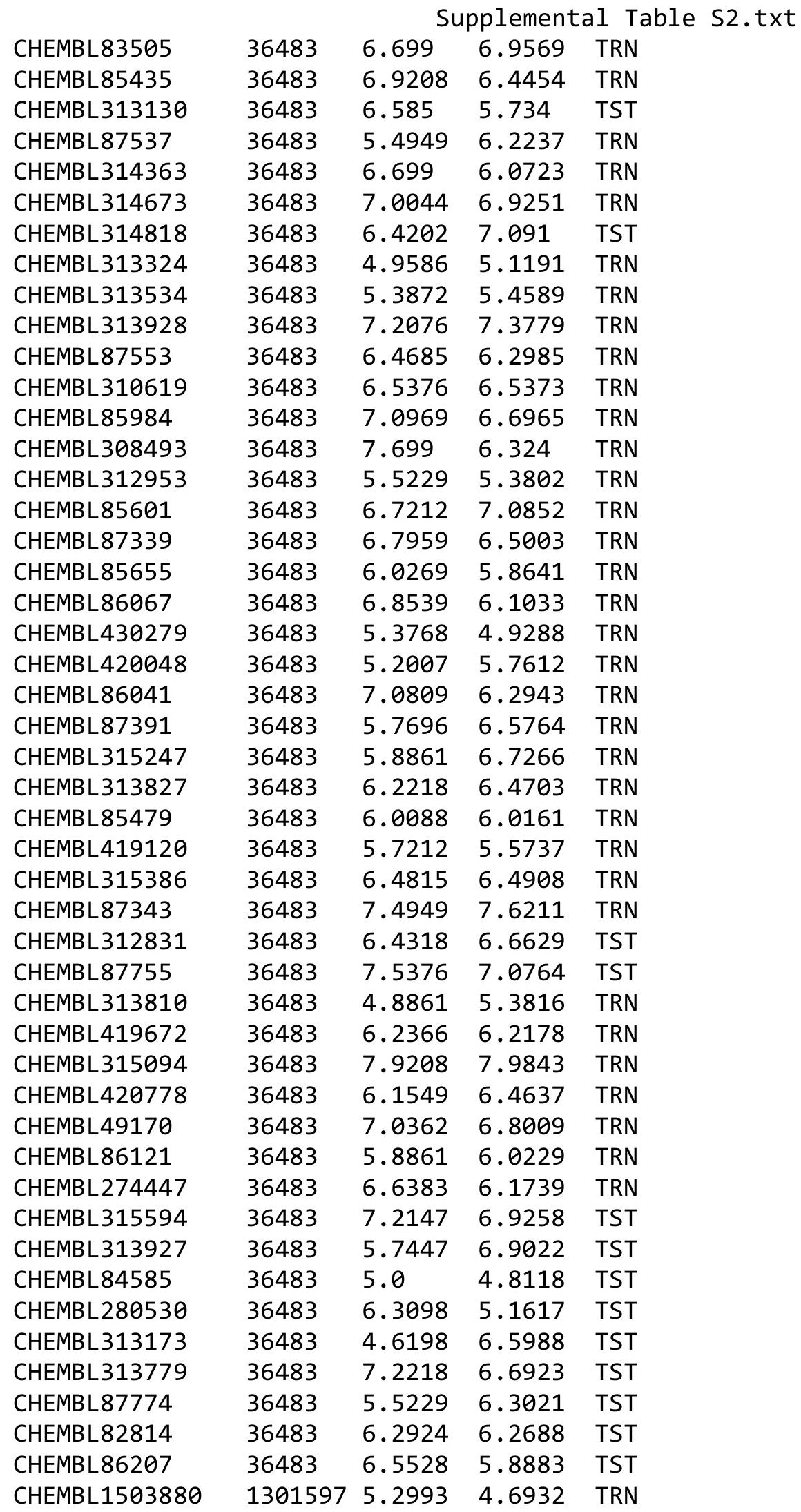

Page 21223 
Supplemental Table S2.txt

\begin{tabular}{|c|c|c|c|c|c|}
\hline CHEMBL1980658 & 1301597 & 4.8645 & 4.6891 & TRN & \\
\hline CHEMBL1728743 & 1301597 & 4.8851 & 4.6764 & TRN & \\
\hline CHEMBL1478996 & 1301597 & 4.585 & 4.3917 & TRN & \\
\hline CHEMBL1468577 & 1301597 & 4.833 & 4.7124 & TRN & \\
\hline CHEMBL1449317 & 1301597 & 4.585 & 4.4098 & TRN & \\
\hline CHEMBL1596072 & 1301597 & 4.585 & 4.3716 & TRN & \\
\hline CHEMBL1508433 & 1301597 & 4.585 & 4.5477 & TRN & \\
\hline CHEMBL1355823 & 1301597 & 4.9041 & 4.7279 & TRN & \\
\hline CHEMBL1421117 & 1301597 & 4.585 & 4.1991 & TRN & \\
\hline CHEMBL1446545 & 1301597 & 4.585 & 4.9114 & TRN & \\
\hline CHEMBL1330958 & 1301597 & 3.284 & 3.9687 & TRN & \\
\hline CHEMBL3191962 & 1301597 & 5.0453 & 4.6245 & TRN & \\
\hline CHEMBL1429902 & 1301597 & 4.585 & 4.6254 & TST & \\
\hline CHEMBL1398450 & 1301597 & 4.3726 & 4.6481 & TRN & \\
\hline CHEMBL1582569 & 1301597 & 4.585 & 4.4001 & TRN & \\
\hline CHEMBL1487582 & 1301597 & 4.48 & 4.5704 & TRN & \\
\hline CHEMBL1585105 & 1301597 & 4.585 & 4.1243 & TRN & \\
\hline CHEMBL1613325 & 1301597 & 4.585 & 4.5073 & TRN & \\
\hline CHEMBL1613483 & 1301597 & 4.585 & 4.86600 & 00000000005 & TRN \\
\hline CHEMBL1423466 & 1301597 & 3.284 & 3.5355 & TRN & \\
\hline CHEMBL1362013 & 1301597 & 4.585 & 4.7937 & TRN & \\
\hline CHEMBL1318793 & 1301597 & 4.585 & 4.5873 & TRN & \\
\hline CHEMBL1531686 & 1301597 & 4.585 & 4.5103 & TST & \\
\hline CHEMBL1327169 & 1301597 & 4.585 & 4.4897 & TRN & \\
\hline CHEMBL1409525 & 1301597 & 4.585 & 4.6068 & TST & \\
\hline CHEMBL3191951 & 1301597 & 4.585 & 4.5857 & TRN & \\
\hline CHEMBL1464042 & 1301597 & 4.6312 & 4.7374 & TRN & \\
\hline CHEMBL3198216 & 1301597 & 4.5974 & 4.6828 & TRN & \\
\hline CHEMBL1527175 & 1301597 & 4.585 & 4.4054 & TRN & \\
\hline CHEMBL1558102 & 1301597 & 4.9208 & 4.6898 & TRN & \\
\hline CHEMBL1493724 & 1301597 & 4.585 & 4.4233 & TRN & \\
\hline CHEMBL1537141 & 1301597 & 4.585 & 4.3976 & TRN & \\
\hline CHEMBL1500193 & 1301597 & 4.585 & 4.4009 & TRN & \\
\hline CHEMBL1438758 & 1301597 & 4.585 & 4.2681 & TRN & \\
\hline CHEMBL1499328 & 1301597 & 4.9208 & 4.8546 & TRN & \\
\hline CHEMBL1491932 & 1301597 & 4.585 & 4.9327 & TRN & \\
\hline CHEMBL578061 & 1301597 & 4.585 & 4.4257 & TRN & \\
\hline CHEMBL1573586 & 1301597 & 4.6503 & 4.7084 & TST & \\
\hline CHEMBL1381322 & 1301597 & 4.585 & 4.5011 & TRN & \\
\hline CHEMBL1732782 & 1301597 & 4.5952 & 4.7194 & TRN & \\
\hline CHEMBL1968085 & 1301597 & 4.6912 & 4.7056 & TRN & \\
\hline CHEMBL1987820 & 1301597 & 4.585 & 4.6968 & TRN & \\
\hline CHEMBL1346297 & 1301597 & 4.287 & 4.35 & TRN & \\
\hline CHEMBL1530137 & 1301597 & 3.284 & 5.1496 & TST & \\
\hline CHEMBL591178 & 1301597 & 4.585 & 4.5199 & TRN & \\
\hline CHEMBL1513156 & 1301597 & 4.71399 & 99999999 & 4.4821 & TRN \\
\hline CHEMBL1545709 & 1301597 & 4.585 & 4.5781 & TRN & \\
\hline CHEMBL1601509 & 1301597 & 4.585 & 4.5955 & TRN & \\
\hline
\end{tabular}


Supplemental Table S2.txt

\begin{tabular}{|c|c|c|c|c|}
\hline HEMB & 301597 & & 6516 & TP \\
\hline UГMDI 151006 & 301597 & & & \\
\hline$A E N$ & & & & \\
\hline HEMBL189738 & 597 & 585 & 7051 & \\
\hline AEMBL1516913 & 301597 & 284 & 9156 & \\
\hline HEMBL1587263 & 301597 & 4.585 & 0471 & \\
\hline HEMBL1330307 & 597 & 4.66 & 009 & \\
\hline IEMBL1341995 & 597 & 85 & & \\
\hline AEMBL1304647 & 597 & 4.9555 & 7359 & \\
\hline HEMBL1464624 & 301597 & 4.585 & 2134 & \\
\hline HEMBL1718182 & 301597 & 4.585 & 9802 & \\
\hline AEMBL153 & 97 & 251 & 3026 & \\
\hline AEMBL1398132 & & 585 & & RN \\
\hline HEMBL1506264 & 597 & 4.585 & 5516 & \\
\hline AEMBL1706436 & 97 & & & \\
\hline AEMBL1391048 & 97 & 105 & 5279 & DI \\
\hline HEMBL156 & 97 & 223 & 432 & (n) \\
\hline HEMBL 142 & 97 & & 28 & \\
\hline HEMBL1557898 & 97 & 208 & 4.2974 & \\
\hline AEMBL1571574 & 97 & 862 & & \\
\hline HEMBL15 & 1 & & 1 & MIN \\
\hline HEMBL56 & 7 & 233 & 79 & RN \\
\hline HEMBL 15 & 97 & 918 & 35 & \\
\hline HEMBL405072 & 597 & 4.757 & 108 & \\
\hline AEMBL2132853 & & 85 & & I RIN \\
\hline HEMBL1440440 & 1 & 85 & 34 & RN \\
\hline AEMBL15 & 1 & & 526 & RN \\
\hline HEMBL 13 & 97 & 85 & 88 & \\
\hline HEMBL1406081 & & 85 & 2514 & I \\
\hline HEMBL1486877 & & 85 & & IK \\
\hline HEMBL1426390 & 97 & & 813 & RN \\
\hline HEMBL1: & 1 & 85 & 23 & RN \\
\hline AEMBL1 & 97 & & 334 & $\mathrm{RN}$ \\
\hline HEMBL1607591 & & 4.7587 & 597 & IRN \\
\hline HEMBL1429443 & 97 & 4.585 & - & 「RN \\
\hline HEMBL1361273 & 97 & 85 & 894 & RN \\
\hline HEMRI $1=$ & 97 & 19 & 94 & $\Gamma \mathrm{RN}$ \\
\hline HEMBL19 & & & & ST \\
\hline HEMBL1434611 & 597 & 4.585 & 8018 & TRN \\
\hline JEMBL1400505 & 97 & & 2976 & TST \\
\hline HEMBL1304389 & 97 & 85 & 4682 & DM \\
\hline CHEMBL286593 & & 6.2596 & & TRN \\
\hline HEMBL1394787 & 597 & 3.284 & 4.2076 & TRN \\
\hline AEMBL1367944 & 597 & 4.8306 & 7704 & TST \\
\hline MBL17 & 97 & & 2363 & IS \\
\hline HEMBL1567827 & 597 & .8465 & .8202 & \\
\hline CHEMBL3189671 & 597 & 4.654 & 4.6357 & SI \\
\hline HEMBL1389833 & 1301597 & 3.284 & 3.5132 & $\Gamma \mathrm{R}$ \\
\hline
\end{tabular}

Page 21225 
Supplemental Table S2.txt

\begin{tabular}{|c|c|c|c|c|}
\hline HEMBL15 & 301597 & & & - \\
\hline & 301597 & 4.585 & & \\
\hline 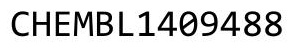 & & & & \\
\hline HEMBL31974 & & 284 & 99 & \\
\hline HEMBL1569333 & 301597 & 1694 & 3066 & \\
\hline HEMBL3199665 & 301597 & 5.2388 & 1657 & \\
\hline HEMBL13 & 97 & 4.585 & 472 & \\
\hline IEMBL13e & 597 & 85 & 5318 & RN \\
\hline AEMBL1405742 & 597 & 4.585 & 5485 & \\
\hline HEMBL1328408 & 301597 & 4.585 & 7238 & \\
\hline AEMBL1550704 & 597 & 4.585 & 1726 & \\
\hline IEMBL14 & 97 & 85 & 138 & \\
\hline AEMBL16 & & 85 & 3705 & \\
\hline HEMBL1354361 & 997 & 4.585 & 3025 & \\
\hline AEMBL587 & 97 & 657 & 1964 & \\
\hline AEMBL1605726 & 97 & 3.284 & 8618 & \\
\hline HEMBL1C & 97 & 208 & 693 & KIV \\
\hline HEMBL15 & 97 & & 468 & \\
\hline HEMBL13€ & 97 & 5.2034 & 1005 & \\
\hline AEMBL14 & 97 & 3 . & 9772 & \\
\hline AEMBL14 & 1 & 3 . & 357 & II \\
\hline AEMBL15 & 1 & 4 & 636 & RI \\
\hline HEMBL13 & 97 & 4. & 184 & \\
\hline HEMBL17 & & 85 & 7598 & \\
\hline HEMBL132 & & & & I RIV \\
\hline HEMBL1C & 1 & & .004 & RN \\
\hline HEMBL1S & 7 & & 356 & וד וכ \\
\hline HFMBI 15 & 97 & 85 & 872 & \\
\hline JEMBL14 & & & 3398 & TS \\
\hline HEMBL14884 & & & & TS \\
\hline HEMBL14 & 97 & 4 . & 7904 & TST \\
\hline HEMBL1: & 1 & 5. & 004 & ST \\
\hline HEMBL15 & 97 & 19 & 153 & IST \\
\hline HEMBL1314882 & & 4.585 & 912 & TS \\
\hline HEMBL141057 & 97 & 3.284 & 764 & TST \\
\hline HEMBL1S & 1 & 85 & 127 & TST \\
\hline HFMRI 1 & 97 & 84 & 124 & ST \\
\hline HEMBL13 & & & 161 & TST \\
\hline HEMBL1994078 & 597 & 5.0904 & 2592 & TST \\
\hline IEMBL1 & 97 & 3.284 & 7044 & TST \\
\hline HEMBL4€ & 97 & 4.7597 & 68 & ST \\
\hline CHEMBL19 & & 4.585 & 9823 & TST \\
\hline HEMBL1440284 & & 3.284 & 7142 & TST \\
\hline AEMBL1373043 & 597 & 3.284 & 6145 & TS \\
\hline MBL1 & 97 & 85 & 5168 & is \\
\hline HEMBL393 & 64 & 9.0223 & 1005 & \\
\hline CHEMBL3892196 & 642150 & 7.5686 & .6786 & \\
\hline CHEMBL3957709 & 1642150 & 7.8861 & 8.0371 & TRN \\
\hline
\end{tabular}

Page 21226 
Supplemental Table S2.txt

\begin{tabular}{|c|c|c|c|c|}
\hline CHEMBL3905350 & 1642150 & 7.0177 & 7.1232 & TRN \\
\hline CHEMBL3937530 & 1642150 & 8.5528 & 8.5774 & TRN \\
\hline CHEMBL3907544 & 1642150 & 7.9208 & 7.7246 & TRN \\
\hline CHEMBL3937976 & 1642150 & 9.1612 & 9.1458 & TRN \\
\hline CHEMBL 3983773 & 1642150 & 7.6021 & 7.6129 & TRN \\
\hline CHEMBL3968754 & 1642150 & 8.2757 & 8.1294 & TRN \\
\hline CHEMBL 3897597 & 1642150 & 7.2924 & 7.2813 & TRN \\
\hline CHEMBL3920149 & 1642150 & 8.2518 & 7.9506 & TST \\
\hline CHEMBL3972193 & 1642150 & 7.9586 & 7.7793 & TRN \\
\hline CHEMBL 3943553 & 1642150 & 7.7959 & 7.7191 & TST \\
\hline CHEMBL 3934466 & 1642150 & 6.9208 & 7.4205 & TST \\
\hline CHEMBL3944014 & 1642150 & 9.2757 & 9.2517 & TRN \\
\hline CHEMBL3957587 & 1642150 & 7.1249 & 7.1502 & TRN \\
\hline CHEMBL3964746 & 1642150 & 8.2676 & 8.0561 & TST \\
\hline CHEMBL 3892006 & 1642150 & 7.4559 & 7.4212 & TRN \\
\hline CHEMBL 3956342 & 1642150 & 7.4202 & 7.483 & TRN \\
\hline CHEMBL3982732 & 1642150 & 7.699 & 7.7579 & TRN \\
\hline CHEMBL3966368 & 1642150 & 7.2007 & 7.4663 & TST \\
\hline CHEMBL 3959837 & 1642150 & 8.699 & 8.796 & TRN \\
\hline CHEMBL3925716 & 1642150 & 7.5686 & 7.5129 & TRN \\
\hline CHEMBL3921123 & 1642150 & 7.4318 & 7.3523 & TRN \\
\hline CHEMBL3904086 & 1642150 & 7.6198 & 7.6707 & TRN \\
\hline CHEMBL3963312 & 1642150 & 7.4815 & 7.4894 & TRN \\
\hline CHEMBL3975319 & 1642150 & 7.1024 & 7.1507 & TRN \\
\hline CHEMBL3945331 & 1642150 & 8.2366 & 8.2607 & TRN \\
\hline CHEMBL3950970 & 1642150 & 7.3768 & 7.5461 & TRN \\
\hline CHEMBL3972989 & 1642150 & 7.3372 & 7.33700 & 3000000001 \\
\hline CHEMBL3906501 & 1642150 & 7.5528 & 8.7145 & TST \\
\hline CHEMBL3971571 & 1642150 & 7.0605 & 7.1977 & TRN \\
\hline CHEMBL3980165 & 1642150 & 7.2518 & 7.0939 & TRN \\
\hline CHEMBL3910344 & 1642150 & 8.9586 & 8.925 & TRN \\
\hline CHEMBL3976619 & 1642150 & 7.7212 & 7.727 & TRN \\
\hline CHEMBL3910035 & 1642150 & 8.8539 & 8.7228 & TRN \\
\hline CHEMBL3928771 & 1642150 & 7.7696 & 7.7559 & TRN \\
\hline CHEMBL3957432 & 1642150 & 7.7959 & 7.7199 & TRN \\
\hline CHEMBL3977243 & 1642150 & 7.5686 & 7.6524 & TRN \\
\hline CHEMBL3906545 & 1642150 & 7.5229 & 7.4987 & TRN \\
\hline CHEMBL 3975934 & 1642150 & 7.1135 & 7.1387 & TRN \\
\hline CHEMBL3890761 & 1642150 & 8.5086 & 8.5663 & TRN \\
\hline CHEMBL3929587 & 1642150 & 8.7212 & 8.6187 & TRN \\
\hline CHEMBL3948774 & 1642150 & 7.8539 & 8.4149 & TST \\
\hline CHEMBL 3904476 & 1642150 & 8.3768 & 8.3578 & TRN \\
\hline CHEMBL3899740 & 1642150 & 7.6198 & 7.6919 & TRN \\
\hline CHEMBL3916502 & 1642150 & 6.9066 & 6.9485 & TRN \\
\hline CHEMBL3964843 & 1642150 & 7.7447 & 7.6709 & TRN \\
\hline CHEMBL 3967221 & 1642150 & 8.9208 & 8.8584 & TRN \\
\hline CHEMBL3932058 & 1642150 & 7.5686 & 7.6037 & TST \\
\hline CHEMBL3909542 & 1642150 & 7.6198 & 7.8034 & TST \\
\hline
\end{tabular}


Supplemental Table S2.txt

\begin{tabular}{|c|c|c|c|c|}
\hline CHEMBL3929036 & 1642150 & 8.0862 & 8.4177 & TST \\
\hline CHEMBL3920970 & 1642150 & 7.4976 & 8.3013 & TST \\
\hline CHEMBL3919645 & 1642150 & 8.0555 & 7.8979 & TRN \\
\hline CHEMBL3946052 & 1642150 & 7.7959 & 7.7132 & TRN \\
\hline CHEMBL3889551 & 1642150 & 8.1871 & 8.3284 & TRN \\
\hline CHEMBL3916050 & 1642150 & 6.8827 & 6.916 & TRN \\
\hline CHEMBL3981263 & 1642150 & 7.1612 & 7.0065 & TRN \\
\hline CHEMBL 3967649 & 1642150 & 9.0757 & 8.9354 & TRN \\
\hline CHEMBL 3943443 & 1642150 & 7.2125 & \multirow{2}{*}{\multicolumn{2}{|c|}{$\begin{array}{l}7.593999999999999 \\
7.337999999999999\end{array}$}} \\
\hline CHEMBL3902068 & 1642150 & 7.3979 & & \\
\hline CHEMBL 3962954 & 1642150 & 7.7212 & 7.7532 & TRN \\
\hline CHEMBL3914141 & 1642150 & 7.585 & 7.8047 & TRN \\
\hline CHEMBL3911082 & 1642150 & 8.7447 & 8.8189 & TRN \\
\hline CHEMBL 3893038 & 1642150 & 8.1938 & 8.1215 & TRN \\
\hline CHEMBL3923232 & 1642150 & 6.9208 & 6.9582 & TRN \\
\hline CHEMBL 3934502 & 1642150 & 7.6478 & 7.6109 & TST \\
\hline CHEMBL3933388 & 1642150 & 8.3098 & 8.2213 & TRN \\
\hline CHEMBL3891592 & 1642150 & 7.5528 & 7.6019 & TRN \\
\hline CHEMBL 3952763 & 1642150 & 8.4202 & 8.6623 & TRN \\
\hline CHEMBL3943454 & 1642150 & 8.9208 & 8.9676 & TRN \\
\hline CHEMBL 3898632 & 1642150 & 8.1308 & 8.2803 & TRN \\
\hline CHEMBL3956576 & 1642150 & 8.7696 & 8.7143 & TRN \\
\hline CHEMBL3901625 & 1642150 & 8.7447 & 8.7528 & TRN \\
\hline CHEMBL 3943598 & 1642150 & 7.8539 & 7.9056 & TRN \\
\hline CHEMBL 3892134 & 1642150 & 8.2218 & 7.6469 & TST \\
\hline CHEMBL 3948942 & 1642150 & 7.2291 & 7.0862 & TRN \\
\hline CHEMBL3964175 & 1642150 & 7.6576 & 7.5788 & TRN \\
\hline CHEMBL3974231 & 1642150 & 7.2676 & 7.3061 & TRN \\
\hline CHEMBL 3934830 & 1642150 & 8.4949 & 8.2086 & TST \\
\hline CHEMBL3967426 & 1642150 & 8.4559 & 8.5056 & TRN \\
\hline CHEMBL 3928514 & 1642150 & 9.1367 & 8.9846 & TRN \\
\hline CHEMBL3898639 & 1642150 & 8.1192 & 7.7074 & TST \\
\hline CHEMBL3912022 & 1642150 & 7.4698 & 8.3301 & TST \\
\hline CHEMBL 3892712 & 1642150 & 7.9586 & 7.9786 & TST \\
\hline CHEMBL3983185 & 1642150 & 7.1427 & 7.336 & TST \\
\hline CHEMBL3984325 & 1642150 & 9.2291 & 8.9187 & TST \\
\hline CHEMBL3919075 & 1642150 & 8.7959 & 8.5844 & TST \\
\hline CHEMBL3928550 & 1642150 & 7.699 & 8.1252 & TST \\
\hline CHEMBL 3926583 & 1642150 & 7.2291 & 7.254 & TST \\
\hline CHEMBL103316 & 195069 & 4.0 & 5.6438 & TST \\
\hline CHEMBL317866 & 195069 & 5.8239 & 5.3968 & TST \\
\hline CHEMBL398764 & 195069 & 6.699 & 6.7261 & TRN \\
\hline CHEMBL147442 & 195069 & 4.0 & 4.9493 & TRN \\
\hline CHEMBL 254413 & 195069 & 6.8239 & 6.7642 & TRN \\
\hline CHEMBL423020 & 195069 & 4.0 & 5.7776 & TST \\
\hline CHEMBL147749 & 195069 & 7.5229 & 5.6969 & TST \\
\hline CHEMBL398766 & 195069 & 8.5229 & 8.7256 & TRN \\
\hline CHEMBL 253995 & 195069 & 6.8239 & 6.8408 & TRN \\
\hline
\end{tabular}




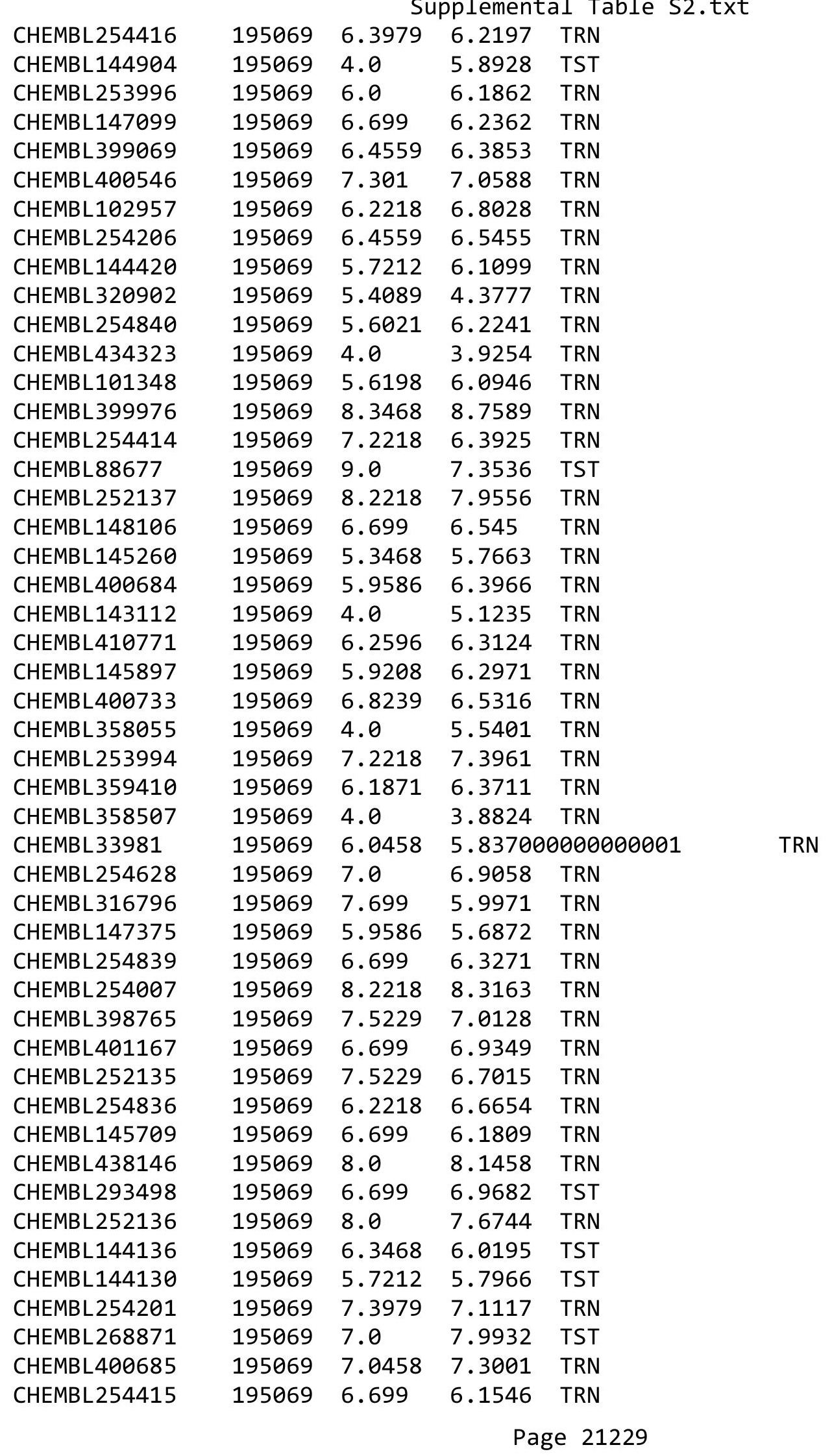




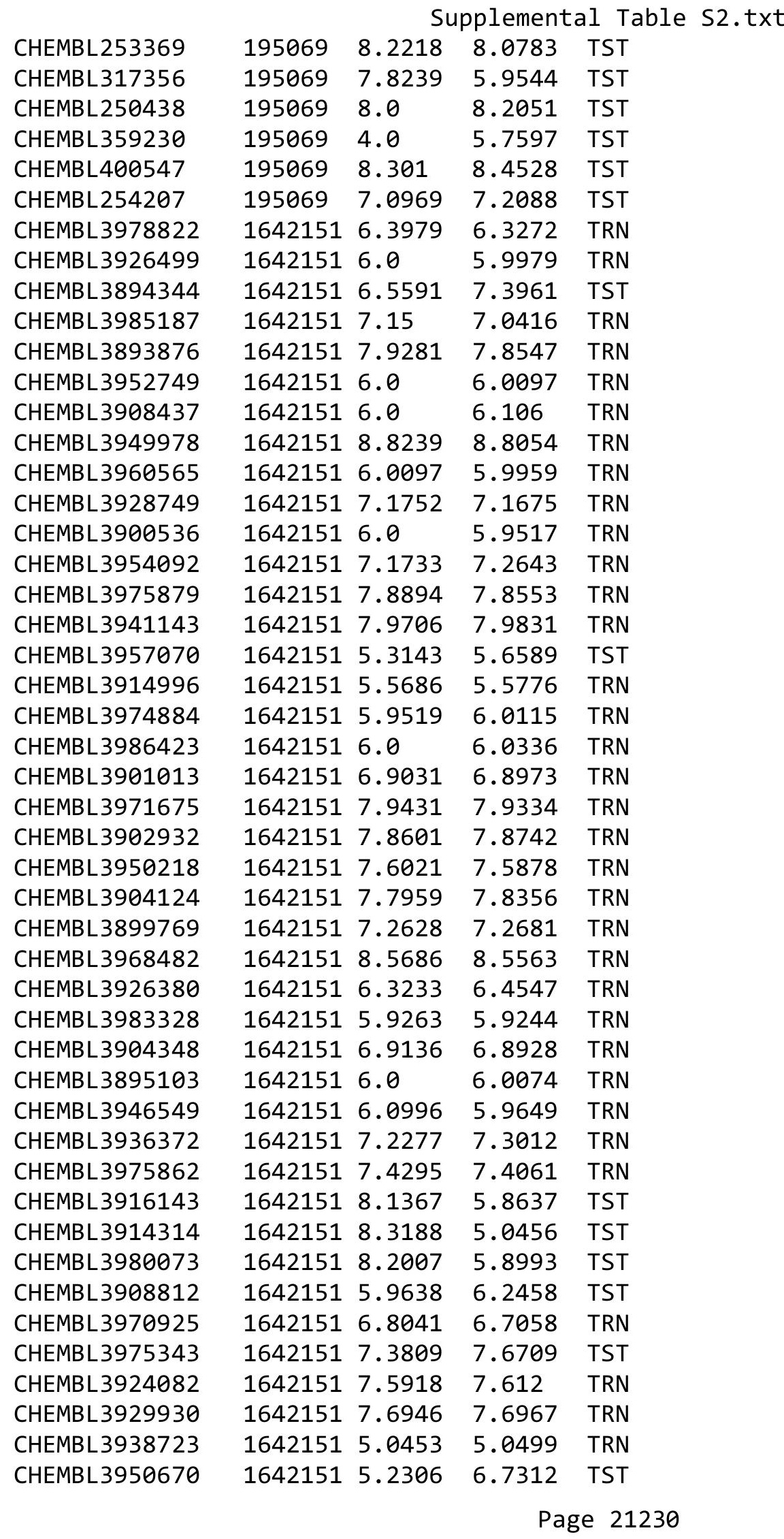


Supplemental Table S2.txt

\begin{tabular}{|c|c|c|c|c|c|}
\hline CHEMBL3953194 & 1642151 & 7.4449 & 7.4412 & TRN & \\
\hline CHEMBL3896925 & 1642151 & 6.4101 & 6.4176 & TRN & \\
\hline CHEMBL3967378 & 1642151 & 7.9136 & 7.91299 & 9999999999 & TRN \\
\hline CHEMBL3922038 & 1642151 & 7.9031 & 7.9338 & TRN & \\
\hline CHEMBL3952859 & 1642151 & 5.8277 & 5.8237 & TRN & \\
\hline CHEMBL3918613 & 1642151 & 6.0 & 6.0093 & TRN & \\
\hline CHEMBL3914885 & 1642151 & 6.0 & 7.1969 & TST & \\
\hline CHEMBL3980492 & 1642151 & 6.0 & 5.9775 & TRN & \\
\hline CHEMBL 3932140 & 1642151 & 7.8996 & 7.9207 & TRN & \\
\hline CHEMBL3981608 & 1642151 & 6.5171 & 6.4959 & TRN & \\
\hline CHEMBL3973257 & 1642151 & 7.0947 & 7.1063 & TRN & \\
\hline CHEMBL3944492 & 1642151 & 6.0 & 5.9116 & TRN & \\
\hline CHEMBL 3933342 & 1642151 & 6.4609 & 6.4702 & TRN & \\
\hline CHEMBL3983905 & 1642151 & 5.9397 & 5.9334 & TRN & \\
\hline CHEMBL3903691 & 1642151 & 7.8356 & 7.8408 & TRN & \\
\hline CHEMBL3954020 & 1642151 & 6.4763 & 6.4425 & TRN & \\
\hline CHEMBL3953612 & 1642151 & 6.0 & 6.0177 & TRN & \\
\hline CHEMBL 3938838 & 1642151 & 8.5086 & 5.0997 & TST & \\
\hline CHEMBL3912805 & 1642151 & 6.5935 & 6.5317 & TRN & \\
\hline CHEMBL3968284 & 1642151 & \multicolumn{3}{|c|}{7.4510000000000005} & TRN \\
\hline CHEMBL3958475 & 1642151 & 6.0 & 6.0865 & TRN & \\
\hline CHEMBL 3962467 & 1642151 & 7.3288 & 6.6661 & TST & \\
\hline CHEMBL3965931 & 1642151 & 6.0 & 6.0121 & TRN & \\
\hline CHEMBL3909576 & 1642151 & 7.0851 & 6.6686 & TST & \\
\hline CHEMBL3913509 & 1642151 & 7.5884 & 6.5495 & TST & \\
\hline CHEMBL 3924408 & 1642151 & 6.8962 & 7.3961 & TST & \\
\hline CHEMBL3902441 & 1642151 & 6.0 & 6.5573 & TST & \\
\hline CHEMBL 3939545 & 1642151 & 5.5136 & 5.5104 & TRN & \\
\hline CHEMBL3969726 & 1642151 & 7.3288 & 7.3253 & TRN & \\
\hline CHEMBL3901872 & 1642151 & 6.0 & 7.1969 & TST & \\
\hline CHEMBL3985728 & 1642151 & 5.4145 & 6.5563 & TST & \\
\hline CHEMBL 3982258 & 1642151 & 5.9038 & 5.9365 & TRN & \\
\hline CHEMBL 3928232 & 1642151 & 6.0 & 6.0644 & TRN & \\
\hline CHEMBL 3977984 & 1642151 & 7.0615 & 7.0543 & TRN & \\
\hline CHEMBL3959728 & 1642151 & 6.0 & 5.9967 & TRN & \\
\hline CHEMBL3976518 & 1642151 & 5.4685 & 5.4648 & TRN & \\
\hline CHEMBL3915412 & 1642151 & 5.4983 & 6.8529 & TST & \\
\hline CHEMBL3982762 & 1642151 & 6.1203 & 6.5628 & TST & \\
\hline CHEMBL3951131 & 1642151 & 7.1681 & 6.8621 & TST & \\
\hline CHEMBL3890921 & 1642151 & 8.2518 & 8.2801 & TRN & \\
\hline CHEMBL3898536 & 1642151 & 7.7878 & 7.78100 & 0000000001 & TRN \\
\hline CHEMBL3982903 & 1642151 & 6.6676 & 6.8222 & TST & \\
\hline CHEMBL516375 & 493905 & 7.46 & 7.6807 & TRN & \\
\hline CHEMBL473543 & 493905 & 7.09 & 7.1384 & TRN & \\
\hline CHEMBL472581 & 493905 & 7.15 & 7.3771 & TRN & \\
\hline CHEMBL505970 & 493905 & 6.27 & 6.4835 & TRN & \\
\hline CHEMBL515082 & 493905 & 8.1 & 7.9083 & TRN & \\
\hline CHEMBL453376 & 493905 & 8.0 & 7.9012 & TRN & \\
\hline
\end{tabular}




\begin{tabular}{|c|c|c|c|c|c|}
\hline & & \multicolumn{4}{|c|}{ Supplemental Table s2.txt } \\
\hline CHEMBL14932 & 493905 & 7.01 & 6.7405 & TRN & \\
\hline CHEMBL273789 & 493905 & 6.63 & 6.308 & TRN & \\
\hline CHEMBL15346 & 493905 & 7.13 & 7.1225 & TRN & \\
\hline CHEMBL15202 & 493905 & 7.17 & 7.2095 & TRN & \\
\hline CHEMBL540701 & 493905 & 7.1 & 7.0667 & TRN & \\
\hline CHEMBL14952 & 493905 & 6.98 & 7.0811 & TRN & \\
\hline CHEMBL14874 & 493905 & 6.08 & 6.1687 & TRN & \\
\hline CHEMBL14627 & 493905 & 7.13 & 7.1851 & TRN & \\
\hline CHEMBL517907 & 493905 & 7.96 & 7.9185 & TRN & \\
\hline CHEMBL460731 & 493905 & 7.7 & 7.5612 & TRN & \\
\hline CHEMBL460732 & 493905 & 7.03 & 7.0377 & TRN & \\
\hline CHEMBL514436 & 493905 & 7.57 & 7.7711 & TRN & \\
\hline CHEMBL493428 & 493905 & 7.62 & 7.3999 & TRN & \\
\hline CHEMBL368891 & 493905 & 5.0 & 6.4184 & TST & \\
\hline CHEMBL181275 & 493905 & 6.7 & 7.5906 & TST & \\
\hline CHEMBL182254 & 493905 & 7.5 & 7.2085 & TST & \\
\hline CHEMBL181742 & 493905 & 7.3 & 7.3118 & TST & \\
\hline CHEMBL361322 & 493905 & 5.3 & 7.5843 & TST & \\
\hline CHEMBL178953 & 493905 & 5.0 & 8.0388 & TST & \\
\hline CHEMBL178306 & 493905 & 5.0 & 7.1331 & TST & \\
\hline CHEMBL181029 & 493905 & 5.0 & 8.421 & TST & \\
\hline CHEMBL178488 & 493905 & 5.0 & 7.5192 & TST & \\
\hline CHEMBL179224 & 493905 & 5.0 & 6.7052 & TST & \\
\hline CHEMBL359830 & 493905 & 5.0 & 7.5288 & TST & \\
\hline CHEMBL454383 & 493905 & 9.15 & 9.3205 & TRN & \\
\hline CHEMBL510155 & 493905 & 7.35 & 7.73799 & 99999999995 & TRN \\
\hline CHEMBL510357 & 493905 & 7.57 & 7.46899 & 9999999999 & TRN \\
\hline CHEMBL516365 & 493905 & 8.77 & 8.5922 & TRN & \\
\hline CHEMBL473747 & 493905 & 8.44 & 8.724 & TRN & \\
\hline CHEMBL473748 & 493905 & 8.41 & 8.3235 & TRN & \\
\hline CHEMBL473944 & 493905 & 8.52 & 8.8613 & TRN & \\
\hline CHEMBL491676 & 493905 & 9.11 & 9.0999 & TRN & \\
\hline CHEMBL522134 & 493905 & 9.38 & 9.4823 & TRN & \\
\hline CHEMBL492077 & 493905 & 8.7 & 8.5252 & TRN & \\
\hline CHEMBL489111 & 493905 & 8.82 & 8.86 & TRN & \\
\hline CHEMBL521571 & 493905 & 9.16 & 8.9732 & TRN & \\
\hline CHEMBL489107 & 493905 & 8.74 & 8.5552 & TRN & \\
\hline CHEMBL447223 & 493905 & 9.12 & 9.1367 & TRN & \\
\hline CHEMBL489306 & 493905 & 8.82 & 8.6917 & TRN & \\
\hline CHEMBL522928 & 493905 & 8.77 & 8.8735 & TRN & \\
\hline CHEMBL524117 & 493905 & 9.12 & 9.1245 & TRN & \\
\hline CHEMBL490496 & 493905 & 9.8 & 9.7504 & TRN & \\
\hline CHEMBL521601 & 493905 & 8.57 & 8.8155 & TRN & \\
\hline CHEMBL490497 & 493905 & 9.02 & 9.2404 & TRN & \\
\hline CHEMBL490498 & 493905 & 9.01 & 9.01100 & 0000000001 & TRN \\
\hline CHEMBL489897 & 493905 & 8.82 & 8.5217 & TRN & \\
\hline CHEMBL490093 & 493905 & 7.7 & 7.5241 & TRN & \\
\hline CHEMBL448172 & 493905 & 8.18 & 8.2265 & TRN & \\
\hline
\end{tabular}




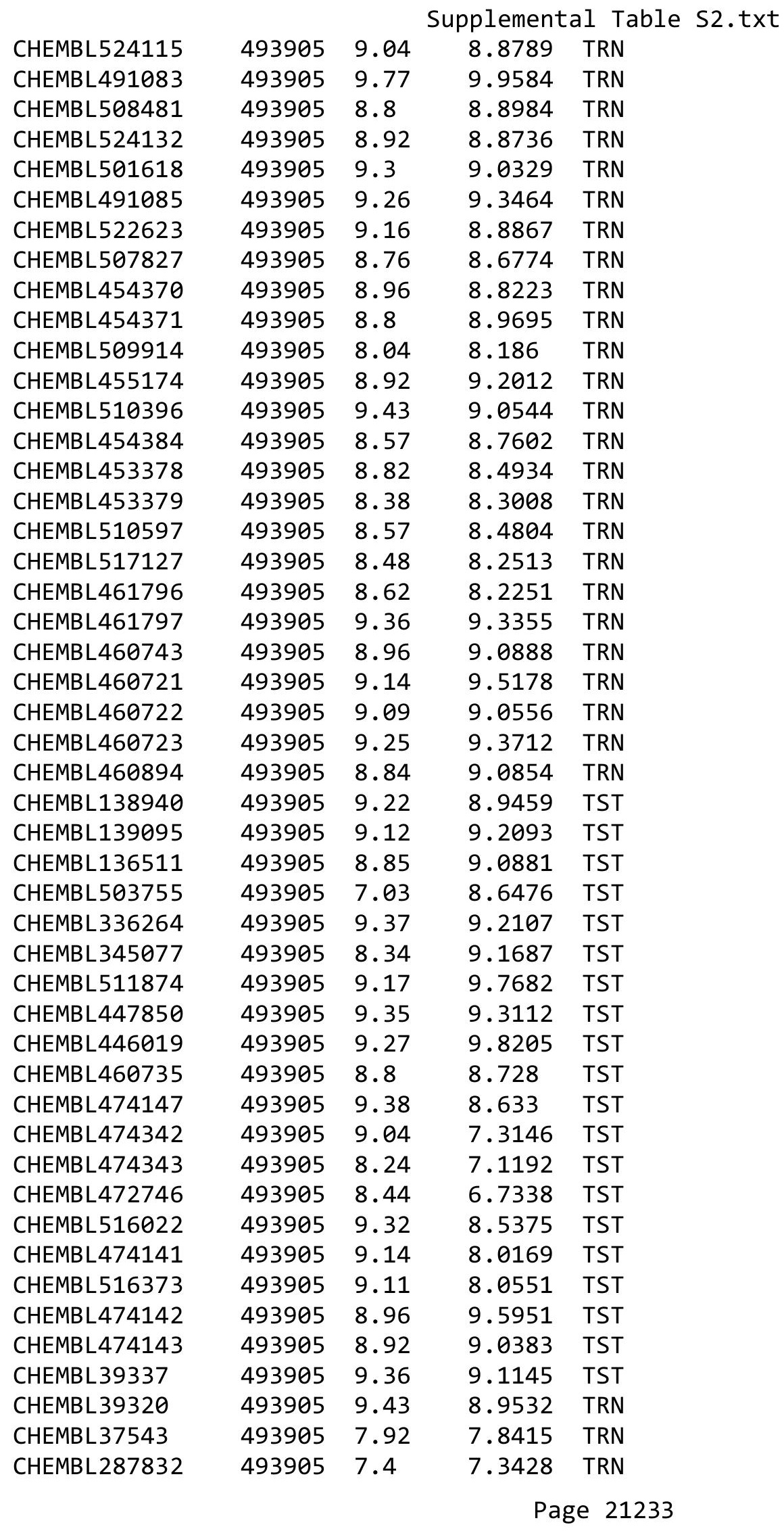




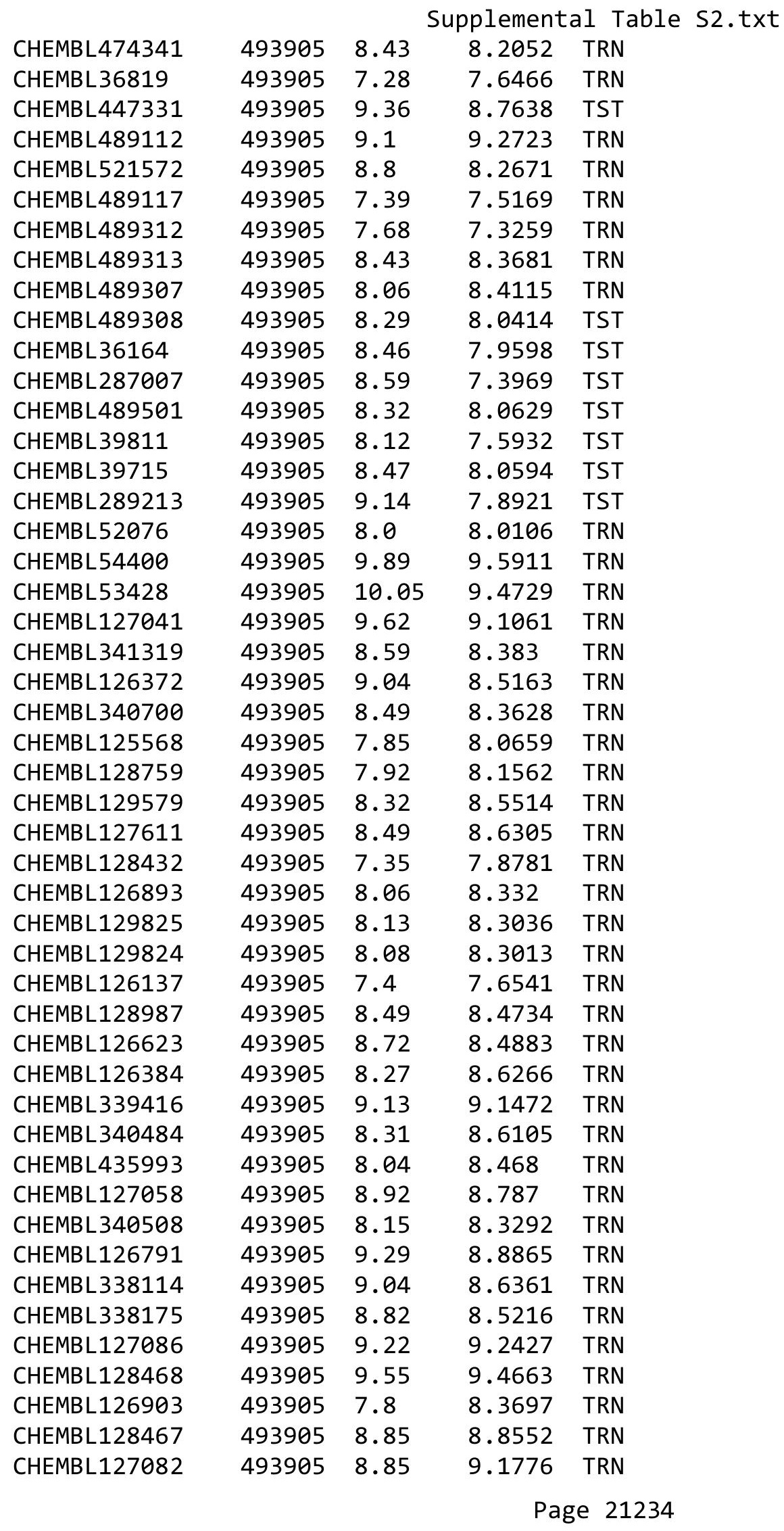




\begin{tabular}{|c|c|c|c|c|c|}
\hline \multicolumn{6}{|c|}{ Supplemental Table S2.txt } \\
\hline CHEMBL338215 & 493905 & 8.27 & 7.8857 & TRN & \\
\hline CHEMBL129509 & 493905 & 8.03 & 8.2606 & TRN & \\
\hline CHEMBL341522 & 493905 & 8.25 & 8.1537 & TRN & \\
\hline CHEMBL340898 & 493905 & 8.46 & 8.7113 & TRN & \\
\hline CHEMBL340399 & 493905 & 8.14 & 8.4534 & TRN & \\
\hline CHEMBL 2003768 & 809121 & 4.2 & 4.0494 & TRN & \\
\hline CHEMBL213505 & 809121 & 5.5 & 5.2291 & TRN & \\
\hline CHEMBL1982880 & 809121 & 5.7 & 4.9816 & TRN & \\
\hline CHEMBL1993941 & 809121 & 4.2 & 3.9117 & TRN & \\
\hline CHEMBL1980435 & 809121 & 7.5 & 7.4734 & TRN & \\
\hline CHEMBL 377383 & 809121 & 4.2 & 4.1552 & TRN & \\
\hline CHEMBL1973142 & 809121 & 7.0 & 7.0865 & TRN & \\
\hline CHEMBL1973145 & 809121 & 4.2 & 4.1509 & TRN & \\
\hline CHEMBL1982924 & 809121 & 6.3 & 5.3026 & TRN & \\
\hline CHEMBL1964948 & 809121 & 4.7 & 4.6603 & TRN & \\
\hline CHEMBL1971141 & 809121 & 4.2 & 3.735 & TRN & \\
\hline CHEMBL1995813 & 809121 & 8.1 & 7.5987 & TRN & \\
\hline CHEMBL1979718 & 809121 & 4.2 & 5.2861 & TRN & \\
\hline CHEMBL206236 & 809121 & 6.1 & 6.3089 & TRN & \\
\hline CHEMBL523823 & 809121 & 7.4 & 5.6751 & TST & \\
\hline CHEMBL 244378 & 809121 & 7.0 & 7.9528 & TRN & \\
\hline CHEMBL1990583 & 809121 & 4.2 & 4.5357 & TRN & \\
\hline CHEMBL289959 & 809121 & 4.5 & 4.331 & TRN & \\
\hline CHEMBL2006263 & 809121 & 5.8 & 4.8647 & TST & \\
\hline CHEMBL1993584 & 809121 & 5.7 & 6.835 & TRN & \\
\hline CHEMBL 2000114 & 809121 & 6.0 & 5.8671 & TRN & \\
\hline CHEMBL210618 & 809121 & 4.2 & 4.2191 & TRN & \\
\hline CHEMBL1971172 & 809121 & 7.2 & 7.6485 & TRN & \\
\hline CHEMBL1975647 & 809121 & 6.5 & 6.1252 & TRN & \\
\hline CHEMBL1968380 & 809121 & 4.2 & 4.48600 & 0000000001 & TRN \\
\hline CHEMBL1991734 & 809121 & 7.2 & 5.6718 & TST & \\
\hline CHEMBL1990912 & 809121 & 7.6 & 7.2085 & TRN & \\
\hline CHEMBL1991782 & 809121 & 4.9 & 4.3066 & TRN & \\
\hline CHEMBL1968394 & 809121 & 3.1 & 4.0159 & TRN & \\
\hline CHEMBL1988163 & 809121 & 6.7 & 6.9405 & TRN & \\
\hline CHEMBL1974480 & 809121 & 5.9 & 5.6388 & TRN & \\
\hline CHEMBL1980671 & 809121 & 3.1 & 4.5973 & TRN & \\
\hline CHEMBL 2006493 & 809121 & 4.2 & 4.6741 & TST & \\
\hline CHEMBL1996923 & 809121 & 5.4 & 4.8955 & TST & \\
\hline CHEMBL1969735 & 809121 & 4.2 & 3.9531 & TRN & \\
\hline CHEMBL 2003524 & 809121 & 5.6 & 5.54299 & 9999999999 & TST \\
\hline CHEMBL 2002649 & 809121 & 6.0 & 6.0326 & TRN & \\
\hline CHEMBL1989423 & 809121 & 4.2 & 3.9202 & TRN & \\
\hline CHEMBL1985367 & 809121 & 4.7 & 5.7652 & TST & \\
\hline CHEMBL1994321 & 809121 & 4.2 & 4.5999 & TRN & \\
\hline CHEMBL1978562 & 809121 & 4.7 & 5.4068 & TST & \\
\hline CHEMBL1964307 & 809121 & 4.2 & 5.5627 & TRN & \\
\hline CHEMBL1989471 & 809121 & 6.3 & 5.7123 & TST & \\
\hline
\end{tabular}




\begin{tabular}{|c|c|c|c|c|}
\hline & & & ipplement & al $\mathrm{T}$ \\
\hline CHEMBL 2000508 & 809121 & 4.2 & 4.2202 & TRN \\
\hline CHEMBL1971694 & 809121 & 5.2 & 5.1306 & TST \\
\hline CHEMBL1978195 & 809121 & 4.7 & 6.3827 & TRN \\
\hline CHEMBL1994361 & 809121 & 6.7 & 6.3857 & TRN \\
\hline CHEMBL1986603 & 809121 & 6.8 & 5.521 & TST \\
\hline CHEMBL1977148 & 809121 & 4.2 & 4.0488 & TRN \\
\hline CHEMBL1966842 & 809121 & 4.8 & 5.0514 & TRN \\
\hline CHEMBL 2003286 & 809121 & 7.5 & 7.5891 & TRN \\
\hline CHEMBL1992306 & 809121 & 4.2 & 3.8048 & TRN \\
\hline CHEMBL 2002165 & 809121 & 4.2 & 4.0155 & TRN \\
\hline CHEMBL1979318 & 809121 & 4.2 & 4.2173 & TRN \\
\hline CHEMBL 206382 & 809121 & 6.2 & 6.3176 & TRN \\
\hline CHEMBL127898 & 809121 & 6.5 & 4.2692 & TST \\
\hline CHEMBL519697 & 809121 & 6.2 & 5.1926 & TST \\
\hline CHEMBL1973516 & 809121 & 4.7 & 6.2406 & TRN \\
\hline CHEMBL1996345 & 809121 & 4.7 & 5.8219 & TST \\
\hline CHEMBL1975128 & 809121 & 7.4 & 7.3742 & TRN \\
\hline CHEMBL1970369 & 809121 & 4.2 & 5.0896 & TRN \\
\hline CHEMBL1965033 & 809121 & 4.7 & 4.3463 & TRN \\
\hline CHEMBL 2001485 & 809121 & 4.2 & 4.2673 & TRN \\
\hline CHEMBL504950 & 809121 & 6.3 & 5.8836 & TRN \\
\hline CHEMBL1966425 & 809121 & 4.2 & 4.9153 & TRN \\
\hline CHEMBL1988608 & 809121 & 6.1 & 6.3248 & TRN \\
\hline CHEMBL184847 & 809121 & 4.2 & 4.2229 & TRN \\
\hline CHEMBL178737 & 809121 & 5.2 & 5.4828 & TST \\
\hline CHEMBL1982563 & 809121 & 4.2 & 4.0454 & TRN \\
\hline CHEMBL539474 & 809121 & 4.2 & 4.7334 & TST \\
\hline CHEMBL575824 & 809121 & 8.1 & 7.9871 & TRN \\
\hline CHEMBL1988387 & 809121 & 4.2 & 4.3304 & TRN \\
\hline CHEMBL1973868 & 809121 & 6.9 & 6.4053 & TRN \\
\hline CHEMBL1965702 & 809121 & 7.0 & 7.4643 & TRN \\
\hline CHEMBL1986970 & 809121 & 6.9 & 5.7509 & TRN \\
\hline CHEMBL1958401 & 809121 & 7.4 & 6.9339 & TRN \\
\hline CHEMBL1984044 & 809121 & 5.9 & 5.3677 & TRN \\
\hline CHEMBL1972584 & 809121 & 4.2 & 4.059 & TRN \\
\hline CHEMBL1982700 & 809121 & 4.7 & 4.5752 & TST \\
\hline CHEMBL326282 & 809121 & 4.2 & 5.4776 & TST \\
\hline CHEMBL1992732 & 809121 & 4.2 & 4.8495 & TST \\
\hline CHEMBL1971186 & 809121 & 4.2 & 4.1921 & TRN \\
\hline CHEMBL 2003482 & 809121 & 4.6 & 4.5756 & TRN \\
\hline CHEMBL1976872 & 809121 & 3.1 & 3.7781 & TRN \\
\hline CHEMBL 2006456 & 809121 & 7.5 & 7.8172 & TRN \\
\hline CHEMBL1969156 & 809121 & 3.1 & 3.7449 & TRN \\
\hline CHEMBL1973211 & 809121 & 4.2 & 4.6262 & TRN \\
\hline CHEMBL1999120 & 809121 & 4.8 & 4.3178 & TST \\
\hline CHEMBL1976134 & 809121 & 6.7 & 6.0664 & TRN \\
\hline CHEMBL1965131 & 809121 & 6.7 & 7.0862 & TRN \\
\hline CHEMBL1981215 & 809121 & 4.7 & 5.5153 & TRN \\
\hline
\end{tabular}




\begin{tabular}{|c|c|c|c|c|}
\hline & & & pplement & al $\mathrm{Ta}$ \\
\hline CHEMBL1974457 & 809121 & 6.3 & 5.5178 & TRN \\
\hline CHEMBL 2006580 & 809121 & 6.1 & 6.2085 & TRN \\
\hline CHEMBL2001228 & 809121 & 4.8 & 4.6813 & TRN \\
\hline CHEMBL 2006581 & 809121 & 4.2 & 4.4054 & TRN \\
\hline CHEMBL1979855 & 809121 & 4.2 & 4.2085 & TRN \\
\hline CHEMBL1970340 & 809121 & 5.7 & 4.6991 & TRN \\
\hline CHEMBL 2005186 & 809121 & 5.6 & 5.4725 & TRN \\
\hline CHEMBL1995927 & 809121 & 4.2 & 4.4442 & TST \\
\hline CHEMBL 2006450 & 809121 & 7.4 & 6.8204 & TRN \\
\hline CHEMBL2001987 & 809121 & 4.7 & 4.8394 & TRN \\
\hline CHEMBL1994555 & 809121 & 4.7 & 5.1212 & TST \\
\hline CHEMBL1997023 & 809121 & 4.2 & 5.3352 & TST \\
\hline CHEMBL1971943 & 809121 & 5.0 & 5.1732 & TRN \\
\hline CHEMBL1997924 & 809121 & 6.4 & 6.2771 & TRN \\
\hline CHEMBL1969049 & 809121 & 4.2 & 4.251 & TRN \\
\hline CHEMBL 2005828 & 809121 & 4.2 & 4.9694 & TRN \\
\hline CHEMBL1991143 & 809121 & 4.2 & 4.1271 & TST \\
\hline CHEMBL1998611 & 809121 & 6.9 & 6.6378 & TRN \\
\hline CHEMBL1975900 & 809121 & 5.7 & 5.0413 & TRN \\
\hline CHEMBL 255822 & 809121 & 8.2 & 7.9848 & TRN \\
\hline CHEMBL2006778 & 809121 & 5.3 & 5.5346 & TRN \\
\hline CHEMBL378627 & 809121 & 4.2 & 3.949 & TRN \\
\hline CHEMBL1996979 & 809121 & 4.3 & 4.9848 & TRN \\
\hline CHEMBL1975911 & 809121 & 4.2 & 4.1904 & TRN \\
\hline CHEMBL1997025 & 809121 & 6.5 & 5.7043 & TRN \\
\hline CHEMBL1968406 & 809121 & 6.1 & 5.6914 & TRN \\
\hline CHEMBL1975921 & 809121 & 5.4 & 4.8853 & TRN \\
\hline CHEMBL1982476 & 809121 & 4.2 & 4.2662 & TRN \\
\hline CHEMBL1975923 & 809121 & 5.0 & 5.2345 & TST \\
\hline CHEMBL 2005449 & 809121 & 4.7 & 5.5933 & TRN \\
\hline CHEMBL 2006010 & 809121 & 4.2 & 4.3216 & TRN \\
\hline CHEMBL1682558 & 809121 & 4.2 & 5.0087 & TRN \\
\hline CHEMBL1990496 & 809121 & 4.4 & 4.3308 & TRN \\
\hline CHEMBL1993166 & 809121 & 4.2 & 5.3108 & TRN \\
\hline CHEMBL1967094 & 809121 & 5.6 & 4.9081 & TRN \\
\hline CHEMBL 2003341 & 809121 & 4.2 & 5.1377 & TRN \\
\hline CHEMBL1992645 & 809121 & 5.3 & 5.1697 & TST \\
\hline CHEMBL1998110 & 809121 & 4.7 & 4.1321 & TRN \\
\hline CHEMBL1999590 & 809121 & 4.2 & 4.0996 & TST \\
\hline CHEMBL1978166 & 809121 & 6.1 & 5.5425 & TRN \\
\hline CHEMBL1980489 & 809121 & 4.2 & 4.1587 & TRN \\
\hline CHEMBL 2000832 & 809121 & 5.3 & 6.1231 & TRN \\
\hline CHEMBL1967116 & 809121 & 4.2 & 4.5116 & TRN \\
\hline CHEMBL1972454 & 809121 & 3.1 & 4.7475 & TRN \\
\hline CHEMBL1990590 & 809121 & 4.7 & 4.3559 & TRN \\
\hline CHEMBL1977814 & 809121 & 4.4 & 4.9851 & TST \\
\hline CHEMBL513846 & 809121 & 6.2 & 5.7603 & TRN \\
\hline CHEMBL1974617 & 809121 & 6.4 & 6.5041 & TRN \\
\hline
\end{tabular}




\begin{tabular}{|c|c|c|c|c|c|}
\hline \multicolumn{6}{|c|}{ Supplemental Table S2.txt } \\
\hline CHEMBL1965660 & 809121 & 9.1 & 8.281 & TST & \\
\hline CHEMBL1998112 & 809121 & 4.2 & 4.6963 & TRN & \\
\hline CHEMBL1969126 & 809121 & 4.2 & 4.4317 & TRN & \\
\hline CHEMBL1980896 & 809121 & 4.2 & 5.021 & TRN & \\
\hline CHEMBL1975208 & 809121 & 4.2 & 4.1441 & TRN & \\
\hline CHEMBL1991429 & 809121 & 4.2 & 4.4158 & TRN & \\
\hline CHEMBL1967612 & 809121 & 4.7 & 4.5223 & TST & \\
\hline CHEMBL1971149 & 809121 & 4.2 & 4.0913 & TRN & \\
\hline CHEMBL1999714 & 809121 & 4.2 & 3.0937 & TRN & \\
\hline CHEMBL1994040 & 809121 & 4.2 & 4.1543 & TRN & \\
\hline CHEMBL388978 & 809121 & 8.6 & 7.1104 & TST & \\
\hline CHEMBL 2004716 & 809121 & 4.2 & 4.2266 & TRN & \\
\hline CHEMBL1975233 & 809121 & 4.2 & 4.3487 & TRN & \\
\hline CHEMBL1421720 & 809121 & 6.3 & 5.6507 & TRN & \\
\hline CHEMBL1982135 & 809121 & 6.4 & 5.6018 & TRN & \\
\hline CHEMBL1976090 & 809121 & 7.1 & 6.9056 & TRN & \\
\hline CHEMBL2004771 & 809121 & 5.7 & 4.7024 & TRN & \\
\hline CHEMBL1992922 & 809121 & 6.7 & 6.4658 & TRN & \\
\hline CHEMBL1997597 & 809121 & 6.0 & 6.0963 & TRN & \\
\hline CHEMBL1976093 & 809121 & 4.2 & 4.4113 & TRN & \\
\hline CHEMBL1996543 & 809121 & 6.7 & 6.9704 & TRN & \\
\hline CHEMBL1975256 & 809121 & 6.1 & 4.2555 & TST & \\
\hline CHEMBL1949855 & 809121 & 5.8 & 5.35 & TRN & \\
\hline CHEMBL1999126 & 809121 & 5.7 & 5.4191 & TST & \\
\hline CHEMBL1997503 & 809121 & 4.2 & 4.3055 & TST & \\
\hline CHEMBL116070 & 809121 & 5.9 & 5.9564 & TRN & \\
\hline CHEMBL1990821 & 809121 & 4.2 & 3.7864 & TST & \\
\hline CHEMBL 2004871 & 809121 & 4.2 & 4.1133 & TRN & \\
\hline CHEMBL2004872 & 809121 & 4.2 & 4.732 & TRN & \\
\hline CHEMBL1727312 & 809121 & 3.3 & 3.0571 & TRN & \\
\hline CHEMBL1969879 & 809121 & 4.2 & 4.0382 & TRN & \\
\hline CHEMBL1964382 & 809121 & 4.7 & 4.8587 & TST & \\
\hline CHEMBL101311 & 809121 & 4.7 & 5.7359 & TRN & \\
\hline CHEMBL1981720 & 809121 & 6.7 & 6.4354 & TRN & \\
\hline CHEMBL419932 & 809121 & 7.0 & 6.2569 & TRN & \\
\hline CHEMBL 2005699 & 809121 & 4.7 & 4.2244 & TRN & \\
\hline CHEMBL1976328 & 809121 & 4.2 & $4.5710 e$ & 0000000001 & TRN \\
\hline CHEMBL1964399 & 809121 & 5.5 & 5.7977 & TRN & \\
\hline CHEMBL1996831 & 809121 & 4.2 & 5.0817 & TST & \\
\hline CHEMBL1980253 & 809121 & 7.9 & 7.7455 & TRN & \\
\hline CHEMBL1978167 & 809121 & 4.7 & 5.3949 & TST & \\
\hline CHEMBL1682357 & 809121 & 7.1 & 6.5988 & TRN & \\
\hline CHEMBL225519 & 809121 & 7.7 & 7.5494 & TRN & \\
\hline CHEMBL1978200 & 809121 & 4.2 & 4.4076 & TRN & \\
\hline CHEMBL1970522 & 809121 & 7.6 & 7.3245 & TRN & \\
\hline CHEMBL1990415 & 809121 & 6.0 & 5.7976 & TRN & \\
\hline CHEMBL1996931 & 809121 & 4.2 & 4.6786 & TRN & \\
\hline CHEMBL1964413 & 809121 & 6.5 & $6.0420 e$ & 2000000001 & TRN \\
\hline & & & & 21238 & \\
\hline
\end{tabular}




\begin{tabular}{|c|c|c|c|c|}
\hline & & & pplement & $\mathrm{a} \perp \mathrm{Ta}$ \\
\hline CHEMBL1998470 & 809121 & 7.6 & 7.2247 & TRN \\
\hline CHEMBL1996980 & 809121 & 8.5 & 8.5017 & TRN \\
\hline CHEMBL1984432 & 809121 & 6.9 & 6.4681 & TRN \\
\hline CHEMBL1975903 & 809121 & 4.7 & 5.5403 & TRN \\
\hline CHEMBL 2004365 & 809121 & 5.6 & 5.1828 & TST \\
\hline CHEMBL1522508 & 809121 & 6.0 & 4.2474 & TRN \\
\hline CHEMBL1989474 & 809121 & 4.5 & 4.2596 & TRN \\
\hline CHEMBL1090360 & 809121 & 4.2 & 4.3602 & TRN \\
\hline CHEMBL210887 & 809121 & 5.8 & 6.0436 & TST \\
\hline CHEMBL1969942 & 809121 & 4.7 & 4.7769 & TRN \\
\hline CHEMBL1978567 & 809121 & 4.7 & 4.1321 & TRN \\
\hline CHEMBL1994693 & 809121 & 7.0 & 5.6797 & TRN \\
\hline CHEMBL86755 & 809121 & 4.7 & 4.5599 & TRN \\
\hline CHEMBL1975138 & 809121 & 4.2 & 4.7732 & TRN \\
\hline CHEMBL424872 & 809121 & 4.5 & 4.2805 & TRN \\
\hline CHEMBL1971947 & 809121 & 4.2 & 4.6302 & TRN \\
\hline CHEMBL 2004447 & 809121 & 4.2 & 3.6635 & TRN \\
\hline CHEMBL1992231 & 809121 & 5.8 & 5.2215 & TRN \\
\hline CHEMBL1983111 & 809121 & 6.2 & 6.0775 & TRN \\
\hline CHEMBL1973860 & 809121 & 6.1 & 6.2584 & TRN \\
\hline CHEMBL1982610 & 809121 & 6.0 & 6.0539 & TRN \\
\hline CHEMBL1999496 & 809121 & 4.2 & 4.1009 & TRN \\
\hline CHEMBL1988300 & 809121 & 5.3 & 4.9843 & TRN \\
\hline CHEMBL1975212 & 809121 & 4.5 & 4.8985 & TRN \\
\hline CHEMBL 2001613 & 809121 & 5.8 & 5.0349 & TRN \\
\hline CHEMBL1993904 & 809121 & 4.7 & 5.6267 & TRN \\
\hline CHEMBL1982660 & 809121 & 6.6 & 6.5602 & TRN \\
\hline CHEMBL1989265 & 809121 & 5.4 & 4.6025 & TRN \\
\hline CHEMBL1965910 & 809121 & 4.2 & 3.9796 & TRN \\
\hline CHEMBL1983963 & 809121 & 4.2 & 4.8803 & TRN \\
\hline CHEMBL1985042 & 809121 & 4.7 & 4.5322 & TST \\
\hline CHEMBL1985092 & 809121 & 6.3 & 5.3665 & TRN \\
\hline CHEMBL1981410 & 809121 & 5.9 & 4.493 & TRN \\
\hline CHEMBL383264 & 809121 & 8.5 & 8.1427 & TRN \\
\hline CHEMBL 2007421 & 809121 & 4.7 & 5.5615 & TST \\
\hline CHEMBL1991434 & 809121 & 5.6 & 5.4302 & TRN \\
\hline CHEMBL1973138 & 809121 & 4.7 & 4.3859 & TRN \\
\hline CHEMBL340384 & 809121 & 6.9 & 6.5266 & TST \\
\hline CHEMBL1969151 & 809121 & 7.4 & 7.9185 & TRN \\
\hline CHEMBL1996587 & 809121 & 4.2 & 5.3305 & TRN \\
\hline CHEMBL1981492 & 809121 & 4.4 & 4.323 & TRN \\
\hline CHEMBL1988692 & 809121 & 4.7 & 4.7533 & TRN \\
\hline CHEMBL592030 & 809121 & 6.0 & 6.7081 & TST \\
\hline CHEMBL 2000071 & 809121 & 6.7 & 6.4264 & TRN \\
\hline CHEMBL1979176 & 809121 & 4.2 & 5.6991 & TRN \\
\hline CHEMBL2002613 & 809121 & 6.8 & 7.1404 & TRN \\
\hline CHEMBL1983195 & 809121 & 5.5 & 4.9923 & TST \\
\hline CHEMBL1964444 & 809121 & 5.0 & 5.4511 & TRN \\
\hline
\end{tabular}




\begin{tabular}{|c|c|c|c|c|}
\hline & & & pplement & al Table S2 \\
\hline CHEMBL1980540 & 809121 & 4.2 & 4.9435 & TRN \\
\hline CHEMBL 278041 & 809121 & 4.7 & 4.9609 & TRN \\
\hline CHEMBL1984162 & 809121 & 4.2 & 5.0737 & TRN \\
\hline CHEMBL1998432 & 809121 & 7.4 & 7.8195 & TRN \\
\hline CHEMBL1870106 & 809121 & 7.0 & 6.5493 & TRN \\
\hline CHEMBL1996791 & 809121 & 6.6 & 6.147 & TRN \\
\hline CHEMBL371206 & 809121 & 5.3 & 5.3046 & TRN \\
\hline CHEMBL1974664 & 809121 & 4.2 & 5.3361 & TST \\
\hline CHEMBL1970104 & 809121 & 6.6 & 6.0407 & TRN \\
\hline CHEMBL482538 & 809121 & 5.3 & 5.261 & TRN \\
\hline CHEMBL1984296 & 809121 & 6.2 & 5.2774 & TST \\
\hline CHEMBL196363 & 809121 & 5.2 & 4.5449 & TRN \\
\hline CHEMBL1996837 & 809121 & 5.1 & 4.5755 & TRN \\
\hline CHEMBL1190711 & 809121 & 6.3 & 6.5769 & TRN \\
\hline CHEMBL1981723 & 809121 & 5.5 & 5.1136 & TST \\
\hline CHEMBL1964441 & 809121 & 4.7 & 4.274 & TRN \\
\hline CHEMBL404367 & 809121 & 6.4 & 5.1652 & TRN \\
\hline CHEMBL1966343 & 809121 & 6.3 & 6.9047 & TRN \\
\hline CHEMBL1967887 & 809121 & 8.0 & 7.8247 & TRN \\
\hline CHEMBL 2000568 & 809121 & 4.7 & 4.8659 & TRN \\
\hline CHEMBL 2000335 & 809121 & 5.5 & 4.8275 & TRN \\
\hline CHEMBL 2007097 & 809121 & 5.0 & 5.1736 & TRN \\
\hline CHEMBL243298 & 809121 & 5.9 & 7.2105 & TRN \\
\hline CHEMBL143703 & 809121 & 3.1 & 4.0934 & TRN \\
\hline CHEMBL1973808 & 809121 & 5.5 & 5.6249 & TRN \\
\hline CHEMBL 2000429 & 809121 & 4.2 & 3.9651 & TRN \\
\hline CHEMBL1972576 & 809121 & 4.2 & 4.4206 & TRN \\
\hline CHEMBL1992555 & 809121 & 4.2 & 4.6637 & TST \\
\hline CHEMBL1988173 & 809121 & 5.8 & 5.5896 & TRN \\
\hline CHEMBL535331 & 809121 & 4.2 & 4.9769 & TRN \\
\hline CHEMBL1989805 & 809121 & 5.7 & 5.1748 & TST \\
\hline CHEMBL1982980 & 809121 & 4.2 & 4.0333 & TST \\
\hline CHEMBL1983025 & 809121 & 4.2 & 4.6671 & TRN \\
\hline CHEMBL1975927 & 809121 & 4.7 & 5.4827 & TRN \\
\hline CHEMBL2002322 & 809121 & 6.2 & 5.7338 & TRN \\
\hline CHEMBL1997119 & 809121 & 4.3 & 4.2906 & TRN \\
\hline CHEMBL 2002323 & 809121 & 4.2 & 4.7425 & TST \\
\hline CHEMBL 2000879 & 809121 & 4.3 & 4.29899 & 99999999995 \\
\hline CHEMBL 2005548 & 809121 & 5.4 & 5.1284 & TRN \\
\hline CHEMBL2001704 & 809121 & 4.4 & 4.9909 & TST \\
\hline CHEMBL1987793 & 809121 & 4.2 & 4.0074 & TST \\
\hline CHEMBL 21156 & 809121 & 4.7 & 5.1468 & TST \\
\hline CHEMBL1992740 & 809121 & 6.8 & 5.9789 & TRN \\
\hline CHEMBL1989267 & 809121 & 4.7 & 5.0873 & TRN \\
\hline CHEMBL2002373 & 809121 & 4.2 & 4.209 & TRN \\
\hline CHEMBL439340 & 809121 & 4.5 & 5.4651 & TRN \\
\hline CHEMBL1974574 & 809121 & 6.0 & 4.5364 & TST \\
\hline CHEMBL 2006188 & 809121 & 5.4 & 4.5389 & TRN \\
\hline
\end{tabular}




\begin{tabular}{|c|c|c|c|c|c|}
\hline \multicolumn{6}{|c|}{ Supplemental Table S2.txt } \\
\hline CHEMBL1973893 & 809121 & 6.1 & 5.97 & TRN & \\
\hline CHEMBL1995736 & 809121 & 5.6 & 5.2597 & TRN & \\
\hline CHEMBL1985095 & 809121 & 7.0 & 6.88899 & 9999999999 & TST \\
\hline CHEMBL1996500 & 809121 & 4.5 & 4.2809 & TRN & \\
\hline CHEMBL1682540 & 809121 & 7.5 & 7.2568 & TRN & \\
\hline CHEMBL1998253 & 809121 & 5.8 & 4.697 & TST & \\
\hline CHEMBL413779 & 809121 & 4.2 & 4.1848 & TST & \\
\hline CHEMBL497151 & 809121 & 6.5 & 6.2508 & TRN & \\
\hline CHEMBL 2000029 & 809121 & 6.1 & 7.455 & TRN & \\
\hline CHEMBL1973961 & 809121 & 4.8 & 4.7816 & TRN & \\
\hline CHEMBL1994977 & 809121 & 4.7 & 4.2728 & TRN & \\
\hline CHEMBL373598 & 809121 & 4.2 & 4.2119 & TST & \\
\hline CHEMBL1999718 & 809121 & 5.5 & 5.0769 & TRN & \\
\hline CHEMBL1987073 & 809121 & 7.0 & 7.2018 & TRN & \\
\hline CHEMBL 2000078 & 809121 & 4.8 & 4.7261 & TRN & \\
\hline CHEMBL1996646 & 809121 & 4.7 & 4.8668 & TRN & \\
\hline CHEMBL1979773 & 809121 & 4.7 & 5.0463 & TRN & \\
\hline CHEMBL1977346 & 809121 & 4.2 & 5.0653 & TRN & \\
\hline CHEMBL1996702 & 809121 & 6.5 & 6.476 & TRN & \\
\hline CHEMBL1998435 & 809121 & 5.8 & 5.7747 & TRN & \\
\hline CHEMBL1969190 & 809121 & 4.2 & 4.7276 & TRN & \\
\hline CHEMBL1973937 & 809121 & 4.2 & 4.4014 & TRN & \\
\hline CHEMBL1987982 & 809121 & 4.2 & 4.1667 & TST & \\
\hline CHEMBL1969102 & 809121 & 4.2 & 4.3953 & TRN & \\
\hline CHEMBL 2004118 & 809121 & 4.7 & 4.6172 & TRN & \\
\hline CHEMBL1682346 & 809121 & 7.1 & 7.50200 & 0000000001 & TRN \\
\hline CHEMBL1996795 & 809121 & 5.8 & 4.9766 & TST & \\
\hline CHEMBL1994241 & 809121 & 8.1 & 7.456 & TRN & \\
\hline CHEMBL 2007044 & 809121 & 4.2 & 4.3446 & TST & \\
\hline CHEMBL 2001998 & 809121 & 4.2 & 4.2397 & TST & \\
\hline CHEMBL50894 & 809121 & 4.4 & 5.2504 & TRN & \\
\hline CHEMBL1995211 & 809121 & 5.9 & 5.8642 & TRN & \\
\hline CHEMBL1988838 & 809121 & 5.7 & 6.3271 & TRN & \\
\hline CHEMBL1981725 & 809121 & 4.2 & 4.0688 & TRN & \\
\hline CHEMBL1982753 & 809121 & 5.8 & 5.7432 & TRN & \\
\hline CHEMBL1965169 & 809121 & 4.7 & 5.5627 & TST & \\
\hline CHEMBL1081312 & 809121 & 5.0 & 5.364 & TRN & \\
\hline CHEMBL1965170 & 809121 & 4.7 & 4.5002 & TRN & \\
\hline CHEMBL 2005792 & 809121 & 4.7 & 4.0901 & TRN & \\
\hline CHEMBL1984206 & 809121 & 4.2 & 4.4501 & TRN & \\
\hline CHEMBL462120 & 809121 & 5.6 & 4.9089 & TRN & \\
\hline CHEMBL1991577 & 809121 & 4.2 & 4.4576 & TRN & \\
\hline CHEMBL 2007592 & 809121 & 5.6 & 5.4717 & TRN & \\
\hline CHEMBL1997892 & 809121 & 4.7 & 4.3165 & TRN & \\
\hline CHEMBL1976936 & 809121 & 8.3 & 6.8068 & TRN & \\
\hline CHEMBL210963 & 809121 & 4.2 & 4.0051 & TRN & \\
\hline CHEMBL1984633 & 809121 & 4.2 & 4.9145 & TRN & \\
\hline CHEMBL1965845 & 809121 & 6.8 & 6.5303 & TRN & \\
\hline
\end{tabular}




\begin{tabular}{|c|c|c|c|c|c|}
\hline \multicolumn{6}{|c|}{ Supplemental Table S2.txt } \\
\hline CHEMBL1983715 & 809121 & 6.7 & 6.2879 & TRN & \\
\hline CHEMBL402846 & 809121 & 6.5 & 5.0898 & TRN & \\
\hline CHEMBL1682545 & 809121 & 6.7 & 6.6844 & TRN & \\
\hline CHEMBL1976732 & 809121 & 6.1 & 4.0605 & TRN & \\
\hline CHEMBL1980163 & 809121 & 4.2 & 4.2498 & TRN & \\
\hline CHEMBL1989856 & 809121 & 6.3 & 5.5648 & TST & \\
\hline CHEMBL1972568 & 809121 & 5.7 & 5.5218 & TRN & \\
\hline CHEMBL259850 & 809121 & 4.2 & 4.9967 & TRN & \\
\hline CHEMBL105739 & 809121 & 4.2 & 4.5177 & TRN & \\
\hline CHEMBL203673 & 809121 & 6.7 & 6.3862 & TRN & \\
\hline CHEMBL1972583 & 809121 & 3.1 & 4.4087 & TRN & \\
\hline CHEMBL 2003785 & 809121 & 4.4 & 4.8956 & TST & \\
\hline CHEMBL1983070 & 809121 & 4.7 & 4.4686 & TRN & \\
\hline CHEMBL 2002470 & 809121 & 5.6 & 5.36600 & 00000000005 & TST \\
\hline CHEMBL1981045 & 809121 & 4.2 & 4.5561 & TRN & \\
\hline CHEMBL387971 & 809121 & 4.2 & 4.7366 & TST & \\
\hline CHEMBL1975418 & 809121 & 7.2 & 6.8215 & TRN & \\
\hline CHEMBL1992796 & 809121 & 4.2 & 4.7015 & TRN & \\
\hline CHEMBL1968515 & 809121 & 4.2 & 4.3698 & TST & \\
\hline CHEMBL1164180 & 809121 & 4.7 & 4.9329 & TST & \\
\hline CHEMBL223257 & 809121 & 4.2 & 4.398 & TST & \\
\hline CHEMBL1997611 & 809121 & 6.1 & 5.4546 & TST & \\
\hline CHEMBL1516890 & 809121 & 5.6 & 5.9701 & TRN & \\
\hline CHEMBL 2001751 & 809121 & 8.6 & 7.7532 & TRN & \\
\hline CHEMBL1984586 & 809121 & 4.2 & 4.4355 & TRN & \\
\hline CHEMBL1999774 & 809121 & 4.2 & 4.7597 & TRN & \\
\hline CHEMBL1972659 & 809121 & 4.2 & 4.8489 & TST & \\
\hline CHEMBL1984632 & 809121 & 5.9 & 5.2431 & TST & \\
\hline CHEMBL1973395 & 809121 & 6.4 & 5.2579 & TRN & \\
\hline CHEMBL1984686 & 809121 & 4.7 & 5.5298 & TRN & \\
\hline CHEMBL1969843 & 809121 & 6.4 & 6.4474 & TRN & \\
\hline CHEMBL 2007002 & 809121 & 7.1 & 6.6297 & TRN & \\
\hline CHEMBL1992073 & 809121 & 4.7 & 5.1121 & TRN & \\
\hline CHEMBL484390 & 809121 & 5.4 & 5.3149 & TST & \\
\hline CHEMBL 2007559 & 809121 & 4.7 & 5.0249 & TRN & \\
\hline CHEMBL 2004290 & 809121 & 4.4 & 4.2988 & TRN & \\
\hline CHEMBL 2000393 & 809121 & 5.6 & 5.2315 & TST & \\
\hline CHEMBL 2004072 & 809121 & 6.1 & 5.1208 & TRN & \\
\hline CHEMBL1089101 & 809121 & 5.4 & 5.3104 & TRN & \\
\hline CHEMBL1983573 & 809121 & 3.1 & 4.4948 & TRN & \\
\hline CHEMBL1242373 & 809121 & 6.5 & 5.5514 & TRN & \\
\hline CHEMBL 2000433 & 809121 & 5.3 & 5.4392 & TST & \\
\hline CHEMBL56543 & 809121 & 4.2 & 4.9237 & TRN & \\
\hline CHEMBL1984402 & 809121 & 3.1 & 4.0366 & TRN & \\
\hline CHEMBL1988075 & 809121 & 4.2 & 4.2227 & TRN & \\
\hline CHEMBL1988076 & 809121 & 4.8 & 4.5078 & TRN & \\
\hline CHEMBL 2001239 & 809121 & 4.2 & 4.9282 & TRN & \\
\hline CHEMBL 2001288 & 809121 & 6.4 & 6.0427 & TRN & \\
\hline
\end{tabular}




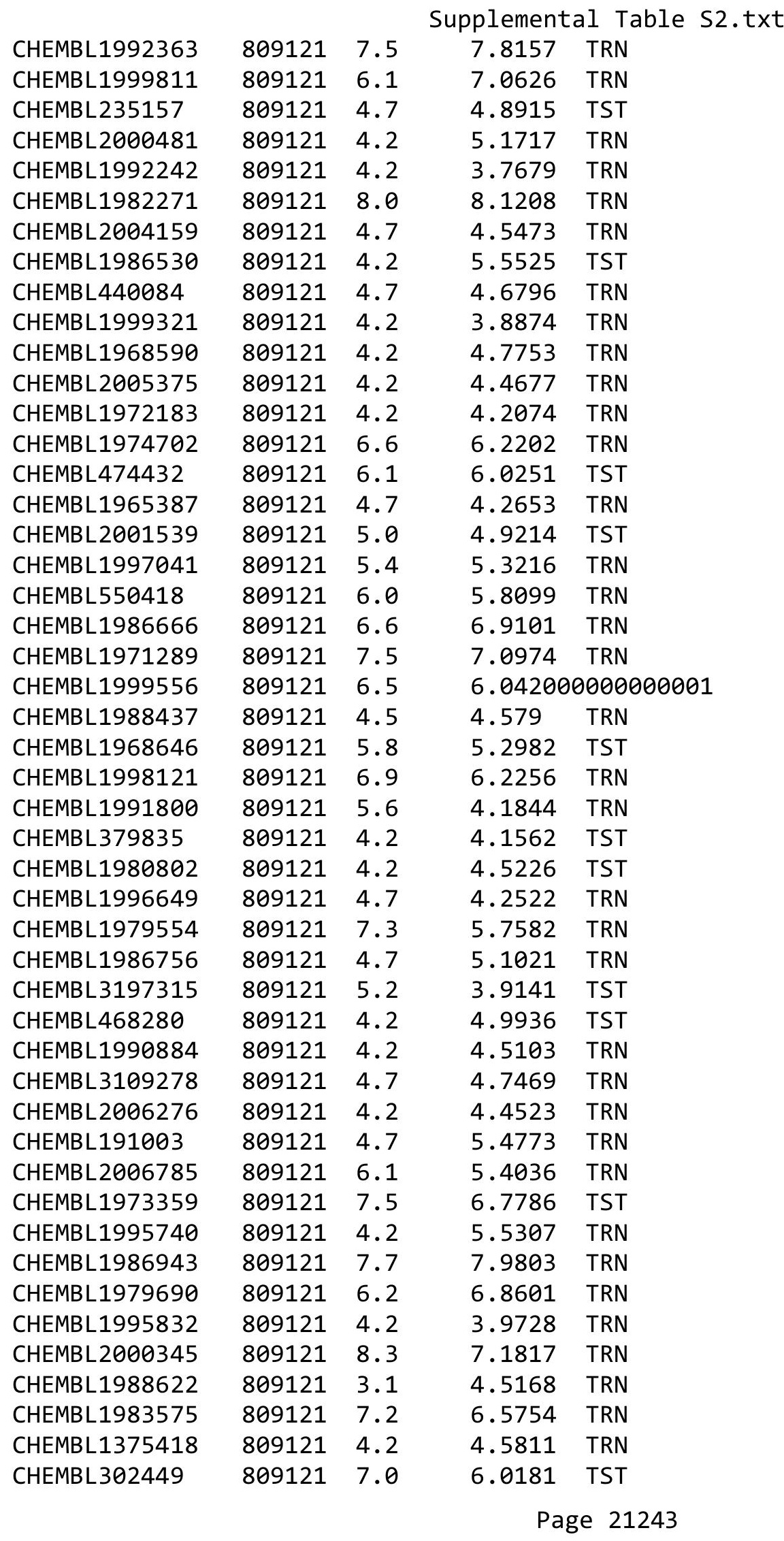




\begin{tabular}{|c|c|c|c|c|c|}
\hline & & & & & \\
\hline CHEMBL1981047 & 809121 & 4.4 & 4.4704 & TRN & \\
\hline CHEMBL1976196 & 809121 & 4.7 & 4.9008 & TST & \\
\hline CHEMBL1976240 & 809121 & 5.3 & 5.1904 & TRN & \\
\hline CHEMBL1987948 & 809121 & 7.3 & 7.7842 & TRN & \\
\hline CHEMBL1983630 & 809121 & 4.4 & 4.4478 & TRN & \\
\hline CHEMBL1979093 & 809121 & 4.2 & 4.79899 & 99999999995 & TRN \\
\hline CHEMBL336961 & 809121 & 5.3 & 5.6195 & TRN & \\
\hline CHEMBL1970083 & 809121 & 4.2 & 4.8364 & TRN & \\
\hline CHEMBL1994938 & 809121 & 4.2 & 4.7491 & TRN & \\
\hline CHEMBL1977223 & 809121 & 7.7 & 7.8301 & TRN & \\
\hline CHEMBL1976290 & 809121 & 3.1 & 4.2695 & TRN & \\
\hline CHEMBL1997846 & 809121 & 6.2 & 5.7767 & TRN & \\
\hline CHEMBL2004419 & 809121 & 5.2 & 4.8485 & TRN & \\
\hline CHEMBL1992937 & 809121 & 6.4 & 6.5771 & TST & \\
\hline CHEMBL1985566 & 809121 & 4.2 & 4.65300 & 00000000005 & TRN \\
\hline CHEMBL1972119 & 809121 & 4.2 & 4.8015 & TRN & \\
\hline CHEMBL95692 & 809121 & 4.2 & 4.4476 & TRN & \\
\hline CHEMBL1976455 & 809121 & 6.4 & 7.1915 & TRN & \\
\hline CHEMBL1983923 & 809121 & 4.7 & 4.9663 & TRN & \\
\hline CHEMBL1983534 & 809121 & 8.2 & 6.6621 & TRN & \\
\hline CHEMBL1982361 & 809121 & 4.3 & 4.1686 & TRN & \\
\hline CHEMBL2000801 & 809121 & 4.4 & 3.7444 & TRN & \\
\hline CHEMBL1991395 & 809121 & 4.2 & 4.2985 & TRN & \\
\hline CHEMBL1971245 & 809121 & 4.2 & 4.4257 & TRN & \\
\hline CHEMBL2003545 & 809121 & 4.6 & 4.7699 & TST & \\
\hline CHEMBL1987648 & 809121 & 5.5 & 3.9777 & TRN & \\
\hline CHEMBL1972142 & 809121 & 4.6 & 4.6439 & TRN & \\
\hline CHEMBL 2002182 & 809121 & 4.4 & 4.152 & TRN & \\
\hline CHEMBL1966514 & 809121 & 4.2 & 4.7243 & TRN & \\
\hline CHEMBL2003638 & 809121 & 7.5 & 7.7895 & TRN & \\
\hline CHEMBL1983393 & 809121 & 4.7 & 5.1789 & TRN & \\
\hline CHEMBL516429 & 809121 & 8.4 & 8.1535 & TRN & \\
\hline CHEMBL1970806 & 809121 & 5.2 & 5.086 & TRN & \\
\hline CHEMBL1992371 & 809121 & 5.9 & 6.46 & TRN & \\
\hline CHEMBL1979970 & 809121 & 7.6 & 6.1701 & TRN & \\
\hline CHEMBL1967252 & 809121 & 7.4 & 7.2419 & TRN & \\
\hline CHEMBL2004637 & 809121 & 4.7 & 5.3792 & TRN & \\
\hline CHEMBL1993374 & 809121 & 4.7 & 5.5192 & TST & \\
\hline CHEMBL1969264 & 809121 & 6.1 & 5.28700 & 0000000001 & TRN \\
\hline CHEMBL2006237 & 809121 & 5.4 & 5.8855 & TRN & \\
\hline CHEMBL2005509 & 809121 & 8.6 & 8.1325 & TRN & \\
\hline CHEMBL1572266 & 809121 & 4.2 & 4.3188 & TRN & \\
\hline CHEMBL1979516 & 809121 & 4.2 & 4.1288 & TRN & \\
\hline CHEMBL1972820 & 809121 & 4.2 & 4.4453 & TST & \\
\hline CHEMBL1605605 & 809121 & 4.7 & 4.6867 & TRN & \\
\hline CHEMBL1989029 & 809121 & 6.2 & 4.8406 & TRN & \\
\hline CHEMBL392642 & 809121 & 5.5 & 5.6094 & TRN & \\
\hline CHEMBL1972849 & 809121 & 4.2 & 4.2038 & TRN & \\
\hline & & & & 21244 & \\
\hline
\end{tabular}




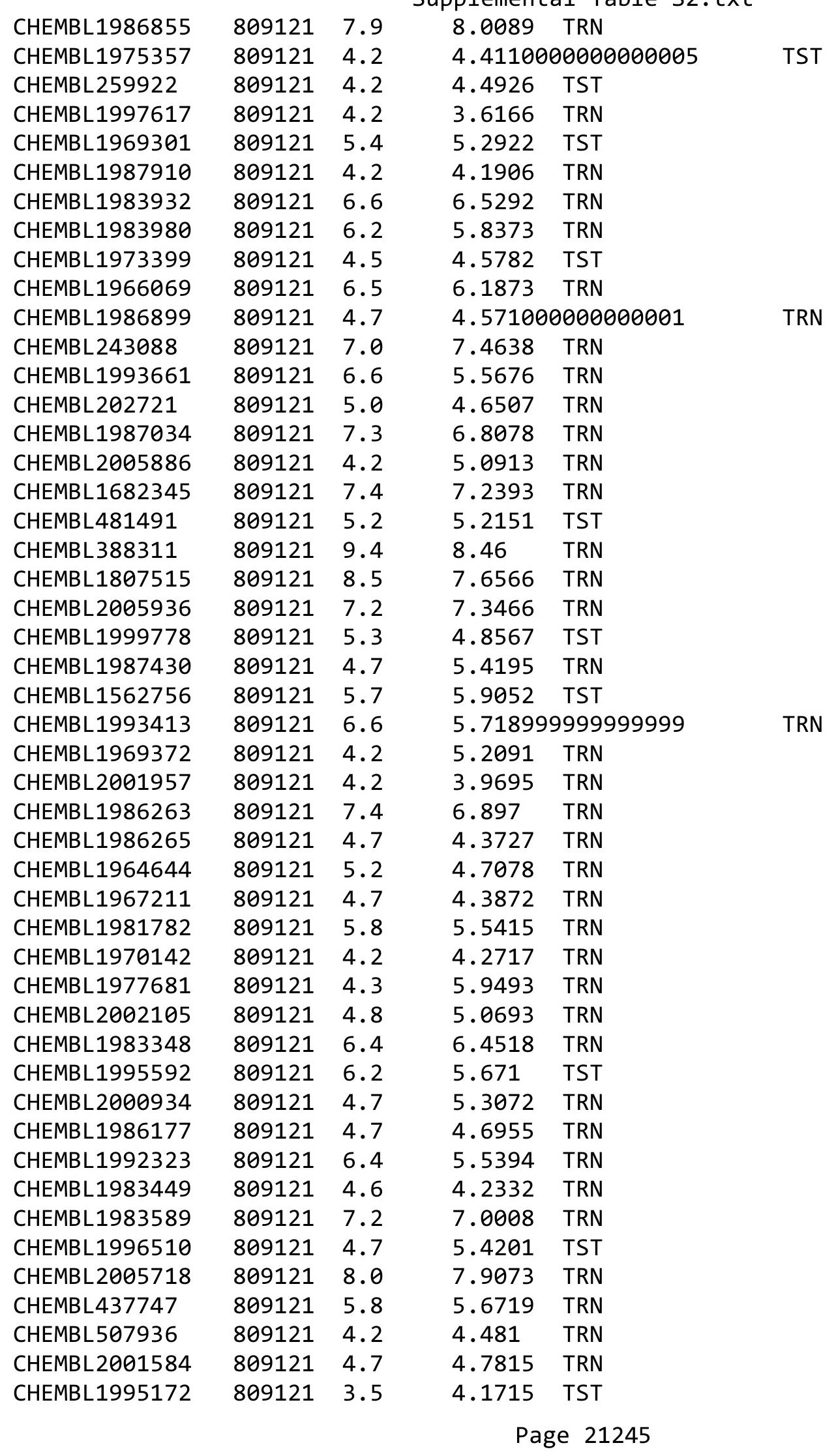




\begin{tabular}{|c|c|c|c|c|}
\hline & & & ipplemen & al Table S \\
\hline CHEMBL1967998 & 809121 & 5.8 & 6.7633 & TRN \\
\hline CHEMBL104264 & 809121 & 4.2 & 5.7570 & 0000000001 \\
\hline CHEMBL1984788 & 809121 & 5.2 & 5.822 & TRN \\
\hline CHEMBL451964 & 809121 & 4.2 & 4.9259 & TRN \\
\hline CHEMBL1996604 & 809121 & 5.2 & 6.2706 & TRN \\
\hline CHEMBL1974875 & 809121 & 5.2 & 4.6568 & TST \\
\hline CHEMBL 2001547 & 809121 & 4.2 & 4.2366 & TRN \\
\hline CHEMBL 210928 & 809121 & 4.2 & 4.1179 & TRN \\
\hline CHEMBL1972840 & 809121 & 7.5 & 7.8909 & TRN \\
\hline CHEMBL 2001668 & 809121 & 4.2 & 5.1574 & TRN \\
\hline CHEMBL1998585 & 809121 & 5.2 & 5.1188 & TRN \\
\hline CHEMBL 2004934 & 809121 & 4.2 & 4.513 & TRN \\
\hline CHEMBL1987261 & 809121 & 8.2 & 7.7931 & TRN \\
\hline CHEMBL1996048 & 809121 & 4.7 & 5.1129 & TST \\
\hline CHEMBL 2004025 & 809121 & 6.5 & 5.4357 & TRN \\
\hline CHEMBL461876 & 809121 & 4.8 & 5.8699 & TRN \\
\hline CHEMBL1971519 & 809121 & 4.6 & 5.4963 & TRN \\
\hline CHEMBL1997335 & 809121 & 7.1 & 6.119 & TRN \\
\hline CHEMBL1978099 & 809121 & 5.4 & 5.8923 & TRN \\
\hline CHEMBL1984363 & 809121 & 5.4 & 5.516 & TRN \\
\hline CHEMBL1977041 & 809121 & 6.3 & 4.6175 & TRN \\
\hline CHEMBL1968070 & 809121 & 5.9 & 5.6065 & TRN \\
\hline CHEMBL1994808 & 809121 & 4.2 & 4.3668 & TRN \\
\hline CHEMBL1985723 & 809121 & 7.2 & 7.7691 & TRN \\
\hline CHEMBL1984367 & 809121 & 4.2 & 4.7706 & TRN \\
\hline CHEMBL1977128 & 809121 & 7.5 & 7.4395 & TRN \\
\hline CHEMBL1997759 & 809121 & 4.2 & 4.3765 & TRN \\
\hline CHEMBL1970074 & 809121 & 4.2 & 4.4987 & TRN \\
\hline CHEMBL1974803 & 809121 & 6.1 & 5.5448 & TRN \\
\hline CHEMBL1984500 & 809121 & 4.7 & 4.0657 & TRN \\
\hline CHEMBL1968103 & 809121 & 5.5 & 4.5128 & TRN \\
\hline CHEMBL 2005112 & 809121 & 5.7 & 5.9454 & TST \\
\hline CHEMBL 2003456 & 809121 & 4.2 & 4.7116 & TRN \\
\hline CHEMBL 2002992 & 809121 & 4.9 & 5.1901 & TRN \\
\hline CHEMBL560813 & 809121 & 6.5 & 5.4747 & TRN \\
\hline CHEMBL207253 & 809121 & 4.2 & 5.2382 & TST \\
\hline CHEMBL1968791 & 809121 & 4.2 & 4.1242 & TRN \\
\hline CHEMBL 2002682 & 809121 & 4.2 & 4.3549 & TST \\
\hline CHEMBL1984700 & 809121 & 4.2 & 4.043 & TRN \\
\hline CHEMBL1998953 & 809121 & 4.7 & 4.8174 & TRN \\
\hline CHEMBL 2007151 & 809121 & 4.2 & 4.1783 & TRN \\
\hline CHEMBL1971606 & 809121 & 4.7 & 4.9865 & TRN \\
\hline CHEMBL1972125 & 809121 & 5.9 & 5.9882 & TRN \\
\hline CHEMBL1461728 & 809121 & 5.6 & 5.4936 & TRN \\
\hline CHEMBL1995448 & 809121 & 5.2 & 5.4933 & TRN \\
\hline CHEMBL1972158 & 809121 & 7.5 & 7.6381 & TRN \\
\hline CHEMBL1999414 & 809121 & 4.7 & 4.405 & TRN \\
\hline CHEMBL1967336 & 809121 & 4.7 & 5.5135 & TRN \\
\hline
\end{tabular}




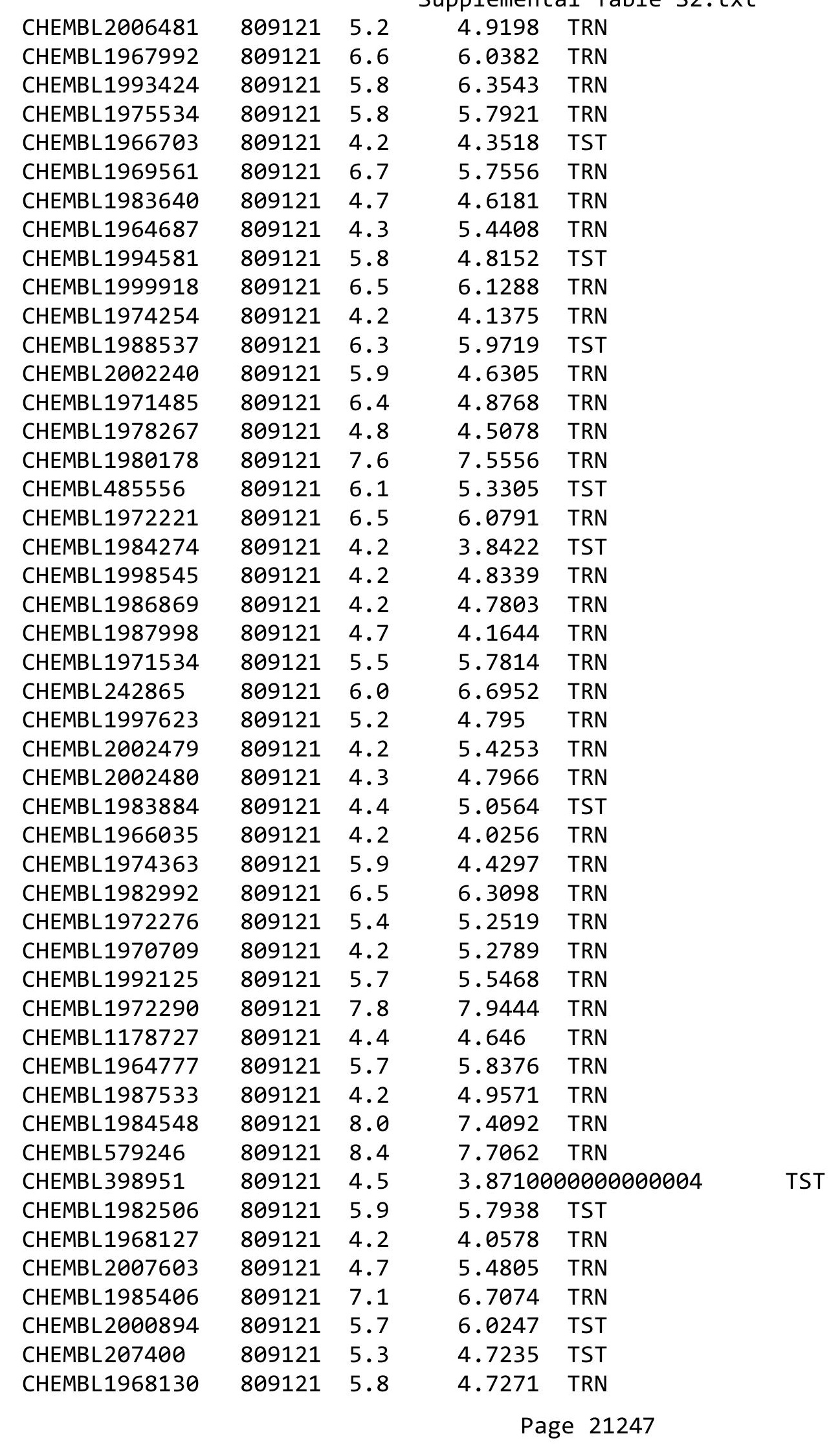




\begin{tabular}{|c|c|c|c|c|}
\hline \multicolumn{5}{|c|}{ Supplemental Table S2.txt } \\
\hline CHEMBL1993243 & 809121 & 4.2 & 4.7089 & TRN \\
\hline CHEMBL399021 & 809121 & 4.2 & 4.0812 & TRN \\
\hline CHEMBL1969537 & 809121 & 5.4 & 5.7534 & TST \\
\hline CHEMBL 210032 & 809121 & 4.2 & 4.7793 & TRN \\
\hline CHEMBL508928 & 809121 & 5.9 & 4.8909 & TRN \\
\hline CHEMBL1991356 & 809121 & 4.2 & 5.223 & TST \\
\hline CHEMBL1983309 & 809121 & 4.2 & 5.0678 & TRN \\
\hline CHEMBL 2004892 & 809121 & 6.1 & 5.8825 & TRN \\
\hline CHEMBL1972339 & 809121 & 7.7 & 7.6785 & TRN \\
\hline CHEMBL1970314 & 809121 & 4.3 & 4.8278 & TRN \\
\hline CHEMBL262433 & 809121 & 4.2 & 4.7367 & TRN \\
\hline CHEMBL 306380 & 809121 & 4.2 & 4.8443 & TRN \\
\hline CHEMBL1983595 & 809121 & 7.4 & 7.1535 & TRN \\
\hline CHEMBL1966722 & 809121 & 5.3 & 5.1354 & TRN \\
\hline CHEMBL1975500 & 809121 & 6.5 & 6.5125 & TRN \\
\hline CHEMBL1988581 & 809121 & 7.6 & 7.2133 & TST \\
\hline CHEMBL394619 & 809121 & 4.2 & 4.5937 & TRN \\
\hline CHEMBL 2006564 & 809121 & 4.7 & 5.4565 & TRN \\
\hline CHEMBL411903 & 809121 & 5.8 & 5.6091 & TRN \\
\hline CHEMBL1965988 & 809121 & 4.2 & 4.7654 & TRN \\
\hline CHEMBL418203 & 809121 & 6.1 & 5.6907 & TST \\
\hline CHEMBL1989646 & 809121 & 7.0 & 7.317 & TRN \\
\hline CHEMBL209534 & 809121 & 4.2 & 4.7151 & TRN \\
\hline CHEMBL1994159 & 809121 & 3.1 & 4.0039 & TRN \\
\hline CHEMBL1966087 & 809121 & 5.9 & 5.7795 & TRN \\
\hline CHEMBL1964692 & 809121 & 6.6 & 5.5752 & TRN \\
\hline CHEMBL1973483 & 809121 & 4.2 & 4.9088 & TRN \\
\hline CHEMBL219722 & 809121 & 5.8 & 5.1191 & TRN \\
\hline CHEMBL1970735 & 809121 & 4.2 & 4.3103 & TRN \\
\hline CHEMBL1997340 & 809121 & 4.2 & 5.1522 & TRN \\
\hline CHEMBL1994669 & 809121 & 8.2 & 7.4775 & TRN \\
\hline CHEMBL458997 & 809121 & 6.4 & 5.8085 & TRN \\
\hline CHEMBL1988805 & 809121 & 4.7 & 5.9906 & TST \\
\hline CHEMBL1971021 & 809121 & 4.2 & 3.7556 & TRN \\
\hline CHEMBL1974310 & 809121 & 5.8 & 6.3025 & TRN \\
\hline CHEMBL583144 & 809121 & 7.0 & 6.5414 & TRN \\
\hline CHEMBL1982957 & 809121 & 7.6 & 6.0003 & TRN \\
\hline CHEMBL1725279 & 809121 & 6.9 & 6.4329 & TST \\
\hline CHEMBL2006836 & 809121 & 5.5 & 5.1256 & TST \\
\hline CHEMBL412142 & 809121 & 4.2 & 4.9434 & TST \\
\hline CHEMBL 2003271 & 809121 & 6.8 & 6.9531 & TRN \\
\hline CHEMBL1980704 & 809121 & 5.2 & 5.0558 & TST \\
\hline CHEMBL1966808 & 809121 & 6.8 & 6.0502 & TRN \\
\hline CHEMBL260135 & 809121 & 5.6 & 5.3231 & TRN \\
\hline CHEMBL220241 & 809121 & 4.2 & 5.2824 & TRN \\
\hline CHEMBL 2004544 & 809121 & 5.8 & 5.1768 & TST \\
\hline CHEMBL1988141 & 809121 & 6.9 & 6.1578 & TST \\
\hline CHEMBL1977134 & 809121 & 4.7 & 4.3203 & TRN \\
\hline
\end{tabular}




\begin{tabular}{|c|c|c|c|c|c|}
\hline & & & & & \\
\hline CHEMBL1970873 & 809121 & 3.4 & 2.9079 & TRN & \\
\hline CHEMBL1986996 & 809121 & 5.8 & 5.0195 & TST & \\
\hline CHEMBL1985206 & 809121 & 4.7 & 5.1975 & TST & \\
\hline CHEMBL2006933 & 809121 & 7.7 & 6.3835 & TST & \\
\hline CHEMBL1991078 & 809121 & 7.0 & 7.5376 & TRN & \\
\hline CHEMBL1987359 & 809121 & 4.2 & 4.6849 & TST & \\
\hline CHEMBL1977749 & 809121 & 4.7 & 6.0397 & TST & \\
\hline CHEMBL 2000685 & 809121 & 4.2 & 5.2693 & TRN & \\
\hline CHEMBL1994438 & 809121 & 7.7 & 7.5303 & TRN & \\
\hline CHEMBL1967513 & 809121 & 4.7 & 5.4369 & TRN & \\
\hline CHEMBL1980376 & 809121 & 4.9 & 4.4251 & TRN & \\
\hline CHEMBL1985311 & 809121 & 5.8 & 5.6685 & TRN & \\
\hline CHEMBL 2000724 & 809121 & 4.7 & 4.3723 & TRN & \\
\hline CHEMBL1982413 & 809121 & 6.2 & 6.1588 & TRN & \\
\hline CHEMBL1682553 & 809121 & 7.7 & 7.6485 & TRN & \\
\hline CHEMBL1969502 & 809121 & 5.2 & 5.8859 & TRN & \\
\hline CHEMBL1971430 & 809121 & 4.2 & 4.0638 & TRN & \\
\hline CHEMBL1997764 & 809121 & 6.1 & 5.1761 & TRN & \\
\hline CHEMBL354676 & 809121 & 3.1 & 3.8322 & TRN & \\
\hline CHEMBL1987535 & 809121 & 6.9 & 6.8091 & TRN & \\
\hline CHEMBL1981792 & 809121 & 4.7 & 4.7302 & TRN & \\
\hline CHEMBL 2002586 & 809121 & 4.7 & 4.7222 & TRN & \\
\hline CHEMBL 2004692 & 809121 & 4.2 & 3.9689 & TST & \\
\hline CHEMBL1987815 & 809121 & 3.1 & 4.8405 & TST & \\
\hline CHEMBL1996234 & 809121 & 4.2 & 4.0171 & TRN & \\
\hline CHEMBL1967544 & 809121 & 6.4 & 6.5192 & TRN & \\
\hline CHEMBL1992673 & 809121 & 4.2 & 4.5119 & TRN & \\
\hline CHEMBL 223367 & 809121 & 4.2 & 4.4171 & TST & \\
\hline CHEMBL1993335 & 809121 & 4.7 & 5.7648 & TST & \\
\hline CHEMBL 2007574 & 809121 & 8.3 & 8.0695 & TRN & \\
\hline CHEMBL1964804 & 809121 & 7.3 & 7.28299 & 99999999995 & TRN \\
\hline CHEMBL443962 & 809121 & 5.6 & 5.8664 & TRN & \\
\hline CHEMBL1965507 & 809121 & 4.2 & 4.5104 & TRN & \\
\hline CHEMBL 2000354 & 809121 & 7.7 & 7.3705 & TRN & \\
\hline CHEMBL1998680 & 809121 & 4.7 & 4.2996 & TRN & \\
\hline CHEMBL274064 & 809121 & 4.2 & 5.4186 & TRN & \\
\hline CHEMBL1967564 & 809121 & 6.3 & $5.4570 e$ & 0000000001 & TRN \\
\hline CHEMBL1970317 & 809121 & 4.7 & 4.0615 & TRN & \\
\hline CHEMBL 2000408 & 809121 & 4.2 & 4.2322 & TRN & \\
\hline CHEMBL1978014 & 809121 & 4.6 & 5.3836 & TRN & \\
\hline CHEMBL248757 & 809121 & 5.5 & 4.6629 & TST & \\
\hline CHEMBL1997007 & 809121 & 5.8 & 5.1579 & TRN & \\
\hline CHEMBL1994538 & 809121 & 6.6 & $5.9620 e$ & 0000000001 & TRN \\
\hline CHEMBL1975490 & 809121 & 4.2 & 4.8418 & TRN & \\
\hline CHEMBL 2002690 & 809121 & 4.7 & 4.8176 & TRN & \\
\hline CHEMBL383527 & 809121 & 6.7 & 5.6822 & TRN & \\
\hline CHEMBL1975503 & 809121 & 3.1 & 4.2012 & TRN & \\
\hline CHEMBL1986139 & 809121 & 5.2 & 5.6539 & TRN & \\
\hline & & & & 21249 & \\
\hline
\end{tabular}




\begin{tabular}{|c|c|c|c|c|c|}
\hline \\
\hline CHEMBL2006567 & 809121 & 5.7 & 5.0909 & TRN & \\
\hline CHEMBL1979883 & 809121 & 4.2 & 4.6645 & TRN & \\
\hline CHEMBL1997051 & 809121 & 4.8 & 4.819 & TRN & \\
\hline CHEMBL491758 & 809121 & 4.2 & 5.032 & TRN & \\
\hline CHEMBL1986590 & 809121 & 4.7 & 4.5364 & TRN & \\
\hline CHEMBL86066 & 809121 & 5.5 & 5.4558 & TST & \\
\hline CHEMBL1682360 & 809121 & 6.2 & 6.1995 & TRN & \\
\hline CHEMBL549730 & 809121 & 4.2 & 4.4097 & TRN & \\
\hline CHEMBL1996473 & 809121 & 5.3 & 5.4761 & TST & \\
\hline CHEMBL1970189 & 809121 & 4.2 & 4.3942 & TRN & \\
\hline CHEMBL406845 & 809121 & 4.7 & 4.7399 & TRN & \\
\hline CHEMBL1974288 & 809121 & 5.6 & 5.13299 & 9999999999 & TRN \\
\hline CHEMBL1964718 & 809121 & 4.9 & 4.2554 & TST & \\
\hline CHEMBL1991410 & 809121 & 6.6 & 5.7092 & TRN & \\
\hline CHEMBL1968705 & 809121 & 4.5 & 5.1045 & TRN & \\
\hline CHEMBL1986684 & 809121 & 3.1 & 4.4722 & TST & \\
\hline CHEMBL1978271 & 809121 & 4.7 & 4.2882 & TRN & \\
\hline CHEMBL 2007266 & 809121 & 4.7 & 4.4075 & TRN & \\
\hline CHEMBL1977604 & 809121 & 4.2 & 4.5545 & TRN & \\
\hline CHEMBL1974328 & 809121 & 4.8 & 6.0626 & TRN & \\
\hline CHEMBL1988717 & 809121 & 4.2 & 4.2472 & TRN & \\
\hline CHEMBL509032 & 809121 & 4.8 & 5.756 & TRN & \\
\hline CHEMBL1992342 & 809121 & 6.2 & 6.1252 & TRN & \\
\hline CHEMBL1973013 & 809121 & 4.7 & 5.897 & TST & \\
\hline CHEMBL1164265 & 809121 & 5.9 & 5.4012 & TST & \\
\hline CHEMBL1966204 & 809121 & 7.9 & 7.8743 & TRN & \\
\hline CHEMBL1965423 & 809121 & 5.4 & 5.3865 & TRN & \\
\hline CHEMBL 205415 & 809121 & 6.6 & 6.4744 & TRN & \\
\hline CHEMBL1977135 & 809121 & 5.4 & 4.9186 & TRN & \\
\hline CHEMBL 2001920 & 809121 & 6.0 & 5.9292 & TRN & \\
\hline CHEMBL1977138 & 809121 & 7.2 & 7.1055 & TST & \\
\hline CHEMBL1241473 & 809121 & 8.2 & 7.3814 & TRN & \\
\hline CHEMBL1978448 & 809121 & 4.4 & 4.7512 & TST & \\
\hline CHEMBL1972258 & 809121 & 5.7 & 6.3178 & TRN & \\
\hline CHEMBL1969483 & 809121 & 4.8 & 4.7298 & TRN & \\
\hline CHEMBL2001257 & 809121 & 4.2 & 3.9338 & TRN & \\
\hline CHEMBL 2004515 & 809121 & 6.2 & 5.8243 & TRN & \\
\hline CHEMBL1980329 & 809121 & 4.7 & 6.1624 & TRN & \\
\hline CHEMBL1992536 & 809121 & 4.6 & 5.2972 & TRN & \\
\hline CHEMBL1994724 & 809121 & 4.7 & 4.852 & TRN & \\
\hline CHEMBL1970290 & 809121 & 4.7 & 4.85 & TRN & \\
\hline CHEMBL1967531 & 809121 & 5.7 & 4.7992 & TRN & \\
\hline CHEMBL1970913 & 809121 & 6.0 & 5.2348 & TRN & \\
\hline CHEMBL1997534 & 809121 & 4.2 & 5.9202 & TRN & \\
\hline CHEMBL1993877 & 809121 & 6.6 & 5.8658 & TRN & \\
\hline CHEMBL1977374 & 809121 & 4.2 & 4.5738 & TRN & \\
\hline CHEMBL1998551 & 809121 & 4.2 & 4.6512 & TRN & \\
\hline CHEMBL1991180 & 809121 & 5.4 & 5.6842 & TST & \\
\hline
\end{tabular}




\begin{tabular}{|c|c|c|c|c|c|}
\hline \multicolumn{6}{|c|}{ Supplemental Table S2.txt } \\
\hline CHEMBL1978656 & 809121 & 4.2 & 4.8577 & TRN & \\
\hline CHEMBL1976420 & 809121 & 4.4 & 4.7031 & TST & \\
\hline CHEMBL1981744 & 809121 & 4.7 & 4.8294 & TRN & \\
\hline CHEMBL1994864 & 809121 & 4.5 & 4.0556 & TRN & \\
\hline CHEMBL 2002446 & 809121 & 4.2 & 5.0081 & TST & \\
\hline CHEMBL246970 & 809121 & 5.6 & 5.5473 & TRN & \\
\hline CHEMBL340921 & 809121 & 5.9 & 5.8743 & TST & \\
\hline CHEMBL 2005478 & 809121 & 4.7 & 5.4801 & TST & \\
\hline CHEMBL1276446 & 809121 & 8.1 & 6.0965 & TST & \\
\hline CHEMBL1995712 & 809121 & 7.3 & 7.4789 & TRN & \\
\hline CHEMBL1971649 & 809121 & 4.2 & 4.6101 & TRN & \\
\hline CHEMBL 2003657 & 809121 & 6.0 & 4.898 & TRN & \\
\hline CHEMBL 2005482 & 809121 & 4.8 & 4.8767 & TRN & \\
\hline CHEMBL1992723 & 809121 & 4.2 & 3.7907 & TRN & \\
\hline CHEMBL 2007124 & 809121 & 4.7 & 4.2347 & TRN & \\
\hline CHEMBL1997909 & 809121 & 4.8 & 4.5408 & TRN & \\
\hline CHEMBL 2006439 & 809121 & 7.7 & 7.2155 & TRN & \\
\hline CHEMBL2006156 & 809121 & 4.2 & 4.913 & TST & \\
\hline CHEMBL1985681 & 809121 & 7.0 & 5.9895 & TST & \\
\hline CHEMBL1991674 & 809121 & 7.3 & 6.8126 & TRN & \\
\hline CHEMBL262623 & 809121 & 5.5 & 5.0285 & TRN & \\
\hline CHEMBL1984842 & 809121 & 4.4 & 4.1559 & TRN & \\
\hline CHEMBL223460 & 809121 & 4.2 & 4.2997 & TST & \\
\hline CHEMBL1998829 & 809121 & 4.3 & 4.9244 & TRN & \\
\hline CHEMBL 2006299 & 809121 & 4.7 & 5.0417 & TRN & \\
\hline CHEMBL375284 & 809121 & 4.2 & 4.5556 & TRN & \\
\hline CHEMBL1972346 & 809121 & 7.5 & 6.3647 & TST & \\
\hline CHEMBL1980562 & 809121 & 7.6 & 7.7957 & TRN & \\
\hline CHEMBL1991818 & 809121 & 6.1 & 5.3117 & TST & \\
\hline CHEMBL1982866 & 809121 & 4.2 & 4.4647 & TRN & \\
\hline CHEMBL1968926 & 809121 & 4.2 & 4.8253 & TRN & \\
\hline CHEMBL1979933 & 809121 & 6.1 & 6.0416 & TRN & \\
\hline CHEMBL1991867 & 809121 & 5.2 & 4.5874 & TST & \\
\hline CHEMBL1965570 & 809121 & 5.6 & 4.8083 & TRN & \\
\hline CHEMBL 2001641 & 809121 & 5.3 & 5.96899 & 9999999999 & TRN \\
\hline CHEMBL1972355 & 809121 & 6.7 & 6.4746 & TRN & \\
\hline CHEMBL1964902 & 809121 & 4.7 & 4.2034 & TRN & \\
\hline CHEMBL1082440 & 809121 & 4.2 & 5.4489 & TST & \\
\hline CHEMBL1972362 & 809121 & 6.0 & 5.9528 & TRN & \\
\hline CHEMBL1614705 & 809121 & 4.2 & 4.6448 & TST & \\
\hline CHEMBL1972988 & 809121 & 7.3 & 7.1547 & TRN & \\
\hline CHEMBL 2007372 & 809121 & 4.2 & 3.9014 & TRN & \\
\hline CHEMBL1982167 & 809121 & 4.2 & 4.8649 & TRN & \\
\hline CHEMBL1986597 & 809121 & 5.5 & 5.4451 & TRN & \\
\hline CHEMBL 2006715 & 809121 & 4.2 & 4.1466 & TRN & \\
\hline CHEMBL1971017 & 809121 & 6.7 & 5.8859 & TRN & \\
\hline CHEMBL1990482 & 809121 & 6.4 & 5.9685 & TRN & \\
\hline CHEMBL1990904 & 809121 & 4.2 & 4.6116 & TRN & \\
\hline
\end{tabular}




\begin{tabular}{|c|c|c|c|c|}
\hline \multicolumn{5}{|c|}{ Supplemental Table s2.txt } \\
\hline CHEMBL1987448 & 809121 & 9.1 & 8.383 & TRN \\
\hline CHEMBL 2005475 & 809121 & 5.9 & 5.1496 & TRN \\
\hline CHEMBL 2000104 & 809121 & 5.7 & 6.2147 & TRN \\
\hline CHEMBL183844 & 809121 & 4.2 & 3.7098 & TRN \\
\hline CHEMBL1997349 & 809121 & 6.0 & 6.0718 & TST \\
\hline CHEMBL220057 & 809121 & 5.3 & 5.1632 & TRN \\
\hline CHEMBL383541 & 809121 & 7.4 & 7.5196 & TRN \\
\hline CHEMBL 2001224 & 809121 & 4.2 & 3.9391 & TRN \\
\hline CHEMBL10 & 809121 & 4.7 & 4.6008 & TRN \\
\hline CHEMBL 2005216 & 809121 & 7.3 & 6.7787 & TRN \\
\hline CHEMBL1964937 & 809121 & 6.2 & 6.2423 & TRN \\
\hline CHEMBL1980763 & 809121 & 4.7 & 4.3885 & TRN \\
\hline CHEMBL1969506 & 809121 & 4.2 & 5.3637 & TRN \\
\hline CHEMBL590109 & 809121 & 6.5 & 6.687 & TST \\
\hline CHEMBL1977931 & 809121 & 4.7 & 4.4408 & TRN \\
\hline CHEMBL1970879 & 809121 & 4.2 & 4.0789 & TRN \\
\hline CHEMBL 2005899 & 809121 & 4.2 & 4.543 & TRN \\
\hline CHEMBL1682552 & 809121 & 7.5 & 7.4236 & TRN \\
\hline CHEMBL 2004601 & 809121 & 5.6 & 5.1624 & TST \\
\hline CHEMBL 2007479 & 809121 & 6.5 & 5.7469 & TRN \\
\hline CHEMBL1996155 & 809121 & 5.3 & 4.7707 & TRN \\
\hline CHEMBL1682359 & 809121 & 6.6 & 6.5549 & TRN \\
\hline CHEMBL 1972220 & 809121 & 4.7 & 4.7212 & TRN \\
\hline CHEMBL1973720 & 809121 & 7.6 & 8.0737 & TRN \\
\hline CHEMBL1969523 & 809121 & 6.0 & $5.7020 e$ & 2000000001 \\
\hline CHEMBL 207995 & 809121 & 4.2 & 4.648 & TRN \\
\hline CHEMBL1988995 & 809121 & 4.2 & 4.0909 & TRN \\
\hline CHEMBL1986781 & 809121 & 4.2 & 3.9193 & TRN \\
\hline CHEMBL 2001923 & 809121 & 4.4 & 4.6127 & TRN \\
\hline CHEMBL 2003514 & 809121 & 4.7 & 4.3052 & TRN \\
\hline CHEMBL526133 & 809121 & 7.8 & 7.1269 & TRN \\
\hline CHEMBL1989043 & 809121 & 4.7 & 5.6469 & TRN \\
\hline CHEMBL1979057 & 809121 & 5.6 & 4.8889 & TRN \\
\hline CHEMBL1967538 & 809121 & 4.6 & 5.0323 & TRN \\
\hline CHEMBL1999428 & 809121 & 4.2 & 4.7026 & TRN \\
\hline CHEMBL1967560 & 809121 & 4.2 & 4.2063 & TRN \\
\hline CHEMBL211378 & 809121 & 4.2 & 5.0764 & TRN \\
\hline CHEMBL1982465 & 809121 & 4.2 & 4.5165 & TRN \\
\hline CHEMBL 2003420 & 809121 & 4.2 & 4.48 & TRN \\
\hline CHEMBL 2002723 & 809121 & 6.0 & 5.4033 & TST \\
\hline CHEMBL272453 & 809121 & 4.2 & 4.1137 & TRN \\
\hline CHEMBL1971801 & 809121 & 4.2 & 4.4522 & TRN \\
\hline CHEMBL1970217 & 809121 & 5.6 & 4.9473 & TRN \\
\hline CHEMBL1968850 & 809121 & 5.3 & 5.0684 & TRN \\
\hline CHEMBL 2005528 & 809121 & 6.3 & 6.2158 & TST \\
\hline CHEMBL185569 & 809121 & 4.2 & 4.4461 & TRN \\
\hline CHEMBL1987007 & 809121 & 4.2 & 4.4599 & TRN \\
\hline CHEMBL1973793 & 809121 & 4.7 & 4.7081 & TST \\
\hline
\end{tabular}

TRN 


\begin{tabular}{|c|c|c|c|c|}
\hline & & & ipplemen & al $\mathrm{T}$ \\
\hline CHEMBL1969588 & 809121 & 8.4 & 8.4795 & TRN \\
\hline CHEMBL1984711 & 809121 & 5.5 & 5.3094 & TRN \\
\hline CHEMBL1990212 & 809121 & 5.4 & 5.0932 & TRN \\
\hline CHEMBL1986143 & 809121 & 4.7 & 5.0112 & TRN \\
\hline CHEMBL1979252 & 809121 & 4.2 & 4.7475 & TRN \\
\hline CHEMBL1972934 & 809121 & 5.4 & 5.2203 & TRN \\
\hline CHEMBL1682341 & 809121 & 6.9 & 6.3352 & TRN \\
\hline CHEMBL1992581 & 809121 & 4.7 & 5.2844 & TRN \\
\hline CHEMBL1972250 & 809121 & 4.2 & 4.6587 & TST \\
\hline CHEMBL1972937 & 809121 & 5.8 & 5.5301 & TRN \\
\hline CHEMBL1986499 & 809121 & 7.4 & 7.3519 & TRN \\
\hline CHEMBL 2004311 & 809121 & 4.2 & 4.0985 & TRN \\
\hline CHEMBL1992634 & 809121 & 6.8 & 6.0572 & TRN \\
\hline CHEMBL 316264 & 809121 & 4.2 & 4.6071 & TRN \\
\hline CHEMBL1984847 & 809121 & 4.7 & 4.6955 & TST \\
\hline CHEMBL1996576 & 809121 & 4.7 & 4.3692 & TST \\
\hline CHEMBL1991678 & 809121 & 4.6 & 4.2498 & TRN \\
\hline CHEMBL1988594 & 809121 & 4.2 & 4.8832 & TRN \\
\hline CHEMBL 260092 & 809121 & 5.7 & 4.8536 & TRN \\
\hline CHEMBL1965495 & 809121 & 6.1 & 5.2618 & TRN \\
\hline CHEMBL1985074 & 809121 & 4.3 & 6.2298 & TST \\
\hline CHEMBL1982874 & 809121 & 6.2 & 4.9193 & TRN \\
\hline CHEMBL1991725 & 809121 & 6.7 & 7.2106 & TRN \\
\hline CHEMBL 2007296 & 809121 & 4.2 & 5.0842 & TRN \\
\hline CHEMBL396523 & 809121 & 7.5 & 8.2576 & TRN \\
\hline CHEMBL208637 & 809121 & 4.2 & 4.1602 & TRN \\
\hline CHEMBL1978371 & 809121 & 5.8 & 5.0125 & TST \\
\hline CHEMBL1970203 & 809121 & 4.2 & 4.564 & TRN \\
\hline CHEMBL1999749 & 809121 & 4.2 & 4.8799 & TRN \\
\hline CHEMBL1983006 & 809121 & 4.2 & 4.4645 & TRN \\
\hline CHEMBL1984191 & 809121 & 4.2 & 4.9793 & TRN \\
\hline CHEMBL1971029 & 809121 & 6.3 & 6.1323 & TRN \\
\hline CHEMBL1971679 & 809121 & 4.2 & 4.3906 & TST \\
\hline CHEMBL 394790 & 809121 & 4.2 & 4.7542 & TRN \\
\hline CHEMBL226471 & 809121 & 8.0 & 6.871 & TRN \\
\hline CHEMBL1996111 & 809121 & 5.8 & 5.8146 & TRN \\
\hline CHEMBL1966175 & 809121 & 4.7 & 4.6201 & TRN \\
\hline CHEMBL 2007375 & 809121 & 4.7 & 5.5555 & TRN \\
\hline CHEMBL1965589 & 809121 & 4.4 & 4.664 & TRN \\
\hline CHEMBL1998193 & 809121 & 4.2 & 4.1241 & TRN \\
\hline CHEMBL379975 & 809121 & 6.7 & 5.8023 & TRN \\
\hline CHEMBL1988153 & 809121 & 6.2 & 5.6969 & TRN \\
\hline CHEMBL1968245 & 809121 & 6.4 & 6.7768 & TRN \\
\hline CHEMBL1233887 & 809121 & 4.7 & 4.9729 & TST \\
\hline CHEMBL1979577 & 809121 & 4.2 & 4.7598 & TRN \\
\hline CHEMBL52387 & 809121 & 5.8 & 5.4981 & TST \\
\hline CHEMBL1979357 & 809121 & 5.7 & 5.2319 & TRN \\
\hline CHEMBL1996817 & 809121 & 7.7 & 6.5359 & TRN \\
\hline
\end{tabular}




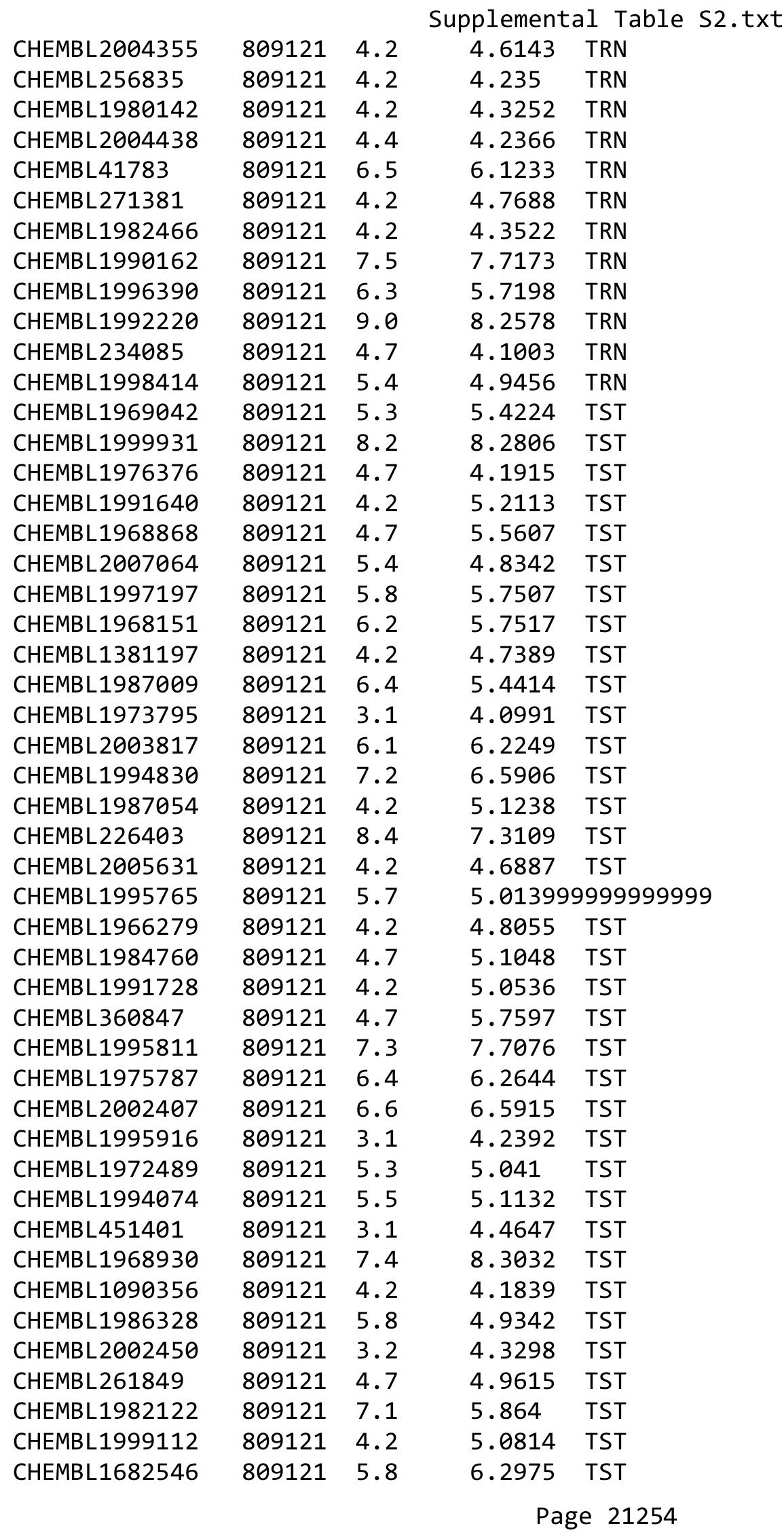




\begin{tabular}{|c|c|c|c|c|}
\hline \multicolumn{5}{|c|}{ Supplemental Table S2.txt } \\
\hline CHEMBL1996780 & 809121 & 4.2 & 5.8259 & TST \\
\hline CHEMBL1996066 & 809121 & 7.3 & 5.9996 & TST \\
\hline CHEMBL 296586 & 809121 & 5.3 & 5.0465 & TST \\
\hline CHEMBL1993722 & 809121 & 5.6 & 5.6312 & TST \\
\hline CHEMBL 2006674 & 809121 & 4.7 & 5.972 & TST \\
\hline CHEMBL1984236 & 809121 & 4.7 & 5.2058 & TST \\
\hline CHEMBL 2002599 & 809121 & 4.7 & 5.8668 & TST \\
\hline CHEMBL1375640 & 809121 & 7.2 & 6.7042 & TST \\
\hline CHEMBL 249282 & 809121 & 4.2 & 3.9229 & TST \\
\hline CHEMBL1973711 & 809121 & 5.8 & 5.6906 & TST \\
\hline CHEMBL1967720 & 809121 & 4.2 & 4.1402 & TST \\
\hline CHEMBL1969755 & 809121 & 4.2 & 4.8512 & TST \\
\hline CHEMBL1991138 & 809121 & 4.2 & 4.2591 & TST \\
\hline CHEMBL514499 & 809121 & 5.3 & 5.4341 & TST \\
\hline CHEMBL1970352 & 809121 & 6.0 & 5.4677 & TST \\
\hline CHEMBL1965631 & 809121 & 6.8 & 7.3998 & TST \\
\hline CHEMBL1980144 & 809121 & 4.2 & 4.716 & TST \\
\hline CHEMBL1991188 & 809121 & 6.0 & 4.8457 & TST \\
\hline CHEMBL 377408 & 809121 & 4.7 & 4.337 & TST \\
\hline CHEMBL 215152 & 809121 & 4.5 & 4.7578 & TST \\
\hline CHEMBL231209 & 809121 & 5.4 & 4.7857 & TST \\
\hline CHEMBL 2006765 & 809121 & 5.8 & 5.6668 & TST \\
\hline CHEMBL1976220 & 809121 & 4.2 & 4.9018 & TST \\
\hline CHEMBL1982383 & 809121 & 4.2 & 3.9572 & TST \\
\hline CHEMBL17370 & 809121 & 4.2 & 4.5531 & TST \\
\hline CHEMBL1980246 & 809121 & 4.7 & 5.4653 & TST \\
\hline CHEMBL1999484 & 809121 & 7.2 & 6.6551 & TST \\
\hline CHEMBL1997822 & 809121 & 5.3 & 5.3532 & TST \\
\hline CHEMBL1991285 & 809121 & 4.2 & 4.7899 & TST \\
\hline CHEMBL1984038 & 809121 & 4.5 & 4.3833 & TST \\
\hline CHEMBL1974416 & 809121 & 6.3 & 5.083 & TST \\
\hline CHEMBL1984039 & 809121 & 4.2 & 4.1002 & TST \\
\hline CHEMBL 2004615 & 809121 & 6.2 & 5.1609 & TST \\
\hline CHEMBL1997872 & 809121 & 4.2 & 4.4564 & TST \\
\hline CHEMBL 316102 & 92484 & 7.7696 & 7.727 & TRN \\
\hline CHEMBL90516 & 92484 & 7.0132 & 7.3002 & TRN \\
\hline CHEMBL 91442 & 92484 & 6.699 & 6.5869 & TRN \\
\hline CHEMBL1199648 & 92484 & 6.8539 & 6.6788 & TRN \\
\hline CHEMBL 92494 & 92484 & 5.6289 & 5.3376 & TRN \\
\hline CHEMBL327464 & 92484 & 6.1805 & 6.2665 & TRN \\
\hline CHEMBL90061 & 92484 & 6.2716 & 6.3995 & TRN \\
\hline CHEMBL93960 & 92484 & 8.6576 & 8.5206 & TRN \\
\hline CHEMBL88719 & 92484 & 8.0 & 7.8378 & TRN \\
\hline CHEMBL1199647 & 92484 & 6.7696 & 6.8729 & TRN \\
\hline CHEMBL91307 & 92484 & 5.8861 & 5.9855 & TST \\
\hline CHEMBL94069 & 92484 & 7.3872 & 7.8373 & TRN \\
\hline CHEMBL316289 & 92484 & 6.6576 & 6.5707 & TRN \\
\hline CHEMBL328988 & 92484 & 6.9586 & 6.4433 & TRN \\
\hline
\end{tabular}




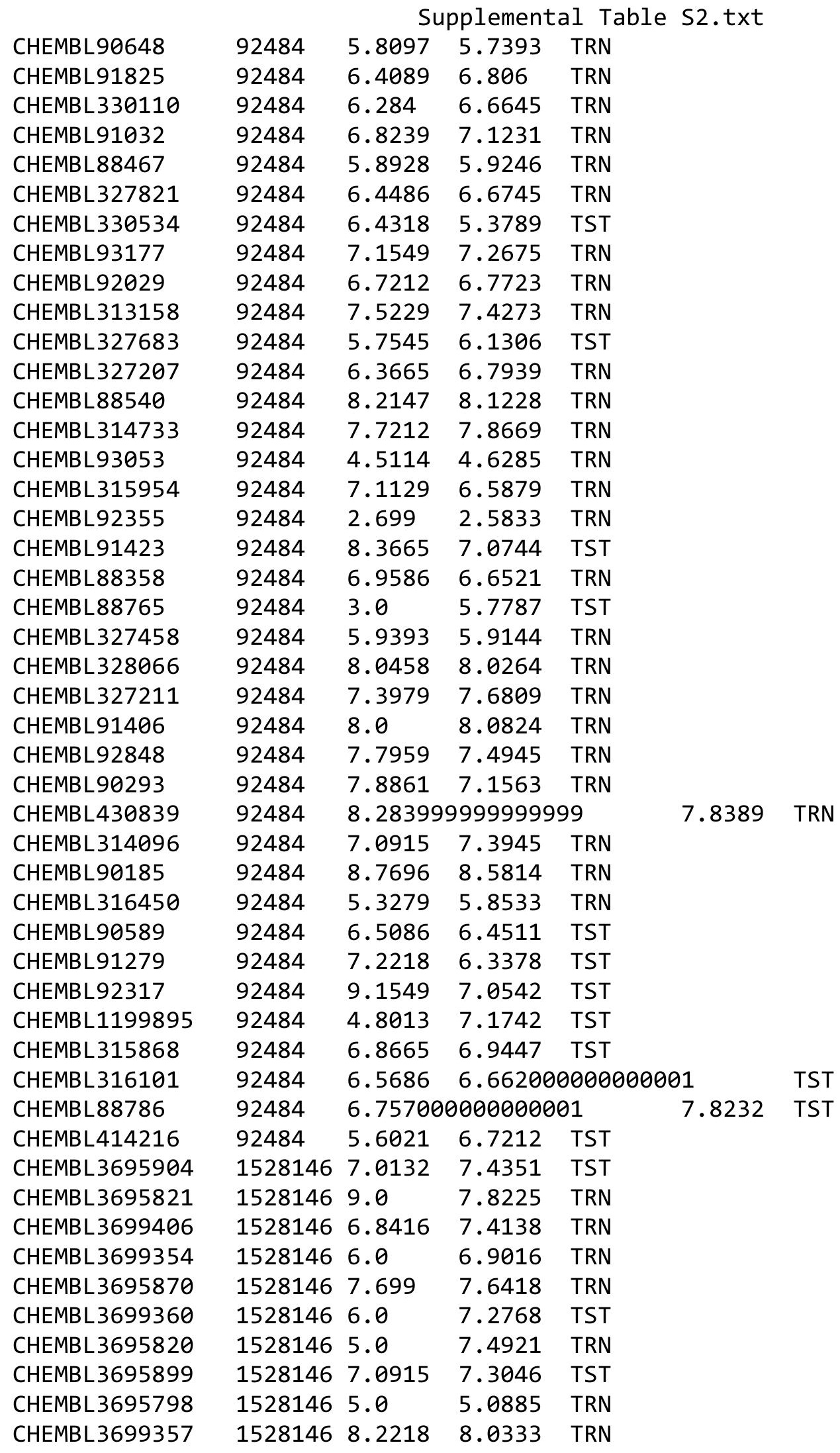

Page 21256 


\begin{tabular}{|c|c|c|c|c|c|}
\hline \multicolumn{6}{|c|}{ Supplemental Table S2.txt } \\
\hline CHEMBL 3699366 & 1528146 & 8.0 & 7.4714 & TRN & \\
\hline CHEMBL 3695803 & 1528146 & 5.0 & 5.1495 & TRN & \\
\hline CHEMBL 3695867 & 1528146 & 8.699 & 7.8136 & TST & \\
\hline CHEMBL 3699442 & 1528146 & 6.0 & 7.2706 & TST & \\
\hline CHEMBL 3695774 & 1528146 & 8.699 & 7.7028 & TRN & \\
\hline CHEMBL 3695812 & 1528146 & 7.1192 & 7.3022 & TRN & \\
\hline CHEMBL 3695849 & 1528146 & 8.699 & 7.3857 & TRN & \\
\hline CHEMBL 3695777 & 1528146 & 7.7959 & 7.4651 & TRN & \\
\hline CHEMBL 3695767 & 1528146 & 7.4685 & 7.6726 & TRN & \\
\hline CHEMBL3695823 & 1528146 & 5.0 & 7.4772 & TST & \\
\hline CHEMBL 3695829 & 1528146 & 7.4949 & 7.5932 & TRN & \\
\hline CHEMBL 3695893 & 1528146 & 6.0 & 7.191 & TRN & \\
\hline CHEMBL3944833 & 1528146 & 7.9586 & 7.4945 & TST & \\
\hline CHEMBL 3695825 & 1528146 & 7.9586 & 7.4278 & TST & \\
\hline CHEMBL3695896 & 1528146 & 7.7959 & 7.8722 & TRN & \\
\hline CHEMBL3639947 & 1528146 & 8.699 & 7.9204 & TRN & \\
\hline CHEMBL3699345 & 1528146 & 7.7212 & 7.1599 & TRN & \\
\hline CHEMBL3699429 & 1528146 & 8.5229 & 7.3541 & TRN & \\
\hline CHEMBL 3695801 & 1528146 & 5.0 & 5.2329 & TRN & \\
\hline CHEMBL 3695845 & 1528146 & 6.0 & 7.5317 & TRN & \\
\hline CHEMBL3699369 & 1528146 & 6.0 & 7.0074 & TRN & \\
\hline CHEMBL 3695850 & 1528146 & 8.5229 & 7.4728 & TRN & \\
\hline CHEMBL602469 & 1528146 & 9.0 & 7.8724 & TRN & \\
\hline CHEMBL 3699372 & 1528146 & 7.9586 & 8.3196 & TRN & \\
\hline CHEMBL 3699391 & 1528146 & 5.0 & 6.1618 & TRN & \\
\hline CHEMBL3699427 & 1528146 & 8.0458 & 7.0108 & TRN & \\
\hline CHEMBL 3695761 & 1528146 & 8.301 & 7.2883 & TRN & \\
\hline CHEMBL3695766 & 1528146 & 8.3979 & 7.7372 & TRN & \\
\hline CHEMBL 3695771 & 1528146 & 7.8539 & 7.903 & TRN & \\
\hline CHEMBL 3639982 & 1528146 & 6.0 & 7.0219 & TRN & \\
\hline CHEMBL 3695882 & 1528146 & 10.0 & 8.3091 & TRN & \\
\hline CHEMBL 3695827 & 1528146 & 7.6021 & 7.7055 & TST & \\
\hline CHEMBL 3695877 & 1528146 & 7.2147 & 7.2617 & TRN & \\
\hline CHEMBL3699441 & 1528146 & 7.2076 & 6.58299 & & TRN \\
\hline CHEMBL 3695863 & 1528146 & 8.0969 & 7.2107 & TST & \\
\hline CHEMBL 3695852 & 1528146 & 7.6198 & 6.8802 & TRN & \\
\hline CHEMBL3921042 & 1528146 & 8.699 & 7.5005 & TST & \\
\hline CHEMBL602263 & 1528146 & 8.699 & 7.0403 & TST & \\
\hline CHEMBL3695856 & 1528146 & 7.6198 & 7.2302 & TRN & \\
\hline CHEMBL3695900 & 1528146 & 7.8861 & 7.8175 & TRN & \\
\hline CHEMBL 3695802 & 1528146 & 5.0 & 5.1716 & TRN & \\
\hline CHEMBL3695768 & 1528146 & 7.6383 & 7.4197 & TRN & \\
\hline CHEMBL3695822 & 1528146 & 7.9208 & 7.5834 & TRN & \\
\hline CHEMBL3695810 & 1528146 & 6.0 & 6.4946 & TST & \\
\hline CHEMBL3695797 & 1528146 & 5.0 & 4.96 & TRN & \\
\hline CHEMBL 3699346 & 1528146 & 6.3478 & 6.933 & TRN & \\
\hline CHEMBL3695787 & 1528146 & 9.2676 & 7.4284 & TRN & \\
\hline CHEMBL3695790 & 1528146 & 5.0 & 7.3371 & TST & \\
\hline
\end{tabular}


Supplemental Table S2.txt

\begin{tabular}{|c|c|c|c|c|c|}
\hline CHEMBL3695804 & 1528146 & 6.1898 & 5.2872 & TRN & \\
\hline CHEMBL3695901 & 1528146 & 9.0 & 7.8501 & TST & \\
\hline CHEMBL3695848 & 1528146 & 7.1938 & 7.4776 & TRN & \\
\hline CHEMBL3699389 & 1528146 & 7.3979 & 6.771 & TST & \\
\hline CHEMBL3695897 & 1528146 & 7.4089 & 7.1161 & TRN & \\
\hline CHEMBL3699401 & 1528146 & 5.9805 & 7.5738 & TRN & \\
\hline CHEMBL3695853 & 1528146 & 6.0 & 7.1874 & TST & \\
\hline CHEMBL3695869 & 1528146 & 7.9208 & 7.6769 & TRN & \\
\hline CHEMBL3699398 & 1528146 & 9.0 & 7.7295 & TRN & \\
\hline CHEMBL3695868 & 1528146 & 10.0 & 8.2402 & TRN & \\
\hline CHEMBL3695830 & 1528146 & 8.3979 & 7.519 & TRN & \\
\hline CHEMBL3699418 & 1528146 & 8.0969 & 7.3098 & TRN & \\
\hline CHEMBL3699371 & 1528146 & 7.3665 & 7.4464 & TRN & \\
\hline CHEMBL3695906 & 1528146 & 8.0 & 6.9526 & TST & \\
\hline CHEMBL3695835 & 1528146 & 6.6819 & 7.3248 & TRN & \\
\hline CHEMBL3695764 & 1528146 & 6.8041 & 7.3907 & TRN & \\
\hline CHEMBL3699411 & 1528146 & 6.0 & 6.9455 & TRN & \\
\hline CHEMBL3699390 & 1528146 & 8.1549 & 6.6145 & TST & \\
\hline CHEMBL3695813 & 1528146 & 7.585 & 7.5584 & TRN & \\
\hline CHEMBL3695799 & 1528146 & 5.0 & 4.7283 & TRN & \\
\hline CHEMBL3699425 & 1528146 & 7.9586 & 7.3873 & TRN & \\
\hline CHEMBL3699362 & 1528146 & 6.0 & 7.66200 & 0000000001 & TRN \\
\hline CHEMBL3695816 & 1528146 & 7.4815 & 7.5332 & TRN & \\
\hline CHEMBL3695881 & 1528146 & 8.0969 & 7.9146 & TRN & \\
\hline CHEMBL3695773 & 1528146 & 8.3979 & 8.1978 & TRN & \\
\hline CHEMBL3695837 & 1528146 & 8.3979 & 7.5699 & TRN & \\
\hline CHEMBL3695841 & 1528146 & 8.2218 & 7.8358 & TRN & \\
\hline CHEMBL3699431 & 1528146 & 7.301 & 7.1746 & TRN & \\
\hline CHEMBL 3695808 & 1528146 & 5.0 & 6.6961 & TST & \\
\hline CHEMBL3695789 & 1528146 & 8.2218 & 7.5531 & TST & \\
\hline CHEMBL3695783 & 1528146 & 5.0 & 7.005 & TRN & \\
\hline CHEMBL3695888 & 1528146 & 8.699 & 7.7226 & TST & \\
\hline CHEMBL3695857 & 1528146 & 8.699 & 7.2379 & TST & \\
\hline CHEMBL 3695800 & 1528146 & 5.0 & 5.2522 & TRN & \\
\hline CHEMBL3695891 & 1528146 & 8.3979 & 8.2353 & TRN & \\
\hline CHEMBL3699383 & 1528146 & 6.0 & 7.55 & TST & \\
\hline CHEMBL3699428 & 1528146 & 8.0969 & 7.9396 & TRN & \\
\hline CHEMBL3699395 & 1528146 & 7.3979 & 7.3809 & TRN & \\
\hline CHEMBL3699402 & 1528146 & 6.0 & 6.6562 & TRN & \\
\hline CHEMBL3699382 & 1528146 & 6.0 & 8.0786 & TRN & \\
\hline CHEMBL3695817 & 1528146 & 7.4318 & 7.5245 & TRN & \\
\hline CHEMBL3699376 & 1528146 & 6.0 & 7.1076 & TRN & \\
\hline CHEMBL3699368 & 1528146 & 7.8239 & 6.9257 & TRN & \\
\hline CHEMBL3695775 & 1528146 & 6.5229 & 6.8652 & TRN & \\
\hline CHEMBL3699378 & 1528146 & 7.7447 & 8.2459 & TRN & \\
\hline CHEMBL3695871 & 1528146 & 7.3872 & 7.8897 & TRN & \\
\hline CHEMBL3695833 & 1528146 & 6.6198 & 7.1177 & TRN & \\
\hline CHEMBL3699392 & 1528146 & 5.0 & 6.2852 & TRN & \\
\hline
\end{tabular}


Supplemental Table S2.txt

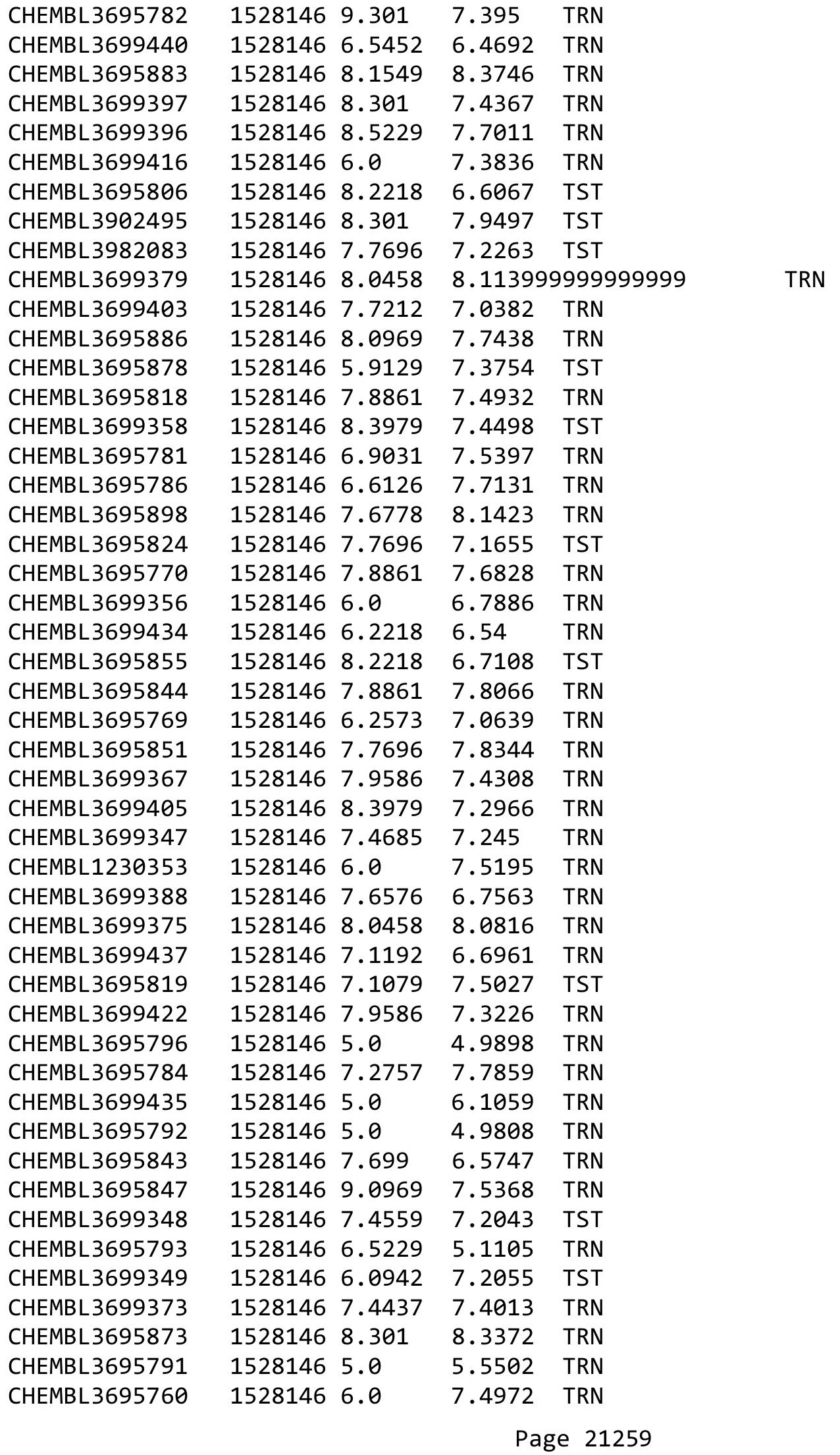


Supplemental Table S2.txt

\begin{tabular}{|c|c|c|c|c|c|}
\hline CHEMBL 3695815 & 1528146 & 7.5086 & 8.1603 & TRN & \\
\hline CHEMBL3695776 & 1528146 & 6.0 & 7.1456 & TRN & \\
\hline CHEMBL 3695887 & 1528146 & 7.7212 & 8.4065 & TST & \\
\hline CHEMBL 3699386 & 1528146 & 7.2366 & 7.3963 & TST & \\
\hline CHEMBL 3695858 & 1528146 & 6.8996 & 5.8388 & TRN & \\
\hline CHEMBL 3695795 & 1528146 & 5.0 & 5.1013 & TRN & \\
\hline CHEMBL 3695875 & 1528146 & 6.5918 & 7.752006 & 0000000001 & TRN \\
\hline CHEMBL 3699420 & 1528146 & 6.0926 & 6.942 & TRN & \\
\hline CHEMBL 3982611 & 1528146 & 10.0 & 7.2523 & TST & \\
\hline CHEMBL 3695778 & 1528146 & 7.8861 & 7.151 & TRN & \\
\hline CHEMBL 3695840 & 1528146 & 8.3979 & 7.851 & TRN & \\
\hline CHEMBL 3695861 & 1528146 & 7.1871 & 7.116006 & 00000000005 & TRN \\
\hline CHEMBL 3695809 & 1528146 & 6.0 & 6.4381 & TST & \\
\hline CHEMBL 3699409 & 1528146 & 8.0969 & 7.2984 & TRN & \\
\hline CHEMBL 3695814 & 1528146 & 8.301 & 7.9305 & TRN & \\
\hline CHEMBL 3695826 & 1528146 & 7.4949 & 7.7071 & TST & \\
\hline CHEMBL3695836 & 1528146 & 6.6073 & 7.8966 & TRN & \\
\hline CHEMBL 3699424 & 1528146 & 8.0 & 7.0612 & TRN & \\
\hline CHEMBL 3695807 & 1528146 & 8.699 & 6.3653 & TST & \\
\hline CHEMBL 3695763 & 1528146 & 6.6383 & 7.2609 & TRN & \\
\hline CHEMBL 3699404 & 1528146 & 8.699 & 7.6356 & TRN & \\
\hline CHEMBL 3699408 & 1528146 & 8.3979 & 7.6937 & TRN & \\
\hline CHEMBL 3699438 & 1528146 & 6.8297 & 6.5354 & TRN & \\
\hline CHEMBL 3699364 & 1528146 & 6.6517 & 6.9149 & TST & \\
\hline CHEMBL 3695915 & 1528146 & 7.7696 & 7.3276 & TRN & \\
\hline CHEMBL 3695828 & 1528146 & 7.7696 & 7.6103 & TRN & \\
\hline CHEMBL 3699421 & 1528146 & 7.6576 & 7.452006 & 0000000001 & TST \\
\hline CHEMBL3699399 & 1528146 & 8.2218 & 7.6119 & TRN & \\
\hline CHEMBL 3695788 & 1528146 & 7.3979 & 7.1894 & TRN & \\
\hline CHEMBL 3695872 & 1528146 & 6.0 & 7.6212 & TRN & \\
\hline CHEMBL 3699433 & 1528146 & 5.301 & 6.2632 & TRN & \\
\hline CHEMBL 3695859 & 1528146 & 7.0969 & 7.0222 & TRN & \\
\hline CHEMBL 3695838 & 1528146 & 8.1549 & 7.5556 & TRN & \\
\hline CHEMBL 3695834 & 1528146 & 6.71899 & 79999999 & 7.2198 & TR \\
\hline CHEMBL 3695865 & 1528146 & 6.0 & 8.1153 & TRN & \\
\hline CHEMBL 3699430 & 1528146 & 8.3979 & 8.0359 & TRN & \\
\hline CHEMBL 3695762 & 1528146 & 6.6861 & 7.7967 & TST & \\
\hline CHEMBL 3695874 & 1528146 & 7.6778 & 7.645 & TRN & \\
\hline CHEMBL 3699426 & 1528146 & 7.5686 & 6.9632 & TRN & \\
\hline CHEMBL 3695854 & 1528146 & 6.7878 & 6.6914 & TRN & \\
\hline CHEMBL3699436 & 1528146 & 5.0 & 6.4207 & TRN & \\
\hline CHEMBL 3695866 & 1528146 & 8.0 & 7.4917 & TST & \\
\hline CHEMBL 3695772 & 1528146 & 6.1759 & 7.3334 & TRN & \\
\hline CHEMBL 3695842 & 1528146 & 8.2218 & 8.0468 & TRN & \\
\hline CHEMBL 3699363 & 1528146 & 6.6383 & 6.5862 & TRN & \\
\hline CHEMBL 3699350 & 1528146 & 6.2708 & 7.4112 & TST & \\
\hline CHEMBL 3699352 & 1528146 & 6.0 & 7.5824 & TRN & \\
\hline CHEMBL 3699439 & 1528146 & 7.1135 & 6.7248 & TRN & \\
\hline
\end{tabular}


Supplemental Table S2.txt

\begin{tabular}{|c|c|c|c|c|}
\hline CHEMBL3695794 & 1528146 & 5.0 & 4.672 & TRN \\
\hline CHEMBL3699432 & 1528146 & 7.0269 & 6.5238 & TRN \\
\hline CHEMBL3695805 & 1528146 & 6.8239 & 5.7458 & TST \\
\hline CHEMBL3695876 & 1528146 & 7.5528 & 7.3907 & TRN \\
\hline CHEMBL3695831 & 1528146 & 7.4202 & 6.4841 & TRN \\
\hline CHEMBL3699400 & 1528146 & 7.4202 & \multicolumn{2}{|c|}{7.3020000000000005} \\
\hline CHEMBL3695839 & 1528146 & 8.301 & 7.7616 & TST \\
\hline CHEMBL3695916 & 1528146 & 8.0458 & 7.1051 & TST \\
\hline CHEMBL3699410 & 1528146 & 6.0 & 7.2225 & TST \\
\hline CHEMBL3695903 & 1528146 & 8.301 & 7.4986 & TST \\
\hline CHEMBL3699393 & 1528146 & 5.0 & 6.2182 & TST \\
\hline CHEMBL3695779 & 1528146 & 8.0 & 7.6374 & TST \\
\hline CHEMBL3699365 & 1528146 & 7.8239 & 7.5982 & TST \\
\hline CHEMBL241365 & 457824 & 3.0 & 3.1762 & TRN \\
\hline CHEMBL238813 & 457824 & 3.0 & 2.8195 & TRN \\
\hline CHEMBL 239030 & 457824 & 3.0 & 4.7498 & TST \\
\hline CHEMBL 8260 & 457824 & 6.0655 & 4.7579 & TRN \\
\hline CHEMBL 238816 & 457824 & 3.0 & 2.7414 & TRN \\
\hline CHEMBL 239893 & 457824 & 4.8239 & 4.7881 & TRN \\
\hline CHEMBL395449 & 457824 & 5.7959 & 4.5747 & TST \\
\hline CHEMBL 391342 & 457824 & 4.585 & 4.6043 & TRN \\
\hline CHEMBL238812 & 457824 & 3.0 & 2.889 & TRN \\
\hline CHEMBL 239023 & 457824 & 3.0 & 2.9239 & TRN \\
\hline CHEMBL239276 & 457824 & 3.0 & 4.2544 & TRN \\
\hline CHEMBL 239677 & 457824 & 4.9586 & 4.9513 & TRN \\
\hline CHEMBL 294009 & 457824 & 3.0 & 3.2799 & TRN \\
\hline CHEMBL147999 & 457824 & 3.0 & 3.0604 & TRN \\
\hline CHEMBL138649 & 457824 & 3.0 & \multicolumn{2}{|c|}{3.0380000000000003} \\
\hline CHEMBL394459 & 457824 & 3.0 & 2.9586 & TRN \\
\hline CHEMBL239156 & 457824 & 5.0605 & 4.8891 & TST \\
\hline CHEMBL241363 & 457824 & 3.0 & 3.0337 & TRN \\
\hline CHEMBL 241815 & 457824 & 6.1079 & 4.5132 & TST \\
\hline CHEMBL395346 & 457824 & 3.0 & 2.9632 & TRN \\
\hline CHEMBL395115 & 457824 & 3.0 & 2.927 & TRN \\
\hline CHEMBL391341 & 457824 & 4.1549 & 4.7028 & TRN \\
\hline CHEMBL 8328 & 457824 & 4.7696 & 4.806 & TRN \\
\hline CHEMBL394257 & 457824 & 3.0 & 4.082 & TRN \\
\hline CHEMBL 241366 & 457824 & 3.0 & 2.9679 & TRN \\
\hline CHEMBL 241364 & 457824 & 3.0 & 3.0818 & TRN \\
\hline CHEMBL 210276 & 457824 & 3.0 & 3.4285 & TRN \\
\hline CHEMBL 241814 & 457824 & 6.3188 & 4.9289 & TST \\
\hline CHEMBL 238814 & 457824 & 3.0 & 2.8719 & TRN \\
\hline CHEMBL 240505 & 457824 & 3.0 & 2.9454 & TRN \\
\hline CHEMBL 239033 & 457824 & 4.8539 & 4.8204 & TRN \\
\hline CHEMBL 239247 & 457824 & 5.1192 & 5.0145 & TRN \\
\hline CHEMBL396673 & 457824 & 3.0 & 3.0269 & TRN \\
\hline CHEMBL239031 & 457824 & 5.7959 & 4.8509 & TRN \\
\hline CHEMBL 239032 & 457824 & 5.4202 & 4.5574 & TST \\
\hline
\end{tabular}




\begin{tabular}{|c|c|c|c|c|c|}
\hline \multirow[b]{2}{*}{ CHEMBL238843 } & \multicolumn{5}{|c|}{ Supplemental Table S2.txt } \\
\hline & 457824 & 5.4437 & 4.4308 & TST & \\
\hline CHEMBL 276915 & 457824 & 3.0 & 3.1374 & TRN & \\
\hline CHEMBL241813 & 457824 & 5.1938 & 3.9663 & TST & \\
\hline CHEMBL1728023 & 457824 & 6.0223 & 5.7082 & TRN & \\
\hline CHEMBL 394258 & 457824 & 3.0 & 2.8837 & TRN & \\
\hline CHEMBL 240713 & 457824 & 3.0 & 2.9718 & TRN & \\
\hline CHEMBL 239053 & 457824 & 3.0 & 4.6623 & TST & \\
\hline CHEMBL241794 & 457824 & 3.0 & 2.6461 & TRN & \\
\hline CHEMBL 239028 & 457824 & 3.0 & 4.7645 & TST & \\
\hline CHEMBL210411 & 457824 & 3.0 & 3.3116 & TRN & \\
\hline CHEMBL238815 & 457824 & 3.0 & 2.7711 & TRN & \\
\hline CHEMBL52 & 457824 & 5.585 & 4.9639 & TST & \\
\hline CHEMBL1173475 & 457824 & 6.3565 & 6.5427 & TRN & \\
\hline CHEMBL 238821 & 457824 & 5.2366 & 4.9837 & TST & \\
\hline CHEMBL 238844 & 457824 & 6.2076 & 4.3669 & TST & \\
\hline CHEMBL 239022 & 457824 & 3.0 & 2.767 & TRN & \\
\hline CHEMBL3794336 & 1571915 & 6.5086 & 6.5078 & TRN & \\
\hline CHEMBL3794013 & 1571915 & 7.6778 & 7.667006 & 3000000001 & TRN \\
\hline CHEMBL 3792438 & 1571915 & 7.983 & 7.9569 & TRN & \\
\hline CHEMBL3792638 & 1571915 & 7.7932 & 7.7918 & TRN & \\
\hline CHEMBL3793169 & 1571915 & 6.7696 & 6.7694 & TRN & \\
\hline CHEMBL3793131 & 1571915 & 7.4437 & 7.4735 & TRN & \\
\hline CHEMBL3793782 & 1571915 & 8.28399 & 79999999ऽ & 8.2824 & TRN \\
\hline CHEMBL3793890 & 1571915 & 6.8861 & 6.8837 & TRN & \\
\hline CHEMBL3792931 & 1571915 & 7.4559 & 6.9789 & TST & \\
\hline CHEMBL3794287 & 1571915 & 7.4437 & 7.433 & TRN & \\
\hline CHEMBL 3794158 & 1571915 & 6.8861 & 6.8809 & TRN & \\
\hline CHEMBL3792803 & 1571915 & 7.9957 & 8.001 & TRN & \\
\hline CHEMBL 3792941 & 1571915 & 7.3665 & 7.3597 & TRN & \\
\hline CHEMBL3792907 & 1571915 & 7.5528 & 7.5203 & TRN & \\
\hline CHEMBL3794079 & 1571915 & 8.1308 & 7.6477 & TST & \\
\hline CHEMBL 3793264 & 1571915 & 7.2291 & 7.2377 & TRN & \\
\hline CHEMBL 3792541 & 1571915 & 6.7959 & 6.8871 & TST & \\
\hline CHEMBL3792725 & 1571915 & 7.5376 & 7.5333 & TRN & \\
\hline CHEMBL3793033 & 1571915 & 7.3279 & 7.3206 & TRN & \\
\hline CHEMBL3794363 & 1571915 & 6.9586 & 6.9622 & TRN & \\
\hline CHEMBL3792728 & 1571915 & 7.7905 & 7.7836 & TRN & \\
\hline CHEMBL3793612 & 1571915 & 7.9666 & 7.96399 & 99999999995 & TRN \\
\hline CHEMBL3792923 & 1571915 & 7.9101 & 7.912006 & 0000000001 & TRN \\
\hline CHEMBL3794375 & 1571915 & 7.2924 & 7.3001 & TRN & \\
\hline CHEMBL3792731 & 1571915 & 8.0269 & 7.1615 & TST & \\
\hline CHEMBL 3792751 & 1571915 & 8.4815 & 8.4872 & TRN & \\
\hline CHEMBL3794529 & 1571915 & 7.9355 & 7.9378 & TRN & \\
\hline CHEMBL3793375 & 1571915 & 7.8827 & 7.8682 & TRN & \\
\hline CHEMBL3793137 & 1571915 & 8.6576 & 8.666 & TRN & \\
\hline CHEMBL 3793438 & 1571915 & 7.7986 & 7.7988 & TRN & \\
\hline CHEMBL3794174 & 1571915 & 7.71899 & 99999999 & 7.7125 & TRN \\
\hline CHEMBL3793112 & 1571915 & 7.3768 & 7.3805 & TRN & \\
\hline
\end{tabular}


Supplemental Table S2.txt

\begin{tabular}{|c|c|c|c|c|c|}
\hline CHEMBL3792532 & 1571915 & 7.1367 & 7.1527 & TRN & \\
\hline CHEMBL3794469 & 1571915 & 7.5686 & 7.567 & TRN & \\
\hline CHEMBL3794199 & 1571915 & 7.983 & 7.99299 & 9999999999 & TRN \\
\hline CHEMBL 3794421 & 1571915 & 7.3768 & 7.3739 & TRN & \\
\hline CHEMBL 3793984 & 1571915 & 7.585 & 7.5929 & TRN & \\
\hline CHEMBL 3793858 & 1571915 & 7.3565 & 7.3614 & TRN & \\
\hline CHEMBL3793072 & 1571915 & 7.0506 & 7.0557 & TRN & \\
\hline CHEMBL3793906 & 1571915 & 7.4318 & 7.4345 & TRN & \\
\hline CHEMBL3793709 & 1571915 & 6.1367 & 6.1381 & TRN & \\
\hline CHEMBL 3793389 & 1571915 & 7.9355 & 7.9556 & TRN & \\
\hline CHEMBL3793910 & 1571915 & 7.8447 & 7.9395 & TST & \\
\hline CHEMBL 3792556 & 1571915 & 7.7496 & 7.2751 & TST & \\
\hline CHEMBL 3793266 & 1571915 & 7.1427 & 7.3131 & TST & \\
\hline CHEMBL3793062 & 1571915 & 6.8239 & 7.3306 & TST & \\
\hline CHEMBL 3792637 & 1571915 & 7.3279 & 7.6475 & TST & \\
\hline CHEMBL3792805 & 1571915 & 8.2676 & 7.9025 & TST & \\
\hline CHEMBL3792813 & 1571915 & 7.4318 & 7.8336 & TST & \\
\hline CHEMBL3793996 & 1571915 & 7.7423 & 7.29799 & 9999999999 & \\
\hline CHEMBL3793347 & 1571915 & 5.9747 & 7.7018 & TST & \\
\hline CHEMBL 3683554 & 1528782 & 7.2441 & 6.7025 & TRN & \\
\hline CHEMBL 3683677 & 1528782 & 6.8069 & 6.84 & TRN & \\
\hline CHEMBL 3678603 & 1528782 & 5.46700 & 00000000 & 6.1845 & \\
\hline CHEMBL 3639824 & 1528782 & 5.0052 & 5.6768 & TRN & \\
\hline CHEMBL 3678580 & 1528782 & 5.909 & 6.2291 & TST & \\
\hline CHEMBL 3678636 & 1528782 & 6.6234 & 6.5053 & TRN & \\
\hline CHEMBL 3678675 & 1528782 & 6.1669 & 5.7413 & TRN & \\
\hline CHEMBL 3683629 & 1528782 & 6.0 & 6.5585 & TRN & \\
\hline CHEMBL 3678573 & 1528782 & 5.9813 & 6.0687 & TST & \\
\hline CHEMBL 3678522 & 1528782 & 5.7972 & 5.4855 & TST & \\
\hline CHEMBL 3678617 & 1528782 & 6.2757 & 5.4072 & TST & \\
\hline CHEMBL 3683572 & 1528782 & 5.1851 & 6.0941 & TST & \\
\hline CHEMBL 3678678 & 1528782 & 6.4413 & 6.5935 & TRN & \\
\hline CHEMBL 3683510 & 1528782 & 6.2518 & 6.2847 & TRN & \\
\hline CHEMBL3683611 & 1528782 & 7.8239 & 7.2478 & TRN & \\
\hline CHEMBL 3683636 & 1528782 & 6.0 & 6.6124 & TRN & \\
\hline CHEMBL 3683544 & 1528782 & 6.8097 & 6.8666 & TRN & \\
\hline CHEMBL 3683504 & 1528782 & 5.9208 & 5.9256 & TRN & \\
\hline CHEMBL 3683545 & 1528782 & 6.8729 & 6.83299 & 9999999999 & \\
\hline CHEMBL3678539 & 1528782 & 6.4283 & 6.3081 & TRN & \\
\hline CHEMBL 3683552 & 1528782 & 6.0 & 6.475 & TRN & \\
\hline CHEMBL 3678538 & 1528782 & 5.9496 & 6.1561 & TRN & \\
\hline CHEMBL 3678526 & 1528782 & 6.3726 & 5.7272 & TRN & \\
\hline CHEMBL 3678592 & 1528782 & 5.3851 & 5.8391 & TRN & \\
\hline CHEMBL3678602 & 1528782 & 5.5186 & 5.7809 & TRN & \\
\hline CHEMBL 3678710 & 1528782 & 6.1972 & 6.7159 & TRN & \\
\hline CHEMBL 3683540 & 1528782 & 6.433 & 6.1633 & TRN & \\
\hline CHEMBL 3678665 & 1528782 & 5.7496 & 5.9152 & TRN & \\
\hline CHEMBL3678591 & 1528782 & 5.857 & 6.9349 & TST & \\
\hline
\end{tabular}


Supplemental Table S2.txt

\begin{tabular}{|c|c|c|c|c|c|}
\hline CHEMBL3683672 & 1528782 & 7.5528 & 7.0651 & TRN & \\
\hline CHEMBL3678597 & 1528782 & 5.2782 & 5.4767 & TST & \\
\hline CHEMBL3683568 & 1528782 & 5.1746 & 5.7259 & TRN & \\
\hline CHEMBL3678662 & 1528782 & 5.3261 & 5.891 & TRN & \\
\hline CHEMBL 3678524 & 1528782 & 5.9626 & 5.8671 & TST & \\
\hline CHEMBL3683511 & 1528782 & 6.1918 & 6.2585 & TRN & \\
\hline CHEMBL3678673 & 1528782 & 6.4711 & 6.3916 & TRN & \\
\hline CHEMBL 3678588 & 1528782 & 5.7212 & 6.329 & TRN & \\
\hline CHEMBL 3678624 & 1528782 & 5.7345 & 5.7749 & TRN & \\
\hline CHEMBL3678692 & 1528782 & 6.1931 & 6.0927 & TRN & \\
\hline CHEMBL3678528 & 1528782 & 6.0057 & 5.9762 & TRN & \\
\hline CHEMBL3678717 & 1528782 & 6.7773 & 7.0783 & TRN & \\
\hline CHEMBL 3678644 & 1528782 & 6.6091 & 6.7745 & TRN & \\
\hline CHEMBL3683537 & 1528782 & 6.1349 & 6.2051 & TRN & \\
\hline CHEMBL3678558 & 1528782 & 5.4029 & 5.4798 & TRN & \\
\hline CHEMBL3678554 & 1528782 & 6.3054 & 5.5586 & TRN & \\
\hline CHEMBL3683495 & 1528782 & 6.2874 & 6.3611 & TRN & \\
\hline CHEMBL3678669 & 1528782 & 6.5229 & 5.9114 & TRN & \\
\hline CHEMBL 3678718 & 1528782 & 6.6198 & 6.4847 & TRN & \\
\hline CHEMBL3683606 & 1528782 & 6.0 & 6.7181 & TRN & \\
\hline CHEMBL3678527 & 1528782 & 5.6546 & 6.3204 & TST & \\
\hline CHEMBL3678716 & 1528782 & 5.9318 & 5.6279 & TRN & \\
\hline CHEMBL3683503 & 1528782 & 7.1427 & 6.9094 & TRN & \\
\hline CHEMBL3678638 & 1528782 & 5.9731 & 6.2297 & TRN & \\
\hline CHEMBL3678646 & 1528782 & 5.1892 & 5.9708 & TRN & \\
\hline CHEMBL3678668 & 1528782 & 6.1798 & 5.8263 & TRN & \\
\hline CHEMBL 3678520 & 1528782 & 5.8794 & 5.8685 & TRN & \\
\hline CHEMBL3678631 & 1528782 & 6.4962 & 6.2779 & TRN & \\
\hline CHEMBL3683560 & 1528782 & 6.0 & 6.3579 & TRN & \\
\hline CHEMBL3683647 & 1528782 & 7.6021 & 7.3333 & TRN & \\
\hline CHEMBL3678533 & 1528782 & 5.3958 & 5.6399 & TRN & \\
\hline CHEMBL 3678543 & 1528782 & 6.6517 & 5.8119 & TRN & \\
\hline CHEMBL3683538 & 1528782 & 6.7799 & 6.432 & TRN & \\
\hline CHEMBL3683678 & 1528782 & 6.2336 & 6.1492 & TRN & \\
\hline CHEMBL3683619 & 1528782 & 6.6946 & 7.045 & TRN & \\
\hline CHEMBL3683531 & 1528782 & 6.0 & 6.8597 & TRN & \\
\hline CHEMBL3683688 & 1528782 & 7.0177 & 6.8005 & TRN & \\
\hline CHEMBL3678676 & 1528782 & 5.54899 & 999999999 & 995 & 5.6685 \\
\hline CHEMBL3683549 & 1528782 & 6.06 & 6.335 & TRN & \\
\hline CHEMBL3678550 & 1528782 & 6.1931 & 5.7499 & TRN & \\
\hline CHEMBL3678608 & 1528782 & 6.0438 & 5.8683 & TRN & \\
\hline CHEMBL3678607 & 1528782 & 5.7557 & 6.1694 & TRN & \\
\hline CHEMBL 3678628 & 1528782 & 6.4306 & 6.5394 & TRN & \\
\hline CHEMBL3678688 & 1528782 & 5.7862 & 6.5079 & TST & \\
\hline CHEMBL 3678557 & 1528782 & 6.1798 & 5.6886 & TRN & \\
\hline CHEMBL 3678583 & 1528782 & 5.8196 & 5.9114 & TRN & \\
\hline CHEMBL3683643 & 1528782 & 7.1739 & 6.9893 & TRN & \\
\hline CHEMBL3683623 & 1528782 & 7.3565 & 7.22 & TRN & \\
\hline
\end{tabular}


Supplemental Table S2.txt

\begin{tabular}{|c|c|c|c|c|c|c|}
\hline CHEMBL3683693 & 1528782 & 7.8539 & \multicolumn{4}{|c|}{$\begin{array}{ll}7.507999999999999 & \text { TRN }\end{array}$} \\
\hline CHEMBL3683681 & 1528782 & 7.6778 & 7.14 & TRN & & \\
\hline CHEMBL3678586 & 1528782 & 6.3288 & 6.3865 & TRN & & \\
\hline CHEMBL3683669 & 1528782 & 6.9469 & 6.7847 & TRN & & \\
\hline CHEMBL 3683574 & 1528782 & 4.8585 & 5.8606 & TST & & \\
\hline CHEMBL 3678724 & 1528782 & 6.2048 & 5.7988 & TST & & \\
\hline CHEMBL3683689 & 1528782 & 6.8761 & 6.8966 & TRN & & \\
\hline CHEMBL 3683521 & 1528782 & 6.4034 & 6.5677 & TRN & & \\
\hline CHEMBL 3678697 & 1528782 & 5.4547 & 5.6717 & TRN & & \\
\hline CHEMBL3683660 & 1528782 & 7.3468 & \multicolumn{3}{|c|}{6.837000000000001} & TRN \\
\hline CHEMBL 3683601 & 1528782 & 7.1367 & 7.0598 & TRN & & \\
\hline CHEMBL3683513 & 1528782 & 6.7721 & 6.8871 & TRN & & \\
\hline CHEMBL 3678632 & 1528782 & 6.5622 & 6.1068 & TRN & & \\
\hline CHEMBL 3683592 & 1528782 & 6.7471 & 6.3176 & TRN & & \\
\hline CHEMBL 3678671 & 1528782 & 6.3429 & 6.1064 & TRN & & \\
\hline CHEMBL 3683646 & 1528782 & 7.2291 & 6.8747 & TRN & & \\
\hline CHEMBL3678656 & 1528782 & 6.3028 & 6.6029 & TRN & & \\
\hline CHEMBL 3678514 & 1528782 & \multicolumn{3}{|c|}{5.7620000000000005} & 5.7221 & \\
\hline CHEMBL 3683578 & 1528782 & 6.0506 & 5.8898 & TRN & & \\
\hline CHEMBL 3678660 & 1528782 & 6.0 & 6.8737 & TRN & & \\
\hline CHEMBL 3683655 & 1528782 & 7.3188 & 6.9462 & TRN & & \\
\hline CHEMBL3678657 & 1528782 & 6.8539 & 6.7198 & TRN & & \\
\hline CHEMBL 3678639 & 1528782 & \multicolumn{3}{|c|}{6.172000000000001} & 6.0454 & \\
\hline CHEMBL 3683680 & 1528782 & 7.7447 & 6.9332 & TRN & & \\
\hline CHEMBL 3678560 & 1528782 & 6.6073 & 5.896 & TRN & & \\
\hline CHEMBL 3678589 & 1528782 & 5.3335 & 5.9663 & TRN & & \\
\hline CHEMBL 3683612 & 1528782 & 7.6198 & 7.1827 & TRN & & \\
\hline CHEMBL 3678518 & 1528782 & 6.1612 & 5.9615 & TRN & & \\
\hline CHEMBL 3678563 & 1528782 & 6.1029 & 5.6313 & TRN & & \\
\hline CHEMBL 3683547 & 1528782 & 6.0 & 6.8892 & TRN & & \\
\hline CHEMBL 3678722 & 1528782 & 5.3936 & 6.0825 & TRN & & \\
\hline CHEMBL3678535 & 1528782 & 6.1791 & 6.2516 & TST & & \\
\hline CHEMBL3678577 & 1528782 & 6.4248 & 5.9828 & TRN & & \\
\hline CHEMBL 3678567 & 1528782 & 6.2749 & 5.7466 & TRN & & \\
\hline CHEMBL 3683676 & 1528782 & 6.6498 & 6.9837 & TRN & & \\
\hline CHEMBL 3678712 & 1528782 & 6.066 & 6.7358 & TRN & & \\
\hline CHEMBL 3678531 & 1528782 & 5.2596 & 5.6144 & TRN & & \\
\hline CHEMBL 3678585 & 1528782 & 6.1124 & 6.5657 & TRN & & \\
\hline CHEMBL 3683584 & 1528782 & 6.0 & 7.1164 & TRN & & \\
\hline CHEMBL 3678723 & 1528782 & 5.8268 & 5.6698 & TST & & \\
\hline CHEMBL 3678569 & 1528782 & 5.4089 & 5.6507 & TST & & \\
\hline CHEMBL 3678530 & 1528782 & 5.6411 & 5.5913 & TRN & & \\
\hline CHEMBL 3639774 & 1528782 & 5.6576 & 5.9263 & TRN & & \\
\hline CHEMBL 3678587 & 1528782 & 6.3595 & 6.3216 & TST & & \\
\hline CHEMBL 3678594 & 1528782 & 6.4868 & 6.4002 & TRN & & \\
\hline CHEMBL 3678595 & 1528782 & 6.0575 & 5.7342 & TRN & & \\
\hline CHEMBL 3639825 & 1528782 & 6.9788 & 6.9054 & TRN & & \\
\hline CHEMBL 3678670 & 1528782 & 6.7352 & 6.2028 & TRN & & \\
\hline
\end{tabular}

Page 21265 
Supplemental Table S2.txt

\begin{tabular}{|c|c|c|c|c|}
\hline CHEMBL3683567 & 1528782 & 4.7476 & 5.386 & TRN \\
\hline CHEMBL3683649 & 1528782 & 7.8861 & 7.0994 & TRN \\
\hline CHEMBL 3678547 & 1528782 & 5.7375 & 5.9461 & TRN \\
\hline CHEMBL3678556 & 1528782 & 5.8069 & 6.0721 & TRN \\
\hline CHEMBL3678683 & 1528782 & 6.5528 & 6.1819 & TRN \\
\hline CHEMBL3678703 & 1528782 & 6.3298 & 6.5377 & TRN \\
\hline CHEMBL3678658 & 1528782 & 6.8601 & 6.8842 & TRN \\
\hline CHEMBL 3678605 & 1528782 & 6.0926 & 5.7973 & TRN \\
\hline CHEMBL 3683523 & 1528782 & 6.0 & 6.9207 & TRN \\
\hline CHEMBL3678715 & 1528782 & 5.7167 & \multicolumn{2}{|c|}{5.792999999999999} \\
\hline CHEMBL3683526 & 1528782 & 6.058 & 6.5248 & TST \\
\hline CHEMBL3678516 & 1528782 & 6.3747 & 6.0636 & TST \\
\hline CHEMBL 3683662 & 1528782 & 7.0969 & 6.7945 & TRN \\
\hline CHEMBL 3683507 & 1528782 & 6.0841 & 6.2331 & TRN \\
\hline CHEMBL3683613 & 1528782 & 7.7212 & 7.182 & TRN \\
\hline CHEMBL3678690 & 1528782 & 6.1918 & 5.7087 & TST \\
\hline CHEMBL3683553 & 1528782 & 6.4522 & \multicolumn{2}{|c|}{6.4479999999999995} \\
\hline CHEMBL3678549 & 1528782 & 6.3382 & 5.6679 & TRN \\
\hline CHEMBL 3683542 & 1528782 & 6.3116 & 6.1041 & TRN \\
\hline CHEMBL3678661 & 1528782 & 6.1314 & 6.1517 & TRN \\
\hline CHEMBL3683692 & 1528782 & 7.3098 & 7.0324 & TRN \\
\hline CHEMBL3683679 & 1528782 & 6.7986 & 6.1829 & TRN \\
\hline CHEMBL3683509 & 1528782 & 6.3206 & 6.5105 & TRN \\
\hline CHEMBL 3678672 & 1528782 & 6.7144 & \multicolumn{2}{|c|}{6.122000000000001} \\
\hline CHEMBL3683536 & 1528782 & 6.5901 & 6.4169 & TRN \\
\hline CHEMBL3683532 & 1528782 & 6.0 & 6.8181 & TRN \\
\hline CHEMBL3678686 & 1528782 & 6.52 & 6.6524 & TST \\
\hline CHEMBL3678679 & 1528782 & 6.3768 & 6.4782 & TRN \\
\hline CHEMBL 3683700 & 1528782 & 5.4609 & 5.4316 & TST \\
\hline CHEMBL3683635 & 1528782 & 6.6271 & 6.425 & TRN \\
\hline CHEMBL3678687 & 1528782 & 5.7602 & 5.6299 & TRN \\
\hline CHEMBL 3678705 & 1528782 & 6.2314 & 6.6533 & TRN \\
\hline CHEMBL3678720 & 1528782 & 6.6345 & 6.1367 & TRN \\
\hline CHEMBL 3683564 & 1528782 & 5.0089 & 5.7251 & TST \\
\hline CHEMBL3678565 & 1528782 & 5.6478 & 5.7026 & TRN \\
\hline CHEMBL3683524 & 1528782 & 6.5157 & 6.2988 & TRN \\
\hline CHEMBL 3678633 & 1528782 & 5.9003 & 6.3178 & TRN \\
\hline CHEMBL3678700 & 1528782 & 6.04 & 6.2244 & TRN \\
\hline CHEMBL 3678659 & 1528782 & 6.2676 & 6.5293 & TRN \\
\hline CHEMBL 3683565 & 1528782 & 4.8399 & 5.5232 & TRN \\
\hline CHEMBL3678620 & 1528782 & 6.0026 & 6.3629 & TRN \\
\hline CHEMBL3683691 & 1528782 & 6.4572 & 6.3331 & TRN \\
\hline CHEMBL3683559 & 1528782 & 6.0 & 7.0349 & TRN \\
\hline CHEMBL 3683618 & 1528782 & 6.6021 & 6.7764 & TST \\
\hline CHEMBL 3678625 & 1528782 & 5.3445 & 5.8558 & TST \\
\hline CHEMBL3683563 & 1528782 & 4.9688 & 5.6305 & TRN \\
\hline CHEMBL3683696 & 1528782 & 4.9788 & 6.7035 & TST \\
\hline CHEMBL 3678693 & 1528782 & 5.5766 & 5.7808 & TRN \\
\hline
\end{tabular}

Page 21266 
Supplemental Table S2.txt

\begin{tabular}{|c|c|c|c|c|}
\hline CHEMBL3683610 & 1528782 & 6.0 & 7.0048 & TST \\
\hline CHEMBL3678664 & 1528782 & 5.9539 & 6.0909 & TRN \\
\hline CHEMBL3678548 & 1528782 & 6.2211 & 5.5422 & TRN \\
\hline CHEMBL3683535 & 1528782 & 6.1599 & 6.0903 & TRN \\
\hline CHEMBL3683576 & 1528782 & 6.3516 & 6.223 & TRN \\
\hline CHEMBL 3678622 & 1528782 & 6.7696 & 6.4126 & TRN \\
\hline CHEMBL 3678544 & 1528782 & 6.6126 & 5.6168 & TRN \\
\hline CHEMBL3678649 & 1528782 & 5.7122 & 6.0485 & TRN \\
\hline CHEMBL3683498 & 1528782 & 6.0013 & 5.9137 & TRN \\
\hline CHEMBL3683577 & 1528782 & 6.1391 & 5.92200 & 000000001 \\
\hline CHEMBL3683657 & 1528782 & 7.2441 & 6.7306 & TRN \\
\hline CHEMBL3683634 & 1528782 & 7.0969 & 7.1237 & TRN \\
\hline CHEMBL 3678598 & 1528782 & 5.295 & 5.6357 & TST \\
\hline CHEMBL3683508 & 1528782 & 6.3585 & 6.5868 & TRN \\
\hline CHEMBL3678559 & 1528782 & 6.4237 & 5.9008 & TRN \\
\hline CHEMBL 3683697 & 1528782 & 7.3188 & 6.9603 & TRN \\
\hline CHEMBL3678529 & 1528782 & 6.3063 & 5.6453 & TRN \\
\hline CHEMBL3683494 & 1528782 & 5.8116 & 6.4963 & TRN \\
\hline CHEMBL3683515 & 1528782 & 7.0088 & 6.9098 & TRN \\
\hline CHEMBL3678713 & 1528782 & 6.5452 & 6.6703 & TRN \\
\hline CHEMBL3678685 & 1528782 & 5.3132 & 5.8995 & TRN \\
\hline CHEMBL3678521 & 1528782 & 6.1255 & 5.9467 & TRN \\
\hline CHEMBL3683654 & 1528782 & 6.9788 & 6.8456 & TRN \\
\hline CHEMBL 3678541 & 1528782 & 5.8321 & 6.1851 & TRN \\
\hline CHEMBL3683687 & 1528782 & 7.0706 & 6.8884 & TRN \\
\hline CHEMBL 3678593 & 1528782 & 6.2907 & 6.2379 & TRN \\
\hline CHEMBL3683617 & 1528782 & 7.6198 & 7.3826 & TST \\
\hline CHEMBL3683570 & 1528782 & 5.1798 & 6.1537 & TST \\
\hline CHEMBL3678681 & 1528782 & 5.5696 & 5.8367 & TRN \\
\hline CHEMBL3678701 & 1528782 & 6.2118 & 6.2416 & TRN \\
\hline CHEMBL 3678561 & 1528782 & 6.0177 & 5.6808 & TRN \\
\hline CHEMBL3683624 & 1528782 & 6.1249 & 6.742999 & 9999999999 \\
\hline CHEMBL 3683518 & 1528782 & 6.6383 & 6.5874 & TRN \\
\hline CHEMBL3683651 & 1528782 & 7.4089 & 7.1529 & TRN \\
\hline CHEMBL 3683573 & 1528782 & 5.0424 & 5.8862 & TRN \\
\hline CHEMBL3678551 & 1528782 & 5.9248 & 5.3503 & TRN \\
\hline CHEMBL 3678719 & 1528782 & 6.4101 & 6.7587 & TRN \\
\hline CHEMBL 3678568 & 1528782 & 5.6064 & 5.6843 & TST \\
\hline CHEMBL 3678674 & 1528782 & 5.3748 & 5.6944 & TRN \\
\hline CHEMBL3683658 & 1528782 & 6.9706 & 6.7504 & TRN \\
\hline CHEMBL 3678627 & 1528782 & 6.52 & 6.5061 & TRN \\
\hline CHEMBL 3678654 & 1528782 & 6.9586 & 6.7835 & TRN \\
\hline CHEMBL3678576 & 1528782 & 6.3757 & 6.2475 & TRN \\
\hline CHEMBL3683648 & 1528782 & 6.9469 & 6.4988 & TRN \\
\hline CHEMBL3678721 & 1528782 & 6.2418 & 6.5167 & TRN \\
\hline CHEMBL 3678616 & 1528782 & 5.3449 & 5.8106 & TRN \\
\hline CHEMBL 3678566 & 1528782 & 5.7178 & 5.5502 & TRN \\
\hline CHEMBL3678596 & 1528782 & 5.7167 & 6.039 & TRN \\
\hline
\end{tabular}


Supplemental Table S2.txt

\begin{tabular}{|c|c|c|c|c|c|c|}
\hline CHEMBL 3678562 & 1528782 & 6.2933 & 6.0099 & TRN & & \\
\hline CHEMBL 3678571 & 1528782 & 7.1367 & 6.032999 & 9999999999 & 95 & TRN \\
\hline CHEMBL3683656 & 1528782 & 7.5086 & 6.9062 & TRN & & \\
\hline CHEMBL 3678696 & 1528782 & 6.3979 & 6.3412 & TST & & \\
\hline CHEMBL3678684 & 1528782 & $5.5870 e$ & 000000000 & & 5.9989 & TST \\
\hline CHEMBL3683663 & 1528782 & 7.3872 & 7.2285 & TRN & & \\
\hline CHEMBL 3678612 & 1528782 & 5.9539 & 6.2212 & TRN & & \\
\hline CHEMBL 3678610 & 1528782 & 6.5969 & 6.2811 & TRN & & \\
\hline CHEMBL 3683653 & 1528782 & 6.7852 & 6.506 & TRN & & \\
\hline CHEMBL3678537 & 1528782 & 6.3565 & 6.0318 & TRN & & \\
\hline CHEMBL 3683668 & 1528782 & 6.5834 & 6.4961 & TRN & & \\
\hline CHEMBL 3683514 & 1528782 & $6.1720 e$ & 000000000 & & 6.032999 & 99999999995 \\
\hline CHEMBL 3683502 & 1528782 & 6.475 & 6.3932 & TRN & & \\
\hline CHEMBL 3683500 & 1528782 & 5.1025 & 5.7066 & TRN & & \\
\hline CHEMBL 3678574 & 1528782 & 5.8867 & 5.739 & TRN & & \\
\hline CHEMBL 3678570 & 1528782 & 5.6073 & 5.5617 & TST & & \\
\hline CHEMBL3683614 & 1528782 & 7.5376 & 6.9558 & TRN & & \\
\hline CHEMBL3683516 & 1528782 & 6.4559 & 6.5645 & TRN & & \\
\hline CHEMBL 3678666 & 1528782 & 5.3055 & 6.3787 & TRN & & \\
\hline CHEMBL 3678635 & 1528782 & 5.5157 & 5.8414 & TRN & & \\
\hline CHEMBL 3678634 & 1528782 & 6.0334 & 6.3245 & TST & & \\
\hline CHEMBL3683562 & 1528782 & 4.8283 & 5.4915 & TRN & & \\
\hline CHEMBL 3683650 & 1528782 & 6.8928 & 6.6866 & TRN & & \\
\hline CHEMBL 3683666 & 1528782 & 7.4685 & 6.9619 & TRN & & \\
\hline CHEMBL 3678655 & 1528782 & 6.4134 & 6.0562 & TRN & & \\
\hline CHEMBL 3683493 & 1528782 & 6.3335 & 6.3258 & TRN & & \\
\hline CHEMBL 3678553 & 1528782 & 5.8225 & 5.8488 & TRN & & \\
\hline CHEMBL3639775 & 1528782 & 6.3655 & 5.8818 & TST & & \\
\hline CHEMBL 3683517 & 1528782 & 7.2291 & 6.8889 & TRN & & \\
\hline CHEMBL 3678650 & 1528782 & 5.9477 & 5.894 & TRN & & \\
\hline CHEMBL 3678677 & 1528782 & 5.7698 & 5.6156 & TST & & \\
\hline CHEMBL 3683625 & 1528782 & 5.8239 & 6.6113 & TRN & & \\
\hline CHEMBL3683698 & 1528782 & 6.3215 & 5.5625 & TST & & \\
\hline CHEMBL 3683597 & 1528782 & 6.4522 & 6.1694 & TRN & & \\
\hline CHEMBL 3678621 & 1528782 & 5.8861 & 6.0929 & TRN & & \\
\hline CHEMBL 3678546 & 1528782 & 5.5575 & 6.2699 & TST & & \\
\hline CHEMBL3678642 & 1528782 & 6.1169 & 5.6758 & TRN & & \\
\hline CHEMBL3683550 & 1528782 & 6.0 & 6.3602 & TRN & & \\
\hline CHEMBL 3678637 & 1528782 & 5.2993 & 5.7891 & TRN & & \\
\hline CHEMBL3678643 & 1528782 & 5.5144 & 5.8043 & TRN & & \\
\hline CHEMBL3678609 & 1528782 & 5.6778 & 5.8963 & TRN & & \\
\hline CHEMBL3683534 & 1528782 & 7.0809 & 6.979 & TRN & & \\
\hline CHEMBL3683571 & 1528782 & 4.9875 & 5.5818 & TRN & & \\
\hline CHEMBL 3683530 & 1528782 & 6.0 & 6.9272 & TRN & & \\
\hline CHEMBL3678540 & 1528782 & 6.0482 & 6.1441 & TRN & & \\
\hline CHEMBL3683682 & 1528782 & 6.4672 & 6.2149 & TRN & & \\
\hline CHEMBL3683627 & 1528782 & 6.1337 & 6.7843 & TRN & & \\
\hline CHEMBL3683607 & 1528782 & 6.9957 & 6.9614 & TRN & & \\
\hline
\end{tabular}


Supplemental Table S2.txt

\begin{tabular}{|c|c|c|c|c|c|c|}
\hline CHEMBL 3678645 & 1528782 & 5.9686 & 5.8599 & TRN & & \\
\hline CHEMBL 3683675 & 1528782 & 7.699 & 7.1908 & TRN & & \\
\hline CHEMBL 3678611 & 1528782 & 6.7399 & 6.4346 & TRN & & \\
\hline CHEMBL 3683686 & 1528782 & 7.8239 & 7.0267 & TRN & & \\
\hline CHEMBL 3678691 & 1528782 & 6.6737 & 6.7164 & TST & & \\
\hline CHEMBL 3683546 & 1528782 & 7.0458 & 7.1265 & TRN & & \\
\hline CHEMBL 3678581 & 1528782 & 6.0996 & 5.834 & TRN & & \\
\hline CHEMBL 3683667 & 1528782 & 7.699 & 6.9106 & TRN & & \\
\hline CHEMBL 3678663 & 1528782 & 6.4045 & 6.4741 & TRN & & \\
\hline CHEMBL 3678517 & 1528782 & 6.4572 & 5.7543 & TRN & & \\
\hline CHEMBL 3683642 & 1528782 & 6.0 & 7.1309 & TRN & & \\
\hline CHEMBL 3683561 & 1528782 & 6.8069 & 6.4617 & TRN & & \\
\hline CHEMBL 3683569 & 1528782 & 5.0092 & 6.2375 & TST & & \\
\hline CHEMBL3683699 & 1528782 & 4.9318 & 5.4728 & TST & & \\
\hline CHEMBL 3683694 & 1528782 & 7.3468 & 6.9501 & TRN & & \\
\hline CHEMBL 3678653 & 1528782 & 6.6038 & 6.8055 & TRN & & \\
\hline CHEMBL 3683671 & 1528782 & 8.1549 & 6.9118 & TRN & & \\
\hline CHEMBL 3678709 & 1528782 & 6.0 & 6.6787 & TRN & & \\
\hline CHEMBL 3678711 & 1528782 & 7.3665 & 6.4102 & TRN & & \\
\hline CHEMBL 3683701 & 1528782 & 5.2596 & 5.4658 & TST & & \\
\hline CHEMBL 3683684 & 1528782 & 7.7447 & 7.1667 & TRN & & \\
\hline CHEMBL 3678647 & 1528782 & 5.7905 & 5.9851 & TRN & & \\
\hline CHEMBL 3683539 & 1528782 & 6.5467 & 6.1029 & TST & & \\
\hline CHEMBL 3683505 & 1528782 & 5.8297 & 6.1675 & TRN & & \\
\hline CHEMBL 3678532 & 1528782 & 5.699 & 5.6604 & TRN & & \\
\hline CHEMBL 3678536 & 1528782 & 6.2104 & 5.9851 & TRN & & \\
\hline CHEMBL3683566 & 1528782 & 5.0991 & 6.0397 & TRN & & \\
\hline CHEMBL 3678698 & 1528782 & 5.5258 & 6.0326 & TRN & & \\
\hline CHEMBL 3678572 & 1528782 & 6.0191 & 6.1266 & TRN & & \\
\hline CHEMBL 3678707 & 1528782 & 6.8268 & 6.6787 & TRN & & \\
\hline CHEMBL 3678706 & 1528782 & 6.0 & 6.7869 & TRN & & \\
\hline CHEMBL 3639773 & 1528782 & 6.0334 & 5.9199 & TST & & \\
\hline CHEMBL 3678578 & 1528782 & 5.5067 & 5.7813 & TRN & & \\
\hline CHEMBL3683492 & 1528782 & 6.3595 & 6.2108 & TST & & \\
\hline CHEMBL 3678623 & 1528782 & 5.5911 & 5.7907 & TST & & \\
\hline CHEMBL 3678652 & 1528782 & 6.6073 & 6.5257 & TST & & \\
\hline CHEMBL 3683497 & 1528782 & 6.1945 & 6.2777 & TST & & \\
\hline CHEMBL 3678515 & 1528782 & 5.5405 & 5.4699 & TST & & \\
\hline CHEMBL3678695 & 1528782 & 5.5308 & 6.2983 & TST & & \\
\hline CHEMBL 3683633 & 1528782 & 7.0223 & 6.2543 & TRN & & \\
\hline CHEMBL 3678694 & 1528782 & 5.4453 & 6.1449 & TST & & \\
\hline CHEMBL 3678534 & 1528782 & 6.1739 & 6.1171 & TST & & \\
\hline CHEMBL 3678682 & 1528782 & 6.08299 & 79999999 & & 6.0235 & TST \\
\hline CHEMBL3683541 & 1528782 & 6.17200 & 30000000 & 1 & 6.1658 & TST \\
\hline CHEMBL 3678545 & 1528782 & 5.7562 & 5.7021 & TST & & \\
\hline CHEMBL 3678600 & 1528782 & 5.3691 & 6.045 & TST & & \\
\hline CHEMBL 3683670 & 1528782 & 6.6459 & 6.4183 & TST & & \\
\hline CHEMBL 3683551 & 1528782 & 7.4202 & 6.8531 & TRN & & \\
\hline
\end{tabular}

Page 21269 
Supplemental Table S2.txt

\begin{tabular}{|c|c|c|c|c|c|}
\hline CHEMBL 3683501 & 1528782 & 6.4318 & 6.6261 & TST & \\
\hline CHEMBL 3683575 & 1528782 & 6.4597 & 6.6428 & TST & \\
\hline CHEMBL 3678714 & 1528782 & 6.0362 & 6.6572 & TST & \\
\hline CHEMBL 3683620 & 1528782 & 6.2557 & 6.9579 & TST & \\
\hline CHEMBL 3683652 & 1528782 & 6.6402 & 6.7072 & TST & \\
\hline CHEMBL 3678708 & 1528782 & 6.1681 & 6.7367 & TRN & \\
\hline CHEMBL3678599 & 1528782 & 5.475 & 5.6173 & TST & \\
\hline CHEMBL 3678618 & 1528782 & 6.0 & 6.6416 & TRN & \\
\hline CHEMBL 3683695 & 1528782 & 7.8861 & 7.7533 & TRN & \\
\hline CHEMBL 3678606 & 1528782 & 5.8114 & 6.3349 & TRN & \\
\hline CHEMBL3683499 & 1528782 & 5.9872 & 6.0963 & TRN & \\
\hline CHEMBL 3678648 & 1528782 & 5.6659 & 5.9383 & TST & \\
\hline CHEMBL 3678614 & 1528782 & 6.1605 & 6.8467 & TST & \\
\hline CHEMBL3683522 & 1528782 & 6.7825 & 6.8156 & TST & \\
\hline CHEMBL 3683622 & 1528782 & 7.0315 & 6.9951 & TRN & \\
\hline CHEMBL 3683665 & 1528782 & 7.2076 & 6.8173 & TRN & \\
\hline CHEMBL3683527 & 1528782 & 6.0 & 6.4008 & TRN & \\
\hline CHEMBL3678629 & 1528782 & 6.4584 & 6.8304 & TST & \\
\hline CHEMBL 3678651 & 1528782 & 5.5694 & 5.9494 & TST & \\
\hline CHEMBL 3678582 & 1528782 & 6.6882 & 6.2667 & TRN & \\
\hline CHEMBL3678519 & 1528782 & 5.3773 & 6.0095 & TST & \\
\hline CHEMBL3683506 & 1528782 & 6.0348 & 6.251 & TRN & \\
\hline CHEMBL 3678604 & 1528782 & 5.8821 & 5.6661 & TST & \\
\hline CHEMBL 3678613 & 1528782 & 6.3706 & 6.0163 & TRN & \\
\hline CHEMBL 3683673 & 1528782 & 7.1367 & 6.8521 & TRN & \\
\hline CHEMBL 3678680 & 1528782 & 5.5696 & 6.5478 & TST & \\
\hline CHEMBL 3678699 & 1528782 & 5.3778 & 5.9796 & TST & \\
\hline CHEMBL 3678564 & 1528782 & 5.8894 & 5.5608 & TRN & \\
\hline CHEMBL3683555 & 1528782 & 6.0 & 6.8003 & TRN & \\
\hline CHEMBL 3683621 & 1528782 & 4.9914 & 5.8595 & TST & \\
\hline CHEMBL 3678552 & 1528782 & 5.8416 & 5.49200 & 0000000001 & TRN \\
\hline CHEMBL3683529 & 1528782 & 6.1481 & 6.5667 & TRN & \\
\hline CHEMBL 3678542 & 1528782 & 5.3931 & 5.933 & TST & \\
\hline CHEMBL 3678641 & 1528782 & 6.0448 & 5.9824 & TST & \\
\hline CHEMBL 3683683 & 1528782 & 6.0022 & 6.4128 & TST & \\
\hline CHEMBL3683661 & 1528782 & 7.6021 & 7.0013 & TRN & \\
\hline CHEMBL 3683496 & 1528782 & 6.0841 & 6.1019 & TST & \\
\hline CHEMBL 3683626 & 1528782 & 6.4622 & 6.6108 & TRN & \\
\hline CHEMBL 3683664 & 1528782 & 7.3979 & 6.9531 & TRN & \\
\hline CHEMBL 3683690 & 1528782 & 7.6021 & 6.9968 & TRN & \\
\hline CHEMBL3683632 & 1528782 & 7.6778 & 7.151 & TRN & \\
\hline CHEMBL 3683525 & 1528782 & 6.7167 & 6.3916 & TRN & \\
\hline CHEMBL 3683589 & 1528782 & 6.7447 & 6.6094 & TST & \\
\hline CHEMBL 3678615 & 1528782 & 5.8239 & 5.6638 & TST & \\
\hline CHEMBL 3678626 & 1528782 & 5.6474 & 5.9176 & TST & \\
\hline CHEMBL 3683608 & 1528782 & 7.1871 & 6.8202 & TRN & \\
\hline CHEMBL 3678704 & 1528782 & 6.1481 & 6.5925 & TRN & \\
\hline CHEMBL 3678513 & 1528782 & 6.3382 & 5.4886 & TST & \\
\hline
\end{tabular}


Supplemental Table S2.txt

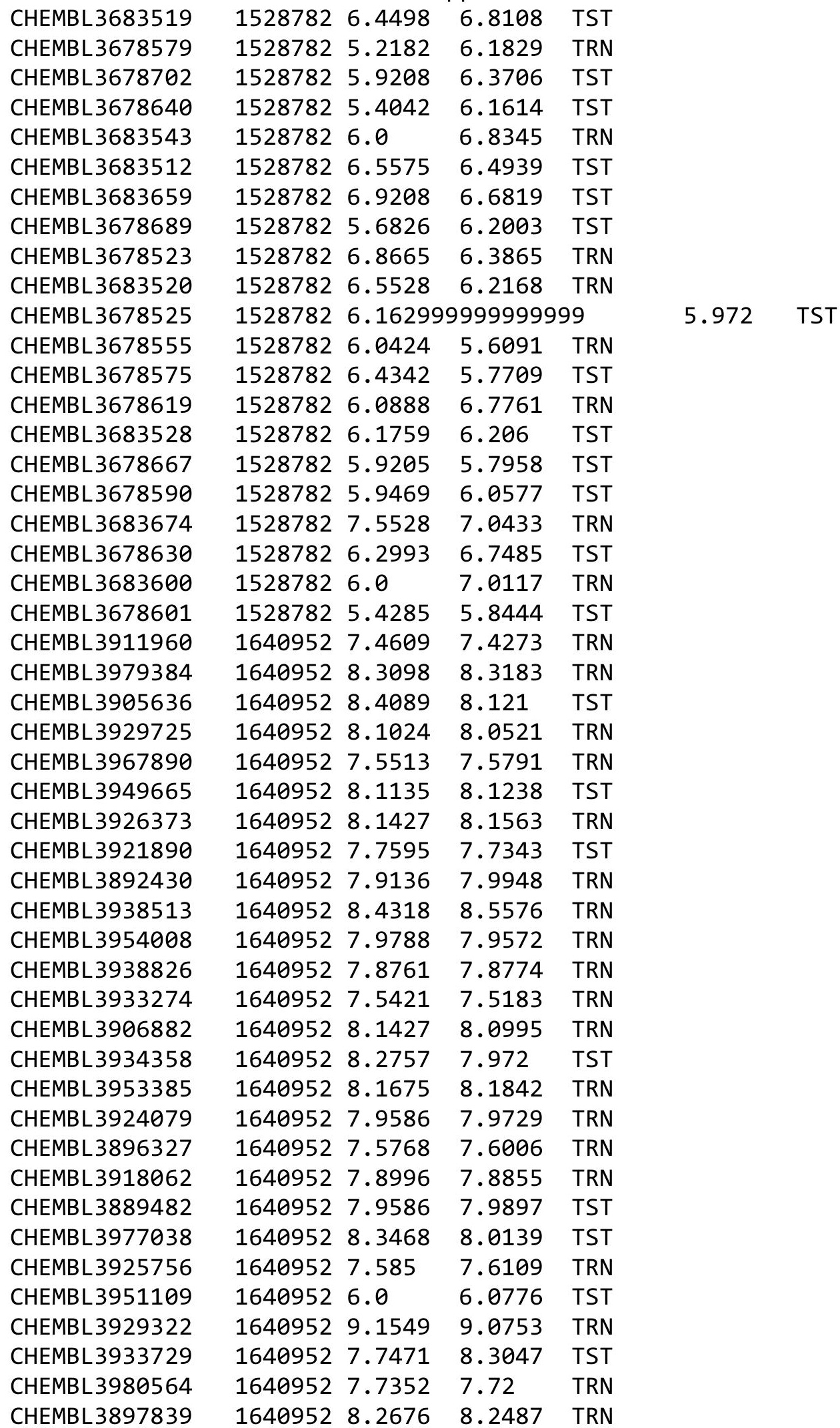

Page 21271 
Supplemental Table S2.txt

\begin{tabular}{|c|c|c|c|c|c|}
\hline CHEMBL3949626 & 1640952 & 8.7447 & 8.6616 & TRN & \\
\hline CHEMBL 3976573 & 1640952 & 8.0269 & 8.1227 & TRN & \\
\hline CHEMBL3895503 & 1640952 & 8.3279 & 8.4375 & TRN & \\
\hline CHEMBL 3983205 & 1640952 & 7.1085 & 7.2295 & TST & \\
\hline CHEMBL 3948076 & 1640952 & 7.7825 & 7.7581 & TRN & \\
\hline CHEMBL3907995 & 1640952 & 8.2441 & 8.2252 & TRN & \\
\hline CHEMBL3924399 & 1640952 & 6.0 & 6.0396 & TRN & \\
\hline CHEMBL3921263 & 1640952 & 8.1549 & 8.1521 & TRN & \\
\hline CHEMBL3939941 & 1640952 & 7.7258 & 7.8823 & TRN & \\
\hline CHEMBL 3938823 & 1640952 & 8.6021 & 8.7386 & TRN & \\
\hline CHEMBL 3924925 & 1640952 & 7.3429 & 7.3349 & TRN & \\
\hline CHEMBL 3969060 & 1640952 & 8.2147 & 8.2429 & TRN & \\
\hline CHEMBL 3944881 & 1640952 & 8.6021 & 8.5839 & TRN & \\
\hline CHEMBL 3985178 & 1640952 & 9.0 & 8.8495 & TRN & \\
\hline CHEMBL 3890365 & 1640952 & 7.2358 & 7.0646 & TST & \\
\hline CHEMBL 3954561 & 1640952 & 8.1675 & 8.2729 & TRN & \\
\hline CHEMBL3905236 & 1640952 & 8.3098 & 8.3168 & TRN & \\
\hline CHEMBL 3915403 & 1640952 & 8.0269 & 7.9061 & TRN & \\
\hline CHEMBL3889953 & 1640952 & 8.6021 & 8.6112 & TRN & \\
\hline CHEMBL 3914178 & 1640952 & 7.433 & 7.4053 & TRN & \\
\hline CHEMBL3951786 & 1640952 & 9.0458 & 8.1143 & TST & \\
\hline CHEMBL 3943773 & 1640952 & 8.8539 & 8.9714 & TRN & \\
\hline CHEMBL3981692 & 1640952 & 7.6091 & 8.1323 & TST & \\
\hline CHEMBL 3892887 & 1640952 & 8.4815 & 8.4878 & TRN & \\
\hline CHEMBL 3934668 & 1640952 & 8.5376 & 8.4523 & TRN & \\
\hline CHEMBL3948716 & 1640952 & 8.0088 & 8.0235 & TRN & \\
\hline CHEMBL3969781 & 1640952 & 8.0809 & 8.0196 & TRN & \\
\hline CHEMBL 3920417 & 1640952 & 8.8539 & 8.7899 & TRN & \\
\hline CHEMBL 3932448 & 1640952 & 7.3778 & 7.4078 & TRN & \\
\hline CHEMBL 3930278 & 1640952 & 7.1945 & 7.88899 & 9999999999 & TST \\
\hline CHEMBL3919371 & 1640952 & 7.7033 & 8.21600 & 2000000001 & TST \\
\hline CHEMBL 3917388 & 1640952 & 7.1844 & 7.1469 & TRN & \\
\hline CHEMBL 3907380 & 1640952 & 8.0132 & 7.9941 & TRN & \\
\hline CHEMBL3965694 & 1640952 & 8.699 & 8.2334 & TST & \\
\hline CHEMBL 3938754 & 1640952 & 6.0 & 5.9857 & TST & \\
\hline CHEMBL3962751 & 1640952 & 7.2815 & 7.3237 & TRN & \\
\hline CHEMBL3957859 & 1640952 & 8.1675 & 8.1938 & TRN & \\
\hline CHEMBL 3974164 & 1640952 & 8.0088 & 8.0262 & TRN & \\
\hline CHEMBL 3909132 & 1640952 & 8.28399 & 79999999 & 8.2798 & TRN \\
\hline CHEMBL3976970 & 1640952 & 7.5072 & 7.2715 & TST & \\
\hline CHEMBL 3950723 & 1640952 & 7.3696 & 7.0765 & TST & \\
\hline CHEMBL 3944496 & 1640952 & 8.1487 & 6.8426 & TST & \\
\hline CHEMBL 3984301 & 1640952 & 8.0132 & 8.1134 & TRN & \\
\hline CHEMBL3968059 & 1640952 & 8.5086 & 8.3754 & TRN & \\
\hline CHEMBL 3945043 & 1640952 & 7.4001 & 7.388 & TRN & \\
\hline CHEMBL3897866 & 1640952 & 7.4895 & 7.5354 & TRN & \\
\hline CHEMBL 3937124 & 1640952 & 9.699 & 9.7673 & TRN & \\
\hline CHEMBL 3916756 & 1640952 & 8.6778 & 8.532 & TST & \\
\hline
\end{tabular}


Supplemental Table S2.txt

\begin{tabular}{|c|c|c|c|c|c|}
\hline CHEMBL3963485 & 1640952 & 6.0 & 6.0246 & TRN & \\
\hline CHEMBL3958993 & 1640952 & 8.1938 & 8.1813 & TRN & \\
\hline CHEMBL3930377 & 1640952 & 8.0915 & 8.0233 & TRN & \\
\hline CHEMBL3929808 & 1640952 & 7.8539 & 7.7338 & TRN & \\
\hline CHEMBL3952635 & 1640952 & 8.4685 & 8.4638 & TRN & \\
\hline CHEMBL3969794 & 1640952 & 8.0177 & 7.9241 & TST & \\
\hline CHEMBL3979989 & 1640952 & 6.0 & 6.0114 & TRN & \\
\hline CHEMBL3906839 & 1640952 & 6.0 & 6.5612 & TST & \\
\hline CHEMBL3923490 & 1640952 & 7.8861 & 7.7851 & TRN & \\
\hline CHEMBL3914307 & 1640952 & 8.0 & 7.94600 & 0000000001 & TRN \\
\hline CHEMBL 2170425 & 1641357 & 6.4248 & 6.4364 & TRN & \\
\hline CHEMBL3986322 & 1641357 & 5.8268 & 3.4045 & TST & \\
\hline CHEMBL3969341 & 1641357 & 5.4437 & 5.41200 & 0000000001 & TRN \\
\hline CHEMBL3965790 & 1641357 & 3.301 & 3.3067 & TRN & \\
\hline CHEMBL2170589 & 1641357 & 8.3468 & 8.3441 & TRN & \\
\hline CHEMBL 2169893 & 1641357 & 8.5376 & 8.5188 & TRN & \\
\hline CHEMBL 2170588 & 1641357 & 7.2993 & 8.2458 & TST & \\
\hline CHEMBL 2170594 & 1641357 & 4.5045 & 4.4558 & TRN & \\
\hline CHEMBL 2170415 & 1641357 & 7.6737 & 7.6475 & TRN & \\
\hline CHEMBL 2170412 & 1641357 & 7.6345 & 7.6189 & TRN & \\
\hline CHEMBL578061 & 1641357 & 6.3737 & 6.3552 & TRN & \\
\hline CHEMBL 2170600 & 1641357 & 3.301 & 3.2931 & TRN & \\
\hline CHEMBL3894354 & 1641357 & 4.6655 & 4.6626 & TRN & \\
\hline CHEMBL 2170587 & 1641357 & 8.0706 & 7.8213 & TST & \\
\hline CHEMBL 2170442 & 1641357 & 7.52 & 7.4594 & TRN & \\
\hline CHEMBL 2170405 & 1641357 & 7.3478 & 7.3485 & TRN & \\
\hline CHEMBL2170595 & 1641357 & 4.6091 & 4.5901 & TRN & \\
\hline CHEMBL244839 & 1641357 & 7.1002 & 7.164 & TRN & \\
\hline CHEMBL 2170590 & 1641357 & 7.5513 & 7.5345 & TRN & \\
\hline CHEMBL 2170439 & 1641357 & 7.4559 & 7.4452 & TRN & \\
\hline CHEMBL 2170404 & 1641357 & 7.7447 & 7.7445 & TRN & \\
\hline CHEMBL3893288 & 1641357 & 4.6383 & 4.8062 & TST & \\
\hline CHEMBL 2170410 & 1641357 & 6.5969 & 6.6252 & TRN & \\
\hline CHEMBL3975642 & 1641357 & 4.8447 & 4.8662 & TRN & \\
\hline CHEMBL 2170413 & 1641357 & 7.9101 & 7.9144 & TRN & \\
\hline CHEMBL 2170419 & 1641357 & 9.0969 & 9.0167 & TRN & \\
\hline CHEMBL2170423 & 1641357 & 5.8268 & 5.8562 & TRN & \\
\hline CHEMBL3971129 & 1641357 & 7.52 & 4.919 & TST & \\
\hline CHEMBL 2170593 & 1641357 & 5.0458 & 5.0729 & TRN & \\
\hline CHEMBL 2170597 & 1641357 & 8.0 & 8.038 & TRN & \\
\hline CHEMBL 2170591 & 1641357 & 6.6655 & 6.6566 & TRN & \\
\hline CHEMBL3954884 & 1641357 & 4.5901 & 4.598 & TRN & \\
\hline CHEMBL 2170414 & 1641357 & 7.8416 & 7.8815 & TRN & \\
\hline CHEMBL 2170417 & 1641357 & \multicolumn{3}{|c|}{7.7620000000000005} & TRN \\
\hline CHEMBL 2170408 & 1641357 & 6.9337 & 6.9607 & TRN & \\
\hline CHEMBL 2170434 & 1641357 & 7.4559 & 7.4695 & TRN & \\
\hline CHEMBL 2170426 & 1641357 & 3.301 & 3.2938 & TRN & \\
\hline CHEMBL2170599 & 1641357 & 6.5513 & 6.5545 & TRN & \\
\hline
\end{tabular}

Page 21273 
Supplemental Table S2.txt

\begin{tabular}{|c|c|c|c|c|}
\hline HEN & 1357 & & & \\
\hline & & & .7327 & \\
\hline & & & & \\
\hline AEMBL39 & & $\partial 521$ & & \\
\hline AEMBL2170416 & 357 & 5086 & 5026 & \\
\hline HEMBL3966220 & 357 & 5.8996 & 1918 & \\
\hline 679 & & & 713 & \\
\hline FMRI & & & & \\
\hline HEMBL2 & 357 & 8.1805 & 1704 & \\
\hline HEMBL3970937 & 357 & 3.301 & 6406 & \\
\hline HEMBL3970534 & 57 & 6.7293 & .7874 & \\
\hline IEMBL2 & ל & 96 & .6962 & \\
\hline AEMBL3 & & & & \\
\hline HEMBL3898475 & & 6.5003 & . 3727 & \\
\hline AEMBL 217 & 57 & 18 & .612 & \\
\hline AEMBL3 & 6 & & 9479 & \\
\hline HEMBL2 & 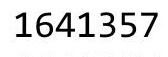 & & 594 & \\
\hline HEMBL 2 & & & 285 & \\
\hline HEMBL3 & & & 5.7216 & \\
\hline AEMBL2 & & 7. & & \\
\hline HEMBL 2 & 6 & 7. & 18 & \\
\hline AEMBL: & & & 94 & 2 \\
\hline HEMBL & & & 37 & \\
\hline HFMRI & & & & \\
\hline AEMBL3 & & & & ISI \\
\hline HEMBL 2 & & & 587 & RIN \\
\hline HEMBL & & & 56 & Niv \\
\hline $\mathrm{HFMBI} 2$ & & & 316 & \\
\hline HEMBL3 & & & & IS \\
\hline HEMBL2] & & & & TRN \\
\hline HEMBL3 & & & & ST \\
\hline HEMBL & & & & RN \\
\hline HEMBL & & & 28 & $\mathrm{R}$ \\
\hline HEMBL3 & & & & ISI \\
\hline HEMBL2170409 & 57 & & 754 & TRN \\
\hline HEMBL3 & & & .07 & ST \\
\hline HEMRI & & & & TRN \\
\hline HEMBL2 & & & 273 & IRN \\
\hline HEMBL 394 & & & 7.2273 & TRN \\
\hline IEMBL 2 & & 79 & 8.4278 & TRN \\
\hline HEMBL2 & & 665 & .4004 & RN \\
\hline CHEMBL 2: & & & 8.6148 & TRN \\
\hline HEMBL 24 & & 4.5686 & 8712 & TRN \\
\hline HEMBL12 & 7 & $\partial 6$ & .1536 & TR \\
\hline $\mathrm{MBL} 2$ & & & 2452 & $\mathrm{~N}$ \\
\hline HEMBL7 & & & .1068 & \\
\hline CHEMBL 24299 & 985 & & 5.1057 & \\
\hline HEMBL341135 & 985247 & 8.3979 & 8.2677 & ГRN \\
\hline
\end{tabular}

Page 21274 


\begin{tabular}{|c|c|c|c|c|c|}
\hline \multirow[b]{2}{*}{ CHEMBL 262070} & \multicolumn{5}{|c|}{ supp so } \\
\hline & 985247 & 3.4318 & 4.6196 & TST & \\
\hline CHEMBL465457 & 985247 & 4.8239 & 4.836 & TST & \\
\hline CHEMBL105496 & 985247 & 4.699 & 4.6509 & TRN & \\
\hline CHEMBL129510 & 985247 & 7.3665 & 7.565 & TRN & \\
\hline CHEMBL33943 & 985247 & 4.7447 & 5.1063 & TRN & \\
\hline CHEMBL1801959 & 985247 & 5.1079 & 4.5726 & TRN & \\
\hline CHEMBL 2430041 & 985247 & 4.3872 & 4.8795 & TRN & \\
\hline CHEMBL 2429955 & 985247 & 4.8539 & 4.7602 & TRN & \\
\hline CHEMBL474682 & 985247 & 4.0362 & 4.6645 & TST & \\
\hline CHEMBL 276473 & 985247 & 3.6383 & 3.5497 & TRN & \\
\hline CHEMBL 2429869 & 985247 & 4.6198 & 4.4562 & TRN & \\
\hline CHEMBL1255773 & 985247 & 4.1938 & 4.2175 & TRN & \\
\hline CHEMBL465025 & 985247 & 5.0458 & 5.2013 & TRN & \\
\hline CHEMBL 2429954 & 985247 & 4.4202 & 5.08 & TRN & \\
\hline CHEMBL318170 & 985247 & 5.1871 & 4.9253 & TRN & \\
\hline CHEMBL 2430043 & 985247 & 4.5686 & 4.8937 & TRN & \\
\hline CHEMBL126804 & 985247 & 4.3768 & 4.1408 & TRN & \\
\hline CHEMBL130639 & 985247 & 4.9208 & 5.2655 & TRN & \\
\hline CHEMBL504473 & 985247 & 3.3979 & 4.723 & TST & \\
\hline CHEMBL130640 & 985247 & 4.7696 & 4.9517 & TRN & \\
\hline CHEMBL 105310 & 985247 & 3.3979 & 3.5504 & TRN & \\
\hline CHEMBL 2429960 & 985247 & 5.3979 & 5.1686 & TRN & \\
\hline CHEMBL 2429962 & 985247 & 6.0 & 4.9301 & TRN & \\
\hline CHEMBL338066 & 985247 & 4.0 & 4.2075 & TRN & \\
\hline CHEMBL144626 & 985247 & 5.0 & 4.8642 & TST & \\
\hline CHEMBL 2429958 & 985247 & 4.7959 & 4.3708 & TRN & \\
\hline CHEMBL128000 & 985247 & 8.3372 & 8.0849 & TRN & \\
\hline CHEMBL 2430038 & 985247 & 4.7696 & 4.867 & TST & \\
\hline CHEMBL104575 & 985247 & 4.3872 & 4.7839 & TRN & \\
\hline CHEMBL1801961 & 985247 & 4.2366 & 4.6877 & TST & \\
\hline CHEMBL 2430039 & 985247 & 5.1079 & 4.9777 & TST & \\
\hline CHEMBL 2429961 & 985247 & 4.9586 & 4.9953 & TRN & \\
\hline CHEMBL61592 & 985247 & 4.7959 & 4.73600 & 0000000001 & TRN \\
\hline CHEMBL104732 & 985247 & 4.5686 & 4.63899 & 9999999999 & TST \\
\hline CHEMBL106771 & 985247 & 4.6383 & 4.6882 & TST & \\
\hline CHEMBL 2430040 & 985247 & 4.3872 & 5.2718 & TST & \\
\hline CHEMBL390381 & 985247 & 5.3279 & 4.9734 & TRN & \\
\hline CHEMBL 227560 & 985247 & 4.0706 & 4.5152 & TRN & \\
\hline CHEMBL1999124 & 985247 & 4.4089 & 4.6471 & TRN & \\
\hline CHEMBL129795 & 985247 & 4.4559 & 4.3777 & TRN & \\
\hline CHEMBL339587 & 985247 & 7.6383 & 7.6942 & TRN & \\
\hline CHEMBL126669 & 985247 & 8.3768 & 8.3075 & TRN & \\
\hline CHEMBL129371 & 985247 & 3.8539 & 3.7468 & TRN & \\
\hline CHEMBL 2429959 & 985247 & 5.2757 & 5.3347 & TRN & \\
\hline CHEMBL375905 & 985247 & 4.1192 & 4.6354 & TST & \\
\hline CHEMBL127409 & 985247 & 6.8539 & 7.4692 & TST & \\
\hline CHEMBL1432638 & 1301477 & 5.6655 & 5.2546 & TRN & \\
\hline CHEMBL316589 & 1301477 & 4.7383 & 5.2555 & TRN & \\
\hline
\end{tabular}


Supplemental Table S2.txt

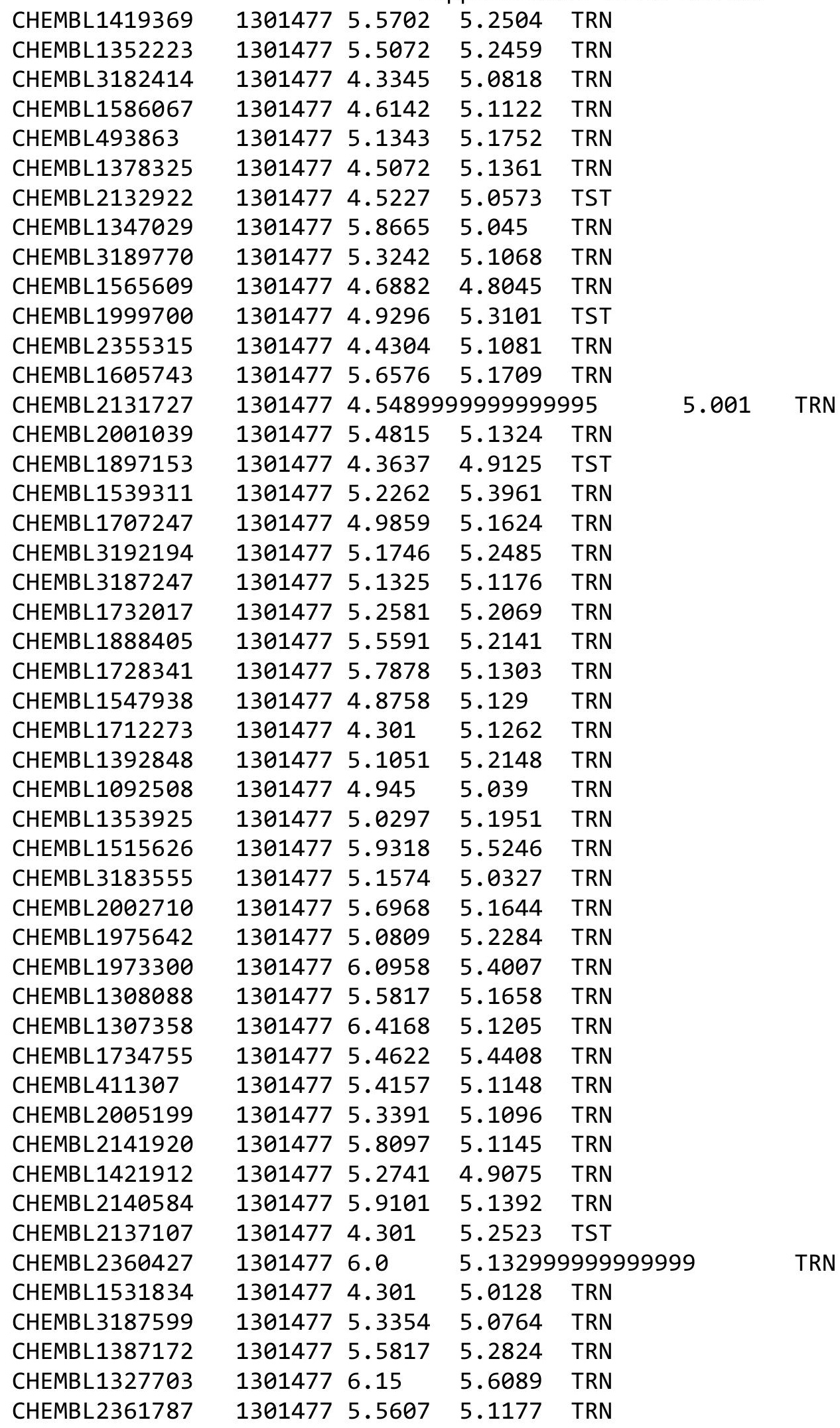

Page 21276 
Supplemental Table S2.txt

\begin{tabular}{|c|c|c|c|c|}
\hline CHEMBL1452972 & 1301477 & 5.4572 & 5.0663 & TRN \\
\hline CHEMBL1904998 & 1301477 & 5.1938 & 5.1195 & TRN \\
\hline CHEMBL1503312 & 1301477 & 5.1662 & 5.1453 & TRN \\
\hline CHEMBL1440464 & 1301477 & 5.2255 & 5.1998 & TRN \\
\hline CHEMBL304291 & 1301477 & 6.0 & 6.1015 & TST \\
\hline CHEMBL1869936 & 1301477 & 4.7959 & 5.0963 & TST \\
\hline CHEMBL1329304 & 1301477 & 5.0926 & 5.0818 & TRN \\
\hline CHEMBL1566367 & 1301477 & 4.7418 & 5.1489 & TRN \\
\hline CHEMBL1559785 & 1301477 & 5.1765 & 5.1785 & TRN \\
\hline CHEMBL 3188988 & 1301477 & 5.317 & 5.0628 & TRN \\
\hline CHEMBL1724098 & 1301477 & 5.0937 & 5.682 & TST \\
\hline CHEMBL1535532 & 1301477 & 5.3468 & 5.1315 & TRN \\
\hline CHEMBL1457440 & 1301477 & 5.9469 & 4.9509 & TRN \\
\hline CHEMBL1533772 & 1301477 & 4.7414 & 5.0485 & TST \\
\hline CHEMBL1329055 & 1301477 & 5.9208 & 5.4742 & TRN \\
\hline CHEMBL1518886 & 1301477 & 6.6216 & 5.1421 & TST \\
\hline CHEMBL1716251 & 1301477 & 4.301 & 4.9958 & TRN \\
\hline CHEMBL1458524 & 1301477 & 5.1778 & 5.0896 & TRN \\
\hline CHEMBL1579525 & 1301477 & 5.5421 & 5.0049 & TRN \\
\hline CHEMBL1472415 & 1301477 & 4.301 & 5.0818 & TRN \\
\hline CHEMBL261118 & 1301477 & 4.7959 & 5.2845 & TRN \\
\hline CHEMBL3186907 & 1301477 & 4.301 & 4.9835 & TRN \\
\hline CHEMBL1305972 & 1301477 & 5.2161 & 5.0924 & TRN \\
\hline CHEMBL1736441 & 1301477 & 5.6904 & 5.3142 & TRN \\
\hline CHEMBL1571682 & 1301477 & 5.5258 & 4.9876 & TRN \\
\hline CHEMBL 3183458 & 1301477 & 4.7959 & 4.9868 & TRN \\
\hline CHEMBL1411328 & 1301477 & 5.0496 & 5.0899 & TRN \\
\hline CHEMBL1887897 & 1301477 & 6.0491 & 5.1075 & TRN \\
\hline CHEMBL1722190 & 1301477 & 5.8182 & 5.21 & TRN \\
\hline CHEMBL1885522 & 1301477 & 4.301 & 5.1054 & TRN \\
\hline CHEMBL1530673 & 1301477 & 6.2848 & 5.765 & TRN \\
\hline CHEMBL1355823 & 1301477 & 5.8447 & 5.1091 & TRN \\
\hline CHEMBL3187957 & 1301477 & 4.8 & 5.0218 & TRN \\
\hline CHEMBL1407572 & 1301477 & 4.4612 & 5.0645 & TRN \\
\hline CHEMBL1602962 & 1301477 & 5.3726 & 5.2803 & TRN \\
\hline CHEMBL1515370 & 1301477 & 5.4828 & 5.102 & TRN \\
\hline CHEMBL1347637 & 1301477 & 4.301 & 5.2906 & TRN \\
\hline CHEMBL1487852 & 1301477 & 5.8508 & 5.0974 & TRN \\
\hline CHEMBL1323140 & 1301477 & 5.5702 & 5.3042 & TRN \\
\hline CHEMBL1474192 & 1301477 & 5.7852 & 5.0891 & TRN \\
\hline CHEMBL1353112 & 1301477 & 5.0195 & 4.8717 & TRN \\
\hline CHEMBL1534889 & 1301477 & 5.4089 & 5.0778 & TRN \\
\hline CHEMBL1492716 & 1301477 & 5.475 & 4.8885 & TRN \\
\hline CHEMBL1438363 & 1301477 & 4.5181 & 4.9499 & TRN \\
\hline CHEMBL1336674 & 1301477 & 5.2798 & \multicolumn{2}{|c|}{5.5120000000000005} \\
\hline CHEMBL1889325 & 1301477 & 4.301 & 5.0232 & TRN \\
\hline CHEMBL1733652 & 1301477 & 4.8887 & 5.1057 & TRN \\
\hline CHEMBL1866258 & 1301477 & 4.8564 & 5.4528 & TRN \\
\hline
\end{tabular}

Page 21277 
Supplemental Table S2.txt

\begin{tabular}{|c|c|c|c|c|c|c|}
\hline CHEMBL1420343 & 1301477 & 5.8447 & 5.2521 & TRN & & \\
\hline CHEMBL1699532 & 1301477 & 5.2716 & 5.1286 & TRN & & \\
\hline CHEMBL1335177 & 1301477 & 5.5867 & 5.2911 & TRN & & \\
\hline CHEMBL1442611 & 1301477 & 5.6144 & 5.081 & TRN & & \\
\hline CHEMBL2145029 & 1301477 & 4.301 & 4.9177 & TRN & & \\
\hline CHEMBL1586560 & 1301477 & 4.5931 & 5.1546 & TRN & & \\
\hline CHEMBL1998863 & 1301477 & 4.8931 & 5.3463 & TRN & & \\
\hline CHEMBL3188578 & 1301477 & 4.7959 & 5.0137 & TRN & & \\
\hline CHEMBL1727680 & 1301477 & 5.1002 & 5.256 & TRN & & \\
\hline CHEMBL1983939 & 1301477 & 5.1979 & 5.2558 & TRN & & \\
\hline CHEMBL1994497 & 1301477 & 5.5702 & 5.1497 & TRN & & \\
\hline CHEMBL3186066 & 1301477 & 4.6094 & 5.1096 & TRN & & \\
\hline CHEMBL1445046 & 1301477 & 5.16299 & 999999999 & 99 & 5.2008 & TRN \\
\hline CHEMBL1366420 & 1301477 & 4.301 & 5.0748 & TRN & & \\
\hline CHEMBL1579523 & 1301477 & 4.3962 & 5.0607 & TST & & \\
\hline CHEMBL1407305 & 1301477 & 4.8573 & 5.1632 & TRN & & \\
\hline CHEMBL1573592 & 1301477 & 4.6857 & 5.2014 & TRN & & \\
\hline CHEMBL1301549 & 1301477 & 4.301 & 5.0897 & TRN & & \\
\hline CHEMBL2007135 & 1301477 & 5.1379 & 5.2368 & TRN & & \\
\hline CHEMBL243664 & 1301477 & 4.301 & 5.2099 & TRN & & \\
\hline CHEMBL1555967 & 1301477 & 5.1113 & 5.0287 & TRN & & \\
\hline CHEMBL1558695 & 1301477 & 5.6925 & 5.5216 & TRN & & \\
\hline CHEMBL1704858 & 1301477 & 5.7055 & 5.026 & TRN & & \\
\hline CHEMBL1558527 & 1301477 & 4.2545 & 5.0821 & TRN & & \\
\hline CHEMBL1897960 & 1301477 & 4.301 & 4.9714 & TRN & & \\
\hline CHEMBL1371395 & 1301477 & 5.5171 & 5.2106 & TRN & & \\
\hline CHEMBL1354439 & 1301477 & 5.7352 & 5.0835 & TRN & & \\
\hline CHEMBL1906256 & 1301477 & 5.1662 & 5.2637 & TRN & & \\
\hline CHEMBL1348038 & 1301477 & 6.00700 & 300000000 & $\partial 1$ & 5.2057 & TRN \\
\hline CHEMBL124006 & 1301477 & 6.056 & 5.1398 & TRN & & \\
\hline CHEMBL600778 & 1301477 & 5.58 & 5.3633 & TRN & & \\
\hline CHEMBL1612459 & 1301477 & 5.17200 & 000000000 & $\partial 1$ & 5.2141 & TRN \\
\hline CHEMBL1502189 & 1301477 & 5.4522 & 5.2818 & TRN & & \\
\hline CHEMBL1465322 & 1301477 & 4.797 & 4.8656 & TRN & & \\
\hline CHEMBL29539 & 1301477 & 5.7167 & 5.3634 & TRN & & \\
\hline CHEMBL1728459 & 1301477 & 4.7959 & 5.0935 & TRN & & \\
\hline CHEMBL1890759 & 1301477 & 4.301 & 4.9462 & TRN & & \\
\hline CHEMBL3192547 & 1301477 & 5.7352 & 5.2866 & TRN & & \\
\hline CHEMBL1326584 & 1301477 & 5.4365 & 5.3027 & TRN & & \\
\hline CHEMBL1708695 & 1301477 & 4.4123 & 4.9155 & TRN & & \\
\hline CHEMBL2007450 & 1301477 & 5.2823 & 5.1567 & TRN & & \\
\hline CHEMBL1372920 & 1301477 & 4.7752 & 5.2667 & TRN & & \\
\hline CHEMBL1405118 & 1301477 & 4.6983 & 5.0126 & TRN & & \\
\hline CHEMBL1712755 & 1301477 & 4.7959 & 5.0288 & TRN & & \\
\hline CHEMBL2361967 & 1301477 & 4.301 & 5.087 & TRN & & \\
\hline CHEMBL1599283 & 1301477 & 5.6635 & 4.9603 & TST & & \\
\hline CHEMBL338474 & 1301477 & 6.0048 & 5.1287 & TST & & \\
\hline CHEMBL1600403 & 1301477 & 5.7352 & 5.0331 & TRN & & \\
\hline
\end{tabular}


Supplemental Table S2.txt

\begin{tabular}{|c|c|c|c|c|}
\hline . & & & & \\
\hline HEMBL 2028187 & 301477 & 4.7781 & 0892 & \\
\hline HEMBL 547269 & 301477 & 5.7932 & 927 & \\
\hline 64 & 77 & 5. & 2161 & \\
\hline EMBL1S & 301477 & 959 & 5766 & \\
\hline HEMBL1380592 & 301477 & 5.1778 & 5905 & \\
\hline HEMBL1376675 & 301477 & 4.301 & 8441 & \\
\hline HEMBL $20 \Theta$ & 301477 & 4.5505 & 2098 & \\
\hline IEMBL19e & 77 & & 1121 & \\
\hline IEMBL14 & 301477 & & .2126 & \\
\hline HEMBL199868 & 301477 & 5 . & 3963 & \\
\hline HEMBL1357620 & 301477 & 5.4685 & 0051 & \\
\hline AEMBL1255660 & 301477 & 4.301 & 334 & \\
\hline HEMBL136 & & & 1438 & \\
\hline HEMBL16 & 301477 & 5 . & 1271 & \\
\hline HEMBL130 & 301477 & & 23 & \\
\hline HEMBL1703925 & 301477 & 5 . & 4481 & \\
\hline HEMBL14 & 7 & 5 & 18 & \\
\hline HEMBL 23 & 77 & & & \\
\hline HEMBL1\& & 77 & & & \\
\hline HEMBL 14 & 77 & & & \\
\hline HEMBL140 & 301477 & 5 . & 97 & \\
\hline HEMBL 14 & 30 & 4. & 56 & \\
\hline HEME & & & & \\
\hline HEMBL1] & 77 & & 992 & $5 T$ \\
\hline AEME & 77 & & & \\
\hline HEMBL139 & 301477 & 4. & 89 & ГRN \\
\hline HEMBL15 & 77 & & 36 & $\mathrm{RN}$ \\
\hline HEM & 77 & & & RN \\
\hline HEME & 77 & & & RN \\
\hline AEMBL135 & 3014 & & & RN \\
\hline HEMBL16098 & 301477 & 4. & & $\mathrm{RN}$ \\
\hline JEMBL147 & 30 & & 51 & 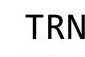 \\
\hline 8 & 77 & & & RN \\
\hline HEMBL19 & 301477 & & & RN \\
\hline HEMBL1988500 & 301477 & & & ГRN \\
\hline HEMBL151 & 301477 & & 421 & IRN \\
\hline JEMBL133 & 39 & & 22 & to \\
\hline 8 & & & & RN \\
\hline HEMBL13 & 77 & & & RN \\
\hline HEMBL14ع & 301477 & & 47 & ST \\
\hline HEMBL17e & 301 & & 708 & RN \\
\hline HEMBL15€ & 3014 & & & \\
\hline HEMBL1996360 & 301477 & & & RN \\
\hline HEMBL1556278 & 1301477 & & 5.2444 & RN \\
\hline HEMBL151S & 301477 & 5.6 & 507 & RN \\
\hline HEN & 301 & & & \\
\hline & & & & \\
\hline
\end{tabular}

Page 21279 
Supplemental Table S2.txt

\begin{tabular}{|c|c|c|c|c|c|}
\hline CHEMBL1965630 & 1301477 & 5.308 & 5.2806 & TRN & \\
\hline CHEMBL1415501 & 1301477 & 5.5003 & 5.0579 & TRN & \\
\hline CHEMBL1362856 & 1301477 & 5.4763 & 5.1934 & TRN & \\
\hline CHEMBL1352668 & 1301477 & 5.7328 & 4.7571 & TRN & \\
\hline CHEMBL1462630 & 1301477 & 6.5017 & 5.3722 & TRN & \\
\hline CHEMBL1601399 & 1301477 & 4.9393 & 5.1434 & TRN & \\
\hline CHEMBL1400459 & 1301477 & 5.202006 & 000000000 & 5.1761 & TRN \\
\hline CHEMBL1573639 & 1301477 & 5.5391 & \multicolumn{3}{|c|}{$5.252000000000001 \quad$ TRN } \\
\hline CHEMBL1455772 & 1301477 & 4.605 & 5.0431 & TRN & \\
\hline CHEMBL1497681 & 1301477 & 5.5901 & 5.1237 & TST & \\
\hline CHEMBL1451790 & 1301477 & 4.8788 & 5.0324 & TRN & \\
\hline CHEMBL3199110 & 1301477 & 4.3967 & 5.2948 & TRN & \\
\hline CHEMBL1998521 & 1301477 & 6.2299 & 5.9603 & TRN & \\
\hline CHEMBL153078 & 1301477 & 4.8435 & 5.3081 & TST & \\
\hline CHEMBL1989298 & 1301477 & 5.4023 & 5.2658 & TRN & \\
\hline CHEMBL1443504 & 1301477 & 5.1319 & 4.9723 & TRN & \\
\hline CHEMBL1703625 & 1301477 & 4.5194 & 5.2843 & TRN & \\
\hline CHEMBL1543673 & 1301477 & 4.8904 & 5.2334 & TST & \\
\hline CHEMBL 2358540 & 1301477 & 5.8041 & 5.1002 & TRN & \\
\hline CHEMBL1307781 & 1301477 & 4.301 & 5.0491 & TRN & \\
\hline CHEMBL 2134785 & 1301477 & 4.301 & 5.0638 & TRN & \\
\hline CHEMBL1542705 & 1301477 & 5.5607 & 5.0346 & TRN & \\
\hline CHEMBL1727228 & 1301477 & 5.2933 & 5.2513 & TRN & \\
\hline CHEMBL1873136 & 1301477 & 5.6676 & 5.2551 & TRN & \\
\hline CHEMBL1518085 & 1301477 & 5.5575 & 5.1279 & TRN & \\
\hline CHEMBL1367036 & 1301477 & 4.8145 & \multicolumn{2}{|c|}{5.167999999999999} & TST \\
\hline CHEMBL1401175 & 1301477 & 5.4225 & 5.345 & TST & \\
\hline CHEMBL1698316 & 1301477 & 6.3019 & 5.2816 & TRN & \\
\hline CHEMBL1340291 & 1301477 & 5.1805 & 5.1544 & TRN & \\
\hline CHEMBL1528120 & 1301477 & 6.1319 & 5.5118 & TRN & \\
\hline CHEMBL1473521 & 1301477 & 4.5432 & 5.1375 & TST & \\
\hline CHEMBL1405120 & 1301477 & 4.6043 & 5.2599 & TRN & \\
\hline CHEMBL1888764 & 1301477 & 4.4369 & 5.1575 & TRN & \\
\hline CHEMBL1613732 & 1301477 & 5.1904 & 5.0745 & TST & \\
\hline CHEMBL1425372 & 1301477 & 5.0878 & 5.0551 & TRN & \\
\hline CHEMBL1490332 & 1301477 & 5.9586 & 5.1113 & TRN & \\
\hline CHEMBL17639 & 1301477 & 5.5638 & 5.4747 & TST & \\
\hline CHEMBL1494887 & 1301477 & 5.0899 & 5.1857 & TRN & \\
\hline CHEMBL1975368 & 1301477 & 6.0119 & 5.1558 & TRN & \\
\hline CHEMBL1557243 & 1301477 & 4.5654 & 4.9606 & TST & \\
\hline CHEMBL605003 & 1301477 & 5.1811 & 5.1639 & TRN & \\
\hline CHEMBL3184422 & 1301477 & 4.871 & 5.0617 & TRN & \\
\hline CHEMBL3191453 & 1301477 & 6.3354 & 5.7061 & TRN & \\
\hline CHEMBL1358066 & 1301477 & 5.5969 & \multicolumn{2}{|c|}{5.093999999999999} & TRN \\
\hline CHEMBL1721855 & 1301477 & 5.4535 & 5.2335 & TST & \\
\hline CHEMBL1602334 & 1301477 & 4.8063 & 5.2997 & TRN & \\
\hline CHEMBL1509440 & 1301477 & 5.0329 & 5.098 & TRN & \\
\hline CHEMBL1729978 & 1301477 & 5.4401 & 5.5138 & TRN & \\
\hline
\end{tabular}

Page 21280 
Supplemental Table S2.txt

\begin{tabular}{|c|c|c|c|c|}
\hline W & 301477 & & & \\
\hline & 301477 & 8.6289 & & \\
\hline & & & & \\
\hline AEMBL1 & 1477 & & 59 & \\
\hline AEMBL1431810 & 301477 & 708 & 357 & \\
\hline HEMBL2361035 & 301477 & 4.301 & 0722 & \\
\hline 1328 & 301477 & & 07 & \\
\hline IFMRI 1 & & & & \\
\hline AEMBL1599630 & 301477 & & & \\
\hline HEMBL1563899 & 301477 & & 5968 & \\
\hline HEMBL1346789 & 301477 & 5 . & 85 & \\
\hline IEMBL16 & 77 & & 01 & \\
\hline IEMBL1 & & & & \\
\hline HEMBL3190203 & 301477 & & & \\
\hline AEMBL14 & 301477 & & & \\
\hline AEMBL13 & 301 & 79 & 08 & \\
\hline AEMBL16 & 5 & & & RN \\
\hline HEMBL1C & 1 & & & \\
\hline HEMBL 518494 & 77 & & & \\
\hline IEMBL14 & 77 & & & \\
\hline EIMBLI & 36 & & 46 & II \\
\hline AEMBL: & 36 & & 44 & ST \\
\hline HEMBL3 & 7 & & & \\
\hline 5959 & 77 & & & \\
\hline AEMBL15 & & & & RIN \\
\hline HEMBL1 & 30 & & & $2 \mathrm{~N}$ \\
\hline HEMBL: & 30 & & & 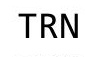 \\
\hline HFMBI 1 & 77 & & & \\
\hline HEMBL3 & & & & I RIV \\
\hline HEMBL1999458 & 20. & & & I RN \\
\hline HEMBL1 & 30 & & & RN \\
\hline HEMBL: & 1 & & 45 & RN \\
\hline HEMP & 7 & & & TRN \\
\hline HEMBL1255657 & 30 & & & Is \\
\hline HEMBL3184739 & 3014 & & 69 & TRN \\
\hline HEMBL1 & 30 & & & RN \\
\hline HᄃMP I 1 & r & & & TRN \\
\hline HEMBL1 & 77 & & & ST \\
\hline HEMBL1894909 & 301477 & & 5.1932 & TST \\
\hline IEMBL1E & 301 & & 95 & TST \\
\hline HEMBL5E & 30 & & 58 & DN \\
\hline HEMBL 31 & & & & TRN \\
\hline HEMBL1€ & 77 & & & RN \\
\hline AEMBL1988511 & 301 & 5 . & 69 & TR \\
\hline MPI 1 & $2 a$. & & 44 & TS \\
\hline HEMBL1 & & & .5126 & \\
\hline HEMBL1428307 & 301 & 19 & 5.1782 & \\
\hline HEMBL1368683 & 1301477 & 6.3458 & 5.3393 & \\
\hline
\end{tabular}

Page 21281 


\begin{tabular}{|c|c|c|c|c|c|c|}
\hline \multicolumn{7}{|c|}{ Supplemental Table S2.txt } \\
\hline CHEMBL1332061 & 1301477 & 5.15 & 4.8942 & TRN & & \\
\hline CHEMBL1397985 & 1301477 & 4.301 & 5.0547 & TRN & & \\
\hline CHEMBL1598159 & 1301477 & 5.1232 & 5.1232 & TRN & & \\
\hline CHEMBL1984509 & 1301477 & 6.1791 & 5.4457 & TRN & & \\
\hline CHEMBL1405483 & 1301477 & 4.301 & 4.9125 & TRN & & \\
\hline CHEMBL1734236 & 1301477 & 4.2325 & 5.1805 & TRN & & \\
\hline CHEMBL1460978 & 1301477 & 4.301 & 5.0059 & TST & & \\
\hline CHEMBL3184153 & 1301477 & 6.0 & 5.0025 & TRN & & \\
\hline CHEMBL1412067 & 1301477 & 4.7385 & 5.2209 & TRN & & \\
\hline CHEMBL1337952 & 1301477 & 6.0453 & 5.0467 & TRN & & \\
\hline CHEMBL1522033 & 1301477 & 4.9897 & 4.9948 & TRN & & \\
\hline CHEMBL1396619 & 1301477 & 5.32700 & 30000000 & 01 & 5.106 & TRN \\
\hline CHEMBL1732747 & 1301477 & 6.2262 & 5.1899 & TRN & & \\
\hline CHEMBL1336887 & 1301477 & 5.6596 & 5.1547 & TRN & & \\
\hline CHEMBL3197126 & 1301477 & 5.9281 & 5.3949 & TST & & \\
\hline CHEMBL1736254 & 1301477 & 5.4776 & 5.1855 & TST & & \\
\hline CHEMBL1328523 & 1301477 & 4.301 & 5.1358 & TST & & \\
\hline CHEMBL1887620 & 1301477 & 4.6523 & 5.2018 & TRN & & \\
\hline CHEMBL1991242 & 1301477 & 4.7174 & 5.3415 & TRN & & \\
\hline CHEMBL1553368 & 1301477 & 6.7423 & 5.1421 & TRN & & \\
\hline CHEMBL1906254 & 1301477 & 4.9245 & 5.12700 & 0000000001 & & TRN \\
\hline CHEMBL1985707 & 1301477 & 5.7258 & 5.1864 & TRN & & \\
\hline CHEMBL 2356617 & 1301477 & 5.3497 & 5.1363 & TRN & & \\
\hline CHEMBL564936 & 1301477 & 6.0119 & 5.6851 & TRN & & \\
\hline CHEMBL1893379 & 1301477 & 5.6737 & 5.307 & TRN & & \\
\hline CHEMBL1415172 & 1301477 & 4.301 & 5.1959 & TRN & & \\
\hline CHEMBL1729036 & 1301477 & 5.4295 & 5.33 & TRN & & \\
\hline CHEMBL1585715 & 1301477 & 5.2518 & 5.5906 & TST & & \\
\hline CHEMBL1897801 & 1301477 & 4.301 & 5.1933 & TRN & & \\
\hline CHEMBL1457561 & 1301477 & 5.7721 & 5.6525 & TRN & & \\
\hline CHEMBL1306238 & 1301477 & 5.0726 & 5.0551 & TRN & & \\
\hline CHEMBL1491621 & 1301477 & 4.301 & 5.2002 & TRN & & \\
\hline CHEMBL244683 & 1301477 & 4.7411 & 5.1953 & TRN & & \\
\hline CHEMBL1975754 & 1301477 & 6.0706 & 5.4823 & TRN & & \\
\hline CHEMBL1588813 & 1301477 & 5.3261 & 5.2185 & TRN & & \\
\hline CHEMBL1377699 & 1301477 & 6.1267 & 5.6038 & TRN & & \\
\hline CHEMBL3198332 & 1301477 & 5.6576 & 5.2948 & TRN & & \\
\hline CHEMBL1316565 & 1301477 & 4.301 & 5.3367 & TRN & & \\
\hline CHEMBL2357760 & 1301477 & 4.7165 & 5.2008 & TRN & & \\
\hline CHEMBL2360506 & 1301477 & 4.9863 & 5.0527 & TRN & & \\
\hline CHEMBL1592774 & 1301477 & 6.27 & 5.4996 & TRN & & \\
\hline CHEMBL1541485 & 1301477 & 4.3557 & 4.9651 & TRN & & \\
\hline CHEMBL1543268 & 1301477 & 5.4191 & 5.0993 & TST & & \\
\hline CHEMBL1400242 & 1301477 & 5.4647 & 5.1762 & TRN & & \\
\hline CHEMBL1964924 & 1301477 & 5.5331 & 5.2922 & TRN & & \\
\hline CHEMBL1527008 & 1301477 & 4.7192 & 5.2061 & TRN & & \\
\hline CHEMBL1726644 & 1301477 & 5.266 & 5.05 & TRN & & \\
\hline CHEMBL1479769 & 1301477 & 5.3107 & 5.0789 & TRN & & \\
\hline
\end{tabular}


Supplemental Table S2.txt

\begin{tabular}{|c|c|c|c|c|c|}
\hline CHEMBL1575441 & 1301477 & 5.6904 & 5.1974 & TST & \\
\hline CHEMBL 2002945 & 1301477 & 4.301 & 5.2568 & TRN & \\
\hline CHEMBL1882588 & 1301477 & 5.2204 & 5.391 & TRN & \\
\hline CHEMBL1712932 & 1301477 & 5.3233 & 5.0127 & TRN & \\
\hline CHEMBL1490140 & 1301477 & 4.7118 & 5.1624 & TRN & \\
\hline CHEMBL1445156 & 1301477 & 4.301 & 4.8921 & TRN & \\
\hline CHEMBL1982471 & 1301477 & 6.098 & \multicolumn{2}{|c|}{5.2829999999999995} & TRN \\
\hline CHEMBL1714214 & 1301477 & 4.301 & 4.9316 & TRN & \\
\hline CHEMBL47505 & 1301477 & 5.5654 & 5.225 & TRN & \\
\hline CHEMBL1965780 & 1301477 & 4.3805 & 5.2447 & TRN & \\
\hline CHEMBL1520536 & 1301477 & 4.7637 & 4.864 & TRN & \\
\hline CHEMBL1491750 & 1301477 & 5.2132 & 5.2513 & TST & \\
\hline CHEMBL1305278 & 1301477 & 4.7194 & 5.1788 & TRN & \\
\hline CHEMBL1613471 & 1301477 & 5.5901 & 5.2759 & TRN & \\
\hline CHEMBL1405122 & 1301477 & 5.8477 & 5.2393 & TST & \\
\hline CHEMBL1981108 & 1301477 & 5.3143 & 5.1278 & TRN & \\
\hline CHEMBL1790033 & 1301477 & 5.9747 & 5.2734 & TST & \\
\hline CHEMBL1890358 & 1301477 & 5.1593 & \multicolumn{2}{|c|}{5.167000000000001} & TRN \\
\hline CHEMBL1712719 & 1301477 & 4.5546 & 4.9567 & TRN & \\
\hline CHEMBL1556655 & 1301477 & 5.1979 & 5.0468 & TRN & \\
\hline CHEMBL1897033 & 1301477 & 4.9007 & 5.2713 & TRN & \\
\hline CHEMBL1362125 & 1301477 & 5.0246 & 5.2573 & TRN & \\
\hline CHEMBL 3186744 & 1301477 & 5.3497 & 5.0416 & TRN & \\
\hline CHEMBL1531170 & 1301477 & 5.9469 & 5.1294 & TRN & \\
\hline CHEMBL1871487 & 1301477 & 6.0825 & 5.0371 & TRN & \\
\hline CHEMBL1331195 & 1301477 & 5.2596 & 5.1626 & TRN & \\
\hline CHEMBL154358 & 1301477 & 5.5986 & 5.5485 & TRN & \\
\hline CHEMBL272945 & 1301477 & 4.9792 & 5.0859 & TRN & \\
\hline CHEMBL2361187 & 1301477 & 4.301 & 5.1349 & TRN & \\
\hline CHEMBL 3182009 & 1301477 & 6.0 & 4.9928 & TRN & \\
\hline CHEMBL1546722 & 1301477 & 5.4881 & 5.7336 & TRN & \\
\hline CHEMBL 2359879 & 1301477 & 4.7959 & 5.0316 & TRN & \\
\hline CHEMBL1558156 & 1301477 & 5.1778 & 5.3732 & TRN & \\
\hline CHEMBL1546347 & 1301477 & 5.8601 & 5.0866 & TRN & \\
\hline CHEMBL1602106 & 1301477 & 5.3089 & 5.267 & TRN & \\
\hline CHEMBL3199752 & 1301477 & 5.0894 & 5.2159 & TRN & \\
\hline CHEMBL1478263 & 1301477 & 5.4342 & 5.1304 & TRN & \\
\hline CHEMBL1567256 & 1301477 & 5.3143 & \multicolumn{2}{|c|}{5.1160000000000005} & TRN \\
\hline CHEMBL1611674 & 1301477 & 5.6253 & 5.2288 & TRN & \\
\hline CHEMBL1436404 & 1301477 & 5.0762 & 5.1101 & TRN & \\
\hline CHEMBL1408593 & 1301477 & 5.75200 & \multicolumn{2}{|c|}{2000000001} & TST \\
\hline CHEMBL1428163 & 1301477 & 5.6308 & 5.1661 & TRN & \\
\hline CHEMBL3195724 & 1301477 & 4.3197 & 5.0615 & TST & \\
\hline CHEMBL 3184752 & 1301477 & 5.0325 & \multicolumn{2}{|c|}{5.207000000000001} & TRN \\
\hline CHEMBL1327163 & 1301477 & 5.2069 & 5.0823 & TRN & \\
\hline CHEMBL28250 & 1301477 & 5.4067 & 5.2879 & TRN & \\
\hline CHEMBL1976786 & 1301477 & 4.4394 & 5.7049 & TRN & \\
\hline CHEMBL1882642 & 1301477 & 4.9759 & 5.1208 & TRN & \\
\hline
\end{tabular}

Page 21283 
Supplemental Table S2.txt

\begin{tabular}{|c|c|c|c|c|c|}
\hline CHEMBL1735077 & 1301477 & 5.5702 & 4.98 & TRN & \\
\hline CHEMBL1390428 & 1301477 & 4.7354 & 4.8506 & TRN & \\
\hline CHEMBL3195997 & 1301477 & 5.8827 & 5.352 & TRN & \\
\hline CHEMBL1431376 & 1301477 & 5.4271 & 5.5118 & TRN & \\
\hline CHEMBL1572278 & 1301477 & 5.7696 & 5.8376 & TRN & \\
\hline CHEMBL1306148 & 1301477 & 4.301 & 5.0661 & TST & \\
\hline CHEMBL1404047 & 1301477 & 4.5553 & 5.2039 & TST & \\
\hline CHEMBL1408708 & 1301477 & 5.7773 & 5.3084 & TRN & \\
\hline CHEMBL1586088 & 1301477 & 6.0904 & 5.2954 & TRN & \\
\hline CHEMBL1381248 & 1301477 & 4.8277 & 4.9799 & TRN & \\
\hline CHEMBL1543609 & 1301477 & 5.1726 & 5.2386 & TRN & \\
\hline CHEMBL3195680 & 1301477 & 6.0066 & 5.1737 & TRN & \\
\hline CHEMBL1607906 & 1301477 & 5.8996 & 5.4492 & TRN & \\
\hline CHEMBL1350780 & 1301477 & 4.301 & \multicolumn{2}{|c|}{5.446000000000001} & TRN \\
\hline CHEMBL455399 & 1301477 & 4.6171 & 5.1902 & TRN & \\
\hline CHEMBL1897162 & 1301477 & 4.5426 & 5.0092 & TRN & \\
\hline CHEMBL1372616 & 1301477 & 5.1785 & 4.9408 & TRN & \\
\hline CHEMBL1708493 & 1301477 & 4.7959 & 5.0891 & TRN & \\
\hline CHEMBL33884 & 1301477 & 4.301 & 4.9436 & TRN & \\
\hline CHEMBL1594114 & 1301477 & 5.7986 & 5.3059 & TRN & \\
\hline CHEMBL1901576 & 1301477 & 4.4131 & 4.8823 & TRN & \\
\hline CHEMBL2006909 & 1301477 & 5.2573 & 5.1177 & TRN & \\
\hline CHEMBL1542074 & 1301477 & 4.301 & 4.9426 & TRN & \\
\hline CHEMBL1998221 & 1301477 & 5.9586 & 5.1569 & TRN & \\
\hline CHEMBL287584 & 1301477 & 5.5901 & 4.9998 & TST & \\
\hline CHEMBL1465610 & 1301477 & 5.8794 & 5.1599 & TRN & \\
\hline CHEMBL1567413 & 1301477 & 5.1791 & 5.5716 & TRN & \\
\hline CHEMBL2357936 & 1301477 & 6.0 & 5.2071 & TRN & \\
\hline CHEMBL1731948 & 1301477 & 4.574 & 5.3442 & TRN & \\
\hline CHEMBL1543383 & 1301477 & 5.5017 & 5.5282 & TRN & \\
\hline CHEMBL1417393 & 1301477 & 5.3298 & 5.1337 & TST & \\
\hline CHEMBL1997978 & 1301477 & 5.0052 & 4.9829 & TRN & \\
\hline CHEMBL1318352 & 1301477 & 4.4543 & 5.1125 & TRN & \\
\hline CHEMBL1371056 & 1301477 & 6.2684 & 6.0509 & TRN & \\
\hline CHEMBL567340 & 1301477 & 4.7959 & 4.9872 & TST & \\
\hline CHEMBL3183652 & 1301477 & 5.1838 & 5.1829 & TRN & \\
\hline CHEMBL1417151 & 1301477 & 4.357 & 5.0553 & TRN & \\
\hline CHEMBL1508220 & 1301477 & 5.4145 & 5.048 & TRN & \\
\hline CHEMBL1362746 & 1301477 & 6.0232 & 5.1478 & TST & \\
\hline CHEMBL1885708 & 1301477 & 4.301 & 5.1912 & TST & \\
\hline CHEMBL1404493 & 1301477 & 5.0044 & 5.3139 & TST & \\
\hline CHEMBL1599776 & 1301477 & 5.9172 & 5.01399 & 9999999999 & TRN \\
\hline CHEMBL1329398 & 1301477 & 5.8761 & 5.4427 & TRN & \\
\hline CHEMBL379005 & 1301477 & 4.301 & 5.2219 & TRN & \\
\hline CHEMBL1514460 & 1301477 & 5.3372 & 5.2174 & TRN & \\
\hline CHEMBL1544634 & 1301477 & 4.7959 & 5.1854 & TST & \\
\hline CHEMBL1398345 & 1301477 & 4.934 & 5.1566 & TRN & \\
\hline CHEMBL1324061 & 1301477 & 5.7077 & 5.9553 & TRN & \\
\hline
\end{tabular}

Page 21284 


\begin{tabular}{|c|c|c|c|c|c|c|}
\hline \multicolumn{7}{|c|}{ Supplemental Table S2.txt } \\
\hline CHEMBL1888857 & 1301477 & 5.0721 & 5.1594 & TRN & & \\
\hline CHEMBL1448282 & 1301477 & 4.301 & 5.3198 & TRN & & \\
\hline CHEMBL1985829 & 1301477 & 4.5096 & 4.9999 & TRN & & \\
\hline CHEMBL1320855 & 1301477 & 4.334 & 4.9478 & TRN & & \\
\hline CHEMBL1990210 & 1301477 & 5.2027 & 5.4453 & TRN & & \\
\hline CHEMBL1311991 & 1301477 & 4.8684 & 5.2751 & TRN & & \\
\hline CHEMBL1395308 & 1301477 & 4.3647 & 5.0852 & TRN & & \\
\hline CHEMBL1900055 & 1301477 & 4.7959 & 5.0467 & TRN & & \\
\hline CHEMBL1550672 & 1301477 & 4.9187 & 4.899 & TRN & & \\
\hline CHEMBL1302519 & 1301477 & 5.6108 & 5.0293 & TST & & \\
\hline CHEMBL1563920 & 1301477 & 5.7235 & 5.2493 & TRN & & \\
\hline CHEMBL1409525 & 1301477 & 4.7975 & 5.0569 & TST & & \\
\hline CHEMBL1448290 & 1301477 & 5.1319 & 5.0767 & TST & & \\
\hline CHEMBL2361835 & 1301477 & 5.4353 & 5.1639 & TRN & & \\
\hline CHEMBL1865354 & 1301477 & 4.301 & 4.9897 & TRN & & \\
\hline CHEMBL1392785 & 1301477 & 4.3166 & 5.0601 & TRN & & \\
\hline CHEMBL1479947 & 1301477 & 5.5272 & 5.426 & TRN & & \\
\hline CHEMBL1996555 & 1301477 & 5.0716 & 5.1196 & TST & & \\
\hline CHEMBL1709562 & 1301477 & 5.6925 & 5.0558 & TRN & & \\
\hline CHEMBL 22062 & 1301477 & 5.3372 & 5.1284 & TRN & & \\
\hline CHEMBL1978180 & 1301477 & 5.4067 & 5.1596 & TST & & \\
\hline CHEMBL1870007 & 1301477 & 4.5737 & 4.9481 & TRN & & \\
\hline CHEMBL 2144655 & 1301477 & 4.9809 & 5.0079 & TRN & & \\
\hline CHEMBL1380996 & 1301477 & 5.6517 & 5.5455 & TRN & & \\
\hline CHEMBL1706977 & 1301477 & 5.75200 & 00000000 & $\partial 1$ & 5.0301 & TST \\
\hline CHEMBL1587301 & 1301477 & 4.9352 & 5.1107 & TRN & & \\
\hline CHEMBL1896153 & 1301477 & 4.301 & 5.1602 & TST & & \\
\hline CHEMBL1991056 & 1301477 & 5.0964 & 5.1717 & TRN & & \\
\hline CHEMBL1419909 & 1301477 & 5.1871 & 5.2408 & TRN & & \\
\hline CHEMBL1491529 & 1301477 & 4.3606 & 5.1986 & TRN & & \\
\hline CHEMBL 3185201 & 1301477 & 4.7959 & 5.0678 & TRN & & \\
\hline CHEMBL1363043 & 1301477 & 5.4486 & 5.2697 & TRN & & \\
\hline CHEMBL1707398 & 1301477 & 4.301 & 5.0128 & TRN & & \\
\hline CHEMBL1450748 & 1301477 & 5.6326 & 5.1552 & TRN & & \\
\hline CHEMBL1437648 & 1301477 & 5.2857 & 5.0361 & TRN & & \\
\hline CHEMBL1330793 & 1301477 & 5.3799 & 5.6652 & TST & & \\
\hline CHEMBL1372657 & 1301477 & 4.301 & 5.0448 & TST & & \\
\hline CHEMBL1533481 & 1301477 & 5.4112 & 5.1742 & TRN & & \\
\hline CHEMBL1733120 & 1301477 & 4.301 & 5.0436 & TRN & & \\
\hline CHEMBL3191106 & 1301477 & 4.301 & 5.1543 & TRN & & \\
\hline CHEMBL1553837 & 1301477 & 4.301 & 5.1247 & TRN & & \\
\hline CHEMBL1571034 & 1301477 & 5.0926 & 5.1907 & TRN & & \\
\hline CHEMBL1316831 & 1301477 & 5.1284 & 5.71200 & 0000000001 & & TST \\
\hline CHEMBL566096 & 1301477 & 5.6737 & 5.1436 & TRN & & \\
\hline CHEMBL1368013 & 1301477 & 4.301 & 4.95 & TRN & & \\
\hline CHEMBL1608793 & 1301477 & 5.3098 & 5.1983 & TRN & & \\
\hline CHEMBL1353221 & 1301477 & 4.58 & 5.1565 & TRN & & \\
\hline CHEMBL1304179 & 1301477 & 5.2111 & 5.252006 & 0000000001 & & TRN \\
\hline & & & & 21285 & & \\
\hline
\end{tabular}


Supplemental Table S2.txt

\begin{tabular}{|c|c|c|c|c|}
\hline CHEMBL3191127 & 1301477 & 5.4134 & 5.2285 & TRN \\
\hline CHEMBL 2004458 & 1301477 & 4.301 & 5.1444 & TST \\
\hline CHEMBL1969300 & 1301477 & 5.0273 & 5.2115 & TRN \\
\hline CHEMBL1711677 & 1301477 & 5.0501 & 5.0687 & TRN \\
\hline CHEMBL3182070 & 1301477 & 5.0462 & 5.0614 & TRN \\
\hline CHEMBL1711814 & 1301477 & 4.7959 & 5.0329 & TRN \\
\hline CHEMBL1344825 & 1301477 & 4.6045 & 5.0555 & TRN \\
\hline CHEMBL1598986 & 1301477 & 5.433 & 5.6218 & TRN \\
\hline CHEMBL1457749 & 1301477 & 5.2612 & 5.1102 & TRN \\
\hline CHEMBL1578580 & 1301477 & 4.437 & 5.0309 & TRN \\
\hline CHEMBL1506827 & 1301477 & 5.4067 & 4.9171 & TRN \\
\hline CHEMBL1977301 & 1301477 & 5.585 & 5.4361 & TRN \\
\hline CHEMBL2362276 & 1301477 & 5.4225 & 5.0292 & TRN \\
\hline CHEMBL1390968 & 1301477 & 5.4089 & 5.2465 & TRN \\
\hline CHEMBL1408150 & 1301477 & 5.7328 & 5.4639 & TRN \\
\hline CHEMBL1418611 & 1301477 & 4.9855 & 5.2137 & TRN \\
\hline CHEMBL1714939 & 1301477 & 4.9352 & 4.9883 & TRN \\
\hline CHEMBL1315701 & 1301477 & 4.6838 & 5.0704 & TRN \\
\hline CHEMBL1458083 & 1301477 & 5.4815 & 5.2156 & TST \\
\hline CHEMBL3196920 & 1301477 & 4.301 & 4.9703 & TRN \\
\hline CHEMBL3189791 & 1301477 & 6.1726 & 5.2947 & TRN \\
\hline CHEMBL2136643 & 1301477 & 6.2218 & 5.0072 & TST \\
\hline CHEMBL1884965 & 1301477 & 5.7011 & 5.0391 & TRN \\
\hline CHEMBL1700268 & 1301477 & 4.997 & 5.4517 & TST \\
\hline CHEMBL1985678 & 1301477 & 4.301 & 5.0256 & TST \\
\hline CHEMBL1705713 & 1301477 & 5.0218 & 5.3791 & TRN \\
\hline CHEMBL1704261 & 1301477 & 4.927 & 5.0906 & TRN \\
\hline CHEMBL1520559 & 1301477 & 5.0395 & 5.2958 & TRN \\
\hline CHEMBL1416268 & 1301477 & 5.27 & 5.0481 & TST \\
\hline CHEMBL1644341 & 1301477 & 5.0731 & 5.2327 & TRN \\
\hline CHEMBL1869878 & 1301477 & 5.7055 & 5.0177 & TST \\
\hline CHEMBL1478997 & 1301477 & 4.7937 & 5.0911 & TST \\
\hline CHEMBL1323313 & 1301477 & 5.7055 & 5.3996 & TST \\
\hline CHEMBL1884332 & 1301477 & 5.7235 & 5.2668 & TST \\
\hline CHEMBL1531003 & 1301477 & 4.8167 & 5.2091 & TST \\
\hline CHEMBL1464146 & 1301477 & 5.1772 & 5.1527 & TST \\
\hline CHEMBL1890488 & 1301477 & 5.0883 & 5.0745 & TST \\
\hline CHEMBL1892428 & 1301477 & 5.5654 & 5.1763 & TST \\
\hline CHEMBL3185517 & 1301477 & 4.301 & 5.1 & TST \\
\hline CHEMBL1599005 & 1301477 & 4.9144 & 5.1699 & TST \\
\hline CHEMBL3186666 & 1301477 & 4.7959 & 5.0686 & TST \\
\hline CHEMBL1877857 & 1301477 & 4.4836 & 4.9673 & TST \\
\hline CHEMBL1981361 & 1301477 & 6.1007 & 5.192 & TST \\
\hline CHEMBL1316836 & 1301477 & 4.301 & 4.9988 & TST \\
\hline CHEMBL1352607 & 1301477 & 4.7333 & 5.05 & TST \\
\hline CHEMBL1341947 & 1301477 & 5.5834 & 5.2224 & TST \\
\hline CHEMBL600111 & 1301477 & 4.6755 & 5.2352 & TST \\
\hline CHEMBL1579644 & 1301477 & 5.4547 & 4.9583 & TST \\
\hline
\end{tabular}

Page 21286 
Supplemental Table S2.txt

\begin{tabular}{|c|c|c|c|c|}
\hline CHEMBL1595952 & 1301477 & 6.0155 & 5.5553 & TST \\
\hline CHEMBL1732657 & 1301477 & 5.7447 & 5.0642 & TST \\
\hline CHEMBL1399388 & 1301477 & 5.7447 & 5.3114 & TST \\
\hline CHEMBL1985667 & 1301477 & 5.0009 & \multicolumn{2}{|c|}{5.247999999999999} \\
\hline CHEMBL1229721 & 1301477 & 4.301 & 5.0531 & TST \\
\hline CHEMBL1346185 & 1301477 & 5.6778 & 5.5941 & TST \\
\hline CHEMBL3185531 & 1301477 & 4.622 & 5.029 & TST \\
\hline CHEMBL1352402 & 1301477 & 4.8496 & 4.8868 & TST \\
\hline CHEMBL 3183640 & 1301477 & 4.7959 & 5.0441 & TST \\
\hline CHEMBL1866919 & 1301477 & 5.6615 & \multicolumn{2}{|c|}{5.132000000000001} \\
\hline CHEMBL1500408 & 1301477 & 5.0278 & 5.2295 & TST \\
\hline CHEMBL1375578 & 1301477 & 5.6144 & 5.0645 & TST \\
\hline CHEMBL 2133426 & 1301477 & 5.6737 & 4.9882 & TST \\
\hline CHEMBL1305128 & 1301477 & 5.0752 & 5.3737 & TST \\
\hline CHEMBL1397445 & 1301477 & 6.5654 & 5.2361 & TST \\
\hline CHEMBL1898462 & 1301477 & 5.1518 & 5.3013 & TST \\
\hline CHEMBL1520702 & 1301477 & 5.7122 & 5.0926 & TST \\
\hline CHEMBL1724826 & 1301477 & 5.4976 & 5.2778 & TST \\
\hline CHEMBL1387366 & 1301477 & 5.1198 & 5.1922 & TST \\
\hline CHEMBL1380319 & 1301477 & 5.3382 & 5.2141 & TST \\
\hline CHEMBL1437715 & 1301477 & 6.1669 & 5.1827 & TST \\
\hline CHEMBL1504676 & 1301477 & 5.1035 & 5.2732 & TST \\
\hline CHEMBL 3184100 & 1301477 & 5.2604 & 4.9841 & TST \\
\hline CHEMBL 3184491 & 1301477 & 6.8861 & 5.0734 & TST \\
\hline CHEMBL559461 & 1301477 & 4.6521 & 5.528 & TST \\
\hline CHEMBL1543131 & 1301477 & 5.0491 & 5.0388 & TST \\
\hline CHEMBL1376969 & 1301477 & 4.301 & 5.0283 & TST \\
\hline CHEMBL1435879 & 1301477 & 4.301 & 4.9892 & TST \\
\hline CHEMBL1529290 & 1301477 & 4.301 & 5.0115 & TST \\
\hline CHEMBL1330306 & 1301477 & 5.5186 & 5.2378 & TST \\
\hline CHEMBL1977480 & 1301477 & 5.6882 & 5.2332 & TST \\
\hline CHEMBL1983311 & 1301477 & 5.5436 & 5.1837 & TST \\
\hline CHEMBL1473821 & 1301477 & 4.4802 & 4.9217 & TST \\
\hline CHEMBL1325489 & 1301477 & 4.8377 & 5.2728 & TST \\
\hline CHEMBL1416671 & 1301477 & 5.0665 & 4.8998 & TST \\
\hline CHEMBL1456226 & 1301477 & 4.797 & 5.1809 & TST \\
\hline CHEMBL1604962 & 1301477 & 4.5499 & 5.1349 & TST \\
\hline CHEMBL1411632 & 1301477 & 4.301 & 5.1061 & TST \\
\hline CHEMBL1553246 & 1301477 & 6.1805 & 5.3889 & TST \\
\hline CHEMBL1419147 & 1301477 & 5.0721 & 5.1629 & TST \\
\hline CHEMBL1315536 & 1301477 & 5.3737 & 5.0109 & TST \\
\hline CHEMBL1585345 & 1301477 & 5.8297 & 5.8363 & TST \\
\hline CHEMBL1450195 & 1301477 & 4.7263 & 5.5846 & TST \\
\hline CHEMBL1611670 & 1301477 & 5.5361 & 5.08899 & \\
\hline CHEMBL1980322 & 1301477 & 5.4737 & 5.3721 & TST \\
\hline CHEMBL1881344 & 1301477 & 4.5293 & 5.1085 & TST \\
\hline CHEMBL546493 & 1301477 & 5.5591 & 5.0071 & TST \\
\hline CHEMBL1525948 & 1301477 & 5.3655 & 4.9057 & TST \\
\hline
\end{tabular}

Page 21287 


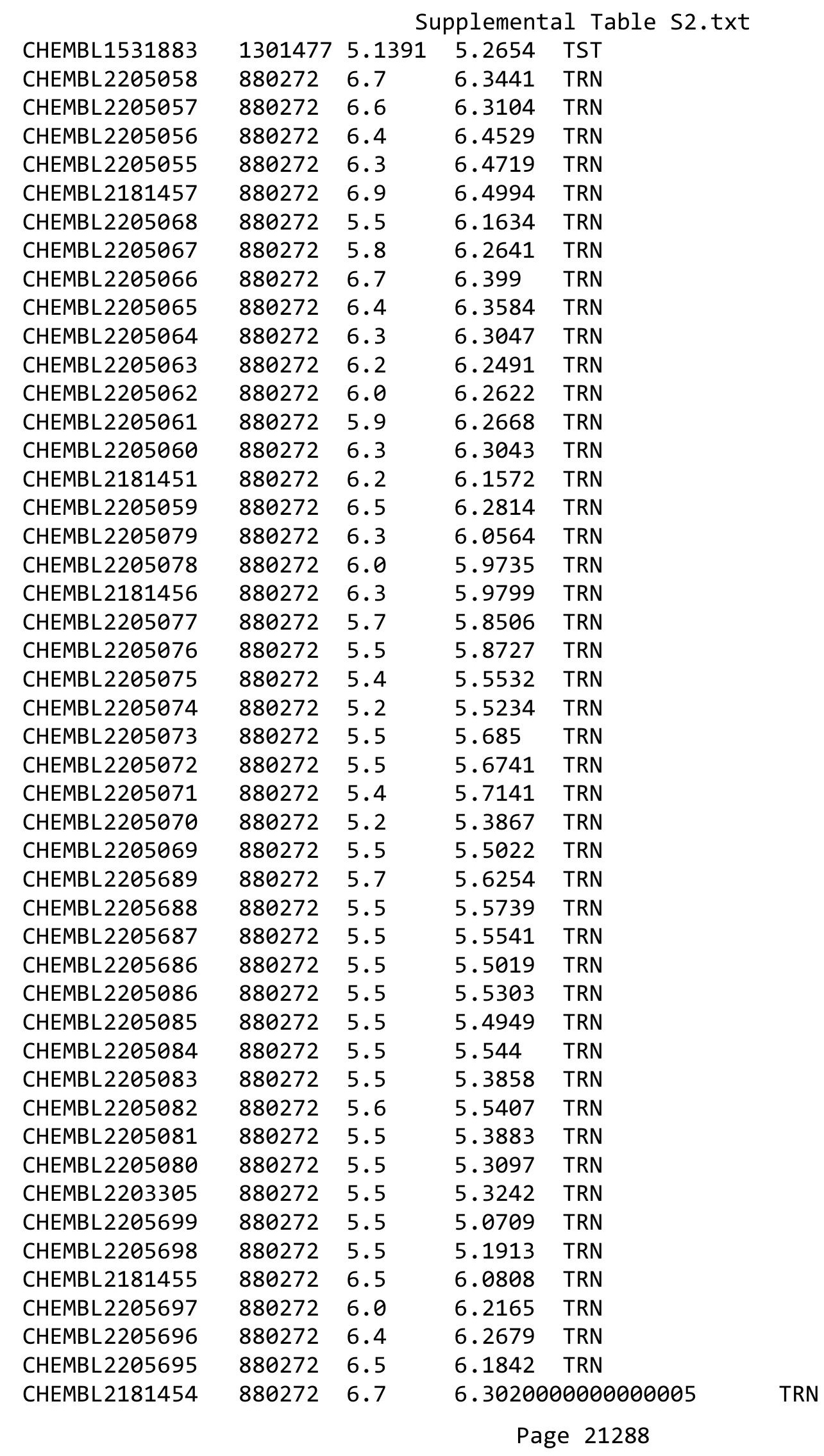




\begin{tabular}{|c|c|c|c|c|c|}
\hline \\
\hline CHEMBL2205694 & 880272 & 5.9 & 6.0006 & TRN & \\
\hline CHEMBL 2205693 & 880272 & 5.6 & 5.5636 & TST & \\
\hline CHEMBL2181453 & 880272 & 5.4 & 5.705 & TRN & \\
\hline CHEMBL2205692 & 880272 & 5.8 & 5.7786 & TRN & \\
\hline CHEMBL2205691 & 880272 & 5.7 & 5.9276 & TRN & \\
\hline CHEMBL2205690 & 880272 & 5.5 & 5.2739 & TRN & \\
\hline CHEMBL 2205714 & 880272 & 5.3 & 5.5959 & TRN & \\
\hline CHEMBL2205713 & 880272 & 5.5 & 5.572 & TRN & \\
\hline CHEMBL2205712 & 880272 & 5.5 & 5.371 & TRN & \\
\hline CHEMBL2205711 & 880272 & 5.6 & 5.4951 & TRN & \\
\hline CHEMBL 2205710 & 880272 & 5.2 & 5.2427 & TRN & \\
\hline CHEMBL2205709 & 880272 & 4.9 & 5.4756 & TST & \\
\hline CHEMBL2205708 & 880272 & 4.8 & 4.8895 & TRN & \\
\hline CHEMBL2205707 & 880272 & 5.3 & 5.1723 & TST & \\
\hline CHEMBL2205706 & 880272 & 5.1 & 5.2379 & TST & \\
\hline CHEMBL 2205705 & 880272 & 6.2 & 5.9496 & TST & \\
\hline CHEMBL2205704 & 880272 & 6.6 & 6.1043 & TST & \\
\hline CHEMBL2205703 & 880272 & 5.8 & 5.9143 & TST & \\
\hline CHEMBL2205702 & 880272 & 6.0 & 5.9249 & TST & \\
\hline CHEMBL2205701 & 880272 & 6.2 & 6.0095 & TST & \\
\hline CHEMBL 2205700 & 880272 & 5.7 & 5.9989 & TST & \\
\hline CHEMBL2205723 & 880272 & 6.1 & 5.985 & TST & \\
\hline CHEMBL2205722 & 880272 & 5.4 & 5.5238 & TST & \\
\hline CHEMBL2205721 & 880272 & 5.5 & 5.2949 & TST & \\
\hline CHEMBL2205720 & 880272 & 5.1 & 5.3778 & TST & \\
\hline CHEMBL2205719 & 880272 & 5.1 & 5.2919 & TST & \\
\hline CHEMBL2205718 & 880272 & 5.3 & 5.32799 & 9999999999 & TST \\
\hline CHEMBL 2205716 & 880272 & 5.1 & 5.3211 & TST & \\
\hline CHEMBL2205715 & 880272 & 5.6 & 5.7712 & TST & \\
\hline CHEMBL1484738 & 880272 & 5.4 & 5.6274 & TST & \\
\hline CHEMBL 397983 & 880272 & 7.4 & 5.6792 & TST & \\
\hline CHEMBL1086345 & 634029 & 5.7959 & 6.53100 & 0000000001 & TRN \\
\hline CHEMBL1082938 & 634029 & 4.8386 & 5.6308 & TRN & \\
\hline CHEMBL1086563 & 634029 & 5.8861 & 6.0433 & TRN & \\
\hline CHEMBL1082814 & 634029 & 6.1244 & 5.7326 & TRN & \\
\hline CHEMBL1084897 & 634029 & 6.0 & 5.6437 & TRN & \\
\hline CHEMBL1085367 & 634029 & 6.2306 & 5.9548 & TRN & \\
\hline CHEMBL1085146 & 634029 & 7.0315 & 6.4107 & TRN & \\
\hline CHEMBL1085720 & 634029 & 6.0057 & 5.8777 & TST & \\
\hline CHEMBL1082499 & 634029 & 5.6778 & 5.8728 & TRN & \\
\hline CHEMBL1083753 & 634029 & 5.9101 & 5.3887 & TST & \\
\hline CHEMBL1083883 & 634029 & 5.6615 & 5.4685 & TRN & \\
\hline CHEMBL1082769 & 634029 & 4.0 & 4.8903 & TRN & \\
\hline CHEMBL1084304 & 634029 & 6.0057 & 6.2369 & TRN & \\
\hline CHEMBL1085145 & 634029 & 5.8386 & 5.7423 & TRN & \\
\hline CHEMBL1085963 & 634029 & 6.3072 & 5.6259 & TRN & \\
\hline CHEMBL1082497 & 634029 & 6.0128 & 6.3237 & TST & \\
\hline CHEMBL1085144 & 634029 & 5.7799 & 5.5618 & TRN & \\
\hline
\end{tabular}




\begin{tabular}{|c|c|c|c|c|c|}
\hline & & & & & \\
\hline CHEMBL1082490 & 634029 & 6.2958 & 5.9129 & TST & \\
\hline CHEMBL1083464 & 634029 & 6.5171 & 6.6722 & TRN & \\
\hline CHEMBL1085614 & 634029 & 5.6576 & 5.9257 & TRN & \\
\hline CHEMBL1086347 & 634029 & 6.5391 & 6.1437 & TRN & \\
\hline CHEMBL1085962 & 634029 & 4.0 & 5.3119 & TRN & \\
\hline CHEMBL1083422 & 634029 & 5.6198 & 5.9705 & TRN & \\
\hline CHEMBL1085868 & 634029 & 5.7696 & 5.6861 & TRN & \\
\hline CHEMBL1086319 & 634029 & 6.0232 & 6.5166 & TRN & \\
\hline CHEMBL1086562 & 634029 & 6.5901 & 6.2663 & TRN & \\
\hline CHEMBL1085400 & 634029 & 5.6108 & 5.8796 & TRN & \\
\hline CHEMBL1085613 & 634029 & 6.2403 & 6.0495 & TRN & \\
\hline CHEMBL1086552 & 634029 & 5.4089 & 6.2753 & TST & \\
\hline CHEMBL1085154 & 634029 & 5.7696 & 5.5862 & TRN & \\
\hline CHEMBL1083125 & 634029 & 6.6676 & 6.6436 & TRN & \\
\hline CHEMBL1084044 & 634029 & 5.3372 & 6.0367 & TST & \\
\hline CHEMBL1086346 & 634029 & 6.9355 & 6.445 & TRN & \\
\hline CHEMBL1085153 & 634029 & 6.0655 & 5.9438 & TRN & \\
\hline CHEMBL1083423 & 634029 & 6.0862 & 5.8951 & TST & \\
\hline CHEMBL1083465 & 634029 & 6.1637 & 6.3979 & TRN & \\
\hline CHEMBL1086553 & 634029 & 5.8239 & 5.9986 & TST & \\
\hline CHEMBL1085143 & 634029 & 6.0205 & 5.7999 & TRN & \\
\hline CHEMBL1084056 & 634029 & 6.0255 & 5.2303 & TST & \\
\hline CHEMBL1084449 & 634029 & 6.4449 & 6.4338 & TRN & \\
\hline CHEMBL1084043 & 634029 & 6.224 & 6.3975 & TRN & \\
\hline CHEMBL1086564 & 634029 & 5.8729 & 6.20299 & 9999999999 & TRN \\
\hline CHEMBL1084968 & 634029 & 6.3706 & 6.579 & TRN & \\
\hline CHEMBL1085216 & 634029 & 5.0969 & 6.1439 & TST & \\
\hline CHEMBL1086231 & 634029 & 5.7447 & 5.7401 & TRN & \\
\hline CHEMBL1082813 & 634029 & 6.0742 & 5.5179 & TRN & \\
\hline CHEMBL1084561 & 634029 & 5.9586 & 6.1737 & TRN & \\
\hline CHEMBL1084305 & 634029 & 6.0386 & 6.2515 & TRN & \\
\hline CHEMBL1084046 & 634029 & 6.2684 & 6.0726 & TRN & \\
\hline CHEMBL1082770 & 634029 & 5.4089 & 5.5779 & TST & \\
\hline CHEMBL1085152 & 634029 & 5.983 & 5.8576 & TRN & \\
\hline CHEMBL1086554 & 634029 & 5.9586 & 6.1107 & TRN & \\
\hline CHEMBL1085612 & 634029 & 6.9431 & 6.6161 & TRN & \\
\hline CHEMBL1083161 & 634029 & 6.5986 & 5.5568 & TRN & \\
\hline CHEMBL1083395 & 634029 & 6.1415 & 5.30200 & 00000000005 & TST \\
\hline CHEMBL1084045 & 634029 & 6.5086 & 6.5739 & TRN & \\
\hline CHEMBL1084562 & 634029 & 6.7375 & 6.0934 & TRN & \\
\hline CHEMBL1082768 & 634029 & 5.9586 & 5.7591 & TST & \\
\hline CHEMBL1085785 & 634029 & 5.3468 & 5.6302 & TST & \\
\hline CHEMBL1085867 & 634029 & 6.3143 & 6.1572 & TRN & \\
\hline CHEMBL1084714 & 634029 & 6.1656 & 5.619 & TST & \\
\hline CHEMBL 3084741 & 634029 & 5.8239 & 6.0279 & TST & \\
\hline CHEMBL1083267 & 634029 & 5.9788 & 6.5142 & TRN & \\
\hline CHEMBL1084898 & 634029 & 5.7959 & 5.7499 & TRN & \\
\hline CHEMBL1085784 & 634029 & 5.7212 & 5.7718 & TST & \\
\hline
\end{tabular}




\begin{tabular}{|c|c|c|c|c|c|}
\hline \multicolumn{6}{|c|}{3} \\
\hline CHEMBL519120 & 518975 & 8.3979 & 8.1991 & TRN & \\
\hline CHEMBL516248 & 518975 & 7.5528 & 7.5429 & TRN & \\
\hline CHEMBL482349 & 518975 & 7.5686 & 7.9964 & TST & \\
\hline CHEMBL473630 & 518975 & 7.4685 & 7.5797 & TST & \\
\hline CHEMBL480383 & 518975 & 7.7696 & 7.7321 & TRN & \\
\hline CHEMBL520284 & 518975 & 7.1367 & 7.0858 & TST & \\
\hline CHEMBL474029 & 518975 & 8.2218 & 8.1333 & TRN & \\
\hline CHEMBL514162 & 518975 & 8.699 & 8.8114 & TRN & \\
\hline CHEMBL474028 & 518975 & 8.699 & 8.8283 & TRN & \\
\hline CHEMBL481156 & 518975 & 7.0 & 6.9102 & TRN & \\
\hline CHEMBL480545 & 518975 & 8.699 & 8.0377 & TST & \\
\hline CHEMBL471789 & 518975 & 7.0706 & 6.8713 & TRN & \\
\hline CHEMBL516362 & 518975 & 7.2147 & 7.6095 & TRN & \\
\hline CHEMBL475783 & 518975 & 7.6778 & 7.8009 & TRN & \\
\hline CHEMBL480382 & 518975 & 7.9586 & 8.0117 & TRN & \\
\hline CHEMBL514826 & 518975 & 7.9208 & 7.3253 & TRN & \\
\hline CHEMBL520080 & 518975 & 7.7696 & 7.6006 & TST & \\
\hline CHEMBL481491 & 518975 & 7.8239 & 7.5852 & TRN & \\
\hline CHEMBL518953 & 518975 & 7.9586 & 8.1955 & TRN & \\
\hline CHEMBL474432 & 518975 & 8.699 & 7.057 & TRN & \\
\hline CHEMBL475616 & 518975 & 7.5086 & 7.3066 & TRN & \\
\hline CHEMBL508763 & 518975 & 7.8539 & 7.7727 & TRN & \\
\hline CHEMBL449608 & 518975 & 7.9208 & 7.1575 & TRN & \\
\hline CHEMBL219899 & 518975 & 7.1249 & 6.7592 & TRN & \\
\hline CHEMBL514634 & 518975 & 7.7696 & 8.4561 & TRN & \\
\hline CHEMBL 374440 & 518975 & 6.1549 & 6.3759 & TST & \\
\hline CHEMBL482151 & 518975 & 8.2218 & 7.7291 & TRN & \\
\hline CHEMBL474054 & 518975 & 8.0969 & 8.596 & TRN & \\
\hline CHEMBL475857 & 518975 & 7.9208 & 7.774 & TRN & \\
\hline CHEMBL481492 & 518975 & 7.6778 & 7.87799 & 9999999999 & TRN \\
\hline CHEMBL474437 & 518975 & 7.4559 & 7.4325 & TRN & \\
\hline CHEMBL475597 & 518975 & 7.9208 & 8.3141 & TRN & \\
\hline CHEMBL514040 & 518975 & 7.0044 & 7.1963 & TRN & \\
\hline CHEMBL474053 & 518975 & 8.301 & 8.382 & TRN & \\
\hline CHEMBL518956 & 518975 & 7.9208 & 7.8615 & TRN & \\
\hline CHEMBL514968 & 518975 & 8.0969 & 8.0862 & TRN & \\
\hline CHEMBL481510 & 518975 & 8.0458 & 8.0323 & TRN & \\
\hline CHEMBL454196 & 518975 & 7.1549 & 6.8516 & TRN & \\
\hline CHEMBL475762 & 518975 & 6.8861 & 7.2178 & TRN & \\
\hline CHEMBL519289 & 518975 & 6.6021 & 6.9816 & TRN & \\
\hline CHEMBL473420 & 518975 & 5.0 & 6.4428 & TRN & \\
\hline CHEMBL482326 & 518975 & 5.0 & 6.0993 & TRN & \\
\hline CHEMBL445277 & 518975 & 7.6576 & 7.2871 & TRN & \\
\hline CHEMBL475763 & 518975 & 7.8539 & 7.7755 & TRN & \\
\hline CHEMBL481724 & 518975 & 7.2147 & 7.1654 & TRN & \\
\hline CHEMBL474843 & 518975 & 8.699 & 8.4038 & TRN & \\
\hline CHEMBL473629 & 518975 & 6.8861 & 7.74100 & 00000000005 & TST \\
\hline CHEMBL480371 & 518975 & 6.5229 & 7.6923 & TST & \\
\hline
\end{tabular}




\begin{tabular}{|c|c|c|c|c|c|}
\hline \multicolumn{6}{|c|}{ Supplemental Table s2.txt } \\
\hline CHEMBL514643 & 518975 & 7.8861 & 7.6004 & TST & \\
\hline CHEMBL518968 & 518975 & 5.0 & 6.7098 & TST & \\
\hline CHEMBL474603 & 518975 & 7.9208 & 8.1962 & TST & \\
\hline CHEMBL519286 & 518975 & 6.7212 & 7.6698 & TST & \\
\hline CHEMBL514499 & 518975 & 8.699 & 8.3059 & TST & \\
\hline CHEMBL475215 & 518975 & 7.5086 & 7.8844 & TST & \\
\hline CHEMBL3338029 & 1435307 & 3.1938 & 3.1477 & TRN & \\
\hline CHEMBL470025 & 1435307 & 4.7796 & 4.5494 & TRN & \\
\hline CHEMBL3338016 & 1435307 & 3.4948 & 3.57 & TRN & \\
\hline CHEMBL3338021 & 1435307 & 3.1938 & 3.1039 & TRN & \\
\hline CHEMBL3338030 & 1435307 & 5.6737 & 5.6351 & TRN & \\
\hline CHEMBL3338013 & 1435307 & 5.2336 & 5.2403 & TRN & \\
\hline CHEMBL3338014 & 1435307 & 3.4948 & 3.6383 & TRN & \\
\hline CHEMBL3338011 & 1435307 & 3.4948 & 3.7157 & TRN & \\
\hline CHEMBL3338009 & 1435307 & 5.2534 & 5.2091 & TRN & \\
\hline CHEMBL3338007 & 1435307 & 3.1938 & 3.2803 & TRN & \\
\hline CHEMBL71521 & 1435307 & 5.1261 & 4.9346 & TRN & \\
\hline CHEMBL3338000 & 1435307 & 3.1938 & 2.6198 & TST & \\
\hline CHEMBL3338018 & 1435307 & 6.284 & 6.1777 & TRN & \\
\hline CHEMBL3338020 & 1435307 & 3.4948 & 4.0964 & TRN & \\
\hline CHEMBL3338039 & 1435307 & 3.1938 & 3.8326 & TRN & \\
\hline CHEMBL3338026 & 1435307 & 4.6276 & 4.5838 & TRN & \\
\hline CHEMBL3338015 & 1435307 & 3.1938 & 3.3267 & TRN & \\
\hline CHEMBL578061 & 1435307 & 4.8794 & 4.2358 & TST & \\
\hline CHEMBL3338012 & 1435307 & 3.1938 & 3.3245 & TRN & \\
\hline CHEMBL3338034 & 1435307 & 5.2487 & 5.5138 & TRN & \\
\hline CHEMBL3338032 & 1435307 & 5.6757 & 5.5773 & TRN & \\
\hline CHEMBL3338010 & 1435307 & 3.4948 & 3.1046 & TRN & \\
\hline CHEMBL72529 & 1435307 & 4.3658 & 4.0398 & TRN & \\
\hline CHEMBL69503 & 1435307 & 5.5498 & 5.1057 & TRN & \\
\hline CHEMBL3338017 & 1435307 & 3.4948 & 2.9169 & TRN & \\
\hline CHEMBL 74174 & 1435307 & 4.688 & 4.5452 & TRN & \\
\hline CHEMBL71659 & 1435307 & 5.2798 & 4.9874 & TRN & \\
\hline CHEMBL3338001 & 1435307 & 3.4948 & 3.4028 & TRN & \\
\hline CHEMBL3338035 & 1435307 & 5.3585 & 4.4871 & TST & \\
\hline CHEMBL3338023 & 1435307 & 5.1244 & 5.1706 & TRN & \\
\hline CHEMBL3338019 & 1435307 & 3.4948 & 3.6275 & TRN & \\
\hline CHEMBL3338037 & 1435307 & 3.1938 & 3.1616 & TRN & \\
\hline CHEMBL3338022 & 1435307 & 3.1938 & 3.2753 & TRN & \\
\hline CHEMBL3338004 & 1435307 & 3.4948 & 3.2566 & TRN & \\
\hline CHEMBL71728 & 1435307 & 3.1938 & 3.5389 & TRN & \\
\hline CHEMBL3338043 & 1435307 & 5.1965 & 5.1127 & TRN & \\
\hline CHEMBL3338054 & 1435307 & 4.5864 & 4.5621 & TRN & \\
\hline CHEMBL3338038 & 1435307 & 5.1355 & 5.25700 & 0000000001 & TRN \\
\hline CHEMBL3338044 & 1435307 & 5.0 & 5.274 & TRN & \\
\hline CHEMBL3338036 & 1435307 & 3.1938 & 3.513 & TST & \\
\hline CHEMBL3338042 & 1435307 & 3.1938 & 2.7375 & TRN & \\
\hline CHEMBL3338053 & 1435307 & 3.1938 & 3.534 & TRN & \\
\hline
\end{tabular}


Supplemental Table S2.txt

\begin{tabular}{|c|c|c|c|c|}
\hline CHEMBL3338048 & 1435307 & 5.0964 & 5.0 & TRN \\
\hline CHEMBL3338046 & 1435307 & 3.1938 & 3.2564 & TRN \\
\hline CHEMBL3337999 & 1435307 & 3.1938 & 3.3847 & TST \\
\hline CHEMBL3338024 & 1435307 & 4.4693 & 4.2671 & TRN \\
\hline CHEMBL3338050 & 1435307 & 3.1938 & 3.105 & TRN \\
\hline CHEMBL3338028 & 1435307 & 4.2716 & 4.7341 & TRN \\
\hline CHEMBL3337998 & 1435307 & 3.1938 & 4.2992 & TST \\
\hline CHEMBL3338045 & 1435307 & 4.7592 & 4.7332 & TRN \\
\hline CHEMBL3338033 & 1435307 & 3.1938 & 3.1132 & TRN \\
\hline CHEMBL302791 & 1435307 & 5.1175 & 5.1572 & TRN \\
\hline CHEMBL3338002 & 1435307 & 3.4948 & 3.5114 & TRN \\
\hline CHEMBL54893 & 1435307 & 3.1938 & 1.3365 & TST \\
\hline CHEMBL3338040 & 1435307 & 5.0878 & 4.3489 & TRN \\
\hline CHEMBL3337461 & 1435307 & 3.4948 & 3.7496 & TRN \\
\hline CHEMBL3338049 & 1435307 & 3.1938 & 3.8008 & TRN \\
\hline CHEMBL3338051 & 1435307 & 3.1938 & 3.3306 & TRN \\
\hline CHEMBL3338041 & 1435307 & 5.0496 & 4.6456 & TST \\
\hline CHEMBL3338006 & 1435307 & 3.1938 & 4.053 & TST \\
\hline CHEMBL3338025 & 1435307 & 5.1713 & 4.2792 & TST \\
\hline CHEMBL3338027 & 1435307 & 5.9872 & 5.7667 & TST \\
\hline CHEMBL3338055 & 1435307 & 3.1938 & 1.89699 & 99999999998 \\
\hline CHEMBL3338047 & 1435307 & 4.5935 & 4.6992 & TST \\
\hline CHEMBL421114 & 1435307 & 3.1938 & 3.6679 & TST \\
\hline CHEMBL3338031 & 1435307 & 4.6398 & 4.9683 & TST \\
\hline CHEMBL3338008 & 1435307 & 3.1938 & 3.6836 & TST \\
\hline CHEMBL3338052 & 1435307 & 4.4679 & 4.0759 & TST \\
\hline CHEMBL3338003 & 1435307 & 3.4948 & 2.8865 & TST \\
\hline CHEMBL 7092 & 45075 & 6.9586 & 7.334 & TST \\
\hline CHEMBL265674 & 45075 & 7.2218 & 7.4608 & TST \\
\hline CHEMBL102922 & 45075 & 7.8239 & 7.8291 & TRN \\
\hline CHEMBL319090 & 45075 & 6.8861 & 6.7917 & TRN \\
\hline CHEMBL318047 & 45075 & 6.699 & 6.8159 & TRN \\
\hline CHEMBL327742 & 45075 & 7.8239 & 7.7423 & TRN \\
\hline CHEMBL101190 & 45075 & 8.2218 & 8.3332 & TRN \\
\hline CHEMBL420105 & 45075 & 8.0969 & 8.1042 & TRN \\
\hline CHEMBL319297 & 45075 & 8.1549 & 8.1036 & TRN \\
\hline CHEMBL102870 & 45075 & 7.4318 & 7.4402 & TRN \\
\hline CHEMBL14182 & 45075 & 8.0458 & 8.1208 & TST \\
\hline CHEMBL99958 & 45075 & 6.6021 & 6.5371 & TRN \\
\hline CHEMBL101196 & 45075 & 7.4202 & 7.4177 & TRN \\
\hline CHEMBL102904 & 45075 & 7.9208 & 7.9644 & TRN \\
\hline CHEMBL100748 & 45075 & 7.8239 & 7.8222 & TRN \\
\hline CHEMBL419536 & 45075 & 7.6021 & 7.5353 & TRN \\
\hline CHEMBL318839 & 45075 & 8.0 & 7.9455 & TRN \\
\hline CHEMBL316529 & 45075 & 7.3665 & 7.34 & TRN \\
\hline CHEMBL6852 & 45075 & 6.6198 & 6.8354 & TST \\
\hline CHEMBL320840 & 45075 & 6.5376 & 6.598 & TRN \\
\hline CHEMBL319364 & 45075 & 7.1549 & 7.2105 & TRN \\
\hline
\end{tabular}




\begin{tabular}{|c|c|c|c|c|c|}
\hline & & \multicolumn{4}{|c|}{ Supplemental Table S2.txt } \\
\hline CHEMBL100873 & 45075 & 6.5607 & 6.5412 & TRN & \\
\hline CHEMBL100580 & 45075 & 6.4949 & 6.4079 & TRN & \\
\hline CHEMBL103757 & 45075 & 7.3372 & 7.32100 & 0000000001 & TRN \\
\hline CHEMBL319363 & 45075 & 7.3468 & 7.4779 & TRN & \\
\hline CHEMBL 99641 & 45075 & 6.6383 & 6.70700 & 0000000001 & TRN \\
\hline CHEMBL103302 & 45075 & 6.9586 & 7.0182 & TRN & \\
\hline CHEMBL318014 & 45075 & 7.7696 & 7.7327 & TRN & \\
\hline CHEMBL317015 & 45075 & 7.3768 & 7.3569 & TRN & \\
\hline CHEMBL 269628 & 45075 & 7.5528 & 7.4709 & TST & \\
\hline CHEMBL103524 & 45075 & 8.1549 & 8.1068 & TRN & \\
\hline CHEMBL103630 & 45075 & 8.699 & 8.5752 & TRN & \\
\hline CHEMBL439957 & 45075 & 8.1549 & 8.2114 & TRN & \\
\hline CHEMBL100860 & 45075 & 8.301 & 8.3582 & TRN & \\
\hline CHEMBL13630 & 45075 & 9.2218 & 8.9971 & TST & \\
\hline CHEMBL97795 & 45075 & 8.3979 & 8.379 & TRN & \\
\hline CHEMBL6633 & 45075 & 7.9208 & 7.3982 & TST & \\
\hline CHEMBL321795 & 45075 & 7.8239 & 7.8499 & TRN & \\
\hline CHEMBL102722 & 45075 & 8.301 & 8.4561 & TRN & \\
\hline CHEMBL319487 & 45075 & 8.699 & 8.5543 & TRN & \\
\hline CHEMBL6919 & 45075 & 6.9031 & 6.8196 & TST & \\
\hline CHEMBL 6724 & 45075 & 7.3979 & 7.2386 & TST & \\
\hline CHEMBL6685 & 45075 & 8.0969 & 8.1594 & TRN & \\
\hline CHEMBL318101 & 45075 & 7.7959 & 7.8284 & TRN & \\
\hline CHEMBL319897 & 45075 & 8.0969 & 8.1188 & TRN & \\
\hline CHEMBL330413 & 45075 & 7.7447 & 7.7507 & TRN & \\
\hline CHEMBL 6784 & 45075 & 6.9586 & 6.8475 & TST & \\
\hline CHEMBL101174 & 45075 & 6.6676 & 6.7629 & TRN & \\
\hline CHEMBL103398 & 45075 & 7.8861 & 7.7529 & TRN & \\
\hline CHEMBL317328 & 45075 & 7.7959 & 7.751 & TRN & \\
\hline CHEMBL103802 & 45075 & 7.2924 & 7.2567 & TRN & \\
\hline CHEMBL100906 & 45075 & 8.3979 & 8.3553 & TRN & \\
\hline CHEMBL318969 & 45075 & 8.0 & 7.9615 & TRN & \\
\hline CHEMBL6705 & 45075 & 6.5302 & 6.6943 & TST & \\
\hline CHEMBL100757 & 45075 & 7.4685 & 7.4814 & TRN & \\
\hline CHEMBL319794 & 45075 & 7.4089 & 7.4773 & TRN & \\
\hline CHEMBL99638 & 45075 & 7.1079 & 7.1416 & TRN & \\
\hline CHEMBL102316 & 45075 & 7.4949 & 7.5239 & TRN & \\
\hline CHEMBL101183 & 45075 & 7.3098 & 7.4088 & TRN & \\
\hline CHEMBL103407 & 45075 & 7.4437 & 7.3968 & TRN & \\
\hline CHEMBL268439 & 45075 & 8.699 & 8.6201 & TST & \\
\hline CHEMBL100456 & 45075 & 8.1549 & 8.1802 & TRN & \\
\hline CHEMBL318486 & 45075 & 7.8861 & 7.8386 & TRN & \\
\hline CHEMBL103615 & 45075 & 8.2218 & 8.1871 & TRN & \\
\hline CHEMBL103392 & 45075 & 8.301 & 8.2779 & TRN & \\
\hline CHEMBL102068 & 45075 & 7.7447 & 7.7304 & TRN & \\
\hline CHEMBL317256 & 45075 & 8.5229 & 8.4738 & TRN & \\
\hline CHEMBL99697 & 45075 & 7.8239 & 7.8014 & TRN & \\
\hline CHEMBL102656 & 45075 & 7.6778 & 7.7027 & TRN & \\
\hline
\end{tabular}




\begin{tabular}{|c|c|c|c|c|c|}
\hline \multicolumn{6}{|c|}{ Supplemental Table S2.txt } \\
\hline CHEMBL430667 & 45075 & 7.1024 & 7.0903 & TRN & \\
\hline CHEMBL103415 & 45075 & 7.8539 & 7.8208 & TRN & \\
\hline CHEMBL103361 & 45075 & 7.6778 & 7.6142 & TRN & \\
\hline CHEMBL316957 & 45075 & 7.7696 & 7.7412 & TRN & \\
\hline CHEMBL323550 & 45075 & 7.4559 & 7.4016 & TRN & \\
\hline CHEMBL98673 & 45075 & 7.8239 & 7.8317 & TRN & \\
\hline CHEMBL103825 & 45075 & 7.9586 & 7.9008 & TRN & \\
\hline CHEMBL102705 & 45075 & 8.0458 & 8.0532 & TRN & \\
\hline CHEMBL329756 & 45075 & 7.4437 & 7.5059 & TRN & \\
\hline CHEMBL103325 & 45075 & 6.9031 & 6.9135 & TRN & \\
\hline CHEMBL100733 & 45075 & 8.2218 & 8.2892 & TRN & \\
\hline CHEMBL320436 & 45075 & 8.0969 & 8.0276 & TRN & \\
\hline CHEMBL266240 & 45075 & 7.1249 & 7.3743 & TST & \\
\hline CHEMBL101330 & 45075 & 8.301 & 8.3851 & TRN & \\
\hline CHEMBL 35118 & 45075 & 8.0458 & 8.1044 & TRN & \\
\hline CHEMBL316576 & 45075 & 6.8386 & 6.7688 & TRN & \\
\hline CHEMBL100075 & 45075 & 8.1549 & 8.1753 & TRN & \\
\hline CHEMBL 418 & 45075 & 7.2076 & 7.428 & TST & \\
\hline CHEMBL318953 & 45075 & 8.2218 & 8.3152 & TRN & \\
\hline CHEMBL321281 & 45075 & 7.7212 & 7.7701 & TRN & \\
\hline CHEMBL287117 & 45075 & 8.1549 & 8.1706 & TRN & \\
\hline CHEMBL320591 & 45075 & 7.9208 & 7.9582 & TRN & \\
\hline CHEMBL421200 & 45075 & 8.301 & 8.2922 & TRN & \\
\hline CHEMBL317249 & 45075 & 7.7447 & 7.7826 & TRN & \\
\hline CHEMBL6853 & 45075 & 7.2218 & 7.3941 & TST & \\
\hline CHEMBL319030 & 45075 & 8.0 & 7.9571 & TRN & \\
\hline CHEMBL 7204 & 45075 & 6.4949 & 6.6347 & TST & \\
\hline CHEMBL102401 & 45075 & 8.0458 & 7.9792 & TRN & \\
\hline CHEMBL103015 & 45075 & 8.3979 & 8.3815 & TRN & \\
\hline CHEMBL411850 & 45075 & 7.7212 & 7.7171 & TRN & \\
\hline CHEMBL103346 & 45075 & 6.5528 & 6.5204 & TRN & \\
\hline CHEMBL6753 & 45075 & 7.7212 & 7.5551 & TST & \\
\hline CHEMBL268177 & 45075 & 7.1549 & 7.2148 & TST & \\
\hline CHEMBL103478 & 45075 & 8.0969 & 8.0802 & TRN & \\
\hline CHEMBL554264 & 45075 & 7.7212 & 7.7436 & TRN & \\
\hline CHEMBL103945 & 45075 & 7.9586 & 7.9579 & TRN & \\
\hline CHEMBL100760 & 45075 & 7.7959 & 7.8175 & TRN & \\
\hline CHEMBL103413 & 45075 & 7.9208 & 7.9501 & TRN & \\
\hline CHEMBL 7087 & 45075 & 6.7959 & 6.9228 & TST & \\
\hline CHEMBL103420 & 45075 & 8.301 & 8.2537 & TRN & \\
\hline CHEMBL99855 & 45075 & 8.3979 & 8.4838 & TRN & \\
\hline CHEMBL99694 & 45075 & 7.8239 & 7.8454 & TRN & \\
\hline CHEMBL420096 & 45075 & 7.6778 & 7.65600 & 0000000001 & TRN \\
\hline CHEMBL103770 & 45075 & 8.301 & 8.1952 & TRN & \\
\hline CHEMBL327964 & 45075 & 7.7212 & 7.7527 & TRN & \\
\hline CHEMBL101002 & 45075 & 7.1487 & 7.1548 & TRN & \\
\hline CHEMBL102793 & 45075 & 6.6289 & 6.619 & TST & \\
\hline CHEMBL13646 & 45075 & 8.5229 & 7.7947 & TST & \\
\hline
\end{tabular}




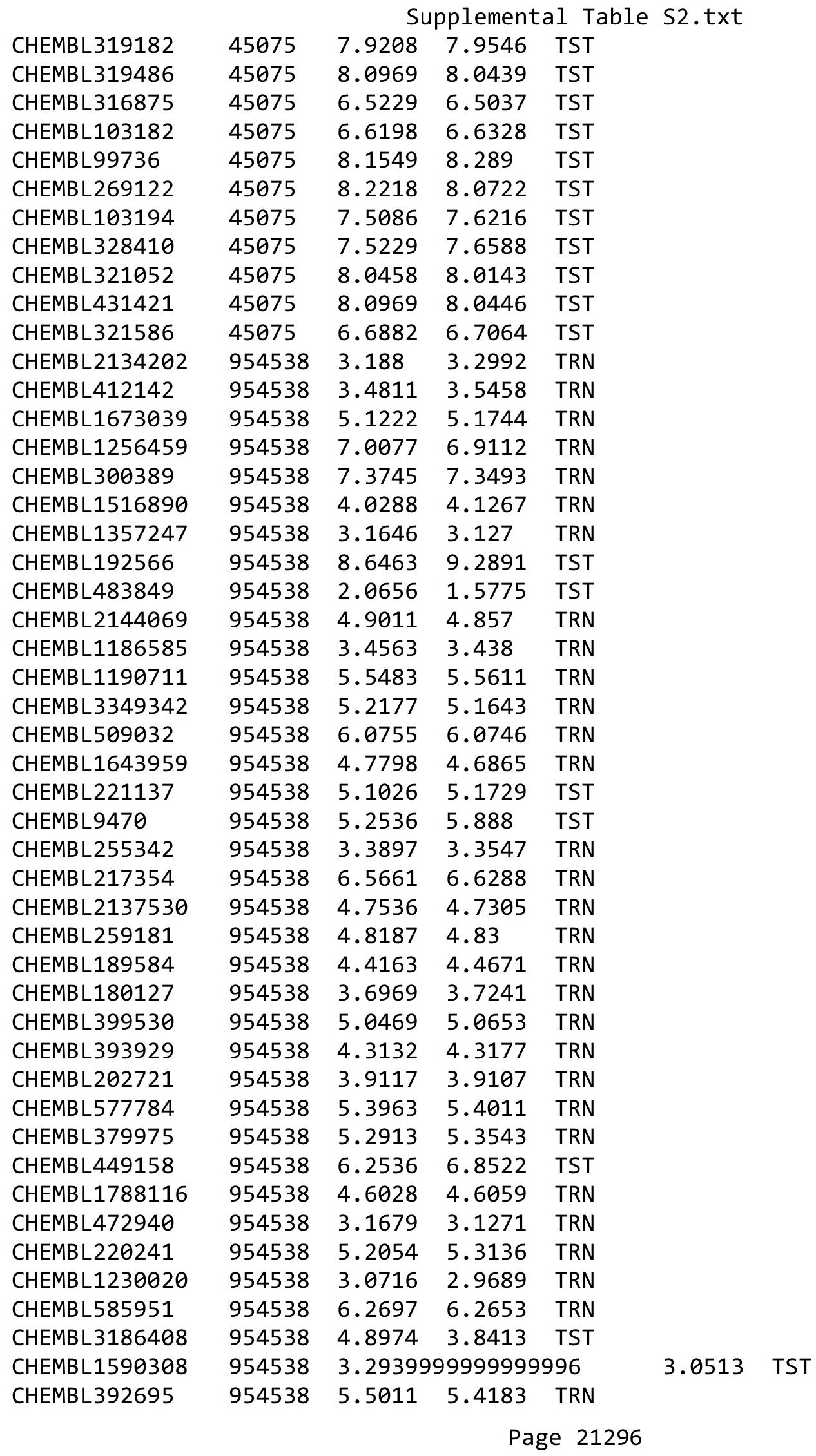


Supplemental Table S2.txt

\begin{tabular}{|c|c|c|c|c|}
\hline 918 & 54538 & 2.7003 & 6492 & \\
\hline HEMBL 209148 & 54538 & 4.9409 & 4.8238 & \\
\hline & & 2809 & & \\
\hline IEMBL 213100 & 38 & 5044 & 331 & \\
\hline IEMBL515416 & 54538 & 2982 & 978 & \\
\hline AEMBL558642 & 54538 & .7945 & 4.7145 & \\
\hline HEMBL1970879 & 54538 & .4022 & 5.3868 & \\
\hline EMBL & 38 & $\partial 114$ & 9742 & \\
\hline IEMBL 373751 & 38 & .4551 & 3.5729 & \\
\hline AEMBL188678 & 54538 & .2125 & 4.1332 & \\
\hline AEMBL379300 & 38 & 5441 & 5.6171 & \\
\hline AEMBL240954 & 38 & .3732 & 2293 & \\
\hline EMBL5 & & & 987 & \\
\hline IEMBL 258844 & 38 & 199 & 4.8762 & \\
\hline AEMBL222102 & 38 & .3052 & 3.3623 & \\
\hline AEMBL 2005886 & 38 & 517 & 05 & \\
\hline AEMBL65 & 38 & 12 & 12 & \\
\hline IEMBL 319 & & & & RN \\
\hline AEMBL12 & 38 & & 993 & RN \\
\hline IEMBL210618 & 38 & 808 & 3298 & \\
\hline AEMBL135561 & 38 & 5.0132 & 4.8481 & \\
\hline AEMBL102714 & 8 & 19 & 849 & \\
\hline IEMBL191334 & & 56 & 62 & ST \\
\hline AEMB & & 01 & 67 & \\
\hline IEMBL92309 & & & 316 & S \\
\hline fEMBL483847 & 8 & 83 & 4. & 1 \\
\hline AEMBL1909414 & 8 & 98 & 3. & ST \\
\hline AEMBL3392440 & & & 92 & ונב \\
\hline 42 & & 82 & 01 & ST \\
\hline IEMBL1306769 & & & & RN \\
\hline IEMBL1540815 & 8 & 798 & 16 & RI \\
\hline AEMBL1382640 & 98 & 53 & 187 & 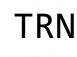 \\
\hline IEMBL578944 & & & 78 & ST \\
\hline 15 & & & & RN \\
\hline IEMBL1320494 & & & & RN \\
\hline IEMBL1341697 & 8 & 43 & 792 & RI \\
\hline IEMBL1416848 & 98 & 12 & 197 & . \\
\hline 7335 & & & & 81 \\
\hline AEMBL1525735 & & 5.2716 & & $\mathrm{RN}$ \\
\hline IEMBL 3145330 & 8 & 261 & & $\mathrm{RI}$ \\
\hline AEMBL1573242 & 98 & 45 & 53 & RI \\
\hline HEMBL1583236 & 98 & 328 & 5.2872 & \\
\hline & & & 4.8938 & ST \\
\hline HEMBL1382232 & 98 & .699 & 4.6893 & RI \\
\hline IEMBL1451348 & 98 & 5659 & 5.1827 & RI \\
\hline EMBL14 & & & & \\
\hline CHEMBL14 & 98 & & 4.881 & \\
\hline ZHEMBL15721 & 737098 & & 5.0744 & \\
\hline
\end{tabular}

Page 21297 


\begin{tabular}{|c|c|c|c|c|c|}
\hline & & & & & \\
\hline CHEMBL1472748 & 737098 & 5.8069 & 5.0267 & TRN & \\
\hline CHEMBL1483105 & 737098 & 5.4776 & 5.2318 & TRN & \\
\hline CHEMBL1306900 & 737098 & 5.0839 & 4.775 & TST & \\
\hline CHEMBL1573795 & 737098 & 3.699 & 4.2062 & TRN & \\
\hline CHEMBL1359986 & 737098 & 5.4711 & 5.0402 & TRN & \\
\hline CHEMBL1431684 & 737098 & 4.7545 & 4.9636 & TRN & \\
\hline CHEMBL1384893 & 737098 & 5.4112 & 5.2772 & TRN & \\
\hline CHEMBL1519651 & 737098 & 5.5901 & 5.1015 & TRN & \\
\hline CHEMBL1556615 & 737098 & 5.3215 & 5.23799 & 99999999995 & TRN \\
\hline CHEMBL1394121 & 737098 & 5.1068 & 4.7843 & TRN & \\
\hline CHEMBL1361922 & 737098 & 5.0032 & 6.0353 & TST & \\
\hline CHEMBL579621 & 737098 & 5.6144 & 5.0434 & TRN & \\
\hline CHEMBL3195322 & 737098 & 4.9245 & 5.3437 & TRN & \\
\hline CHEMBL1982381 & 737098 & 5.7144 & 4.5224 & TRN & \\
\hline CHEMBL1602759 & 737098 & 3.699 & 4.7359 & TST & \\
\hline CHEMBL3195226 & 737098 & 5.2068 & 4.6676 & TRN & \\
\hline CHEMBL1968085 & 737098 & 3.699 & 3.6728 & TRN & \\
\hline CHEMBL1385296 & 737098 & 5.2588 & 5.0498 & TRN & \\
\hline CHEMBL1502127 & 737098 & 5.0872 & 5.2837 & TRN & \\
\hline CHEMBL1421605 & 737098 & 4.9323 & 4.9842 & TST & \\
\hline CHEMBL1495358 & 737098 & 5.1978 & 5.0651 & TRN & \\
\hline CHEMBL1545677 & 737098 & 3.699 & 4.6017 & TRN & \\
\hline CHEMBL3199216 & 737098 & 4.7447 & 4.5979 & TRN & \\
\hline CHEMBL588028 & 737098 & 3.699 & 4.9777 & TRN & \\
\hline CHEMBL1334593 & 737098 & 5.5086 & 5.2963 & TST & \\
\hline CHEMBL1415844 & 737098 & 5.6904 & 5.4148 & TRN & \\
\hline CHEMBL1887153 & 737098 & 3.699 & 3.9681 & TRN & \\
\hline CHEMBL1347270 & 737098 & 5.3224 & 5.1847 & TRN & \\
\hline CHEMBL577660 & 737098 & 5.5884 & 5.5478 & TRN & \\
\hline CHEMBL1306839 & 737098 & 5.0255 & 4.8672 & TRN & \\
\hline CHEMBL1507251 & 737098 & 5.0237 & 5.32700 & 0000000001 & TRN \\
\hline CHEMBL1455507 & 737098 & 5.6574 & 4.9985 & TRN & \\
\hline CHEMBL1507128 & 737098 & 3.699 & 4.5855 & TRN & \\
\hline CHEMBL1569954 & 737098 & 6.1024 & 4.6739 & TRN & \\
\hline CHEMBL1447831 & 737098 & 5.2381 & 4.9908 & TRN & \\
\hline CHEMBL1332013 & 737098 & 4.7645 & 5.1466 & TRN & \\
\hline CHEMBL1570111 & 737098 & 5.1599 & 5.2823 & TRN & \\
\hline CHEMBL1611774 & 737098 & 5.6498 & 5.1937 & TST & \\
\hline CHEMBL1375966 & 737098 & 4.8447 & 5.0844 & TRN & \\
\hline CHEMBL1420606 & 737098 & 5.0605 & 4.7351 & TRN & \\
\hline CHEMBL1536767 & 737098 & 5.025 & 5.0223 & TRN & \\
\hline CHEMBL1595790 & 737098 & 7.5086 & 5.4907 & TST & \\
\hline CHEMBL1347256 & 737098 & 3.699 & 4.4059 & TRN & \\
\hline CHEMBL3197790 & 737098 & 3.699 & 4.0336 & TRN & \\
\hline CHEMBL1346468 & 737098 & 3.699 & 4.4924 & TRN & \\
\hline CHEMBL3145280 & 737098 & 5.0737 & 4.1609 & TRN & \\
\hline CHEMBL1522043 & 737098 & 5.1391 & 4.856 & TRN & \\
\hline CHEMBL1568877 & 737098 & 5.5157 & 4.9704 & TRN & \\
\hline
\end{tabular}




\begin{tabular}{|c|c|c|c|c|}
\hline & & & oplement & al $\mathrm{T}$ \\
\hline CHEMBL1586593 & 737098 & 4.9355 & 5.2693 & TRN \\
\hline CHEMBL1431608 & 737098 & 5.1746 & 5.1831 & TRN \\
\hline CHEMBL1351128 & 737098 & 5.3737 & 5.1796 & TRN \\
\hline CHEMBL1449912 & 737098 & 5.5287 & 5.3479 & TST \\
\hline CHEMBL1336374 & 737098 & 5.3372 & 5.019 & TRN \\
\hline CHEMBL600778 & 737098 & 3.699 & 3.5219 & TRN \\
\hline CHEMBL1612381 & 737098 & 5.1379 & 5.1003 & TRN \\
\hline CHEMBL1525940 & 737098 & 5.082 & 4.1197 & TRN \\
\hline CHEMBL3197607 & 737098 & 3.699 & 4.4945 & TST \\
\hline CHEMBL1347586 & 737098 & 4.8601 & 4.3219 & TST \\
\hline CHEMBL1424118 & 737098 & 4.9547 & 4.8047 & TST \\
\hline CHEMBL1531328 & 737098 & 6.2076 & 5.9425 & TST \\
\hline CHEMBL1586285 & 737098 & 5.2117 & 5.3454 & TRN \\
\hline CHEMBL1509539 & 737098 & 4.8097 & 5.2205 & TRN \\
\hline CHEMBL1560679 & 737098 & 4.8827 & 4.6567 & TRN \\
\hline CHEMBL1324011 & 737098 & 5.3848 & 4.6658 & TRN \\
\hline CHEMBL1543588 & 737098 & 3.699 & 4.5756 & TST \\
\hline CHEMBL1301943 & 737098 & 3.699 & 5.0668 & TST \\
\hline CHEMBL1426966 & 737098 & 5.0275 & 5.0236 & TRN \\
\hline CHEMBL 3189344 & 737098 & 3.699 & 3.943 & TRN \\
\hline CHEMBL1374160 & 737098 & 5.2464 & 5.0852 & TRN \\
\hline CHEMBL1490169 & 737098 & 5.6757 & 4.9538 & TRN \\
\hline CHEMBL1302130 & 737098 & 5.8665 & 5.4977 & TRN \\
\hline CHEMBL1561275 & 737098 & 4.9077 & 4.8735 & TST \\
\hline CHEMBL1467187 & 737098 & 4.7212 & 5.0928 & TRN \\
\hline CHEMBL1442136 & 737098 & 5.2761 & 4.4932 & TRN \\
\hline CHEMBL1534959 & 737098 & 3.699 & 4.1998 & TST \\
\hline CHEMBL1373339 & 737098 & 3.699 & 4.8768 & TRN \\
\hline CHEMBL1494575 & 737098 & 5.556 & 5.2101 & TRN \\
\hline CHEMBL1523659 & 737098 & 5.5513 & 5.2169 & TRN \\
\hline CHEMBL1367597 & 737098 & 5.4318 & 4.9636 & TRN \\
\hline CHEMBL1333987 & 737098 & 5.4312 & 4.7076 & TRN \\
\hline CHEMBL1568614 & 737098 & 3.699 & 4.2393 & TRN \\
\hline CHEMBL1507713 & 737098 & 5.7867 & 5.6293 & TRN \\
\hline CHEMBL1481778 & 737098 & 5.5186 & 5.0283 & TRN \\
\hline CHEMBL1468596 & 737098 & 5.3125 & 5.3233 & TRN \\
\hline CHEMBL472646 & 737098 & 5.644 & 5.0271 & TST \\
\hline CHEMBL1504685 & 737098 & 5.6498 & 5.1471 & TST \\
\hline CHEMBL1586359 & 737098 & 5.1917 & 4.9806 & TST \\
\hline CHEMBL1501527 & 737098 & 4.8243 & 4.8585 & TRN \\
\hline CHEMBL1323456 & 737098 & 4.7493 & 4.8968 & TRN \\
\hline CHEMBL1346782 & 737098 & 4.8386 & 4.3825 & TRN \\
\hline CHEMBL1540477 & 737098 & 4.9136 & 5.1329 & TRN \\
\hline CHEMBL1505474 & 737098 & 5.062 & 4.8177 & TRN \\
\hline CHEMBL1418948 & 737098 & 5.3242 & 4.981 & TST \\
\hline CHEMBL1571872 & 737098 & 5.1175 & 5.2722 & TRN \\
\hline CHEMBL1444690 & 737098 & 3.699 & 4.7276 & TST \\
\hline CHEMBL1613298 & 737098 & 4.9172 & 4.7568 & TRN \\
\hline
\end{tabular}




\begin{tabular}{|c|c|c|c|c|c|c|}
\hline & & \multicolumn{5}{|c|}{ Supplemental Table S2.txt } \\
\hline CHEMBL1525546 & 737098 & 5.2759 & 4.8282 & TST & & \\
\hline CHEMBL1380661 & 737098 & 5.5867 & 5.3098 & TRN & & \\
\hline CHEMBL1422976 & 737098 & 4.8447 & 4.9938 & TRN & & \\
\hline CHEMBL1444822 & 737098 & 3.699 & 4.5614 & TST & & \\
\hline CHEMBL1457068 & 737098 & 3.699 & 4.237 & TRN & & \\
\hline CHEMBL1436964 & 737098 & 5.4841 & 4.9726 & TRN & & \\
\hline CHEMBL1581425 & 737098 & 5.3253 & 4.8812 & TRN & & \\
\hline CHEMBL1361883 & 737098 & 4.7986 & 4.9236 & TRN & & \\
\hline CHEMBL1510940 & 737098 & \multicolumn{3}{|c|}{5.236000000000001} & 4.9547 & TRN \\
\hline CHEMBL1468181 & 737098 & 5.5638 & 5.2335 & TRN & & \\
\hline CHEMBL1583186 & 737098 & 5.5817 & 5.3497 & TRN & & \\
\hline CHEMBL 3192230 & 737098 & 5.6635 & 4.3177 & TRN & & \\
\hline CHEMBL1349185 & 737098 & 3.699 & 4.2555 & TRN & & \\
\hline CHEMBL1498038 & 737098 & 5.2676 & 5.2033 & TRN & & \\
\hline CHEMBL1499195 & 737098 & \multicolumn{3}{|c|}{ 5. 382999999999999} & 5.2842 & TRN \\
\hline CHEMBL1466286 & 737098 & 5.3391 & 4.9592 & TRN & & \\
\hline CHEMBL1310435 & 737098 & 3.699 & 4.9582 & TRN & & \\
\hline CHEMBL1579602 & 737098 & 5.2765 & 4.6231 & TST & & \\
\hline CHEMBL1473402 & 737098 & 5.4711 & 5.0882 & TRN & & \\
\hline CHEMBL1440314 & 737098 & 3.699 & 4.8589 & TRN & & \\
\hline CHEMBL1586263 & 737098 & 5.3273 & 4.6858 & TRN & & \\
\hline CHEMBL 3198251 & 737098 & 5.2161 & 4.8273 & TRN & & \\
\hline CHEMBL1376195 & 737098 & 5.1553 & 4.7475 & TRN & & \\
\hline CHEMBL1543473 & 737098 & 5.5784 & 5.0344 & TRN & & \\
\hline CHEMBL1318773 & 737098 & 4.9431 & 4.9372 & TST & & \\
\hline CHEMBL1449663 & 737098 & 5.1818 & 4.5027 & TRN & & \\
\hline CHEMBL1318742 & 737098 & 4.8827 & 4.5705 & TRN & & \\
\hline CHEMBL1338804 & 737098 & 5.2129 & 5.1822 & TRN & & \\
\hline CHEMBL 3197201 & 737098 & 5.0438 & 4.5454 & TRN & & \\
\hline CHEMBL1412853 & 737098 & 6.3372 & 4.709 & TRN & & \\
\hline CHEMBL1309210 & 737098 & 5.3585 & 5.3368 & TRN & & \\
\hline CHEMBL257286 & 737098 & 3.699 & 5.0136 & TRN & & \\
\hline CHEMBL1454614 & 737098 & 5.0562 & 4.9481 & TST & & \\
\hline CHEMBL1325644 & 737098 & 5.3916 & 4.6373 & TRN & & \\
\hline CHEMBL1457134 & 737098 & 4.9066 & 5.2255 & TRN & & \\
\hline CHEMBL1575051 & 737098 & 5.2941 & 5.3516 & TRN & & \\
\hline CHEMBL1407286 & 737098 & 5.4935 & 5.2852 & TRN & & \\
\hline CHEMBL1612423 & 737098 & 5.6402 & 5.0223 & TRN & & \\
\hline CHEMBL190346 & 737098 & 5.3696 & 5.2364 & TRN & & \\
\hline CHEMBL1481689 & 737098 & 5.5607 & 4.8774 & TRN & & \\
\hline CHEMBL1387990 & 737098 & 4.8053 & 4.7429 & TST & & \\
\hline CHEMBL1538692 & 737098 & 5.5031 & 5.3774 & TST & & \\
\hline CHEMBL1427059 & 737098 & 5.4921 & 5.1727 & TRN & & \\
\hline CHEMBL1350780 & 737098 & 3.699 & 4.6724 & TRN & & \\
\hline CHEMBL1453730 & 737098 & 5.3546 & 5.2955 & TRN & & \\
\hline CHEMBL1610725 & 737098 & 5.5577 & 4.9926 & TRN & & \\
\hline CHEMBL1305930 & 737098 & 5.4559 & 5.0847 & TRN & & \\
\hline CHEMBL1426245 & 737098 & 5.1694 & 4.9613 & TRN & & \\
\hline
\end{tabular}




\begin{tabular}{|c|c|c|c|c|c|c|}
\hline & & \multicolumn{5}{|c|}{ Supplemental Table S2.txt } \\
\hline CHEMBL1550032 & 737098 & 3.699 & 4.6773 & TRN & & \\
\hline CHEMBL1385087 & 737098 & 5.153 & 4.6512 & TRN & & \\
\hline CHEMBL1372398 & 737098 & 4.9957 & 5.4733 & TRN & & \\
\hline CHEMBL1562608 & 737098 & 3.699 & 4.7913 & TRN & & \\
\hline CHEMBL1542483 & 737098 & 5.3645 & 4.6659 & TRN & & \\
\hline CHEMBL1573929 & 737098 & 3.699 & 4.7401 & TRN & & \\
\hline CHEMBL1500227 & 737098 & 4.7905 & 4.928 & TST & & \\
\hline CHEMBL1306524 & 737098 & 6.1024 & 4.9588 & TRN & & \\
\hline CHEMBL1493633 & 737098 & 4.8729 & 5.1362 & TRN & & \\
\hline CHEMBL1491541 & 737098 & 5.2627 & 5.1455 & TRN & & \\
\hline CHEMBL1333821 & 737098 & 5.2434 & 5.3302 & TRN & & \\
\hline CHEMBL1366153 & 737098 & 3.699 & 4.3474 & TRN & & \\
\hline CHEMBL1446570 & 737098 & 5.2596 & 4.8801 & TRN & & \\
\hline CHEMBL1565083 & 737098 & 5.7721 & 5.20299 & 99999995 & 99 & TRN \\
\hline CHEMBL1409963 & 737098 & 5.1993 & 4.8395 & TST & & \\
\hline CHEMBL1472304 & 737098 & 5.4389 & 5.0833 & TRN & & \\
\hline CHEMBL1546996 & 737098 & 3.699 & 4.2396 & TRN & & \\
\hline CHEMBL272945 & 737098 & 5.556 & 5.2663 & TRN & & \\
\hline CHEMBL1400385 & 737098 & 5.6308 & 5.15 & TRN & & \\
\hline CHEMBL1325227 & 737098 & 5.1085 & 5.3978 & TRN & & \\
\hline CHEMBL3190198 & 737098 & 3.699 & 4.3116 & TRN & & \\
\hline CHEMBL1417054 & 737098 & 3.699 & 4.7179 & TRN & & \\
\hline CHEMBL1490563 & 737098 & 3.699 & 4.8261 & TRN & & \\
\hline CHEMBL1489361 & 737098 & 4.9245 & 4.8301 & TST & & \\
\hline CHEMBL1544114 & 737098 & 5.4267 & 4.6736 & TRN & & \\
\hline CHEMBL1526479 & 737098 & 5.1945 & 4.8346 & TST & & \\
\hline CHEMBL1370276 & 737098 & 5.0376 & 5.2766 & TRN & & \\
\hline CHEMBL1375884 & 737098 & 5.0746 & 4.8858 & TRN & & \\
\hline CHEMBL1300239 & 737098 & 5.1692 & 5.0801 & TRN & & \\
\hline CHEMBL1333757 & 737098 & 5.0097 & 4.8065 & TST & & \\
\hline CHEMBL1310479 & 737098 & 4.9547 & 4.824 & TRN & & \\
\hline CHEMBL1595779 & 737098 & 5.6799 & 5.1979 & TRN & & \\
\hline CHEMBL1520241 & 737098 & 4.7959 & 5.1001 & TRN & & \\
\hline CHEMBL599890 & 737098 & 5.0438 & 4.3728 & TRN & & \\
\hline CHEMBL3195658 & 737098 & 4.9872 & 4.8001 & TRN & & \\
\hline CHEMBL1322356 & 737098 & 4.7352 & 4.7491 & TRN & & \\
\hline CHEMBL1351458 & 737098 & 3.699 & 5.1574 & TRN & & \\
\hline CHEMBL1505956 & 737098 & 5.5143 & 5.3199 & TRN & & \\
\hline CHEMBL1503006 & 737098 & 3.699 & 4.7859 & TRN & & \\
\hline CHEMBL1543504 & 737098 & 5.1273 & 5.0606 & TST & & \\
\hline CHEMBL1376861 & 737098 & $5.4220 e$ & 00000000 & 01 & 4.9114 & $1 \mathrm{KI}$ \\
\hline CHEMBL1556239 & 737098 & 5.0191 & 5.0101 & TST & & \\
\hline CHEMBL1423286 & 737098 & 5.2597 & 4.5605 & TRN & & \\
\hline CHEMBL1337226 & 737098 & 4.9957 & 5.0332 & TRN & & \\
\hline CHEMBL3189997 & 737098 & 5.2403 & 4.7227 & TST & & \\
\hline CHEMBL1398541 & 737098 & 4.9666 & 5.0585 & TRN & & \\
\hline CHEMBL1386754 & 737098 & 5.3413 & 5.0109 & TRN & & \\
\hline CHEMBL3213107 & 737098 & 3.699 & 4.4306 & TRN & & \\
\hline
\end{tabular}




\begin{tabular}{|c|c|c|c|c|c|c|}
\hline & & \multicolumn{5}{|c|}{ Supplemental Table S2.txt } \\
\hline CHEMBL1452267 & 737098 & 3.699 & 5.0003 & TRN & & \\
\hline CHEMBL1362734 & 737098 & 5.1586 & 5.0859 & TST & & \\
\hline CHEMBL1323622 & 737098 & 5.27 & 4.7301 & TRN & & \\
\hline CHEMBL1486619 & 737098 & 5.3536 & 5.6054 & TRN & & \\
\hline CHEMBL1299319 & 737098 & 5.2457 & 5.2957 & TRN & & \\
\hline CHEMBL1497078 & 737098 & 4.9957 & 5.0572 & TRN & & \\
\hline CHEMBL1332003 & 737098 & 3.699 & 4.8218 & TRN & & \\
\hline CHEMBL1562819 & 737098 & 5.6478 & 4.9952 & TRN & & \\
\hline CHEMBL1516853 & 737098 & 5.1209 & 5.1256 & TRN & & \\
\hline CHEMBL1434502 & 737098 & 5.0306 & 5.0214 & TRN & & \\
\hline CHEMBL1462906 & 737098 & 5.1838 & 5.0402 & TRN & & \\
\hline CHEMBL1332761 & 737098 & \multicolumn{3}{|c|}{5.013999999999999} & 5.1221 & TRN \\
\hline CHEMBL1393375 & 737098 & 4.9208 & 4.9401 & TRN & & \\
\hline CHEMBL1602150 & 737098 & 5.4672 & 5.3334 & TRN & & \\
\hline CHEMBL1349713 & 737098 & 5.6091 & 5.2674 & TRN & & \\
\hline CHEMBL1484482 & 737098 & 3.699 & 4.8042 & TRN & & \\
\hline CHEMBL1576555 & 737098 & 5.325 & 5.1125 & TRN & & \\
\hline CHEMBL1344292 & 737098 & 3.699 & 4.9614 & TRN & & \\
\hline CHEMBL1567973 & 737098 & 4.7959 & 5.1456 & TST & & \\
\hline CHEMBL1497669 & 737098 & 5.194 & 5.3353 & TRN & & \\
\hline CHEMBL1528004 & 737098 & 5.1805 & 5.2905 & TRN & & \\
\hline CHEMBL1531428 & 737098 & 3.699 & 4.9842 & TST & & \\
\hline CHEMBL1342784 & 737098 & 3.699 & 4.9151 & TRN & & \\
\hline CHEMBL1439435 & 737098 & 3.699 & 4.306 & TRN & & \\
\hline CHEMBL1508723 & 737098 & 5.4353 & 4.9718 & TRN & & \\
\hline CHEMBL1439315 & 737098 & 5.032 & 5.5037 & TRN & & \\
\hline CHEMBL1413208 & 737098 & 3.699 & 4.8689 & TRN & & \\
\hline CHEMBL 3210725 & 737098 & 5.5302 & 5.7422 & TRN & & \\
\hline CHEMBL1416682 & 737098 & 4.9066 & 4.7303 & TST & & \\
\hline CHEMBL1612227 & 737098 & 5.1952 & 5.2139 & TRN & & \\
\hline CHEMBL1529741 & 737098 & 5.2708 & 5.0446 & TST & & \\
\hline CHEMBL1608707 & 737098 & 5.27 & 4.9093 & TRN & & \\
\hline CHEMBL 3194944 & 737098 & 7.5086 & 5.7879 & TRN & & \\
\hline CHEMBL1332684 & 737098 & 5.2259 & 5.3684 & TST & & \\
\hline CHEMBL1570792 & 737098 & 5.0453 & 5.1243 & TRN & & \\
\hline CHEMBL1446827 & 737098 & 3.699 & 4.3989 & TRN & & \\
\hline CHEMBL1382616 & 737098 & 5.3391 & 5.0214 & TRN & & \\
\hline CHEMBL1321987 & 737098 & 5.0381 & 4.8364 & TRN & & \\
\hline CHEMBL1428415 & 737098 & 3.699 & 4.908 & TRN & & \\
\hline CHEMBL1483882 & 737098 & 4.9872 & 5.1795 & TRN & & \\
\hline CHEMBL1337833 & 737098 & 5.5017 & 4.8434 & TRN & & \\
\hline CHEMBL1369425 & 737098 & 5.0458 & 5.37700 & 0000000001 & & $|\mathrm{R}|$ \\
\hline CHEMBL583558 & 737098 & 4.8761 & 4.8484 & TST & & \\
\hline CHEMBL1491893 & 737098 & 4.857 & 4.8742 & TST & & \\
\hline CHEMBL1568646 & 737098 & 4.9747 & 4.9694 & TRN & & \\
\hline CHEMBL1525315 & 737098 & 4.8827 & 4.6196 & TRN & & \\
\hline CHEMBL3197098 & 737098 & 5.1192 & 4.4855 & TRN & & \\
\hline CHEMBL1413565 & 737098 & 5.0875 & 4.9565 & TRN & & \\
\hline
\end{tabular}




\begin{tabular}{|c|c|c|c|c|c|}
\hline & & \multicolumn{4}{|c|}{ Supplemental Table S2.txt } \\
\hline CHEMBL1335978 & 737098 & 5.3809 & 4.8585 & TRN & \\
\hline CHEMBL1475198 & 737098 & 5.2284 & 5.0288 & TRN & \\
\hline CHEMBL1301855 & 737098 & 3.699 & 4.4779 & TRN & \\
\hline CHEMBL1585147 & 737098 & 5.1624 & 5.3388 & TRN & \\
\hline CHEMBL1529494 & 737098 & 5.2882 & 4.9871 & TRN & \\
\hline CHEMBL1431769 & 737098 & 5.2384 & 4.493 & TRN & \\
\hline CHEMBL1570135 & 737098 & 4.9788 & 5.3457 & TRN & \\
\hline CHEMBL1351584 & 737098 & 3.699 & 5.3884 & TRN & \\
\hline CHEMBL1351159 & 737098 & 5.5129 & 4.5175 & TRN & \\
\hline CHEMBL1425921 & 737098 & 5.0031 & 5.3554 & TRN & \\
\hline CHEMBL1558928 & 737098 & 5.3872 & 5.0573 & TRN & \\
\hline CHEMBL1493793 & 737098 & 5.0583 & 4.9874 & TRN & \\
\hline CHEMBL590706 & 737098 & 5.2132 & 5.2018 & TST & \\
\hline CHEMBL1597042 & 737098 & 3.699 & 4.1769 & TST & \\
\hline CHEMBL1603938 & 737098 & 3.699 & 4.6936 & TRN & \\
\hline CHEMBL1984298 & 737098 & 5.2151 & 4.5894 & TRN & \\
\hline CHEMBL1374703 & 737098 & 3.699 & 4.3494 & TRN & \\
\hline CHEMBL1380813 & 737098 & 5.0729 & 5.2801 & TRN & \\
\hline CHEMBL1370183 & 737098 & 4.9136 & 4.3643 & TRN & \\
\hline CHEMBL1486981 & 737098 & 3.699 & 4.6793 & TRN & \\
\hline CHEMBL1467115 & 737098 & 4.9706 & 5.193 & TRN & \\
\hline CHEMBL1497439 & 737098 & 3.699 & 4.1887 & TRN & \\
\hline CHEMBL1332060 & 737098 & 5.4841 & 4.8472 & TRN & \\
\hline CHEMBL1538154 & 737098 & 5.4776 & 5.3523 & TRN & \\
\hline CHEMBL1506728 & 737098 & 5.1529 & 5.0869 & TRN & \\
\hline CHEMBL1986274 & 737098 & 5.2823 & 4.7434 & TRN & \\
\hline CHEMBL1312200 & 737098 & 5.21399 & و9999999 & 5.206 & TRN \\
\hline CHEMBL1598294 & 737098 & 5.52 & 5.1127 & TRN & \\
\hline CHEMBL1311887 & 737098 & 4.9626 & 5.086 & TRN & \\
\hline CHEMBL1464332 & 737098 & 5.1158 & 4.8363 & TRN & \\
\hline CHEMBL1542713 & 737098 & 6.1249 & 4.852 & TRN & \\
\hline CHEMBL1443448 & 737098 & 5.0278 & 4.6339 & TRN & \\
\hline CHEMBL1374797 & 737098 & 3.699 & 4.801 & TRN & \\
\hline CHEMBL1351908 & 737098 & 5.3306 & 5.7041 & TRN & \\
\hline CHEMBL1580556 & 737098 & 3.699 & 5.0439 & TRN & \\
\hline CHEMBL1571360 & 737098 & 4.9547 & 4.7474 & TRN & \\
\hline CHEMBL1391279 & 737098 & 5.3116 & 4.8761 & TST & \\
\hline CHEMBL1414898 & 737098 & 5.3546 & 4.9566 & TRN & \\
\hline CHEMBL1445206 & 737098 & 3.699 & 4.9684 & TRN & \\
\hline CHEMBL1598561 & 737098 & 4.7471 & 4.6703 & TRN & \\
\hline CHEMBL1550862 & 737098 & 3.699 & 4.71399 & 99999999995 & TRN \\
\hline CHEMBL1347274 & 737098 & 4.9872 & 5.1244 & TRN & \\
\hline CHEMBL3189810 & 737098 & 3.699 & 4.59699 & 99999999995 & TRN \\
\hline CHEMBL1501375 & 737098 & 3.699 & 4.7649 & TRN & \\
\hline CHEMBL1555716 & 737098 & 3.699 & 4.6629 & TRN & \\
\hline CHEMBL3195760 & 737098 & 3.699 & 4.4377 & TRN & \\
\hline CHEMBL1409423 & 737098 & 5.2396 & 5.064 & TRN & \\
\hline CHEMBL1482357 & 737098 & 3.699 & 4.7448 & TRN & \\
\hline
\end{tabular}




\begin{tabular}{|c|c|c|c|c|c|}
\hline & & \multicolumn{4}{|c|}{ Supplemental Table S2.txt } \\
\hline CHEMBL1541329 & 737098 & 5.2486 & 5.2356 & TRN & \\
\hline CHEMBL1530557 & 737098 & 5.6676 & 5.3364 & TRN & \\
\hline CHEMBL1577792 & 737098 & 3.699 & 5.0918 & TST & \\
\hline CHEMBL1427972 & 737098 & 3.699 & 3.635 & TRN & \\
\hline CHEMBL1569174 & 737098 & 6.0706 & 5.2428 & TRN & \\
\hline CHEMBL1997659 & 737098 & 5.1367 & 4.8248 & TRN & \\
\hline CHEMBL1496313 & 737098 & 4.9393 & 4.5398 & TST & \\
\hline CHEMBL1588806 & 737098 & $4.9830 e$ & 00000000 & 5.1329 & TRN \\
\hline CHEMBL1379347 & 737098 & 5.6635 & 5.1766 & TRN & \\
\hline CHEMBL1477197 & 737098 & 3.699 & 4.2585 & TRN & \\
\hline CHEMBL1437979 & 737098 & 5.2314 & 5.2179 & TRN & \\
\hline CHEMBL1493896 & 737098 & 3.699 & 4.6462 & TRN & \\
\hline CHEMBL1468075 & 737098 & 5.3768 & 5.4277 & TRN & \\
\hline CHEMBL1446989 & 737098 & 5.2581 & 4.77800 & 00000000005 & TRN \\
\hline CHEMBL600100 & 737098 & 5.3152 & 4.8092 & TRN & \\
\hline CHEMBL1608077 & 737098 & 5.2764 & 5.4036 & TRN & \\
\hline CHEMBL1411639 & 737098 & 5.6799 & 5.2282 & TRN & \\
\hline CHEMBL1424697 & 737098 & 5.2534 & 5.3699 & TRN & \\
\hline CHEMBL1464490 & 737098 & 3.699 & 4.306 & TRN & \\
\hline CHEMBL1996376 & 737098 & 4.8297 & 4.2349 & TST & \\
\hline CHEMBL1401026 & 737098 & 5.8861 & 5.4971 & TRN & \\
\hline CHEMBL1377693 & 737098 & 5.6198 & 5.0169 & TRN & \\
\hline CHEMBL1364018 & 737098 & 5.0953 & 4.949 & TST & \\
\hline CHEMBL1415184 & 737098 & 6.7696 & 5.7026 & TST & \\
\hline CHEMBL1555568 & 737098 & 5.2204 & 4.987 & TRN & \\
\hline CHEMBL1480238 & 737098 & 5.5186 & 5.3699 & TRN & \\
\hline CHEMBL1567684 & 737098 & 5.7447 & 4.9741 & TRN & \\
\hline CHEMBL1320669 & 737098 & 6.2472 & 5.4185 & TRN & \\
\hline CHEMBL1424366 & 737098 & 4.8906 & 4.3827 & TRN & \\
\hline CHEMBL1470314 & 737098 & 5.3439 & 4.7684 & TRN & \\
\hline CHEMBL1993613 & 737098 & 5.2067 & 4.8805 & TRN & \\
\hline CHEMBL1597561 & 737098 & 3.699 & 5.8029 & TRN & \\
\hline CHEMBL1466929 & 737098 & 3.699 & 4.4698 & TST & \\
\hline CHEMBL1411209 & 737098 & 5.1118 & 5.4068 & TRN & \\
\hline CHEMBL1344875 & 737098 & 5.0888 & 4.9995 & TRN & \\
\hline CHEMBL1549092 & 737098 & 3.699 & 4.4457 & TRN & \\
\hline CHEMBL 1468750 & 737098 & 5.3655 & 5.1245 & TRN & \\
\hline CHEMBL1330503 & 737098 & 4.8442 & 4.5907 & TRN & \\
\hline CHEMBL1383777 & 737098 & 4.762 & 5.1127 & TRN & \\
\hline CHEMBL1544150 & 737098 & 3.699 & 4.3729 & TRN & \\
\hline CHEMBL454580 & 737098 & 5.3206 & 4.9055 & TST & \\
\hline CHEMBL1597716 & 737098 & 4.8447 & 4.7916 & TRN & \\
\hline CHEMBL1466495 & 737098 & 5.1707 & 4.8144 & TRN & \\
\hline CHEMBL1604797 & 737098 & 4.9803 & 5.2254 & TRN & \\
\hline CHEMBL1586401 & 737098 & 3.699 & 4.5667 & TRN & \\
\hline CHEMBL1607172 & 737098 & 5.3363 & 5.2667 & TRN & \\
\hline CHEMBL1422567 & 737098 & 5.6092 & 5.1449 & TRN & \\
\hline CHEMBL585502 & 737098 & 5.4389 & 5.0966 & TRN & \\
\hline
\end{tabular}




\begin{tabular}{|c|c|c|c|c|c|}
\hline & & \\
\hline CHEMBL1514917 & 737098 & 5.2137 & 5.246 & TST & \\
\hline CHEMBL 3193234 & 737098 & 3.699 & 4.0364 & TRN & \\
\hline CHEMBL169272 & 737098 & 5.1085 & 4.9689 & TRN & \\
\hline CHEMBL1444020 & 737098 & 4.8069 & 4.9036 & TRN & \\
\hline CHEMBL1378118 & 737098 & 4.9706 & 4.9795 & TRN & \\
\hline CHEMBL1600776 & 737098 & 5.5686 & 4.9368 & TRN & \\
\hline CHEMBL1299634 & 737098 & 5.083 & 4.8044 & TRN & \\
\hline CHEMBL1994623 & 737098 & 3.699 & 3.9146 & TRN & \\
\hline CHEMBL1313978 & 737098 & 3.699 & 5.2689 & TRN & \\
\hline CHEMBL1457600 & 737098 & 3.699 & 4.4328 & TRN & \\
\hline CHEMBL1304363 & 737098 & 5.1512 & 4.4305 & TRN & \\
\hline CHEMBL1369671 & 737098 & 5.3205 & 4.6846 & TRN & \\
\hline CHEMBL1459111 & 737098 & 5.4789 & 5.0492 & TRN & \\
\hline CHEMBL3194040 & 737098 & 3.699 & 4.4446 & TRN & \\
\hline CHEMBL1407708 & 737098 & 4.7144 & 4.5357 & TST & \\
\hline CHEMBL1348555 & 737098 & 4.9914 & 4.8763 & TST & \\
\hline CHEMBL1555482 & 737098 & 5.1959 & 5.154 & TRN & \\
\hline CHEMBL1536849 & 737098 & 5.0237 & 4.9156 & TRN & \\
\hline CHEMBL1384652 & 737098 & 5.1537 & 5.0482 & TRN & \\
\hline CHEMBL1380946 & 737098 & 5.3261 & 4.7838 & TRN & \\
\hline CHEMBL1599462 & 737098 & 5.3747 & 5.0997 & TRN & \\
\hline CHEMBL1991112 & 737098 & 3.699 & 4.7534 & TST & \\
\hline CHEMBL1431014 & 737098 & 3.699 & 4.69 & TRN & \\
\hline CHEMBL1308615 & 737098 & 3.699 & 5.1717 & TRN & \\
\hline CHEMBL1377340 & 737098 & 5.2097 & 5.1584 & TST & \\
\hline CHEMBL1437053 & 737098 & 5.3696 & 5.0907 & TRN & \\
\hline CHEMBL1426152 & 737098 & 5.1522 & 5.0134 & TRN & \\
\hline CHEMBL1519375 & 737098 & 5.1959 & 5.0656 & TST & \\
\hline CHEMBL1390866 & 737098 & 5.0108 & 4.9374 & TRN & \\
\hline CHEMBL1425054 & 737098 & 3.699 & 4.4501 & TRN & \\
\hline CHEMBL1369879 & 737098 & 5.4989 & 5.0944 & TRN & \\
\hline CHEMBL1445071 & 737098 & 5.067 & 4.3663 & TRN & \\
\hline CHEMBL1462451 & 737098 & 5.1818 & 5.1226 & TST & \\
\hline CHEMBL3189325 & 737098 & 5.0401 & 3.94100 & 00000000003 & TRN \\
\hline CHEMBL1442742 & 737098 & 3.699 & 5.0146 & TRN & \\
\hline CHEMBL3196263 & 737098 & 5.3333 & 5.59399 & 9999999999 & TRN \\
\hline CHEMBL1546267 & 737098 & 4.9198 & 4.615 & TRN & \\
\hline CHEMBL1586616 & 737098 & 5.3605 & 4.6761 & TST & \\
\hline CHEMBL1502883 & 737098 & 5.9626 & 5.2985 & TRN & \\
\hline CHEMBL1583914 & 737098 & 5.4486 & 5.0655 & TRN & \\
\hline CHEMBL1304065 & 737098 & 5.3365 & 4.7111 & TRN & \\
\hline CHEMBL1299637 & 737098 & 5.0747 & 4.5795 & TST & \\
\hline CHEMBL1408320 & 737098 & 3.699 & 4.2095 & TST & \\
\hline CHEMBL1528265 & 737098 & 5.2823 & 5.2539 & TRN & \\
\hline CHEMBL1542558 & 737098 & 4.8628 & 4.585 & TRN & \\
\hline CHEMBL1320446 & 737098 & 5.0726 & 4.762 & TRN & \\
\hline CHEMBL1581233 & 737098 & 3.699 & 4.9069 & TRN & \\
\hline CHEMBL1360862 & 737098 & 5.3706 & 5.495 & TRN & \\
\hline
\end{tabular}




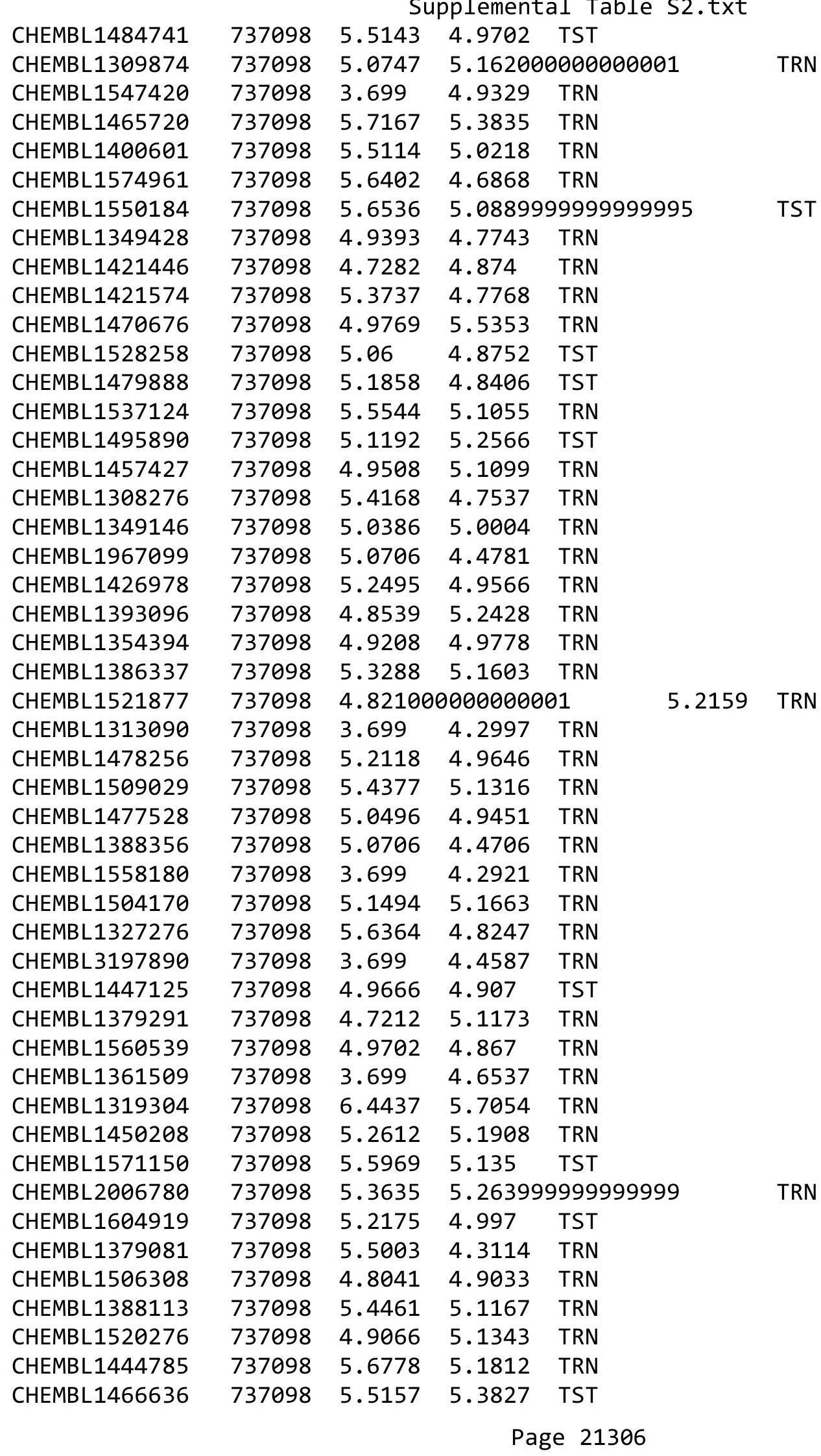




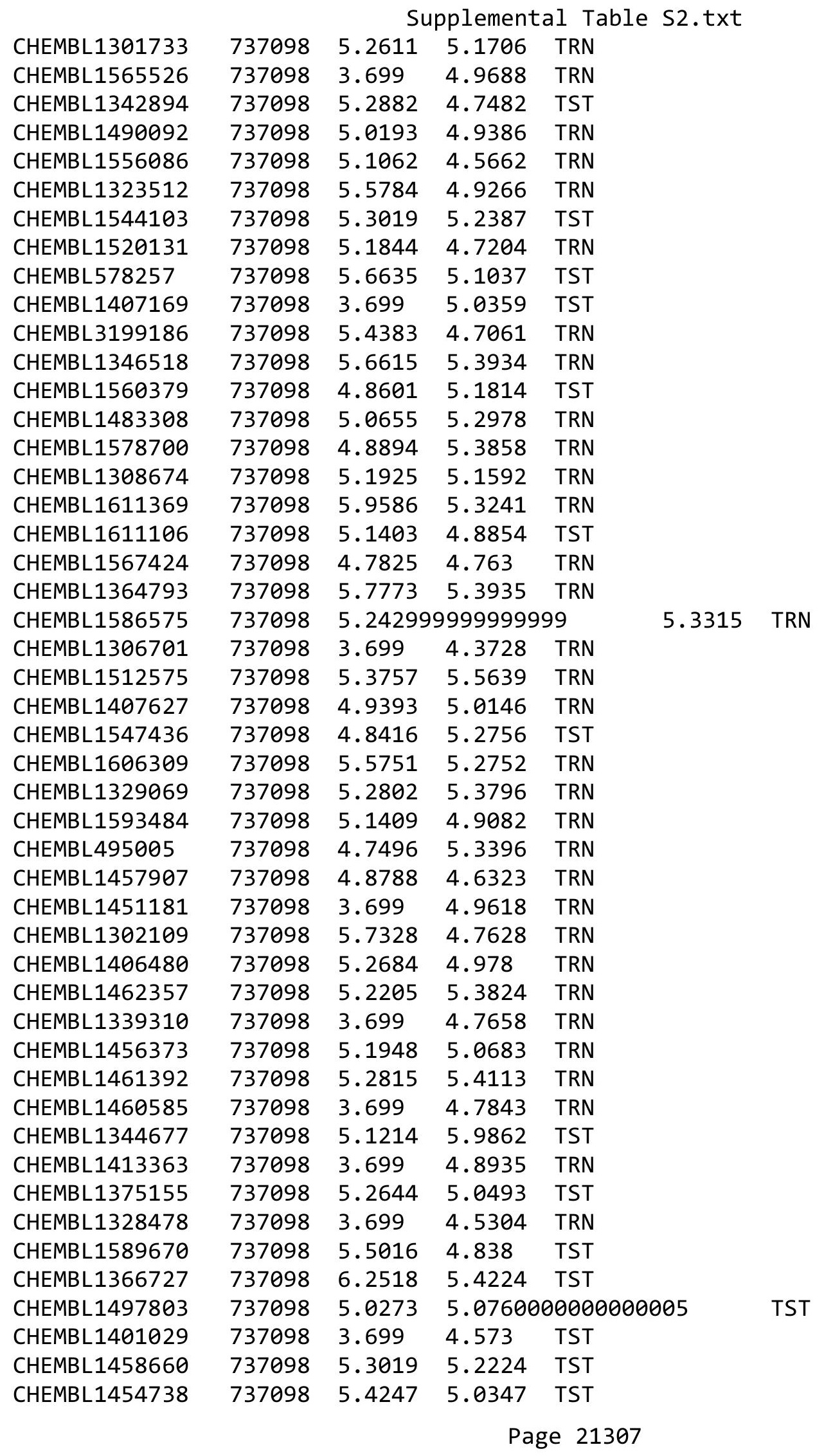




\begin{tabular}{|c|c|c|c|c|c|c|}
\hline \multirow[b]{2}{*}{ CHEMBL1588455 } & \multicolumn{6}{|c|}{ Supplemental Table S2.txt } \\
\hline & 737098 & 5.3635 & 5.1044 & TST & & \\
\hline CHEMBL1461225 & 737098 & 3.699 & 5.1283 & TST & & \\
\hline CHEMBL1407401 & 737098 & 3.699 & 4.7878 & TST & & \\
\hline CHEMBL1446753 & 737098 & 4.7282 & 4.8974 & TST & & \\
\hline CHEMBL1433943 & 737098 & 5.5784 & 4.9742 & TST & & \\
\hline CHEMBL1544947 & 737098 & 5.3458 & 4.8654 & TST & & \\
\hline CHEMBL1308936 & 737098 & 4.9747 & 5.3977 & TST & & \\
\hline CHEMBL1414053 & 737098 & 3.699 & 5.2582 & TST & & \\
\hline CHEMBL1440735 & 737098 & 3.699 & 4.3553 & TST & & \\
\hline CHEMBL1400275 & 737098 & 5.2684 & 5.2373 & TST & & \\
\hline CHEMBL1345481 & 737098 & 5.6162 & 5.2401 & TST & & \\
\hline CHEMBL1489105 & 737098 & 5.0092 & 4.8115 & TST & & \\
\hline CHEMBL1503962 & 737098 & 5.1062 & 4.8338 & TST & & \\
\hline CHEMBL1466121 & 737098 & 5.0841 & 5.0939 & TST & & \\
\hline CHEMBL 1478220 & 737098 & 5.3251 & 4.9556 & TST & & \\
\hline CHEMBL1509707 & 737098 & 5.0269 & 5.003 & TST & & \\
\hline CHEMBL1346232 & 737098 & 4.9943 & 5.1263 & TST & & \\
\hline CHEMBL1611733 & 737098 & 5.1972 & 5.15 & TST & & \\
\hline CHEMBL1582794 & 737098 & 5.5935 & 4.9057 & TST & & \\
\hline CHEMBL1299751 & 737098 & 4.9281 & 5.4116 & TST & & \\
\hline CHEMBL1333593 & 737098 & 5.4012 & 4.9101 & TST & & \\
\hline CHEMBL1504069 & 737098 & 3.699 & 4.9543 & TST & & \\
\hline CHEMBL1606583 & 737098 & 5.3391 & 5.0699 & TST & & \\
\hline CHEMBL1569724 & 737098 & 5.7825 & 5.3083 & TST & & \\
\hline CHEMBL1599782 & 737098 & 5.1613 & 5.1544 & TST & & \\
\hline CHEMBL1332756 & 737098 & 3.699 & 3.6512 & TST & & \\
\hline CHEMBL1299281 & 737098 & 5.3737 & 5.3489 & TST & & \\
\hline CHEMBL1588452 & 737098 & 5.437 & 4.7314 & TST & & \\
\hline CHEMBL3195189 & 737098 & 5.3826 & 5.5369 & TST & & \\
\hline CHEMBL 1415786 & 737098 & 3.699 & 4.2171 & TST & & \\
\hline CHEMBL1349532 & 737098 & 4.8962 & 5.0067 & TST & & \\
\hline CHEMBL1549094 & 737098 & 5.1959 & 5.0192 & TST & & \\
\hline CHEMBL1495687 & 737098 & 3.699 & 5.4874 & TST & & \\
\hline CHEMBL1540795 & 737098 & 3.699 & 4.9164 & TST & & \\
\hline CHEMBL1483975 & 737098 & 3.699 & 5.1084 & TST & & \\
\hline CHEMBL1456848 & 737098 & 5.38200 & 00000000 & 01 & 4.9177 & $\mathrm{TS}^{-}$ \\
\hline CHEMBL1525854 & 737098 & 5.0334 & 4.6489 & TST & & \\
\hline CHEMBL1372308 & 737098 & 4.7878 & 5.0458 & TST & & \\
\hline CHEMBL1498436 & 737098 & 5.356 & 4.9403 & TST & & \\
\hline CHEMBL1605213 & 737098 & 3.699 & 5.0493 & TST & & \\
\hline CHEMBL321747 & 737098 & 3.699 & 5.1121 & TST & & \\
\hline CHEMBL1465119 & 737098 & 5.0813 & 4.4992 & TST & & \\
\hline CHEMBL1418614 & 737098 & 5.0209 & 5.1224 & TST & & \\
\hline CHEMBL3965174 & 1640565 & 9.0 & 8.0274 & TRN & & \\
\hline CHEMBL3893676 & 1640565 & 8.699 & 8.621 & TRN & & \\
\hline CHEMBL3969508 & 1640565 & 9.0 & 8.4943 & TRN & & \\
\hline CHEMBL 3953860 & 1640565 & 6.0 & 7.9435 & TRN & & \\
\hline CHEMBL3973615 & 1640565 & 7.7212 & 8.0457 & TST & & \\
\hline
\end{tabular}

Page 21308 


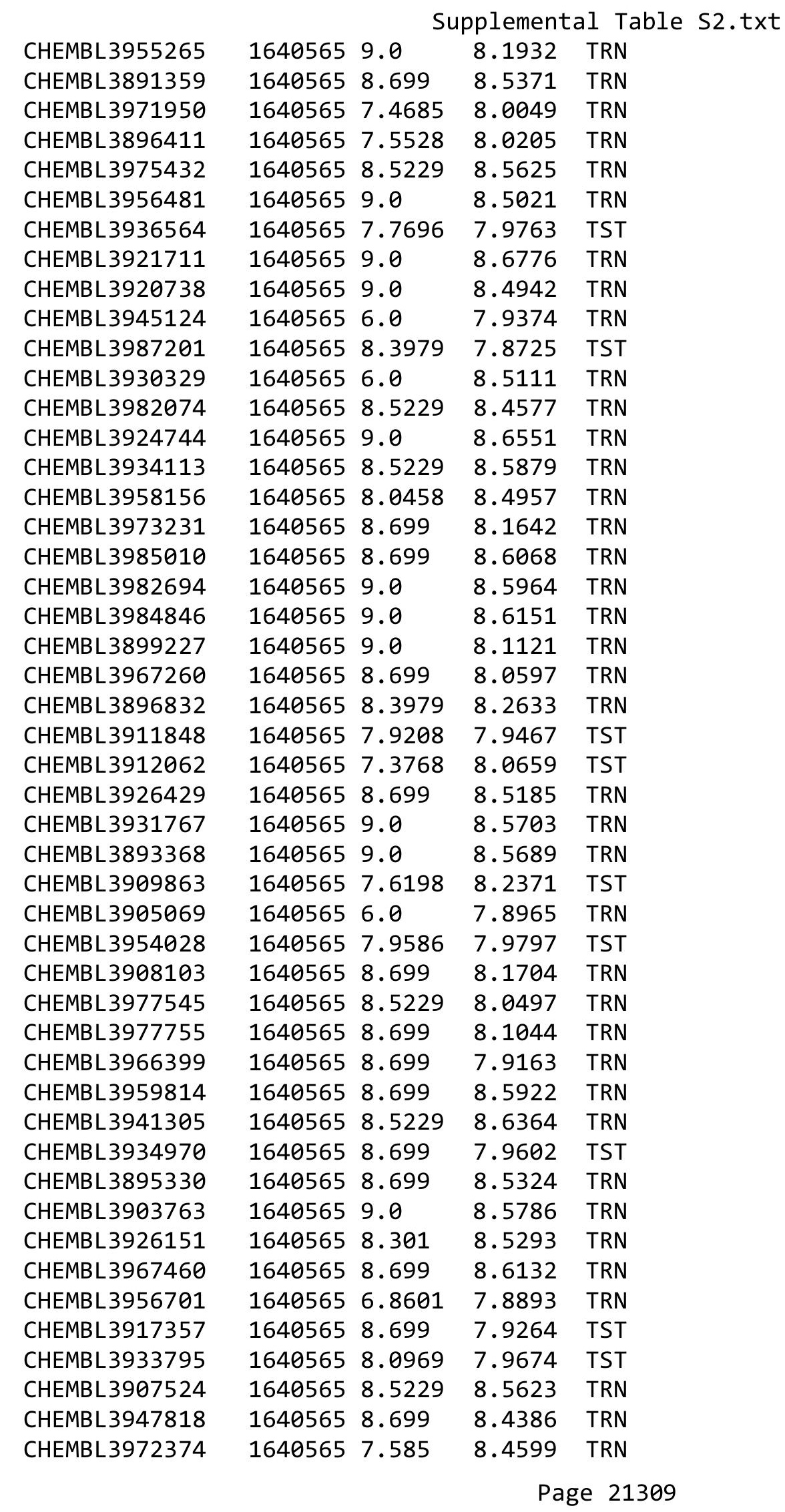




\begin{tabular}{|c|c|c|c|c|c|}
\hline \multicolumn{6}{|c|}{ Supplemental Table S2.txt } \\
\hline CHEMBL3925331 & 1640565 & 9.0 & 8.5867 & TRN & \\
\hline CHEMBL3891321 & 1640565 & 8.699 & 8.1779 & TRN & \\
\hline CHEMBL3924216 & 1640565 & 7.2518 & 8.0867 & TST & \\
\hline CHEMBL 3928564 & 1640565 & 7.3372 & 7.9686 & TRN & \\
\hline CHEMBL3900803 & 1640565 & 8.301 & 7.9721 & TRN & \\
\hline CHEMBL 3894530 & 1640565 & 8.0458 & 8.4805 & TRN & \\
\hline CHEMBL3957816 & 1640565 & 8.0969 & 7.9661 & TST & \\
\hline CHEMBL3943178 & 1640565 & 8.699 & 7.9204 & TRN & \\
\hline CHEMBL3927638 & 1640565 & 7.7696 & 8.0008 & TST & \\
\hline CHEMBL3985897 & 1640565 & 8.5229 & 8.5868 & TRN & \\
\hline CHEMBL 3902300 & 1640565 & 8.5229 & 8.4385 & TRN & \\
\hline CHEMBL3942497 & 1640565 & 9.0 & 8.6167 & TRN & \\
\hline CHEMBL3969689 & 1640565 & 8.5229 & 7.9722 & TRN & \\
\hline CHEMBL3986513 & 1640565 & 9.0 & 8.5137 & TRN & \\
\hline CHEMBL3953178 & 1640565 & 8.2218 & 8.0408 & TRN & \\
\hline CHEMBL3973647 & 1640565 & 8.699 & 8.1224 & TRN & \\
\hline CHEMBL3922022 & 1640565 & 7.8861 & 7.9132 & TRN & \\
\hline CHEMBL 3978554 & 1640565 & 7.9208 & 8.0621 & TRN & \\
\hline CHEMBL3897283 & 1640565 & 8.5229 & 8.4593 & TRN & \\
\hline CHEMBL3912647 & 1640565 & 8.699 & 8.5369 & TRN & \\
\hline CHEMBL3902565 & 1640565 & 6.0 & 7.9422 & TRN & \\
\hline CHEMBL3958725 & 1640565 & 9.0 & 8.5117 & TRN & \\
\hline CHEMBL3936235 & 1640565 & 8.2218 & 7.9397 & TRN & \\
\hline CHEMBL3951454 & 1640565 & 8.5229 & 7.99 & TST & \\
\hline CHEMBL3933086 & 1640565 & 8.0969 & 7.9889 & TST & \\
\hline CHEMBL3983853 & 1640565 & 6.0 & 7.83899 & 99999999995 & TRN \\
\hline CHEMBL3971651 & 1640565 & 8.0458 & 7.9584 & TRN & \\
\hline CHEMBL 3899248 & 1640565 & 7.2676 & 7.8894 & TRN & \\
\hline CHEMBL3981931 & 1640565 & 9.0 & 8.0678 & TRN & \\
\hline CHEMBL3913743 & 1640565 & 8.0458 & 8.5054 & TRN & \\
\hline CHEMBL3951911 & 1640565 & 8.699 & 8.4986 & TRN & \\
\hline CHEMBL3911678 & 1640565 & 8.699 & 8.1498 & TRN & \\
\hline CHEMBL3928922 & 1640565 & 8.699 & 8.2557 & TRN & \\
\hline CHEMBL3976395 & 1640565 & 8.0 & 8.1861 & TST & \\
\hline CHEMBL3973786 & 1640565 & 8.1549 & 7.978 & TST & \\
\hline CHEMBL3972098 & 1640565 & 8.5229 & 8.1327 & TRN & \\
\hline CHEMBL3921029 & 1640565 & 8.3979 & 8.1065 & TRN & \\
\hline CHEMBL3900354 & 1640565 & 8.3979 & 8.1189 & TRN & \\
\hline CHEMBL3962854 & 1640565 & 8.699 & 8.5535 & TRN & \\
\hline CHEMBL3956958 & 1640565 & 8.3979 & 8.4494 & TRN & \\
\hline CHEMBL3980743 & 1640565 & 8.5229 & 8.1441 & TRN & \\
\hline CHEMBL3908740 & 1640565 & 8.0 & 8.4929 & TRN & \\
\hline CHEMBL3916375 & 1640565 & 8.699 & 8.5675 & TRN & \\
\hline CHEMBL3933174 & 1640565 & 8.699 & 8.5836 & TRN & \\
\hline CHEMBL3930275 & 1640565 & 8.5229 & 8.4918 & TRN & \\
\hline CHEMBL3968571 & 1640565 & 9.0 & 8.0734 & TST & \\
\hline CHEMBL3958600 & 1640565 & 8.699 & 7.9919 & TRN & \\
\hline CHEMBL3905779 & 1640565 & 6.0 & 8.4744 & TRN & \\
\hline
\end{tabular}




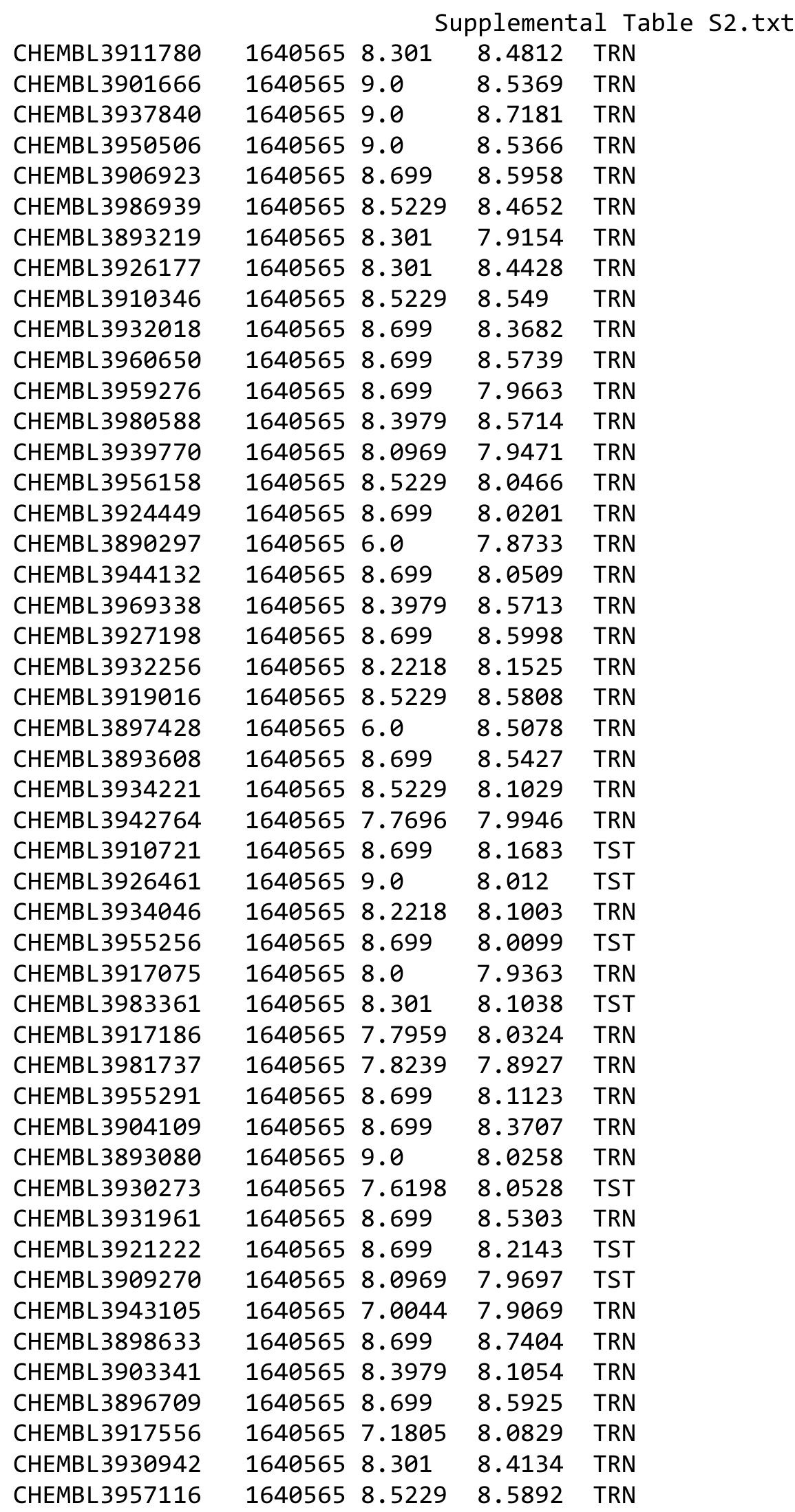

Page 21311 
Supplemental Table S2.txt

\begin{tabular}{|c|c|c|c|c|}
\hline 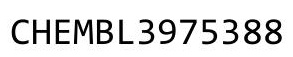 & 640565 & & 8.1651 & \\
\hline & 640565 & 9.0 & & \\
\hline HFMRI & 565 & 8.699 & 09 & \\
\hline HEMBL & 565 & 699 & 5897 & \\
\hline HEMBL3948515 & 640565 & 8.699 & 583 & \\
\hline HEMBL3906775 & 565 & 7.7696 & 7.8974 & \\
\hline 99 & 65 & 9.0 & 5467 & \\
\hline HEMBL 393 & & 9.0 & 5778 & DN \\
\hline HEMBL3926481 & 640565 & 9.0 & 5367 & \\
\hline HEMBL3911985 & 565 & 6.0 & 9703 & ГST \\
\hline HEMBL 392 & 64 & 8.5229 & .497 & \\
\hline AEMBL3S & 65 & 9.0 & 479 & ST \\
\hline HEMBL3S & & & & \\
\hline HEMBL3941499 & 65 & 7.6021 & 1078 & |SI \\
\hline HEMBL3967951 & 65 & 8.699 & 5025 & InIV \\
\hline HEMBL3 & 6 & 8.2218 & 913 & ГRN \\
\hline HEMBL3 & 5 & 8.301 & 88 & ST \\
\hline HEMBL3 & 65 & 9.0 & 263 & RN \\
\hline HEMBL3 & 65 & 8.699 & 358 & \\
\hline AEMBL3S & & 8.3979 & 593 & I KIV \\
\hline HEMBL3 & 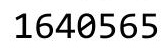 & 229 & 915 & RI \\
\hline HEM & & & & RN \\
\hline HEMBL & 65 & 8.699 & 896 & ST \\
\hline HEMBL3 & & 8.5229 & 322 & ST \\
\hline HEMBL397 & ל & 8.5229 & 958 & |SI \\
\hline HEMBL3 & 55 & 8 & 529 & 「RN \\
\hline HEME & & 7 & 96 & ST \\
\hline 29 & 55 & 8.699 & 604 & 「RN \\
\hline HEMBL3 & & 6. & & IR \\
\hline HEMBL395 & 55 & 6. & 5707 & TRN \\
\hline HEMBL; & & & 569 & ST \\
\hline 9 & & 8. & & 「RN \\
\hline 32 & & & 1712 & 「RN \\
\hline HEMBL39 & & 8.5229 & 947 & 「RN \\
\hline HEMBL 397 & 62 & 8. & 1862 & ГRN \\
\hline (IFMD 2 & 55 & 8. & 65 & TRN \\
\hline 5 & & & & TRN \\
\hline HEMBL39 & & 7.9586 & 7.8788 & TRN \\
\hline HEMBL396 & & 8.699 & 711 & $\Gamma R$ \\
\hline IEIMIDL & כנד & 8. & $\partial 82$ & RN \\
\hline HEMBL3 & & 6.7212 & 611 & ГST \\
\hline HEMBL3 & & 8.0969 & 7.9256 & TRN \\
\hline HEMBL396 & 65 & 7.5376 & 7.977 & TST \\
\hline HEMBL $39 e$ & 65 & 9 . & 284 & R \\
\hline CHFMRI 39420 & & & & 31 \\
\hline HEMBL3977492 & & 8.2218 & .1238 & \\
\hline CHEMBL 3906036 & & 8.3979 & 8.5509 & RN \\
\hline CHEMBL3973876 & 1640565 & 8.699 & 7.9302 & - \\
\hline
\end{tabular}

Page 21312 


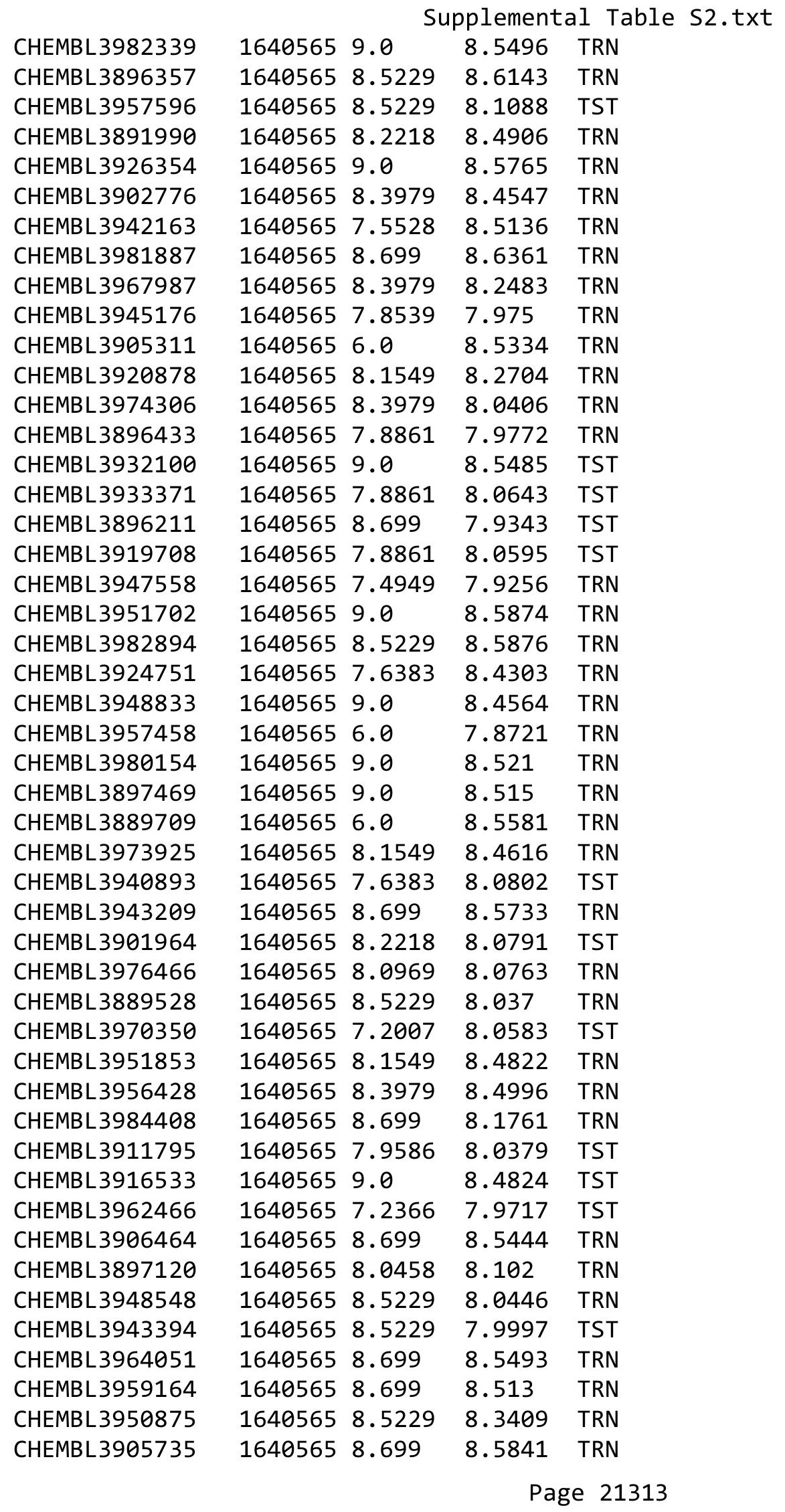




\begin{tabular}{|c|c|c|c|c|c|}
\hline \multirow[b]{2}{*}{ CHEMBL3915761 } & \multicolumn{5}{|c|}{ Supplemental Table S2.txt } \\
\hline & 1640565 & 9.0 & 7.9711 & TRN & \\
\hline CHEMBL3936056 & 1640565 & 8.2218 & 8.1311 & TRN & \\
\hline CHEMBL3909706 & 1640565 & 8.3979 & 7.9406 & TRN & \\
\hline CHEMBL 3893800 & 1640565 & 8.0 & 7.9744 & TST & \\
\hline CHEMBL 3889704 & 1640565 & 8.5229 & 8.2365 & TRN & \\
\hline CHEMBL3904610 & 1640565 & 8.699 & 8.6009 & TRN & \\
\hline CHEMBL3957111 & 1640565 & 8.699 & 8.5852 & TRN & \\
\hline CHEMBL3919671 & 1640565 & 8.699 & 7.9022 & TRN & \\
\hline CHEMBL 3897185 & 1640565 & 9.0 & 8.7119 & TRN & \\
\hline CHEMBL3967450 & 1640565 & 7.7447 & 8.1557 & TRN & \\
\hline CHEMBL3904562 & 1640565 & 9.0 & 7.9303 & TST & \\
\hline CHEMBL 3972678 & 1640565 & 7.2518 & 7.9371 & TST & \\
\hline CHEMBL 3944221 & 1640565 & 8.699 & 8.6071 & TRN & \\
\hline CHEMBL3917005 & 1640565 & 8.0458 & 8.0094 & TST & \\
\hline CHEMBL3971656 & 1640565 & 8.699 & 8.5325 & TRN & \\
\hline CHEMBL3985153 & 1640565 & 8.301 & 8.2166 & TST & \\
\hline CHEMBL3963888 & 1640565 & 9.0 & 7.8236 & TST & \\
\hline CHEMBL3921876 & 1640565 & 8.301 & 8.0363 & TST & \\
\hline CHEMBL 3898505 & 1640565 & 8.301 & 8.6185 & TST & \\
\hline CHEMBL3908206 & 1640565 & 7.4815 & 7.9643 & TST & \\
\hline CHEMBL3982214 & 1640565 & 8.5229 & 8.4872 & TRN & \\
\hline CHEMBL 3980714 & 1640565 & 9.0 & 8.0949 & TST & \\
\hline CHEMBL3903557 & 1640565 & 8.3979 & 8.1197 & TST & \\
\hline CHEMBL3933675 & 1640565 & 8.0969 & 7.9621 & TST & \\
\hline CHEMBL 3899161 & 1640565 & 6.0 & 7.9581 & TST & \\
\hline CHEMBL3922539 & 1640565 & 7.699 & 8.052 & TST & \\
\hline CHEMBL3949458 & 1640565 & 7.8239 & 8.051 & TST & \\
\hline CHEMBL3919902 & 1640565 & 8.3979 & 8.5149 & TRN & \\
\hline CHEMBL 3944472 & 1640565 & 8.2218 & 8.4025 & TST & \\
\hline CHEMBL3908621 & 1640565 & 8.0969 & 7.9133 & TST & \\
\hline CHEMBL3920924 & 1640565 & 9.0 & 8.0799 & TST & \\
\hline CHEMBL 3732671 & 1537084 & 6.4895 & 6.4771 & TRN & \\
\hline CHEMBL3732382 & 1537084 & 7.2596 & 7.2813 & TRN & \\
\hline CHEMBL3730174 & 1537084 & 7.0862 & 7.0781 & TRN & \\
\hline CHEMBL3729724 & 1537084 & 7.1739 & 7.1993 & TRN & \\
\hline CHEMBL3733189 & 1537084 & 7.3768 & 7.4049 & TRN & \\
\hline CHEMBL3731305 & 1537084 & 6.8962 & 6.9023 & TRN & \\
\hline CHEMBL3728519 & 1537084 & 6.1785 & 6.4958 & TST & \\
\hline CHEMBL3731191 & 1537084 & 6.4881 & 6.4948 & TRN & \\
\hline CHEMBL3731921 & 1537084 & 5.7635 & 5.6851 & TRN & \\
\hline CHEMBL3731610 & 1537084 & 6.2708 & 6.2615 & TRN & \\
\hline CHEMBL3730941 & 1537084 & 5.871 & 5.8856 & TRN & \\
\hline CHEMBL3730212 & 1537084 & 6.4168 & 6.4443 & TRN & \\
\hline CHEMBL3730896 & 1537084 & 6.0339 & 6.01399 & 9999999999 & TRN \\
\hline CHEMBL3731729 & 1537084 & 6.0 & 5.9445 & TST & \\
\hline CHEMBL3730205 & 1537084 & 7.0362 & 7.03700 & 0000000001 & TRN \\
\hline CHEMBL3728453 & 1537084 & 6.58 & 6.5999 & TST & \\
\hline CHEMBL3732909 & 1537084 & 7.5686 & 7.5859 & TRN & \\
\hline
\end{tabular}

Page 21314 
Supplemental Table S2.txt

\begin{tabular}{|c|c|c|c|c|c|}
\hline CHEMBL3730584 & 1537084 & 7.3468 & 7.353 & TRN & \\
\hline CHEMBL3731248 & 1537084 & 5.9614 & 5.944 & TRN & \\
\hline CHEMBL3728126 & 1537084 & 6.5436 & 6.5427 & TRN & \\
\hline CHEMBL3730868 & 1537084 & 7.0362 & 7.0497 & TRN & \\
\hline CHEMBL3728579 & 1537084 & 4.0 & 4.0533 & TRN & \\
\hline CHEMBL3727749 & 1537084 & 6.4237 & 6.7313 & TST & \\
\hline CHEMBL3730913 & 1537084 & 7.699 & 7.6411 & TRN & \\
\hline CHEMBL3731366 & 1537084 & 7.4815 & 7.0744 & TST & \\
\hline CHEMBL3732185 & 1537084 & 6.699 & 6.6255 & TRN & \\
\hline CHEMBL3732062 & 1537084 & 6.1232 & 6.0773 & TST & \\
\hline CHEMBL3728949 & 1537084 & 7.3768 & 7.331 & TRN & \\
\hline CHEMBL3729871 & 1537084 & 6.61799 & 99999999 & 6.5942 & TRN \\
\hline CHEMBL3732959 & 1537084 & 7.3665 & 7.3775 & TRN & \\
\hline CHEMBL3727639 & 1537084 & 5.7762 & 6.8846 & TST & \\
\hline CHEMBL3731419 & 1537084 & 7.0862 & 7.0896 & TRN & \\
\hline CHEMBL3729987 & 1537084 & 6.6478 & 6.6742 & TRN & \\
\hline CHEMBL3730748 & 1537084 & 6.4012 & 6.3979 & TRN & \\
\hline CHEMBL3728833 & 1537084 & 6.0685 & 6.1239 & TRN & \\
\hline CHEMBL3730649 & 1537084 & 7.2076 & 7.1929 & TRN & \\
\hline CHEMBL3732208 & 1537084 & 6.6091 & 6.617006 & 0000000001 & TRN \\
\hline CHEMBL3728818 & 1537084 & 5.8874 & 5.8979 & TRN & \\
\hline CHEMBL3731936 & 1537084 & 7.5086 & 7.5225 & TRN & \\
\hline CHEMBL3733209 & 1537084 & 6.8182 & 7.482 & TST & \\
\hline CHEMBL3731764 & 1537084 & 7.4815 & 7.4112 & TRN & \\
\hline CHEMBL3731443 & 1537084 & 4.9419 & 4.9349 & TRN & \\
\hline CHEMBL3728605 & 1537084 & 6.1733 & 6.0835 & TRN & \\
\hline CHEMBL3729325 & 1537084 & 6.0747 & 6.0843 & TRN & \\
\hline CHEMBL 3727382 & 1537084 & 7.5528 & 7.6538 & TRN & \\
\hline CHEMBL3729611 & 1537084 & 6.7595 & 6.7838 & TRN & \\
\hline CHEMBL3732341 & 1537084 & 6.3206 & 6.3266 & TRN & \\
\hline CHEMBL3732414 & 1537084 & 6.8861 & 6.9143 & TRN & \\
\hline CHEMBL 3732421 & 1537084 & 6.5638 & 6.5545 & TRN & \\
\hline CHEMBL3731357 & 1537084 & 5.9935 & 6.0211 & TRN & \\
\hline CHEMBL3731465 & 1537084 & 6.0 & 6.0906 & TRN & \\
\hline CHEMBL3733326 & 1537084 & 6.0 & 5.7598 & TST & \\
\hline CHEMBL3730253 & 1537084 & 5.311 & 6.0966 & TST & \\
\hline CHEMBL3729172 & 1537084 & 4.0 & 3.9799 & TRN & \\
\hline CHEMBL3729851 & 1537084 & 5.7757 & 5.7419 & TRN & \\
\hline CHEMBL 3728853 & 1537084 & 6.3936 & 6.4483 & TRN & \\
\hline CHEMBL3731231 & 1537084 & 7.1487 & 7.1071 & TRN & \\
\hline CHEMBL3728501 & 1537084 & 6.6498 & 6.7244 & TRN & \\
\hline CHEMBL3729764 & 1537084 & 4.0 & 6.2441 & TST & \\
\hline CHEMBL3730477 & 1537084 & 7.2147 & 7.1769 & TRN & \\
\hline CHEMBL 3729478 & 1537084 & 6.9066 & 6.916 & TRN & \\
\hline CHEMBL3730650 & 1537084 & 5.9477 & 6.2194 & TST & \\
\hline CHEMBL3731410 & 1537084 & 7.6198 & 7.6067 & TRN & \\
\hline CHEMBL3731731 & 1537084 & 5.9504 & 5.9449 & TRN & \\
\hline CHEMBL 3728033 & 1537084 & 5.9245 & 5.9255 & TRN & \\
\hline
\end{tabular}


Supplemental Table S2.txt

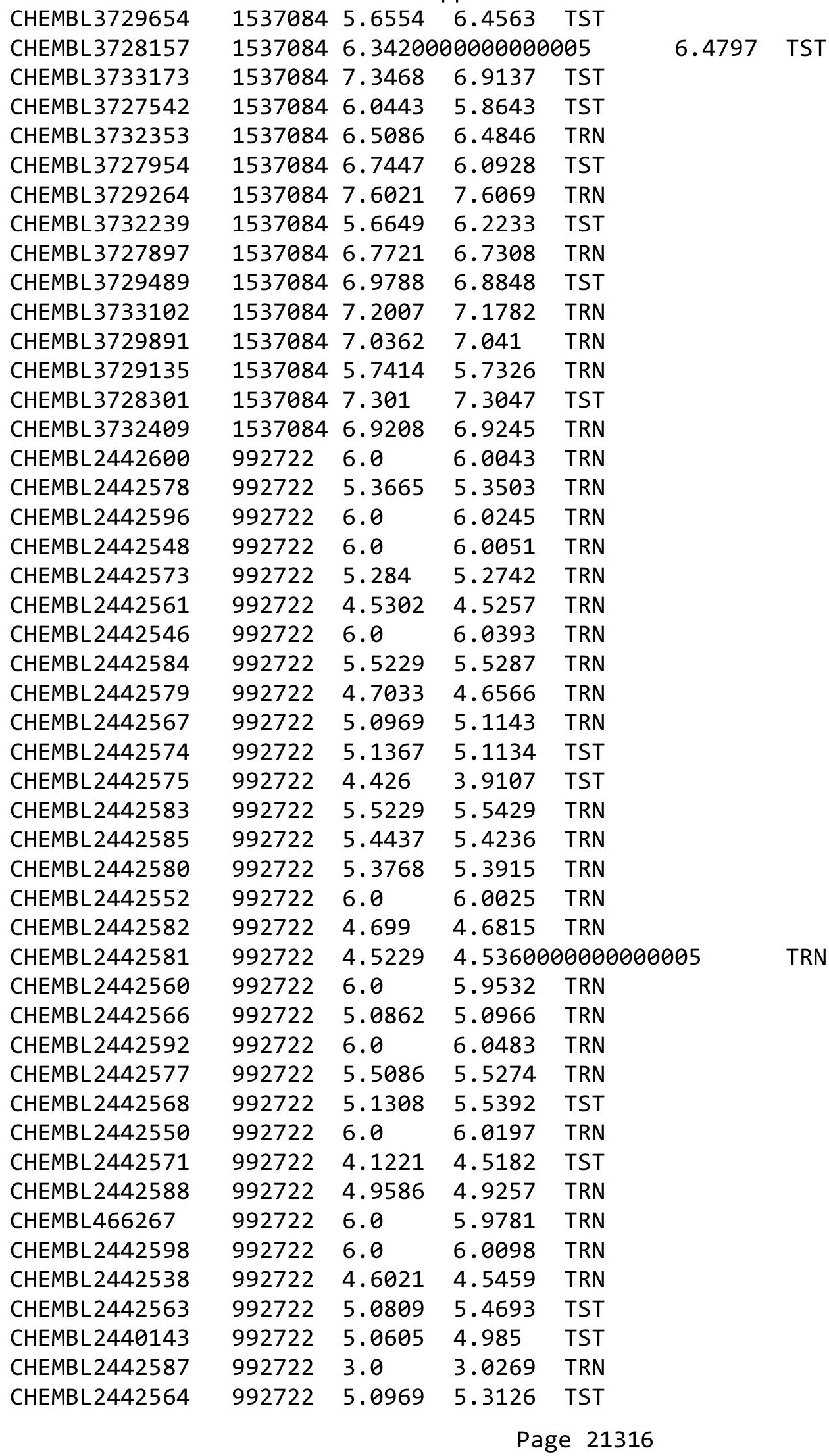




\begin{tabular}{|c|c|c|c|c|}
\hline \multicolumn{5}{|c|}{ Supplemental Table S2.txt } \\
\hline CHEMBL 2442541 & 992722 & 4.6946 & 4.6764 & TRN \\
\hline CHEMBL 2442565 & 992722 & 5.0088 & 4.9053 & TST \\
\hline CHEMBL2442576 & 992722 & 4.7496 & 4.7781 & TRN \\
\hline CHEMBL 2442555 & 992722 & 4.0 & 4.0071 & TRN \\
\hline CHEMBL 2442572 & 992722 & 5.284 & 5.0588 & TST \\
\hline CHEMBL 2442589 & 992722 & 4.4248 & 4.4265 & TRN \\
\hline CHEMBL 2442594 & 992722 & 6.0 & 5.9479 & TRN \\
\hline CHEMBL2442562 & 992722 & 5.0223 & 5.2012 & TST \\
\hline CHEMBL 2442554 & 992722 & 6.0 & 6.0154 & TRN \\
\hline CHEMBL 2442544 & 992722 & 4.6676 & 4.7065 & TRN \\
\hline CHEMBL 2442558 & 992722 & 4.3215 & 4.329 & TRN \\
\hline CHEMBL 2442557 & 992722 & 6.0 & 5.9613 & TRN \\
\hline CHEMBL373777 & 992722 & 3.0 & 3.8329 & TST \\
\hline CHEMBL 2442569 & 992722 & 5.0 & 4.8888 & TST \\
\hline CHEMBL 2442586 & 992722 & 3.0 & 3.0029 & TRN \\
\hline CHEMBL 2442590 & 992722 & 4.0186 & 4.0175 & TRN \\
\hline CHEMBL 2442570 & 992722 & 5.1249 & 4.8151 & TST \\
\hline CHEMBL189584 & 954928 & 4.4779 & 4.4826 & TRN \\
\hline CHEMBL1788116 & 954928 & 5.5636 & 5.2751 & TRN \\
\hline CHEMBL399530 & 954928 & 3.678 & 4.1065 & TRN \\
\hline CHEMBL 213100 & 954928 & 4.1404 & 3.3506 & TRN \\
\hline CHEMBL3349342 & 954928 & 5.3776 & 5.3355 & TRN \\
\hline CHEMBL558642 & 954928 & 5.3854 & 5.5207 & TRN \\
\hline CHEMBL1256459 & 954928 & 7.5351 & 7.7559 & TRN \\
\hline CHEMBL151176 & 954928 & 5.9062 & 5.3907 & TRN \\
\hline CHEMBL1190711 & 954928 & 5.5668 & 5.8058 & TRN \\
\hline CHEMBL573107 & 954928 & 4.9451 & 4.8397 & TRN \\
\hline CHEMBL483849 & 954928 & 3.0659 & 2.3897 & TST \\
\hline CHEMBL3392440 & 954928 & 3.759 & 3.7977 & TRN \\
\hline CHEMBL1516890 & 954928 & 4.3804 & 4.3844 & TRN \\
\hline CHEMBL1404918 & 954928 & 2.9131 & 3.0571 & TRN \\
\hline CHEMBL 255342 & 954928 & 3.3369 & 3.4156 & TRN \\
\hline CHEMBL472940 & 954928 & 3.6355 & 3.7257 & TRN \\
\hline CHEMBL3199475 & 954928 & 3.6735 & 4.3506 & TRN \\
\hline CHEMBL92309 & 954928 & 3.8155 & 3.3343 & TST \\
\hline CHEMBL191334 & 954928 & 3.1075 & 3.4494 & TRN \\
\hline CHEMBL192566 & 954928 & 8.6223 & 8.6015 & TST \\
\hline CHEMBL300389 & 954928 & 7.0306 & 7.0587 & TRN \\
\hline CHEMBL188678 & 954928 & 5.3686 & 4.816 & TRN \\
\hline CHEMBL392695 & 954928 & 5.8567 & 5.9152 & TRN \\
\hline CHEMBL65 & 954928 & 7.9208 & 7.7621 & TRN \\
\hline CHEMBL1970879 & 954928 & 5.1093 & 4.8591 & TRN \\
\hline CHEMBL 2363137 & 954928 & 5.515 & 5.2507 & TRN \\
\hline CHEMBL135561 & 954928 & 6.02 & 5.4956 & TRN \\
\hline CHEMBL1643959 & 954928 & 4.0162 & 3.8936 & TRN \\
\hline CHEMBL 202721 & 954928 & 4.6619 & 4.7724 & TRN \\
\hline CHEMBL577784 & 954928 & 5.3139 & 5.1636 & TRN \\
\hline CHEMBL 2137530 & 954928 & 4.8456 & 4.8023 & TRN \\
\hline
\end{tabular}

Page 21317 
Supplemental Table S2.txt

\begin{tabular}{|c|c|c|c|c|}
\hline CHEMBL1230020 & 954928 & 4.7371 & 4.3025 & TRN \\
\hline CHEMBL 221137 & 954928 & 5.6524 & 4.9347 & TST \\
\hline CHEMBL379975 & 954928 & 4.1104 & 4.3253 & TRN \\
\hline CHEMBL259181 & 954928 & 5.2287 & 5.3901 & TRN \\
\hline CHEMBL1186585 & 954928 & 3.7695 & 3.8624 & TRN \\
\hline CHEMBL514499 & 954928 & 7.9512 & 7.845 & TRN \\
\hline CHEMBL449158 & 954928 & 6.2435 & 6.9002 & TST \\
\hline CHEMBL1357247 & 954928 & 3.1357 & 3.4104 & TRN \\
\hline CHEMBL 209148 & 954928 & 5.2684 & 5.151 & TRN \\
\hline CHEMBL210618 & 954928 & 3.7507 & 3.6168 & TRN \\
\hline CHEMBL 379300 & 954928 & 6.699 & 6.8723 & TRN \\
\hline CHEMBL393929 & 954928 & 4.6582 & 4.3744 & TRN \\
\hline CHEMBL483847 & 954928 & 4.0653 & 4.2299 & TRN \\
\hline CHEMBL 217354 & 954928 & 5.8075 & 6.3794 & TRN \\
\hline CHEMBL 2134202 & 954928 & 4.095 & 3.8507 & TRN \\
\hline CHEMBL412142 & 954928 & 3.7037 & 3.9577 & TRN \\
\hline CHEMBL585951 & 954928 & 6.4302 & 6.4524 & TRN \\
\hline CHEMBL1242367 & 954928 & 3.8868 & 4.4853 & TRN \\
\hline CHEMBL9470 & 954928 & 5.6818 & 5.8749 & TST \\
\hline CHEMBL512504 & 954928 & 4.6502 & 4.6066 & TST \\
\hline CHEMBL102714 & 954928 & 3.6824 & 3.5438 & TST \\
\hline CHEMBL 2005886 & 954928 & 5.0151 & 5.8035 & TST \\
\hline CHEMBL 240954 & 954928 & 3.5749 & 3.6088 & TST \\
\hline CHEMBL 258844 & 954928 & 5.5103 & 4.8169 & TST \\
\hline CHEMBL222102 & 954928 & 4.4199 & 4.044 & TST \\
\hline CHEMBL509032 & 954928 & 4.8453 & 5.9422 & TST \\
\hline CHEMBL515416 & 954928 & 5.49299 & 99999999 & 4.723 \\
\hline CHEMBL1909414 & 954928 & 4.4829 & 3.8771 & TST \\
\hline CHEMBL559943 & 580625 & 7.7212 & 6.9381 & TRN \\
\hline CHEMBL564462 & 580625 & 8.0 & 7.3167 & TRN \\
\hline CHEMBL551406 & 580625 & 6.5901 & 6.7418 & TRN \\
\hline CHEMBL564878 & 580625 & 6.9031 & 6.7648 & TRN \\
\hline CHEMBL564491 & 580625 & 7.1805 & 6.9271 & TRN \\
\hline CHEMBL560591 & 580625 & 6.9508 & 7.0075 & TRN \\
\hline CHEMBL562685 & 580625 & 7.0605 & 6.9548 & TRN \\
\hline CHEMBL561476 & 580625 & 6.1518 & 6.8273 & TRN \\
\hline CHEMBL551674 & 580625 & 6.8125 & 7.1384 & TRN \\
\hline CHEMBL553220 & 580625 & 8.301 & 7.6582 & TST \\
\hline CHEMBL557521 & 580625 & 7.1024 & 6.7581 & TRN \\
\hline CHEMBL564012 & 580625 & 4.9922 & 7.4503 & TST \\
\hline CHEMBL561595 & 580625 & 6.7258 & 6.6986 & TRN \\
\hline CHEMBL559685 & 580625 & 6.0467 & 6.7535 & TST \\
\hline CHEMBL564246 & 580625 & 7.5058 & 7.3884 & TRN \\
\hline CHEMBL562808 & 580625 & 7.2924 & 7.7545 & TST \\
\hline CHEMBL558852 & 580625 & 7.7959 & 7.7579 & TRN \\
\hline CHEMBL 243876 & 580625 & 5.0 & 7.5171 & TST \\
\hline CHEMBL558134 & 580625 & 6.6234 & 6.8532 & TST \\
\hline \multirow[t]{2}{*}{ CHEMBL564363 } & 580625 & 7.5346 & 7.19600 & 0000000001 \\
\hline & & \multicolumn{3}{|c|}{ Page 21318} \\
\hline
\end{tabular}




\begin{tabular}{|c|c|c|c|c|}
\hline & \multicolumn{2}{|r|}{ plemen } & al Table \\
\hline CHEMBL557048 & 580625 & 7.2076 & 7.193 & TRN \\
\hline CHEMBL564284 & 580625 & 6.6198 & 6.7305 & TRN \\
\hline CHEMBL551609 & 580625 & 6.6861 & 6.5873 & TRN \\
\hline CHEMBL564632 & 580625 & 6.5834 & 6.6438 & TRN \\
\hline CHEMBL552275 & 580625 & 6.6162 & 6.8687 & TRN \\
\hline CHEMBL563264 & 580625 & 7.2418 & 7.1163 & TST \\
\hline CHEMBL562535 & 580625 & 7.1487 & 6.7562 & TRN \\
\hline CHEMBL556086 & 580625 & 7.3468 & 7.4453 & TRN \\
\hline CHEMBL557526 & 580625 & 7.2628 & 7.5165 & TST \\
\hline CHEMBL551335 & 580625 & 8.0458 & 7.78 & TRN \\
\hline CHEMBL550929 & 580625 & 8.1367 & 7.7081 & TST \\
\hline CHEMBL556435 & 580625 & 6.5452 & 6.5409 & TST \\
\hline CHEMBL561395 & 580625 & 7.6383 & 7.7159 & TRN \\
\hline CHEMBL549852 & 580625 & 5.9469 & 7.34 & TRN \\
\hline CHEMBL550665 & 580625 & 6.585 & 6.7021 & TRN \\
\hline CHEMBL561801 & 580625 & 6.6383 & 6.7892 & TST \\
\hline CHEMBL554932 & 580625 & 7.2291 & 6.6879 & TRN \\
\hline CHEMBL550867 & 580625 & 6.7167 & 6.6933 & TRN \\
\hline CHEMBL563332 & 580625 & 6.8508 & 6.9279 & TRN \\
\hline CHEMBL549918 & 580625 & 7.9031 & 7.3486 & TRN \\
\hline CHEMBL551877 & 580625 & 6.5376 & 6.5019 & TRN \\
\hline CHEMBL557322 & 580625 & 7.51 & 7.5604 & TRN \\
\hline CHEMBL556502 & 580625 & 6.1858 & 6.4238 & TRN \\
\hline CHEMBL560199 & 580625 & 5.5622 & 6.6013 & TRN \\
\hline CHEMBL561536 & 580625 & 7.1938 & 6.6817 & TRN \\
\hline CHEMBL561742 & 580625 & 7.0325 & 7.0201 & TST \\
\hline CHEMBL562733 & 580625 & 7.644 & 7.39 & TST \\
\hline CHEMBL562140 & 580625 & 8.0 & 7.3368 & TRN \\
\hline CHEMBL559743 & 580625 & 6.5302 & 7.0782 & TRN \\
\hline CHEMBL557251 & 580625 & 6.4318 & 6.7332 & TRN \\
\hline CHEMBL554064 & 580625 & 7.1871 & 6.9363 & TRN \\
\hline CHEMBL556646 & 580625 & 7.3036 & 7.5419 & TST \\
\hline CHEMBL562889 & 580625 & 6.4157 & 6.4368 & TRN \\
\hline CHEMBL562536 & 580625 & 7.098 & 7.3758 & TST \\
\hline CHEMBL551073 & 580625 & 7.266 & 7.6503 & TRN \\
\hline CHEMBL562141 & 580625 & 7.3655 & 7.4839 & TST \\
\hline CHEMBL561877 & 580625 & 4.9749 & 7.41700 & 0000000001 \\
\hline CHEMBL557658 & 580625 & 6.1662 & 6.5172 & TRN \\
\hline CHEMBL560936 & 580625 & 7.5229 & 7.4646 & TRN \\
\hline CHEMBL563950 & 580625 & 7.301 & 7.4458 & TRN \\
\hline CHEMBL561876 & 580625 & 6.8182 & 6.6084 & TRN \\
\hline CHEMBL550193 & 580625 & 7.3372 & 6.9804 & TRN \\
\hline CHEMBL560478 & 580625 & 7.2083 & 7.4224 & TRN \\
\hline CHEMBL564964 & 580625 & 6.0292 & 6.7245 & TRN \\
\hline CHEMBL556917 & 580625 & 6.3686 & 6.6893 & TRN \\
\hline CHEMBL563059 & 580625 & 7.585 & 7.1399 & TRN \\
\hline CHEMBL563169 & 580625 & 6.6946 & 7.0966 & TRN \\
\hline CHEMBL560003 & 580625 & 7.5229 & 7.3523 & TRN \\
\hline
\end{tabular}




\begin{tabular}{|c|c|c|c|c|c|c|}
\hline & & \multicolumn{5}{|c|}{ Supplemental Table S2.txt } \\
\hline CHEMBL549588 & 580625 & 7.5229 & 6.7011 & TRN & & \\
\hline CHEMBL556228 & 580625 & 6.8327 & 6.6988 & TRN & & \\
\hline CHEMBL550056 & 580625 & 7.5376 & 7.4122 & TST & & \\
\hline CHEMBL562277 & 580625 & 7.6383 & 7.7034 & TRN & & \\
\hline CHEMBL562885 & 580625 & 7.0177 & 6.5797 & TRN & & \\
\hline CHEMBL558258 & 580625 & 6.426 & 6.9672 & TRN & & \\
\hline CHEMBL556295 & 580625 & 7.9066 & 7.3373 & TRN & & \\
\hline CHEMBL561137 & 580625 & 7.7471 & 7.7754 & TRN & & \\
\hline CHEMBL560533 & 580625 & 6.6091 & 6.5138 & TRN & & \\
\hline CHEMBL559116 & 580625 & 7.7825 & 7.7678 & TRN & & \\
\hline CHEMBL551336 & 580625 & 7.9208 & 7.6547 & TST & & \\
\hline CHEMBL552416 & 580625 & 6.9747 & 7.3897 & TRN & & \\
\hline CHEMBL3359210 & 1437208 & 5.971 & 5.8123 & TST & & \\
\hline CHEMBL3358646 & 1437208 & 5.9165 & 5.8884 & TRN & & \\
\hline CHEMBL3359221 & 1437208 & 5.845 & 5.8746 & TRN & & \\
\hline CHEMBL3359239 & 1437208 & 5.8462 & 5.8336 & TRN & & \\
\hline CHEMBL3359233 & 1437208 & 4.699 & 5.1803 & TST & & \\
\hline CHEMBL3359218 & 1437208 & 5.9133 & 5.9158 & TRN & & \\
\hline CHEMBL3359230 & 1437208 & 5.7737 & 5.7553 & TRN & & \\
\hline CHEMBL3358637 & 1437208 & 4.699 & 4.7648 & TRN & & \\
\hline CHEMBL3358648 & 1437208 & 5.9289 & 5.9234 & TRN & & \\
\hline CHEMBL3358639 & 1437208 & 5.7158 & 5.7353 & TRN & & \\
\hline CHEMBL3359241 & 1437208 & 4.699 & 4.6892 & TRN & & \\
\hline CHEMBL 3359227 & 1437208 & 4.699 & 4.7141 & TRN & & \\
\hline CHEMBL3358653 & 1437208 & 4.699 & 5.7381 & TST & & \\
\hline CHEMBL3359235 & 1437208 & 5.8901 & 5.9159 & TRN & & \\
\hline CHEMBL3359223 & 1437208 & 5.9618 & 5.8531 & TRN & & \\
\hline CHEMBL 3359236 & 1437208 & 5.7506 & 5.7574 & TRN & & \\
\hline CHEMBL 3359234 & 1437208 & 5.8085 & 5.8112 & TRN & & \\
\hline CHEMBL3359219 & 1437208 & 5.8661 & 5.8448 & TRN & & \\
\hline CHEMBL3359220 & 1437208 & 5.7828 & 5.7623 & TRN & & \\
\hline CHEMBL3359213 & 1437208 & 5.7361 & 5.848 & TRN & & \\
\hline CHEMBL3358647 & 1437208 & 5.8778 & 5.8805 & TRN & & \\
\hline CHEMBL3359216 & 1437208 & 4.699 & 4.6784 & TRN & & \\
\hline CHEMBL3359232 & 1437208 & 5.7222 & 5.371 & TST & & \\
\hline CHEMBL3352885 & 1437208 & 5.7176 & 5.2073 & TST & & \\
\hline CHEMBL3359228 & 1437208 & 5.8931 & 5.9288 & TRN & & \\
\hline CHEMBL3359243 & 1437208 & 5.9662 & 5.9702 & TRN & & \\
\hline CHEMBL3359224 & 1437208 & 6.0496 & 6.0805 & TRN & & \\
\hline CHEMBL3359225 & 1437208 & 5.8771 & 5.8766 & TRN & & \\
\hline CHEMBL3359229 & 1437208 & 5.92299 & 999999999 & 99 & 5.8683 & TST \\
\hline CHEMBL3358636 & 1437208 & 4.699 & 4.7648 & TRN & & \\
\hline CHEMBL3358642 & 1437208 & 5.7794 & 5.7613 & TRN & & \\
\hline CHEMBL3359211 & 1437208 & 5.9427 & 5.8663 & TRN & & \\
\hline CHEMBL3358644 & 1437208 & 5.7537 & 5.7495 & TRN & & \\
\hline CHEMBL3358650 & 1437208 & 4.699 & 4.7433 & TRN & & \\
\hline CHEMBL3358645 & 1437208 & 5.8262 & 5.8397 & TRN & & \\
\hline CHEMBL3358649 & 1437208 & 5.8877 & 5.8664 & TRN & & \\
\hline
\end{tabular}




$$
\text { Supplemental Table S2.txt }
$$

\begin{tabular}{|c|c|c|c|c|c|}
\hline CHEMBL 3358640 & 1437208 & 5.9784 & 5.9484 & TRN & \\
\hline CHEMBL3359240 & 1437208 & 4.699 & 5.1873 & TST & \\
\hline CHEMBL3359222 & 1437208 & 5.8551 & 5.891 & TRN & \\
\hline CHEMBL3359212 & 1437208 & 5.8368 & 5.8708 & TRN & \\
\hline CHEMBL3358654 & 1437208 & 5.8804 & 5.7635 & TST & \\
\hline CHEMBL3359244 & 1437208 & 5.8768 & 5.6005 & TST & \\
\hline CHEMBL3359226 & 1437208 & 4.699 & 4.6891 & TRN & \\
\hline CHEMBL3358635 & 1437208 & 5.9698 & 5.8033 & TRN & \\
\hline CHEMBL3358638 & 1437208 & 5.8383 & 5.8028 & TRN & \\
\hline CHEMBL3358634 & 1437208 & 6.0227 & 6.1183 & TRN & \\
\hline CHEMBL3359215 & 1437208 & 5.8771 & 5.861000 & 0000000001 & TRN \\
\hline CHEMBL3352879 & 1437208 & 5.7841 & 5.558 & TST & \\
\hline CHEMBL3359238 & 1437208 & 6.0255 & 5.8358 & TST & \\
\hline CHEMBL3359217 & 1437208 & 4.699 & 4.6718 & TRN & \\
\hline CHEMBL3359237 & 1437208 & 5.8765 & 5.8051 & TST & \\
\hline CHEMBL3359214 & 1437208 & 6.0496 & 6.0657 & TRN & \\
\hline CHEMBL3358633 & 1437208 & 4.699 & 4.6542 & TRN & \\
\hline CHEMBL3359231 & 1437208 & 5.7889 & 5.3701 & TST & \\
\hline CHEMBL3358651 & 1437208 & 4.699 & 4.68 & TRN & \\
\hline CHEMBL3358641 & 1437208 & 5.8489 & 5.8596 & TRN & \\
\hline CHEMBL3359242 & 1437208 & 5.95700 & 000000000 & 5.7492 & TST \\
\hline CHEMBL3358643 & 1437208 & 4.699 & 5.5634 & TST & \\
\hline CHEMBL3358652 & 1437208 & 5.902 & 5.9484 & TRN & \\
\hline CHEMBL3964343 & 1641497 & 9.0 & 8.2368 & TRN & \\
\hline CHEMBL 3948506 & 1641497 & 8.0 & 8.4398 & TRN & \\
\hline CHEMBL3907165 & 1641497 & 9.0 & 9.1083 & TRN & \\
\hline CHEMBL3902781 & 1641497 & 9.0 & 8.7603 & TRN & \\
\hline CHEMBL 3919052 & 1641497 & 8.0 & 7.9201 & TRN & \\
\hline CHEMBL3979737 & 1641497 & 9.0 & 8.2891 & TRN & \\
\hline CHEMBL 3972354 & 1641497 & 8.0 & 8.3661 & TRN & \\
\hline CHEMBL3919211 & 1641497 & 8.0 & 8.4926 & TST & \\
\hline CHEMBL 3900837 & 1641497 & 9.0 & 8.257 & TRN & \\
\hline CHEMBL 3945959 & 1641497 & 9.0 & 8.0957 & TRN & \\
\hline CHEMBL3935707 & 1641497 & 9.0 & 8.7546 & TRN & \\
\hline CHEMBL 3921643 & 1641497 & 9.0 & 8.9753 & TRN & \\
\hline CHEMBL 3900446 & 1641497 & 8.0 & 8.7422 & TRN & \\
\hline CHEMBL3911396 & 1641497 & 8.0 & 8.6922 & TRN & \\
\hline CHEMBL3934699 & 1641497 & 9.0 & 8.5366 & TST & \\
\hline CHEMBL3972048 & 1641497 & 8.0 & 8.7741 & TRN & \\
\hline CHEMBL 3986306 & 1641497 & 9.0 & 8.9443 & TRN & \\
\hline CHEMBL3896032 & 1641497 & 9.0 & 8.7319 & TRN & \\
\hline CHEMBL3966659 & 1641497 & 8.0 & 8.3423 & TRN & \\
\hline CHEMBL3901002 & 1641497 & 9.0 & 8.4489 & TRN & \\
\hline CHEMBL3933943 & 1641497 & 8.0 & 8.3034 & TRN & \\
\hline CHEMBL 3935878 & 1641497 & 9.0 & 8.7649 & TRN & \\
\hline CHEMBL3936032 & 1641497 & 7.0 & 8.7669 & TST & \\
\hline CHEMBL3941367 & 1641497 & 9.0 & 8.7129 & TRN & \\
\hline CHEMBL3907273 & 1641497 & 9.0 & 8.2634 & TRN & \\
\hline
\end{tabular}




\begin{tabular}{|c|c|c|c|c|c|}
\hline \multirow{3}{*}{ CHEMBL 3950621} & \multirow{2}{*}{1641497} & \\
\hline & & 8.0 & 8.997 & \multicolumn{2}{|l|}{ TRN } \\
\hline & 1641497 & 8.0 & 8.7246 & \multicolumn{2}{|l|}{ TST } \\
\hline CHEMBL3980481 & 1641497 & 9.0 & 8.3311 & \multicolumn{2}{|l|}{ TRN } \\
\hline CHEMBL 3973717 & 1641497 & 9.0 & 8.9885 & \multicolumn{2}{|l|}{ TRN } \\
\hline CHEMBL 3896853 & 1641497 & 9.0 & 9.2179 & \multicolumn{2}{|l|}{ TRN } \\
\hline CHEMBL 3909455 & 1641497 & 8.0 & 8.1607 & \multicolumn{2}{|l|}{ TRN } \\
\hline CHEMBL3982380 & 1641497 & 9.0 & 8.8507 & \multicolumn{2}{|l|}{ TRN } \\
\hline CHEMBL3950229 & 1641497 & 8.0 & 8.2969 & \multicolumn{2}{|l|}{ TST } \\
\hline CHEMBL3986790 & 1641497 & 9.0 & 8.8148 & \multicolumn{2}{|l|}{ TRN } \\
\hline CHEMBL3974348 & 1641497 & 9.0 & 8.9497 & \multicolumn{2}{|l|}{ TRN } \\
\hline CHEMBL 3895765 & 1641497 & 9.0 & 8.3461 & \multicolumn{2}{|l|}{ TST } \\
\hline CHEMBL 3980802 & 1641497 & 9.0 & 8.7094 & \multicolumn{2}{|l|}{ TRN } \\
\hline CHEMBL 3947644 & 1641497 & 9.0 & 8.9874 & \multicolumn{2}{|l|}{ TRN } \\
\hline CHEMBL 3895013 & 1641497 & 7.0 & 8.1862 & \multicolumn{2}{|l|}{ TST } \\
\hline CHEMBL3944949 & 1641497 & 8.0 & 8.4484 & \multicolumn{2}{|l|}{ TRN } \\
\hline CHEMBL 3908708 & 1641497 & 9.0 & 8.8186 & \multicolumn{2}{|l|}{ TST } \\
\hline CHEMBL3962483 & 1641497 & 8.0 & 8.1918 & \multicolumn{2}{|l|}{ TRN } \\
\hline CHEMBL3937818 & 1641497 & 8.0 & 8.3197 & \multicolumn{2}{|l|}{ TST } \\
\hline CHEMBL3901645 & 1641497 & 9.0 & 9.1497 & TRN & \\
\hline CHEMBL3984042 & 1641497 & 9.0 & 8.9604 & TRN & \\
\hline CHEMBL 3897470 & 1641497 & 9.0 & 8.9013 & TRN & \\
\hline CHEMBL3901762 & 1641497 & 8.0 & 8.2853 & TRN & \\
\hline CHEMBL 3889617 & 1641497 & 9.0 & 8.786 & TST & \\
\hline CHEMBL 3982344 & 1641497 & 9.0 & 8.8877 & TRN & \\
\hline CHEMBL3901452 & 1641497 & 8.0 & 8.6011 & TST & \\
\hline CHEMBL3925178 & 1641497 & 9.0 & 8.2696 & TRN & \\
\hline CHEMBL3963501 & 1641497 & 8.0 & 8.0885 & TRN & \\
\hline CHEMBL3965264 & 1641497 & 9.0 & 8.8078 & TST & \\
\hline CHEMBL 3904843 & 1641497 & 9.0 & 8.9391 & TRN & \\
\hline CHEMBL3918043 & 1641497 & 9.0 & 8.8802 & TST & \\
\hline CHEMBL3905820 & 1641497 & 9.0 & 8.8779 & TRN & \\
\hline CHEMBL3956154 & 1641497 & 8.0 & 8.1906 & TRN & \\
\hline CHEMBL 3973926 & 1641497 & 9.0 & 8.8371 & TRN & \\
\hline CHEMBL3922975 & 1641497 & 8.0 & 7.83299 & 9999999999 & TRN \\
\hline CHEMBL3904119 & 1641497 & 9.0 & 8.787 & TRN & \\
\hline CHEMBL3950568 & 1641497 & 8.0 & 8.0901 & TRN & \\
\hline CHEMBL3958136 & 1641497 & 9.0 & 8.898 & TRN & \\
\hline CHEMBL3921597 & 1641497 & 8.0 & 8.2435 & TRN & \\
\hline CHEMBL3926092 & 1641497 & 8.0 & 8.6955 & TST & \\
\hline CHEMBL3960633 & 1641497 & 9.0 & 8.9492 & TRN & \\
\hline CHEMBL3950775 & 1641497 & 9.0 & 8.4848 & TRN & \\
\hline CHEMBL3984800 & 1641497 & 8.0 & 8.3462 & TRN & \\
\hline CHEMBL3902965 & 1641497 & 9.0 & 9.0089 & TRN & \\
\hline CHEMBL 3927273 & 1641497 & 8.0 & 8.1236 & TRN & \\
\hline CHEMBL3962149 & 1641497 & 9.0 & 8.8087 & TRN & \\
\hline CHEMBL3960211 & 1641497 & 8.0 & 8.2258 & TRN & \\
\hline CHEMBL 3896470 & 1641497 & 8.0 & 8.8373 & TST & \\
\hline CHEMBL3983771 & 1641497 & 8.0 & 8.3398 & TRN & \\
\hline & & & $\mathrm{P}$ & 21322 & \\
\hline
\end{tabular}




\begin{tabular}{|c|c|c|c|c|}
\hline & & & ent & al T \\
\hline CHEMBL 3946280 & 1641497 & 8.0 & 8.3361 & TRN \\
\hline CHEMBL3954025 & 1641497 & 8.0 & 8.8678 & TST \\
\hline CHEMBL3909971 & 1641497 & 9.0 & 8.4463 & TRN \\
\hline CHEMBL3971190 & 1641497 & 9.0 & 8.3025 & TRN \\
\hline CHEMBL3959771 & 1641497 & 8.0 & 8.5745 & TRN \\
\hline CHEMBL3902599 & 1641497 & 8.0 & 8.2102 & TRN \\
\hline CHEMBL3910294 & 1641497 & 9.0 & 8.3523 & TST \\
\hline CHEMBL 3898884 & 1641497 & 9.0 & 8.8509 & TRN \\
\hline CHEMBL 3983802 & 1641497 & 7.0 & 8.0045 & TRN \\
\hline CHEMBL3923035 & 1641497 & 9.0 & 8.6459 & TRN \\
\hline CHEMBL 3947780 & 1641497 & 7.0 & 8.0011 & TRN \\
\hline CHEMBL3959804 & 1641497 & 8.0 & 8.612 & TST \\
\hline CHEMBL3968136 & 1641497 & 8.0 & 8.0955 & TRN \\
\hline CHEMBL3900905 & 1641497 & 9.0 & 8.5647 & TRN \\
\hline CHEMBL3976123 & 1641497 & 8.0 & 8.8 & TRN \\
\hline CHEMBL 3966549 & 1641497 & 8.0 & 8.738 & TRN \\
\hline CHEMBL3973008 & 1641497 & 8.0 & 8.0913 & TRN \\
\hline CHEMBL 3913207 & 1641497 & 9.0 & 8.0236 & TRN \\
\hline CHEMBL3890988 & 1641497 & 8.0 & 7.8039 & TRN \\
\hline CHEMBL 3895873 & 1641497 & 9.0 & 8.2786 & TRN \\
\hline CHEMBL3969315 & 1641497 & 9.0 & 8.0897 & TRN \\
\hline CHEMBL3904088 & 1641497 & 9.0 & 8.9707 & TRN \\
\hline CHEMBL 3975730 & 1641497 & 8.0 & 8.1134 & TRN \\
\hline CHEMBL3929829 & 1641497 & 9.0 & 9.0656 & TRN \\
\hline CHEMBL 3917350 & 1641497 & 9.0 & 8.7103 & TRN \\
\hline CHEMBL 3928296 & 1641497 & 9.0 & 8.571 & TST \\
\hline CHEMBL3982528 & 1641497 & 8.0 & 8.2074 & TRN \\
\hline CHEMBL 3920670 & 1641497 & 9.0 & 8.9572 & TRN \\
\hline CHEMBL3985878 & 1641497 & 9.0 & 8.4742 & TST \\
\hline CHEMBL 3890654 & 1641497 & 8.0 & 8.123 & TRN \\
\hline CHEMBL3935611 & 1641497 & 8.0 & 8.1419 & TRN \\
\hline CHEMBL3967708 & 1641497 & 7.0 & 8.2766 & TRN \\
\hline CHEMBL3967199 & 1641497 & 8.0 & 8.4828 & TST \\
\hline CHEMBL3909142 & 1641497 & 9.0 & 8.1222 & TRN \\
\hline CHEMBL3903727 & 1641497 & 8.0 & 8.1115 & TRN \\
\hline CHEMBL 3904250 & 1641497 & 7.0 & 8.5018 & TST \\
\hline CHEMBL3911779 & 1641497 & 9.0 & 8.2828 & TST \\
\hline CHEMBL 3934927 & 1641497 & 9.0 & 8.7518 & TRN \\
\hline CHEMBL 3910020 & 1641497 & 8.0 & 8.0013 & TRN \\
\hline CHEMBL 3956122 & 1641497 & 9.0 & 8.1833 & TRN \\
\hline CHEMBL 3910585 & 1641497 & 9.0 & 8.6578 & TRN \\
\hline CHEMBL3934096 & 1641497 & 9.0 & 8.6991 & TST \\
\hline CHEMBL 3957028 & 1641497 & 9.0 & 8.9512 & TRN \\
\hline CHEMBL3901960 & 1641497 & 9.0 & 8.3984 & TRN \\
\hline CHEMBL3962963 & 1641497 & 9.0 & 9.0503 & TRN \\
\hline CHEMBL3925747 & 1641497 & 9.0 & 8.1223 & TRN \\
\hline CHEMBL3937018 & 1641497 & 8.0 & 8.7709 & TST \\
\hline CHEMBL3979917 & 1641497 & 8.0 & 8.3407 & TRN \\
\hline
\end{tabular}




\begin{tabular}{|c|c|c|c|c|c|}
\hline \multirow[b]{2}{*}{ CHEMBL 3950884} & \multirow{2}{*}{\multicolumn{2}{|c|}{16414978.0}} & \\
\hline & & & 8.3113 & TRN & \\
\hline CHEMBL3924091 & 1641497 & 7.0 & 8.1991 & TST & \\
\hline CHEMBL3907563 & 1641497 & 9.0 & 8.0672 & TST & \\
\hline CHEMBL3916675 & 1641497 & 9.0 & 8.0652 & TRN & \\
\hline CHEMBL3941488 & 1641497 & 8.0 & 8.5271 & TST & \\
\hline CHEMBL3979163 & 1641497 & 8.0 & 8.1592 & TRN & \\
\hline CHEMBL3908859 & 1641497 & 7.0 & 8.5251 & TST & \\
\hline CHEMBL3901300 & 1641497 & 9.0 & 8.5641 & TRN & \\
\hline CHEMBL3919360 & 1641497 & 8.0 & 8.1725 & TRN & \\
\hline CHEMBL3931729 & 1641497 & 9.0 & 8.2487 & TRN & \\
\hline CHEMBL3984073 & 1641497 & 9.0 & 8.7106 & TRN & \\
\hline CHEMBL3942081 & 1641497 & 8.0 & 8.0972 & TRN & \\
\hline CHEMBL3940616 & 1641497 & 8.0 & 9.0511 & TST & \\
\hline CHEMBL3963967 & 1641497 & 8.0 & 8.1455 & TRN & \\
\hline CHEMBL3903634 & 1641497 & 8.0 & 8.2472 & TST & \\
\hline CHEMBL3949975 & 1641497 & 9.0 & 8.8942 & TST & \\
\hline CHEMBL3949007 & 1641497 & 7.0 & 7.7615 & TRN & \\
\hline CHEMBL3895924 & 1641497 & 9.0 & 8.2883 & TRN & \\
\hline CHEMBL3893658 & 1641497 & 9.0 & 8.8993 & TRN & \\
\hline CHEMBL3919649 & 1641497 & 9.0 & 8.6731 & TRN & \\
\hline CHEMBL3930058 & 1641497 & 8.0 & 9.1667 & TST & \\
\hline CHEMBL3958364 & 1641497 & 9.0 & 8.2919 & TRN & \\
\hline CHEMBL3950759 & 1641497 & 8.0 & 8.4056 & TST & \\
\hline CHEMBL3931853 & 1641497 & 8.0 & 8.3746 & TRN & \\
\hline CHEMBL3893764 & 1641497 & 8.0 & 8.4191 & TST & \\
\hline CHEMBL3907197 & 1641497 & 9.0 & 9.008 & TRN & \\
\hline CHEMBL3928701 & 1641497 & 8.0 & 8.1086 & TRN & \\
\hline CHEMBL3899707 & 1641497 & 8.0 & 8.1364 & TRN & \\
\hline CHEMBL3927192 & 1641497 & 7.0 & 7.9778 & TST & \\
\hline CHEMBL3947379 & 1641497 & 8.0 & 8.1707 & TRN & \\
\hline CHEMBL3933779 & 1641497 & 9.0 & 8.7834 & TST & \\
\hline CHEMBL3964406 & 1641497 & 7.0 & 7.7924 & TRN & \\
\hline CHEMBL3949441 & 1641497 & 9.0 & 8.7154 & TRN & \\
\hline CHEMBL3900136 & 1641497 & 8.0 & 8.71600 & 0000000001 & TRN \\
\hline CHEMBL3935481 & 1641497 & 11.0 & 7.9662 & TST & \\
\hline CHEMBL3905032 & 1641497 & 9.0 & 8.8666 & TRN & \\
\hline CHEMBL3987142 & 1641497 & 8.0 & 8.3972 & TST & \\
\hline CHEMBL3927544 & 1641497 & 4.301 & 7.9052 & TST & \\
\hline CHEMBL3935935 & 1641497 & 9.0 & 8.7452 & TRN & \\
\hline CHEMBL3919262 & 1641497 & 9.0 & 9.2999 & TRN & \\
\hline CHEMBL3974647 & 1641497 & 9.0 & 8.5212 & TST & \\
\hline CHEMBL3963628 & 1641497 & 5.0 & 7.5073 & TRN & \\
\hline CHEMBL3900076 & 1641497 & 9.0 & 8.8958 & TST & \\
\hline CHEMBL3986704 & 1641497 & 8.0 & 8.2353 & TRN & \\
\hline CHEMBL3933040 & 1641497 & 9.0 & 8.7219 & TRN & \\
\hline CHEMBL3938059 & 1641497 & 9.0 & 8.9105 & TRN & \\
\hline CHEMBL3962209 & 1641497 & 9.0 & 9.0425 & TRN & \\
\hline CHEMBL3948870 & 1641497 & 8.0 & 8.8761 & TST & \\
\hline & & & & 21324 & \\
\hline
\end{tabular}




\begin{tabular}{|c|c|c|c|c|}
\hline & & & upplement & al $\mathrm{T}$ \\
\hline CHEMBL3950212 & 1641497 & 9.0 & 8.3609 & TST \\
\hline CHEMBL3971654 & 1641497 & 9.0 & 8.9621 & TRN \\
\hline CHEMBL 3896234 & 1641497 & 9.0 & 8.9307 & TRN \\
\hline CHEMBL 3896075 & 1641497 & 8.0 & 8.8788 & TST \\
\hline CHEMBL3963684 & 1641497 & 9.0 & 8.8993 & TST \\
\hline CHEMBL3918068 & 1641497 & 9.0 & 8.3335 & TRN \\
\hline CHEMBL3936917 & 1641497 & 8.0 & 8.3449 & TRN \\
\hline CHEMBL3962151 & 1641497 & 9.0 & 8.8913 & TST \\
\hline CHEMBL3924931 & 1641497 & 9.0 & 8.9734 & TRN \\
\hline CHEMBL3918554 & 1641497 & 7.0 & 8.3233 & TRN \\
\hline CHEMBL3917727 & 1641497 & 9.0 & 8.1629 & TRN \\
\hline CHEMBL3986376 & 1641497 & 8.0 & 8.8137 & TST \\
\hline CHEMBL3925777 & 1641497 & 8.0 & 8.6368 & TRN \\
\hline CHEMBL3957372 & 1641497 & 9.0 & 8.5914 & TST \\
\hline CHEMBL3907131 & 1641497 & 9.0 & 8.3147 & TRN \\
\hline CHEMBL3943271 & 1641497 & 9.0 & 8.7643 & TST \\
\hline CHEMBL3902165 & 1641497 & 9.0 & 9.2301 & TRN \\
\hline CHEMBL 3942761 & 1641497 & 8.0 & 8.8677 & TRN \\
\hline CHEMBL3933603 & 1641497 & 8.0 & 8.5234 & TRN \\
\hline CHEMBL3948410 & 1641497 & 8.0 & 8.4907 & TST \\
\hline CHEMBL3935741 & 1641497 & 8.0 & 8.5626 & TST \\
\hline CHEMBL3921500 & 1641497 & 9.0 & 8.9885 & TRN \\
\hline CHEMBL3894505 & 1641497 & 8.0 & 8.7665 & TST \\
\hline CHEMBL3974603 & 1641497 & 9.0 & 8.3653 & TRN \\
\hline CHEMBL 3928148 & 1641497 & 9.0 & 8.8313 & TRN \\
\hline CHEMBL3983851 & 1641497 & 9.0 & 8.4888 & TST \\
\hline CHEMBL3927720 & 1641497 & 8.0 & 8.2739 & TRN \\
\hline CHEMBL 3953448 & 1641497 & 9.0 & 8.1092 & TRN \\
\hline CHEMBL3986251 & 1641497 & 7.0 & 8.4143 & TST \\
\hline CHEMBL3915392 & 1641497 & 7.0 & 8.4807 & TST \\
\hline CHEMBL 3953242 & 1641497 & 9.0 & 8.5548 & TRN \\
\hline CHEMBL3985598 & 1641497 & 9.0 & 8.9013 & TRN \\
\hline CHEMBL3950973 & 1641497 & 9.0 & 8.3292 & TRN \\
\hline CHEMBL3949493 & 1641497 & 8.0 & 8.6682 & TRN \\
\hline CHEMBL3971122 & 1641497 & 8.0 & 8.0928 & TRN \\
\hline CHEMBL3955883 & 1641497 & 9.0 & 8.8157 & TST \\
\hline CHEMBL3965601 & 1641497 & 9.0 & 8.1083 & TRN \\
\hline CHEMBL3938503 & 1641497 & 9.0 & 8.2463 & TRN \\
\hline CHEMBL3965824 & 1641497 & 8.0 & 8.702 & TRN \\
\hline CHEMBL 3929589 & 1641497 & 9.0 & 8.3676 & TRN \\
\hline CHEMBL3953667 & 1641497 & 9.0 & 8.9093 & TRN \\
\hline CHEMBL3913323 & 1641497 & 8.0 & 8.2455 & TRN \\
\hline CHEMBL3942613 & 1641497 & 9.0 & 9.0407 & TRN \\
\hline CHEMBL3923322 & 1641497 & 8.0 & 8.2778 & TRN \\
\hline CHEMBL 3930332 & 1641497 & 8.0 & 8.2638 & TST \\
\hline CHEMBL3947407 & 1641497 & 9.0 & 8.4403 & TRN \\
\hline CHEMBL3936125 & 1641497 & 9.0 & 8.8855 & TST \\
\hline CHEMBL3969313 & 1641497 & 8.0 & 8.0861 & TRN \\
\hline
\end{tabular}




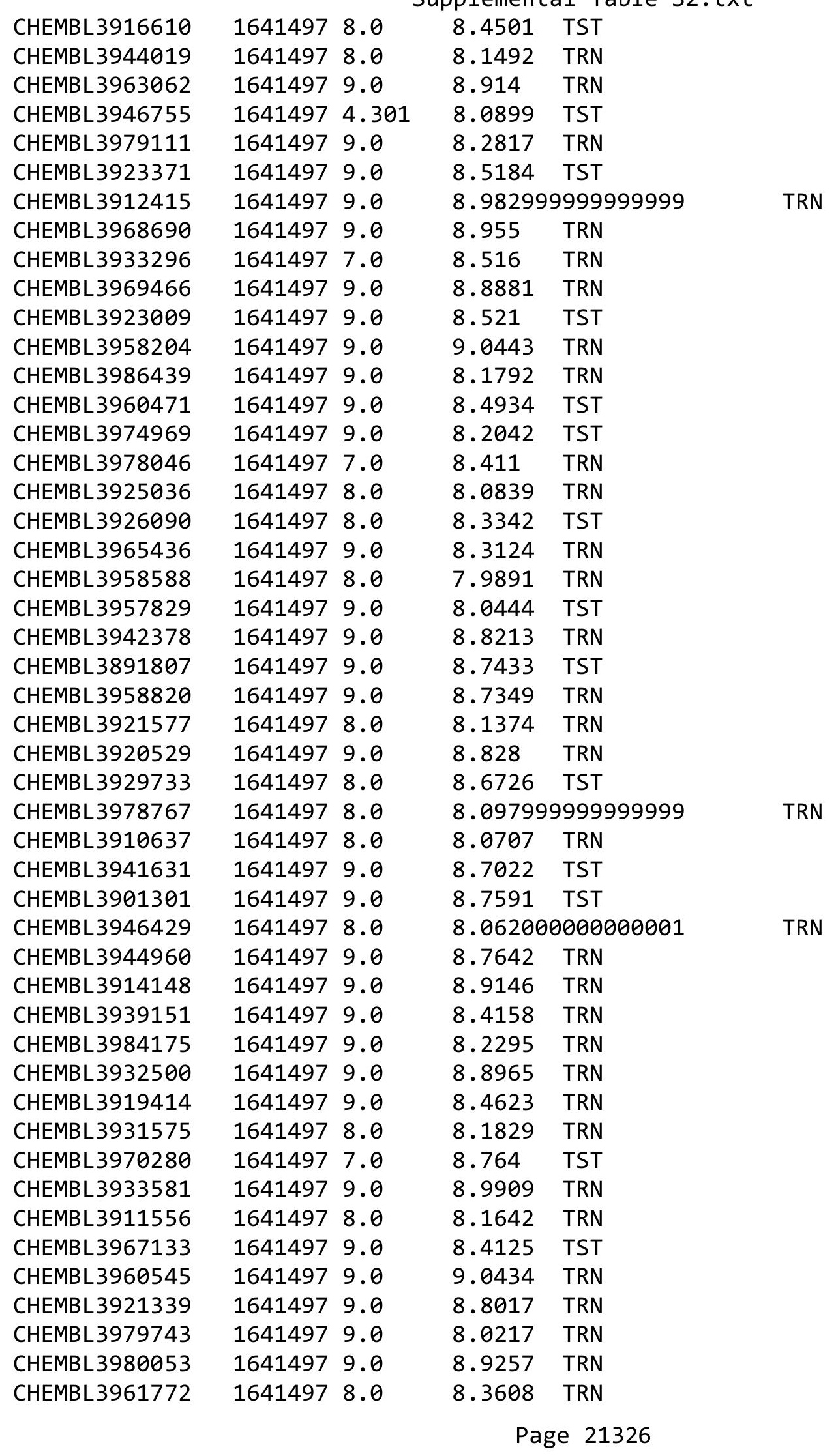




\begin{tabular}{|c|c|c|c|c|c|}
\hline \multirow[b]{2}{*}{ CHEMBL 3937764} & \multirow[b]{2}{*}{1641497} & \\
\hline & & 8.0 & 8.7406 & TRN & \\
\hline CHEMBL3962893 & 1641497 & 8.0 & 8.4017 & TRN & \\
\hline CHEMBL3895467 & 1641497 & 9.0 & 8.5227 & TRN & \\
\hline CHEMBL3893995 & 1641497 & 9.0 & 8.8959 & TRN & \\
\hline CHEMBL3903284 & 1641497 & 9.0 & 8.9833 & TRN & \\
\hline CHEMBL3971393 & 1641497 & 8.0 & 8.151 & TRN & \\
\hline CHEMBL3919584 & 1641497 & 8.0 & 8.2353 & TST & \\
\hline CHEMBL3960829 & 1641497 & 8.0 & 8.417 & TST & \\
\hline CHEMBL3923271 & 1641497 & 8.0 & 8.1766 & TRN & \\
\hline CHEMBL3966464 & 1641497 & 9.0 & 8.3197 & TRN & \\
\hline CHEMBL3941130 & 1641497 & 8.0 & 8.4384 & TRN & \\
\hline CHEMBL3977133 & 1641497 & 9.0 & 8.9048 & TRN & \\
\hline CHEMBL3950473 & 1641497 & 9.0 & 8.7889 & TRN & \\
\hline CHEMBL3952701 & 1641497 & 9.0 & 8.8637 & TRN & \\
\hline CHEMBL3941242 & 1641497 & 4.301 & 8.1565 & TST & \\
\hline CHEMBL3965689 & 1641497 & 9.0 & 8.4858 & TST & \\
\hline CHEMBL3928189 & 1641497 & 9.0 & 8.8099 & TRN & \\
\hline CHEMBL3942463 & 1641497 & 9.0 & 8.7566 & TRN & \\
\hline CHEMBL3940803 & 1641497 & 9.0 & 8.3503 & TRN & \\
\hline CHEMBL3977781 & 1641497 & 8.0 & 8.4005 & TST & \\
\hline CHEMBL3924142 & 1641497 & 9.0 & 8.9703 & TRN & \\
\hline CHEMBL3967795 & 1641497 & 8.0 & 8.4193 & TST & \\
\hline CHEMBL3932580 & 1641497 & 9.0 & 8.6335 & TRN & \\
\hline CHEMBL3930049 & 1641497 & 9.0 & 8.7619 & TRN & \\
\hline CHEMBL3940752 & 1641497 & 9.0 & 8.9102 & TRN & \\
\hline CHEMBL3950185 & 1641497 & 9.0 & 8.88 & TRN & \\
\hline CHEMBL3900606 & 1641497 & 9.0 & 8.3208 & TRN & \\
\hline CHEMBL3890774 & 1641497 & 8.0 & 8.0852 & TRN & \\
\hline CHEMBL3926841 & 1641497 & 8.0 & 8.8766 & TRN & \\
\hline CHEMBL3983384 & 1641497 & 9.0 & 8.77799 & 9999999999 & TRN \\
\hline CHEMBL3896697 & 1641497 & 9.0 & 8.6857 & TRN & \\
\hline CHEMBL3897914 & 1641497 & 9.0 & 8.8647 & TRN & \\
\hline CHEMBL3961319 & 1641497 & 8.0 & 8.1968 & TRN & \\
\hline CHEMBL3981518 & 1641497 & 8.0 & 8.0561 & TST & \\
\hline CHEMBL3945278 & 1641497 & 9.0 & 8.1465 & TRN & \\
\hline CHEMBL3961964 & 1641497 & 9.0 & 9.1906 & TRN & \\
\hline CHEMBL3958226 & 1641497 & 9.0 & 8.3574 & TRN & \\
\hline CHEMBL3926144 & 1641497 & 9.0 & 8.9773 & TRN & \\
\hline CHEMBL3928053 & 1641497 & 9.0 & 8.5907 & TRN & \\
\hline CHEMBL3923991 & 1641497 & 7.0 & 8.3918 & TRN & \\
\hline CHEMBL3941199 & 1641497 & 9.0 & 8.2983 & TRN & \\
\hline CHEMBL3938861 & 1641497 & 8.0 & 8.3388 & TST & \\
\hline CHEMBL3903159 & 1641497 & 8.0 & 8.0893 & TRN & \\
\hline CHEMBL3981797 & 1641497 & 9.0 & 8.0677 & TRN & \\
\hline CHEMBL3972553 & 1641497 & 8.0 & 8.7358 & TST & \\
\hline CHEMBL3948868 & 1641497 & 8.0 & 8.1465 & TRN & \\
\hline CHEMBL3932791 & 1641497 & 7.0 & 7.9687 & TST & \\
\hline CHEMBL3969612 & 1641497 & 8.0 & 8.6414 & TRN & \\
\hline & & & & 21327 & \\
\hline
\end{tabular}




\begin{tabular}{|c|c|c|c|c|c|}
\hline & & & & & \\
\hline CHEMBL3940239 & 1641497 & 8.0 & 8.9072 & TST & \\
\hline CHEMBL3965226 & 1641497 & 8.0 & 8.2163 & TRN & \\
\hline CHEMBL3951494 & 1641497 & 9.0 & 8.5889 & TRN & \\
\hline CHEMBL3905351 & 1641497 & 8.0 & 8.2547 & TRN & \\
\hline CHEMBL3893550 & 1641497 & 9.0 & 9.0229 & TST & \\
\hline CHEMBL 3894196 & 1641497 & 7.0 & 8.3252 & TRN & \\
\hline CHEMBL3935120 & 1641497 & 8.0 & 8.6192 & TRN & \\
\hline CHEMBL3969595 & 1641497 & 8.0 & 8.571 & TST & \\
\hline CHEMBL3943063 & 1641497 & 9.0 & 8.3537 & TST & \\
\hline CHEMBL3900641 & 1641497 & 8.0 & 8.6804 & TRN & \\
\hline CHEMBL 3908042 & 1641497 & 8.0 & 8.6848 & TST & \\
\hline CHEMBL3895842 & 1641497 & 9.0 & 8.2868 & TRN & \\
\hline CHEMBL3976978 & 1641497 & 8.0 & 8.3059 & TRN & \\
\hline CHEMBL3949736 & 1641497 & 9.0 & 8.4615 & TST & \\
\hline CHEMBL 3969444 & 1641497 & 9.0 & 8.4143 & TRN & \\
\hline CHEMBL 3985670 & 1641497 & 9.0 & 8.9962 & TRN & \\
\hline CHEMBL3950797 & 1641497 & 8.0 & 8.099 & TRN & \\
\hline CHEMBL3936970 & 1641497 & 9.0 & 8.7774 & TRN & \\
\hline CHEMBL3918684 & 1641497 & 9.0 & 8.8111 & TRN & \\
\hline CHEMBL 3984084 & 1641497 & 9.0 & 8.84700 & 0000000001 & TRN \\
\hline CHEMBL3920901 & 1641497 & 8.0 & 8.1015 & TRN & \\
\hline CHEMBL3986917 & 1641497 & 9.0 & 8.8665 & TST & \\
\hline CHEMBL3907886 & 1641497 & 8.0 & 8.2752 & TRN & \\
\hline CHEMBL3904275 & 1641497 & 8.0 & 8.3186 & TRN & \\
\hline CHEMBL3963462 & 1641497 & 8.0 & 8.1699 & TRN & \\
\hline CHEMBL3962135 & 1641497 & 8.0 & 8.4304 & TST & \\
\hline CHEMBL3902320 & 1641497 & 9.0 & 8.8619 & TRN & \\
\hline CHEMBL3984526 & 1641497 & 8.0 & 8.5655 & TST & \\
\hline CHEMBL3935434 & 1641497 & 8.0 & 8.26100 & 0000000001 & TRN \\
\hline CHEMBL3955320 & 1641497 & 8.0 & 8.1158 & TRN & \\
\hline CHEMBL3971993 & 1641497 & 9.0 & 9.1045 & TRN & \\
\hline CHEMBL 3973503 & 1641497 & 9.0 & 8.9231 & TRN & \\
\hline CHEMBL3972840 & 1641497 & 8.0 & 8.0775 & TRN & \\
\hline CHEMBL3948806 & 1641497 & 8.0 & 9.0522 & TST & \\
\hline CHEMBL3907012 & 1641497 & 8.0 & 8.3717 & TRN & \\
\hline CHEMBL3901384 & 1641497 & 7.0 & 8.7231 & TST & \\
\hline CHEMBL3912390 & 1641497 & 7.0 & 8.7727 & TST & \\
\hline CHEMBL3941347 & 1641497 & 9.0 & 8.8493 & TRN & \\
\hline CHEMBL3899126 & 1641497 & 8.0 & 8.4495 & TST & \\
\hline CHEMBL3967701 & 1641497 & 9.0 & 8.5012 & TST & \\
\hline CHEMBL3919980 & 1641497 & 8.0 & 8.247 & TRN & \\
\hline CHEMBL3954706 & 1641497 & 7.0 & 8.826 & TST & \\
\hline CHEMBL3954928 & 1641497 & 7.0 & 8.0325 & TST & \\
\hline CHEMBL3929369 & 1641497 & 9.0 & 9.0724 & TRN & \\
\hline CHEMBL3949588 & 1641497 & 9.0 & 8.3327 & TRN & \\
\hline CHEMBL 3902443 & 1641497 & 8.0 & 8.6998 & TRN & \\
\hline CHEMBL3950893 & 1641497 & 8.0 & 8.5008 & TST & \\
\hline CHEMBL3917114 & 1641497 & 8.0 & 8.2076 & TRN & \\
\hline
\end{tabular}




\begin{tabular}{|c|c|c|c|c|}
\hline & & & ment & al Ta \\
\hline CHEMBL3922166 & 1641497 & 9.0 & 8.9412 & TRN \\
\hline CHEMBL 3927210 & 1641497 & 8.0 & 8.5332 & TRN \\
\hline CHEMBL3949686 & 1641497 & 9.0 & 8.1695 & TRN \\
\hline CHEMBL3922479 & 1641497 & 9.0 & 8.5819 & TRN \\
\hline CHEMBL3923839 & 1641497 & 8.0 & 8.1563 & TRN \\
\hline CHEMBL3903736 & 1641497 & 9.0 & 8.3826 & TRN \\
\hline CHEMBL3933068 & 1641497 & 8.0 & 8.5168 & TST \\
\hline CHEMBL3962942 & 1641497 & 9.0 & 8.3538 & TRN \\
\hline CHEMBL3946973 & 1641497 & 8.0 & 8.8922 & TST \\
\hline CHEMBL3977891 & 1641497 & 8.0 & 7.7543 & TRN \\
\hline CHEMBL3923716 & 1641497 & 9.0 & 8.9916 & TST \\
\hline CHEMBL3928789 & 1641497 & 8.0 & 8.1868 & TRN \\
\hline CHEMBL3963002 & 1641497 & 9.0 & 8.2505 & TRN \\
\hline CHEMBL3900715 & 1641497 & 9.0 & 8.2957 & TRN \\
\hline CHEMBL3892566 & 1641497 & 7.0 & 8.2076 & TRN \\
\hline CHEMBL3894831 & 1641497 & 8.0 & 8.2578 & TRN \\
\hline CHEMBL3894841 & 1641497 & 9.0 & 8.2758 & TRN \\
\hline CHEMBL 3974248 & 1641497 & 8.0 & 8.0763 & TRN \\
\hline CHEMBL3963106 & 1641497 & 8.0 & 8.9828 & TST \\
\hline CHEMBL3966714 & 1641497 & 9.0 & 8.7544 & TRN \\
\hline CHEMBL3974335 & 1641497 & 8.0 & 8.1844 & TRN \\
\hline CHEMBL 3937854 & 1641497 & 8.0 & 8.8694 & TRN \\
\hline CHEMBL3978427 & 1641497 & 8.0 & 8.9517 & TST \\
\hline CHEMBL3970679 & 1641497 & 8.0 & 8.5359 & TRN \\
\hline CHEMBL3963356 & 1641497 & 9.0 & 8.2216 & TRN \\
\hline CHEMBL3964265 & 1641497 & 9.0 & 8.9548 & TRN \\
\hline CHEMBL3895687 & 1641497 & 9.0 & 8.7399 & TST \\
\hline CHEMBL 3934541 & 1641497 & 9.0 & 8.8813 & TRN \\
\hline CHEMBL3942940 & 1641497 & 9.0 & 8.7073 & TRN \\
\hline CHEMBL3911772 & 1641497 & 9.0 & 9.1292 & TRN \\
\hline CHEMBL 3897258 & 1641497 & 9.0 & 8.1529 & TRN \\
\hline CHEMBL3929991 & 1641497 & 9.0 & 8.8486 & TRN \\
\hline CHEMBL 3918782 & 1641497 & 7.0 & 8.0359 & TRN \\
\hline CHEMBL3965145 & 1641497 & 9.0 & 8.7306 & TRN \\
\hline CHEMBL 3948295 & 1641497 & 5.0 & 7.5098 & TRN \\
\hline CHEMBL3966868 & 1641497 & 9.0 & 9.0478 & TST \\
\hline CHEMBL3898009 & 1641497 & 7.0 & 8.5737 & TST \\
\hline CHEMBL3952044 & 1641497 & 9.0 & 8.8819 & TRN \\
\hline CHEMBL3926944 & 1641497 & 8.0 & 8.3012 & TRN \\
\hline CHEMBL 3957383 & 1641497 & 9.0 & 8.3459 & TRN \\
\hline CHEMBL3945155 & 1641497 & 8.0 & 8.3736 & TST \\
\hline CHEMBL3912161 & 1641497 & 8.0 & 8.2117 & TRN \\
\hline CHEMBL3894194 & 1641497 & 9.0 & 8.474 & TST \\
\hline CHEMBL3935439 & 1641497 & 8.0 & 8.1114 & TRN \\
\hline CHEMBL 3981522 & 1641497 & 8.0 & 8.4638 & TRN \\
\hline CHEMBL3910993 & 1641497 & 8.0 & 8.215 & TST \\
\hline CHEMBL3917326 & 1641497 & 8.0 & 8.3236 & TRN \\
\hline CHEMBL3974228 & 1641497 & 9.0 & 8.9256 & TRN \\
\hline
\end{tabular}




\begin{tabular}{|c|c|c|c|c|}
\hline \multicolumn{5}{|c|}{ Supplemental Table S2.txt } \\
\hline CHEMBL3898728 & 1641497 & 8.0 & 8.3922 & TST \\
\hline CHEMBL3946468 & 1641497 & 8.0 & 8.2682 & TRN \\
\hline CHEMBL 3984229 & 1641497 & 8.0 & 8.3393 & TST \\
\hline CHEMBL3918958 & 1641497 & 8.0 & 8.1473 & TRN \\
\hline CHEMBL3934224 & 1641497 & 9.0 & 8.9093 & TRN \\
\hline CHEMBL3897403 & 1641497 & 9.0 & 8.6444 & TRN \\
\hline CHEMBL3894485 & 1641497 & 9.0 & 8.8152 & TRN \\
\hline CHEMBL3973200 & 1641497 & 9.0 & 9.1431 & TRN \\
\hline CHEMBL 3985203 & 1641497 & 9.0 & 8.8732 & TRN \\
\hline CHEMBL3970764 & 1641497 & 8.0 & 8.095 & TRN \\
\hline CHEMBL3969875 & 1641497 & 8.0 & 8.3787 & TRN \\
\hline CHEMBL3889837 & 1641497 & 9.0 & 8.3037 & TRN \\
\hline CHEMBL3892031 & 1641497 & 9.0 & 8.5699 & TST \\
\hline CHEMBL3934689 & 1641497 & 8.0 & 8.1243 & TRN \\
\hline CHEMBL3954753 & 1641497 & 9.0 & 8.5877 & TRN \\
\hline CHEMBL3897057 & 1641497 & 9.0 & 9.1031 & TRN \\
\hline CHEMBL3922738 & 1641497 & 8.0 & 8.2583 & TRN \\
\hline CHEMBL3896820 & 1641497 & 7.0 & 8.7364 & TST \\
\hline CHEMBL3949166 & 1641497 & 9.0 & 8.9096 & TRN \\
\hline CHEMBL3983199 & 1641497 & 5.0 & 8.077 & TRN \\
\hline CHEMBL3920597 & 1641497 & 9.0 & 8.6729 & TRN \\
\hline CHEMBL3961330 & 1641497 & 9.0 & 8.8726 & TRN \\
\hline CHEMBL 3942838 & 1641497 & 9.0 & 8.8251 & TRN \\
\hline CHEMBL 3933490 & 1641497 & 9.0 & 8.6825 & TRN \\
\hline CHEMBL3898094 & 1641497 & 9.0 & 8.9555 & TRN \\
\hline CHEMBL3972559 & 1641497 & 9.0 & 8.2001 & TRN \\
\hline CHEMBL3952403 & 1641497 & 9.0 & 8.9946 & TRN \\
\hline CHEMBL 3912280 & 1641497 & 7.0 & 8.0662 & TRN \\
\hline CHEMBL 3949228 & 1641497 & 8.0 & 8.2139 & TRN \\
\hline CHEMBL3896971 & 1641497 & 9.0 & 9.0241 & TRN \\
\hline CHEMBL3903869 & 1641497 & 9.0 & 8.3946 & TRN \\
\hline CHEMBL3904713 & 1641497 & 9.0 & 8.4964 & TST \\
\hline CHEMBL3966556 & 1641497 & 8.0 & 8.1576 & TRN \\
\hline CHEMBL3918075 & 1641497 & 7.0 & 8.2751 & TST \\
\hline CHEMBL3975204 & 1641497 & 9.0 & 8.7792 & TST \\
\hline CHEMBL3933070 & 1641497 & 8.0 & 8.1296 & TRN \\
\hline CHEMBL3918993 & 1641497 & 7.0 & 8.4258 & TST \\
\hline CHEMBL3975960 & 1641497 & 9.0 & 8.9748 & TRN \\
\hline CHEMBL 3968207 & 1641497 & 9.0 & 8.7459 & TRN \\
\hline CHEMBL3893579 & 1641497 & 8.0 & 8.4011 & TST \\
\hline CHEMBL3946896 & 1641497 & 8.0 & 8.8022 & TST \\
\hline CHEMBL3929055 & 1641497 & 8.0 & 8.4675 & TRN \\
\hline CHEMBL3937823 & 1641497 & 9.0 & 8.4242 & TRN \\
\hline CHEMBL 3913702 & 1641497 & 9.0 & 8.1393 & TRN \\
\hline CHEMBL3898695 & 1641497 & 8.0 & 8.269 & TRN \\
\hline CHEMBL3970369 & 1641497 & 9.0 & 8.6158 & TRN \\
\hline CHEMBL3901345 & 1641497 & 5.0 & 7.4603 & TRN \\
\hline CHEMBL3916105 & 1641497 & 9.0 & 8.5041 & TST \\
\hline
\end{tabular}




\begin{tabular}{|c|c|c|c|c|}
\hline & & & pplement & al $\mathrm{Ta}$ \\
\hline CHEMBL 3943207 & 1641497 & 9.0 & 8.38 & TRN \\
\hline CHEMBL3980859 & 1641497 & 9.0 & 9.0265 & TST \\
\hline CHEMBL3917668 & 1641497 & 7.0 & 7.7398 & TRN \\
\hline CHEMBL 3981449 & 1641497 & 9.0 & 9.2124 & TRN \\
\hline CHEMBL3924407 & 1641497 & 9.0 & 8.3115 & TRN \\
\hline CHEMBL3956043 & 1641497 & 9.0 & 8.9834 & TRN \\
\hline CHEMBL3894659 & 1641497 & 8.0 & 8.0553 & TRN \\
\hline CHEMBL 3980907 & 1641497 & 8.0 & 8.2868 & TRN \\
\hline CHEMBL3908590 & 1641497 & 7.0 & 8.5734 & TST \\
\hline CHEMBL3965131 & 1641497 & 9.0 & 8.1876 & TST \\
\hline CHEMBL3966987 & 1641497 & 8.0 & 8.1961 & TRN \\
\hline CHEMBL3896769 & 1641497 & 8.0 & 8.538 & TST \\
\hline CHEMBL 3955872 & 1641497 & 8.0 & 8.1559 & TRN \\
\hline CHEMBL3962682 & 1641497 & 9.0 & 9.0881 & TRN \\
\hline CHEMBL3944605 & 1641497 & 9.0 & 8.1322 & TRN \\
\hline CHEMBL3931188 & 1641497 & 9.0 & 9.0796 & TRN \\
\hline CHEMBL3977797 & 1641497 & 8.0 & 8.0579 & TRN \\
\hline CHEMBL3924435 & 1641497 & 8.0 & 8.4692 & TST \\
\hline CHEMBL 3903748 & 1641497 & 9.0 & 8.1695 & TST \\
\hline CHEMBL3981503 & 1641497 & 8.0 & 8.2555 & TRN \\
\hline CHEMBL3976346 & 1641497 & 7.0 & 7.6732 & TRN \\
\hline CHEMBL3946556 & 1641497 & 9.0 & 9.061 & TRN \\
\hline CHEMBL 3938384 & 1641497 & 7.0 & 8.7345 & TST \\
\hline CHEMBL3961830 & 1641497 & 8.0 & 8.2456 & TRN \\
\hline CHEMBL 3902426 & 1641497 & 9.0 & 8.7098 & TRN \\
\hline CHEMBL3922615 & 1641497 & 9.0 & 8.9892 & TRN \\
\hline CHEMBL3905004 & 1641497 & 9.0 & 8.3724 & TST \\
\hline CHEMBL3961225 & 1641497 & 8.0 & 8.3055 & TRN \\
\hline CHEMBL 3976352 & 1641497 & 9.0 & 8.7268 & TRN \\
\hline CHEMBL3915246 & 1641497 & 8.0 & 8.3645 & TRN \\
\hline CHEMBL3956780 & 1641497 & 7.0 & 8.4983 & TST \\
\hline CHEMBL3949243 & 1641497 & 9.0 & 8.7119 & TRN \\
\hline CHEMBL3931160 & 1641497 & 9.0 & 8.4371 & TRN \\
\hline CHEMBL 3898793 & 1641497 & 8.0 & 8.969 & TST \\
\hline CHEMBL 3985479 & 1641497 & 8.0 & 8.2238 & TRN \\
\hline CHEMBL3964394 & 1641497 & 9.0 & 8.2008 & TRN \\
\hline CHEMBL3891837 & 1641497 & 8.0 & 8.1702 & TRN \\
\hline CHEMBL 3889467 & 1641497 & 7.0 & 7.8652 & TRN \\
\hline CHEMBL 3894984 & 1641497 & 8.0 & 8.4068 & TRN \\
\hline CHEMBL3959309 & 1641497 & 9.0 & 8.8637 & TST \\
\hline CHEMBL3922927 & 1641497 & 9.0 & 8.3334 & TRN \\
\hline CHEMBL3910421 & 1641497 & 8.0 & 8.8565 & TST \\
\hline CHEMBL3921764 & 1641497 & 7.0 & 8.4457 & TST \\
\hline CHEMBL 3978979 & 1641497 & 8.0 & 8.4847 & TRN \\
\hline CHEMBL 3905020 & 1641497 & 8.0 & 8.2051 & TRN \\
\hline CHEMBL 3892345 & 1641497 & 9.0 & 8.9059 & TRN \\
\hline CHEMBL3960821 & 1641497 & 9.0 & 9.073 & TRN \\
\hline CHEMBL3912048 & 1641497 & 9.0 & 8.821 & TRN \\
\hline
\end{tabular}




\begin{tabular}{|c|c|c|c|c|c|}
\hline & & & & & \\
\hline CHEMBL3914417 & 1641497 & 9.0 & 8.8037 & TRN & \\
\hline CHEMBL3921379 & 1641497 & 8.0 & 9.1621 & TRN & \\
\hline CHEMBL3935665 & 1641497 & 9.0 & 8.2473 & TRN & \\
\hline CHEMBL3919525 & 1641497 & 9.0 & 8.5684 & TRN & \\
\hline CHEMBL3982453 & 1641497 & 8.0 & 8.379 & TRN & \\
\hline CHEMBL3929226 & 1641497 & 8.0 & 8.4782 & TST & \\
\hline CHEMBL3903789 & 1641497 & 8.0 & 8.2579 & TRN & \\
\hline CHEMBL3906292 & 1641497 & 9.0 & 8.2284 & TRN & \\
\hline CHEMBL3933725 & 1641497 & 9.0 & 8.9051 & TRN & \\
\hline CHEMBL3957598 & 1641497 & 9.0 & 9.0682 & TRN & \\
\hline CHEMBL3908672 & 1641497 & 7.0 & 8.0898 & TRN & \\
\hline CHEMBL3920779 & 1641497 & 9.0 & 9.0231 & TRN & \\
\hline CHEMBL3903840 & 1641497 & 9.0 & 8.1824 & TRN & \\
\hline CHEMBL3982566 & 1641497 & 8.0 & 8.1406 & TRN & \\
\hline CHEMBL3900821 & 1641497 & 8.0 & 8.2005 & TRN & \\
\hline CHEMBL3908628 & 1641497 & 8.0 & 8.5274 & TRN & \\
\hline CHEMBL3957790 & 1641497 & 9.0 & 8.7935 & TRN & \\
\hline CHEMBL3955936 & 1641497 & 8.0 & 8.2783 & TRN & \\
\hline CHEMBL3933841 & 1641497 & 8.0 & 8.2328 & TRN & \\
\hline CHEMBL3953536 & 1641497 & 8.0 & 8.28399 & 7999999999 & TRN \\
\hline CHEMBL3963028 & 1641497 & 7.0 & 8.15899 & 7999999999 & TRN \\
\hline CHEMBL3922928 & 1641497 & 8.0 & 8.4914 & TST & \\
\hline CHEMBL3915887 & 1641497 & 9.0 & 8.6101 & TRN & \\
\hline CHEMBL3928418 & 1641497 & 8.0 & 8.4176 & TST & \\
\hline CHEMBL3932935 & 1641497 & 7.0 & 7.6547 & TRN & \\
\hline CHEMBL3981868 & 1641497 & 9.0 & 8.244 & TRN & \\
\hline CHEMBL3929690 & 1641497 & 9.0 & 9.1769 & TRN & \\
\hline CHEMBL3916106 & 1641497 & 8.0 & 8.8165 & TST & \\
\hline CHEMBL3951552 & 1641497 & 8.0 & 8.2553 & TRN & \\
\hline CHEMBL3975604 & 1641497 & 9.0 & 8.7125 & TRN & \\
\hline CHEMBL3902029 & 1641497 & 9.0 & 9.0048 & TRN & \\
\hline CHEMBL3954693 & 1641497 & 9.0 & 8.6259 & TST & \\
\hline CHEMBL3931967 & 1641497 & 9.0 & 8.654 & TRN & \\
\hline CHEMBL3960121 & 1641497 & 8.0 & 8.2229 & TRN & \\
\hline CHEMBL3914335 & 1641497 & 9.0 & 8.2517 & TRN & \\
\hline CHEMBL3929840 & 1641497 & 8.0 & 8.4499 & TST & \\
\hline CHEMBL3933333 & 1641497 & 9.0 & 8.1595 & TRN & \\
\hline CHEMBL3966703 & 1641497 & 9.0 & 8.8061 & TRN & \\
\hline CHEMBL3923171 & 1641497 & 8.0 & 8.387 & TST & \\
\hline CHEMBL3956779 & 1641497 & 8.0 & 8.7591 & TRN & \\
\hline CHEMBL3978900 & 1641497 & 9.0 & 8.2264 & TRN & \\
\hline CHEMBL3895043 & 1641497 & 9.0 & 8.5231 & TRN & \\
\hline CHEMBL3973959 & 1641497 & 9.0 & 8.1352 & TRN & \\
\hline CHEMBL3905990 & 1641497 & 7.0 & 8.1266 & TRN & \\
\hline CHEMBL3932280 & 1641497 & 7.0 & 8.2233 & TRN & \\
\hline CHEMBL3926517 & 1641497 & 9.0 & 8.1017 & TRN & \\
\hline CHEMBL3943952 & 1641497 & 9.0 & 9.0394 & TRN & \\
\hline CHEMBL3916305 & 1641497 & 8.0 & 8.4952 & TRN & \\
\hline
\end{tabular}




\begin{tabular}{|c|c|c|c|c|}
\hline & & & pplement & al $\mathrm{Ta}$ \\
\hline CHEMBL3934101 & 1641497 & 9.0 & 8.7183 & TRN \\
\hline CHEMBL3898169 & 1641497 & 9.0 & 8.9664 & TRN \\
\hline CHEMBL3893709 & 1641497 & 8.0 & 8.1993 & TRN \\
\hline CHEMBL3932647 & 1641497 & 9.0 & 8.2463 & TRN \\
\hline CHEMBL3933846 & 1641497 & 9.0 & 8.3982 & TRN \\
\hline CHEMBL3927197 & 1641497 & 9.0 & 8.6983 & TRN \\
\hline CHEMBL3960175 & 1641497 & 8.0 & 8.2758 & TRN \\
\hline CHEMBL 3978793 & 1641497 & 9.0 & 8.5348 & TST \\
\hline CHEMBL3955710 & 1641497 & 9.0 & 8.755 & TRN \\
\hline CHEMBL3924427 & 1641497 & 9.0 & 8.8708 & TRN \\
\hline CHEMBL3964036 & 1641497 & 9.0 & 8.2322 & TRN \\
\hline CHEMBL3927223 & 1641497 & 9.0 & 8.1941 & TRN \\
\hline CHEMBL 3965468 & 1641497 & 9.0 & 8.182 & TRN \\
\hline CHEMBL3950119 & 1641497 & 9.0 & 8.8029 & TRN \\
\hline CHEMBL3921801 & 1641497 & 7.0 & 8.3239 & TRN \\
\hline CHEMBL3897924 & 1641497 & 9.0 & 9.0435 & TRN \\
\hline CHEMBL3974316 & 1641497 & 9.0 & 8.7614 & TRN \\
\hline CHEMBL3900868 & 1641497 & 9.0 & 8.2656 & TRN \\
\hline CHEMBL 3963958 & 1641497 & 9.0 & 9.0323 & TRN \\
\hline CHEMBL3895918 & 1641497 & 8.0 & 8.3186 & TRN \\
\hline CHEMBL3954260 & 1641497 & 6.699 & 8.0738 & TRN \\
\hline CHEMBL3987091 & 1641497 & 9.0 & 8.1759 & TRN \\
\hline CHEMBL3953125 & 1641497 & 9.0 & 8.281 & TRN \\
\hline CHEMBL 3923210 & 1641497 & 8.0 & 8.2477 & TST \\
\hline CHEMBL3913856 & 1641497 & 8.0 & 8.3031 & TRN \\
\hline CHEMBL3971759 & 1641497 & 9.0 & 8.7717 & TRN \\
\hline CHEMBL3917568 & 1641497 & 8.0 & 8.5059 & TRN \\
\hline CHEMBL3931631 & 1641497 & 9.0 & 8.5382 & TST \\
\hline CHEMBL 3965752 & 1641497 & 9.0 & 8.6688 & TRN \\
\hline CHEMBL 3898247 & 1641497 & 7.0 & 8.4453 & TRN \\
\hline CHEMBL3981867 & 1641497 & 9.0 & 8.8646 & TRN \\
\hline CHEMBL3982383 & 1641497 & 9.0 & 8.8265 & TRN \\
\hline CHEMBL3909628 & 1641497 & 5.0 & 8.4098 & TRN \\
\hline CHEMBL 3985801 & 1641497 & 8.0 & 8.1432 & TRN \\
\hline CHEMBL 3901970 & 1641497 & 9.0 & 8.2326 & TRN \\
\hline CHEMBL3955260 & 1641497 & 9.0 & 9.0747 & TRN \\
\hline CHEMBL3939079 & 1641497 & 9.0 & 9.2767 & TRN \\
\hline CHEMBL 3897273 & 1641497 & 9.0 & 8.7453 & TRN \\
\hline CHEMBL 3897992 & 1641497 & 8.0 & 8.4504 & TST \\
\hline CHEMBL3910508 & 1641497 & 8.0 & 8.5491 & TST \\
\hline CHEMBL3941273 & 1641497 & 9.0 & 8.2391 & TRN \\
\hline CHEMBL3919760 & 1641497 & 9.0 & 8.8255 & TRN \\
\hline CHEMBL3947630 & 1641497 & 9.0 & 9.0037 & TRN \\
\hline CHEMBL 3890413 & 1641497 & 9.0 & 8.4078 & TST \\
\hline CHEMBL3907828 & 1641497 & 9.0 & 8.7725 & TRN \\
\hline CHEMBL3958073 & 1641497 & 8.0 & 8.3512 & TST \\
\hline CHEMBL3977932 & 1641497 & 8.0 & 8.4065 & TRN \\
\hline CHEMBL 3893249 & 1641497 & 9.0 & 8.7365 & TRN \\
\hline
\end{tabular}




\begin{tabular}{|c|c|c|c|c|}
\hline & & & ement & al Ta \\
\hline CHEMBL3890154 & 1641497 & 9.0 & 8.8372 & TRN \\
\hline CHEMBL3985177 & 1641497 & 9.0 & 9.0867 & TRN \\
\hline CHEMBL3935811 & 1641497 & 7.0 & 8.3057 & TRN \\
\hline CHEMBL 3979608 & 1641497 & 9.0 & 8.9818 & TRN \\
\hline CHEMBL 3935146 & 1641497 & 9.0 & 9.0355 & TRN \\
\hline CHEMBL3936378 & 1641497 & 9.0 & 8.8909 & TST \\
\hline CHEMBL3969495 & 1641497 & 8.0 & 8.721 & TRN \\
\hline CHEMBL3900381 & 1641497 & 9.0 & 8.8849 & TRN \\
\hline CHEMBL3938553 & 1641497 & 9.0 & 8.821 & TRN \\
\hline CHEMBL3908575 & 1641497 & 7.0 & 8.1858 & TRN \\
\hline CHEMBL3973509 & 1641497 & 9.0 & 8.3566 & TRN \\
\hline CHEMBL 3904224 & 1641497 & 9.0 & 8.9386 & TRN \\
\hline CHEMBL3955274 & 1641497 & 9.0 & 8.932 & TRN \\
\hline CHEMBL3896618 & 1641497 & 9.0 & 8.5841 & TRN \\
\hline CHEMBL 3947286 & 1641497 & 9.0 & 8.1911 & TST \\
\hline CHEMBL 3983580 & 1641497 & 9.0 & 8.7458 & TRN \\
\hline CHEMBL3954658 & 1641497 & 9.0 & 8.2578 & TRN \\
\hline CHEMBL3961263 & 1641497 & 9.0 & 8.748 & TRN \\
\hline CHEMBL3947875 & 1641497 & 9.0 & 9.0341 & TRN \\
\hline CHEMBL3895036 & 1641497 & 8.0 & 8.2129 & TRN \\
\hline CHEMBL3923354 & 1641497 & 8.0 & 8.5572 & TST \\
\hline CHEMBL 3980741 & 1641497 & 7.0 & 8.2646 & TRN \\
\hline CHEMBL3933489 & 1641497 & 8.0 & 9.0142 & TST \\
\hline CHEMBL3966102 & 1641497 & 9.0 & 8.3469 & TRN \\
\hline CHEMBL 3933340 & 1641497 & 7.0 & 8.4572 & TRN \\
\hline CHEMBL3943522 & 1641497 & 8.0 & 8.2695 & TST \\
\hline CHEMBL3924638 & 1641497 & 9.0 & 8.8727 & TRN \\
\hline CHEMBL3895729 & 1641497 & 9.0 & 8.6356 & TRN \\
\hline CHEMBL3968403 & 1641497 & 8.0 & 8.2409 & TRN \\
\hline CHEMBL 3984802 & 1641497 & 8.0 & 8.1471 & TST \\
\hline CHEMBL3945809 & 1641497 & 8.0 & 8.4582 & TST \\
\hline CHEMBL3967449 & 1641497 & 9.0 & 8.9311 & TRN \\
\hline CHEMBL 3940234 & 1641497 & 7.0 & 7.7568 & TRN \\
\hline CHEMBL3928659 & 1641497 & 8.0 & 8.6296 & TRN \\
\hline CHEMBL3917369 & 1641497 & 9.0 & 8.6439 & TST \\
\hline CHEMBL3967499 & 1641497 & 8.0 & 8.5429 & TRN \\
\hline CHEMBL 3981988 & 1641497 & 9.0 & 8.8616 & TRN \\
\hline CHEMBL3920704 & 1641497 & 9.0 & 8.9925 & TRN \\
\hline CHEMBL3933417 & 1641497 & 9.0 & 9.0561 & TST \\
\hline CHEMBL 3898992 & 1641497 & 9.0 & 8.9319 & TRN \\
\hline CHEMBL3959984 & 1641497 & 8.0 & 8.7237 & TRN \\
\hline CHEMBL 3924670 & 1641497 & 9.0 & 8.9166 & TRN \\
\hline CHEMBL3978929 & 1641497 & 8.0 & 8.32 & TRN \\
\hline CHEMBL3970693 & 1641497 & 9.0 & 8.523 & TRN \\
\hline CHEMBL 3920017 & 1641497 & 8.0 & 8.2236 & TRN \\
\hline CHEMBL3980668 & 1641497 & 8.0 & 8.385 & TRN \\
\hline CHEMBL 3969132 & 1641497 & 9.0 & 8.7578 & TRN \\
\hline CHEMBL3967045 & 1641497 & 8.0 & 8.443 & TST \\
\hline
\end{tabular}




\begin{tabular}{|c|c|c|c|c|}
\hline & & & pplement & $\mathrm{a} \perp \mathrm{Ta}$ \\
\hline CHEMBL3962481 & 1641497 & 7.0 & 8.4831 & TST \\
\hline CHEMBL3936263 & 1641497 & 9.0 & 8.4279 & TRN \\
\hline CHEMBL3912333 & 1641497 & 8.0 & 8.5083 & TST \\
\hline CHEMBL3948958 & 1641497 & 9.0 & 8.9932 & TRN \\
\hline CHEMBL3911397 & 1641497 & 7.0 & 8.9042 & TST \\
\hline CHEMBL3903070 & 1641497 & 9.0 & 8.9338 & TRN \\
\hline CHEMBL3951363 & 1641497 & 8.0 & 8.5244 & TST \\
\hline CHEMBL3906007 & 1641497 & 8.0 & 8.2158 & TRN \\
\hline CHEMBL3985204 & 1641497 & 9.0 & 9.1185 & TRN \\
\hline CHEMBL3963041 & 1641497 & 9.0 & 8.3327 & TRN \\
\hline CHEMBL3910845 & 1641497 & 9.0 & 8.8979 & TRN \\
\hline CHEMBL3953721 & 1641497 & 8.0 & 8.4709 & TST \\
\hline CHEMBL3971456 & 1641497 & 9.0 & 8.0417 & TRN \\
\hline CHEMBL3913518 & 1641497 & 8.0 & 8.3924 & TST \\
\hline CHEMBL3921474 & 1641497 & 9.0 & 8.9068 & TRN \\
\hline CHEMBL3889772 & 1641497 & 8.0 & 8.7004 & TRN \\
\hline CHEMBL3931752 & 1641497 & 9.0 & 8.7564 & TRN \\
\hline CHEMBL 3917549 & 1641497 & 9.0 & 8.3792 & TST \\
\hline CHEMBL3932654 & 1641497 & 9.0 & 8.1362 & TRN \\
\hline CHEMBL3959057 & 1641497 & 8.0 & 8.1363 & TRN \\
\hline CHEMBL3940271 & 1641497 & 9.0 & 8.6422 & TRN \\
\hline CHEMBL 3978570 & 1641497 & 8.0 & 8.6063 & TRN \\
\hline CHEMBL3894697 & 1641497 & 8.0 & 8.4353 & TST \\
\hline CHEMBL3895196 & 1641497 & 9.0 & 8.7973 & TRN \\
\hline CHEMBL 3943255 & 1641497 & 8.0 & 8.3479 & TST \\
\hline CHEMBL 3944684 & 1641497 & 8.0 & 8.457 & TST \\
\hline CHEMBL3977990 & 1641497 & 8.0 & 8.1987 & TRN \\
\hline CHEMBL3904161 & 1641497 & 8.0 & 8.7827 & TRN \\
\hline CHEMBL3911588 & 1641497 & 8.0 & 8.2917 & TRN \\
\hline CHEMBL3921670 & 1641497 & 9.0 & 9.1192 & TRN \\
\hline CHEMBL 3897042 & 1641497 & 9.0 & 8.1679 & TRN \\
\hline CHEMBL3940916 & 1641497 & 8.0 & 8.1822 & TRN \\
\hline CHEMBL 3977726 & 1641497 & 9.0 & 8.1912 & TRN \\
\hline CHEMBL3921343 & 1641497 & 8.0 & 8.8467 & TST \\
\hline CHEMBL3960928 & 1641497 & 8.0 & 8.1532 & TRN \\
\hline CHEMBL3941900 & 1641497 & 9.0 & 8.287 & TRN \\
\hline CHEMBL3951044 & 1641497 & 8.0 & 8.3308 & TRN \\
\hline CHEMBL3972150 & 1641497 & 9.0 & 9.2435 & TRN \\
\hline CHEMBL3976006 & 1641497 & 7.0 & 8.058 & TRN \\
\hline CHEMBL 3974287 & 1641497 & 8.0 & 9.1489 & TST \\
\hline CHEMBL3953645 & 1641497 & 7.0 & 7.8735 & TRN \\
\hline CHEMBL3895311 & 1641497 & 9.0 & 8.256 & TRN \\
\hline CHEMBL3902846 & 1641497 & 8.0 & 8.1943 & TRN \\
\hline CHEMBL3892195 & 1641497 & 9.0 & 8.8585 & TRN \\
\hline CHEMBL 3890930 & 1641497 & 9.0 & 8.4617 & TRN \\
\hline CHEMBL3942401 & 1641497 & 9.0 & 8.9845 & TRN \\
\hline CHEMBL 3970404 & 1641497 & 8.0 & 8.1885 & TRN \\
\hline CHEMBL 3934380 & 1641497 & 9.0 & 8.8021 & TRN \\
\hline
\end{tabular}




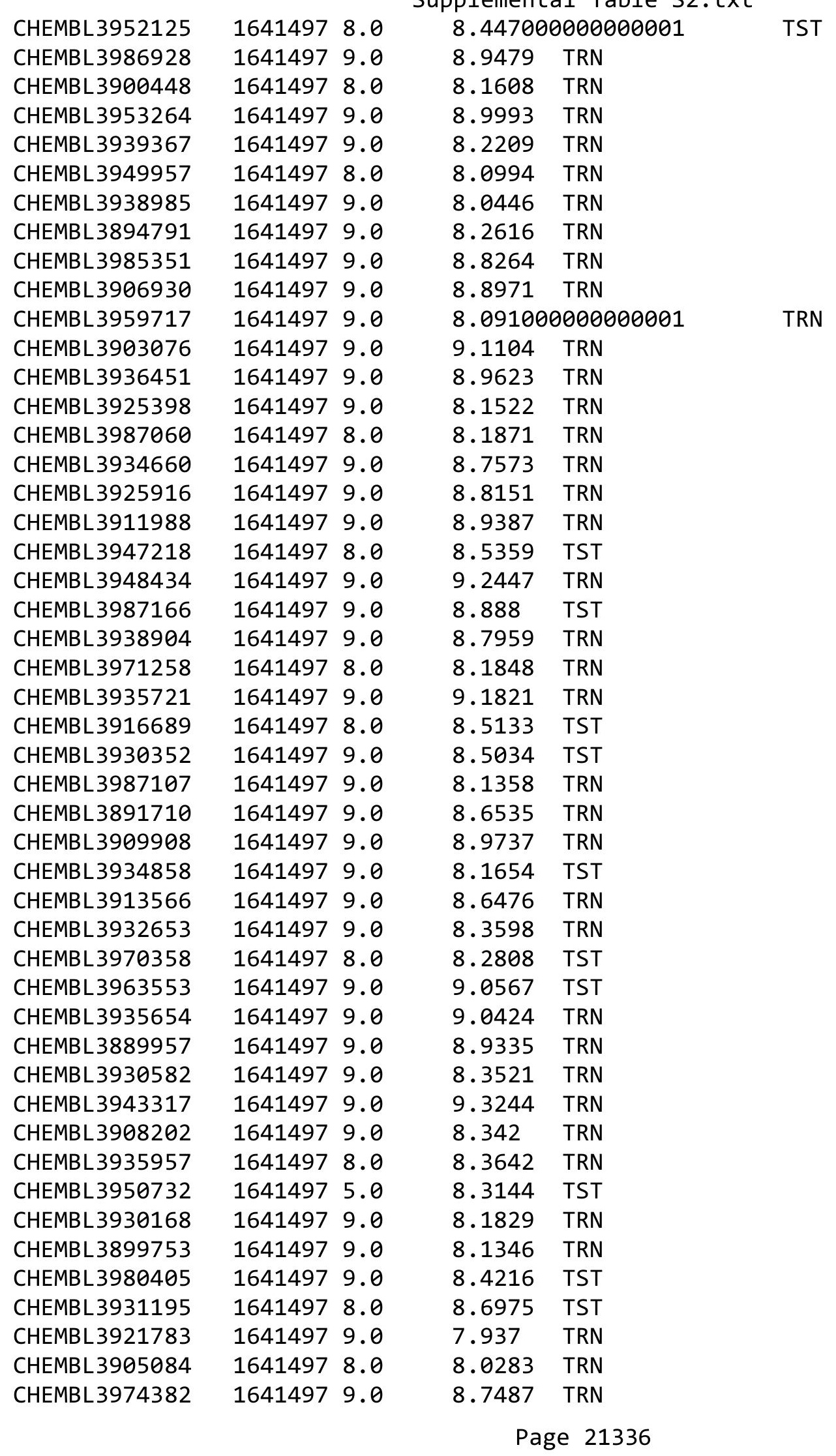




\begin{tabular}{|c|c|c|c|c|}
\hline & & & premert & \\
\hline CHEMBL3926770 & 1641497 & 9.0 & 8.55 & TST \\
\hline CHEMBL3930204 & 1641497 & 9.0 & 8.99 & TRN \\
\hline CHEMBL 3981740 & 1641497 & 9.0 & 9.0081 & TRN \\
\hline CHEMBL3908031 & 1641497 & 9.0 & 9.0302 & TRN \\
\hline CHEMBL3946615 & 1641497 & 9.0 & 8.0927 & TRN \\
\hline CHEMBL3943780 & 1641497 & 9.0 & 8.0767 & TST \\
\hline CHEMBL3956269 & 1641497 & 7.0 & 8.1509 & TST \\
\hline CHEMBL 3942128 & 1641497 & 8.0 & 8.2497 & TRN \\
\hline CHEMBL3964026 & 1641497 & 9.0 & 8.4707 & TST \\
\hline CHEMBL3922378 & 1641497 & 9.0 & 8.6504 & TRN \\
\hline CHEMBL3969007 & 1641497 & 9.0 & 8.2833 & TRN \\
\hline CHEMBL3918480 & 1641497 & 8.0 & 8.172 & TRN \\
\hline CHEMBL 3934710 & 1641497 & 8.0 & 8.9976 & TST \\
\hline CHEMBL3942337 & 1641497 & 8.0 & 8.2311 & TRN \\
\hline CHEMBL3889942 & 1641497 & 8.0 & 8.3221 & TRN \\
\hline CHEMBL3932249 & 1641497 & 9.0 & 8.4404 & TST \\
\hline CHEMBL3977510 & 1641497 & 9.0 & 8.9924 & TRN \\
\hline CHEMBL3970185 & 1641497 & 8.0 & 9.0929 & TRN \\
\hline CHEMBL3948487 & 1641497 & 8.0 & 8.581 & TST \\
\hline CHEMBL 3974243 & 1641497 & 8.0 & 8.4172 & TST \\
\hline CHEMBL3984790 & 1641497 & 8.0 & 8.3107 & TRN \\
\hline CHEMBL3930023 & 1641497 & 9.0 & 8.7068 & TST \\
\hline CHEMBL3978531 & 1641497 & 8.0 & 8.1371 & TRN \\
\hline CHEMBL3969071 & 1641497 & 8.0 & 8.5516 & TRN \\
\hline CHEMBL 3907103 & 1641497 & 8.0 & 9.0214 & TST \\
\hline CHEMBL3946267 & 1641497 & 9.0 & 8.1511 & TRN \\
\hline CHEMBL3909815 & 1641497 & 4.301 & 7.9799 & TST \\
\hline CHEMBL3914111 & 1641497 & 8.0 & 8.8172 & TST \\
\hline CHEMBL3956953 & 1641497 & 7.0 & 8.2277 & TST \\
\hline CHEMBL3969351 & 1641497 & 8.0 & 8.1453 & TRN \\
\hline CHEMBL 3911024 & 1641497 & 9.0 & 8.1187 & TRN \\
\hline CHEMBL3909866 & 1641497 & 9.0 & 8.941 & TRN \\
\hline CHEMBL 3925888 & 1641497 & 7.0 & 7.5651 & TRN \\
\hline CHEMBL3923742 & 1641497 & 9.0 & 8.8853 & TRN \\
\hline CHEMBL 3900029 & 1641497 & 8.0 & 8.1622 & TRN \\
\hline CHEMBL3948136 & 1641497 & 9.0 & 8.4224 & TST \\
\hline CHEMBL3939823 & 1641497 & 8.0 & 8.2252 & TRN \\
\hline CHEMBL 3918964 & 1641497 & 9.0 & 8.9035 & TRN \\
\hline CHEMBL3924983 & 1641497 & 8.0 & 8.1609 & TRN \\
\hline CHEMBL 3962479 & 1641497 & 9.0 & 8.921 & TRN \\
\hline CHEMBL3930545 & 1641497 & 9.0 & 8.2369 & TRN \\
\hline CHEMBL3964004 & 1641497 & 9.0 & 8.952 & TST \\
\hline CHEMBL3961757 & 1641497 & 7.0 & 8.342 & TRN \\
\hline CHEMBL3982575 & 1641497 & 8.0 & 8.0846 & TST \\
\hline CHEMBL 3893787 & 1641497 & 8.0 & 7.8875 & TRN \\
\hline CHEMBL3943821 & 1641497 & 9.0 & 8.8696 & TRN \\
\hline CHEMBL3926338 & 1641497 & 7.0 & 8.898 & TST \\
\hline CHEMBL 3929223 & 1641497 & 8.0 & 8.7115 & TRN \\
\hline
\end{tabular}




\begin{tabular}{|c|c|c|c|c|c|}
\hline & & & & & \\
\hline CHEMBL3974366 & 1641497 & 8.0 & 8.4212 & TRN & \\
\hline CHEMBL3969633 & 1641497 & 7.0 & 8.3326 & TRN & \\
\hline CHEMBL3903001 & 1641497 & 8.0 & 8.2102 & TRN & \\
\hline CHEMBL3895188 & 1641497 & 9.0 & 8.7813 & TRN & \\
\hline CHEMBL3976827 & 1641497 & 9.0 & 9.2319 & TRN & \\
\hline CHEMBL3949438 & 1641497 & 7.0 & 8.8988 & TST & \\
\hline CHEMBL3929751 & 1641497 & 9.0 & 8.8937 & TRN & \\
\hline CHEMBL3953661 & 1641497 & 8.0 & 8.17799 & 9999999999 & TRN \\
\hline CHEMBL3895989 & 1641497 & 8.0 & 8.3237 & TRN & \\
\hline CHEMBL3936490 & 1641497 & 9.0 & 8.7482 & TST & \\
\hline CHEMBL3963392 & 1641497 & 9.0 & 8.384 & TRN & \\
\hline CHEMBL3893330 & 1641497 & 9.0 & 8.56299 & & TRN \\
\hline CHEMBL3975232 & 1641497 & 8.0 & 8.1948 & TRN & \\
\hline CHEMBL3959176 & 1641497 & 7.0 & 8.8245 & TST & \\
\hline CHEMBL3933273 & 1641497 & 9.0 & 9.2485 & TRN & \\
\hline CHEMBL3939939 & 1641497 & 8.0 & 8.8252 & TRN & \\
\hline CHEMBL3927916 & 1641497 & 8.0 & 8.2128 & TRN & \\
\hline CHEMBL3950101 & 1641497 & 9.0 & 8.9587 & TRN & \\
\hline CHEMBL3952887 & 1641497 & 8.0 & 8.9299 & TST & \\
\hline CHEMBL3926628 & 1641497 & 7.0 & 7.73799 & 99999999995 & TRN \\
\hline CHEMBL3906531 & 1641497 & 9.0 & 8.9828 & TRN & \\
\hline CHEMBL3935922 & 1641497 & 9.0 & 8.9741 & TRN & \\
\hline CHEMBL3925300 & 1641497 & 8.0 & 7.9123 & TRN & \\
\hline CHEMBL3903854 & 1641497 & 9.0 & 8.9955 & TRN & \\
\hline CHEMBL3959447 & 1641497 & 8.0 & 8.3845 & TST & \\
\hline CHEMBL 3948930 & 1641497 & 9.0 & 8.9094 & TRN & \\
\hline CHEMBL3890127 & 1641497 & 8.0 & 8.7736 & TST & \\
\hline CHEMBL3905261 & 1641497 & 9.0 & 9.1116 & TRN & \\
\hline CHEMBL3906100 & 1641497 & 9.0 & 8.7931 & TRN & \\
\hline CHEMBL3947068 & 1641497 & 7.0 & 8.6182 & TRN & \\
\hline CHEMBL 3970208 & 1641497 & 9.0 & 8.1374 & TRN & \\
\hline CHEMBL3970820 & 1641497 & 8.0 & 8.5054 & TRN & \\
\hline CHEMBL3894600 & 1641497 & 9.0 & 8.1626 & TRN & \\
\hline CHEMBL3949912 & 1641497 & 9.0 & 9.0085 & TRN & \\
\hline CHEMBL3896199 & 1641497 & 9.0 & 7.9476 & TST & \\
\hline CHEMBL 3934270 & 1641497 & 9.0 & 8.3473 & TRN & \\
\hline CHEMBL3968111 & 1641497 & 9.0 & 8.9967 & TRN & \\
\hline CHEMBL3926316 & 1641497 & 8.0 & 8.0605 & TRN & \\
\hline CHEMBL3973066 & 1641497 & 8.0 & 7.7522 & TRN & \\
\hline CHEMBL3928283 & 1641497 & 9.0 & 8.9883 & TRN & \\
\hline CHEMBL3931738 & 1641497 & 7.0 & 8.209 & TRN & \\
\hline CHEMBL3936971 & 1641497 & 9.0 & 8.9518 & TRN & \\
\hline CHEMBL3914346 & 1641497 & 9.0 & 8.8524 & TRN & \\
\hline CHEMBL3933383 & 1641497 & 8.0 & 8.3683 & TRN & \\
\hline CHEMBL3917705 & 1641497 & 9.0 & 8.8755 & TRN & \\
\hline CHEMBL 3937427 & 1641497 & 8.0 & 8.3626 & TRN & \\
\hline CHEMBL 3983458 & 1641497 & 8.0 & 8.1777 & TST & \\
\hline CHEMBL3928115 & 1641497 & 9.0 & 8.6431 & TRN & \\
\hline & & & & 21338 & \\
\hline
\end{tabular}




\begin{tabular}{|c|c|c|c|c|}
\hline & & & ment & al Ta \\
\hline CHEMBL3964887 & 1641497 & 9.0 & 8.8546 & TRN \\
\hline CHEMBL3975622 & 1641497 & 8.0 & 8.3224 & TST \\
\hline CHEMBL 3960014 & 1641497 & 9.0 & 9.0279 & TRN \\
\hline CHEMBL3931567 & 1641497 & 9.0 & 8.9261 & TST \\
\hline CHEMBL3976119 & 1641497 & 8.0 & 8.2328 & TRN \\
\hline CHEMBL3920846 & 1641497 & 9.0 & 8.9101 & TRN \\
\hline CHEMBL3943068 & 1641497 & 8.0 & 8.8329 & TRN \\
\hline CHEMBL 3941544 & 1641497 & 8.0 & 8.9039 & TRN \\
\hline CHEMBL3947199 & 1641497 & 9.0 & 8.3712 & TRN \\
\hline CHEMBL3966010 & 1641497 & 8.0 & 8.3826 & TRN \\
\hline CHEMBL3922569 & 1641497 & 9.0 & 8.9438 & TRN \\
\hline CHEMBL3928960 & 1641497 & 9.0 & 8.2224 & TRN \\
\hline CHEMBL3955319 & 1641497 & 8.0 & 8.3088 & TRN \\
\hline CHEMBL3930544 & 1641497 & 8.0 & 8.432 & TST \\
\hline CHEMBL3911259 & 1641497 & 9.0 & 8.0618 & TRN \\
\hline CHEMBL3968807 & 1641497 & 9.0 & 8.1464 & TRN \\
\hline CHEMBL3955259 & 1641497 & 8.0 & 8.1906 & TRN \\
\hline CHEMBL 3955156 & 1641497 & 8.0 & 8.3843 & TRN \\
\hline CHEMBL3947317 & 1641497 & 9.0 & 8.9318 & TRN \\
\hline CHEMBL3967371 & 1641497 & 8.0 & 8.1215 & TRN \\
\hline CHEMBL3897318 & 1641497 & 9.0 & 9.3023 & TRN \\
\hline CHEMBL3935053 & 1641497 & 8.0 & 8.2842 & TRN \\
\hline CHEMBL3943756 & 1641497 & 8.0 & 8.4615 & TRN \\
\hline CHEMBL3983992 & 1641497 & 9.0 & 8.8162 & TRN \\
\hline CHEMBL 3973324 & 1641497 & 8.0 & 8.4675 & TST \\
\hline CHEMBL3966391 & 1641497 & 8.0 & 8.9899 & TRN \\
\hline CHEMBL3939167 & 1641497 & 9.0 & 8.7626 & TRN \\
\hline CHEMBL 3928488 & 1641497 & 9.0 & 8.3475 & TRN \\
\hline CHEMBL3904795 & 1641497 & 8.0 & 8.436 & TRN \\
\hline CHEMBL 3957151 & 1641497 & 9.0 & 8.1896 & TRN \\
\hline CHEMBL3904683 & 1641497 & 8.0 & 8.6936 & TRN \\
\hline CHEMBL3959557 & 1641497 & 8.0 & 8.1685 & TST \\
\hline CHEMBL3902036 & 1641497 & 7.0 & 7.8785 & TRN \\
\hline CHEMBL3952209 & 1641497 & 8.0 & 8.149 & TRN \\
\hline CHEMBL3905676 & 1641497 & 8.0 & 8.7762 & TRN \\
\hline CHEMBL3936951 & 1641497 & 9.0 & 8.7713 & TRN \\
\hline CHEMBL3913365 & 1641497 & 9.0 & 8.873 & TRN \\
\hline CHEMBL3946288 & 1641497 & 9.0 & 8.407 & TRN \\
\hline CHEMBL3941843 & 1641497 & 8.0 & 8.2203 & TRN \\
\hline CHEMBL 3942029 & 1641497 & 9.0 & 8.7583 & TRN \\
\hline CHEMBL3939678 & 1641497 & 9.0 & 8.1761 & TRN \\
\hline CHEMBL3948395 & 1641497 & 9.0 & 8.6534 & TST \\
\hline CHEMBL 3892778 & 1641497 & 9.0 & 9.031 & TRN \\
\hline CHEMBL 3900147 & 1641497 & 9.0 & 8.1541 & TRN \\
\hline CHEMBL 3925647 & 1641497 & 8.0 & 8.1378 & TRN \\
\hline CHEMBL3976614 & 1641497 & 9.0 & 8.8448 & TRN \\
\hline CHEMBL3941212 & 1641497 & 9.0 & 9.0113 & TRN \\
\hline CHEMBL 3983244 & 1641497 & 9.0 & 8.6237 & TRN \\
\hline
\end{tabular}




\begin{tabular}{|c|c|c|c|c|}
\hline & & & prement & \\
\hline CHEMBL3927909 & 1641497 & 7.0 & 8.2681 & TRN \\
\hline CHEMBL3928114 & 1641497 & 7.0 & 8.7423 & TST \\
\hline CHEMBL3918713 & 1641497 & 9.0 & 9.2299 & TRN \\
\hline CHEMBL 3896981 & 1641497 & 8.0 & 8.385 & TST \\
\hline CHEMBL3963504 & 1641497 & 9.0 & 8.9035 & TRN \\
\hline CHEMBL3963468 & 1641497 & 8.0 & 8.3003 & TRN \\
\hline CHEMBL3939927 & 1641497 & 9.0 & 8.0013 & TRN \\
\hline CHEMBL3897257 & 1641497 & 9.0 & 8.9385 & TRN \\
\hline CHEMBL3891409 & 1641497 & 8.0 & 8.1161 & TRN \\
\hline CHEMBL3947824 & 1641497 & 9.0 & 8.8633 & TRN \\
\hline CHEMBL3957525 & 1641497 & 9.0 & 8.1105 & TRN \\
\hline CHEMBL3893110 & 1641497 & 8.0 & 8.4197 & TST \\
\hline CHEMBL3941096 & 1641497 & 8.0 & 7.8862 & TRN \\
\hline CHEMBL3907695 & 1641497 & 9.0 & 9.0113 & TRN \\
\hline CHEMBL3889683 & 1641497 & 9.0 & 8.9571 & TRN \\
\hline CHEMBL3917809 & 1641497 & 9.0 & 8.9968 & TRN \\
\hline CHEMBL3975611 & 1641497 & 8.0 & 8.2748 & TST \\
\hline CHEMBL3911665 & 1641497 & 9.0 & 8.9922 & TRN \\
\hline CHEMBL3891189 & 1641497 & 8.0 & 9.1242 & TRN \\
\hline CHEMBL3967104 & 1641497 & 9.0 & 8.967 & TST \\
\hline CHEMBL3978219 & 1641497 & 8.0 & 8.1283 & TRN \\
\hline CHEMBL3910510 & 1641497 & 9.0 & 8.2213 & TRN \\
\hline CHEMBL3894683 & 1641497 & 5.0 & 7.529 & TRN \\
\hline CHEMBL3907663 & 1641497 & 9.0 & 9.0763 & TST \\
\hline CHEMBL3979019 & 1641497 & 9.0 & 9.0064 & TST \\
\hline CHEMBL3899462 & 1641497 & 9.0 & 8.4014 & TST \\
\hline CHEMBL3958021 & 1641497 & 8.0 & 8.6663 & TRN \\
\hline CHEMBL 3953240 & 1641497 & 8.0 & 7.782 & TRN \\
\hline CHEMBL 3962867 & 1641497 & 8.0 & 8.5718 & TST \\
\hline CHEMBL3917709 & 1641497 & 8.0 & 8.2712 & TRN \\
\hline CHEMBL3894819 & 1641497 & 9.0 & 8.8376 & TRN \\
\hline CHEMBL3941959 & 1641497 & 9.0 & 9.0617 & TRN \\
\hline CHEMBL3960931 & 1641497 & 8.0 & 8.7511 & TRN \\
\hline CHEMBL3970951 & 1641497 & 8.0 & 8.2415 & TST \\
\hline CHEMBL 3927967 & 1641497 & 9.0 & 8.6108 & TRN \\
\hline CHEMBL3923990 & 1641497 & 9.0 & 8.2862 & TST \\
\hline CHEMBL3973331 & 1641497 & 8.0 & 8.6957 & TRN \\
\hline CHEMBL3939600 & 1641497 & 9.0 & 8.2685 & TRN \\
\hline CHEMBL3978501 & 1641497 & 9.0 & 8.8187 & TRN \\
\hline CHEMBL 3938392 & 1641497 & 8.0 & 8.7119 & TRN \\
\hline CHEMBL3941903 & 1641497 & 7.0 & 8.1895 & TST \\
\hline CHEMBL3976552 & 1641497 & 9.0 & 8.7487 & TRN \\
\hline CHEMBL3957320 & 1641497 & 9.0 & 9.0812 & TRN \\
\hline CHEMBL3918299 & 1641497 & 9.0 & 8.9698 & TRN \\
\hline CHEMBL 3914362 & 1641497 & 8.0 & 8.2618 & TRN \\
\hline CHEMBL3961966 & 1641497 & 8.0 & 8.0343 & TRN \\
\hline CHEMBL3949151 & 1641497 & 8.0 & 8.3001 & TRN \\
\hline CHEMBL3929183 & 1641497 & 9.0 & 8.4013 & TST \\
\hline
\end{tabular}




\begin{tabular}{|c|c|c|c|c|}
\hline & & & ement & al Ta \\
\hline CHEMBL3953595 & 1641497 & 9.0 & 8.8918 & TST \\
\hline CHEMBL3919982 & 1641497 & 9.0 & 8.8176 & TRN \\
\hline CHEMBL3938750 & 1641497 & 9.0 & 9.0101 & TRN \\
\hline CHEMBL3893056 & 1641497 & 9.0 & 9.0321 & TRN \\
\hline CHEMBL 3908517 & 1641497 & 9.0 & 8.3849 & TST \\
\hline CHEMBL3914812 & 1641497 & 9.0 & 7.9626 & TST \\
\hline CHEMBL3898774 & 1641497 & 9.0 & 8.9413 & TRN \\
\hline CHEMBL3955237 & 1641497 & 9.0 & 8.2446 & TRN \\
\hline CHEMBL3985559 & 1641497 & 8.0 & 8.0104 & TRN \\
\hline CHEMBL3962196 & 1641497 & 9.0 & 8.8012 & TRN \\
\hline CHEMBL3940622 & 1641497 & 9.0 & 8.2283 & TRN \\
\hline CHEMBL3965082 & 1641497 & 9.0 & 8.3513 & TST \\
\hline CHEMBL3940805 & 1641497 & 8.0 & 8.1959 & TRN \\
\hline CHEMBL3965648 & 1641497 & 9.0 & 9.0933 & TRN \\
\hline CHEMBL 3974122 & 1641497 & 9.0 & 8.9178 & TRN \\
\hline CHEMBL3936159 & 1641497 & 8.0 & 8.5176 & TST \\
\hline CHEMBL3979160 & 1641497 & 9.0 & 8.5195 & TST \\
\hline CHEMBL3917523 & 1641497 & 8.0 & 7.8794 & TST \\
\hline CHEMBL3915115 & 1641497 & 9.0 & 8.4553 & TST \\
\hline CHEMBL3931205 & 1641497 & 9.0 & 8.1261 & TRN \\
\hline CHEMBL3916259 & 1641497 & 9.0 & 8.6539 & TRN \\
\hline CHEMBL3985773 & 1641497 & 9.0 & 8.8755 & TRN \\
\hline CHEMBL3968050 & 1641497 & 8.0 & 8.1082 & TST \\
\hline CHEMBL 3982318 & 1641497 & 7.0 & 8.7346 & TST \\
\hline CHEMBL 3910258 & 1641497 & 8.0 & 8.589 & TRN \\
\hline CHEMBL3976433 & 1641497 & 8.0 & 8.4319 & TRN \\
\hline CHEMBL3955628 & 1641497 & 9.0 & 8.5197 & TST \\
\hline CHEMBL3983296 & 1641497 & 9.0 & 8.7548 & TRN \\
\hline CHEMBL3933087 & 1641497 & 9.0 & 8.9537 & TRN \\
\hline CHEMBL3951106 & 1641497 & 9.0 & 8.9864 & TRN \\
\hline CHEMBL3933986 & 1641497 & 7.0 & 8.5824 & TST \\
\hline CHEMBL3945554 & 1641497 & 8.0 & 8.7973 & TST \\
\hline CHEMBL3974695 & 1641497 & 8.0 & 8.1181 & TRN \\
\hline CHEMBL3916312 & 1641497 & 9.0 & 8.1783 & TST \\
\hline CHEMBL 3904657 & 1641497 & 8.0 & 8.5267 & TRN \\
\hline CHEMBL3960234 & 1641497 & 8.0 & 8.7681 & TRN \\
\hline CHEMBL 3895248 & 1641497 & 8.0 & 8.616 & TRN \\
\hline CHEMBL3954481 & 1641497 & 8.0 & 8.3727 & TRN \\
\hline CHEMBL 3973837 & 1641497 & 8.0 & 8.1048 & TRN \\
\hline CHEMBL 3948284 & 1641497 & 9.0 & 8.6359 & TRN \\
\hline CHEMBL3958383 & 1641497 & 9.0 & 8.3492 & TST \\
\hline CHEMBL 3903626 & 1641497 & 8.0 & 8.123 & TRN \\
\hline CHEMBL 3953882 & 1641497 & 9.0 & 8.1095 & TRN \\
\hline CHEMBL3940465 & 1641497 & 8.0 & 8.4388 & TST \\
\hline CHEMBL3963112 & 1641497 & 8.0 & 8.207 & TRN \\
\hline CHEMBL3953124 & 1641497 & 8.0 & 9.009 & TST \\
\hline CHEMBL 3926977 & 1641497 & 9.0 & 8.5971 & TST \\
\hline CHEMBL3938004 & 1641497 & 9.0 & 8.2069 & TRN \\
\hline
\end{tabular}




\begin{tabular}{|c|c|c|c|c|}
\hline & & & upplement & \\
\hline CHEMBL3965903 & 1641497 & 9.0 & 8.8352 & TST \\
\hline CHEMBL3906445 & 1641497 & 9.0 & 8.3077 & TST \\
\hline CHEMBL 3965414 & 1641497 & 8.0 & 7.809 & TRN \\
\hline CHEMBL3933096 & 1641497 & 8.0 & 8.1304 & TRN \\
\hline CHEMBL3924815 & 1641497 & 9.0 & 8.3499 & TST \\
\hline CHEMBL3944867 & 1641497 & 8.0 & 8.6969 & TRN \\
\hline CHEMBL 3915346 & 1641497 & 9.0 & 8.9157 & TRN \\
\hline CHEMBL3966720 & 1641497 & 9.0 & 8.9095 & TST \\
\hline CHEMBL 3969078 & 1641497 & 8.0 & 8.1691 & TST \\
\hline CHEMBL3924705 & 1641497 & 9.0 & 8.1105 & TRN \\
\hline CHEMBL3934593 & 1641497 & 8.0 & 8.257 & TRN \\
\hline CHEMBL 3893280 & 1641497 & 8.0 & 8.3067 & TRN \\
\hline CHEMBL3903735 & 1641497 & 7.0 & 8.5401 & TST \\
\hline CHEMBL 3942118 & 1641497 & 9.0 & 8.8838 & TRN \\
\hline CHEMBL3982683 & 1641497 & 9.0 & 7.8629 & TRN \\
\hline CHEMBL3932116 & 1641497 & 9.0 & 9.0212 & TST \\
\hline CHEMBL3901455 & 1641497 & 9.0 & 8.1303 & TRN \\
\hline CHEMBL3981051 & 1641497 & 9.0 & 8.4294 & TST \\
\hline CHEMBL 3961884 & 1641497 & 9.0 & 8.6137 & TST \\
\hline CHEMBL3942253 & 1641497 & 9.0 & 8.9598 & TRN \\
\hline CHEMBL3944311 & 1641497 & 8.0 & 8.2054 & TRN \\
\hline CHEMBL3894996 & 1641497 & 7.0 & 7.7265 & TRN \\
\hline CHEMBL3904199 & 1641497 & 8.0 & 8.2796 & TRN \\
\hline CHEMBL3911038 & 1641497 & 9.0 & 7.86 & TRN \\
\hline CHEMBL3920480 & 1641497 & 7.0 & 7.5761 & TRN \\
\hline CHEMBL3935699 & 1641497 & 8.0 & 8.0545 & TRN \\
\hline CHEMBL3965883 & 1641497 & 9.0 & 8.8329 & TRN \\
\hline CHEMBL 3895486 & 1641497 & 9.0 & 8.4638 & TRN \\
\hline CHEMBL3925836 & 1641497 & 9.0 & 8.6851 & TST \\
\hline CHEMBL3892843 & 1641497 & 8.0 & 8.3996 & TST \\
\hline CHEMBL3891486 & 1641497 & 9.0 & 8.3086 & TST \\
\hline CHEMBL3901532 & 1641497 & 9.0 & 8.3672 & TST \\
\hline CHEMBL3949892 & 1641497 & 8.0 & 8.2014 & TRN \\
\hline CHEMBL3934136 & 1641497 & 8.0 & 8.1989 & TRN \\
\hline CHEMBL3911206 & 1641497 & 9.0 & 8.7146 & TRN \\
\hline CHEMBL3939665 & 1641497 & 9.0 & 8.4585 & TST \\
\hline CHEMBL3960933 & 1641497 & 9.0 & 8.9101 & TRN \\
\hline CHEMBL3908943 & 1641497 & 7.0 & 8.5825 & TRN \\
\hline CHEMBL 3936530 & 1641497 & 9.0 & 8.7376 & TRN \\
\hline CHEMBL3913934 & 1641497 & 9.0 & 8.4194 & TST \\
\hline CHEMBL 3912234 & 1641497 & 7.0 & 7.8417 & TRN \\
\hline CHEMBL3959059 & 1641497 & 9.0 & 8.1388 & TRN \\
\hline CHEMBL3943376 & 1641497 & 8.0 & 8.0442 & TRN \\
\hline CHEMBL 3962994 & 1641497 & 9.0 & 8.7812 & TRN \\
\hline CHEMBL3963535 & 1641497 & 9.0 & 8.1312 & TRN \\
\hline CHEMBL3961551 & 1641497 & 8.0 & 8.2039 & TRN \\
\hline CHEMBL3948375 & 1641497 & 8.0 & 8.6799 & TST \\
\hline CHEMBL3959173 & 1641497 & 8.0 & 8.327 & TRN \\
\hline
\end{tabular}




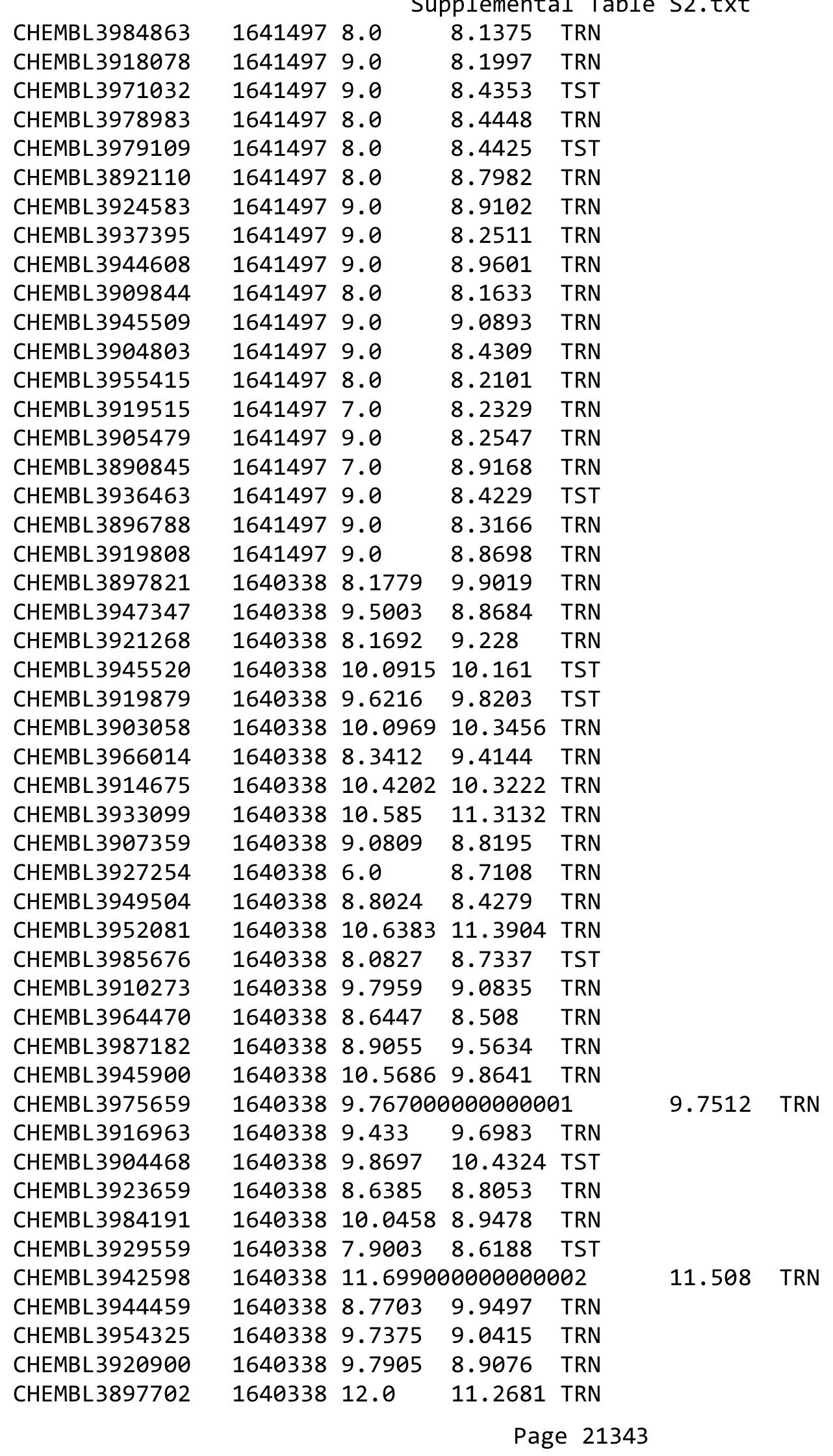


Supplemental Table S2.txt

\begin{tabular}{|c|c|c|c|c|c|}
\hline CHEMBL 3912830 & 1640338 & 9.1726 & 8.8978 & TRN & \\
\hline CHEMBL 3983103 & 1640338 & 9.5986 & 10.0868 & TRN & \\
\hline CHEMBL 3980509 & 1640338 & 9.2518 & 8.7729 & TRN & \\
\hline CHEMBL 3952543 & 1640338 & 9.8996 & 9.64 & TRN & \\
\hline CHEMBL 3983530 & 1640338 & 9.5768 & 8.846 & TRN & \\
\hline CHEMBL 3965841 & 1640338 & 9.8539 & 8.9911 & TRN & \\
\hline CHEMBL 3959426 & 1640338 & 10.5086 & 9.4641 & TRN & \\
\hline CHEMBL 3931033 & 1640338 & 10.1135 & 9.7732 & TRN & \\
\hline CHEMBL3954959 & 1640338 & 8.4608 & 8.0493 & TRN & \\
\hline CHEMBL3975336 & 1640338 & 9.7258 & 9.4353 & TST & \\
\hline CHEMBL 3952752 & 1640338 & 9.5867 & 9.3066 & TRN & \\
\hline CHEMBL 3934685 & 1640338 & 10.8239 & 10.5962 & TRN & \\
\hline CHEMBL 3936986 & 1640338 & 8.2063 & 9.8047 & TRN & \\
\hline CHEMBL 3960779 & 1640338 & 10.284 & 10.1983 & TST & \\
\hline CHEMBL3954930 & 1640338 & 7.2822 & 7.997000 & 0000000001 & TST \\
\hline CHEMBL 3900297 & 1640338 & 8.3549 & 8.5677 & TRN & \\
\hline CHEMBL 3933426 & 1640338 & 6.0767 & 8.7853 & TRN & \\
\hline CHEMBL 3947666 & 1640338 & 9.7905 & 9.6321 & TST & \\
\hline CHEMBL3917378 & 1640338 & 9.7932 & 9.277999 & 7999999999 & TRN \\
\hline CHEMBL 3947235 & 1640338 & 9.5986 & 9.3234 & TRN & \\
\hline CHEMBL 3946682 & 1640338 & 9.752 & 8.693999 & 9999999999 & TST \\
\hline CHEMBL 3939500 & 1640338 & 10.7696 & 10.1804 & TRN & \\
\hline CHEMBL 3919569 & 1640338 & 8.3365 & 8.6787 & TRN & \\
\hline CHEMBL 3903974 & 1640338 & 8.6708 & 9.3624 & TRN & \\
\hline CHEMBL 3925983 & 1640338 & 11.3979 & 11.8493 & TRN & \\
\hline CHEMBL 3905693 & 1640338 & 6.0 & 8.6863 & TRN & \\
\hline CHEMBL3912991 & 1640338 & 10.1612 & 10.1879 & TRN & \\
\hline CHEMBL 3934225 & 1640338 & 8.9393 & 8.5253 & TST & \\
\hline CHEMBL 3901008 & 1640338 & 9.3307 & 9.4419 & TRN & \\
\hline CHEMBL 3981699 & 1640338 & 11.3009 & 999999999 & 10.9286 & TRN \\
\hline CHEMBL 3935047 & 1640338 & 12.0 & 12.198 & TRN & \\
\hline CHEMBL3979716 & 1640338 & 9.8894 & 10.0808 & TRN & \\
\hline CHEMBL 3959642 & 1640338 & 7.4724 & 8.3237 & TST & \\
\hline CHEMBL 3978678 & 1640338 & 10.0605 & 9.0352 & TRN & \\
\hline CHEMBL 3944215 & 1640338 & 10.284 & 10.3746 & TRN & \\
\hline CHEMBL 3926217 & 1640338 & 8.4016 & 8.9137 & TRN & \\
\hline CHEMBL 3940891 & 1640338 & 9.8761 & 10.1499 & TRN & \\
\hline CHEMBL 3917958 & 1640338 & 9.9031 & 9.2838 & TRN & \\
\hline CHEMBL 3975130 & 1640338 & 10.0915 & 10.1554 & TRN & \\
\hline CHEMBL 3958123 & 1640338 & 8.3308 & 9.1585 & TRN & \\
\hline CHEMBL 3916807 & 1640338 & 10.8861 & 9.2427 & TRN & \\
\hline CHEMBL 3958980 & 1640338 & 9.5751 & 9.0704 & TRN & \\
\hline CHEMBL3976629 & 1640338 & 8.3512 & 8.9013 & TRN & \\
\hline CHEMBL 3976802 & 1640338 & 8.7913 & 8.6114 & TRN & \\
\hline CHEMBL 3951497 & 1640338 & 9.6421 & 9.8013 & TST & \\
\hline CHEMBL 3935432 & 1640338 & 9.5346 & 8.7603 & TRN & \\
\hline CHEMBL 3903984 & 1640338 & 8.9408 & 8.7119 & TST & \\
\hline CHEMBL 3898202 & 1640338 & 8.451 & 9.2388 & TST & \\
\hline
\end{tabular}


Supplemental Table S2.txt

\begin{tabular}{|c|c|c|c|c|c|}
\hline CHEMBL 3978720 & 1640338 & 9.3152 & 9.4548 & TRN & \\
\hline CHEMBL 3979321 & 1640338 & 8.5197 & 9.5668 & TRN & \\
\hline CHEMBL 3924145 & 1640338 & 9.7986 & 10.043 & TRN & \\
\hline CHEMBL 3891608 & 1640338 & 7.1008 & 9.7251 & TST & \\
\hline CHEMBL3927297 & 1640338 & 9.5735 & 9.1081 & TRN & \\
\hline CHEMBL 3915240 & 1640338 & 12.0 & 10.5394 & TRN & \\
\hline CHEMBL 3897950 & 1640338 & 9.9788 & 9.2744 & TRN & \\
\hline CHEMBL 3958388 & 1640338 & 8.0546 & 8.7195 & TST & \\
\hline CHEMBL 3962964 & 1640338 & 8.1553 & 8.7025 & TST & \\
\hline CHEMBL3975869 & 1640338 & 11.2218 & 9.9258 & TST & \\
\hline CHEMBL 3890563 & 1640338 & 7.9241 & 8.4306 & TST & \\
\hline CHEMBL 3931934 & 1640338 & 8.7307 & 8.3578 & TRN & \\
\hline CHEMBL 3946032 & 1640338 & 12.0 & 11.0359 & TRN & \\
\hline CHEMBL 3909326 & 1640338 & 11.30099 & 99999999 & 998 & 10.6852 TST \\
\hline CHEMBL3985319 & 1640338 & 10.4559 & 10.2445 & TRN & \\
\hline CHEMBL 3928046 & 1640338 & 6.9488 & 8.2549 & TST & \\
\hline CHEMBL3920020 & 1640338 & 9.9208 & 9.0089 & TST & \\
\hline CHEMBL 3980144 & 1640338 & 7.2007 & 8.4208 & TRN & \\
\hline CHEMBL 3943999 & 1640338 & 9.8539 & 9.0841 & TRN & \\
\hline CHEMBL3931993 & 1640338 & 8.8297 & 8.8125 & TRN & \\
\hline CHEMBL 3927183 & 1640338 & 10.1367 & 10.3935 & TRN & \\
\hline CHEMBL3919112 & 1640338 & 10.2518 & 10.0173 & TRN & \\
\hline CHEMBL 3918014 & 1640338 & 10.3279 & 9.9613 & TRN & \\
\hline CHEMBL 3950951 & 1640338 & 9.9706 & 9.7898 & TRN & \\
\hline CHEMBL 3926562 & 1640338 & 9.5361 & 9.0353 & TRN & \\
\hline CHEMBL 3939067 & 1640338 & 8.6513 & 9.4232 & TRN & \\
\hline CHEMBL 3920580 & 1640338 & 11.0458 & 11.0297 & TST & \\
\hline CHEMBL 3973269 & 1640338 & 8.5227 & 8.9097 & TRN & \\
\hline CHEMBL 3891258 & 1640338 & 10.4089 & 10.0109 & TRN & \\
\hline CHEMBL 3969006 & 1640338 & 9.7122 & 8.7994 & TRN & \\
\hline CHEMBL 3908558 & 1640338 & 8.6304 & 9.8711 & TRN & \\
\hline CHEMBL 3946863 & 1640338 & 10.8861 & 9.2732 & TRN & \\
\hline CHEMBL 3901351 & 1640338 & 10.3188 & 10.5476 & TRN & \\
\hline CHEMBL 3985747 & 1640338 & 9.9788 & 9.5322 & TRN & \\
\hline CHEMBL 3953668 & 1640338 & 11.0 & 10.1775 & TRN & \\
\hline CHEMBL3976616 & 1640338 & 9.6289 & 8.4675 & TRN & \\
\hline CHEMBL 3923879 & 1640338 & 9.5467 & 8.5885 & TRN & \\
\hline CHEMBL 3962755 & 1640338 & 9.097999 & 99999999 & 99 & 10.3199 TST \\
\hline CHEMBL 3915389 & 1640338 & 12.0 & 11.3886 & TRN & \\
\hline CHEMBL 3904016 & 1640338 & 8.263 & 9.0385 & TRN & \\
\hline CHEMBL 3984987 & 1640338 & 10.4437 & 9.781 & TRN & \\
\hline CHEMBL 3967495 & 1640338 & 9.0438 & 8.7795 & TRN & \\
\hline CHEMBL3977122 & 1640338 & 8.436 & 9.2287 & TRN & \\
\hline CHEMBL 3970500 & 1640338 & 9.7825 & 9.2813 & TRN & \\
\hline CHEMBL 3943823 & 1640338 & 10.0809 & 10.2699 & TST & \\
\hline CHEMBL 3926508 & 1640338 & 9.2725 & 8.7068 & TRN & \\
\hline CHEMBL3938599 & 1640338 & 9.2573 & 9.1889 & TRN & \\
\hline CHEMBL 3926441 & 1640338 & 12.0 & 11.411 & TST & \\
\hline
\end{tabular}


Supplemental Table S2.txt

\begin{tabular}{|c|c|c|c|c|c|}
\hline CHEMBL 3967294 & 1640338 & 6.9875 & 8.3971 & TST & \\
\hline CHEMBL 3948599 & 1640338 & 12.0 & 9.0629 & TRN & \\
\hline CHEMBL 3930644 & 1640338 & 7.3062 & 8.6286 & TRN & \\
\hline CHEMBL 3921813 & 1640338 & 8.6325 & 9.3856 & TST & \\
\hline CHEMBL 3986307 & 1640338 & 9.1487 & 8.5325 & TRN & \\
\hline CHEMBL 3902739 & 1640338 & 9.821 & 10.0839 & TRN & \\
\hline CHEMBL 3981492 & 1640338 & 11.0969 & 10.3008 & TRN & \\
\hline CHEMBL 3946283 & 1640338 & 8.8294 & 8.3522 & TRN & \\
\hline CHEMBL 3963584 & 1640338 & 7.2684 & 9.5684 & TRN & \\
\hline CHEMBL 3913473 & 1640338 & 9.3429 & 8.454 & TRN & \\
\hline CHEMBL 3987116 & 1640338 & 10.0177 & 10.0497 & TRN & \\
\hline CHEMBL 3946628 & 1640338 & 10.1192 & 8.6232 & TRN & \\
\hline CHEMBL 3965940 & 1640338 & 8.9112 & 9.3552 & TRN & \\
\hline CHEMBL 3947358 & 1640338 & 7.1886 & 8.8092 & TST & \\
\hline CHEMBL3933569 & 1640338 & 10.5229 & 10.3641 & TRN & \\
\hline CHEMBL 3913251 & 1640338 & 9.3382 & 8.9041 & TRN & \\
\hline CHEMBL3927396 & 1640338 & 8.6882 & 9.3789 & TRN & \\
\hline CHEMBL 3936065 & 1640338 & 8.1655 & 9.5191 & TRN & \\
\hline CHEMBL 3962052 & 1640338 & 8.2107 & 8.2456 & TRN & \\
\hline CHEMBL 3941252 & 1640338 & 10.3979 & 10.3094 & TRN & \\
\hline CHEMBL 3961090 & 1640338 & 8.767006 & 00000000 & 9.5975 & TST \\
\hline CHEMBL 3896724 & 1640338 & 9.7375 & 9.6281 & TRN & \\
\hline CHEMBL 3952778 & 1640338 & 10.1135 & 8.7105 & TST & \\
\hline CHEMBL 3920522 & 1640338 & 9.5986 & 9.6772 & TRN & \\
\hline CHEMBL 3940219 & 1640338 & 11.5229 & 10.4754 & TRN & \\
\hline CHEMBL 3966122 & 1640338 & 8.5532 & 8.4963 & TRN & \\
\hline CHEMBL 3980846 & 1640338 & 7.5892 & 8.2794 & TRN & \\
\hline CHEMBL 3947179 & 1640338 & 9.3382 & 10.431 & TRN & \\
\hline CHEMBL 3896974 & 1640338 & 8.1785 & 9.4945 & TRN & \\
\hline CHEMBL3965609 & 1640338 & 9.7167 & 9.122 & TRN & \\
\hline CHEMBL 3921240 & 1640338 & 9.8416 & 9.2262 & TRN & \\
\hline CHEMBL3910395 & 1640338 & 9.2233 & 8.5856 & TRN & \\
\hline CHEMBL 3898982 & 1640338 & 10.9586 & 8.9957 & TRN & \\
\hline CHEMBL 3931638 & 1640338 & 10.30099 & 99999999 & 9.0581 & TRN \\
\hline CHEMBL 3936256 & 1640338 & 11.0458 & 10.1427 & TRN & \\
\hline CHEMBL 3907427 & 1640338 & 9.5817 & 9.9509 & TST & \\
\hline CHEMBL 3961388 & 1640338 & 8.7001 & 8.6945 & TRN & \\
\hline CHEMBL 3917155 & 1640338 & 8.1196 & 9.3147 & TRN & \\
\hline CHEMBL 3957265 & 1640338 & 9.2984 & 9.478 & TRN & \\
\hline CHEMBL3925998 & 1640338 & 8.4796 & 8.2842 & TRN & \\
\hline CHEMBL 3953161 & 1640338 & 8.4286 & 8.923 & TST & \\
\hline CHEMBL 3946056 & 1640338 & 9.0164 & 9.3537 & TRN & \\
\hline CHEMBL 3890393 & 1640338 & 9.118 & 9.2542 & TST & \\
\hline CHEMBL 3952850 & 1640338 & 10.1487 & 10.57599 & 99999999999 & TS \\
\hline CHEMBL 3947654 & 1640338 & 9.3969 & 9.4522 & TRN & \\
\hline CHEMBL 3921893 & 1640338 & 9.6615 & 8.8953 & TRN & \\
\hline CHEMBL 3897955 & 1640338 & 8.2997 & 8.8806 & TRN & \\
\hline CHEMBL 3905314 & 1640338 & 8.7701 & 8.8133 & TRN & \\
\hline
\end{tabular}

Page 21346 


$$
\text { Supplemental Table S2.txt }
$$

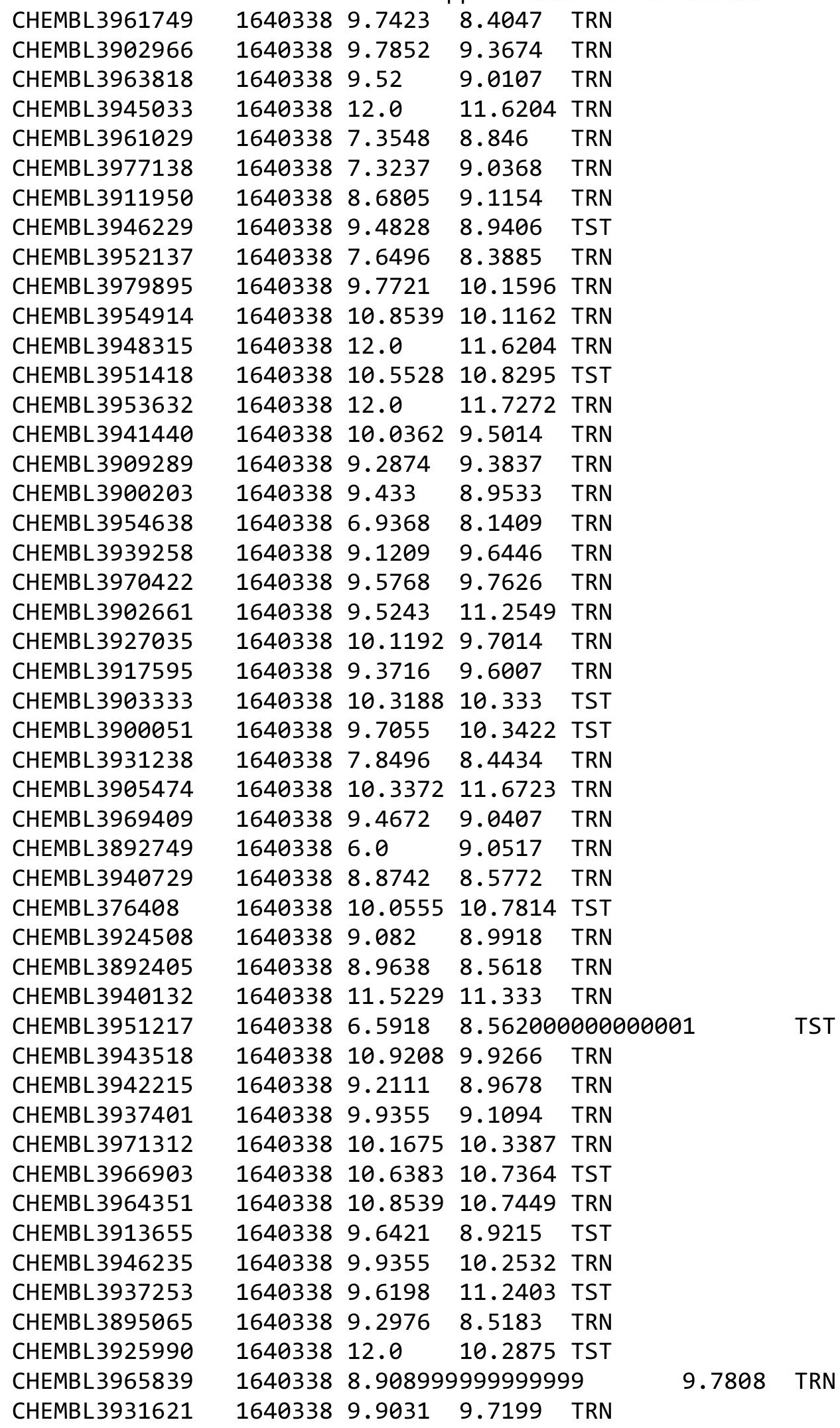


Supplemental Table S2.txt

\begin{tabular}{|c|c|c|c|c|c|}
\hline CHEMBL3935346 & 1640338 & 6.0 & 9.1844 & TRN & \\
\hline CHEMBL3910443 & 1640338 & 7.2412 & 8.7504 & TST & \\
\hline CHEMBL3982254 & 1640338 & 8.6262 & 9.3589 & TRN & \\
\hline CHEMBL3949068 & 1640338 & 7.5275 & 8.5675 & TRN & \\
\hline CHEMBL3969223 & 1640338 & 10.585 & 11.6226 & TRN & \\
\hline CHEMBL 3903437 & 1640338 & 9.7471 & 8.9079 & TRN & \\
\hline CHEMBL3959296 & 1640338 & 9.5884 & 10.0888 & TRN & \\
\hline CHEMBL 3891462 & 1640338 & 8.359 & 9.2145 & TST & \\
\hline CHEMBL3915506 & 1640338 & 9.7545 & 9.855 & TRN & \\
\hline CHEMBL3918447 & 1640338 & 9.6737 & 9.9793 & TRN & \\
\hline CHEMBL3959998 & 1640338 & 9.9957 & 10.5004 & TRN & \\
\hline CHEMBL3919328 & 1640338 & 9.4377 & 8.9745 & TRN & \\
\hline CHEMBL3981941 & 1640338 & 8.7457 & 8.7623 & TRN & \\
\hline CHEMBL3940742 & 1640338 & 10.3098 & 9.8367 & TRN & \\
\hline CHEMBL 3962385 & 1640338 & 12.0 & 11.7082 & TRN & \\
\hline CHEMBL 3950508 & 1640338 & 9.1141 & 8.9307 & TRN & \\
\hline CHEMBL3978975 & 1640338 & 12.0 & 10.446 & TRN & \\
\hline CHEMBL3932261 & 1640338 & 10.0362 & 10.2502 & TRN & \\
\hline CHEMBL 3946148 & 1640338 & 10.5528 & 10.074 & TST & \\
\hline CHEMBL3909113 & 1640338 & 8.077 & 8.5137 & TRN & \\
\hline CHEMBL 3930022 & 1640338 & 9.1325 & 8.988 & TRN & \\
\hline CHEMBL3937978 & 1640338 & 10.9586 & 10.8305 & TRN & \\
\hline CHEMBL3971663 & 1640338 & 10.6021 & 10.6658 & TST & \\
\hline CHEMBL3966012 & 1640338 & 7.8703 & 8.6322 & TRN & \\
\hline CHEMBL3891905 & 1640338 & 9.1062 & 9.3779 & TRN & \\
\hline CHEMBL 3954743 & 1640338 & 9.9208 & 10.5314 & TST & \\
\hline CHEMBL3904516 & 1640338 & 9.8539 & 8.8569 & TRN & \\
\hline CHEMBL 3891501 & 1640338 & 4.9226 & 8.597999 & 9999999999 & TR \\
\hline CHEMBL 3944877 & 1640338 & 9.6144 & 8.8501 & TRN & \\
\hline CHEMBL3923448 & 1640338 & 10.1549 & $10.0170 €$ & 00000000001 & TST \\
\hline CHEMBL 3945131 & 1640338 & 12.0 & 11.3801 & TRN & \\
\hline CHEMBL3936872 & 1640338 & 10.7696 & 10.6949 & TRN & \\
\hline CHEMBL3960553 & 1640338 & 11.1549 & 11.1418 & TST & \\
\hline CHEMBL 3915578 & 1640338 & 10.2007 & 10.3252 & TST & \\
\hline CHEMBL3900060 & 1640338 & 10.3009 & 99999999 & 8.9085 & \\
\hline CHEMBL3917229 & 1640338 & 12.0 & 12.0608 & TRN & \\
\hline CHEMBL3976473 & 1640338 & 9.0846 & 9.0925 & TRN & \\
\hline CHEMBL3956351 & 1640338 & 10.0088 & 9.155 & TRN & \\
\hline CHEMBL 3894550 & 1640338 & 8.9048 & 9.2628 & TRN & \\
\hline CHEMBL3903842 & 1640338 & 12.0 & 11.3816 & TRN & \\
\hline CHEMBL 3938058 & 1640338 & 9.8996 & 9.9808 & TST & \\
\hline CHEMBL3977628 & 1640338 & 9.7447 & 9.7552 & TRN & \\
\hline CHEMBL3944216 & 1640338 & 10.3979 & 10.1519 & TST & \\
\hline CHEMBL3917217 & 1640338 & 10.4949 & 9.3248 & TRN & \\
\hline CHEMBL3936143 & 1640338 & 12.0 & 11.4097 & TST & \\
\hline CHEMBL 3974371 & 1640338 & 10.0506 & 8.9191 & TST & \\
\hline CHEMBL3916510 & 1640338 & 10.1135 & 9.8415 & TRN & \\
\hline CHEMBL3937050 & 1640338 & 7.9488 & 8.2365 & TRN & \\
\hline
\end{tabular}

Page 21348 
Supplemental Table S2.txt

\begin{tabular}{|c|c|c|c|c|c|}
\hline CHEMBL 3925951 & 1640338 & 8.6887 & 9.7504 & TRN & \\
\hline CHEMBL 3927113 & 1640338 & 12.0 & 11.6278 & TRN & \\
\hline CHEMBL3928478 & 1640338 & 8.9678 & 9.2904 & TST & \\
\hline CHEMBL3944409 & 1640338 & 10.0969 & 9.5258 & TRN & \\
\hline CHEMBL 3957503 & 1640338 & 10.2366 & 10.456 & TRN & \\
\hline CHEMBL3929366 & 1640338 & 9.3372 & 9.1041 & TRN & \\
\hline CHEMBL 3926835 & 1640338 & 10.2218 & 9.8505 & TRN & \\
\hline CHEMBL3920721 & 1640338 & 10.6021 & 9.9403 & TRN & \\
\hline CHEMBL 3924048 & 1640338 & 10.5229 & 10.9773 & TRN & \\
\hline CHEMBL3953600 & 1640338 & 9.0372 & 9.068 & TRN & \\
\hline CHEMBL3952965 & 1640338 & 9.8386 & 10.0286 & TRN & \\
\hline CHEMBL 3909402 & 1640338 & 9.2907 & 9.84 & TRN & \\
\hline CHEMBL 3964784 & 1640338 & 8.175 & 8.9692 & TST & \\
\hline CHEMBL 3972201 & 1640338 & 8.2506 & 8.6623 & TRN & \\
\hline CHEMBL3954269 & 1640338 & 8.5391 & 9.1809 & TRN & \\
\hline CHEMBL3939679 & 1640338 & 11.3979 & 11.9077 & TRN & \\
\hline CHEMBL3903494 & 1640338 & 8.2053 & 8.5607 & TRN & \\
\hline CHEMBL 3960071 & 1640338 & 9.4841 & 8.7409 & TRN & \\
\hline CHEMBL 3896889 & 1640338 & 8.147 & 8.4125 & TST & \\
\hline CHEMBL3940998 & 1640338 & 8.4337 & 8.6838 & TRN & \\
\hline CHEMBL3980397 & 1640338 & 9.8477 & 9.1225 & TRN & \\
\hline CHEMBL 3914764 & 1640338 & 9.9914 & 9.336 & TRN & \\
\hline CHEMBL 3970318 & 1640338 & 10.5086 & 10.4187 & TRN & \\
\hline CHEMBL 3901850 & 1640338 & 10.4437 & 10.4341 & TRN & \\
\hline CHEMBL 3937273 & 1640338 & 8.9646 & 9.4082 & TRN & \\
\hline CHEMBL 3958471 & 1640338 & 9.5528 & 9.1957 & TRN & \\
\hline CHEMBL 3894022 & 1640338 & 8.8091 & 8.6099 & TRN & \\
\hline CHEMBL 3942674 & 1640338 & 8.5134 & 8.8104 & TRN & \\
\hline CHEMBL 3942371 & 1640338 & 12.0 & 10.9692 & TRN & \\
\hline CHEMBL 3895642 & 1640338 & 4.9226 & 7.7886 & TRN & \\
\hline CHEMBL 3896071 & 1640338 & 10.284 & 10.1455 & TRN & \\
\hline CHEMBL 3902924 & 1640338 & 9.6271 & 9.9693 & TRN & \\
\hline CHEMBL 3958568 & 1640338 & 10.0809 & 9.5735 & TST & \\
\hline CHEMBL 3963704 & 1640338 & 9.5719 & 10.2053 & TRN & \\
\hline CHEMBL3967910 & 1640338 & 11.69906 & 00000000 & 02 & 11.1826 TRN \\
\hline CHEMBL 3904260 & 1640338 & 9.9355 & 9.8165 & TRN & \\
\hline CHEMBL3971139 & 1640338 & 8.9237 & 9.4659 & TRN & \\
\hline CHEMBL3966367 & 1640338 & 9.6364 & 10.0648 & TRN & \\
\hline CHEMBL3913997 & 1640338 & 9.0991 & 9.7612 & TRN & \\
\hline CHEMBL 3983548 & 1640338 & 7.7228 & 7.6808 & TST & \\
\hline CHEMBL 3910432 & 1640338 & 10.0315 & 10.8671 & TST & \\
\hline CHEMBL3907686 & 1640338 & 9.7496 & 10.0702 & TRN & \\
\hline CHEMBL3985947 & 1640338 & 10.0862 & 9.66 & TRN & \\
\hline CHEMBL 3899530 & 1640338 & 7.4364 & 8.073 & TST & \\
\hline CHEMBL 3938448 & 1640338 & 10.3468 & 10.7573 & TRN & \\
\hline CHEMBL 3963754 & 1640338 & 9.5452 & 8.8644 & TST & \\
\hline CHEMBL 3960525 & 1640338 & 9.9666 & 9.8259 & TRN & \\
\hline CHEMBL 3910577 & 1640338 & 11.0458 & 10.1467 & TRN & \\
\hline
\end{tabular}

Page 21349 
Supplemental Table S2.txt

\begin{tabular}{|c|c|c|c|c|c|c|}
\hline CHEMBL 3936165 & 1640338 & 6.5396 & 8.9362 & TRN & & \\
\hline CHEMBL3921039 & 1640338 & 9.2062 & 9.6111 & TRN & & \\
\hline CHEMBL 3942110 & 1640338 & 10.2596 & 10.3617 & TST & & \\
\hline CHEMBL 3965616 & 1640338 & 9.7077 & 9.838 & TRN & & \\
\hline CHEMBL3972195 & 1640338 & 11.1549 & 10.0544 & TST & & \\
\hline CHEMBL 3898333 & 1640338 & 9.3665 & 8.7625 & TRN & & \\
\hline CHEMBL 3926141 & 1640338 & \multicolumn{3}{|c|}{11.699000000000002} & 10.3577 & TST \\
\hline CHEMBL 3935266 & 1640338 & 10.2676 & 9.4364 & TST & & \\
\hline CHEMBL 3939519 & 1640338 & 8.5342 & 8.862 & TRN & & \\
\hline CHEMBL3894778 & 1640338 & 8.8333 & 9.301 & TRN & & \\
\hline CHEMBL 3973865 & 1640338 & 9.3947 & 9.0708 & TRN & & \\
\hline CHEMBL 3936786 & 1640338 & 9.8827 & 9.717 & TRN & & \\
\hline CHEMBL 3894614 & 1640338 & 9.3585 & 9.0247 & TRN & & \\
\hline CHEMBL 3963689 & 1640338 & 8.224 & 8.9998 & TST & & \\
\hline CHEMBL3985520 & 1640338 & 9.9508 & 8.9684 & TRN & & \\
\hline CHEMBL 3955668 & 1640338 & 9.2716 & 9.4352 & TRN & & \\
\hline CHEMBL3899864 & 1640338 & 7.8861 & 8.4489 & TRN & & \\
\hline CHEMBL 3978226 & 1640338 & 10.1192 & 9.4633 & TRN & & \\
\hline CHEMBL 3910657 & 1640338 & 11.5229 & 11.4791 & TRN & & \\
\hline CHEMBL3913455 & 1640338 & 8.3255 & 9.1114 & TRN & & \\
\hline CHEMBL3986974 & 1640338 & 10.4089 & 10.2426 & TRN & & \\
\hline CHEMBL 3894740 & 1640338 & 8.454 & 8.7779 & TST & & \\
\hline CHEMBL 3974863 & 1640338 & 9.7144 & 9.5976 & TST & & \\
\hline CHEMBL 3969380 & 1640338 & 10.585 & 10.4884 & TRN & & \\
\hline CHEMBL 3893467 & 1640338 & \multicolumn{3}{|c|}{10.699000000000002} & 9.5357 & TRN \\
\hline CHEMBL3896412 & 1640338 & 10.2441 & 9.8171 & TST & & \\
\hline CHEMBL 3976891 & 1640338 & 7.6388 & 8.0938 & TRN & & \\
\hline CHEMBL 3955794 & 1640338 & 9.0132 & 8.9801 & TST & & \\
\hline CHEMBL 3923781 & 1640338 & 11.0 & 10.3026 & TRN & & \\
\hline CHEMBL 3958319 & 1640338 & 9.2299 & 9.189 & TRN & & \\
\hline CHEMBL 3962175 & 1640338 & 9.475 & 9.8757 & TST & & \\
\hline CHEMBL 3941238 & 1640338 & 10.2924 & 10.0057 & TST & & \\
\hline CHEMBL 3937341 & 1640338 & 9.8416 & 9.6512 & TRN & & \\
\hline CHEMBL 3924651 & 1640338 & 9.289 & 8.846 & TRN & & \\
\hline CHEMBL 3975773 & 1640338 & 7.2138 & 8.4708 & TST & & \\
\hline CHEMBL 3903430 & 1640338 & 9.4202 & 9.7789 & TST & & \\
\hline CHEMBL3905937 & 1640338 & 9.1864 & 8.3226 & TRN & & \\
\hline CHEMBL 3912324 & 1640338 & 9.0721 & 9.729 & TRN & & \\
\hline CHEMBL 3794549 & 1640338 & 10.2518 & 9.7662 & TST & & \\
\hline CHEMBL 3951040 & 1640338 & 9.327 & 9.4139 & TRN & & \\
\hline CHEMBL3933631 & 1640338 & 8.8703 & 9.257 & TST & & \\
\hline CHEMBL 3909627 & 1640338 & 12.0 & 10.5464 & TRN & & \\
\hline CHEMBL3903991 & 1640338 & 9.1688 & 8.4888 & TRN & & \\
\hline CHEMBL 3974950 & 1640338 & 11.5229 & 10.6283 & TRN & & \\
\hline CHEMBL 3940524 & 1640338 & 10.0809 & 8.9176 & TST & & \\
\hline CHEMBL 3945758 & 1640338 & 9.6216 & 9.4085 & TRN & & \\
\hline CHEMBL3896756 & 1640338 & 9.6234 & 9.8433 & TRN & & \\
\hline CHEMBL3891073 & 1640338 & 10.585 & 10.2748 & TST & & \\
\hline
\end{tabular}

Page 21350 
Supplemental Table S2.txt

\begin{tabular}{|c|c|c|c|c|}
\hline CHEMBL 3968162 & 1640338 & 9.9747 & 9.3761 & TST \\
\hline CHEMBL3913917 & 1640338 & 9.3841 & 9.1441 & TRN \\
\hline CHEMBL3978581 & 1640338 & 8.1659 & 8.8226 & TST \\
\hline CHEMBL3906823 & 1640338 & 8.2654 & 9.6773 & TRN \\
\hline CHEMBL3923705 & 1640338 & 9.9508 & 10.2948 & TST \\
\hline CHEMBL3964700 & 1640338 & 8.2153 & 9.2567 & TRN \\
\hline CHEMBL3980235 & 1640338 & 10.6778 & 10.3777 & TRN \\
\hline CHEMBL3899475 & 1640338 & 6.0 & 8.7603 & TRN \\
\hline CHEMBL3963652 & 1640338 & 9.2048 & 9.2635 & TRN \\
\hline CHEMBL3980451 & 1640338 & 9.8268 & 9.5721 & TRN \\
\hline CHEMBL3949367 & 1640338 & 8.6008 & 7.3517 & TRN \\
\hline CHEMBL3961726 & 1640338 & 8.6635 & 9.0995 & TST \\
\hline CHEMBL3942015 & 1640338 & 9.5157 & 10.5158 & TST \\
\hline CHEMBL3970059 & 1640338 & 9.2396 & 8.6185 & TRN \\
\hline CHEMBL3966550 & 1640338 & 9.6271 & 9.9495 & TRN \\
\hline CHEMBL 3898157 & 1640338 & 8.2662 & 8.7133 & TST \\
\hline CHEMBL3972754 & 1640338 & 10.2076 & 9.7512 & TST \\
\hline CHEMBL3976157 & 1640338 & 9.7258 & 9.5527 & TST \\
\hline CHEMBL3975600 & 1640338 & 9.0227 & 8.5961 & TRN \\
\hline CHEMBL3920666 & 1640338 & 6.0 & 10.5322 & TST \\
\hline CHEMBL 3925354 & 1640338 & 7.1254 & 8.786 & TST \\
\hline CHEMBL3898457 & 1640338 & 9.3335 & 9.4064 & TST \\
\hline CHEMBL 3953586 & 1640338 & 8.5314 & 9.4894 & TRN \\
\hline CHEMBL3935970 & 1640338 & 10.0132 & 8.9683 & TRN \\
\hline CHEMBL3889500 & 1640338 & 8.702 & 9.6785 & TST \\
\hline CHEMBL3903112 & 1640338 & 10.9208 & 10.657 & TST \\
\hline CHEMBL3933468 & 1640338 & 12.0 & 10.7423 & TST \\
\hline CHEMBL3960235 & 1640338 & 9.2815 & 9.3314 & TST \\
\hline CHEMBL3945547 & 1640338 & 10.0862 & 8.9892 & TRN \\
\hline CHEMBL3952182 & 1640338 & 10.4559 & 10.7123 & TST \\
\hline CHEMBL3948846 & 1640338 & 9.3536 & 9.9514 & TST \\
\hline CHEMBL3979135 & 1640338 & 9.2464 & 8.7223 & TRN \\
\hline CHEMBL3976936 & 1640338 & 9.5017 & 8.8803 & TRN \\
\hline CHEMBL3947864 & 1640338 & 9.172 & 9.2287 & TRN \\
\hline CHEMBL3983012 & 1640338 & 10.0223 & 8.6041 & TRN \\
\hline CHEMBL3966191 & 1640338 & 9.5513 & 9.2362 & TST \\
\hline CHEMBL3954186 & 1640338 & 10.8239 & 11.7756 & TRN \\
\hline CHEMBL1916123 & 787236 & 9.301 & 9.2658 & TRN \\
\hline CHEMBL1916112 & 787236 & 8.699 & 8.6693 & TRN \\
\hline CHEMBL1916110 & 787236 & 7.0996 & 6.8845 & TRN \\
\hline CHEMBL1916109 & 787236 & 8.1675 & 8.1318 & TRN \\
\hline CHEMBL1916118 & 787236 & 8.7212 & 8.357000 & 0000000001 \\
\hline CHEMBL1915889 & 787236 & 7.6198 & 7.4243 & TRN \\
\hline CHEMBL1916132 & 787236 & 9.1549 & 9.0168 & TRN \\
\hline CHEMBL1916097 & 787236 & 7.8268 & 8.0616 & TRN \\
\hline CHEMBL1916089 & 787236 & 7.8761 & 7.8289 & TRN \\
\hline CHEMBL1915896 & 787236 & 8.7447 & 8.7033 & TRN \\
\hline CHEMBL1916105 & 787236 & 7.3372 & 7.4826 & TRN \\
\hline
\end{tabular}




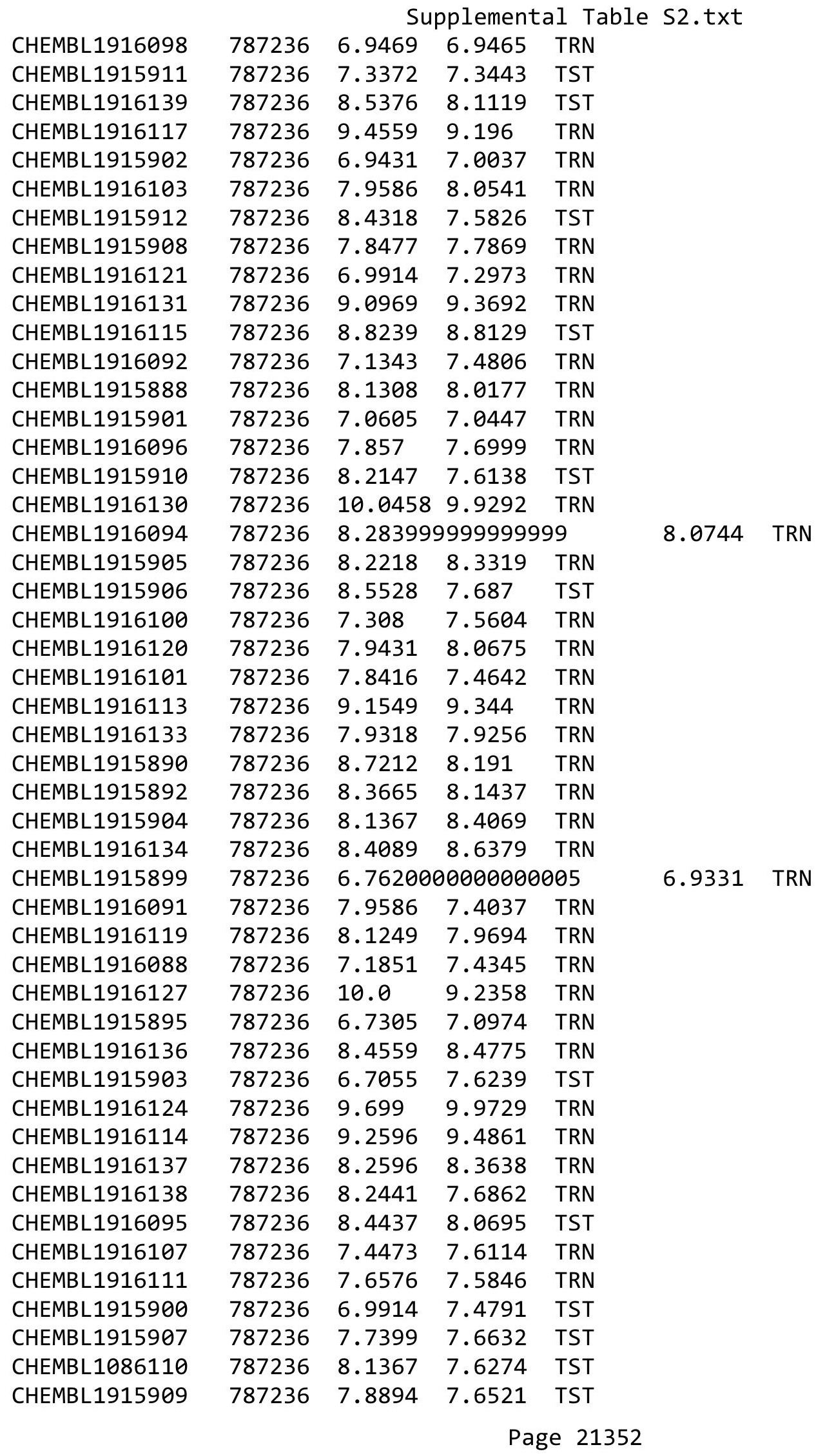




\begin{tabular}{|c|c|c|c|c|c|c|}
\hline \multirow{3}{*}{$\begin{array}{l}\text { CHEMBL1916128 } \\
\text { CHEMBL1916102 }\end{array}$} & & \multicolumn{5}{|c|}{ Supplemental Table S2.txt } \\
\hline & 787236 & \multicolumn{3}{|c|}{10.300999999999998} & \multirow{2}{*}{10.2443} & \multirow{2}{*}{ TRN } \\
\hline & 787236 & 7.5391 & 7.3373 & TRN & & \\
\hline CHEMBL1915893 & 787236 & 7.6882 & 8.4944 & TST & & \\
\hline CHEMBL1916116 & 787236 & 9.0706 & 8.9418 & TST & & \\
\hline CHEMBL1916122 & 787236 & 7.1945 & 7.5525 & TRN & & \\
\hline CHEMBL1915891 & 787236 & 8.1308 & \multicolumn{3}{|c|}{7.627000000000001} & TST \\
\hline CHEMBL1915897 & 787236 & 7.2218 & 7.3456 & TST & & \\
\hline CHEMBL1916106 & 787236 & 8.0809 & 8.1905 & TRN & & \\
\hline CHEMBL1916099 & 787236 & 6.8013 & 6.8662 & TRN & & \\
\hline CHEMBL1915894 & 787236 & 7.8416 & 7.9138 & TST & & \\
\hline CHEMBL1916126 & 787236 & 8.7696 & 9.1757 & TRN & & \\
\hline CHEMBL1916135 & 787236 & 8.8239 & 8.6822 & TRN & & \\
\hline CHEMBL1916125 & 787236 & 9.8539 & 9.993 & TRN & & \\
\hline CHEMBL1916129 & 787236 & 10.2218 & 10.1413 & TRN & & \\
\hline CHEMBL1916090 & 787236 & 8.3768 & 8.0698 & TST & & \\
\hline CHEMBL1916104 & 787236 & 7.6162 & 7.9042 & TRN & & \\
\hline CHEMBL1916108 & 787236 & 8.1308 & 8.3099 & TRN & & \\
\hline CHEMBL1915898 & 787236 & 7.3565 & 7.483 & TST & & \\
\hline CHEMBL1916093 & 787236 & 8.1024 & 7.8191 & TST & & \\
\hline CHEMBL 3717382 & 1536654 & 4.0 & 4.0051 & TRN & & \\
\hline CHEMBL3716790 & 1536654 & 8.0458 & 8.0919 & TRN & & \\
\hline CHEMBL3716756 & 1536654 & 8.5229 & 8.5749 & TRN & & \\
\hline CHEMBL 3716408 & 1536654 & \multicolumn{3}{|c|}{5.207999999999999} & \multirow[t]{24}{*}{4.1829} & \multirow[t]{24}{*}{ TST } \\
\hline CHEMBL3717015 & 1536654 & 6.011 & 6.0064 & TRN & & \\
\hline CHEMBL3715791 & 1536654 & 4.0 & 5.9236 & TST & & \\
\hline CHEMBL 3717720 & 1536654 & 7.0044 & 6.5723 & TST & & \\
\hline CHEMBL 3719200 & 1536654 & 4.0 & 6.5257 & TST & & \\
\hline CHEMBL 3717652 & 1536654 & 6.556 & 6.556 & TRN & & \\
\hline CHEMBL3718305 & 1536654 & 5.364 & 6.0164 & TST & & \\
\hline CHEMBL3718133 & 1536654 & 7.0706 & 7.0628 & TRN & & \\
\hline CHEMBL 3716374 & 1536654 & 5.0089 & 5.0013 & TRN & & \\
\hline CHEMBL3718082 & 1536654 & 6.3655 & 6.3677 & TRN & & \\
\hline CHEMBL 3716594 & 1536654 & 5.2731 & 4.7049 & TST & & \\
\hline CHEMBL3717458 & 1536654 & 6.7167 & 6.7248 & TRN & & \\
\hline CHEMBL 3718524 & 1536654 & 4.0 & 5.1439 & TST & & \\
\hline CHEMBL3717844 & 1536654 & 4.0 & 5.9173 & TST & & \\
\hline CHEMBL3718351 & 1536654 & 5.8297 & 5.8237 & TRN & & \\
\hline CHEMBL 3717457 & 1536654 & 5.6112 & 5.6154 & TRN & & \\
\hline CHEMBL3718396 & 1536654 & 7.3098 & 7.3115 & TRN & & \\
\hline CHEMBL3716075 & 1536654 & 6.2749 & 6.6998 & TST & & \\
\hline CHEMBL 3717851 & 1536654 & 7.0969 & 7.0918 & TRN & & \\
\hline CHEMBL 3718777 & 1536654 & 8.699 & 8.6985 & TRN & & \\
\hline CHEMBL3718171 & 1536654 & 8.699 & 8.651 & TRN & & \\
\hline CHEMBL3714907 & 1536654 & 7.6198 & 7.6187 & TRN & & \\
\hline CHEMBL 3715076 & 1536654 & 7.9586 & 7.959 & TRN & & \\
\hline CHEMBL3715397 & 1536654 & 6.7399 & 7.4673 & TST & & \\
\hline CHEMBL 3716429 & 1536654 & \multicolumn{3}{|c|}{6.007000000000001} & \multirow[t]{3}{*}{5.9991} & \multirow[t]{3}{*}{ TRN } \\
\hline CHEMBL3718315 & 1536654 & 4.0 & 6.4862 & TST & & \\
\hline \multicolumn{5}{|c|}{ Page 21353} & & \\
\hline
\end{tabular}


Supplemental Table S2.txt

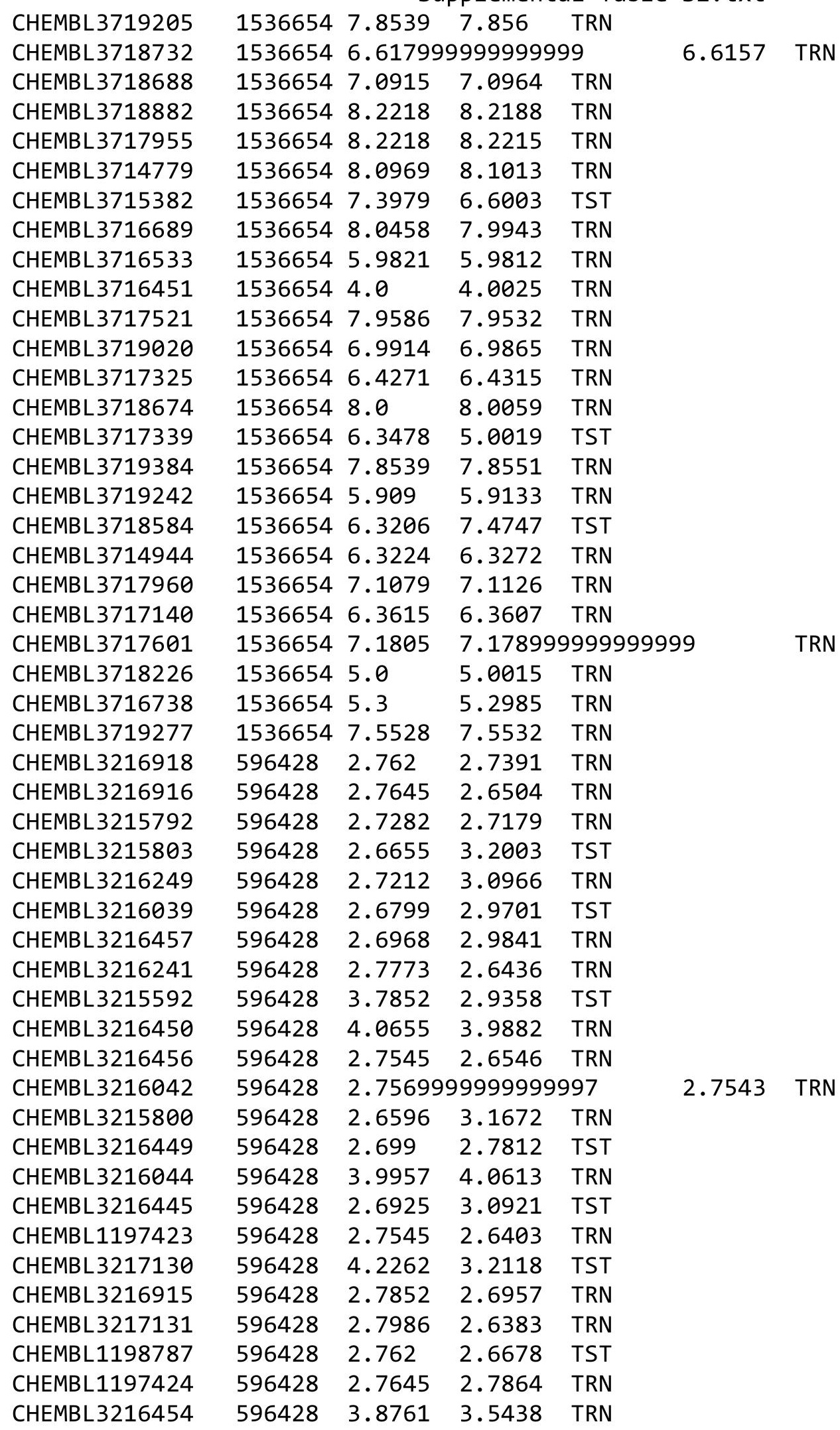

Page 21354 
Supplemental Table S2.txt

\begin{tabular}{|c|c|c|c|c|c|c|}
\hline CHEMBL 3216248 & 596428 & 2.7375 & 2.5073 & TRN & & \\
\hline CHEMBL 3215795 & 596428 & 3.7144 & 3.4733 & TRN & & \\
\hline CHEMBL3215799 & 596428 & 2.7696 & 2.5425 & TRN & & \\
\hline CHEMBL 3216685 & 596428 & 3.8962 & 3.7732 & TRN & & \\
\hline CHEMBL 3215793 & 596428 & 2.7212 & 2.8843 & TRN & & \\
\hline CHEMBL 3216043 & 596428 & 2.7496 & 2.7727 & TRN & & \\
\hline CHEMBL3216692 & 596428 & 3.8477 & 3.1323 & TRN & & \\
\hline CHEMBL 3216693 & 596428 & 2.7375 & 2.9115 & TRN & & \\
\hline CHEMBL 3216686 & 596428 & 5.0915 & 4.4373 & TRN & & \\
\hline CHEMBL3216687 & 596428 & 2.8665 & 2.8771 & TRN & & \\
\hline CHEMBL 3216921 & 596428 & 2.6498 & 2.8805 & TRN & & \\
\hline CHEMBL3216691 & 596428 & 2.7375 & 3.8395 & TRN & & \\
\hline CHEMBL 3215593 & 596428 & 2.7696 & 2.7796 & TRN & & \\
\hline CHEMBL 3215594 & 596428 & 2.7799 & 2.948 & TRN & & \\
\hline CHEMBL 3216688 & 596428 & 2.7352 & 3.301 & TRN & & \\
\hline CHEMBL 3216463 & 596428 & 3.8827 & 2.6906 & TRN & & \\
\hline CHEMBL3216919 & 596428 & 2.7696 & 2.7826 & TST & & \\
\hline CHEMBL 3216458 & 596428 & 2.7282 & 2.7109 & TST & & \\
\hline CHEMBL 3216045 & 596428 & 5.0655 & 4.17899 & 999999999 & & TRN \\
\hline CHEMBL 3216451 & 596428 & 2.7696 & 2.6807 & TRN & & \\
\hline CHEMBL3216690 & 596428 & 2.7033 & 2.843 & TST & & \\
\hline CHEMBL3216922 & 596428 & 2.7447 & 2.9479 & TRN & & \\
\hline CHEMBL 3215590 & 596428 & 2.7545 & 2.7957 & TST & & \\
\hline CHEMBL1197563 & 596428 & 2.7033 & 3.0929 & TST & & \\
\hline CHEMBL 3216040 & 596428 & 3.6596 & 3.7719 & TRN & & \\
\hline CHEMBL 3215588 & 596428 & 2.6778 & 3.1228 & TRN & & \\
\hline CHEMBL3216243 & 596428 & 2.7375 & 2.717 & TRN & & \\
\hline CHEMBL569952 & 596428 & 2.7471 & 2.7464 & TRN & & \\
\hline CHEMBL3216046 & 596428 & 2.7258 & 2.947 & TRN & & \\
\hline CHEMBL 3217128 & 596428 & 2.7167 & 2.8342 & TRN & & \\
\hline CHEMBL 3216242 & 596428 & 2.7212 & 3.5836 & TRN & & \\
\hline CHEMBL 3215589 & 596428 & 2.7595 & 2.6432 & TST & & \\
\hline CHEMBL 3216683 & 596428 & \multicolumn{3}{|c|}{ 2.7569999999999997 } & 2.7596 & TST \\
\hline CHEMBL3215801 & 596428 & 2.752 & 2.8368 & TRN & & \\
\hline CHEMBL3216920 & 596428 & 4.3072 & 3.4201 & TRN & & \\
\hline CHEMBL3215791 & 596428 & 2.6799 & 3.1052 & TST & & \\
\hline CHEMBL 3216459 & 596428 & 2.7055 & 3.378 & TRN & & \\
\hline CHEMBL1451348 & 954318 & 5.284 & 4.6387 & TRN & & \\
\hline CHEMBL1600400 & 954318 & 4.7737 & 4.6264 & TRN & & \\
\hline CHEMBL1440643 & 954318 & 4.5919 & 4.314 & TRN & & \\
\hline CHEMBL1595687 & 954318 & 4.2455 & 4.5444 & TST & & \\
\hline CHEMBL1724732 & 954318 & 5.0888 & 5.1651 & TRN & & \\
\hline CHEMBL1585652 & 954318 & \multicolumn{3}{|c|}{ 4.2669999999999995 } & 4.4609 & TRN \\
\hline CHEMBL1718302 & 954318 & 4.2884 & 4.6478 & TRN & & \\
\hline CHEMBL1867339 & 954318 & 4.6718 & 4.7764 & TRN & & \\
\hline CHEMBL1863833 & 954318 & 4.5006 & 4.2252 & TRN & & \\
\hline CHEMBL1333750 & 954318 & 4.4725 & 4.6918 & TRN & & \\
\hline CHEMBL1595792 & 954318 & 4.3338 & 4.7295 & TRN & & \\
\hline
\end{tabular}

Page 21355 
Supplemental Table S2.txt

\begin{tabular}{|c|c|c|c|c|}
\hline AEMBL1500480 & 54318 & 4.5719 & 4.6749 & \\
\hline & & 4.2918 & 4.3556 & \\
\hline 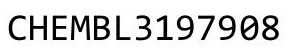 & & & & \\
\hline IEMBL1877605 & & 7865 & & \\
\hline AEMBL1360319 & 18 & 443 & 372 & \\
\hline AEMBL] & 18 & 963 & 55 & \\
\hline 37 & & 235 & & \\
\hline IEMBL & & & & \\
\hline AEMBL1429297 & 18 & & & \\
\hline AEMBL1570857 & 18 & & & \\
\hline AEMBL & 18 & 555 & & \\
\hline 6 & & 24 & & \\
\hline HEME & & & & \\
\hline IEMBL: & & 4.3175 & & \\
\hline AEMBL & 18 & & & \\
\hline 3 & & 4.7003 & & \\
\hline 5 & & & & \\
\hline AEMB & & & & \\
\hline 67 & & 998 & & \\
\hline 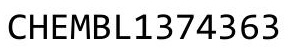 & & & & \\
\hline 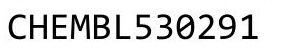 & & & & \\
\hline ? & & & & \\
\hline 3 & & 71 & & \\
\hline 8 & & & & \\
\hline 9 & & & & \\
\hline I & & & & \\
\hline & & & & \\
\hline & & & & \\
\hline & & & & \\
\hline HEMBL & & & & \\
\hline & & & & \\
\hline & & & & \\
\hline & & & & \\
\hline & & & & \\
\hline 56526 & & & & \\
\hline & & & & \\
\hline $\mathrm{Cl}$ & & 4. & & \\
\hline & & & & \\
\hline CHEMBL & & & & $\mathrm{R}$ \\
\hline & & & & \\
\hline $\mathrm{CH}$ & & & & \\
\hline CHEMBL & & & & \\
\hline CHEMBL & & 4.3301 & 445 & \\
\hline AEMBL & 95 & 5.3098 & & \\
\hline 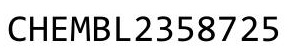 & & & & \\
\hline & & & & \\
\hline CHEMBL 1 & & 4.4675 & 4.7265 & \\
\hline CHEMBL1380943 & 954318 & 4.8348 & 4.6564 & \\
\hline
\end{tabular}

Page 21356 
Supplemental Table S2.txt

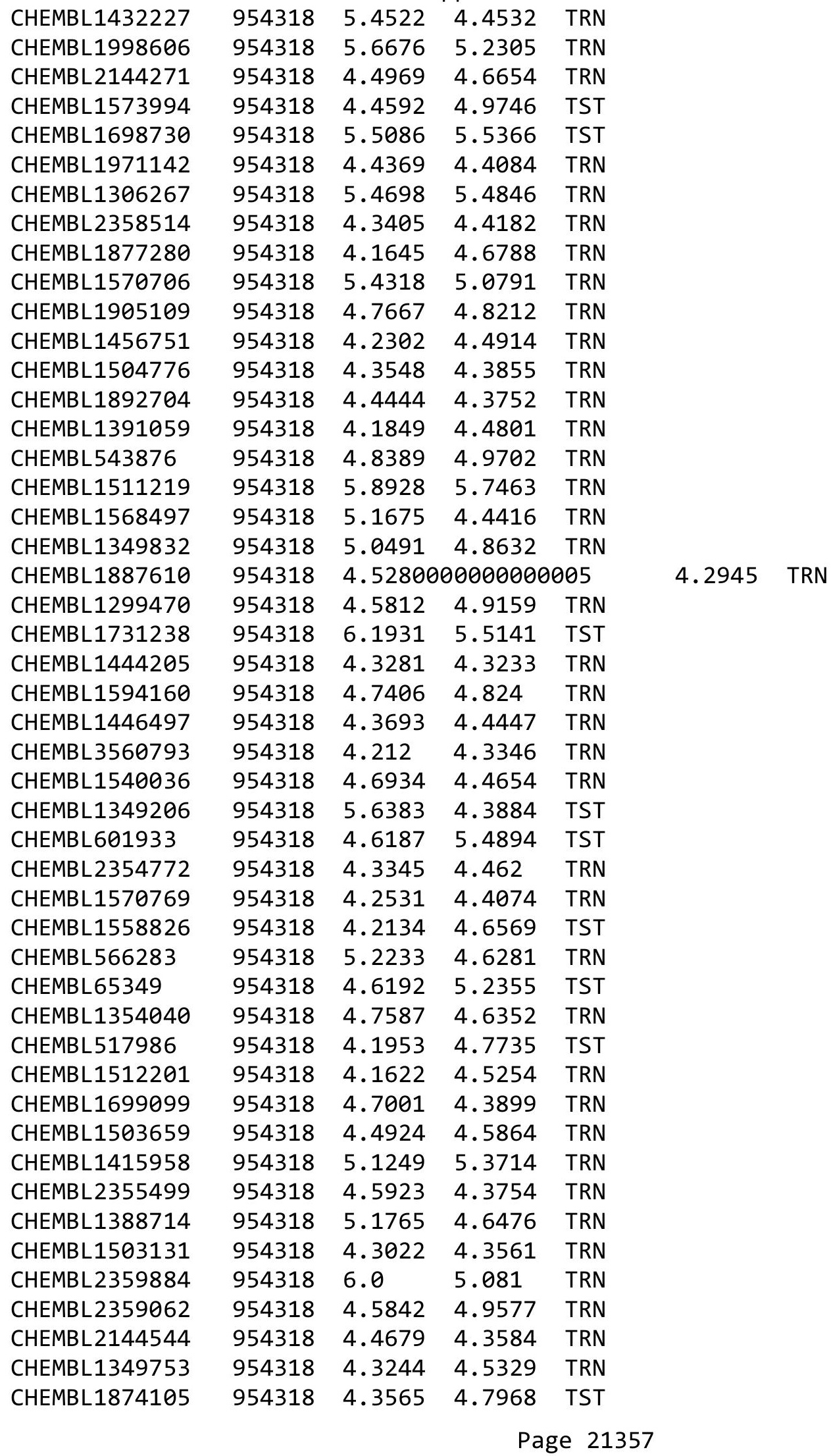


Supplemental Table S2.txt

\begin{tabular}{|c|c|c|c|c|}
\hline CHEMBL1313978 & 954318 & 4.8671 & 4.7591 & TRN \\
\hline CHEMBL1353797 & 954318 & 4.7086 & 4.6978 & TST \\
\hline CHEMBL1575537 & 954318 & 4.4412 & 4.4375 & TRN \\
\hline CHEMBL1325192 & 954318 & 5.1586 & 5.2169 & TRN \\
\hline CHEMBL 2357719 & 954318 & 5.2168 & 4.7874 & TRN \\
\hline CHEMBL 2362381 & 954318 & 4.5624 & 4.1457 & TRN \\
\hline CHEMBL1481347 & 954318 & 5.4685 & 6.0378 & TST \\
\hline CHEMBL1487901 & 954318 & 5.3382 & 4.5105 & TST \\
\hline CHEMBL530499 & 954318 & 4.601 & 4.7319 & TRN \\
\hline CHEMBL1452795 & 954318 & 5.7696 & 5.6266 & TRN \\
\hline CHEMBL1315948 & 954318 & 4.9662 & 4.7249 & TRN \\
\hline CHEMBL1385388 & 954318 & 4.2782 & 4.3755 & TRN \\
\hline CHEMBL1732521 & 954318 & 4.7462 & 5.2599 & TST \\
\hline CHEMBL1420768 & 954318 & 4.4973 & 4.2688 & TST \\
\hline CHEMBL 2357938 & 954318 & 4.4011 & 4.6152 & TRN \\
\hline CHEMBL1432670 & 954318 & 4.3803 & 4.8093 & TRN \\
\hline CHEMBL1448198 & 954318 & 5.0048 & 4.8316 & TRN \\
\hline CHEMBL1314757 & 954318 & 4.2914 & 4.2738 & TRN \\
\hline CHEMBL 2361351 & 954318 & 4.2071 & 4.1311 & TRN \\
\hline CHEMBL1733422 & 954318 & 5.2336 & 4.9295 & TRN \\
\hline CHEMBL1505743 & 954318 & 4.5459 & 4.4119 & TRN \\
\hline CHEMBL1521704 & 954318 & 4.4987 & 4.7246 & TRN \\
\hline CHEMBL 2355448 & 954318 & 4.1741 & 4.4574 & TRN \\
\hline CHEMBL1488010 & 954318 & 4.8312 & 5.0515 & TRN \\
\hline CHEMBL274070 & 954318 & 6.0 & 5.1867 & TST \\
\hline CHEMBL1707441 & 954318 & 4.8844 & 5.0033 & TRN \\
\hline CHEMBL1430094 & 954318 & 4.8483 & 4.9393 & TRN \\
\hline CHEMBL1602800 & 954318 & 4.4825 & 4.9877 & TRN \\
\hline CHEMBL1320042 & 954318 & 4.3049 & 4.5964 & TRN \\
\hline CHEMBL 2357859 & 954318 & 4.2545 & 3.9853 & TRN \\
\hline CHEMBL1596891 & 954318 & 4.6515 & 4.338999 & 99999999995 \\
\hline CHEMBL 2358913 & 954318 & 4.4579 & 4.5063 & TRN \\
\hline CHEMBL1423575 & 954318 & 4.7206 & 4.2569 & TRN \\
\hline CHEMBL1581715 & 954318 & 4.3055 & 4.1847 & TRN \\
\hline CHEMBL 2140460 & 954318 & 4.1898 & 4.1534 & TRN \\
\hline CHEMBL1570537 & 954318 & 4.1695 & 4.1913 & TRN \\
\hline CHEMBL 2361075 & 954318 & 4.3359 & 4.4804 & TRN \\
\hline CHEMBL 2360109 & 954318 & 4.6927 & 4.2953 & TRN \\
\hline CHEMBL 393287 & 954318 & 5.0804 & 4.5742 & TRN \\
\hline CHEMBL 2360993 & 954318 & 4.2357 & 4.2524 & TRN \\
\hline CHEMBL1522331 & 954318 & 4.4087 & 4.341 & TRN \\
\hline CHEMBL 2134576 & 954318 & 4.2146 & 4.3131 & TRN \\
\hline CHEMBL3195410 & 954318 & 5.1851 & 5.2836 & TRN \\
\hline CHEMBL102397 & 954318 & 7.585 & 5.9125 & TST \\
\hline CHEMBL1515360 & 954318 & 4.5572 & 4.5297 & TRN \\
\hline CHEMBL1704377 & 954318 & 4.3255 & 4.9846 & TST \\
\hline CHEMBL1523019 & 954318 & 5.1355 & 5.0121 & TRN \\
\hline CHEMBL1349146 & 954318 & 5.3757 & 5.0779 & TST \\
\hline
\end{tabular}




\begin{tabular}{|c|c|c|c|c|c|c|}
\hline & & \multicolumn{5}{|c|}{ Supplemental Table S2.txt } \\
\hline CHEMBL1402422 & 954318 & 4.8959 & 4.6833 & TRN & & \\
\hline CHEMBL 2135379 & 954318 & 4.232 & 4.602 & TRN & & \\
\hline CHEMBL 2360977 & 954318 & 4.212 & 4.3708 & TRN & & \\
\hline CHEMBL1418276 & 954318 & 4.3931 & 4.3521 & TRN & & \\
\hline CHEMBL1605995 & 954318 & 4.2931 & 4.6881 & TST & & \\
\hline CHEMBL1720535 & 954318 & 4.3017 & 4.6142 & TRN & & \\
\hline CHEMBL1899185 & 954318 & 4.4186 & 4.7878 & TRN & & \\
\hline CHEMBL1390450 & 954318 & 4.1797 & 4.3062 & TRN & & \\
\hline CHEMBL1349063 & 954318 & 6.5421 & 6.0563 & TRN & & \\
\hline CHEMBL51931 & 954318 & 5.7144 & 5.3915 & TRN & & \\
\hline CHEMBL1394527 & 954318 & 4.5272 & 4.5442 & TST & & \\
\hline CHEMBL1303152 & 954318 & 4.2307 & 4.6191 & TST & & \\
\hline CHEMBL290077 & 954318 & 6.567 & 5.938 & TST & & \\
\hline CHEMBL1464202 & 954318 & 4.215 & 4.2162 & TRN & & \\
\hline CHEMBL1579968 & 954318 & 4.5465 & 4.4146 & TRN & & \\
\hline CHEMBL 2133625 & 954318 & 4.3175 & 4.535 & TRN & & \\
\hline CHEMBL1886332 & 954318 & 5.0315 & 4.8016 & TRN & & \\
\hline CHEMBL1458403 & 954318 & 4.8775 & 4.7103 & TRN & & \\
\hline CHEMBL1428181 & 954318 & 4.5289 & 4.805 & TRN & & \\
\hline CHEMBL1457403 & 954318 & 5.4881 & 5.2044 & TST & & \\
\hline CHEMBL171699 & 954318 & 6.4634 & 6.1234 & TST & & \\
\hline CHEMBL3126906 & 954318 & 5.857 & 5.5093 & TST & & \\
\hline CHEMBL1383554 & 954318 & 4.1576 & 4.3125 & TRN & & \\
\hline CHEMBL 2360927 & 954318 & 4.6934 & 4.697 & TRN & & \\
\hline CHEMBL1349451 & 954318 & 4.2821 & 4.6252 & TRN & & \\
\hline CHEMBL 2357490 & 954318 & 4.63399 & و9999999 & 995 & 4.5829 & TRN \\
\hline CHEMBL1327046 & 954318 & 4.6872 & 4.5408 & TRN & & \\
\hline CHEMBL1302366 & 954318 & 4.3791 & 4.4961 & TRN & & \\
\hline CHEMBL1411646 & 954318 & 5.0325 & 4.9676 & TRN & & \\
\hline CHEMBL1450615 & 954318 & 5.3072 & 5.2837 & TRN & & \\
\hline CHEMBL 2356206 & 954318 & 4.3237 & 4.6864 & TRN & & \\
\hline CHEMBL1519965 & 954318 & $5.3270 e$ & 00000000 & & 5.0655 & TRN \\
\hline CHEMBL464467 & 954318 & 4.4483 & 4.5513 & TST & & \\
\hline CHEMBL1310617 & 954318 & 6.3788 & 5.50700 & 0000000001 & & TRN \\
\hline CHEMBL 2359943 & 954318 & 4.3016 & 4.255 & TRN & & \\
\hline CHEMBL601146 & 954318 & 5.0778 & 5.1497 & TRN & & \\
\hline CHEMBL1442319 & 954318 & 4.2063 & 4.47 & TRN & & \\
\hline CHEMBL 2359472 & 954318 & 4.4885 & 4.452 & TRN & & \\
\hline CHEMBL1522721 & 954318 & 4.2818 & 4.5069 & TRN & & \\
\hline CHEMBL1723968 & 954318 & 5.0273 & 5.0488 & TST & & \\
\hline CHEMBL1536958 & 954318 & 4.6882 & 4.7245 & TRN & & \\
\hline CHEMBL1348545 & 954318 & 4.2385 & 4.2194 & TRN & & \\
\hline CHEMBL1439985 & 954318 & 4.408 & 4.7362 & TRN & & \\
\hline CHEMBL1524929 & 954318 & 4.8626 & 4.8841 & TRN & & \\
\hline CHEMBL1341816 & 954318 & 4.6657 & 4.7813 & TRN & & \\
\hline CHEMBL 2356943 & 954318 & 6.0 & 4.6083 & TRN & & \\
\hline CHEMBL1884536 & 954318 & 4.1796 & 4.5055 & TRN & & \\
\hline CHEMBL3191106 & 954318 & 5.4498 & 5.1198 & TRN & & \\
\hline
\end{tabular}




\begin{tabular}{|c|c|c|c|c|c|}
\hline & & \multicolumn{4}{|c|}{ Supplemental Table S2.txt } \\
\hline CHEMBL1322078 & 954318 & 5.0665 & 4.8157 & TRN & \\
\hline CHEMBL 2358078 & 954318 & 4.2162 & 4.2402 & TRN & \\
\hline CHEMBL1705854 & 954318 & 5.2449 & 4.9348 & TST & \\
\hline CHEMBL 3193168 & 954318 & 4.305 & 4.5856 & TRN & \\
\hline CHEMBL1981570 & 954318 & 5.2204 & 5.2243 & TRN & \\
\hline CHEMBL602828 & 954318 & 4.4499 & 5.1242 & TST & \\
\hline CHEMBL1508914 & 954318 & 4.2844 & 4.2819 & TRN & \\
\hline CHEMBL1459767 & 954318 & 4.3425 & 4.7612 & TST & \\
\hline CHEMBL1728514 & 954318 & 6.1319 & 4.91100 & 00000000005 & TST \\
\hline CHEMBL1337961 & 954318 & 4.3862 & 4.4743 & TRN & \\
\hline CHEMBL1368039 & 954318 & 4.3035 & 4.7043 & TRN & \\
\hline CHEMBL1527341 & 954318 & 5.1605 & 5.0821 & TRN & \\
\hline CHEMBL1384205 & 954318 & 4.4995 & 4.5883 & TST & \\
\hline CHEMBL1427272 & 954318 & 4.5682 & 4.4524 & TRN & \\
\hline CHEMBL1601295 & 954318 & 4.7131 & 4.6836 & TRN & \\
\hline CHEMBL1586355 & 954318 & 4.1927 & 4.0007 & TRN & \\
\hline CHEMBL1339433 & 954318 & 4.8665 & 4.9379 & TRN & \\
\hline CHEMBL 2139561 & 954318 & 4.301 & 4.1758 & TRN & \\
\hline CHEMBL1600986 & 954318 & 4.7124 & 4.7375 & TRN & \\
\hline CHEMBL1902622 & 954318 & 4.7435 & 4.77800 & 00000000005 & TRN \\
\hline CHEMBL 2361810 & 954318 & 4.3885 & 4.2514 & TRN & \\
\hline CHEMBL2362170 & 954318 & 4.2142 & 4.3988 & TRN & \\
\hline CHEMBL1543358 & 954318 & 4.3166 & 4.684 & TST & \\
\hline CHEMBL 2355799 & 954318 & 4.4878 & 4.9852 & TST & \\
\hline CHEMBL1375740 & 954318 & 5.2865 & 5.5951 & TRN & \\
\hline CHEMBL1727847 & 954318 & 7.585 & 5.3049 & TST & \\
\hline CHEMBL1458905 & 954318 & 4.2199 & 4.4769 & TRN & \\
\hline CHEMBL1392611 & 954318 & 4.4557 & 4.2502 & TRN & \\
\hline CHEMBL1312953 & 954318 & 4.2267 & 4.9138 & TST & \\
\hline CHEMBL1529294 & 954318 & 4.766 & 4.2645 & TRN & \\
\hline CHEMBL 2357813 & 954318 & 4.4853 & 4.3908 & TRN & \\
\hline CHEMBL1538246 & 954318 & 4.1886 & 4.9266 & TRN & \\
\hline CHEMBL 2357774 & 954318 & 4.668 & 4.2983 & TRN & \\
\hline CHEMBL1451002 & 954318 & 4.1706 & 4.5596 & TRN & \\
\hline CHEMBL1302274 & 954318 & 4.2189 & 4.4425 & TRN & \\
\hline CHEMBL1359848 & 954318 & 5.0223 & 4.7061 & TRN & \\
\hline CHEMBL2140727 & 954318 & 4.6002 & 4.3971 & TRN & \\
\hline CHEMBL18115 & 954318 & 5.5317 & 5.4509 & TST & \\
\hline CHEMBL1431378 & 954318 & 4.2945 & 4.8764 & TRN & \\
\hline CHEMBL1437560 & 954318 & 5.0195 & 4.8811 & TRN & \\
\hline CHEMBL 3187467 & 954318 & 4.6472 & 4.1521 & TRN & \\
\hline CHEMBL1323459 & 954318 & 4.6674 & 4.6773 & TRN & \\
\hline CHEMBL1425438 & 954318 & 4.3346 & 4.8085 & TRN & \\
\hline CHEMBL 2354532 & 954318 & 5.1421 & 4.7408 & TRN & \\
\hline CHEMBL 2136129 & 954318 & 4.3289 & 4.5336 & TRN & \\
\hline CHEMBL1459468 & 954318 & 5.767 & 5.7148 & TRN & \\
\hline CHEMBL1420175 & 954318 & 4.7249 & 4.4633 & TST & \\
\hline CHEMBL1445858 & 954318 & 4.2786 & 4.4143 & TRN & \\
\hline
\end{tabular}




\begin{tabular}{|c|c|c|c|c|c|}
\hline & & \multicolumn{4}{|c|}{ Supplemental Table S2.txt } \\
\hline CHEMBL1567814 & 954318 & 4.6336 & 4.5859 & TRN & \\
\hline CHEMBL193627 & 954318 & 5.3288 & 5.4433 & TST & \\
\hline CHEMBL 2359890 & 954318 & 4.657 & 4.4711 & TRN & \\
\hline CHEMBL1384874 & 954318 & 4.172 & 4.2598 & TRN & \\
\hline CHEMBL1501091 & 954318 & 4.3211 & 4.2673 & TRN & \\
\hline CHEMBL1372725 & 954318 & 4.2361 & 4.5627 & TRN & \\
\hline CHEMBL1422386 & 954318 & 4.7414 & 4.8309 & TRN & \\
\hline CHEMBL1496004 & 954318 & 4.4199 & 4.8427 & TRN & \\
\hline CHEMBL 2357005 & 954318 & 4.5827 & 4.21399 & 99999999995 & TRN \\
\hline CHEMBL598679 & 954318 & 4.765 & 4.8168 & TRN & \\
\hline CHEMBL1474759 & 954318 & 5.1113 & 4.8751 & TST & \\
\hline CHEMBL1699398 & 954318 & 5.3188 & 5.0292 & TRN & \\
\hline CHEMBL1322589 & 954318 & 4.2944 & 4.8323 & TRN & \\
\hline CHEMBL1385727 & 954318 & 4.4376 & 4.5625 & TRN & \\
\hline CHEMBL16288 & 954318 & 7.585 & 5.8244 & TST & \\
\hline CHEMBL1523841 & 954318 & 6.2725 & 4.6149 & TST & \\
\hline CHEMBL1388405 & 954318 & 4.5328 & 4.7991 & TRN & \\
\hline CHEMBL 2356346 & 954318 & 4.2729 & 4.4269 & TRN & \\
\hline CHEMBL1375894 & 954318 & 5.1367 & 4.9713 & TRN & \\
\hline CHEMBL1447479 & 954318 & 4.2656 & 4.7186 & TRN & \\
\hline CHEMBL1374384 & 954318 & 5.2388 & 5.0904 & TRN & \\
\hline CHEMBL1373252 & 954318 & 4.4159 & 4.6641 & TRN & \\
\hline CHEMBL3185201 & 954318 & 4.1921 & 4.5031 & TRN & \\
\hline CHEMBL 2358094 & 954318 & 4.3821 & 4.7288 & TRN & \\
\hline CHEMBL1550670 & 954318 & 4.6375 & 4.4412 & TST & \\
\hline CHEMBL1541329 & 954318 & 4.5016 & 4.3288 & TRN & \\
\hline CHEMBL 2360104 & 954318 & 4.6724 & 4.6022 & TRN & \\
\hline CHEMBL 2137652 & 954318 & 4.3008 & 4.4961 & TRN & \\
\hline CHEMBL1346904 & 954318 & 4.5743 & 4.6027 & TRN & \\
\hline CHEMBL1448592 & 954318 & 5.284 & 5.2316 & TST & \\
\hline CHEMBL1897998 & 954318 & 4.2094 & 4.2331 & TRN & \\
\hline CHEMBL3560302 & 954318 & 4.2225 & 4.2624 & TRN & \\
\hline CHEMBL1405122 & 954318 & 6.2125 & 4.9125 & TST & \\
\hline CHEMBL1435072 & 954318 & 4.6394 & 4.7658 & TRN & \\
\hline CHEMBL1460004 & 954318 & 5.0227 & 5.2617 & TRN & \\
\hline CHEMBL1469557 & 954318 & 4.4425 & 4.2736 & TST & \\
\hline CHEMBL3194760 & 954318 & 5.3439 & 4.6257 & TST & \\
\hline CHEMBL1462457 & 954318 & 4.5441 & 4.3699 & TRN & \\
\hline CHEMBL1533776 & 954318 & 4.6444 & 4.8776 & TRN & \\
\hline CHEMBL3197091 & 954318 & 5.0315 & 5.1329 & TRN & \\
\hline CHEMBL1489131 & 954318 & 4.845 & 4.6365 & TRN & \\
\hline CHEMBL 2139915 & 954318 & 4.4298 & 4.5776 & TRN & \\
\hline CHEMBL1869216 & 954318 & 5.7986 & 4.9697 & TRN & \\
\hline CHEMBL1500372 & 954318 & 4.225 & 4.62 & TRN & \\
\hline CHEMBL1610579 & 954318 & 4.2185 & 4.2805 & TRN & \\
\hline CHEMBL1365395 & 954318 & 4.5984 & 4.4848 & TRN & \\
\hline CHEMBL1881663 & 954318 & 4.9446 & 4.7535 & TRN & \\
\hline CHEMBL1563968 & 954318 & 4.3448 & 4.687 & TRN & \\
\hline
\end{tabular}




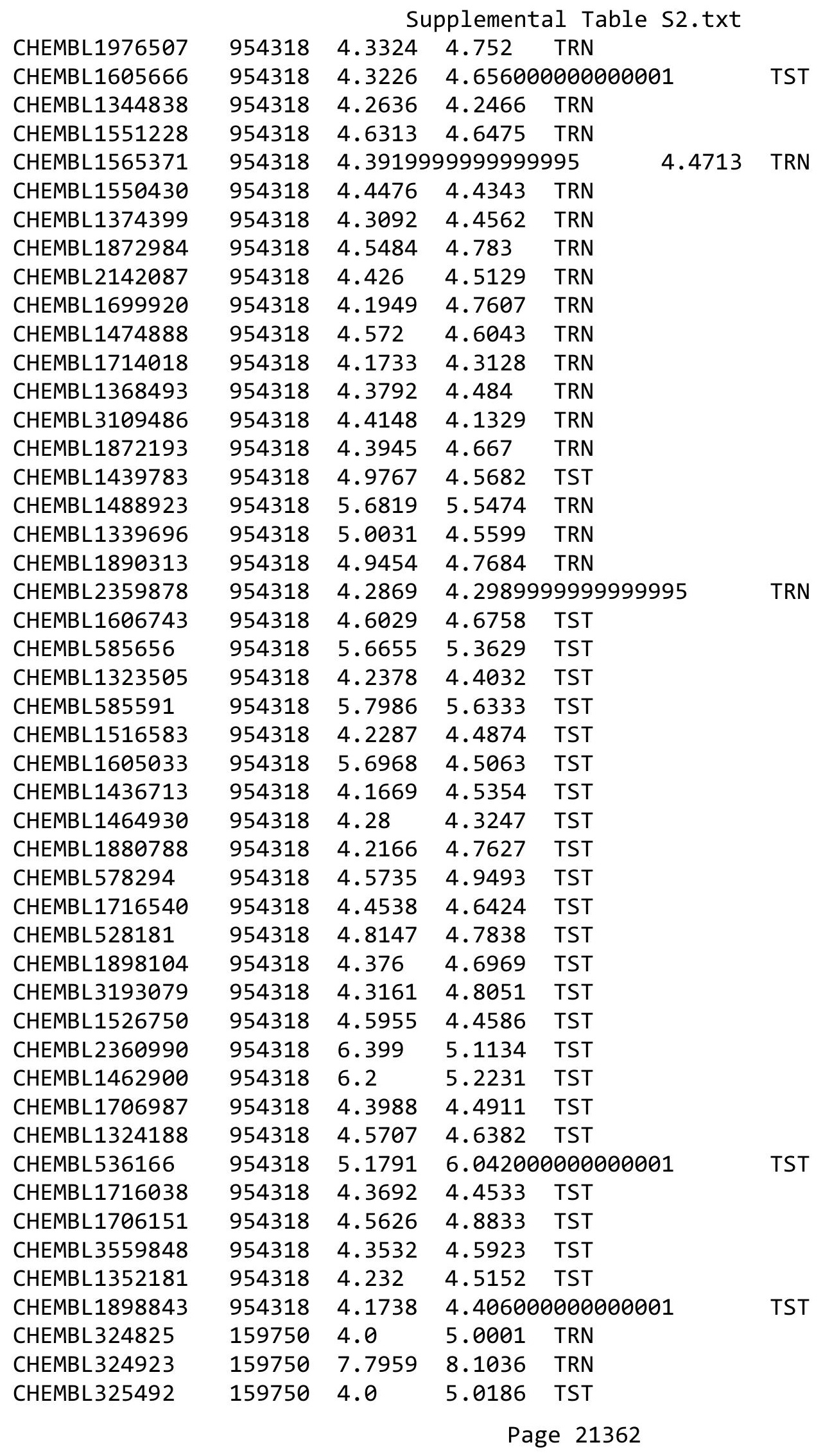




\begin{tabular}{|c|c|c|c|c|c|}
\hline \multirow[b]{2}{*}{ CHEMBL324312 } & \multicolumn{5}{|c|}{ Supplemental Table S2.txt } \\
\hline & 159750 & 8.699 & 7.6722 & TRN & \\
\hline CHEMBL332251 & 159750 & 8.5229 & 7.9612 & TRN & \\
\hline CHEMBL325298 & 159750 & 8.2218 & 7.3891 & TRN & \\
\hline CHEMBL115979 & 159750 & 8.301 & 9.0703 & TRN & \\
\hline CHEMBL116365 & 159750 & 5.0 & 6.428999 & 9999999999 & TRN \\
\hline CHEMBL333755 & 159750 & 4.0 & 5.9675 & TST & \\
\hline CHEMBL117917 & 159750 & 8.1549 & 8.4234 & TRN & \\
\hline CHEMBL114162 & 159750 & 4.0 & 5.0186 & TST & \\
\hline CHEMBL324275 & 159750 & 7.1308 & 7.1338 & TST & \\
\hline CHEMBL325894 & 159750 & 8.0458 & 7.325 & TRN & \\
\hline CHEMBL326291 & 159750 & 7.9586 & 7.6588 & TRN & \\
\hline CHEMBL116199 & 159750 & 4.0 & 6.0111 & TST & \\
\hline CHEMBL333084 & 159750 & 4.0 & 6.7825 & TRN & \\
\hline CHEMBL325297 & 159750 & 4.0 & 4.6537 & TST & \\
\hline CHEMBL116253 & 159750 & 6.5467 & 6.6827 & TST & \\
\hline CHEMBL327150 & 159750 & 8.1549 & 7.5841 & TRN & \\
\hline CHEMBL324700 & 159750 & 4.0 & 6.5525 & TRN & \\
\hline CHEMBL116933 & 159750 & 4.0 & 5.9675 & TST & \\
\hline CHEMBL333170 & 159750 & 4.0 & 5.0217 & TRN & \\
\hline CHEMBL420869 & 159750 & 7.0969 & 6.5526 & TRN & \\
\hline CHEMBL115458 & 159750 & 4.0 & 5.1995 & TST & \\
\hline CHEMBL117618 & 159750 & 4.0 & 4.6517 & TRN & \\
\hline CHEMBL117947 & 159750 & 7.699 & 8.1894 & TRN & \\
\hline CHEMBL324957 & 159750 & 6.8416 & 5.3229 & TRN & \\
\hline CHEMBL 324472 & 159750 & 5.0 & 6.8725 & TRN & \\
\hline CHEMBL118064 & 159750 & 8.0458 & 7.4036 & TRN & \\
\hline CHEMBL418859 & 159750 & 7.8539 & 6.1289 & TRN & \\
\hline CHEMBL 325437 & 159750 & 7.7447 & 7.2878 & TRN & \\
\hline CHEMBL324826 & 159750 & 8.2218 & 7.1703 & TRN & \\
\hline CHEMBL114783 & 159750 & 7.8539 & 5.8012 & TRN & \\
\hline CHEMBL331135 & 159750 & 6.9101 & 6.5254 & TRN & \\
\hline CHEMBL119852 & 159750 & 7.1871 & 6.8307 & TRN & \\
\hline CHEMBL116343 & 159750 & 7.2924 & 5.1403 & TRN & \\
\hline CHEMBL324093 & 159750 & 7.3188 & 5.1062 & TRN & \\
\hline CHEMBL117852 & 159750 & 7.0 & 6.4178 & TRN & \\
\hline CHEMBL326335 & 159750 & 8.2218 & 7.2109 & TRN & \\
\hline CHEMBL333651 & 159750 & 7.9586 & 7.5203 & TRN & \\
\hline CHEMBL115864 & 159750 & 4.0 & 5.7521 & TST & \\
\hline CHEMBL117862 & 159750 & 8.3979 & 8.0696 & TRN & \\
\hline CHEMBL 326270 & 159750 & 7.7447 & 7.0581 & TRN & \\
\hline CHEMBL326577 & 159750 & 7.4437 & 5.345 & TRN & \\
\hline CHEMBL116848 & 159750 & 4.0 & 4.7162 & TRN & \\
\hline CHEMBL324048 & 159750 & 7.5686 & 7.5807 & TRN & \\
\hline CHEMBL117295 & 159750 & 8.0969 & 8.2349 & TRN & \\
\hline CHEMBL419407 & 159750 & 8.699 & 8.2479 & TRN & \\
\hline CHEMBL324580 & 159750 & 7.1249 & 6.7514 & TRN & \\
\hline CHEMBL 324841 & 159750 & 5.0 & 7.0902 & TST & \\
\hline CHEMBL115410 & 159750 & 7.9586 & 6.88899 & 9999999999 & TRN \\
\hline & & & & 21362 & \\
\hline
\end{tabular}




\begin{tabular}{|c|c|c|c|c|c|c|}
\hline \multicolumn{7}{|c|}{ Supplemental Table S2.txt } \\
\hline CHEMBL 324823 & 159750 & 5.0 & 6.599 & TST & & \\
\hline CHEMBL117491 & 159750 & 4.0 & 6.2362 & TRN & & \\
\hline CHEMBL117146 & 159750 & 7.2924 & 5.0973 & TST & & \\
\hline CHEMBL117528 & 159750 & 7.8239 & 7.9289 & TRN & & \\
\hline CHEMBL118936 & 159750 & 5.0 & 4.9177 & TRN & & \\
\hline CHEMBL119002 & 159750 & 4.0 & 4.6517 & TRN & & \\
\hline CHEMBL118962 & 159750 & 6.5622 & 6.7552 & TST & & \\
\hline CHEMBL119076 & 159750 & 4.0 & 4.6731 & TRN & & \\
\hline CHEMBL119853 & 159750 & 4.0 & 5.345 & TRN & & \\
\hline CHEMBL119089 & 159750 & 4.0 & 6.1289 & TRN & & \\
\hline CHEMBL116252 & 159750 & 7.3665 & 6.7352 & TST & & \\
\hline CHEMBL116016 & 159750 & 8.1549 & 7.7879 & TRN & & \\
\hline CHEMBL333505 & 159750 & 5.0 & 6.3377 & TST & & \\
\hline CHEMBL324509 & 159750 & 8.3979 & 6.8298 & TRN & & \\
\hline CHEMBL117650 & 159750 & 7.5528 & 6.9224 & TRN & & \\
\hline CHEMBL117708 & 159750 & 6.7282 & 6.9733 & TRN & & \\
\hline CHEMBL115905 & 159750 & 5.0 & 7.3027 & TST & & \\
\hline CHEMBL331148 & 159750 & 7.7959 & 7.0607 & TRN & & \\
\hline CHEMBL331278 & 159750 & 7.5229 & 4.6537 & TST & & \\
\hline CHEMBL326097 & 159750 & 7.8239 & 8.1436 & TRN & & \\
\hline CHEMBL117547 & 159750 & 7.2757 & 6.7957 & TRN & & \\
\hline CHEMBL332725 & 159750 & 7.6021 & 7.4037 & TRN & & \\
\hline CHEMBL117855 & 159750 & 7.4089 & 6.77 & TRN & & \\
\hline CHEMBL115752 & 159750 & 8.1549 & 6.9189 & TRN & & \\
\hline CHEMBL118081 & 159750 & 7.8861 & 8.1964 & TRN & & \\
\hline CHEMBL 324042 & 159750 & 4.0 & 6.1553 & TST & & \\
\hline CHEMBL117306 & 159750 & 7.3768 & 7.6423 & TRN & & \\
\hline CHEMBL117946 & 159750 & 4.0 & 5.8012 & TST & & \\
\hline CHEMBL118067 & 159750 & 4.0 & 7.0442 & TRN & & \\
\hline CHEMBL116683 & 159750 & 8.0969 & 8.8913 & TRN & & \\
\hline CHEMBL119001 & 159750 & 4.0 & 4.7994 & TST & & \\
\hline CHEMBL442018 & 159750 & 5.0 & 6.6583 & TRN & & \\
\hline CHEMBL116498 & 159750 & 4.0 & 6.2956 & TRN & & \\
\hline CHEMBL 3670287 & 1527985 & 9.0 & 8.3094 & TRN & & \\
\hline CHEMBL3675191 & 1527985 & 5.7739 & 5.7352 & TRN & & \\
\hline CHEMBL 3670280 & 1527985 & 6.5229 & 6.2802 & TRN & & \\
\hline CHEMBL1922623 & 1527985 & 6.7055 & 6.9892 & TRN & & \\
\hline CHEMBL1668502 & 1527985 & 5.9547 & 5.6497 & TRN & & \\
\hline CHEMBL 3670283 & 1527985 & 6.289 & 5.6595 & TRN & & \\
\hline CHEMBL1668589 & 1527985 & 7.6198 & 7.5438 & TRN & & \\
\hline CHEMBL 3670282 & 1527985 & 4.0 & 4.297 & TRN & & \\
\hline CHEMBL1668587 & 1527985 & 6.9957 & 7.2262 & TRN & & \\
\hline CHEMBL3670292 & 1527985 & 6.4672 & 6.8204 & TRN & & \\
\hline CHEMBL1922624 & 1527985 & 6.76200 & 00000000 & 005 & 6.8051 & TRN \\
\hline CHEMBL1668565 & 1527985 & 8.3979 & 8.1378 & TRN & & \\
\hline CHEMBL1668581 & 1527985 & 6.7282 & 6.6994 & TRN & & \\
\hline CHEMBL1922634 & 1527985 & 7.5988 & 7.3093 & TRN & & \\
\hline CHEMBL1668501 & 1527985 & 6.3468 & 6.6566 & TRN & & \\
\hline
\end{tabular}


Supplemental Table S2.txt

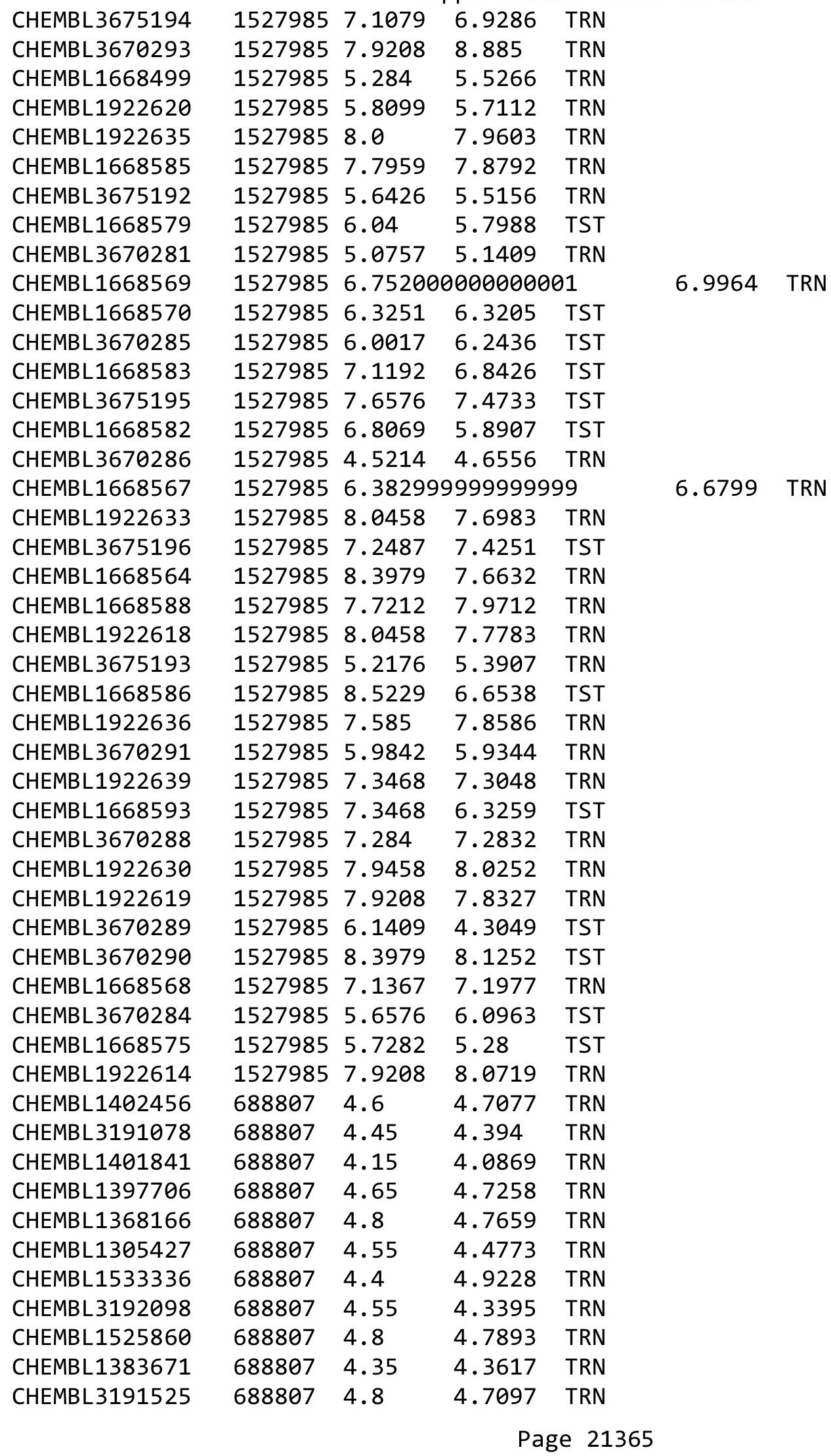




\begin{tabular}{|c|c|c|c|c|c|}
\hline \multicolumn{6}{|c|}{ Supplemental Table S2.txt } \\
\hline CHEMBL1596811 & 688807 & 4.65 & 5.5202 & TST & \\
\hline CHEMBL1990342 & 688807 & 4.4 & 4.4494 & TRN & \\
\hline CHEMBL1537149 & 688807 & 4.5 & 4.5336 & TRN & \\
\hline CHEMBL1483809 & 688807 & 4.25 & 4.2239 & TRN & \\
\hline CHEMBL1341913 & 688807 & 4.45 & 4.5633 & TRN & \\
\hline CHEMBL1383986 & 688807 & 4.45 & 4.5587 & TRN & \\
\hline CHEMBL1312989 & 688807 & 9.5229 & 9.4898 & TRN & \\
\hline CHEMBL1362933 & 688807 & 4.6 & 5.8269 & TST & \\
\hline CHEMBL1543904 & 688807 & 7.6498 & 7.6127 & TRN & \\
\hline CHEMBL1350237 & 688807 & 5.2 & 5.0128 & TRN & \\
\hline CHEMBL1503523 & 688807 & 4.4 & 4.2477 & TRN & \\
\hline CHEMBL1522941 & 688807 & 5.1 & 5.0153 & TRN & \\
\hline CHEMBL1596192 & 688807 & 4.25 & 4.3788 & TRN & \\
\hline CHEMBL1492541 & 688807 & 4.5 & 4.3614 & TRN & \\
\hline CHEMBL1325945 & 688807 & 6.8499 & 7.1973 & TST & \\
\hline CHEMBL1388300 & 688807 & 4.9 & 4.6598 & TRN & \\
\hline CHEMBL3145176 & 688807 & 4.25 & 4.4574 & TRN & \\
\hline CHEMBL3144999 & 688807 & 4.9 & 5.1642 & TRN & \\
\hline CHEMBL3216654 & 688807 & 5.55 & 5.3743 & TRN & \\
\hline CHEMBL1566134 & 688807 & 7.2 & 6.0917 & TST & \\
\hline CHEMBL1539121 & 688807 & 4.45 & 4.4425 & TRN & \\
\hline CHEMBL346516 & 688807 & 4.85 & 4.8089 & TRN & \\
\hline CHEMBL1528757 & 688807 & 6.7501 & 3.885 & TST & \\
\hline CHEMBL1573910 & 688807 & 5.5 & 5.2628 & TRN & \\
\hline CHEMBL1335040 & 688807 & 10.1 & 9.8827 & TRN & \\
\hline CHEMBL1421993 & 688807 & 5.05 & 5.1967 & TRN & \\
\hline CHEMBL1306199 & 688807 & 5.05 & 4.9566 & TRN & \\
\hline CHEMBL1457022 & 688807 & 4.9 & 5.0183 & TRN & \\
\hline CHEMBL1383058 & 688807 & 4.45 & 4.6983 & TRN & \\
\hline CHEMBL1339461 & 688807 & 4.5 & 4.31800 & 00000000005 & TRN \\
\hline CHEMBL1596010 & 688807 & 4.3 & 4.3328 & TRN & \\
\hline CHEMBL1570497 & 688807 & 4.5 & 4.513 & TRN & \\
\hline CHEMBL3209291 & 688807 & 9.2218 & 9.3351 & TRN & \\
\hline CHEMBL1321739 & 688807 & 4.95 & 5.0123 & TRN & \\
\hline CHEMBL1358678 & 688807 & 4.8 & 4.7932 & TRN & \\
\hline CHEMBL1430956 & 688807 & 4.5 & 4.6025 & TRN & \\
\hline CHEMBL1340437 & 688807 & 4.3 & 4.2792 & TRN & \\
\hline CHEMBL1382733 & 688807 & 4.1 & 4.1295 & TRN & \\
\hline CHEMBL 3190629 & 688807 & 5.1 & 5.044 & TRN & \\
\hline CHEMBL1499258 & 688807 & 6.6499 & 6.4725 & TRN & \\
\hline CHEMBL1422292 & 688807 & 8.8539 & 9.0609 & TRN & \\
\hline CHEMBL 22304 & 688807 & 3.95 & 5.4554 & TST & \\
\hline CHEMBL1489362 & 688807 & 5.3 & 5.2837 & TRN & \\
\hline CHEMBL1514936 & 688807 & 4.35 & 4.3648 & TRN & \\
\hline CHEMBL1346049 & 688807 & 4.95 & 4.9254 & TRN & \\
\hline CHEMBL1561548 & 688807 & 9.0 & 4.8272 & TST & \\
\hline CHEMBL1432973 & 688807 & 5.0 & 5.13 & TRN & \\
\hline CHEMBL1356812 & 688807 & 4.3 & 4.1509 & TRN & \\
\hline
\end{tabular}




\begin{tabular}{|c|c|c|c|c|c|}
\hline \multirow[b]{2}{*}{ CHEMBL1376246 } & \multicolumn{5}{|c|}{ Supplemental Table s2.txt } \\
\hline & 688807 & 6.2 & 6.8672 & TST & \\
\hline CHEMBL1465144 & 688807 & 5.15 & 4.7021 & TST & \\
\hline CHEMBL1590938 & 688807 & 4.15 & 5.25799 & 9999999999 & TST \\
\hline CHEMBL1591431 & 688807 & 4.45 & 3.6077 & TST & \\
\hline CHEMBL1368433 & 688807 & 5.45 & 7.2026 & TST & \\
\hline CHEMBL1332240 & 688807 & 4.45 & 5.1056 & TST & \\
\hline CHEMBL1605269 & 688807 & 4.35 & 2.905 & TST & \\
\hline CHEMBL1541259 & 688807 & 5.35 & 4.5897 & TST & \\
\hline CHEMBL1974319 & 688807 & 4.5 & 5.1128 & TST & \\
\hline CHEMBL1418852 & 688807 & 4.8 & 3.5811 & TST & \\
\hline CHEMBL1584739 & 688807 & 4.1 & 5.5037 & TST & \\
\hline CHEMBL83803 & 42878 & 6.8239 & 7.1148 & TRN & \\
\hline CHEMBL310169 & 42878 & 7.0555 & 7.1041 & TRN & \\
\hline CHEMBL 309973 & 42878 & 6.71 & 6.6759 & TRN & \\
\hline CHEMBL78588 & 42878 & 6.8239 & 6.8046 & TRN & \\
\hline CHEMBL3706590 & 42878 & 6.0315 & 6.0556 & TRN & \\
\hline CHEMBL80012 & 42878 & 7.6778 & 7.5455 & TRN & \\
\hline CHEMBL532012 & 42878 & 6.4815 & 6.6989 & TST & \\
\hline CHEMBL3706595 & 42878 & 6.7447 & 6.65799 & 99999999995 & TST \\
\hline CHEMBL309734 & 42878 & 6.6778 & 6.6979 & TRN & \\
\hline CHEMBL78725 & 42878 & 6.75200 & 00000000 & 6.7151 & TRN \\
\hline CHEMBL81815 & 42878 & 7.5229 & 7.5596 & TRN & \\
\hline CHEMBL 275447 & 42878 & 7.2218 & 7.2917 & TRN & \\
\hline CHEMBL3706587 & 42878 & 6.9586 & 6.8782 & TRN & \\
\hline CHEMBL81789 & 42878 & 7.6576 & 7.7176 & TRN & \\
\hline CHEMBL81634 & 42878 & 7.4437 & 7.3018 & TRN & \\
\hline CHEMBL82082 & 42878 & 7.0969 & 7.08299 & 9999999999 & TRN \\
\hline CHEMBL 81515 & 42878 & 7.4318 & 7.3607 & TRN & \\
\hline CHEMBL3706600 & 42878 & 7.301 & 6.9286 & TST & \\
\hline CHEMBL309650 & 42878 & 7.6778 & 7.6724 & TRN & \\
\hline CHEMBL77905 & 42878 & 7.6778 & 7.7018 & TRN & \\
\hline CHEMBL3706598 & 42878 & 6.2924 & 6.2828 & TRN & \\
\hline CHEMBL 82875 & 42878 & 6.6778 & 7.2284 & TST & \\
\hline CHEMBL 78735 & 42878 & 5.9586 & 6.3112 & TST & \\
\hline CHEMBL77560 & 42878 & 6.8097 & 6.9417 & TST & \\
\hline CHEMBL309731 & 42878 & 6.7447 & 6.7377 & TRN & \\
\hline CHEMBL3706593 & 42878 & 6.2596 & 6.3103 & TRN & \\
\hline CHEMBL78309 & 42878 & 7.3468 & 7.3959 & TRN & \\
\hline CHEMBL431789 & 42878 & 6.4318 & 6.7571 & TRN & \\
\hline CHEMBL 312428 & 42878 & 7.0458 & 7.0694 & TRN & \\
\hline CHEMBL3706596 & 42878 & 6.1427 & 6.2 & TRN & \\
\hline CHEMBL82036 & 42878 & 7.3665 & 7.4484 & TRN & \\
\hline CHEMBL3706588 & 42878 & 6.3372 & 6.3668 & TRN & \\
\hline CHEMBL81918 & 42878 & 7.3979 & 7.5273 & TRN & \\
\hline CHEMBL546783 & 42878 & 7.0458 & 7.153 & TRN & \\
\hline CHEMBL3706589 & 42878 & 6.6778 & 6.5639 & TST & \\
\hline CHEMBL543357 & 42878 & 6.1805 & 6.1292 & TRN & \\
\hline CHEMBL310640 & 42878 & 6.5528 & 6.5935 & TRN & \\
\hline
\end{tabular}




\begin{tabular}{|c|c|c|c|c|c|}
\hline \multirow[b]{2}{*}{ CHEMBL82025 } & & \multicolumn{4}{|c|}{ Supplemental Table S2.txt } \\
\hline & 42878 & 7.0458 & \multirow{2}{*}{\multicolumn{2}{|c|}{$\begin{array}{l}7.0920000000000005 \\
6.117999999999999\end{array}$}} & TRN \\
\hline CHEMBL3706601 & 42878 & 6.0969 & & & TRN \\
\hline CHEMBL310542 & 42878 & 6.1612 & \multicolumn{2}{|c|}{$\begin{array}{l}6.117999999999999 \\
6.1085 \text { TRN }\end{array}$} & \\
\hline CHEMBL84460 & 42878 & 6.9208 & 6.8191 & TRN & \\
\hline CHEMBL3706592 & 42878 & 5.8239 & 5.7628 & TRN & \\
\hline CHEMBL 311200 & 42878 & 6.5686 & 6.5811 & TRN & \\
\hline CHEMBL 78910 & 42878 & 6.4815 & 6.5217 & TRN & \\
\hline CHEMBL82721 & 42878 & 7.0315 & 7.0355 & TRN & \\
\hline CHEMBL 309747 & 42878 & 7.5686 & 7.3912 & TRN & \\
\hline CHEMBL3706597 & 42878 & 6.6198 & \multicolumn{2}{|c|}{6.587999999999999} & TRN \\
\hline CHEMBL 78571 & 42878 & 7.7447 & 7.6931 & TRN & \\
\hline CHEMBL 78077 & 42878 & 7.2007 & 7.0552 & TRN & \\
\hline CHEMBL3706594 & 42878 & 6.1871 & 6.1147 & TRN & \\
\hline CHEMBL 84388 & 42878 & 7.4815 & 7.2529 & TST & \\
\hline CHEMBL310318 & 42878 & 6.5157 & 6.7451 & TST & \\
\hline CHEMBL81344 & 42878 & 7.5229 & 7.2271 & TRN & \\
\hline CHEMBL312112 & 42878 & 7.3468 & 7.1789 & TST & \\
\hline CHEMBL77500 & 42878 & 6.3325 & 6.9898 & TST & \\
\hline CHEMBL82028 & 42878 & 6.2328 & 7.0569 & TST & \\
\hline CHEMBL3706599 & 42878 & 6.2798 & 6.9324 & TST & \\
\hline CHEMBL81323 & 42878 & 7.0458 & 6.8621 & TST & \\
\hline CHEMBL77516 & 42878 & 7.3188 & 6.9732 & TST & \\
\hline CHEMBL3093216 & 1278709 & 4.8239 & 4.8177 & TRN & \\
\hline CHEMBL 3093332 & 1278709 & 6.6421 & 6.6361 & TRN & \\
\hline CHEMBL 3093235 & 1278709 & 4.0 & 4.0026 & TRN & \\
\hline CHEMBL282038 & 1278709 & 4.9586 & 6.4475 & TST & \\
\hline CHEMBL3093221 & 1278709 & 4.8239 & 4.8306 & TRN & \\
\hline CHEMBL 3093226 & 1278709 & 4.0 & 3.9937 & TRN & \\
\hline CHEMBL 3093331 & 1278709 & 6.5045 & 6.5065 & TRN & \\
\hline CHEMBL3093330 & 1278709 & 6.3288 & 6.3257 & TRN & \\
\hline CHEMBL 3093233 & 1278709 & 3.6021 & 3.6012 & TRN & \\
\hline CHEMBL 3093214 & 1278709 & 4.8239 & 4.8222 & TRN & \\
\hline CHEMBL 3093222 & 1278709 & 4.8239 & 4.8301 & TRN & \\
\hline CHEMBL3093315 & 1278709 & 6.9431 & 6.9398 & TRN & \\
\hline CHEMBL 3093230 & 1278709 & 6.4935 & 5.8693 & TST & \\
\hline CHEMBL 3093238 & 1278709 & 5.7545 & 5.7506 & TRN & \\
\hline CHEMBL 3093311 & 1278709 & 5.9747 & 5.9804 & TRN & \\
\hline CHEMBL3093320 & 1278709 & 6.0044 & 6.0084 & TRN & \\
\hline CHEMBL 3091481 & 1278709 & 4.8239 & 4.8023 & TRN & \\
\hline CHEMBL3091482 & 1278709 & 5.9706 & 5.9806 & TRN & \\
\hline CHEMBL 3093220 & 1278709 & 4.8239 & 4.8418 & TRN & \\
\hline CHEMBL 3093225 & 1278709 & 6.2958 & 6.2921 & TRN & \\
\hline CHEMBL3093321 & 1278709 & 6.2882 & 6.2901 & TRN & \\
\hline CHEMBL 3093240 & 1278709 & 4.8239 & 4.8163 & TRN & \\
\hline CHEMBL239230 & 1278709 & 5.5186 & 5.5151 & TRN & \\
\hline CHEMBL 241618 & 1278709 & 6.3645 & 6.3688 & TRN & \\
\hline CHEMBL3093326 & 1278709 & 4.0 & 5.1955 & TST & \\
\hline CHEMBL3093229 & 1278709 & 4.0 & 4.0088 & TRN & \\
\hline
\end{tabular}


Supplemental Table S2.txt

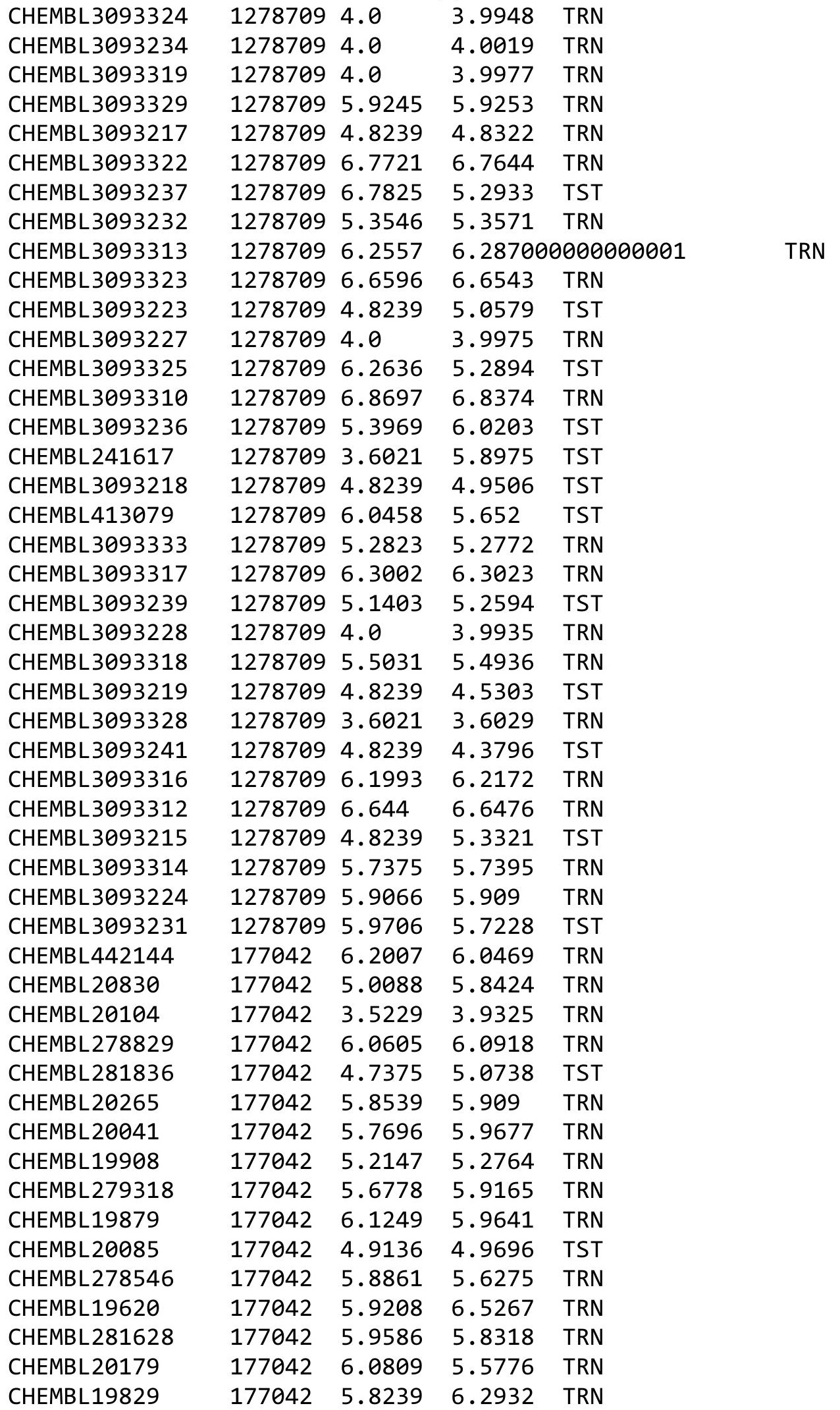

Page 21369 


\begin{tabular}{|c|c|c|c|c|c|}
\hline \multicolumn{6}{|c|}{ Supplemental Table s2.txt } \\
\hline CHEMBL20052 & 177042 & 6.5528 & 6.0692 & TRN & \\
\hline CHEMBL 278536 & 177042 & 3.5229 & 3.4755 & TRN & \\
\hline CHEMBL283127 & 177042 & 5.3188 & 5.4262 & TRN & \\
\hline CHEMBL 280885 & 177042 & 3.5229 & 4.6728 & TST & \\
\hline CHEMBL19398 & 177042 & 6.5376 & 6.2316 & TRN & \\
\hline CHEMBL 20578 & 177042 & 6.5686 & 5.7081 & TRN & \\
\hline CHEMBL20186 & 177042 & 5.5229 & 5.6836 & TRN & \\
\hline CHEMBL21080 & 177042 & 3.5229 & 4.5383 & TST & \\
\hline CHEMBL 277719 & 177042 & 6.7447 & 6.5368 & TRN & \\
\hline CHEMBL20119 & 177042 & 5.1249 & 5.3874 & TRN & \\
\hline CHEMBL19516 & 177042 & 5.699 & 6.4329 & TRN & \\
\hline CHEMBL20101 & 177042 & 6.2757 & 6.4335 & TRN & \\
\hline CHEMBL283995 & 177042 & 4.8539 & 5.1463 & TRN & \\
\hline CHEMBL 281790 & 177042 & 4.8416 & 5.6707 & TST & \\
\hline CHEMBL 2062143 & 177042 & 7.0 & 5.4388 & TST & \\
\hline CHEMBL 20062 & 177042 & 5.3565 & 5.678 & TRN & \\
\hline CHEMBL19694 & 177042 & 5.7959 & 5.5031 & TRN & \\
\hline CHEMBL19909 & 177042 & 5.4685 & 5.33799 & 9999999999 & TRN \\
\hline CHEMBL19799 & 177042 & 6.699 & 6.5408 & TRN & \\
\hline CHEMBL 277842 & 177042 & 5.9586 & 6.0897 & TRN & \\
\hline CHEMBL19105 & 177042 & 6.8861 & 6.9779 & TRN & \\
\hline CHEMBL 2062142 & 177042 & 7.0458 & 5.8414 & TST & \\
\hline CHEMBL282250 & 177042 & 3.6108 & 5.0768 & TST & \\
\hline CHEMBL20352 & 177042 & 6.6778 & 6.5167 & TRN & \\
\hline CHEMBL 20072 & 177042 & 3.5229 & 3.4374 & TRN & \\
\hline CHEMBL 280209 & 177042 & 5.1871 & 5.5001 & TRN & \\
\hline CHEMBL19918 & 177042 & 3.5229 & 3.3473 & TRN & \\
\hline CHEMBL 283581 & 177042 & 6.5086 & 6.1464 & TRN & \\
\hline CHEMBL19818 & 177042 & 6.6576 & 6.2918 & TRN & \\
\hline CHEMBL19775 & 177042 & 5.4089 & 5.494 & TRN & \\
\hline CHEMBL 278369 & 177042 & 6.7959 & 6.9412 & TRN & \\
\hline CHEMBL417098 & 177042 & 6.585 & 6.2619 & TRN & \\
\hline CHEMBL70996 & 177042 & 6.0315 & 5.5993 & TST & \\
\hline CHEMBL19556 & 177042 & 6.4685 & 6.0956 & TRN & \\
\hline CHEMBL 20285 & 177042 & 5.585 & 5.3286 & TRN & \\
\hline CHEMBL19922 & 177042 & 3.5229 & 3.3547 & TRN & \\
\hline CHEMBL418005 & 177042 & 3.5229 & 4.4066 & TRN & \\
\hline CHEMBL 20158 & 177042 & 5.0269 & 4.7283 & TST & \\
\hline CHEMBL19877 & 177042 & 3.5229 & 4.6092 & TST & \\
\hline CHEMBL20288 & 177042 & 5.8239 & 6.1612 & TRN & \\
\hline CHEMBL19605 & 177042 & 6.6198 & 6.4889 & TRN & \\
\hline CHEMBL19937 & 177042 & 4.6596 & 4.2771 & TRN & \\
\hline CHEMBL19558 & 177042 & 6.8539 & 6.5499 & TRN & \\
\hline CHEMBL 278827 & 177042 & 6.4437 & 6.5103 & TRN & \\
\hline CHEMBL 277892 & 177042 & 5.8861 & 6.1395 & TRN & \\
\hline CHEMBL 20073 & 177042 & 4.9914 & 5.1235 & TRN & \\
\hline CHEMBL 280355 & 177042 & 4.9393 & 6.1093 & TST & \\
\hline CHEMBL281629 & 177042 & 6.5686 & 6.6731 & TRN & \\
\hline
\end{tabular}




\begin{tabular}{|c|c|c|c|c|c|}
\hline \multicolumn{6}{|c|}{ Supplemental Table S2.txt } \\
\hline CHEMBL19999 & 177042 & 6.9586 & 6.8489 & TRN & \\
\hline CHEMBL279392 & 177042 & 7.5229 & 5.9734 & TST & \\
\hline CHEMBL19720 & 177042 & 5.2518 & 5.5702 & TRN & \\
\hline CHEMBL19446 & 177042 & 6.6576 & 6.0231 & TRN & \\
\hline CHEMBL20305 & 177042 & 4.9393 & 4.6601 & TRN & \\
\hline CHEMBL20018 & 177042 & 5.6778 & 5.6164 & TST & \\
\hline CHEMBL21134 & 177042 & 4.6716 & 5.7845 & TST & \\
\hline CHEMBL278370 & 177042 & 6.5686 & 5.7302 & TST & \\
\hline CHEMBL441956 & 177042 & 5.6198 & 4.7655 & TST & \\
\hline CHEMBL19477 & 177042 & 5.9586 & 5.7116 & TST & \\
\hline CHEMBL19858 & 177042 & 5.7212 & 6.4758 & TST & \\
\hline CHEMBL3975423 & 1640730 & 12.0 & 11.432 & TRN & \\
\hline CHEMBL 3980272 & 1640730 & 10.284 & 10.8701 & TRN & \\
\hline CHEMBL3935048 & 1640730 & 12.0 & 11.1109 & 99999999999 & TST \\
\hline CHEMBL 3977224 & 1640730 & 10.2757 & 10.6729 & TRN & \\
\hline CHEMBL3933925 & 1640730 & 9.8069 & 10.4466 & TST & \\
\hline CHEMBL3944117 & 1640730 & 10.7696 & 11.0187 & TRN & \\
\hline CHEMBL3889974 & 1640730 & 12.0 & 11.4978 & TRN & \\
\hline CHEMBL 3925824 & 1640730 & 12.0 & 11.7098 & TRN & \\
\hline CHEMBL3956131 & 1640730 & 12.0 & 11.4719 & TRN & \\
\hline CHEMBL 3944880 & 1640730 & 12.0 & 12.3236 & TRN & \\
\hline CHEMBL3916796 & 1640730 & 12.0 & 11.9005 & TRN & \\
\hline CHEMBL3974997 & 1640730 & 12.0 & 11.5583 & TRN & \\
\hline CHEMBL3981705 & 1640730 & 10.2291 & 11.08406 & 00000000001 & TRN \\
\hline CHEMBL3940505 & 1640730 & 10.4559 & 10.8213 & TRN & \\
\hline CHEMBL3957863 & 1640730 & 12.0 & 11.3594 & TRN & \\
\hline CHEMBL3935346 & 1640730 & 9.6459 & 10.4422 & TST & \\
\hline CHEMBL3975854 & 1640730 & 10.041 & 10.4428 & TST & \\
\hline CHEMBL3902943 & 1640730 & 12.0 & 11.4899 & TRN & \\
\hline CHEMBL3928802 & 1640730 & 12.0 & 11.2329 & 99999999999 & TRN \\
\hline CHEMBL3904327 & 1640730 & 12.0 & 10.6568 & TRN & \\
\hline CHEMBL3981966 & 1640730 & 9.8239 & 10.1923 & TRN & \\
\hline CHEMBL3906596 & 1640730 & 10.7959 & 10.0806 & TRN & \\
\hline CHEMBL3903488 & 1640730 & 12.0 & 12.2023 & TRN & \\
\hline CHEMBL3915564 & 1640730 & 10.3279 & 10.1853 & TRN & \\
\hline CHEMBL3960804 & 1640730 & 10.3979 & 9.5991 & TST & \\
\hline CHEMBL3967302 & 1640730 & 12.0 & 11.5218 & TRN & \\
\hline CHEMBL3943039 & 1640730 & 10.4559 & 10.9015 & TST & \\
\hline CHEMBL3966962 & 1640730 & 10.6383 & 10.6832 & TRN & \\
\hline CHEMBL3907082 & 1640730 & 12.0 & 11.5199 & TRN & \\
\hline CHEMBL3926508 & 1640730 & 9.209 & 11.6564 & TST & \\
\hline CHEMBL3932630 & 1640730 & 12.0 & 11.3573 & TRN & \\
\hline CHEMBL3932734 & 1640730 & 9.5229 & 9.5155 & TRN & \\
\hline CHEMBL 3982090 & 1640730 & 10.6383 & 11.3829 & TRN & \\
\hline CHEMBL3928884 & 1640730 & 12.0 & 11.784 & TRN & \\
\hline CHEMBL3985489 & 1640730 & 12.0 & 11.823 & TRN & \\
\hline CHEMBL3907059 & 1640730 & 10.7959 & 11.4285 & TRN & \\
\hline CHEMBL3976152 & 1640730 & 12.0 & 12.6089 & TRN & \\
\hline
\end{tabular}


Supplemental Table S2.txt

\begin{tabular}{|c|c|c|c|c|c|}
\hline CHEMBL 3891790 & 1640730 & 12.0 & 11.0406 & TST & \\
\hline CHEMBL 3980884 & 1640730 & 12.0 & 12.1178 & TRN & \\
\hline CHEMBL3961749 & 1640730 & 9.7423 & 11.0838 & TST & \\
\hline CHEMBL3904632 & 1640730 & 9.9245 & 9.8855 & TRN & \\
\hline CHEMBL 3907026 & 1640730 & 12.0 & 12.0054 & TRN & \\
\hline CHEMBL3921098 & 1640730 & 12.0 & 10.6362 & TRN & \\
\hline CHEMBL3911961 & 1640730 & 12.0 & 11.6769 & TRN & \\
\hline CHEMBL3981616 & 1640730 & 9.3028 & 9.0791 & TRN & \\
\hline CHEMBL 3943815 & 1640730 & 9.98299 & 79999999 & 10.0493 & TRN \\
\hline CHEMBL 3942884 & 1640730 & 9.8729 & 9.6093 & TST & \\
\hline CHEMBL 3986694 & 1640730 & 12.0 & 11.1021 & TRN & \\
\hline CHEMBL3938477 & 1640730 & 8.6847 & 9.4349 & TRN & \\
\hline CHEMBL 3900610 & 1640730 & 9.8761 & 11.6681 & TRN & \\
\hline CHEMBL3901483 & 1640730 & 10.4815 & 9.9827 & TRN & \\
\hline CHEMBL 3918129 & 1640730 & 12.0 & 11.0887 & TRN & \\
\hline CHEMBL 3971470 & 1640730 & 10.4559 & 11.2671 & TST & \\
\hline CHEMBL3961007 & 1640730 & 9.0052 & 10.2204 & TRN & \\
\hline CHEMBL 3924723 & 1640730 & 9.2211 & 9.3499 & TRN & \\
\hline CHEMBL 3975200 & 1640730 & 10.0915 & 9.9866 & TRN & \\
\hline CHEMBL 3987176 & 1640730 & 9.2916 & 9.7 & TRN & \\
\hline CHEMBL 3936893 & 1640730 & 10.5086 & 11.0270 & 00000000001 & TRN \\
\hline CHEMBL 3907400 & 1640730 & 10.7447 & 11.422 & TRN & \\
\hline CHEMBL3900365 & 1640730 & 10.9586 & 10.8038 & TRN & \\
\hline CHEMBL3969715 & 1640730 & 12.0 & 11.8857 & TRN & \\
\hline CHEMBL 3983118 & 1640730 & 12.0 & 12.4738 & TRN & \\
\hline CHEMBL3902290 & 1640730 & 10.9208 & 10.605 & TRN & \\
\hline CHEMBL3933905 & 1640730 & 13.0 & 12.3669 & TRN & \\
\hline CHEMBL3934632 & 1640730 & 12.0 & 11.239 & TRN & \\
\hline CHEMBL3933542 & 1640730 & 8.6759 & 10.8167 & TRN & \\
\hline CHEMBL3900835 & 1640730 & 12.0 & 11.6492 & TRN & \\
\hline CHEMBL 3934333 & 1640730 & 10.4089 & 11.515 & TST & \\
\hline CHEMBL3963537 & 1640730 & 10.6576 & 11.5732 & TRN & \\
\hline CHEMBL3918093 & 1640730 & 12.0 & 12.1698 & TRN & \\
\hline CHEMBL3919712 & 1640730 & 12.0 & 11.3586 & TRN & \\
\hline CHEMBL3913630 & 1640730 & 12.0 & 11.394 & TRN & \\
\hline CHEMBL3901190 & 1640730 & 12.0 & 11.8318 & TRN & \\
\hline CHEMBL 3891021 & 1640730 & 9.2434 & 10.3586 & TRN & \\
\hline CHEMBL3951058 & 1640730 & 12.0 & 11.8715 & TRN & \\
\hline CHEMBL 3932238 & 1640730 & 10.2441 & 9.9451 & TRN & \\
\hline CHEMBL3893990 & 1640730 & 12.0 & 11.558 & TRN & \\
\hline CHEMBL 3912171 & 1640730 & 12.0 & 10.9837 & TRN & \\
\hline CHEMBL 3899873 & 1640730 & 9.6925 & 10.9878 & TST & \\
\hline CHEMBL3901926 & 1640730 & 12.0 & 11.5188 & TRN & \\
\hline CHEMBL 3904899 & 1640730 & 12.0 & 11.695 & TRN & \\
\hline CHEMBL 3943608 & 1640730 & 12.0 & 11.9255 & TRN & \\
\hline CHEMBL 3954322 & 1640730 & 12.0 & 11.6097 & TRN & \\
\hline CHEMBL 3893089 & 1640730 & 12.0 & 9.9662 & TRN & \\
\hline CHEMBL3969902 & 1640730 & 13.0 & 11.4003 & TRN & \\
\hline
\end{tabular}

Page 21372 
Supplemental Table S2.txt

\begin{tabular}{|c|c|c|c|c|}
\hline CHEMBL 3912344 & 1640730 & 12.0 & 11.7517 & TRN \\
\hline CHEMBL3958966 & 1640730 & 12.0 & 11.5447 & TRN \\
\hline CHEMBL3977435 & 1640730 & 9.5452 & 9.7732 & TST \\
\hline CHEMBL3965818 & 1640730 & 10.0269 & 10.6041 & TRN \\
\hline CHEMBL3983051 & 1640730 & 10.6198 & 9.9038 & TRN \\
\hline CHEMBL3934982 & 1640730 & 12.0 & 11.7169 & TRN \\
\hline CHEMBL3928486 & 1640730 & 12.0 & 12.5421 & TRN \\
\hline CHEMBL3948144 & 1640730 & 9.6596 & 9.3254 & TRN \\
\hline CHEMBL3934907 & 1640730 & 9.0278 & 10.5606 & TST \\
\hline CHEMBL3903167 & 1640730 & 12.0 & 11.94906 & 00000000002 \\
\hline CHEMBL3896980 & 1640730 & 10.4437 & 11.0831 & TST \\
\hline CHEMBL3906350 & 1640730 & 12.0 & 11.2551 & TRN \\
\hline CHEMBL3899140 & 1640730 & 12.0 & $12.0840 t$ & 00000000001 \\
\hline CHEMBL3978678 & 1640730 & 10.0809 & 12.4344 & TST \\
\hline CHEMBL3963984 & 1640730 & 10.9208 & 10.6818 & TST \\
\hline CHEMBL3970055 & 1640730 & 8.9367 & 9.6661 & TRN \\
\hline CHEMBL3948418 & 1640730 & 9.8508 & 11.0204 & TRN \\
\hline CHEMBL3897737 & 1640730 & 9.7825 & 10.2099 & TRN \\
\hline CHEMBL3916807 & 1640730 & 10.8861 & 12.0945 & TST \\
\hline CHEMBL3932065 & 1640730 & 10.6778 & 11.4811 & TRN \\
\hline CHEMBL3906125 & 1640730 & 12.0 & 11.5673 & TRN \\
\hline CHEMBL3946197 & 1640730 & 12.0 & 12.4308 & TRN \\
\hline CHEMBL3889933 & 1640730 & 12.0 & 11.0678 & TRN \\
\hline CHEMBL3918831 & 1640730 & 12.0 & 9.7585 & TRN \\
\hline CHEMBL3894323 & 1640730 & 12.0 & 12.8369 & TRN \\
\hline CHEMBL3931411 & 1640730 & 12.0 & 11.9401 & TRN \\
\hline CHEMBL3916323 & 1640730 & 9.6478 & 11.5577 & TST \\
\hline CHEMBL3935082 & 1640730 & 12.0 & 11.4651 & TRN \\
\hline CHEMBL3966699 & 1640730 & 9.8386 & 9.7671 & TST \\
\hline CHEMBL3955355 & 1640730 & 6.0 & 8.9533 & TRN \\
\hline CHEMBL3918033 & 1640730 & 12.0 & 11.8241 & TRN \\
\hline CHEMBL3928305 & 1640730 & 9.9547 & 10.6065 & TRN \\
\hline CHEMBL3906710 & 1640730 & 10.3372 & 10.3029 & TRN \\
\hline CHEMBL3982226 & 1640730 & 12.0 & 11.4344 & TST \\
\hline CHEMBL3986183 & 1640730 & 12.0 & 11.1431 & TRN \\
\hline CHEMBL3958919 & 1640730 & 12.0 & 12.8588 & TRN \\
\hline CHEMBL3918493 & 1640730 & 10.7959 & 10.0809 & TRN \\
\hline CHEMBL3945773 & 1640730 & 9.7077 & 10.0551 & TRN \\
\hline CHEMBL3917124 & 1640730 & 12.0 & 11.0246 & TRN \\
\hline CHEMBL3925316 & 1640730 & 10.8861 & 11.3918 & TRN \\
\hline CHEMBL3945470 & 1640730 & 13.0 & 12.6211 & TRN \\
\hline CHEMBL3927982 & 1640730 & 12.0 & 11.6767 & TRN \\
\hline CHEMBL3918900 & 1640730 & 10.5086 & 10.5324 & TST \\
\hline CHEMBL3899475 & 1640730 & 9.8928 & 9.9837 & TST \\
\hline CHEMBL3940196 & 1640730 & 12.0 & 12.1882 & TRN \\
\hline CHEMBL3985747 & 1640730 & 9.3125 & 11.4346 & TST \\
\hline CHEMBL3916715 & 1640730 & 12.0 & 10.9567 & TRN \\
\hline CHEMBL3970337 & 1640730 & 12.0 & 11.9383 & TRN \\
\hline
\end{tabular}

Page 21373 
Supplemental Table S2.txt

\begin{tabular}{|c|c|c|c|c|}
\hline IE & 30 & 12.0 & 66 & TS \\
\hline & 640730 & 12.0 & 657 & \\
\hline 14 & 730 & 11.0 & & \\
\hline AEMBL3903355 & 0730 & 9.8962 & & \\
\hline AEMBL3892616 & 640730 & 12.0 & 462 & \\
\hline HEMBL3961383 & 540730 & 12.0 & 413 & \\
\hline & & 8.9578 & & \\
\hline IFMR $39 /$ & & 10.4815 & 869 & \\
\hline AEMBL3965909 & 730 & 10.6778 & 189 & \\
\hline HEMBL3968384 & 640730 & 12.0 & 397 & \\
\hline HEMBL3966838 & 30 & 7.5725 & $\partial 1$ & \\
\hline EMBL392 & 30 & 12.0 & & \\
\hline AEMBL39 & & 12.0 & & \\
\hline HEMBL 389 & 30 & 12.0 & & \\
\hline HEMBL390 & 30 & 12.0 & & \\
\hline IEMBL394 & 30 & 12.0 & 993 & \\
\hline AEMBL39 & 36 & 10.03 & & \\
\hline AEMBL39 & & 12.0 & & \\
\hline HEMBL394 & 30 & 13.0 & & \\
\hline AEMBL38 & & 9.2907 & & \\
\hline HEIMBLSS & 30 & 9.35 & & KIV \\
\hline AEMBL39 & & 6.0 & & \\
\hline AEMBL39 & & 12.0 & 78 & \\
\hline AFMRI 39 & & 9.1135 & & \\
\hline AEMBL39 & & 8.308 & &. \\
\hline HEMBL3S & 62 & 12.0 & 1 & TRN \\
\hline AEMBL3 & & 12.0 & 23 & Niv \\
\hline AFMBI 36 & 30 & 9.6003 & & \\
\hline HEMBL398 & & 12.0 & & Th \\
\hline HEMBL3939 & & 12.0 & & IR \\
\hline HEMBL 396 & 64 & 12.0 & 909 & RN \\
\hline HEMBL3 & & 8.923 & & KIV \\
\hline $15 \mathrm{MPI}$ & & $9.8 \varepsilon$ & & 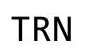 \\
\hline HEMBL 397 & & 10.4318 & 138 & TRN \\
\hline HEMBL3975145 & & 9.671 & 611 & TS \\
\hline HEMBL3 & 30 & 9.407 & & RN \\
\hline HFMRI 3 & 0 & 12.0 & 822 & TRN \\
\hline HEMBL3 & & 10.58 & 34 & TRN \\
\hline HEMBL3954669 & 30 & 12.0 & 959 & TRN \\
\hline HEMBL395 & & 12.0 & 844 & TR \\
\hline HEMBL3S & 30 & 8.787 & 876 & RN \\
\hline HEMBL 396 & 0 & 10.35 & & RN \\
\hline HEMBL392 & 30 & 9.4789 & & TST \\
\hline HEMBL3950071 & 640730 & 9.2628 & 622 & TS \\
\hline HEMBL39 & 30 & 10.09 & 222 & TR \\
\hline HEMBL 394 & & 10.4437 & 023 & TST \\
\hline HEMBL3915983 & & 9.0482 & 9.4359 & RN \\
\hline LHEMBL 3944513 & 1640730 & 9.7033 & 9.7215 & RN \\
\hline
\end{tabular}

Page 21374 
Supplemental Table S2.txt

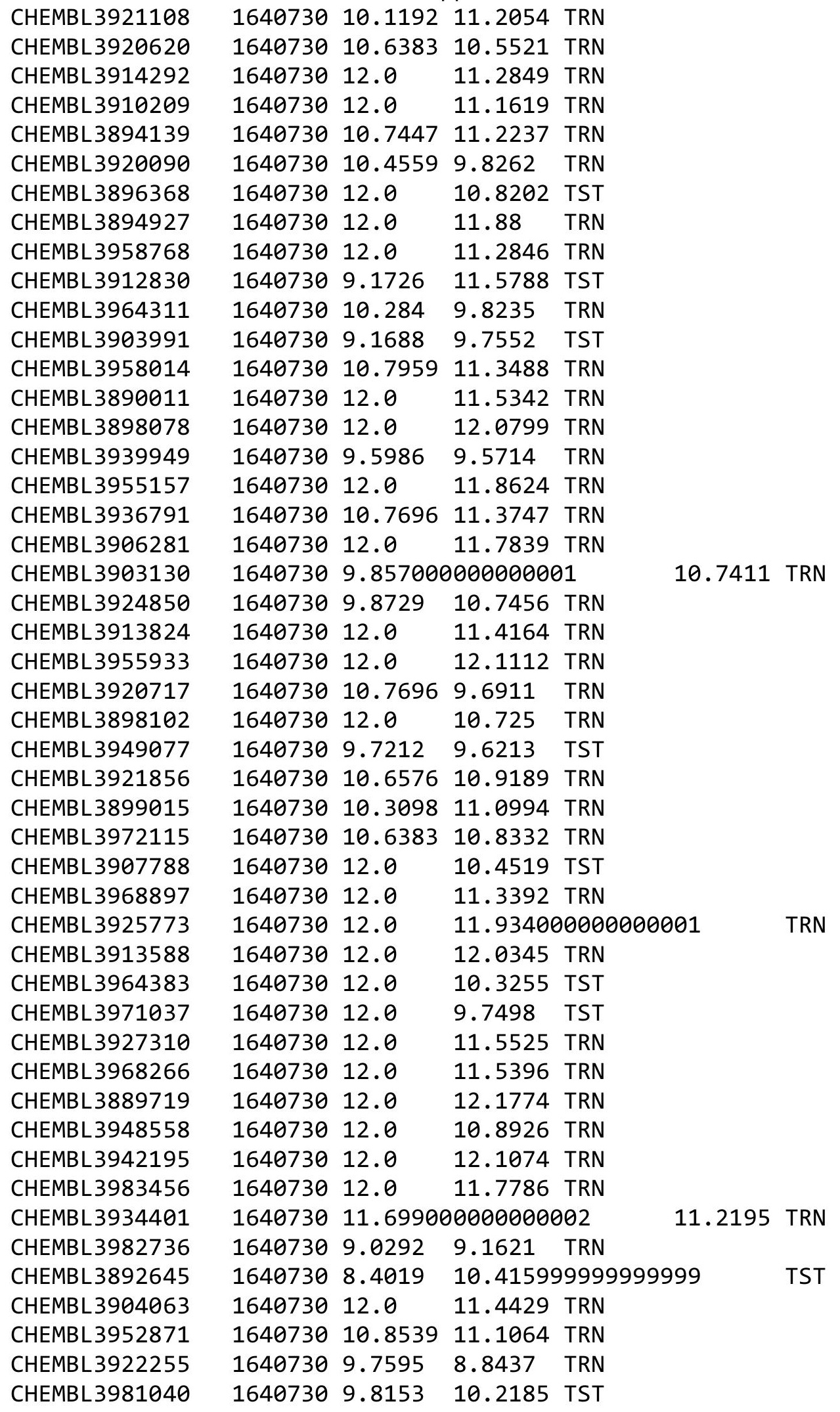

Page 21375 
Supplemental Table S2.txt

\begin{tabular}{|c|c|c|c|c|c|}
\hline CHEMBL3958490 & 1640730 & 9.2069 & 10.0957 & TRN & \\
\hline CHEMBL3926923 & 1640730 & 9.9393 & 11.1157 & TRN & \\
\hline CHEMBL3892749 & 1640730 & 6.0 & 10.5761 & TST & \\
\hline CHEMBL 3897450 & 1640730 & 12.0 & 12.0298 & TRN & \\
\hline CHEMBL3983989 & 1640730 & 9.982999 & 99999999 & 99 & 9.8837 \\
\hline CHEMBL3976783 & 1640730 & 10.8539 & 10.6484 & TRN & \\
\hline CHEMBL3938700 & 1640730 & 9.6326 & 10.2486 & TRN & \\
\hline CHEMBL3897726 & 1640730 & 9.4841 & 10.5783 & TST & \\
\hline CHEMBL3970001 & 1640730 & 12.0 & 11.8942 & TRN & \\
\hline CHEMBL3978223 & 1640730 & 6.0 & 10.5026 & TRN & \\
\hline CHEMBL3905915 & 1640730 & 12.0 & 10.9314 & TRN & \\
\hline CHEMBL3974238 & 1640730 & 10.6198 & 11.0429 & TRN & \\
\hline CHEMBL3910087 & 1640730 & 12.0 & 12.3493 & TRN & \\
\hline CHEMBL3923293 & 1640730 & 12.0 & 9.9478 & TRN & \\
\hline CHEMBL3940244 & 1640730 & 10.284 & 10.9011 & TRN & \\
\hline CHEMBL3973733 & 1640730 & 12.0 & 10.645 & TRN & \\
\hline CHEMBL3947479 & 1640730 & 12.0 & 12.3651 & TRN & \\
\hline CHEMBL3912248 & 1640730 & 10.3768 & 9.5748 & TRN & \\
\hline CHEMBL3908916 & 1640730 & 10.2007 & 9.6811 & TRN & \\
\hline CHEMBL3960525 & 1640730 & 10.1367 & 11.7149 & TST & \\
\hline CHEMBL3898008 & 1640730 & 12.0 & 11.8025 & TRN & \\
\hline CHEMBL3919078 & 1640730 & 9.3851 & 9.5037 & TST & \\
\hline CHEMBL3980718 & 1640730 & 12.0 & 10.4739 & TST & \\
\hline CHEMBL3921409 & 1640730 & 10.7696 & 11.308 & TRN & \\
\hline CHEMBL3891510 & 1640730 & 12.0 & 12.0731 & TRN & \\
\hline CHEMBL3936894 & 1640730 & 10.5376 & 11.9293 & TRN & \\
\hline CHEMBL3891622 & 1640730 & 6.0 & 9.5079 & TRN & \\
\hline CHEMBL3985756 & 1640730 & 9.9586 & 9.8934 & TRN & \\
\hline CHEMBL 3892563 & 1640730 & 9.9101 & 10.0444 & TRN & \\
\hline CHEMBL3927433 & 1640730 & 12.0 & 12.2538 & TRN & \\
\hline CHEMBL3925727 & 1640730 & 10.1308 & 9.3933 & TRN & \\
\hline CHEMBL3918688 & 1640730 & 10.5229 & 11.0697 & TRN & \\
\hline CHEMBL3974308 & 1640730 & 12.0 & 11.0528 & TRN & \\
\hline CHEMBL3972476 & 1640730 & 10.7696 & 12.0938 & TST & \\
\hline CHEMBL3942992 & 1640730 & 8.9642 & 9.7502 & TRN & \\
\hline CHEMBL3914513 & 1640730 & 12.0 & 11.4862 & TRN & \\
\hline CHEMBL3933894 & 1640730 & 10.6198 & 11.7925 & TRN & \\
\hline CHEMBL3954959 & 1640730 & 8.4608 & 9.3261 & TST & \\
\hline CHEMBL3969574 & 1640730 & 12.0 & 12.5829 & TRN & \\
\hline CHEMBL3915244 & 1640730 & 12.0 & 11.6345 & TST & \\
\hline CHEMBL3926563 & 1640730 & 10.585 & 10.0022 & TRN & \\
\hline CHEMBL3944779 & 1640730 & 12.0 & 12.1103 & TRN & \\
\hline CHEMBL3898859 & 1640730 & 10.1487 & 9.9178 & TST & \\
\hline CHEMBL 3974094 & 1640730 & 10.0458 & 9.5236 & TST & \\
\hline CHEMBL3923292 & 1640730 & 12.0 & 11.4344 & TRN & \\
\hline CHEMBL3922626 & 1640730 & 12.0 & 11.5041 & TRN & \\
\hline CHEMBL3965552 & 1640730 & 12.0 & 12.3111 & TRN & \\
\hline CHEMBL3959963 & 1640730 & 12.0 & 11.026 & TRN & \\
\hline
\end{tabular}




\begin{tabular}{|c|c|c|c|c|c|c|}
\hline \multicolumn{7}{|c|}{ Supplemental Table S2.txt } \\
\hline CHEMBL3967969 & 1640730 & 12.0 & 12.1694 & TRN & & \\
\hline CHEMBL3906575 & 1640730 & 9.7077 & 9.5667 & TRN & & \\
\hline CHEMBL3950070 & 1640730 & 10.6778 & 11.6997 & TRN & & \\
\hline CHEMBL3941326 & 1640730 & 12.0 & 11.3999 & TRN & & \\
\hline CHEMBL3974315 & 1640730 & 13.0 & 10.5043 & TST & & \\
\hline CHEMBL3984107 & 1640730 & 8.6838 & 8.9017 & TRN & & \\
\hline CHEMBL3938023 & 1640730 & 8.5532 & 9.4131 & TST & & \\
\hline CHEMBL 3898763 & 1640730 & 9.9431 & 9.2977 & TRN & & \\
\hline CHEMBL3968309 & 1640730 & 12.0 & 11.7624 & TST & & \\
\hline CHEMBL3952489 & 1640730 & 11.0 & 10.8899 & TST & & \\
\hline CHEMBL3949815 & 1640730 & 9.2426 & 9.2039 & TST & & \\
\hline CHEMBL3906643 & 1640730 & 10.3768 & 11.6695 & TST & & \\
\hline CHEMBL 3970500 & 1640730 & 10.7696 & 11.4405 & TST & & \\
\hline CHEMBL3902916 & 1640730 & 9.2541 & 10.009 & TST & & \\
\hline CHEMBL3956368 & 1640730 & 10.5376 & 10.5691 & TST & & \\
\hline CHEMBL3904600 & 1640730 & 12.0 & 11.5527 & TST & & \\
\hline CHEMBL3978257 & 1640730 & 12.0 & 10.7753 & TST & & \\
\hline CHEMBL3920467 & 1640730 & 10.5229 & 9.8245 & TST & & \\
\hline CHEMBL3894200 & 1640730 & 12.0 & 11.2706 & TST & & \\
\hline CHEMBL3899170 & 1640730 & 12.0 & 9.5474 & TST & & \\
\hline CHEMBL3925523 & 1640730 & 12.0 & 11.8742 & TST & & \\
\hline CHEMBL 3980454 & 1640730 & 10.0458 & 9.6183 & TST & & \\
\hline CHEMBL3950077 & 1640730 & 10.4089 & 10.7978 & TST & & \\
\hline CHEMBL3911298 & 1640730 & 12.0 & 11.2394 & TST & & \\
\hline CHEMBL3943297 & 1640730 & 12.0 & 12.8529 & TST & & \\
\hline CHEMBL3941155 & 1640730 & 12.0 & 12.1321 & TST & & \\
\hline CHEMBL3948416 & 1640730 & 12.0 & 11.4548 & TST & & \\
\hline CHEMBL1788116 & 954837 & 4.9673 & 4.9617 & TRN & & \\
\hline CHEMBL483847 & 954837 & 4.0752 & 4.0907 & TRN & & \\
\hline CHEMBL135561 & 954837 & 4.7314 & 4.7052 & TRN & & \\
\hline CHEMBL514499 & 954837 & 7.9805 & 7.9838 & TRN & & \\
\hline CHEMBL412142 & 954837 & 4.5562 & 4.5532 & TRN & & \\
\hline CHEMBL 213100 & 954837 & 4.2989 & 4.3191 & TRN & & \\
\hline CHEMBL 221137 & 954837 & 4.8524 & 5.0551 & TST & & \\
\hline CHEMBL259181 & 954837 & 3.6571 & 3.6608 & TRN & & \\
\hline CHEMBL 222102 & 954837 & 4.4572 & 4.482 & TRN & & \\
\hline CHEMBL192566 & 954837 & 7.7423 & 9.2822 & TST & & \\
\hline CHEMBL1190711 & 954837 & 5.2231 & 5.2224 & TRN & & \\
\hline CHEMBL 2005886 & 954837 & 5.6376 & 5.6368 & TRN & & \\
\hline CHEMBL 2144069 & 954837 & 4.5832 & 4.5824 & TRN & & \\
\hline CHEMBL472940 & 954837 & 3.5326 & 3.5265 & TRN & & \\
\hline CHEMBL1230020 & 954837 & 2.9238 & 2.9053 & TRN & & \\
\hline CHEMBL92309 & 954837 & 3.171999 & 79999999 & 997 & 3.5228 & TST \\
\hline CHEMBL392695 & 954837 & 6.3647 & 6.3735 & TRN & & \\
\hline CHEMBL509032 & 954837 & 6.1251 & 6.1207 & TRN & & \\
\hline CHEMBL 379300 & 954837 & 6.8206 & 6.808 & TRN & & \\
\hline CHEMBL393929 & 954837 & 4.7616 & 4.7623 & TRN & & \\
\hline CHEMBL1909414 & 954837 & 4.1011 & 4.1121 & TRN & & \\
\hline
\end{tabular}


Supplemental Table S2.txt

\begin{tabular}{|c|c|c|c|c|}
\hline 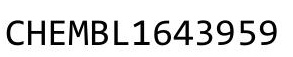 & & 623 & 2 & TRN \\
\hline HFMBI 191334 & & & & \\
\hline AEMBL300389 & 837 & & & \\
\hline IEMBL 2363137 & 54837 & & 352 & \\
\hline HEMBL1404918 & 54837 & 9638 & 9734 & \\
\hline HEMBL1357247 & 37 & 396 & 186 & \\
\hline EMBL & & & & \\
\hline HEMBL1242367 & 37 & & 113 & \\
\hline AEMBL1970879 & 37 & & 575 & \\
\hline HEMBL 202721 & 37 & 27 & 032 & \\
\hline HEMBL 379975 & 37 & 82 & 984 & \\
\hline IEMBL & & & 349 & \\
\hline AEMBL & 37 & & 717 & \\
\hline AEMBL: & 37 & 208 & 032 & \\
\hline HEMBL3199475 & 37 & 26 & 384 & \\
\hline IEMBL & & & 564 & \\
\hline IEMBL & & & 95 & \\
\hline AEMBL & 37 & & & \\
\hline IEMBL: & & & & \\
\hline AEMBL: & 37 & & 15 & \\
\hline EMBL & & & 14 & \\
\hline EMBL & & & & \\
\hline AFMRI & & & & \\
\hline IEMBL & & & & \\
\hline AEMBL: & 37 & & 73 & \\
\hline EMBL & & & 37 & \\
\hline FMR & & & & \\
\hline & & & & \\
\hline IEMBL & & & & \\
\hline AEMBL: & 7 & & 26 & \\
\hline EMRI & & & 78 & \\
\hline 59 & & & & \\
\hline & & & & \\
\hline IEMBL: & & & & \\
\hline EMBL & & & 86 & $S$ \\
\hline EMPI & & & 87 & \\
\hline ליבנזו & & & & \\
\hline & & & & \\
\hline IEMBL: & & & 328 & 5 \\
\hline ABL & & & & 3 \\
\hline EMBL & & & & \\
\hline & & & & S \\
\hline HEMBL 217354 & & & & \\
\hline IEMBL: & 37 & & 65 & \\
\hline СИгМ口 2602 & & & & \\
\hline CHEMBL3662687 & 152 & & 7.7406 & \\
\hline CHEMBL391334 & 1528515 & 8.3979 & 7.776 & \\
\hline CHEMBL3662654 & 1528515 & 7.6676 & 7.3748 & \\
\hline
\end{tabular}

Page 21378 
Supplemental Table S2.txt

\begin{tabular}{|c|c|c|c|c|}
\hline CHEMBL 3667353 & 1528515 & 8.2218 & 8.1683 & TRN \\
\hline CHEMBL 3662591 & 1528515 & 7.9245 & 8.0155 & TST \\
\hline CHEMBL 3667339 & 1528515 & 7.6861 & 6.9836 & TST \\
\hline CHEMBL 3662620 & 1528515 & 7.5867 & 7.7636 & TST \\
\hline CHEMBL 3667360 & 1528515 & 8.0044 & 7.6398 & TRN \\
\hline CHEMBL 3662592 & 1528515 & 6.0 & 7.2227 & TRN \\
\hline CHEMBL 3667323 & 1528515 & 7.5391 & 8.0061 & TST \\
\hline CHEMBL 3954228 & 1528515 & 8.0132 & 7.6776 & TRN \\
\hline CHEMBL 3662593 & 1528515 & 7.9208 & 8.0636 & TRN \\
\hline CHEMBL 3662642 & 1528515 & 5.6211 & 6.7291 & TRN \\
\hline CHEMBL 3667373 & 1528515 & 9.0 & 8.1006 & TRN \\
\hline CHEMBL 3662709 & 1528515 & 7.82100 & 000000000 & 7.7172 \\
\hline CHEMBL 3667398 & 1528515 & 7.4134 & 7.8241 & TRN \\
\hline CHEMBL 3662639 & 1528515 & 6.6861 & 7.92 & TRN \\
\hline CHEMBL 3667352 & 1528515 & 8.301 & 8.1054 & TST \\
\hline CHEMBL 3662668 & 1528515 & 7.8697 & 7.6833 & TRN \\
\hline CHEMBL 3667280 & 1528515 & 8.7447 & 8.5673 & TRN \\
\hline CHEMBL 3662585 & 1528515 & 7.9666 & 7.9779 & TRN \\
\hline CHEMBL 3662587 & 1528515 & 7.9508 & 7.7253 & TRN \\
\hline CHEMBL 3662650 & 1528515 & 7.9914 & 7.507999 & 9999999999 \\
\hline CHEMBL 3662691 & 1528515 & 8.1308 & 7.9251 & TRN \\
\hline CHEMBL 3662566 & 1528515 & 8.1249 & 8.1399 & TRN \\
\hline CHEMBL 3662667 & 1528515 & 8.4202 & 7.7628 & TRN \\
\hline CHEMBL 3662699 & 1528515 & 8.0177 & 7.9762 & TRN \\
\hline CHEMBL 3667279 & 1528515 & 8.7696 & 8.7952 & TRN \\
\hline CHEMBL 3662532 & 1528515 & 8.585 & 8.4946 & TRN \\
\hline CHEMBL3667316 & 1528515 & 7.3595 & 7.7448 & TST \\
\hline CHEMBL 3662594 & 1528515 & 7.9066 & 8.0924 & TST \\
\hline CHEMBL 3662685 & 1528515 & 8.28399 & 999999999 & 8.214 \\
\hline CHEMBL 3662626 & 1528515 & 7.4776 & 7.7758 & TST \\
\hline CHEMBL 3662711 & 1528515 & 7.8013 & 8.2067 & TRN \\
\hline CHEMBL 3662671 & 1528515 & 9.0458 & 8.4829 & TRN \\
\hline CHEMBL 3662617 & 1528515 & 7.6038 & 7.9399 & TRN \\
\hline CHEMBL 3662577 & 1528515 & 8.041 & 7.91 & TRN \\
\hline CHEMBL 3667290 & 1528515 & 8.2147 & 8.3188 & TRN \\
\hline CHEMBL 3667391 & 1528515 & 8.3468 & 8.1077 & TRN \\
\hline CHEMBL 3662557 & 1528515 & 8.2757 & 8.196 & TRN \\
\hline CHEMBL 3667293 & 1528515 & 8.3188 & 7.42 & TRN \\
\hline CHEMBL 3662656 & 1528515 & 7.2 & 7.2853 & TRN \\
\hline CHEMBL 3667359 & 1528515 & 8.0269 & 8.1478 & TRN \\
\hline CHEMBL 3667355 & 1528515 & 8.1549 & 7.8348 & TRN \\
\hline CHEMBL 3662528 & 1528515 & 8.7212 & 7.834 & TRN \\
\hline CHEMBL 3667270 & 1528515 & 6.5969 & 6.9206 & TST \\
\hline CHEMBL 3667386 & 1528515 & 7.3536 & 7.7287 & TRN \\
\hline CHEMBL 3662715 & 1528515 & 7.6402 & 8.0317 & TRN \\
\hline CHEMBL 3667296 & 1528515 & 8.2291 & 8.2836 & TRN \\
\hline CHEMBL 3662576 & 1528515 & 8.0605 & 8.4127 & TST \\
\hline CHEMBL3667328 & 1528515 & 9.0 & 8.433 & TRN \\
\hline
\end{tabular}


Supplemental Table S2.txt

\begin{tabular}{|c|c|c|c|c|c|}
\hline CHEMBL 3667387 & 1528515 & 8.8861 & 8.4893 & TRN & \\
\hline CHEMBL3667302 & 1528515 & 8.4202 & 8.0573 & TRN & \\
\hline CHEMBL 3662527 & 1528515 & 8.7212 & 7.9453 & TRN & \\
\hline CHEMBL 3667272 & 1528515 & 8.6576 & 7.7487 & TRN & \\
\hline CHEMBL3662615 & 1528515 & 7.6216 & 7.75299 & 9999999999 & TST \\
\hline CHEMBL 3662565 & 1528515 & 6.0 & 7.6808 & TRN & \\
\hline CHEMBL 3662614 & 1528515 & 7.6517 & 8.1574 & TRN & \\
\hline CHEMBL 3662721 & 1528515 & 7.5258 & 8.0052 & TRN & \\
\hline CHEMBL 3667402 & 1528515 & 8.1675 & 7.8569 & TRN & \\
\hline CHEMBL3662725 & 1528515 & 6.5294 & 7.0361 & TST & \\
\hline CHEMBL 3667375 & 1528515 & 8.7212 & 7.2509 & TST & \\
\hline CHEMBL 3667284 & 1528515 & 8.4202 & 8.7205 & TRN & \\
\hline CHEMBL3662610 & 1528515 & 7.7033 & 7.36 & TRN & \\
\hline CHEMBL 3662616 & 1528515 & 7.6055 & 7.9395 & TRN & \\
\hline CHEMBL3662586 & 1528515 & 7.9666 & 8.2639 & TRN & \\
\hline CHEMBL 3662618 & 1528515 & 7.6038 & 7.7321 & TRN & \\
\hline CHEMBL3662596 & 1528515 & 7.8827 & 7.725 & TST & \\
\hline CHEMBL 3639614 & 1528515 & 8.0315 & 7.9585 & TRN & \\
\hline CHEMBL3667338 & 1528515 & 8.6021 & 8.5705 & TRN & \\
\hline CHEMBL3667303 & 1528515 & 7.9586 & 8.0749 & TST & \\
\hline CHEMBL3662681 & 1528515 & 8.4318 & 7.586 & TST & \\
\hline CHEMBL3662689 & 1528515 & 8.1805 & 7.7758 & TRN & \\
\hline CHEMBL3667331 & 1528515 & 8.4318 & 8.0365 & TST & \\
\hline CHEMBL 3662533 & 1528515 & 8.5686 & 8.2975 & TRN & \\
\hline CHEMBL 3662516 & 1528515 & 8.0655 & 8.103 & TRN & \\
\hline CHEMBL 3662633 & 1528515 & 7.2907 & 7.2719 & TST & \\
\hline CHEMBL 3667324 & 1528515 & 8.1871 & 8.0257 & TRN & \\
\hline CHEMBL3662606 & 1528515 & 7.75200 & 300000006 & 7.9615 & TST \\
\hline CHEMBL 3662541 & 1528515 & 8.3979 & 7.8398 & TRN & \\
\hline CHEMBL3662638 & 1528515 & 6.7284 & 7.6742 & TST & \\
\hline CHEMBL 3662694 & 1528515 & 8.0655 & 8.1104 & TRN & \\
\hline CHEMBL 3667401 & 1528515 & 8.1871 & 7.9724 & TRN & \\
\hline CHEMBL3662609 & 1528515 & 7.7167 & 8.0501 & TRN & \\
\hline CHEMBL 3667307 & 1528515 & 7.399 & 7.9926 & TRN & \\
\hline CHEMBL3662669 & 1528515 & 9.0969 & 8.401 & TRN & \\
\hline CHEMBL 3667389 & 1528515 & 8.1192 & 7.6388 & TRN & \\
\hline CHEMBL 3667364 & 1528515 & 7.8697 & 7.6106 & TST & \\
\hline CHEMBL 3662720 & 1528515 & 7.5361 & 7.9809 & TRN & \\
\hline CHEMBL 3662677 & 1528515 & 8.6778 & 7.9155 & TRN & \\
\hline CHEMBL3667350 & 1528515 & 8.3468 & 8.1351 & TRN & \\
\hline CHEMBL3662568 & 1528515 & 6.0 & 7.5423 & TRN & \\
\hline CHEMBL3662649 & 1528515 & 6.5441 & 7.5081 & TST & \\
\hline CHEMBL3667295 & 1528515 & 8.2291 & 8.1101 & TRN & \\
\hline CHEMBL3662551 & 1528515 & 8.3279 & 7.9932 & TRN & \\
\hline CHEMBL3662571 & 1528515 & 8.0809 & 8.0242 & TRN & \\
\hline CHEMBL3662623 & 1528515 & 7.5702 & 7.8103 & TST & \\
\hline CHEMBL 3662680 & 1528515 & 8.4685 & 8.17 & TRN & \\
\hline CHEMBL 3662708 & 1528515 & 7.8327 & 7.8345 & TRN & \\
\hline
\end{tabular}


Supplemental Table S2.txt

\begin{tabular}{|c|c|c|c|c|}
\hline HEMBL 36 & 528515 & 6.0 & 7.9057 & \\
\hline & & 8.2291 & 7.7638 & \\
\hline $\mathrm{F}$ & 28515 & & & \\
\hline IEMBL & 8515 & 8069 & & \\
\hline AEMBL3662559 & 528515 & 6.0 & 8543 & \\
\hline HEMBL3662540 & 528515 & 8.4089 & 0006 & \\
\hline 346 & & & 2479 & \\
\hline AEMBL: & & & 2745 & \\
\hline HEMBL3667325 & 528515 & 7.4815 & .9433 & \\
\hline HEMBL3662644 & 528515 & 7.3615 & 4525 & \\
\hline HEMBL3662700 & 8515 & 8.0088 & 8132 & \\
\hline 74 & 15 & 861 & 443 & W \\
\hline AEMBL: & & 626 & 0752 & \\
\hline HEMBL3662621 & 528515 & 7.5867 & 0904 & \\
\hline HEMBL3639661 & 528515 & 8.4815 & 989 & \\
\hline HEMBL & 15 & 235 & 3749 & RIV \\
\hline AEME & 15 & & & 年 \\
\hline AEMBL & 15 & 77 & & \\
\hline HFMBL $=$ & & 55 & & \\
\hline HEMBL366 & 15 & 8. & 581 & I KIV \\
\hline HEMBL & 15 & 36 & 45 & ST \\
\hline HEM & & & & RN \\
\hline HEMBL & 15 & 68 & 3727 & RN \\
\hline AEMPI & & & 1577 & RIV \\
\hline AEMBL3 & 15 & 8.3372 & 18 & RN \\
\hline HEMBL; & 15 & 326 & 672 & RN \\
\hline 5 & & & 42 & 「RN \\
\hline 98 & & & 47 & $T$ \\
\hline HEMBL & & & & SI \\
\hline AEMBL3662536 & 15 & 6. & 7596 & TRN \\
\hline AEMBL & 15 & & 1448 & TRN \\
\hline 9 & & & 56 & ГST \\
\hline & & & & 「RN \\
\hline HEMBL3 & & & & 「RN \\
\hline HEMBL3667392 & 15 & & 8805 & ГRN \\
\hline 82 & כ. & & 893 & TRN \\
\hline & & & & RN \\
\hline HEMBL3 & & & 1047 & TST \\
\hline HEMBL3 & 15 & 7. & & TST \\
\hline 14 & & & 07 & RN \\
\hline HEMBL3 & & 12 & 142 & TRN \\
\hline HEMBL3 & & & 1908 & IST \\
\hline HEMBL 366 & & 7.9626 & 9571 & TRN \\
\hline HEMBL 366 & 15 & 7. & 218 & TR \\
\hline$\perp$ & & & & \\
\hline HEMBL3 & & & & \\
\hline CHEMBL3 & & 7.4023 & 7.8355 & \\
\hline CHEMBL3667301 & 1528515 & 7.9393 & 7.8023 & TST \\
\hline
\end{tabular}

Page 21381 
Supplemental Table S2.txt

\begin{tabular}{|c|c|c|c|c|}
\hline CHEMBL 3662673 & 1528515 & 8.7959 & 7.9329 & TRN \\
\hline CHEMBL3662563 & 1528515 & 8.1427 & 8.0327 & TRN \\
\hline CHEMBL3667330 & 1528515 & 7.6737 & 7.8805 & TRN \\
\hline CHEMBL 3662630 & 1528515 & 7.4078 & 7.8108 & TRN \\
\hline CHEMBL3667344 & 1528515 & 8.6778 & 7.8494 & TRN \\
\hline CHEMBL3662629 & 1528515 & 7.4225 & 8.1556 & TRN \\
\hline CHEMBL3662675 & 1528515 & 8.7212 & 8.5547 & TRN \\
\hline CHEMBL 3662653 & 1528515 & 7.9318 & 7.3604 & TRN \\
\hline CHEMBL 3662719 & 1528515 & 7.58 & 7.2242 & TST \\
\hline CHEMBL3667336 & 1528515 & 7.4012 & 7.7371 & TRN \\
\hline CHEMBL3662634 & 1528515 & 7.2549 & 8.1245 & TST \\
\hline CHEMBL3667308 & 1528515 & 8.1024 & 7.9765 & TRN \\
\hline CHEMBL 3662578 & 1528515 & 8.0315 & 8.0591 & TRN \\
\hline CHEMBL3662698 & 1528515 & 8.0458 & 8.4404 & TRN \\
\hline CHEMBL3662726 & 1528515 & 6.2083 & 6.9441 & TRN \\
\hline CHEMBL3667329 & 1528515 & 8.2596 & 8.3308 & TRN \\
\hline CHEMBL3667309 & 1528515 & 8.2218 & 7.7196 & TRN \\
\hline CHEMBL 3662702 & 1528515 & 7.983 & 7.9172 & TST \\
\hline CHEMBL3662686 & 1528515 & 8.2596 & 7.98 & TST \\
\hline CHEMBL3662661 & 1528515 & 8.2076 & 7.4796 & TRN \\
\hline CHEMBL3662583 & 1528515 & 8.0044 & 7.7878 & TRN \\
\hline CHEMBL3667354 & 1528515 & 8.1612 & 8.3116 & TST \\
\hline CHEMBL 3662529 & 1528515 & 6.0 & 7.9541 & TRN \\
\hline CHEMBL3667269 & 1528515 & 7.4271 & 7.2155 & TRN \\
\hline CHEMBL 3662632 & 1528515 & 7.3536 & 7.9656 & TRN \\
\hline CHEMBL3667380 & 1528515 & 8.0315 & 7.7582 & TRN \\
\hline CHEMBL 3662518 & 1528515 & 6.0 & 7.8134 & TRN \\
\hline CHEMBL3667405 & 1528515 & 7.4711 & 7.80399 & 9999999999 \\
\hline CHEMBL3662612 & 1528515 & 7.6925 & 7.9478 & TRN \\
\hline CHEMBL 3662560 & 1528515 & 8.2007 & 8.111 & TST \\
\hline CHEMBL 3662597 & 1528515 & 7.8761 & 7.954 & TRN \\
\hline CHEMBL3667267 & 1528515 & 8.4318 & 8.1114 & TRN \\
\hline CHEMBL 3667289 & 1528515 & 8.4685 & 7.915 & TRN \\
\hline CHEMBL3667385 & 1528515 & 7.5498 & 7.7119 & TRN \\
\hline CHEMBL 3662676 & 1528515 & 8.699 & 8.0862 & TRN \\
\hline CHEMBL 3662640 & 1528515 & 6.5605 & 7.8474 & TRN \\
\hline CHEMBL3662573 & 1528515 & 8.0757 & 7.8491 & TRN \\
\hline CHEMBL 3662693 & 1528515 & 8.1135 & 7.3351 & TRN \\
\hline CHEMBL3667319 & 1528515 & 8.0269 & 7.8606 & TRN \\
\hline CHEMBL 3667403 & 1528515 & 7.6498 & 7.7938 & TRN \\
\hline CHEMBL3662682 & 1528515 & 8.3872 & 8.1932 & TRN \\
\hline CHEMBL3667282 & 1528515 & 8.6576 & 8.7957 & TRN \\
\hline CHEMBL3662652 & 1528515 & 7.8386 & 7.3462 & TRN \\
\hline CHEMBL3662589 & 1528515 & 7.9431 & 7.2357 & TRN \\
\hline CHEMBL 3662542 & 1528515 & 8.3979 & 8.1606 & TRN \\
\hline CHEMBL3662664 & 1528515 & 7.4134 & 7.6237 & TRN \\
\hline CHEMBL3667370 & 1528515 & 7.2457 & 7.8983 & TRN \\
\hline CHEMBL3667317 & 1528515 & 7.9788 & 7.9648 & TRN \\
\hline
\end{tabular}

Page 21382 
Supplemental Table S2.txt

\begin{tabular}{|c|c|c|c|c|c|c|}
\hline CHEMBL 3662670 & 1528515 & 9.2218 & 7.8943 & TRN & & \\
\hline CHEMBL 3667322 & 1528515 & 8.1675 & 7.8648 & TRN & & \\
\hline CHEMBL 3667400 & 1528515 & \multicolumn{3}{|c|}{7.7620000000000005} & 7.693 & TRN \\
\hline CHEMBL 3662588 & 1528515 & 7.9431 & 7.8188 & TRN & & \\
\hline CHEMBL 3662712 & 1528515 & 7.7959 & 8.2555 & TRN & & \\
\hline CHEMBL 3662658 & 1528515 & 7.58 & 7.3339 & TRN & & \\
\hline CHEMBL 3667382 & 1528515 & 7.8153 & 7.8096 & TRN & & \\
\hline CHEMBL 3662663 & 1528515 & 7.4123 & 7.6556 & TRN & & \\
\hline CHEMBL 3667274 & 1528515 & 8.9208 & 8.1081 & TRN & & \\
\hline CHEMBL 3667275 & 1528515 & 9.0969 & 8.9583 & TRN & & \\
\hline CHEMBL 3667367 & 1528515 & 6.6737 & 8.1004 & TRN & & \\
\hline CHEMBL 3662704 & 1528515 & 7.9508 & 7.8265 & TRN & & \\
\hline CHEMBL 3667291 & 1528515 & 8.1675 & 8.4038 & TRN & & \\
\hline CHEMBL 3667384 & 1528515 & 7.6108 & 7.7098 & TRN & & \\
\hline CHEMBL 3662647 & 1528515 & 7.7932 & 7.9724 & TRN & & \\
\hline CHEMBL 3662590 & 1528515 & 7.9318 & 8.1829 & TRN & & \\
\hline CHEMBL 3667368 & 1528515 & \multicolumn{3}{|c|}{7.757000000000001} & 7.8306 & TRN \\
\hline CHEMBL 3667287 & 1528515 & 8.3372 & 8.5795 & TRN & & \\
\hline CHEMBL 3662580 & 1528515 & 8.0269 & 7.7625 & TST & & \\
\hline CHEMBL 3662625 & 1528515 & 7.4976 & 7.6662 & TST & & \\
\hline CHEMBL 3662672 & 1528515 & 8.8239 & 8.3302 & TRN & & \\
\hline CHEMBL 3667397 & 1528515 & 7.6861 & 7.8707 & TRN & & \\
\hline CHEMBL 3662660 & 1528515 & 7.5157 & 7.2677 & TRN & & \\
\hline CHEMBL 3662643 & 1528515 & 7.0825 & 7.6104 & TST & & \\
\hline CHEMBL 3662572 & 1528515 & 8.0809 & 7.7697 & TRN & & \\
\hline CHEMBL 3667327 & 1528515 & 8.5229 & 8.4093 & TRN & & \\
\hline CHEMBL 3667394 & 1528515 & 9.0 & 8.3574 & TST & & \\
\hline CHEMBL 3667273 & 1528515 & 8.2291 & 8.2374 & TST & & \\
\hline CHEMBL 3662714 & 1528515 & 7.6968 & 7.8127 & TRN & & \\
\hline CHEMBL 3662645 & 1528515 & 6.8579 & 7.4445 & TRN & & \\
\hline CHEMBL 3662717 & 1528515 & 7.6108 & 7.9261 & TRN & & \\
\hline CHEMBL 3662674 & 1528515 & 8.7696 & 8.022 & TRN & & \\
\hline CHEMBL 3667326 & 1528515 & 7.8508 & 8.0006 & TRN & & \\
\hline CHEMBL 3667343 & 1528515 & 6.0 & 7.1425 & TRN & & \\
\hline CHEMBL 3662543 & 1528515 & 8.3872 & 7.6704 & TRN & & \\
\hline CHEMBL 3667278 & 1528515 & 8.7959 & 8.8579 & TRN & & \\
\hline CHEMBL 3662703 & 1528515 & 7.9626 & 7.8267 & TRN & & \\
\hline CHEMBL 3662567 & 1528515 & 8.1192 & 8.0738 & TRN & & \\
\hline CHEMBL 3667351 & 1528515 & 8.3279 & 8.1493 & TRN & & \\
\hline CHEMBL 3662718 & 1528515 & 7.5867 & 7.6574 & TRN & & \\
\hline CHEMBL 3662521 & 1528515 & 7.9706 & 7.9518 & TRN & & \\
\hline CHEMBL 3667407 & 1528515 & 8.0555 & 8.0628 & TST & & \\
\hline CHEMBL 3662659 & 1528515 & 7.2692 & 7.3613 & TRN & & \\
\hline CHEMBL 3667357 & 1528515 & 8.0809 & 7.8099 & TRN & & \\
\hline CHEMBL 3667404 & 1528515 & 7.699 & 7.8019 & TRN & & \\
\hline CHEMBL 3667378 & 1528515 & 8.1549 & 7.7006 & TRN & & \\
\hline CHEMBL 3662690 & 1528515 & 8.1308 & 8.2969 & TRN & & \\
\hline CHEMBL 3662678 & 1528515 & 8.5686 & 8.7012 & TRN & & \\
\hline
\end{tabular}

Page 21383 
Supplemental Table S2.txt

\begin{tabular}{|c|c|c|c|c|c|}
\hline CHEMBL3662635 & 1528515 & 6.8055 & 7.9286 & TST & \\
\hline CHEMBL3662627 & 1528515 & 7.4389 & 7.5193 & TST & \\
\hline CHEMBL3667406 & 1528515 & 7.6576 & 7.9327 & TRN & \\
\hline CHEMBL3896738 & 1528515 & 6.0889 & 7.925 & TST & \\
\hline CHEMBL3662574 & 1528515 & 8.0706 & 7.9906 & TST & \\
\hline CHEMBL3667281 & 1528515 & 8.6576 & 8.8126 & TRN & \\
\hline CHEMBL3662581 & 1528515 & 8.0177 & 7.6473 & TST & \\
\hline CHEMBL 3667285 & 1528515 & 8.3279 & 8.4716 & TRN & \\
\hline CHEMBL3662523 & 1528515 & 6.1679 & 7.427000 & 00000000005 & TST \\
\hline CHEMBL3662706 & 1528515 & 7.9101 & 7.6848 & TRN & \\
\hline CHEMBL3667333 & 1528515 & 7.8601 & 7.7367 & TRN & \\
\hline CHEMBL3667276 & 1528515 & 9.0458 & 8.8088 & TRN & \\
\hline CHEMBL3662604 & 1528515 & 7.7959 & 7.7116 & TST & \\
\hline CHEMBL3662519 & 1528515 & 6.0 & 7.6233 & TRN & \\
\hline CHEMBL3662679 & 1528515 & 8.4815 & 7.8709 & TRN & \\
\hline CHEMBL3667341 & 1528515 & 9.0458 & 8.0919 & TRN & \\
\hline CHEMBL3667298 & 1528515 & 7.7447 & 7.8651 & TRN & \\
\hline CHEMBL3662561 & 1528515 & 8.1612 & 8.0089 & TST & \\
\hline CHEMBL 3667277 & 1528515 & 9.0 & 8.9028 & TRN & \\
\hline CHEMBL3662524 & 1528515 & 8.0177 & 7.1167 & TRN & \\
\hline CHEMBL3667399 & 1528515 & 7.08200 & 000000000 & 7.6752 & TST \\
\hline CHEMBL3667383 & 1528515 & 7.6576 & 8.2493 & TST & \\
\hline CHEMBL3662637 & 1528515 & 6.7291 & 7.1598 & TRN & \\
\hline CHEMBL3662710 & 1528515 & 7.8069 & 7.8016 & TRN & \\
\hline CHEMBL3662570 & 1528515 & 8.0862 & 8.0008 & TRN & \\
\hline CHEMBL3662648 & 1528515 & 7.7496 & 7.5248 & TRN & \\
\hline CHEMBL3662535 & 1528515 & 8.5086 & 7.9177 & TRN & \\
\hline CHEMBL3667390 & 1528515 & 8.8861 & 8.2994 & TRN & \\
\hline CHEMBL3662562 & 1528515 & 8.1427 & 6.9973 & TST & \\
\hline CHEMBL3667271 & 1528515 & 8.4318 & 7.9721 & TST & \\
\hline CHEMBL3667286 & 1528515 & 8.7959 & 8.2426 & TRN & \\
\hline CHEMBL3662651 & 1528515 & 7.224 & 7.3658 & TST & \\
\hline CHEMBL3667377 & 1528515 & 8.3768 & 7.8451 & TRN & \\
\hline CHEMBL3662556 & 1528515 & 8.2757 & 7.9863 & TRN & \\
\hline CHEMBL3662595 & 1528515 & 7.8827 & 8.2645 & TST & \\
\hline CHEMBL3667320 & 1528515 & 8.2007 & 7.772 & TRN & \\
\hline CHEMBL3667297 & 1528515 & 8.0757 & 7.9845 & TRN & \\
\hline CHEMBL3662692 & 1528515 & 8.1249 & 8.2053 & TRN & \\
\hline CHEMBL3639615 & 1528515 & 8.6383 & 8.5147 & TRN & \\
\hline CHEMBL3662600 & 1528515 & 7.8508 & 7.9127 & TRN & \\
\hline CHEMBL3662724 & 1528515 & 7.21399 & 999999999 & 7.9823 & IN \\
\hline CHEMBL3667268 & 1528515 & 7.7235 & 7.606 & TRN & \\
\hline CHEMBL3662548 & 1528515 & 8.3468 & 7.9659 & TRN & \\
\hline CHEMBL3662538 & 1528515 & 8.4318 & 7.8833 & TRN & \\
\hline CHEMBL3662539 & 1528515 & 8.4318 & 8.2681 & TST & \\
\hline CHEMBL3667395 & 1528515 & 8.0706 & 8.0584 & TST & \\
\hline CHEMBL3662666 & 1528515 & 8.6778 & 8.0436 & TRN & \\
\hline CHEMBL3662722 & 1528515 & 7.3391 & 7.0781 & TST & \\
\hline
\end{tabular}


Supplemental Table S2.txt

\begin{tabular}{|c|c|c|c|c|c|}
\hline CHEMBL 3667340 & 1528515 & 8.2291 & 8.071 & TRN & \\
\hline CHEMBL 3667337 & 1528515 & 8.6383 & 8.2497 & TRN & \\
\hline CHEMBL3662622 & 1528515 & 7.5784 & 7.92 & TRN & \\
\hline CHEMBL 3667376 & 1528515 & 8.4685 & 7.8499 & TRN & \\
\hline CHEMBL 3667365 & 1528515 & 7.3726 & 6.8036 & TST & \\
\hline CHEMBL3662697 & 1528515 & 8.0555 & 7.9366 & TRN & \\
\hline CHEMBL3662683 & 1528515 & 8.3768 & 8.5218 & TRN & \\
\hline CHEMBL3662695 & 1528515 & 8.0555 & 7.9007 & TRN & \\
\hline CHEMBL3667396 & 1528515 & 7.7545 & 7.7792 & TRN & \\
\hline CHEMBL 3662537 & 1528515 & 6.0 & 8.1272 & TRN & \\
\hline CHEMBL3662525 & 1528515 & 8.8239 & 8.1883 & TRN & \\
\hline CHEMBL3667266 & 1528515 & 6.0546 & 7.4612 & TST & \\
\hline CHEMBL 3662707 & 1528515 & 7.8761 & 7.9223 & TST & \\
\hline CHEMBL3662655 & 1528515 & 7.4365 & 7.3809 & TRN & \\
\hline CHEMBL 3662558 & 1528515 & 6.0 & 7.7418 & TRN & \\
\hline CHEMBL 3667314 & 1528515 & 7.7696 & 7.70799 & 9999999999 & TRN \\
\hline CHEMBL3667366 & 1528515 & 7.284 & 7.6576 & TST & \\
\hline CHEMBL 3667388 & 1528515 & 8.7447 & 8.4503 & TRN & \\
\hline CHEMBL3662555 & 1528515 & 8.2924 & 7.655 & TST & \\
\hline CHEMBL 3667379 & 1528515 & 8.1079 & 7.9607 & TRN & \\
\hline CHEMBL 3662713 & 1528515 & 7.7825 & 7.9028 & TRN & \\
\hline CHEMBL 3662613 & 1528515 & 7.6757 & 7.66100 & 00000000005 & TST \\
\hline CHEMBL 3667362 & 1528515 & 7.8665 & 7.7992 & TST & \\
\hline CHEMBL 3667348 & 1528515 & 8.4949 & 7.8879 & TST & \\
\hline CHEMBL3667381 & 1528515 & 7.8894 & 8.0917 & TST & \\
\hline CHEMBL3662636 & 1528515 & 6.7406 & 7.4547 & TST & \\
\hline CHEMBL 3667347 & 1528515 & 8.4949 & 7.9921 & TST & \\
\hline CHEMBL 3662628 & 1528515 & 7.4353 & 7.7479 & TRN & \\
\hline CHEMBL3662554 & 1528515 & 6.0 & 7.8937 & TRN & \\
\hline CHEMBL 3667288 & 1528515 & 7.8447 & 8.3923 & TRN & \\
\hline CHEMBL3667356 & 1528515 & 8.1427 & 8.2202 & TST & \\
\hline CHEMBL 3662584 & 1528515 & 7.9914 & 7.3925 & TST & \\
\hline CHEMBL 3662701 & 1528515 & 6.0 & 7.8677 & TRN & \\
\hline CHEMBL3667358 & 1528515 & 8.041 & 8.0406 & TST & \\
\hline CHEMBL3667318 & 1528515 & 7.9547 & 7.8219 & TRN & \\
\hline CHEMBL3662599 & 1528515 & 7.8539 & 8.2734 & TRN & \\
\hline CHEMBL 3667315 & 1528515 & 7.2027 & 7.983 & TST & \\
\hline CHEMBL 3667304 & 1528515 & 8.699 & 8.1082 & TRN & \\
\hline CHEMBL3662546 & 1528515 & 8.3665 & 8.3057 & TST & \\
\hline CHEMBL3662601 & 1528515 & 7.8477 & 7.897 & TRN & \\
\hline CHEMBL 3667335 & 1528515 & 7.4101 & 7.6705 & TRN & \\
\hline CHEMBL 3667283 & 1528515 & 8.6576 & 8.8816 & TRN & \\
\hline CHEMBL3667313 & 1528515 & 7.9281 & 7.9906 & TRN & \\
\hline CHEMBL3662641 & 1528515 & 6.0657 & 7.3793 & TST & \\
\hline CHEMBL 3667363 & 1528515 & 7.8539 & 7.7988 & TST & \\
\hline CHEMBL400126 & 457860 & 6.9208 & 7.0311 & TRN & \\
\hline CHEMBL436642 & 457860 & 5.8539 & 6.3278 & TRN & \\
\hline CHEMBL436834 & 457860 & 7.1739 & 7.0302 & TRN & \\
\hline
\end{tabular}

Page 21385 


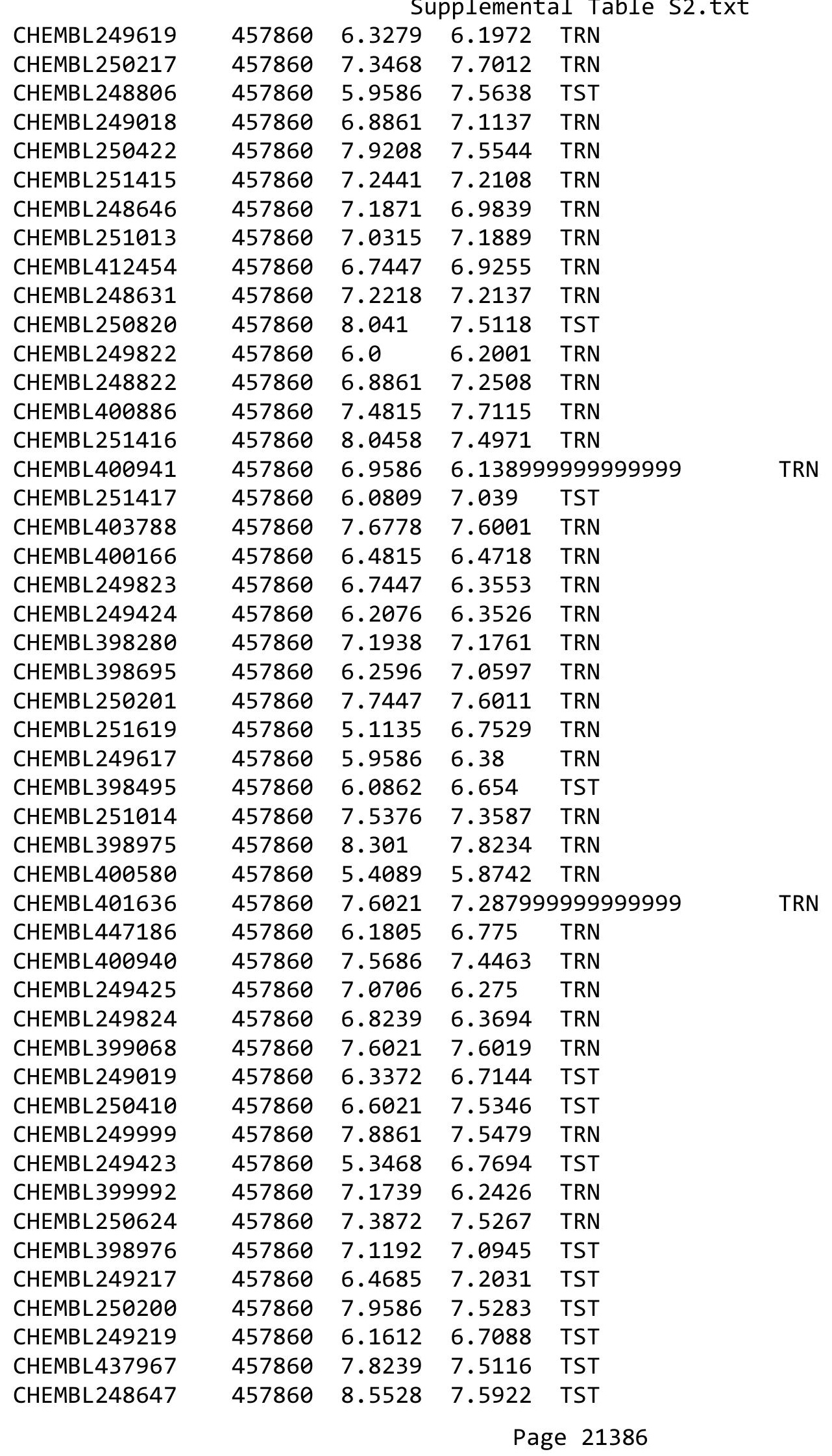




\begin{tabular}{|c|c|c|c|c|c|}
\hline \multicolumn{6}{|c|}{ Supplemental Table S2.txt } \\
\hline CHEMBL3931533 & 1637327 & 6.41 & 6.4615 & TRN & \\
\hline CHEMBL3947740 & 1637327 & 6.3 & 6.2078 & TRN & \\
\hline CHEMBL3963816 & 1637327 & 5.72 & 5.084 & TRN & \\
\hline CHEMBL3909951 & 1637327 & 5.95 & 5.2338 & TRN & \\
\hline CHEMBL3912630 & 1637327 & 5.49 & 5.2502 & TRN & \\
\hline CHEMBL3933449 & 1637327 & 6.53 & 6.4263 & TRN & \\
\hline CHEMBL3898908 & 1637327 & 6.42 & 6.8534 & TST & \\
\hline CHEMBL3986163 & 1637327 & 5.79 & 5.8189 & TRN & \\
\hline CHEMBL3898120 & 1637327 & 5.59 & 5.4006 & TRN & \\
\hline CHEMBL3955288 & 1637327 & 6.12 & 5.5487 & TRN & \\
\hline CHEMBL3957914 & 1637327 & 5.73 & 5.5006 & TRN & \\
\hline CHEMBL3908978 & 1637327 & 4.0 & 3.1722 & TRN & \\
\hline CHEMBL3906155 & 1637327 & 6.7 & 6.5112 & TRN & \\
\hline CHEMBL3940334 & 1637327 & 6.44 & 6.0831 & TRN & \\
\hline CHEMBL3958153 & 1637327 & 6.56 & 6.9015 & TRN & \\
\hline CHEMBL3925254 & 1637327 & 6.36 & 5.7392 & TRN & \\
\hline CHEMBL3907600 & 1637327 & 6.45 & 5.8583 & TRN & \\
\hline CHEMBL3954368 & 1637327 & 4.0 & 4.2312 & TRN & \\
\hline CHEMBL3951714 & 1637327 & 5.69 & 5.9016 & TRN & \\
\hline CHEMBL3965364 & 1637327 & 4.0 & 3.1131 & TRN & \\
\hline CHEMBL3969446 & 1637327 & 5.8 & 5.9238 & TRN & \\
\hline CHEMBL3951126 & 1637327 & 6.36 & 6.8457 & TRN & \\
\hline CHEMBL3933015 & 1637327 & 4.0 & 4.5884 & TRN & \\
\hline CHEMBL3898881 & 1637327 & 7.24 & 7.1671 & TRN & \\
\hline CHEMBL 3901644 & 1637327 & 6.71 & 6.5488 & TRN & \\
\hline CHEMBL3944665 & 1637327 & 5.05 & 5.2861 & TST & \\
\hline CHEMBL3947293 & 1637327 & 5.44 & 5.1604 & TRN & \\
\hline CHEMBL3947826 & 1637327 & 4.0 & 4.2797 & TST & \\
\hline CHEMBL3985692 & 1637327 & 6.73 & 6.7603 & TST & \\
\hline CHEMBL3947990 & 1637327 & 5.64 & 5.5156 & TST & \\
\hline CHEMBL3925306 & 1637327 & 5.88 & 5.8308 & TRN & \\
\hline CHEMBL3951245 & 1637327 & 7.02 & 6.7559 & TST & \\
\hline CHEMBL3948623 & 1637327 & 6.0 & 5.75799 & 9999999999 & TRN \\
\hline CHEMBL3892018 & 1637327 & 5.96 & 7.0286 & TRN & \\
\hline CHEMBL3987037 & 1637327 & 5.94 & 6.601 & TRN & \\
\hline CHEMBL3921313 & 1637327 & 6.0 & 6.2265 & TRN & \\
\hline CHEMBL3927327 & 1637327 & 5.75 & 6.0762 & TRN & \\
\hline CHEMBL3976280 & 1637327 & 6.09 & 5.8219 & TRN & \\
\hline CHEMBL3973820 & 1637327 & 5.71 & 5.8762 & TRN & \\
\hline CHEMBL3918011 & 1637327 & 6.34 & 5.9431 & TRN & \\
\hline CHEMBL3915235 & 1637327 & 5.7 & 5.876 & TRN & \\
\hline CHEMBL3965673 & 1637327 & 4.0 & 3.1444 & TST & \\
\hline CHEMBL3968094 & 1637327 & 6.17 & 5.7393 & TRN & \\
\hline CHEMBL3918751 & 1637327 & 6.66 & 6.8546 & TRN & \\
\hline CHEMBL3956164 & 1637327 & 5.2 & 5.3715 & TRN & \\
\hline CHEMBL3908829 & 1637327 & 6.16 & 5.8016 & TRN & \\
\hline CHEMBL3911573 & 1637327 & 5.72 & 5.7794 & TRN & \\
\hline CHEMBL3969879 & 1637327 & 5.55 & 5.9431 & TRN & \\
\hline
\end{tabular}


Supplemental Table S2.txt

\begin{tabular}{|c|c|c|c|c|}
\hline CHEMBL3972564 & 1637327 & 5.16 & 4.7719 & TRN \\
\hline CHEMBL 3927875 & 1637327 & 6.2 & 6.8011 & TRN \\
\hline CHEMBL 3930634 & 637327 & 4.0 & 4.7027 & \\
\hline HEMBL3901627 & 637327 & 6.51 & 6.8143 & ST \\
\hline CHEMBL 3904329 & 637327 & 6.71 & 6.9013 & \\
\hline CHEMBL3969408 & 637327 & 4.0 & .1834 & \\
\hline HEMBL3985853 & 637327 & 5.94 & 5.7015 & D. \\
\hline CHEMBL3908326 & 1637327 & 6.08 & 5.479 & \\
\hline HEMBL3918092 & 637327 & 7.97 & 7.9201 & \\
\hline CHEMBL3964675 & 637327 & 6.1 & 5.6417 & \\
\hline CHEMBL3955706 & 1637327 & 6.96 & 6.7881 & \\
\hline CHEMBL3937533 & 1637327 & 6.01 & 5.7424 & RN \\
\hline CHEMBL 3962814 & 1637327 & 5.84 & 5.5503 & \\
\hline HEMBL 3931674 & 1637327 & 6.91 & 6.3125 & \\
\hline CHEMBL3976219 & 1637327 & 5.69 & 5.8049 & \\
\hline HEMBL 3924872 & 1637327 & 5.97 & .4592 & RIV \\
\hline CHEMBL 3908529 & 1637327 & 6.55 & 1239 & RN \\
\hline CHEMBL3962805 & 1637327 & 5.73 & 5.8378 & RN \\
\hline HEMBL 3960128 & 1637327 & 5.31 & 5.1587 & \\
\hline CHEMBL3909565 & 1637327 & 6.75 & 7834 & TRN \\
\hline HEMBL 3948321 & 1637327 & 6.1 & 7616 & RN \\
\hline CHEMBL 3985750 & 1637327 & 5.92 & 369 & $\mathrm{RN}$ \\
\hline CHEMBL 3983115 & 1637327 & 6.13 & 5.9243 & $\mathrm{RN}$ \\
\hline HEMBL3926311 & 1637327 & 6.14 & 1927 & TRN \\
\hline CHEMBL 3926406 & 1637327 & 6.91 & 4275 & RI \\
\hline CHEMBL 3979490 & 1637327 & 7.0 & .7404 & ST \\
\hline CHEMBL: & 1637327 & 6.85 & 902 & ST \\
\hline HEMBL3940725 & 1637327 & 6.46 & 6.1537 & RN \\
\hline HEMBL 3973531 & 1637327 & 6.36 & 5722 & TRI \\
\hline CHEMBL 3913757 & 1637327 & 7.24 & 7.0382 & TRN \\
\hline CHEMBL3961210 & 1637327 & 7.2 & 8978 & TRN \\
\hline CHEMBL & 1637327 & 5.67 & 25 & ST \\
\hline CHEMBL3951156 & 1637327 & 6.19 & 929 & RN \\
\hline CHEMBL 3979170 & 1637327 & 5.96 & 6.8728 & TST \\
\hline CHEMBL 3921618 & 1637327 & 7.74 & 7.8688 & TRN \\
\hline CHEMBL3969815 & 1637327 & 7.35 & 7.2311 & TRN \\
\hline CHEMBL: & 1637327 & 6.72 & 5925 & TST \\
\hline CHEMBL3985222 & 1637327 & 7.47 & 7.5187 & TRN \\
\hline CHEMBL 3974664 & 1637327 & 7.18 & 6.6724 & TRN \\
\hline CHEMBL 3972173 & 1637327 & 5.69 & 5.6794 & TRN \\
\hline CHEMBL3919173 & 1637327 & 7.74 & 7.8505 & TRN \\
\hline CHEMBL3956737 & 1637327 & 4.0 & 3.903 & $\mathrm{RN}$ \\
\hline CHEMBL 3966022 & 1637327 & 6.14 & 5.8539 & TRN \\
\hline CHEMBL 3968499 & 1637327 & 7.36 & 7.4593 & TRN \\
\hline CHEMBL 3912505 & 1637327 & 5.73 & 5.3222 & TRN \\
\hline CHEMBL 3915158 & 1637327 & 4.0 & 3.818 & \\
\hline CHEMBL3950262 & 1637327 & 6.14 & 5.8461 & \\
\hline CHEMBL3949470 & 1637327 & 6.99 & 7.1017 & TR \\
\hline
\end{tabular}

Page 21388 


\begin{tabular}{|c|c|c|c|c|c|}
\hline \multicolumn{6}{|c|}{ Supplemental Table S2.txt } \\
\hline CHEMBL3893008 & 1637327 & 7.15 & 7.0481 & TRN & \\
\hline CHEMBL3889493 & 1637327 & 5.88 & 5.5346 & TRN & \\
\hline CHEMBL3984548 & 1637327 & 5.92 & 7.0647 & TRN & \\
\hline CHEMBL3920908 & 1637327 & 5.76 & 6.943 & TST & \\
\hline CHEMBL3939278 & 1637327 & 6.94 & 7.3242 & TRN & \\
\hline CHEMBL3974693 & 1637327 & 7.33 & 7.1261 & TRN & \\
\hline CHEMBL3972208 & 1637327 & 5.23 & 4.9111 & TRN & \\
\hline CHEMBL3950907 & 1637327 & 6.57 & 6.5643 & TRN & \\
\hline CHEMBL3931421 & 1637327 & 7.56 & 7.5677 & TRN & \\
\hline CHEMBL3923296 & 1637327 & 7.24 & 7.1375 & TRN & \\
\hline CHEMBL3918495 & 1637327 & 6.38 & 6.7324 & TRN & \\
\hline CHEMBL3945369 & 1637327 & 4.0 & 4.6783 & TRN & \\
\hline CHEMBL3961267 & 1637327 & 5.15 & 6.5076 & TRN & \\
\hline CHEMBL3984039 & 1637327 & 7.72 & 7.7462 & TRN & \\
\hline CHEMBL3928627 & 1637327 & 4.0 & 3.97899 & 99999999996 & TRN \\
\hline CHEMBL3908877 & 1637327 & 5.78 & 6.8277 & TST & \\
\hline CHEMBL3907488 & 1637327 & 6.17 & 5.4451 & TRN & \\
\hline CHEMBL3929803 & 1637327 & 6.07 & 5.7741 & TRN & \\
\hline CHEMBL3970430 & 1637327 & 7.97 & 7.7694 & TRN & \\
\hline CHEMBL3969475 & 1637327 & 7.47 & 7.3686 & TRN & \\
\hline CHEMBL3963728 & 1637327 & 4.0 & 3.5423 & TST & \\
\hline CHEMBL3944224 & 1637327 & 5.35 & 5.8403 & TRN & \\
\hline CHEMBL3909318 & 1637327 & 6.71 & 6.7744 & TRN & \\
\hline CHEMBL3982668 & 1637327 & 6.81 & 6.8669 & TRN & \\
\hline CHEMBL3980232 & 1637327 & 7.13 & 6.9199 & TST & \\
\hline CHEMBL3937633 & 1637327 & 6.8 & 6.5317 & TRN & \\
\hline CHEMBL3955563 & 1637327 & 7.93 & 7.7348 & TRN & \\
\hline CHEMBL3890607 & 1637327 & 6.73 & 6.5434 & TRN & \\
\hline CHEMBL3893373 & 1637327 & 5.74 & 6.9205 & TRN & \\
\hline CHEMBL3928646 & 1637327 & 6.38 & 6.2186 & TRN & \\
\hline CHEMBL3931381 & 1637327 & 5.83 & 5.42299 & 9999999999 & TRN \\
\hline CHEMBL3938610 & 1637327 & 5.74 & 5.5268 & TRN & \\
\hline CHEMBL3923808 & 1637327 & 5.74 & 5.58799 & 9999999999 & TRN \\
\hline CHEMBL3890896 & 1637327 & 6.1 & 6.8022 & TRN & \\
\hline CHEMBL3986607 & 1637327 & 6.38 & 6.0459 & TRN & \\
\hline CHEMBL3902581 & 1637327 & 5.76 & 5.806 & TRN & \\
\hline CHEMBL3954298 & 1637327 & 6.56 & 6.9773 & TRN & \\
\hline CHEMBL3892025 & 1637327 & 5.92 & 5.9084 & TRN & \\
\hline CHEMBL3935912 & 1637327 & 6.71 & 6.3467 & TRN & \\
\hline CHEMBL 3900620 & 1637327 & 5.93 & 6.4353 & TRN & \\
\hline CHEMBL3897858 & 1637327 & 6.6 & 6.04 & TRN & \\
\hline CHEMBL3896104 & 1637327 & 7.43 & 7.555 & TRN & \\
\hline CHEMBL3893398 & 1637327 & 7.44 & 7.4754 & TRN & \\
\hline CHEMBL3983996 & 1637327 & 6.6 & 6.819 & TRN & \\
\hline CHEMBL3935124 & 1637327 & 5.92 & 5.955 & TRN & \\
\hline CHEMBL3973645 & 1637327 & 4.0 & 4.3956 & TST & \\
\hline CHEMBL3971073 & 1637327 & 5.56 & 5.6477 & TRN & \\
\hline CHEMBL3957264 & 1637327 & 7.12 & 7.4818 & TRN & \\
\hline
\end{tabular}


Supplemental Table S2.txt

\begin{tabular}{|c|c|c|c|c|}
\hline CHEMBL 3969096 & 1637327 & 5.79 & 6.0924 & TRN \\
\hline CHEMBL 3905212 & 1637327 & 4.0 & 4.7865 & TST \\
\hline HEMBL3897034 & 1637327 & 6.18 & 6.2388 & \\
\hline HEMBL3979885 & 637327 & 6.68 & .8812 & RN \\
\hline HEMBL3982334 & 637327 & 4.0 & 4.7377 & $\mathrm{RN}$ \\
\hline HEMBL3919730 & 637327 & 6.94 & .2211 & \\
\hline HEMBL3922453 & 637327 & 6.49 & 6.9336 & RN \\
\hline HEMBL3959345 & 1637327 & 7.27 & 7.5081 & \\
\hline HEMBL3959201 & 1637327 & 5.68 & 6.2094 & \\
\hline CHEMBL3915233 & 1637327 & 4.0 & 4.9801 & \\
\hline CHEMBL3912569 & 1637327 & 7.13 & 7.6745 & \\
\hline HEMBL3975 & 1637327 & 6.36 & 6.6579 & \\
\hline HEMBL3966748 & 1637327 & 6.52 & 6.9982 & \\
\hline HEMBL 3929648 & 1637327 & 5.92 & 6.1789 & \\
\hline CHEMBL3926964 & 1637327 & 4.0 & 4.805 & W \\
\hline HEMBL3891619 & 1637327 & 6.1 & .8735 & RN \\
\hline HEMBL3986661 & 1637327 & 6.54 & 6284 & v \\
\hline HEMBL 3943043 & 1637327 & 7.31 & 7.4569 & RN \\
\hline HEMBL3904745 & 1637327 & 6.52 & 6.6731 & RN \\
\hline CHEMBL3965614 & 1637327 & 6.9 & 7.0216 & TRN \\
\hline HEMBL3968009 & 1637327 & 6.85 & 8777 & ST \\
\hline HEMBL390 & 1637327 & 5.82 & 9807 & \\
\hline CHEMBL3900268 & 1637327 & 5.17 & 5.7169 & RN \\
\hline CHEMBL3951728 & 1637327 & 6.21 & 6.5935 & $\mathrm{RN}$ \\
\hline CHEMBL3962554 & 1637327 & 5.93 & 5529 & RI \\
\hline HEMBL3913970 & 1637327 & 6.33 & 504 & ודס \\
\hline CHEMBL 3 & 1637327 & 7.5 & .67 & RN \\
\hline CHEMBL 3975447 & 1637327 & 7.51 & 7.7044 & TRN \\
\hline CHEMBL3911516 & 1637327 & 6. & 6.4853 & TRN \\
\hline CHEMBL3958756 & 1637327 & 5.19 & 4544 & TRN \\
\hline HEMBL3956120 & 1637327 & 6. & 1495 & TRN \\
\hline CHEMBL3 & 1637327 & 4.0 & 442 & ST \\
\hline CHEMBL3904777 & 1637327 & 4.0 & 5.4848 & ST \\
\hline CHEMBL 3975007 & 1637327 & 5.44 & 5.0186 & TST \\
\hline CHEMBL3972517 & 1637327 & 6.91 & 7.353 & TRN \\
\hline CHEMBL3928956 & 1637327 & 4. & 5.3173 & TRN \\
\hline CHEMBL 3 & 1637327 & 5.69 & 5.9516 & RN \\
\hline CHEMBL3941705 & 1637327 & 5.5 & 5.7221 & TRN \\
\hline CHEMBL 3982570 & 1637327 & 5.67 & 5.9533 & TRN \\
\hline CHEMBL3920007 & 1637327 & 6.6 & 7.2118 & TRN \\
\hline CHEMBL3922698 & 1637327 & 5.8 & 6.7013 & TRN \\
\hline CHEMBL3957533 & 1637327 & 5.94 & 6.4516 & TRN \\
\hline CHEMBL3969373 & 1637327 & 6.29 & 6.7428 & TRN \\
\hline CHEMBL 3905485 & 1637327 & 7.23 & 7.7699 & TRN \\
\hline CHEMBL 3904674 & 1637327 & 7.17 & 7.7675 & 12 \\
\hline CHEMBL 3945845 & 1637327 & 7.92 & 7.3356 & \\
\hline CHEMBL 3951694 & 1637327 & 5.93 & 6.5581 & \\
\hline CHEMBL3929914 & 1637327 & 5.95 & 6.2378 & 15 \\
\hline
\end{tabular}

Page 21390 


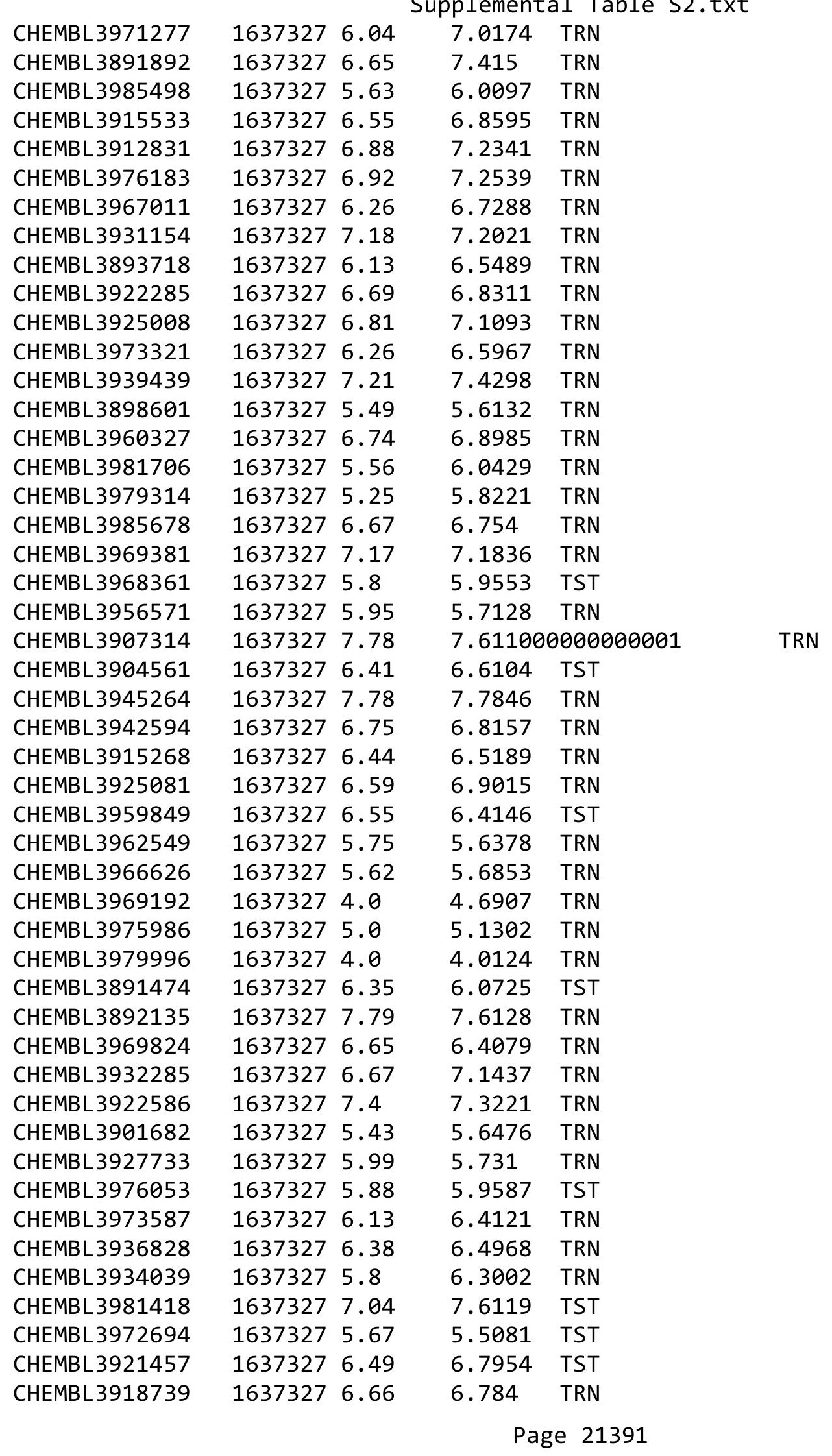




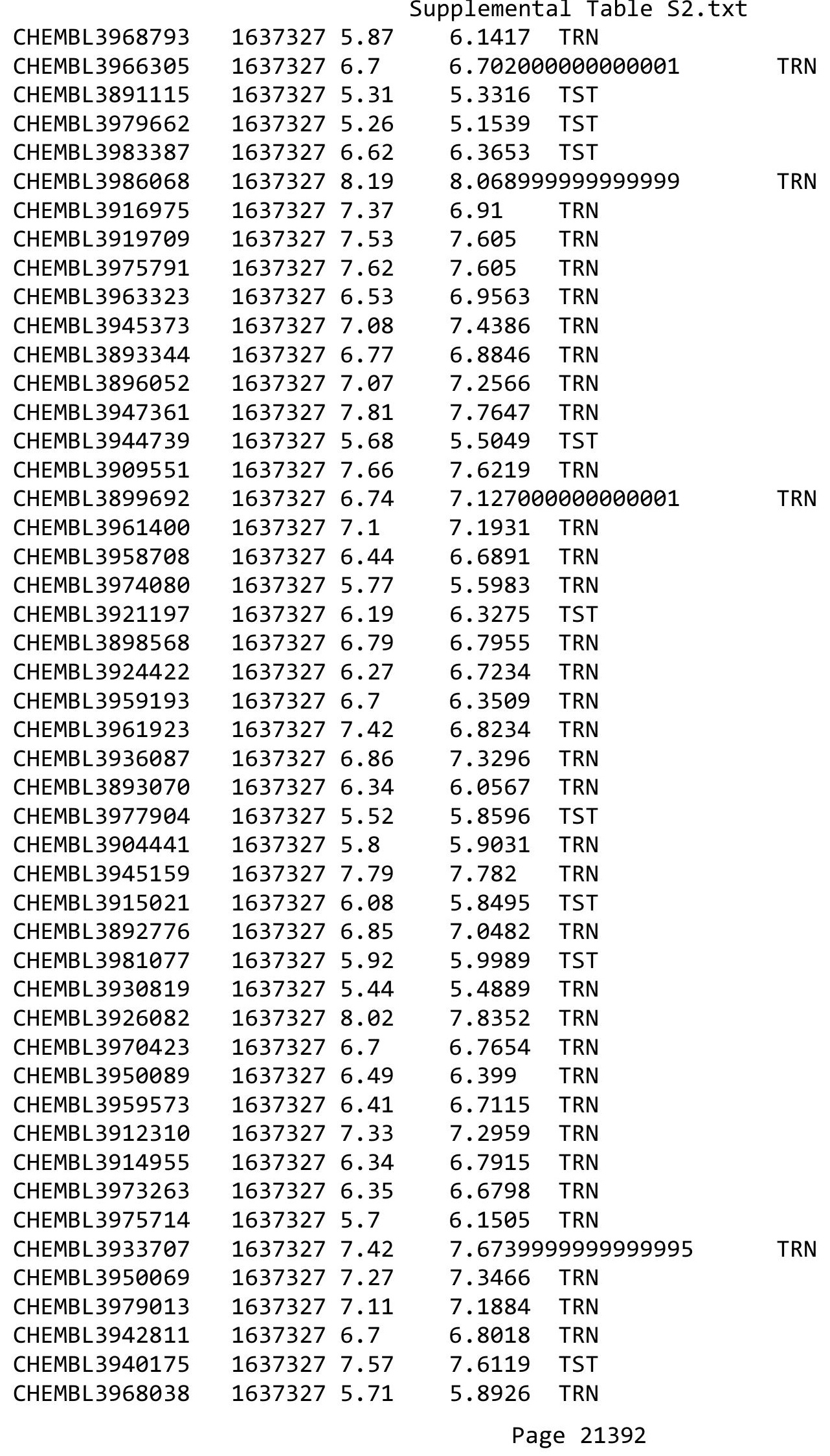




\begin{tabular}{|c|c|c|c|c|c|}
\hline CHEMBL3965640 & 1637327 & 6.73 & $6.3870 e$ & 00000000005 & TRN \\
\hline CHEMBL3928393 & 1637327 & 7.54 & 7.6188 & TST & \\
\hline CHEMBL3918704 & 1637327 & 6.64 & 6.1597 & TRN & \\
\hline CHEMBL3947189 & 1637327 & 7.39 & 7.6523 & TRN & \\
\hline CHEMBL3944438 & 1637327 & 7.06 & 6.4855 & TRN & \\
\hline CHEMBL3964574 & 1637327 & 7.83 & 7.8792 & TRN & \\
\hline CHEMBL3942328 & 1637327 & 6.95 & 6.6653 & TRN & \\
\hline CHEMBL3951847 & 1637327 & 6.42 & 6.9765 & TRN & \\
\hline CHEMBL3930298 & 1637327 & 6.44 & 6.1053 & TST & \\
\hline CHEMBL3933000 & 1637327 & 9.0 & 7.2468 & TST & \\
\hline CHEMBL3891464 & 1637327 & 6.95 & 6.5993 & TRN & \\
\hline CHEMBL3950910 & 1637327 & 6.86 & 6.865 & TRN & \\
\hline CHEMBL3901420 & 1637327 & 7.71 & 7.7738 & TRN & \\
\hline CHEMBL3905866 & 1637327 & 7.12 & 7.1075 & TRN & \\
\hline CHEMBL3903198 & 1637327 & 6.91 & 6.8215 & TRN & \\
\hline CHEMBL3943933 & 1637327 & 6.13 & 6.4148 & TRN & \\
\hline CHEMBL3925077 & 1637327 & 6.77 & 7.0503 & TRN & \\
\hline CHEMBL3946674 & 1637327 & 7.02 & 7.432 & TRN & \\
\hline CHEMBL3931790 & 1637327 & 7.5 & 7.2038 & TRN & \\
\hline CHEMBL3934487 & 1637327 & 7.07 & 7.1053 & TRN & \\
\hline CHEMBL3893786 & 1637327 & 8.17 & 8.0555 & TRN & \\
\hline CHEMBL3917141 & 1637327 & 7.52 & 7.4235 & TRN & \\
\hline CHEMBL3941700 & 1637327 & 6.85 & 7.1106 & TRN & \\
\hline CHEMBL3969665 & 1637327 & 6.32 & 6.4431 & TST & \\
\hline CHEMBL3981076 & 1637327 & 6.66 & 6.8827 & TRN & \\
\hline CHEMBL3983529 & 1637327 & 6.89 & 7.0741 & TRN & \\
\hline CHEMBL3935457 & 1637327 & 7.27 & 7.2166 & TRN & \\
\hline CHEMBL3905048 & 1637327 & 6.92 & 7.1167 & TRN & \\
\hline CHEMBL3925610 & 1637327 & 6.97 & 6.769 & TST & \\
\hline CHEMBL3928261 & 1637327 & 7.36 & 7.5079 & TRN & \\
\hline CHEMBL3985259 & 1637327 & 6.35 & 6.2603 & TST & \\
\hline CHEMBL3890205 & 1637327 & 5.82 & 5.9184 & TST & \\
\hline CHEMBL3944610 & 1637327 & 7.37 & 7.2839 & TRN & \\
\hline CHEMBL3944320 & 1637327 & 7.41 & 7.4306 & TRN & \\
\hline CHEMBL3979908 & 1637327 & 5.39 & 5.3411 & TRN & \\
\hline CHEMBL3934355 & 1637327 & 6.45 & 6.3661 & TRN & \\
\hline CHEMBL3919750 & 1637327 & 6.5 & 6.566 & TRN & \\
\hline CHEMBL3969112 & 1637327 & 7.52 & 7.3483 & TRN & \\
\hline CHEMBL3966560 & 1637327 & 7.24 & 7.2398 & TRN & \\
\hline CHEMBL3910444 & 1637327 & 7.67 & 7.6566 & TRN & \\
\hline CHEMBL3907642 & 1637327 & 6.67 & 6.2852 & TRN & \\
\hline CHEMBL3973929 & 1637327 & 7.52 & 7.4373 & TRN & \\
\hline CHEMBL3972617 & 1637327 & 6.66 & 6.7402 & TRN & \\
\hline CHEMBL3908149 & 1637327 & 7.35 & 7.0313 & TRN & \\
\hline CHEMBL3943080 & 1637327 & 6.13 & 6.2454 & TRN & \\
\hline CHEMBL3904294 & 1637327 & 6.88 & 6.947 & TRN & \\
\hline CHEMBL3907063 & 1637327 & 7.35 & 6.5996 & TRN & \\
\hline CHEMBL3896623 & 1637327 & 7.26 & 7.0622 & TRN & \\
\hline
\end{tabular}




\begin{tabular}{|c|c|c|c|c|c|}
\hline \\
\hline CHEMBL3893950 & 1637327 & 7.14 & 6.9967 & TRN & \\
\hline CHEMBL 3955745 & 1637327 & 6.23 & 6.1505 & TRN & \\
\hline CHEMBL3953117 & 1637327 & 6.09 & 6.0508 & TST & \\
\hline CHEMBL 3951360 & 1637327 & 7.01 & 6.9839 & TRN & \\
\hline CHEMBL3930158 & 1637327 & 6.2 & 6.2648 & TRN & \\
\hline CHEMBL3911746 & 1637327 & 6.23 & 6.1382 & TST & \\
\hline CHEMBL 3917295 & 1637327 & 7.11 & 6.8934 & TRN & \\
\hline CHEMBL3902110 & 1637327 & 6.44 & 6.4652 & TRN & \\
\hline CHEMBL 3904814 & 1637327 & 5.83 & 5.8854 & TST & \\
\hline CHEMBL3911948 & 1637327 & 6.1 & 6.0417 & TST & \\
\hline CHEMBL3928239 & 1637327 & 6.85 & 6.4708 & TRN & \\
\hline CHEMBL 3979028 & 1637327 & 5.85 & 6.0369 & TRN & \\
\hline CHEMBL 3890378 & 1637327 & 6.98 & 6.7568 & TRN & \\
\hline CHEMBL3932363 & 1637327 & 7.46 & 7.435 & TRN & \\
\hline CHEMBL 3932756 & 1637327 & 7.74 & 7.3878 & TRN & \\
\hline CHEMBL3919479 & 1637327 & 8.03 & 7.857 & TRN & \\
\hline CHEMBL 3968818 & 1637327 & 7.82 & 7.5052 & TRN & \\
\hline CHEMBL3966316 & 1637327 & 5.5 & 5.8278 & TRN & \\
\hline CHEMBL 3943610 & 1637327 & 7.2 & 6.7642 & TRN & \\
\hline CHEMBL 3940940 & 1637327 & 6.68 & 6.4178 & TST & \\
\hline CHEMBL3982107 & 1637327 & 6.74 & 6.61299 & 99999999995 & TRN \\
\hline CHEMBL 3979670 & 1637327 & 7.75 & 7.4331 & TRN & \\
\hline CHEMBL3911738 & 1637327 & 6.68 & 6.6562 & TRN & \\
\hline CHEMBL 3960571 & 1637327 & 6.77 & 7.0038 & TRN & \\
\hline CHEMBL 3974206 & 1637327 & 7.1 & 7.2682 & TST & \\
\hline CHEMBL 3889711 & 1637327 & 6.28 & 6.3188 & TRN & \\
\hline CHEMBL 3927585 & 1637327 & 6.59 & 6.2728 & TRN & \\
\hline CHEMBL3946103 & 1637327 & 6.75 & 6.3925 & TRN & \\
\hline CHEMBL3936421 & 1637327 & 5.28 & 5.3745 & TRN & \\
\hline CHEMBL3901119 & 1637327 & 7.59 & 7.2428 & TST & \\
\hline CHEMBL 3919884 & 1637327 & 7.26 & 6.7414 & TST & \\
\hline CHEMBL 3942606 & 1637327 & 7.3 & 7.7192 & TST & \\
\hline CHEMBL3945277 & 1637327 & 7.43 & 7.2656 & TRN & \\
\hline CHEMBL 3897523 & 1637327 & 7.79 & 7.2844 & TRN & \\
\hline CHEMBL3907327 & 1637327 & 6.35 & 5.7705 & TRN & \\
\hline CHEMBL3956579 & 1637327 & 6.81 & 6.8669 & TST & \\
\hline CHEMBL3959260 & 1637327 & 6.01 & 6.6524 & TRN & \\
\hline CHEMBL3890852 & 1637327 & 6.98 & 7.0596 & TST & \\
\hline CHEMBL 3893642 & 1637327 & 7.27 & 7.0464 & TRN & \\
\hline CHEMBL3950156 & 1637327 & 6.26 & 6.6275 & TRN & \\
\hline CHEMBL3952866 & 1637327 & 6.36 & 6.3388 & TST & \\
\hline CHEMBL 3925114 & 1637327 & 7.56 & 7.0344 & TRN & \\
\hline CHEMBL3897155 & 1637327 & 6.07 & 6.2032 & TST & \\
\hline CHEMBL 3937972 & 1637327 & 7.34 & 7.2396 & TRN & \\
\hline CHEMBL3935177 & 1637327 & 6.0 & 6.2388 & TRN & \\
\hline CHEMBL3962492 & 1637327 & 6.49 & 6.5247 & TRN & \\
\hline CHEMBL 3903823 & 1637327 & 6.09 & 6.0163 & TRN & \\
\hline CHEMBL3964096 & 1637327 & 6.88 & 7.1142 & TST & \\
\hline
\end{tabular}


Supplemental Table S2.txt

\begin{tabular}{|c|c|c|c|c|c|}
\hline CHEMBL 3948755 & 1637327 & 5.92 & 6.1313 & TST & \\
\hline CHEMBL3892155 & 1637327 & 6.22 & 6.1633 & TRN & \\
\hline CHEMBL 3987162 & 1637327 & 5.75 & 5.9519 & TRN & \\
\hline CHEMBL 3921441 & 1637327 & 7.24 & 7.1671 & TRN & \\
\hline CHEMBL3905015 & 1637327 & 5.65 & 5.566 & TRN & \\
\hline CHEMBL3921817 & 1637327 & 7.22 & 7.1479 & TRN & \\
\hline CHEMBL3927219 & 1637327 & 7.07 & 6.1417 & TRN & \\
\hline CHEMBL 3902434 & 1637327 & 7.23 & 6.8772 & TRN & \\
\hline CHEMBL3927158 & 1637327 & 5.58 & 5.5932 & TRN & \\
\hline CHEMBL3985182 & 1637327 & 7.49 & 7.1766 & TRN & \\
\hline CHEMBL3933442 & 1637327 & 6.97 & 6.5858 & TRN & \\
\hline CHEMBL3934080 & 1637327 & 7.19 & 6.779 & TRN & \\
\hline CHEMBL 3895443 & 1637327 & 5.61 & 5.8509 & TRN & \\
\hline CHEMBL3904736 & 1637327 & 4.0 & 4.32 & TRN & \\
\hline CHEMBL3914473 & 1637327 & 4.0 & 4.5412 & TRN & \\
\hline CHEMBL3898926 & 1637327 & 5.62 & 5.8202 & TRN & \\
\hline CHEMBL3952277 & 1637327 & 7.3 & 6.9218 & TRN & \\
\hline CHEMBL 3926245 & 1637327 & 6.17 & 6.2181 & TST & \\
\hline CHEMBL3978617 & 1637327 & 7.29 & 6.8536 & TRN & \\
\hline CHEMBL3966071 & 1637327 & 7.44 & 7.1275 & TST & \\
\hline CHEMBL3966200 & 1637327 & 6.87 & 6.5466 & TRN & \\
\hline CHEMBL3940672 & 1637327 & 6.87 & 6.7125 & TST & \\
\hline CHEMBL3979328 & 1637327 & 7.68 & 7.3001 & TRN & \\
\hline CHEMBL3983918 & 1637327 & 7.52 & 7.1303 & TST & \\
\hline CHEMBL 3975193 & 1637327 & 7.28 & 7.1541 & TRN & \\
\hline CHEMBL 3924172 & 1637327 & 6.9 & 6.8436 & TRN & \\
\hline CHEMBL3921469 & 1637327 & 7.8 & 6.9288 & TRN & \\
\hline CHEMBL3900551 & 1637327 & 4.0 & 4.5193 & TRN & \\
\hline CHEMBL3891525 & 1637327 & 6.6 & 6.3873 & TRN & \\
\hline CHEMBL 3935838 & 1637327 & 6.65 & 6.2732 & TST & \\
\hline CHEMBL 3977010 & 1637327 & 6.54 & 6.3323 & TRN & \\
\hline CHEMBL3967761 & 1637327 & 7.21 & 6.7104 & TRN & \\
\hline CHEMBL 3893556 & 1637327 & 7.0 & 7.3042 & TRN & \\
\hline CHEMBL3896249 & 1637327 & 7.05 & 6.9246 & TRN & \\
\hline CHEMBL 3952789 & 1637327 & 8.17 & 7.7285 & TRN & \\
\hline CHEMBL3955385 & 1637327 & 6.51 & 5.9753 & TRN & \\
\hline CHEMBL3977708 & 1637327 & 7.68 & 7.3827 & TRN & \\
\hline CHEMBL3980069 & 1637327 & 8.15 & 7.6134 & TRN & \\
\hline CHEMBL3946938 & 1637327 & 7.21 & 6.9015 & TRN & \\
\hline CHEMBL 3941337 & 1637327 & 5.55 & 5.20200 & 0000000001 & TRN \\
\hline CHEMBL3983585 & 1637327 & 5.98 & 6.1221 & TRN & \\
\hline CHEMBL3918638 & 1637327 & 7.81 & 7.605 & TRN & \\
\hline CHEMBL3920637 & 1637327 & 6.41 & 6.0101 & TRN & \\
\hline CHEMBL3917908 & 1637327 & 7.28 & 7.4032 & TRN & \\
\hline CHEMBL3980712 & 1637327 & 5.23 & 4.9916 & TRN & \\
\hline CHEMBL3978349 & 1637327 & 6.72 & 6.6905 & TST & \\
\hline CHEMBL3976721 & 1637327 & 6.56 & 6.1253 & TRN & \\
\hline CHEMBL3974273 & 1637327 & 6.62 & 6.1255 & TRN & \\
\hline
\end{tabular}




\begin{tabular}{|c|c|c|c|c|c|}
\hline & & \multicolumn{4}{|c|}{ Supplemental Table S2.txt } \\
\hline CHEMBL3898255 & 1637327 & 5.57 & \multicolumn{2}{|c|}{5.882000000000001} & TST \\
\hline CHEMBL3927794 & 1637327 & 5.64 & 5.8034 & TST & \\
\hline CHEMBL3953833 & 1637327 & 8.54 & 7.4236 & TRN & \\
\hline CHEMBL 3964043 & 1637327 & 7.72 & 7.4757 & TRN & \\
\hline CHEMBL 3945658 & 1637327 & 5.85 & 6.1562 & TRN & \\
\hline CHEMBL3948306 & 1637327 & 5.38 & 5.5011 & TRN & \\
\hline CHEMBL3984035 & 1637327 & 5.73 & 5.4756 & TST & \\
\hline CHEMBL3986725 & 1637327 & 6.2 & 6.1996 & TST & \\
\hline CHEMBL 3896142 & 1637327 & 7.67 & 7.5125 & TST & \\
\hline CHEMBL3908707 & 1637327 & 7.5 & 7.2811 & TRN & \\
\hline CHEMBL 3941227 & 1637327 & 6.11 & 5.7872 & TST & \\
\hline CHEMBL3943917 & 1637327 & 7.8 & \multicolumn{2}{|c|}{7.7860000000000005} & TRN \\
\hline CHEMBL3979972 & 1637327 & 6.32 & 6.1359 & TRN & \\
\hline CHEMBL3982399 & 1637327 & 7.61 & 7.3122 & TRN & \\
\hline CHEMBL3932817 & 1637327 & 6.76 & 7.0254 & TST & \\
\hline CHEMBL3930088 & 1637327 & 5.72 & 5.8494 & TST & \\
\hline CHEMBL3972445 & 1637327 & 5.15 & 5.3061 & TRN & \\
\hline CHEMBL3969747 & 1637327 & 5.75 & 5.8001 & TST & \\
\hline CHEMBL3918426 & 1637327 & 7.16 & 7.2145 & TST & \\
\hline CHEMBL3906938 & 1637327 & 7.18 & 7.3531 & TRN & \\
\hline CHEMBL3956028 & 1637327 & 4.0 & 4.5089 & TRN & \\
\hline CHEMBL3964762 & 1637327 & 7.07 & 6.9401 & TRN & \\
\hline CHEMBL3948234 & 1637327 & 6.46 & 6.6662 & TST & \\
\hline CHEMBL 3932022 & 1637327 & 7.5 & 7.3641 & TST & \\
\hline CHEMBL3957473 & 1637327 & 7.22 & 7.2821 & TRN & \\
\hline CHEMBL3950496 & 1637327 & 7.33 & 7.0255 & TRN & \\
\hline CHEMBL3902961 & 1637327 & 7.98 & 7.9401 & TRN & \\
\hline CHEMBL3905633 & 1637327 & 6.32 & 6.4676 & TST & \\
\hline CHEMBL 3937212 & 1637327 & 6.41 & 6.6365 & TST & \\
\hline CHEMBL3966929 & 1637327 & 6.71 & 6.1417 & TRN & \\
\hline CHEMBL3922100 & 1637327 & 6.75 & 6.2415 & TST & \\
\hline CHEMBL3906284 & 1637327 & 7.17 & 7.1671 & TRN & \\
\hline CHEMBL3921787 & 1637327 & 6.98 & 7.3196 & TRN & \\
\hline CHEMBL3951171 & 1637327 & 7.59 & 7.3263 & TRN & \\
\hline CHEMBL3983694 & 1637327 & 7.96 & \multicolumn{2}{|c|}{7.952999999999999} & TRN \\
\hline CHEMBL3981207 & 1637327 & 6.3 & 6.2643 & TRN & \\
\hline CHEMBL3986631 & 1637327 & 5.4 & 5.8633 & TRN & \\
\hline CHEMBL3969667 & 1637327 & 8.58 & 8.01 & TRN & \\
\hline CHEMBL3933908 & 1637327 & 7.72 & 7.6709 & TRN & \\
\hline CHEMBL3936673 & 1637327 & 7.31 & 7.5155 & TRN & \\
\hline CHEMBL3980417 & 1637327 & 8.35 & 8.3216 & TRN & \\
\hline CHEMBL3921190 & 1637327 & 8.55 & 8.5169 & TRN & \\
\hline CHEMBL3920274 & 1637327 & 5.21 & 4.9084 & TST & \\
\hline CHEMBL3953771 & 1637327 & 8.11 & 8.2163 & TST & \\
\hline CHEMBL3950292 & 1637327 & 7.33 & 7.3573 & TRN & \\
\hline CHEMBL 3959787 & 1637327 & 6.94 & 6.7097 & TRN & \\
\hline CHEMBL3986861 & 1637327 & 6.51 & \multicolumn{2}{|c|}{5.747000000000001} & TST \\
\hline CHEMBL3891816 & 1637327 & 6.16 & 5.926 & TST & \\
\hline
\end{tabular}




\begin{tabular}{|c|c|c|c|c|}
\hline \multicolumn{5}{|c|}{ Supplemental Table S2.txt } \\
\hline CHEMBL 3927140 & 1637327 & 8.32 & 8.4382 & TRN \\
\hline CHEMBL3929849 & 1637327 & 6.83 & 7.0276 & TRN \\
\hline CHEMBL3966941 & 1637327 & 6.08 & 6.0794 & TST \\
\hline CHEMBL 3939018 & 1637327 & 6.69 & 6.8209 & TRN \\
\hline CHEMBL3912757 & 1637327 & 6.0 & 6.1003 & TRN \\
\hline CHEMBL3915450 & 1637327 & 6.76 & 6.3976 & TRN \\
\hline CHEMBL3956493 & 1637327 & 6.76 & 6.85 & TRN \\
\hline CHEMBL3964931 & 1637327 & 6.66 & 6.8394 & TRN \\
\hline CHEMBL3918956 & 1637327 & 5.74 & 5.7621 & TRN \\
\hline CHEMBL3894754 & 1637327 & 8.44 & 8.2849 & TRN \\
\hline CHEMBL3963296 & 1637327 & 7.13 & 7.4336 & TRN \\
\hline CHEMBL 3890187 & 1637327 & 5.14 & 5.3801 & TST \\
\hline CHEMBL3978313 & 1637327 & 7.47 & 7.3606 & TRN \\
\hline CHEMBL 3889604 & 1637327 & 6.26 & 6.0828 & TRN \\
\hline CHEMBL3939332 & 1637327 & 6.59 & 6.4168 & TRN \\
\hline CHEMBL3912250 & 1637327 & 6.14 & 5.9145 & TRN \\
\hline CHEMBL3901265 & 1637327 & 7.07 & 6.5265 & TRN \\
\hline CHEMBL3903973 & 1637327 & 8.63 & 8.2253 & TRN \\
\hline CHEMBL3957928 & 1637327 & 7.03 & 7.0472 & TRN \\
\hline CHEMBL3960591 & 1637327 & 6.42 & 6.0343 & TST \\
\hline CHEMBL3899721 & 1637327 & 6.81 & 6.749 & TRN \\
\hline CHEMBL3934772 & 1637327 & 7.35 & 7.3196 & TRN \\
\hline CHEMBL3909752 & 1637327 & 5.82 & 5.7568 & TRN \\
\hline CHEMBL3906945 & 1637327 & 6.28 & 6.0634 & TRN \\
\hline CHEMBL3954396 & 1637327 & 9.0 & 8.5241 & TRN \\
\hline CHEMBL3944937 & 1637327 & 5.74 & 6.2078 & TRN \\
\hline CHEMBL3895267 & 1637327 & 7.23 & 6.7172 & TRN \\
\hline CHEMBL3892529 & 1637327 & 9.0 & 8.4716 & TRN \\
\hline CHEMBL 3935597 & 1637327 & 7.82 & 7.7468 & TRN \\
\hline CHEMBL3932893 & 1637327 & 5.71 & 5.812 & TST \\
\hline CHEMBL3952706 & 1637327 & 6.04 & 6.2062 & TST \\
\hline CHEMBL3939860 & 1637327 & 6.64 & 6.5233 & TST \\
\hline CHEMBL3976275 & 1637327 & 9.22 & 9.0785 & TRN \\
\hline CHEMBL 3978754 & 1637327 & 9.2 & 9.195 & TST \\
\hline CHEMBL3942716 & 1637327 & 7.12 & 7.0032 & TRN \\
\hline CHEMBL3982718 & 1637327 & 8.22 & 8.0249 & TRN \\
\hline CHEMBL3894762 & 1637327 & 7.55 & 7.1592 & TST \\
\hline CHEMBL3896514 & 1637327 & 5.64 & 5.6368 & TST \\
\hline CHEMBL3906253 & 1637327 & 6.13 & 6.9602 & TRN \\
\hline CHEMBL3946877 & 1637327 & 5.02 & 4.421 & TST \\
\hline CHEMBL 3944241 & 1637327 & 5.54 & 5.7673 & TST \\
\hline CHEMBL3947664 & 1637327 & 7.07 & 6.9067 & TRN \\
\hline CHEMBL3960877 & 1637327 & 7.5 & 6.914 & TRN \\
\hline CHEMBL3958209 & 1637327 & 9.0 & 7.6413 & TRN \\
\hline CHEMBL3951253 & 1637327 & 7.05 & 7.0843 & TRN \\
\hline CHEMBL3948629 & 1637327 & 4.0 & 5.9303 & TST \\
\hline CHEMBL3913492 & 1637327 & 9.0 & 7.6254 & TRN \\
\hline CHEMBL3933492 & 1637327 & 4.0 & 3.15100 & 00000000002 \\
\hline & & & & 21397 \\
\hline
\end{tabular}


Supplemental Table S2.txt

\begin{tabular}{|c|c|c|c|c|}
\hline CHEMBL 3982416 & 1637327 & 4.0 & 3.7118 & TST \\
\hline CHEMBL 3984969 & 1637327 & 4.0 & 3.0626 & TST \\
\hline CHEMBL 3953206 & 1637327 & 4.0 & 4.085 & TST \\
\hline CHEMBL 3946591 & 1637327 & 5.33 & 6.3557 & TST \\
\hline CHEMBL 3942179 & 1637327 & 5.51 & 5.8652 & TST \\
\hline CHEMBL 3930685 & 1637327 & 5.4 & 5.3891 & TST \\
\hline CHEMBL 3910555 & 1637327 & 5.27 & 5.7316 & TST \\
\hline CHEMBL 3918036 & 1637327 & 4.0 & 3.5104 & TST \\
\hline CHEMBL 3926088 & 1637327 & 5.04 & 4.1055 & TST \\
\hline CHEMBL 3972657 & 1637327 & 5.44 & 5.5517 & TST \\
\hline CHEMBL 3918892 & 1637327 & 5.15 & 4.3402 & TST \\
\hline CHEMBL 3966660 & 1637327 & 5.39 & 5.2929 & TST \\
\hline CHEMBL 3899891 & 1637327 & 5.32 & 5.6264 & TST \\
\hline CHEMBL 3890118 & 1637327 & 6.37 & 6.3768 & TST \\
\hline CHEMBL 3950169 & 1637327 & 4.0 & 4.7925 & TST \\
\hline CHEMBL 3952885 & 1637327 & 4.0 & 4.4789 & TST \\
\hline CHEMBL 3890870 & 1637327 & 5.73 & 5.9378 & TST \\
\hline CHEMBL 3893659 & 1637327 & 4.0 & 3.4013 & TST \\
\hline CHEMBL 3928923 & 1637327 & 5.21 & 5.4367 & TST \\
\hline CHEMBL 3938712 & 1637327 & 5.12 & 4.9949 & TST \\
\hline CHEMBL 3975295 & 1637327 & 7.01 & 4.977 & TST \\
\hline CHEMBL 3977791 & 1637327 & 5.2 & 4.8583 & TST \\
\hline CHEMBL 3916904 & 1637327 & 5.12 & 4.3885 & TST \\
\hline CHEMBL 3974131 & 1637327 & 5.04 & 5.2097 & TST \\
\hline CHEMBL 3925322 & 1637327 & 5.59 & 5.3148 & TST \\
\hline CHEMBL 3922592 & 1637327 & 5.1 & 5.0827 & TST \\
\hline CHEMBL 3985007 & 1637327 & 5.08 & 4.9599 & TST \\
\hline CHEMBL 3982466 & 1637327 & 4.0 & 4.1683 & TST \\
\hline CHEMBL 3910921 & 1637327 & 6.91 & 6.2944 & TST \\
\hline CHEMBL 3908141 & 1637327 & 5.0 & 5.5645 & TST \\
\hline CHEMBL 3971947 & 1637327 & 5.7 & 5.5492 & TST \\
\hline CHEMBL 3960102 & 1637327 & 4.0 & 4.7568 & TST \\
\hline CHEMBL 3891736 & 1637327 & 5.6 & 5.7922 & TST \\
\hline CHEMBL 3975903 & 1637327 & 4.0 & 6.1122 & TST \\
\hline CHEMBL 3952488 & 1637327 & 5.2 & 5.6727 & TST \\
\hline CHEMBL1606561 & 1301888 & 4.9052 & 4.5288 & TST \\
\hline CHEMBL 1880656 & 1301888 & 3.699 & 3.7935 & TRN \\
\hline CHEMBL 3185724 & 1301888 & 3.699 & 3.5945 & TRN \\
\hline CHEMBL1484167 & 1301888 & 4.8179 & 4.8044 & TST \\
\hline CHEMBL 3190269 & 1301888 & 3.699 & 3.5776 & TRN \\
\hline CHEMBL1733408 & 1301888 & 3.699 & 3.6512 & TRN \\
\hline CHEMBL1698835 & 1301888 & 4.8125 & 4.7432 & TRN \\
\hline CHEMBL72504 & 1301888 & 4.9404 & 4.9575 & TRN \\
\hline CHEMBL1452938 & 1301888 & 3.699 & \multicolumn{2}{|c|}{3.5839999999999996} \\
\hline CHEMBL 1384158 & 1301888 & 3.699 & 3.8582 & TRN \\
\hline CHEMBL1456606 & 1301888 & 3.699 & 3.7153 & TRN \\
\hline CHEMBL 7747 & 1301888 & 4.7147 & 4.6828 & TRN \\
\hline CHEMBL 3194737 & 1301888 & 3.699 & 3.8116 & TRN \\
\hline
\end{tabular}


Supplemental Table S2.txt

\begin{tabular}{|c|c|c|c|c|}
\hline CHEMBL1534784 & 1301888 & 4.7959 & 4.6052 & TRN \\
\hline CHEMBL3181900 & 1301888 & 3.699 & 3.5524 & TRN \\
\hline CHEMBL251055 & 1301888 & 3.699 & 3.5306 & TRN \\
\hline CHEMBL1971727 & 1301888 & 3.699 & 3.6449 & TRN \\
\hline CHEMBL1551662 & 1301888 & 4.783 & 4.8115 & TRN \\
\hline CHEMBL3199564 & 1301888 & 4.7215 & 4.5625 & TRN \\
\hline CHEMBL3194014 & 1301888 & 3.699 & 3.5645 & TRN \\
\hline CHEMBL1554827 & 1301888 & 3.699 & \multicolumn{2}{|c|}{3.6830000000000003} \\
\hline CHEMBL1410192 & 1301888 & 4.9519 & 5.0501 & TRN \\
\hline CHEMBL1542508 & 1301888 & 3.699 & 3.7355 & TRN \\
\hline CHEMBL1522595 & 1301888 & 3.699 & 3.8243 & TRN \\
\hline CHEMBL1708067 & 1301888 & 5.4815 & 5.1269 & TST \\
\hline CHEMBL1594057 & 1301888 & 3.699 & 4.8833 & TST \\
\hline CHEMBL571436 & 1301888 & 4.7268 & 4.6628 & TRN \\
\hline CHEMBL 2138455 & 1301888 & 4.9454 & 4.7929 & TRN \\
\hline CHEMBL1342109 & 1301888 & 3.699 & 4.5745 & TST \\
\hline CHEMBL1343743 & 1301888 & 5.3872 & 5.3724 & TRN \\
\hline CHEMBL1505670 & 1301888 & 3.699 & 3.6298 & TRN \\
\hline CHEMBL2142609 & 1301888 & 3.699 & 3.8066 & TRN \\
\hline CHEMBL1458674 & 1301888 & 4.8655 & 4.7903 & TRN \\
\hline CHEMBL3191337 & 1301888 & 3.699 & 3.5583 & TRN \\
\hline CHEMBL1304473 & 1301888 & 4.8374 & 4.795 & TRN \\
\hline CHEMBL3192198 & 1301888 & 3.699 & 3.8732 & TRN \\
\hline CHEMBL 3189481 & 1301888 & 4.7025 & 4.6565 & TRN \\
\hline CHEMBL 3183783 & 1301888 & 3.699 & 3.7927 & TRN \\
\hline CHEMBL266997 & 1301888 & 4.8604 & 4.8629 & TRN \\
\hline CHEMBL1729403 & 1301888 & 3.699 & 3.7328 & TRN \\
\hline CHEMBL1551105 & 1301888 & 4.8187 & 4.7686 & TRN \\
\hline CHEMBL1726267 & 1301888 & 4.9389 & 5.1375 & TRN \\
\hline CHEMBL 3184663 & 1301888 & 3.699 & 3.8741 & TRN \\
\hline CHEMBL1547822 & 1301888 & 6.0814 & 6.1064 & TRN \\
\hline CHEMBL1190214 & 1301888 & 3.699 & 4.0614 & TST \\
\hline CHEMBL 2132810 & 1301888 & 3.699 & 3.8692 & TRN \\
\hline CHEMBL1450748 & 1301888 & 3.699 & 3.7349 & TRN \\
\hline CHEMBL1426334 & 1301888 & 3.699 & 3.6101 & TRN \\
\hline CHEMBL1992564 & 1301888 & 3.699 & 3.9912 & TST \\
\hline CHEMBL 2134096 & 1301888 & 4.8969 & 4.7651 & TRN \\
\hline CHEMBL1723818 & 1301888 & 5.0315 & 4.4003 & TST \\
\hline CHEMBL3192403 & 1301888 & 4.7062 & 4.5879 & TRN \\
\hline CHEMBL1868772 & 1301888 & 4.8125 & 4.5663 & TRN \\
\hline CHEMBL1404333 & 1301888 & 3.699 & 3.7672 & TRN \\
\hline CHEMBL1507198 & 1301888 & 3.699 & 3.6181 & TRN \\
\hline CHEMBL1325776 & 1301888 & 3.699 & 3.7436 & TRN \\
\hline CHEMBL3194690 & 1301888 & 3.699 & 3.6737 & TRN \\
\hline CHEMBL1543989 & 1301888 & 4.0 & 3.9904 & TRN \\
\hline CHEMBL1600874 & 1301888 & 4.8523 & 4.7733 & TRN \\
\hline CHEMBL3196216 & 1301888 & 3.699 & 3.7425 & TRN \\
\hline CHEMBL347345 & 1301888 & 3.699 & 4.0858 & TST \\
\hline
\end{tabular}


Supplemental Table S2.txt

\begin{tabular}{|c|c|c|c|c|}
\hline CHEMBL1602959 & 1301888 & 3.699 & 3.6828 & TRN \\
\hline CHEMBL1507177 & 1301888 & 3.699 & 3.7021 & TRN \\
\hline CHEMBL 3185767 & 1301888 & 3.699 & 3.5854 & TRN \\
\hline CHEMBL1334768 & 1301888 & 4.7347 & 4.7914 & TRN \\
\hline CHEMBL1473205 & 1301888 & 5.2993 & 5.3855 & TRN \\
\hline CHEMBL1872355 & 1301888 & 3.699 & 3.9536 & TRN \\
\hline CHEMBL3182511 & 1301888 & 3.7447 & 3.7673 & TRN \\
\hline CHEMBL1880686 & 1301888 & 4.8395 & 4.7395 & TRN \\
\hline CHEMBL 2135960 & 1301888 & 3.699 & 3.7124 & TRN \\
\hline CHEMBL1398983 & 1301888 & 4.9698 & 5.0286 & TRN \\
\hline CHEMBL1313346 & 1301888 & 3.699 & 3.6815 & TRN \\
\hline CHEMBL1509162 & 1301888 & 5.9626 & 5.8268 & TRN \\
\hline CHEMBL 3193202 & 1301888 & 3.699 & 3.7925 & TRN \\
\hline CHEMBL1727014 & 1301888 & 4.9465 & 4.9557 & TRN \\
\hline CHEMBL1441534 & 1301888 & 4.8914 & 3.4357 & TST \\
\hline CHEMBL 3184373 & 1301888 & 3.699 & 3.7583 & TRN \\
\hline CHEMBL3193668 & 1301888 & 3.699 & 4.0814 & TRN \\
\hline CHEMBL1606437 & 1301888 & 3.699 & 3.103 & TST \\
\hline CHEMBL1520808 & 1301888 & 4.7077 & 4.6532 & TST \\
\hline CHEMBL 2130961 & 1301888 & 3.6576 & 3.6877 & TRN \\
\hline CHEMBL1417689 & 1301888 & 3.699 & 3.8808 & TST \\
\hline CHEMBL3189898 & 1301888 & 4.8526 & 4.8885 & TRN \\
\hline CHEMBL1343259 & 1301888 & 3.699 & 4.5829 & TST \\
\hline CHEMBL1328249 & 1301888 & 3.699 & 3.573 & TRN \\
\hline CHEMBL1698013 & 1301888 & 5.2612 & 4.4262 & TST \\
\hline CHEMBL1700724 & 1301888 & 3.699 & 3.6444 & TRN \\
\hline CHEMBL1439343 & 1301888 & 3.699 & 3.6446 & TRN \\
\hline CHEMBL1866557 & 1301888 & 5.1979 & 5.2726 & TRN \\
\hline CHEMBL565758 & 1301888 & 3.699 & 3.7875 & TRN \\
\hline CHEMBL 2139673 & 1301888 & 4.9119 & 4.8746 & TRN \\
\hline CHEMBL1897379 & 1301888 & 3.699 & 3.6746 & TRN \\
\hline CHEMBL1504159 & 1301888 & 3.699 & 3.7679 & TRN \\
\hline CHEMBL1464022 & 1301888 & 5.2111 & 5.0359 & TRN \\
\hline CHEMBL3188568 & 1301888 & 3.699 & 3.6223 & TRN \\
\hline CHEMBL 3182263 & 1301888 & 3.699 & 3.9259 & TRN \\
\hline CHEMBL87706 & 1301888 & 4.9401 & 5.1269 & TRN \\
\hline CHEMBL1579884 & 1301888 & 4.7183 & 4.8739 & TRN \\
\hline CHEMBL1380978 & 1301888 & 3.699 & 3.655 & TRN \\
\hline CHEMBL492468 & 1301888 & 3.699 & 4.309 & TST \\
\hline CHEMBL1501009 & 1301888 & 3.699 & 3.5595 & TST \\
\hline CHEMBL 3195143 & 1301888 & 3.699 & 4.3206 & TST \\
\hline CHEMBL1730544 & 1301888 & 3.699 & 4.1948 & TST \\
\hline CHEMBL1761063 & 1301888 & 5.061 & 4.9171 & TST \\
\hline CHEMBL1534979 & 1301888 & 3.699 & 4.3215 & TST \\
\hline CHEMBL1400117 & 1301888 & 4.7921 & 3.4964 & TST \\
\hline CHEMBL1403092 & 1301888 & 4.8901 & 4.5741 & TST \\
\hline CHEMBL1536877 & 1301888 & 4.7975 & 4.2862 & TST \\
\hline CHEMBL1432762 & 1301888 & 3.699 & 5.6774 & TST \\
\hline
\end{tabular}




\begin{tabular}{|c|c|c|c|c|c|c|}
\hline & & \multicolumn{5}{|c|}{ Supplemental Table S2.txt } \\
\hline CHEMBL3191096 & 1301888 & 3.699 & 3.488 & TST & & \\
\hline CHEMBL1417963 & 1301888 & 3.699 & 3.843 & TST & & \\
\hline CHEMBL3189445 & 301888 & 4.7883 & 4.995 & TST & & \\
\hline CHEMBL1320935 & 688810 & 4.583 & 5.1289 & TRN & & \\
\hline CHEMBL1333987 & 688810 & \multicolumn{3}{|c|}{4.9830000000000005} & 5.6751 & TRN \\
\hline CHEMBL603967 & 688810 & 5.083 & 4.852 & TRN & & \\
\hline CHEMBL1303653 & 688810 & 5.033 & 4.5521 & TRN & & \\
\hline CHEMBL1445402 & 688810 & \multicolumn{3}{|c|}{4.9830000000000005} & 5.0474 & $\mathrm{~T}$ \\
\hline CHEMBL1563370 & 688810 & 4.633 & 5.2728 & TST & & \\
\hline CHEMBL3193947 & 688810 & 5.083 & 4.9453 & TRN & & \\
\hline CHEMBL1375729 & 688810 & \multicolumn{3}{|c|}{5.582999999999999} & 4.9676 & TRN \\
\hline CHEMBL1499515 & 688810 & \multicolumn{3}{|c|}{6.382999999999999} & 4.9255 & TRN \\
\hline CHEMBL1603921 & 688810 & \multicolumn{3}{|c|}{5.2829999999999995} & 5.3359 & TRN \\
\hline CHEMBL1338640 & 688810 & \multicolumn{3}{|c|}{4.9830000000000005} & 5.6318 & \\
\hline CHEMBL1414603 & 688810 & 4.633 & 4.9388 & TRN & & \\
\hline CHEMBL3191763 & 688810 & 6.4829 & 5.5268 & TRN & & \\
\hline CHEMBL1331509 & 688810 & \multicolumn{3}{|c|}{6.582999999999999} & 5.9043 & TRN \\
\hline CHEMBL1495474 & 688810 & \multicolumn{3}{|c|}{5.632999999999999} & & \\
\hline CHEMBL1 & 688810 & 4.783 & 4.8973 & TST & & \\
\hline CHEMBL1433045 & 688810 & 5.683 & 5.2965 & TST & & \\
\hline CHEMBL1612746 & 688810 & 4.883 & 5.1861 & TRN & & \\
\hline CHEMBL15 & 688810 & \multicolumn{3}{|c|}{6.0329999999999995} & & \\
\hline CHEMBL 2 & 688810 & \multicolumn{3}{|c|}{5.332999999999999} & & \\
\hline CHEMBL1 & 688810 & 4.833 & 5.2705 & TRN & & \\
\hline CHEMBL1 & 688810 & 4.833 & 5.0121 & TRN & & \\
\hline CHEMBL 1 & 688810 & \multicolumn{3}{|c|}{5.2829999999999995} & & TST \\
\hline CHEMBL 1 & 688810 & \multicolumn{3}{|c|}{4.7330000000000005} & & \\
\hline CHEMBL1 & 688810 & 4.783 & 5.0679 & TST & & \\
\hline CHEMBL1 & 688810 & \multicolumn{3}{|c|}{6.082999999999999} & 5 . & TP \\
\hline CHEMBL1601733 & 688810 & 4.933 & 5.2976 & TRN & & \\
\hline CHEMBL1574288 & 688810 & 6.183 & 5.665 & TRN & & \\
\hline CHEMBL: & 688810 & \multicolumn{3}{|c|}{5.832999999999999} & & וכנו \\
\hline CHEMBL1 & 688810 & \multicolumn{3}{|c|}{6.2829999999999995} & 5.68 & TRN \\
\hline CHEMBL1339028 & 688810 & 4.783 & 5.0914 & TST & & \\
\hline CHEMBL1336806 & 688810 & \multicolumn{3}{|c|}{5.132999999999999} & & TRN \\
\hline CHEMBL65652 & 688810 & \multicolumn{3}{|c|}{5.832999999999999} & & \\
\hline CHEMBL13 & 688810 & \multicolumn{3}{|c|}{5.2829999999999995} & & (1) \\
\hline CHEMBL 31 & 688810 & \multicolumn{3}{|c|}{5.882999999999999} & 4.9036 & TST \\
\hline CHEMBL3191413 & 688810 & \multicolumn{3}{|c|}{5.632999999999999} & 5.529 & TRN \\
\hline CHEMBL1344968 & 688810 & 4.73300 & 00000000 & 005 & 5.8377 & $T D M$ \\
\hline CHEMBL1429966 & 688810 & 5.483 & 4.9764 & TST & & \\
\hline CHEMBL1376554 & 688810 & 6.28299 & 99999999 & 995 & 5.6801 & 11 \\
\hline CHEMBL1373664 & 688810 & 6.9329 & 5.6218 & TRN & & \\
\hline CHEMBL1601595 & 688810 & 4.833 & 5.0358 & TRN & & \\
\hline CHEMBL1351501 & 688810 & 4.73300 & 00000000 & 005 & 4.9734 & TRN \\
\hline CHEMBL1491120 & 688810 & 6.8831 & 5.75700 & 0000000 & & \\
\hline CHEMBL1574905 & 688810 & 4.73300 & 00000000 & 005 & 5.5586 & in \\
\hline CHEMBL1562878 & 688810 & 4.883 & 5.3445 & TRN & & \\
\hline
\end{tabular}




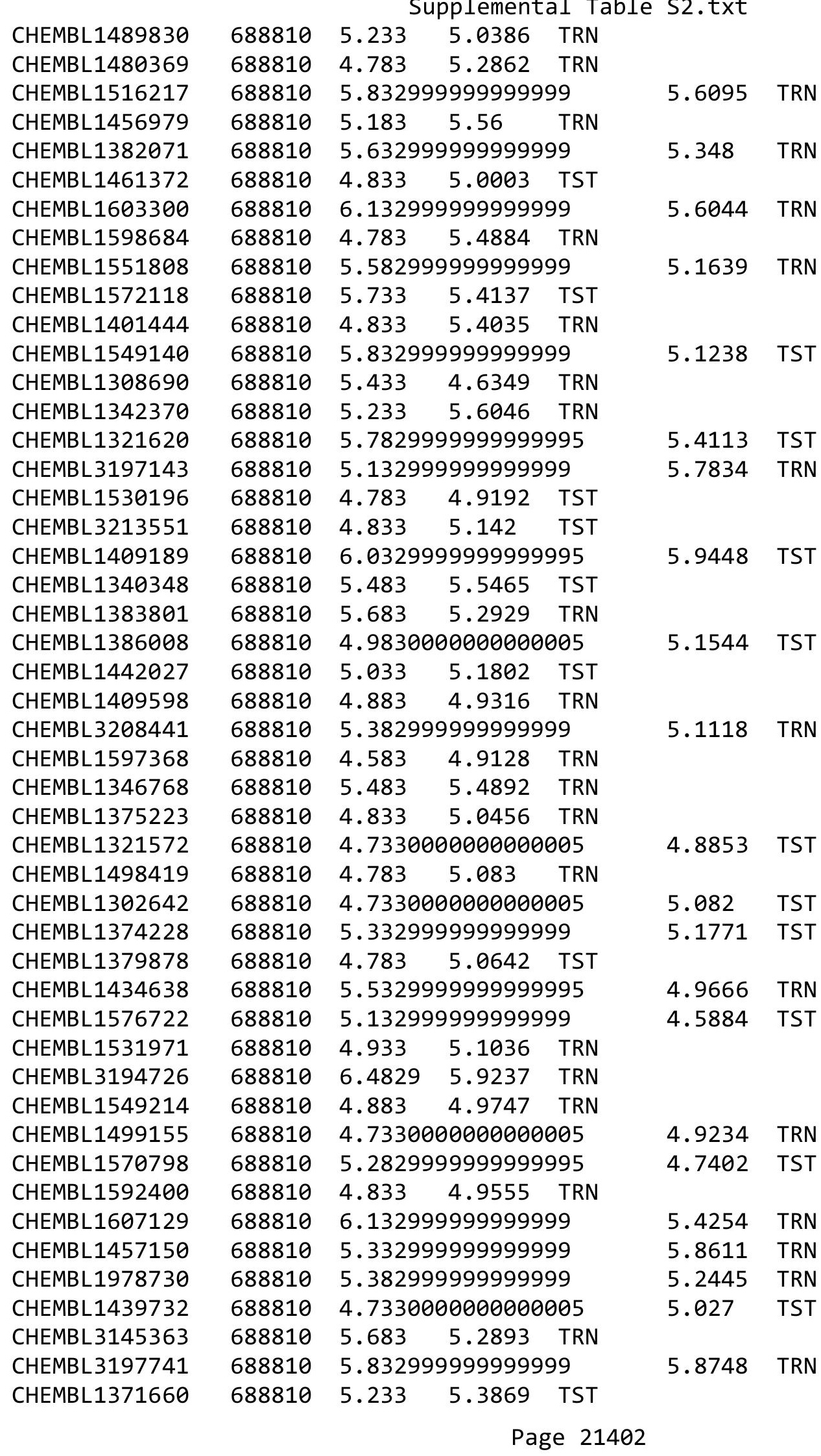




\begin{tabular}{|c|c|c|c|c|c|c|}
\hline \multicolumn{7}{|c|}{ o } \\
\hline CHEMBL1528247 & 688810 & 6.233 & 5.2679 & TRN & & \\
\hline CHEMBL1607399 & 688810 & 4.933 & 5.4361 & TRN & & \\
\hline CHEMBL1537051 & 688810 & 5.65 & 5.0746 & TRN & & \\
\hline CHEMBL1399377 & 688810 & 4.933 & 4.7753 & TRN & & \\
\hline CHEMBL1470168 & 688810 & 4.933 & 5.142 & TRN & & \\
\hline CHEMBL1341156 & 688810 & 4.933 & 4.9202 & TST & & \\
\hline CHEMBL1996536 & 688810 & 4.633 & 5.1897 & TRN & & \\
\hline CHEMBL3193873 & 688810 & 5.733 & 6.2748 & TRN & & \\
\hline CHEMBL1470519 & 688810 & 6.233 & 5.4235 & TRN & & \\
\hline CHEMBL1490498 & 688810 & 6.3829 & 99999999 & 99 & 6.0082 & TST \\
\hline CHEMBL1939687 & 688810 & 5.233 & 5.7338 & TRN & & \\
\hline CHEMBL1455962 & 688810 & 5.183 & 4.9991 & TRN & & \\
\hline CHEMBL3209355 & 688810 & 4.833 & 5.1802 & TST & & \\
\hline CHEMBL1608597 & 688810 & 4.933 & 5.4688 & TRN & & \\
\hline CHEMBL1563660 & 688810 & 4.833 & 5.1355 & TST & & \\
\hline CHEMBL1482683 & 688810 & 5.683 & 5.7267 & TRN & & \\
\hline CHEMBL1313477 & 688810 & 5.2829 & 99999999 & 995 & 5.4505 & TRN \\
\hline CHEMBL1301809 & 688810 & 4.7336 & 00000000 & 005 & 4.5835 & TRN \\
\hline CHEMBL1443082 & 688810 & 5.083 & 4.9947 & TRN & & \\
\hline CHEMBL1399550 & 688810 & 5.7829 & 99999999 & 995 & 5.2794 & TRN \\
\hline CHEMBL1367078 & 688810 & 4.883 & 5.5149 & TRN & & \\
\hline CHEMBL1600299 & 688810 & 4.783 & 5.33899 & 9999 & 995 & TRN \\
\hline CHEMBL1532699 & 688810 & 4.7336 & 00000000 & 005 & 4.976 & TRN \\
\hline CHEMBL1345273 & 688810 & 5.6325 & 99999999 & & 5.2545 & TRN \\
\hline CHEMBL1337121 & 688810 & 4.783 & 4.7755 & TRN & & \\
\hline CHEMBL1468638 & 688810 & 4.883 & 4.9946 & TRN & & \\
\hline CHEMBL1521886 & 688810 & 5.3329 & 99999999 & & 5.9714 & TR \\
\hline CHEMBL1355404 & 688810 & 4.883 & 4.9715 & TST & & \\
\hline CHEMBL1315403 & 688810 & 5.483 & 5.4855 & TST & & \\
\hline CHEMBL1433460 & 688810 & 5.933 & 5.1328 & TRN & & \\
\hline CHEMBL1573766 & 688810 & 6.983 & 5.9548 & TRN & & \\
\hline CHEMBL1581517 & 688810 & 4.633 & 5.0651 & TST & & \\
\hline CHEMBL1342833 & 688810 & 4.9836 & 00000000 & 005 & 4.8265 & TST \\
\hline CHEMBL1311005 & 688810 & 4.783 & 4.8252 & TRN & & \\
\hline CHEMBL1323853 & 688810 & 4.833 & 5.0029 & TST & & \\
\hline CHEMBL1494389 & 688810 & 5.7829 & 99999999 & 995 & 5.5363 & TRN \\
\hline CHEMBL1536786 & 688810 & 5.6329 & 99999999 & & 5.6465 & TR \\
\hline CHEMBL1516203 & 688810 & 4.783 & 4.8214 & TRN & & \\
\hline CHEMBL1469777 & 688810 & 4.933 & 4.8896 & TRN & & \\
\hline CHEMBL1381126 & 688810 & 6.3325 & 99999999 & & 5.6106 & TST \\
\hline CHEMBL1393074 & 688810 & 4.7336 & 00000000 & 005 & 5.2684 & TRN \\
\hline CHEMBL1347533 & 688810 & 6.0329 & 99999999 & 995 & 5.3005 & TRN \\
\hline CHEMBL1338789 & 688810 & 4.783 & 5.0365 & TRN & & \\
\hline CHEMBL1443418 & 688810 & 5.7829 & 99999999 & 995 & 5.3795 & TRN \\
\hline CHEMBL1511388 & 688810 & 4.9836 & 00000000 & 005 & 5.3181 & TST \\
\hline CHEMBL1436021 & 688810 & 4.7336 & 00000000 & 005 & 5.1844 & TST \\
\hline CHEMBL1469857 & 688810 & 5.433 & 5.1834 & TRN & & \\
\hline CHEMBL1545996 & 688810 & 4.883 & 4.9857 & TRN & & \\
\hline
\end{tabular}




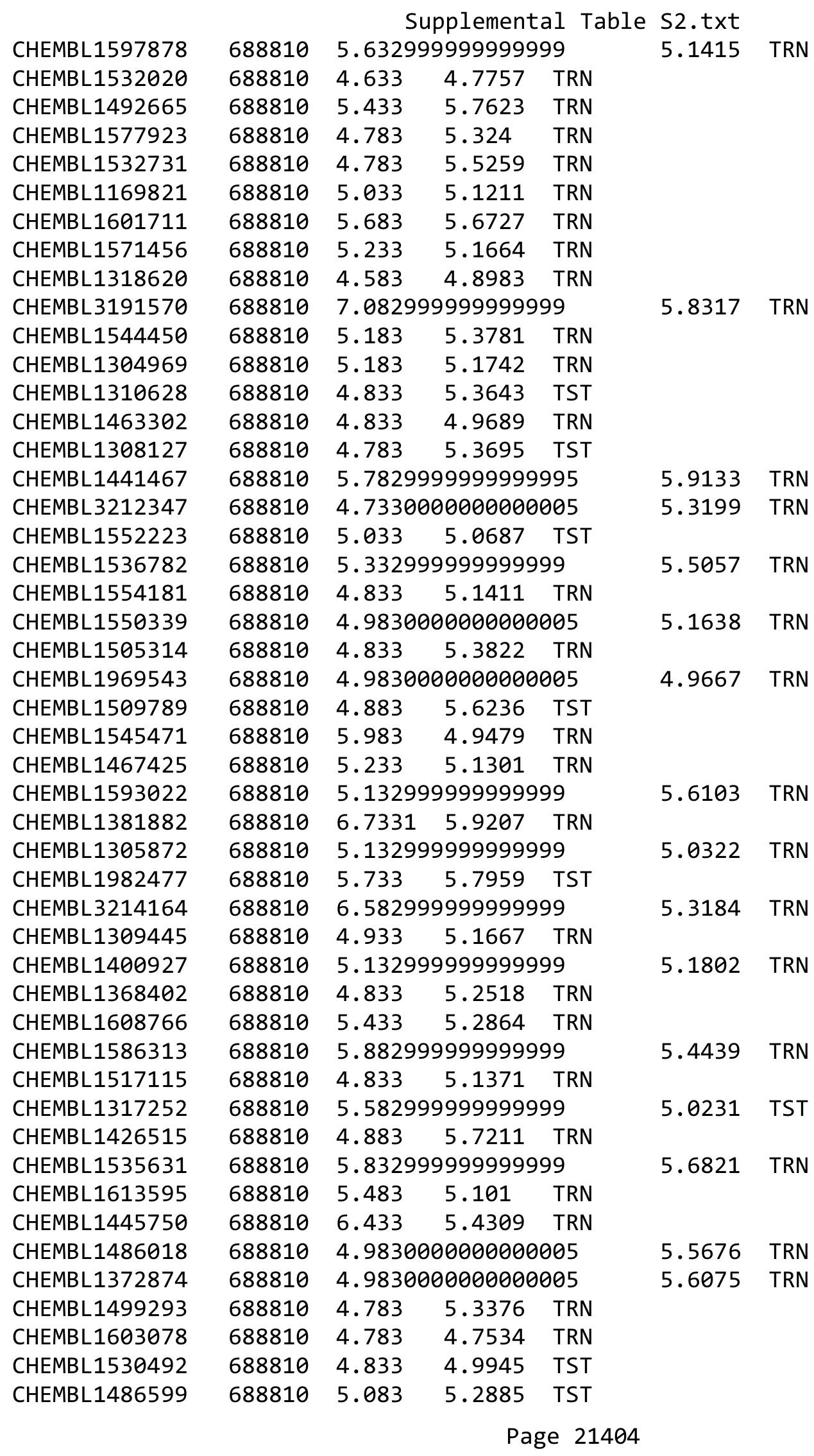




\begin{tabular}{|c|c|c|c|c|c|c|}
\hline \multicolumn{7}{|c|}{ Supplemental Table S2.txt } \\
\hline CHEMBL1308950 & 688810 & 5.483 & 5.1482 & TRN & & \\
\hline CHEMBL1478643 & 688810 & 5.033 & 5.4428 & TRN & & \\
\hline CHEMBL1555994 & 688810 & \multicolumn{3}{|c|}{5.2829999999999995} & 5.4695 & $\mathrm{TP}$ \\
\hline CHEMBL1352099 & 688810 & 4.883 & 4.8911 & TRN & & \\
\hline CHEMBL1387295 & 688810 & 5.683 & 5.5104 & TRN & & \\
\hline CHEMBL1542333 & 688810 & \multicolumn{3}{|c|}{5.332999999999999} & 5.4077 & TRN \\
\hline CHEMBL1503076 & 688810 & \multicolumn{3}{|c|}{5.632999999999999} & 5.7017 & \\
\hline CHEMBL1337846 & 688810 & 6.433 & 5.3477 & TST & & \\
\hline CHEMBL1339235 & 688810 & 4.933 & 5.2815 & TRN & & \\
\hline CHEMBL1519404 & 688810 & 5.433 & 5.5017 & TRN & & \\
\hline CHEMBL1456709 & 688810 & 7.1831 & 6.1182 & TRN & & \\
\hline CHEMBL1519868 & 688810 & \multicolumn{3}{|c|}{6.132999999999999} & 5.4357 & \\
\hline CHEMBL1375506 & 688810 & \multicolumn{3}{|c|}{5.832999999999999} & 5.1787 & \\
\hline CHEMBL1312613 & 688810 & \multicolumn{3}{|c|}{6.132999999999999} & 6.0844 & \\
\hline CHEMBL1310111 & 688810 & 4.783 & 5.4298 & TST & & \\
\hline CHEMBL1406891 & 688810 & 4.833 & 5.2374 & TRN & & \\
\hline CHEMBL1312632 & 688810 & \multicolumn{3}{|c|}{4.7330000000000005} & 8 & \\
\hline CHEMBL1370361 & 688810 & 4.633 & 5.1508 & TRN & & \\
\hline CHEMBL31 & 688810 & 4.833 & 5.51 & TST & & \\
\hline CHEMBL1535245 & 688810 & \multicolumn{3}{|c|}{5.882999999999999} & 5.4491 & \\
\hline CHEMBL1536912 & 688810 & 4.783 & 5.2144 & TST & & \\
\hline CHEMBL1460534 & 688810 & \multicolumn{3}{|c|}{5.582999999999999} & 5.2936 & \\
\hline CHEMBL13 & 688810 & \multicolumn{3}{|c|}{$6.983 \quad 6.2029999$} & 99 & \\
\hline CHEMBL1410552 & 688810 & 5.483 & 5.2482 & TRN & & \\
\hline CHEMBL1461196 & 688810 & 5.683 & 5.9211 & TRN & & \\
\hline CHEMBL1590410 & 688810 & 5.233 & 5.2909 & TST & & \\
\hline CHEMBL1453809 & 688810 & \multicolumn{3}{|c|}{4.7330000000000005} & 4.8302 & \\
\hline CHEMBL1436025 & 688810 & \multicolumn{3}{|c|}{5.132999999999999} & 5.0707 & \\
\hline CHEMBL 3197002 & 688810 & \multicolumn{3}{|c|}{5.132999999999999} & 5.2567 & \\
\hline CHEMBL1330989 & 688810 & \multicolumn{3}{|c|}{5.7829999999999995} & 5.8234 & TRN \\
\hline CHEMBL1486170 & 688810 & \multicolumn{3}{|c|}{5.882999999999999} & 5.5148 & \\
\hline CHEMBL1571629 & 688810 & 4.883 & 4.8191 & TRN & & \\
\hline CHEMBL13 & 688810 & \multirow{2}{*}{\multicolumn{3}{|c|}{$\begin{array}{l}4.883 \quad 5.0283 \text { TRN } \\
5.382999999999999\end{array}$}} & & \\
\hline CHEMBL1450586 & 688810 & & & & 5.1056 & \\
\hline CHEMBL 3198090 & 688810 & \multicolumn{3}{|c|}{5.2829999999999995} & 5.2778 & $T R$ \\
\hline CHEMBL1301780 & 688810 & \multicolumn{3}{|c|}{5.632999999999999} & 5.126 & \\
\hline CHEMBL1 & 688810 & 5.933 & 5.8846 & TRN & & \\
\hline CHEMBL1 & 688810 & \multirow{2}{*}{\multicolumn{3}{|c|}{$\begin{array}{l}5.033 \\
5.2829999999999995\end{array}$}} & & \\
\hline CHEMBL1498513 & 688810 & & & & 6.04 & $T P$ \\
\hline CHEMBL1589050 & 688810 & 4.833 & 4.6903 & TST & & \\
\hline CHEMBL1560329 & 688810 & \multicolumn{3}{|c|}{ 5.332999999999999 } & 5.1576 & To \\
\hline CHEMBL 3193348 & 688810 & 5.683 & 4.9949 & TRN & & \\
\hline CHEMBL1536358 & 688810 & $4.9830 e$ & $\partial 0000000$ & 205 & 5.6621 & TRI \\
\hline CHEMBL1402816 & 688810 & 4.783 & 5.3959 & TST & & \\
\hline CHEMBL1592527 & 688810 & 5.083 & 5.7235 & TRN & & \\
\hline CHEMBL1442986 & 688810 & 5.433 & 4.7449 & TRN & & \\
\hline CHEMBL525098 & 688810 & 5.13299 & 99999999 & & .2881 & \\
\hline CHEMBL1411113 & 688810 & 4.833 & 5.41 & TST & & \\
\hline
\end{tabular}




\begin{tabular}{|c|c|c|c|c|c|c|c|}
\hline \multirow{3}{*}{$\begin{array}{l}\text { CHEMBL1346182 } \\
\text { CHEMBL3199891 }\end{array}$} & \multicolumn{6}{|c|}{ Supplemental Table S2.txt } & \\
\hline & 688810 & \multicolumn{3}{|c|}{6.382999999999999} & 5.5426 & TRN & \\
\hline & 688810 & 5.033 & 4.9347 & TRN & & & \\
\hline CHEMBL1309268 & 688810 & \multicolumn{3}{|c|}{5.832999999999999} & 5.3225 & TST & \\
\hline CHEMBL1369867 & 688810 & \multicolumn{3}{|c|}{5.632999999999999} & 5.5419 & TST & \\
\hline CHEMBL1594418 & 688810 & 4.933 & 5.4244 & TRN & & & \\
\hline CHEMBL1487587 & 688810 & 5.083 & 4.9321 & TRN & & & \\
\hline CHEMBL1543054 & 688810 & \multicolumn{3}{|c|}{5.632999999999999} & 5.7644 & TRN & \\
\hline CHEMBL1305411 & 688810 & \multicolumn{3}{|c|}{6.082999999999999} & 5.6502 & TRN & \\
\hline CHEMBL1495394 & 688810 & 6.183 & 5.6686 & TRN & & & \\
\hline CHEMBL1443965 & 688810 & \multicolumn{3}{|c|}{$6.233 \quad 5.6557 \quad$ TRN } & & & \\
\hline CHEMBL1570869 & 688810 & \multicolumn{3}{|c|}{5.7829999999999995} & 5.3542 & TST & \\
\hline CHEMBL1507644 & 688810 & 4.933 & 4.8349 & TRN & & & \\
\hline CHEMBL3199380 & 688810 & \multirow{2}{*}{\multicolumn{3}{|c|}{$\begin{array}{l}4.933 \text { I. } \\
5.382999999999999\end{array}$}} & & & \\
\hline CHEMBL1328285 & 688810 & & & & 5.7597 & TRN & \\
\hline CHEMBL1550842 & 688810 & 5.233 & 4.9929 & TRN & & & \\
\hline CHEMBL1464657 & 688810 & 5.183 & 5.0921 & TRN & & & \\
\hline CHEMBL1512970 & 688810 & 4.633 & 4.7271 & TRN & & & \\
\hline CHEMBL1470634 & 688810 & 5.083 & 5.079 & TRN & & & \\
\hline CHEMBL1563971 & 688810 & 5.183 & 5.2866 & TRN & & & \\
\hline CHEMBL1412940 & 688810 & 5.683 & 5.5348 & TRN & & & \\
\hline CHEMBL1458884 & 688810 & 5.483 & 5.0948 & TRN & & & \\
\hline CHEMBL1404909 & 688810 & 4.633 & 4.9846 & TST & & & \\
\hline CHEMBL1431742 & 688810 & \multicolumn{3}{|c|}{5.882999999999999} & 5.2772 & TRN & \\
\hline CHEMBL1491651 & 688810 & 6.4829 & 5.9892 & TRN & & & \\
\hline CHEMBL1442010 & 688810 & 5.183 & 5.1427 & TRN & & & \\
\hline CHEMBL1483214 & 688810 & 4.883 & 5.0125 & TRN & & & \\
\hline CHEMBL3197662 & 688810 & 4.833 & 4.8726 & TRN & & & \\
\hline CHEMBL 3198019 & 688810 & 5.483 & 5.086 & TRN & & & \\
\hline CHEMBL1411631 & 688810 & \multicolumn{3}{|c|}{5.382999999999999} & 4.7604 & TRN & \\
\hline CHEMBL1314667 & 688810 & \multicolumn{3}{|c|}{4.9830000000000005} & 5.1343 & TRN & \\
\hline CHEMBL1486782 & 688810 & 4.833 & 4.9705 & TRN & & & \\
\hline CHEMBL3190723 & 688810 & \multicolumn{3}{|c|}{5.332999999999999} & 5.0710 & 0000000001 & TRN \\
\hline CHEMBL1470903 & 688810 & \multicolumn{3}{|c|}{5.7829999999999995} & 5.6662 & TRN & \\
\hline CHEMBL1408374 & 688810 & 4.583 & 4.9579 & TST & & & \\
\hline CHEMBL1501957 & 688810 & \multicolumn{3}{|c|}{5.5329999999999995} & 5.6763 & TST & \\
\hline CHEMBL1403365 & 688810 & 4.883 & 5.0519 & TST & & & \\
\hline CHEMBL1571348 & 688810 & 4.883 & 4.89 & TRN & & & \\
\hline CHEMBL1353185 & 688810 & 4.883 & 5.0117 & TRN & & & \\
\hline CHEMBL1600144 & 688810 & 4.783 & 5.2309 & TRN & & & \\
\hline CHEMBL 3192470 & 688810 & \multicolumn{3}{|c|}{4.7330000000000005} & 5.178 & TRN & \\
\hline CHEMBL1530583 & 688810 & \multicolumn{3}{|c|}{5.5329999999999995} & \multicolumn{2}{|c|}{5.457000000000001} & TRN \\
\hline CHEMBL1333060 & 688810 & 4.783 & 5.081 & TRN & & & \\
\hline CHEMBL1490451 & 688810 & 4.933 & 5.3323 & TRN & & & \\
\hline CHEMBL 3193058 & 688810 & 4.933 & 5.0241 & TST & & & \\
\hline CHEMBL1450448 & 688810 & 5.933 & 5.5981 & TRN & & & \\
\hline CHEMBL1461432 & 688810 & \multicolumn{3}{|c|}{4.7330000000000005} & 5.5267 & TST & \\
\hline CHEMBL1365364 & 688810 & \multicolumn{3}{|c|}{4.9830000000000005} & 5.0168 & TRN & \\
\hline CHEMBL1594921 & 688810 & 5.8829 & 99999999 & & 5.5988 & TRN & \\
\hline
\end{tabular}




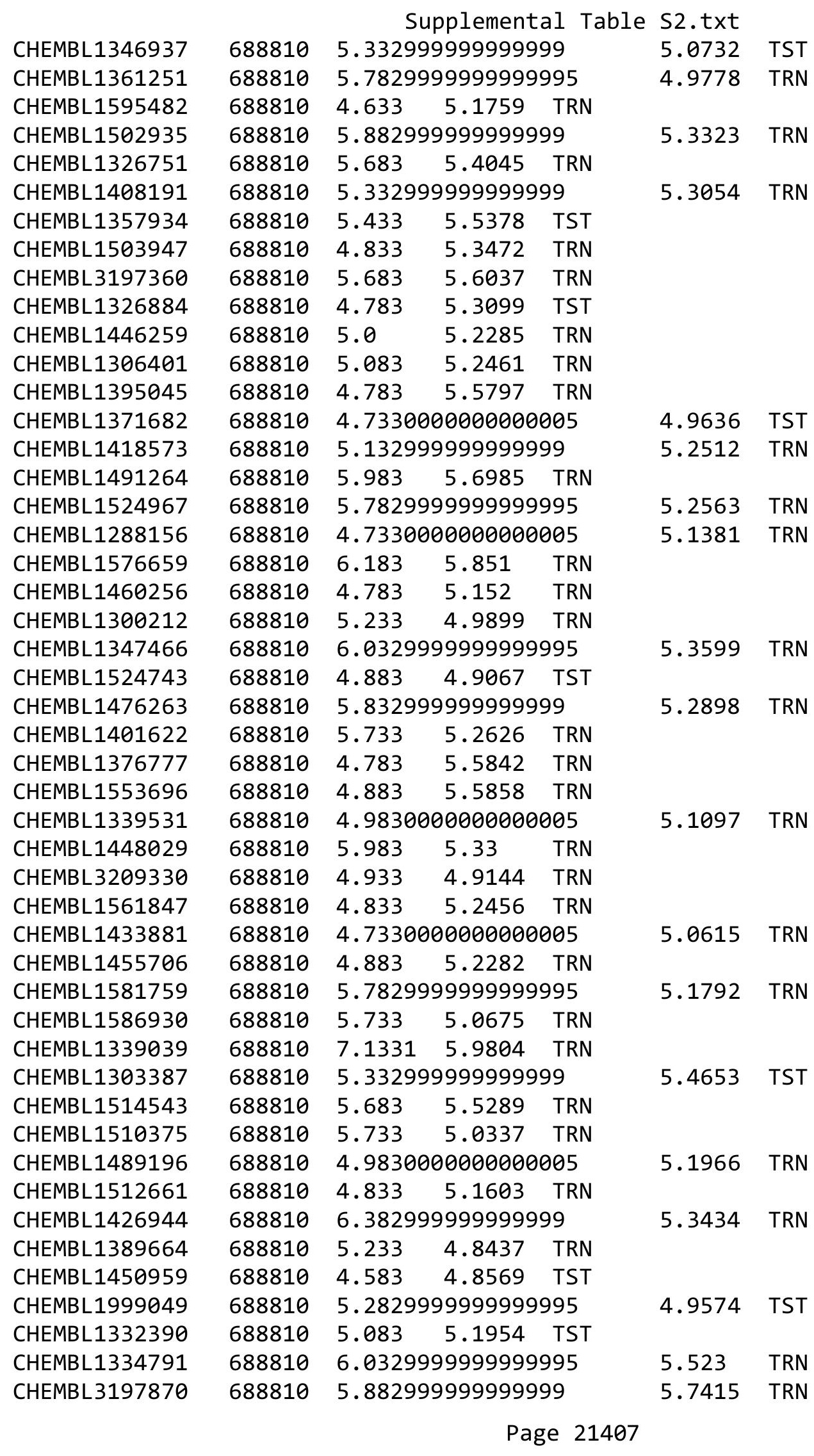




\begin{tabular}{|c|c|c|c|c|c|c|}
\hline \multirow[b]{2}{*}{ CHEMBL1376594 } & \multirow[b]{2}{*}{688810} & \multicolumn{5}{|c|}{ Supplemental Table S2.txt } \\
\hline & & \multirow{2}{*}{\multicolumn{3}{|c|}{$\begin{array}{lcc}4.833 & 4.9809 & \text { TRN } \\
5.132999999999999\end{array}$}} & & \\
\hline CHEMBL1607021 & 688810 & & & & 5.0322 & TRN \\
\hline CHEMBL1511729 & 688810 & \multicolumn{3}{|c|}{5.582999999999999} & 5.566 & TRN \\
\hline CHEMBL1366811 & 688810 & 4.833 & 5.2583 & TRN & & \\
\hline CHEMBL1495607 & 688810 & \multicolumn{3}{|c|}{5.582999999999999} & 5.3161 & TRN \\
\hline CHEMBL1301465 & 688810 & 4.883 & 4.8676 & TRN & & \\
\hline CHEMBL1539640 & 688810 & 4.883 & 4.9846 & TRN & & \\
\hline CHEMBL1468030 & 688810 & \multicolumn{3}{|c|}{5.7829999999999995} & 5.4552 & TRN \\
\hline CHEMBL 3199178 & 688810 & \multicolumn{3}{|c|}{6.5329999999999995} & 5.8814 & TST \\
\hline CHEMBL1340458 & 688810 & 5.033 & 5.437 & TRN & & \\
\hline CHEMBL1517352 & 688810 & 4.633 & & TST & & \\
\hline CHEMBL1567347 & 688810 & \multicolumn{3}{|c|}{5.2829999999999995} & 5.1376 & TRN \\
\hline CHEMBL1497463 & 688810 & 4.883 & 5.5934 & TRN & & \\
\hline CHEMBL1542140 & 688810 & 5.683 & 5.8376 & TRN & & \\
\hline CHEMBL1594185 & 688810 & 4.783 & 5.1517 & TRN & & \\
\hline CHEMBL526468 & 688810 & 4.683 & 4.8764 & TRN & & \\
\hline CHEMBL1587981 & 688810 & 4.583 & 4.4917 & TRN & & \\
\hline CHEMBL1333254 & 688810 & \multicolumn{3}{|c|}{6.132999999999999} & 5.7695 & TRN \\
\hline CHEMBL1548269 & 688810 & 4.833 & 5.3828 & TRN & & \\
\hline CHEMBL3193913 & 688810 & \multicolumn{3}{|c|}{6.382999999999999} & 5.5032 & TRN \\
\hline CHEMBL1561989 & 688810 & \multicolumn{3}{|c|}{6.2829999999999995} & 5.7371 & TRN \\
\hline CHEMBL3189401 & 688810 & 4.833 & 5.1241 & TRN & & \\
\hline CHEMBL1466186 & 688810 & 4.783 & 5.1895 & TST & & \\
\hline CHEMBL1387649 & 688810 & 4.783 & 5.1951 & TRN & & \\
\hline CHEMBL 3194445 & 688810 & 4.783 & 4.9192 & TST & & \\
\hline CHEMBL1337816 & 688810 & \multicolumn{3}{|c|}{4.9830000000000005} & 4.9039 & TRN \\
\hline CHEMBL1530177 & 688810 & 4.633 & 5.0961 & TRN & & \\
\hline CHEMBL1327356 & 688810 & 4.883 & 4.9895 & TRN & & \\
\hline CHEMBL1310097 & 688810 & 4.883 & 5.2573 & TRN & & \\
\hline CHEMBL1401959 & 688810 & \multicolumn{3}{|c|}{5.5329999999999995} & 5.5063 & TRN \\
\hline CHEMBL1497608 & 688810 & 5.683 & 5.4722 & TRN & & \\
\hline CHEMBL1344681 & 688810 & 4.933 & 5.0411 & TRN & & \\
\hline CHEMBL1564217 & 688810 & 4.783 & 4.9402 & TRN & & \\
\hline CHEMBL1395858 & 688810 & 5.483 & 4.8428 & TST & & \\
\hline CHEMBL1311378 & 688810 & 5.083 & 5.0682 & TRN & & \\
\hline CHEMBL1347506 & 688810 & 5.083 & 5.3203 & TRN & & \\
\hline CHEMBL1395800 & 688810 & 5.683 & 4.9079 & TRN & & \\
\hline CHEMBL1427898 & 688810 & \multicolumn{3}{|c|}{6.2829999999999995} & 5.6778 & TRN \\
\hline CHEMBL1464924 & 688810 & \multicolumn{3}{|c|}{5.882999999999999} & 5.2737 & TRN \\
\hline CHEMBL1382760 & 688810 & \multicolumn{3}{|c|}{5.332999999999999} & 5.5101 & TST \\
\hline CHEMBL1487460 & 688810 & 5.233 & 5.1296 & TST & & \\
\hline CHEMBL1509675 & 688810 & 4.783 & 4.8022 & TST & & \\
\hline CHEMBL1324490 & 688810 & 4.883 & 5.8846 & TST & & \\
\hline CHEMBL1534605 & 688810 & 4.883 & 5.1133 & TST & & \\
\hline CHEMBL1570219 & 688810 & 5.2829 & 99999995 & 995 & 5.3763 & TRN \\
\hline CHEMBL1420037 & 688810 & 5.8829 & 99999995 & & 5.1713 & TRN \\
\hline CHEMBL1560235 & 688810 & 5.183 & 5.3876 & TRN & & \\
\hline CHEMBL1534666 & 688810 & 4.583 & 5.5825 & TRN & & \\
\hline
\end{tabular}




\begin{tabular}{|c|c|c|c|c|c|c|c|}
\hline \multirow[b]{2}{*}{ CHEMBL1553168 } & \multicolumn{6}{|c|}{ Supplemental Table S2.txt } & \\
\hline & 688810 & 5.433 & 5.0286 & TRN & & & \\
\hline CHEMBL1499422 & 688810 & 4.933 & 5.1665 & TRN & & & \\
\hline CHEMBL1405890 & 688810 & 4.683 & 5.2026 & TRN & & & \\
\hline CHEMBL1378852 & 688810 & 5.433 & 5.9414 & TRN & & & \\
\hline CHEMBL1505808 & 688810 & 5.183 & 5.0026 & TRN & & & \\
\hline CHEMBL3192267 & 688810 & 5.183 & 5.2261 & TRN & & & \\
\hline CHEMBL1384904 & 688810 & 5.5329 & 99999999 & 995 & 5.3896 & TRN & \\
\hline CHEMBL1564062 & 688810 & 5.8829 & 99999999 & & 5.8355 & TRN & \\
\hline CHEMBL1600525 & 688810 & 4.633 & 5.3762 & TRN & & & \\
\hline CHEMBL1256737 & 688810 & 4.7330 & $\partial 0000000$ & 005 & 4.7641 & TST & \\
\hline CHEMBL1368383 & 688810 & 6.983 & 5.9058 & TRN & & & \\
\hline CHEMBL1577072 & 688810 & 5.3829 & 99999999 & & 6.0095 & TRN & \\
\hline CHEMBL1512962 & 688810 & 4.7330 & 00000000 & 005 & 5.3853 & TRN & \\
\hline CHEMBL1591295 & 688810 & 4.833 & 5.2724 & TRN & & & \\
\hline CHEMBL1557663 & 688810 & 6.0329 & 99999999 & 995 & 6.1341 & TRN & \\
\hline CHEMBL1371080 & 688810 & 7.2328 & 5.6962 & TRN & & & \\
\hline CHEMBL1346454 & 688810 & 4.7330 & $\partial 0000000$ & 005 & 5.4270 & 00000000005 & TRN \\
\hline CHEMBL3207305 & 688810 & 4.783 & 5.0089 & TST & & & \\
\hline CHEMBL1308188 & 688810 & 5.7829 & 99999999 & 995 & 5.5487 & TRN & \\
\hline CHEMBL1329715 & 688810 & 5.683 & 5.3517 & TRN & & & \\
\hline CHEMBL1440455 & 688810 & 6.2829 & 99999999 & 995 & 5.7156 & TRN & \\
\hline CHEMBL1365313 & 688810 & 6.0329 & 99999999 & 995 & 6.0283 & TST & \\
\hline CHEMBL3190958 & 688810 & 6.4829 & 5.9576 & TRN & & & \\
\hline CHEMBL1409297 & 688810 & 5.6329 & 99999999 & & 5.1731 & TRN & \\
\hline CHEMBL1412194 & 688810 & 4.783 & 5.3065 & TST & & & \\
\hline CHEMBL1429258 & 688810 & 4.883 & 4.9382 & TRN & & & \\
\hline CHEMBL1606449 & 688810 & 4.933 & 4.9185 & TST & & & \\
\hline CHEMBL3196983 & 688810 & 5.183 & 5.6745 & TRN & & & \\
\hline CHEMBL1337279 & 688810 & 5.1329 & 99999999 & & 5.1359 & TRN & \\
\hline CHEMBL1493875 & 688810 & 5.183 & 5.5237 & TRN & & & \\
\hline CHEMBL1351458 & 688810 & 4.783 & 4.58 & TRN & & & \\
\hline CHEMBL1490825 & 688810 & 5.1329 & 99999999 & & 5.1732 & TRN & \\
\hline CHEMBL1417277 & 688810 & 6.433 & 5.8253 & TRN & & & \\
\hline CHEMBL1576496 & 688810 & 5.1329 & 99999999 & & 4.874 & TRN & \\
\hline CHEMBL1519731 & 688810 & 5.5829 & 99999999 & & 6.3316 & TRN & \\
\hline CHEMBL1378500 & 688810 & 5.1329 & 99999999 & & 5.6438 & TST & \\
\hline CHEMBL1450833 & 688810 & 4.883 & 5.2138 & TST & & & \\
\hline CHEMBL1595853 & 688810 & 5.233 & 5.0853 & TRN & & & \\
\hline CHEMBL2269362 & 688810 & 4.633 & 5.2407 & TST & & & \\
\hline CHEMBL1364270 & 688810 & 4.783 & 5.2206 & TRN & & & \\
\hline CHEMBL1420766 & 688810 & 5.183 & 5.3804 & TRN & & & \\
\hline CHEMBL1610206 & 688810 & 4.833 & 5.2686 & TRN & & & \\
\hline CHEMBL1400655 & 688810 & 4.633 & 6.0102 & TRN & & & \\
\hline CHEMBL1558789 & 688810 & 5.5329 & 99999999 & 995 & 5.4121 & TRN & \\
\hline CHEMBL1581818 & 688810 & 5.083 & 5.4253 & TST & & & \\
\hline CHEMBL1333621 & 688810 & 7.2328 & 5.5824 & TRN & & & \\
\hline CHEMBL1501848 & 688810 & 5.1329 & 99999999 & & 5.9274 & TRN & \\
\hline CHEMBL1365411 & 688810 & 5.3329 & 99999999 & & 5.395 & TRN & \\
\hline
\end{tabular}




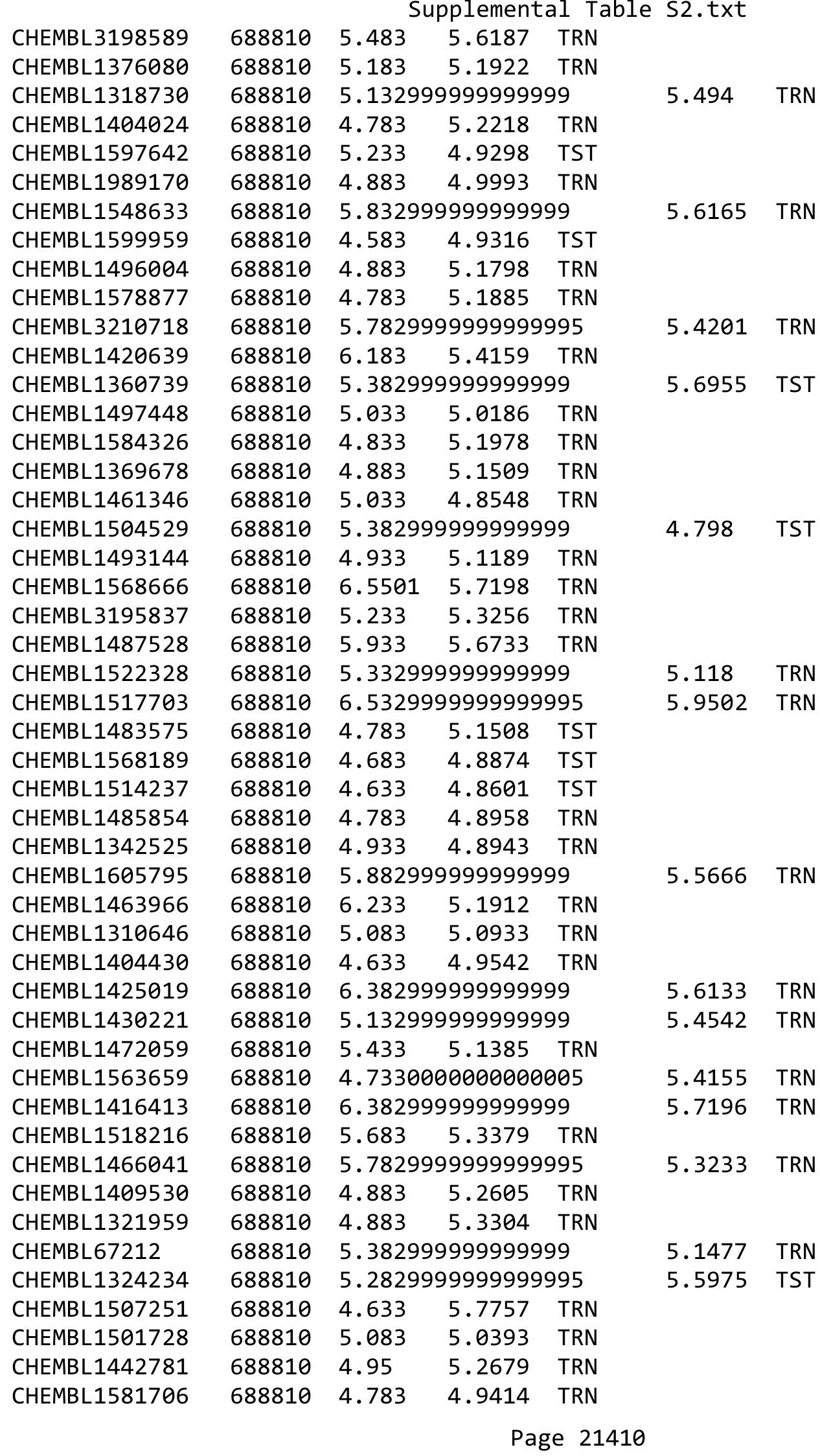




\begin{tabular}{|c|c|c|c|c|c|c|}
\hline & & \multicolumn{5}{|c|}{ Supplemental Table S2.txt } \\
\hline CHEMBL1428659 & 688810 & \multicolumn{3}{|c|}{6.2829999999999995} & 5.8744 & TRN \\
\hline CHEMBL1408640 & 688810 & \multicolumn{3}{|c|}{5.382999999999999} & 5.2848 & \\
\hline CHEMBL1563716 & 688810 & 5.083 & 5.2181 & TRN & & \\
\hline CHEMBL1309675 & 688810 & \multicolumn{3}{|c|}{5.132999999999999} & 4.9479 & \\
\hline CHEMBL1439363 & 688810 & \multicolumn{3}{|c|}{5.382999999999999} & 5.1133 & \\
\hline CHEMBL1534523 & 688810 & 4.883 & 4.8094 & TRN & & \\
\hline CHEMBL1465342 & 688810 & 4.633 & 4.8034 & TRN & & \\
\hline CHEMBL1424131 & 688810 & 5.683 & 5.0758 & TRN & & \\
\hline CHEMBL3214441 & 688810 & 5.033 & 5.0358 & TRN & & \\
\hline CHEMBL1331213 & 688810 & 5.683 & 5.312 & TRN & & \\
\hline CHEMBL1580192 & 688810 & \multicolumn{3}{|c|}{5.332999999999999} & 4.8455 & \\
\hline CHEMBL1508375 & 688810 & 6.0 & 5.3536 & TRN & & \\
\hline CHEMBL1519554 & 688810 & 6.433 & 5.3541 & TRN & & \\
\hline CHEMBL1498636 & 688810 & 5.733 & 5.7306 & TRN & & \\
\hline CHEMBL194594 & 688810 & 6.7331 & 5.9107 & TST & & \\
\hline CHEMBL1552221 & 688810 & \multicolumn{3}{|c|}{5.882999999999999} & 8 & \\
\hline CHEMBL1307014 & 688810 & 4.833 & 4.941 & TRN & & \\
\hline CHEMBL530049 & 688810 & 5.2 & 5.5386 & TST & & \\
\hline CHEMBL1527851 & 688810 & \multicolumn{3}{|c|}{6.132999999999999} & 5.1924 & \\
\hline CHEMBL1389542 & 688810 & 4.633 & 5.3905 & TRN & & \\
\hline CHEMBL1523093 & 688810 & 6.683 & 5.9401 & TRN & & \\
\hline CHEMBL32 & 688 & 4.783 & 5.2 & TRN & & \\
\hline CHEMBL1563611 & 688810 & 4.783 & 5.3207 & TRN & & \\
\hline CHEMBL1404034 & 688810 & 4.683 & 4.8594 & TRN & & \\
\hline CHEMBL1521977 & 688810 & 5.033 & 4.9047 & TRN & & \\
\hline CHEMBL1435903 & 688810 & 4.633 & 4.9267 & TST & & \\
\hline CHEMBL1 & 688 & 4.883 & 4.6 & TST & & \\
\hline CHEMBL1476523 & 688810 & 5.083 & 5.1288 & TRN & & \\
\hline CHEMBL1558234 & 688810 & \multicolumn{3}{|c|}{4.9830000000000005} & 5.6311 & $\mathrm{~T}$ \\
\hline CHEMBL1357048 & 688810 & 4.583 & 4.5721 & TST & & \\
\hline CHEMBL1600857 & 688810 & \multicolumn{3}{|c|}{5.7829999999999995} & 5.1005 & \\
\hline CHEMBL & 688810 & 4.633 & 4.6669 & TRN & & \\
\hline CHEMBL & 688810 & 5.233 & 5.2293 & TRN & & \\
\hline CHEMBL1492108 & 688810 & \multicolumn{3}{|c|}{6.2829999999999995} & 5.9084 & TRN \\
\hline CHEMBL1605021 & 688810 & \multicolumn{3}{|c|}{5.5329999999999995} & 6.3661 & TST \\
\hline CHEMBL1447517 & 688810 & \multicolumn{3}{|c|}{5.132999999999999} & 5.6601 & TRN \\
\hline CHEMBL1982304 & 688810 & 4.883 & 5.5497 & TRN & & \\
\hline CHEMBL3195962 & 688810 & \multicolumn{3}{|c|}{5.132999999999999} & 5.2473 & TR \\
\hline CHEMBL1490789 & 688810 & 5.983 & 4.9738 & TST & & \\
\hline CHEMBL1373385 & 688810 & 4.633 & 5.0921 & TST & & \\
\hline CHEMBL 2021431 & 688810 & 4.883 & 5.1972 & TST & & \\
\hline CHEMBL1468324 & 688810 & 4.833 & 4.817 & TRN & & \\
\hline CHEMBL1349115 & 688810 & \multicolumn{3}{|c|}{5.632999999999999} & 5.3696 & \\
\hline CHEMBL 3210447 & 688810 & \multicolumn{3}{|c|}{5.332999999999999} & 5.1079 & TST \\
\hline CHEMBL1520146 & 688810 & 4.883 & 5.01699 & 9999 & 995 & $\pi$ \\
\hline CHEMBL1436424 & 688810 & \multicolumn{3}{|c|}{4.7330000000000005} & 4.9052 & \\
\hline CHEMBL1366178 & 688810 & 4.683 & 4.9849 & TRN & & \\
\hline CHEMBL1597184 & 688810 & 4.833 & 5.3489 & TST & & \\
\hline
\end{tabular}




\begin{tabular}{|c|c|c|c|c|c|c|}
\hline \multirow[b]{2}{*}{ CHEMBL1489077 } & \\
\hline & 688810 & 5.033 & 5.3316 & TST & & \\
\hline CHEMBL1476676 & 688810 & 4.783 & 5.0185 & TRN & & \\
\hline CHEMBL1567689 & 688810 & 4.883 & 5.0715 & TRN & & \\
\hline CHEMBL1594765 & 688810 & 4.683 & 5.0678 & TRN & & \\
\hline CHEMBL1590470 & 688810 & 4.833 & 5.2136 & TRN & & \\
\hline CHEMBL1541919 & 688810 & 5.433 & 5.4114 & TRN & & \\
\hline CHEMBL388978 & 688810 & 6.9329 & 5.8711 & TST & & \\
\hline CHEMBL1470779 & 688810 & \multicolumn{3}{|c|}{5.5329999999999995} & 5.3832 & \\
\hline CHEMBL1560526 & 688810 & \multicolumn{3}{|c|}{4.9830000000000005} & 5.1473 & \\
\hline CHEMBL1372605 & 688810 & \multicolumn{3}{|c|}{5.832999999999999} & 5.1855 & \\
\hline CHEMBL1536480 & 688810 & 4.833 & 5.0698 & TRN & & \\
\hline CHEMBL1486954 & 688810 & 4.783 & 5.2994 & TST & & \\
\hline CHEMBL1532663 & 688810 & 5.683 & 5.187 & TRN & & \\
\hline CHEMBL1430278 & 688810 & 5.083 & 5.4465 & TRN & & \\
\hline CHEMBL1565857 & 688810 & 4.883 & 5.5973 & TRN & & \\
\hline CHEMBL1382364 & 688810 & 4.833 & 5.3317 & TRN & & \\
\hline CHEMBL1540655 & 688810 & 4.933 & 4.8943 & TST & & \\
\hline CHEMBL3208374 & 688810 & 4.833 & 5.2382 & TST & & \\
\hline CHEMBL1339283 & 688810 & \multicolumn{3}{|c|}{5.632999999999999} & 5.5142 & \\
\hline CHEMBL1545526 & 688810 & 5.983 & 5.6507 & TRN & & \\
\hline CHEMBL1469609 & 688810 & \multicolumn{3}{|c|}{5.382999999999999} & 5.1184 & \\
\hline CHEMBL1455362 & 688810 & 5.933 & 5.6674 & TRN & & \\
\hline CHEMBL1464316 & 688810 & 4.783 & 5.22 & TRN & & \\
\hline CHEMBL1444980 & 688810 & 4.783 & 5.7062 & TRN & & \\
\hline CHEMBL1610025 & 688810 & 4.783 & 4.7019 & TRN & & \\
\hline CHEMBL1513416 & 688810 & 5.083 & 5.6352 & TRN & & \\
\hline CHEMBL1439115 & 688810 & \multicolumn{3}{|c|}{5.382999999999999} & 5.4517 & \\
\hline CHEMBL1559871 & 688810 & \multicolumn{3}{|c|}{5.2829999999999995} & 4.773 & \\
\hline CHEMBL1608887 & 688810 & 5.183 & 5.1697 & TRN & & \\
\hline CHEMBL1544489 & 688810 & \multicolumn{3}{|c|}{6.382999999999999} & 5.5683 & \\
\hline CHEMBL1409773 & 688810 & 5.483 & 5.5346 & TRN & & \\
\hline CHEMBL1406359 & 688810 & 4.933 & 5.0412 & TST & & \\
\hline CHEMBL1482579 & 688810 & \multicolumn{3}{|c|}{6.2829999999999995} & 5.3997 & \\
\hline CHEMBL1394461 & 688810 & 4.883 & 5.388 & TRN & & \\
\hline CHEMBL1392787 & 688810 & \multicolumn{3}{|c|}{5.5329999999999995} & 5.1784 & \\
\hline CHEMBL1435513 & 688810 & \multicolumn{3}{|c|}{6.2829999999999995} & 5.709 & \\
\hline CHEMBL1418237 & 688810 & 5.933 & 5.5498 & TRN & & \\
\hline CHEMBL1431068 & 688810 & \multicolumn{3}{|c|}{6.082999999999999} & 5.6785 & \\
\hline CHEMBL1369100 & 688810 & 4.583 & 5.0381 & TRN & & \\
\hline CHEMBL1604911 & 688810 & \multirow{2}{*}{\multicolumn{3}{|c|}{$\begin{array}{lll}5.433 & 5.4334 & \text { TRN } \\
6.0329999999999995\end{array}$}} & & \\
\hline CHEMBL1569043 & 688810 & & & & 5.4925 & \\
\hline CHEMBL1533959 & 688810 & 4.633 & 4.7408 & TRN & & \\
\hline CHEMBL3199454 & 688810 & \multicolumn{3}{|c|}{5.2829999999999995} & 5.1221 & \\
\hline CHEMBL1311404 & 688810 & 4.833 & 5.0277 & TRN & & \\
\hline CHEMBL1568803 & 688810 & \multicolumn{3}{|c|}{5.7829999999999995} & 5.2784 & \\
\hline CHEMBL1346565 & 688810 & 5.733 & 5.5374 & TRN & & \\
\hline CHEMBL1430641 & 688810 & \multicolumn{3}{|c|}{5.632999999999999} & 5.2486 & \\
\hline CHEMBL3196413 & 688810 & \multicolumn{3}{|c|}{4.9830000000000005} & 5.3215 & \\
\hline
\end{tabular}




\begin{tabular}{|c|c|c|c|c|c|c|c|}
\hline \multicolumn{8}{|c|}{ pplemental Table S2.txt } \\
\hline CHEMBL1471723 & 688810 & 4.633 & 4.8486 & TST & & & \\
\hline CHEMBL2369311 & 688810 & 5.983 & 5.7027 & TRN & & & \\
\hline CHEMBL1373327 & 688810 & 5.083 & 5.2625 & TRN & & & \\
\hline CHEMBL1587945 & 688810 & \multicolumn{3}{|c|}{5.332999999999999} & 5.1415 & TRN & \\
\hline CHEMBL1560861 & 688810 & 4.883 & 5.0249 & TRN & & & \\
\hline CHEMBL1323028 & 688810 & 6.4829 & 5.4622 & TRN & & & \\
\hline CHEMBL1526016 & 688810 & 5.083 & 5.4328 & TRN & & & \\
\hline CHEMBL1536303 & 688810 & 4.833 & 4.8664 & TST & & & \\
\hline CHEMBL1548890 & 688810 & 4.583 & 4.8864 & TRN & & & \\
\hline CHEMBL1543875 & 688810 & \multicolumn{3}{|c|}{4.7330000000000005} & 5.2438 & TRN & \\
\hline CHEMBL1445203 & 688810 & \multicolumn{3}{|c|}{6.382999999999999} & 5.2997 & TRN & \\
\hline CHEMBL1609903 & 688810 & \multicolumn{3}{|c|}{5.882999999999999} & 4.8734 & TST & \\
\hline CHEMBL1490453 & 688810 & 4.633 & 5.1232 & TRN & & & \\
\hline CHEMBL 3193763 & 688810 & \multicolumn{3}{|c|}{5.7829999999999995} & 5.6512 & TRN & \\
\hline CHEMBL1473984 & 688810 & 4.583 & 5.0265 & TRN & & & \\
\hline CHEMBL9352 & 688810 & 5.033 & 4.7617 & TST & & & \\
\hline CHEMBL1971282 & 688810 & \multicolumn{3}{|c|}{5.2829999999999995} & 5.329 & TRN & \\
\hline CHEMBL1586036 & 688810 & 4.883 & 4.958 & TRN & & & \\
\hline CHEMBL 2004226 & 688810 & \multicolumn{3}{|c|}{4.7330000000000005} & \multicolumn{2}{|c|}{5.757999999999999} & TST \\
\hline CHEMBL1445698 & 688810 & \multicolumn{3}{|c|}{5.7829999999999995} & 5.5072 & TRN & \\
\hline CHEMBL1352538 & 688810 & 5.733 & 5.4102 & TRN & & & \\
\hline CHEMBL1470566 & 688810 & \multicolumn{3}{|c|}{4.9830000000000005} & 5.4535 & TRN & \\
\hline CHEMBL1551585 & 688810 & 4.633 & 5.1558 & TST & & & \\
\hline CHEMBL1348198 & 688810 & \multicolumn{3}{|c|}{6.2829999999999995} & 5.3506 & TST & \\
\hline CHEMBL1586441 & 688810 & \multicolumn{3}{|c|}{5.5329999999999995} & 5.2841 & TST & \\
\hline CHEMBL1300613 & 688810 & 6.183 & 5.6471 & TRN & & & \\
\hline CHEMBL1314968 & 688810 & 4.883 & 5.1095 & TRN & & & \\
\hline CHEMBL1439868 & 688810 & \multicolumn{3}{|c|}{5.382999999999999} & 5.3238 & TRN & \\
\hline CHEMBL1425046 & 688810 & 5.983 & \multicolumn{3}{|c|}{6.257000000000001} & TRN & \\
\hline CHEMBL1585195 & 688810 & \multicolumn{3}{|c|}{4.7330000000000005} & 5.4275 & TST & \\
\hline CHEMBL1559308 & 688810 & \multicolumn{3}{|c|}{5.382999999999999} & 5.3642 & TRN & \\
\hline CHEMBL1574776 & 688810 & 4.883 & 5.2848 & TRN & & & \\
\hline CHEMBL1362509 & 688810 & \multicolumn{3}{|c|}{4.7330000000000005} & 5.2388 & TRN & \\
\hline CHEMBL1580695 & 688810 & \multicolumn{3}{|c|}{4.7330000000000005} & 5.0651 & TRN & \\
\hline CHEMBL1541062 & 688810 & 4.933 & 5.0664 & TRN & & & \\
\hline CHEMBL1546980 & 688810 & 4.833 & 4.9216 & TRN & & & \\
\hline CHEMBL1323333 & 688810 & 4.783 & 5.2873 & TRN & & & \\
\hline CHEMBL1348299 & 688810 & \multicolumn{3}{|c|}{4.9830000000000005} & 5.1829 & TRN & \\
\hline CHEMBL1496911 & 688810 & 6.4829 & 5.3273 & TRN & & & \\
\hline CHEMBL1352417 & 688810 & 6.233 & 5.7369 & TRN & & & \\
\hline CHEMBL1410081 & 688810 & 5.733 & 5.2099 & TRN & & & \\
\hline CHEMBL1326481 & 688810 & 5.733 & 5.3186 & TRN & & & \\
\hline CHEMBL1391330 & 688810 & \multicolumn{3}{|c|}{5.332999999999999} & 4.8699 & TRN & \\
\hline CHEMBL1483948 & 688810 & 4.933 & 5.1358 & TRN & & & \\
\hline CHEMBL1371027 & 688810 & 4.883 & 4.8789 & TRN & & & \\
\hline CHEMBL546649 & 688810 & 5.183 & 5.4957 & TRN & & & \\
\hline CHEMBL3192101 & 688810 & 5.53299 & 99999999 & 995 & 5.2488 & TRN & \\
\hline CHEMBL1329309 & 688810 & 4.783 & 5.1304 & TRN & & & \\
\hline
\end{tabular}




\begin{tabular}{|c|c|c|c|c|c|c|c|}
\hline CHEMBL1359337 & 688810 & 7.2832 & 6.0567 & TRN & & & \\
\hline CHEMBL1499828 & 688810 & \multicolumn{3}{|c|}{4.7330000000000005} & 5.0549 & TST & \\
\hline CHEMBL3193828 & 688810 & 5.683 & 5.5517 & TRN & & & \\
\hline CHEMBL1440422 & 688810 & \multicolumn{3}{|c|}{5.632999999999999} & 6.3417 & TRN & \\
\hline CHEMBL1540377 & 688810 & 5.233 & 4.9803 & TST & & & \\
\hline CHEMBL1585720 & 688810 & \multicolumn{3}{|c|}{6.582999999999999} & 5.6188 & TRN & \\
\hline CHEMBL1514097 & 688810 & 6.433 & 6.3416 & TRN & & & \\
\hline CHEMBL1564230 & 688810 & 5.083 & 4.8735 & TRN & & & \\
\hline CHEMBL1349530 & 688810 & 5.683 & 5.4807 & TRN & & & \\
\hline CHEMBL1547262 & 688810 & 4.833 & 5.0687 & TST & & & \\
\hline CHEMBL1550796 & 688810 & \multicolumn{3}{|c|}{6.582999999999999} & 6.1827 & TRN & \\
\hline CHEMBL1330717 & 688810 & 4.883 & 5.2884 & TRN & & & \\
\hline CHEMBL1388311 & 688810 & 4.783 & 5.3161 & TST & & & \\
\hline CHEMBL1498359 & 688810 & \multicolumn{3}{|c|}{6.2829999999999995} & 5.2495 & TRN & \\
\hline CHEMBL1441583 & 688810 & 5.983 & 5.5662 & TRN & & & \\
\hline CHEMBL1521563 & 688810 & 5.183 & 5.1743 & TST & & & \\
\hline CHEMBL512387 & 688810 & 5.183 & 5.2757 & TRN & & & \\
\hline CHEMBL1576096 & 688810 & 4.883 & 5.2493 & TRN & & & \\
\hline CHEMBL1347564 & 688810 & \multicolumn{3}{|c|}{4.9830000000000005} & 5.0033 & TRN & \\
\hline CHEMBL1454614 & 688810 & \multicolumn{3}{|c|}{4.7330000000000005} & 5.0343 & TRN & \\
\hline CHEMBL1445676 & 688810 & \multicolumn{3}{|c|}{6.2829999999999995} & 5.6776 & TRN & \\
\hline CHEMBL1531640 & 688810 & 5.083 & 5.647 & TRN & & & \\
\hline CHEMBL1582494 & 688810 & \multicolumn{3}{|c|}{6.382999999999999} & 5.7029 & TRN & \\
\hline CHEMBL1431126 & 688810 & \multicolumn{3}{|c|}{4.9830000000000005} & 5.16700 & 0000000001 & TST \\
\hline CHEMBL1383461 & 688810 & \multicolumn{3}{|c|}{5.132999999999999} & 5.2353 & TRN & \\
\hline CHEMBL1524253 & 688810 & 5.683 & 5.278 & TRN & & & \\
\hline CHEMBL1606631 & 688810 & \multicolumn{3}{|c|}{5.832999999999999} & 5.5538 & TRN & \\
\hline CHEMBL1469590 & 688810 & \multicolumn{3}{|c|}{5.832999999999999} & 5.6936 & TRN & \\
\hline CHEMBL1591478 & 688810 & \multicolumn{3}{|c|}{5.132999999999999} & 4.9329 & TRN & \\
\hline CHEMBL1351624 & 688810 & 5.033 & 5.3336 & TRN & & & \\
\hline CHEMBL1491253 & 688810 & 4.883 & 5.1212 & TRN & & & \\
\hline CHEMBL1497626 & 688810 & 4.783 & 5.3664 & TST & & & \\
\hline CHEMBL1320926 & 688810 & 5.683 & 5.7313 & TST & & & \\
\hline CHEMBL1389974 & 688810 & 4.833 & 5.232 & TST & & & \\
\hline CHEMBL1411450 & 688810 & \multicolumn{3}{|c|}{5.632999999999999} & 5.2789 & TRN & \\
\hline CHEMBL1565686 & 688810 & 6.4829 & 5.5453 & TRN & & & \\
\hline CHEMBL1592036 & 688810 & 5.683 & 5.1524 & TRN & & & \\
\hline CHEMBL1335945 & 688810 & \multicolumn{3}{|c|}{5.882999999999999} & 5.3468 & TST & \\
\hline CHEMBL1327494 & 688810 & 5.083 & 5.4219 & TRN & & & \\
\hline CHEMBL1570624 & 688810 & 7.2832 & 5.8729 & TST & & & \\
\hline CHEMBL 2369229 & 688810 & 4.933 & 5.3367 & TRN & & & \\
\hline CHEMBL1601117 & 688810 & 5.083 & 5.4084 & TRN & & & \\
\hline CHEMBL1300635 & 688810 & 4.833 & 5.0977 & TRN & & & \\
\hline CHEMBL1553504 & 688810 & 4.583 & 4.7939 & TST & & & \\
\hline CHEMBL1428465 & 688810 & \multicolumn{3}{|c|}{4.7330000000000005} & 5.3055 & TRN & \\
\hline CHEMBL1508764 & 688810 & 4.933 & 5.3207 & TST & & & \\
\hline CHEMBL1427394 & 688810 & 4.883 & 5.3155 & TRN & & & \\
\hline CHEMBL1504500 & 688810 & 4.683 & 5.2195 & TST & & & \\
\hline
\end{tabular}




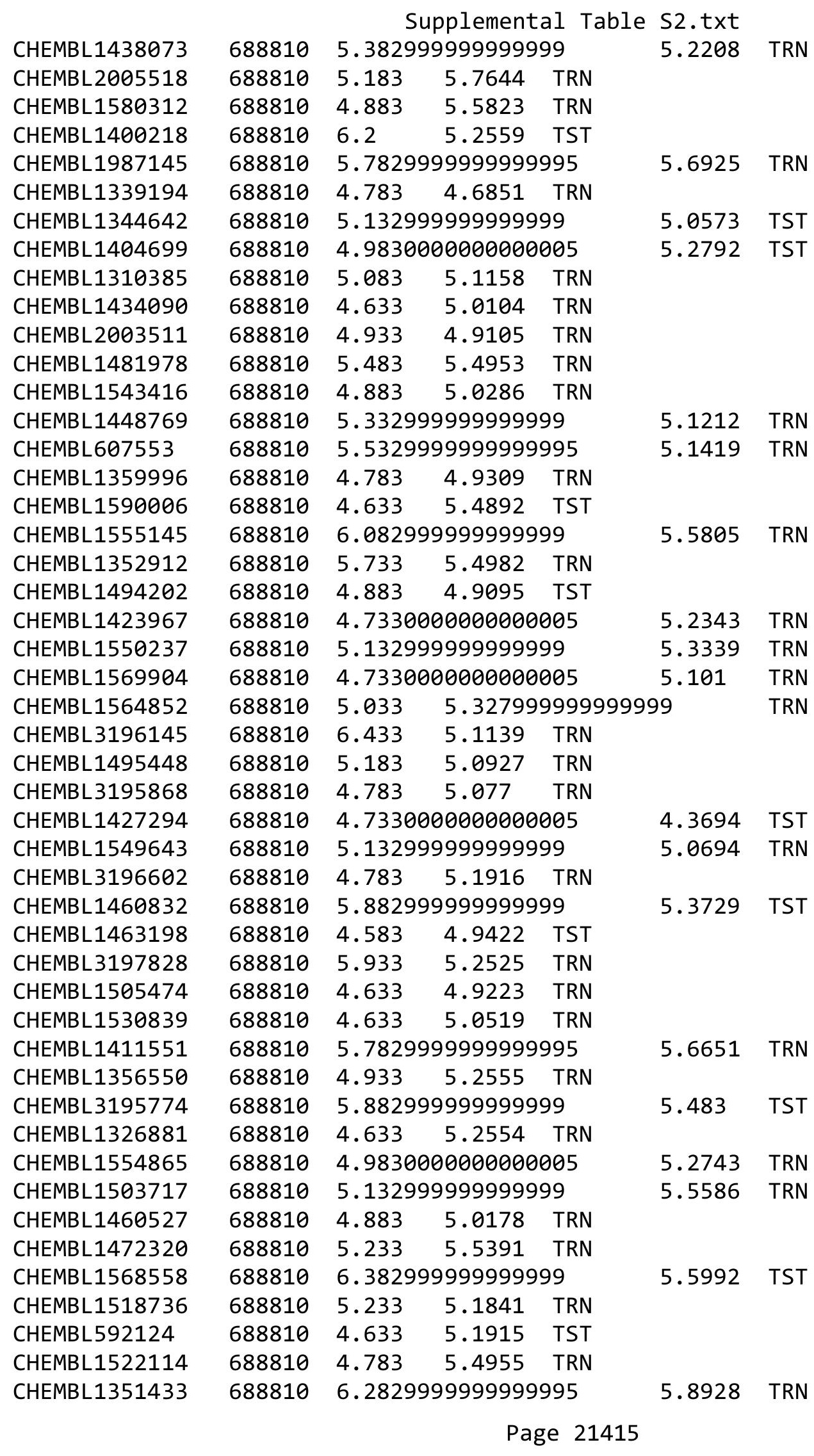




\begin{tabular}{|c|c|c|c|c|c|c|}
\hline & & & & & & \\
\hline CHEMBL1534435 & 688810 & 5.033 & 5.2789 & TST & & \\
\hline CHEMBL1555331 & 688810 & 6.2829 & 999999999 & 995 & 5.2607 & TRN \\
\hline CHEMBL1304950 & 688810 & 4.7330 & 000000000 & 305 & 4.9689 & \\
\hline CHEMBL1391722 & 688810 & 4.933 & 5.4421 & TRN & & \\
\hline CHEMBL1554992 & 688810 & 5.8829 & 999999999 & & 5.1998 & \\
\hline CHEMBL1420252 & 688810 & 6.2829 & 999999999 & 995 & 5.2491 & \\
\hline CHEMBL1336101 & 688810 & 4.7330 & 000000000 & 305 & 5.5487 & \\
\hline CHEMBL1471162 & 688810 & 5.183 & 5.1418 & TRN & & \\
\hline CHEMBL1522020 & 688810 & 4.883 & 4.9586 & TST & & \\
\hline CHEMBL1551243 & 688810 & 4.583 & 4.9097 & TST & & \\
\hline CHEMBL1411831 & 688810 & 4.883 & 5.4942 & TRN & & \\
\hline CHEMBL1420985 & 688810 & 4.7330 & 000000000 & & 4.8796 & \\
\hline CHEMBL 3194828 & 688810 & 6.0329 & 999999999 & 995 & 5.718 & \\
\hline CHEMBL1540982 & 688810 & 4.7330 & 000000000 & 305 & 5.4875 & \\
\hline CHEMBL1575970 & 688810 & 7.0829 & 999999999 & & 6.1562 & \\
\hline CHEMBL1426739 & 688810 & 4.9830 & 000000000 & 005 & 5.1896 & \\
\hline CHEMBL1348555 & 688810 & 5.5829 & 999999999 & & 5.2281 & \\
\hline CHEMBL1582269 & 688810 & 5.683 & 5.2273 & TRN & & \\
\hline CHEMBL1433782 & 688810 & 5.733 & 5.2694 & TRN & & \\
\hline CHEMBL1971872 & 688810 & 4.833 & 5.2008 & TRN & & \\
\hline CHEMBL 1473110 & 688810 & 5.2829 & 999999999 & 995 & 5.8986 & \\
\hline CHEMBL1500243 & 688810 & 4.933 & 5.2737 & TRN & & \\
\hline CHEMBL 3198581 & 688810 & 5.033 & 5.4553 & TRN & & \\
\hline CHEMBL 3197200 & 688810 & 7.0829 & 999999999 & & 5.6504 & \\
\hline CHEMBL1374893 & 688810 & 5.8829 & 999999999 & & 5.2603 & TST \\
\hline CHEMBL1511492 & 688810 & 4.7330 & 000000000 & 305 & 5.273 & \\
\hline CHEMBL1542645 & 688810 & 5.683 & 5.5133 & TRN & & \\
\hline CHEMBL 1455646 & 688810 & 4.833 & 4.9997 & TRN & & \\
\hline CHEMBL 1565523 & 688810 & 5.5829 & 999999999 & & 5.2621 & 10 \\
\hline CHEMBL1369858 & 688810 & 4.833 & 5.4659 & TRN & & \\
\hline CHEMBL 3209085 & 688810 & 4.7330 & 000000000 & 05 & 4.8245 & TS \\
\hline CHEMBL1456954 & 688810 & 4.883 & 5.7619 & TRN & & \\
\hline CHEMBL 1502856 & 688810 & 4.583 & 5.8383 & TRN & & \\
\hline CHEMBL1529294 & 688810 & 5.233 & 4.7293 & TRN & & \\
\hline CHEMBL1502641 & 688810 & 4.783 & 5.3311 & TST & & \\
\hline CHEMBL1497494 & 688810 & 4.833 & 5.5761 & TRN & & \\
\hline CHEMBL1507382 & 688810 & 5.483 & 4.5391 & TRN & & \\
\hline CHEMBL 1572780 & 688810 & 5.5329 & 999999999 & 995 & 5.4559 & \\
\hline CHEMBL1536135 & 688810 & 6.433 & 5.4143 & TRN & & \\
\hline CHEMBL 71271 & 688810 & 5.3329 & 999999999 & & 5.8089 & TRN \\
\hline CHEMBL 1553190 & 688810 & 4.583 & 4.9912 & TST & & \\
\hline CHEMBL1578487 & 688810 & 5.183 & 4.6432 & TRN & & \\
\hline CHEMBL1534030 & 688810 & 5.433 & 5.1801 & TRN & & \\
\hline CHEMBL1495092 & 688810 & 5.183 & 5.4996 & TRN & & \\
\hline CHEMBL1356410 & 688810 & 4.783 & 5.1257 & TRN & & \\
\hline CHEMBL 3208161 & 688810 & 5.933 & 5.2138 & TRN & & \\
\hline CHEMBL1565959 & 688810 & 5.8829 & 999999999 & & 5.4586 & $\mathrm{IRI}$ \\
\hline CHEMBL1494586 & 688810 & 4.633 & 4.7687 & TST & & \\
\hline
\end{tabular}




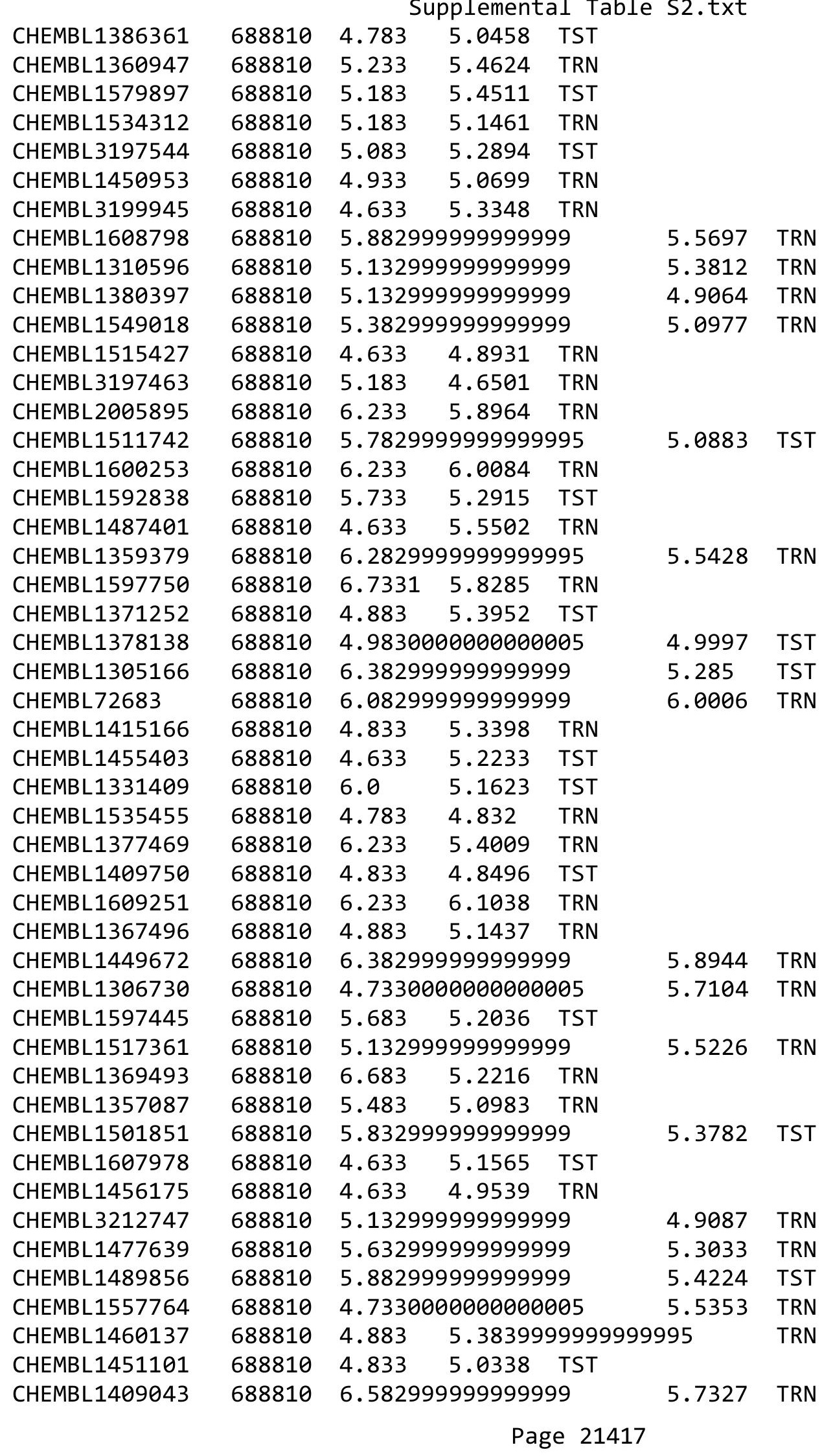




\begin{tabular}{|c|c|c|c|c|c|c|}
\hline \multirow{3}{*}{$\begin{array}{l}\text { CHEMBL1577117 } \\
\text { CHEMBL1489167 }\end{array}$} & \multirow{3}{*}{$\begin{array}{l}688810 \\
688810\end{array}$} & \multicolumn{5}{|c|}{ Supplemental Table S2.txt } \\
\hline & & \multicolumn{3}{|c|}{5.332999999999999} & \multirow{4}{*}{5.5539} & \multirow[t]{4}{*}{ TRN } \\
\hline & & 4.783 & 5.2124 & TRN & & \\
\hline CHEMBL1471612 & 688810 & 4.633 & 4.9509 & TRN & & \\
\hline CHEMBL1534598 & 688810 & 5.733 & 5.6289 & TRN & & \\
\hline CHEMBL1492209 & 688810 & \multicolumn{3}{|c|}{6.332999999999999} & \multirow[t]{4}{*}{4.9628} & \multirow[t]{4}{*}{ TRN } \\
\hline CHEMBL1478666 & 688810 & 4.783 & 5.6554 & TRN & & \\
\hline CHEMBL1323748 & 688810 & 4.633 & 4.7349 & TRN & & \\
\hline CHEMBL1462611 & 688810 & 5.15 & 4.9238 & TRN & & \\
\hline CHEMBL1501191 & 688810 & \multicolumn{3}{|c|}{5.332999999999999} & \multirow[t]{2}{*}{5.8647} & \multirow[t]{2}{*}{ TRN } \\
\hline CHEMBL3209019 & 688810 & 5.083 & 5.2104 & TRN & & \\
\hline CHEMBL1547194 & 688810 & \multicolumn{3}{|c|}{4.7330000000000005} & \multirow[t]{3}{*}{5.2646} & \multirow[t]{3}{*}{ TRA } \\
\hline CHEMBL1316329 & 688810 & 4.583 & 5.0642 & TRN & & \\
\hline CHEMBL1388168 & 688810 & 5.683 & 5.28 & TRN & & \\
\hline CHEMBL1300711 & 688810 & \multicolumn{3}{|c|}{5.882999999999999} & \multirow[t]{3}{*}{5.1512} & \multirow[t]{3}{*}{ TST } \\
\hline CHEMBL1554987 & 688810 & 4.633 & 4.6783 & TRN & & \\
\hline CHEMBL3192004 & 688810 & 5.733 & 5.1136 & TRN & & \\
\hline CHEMBL1375273 & 688810 & \multicolumn{3}{|c|}{6.582999999999999} & \multirow[t]{2}{*}{6.3354} & \multirow[t]{2}{*}{ TRA } \\
\hline CHEMBL1301409 & 688810 & 4.783 & 5.2798 & TST & & \\
\hline CHEMBL1315281 & 688810 & 5.7829 & 99999999 & 995 & 5.6854 & TST \\
\hline CHEMBL1390799 & 688810 & 5.183 & 5.352 & TST & & \\
\hline CHEMBL1504019 & 688810 & 6.0329 & 99999999 & 995 & 5.7412 & TRN \\
\hline CHEMBL1349007 & 688810 & 6.2829 & 99999999 & 995 & 5.4904 & TRN \\
\hline CHEMBL1515468 & 688810 & 6.8831 & 5.9651 & TRN & & \\
\hline CHEMBL1374722 & 688810 & 4.783 & 5.67 & TRN & & \\
\hline CHEMBL1410070 & 688810 & 4.883 & 5.1616 & TRN & & \\
\hline CHEMBL1551346 & 688810 & 4.633 & 4.7918 & TRN & & \\
\hline CHEMBL1553117 & 688810 & 6.183 & 5.5992 & TRN & & \\
\hline CHEMBL3214291 & 688810 & 4.9830 & 00000000 & 005 & 5.3629 & TST \\
\hline CHEMBL1390258 & 688810 & 4.7330 & 00000000 & 005 & 5.1616 & TRN \\
\hline CHEMBL1578238 & 688810 & 4.883 & 5.6065 & TST & & \\
\hline CHEMBL1401633 & 688810 & 5.3829 & 99999999 & & 5.2322 & TRN \\
\hline CHEMBL1443051 & 688810 & 4.833 & 4.873 & TST & & \\
\hline CHEMBL1360398 & 688810 & 6.3329 & 99999999 & & 5.2592 & TRN \\
\hline CHEMBL1321669 & 688810 & 6.0 & 5.7037 & TRN & & \\
\hline CHEMBL1523960 & 688810 & 5.1329 & 99999999 & & 5.2361 & TRN \\
\hline CHEMBL 1485588 & 688810 & 4.7330 & 00000000 & 005 & 4.9532 & TST \\
\hline CHEMBL1460819 & 688810 & 5.683 & 5.3356 & TRN & & \\
\hline CHEMBL1466201 & 688810 & 4.633 & 5.0171 & TRN & & \\
\hline CHEMBL1600868 & 688810 & 4.9830 & 00000000 & 005 & 5.7041 & TRN \\
\hline CHEMBL1598804 & 688810 & 4.833 & 4.9702 & TST & & \\
\hline CHEMBL1537246 & 688810 & 5.233 & 5.0636 & TRN & & \\
\hline CHEMBL1594589 & 688810 & 4.7330 & 00000000 & 005 & 4.8459 & TRN \\
\hline CHEMBL1511267 & 688810 & 4.7330 & 00000000 & 005 & 5.2843 & TST \\
\hline CHEMBL1583838 & 688810 & 5.6329 & 99999999 & & 5.2481 & TST \\
\hline CHEMBL 3192789 & 688810 & 5.433 & 5.4774 & TRN & & \\
\hline CHEMBL1368004 & 688810 & 5.933 & 5.2203 & TRN & & \\
\hline CHEMBL1596699 & 688810 & 4.633 & 5.0557 & TRN & & \\
\hline CHEMBL1444899 & 688810 & 4.9830 & 00000000 & 005 & 4.8937 & TRN \\
\hline
\end{tabular}




\begin{tabular}{|c|c|c|c|c|c|c|}
\hline & & \multicolumn{4}{|c|}{ Supplemental Table S2.txt } & \\
\hline CHEMBL1353759 & 688810 & \multicolumn{3}{|c|}{6.632999999999999} & 6.2708 & TRN \\
\hline CHEMBL1501774 & 688810 & \multicolumn{3}{|c|}{4.7330000000000005} & 5.7375 & \\
\hline CHEMBL1508377 & 688810 & \multicolumn{3}{|c|}{6.332999999999999} & 5.9048 & \\
\hline CHEMBL1473750 & 688810 & 4.883 & 5.3025 & TRN & & \\
\hline CHEMBL1545554 & 688810 & \multicolumn{3}{|c|}{5.332999999999999} & 5.5479 & \\
\hline CHEMBL1463581 & 688810 & 4.833 & 4.9734 & TRN & & \\
\hline CHEMBL1548329 & 688810 & \multicolumn{3}{|c|}{5.632999999999999} & 5.1743 & \\
\hline CHEMBL1353847 & 688810 & \multicolumn{3}{|c|}{6.0329999999999995} & 5.2412 & \\
\hline CHEMBL1444292 & 688810 & \multicolumn{3}{|c|}{4.7330000000000005} & 5.0451 & \\
\hline CHEMBL1965873 & 688810 & 4.783 & 5.2534 & TST & & \\
\hline CHEMBL1444274 & 688810 & \multicolumn{3}{|c|}{5.332999999999999} & 5.5894 & \\
\hline CHEMBL3189752 & 688810 & 4.833 & 5.1325 & TST & & \\
\hline CHEMBL1328797 & 688810 & 5.083 & 5.0388 & TST & & \\
\hline CHEMBL1310489 & 688810 & \multicolumn{3}{|c|}{4.7330000000000005} & 5.2509 & \\
\hline CHEMBL1369606 & 688810 & \multicolumn{3}{|c|}{4.7330000000000005} & 4.9423 & \\
\hline CHEMBL1346947 & 688810 & 5.183 & 5.4474 & TRN & & \\
\hline CHEMBL1411125 & 688810 & 4.883 & 4.8989 & TRN & & \\
\hline CHEMBL1556166 & 688810 & 4.833 & 5.2643 & TRN & & \\
\hline CHEMBL1601738 & 688810 & \multicolumn{3}{|c|}{5.832999999999999} & 5.3168 & 15 \\
\hline CHEMBL1363870 & 688810 & 5.033 & 4.8771 & TST & & \\
\hline CHEMBL1560988 & 688810 & 5.683 & & TRN & & \\
\hline CHEMBL13 & 688810 & \multicolumn{3}{|c|}{5.382999999999999} & .9196 & \\
\hline CHEMBL 260148 & 688810 & 4.633 & 5.1442 & TRN & & \\
\hline CHEMBL1456424 & 688810 & 5.033 & 5.2212 & TRN & & \\
\hline CHEMBL1466023 & 688810 & 5.183 & 5.3908 & TST & & \\
\hline CHEMBL1389083 & 688810 & 4.783 & 5.5237 & TRN & & \\
\hline CHEMBL1 & 688810 & 6.0 & 5.515 & TST & & \\
\hline CHEMBL1598490 & 688810 & 5.483 & 4.8935 & TST & & \\
\hline CHEMBL 3192129 & 688810 & 5.733 & 4.8478 & TST & & \\
\hline CHEMBL1455227 & 688810 & 5.483 & 5.1224 & TRN & & \\
\hline CHEMBL1363130 & 688810 & 5.933 & 5.0682 & TRN & & \\
\hline CHEMBL1 & 688810 & 6.433 & 5.8906 & TRN & & \\
\hline CHEMBL1512137 & 688810 & 4.633 & 4.9138 & TRN & & \\
\hline CHEMBL1546291 & 688810 & \multicolumn{3}{|c|}{5.5329999999999995} & 4.989 & $T$ \\
\hline CHEMBL1600268 & 688810 & 4.833 & 4.9821 & TST & & \\
\hline CHEMBL1597850 & 688810 & 5. & 5.2798 & TRN & & \\
\hline CHEMBL1486215 & 688810 & 4.683 & 5.3753 & TRN & & \\
\hline CHEMBL1534181 & 688810 & 4.783 & 5.3462 & TRN & & \\
\hline CHEMBL1336660 & 688810 & 5.183 & 5.5795 & TRN & & \\
\hline CHEMBL1603540 & 688810 & 5.233 & 5.3357 & TRN & & \\
\hline CHEMBL1439982 & 688810 & 4.783 & 4.9919 & TRN & & \\
\hline CHEMBL1453218 & 688810 & \multicolumn{3}{|c|}{4.7330000000000005} & 5.7251 & \\
\hline CHEMBL1455056 & 688810 & 4.883 & 4.746 & TST & & \\
\hline CHEMBL 3195420 & 688810 & \multicolumn{3}{|c|}{5.132999999999999} & 5.0418 & 13 \\
\hline CHEMBL1468183 & 688810 & 4.683 & 4.6216 & TST & & \\
\hline CHEMBL1594875 & 688810 & \multicolumn{3}{|c|}{4.9830000000000005} & 4.8919 & 17 \\
\hline CHEMBL1387072 & 688810 & \multicolumn{3}{|c|}{5.882999999999999} & 5.3338 & \\
\hline CHEMBL1367494 & 688810 & 4.833 & 5.3208 & TRN & & \\
\hline
\end{tabular}




\begin{tabular}{|c|c|c|c|c|c|c|}
\hline \multirow[b]{2}{*}{ CHEMBL1385679 } & \multicolumn{6}{|c|}{ Supplemental Table S2.txt } \\
\hline & 688810 & 4.683 & 5.154 & TST & & \\
\hline CHEMBL1567041 & 688810 & \multicolumn{3}{|c|}{5.332999999999999} & 5.1563 & $\mathrm{TR}$ \\
\hline CHEMBL1303844 & 688810 & 5.683 & 5.4374 & TRN & & \\
\hline CHEMBL1596931 & 688810 & 5.233 & 5.355 & TST & & \\
\hline CHEMBL1410897 & 688810 & 4.633 & 5.226 & TRN & & \\
\hline CHEMBL1406961 & 688810 & \multicolumn{3}{|c|}{4.7330000000000005} & 5.3575 & \\
\hline CHEMBL1343061 & 688810 & 5.033 & 5.3734 & TRN & & \\
\hline CHEMBL1513884 & 688810 & 5.433 & 5.1904 & TRN & & \\
\hline CHEMBL1507063 & 688810 & 5.683 & 5.2443 & TST & & \\
\hline CHEMBL1397848 & 688810 & \multicolumn{3}{|c|}{4.7330000000000005} & 5.0903 & $\mathrm{~T}$ \\
\hline CHEMBL3214595 & 688810 & 5.083 & 5.1615 & TRN & & \\
\hline CHEMBL1498364 & 688810 & 5.683 & 5.4685 & TRN & & \\
\hline CHEMBL3212989 & 688810 & 5.033 & 5.0975 & TRN & & \\
\hline CHEMBL1444626 & 688810 & 5.433 & 5.5502 & TRN & & \\
\hline CHEMBL 3191400 & 688810 & 4.883 & 5.0656 & TST & & \\
\hline CHEMBL1444690 & 688810 & \multicolumn{3}{|c|}{5.2829999999999995} & 5.0096 & \\
\hline CHEMBL1410130 & 688810 & \multicolumn{3}{|c|}{5.332999999999999} & 5.2294 & \\
\hline CHEMBL1501662 & 688810 & 5.033 & 4.8925 & TRN & & \\
\hline CHEMBL 2001895 & 688810 & \multicolumn{3}{|c|}{6.332999999999999} & 5.7724 & TRN \\
\hline CHEMBL1386061 & 688810 & \multicolumn{3}{|c|}{5.832999999999999} & 5.1901 & \\
\hline CHEMBL3192121 & 688810 & 5.683 & 5.666 & TRN & & \\
\hline CHEMBL1317857 & 688810 & 4.683 & 5.0558 & TRN & & \\
\hline CHEMBL1373917 & 688810 & \multicolumn{3}{|c|}{5.2829999999999995} & 5.4399 & \\
\hline CHEMBL1582310 & 688810 & \multicolumn{3}{|c|}{4.7330000000000005} & 5.1173 & \\
\hline CHEMBL1575704 & 688810 & 5.233 & 5.2301 & TRN & & \\
\hline CHEMBL1304900 & 688810 & 5.483 & 5.1318 & TRN & & \\
\hline CHEMBL1505121 & 688810 & 4.833 & 5.0596 & TST & & \\
\hline CHEMBL1584570 & 688810 & 5.3 & 5.5542 & TST & & \\
\hline CHEMBL1374416 & 688810 & \multicolumn{3}{|c|}{4.7330000000000005} & 4.7655 & \\
\hline CHEMBL1342056 & 688810 & 4.683 & 5.3296 & TRN & & \\
\hline CHEMBL1516672 & 688810 & \multicolumn{3}{|c|}{4.7330000000000005} & 5.2849 & TS \\
\hline CHEMBL1529881 & 688810 & 4.833 & 5.4063 & TRN & & \\
\hline CHEMBL1589241 & 688810 & \multirow{2}{*}{\multicolumn{3}{|c|}{5.332999999999999}} & & \\
\hline CHEMBL1428684 & 688810 & & & & 5.5375 & $\mathrm{~T}$ \\
\hline CHEMBL1311290 & 688810 & 5.083 & 5.391 & TST & & \\
\hline CHEMBL1376390 & 688810 & 5.933 & 5.5843 & TRN & & \\
\hline CHEMBL1499127 & 688810 & 4.883 & 4.7883 & TRN & & \\
\hline CHEMBL1613447 & 688810 & \multicolumn{3}{|c|}{6.332999999999999} & 5.7483 & 12 \\
\hline CHEMBL1556391 & 688810 & 4.683 & 4.9254 & TST & & \\
\hline CHEMBL1414937 & 688810 & 4.783 & 5.4287 & TST & & \\
\hline CHEMBL1376387 & 688810 & \multicolumn{3}{|c|}{5.832999999999999} & 4.8231 & TRN \\
\hline CHEMBL1357550 & 688810 & \multicolumn{3}{|c|}{5.582999999999999} & 5.0306 & TS \\
\hline CHEMBL3199458 & 688810 & 5.083 & 5.3301 & TRN & & \\
\hline CHEMBL1455756 & 688810 & \multicolumn{3}{|c|}{7.082999999999999} & 5.7378 & Tt \\
\hline CHEMBL1467438 & 688810 & 4.783 & 5.2632 & TRN & & \\
\hline CHEMBL1499925 & 688810 & \multicolumn{3}{|c|}{5.632999999999999} & 5.8729 & TRN \\
\hline CHEMBL1610215 & 688810 & \multicolumn{3}{|c|}{5.2829999999999995} & 5.4392 & . \\
\hline CHEMBL1327155 & 688810 & 4.783 & 5.7887 & TST & & \\
\hline
\end{tabular}




\begin{tabular}{|c|c|c|c|c|c|c|}
\hline \multirow[b]{2}{*}{ CHEMBL1612227 } & \\
\hline & 688810 & 4.783 & 4.9894 & TST & & \\
\hline CHEMBL1545275 & 688810 & 5.183 & 5.0269 & TRN & & \\
\hline CHEMBL1386240 & 688810 & \multicolumn{3}{|c|}{4.7330000000000005} & 4.9672 & TST \\
\hline CHEMBL1421228 & 688810 & 6.0 & 5.2538 & TRN & & \\
\hline CHEMBL1603408 & 688810 & 4.883 & 5.347 & TRN & & \\
\hline CHEMBL1306432 & 688810 & 5.433 & 5.038 & TRN & & \\
\hline CHEMBL1366145 & 688810 & 4.883 & 5.4743 & TRN & & \\
\hline CHEMBL1453903 & 688810 & 5.433 & 4.9827 & TRN & & \\
\hline CHEMBL1304926 & 688810 & \multicolumn{3}{|c|}{5.382999999999999} & 5.0186 & TRN \\
\hline CHEMBL1523124 & 688810 & 6.183 & \multicolumn{3}{|c|}{5.763999999999999} & \\
\hline CHEMBL1516913 & 688810 & 5.733 & 5.4195 & TRN & & \\
\hline CHEMBL1607848 & 688810 & \multicolumn{3}{|c|}{4.7330000000000005} & 4.9073 & I \\
\hline CHEMBL1569864 & 688810 & \multicolumn{3}{|c|}{5.2829999999999995} & 5.3214 & \\
\hline CHEMBL1337659 & 688810 & \multicolumn{3}{|c|}{5.132999999999999} & 5.1736 & \\
\hline CHEMBL1387514 & 688810 & 5.733 & 5.3148 & TST & & \\
\hline CHEMBL 3190350 & 688810 & 5.233 & 5.1846 & TRN & & \\
\hline CHEMBL1398208 & 688810 & \multicolumn{3}{|c|}{5.332999999999999} & 5.1296 & $\mathrm{Tr}$ \\
\hline CHEMBL1546122 & 688810 & \multicolumn{3}{|c|}{5.2829999999999995} & 5.0999 & \\
\hline CHEMBL 3195785 & 688810 & 5.183 & 5.1995 & TRN & & \\
\hline CHEMBL 3191116 & 688810 & 4.633 & 5.117 & TRN & & \\
\hline CHEMBL 3197703 & 688810 & 5.983 & 5.0625 & TST & & \\
\hline CHEMBL1331338 & 688810 & 5.483 & 5.0949 & TRN & & \\
\hline CHEMBL1435221 & 688810 & 6.8831 & \multicolumn{3}{|c|}{5.877000000000001} & \\
\hline CHEMBL1478032 & 688810 & 6.433 & 5.8 & TRN & & \\
\hline CHEMBL1520758 & 688810 & \multicolumn{3}{|c|}{4.7330000000000005} & 5.165 & \\
\hline CHEMBL1432357 & 688810 & \multicolumn{3}{|c|}{5.7829999999999995} & 5.3395 & \\
\hline CHEMBL1398298 & 688810 & 5.233 & 5.1794 & TRN & & \\
\hline CHEMBL1444035 & 688810 & 5.083 & 5.1504 & TST & & \\
\hline CHEMBL1387637 & 688810 & \multicolumn{3}{|c|}{4.7330000000000005} & 5.8872 & $\mathrm{TP}$ \\
\hline CHEMBL1352651 & 688810 & \multicolumn{3}{|c|}{5.632999999999999} & 5.0063 & \\
\hline CHEMBL1472481 & 688810 & 4.933 & 5.1844 & TST & & \\
\hline CHEMBL1477767 & 688810 & 5.183 & 5.0961 & TRN & & \\
\hline CHEMBL1311218 & 688810 & 4.833 & \multicolumn{3}{|c|}{4.986000000000001} & \\
\hline CHEMBL1422916 & 688810 & 4.833 & 5.024 & TST & & \\
\hline CHEMBL1424923 & 688810 & 4.783 & 5.3244 & TRN & & \\
\hline CHEMBL1602171 & 688810 & \multicolumn{3}{|c|}{4.7330000000000005} & 5.0945 & TS \\
\hline CHEMBL1336312 & 688810 & 4.683 & 5.3749 & TRN & & \\
\hline CHEMBL1363094 & 688810 & \multicolumn{3}{|c|}{4.9830000000000005} & 5.1558 & $\because$ \\
\hline CHEMBL1362195 & 688810 & \multicolumn{3}{|c|}{4.7330000000000005} & 4.8792 & . \\
\hline CHEMBL1527491 & 688810 & 4.833 & 4.9935 & TRN & & \\
\hline CHEMBL1425330 & 688810 & & & TRN & & \\
\hline CHEMBL1538845 & 688810 & \multicolumn{3}{|c|}{5.832999999999999} & 5.2313 & 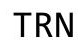 \\
\hline CHEMBL1986073 & 688810 & 4.583 & 5.1764 & TST & & \\
\hline CHEMBL 3195525 & 688810 & 5.05 & 5.3035 & TRN & & \\
\hline CHEMBL 3191027 & 688810 & 5.433 & 5.2133 & TRN & & \\
\hline CHEMBL1377625 & 688810 & 4.683 & 4.8995 & TRN & & \\
\hline CHEMBL1582238 & 688810 & 5.233 & 5.3682 & TRN & & \\
\hline CHEMBL1421460 & 688810 & 5.733 & 5.4435 & TRN & & \\
\hline
\end{tabular}




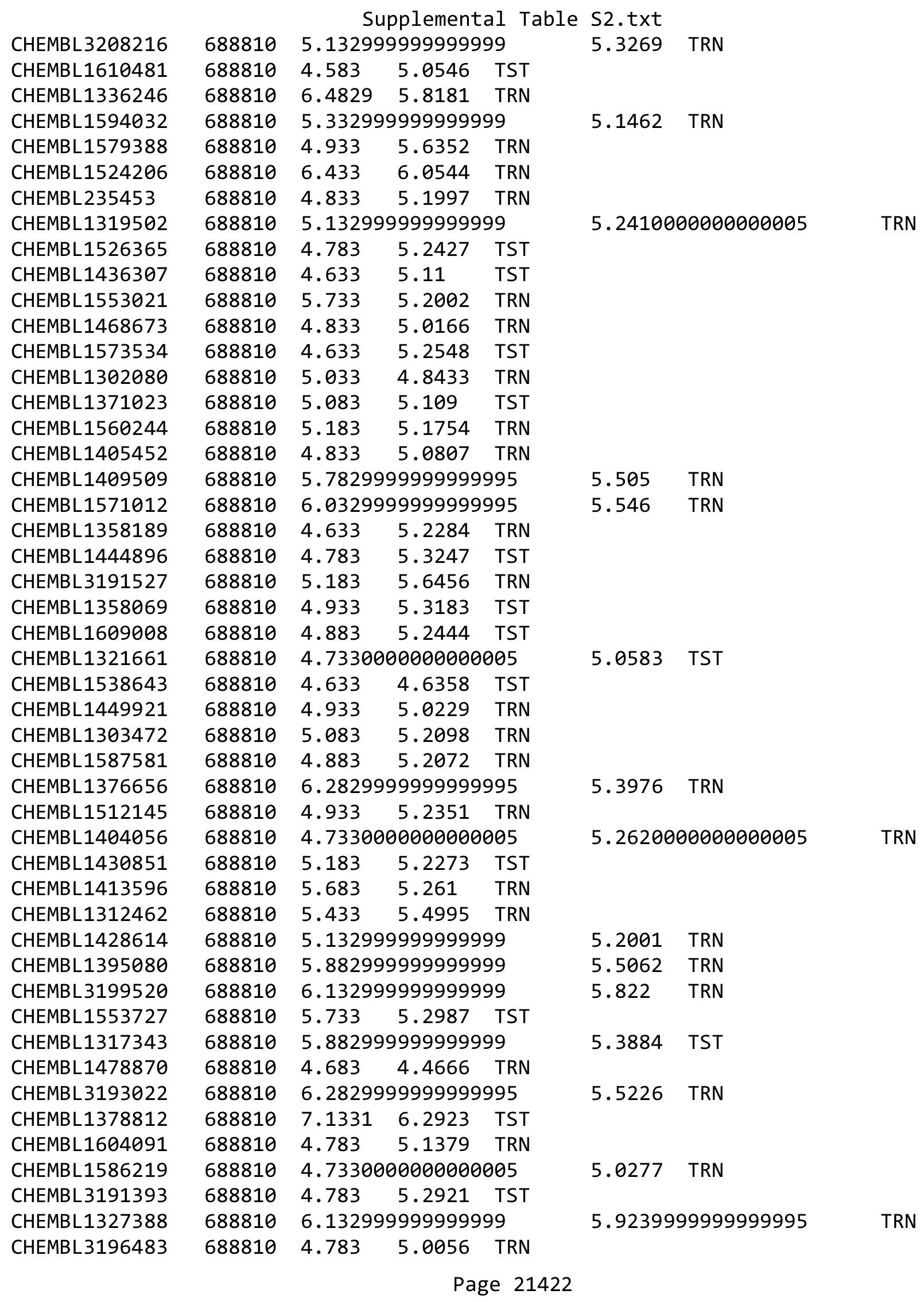




\begin{tabular}{|c|c|c|c|c|c|c|c|}
\hline \multicolumn{8}{|c|}{ terene } \\
\hline CHEMBL3193928 & 688810 & 4.783 & 5.0912 & TRN & & & \\
\hline CHEMBL1320891 & 688810 & 4.883 & 4.9175 & TRN & & & \\
\hline CHEMBL1968356 & 688810 & 6.4829 & 5.4531 & TST & & & \\
\hline CHEMBL1490810 & 688810 & 4.783 & 4.6542 & TST & & & \\
\hline CHEMBL1451528 & 688810 & 6.53299 & 999999999 & 995 & 5.731 & TST & \\
\hline CHEMBL1518682 & 688810 & 6.83299 & 999999999 & & 5.2479 & TRN & \\
\hline CHEMBL 1471341 & 688810 & 5.033 & 5.4651 & TRN & & & \\
\hline CHEMBL1514917 & 688810 & 4.683 & 5.2521 & TST & & & \\
\hline CHEMBL1382089 & 688810 & 4.833 & 5.5746 & TRN & & & \\
\hline CHEMBL1324089 & 688810 & 6.03299 & 999999999 & 995 & 5.1956 & TST & \\
\hline CHEMBL1361798 & 688810 & 4.783 & 5.4126 & TST & & & \\
\hline CHEMBL1399129 & 688810 & 4.73300 & 000000000 & 305 & 5.3432 & TRN & \\
\hline CHEMBL1580658 & 688810 & 5.183 & 5.8063 & TRN & & & \\
\hline CHEMBL3194846 & 688810 & 6.53299 & 999999999 & 995 & 6.0921 & TRN & \\
\hline CHEMBL1451830 & 688810 & 4.933 & 5.0959 & TRN & & & \\
\hline CHEMBL1493886 & 688810 & 6.233 & 6.0768 & TRN & & & \\
\hline CHEMBL1383306 & 688810 & 5.733 & 5.1794 & TRN & & & \\
\hline CHEMBL1387774 & 688810 & 4.833 & 5.2909 & TST & & & \\
\hline CHEMBL1487527 & 688810 & 5.683 & 5.4487 & TRN & & & \\
\hline CHEMBL1476045 & 688810 & 5.433 & 5.239 & TRN & & & \\
\hline CHEMBL1477383 & 688810 & 5.38299 & 999999999 & & 5.41700 & 0000000001 & TST \\
\hline CHEMBL1601707 & 688810 & 4.783 & 5.6908 & TRN & & & \\
\hline CHEMBL1300411 & 688810 & 6.8831 & 5.8801 & TRN & & & \\
\hline CHEMBL1509061 & 688810 & 4.583 & 5.3115 & TRN & & & \\
\hline CHEMBL 3197987 & 688810 & 5.33299 & 999999999 & & 5.4607 & TRN & \\
\hline CHEMBL1496708 & 688810 & 4.783 & 4.5976 & TRN & & & \\
\hline CHEMBL1385485 & 688810 & 5.53299 & 999999999 & 995 & 5.0535 & TST & \\
\hline CHEMBL1545892 & 688810 & 4.933 & 5.3784 & TRN & & & \\
\hline CHEMBL1531521 & 688810 & 4.73300 & 000000000 & 305 & 5.4092 & TRN & \\
\hline CHEMBL1546185 & 688810 & 5.733 & 5.4354 & TST & & & \\
\hline CHEMBL1303349 & 688810 & 4.783 & 5.4419 & TRN & & & \\
\hline CHEMBL1335591 & 688810 & 5.033 & 4.9919 & TRN & & & \\
\hline CHEMBL1425259 & 688810 & 4.883 & 4.9474 & TST & & & \\
\hline CHEMBL1455809 & 688810 & 5.38299 & 999999999 & & 5.5043 & TST & \\
\hline CHEMBL1601460 & 688810 & 5.033 & 4.8312 & TRN & & & \\
\hline CHEMBL1511679 & 688810 & 5.63299 & 999999999 & & 5.5818 & TRN & \\
\hline CHEMBL1386172 & 688810 & 5.483 & 5.3275 & TRN & & & \\
\hline CHEMBL1402956 & 688810 & 5.33299 & 999999999 & 99 & 5.3996 & TRN & \\
\hline CHEMBL1435945 & 688810 & 4.583 & 4.935 & TRN & & & \\
\hline CHEMBL1341740 & 688810 & 4.933 & 5.206 & TST & & & \\
\hline CHEMBL1562170 & 688810 & 5.183 & 5.9672 & TRN & & & \\
\hline CHEMBL1388090 & 688810 & 4.583 & 4.8431 & TST & & & \\
\hline CHEMBL3213394 & 688810 & 4.633 & 5.0047 & TRN & & & \\
\hline CHEMBL 3145201 & 688810 & 4.833 & 5.4358 & TRN & & & \\
\hline CHEMBL 3191937 & 688810 & 4.833 & 5.1031 & TRN & & & \\
\hline CHEMBL1558960 & 688810 & 5.33299 & 999999999 & & 5.6711 & TRN & \\
\hline CHEMBL1438831 & 688810 & 4.783 & 5.1379 & TRN & & & \\
\hline CHEMBL 3192430 & 688810 & 4.933 & 5.6596 & TST & & & \\
\hline
\end{tabular}




\begin{tabular}{|c|c|c|c|c|c|c|}
\hline & & \multicolumn{5}{|c|}{ Supplemental Table s2.txt } \\
\hline CHEMBL1360465 & 688810 & 4.883 & 5.5976 & TRN & & \\
\hline CHEMBL1555166 & 688810 & 5.183 & 5.4477 & TRN & & \\
\hline CHEMBL1321504 & 688810 & 5.733 & 5.1575 & TRN & & \\
\hline CHEMBL1406960 & 688810 & \multicolumn{3}{|c|}{6.082999999999999} & 5.4663 & TRN \\
\hline CHEMBL3190543 & 688810 & \multicolumn{3}{|c|}{5.2829999999999995} & 5.4707 & TRN \\
\hline CHEMBL1606513 & 688810 & \multicolumn{3}{|c|}{6.2829999999999995} & 5.745 & TRN \\
\hline CHEMBL1336056 & 688810 & \multicolumn{3}{|c|}{5.2829999999999995} & 4.824 & TST \\
\hline CHEMBL358692 & 688810 & 5.083 & 5.645 & TRN & & \\
\hline CHEMBL1335052 & 688810 & 5.933 & 6.0187 & TRN & & \\
\hline CHEMBL3192405 & 688810 & 5.983 & 5.6366 & TRN & & \\
\hline CHEMBL1353222 & 688810 & 6.233 & 5.2281 & TRN & & \\
\hline CHEMBL1318283 & 688810 & 4.783 & 5.2123 & TRN & & \\
\hline CHEMBL1572722 & 688810 & 5.733 & 5.3725 & TST & & \\
\hline CHEMBL1396284 & 688810 & \multicolumn{3}{|c|}{5.5329999999999995} & 6.3908 & TRN \\
\hline CHEMBL1387511 & 688810 & 4.883 & 5.2967 & TST & & \\
\hline CHEMBL1594800 & 688810 & 5.083 & \multicolumn{3}{|c|}{5.292000000000001} & TST \\
\hline CHEMBL1424095 & 688810 & \multicolumn{3}{|c|}{4.9830000000000005} & 5.1907 & TST \\
\hline CHEMBL1434392 & 688810 & 4.833 & 4.9509 & TRN & & \\
\hline CHEMBL1330039 & 688810 & 4.583 & 4.7688 & TST & & \\
\hline CHEMBL1428664 & 688810 & 6.0 & 5.2317 & TST & & \\
\hline CHEMBL1479486 & 688810 & 5.733 & 5.2298 & TRN & & \\
\hline CHEMBL1488730 & 688810 & 5.233 & 6.6427 & TST & & \\
\hline CHEMBL1581532 & 688810 & 4.933 & 5.3278 & TRN & & \\
\hline CHEMBL1532369 & 688810 & 4.883 & 4.4829 & TST & & \\
\hline CHEMBL1453321 & 688810 & 4.933 & 4.967 & TRN & & \\
\hline CHEMBL1411457 & 688810 & 5.183 & 5.0812 & TRN & & \\
\hline CHEMBL1510147 & 688810 & 4.883 & 5.0319 & TRN & & \\
\hline CHEMBL1305131 & 688810 & 5.683 & 4.8078 & TST & & \\
\hline CHEMBL1601620 & 688810 & \multicolumn{3}{|c|}{4.9830000000000005} & 5.2098 & TRN \\
\hline CHEMBL1596622 & 688810 & 5.683 & \multicolumn{3}{|c|}{5.882000000000001} & TRN \\
\hline CHEMBL1449841 & 688810 & 4.633 & 5.0822 & TRN & & \\
\hline CHEMBL1444768 & 688810 & \multicolumn{3}{|c|}{5.7829999999999995} & 5.3628 & TRN \\
\hline CHEMBL1340331 & 688810 & 5.733 & 5.4632 & TRN & & \\
\hline CHEMBL1523756 & 688810 & 5.433 & 5.5048 & TRN & & \\
\hline CHEMBL1340115 & 688810 & 4.783 & 4.9422 & TRN & & \\
\hline CHEMBL1308275 & 688810 & 4.783 & 5.2273 & TST & & \\
\hline CHEMBL1451548 & 688810 & \multicolumn{3}{|c|}{4.9830000000000005} & 5.2042 & TRN \\
\hline CHEMBL1443205 & 688810 & \multicolumn{3}{|c|}{5.382999999999999} & 5.6229 & TRN \\
\hline CHEMBL1604138 & 688810 & 4.833 & 4.9154 & TST & & \\
\hline CHEMBL1376169 & 688810 & 4.783 & 5.0972 & TRN & & \\
\hline CHEMBL1397041 & 688810 & 4.783 & 5.5575 & TST & & \\
\hline CHEMBL1350513 & 688810 & 5.733 & 5.1474 & TRN & & \\
\hline CHEMBL1440488 & 688810 & 5.183 & 5.2442 & TRN & & \\
\hline CHEMBL1518524 & 688810 & 5.733 & 5.1239 & TRN & & \\
\hline CHEMBL1496649 & 688810 & 5.733 & 5.1397 & TRN & & \\
\hline CHEMBL1468618 & 688810 & 5.683 & 5.2737 & TRN & & \\
\hline CHEMBL1976507 & 688810 & \multicolumn{3}{|c|}{5.132999999999999} & 6.6134 & TRN \\
\hline CHEMBL3193266 & 688810 & 4.883 & 5.5996 & TRN & & \\
\hline
\end{tabular}




\begin{tabular}{|c|c|c|c|c|c|c|c|}
\hline \multicolumn{8}{|c|}{ Supplemental Table S2.txt } \\
\hline CHEMBL1422577 & 688810 & 4.883 & 5.55 & TRN & & & \\
\hline CHEMBL1405036 & 688810 & 5.433 & 5.8228 & TRN & & & \\
\hline CHEMBL1389131 & 688810 & 4.833 & 5.0434 & TRN & & & \\
\hline CHEMBL1492286 & 688810 & 4.783 & 4.7406 & TST & & & \\
\hline CHEMBL1581941 & 688810 & \multicolumn{3}{|c|}{5.7829999999999995} & 5.4083 & TRN & \\
\hline CHEMBL1353144 & 688810 & \multicolumn{3}{|c|}{5.832999999999999} & 5.686 & TRN & \\
\hline CHEMBL1457855 & 688810 & \multicolumn{3}{|c|}{4.7330000000000005} & 4.8384 & TST & \\
\hline CHEMBL1399952 & 688810 & \multicolumn{3}{|c|}{6.332999999999999} & 5.5222 & TRN & \\
\hline CHEMBL1309015 & 688810 & \multicolumn{3}{|c|}{5.582999999999999} & 5.2884 & TRN & \\
\hline CHEMBL1426230 & 688810 & 4.833 & 5.1346 & TRN & & & \\
\hline CHEMBL 254530 & 688810 & \multicolumn{3}{|c|}{4.7330000000000005} & 4.9851 & TRN & \\
\hline CHEMBL 3189485 & 688810 & \multicolumn{3}{|c|}{5.7829999999999995} & 5.374 & TRN & \\
\hline CHEMBL1590906 & 688810 & 4.883 & 4.8066 & TRN & & & \\
\hline CHEMBL1550687 & 688810 & \multicolumn{3}{|c|}{4.7330000000000005} & 4.8425 & TRN & \\
\hline CHEMBL1312588 & 688810 & 4.833 & 5.0903 & TST & & & \\
\hline CHEMBL1599747 & 688810 & 4.933 & 5.0483 & TRN & & & \\
\hline CHEMBL1355104 & 688810 & 5.683 & 5.206 & TRN & & & \\
\hline CHEMBL1317615 & 688810 & 4.633 & 5.0444 & TRN & & & \\
\hline CHEMBL1390713 & 688810 & 6.433 & 6.1609 & TRN & & & \\
\hline CHEMBL1593000 & 688810 & 4.633 & 4.941 & TST & & & \\
\hline CHEMBL603728 & 688810 & \multicolumn{3}{|c|}{5.132999999999999} & 5.7949 & TRN & \\
\hline CHEMBL1554801 & 688810 & 4.883 & 4.8168 & TRN & & & \\
\hline CHEMBL1390467 & 688810 & 4.783 & 5.0557 & TST & & & \\
\hline CHEMBL1458038 & 688810 & 7.1331 & 6.0252 & TRN & & & \\
\hline CHEMBL1425460 & 688810 & \multicolumn{3}{|c|}{4.7330000000000005} & 5.3223 & TRN & \\
\hline CHEMBL3190403 & 688810 & 4.833 & 5.439 & TRN & & & \\
\hline CHEMBL579324 & 688810 & \multicolumn{3}{|c|}{5.332999999999999} & 5.1819 & TST & \\
\hline CHEMBL1496868 & 688810 & \multicolumn{3}{|c|}{4.7330000000000005} & 5.4716 & TRN & \\
\hline CHEMBL1453873 & 688810 & \multicolumn{3}{|c|}{4.7330000000000005} & 5.14 & TRN & \\
\hline CHEMBL1560004 & 688810 & \multicolumn{3}{|c|}{5.132999999999999} & 5.32 & TRN & \\
\hline CHEMBL1450115 & 688810 & \multicolumn{3}{|c|}{4.7330000000000005} & 5.0412 & TRN & \\
\hline CHEMBL1447831 & 688810 & 5.683 & 5.17 & TRN & & & \\
\hline CHEMBL1443659 & 688810 & \multicolumn{3}{|c|}{5.832999999999999} & 5.5874 & TRN & \\
\hline CHEMBL1382264 & 688810 & \multicolumn{3}{|c|}{5.2829999999999995} & 5.49200 & 0000000001 & TRN \\
\hline CHEMBL2004417 & 688810 & 4.583 & 5.5096 & TRN & & & \\
\hline CHEMBL1497198 & 688810 & \multicolumn{3}{|c|}{5.132999999999999} & 5.0888 & TRN & \\
\hline CHEMBL1416171 & 688810 & 4.883 & 4.8402 & TST & & & \\
\hline CHEMBL1335805 & 688810 & \multirow{2}{*}{\multicolumn{3}{|c|}{$\begin{array}{lcc}4.883 & 4.9341 & \text { TST } \\
4.7330000000000005\end{array}$}} & & & \\
\hline CHEMBL1450361 & 688810 & & & & 5.2116 & TRN & \\
\hline CHEMBL1525545 & 688810 & 5.183 & 5.5667 & TST & & & \\
\hline CHEMBL1368496 & 688810 & \multicolumn{3}{|c|}{5.2829999999999995} & 5.5736 & TRN & \\
\hline CHEMBL1596433 & 688810 & 4.583 & 5.0642 & TST & & & \\
\hline CHEMBL1490895 & 688810 & 4.783 & 5.31 & TRN & & & \\
\hline CHEMBL1435894 & 688810 & 5.933 & 5.4689 & 99995 & 99 & TRN & \\
\hline CHEMBL1311224 & 688810 & 5.5329 & 9999999 & 995 & 4.877 & TST & \\
\hline CHEMBL3211743 & 688810 & 5.733 & 5.3706 & TRN & & & \\
\hline CHEMBL1328836 & 688810 & 4.7330 & 0000000 & 005 & 5.3696 & TRN & \\
\hline CHEMBL1505070 & 688810 & 4.7330 & 0000000 & 005 & 5.3431 & TRN & \\
\hline
\end{tabular}




\begin{tabular}{|c|c|c|c|c|c|c|}
\hline \multirow[b]{2}{*}{ CHEMBL1326118 } & \multirow[b]{2}{*}{688810} & \multicolumn{5}{|c|}{ Supplemental Table s2.txt } \\
\hline & & 4.683 & 4.644 & TRN & & \\
\hline CHEMBL1382609 & 688810 & 5.433 & 5.4698 & TRN & & \\
\hline CHEMBL1529310 & 688810 & 4.783 & 6.6461 & TRN & & \\
\hline CHEMBL1338998 & 688810 & 5.683 & 5.9445 & TRN & & \\
\hline CHEMBL1409797 & 688810 & 4.783 & 5.1178 & TRN & & \\
\hline CHEMBL1489459 & 688810 & \multicolumn{3}{|c|}{4.7330000000000005} & 5.2831 & TRN \\
\hline CHEMBL1554886 & 688810 & 5.683 & 5.5479 & TRN & & \\
\hline CHEMBL 3214026 & 688810 & \multicolumn{3}{|c|}{4.7330000000000005} & 5.4704 & TST \\
\hline CHEMBL1587764 & 688810 & \multicolumn{3}{|c|}{4.7330000000000005} & 5.3055 & TST \\
\hline CHEMBL1463268 & 688810 & \multicolumn{3}{|c|}{5.632999999999999} & 5.7021 & TRN \\
\hline CHEMBL1538354 & 688810 & 4.883 & 5.1903 & TST & & \\
\hline CHEMBL1467152 & 688810 & 5.483 & 5.5826 & TST & & \\
\hline CHEMBL1307262 & 688810 & 5.483 & 5.3782 & TRN & & \\
\hline CHEMBL1586297 & 688810 & 5.083 & 5.0484 & TST & & \\
\hline CHEMBL1425649 & 688810 & \multicolumn{3}{|c|}{4.7330000000000005} & 5.4281 & TST \\
\hline CHEMBL1538710 & 688810 & 5.483 & 5.8528 & TRN & & \\
\hline CHEMBL1335183 & 688810 & 5.183 & 5.062 & TRN & & \\
\hline CHEMBL1365153 & 688810 & 4.933 & 4.8987 & TST & & \\
\hline CHEMBL1599168 & 688810 & \multicolumn{3}{|c|}{5.132999999999999} & 5.7093 & TRN \\
\hline CHEMBL1448963 & 688810 & 5.083 & 5.2295 & TST & & \\
\hline CHEMBL1592892 & 688810 & 5.733 & 5.3132 & TRN & & \\
\hline CHEMBL1569927 & 688810 & 4.683 & 5.3385 & TRN & & \\
\hline CHEMBL1530088 & 688810 & 5.733 & 5.8621 & TST & & \\
\hline CHEMBL1383996 & 688810 & \multicolumn{3}{|c|}{5.632999999999999} & 5.5202 & TST \\
\hline CHEMBL29213 & 688810 & 4.883 & 5.2562 & TRN & & \\
\hline CHEMBL1360115 & 688810 & 7.1831 & 5.6579 & TRN & & \\
\hline CHEMBL1453484 & 688810 & 5.483 & 5.5095 & TRN & & \\
\hline CHEMBL1303800 & 688810 & \multicolumn{3}{|c|}{4.7330000000000005} & 5.0121 & TRN \\
\hline CHEMBL1363322 & 688810 & \multicolumn{3}{|c|}{5.582999999999999} & 5.3991 & TRN \\
\hline CHEMBL1558170 & 688810 & 4.883 & 5.2367 & TRN & & \\
\hline CHEMBL1466389 & 688810 & 6.183 & 5.2271 & TRN & & \\
\hline CHEMBL1515582 & 688810 & \multicolumn{3}{|c|}{5.582999999999999} & 5.1859 & TRN \\
\hline CHEMBL1489396 & 688810 & 5.683 & 5.0107 & TRN & & \\
\hline CHEMBL1306686 & 688810 & 4.883 & 5.3205 & TRN & & \\
\hline CHEMBL31840 & 688810 & \multicolumn{3}{|c|}{5.5329999999999995} & 5.1717 & TST \\
\hline CHEMBL1499350 & 688810 & \multicolumn{3}{|c|}{5.2829999999999995} & 5.188 & TST \\
\hline CHEMBL1379011 & 688810 & 6.0 & 5.8375 & TRN & & \\
\hline CHEMBL1450813 & 688810 & \multicolumn{3}{|c|}{4.9830000000000005} & 4.9636 & TRN \\
\hline CHEMBL1490937 & 688810 & \multicolumn{3}{|c|}{4.7330000000000005} & 4.6244 & TRN \\
\hline CHEMBL3189565 & 688810 & \multicolumn{3}{|c|}{5.7829999999999995} & 5.4522 & TST \\
\hline CHEMBL1469108 & 688810 & \multicolumn{3}{|c|}{4.7330000000000005} & 5.3768 & TRN \\
\hline CHEMBL1531692 & 688810 & \multicolumn{3}{|c|}{5.2829999999999995} & 4.9508 & TRN \\
\hline CHEMBL1454245 & 688810 & \multicolumn{3}{|c|}{5.7829999999999995} & 6.1793 & TRN \\
\hline CHEMBL1431130 & 688810 & 5.733 & 5.28799 & 999999999 & & TRN \\
\hline CHEMBL1399938 & 688810 & 4.73300 & 00000000 & 005 & 4.9104 & TRN \\
\hline CHEMBL1542439 & 688810 & 5.13299 & 99999999 & & 5.609 & TRN \\
\hline CHEMBL1367932 & 688810 & 5.033 & 5.2593 & TST & & \\
\hline CHEMBL1380546 & 688810 & 4.833 & 5.0804 & TRN & & \\
\hline
\end{tabular}




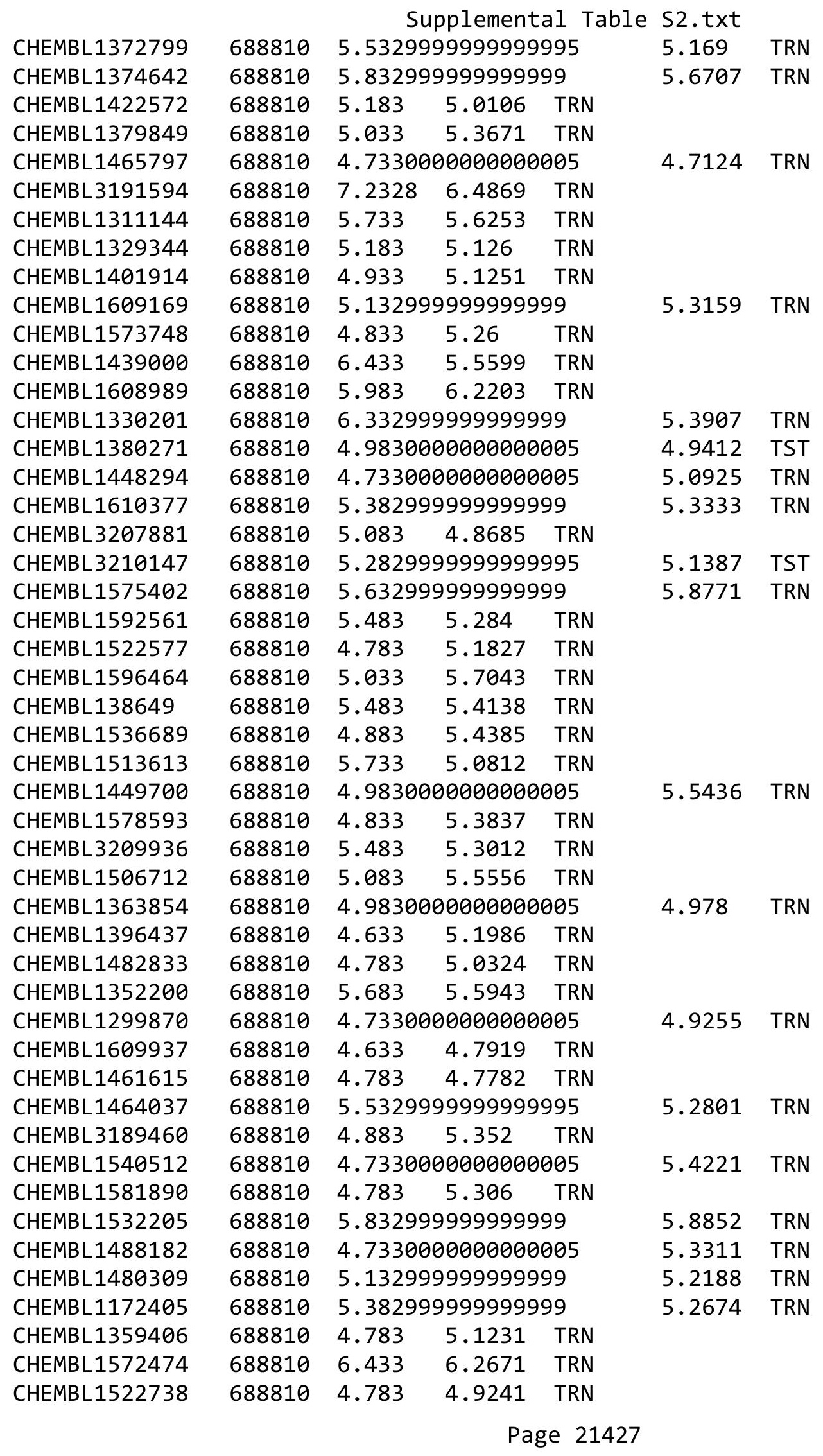




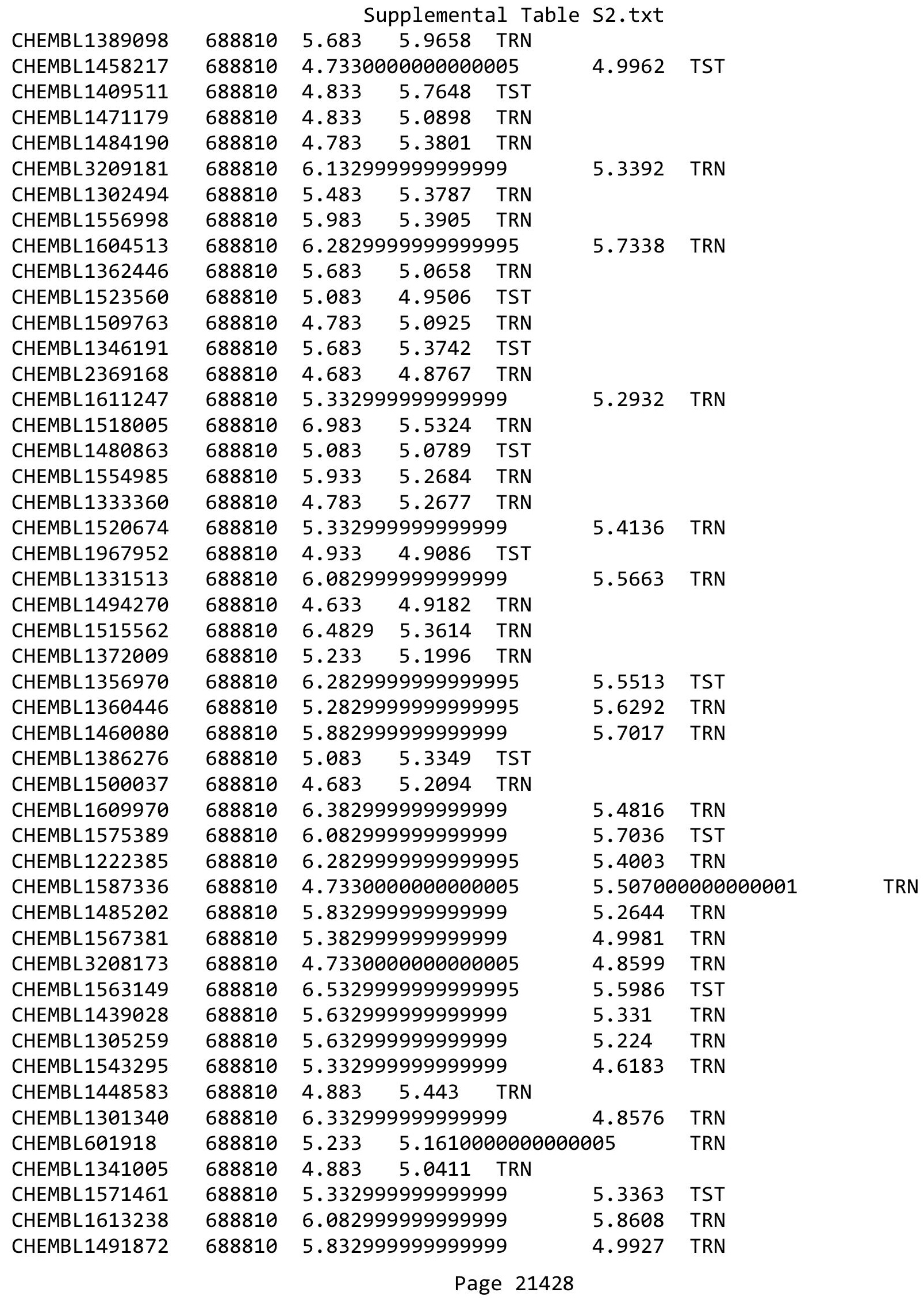




\begin{tabular}{|c|c|c|c|c|c|c|c|}
\hline \multicolumn{7}{|c|}{ Supplemental Table S2.txt } & \\
\hline CHEMBL1546292 & 688810 & \multicolumn{3}{|c|}{4.7330000000000005} & 5.0855 & TST & \\
\hline CHEMBL1430335 & 688810 & \multicolumn{3}{|c|}{5.5329999999999995} & 5.4581 & TRN & \\
\hline CHEMBL1325502 & 688810 & 5.083 & 4.9966 & TRN & & & \\
\hline CHEMBL1609865 & 688810 & 4.783 & 5.3611 & TRN & & & \\
\hline CHEMBL1530033 & 688810 & 4.833 & 5.0344 & TST & & & \\
\hline CHEMBL1432548 & 688810 & 4.633 & 5.0987 & TRN & & & \\
\hline CHEMBL1526806 & 688810 & \multicolumn{3}{|c|}{4.7330000000000005} & 5.1901 & TST & \\
\hline CHEMBL1325794 & 688810 & 4.833 & 5.5405 & TST & & & \\
\hline CHEMBL1436678 & 688810 & 4.633 & 4.7663 & TST & & & \\
\hline CHEMBL1315327 & 688810 & 5.083 & 5.0156 & TRN & & & \\
\hline CHEMBL1301718 & 688810 & 5.733 & 5.2681 & TRN & & & \\
\hline CHEMBL1340619 & 688810 & \multicolumn{3}{|c|}{4.7330000000000005} & 4.8093 & TRN & \\
\hline CHEMBL1379005 & 688810 & 5.083 & 5.0473 & TST & & & \\
\hline CHEMBL1345595 & 688810 & 4.783 & 4.81 & TRN & & & \\
\hline CHEMBL1528977 & 688810 & \multicolumn{3}{|c|}{4.7330000000000005} & 5.2898 & TST & \\
\hline CHEMBL 3209218 & 688810 & \multicolumn{3}{|c|}{5.382999999999999} & 5.1024 & TST & \\
\hline CHEMBL3211386 & 688810 & \multicolumn{3}{|c|}{4.7330000000000005} & 5.17399 & 99999999995 & TRN \\
\hline CHEMBL1546016 & 688810 & \multicolumn{3}{|c|}{5.2829999999999995} & 5.2319 & TRN & \\
\hline CHEMBL1573280 & 688810 & \multicolumn{3}{|c|}{4.9830000000000005} & 5.4775 & TST & \\
\hline CHEMBL1565691 & 688810 & \multicolumn{3}{|c|}{5.132999999999999} & 5.7023 & TRN & \\
\hline CHEMBL1328375 & 688810 & \multicolumn{3}{|c|}{5.5329999999999995} & 5.2012 & TRN & \\
\hline CHEMBL1414133 & 688810 & 4.883 & 4.7617 & TST & & & \\
\hline CHEMBL 1481348 & 688810 & 4.633 & 5.0622 & TST & & & \\
\hline CHEMBL1528475 & 688810 & 5.183 & 5.0558 & TRN & & & \\
\hline CHEMBL3198494 & 688810 & 4.833 & 5.3816 & TRN & & & \\
\hline CHEMBL1356554 & 688810 & 7.0329 & 5.6389 & TRN & & & \\
\hline CHEMBL1376470 & 688810 & 5.033 & 5.7996 & TST & & & \\
\hline CHEMBL1393107 & 688810 & \multicolumn{3}{|c|}{4.7330000000000005} & 4.967 & TST & \\
\hline CHEMBL1581682 & 688810 & 4.633 & 5.2908 & TRN & & & \\
\hline CHEMBL1399980 & 688810 & \multicolumn{3}{|c|}{6.582999999999999} & 5.5039 & TRN & \\
\hline CHEMBL1310884 & 688810 & 5.733 & 5.3575 & TRN & & & \\
\hline CHEMBL1468812 & 688810 & 4.783 & 4.9364 & TST & & & \\
\hline CHEMBL1599174 & 688810 & \multicolumn{3}{|c|}{5.2829999999999995} & 5.164 & TRN & \\
\hline CHEMBL1309762 & 688810 & \multicolumn{3}{|c|}{4.7330000000000005} & 5.4969 & TRN & \\
\hline CHEMBL1481816 & 688810 & \multicolumn{3}{|c|}{6.132999999999999} & 5.0768 & TRN & \\
\hline CHEMBL1304270 & 688810 & \multicolumn{3}{|c|}{4.7330000000000005} & 5.3295 & TRN & \\
\hline CHEMBL1349436 & 688810 & 5.933 & 5.5557 & TRN & & & \\
\hline CHEMBL1340434 & 688810 & 4.883 & 5.3109 & TST & & & \\
\hline CHEMBL1344245 & 688810 & 4.833 & 4.9776 & TRN & & & \\
\hline CHEMBL1461783 & 688810 & \multicolumn{3}{|c|}{5.832999999999999} & 5.1822 & TRN & \\
\hline CHEMBL1360588 & 688810 & 4.683 & 5.5474 & TST & & & \\
\hline CHEMBL1494160 & 688810 & 5.183 & 5.088 & TRN & & & \\
\hline CHEMBL1340589 & 688810 & 4.783 & 5.4554 & TRN & & & \\
\hline CHEMBL3189191 & 688810 & 4.783 & 4.7034 & TST & & & \\
\hline CHEMBL1400683 & 688810 & \multicolumn{3}{|c|}{5.5329999999999995} & 5.1176 & TRN & \\
\hline CHEMBL1529656 & 688810 & 6.8831 & 5.8814 & TRN & & & \\
\hline CHEMBL1356456 & 688810 & 5.433 & 5.3033 & TRN & & & \\
\hline CHEMBL586465 & 688810 & 5.733 & 5.3901 & TRN & & & \\
\hline
\end{tabular}




\begin{tabular}{|c|c|c|c|c|c|c|}
\hline & & \multicolumn{5}{|c|}{ Supplemental Table s2.txt } \\
\hline CHEMBL1449997 & 688810 & 4.933 & 5.1955 & TRN & & \\
\hline CHEMBL1486963 & 688810 & 5.233 & 5.2493 & TRN & & \\
\hline CHEMBL602174 & 688810 & 4.783 & 5.2345 & TST & & \\
\hline CHEMBL1526913 & 688810 & 4.933 & 5.0467 & TRN & & \\
\hline CHEMBL1543930 & 688810 & 4.783 & 5.4157 & TRN & & \\
\hline CHEMBL1442256 & 688810 & \multicolumn{3}{|c|}{5.832999999999999} & 5.2197 & TST \\
\hline CHEMBL3189899 & 688810 & 5.083 & 5.2356 & TRN & & \\
\hline CHEMBL1416783 & 688810 & 4.933 & 5.4042 & TRN & & \\
\hline CHEMBL1331093 & 688810 & 5.683 & 5.5174 & TRN & & \\
\hline CHEMBL1385520 & 688810 & \multicolumn{3}{|c|}{4.7330000000000005} & 5.7282 & TRN \\
\hline CHEMBL584015 & 688810 & 4.883 & 4.796 & TST & & \\
\hline CHEMBL1439178 & 688810 & 4.883 & 5.5687 & TRN & & \\
\hline CHEMBL1599388 & 688810 & 4.883 & 5.0779 & TST & & \\
\hline CHEMBL1571319 & 688810 & 5.933 & 5.4509 & TRN & & \\
\hline CHEMBL3198241 & 688810 & \multicolumn{3}{|c|}{4.9830000000000005} & 5.0894 & TRN \\
\hline CHEMBL1469510 & 688810 & \multicolumn{3}{|c|}{5.132999999999999} & 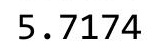 & TRN \\
\hline CHEMBL1418643 & 688810 & 4.833 & 5.2895 & TRN & & \\
\hline CHEMBL137 & 688810 & 6.4829 & 6.062 & TRN & & \\
\hline CHEMBL160 & 688810 & \multicolumn{3}{|c|}{4.7330000000000005} & 4.899 & TS \\
\hline CHEMBL1299906 & 688810 & 5.483 & 5.7563 & TRN & & \\
\hline CHEMBL1363396 & 688810 & \multicolumn{3}{|c|}{5.5329999999999995} & 51 & TST \\
\hline CHEMBL1426980 & 688810 & \multicolumn{3}{|c|}{4.7330000000000005} & 5.2079 & TST \\
\hline CHEMBL1593357 & 688810 & \multicolumn{3}{|c|}{5.7829999999999995} & 5.1005 & \\
\hline CHEMBL1311605 & 688810 & 6.15 & 5.19 & TRN & & \\
\hline CHEMBL1602231 & 688810 & 6.233 & \multicolumn{3}{|c|}{5.8420000000000005} & TRN \\
\hline CHEMBL1386650 & 688810 & \multicolumn{3}{|c|}{5.382999999999999} & 5.2 & TST \\
\hline CHEMBL1403536 & 688810 & 4.583 & 4.8239 & TRN & & \\
\hline CHEMBL1483293 & 688810 & 4.783 & 5.812 & TRN & & \\
\hline CHEMBL1335650 & 688810 & 4.583 & 5.1033 & TST & & \\
\hline CHEMBL1430987 & 688810 & 4.933 & 5.1556 & TST & & \\
\hline CHEMBL3207622 & 688810 & \multicolumn{3}{|c|}{5.132999999999999} & 5.6664 & \\
\hline CHEMBL15 & 688810 & 4.933 & 5.3779 & TRN & & \\
\hline CHEMBL1582771 & 688810 & \multicolumn{3}{|c|}{4.7330000000000005} & 5.4955 & TST \\
\hline CHEMBL1326488 & 688810 & \multicolumn{3}{|c|}{4.9830000000000005} & 5.3356 & TST \\
\hline CHEMBL1533996 & 688810 & 6.233 & 5.0255 & TRN & & \\
\hline CHEMBL1336309 & 688810 & \multicolumn{3}{|c|}{5.132999999999999} & 4.9444 & TF \\
\hline CHEMBL15 & 688810 & 4.683 & 4.8658 & TST & & \\
\hline CHEMBL1404780 & 688810 & \multicolumn{3}{|c|}{5.2829999999999995} & 5.4361 & TR \\
\hline CHEMBL1429007 & 688810 & 5.733 & 5.6067 & TRN & & \\
\hline CHEMBL1556732 & 688810 & 5.433 & 5.5138 & TRN & & \\
\hline CHEMBL460517 & 688810 & 5.983 & 6.0956 & TRN & & \\
\hline CHEMBL1414551 & 688810 & 4.883 & 5.0715 & TRN & & \\
\hline CHEMBL1566066 & 688810 & 4.783 & 5.0924 & TRN & & \\
\hline CHEMBL1485910 & 688810 & \multicolumn{3}{|c|}{5.832999999999999} & 5.5871 & נוז \\
\hline CHEMBL1488909 & 688810 & 5.233 & 5.0725 & TRN & & \\
\hline CHEMBL1518716 & 688810 & \multicolumn{3}{|c|}{5.7829999999999995} & 5.1988 & כו \\
\hline CHEMBL1447700 & 688810 & 4.833 & 5.0762 & TST & & \\
\hline CHEMBL1606991 & 688810 & \multicolumn{3}{|c|}{4.9830000000000005} & 5.4762 & J \\
\hline
\end{tabular}




\begin{tabular}{|c|c|c|c|c|c|c|}
\hline & & \multicolumn{5}{|c|}{ Supplemental Table s2.txt } \\
\hline CHEMBL1503880 & 688810 & 6.9329 & 5.5634 & TRN & & \\
\hline CHEMBL 1425040 & 688810 & 5.233 & 5.1475 & TRN & & \\
\hline CHEMBL1477100 & 688810 & \multicolumn{3}{|c|}{6.5329999999999995} & 5.9216 & 10 \\
\hline CHEMBL1591007 & 688810 & 5.183 & 4.9439 & TRN & & \\
\hline CHEMBL1448598 & 688810 & 4.883 & 5.0416 & TST & & \\
\hline CHEMBL1439663 & 688810 & \multicolumn{3}{|c|}{5.2829999999999995} & 5.4198 & \\
\hline CHEMBL1518712 & 688810 & 4.933 & 5.1211 & TRN & & \\
\hline CHEMBL1545397 & 688810 & 4.783 & 5.3491 & TST & & \\
\hline CHEMBL1346046 & 688810 & 5.483 & 5.3985 & TRN & & \\
\hline CHEMBL1518000 & 688810 & 4.833 & 5.3023 & TST & & \\
\hline CHEMBL252925 & 688810 & \multicolumn{3}{|c|}{4.7330000000000005} & 5.0525 & \\
\hline CHEMBL 3199835 & 688810 & 4.783 & 5.3347 & TRN & & \\
\hline CHEMBL1328241 & 688810 & 4.783 & 5.3608 & TST & & \\
\hline CHEMBL1593398 & 688810 & 4.833 & 5.1513 & TST & & \\
\hline CHEMBL1185172 & 688810 & \multicolumn{3}{|c|}{4.9830000000000005} & 4.6668 & \\
\hline CHEMBL1363600 & 688810 & 4.783 & 5.1768 & TRN & & \\
\hline CHEMBL1580740 & 688810 & \multicolumn{3}{|c|}{4.7330000000000005} & 5.1865 & \\
\hline CHEMBL1322476 & 688810 & \multicolumn{3}{|c|}{5.132999999999999} & 4.9604 & \\
\hline CHEMBL1558532 & 688810 & 4.683 & 5.6728 & TST & & \\
\hline CHEMBL1319454 & 688810 & \multicolumn{3}{|c|}{6.132999999999999} & 5.7569 & \\
\hline CHEMBL1303599 & 688810 & 5.033 & 5.3198 & TST & & \\
\hline CHEMBL1396641 & 688810 & 6.7331 & 5.5404 & TRN & & \\
\hline CHEMBL1333029 & 688810 & 4.583 & 4.8826 & TST & & \\
\hline CHEMBL1544122 & 688810 & \multicolumn{3}{|c|}{6.332999999999999} & 5.3825 & \\
\hline CHEMBL1479637 & 688810 & 4.683 & 4.9484 & TRN & & \\
\hline CHEMBL1487958 & 688810 & \multicolumn{3}{|c|}{6.132999999999999} & 5.2006 & \\
\hline CHEMBL1518800 & 688810 & \multicolumn{3}{|c|}{5.832999999999999} & 5.2302 & \\
\hline CHEMBL1465893 & 688810 & 4.783 & 5.1155 & TRN & & \\
\hline CHEMBL1436067 & 688810 & 4.783 & 5.0261 & TRN & & \\
\hline CHEMBL1420357 & 688810 & 5.083 & 5.4378 & TRN & & \\
\hline CHEMBL1459472 & 688810 & 5.183 & 5.7203 & TRN & & \\
\hline CHEMBL1390654 & 688810 & 4.633 & 4.9173 & TST & & \\
\hline CHEMBL1363871 & 688810 & \multicolumn{3}{|c|}{5.832999999999999} & 5.443 & \\
\hline CHEMBL1442692 & 688810 & 4.783 & 4.9586 & TRN & & \\
\hline CHEMBL1366334 & 688810 & \multicolumn{3}{|c|}{5.132999999999999} & 5.1382 & $T$ \\
\hline CHEMBL1496470 & 688810 & 4.883 & 4.9094 & TRN & & \\
\hline CHEMBL1557496 & 688810 & 4.883 & 4.9117 & TRN & & \\
\hline CHEMBL1605575 & 688810 & \multicolumn{3}{|c|}{6.082999999999999} & 5.8113 & 10 \\
\hline CHEMBL1490145 & 688810 & 4.833 & 4.8496 & TRN & & \\
\hline CHEMBL1529895 & 688810 & 5.033 & 5.4904 & TRN & & \\
\hline CHEMBL1437755 & 688810 & 5.233 & 5.9894 & TRN & & \\
\hline CHEMBL1419759 & 688810 & 4.933 & 5.3099 & TRN & & \\
\hline CHEMBL1539789 & 688810 & \multicolumn{3}{|c|}{6.2829999999999995} & 5.9908 & \\
\hline CHEMBL 2369190 & 688810 & 5.483 & 5.1888 & TST & & \\
\hline CHEMBL1478139 & 688810 & 4.783 & 5.4801 & TRN & & \\
\hline CHEMBL1519655 & 688810 & 4.633 & 4.9185 & TST & & \\
\hline CHEMBL1561370 & 688810 & 5.433 & 5.3531 & TST & & \\
\hline CHEMBL1343143 & 688810 & \multicolumn{3}{|c|}{5.582999999999999} & .0662 & \\
\hline
\end{tabular}




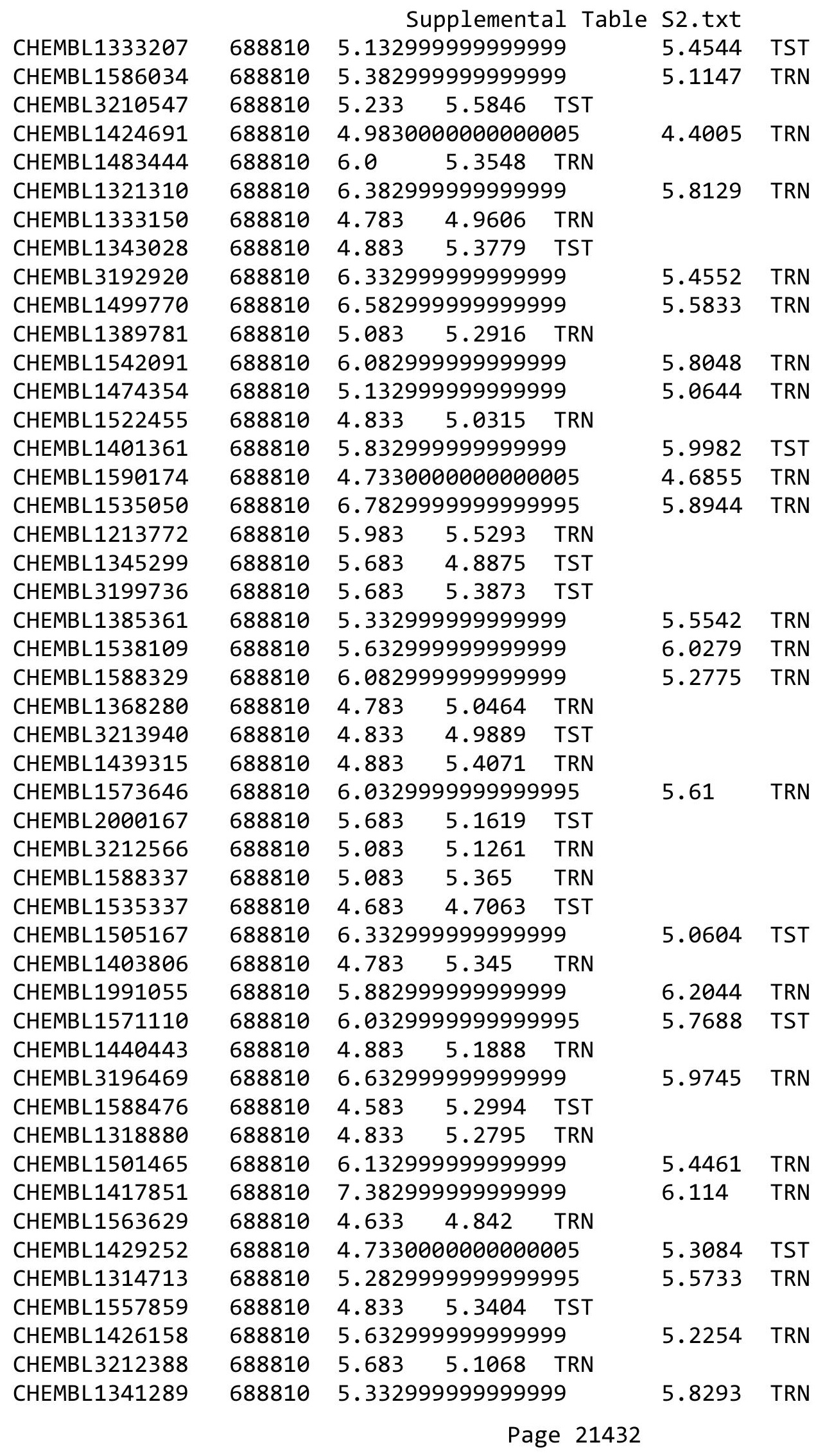




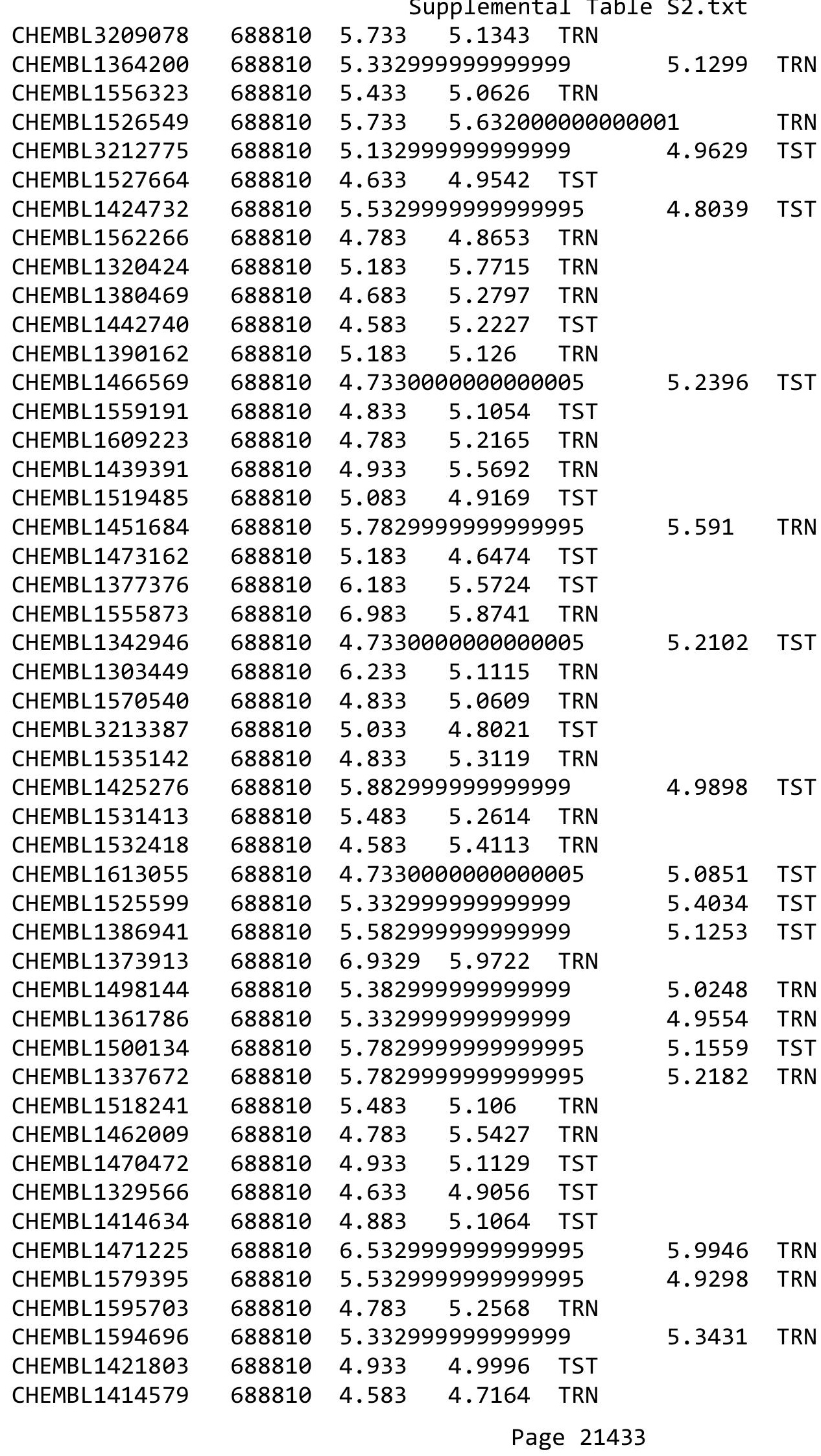




\begin{tabular}{|c|c|c|c|c|c|c|}
\hline \multirow[b]{2}{*}{ CHEMBL1436988 } & \multirow[b]{2}{*}{688810} & \multicolumn{5}{|c|}{ Supplemental Table s2.txt } \\
\hline & & 4.783 & 4.8559 & TRN & & \\
\hline CHEMBL1529779 & 688810 & \multicolumn{3}{|c|}{5.632999999999999} & 5.0662 & TRN \\
\hline CHEMBL1478303 & 688810 & 4.633 & 4.7099 & TST & & \\
\hline CHEMBL1540089 & 688810 & \multicolumn{3}{|c|}{6.582999999999999} & 5.8134 & TST \\
\hline CHEMBL1321101 & 688810 & \multicolumn{3}{|c|}{5.7829999999999995} & 5.5597 & TRN \\
\hline CHEMBL1613331 & 688810 & 4.783 & 5.7094 & TRN & & \\
\hline CHEMBL1363834 & 688810 & 5.933 & 5.2831 & TRN & & \\
\hline CHEMBL1570979 & 688810 & \multicolumn{3}{|c|}{4.7330000000000005} & 5.6034 & TRN \\
\hline CHEMBL1377903 & 688810 & 4.583 & 5.3007 & TST & & \\
\hline CHEMBL1326357 & 688810 & \multicolumn{3}{|c|}{6.0329999999999995} & 5.4586 & TRN \\
\hline CHEMBL1353240 & 688810 & 4.783 & 5.2873 & TST & & \\
\hline CHEMBL1354238 & 688810 & 4.933 & 5.0462 & TRN & & \\
\hline CHEMBL1388375 & 688810 & 4.883 & 4.95 & TRN & & \\
\hline CHEMBL1450244 & 688810 & \multicolumn{3}{|c|}{4.7330000000000005} & 5.2119 & TRN \\
\hline CHEMBL1428107 & 688810 & \multicolumn{3}{|c|}{5.332999999999999} & 5.2788 & TRN \\
\hline CHEMBL1386027 & 688810 & 4.683 & 4.8377 & TRN & & \\
\hline CHEMBL1533600 & 688810 & 4.783 & 5.1062 & TST & & \\
\hline CHEMBL1607872 & 688810 & 4.883 & 4.6988 & TST & & \\
\hline CHEMBL1423202 & 688810 & 5.733 & 5.9184 & TRN & & \\
\hline CHEMBL1468660 & 688810 & 4.883 & 5.3086 & TRN & & \\
\hline CHEMBL3193174 & 688810 & 4.833 & 5.4136 & TRN & & \\
\hline CHEMBL1431684 & 688810 & 4.583 & 4.9632 & TRN & & \\
\hline CHEMBL1453947 & 688810 & \multicolumn{3}{|c|}{5.882999999999999} & 5.1689 & TRN \\
\hline CHEMBL1970896 & 688810 & 4.883 & 5.4664 & TST & & \\
\hline CHEMBL1357391 & 688810 & 4.633 & 4.9967 & TRN & & \\
\hline CHEMBL1313072 & 688810 & 6.233 & 5.3836 & TRN & & \\
\hline CHEMBL1496608 & 688810 & 4.633 & 5.4594 & TRN & & \\
\hline CHEMBL1536850 & 688810 & 4.883 & 4.8986 & TST & & \\
\hline CHEMBL1417354 & 688810 & 6.4829 & 6.0137 & TRN & & \\
\hline CHEMBL77285 & 688810 & 4.633 & 5.0408 & TRN & & \\
\hline CHEMBL1527565 & 688810 & 4.633 & 5.1071 & TST & & \\
\hline CHEMBL1358368 & 688810 & 4.783 & 4.9462 & TRN & & \\
\hline CHEMBL1525698 & 688810 & 4.783 & 5.0433 & TRN & & \\
\hline CHEMBL1564136 & 688810 & \multicolumn{3}{|c|}{5.332999999999999} & 5.7462 & TST \\
\hline CHEMBL1496233 & 688810 & 4.633 & 5.1138 & TRN & & \\
\hline CHEMBL1456981 & 688810 & 5.683 & 4.922 & TRN & & \\
\hline CHEMBL3189699 & 688810 & \multicolumn{3}{|c|}{4.9830000000000005} & 5.32 & TST \\
\hline CHEMBL1484854 & 688810 & \multicolumn{3}{|c|}{5.832999999999999} & 5.4082 & TRN \\
\hline CHEMBL1566026 & 688810 & \multicolumn{3}{|c|}{6.332999999999999} & 5.7237 & TST \\
\hline CHEMBL1366626 & 688810 & \multicolumn{3}{|c|}{4.9830000000000005} & 5.2873 & TST \\
\hline CHEMBL1381834 & 688810 & 5.483 & 5.1561 & TRN & & \\
\hline CHEMBL1515201 & 688810 & 5.983 & 5.5128 & TRN & & \\
\hline CHEMBL1596015 & 688810 & 4.783 & 5.0045 & TRN & & \\
\hline CHEMBL1455957 & 688810 & 4.583 & 4.9617 & TST & & \\
\hline CHEMBL1586234 & 688810 & 5.733 & 5.694 & TRN & & \\
\hline CHEMBL1477793 & 688810 & 5.183 & 5.0153 & TRN & & \\
\hline CHEMBL3189976 & 688810 & 4.833 & 5.1865 & TRN & & \\
\hline CHEMBL1319090 & 688810 & 4.783 & 5.0201 & TRN & & \\
\hline
\end{tabular}




\begin{tabular}{|c|c|c|c|c|c|c|c|}
\hline \multicolumn{8}{|c|}{ Supplemental Table S2.txt } \\
\hline CHEMBL1399122 & 688810 & 4.883 & 5.2584 & TRN & & & \\
\hline CHEMBL1366301 & 688810 & 4.783 & 5.9337 & TRN & & & \\
\hline CHEMBL171699 & 688810 & \multicolumn{3}{|c|}{6.382999999999999} & 5.8182 & TRN & \\
\hline CHEMBL1330204 & 688810 & \multicolumn{3}{|c|}{5.5329999999999995} & 5.7135 & TRN & \\
\hline CHEMBL1584829 & 688810 & \multicolumn{3}{|c|}{5.5329999999999995} & 5.2306 & TRN & \\
\hline CHEMBL3190044 & 688810 & 4.583 & 5.0443 & TST & & & \\
\hline CHEMBL1509197 & 688810 & \multicolumn{3}{|c|}{4.7330000000000005} & 5.2892 & TRN & \\
\hline CHEMBL1515602 & 688810 & 5.733 & 5.0955 & TRN & & & \\
\hline CHEMBL1583446 & 688810 & 4.833 & 5.0963 & TST & & & \\
\hline CHEMBL1525466 & 688810 & \multicolumn{3}{|c|}{4.7330000000000005} & \multirow{2}{*}{\multicolumn{2}{|c|}{5.1080000000000005}} & TST \\
\hline CHEMBL1483199 & 688810 & 4.783 & 5.4569 & TST & & & \\
\hline CHEMBL1370936 & 688810 & \multicolumn{3}{|c|}{4.7330000000000005} & 5.6552 & TRN & \\
\hline CHEMBL1608991 & 688810 & \multicolumn{3}{|c|}{5.332999999999999} & 5.2728 & TRN & \\
\hline CHEMBL1449168 & 688810 & 5.233 & 5.5188 & TRN & & & \\
\hline CHEMBL 3211514 & 688810 & \multicolumn{3}{|c|}{4.9830000000000005} & 4.8193 & TST & \\
\hline CHEMBL1545504 & 688810 & 4.783 & 5.0127 & TRN & & & \\
\hline CHEMBL1497442 & 688810 & 4.833 & 5.2473 & TRN & & & \\
\hline CHEMBL1472478 & 688810 & 5.183 & 5.1974 & TRN & & & \\
\hline CHEMBL1491017 & 688810 & 4.783 & 4.8738 & TRN & & & \\
\hline CHEMBL1314740 & 688810 & 4.883 & 4.7524 & TRN & & & \\
\hline CHEMBL1485481 & 688810 & 4.783 & 5.1216 & TRN & & & \\
\hline CHEMBL1459360 & 688810 & 4.883 & 5.0283 & TST & & & \\
\hline CHEMBL1464431 & 688810 & 4.833 & 5.1121 & TRN & & & \\
\hline CHEMBL1550486 & 688810 & \multicolumn{3}{|c|}{6.582999999999999} & 6.0198 & TRN & \\
\hline CHEMBL3193571 & 688810 & 4.783 & \multicolumn{3}{|c|}{5.321000000000001} & TRN & \\
\hline CHEMBL1358453 & 688810 & 4.633 & 5.0848 & TRN & & & \\
\hline CHEMBL1987655 & 688810 & \multicolumn{3}{|c|}{6.582999999999999} & 5.6482 & TRN & \\
\hline CHEMBL1323212 & 688810 & 4.833 & 5.3602 & TRN & & & \\
\hline CHEMBL1326785 & 688810 & 6.433 & 6.0375 & TRN & & & \\
\hline CHEMBL1460324 & 688810 & 4.633 & 4.8066 & TST & & & \\
\hline CHEMBL1603289 & 688810 & 4.833 & 5.4007 & TRN & & & \\
\hline CHEMBL1303429 & 688810 & 5.933 & 5.6763 & TST & & & \\
\hline CHEMBL1494362 & 688810 & 4.883 & 5.6537 & TRN & & & \\
\hline CHEMBL1361236 & 688810 & 5.733 & 5.7408 & TRN & & & \\
\hline CHEMBL1485736 & 688810 & \multicolumn{3}{|c|}{5.132999999999999} & 5.0869 & TRN & \\
\hline CHEMBL1348197 & 688810 & 5.733 & 5.99100 & 000000000 & 005 & TST & \\
\hline CHEMBL1344731 & 688810 & \multicolumn{3}{|c|}{5.632999999999999} & 5.4748 & TST & \\
\hline CHEMBL1299494 & 688810 & 4.833 & 5.1533 & TST & & & \\
\hline CHEMBL1528917 & 688810 & 4.933 & 5.263 & TST & & & \\
\hline CHEMBL1610169 & 688810 & \multicolumn{3}{|c|}{5.7829999999999995} & 5.3406 & TRN & \\
\hline CHEMBL1339952 & 688810 & \multicolumn{3}{|c|}{4.9830000000000005} & 5.3958 & TRN & \\
\hline CHEMBL1497129 & 688810 & \multicolumn{3}{|c|}{4.7330000000000005} & 5.2294 & TRN & \\
\hline CHEMBL1389904 & 688810 & 5.083 & 5.2352 & TRN & & & \\
\hline CHEMBL1455485 & 688810 & 4.833 & 6.0012 & TST & & & \\
\hline CHEMBL1535321 & 688810 & 4.633 & 4.7849 & TRN & & & \\
\hline CHEMBL1554178 & 688810 & \multicolumn{3}{|c|}{5.382999999999999} & 4.8591 & TST & \\
\hline CHEMBL1389157 & 688810 & \multicolumn{3}{|c|}{4.7330000000000005} & 5.2417 & TRN & \\
\hline CHEMBL3191521 & 688810 & 5.083 & 5.125 & TRN & & & \\
\hline
\end{tabular}




\begin{tabular}{|c|c|c|c|c|c|c|c|}
\hline \multicolumn{8}{|c|}{ 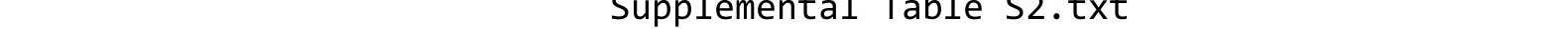 } \\
\hline CHEMBL1612277 & 688810 & 5.733 & 5.4556 & TRN & & & \\
\hline CHEMBL1490743 & 688810 & 5.083 & 5.0204 & TRN & & & \\
\hline CHEMBL1506203 & 688810 & 5.88299 & 999999999 & & 5.245 & TST & \\
\hline CHEMBL3213140 & 688810 & 4.883 & 5.43 & TST & & & \\
\hline CHEMBL1427103 & 688810 & 5.83299 & 999999995 & & 5.8211 & TRN & \\
\hline CHEMBL1443174 & 688810 & 6.13299 & 999999999 & & 6.0246 & TRN & \\
\hline CHEMBL1421995 & 688810 & 4.783 & 5.7476 & TST & & & \\
\hline CHEMBL1371765 & 688810 & 4.73300 & 000000006 & 005 & 5.3565 & TRN & \\
\hline CHEMBL1326979 & 688810 & 6.38299 & 999999995 & & 5.4513 & TRN & \\
\hline CHEMBL1352280 & 688810 & 4.933 & 5.1219 & TRN & & & \\
\hline CHEMBL1492611 & 688810 & 5.78299 & 999999999 & 995 & 5.4555 & TRN & \\
\hline CHEMBL473074 & 688810 & 4.833 & 5.011 & TST & & & \\
\hline CHEMBL1401761 & 688810 & 4.98300 & 000000006 & 005 & 5.126 & TRN & \\
\hline CHEMBL1522280 & 688810 & 5.78299 & 999999995 & 995 & 5.5148 & TRN & \\
\hline CHEMBL1339358 & 688810 & 4.833 & 5.5411 & TRN & & & \\
\hline CHEMBL1325640 & 688810 & 4.783 & 5.1259 & TST & & & \\
\hline CHEMBL1452465 & 688810 & 5.78299 & 999999999 & 995 & 5.7408 & TRN & \\
\hline CHEMBL1466455 & 688810 & 4.73300 & 000000006 & 005 & 4.9866 & TRN & \\
\hline CHEMBL1487668 & 688810 & 5.38299 & 999999995 & & 5.1643 & TRN & \\
\hline CHEMBL1495809 & 688810 & 4.933 & 5.0667 & TRN & & & \\
\hline CHEMBL1506417 & 688810 & 4.783 & 5.4241 & TRN & & & \\
\hline CHEMBL3196807 & 688810 & 4.933 & 5.0796 & TRN & & & \\
\hline CHEMBL1340336 & 688810 & 4.73300 & 000000006 & 005 & 5.1328 & TRN & \\
\hline CHEMBL1342493 & 688810 & 5.33299 & 999999995 & & 5.2744 & TRN & \\
\hline CHEMBL1577298 & 688810 & 4.783 & 5.2263 & TRN & & & \\
\hline CHEMBL1425389 & 688810 & 4.883 & 4.9853 & TRN & & & \\
\hline CHEMBL1490643 & 688810 & 4.833 & 5.3685 & TRN & & & \\
\hline CHEMBL3199762 & 688810 & 4.73300 & 000000006 & 005 & 5.0067 & TST & \\
\hline CHEMBL1492864 & 688810 & 4.833 & 4.8793 & TRN & & & \\
\hline CHEMBL1612693 & 688810 & 5.083 & 5.0255 & TRN & & & \\
\hline CHEMBL1303560 & 688810 & 4.783 & 5.1393 & TRN & & & \\
\hline CHEMBL1602303 & 688810 & 4.883 & 5.0845 & TRN & & & \\
\hline CHEMBL1582071 & 688810 & 4.833 & 5.2923 & TRN & & & \\
\hline CHEMBL1311185 & 688810 & 5.433 & 5.4341 & TST & & & \\
\hline CHEMBL1338330 & 688810 & 4.833 & 5.0265 & TST & & & \\
\hline CHEMBL1356773 & 688810 & 4.883 & 4.9352 & TST & & & \\
\hline CHEMBL1352339 & 688810 & 5.83299 & 999999999 & & 5.4629 & 9999999999 & TST \\
\hline CHEMBL1555812 & 688810 & 4.783 & 4.9507 & TRN & & & \\
\hline CHEMBL1300928 & 688810 & 5.33299 & 999999995 & & 5.4802 & TRN & \\
\hline CHEMBL1311511 & 688810 & 4.833 & 5.3624 & TRN & & & \\
\hline CHEMBL1366436 & 688810 & 5.083 & 5.2724 & TRN & & & \\
\hline CHEMBL1535660 & 688810 & 4.583 & 4.7334 & TRN & & & \\
\hline CHEMBL3212478 & 688810 & 5.733 & 5.5795 & TRN & & & \\
\hline CHEMBL1541644 & 688810 & 4.73300 & 00000000 & 005 & 4.8472 & TST & \\
\hline CHEMBL1565801 & 688810 & 5.683 & 5.4201 & TRN & & & \\
\hline CHEMBL 225903 & 688810 & 5.233 & 6.3303 & TRN & & & \\
\hline CHEMBL1503017 & 688810 & 4.783 & 5.2733 & TST & & & \\
\hline CHEMBL1450032 & 688810 & 4.683 & 5.7989 & TRN & & & \\
\hline
\end{tabular}




\begin{tabular}{|c|c|c|c|c|c|c|}
\hline \multicolumn{7}{|c|}{ Supplemental Table S2.txt } \\
\hline CHEMBL1500876 & 688810 & 4.633 & 5.7883 & TRN & & \\
\hline CHEMBL1592696 & 688810 & 5.233 & 5.2725 & TST & & \\
\hline CHEMBL1314454 & 688810 & 5.233 & 5.9333 & TRN & & \\
\hline CHEMBL1509958 & 688810 & 5.683 & 5.8307 & TRN & & \\
\hline CHEMBL1361403 & 688810 & 4.633 & 4.2333 & TRN & & \\
\hline CHEMBL1509779 & 688810 & 4.783 & 5.1623 & TRN & & \\
\hline CHEMBL1378967 & 688810 & \multicolumn{3}{|c|}{5.832999999999999} & 5.5307 & TRN \\
\hline CHEMBL1471415 & 688810 & \multicolumn{3}{|c|}{6.082999999999999} & 5.4527 & \\
\hline CHEMBL3199117 & 688810 & 4.833 & 5.1647 & TST & & \\
\hline CHEMBL1517954 & 688810 & 4.883 & 4.9845 & TRN & & \\
\hline CHEMBL1342028 & 688810 & \multicolumn{3}{|c|}{4.7330000000000005} & 5.7624 & TRN \\
\hline CHEMBL1536674 & 688810 & \multicolumn{3}{|c|}{5.5329999999999995} & 5.3417 & \\
\hline CHEMBL1488253 & 688810 & 5.983 & 5.4268 & TRN & & \\
\hline CHEMBL1509479 & 688810 & 4.833 & 4.9858 & TRN & & \\
\hline CHEMBL1312173 & 688810 & 5.183 & 5.3684 & TRN & & \\
\hline CHEMBL581257 & 688810 & 5.183 & 5.1319 & TST & & \\
\hline CHEMBL1451358 & 688810 & \multicolumn{3}{|c|}{5.382999999999999} & 5.1618 & \\
\hline CHEMBL1328142 & 688810 & 4.883 & 5.2735 & TRN & & \\
\hline CHEMBL1594960 & 688810 & 5.433 & 5.1068 & TRN & & \\
\hline CHEMBL1431829 & 688810 & 6.433 & 4.8853 & TST & & \\
\hline CHEMBL1300331 & 688810 & 4.833 & 5.3946 & TST & & \\
\hline CHEMBL1601427 & 688810 & 5.033 & 5.1689 & TST & & \\
\hline CHEMBL1611982 & 688810 & \multicolumn{3}{|c|}{5.2829999999999995} & 5.4492 & \\
\hline CHEMBL1586147 & 688810 & 6.4829 & 5.8513 & TRN & & \\
\hline CHEMBL1524630 & 688810 & \multicolumn{3}{|c|}{5.5329999999999995} & 5.2702 & TRN \\
\hline CHEMBL1386956 & 688810 & \multicolumn{3}{|c|}{5.5329999999999995} & & TRN \\
\hline CHEMBL1337632 & 688810 & 6.433 & 5.5934 & TRN & & \\
\hline CHEMBL1568835 & 688810 & 6.4829 & 5.8046 & TRN & & \\
\hline CHEMBL1382731 & 688810 & 4.583 & 5.2572 & TRN & & \\
\hline CHEMBL1451336 & 688810 & 4.883 & 4.7992 & TST & & \\
\hline CHEMBL1309252 & 688810 & 4.633 & 4.6828 & TRN & & \\
\hline CHEMBL1548988 & 688810 & 4.783 & 5.6716 & TRN & & \\
\hline CHEMBL1593295 & 688810 & \multicolumn{3}{|c|}{4.9830000000000005} & 5.2113 & $\mathrm{TH}$ \\
\hline CHEMBL1520210 & 688810 & 5.233 & 5.0319 & TST & & \\
\hline CHEMBL1493302 & 688810 & \multicolumn{3}{|c|}{5.5329999999999995} & 5.2997 & TRN \\
\hline CHEMBL1583188 & 688810 & \multicolumn{3}{|c|}{4.9830000000000005} & 5.0014 & TS \\
\hline CHEMBL1582419 & 688810 & 4.583 & 5.073 & TST & & \\
\hline CHEMBL1456328 & 688810 & \multirow{2}{*}{\multicolumn{3}{|c|}{$\begin{array}{lll}6.183 & 5313 \\
5.382999999999999\end{array}$}} & & \\
\hline CHEMBL1499414 & 688810 & & & & 5.006 & TST \\
\hline CHEMBL1473071 & 688810 & 4.783 & 4.9815 & TRN & & \\
\hline CHEMBL3213798 & 688810 & 5.233 & 5.1639 & TST & & \\
\hline CHEMBL1301875 & 688810 & \multicolumn{3}{|c|}{4.7330000000000005} & 5.1671 & $\mathrm{TI}$ \\
\hline CHEMBL1331880 & 688810 & 5.683 & 5.4682 & TST & & \\
\hline CHEMBL3195463 & 688810 & \multicolumn{3}{|c|}{5.582999999999999} & 5.3188 & TST \\
\hline CHEMBL1343817 & 688810 & \multicolumn{3}{|c|}{6.332999999999999} & 6.1169 & TRN \\
\hline CHEMBL1434983 & 688810 & 4.633 & 5.0281 & TST & & \\
\hline CHEMBL1525701 & 688810 & 4.783 & 5.3435 & TST & & \\
\hline CHEMBL1447542 & 688810 & 5.05 & 5.3435 & TRN & & \\
\hline
\end{tabular}




\begin{tabular}{|c|c|c|c|c|c|c|}
\hline \multicolumn{7}{|c|}{ Supplemental Table s2.txt } \\
\hline CHEMBL1344875 & 688810 & \multicolumn{3}{|c|}{5.132999999999999} & 4.9093 & TRN \\
\hline CHEMBL1530807 & 688810 & 4.833 & 5.0428 & TST & & \\
\hline CHEMBL1518085 & 688810 & \multicolumn{3}{|c|}{5.332999999999999} & 5.1403 & TRN \\
\hline CHEMBL1599433 & 688810 & \multicolumn{3}{|c|}{5.332999999999999} & 5.5076 & TRN \\
\hline CHEMBL1343936 & 688810 & \multicolumn{3}{|c|}{5.132999999999999} & 5.7844 & TST \\
\hline CHEMBL1497081 & 688810 & 4.633 & 4.9821 & TST & & \\
\hline CHEMBL1300612 & 688810 & 4.683 & 5.1847 & TST & & \\
\hline CHEMBL1601355 & 688810 & \multicolumn{3}{|c|}{6.832999999999999} & 5.7392 & TRN \\
\hline CHEMBL1530937 & 688810 & 5.483 & 5.0974 & TRN & & \\
\hline CHEMBL1452558 & 688810 & 5.683 & 5.266 & TRN & & \\
\hline CHEMBL 2369244 & 688810 & 5.233 & 5.5002 & TRN & & \\
\hline CHEMBL1580075 & 688810 & \multicolumn{3}{|c|}{5.632999999999999} & 5.3407 & TRN \\
\hline CHEMBL1366559 & 688810 & 5.233 & 5.2381 & TRN & & \\
\hline CHEMBL1547425 & 688810 & 5.683 & 5.1544 & TRN & & \\
\hline CHEMBL1364522 & 688810 & 4.833 & 4.7789 & TST & & \\
\hline CHEMBL1371588 & 688810 & 4.783 & 5.0748 & TST & & \\
\hline CHEMBL1590040 & 688810 & \multicolumn{3}{|c|}{5.382999999999999} & \multicolumn{2}{|c|}{5.1370000000000005} \\
\hline CHEMBL1312776 & 688810 & 5.183 & 5.0492 & TRN & & \\
\hline CHEMBL1480898 & 688810 & 5.033 & 5.5057 & TRN & & \\
\hline CHEMBL1404802 & 688810 & 4.783 & 5.1799 & TST & & \\
\hline CHEMBL1335944 & 688810 & 5.033 & 4.7762 & TRN & & \\
\hline CHEMBL 3213600 & 688810 & 5.183 & 5.7736 & TRN & & \\
\hline CHEMBL1539537 & 688810 & 4.833 & 5.0362 & TST & & \\
\hline CHEMBL1531220 & 688810 & 5.483 & 4.9283 & TRN & & \\
\hline CHEMBL1530574 & 688810 & 4.933 & 5.2839 & TST & & \\
\hline CHEMBL 3194408 & 688810 & \multicolumn{3}{|c|}{5.2829999999999995} & 4.877 & TRN \\
\hline CHEMBL 2094456 & 688810 & \multicolumn{3}{|c|}{5.5329999999999995} & 5.439 & TRN \\
\hline CHEMBL1437426 & 688810 & 4.833 & 5.0196 & TRN & & \\
\hline CHEMBL1599764 & 688810 & 5.683 & 5.7405 & TRN & & \\
\hline CHEMBL1479055 & 688810 & 4.783 & 4.8592 & TRN & & \\
\hline CHEMBL1414627 & 688810 & \multicolumn{3}{|c|}{4.9830000000000005} & 5.0214 & TRN \\
\hline CHEMBL1363025 & 688810 & 4.833 & 5.4923 & TST & & \\
\hline CHEMBL1543393 & 688810 & \multicolumn{3}{|c|}{5.5329999999999995} & 5.3143 & TRN \\
\hline CHEMBL1525077 & 688810 & 5.183 & 5.4292 & TRN & & \\
\hline CHEMBL1365565 & 688810 & 5.083 & 5.2544 & TST & & \\
\hline CHEMBL1507127 & 688810 & \multicolumn{3}{|c|}{5.332999999999999} & 5.2965 & TRN \\
\hline CHEMBL1550013 & 688810 & \multicolumn{3}{|c|}{5.832999999999999} & 5.5532 & TRN \\
\hline CHEMBL 3195637 & 688810 & 5.083 & 5.056 & TRN & & \\
\hline CHEMBL1606113 & 688810 & \multicolumn{3}{|c|}{5.582999999999999} & 5.7826 & TRN \\
\hline CHEMBL1583174 & 688810 & \multicolumn{3}{|c|}{5.7829999999999995} & 5.5264 & TRN \\
\hline CHEMBL1380932 & 688810 & 4.833 & 5.0798 & TRN & & \\
\hline CHEMBL1463023 & 688810 & 4.783 & 5.0286 & TRN & & \\
\hline CHEMBL1344179 & 688810 & 5.183 & 4.9975 & TRN & & \\
\hline CHEMBL1535021 & 688810 & 7.1331 & 5.8434 & TST & & \\
\hline CHEMBL1322332 & 688810 & 4.833 & 5.0461 & TRN & & \\
\hline CHEMBL1557125 & 688810 & 4.783 & 5.1099 & TRN & & \\
\hline CHEMBL1371190 & 688810 & \multicolumn{3}{|c|}{4.9830000000000005} & 5.5146 & TST \\
\hline CHEMBL1528061 & 688810 & 4.783 & 5.1223 & TST & & \\
\hline
\end{tabular}




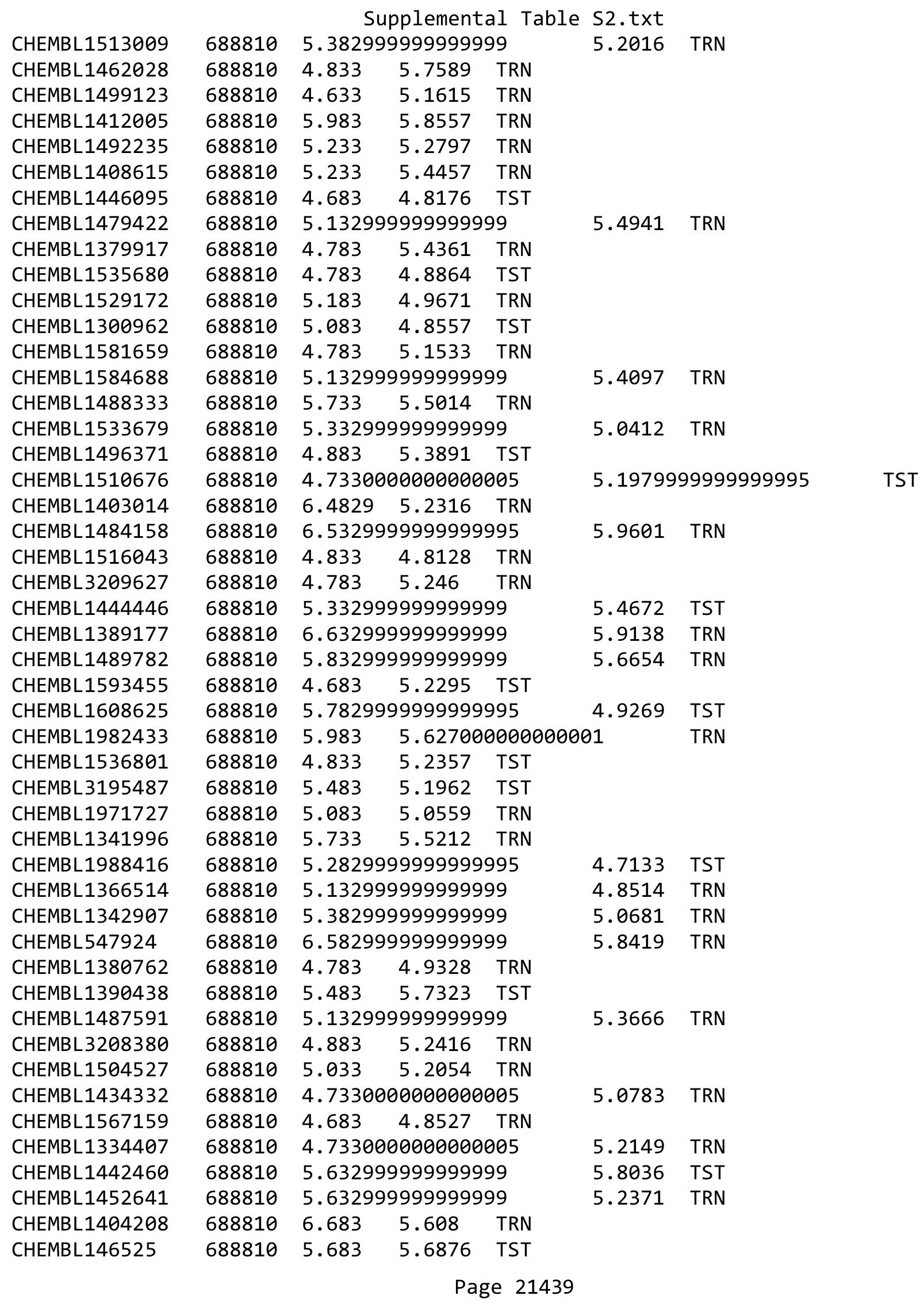




\begin{tabular}{|c|c|c|c|c|c|c|}
\hline \multirow{3}{*}{$\begin{array}{l}\text { CHEMBL1592113 } \\
\text { CHEMBL1977242 }\end{array}$} & & \multicolumn{5}{|c|}{ Supplemental Table S2.txt } \\
\hline & 688810 & \multicolumn{3}{|c|}{5.5329999999999995} & 5.2548 & TRN \\
\hline & 688810 & 6.0 & 5.5546 & TRN & & \\
\hline CHEMBL1408307 & 688810 & \multicolumn{3}{|c|}{5.132999999999999} & 6.0378 & TRN \\
\hline CHEMBL1542928 & 688810 & \multicolumn{3}{|c|}{6.5329999999999995} & 5.4993 & TRN \\
\hline CHEMBL1450912 & 688810 & 4.783 & 4.9243 & TRN & & \\
\hline CHEMBL1450928 & 688810 & \multicolumn{3}{|c|}{5.382999999999999} & 4.9538 & TST \\
\hline CHEMBL1465186 & 688810 & 4.583 & 5.136 & TST & & \\
\hline CHEMBL1999137 & 688810 & 4.783 & 5.1584 & TRN & & \\
\hline CHEMBL1334059 & 688810 & 5.033 & 5.6248 & TRN & & \\
\hline CHEMBL1468583 & 688810 & \multicolumn{3}{|c|}{5.632999999999999} & 5.7035 & TRN \\
\hline CHEMBL3212851 & 688810 & 4.933 & 5.6738 & TRN & & \\
\hline CHEMBL13097 & 688810 & 5.183 & 5.6094 & TRN & & \\
\hline CHEMBL1610810 & 688810 & 5.483 & 5.5322 & TRN & & \\
\hline CHEMBL1311157 & 688810 & 4.833 & 5.0344 & TST & & \\
\hline CHEMBL1532112 & 688810 & 4.633 & 5.244 & TST & & \\
\hline CHEMBL1480541 & 688810 & 4.883 & 5.3985 & TRN & & \\
\hline CHEMBL1578091 & 688810 & 4.883 & 5.516 & TRN & & \\
\hline CHEMBL1604517 & 688810 & 4.633 & 4.9168 & TST & & \\
\hline CHEMBL1527300 & 688810 & 4.633 & 4.8269 & TST & & \\
\hline CHEMBL3193435 & 688810 & 6.433 & 5.0711 & TST & & \\
\hline CHEMBL 3198530 & 688810 & 5.183 & 5.5163 & TST & & \\
\hline CHEMBL1582255 & 688810 & 4.783 & 5.004 & TRN & & \\
\hline CHEMBL1382300 & 688810 & \multicolumn{3}{|c|}{5.382999999999999} & 5.5302 & TRN \\
\hline CHEMBL1387036 & 688810 & 4.783 & 5.2329 & TRN & & \\
\hline CHEMBL1331760 & 688810 & 4.783 & 5.3357 & TST & & \\
\hline CHEMBL1465138 & 688810 & 5.483 & 5.7259 & TRN & & \\
\hline CHEMBL1596590 & 688810 & \multicolumn{3}{|c|}{5.7829999999999995} & 5.6248 & TRN \\
\hline CHEMBL1531615 & 688810 & \multicolumn{3}{|c|}{4.7330000000000005} & 5.273 & TST \\
\hline CHEMBL1454850 & 688810 & \multicolumn{3}{|c|}{5.632999999999999} & 5.0409 & TRN \\
\hline CHEMBL1500957 & 688810 & 4.933 & 5.0985 & TRN & & \\
\hline CHEMBL1367508 & 688810 & 4.883 & 5.1496 & TRN & & \\
\hline CHEMBL260342 & 688810 & \multicolumn{3}{|c|}{6.832999999999999} & 6.1973 & TRN \\
\hline CHEMBL1602290 & 688810 & 4.633 & 4.8555 & TRN & & \\
\hline CHEMBL1464734 & 688810 & 5.483 & 5.3577 & TRN & & \\
\hline CHEMBL3209899 & 688810 & 4.783 & 5.3319 & TRN & & \\
\hline CHEMBL3197628 & 688810 & 5.183 & 5.1287 & TRN & & \\
\hline CHEMBL3198613 & 688810 & 5.733 & \multicolumn{3}{|c|}{5.297000000000001} & TRN \\
\hline CHEMBL1564134 & 688810 & 4.933 & 4.9056 & TRN & & \\
\hline CHEMBL1452571 & 688810 & 4.783 & 5.1561 & TRN & & \\
\hline CHEMBL1343099 & 688810 & 5.733 & 5.3632 & TST & & \\
\hline CHEMBL1327052 & 688810 & \multicolumn{3}{|c|}{4.7330000000000005} & 5.0883 & TST \\
\hline CHEMBL1394808 & 688810 & 5.683 & 5.7328 & TRN & & \\
\hline CHEMBL1441026 & 688810 & 6.4829 & 5.7416 & TRN & & \\
\hline CHEMBL3197252 & 688810 & 5.183 & 5.3306 & TST & & \\
\hline CHEMBL1544141 & 688810 & 5.033 & 5.4444 & TRN & & \\
\hline CHEMBL1397613 & 688810 & 4.833 & 5.1704 & TRN & & \\
\hline CHEMBL1468061 & 688810 & 4.783 & 5.3098 & TRN & & \\
\hline \multirow[t]{2}{*}{ CHEMBL1349399 } & 688810 & \multicolumn{3}{|c|}{5.7829999999999995} & 5.6735 & TRN \\
\hline & & & & 27 & & \\
\hline
\end{tabular}




\begin{tabular}{|c|c|c|c|c|c|c|c|}
\hline \multicolumn{8}{|c|}{ Supplemental Table S2.txt } \\
\hline CHEMBL1965808 & 688810 & 5.733 & 5.5862 & TST & & & \\
\hline CHEMBL1401763 & 688810 & 5.033 & 5.4089 & TST & & & \\
\hline CHEMBL1436938 & 688810 & 4.633 & 5.1202 & TRN & & & \\
\hline CHEMBL1310110 & 688810 & 4.783 & 4.8819 & TST & & & \\
\hline CHEMBL1572518 & 688810 & \multicolumn{3}{|c|}{4.7330000000000005} & 5.0096 & TRN & \\
\hline CHEMBL502315 & 688810 & 5.683 & 5.7279 & TRN & & & \\
\hline CHEMBL1407407 & 688810 & \multicolumn{3}{|c|}{5.332999999999999} & 5.062 & TST & \\
\hline CHEMBL1339172 & 688810 & 5.683 & 5.3674 & TST & & & \\
\hline CHEMBL1436944 & 688810 & 5.233 & 5.1727 & TST & & & \\
\hline CHEMBL1603319 & 688810 & \multicolumn{3}{|c|}{5.632999999999999} & 5.0704 & TST & \\
\hline CHEMBL1299450 & 688810 & \multicolumn{3}{|c|}{5.832999999999999} & 5.0378 & TRN & \\
\hline CHEMBL1443896 & 688810 & 4.783 & 5.1891 & TST & & & \\
\hline CHEMBL1349033 & 688810 & 4.783 & 4.9288 & TRN & & & \\
\hline CHEMBL1586754 & 688810 & 4.883 & 4.9285 & TRN & & & \\
\hline CHEMBL1504150 & 688810 & 5.183 & 5.3273 & TRN & & & \\
\hline CHEMBL1476591 & 688810 & 5.083 & 6.1668 & TRN & & & \\
\hline CHEMBL1473738 & 688810 & 4.833 & 4.8812 & TRN & & & \\
\hline CHEMBL3211626 & 688810 & 4.933 & 4.6375 & TST & & & \\
\hline CHEMBL3145313 & 688810 & \multicolumn{3}{|c|}{4.7330000000000005} & 5.0846 & TST & \\
\hline CHEMBL1350735 & 688810 & 5.183 & 5.3244 & TRN & & & \\
\hline CHEMBL1559608 & 688810 & \multicolumn{3}{|c|}{5.132999999999999} & 5.3243 & TRN & \\
\hline CHEMBL1307453 & 688810 & 5.233 & 5.0795 & TRN & & & \\
\hline CHEMBL1365820 & 688810 & \multicolumn{3}{|c|}{5.2829999999999995} & 4.8117 & TRN & \\
\hline CHEMBL1340078 & 688810 & \multicolumn{3}{|c|}{4.9830000000000005} & 5.0548 & TRN & \\
\hline CHEMBL1408452 & 688810 & \multicolumn{3}{|c|}{5.832999999999999} & 5.8543 & TRN & \\
\hline CHEMBL1499941 & 688810 & 5.033 & 5.2774 & TRN & & & \\
\hline CHEMBL1510185 & 688810 & 5.433 & 5.1949 & TRN & & & \\
\hline CHEMBL1476095 & 688810 & \multicolumn{3}{|c|}{5.632999999999999} & 5.3754 & TRN & \\
\hline CHEMBL1423234 & 688810 & \multicolumn{3}{|c|}{5.5329999999999995} & 5.3913 & TRN & \\
\hline CHEMBL1552724 & 688810 & 4.883 & 5.0267 & TST & & & \\
\hline CHEMBL1432432 & 688810 & 4.633 & 5.0811 & TST & & & \\
\hline CHEMBL1478212 & 688810 & 5.983 & 5.5209 & TRN & & & \\
\hline CHEMBL 3144984 & 688810 & 5.433 & 5.2421 & TST & & & \\
\hline CHEMBL1380848 & 688810 & 4.883 & 5.3059 & TRN & & & \\
\hline CHEMBL1532305 & 688810 & \multicolumn{3}{|c|}{5.832999999999999} & 4.8254 & TST & \\
\hline CHEMBL3197590 & 688810 & 4.883 & 5.1773 & TRN & & & \\
\hline CHEMBL 1389220 & 688810 & \multicolumn{3}{|c|}{6.332999999999999} & 5.3055 & TST & \\
\hline CHEMBL455571 & 688810 & 4.833 & 5.4509 & TRN & & & \\
\hline CHEMBL3191593 & 688810 & 4.833 & 4.9592 & TST & & & \\
\hline CHEMBL1564212 & 688810 & 5.683 & 5.3323 & TRN & & & \\
\hline CHEMBL1302189 & 688810 & \multicolumn{3}{|c|}{5.832999999999999} & 5.0113 & TRN & \\
\hline CHEMBL 1302718 & 688810 & 4.883 & 5.3848 & TST & & & \\
\hline CHEMBL1344667 & 688810 & 5.083 & 5.2896 & TST & & & \\
\hline CHEMBL1315549 & 688810 & 4.833 & 4.6831 & TRN & & & \\
\hline CHEMBL1603383 & 688810 & 4.783 & 5.3375 & TST & & & \\
\hline CHEMBL1357980 & 688810 & 4.633 & 4.8801 & TRN & & & \\
\hline CHEMBL1596533 & 688810 & 5.433 & 5.5707 & TRN & & & \\
\hline CHEMBL1358621 & 688810 & 5.7829 & 99999999 & 995 & $3.40 \%$ & 0000005 & $1 \mathrm{NIV}$ \\
\hline
\end{tabular}




\begin{tabular}{|c|c|c|c|c|c|c|c|}
\hline \multicolumn{8}{|c|}{ Supplemental Table S2.txt } \\
\hline CHEMBL1506816 & 688810 & 4.783 & 5.1279 & TRN & & & \\
\hline CHEMBL1492508 & 688810 & 5.28299 & 99999999 & 995 & 5.4346 & TRN & \\
\hline CHEMBL1431321 & 688810 & 4.73300 & 00000000 & 005 & 5.0245 & TRN & \\
\hline CHEMBL1566123 & 688810 & 6.53299 & 99999999 & 995 & 4.9446 & TRN & \\
\hline CHEMBL1585868 & 688810 & 4.783 & 5.3339 & TST & & & \\
\hline CHEMBL1433523 & 688810 & 6.28299 & 99999999 & 995 & 5.4567 & TRN & \\
\hline CHEMBL1456238 & 688810 & 5.13299 & 99999999 & & 4.7826 & TST & \\
\hline CHEMBL1465548 & 688810 & 4.783 & 5.1726 & TST & & & \\
\hline CHEMBL1521472 & 688810 & 4.833 & 5.6891 & TRN & & & \\
\hline CHEMBL1465824 & 688810 & 4.883 & 5.4414 & TRN & & & \\
\hline CHEMBL1535529 & 688810 & 4.98300 & 00000000 & 005 & 5.1971 & TST & \\
\hline CHEMBL 3197844 & 688810 & 7.1831 & 5.8662 & TRN & & & \\
\hline CHEMBL1612240 & 688810 & 5.183 & 5.3821 & TST & & & \\
\hline CHEMBL1362754 & 688810 & 5.28299 & 99999999 & 995 & 5.5795 & TRN & \\
\hline CHEMBL1510643 & 688810 & 4.633 & 4.8406 & TST & & & \\
\hline CHEMBL1470952 & 688810 & 5.983 & 5.4719 & TRN & & & \\
\hline CHEMBL1319713 & 688810 & 5.033 & 4.9527 & TST & & & \\
\hline CHEMBL1549871 & 688810 & 5.28299 & 99999999 & 995 & 5.4538 & TRN & \\
\hline CHEMBL1406325 & 688810 & 4.73300 & 00000000 & 005 & 5.0954 & TST & \\
\hline CHEMBL1464624 & 688810 & 4.933 & 5.9438 & TRN & & & \\
\hline CHEMBL1485865 & 688810 & 5.233 & 4.9896 & TST & & & \\
\hline CHEMBL1530364 & 688810 & 4.783 & 5.0671 & TRN & & & \\
\hline CHEMBL1497195 & 688810 & 5.183 & 5.2604 & TRN & & & \\
\hline CHEMBL1483847 & 688810 & 5.83299 & 99999999 & & 6.08299 & 9999999999 & TRN \\
\hline CHEMBL1519705 & 688810 & 4.73300 & 00000000 & 005 & 4.9321 & TRN & \\
\hline CHEMBL1351832 & 688810 & 5.13299 & 99999999 & & 5.2345 & TST & \\
\hline CHEMBL1464753 & 688810 & 5.78299 & 99999999 & 995 & 5.1127 & TRN & \\
\hline CHEMBL1986444 & 688810 & 5.733 & 5.5198 & TRN & & & \\
\hline CHEMBL1582502 & 688810 & 5.183 & 5.1382 & TRN & & & \\
\hline CHEMBL1341336 & 688810 & 5.13299 & 99999999 & & 5.1889 & TST & \\
\hline CHEMBL1349701 & 688810 & 6.433 & 6.1331 & TRN & & & \\
\hline CHEMBL1459525 & 688810 & 4.73300 & 00000000 & 005 & 5.2183 & TRN & \\
\hline CHEMBL3196350 & 688810 & 4.783 & 5.2565 & TST & & & \\
\hline CHEMBL1527433 & 688810 & 6.983 & 5.9411 & TRN & & & \\
\hline CHEMBL1411645 & 688810 & 5.033 & 5.0437 & TRN & & & \\
\hline CHEMBL1455675 & 688810 & 4.73300 & 00000000 & 005 & 5.4025 & TRN & \\
\hline CHEMBL1438580 & 688810 & 5.733 & 5.2066 & TRN & & & \\
\hline CHEMBL1497859 & 688810 & 5.033 & 5.3876 & TRN & & & \\
\hline CHEMBL1389742 & 688810 & 4.73300 & 00000000 & 005 & 5.3071 & TRN & \\
\hline CHEMBL 3199856 & 688810 & 4.98300 & 00000000 & 005 & 5.4956 & TRN & \\
\hline CHEMBL1547437 & 688810 & 5.28299 & 99999999 & 995 & 5.0408 & TST & \\
\hline CHEMBL1471684 & 688810 & 5.83299 & 99999999 & & 5.5193 & TST & \\
\hline CHEMBL1406395 & 688810 & 5.33299 & 99999999 & & 5.473 & TRN & \\
\hline CHEMBL1321882 & 688810 & 5.033 & 5.2005 & TST & & & \\
\hline CHEMBL1400508 & 688810 & 5.733 & 5.5791 & TRN & & & \\
\hline CHEMBL1567862 & 688810 & 5.233 & 5.0942 & TRN & & & \\
\hline CHEMBL1453801 & 688810 & 6.233 & 5.6083 & TRN & & & \\
\hline CHEMBL1486672 & 688810 & 4.833 & 5.2877 & TST & & & \\
\hline
\end{tabular}




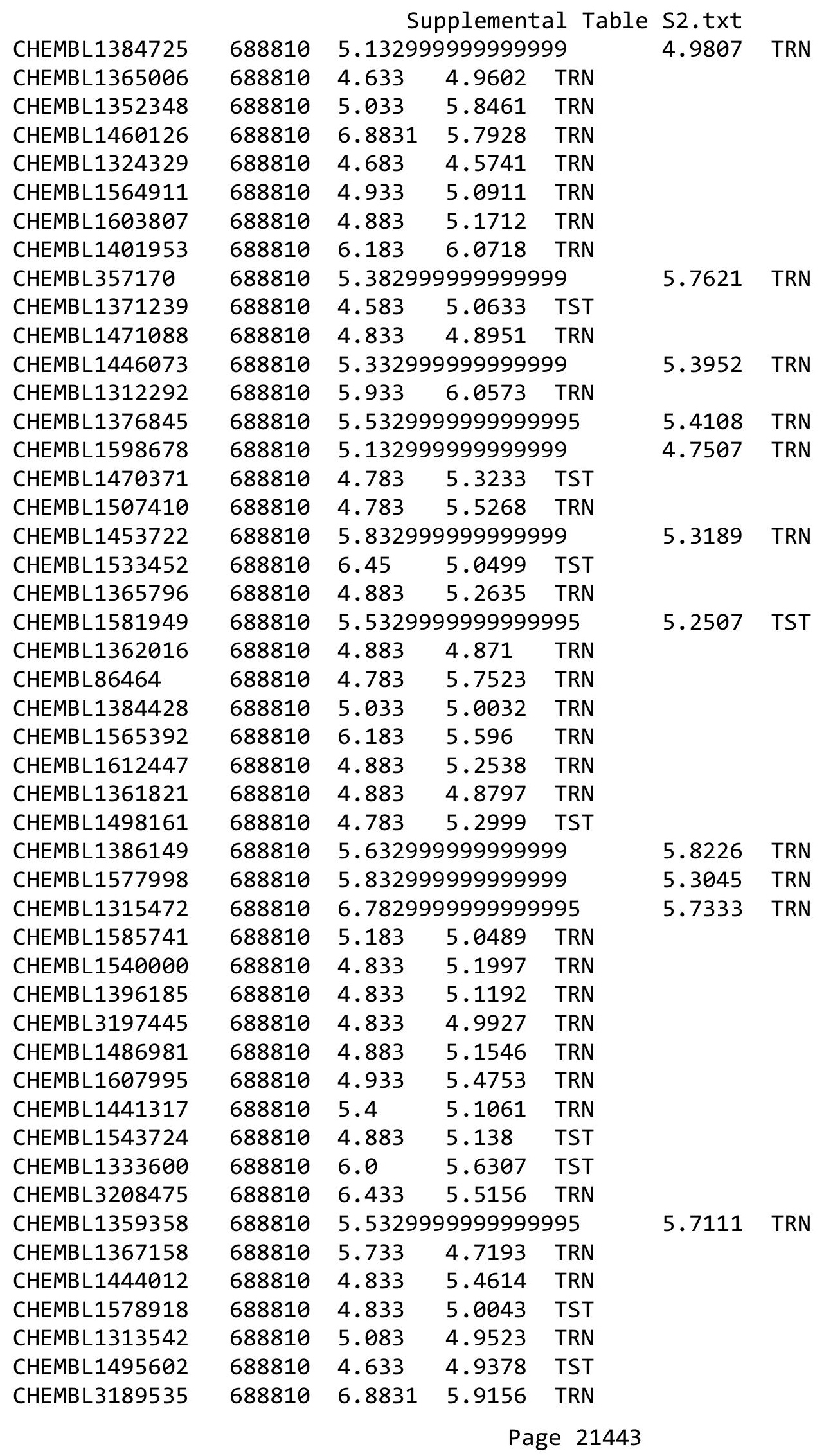




\begin{tabular}{|c|c|c|c|c|c|c|}
\hline CHEMBL1494628 & 688810 & 4.633 & 5.4366 & TST & & \\
\hline CHEMBL1501345 & 688810 & \multicolumn{3}{|c|}{5.2829999999999995} & 5.3071 & $\mathrm{TR}$ \\
\hline CHEMBL1605478 & 688810 & 6.233 & 6.0841 & TRN & & \\
\hline CHEMBL1528357 & 688810 & 4.833 & 5.0573 & TST & & \\
\hline CHEMBL1539723 & 588810 & 4.833 & 4.9407 & TRN & & \\
\hline CHEMBL 3192704 & 688810 & 5.033 & 4.9151 & TRN & & \\
\hline CHEMBL1455617 & 688810 & \multicolumn{3}{|c|}{5.332999999999999} & 5.0721 & TRN \\
\hline CHEMBL1386963 & 688810 & \multicolumn{3}{|c|}{5.832999999999999} & 5.1078 & \\
\hline CHEMBL1409706 & 688810 & 5.083 & 4.8991 & TRN & & \\
\hline CHEMBL1552887 & 688810 & 5.183 & 4.8621 & TRN & & \\
\hline CHEMBL1612177 & 688810 & \multicolumn{3}{|c|}{5.132999999999999} & 5.0701 & $\mathrm{TI}$ \\
\hline CHEMBL1590096 & 688810 & 4.783 & 5.4386 & TRN & & \\
\hline CHEMBL1377789 & 688810 & 4.683 & 5.0026 & TST & & \\
\hline CHEMBL1355892 & 688810 & \multicolumn{3}{|c|}{5.132999999999999} & $4 . \varepsilon$ & \\
\hline CHEMBL1512956 & 688810 & 5.683 & 5.4327 & TRN & & \\
\hline CHEMBL1503688 & 688810 & 4.933 & 5.2235 & TRN & & \\
\hline CHEMBL1518405 & 688810 & \multicolumn{3}{|c|}{6.382999999999999} & 5.6544 & \\
\hline CHEMBL1473234 & 688810 & 4.633 & 4.9198 & TST & & \\
\hline CHEMBL 1514570 & 688810 & 4.783 & 4.8764 & TRN & & \\
\hline CHEMBL1534071 & 688810 & \multicolumn{3}{|c|}{5.332999999999999} & 339 & \\
\hline CHEMBL1412675 & 688810 & 5.083 & 4.8943 & TRN & & \\
\hline CHEMBL1587328 & 688810 & 5.183 & 5.0488 & TST & & \\
\hline CHEMBL1381216 & 688810 & 5.033 & 5.1818 & TRN & & \\
\hline CHEMBL1576493 & 688810 & \multicolumn{3}{|c|}{5.2829999999999995} & & \\
\hline CHEMBL1452784 & 688810 & \multicolumn{3}{|c|}{4.9830000000000005} & 5.3128 & \\
\hline CHEMBL1522987 & 688810 & 4.633 & 5.1776 & TRN & & \\
\hline CHEMBL1928491 & 688810 & 4.633 & 5.6667 & TRN & & \\
\hline CHEMBL1384668 & 688810 & 5.433 & 5.1606 & TRN & & \\
\hline CHEMBL1410437 & 688810 & \multicolumn{3}{|c|}{5.882999999999999} & & \\
\hline CHEMBL1315216 & 688810 & \multicolumn{3}{|c|}{5.132999999999999} & 5.8306 & \\
\hline CHEMBL1438983 & 688810 & 4.583 & 5.0074 & TST & & \\
\hline CHEMBL 3194014 & 688810 & 4.833 & 4.8542 & TRN & & \\
\hline CHEMBL1505303 & 688810 & 6.183 & 5.7591 & TRN & & \\
\hline CHEMBL1577737 & 688810 & 5.983 & 5.405 & TRN & & \\
\hline CHEMBL1495458 & 688810 & 4.683 & 5.0664 & TRN & & \\
\hline CHEMBL1342461 & 688810 & \multicolumn{3}{|c|}{5.132999999999999} & 5.0887 & \\
\hline CHEMBL1350356 & 688810 & 5.483 & 5.2879 & TRN & & \\
\hline CHEMBL1464307 & 688810 & 4.583 & 4.92 & TRN & & \\
\hline CHEMBL1434786 & 688810 & \multicolumn{3}{|c|}{6.332999999999999} & & \\
\hline CHEMBL1382086 & 688810 & \multicolumn{3}{|c|}{5.5329999999999995} & 5.2089 & \\
\hline CHEMBL1370615 & 688810 & \multicolumn{3}{|c|}{5.632999999999999} & 5.7325 & \\
\hline CHEMBL1354700 & 688810 & 4.683 & 5.3161 & TRN & & \\
\hline CHEMBL1988056 & 688810 & 4.833 & 5.3372 & TST & & \\
\hline CHEMBL1557622 & 688810 & 4.583 & 4.7272 & TRN & & \\
\hline CHEMBL1400943 & 688810 & \multicolumn{3}{|c|}{5.882999999999999} & 3.2413 & \\
\hline CHEMBL1452680 & 688810 & \multicolumn{3}{|c|}{5.382999999999999} & 5.0506 & \\
\hline CHEMBL1605726 & 688810 & \multicolumn{3}{|c|}{5.832999999999999} & 5.169 & rRN \\
\hline CHEMBL1523410 & 688810 & 4.633 & 4.5384 & TRN & & \\
\hline
\end{tabular}




\begin{tabular}{|c|c|c|c|c|c|c|}
\hline & \\
\hline CHEMBL1330440 & 688810 & 4.883 & 5.0717 & TST & & \\
\hline CHEMBL1523019 & 688810 & 5.8329 & 99999999 & & 5.4432 & TST \\
\hline CHEMBL3213598 & 688810 & 5.83299 & 99999999 & & 4.6396 & TST \\
\hline CHEMBL1550603 & 688810 & 4.833 & 5.0695 & TRN & & \\
\hline CHEMBL1449967 & 688810 & 5.033 & 5.2118 & TST & & \\
\hline CHEMBL 2005446 & 688810 & 6.63299 & 99999999 & & 6.3108 & TRN \\
\hline CHEMBL1596930 & 688810 & 4.583 & 4.9263 & TRN & & \\
\hline CHEMBL1567747 & 688810 & 5.483 & 4.8556 & TRN & & \\
\hline CHEMBL1337492 & 688810 & 4.583 & 4.6935 & TRN & & \\
\hline CHEMBL3144909 & 688810 & 5.183 & 5.4896 & TRN & & \\
\hline CHEMBL1483585 & 688810 & 5.183 & 5.3242 & TRN & & \\
\hline CHEMBL1541177 & 688810 & 4.783 & 4.90600 & 000000000 & & TRN \\
\hline CHEMBL1443852 & 688810 & 5.733 & 5.5662 & TRN & & \\
\hline CHEMBL1307069 & 688810 & 5.63299 & 99999999 & & 5.4909 & TRN \\
\hline CHEMBL1578985 & 688810 & 5.733 & 5.1382 & TRN & & \\
\hline CHEMBL1389745 & 688810 & 5.733 & 5.7097 & TRN & & \\
\hline CHEMBL1444275 & 688810 & 4.933 & 4.9282 & TRN & & \\
\hline CHEMBL 3193303 & 688810 & 5.483 & 5.6379 & TRN & & \\
\hline CHEMBL1324994 & 688810 & 4.783 & 5.2938 & TRN & & \\
\hline CHEMBL1434768 & 688810 & 6.7331 & 5.6701 & TRN & & \\
\hline CHEMBL1334244 & 688810 & 6.183 & 5.3719 & TRN & & \\
\hline CHEMBL1514773 & 688810 & 4.933 & 5.5267 & TRN & & \\
\hline CHEMBL1373411 & 688810 & 4.783 & 5.2787 & TRN & & \\
\hline CHEMBL3192580 & 688810 & 4.833 & 4.9908 & TRN & & \\
\hline CHEMBL1589647 & 688810 & 5.88299 & 99999999 & & 5.8207 & TRN \\
\hline CHEMBL1496621 & 688810 & 4.783 & 5.3598 & TRN & & \\
\hline CHEMBL1596598 & 688810 & 5.183 & 5.4188 & TRN & & \\
\hline CHEMBL1445087 & 688810 & 5.183 & 5.8312 & TRN & & \\
\hline CHEMBL1510193 & 688810 & 5.483 & 5.157 & TRN & & \\
\hline CHEMBL1390106 & 688810 & 5.28299 & 99999999 & 995 & 5.1101 & TST \\
\hline CHEMBL1381979 & 688810 & 5.083 & 4.8723 & TRN & & \\
\hline CHEMBL1455846 & 688810 & 5.33299 & 99999999 & & 5.7394 & TRN \\
\hline CHEMBL1497490 & 688810 & 5.233 & 5.3319 & TRN & & \\
\hline CHEMBL1344082 & 688810 & 4.73306 & 20000000 & 005 & 5.2849 & TRN \\
\hline CHEMBL1538448 & 688810 & 5.83299 & 99999999 & & 5.3914 & TRN \\
\hline CHEMBL 3197734 & 688810 & 4.933 & 5.3821 & TST & & \\
\hline CHEMBL1980658 & 688810 & 5.483 & 5.6226 & TRN & & \\
\hline CHEMBL1425652 & 688810 & 4.833 & 5.2275 & TST & & \\
\hline CHEMBL1526904 & 688810 & 5.683 & 5.474 & TRN & & \\
\hline CHEMBL1408208 & 688810 & 4.883 & 4.6152 & TST & & \\
\hline CHEMBL1400807 & 688810 & 5.13299 & 99999999 & & 5.1913 & TRN \\
\hline CHEMBL1377323 & 688810 & 5.88299 & 99999999 & & 5.6322 & TST \\
\hline CHEMBL1556139 & 688810 & 5.53290 & 99999999 & 995 & 5.2503 & TRN \\
\hline CHEMBL1534463 & 688810 & 4.783 & 5.1979 & TRN & & \\
\hline CHEMBL1326458 & 688810 & 4.583 & 4.9118 & TRN & & \\
\hline CHEMBL3213769 & 688810 & 5.083 & 5.3913 & TRN & & \\
\hline CHEMBL1321914 & 688810 & 4.933 & 4.7993 & TRN & & \\
\hline CHEMBL1492412 & 688810 & 5.7829 & 99999999 & 995 & 5.7661 & TRN \\
\hline
\end{tabular}




\begin{tabular}{|c|c|c|c|c|c|c|}
\hline & & & pplementa & al Table & S2.txt & \\
\hline CHEMBL1469317 & 688810 & 4.73300 & 000000000 & 005 & 5.3409 & TRN \\
\hline CHEMBL1386446 & 688810 & 5.933 & 5.8399 & TRN & & \\
\hline CHEMBL1378106 & 688810 & 4.783 & 4.9888 & TRN & & \\
\hline CHEMBL1381205 & 688810 & 6.28299 & 999999999 & 995 & 5.7879 & TRN \\
\hline CHEMBL1450799 & 688810 & 4.633 & 4.8303 & TRN & & \\
\hline CHEMBL1513449 & 688810 & 4.73300 & 000000000 & 005 & 4.8316 & TRN \\
\hline CHEMBL1418976 & 688810 & 5.33299 & 999999999 & & 5.3228 & TRN \\
\hline CHEMBL1366485 & 688810 & 4.783 & 5.2424 & TRN & & \\
\hline CHEMBL581929 & 688810 & 5.33299 & 999999999 & & 5.1166 & TRN \\
\hline CHEMBL1567438 & 688810 & 4.833 & 5.0315 & TRN & & \\
\hline CHEMBL1335236 & 688810 & 4.933 & 5.2024 & TST & & \\
\hline CHEMBL1426852 & 688810 & 6.4829 & 5.2761 & TRN & & \\
\hline CHEMBL1359288 & 688810 & 4.883 & 5.1269 & TST & & \\
\hline CHEMBL1459129 & 688810 & 4.883 & 5.1466 & TRN & & \\
\hline CHEMBL1465762 & 688810 & 5.13299 & 999999999 & & 5.1006 & TRN \\
\hline CHEMBL1490587 & 688810 & 4.783 & 5.5087 & TRN & & \\
\hline CHEMBL1990174 & 688810 & 5.78299 & 999999999 & 995 & 6.2827 & TRN \\
\hline CHEMBL1376371 & 688810 & 4.633 & 5.335 & TST & & \\
\hline CHEMBL1457670 & 688810 & 5.983 & 5.1153 & TST & & \\
\hline CHEMBL1546083 & 688810 & 5.733 & 5.2886 & TST & & \\
\hline CHEMBL1499809 & 688810 & 4.783 & 4.7848 & TRN & & \\
\hline CHEMBL1305277 & 688810 & 4.73300 & 000000000 & 005 & 5.1598 & TRN \\
\hline CHEMBL1328595 & 688810 & 5.033 & 5.2324 & TRN & & \\
\hline CHEMBL1533877 & 688810 & 4.933 & 5.2109 & TRN & & \\
\hline CHEMBL1519919 & 688810 & 5.88299 & 999999999 & & 5.8968 & TRN \\
\hline CHEMBL1377511 & 688810 & 5.033 & 5.0665 & TRN & & \\
\hline CHEMBL3195162 & 688810 & 5.733 & 5.7164 & TRN & & \\
\hline CHEMBL1315699 & 688810 & 6.58299 & 999999999 & & 5.6438 & TRN \\
\hline CHEMBL1485168 & 688810 & 4.933 & 5.3947 & TRN & & \\
\hline CHEMBL1382429 & 688810 & 5.78299 & 999999999 & 995 & 5.2178 & TRN \\
\hline CHEMBL1404086 & 688810 & 4.783 & 5.4411 & TRN & & \\
\hline CHEMBL1357227 & 688810 & 4.783 & 5.3739 & TRN & & \\
\hline CHEMBL1534212 & 688810 & 5.78299 & 999999999 & 995 & 5.41 & TRN \\
\hline CHEMBL1413568 & 688810 & 6.0 & 5.3299 & TRN & & \\
\hline CHEMBL1599515 & 688810 & 4.833 & 4.9375 & TRN & & \\
\hline CHEMBL1308879 & 688810 & 4.833 & 4.8048 & TRN & & \\
\hline CHEMBL1538934 & 688810 & 4.833 & 5.1762 & TST & & \\
\hline CHEMBL1565220 & 688810 & 5.53299 & 999999999 & 995 & 5.3359 & TRN \\
\hline CHEMBL1420490 & 688810 & 5.183 & 5.7924 & TRN & & \\
\hline CHEMBL1577231 & 688810 & 5.683 & 5.755 & TRN & & \\
\hline CHEMBL1564490 & 688810 & 6.4829 & 5.7853 & TRN & & \\
\hline CHEMBL1504878 & 688810 & 4.833 & 4.9767 & TRN & & \\
\hline CHEMBL1546895 & 688810 & 5.483 & 5.2656 & TRN & & \\
\hline CHEMBL 3214284 & 688810 & 5.033 & 5.1443 & TRN & & \\
\hline CHEMBL1407138 & 688810 & 6.13299 & 999999999 & & 5.8048 & TRN \\
\hline CHEMBL1516606 & 688810 & 5.433 & 5.1111 & TRN & & \\
\hline CHEMBL1388416 & 688810 & 5.38299 & 999999999 & & 5.1113 & TST \\
\hline CHEMBL1449106 & 688810 & 4.833 & 4.9909 & TRN & & \\
\hline
\end{tabular}




\begin{tabular}{|c|c|c|c|c|c|c|c|}
\hline \multicolumn{8}{|c|}{ 年 } \\
\hline CHEMBL1508184 & 688810 & 4.833 & 5.2467 & TST & & & \\
\hline CHEMBL3208758 & 688810 & 4.783 & 4.9243 & TRN & & & \\
\hline CHEMBL1483048 & 688810 & 5.683 & 4.9901 & TST & & & \\
\hline CHEMBL1339878 & 688810 & 4.933 & 5.1683 & TRN & & & \\
\hline CHEMBL1533602 & 688810 & 5.2829 & 999999999 & 995 & 5.6712 & TRN & \\
\hline CHEMBL3208106 & 688810 & 4.833 & 5.1319 & TRN & & & \\
\hline CHEMBL3195151 & 688810 & 4.783 & 5.3897 & TST & & & \\
\hline CHEMBL1080213 & 688810 & 5.3329 & 999999999 & & 5.5738 & TRN & \\
\hline CHEMBL1385339 & 688810 & 4.7330 & 00000000 & 005 & 4.5333 & TST & \\
\hline CHEMBL1467426 & 688810 & 4.783 & 5.2088 & TRN & & & \\
\hline CHEMBL1306280 & 688810 & 5.433 & 5.6867 & TRN & & & \\
\hline CHEMBL1451126 & 688810 & 4.7330 & 000000006 & 005 & 5.2348 & TRN & \\
\hline CHEMBL1537906 & 688810 & 5.8829 & $99999999 \mathrm{C}$ & & 4.91100 & 00000000005 & TST \\
\hline CHEMBL1578578 & 688810 & 4.783 & 4.8383 & TRN & & & \\
\hline CHEMBL1574242 & 688810 & 5.3329 & 999999995 & & 5.4132 & TRN & \\
\hline CHEMBL1541324 & 688810 & 4.833 & 5.0245 & TRN & & & \\
\hline CHEMBL1384135 & 688810 & 4.783 & 5.216 & TRN & & & \\
\hline CHEMBL1370731 & 688810 & 5.8829 & 999999999 & & 5.6337 & TRN & \\
\hline CHEMBL1565921 & 688810 & 5.083 & 5.2725 & TRN & & & \\
\hline CHEMBL1478565 & 688810 & 4.683 & 5.3477 & TST & & & \\
\hline CHEMBL1414966 & 688810 & 4.7330 & 000000006 & 005 & 4.9835 & TRN & \\
\hline CHEMBL1426578 & 688810 & 5.083 & 5.2915 & TRN & & & \\
\hline CHEMBL1563519 & 688810 & 5.5329 & 999999999 & 995 & 5.5788 & TST & \\
\hline CHEMBL1454165 & 688810 & 4.933 & 5.0061 & TST & & & \\
\hline CHEMBL1594333 & 688810 & 6.183 & 5.8016 & TRN & & & \\
\hline CHEMBL1375520 & 688810 & 5.2829 & 999999999 & 995 & 5.1087 & TRN & \\
\hline CHEMBL1328510 & 688810 & 6.0 & 5.3582 & TRN & & & \\
\hline CHEMBL1532811 & 688810 & 5.1329 & 999999999 & & 5.7539 & TRN & \\
\hline CHEMBL1586660 & 688810 & 4.633 & 5.1353 & TRN & & & \\
\hline CHEMBL211740 & 688810 & 6.2829 & 999999995 & 995 & 5.8651 & TRN & \\
\hline CHEMBL1490799 & 688810 & 4.633 & 5.2018 & TRN & & & \\
\hline CHEMBL 2006221 & 688810 & 4.633 & 4.8976 & TST & & & \\
\hline CHEMBL1334928 & 688810 & 4.633 & 5.0456 & TRN & & & \\
\hline CHEMBL1611697 & 688810 & 5.733 & 5.5715 & TRN & & & \\
\hline CHEMBL1533244 & 688810 & 5.2829 & 99999999 & 995 & 5.8356 & TRN & \\
\hline CHEMBL1473320 & 688810 & 4.583 & 4.7837 & TRN & & & \\
\hline CHEMBL1364022 & 688810 & 5.1329 & 999999999 & & 5.1987 & TST & \\
\hline CHEMBL1380958 & 688810 & 4.833 & 5.1857 & TST & & & \\
\hline CHEMBL1544256 & 688810 & 5.1329 & 999999995 & & 5.0598 & TRN & \\
\hline CHEMBL1320643 & 688810 & 6.4829 & 5.5112 & TRN & & & \\
\hline CHEMBL1331206 & 688810 & 4.633 & 5.1082 & TST & & & \\
\hline CHEMBL1542868 & 688810 & 5.2829 & 999999999 & 995 & 5.0281 & TST & \\
\hline CHEMBL1326031 & 688810 & 5.183 & 5.4964 & TST & & & \\
\hline CHEMBL1557226 & 688810 & 5.7829 & 999999995 & 995 & 5.1994 & TRN & \\
\hline CHEMBL1613127 & 688810 & 4.883 & 5.5582 & TRN & & & \\
\hline CHEMBL1555665 & 688810 & 4.783 & 5.1373 & TRN & & & \\
\hline CHEMBL1538410 & 688810 & 4.7330 & 000000006 & 005 & 5.2536 & TRN & \\
\hline CHEMBL1350441 & 688810 & 4.783 & 5.0191 & TST & & & \\
\hline
\end{tabular}




\begin{tabular}{|c|c|c|c|c|c|c|c|}
\hline \multirow[b]{2}{*}{ CHEMBL1609306 } & \multicolumn{6}{|c|}{ 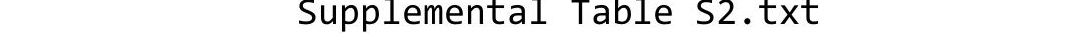 } & \\
\hline & 688810 & 5.183 & 5.1451 & TRN & & & \\
\hline CHEMBL1593392 & 688810 & 5.033 & 5.4177 & TRN & & & \\
\hline CHEMBL3190829 & 688810 & 6.63299 & 99999999 & & 5.83700 & 0000000001 & TRN \\
\hline CHEMBL1411488 & 688810 & 5.433 & 5.0189 & TRN & & & \\
\hline CHEMBL1468306 & 688810 & 5.13299 & 99999999 & & 5.1505 & TRN & \\
\hline CHEMBL1574505 & 688810 & 4.98300 & 00000000 & 005 & 5.1711 & TST & \\
\hline CHEMBL1303865 & 688810 & 4.833 & 5.1122 & TST & & & \\
\hline CHEMBL1555525 & 688810 & 5.33299 & 99999999 & & 5.1894 & TST & \\
\hline CHEMBL1488910 & 688810 & 6.58299 & 99999999 & & 5.79299 & 9999999999 & TRN \\
\hline CHEMBL1384293 & 688810 & 6.08299 & 99999999 & & 5.107 & TRN & \\
\hline CHEMBL1490577 & 688810 & 5.55 & 5.3333 & TRN & & & \\
\hline CHEMBL1322094 & 688810 & 5.233 & 5.2327 & TRN & & & \\
\hline CHEMBL1357571 & 688810 & 4.633 & 4.9841 & TST & & & \\
\hline CHEMBL1438369 & 688810 & 4.783 & 5.5518 & TRN & & & \\
\hline CHEMBL1388490 & 688810 & 4.783 & 5.1466 & TST & & & \\
\hline CHEMBL1335404 & 688810 & 6.33299 & 99999999 & & 5.8478 & TRN & \\
\hline CHEMBL1345988 & 688810 & 4.883 & 5.8673 & TRN & & & \\
\hline CHEMBL1325491 & 688810 & 5.183 & 4.8286 & TRN & & & \\
\hline CHEMBL1374835 & 688810 & 4.683 & 5.3434 & TST & & & \\
\hline CHEMBL1382438 & 688810 & 5.733 & 5.2519 & TRN & & & \\
\hline CHEMBL1604144 & 688810 & 4.683 & 4.8738 & TST & & & \\
\hline CHEMBL1491411 & 688810 & 4.833 & 4.8963 & TRN & & & \\
\hline CHEMBL1342703 & 688810 & 4.883 & 4.816 & TRN & & & \\
\hline CHEMBL1489045 & 688810 & 6.33299 & 99999999 & & 5.7385 & TRN & \\
\hline CHEMBL1578914 & 688810 & 4.783 & 5.4308 & TRN & & & \\
\hline CHEMBL1577720 & 688810 & 6.9329 & 5.3603 & TRN & & & \\
\hline CHEMBL1329440 & 688810 & 4.73300 & 00000000 & 005 & 4.9681 & TRN & \\
\hline CHEMBL1327939 & 688810 & 4.933 & 4.9043 & TRN & & & \\
\hline CHEMBL1582073 & 688810 & 5.13299 & 99999999 & & 5.2752 & TST & \\
\hline CHEMBL1526676 & 688810 & 5.88299 & 99999999 & & 5.2535 & TRN & \\
\hline CHEMBL1435240 & 688810 & 5.183 & 5.2181 & TST & & & \\
\hline CHEMBL1522113 & 688810 & 4.633 & 5.4078 & TST & & & \\
\hline CHEMBL1311077 & 688810 & 5.13299 & 99999999 & & 5.4746 & TRN & \\
\hline CHEMBL1550083 & 688810 & 5.53299 & 99999999 & 995 & 5.6211 & TRN & \\
\hline CHEMBL1534744 & 688810 & 4.883 & 4.9278 & TST & & & \\
\hline CHEMBL1384734 & 688810 & 6.13299 & 99999999 & 99 & 5.58899 & 99999999995 & TRN \\
\hline CHEMBL3213353 & 688810 & 5.033 & 5.1642 & TST & & & \\
\hline CHEMBL1313883 & 688810 & 4.933 & 4.9445 & TRN & & & \\
\hline CHEMBL1554696 & 688810 & 5.38299 & 99999999 & & 4.9431 & TRN & \\
\hline CHEMBL1490334 & 688810 & 6.13299 & 99999999 & & 6.1438 & TRN & \\
\hline CHEMBL1428735 & 688810 & 5.83299 & 99999999 & & 5.4597 & TRN & \\
\hline CHEMBL3209477 & 688810 & 5.58299 & 99999999 & & 5.5198 & TRN & \\
\hline CHEMBL1328903 & 688810 & 5.233 & 5.0376 & TRN & & & \\
\hline CHEMBL1353902 & 688810 & 5.733 & 5.3848 & TRN & & & \\
\hline CHEMBL1522607 & 688810 & 5.13299 & 99999999 & & 5.4232 & TRN & \\
\hline CHEMBL1410042 & 688810 & 6.8831 & 6.0056 & TRN & & & \\
\hline CHEMBL3192328 & 688810 & 5.733 & 5.4413 & TRN & & & \\
\hline CHEMBL1528452 & 688810 & 4.633 & 5.1085 & TRN & & & \\
\hline
\end{tabular}




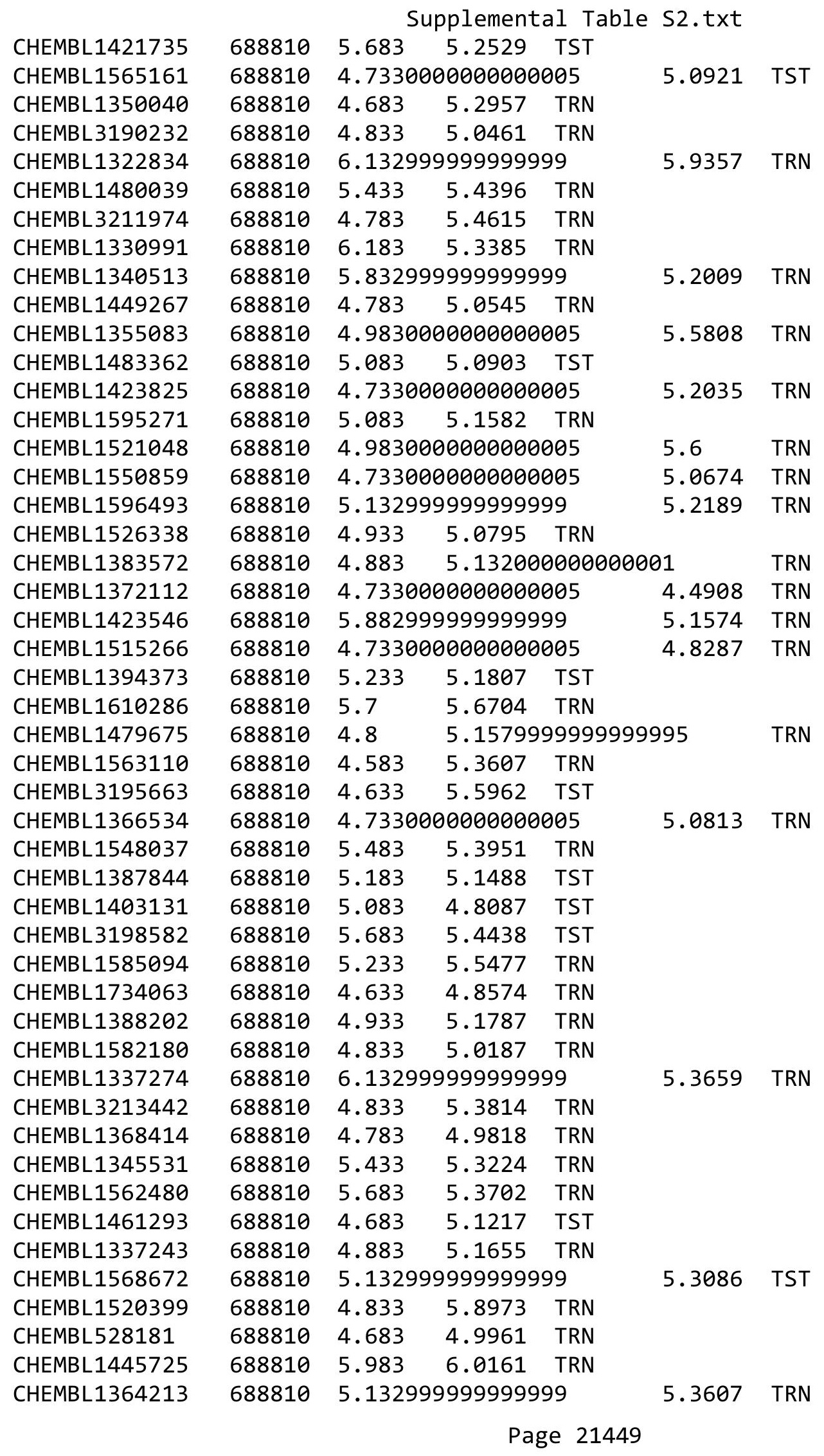




\begin{tabular}{|c|c|c|c|c|c|c|}
\hline \multirow[b]{2}{*}{ CHEMBL581880 } & \multirow[b]{2}{*}{688810} & \multicolumn{5}{|c|}{ Supplemental Table s2.txt } \\
\hline & & \multicolumn{3}{|c|}{$5.233 \quad 4.8418$ TRN } & & \\
\hline CHEMBL1540631 & 688810 & 5.433 & 5.1468 & TST & & \\
\hline CHEMBL1399085 & 688810 & \multicolumn{3}{|c|}{4.7330000000000005} & 5.3468 & TRN \\
\hline CHEMBL1574779 & 688810 & 4.883 & 5.0072 & TRN & & \\
\hline CHEMBL1580545 & 688810 & \multicolumn{3}{|c|}{5.132999999999999} & 4.9512 & TRN \\
\hline CHEMBL1395996 & 688810 & 4.933 & 5.4753 & TRN & & \\
\hline CHEMBL1343231 & 688810 & 4.833 & 4.9443 & TRN & & \\
\hline CHEMBL1334562 & 688810 & 5.033 & 5.265 & TRN & & \\
\hline CHEMBL114544 & 688810 & 6.0 & 5.8327 & TST & & \\
\hline CHEMBL3212351 & 688810 & \multicolumn{3}{|c|}{5.632999999999999} & 5.9638 & TRN \\
\hline CHEMBL3209756 & 688810 & 5.033 & \multicolumn{3}{|c|}{5.242000000000001} & TST \\
\hline CHEMBL1418940 & 688810 & 4.583 & 5.1875 & TST & & \\
\hline CHEMBL1507946 & 688810 & 4.933 & 5.4501 & TST & & \\
\hline CHEMBL1331788 & 688810 & 4.883 & 5.3085 & TRN & & \\
\hline CHEMBL441370 & 688810 & 4.883 & 4.914 & TST & & \\
\hline CHEMBL1458772 & 688810 & 5.483 & 5.1252 & TRN & & \\
\hline CHEMBL1577648 & 688810 & 4.883 & 5.1828 & TRN & & \\
\hline CHEMBL1496274 & 688810 & 4.783 & 5.409 & TRN & & \\
\hline CHEMBL1333076 & 688810 & 4.783 & 4.8533 & TST & & \\
\hline CHEMBL424581 & 688810 & \multicolumn{3}{|c|}{5.7829999999999995} & 5.4808 & TRN \\
\hline CHEMBL581574 & 688810 & 4.883 & 5.2211 & TRN & & \\
\hline CHEMBL1439277 & 688810 & 5.183 & 5.1396 & TRN & & \\
\hline CHEMBL1549578 & 688810 & 4.783 & 5.2311 & TST & & \\
\hline CHEMBL1364036 & 688810 & 4.783 & 5.194 & TRN & & \\
\hline CHEMBL1502407 & 688810 & 4.833 & 5.4234 & TST & & \\
\hline CHEMBL3195010 & 688810 & 5.733 & 5.6082 & TRN & & \\
\hline CHEMBL1413470 & 688810 & 5.233 & 5.5196 & TRN & & \\
\hline CHEMBL1588024 & 688810 & 4.833 & 5.041 & TRN & & \\
\hline CHEMBL1335323 & 688810 & \multicolumn{3}{|c|}{5.582999999999999} & 5.2236 & TRN \\
\hline CHEMBL1405550 & 688810 & 5.233 & 5.1774 & TRN & & \\
\hline CHEMBL1368699 & 688810 & 4.883 & 5.1948 & TST & & \\
\hline CHEMBL1555814 & 688810 & 5.183 & 5.3408 & TRN & & \\
\hline CHEMBL1592018 & 688810 & 4.633 & 4.979 & TST & & \\
\hline CHEMBL1409944 & 688810 & 5.183 & 5.0273 & TRN & & \\
\hline CHEMBL1493993 & 688810 & 6.433 & 6.1179 & TRN & & \\
\hline CHEMBL1528180 & 688810 & \multicolumn{3}{|c|}{5.132999999999999} & 4.8978 & TRN \\
\hline CHEMBL1316483 & 688810 & 4.633 & 5.1373 & TRN & & \\
\hline CHEMBL1466421 & 688810 & 5.733 & 5.7962 & TRN & & \\
\hline CHEMBL3194392 & 688810 & 4.833 & 5.1411 & TRN & & \\
\hline CHEMBL1350376 & 688810 & 4.883 & 5.4975 & TST & & \\
\hline CHEMBL1610226 & 688810 & \multicolumn{3}{|c|}{5.882999999999999} & 5.2457 & TRN \\
\hline CHEMBL1379173 & 688810 & \multicolumn{3}{|c|}{5.132999999999999} & 5.5929 & TRN \\
\hline CHEMBL3208892 & 688810 & 4.883 & 5.1146 & TRN & & \\
\hline CHEMBL1559605 & 688810 & \multicolumn{3}{|c|}{6.132999999999999} & 5.8444 & TRN \\
\hline CHEMBL1329457 & 688810 & \multicolumn{3}{|c|}{6.2829999999999995} & 5.65 & TRN \\
\hline CHEMBL1241420 & 688810 & \multicolumn{3}{|c|}{4.7330000000000005} & 5.7926 & TST \\
\hline CHEMBL1486479 & 688810 & 4.883 & 5.5007 & TRN & & \\
\hline \multirow[t]{2}{*}{ CHEMBL1561204 } & 688810 & \multicolumn{3}{|c|}{5.632999999999999} & 5.4043 & TRN \\
\hline & & & & 2 & & \\
\hline
\end{tabular}




\begin{tabular}{|c|c|c|c|c|c|c|}
\hline \multirow[b]{2}{*}{ CHEMBL1524752 } & & \multicolumn{5}{|c|}{ Supplemental Table S2.txt } \\
\hline & 688810 & 5.683 & 5.6649 & TRN & & \\
\hline CHEMBL1551391 & 688810 & \multicolumn{3}{|c|}{6.832999999999999} & 5.8961 & TRN \\
\hline CHEMBL1350199 & 688810 & \multicolumn{3}{|c|}{5.332999999999999} & 5.41 & \\
\hline CHEMBL1372480 & 688810 & 5.183 & 5.5154 & TRN & & \\
\hline CHEMBL3194494 & 688810 & 5.683 & 4.7821 & TST & & \\
\hline CHEMBL1306163 & 688810 & 4.883 & 5.0512 & TRN & & \\
\hline CHEMBL1453029 & 688810 & \multicolumn{3}{|c|}{6.132999999999999} & 5.5334 & \\
\hline CHEMBL1371052 & 688810 & 5.083 & 5.1235 & TST & & \\
\hline CHEMBL1390212 & 688810 & 4.783 & 5.2107 & TRN & & \\
\hline CHEMBL3191061 & 688810 & 5.083 & 5.0367 & TRN & & \\
\hline CHEMBL1503305 & 688810 & 4.783 & 5.477 & TRN & & \\
\hline CHEMBL1337266 & 688810 & 4.833 & 5.1548 & TST & & \\
\hline CHEMBL1597768 & 688810 & \multicolumn{3}{|c|}{5.582999999999999} & 5.8556 & \\
\hline CHEMBL1520849 & 688810 & 6.233 & 5.635 & TRN & & \\
\hline CHEMBL1354290 & 688810 & \multicolumn{3}{|c|}{5.882999999999999} & 5.5022 & \\
\hline CHEMBL1581487 & 688810 & 5.033 & 5.0904 & TRN & & \\
\hline CHEMBL3198282 & 688810 & 4.833 & 4.9766 & TST & & \\
\hline CHEMBL1555580 & 688810 & 4.833 & 5.4331 & TRN & & \\
\hline CHEMBL1965471 & 688810 & \multicolumn{3}{|c|}{4.7330000000000005} & 5.4496 & \\
\hline CHEMBL1563664 & 688810 & 5.683 & 5.438 & TST & & \\
\hline CHEMBL1538399 & 688810 & 5.683 & 4.8702 & TST & & \\
\hline CHEMBL1453723 & 688810 & 5.433 & 6.2126 & TRN & & \\
\hline CHEMBL3145312 & 688810 & \multicolumn{3}{|c|}{6.132999999999999} & 5.2661 & $\mathrm{~T}$ \\
\hline CHEMBL1338747 & 688810 & 4.933 & 5.5614 & TST & & \\
\hline CHEMBL1380712 & 688810 & \multicolumn{3}{|c|}{4.9830000000000005} & 5.0746 & \\
\hline CHEMBL1494788 & 688810 & 5.233 & 5.2273 & TRN & & \\
\hline CHEMBL1 & 688 & \multirow{2}{*}{\multicolumn{3}{|c|}{$\begin{array}{l}4.833 \quad 5.26 \\
5.2829999999999995\end{array}$}} & & \\
\hline CHEMBL13 & 688810 & & & & 5.1365 & $\mathrm{TI}$ \\
\hline CHEMBL1440893 & 688810 & 5.433 & 5.9546 & TRN & & \\
\hline CHEMBL1300843 & 688810 & 4.833 & 5.0928 & TRN & & \\
\hline CHEMBL1344132 & 688810 & 4.833 & 5.1621 & TRN & & \\
\hline CHEMBL3 & 688810 & 4.633 & 5.4651 & TRN & & \\
\hline CHEMBL1405423 & 688810 & \multicolumn{3}{|c|}{4.7330000000000005} & 5.0667 & TRN \\
\hline CHEMBL1558986 & 688810 & \multicolumn{3}{|c|}{5.882999999999999} & 5.1463 & TRN \\
\hline CHEMBL193872 & 688810 & \multicolumn{3}{|c|}{5.832999999999999} & 5.5156 & TRN \\
\hline CHEMBL1324984 & 688810 & \multicolumn{3}{|c|}{4.9830000000000005} & 5.3907 & TRN \\
\hline CHEMBL1412392 & 688810 & 5.683 & 5.3836 & TST & & \\
\hline CHEMBL1321775 & 688810 & 5.233 & 5.3803 & TST & & \\
\hline CHEMBL1392897 & 688810 & 4.833 & 5.6202 & TRN & & \\
\hline CHEMBL3198439 & 688810 & 5.483 & 5.7002 & TRN & & \\
\hline CHEMBL1380341 & 688810 & 5.483 & 5.5165 & TRN & & \\
\hline CHEMBL1568828 & 688810 & 5.083 & 5.3048 & TRN & & \\
\hline CHEMBL1611994 & 688810 & 5.733 & 5.0923 & TST & & \\
\hline CHEMBL1466593 & 688810 & 5.132 & 99999999 & & 5.2273 & $\mathrm{TR}$ \\
\hline CHEMBL3210013 & 688810 & 5.733 & 5.2325 & TRN & & \\
\hline CHEMBL1977734 & 688810 & 4.983 & 00000000 & 005 & 5.4172 & $1 \mathrm{KI}$ \\
\hline CHEMBL1485663 & 688810 & 5.183 & 5.2482 & TRN & & \\
\hline CHEMBL1344180 & 688810 & 5.132 & 9999999 & & 4.8369 & נו \\
\hline
\end{tabular}




\begin{tabular}{|c|c|c|c|c|c|c|}
\hline \multirow{2}{*}{ CHEMBL1301700 } & \multicolumn{6}{|c|}{ 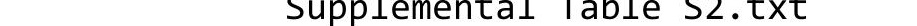 } \\
\hline & 688810 & 4.933 & 4.7819 & TST & & \\
\hline CHEMBL1504658 & 688810 & 4.833 & 5.2982 & TST & & \\
\hline CHEMBL1371834 & 688810 & 4.7330 & 20000000 & 005 & 4.9042 & TRN \\
\hline CHEMBL1555223 & 688810 & 4.7330 & 20000000 & 005 & 5.0736 & TRN \\
\hline CHEMBL1581382 & 688810 & 5.2829 & 99999999 & 995 & 4.6753 & TRN \\
\hline CHEMBL1477805 & 688810 & 4.633 & 5.2463 & TRN & & \\
\hline CHEMBL3198344 & 688810 & 4.783 & 5.3258 & TST & & \\
\hline CHEMBL1434514 & 688810 & 4.633 & 4.7625 & TRN & & \\
\hline CHEMBL563503 & 688810 & 5.2829 & 99999999 & 995 & 5.2119 & TRN \\
\hline CHEMBL1408059 & 688810 & 4.833 & 5.1337 & TRN & & \\
\hline CHEMBL1549290 & 688810 & 5.183 & 5.1427 & TRN & & \\
\hline CHEMBL1327089 & 688810 & 5.683 & 5.42899 & 99999 & 99 & TRN \\
\hline CHEMBL1576330 & 688810 & 4.833 & 5.3511 & TRN & & \\
\hline CHEMBL1467690 & 688810 & 4.7330 & 00000000 & 005 & 5.295 & TRN \\
\hline CHEMBL 3212409 & 688810 & 5.6329 & 99999999 & & 4.9606 & TRN \\
\hline CHEMBL1343988 & 688810 & 4.683 & 5.4316 & TRN & & \\
\hline CHEMBL1444771 & 688810 & 6.3829 & 99999999 & 99 & 5.8428 & TRN \\
\hline CHEMBL3196800 & 688810 & 5.433 & 5.7278 & TRN & & \\
\hline CHEMBL1372905 & 688810 & 5.183 & 5.7085 & TRN & & \\
\hline CHEMBL 3214022 & 688810 & 4.933 & 5.2394 & TRN & & \\
\hline CHEMBL1303884 & 688810 & 5.1329 & 99999999 & & 5.1771 & TRN \\
\hline CHEMBL1387287 & 688810 & 5.033 & 4.8579 & TST & & \\
\hline CHEMBL1472609 & 688810 & 4.633 & 4.8186 & TST & & \\
\hline CHEMBL1342451 & 688810 & 5.3829 & 99999999 & & 5.018 & TRN \\
\hline CHEMBL3194539 & 688810 & 4.883 & 5.3865 & TRN & & \\
\hline CHEMBL1603314 & 688810 & 5.8829 & 99999999 & & 5.4882 & TRN \\
\hline CHEMBL1340573 & 688810 & 4.7330 & 00000000 & 005 & 4.8012 & TST \\
\hline CHEMBL1540897 & 688810 & 4.783 & 4.9253 & TRN & & \\
\hline CHEMBL1509595 & 688810 & 6.0329 & 99999999 & 995 & 5.3557 & TRN \\
\hline CHEMBL1408788 & 688810 & 4.783 & 5.6521 & TRN & & \\
\hline CHEMBL1443113 & 688810 & 5.933 & 5.5735 & TRN & & \\
\hline CHEMBL1332437 & 688810 & 5.483 & 5.1583 & TST & & \\
\hline CHEMBL1493424 & 688810 & 5.683 & 5.0431 & TST & & \\
\hline CHEMBL1559122 & 688810 & 4.833 & 4.874 & TST & & \\
\hline CHEMBL1464490 & 688810 & 5.733 & 5.1841 & TST & & \\
\hline CHEMBL1526488 & 688810 & 5.85 & 5.5252 & TST & & \\
\hline CHEMBL1408789 & 688810 & 5.983 & 5.8431 & TRN & & \\
\hline CHEMBL1602826 & 688810 & 5.1329 & 99999999 & 99 & 5.3644 & TRN \\
\hline CHEMBL1404018 & 688810 & 4.883 & 5.4144 & TRN & & \\
\hline CHEMBL3211021 & 688810 & 5.1329 & 99999999 & & 5.1072 & TST \\
\hline CHEMBL1489757 & 688810 & 4.7330 & $\partial 0000000$ & 005 & 4.6698 & TST \\
\hline CHEMBL1306590 & 688810 & 6.4829 & 6.0202 & TRN & & \\
\hline CHEMBL1425720 & 688810 & 5.5329 & 99999999 & 995 & 5.5364 & TST \\
\hline CHEMBL3192749 & 688810 & 4.933 & 4.9906 & TRN & & \\
\hline CHEMBL1423521 & 688810 & 5.6329 & 99999999 & 99 & 4.7071 & TRN \\
\hline CHEMBL1562462 & 688810 & 4.883 & 4.9123 & TST & & \\
\hline CHEMBL1571483 & 688810 & 6.183 & 6.1108 & TRN & & \\
\hline CHEMBL1504927 & 688810 & 4.883 & 5.0885 & TRN & & \\
\hline
\end{tabular}




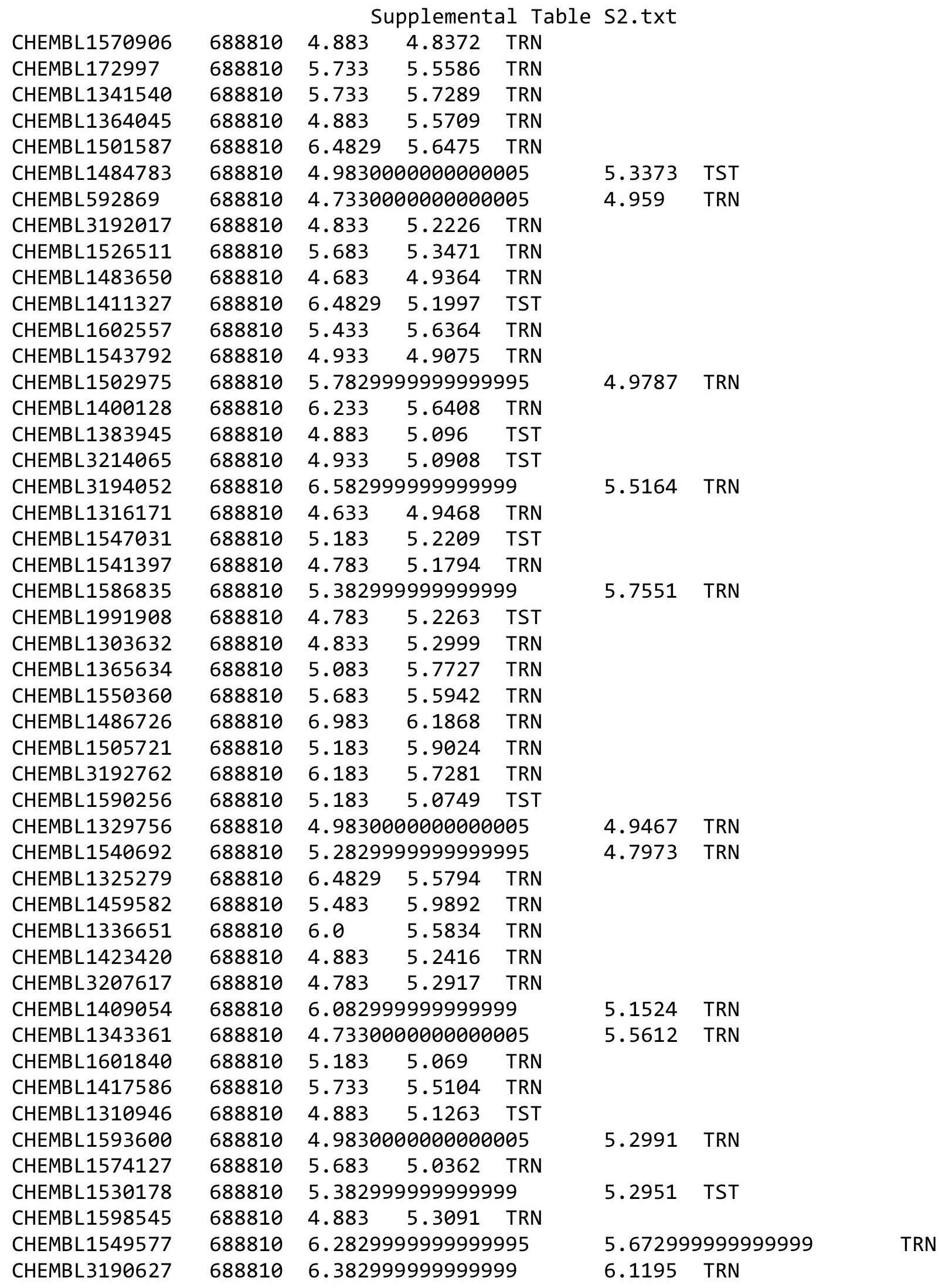




\begin{tabular}{|c|c|c|c|c|c|c|}
\hline & \multicolumn{5}{|c|}{ oplemental Ta } \\
\hline CHEMBL1461508 & 688810 & 4.633 & 5.2657 & TST & & \\
\hline CHEMBL1442361 & 688810 & 4.73300 & 000000000 & 305 & 5.0003 & TST \\
\hline CHEMBL1440656 & 688810 & 4.783 & 5.3874 & TST & & \\
\hline CHEMBL1607947 & 688810 & 4.783 & 5.0187 & TRN & & \\
\hline CHEMBL1590694 & 588810 & 4.783 & 4.9805 & TRN & & \\
\hline CHEMBL1439076 & 688810 & 4.73300 & 000000000 & 005 & 5.273 & TST \\
\hline CHEMBL3212666 & 688810 & 5.78299 & 999999999 & 995 & 5.0831 & \\
\hline CHEMBL1383152 & 688810 & 4.783 & 4.7718 & TST & & \\
\hline CHEMBL1520731 & 688810 & 5.78299 & 999999999 & 995 & 5.3836 & \\
\hline CHEMBL1487582 & 688810 & 5.733 & 5.4034 & TRN & & \\
\hline CHEMBL1391090 & 688810 & 4.883 & 5.0757 & TST & & \\
\hline CHEMBL1454626 & 688810 & 4.633 & 4.943000 & 300000000 & 305 & \\
\hline CHEMBL1543952 & 688810 & 5.13299 & 999999999 & & 5.1 & \\
\hline CHEMBL1460837 & 688810 & 5.483 & 5.5534 & TRN & & \\
\hline CHEMBL3198715 & 688810 & 5.28299 & 999999999 & 995 & 5.0923 & \\
\hline CHEMBL1418432 & 688810 & 5.483 & 5.3121 & TST & & \\
\hline CHEMBL1523638 & 688810 & 5.28299 & 999999999 & 995 & 5.3426 & TRN \\
\hline CHEMBL1378912 & 688810 & 6.33299 & 999999999 & & 5.7589 & TST \\
\hline CHEMBL1489601 & 688810 & 5.683 & 5.7311 & TRN & & \\
\hline CHEMBL144 & 688810 & 4.933 & 5.6448 & TST & & \\
\hline CHEMBL1573125 & 688810 & 5.233 & 5.5474 & TRN & & \\
\hline CHEMBL1470269 & 688810 & 6.28299 & 999999999 & 995 & 5.3065 & TR \\
\hline CHEMBL1410006 & 688810 & 7.1331 & 5.9632 & TRN & & \\
\hline CHEMBL 1 & 688 & 4.933 & 5.2986 & TRN & & \\
\hline CHEMBL1399794 & 688810 & 5.483 & 5.3533 & TRN & & \\
\hline CHEMBL1352690 & 688810 & 6.38299 & 999999999 & & 3605 & TR \\
\hline CHEMBL1213771 & 688810 & 4.933 & 5.1885 & TRN & & \\
\hline CHEMBL1385662 & 688810 & 5.58299 & 999999999 & & 4.9941 & \\
\hline CHEMBL13. & 688810 & 5.733 & 5.3293 & TRN & & \\
\hline CHEMBL1397745 & 688810 & 5.83299 & 999999999 & & 5.2016 & TRN \\
\hline CHEMBL1581508 & 688810 & 4.73300 & 000000000 & 305 & 474 & TS \\
\hline CHEMBL1392984 & 688810 & 4.783 & 5.3066 & TST & & \\
\hline CHEMBL1598552 & 688810 & 4.883 & 5.4565 & TRN & & \\
\hline CHEMBL14 & 688 & 4.73300 & 000000000 & 305 & 5.3711 & I KIV \\
\hline CHEMBL1565441 & 688810 & 6.58299 & 999999999 & & 5.9307 & TRN \\
\hline CHEMBL1529331 & 688810 & 4.833 & 5.0289 & TST & & \\
\hline CHEMBL1579918 & 688810 & 5.733 & 5.242000 & 300000000 & & In \\
\hline CHEMBL 3199840 & 688810 & 4.833 & 5.0021 & TRN & & \\
\hline CHEMBL1419965 & 688810 & 5.433 & 5.0832 & TRN & & \\
\hline CHEMBL1343311 & 688810 & 6.433 & 5.9969 & TRN & & \\
\hline CHEMBL1463374 & 688810 & 4.883 & 5.1378 & TRN & & \\
\hline CHEMBL3192560 & 688810 & 4.683 & 5.4384 & TRN & & \\
\hline CHEMBL1349292 & 688810 & 5.83299 & 999999999 & & 5.5805 & TST \\
\hline CHEMBL1493796 & 688810 & 5.033 & 5.1128 & TRN & & \\
\hline CHEMBL1303684 & 688810 & 4.783 & 5.4055 & TRN & & \\
\hline CHEMBL1550800 & 688810 & 7.1831 & 6.1235 & TRN & & \\
\hline CHEMBL1328930 & 688810 & 6.33299 & 999999999 & & 5.5211 & I KI \\
\hline CHEMBL 3189873 & 688810 & 4.783 & 4.8819 & TST & & \\
\hline
\end{tabular}




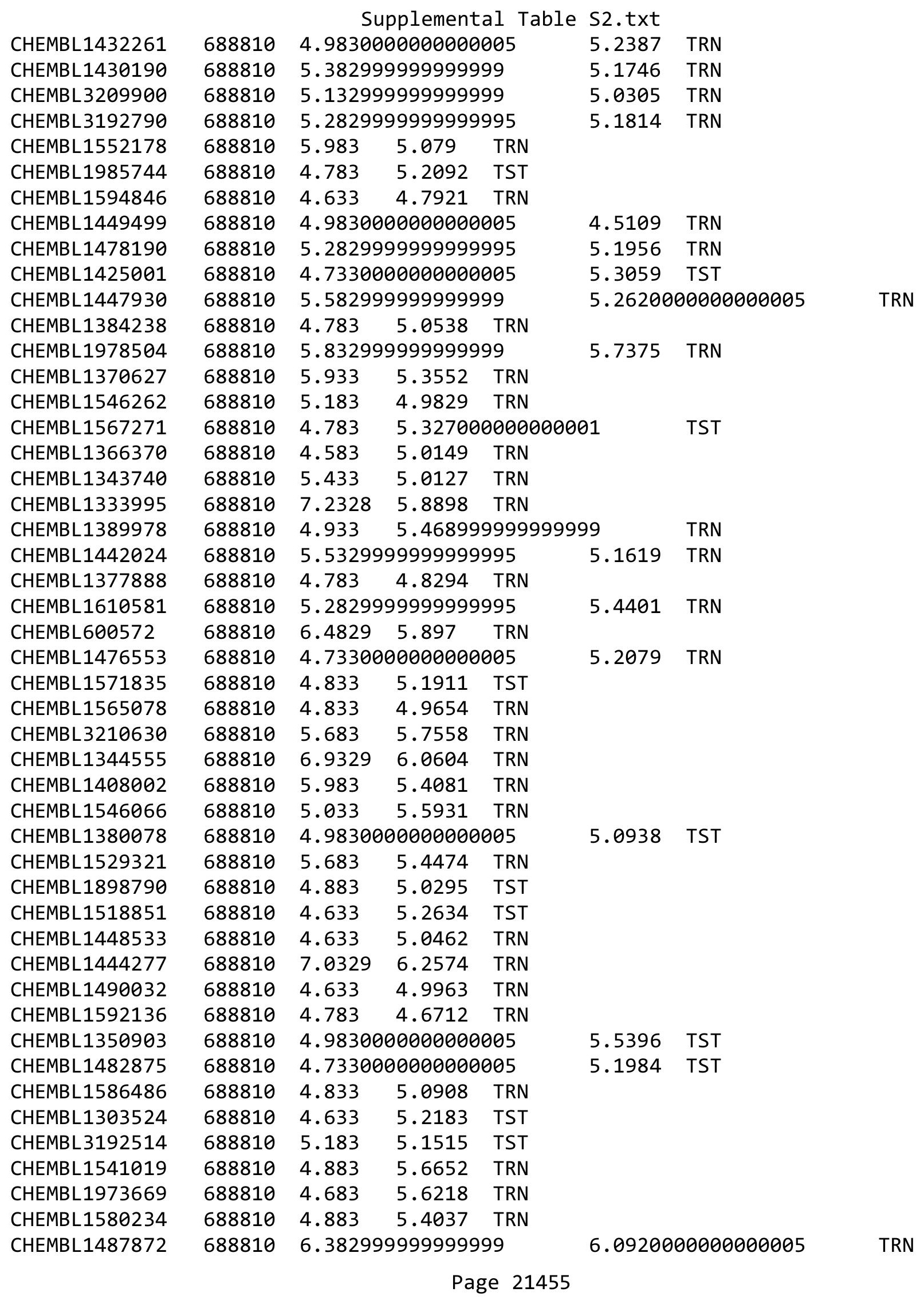




\begin{tabular}{|c|c|c|c|c|c|c|}
\hline \multirow{3}{*}{$\begin{array}{l}\text { CHEMBL1337299 } \\
\text { CHEMBL1597869 }\end{array}$} & \multirow{3}{*}{$\begin{array}{l}688810 \\
688810\end{array}$} & \multicolumn{5}{|c|}{ Supplemental Table S2.txt } \\
\hline & & \multicolumn{3}{|c|}{4.7330000000000005} & \multirow[t]{3}{*}{5.1473} & \multirow[t]{3}{*}{ TRN } \\
\hline & & 6.433 & 5.3245 & TRN & & \\
\hline CHEMBL1300305 & 688810 & 4.783 & 5.0667 & TRN & & \\
\hline CHEMBL417727 & 688810 & \multicolumn{3}{|c|}{5.382999999999999} & \multirow[t]{3}{*}{5.4102} & \multirow[t]{2}{*}{ TRN } \\
\hline CHEMBL1336032 & 688810 & 4.583 & 5.0061 & TRN & & \\
\hline CHEMBL1504415 & 688810 & 5.233 & 5.1466 & TRN & & \\
\hline CHEMBL1424463 & 688810 & \multicolumn{3}{|c|}{5.132999999999999} & \multirow[t]{2}{*}{5.032} & \multirow[t]{2}{*}{ TRN } \\
\hline CHEMBL1604921 & 688810 & 4.883 & 4.8912 & TRN & & \\
\hline CHEMBL1503325 & 688810 & \multicolumn{3}{|c|}{6.382999999999999} & \multirow[t]{2}{*}{6.3195} & \\
\hline CHEMBL1556863 & 688810 & 4.883 & 5.1475 & TST & & \\
\hline CHEMBL1501528 & 688810 & \multicolumn{3}{|c|}{5.7829999999999995} & \multirow[t]{3}{*}{5.4356} & \\
\hline CHEMBL1309645 & 688810 & 4.633 & 5.0334 & TST & & \\
\hline CHEMBL1383180 & 688810 & 4.833 & 4.8698 & TRN & & \\
\hline CHEMBL1506967 & 688810 & \multicolumn{3}{|c|}{5.5329999999999995} & \multirow[t]{2}{*}{4.7416} & \\
\hline CHEMBL1338085 & 688810 & 5.233 & 5.8294 & TRN & & \\
\hline CHEMBL1445954 & 688810 & \multicolumn{3}{|c|}{4.9830000000000005} & \multirow[t]{3}{*}{4.7907} & \\
\hline CHEMBL1476282 & 688810 & 4.833 & 5.6386 & TRN & & \\
\hline CHEMBL1444417 & 688810 & 4.933 & 5.4535 & TRN & & \\
\hline CHEMBL1360165 & 688810 & 5.7829 & 99999999 & 995 & 5.2021 & \\
\hline CHEMBL1322054 & 688810 & 5.3329 & 99999999 & & 5.6513 & \\
\hline CHEMBL1496045 & 688810 & 4.7336 & 00000000 & 005 & 5.2624 & \\
\hline CHEMBL1437230 & 688810 & 4.833 & 5.0734 & TRN & & \\
\hline CHEMBL1557016 & 688810 & 5.183 & 5.5241 & TRN & & \\
\hline CHEMBL1510958 & 688810 & 5.683 & 5.3546 & TRN & & \\
\hline CHEMBL1520582 & 688810 & 5.6329 & 99999999 & & 5.5402 & \\
\hline CHEMBL1382027 & 688810 & 5.6329 & 99999999 & & 5.4906 & \\
\hline CHEMBL1534927 & 688810 & 4.7336 & 00000000 & 005 & 5.3708 & \\
\hline CHEMBL544584 & 688810 & 5.083 & 5.1259 & TRN & & \\
\hline CHEMBL1478629 & 688810 & 6.433 & 5.3292 & TRN & & \\
\hline CHEMBL1503623 & 688810 & 5.7829 & 99999999 & 995 & 5.2564 & \\
\hline CHEMBL1582340 & 688810 & 4.783 & 5.2436 & TRN & & \\
\hline CHEMB & 688 & 6.0 & 5.0309 & TRN & & \\
\hline CHEMBL1528795 & 688810 & 4.7336 & 00000000 & 005 & 5.0291 & \\
\hline CHEMBL1555030 & 688810 & 4.783 & 4.865 & TRN & & \\
\hline CHEMBL1602564 & 688810 & 5.3829 & 99999999 & & $3.2<47$ & \\
\hline CHEMBL1491844 & 688810 & 5.28 & 99999999 & 995 & 5.3872 & \\
\hline CHEMBL1322076 & 688810 & 8.3372 & 5.8952 & TRN & & \\
\hline CHEMBL1540493 & 688810 & 5.5320 & 99999999 & 995 & 5.1513 & \\
\hline CHEMBL1422046 & 688810 & 5.433 & 5.9014 & TRN & & \\
\hline CHEMBL1556289 & 688810 & 5.683 & 5.4536 & TRN & & \\
\hline CHEMBL1586235 & 688810 & 5.433 & 5.2434 & TRN & & \\
\hline CHEMBL1546464 & 688810 & 4.883 & 5.3942 & TRN & & \\
\hline CHEMBL1555091 & 688810 & 4.583 & 4.713 & TRN & & \\
\hline CHEMBL3193661 & 688810 & 5.483 & 5.6748 & TRN & & \\
\hline CHEMBL1497557 & 688810 & 6.6329 & 99999999 & & 5.4695 & \\
\hline CHEMBL1608952 & 688810 & 6.3829 & 99999999 & & 5.8563 & \\
\hline CHEMBL1334223 & 688810 & 5.1320 & 99999999 & & 5.3177 & $\mathrm{TR}$ \\
\hline CHEMBL1513728 & 688810 & 4.7336 & 00000000 & 005 & 4.8227 & TRI \\
\hline
\end{tabular}




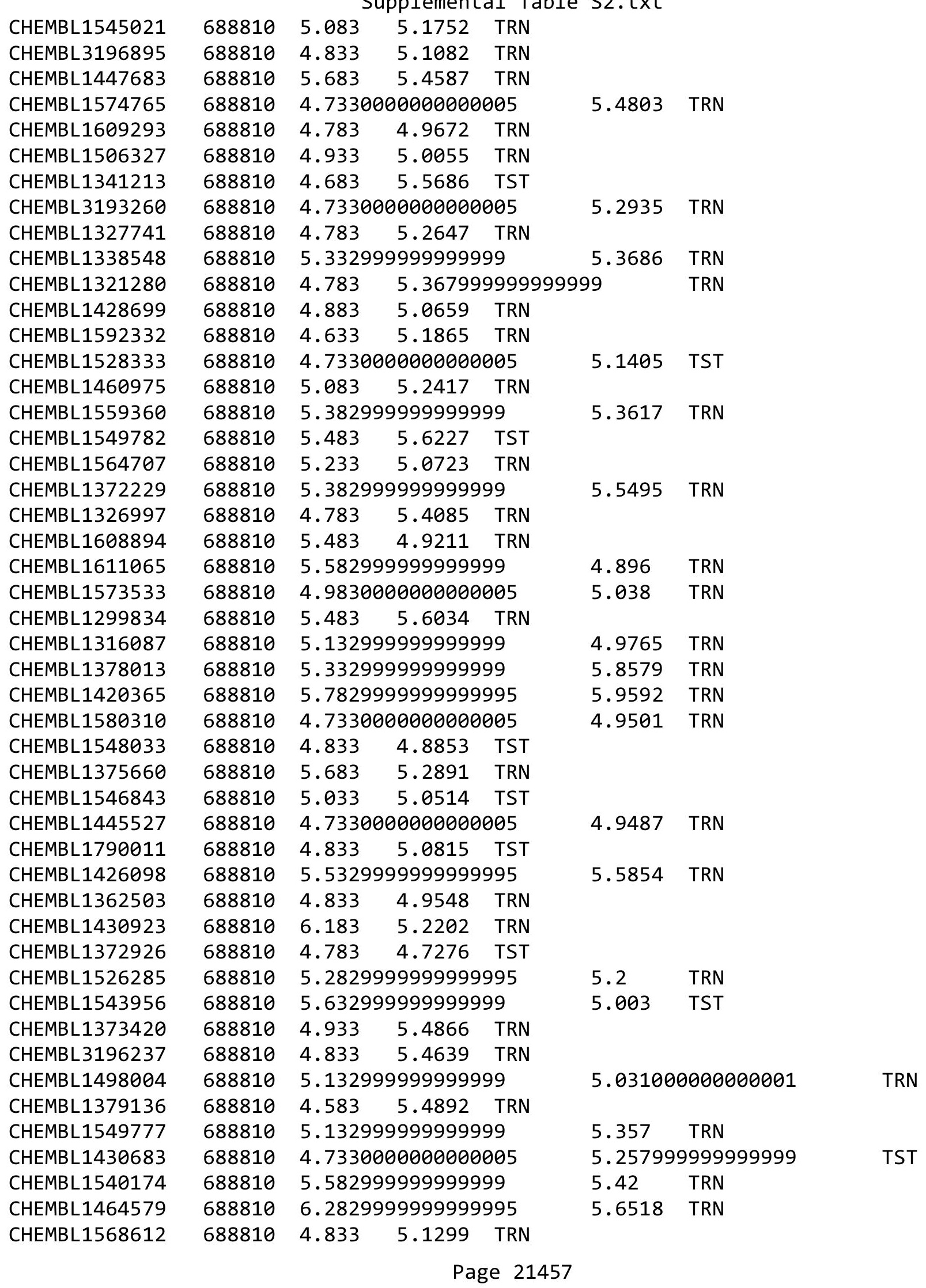




\begin{tabular}{|c|c|c|c|c|c|c|}
\hline \multirow[b]{2}{*}{ CHEMBL1324690 } & \multicolumn{6}{|c|}{ Supplemental Ta } \\
\hline & 688810 & 4.683 & 5.0814 & TRN & & \\
\hline CHEMBL1613429 & 688810 & 4.583 & 4.9914 & TST & & \\
\hline CHEMBL1364954 & 688810 & 4.73300 & 000000006 & 005 & 5.2475 & TRN \\
\hline CHEMBL1367032 & 688810 & 4.73300 & 000000006 & 005 & 4.6611 & \\
\hline CHEMBL1567235 & 688810 & 4.98300 & 000000000 & 005 & 5.2592 & \\
\hline CHEMBL1532501 & 688810 & 6.03299 & 999999999 & 995 & 5.3668 & \\
\hline CHEMBL 3213402 & 688810 & 4.73300 & 000000006 & 005 & 5.2957 & \\
\hline CHEMBL1409202 & 688810 & 4.633 & 4.8149 & TST & & \\
\hline CHEMBL1513354 & 688810 & 5.33299 & 999999999 & & 5.5054 & \\
\hline CHEMBL1491296 & 688810 & 4.73300 & 000000000 & 005 & 5.1439 & \\
\hline CHEMBL1500749 & 688810 & 5.733 & 4.968 & TST & & \\
\hline CHEMBL1377059 & 688810 & 4.833 & 4.883999 & 99999 & 995 & \\
\hline CHEMBL 3191670 & 688810 & 4.73300 & 000000000 & 005 & 5.4089 & \\
\hline CHEMBL1573981 & 688810 & 5.183 & 5.3677 & TRN & & \\
\hline CHEMBL1523640 & 688810 & 6.58299 & 999999999 & & 5.7092 & \\
\hline CHEMBL1484093 & 688810 & 5.28299 & 999999999 & 995 & 5.0608 & \\
\hline CHEMBL1429432 & 688810 & 6.9329 & 5.8795 & TST & & \\
\hline CHEMBL1437014 & 688810 & 4.633 & 5.6694 & TRN & & \\
\hline CHEMBL1525161 & 688810 & 6.183 & 5.3168 & TRN & & \\
\hline CHEMBL1419772 & 688810 & 4.833 & 4.8917 & TST & & \\
\hline CHEMBL1342602 & 688810 & 5.78299 & 999999999 & 995 & 5.7161 & \\
\hline CHEMBL1570216 & 688810 & 4.5 & 6.8015 & TRN & & \\
\hline CHEMBL1327916 & 688810 & 4.73300 & 000000000 & 005 & 978 & \\
\hline CHEMBL1341132 & 688810 & 4.98300 & 000000006 & 005 & 5.6616 & \\
\hline CHEMBL1442788 & 688810 & 5.083 & 5.2098 & TST & & \\
\hline CHEMBL 3193476 & 688810 & 4.883 & 5.4163 & TRN & & \\
\hline CHEMBL1593396 & 688810 & 4.883 & 4.9375 & TRN & & \\
\hline CHEMBL1311194 & 688810 & 6.4829 & 5.4467 & TRN & & \\
\hline CHEMBL1354470 & 688810 & 5.83299 & 999999999 & & 5.8574 & \\
\hline CHEMBL1527214 & 688810 & 5.483 & 6.1576 & TRN & & \\
\hline CHEMBL1443770 & 688810 & 5.733 & 5.5471 & TRN & & \\
\hline CHEMBL1537520 & 688810 & 4.73300 & 000000000 & 005 & 5.0043 & \\
\hline CHEMBL1420410 & 688810 & 4.833 & 4.8637 & TRN & & \\
\hline CHEMBL1436964 & 688810 & 5.28299 & 999999999 & 995 & 4.7464 & कातार \\
\hline CHEMBL1541239 & 688810 & 6.03299 & 999999999 & 995 & 5.2687 & \\
\hline CHEMBL1397866 & 688810 & 4.73300 & 000000000 & 005 & 4.8557 & $T$ \\
\hline CHEMBL1389850 & 688810 & 6.183 & 5.2022 & TRN & & \\
\hline CHEMBL1499026 & 688810 & 6.8831 & 5.3313 & TST & & \\
\hline CHEMBL1366592 & 688810 & 5.483 & 5.5084 & TRN & & \\
\hline CHEMBL1339737 & 688810 & 4.73300 & 000000000 & 205 & 5.5758 & \\
\hline CHEMBL1517587 & 688810 & 4.833 & 5.441 & TRN & & \\
\hline CHEMBL1319973 & 688810 & 5.83299 & 999999999 & & 5.4942 & TIN \\
\hline CHEMBL1588270 & & 4.583 & 5.2944 & TRN & & \\
\hline CHEMBL1469111 & 688810 & 5.183 & 5.5331 & TRN & & \\
\hline CHEMBL1495176 & 688810 & 5.78299 & 999999999 & 995 & 5.2533 & T. \\
\hline CHEMBL1423047 & 688810 & 5.183 & 5.8137 & TRN & & \\
\hline CHEMBL1424475 & 688810 & 5.183 & 5.2123 & TST & & \\
\hline CHEMBL1385207 & 688810 & 4.783 & 5.4702 & TRN & & \\
\hline
\end{tabular}




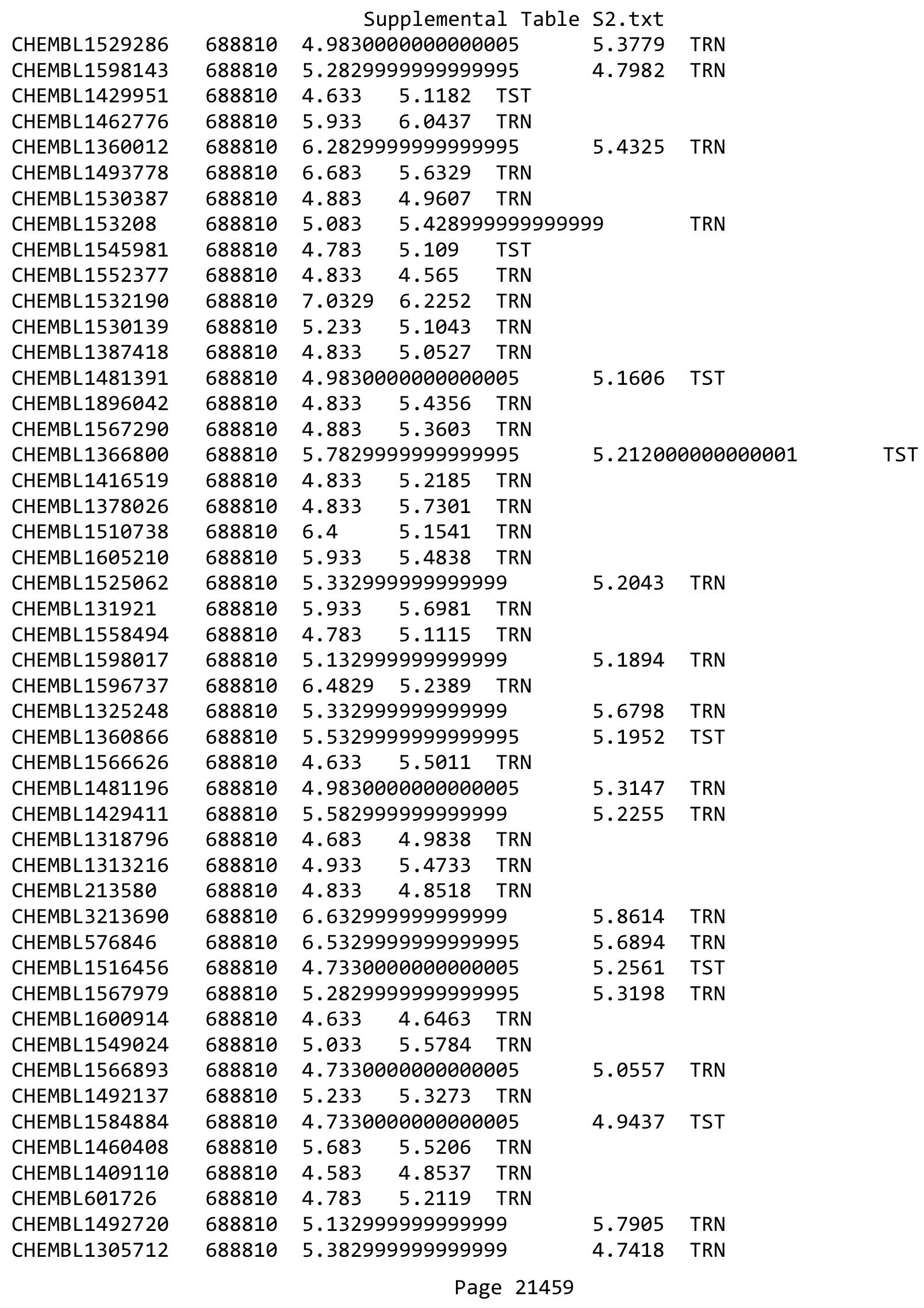




\begin{tabular}{|c|c|c|c|c|c|c|}
\hline \multirow{3}{*}{$\begin{array}{l}\text { CHEMBL1488092 } \\
\text { CHFMBI } 1464482\end{array}$} & \multirow[b]{2}{*}{688810} & \multicolumn{5}{|c|}{ Supplemental Table S2.txt } \\
\hline & & 4.783 & \multicolumn{3}{|c|}{5.553999999999999} & TST \\
\hline & 688810 & \multicolumn{3}{|c|}{6.582999999999999} & 5.5194 & TST \\
\hline CHEMBL1411072 & 688810 & \multicolumn{3}{|c|}{4.7330000000000005} & 5.5106 & TRN \\
\hline CHEMBL1434662 & 688810 & \multicolumn{3}{|c|}{6.382999999999999} & 5.8176 & TRN \\
\hline CHEMBL1427221 & 688810 & 5.483 & 5.3333 & TRN & & \\
\hline CHEMBL1450992 & 688810 & 5.933 & 5.6537 & TRN & & \\
\hline CHEMBL1605973 & 688810 & 4.833 & 4.9845 & TST & & \\
\hline CHEMBL1473991 & 88810 & 4.833 & 5.1436 & TRN & & \\
\hline CHEMBL1524471 & 688810 & 4.883 & 4.9115 & TRN & & \\
\hline CHEMBL1331520 & 688810 & 5.183 & 5.1794 & TST & & \\
\hline CHEMBL 393244 & 588810 & 6.683 & 5.8798 & TRN & & \\
\hline CHEMBL1420515 & 688810 & \multicolumn{3}{|c|}{4.9830000000000005} & 5.1931 & \\
\hline CHEMBL1375689 & 688810 & \multicolumn{3}{|c|}{4.7330000000000005} & & \\
\hline CHEMBL578512 & 688810 & 5.233 & 5.5237 & TRN & & \\
\hline CHEMBL1565533 & 688810 & \multicolumn{3}{|c|}{4.7330000000000005} & 5.7178 & 11 \\
\hline CHEMBL1378286 & 688810 & 4.883 & 4.8622 & TRN & & \\
\hline CHEMBL1328865 & 688810 & 5.733 & 5.6098 & TRN & & \\
\hline CHEMBL32: & 688810 & \multicolumn{3}{|c|}{5.7829999999999995} & 5.2111 & TRN \\
\hline CHEMBL13 & 688810 & \multicolumn{3}{|c|}{4.9830000000000005} & 4.7027 & \\
\hline CHEMBL1509469 & 688810 & 4.833 & 5.2178 & TRN & & \\
\hline CHEMBL1329107 & 688810 & \multicolumn{3}{|c|}{6.382999999999999} & 59 & TST \\
\hline CHEMBL161 & 688810 & \multicolumn{3}{|c|}{4.7330000000000005} & & \\
\hline CHEMBL13 & 688810 & 6.433 & 6.0016 & TRN & & \\
\hline CHEMBL15 & 688810 & \multicolumn{3}{|c|}{5.632999999999999} & 122 & TR \\
\hline CHEMBL137 & 688810 & 4.883 & 5.2549 & TRN & & \\
\hline CHEMBL1419939 & 688810 & 4.783 & 5.2529 & TRN & & \\
\hline CHEMBL1 & 688810 & 4.633 & 5.0965 & TRN & & \\
\hline CHEMBL1 & 688810 & 4.833 & 5.4761 & TRN & & \\
\hline CHEMBL14e & 688810 & \multicolumn{3}{|c|}{4.9830000000000005} & 5.745 & $\mathrm{TI}$ \\
\hline CHEMBL321 & 688810 & \multicolumn{3}{|c|}{5.832999999999999} & 297 & TP \\
\hline CHEMBL1399193 & 688810 & \multicolumn{3}{|c|}{6.5329999999999995} & 843 & $\mathrm{TI}$ \\
\hline CHEMBL1 & 688 & \multicolumn{3}{|c|}{4.9830000000000005} & & ונדו \\
\hline CHEMBL 32 & 688810 & \multicolumn{3}{|c|}{4.7330000000000005} & 4.5509 & TST \\
\hline CHEMBL1599558 & 688810 & 4.783 & 5.4944 & TRN & & \\
\hline CHEMBL1490152 & 688810 & \multicolumn{3}{|c|}{5.5329999999999995} & & TP \\
\hline CHEMBL1564261 & 688810 & 6.5325 & 99999999 & 995 & & $\mathrm{TH}$ \\
\hline CHEMBL15£ & 688810 & 6.03 & 99999999 & & & ТК \\
\hline CHEMBL1575407 & 688810 & 4.7336 & 0000000 & 005 & 5.1733 & TRN \\
\hline CHEMBL1382938 & 688810 & 5.132 & 99999995 & & 4.945 & TRN \\
\hline CHEMBL3196749 & 688810 & 6.3325 & 9999999 & & 5.2301 & TST \\
\hline CHEMBL3191198 & 688810 & 5.183 & 5.2226 & TRN & & \\
\hline CHEMBL1338745 & 688810 & 5.132 & 9999999 & & & TST \\
\hline CHEMBL1489126 & 688810 & 4.9836 & 0000000 & 005 & 5.0255 & TRN \\
\hline CHEMBL1547970 & 688810 & 4.7336 & 00000006 & 005 & 5.1215 & TST \\
\hline CHEMBL1375492 & 688810 & 4.7336 & 00000006 & 005 & 5.3644 & TRN \\
\hline CHEMBL1514096 & 688810 & 5.532 & 99999995 & 995 & 5.1747 & TS \\
\hline CHEMBL1498673 & 688810 & 5.433 & 5.1943 & TRN & & \\
\hline CHEMBL1418545 & 688810 & 5.782 & 9999999 & 95 & 5.0905 & 3 \\
\hline
\end{tabular}




\begin{tabular}{|c|c|c|c|c|c|c|}
\hline \multirow{3}{*}{$\begin{array}{l}\text { CHEMBL1601222 } \\
\text { CHEMBL1409856 }\end{array}$} & \multicolumn{5}{|c|}{ Supplemental Table S2.txt } & \multirow[b]{2}{*}{ TRN } \\
\hline & 688810 & \multicolumn{4}{|c|}{$4.7330000000000005 \quad 5.1077$} & \\
\hline & 688810 & 4.783 & 5.13297 & TRN & & \\
\hline CHEMBL1330583 & 688810 & \multicolumn{3}{|c|}{7.082999999999999} & 6.1711 & TRN \\
\hline CHEMBL1496367 & 688810 & 4.883 & 5.27337 & TST & & \\
\hline CHEMBL1501051 & 688810 & 5.233 & 5.35137 & TRN & & \\
\hline CHEMBL3190294 & 688810 & \multicolumn{3}{|c|}{4.7330000000000005} & 5.0668 & TRN \\
\hline CHEMBL1485458 & 688810 & 5.083 & 5.54077 & TRN & & \\
\hline CHEMBL1366622 & 688810 & 4.783 & 5.26667 & TRN & & \\
\hline CHEMBL1410773 & 688810 & 5.183 & \multicolumn{3}{|c|}{5.3229999999999995} & TST \\
\hline CHEMBL580324 & 688810 & \multicolumn{3}{|c|}{5.632999999999999} & 5.7067 & TST \\
\hline CHEMBL1450094 & 688810 & 4.633 & 5.346 & TRN & & \\
\hline CHEMBL1348011 & 688810 & \multicolumn{3}{|c|}{6.082999999999999} & 5.6915 & TRN \\
\hline CHEMBL1386616 & 688810 & \multicolumn{3}{|c|}{5.332999999999999} & 5.3283 & TRN \\
\hline CHEMBL1530943 & 688810 & \multicolumn{3}{|c|}{6.382999999999999} & 6.6584 & TRN \\
\hline CHEMBL1515197 & 688810 & 4.633 & 4.98147 & TRN & & \\
\hline CHEMBL1543433 & 688810 & 4.783 & \multicolumn{3}{|c|}{5.3260000000000005} & TST \\
\hline CHEMBL1450335 & 688810 & 5.983 & 5.3397 & TRN & & \\
\hline CHEMBL1447796 & 688810 & 4.783 & 5.09227 & TST & & \\
\hline CHEMBL1531268 & 688810 & \multicolumn{3}{|c|}{5.132999999999999} & 5.2905 & TRN \\
\hline CHEMBL1383379 & 688810 & 5.733 & 5.9151 & TRN & & \\
\hline CHEMBL1545267 & 688810 & \multicolumn{3}{|c|}{5.132999999999999} & 4.9472 & TRN \\
\hline CHEMBL1570359 & 688810 & \multicolumn{3}{|c|}{5.2829999999999995} & 4.9332 & TRN \\
\hline CHEMBL1572642 & 688810 & 5.033 & 4.84467 & TST & & \\
\hline CHEMBL1408596 & 688810 & 4.833 & 4.64517 & TRN & & \\
\hline CHEMBL1368480 & 688810 & \multicolumn{3}{|c|}{4.7330000000000005} & 5.2413 & TRN \\
\hline CHEMBL3196718 & 688810 & 5.433 & 5.59 & TRN & & \\
\hline CHEMBL1517690 & 688810 & \multicolumn{3}{|c|}{4.7330000000000005} & 4.8306 & TRN \\
\hline CHEMBL1523707 & 688810 & 5.083 & 5.17897 & TRN & & \\
\hline CHEMBL1570904 & 688810 & 5.083 & 4.90197 & TRN & & \\
\hline CHEMBL1529019 & 688810 & \multicolumn{3}{|c|}{5.132999999999999} & 5.6438 & TRN \\
\hline CHEMBL3194109 & 688810 & 5.083 & 5.42057 & TRN & & \\
\hline CHEMBL1437454 & 688810 & 4.833 & 4.94467 & TRN & & \\
\hline CHEMBL1533234 & 688810 & 4.933 & 5.2917 & TST & & \\
\hline CHEMBL1604546 & 688810 & 4.833 & \multicolumn{3}{|c|}{4.8180000000000005} & TST \\
\hline CHEMBL1363829 & 688810 & \multicolumn{3}{|c|}{5.882999999999999} & 5.5369 & TRN \\
\hline CHEMBL1331593 & 688810 & 5.933 & 4.8101 & TRN & & \\
\hline CHEMBL3207466 & 688810 & 5.983 & \multicolumn{3}{|c|}{5.593999999999999} & TRN \\
\hline CHEMBL581910 & 688810 & 5.733 & 4.97987 & TRN & & \\
\hline CHEMBL1524487 & 688810 & 4.883 & 5.1818 & TST & & \\
\hline CHEMBL1547873 & 688810 & 5.083 & 5.04737 & TST & & \\
\hline CHEMBL1372051 & 688810 & 4.783 & 5.1156 & TRN & & \\
\hline CHEMBL1494676 & 688810 & 6.1329 & 999999999 & & 5.5264 & TRN \\
\hline CHEMBL3210383 & 688810 & 4.633 & 5.0333 & TRN & & \\
\hline CHEMBL1368149 & 688810 & 5.1329 & 999999999 & & 5.2796 & TRN \\
\hline CHEMBL1327755 & 688810 & 4.783 & 5.0279 & TRN & & \\
\hline CHEMBL339587 & 688810 & 4.933 & 5.294 & TRN & & \\
\hline CHEMBL1516956 & 688810 & 4.7330 & 000000000 & 305 & 5.49299 & 9999999999 \\
\hline CHEMBL1528843 & 688810 & 5.483 & 5.2372 & TRN & & \\
\hline
\end{tabular}


Supplemental Table S2.txt

\begin{tabular}{|c|c|c|c|c|c|c|}
\hline CHEMBL1538292 & 688810 & 5.083 & \multicolumn{3}{|c|}{5.297000000000001} & \multirow[t]{2}{*}{ TRN } \\
\hline CHEMBL1557130 & 688810 & 4.783 & 5.2695 & TRN & & \\
\hline CHEMBL1602449 & 688810 & 6.433 & 5.636 & TRN & & \\
\hline CHEMBL1540986 & 688810 & \multicolumn{3}{|c|}{5.132999999999999} & 5.2324 & TRN \\
\hline CHEMBL1359054 & 688810 & \multicolumn{3}{|c|}{5.5329999999999995} & 5.3074 & TST \\
\hline CHEMBL1362660 & 688810 & \multicolumn{3}{|c|}{5.5329999999999995} & 5.3195 & TST \\
\hline CHEMBL1417554 & 688810 & \multicolumn{3}{|c|}{5.582999999999999} & 5.7325 & TRN \\
\hline CHEMBL3199914 & 688810 & \multicolumn{3}{|c|}{5.132999999999999} & 5.3885 & TRN \\
\hline CHEMBL1544911 & 688810 & \multicolumn{3}{|c|}{4.7330000000000005} & 5.2367 & TST \\
\hline CHEMBL1299726 & 688810 & 4.783 & 5.2348 & TRN & & \\
\hline CHEMBL3191671 & 688810 & 5.083 & 5.4152 & TRN & & \\
\hline CHEMBL1409289 & 688810 & \multicolumn{3}{|c|}{4.9830000000000005} & 5.3577 & TRN \\
\hline CHEMBL1467611 & 688810 & \multicolumn{3}{|c|}{4.9830000000000005} & 5.1829 & TRN \\
\hline CHEMBL1368809 & 688810 & \multicolumn{3}{|c|}{4.7330000000000005} & \multicolumn{2}{|c|}{5.3260000000000005} \\
\hline CHEMBL1448776 & 688810 & 5.733 & 5.3995 & TRN & & \\
\hline CHEMBL3190714 & 688810 & \multicolumn{3}{|c|}{5.382999999999999} & 5.2857 & TST \\
\hline CHEMBL1594404 & 688810 & \multicolumn{3}{|c|}{4.7330000000000005} & 5.0768 & TST \\
\hline CHEMBL8950 & 688810 & 4.633 & 5.6279 & TST & & \\
\hline CHEMBL1567170 & 688810 & \multicolumn{3}{|c|}{5.7829999999999995} & 5.5157 & TRN \\
\hline CHEMBL1314951 & 688810 & 4.583 & 4.702 & TRN & & \\
\hline CHEMBL1557761 & 688810 & 5.183 & 5.3182 & TRN & & \\
\hline CHEMBL1383277 & 688810 & \multicolumn{3}{|c|}{4.7330000000000005} & 5.5305 & TRN \\
\hline CHEMBL1595549 & 688810 & 5.683 & 5.0861 & TST & & \\
\hline CHEMBL1320794 & 688810 & 5.033 & 6.3491 & TRN & & \\
\hline CHEMBL1979295 & 688810 & 6.683 & 5.5815 & TRN & & \\
\hline CHEMBL1473887 & 688810 & \multicolumn{3}{|c|}{4.9830000000000005} & 5.3589 & TRN \\
\hline CHEMBL3196845 & 688810 & 4.833 & 5.5864 & TRN & & \\
\hline CHEMBL1560630 & 688810 & \multicolumn{3}{|c|}{5.5329999999999995} & 5.26 & TST \\
\hline CHEMBL1398826 & 688810 & 4.633 & 5.1008 & TST & & \\
\hline CHEMBL1521754 & 688810 & \multicolumn{3}{|c|}{5.2829999999999995} & 5.3174 & TST \\
\hline CHEMBL1427421 & 688810 & 5.033 & 5.4487 & TRN & & \\
\hline CHEMBL1610863 & 688810 & \multicolumn{3}{|c|}{5.7829999999999995} & 5.4304 & TRN \\
\hline CHEMBL1549537 & 688810 & \multicolumn{3}{|c|}{4.7330000000000005} & 5.5088 & TST \\
\hline CHEMBL1372428 & 688810 & \multicolumn{3}{|c|}{6.632999999999999} & 6.2011 & TRN \\
\hline CHEMBL1412714 & 688810 & 5.033 & 5.1443 & TRN & & \\
\hline CHEMBL1519891 & 688810 & 4.583 & 4.9726 & TRN & & \\
\hline CHEMBL1443873 & 688810 & 5.63299 & 99999999 & & 5.6695 & TRN \\
\hline CHEMBL1300242 & 688810 & 4.633 & 4.8493 & TRN & & \\
\hline CHEMBL1428507 & 688810 & 4.633 & 4.8638 & TRN & & \\
\hline CHEMBL1441911 & 688810 & 4.833 & 5.2427 & TST & & \\
\hline CHEMBL1400921 & 688810 & 4.883 & 4.8497 & TRN & & \\
\hline CHEMBL3208820 & 688810 & 5.033 & 4.8919 & TRN & & \\
\hline CHEMBL1575565 & 688810 & 4.833 & 5.1232 & TST & & \\
\hline CHEMBL1398812 & 688810 & $4.7330 e$ & 00000000 & 005 & 5.1385 & TST \\
\hline CHEMBL1420593 & 688810 & 6.28299 & 99999999 & 995 & 5.9547 & TRN \\
\hline CHEMBL582030 & 688810 & 5.38299 & 99999999 & & 5.1272 & TRN \\
\hline CHEMBL569750 & 688810 & 4.833 & 5.316 & TST & & \\
\hline CHEMBL1480615 & 688810 & 5.33299 & 99999999 & & 5.1017 & TRN \\
\hline
\end{tabular}




\begin{tabular}{|c|c|c|c|c|c|c|c|}
\hline \multicolumn{8}{|c|}{ supplemental lable s2.txt } \\
\hline CHEMBL3191072 & 688810 & 4.783 & 5.4314 & TRN & & & \\
\hline CHEMBL1469485 & 688810 & 4.783 & 5.1236 & TRN & & & \\
\hline CHEMBL1377709 & 688810 & 5.483 & 5.0256 & TRN & & & \\
\hline CHEMBL1610709 & 688810 & 4.883 & 5.0439 & TRN & & & \\
\hline CHEMBL1370404 & 688810 & 5.78299 & 999999999 & 995 & 5.3611 & TRN & \\
\hline CHEMBL1544034 & 688810 & 5.083 & 5.0687 & TRN & & & \\
\hline CHEMBL1342256 & 688810 & 5.983 & 5.0478 & TST & & & \\
\hline CHEMBL1345979 & 688810 & 5.28299 & 999999999 & 995 & 5.40799 & 99999999995 & TST \\
\hline CHEMBL1480759 & 688810 & 5.933 & 5.7512 & TRN & & & \\
\hline CHEMBL2369157 & 688810 & 4.98300 & 000000000 & 005 & 5.3895 & TST & \\
\hline CHEMBL1408710 & 688810 & 4.98300 & 000000000 & 005 & 5.4474 & TRN & \\
\hline CHEMBL127579 & 688810 & 7.1331 & 6.1228 & TRN & & & \\
\hline CHEMBL1323846 & 688810 & 4.783 & 5.2084 & TRN & & & \\
\hline CHEMBL 3211022 & 688810 & 5.733 & 5.2176 & TRN & & & \\
\hline CHEMBL1302824 & 688810 & 4.633 & 4.8953 & TRN & & & \\
\hline CHEMBL1526537 & 688810 & 4.583 & 4.8875 & TRN & & & \\
\hline CHEMBL1378717 & 688810 & 4.583 & 4.6857 & TRN & & & \\
\hline CHEMBL1300285 & 688810 & 4.783 & 5.4636 & TRN & & & \\
\hline CHEMBL1596955 & 688810 & 5.38299 & 999999999 & & 5.17899 & 9999999999 & TRN \\
\hline CHEMBL1422992 & 688810 & 5.13299 & 999999999 & & 5.1261 & TRN & \\
\hline CHEMBL1396027 & 688810 & 4.583 & 4.856 & TRN & & & \\
\hline CHEMBL1405223 & 688810 & 4.833 & 5.1726 & TRN & & & \\
\hline CHEMBL1539648 & 688810 & 4.883 & 5.133999 & 99999999 & 995 & TRN & \\
\hline CHEMBL1418483 & 688810 & 4.833 & 5.3667 & TRN & & & \\
\hline CHEMBL3214309 & 688810 & 4.583 & 5.5273 & TST & & & \\
\hline CHEMBL1511037 & 688810 & 5.683 & 5.2492 & TRN & & & \\
\hline CHEMBL1418789 & 688810 & 5.733 & 5.6532 & TRN & & & \\
\hline CHEMBL1501480 & 688810 & 6.63299 & 999999999 & & 5.8715 & TRN & \\
\hline CHEMBL1559858 & 688810 & 5.733 & 6.0362 & TRN & & & \\
\hline CHEMBL1368428 & 688810 & 4.583 & 5.544 & TRN & & & \\
\hline CHEMBL 365257 & 688810 & 4.933 & 5.0847 & TRN & & & \\
\hline CHEMBL1327292 & 688810 & 5.13299 & 999999999 & & 4.8372 & TRN & \\
\hline CHEMBL1986805 & 688810 & 6.13299 & 999999999 & & 5.6557 & TRN & \\
\hline CHEMBL 3199003 & 688810 & 4.783 & 4.842 & TRN & & & \\
\hline CHEMBL1526829 & 688810 & 4.98300 & 000000000 & 005 & 5.301 & TRN & \\
\hline CHEMBL1343611 & 688810 & 4.833 & 5.4382 & TST & & & \\
\hline CHEMBL3212794 & 688810 & 4.833 & 5.3196 & TRN & & & \\
\hline CHEMBL3195002 & 688810 & 6.433 & 5.2323 & TRN & & & \\
\hline CHEMBL1451630 & 688810 & 4.933 & 4.9157 & TRN & & & \\
\hline CHEMBL1512749 & 688810 & 4.98300 & 000000000 & 005 & 5.0404 & TRN & \\
\hline CHEMBL1603007 & 688810 & 4.883 & 5.0236 & TST & & & \\
\hline CHEMBL1312116 & 688810 & 6.433 & 5.7958 & TRN & & & \\
\hline CHEMBL1539405 & 688810 & 4.783 & 4.8567 & TST & & & \\
\hline CHEMBL1606027 & 688810 & 4.783 & 5.0392 & TRN & & & \\
\hline CHEMBL1512819 & 688810 & 4.883 & 5.4696 & TRN & & & \\
\hline CHEMBL1587430 & 688810 & 4.783 & 5.2639 & TRN & & & \\
\hline CHEMBL1408325 & 688810 & 6.13299 & 999999999 & & 5.6465 & TRN & \\
\hline CHEMBL3195455 & 688810 & 4.783 & 4.8639 & TST & & & \\
\hline
\end{tabular}




\begin{tabular}{|c|c|c|c|c|c|c|}
\hline \multirow[b]{2}{*}{ CHEMBL1392151 } & \multicolumn{6}{|c|}{ tits } \\
\hline & 688810 & 4.883 & 5.1122 & TST & & \\
\hline CHEMBL1592752 & 688810 & \multicolumn{3}{|c|}{5.332999999999999} & 5.024 & TST \\
\hline CHEMBL1607986 & 688810 & \multicolumn{3}{|c|}{5.132999999999999} & 5.3622 & TRN \\
\hline CHEMBL1548093 & 688810 & \multicolumn{3}{|c|}{6.5329999999999995} & 6.0471 & \\
\hline CHEMBL 3189227 & 688810 & 4.933 & 5.5962 & TRN & & \\
\hline CHEMBL 3194766 & 688810 & 5.683 & 5.5696 & TRN & & \\
\hline CHEMBL1612208 & 688810 & 4.783 & 4.7728 & TRN & & \\
\hline CHEMBL3207982 & 688810 & 4.583 & 5.4212 & TRN & & \\
\hline CHEMBL 1450550 & 688810 & 4.583 & 5.2892 & TRN & & \\
\hline CHEMBL1342748 & 688810 & \multicolumn{3}{|c|}{5.132999999999999} & 5.3706 & I KIV \\
\hline CHEMBL1479057 & 688810 & \multicolumn{3}{|c|}{4.9830000000000005} & 5.1097 & \\
\hline CHEMBL1368493 & 688810 & 4.783 & 4.8227 & TRN & & \\
\hline CHEMBL1553121 & 688810 & 5.733 & 5.4213 & TST & & \\
\hline CHEMBL1534731 & 688810 & 4.933 & 5.0594 & TST & & \\
\hline CHEMBL1468181 & 688810 & 4.833 & 6.4036 & TRN & & \\
\hline CHEMBL1324974 & 688810 & \multicolumn{3}{|c|}{4.7330000000000005} & 4.9297 & TRN \\
\hline CHEMBL1301904 & 688810 & \multicolumn{3}{|c|}{4.7330000000000005} & 4.9459 & TRN \\
\hline CHEMBL1519349 & 688810 & \multicolumn{3}{|c|}{4.7330000000000005} & 5.155 & \\
\hline CHEMBL1549899 & 688810 & 4.933 & 5.2603 & TRN & & \\
\hline CHEMBL1451592 & 688810 & 5.933 & 5.2492 & TRN & & \\
\hline CHEMBL1494620 & 688810 & \multicolumn{3}{|c|}{4.7330000000000005} & 5.593 & ונדו \\
\hline CHEMBL1383650 & 688810 & \multicolumn{3}{|c|}{5.132999999999999} & 5.0917 & \\
\hline CHEMBL1374655 & 688810 & \multicolumn{3}{|c|}{6.382999999999999} & 5.8224 & \\
\hline CHEMBL1569542 & 688810 & 4.783 & 5.4381 & TRN & & \\
\hline CHEMBL1464502 & 688810 & 5.233 & 6.0144 & TRN & & \\
\hline CHEMBL1496830 & 688810 & \multicolumn{3}{|c|}{5.2829999999999995} & 312 & TRN \\
\hline CHEMBL1436105 & 688810 & \multicolumn{3}{|c|}{6.0329999999999995} & 5.3363 & \\
\hline CHEMBL1610569 & 688810 & 4.833 & 4.7999 & TRN & & \\
\hline CHEMBL1337221 & 688810 & 5.033 & 5.1477 & TST & & \\
\hline CHEMBL1353285 & 688810 & 4.783 & 4.9438 & TST & & \\
\hline CHEMBL1365154 & 688810 & \multicolumn{3}{|c|}{4.7330000000000005} & 5.1971 & TST \\
\hline CHEMBL 3197323 & 688810 & \multicolumn{3}{|c|}{5.882999999999999} & 6.1635 & TRN \\
\hline CHEMBL1367947 & 688810 & 5.083 & 4.8708 & TRN & & \\
\hline CHEMBL1417683 & 688810 & 5.683 & 5.599 & TRN & & \\
\hline CHEMBL 3196546 & 688810 & 5.683 & 5.2986 & TRN & & \\
\hline CHEMBL1523438 & 688810 & \multicolumn{3}{|c|}{5.382999999999999} & 5.2646 & $\mathrm{TR}$ \\
\hline CHEMBL1573272 & 688810 & 5.733 & 5.1399 & TST & & \\
\hline CHEMBL 3199418 & 688810 & 5.233 & 5.2567 & TST & & \\
\hline CHEMBL1488963 & 688810 & \multicolumn{3}{|c|}{5.7829999999999995} & & \\
\hline CHEMBL1505608 & 688810 & \multicolumn{3}{|c|}{4.9830000000000005} & 5.2575 & \\
\hline CHEMBL1427404 & 688810 & \multicolumn{3}{|c|}{6.2829999999999995} & 5.1555 & TRN \\
\hline CHEMBL379376 & 688810 & 4.7330 & 00000006 & 205 & 5.7585 & TRN \\
\hline CHEMBL1462495 & 688810 & 5.7829 & 9999999 & 995 & 5.2749 & TRN \\
\hline CHEMBL1603130 & 688810 & 5.233 & 5.58899 & 9999 & 995 & 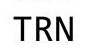 \\
\hline CHEMBL1610836 & 688810 & 5.1329 & 99999999 & & 5.0 & TRN \\
\hline CHEMBL1544297 & 688810 & 4.833 & 4.961 & TRN & & \\
\hline CHEMBL1364704 & 688810 & 5.733 & 5.3751 & TRN & & \\
\hline CHEMBL1611200 & 688810 & 5.483 & 5.2035 & TST & & \\
\hline
\end{tabular}




\begin{tabular}{|c|c|c|c|c|c|c|c|}
\hline \multicolumn{8}{|c|}{ oplemental Table S2.txt } \\
\hline CHEMBL1339609 & 688810 & 5.733 & 5.2439 & TRN & & & \\
\hline CHEMBL1519124 & 688810 & 4.783 & 5.3825 & TRN & & & \\
\hline CHEMBL1388823 & 688810 & \multicolumn{3}{|c|}{6.382999999999999} & 5.0598 & TRN & \\
\hline CHEMBL1419293 & 688810 & 4.783 & 5.6438 & TRN & & & \\
\hline CHEMBL1346887 & 688810 & 4.933 & 5.3589 & TRN & & & \\
\hline CHEMBL1536569 & 688810 & 4.583 & 5.2 & TRN & & & \\
\hline CHEMBL1554140 & 688810 & 4.783 & 4.7769 & TRN & & & \\
\hline CHEMBL1488007 & 688810 & 4.833 & 4.7999 & TRN & & & \\
\hline CHEMBL1340835 & 688810 & \multicolumn{3}{|c|}{4.9830000000000005} & 5.015 & TST & \\
\hline CHEMBL1555311 & 688810 & \multicolumn{3}{|c|}{4.7330000000000005} & 5.0779 & TRN & \\
\hline CHEMBL1577893 & 688810 & \multicolumn{3}{|c|}{5.5329999999999995} & 5.3732 & TST & \\
\hline CHEMBL1409180 & 688810 & \multicolumn{3}{|c|}{5.632999999999999} & 5.74200 & 0000000001 & TRN \\
\hline CHEMBL1984129 & 688810 & \multicolumn{3}{|c|}{6.5329999999999995} & 4.7275 & TST & \\
\hline CHEMBL1559088 & 688810 & 4.633 & 4.8226 & TRN & & & \\
\hline CHEMBL1448380 & 688810 & 5.983 & 5.4586 & TRN & & & \\
\hline CHEMBL1580736 & 688810 & \multicolumn{3}{|c|}{5.832999999999999} & 5.2674 & TRN & \\
\hline CHEMBL1444042 & 688810 & \multicolumn{3}{|c|}{5.832999999999999} & 5.3403 & TST & \\
\hline CHEMBL1498993 & 688810 & \multicolumn{3}{|c|}{4.7330000000000005} & 5.4972 & TRN & \\
\hline CHEMBL1597089 & 688810 & \multicolumn{3}{|c|}{5.832999999999999} & 5.4012 & TRN & \\
\hline CHEMBL1417614 & 688810 & \multicolumn{3}{|c|}{6.082999999999999} & 5.9232 & TRN & \\
\hline CHEMBL1314196 & 688810 & 4.633 & 4.8579 & TRN & & & \\
\hline CHEMBL1559283 & 688810 & 5.733 & 5.5793 & TRN & & & \\
\hline CHEMBL1512794 & 688810 & 4.583 & 4.7501 & TRN & & & \\
\hline CHEMBL1547381 & 688810 & 4.883 & 5.3283 & TRN & & & \\
\hline CHEMBL1329411 & 688810 & 4.683 & 5.685 & TST & & & \\
\hline CHEMBL1463842 & 688810 & \multicolumn{3}{|c|}{4.7330000000000005} & 5.3279 & TRN & \\
\hline CHEMBL1520179 & 688810 & 4.783 & 5.0864 & TRN & & & \\
\hline CHEMBL1481523 & 688810 & 5.033 & 5.0431 & TRN & & & \\
\hline CHEMBL1502465 & 688810 & \multicolumn{3}{|c|}{5.832999999999999} & 5.5948 & TRN & \\
\hline CHEMBL1305980 & 688810 & 5.183 & 5.6233 & TRN & & & \\
\hline CHEMBL1436502 & 688810 & 4.783 & 5.0649 & TRN & & & \\
\hline CHEMBL1311922 & 688810 & 6.183 & 4.9165 & TRN & & & \\
\hline CHEMBL1541158 & 688810 & \multicolumn{3}{|c|}{4.7330000000000005} & 5.6197 & TRN & \\
\hline CHEMBL1465726 & 688810 & \multicolumn{3}{|c|}{4.9830000000000005} & 5.4985 & TRN & \\
\hline CHEMBL1460414 & 688810 & 5.083 & 4.7653 & TRN & & & \\
\hline CHEMBL1545060 & 688810 & \multicolumn{3}{|c|}{5.7829999999999995} & 5.4921 & TRN & \\
\hline CHEMBL1305637 & 688810 & \multicolumn{3}{|c|}{5.332999999999999} & 5.096 & TRN & \\
\hline CHEMBL1597558 & 688810 & 5.233 & 5.2733 & TST & & & \\
\hline CHEMBL1423144 & 688810 & 5.483 & 5.6467 & TRN & & & \\
\hline CHEMBL3198453 & 688810 & 5.483 & 5.4905 & TRN & & & \\
\hline CHEMBL 2369277 & 688810 & 4.583 & 5.052 & TRN & & & \\
\hline CHEMBL1593678 & 688810 & 4.833 & 5.3142 & TRN & & & \\
\hline CHEMBL1484497 & 688810 & \multicolumn{3}{|c|}{5.2829999999999995} & 5.1295 & TST & \\
\hline CHEMBL1337332 & 688810 & 4.683 & 4.9007 & TRN & & & \\
\hline CHEMBL 2000499 & 688810 & 5.183 & \multicolumn{3}{|c|}{5.457999999999999} & TRN & \\
\hline CHEMBL1492358 & 688810 & 4.883 & 5.2557 & TRN & & & \\
\hline CHEMBL1357326 & 688810 & \multicolumn{3}{|c|}{6.632999999999999} & 5.9809 & TRN & \\
\hline CHEMBL1342520 & 688810 & 4.883 & 4.9626 & TRN & & & \\
\hline
\end{tabular}




\begin{tabular}{|c|c|c|c|c|c|c|}
\hline \multirow{2}{*}{\multicolumn{2}{|c|}{688810}} & \\
\hline & 688810 & 5.033 & 5.1788 & TRN & & \\
\hline CHEMBL1301826 & 688810 & 5.033 & 5.3035 & TRN & & \\
\hline CHEMBL1589529 & 688810 & 4.73300 & 000000000 & 205 & 5.3925 & זעו \\
\hline CHEMBL1582277 & 688810 & 6.53299 & 999999999 & 995 & 5.5322 & \\
\hline CHEMBL3195544 & 688810 & 5.13299 & 999999999 & & 5.6003 & \\
\hline CHEMBL1479676 & 688810 & 4.783 & 4.8832 & TRN & & \\
\hline CHEMBL1416159 & 688810 & 5.83299 & 999999999 & & 6.0726 & \\
\hline CHEMBL1555387 & 688810 & 5.13299 & 999999999 & & 4821 & \\
\hline CHEMBL451208 & 688810 & 4.783 & 5.5363 & TRN & & \\
\hline CHEMBL1335444 & 688810 & 4.633 & 4.8997 & TRN & & \\
\hline CHEMBL1589173 & 688810 & 5.483 & 4.9128 & TRN & & \\
\hline CHEMBL1330058 & 688810 & 7.1331 & 6.4563 & TRN & & \\
\hline CHEMBL1475072 & 688810 & 5.033 & 5.4374 & TRN & & \\
\hline CHEMBL1457052 & 688810 & 4.98300 & 000000000 & 005 & 5.1453 & \\
\hline CHEMBL1410609 & 688810 & 5.083 & 5.596 & TRN & & \\
\hline CHEMBL1309149 & 688810 & 5.733 & 5.0857 & TRN & & \\
\hline CHEMBL1520757 & 688810 & 5.33299 & 999999999 & & 366 & \\
\hline CHEMBL1382105 & 688810 & 7.684 & 5.9155 & TRN & & \\
\hline CHEMBL1376693 & 688810 & 5.433 & 5.5103 & TRN & & \\
\hline CHEMBL1442615 & 688810 & 5.233 & 5.1581 & TRN & & \\
\hline CHEMBL1537629 & 688810 & 4.833 & 5.2647 & TRN & & \\
\hline CHEMBL1318589 & 688810 & 4.833 & 5.1691 & TST & & \\
\hline CHEMBL1310326 & 688810 & 4.883 & 4.9061 & TRN & & \\
\hline CHEMBL 2005284 & 688810 & 4.883 & 5.558 & TRN & & \\
\hline CHEMBL1609015 & 688810 & 5.233 & 5.9165 & TST & & \\
\hline CHEMBL1549665 & 688810 & 5.483 & 5.745 & TRN & & \\
\hline CHEMBL1317176 & 688810 & 5.83299 & 999999999 & & 5.2677 & \\
\hline CHEMBL3196599 & 688810 & 5.233 & 5.1792 & TRN & & \\
\hline CHEMBL1451423 & 688810 & 4.933 & 4.8891 & TRN & & \\
\hline CHEMBL1558486 & 688810 & 4.833 & 5.3301 & TRN & & \\
\hline CHEMBL1451511 & 688810 & 5.13299 & 999999999 & & 5.2879 & \\
\hline CHEMBL1427115 & 688810 & 4.783 & 5.7169 & TRN & & \\
\hline CHEMBL84316 & 688810 & 4.883 & 5.2105 & TST & & \\
\hline CHEMBL1379003 & 688810 & 5.13299 & 999999999 & & 5.13 & \\
\hline CHEMBL1411869 & 688810 & 6.28299 & 999999999 & 995 & 5.5558 & TR \\
\hline CHEMBL1488040 & 688810 & 4.833 & 5.4041 & TRN & & \\
\hline CHEMBL1440273 & 688810 & 4.933 & 4.9531 & TRN & & \\
\hline CHEMBL1310832 & 688810 & 5.683 & 4.8929 & TST & & \\
\hline CHEMBL1502403 & 688810 & 5.33299 & 999999999 & & 5.5698 & \\
\hline CHEMBL1427626 & 688810 & 5.233 & 5.0096 & TST & & \\
\hline CHEMBL1370529 & 688810 & 5.28299 & 999999999 & 995 & 5.1376 & \\
\hline CHEMBL1410981 & 688810 & 4.933 & 5.7206 & TRN & & \\
\hline CHEMBL1583647 & 688810 & 5.83299 & 999999999 & & 5.3905 & \\
\hline CHEMBL3191511 & 688810 & 4.73300 & 000000000 & 005 & 5.2754 & $\pi$ \\
\hline CHEMBL1367793 & 688810 & 4.783 & 5.0592 & TRN & & \\
\hline CHEMBL329836 & 688810 & 4.73300 & 000000000 & 005 & 5.4271 & \\
\hline CHEMBL1325513 & 688810 & 4.933 & 5.3202 & TRN & & \\
\hline CHEMBL3207825 & 688810 & 6.28299 & 999999999 & 995 & 5.7752 & \\
\hline
\end{tabular}




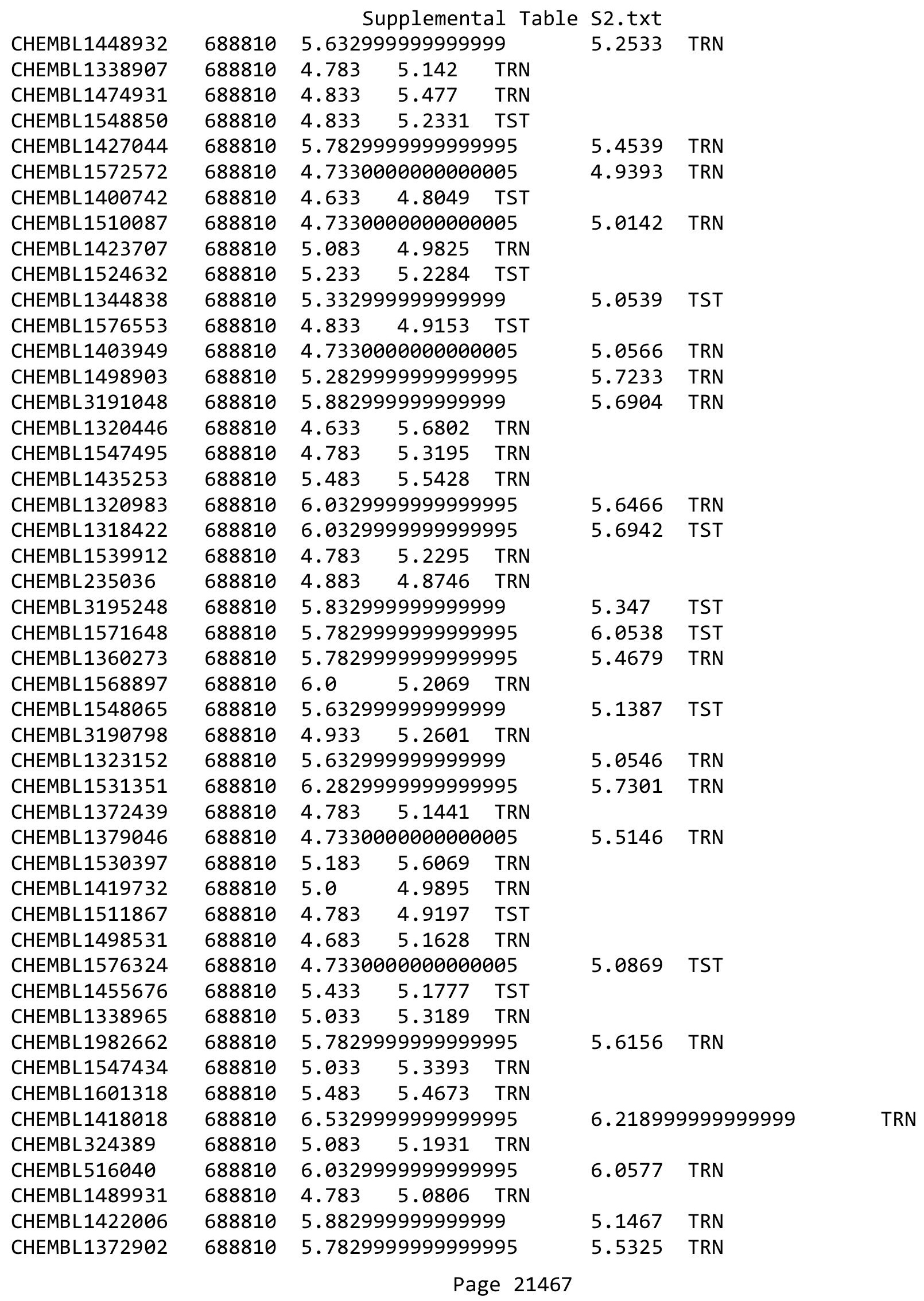




\begin{tabular}{|c|c|c|c|c|c|c|}
\hline & \multicolumn{5}{|c|}{ oplemen } \\
\hline CHEMBL1519021 & 688810 & 5.183 & 5.394 & TRN & & \\
\hline CHEMBL 3191975 & 688810 & \multicolumn{3}{|c|}{5.832999999999999} & 5.8389 & $\mathrm{TR}$ \\
\hline CHEMBL1606338 & 688810 & 4.833 & 5.2753 & TRN & & \\
\hline CHEMBL1426951 & 688810 & .733 & 5.3061 & TST & & \\
\hline CHEMBL1448755 & 688810 & \multicolumn{3}{|c|}{4.9830000000000005} & 4.5705 & \\
\hline CHEMBL1517047 & 688810 & 4.783 & 5.3366 & TST & & \\
\hline CHEMBL1471740 & 688810 & 4.783 & 5.2696 & TST & & \\
\hline CHEMBL1545365 & 688810 & 4.883 & 4.9943 & TRN & & \\
\hline CHEMBL1336351 & 688810 & 5.183 & 5.2926 & TRN & & \\
\hline CHEMBL3213249 & 688810 & 5.683 & \multicolumn{3}{|c|}{5.093999999999999} & \\
\hline CHEMBL1450643 & 688810 & 5.433 & \multicolumn{3}{|c|}{5.8922 TRN } & \\
\hline CHEMBL 3209816 & 688810 & 5.983 & \multicolumn{3}{|c|}{5.827000000000001} & \\
\hline CHEMBL1543804 & 688810 & 6.4829 & \multicolumn{3}{|c|}{5.9436 TRN } & \\
\hline CHEMBL1564720 & 688810 & \multicolumn{3}{|c|}{5.132999999999999} & 5.0431 & 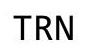 \\
\hline CHEMBL1443305 & 688810 & \multicolumn{3}{|c|}{5.2829999999999995} & 5.3683 & \\
\hline CHEMBL1338596 & 688810 & \multicolumn{3}{|c|}{5.332999999999999} & 5.1495 & \\
\hline CHEMBL1506611 & 688810 & \multicolumn{3}{|c|}{4.9830000000000005} & 4.9831 & \\
\hline CHEMBL1306181 & 688810 & \multicolumn{3}{|c|}{4.7330000000000005} & 4.9016 & \\
\hline CHEMBL1495434 & 688 & 4.633 & 4.9023 & TST & & \\
\hline CHEMBL15 & 688810 & \multicolumn{3}{|c|}{4.7330000000000005} & 5.306 & \\
\hline CHEMBL1300975 & 688810 & 4.783 & 5.1609 & TST & & \\
\hline CHEMBL407817 & 688810 & \multicolumn{3}{|c|}{5.882999999999999} & 5.6882 & $\mathrm{TP}$ \\
\hline CHEMBL1405116 & 688810 & \multicolumn{3}{|c|}{5.2829999999999995} & 5.527 & \\
\hline CHEMBL1537418 & 688 & \multicolumn{3}{|c|}{5.832999999999999} & 371 & \\
\hline CHEMBL1489948 & 688810 & 4.683 & 4.8947 & TRN & & \\
\hline CHEMBL1569180 & 688810 & 5.183 & 5.25 & TRN & & \\
\hline CHEMBL1459699 & 688810 & \multicolumn{3}{|c|}{5.132999999999999} & 5.3208 & TS \\
\hline CHEMBL1309809 & 688810 & \multicolumn{3}{|c|}{5.2829999999999995} & 015 & $\mathrm{TI}$ \\
\hline CHEMBL15 & 810 & \multicolumn{3}{|c|}{5.882999999999999} & 5.7307 & \\
\hline CHEMBL1540808 & 688810 & 4.883 & 4.6419 & TRN & & \\
\hline CHEMBL1370787 & 688810 & 5.25 & 5.527 & TRN & & \\
\hline CHEMBL1579235 & 688810 & 5.083 & 5.5237 & TRN & & \\
\hline CHEMBL1368243 & 688810 & \multicolumn{3}{|c|}{5.632999999999999} & 5.2504 & 10 \\
\hline CHEMBL15 & 688810 & 4.833 & 5.7824 & TRN & & \\
\hline CHEMBL1533229 & 688 & & & TRN & & \\
\hline CHEMBL1327688 & 688810 & 6.3329 & 99999999 & & 5.6999 & TRN \\
\hline CHEMBL1347657 & 688810 & 4.9830 & 00000000 & 005 & & \\
\hline CHEMBL1513797 & 688810 & 4.783 & 5.4213 & TRN & & \\
\hline CHEMBL1509804 & 688810 & 4.833 & 5.4864 & TST & & \\
\hline CHEMBL1477496 & 688810 & 4.833 & 5.1868 & TST & & \\
\hline CHEMBL1602160 & 688810 & 6.0 & 5.2846 & TST & & \\
\hline CHEMBL1562506 & 688810 & 5.5329 & 99999999 & 995 & 4.6152 & \\
\hline CHEMBL1509065 & 688810 & 6.2829 & 99999999 & 995 & 5.7192 & \\
\hline CHEMBL1366578 & 688810 & 5.2829 & 99999999 & 995 & 5.4214 & 7 \\
\hline CHEMBL1611513 & 688810 & 4.633 & 4.8459 & TRN & & \\
\hline CHEMBL1559226 & 688810 & 5.733 & 5.3248 & TRN & & \\
\hline CHEMBL1312057 & 688810 & 6.0329 & 99999999 & 995 & 5.676 & 10 \\
\hline CHEMBL1419834 & 688810 & 4.783 & 5.3418 & TRN & & \\
\hline
\end{tabular}




\begin{tabular}{|c|c|c|c|c|c|c|}
\hline \multicolumn{7}{|c|}{ Supplemental Table S2.txt } \\
\hline CHEMBL1435501 & 688810 & \multicolumn{3}{|c|}{5.332999999999999} & 4.9513 & TRN \\
\hline CHEMBL1970478 & 688810 & \multicolumn{3}{|c|}{5.632999999999999} & 6.0631 & TRN \\
\hline CHEMBL3189201 & 688810 & 6.4829 & 6.0035 & TRN & & \\
\hline CHEMBL1552351 & 688810 & \multicolumn{3}{|c|}{6.382999999999999} & 5.3748 & TRN \\
\hline CHEMBL1349405 & 688810 & 4.583 & 4.7841 & TRN & & \\
\hline CHEMBL1488733 & 688810 & 6.4829 & 5.8287 & TRN & & \\
\hline CHEMBL1514737 & 688810 & 7.3325 & 6.1754 & TRN & & \\
\hline CHEMBL1547823 & 688810 & \multicolumn{3}{|c|}{5.832999999999999} & 5.8528 & TRN \\
\hline CHEMBL1366790 & 688810 & 4.883 & 5.9769 & TRN & & \\
\hline CHEMBL1571426 & 688810 & 5.983 & 5.5906 & TRN & & \\
\hline CHEMBL1400514 & 688810 & \multicolumn{3}{|c|}{7.082999999999999} & 5.8215 & TRN \\
\hline CHEMBL1451735 & 688810 & \multicolumn{3}{|c|}{6.832999999999999} & 5.431 & TST \\
\hline CHEMBL1473000 & 688810 & 4.883 & 5.519 & TST & & \\
\hline CHEMBL1443958 & 688810 & 4.683 & 5.3065 & TRN & & \\
\hline CHEMBL1317959 & 688810 & 4.633 & 5.4212 & TRN & & \\
\hline CHEMBL1425287 & 688810 & \multicolumn{3}{|c|}{6.382999999999999} & \multicolumn{2}{|c|}{5.372999999999999} \\
\hline CHEMBL1428712 & 688810 & \multicolumn{3}{|c|}{5.332999999999999} & 5.1843 & TRN \\
\hline CHEMBL1585608 & 688810 & \multicolumn{3}{|c|}{4.7330000000000005} & 5.8854 & TRN \\
\hline CHEMBL1480410 & 688810 & 4.833 & 5.103 & TST & & \\
\hline CHEMBL1566864 & 688810 & \multicolumn{3}{|c|}{6.582999999999999} & 5.272 & TRN \\
\hline CHEMBL1570474 & 688810 & 5.233 & 4.9122 & TRN & & \\
\hline CHEMBL1335529 & 688810 & 4.833 & 5.3823 & TST & & \\
\hline CHEMBL1469650 & 688810 & 5.983 & 5.2257 & TST & & \\
\hline CHEMBL1596373 & 688810 & \multicolumn{3}{|c|}{5.7829999999999995} & 5.6832 & TRN \\
\hline CHEMBL1331050 & 688810 & 4.683 & 4.8184 & TST & & \\
\hline CHEMBL1317948 & 688810 & 4.933 & 4.9594 & TRN & & \\
\hline CHEMBL1481621 & 688810 & \multicolumn{3}{|c|}{5.2829999999999995} & 5.9995 & TRN \\
\hline CHEMBL3213113 & 688810 & 5.083 & 5.0394 & TRN & & \\
\hline CHEMBL1402589 & 688810 & 5.433 & 5.3253 & TRN & & \\
\hline CHEMBL3208147 & 688810 & 4.783 & 5.1098 & TST & & \\
\hline CHEMBL1547800 & 688810 & \multicolumn{3}{|c|}{5.832999999999999} & 5.2259 & TRN \\
\hline CHEMBL1513604 & 688810 & 4.783 & 5.1237 & TRN & & \\
\hline CHEMBL1309562 & 688810 & 4.833 & 5.3082 & TRN & & \\
\hline CHEMBL1509222 & 688810 & 4.783 & \multicolumn{3}{|c|}{5.242000000000001} & TRN \\
\hline CHEMBL1524508 & 688810 & 4.683 & 4.6648 & TST & & \\
\hline CHEMBL1499772 & 688810 & 4.783 & 5.3559 & TRN & & \\
\hline CHEMBL 3195647 & 688810 & 5.483 & 5.4697 & TRN & & \\
\hline CHEMBL1486352 & 688810 & \multicolumn{3}{|c|}{6.082999999999999} & 5.2278 & TRN \\
\hline CHEMBL1494135 & 688810 & \multicolumn{3}{|c|}{4.7330000000000005} & 5.0291 & TST \\
\hline CHEMBL1318070 & 688810 & 6.183 & 5.605 & TRN & & \\
\hline CHEMBL1341629 & 688810 & 4.583 & 5.5409 & TRN & & \\
\hline CHEMBL1362428 & 688810 & 4.833 & 5.0768 & TRN & & \\
\hline CHEMBL1313649 & 688810 & 4.833 & 5.1805 & TRN & & \\
\hline CHEMBL1321449 & 688810 & 4.783 & 5.1181 & TST & & \\
\hline CHEMBL1372990 & 688810 & \multicolumn{3}{|c|}{4.7330000000000005} & 5.0205 & TST \\
\hline CHEMBL1358295 & 688810 & 4.833 & 5.0123 & TST & & \\
\hline CHEMBL1324593 & 688810 & \multicolumn{3}{|c|}{4.7330000000000005} & 4.8485 & TRN \\
\hline CHEMBL1608143 & 688810 & 4.633 & 4.7956 & TST & & \\
\hline
\end{tabular}




\begin{tabular}{|c|c|c|c|c|c|c|c|}
\hline \multicolumn{7}{|c|}{ Supplemental Table S2.txt } & \\
\hline CHEMBL1594331 & 688810 & 4.783 & 5.2207 & TRN & & & \\
\hline CHEMBL1563784 & 688810 & 4.783 & 5.3615 & TRN & & & \\
\hline CHEMBL1383664 & 688810 & 4.583 & 4.7794 & TST & & & \\
\hline CHEMBL1341142 & 688810 & 5.033 & 5.8454 & TST & & & \\
\hline CHEMBL1539786 & 688810 & 4.98300 & 00000000 & 005 & 5.1895 & TRN & \\
\hline CHEMBL576200 & 688810 & 6.183 & 5.6754 & TRN & & & \\
\hline CHEMBL1356105 & 688810 & 4.98300 & 00000000 & 005 & 5.0351 & TST & \\
\hline CHEMBL1609790 & 688810 & 4.833 & 5.4071 & TRN & & & \\
\hline CHEMBL1573581 & 688810 & 6.983 & 6.0653 & TRN & & & \\
\hline CHEMBL1984447 & 688810 & 4.783 & 5.3012 & TRN & & & \\
\hline CHEMBL1395133 & 688810 & 5.78299 & 99999999 & 995 & 5.6121 & TRN & \\
\hline CHEMBL1490037 & 688810 & 4.73300 & 00000000 & 005 & 5.4583 & TRN & \\
\hline CHEMBL108660 & 688810 & 5.733 & 5.5499 & TRN & & & \\
\hline CHEMBL1448292 & 688810 & 4.73300 & 00000000 & 005 & 5.1245 & TRN & \\
\hline CHEMBL1478478 & 688810 & 5.183 & 5.2398 & TRN & & & \\
\hline CHEMBL1335592 & 688810 & 4.73300 & 00000000 & 005 & 4.9782 & TST & \\
\hline CHEMBL1586233 & 688810 & 4.783 & 5.6018 & TRN & & & \\
\hline CHEMBL29542 & 688810 & 5.733 & 5.4747 & TRN & & & \\
\hline CHEMBL469036 & 688810 & 5.433 & 5.0156 & TST & & & \\
\hline CHEMBL1591304 & 688810 & 5.183 & 5.4487 & TST & & & \\
\hline CHEMBL1593441 & 688810 & 4.633 & 5.1564 & TRN & & & \\
\hline CHEMBL1376796 & 688810 & 5.683 & 5.3089 & TRN & & & \\
\hline CHEMBL1417538 & 688810 & 4.933 & 5.0916 & TST & & & \\
\hline CHEMBL1492474 & 688810 & 5.483 & 5.581 & TST & & & \\
\hline CHEMBL1414508 & 688810 & 4.583 & 4.7715 & TRN & & & \\
\hline CHEMBL1593924 & 688810 & 6.33299 & 99999999 & & 5.5738 & TRN & \\
\hline CHEMBL1412563 & 688810 & 4.783 & 5.354 & TST & & & \\
\hline CHEMBL1501060 & 688810 & 4.73300 & 00000000 & 005 & 5.28100 & 0000000001 & TRN \\
\hline CHEMBL1483605 & 688810 & 5.183 & 5.1677 & TRN & & & \\
\hline CHEMBL3145376 & 688810 & 5.733 & 5.3034 & TRN & & & \\
\hline CHEMBL1461493 & 688810 & 5.183 & 5.231 & TRN & & & \\
\hline CHEMBL1332584 & 688810 & 6.0 & 5.29200 & 000000000 & & TST & \\
\hline CHEMBL1567375 & 688810 & 5.33299 & 99999999 & & 5.4459 & TRN & \\
\hline CHEMBL1426481 & 688810 & 5.233 & 5.5058 & TRN & & & \\
\hline CHEMBL3196478 & 688810 & 5.88299 & 99999999 & 99 & 5.2912 & TRN & \\
\hline CHEMBL1310407 & 688810 & 4.883 & 5.4292 & TRN & & & \\
\hline CHEMBL3193628 & 688810 & 6.9329 & 5.4392 & TRN & & & \\
\hline CHEMBL1413316 & 688810 & 5.483 & 5.4385 & TRN & & & \\
\hline CHEMBL1329077 & 688810 & 4.883 & 5.2458 & TRN & & & \\
\hline CHEMBL1346630 & 688810 & 5.28299 & 99999999 & 995 & 5.3096 & TST & \\
\hline CHEMBL1585390 & 688810 & 5.083 & 4.7803 & TRN & & & \\
\hline CHEMBL1450794 & 688810 & 4.883 & 5.2302 & TRN & & & \\
\hline CHEMBL1341942 & 688810 & 5.13299 & 99999999 & 99 & 5.6077 & TRN & \\
\hline CHEMBL3210519 & 688810 & 4.783 & 5.2311 & TRN & & & \\
\hline CHEMBL1613388 & 688810 & 4.683 & 4.7854 & TST & & & \\
\hline CHEMBL1591376 & 688810 & 5.78299 & 99999999 & 995 & 5.7325 & TRN & \\
\hline CHEMBL1415573 & 688810 & 4.783 & 5.4213 & TST & & & \\
\hline CHEMBL1419814 & 688810 & 4.583 & 5.0704 & TRN & & & \\
\hline
\end{tabular}




\begin{tabular}{|c|c|c|c|c|c|c|}
\hline \multicolumn{7}{|c|}{ Supplemental Table S2.txt } \\
\hline CHEMBL1446987 & 688810 & \multicolumn{3}{|c|}{5.832999999999999} & 4.9786 & TRN \\
\hline CHEMBL1437633 & 688810 & \multicolumn{3}{|c|}{4.7330000000000005} & 4.7705 & TRN \\
\hline CHEMBL1481398 & 688810 & 4.833 & 4.98 & TRN & & \\
\hline CHEMBL1610510 & 688810 & \multicolumn{3}{|c|}{6.0329999999999995} & 5.0206 & TST \\
\hline CHEMBL 252403 & 688810 & 7.3325 & 6.0495 & TRN & & \\
\hline CHEMBL1305536 & 688810 & 5.733 & 5.3482 & TRN & & \\
\hline CHEMBL1524800 & 688810 & \multicolumn{3}{|c|}{6.0329999999999995} & 5.689 & TRN \\
\hline CHEMBL1531094 & 688810 & 5.933 & 5.2977 & TRN & & \\
\hline CHEMBL1534112 & 688810 & 5.183 & 5.2938 & TRN & & \\
\hline CHEMBL1382906 & 688810 & \multicolumn{3}{|c|}{4.7330000000000005} & 5.0739 & TST \\
\hline CHEMBL1468262 & 688810 & 4.783 & 5.6594 & TST & & \\
\hline CHEMBL1491836 & 688810 & 4.783 & 5.0505 & TRN & & \\
\hline CHEMBL1607142 & 688810 & 5.183 & 5.3366 & TRN & & \\
\hline CHEMBL 262083 & 688810 & 5.433 & 5.9786 & TRN & & \\
\hline CHEMBL1534876 & 688810 & 5.433 & 5.4409 & TRN & & \\
\hline CHEMBL1593303 & 688810 & \multicolumn{3}{|c|}{4.7330000000000005} & 5.3691 & TRN \\
\hline CHEMBL1348853 & 688810 & 4.633 & 5.2697 & TST & & \\
\hline CHEMBL1605586 & 688810 & 4.783 & 4.9108 & TRN & & \\
\hline CHEMBL1514373 & 688810 & 4.883 & 5.5439 & TRN & & \\
\hline CHEMBL1555418 & 688810 & \multicolumn{3}{|c|}{4.9830000000000005} & 5.3044 & TRN \\
\hline CHEMBL1315948 & 688810 & \multicolumn{3}{|c|}{4.9830000000000005} & 5.1754 & TRN \\
\hline CHEMBL1423903 & 688810 & 4.783 & 5.0544 & TRN & & \\
\hline CHEMBL1502620 & 688810 & 4.783 & 5.3523 & TRN & & \\
\hline CHEMBL1589227 & 688810 & 4.683 & 5.2754 & TST & & \\
\hline CHEMBL1600668 & 688810 & \multicolumn{3}{|c|}{6.382999999999999} & 6.0262 & TRN \\
\hline CHEMBL1613168 & 688810 & \multicolumn{3}{|c|}{5.132999999999999} & 5.2298 & TRN \\
\hline CHEMBL1421547 & 688810 & \multicolumn{3}{|c|}{5.832999999999999} & 5.6836 & TRN \\
\hline CHEMBL1583461 & 688810 & 4.633 & 5.1456 & TRN & & \\
\hline CHEMBL1609062 & 688810 & \multicolumn{3}{|c|}{5.832999999999999} & 5.8172 & TRN \\
\hline CHEMBL1475188 & 688810 & \multicolumn{3}{|c|}{4.9830000000000005} & 5.2291 & TRN \\
\hline CHEMBL1567070 & 688810 & 5.233 & 5.3447 & TRN & & \\
\hline CHEMBL1501515 & 688810 & \multicolumn{3}{|c|}{6.2829999999999995} & 5.91700 & 0000000001 \\
\hline CHEMBL1394726 & 688810 & \multicolumn{3}{|c|}{5.132999999999999} & 5.1007 & TRN \\
\hline CHEMBL1579291 & 688810 & 4.833 & 5.3213 & TRN & & \\
\hline CHEMBL1535055 & 688810 & 4.783 & 4.5549 & TRN & & \\
\hline CHEMBL1534937 & 688810 & 4.833 & 5.2775 & TRN & & \\
\hline CHEMBL1336236 & 688810 & \multicolumn{3}{|c|}{5.2829999999999995} & 4.8491 & TRN \\
\hline CHEMBL1373585 & 688810 & \multicolumn{3}{|c|}{5.132999999999999} & 4.9605 & TRN \\
\hline CHEMBL1592688 & 688810 & 5.183 & 4.6129 & TRN & & \\
\hline CHEMBL1530391 & 688810 & 5.683 & 6.1891 & TRN & & \\
\hline CHEMBL1349194 & 688810 & 4.783 & 4.9952 & TST & & \\
\hline CHEMBL1454373 & 688810 & 4.833 & 4.756 & TRN & & \\
\hline CHEMBL1528497 & 688810 & 4.933 & 4.9493 & TRN & & \\
\hline CHEMBL 935 & 688810 & 5.483 & 5.2825 & TST & & \\
\hline CHEMBL1556365 & 688810 & \multicolumn{3}{|c|}{4.9830000000000005} & 5.2054 & TST \\
\hline CHEMBL578716 & 688810 & 5.233 & 5.1327 & TST & & \\
\hline CHEMBL1592525 & 688810 & 5.033 & 5.2222 & TST & & \\
\hline CHEMBL1319960 & 688810 & 4.883 & 5.3763 & TRN & & \\
\hline
\end{tabular}




\begin{tabular}{|c|c|c|c|c|c|c|}
\hline \multirow[b]{2}{*}{ CHEMBL1452630 } & \\
\hline & 688810 & 5.183 & 5.1395 & TRN & & \\
\hline CHEMBL1534076 & 688810 & 4.683 & 4.9115 & TRN & & \\
\hline CHEMBL1536087 & 688810 & 6.233 & 5.3512 & TRN & & \\
\hline CHEMBL1543704 & 688810 & 4.883 & 5.1145 & TST & & \\
\hline CHEMBL1365019 & 688810 & \multicolumn{3}{|c|}{5.7829999999999995} & 5.7251 & TRN \\
\hline CHEMBL1365827 & 688810 & \multicolumn{3}{|c|}{5.2829999999999995} & 5.7281 & TST \\
\hline CHEMBL1448946 & 688810 & 4.633 & 4.8464 & TRN & & \\
\hline CHEMBL1435131 & 688810 & 4.583 & 5.0905 & TRN & & \\
\hline CHEMBL1386989 & 688810 & 5.933 & 5.4689 & TRN & & \\
\hline CHEMBL3196864 & 688810 & 4.883 & 5.5049 & TRN & & \\
\hline CHEMBL1555930 & 688810 & \multicolumn{3}{|c|}{6.382999999999999} & 6.0171 & TRN \\
\hline CHEMBL1479283 & 688810 & 4.783 & 5.2902 & TST & & \\
\hline CHEMBL1379646 & 688810 & \multicolumn{3}{|c|}{5.882999999999999} & 5.1987 & TRN \\
\hline CHEMBL1431795 & 688810 & 4.833 & 5.4563 & TRN & & \\
\hline CHEMBL1479133 & 688810 & 5.433 & 5.4904 & TRN & & \\
\hline CHEMBL1545403 & 688810 & 4.883 & 5.3128 & TST & & \\
\hline CHEMBL1517865 & 688810 & 5.983 & 5.53 & TRN & & \\
\hline CHEMBL1535049 & 688810 & \multicolumn{3}{|c|}{4.7330000000000005} & 4.8272 & TST \\
\hline CHEMBL1449740 & 688810 & \multicolumn{3}{|c|}{5.7829999999999995} & 5.1956 & TRN \\
\hline CHEMBL1393735 & 688810 & 5.233 & 5.4544 & TST & & \\
\hline CHEMBL1329295 & 688810 & 4.683 & 5.2445 & TRN & & \\
\hline CHEMBL1392152 & 688810 & 4.883 & 4.7686 & TRN & & \\
\hline CHEMBL1308658 & 688810 & 5.733 & 5.9611 & TRN & & \\
\hline CHEMBL1342080 & 688810 & 5.433 & 5.534 & TRN & & \\
\hline CHEMBL 2006568 & 688810 & 4.883 & 5.3262 & TRN & & \\
\hline CHEMBL1495891 & 688810 & 5.183 & 5.3821 & TRN & & \\
\hline CHEMBL1509072 & 688810 & 4.833 & 4.9798 & TRN & & \\
\hline CHEMBL1493808 & 688810 & 4.783 & 5.1472 & TST & & \\
\hline CHEMBL3196267 & 688810 & \multicolumn{3}{|c|}{6.332999999999999} & 5.6238 & TRN \\
\hline CHEMBL1330332 & 688810 & 4.933 & 5.2123 & TRN & & \\
\hline CHEMBL1504879 & 688810 & 5.733 & 5.5102 & TRN & & \\
\hline CHEMBL1567324 & 688810 & \multicolumn{3}{|c|}{5.332999999999999} & 5.1315 & TST \\
\hline CHEMBL1455630 & 688810 & 4.633 & 5.6844 & TST & & \\
\hline CHEMBL1347130 & 688810 & \multicolumn{3}{|c|}{5.5329999999999995} & 5.2558 & TRN \\
\hline CHEMBL1536102 & 688810 & 4.833 & 5.157 & TRN & & \\
\hline CHEMBL1572391 & 688810 & \multicolumn{3}{|c|}{5.132999999999999} & 5.1938 & TRN \\
\hline CHEMBL1442886 & 688810 & \multicolumn{3}{|c|}{4.7330000000000005} & 5.6265 & TST \\
\hline CHEMBL1520559 & 688810 & \multicolumn{3}{|c|}{5.5329999999999995} & 5.6797 & TRN \\
\hline CHEMBL1481155 & 688810 & 4.883 & 5.5416 & TST & & \\
\hline CHEMBL1212984 & 688810 & 4.783 & 5.2167 & TRN & & \\
\hline CHEMBL3207942 & 688810 & 4.833 & 5.2556 & TST & & \\
\hline CHEMBL1323791 & 688810 & 6.183 & 5.2967 & TRN & & \\
\hline CHEMBL1308048 & 688810 & \multicolumn{3}{|c|}{6.382999999999999} & 5.6199 & TRN \\
\hline CHEMBL1352372 & 688810 & \multicolumn{3}{|c|}{5.132999999999999} & 5.4272 & TST \\
\hline CHEMBL1610691 & 688810 & 7.3325 & 6.2528 & TRN & & \\
\hline CHEMBL1317352 & 688810 & 4.633 & \multicolumn{3}{|c|}{4.6819999999999995} & TRN \\
\hline CHEMBL1311826 & 688810 & \multicolumn{3}{|c|}{5.382999999999999} & 5.7458 & TRN \\
\hline CHEMBL1531927 & 688810 & 5.683 & 5.4083 & TRN & & \\
\hline
\end{tabular}




\begin{tabular}{|c|c|c|c|c|c|c|c|}
\hline \\
\hline CHEMBL1613402 & 688810 & 5.033 & 5.2903 & TST & & & \\
\hline CHEMBL1464170 & 688810 & 5.683 & 4.8729 & TRN & & & \\
\hline CHEMBL1360346 & 688810 & 5.933 & 5.49200 & 0000 & & TRN & \\
\hline CHEMBL1503359 & 688810 & 4.883 & 5.3371 & TST & & & \\
\hline CHEMBL1573350 & 688810 & 6.0329 & 99999999 & 995 & 5.3356 & TRN & \\
\hline CHEMBL1549315 & 688810 & 4.933 & 4.7109 & TRN & & & \\
\hline CHEMBL1553867 & 688810 & 4.633 & 5.1094 & TST & & & \\
\hline CHEMBL1536018 & 688810 & 5.1329 & 99999999 & & 5.2867 & TST & \\
\hline CHEMBL1554881 & 688810 & 6.0 & 5.8585 & TRN & & & \\
\hline CHEMBL1575036 & 688810 & 6.233 & 5.4944 & TRN & & & \\
\hline CHEMBL1523197 & 688810 & 4.783 & 5.1958 & TST & & & \\
\hline CHEMBL1480190 & 688810 & 4.883 & 5.5575 & TRN & & & \\
\hline CHEMBL1502629 & 688810 & 5.3329 & 99999999 & & 4.8451 & TST & \\
\hline CHEMBL3214035 & 688810 & 5.233 & 5.1668 & TRN & & & \\
\hline CHEMBL1453871 & 688810 & 4.933 & 4.7399 & TRN & & & \\
\hline CHEMBL1464644 & 688810 & 5.683 & 5.6723 & TRN & & & \\
\hline CHEMBL3191971 & 688810 & 4.933 & 4.8928 & TST & & & \\
\hline CHEMBL1326502 & 688810 & 5.7829 & 99999999 & 995 & 5.5262 & TRN & \\
\hline CHEMBL1416403 & 688810 & 4.883 & 5.2705 & TRN & & & \\
\hline CHEMBL1564605 & 688810 & 4.583 & 5.3669 & TST & & & \\
\hline CHEMBL1310006 & 688810 & 6.433 & 5.8795 & TRN & & & \\
\hline CHEMBL1566868 & 688810 & 4.883 & 5.0412 & TRN & & & \\
\hline CHEMBL1422976 & 688810 & 6.0829 & 99999999 & & 5.7053 & TRN & \\
\hline CHEMBL1348429 & 688810 & 4.783 & 5.7388 & TRN & & & \\
\hline CHEMBL 336718 & 688810 & 6.183 & 5.6877 & TRN & & & \\
\hline CHEMBL1305825 & 688810 & 4.833 & 5.2616 & TRN & & & \\
\hline CHEMBL1528803 & 688810 & 5.8329 & 99999999 & & 5.1781 & TRN & \\
\hline CHEMBL1531363 & 688810 & $4.983 e$ & 00000000 & 005 & 5.2696 & TRN & \\
\hline CHEMBL1517007 & 688810 & 5.7829 & 99999999 & 995 & 5.7645 & TRN & \\
\hline CHEMBL1583889 & 688810 & 5.5329 & 99999999 & 995 & 5.12700 & 0000000001 & TRN \\
\hline CHEMBL1527518 & 688810 & $4.983 e$ & 00000000 & 005 & 5.7348 & TRN & \\
\hline CHEMBL1548315 & 688810 & 4.933 & 4.7951 & TRN & & & \\
\hline CHEMBL1433053 & 688810 & 5.983 & 5.6887 & TRN & & & \\
\hline CHEMBL1598327 & 688810 & 5.683 & 5.718 & TRN & & & \\
\hline CHEMBL1384809 & 688810 & $4.733 e$ & 00000000 & 005 & 5.3688 & TRN & \\
\hline CHEMBL1389591 & 688810 & 4.583 & 5.0915 & TRN & & & \\
\hline CHEMBL1467203 & 688810 & 5.083 & 5.3616 & TRN & & & \\
\hline CHEMBL1361002 & 688810 & 5.2829 & 99999999 & 995 & 5.4757 & TST & \\
\hline CHEMBL1579853 & 688810 & 5.6329 & 99999999 & & 5.1763 & TRN & \\
\hline CHEMBL1598973 & 688810 & 5.083 & 5.4959 & TRN & & & \\
\hline CHEMBL1324384 & 688810 & $4.733 e$ & 00000000 & 005 & 5.2244 & TRN & \\
\hline CHEMBL1471717 & 688810 & 6.3829 & 99999999 & & 5.2866 & TRN & \\
\hline CHEMBL1466658 & 688810 & 4.833 & 5.2046 & TRN & & & \\
\hline CHEMBL1545515 & 688810 & 5.7829 & 99999999 & 995 & 5.8273 & TRN & \\
\hline CHEMBL1397645 & 688810 & 4.583 & 5.1468 & TRN & & & \\
\hline CHEMBL1599634 & 688810 & 4.633 & 5.0881 & TRN & & & \\
\hline CHEMBL1386466 & 688810 & 6.8329 & 99999999 & & 5.7633 & TRN & \\
\hline CHEMBL1525554 & 688810 & 5.2829 & 99999999 & 995 & 5.1722 & TRN & \\
\hline
\end{tabular}




\begin{tabular}{|c|c|c|c|c|c|c|c|}
\hline \multicolumn{7}{|c|}{ Supplemental Table S2.txt } & \\
\hline CHEMBL1499121 & 688810 & 6.183 & 5.62447 & TRN & & & \\
\hline CHEMBL3191343 & 688810 & 4.98300 & 000000000 & 205 & 5.3242 & TRN & \\
\hline CHEMBL1475334 & 688810 & 4.783 & 5.38887 & TST & & & \\
\hline CHEMBL1517622 & 688810 & 5.033 & 4.96857 & TRN & & & \\
\hline CHEMBL1320838 & 688810 & 4.783 & 4.941 & TRN & & & \\
\hline CHEMBL1589769 & 688810 & 5.83299 & 999999999 & & 5.6168 & TRN & \\
\hline CHEMBL1383279 & 688810 & 6.38299 & 999999999 & & 5.324 & TRN & \\
\hline CHEMBL1576307 & 688810 & 5.88299 & 999999999 & & 5.5975 & TRN & \\
\hline CHEMBL1398946 & 688810 & 5.433 & 5.31087 & TST & & & \\
\hline CHEMBL1599023 & 688810 & 4.633 & 5.3143 & TST & & & \\
\hline CHEMBL1977570 & 688810 & 5.63299 & 999999999 & & 5.7435 & TRN & \\
\hline CHEMBL1573880 & 688810 & 5.33299 & 999999999 & & 4.9514 & TRN & \\
\hline CHEMBL1328587 & 688810 & 6.53299 & 999999999 & 995 & 5.7895 & TRN & \\
\hline CHEMBL1421117 & 688810 & 6.78299 & 999999999 & 995 & 5.92899 & 9999999999 & TRN \\
\hline CHEMBL3208851 & 688810 & 6.433 & 5.54327 & TRN & & & \\
\hline CHEMBL1441548 & 688810 & 5.733 & 5.417999 & 999999999 & & TRN & \\
\hline CHEMBL1525277 & 688810 & 4.783 & 5.212000 & 000000000 & & TRN & \\
\hline CHEMBL1370549 & 688810 & 5.483 & 5.3638 & TRN & & & \\
\hline CHEMBL1428175 & 688810 & 4.98300 & 000000000 & 205 & 5.1645 & TST & \\
\hline CHEMBL1382884 & 688810 & 5.083 & 4.8992 & TST & & & \\
\hline CHEMBL1335023 & 688810 & 5.63299 & 999999999s & & 5.4477 & TRN & \\
\hline CHEMBL1543818 & 688810 & 7.2328 & 6.1694 & TRN & & & \\
\hline CHEMBL1416030 & 688810 & 4.883 & 5.0345 & TRN & & & \\
\hline CHEMBL1344119 & 688810 & 5.28299 & 999999999 & 995 & 5.224 & TST & \\
\hline CHEMBL 2007163 & 688810 & 4.98300 & 000000000 & 205 & 5.4557 & TRN & \\
\hline CHEMBL1480891 & 688810 & 5.13299 & 999999999s & & 5.6324 & TRN & \\
\hline CHEMBL1347777 & 688810 & 5.13299 & 999999999 & & 5.4855 & TRN & \\
\hline CHEMBL1348675 & 688810 & 7.2328 & 5.8738 & TRN & & & \\
\hline CHEMBL1980667 & 688810 & 6.38299 & 999999999 & & 5.8617 & TRN & \\
\hline CHEMBL1540038 & 688810 & 4.683 & 5.5782 & TST & & & \\
\hline CHEMBL1559067 & 688810 & 5.683 & 5.0477 & TRN & & & \\
\hline CHEMBL1471305 & 688810 & 4.73300 & 000000000 & 205 & 5.0932 & TRN & \\
\hline CHEMBL1519874 & 688810 & 5.233 & 5.2555 & TST & & & \\
\hline CHEMBL1583990 & 688810 & 4.783 & 4.9931 & TST & & & \\
\hline CHEMBL1417712 & 688810 & 5.88299 & 999999999 & & 5.7387 & TRN & \\
\hline CHEMBL1313595 & 688810 & 5.13299 & 999999999 & & 5.1136 & TRN & \\
\hline CHEMBL1411158 & 688810 & 5.033 & 4.7491 & TST & & & \\
\hline CHEMBL1580202 & 688810 & 6.58299 & 999999999 & & 5.6416 & TRN & \\
\hline CHEMBL3195697 & 688810 & 4.883 & 5.2232 & TRN & & & \\
\hline CHEMBL1571556 & 688810 & 4.583 & 4.8438 & TST & & & \\
\hline CHEMBL1559414 & 688810 & 6.433 & 6.1177 & TRN & & & \\
\hline CHEMBL1580184 & 688810 & 4.833 & 5.3586 & TRN & & & \\
\hline CHEMBL1447669 & 688810 & 6.0 & 5.6098 & TRN & & & \\
\hline CHEMBL1600515 & 688810 & 5.233 & 4.6742 & TRN & & & \\
\hline CHEMBL1577756 & 688810 & 5.88299 & 999999999 & & 5.897 & TRN & \\
\hline CHEMBL1463306 & 688810 & 5.433 & 4.9778 & TRN & & & \\
\hline CHEMBL3198269 & 688810 & 4.883 & 5.3524 & TRN & & & \\
\hline CHEMBL603522 & 688810 & 5.483 & 5.2164 & TST & & & \\
\hline
\end{tabular}




\begin{tabular}{|c|c|c|c|c|c|c|}
\hline \multicolumn{7}{|c|}{ Supplemental Table S2.txt } \\
\hline CHEMBL1527913 & 688810 & \multicolumn{3}{|c|}{6.082999999999999} & 5.5326 & TRN \\
\hline CHEMBL1364577 & 688810 & \multicolumn{3}{|c|}{7.082999999999999} & 6.0061 & TRN \\
\hline CHEMBL1599306 & 688810 & 6.8831 & 5.4074 & TRN & & \\
\hline CHEMBL 3207546 & 688810 & \multicolumn{3}{|c|}{6.332999999999999} & 5.5306 & TRN \\
\hline CHEMBL1551247 & 688810 & 4.633 & 5.1783 & TRN & & \\
\hline CHEMBL1327335 & 688810 & \multicolumn{3}{|c|}{5.132999999999999} & 5.2178 & TST \\
\hline CHEMBL1362662 & 688810 & \multicolumn{3}{|c|}{6.082999999999999} & 5.6859 & TRN \\
\hline CHEMBL1348582 & 688810 & 4.633 & 5.1986 & TST & & \\
\hline CHEMBL1545164 & 688810 & 4.683 & 4.8972 & TRN & & \\
\hline CHEMBL1967241 & 688810 & 5.683 & 6.0229 & TRN & & \\
\hline CHEMBL1482719 & 688810 & \multicolumn{3}{|c|}{4.7330000000000005} & 5.4897 & TRN \\
\hline CHEMBL1465409 & 688810 & 4.633 & 4.9836 & TRN & & \\
\hline CHEMBL1391531 & 688810 & 5.183 & 5.5908 & TRN & & \\
\hline CHEMBL1340213 & 688810 & \multicolumn{3}{|c|}{5.382999999999999} & 5.0522 & TST \\
\hline CHEMBL1343490 & 688810 & \multicolumn{3}{|c|}{5.332999999999999} & 5.33899 & 99999999995 \\
\hline CHEMBL 3197504 & 688810 & \multicolumn{3}{|c|}{5.382999999999999} & 4.7524 & TRN \\
\hline CHEMBL1366269 & 688810 & 5.683 & 5.6505 & TRN & & \\
\hline CHEMBL1326212 & 688810 & \multicolumn{3}{|c|}{6.582999999999999} & 6.1436 & TRN \\
\hline CHEMBL1491406 & 688810 & 4.883 & 5.454 & TST & & \\
\hline CHEMBL1491863 & 688810 & 5.183 & 4.9327 & TST & & \\
\hline CHEMBL1462330 & 688810 & 4.783 & 5.0339 & TRN & & \\
\hline CHEMBL1568702 & 688810 & 5.933 & 5.5195 & TRN & & \\
\hline CHEMBL1401302 & 688810 & \multicolumn{3}{|c|}{6.832999999999999} & 5.6802 & TST \\
\hline CHEMBL1429536 & 688810 & 4.683 & 5.2439 & TRN & & \\
\hline CHEMBL 3195761 & 688810 & 7.3325 & 6.096 & TRN & & \\
\hline CHEMBL1490176 & 688810 & 5.183 & 4.9584 & TRN & & \\
\hline CHEMBL1357388 & 688810 & 4.933 & 5.6139 & TRN & & \\
\hline CHEMBL1327941 & 688810 & 4.783 & 4.7855 & TRN & & \\
\hline CHEMBL1529427 & 688810 & 4.633 & 5.0454 & TRN & & \\
\hline CHEMBL1314235 & 688810 & 4.783 & 5.2326 & TRN & & \\
\hline CHEMBL1369506 & 688810 & \multicolumn{3}{|c|}{6.382999999999999} & 5.5712 & TRN \\
\hline CHEMBL1524862 & 688810 & 5.733 & 5.7202 & TRN & & \\
\hline CHEMBL1484818 & 688810 & 4.833 & 5.646 & TRN & & \\
\hline CHEMBL1331850 & 688810 & 4.833 & 4.7855 & TST & & \\
\hline CHEMBL1510724 & 688810 & 4.633 & 5.0999 & TST & & \\
\hline CHEMBL1610168 & 688810 & \multicolumn{3}{|c|}{5.132999999999999} & 4.6644 & TST \\
\hline CHEMBL1517864 & 688810 & 4.783 & 4.7615 & TST & & \\
\hline CHEMBL1611167 & 688810 & \multicolumn{3}{|c|}{5.5329999999999995} & 5.1632 & TST \\
\hline CHEMBL1525877 & 688810 & 5.183 & 5.1308 & TRN & & \\
\hline CHEMBL1607195 & 688810 & 4.933 & 5.0354 & TRN & & \\
\hline CHEMBL1539742 & 688810 & \multicolumn{3}{|c|}{5.7829999999999995} & 5.3789 & TRN \\
\hline CHEMBL1372210 & 688810 & 4.783 & 5.1459 & TST & & \\
\hline CHEMBL1538636 & 688810 & \multicolumn{3}{|c|}{5.132999999999999} & 5.0105 & TRN \\
\hline CHEMBL1366463 & 688810 & \multicolumn{3}{|c|}{4.9830000000000005} & 5.4742 & TRN \\
\hline CHEMBL1590521 & 688810 & 4.583 & \multicolumn{3}{|c|}{5.0169999999999995} & TRN \\
\hline CHEMBL1312712 & 688810 & 5.983 & 5.8537 & TRN & & \\
\hline CHEMBL1544159 & 688810 & \multicolumn{3}{|c|}{6.582999999999999} & 5.5794 & TRN \\
\hline CHEMBL2004186 & 688810 & \multicolumn{3}{|c|}{5.132999999999999} & 5.1717 & TRN \\
\hline
\end{tabular}




\begin{tabular}{|c|c|c|c|c|c|c|}
\hline & & \multicolumn{5}{|c|}{ Supplemental Table s2.txt } \\
\hline CHEMBL3194956 & 688810 & \multicolumn{3}{|c|}{4.7330000000000005} & 5.1907 & TST \\
\hline CHEMBL1573326 & 688810 & \multicolumn{3}{|c|}{5.5329999999999995} & 5.4684 & TRN \\
\hline CHEMBL551004 & 688810 & \multicolumn{3}{|c|}{5.7829999999999995} & 5.4013 & TRN \\
\hline CHEMBL1581760 & 688810 & 5.183 & 5.2429 & TST & & \\
\hline CHEMBL1567790 & 688810 & \multicolumn{3}{|c|}{6.132999999999999} & 5.2161 & TRN \\
\hline CHEMBL1429408 & 688810 & \multicolumn{3}{|c|}{5.7829999999999995} & 5.1489 & TRN \\
\hline CHEMBL1393198 & 688810 & 4.783 & 5.3654 & TRN & & \\
\hline CHEMBL210266 & 688810 & 6.4829 & 5.6799 & TRN & & \\
\hline CHEMBL1558550 & 688810 & 5.233 & 5.2267 & TRN & & \\
\hline CHEMBL1536095 & 688810 & \multicolumn{3}{|c|}{4.7330000000000005} & 5.2115 & TST \\
\hline CHEMBL1551648 & 688810 & 4.583 & 5.0074 & TRN & & \\
\hline CHEMBL1568958 & 688810 & 6.4829 & 6.058 & TRN & & \\
\hline CHEMBL1461408 & 688810 & \multicolumn{3}{|c|}{5.2829999999999995} & 4.9436 & TST \\
\hline CHEMBL1428141 & 688810 & 5.083 & 5.3969 & TRN & & \\
\hline CHEMBL1410538 & 688810 & 4.833 & 4.9926 & TRN & & \\
\hline CHEMBL1580543 & 688810 & 5.483 & 5.3471 & TRN & & \\
\hline CHEMBL1509431 & 688810 & 5.683 & 5.3752 & TRN & & \\
\hline CHEMBL1324664 & 688810 & 5.933 & 5.4952 & TRN & & \\
\hline CHEMBL1307038 & 688810 & 4.883 & 5.0576 & TRN & & \\
\hline CHEMBL1332140 & 688810 & \multicolumn{3}{|c|}{5.832999999999999} & 5.8431 & TRN \\
\hline CHEMBL1441848 & 688810 & 5.083 & 5.5927 & TRN & & \\
\hline CHEMBL1359746 & 688810 & 4.633 & 5.1202 & TRN & & \\
\hline CHEMBL3192205 & 688810 & \multicolumn{3}{|c|}{5.382999999999999} & 5.1982 & TRN \\
\hline CHEMBL3199050 & 688810 & 4.883 & 4.9156 & TRN & & \\
\hline CHEMBL1303426 & 688810 & 5.433 & 4.7747 & TRN & & \\
\hline CHEMBL1464088 & 688810 & 5.733 & 5.1532 & TRN & & \\
\hline CHEMBL1346192 & 688810 & \multicolumn{3}{|c|}{5.5329999999999995} & 5.4358 & TRN \\
\hline CHEMBL1579629 & 688810 & \multicolumn{3}{|c|}{5.5329999999999995} & 5.6783 & TRN \\
\hline CHEMBL1516336 & 688810 & 4.833 & 4.9521 & TRN & & \\
\hline CHEMBL 3193425 & 688810 & \multicolumn{3}{|c|}{6.332999999999999} & 5.3305 & TRN \\
\hline CHEMBL1452572 & 688810 & 4.883 & 5.2572 & TRN & & \\
\hline CHEMBL1391710 & 688810 & 4.833 & 5.3503 & TRN & & \\
\hline CHEMBL1323360 & 688810 & 5.183 & 5.235 & TST & & \\
\hline CHEMBL1377418 & 688810 & \multicolumn{3}{|c|}{4.7330000000000005} & 4.8602 & TST \\
\hline CHEMBL1366971 & 688810 & \multicolumn{3}{|c|}{5.582999999999999} & 5.2326 & TRN \\
\hline CHEMBL1533907 & 688810 & 4.783 & 5.6258 & TST & & \\
\hline CHEMBL1330392 & 688810 & 4.933 & 5.461 & TRN & & \\
\hline CHEMBL1455137 & 688810 & \multicolumn{3}{|c|}{5.2829999999999995} & 5.2832 & TRN \\
\hline CHEMBL1597924 & 688810 & \multicolumn{3}{|c|}{5.332999999999999} & 5.5855 & TRN \\
\hline CHEMBL1440471 & 688810 & 5.983 & 5.5993 & TRN & & \\
\hline CHEMBL3208184 & 688810 & 4.783 & 5.2134 & TST & & \\
\hline CHEMBL1600839 & 688810 & \multicolumn{3}{|c|}{5.832999999999999} & 5.2041 & TST \\
\hline CHEMBL1500819 & 688810 & \multicolumn{3}{|c|}{6.0329999999999995} & 5.267 & TRN \\
\hline CHEMBL3198351 & 688810 & 4.783 & 5.2248 & TRN & & \\
\hline CHEMBL1580997 & 688810 & 4.583 & 5.3831 & TRN & & \\
\hline CHEMBL1582550 & 688810 & \multicolumn{3}{|c|}{5.882999999999999} & 5.7964 & TRN \\
\hline CHEMBL1408646 & 688810 & \multicolumn{3}{|c|}{5.382999999999999} & 5.4823 & TRN \\
\hline CHEMBL1532928 & 688810 & 5.733 & 6.0542 & TRN & & \\
\hline
\end{tabular}




\begin{tabular}{|c|c|c|c|c|c|c|}
\hline \multirow[b]{2}{*}{ CHEMBL1386649 } & \\
\hline & 688810 & 4.833 & 764 & TST & & \\
\hline CHEMBL1394119 & 688810 & 6.2829 & 99999999 & 995 & 5.5427 & TRN \\
\hline CHEMBL3213501 & 688810 & 6.3329 & 99999999 & & 6.2499 & TRN \\
\hline CHEMBL1305196 & 688810 & 4.7330 & 00000000 & 005 & 5.2052 & \\
\hline CHEMBL1404702 & 688810 & 4.883 & 4.958 & TST & & \\
\hline CHEMBL3191806 & 688810 & 5.8829 & 99999999 & & 5.2557 & TRN \\
\hline CHEMBL1502124 & 688810 & 5.2829 & 99999999 & 995 & 4.9684 & \\
\hline CHEMBL1538034 & 688810 & 4.783 & 5.0069 & TRN & & \\
\hline CHEMBL1564962 & 688810 & 6.8329 & 99999999 & & 5.8849 & $1 \mathrm{~K}$ \\
\hline CHEMBL1502635 & 688810 & 6.233 & 5.4514 & TRN & & \\
\hline CHEMBL 3191563 & 688810 & 5.933 & 5.5028 & TRN & & \\
\hline CHEMBL1329585 & 688810 & 4.883 & 5.0831 & TRN & & \\
\hline CHEMBL1352910 & 688810 & 4.783 & 5.0721 & TST & & \\
\hline CHEMBL1471344 & 688810 & 4.933 & 5.2045 & TRN & & \\
\hline CHEMBL1306814 & 688810 & 4.95 & 5.2671 & TRN & & \\
\hline CHEMBL1585728 & 688810 & 5.7829 & 99999999 & 995 & 5.1923 & TST \\
\hline CHEMBL 3208158 & 688810 & 5.7829 & 99999999 & 995 & 5.3156 & \\
\hline CHEMBL1475193 & 688810 & 4.583 & 4.5071 & TST & & \\
\hline CHEMBL1507349 & 688810 & 5.183 & 5.3908 & TRN & & \\
\hline CHEMBL1398705 & 688810 & 4.9830 & 00000000 & 005 & 5 & \\
\hline CHEMBL1557611 & 688810 & 4.583 & 5.2112 & TRN & & \\
\hline CHEMBL1386394 & 688810 & 4.7330 & 00000000 & 005 & 5.2192 & TRN \\
\hline CHEMBL1543831 & 688810 & 4.9830 & 00000000 & 005 & 5.1397 & TS \\
\hline CHEMBL1242180 & 688810 & 5.683 & 6.1373 & TRN & & \\
\hline CHEMBL1435972 & 688810 & 4.883 & 5.5913 & TRN & & \\
\hline CHEMBL1609710 & 688810 & 4.9830 & 00000000 & 005 & 5.1845 & IST \\
\hline CHEMBL3210106 & 688810 & 5.183 & 5.3591 & TRN & & \\
\hline CHEMBL1544811 & 688810 & 5.3829 & 99999999 & & 5.7844 & TRN \\
\hline CHEMBL1584466 & 688810 & 5.7829 & 99999999 & 995 & 5.2801 & TST \\
\hline CHEMBL1488337 & 688810 & 5.033 & 5.46299 & 9999 & 99 & TRN \\
\hline CHEMBL1512920 & 688810 & 4.9830 & 00000000 & 005 & 5.2025 & TST \\
\hline CHEMBL1353607 & 688810 & 4.883 & 5.2805 & TST & & \\
\hline CHEMBL1457777 & 688810 & 4.7330 & 00000000 & 005 & 5.0544 & TR \\
\hline CHEMBL1588417 & 688810 & 4.883 & 5.0385 & TRN & & \\
\hline CHEMBL1505517 & 688810 & 4.783 & 5.4272 & TRN & & \\
\hline CHEMBL1413749 & 688810 & 4.833 & 5.2134 & TST & & \\
\hline CHEMBL1606319 & 688810 & 6.5329 & 99999999 & 995 & 5.9271 & TRN \\
\hline CHEMBL1424158 & 688810 & 5.483 & 5.08899 & 99999 & 995 & TST \\
\hline CHEMBL1571596 & 688810 & 4.7330 & 00000000 & 205 & 4.83 & TST \\
\hline CHEMBL 3190638 & 688810 & 4.783 & 5.1295 & TST & & \\
\hline CHEMBL1451172 & 688810 & 4.783 & 4.8734 & TRN & & \\
\hline CHEMBL1367677 & 688810 & 4.933 & 5.0025 & TRN & & \\
\hline CHEMBL3209425 & 688810 & 5.683 & 5.3415 & TRN & & \\
\hline CHEMBL1561649 & 688810 & 5.933 & 5.8953 & TRN & & \\
\hline CHEMBL1543986 & 688810 & 4.833 & 5.1584 & TRN & & \\
\hline CHEMBL 3212751 & 688810 & 5.433 & 5.2431 & TST & & \\
\hline CHEMBL1527114 & 688810 & 4.9830 & 00000000 & 205 & 5.1498 & ה \\
\hline CHEMBL3196809 & 688810 & 6.8831 & 5.8022 & TRN & & \\
\hline
\end{tabular}




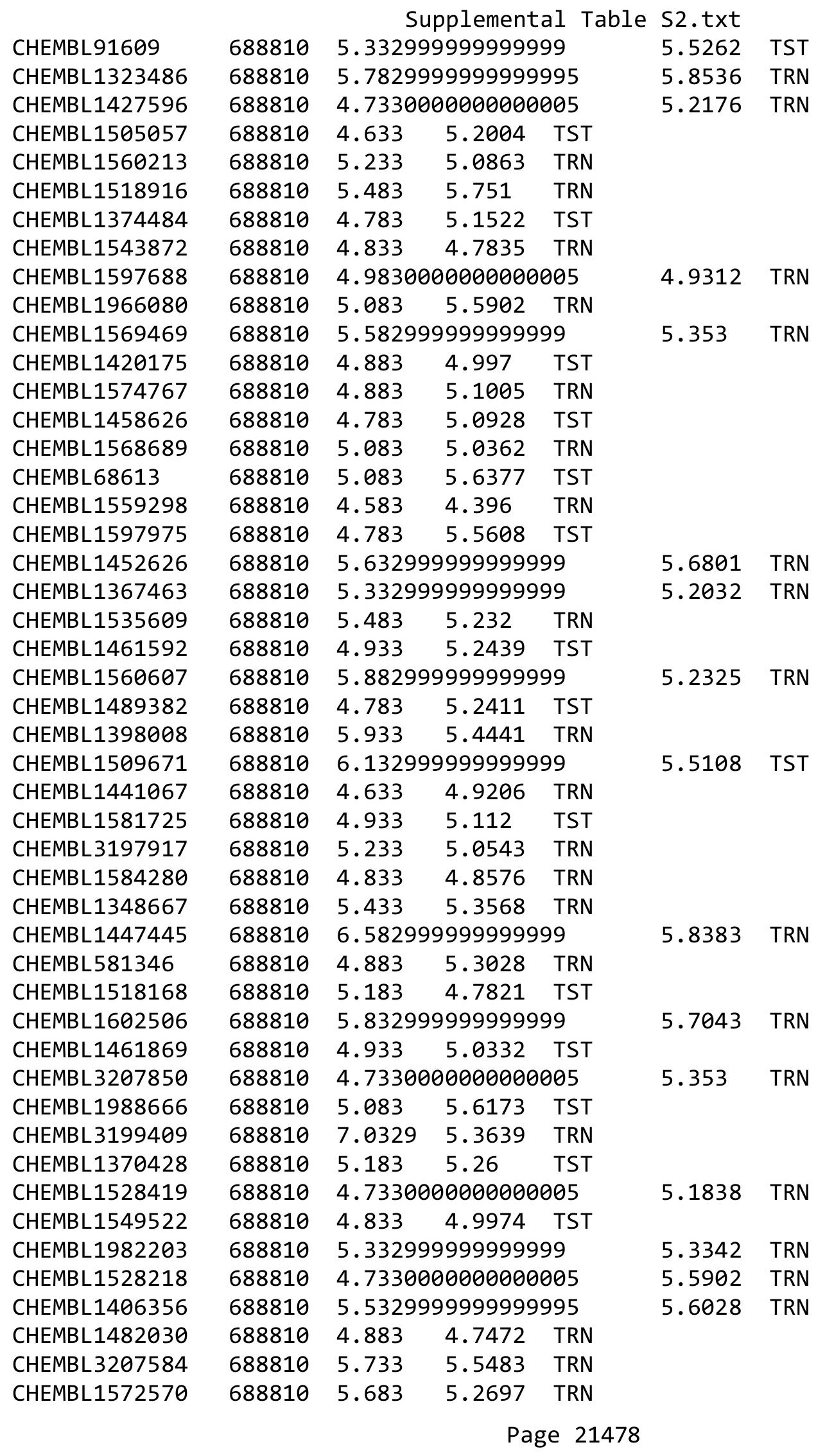




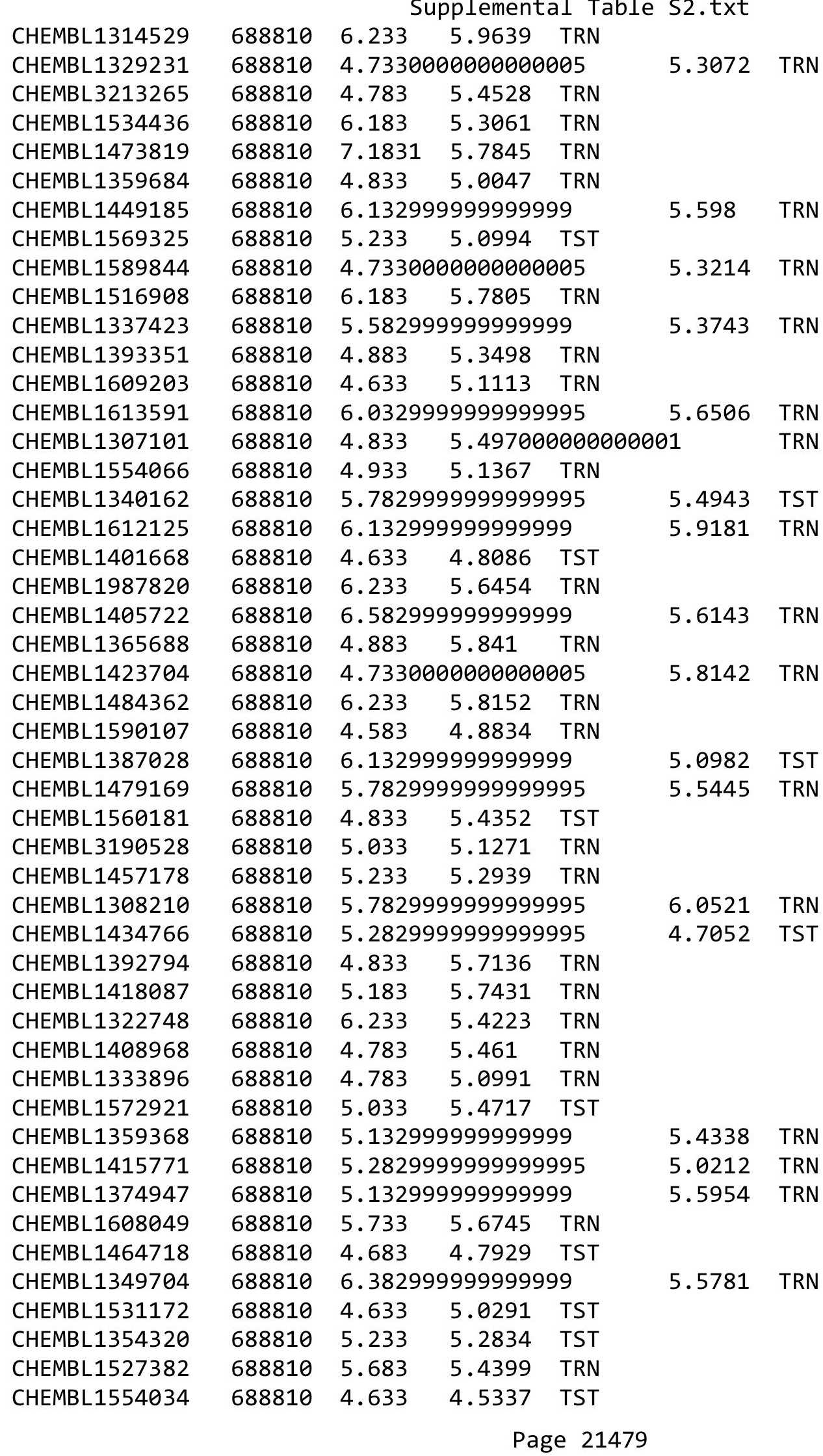




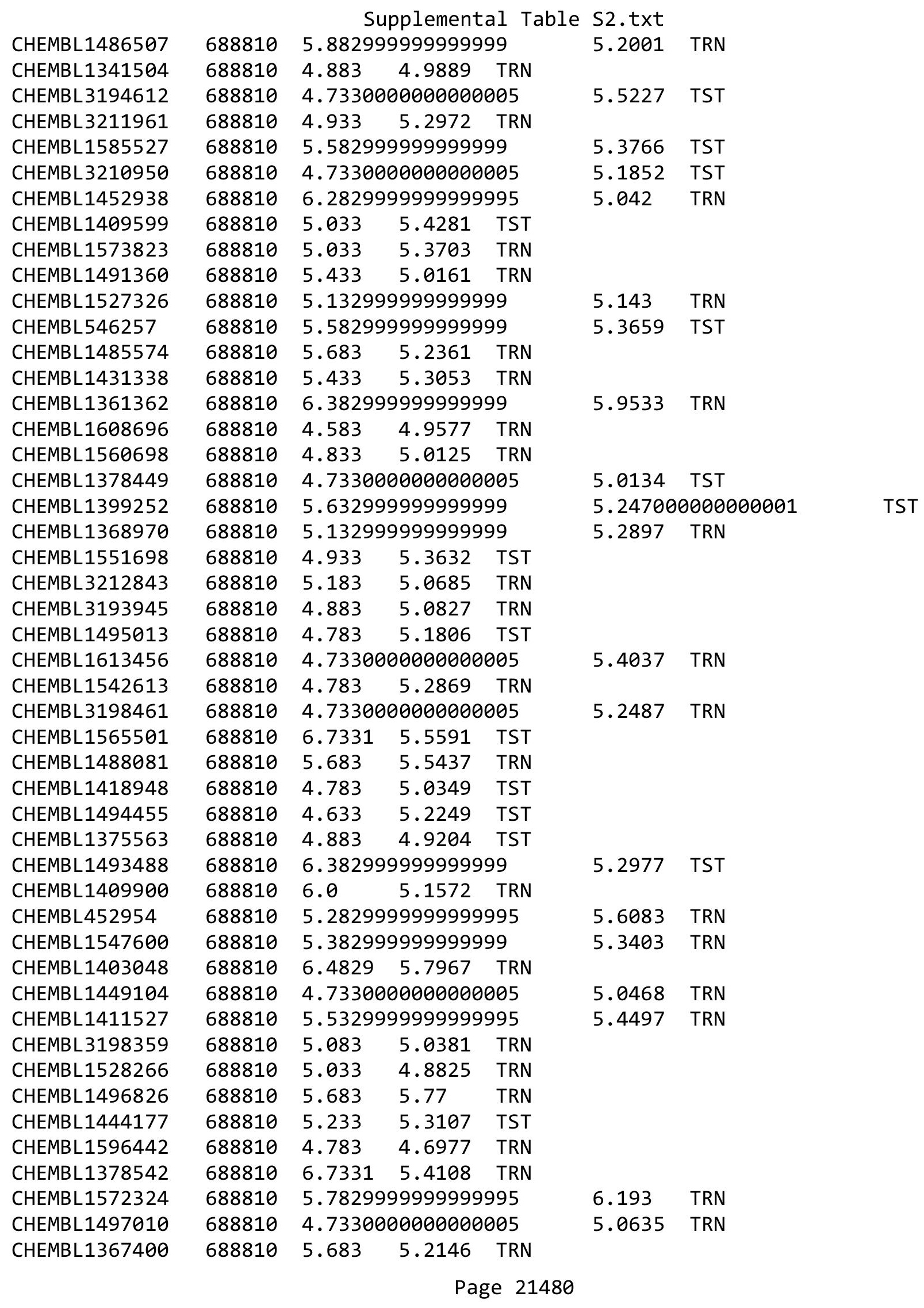




\begin{tabular}{|c|c|c|c|c|c|c|}
\hline \multicolumn{7}{|c|}{ oplemental Table s2.txt } \\
\hline CHEMBL1429205 & 688810 & 5.733 & 5.4982 & TRN & & \\
\hline CHEMBL1309858 & 688810 & 5.683 & 5.3168 & TST & & \\
\hline CHEMBL1999538 & 688810 & 4.833 & 5.1518 & TST & & \\
\hline CHEMBL 3189714 & 688810 & 5.2829 & 999999999 & 995 & 5.4149 & TRN \\
\hline CHEMBL1365290 & 688810 & 5.233 & 4.9346 & TRN & & \\
\hline CHEMBL1982152 & 688810 & 5.3829 & 999999999 & & 5.5895 & TRN \\
\hline CHEMBL1566949 & 688810 & 5.1329 & 999999999 & & 5.6641 & \\
\hline CHEMBL1357947 & 688810 & 4.583 & 4.8003 & TRN & & \\
\hline CHEMBL1573365 & 688810 & 4.7330 & 000000006 & 005 & 5.2753 & \\
\hline CHEMBL1310929 & 688810 & 4.683 & $5.24200 e$ & 0000000001 & $\partial 1$ & \\
\hline CHEMBL1463121 & 688810 & 4.883 & 5.0401 & TST & & \\
\hline CHEMBL1501377 & 688810 & 5.3829 & 999999999 & & 5.4745 & \\
\hline CHEMBL1446154 & 688810 & 5.033 & 5.2332 & TST & & \\
\hline CHEMBL 3211480 & 688810 & 4.833 & 5.4483 & TRN & & \\
\hline CHEMBL1441880 & 688810 & 4.683 & 5.2769 & TRN & & \\
\hline CHEMBL1325062 & 688810 & 5.083 & 5.2951 & TRN & & \\
\hline CHEMBL1389932 & 688810 & 4.933 & 5.3218 & TRN & & \\
\hline CHEMBL1472696 & 688810 & 4.833 & 5.3988 & TRN & & \\
\hline CHEMBL1462244 & 688810 & 5.933 & 6.0112 & TRN & & \\
\hline CHEMBL1408363 & 688810 & 4.933 & 4.93 & TRN & & \\
\hline CHEMBL 83170 & 688810 & 4.783 & 5.3713 & TST & & \\
\hline CHEMBL1402255 & 688810 & 4.9830 & 000000006 & 005 & 5.1929 & \\
\hline CHEMBL1481327 & 688810 & 4.633 & 4.5983 & TRN & & \\
\hline CHEMBL1600352 & 688810 & 4.783 & 5.1155 & TRN & & \\
\hline CHEMBL1301075 & 688810 & 5.233 & 5.2611 & TST & & \\
\hline CHEMBL1576791 & 688810 & 5.2829 & 999999999 & 995 & 5.0409 & \\
\hline CHEMBL407501 & 688810 & 5.233 & 5.4397 & TRN & & \\
\hline CHEMBL 1406680 & 688810 & 4.7330 & 000000000 & 005 & 5.0629 & \\
\hline CHEMBL1603877 & 688810 & 4.7330 & 000000000 & 005 & 4.8263 & \\
\hline CHEMBL1415686 & 688810 & 5.1329 & 999999999 & & 5.1864 & \\
\hline CHEMBL1544598 & 688810 & 4.783 & 5.2788 & TRN & & \\
\hline CHEMBL1414486 & 688810 & 5.983 & 5.3963 & TRN & & \\
\hline CHEMBL1310715 & 688810 & 5.3829 & 999999999 & & 4.9835 & \\
\hline CHEMBL1424910 & 688810 & 4.933 & 5.2183 & TRN & & \\
\hline CHEMBL1307312 & 688810 & 5.7829 & 999999999 & 995 & 4.9711 & $T$ \\
\hline CHEMBL 3192060 & 688810 & 4.833 & 5.3064 & TRN & & \\
\hline CHEMBL1324899 & 688810 & 5.3329 & 999999999 & 99 & 5.0499 & 1 \\
\hline CHEMBL1418155 & 688810 & 4.833 & 5.3271 & TRN & & \\
\hline CHEMBL1607059 & 688810 & 5.183 & 5.5875 & TRN & & \\
\hline CHEMBL1450748 & 688810 & 5.933 & 6.2752 & TRN & & \\
\hline CHEMBL1362580 & 688810 & 5.3329 & 999999999 & 99 & 5.0412 & TST \\
\hline CHEMBL1444505 & 688810 & 4.783 & 4.9491 & TST & & \\
\hline CHEMBL1351863 & 688810 & 4.583 & 4.9663 & TRN & & \\
\hline CHEMBL1597989 & 688810 & 4.783 & 5.0237 & TRN & & \\
\hline CHEMBL1318974 & 688810 & 5.2829 & 999999999 & 995 & 5.2381 & TRN \\
\hline CHEMBL1501189 & 688810 & 4.783 & 5.2664 & TRN & & \\
\hline CHEMBL1420866 & 688810 & 5.033 & 4.8515 & TST & & \\
\hline CHEMBL1475634 & 688810 & 4.583 & 4.6669 & TRN & & \\
\hline
\end{tabular}




\begin{tabular}{|c|c|c|c|c|c|c|}
\hline & & & pplemen & al Table & s2.txt & \\
\hline CHEMBL1443307 & 688810 & 5.13299 & 99999999 & & 4.9397 & TRN \\
\hline CHEMBL1486195 & 688810 & 5.483 & 5.4191 & TRN & & \\
\hline CHEMBL1583507 & 688810 & 5.483 & 5.2133 & TRN & & \\
\hline CHEMBL1408561 & 688810 & 6.0 & 5.4473 & TRN & & \\
\hline CHEMBL1471230 & 688810 & 5.1329 & 99999999 & & 4.9409 & TRN \\
\hline CHEMBL1303619 & 688810 & 5.88299 & 99999999 & & 5.3693 & TST \\
\hline CHEMBL1537363 & 688810 & 4.633 & 5.3152 & TRN & & \\
\hline CHEMBL1521005 & 688810 & 6.0829 & 99999999 & & 5.2933 & TRN \\
\hline CHEMBL1445707 & 688810 & 6.03299 & 99999999 & 995 & 5.2792 & TST \\
\hline CHEMBL1455249 & 688810 & 5.083 & 5.16200 & 000000000 & & TST \\
\hline CHEMBL1256686 & 688810 & 5.13299 & 99999999 & 99 & 5.5415 & TST \\
\hline CHEMBL1454230 & 688810 & 4.783 & 5.362 & TST & & \\
\hline CHEMBL1423871 & 688810 & 4.833 & 5.2571 & TRN & & \\
\hline CHEMBL2001211 & 688810 & 5.983 & 5.5827 & TST & & \\
\hline CHEMBL1426499 & 688810 & 4.933 & 5.0376 & TRN & & \\
\hline CHEMBL1569881 & 688810 & 5.483 & 4.7395 & TST & & \\
\hline CHEMBL1598614 & 688810 & 7.1331 & 5.974 & TRN & & \\
\hline CHEMBL1550430 & 688810 & 4.883 & 5.3422 & TRN & & \\
\hline CHEMBL1480352 & 688810 & 5.88299 & 99999999 & & 5.9273 & TRN \\
\hline CHEMBL3211295 & 688810 & 4.683 & 4.7712 & TRN & & \\
\hline CHEMBL1426574 & 688810 & 4.683 & 5.1187 & TRN & & \\
\hline CHEMBL1396458 & 688810 & 4.833 & 4.8918 & TST & & \\
\hline CHEMBL1358695 & 688810 & 6.7331 & 5.7096 & TST & & \\
\hline CHEMBL1324319 & 688810 & 5.88299 & 99999999 & & 4.7917 & TRN \\
\hline CHEMBL1984804 & 688810 & 5.63299 & 99999999 & & 5.4428 & TST \\
\hline CHEMBL3195091 & 688810 & 5.63299 & 99999999 & & 5.0331 & TST \\
\hline CHEMBL1402478 & 688810 & 4.73306 & 00000000 & 005 & 5.1069 & TST \\
\hline CHEMBL1558379 & 688810 & 5.933 & 5.3038 & TRN & & \\
\hline CHEMBL1599438 & 688810 & 5.28299 & 99999999 & 995 & 5.5527 & TST \\
\hline CHEMBL1320405 & 688810 & 4.783 & 5.1815 & TRN & & \\
\hline CHEMBL3192497 & 688810 & 5.733 & 5.8317 & TRN & & \\
\hline CHEMBL1420159 & 688810 & 5.13299 & 99999999 & & 5.4208 & TRN \\
\hline CHEMBL1354645 & 688810 & 5.13299 & 99999999 & & 5.4889 & TRN \\
\hline CHEMBL590672 & 688810 & $4.7330 e$ & 00000000 & 005 & 5.3979 & TST \\
\hline CHEMBL482116 & 688810 & 5.483 & 5.7926 & TRN & & \\
\hline CHEMBL1394695 & 688810 & 4.633 & 4.7251 & TRN & & \\
\hline CHEMBL1437375 & 688810 & 4.583 & 4.8487 & TST & & \\
\hline CHEMBL1373752 & 688810 & 5.483 & 5.4075 & TRN & & \\
\hline CHEMBL1372214 & 688810 & 5.683 & 5.5118 & TRN & & \\
\hline CHEMBL1387309 & 688810 & 4.933 & 4.9776 & TRN & & \\
\hline CHEMBL1995922 & 688810 & 6.4829 & 5.5617 & TST & & \\
\hline CHEMBL3213994 & 688810 & $4.7330 e$ & 00000000 & 005 & 5.1488 & TRN \\
\hline CHEMBL1571885 & 688810 & 5.33299 & 99999999 & & 4.8511 & TRN \\
\hline CHEMBL1381392 & 688810 & $4.9830 e$ & 00000000 & 005 & 5.6067 & TRN \\
\hline CHEMBL1398242 & 688810 & 5.3829 & 99999999 & & 5.2098 & TRN \\
\hline CHEMBL581870 & 688810 & 4.583 & 4.7295 & TST & & \\
\hline CHEMBL1604930 & 688810 & 4.633 & 5.3255 & TRN & & \\
\hline CHEMBL1576610 & 688810 & 4.833 & 5.0403 & TST & & \\
\hline
\end{tabular}




\begin{tabular}{|c|c|c|c|c|c|c|}
\hline \multirow[b]{2}{*}{ CHEMBL1522700 } & \multirow[b]{2}{*}{688810} & \multicolumn{5}{|c|}{ Supplemental Table S2.txt } \\
\hline & & \multicolumn{3}{|c|}{5.5739 TRN } & & \\
\hline CHEMBL1328811 & 688810 & \multicolumn{3}{|c|}{5.832999999999999} & 5.5211 & TRN \\
\hline CHEMBL1554006 & 688810 & 5.183 & 5.3361 & TRN & & \\
\hline CHEMBL3190990 & 688810 & 5.683 & 5.2394 & TST & & \\
\hline CHEMBL3196819 & 688810 & 4.783 & 5.2232 & TRN & & \\
\hline CHEMBL1612698 & 688810 & 5.183 & 5.1663 & TRN & & \\
\hline CHEMBL1553169 & 688810 & 5.683 & 5.4827 & TRN & & \\
\hline CHEMBL1494619 & 688810 & 5.033 & 5.3922 & TST & & \\
\hline CHEMBL1377584 & 688810 & 5.433 & 5.1885 & TST & & \\
\hline CHEMBL1307376 & 688810 & 4.783 & 5.0766 & TST & & \\
\hline CHEMBL3192277 & 688810 & 5.233 & 5.3313 & TRN & & \\
\hline CHEMBL1354702 & 688810 & \multicolumn{3}{|c|}{4.7330000000000005} & 5.3443 & TRN \\
\hline CHEMBL1524966 & 688810 & 5.483 & 5.6194 & TRN & & \\
\hline CHEMBL1448732 & 688810 & 4.833 & 5.0231 & TST & & \\
\hline CHEMBL1307854 & 688810 & 4.683 & 5.5988 & TST & & \\
\hline CHEMBL1569891 & 688810 & 5.183 & 5.7157 & TRN & & \\
\hline CHEMBL3193766 & 688810 & 4.833 & 4.6982 & TRN & & \\
\hline CHEMBL1965791 & 688810 & 6.183 & \multicolumn{3}{|c|}{5.162999999999999} & TRN \\
\hline CHEMBL1554951 & 688810 & \multicolumn{3}{|c|}{6.0329999999999995} & 5.5356 & TRN \\
\hline CHEMBL1531243 & 688810 & 4.783 & 4.8051 & TST & & \\
\hline CHEMBL3198006 & 688810 & 4.933 & 5.5588 & TRN & & \\
\hline CHEMBL1531987 & 688810 & \multicolumn{3}{|c|}{5.832999999999999} & 5.1537 & TST \\
\hline CHEMBL1497464 & 688810 & \multicolumn{3}{|c|}{4.9830000000000005} & 5.0076 & TST \\
\hline CHEMBL1558102 & 688810 & 6.433 & 5.687 & TRN & & \\
\hline CHEMBL1536701 & 688810 & \multicolumn{3}{|c|}{4.7330000000000005} & 5.2043 & TRN \\
\hline CHEMBL1457048 & 688810 & 4.833 & 4.8792 & TRN & & \\
\hline CHEMBL1438406 & 688810 & \multicolumn{3}{|c|}{6.5329999999999995} & 5.65 & TRN \\
\hline CHEMBL1493566 & 688810 & \multicolumn{3}{|c|}{5.7829999999999995} & 5.2768 & TRN \\
\hline CHEMBL1463860 & 688810 & \multicolumn{3}{|c|}{5.832999999999999} & 5.1125 & TRN \\
\hline CHEMBL1310615 & 688810 & 4.883 & 5.6985 & TRN & & \\
\hline CHEMBL1369487 & 688810 & \multicolumn{3}{|c|}{6.2829999999999995} & 5.8743 & TRN \\
\hline CHEMBL1560015 & 688810 & 5.183 & 5.2898 & TRN & & \\
\hline CHEMBL1518094 & 688810 & \multirow{2}{*}{\multicolumn{3}{|c|}{$\begin{array}{l}4.683 \quad 5.1443 \text { TRN } \\
4.9830000000000005\end{array}$}} & & \\
\hline CHEMBL1491864 & 688810 & & & & 5.729 & TRN \\
\hline CHEMBL1504712 & 688810 & 4.783 & 4.8411 & TST & & \\
\hline CHEMBL3192697 & 688810 & 4.783 & 5.5468 & TRN & & \\
\hline CHEMBL1332984 & 688810 & 4.633 & 5.6379 & TST & & \\
\hline CHEMBL1557075 & 688810 & 4.833 & 5.3851 & TST & & \\
\hline CHEMBL1584523 & 688810 & 5.933 & 5.5229 & TRN & & \\
\hline CHEMBL3208467 & 688810 & 4.783 & 5.0295 & TRN & & \\
\hline CHEMBL1377193 & 688810 & \multicolumn{3}{|c|}{5.832999999999999} & 5.2151 & TRN \\
\hline CHEMBL1325466 & 688810 & 4.933 & 4.7705 & TRN & & \\
\hline CHEMBL1607139 & 688810 & \multicolumn{3}{|c|}{5.382999999999999} & 5.3423 & TST \\
\hline CHEMBL1398454 & 688810 & \multicolumn{3}{|c|}{5.332999999999999} & 4.9798 & TRN \\
\hline CHEMBL1379675 & 688810 & \multicolumn{3}{|c|}{5.332999999999999} & 4.9454 & TRN \\
\hline CHEMBL1533982 & 688810 & 4.933 & 5.2484 & TRN & & \\
\hline CHEMBL1590442 & 688810 & 6.183 & 5.6359 & TRN & & \\
\hline CHEMBL1594975 & 688810 & 4.883 & 4.7563 & TRN & & \\
\hline
\end{tabular}




\begin{tabular}{|c|c|c|c|c|c|c|}
\hline CHEMBL1421101 & 688810 & \multicolumn{4}{|c|}{ Supplemental Table S2.txt } & TRN \\
\hline CHEMBL1428095 & 688810 & 4.783 & 5.3333 & TRN & & \\
\hline CHEMBL1544793 & 688810 & 4.783 & 5.1685 & TRN & & \\
\hline CHEMBL1504368 & 688810 & 5.45 & 5.0244 & TRN & & \\
\hline CHEMBL1506644 & 688810 & \multicolumn{3}{|c|}{4.7330000000000005} & 5.2273 & TRN \\
\hline CHEMBL589469 & 688810 & 5.233 & 6.0458 & TRN & & \\
\hline CHEMBL1421477 & 688810 & 5.083 & 5.0353 & TRN & & \\
\hline CHEMBL3212728 & 688810 & 4.783 & 5.2522 & TRN & & \\
\hline CHEMBL1566906 & 688810 & 4.883 & 5.5607 & TRN & & \\
\hline CHEMBL1426170 & 688810 & \multicolumn{3}{|c|}{4.7330000000000005} & 5.5223 & TRN \\
\hline CHEMBL1382847 & 688810 & 5.983 & 5.1572 & TST & & \\
\hline CHEMBL1572244 & 688810 & 4.933 & 5.0681 & TRN & & \\
\hline CHEMBL1460750 & 688810 & \multicolumn{3}{|c|}{5.582999999999999} & 5.8185 & TRN \\
\hline CHEMBL1355754 & 688810 & \multicolumn{3}{|c|}{4.7330000000000005} & 5.0221 & TRN \\
\hline CHEMBL1454397 & 688810 & 5.683 & 4.9722 & TRN & & \\
\hline CHEMBL1574206 & 688810 & 6.4829 & 5.2728 & TST & & \\
\hline CHEMBL1607102 & 688810 & \multicolumn{3}{|c|}{4.7330000000000005} & 5.0848 & TRN \\
\hline CHEMBL1538458 & 688810 & 4.833 & 5.0786 & TRN & & \\
\hline CHEMBL1309701 & 688810 & 5.083 & 5.3683 & TRN & & \\
\hline CHEMBL1426328 & 688810 & \multicolumn{3}{|c|}{5.332999999999999} & 5.1054 & TRN \\
\hline CHEMBL1421710 & 688810 & 4.783 & 5.3795 & TST & & \\
\hline CHEMBL1477844 & 688810 & 5.183 & 5.0015 & TST & & \\
\hline CHEMBL1496279 & 688810 & 4.783 & 5.5555 & TRN & & \\
\hline CHEMBL1495815 & 688810 & 4.933 & 5.1133 & TRN & & \\
\hline CHEMBL3213340 & 688810 & 4.933 & 5.0046 & TRN & & \\
\hline CHEMBL1440345 & 688810 & 5.433 & 5.2796 & TRN & & \\
\hline CHEMBL1434043 & 688810 & 4.883 & 4.9751 & TST & & \\
\hline CHEMBL3214372 & 688810 & 4.883 & 5.3513 & TST & & \\
\hline CHEMBL1502470 & 688810 & 4.833 & 4.8078 & TST & & \\
\hline CHEMBL1519943 & 688810 & \multicolumn{3}{|c|}{5.382999999999999} & 5.1141 & TRN \\
\hline CHEMBL1501463 & 688810 & 4.883 & 5.0244 & TRN & & \\
\hline CHEMBL1472888 & 688810 & \multicolumn{3}{|c|}{5.832999999999999} & 5.3261 & TRN \\
\hline CHEMBL1507820 & 688810 & 7.1331 & 5.4435 & TRN & & \\
\hline CHEMBL1487319 & 688810 & 4.783 & 5.3523 & TRN & & \\
\hline CHEMBL1312667 & 688810 & \multicolumn{3}{|c|}{5.132999999999999} & 5.2186 & TRN \\
\hline CHEMBL3213241 & 688810 & \multicolumn{3}{|c|}{4.9830000000000005} & 5.3896 & TRN \\
\hline CHEMBL1585742 & 688810 & 4.633 & 4.7915 & TRN & & \\
\hline CHEMBL1483218 & 688810 & \multicolumn{3}{|c|}{5.882999999999999} & 5.4779 & TRN \\
\hline CHEMBL1445523 & 688810 & 5.683 & 5.7071 & TRN & & \\
\hline CHEMBL1340431 & 688810 & 4.833 & 4.7482 & TST & & \\
\hline CHEMBL 3214274 & 688810 & 4.883 & 5.1839 & TRN & & \\
\hline CHEMBL1391227 & 688810 & 4.883 & 4.9968 & TRN & & \\
\hline CHEMBL1428079 & 688810 & 5.083 & 5.4491 & TST & & \\
\hline CHEMBL1395199 & 688810 & 4.633 & 5.3772 & TST & & \\
\hline CHEMBL1422217 & 688810 & 4.833 & 4.6644 & TRN & & \\
\hline CHEMBL3195501 & 688810 & 5.183 & 5.1999 & TST & & \\
\hline CHEMBL1588660 & 688810 & 4.683 & 5.0006 & TRN & & \\
\hline CHEMBL1604521 & 688810 & 4.783 & 5.6444 & TRN & & \\
\hline
\end{tabular}





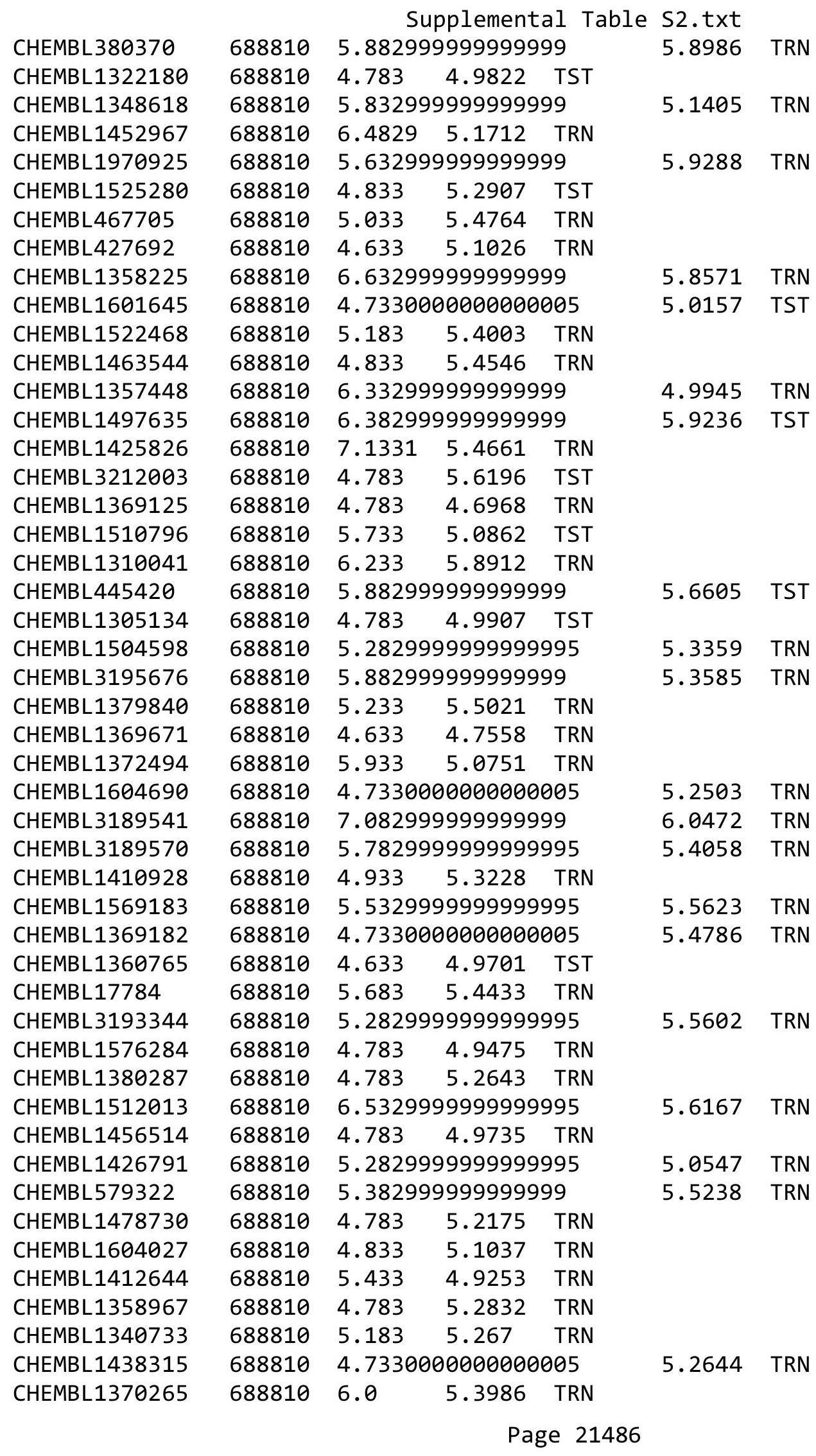




\begin{tabular}{|c|c|c|c|c|c|c|}
\hline \multirow[b]{2}{*}{ CHEMBL1572127 } & \multirow[b]{2}{*}{688810} & \multicolumn{5}{|c|}{ Supplemental Table S2.txt } \\
\hline & & \multicolumn{5}{|c|}{$6.183 \quad 5.5376 \quad$ TRN } \\
\hline CHEMBL3196868 & 688810 & \multicolumn{3}{|c|}{5.582999999999999} & 5.6312 & TST \\
\hline CHEMBL1466758 & 688810 & \multicolumn{3}{|c|}{5.7829999999999995} & 5.2802 & TRN \\
\hline CHEMBL1988310 & 688810 & \multicolumn{3}{|c|}{7.082999999999999} & 5.4918 & TRN \\
\hline CHEMBL1310629 & 688810 & 4.633 & 4.8601 & TRN & & \\
\hline CHEMBL1325851 & 688810 & 4.883 & 5.6222 & TST & & \\
\hline CHEMBL1444655 & 688810 & 4.933 & 4.9856 & TRN & & \\
\hline CHEMBL1492505 & 688810 & 5.033 & 4.9698 & TST & & \\
\hline CHEMBL1543780 & 688810 & \multicolumn{3}{|c|}{5.882999999999999} & 5.0156 & TRN \\
\hline CHEMBL1464609 & 688810 & 6.683 & 5.6674 & TRN & & \\
\hline CHEMBL3193541 & 688810 & 5.183 & 5.449 & TRN & & \\
\hline CHEMBL1362237 & 688810 & 4.683 & 4.8692 & TST & & \\
\hline CHEMBL1587212 & 688810 & \multicolumn{3}{|c|}{5.832999999999999} & 5.5785 & TRN \\
\hline CHEMBL1482610 & 688810 & \multicolumn{3}{|c|}{5.832999999999999} & 5.7073 & TRN \\
\hline CHEMBL1320962 & 688810 & 5.183 & 5.2195 & TRN & & \\
\hline CHEMBL1588460 & 688810 & \multicolumn{3}{|c|}{4.7330000000000005} & 5.1602 & TRN \\
\hline CHEMBL1575391 & 688810 & \multicolumn{3}{|c|}{5.332999999999999} & 5.7215 & TRN \\
\hline CHEMBL1563671 & 688810 & \multicolumn{3}{|c|}{6.082999999999999} & 5.9867 & TRN \\
\hline CHEMBL 78010 & 688810 & 6.183 & 5.9127 & TRN & & \\
\hline CHEMBL1381148 & 688810 & \multicolumn{3}{|c|}{4.7330000000000005} & 5.2825 & TST \\
\hline CHEMBL1502104 & 688810 & 4.683 & 5.4545 & TST & & \\
\hline CHEMBL1365350 & 688810 & \multirow{2}{*}{\multicolumn{3}{|c|}{$\begin{array}{lcc}4.883 & 4.9163 & \text { TRN } \\
5.2829999999999995\end{array}$}} & & \\
\hline CHEMBL1402080 & 688810 & & & & 4.9585 & TST \\
\hline CHEMBL1383394 & 688810 & \multicolumn{3}{|c|}{$5.433 \quad 5.3419$ TRN } & & \\
\hline CHEMBL1480798 & 688810 & 5.083 & 5.9377 & TRN & & \\
\hline CHEMBL1558556 & 688810 & \multicolumn{3}{|c|}{5.132999999999999} & 5.7047 & TRN \\
\hline CHEMBL1511652 & 688810 & \multicolumn{3}{|c|}{4.7330000000000005} & 5.0346 & TST \\
\hline CHEMBL1567571 & 688810 & 5.433 & 5.3165 & TST & & \\
\hline CHEMBL1521917 & 688810 & 4.833 & 5.2606 & TRN & & \\
\hline CHEMBL1882125 & 688810 & 4.633 & 5.1846 & TST & & \\
\hline CHEMBL1573641 & 688810 & 4.783 & 5.2544 & TRN & & \\
\hline CHEMBL1450047 & 688810 & 4.833 & 5.3677 & TRN & & \\
\hline CHEMBL1431090 & 688810 & 4.833 & 5.2096 & TST & & \\
\hline CHEMBL3192618 & 688810 & \multicolumn{3}{|c|}{5.5329999999999995} & 5.2138 & TRN \\
\hline CHEMBL1438507 & 688810 & \multicolumn{3}{|c|}{6.0329999999999995} & 5.441 & TRN \\
\hline CHEMBL1477689 & 688810 & \multicolumn{3}{|c|}{5.882999999999999} & 5.1729 & TRN \\
\hline CHEMBL1469404 & 688810 & 4.933 & 4.9396 & TRN & & \\
\hline CHEMBL300685 & 688810 & 5.6320 & 99999999 & & 5.0634 & TRN \\
\hline CHEMBL1373967 & 688810 & 4.833 & 4.9796 & TRN & & \\
\hline CHEMBL3197228 & 688810 & 5.183 & 5.4913 & TRN & & \\
\hline CHEMBL1407579 & 688810 & 5.5829 & 99999999 & & 5.3534 & TRN \\
\hline CHEMBL1480424 & 688810 & 4.783 & 4.9483 & TRN & & \\
\hline CHEMBL1354789 & 688810 & 4.833 & 5.0429 & TRN & & \\
\hline CHEMBL1317024 & 688810 & 4.583 & 5.1964 & TRN & & \\
\hline CHEMBL1445358 & 688810 & 4.7336 & j000000e & 005 & 5.5106 & TST \\
\hline CHEMBL1547237 & 688810 & 5.733 & 5.2128 & TRN & & \\
\hline CHEMBL1377336 & 688810 & 4.633 & 5.34 & TRN & & \\
\hline CHEMBL1528245 & 688810 & 5.033 & 5.2816 & TRN & & \\
\hline
\end{tabular}




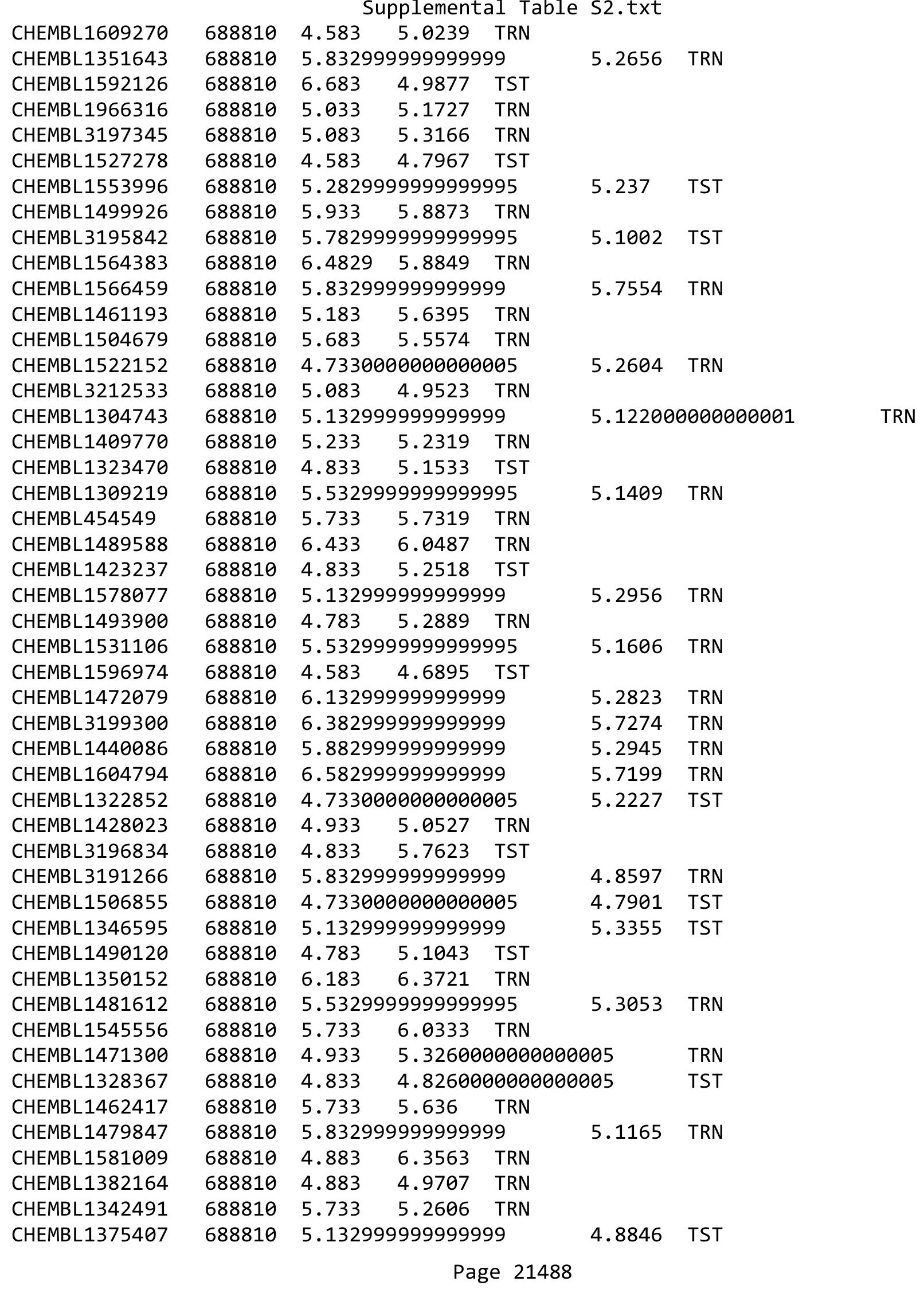




\begin{tabular}{|c|c|c|c|c|c|c|}
\hline \multicolumn{7}{|c|}{ Supplemental Tak } \\
\hline CHEMBL1537451 & 688810 & 5.183 & 5.2942 & TRN & & \\
\hline CHEMBL1396877 & 688810 & 4.583 & 4.6253 & TRN & & \\
\hline CHEMBL1588219 & 688810 & 6.183 & 5.482 & TRN & & \\
\hline CHEMBL1461477 & 688810 & 5.7829 & 99999999 & 995 & 4.9367 & TRN \\
\hline CHEMBL 3193543 & 688810 & 5.1329 & 99999999 & 99 & 5.319 & TRN \\
\hline CHEMBL1564737 & 688810 & 5.183 & 5.1129 & TRN & & \\
\hline CHEMBL1514563 & 688810 & 5.083 & 4.8467 & TST & & \\
\hline CHEMBL1330251 & 688810 & 4.633 & 5.3587 & TST & & \\
\hline CHEMBL1412978 & 688810 & 4.833 & 5.0688 & TRN & & \\
\hline CHEMBL3197616 & 688810 & 4.7330 & 00000000 & 005 & 5.0447 & TST \\
\hline CHEMBL1382721 & 688810 & 4.7330 & 00000000 & 005 & 5.2192 & TRN \\
\hline CHEMBL1313212 & 688810 & 4.9830 & 00000000 & 005 & 4.9592 & TST \\
\hline CHEMBL1556540 & 688810 & 5.1329 & 99999999 & & 5.1654 & TRN \\
\hline CHEMBL1595640 & 688810 & 4.883 & 5.3556 & TST & & \\
\hline CHEMBL1417275 & 688810 & 4.883 & 5.0721 & TRN & & \\
\hline CHEMBL1380281 & 688810 & 4.7330 & 00000000 & 005 & 4.9834 & TRIV \\
\hline CHEMBL1503962 & 688810 & 4.883 & 4.9637 & TST & & \\
\hline CHEMBL1527484 & 688810 & 5.733 & 5.3641 & TST & & \\
\hline CHEMBL1540513 & 688810 & 4.783 & 5.7255 & TRN & & \\
\hline CHEMBL1992104 & 688810 & 5.483 & 5.7589 & TRN & & \\
\hline CHEMBL1300639 & 688810 & 4.7330 & 00000000 & 005 & 5.1266 & TRN \\
\hline CHEMBL1443306 & 688810 & 4.833 & 5.2594 & TRN & & \\
\hline CHEMBL1310182 & 688810 & 5.733 & 5.8157 & TRN & & \\
\hline CHEMBL1352355 & 688810 & 6.0329 & 99999999 & 995 & 5.2935 & TRN \\
\hline CHEMBL1496625 & 688810 & 5.7829 & 99999999 & 995 & 5.362 & TRN \\
\hline CHEMBL1582137 & 688810 & 6.8831 & 5.6816 & TRN & & \\
\hline CHEMBL1513883 & 688810 & 4.583 & 4.87 & TRN & & \\
\hline CHEMBL1489151 & 688810 & 6.0329 & 99999999 & 995 & 5.0563 & ThN \\
\hline CHEMBL 3196853 & 688810 & 6.183 & 5.4148 & TRN & & \\
\hline CHEMBL1331875 & 688810 & 5.1329 & 99999999 & & 5.8314 & TRN \\
\hline CHEMBL1409890 & 688810 & 6.0829 & 99999999 & & 5.2461 & TRN \\
\hline CHEMBL1412106 & 688810 & 5.8329 & 99999999 & & 5.09 & TST \\
\hline CHEMBL1399939 & 688810 & 5.433 & 5.0176 & TST & & \\
\hline CHEMBL1571206 & 688810 & 4.883 & 5.1303 & TRN & & \\
\hline CHEMBL1463856 & 688810 & 4.9830 & 20000000 & 005 & 5.4587 & TRN \\
\hline CHEMBL1518866 & 688810 & 6.5329 & 99999999 & 995 & 5.966 & TRN \\
\hline CHEMBL1463025 & 688810 & 5.8829 & 99999999 & & 5.6445 & TRN \\
\hline CHEMBL1383022 & 688810 & 6.3329 & 99999999 & & 5.6025 & TRN \\
\hline CHEMBL1555344 & 688810 & 5.6329 & 99999999 & & 5.22 & 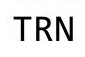 \\
\hline CHEMBL1498306 & 688810 & 5.183 & 5.586 & TRN & & \\
\hline CHEMBL1319106 & 688810 & 4.783 & 4.7815 & TRN & & \\
\hline CHEMBL1522803 & 688810 & 5.683 & 5.24299 & 99999 & & ST \\
\hline CHEMBL3209400 & 688810 & 5.683 & 5.4034 & TST & & \\
\hline CHEMBL1598418 & 688810 & 6.433 & 5.4603 & TRN & & \\
\hline CHEMBL1540556 & 688810 & 4.883 & 5.4545 & TST & & \\
\hline CHEMBL1592923 & 688810 & 4.633 & 5.1173 & TRN & & \\
\hline CHEMBL1604632 & 688810 & 6.183 & 5.081 & TRN & & \\
\hline CHEMBL1569489 & 688810 & 5.183 & 5.3703 & TRN & & \\
\hline
\end{tabular}




\begin{tabular}{|c|c|c|c|c|c|c|}
\hline & \multicolumn{5}{|c|}{ ent } \\
\hline CHEMBL1411426 & 688810 & 4.783 & 4.7335 & TRN & & \\
\hline CHEMBL1488418 & 688810 & \multicolumn{3}{|c|}{5.132999999999999} & 5.4182 & TRN \\
\hline CHEMBL1573043 & 688810 & \multicolumn{3}{|c|}{6.7829999999999995} & 6.0092 & \\
\hline CHEMBL1379442 & 688810 & 4.883 & 4.8814 & TRN & & \\
\hline CHEMBL1507515 & 688810 & 6.233 & 5.6062 & TRN & & \\
\hline CHEMBL3190397 & 688810 & 7.2832 & 6.103 & TRN & & \\
\hline CHEMBL1571946 & 688810 & \multicolumn{3}{|c|}{5.5329999999999995} & 5.2287 & $\mathrm{TI}$ \\
\hline CHEMBL1518799 & 688810 & 4.833 & 5.2529 & TRN & & \\
\hline CHEMBL1401346 & 688810 & 5.433 & 5.3562 & TRN & & \\
\hline CHEMBL1603315 & 688810 & 5.083 & 5.4464 & TST & & \\
\hline CHEMBL1583236 & 688810 & 5.033 & 5.7788 & TRN & & \\
\hline CHEMBL3193230 & 688810 & 5.183 & 5.9439 & TRN & & \\
\hline CHEMBL1537604 & 688810 & \multicolumn{3}{|c|}{4.7330000000000005} & 5.2366 & \\
\hline CHEMBL1334844 & 688810 & 5.683 & 5.7012 & TRN & & \\
\hline CHEMBL1342992 & 688810 & 4.783 & 4.9327 & TST & & \\
\hline CHEMBL1569800 & 688810 & 5.183 & 5.0419 & TST & & \\
\hline CHEMBL1397791 & 688810 & 4.783 & 4.9217 & TRN & & \\
\hline CHEMBL1397276 & 688810 & 5.683 & 5.7497 & TRN & & \\
\hline CHEMBL1464988 & 688810 & \multicolumn{3}{|c|}{4.7330000000000005} & 2 & \\
\hline CHEMBL3198091 & 688810 & 5.433 & 5.4815 & TST & & \\
\hline CHEMBL1301261 & 688810 & \multicolumn{3}{|c|}{5.132999999999999} & 5.5996 & TRN \\
\hline CHEMBL1314457 & 688810 & 4.783 & \multicolumn{3}{|c|}{5.292000000000001} & \\
\hline CHEMBL1444204 & 688810 & 4.783 & 5.0776 & TRN & & \\
\hline CHEMBL1427299 & 688810 & 5.183 & 5.4532 & TST & & \\
\hline CHEMBL3. & 688810 & 4.683 & 5.441 & TRN & & \\
\hline CHEMBL1520180 & 688810 & \multicolumn{3}{|c|}{6.382999999999999} & 5.7599 & \\
\hline CHEMBL1302973 & 688810 & 4.783 & 5.0253 & TRN & & \\
\hline CHEMBL1329491 & 688810 & \multicolumn{3}{|c|}{4.7330000000000005} & 5.0317 & \\
\hline CHEMBL1491374 & 688810 & 4.633 & 4.8697 & TRN & & \\
\hline CHEMBL1431377 & 688810 & \multicolumn{3}{|c|}{6.2829999999999995} & 5.9999 & \\
\hline CHEMBL136 & 688810 & 4.833 & 5.1539 & TRN & & \\
\hline CHEMBL1434194 & 688810 & \multicolumn{3}{|c|}{4.7330000000000005} & 5.3885 & $\mathrm{~T}$ \\
\hline CHEMBL1331097 & 688810 & 6.183 & 5.3866 & TRN & & \\
\hline CHEMBL3213465 & 688810 & 4.933 & 4.9198 & TRN & & \\
\hline CHEMBL1440055 & 688810 & \multicolumn{3}{|c|}{5.132999999999999} & 5.2873 & $\mathrm{~T}$ \\
\hline CHEMBL1471607 & 688810 & 4.883 & 5.3926 & TRN & & \\
\hline CHEMBL1525243 & 688810 & \multicolumn{3}{|c|}{5.632999999999999} & 5.3126 & $\mathrm{~T}$ \\
\hline CHEMBL1581866 & 688810 & 4.883 & 4.8584 & TRN & & \\
\hline CHEMBL1302338 & 688810 & \multicolumn{3}{|c|}{5.2829999999999995} & 5.3213 & TRN \\
\hline CHEMBL1490077 & 688810 & \multicolumn{3}{|c|}{4.9830000000000005} & 5.6401 & \\
\hline CHEMBL1517904 & 688810 & 4.833 & 5.2025 & TST & & \\
\hline CHEMBL3198276 & 688810 & \multicolumn{3}{|c|}{6.382999999999999} & 5.8737 & $\mathrm{~T}$ \\
\hline CHEMBL3194870 & 688810 & 4.933 & 6.0647 & TRN & & \\
\hline CHEMBL1327983 & 688810 & \multicolumn{3}{|c|}{4.9830000000000005} & 5.4002 & 15 \\
\hline CHEMBL1550184 & 688810 & 5.433 & 5.1774 & TRN & & \\
\hline CHEMBL1966700 & 688810 & 5.483 & 5.4005 & TRN & & \\
\hline CHEMBL3195897 & 688810 & \multicolumn{3}{|c|}{5.832999999999999} & 4.8699 & $1 \mathrm{~K}$ \\
\hline CHEMBL1451763 & 688810 & 4.933 & 5.445 & TST & & \\
\hline
\end{tabular}




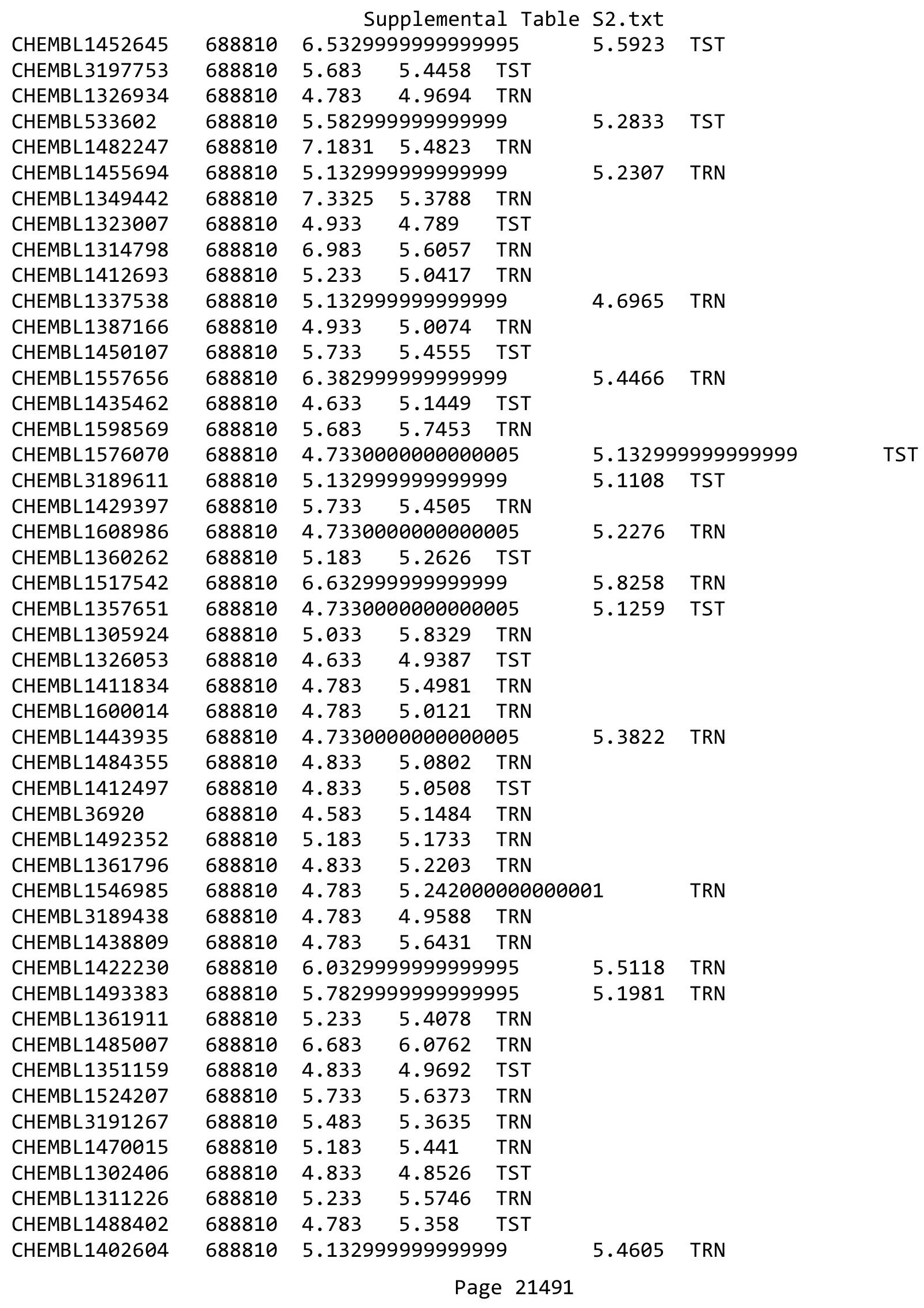




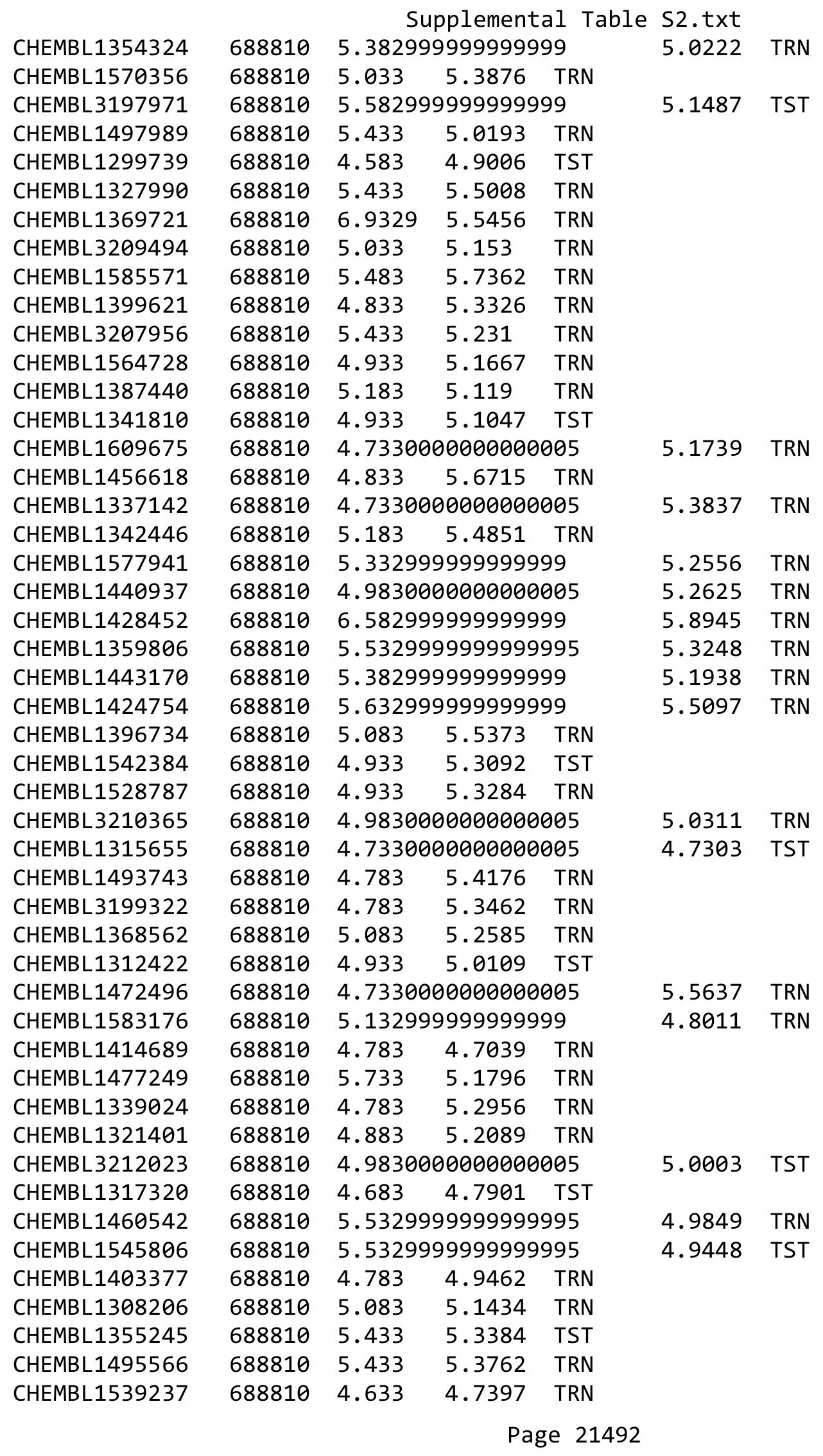




\begin{tabular}{|c|c|c|c|c|c|c|}
\hline \multirow[b]{2}{*}{ CHEMBL1448013 } & \multicolumn{6}{|c|}{ Supplemental Table S2.txt } \\
\hline & 688810 & 4.783 & 5.2193 & TRN & & \\
\hline CHEMBL1334130 & 688810 & 4.633 & 5.9263 & TST & & \\
\hline CHEMBL1404457 & 688810 & 4.9830 & 2000000e & 005 & 5.9239 & TRN \\
\hline CHEMBL 3189400 & 688810 & 6.8329 & 99999999 & 99 & 5.6696 & TRN \\
\hline CHEMBL1378441 & 688810 & 4.833 & 5.1378 & TRN & & \\
\hline CHEMBL 3197798 & 688810 & 4.783 & 5.0788 & TRN & & \\
\hline CHEMBL1414961 & 688810 & 4.933 & 4.8133 & TRN & & \\
\hline CHEMBL1505814 & 688810 & 4.933 & 5.2091 & TST & & \\
\hline CHEMBL1469953 & 688810 & 4.583 & 4.9707 & TST & & \\
\hline CHEMBL1536437 & 688810 & 5.483 & 5.4949 & TRN & & \\
\hline CHEMBL1316146 & 688810 & 4.883 & 4.8874 & TRN & & \\
\hline CHEMBL1562012 & 688810 & 6.433 & 5.9541 & TRN & & \\
\hline CHEMBL1527862 & 688810 & 5.7829 & 99999999 & 995 & 5.659 & TRN \\
\hline CHEMBL1392142 & 688810 & 5.3329 & 9999999 & & 6.3148 & \\
\hline CHEMBL1506407 & 688810 & 5.683 & 5.8701 & TRN & & \\
\hline CHEMBL1307285 & 688810 & 5.6329 & 99999999 & & 5.6015 & TRN \\
\hline CHEMBL1468008 & 688810 & 4.9830 & 00000000 & 005 & 5.005 & \\
\hline CHEMBL1577064 & 688810 & 4.883 & 5.0638 & TST & & \\
\hline CHEMBL1338404 & 688810 & 4.783 & 5.2578 & TRN & & \\
\hline CHEMBL1561277 & 688810 & 5.7829 & 99999999 & 995 & 5.104 & 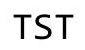 \\
\hline CHEMBL1303034 & 688810 & 5.983 & 5.3364 & TRN & & \\
\hline CHEMBL1998984 & 688810 & 6.0829 & 99999999 & & 5.638 & \\
\hline CHEMBL1473575 & 688810 & 5.183 & 5.2874 & TRN & & \\
\hline CHEMBL1451476 & 688810 & 5.083 & 5.3285 & TRN & & \\
\hline CHEMBL1605091 & 688810 & 4.7330 & $0000000 €$ & 005 & 5.2303 & TRN \\
\hline CHEMBL1420649 & 688810 & 4.833 & $4.9110 €$ & 00000 & 205 & TRN \\
\hline CHEMBL1574074 & 688810 & 5.2829 & 99999999 & 995 & 4.9712 & TRN \\
\hline CHEMBL1416927 & 688810 & 7.0829 & 99999999 & & 5.768 & 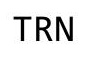 \\
\hline CHEMBL1533788 & 688810 & 4.833 & 4.7238 & TRN & & \\
\hline CHEMBL1601036 & 688810 & 5.2829 & 99999999 & 995 & 5.4595 & TRN \\
\hline CHEMBL1546438 & 688810 & 5.233 & 4.7774 & TST & & \\
\hline CHEMBL1313356 & 688810 & 4.633 & 4.7517 & TRN & & \\
\hline CHEMBL1491234 & 688810 & 4.783 & 5.5176 & TST & & \\
\hline CHEMBL1381901 & 688810 & 4.833 & 4.9208 & TRN & & \\
\hline CHEMBL 3195090 & 688810 & 4.933 & 5.1962 & TRN & & \\
\hline CHEMBL1495918 & 688810 & 5.8329 & 99999999 & & 5.5296 & $1 \pi$ \\
\hline CHEMBL1363469 & 688810 & 5.933 & 5.7121 & TRN & & \\
\hline CHEMBL1486935 & 688810 & 5.2829 & 99999999 & 995 & 5.4337 & TRN \\
\hline CHEMBL1578449 & 688810 & 5.3329 & 99999999 & & 5.7847 & TRN \\
\hline CHEMBL1605061 & 688810 & 5.1329 & 99999999 & & 5.3755 & TRN \\
\hline CHEMBL1563996 & 688810 & 4.883 & 5.25 & TRN & & \\
\hline CHEMBL 1458788 & 688810 & 5.1329 & 99999999 & & 5.4283 & TST \\
\hline CHEMBL1523803 & 688810 & 6.0829 & 99999999 & & 6.0621 & TRN \\
\hline CHEMBL1548843 & 688810 & 4.7330 & 20000006 & 005 & 5.3038 & TST \\
\hline CHEMBL 3210181 & 688810 & 5.1329 & 9999999 & & 5.2668 & TST \\
\hline CHEMBL1403315 & 688810 & 6.183 & 5.2603 & TST & & \\
\hline CHEMBL1532619 & 688810 & 5.5329 & 99999999 & 995 & 4.7639 & SI \\
\hline CHEMBL1410241 & 688810 & 4.883 & 5.1524 & TRN & & \\
\hline
\end{tabular}




\begin{tabular}{|c|c|c|c|c|c|c|}
\hline \multirow[b]{2}{*}{ CHEMBL1373589 } & \multicolumn{6}{|c|}{ Supplemental Table S2.txt } \\
\hline & 688810 & 5.733 & 5.5225 & TRN & & \\
\hline CHEMBL1459270 & 688810 & 5.933 & 5.2067 & TRN & & \\
\hline CHEMBL1490415 & 688810 & 4.783 & 4.9963 & TST & & \\
\hline CHEMBL582717 & 688810 & 5.433 & 4.9422 & TST & & \\
\hline CHEMBL1456797 & 688810 & \multicolumn{3}{|c|}{6.5329999999999995} & 5.5139 & TRN \\
\hline CHEMBL1348803 & 688810 & \multicolumn{3}{|c|}{5.2829999999999995} & 5.3879 & TST \\
\hline CHEMBL1496820 & 688810 & 4.783 & 5.5545 & TST & & \\
\hline CHEMBL1408238 & 688810 & 6.983 & 5.7326 & TRN & & \\
\hline CHEMBL1528631 & 688810 & 5.033 & 4.8341 & TRN & & \\
\hline CHEMBL483768 & 688810 & 5.183 & 5.4641 & TRN & & \\
\hline CHEMBL1362394 & 688810 & 4.833 & 5.5397 & TRN & & \\
\hline CHEMBL1403374 & 688810 & 4.883 & 5.0944 & TRN & & \\
\hline CHEMBL1379940 & 688810 & \multicolumn{3}{|c|}{5.7829999999999995} & 5.7176 & TRN \\
\hline CHEMBL1425572 & 688810 & 6.683 & 5.8448 & TRN & & \\
\hline CHEMBL1496380 & 688810 & 5.183 & 5.3836 & TRN & & \\
\hline CHEMBL1325218 & 688810 & \multicolumn{3}{|c|}{5.382999999999999} & 5.4419 & TRN \\
\hline CHEMBL1986681 & 688810 & 5.233 & 5.2505 & TRN & & \\
\hline CHEMBL1392867 & 688810 & 4.833 & 4.8474 & TRN & & \\
\hline CHEMBL1489706 & 688810 & 4.783 & 5.0555 & TST & & \\
\hline CHEMBL1550406 & 688810 & \multicolumn{3}{|c|}{5.382999999999999} & 4.7366 & TST \\
\hline CHEMBL1484209 & 688810 & 4.833 & 5.1232 & TST & & \\
\hline CHEMBL1442025 & 688810 & \multicolumn{3}{|c|}{5.832999999999999} & 5.5285 & TRN \\
\hline CHEMBL3198821 & 688810 & 6.8831 & 5.5351 & TRN & & \\
\hline CHEMBL1458079 & 688810 & \multicolumn{3}{|c|}{4.7330000000000005} & 5.3603 & TST \\
\hline CHEMBL1469802 & 688810 & \multicolumn{3}{|c|}{5.132999999999999} & 5.0912 & TRN \\
\hline CHEMBL1587150 & 688810 & 4.883 & 5.0818 & TST & & \\
\hline CHEMBL1602662 & 688810 & \multicolumn{3}{|c|}{5.2829999999999995} & 5.1808 & TRN \\
\hline CHEMBL1458184 & 688810 & 4.833 & 5.1368 & TRN & & \\
\hline CHEMBL1473394 & 688810 & 4.783 & 4.7842 & TRN & & \\
\hline CHEMBL1482199 & 688810 & \multicolumn{3}{|c|}{4.7330000000000005} & 5.7016 & TST \\
\hline CHEMBL1337616 & 688810 & 4.883 & \multicolumn{3}{|c|}{5.3020000000000005} & TRN \\
\hline CHEMBL1387395 & 688810 & 5.733 & 5.7752 & TRN & & \\
\hline CHEMBL1384870 & 688810 & 6.0 & 4.9578 & TRN & & \\
\hline CHEMBL 258853 & 688810 & 4.883 & 5.4551 & TST & & \\
\hline CHEMBL1430846 & 688810 & \multicolumn{3}{|c|}{5.7829999999999995} & 5.3967 & TRN \\
\hline CHEMBL1447121 & 688810 & \multicolumn{3}{|c|}{4.9830000000000005} & 5.2007 & TRN \\
\hline CHEMBL133576 & 688810 & 4.633 & 4.834 & TST & & \\
\hline CHEMBL1439493 & 688810 & 4.783 & 5.2661 & TST & & \\
\hline CHEMBL1452048 & 688810 & \multicolumn{3}{|c|}{5.132999999999999} & 5.4359 & TRN \\
\hline CHEMBL3198653 & 688810 & 4.883 & 5.1617 & TRN & & \\
\hline CHEMBL1213608 & 688810 & 5.233 & 5.8039 & TRN & & \\
\hline CHEMBL3198870 & 688810 & \multicolumn{3}{|c|}{6.2829999999999995} & 5.7029 & TRN \\
\hline CHEMBL3195662 & 688810 & \multicolumn{3}{|c|}{5.582999999999999} & 4.8069 & TST \\
\hline CHEMBL1358333 & 688810 & 4.783 & 5.6048 & TRN & & \\
\hline CHEMBL1556325 & 688810 & 4.833 & 5.1306 & TRN & & \\
\hline CHEMBL1479485 & 688810 & 5.183 & 5.4694 & TRN & & \\
\hline CHEMBL1460303 & 688810 & 5.683 & 5.2669 & TRN & & \\
\hline CHEMBL1360023 & 688810 & \multicolumn{3}{|c|}{5.132999999999999} & 5.4342 & TRN \\
\hline
\end{tabular}




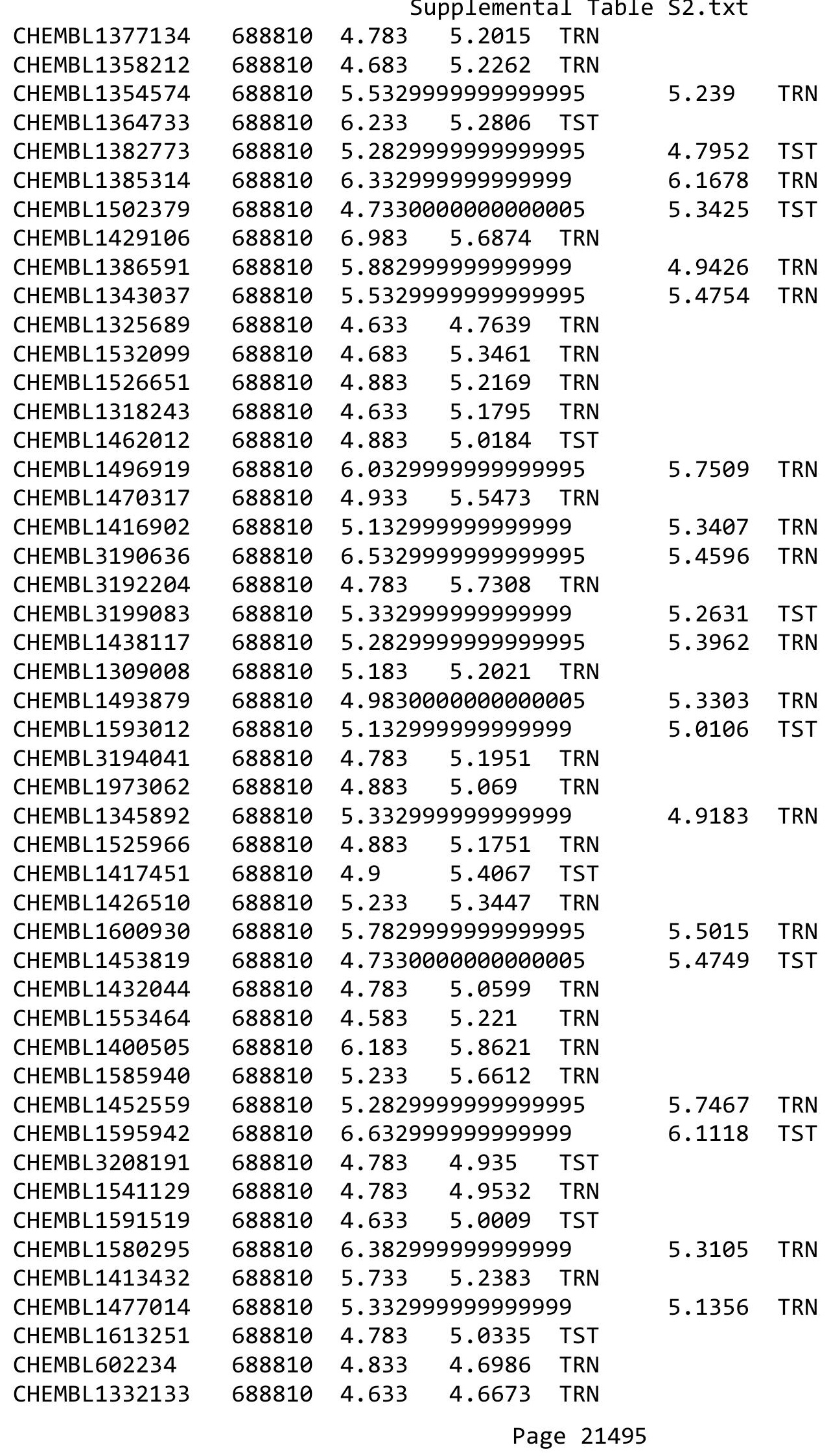




\begin{tabular}{|c|c|c|c|c|c|c|}
\hline \multirow[b]{2}{*}{ CHEMBL 3193470} & \multicolumn{6}{|c|}{ Supplemental Table S2.txt } \\
\hline & 688810 & 5.183 & 5.3963 & TRN & & \\
\hline CHEMBL1419517 & 688810 & 4.933 & \multicolumn{3}{|c|}{5.337999999999999} & TRN \\
\hline CHEMBL1498440 & 688810 & \multicolumn{3}{|c|}{5.882999999999999} & 5.7322 & \\
\hline CHEMBL1330197 & 688810 & 4.883 & 5.3712 & TRN & & \\
\hline CHEMBL1571574 & 688810 & \multicolumn{3}{|c|}{6.332999999999999} & 5.7017 & \\
\hline CHEMBL 3195830 & 688810 & \multicolumn{3}{|c|}{4.7330000000000005} & 5.0946 & \\
\hline CHEMBL1312546 & 688810 & 5.733 & 5.1536 & TRN & & \\
\hline CHEMBL1419794 & 688810 & 6.3 & 5.8397 & TRN & & \\
\hline CHEMBL201221 & 688810 & 5.183 & 5.6655 & TRN & & \\
\hline CHEMBL1435533 & 688810 & \multicolumn{3}{|c|}{6.5329999999999995} & 5.7501 & \\
\hline CHEMBL 3207648 & 688810 & 4.883 & \multicolumn{3}{|c|}{5.071000000000001} & \\
\hline CHEMBL1345815 & 688810 & 5.083 & 5.5416 & TRN & & \\
\hline CHEMBL1394287 & 688810 & 5.433 & 6.0375 & TRN & & \\
\hline CHEMBL1338256 & 688810 & \multicolumn{3}{|c|}{4.9830000000000005} & 5.6564 & \\
\hline CHEMBL1486831 & 688810 & \multicolumn{3}{|c|}{6.0329999999999995} & 5.7234 & \\
\hline CHEMBL1491135 & 688810 & \multirow{2}{*}{\multicolumn{3}{|c|}{5.2829999999999995}} & 5.6343 & \\
\hline CHEMBL1333985 & 688810 & & & 4.9830000000000005 & 5.651 & \\
\hline CHEMBL156 & 688810 & \multicolumn{3}{|c|}{5.882999999999999} & 5.148 & \\
\hline CHEMBL31S & 688810 & \multicolumn{3}{|c|}{5.632999999999999} & 5.2486 & \\
\hline CHEMBL 3194040 & 688810 & 4.933 & 5.3297 & TRN & & \\
\hline CHEMBL1398943 & 688810 & 5.083 & 5.1266 & TRN & & \\
\hline CHEMBL1489144 & 688810 & \multicolumn{3}{|c|}{4.7330000000000005} & 5.0419 & \\
\hline CHEMBL 31 & 688810 & \multicolumn{3}{|c|}{5.5329999999999995} & 5.3094 & \\
\hline CHEMBL14 & 688810 & \multicolumn{3}{|c|}{4.7330000000000005} & 5.2044 & \\
\hline CHEMBL1443173 & 688810 & 4.833 & 5.0856 & TRN & & \\
\hline CHEMBL1552079 & 688810 & 5.083 & 5.2067 & TRN & & \\
\hline CHEMBL1410975 & 688810 & \multicolumn{3}{|c|}{5.832999999999999} & 5.6693 & \\
\hline CHEMBL1 & 688810 & 4.833 & 5.2506 & TRN & & \\
\hline CHEMBL1 & 688810 & 4.783 & 5.284 & TRN & & \\
\hline CHEMBL1 & 688810 & 4.833 & 5.0577 & TRN & & \\
\hline CHEMBL157 & 688810 & 5.933 & 5.5539 & TRN & & \\
\hline CHEMBL1 & 688810 & 4.883 & 5.1366 & TRN & & \\
\hline CHEMBL1512126 & 688810 & 4.933 & \multicolumn{3}{|c|}{5.071000000000001} & TS \\
\hline CHEMBL1393575 & 688810 & \multicolumn{3}{|c|}{6.082999999999999} & 5.5241 & TR \\
\hline CHEMBL1407880 & 688810 & 5.483 & 5.1445 & TST & & \\
\hline CHEMBL1516092 & 688810 & 4.883 & 5.3795 & TRN & & \\
\hline CHEMBL 15 & 688810 & 5.033 & 4.6072 & TST & & \\
\hline CHEMBL1425794 & 688810 & \multicolumn{3}{|c|}{6.332999999999999} & 5.4842 & $\mathrm{TH}$ \\
\hline CHEMBL 3191000 & 688810 & 5.033 & 5.4329 & TRN & & \\
\hline CHEMBL1549213 & 688810 & 5.58299 & 999999999 & & 5.4847 & $1 \mathrm{~K}$ \\
\hline CHEMBL1379313 & 688810 & 5.933 & 5.1476 & TRN & & \\
\hline CHEMBL1353437 & 688810 & 5.233 & 5.3875 & TRN & & \\
\hline CHEMBL1567608 & 688810 & 4.933 & 5.1793 & TRN & & \\
\hline CHEMBL1426572 & 688810 & 5.13299 & 999999999 & & 5.1507 & . \\
\hline CHEMBL1359983 & 688810 & 4.73300 & 000000000 & 305 & 4.8977 & 政 \\
\hline CHEMBL1378017 & 688810 & 5.183 & 5.2977 & TRN & & \\
\hline CHEMBL1300618 & 688810 & 4.583 & 4.8384 & TST & & \\
\hline CHEMBL1346308 & 688810 & 5.183 & 4.9649 & TST & & \\
\hline
\end{tabular}




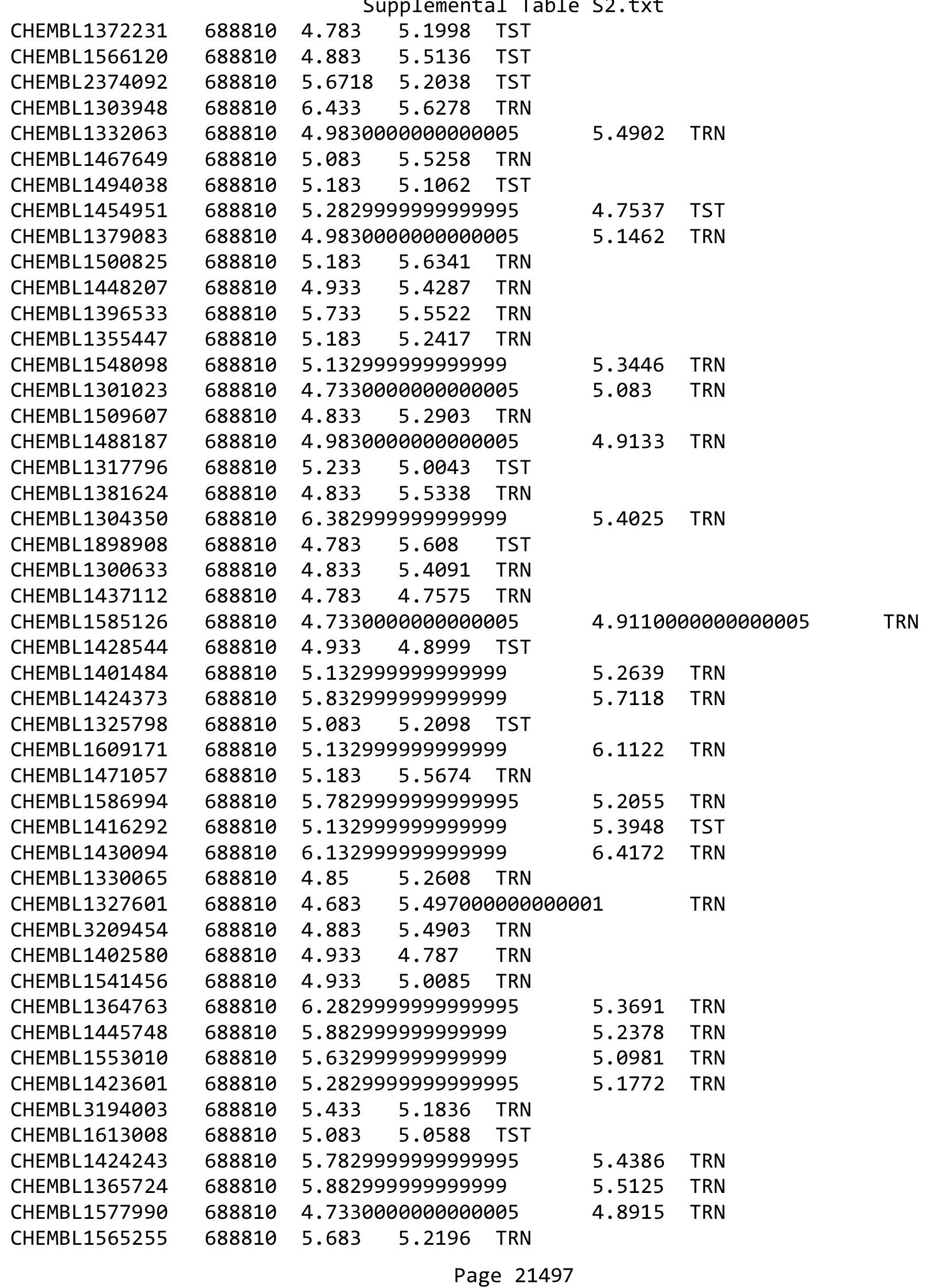




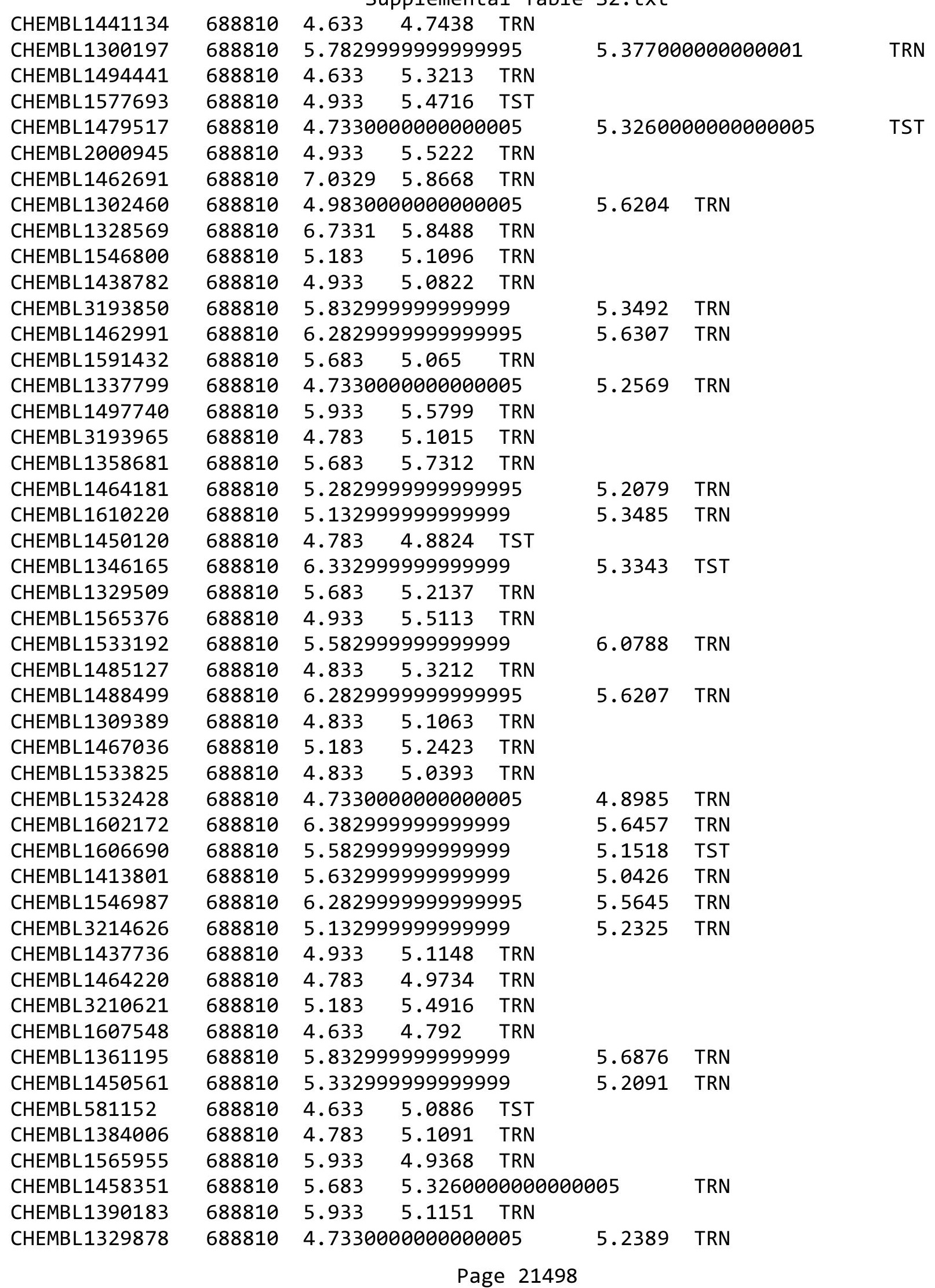




\begin{tabular}{|c|c|c|c|c|c|c|}
\hline CHEMBL1584875 & 688810 & 6.8831 & 5.8201 & TRN & & \\
\hline CHEMBL1485611 & 688810 & \multicolumn{3}{|c|}{4.7330000000000005} & 5.4959 & TRN \\
\hline CHEMBL1393303 & 688810 & 5.683 & 5.2345 & TRN & & \\
\hline CHEMBL1425095 & 688810 & 4.883 & 5.2204 & TRN & & \\
\hline CHEMBL 3197524 & 688810 & \multicolumn{3}{|c|}{5.132999999999999} & 5.2657 & TST \\
\hline CHEMBL3196158 & 688810 & 4.783 & 5.2225 & TST & & \\
\hline CHEMBL1506301 & 688810 & 5.183 & 5.5115 & TRN & & \\
\hline CHEMBL1420864 & 688810 & 5.233 & 5.3213 & TRN & & \\
\hline CHEMBL1476428 & 688810 & 4.783 & 5.3034 & TST & & \\
\hline CHEMBL1343919 & 688810 & 5.683 & 5.5569 & TRN & & \\
\hline CHEMBL1456521 & 688810 & 7.1331 & 5.8184 & TRN & & \\
\hline CHEMBL1453896 & 688810 & 5.083 & 5.1362 & TRN & & \\
\hline CHEMBL1487795 & 688810 & 5.733 & 5.6172 & TRN & & \\
\hline CHEMBL1579919 & 688810 & 4.783 & 5.1308 & TRN & & \\
\hline CHEMBL1455606 & 688810 & \multicolumn{3}{|c|}{4.7330000000000005} & 5.3843 & TRN \\
\hline CHEMBL1406565 & 688810 & 4.583 & 5.2693 & TST & & \\
\hline CHEMBL1537753 & 688810 & 5.033 & 4.9731 & TRN & & \\
\hline CHEMBL1606328 & 688810 & 6.0 & 5.3144 & TST & & \\
\hline CHEMBL1415560 & 688810 & \multicolumn{3}{|c|}{6.5329999999999995} & 5.5042 & TST \\
\hline CHEMBL1386822 & 688810 & 5.683 & 6.1305 & TRN & & \\
\hline CHEMBL1325934 & 688810 & 4.883 & 5.1438 & TST & & \\
\hline CHEMBL1594707 & 688810 & 4.783 & 5.1796 & TST & & \\
\hline CHEMBL 3197539 & 688810 & 5.233 & 4.6002 & TRN & & \\
\hline CHEMBL1587605 & 688810 & 4.783 & 5.1685 & TRN & & \\
\hline CHEMBL1602928 & 688810 & 5.233 & 5.4632 & TST & & \\
\hline CHEMBL1580096 & 688810 & \multicolumn{3}{|c|}{6.2829999999999995} & 5.7785 & TRN \\
\hline CHEMBL1320414 & 688810 & \multicolumn{3}{|c|}{5.132999999999999} & 5.6381 & TRN \\
\hline CHEMBL1345956 & 688810 & \multicolumn{3}{|c|}{4.7330000000000005} & 5.0993 & TRN \\
\hline CHEMBL1386556 & 688810 & 4.883 & 4.7142 & TRN & & \\
\hline CHEMBL1429551 & 688810 & 4.783 & 4.8228 & TRN & & \\
\hline CHEMBL 3189538 & 688810 & \multicolumn{3}{|c|}{5.7829999999999995} & 5.6729 & TRN \\
\hline CHEMBL1337931 & 688810 & 5.483 & 5.5953 & TRN & & \\
\hline CHEMBL1592430 & 688810 & \multicolumn{3}{|c|}{5.632999999999999} & 5.2728 & TRN \\
\hline CHEMBL1589122 & 688810 & 4.95 & 5.3215 & TRN & & \\
\hline CHEMBL1582546 & 688810 & 4.933 & 4.9777 & TRN & & \\
\hline CHEMBL1370390 & 688810 & 4.933 & 4.9782 & TST & & \\
\hline CHEMBL1606956 & 688810 & 5.983 & 5.3843 & TRN & & \\
\hline CHEMBL1514829 & 688810 & 4.683 & 5.077 & TRN & & \\
\hline CHEMBL1419578 & 688810 & \multicolumn{3}{|c|}{5.132999999999999} & 5.2665 & TRN \\
\hline CHEMBL1574553 & 688810 & \multicolumn{3}{|c|}{6.7829999999999995} & 6.7274 & TST \\
\hline CHEMBL1465044 & 688810 & \multicolumn{3}{|c|}{5.132999999999999} & 5.5547 & TRN \\
\hline CHEMBL1441604 & 688810 & 5.233 & 4.84 & TRN & & \\
\hline CHEMBL1531035 & 688810 & 5.083 & 4.7611 & TRN & & \\
\hline CHEMBL2002332 & 688810 & 5.683 & 5.3231 & TST & & \\
\hline CHEMBL1590064 & 688810 & 4.833 & 5.0024 & TRN & & \\
\hline CHEMBL1582642 & 688810 & \multicolumn{3}{|c|}{5.332999999999999} & 5.1195 & TRN \\
\hline CHEMBL1438799 & 688810 & \multicolumn{3}{|c|}{4.7330000000000005} & 5.0244 & TST \\
\hline CHEMBL3197936 & 688810 & \multicolumn{3}{|c|}{5.2829999999999995} & 5.1176 & TRN \\
\hline
\end{tabular}




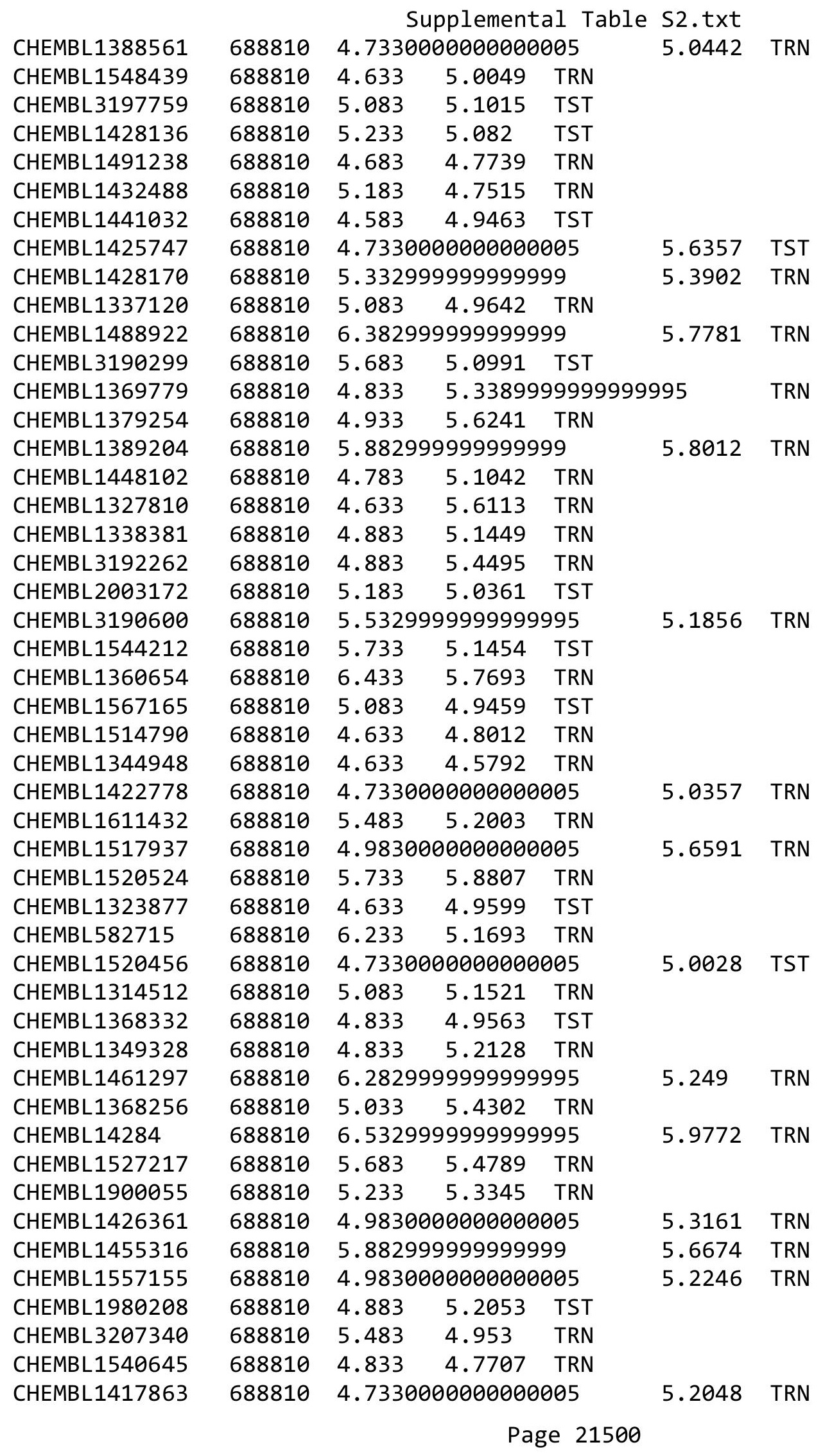




\begin{tabular}{|c|c|c|c|c|c|c|}
\hline & & & oplement & al & s2.txt & \\
\hline CHEMBL3196403 & 688810 & 4.7330 & 00000000 & 205 & 5.2028 & TST \\
\hline CHEMBL3212856 & 688810 & 6.0329 & 99999999 & 995 & 5.1545 & TRN \\
\hline CHEMBL1399398 & 688810 & 6.2829 & 99999999 & 995 & 5.5503 & TRN \\
\hline CHEMBL1491220 & 688810 & 5.683 & 5.5701 & TRN & & \\
\hline CHEMBL1581590 & 688810 & 5.683 & 6.0029 & TRN & & \\
\hline CHEMBL1404544 & 688810 & 4.683 & 5.1882 & TST & & \\
\hline CHEMBL1359476 & 688810 & 5.6329 & 99999999 & & 5.3971 & TRN \\
\hline CHEMBL1452399 & 688810 & 5.483 & 5.3573 & TRN & & \\
\hline CHEMBL1452318 & 688810 & 5.683 & 5.3173 & TRN & & \\
\hline CHEMBL1507477 & 688810 & 5.5829 & 79999999 & & 5.3444 & TRN \\
\hline CHEMBL3197982 & 688810 & 7.0329 & 5.8168 & TST & & \\
\hline CHEMBL1412052 & 688810 & 5.683 & 5.6417 & TRN & & \\
\hline CHEMBL1568979 & 688810 & 7.3325 & 5.8833 & TRN & & \\
\hline CHEMBL1335034 & 688810 & 4.833 & 5.2414 & TRN & & \\
\hline CHEMBL1300939 & 688810 & 5.7829 & 79999999 & 995 & 5.1946 & TST \\
\hline CHEMBL1458255 & 688810 & 5.233 & 5.2319 & TST & & \\
\hline CHEMBL1341992 & 688810 & 5.033 & 5.5492 & TST & & \\
\hline CHEMBL1421270 & 688810 & 5.983 & 5.647 & TST & & \\
\hline CHEMBL1392484 & 688810 & 4.833 & 5.2108 & TST & & \\
\hline CHEMBL1334132 & 688810 & 6.183 & 5.4554 & TRN & & \\
\hline CHEMBL1333570 & 688810 & 5.733 & 5.7675 & TRN & & \\
\hline CHEMBL1563492 & 688810 & 4.933 & 5.3109 & TRN & & \\
\hline CHEMBL1380153 & 688810 & 4.833 & 4.8753 & TRN & & \\
\hline CHEMBL3194762 & 688810 & 4.633 & 5.1569 & TST & & \\
\hline CHEMBL1333059 & 688810 & 4.7330 & 30000000 & 005 & 5.2691 & TRN \\
\hline CHEMBL1609723 & 688810 & 4.633 & 5.3407 & TRN & & \\
\hline CHEMBL1434497 & 688810 & 4.833 & 5.0309 & TRN & & \\
\hline CHEMBL1474094 & 688810 & 4.883 & 5.0197 & TRN & & \\
\hline CHEMBL1418503 & 688810 & 6.433 & 5.8725 & TRN & & \\
\hline CHEMBL1448851 & 688810 & 5.733 & 5.8305 & TRN & & \\
\hline CHEMBL1351105 & 688810 & 4.633 & 4.5871 & TST & & \\
\hline CHEMBL526776 & 688810 & 5.733 & 5.6751 & TRN & & \\
\hline CHEMBL1386999 & 688810 & 5.733 & 5.1088 & TRN & & \\
\hline CHEMBL1503145 & 688810 & 5.3829 & 99999999 & & 5.6237 & TRN \\
\hline CHEMBL1558092 & 688810 & 7.0829 & 99999999 & & 5.8264 & TRN \\
\hline CHEMBL1541071 & 688810 & 4.883 & 5.439 & TRN & & \\
\hline CHEMBL1401676 & 688810 & 7.2832 & 5.8783 & TRN & & \\
\hline CHEMBL1509578 & 688810 & 4.9830 & 30000000 & 005 & 5.0439 & TRN \\
\hline CHEMBL3211931 & 688810 & 6.5829 & 99999999 & & 5.511 & TST \\
\hline CHEMBL1535538 & 688810 & 4.783 & 4.7454 & TST & & \\
\hline CHEMBL3213091 & 688810 & 4.883 & 5.527 & TRN & & \\
\hline CHEMBL1339229 & 688810 & 4.583 & 5.2795 & TST & & \\
\hline CHEMBL1520326 & 688810 & 4.833 & 5.6592 & TRN & & \\
\hline CHEMBL1314167 & 688810 & 4.833 & 4.9969 & TST & & \\
\hline CHEMBL1452502 & 688810 & 6.3329 & 79999999 & & 5.6858 & TRN \\
\hline CHEMBL1494877 & 688810 & 4.683 & 5.4591 & TST & & \\
\hline CHEMBL1534313 & 688810 & 4.833 & 5.1209 & TST & & \\
\hline CHEMBL1459709 & 688810 & 5.933 & 5.7809 & TRN & & \\
\hline
\end{tabular}




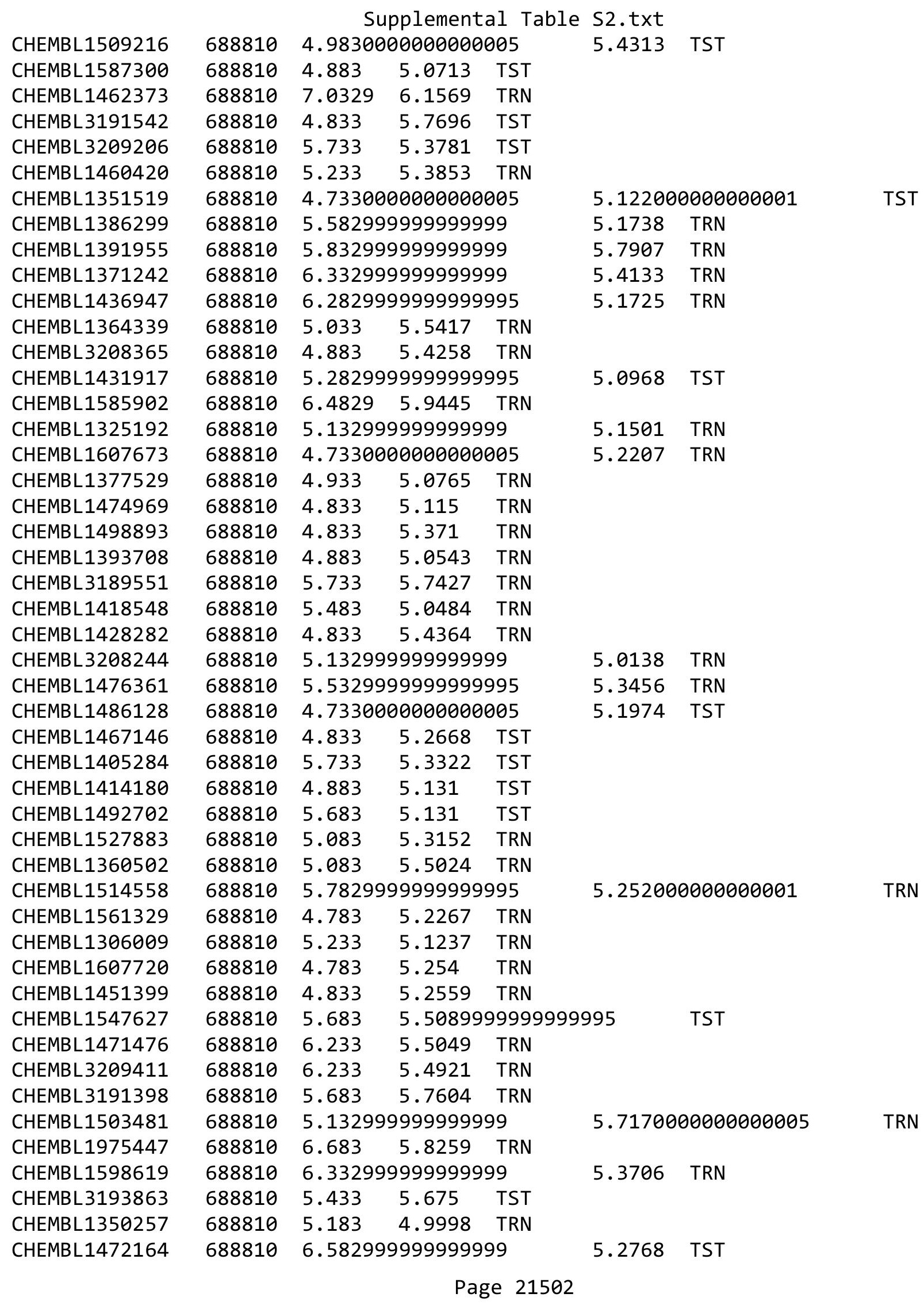




\begin{tabular}{|c|c|c|c|c|c|c|}
\hline & & \multicolumn{5}{|c|}{ Supplemental Table s2.txt } \\
\hline CHEMBL1509380 & 688810 & 4.583 & 5.0155 & TRN & & \\
\hline CHEMBL1351956 & 688810 & 4.833 & 5.1435 & TRN & & \\
\hline CHEMBL1412678 & 688810 & \multicolumn{3}{|c|}{5.332999999999999} & 5.0495 & TRN \\
\hline CHEMBL1525535 & 688810 & 5.183 & 5.3817 & TST & & \\
\hline CHEMBL1519338 & 688810 & 4.833 & 5.0389 & TRN & & \\
\hline CHEMBL1515797 & 688810 & 5.183 & 4.934 & TRN & & \\
\hline CHEMBL1990383 & 688810 & \multicolumn{3}{|c|}{5.632999999999999} & 5.0744 & \\
\hline CHEMBL1573190 & 688810 & 5.483 & 5.0034 & TRN & & \\
\hline CHEMBL1469715 & 688810 & 5.183 & 5.3892 & TST & & \\
\hline CHEMBL1541440 & 688810 & 5.683 & 5.1166 & TST & & \\
\hline CHEMBL1538954 & 688810 & 5.733 & 5.7484 & TRN & & \\
\hline CHEMBL1477540 & 688810 & \multicolumn{3}{|c|}{5.332999999999999} & 5.1413 & \\
\hline CHEMBL1480895 & 688810 & 4.883 & 5.2358 & TST & & \\
\hline CHEMBL 3189855 & 688810 & 4.783 & 5.7512 & TST & & \\
\hline CHEMBL1464812 & 688810 & \multicolumn{3}{|c|}{5.2829999999999995} & 5.3169 & ThN \\
\hline CHEMBL119247 & 688810 & 5.183 & 4.685 & TST & & \\
\hline CHEMBL1302457 & 688810 & 5.733 & 5.596 & TRN & & \\
\hline CHEMBL1444631 & 688810 & 4.833 & 5.3472 & TRN & & \\
\hline CHEMBL 2003964 & 688810 & \multicolumn{3}{|c|}{5.7829999999999995} & 5.6561 & $\mathrm{TP}$ \\
\hline CHEMBL1331233 & 688810 & 4.683 & 4.8909 & TRN & & \\
\hline CHEMBL1342444 & 688810 & 5.683 & 5.1408 & TRN & & \\
\hline CHEMBL1492469 & 688810 & 5.733 & 5.5599 & TRN & & \\
\hline CHEMBL1544420 & 688810 & 5.083 & 5.6315 & TRN & & \\
\hline CHEMBL3190016 & 688810 & 4.883 & 5.5117 & TRN & & \\
\hline CHEMBL1541638 & 688810 & 4.833 & 5.5522 & TST & & \\
\hline CHEMBL3213155 & 688810 & \multicolumn{3}{|c|}{6.382999999999999} & 768 & \\
\hline CHEMBL1352081 & 688810 & 4.833 & 5.0552 & TRN & & \\
\hline CHEMBL1563894 & 688810 & 6.983 & 6.1799 & TRN & & \\
\hline CHEMBL1451192 & 688810 & \multicolumn{3}{|c|}{5.832999999999999} & 5.5287 & TP \\
\hline CHEMBL3213405 & 688810 & 4.833 & 4.9854 & TST & & \\
\hline CHEMBL1397330 & 688810 & 4.683 & 5.2654 & TST & & \\
\hline CHEMBL1333318 & 688810 & \multicolumn{3}{|c|}{5.7829999999999995} & 5.3575 & ובנו \\
\hline CHEMBL1318614 & 688810 & 4.933 & 5.4231 & TRN & & \\
\hline CHEMBL1556708 & 688810 & 4.833 & 5.4041 & TRN & & \\
\hline CHEMBL1409318 & 688810 & \multicolumn{3}{|c|}{6.382999999999999} & 5.7938 & $\mathrm{TR}$ \\
\hline CHEMBL577752 & 688810 & 4.833 & 5.1841 & TRN & & \\
\hline CHEMBL2004183 & 688810 & 5.683 & 5.142 & TST & & \\
\hline CHEMBL1407513 & 688810 & \multicolumn{3}{|c|}{6.582999999999999} & 5.9492 & TST \\
\hline CHEMBL 3199264 & 688810 & \multicolumn{3}{|c|}{5.2829999999999995} & 5.1068 & TRN \\
\hline CHEMBL1576677 & 688810 & 7.1331 & 5.4978 & TRN & & \\
\hline CHEMBL1397986 & 688810 & 4.583 & 4.7058 & TRN & & \\
\hline CHEMBL1535856 & 688810 & 4.633 & 4.9809 & TST & & \\
\hline CHEMBL1600873 & 688810 & 4.783 & 5.4347 & TRN & & \\
\hline CHEMBL1304754 & 688810 & \multicolumn{3}{|c|}{4.9830000000000005} & 4.973 & נתו \\
\hline CHEMBL1418980 & 688810 & 4.783 & 4.8361 & TRN & & \\
\hline CHEMBL1442145 & 688810 & 4.933 & 5.3675 & TRN & & \\
\hline CHEMBL1313187 & 688810 & \multicolumn{3}{|c|}{6.5329999999999995} & 5.914 & Tार \\
\hline CHEMBL1530181 & 688810 & \multicolumn{3}{|c|}{5.332999999999999} & 5.0559 & TRN \\
\hline
\end{tabular}




\begin{tabular}{|c|c|c|c|c|c|c|}
\hline CHEMBL3209796 & 688810 & 6.7331 & 5.9176 & TRN & & \\
\hline CHEMBL1431326 & 688810 & \multicolumn{3}{|c|}{6.582999999999999} & 5.8163 & TR \\
\hline CHEMBL1464620 & 688810 & 6.683 & 5.5246 & TRN & & \\
\hline CHEMBL1602424 & 588810 & \multicolumn{3}{|c|}{5.132999999999999} & 5.2636 & \\
\hline CHEMBL1581580 & 588810 & 5.033 & 5.5225 & TRN & & \\
\hline CHEMBL1471326 & 688810 & 6.4829 & 5.6836 & TRN & & \\
\hline CHEMBL1474743 & 688810 & \multicolumn{3}{|c|}{5.7829999999999995} & 5.1822 & \\
\hline HEMBL1318038 & 588810 & 5.083 & 5.1737 & TRN & & \\
\hline CHEMBL 1445876 & 88810 & \multicolumn{3}{|c|}{5.132999999999999} & 5.03 & \\
\hline CHEMBL1417917 & 688810 & \multicolumn{3}{|c|}{5.882999999999999} & 142 & \\
\hline CHEMBL1424249 & 688810 & 5.483 & 5.1489 & TRN & & \\
\hline CHEMBL1528501 & 688810 & 4.883 & 4.9659 & TST & & \\
\hline HEMBL3196340 & 88810 & 5.233 & 5.3793 & TRN & & \\
\hline CHEMBL1479763 & 88810 & 5.483 & 5.3927 & TRN & & \\
\hline CHEMBL1309087 & 588810 & 4.783 & 5.0046 & TRN & & \\
\hline HEMBL1305809 & 688810 & \multicolumn{3}{|c|}{5.332999999999999} & 5.0 & \\
\hline CHEMBL1488731 & 688810 & 4.633 & 5.1624 & TST & & \\
\hline HEMBL1607080 & 688810 & \multicolumn{3}{|c|}{4.7330000000000005} & 5.185 & \\
\hline CHEMBL575862 & 688810 & \multicolumn{3}{|c|}{5.332999999999999} & & \\
\hline CHEMBL1504973 & 688810 & \multicolumn{3}{|c|}{5.632999999999999} & 381 & \\
\hline CHEMBL1456522 & 688810 & \multicolumn{3}{|c|}{4.9830000000000005} & 4. & \\
\hline CHEMBL1352679 & 688810 & 5.683 & 5.755 & TRN & & \\
\hline CHEMBL1980306 & 688810 & \multicolumn{3}{|c|}{6.082999999999999} & 37 & \\
\hline CHEMBL1493070 & 688810 & 4.783 & 5.0591 & TRN & & \\
\hline CHEMBL1595927 & 688810 & \multicolumn{3}{|c|}{5.582999999999999} & P & \\
\hline CHEMBL1559145 & 688810 & 4.683 & 5.3154 & TRN & & \\
\hline CHEMBL1566939 & 688810 & 5.683 & 5.778 & TRN & & \\
\hline CHEMBL 3191715 & 688810 & \multicolumn{3}{|c|}{6.5329999999999995} & 6.392 & \\
\hline CHEMBL1343561 & 688810 & 4.833 & 4.9884 & TRN & & \\
\hline CHEMBL1395046 & 688810 & \multicolumn{3}{|c|}{5.382999999999999} & 10 & \\
\hline CHEMBL1329318 & 688810 & \multicolumn{3}{|c|}{5.5329999999999995} & 52 & \\
\hline CHEMBL1501168 & 688810 & \multicolumn{3}{|c|}{5.7829999999999995} & 5.7001 & \\
\hline CHEMBL1432533 & 688810 & \multicolumn{3}{|c|}{6.082999999999999} & 5.6247 & \\
\hline CHEMBL 3212126 & 688810 & 4.783 & 5.0651 & TST & & \\
\hline CHEMBL1341522 & 688810 & \multicolumn{3}{|c|}{5.632999999999999} & 5.2 & r \\
\hline CHEMBL1308477 & 688810 & 4.933 & \multicolumn{3}{|c|}{5.2410000000000005} & \\
\hline CHEMBL1593951 & 688810 & 5.183 & 4.8689 & TST & & \\
\hline CHEMBL1436721 & 688810 & 4.833 & 4.9013 & TRN & & \\
\hline CHEMBL1571954 & 688810 & 4.783 & 5.1741 & TRN & & \\
\hline CHEMBL1545411 & 688810 & \multicolumn{3}{|c|}{4.9830000000000005} & 5.1616 & \\
\hline CHEMBL 3211012 & 688810 & 4.783 & 5.3101 & TRN & & \\
\hline CHEMBL1564638 & 688810 & 4.933 & 5.038 & TRN & & \\
\hline CHEMBL1376817 & 688810 & \multicolumn{3}{|c|}{6.0329999999999995} & 3.1003 & \\
\hline CHEMBL1439324 & 688810 & \multicolumn{3}{|c|}{6.2829999999999995} & 4.8972 & \\
\hline CHEMBL1449742 & 688810 & 5.33299 & 99999999 & 99 & 5.5291 & \\
\hline CHEMBL1312928 & 688810 & 6.0 & 5.3467 & TRN & & \\
\hline CHEMBL1358420 & 688810 & 5.083 & 5.2814 & TRN & & \\
\hline CHEMBL1425932 & 688810 & 5.483 & 5.4211 & TRN & & \\
\hline
\end{tabular}




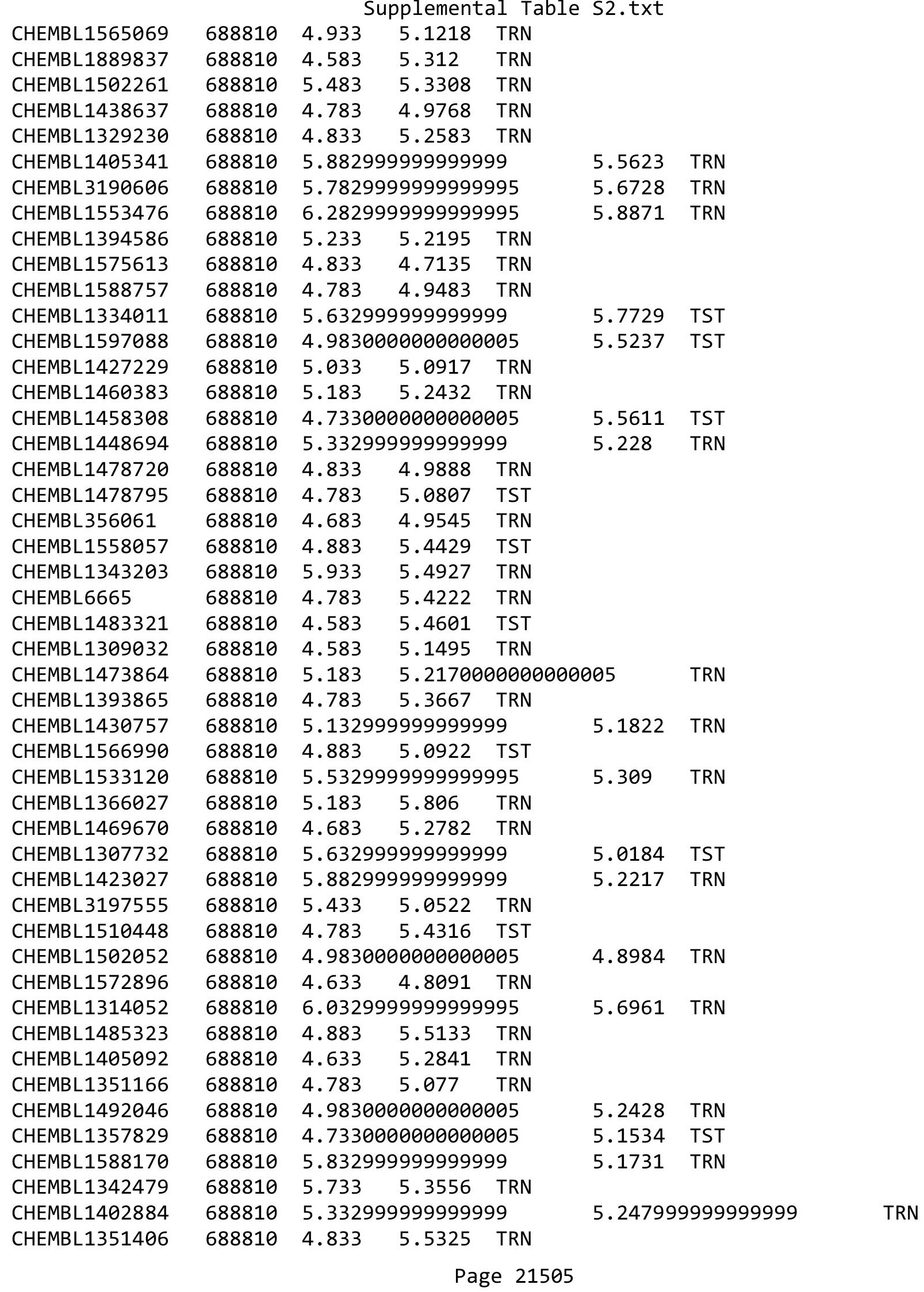




\begin{tabular}{|c|c|c|c|c|c|c|}
\hline CHEMBL1398003 & 688810 & 4.883 & 5.1242 & TRN & & \\
\hline CHEMBL1376200 & 688810 & \multicolumn{3}{|c|}{4.7330000000000005} & 5.3855 & TST \\
\hline CHEMBL1300339 & 688810 & 5.233 & 5.1349 & TRN & & \\
\hline HEMBL1299977 & 88810 & 5.983 & 5.9626 & TRN & & \\
\hline HEMBL1453129 & 88810 & 1.833 & 5.3737 & TRN & & \\
\hline HEMBL1476957 & 588810 & \multicolumn{3}{|c|}{6.332999999999999} & 5.8558 & TRN \\
\hline HEMBL1348693 & 688810 & \multicolumn{3}{|c|}{5.7829999999999995} & 5.1403 & TRN \\
\hline HEMBL1539604 & 688810 & 4.833 & 4.998 & TST & & \\
\hline HEMBL1451800 & 88810 & 4.883 & 4.8854 & TRN & & \\
\hline CHEMBL1353188 & 688810 & \multicolumn{3}{|c|}{5.632999999999999} & 5.4492 & TRN \\
\hline HEMBL1452264 & 688810 & 5.733 & 5.1529 & TRN & & \\
\hline HEMBL1390720 & 688810 & \multicolumn{3}{|c|}{4.7330000000000005} & 4.8437 & TST \\
\hline HEMBL3192451 & 688810 & 4.683 & 5.0378 & TST & & \\
\hline HEMBL1512157 & 88810 & 4.583 & 4.9746 & TST & & \\
\hline HEMBL1545169 & 588810 & 6.8831 & 5.4549 & TST & & \\
\hline HEMBL1 & 10 & 5.233 & 5.1137 & TRN & & \\
\hline HEMBL135 & 10 & 4.683 & 4.9969 & TRN & & \\
\hline HEMBL1567422 & 588810 & \multicolumn{3}{|c|}{5.582999999999999} & 995 & TRN \\
\hline HEMBL3198443 & 88810 & 4.933 & 5.3515 & TRN & & \\
\hline HEMBL1510792 & 688810 & \multicolumn{3}{|c|}{6.2829999999999995} & 898 & TRN \\
\hline HEMBL1 & 688 & \multicolumn{3}{|c|}{6.7829999999999995} & & TRN \\
\hline HEMBL13 & 68 & 4.833 & 5.184 & TRN & & \\
\hline HEMBL1449330 & 688810 & 4.933 & 5.2859 & TRN & & \\
\hline HEMBL1399949 & 10 & 4.583 & 5.0763 & TST & & \\
\hline CHEMBL1507903 & 688810 & 4.883 & 5.12 & TRN & & \\
\hline HEMBL1 & LO & 5.683 & 5.0707 & TRN & & \\
\hline HEMBL1447872 & 10 & \multicolumn{3}{|c|}{4.9830000000000005} & 718 & TRN \\
\hline CHEMBL3192399 & 688810 & \multicolumn{3}{|c|}{5.132999999999999} & & TRN \\
\hline CHEMBL1547979 & 688810 & 5.183 & 5.3186 & TST & & \\
\hline CHEMBL1605300 & 688810 & 6.183 & 5.8608 & TRN & & \\
\hline HEMBL1 & $68 \varepsilon$ & \multicolumn{3}{|c|}{5.132999999999999} & 857 & $\mathrm{TP}$ \\
\hline CHEMBL1445115 & 10 & 4.683 & 5.0751 & TRN & & \\
\hline HEMBL1349757 & 10 & 4.933 & 5.4514 & TRN & & \\
\hline CHEMBL1403178 & 688810 & \multicolumn{3}{|c|}{4.7330000000000005} & & \\
\hline CHEMBL1424489 & 688810 & \multicolumn{3}{|c|}{4.9830000000000005} & 48 & TST \\
\hline CHEMBL1 & 688810 & \multicolumn{3}{|c|}{5.832999999999999} & 97 & TRN \\
\hline CHEMBL1605045 & $68 \varepsilon$ & 5.183 & 5.2417 & TRN & & \\
\hline CHEMBL1479900 & 688810 & \multicolumn{3}{|c|}{5.382999999999999} & 4.9819 & 11 \\
\hline CHEMBL1594789 & 688810 & 4.783 & 4.8407 & TST & & \\
\hline CHEMBL1 & & 5.083 & 5.4056 & TRN & & \\
\hline CHEMBL3207307 & 688810 & 4.933 & \multicolumn{3}{|c|}{4.946000000000001} & T \\
\hline CHEMBL1430074 & 688810 & 5.233 & 4.7594 & TST & & \\
\hline CHEMBL1544881 & 688810 & 5.183 & 5.2629 & TST & & \\
\hline CHEMBL1550734 & 688810 & 7.6326 & 6.7227 & TRN & & \\
\hline CHEMBL1531311 & 688810 & 7.0329 & 5.6587 & TRN & & \\
\hline CHEMBL1500292 & 588810 & 4.783 & 5.2513 & TST & & \\
\hline CHEMBL1368977 & 688810 & \multirow{2}{*}{\multicolumn{3}{|c|}{$\begin{array}{l}4.7330000000000005 \\
5.382999999999999\end{array}$}} & 5.1318 & N \\
\hline CHEMBL1483745 & 688810 & & & & 6.0998 & TRN \\
\hline
\end{tabular}




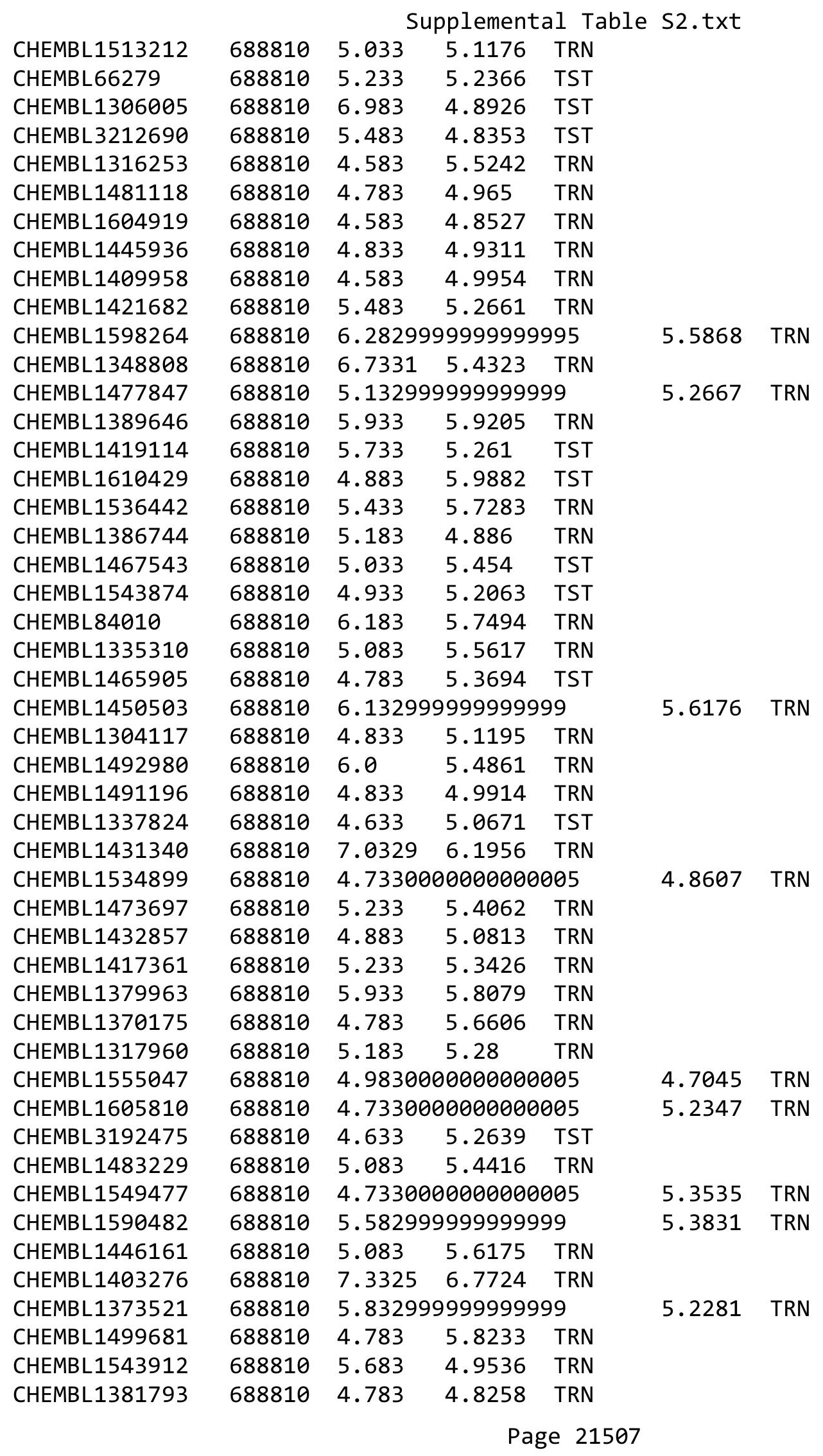




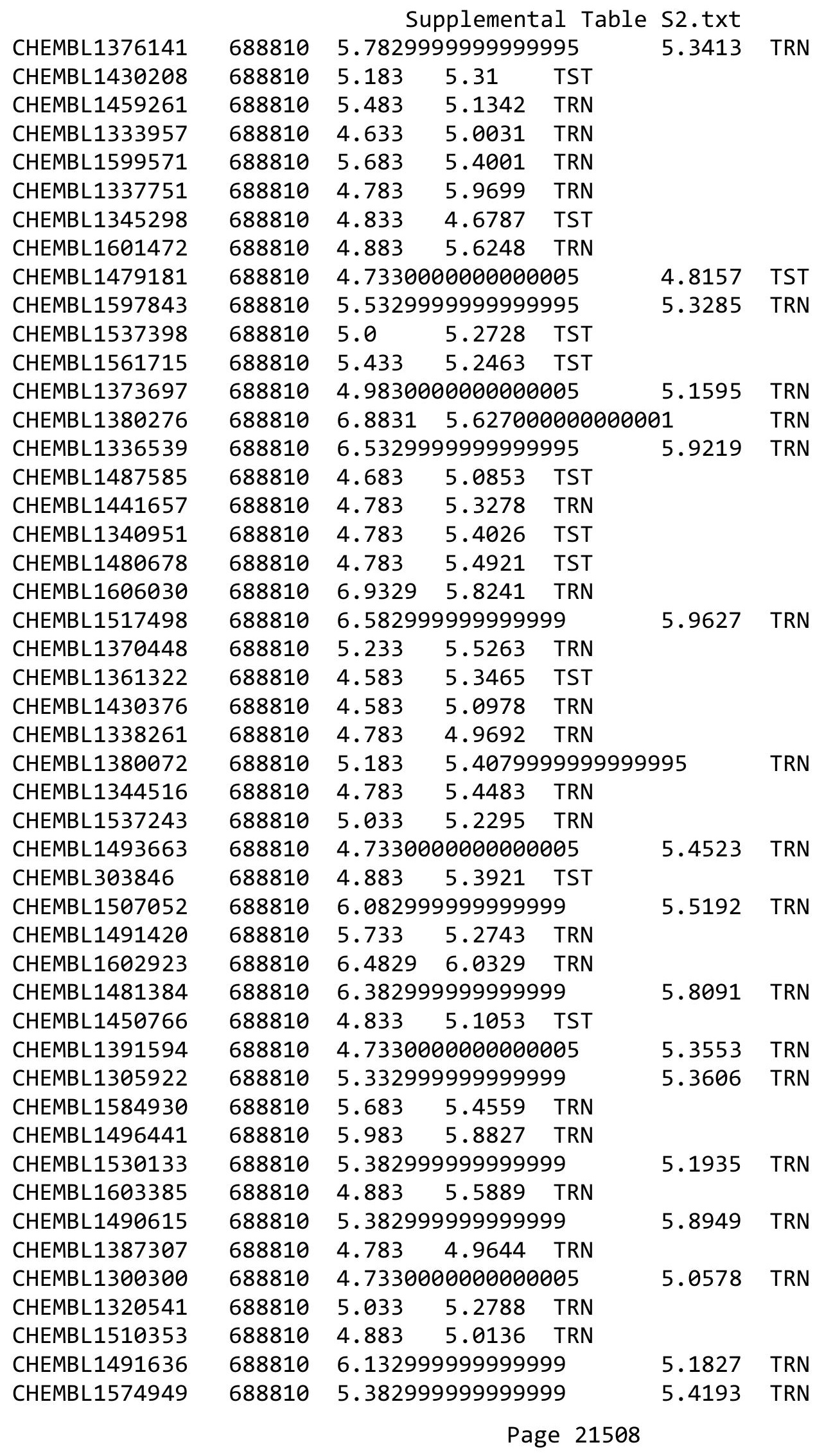




\begin{tabular}{|c|c|c|c|c|c|c|}
\hline & & \multicolumn{5}{|c|}{ Supplemental Table S2.txt } \\
\hline CHEMBL1450134 & 688810 & 4.833 & 5.1065 & TRN & & \\
\hline CHEMBL1397140 & 688810 & 4.633 & 5.5426 & TST & & \\
\hline CHEMBL1574562 & 688810 & 5.683 & 5.0733 & TRN & & \\
\hline CHEMBL1394675 & 688810 & 4.583 & 4.9022 & TRN & & \\
\hline CHEMBL1386233 & 688810 & 4.783 & 5.1682 & TRN & & \\
\hline CHEMBL1520345 & 688810 & \multicolumn{3}{|c|}{5.7829999999999995} & 5.2052 & TRN \\
\hline CHEMBL1385557 & 688810 & \multicolumn{3}{|c|}{5.882999999999999} & 5.6979 & TRN \\
\hline CHEMBL1602538 & 688810 & 6.433 & 5.7708 & TRN & & \\
\hline CHEMBL1330731 & 688810 & 6.0 & 5.4263 & TRN & & \\
\hline CHEMBL1977589 & 688810 & 6.183 & 5.9314 & TRN & & \\
\hline CHEMBL1612368 & 688810 & 5.733 & 5.6168 & TRN & & \\
\hline CHEMBL1539454 & 688810 & \multicolumn{3}{|c|}{5.632999999999999} & 5.4934 & TRN \\
\hline CHEMBL1435875 & 688810 & 4.883 & 5.2153 & TRN & & \\
\hline CHEMBL1382470 & 688810 & \multicolumn{3}{|c|}{6.132999999999999} & 5.4711 & TRN \\
\hline CHEMBL1517410 & 688810 & 4.683 & 4.9419 & TST & & \\
\hline CHEMBL1557320 & 688810 & 5.083 & 5.3972 & TST & & \\
\hline CHEMBL1378316 & 688810 & 5.683 & 5.8727 & TRN & & \\
\hline CHEMBL1485551 & 688810 & 4.683 & 4.4471 & TRN & & \\
\hline CHEMBL1579212 & 688810 & 4.883 & 5.2867 & TST & & \\
\hline CHEMBL1490043 & 688810 & \multicolumn{3}{|c|}{6.5329999999999995} & 6.0334 & TRN \\
\hline CHEMBL1355304 & 688810 & 5.683 & 5.5908 & TRN & & \\
\hline CHEMBL1541678 & 688810 & 5.933 & 5.4245 & TRN & & \\
\hline CHEMBL1998425 & 688810 & 4.883 & 4.8692 & TRN & & \\
\hline CHEMBL1472212 & 688810 & \multicolumn{3}{|c|}{6.632999999999999} & 5.9777 & TRA \\
\hline CHEMBL1599520 & 688810 & \multicolumn{3}{|c|}{4.7330000000000005} & 5.0913 & TST \\
\hline CHEMBL1351106 & 688810 & 4.633 & 4.8403 & TRN & & \\
\hline CHEMBL1409406 & 688810 & \multicolumn{3}{|c|}{4.7330000000000005} & 5.2628 & TST \\
\hline CHEMBL1483304 & 688810 & \multicolumn{3}{|c|}{5.332999999999999} & 5.1143 & TST \\
\hline CHEMBL1440034 & 688810 & \multicolumn{3}{|c|}{4.7330000000000005} & 5.5556 & TRA \\
\hline CHEMBL1548026 & 688810 & 4.583 & 4.5759 & TRN & & \\
\hline CHEMBL1323644 & 688810 & \multicolumn{3}{|c|}{5.882999999999999} & 6.0472 & TRN \\
\hline CHEMBL1449697 & 688810 & \multicolumn{3}{|c|}{4.7330000000000005} & 5.0801 & TRA \\
\hline CHEMBL1520852 & 688810 & 4.833 & 4.5218 & TST & & \\
\hline CHEMBL3210474 & 688810 & \multicolumn{3}{|c|}{5.382999999999999} & 5.1313 & TRA \\
\hline CHEMBL1353675 & 688810 & 4.883 & 5.114 & TRN & & \\
\hline CHEMBL1990071 & 688810 & \multicolumn{3}{|c|}{5.882999999999999} & 5.4034 & TST \\
\hline CHEMBL3211733 & 688810 & \multicolumn{3}{|c|}{4.7330000000000005} & 5.3071 & TST \\
\hline CHEMBL1413823 & 688810 & 5.983 & 6.0567 & TRN & & \\
\hline CHEMBL1323174 & 688810 & 6.433 & 6.0695 & TRN & & \\
\hline CHEMBL1484569 & 688810 & 4.583 & 4.7438 & TRN & & \\
\hline CHEMBL1571983 & 688810 & 4.883 & 4.7444 & TRN & & \\
\hline CHEMBL1610770 & 688810 & \multicolumn{3}{|c|}{5.332999999999999} & 5.2588 & TST \\
\hline CHEMBL1341284 & 688810 & \multicolumn{3}{|c|}{6.2829999999999995} & 5.1322 & TRN \\
\hline CHEMBL1459184 & 688810 & 4.833 & 5.2757 & TRN & & \\
\hline CHEMBL1476086 & 688810 & \multicolumn{3}{|c|}{4.7330000000000005} & 5.6357 & TST \\
\hline CHEMBL1519118 & 688810 & 4.85 & 5.5089 & TRN & & \\
\hline CHEMBL3194199 & 688810 & 5.683 & 5.5729 & TRN & & \\
\hline CHEMBL1389590 & 688810 & 4.783 & 5.0844 & TRN & & \\
\hline
\end{tabular}




\begin{tabular}{|c|c|c|c|c|c|c|}
\hline \multicolumn{7}{|c|}{ oplemental Tá } \\
\hline CHEMBL1568201 & 688810 & 5.433 & 6.1624 & TRN & & \\
\hline CHEMBL1559071 & 688810 & 5.233 & 5.2788 & TRN & & \\
\hline CHEMBL1525050 & 688810 & 4.783 & 4.985 & TST & & \\
\hline CHEMBL1587862 & 688810 & 7.1331 & 5.9638 & TRN & & \\
\hline CHEMBL1441350 & 688810 & 6.7331 & 5.5715 & TRN & & \\
\hline CHEMBL1454563 & 688810 & 4.583 & 5.0644 & TRN & & \\
\hline CHEMBL 278779 & 688810 & 4.783 & 5.2741 & TRN & & \\
\hline CHEMBL 255068 & 688810 & \multicolumn{3}{|c|}{5.632999999999999} & 5.1401 & TRN \\
\hline CHEMBL 3193940 & 688810 & 4.833 & 5.2744 & TRN & & \\
\hline CHEMBL1411420 & 688810 & \multicolumn{3}{|c|}{5.132999999999999} & 5.1115 & $\mathrm{Tr}$ \\
\hline CHEMBL1474327 & 688810 & 4.633 & 4.9479 & TRN & & \\
\hline CHEMBL1549707 & 688810 & 5.233 & 4.7954 & TRN & & \\
\hline CHEMBL1435700 & 688810 & \multicolumn{3}{|c|}{6.382999999999999} & 5.6948 & TRN \\
\hline CHEMBL1608932 & 688810 & \multicolumn{3}{|c|}{4.7330000000000005} & 4.561 & \\
\hline CHEMBL1386815 & 688810 & \multicolumn{3}{|c|}{4.7330000000000005} & 5.5707 & \\
\hline CHEMBL1345535 & 688810 & \multicolumn{3}{|c|}{5.132999999999999} & 5.1351 & \\
\hline CHEMBL 3208363 & 688810 & 4.933 & 5.4499 & TRN & & \\
\hline CHEMBL1565837 & 688810 & \multicolumn{3}{|c|}{5.132999999999999} & 5.5 & \\
\hline CHEMBL1504575 & 688810 & 6.8831 & 6.046 & TRN & & \\
\hline CHEMBL1372686 & 68 & & 5.0273 & TST & & \\
\hline CHEMBL 3210882 & 688810 & \multicolumn{3}{|c|}{5.582999999999999} & 5.6126 & $\mathrm{TR}$ \\
\hline CHEMBL1518326 & 688810 & 4.883 & 4.7819 & TST & & \\
\hline CHEMBL1528373 & 688810 & 5.683 & 5.2129 & TRN & & \\
\hline CHEMBL1504412 & $68 \varepsilon$ & 4.883 & \multicolumn{3}{|c|}{4.986000000000001} & \\
\hline CHEMBL1328232 & 688810 & \multicolumn{3}{|c|}{5.2829999999999995} & 5.1334 & \\
\hline CHEMBL1533321 & 688810 & \multicolumn{3}{|c|}{5.5329999999999995} & 4.9873 & \\
\hline CHEMBL1309243 & 688810 & \multicolumn{3}{|c|}{5.7829999999999995} & 5.2055 & TRN \\
\hline CHEMBL1447253 & 688810 & 6.433 & \multicolumn{3}{|c|}{5.422000000000001} & \\
\hline CHEMBL1480918 & 688810 & 4.833 & 5.1286 & TRN & & \\
\hline CHEMBL 3190880 & 688810 & 4.583 & 5.5068 & TRN & & \\
\hline CHEMBL1499314 & 688810 & \multicolumn{3}{|c|}{4.7330000000000005} & 5.3496 & $\mathrm{TH}$ \\
\hline CHEMBL1454046 & 688810 & 5.183 & 5.4599 & TRN & & \\
\hline CHEMBL1388646 & 688810 & 5.183 & 5.1928 & TRN & & \\
\hline CHEMBL 3392037 & 68 & 4.633 & 5.2532 & TST & & \\
\hline CHEMBL1475873 & 688810 & \multicolumn{3}{|c|}{5.132999999999999} & 5.075 & $\mathrm{TP}$ \\
\hline CHEMBL1576634 & 688810 & \multicolumn{3}{|c|}{5.132999999999999} & 5.3536 & $T$ \\
\hline CHEMBL1339638 & 688810 & 4.833 & 4.9769 & TRN & & \\
\hline CHEMBL1581560 & 688810 & \multicolumn{3}{|c|}{5.5329999999999995} & 5.1 & 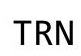 \\
\hline CHEMBL1892270 & 688810 & \multicolumn{3}{|c|}{5.882999999999999} & 5.46 & TRI \\
\hline CHEMBL1349151 & 688810 & 4.833 & 5.1245 & TRN & & \\
\hline CHEMBL 2369285 & 688810 & 6.433 & 5.6166 & TRN & & \\
\hline CHEMBL1450191 & 688810 & 4.783 & 5.7746 & TST & & \\
\hline CHEMBL1386311 & 688 & 4.883 & 5.2089 & TRN & & \\
\hline CHEMBL1327234 & 688810 & \multicolumn{3}{|c|}{6.5329999999999995} & 5.338 & \\
\hline CHEMBL1370476 & 688810 & 4.783 & 5.3365 & TRN & & \\
\hline CHEMBL1578386 & 688810 & 4.633 & 4.6191 & TRN & & \\
\hline CHEMBL1466983 & 688810 & 4.883 & 5.1235 & TRN & & \\
\hline CHEMBL1302818 & 688810 & 5.38299 & 999999999 & & 4.994 & \\
\hline
\end{tabular}




\begin{tabular}{|c|c|c|c|c|c|c|}
\hline \multirow[b]{2}{*}{ CHEMBL1376566 } & \multicolumn{6}{|c|}{ Supplemental Table S2.txt } \\
\hline & 688810 & 4.883 & 5.4829 & TRN & & \\
\hline CHEMBL1380201 & 688810 & 5.083 & 6.1376 & TRN & & \\
\hline CHEMBL1559632 & 688810 & 5.433 & 5.8758 & TRN & & \\
\hline CHEMBL1360872 & 688810 & 5.1329 & 99999999 & & 5.1181 & TRN \\
\hline CHEMBL1365633 & 688810 & 5.233 & 5.4338 & TRN & & \\
\hline CHEMBL3194310 & 688810 & 6.0829 & 99999999 & & 5.6849 & TRN \\
\hline CHEMBL1584315 & 688810 & 5.8829 & 99999999 & & 5.5033 & TST \\
\hline CHEMBL1532364 & 688810 & 5.3329 & 99999999 & 99 & 5.2184 & TRA \\
\hline CHEMBL1324095 & 688810 & 4.633 & 4.8123 & TRN & & \\
\hline CHEMBL1501925 & 688810 & 5.433 & 5.1551 & TST & & \\
\hline CHEMBL1458800 & 688810 & 4.833 & 5.1319 & TRN & & \\
\hline CHEMBL1562298 & 688810 & 5.8329 & 99999999 & & 5.3104 & TRN \\
\hline CHEMBL1348831 & 688810 & 4.833 & 5.3652 & TST & & \\
\hline CHEMBL1601745 & 688810 & 5.083 & 5.1253 & TRN & & \\
\hline CHEMBL1390498 & 688810 & 4.783 & 5.1468 & TRN & & \\
\hline CHEMBL1424783 & 688810 & 5.1329 & 99999999 & & 4.5019 & TRN \\
\hline CHEMBL1588953 & 688810 & 4.7330 & 00000000 & 005 & 5.1929 & TST \\
\hline CHEMBL1553055 & 688810 & 4.933 & 5.2336 & TRN & & \\
\hline CHEMBL1596270 & 688810 & 5.8829 & 99999999 & & 5.6776 & TRN \\
\hline CHEMBL1466810 & 688810 & 5.033 & 4.8294 & TRN & & \\
\hline CHEMBL3196814 & 688810 & 4.7330 & 00000000 & 005 & 5.4072 & TRN \\
\hline CHEMBL1318039 & 688810 & 4.633 & 4.9264 & TRN & & \\
\hline CHEMBL601584 & 688810 & 4.883 & 5.0272 & TRN & & \\
\hline CHEMBL1554227 & 688810 & 7.1831 & 5.595 & TRN & & \\
\hline CHEMBL1368263 & 688810 & 5.233 & 4.6107 & TRN & & \\
\hline CHEMBL1558082 & 688810 & 5.3829 & 99999999 & & 5.2098 & TRN \\
\hline CHEMBL1409658 & 688810 & 7.2328 & 6.2039 & TRN & & \\
\hline CHEMBL3211298 & 688810 & 5.5829 & 99999999 & & 5.4619 & TRN \\
\hline CHEMBL1503105 & 688810 & 5.3329 & 99999999 & & 5.6816 & TRN \\
\hline CHEMBL1471601 & 688810 & 4.7330 & 00000000 & 005 & 5.046 & TST \\
\hline CHEMBL3190666 & 688810 & 5.483 & 5.3644 & TRN & & \\
\hline CHEMBL1300747 & 688810 & 4.833 & 5.0554 & TRN & & \\
\hline CHEMBL1473861 & 688810 & 5.983 & 5.0875 & TRN & & \\
\hline CHEMBL1585689 & 688810 & 4.583 & 5.1217 & TRN & & \\
\hline CHEMBL1342313 & 688810 & 5.183 & 5.0939 & TRN & & \\
\hline CHEMBL1509384 & 688810 & 4.783 & 5.401 & TRN & & \\
\hline CHEMBL1381119 & 688810 & 5.3329 & 99999999 & & 5.2654 & TRN \\
\hline CHEMBL1402579 & 688810 & 4.9830 & 00000000 & 005 & 5.1273 & TRN \\
\hline CHEMBL1472780 & 688810 & 5.7829 & 99999999 & 995 & 5.606 & TRA \\
\hline CHEMBL1552281 & 688810 & 6.0329 & 99999999 & 995 & 5.1469 & TRN \\
\hline CHEMBL1398957 & 688810 & 5.683 & 5.3585 & TRN & & \\
\hline CHEMBL1469874 & 688810 & 4.833 & 4.9248 & TRN & & \\
\hline CHEMBL1969934 & 688810 & 5.183 & 4.9225 & TRN & & \\
\hline CHEMBL1530759 & 688810 & 5.6329 & 99999999 & & 5.9519 & TST \\
\hline CHEMBL1481417 & 688810 & 4.833 & 5.6034 & TST & & \\
\hline CHEMBL1347927 & 688810 & 4.633 & 4.9974 & TRN & & \\
\hline CHEMBL1322878 & 688810 & 5.3329 & 99999999 & 99 & 4.6775 & TRN \\
\hline CHEMBL3193223 & 688810 & 4.833 & 4.9445 & TRN & & \\
\hline
\end{tabular}




\begin{tabular}{|c|c|c|c|c|c|c|c|}
\hline \\
\hline CHEMBL1507780 & 688810 & 5.233 & 5.1989 & TRN & & & \\
\hline CHEMBL1583149 & 688810 & 4.783 & 5.6267 & TST & & & \\
\hline CHEMBL1612923 & 688810 & \multicolumn{3}{|c|}{5.5329999999999995} & 4.8496 & TRN & \\
\hline CHEMBL1438124 & 688810 & 4.633 & 4.8375 & TST & & & \\
\hline CHEMBL1428368 & 688810 & 4.633 & 4.922 & TRN & & & \\
\hline CHEMBL3197688 & 688810 & 5.683 & 4.8763 & TRN & & & \\
\hline CHEMBL1414808 & 688810 & \multicolumn{3}{|c|}{4.7330000000000005} & 4.7669 & TRN & \\
\hline CHEMBL1352452 & 688810 & 4.833 & 5.0438 & TRN & & & \\
\hline CHEMBL1418846 & 688810 & 4.783 & 5.8901 & TRN & & & \\
\hline CHEMBL1532140 & 688810 & \multicolumn{3}{|c|}{5.382999999999999} & 4.9737 & TRN & \\
\hline CHEMBL1382927 & 688810 & \multicolumn{3}{|c|}{6.332999999999999} & 5.8652 & TRN & \\
\hline CHEMBL1503492 & 688810 & 5.433 & 5.4402 & TRN & & & \\
\hline CHEMBL1333761 & 688810 & \multicolumn{3}{|c|}{4.9830000000000005} & 5.29 & TST & \\
\hline CHEMBL1368672 & 688810 & 5.483 & 5.1334 & TRN & & & \\
\hline CHEMBL3211078 & 688810 & 5.233 & 5.1748 & TST & & & \\
\hline CHEMBL1335686 & 688810 & 4.783 & 4.9758 & TRN & & & \\
\hline CHEMBL1489467 & 688810 & 4.783 & 5.2172 & TRN & & & \\
\hline CHEMBL1523775 & 688810 & 4.883 & 5.8098 & TST & & & \\
\hline CHEMBL3194194 & 688810 & 4.833 & 5.0691 & TRN & & & \\
\hline CHEMBL1463869 & 688810 & \multicolumn{3}{|c|}{6.5329999999999995} & 6.1565 & TRN & \\
\hline CHEMBL1369039 & 688810 & 4.883 & 4.9565 & TRN & & & \\
\hline CHEMBL1374010 & 688810 & 4.633 & 5.092 & TRN & & & \\
\hline CHEMBL1530730 & 688810 & 4.883 & 5.0575 & TRN & & & \\
\hline CHEMBL1504121 & 688810 & \multicolumn{3}{|c|}{6.082999999999999} & 5.6223 & TRN & \\
\hline CHEMBL42288 & 688810 & 4.883 & 5.4382 & TRN & & & \\
\hline CHEMBL1490429 & 688810 & \multicolumn{3}{|c|}{5.882999999999999} & 5.75 & TRN & \\
\hline CHEMBL1512803 & 688810 & 4.633 & 5.141 & TST & & & \\
\hline CHEMBL1339052 & 688810 & 5.483 & 5.3926 & TST & & & \\
\hline CHEMBL1487783 & 688810 & \multicolumn{3}{|c|}{5.132999999999999} & 5.5012 & TRN & \\
\hline CHEMBL1576870 & 688810 & 6.7331 & 5.5416 & TRN & & & \\
\hline CHEMBL1451512 & 688810 & \multicolumn{3}{|c|}{6.5329999999999995} & 5.2317 & TRN & \\
\hline CHEMBL1610066 & 688810 & 5.233 & 6.1188 & TRN & & & \\
\hline CHEMBL1373110 & 688810 & \multicolumn{3}{|c|}{5.132999999999999} & 5.4265 & TRN & \\
\hline CHEMBL1553793 & 688810 & 4.783 & 4.997 & TRN & & & \\
\hline CHEMBL1509067 & 688810 & 4.783 & 5.5608 & TRN & & & \\
\hline CHEMBL1458698 & 688810 & 4.933 & 5.0482 & TRN & & & \\
\hline CHEMBL1449313 & 688810 & \multicolumn{3}{|c|}{4.7330000000000005} & 4.989 & TST & \\
\hline CHEMBL1535261 & 688810 & 5.233 & 4.7652 & TST & & & \\
\hline CHEMBL1379985 & 688810 & 4.833 & \multicolumn{3}{|c|}{5.212000000000001} & TST & \\
\hline CHEMBL1609980 & 688810 & 4.633 & 5.3221 & TST & & & \\
\hline CHEMBL1558835 & 688810 & 4.933 & 5.1422 & TRN & & & \\
\hline CHEMBL1497255 & 688810 & 4.883 & 4.9724 & TRN & & & \\
\hline CHEMBL1350534 & 688810 & 5.183 & 5.4185 & TRN & & & \\
\hline CHEMBL1598005 & 688810 & \multicolumn{3}{|c|}{6.0329999999999995} & 5.7489 & TRN & \\
\hline CHEMBL1359019 & 688810 & \multicolumn{3}{|c|}{6.5329999999999995} & 6.00299 & 9999999999 & TRN \\
\hline CHEMBL1501030 & 688810 & \multicolumn{3}{|c|}{4.7330000000000005} & 5.6459 & TST & \\
\hline CHEMBL1554240 & 688810 & 6.683 & 5.4814 & TRN & & & \\
\hline CHEMBL3198883 & 688810 & 4.933 & 5.207999 & 999999999 & & TRN & \\
\hline
\end{tabular}




\begin{tabular}{|c|c|c|c|c|c|c|}
\hline \multirow[b]{2}{*}{ CHEMBL1544669 } & \multicolumn{6}{|c|}{3} \\
\hline & 688810 & 5.733 & 5.1056 & TRN & & \\
\hline CHEMBL1601546 & 688810 & 4.583 & 5.07 & TRN & & \\
\hline CHEMBL1484885 & 688810 & 5.083 & 5.2116 & TRN & & \\
\hline CHEMBL3196733 & 688810 & 4.833 & 5.3647 & TRN & & \\
\hline CHEMBL1610501 & 688810 & \multicolumn{3}{|c|}{4.9830000000000005} & 4.9799 & TST \\
\hline CHEMBL1384751 & 688810 & 5.083 & 4.8851 & TST & & \\
\hline CHEMBL1319488 & 688810 & 5.233 & 5.0614 & TRN & & \\
\hline CHEMBL1379745 & 688810 & \multicolumn{3}{|c|}{6.582999999999999} & 5.4769 & TRN \\
\hline CHEMBL1611170 & 688810 & 4.633 & 4.7388 & TRN & & \\
\hline CHEMBL3191697 & 688810 & 5.033 & 5.312 & TRN & & \\
\hline CHEMBL1456215 & 688810 & \multicolumn{3}{|c|}{6.082999999999999} & 6.0208 & TRN \\
\hline CHEMBL1417238 & 688810 & 6.233 & 5.6466 & TRN & & \\
\hline CHEMBL1307988 & 688810 & 4.633 & 5.5097 & TST & & \\
\hline CHEMBL1335880 & 688810 & 4.833 & 5.362 & TRN & & \\
\hline CHEMBL1601205 & 688810 & 4.833 & 5.3015 & TST & & \\
\hline CHEMBL1343332 & 688810 & 4.783 & 5.3603 & TST & & \\
\hline CHEMBL1423941 & 688810 & 4.783 & 5.029 & TRN & & \\
\hline CHEMBL1477474 & 688810 & 5.033 & 5.3999 & TRN & & \\
\hline CHEMBL1375414 & 688810 & \multicolumn{3}{|c|}{5.582999999999999} & 4.9655 & TST \\
\hline CHEMBL3189938 & 688810 & \multicolumn{3}{|c|}{6.2829999999999995} & 5.479 & TRN \\
\hline CHEMBL1448464 & 688810 & 4.633 & 4.9395 & TST & & \\
\hline CHEMBL1539128 & 688810 & 5.083 & 5.6893 & TRN & & \\
\hline CHEMBL1467190 & 688810 & \multicolumn{3}{|c|}{4.7330000000000005} & 4.7558 & TST \\
\hline CHEMBL1499433 & 688810 & 5.683 & 5.2399 & TRN & & \\
\hline CHEMBL1447148 & 688810 & 4.633 & 4.8415 & TRN & & \\
\hline CHEMBL1523885 & 688810 & 5.733 & 5.1723 & TST & & \\
\hline CHEMBL1574999 & 688810 & \multicolumn{3}{|c|}{5.2829999999999995} & 5.8606 & TRN \\
\hline CHEMBL1578663 & 688810 & \multicolumn{3}{|c|}{4.7330000000000005} & 5.1895 & TRN \\
\hline CHEMBL1531222 & 688810 & 5.233 & 5.7357 & TST & & \\
\hline CHEMBL1594161 & 688810 & \multicolumn{3}{|c|}{5.882999999999999} & 5.586 & TRN \\
\hline CHEMBL1343527 & 688810 & 6.0 & 6.0521 & TRN & & \\
\hline CHEMBL1593646 & 688810 & \multicolumn{3}{|c|}{5.132999999999999} & 5.6598 & TRN \\
\hline CHEMBL1405293 & 688810 & \multicolumn{3}{|c|}{4.9830000000000005} & 5.3056 & TRN \\
\hline CHEMBL1387896 & 688810 & \multicolumn{3}{|c|}{5.882999999999999} & 5.1014 & TRN \\
\hline CHEMBL1463739 & 688810 & 4.783 & 5.3937 & TRN & & \\
\hline CHEMBL1570257 & 688810 & 5.183 & 5.9283 & TST & & \\
\hline CHEMBL1327162 & 688810 & 5.933 & 5.2038 & TRN & & \\
\hline CHEMBL1444938 & 688810 & \multicolumn{3}{|c|}{5.2829999999999995} & 5.1894 & TRN \\
\hline CHEMBL1187074 & 688810 & 5.683 & 5.5809 & TRN & & \\
\hline CHEMBL1300211 & 688810 & \multicolumn{3}{|c|}{5.632999999999999} & 5.3013 & TRN \\
\hline CHEMBL1523268 & 688810 & 6.433 & 5.4362 & TRN & & \\
\hline CHEMBL1392348 & 688810 & 6.7331 & 5.7175 & TST & & \\
\hline CHEMBL1394881 & 688810 & 4.633 & 5.0782 & TRN & & \\
\hline CHEMBL1301832 & 688810 & \multicolumn{3}{|c|}{4.9830000000000005} & 4.9062 & TRN \\
\hline CHEMBL1475743 & 688810 & 6.433 & 5.9298 & TRN & & \\
\hline CHEMBL1436006 & 688810 & 4.633 & 5.1449 & TRN & & \\
\hline CHEMBL1518770 & 688810 & 4.833 & 5.0633 & TST & & \\
\hline \multirow[t]{2}{*}{ CHEMBL1357013 } & 688810 & 4.683 & 4.9956 & TST & & \\
\hline & & \multicolumn{5}{|c|}{ Page 21513} \\
\hline
\end{tabular}




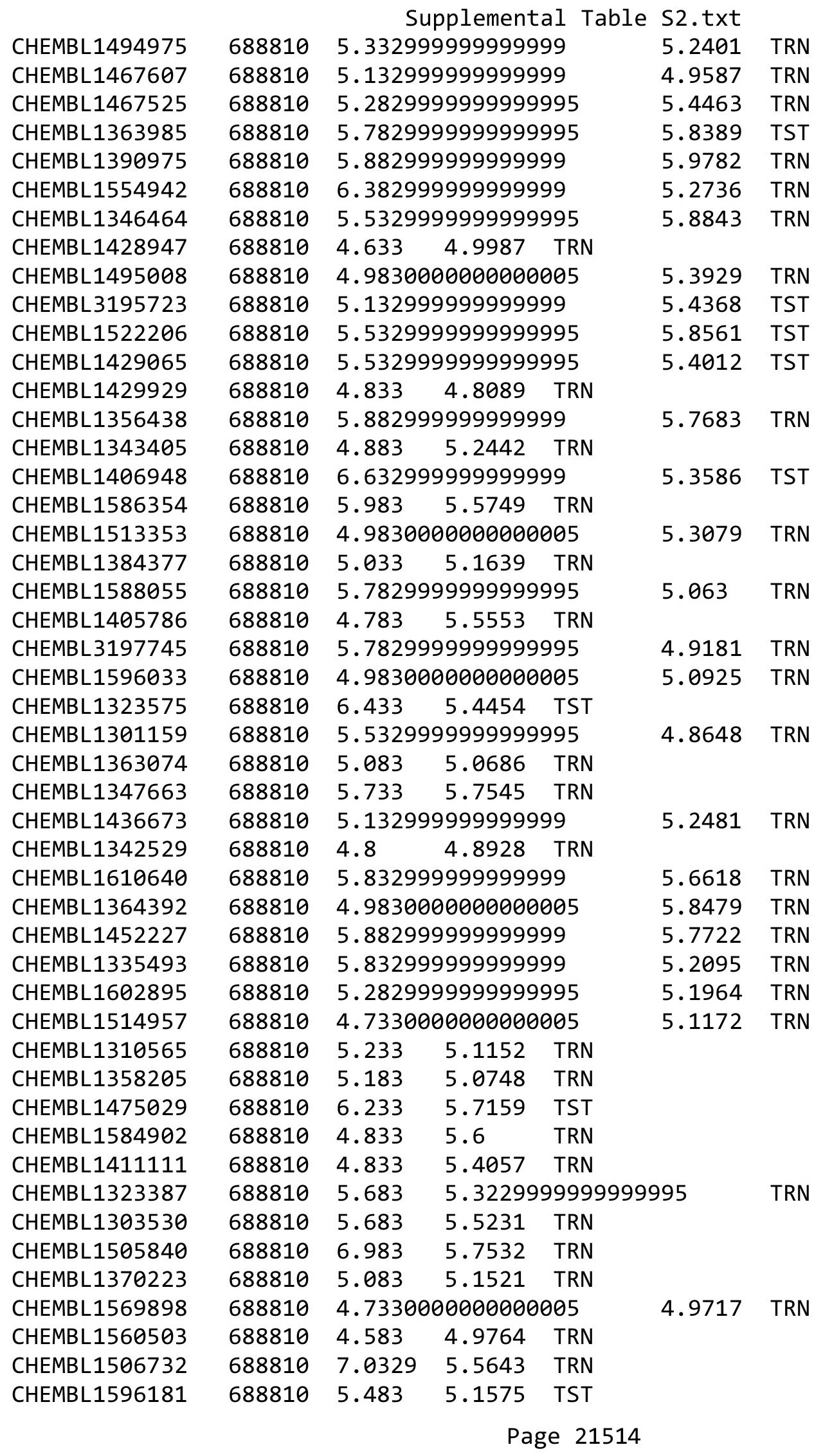




\begin{tabular}{|c|c|c|c|c|c|c|}
\hline \multirow{3}{*}{$\begin{array}{l}\text { CHEMBL1313355 } \\
\text { CHEMBL1450089 }\end{array}$} & \multicolumn{6}{|c|}{ Supplemental Table S2.txt } \\
\hline & 688810 & \multicolumn{3}{|c|}{4.7330000000000005} & 5.0546 & TRA \\
\hline & 688810 & 4.933 & 5.1306 & TST & & \\
\hline CHEMBL3195654 & 688810 & \multicolumn{3}{|c|}{5.332999999999999} & 5.3173 & TS \\
\hline CHEMBL 261870 & 688810 & 5.183 & 5.1665 & TRN & & \\
\hline CHEMBL1399456 & 688810 & \multicolumn{3}{|c|}{4.9830000000000005} & 5.2836 & TR \\
\hline CHEMBL1476749 & 688810 & 4.683 & 4.7212 & TRN & & \\
\hline CHEMBL1612489 & 688810 & 5.183 & 5.3797 & TRN & & \\
\hline CHEMBL1998940 & 688810 & \multicolumn{3}{|c|}{5.132999999999999} & 4.8982 & \\
\hline CHEMBL1462302 & 688810 & 6.233 & 5.4376 & TRN & & \\
\hline CHEMBL1543599 & 688810 & 5.433 & 4.6206 & TRN & & \\
\hline CHEMBL1519639 & 688810 & \multicolumn{3}{|c|}{5.832999999999999} & 5.5872 & \\
\hline CHEMBL1349937 & 688810 & 5.733 & 5.6399 & TRN & & \\
\hline CHEMBL1452159 & 688810 & 4.933 & 5.4887 & TRN & & \\
\hline CHEMBL 3197234 & 688810 & \multicolumn{3}{|c|}{6.2829999999999995} & 5.9515 & \\
\hline CHEMBL1492530 & 688810 & 5.683 & 5.5336 & TRN & & \\
\hline CHEMBL1551433 & 688 & 4.633 & 5.0942 & TRN & & \\
\hline CHEMBL15 & $68 \varepsilon$ & 5.233 & 5.4144 & TRN & & \\
\hline CHEMBL1453649 & 688810 & \multicolumn{3}{|c|}{5.2829999999999995} & 5.0576 & TRN \\
\hline CHEMBL1515494 & 688810 & \multicolumn{3}{|c|}{5.832999999999999} & & \\
\hline CHEMBL1463050 & 688810 & 5.233 & 5.3718 & TRN & & \\
\hline CHEMBL1 & 10 & 4.933 & 5.6184 & TRN & & \\
\hline CHEMBL: & 10 & 4.783 & 5.0201 & TRN & & \\
\hline CHEMBL1597963 & 688810 & 5.183 & \multicolumn{3}{|c|}{5.071000000000001} & $\mathrm{TI}$ \\
\hline CHEMBL1479700 & 688810 & 5.183 & \multicolumn{3}{|c|}{5.5729999999999995} & \\
\hline CHEMBL1481261 & 688810 & 4.833 & 5.4006 & TRN & & \\
\hline CHEMBL1 & 688 & 5.683 & 5.5552 & TRN & & \\
\hline CHEMBL1968462 & 688 & 4.633 & 4.7561 & TRN & & \\
\hline CHEMBL1584750 & 688810 & \multicolumn{3}{|c|}{4.9830000000000005} & 424 & $T$ \\
\hline CHEMBL169272 & 688810 & 4.783 & 4.9329 & TST & & \\
\hline CHEMBL1499023 & 688 & 4. & 5.151 & TST & & \\
\hline CHEMBL 1 & 10 & 5.683 & 5.4299 & TST & & \\
\hline CHEMBL1316175 & 688 & 4.633 & 4.7979 & TRN & & \\
\hline CHEMBL1538864 & 688 & 4.833 & 5.0173 & TRN & & \\
\hline CHEMBL1448001 & 688810 & \multicolumn{3}{|c|}{4.9830000000000005} & נ. & \\
\hline CHEMBL1 & $68 \varepsilon$ & 4.55 & 5.2813 & TRN & & \\
\hline CHEMBL1453995 & 688 & \multicolumn{3}{|c|}{5.132999999999999} & 5.2084 & TRN \\
\hline CHEMBL1536808 & 688810 & \multicolumn{3}{|c|}{5.582999999999999} & 5.2865 & TST \\
\hline CHEMBL1368072 & 688810 & \multicolumn{3}{|c|}{5.132999999999999} & 5.3264 & TRN \\
\hline CHEMBL1361502 & 688810 & \multicolumn{3}{|c|}{5.332999999999999} & 5.0445 & $\mathrm{TI}$ \\
\hline CHEMBL1446422 & 688 & & 4.9717 & TST & & \\
\hline CHEMBL1413495 & 688810 & 4.783 & 4.8625 & TRN & & \\
\hline CHEMBL3212403 & 688810 & 5.033 & 5.1106 & TST & & \\
\hline CHEMBL1570658 & 688810 & 5.233 & 5.5993 & TRN & & \\
\hline CHEMBL1352606 & 688810 & 4.783 & 4.8843 & TRN & & \\
\hline CHEMBL1306564 & 688810 & & 4.9317 & TRN & & \\
\hline CHEMBL1451293 & 688810 & 7.2328 & 5.9741 & TRN & & \\
\hline CHEMBL1407587 & 688810 & \multicolumn{3}{|c|}{5.882999999999999} & 4.984 & $r$ \\
\hline CHEMBL1485948 & 688810 & \multicolumn{3}{|c|}{5.5329999999999995} & 4.9453 & \\
\hline
\end{tabular}




\begin{tabular}{|c|c|c|c|c|c|c|}
\hline \multirow[b]{2}{*}{ CHEMBL1545104 } & & & & & & \\
\hline & 688810 & 5.683 & 5.4191 & TRN & & \\
\hline CHEMBL1575159 & 688810 & 4.783 & 4.8852 & TRN & & \\
\hline CHEMBL1549029 & 688810 & 5.58299 & 99999999 & & 5.3056 & TRN \\
\hline CHEMBL1573588 & 688810 & 5.78299 & 99999999 & 995 & 5.3801 & TRN \\
\hline CHEMBL 3196261 & 688810 & 5.88299 & 99999999 & & 4.9721 & TST \\
\hline CHEMBL1337171 & 688810 & 5.28299 & 99999999 & 995 & 5.2488 & TRN \\
\hline CHEMBL1310458 & 688810 & 6.03299 & 99999999 & 995 & 5.0897 & TRN \\
\hline CHEMBL1535899 & 688810 & 5.683 & 5.2563 & TRN & & \\
\hline CHEMBL1531825 & 688810 & 4.633 & 4.5501 & TRN & & \\
\hline CHEMBL1549857 & 688810 & 4.833 & 5.0135 & TST & & \\
\hline CHEMBL1315348 & 688810 & 5.78299 & 99999999 & 995 & 5.465 & I KIV \\
\hline CHEMBL1331109 & 688810 & 6.53299 & 99999999 & 995 & 5.7199 & TRN \\
\hline CHEMBL1475403 & 688810 & $4.9830 e$ & 00000000 & 005 & 5.0418 & \\
\hline CHEMBL1313467 & 688810 & 4.833 & 5.1421 & TRN & & \\
\hline CHEMBL1460356 & 688810 & 5.83299 & 99999999 & & 5.1524 & I KIV \\
\hline CHEMBL1501859 & 688810 & 5.28299 & 99999999 & 995 & 5.4664 & \\
\hline CHEMBL1486968 & 688810 & 4.583 & 5.1275 & TST & & \\
\hline CHEMBL1577946 & 688810 & 5.33299 & 99999999 & & 5.2548 & TST \\
\hline CHEMBL1565613 & 688810 & 4.833 & 4.773 & TRN & & \\
\hline CHEMBL1368552 & 688810 & 5.13299 & 99999999 & & 5127 & \\
\hline CHEMBL1611905 & 688810 & 8.3872 & 5.1354 & TRN & & \\
\hline CHEMBL1507404 & 688810 & 4.633 & 5.4593 & TST & & \\
\hline CHEMBL1481068 & 688810 & 4.833 & 5.3021 & TRN & & \\
\hline CHEMBL1349881 & 688810 & 5.233 & 5.2907 & TRN & & \\
\hline CHEMBL1523002 & 688810 & 5.733 & 5.317 & TRN & & \\
\hline CHEMBL1437615 & 688810 & $4.9830 e$ & $00000000 t$ & 005 & 5.0765 & \\
\hline CHEMBL1449472 & 688810 & $4.7330 e$ & 00000000 & 005 & 5.01 & \\
\hline CHEMBL1419210 & 688810 & 5.733 & 5.5694 & TRN & & \\
\hline CHEMBL1992745 & 688810 & 6.183 & 5.4429 & TRN & & \\
\hline CHEMBL1395211 & 688810 & 4.833 & 5.15 & TRN & & \\
\hline CHEMBL1388152 & 688810 & 4.583 & 5.0705 & TST & & \\
\hline CHEMBL1361936 & 688810 & 7.1831 & 6.3176 & TRN & & \\
\hline CHEMBL1402732 & 688810 & 6.38299 & 99999999 & & 5.84 & TR \\
\hline CHEMBL1551338 & 688810 & 4.633 & 4.8479 & TRN & & \\
\hline CHEMBL1516976 & 688810 & 6.2829 & 99999999 & 995 & 5.3226 & \\
\hline CHEMBL1545225 & 688810 & 4.633 & 4.7238 & TRN & & \\
\hline CHEMBL1494080 & 688810 & 5.78299 & 99999999 & 995 & 6.1612 & TRN \\
\hline CHEMBL1503742 & 688810 & 5.53299 & 99999999 & 995 & 5.3289 & TRN \\
\hline CHEMBL1398625 & 688810 & $4.7330 t$ & 00000000 & 005 & 5.4603 & TRN \\
\hline CHEMBL1600947 & 688810 & 6.5829 & 99999999 & & 5.7779 & TRI \\
\hline CHEMBL1599498 & 688810 & 4.583 & 5.2509 & TRN & & \\
\hline CHEMBL1321276 & 688810 & 5.233 & 5.3703 & TRN & & \\
\hline CHEMBL1435592 & 688810 & 4.833 & 4.899 & TRN & & \\
\hline CHEMBL1328288 & 688810 & 4.883 & 5.2923 & TRN & & \\
\hline CHEMBL1510806 & 688810 & 5.983 & 5.5691 & TRN & & \\
\hline CHEMBL1346898 & 688810 & 4.73306 & 00000000 & 005 & 4.9044 & TRN \\
\hline CHEMBL1516916 & 688810 & 4.933 & 5.5737 & TRN & & \\
\hline CHEMBL1453521 & 688810 & 5.683 & 4.9876 & TRN & & \\
\hline
\end{tabular}




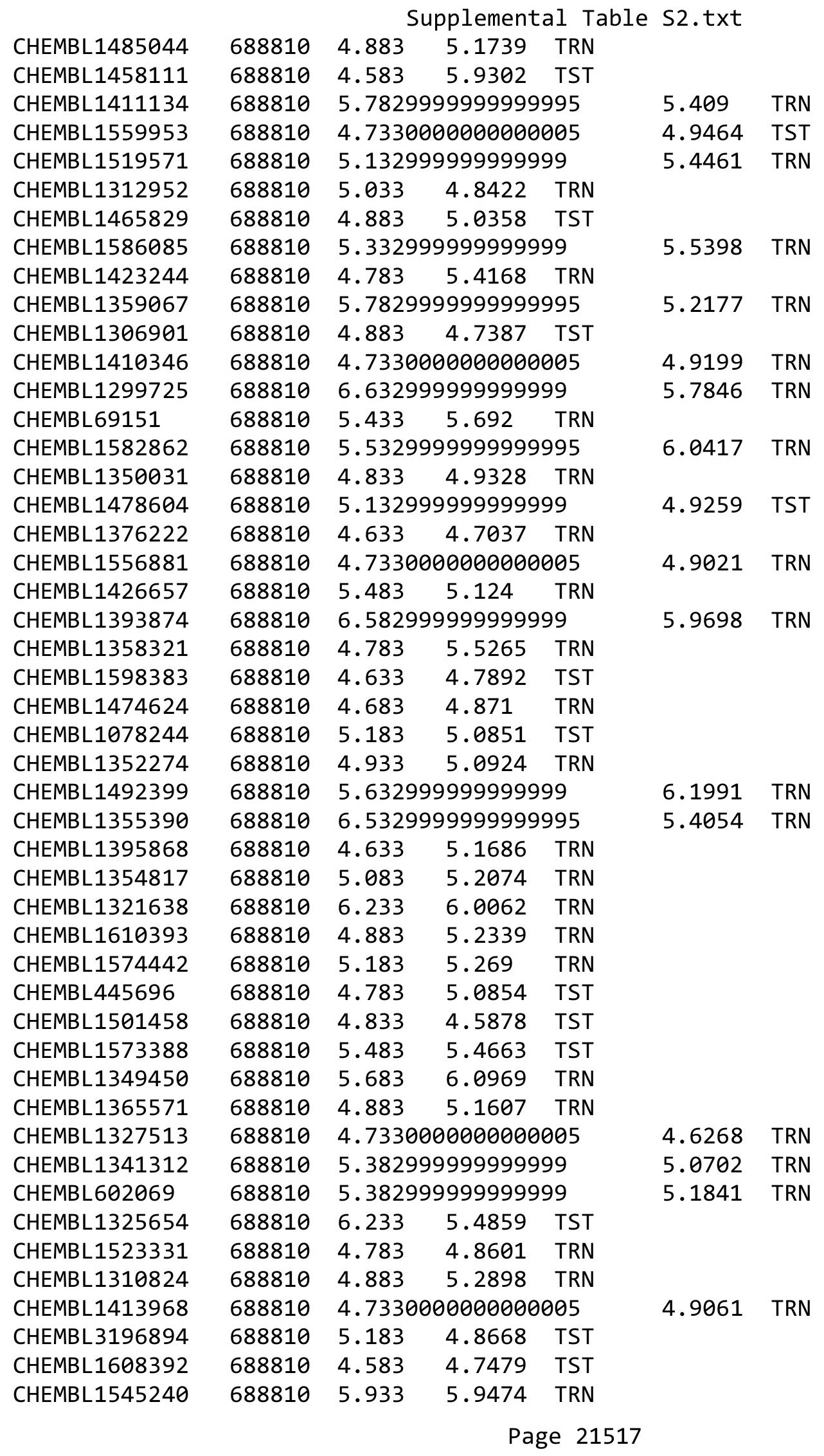




\begin{tabular}{|c|c|c|c|c|c|c|}
\hline \multirow[b]{2}{*}{ CHEMBL1342141 } & \multirow[b]{2}{*}{688810} & \multicolumn{5}{|c|}{ Supplemental Table S2.txt } \\
\hline & & 4.633 & 5.4585 & TST & & \\
\hline CHEMBL1483639 & 688810 & \multicolumn{3}{|c|}{4.7330000000000005} & 5.0598 & TRN \\
\hline CHEMBL1510319 & 688810 & 5.033 & 5.0644 & TRN & & \\
\hline CHEMBL3190953 & 688810 & 5.683 & 5.7482 & TRN & & \\
\hline CHEMBL1549861 & 688810 & 4.783 & 5.349 & TRN & & \\
\hline CHEMBL1580050 & 688810 & \multicolumn{3}{|c|}{5.832999999999999} & 5.334 & TRN \\
\hline CHEMBL1454798 & 688810 & 4.933 & 5.2835 & TRN & & \\
\hline CHEMBL1351437 & 688810 & 4.783 & 5.6764 & TRN & & \\
\hline CHEMBL1377154 & 688810 & 4.95 & 5.2616 & TRN & & \\
\hline CHEMBL117966 & 688810 & 5.433 & 5.6937 & TRN & & \\
\hline CHEMBL1446305 & 688810 & 5.483 & 4.8165 & TRN & & \\
\hline CHEMBL1585774 & 688810 & 4.833 & 4.9092 & TRN & & \\
\hline CHEMBL1495290 & 688810 & \multicolumn{3}{|c|}{5.5329999999999995} & 5.4422 & TST \\
\hline CHEMBL1525348 & 688810 & \multicolumn{3}{|c|}{5.832999999999999} & 5.5887 & TRN \\
\hline CHEMBL1423257 & 688810 & \multicolumn{3}{|c|}{6.5329999999999995} & 5.8862 & TRN \\
\hline CHEMBL1582580 & 688810 & 4.933 & 4.9863 & TRN & & \\
\hline CHEMBL1530260 & 688810 & \multicolumn{3}{|c|}{4.7330000000000005} & 4.7855 & TST \\
\hline CHEMBL1606179 & 688810 & 4.783 & 5.3519 & TRN & & \\
\hline CHEMBL1318502 & 688810 & 5.733 & 4.7853 & TRN & & \\
\hline CHEMBL1494964 & 688810 & 4.783 & 5.1457 & TRN & & \\
\hline CHEMBL1435117 & 688810 & 4.883 & 4.9954 & TRN & & \\
\hline CHEMBL1528571 & 688810 & 4.933 & 5.31 & TRN & & \\
\hline CHEMBL1561921 & 688810 & 4.783 & 5.0722 & TRN & & \\
\hline CHEMBL3208040 & 688810 & 5.083 & 5.3152 & TRN & & \\
\hline CHEMBL1516315 & 688810 & 4.933 & 5.1036 & TRN & & \\
\hline CHEMBL1610953 & 688810 & 5.733 & 5.4254 & TRN & & \\
\hline CHEMBL1406952 & 688810 & \multicolumn{3}{|c|}{6.2829999999999995} & 5.7699 & TRN \\
\hline CHEMBL1483981 & 688810 & 5.733 & 5.0485 & TST & & \\
\hline CHEMBL1378896 & 688810 & \multicolumn{3}{|c|}{5.5329999999999995} & 5.3265 & TRN \\
\hline CHEMBL1371349 & 688810 & 5.233 & 5.0062 & TST & & \\
\hline CHEMBL1563710 & 688810 & \multicolumn{3}{|c|}{5.5329999999999995} & 5.2106 & TRN \\
\hline CHEMBL1333792 & 688810 & 4.783 & 5.1455 & TST & & \\
\hline CHEMBL1567453 & 688810 & & 4.7125 & TRN & & \\
\hline CHEMBL1438881 & 688810 & \multicolumn{3}{|c|}{5.332999999999999} & 5.3267 & TRN \\
\hline CHEMBL376353 & 688810 & 5.983 & 6.1687 & TRN & & \\
\hline CHEMBL1392037 & 688810 & \multicolumn{3}{|c|}{5.832999999999999} & 5.5329 & TRN \\
\hline CHEMBL1455814 & 688810 & 6.233 & 6.0797 & TRN & & \\
\hline CHEMBL1483769 & 688810 & & 5.3277 & TRN & & \\
\hline CHEMBL1596813 & 688810 & \multicolumn{3}{|c|}{5.832999999999999} & 5.495 & TRN \\
\hline CHEMBL1430621 & 688810 & 5.083 & 5.1068 & TST & & \\
\hline CHEMBL1508701 & 688810 & 4.783 & 5.2456 & TRN & & \\
\hline CHEMBL1311302 & 688810 & 5.033 & 5.3243 & TST & & \\
\hline CHEMBL1419694 & 688810 & \multicolumn{3}{|c|}{5.2829999999999995} & 5.5308 & TST \\
\hline CHEMBL1472429 & 688810 & 5.483 & 5.0115 & TST & & \\
\hline CHEMBL1351016 & 688810 & 4.583 & 4.8603 & TST & & \\
\hline CHEMBL1400439 & 688810 & \multicolumn{3}{|c|}{4.7330000000000005} & 5.5088 & TST \\
\hline CHEMBL1523716 & 688810 & \multicolumn{3}{|c|}{5.832999999999999} & 5.8496 & TRN \\
\hline CHEMBL1547908 & 688810 & 4.783 & 5.7351 & TRN & & \\
\hline
\end{tabular}




\begin{tabular}{|c|c|c|c|c|c|c|c|}
\hline & & & & & & & \\
\hline CHEMBL1341822 & 688810 & 5.483 & 5.5948 & TRN & & & \\
\hline CHEMBL1424280 & 688810 & 5.83299 & 999999999 & & 5.0369 & TST & \\
\hline CHEMBL1531336 & 688810 & 5.33299 & 999999999 & & 5.0256 & TRN & \\
\hline CHEMBL3189735 & 688810 & 5.13299 & 999999999 & & 5.3348 & TRN & \\
\hline CHEMBL1966283 & 688810 & 4.883 & 5.019 & TST & & & \\
\hline CHEMBL579318 & 688810 & 5.53299 & 999999999 & 995 & 5.5265 & TRN & \\
\hline CHEMBL1383500 & 688810 & 5.083 & 4.9612 & TRN & & & \\
\hline CHEMBL1568011 & 688810 & 6.38299 & 999999999 & & 5.3204 & TRN & \\
\hline CHEMBL1388873 & 688810 & 4.73300 & 000000000 & 005 & 5.0814 & TRN & \\
\hline CHEMBL1310009 & 688810 & 4.633 & 5.2372 & TRN & & & \\
\hline CHEMBL1307583 & 688810 & 4.883 & 5.5952 & TRN & & & \\
\hline CHEMBL1392565 & 688810 & 6.38299 & 999999999 & & 5.5406 & TRN & \\
\hline CHEMBL1508411 & 688810 & 5.683 & 5.1257 & TRN & & & \\
\hline CHEMBL3198490 & 688810 & 4.933 & 4.8777 & TRN & & & \\
\hline CHEMBL1354109 & 688810 & 4.783 & 5.3822 & TRN & & & \\
\hline CHEMBL3196976 & 688810 & 5.38299 & 999999999 & & 4.6476 & TRN & \\
\hline CHEMBL1398963 & 688810 & 4.833 & 4.9611 & TRN & & & \\
\hline CHEMBL1441721 & 688810 & 4.833 & 5.7672 & TRN & & & \\
\hline CHEMBL1360653 & 688810 & 4.633 & 4.7152 & TRN & & & \\
\hline CHEMBL1482168 & 688810 & 4.583 & 5.574 & TRN & & & \\
\hline CHEMBL1967857 & 688810 & 7.2832 & 5.6742 & TRN & & & \\
\hline CHEMBL1336578 & 688810 & 4.883 & 4.9052 & TRN & & & \\
\hline CHEMBL1402339 & 688810 & 5.28299 & 999999999 & 995 & 5.0941 & TRN & \\
\hline CHEMBL600554 & 688810 & 5.733 & 5.8105 & TRN & & & \\
\hline CHEMBL1466494 & 688810 & 4.783 & 5.0002 & TRN & & & \\
\hline CHEMBL3194386 & 688810 & 4.73300 & 000000000 & 005 & 5.5444 & TRN & \\
\hline CHEMBL1487935 & 688810 & 4.73300 & 000000000 & 005 & 5.3443 & TRN & \\
\hline CHEMBL1377744 & 688810 & 5.28299 & 999999999 & 995 & 5.3345 & TST & \\
\hline CHEMBL1414596 & 688810 & 7.0329 & 5.5444 & TRN & & & \\
\hline CHEMBL1337225 & 688810 & 6.183 & 5.4509 & TRN & & & \\
\hline CHEMBL1363489 & 688810 & 5.13299 & 999999999 & & 4.8182 & TST & \\
\hline CHEMBL1988780 & 688810 & 5.83299 & 999999999 & & 5.3447 & TRN & \\
\hline CHEMBL1530208 & 688810 & 4.783 & 5.3303 & TRN & & & \\
\hline CHEMBL1439781 & 688810 & 5.38299 & 999999999 & & 5.3692 & TRN & \\
\hline CHEMBL1472693 & 688810 & 4.883 & 5.4205 & TRN & & & \\
\hline CHEMBL1314580 & 688810 & 5.13299 & 999999999 & & 5.0645 & TRN & \\
\hline CHEMBL1335250 & 688810 & 6.38299 & 999999999 & & 5.7147 & TRN & \\
\hline CHEMBL1365259 & 688810 & 5.483 & 5.4755 & TST & & & \\
\hline CHEMBL1399904 & 688810 & 4.633 & 4.8731 & TRN & & & \\
\hline CHEMBL1539075 & 688810 & 4.633 & 5.5104 & TST & & & \\
\hline CHEMBL1536460 & 688810 & 5.58299 & 999999999 & & 5.096999 & 99999999995 & TRN \\
\hline CHEMBL1552488 & 688810 & 5.983 & 5.2706 & TRN & & & \\
\hline CHEMBL1511288 & 688810 & 4.833 & 5.3466 & TRN & & & \\
\hline CHEMBL1447210 & 688810 & 7.08299 & 999999999 & & 5.5969 & TRN & \\
\hline CHEMBL3199855 & 688810 & 7.1331 & 6.1928 & TRN & & & \\
\hline CHEMBL1378442 & 688810 & 6.53299 & 999999999 & 995 & 5.984 & TRN & \\
\hline CHEMBL1505598 & 688810 & 4.833 & 4.9668 & TRN & & & \\
\hline CHEMBL1970707 & 688810 & 5.433 & 5.3071 & TRN & & & \\
\hline
\end{tabular}




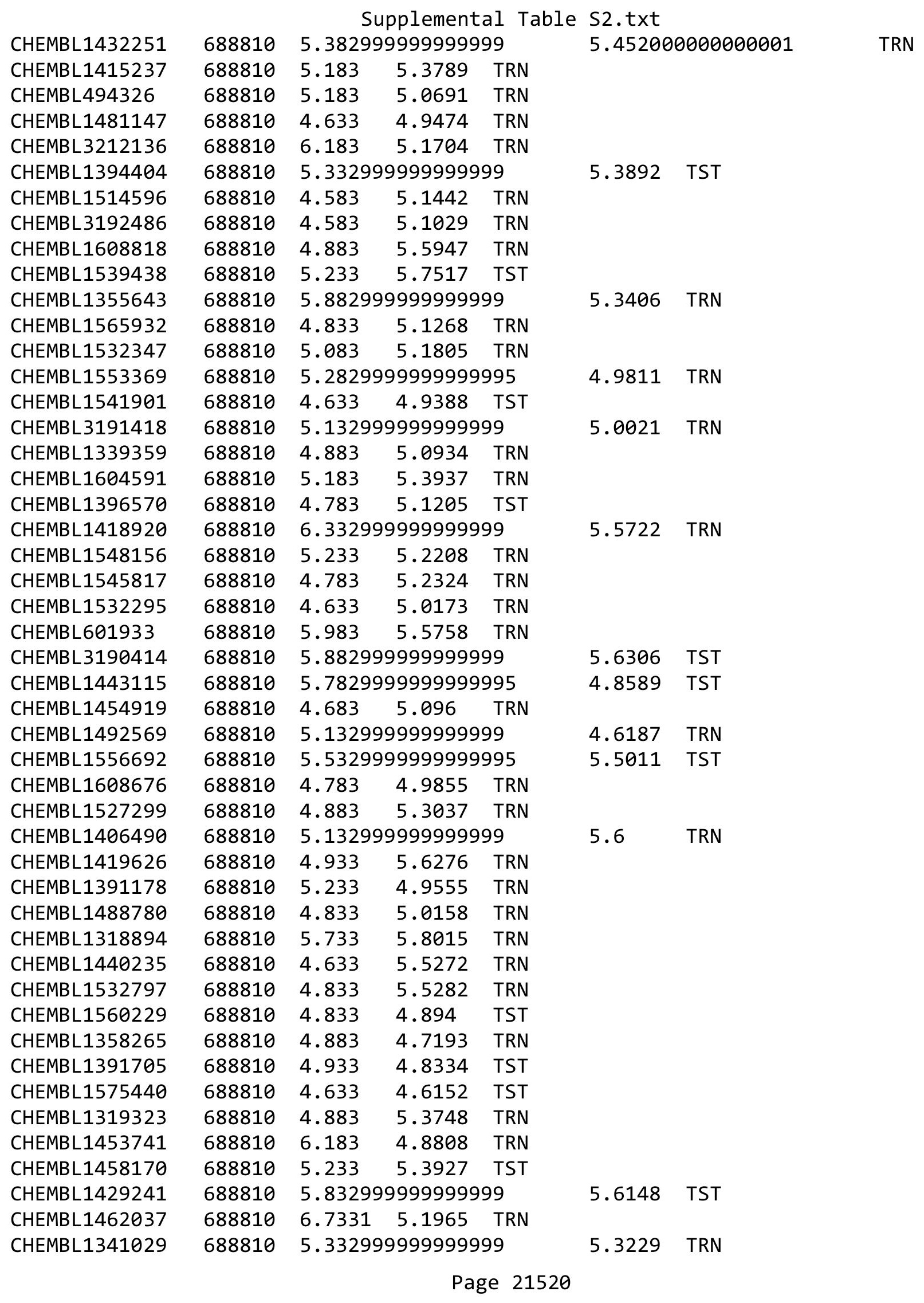




\begin{tabular}{|c|c|c|c|c|c|c|}
\hline & & \multicolumn{5}{|c|}{ Supplemental Table S2.txt } \\
\hline CHEMBL356828 & 688810 & 6.983 & 5.5905 & TRN & & \\
\hline CHEMBL1540273 & 688810 & 4.98300 & 00000000 & 005 & 5.3549 & TST \\
\hline CHEMBL1397263 & 688810 & 5.183 & 5.0655 & TST & & \\
\hline CHEMBL 3207673 & 688810 & 4.933 & 4.9682 & TST & & \\
\hline CHEMBL1334342 & 688810 & 5.35 & 5.5513 & TST & & \\
\hline CHEMBL1563714 & 688810 & 4.833 & 5.3498 & TST & & \\
\hline CHEMBL1966180 & 688810 & 6.7331 & 5.42 & TST & & \\
\hline CHEMBL1464798 & 688810 & 4.833 & 4.7312 & TRN & & \\
\hline CHEMBL 3190922 & 688810 & 4.783 & 5.1332 & TRN & & \\
\hline CHEMBL1515951 & 688810 & 4.833 & 5.0826 & TRN & & \\
\hline CHEMBL1531385 & 688810 & 4.633 & 4.832 & TST & & \\
\hline CHEMBL1416329 & 688810 & 4.633 & 4.5747 & TRN & & \\
\hline CHEMBL 3193424 & 688810 & 6.53299 & 99999999 & 995 & 5.5401 & \\
\hline CHEMBL1482284 & 688810 & 4.73300 & g0000000 & 005 & 5.0693 & \\
\hline CHEMBL1447606 & 688810 & 4.833 & 5.2214 & TST & & \\
\hline CHEMBL1412101 & 688810 & 5.183 & 5.4191 & TRN & & \\
\hline CHEMBL1365021 & 688810 & 4.583 & 5.0421 & TRN & & \\
\hline CHEMBL1344936 & 688810 & 4.833 & 5.0464 & TRN & & \\
\hline CHEMBL 3198350 & 688810 & 6.33299 & 99999999 & & 5.6534 & 11 \\
\hline CHEMBL1534684 & 688810 & 4.833 & 5.0215 & TRN & & \\
\hline CHEMBL1479365 & 688810 & 4.783 & 4.9934 & TRN & & \\
\hline CHEMBL1429218 & 688810 & 6.683 & 5.9648 & TRN & & \\
\hline CHEMBL1306258 & 688810 & 5.33299 & 99999999 & & 5.276 & \\
\hline CHEMBL1484849 & 688810 & 5.33299 & 99999999 & & 5.1444 & \\
\hline CHEMBL1480801 & 688810 & 6.28299 & 99999999 & 995 & 6.0462 & TRN \\
\hline CHEMBL1412124 & 688810 & 4.73300 & 00000000 & 005 & 5.1738 & TST \\
\hline CHEMBL1429625 & 688810 & 5.53299 & 99999999 & 995 & 5.2491 & TCT \\
\hline CHEMBL1312368 & 688810 & 5.433 & 5.1484 & TST & & \\
\hline CHEMBL1348884 & 688810 & 6.78299 & 99999999 & 995 & 5.9647 & 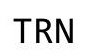 \\
\hline CHEMBL1351668 & 688810 & 4.633 & 4.5989 & TRN & & \\
\hline CHEMBL1339320 & 688810 & 5.13299 & 99999999 & 99 & 5.553 & TST \\
\hline CHEMBL1579316 & 688810 & 5.183 & 4.9222 & TST & & \\
\hline CHEMBL1571239 & 688810 & 6.4 & 5.7323 & TRN & & \\
\hline CHEMBL1995726 & 688810 & 5.033 & 5.1995 & TST & & \\
\hline CHEMBL1487765 & 688810 & 6.0 & 5.4061 & TRN & & \\
\hline CHEMBL1469756 & 688810 & 4.883 & 4.9705 & TRN & & \\
\hline CHEMBL 1450420 & 688810 & 5.53299 & 99999999 & 995 & 5.3624 & $\mathrm{Int}$ \\
\hline CHEMBL1487358 & 688810 & 4.833 & 4.9415 & TRN & & \\
\hline CHEMBL1523446 & 688810 & 4.883 & 5.2026 & TST & & \\
\hline CHEMBL 3209023 & 688810 & 5.233 & 5.3749 & TRN & & \\
\hline CHEMBL1544255 & 688810 & 4.833 & 4.8884 & TRN & & \\
\hline CHEMBL1416494 & 688810 & 4.833 & 5.1695 & TST & & \\
\hline CHEMBL1464583 & 688810 & 5.683 & 5.3042 & TRN & & \\
\hline CHEMBL1412778 & 688810 & 5.733 & 5.5719 & TRN & & \\
\hline CHEMBL1335083 & 688810 & 5.55 & 5.4197 & TRN & & \\
\hline CHEMBL1585124 & 688810 & 6.28299 & 99999999 & 995 & 5.7974 & 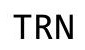 \\
\hline CHEMBL1416757 & 688810 & 4.833 & 5.2627 & TRN & & \\
\hline CHEMBL1330725 & 688810 & 5.233 & 4.8268 & TRN & & \\
\hline
\end{tabular}




\begin{tabular}{|c|c|c|c|c|c|c|c|}
\hline \multirow[b]{2}{*}{ CHEMBL1421255 } & & \\
\hline & 688810 & 7.3325 & 6.1932 & TRN & & & \\
\hline CHEMBL1439514 & 688810 & 5.033 & 5.3628 & TRN & & & \\
\hline CHEMBL1567343 & 688810 & 4.633 & 5.13 & TRN & & & \\
\hline CHEMBL1489315 & 688810 & \multicolumn{3}{|c|}{4.7330000000000005} & 5.5616 & TST & \\
\hline CHEMBL1537713 & 688810 & 4.783 & 4.9317 & TRN & & & \\
\hline CHEMBL3198855 & 688810 & 4.933 & 5.0452 & TRN & & & \\
\hline CHEMBL1466755 & 688810 & 4.833 & 5.2527 & TRN & & & \\
\hline CHEMBL1403890 & 688810 & 4.633 & 4.7481 & TST & & & \\
\hline CHEMBL1449023 & 688810 & \multicolumn{3}{|c|}{5.2829999999999995} & 5.5041 & TRN & \\
\hline CHEMBL62044 & 688810 & 4.783 & 5.0598 & TRN & & & \\
\hline CHEMBL1393855 & 688810 & \multicolumn{3}{|c|}{4.7330000000000005} & 5.0211 & TRN & \\
\hline CHEMBL1388369 & 688810 & \multicolumn{3}{|c|}{4.7330000000000005} & 5.2198 & TRN & \\
\hline CHEMBL1342842 & 688810 & 4.633 & 4.7718 & TST & & & \\
\hline CHEMBL1528258 & 688810 & 4.633 & 4.9982 & TRN & & & \\
\hline CHEMBL1611342 & 688810 & \multicolumn{3}{|c|}{4.7330000000000005} & 5.0892 & TRN & \\
\hline CHEMBL1366458 & 688810 & 5.233 & 5.4086 & TRN & & & \\
\hline CHEMBL1385576 & 688810 & 4.833 & 5.095 & TRN & & & \\
\hline CHEMBL3194091 & 688810 & \multicolumn{3}{|c|}{4.9830000000000005} & 4.9997 & TST & \\
\hline CHEMBL1601966 & 688810 & \multicolumn{3}{|c|}{5.882999999999999} & 5.2896 & TRN & \\
\hline CHEMBL1402351 & 688810 & \multicolumn{3}{|c|}{4.7330000000000005} & 4.9979 & TRN & \\
\hline CHEMBL1361670 & 688810 & 5.733 & 5.2761 & TRN & & & \\
\hline CHEMBL1408512 & 688810 & \multicolumn{3}{|c|}{4.7330000000000005} & 5.059 & TRN & \\
\hline CHEMBL1594218 & 688810 & \multicolumn{3}{|c|}{6.5329999999999995} & 6.0506 & TRN & \\
\hline CHEMBL1329986 & 688810 & 6.0 & 5.575 & TRN & & & \\
\hline CHEMBL1424899 & 688810 & \multicolumn{3}{|c|}{5.882999999999999} & 4.9531 & TRN & \\
\hline CHEMBL1512156 & 688810 & 4.783 & 5.2611 & TRN & & & \\
\hline CHEMBL3198047 & 688810 & 6.233 & 5.4973 & TRN & & & \\
\hline CHEMBL1447385 & 688810 & 5.983 & 5.13 & TRN & & & \\
\hline CHEMBL1426259 & 688810 & 5.033 & 5.144 & TRN & & & \\
\hline CHEMBL1499976 & 688810 & 6.183 & 5.2838 & TST & & & \\
\hline CHEMBL1429052 & 688810 & \multicolumn{3}{|c|}{5.832999999999999} & 5.3629 & TRN & \\
\hline CHEMBL1538639 & 688810 & 5.033 & 5.1861 & TST & & & \\
\hline CHEMBL1485566 & 688810 & \multicolumn{3}{|c|}{5.132999999999999} & 5.1729 & TRN & \\
\hline CHEMBL1549875 & 688810 & \multicolumn{3}{|c|}{5.132999999999999} & 5.0023 & TRN & \\
\hline CHEMBL1333162 & 688810 & \multicolumn{3}{|c|}{5.832999999999999} & 5.4682 & TRN & \\
\hline CHEMBL1452978 & 688810 & 4.933 & 5.2528 & TRN & & & \\
\hline CHEMBL1489637 & 688810 & \multicolumn{3}{|c|}{6.832999999999999} & \multicolumn{2}{|c|}{5.9510000000000005} & TRN \\
\hline CHEMBL1300942 & 688810 & \multicolumn{3}{|c|}{4.9830000000000005} & 5.3207 & TST & \\
\hline CHEMBL1348350 & 688810 & 5.233 & 5.3806 & TRN & & & \\
\hline CHEMBL1496360 & 688810 & 5.933 & 5.7007 & TRN & & & \\
\hline CHEMBL1611142 & 688810 & 6.08299 & 99999999 & 99 & 5.4991 & TRN & \\
\hline CHEMBL1337624 & 688810 & 5.233 & 5.7981 & TRN & & & \\
\hline CHEMBL1549525 & 688810 & 5.33299 & 99999999 & 99 & 5.4388 & TST & \\
\hline CHEMBL1567655 & 688810 & 5.483 & 4.9494 & TRN & & & \\
\hline CHEMBL1500981 & 688810 & 4.633 & 4.7771 & TST & & & \\
\hline CHEMBL1494831 & 688810 & 4.833 & 5.8128 & TRN & & & \\
\hline CHEMBL1409101 & 688810 & 7.2328 & 6.1235 & TRN & & & \\
\hline CHEMBL1997130 & 688810 & 5.28299 & 99999999 & 995 & 5.2743 & TRN & \\
\hline
\end{tabular}




\begin{tabular}{|c|c|c|c|c|c|c|}
\hline \multirow[b]{2}{*}{ CHEMBL3190177 } & \multicolumn{6}{|c|}{ plemental Table S2.t) } \\
\hline & 688810 & 5.083 & 4.9393 & TRN & & \\
\hline CHEMBL1567639 & 688810 & 4.73300 & 000000006 & 005 & 5.1596 & TRN \\
\hline CHEMBL1347724 & 688810 & 5.38299 & 999999999 & & 5.2289 & \\
\hline CHEMBL1525786 & 688810 & 4.883 & $5.41200 e$ & 000000000 & 91 & \\
\hline CHEMBL1441706 & 688810 & 4.73300 & 000000006 & 005 & 4.9213 & TRN \\
\hline CHEMBL1306451 & 688810 & 5.38299 & 999999999 & & 5.0766 & \\
\hline CHEMBL1571842 & 688810 & 4.783 & 5.5478 & TRN & & \\
\hline CHEMBL1604250 & 688810 & 5.33299 & 999999999 & & 5.3618 & \\
\hline CHEMBL1333235 & 688810 & 5.733 & 4.9967 & TRN & & \\
\hline CHEMBL1390241 & 688810 & 5.083 & 5.0196 & TRN & & \\
\hline CHEMBL1365177 & 688810 & 5.53299 & 999999999 & 995 & 5.5974 & TR \\
\hline CHEMBL1303316 & 688810 & 4.583 & 5.5636 & TRN & & \\
\hline CHEMBL1531738 & 688810 & 4.633 & 5.388 & TST & & \\
\hline CHEMBL1371533 & 688810 & 4.783 & 5.2524 & TRN & & \\
\hline CHEMBL1426702 & 688810 & 4.883 & 5.0832 & TST & & \\
\hline CHEMBL 576317 & 688810 & 5.183 & 5.2452 & TRN & & \\
\hline CHEMBL1365205 & 688810 & 6.7331 & 5.2778 & TRN & & \\
\hline CHEMBL1605113 & 688810 & 5.38299 & 999999999 & & 3285 & TST \\
\hline CHEMBL1489141 & 688810 & 6.433 & 5.7626 & TST & & \\
\hline CHEMBL1575850 & 688810 & 4.933 & 4.7349 & TRN & & \\
\hline CHEMBL1511409 & 688810 & 4.73300 & 000000006 & 005 & 4.6925 & TRN \\
\hline CHEMBL1594855 & 688810 & 5.13299 & 999999999 & & 4.9497 & TRN \\
\hline CHEMBL1469698 & 688810 & 4.633 & 4.9767 & TRN & & \\
\hline CHEMBL1481425 & 688810 & 5.483 & 5.4197 & TRN & & \\
\hline CHEMBL1467288 & 688810 & 5.183 & 5.4313 & TRN & & \\
\hline CHEMBL1583282 & 688810 & 5.183 & 5.3953 & TST & & \\
\hline CHEMBL476513 & 688810 & 5.983 & 5.768 & TRN & & \\
\hline CHEMBL1546068 & 688810 & 4.633 & 5.1002 & TST & & \\
\hline CHEMBL3208179 & 688810 & 4.73300 & 000000000 & 005 & 5.0458 & \\
\hline CHEMBL1541890 & 688810 & 4.98300 & 000000000 & 005 & 5.2815 & TST \\
\hline CHEMBL1544460 & 688810 & 5.58299 & 999999999 & & 5.2672 & TRN \\
\hline CHEMBL1534367 & 688810 & 5.083 & 5.3746 & TST & & \\
\hline CHEMBL1553692 & 688810 & 4.633 & 5.0606 & TRN & & \\
\hline CHEMBL1312595 & 688810 & 4.783 & 5.013 & TRN & & \\
\hline CHEMBL1990825 & 688810 & 5.33299 & 999999999 & & 5.7078 & II \\
\hline CHEMBL1385381 & 688810 & 5.033 & 5.2654 & TRN & & \\
\hline CHEMBL1470920 & 688810 & 5.28299 & 999999999 & 995 & 5.4562 & TRN \\
\hline CHEMBL3207541 & 688810 & 5.53299 & 999999999 & 995 & 5.5283 & TS \\
\hline CHEMBL1453880 & 688810 & 4.883 & 5.0209 & TRN & & \\
\hline CHEMBL1400587 & 688810 & 5.733 & 5.0154 & TRN & & \\
\hline CHEMBL1325869 & 688810 & 6.7331 & 5.6961 & TRN & & \\
\hline CHEMBL1385171 & 688810 & 5.033 & 5.4222 & TRN & & \\
\hline CHEMBL1430765 & 688810 & 4.583 & 5.7559 & TRN & & \\
\hline CHEMBL1307618 & 688810 & 5.58299 & 999999999 & & 5.6082 & . \\
\hline CHEMBL3197353 & 688810 & 4.783 & 5.3729 & TRN & & \\
\hline CHEMBL1429120 & 688810 & 4.73300 & 000000000 & 205 & 5.1701 & $n$ \\
\hline CHEMBL1526670 & 688810 & 4.883 & 4.9854 & TRN & & \\
\hline CHEMBL1383419 & 688810 & 5.033 & 5.5302 & TST & & \\
\hline
\end{tabular}




\begin{tabular}{|c|c|c|c|c|c|c|}
\hline \multicolumn{7}{|c|}{ Supplemental Table S2.txt } \\
\hline CHEMBL1397872 & 688810 & 4.633 & 5.0861 & TRN & & \\
\hline CHEMBL1475991 & 688810 & 4.783 & 5.0984 & TST & & \\
\hline CHEMBL1428568 & 688810 & 4.833 & 5.2952 & TRN & & \\
\hline CHEMBL1452555 & 688810 & 5.3829 & 99999999 & & 5.1254 & TRN \\
\hline CHEMBL1510161 & 688810 & 5.5329 & 99999999 & 995 & 5.3984 & TRN \\
\hline CHEMBL1324612 & 688810 & 4.833 & 5.2369 & TST & & \\
\hline CHEMBL1350861 & 688810 & 5.8829 & 99999999 & & 5.9847 & TRN \\
\hline CHEMBL1354241 & 688810 & 4.7330 & 00000000 & 005 & 5.3007 & TRN \\
\hline CHEMBL1427981 & 688810 & 6.433 & 5.5197 & TRN & & \\
\hline CHEMBL1348057 & 688810 & 4.883 & 4.5884 & TRN & & \\
\hline CHEMBL1508616 & 688810 & 4.833 & 5.4221 & TST & & \\
\hline CHEMBL1394544 & 688810 & 4.583 & 4.6915 & TRN & & \\
\hline CHEMBL 3212307 & 688810 & 5.183 & 5.2724 & TST & & \\
\hline CHEMBL1990598 & 688810 & 5.8329 & 99999999 & & 4.8994 & TST \\
\hline CHEMBL1437533 & 688810 & 4.7330 & 00000000 & 005 & 5.3091 & rRN \\
\hline CHEMBL1585826 & 688810 & 4.7330 & 00000000 & 005 & 5.0832 & \\
\hline CHEMBL1450797 & 688810 & 5.433 & 6.0864 & TRN & & \\
\hline CHEMBL1483480 & 688810 & 4.9830 & 00000000 & 005 & 905 & \\
\hline CHEMBL1536809 & 688810 & 4.883 & 5.2048 & TST & & \\
\hline CHEMBL1482288 & 688810 & 4.783 & 5.0885 & TRN & & \\
\hline CHEMBL 3189394 & 688810 & 5.8829 & 99999999 & & 5.434 & TRI \\
\hline CHEMBL 3192197 & 688810 & 5.033 & 4.8746 & TRN & & \\
\hline CHEMBL1343819 & 688810 & 5.8829 & 99999999 & & 6 & \\
\hline CHEMBL1497107 & 688810 & 5.5329 & 99999999 & 995 & 5.6848 & TRN \\
\hline CHEMBL1410316 & 688810 & 4.7330 & 00000000 & 005 & 5.353 & TRN \\
\hline CHEMBL1581662 & 688810 & 5.233 & 4.8123 & TRN & & \\
\hline CHEMBL1344475 & 688810 & 5.7829 & 99999999 & 995 & 5.3205 & TR \\
\hline CHEMBL 3190389 & 688810 & 4.883 & 5.2303 & TST & & \\
\hline CHEMBL1607844 & 688810 & 6.3829 & 99999999 & & 5.7799 & I KIV \\
\hline CHEMBL1302425 & 688810 & 5.1329 & 99999999 & & 5.4309 & TST \\
\hline CHEMBL1438476 & 688810 & 4.7330 & $\partial 0000000$ & 005 & 5.8063 & TST \\
\hline CHEMBL1526076 & 688810 & 5.5829 & 99999999 & & 5.2362 & TST \\
\hline CHEMBL1547975 & 688810 & 5.683 & 5.2884 & TRN & & \\
\hline CHEMBL1324790 & 688810 & 4.583 & 5.0324 & TRN & & \\
\hline CHEMBL1517603 & 688810 & 6.0329 & 99999999 & 995 & 5.5834 & TRI \\
\hline CHEMBL1531962 & 688810 & 4.883 & 5.5763 & TRN & & \\
\hline CHEMBL1580515 & 688810 & 4.933 & 5.3414 & TST & & \\
\hline CHEMBL1388044 & 688810 & 4.783 & 5.0387 & TST & & \\
\hline CHEMBL1380182 & 688810 & 5.2829 & 99999999 & 995 & 5.2445 & TRN \\
\hline CHEMBL1417225 & 688810 & 5.7829 & 99999999 & 995 & 5.4182 & TST \\
\hline CHEMBL1350254 & 688810 & 4.933 & 5.3351 & TRN & & \\
\hline CHEMBL1384275 & 688810 & 4.7330 & 00000000 & 005 & 5.1017 & $1 \mathrm{NI}$ \\
\hline CHEMBL1322507 & 688810 & 6.183 & 6.0844 & TRN & & \\
\hline CHEMBL1405698 & 688810 & 4.933 & 5.2931 & TRN & & \\
\hline CHEMBL1610789 & 688810 & 5.5829 & 99999999 & & 5.5437 & TRN \\
\hline CHEMBL1322174 & 688810 & 6.0829 & 99999999 & & 5.3702 & 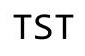 \\
\hline CHEMBL 3192234 & 688810 & 5.983 & 5.3324 & TST & & \\
\hline CHEMBL 1456703 & 688810 & 4.933 & 5.1835 & TRN & & \\
\hline
\end{tabular}




\begin{tabular}{|c|c|c|c|c|c|c|c|}
\hline \multicolumn{7}{|c|}{ Supplemental Table S2.txt } & \\
\hline CHEMBL1451023 & 688810 & \multicolumn{3}{|c|}{4.7330000000000005} & 5.0716 & TRN & \\
\hline CHEMBL1527929 & 688810 & 4.833 & 4.8652 & TRN & & & \\
\hline CHEMBL1370573 & 688810 & \multicolumn{3}{|c|}{5.832999999999999} & 5.0639 & TRN & \\
\hline CHEMBL1309448 & 688810 & 4.683 & 5.0372 & TRN & & & \\
\hline CHEMBL1368400 & 688810 & \multicolumn{3}{|c|}{6.2829999999999995} & 5.4229 & TRN & \\
\hline CHEMBL1567587 & 688810 & \multicolumn{3}{|c|}{5.7829999999999995} & 5.2232 & TRN & \\
\hline CHEMBL1533776 & 688810 & 4.583 & 5.0224 & TST & & & \\
\hline CHEMBL3210669 & 688810 & \multicolumn{3}{|c|}{6.2829999999999995} & \multicolumn{2}{|c|}{5.412000000000001} & TRN \\
\hline CHEMBL1301770 & 688810 & \multicolumn{3}{|c|}{6.2829999999999995} & 5.6553 & TRN & \\
\hline CHEMBL1545642 & 688810 & 4.933 & 5.2982 & TST & & & \\
\hline CHEMBL1388491 & 688810 & 5.483 & 5.4204 & TRN & & & \\
\hline CHEMBL1538726 & 688810 & 5.083 & 5.0905 & TRN & & & \\
\hline CHEMBL1327134 & 688810 & 6.683 & 5.8662 & TRN & & & \\
\hline CHEMBL1473219 & 688810 & 4.683 & 4.6263 & TRN & & & \\
\hline CHEMBL1509294 & 688810 & \multicolumn{3}{|c|}{4.7330000000000005} & 5.1803 & TRN & \\
\hline CHEMBL1326028 & 688810 & \multicolumn{3}{|c|}{6.7829999999999995} & 5.5199 & TRN & \\
\hline CHEMBL1518450 & 688810 & 5.683 & 5.4993 & TRN & & & \\
\hline CHEMBL1563809 & 688810 & 4.933 & 5.73 & TRN & & & \\
\hline CHEMBL1608401 & 688810 & 5.033 & 4.7944 & TRN & & & \\
\hline CHEMBL1464188 & 688810 & \multicolumn{3}{|c|}{4.9830000000000005} & 5.7029 & TST & \\
\hline CHEMBL1611715 & 688810 & \multicolumn{3}{|c|}{4.9830000000000005} & 4.9151 & TST & \\
\hline CHEMBL1391942 & 688810 & 4.933 & 5.2431 & TRN & & & \\
\hline CHEMBL1407931 & 688810 & \multirow{2}{*}{\multicolumn{3}{|c|}{$\begin{array}{ll}5.183 & 5.1842 \\
4.7330000000000005\end{array}$}} & & & \\
\hline CHEMBL1502746 & 688810 & & & & 5.1564 & TRN & \\
\hline CHEMBL 3210260 & 688810 & 4.783 & 5.334 & TRN & & & \\
\hline CHEMBL1301715 & 688810 & 4.783 & 5.1196 & TRN & & & \\
\hline CHEMBL1531935 & 688810 & \multicolumn{3}{|c|}{5.832999999999999} & 5.2781 & TRN & \\
\hline CHEMBL1522988 & 688810 & \multicolumn{3}{|c|}{5.632999999999999} & 4.8781 & TRN & \\
\hline CHEMBL3199213 & 688810 & 5.183 & 5.1299 & TRN & & & \\
\hline CHEMBL1449415 & 688810 & \multicolumn{3}{|c|}{5.832999999999999} & 5.7069 & TRN & \\
\hline CHEMBL1354317 & 688810 & \multicolumn{3}{|c|}{6.5329999999999995} & 5.3101 & TRN & \\
\hline CHEMBL1397197 & 688810 & 5.433 & 5.2388 & TRN & & & \\
\hline CHEMBL1311883 & 688810 & \multicolumn{3}{|c|}{5.132999999999999} & 5.3532 & TRN & \\
\hline CHEMBL1543889 & 688810 & \multicolumn{3}{|c|}{4.9830000000000005} & 5.3519 & TRN & \\
\hline CHEMBL1390512 & 688810 & 5.433 & 5.2162 & TRN & & & \\
\hline CHEMBL1386738 & 688810 & \multicolumn{3}{|c|}{5.2829999999999995} & 5.2722 & TST & \\
\hline CHEMBL3192332 & 688810 & \multicolumn{3}{|c|}{5.2829999999999995} & 5.3062 & TST & \\
\hline CHEMBL1613313 & 688810 & 5.6329 & 99999999 & & 5.4224 & TRN & \\
\hline CHEMBL1354064 & 688810 & 5.733 & 5.9163 & TRN & & & \\
\hline CHEMBL1343509 & 688810 & 5.3329 & 99999999 & & 5.47 & TRN & \\
\hline CHEMBL1379110 & 688810 & 6.683 & 6.0024 & TRN & & & \\
\hline CHEMBL1536462 & 688810 & 4.783 & 5.2036 & TST & & & \\
\hline CHEMBL1453948 & 688810 & 4.833 & 5.3724 & TRN & & & \\
\hline CHEMBL1308583 & 688810 & 5.1329 & 99999999 & & 4.8581 & TST & \\
\hline CHEMBL1605926 & 688810 & 5.3829 & 99999999 & & 5.246 & TRN & \\
\hline CHEMBL 203543 & 688810 & 5.033 & 5.4842 & TRN & & & \\
\hline CHEMBL1541425 & 688810 & 5.1329 & 99999999 & & 5.1715 & TRN & \\
\hline CHEMBL1604123 & 688810 & 5.8829 & 99999999 & & 5.3953 & TRN & \\
\hline
\end{tabular}




\begin{tabular}{|c|c|c|c|c|c|c|c|}
\hline \multirow[b]{2}{*}{ CHEMBL1498470 } & \multicolumn{6}{|c|}{ 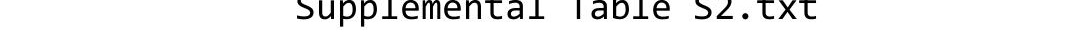 } & \\
\hline & 688810 & 6.183 & 5.7715 & TRN & & & \\
\hline CHEMBL1610183 & 688810 & 4.883 & 5.8552 & TRN & & & \\
\hline CHEMBL1363154 & 688810 & 4.73300 & 000000006 & 005 & 5.2869 & TST & \\
\hline CHEMBL1528847 & 688810 & 5.78299 & 999999995 & 995 & 5.6713 & TRN & \\
\hline CHEMBL1530854 & 688810 & 5.083 & 5.2388 & TRN & & & \\
\hline CHEMBL233531 & 688810 & 6.4829 & 5.9995 & TRN & & & \\
\hline CHEMBL1269633 & 688810 & 4.833 & 5.4101 & TRN & & & \\
\hline CHEMBL1565863 & 688810 & 6.28299 & 99999999 & 995 & 5.4516 & TRN & \\
\hline CHEMBL3212000 & 688810 & 5.733 & 5.3488 & TST & & & \\
\hline CHEMBL1472362 & 688810 & 5.63299 & 999999995 & & 5.3144 & TRN & \\
\hline CHEMBL1366388 & 688810 & 4.73300 & 000000006 & 005 & 5.0414 & TRN & \\
\hline CHEMBL1524192 & 688810 & 6.4829 & 5.3511 & TRN & & & \\
\hline CHEMBL1409066 & 688810 & 6.38299 & 999999999 & & 5.3263 & TRN & \\
\hline CHEMBL1382137 & 688810 & 4.883 & 5.4004 & TRN & & & \\
\hline CHEMBL1474819 & 688810 & 4.883 & 5.188 & TRN & & & \\
\hline CHEMBL 2004950 & 688810 & 6.28299 & 999999995 & 995 & 5.5037 & TRN & \\
\hline CHEMBL1479071 & 688810 & 4.833 & 5.2052 & TRN & & & \\
\hline CHEMBL1578756 & 688810 & 5.683 & 5.0747 & TRN & & & \\
\hline CHEMBL1467470 & 688810 & 4.933 & 4.9773 & TST & & & \\
\hline CHEMBL1337378 & 688810 & 5.38299 & 999999995 & & 5.49299 & 9999999999 & TRN \\
\hline CHEMBL1532162 & 688810 & 6.63299 & 999999995 & & 5.3685 & TRN & \\
\hline CHEMBL1358939 & 688810 & 5.183 & 5.0118 & TRN & & & \\
\hline CHEMBL1312050 & 688810 & 4.633 & 5.3539 & TST & & & \\
\hline CHEMBL1508320 & 688810 & 6.58299 & 999999999 & & 5.2623 & TST & \\
\hline CHEMBL1519352 & 688810 & 5.483 & 5.3897 & TRN & & & \\
\hline CHEMBL1363084 & 688810 & 4.833 & 5.3338 & TRN & & & \\
\hline CHEMBL1539893 & 688810 & 5.733 & 4.9636 & TST & & & \\
\hline CHEMBL1386295 & 688810 & 4.783 & 5.4023 & TRN & & & \\
\hline CHEMBL1304531 & 688810 & 4.783 & 5.265 & TRN & & & \\
\hline CHEMBL1522922 & 688810 & 5.483 & 5.6414 & TRN & & & \\
\hline CHEMBL1488893 & 688810 & 5.88299 & 999999999 & & 5.603 & TRN & \\
\hline CHEMBL1336853 & 688810 & 4.98300 & 000000000 & 005 & 5.3635 & TST & \\
\hline CHEMBL1585149 & 688810 & 6.08299 & 999999999 & & 5.3543 & TRN & \\
\hline CHEMBL1342679 & 688810 & 5.733 & 5.2699 & TRN & & & \\
\hline CHEMBL1312582 & 688810 & 6.433 & 5.6211 & TRN & & & \\
\hline CHEMBL1313107 & 688810 & 6.4829 & 5.3684 & TRN & & & \\
\hline CHEMBL1464259 & 688810 & 5.53299 & 999999999 & 995 & 5.07600 & 00000000005 & TRN \\
\hline CHEMBL1456038 & 688810 & 4.833 & 5.2701 & TRN & & & \\
\hline CHEMBL1391583 & 688810 & 4.833 & 5.2169 & TRN & & & \\
\hline CHEMBL1590384 & 688810 & 5.483 & 5.2663 & TRN & & & \\
\hline CHEMBL1369200 & 688810 & 4.583 & 5.0771 & TST & & & \\
\hline CHEMBL1425560 & 688810 & 5.13299 & 999999999 & & 5.8962 & TRN & \\
\hline CHEMBL1389372 & 688810 & 5.233 & 5.5667 & TST & & & \\
\hline CHEMBL 1358546 & 688810 & 5.53299 & 999999999 & 995 & 5.1167 & TST & \\
\hline CHEMBL1594786 & 688810 & 5.983 & 5.374 & TRN & & & \\
\hline CHEMBL1508551 & 688810 & 6.38299 & 999999999 & & 5.3978 & TST & \\
\hline CHEMBL1566346 & 688810 & 5.183 & 5.2558 & TRN & & & \\
\hline CHEMBL1613173 & 688810 & 4.833 & 5.2538 & TRN & & & \\
\hline
\end{tabular}




\begin{tabular}{|c|c|c|c|c|c|c|c|}
\hline & & & & & & & \\
\hline CHEMBL1500007 & 688810 & 5.433 & 5.1153 & TST & & & \\
\hline CHEMBL 3210765 & 688810 & 4.73300 & 000000006 & 005 & 5.317 & TST & \\
\hline CHEMBL1359062 & 688810 & 4.783 & 5.027 & TST & & & \\
\hline CHEMBL1331702 & 688810 & 5.28299 & 999999995 & 995 & 5.2847 & TRN & \\
\hline CHEMBL3212224 & 688810 & 5.83299 & 99999999؛ & & 4.8044 & TRN & \\
\hline CHEMBL1349500 & 688810 & 6.38299 & 999999999 & & 5.6481 & TRN & \\
\hline CHEMBL1344934 & 688810 & 5.233 & 5.1627 & TST & & & \\
\hline CHEMBL1418216 & 688810 & 5.683 & 5.3962 & TRN & & & \\
\hline CHEMBL1588833 & 688810 & 6.4829 & 5.3859 & TRN & & & \\
\hline CHEMBL1461857 & 688810 & 6.8831 & 5.8572 & TRN & & & \\
\hline CHEMBL1524390 & 688810 & 4.833 & 5.1775 & TRN & & & \\
\hline CHEMBL1565719 & 688810 & 4.883 & 4.8665 & TRN & & & \\
\hline CHEMBL355159 & 688810 & 6.38299 & 99999999 & & 5.565 & TRN & \\
\hline CHEMBL1478726 & 688810 & 5.233 & 4.9891 & TRN & & & \\
\hline CHEMBL1330076 & 688810 & 6.38299 & 99999999؛ & & 5.3558 & TRN & \\
\hline CHEMBL1502010 & 688810 & 4.633 & 5.3367 & TST & & & \\
\hline CHEMBL1539111 & 688810 & 5.13299 & 999999995 & & 5.135 & TST & \\
\hline CHEMBL1424464 & 688810 & 5.683 & 5.7723 & TRN & & & \\
\hline CHEMBL1349635 & 688810 & 5.733 & 6.1436 & TRN & & & \\
\hline CHEMBL1309779 & 688810 & $4.9830 e$ & 000000006 & 005 & 4.9989 & TRN & \\
\hline CHEMBL1554923 & 688810 & 7.1831 & 6.2238 & TRN & & & \\
\hline CHEMBL1386604 & 688810 & 5.733 & $5.28700 e$ & 000000000 & & TRN & \\
\hline CHEMBL3195155 & 688810 & 5.88299 & 99999999 & & 5.1967 & TRN & \\
\hline CHEMBL1522602 & 688810 & 4.783 & 4.6762 & TRN & & & \\
\hline CHEMBL1335070 & 688810 & 5.28299 & 999999999 & 995 & 5.16100 & 00000000005 & TRN \\
\hline CHEMBL1577200 & 688810 & 6.183 & 5.3074 & TST & & & \\
\hline CHEMBL3193135 & 688810 & 5.28299 & 999999999 & 995 & 5.2948 & TST & \\
\hline CHEMBL1409285 & 688810 & 4.783 & 4.8541 & TST & & & \\
\hline CHEMBL1412396 & 688810 & 5.483 & 4.9716 & TRN & & & \\
\hline CHEMBL1453539 & 688810 & 5.33299 & 999999999 & & 5.4007 & TRN & \\
\hline CHEMBL1531619 & 688810 & 5.433 & 5.3624 & TRN & & & \\
\hline CHEMBL1399486 & 688810 & 5.933 & 5.5377 & TRN & & & \\
\hline CHEMBL1407950 & 688810 & 5.78299 & 999999999 & 995 & 5.5896 & TST & \\
\hline CHEMBL1516527 & 688810 & 6.183 & 5.0882 & TRN & & & \\
\hline CHEMBL1583685 & 688810 & 4.783 & 5.5303 & TST & & & \\
\hline CHEMBL1575294 & 688810 & 6.38299 & 999999999 & & 5.5284 & TRN & \\
\hline CHEMBL1409860 & 688810 & 4.883 & 5.5003 & TRN & & & \\
\hline CHEMBL1454894 & 688810 & 6.433 & 5.5501 & TRN & & & \\
\hline CHEMBL1531480 & 688810 & 4.73300 & 000000000 & 205 & 5.3278 & TRN & \\
\hline CHEMBL1352430 & 688810 & 4.73300 & 000000000 & 205 & 5.5014 & TRN & \\
\hline CHEMBL3191416 & 688810 & 7.38299 & 999999999 & & 5.9366 & TRN & \\
\hline CHEMBL1439989 & 688810 & 5.433 & 5.1687 & TRN & & & \\
\hline CHEMBL1417692 & 688810 & 4.783 & 5.0079 & TRN & & & \\
\hline CHEMBL1370832 & 688810 & $4.9830 e$ & 000000000 & 205 & 4.8093 & TRN & \\
\hline CHEMBL1315018 & 688810 & 4.783 & 4.8843 & TRN & & & \\
\hline CHEMBL1387412 & 688810 & 5.53299 & 999999999 & 995 & 5.5663 & TRN & \\
\hline CHEMBL1312299 & 688810 & 5.38299 & 999999999 & & 5.2856 & TRN & \\
\hline CHEMBL 1418750 & 688810 & 4.583 & 5.0517 & TRN & & & \\
\hline
\end{tabular}


CHEMBL1372203

CHEMBL1542791

CHEMBL3189474

CHEMBL1399860

CHEMBL1408205

CHEMBL1541933

CHEMBL1369617

CHEMBL1553347

CHEMBL1545580

CHEMBL1312656

CHEMBL1604614

CHEMBL1427637

CHEMBL1542748

CHEMBL1525669

CHEMBL1395224

CHEMBL1426063

CHEMBL1330762

CHEMBL1331629

CHEMBL 3145367

CHEMBL1477212

CHEMBL1442582

CHEMBL1493134

CHEMBL1973272

CHEMBL1471497

CHEMBL1501202

CHEMBL1426177

CHEMBL1420725

CHEMBL1485537

CHEMBL1597978

CHEMBL1464706

CHEMBL1375793

CHEMBL1425034

CHEMBL1517983

CHEMBL1407918

CHEMBL1578093

CHEMBL1419173

CHEMBL1598540

CHEMBL1525869

CHEMBL 3194802

CHEMBL1492240

CHEMBL1425705

CHEMBL 1454900

CHEMBL1377053

CHEMBL1493705

CHEMBL3208389

CHEMBL 3198502

CHEMBL1429920

CHEMBL1419974
Supplemental Table S2.txt

$\begin{array}{llllll}688810 & 5.183 & 5.3469 & \text { TRN } & & \\ 688810 & 5.7829999999999995 & 5.724 & \text { TRN } \\ 688810 & 4.883 & 5.3704 & \text { TRN } & & \\ 688810 & 4.883 & 5.1770000000000005 & \text { TST } \\ 688810 & 5.632999999999999 & 5.3745 & \text { TRN } \\ 688810 & 6.233 & 5.1578 & \text { TRN } & & \\ 688810 & 4.833 & 5.075 & \text { TRN } & & \\ 688810 & 5.132999999999999 & 5.7854 & \text { TRN } \\ 688810 & 6.582999999999999 & 5.7853 & \text { TRN } \\ 688810 & 6.0 & 5.9015 & \text { TRN } & & \\ 688810 & 4.583 & 5.2686 & \text { TRN } & & \\ 688810 & 4.583 & 4.7527 & \text { TST } & & \\ 688810 & 5.983 & 6.0069 & \text { TRN } & & \\ 688810 & 4.783 & 4.6016 & \text { TRN } & & \\ 688810 & 4.633 & 4.8495 & \text { TRN } & & \\ 688810 & 5.2829999999999995 & 5.3136 & \text { TST } \\ 688810 & 6.382999999999999 & 5.1888 & \text { TST } \\ 688810 & 5.033 & 4.7016 & \text { TRN } & & \\ 688810 & 4.933 & 5.4128 & \text { TRN } & & \\ 688810 & 4.633 & 5.2771 & \text { TST } & & \\ 688810 & 4.7330000000000005 & 5.3394 & \text { TRN } \\ 688810 & 4.9830000000000005 & 5.394 & \text { TST } \\ 688810 & 5.433 & 5.4727 & \text { TST } & & \end{array}$

688810

688810

688810

688810

688810

688810

688810

688810

688810

688810

688810

688810

688810

688810

688810

688810

688810

688810

688810

688810

688810

688810

688810

688810

688810

5.433

5.4727 TST

4.833

4.979 TRN

4.833

5.2453 TRN

4.633

4.7297 TRN

5.083

5.2253 TRN

5.832999999999999

$4.833 \quad 5.1304$ TST

4.7330000000000005

$\begin{array}{lll}4.583 & 4.8588 & \text { TRN }\end{array}$

$\begin{array}{lll}5.033 & 6.3883 & \text { TRN }\end{array}$

5.4334 .9991 TRN

$5.683 \quad 5.8258$ TRN

$5.983 \quad 5.6579999999999995 \quad$ TRN

$4.633 \quad 4.8191$ TST

$4.783 \quad 5.0206$ TST

4.9830000000000005

4.9830000000000005

4.6139 TST

5.3611 TRN

5.5329999999999995

5.3751 TST

4.9651 TRN

5.132999999999999

5.4495 TRN

5.4804 TRN

5.2829999999999995

4.8987 TRN

$4.7330000000000005 \quad 5.2332$ TST

$6.382999999999999 \quad 6.2105$ TST

$\begin{array}{lll}5.2829999999999995 & 5.6422 & \text { TRN }\end{array}$

$5.933 \quad 5.5175$ TRN

$5.733 \quad 5.2718$ TRN

4.7330000000000005
4.7410000000000005

TRN 


\begin{tabular}{|c|c|c|c|c|c|c|}
\hline \multirow[b]{2}{*}{ CHEMBL1327870 } & \multirow[b]{2}{*}{688810} & \multicolumn{5}{|c|}{ Supplemental Table S2.txt } \\
\hline & & 4.783 & 5.1467 & TRN & & \\
\hline CHEMBL1475818 & 688810 & \multicolumn{3}{|c|}{7.082999999999999} & 5.8704 & TRN \\
\hline CHEMBL1550123 & 688810 & 5.983 & 5.5955 & TRN & & \\
\hline CHEMBL1379819 & 688810 & 4.833 & 5.4186 & TRN & & \\
\hline CHEMBL 3192337 & 688810 & \multicolumn{3}{|c|}{6.332999999999999} & 5.1838 & TRN \\
\hline CHEMBL1553829 & 688810 & \multicolumn{3}{|c|}{5.332999999999999} & 5.2145 & TRN \\
\hline CHEMBL 3198370 & 688810 & 5.083 & 5.407 & TRN & & \\
\hline CHEMBL3209203 & 688810 & 5.483 & 4.9177 & TRN & & \\
\hline CHEMBL1573487 & 688810 & \multicolumn{3}{|c|}{4.7330000000000005} & 5.1874 & TRN \\
\hline CHEMBL1497927 & 688810 & 5.933 & 5.5166 & TRN & & \\
\hline CHEMBL1309678 & 688810 & 7.2832 & 5.9055 & TST & & \\
\hline CHEMBL3210136 & 688810 & 4.783 & 5.0651 & TST & & \\
\hline CHEMBL1411306 & 688810 & 6.233 & 5.7703 & TRN & & \\
\hline CHEMBL1378255 & 688810 & 4.783 & 5.1222 & TRN & & \\
\hline CHEMBL1389668 & 688810 & \multicolumn{3}{|c|}{5.882999999999999} & 5.5078 & TRN \\
\hline CHEMBL3145136 & 688810 & 5.083 & 5.2809 & TRN & & \\
\hline CHEMBL1502503 & 688810 & \multicolumn{3}{|c|}{5.7829999999999995} & 6.0565 & TRN \\
\hline CHEMBL1385440 & 688810 & \multicolumn{3}{|c|}{5.882999999999999} & 5.6703 & TRN \\
\hline CHEMBL1973778 & 688810 & \multicolumn{3}{|c|}{5.5329999999999995} & 5.5952 & TRN \\
\hline CHEMBL1394510 & 688810 & 4.583 & 4.8484 & TRN & & \\
\hline CHEMBL1479897 & 688810 & \multirow{2}{*}{\multicolumn{3}{|c|}{$\begin{array}{ll}4.633 & 5.2419 \\
5.582999999999999\end{array}$}} & & \\
\hline CHEMBL1334340 & 688810 & & & & 5.5265 & TRN \\
\hline CHEMBL567337 & 688810 & 4.783 & 5.352 & TRN & & \\
\hline CHEMBL1367602 & 688810 & \multicolumn{3}{|c|}{6.132999999999999} & 5.6468 & TST \\
\hline CHEMBL1361230 & 688810 & \multicolumn{3}{|c|}{5.132999999999999} & 5.2342 & TRN \\
\hline CHEMBL1338918 & 688810 & \multicolumn{3}{|c|}{6.0329999999999995} & 5.2134 & TRN \\
\hline CHEMBL1371859 & 688810 & 5.683 & 5.1691 & TST & & \\
\hline CHEMBL1409624 & 688810 & \multirow{2}{*}{\multicolumn{3}{|c|}{$\begin{array}{lcc}5.433 & 5.405 & \text { TRN } \\
4.7330000000000005\end{array}$}} & & \\
\hline CHEMBL1493135 & 688810 & & & & 4.9982 & TST \\
\hline CHEMBL1447125 & 688810 & \multicolumn{3}{|c|}{$\begin{array}{lll}4.933 & 4.9943 & \text { TRN }\end{array}$} & & \\
\hline CHEMBL1321832 & 688810 & 5.083 & 5.4413 & TRN & & \\
\hline CHEMBL1530137 & 688810 & \multicolumn{3}{|c|}{5.332999999999999} & 5.0538 & TRN \\
\hline CHEMBL1974800 & 688810 & \multicolumn{3}{|c|}{4.7330000000000005} & 5.1666 & TRN \\
\hline CHEMBL1445195 & 688810 & 5.233 & 5.2214 & TRN & & \\
\hline CHEMBL1511480 & 688810 & \multicolumn{3}{|c|}{5.2829999999999995} & 5.0785 & TRN \\
\hline CHEMBL1392438 & 688810 & 4.783 & 4.953 & TRN & & \\
\hline CHEMBL1565419 & 688810 & \multicolumn{3}{|c|}{5.2829999999999995} & 5.3593 & TRN \\
\hline CHEMBL1490406 & 688810 & 5.2829 & 7999999 & 995 & 5.6573 & TRN \\
\hline CHEMBL1451019 & 688810 & 5.7829 & 7999999 & 995 & 5.8294 & TRN \\
\hline CHEMBL1391187 & 688810 & 4.883 & 5.1685 & TST & & \\
\hline CHEMBL1337331 & 688810 & 5.5829 & 9999999 & & 5.0127 & TRN \\
\hline CHEMBL1332880 & 688810 & 6.0 & 5.745 & TRN & & \\
\hline CHEMBL1457700 & 688810 & 4.783 & 5.5377 & TRN & & \\
\hline CHEMBL1970554 & 688810 & 4.883 & 5.0173 & TST & & \\
\hline CHEMBL1579428 & 688810 & 4.833 & 5.1071 & TRN & & \\
\hline CHEMBL1409525 & 688810 & 6.2829 & 9999999 & 995 & 5.9508 & TRN \\
\hline CHEMBL1480744 & 688810 & 5.5329 & 7999999 & 995 & 5.5054 & TRN \\
\hline CHEMBL1530872 & 688810 & 5.3829 & 7999999 & & 5.1369 & TST \\
\hline & & & & & & \\
\hline
\end{tabular}




\begin{tabular}{|c|c|c|c|c|c|c|}
\hline & \\
\hline CHEMBL1413341 & 688810 & 4.783 & 5.1118 & TRN & & \\
\hline CHEMBL1545868 & 688810 & \multicolumn{3}{|c|}{6.0329999999999995} & 5.3871 & TST \\
\hline CHEMBL1411343 & 688810 & \multicolumn{3}{|c|}{6.132999999999999} & 5.1446 & \\
\hline CHEMBL1541661 & 688810 & 4.883 & 5.4398 & TRN & & \\
\hline CHEMBL1598110 & 688810 & 4.933 & 5.36 & TRN & & \\
\hline CHEMBL1556830 & 688810 & \multicolumn{3}{|c|}{4.7330000000000005} & 5.0417 & $\mathrm{TI}$ \\
\hline CHEMBL1408542 & 688810 & 7.1831 & 6.1104 & TRN & & \\
\hline CHEMBL1423496 & 688810 & 5.233 & 5.1791 & TST & & \\
\hline CHEMBL1511922 & 688810 & 6.433 & 5.9982 & TRN & & \\
\hline CHEMBL1510402 & 688810 & 4.883 & 5.0733 & TRN & & \\
\hline CHEMBL 3214548 & 688810 & 4.783 & 5.4392 & TRN & & \\
\hline CHEMBL1476141 & 688810 & 5.233 & 5.1136 & TRN & & \\
\hline CHEMBL1485228 & 688810 & \multicolumn{3}{|c|}{5.882999999999999} & 5.21 & IRIN \\
\hline CHEMBL1601492 & 688810 & \multicolumn{3}{|c|}{5.832999999999999} & 5.1393 & \\
\hline CHEMBL1307168 & 688810 & \multicolumn{3}{|c|}{5.582999999999999} & 4.8503 & \\
\hline CHEMBL1480356 & 688810 & 4.783 & 5.2987 & TRN & & \\
\hline CHEMBL 1445784 & 688810 & 5.083 & 5.1935 & TST & & \\
\hline CHEMBL1409399 & 688810 & \multicolumn{3}{|c|}{5.132999999999999} & 5.2235 & IRIN \\
\hline CHEMBL1310319 & 688810 & \multicolumn{3}{|c|}{4.7330000000000005} & 5.3172 & \\
\hline CHEMBL 2369189 & 688810 & 5.033 & 5.4829 & TST & & \\
\hline CHEMBL1969492 & 688810 & 5.183 & 5.3604 & TST & & \\
\hline CHEMBL 3196398 & 688810 & \multicolumn{3}{|c|}{5.132999999999999} & 5.5424 & Th \\
\hline CHEMBL1585520 & 688810 & 4.783 & 5.4034 & TRN & & \\
\hline CHEMBL1562465 & 688810 & 4.933 & 5.4895 & TRN & & \\
\hline CHEMBL1317578 & 688810 & 4.833 & 4.8765 & TRN & & \\
\hline CHEMBL1987441 & 688810 & 5.733 & 5.5503 & TRN & & \\
\hline CHEMBL1564641 & 688810 & 4.633 & 5.593 & TRN & & \\
\hline CHEMBL1427415 & 688810 & \multicolumn{3}{|c|}{4.7330000000000005} & 5.4562 & $\mathrm{TP}$ \\
\hline CHEMBL1390081 & 688810 & 6.7331 & 5.7068 & TRN & & \\
\hline CHEMBL1407995 & 688810 & \multicolumn{3}{|c|}{5.132999999999999} & 5.4249 & IRIV \\
\hline CHEMBL1601133 & 688810 & \multicolumn{3}{|c|}{5.5329999999999995} & 5.2547 & TST \\
\hline CHEMBL1579500 & 688810 & \multicolumn{3}{|c|}{5.382999999999999} & 5.1059 & TRN \\
\hline CHEMBL1514592 & 688810 & \multicolumn{3}{|c|}{6.832999999999999} & 6.0933 & TRN \\
\hline CHEMBL1606064 & 688810 & \multicolumn{3}{|c|}{4.7330000000000005} & 4.7317 & TRN \\
\hline CHEMBL1310857 & 688810 & \multicolumn{3}{|c|}{5.2829999999999995} & 5.2642 & TS \\
\hline CHEMBL 2005947 & 688810 & 6.233 & 5.468 & TST & & \\
\hline CHEMBL 1474584 & 688810 & 5.233 & 5.7052 & TRN & & \\
\hline CHEMBL 3193844 & 688810 & 6.3329 & 99999999 & & 6.0148 & TRN \\
\hline CHEMBL 1440866 & 688810 & 5.5329 & 99999999 & 995 & 5.8178 & $\mathrm{TP}$ \\
\hline CHEMBL 1468789 & 688810 & 4.7330 & o000000e & 005 & 5.1206 & TRN \\
\hline CHEMBL1309842 & 688810 & 4.7330 & 00000006 & 005 & 5.3153 & TRN \\
\hline CHEMBL1426754 & 688810 & 6.0329 & 99999999 & 995 & 5.3669 & TST \\
\hline CHEMBL1406980 & 688810 & 4.633 & 4.825 & TST & & \\
\hline CHEMBL1537234 & 688810 & 5.2829 & 99999999 & 995 & 5.3715 & TRN \\
\hline CHEMBL 1353379 & 688810 & 6.3829 & 99999999 & & 5.8553 & 11 \\
\hline CHEMBL1416658 & 688810 & 5.733 & 5.5127 & TST & & \\
\hline CHEMBL 1988042 & 688810 & 5.683 & 5.3474 & TRN & & \\
\hline CHEMBL 3144938 & 688810 & 5.683 & 5.44 & TST & & \\
\hline
\end{tabular}




\begin{tabular}{|c|c|c|c|c|c|c|c|}
\hline \multirow[b]{2}{*}{ CHEMBL3195826 } & \multicolumn{6}{|c|}{ 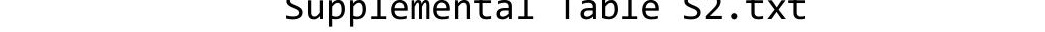 } & \\
\hline & 688810 & 5.083 & 5.0557 & TRN & & & \\
\hline CHEMBL1330157 & 688810 & 5.733 & 5.2738 & TRN & & & \\
\hline CHEMBL1409157 & 688810 & 4.633 & 5.334 & TRN & & & \\
\hline CHEMBL1403495 & 688810 & 4.883 & 4.9441 & TRN & & & \\
\hline CHEMBL1399771 & 688810 & 5.033 & 5.2152 & TRN & & & \\
\hline CHEMBL1371815 & 688810 & 6.5829 & 99999999 & & 5.7194 & TRN & \\
\hline CHEMBL3189266 & 688810 & 4.883 & 5.319 & TRN & & & \\
\hline CHEMBL1459739 & 688810 & 4.783 & 4.9252 & TRN & & & \\
\hline CHEMBL1376731 & 688810 & 4.833 & 5.0783 & TRN & & & \\
\hline CHEMBL1335452 & 688810 & 5.8329 & 99999999 & & $5.6720 e$ & 0000000001 & TRN \\
\hline CHEMBL1573955 & 688810 & 5.5329 & 99999999 & 995 & 5.5084 & TRN & \\
\hline CHEMBL1546037 & 688810 & 6.0829 & 99999999 & & 5.8133 & TRN & \\
\hline CHEMBL1327703 & 688810 & 6.0 & 5.0562 & TRN & & & \\
\hline CHEMBL1573296 & 688810 & 4.7330 & 00000000 & 005 & 5.1189 & TRN & \\
\hline CHEMBL1509014 & 688810 & 4.933 & 5.2073 & TST & & & \\
\hline CHEMBL1496488 & 688810 & 5.2829 & 99999999 & 995 & 5.3304 & TST & \\
\hline CHEMBL1521276 & 688810 & 5.5829 & 99999999 & & 4.9144 & TRN & \\
\hline CHEMBL1467311 & 688810 & 4.7330 & 00000000 & 005 & 5.0256 & TRN & \\
\hline CHEMBL1456062 & 688810 & 6.233 & 5.9031 & TRN & & & \\
\hline CHEMBL1493226 & 688810 & 5.433 & 5.3127 & TST & & & \\
\hline CHEMBL1542242 & 688810 & 5.5829 & 99999999 & & 5.7763 & TRN & \\
\hline CHEMBL1543647 & 688810 & 4.583 & 5.3113 & TST & & & \\
\hline CHEMBL1306023 & 688810 & 6.2829 & 99999999 & 995 & 5.9487 & TRN & \\
\hline CHEMBL1349737 & 688810 & 5.2829 & 99999999 & 995 & 5.9344 & TRN & \\
\hline CHEMBL1311007 & 688810 & 5.7829 & 99999999 & 995 & 5.1198 & TRN & \\
\hline CHEMBL1506264 & 688810 & 5.683 & 5.4462 & TRN & & & \\
\hline CHEMBL1326282 & 688810 & 4.783 & 5.0982 & TRN & & & \\
\hline CHEMBL3207602 & 688810 & 4.7330 & 00000000 & 005 & 5.5535 & TRN & \\
\hline CHEMBL1608557 & 688810 & 4.583 & 5.1993 & TRN & & & \\
\hline CHEMBL1592847 & 688810 & 5.183 & 5.16100 & 00006 & 205 & TRN & \\
\hline CHEMBL1578527 & 688810 & 6.0329 & 99999999 & 995 & 5.5393 & TRN & \\
\hline CHEMBL1354830 & 688810 & 4.583 & 4.9656 & TST & & & \\
\hline CHEMBL1491467 & 688810 & 5.5329 & 99999999 & 995 & 5.1834 & TRN & \\
\hline CHEMBL1319630 & 688810 & 5.5329 & 99999999 & 995 & 5.1413 & TRN & \\
\hline CHEMBL1450104 & 688810 & 4.783 & 4.9677 & TST & & & \\
\hline CHEMBL1371403 & 688810 & 5.033 & 5.0948 & TST & & & \\
\hline CHEMBL1579839 & 688810 & 4.633 & 5.4508 & TRN & & & \\
\hline CHEMBL1407301 & 688810 & 4.633 & 5.0693 & TRN & & & \\
\hline CHEMBL1604951 & 688810 & 4.833 & 5.2466 & TRN & & & \\
\hline CHEMBL1526506 & 688810 & 5.233 & 5.1761 & TRN & & & \\
\hline CHEMBL1466028 & 688810 & 6.3829 & 99999999 & & 5.5427 & TRN & \\
\hline CHEMBL1458395 & 688810 & 5.233 & 5.357 & TRN & & & \\
\hline CHEMBL1304638 & 688810 & 4.7330 & 00000000 & 205 & 4.8729 & TST & \\
\hline CHEMBL1420951 & 688810 & 4.783 & 4.8564 & TST & & & \\
\hline CHEMBL1609033 & 688810 & 5.8329 & 99999999 & 99 & 5.7059 & TST & \\
\hline CHEMBL3198362 & 688810 & 7.0329 & 5.562 & TRN & & & \\
\hline CHEMBL1348468 & 688810 & 4.833 & 5.0236 & TST & & & \\
\hline CHEMBL1443895 & 688810 & 6.4829 & 5.4952 & TST & & & \\
\hline
\end{tabular}




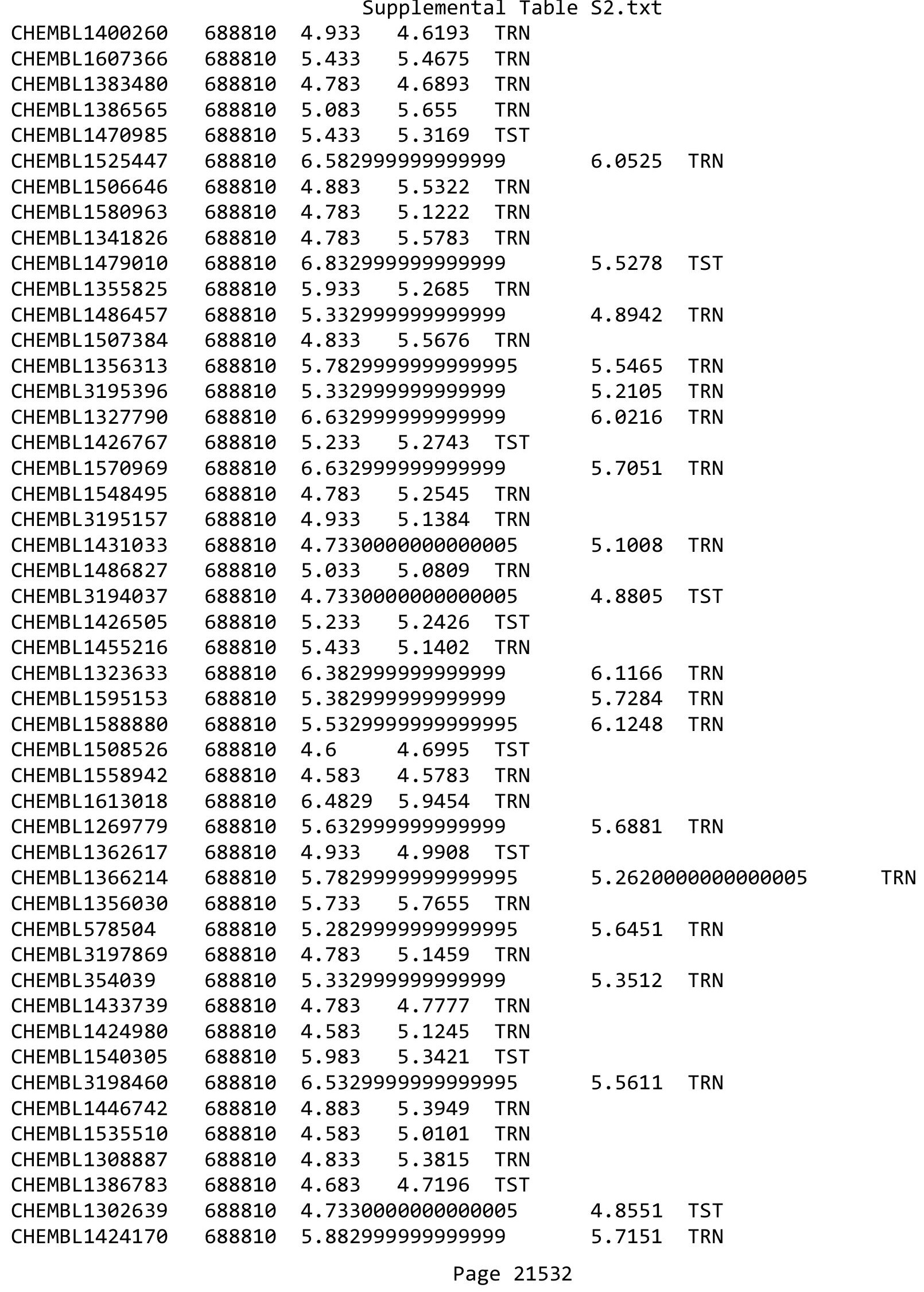




\begin{tabular}{|c|c|c|c|c|c|c|}
\hline & \multicolumn{5}{|c|}{ S2.txt } \\
\hline CHEMBL1518730 & 688810 & 4.933 & 5.562 & TRN & & \\
\hline CHEMBL1308485 & 688810 & 4.7330 & 0000000 & 005 & 5.4645 & TRN \\
\hline CHEMBL1467838 & 688810 & 5.2829 & 9999999 & 995 & 4.9084 & TRN \\
\hline CHEMBL1365811 & 688810 & 5.8829 & 9999999 & 99 & 4.9827 & TRN \\
\hline CHEMBL1522758 & 688810 & 4.833 & 5.2442 & TRN & & \\
\hline CHEMBL1509158 & 688810 & 4.833 & 5.3078 & TST & & \\
\hline CHEMBL 3189846 & 688810 & 4.633 & 5.2194 & TRN & & \\
\hline CHEMBL1587422 & 688810 & 5.1329 & 9999999 & & 5.6201 & TST \\
\hline CHEMBL1377696 & 688810 & 6.3829 & 9999999 & & 5.3907 & \\
\hline CHEMBL1377972 & 688810 & 4.683 & 5.1291 & TRN & & \\
\hline CHEMBL 3199425 & 688810 & 4.883 & 5.3634 & TRN & & \\
\hline CHEMBL1453609 & 688810 & 5.5829 & 9999999 & & 5.5649 & TRN \\
\hline CHEMBL1365140 & 688810 & 5.1329 & 9999999 & & 4.8714 & TST \\
\hline CHEMBL1546668 & 688810 & 5.3829 & 9999999 & & 5.5174 & \\
\hline CHEMBL1490022 & 688810 & 4.933 & 5.3255 & TST & & \\
\hline CHEMBL 3189577 & 688810 & 5.8329 & 9999999 & & 5.4739 & $1 \mathrm{NN}$ \\
\hline CHEMBL1568747 & 688810 & 5.683 & 5.2749 & TST & & \\
\hline CHEMBL 3208952 & 688810 & 4.783 & 5.3635 & TRN & & \\
\hline CHEMBL 3190635 & 688810 & 5.983 & 5.223 & TRN & & \\
\hline CHEMBL1489764 & 688810 & 5.983 & 5.4364 & TRN & & \\
\hline CHEMBL1563483 & 688810 & 5.733 & 5.2111 & TST & & \\
\hline CHEMBL1315049 & 688810 & 4.633 & 5.3641 & TRN & & \\
\hline CHEMBL 3212167 & 688810 & 5.6329 & 9999999 & & 5.5994 & \\
\hline CHEMBL 3198203 & 688810 & 6.183 & 5.4628 & TRN & & \\
\hline CHEMBL 3145000 & 688810 & 5.3329 & 9999999 & & 5.0961 & TRN \\
\hline CHEMBL1549320 & 688810 & 4.883 & 4.6878 & TRN & & \\
\hline CHEMBL1471200 & 688810 & 4.783 & 5.5272 & TRN & & \\
\hline CHEMBL1528371 & 688810 & 5.5829 & 9999999 & & 5.3629 & II \\
\hline CHEMBL1476839 & 688810 & 4.783 & 5.249 & TRN & & \\
\hline CHEMBL1345171 & 688810 & 4.833 & 5.2885 & TRN & & \\
\hline CHEMBL 2004942 & 688810 & 5.233 & 5.2474 & TRN & & \\
\hline CHEMBL1986214 & 688810 & 7.0829 & 9999999 & & 5.9272 & TRN \\
\hline CHEMBL1974563 & 688810 & 6.1329 & 9999999 & & 6.3692 & TRN \\
\hline CHEMBL1420325 & 688810 & 5.3329 & 9999999 & & 5.098 & \\
\hline CHEMBL1540112 & 688810 & 7.3325 & 6.2741 & TRN & & \\
\hline CHEMBL1500169 & 688810 & 4.633 & 4.9117 & TRN & & \\
\hline CHEMBL1464372 & 688810 & 4.783 & 5.0412 & TRN & & \\
\hline CHEMBL1514417 & 688810 & 5.733 & 5.9991 & TRN & & \\
\hline CHEMBL1357107 & 688810 & 5.183 & 5.2248 & TRN & & \\
\hline CHEMBL1315645 & 688810 & 5.2829 & 9999999 & 995 & 5.1091 & TRN \\
\hline CHEMBL1528225 & 688810 & 5.3329 & 7999999 & & 4.9401 & TRN \\
\hline CHEMBL1336872 & 688810 & 5.1329 & 7999999 & & 4.8639 & TRN \\
\hline CHEMBL1434127 & 688810 & 4.7330 & 0000000 & 005 & 5.1636 & TRI \\
\hline CHEMBL1445710 & 688810 & 5.183 & 5.1175 & TST & & \\
\hline CHEMBL1413012 & 688810 & 4.833 & 5.1765 & TRN & & \\
\hline CHEMBL1411680 & 688810 & 5.683 & 5.2896 & TRN & & \\
\hline CHEMBL602718 & 688810 & 5.3329 & 7999999 & 99 & 5.2526 & $1 \mathrm{NN}$ \\
\hline CHEMBL1515448 & 688810 & 4.783 & 4.7337 & TRN & & \\
\hline
\end{tabular}




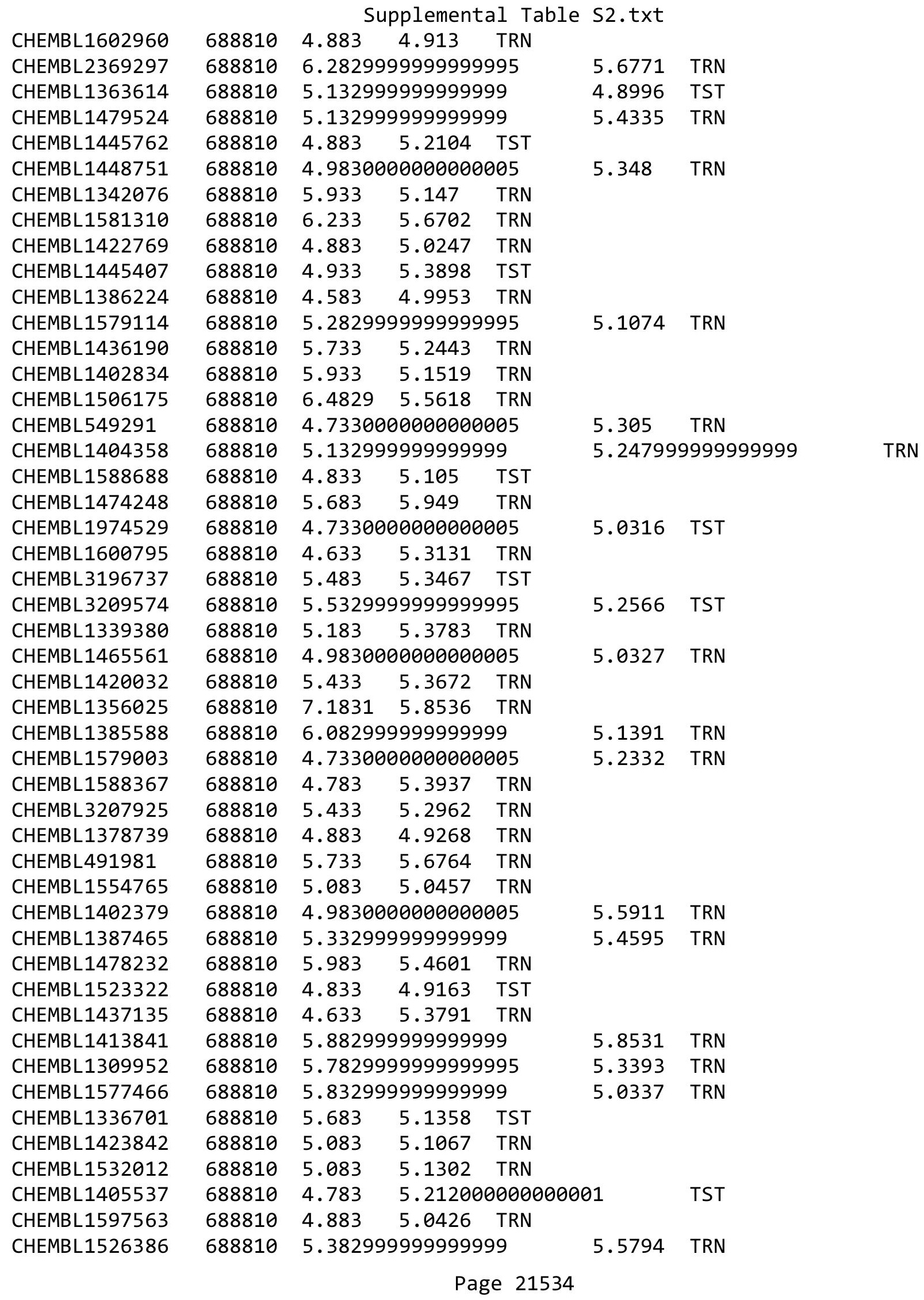




\begin{tabular}{|c|c|c|c|c|c|c|c|}
\hline \multicolumn{8}{|c|}{ 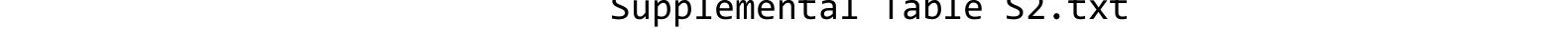 } \\
\hline CHEMBL3209352 & 688810 & 5.083 & 5.17 & TRN & & & \\
\hline CHEMBL1376292 & 688810 & 5.033 & 5.1201 & TRN & & & \\
\hline CHEMBL1330126 & 688810 & 4.883 & 4.9959 & TRN & & & \\
\hline CHEMBL1339995 & 688810 & 5.63299 & 999999995 & & 5.5631 & TRN & \\
\hline CHEMBL1441262 & 688810 & 4.683 & 4.6549 & TRN & & & \\
\hline CHEMBL1398038 & 688810 & 6.683 & 5.367999 & 999999999 & & TRN & \\
\hline CHEMBL3145322 & 688810 & 6.28299 & 999999995 & 995 & 5.4646 & TRN & \\
\hline CHEMBL1361088 & 688810 & 4.683 & 5.3277 & TRN & & & \\
\hline CHEMBL1556326 & 688810 & 4.833 & 5.2805 & TRN & & & \\
\hline CHEMBL1593338 & 688810 & 6.33299 & 999999995 & & 5.7471 & TST & \\
\hline CHEMBL1309725 & 688810 & 4.583 & 5.3723 & TRN & & & \\
\hline CHEMBL 3189242 & 688810 & 7.08299 & 999999995 & & 6.1122 & TRN & \\
\hline CHEMBL1527993 & 688810 & 5.88299 & 999999999 & & 5.2257 & TST & \\
\hline CHEMBL1531101 & 688810 & 4.73300 & 000000006 & 205 & 5.052 & TRN & \\
\hline CHEMBL1610542 & 688810 & 4.833 & 5.0793 & TRN & & & \\
\hline CHEMBL1558342 & 688810 & 5.53299 & 999999995 & 995 & 5.6699 & TRN & \\
\hline CHEMBL1312502 & 688810 & 4.833 & 5.5474 & TRN & & & \\
\hline CHEMBL1596751 & 688810 & 4.783 & 5.1808 & TRN & & & \\
\hline CHEMBL1597594 & 688810 & 5.83299 & 999999995 & & 5.3064 & TRN & \\
\hline CHEMBL1557231 & 688810 & 6.03299 & 999999995 & 995 & 5.7257 & TRN & \\
\hline CHEMBL1418720 & 688810 & 4.933 & 5.3116 & TST & & & \\
\hline CHEMBL1461971 & 688810 & 4.783 & 5.1972 & TRN & & & \\
\hline CHEMBL1480652 & 688810 & 5.63299 & 999999999 & & 5.1663 & TRN & \\
\hline CHEMBL1496941 & 688810 & 4.73300 & 00000000 & 005 & 5.6082 & TRN & \\
\hline CHEMBL 3191063 & 688810 & 5.733 & 5.1759 & TRN & & & \\
\hline CHEMBL1429893 & 688810 & 5.63299 & 999999999 & & 5.0248 & TRN & \\
\hline CHEMBL1375712 & 688810 & 5.13299 & 999999999 & & 5.3888 & TRN & \\
\hline CHEMBL1482122 & 688810 & 5.183 & 5.1137 & TRN & & & \\
\hline CHEMBL 3193566 & 688810 & 5.83299 & 999999999 & & 5.6676 & TST & \\
\hline CHEMBL1528874 & 688810 & 5.88299 & 999999999 & & 5.454 & TRN & \\
\hline CHEMBL 3193641 & 688810 & 5.53299 & 999999999 & 995 & 5.2052 & TST & \\
\hline CHEMBL1465815 & 688810 & 5.083 & 5.2305 & TRN & & & \\
\hline CHEMBL1528168 & 688810 & 4.783 & 5.3431 & TRN & & & \\
\hline CHEMBL 3190048 & 688810 & 5.83299 & 999999999 & & 5.40799 & 99999999995 & TRN \\
\hline CHEMBL1420618 & 688810 & 5.083 & 5.2453 & TRN & & & \\
\hline CHEMBL1578372 & 688810 & 5.983 & 5.5837 & TRN & & & \\
\hline CHEMBL1334744 & 688810 & 4.883 & 5.6067 & TRN & & & \\
\hline CHEMBL1390567 & 688810 & 5.183 & 5.6964 & TST & & & \\
\hline CHEMBL1560009 & 688810 & 4.73300 & 000000000 & 205 & 5.4454 & TRN & \\
\hline CHEMBL1299791 & 688810 & 5.933 & 5.1976 & TST & & & \\
\hline CHEMBL1380214 & 688810 & 5.983 & 5.4418 & TRN & & & \\
\hline CHEMBL1382801 & 688810 & 4.883 & 5.1868 & TRN & & & \\
\hline CHEMBL1519862 & 688810 & 5.28299 & 999999999 & 995 & 5.2735 & TRN & \\
\hline CHEMBL1489433 & 688810 & 4.833 & 5.2455 & TRN & & & \\
\hline CHEMBL1375571 & 688810 & 6.433 & 6.1555 & TRN & & & \\
\hline CHEMBL1371255 & 688810 & 4.783 & 5.2069 & TST & & & \\
\hline CHEMBL1473645 & 688810 & 6.33299 & 999999999 & & 5.5021 & TRN & \\
\hline CHEMBL1484485 & 688810 & 4.883 & 5.2629 & TRN & & & \\
\hline
\end{tabular}




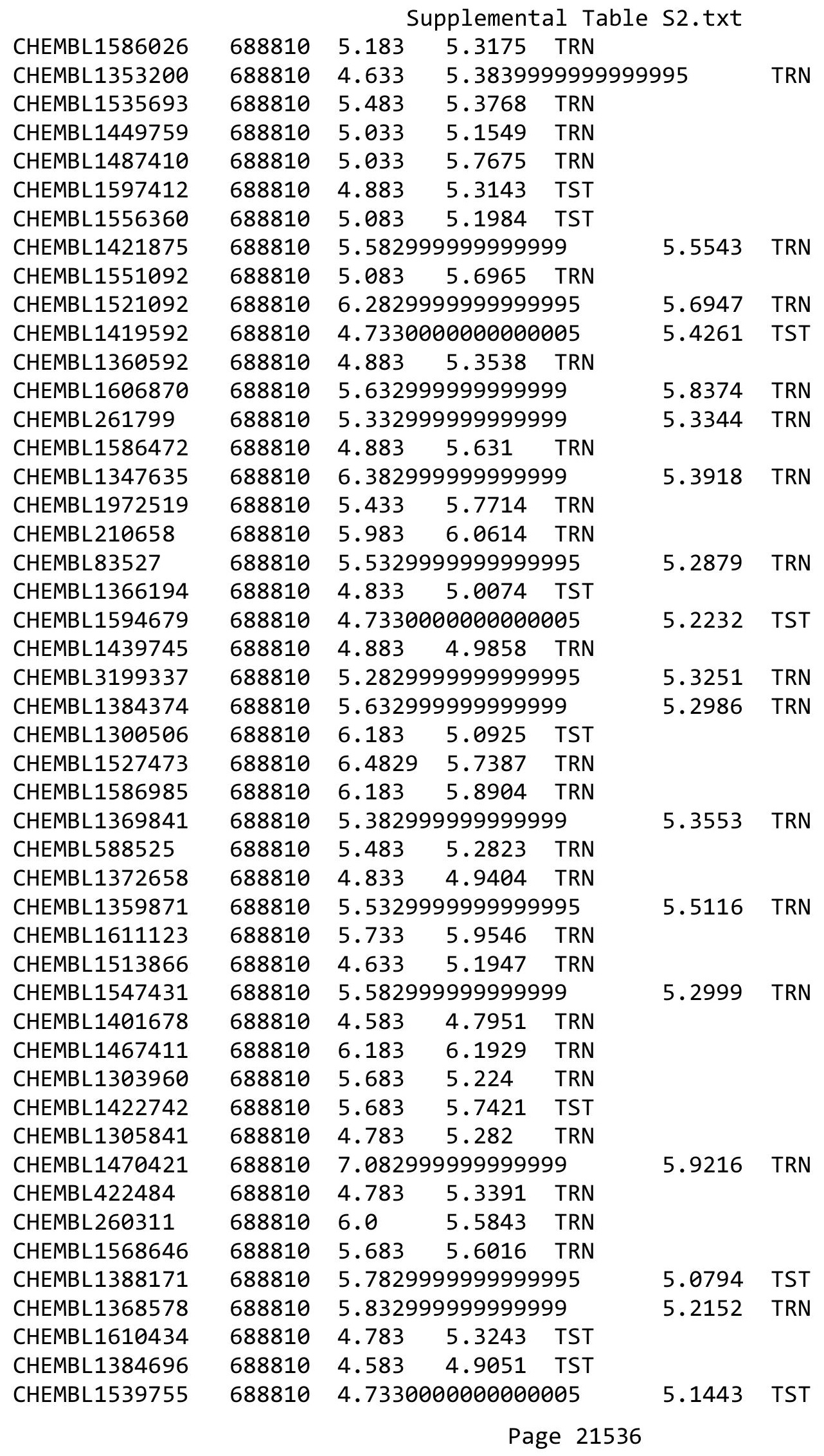




\begin{tabular}{|c|c|c|c|c|c|c|}
\hline \multirow[b]{2}{*}{ CHEMBL1554819 } & \multicolumn{6}{|c|}{ Supplemental Table S2.txt } \\
\hline & 688810 & 4.633 & 5.5193 & TRN & & \\
\hline CHEMBL1537522 & 688810 & 4.683 & 5.3653 & TRN & & \\
\hline CHEMBL1530990 & 688810 & 5.2829 & 999999995 & 995 & 5.1225 & \\
\hline CHEMBL1393635 & 688810 & 6.6329 & 999999999 & & 6.1309 & \\
\hline CHEMBL1992492 & 688810 & 4.783 & 5.4645 & TRN & & \\
\hline CHEMBL1971151 & 688810 & 4.583 & 5.034 & TRN & & \\
\hline CHEMBL1548295 & 688810 & 4.633 & 4.8363 & TRN & & \\
\hline CHEMBL 3189607 & 688810 & 5.8829 & 999999995 & & 5.7254 & \\
\hline CHEMBL1503246 & 688810 & 5.3329 & 999999995 & & 5.6427 & \\
\hline CHEMBL3214133 & 688810 & 4.833 & 5.0113 & TRN & & \\
\hline CHEMBL97542 & 688810 & 4.833 & 4.9141 & TRN & & \\
\hline CHEMBL1438775 & 688810 & 5.6329 & 999999999 & & 5.4266 & \\
\hline CHEMBL1500992 & 688810 & 4.783 & 5.0005 & TRN & & \\
\hline CHEMBL1507104 & 688810 & 4.7330 & 000000006 & 005 & 4.9995 & \\
\hline CHEMBL1343389 & 688810 & 6.8831 & 6.1476 & TRN & & \\
\hline CHEMBL1483638 & 688810 & 5.5829 & 999999999 & & 5.26 & \\
\hline CHEMBL1440956 & 688810 & 5.683 & 5.0019 & TRN & & \\
\hline CHEMBL1422624 & 688810 & 5.233 & 5.2496 & TRN & & \\
\hline CHEMBL1541862 & 688810 & 4.783 & 5.3835 & TRN & & \\
\hline CHEMBL1378446 & 688810 & 4.683 & 4.8205 & TST & & \\
\hline CHEMBL1521251 & 688810 & 4.833 & 4.8541 & TRN & & \\
\hline CHEMBL1470900 & 688810 & 5.233 & 5.2454 & TRN & & \\
\hline CHEMBL1380957 & 688810 & 6.0 & 5.3641 & TRN & & \\
\hline CHEMBL1451939 & 688810 & 5.8329 & 999999999 & & 5.4442 & \\
\hline CHEMBL1456499 & 688810 & 5.1329 & 999999999 & & 5.2603 & \\
\hline CHEMBL1441525 & 688810 & 5.1329 & 999999999 & & 5.67899 & \\
\hline CHEMBL1587456 & 688810 & 4.7330 & 000000006 & 005 & 4.9344 & \\
\hline CHEMBL1442140 & 688810 & 5.433 & 5.4589 & TRN & & \\
\hline CHEMBL1319970 & 688810 & 4.7330 & 000000006 & 005 & 4.8919 & \\
\hline CHEMBL1442624 & 688810 & 5.733 & 5.5107 & TRN & & \\
\hline CHEMBL1340855 & 688810 & 5.033 & 5.8313 & TRN & & \\
\hline CHEMBL1414146 & 688810 & 4.583 & 5.4232 & TRN & & \\
\hline CHEMBL1572145 & 688810 & 6.3829 & 999999999 & & 5.865 & 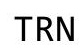 \\
\hline CHEMBL1503292 & 688810 & 4.583 & 4.8066 & TST & & \\
\hline CHEMBL1455566 & 688810 & 4.783 & 5.3339 & TRN & & \\
\hline CHEMBL1499948 & 688810 & 5.3829 & 999999995 & & 5.2956 & \\
\hline CHEMBL1423940 & 688810 & 5.183 & 4.9955 & TRN & & \\
\hline CHEMBL1349539 & 688810 & 4.7330 & 000000006 & 005 & 5.0837 & \\
\hline CHEMBL1322896 & 688810 & 5.233 & 5.2299 & TRN & & \\
\hline CHEMBL1327283 & 688810 & 4.633 & 4.758999 & 9999999 & 995 & \\
\hline CHEMBL1560024 & 688810 & 5.3829 & 999999995 & & 5.4838 & \\
\hline CHEMBL1342970 & 688810 & 4.833 & 5.2941 & TRN & & \\
\hline CHEMBL1459476 & 688810 & 4.7330 & 000000006 & 005 & 4.8398 & . \\
\hline CHEMBL1444348 & 688810 & 5.183 & 5.452999 & 999999999 & & 「RN \\
\hline CHEMBL1573794 & 688810 & 4.7330 & 00000000 & 005 & 4.8931 & TST \\
\hline CHEMBL1331976 & 688810 & 5.1329 & 999999995 & & 4.7175 & \\
\hline CHEMBL1521536 & 688810 & 4.633 & 4.8728 & TST & & \\
\hline CHEMBL1482427 & 688810 & 4.683 & 4.9123 & TRN & & \\
\hline
\end{tabular}




\begin{tabular}{|c|c|c|c|c|c|c|}
\hline \multirow[b]{2}{*}{ CHEMBL1609231 } & & \multicolumn{5}{|c|}{ Supplemental Table S2.txt } \\
\hline & 688810 & 5.233 & 5.1029 & TRN & & \\
\hline CHEMBL1396899 & 688810 & \multicolumn{3}{|c|}{4.7330000000000005} & 4.9141 & $\mathrm{~T}$ \\
\hline CHEMBL1506708 & 688810 & \multicolumn{3}{|c|}{5.832999999999999} & 5.3399 & TCT \\
\hline CHEMBL1305287 & 688810 & 4.883 & 6.0827 & TRN & & \\
\hline CHEMBL1384800 & 688810 & \multicolumn{3}{|c|}{5.7829999999999995} & 5.4764 & TRN \\
\hline CHEMBL1500966 & 688810 & \multicolumn{3}{|c|}{4.9830000000000005} & 4.5064 & \\
\hline CHEMBL1516958 & 688810 & 4.633 & 5.144 & TST & & \\
\hline CHEMBL253989 & 688810 & \multicolumn{3}{|c|}{6.7829999999999995} & 5.4319 & \\
\hline CHEMBL1509262 & 688810 & 4.833 & 4.9871 & TRN & & \\
\hline CHEMBL1580271 & 688810 & \multicolumn{3}{|c|}{5.882999999999999} & 6.0197 & 11 \\
\hline CHEMBL3199923 & 688810 & 4.833 & 5.1137 & TST & & \\
\hline CHEMBL1519385 & 688810 & \multirow{2}{*}{\multicolumn{3}{|c|}{$\begin{array}{l}4.383 \quad 5.0635 \text { IRIN } \\
5.332999999999999\end{array}$}} & & \\
\hline CHEMBL1595519 & 688810 & & & & 5.8137 & $T$ \\
\hline CHEMBL1356240 & 688810 & 5.733 & 5.6145 & TRN & & \\
\hline CHEMBL1524934 & 688810 & \multicolumn{3}{|c|}{4.7330000000000005} & 5.79 & In \\
\hline CHEMBL1388808 & 688810 & 6.183 & 5.1292 & TRN & & \\
\hline CHEMBL 2007357 & 688810 & \multicolumn{3}{|c|}{5.7829999999999995} & 5995 & TST \\
\hline CHEMBL1440763 & 688810 & \multicolumn{3}{|c|}{5.132999999999999} & 05 & \\
\hline CHEMBL1302170 & 688810 & 4.833 & 4.8954 & TST & & \\
\hline CHEMBL1458023 & 688810 & 6.233 & 5.8189 & TRN & & \\
\hline CHEMBL1576270 & 688810 & 4.833 & 5.5935 & TRN & & \\
\hline CHEMBL1596329 & 688810 & 6.233 & 5.9459 & TRN & & \\
\hline CHEMBL1432252 & 688810 & 6.183 & 5.5033 & TRN & & \\
\hline CHEMBL1974432 & 688810 & \multicolumn{3}{|c|}{6.332999999999999} & 801 & TP \\
\hline CHEMBL1469733 & 688810 & 6.433 & 6.2428 & TRN & & \\
\hline CHEMBL1973192 & 688810 & \multicolumn{3}{|c|}{5.132999999999999} & & TST \\
\hline CHEMBL1503455 & 688810 & \multicolumn{3}{|c|}{4.9830000000000005} & 61 & T15 \\
\hline CHEMBL1546176 & 688810 & \multicolumn{3}{|c|}{5.382999999999999} & 5.4947 & TRN \\
\hline CHEMBL1299925 & 688810 & 4.633 & 4.8293 & TRN & & \\
\hline CHEMBL1405475 & 688810 & 6. & 6.4041 & TRN & & \\
\hline CHEMBL1491943 & 688810 & & 5.18 & TRN & & \\
\hline CHEMBL3208072 & 688 & 4.833 & 5.2192 & TST & & \\
\hline CHEMBL1410988 & 688810 & \multicolumn{3}{|c|}{5.132999999999999} & 5.5589 & TRN \\
\hline CHEMBL1997098 & 688810 & \multicolumn{3}{|c|}{4.7330000000000005} & & TR \\
\hline CHEMBL1303155 & 688810 & 5.233 & 5.3978 & TRN & & \\
\hline CHEMBL1416001 & 688810 & \multirow{2}{*}{\multicolumn{3}{|c|}{$\begin{array}{lcc}4.783 & 5.1003 & \text { TRN } \\
4.7330000000000005\end{array}$}} & & \\
\hline CHEMBL1336164 & 688810 & & & & 4.9688 & TI \\
\hline CHEMBL1315177 & 688810 & \multicolumn{3}{|c|}{$\begin{array}{l}4.133000000000000 \mathrm{~S} \\
5.683 \quad 5.2737 \text { TRN }\end{array}$} & & \\
\hline CHEMBL1511866 & 688810 & 4.683 & 4.9037 & TRN & & \\
\hline CHEMBL1502070 & 688810 & \multicolumn{3}{|c|}{ 4.883 5.518 TRN } & & \\
\hline CHEMBL1321291 & 688810 & 4.9830 & 00000000 & 005 & 5.1979 & $\mid \mathrm{KI}$ \\
\hline CHEMBL1537298 & 688810 & & 4.9518 & TST & & \\
\hline CHEMBL1377013 & 688810 & 4.833 & 5.2436 & TRN & & \\
\hline CHEMBL1612979 & 688810 & 4.583 & 5.7909 & TST & & \\
\hline CHEMBL1522136 & 688810 & 4.833 & 5.0966 & TRN & & \\
\hline CHEMBL1379054 & 688810 & 6.2829 & 99999999 & 995 & 052 & . \\
\hline CHEMBL1331100 & 688810 & 5.6329 & 99999999 & & 5.3526 & 年 \\
\hline CHEMBL513436 & 688810 & 6.1329 & 99999999 & & 5.0398 & TRI \\
\hline
\end{tabular}




\begin{tabular}{|c|c|c|c|c|c|c|}
\hline & & & & & & \\
\hline CHEMBL1330068 & 688810 & 5.083 & 5.1076 & TRN & & \\
\hline CHEMBL580727 & 688810 & 5.433 & 5.6425 & TRN & & \\
\hline CHEMBL1607984 & 588810 & 5.183 & 5.2033 & TRN & & \\
\hline CHEMBL1490617 & 688810 & 5.5829 & 99999999 & & 5.5762 & 1 \\
\hline CHEMBL1389506 & 688810 & 4.933 & 5.3569 & TRN & & \\
\hline CHEMBL1542197 & 688810 & 5.1329 & 99999999 & 99 & 5.1131 & \\
\hline CHEMBL1364328 & 688810 & 4.783 & 5.1595 & TRN & & \\
\hline CHEMBL1390956 & 688810 & 5.033 & 5.3519 & TST & & \\
\hline CHEMBL1304261 & 688810 & 4.9830 & 00000000 & 005 & 5.2247 & \\
\hline CHEMBL1332088 & 688810 & 4.883 & 4.9598 & TRN & & \\
\hline HEMBL1519966 & 688810 & 4.833 & 5.1002 & TRN & & \\
\hline CHEMBL 3214388 & 688810 & 5.3829 & 99999999 & & 5.0453 & \\
\hline CHEMBL1323451 & 688810 & 4.783 & 5.1304 & TST & & \\
\hline CHEMBL1315554 & 688810 & 4.7330 & 00000000 & 005 & 5.3884 & \\
\hline CHEMBL 3193327 & 688810 & 4.683 & 5.2118 & TRN & & \\
\hline CHEMBL1593154 & 688810 & 5.2829 & 99999999 & 995 & 5.5005 & \\
\hline CHEMBL1414835 & 688810 & 5.5329 & 99999999 & 995 & 5.3977 & \\
\hline CHEMBL1441476 & 688810 & 5.083 & 5.8182 & TRN & & \\
\hline CHEMBL1530409 & 688810 & 4.883 & 5.1259 & TRN & & \\
\hline CHEMBL1468110 & 688810 & 7.0829 & 99999999 & & 5.2754 & \\
\hline CHEMBL1382445 & 688810 & 6.5829 & 99999999 & & 6.1285 & \\
\hline CHEMBL1491705 & 688810 & 5.983 & 5.6726 & TRN & & \\
\hline CHEMBL3192075 & 688810 & 4.783 & 4.7883 & TRN & & \\
\hline CHEMBL1451586 & 688810 & 5.5329 & 99999999 & 995 & 6 & \\
\hline CHEMBL1468340 & 688810 & 5.983 & 5.136 & TST & & \\
\hline CHEMBL1582739 & 688810 & 4.783 & 4.7663 & TRN & & \\
\hline CHEMBL1443766 & 688810 & 6.4829 & 5.9715 & TRN & & \\
\hline CHEMBL1301852 & 688810 & 5.033 & 5.0787 & TRN & & \\
\hline CHEMBL 2000592 & 688810 & 5.733 & 5.6443 & TST & & \\
\hline CHEMBL1494034 & 688810 & 4.7330 & 00000000 & 005 & 5.3268 & \\
\hline CHEMBL1457518 & 688810 & 5.3829 & 99999999 & & 5.1057 & \\
\hline CHEMBL1350568 & 688810 & 5.6329 & 99999999 & & 5.2135 & \\
\hline CHEMBL1493576 & 688810 & 4.783 & 5.5281 & TRN & & \\
\hline CHEMBL1353013 & 688810 & 5.3329 & 99999999 & & 5.0294 & \\
\hline CHEMBL1419535 & 688810 & 4.683 & 5.5202 & TRN & & \\
\hline CHEMBL1576840 & 688810 & 5.683 & 5.1594 & TRN & & \\
\hline CHEMBL1311825 & 688810 & 6.0 & 4.921 & TRN & & \\
\hline CHEMBL 3189498 & 688810 & 4.9830 & 00000000 & 005 & 5.1709 & \\
\hline CHEMBL1483697 & 688810 & 4.783 & 5.1194 & TRN & & \\
\hline CHEMBL1360203 & 688810 & 4.7330 & 00000000 & 005 & 5.45 & \\
\hline CHEMBL1598694 & 688810 & 4.833 & 5.2061 & TST & & \\
\hline CHEMBL1346926 & 688810 & 5.1329 & 99999999 & & 5.2968 & \\
\hline CHEMBL1337345 & 688810 & 5.733 & 5.3719 & TRN & & \\
\hline CHEMBL1535329 & 688810 & 4.7330 & 00000000 & 005 & & \\
\hline CHEMBL1330590 & 688810 & 5.1329 & 99999999 & & 5.1645 & \\
\hline CHEMBL1389411 & 688810 & 4.783 & 5.1632 & TRN & & \\
\hline CHEMBL1579009 & 688810 & 5.2829 & 99999999 & 995 & 4.8923 & \\
\hline CHEMBL 1584363 & 688810 & 6.0829 & 99999999 & & 5.8091 & \\
\hline
\end{tabular}




\begin{tabular}{|c|c|c|c|c|c|c|c|}
\hline \multicolumn{7}{|c|}{ Supplemental Table S2.txt } & \\
\hline CHEMBL1311749 & 688810 & \multicolumn{3}{|c|}{6.2829999999999995} & 5.4381 & TRN & \\
\hline CHEMBL1594312 & 688810 & 5.233 & 5.0046 & TST & & & \\
\hline CHEMBL1353364 & 688810 & \multicolumn{3}{|c|}{5.132999999999999} & 5.3664 & TRN & \\
\hline CHEMBL1437182 & 688810 & \multicolumn{3}{|c|}{5.5329999999999995} & 5.4629 & TRN & \\
\hline CHEMBL1510866 & 688810 & 4.783 & 5.2951 & TRN & & & \\
\hline CHEMBL1308121 & 688810 & 4.783 & 5.3856 & TST & & & \\
\hline CHEMBL3196421 & 688810 & 5.233 & 5.4409 & TRN & & & \\
\hline CHEMBL1321922 & 688810 & 4.833 & 4.9335 & TST & & & \\
\hline CHEMBL1565009 & 688810 & 5.233 & 5.0436 & TST & & & \\
\hline CHEMBL1967821 & 688810 & 5.183 & 5.2328 & TST & & & \\
\hline CHEMBL1367568 & 688810 & 5.233 & 4.9793 & TRN & & & \\
\hline CHEMBL1335814 & 688810 & 5.683 & 5.2562 & TRN & & & \\
\hline CHEMBL3193086 & 688810 & 4.833 & \multicolumn{3}{|c|}{4.968999999999999} & TRN & \\
\hline CHEMBL1592622 & 688810 & \multicolumn{3}{|c|}{4.7330000000000005} & 5.1849 & TRN & \\
\hline CHEMBL 2003564 & 688810 & \multicolumn{3}{|c|}{6.832999999999999} & 5.928999 & 9999999999 & TRN \\
\hline CHEMBL1320007 & 688810 & \multicolumn{3}{|c|}{6.0329999999999995} & 5.21 & TRN & \\
\hline CHEMBL1319258 & 688810 & 4.633 & 5.3382 & TRN & & & \\
\hline CHEMBL1324273 & 688810 & 5.483 & 5.3665 & TRN & & & \\
\hline CHEMBL1370316 & 688810 & 4.933 & 6.1007 & TRN & & & \\
\hline CHEMBL1601652 & 688810 & 6.7331 & 5.4388 & TRN & & & \\
\hline CHEMBL1314330 & 688810 & 4.783 & 5.0319 & TRN & & & \\
\hline CHEMBL1596217 & 688810 & 4.683 & 5.4614 & TST & & & \\
\hline CHEMBL1607172 & 688810 & \multicolumn{3}{|c|}{5.332999999999999} & 5.5115 & TRN & \\
\hline CHEMBL1319307 & 688810 & 4.783 & 5.0 & TST & & & \\
\hline CHEMBL1319037 & 688810 & \multicolumn{3}{|c|}{6.582999999999999} & 5.8163 & TRN & \\
\hline CHEMBL1563983 & 688810 & 4.933 & 5.1705 & TRN & & & \\
\hline CHEMBL3189961 & 688810 & 4.833 & 5.1256 & TST & & & \\
\hline CHEMBL1547917 & 688810 & 4.833 & 5.2587 & TRN & & & \\
\hline CHEMBL1568559 & 688810 & 4.833 & 5.0686 & TRN & & & \\
\hline CHEMBL1483298 & 688810 & 4.933 & 5.1115 & TRN & & & \\
\hline CHEMBL1441941 & 688810 & \multicolumn{3}{|c|}{4.9830000000000005} & 5.23 & TRN & \\
\hline CHEMBL 1479252 & 688810 & 4.883 & 5.0888 & TRN & & & \\
\hline CHEMBL1522537 & 688810 & 4.883 & 4.9359 & TRN & & & \\
\hline CHEMBL 3196346 & 688810 & 4.833 & 4.8556 & TRN & & & \\
\hline CHEMBL1377307 & 688810 & 5.083 & 4.9751 & TRN & & & \\
\hline CHEMBL1547444 & 688810 & \multicolumn{3}{|c|}{4.7330000000000005} & 5.4968 & TST & \\
\hline CHEMBL 1367303 & 688810 & 4.883 & 5.0645 & TST & & & \\
\hline CHEMBL 3199471 & 688810 & 4.883 & 5.3282 & TST & & & \\
\hline CHEMBL1502464 & 688810 & 4.833 & 5.2553 & TRN & & & \\
\hline CHEMBL1429108 & 688810 & 4.583 & 4.8357 & TRN & & & \\
\hline CHEMBL1343462 & 688810 & \multicolumn{3}{|c|}{4.9830000000000005} & 5.5557 & TST & \\
\hline CHEMBL1501950 & 688810 & \multicolumn{3}{|c|}{4.7330000000000005} & 5.3916 & TST & \\
\hline CHEMBL1605120 & 688810 & 4.833 & 5.1681 & TST & & & \\
\hline CHEMBL1380592 & 688810 & \multicolumn{3}{|c|}{5.632999999999999} & 5.1353 & TRN & \\
\hline CHEMBL1306522 & 688810 & \multicolumn{3}{|c|}{6.382999999999999} & 5.8639 & TRN & \\
\hline CHEMBL1380071 & 688810 & 4.683 & 5.3501 & TST & & & \\
\hline CHEMBL 1492830 & 688810 & 4.933 & 5.3504 & TRN & & & \\
\hline CHEMBL1530375 & 688810 & 5.433 & 5.6313 & TRN & & & \\
\hline
\end{tabular}




\begin{tabular}{|c|c|c|c|c|c|c|}
\hline \multicolumn{7}{|c|}{ Supplemental Table S2.txt } \\
\hline CHEMBL1414439 & 688810 & 5.683 & 5.21 & TRN & & \\
\hline CHEMBL417294 & 688810 & 5.13299 & 99999999 & & 5.316 & TRN \\
\hline CHEMBL1307956 & 688810 & 6.33299 & 99999999 & & 5.4371 & TRN \\
\hline CHEMBL1460315 & 688810 & 4.633 & 5.2011 & TRN & & \\
\hline CHEMBL1555347 & 688810 & 4.583 & 5.1983 & TRN & & \\
\hline CHEMBL1497537 & 688810 & 5.28299 & 99999999 & 995 & 5.0524 & TRN \\
\hline CHEMBL1484604 & 688810 & 5.683 & 5.473 & TRN & & \\
\hline CHEMBL1568028 & 688810 & 6.38299 & 99999999 & & 5.4603 & 11 \\
\hline CHEMBL1363275 & 688810 & 4.883 & 5.1258 & TRN & & \\
\hline CHEMBL1587707 & 688810 & 6.08299 & 99999999 & 99 & 5.2341 & 1. \\
\hline CHEMBL1416184 & 688810 & 4.633 & 4.9196 & TRN & & \\
\hline CHEMBL1547175 & 688810 & 4.833 & 5.1701 & TST & & \\
\hline CHEMBL1304087 & 688810 & 5.28299 & 99999999 & 995 & 5.5787 & I KIV \\
\hline CHEMBL1504859 & 688810 & 5.63299 & 99999999s & & 5.5649 & \\
\hline CHEMBL1352479 & 688810 & 4.833 & 5.2109 & TRN & & \\
\hline CHEMBL1408982 & 688810 & 5.733 & 5.43 & TRN & & \\
\hline CHEMBL1436850 & 688810 & 5.233 & 5.3885 & TRN & & \\
\hline CHEMBL1611868 & 688810 & 4.73300 & 00000000 & 005 & 5.1402 & TRN \\
\hline CHEMBL1549407 & 688810 & 5.78299 & 99999999 & 995 & 5.0809 & \\
\hline CHEMBL1363516 & 688810 & 4.633 & 5.1022 & TRN & & \\
\hline CHEMBL1392292 & 688810 & 5.683 & 5.7369 & TST & & \\
\hline CHEMBL1562360 & 688810 & 6.4829 & 5.682 & TRN & & \\
\hline CHEMBL1416516 & 688810 & 5.13299 & 99999999 & & 5.0741 & \\
\hline CHEMBL1462462 & 688810 & 6.233 & 5.7079 & TRN & & \\
\hline CHEMBL1355586 & 688810 & 4.633 & 5.27 & TRN & & \\
\hline CHEMBL1565257 & 688810 & 4.683 & 5.444 & TRN & & \\
\hline CHEMBL1538484 & 688810 & 5.483 & 5.494 & TRN & & \\
\hline CHEMBL1457817 & 688810 & 5.33299 & 99999999 & & 5.2218 & \\
\hline CHEMBL31 & 688810 & 5.933 & $5.50200 t$ & 00000 & 31 & \\
\hline CHEMBL1348935 & 688810 & 4.883 & 5.2305 & TRN & & \\
\hline CHEMBL1594160 & 688810 & 4.633 & 4.9345 & TRN & & \\
\hline CHEMBL1342082 & 688810 & 5.53299 & 99999999 & 995 & 5.6853 & \\
\hline CHEMBL 1408080 & 688810 & 5.83299 & 99999999 & & 5.5293 & \\
\hline CHEMBL1312888 & 688810 & 5.433 & 5.3482 & TRN & & \\
\hline CHEMBL1350621 & 688810 & 5.53299 & 99999999 & 995 & 5.4119 & TE \\
\hline CHEMBL1602413 & 688810 & 4.833 & 5.4759 & TST & & \\
\hline CHEMBL1300280 & 688810 & 5.233 & 5.7522 & TST & & \\
\hline CHEMBL1356488 & 10 & 4.833 & 4.8653 & TRN & & \\
\hline CHEMBL1554304 & 688810 & 4.783 & 4.9236 & TRN & & \\
\hline CHEMBL 3192666 & 688810 & 5.88299 & 99999999 & & 5.4586 & TRN \\
\hline CHEMBL1482652 & 688810 & 5.28299 & 99999999 & 995 & 5.0232 & -80 \\
\hline CHEMBL1340602 & 688810 & 5.183 & 5.2493 & TRN & & \\
\hline CHEMBL578257 & & 5.28299 & 99999999 & 995 & 5.4464 & \\
\hline CHEMBL1570497 & 688810 & 4.73300 & 00000000 & 005 & 5.0935 & . \\
\hline CHEMBL1437051 & 688810 & 6.13299 & 99999999 & & 5.2176 & TRN \\
\hline CHEMBL1590611 & 688810 & 4.98300 & 00000000 & 005 & 4.9605 & 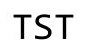 \\
\hline CHEMBL1521187 & 688810 & 6.983 & 5.9541 & TRN & & \\
\hline CHEMBL1547170 & 688810 & 5.183 & 5.2632 & TRN & & \\
\hline
\end{tabular}




\begin{tabular}{|c|c|c|c|c|c|c|c|}
\hline \multicolumn{8}{|c|}{ pplemental Table S2.txt } \\
\hline CHEMBL1590179 & 688810 & 4.783 & 5.2695 & TST & & & \\
\hline CHEMBL1436981 & 688810 & 4.583 & 5.2633 & TRN & & & \\
\hline CHEMBL1485831 & 688810 & \multicolumn{3}{|c|}{4.7330000000000005} & 4.9188 & TRN & \\
\hline CHEMBL1319385 & 688810 & 5.033 & 5.2769 & TST & & & \\
\hline CHEMBL1580743 & 688810 & 4.833 & 5.1239 & TRN & & & \\
\hline CHEMBL1351535 & 688810 & \multicolumn{3}{|c|}{6.382999999999999} & \multicolumn{2}{|c|}{5.8420000000000005} & TRN \\
\hline CHEMBL1612515 & 688810 & 4.883 & 5.4817 & TRN & & & \\
\hline CHEMBL1582048 & 688810 & 6.433 & 5.791 & TRN & & & \\
\hline CHEMBL1320964 & 688810 & 4.783 & 5.0483 & TRN & & & \\
\hline CHEMBL1338359 & 688810 & 5.733 & 5.0387 & TRN & & & \\
\hline CHEMBL1392868 & 688810 & 4.883 & 5.098 & TRN & & & \\
\hline CHEMBL 3193893 & 688810 & \multicolumn{3}{|c|}{5.832999999999999} & 5.4529 & TRN & \\
\hline CHEMBL 3197268 & 688810 & \multicolumn{3}{|c|}{5.882999999999999} & 5.2612 & TRN & \\
\hline CHEMBL 2000340 & 688810 & \multicolumn{3}{|c|}{4.7330000000000005} & 5.1974 & TRN & \\
\hline CHEMBL1439085 & 688810 & \multicolumn{3}{|c|}{5.132999999999999} & 5.3257 & TRN & \\
\hline CHEMBL 3207894 & 688810 & 4.783 & 4.9471 & TST & & & \\
\hline CHEMBL1367311 & 688810 & 5.683 & 4.9227 & TRN & & & \\
\hline CHEMBL1340428 & 688810 & \multicolumn{3}{|c|}{4.7330000000000005} & 5.6607 & TST & \\
\hline CHEMBL1483198 & 688810 & 4.783 & \multicolumn{3}{|c|}{4.9639999999999995} & TST & \\
\hline CHEMBL1588015 & 688810 & 5.033 & 5.4271 & TRN & & & \\
\hline CHEMBL1488721 & 688810 & 4.633 & 5.103 & TST & & & \\
\hline CHEMBL 3212243 & 688810 & 4.783 & 5.136 & TRN & & & \\
\hline CHEMBL1477575 & 688810 & 6.7331 & 6.0276 & TRN & & & \\
\hline CHEMBL1419149 & 688810 & 4.833 & 5.0485 & TST & & & \\
\hline CHEMBL1472921 & 688810 & 4.833 & 4.9455 & TRN & & & \\
\hline CHEMBL 3195747 & 688810 & \multicolumn{3}{|c|}{6.582999999999999} & 5.7843 & TRN & \\
\hline CHEMBL1610039 & 688810 & 4.783 & 5.1487 & TRN & & & \\
\hline CHEMBL1985103 & 688810 & 4.683 & 5.2317 & TRN & & & \\
\hline CHEMBL1483686 & 688810 & \multicolumn{3}{|c|}{5.2829999999999995} & 5.0708 & TRN & \\
\hline CHEMBL1524027 & 688810 & \multicolumn{3}{|c|}{4.7330000000000005} & 4.7985 & TST & \\
\hline CHEMBL1588969 & 688810 & \multicolumn{3}{|c|}{6.082999999999999} & 4.9041 & TST & \\
\hline CHEMBL1468793 & 688810 & \multicolumn{3}{|c|}{5.132999999999999} & 5.9297 & TST & \\
\hline CHEMBL1587397 & 688810 & 4.783 & 5.1927 & TRN & & & \\
\hline CHEMBL1339491 & 688810 & 4.783 & 5.2789 & TST & & & \\
\hline CHEMBL1455939 & 688810 & 4.783 & 4.8396 & TRN & & & \\
\hline CHEMBL1493782 & 688810 & \multicolumn{3}{|c|}{5.132999999999999} & 4.9561 & TRN & \\
\hline CHEMBL1488193 & 688810 & 4.783 & 4.9543 & TRN & & & \\
\hline CHEMBL1303203 & 688810 & \multicolumn{3}{|c|}{5.7829999999999995} & 5.466 & TRN & \\
\hline CHEMBL1372568 & 688810 & \multicolumn{3}{|c|}{5.882999999999999} & 5.2889 & TRN & \\
\hline CHEMBL1600906 & 688810 & \multicolumn{3}{|c|}{5.382999999999999} & 5.4063 & TRN & \\
\hline CHEMBL1609578 & 688810 & 6.183 & 5.4827 & TRN & & & \\
\hline CHEMBL1582905 & 688810 & \multicolumn{3}{|c|}{6.582999999999999} & 5.4139 & TRN & \\
\hline CHEMBL1539502 & 688810 & \multicolumn{3}{|c|}{7.082999999999999} & 6.0811 & TRN & \\
\hline CHEMBL1595849 & 688810 & 6.6329 & 99999999 & & 5.5078 & TRN & \\
\hline CHEMBL1340871 & 688810 & 5.8329 & 99999999 & & 5.2982 & TRN & \\
\hline CHEMBL1407683 & 688810 & 7.0829 & 99999999 & & 6.1762 & TRN & \\
\hline CHEMBL 3209407 & 688810 & 4.933 & 5.1308 & TRN & & & \\
\hline CHEMBL1344521 & 688810 & 4.833 & 5.0734 & TST & & & \\
\hline
\end{tabular}




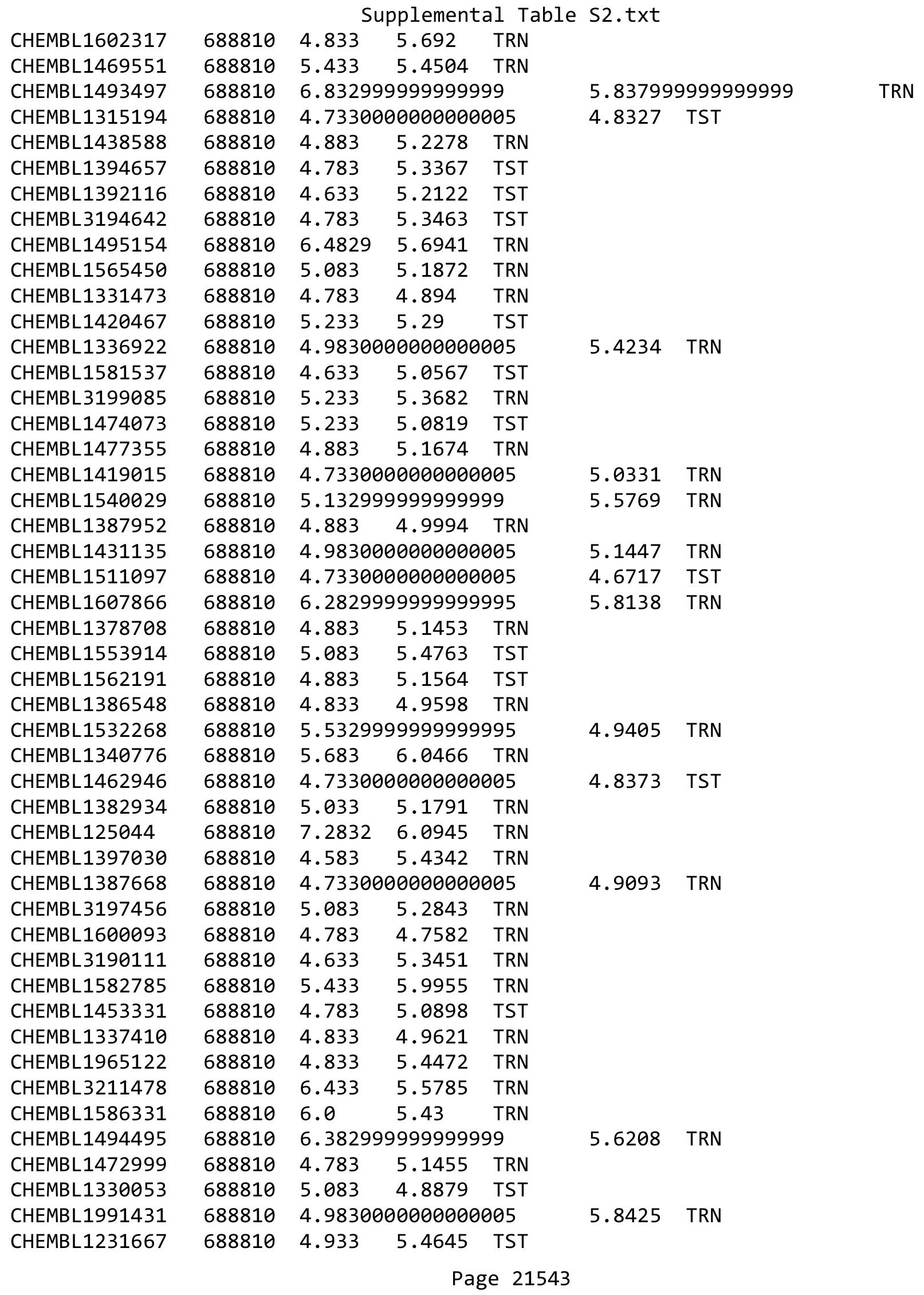




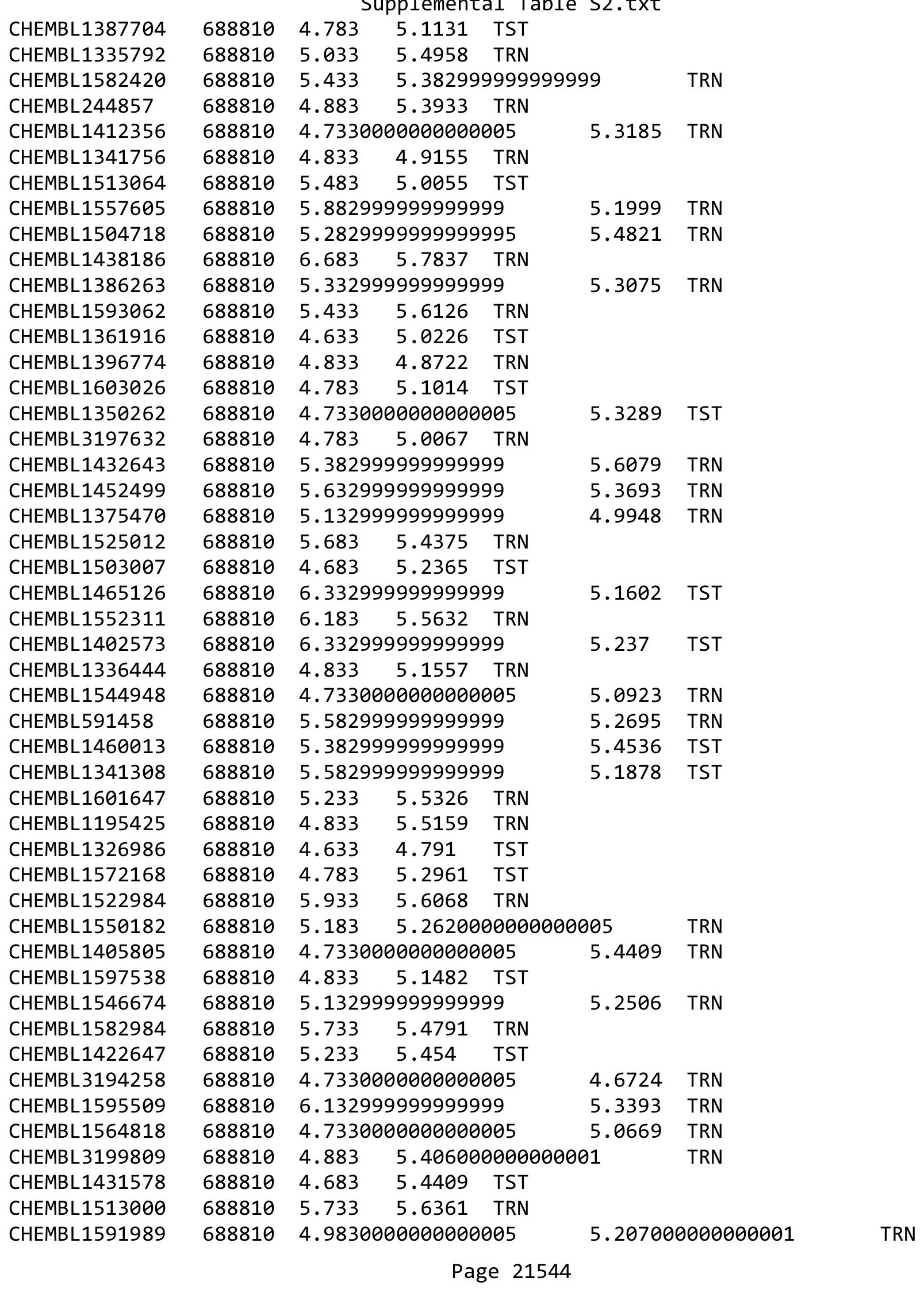




\begin{tabular}{|c|c|c|c|c|c|c|}
\hline & & & & & & \\
\hline CHEMBL1316269 & 688810 & 5.433 & 5.1181 & TRN & & \\
\hline CHEMBL1446198 & 688810 & 5.3829 & 99999999 & 99 & 5.6006 & TRN \\
\hline CHEMBL1378118 & 688810 & 5.5329 & 99999999 & 995 & 4.6452 & TRN \\
\hline CHEMBL3199837 & 688810 & 4.783 & 4.9874 & TRN & & \\
\hline CHEMBL1455505 & 688810 & 4.7330 & 00000000 & 005 & 5.3946 & TRN \\
\hline CHEMBL1375588 & 688810 & 4.683 & 5.2571 & TST & & \\
\hline CHEMBL1520341 & 688810 & 4.783 & 5.0916 & TRN & & \\
\hline CHEMBL1443772 & 688810 & 4.833 & 5.2102 & TRN & & \\
\hline CHEMBL1597602 & 688810 & 4.783 & 5.3814 & TRN & & \\
\hline CHEMBL1598909 & 688810 & 5.5329 & 99999999 & 995 & 5.3195 & TRN \\
\hline CHEMBL1409344 & 688810 & 4.783 & 5.3044 & TST & & \\
\hline CHEMBL1370034 & 688810 & 5.7829 & 99999999 & 995 & 6.0656 & TRN \\
\hline CHEMBL1547509 & 688810 & 5.733 & 5.6891 & TRN & & \\
\hline CHEMBL1500014 & 688810 & 4.683 & 4.8815 & TRN & & \\
\hline CHEMBL1308497 & 688810 & 5.3329 & 99999999 & & 5.1049 & TRN \\
\hline CHEMBL1339206 & 688810 & 4.883 & 4.9577 & TRN & & \\
\hline CHEMBL1301606 & 688810 & 5.2829 & 99999999 & 995 & 4.9209 & TRN \\
\hline CHEMBL1375105 & 688810 & 6.0829 & 99999999 & 99 & 5.565 & TRN \\
\hline CHEMBL1447423 & 688810 & 4.883 & 5.3078 & TRN & & \\
\hline CHEMBL1315282 & 688810 & 4.833 & 5.1076 & TST & & \\
\hline CHEMBL1512952 & 688810 & 4.883 & 5.0341 & TRN & & \\
\hline CHEMBL1502518 & 688810 & 4.7330 & 00000000 & 005 & 5.2123 & TRN \\
\hline CHEMBL1567682 & 688810 & 5.733 & 5.1273 & TRN & & \\
\hline CHEMBL3191310 & 688810 & 6.0829 & 99999999 & & 5.2408 & TRN \\
\hline CHEMBL 3195034 & 688810 & 4.833 & 5.4598 & TRN & & \\
\hline CHEMBL1349790 & 688810 & 4.833 & 5.19 & TRN & & \\
\hline CHEMBL1343814 & 688810 & 4.633 & 5.0631 & TST & & \\
\hline CHEMBL1455179 & 688810 & 4.7330 & 00000000 & 005 & 5.3417 & TST \\
\hline CHEMBL1337347 & 688810 & 4.883 & 5.1685 & TRN & & \\
\hline CHEMBL1502853 & 688810 & 4.7330 & 00000000 & 005 & 5.0706 & TST \\
\hline CHEMBL1581013 & 688810 & 4.633 & 4.8958 & TRN & & \\
\hline CHEMBL1447697 & 688810 & 4.633 & 5.1325 & TST & & \\
\hline CHEMBL1092508 & 688810 & 5.683 & 5.0343 & TRN & & \\
\hline CHEMBL1418374 & 688810 & 4.883 & 5.5307 & TRN & & \\
\hline CHEMBL1518936 & 688810 & 5.233 & 4.6039 & TST & & \\
\hline CHEMBL1559434 & 688810 & 4.783 & 5.2591 & TRN & & \\
\hline CHEMBL3199294 & 688810 & 6.0329 & 99999999 & 995 & 5.5634 & TRN \\
\hline CHEMBL 3213280 & 688810 & 4.7330 & 00000000 & 005 & 5.2211 & TRN \\
\hline CHEMBL1313428 & 688810 & 5.1329 & 99999999 & & 6.2884 & TRN \\
\hline CHEMBL3199780 & 688810 & 5.433 & 5.5528 & TRN & & \\
\hline CHEMBL1532424 & 688810 & 4.7330 & 00000000 & 005 & 4.9092 & TST \\
\hline CHEMBL1313548 & 688810 & 6.3829 & 99999999 & & 5.9158 & TRN \\
\hline CHEMBL1358294 & 688810 & 5.7829 & 99999999 & 995 & 5.6662 & TRN \\
\hline CHEMBL1367600 & 688810 & 5.1329 & 99999999 & & 5.192 & TRN \\
\hline CHEMBL1765369 & 688810 & 5.483 & 5.20799 & 99999 & 99 & TST \\
\hline CHEMBL1558535 & 688810 & 5.3329 & 99999999 & 99 & 5.1141 & TRN \\
\hline CHEMBL1578502 & 688810 & 4.583 & 5.4345 & TRN & & \\
\hline CHEMBL1591023 & 688810 & 6.683 & 5.1809 & TRN & & \\
\hline
\end{tabular}




\begin{tabular}{|c|c|c|c|c|c|c|c|}
\hline \multicolumn{7}{|c|}{ Supplemental Table S2.txt } & \\
\hline CHEMBL1389304 & 688810 & \multicolumn{3}{|c|}{5.5329999999999995} & 5.7912 & TRN & \\
\hline CHEMBL1352283 & 688810 & 4.783 & 5.0106 & TST & & & \\
\hline CHEMBL1329114 & 688810 & \multicolumn{3}{|c|}{5.5329999999999995} & 5.7676 & TRN & \\
\hline CHEMBL1327057 & 688810 & 5.183 & 5.3741 & TRN & & & \\
\hline CHEMBL1433999 & 688810 & 4.833 & 5.2192 & TRN & & & \\
\hline CHEMBL1513901 & 688810 & \multicolumn{3}{|c|}{5.132999999999999} & 5.551 & TRN & \\
\hline CHEMBL1484014 & 688810 & 4.833 & 5.4441 & TRN & & & \\
\hline CHEMBL3199576 & 688810 & \multicolumn{3}{|c|}{6.0329999999999995} & 5.1721 & TRN & \\
\hline CHEMBL1339223 & 688810 & 4.783 & 5.1188 & TST & & & \\
\hline CHEMBL1556576 & 688810 & 4.583 & 4.8832 & TST & & & \\
\hline CHEMBL1510664 & 688810 & 4.833 & 5.0662 & TST & & & \\
\hline CHEMBL1388803 & 688810 & 5.183 & 5.223 & TST & & & \\
\hline CHEMBL1558183 & 688810 & \multicolumn{3}{|c|}{4.9830000000000005} & 5.3081 & TST & \\
\hline CHEMBL1543589 & 688810 & 4.783 & 5.2019 & TRN & & & \\
\hline CHEMBL1401284 & 688810 & 5.683 & 5.5395 & TRN & & & \\
\hline CHEMBL1595014 & 688810 & 6.4829 & 5.9374 & TRN & & & \\
\hline CHEMBL1584870 & 688810 & \multicolumn{3}{|c|}{5.832999999999999} & 5.5616 & TRN & \\
\hline CHEMBL1405318 & 688810 & 4.883 & 5.0049 & TRN & & & \\
\hline CHEMBL1346277 & 688810 & 5.183 & 5.1978 & TRN & & & \\
\hline CHEMBL1421919 & 688810 & 4.783 & 4.8679 & TST & & & \\
\hline CHEMBL1429805 & 688810 & 5.033 & 5.2656 & TRN & & & \\
\hline CHEMBL1404435 & 688810 & \multicolumn{3}{|c|}{5.2829999999999995} & 5.3246 & TRN & \\
\hline CHEMBL1359648 & 688810 & 7.3325 & 5.9212 & TRN & & & \\
\hline CHEMBL1456762 & 688810 & 5.483 & 5.494 & TRN & & & \\
\hline CHEMBL1476415 & 688810 & 5.483 & 5.6559 & TST & & & \\
\hline CHEMBL1560442 & 688810 & 4.933 & 5.0516 & TRN & & & \\
\hline CHEMBL1431732 & 688810 & \multicolumn{3}{|c|}{5.382999999999999} & 5.822 & TRN & \\
\hline CHEMBL1430358 & 688810 & \multicolumn{3}{|c|}{5.832999999999999} & 5.0776 & TST & \\
\hline CHEMBL1574785 & 688810 & \multicolumn{3}{|c|}{5.832999999999999} & 5.6539 & TRN & \\
\hline CHEMBL1448111 & 688810 & 4.883 & 5.0714 & TRN & & & \\
\hline CHEMBL1505141 & 688810 & 4.833 & \multicolumn{3}{|c|}{5.281000000000001} & TST & \\
\hline CHEMBL1548492 & 688810 & \multicolumn{3}{|c|}{5.2829999999999995} & 5.6628 & TRN & \\
\hline CHEMBL172350 & 688810 & \multicolumn{3}{|c|}{5.2829999999999995} & 5.7371 & TRN & \\
\hline CHEMBL1511377 & 688810 & 4.783 & 5.3243 & TRN & & & \\
\hline CHEMBL1423815 & 688810 & 4.833 & 5.0983 & TST & & & \\
\hline CHEMBL1569634 & 688810 & 5.033 & 5.1422 & TRN & & & \\
\hline CHEMBL1481249 & 688810 & 4.783 & 5.0296 & TRN & & & \\
\hline CHEMBL1505219 & 688810 & 5.733 & 5.3305 & TST & & & \\
\hline CHEMBL1419205 & 688810 & 5.433 & 5.4036 & TRN & & & \\
\hline CHEMBL1314820 & 688810 & \multicolumn{3}{|c|}{5.132999999999999} & 5.12799 & 9999999999 & TRN \\
\hline CHEMBL1489690 & 688810 & \multicolumn{3}{|c|}{6.5329999999999995} & 6.0476 & TRN & \\
\hline CHEMBL1548927 & 688810 & \multicolumn{3}{|c|}{4.7330000000000005} & 4.8196 & TST & \\
\hline CHEMBL1418045 & 688810 & 5.683 & 5.4362 & TRN & & & \\
\hline CHEMBL1526738 & 688810 & \multicolumn{3}{|c|}{6.2829999999999995} & 6.0198 & TRN & \\
\hline CHEMBL1437275 & 688810 & 5.183 & 5.3297 & TRN & & & \\
\hline CHEMBL 3194672 & 688810 & 5.683 & 5.4065 & TRN & & & \\
\hline CHEMBL1524612 & 688810 & 4.883 & 5.2727 & TST & & & \\
\hline CHEMBL1440667 & 688810 & \multicolumn{3}{|c|}{4.7330000000000005} & 5.1417 & TRN & \\
\hline
\end{tabular}




\begin{tabular}{|c|c|c|c|c|c|c|c|}
\hline \multicolumn{8}{|c|}{ Supplemental Tab. } \\
\hline CHEMBL1355316 & 688810 & 4.933 & 5.0893 & TRN & & & \\
\hline CHEMBL1558598 & 688810 & 4.883 & \multicolumn{3}{|c|}{5.212000000000001} & TST & \\
\hline CHEMBL1585273 & 688810 & \multicolumn{3}{|c|}{6.082999999999999} & 5.7566 & TST & \\
\hline CHEMBL1326533 & 688810 & \multicolumn{3}{|c|}{6.132999999999999} & 5.5515 & TRN & \\
\hline CHEMBL1574691 & 688810 & \multicolumn{3}{|c|}{5.582999999999999} & 5.5451 & TRN & \\
\hline CHEMBL1332160 & 688810 & \multicolumn{3}{|c|}{5.2829999999999995} & 5.3356 & TST & \\
\hline CHEMBL1569547 & 688810 & 5.9718 & 5.4961 & TST & & & \\
\hline CHEMBL1410840 & 688810 & 4.783 & 5.1177 & TRN & & & \\
\hline CHEMBL1321769 & 688810 & 4.933 & 5.27 & TRN & & & \\
\hline CHEMBL1356739 & 688810 & 7.1831 & 5.9014 & TRN & & & \\
\hline CHEMBL1315578 & 688810 & \multicolumn{3}{|c|}{5.2829999999999995} & 5.9212 & TRN & \\
\hline CHEMBL1532845 & 688810 & 5.483 & 5.1187 & TRN & & & \\
\hline CHEMBL1399851 & 688810 & \multicolumn{3}{|c|}{4.7330000000000005} & 4.9042 & TST & \\
\hline CHEMBL1573167 & 688810 & 5.083 & 5.3609 & TRN & & & \\
\hline CHEMBL 2003794 & 688810 & \multicolumn{3}{|c|}{5.382999999999999} & 5.4421 & TRN & \\
\hline CHEMBL1340541 & 688810 & \multicolumn{3}{|c|}{6.382999999999999} & 5.239 & TST & \\
\hline CHEMBL1608043 & 688810 & \multicolumn{3}{|c|}{5.382999999999999} & 5.4441 & TRN & \\
\hline CHEMBL1425260 & 688810 & 4.783 & 5.1783 & TRN & & & \\
\hline CHEMBL1395406 & 688810 & \multicolumn{3}{|c|}{4.7330000000000005} & 5.3711 & TRN & \\
\hline CHEMBL1319467 & 688810 & \multicolumn{3}{|c|}{5.582999999999999} & 5.4836 & TST & \\
\hline CHEMBL1368307 & 688810 & 5.433 & 5.1585 & TRN & & & \\
\hline CHEMBL1544022 & 688810 & 4.883 & 4.9297 & TRN & & & \\
\hline CHEMBL 1422810 & 688810 & 5.933 & 5.2779 & TRN & & & \\
\hline CHEMBL1404601 & 688810 & \multicolumn{3}{|c|}{5.7829999999999995} & \multicolumn{2}{|c|}{5.672999999999999} & TRN \\
\hline CHEMBL1482670 & 688810 & 5.933 & 5.4537 & TRN & & & \\
\hline CHEMBL1390516 & 688810 & 4.683 & 5.2103 & TRN & & & \\
\hline CHEMBL1568340 & 688810 & \multicolumn{3}{|c|}{6.382999999999999} & 6.2261 & TRN & \\
\hline CHEMBL475813 & 688810 & 4.833 & 5.4653 & TST & & & \\
\hline CHEMBL1317784 & 688810 & 4.633 & 5.0704 & TRN & & & \\
\hline CHEMBL1489726 & 688810 & 5.683 & 4.9877 & TST & & & \\
\hline CHEMBL1494693 & 688810 & 5.683 & 4.9984 & TRN & & & \\
\hline CHEMBL1431380 & 688810 & 4.833 & 5.0498 & TRN & & & \\
\hline CHEMBL1453088 & 688810 & \multicolumn{3}{|c|}{5.832999999999999} & 5.7098 & TRN & \\
\hline CHEMBL1304861 & 688810 & \multicolumn{3}{|c|}{6.5329999999999995} & 5.8479 & TRN & \\
\hline CHEMBL1331548 & 688810 & 5.183 & 5.5305 & TRN & & & \\
\hline CHEMBL1519110 & 688810 & \multicolumn{3}{|c|}{5.382999999999999} & 5.4778 & TST & \\
\hline CHEMBL1481659 & 688810 & \multicolumn{3}{|c|}{5.382999999999999} & 5.0582 & TRN & \\
\hline CHEMBL1353940 & 688810 & 4.833 & 5.3749 & TST & & & \\
\hline CHEMBL1255733 & 688810 & \multirow{2}{*}{\multicolumn{3}{|c|}{$\begin{array}{lcc}5.933 & 5.8247 & \text { TST } \\
4.7330000000000005\end{array}$}} & & & \\
\hline CHEMBL1438534 & 688810 & & & & 4.9916 & TST & \\
\hline CHEMBL1366891 & 688810 & 4.783 & 5.2915 & TST & & & \\
\hline CHEMBL1492739 & 688810 & 6.33299 & 999999999 & & 5.3855 & TRN & \\
\hline CHEMBL1483310 & 688810 & 5.033 & 5.2285 & TRN & & & \\
\hline CHEMBL1587229 & 688810 & 5.13299 & 999999999 & & 4.8367 & TST & \\
\hline CHEMBL1515551 & 688810 & 5.483 & 4.9681 & TRN & & & \\
\hline CHEMBL1440703 & 688810 & 5.33299 & 999999999 & & 4.995 & TST & \\
\hline CHEMBL3196798 & 688810 & 6.183 & 5.6567 & TRN & & & \\
\hline CHEMBL1347071 & 688810 & 5.88299 & 999999999 & 99 & 5.5497 & TRN & \\
\hline
\end{tabular}




\begin{tabular}{|c|c|c|c|c|c|c|}
\hline \multirow{3}{*}{$\begin{array}{l}\text { CHEMBL1314051 } \\
\text { CHEMBL1375767 }\end{array}$} & \multirow{3}{*}{$\begin{array}{l}688810 \\
688810\end{array}$} & \multicolumn{4}{|c|}{ Supplemental Table S2.txt } & \multirow{2}{*}{ TRN } \\
\hline & & \multicolumn{3}{|c|}{5.382999999999999} & 5.8063 & \\
\hline & & 4.783 & 5.1146 & TRN & & \\
\hline CHEMBL3210011 & 688810 & 5.483 & 5.5811 & TRN & & \\
\hline CHEMBL1534488 & 688810 & 5.733 & 5.5962 & TRN & & \\
\hline CHEMBL1590627 & 688810 & \multicolumn{3}{|c|}{4.7330000000000005} & 5.1285 & TRN \\
\hline CHEMBL1564386 & 688810 & 5.933 & 5.2796 & TRN & & \\
\hline CHEMBL1606243 & 688810 & \multicolumn{3}{|c|}{4.7330000000000005} & 5.6056 & TRN \\
\hline CHEMBL1969298 & 688810 & 5.733 & 5.6395 & TRN & & \\
\hline CHEMBL1432452 & 688810 & \multicolumn{3}{|c|}{4.7330000000000005} & 5.2296 & TRN \\
\hline CHEMBL1501183 & 688810 & 4.833 & 5.4263 & TRN & & \\
\hline CHEMBL1995193 & 688810 & 6.433 & 5.4101 & TRN & & \\
\hline CHEMBL1377580 & 688810 & 5.433 & 5.3696 & TST & & \\
\hline CHEMBL1365927 & 688810 & 5.683 & 5.2165 & TRN & & \\
\hline CHEMBL1323831 & 688810 & \multicolumn{3}{|c|}{5.7829999999999995} & 5.4858 & TST \\
\hline CHEMBL1517390 & 688810 & 4.933 & 5.5141 & TRN & & \\
\hline CHEMBL1438407 & 688810 & 4.933 & 5.2021 & TRN & & \\
\hline CHEMBL1457301 & 688810 & 6.983 & 5.6137 & TST & & \\
\hline CHEMBL3193181 & 688810 & \multicolumn{3}{|c|}{5.2829999999999995} & 5.1873 & TST \\
\hline CHEMBL1377457 & 688810 & 4.783 & 4.9976 & TST & & \\
\hline CHEMBL1526966 & 688810 & 4.783 & 4.8867 & TST & & \\
\hline CHEMBL1471516 & 688810 & 5.033 & 5.2704 & TST & & \\
\hline CHEMBL1455078 & 688810 & 4.783 & 4.9433 & TST & & \\
\hline CHEMBL464433 & 688810 & \multicolumn{3}{|c|}{6.082999999999999} & 5.652 & TRN \\
\hline CHEMBL1395578 & 688810 & 4.783 & 5.3683 & TST & & \\
\hline CHEMBL1984604 & 688810 & 4.783 & 5.066 & TRN & & \\
\hline CHEMBL1568184 & 688810 & \multicolumn{3}{|c|}{5.832999999999999} & 5.3948 & TRN \\
\hline CHEMBL1311653 & 688810 & 5.083 & 4.7969 & TRN & & \\
\hline CHEMBL1344491 & 688810 & 4.783 & 4.5832 & TRN & & \\
\hline CHEMBL1370486 & 688810 & \multicolumn{3}{|c|}{5.132999999999999} & 5.4148 & TST \\
\hline CHEMBL3213707 & 688810 & 4.783 & 5.1405 & TST & & \\
\hline CHEMBL1571793 & 688810 & 4.833 & 5.1416 & TRN & & \\
\hline CHEMBL1383774 & 688810 & 4.633 & 4.8719 & TRN & & \\
\hline CHEMBL1420641 & 688810 & 5.083 & \multicolumn{3}{|c|}{5.4479999999999995} & TRN \\
\hline CHEMBL3189974 & 688810 & \multicolumn{3}{|c|}{5.132999999999999} & 5.2154 & TRN \\
\hline CHEMBL1603890 & 688810 & 4.833 & 5.1797 & TST & & \\
\hline CHEMBL1491703 & 688810 & \multicolumn{3}{|c|}{4.7330000000000005} & 5.0316 & TST \\
\hline CHEMBL1601808 & 688810 & 5.733 & 5.5106 & TRN & & \\
\hline CHEMBL1493414 & 688810 & \multicolumn{3}{|c|}{4.7330000000000005} & 4.9186 & TST \\
\hline CHEMBL1591136 & 688810 & 4.783 & 5.4542 & TRN & & \\
\hline CHEMBL1343554 & 688810 & \multicolumn{3}{|c|}{5.882999999999999} & 5.5191 & TRN \\
\hline CHEMBL1565660 & 688810 & 4.933 & 5.3705 & TST & & \\
\hline CHEMBL1474777 & 688810 & 4.883 & 4.726 & TRN & & \\
\hline CHEMBL1604833 & 688810 & 5.983 & 5.7365 & TRN & & \\
\hline CHEMBL3191729 & 688810 & 5.083 & 5.3494 & TRN & & \\
\hline CHEMBL1430579 & 688810 & 5.933 & 5.3005 & TRN & & \\
\hline CHEMBL1463234 & 688810 & 4.633 & 4.5442 & TRN & & \\
\hline CHEMBL1422395 & 688810 & 4.783 & 5.444 & TST & & \\
\hline CHEMBL1424718 & 688810 & 4.833 & 5.1395 & TRN & & \\
\hline
\end{tabular}




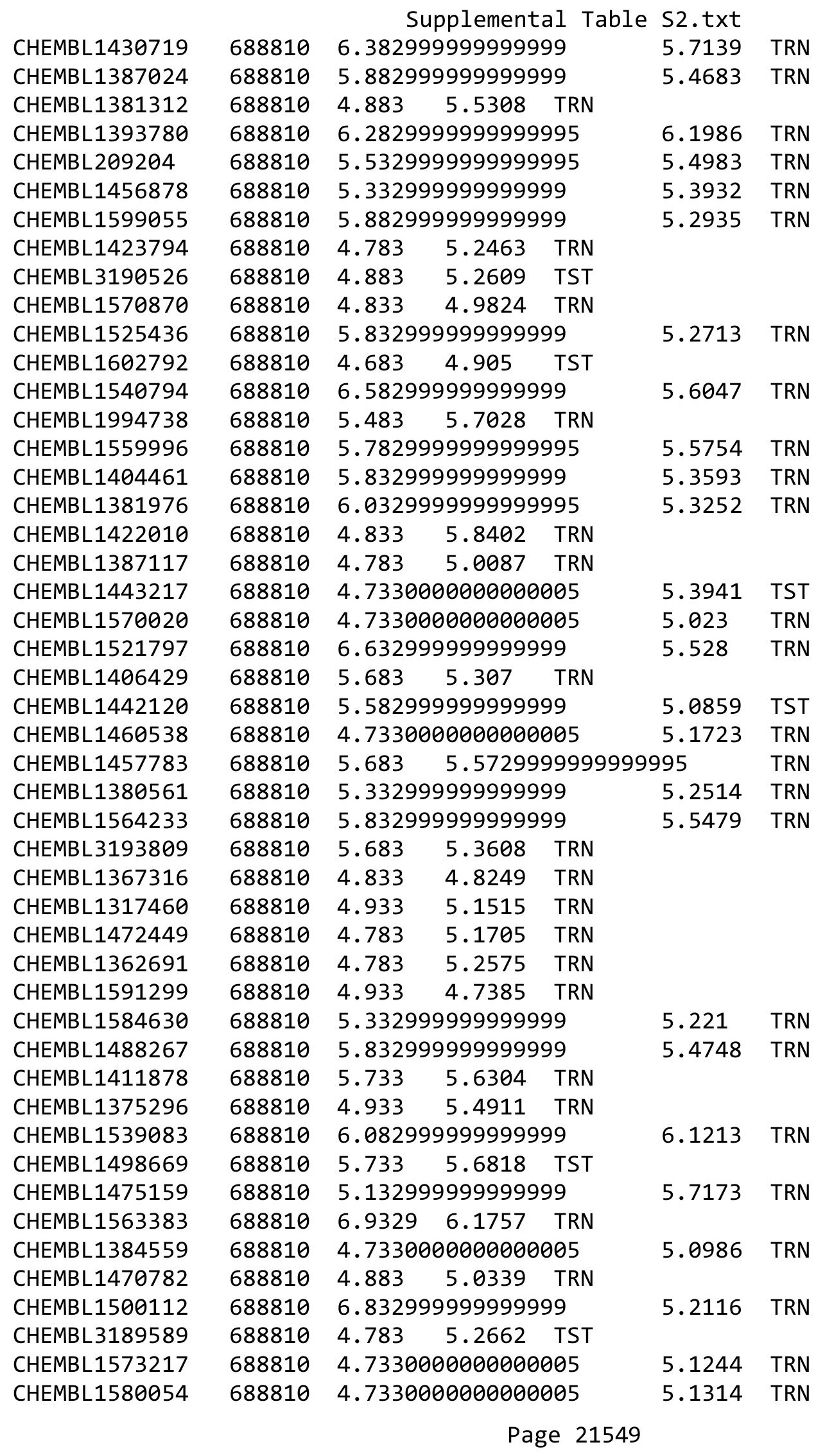




\begin{tabular}{|c|c|c|c|c|c|c|c|}
\hline \multirow{3}{*}{$\begin{array}{l}\text { CHEMBL1452771 } \\
\text { CHEMBL1414333 }\end{array}$} & \multicolumn{6}{|c|}{ Supplemental Table S2.txt } & \multirow{4}{*}{ TRN } \\
\hline & 688810 & \multicolumn{3}{|c|}{5.632999999999999} & 5.2029 & TST & \\
\hline & 688810 & \multicolumn{3}{|c|}{5.882999999999999} & \multicolumn{2}{|c|}{5.5520000000000005} & \\
\hline CHEMBL1588338 & 688810 & 4.933 & 5.3503 & TRN & & & \\
\hline CHEMBL1380456 & 688810 & 5.083 & 5.4426 & TST & & & \\
\hline CHEMBL1557592 & 688810 & 5.433 & 5.3529 & TRN & & & \\
\hline CHEMBL1397418 & 688810 & \multicolumn{3}{|c|}{5.882999999999999} & 4.9551 & TRN & \\
\hline CHEMBL1483465 & 688810 & 4.833 & 5.3677 & TRN & & & \\
\hline CHEMBL1329228 & 688810 & 5.433 & 5.5797 & TRN & & & \\
\hline CHEMBL1447472 & 688810 & \multicolumn{3}{|c|}{4.9830000000000005} & 5.0741 & TRN & \\
\hline CHEMBL1483160 & 688810 & 5.983 & 5.6846 & TRN & & & \\
\hline CHEMBL1519983 & 688810 & 4.833 & 5.2302 & TRN & & & \\
\hline CHEMBL1440395 & 688810 & 5.483 & 5.9179 & TRN & & & \\
\hline CHEMBL1567635 & 688810 & 4.833 & 4.8073 & TRN & & & \\
\hline CHEMBL327209 & 688810 & \multicolumn{3}{|c|}{5.132999999999999} & 5.6681 & TRN & \\
\hline CHEMBL1351912 & 688810 & \multicolumn{3}{|c|}{5.132999999999999} & 5.2268 & TRN & \\
\hline CHEMBL1363356 & 688810 & \multicolumn{3}{|c|}{5.5329999999999995} & 5.2301 & TRN & \\
\hline CHEMBL584668 & 688810 & \multicolumn{3}{|c|}{6.082999999999999} & 5.6345 & TRN & \\
\hline CHEMBL1400797 & 688810 & \multicolumn{3}{|c|}{5.332999999999999} & 5.6534 & TRN & \\
\hline CHEMBL3214285 & 688810 & 4.933 & 5.5309 & TST & & & \\
\hline CHEMBL1311937 & 688810 & 4.833 & 5.0802 & TRN & & & \\
\hline CHEMBL1411705 & 688810 & 5.733 & 5.1617 & TRN & & & \\
\hline CHEMBL3196867 & 688810 & \multicolumn{3}{|c|}{6.582999999999999} & 5.6762 & TRN & \\
\hline CHEMBL1512405 & 688810 & 5.183 & 5.3559 & TRN & & & \\
\hline CHEMBL1970469 & 688810 & 5.083 & 5.226 & TRN & & & \\
\hline CHEMBL1535252 & 688810 & \multicolumn{3}{|c|}{4.7330000000000005} & 4.8902 & TST & \\
\hline CHEMBL1369668 & 688810 & 5.033 & 5.1664 & TRN & & & \\
\hline CHEMBL1371171 & 688810 & \multicolumn{3}{|c|}{6.5329999999999995} & 5.3707 & TRN & \\
\hline CHEMBL1386002 & 688810 & \multicolumn{3}{|c|}{5.632999999999999} & 4.9339 & TST & \\
\hline CHEMBL1309808 & 688810 & \multicolumn{3}{|c|}{4.7330000000000005} & 4.9528 & TRN & \\
\hline CHEMBL1461972 & 688810 & 7.0329 & 5.7256 & TRN & & & \\
\hline CHEMBL1420526 & 688810 & 4.833 & 5.3673 & TRN & & & \\
\hline CHEMBL1504017 & 688810 & 4.883 & 4.6751 & TRN & & & \\
\hline CHEMBL1510417 & 688810 & \multicolumn{3}{|c|}{5.332999999999999} & 5.4203 & TST & \\
\hline CHEMBL2003806 & 688810 & 4.583 & 5.3607 & TRN & & & \\
\hline CHEMBL1406145 & 688810 & 4.883 & 4.9124 & TST & & & \\
\hline CHEMBL3190322 & 688810 & 5.683 & 5.535 & TRN & & & \\
\hline CHEMBL1315947 & 688810 & 4.883 & 4.9609 & TST & & & \\
\hline CHEMBL1463476 & 688810 & 4.833 & 5.146 & TST & & & \\
\hline CHEMBL1427426 & 688810 & 5.983 & 5.7409 & TRN & & & \\
\hline CHEMBL1581417 & 688810 & 5.083 & 5.5411 & TRN & & & \\
\hline CHEMBL600107 & 688810 & 4.633 & 5.1189 & TST & & & \\
\hline CHEMBL1569633 & 688810 & 4.9830 & 30000000 & 005 & 5.2231 & TRN & \\
\hline CHEMBL1585557 & 688810 & 5.1329 & 99999999 & & 5.7674 & TRN & \\
\hline CHEMBL3190794 & 688810 & 4.9830 & 00000000 & 005 & 5.3239 & TRN & \\
\hline CHEMBL1447044 & 688810 & 4.783 & 5.1192 & TRN & & & \\
\hline CHEMBL1461992 & 688810 & 5.7829 & 99999999 & 995 & 5.3474 & TRN & \\
\hline CHEMBL1309061 & 688810 & 4.7330 & 30000000 & 005 & 5.0702 & TRN & \\
\hline CHEMBL1369641 & 688810 & 4.933 & 5.9333 & TRN & & & \\
\hline
\end{tabular}




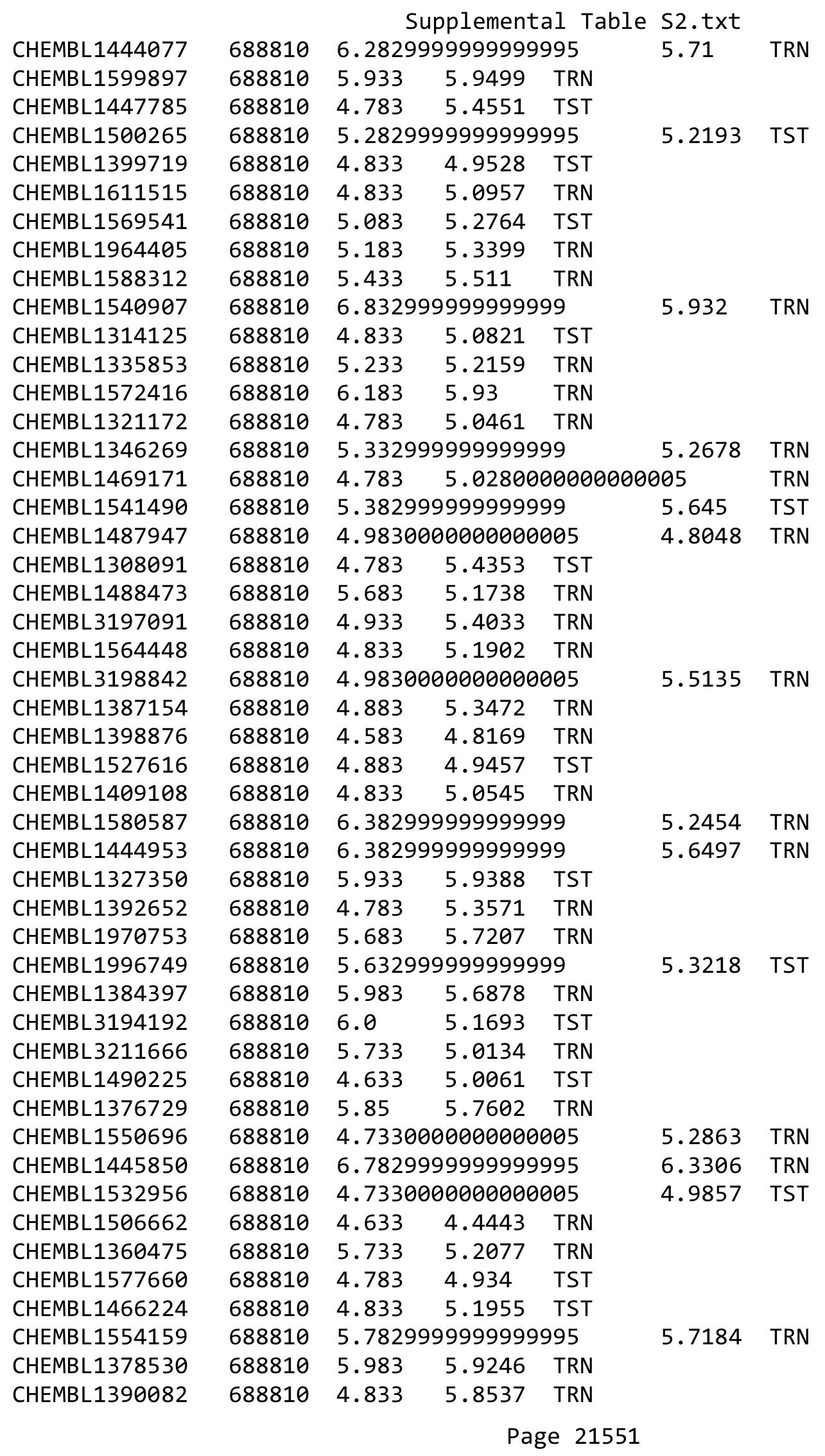




\begin{tabular}{|c|c|c|c|c|c|c|c|}
\hline \multicolumn{8}{|c|}{ supplemental la } \\
\hline CHEMBL1507620 & 688810 & 6.183 & 5.58 & TRN & & & \\
\hline CHEMBL1368235 & 688810 & \multicolumn{3}{|c|}{5.7829999999999995} & 5.4519 & TRN & \\
\hline CHEMBL1462345 & 688810 & 4.833 & 5.0161 & TRN & & & \\
\hline CHEMBL3213666 & 688810 & 4.933 & 5.325 & TRN & & & \\
\hline CHEMBL1407635 & 688810 & 4.833 & 4.9295 & TST & & & \\
\hline CHEMBL1612190 & 688810 & \multicolumn{3}{|c|}{5.132999999999999} & 5.2051 & TRN & \\
\hline CHEMBL1581766 & 688810 & \multicolumn{3}{|c|}{5.2829999999999995} & 5.5655 & TRN & \\
\hline CHEMBL1349634 & 688810 & 4.833 & 4.7328 & TRN & & & \\
\hline CHEMBL1551605 & 688810 & 5.433 & 5.1794 & TRN & & & \\
\hline CHEMBL1427423 & 688810 & 5.483 & 5.5264 & TRN & & & \\
\hline CHEMBL1600710 & 688810 & 5.033 & 5.1988 & TRN & & & \\
\hline CHEMBL1518386 & 688810 & 5.65 & 5.1838 & TRN & & & \\
\hline CHEMBL1388353 & 688810 & 5.683 & 5.1695 & TRN & & & \\
\hline CHEMBL1501923 & 688810 & \multicolumn{3}{|c|}{6.382999999999999} & 6.0931 & TRN & \\
\hline CHEMBL1486387 & 688810 & 4.633 & 5.197 & TRN & & & \\
\hline CHEMBL1584108 & 688810 & 4.883 & 5.2327 & TRN & & & \\
\hline CHEMBL1569537 & 688810 & 4.883 & 5.1442 & TRN & & & \\
\hline CHEMBL1488743 & 688810 & 4.933 & 5.0042 & TRN & & & \\
\hline CHEMBL1369612 & 688810 & 5.183 & 5.4673 & TRN & & & \\
\hline CHEMBL3194385 & 688810 & 4.833 & 5.0566 & TRN & & & \\
\hline CHEMBL1383520 & 688810 & 4.833 & 5.3306 & TRN & & & \\
\hline CHEMBL1525735 & 688810 & \multicolumn{3}{|c|}{4.9830000000000005} & 4.5486 & TRN & \\
\hline CHEMBL1438282 & 688810 & \multicolumn{3}{|c|}{5.2829999999999995} & 5.4666 & TRN & \\
\hline CHEMBL1558523 & 688810 & 6.4829 & 5.8883 & TRN & & & \\
\hline CHEMBL1588668 & 688810 & 4.883 & 5.074 & TRN & & & \\
\hline CHEMBL1476466 & 688810 & 4.583 & 4.9481 & TRN & & & \\
\hline CHEMBL1352202 & 688810 & 5.933 & 5.39 & TST & & & \\
\hline CHEMBL3213125 & 688810 & \multicolumn{3}{|c|}{4.7330000000000005} & 5.3616 & TRN & \\
\hline CHEMBL1355106 & 688810 & 4.583 & 4.7773 & TST & & & \\
\hline CHEMBL1982575 & 688810 & \multicolumn{3}{|c|}{6.382999999999999} & 5.7592 & TRN & \\
\hline CHEMBL1373045 & 688810 & 4.783 & 4.9616 & TST & & & \\
\hline CHEMBL1535024 & 688810 & 4.883 & 5.3193 & TRN & & & \\
\hline CHEMBL1369101 & 688810 & \multicolumn{3}{|c|}{4.7330000000000005} & 5.0058 & TST & \\
\hline CHEMBL1382290 & 688810 & 5.433 & 5.6423 & TRN & & & \\
\hline CHEMBL1605218 & 688810 & 4.883 & 5.2236 & TRN & & & \\
\hline CHEMBL112597 & 688810 & 6.0 & 5.996 & TRN & & & \\
\hline CHEMBL1567184 & 688810 & 5.933 & 5.7358 & TRN & & & \\
\hline CHEMBL1552495 & 688810 & \multicolumn{3}{|c|}{5.332999999999999} & 5.485 & TST & \\
\hline CHEMBL1564952 & 688810 & \multicolumn{3}{|c|}{5.632999999999999} & 4.976 & TRN & \\
\hline CHEMBL1557142 & 688810 & 5.733 & 5.3381 & TST & & & \\
\hline CHEMBL1602525 & 688810 & 4.783 & 4.9014 & TRN & & & \\
\hline CHEMBL1448332 & 688810 & \multicolumn{3}{|c|}{6.7829999999999995} & 5.8020 & 00000000005 & TRN \\
\hline CHEMBL1359059 & 688810 & 5.233 & 5.4036 & TRN & & & \\
\hline CHEMBL1392073 & 688810 & \multicolumn{3}{|c|}{5.5329999999999995} & 5.2239 & TRN & \\
\hline CHEMBL596839 & 688810 & 5.933 & 5.6848 & TRN & & & \\
\hline CHEMBL1506977 & 688810 & 4.883 & 5.1 & TRN & & & \\
\hline CHEMBL1432841 & 688810 & \multicolumn{3}{|c|}{4.7330000000000005} & 4.8598 & TRN & \\
\hline CHEMBL1605165 & 688810 & \multicolumn{3}{|c|}{4.9830000000000005} & 5.8008 & TRN & \\
\hline
\end{tabular}




\begin{tabular}{|c|c|c|c|c|c|c|c|}
\hline \multicolumn{8}{|c|}{ E- } \\
\hline CHEMBL1588860 & 688810 & 5.733 & 6.05 & TRN & & & \\
\hline CHEMBL1542925 & 688810 & 4.833 & 5.3758 & TRN & & & \\
\hline CHEMBL1442009 & 688810 & 4.783 & 4.9892 & TRN & & & \\
\hline CHEMBL1407806 & 688810 & 5.28299 & 999999995 & 995 & 5.2735 & TRN & \\
\hline CHEMBL1339913 & 688810 & 4.583 & 4.8347 & TST & & & \\
\hline CHEMBL1455934 & 688810 & 4.583 & 5.0958 & TRN & & & \\
\hline CHEMBL1542328 & 688810 & 5.983 & 5.2473 & TST & & & \\
\hline CHEMBL 2006274 & 688810 & 5.63299 & 99999999 & & 5.2255 & TRN & \\
\hline CHEMBL323936 & 688810 & 5.38299 & 999999995 & & 5.6246 & TRN & \\
\hline CHEMBL1390641 & 688810 & 6.7331 & 5.9601 & TRN & & & \\
\hline CHEMBL1311510 & 688810 & 5.13299 & 99999999 & & 4.8899 & TST & \\
\hline CHEMBL1596703 & 688810 & 4.98300 & 000000006 & 005 & 5.1081 & TRN & \\
\hline CHEMBL3197868 & 688810 & 4.783 & 5.0529 & TRN & & & \\
\hline CHEMBL1577980 & 688810 & 5.183 & 5.2363 & TRN & & & \\
\hline CHEMBL3189361 & 688810 & 6.33299 & 999999995 & & 5.9927 & TRN & \\
\hline CHEMBL1299462 & 688810 & 4.833 & 5.1576 & TST & & & \\
\hline CHEMBL1337976 & 688810 & 4.98300 & 000000006 & 005 & 5.7872 & TRN & \\
\hline CHEMBL3198130 & 688810 & 5.33299 & 999999995 & & 5.4477 & TRN & \\
\hline CHEMBL1371165 & 688810 & 5.083 & 5.1915 & TRN & & & \\
\hline CHEMBL1587710 & 688810 & 4.73300 & 000000006 & 005 & 5.1582 & TRN & \\
\hline CHEMBL1498158 & 688810 & 4.73300 & 000000006 & 005 & 5.3498 & TST & \\
\hline CHEMBL1323584 & 688810 & 6.183 & 5.7831 & TRN & & & \\
\hline CHEMBL1566915 & 688810 & 5.78299 & 999999999 & 995 & 5.8771 & TRN & \\
\hline CHEMBL1418942 & 688810 & 6.433 & 5.8007 & TRN & & & \\
\hline CHEMBL1385727 & 688810 & 4.833 & 5.5529 & TST & & & \\
\hline CHEMBL1372449 & 688810 & 5.88299 & 999999999 & & 5.37799 & 9999999999 & TRN \\
\hline CHEMBL1407292 & 688810 & 5.13299 & 999999999 & & 5.4178 & TRN & \\
\hline CHEMBL1531960 & 688810 & 4.833 & 5.3041 & TRN & & & \\
\hline CHEMBL1483674 & 688810 & 4.833 & 5.3163 & TST & & & \\
\hline CHEMBL1317276 & 688810 & 5.233 & 4.9534 & TST & & & \\
\hline CHEMBL1402010 & 688810 & 5.83299 & 999999999 & & 5.3967 & TST & \\
\hline CHEMBL1301037 & 688810 & 5.683 & 5.5008 & TST & & & \\
\hline CHEMBL1501573 & 688810 & 4.933 & 5.4542 & TST & & & \\
\hline CHEMBL1364018 & 688810 & 4.833 & 4.963 & TST & & & \\
\hline CHEMBL1381586 & 688810 & 4.833 & 5.1963 & TST & & & \\
\hline CHEMBL3197575 & 688810 & 5.28299 & 999999999 & 995 & 5.2865 & TRN & \\
\hline CHEMBL1502783 & 688810 & 4.833 & 5.1554 & TRN & & & \\
\hline CHEMBL1487762 & 688810 & 5.183 & 5.2524 & TRN & & & \\
\hline CHEMBL1431160 & 688810 & 4.883 & 5.3322 & TRN & & & \\
\hline CHEMBL3211339 & 688810 & 4.783 & 5.3104 & TST & & & \\
\hline CHEMBL1373785 & 688810 & 5.28299 & 999999999 & 995 & 5.3557 & TRN & \\
\hline CHEMBL1575202 & 688810 & 4.783 & 5.3867 & TST & & & \\
\hline CHEMBL3189207 & 688810 & 4.583 & 5.1405 & TST & & & \\
\hline CHEMBL1367262 & 688810 & 4.583 & 4.6739 & TST & & & \\
\hline CHEMBL1325327 & 688810 & 5.35 & 5.2007 & TRN & & & \\
\hline CHEMBL1420428 & 688810 & 6.33299 & 999999999 & & 5.4667 & TRN & \\
\hline CHEMBL582070 & 688810 & 4.933 & 4.9882 & TRN & & & \\
\hline CHEMBL1329884 & 688810 & 4.933 & 5.3637 & TRN & & & \\
\hline
\end{tabular}




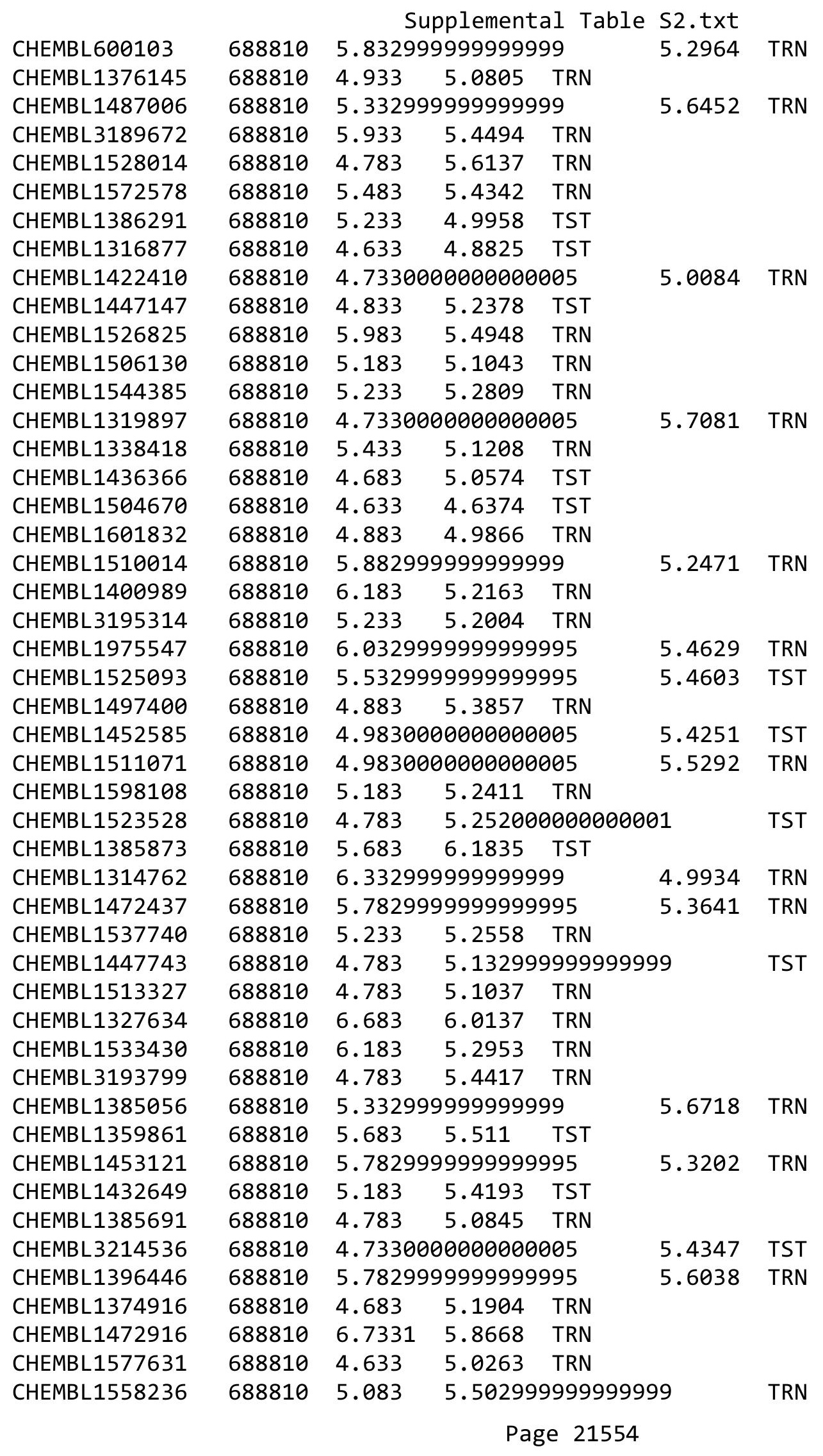




\begin{tabular}{|c|c|c|c|c|c|c|}
\hline \multirow[b]{2}{*}{ CHEMBL1336321 } & \multirow[b]{2}{*}{688810} & \multicolumn{5}{|c|}{ Supplemental Table s2.txt } \\
\hline & & 4.783 & & TRN & \multirow{3}{*}{5.5806} & \multirow{3}{*}{ TRN } \\
\hline CHEMBL1389630 & 688810 & \multicolumn{3}{|c|}{5.5329999999999995} & & \\
\hline CHEMBL1966622 & 688810 & 5.733 & 5.4995 & TRN & & \\
\hline CHEMBL1522105 & 688810 & \multicolumn{3}{|c|}{5.382999999999999} & 5.2137 & TST \\
\hline CHEMBL1389324 & 688810 & \multicolumn{3}{|c|}{6.332999999999999} & 5.7606 & TRN \\
\hline CHEMBL1970872 & 688810 & 4.633 & 5.0668 & TRN & & \\
\hline CHEMBL1375699 & 688810 & 4.883 & 5.4046 & TST & & \\
\hline CHEMBL1412085 & 688810 & 4.883 & 5.2513 & TRN & & \\
\hline CHEMBL1489294 & 688810 & \multicolumn{3}{|c|}{5.582999999999999} & 5.6276 & TRN \\
\hline CHEMBL1544192 & 688810 & 5.183 & 4.7776 & TRN & & \\
\hline CHEMBL1352758 & 688810 & \multicolumn{3}{|c|}{5.832999999999999} & 5.776 & TRN \\
\hline CHEMBL1562457 & 688810 & 4.783 & 5.6418 & TRN & & \\
\hline CHEMBL1380443 & 688810 & 4.783 & 5.0405 & TRN & & \\
\hline CHEMBL1598379 & 688810 & \multicolumn{3}{|c|}{5.2829999999999995} & 5.0173 & TRN \\
\hline CHEMBL1534650 & 688810 & 4.783 & \multicolumn{3}{|c|}{5.053999999999999} & TST \\
\hline CHEMBL1313139 & 688810 & \multicolumn{3}{|c|}{5.132999999999999} & 5.7662 & TST \\
\hline CHEMBL1318384 & 688810 & \multicolumn{3}{|c|}{5.132999999999999} & 4.9884 & TRN \\
\hline CHEMBL1382797 & 688810 & \multicolumn{3}{|c|}{6.0329999999999995} & 5.6189 & TRN \\
\hline CHEMBL1420142 & 688810 & \multicolumn{3}{|c|}{5.5329999999999995} & 5.1699 & TST \\
\hline CHEMBL3190669 & 688810 & 5.733 & 5.6574 & TRN & & \\
\hline CHEMBL1324270 & 688810 & 4.683 & 4.8644 & TST & & \\
\hline CHEMBL1337367 & 688810 & 6.4829 & 5.7071 & TRN & & \\
\hline CHEMBL1519164 & 688810 & 5.433 & 5.6278 & TRN & & \\
\hline CHEMBL1471462 & 688810 & 4.783 & 5.2642 & TRN & & \\
\hline CHEMBL1499814 & 688810 & 4.833 & 5.0495 & TST & & \\
\hline CHEMBL1530173 & 688810 & 4.633 & 5.1303 & TRN & & \\
\hline CHEMBL1396563 & 688810 & 4.783 & 4.9519 & TRN & & \\
\hline CHEMBL1544699 & 688810 & 5.033 & 5.2624 & TST & & \\
\hline CHEMBL1475952 & 688810 & 4.633 & 5.0958 & TRN & & \\
\hline CHEMBL3211832 & 688810 & 4.833 & 5.3894 & TRN & & \\
\hline CHEMBL1418366 & 688810 & 4.833 & 5.046 & TRN & & \\
\hline CHEMBL3191239 & 688810 & \multicolumn{3}{|c|}{6.582999999999999} & 5.9152 & TRN \\
\hline CHEMBL1540034 & 688810 & 4.933 & 4.6177 & TRN & & \\
\hline CHEMBL1420007 & 688810 & 5.233 & 4.9917 & TRN & & \\
\hline CHEMBL1568820 & 688810 & \multicolumn{3}{|c|}{4.7330000000000005} & 5.3548 & TRN \\
\hline CHEMBL1543757 & 688810 & 4.683 & 5.1327 & TST & & \\
\hline CHEMBL1559385 & 688810 & \multicolumn{3}{|c|}{6.382999999999999} & 5.5045 & TRN \\
\hline CHEMBL1359188 & 688810 & 4.583 & 5.1024 & TST & & \\
\hline CHEMBL1993662 & 688810 & \multicolumn{3}{|c|}{6.382999999999999} & 5.6957 & TRN \\
\hline CHEMBL1543847 & 688810 & \multicolumn{3}{|c|}{5.332999999999999} & 5.4793 & TRN \\
\hline CHEMBL1339696 & 688810 & 4.633 & 4.7345 & TST & & \\
\hline CHEMBL1499666 & 688810 & 4.783 & 4.8446 & TRN & & \\
\hline CHEMBL3213774 & 688810 & 4.883 & 5.1703 & TRN & & \\
\hline CHEMBL1562164 & 688810 & 5.083 & 5.2875 & TST & & \\
\hline CHEMBL1570450 & 688810 & 7.1331 & 5.5393 & TRN & & \\
\hline CHEMBL1455601 & 688810 & 5.233 & 5.0927 & TST & & \\
\hline CHEMBL1579359 & 688810 & 5.033 & 5.0247 & TRN & & \\
\hline CHEMBL3197922 & 688810 & 5.58299 & 99999999 & & 5.4114 & TRN \\
\hline & & & & 21 & & \\
\hline
\end{tabular}




\begin{tabular}{|c|c|c|c|c|c|c|c|}
\hline CHEMBL1540841 & 688810 & 5.733 & 5.561 & TRN & & & \\
\hline CHEMBL3199619 & 688810 & \multicolumn{3}{|c|}{5.7829999999999995} & 4.9608 & TST & \\
\hline CHEMBL1403754 & 688810 & 4.833 & 5.5711 & TRN & & & \\
\hline CHEMBL1348307 & 688810 & 4.883 & 5.091 & TRN & & & \\
\hline CHEMBL3195945 & 688810 & \multicolumn{3}{|c|}{5.382999999999999} & 5.5436 & TRN & \\
\hline CHEMBL3190128 & 688810 & \multicolumn{3}{|c|}{5.132999999999999} & 5.466 & TRN & \\
\hline CHEMBL1534844 & 688810 & 4.633 & 4.8221 & TST & & & \\
\hline CHEMBL1326664 & 688810 & 5.05 & 4.9535 & TRN & & & \\
\hline CHEMBL1303789 & 688810 & \multicolumn{3}{|c|}{4.7330000000000005} & 5.1846 & TST & \\
\hline CHEMBL1538332 & 688810 & \multicolumn{3}{|c|}{5.7829999999999995} & 5.1821 & TRN & \\
\hline CHEMBL1404854 & 688810 & 4.833 & 4.9448 & TRN & & & \\
\hline CHEMBL1396942 & 688810 & \multicolumn{3}{|c|}{5.382999999999999} & 5.0977 & TRN & \\
\hline CHEMBL1471619 & 688810 & 4.883 & 5.8191 & TRN & & & \\
\hline CHEMBL260451 & 688810 & 7.2832 & 6.3213 & TRN & & & \\
\hline CHEMBL1163763 & 688810 & 6.233 & 5.1789 & TRN & & & \\
\hline CHEMBL1461809 & 688810 & 5.233 & 5.1412 & TST & & & \\
\hline CHEMBL1418762 & 688810 & 5.083 & 5.2858 & TRN & & & \\
\hline CHEMBL1337898 & 688810 & 7.2832 & 5.6795 & TRN & & & \\
\hline CHEMBL1376513 & 688810 & 5.733 & 5.2918 & TRN & & & \\
\hline CHEMBL1323477 & 688810 & 4.833 & 5.3818 & TRN & & & \\
\hline CHEMBL1541480 & 688810 & \multicolumn{3}{|c|}{4.7330000000000005} & 5.2184 & TRN & \\
\hline CHEMBL1386791 & 688810 & 4.833 & 5.0112 & TST & & & \\
\hline CHEMBL1423437 & 688810 & 4.833 & 4.9127 & TST & & & \\
\hline CHEMBL1479021 & 688810 & \multicolumn{3}{|c|}{5.2829999999999995} & 5.5322 & TRN & \\
\hline CHEMBL1502698 & 688810 & 4.833 & 5.2556 & TRN & & & \\
\hline CHEMBL1424752 & 688810 & \multicolumn{3}{|c|}{4.7330000000000005} & 5.5494 & TST & \\
\hline CHEMBL1510089 & 688810 & \multicolumn{3}{|c|}{5.632999999999999} & 5.4398 & TRN & \\
\hline CHEMBL1349851 & 688810 & 5.433 & 5.4851 & TRN & & & \\
\hline CHEMBL 3208846 & 688810 & 4.883 & 5.3737 & TRN & & & \\
\hline CHEMBL1337458 & 688810 & \multicolumn{3}{|c|}{4.7330000000000005} & 5.5606 & TRN & \\
\hline CHEMBL1579812 & 688810 & \multicolumn{3}{|c|}{5.882999999999999} & 5.5662 & TRN & \\
\hline CHEMBL3197825 & 688810 & 4.933 & 5.1773 & TST & & & \\
\hline CHEMBL1354155 & 688810 & \multicolumn{3}{|c|}{5.5329999999999995} & 5.37200 & 0000000001 & TRN \\
\hline CHEMBL1328036 & 688810 & \multicolumn{3}{|c|}{6.5329999999999995} & 6.0223 & TRN & \\
\hline CHEMBL1430455 & 688810 & 5.683 & 5.4792 & TRN & & & \\
\hline CHEMBL1551178 & 688810 & & & TRN & & & \\
\hline CHEMBL609899 & 688810 & \multicolumn{3}{|c|}{4.7330000000000005} & 4.8547 & TRN & \\
\hline CHEMBL1499296 & 688810 & 5.933 & 5.7188 & TRN & & & \\
\hline CHEMBL1411186 & 688810 & 5.033 & 5.1903 & TRN & & & \\
\hline CHEMBL1352489 & 688810 & \multicolumn{3}{|c|}{6.382999999999999} & 5.5917 & TST & \\
\hline CHEMBL1394612 & 688810 & \multicolumn{3}{|c|}{4.7330000000000005} & 4.7862 & TRN & \\
\hline CHEMBL1547349 & 688810 & \multicolumn{3}{|c|}{6.0329999999999995} & 5.9395 & TRN & \\
\hline CHEMBL1360460 & 688810 & 4.883 & 5.0012 & TRN & & & \\
\hline CHEMBL1368342 & 688810 & 4.933 & 5.067 & TRN & & & \\
\hline CHEMBL1340992 & 688810 & 5.083 & 5.4997 & TST & & & \\
\hline CHEMBL1435202 & 688810 & 4.833 & 4.931 & TST & & & \\
\hline CHEMBL1495905 & 688810 & 5.83299 & 99999999 & & 6.1741 & TRN & \\
\hline CHEMBL1374554 & 688810 & 4.883 & 4.9617 & TRN & & & \\
\hline
\end{tabular}




\begin{tabular}{|c|c|c|c|c|c|c|c|}
\hline \multicolumn{8}{|c|}{ oplemental lable s2.txt } \\
\hline CHEMBL1334637 & 688810 & 5.083 & 5.3053 & TRN & & & \\
\hline CHEMBL1578743 & 688810 & \multicolumn{3}{|c|}{5.332999999999999} & 5.3686 & TST & \\
\hline CHEMBL1300307 & 688810 & 5.983 & 5.6661 & TRN & & & \\
\hline CHEMBL1477650 & 688810 & 4.833 & 5.1218 & TRN & & & \\
\hline CHEMBL1327845 & 688810 & 4.633 & 4.8611 & TRN & & & \\
\hline CHEMBL1465667 & 688810 & \multicolumn{3}{|c|}{4.7330000000000005} & 5.3816 & TST & \\
\hline CHEMBL1432468 & 688810 & 5.233 & 4.9076 & TST & & & \\
\hline CHEMBL3195123 & 688810 & \multicolumn{3}{|c|}{6.332999999999999} & 5.343 & TST & \\
\hline CHEMBL1551080 & 688810 & \multicolumn{3}{|c|}{4.7330000000000005} & 4.6436 & TRN & \\
\hline CHEMBL1334888 & 688810 & \multicolumn{3}{|c|}{5.132999999999999} & 5.0339 & TRN & \\
\hline CHEMBL1554151 & 688810 & 5.683 & 5.4125 & TRN & & & \\
\hline CHEMBL 1479647 & 688810 & 4.633 & 4.9142 & TRN & & & \\
\hline CHEMBL1346791 & 688810 & 5.033 & 4.9767 & TRN & & & \\
\hline CHEMBL1504970 & 688810 & \multicolumn{3}{|c|}{5.5329999999999995} & 5.0087 & TST & \\
\hline CHEMBL1491570 & 688810 & 4.833 & 5.2505 & TST & & & \\
\hline CHEMBL1367817 & 688810 & 4.583 & 4.8485 & TRN & & & \\
\hline CHEMBL1481721 & 688810 & 5.233 & 5.499 & TRN & & & \\
\hline CHEMBL1391340 & 688810 & 5.083 & 5.0522 & TST & & & \\
\hline CHEMBL1384533 & 688810 & 6.45 & 5.7431 & TRN & & & \\
\hline CHEMBL1606553 & 688810 & 4.633 & 4.7969 & TRN & & & \\
\hline CHEMBL1491322 & 688810 & 4.633 & 4.9008 & TST & & & \\
\hline CHEMBL1527882 & 688810 & \multicolumn{3}{|c|}{4.9830000000000005} & 5.4808 & TRN & \\
\hline CHEMBL3209866 & 688810 & 4.783 & 5.4114 & TST & & & \\
\hline CHEMBL 3196341 & 688810 & \multicolumn{3}{|c|}{5.582999999999999} & 5.1013 & TST & \\
\hline CHEMBL1453239 & 688810 & \multicolumn{3}{|c|}{4.7330000000000005} & 5.3868 & TST & \\
\hline CHEMBL1374795 & 688810 & 6.183 & 5.4654 & TRN & & & \\
\hline CHEMBL1520913 & 688810 & \multicolumn{3}{|c|}{4.7330000000000005} & 4.7656 & TST & \\
\hline CHEMBL1468473 & 688810 & 4.633 & 4.8245 & TRN & & & \\
\hline CHEMBL1590717 & 688810 & 4.583 & 5.0467 & TRN & & & \\
\hline CHEMBL1432811 & 688810 & 4.833 & 5.2892 & TRN & & & \\
\hline CHEMBL1311906 & 688810 & \multicolumn{3}{|c|}{5.132999999999999} & 4.954 & TST & \\
\hline CHEMBL1320542 & 688810 & 4.783 & 5.1556 & TRN & & & \\
\hline CHEMBL1530023 & 688810 & 5.683 & 5.3518 & TST & & & \\
\hline CHEMBL 3210893 & 688810 & \multicolumn{3}{|c|}{5.5329999999999995} & 5.38299 & 9999999999 & TRN \\
\hline CHEMBL1403565 & 688810 & 6.183 & 5.3371 & TRN & & & \\
\hline CHEMBL1604679 & 688810 & \multicolumn{3}{|c|}{5.832999999999999} & 5.3201 & TRN & \\
\hline CHEMBL1400469 & 688810 & 4.783 & 4.6103 & TST & & & \\
\hline CHEMBL1566411 & 688810 & 4.783 & 5.6414 & TRN & & & \\
\hline CHEMBL1597829 & 688810 & 5.433 & 4.9759 & TST & & & \\
\hline CHEMBL1096706 & 688810 & 6.183 & 5.7549 & TRN & & & \\
\hline CHEMBL1483507 & 688810 & \multicolumn{3}{|c|}{6.832999999999999} & 5.5743 & TRN & \\
\hline CHEMBL1472143 & 688810 & 4.783 & \multicolumn{3}{|c|}{5.4270000000000005} & TRN & \\
\hline CHEMBL1483169 & 688810 & 4.833 & 4.9075 & TRN & & & \\
\hline CHEMBL162808 & 688810 & 5.033 & 5.1902 & TRN & & & \\
\hline CHEMBL1483562 & 688810 & 4.833 & 5.2011 & TST & & & \\
\hline CHEMBL1560799 & 688810 & \multicolumn{3}{|c|}{5.832999999999999} & 4.9837 & TRN & \\
\hline CHEMBL1352854 & 688810 & \multicolumn{3}{|c|}{8.283999999999999} & 5.7271 & TST & \\
\hline CHEMBL1584331 & 688810 & \multicolumn{3}{|c|}{5.132999999999999} & 5.2094 & TRN & \\
\hline
\end{tabular}




\begin{tabular}{|c|c|c|c|c|c|c|}
\hline \multicolumn{7}{|c|}{ Supplemental Table S2.txt } \\
\hline CHEMBL1332340 & 688810 & \multicolumn{3}{|c|}{5.132999999999999} & 5.3789 & TRN \\
\hline CHEMBL1528905 & 688810 & \multicolumn{3}{|c|}{6.082999999999999} & 5.4777 & TRN \\
\hline CHEMBL 3212522 & 688810 & 5.183 & 5.1579 & TRN & & \\
\hline CHEMBL1352269 & 688810 & \multicolumn{3}{|c|}{5.5329999999999995} & 5.4707 & TRN \\
\hline CHEMBL1448774 & 688810 & 7.0329 & 5.8845 & TRN & & \\
\hline CHEMBL1528562 & 688810 & 4.833 & 5.5678 & TRN & & \\
\hline CHEMBL1301396 & 688810 & 4.883 & 4.7339 & TRN & & \\
\hline CHEMBL1596014 & 688810 & \multicolumn{3}{|c|}{4.7330000000000005} & 5.4372 & TST \\
\hline CHEMBL1375320 & 688810 & \multicolumn{3}{|c|}{4.7330000000000005} & 4.8474 & TST \\
\hline CHEMBL1555728 & 688810 & 4.833 & 4.9421 & TST & & \\
\hline CHEMBL1547372 & 688810 & 5.483 & 5.4622 & TRN & & \\
\hline CHEMBL1506034 & 688810 & \multicolumn{3}{|c|}{5.332999999999999} & 5.1496 & TRN \\
\hline CHEMBL1494595 & 688810 & \multicolumn{3}{|c|}{6.2829999999999995} & 5.3568 & TRN \\
\hline CHEMBL1415404 & 688810 & 5.0 & 5.4222 & TRN & & \\
\hline CHEMBL1999161 & 688810 & 5.233 & 5.4499 & TST & & \\
\hline CHEMBL1982381 & 688810 & 5.983 & 5.7163 & TST & & \\
\hline CHEMBL1512730 & 688810 & 4.833 & 5.2404 & TRN & & \\
\hline CHEMBL1577482 & 688810 & 5.733 & 5.0226 & TRN & & \\
\hline CHEMBL1389445 & 688810 & 5.683 & 5.1164 & TRN & & \\
\hline CHEMBL1580001 & 688810 & \multicolumn{3}{|c|}{5.332999999999999} & 5.0922 & TRN \\
\hline CHEMBL1492000 & 688810 & \multicolumn{3}{|c|}{5.2829999999999995} & 5.3989 & TST \\
\hline CHEMBL1497432 & 688810 & \multicolumn{3}{|c|}{5.2829999999999995} & 5.0718 & TRN \\
\hline CHEMBL1472208 & 688810 & \multicolumn{3}{|c|}{4.9830000000000005} & 5.3074 & TST \\
\hline CHEMBL1589679 & 688810 & \multicolumn{3}{|c|}{5.832999999999999} & 5.1775 & TRN \\
\hline CHEMBL1370760 & 688810 & \multicolumn{3}{|c|}{4.7330000000000005} & 5.0194 & TRN \\
\hline CHEMBL1359308 & 688810 & 5.683 & 5.6704 & TRN & & \\
\hline CHEMBL1333655 & 688810 & & & TST & & \\
\hline CHEMBL1310534 & 688810 & \multicolumn{3}{|c|}{5.132999999999999} & 5.0826 & TRN \\
\hline CHEMBL1361203 & 688810 & \multicolumn{3}{|c|}{5.832999999999999} & 5.58899 & 99999999995 \\
\hline CHEMBL1309869 & 688810 & 4.833 & 5.2438 & TRN & & \\
\hline CHEMBL1412597 & 688810 & 6.4829 & 5.8628 & TRN & & \\
\hline CHEMBL1513630 & 688810 & \multicolumn{3}{|c|}{5.332999999999999} & 5.5908 & TRN \\
\hline CHEMBL1520098 & 688810 & \multicolumn{3}{|c|}{5.382999999999999} & 5.1134 & TRN \\
\hline CHEMBL1451931 & 688810 & \multicolumn{3}{|c|}{4.7330000000000005} & 5.0121 & TST \\
\hline CHEMBL 3197876 & 688810 & 4.783 & 5.4387 & TRN & & \\
\hline CHEMBL1480878 & 688810 & 4.633 & 4.9166 & TRN & & \\
\hline CHEMBL1479814 & 688810 & 4.633 & 5.1196 & TRN & & \\
\hline CHEMBL1347186 & 688810 & \multicolumn{3}{|c|}{6.132999999999999} & 5.7809 & TST \\
\hline CHEMBL1605551 & 688810 & 5.183 & 5.5503 & TST & & \\
\hline CHEMBL1300116 & 688810 & \multicolumn{3}{|c|}{6.082999999999999} & 4.8631 & TRN \\
\hline CHEMBL1336308 & 688810 & 4.883 & 5.0417 & TST & & \\
\hline CHEMBL1321343 & 688810 & 4.783 & 5.0576 & TST & & \\
\hline CHEMBL1459751 & 688810 & 4.933 & 5.2344 & TRN & & \\
\hline CHEMBL1347021 & 688810 & 4.73300 & 00000000 & 005 & 5.7173 & TST \\
\hline CHEMBL1311391 & 688810 & 5.083 & 5.0256 & TRN & & \\
\hline CHEMBL1390421 & 688810 & 6.683 & 5.9472 & TRN & & \\
\hline CHEMBL570468 & 688810 & 5.683 & 5.699 & TRN & & \\
\hline CHEMBL1450513 & 688810 & 5.78299 & 99999999 & 995 & 5.5272 & TRN \\
\hline
\end{tabular}




\begin{tabular}{|c|c|c|c|c|c|c|}
\hline \multicolumn{7}{|c|}{ Supplemental Table S2.txt } \\
\hline CHEMBL1385176 & 688810 & \multicolumn{3}{|c|}{6.632999999999999} & 5.7138 & TRN \\
\hline CHEMBL1584890 & 688810 & 5.083 & 4.7902 & TST & & \\
\hline CHEMBL1447047 & 688810 & 4.833 & 5.2322 & TST & & \\
\hline CHEMBL1364528 & 688810 & \multicolumn{3}{|c|}{5.382999999999999} & 5.9095 & TRN \\
\hline CHEMBL1548454 & 688810 & 4.933 & 5.2242 & TRN & & \\
\hline CHEMBL1990027 & 688810 & \multicolumn{3}{|c|}{5.132999999999999} & 5.3857 & TRN \\
\hline CHEMBL1311348 & 688810 & \multicolumn{3}{|c|}{5.832999999999999} & 5.5556 & TST \\
\hline CHEMBL2369172 & 688810 & 4.883 & 4.967 & TRN & & \\
\hline CHEMBL3192599 & 688810 & 5.183 & 5.0737 & TRN & & \\
\hline CHEMBL1431577 & 688810 & 6.0 & \multicolumn{3}{|c|}{5.9239999999999995} & TRN \\
\hline CHEMBL1348796 & 688810 & \multicolumn{3}{|c|}{5.582999999999999} & 5.1244 & TST \\
\hline CHEMBL1333754 & 688810 & \multicolumn{3}{|c|}{4.7330000000000005} & 5.0174 & TRN \\
\hline CHEMBL1334212 & 688810 & \multicolumn{3}{|c|}{4.7330000000000005} & 5.4027 & TRN \\
\hline CHEMBL1556714 & 688810 & \multicolumn{3}{|c|}{4.7330000000000005} & 5.20299 & 9999999999 \\
\hline CHEMBL1417091 & 688810 & \multicolumn{3}{|c|}{4.7330000000000005} & 5.2941 & TRN \\
\hline CHEMBL1332932 & 688810 & 4.933 & 5.2336 & TRN & & \\
\hline CHEMBL1545553 & 688810 & \multicolumn{3}{|c|}{4.7330000000000005} & 5.2289 & TST \\
\hline CHEMBL1568996 & 688810 & \multicolumn{3}{|c|}{6.0329999999999995} & 5.5882 & TST \\
\hline CHEMBL1385784 & 688810 & 5.033 & 4.9175 & TRN & & \\
\hline CHEMBL1472422 & 688810 & \multicolumn{3}{|c|}{5.832999999999999} & 5.0015 & TRN \\
\hline CHEMBL1556219 & 688810 & \multicolumn{3}{|c|}{4.7330000000000005} & 4.8099 & TRN \\
\hline CHEMBL1323071 & 688810 & 4.783 & 5.3374 & TST & & \\
\hline CHEMBL600908 & 688810 & 4.833 & 5.1366 & TRN & & \\
\hline CHEMBL1495974 & 688810 & \multicolumn{3}{|c|}{4.7330000000000005} & 5.0134 & TST \\
\hline CHEMBL1535386 & 688810 & \multicolumn{3}{|c|}{5.7829999999999995} & 5.4721 & TST \\
\hline CHEMBL57171 & 688810 & \multicolumn{3}{|c|}{4.9830000000000005} & 5.6082 & TRN \\
\hline CHEMBL1570417 & 688810 & \multicolumn{3}{|c|}{6.082999999999999} & 5.1754 & TRN \\
\hline CHEMBL1481547 & 688810 & \multicolumn{3}{|c|}{5.332999999999999} & 4.7857 & TRN \\
\hline CHEMBL1595264 & 688810 & 5.233 & 6.0772 & TRN & & \\
\hline CHEMBL1326042 & 688810 & \multicolumn{3}{|c|}{6.332999999999999} & 5.1662 & TRN \\
\hline CHEMBL1522937 & 688810 & 4.783 & 5.0955 & TRN & & \\
\hline CHEMBL 3191012 & 688810 & 5.83299 & 99999999 & & 5.3153 & TRN \\
\hline CHEMBL1527359 & 688810 & 4.783 & 5.095 & TRN & & \\
\hline CHEMBL1333377 & 688810 & 4.933 & 5.4056 & TRN & & \\
\hline CHEMBL1513053 & 688810 & 5.83299 & 99999999 & 99 & 5.3112 & TRN \\
\hline CHEMBL1471889 & 688810 & 4.833 & 5.1813 & TST & & \\
\hline CHEMBL1440489 & 688810 & 5.58299 & 99999999 & & 5.2337 & TRN \\
\hline CHEMBL1559914 & 688810 & 5.233 & 5.5755 & TRN & & \\
\hline CHEMBL1527590 & 688810 & 5.13299 & 99999999 & & 5.3791 & TST \\
\hline CHEMBL1380516 & 688810 & 5.183 & 5.6838 & TST & & \\
\hline CHEMBL1596530 & 688810 & 4.783 & $5.03100 t$ & 000000000 & & TRN \\
\hline CHEMBL1480062 & 688810 & 4.683 & 5.1574 & TRN & & \\
\hline CHEMBL1578622 & 688810 & 4.883 & 5.2692 & TRN & & \\
\hline CHEMBL73451 & 688810 & 4.883 & 5.2172 & TST & & \\
\hline CHEMBL1414345 & 688810 & 5.433 & 5.1056 & TRN & & \\
\hline CHEMBL1414516 & 688810 & 5.433 & 5.6594 & TRN & & \\
\hline CHEMBL1471417 & 688810 & 6.63299 & 999999995 & 99 & 5.6285 & TRN \\
\hline CHEMBL1322624 & 688810 & 5.683 & 5.5471 & TRN & & \\
\hline
\end{tabular}




\begin{tabular}{|c|c|c|c|c|c|c|}
\hline \multirow[b]{2}{*}{ CHEMBL3207762 } & \\
\hline & 688810 & 4.783 & 5.2578 & TST & & \\
\hline CHEMBL1362831 & 688810 & 4.98306 & 000000006 & 005 & 5.2706 & TRN \\
\hline CHEMBL1416701 & 688810 & $4.7330 e$ & 00000000 & 005 & 5.0368 & \\
\hline CHEMBL1524554 & 688810 & 5.38299 & 999999999 & & 5.0213 & \\
\hline CHEMBL1599107 & 688810 & 4.633 & 4.8653 & TRN & & \\
\hline CHEMBL1559775 & 688810 & $4.9830 e$ & 00000000 & 005 & 4.9135 & \\
\hline CHEMBL1349769 & 688810 & 5.5329 & 999999999 & 995 & 5.5009 & \\
\hline CHEMBL1480323 & 688810 & 5.78299 & 999999999 & 995 & 5.3737 & \\
\hline CHEMBL1584691 & 688810 & 5.433 & 5.3455 & TRN & & \\
\hline CHEMBL1611047 & 688810 & 5.88299 & 999999999 & & 5.2228 & \\
\hline CHEMBL1371395 & 688810 & 5.233 & 5.0788 & TST & & \\
\hline CHEMBL1600759 & 688810 & 4.783 & 4.9209 & TST & & \\
\hline CHEMBL1444869 & 688810 & 5.38299 & 999999999 & & 5.3376 & \\
\hline CHEMBL1354314 & 688810 & 5.233 & 5.4678 & TRN & & \\
\hline CHEMBL 3211100 & 688810 & 5.28299 & 999999999 & 995 & 5.1729 & \\
\hline CHEMBL1335171 & 688810 & 5.28299 & 999999999 & 995 & 5.5084 & \\
\hline CHEMBL1467322 & 688810 & 5.683 & 5.1915 & TRN & & \\
\hline CHEMBL1448729 & 688810 & 6.13299 & 999999999 & & 5.6523 & \\
\hline CHEMBL1597655 & 688810 & 5.53299 & 999999999 & 995 & 5.1931 & \\
\hline CHEMBL1364962 & 688810 & 4.833 & 5.0859 & TST & & \\
\hline CHEMBL1563668 & 688810 & 5.63299 & 999999999 & & 5.3771 & \\
\hline CHEMBL1522508 & 688810 & 5.63290 & 999999999 & & 5.3649 & \\
\hline CHEMBL1314425 & 688810 & 5.033 & 5.4429 & TRN & & \\
\hline CHEMBL1537269 & 688810 & 5.233 & 5.0317 & TST & & \\
\hline CHEMBL 3208570 & 688810 & 5.83299 & 999999999 & & 5.8086 & \\
\hline CHEMBL1415527 & 688810 & 6.38299 & 999999999 & & 5.7626 & \\
\hline CHEMBL1968383 & 688810 & 5.683 & 6.0924 & TRN & & \\
\hline CHEMBL1481868 & 688810 & 4.633 & 5.0018 & TST & & \\
\hline CHEMBL1547091 & 688810 & $4.7330 e$ & 000000006 & 005 & 4.8947 & \\
\hline CHEMBL1461906 & 688810 & 5.83299 & 999999999 & & 6.0263 & \\
\hline CHEMBL 3207633 & 688810 & $4.7330 e$ & 000000006 & 005 & 5.2071 & \\
\hline CHEMBL1494784 & 688810 & 4.583 & 4.5095 & TST & & \\
\hline CHEMBL1490882 & 688810 & 5.58299 & 999999999 & 99 & 5.5804 & \\
\hline CHEMBL1441085 & 688810 & 5.433 & 5.4308 & TST & & \\
\hline CHEMBL1449231 & 688810 & 4.883 & 5.1475 & TRN & & \\
\hline CHEMBL1406209 & 688810 & 4.883 & 4.9516 & TRN & & \\
\hline CHEMBL1409389 & 688810 & 5.53299 & 999999999 & 995 & 5.9401 & \\
\hline CHEMBL1370818 & 688810 & 5.983 & 5.2726 & TRN & & \\
\hline CHEMBL1449208 & 688810 & 5.78299 & 999999999 & 995 & 5.2377 & \\
\hline CHEMBL1470295 & 688810 & 5.933 & 5.3739 & TRN & & \\
\hline CHEMBL1503383 & 688810 & 4.833 & 5.0976 & TRN & & \\
\hline CHEMBL1447513 & 688810 & 6.433 & 5.5724 & TRN & & \\
\hline CHEMBL1384511 & 688810 & $4.7330 e$ & 00000000 & 005 & 5.2842 & \\
\hline CHEMBL1501673 & 688810 & 5.183 & 5.2686 & TST & & \\
\hline CHEMBL3190592 & 688810 & 5.683 & 5.3818 & TRN & & \\
\hline CHEMBL 3194277 & 688810 & 5.483 & 5.5023 & TRN & & \\
\hline CHEMBL1343260 & 688810 & 4.633 & 5.3058 & TST & & \\
\hline CHEMBL599100 & 688810 & 5.78299 & 999999999 & 995 & 5.7381 & \\
\hline
\end{tabular}




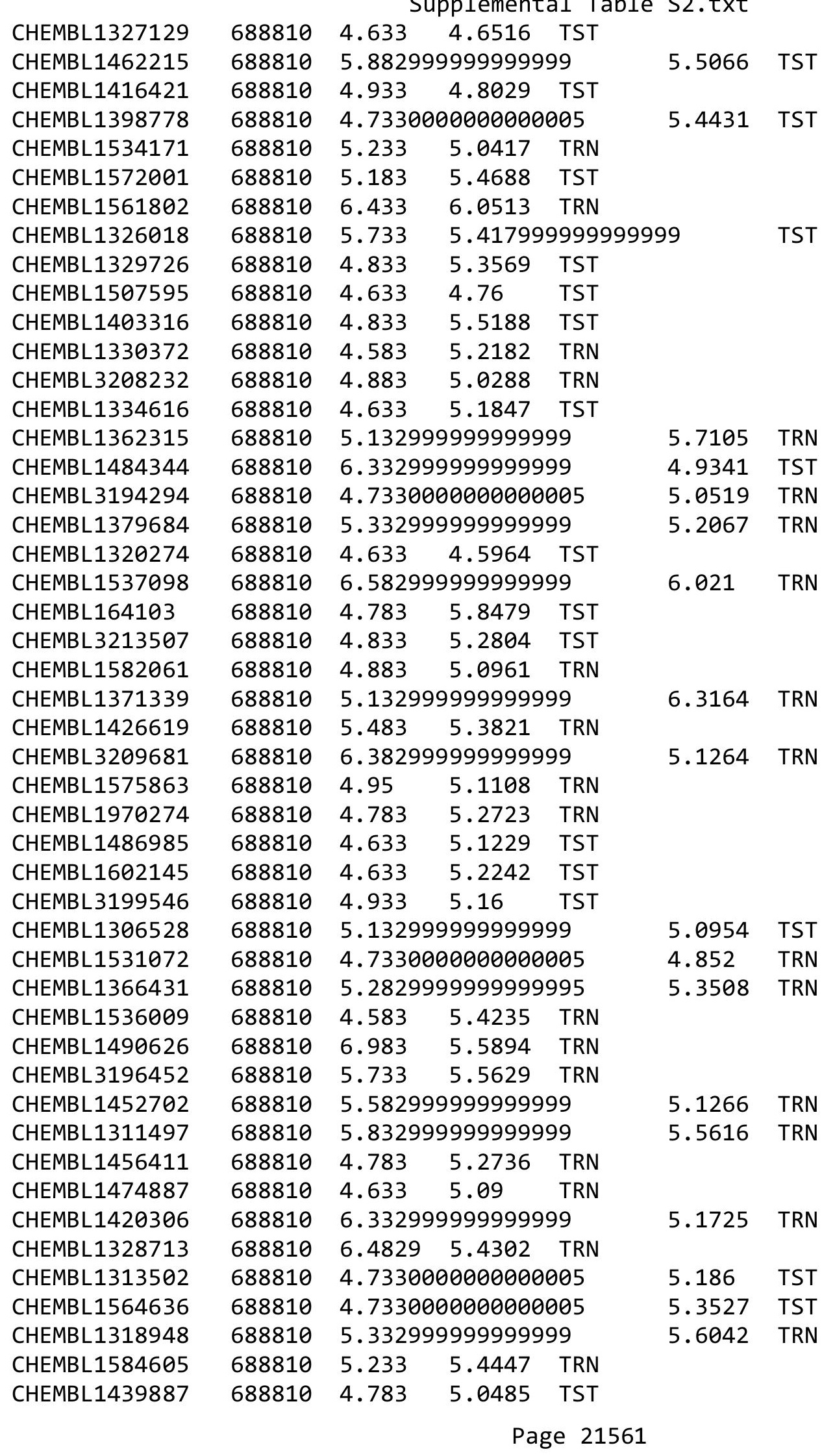




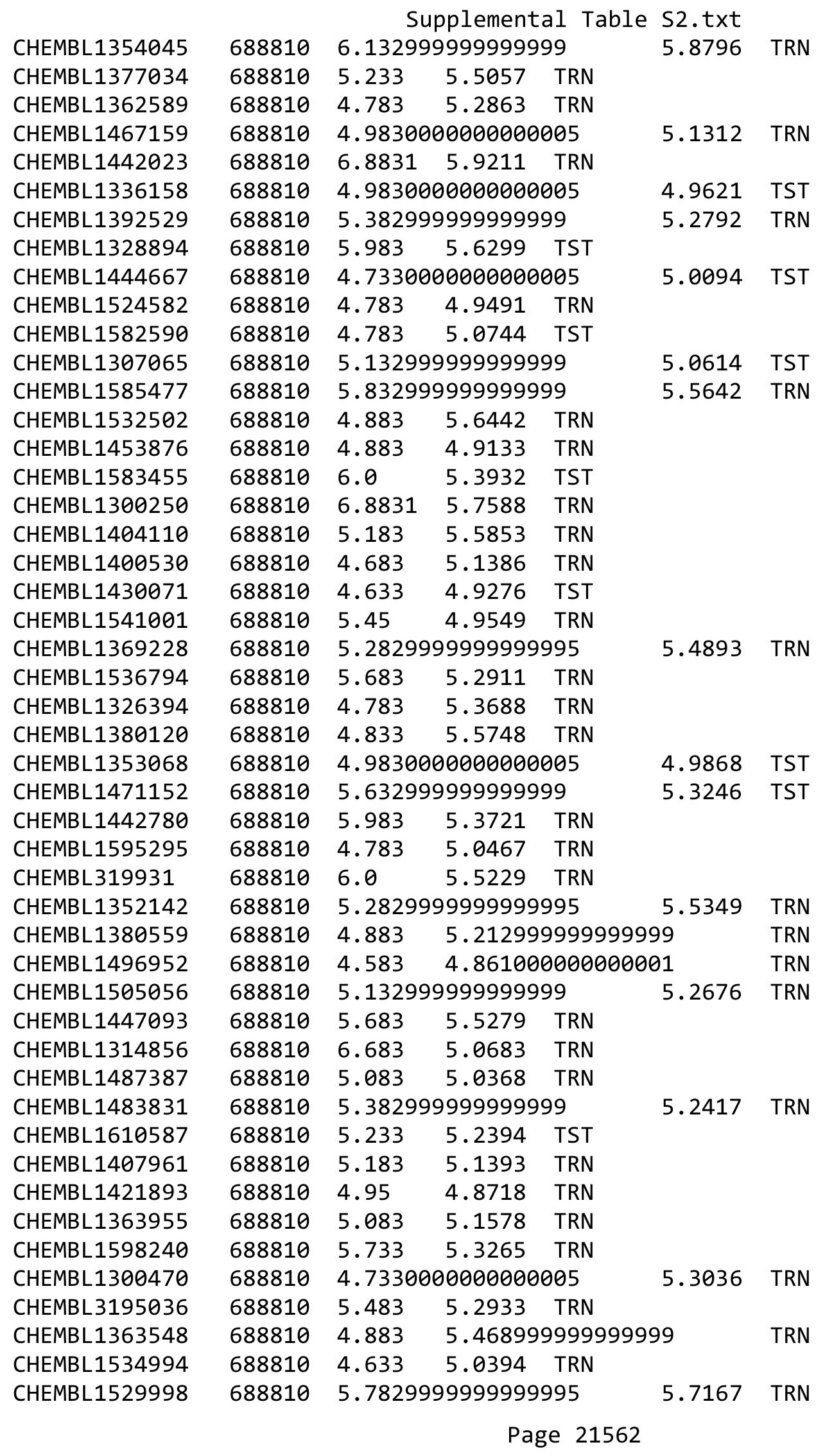




\begin{tabular}{|c|c|c|c|c|c|c|c|}
\hline \multicolumn{7}{|c|}{ Supplemental Table S2.txt } & \\
\hline CHEMBL1580875 & 688810 & 5.33299 & 99999999 & & 5.2639 & TRN & \\
\hline CHEMBL1495733 & 688810 & 5.183 & 4.9538 & TRN & & & \\
\hline CHEMBL1549960 & 688810 & 4.833 & 5.5147 & TRN & & & \\
\hline CHEMBL1471498 & 688810 & 4.833 & 5.291 & TST & & & \\
\hline CHEMBL1343664 & 688810 & 6.53299 & 999999995 & 995 & 5.90600 & 0000000001 & TST \\
\hline CHEMBL1555805 & 688810 & 6.03299 & 99999999 & 995 & 5.6537 & TST & \\
\hline CHEMBL1407182 & 688810 & 4.98300 & 00000000 & 005 & 5.1405 & TRN & \\
\hline CHEMBL1458464 & 688810 & 4.98300 & 00000000 & 005 & 4.9102 & TRN & \\
\hline CHEMBL1371257 & 688810 & 4.683 & 5.1128 & TRN & & & \\
\hline CHEMBL1547367 & 688810 & 5.38299 & 999999995 & & 4.9732 & TST & \\
\hline CHEMBL528696 & 688810 & 4.883 & 5.3452 & TST & & & \\
\hline CHEMBL1415042 & 688810 & 4.883 & 5.3364 & TRN & & & \\
\hline CHEMBL3190318 & 688810 & 6.58299 & 99999999 & & 5.755 & TST & \\
\hline CHEMBL1593028 & 688810 & 4.73300 & 00000000 & 005 & 5.1178 & TRN & \\
\hline CHEMBL3198953 & 688810 & 4.833 & 4.9192 & TRN & & & \\
\hline CHEMBL1370582 & 688810 & 4.883 & 5.6521 & TRN & & & \\
\hline CHEMBL1603941 & 688810 & 6.28299 & 99999999 & 995 & 5.6592 & TRN & \\
\hline CHEMBL1376011 & 688810 & 5.28299 & 99999999 & 995 & 5.6383 & TRN & \\
\hline CHEMBL1325385 & 688810 & 5.53299 & 99999999 & 995 & 5.1179 & TRN & \\
\hline CHEMBL1309247 & 688810 & 4.73300 & 000000006 & 005 & 4.7669 & TST & \\
\hline CHEMBL1394961 & 688810 & 6.4829 & 5.7862 & TRN & & & \\
\hline CHEMBL1471762 & 688810 & 5.683 & 5.0083 & TRN & & & \\
\hline CHEMBL1408463 & 688810 & 5.183 & 4.998 & TRN & & & \\
\hline CHEMBL1458790 & 688810 & 6.38299 & 99999999 & & 5.8311 & TRN & \\
\hline CHEMBL1375239 & 688810 & 4.783 & 5.2124 & TST & & & \\
\hline CHEMBL1345643 & 688810 & 5.63299 & 99999999 & & 5.6855 & TRN & \\
\hline CHEMBL1308382 & 688810 & 4.833 & 5.4916 & TST & & & \\
\hline CHEMBL1454714 & 688810 & 5.033 & 5.1143 & TRN & & & \\
\hline CHEMBL3197219 & 688810 & 5.83299 & 99999999 & & 5.5925 & TRN & \\
\hline CHEMBL3212798 & 688810 & 4.833 & 4.9939 & TRN & & & \\
\hline CHEMBL1560223 & 688810 & 5.9 & 5.6364 & TRN & & & \\
\hline CHEMBL1483747 & 688810 & 4.73300 & 00000000 & 005 & 4.9723 & TRN & \\
\hline CHEMBL1565207 & 688810 & 4.783 & 5.1239 & TRN & & & \\
\hline CHEMBL2002223 & 688810 & 6.03299 & 99999999 & 995 & 5.7374 & TST & \\
\hline CHEMBL1450072 & 688810 & 6.33299 & 99999999 & & 5.9776 & TRN & \\
\hline CHEMBL1466745 & 688810 & 4.933 & 5.4498 & TRN & & & \\
\hline CHEMBL1340957 & 688810 & 4.883 & $5.76200 t$ & 000000000 & 005 & TRN & \\
\hline CHEMBL1347736 & 688810 & 5.083 & 5.2571 & TRN & & & \\
\hline CHEMBL3195378 & 688810 & 4.73300 & 00000000 & 005 & 5.3664 & TST & \\
\hline CHEMBL1459020 & 688810 & 5.83299 & 99999999 & & 5.2705 & TRN & \\
\hline CHEMBL1338984 & 688810 & 4.833 & 5.4209 & TST & & & \\
\hline CHEMBL1529489 & 688810 & 4.933 & 5.4077 & TRN & & & \\
\hline CHEMBL1533132 & 688810 & 4.633 & 5.37200 & 000000000 & & TRN & \\
\hline CHEMBL1430486 & 688810 & 5.78299 & 99999999 & 995 & 5.8317 & TRN & \\
\hline CHEMBL1370071 & 688810 & 6.28299 & 99999999 & 995 & 5.8074 & TRN & \\
\hline CHEMBL1324122 & 688810 & 5.63299 & 99999999 & & 5.2478 & TRN & \\
\hline CHEMBL1529055 & 688810 & 4.883 & 5.1795 & TST & & & \\
\hline CHEMBL1337224 & 688810 & 4.633 & 5.6401 & TRN & & & \\
\hline
\end{tabular}




\begin{tabular}{|c|c|c|c|c|c|c|}
\hline \multirow{3}{*}{$\begin{array}{l}\text { CHEMBL } 3192707 \\
\text { CHEMBL1535200 }\end{array}$} & \multicolumn{6}{|c|}{ Supplemental Table S2.txt } \\
\hline & 688810 & \multicolumn{3}{|c|}{4.7330000000000005} & 5.4337 & TST \\
\hline & 688810 & 6.4829 & 4.7967 & TRN & & \\
\hline CHEMBL1422132 & 688810 & \multicolumn{3}{|c|}{5.7829999999999995} & 5.271 & $\mathrm{TI}$ \\
\hline CHEMBL1362849 & 688810 & \multicolumn{3}{|c|}{5.2829999999999995} & 5.2922 & \\
\hline CHEMBL1379886 & 688810 & \multicolumn{3}{|c|}{5.7829999999999995} & 5.4193 & \\
\hline CHEMBL1578310 & 688810 & 4.683 & 5.3704 & TRN & & \\
\hline CHEMBL1975210 & 688810 & \multicolumn{3}{|c|}{5.582999999999999} & 5.4635 & TRN \\
\hline CHEMBL1489218 & 688810 & 4.933 & 5.1184 & TST & & \\
\hline CHEMBL1367720 & 688810 & \multicolumn{3}{|c|}{4.7330000000000005} & 4.9238 & \\
\hline CHEMBL1360618 & 688810 & 7.0329 & 6.0955 & TRN & & \\
\hline CHEMBL1532141 & 688810 & 4.633 & 5.1247 & TRN & & \\
\hline CHEMBL1570587 & 688810 & 5.033 & 5.5824 & TRN & & \\
\hline CHEMBL1609799 & 688810 & 5.183 & 4.8779 & TRN & & \\
\hline CHEMBL1371386 & 688810 & \multicolumn{3}{|c|}{5.582999999999999} & 5.524 & \\
\hline CHEMBL1609667 & 688 & 4.633 & 5.1125 & TRN & & \\
\hline CHEMBL1371455 & 688 & \multicolumn{3}{|c|}{5.7829999999999995} & 5.8234 & TRN \\
\hline CHEMBL13 & 688 & \multicolumn{3}{|c|}{5.882999999999999} & 5.6818 & \\
\hline CHEMBL1609852 & 688810 & 4.883 & 5.4964 & TRN & & \\
\hline CHEMBL1532318 & 688810 & \multicolumn{3}{|c|}{5.132999999999999} & 5.6272 & TRN \\
\hline CHEMBL1565124 & 688810 & \multicolumn{3}{|c|}{4.7330000000000005} & 5.0352 & TRN \\
\hline CHEMBL1308660 & 688 & \multicolumn{3}{|c|}{5.7829999999999995} & 5.2505 & TRN \\
\hline CHEMBL1 & $68 \varepsilon$ & \multicolumn{3}{|c|}{5.7829999999999995} & 5.8652 & \\
\hline CHEMBL1580434 & 688810 & \multicolumn{3}{|c|}{5.132999999999999} & 5.3978 & TST \\
\hline CHEMBL1514521 & 688810 & 4.833 & 5.0807 & TRN & & \\
\hline CHEMBL1325360 & 688810 & \multicolumn{3}{|c|}{5.2829999999999995} & ד. & \\
\hline CHEMBL1 & 688 & 5.433 & 5.9642 & TRN & & \\
\hline CHEMBL1461168 & 688 & \multicolumn{3}{|c|}{5.832999999999999} & 5.1594 & TP \\
\hline CHEMBL1435262 & 688810 & 4.633 & 4.7723 & TRN & & \\
\hline CHEMBL1575616 & 688810 & 5 & 5.2934 & TRN & & \\
\hline CHEMBL1425867 & 688810 & 4.883 & 5.3224 & TRN & & \\
\hline CHEMBL: & 688 & \multicolumn{3}{|c|}{5.582999999999999} & 5.5323 & $\mathrm{~T}$ \\
\hline CHEMBL & 688 & 5.733 & 5.9411 & TRN & & \\
\hline CHEMBL1566877 & 688810 & \multicolumn{3}{|c|}{6.132999999999999} & 6.5456 & TRN \\
\hline CHEMBL1330469 & 688810 & \multicolumn{3}{|c|}{5.582999999999999} & 5.6679 & \\
\hline CHEMBL1426792 & 688810 & 5.233 & 5.1355 & TRN & & \\
\hline CHEMBL: & 688 & 5. & 5.2 & TST & & \\
\hline CHEMBL1388864 & 688 & 6.233 & 5.5427 & TRN & & \\
\hline CHEMBL1402711 & 688810 & 5.183 & 5.7635 & TRN & & \\
\hline CHEMBL1339084 & 688810 & 5.13299 & 99999999 & & 5.5317 & TP \\
\hline CHEMBL1519844 & 688810 & 5.88299 & 99999999 & & 5.8712 & $\mathrm{TP}$ \\
\hline CHEMBL1390926 & 688810 & 4.783 & 5.1571 & TRN & & \\
\hline CHEMBL1578738 & 688810 & 4.683 & 5.4093 & TRN & & \\
\hline CHEMBL1305478 & 688810 & 4.633 & 5.4287 & TST & & \\
\hline CHEMBL1517600 & 688810 & 6.233 & 5.6018 & TRN & & \\
\hline CHEMBL1355848 & 6888 & 4.583 & 4.5584 & TRN & & \\
\hline CHEMBL1364728 & 688810 & 5.63299 & 99999999 & & 5.2358 & TRN \\
\hline CHEMBL1348066 & 688810 & 6.38299 & 99999999 & & 6.2843 & TST \\
\hline CHEMBL1406878 & 688810 & 5.33299 & 9999999 & & 5.5123 & TRN \\
\hline
\end{tabular}




\begin{tabular}{|c|c|c|c|c|c|c|}
\hline & \multicolumn{5}{|c|}{ oplemental Table } \\
\hline CHEMBL1401867 & 688810 & 5.683 & 5.9448 & TRN & & \\
\hline CHEMBL1555935 & 688810 & 5.3329 & 99999999 & & 6.0628 & TRN \\
\hline CHEMBL 3196535 & 688810 & 5.083 & 5.0067 & TRN & & \\
\hline CHEMBL 3194301 & 688810 & 5.183 & 5.7704 & TRN & & \\
\hline CHEMBL1517848 & 688810 & 4.95 & 5.3198 & TST & & \\
\hline CHEMBL1531705 & 688810 & 6.983 & 5.8047 & TRN & & \\
\hline CHEMBL1384292 & 688810 & 5.933 & 6.2191 & TRN & & \\
\hline CHEMBL1323308 & 688810 & 5.5329 & 99999999 & 995 & 5.6896 & TRN \\
\hline CHEMBL1488483 & 688810 & 4.883 & 5.0489 & TRN & & \\
\hline CHEMBL1314949 & 688810 & 4.9830 & 00000000 & 005 & 5.0349 & $\mathrm{Tr}$ \\
\hline CHEMBL1333810 & 688810 & 4.633 & 4.6977 & TST & & \\
\hline CHEMBL1537074 & 688810 & 4.783 & 5.0353 & TRN & & \\
\hline CHEMBL1383978 & 688810 & 4.9 & 5.415 & TRN & & \\
\hline CHEMBL1585539 & 688810 & 4.7330 & 00000000 & 005 & 5.4041 & TRN \\
\hline CHEMBL1532242 & 688810 & 5.1329 & 99999999 & & 4.9289 & \\
\hline CHEMBL1511424 & 688810 & 4.933 & 4.9639 & TRN & & \\
\hline CHEMBL1570104 & 688810 & 4.683 & 5.3141 & TST & & \\
\hline CHEMBL1362507 & 688810 & 6.0 & 6.3902 & TST & & \\
\hline CHEMBL1387510 & 688810 & 5.1329 & 99999999 & & 3 & זענו \\
\hline CHEMBL1532476 & 688810 & 4.7330 & 00000000 & 005 & 5.4 & \\
\hline CHEMBL1607316 & 688810 & 4.85 & 5.0828 & TRN & & \\
\hline CHEMBL1367487 & 688810 & 6.0829 & 99999999 & & 5.2138 & TRN \\
\hline CHEMBL1304864 & 688810 & 4.7330 & 00000000 & 005 & 4.9597 & TST \\
\hline CHEMBL 3193361 & 688810 & 5.1329 & 99999999 & & 4.9125 & \\
\hline CHEMBL1550087 & 688810 & 5.983 & 5.6991 & TRN & & \\
\hline CHEMBL1568104 & 688810 & 5.483 & 5.7489 & TRN & & \\
\hline CHEMBL1348239 & 688810 & 5.483 & 5.5533 & TRN & & \\
\hline CHEMBL1495889 & 688810 & 6.0829 & 99999999 & & 5.3039 & II \\
\hline CHEMBL1607026 & 688810 & 4.783 & 5.4096 & TRN & & \\
\hline CHEMBL1365960 & 688810 & 4.883 & 5.0019 & TRN & & \\
\hline CHEMBL1321703 & 688810 & 5.1329 & 99999999 & & 5.6923 & $\mathrm{TP}$ \\
\hline CHEMBL1469035 & 688810 & 5.233 & 5.2592 & TRN & & \\
\hline CHEMBL1598598 & 688810 & 5.8329 & 99999999 & & .4846 & \\
\hline CHEMBL1517473 & 688810 & 5.1329 & 99999999 & & 5.3 & कातार \\
\hline CHEMBL1577975 & 688810 & 5.5329 & 99999999 & 995 & 5.5831 & TRN \\
\hline CHEMBL1380478 & 688810 & 5.083 & 5.3206 & TST & & \\
\hline CHEMBL3209392 & 688810 & 5.183 & 4.8043 & TST & & \\
\hline CHEMBL 2369211 & 688810 & 6.233 & 5.5648 & TRN & & \\
\hline CHEMBL1413172 & 688810 & 4.633 & 4.9632 & TST & & \\
\hline CHEMBL1310440 & 688810 & 4.7330 & 00000000 & 005 & 5.2349 & TST \\
\hline CHEMBL1327684 & 688810 & 5.033 & 5.37200 & 000000000 & 01 & TRN \\
\hline CHEMBL1599273 & 688810 & 4.683 & 5.1572 & TRN & & \\
\hline CHEMBL1568945 & 688810 & 4.783 & 5.1261 & TRN & & \\
\hline CHEMBL1540740 & 688810 & 4.833 & 5.7727 & TST & & \\
\hline CHEMBL1603503 & 688810 & 4.7330 & 00000000 & 005 & 5.1814 & I RIV \\
\hline CHEMBL1579693 & 688810 & 5.7829 & 99999999 & 995 & 5.3404 & TRN \\
\hline CHEMBL1598568 & 688810 & 5.8329 & 99999999 & & 5.5743 & In \\
\hline CHEMBL254216 & 688810 & 4.933 & 5.5095 & TRN & & \\
\hline
\end{tabular}




\begin{tabular}{|c|c|c|c|c|c|c|c|}
\hline \multicolumn{8}{|c|}{ pplemental Table S2. } \\
\hline CHEMBL1533579 & 688810 & 4.783 & 5.3624 & TRN & & & \\
\hline CHEMBL1567888 & 688810 & 4.783 & 4.8342 & TST & & & \\
\hline CHEMBL1468761 & 688810 & 5.933 & 5.20100 & 0000000006 & & TRN & \\
\hline CHEMBL1426292 & 688810 & 5.033 & 5.1228 & TST & & & \\
\hline CHEMBL1331634 & 688810 & 4.783 & 5.1378 & TRN & & & \\
\hline CHEMBL1494750 & 688810 & 4.583 & 4.883 & TRN & & & \\
\hline CHEMBL1583129 & 688810 & 5.1329 & 99999999 & 99 & 4.8019 & TST & \\
\hline CHEMBL1450085 & 688810 & 5.083 & 5.1779 & TRN & & & \\
\hline CHEMBL1604964 & 688810 & 5.083 & 5.1828 & TRN & & & \\
\hline CHEMBL1448415 & 688810 & 4.583 & 5.5072 & TRN & & & \\
\hline CHEMBL1470875 & 688810 & 5.683 & 5.1402 & TST & & & \\
\hline CHEMBL3191854 & 688810 & 4.783 & 5.3722 & TST & & & \\
\hline CHEMBL1566723 & 688810 & 4.7330 & 00000000 & 005 & 5.0921 & TST & \\
\hline CHEMBL1311047 & 688810 & 5.733 & 5.0002 & TST & & & \\
\hline CHEMBL1356590 & 688810 & 4.783 & 5.2174 & TST & & & \\
\hline CHEMBL1496862 & 688810 & 4.833 & 5.1334 & TRN & & & \\
\hline CHEMBL1541975 & 688810 & 4.833 & 5.3026 & TST & & & \\
\hline CHEMBL3208555 & 688810 & 4.883 & 5.6068 & TRN & & & \\
\hline CHEMBL 3193141 & 688810 & 5.233 & 5.3403 & TRN & & & \\
\hline CHEMBL1434948 & 688810 & 4.633 & 4.8446 & TRN & & & \\
\hline CHEMBL1561929 & 688810 & 4.833 & 5.0964 & TRN & & & \\
\hline CHEMBL1964467 & 688810 & 6.183 & 5.6587 & TRN & & & \\
\hline CHEMBL1476813 & 688810 & 5.8329 & 99999999 & & 5.5404 & TRN & \\
\hline CHEMBL1300733 & 688810 & 5.933 & 5.8346 & TRN & & & \\
\hline CHEMBL1603029 & 688810 & 4.783 & 4.8368 & TST & & & \\
\hline CHEMBL190880 & 688810 & 4.7330 & 00000000 & 005 & 4.939 & TRN & \\
\hline CHEMBL1338187 & 688810 & 4.7330 & 00000000 & 005 & 5.0856 & TST & \\
\hline CHEMBL1391313 & 688810 & 5.083 & 5.358 & TRN & & & \\
\hline CHEMBL1311403 & 688810 & 5.3 & 4.8219 & TRN & & & \\
\hline CHEMBL1581549 & 688810 & 4.783 & 5.7014 & TST & & & \\
\hline CHEMBL1435346 & 688810 & 5.1329 & 99999999 & & 5.3796 & TRN & \\
\hline CHEMBL1342936 & 688810 & 4.933 & 5.011 & TRN & & & \\
\hline CHEMBL1364306 & 688810 & 5.683 & 5.58299 & 9999999999 & & TRN & \\
\hline CHEMBL1519399 & 688810 & 4.783 & 5.3593 & TRN & & & \\
\hline CHEMBL1601447 & 688810 & 4.883 & 5.3152 & TST & & & \\
\hline CHEMBL1425422 & 688810 & 5.183 & 4.7393 & TST & & & \\
\hline CHEMBL1992764 & 688810 & 6.3329 & 99999999 & & 5.3188 & TST & \\
\hline CHEMBL1532656 & 688810 & 6.0329 & 99999999 & 995 & 5.50799 & 9999999999 & TRN \\
\hline CHEMBL1533140 & 688810 & 4.7330 & 00000000 & 005 & 5.261 & TRN & \\
\hline CHEMBL1579777 & 688810 & 6.2829 & 99999999 & 995 & 5.5223 & TRN & \\
\hline CHEMBL1501506 & 688810 & 5.3829 & 99999999 & & 5.2451 & TST & \\
\hline CHEMBL1333002 & 688810 & 4.833 & 5.3938 & TRN & & & \\
\hline CHEMBL3189196 & 688810 & 5.3329 & 99999999 & & 5.0708 & TST & \\
\hline CHEMBL1500810 & 688810 & 4.783 & 5.15799 & 9999999999 & & TRN & \\
\hline CHEMBL1590657 & 688810 & 4.783 & 4.8615 & TRN & & & \\
\hline CHEMBL1313977 & 688810 & 5.1329 & 99999999 & & 4.8676 & TRN & \\
\hline CHEMBL1421092 & 688810 & 5.683 & 5.6205 & TRN & & & \\
\hline CHEMBL1403965 & 688810 & 5.183 & 4.8793 & TRN & & & \\
\hline
\end{tabular}




\begin{tabular}{|c|c|c|c|c|c|c|}
\hline \multirow[b]{2}{*}{ CHEMBL1603170 } & \multicolumn{6}{|c|}{$\perp$ Tabıe } \\
\hline & 688810 & 6.433 & 6.05 & TRN & & \\
\hline CHEMBL1580031 & 688810 & \multicolumn{3}{|c|}{6.0329999999999995} & 5.1557 & $\mathrm{TR}$ \\
\hline CHEMBL1412413 & 688810 & 4.933 & 5.4191 & TST & & \\
\hline CHEMBL1563130 & 688810 & 5.183 & 5.2415 & TRN & & \\
\hline CHEMBL1371117 & 688810 & 4.783 & 4.8478 & TST & & \\
\hline CHEMBL1349165 & 688810 & 4.933 & 5.2912 & TRN & & \\
\hline CHEMBL1407442 & 688810 & \multicolumn{3}{|c|}{5.382999999999999} & 5.2759 & TRN \\
\hline CHEMBL3191502 & 688810 & 4.833 & \multicolumn{3}{|c|}{5.297000000000001} & \\
\hline CHEMBL1505245 & 688810 & 4.783 & 5.5567 & TRN & & \\
\hline CHEMBL1450006 & 688810 & 4.933 & 5.1723 & TRN & & \\
\hline CHEMBL 3195343 & 688810 & 4.883 & 5.3231 & TST & & \\
\hline CHEMBL1338304 & 688810 & 5.433 & 5.2282 & TRN & & \\
\hline CHEMBL1374813 & 688810 & 5.483 & 5.2908 & TRN & & \\
\hline CHEMBL1583479 & 688810 & 4.583 & 4.8538 & TST & & \\
\hline CHEMBL1430768 & 688810 & 4.883 & 4.9412 & TST & & \\
\hline CHEMBL1598466 & 688810 & 4.783 & 5.3545 & TRN & & \\
\hline CHEMBL1362072 & 688810 & 4.783 & 5.0652 & TRN & & \\
\hline CHEMBL1334795 & 688810 & 5.733 & \multicolumn{3}{|c|}{5.212000000000001} & \\
\hline CHEMBL1333349 & 688810 & 6.0 & 5.5995 & TRN & & \\
\hline CHEMBL 3194360 & 688810 & \multicolumn{3}{|c|}{5.7829999999999995} & 5 . & \\
\hline CHEMBL1440008 & 688810 & 5.033 & 5.2807 & TRN & & \\
\hline CHEMBL1551653 & 688810 & \multicolumn{3}{|c|}{4.7330000000000005} & 5.432 & \\
\hline CHEMBL1425380 & 688810 & 5.233 & 5.2359 & TRN & & \\
\hline CHEMBL1353731 & 688810 & 6.233 & 5.6263 & TRN & & \\
\hline CHEMBL14 & 688810 & 4.933 & 5.1332 & TRN & & \\
\hline CHEMBL1493860 & 688810 & 4.933 & 5.4014 & TRN & & \\
\hline CHEMBL3208012 & 688810 & \multicolumn{3}{|c|}{6.332999999999999} & 5.4316 & \\
\hline CHEMBL1501872 & 688810 & \multicolumn{3}{|c|}{6.132999999999999} & 5.6791 & \\
\hline CHEMBL1545616 & 688810 & 5.733 & \multicolumn{3}{|c|}{5.327999999999999} & \\
\hline CHEMBL1387910 & 688810 & 5.183 & 5.4133 & TRN & & \\
\hline CHEMBL1388015 & 688810 & \multicolumn{3}{|c|}{5.7829999999999995} & 5.2002 & \\
\hline CHEMBL1609840 & 688810 & \multicolumn{3}{|c|}{6.132999999999999} & 5.4858 & \\
\hline CHEMBL1460032 & 688810 & 4.833 & 5.0277 & TST & & \\
\hline CHEMBL1551768 & 688810 & \multicolumn{3}{|c|}{4.9830000000000005} & 5.3589 & In \\
\hline CHEMBL1450119 & 688810 & 7.0329 & 5.9544 & TRN & & \\
\hline CHEMBL1379666 & 688810 & \multicolumn{3}{|c|}{5.832999999999999} & 5.3319 & $\mathrm{TR}$ \\
\hline CHEMBL1360200 & 688810 & 4.583 & 4.8426 & TRN & & \\
\hline CHEMBL1545250 & 688810 & 6.8831 & 6.2777 & TRN & & \\
\hline CHEMBL3197943 & 688810 & 4.883 & 5.1869 & TRN & & \\
\hline CHEMBL1398820 & 688810 & 5.983 & 5.1059 & TST & & \\
\hline CHEMBL1483026 & 688810 & 4.833 & 5.0266 & TRN & & \\
\hline CHEMBL1419847 & 688810 & 5.683 & 5.9101 & TRN & & \\
\hline CHEMBL1316700 & 688810 & 4.833 & 5.3749 & TRN & & \\
\hline CHEMBL1321190 & 688810 & \multicolumn{3}{|c|}{5.5329999999999995} & 5.3665 & \\
\hline CHEMBL1313698 & 688810 & 5.683 & 5.3812 & TRN & & \\
\hline CHEMBL1315376 & 688810 & \multicolumn{3}{|c|}{4.7330000000000005} & 5.1422 & TRN \\
\hline CHEMBL1528584 & 688810 & 4.883 & 4.9315 & TRN & & \\
\hline CHEMBL 3207566 & 688810 & \multicolumn{3}{|c|}{5.582999999999999} & 5.1419 & \\
\hline
\end{tabular}




\begin{tabular}{|c|c|c|c|c|c|c|c|}
\hline \multicolumn{8}{|c|}{ supplemental Iable s2.txt } \\
\hline CHEMBL1513046 & 688810 & 7.2328 & 6.0403 & TRN & & & \\
\hline CHEMBL1602717 & 688810 & 7.08299 & 999999995 & & 6.0555 & TRN & \\
\hline CHEMBL1401765 & 688810 & 4.783 & 5.2889 & TST & & & \\
\hline CHEMBL1374666 & 688810 & 5.13299 & 99999999 & & 5.1986 & TRN & \\
\hline CHEMBL1418631 & 688810 & 4.933 & 5.2771 & TRN & & & \\
\hline CHEMBL1541791 & 688810 & 5.033 & 4.9841 & TRN & & & \\
\hline CHEMBL1328373 & 688810 & 4.833 & 5.7802 & TST & & & \\
\hline CHEMBL1362119 & 688810 & 4.98300 & 000000006 & 005 & 4.9806 & TRN & \\
\hline CHEMBL261123 & 688810 & 7.1831 & 6.3946 & TRN & & & \\
\hline CHEMBL1609819 & 688810 & 4.633 & 4.8559 & TRN & & & \\
\hline CHEMBL1524795 & 688810 & 4.73300 & 000000006 & 005 & 5.26200 & 00000000005 & TRN \\
\hline CHEMBL3190023 & 688810 & 5.28299 & 999999995 & 995 & 5.29299 & 9999999999 & TRN \\
\hline CHEMBL1479084 & 688810 & 4.633 & 5.4657 & TST & & & \\
\hline CHEMBL1484036 & 688810 & 4.73300 & 000000006 & 005 & 5.6437 & TST & \\
\hline CHEMBL1334984 & 688810 & 5.33299 & 999999995 & & 5.0689 & TRN & \\
\hline CHEMBL1420195 & 688810 & 4.883 & 4.8798 & TRN & & & \\
\hline CHEMBL1498405 & 688810 & 4.883 & 5.2754 & TRN & & & \\
\hline CHEMBL1542050 & 688810 & 5.38299 & 999999999 & & 5.481 & TRN & \\
\hline CHEMBL1391585 & 688810 & 4.833 & 5.3856 & TRN & & & \\
\hline CHEMBL1452487 & 688810 & 4.633 & 4.8036 & TRN & & & \\
\hline CHEMBL1547213 & 688810 & 5.78299 & 999999995 & 995 & 5.7211 & TRN & \\
\hline CHEMBL1569846 & 688810 & 5.13299 & 999999995 & & 5.2695 & TST & \\
\hline CHEMBL1485549 & 688810 & 6.53299 & 999999995 & 995 & 6.3966 & TRN & \\
\hline CHEMBL1568952 & 688810 & 5.433 & 5.2677 & TRN & & & \\
\hline CHEMBL 3212258 & 688810 & 4.98300 & 000000000 & & 5.2164 & TRN & \\
\hline CHEMBL1577912 & 688810 & 6.13299 & 999999999 & & 5.5098 & TRN & \\
\hline CHEMBL1475259 & 688810 & 6.28299 & 999999999 & 995 & 5.8471 & TRN & \\
\hline CHEMBL1481470 & 688810 & 4.933 & 5.4611 & TRN & & & \\
\hline CHEMBL1331422 & 688810 & 6.03299 & 999999999 & 995 & 5.732 & TRN & \\
\hline CHEMBL246447 & 688810 & 5.183 & 5.9899 & TST & & & \\
\hline CHEMBL1549011 & 688810 & 6.58299 & 999999999 & & 5.5479 & TRN & \\
\hline CHEMBL1311629 & 688810 & 4.683 & 5.0428 & TST & & & \\
\hline CHEMBL1595244 & 688810 & 5.183 & 5.5825 & TST & & & \\
\hline CHEMBL1490771 & 688810 & 5.83299 & 999999999 & & 5.3389 & TRN & \\
\hline CHEMBL1331221 & 688810 & 4.933 & 4.5716 & TRN & & & \\
\hline CHEMBL1327796 & 688810 & 4.683 & 5.1259 & TST & & & \\
\hline CHEMBL1436013 & 688810 & 4.583 & 4.9697 & TRN & & & \\
\hline CHEMBL1539865 & 688810 & 5.083 & 5.0502 & TRN & & & \\
\hline CHEMBL1996150 & 688810 & 6.28299 & 999999999 & 995 & 5.7878 & TRN & \\
\hline CHEMBL1408742 & 688810 & 6.08299 & 999999999 & & 6.0931 & TRN & \\
\hline CHEMBL1601984 & 688810 & 4.98300 & 000000000 & 005 & 5.8322 & TRN & \\
\hline CHEMBL1490084 & 688810 & 4.633 & 5.0427 & TRN & & & \\
\hline CHEMBL1549700 & 688810 & 6.0 & 5.1247 & TST & & & \\
\hline CHEMBL1567019 & 688810 & 5.683 & 5.4548 & TST & & & \\
\hline CHEMBL572531 & 688810 & 4.633 & 5.0774 & TRN & & & \\
\hline CHEMBL1368212 & 688810 & 6.33299 & 999999999 & & 5.6595 & TRN & \\
\hline CHEMBL1425795 & 688810 & 5.683 & 5.4424 & TRN & & & \\
\hline CHEMBL1989636 & 688810 & 5.733 & 5.5259 & TRN & & & \\
\hline
\end{tabular}




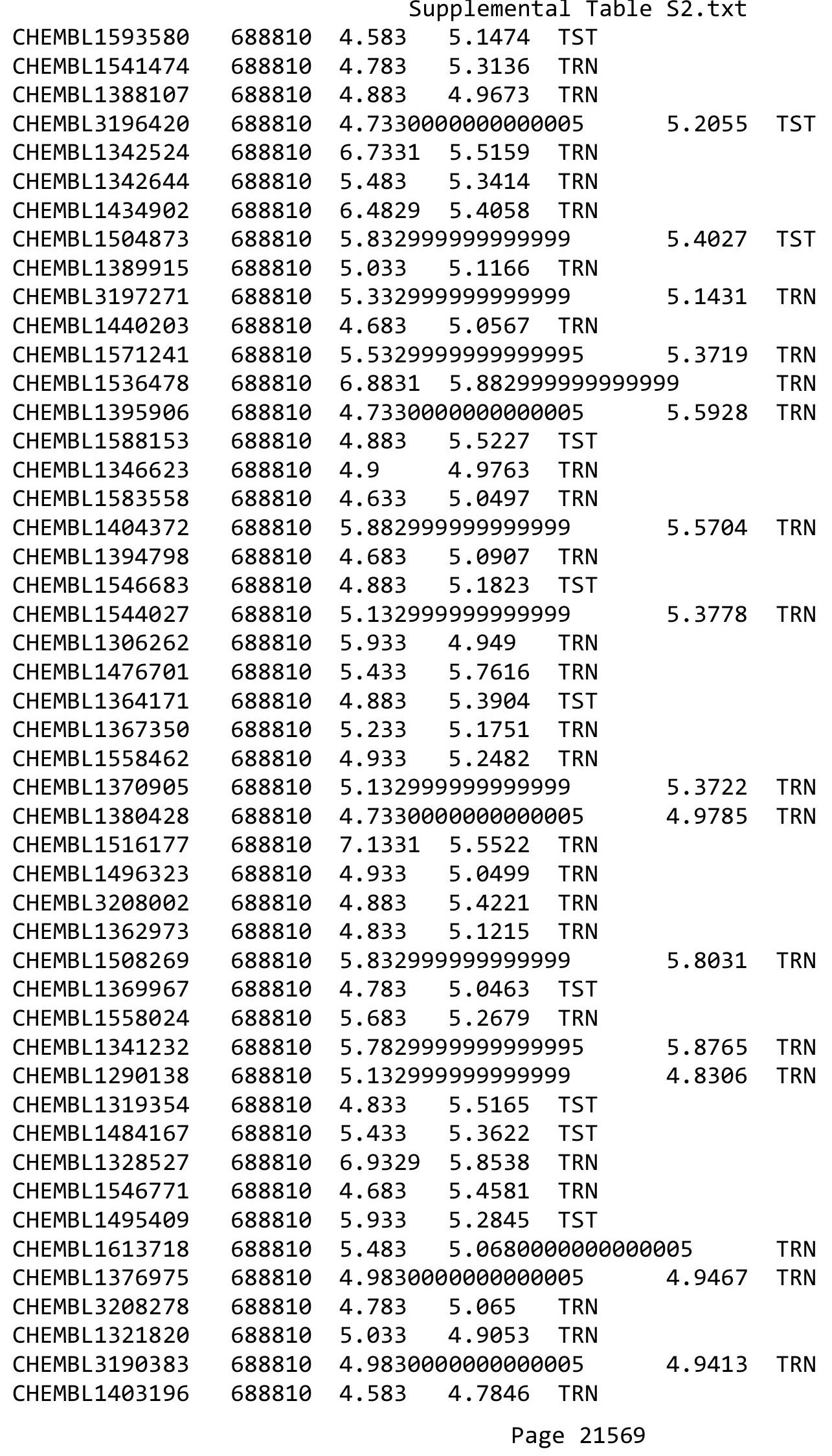




\begin{tabular}{|c|c|c|c|c|c|c|}
\hline \multirow[b]{2}{*}{ CHEMBL1412455 } & \multicolumn{6}{|c|}{ 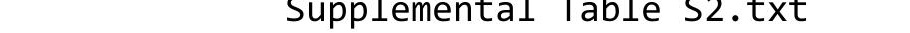 } \\
\hline & 688810 & 5.033 & 5.2272 & TST & & \\
\hline CHEMBL1302239 & 688810 & 5.733 & 5.6546 & TRN & & \\
\hline HEMBL311070 & 588810 & \multicolumn{3}{|c|}{5.632999999999999} & 5.7819 & TRN \\
\hline CHEMBL1598863 & 588810 & \multicolumn{3}{|c|}{4.9830000000000005} & 5.3443 & TST \\
\hline CHEMBL1410362 & 688810 & \multicolumn{3}{|c|}{5.382999999999999} & 5.2893 & TRN \\
\hline CHEMBL1474683 & 688810 & \multicolumn{3}{|c|}{5.7829999999999995} & 5.5069 & TRN \\
\hline CHEMBL1458831 & 688810 & 5.183 & 5.1872 & TRN & & \\
\hline CHEMBL1604715 & 588810 & \multicolumn{3}{|c|}{5.632999999999999} & 5.7352 & TRN \\
\hline CHEMBL3208981 & 688810 & 4.883 & \multicolumn{3}{|c|}{5.382999999999999} & TRN \\
\hline CHEMBL1464469 & 688810 & 5.683 & 4.9739 & TST & & \\
\hline CHEMBL1419024 & 688810 & 4.783 & 5.5442 & TST & & \\
\hline CHEMBL1335925 & 688810 & \multicolumn{3}{|c|}{4.7330000000000005} & 4.6223 & TST \\
\hline CHEMBL1373792 & 688810 & \multicolumn{3}{|c|}{6.0329999999999995} & 5.3832 & TRN \\
\hline CHEMBL1514806 & 688810 & 4.683 & 5.0066 & TRN & & \\
\hline CHEMBL1501204 & 688810 & \multicolumn{3}{|c|}{4.7330000000000005} & 5.3607 & TRN \\
\hline CHEMBL13 & 688810 & 4.783 & \multicolumn{3}{|c|}{5.2379999999999995} & TST \\
\hline CHEMBL1563861 & 688810 & \multicolumn{3}{|c|}{5.332999999999999} & 5.8366 & TRN \\
\hline CHEMBL1384326 & 688810 & \multicolumn{3}{|c|}{5.382999999999999} & 5.2722 & TST \\
\hline CHEMBL1379514 & 688810 & 4.783 & 5.4685 & TRN & & \\
\hline CHEMBL1 & 688 & 3 & 4.9752 & TST & & \\
\hline CHEMBL1 & 688 & 4. & 5.0931 & TRN & & \\
\hline CHEMBL 1 & 688 & 4.883 & 4.8872 & TRN & & \\
\hline CHEMBL1449493 & 688810 & \multicolumn{3}{|c|}{5.832999999999999} & 69 & TP \\
\hline CHEMBL1532358 & 688 & 4.783 & 4.8624 & TRN & & \\
\hline CHEMBL1 & 688810 & \multicolumn{3}{|c|}{5.582999999999999} & 5.8983 & \\
\hline CHEMBL3 & 688810 & 5.683 & 5.3558 & TRN & & \\
\hline CHEMBL1395501 & 688810 & \multirow{2}{*}{\multicolumn{3}{|c|}{$\begin{array}{ll}4.583 & 4.8969 \\
6.332999999999999\end{array}$}} & & \\
\hline CHEMBL1488141 & 688810 & & & & 5.6802 & TR \\
\hline CHEMBL362941 & 688810 & 4.783 & & TRN & & \\
\hline CHEMBL & $68 \varepsilon$ & 5.183 & 5.6372 & TRN & & \\
\hline CHEMBL 1 & $68 \varepsilon$ & \multicolumn{3}{|c|}{4.7330000000000005} & 5.1347 & TRN \\
\hline CHEMBL1505717 & 688810 & \multicolumn{3}{|c|}{5.882999999999999} & 774 & TRN \\
\hline CHEMBL1300722 & 688810 & \multicolumn{3}{|c|}{5.7829999999999995} & 5.0769 & TRN \\
\hline CHEMBL1476852 & 688810 & 6.433 & 5.6758 & TRN & & \\
\hline CHEMBL & 688 & 5 . & 5.1172 & TST & & \\
\hline CHEMBL: & $68 \varepsilon$ & 5 . & 5.5841 & TRN & & \\
\hline CHEMBL1518823 & 688810 & 4.883 & 4.7544 & TRN & & \\
\hline CHEMBL1368559 & 688810 & \multicolumn{3}{|c|}{4.9830000000000005} & & TRN \\
\hline CHEMBL1526629 & 688810 & 6.03299 & 99999999 & 995 & 5.7955 & TRN \\
\hline CHEMBL1 & 688810 & 6.63299 & 99999999 & & 5.7898 & TRN \\
\hline CHEMBL3193604 & 688810 & 5.033 & 4.5181 & TRN & & \\
\hline CHEMBL1329532 & 688810 & 5.58299 & 99999999 & & 5.5495 & $\mathrm{~T}$ \\
\hline CHEMBL1306714 & 688810 & 4.683 & 5.4277 & TST & & \\
\hline CHEMBL1588401 & 688810 & 6.58299 & 99999999 & & 6.1042 & TST \\
\hline CHEMBL1378090 & 688810 & 5.63299 & 99999999 & & 5.3686 & TST \\
\hline CHEMBL1601233 & 688810 & 5.683 & 5.71899 & 999999 & & TST \\
\hline CHEMBL1400312 & 688810 & 5.53299 & 99999999 & 995 & 5.388 & TST \\
\hline CHEMBL1392228 & 688810 & 5.63299 & 99999999 & & 6.5934 & TRA \\
\hline & & & & & & \\
\hline
\end{tabular}


CHEMBL1409400

CHEMBL1380130

CHEMBL1336919

CHEMBL1516425

CHEMBL1459984

CHEMBL1412996

CHEMBL1376413

CHEMBL1523542

CHEMBL1347551

CHEMBL1380816

CHEMBL1459387

CHEMBL1399011

CHEMBL1567272

CHEMBL1543036

CHEMBL1379635

CHEMBL1575550

CHEMBL1544617

CHEMBL1541270

CHEMBL1380195

CHEMBL1486803

CHEMBL1511384

CHEMBL1581314

CHEMBL3189729

CHEMBL1418032

CHEMBL1517715

CHEMBL1494785

CHEMBL1546854

CHEMBL1304798

CHEMBL1504026

CHEMBL1541740

CHEMBL1396810

CHEMBL1346839

CHEMBL1530087

CHEMBL1313955

CHEMBL1494920

CHEMBL1364818

CHEMBL1382799

CHEMBL1537457

CHEMBL493153

CHEMBL1549880

CHEMBL1434355

CHEMBL1485882

CHEMBL1593730

CHEMBL1501452

CHEMBL1420494

CHEMBL1466948

CHEMBL 3196816

CHEMBL1425391
Supplemental Table S2.txt

$\begin{array}{llll}688810 & 6.4829 & 5.6916 & \text { TRN }\end{array}$

688810

688810

688810

688810

688810

688810

4.7330000000000005

5.2410000000000005

TST

4.933

5.5964 TRN

5.233

5.1578 TRN

$4.783 \quad 5.1984$ TRN

5.832999999999999

5.7335 .2396 TRN

688810

688810

688810

688810

688810

688810

688810

688810

688810

688810

688810

688810

688810

688810

688810

688810

688810

688810

688810

688810

688810

4.9830000000000005

6.0329999999999995

6.382999999999999

4.8335 .1206 TRN

$5.683 \quad 5.0092$ TRN

4.9830000000000005

$4.933 \quad 5.0183$ TRN

5.632999999999999

4.8335 .5546 TRN

4.9830000000000005

$4.833 \quad 5.0866$ TRN

$4.783 \quad 5.4451$ TST

4.7330000000000005

4.7330000000000005

$\begin{array}{llll}4.933 & 4.8794 & \text { TST }\end{array}$

$5.733 \quad 5.1162$ TRN

5.382999999999999

4.7330000000000005

$4.883 \quad 4.9613$ TST

4.7330000000000005

$5.683 \quad 5.1432$ TRN

688810

688810

688810

688810

688810

688810

688810

688810

688810

688810

688810

688810

688810

688810

688810

688810

688810

688810

688810

$6.9329 \quad 5.8725$ TRN

4.6335 .3262 TST

4.6334 .6488 TRN

4.5835 .3762 TRN

4.6335 .2665 TRN

4.7330000000000005

5.2829999999999995

$\begin{array}{lll}5.033 & 5.3338 & \text { TRN }\end{array}$

$5.033 \quad 5.3618$ TRN

$5.983 \quad 5.5329$ TST

5.882999999999999

$\begin{array}{lll}4.783 & 4.7415 & \text { TRN }\end{array}$

$4.783 \quad 5.4151$ TRN

5.5329999999999995

4.8834 .9073 TST

5.526 TRN

5.5635 TST

5.1296 TRN

5.9297 TRN

4.9766 TST

5.4398 TRN

5.0858 TRN

5.4509 TST

5.1175 TRN

5.3815 TRN

5.1489 TRN

5.294 TRN

5.1592 TRN

5.1076 TRN

5.132999999999999

$\begin{array}{lll}4.783 & 5.0743 \text { TRN }\end{array}$

6.88316 .3731 TRN

$4.783 \quad 5.0808$ TRN

5.582999999999999

5.5393 TRN

Page 21571 


\begin{tabular}{|c|c|c|c|c|c|c|c|}
\hline \multirow{3}{*}{$\begin{array}{l}\text { CHEMBL466933 } \\
\text { CHEMBL1403065 }\end{array}$} & \multicolumn{6}{|c|}{ C cu } & \\
\hline & 688810 & 4.9 & 5.3932 & TRN & & & \\
\hline & 688810 & \multicolumn{3}{|c|}{5.632999999999999} & 6.0196 & TRN & \\
\hline CHEMBL1556282 & 688810 & 4.683 & 5.3168 & TRN & & & \\
\hline CHEMBL1397664 & 688810 & \multicolumn{3}{|c|}{5.2829999999999995} & 5.3122 & TST & \\
\hline CHEMBL502774 & 688810 & \multicolumn{3}{|c|}{6.2829999999999995} & 6.1418 & TRN & \\
\hline CHEMBL1434938 & 688810 & 4.783 & 4.9166 & TST & & & \\
\hline CHEMBL1408952 & 688810 & \multicolumn{3}{|c|}{6.2829999999999995} & 5.9771 & TRN & \\
\hline CHEMBL1560356 & 688810 & \multicolumn{3}{|c|}{5.7829999999999995} & 5.3353 & TRN & \\
\hline CHEMBL1440334 & 688810 & 5.733 & 5.0879 & TRN & & & \\
\hline CHEMBL1322110 & 688810 & 4.633 & 5.277 & TST & & & \\
\hline CHEMBL1493750 & 688810 & \multicolumn{3}{|c|}{5.332999999999999} & 5.1638 & TRN & \\
\hline CHEMBL1316998 & 688810 & \multicolumn{3}{|c|}{4.7330000000000005} & 5.407 & TRN & \\
\hline CHEMBL1352287 & 688810 & 4.783 & 4.8332 & TST & & & \\
\hline CHEMBL1361217 & 688810 & 4.883 & 4.9103 & TST & & & \\
\hline CHEMBL1329080 & 688810 & \multicolumn{3}{|c|}{5.132999999999999} & 5.1747 & TRN & \\
\hline CHEMBL1519975 & 688810 & \multicolumn{3}{|c|}{5.2829999999999995} & 6.306 & TRN & \\
\hline CHEMBL1425940 & 688810 & 4.883 & 5.1308 & TRN & & & \\
\hline CHEMBL1442690 & 688810 & 4.883 & 4.9838 & TRN & & & \\
\hline CHEMBL1511894 & 688810 & 4.933 & 5.5095 & TRN & & & \\
\hline CHEMBL1602501 & 688810 & 4.883 & 5.0273 & TRN & & & \\
\hline CHEMBL1366883 & 688810 & 6.233 & 5.9595 & TRN & & & \\
\hline CHEMBL1422689 & 688810 & 4.833 & 4.8102 & TRN & & & \\
\hline CHEMBL1490987 & 688810 & 4.833 & 4.7641 & TRN & & & \\
\hline CHEMBL1482193 & 688810 & 4.683 & 4.4534 & TRN & & & \\
\hline CHEMBL 3191254 & 688810 & \multicolumn{3}{|c|}{4.7330000000000005} & 5.2731 & TRN & \\
\hline CHEMBL1577426 & 688810 & \multicolumn{3}{|c|}{5.132999999999999} & \multicolumn{2}{|c|}{5.4670000000000005} & TRN \\
\hline CHEMBL1590956 & 688810 & 5.483 & 5.2994 & TRN & & & \\
\hline CHEMBL1543237 & 688810 & \multicolumn{3}{|c|}{4.9830000000000005} & 5.5907 & TST & \\
\hline CHEMBL1585864 & 688810 & \multicolumn{3}{|c|}{5.2829999999999995} & 5.2989 & TRN & \\
\hline CHEMBL 1402587 & 688810 & 6.9329 & 5.7038 & TRN & & & \\
\hline CHEMBL1595911 & 688810 & 4.633 & 4.8567 & TRN & & & \\
\hline CHEMBL1490792 & 688810 & 5.683 & 5.5326 & TST & & & \\
\hline CHEMBL1306027 & 688810 & 4.883 & 5.3532 & TST & & & \\
\hline CHEMBL1312873 & 688810 & \multicolumn{3}{|c|}{4.7330000000000005} & 5.2344 & TRN & \\
\hline CHEMBL1556098 & 688810 & 4.833 & 5.4036 & TST & & & \\
\hline CHEMBL1582181 & 688810 & \multicolumn{3}{|c|}{5.882999999999999} & 5.6351 & TRN & \\
\hline CHEMBL1501185 & 688810 & 5.683 & \multicolumn{3}{|c|}{5.962999999999999} & TST & \\
\hline CHEMBL602987 & 688810 & 4.783 & \multicolumn{3}{|c|}{5.202999999999999} & TST & \\
\hline CHEMBL1349829 & 688810 & 4.833 & 5.0567 & TRN & & & \\
\hline CHEMBL599469 & 688810 & 5.083 & 5.3926 & TRN & & & \\
\hline CHEMBL1546607 & 688810 & 4.73300 & 00000000 & 005 & 4.7737 & TRN & \\
\hline CHEMBL1365638 & 688810 & 5.733 & 5.4066 & TRN & & & \\
\hline CHEMBL1340591 & 688810 & 4.933 & 5.3131 & TRN & & & \\
\hline CHEMBL1373725 & 688810 & 4.783 & 5.4088 & TRN & & & \\
\hline CHEMBL1392498 & 688810 & 5.13299 & 99999999 & & 5.1572 & TST & \\
\hline CHEMBL1324703 & 688810 & 6.4829 & 5.7442 & TRN & & & \\
\hline CHEMBL3193113 & 688810 & 4.73300 & 00000000 & 005 & 5.4556 & TRN & \\
\hline CHEMBL3196400 & 688810 & 4.783 & 5.1492 & TRN & & & \\
\hline
\end{tabular}




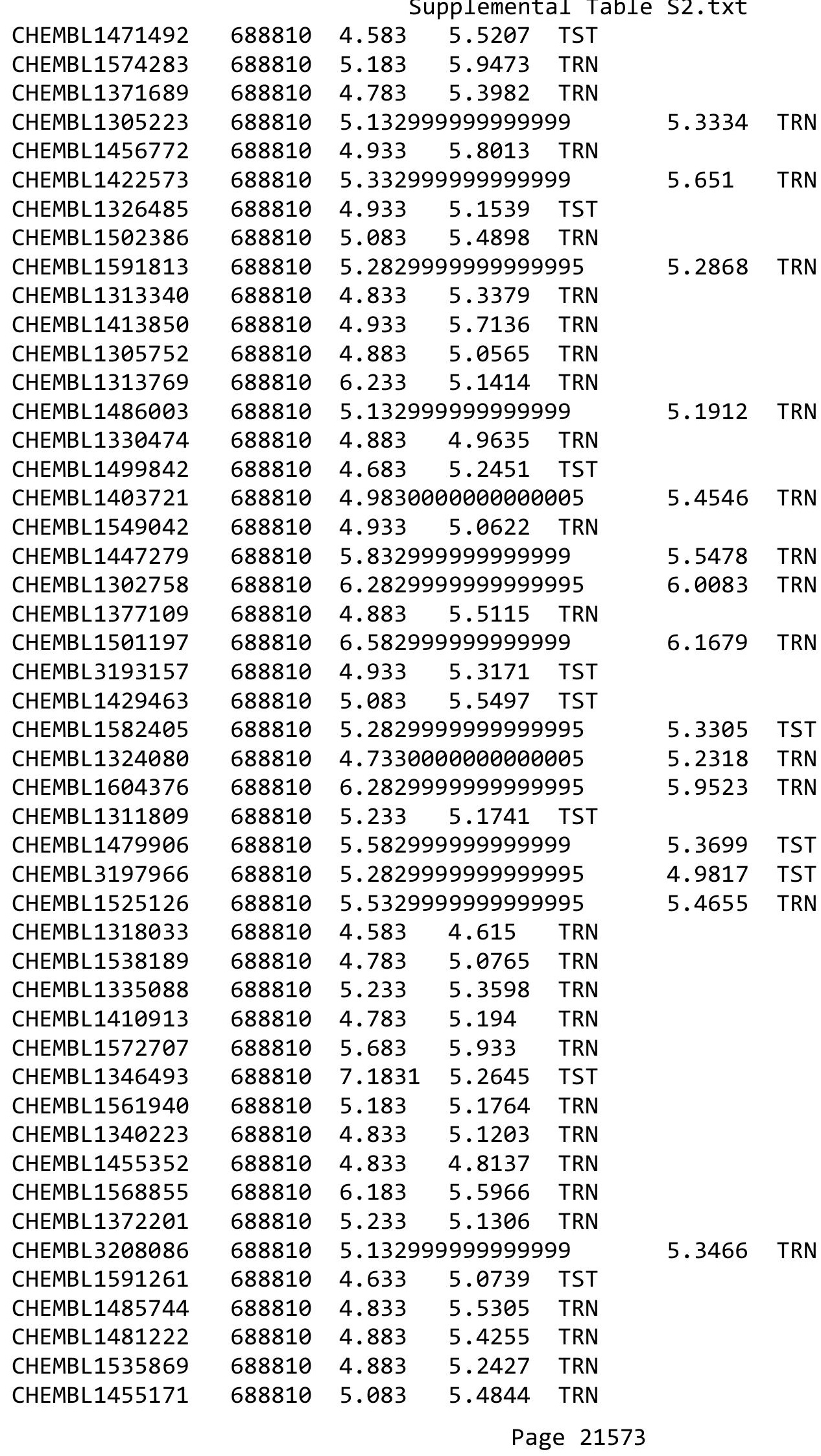




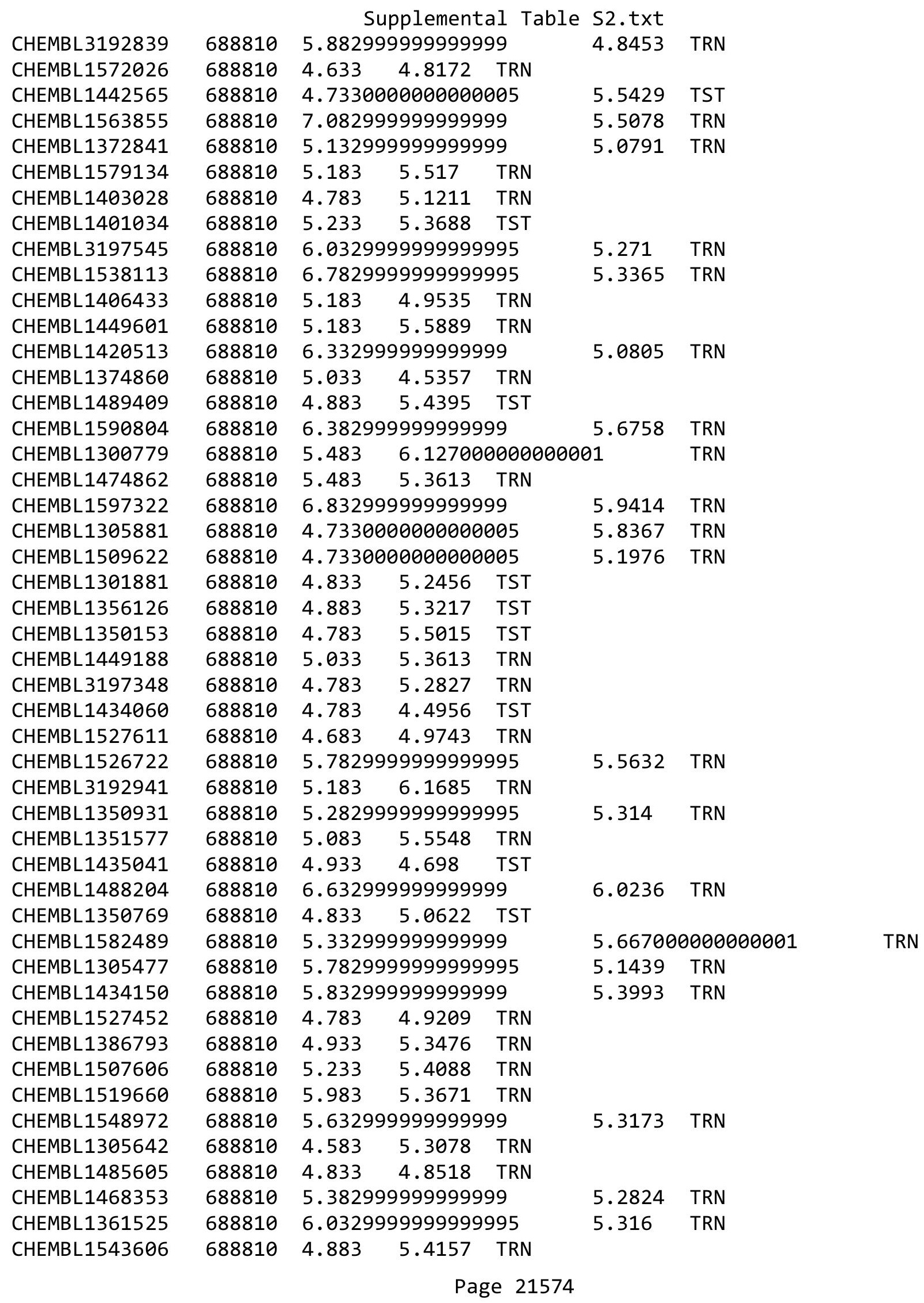




\begin{tabular}{|c|c|c|c|c|c|c|c|}
\hline \multicolumn{7}{|c|}{ Supplemental Table S2.txt } & \\
\hline CHEMBL1385008 & 688810 & \multicolumn{3}{|c|}{5.132999999999999} & 5.1224 & TRN & \\
\hline CHEMBL1554096 & 688810 & 4.783 & 5.1981 & TRN & & & \\
\hline CHEMBL1321316 & 688810 & 4.833 & 5.0366 & TRN & & & \\
\hline CHEMBL1349167 & 688810 & 4.783 & 5.0232 & TRN & & & \\
\hline CHEMBL1344630 & 688810 & 4.95 & 5.1493 & TRN & & & \\
\hline CHEMBL1505655 & 688810 & \multicolumn{3}{|c|}{4.7330000000000005} & 5.041 & TRN & \\
\hline CHEMBL1299820 & 688810 & \multicolumn{3}{|c|}{4.9830000000000005} & 5.3222 & TRN & \\
\hline CHEMBL1465298 & 688810 & 5.683 & 5.4404 & TRN & & & \\
\hline CHEMBL1477375 & 688810 & \multicolumn{3}{|c|}{5.332999999999999} & 6.1756 & TST & \\
\hline CHEMBL1557124 & 688810 & 4.633 & 4.9586 & TST & & & \\
\hline CHEMBL1517847 & 688810 & \multicolumn{3}{|c|}{6.0329999999999995} & 4.9166 & TRN & \\
\hline CHEMBL1605779 & 688810 & 5.683 & 5.4392 & TRN & & & \\
\hline CHEMBL1490159 & 688810 & 5.083 & 5.3879 & TST & & & \\
\hline CHEMBL1479417 & 688810 & 5.683 & 4.79 & TRN & & & \\
\hline CHEMBL1459601 & 688810 & 5.033 & 5.3564 & TST & & & \\
\hline CHEMBL1458741 & 688810 & 6.4829 & 5.6135 & TRN & & & \\
\hline CHEMBL3212994 & 688810 & \multicolumn{3}{|c|}{4.7330000000000005} & 5.1036 & TRN & \\
\hline CHEMBL1310865 & 688810 & 4.633 & 4.7276 & TRN & & & \\
\hline CHEMBL1581770 & 688810 & 5.083 & 5.1303 & TRN & & & \\
\hline CHEMBL1612955 & 688810 & 5.083 & 5.1443 & TST & & & \\
\hline CHEMBL1598153 & 688810 & \multicolumn{3}{|c|}{4.7330000000000005} & 5.5873 & TRN & \\
\hline CHEMBL1479557 & 688810 & 4.933 & 5.57799 & 9999999999 & & TST & \\
\hline CHEMBL1372490 & 688810 & \multicolumn{3}{|c|}{4.7330000000000005} & 4.9339 & TST & \\
\hline CHEMBL1414877 & 688810 & 4.783 & 5.0938 & TRN & & & \\
\hline CHEMBL1443454 & 688810 & 5.233 & 4.6853 & TRN & & & \\
\hline CHEMBL3193177 & 688810 & \multicolumn{3}{|c|}{6.082999999999999} & 5.6028 & TST & \\
\hline CHEMBL1587645 & 688810 & 5.183 & 5.4941 & TST & & & \\
\hline CHEMBL1501221 & 688810 & \multicolumn{3}{|c|}{5.5329999999999995} & 5.6344 & TRN & \\
\hline CHEMBL3195168 & 688810 & 5.083 & 5.2993 & TRN & & & \\
\hline CHEMBL1387251 & 688810 & \multicolumn{3}{|c|}{5.632999999999999} & 5.6495 & TRN & \\
\hline CHEMBL1407668 & 688810 & \multicolumn{3}{|c|}{4.7330000000000005} & 5.942 & TRN & \\
\hline CHEMBL1332730 & 688810 & \multicolumn{3}{|c|}{5.132999999999999} & 5.2946 & TRN & \\
\hline CHEMBL1508694 & 688810 & \multicolumn{3}{|c|}{6.382999999999999} & 6.146 & TRN & \\
\hline CHEMBL1598284 & 688810 & 4.833 & 5.9406 & TRN & & & \\
\hline CHEMBL1508091 & 688810 & \multicolumn{3}{|c|}{6.382999999999999} & 5.9787 & TRN & \\
\hline CHEMBL1559477 & 688810 & 4.833 & 4.9972 & TRN & & & \\
\hline CHEMBL1604402 & 688810 & \multicolumn{3}{|c|}{5.132999999999999} & 5.6585 & TRN & \\
\hline CHEMBL1563973 & 688810 & \multicolumn{3}{|c|}{5.882999999999999} & 5.542999 & 9999999999 & TRN \\
\hline CHEMBL1421415 & 688810 & 4.833 & 5.1738 & TST & & & \\
\hline CHEMBL1362490 & 688810 & 5.483 & 5.2584 & TRN & & & \\
\hline CHEMBL1519381 & 688810 & 4.933 & 5.8596 & TST & & & \\
\hline CHEMBL1537477 & 688810 & 6.05 & 5.5074 & TRN & & & \\
\hline CHEMBL1420307 & 688810 & \multicolumn{3}{|c|}{5.382999999999999} & 5.3811 & TRN & \\
\hline CHEMBL1456090 & 688810 & \multicolumn{3}{|c|}{5.332999999999999} & 4.9124 & TRN & \\
\hline CHEMBL1382536 & 688810 & 4.783 & 5.1736 & TRN & & & \\
\hline CHEMBL1534690 & 688810 & \multicolumn{3}{|c|}{4.7330000000000005} & 4.7588 & TST & \\
\hline CHEMBL1328322 & 688810 & 4.7330 & 00000000 & 005 & 5.5254 & TRN & \\
\hline CHEMBL1321490 & 688810 & 4.833 & 4.94600 & 0000000001 & & TRN & \\
\hline
\end{tabular}




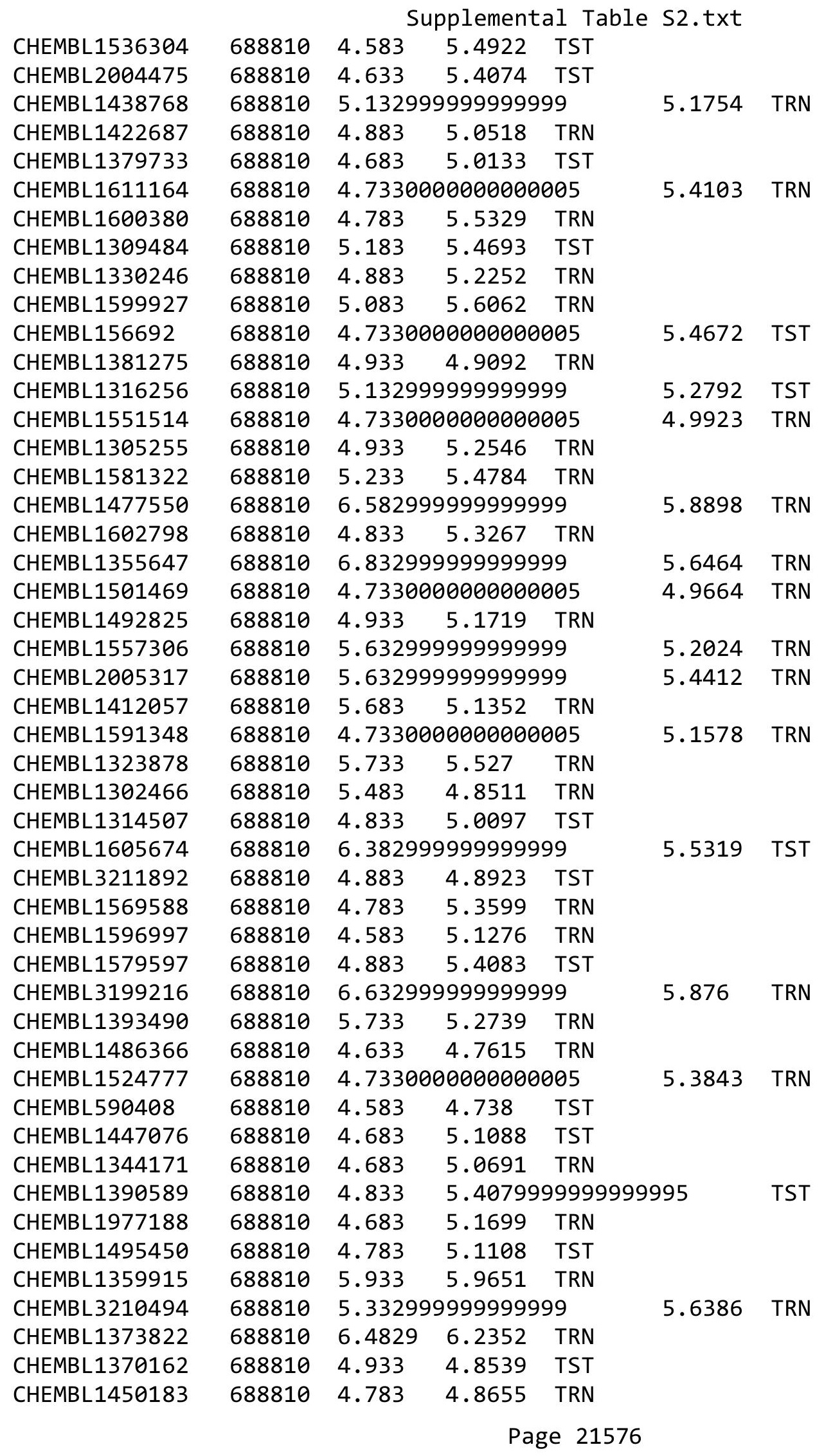




\begin{tabular}{|c|c|c|c|c|c|c|}
\hline & & \multicolumn{5}{|c|}{ Supplemental Table S2.txt } \\
\hline CHEMBL1573741 & 688810 & 5.083 & 5.4061 & TRN & & \\
\hline CHEMBL1403099 & 688810 & 4.833 & 5.3534 & TRN & & \\
\hline CHEMBL377583 & 688810 & 6.983 & 6.336 & TRN & & \\
\hline CHEMBL1588852 & 688810 & 6.233 & 5.5091 & TRN & & \\
\hline CHEMBL1577900 & 688810 & 5.683 & 5.3269 & TST & & \\
\hline CHEMBL3209674 & 688810 & 4.833 & 5.2055 & TST & & \\
\hline CHEMBL1312802 & 688810 & \multicolumn{3}{|c|}{5.332999999999999} & 5.1949 & TRN \\
\hline CHEMBL1546910 & 688810 & 4.933 & 5.2366 & TRN & & \\
\hline CHEMBL1496794 & 688810 & 4.833 & 5.2748 & TRN & & \\
\hline CHEMBL3197431 & 688810 & \multicolumn{3}{|c|}{7.082999999999999} & 6.0349 & TRN \\
\hline CHEMBL3209150 & 688810 & \multicolumn{3}{|c|}{4.7330000000000005} & 5.2086 & TRN \\
\hline CHEMBL1490979 & 688810 & 4.783 & 5.2706 & TST & & \\
\hline CHEMBL3210194 & 688810 & 4.833 & 5.2997 & TRN & & \\
\hline CHEMBL1410156 & 688810 & 4.883 & 5.0946 & TRN & & \\
\hline CHEMBL1535094 & 688810 & 5.433 & 5.2914 & TST & & \\
\hline CHEMBL1580311 & 688810 & 4.833 & 5.0745 & TST & & \\
\hline CHEMBL1528962 & 688810 & 5.733 & 5.4059 & TRN & & \\
\hline CHEMBL1330743 & 688810 & 5.933 & 5.4952 & TST & & \\
\hline CHEMBL1311024 & 688810 & 5.083 & 4.6926 & TRN & & \\
\hline CHEMBL1547377 & 688810 & 4.783 & 5.0005 & TRN & & \\
\hline CHEMBL1323422 & 688810 & 6.0 & 5.7379 & TRN & & \\
\hline CHEMBL1451985 & 688810 & \multicolumn{3}{|c|}{5.582999999999999} & 5.356 & TRN \\
\hline CHEMBL1389107 & 688810 & 5.433 & 4.8494 & TRN & & \\
\hline CHEMBL1306245 & 688810 & 5.233 & 5.2723 & TRN & & \\
\hline CHEMBL1608161 & 688810 & 4.783 & 5.3213 & TRN & & \\
\hline CHEMBL1486156 & 688810 & 5.483 & 5.2841 & TRN & & \\
\hline CHEMBL1343460 & 688810 & 4.833 & 5.3407 & TST & & \\
\hline CHEMBL1480653 & 688810 & 5.433 & 5.6116 & TST & & \\
\hline CHEMBL1511487 & 688810 & 5.483 & 5.3432 & TRN & & \\
\hline CHEMBL1477333 & 688810 & \multicolumn{3}{|c|}{5.632999999999999} & 5.1073 & TST \\
\hline CHEMBL1355543 & 688810 & 4.583 & 4.6894 & TRN & & \\
\hline CHEMBL1567944 & 688810 & 7.4828 & 6.2088 & TST & & \\
\hline CHEMBL1328737 & 688810 & 5.433 & 4.9658 & TRN & & \\
\hline CHEMBL1565981 & 688810 & \multicolumn{3}{|c|}{5.832999999999999} & 5.8052 & TRN \\
\hline CHEMBL1455284 & 688810 & 4.783 & 4.7262 & TST & & \\
\hline CHEMBL1561187 & 688810 & 4.583 & 4.9093 & TRN & & \\
\hline CHEMBL1444463 & 688810 & \multicolumn{3}{|c|}{4.7330000000000005} & 5.4494 & TRN \\
\hline CHEMBL1352371 & 688810 & \multicolumn{3}{|c|}{6.332999999999999} & 5.2853 & TRN \\
\hline CHEMBL1545970 & 688810 & 4.933 & 5.1368 & TST & & \\
\hline CHEMBL1457634 & 688810 & \multicolumn{3}{|c|}{6.582999999999999} & 5.8892 & TRN \\
\hline CHEMBL1989467 & 688810 & 5.233 & 5.2954 & TRN & & \\
\hline CHEMBL1570250 & 688810 & 5.233 & 5.5371 & TRN & & \\
\hline CHEMBL3195345 & 688810 & 4.883 & 5.2728 & TRN & & \\
\hline CHEMBL1303315 & 688810 & \multicolumn{3}{|c|}{5.332999999999999} & 5.2581 & TRN \\
\hline CHEMBL1605751 & 688810 & 4.833 & 5.1814 & TST & & \\
\hline CHEMBL1402959 & 688810 & 4.633 & 6.102 & TRN & & \\
\hline CHEMBL1533745 & 688810 & 4.783 & 5.4731 & TRN & & \\
\hline CHEMBL3199161 & 688810 & 4.783 & 4.6719 & TST & & \\
\hline
\end{tabular}




\begin{tabular}{|c|c|c|c|c|c|c|c|}
\hline \multicolumn{8}{|c|}{ 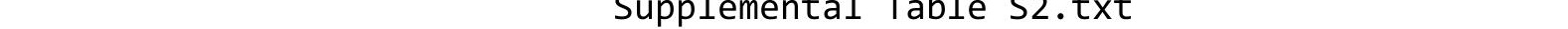 } \\
\hline CHEMBL1544951 & 688810 & 4.783 & 5.4395 & TRN & & & \\
\hline CHEMBL1419585 & 688810 & 4.933 & 4.7306 & TST & & & \\
\hline CHEMBL3209515 & 688810 & 4.933 & 5.0269 & TST & & & \\
\hline CHEMBL1320256 & 688810 & 5.083 & 5.199 & TST & & & \\
\hline CHEMBL1549929 & 688810 & 4.783 & 5.7646 & TST & & & \\
\hline CHEMBL1595329 & 688810 & 4.633 & 4.67899 & 999999999 & & TST & \\
\hline CHEMBL1450023 & 688810 & 4.633 & 4.859 & TRN & & & \\
\hline CHEMBL1372665 & 688810 & 5.38299 & 99999999 & & 5.5089 & 99999999995 & TRN \\
\hline CHEMBL1363543 & 688810 & 4.883 & 5.17706 & 000000000 & 205 & TST & \\
\hline CHEMBL1473461 & 688810 & 5.733 & 5.5428 & TRN & & & \\
\hline CHEMBL1407332 & 688810 & 4.883 & 5.1008 & TRN & & & \\
\hline CHEMBL1418109 & 688810 & 5.483 & 4.9832 & TRN & & & \\
\hline CHEMBL3208558 & 688810 & 4.683 & 5.085 & TST & & & \\
\hline CHEMBL1475263 & 688810 & 5.033 & 5.3481 & TRN & & & \\
\hline CHEMBL1473047 & 688810 & 5.28299 & 99999999 & 995 & 5.2655 & TRN & \\
\hline CHEMBL1598123 & 688810 & 4.833 & 4.9792 & TST & & & \\
\hline CHEMBL1403381 & 688810 & 4.933 & 5.2651 & TRN & & & \\
\hline CHEMBL1330258 & 688810 & 5.13299 & 99999999 & & 5.0166 & TST & \\
\hline CHEMBL1483624 & 688810 & 5.88299 & 99999995 & & 5.4517 & TRN & \\
\hline CHEMBL1303012 & 688810 & 4.783 & 5.3443 & TRN & & & \\
\hline CHEMBL1324360 & 688810 & 4.783 & 5.1287 & TRN & & & \\
\hline CHEMBL1327926 & 688810 & 6.58299 & 99999999 & & 5.5671 & TRN & \\
\hline CHEMBL1582472 & 688810 & 6.183 & 5.5683 & TRN & & & \\
\hline CHEMBL1369752 & 688810 & 4.883 & 5.0366 & TST & & & \\
\hline CHEMBL1366406 & 688810 & 4.783 & 5.4877 & TRN & & & \\
\hline CHEMBL1486661 & 688810 & 5.683 & 5.6639 & TRN & & & \\
\hline CHEMBL1588590 & 688810 & 4.783 & 5.221 & TRN & & & \\
\hline CHEMBL3207376 & 688810 & 5.083 & 5.1417 & TRN & & & \\
\hline CHEMBL1401783 & 688810 & 4.783 & 5.4225 & TRN & & & \\
\hline CHEMBL1321836 & 688810 & 6.433 & 5.4001 & TRN & & & \\
\hline CHEMBL1342667 & 688810 & 5.28299 & 99999990 & 995 & 5.825 & TRN & \\
\hline CHEMBL1333230 & 688810 & 4.933 & 4.9262 & TST & & & \\
\hline CHEMBL1501259 & 688810 & 4.73300 & 00000006 & 005 & 4.8773 & TRN & \\
\hline CHEMBL1305304 & 688810 & 5.83299 & 99999995 & & 5.5797 & TRN & \\
\hline CHEMBL1461728 & 688810 & 5.13299 & 99999995 & & 5.6725 & TRN & \\
\hline CHEMBL1493673 & 688810 & 5.63299 & 99999995 & & 5.2010 & 00000000005 & TRN \\
\hline CHEMBL389723 & 688810 & 4.883 & 5.4039 & TRN & & & \\
\hline CHEMBL1569860 & 688810 & 6.433 & 6.3418 & TRN & & & \\
\hline CHEMBL1430227 & 688810 & 5.033 & 5.0786 & TRN & & & \\
\hline CHEMBL1323036 & 688810 & 4.883 & 4.9664 & TST & & & \\
\hline CHEMBL1514781 & 688810 & 6.58299 & 99999995 & & 5.2574 & TRN & \\
\hline CHEMBL1376710 & 688810 & 5.13299 & 99999999 & & 5.1323 & TRN & \\
\hline CHEMBL1326560 & 688810 & 4.883 & 4.8639 & TRN & & & \\
\hline CHEMBL1342416 & 688810 & 5.28299 & 99999995 & 995 & 5.4858 & TST & \\
\hline CHEMBL1327254 & 688810 & 6.28299 & 99999995 & 995 & 5.6110 & 0000000001 & TRN \\
\hline CHEMBL1412963 & 688810 & 6.38299 & 99999995 & & 6.0064 & TRN & \\
\hline CHEMBL1564201 & 688810 & 4.833 & 4.8377 & TST & & & \\
\hline CHEMBL1582474 & 688810 & 4.783 & 5.3031 & TRN & & & \\
\hline
\end{tabular}




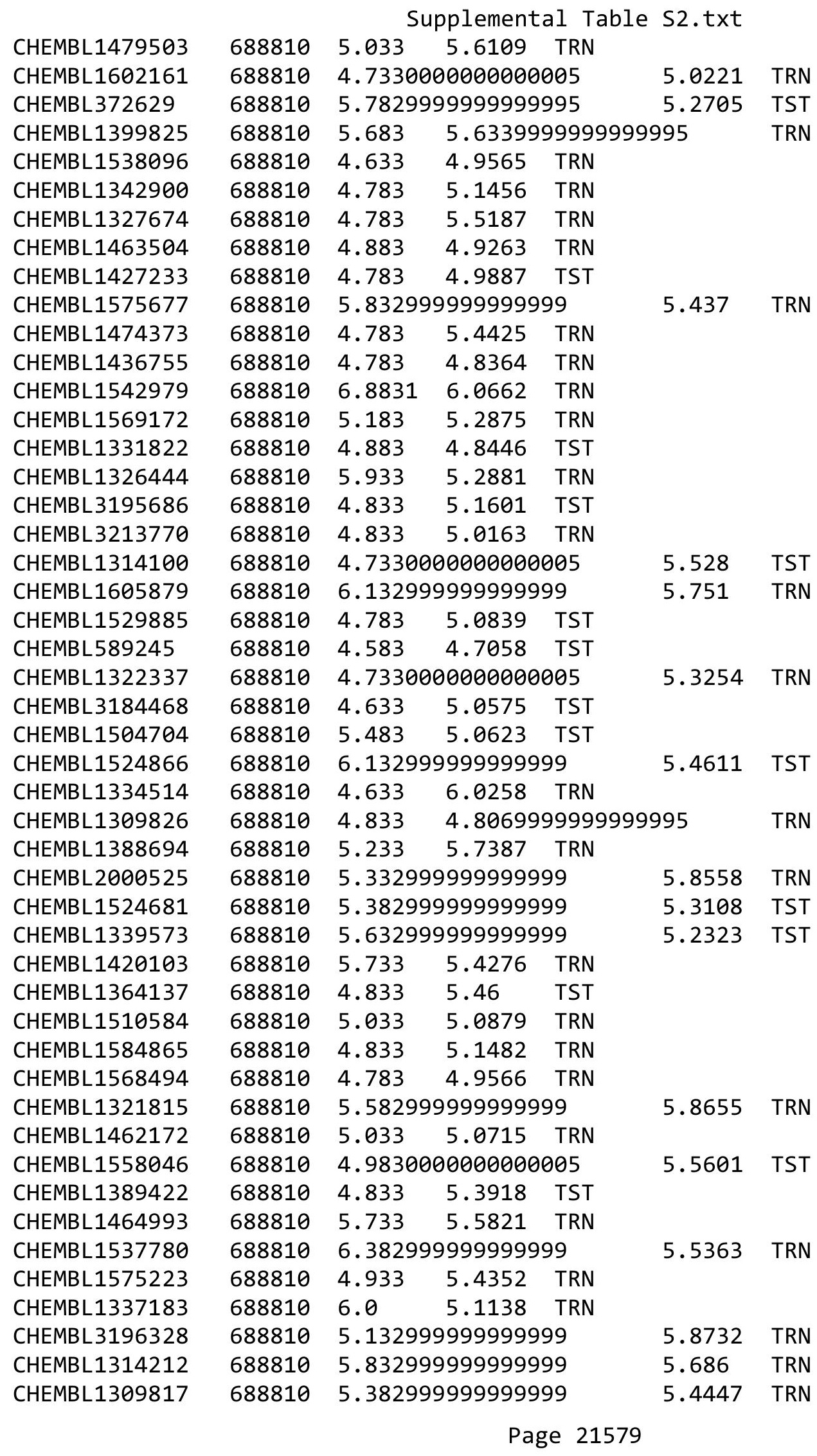




\begin{tabular}{|c|c|c|c|c|c|c|c|}
\hline \multirow[b]{2}{*}{ CHEMBL171596 } & \multicolumn{6}{|c|}{ Supplemental Table s2.txt } & \\
\hline & 688810 & 5.033 & 5.2143 & TRN & & & \\
\hline CHEMBL1308273 & 688810 & 6.983 & 5.4807 & TRN & & & \\
\hline CHEMBL1570241 & 688810 & 6.6329 & 99999999 & & 5.72 & TRN & \\
\hline CHEMBL1417999 & 688810 & 5.933 & 5.4626 & TRN & & & \\
\hline CHEMBL1500106 & 688810 & 6.3329 & 99999999 & 99 & 5.79299 & 9999999999 & TRN \\
\hline CHEMBL1429336 & 688810 & 4.833 & 5.4539 & TRN & & & \\
\hline CHEMBL1986259 & 688810 & 5.183 & 4.8509 & TRN & & & \\
\hline CHEMBL1304997 & 688810 & 4.7330 & 00000000 & 005 & 5.4311 & TRN & \\
\hline CHEMBL394287 & 688810 & 4.883 & 5.2826 & TST & & & \\
\hline CHEMBL1366870 & 688810 & 5.683 & 4.9989 & TRN & & & \\
\hline CHEMBL1364725 & 688810 & 4.9830 & 00000000 & 005 & 5.3112 & TST & \\
\hline CHEMBL1416282 & 688810 & 5.8829 & 99999999 & & 5.5538 & TRN & \\
\hline CHEMBL1347382 & 688810 & 4.833 & 5.0632 & TRN & & & \\
\hline CHEMBL3190064 & 688810 & 5.2829 & 99999999 & 995 & 5.3846 & TRN & \\
\hline CHEMBL1299225 & 688810 & 5.3829 & 99999999 & & 5.4195 & TRN & \\
\hline CHEMBL1584073 & 688810 & 6.683 & 5.4048 & TRN & & & \\
\hline CHEMBL1532051 & 688810 & 4.7330 & 00000000 & 005 & 5.1064 & TRN & \\
\hline CHEMBL1430372 & 688810 & 4.633 & 5.3804 & TST & & & \\
\hline CHEMBL1213834 & 688810 & 6.233 & 5.8463 & TRN & & & \\
\hline CHEMBL1429971 & 688810 & 5.6329 & 99999999 & & 5.3709 & TRN & \\
\hline CHEMBL1326851 & 688810 & 4.783 & 4.846 & TST & & & \\
\hline CHEMBL1598510 & 688810 & 6.6329 & 99999999 & & 5.8004 & TRN & \\
\hline CHEMBL1423156 & 688810 & 5.083 & 5.1054 & TRN & & & \\
\hline CHEMBL1328522 & 688810 & 4.683 & 5.1311 & TST & & & \\
\hline CHEMBL1557224 & 688810 & 4.883 & 5.501 & TST & & & \\
\hline CHEMBL1578365 & 688810 & 4.833 & 5.3872 & TRN & & & \\
\hline CHEMBL1584207 & 688810 & 5.5829 & 99999999 & & 5.0237 & TRN & \\
\hline CHEMBL1544497 & 688810 & 5.733 & 5.8175 & TRN & & & \\
\hline CHEMBL241909 & 688810 & 4.783 & 4.9526 & TRN & & & \\
\hline CHEMBL546865 & 688810 & 6.3829 & 99999999 & & 5.609 & TRN & \\
\hline CHEMBL1496347 & 688810 & 5.683 & 5.254 & TRN & & & \\
\hline CHEMBL1429037 & 688810 & 5.2829 & 99999999 & 995 & 5.6763 & TST & \\
\hline CHEMBL1978063 & 688810 & 5.933 & 6.3506 & TRN & & & \\
\hline CHEMBL1326369 & 688810 & 4.633 & 5.0281 & TRN & & & \\
\hline CHEMBL1398744 & 688810 & 4.783 & 4.8452 & TRN & & & \\
\hline CHEMBL1574671 & 688810 & 5.683 & 5.8454 & TST & & & \\
\hline CHEMBL1360086 & 688810 & 5.8329 & 99999999 & & 6.1288 & TRN & \\
\hline CHEMBL1393509 & 688810 & 5.183 & 5.3486 & TRN & & & \\
\hline CHEMBL1490976 & 688810 & 5.733 & 5.8641 & TRN & & & \\
\hline CHEMBL1585912 & 688810 & 5.3329 & 99999999 & & 5.2257 & TRN & \\
\hline CHEMBL1465339 & 688810 & 5.3329 & 99999999 & & 4.9238 & TRN & \\
\hline CHEMBL 1401103 & 688810 & 5.683 & 5.3475 & TRN & & & \\
\hline CHEMBL1376618 & 688810 & 5.233 & 5.6358 & TRN & & & \\
\hline CHEMBL1602086 & 688810 & 5.8329 & 99999999 & & 6.8427 & TRN & \\
\hline CHEMBL1322289 & 688810 & 5.433 & 4.8733 & TRN & & & \\
\hline CHEMBL1331809 & 688810 & 5.433 & 5.03 & TST & & & \\
\hline CHEMBL1384080 & 688810 & 4.833 & 5.4057 & TRN & & & \\
\hline CHEMBL1431307 & 688810 & 5.3329 & 99999999 & & 4.6805 & TST & \\
\hline
\end{tabular}




\begin{tabular}{|c|c|c|c|c|c|c|c|}
\hline \multirow[b]{2}{*}{ CHEMBL3211050 } & & \\
\hline & 688810 & 5.483 & 5.1544 & TST & & & \\
\hline CHEMBL1509590 & 688810 & 4.7330 & 000000000 & 005 & 4.6474 & TST & \\
\hline CHEMBL1391898 & 688810 & 5.033 & 4.9915 & TRN & & & \\
\hline CHEMBL1340489 & 688810 & 6.2829 & 999999999 & 995 & 5.3215 & TRN & \\
\hline CHEMBL1331926 & 688810 & 5.5829 & 799999999 & & 5.4942 & TRN & \\
\hline CHEMBL1389228 & 688810 & 4.783 & 4.8726 & TRN & & & \\
\hline CHEMBL1513145 & 688810 & 4.633 & 4.9206 & TST & & & \\
\hline CHEMBL1344929 & 688810 & 5.9 & 5.2334 & TRN & & & \\
\hline CHEMBL1342790 & 688810 & 4.683 & 5.2001 & TRN & & & \\
\hline CHEMBL1413808 & 688810 & 5.8329 & 999999999 & & 5.2213 & TRN & \\
\hline CHEMBL1347512 & 688810 & 5.183 & 5.6169 & TRN & & & \\
\hline CHEMBL1564145 & 688810 & 4.833 & 5.3357 & TRN & & & \\
\hline CHEMBL1391684 & 688810 & 5.6329 & 999999999 & & 6.0439 & TRN & \\
\hline CHEMBL1454953 & 688810 & 6.983 & 5.4242 & TST & & & \\
\hline CHEMBL1598442 & 688810 & 4.583 & 5.3298 & TRN & & & \\
\hline CHEMBL1302828 & 688810 & 4.833 & 5.3275 & TRN & & & \\
\hline CHEMBL1529835 & 688810 & 6.433 & 5.4942 & TRN & & & \\
\hline CHEMBL1442881 & 688810 & 4.933 & 5.0544 & TRN & & & \\
\hline CHEMBL1518385 & 688810 & 5.2829 & 999999999 & 995 & 5.1653 & TST & \\
\hline CHEMBL1459714 & 688810 & 5.5329 & 999999999 & 995 & 5.3206 & TRN & \\
\hline CHEMBL1469807 & 688810 & 7.0329 & 5.481 & TRN & & & \\
\hline CHEMBL1525722 & 688810 & 5.6329 & 999999999 & & 5.5837 & TRN & \\
\hline CHEMBL1602071 & 688810 & 5.083 & 4.9791 & TRN & & & \\
\hline CHEMBL1572809 & 688810 & 5.7829 & 999999999 & 995 & 5.4131 & TRN & \\
\hline CHEMBL1370991 & 688810 & 6.7829 & 999999999 & 995 & 6.0526 & TRN & \\
\hline CHEMBL1497047 & 688810 & 4.883 & 5.4956 & TRN & & & \\
\hline CHEMBL1489569 & 688810 & 6.1329 & 99999999 & & 5.251 & TRN & \\
\hline CHEMBL1409760 & 688810 & 5.8329 & 99999999 & & 5.8742 & TRN & \\
\hline CHEMBL1371275 & 688810 & 5.7829 & 99999999 & 995 & 5.7253 & TRN & \\
\hline CHEMBL3194579 & 688810 & 4.833 & 5.5693 & TST & & & \\
\hline CHEMBL1372289 & 688810 & 5.1329 & 199999999 & & 5.3718 & TRN & \\
\hline CHEMBL1521476 & 688810 & 6.5829 & 99999999 & & 5.2420 & 3000000001 & TST \\
\hline CHEMBL1588123 & 688810 & 5.45 & 5.4901 & TRN & & & \\
\hline CHEMBL1496800 & 688810 & 4.9830 & 00000000 & 005 & 5.3836 & TRN & \\
\hline CHEMBL1556513 & 688810 & 4.633 & 5.2254 & TST & & & \\
\hline CHEMBL1420432 & 688810 & 6.3329 & 199999999 & & 4.8944 & TST & \\
\hline CHEMBL 3196474 & 688810 & 5.8329 & 99999999 & & 5.2736 & TRN & \\
\hline CHEMBL1475098 & 688810 & 5.2829 & 99999999 & 995 & 5.8762 & TRN & \\
\hline CHEMBL1544997 & 688810 & 4.683 & 5.2203 & TRN & & & \\
\hline CHEMBL3190073 & 688810 & 6.1329 & 99999999 & & 5.6089 & TRN & \\
\hline CHEMBL1464832 & 688810 & 4.833 & 4.7223 & TST & & & \\
\hline CHEMBL1519457 & 688810 & 4.633 & 4.9571 & TRN & & & \\
\hline CHEMBL1450223 & 688810 & 4.883 & 5.2677 & TST & & & \\
\hline CHEMBL1480202 & 688810 & 5.3329 & 99999999 & & 5.5829 & 9999999999 & TRN \\
\hline CHEMBL528791 & 688810 & 5.233 & 4.6896 & TST & & & \\
\hline CHEMBL1526257 & 688810 & 5.5829 & 99999999 & & 5.59 & TRN & \\
\hline CHEMBL1528978 & 688810 & 4.9830 & 00000000 & 005 & 5.2434 & TST & \\
\hline CHEMBL3195592 & 688810 & 5.3829 & 99999999 & & 5.475 & TRN & \\
\hline
\end{tabular}




\begin{tabular}{|c|c|c|c|c|c|c|c|}
\hline \multirow{2}{*}{ CHEMBL1489325 } & \multicolumn{6}{|c|}{ Supplemental Table S2.txt } & \\
\hline & 688810 & \multicolumn{3}{|c|}{4.9830000000000005} & 4.8785 & TRN & \\
\hline CHEMBL1547222 & 688810 & \multicolumn{3}{|c|}{6.332999999999999} & 5.9791 & TRN & \\
\hline CHEMBL1319249 & 688810 & \multicolumn{3}{|c|}{5.632999999999999} & \multicolumn{2}{|c|}{4.9719999999999995} & TRN \\
\hline CHEMBL1413278 & 688810 & 5.733 & 5.6416 & TRN & & & \\
\hline CHEMBL 3199677 & 688810 & 5.733 & 5.2606 & TST & & & \\
\hline CHEMBL1575756 & 688810 & 5.683 & 5.0632 & TRN & & & \\
\hline CHEMBL1507542 & 688810 & \multicolumn{3}{|c|}{4.9830000000000005} & 5.2751 & TST & \\
\hline CHEMBL1410151 & 688810 & 4.783 & 5.3239 & TST & & & \\
\hline CHEMBL1318736 & 688810 & 5.483 & 6.0264 & TRN & & & \\
\hline CHEMBL1608375 & 688810 & 4.633 & 4.792 & TST & & & \\
\hline CHEMBL1545802 & 688810 & 5.433 & 5.2712 & TRN & & & \\
\hline CHEMBL1317606 & 688810 & 5.683 & 5.5166 & TRN & & & \\
\hline CHEMBL1450530 & 688810 & 4.933 & 5.3961 & TRN & & & \\
\hline CHEMBL1449968 & 688810 & 5.933 & 5.4615 & TST & & & \\
\hline CHEMBL1359153 & 688810 & 4.783 & 5.0339 & TST & & & \\
\hline CHEMBL1605144 & 688810 & \multicolumn{3}{|c|}{5.132999999999999} & 5.473 & TRN & \\
\hline CHEMBL1570790 & 688810 & 5.233 & 5.4841 & TRN & & & \\
\hline CHEMBL1987461 & 688810 & \multicolumn{3}{|c|}{5.2829999999999995} & 5.4611 & TRN & \\
\hline CHEMBL1500818 & 688810 & \multicolumn{3}{|c|}{5.7829999999999995} & 5.6753 & TST & \\
\hline CHEMBL585628 & 688810 & 4.833 & 5.0236 & TST & & & \\
\hline CHEMBL1574685 & 688810 & 4.833 & 4.5788 & TRN & & & \\
\hline CHEMBL1445569 & 688810 & 4.883 & 5.1578 & TRN & & & \\
\hline CHEMBL1352493 & 688810 & 4.783 & 4.9847 & TRN & & & \\
\hline CHEMBL1596777 & 688810 & 4.583 & 4.3671 & TST & & & \\
\hline CHEMBL1479977 & 688810 & \multicolumn{3}{|c|}{4.7330000000000005} & 5.0698 & TRN & \\
\hline CHEMBL1590535 & 688810 & 4.783 & 5.0904 & TST & & & \\
\hline CHEMBL1502933 & 688810 & \multicolumn{3}{|c|}{5.5329999999999995} & 5.4889 & TRN & \\
\hline CHEMBL1498834 & 688810 & 4.833 & 4.7789 & TST & & & \\
\hline CHEMBL1364494 & 688810 & \multicolumn{3}{|c|}{5.832999999999999} & 5.336 & TRN & \\
\hline CHEMBL1424951 & 688810 & 4.633 & 4.6829 & TRN & & & \\
\hline CHEMBL1305316 & 688810 & \multicolumn{3}{|c|}{5.5329999999999995} & 4.8098 & TRN & \\
\hline CHEMBL1391189 & 688810 & \multicolumn{3}{|c|}{6.382999999999999} & 5.3355 & TRN & \\
\hline CHEMBL1339592 & 688810 & 5.183 & 5.4748 & TRN & & & \\
\hline CHEMBL1598996 & 688810 & \multicolumn{3}{|c|}{4.7330000000000005} & 5.1441 & TRN & \\
\hline CHEMBL1320798 & 688810 & 4.883 & 4.9639 & TRN & & & \\
\hline CHEMBL 1466040 & 688810 & 4.883 & 5.1791 & TRN & & & \\
\hline CHEMBL1564049 & 688810 & 4.783 & 5.0728 & TRN & & & \\
\hline CHEMBL1534215 & 688810 & 4.783 & 4.7931 & TRN & & & \\
\hline CHEMBL1409528 & 688810 & 5.933 & 5.6749 & TRN & & & \\
\hline CHEMBL1466625 & 688810 & \multicolumn{3}{|c|}{4.7330000000000005} & 5.2502 & TRN & \\
\hline CHEMBL1319413 & 688810 & 5.183 & 5.5004 & TST & & & \\
\hline CHEMBL1353871 & 688810 & 5.183 & 4.9139 & TRN & & & \\
\hline CHEMBL1318000 & 688810 & 4.833 & 5.6047 & TST & & & \\
\hline CHEMBL1508110 & 688810 & 5.183 & 5.7075 & TST & & & \\
\hline CHEMBL1372026 & 688810 & 4.633 & 5.2199 & TRN & & & \\
\hline CHEMBL1458347 & 688810 & \multicolumn{3}{|c|}{5.7829999999999995} & 5.7005 & TRN & \\
\hline CHEMBL1513175 & 688810 & 4.783 & 5.1728 & TST & & & \\
\hline CHEMBL1329596 & 688810 & 5.2829 & 99999999 & 995 & 5.8928 & TRN & \\
\hline
\end{tabular}




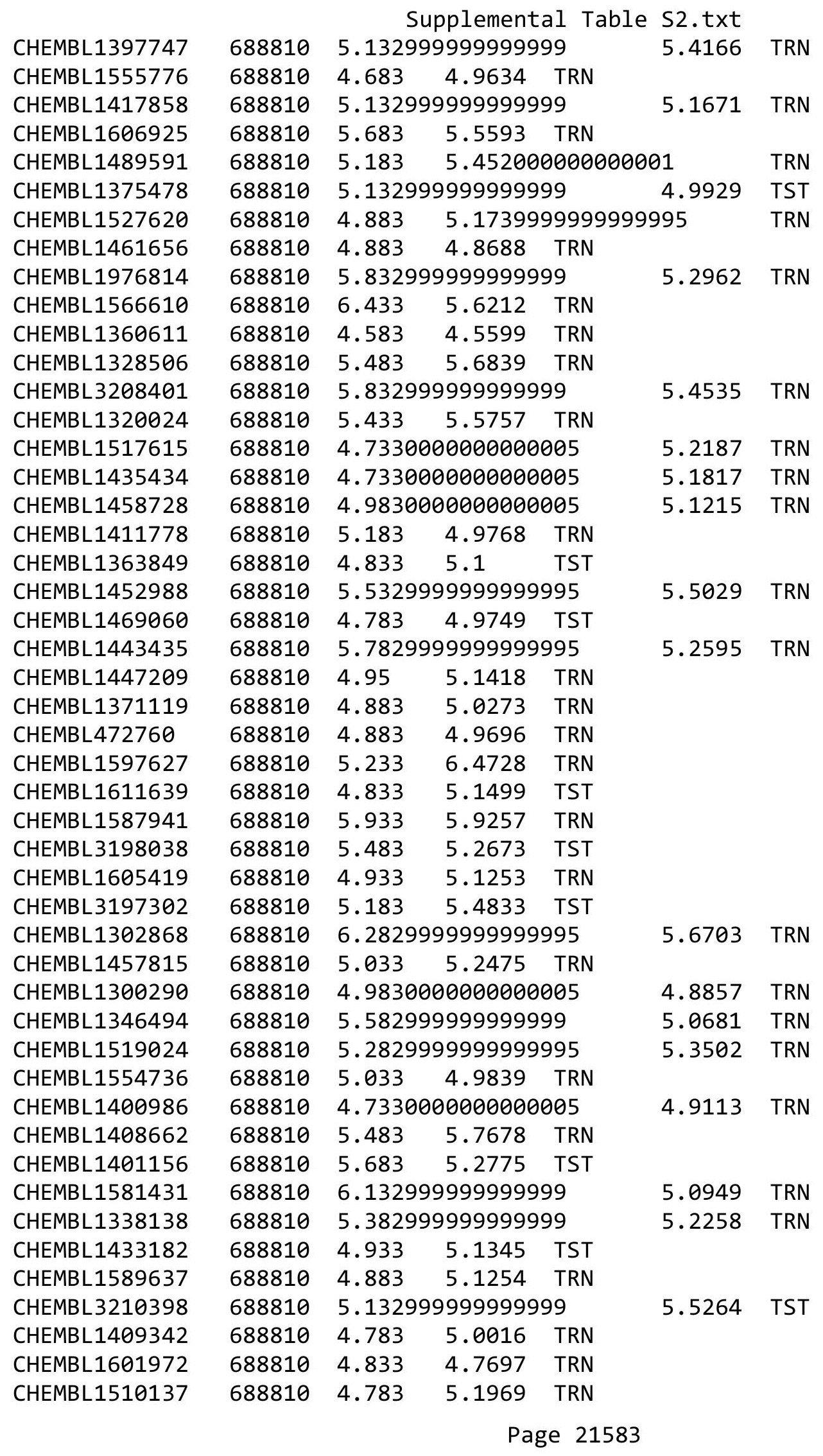




\begin{tabular}{|c|c|c|c|c|c|c|}
\hline \multirow[b]{2}{*}{ CHEMBL1342324 } & \multirow[b]{2}{*}{688810} & \multicolumn{5}{|c|}{ Supplemental Table S2.txt } \\
\hline & & 4.833 & 5.2344 & TRN & \multirow{6}{*}{5.7964} & \multirow{3}{*}{ TRN } \\
\hline CHEMBL1356854 & 688810 & \multicolumn{3}{|c|}{5.882999999999999} & & \\
\hline CHEMBL1428578 & 688810 & 4.633 & 5.2068 & TRN & & \\
\hline CHEMBL1496402 & 688810 & 4.633 & 4.8861 & TRN & & \\
\hline CHEMBL1568436 & 688810 & 4.833 & 5.1239 & TST & & \\
\hline CHEMBL1559667 & 688810 & 5.033 & 4.8892 & TST & & \\
\hline CHEMBL1386863 & 688810 & \multicolumn{3}{|c|}{4.7330000000000005} & 5.0739 & TRN \\
\hline CHEMBL1518767 & 688810 & 4.883 & 5.3775 & TRN & & \\
\hline CHEMBL576353 & 688810 & 4.783 & 5.7232 & TST & & \\
\hline CHEMBL1461987 & 688810 & 4.933 & 5.4589 & TRN & & \\
\hline CHEMBL1311831 & 688810 & 6.0 & 4.6169 & TRN & & \\
\hline CHEMBL1509837 & 688810 & 5.233 & 4.8564 & TRN & & \\
\hline CHEMBL1580946 & 688810 & \multicolumn{3}{|c|}{6.382999999999999} & 5.8238 & TRN \\
\hline CHEMBL1606280 & 688810 & 5.733 & 5.0578 & TST & & \\
\hline CHEMBL1493724 & 688810 & 5.983 & 5.3887 & TST & & \\
\hline CHEMBL1459095 & 688810 & 5.1 & 5.3995 & TRN & & \\
\hline CHEMBL1303584 & 688810 & 4.683 & 5.0599 & TRN & & \\
\hline CHEMBL1375806 & 688810 & 4.783 & 5.022 & TRN & & \\
\hline CHEMBL1991209 & 688810 & 5.483 & 5.2907 & TRN & & \\
\hline CHEMBL1313489 & 688810 & 4.783 & 5.2114 & TRN & & \\
\hline CHEMBL1446875 & 688810 & 5.733 & 5.3915 & TRN & & \\
\hline CHEMBL1470925 & 688810 & 4.833 & 5.5421 & TST & & \\
\hline CHEMBL1600540 & 688810 & \multicolumn{3}{|c|}{5.332999999999999} & 5.2285 & TRN \\
\hline CHEMBL1322134 & 688810 & 5.033 & 5.1755 & TRN & & \\
\hline CHEMBL1543948 & 688810 & \multicolumn{3}{|c|}{6.132999999999999} & 5.2405 & TRN \\
\hline CHEMBL1535140 & 688810 & \multicolumn{3}{|c|}{4.7330000000000005} & 4.9592 & TST \\
\hline CHEMBL1543979 & 688810 & 4.783 & 5.6295 & TST & & \\
\hline CHEMBL3208696 & 688810 & 5.233 & 5.6739 & TRN & & \\
\hline CHEMBL1311341 & 688810 & 5.033 & 5.2101 & TRN & & \\
\hline CHEMBL1367691 & 688810 & 4.583 & 4.9697 & TST & & \\
\hline CHEMBL1450011 & 688810 & \multicolumn{3}{|c|}{4.9830000000000005} & 5.0623 & TRN \\
\hline CHEMBL1384746 & 688810 & 5.483 & 5.1643 & TRN & & \\
\hline CHEMBL1542405 & 688810 & 5.683 & 5.9958 & TRN & & \\
\hline CHEMBL1537083 & 688810 & \multicolumn{3}{|c|}{4.7330000000000005} & 5.3273 & TRN \\
\hline CHEMBL77928 & 688810 & 4.783 & 5.4949 & TRN & & \\
\hline CHEMBL1448869 & 688810 & \multicolumn{3}{|c|}{5.832999999999999} & 5.6716 & TRN \\
\hline CHEMBL1503002 & 688810 & \multicolumn{3}{|c|}{6.2829999999999995} & 6.0294 & TRN \\
\hline CHEMBL1485058 & 688810 & 4.933 & 5.325 & TRN & & \\
\hline CHEMBL334707 & 688810 & 4.633 & 5.3172 & TST & & \\
\hline CHEMBL1444003 & 688810 & \multicolumn{3}{|c|}{5.332999999999999} & 5.2604 & TRN \\
\hline CHEMBL1338462 & 688810 & 5.083 & 5.0821 & TST & & \\
\hline CHEMBL1454871 & 688810 & \multicolumn{3}{|c|}{4.7330000000000005} & 5.2038 & TRN \\
\hline CHEMBL1347073 & 688810 & 4.683 & 5.0428 & TST & & \\
\hline CHEMBL1470135 & 688810 & 5.433 & 4.8555 & TRN & & \\
\hline CHEMBL1590708 & 688810 & 4.633 & 5.0221 & TST & & \\
\hline CHEMBL1481769 & 688810 & 5.233 & 5.316 & TRN & & \\
\hline CHEMBL1338178 & 688810 & 4.833 & 5.5108 & TRN & & \\
\hline \multirow[t]{2}{*}{ CHEMBL3194349 } & 688810 & \multicolumn{3}{|c|}{4.7330000000000005} & 5.2302 & TRN \\
\hline & & \multicolumn{5}{|c|}{ Page 2158} \\
\hline
\end{tabular}




\begin{tabular}{|c|c|c|c|c|c|c|}
\hline & & \multicolumn{4}{|c|}{ Supplemental Table S2.txt } & \\
\hline CHEMBL1516188 & 688810 & \multicolumn{3}{|c|}{6.582999999999999} & 5.9508 & TRN \\
\hline CHEMBL1539758 & 688810 & \multicolumn{3}{|c|}{4.7330000000000005} & 5.1657 & TST \\
\hline CHEMBL1306274 & 688810 & 5.433 & 5.1096 & TRN & & \\
\hline CHEMBL1575744 & 688810 & \multicolumn{3}{|c|}{5.582999999999999} & 5.3849 & TRN \\
\hline CHEMBL1347514 & 688810 & 4.883 & 5.3543 & TST & & \\
\hline CHEMBL1577309 & 688810 & 5.183 & 5.6242 & TRN & & \\
\hline CHEMBL1484934 & 688810 & 4.633 & 4.8616 & TRN & & \\
\hline CHEMBL1383515 & 688810 & 4.833 & 5.2132 & TRN & & \\
\hline CHEMBL1570344 & 688810 & \multicolumn{3}{|c|}{5.832999999999999} & 5.7541 & TRN \\
\hline CHEMBL1309122 & 688810 & 4.783 & 5.3612 & TRN & & \\
\hline CHEMBL1504283 & 688810 & 4.633 & 5.6382 & TST & & \\
\hline CHEMBL589207 & 688810 & 5.083 & 5.346 & TRN & & \\
\hline CHEMBL1396544 & 688810 & 4.583 & 4.9426 & TRN & & \\
\hline CHEMBL1375823 & 688810 & \multicolumn{3}{|c|}{4.9830000000000005} & 5.26 & TRN \\
\hline CHEMBL1483340 & 688810 & 4.783 & 5.0363 & TST & & \\
\hline CHEMBL1344973 & 688810 & 4.783 & 5.4579 & TRN & & \\
\hline CHEMBL3197568 & 688810 & 4.683 & 5.3637 & TST & & \\
\hline CHEMBL 3198899 & 688810 & \multicolumn{3}{|c|}{6.332999999999999} & 5.2017 & TRN \\
\hline CHEMBL3213637 & 688810 & \multicolumn{3}{|c|}{6.382999999999999} & 5.2235 & TRN \\
\hline CHEMBL1486093 & 688810 & 5.233 & 5.7971 & TRN & & \\
\hline CHEMBL1462497 & 688810 & 5.733 & 5.1922 & TST & & \\
\hline CHEMBL3189418 & 688810 & 4.833 & 5.2526 & TRN & & \\
\hline CHEMBL1402597 & 688810 & 5.183 & 5.2863 & TRN & & \\
\hline CHEMBL1299319 & 688810 & 4.833 & 4.8693 & TST & & \\
\hline CHEMBL1529022 & 688810 & 5.233 & 5.7423 & TRN & & \\
\hline CHEMBL1330646 & 688810 & \multicolumn{3}{|c|}{5.132999999999999} & 5.1622 & TRN \\
\hline CHEMBL3193479 & 688810 & \multicolumn{3}{|c|}{5.7829999999999995} & 4.9301 & TST \\
\hline CHEMBL1341735 & 688810 & 5.683 & 5.6728 & TRN & & \\
\hline CHEMBL1509691 & 688810 & 4.933 & 5.3771 & TRN & & \\
\hline CHEMBL1343309 & 688810 & \multicolumn{3}{|c|}{6.082999999999999} & 5.5582 & TRN \\
\hline CHEMBL1579068 & 688810 & 4.933 & 4.4909 & TRN & & \\
\hline CHEMBL1515545 & 688810 & 5.183 & 4.8777 & TRN & & \\
\hline CHEMBL1504462 & 688810 & 6.433 & 5.1651 & TST & & \\
\hline CHEMBL1299537 & 688810 & 4.883 & 5.0893 & TST & & \\
\hline CHEMBL1509795 & 688810 & \multicolumn{3}{|c|}{6.332999999999999} & 4.9458 & TRN \\
\hline CHEMBL1334971 & 688810 & 4.833 & 5.183 & TRN & & \\
\hline CHEMBL1344799 & 688810 & \multicolumn{3}{|c|}{5.132999999999999} & 5.2391 & TRN \\
\hline CHEMBL1416014 & 688810 & 4.883 & 5.2904 & TST & & \\
\hline CHEMBL1488459 & 688810 & 4.933 & 5.4989 & TST & & \\
\hline CHEMBL1403050 & 688810 & 4.783 & 5.0592 & TST & & \\
\hline CHEMBL1386367 & 688810 & 5.183 & 5.1351 & TRN & & \\
\hline CHEMBL1588675 & 688810 & 4.783 & 5.0794 & TRN & & \\
\hline CHEMBL1440081 & 688810 & \multicolumn{3}{|c|}{6.332999999999999} & 5.6402 & TRN \\
\hline CHEMBL1521587 & 688810 & 4.583 & 4.8337 & TRN & & \\
\hline CHEMBL1559104 & 688810 & 5.733 & 5.1886 & TRN & & \\
\hline CHEMBL1593518 & 688810 & 4.783 & 4.6932 & TRN & & \\
\hline CHEMBL1514150 & 688810 & \multicolumn{3}{|c|}{5.882999999999999} & סככש. & TRN \\
\hline CHEMBL1461199 & 688810 & 5.183 & 5.0677 & TST & & \\
\hline
\end{tabular}




\begin{tabular}{|c|c|c|c|c|c|c|}
\hline \multirow{3}{*}{$\begin{array}{l}\text { CHEMBL1586616 } \\
\text { CHEMBL1557805 }\end{array}$} & \multirow{3}{*}{$\begin{array}{l}688810 \\
688810\end{array}$} & \multicolumn{4}{|c|}{ Supplemental Table S2.txt } & \multirow[b]{2}{*}{ TST } \\
\hline & & \multicolumn{3}{|c|}{4.7330000000000005} & 4.8694 & \\
\hline & & 5.983 & 5.2486 & TST & & \\
\hline CHEMBL1449556 & 688810 & 4.833 & 5.0502 & TST & & \\
\hline CHEMBL1390986 & 688810 & 5.083 & 4.8903 & TRN & & \\
\hline CHEMBL1478389 & 688810 & 5.483 & 5.0007 & TRN & & \\
\hline CHEMBL1351090 & 688810 & \multicolumn{3}{|c|}{5.2829999999999995} & 4.9634 & TRN \\
\hline CHEMBL1598052 & 688810 & 4.883 & 4.7719 & TRN & & \\
\hline CHEMBL1494260 & 688810 & \multicolumn{3}{|c|}{4.9830000000000005} & 5.231 & TRN \\
\hline CHEMBL1524725 & 688810 & 4.783 & 5.0203 & TRN & & \\
\hline CHEMBL1370408 & 688810 & \multicolumn{3}{|c|}{4.7330000000000005} & 5.7127 & TST \\
\hline CHEMBL1611081 & 688810 & 4.833 & 4.7 & TRN & & \\
\hline CHEMBL1349318 & 688810 & 4.633 & 5.1643 & TST & & \\
\hline CHEMBL1351925 & 688810 & \multicolumn{3}{|c|}{4.7330000000000005} & 4.9741 & TST \\
\hline CHEMBL1330289 & 688810 & \multicolumn{3}{|c|}{6.132999999999999} & 5.8839 & TRN \\
\hline CHEMBL1394645 & 688810 & 4.633 & 5.2783 & TRN & & \\
\hline CHEMBL1593115 & 688810 & 4.683 & 4.5819 & TRN & & \\
\hline CHEMBL1572197 & 688810 & \multicolumn{3}{|c|}{5.832999999999999} & 4.9641 & TRN \\
\hline CHEMBL3211375 & 688810 & 5.083 & 5.2086 & TST & & \\
\hline CHEMBL1603334 & 688810 & \multicolumn{3}{|c|}{6.132999999999999} & 5.5334 & TRN \\
\hline CHEMBL1372576 & 688810 & 4.633 & 5.7933 & TRN & & \\
\hline CHEMBL3189908 & 688810 & 4.833 & 5.2659 & TRN & & \\
\hline CHEMBL1482571 & 688810 & 5.433 & 5.9822 & TRN & & \\
\hline CHEMBL1396342 & 688810 & \multicolumn{3}{|c|}{6.132999999999999} & 5.2836 & TRN \\
\hline CHEMBL1548933 & 688810 & \multicolumn{3}{|c|}{5.632999999999999} & 5.4225 & TRN \\
\hline CHEMBL1445980 & 688810 & \multicolumn{3}{|c|}{4.7330000000000005} & 5.2685 & TRN \\
\hline CHEMBL1331597 & 688810 & 5.933 & 4.9767 & TRN & & \\
\hline CHEMBL1611028 & 688810 & 4.833 & 5.2724 & TST & & \\
\hline CHEMBL1406220 & 688810 & 5.083 & 5.6448 & TRN & & \\
\hline CHEMBL1563581 & 688810 & 6.5501 & 5.8739 & TRN & & \\
\hline CHEMBL1479424 & 688810 & 4.933 & 5.4189 & TST & & \\
\hline CHEMBL3212796 & 688810 & \multicolumn{3}{|c|}{5.132999999999999} & 5.0204 & TRN \\
\hline CHEMBL1314408 & 688810 & 4.633 & 5.2496 & TST & & \\
\hline CHEMBL3194218 & 688810 & \multicolumn{3}{|c|}{4.9830000000000005} & 5.1538 & TRN \\
\hline CHEMBL1471957 & 688810 & \multicolumn{3}{|c|}{5.132999999999999} & 5.3488 & TRN \\
\hline CHEMBL3195869 & 688810 & \multicolumn{3}{|c|}{6.2829999999999995} & 5.2404 & TST \\
\hline CHEMBL1529920 & 688810 & 4.683 & 4.8379 & TST & & \\
\hline CHEMBL1358016 & 688810 & 4.633 & 5.4455 & TRN & & \\
\hline CHEMBL1353518 & 688810 & 4.633 & 5.2378 & TST & & \\
\hline CHEMBL1557926 & 688810 & 4.883 & 5.1527 & TRN & & \\
\hline CHEMBL1497248 & 688810 & \multicolumn{3}{|c|}{4.7330000000000005} & 5.1909 & TRN \\
\hline CHEMBL1350079 & 688810 & 5.733 & 5.6789 & TRN & & \\
\hline CHEMBL1321743 & 688810 & \multicolumn{3}{|c|}{4.7330000000000005} & 5.3422 & TRN \\
\hline CHEMBL3208776 & 688810 & 4.7330 & 00000000 & 005 & 5.6899 & TRN \\
\hline CHEMBL1612855 & 688810 & 4.933 & 5.4124 & TRN & & \\
\hline CHEMBL1478653 & 688810 & 4.883 & 5.2321 & TST & & \\
\hline CHEMBL1396983 & 688810 & 5.033 & 4.8717 & TRN & & \\
\hline CHEMBL510773 & 688810 & 5.2829 & 99999999 & 995 & 5.392 & TRN \\
\hline CHEMBL1387034 & 688810 & 4.833 & 5.0635 & TST & & \\
\hline
\end{tabular}




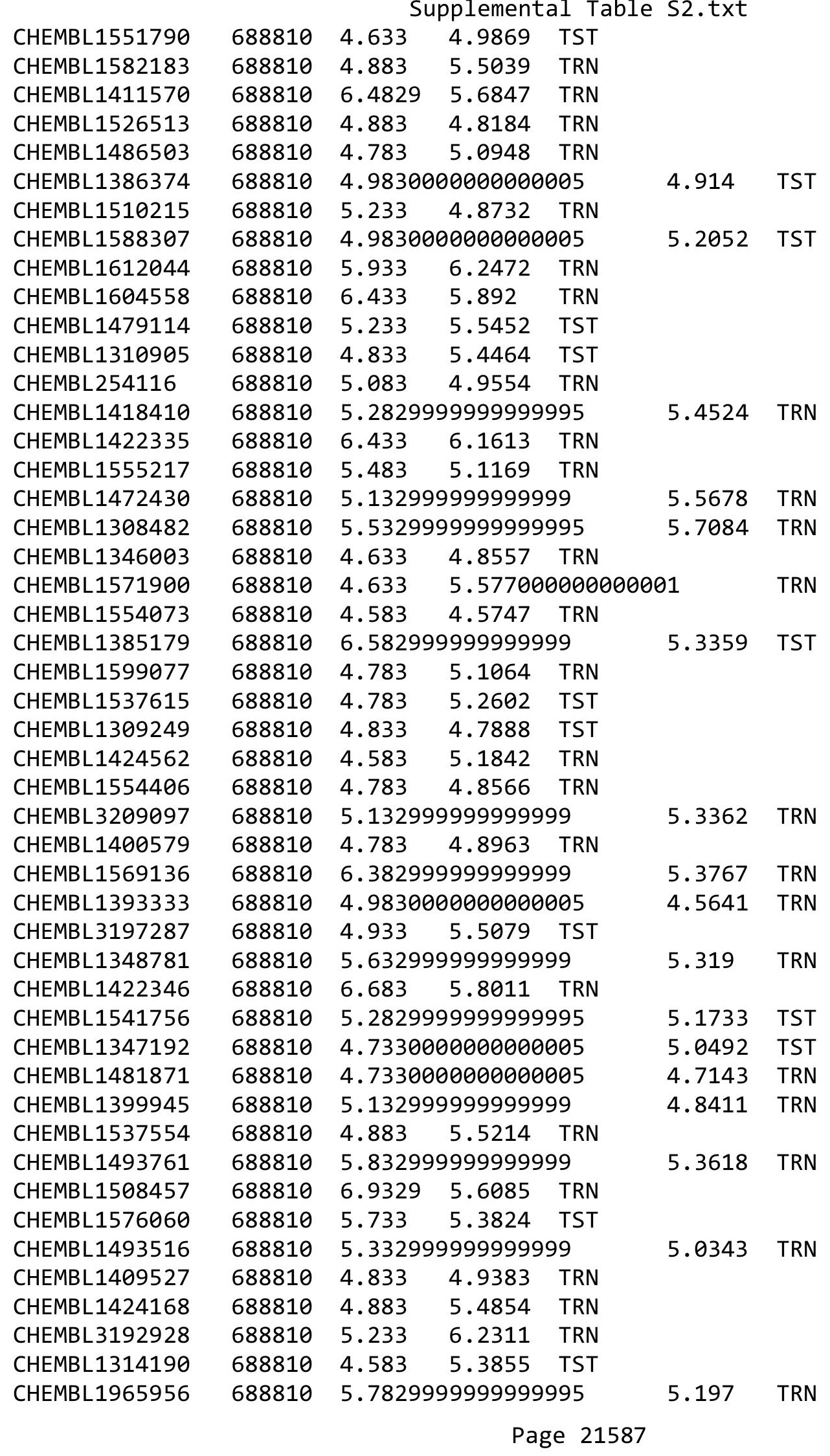




\begin{tabular}{|c|c|c|c|c|c|c|}
\hline \multirow{3}{*}{$\begin{array}{l}\text { CHEMBL } 597874 \\
\text { CHEMBL } 1414549\end{array}$} & & \multicolumn{5}{|c|}{ Supplemental Table S2.txt } \\
\hline & 688810 & \multicolumn{3}{|c|}{5.2829999999999995} & 5.1529 & TRN \\
\hline & 688810 & 4.783 & 5.3467 & TRN & & \\
\hline CHEMBL1544108 & 688810 & \multicolumn{3}{|c|}{5.582999999999999} & 5.1819 & TRN \\
\hline CHEMBL1337227 & 688810 & 4.683 & 4.9234 & TRN & & \\
\hline CHEMBL1547559 & 688810 & 7.0329 & 5.8463 & TST & & \\
\hline CHEMBL1490791 & 688810 & 5.183 & 5.1909 & TRN & & \\
\hline CHEMBL1577450 & 688810 & 4.683 & 5.1059 & TRN & & \\
\hline CHEMBL1443346 & 688810 & 4.783 & 5.1004 & TST & & \\
\hline CHEMBL1484856 & 688810 & \multicolumn{3}{|c|}{5.7829999999999995} & 5.5561 & TRN \\
\hline CHEMBL601135 & 688810 & 4.633 & 4.8979 & TRN & & \\
\hline CHEMBL1469995 & 688810 & 5.233 & 5.0194 & TST & & \\
\hline CHEMBL1523828 & 688810 & 5.183 & 5.691 & TRN & & \\
\hline CHEMBL1341787 & 688810 & 4.783 & 4.9275 & TRN & & \\
\hline CHEMBL1599070 & 688810 & 4.783 & 4.8571 & TRN & & \\
\hline CHEMBL1333785 & 688810 & \multicolumn{3}{|c|}{5.382999999999999} & 5.0607 & TRN \\
\hline CHEMBL3193110 & 688810 & 4.833 & 5.2016 & TRN & & \\
\hline CHEMBL1338475 & 688810 & 5.433 & 5.1315 & TRN & & \\
\hline CHEMBL1608474 & 688810 & \multicolumn{3}{|c|}{5.132999999999999} & 5.0646 & TRN \\
\hline CHEMBL1593453 & 688810 & 4.633 & 5.5287 & TRN & & \\
\hline CHEMBL1572217 & 688810 & \multicolumn{3}{|c|}{4.7330000000000005} & 5.4454 & TST \\
\hline CHEMBL1330605 & 688810 & \multicolumn{3}{|c|}{5.5329999999999995} & 5.5207 & TRN \\
\hline CHEMBL3210623 & 688810 & 4.833 & 4.9685 & TRN & & \\
\hline CHEMBL1347556 & 688810 & \multicolumn{3}{|c|}{4.9830000000000005} & 5.1961 & TST \\
\hline CHEMBL1380978 & 688810 & \multicolumn{3}{|c|}{5.5329999999999995} & 5.5801 & TRN \\
\hline CHEMBL1366373 & 688810 & 4.783 & 5.0122 & TST & & \\
\hline CHEMBL1333579 & 688810 & 5.733 & 5.4252 & TRN & & \\
\hline CHEMBL1326813 & 688810 & \multicolumn{3}{|c|}{6.0329999999999995} & 4.7289 & TRN \\
\hline CHEMBL1531206 & 688810 & \multicolumn{3}{|c|}{5.2829999999999995} & 5.4305 & TRN \\
\hline CHEMBL1454091 & 688810 & 4.783 & 5.1425 & TRN & & \\
\hline CHEMBL1351738 & 688810 & 4.933 & 5.401 & TRN & & \\
\hline CHEMBL1443793 & 688810 & 5.033 & 5.2914 & TRN & & \\
\hline CHEMBL3194426 & 688810 & 4.783 & 5.5722 & TRN & & \\
\hline CHEMBL1538515 & 688810 & \multicolumn{3}{|c|}{6.332999999999999} & 5.3469 & TRN \\
\hline CHEMBL1448327 & 688810 & 4.933 & 5.3169 & TRN & & \\
\hline CHEMBL1443354 & 688810 & \multicolumn{3}{|c|}{5.882999999999999} & 5.3256 & TST \\
\hline CHEMBL1402556 & 688810 & 5.183 & 4.9395 & TST & & \\
\hline CHEMBL1388239 & 688810 & \multicolumn{3}{|c|}{5.7829999999999995} & 5.7171 & TRN \\
\hline CHEMBL1421322 & 688810 & \multicolumn{3}{|c|}{4.7330000000000005} & 4.8968 & TST \\
\hline CHEMBL1322960 & 688810 & 5.233 & 5.2664 & TRN & & \\
\hline CHEMBL1537721 & 688810 & 5.683 & 5.4061 & TRN & & \\
\hline CHEMBL1312318 & 688810 & 7.3325 & 6.0641 & TRN & & \\
\hline CHEMBL1584850 & 688810 & \multicolumn{3}{|c|}{5.832999999999999} & 5.04 & TST \\
\hline CHEMBL1358478 & 688810 & 4.833 & 5.3162 & TRN & & \\
\hline CHEMBL1316521 & 688810 & 4.583 & 5.1927 & TRN & & \\
\hline CHEMBL1608088 & 688810 & 4.783 & 5.1347 & TST & & \\
\hline CHEMBL1359797 & 688810 & 4.933 & 5.3036 & TST & & \\
\hline CHEMBL1970812 & 688810 & 5.933 & 5.4817 & TRN & & \\
\hline \multirow[t]{2}{*}{ CHEMBL3197286 } & 688810 & \multicolumn{3}{|c|}{5.582999999999999} & 4.8109 & TST \\
\hline & & & & & & \\
\hline
\end{tabular}




\begin{tabular}{|c|c|c|c|c|c|c|}
\hline & & & & & & \\
\hline CHEMBL112115 & 688810 & 6.433 & 5.9489 & TRN & & \\
\hline CHEMBL1414272 & 688810 & 4.883 & 5.3482 & TRN & & \\
\hline CHEMBL1489314 & 588810 & 5.28299 & 999999999 & 995 & 5.1736 & TR \\
\hline CHEMBL1583951 & 88810 & 6.233 & 5.4932 & TRN & & \\
\hline CHEMBL1612605 & 88810 & 5.183 & 5.2636 & TST & & \\
\hline CHEMBL1325596 & 88810 & 5.433 & 5.2904 & TST & & \\
\hline CHEMBL1549711 & 588810 & 5.28299 & 999999999 & 995 & 4.7644 & $T$ \\
\hline HEMBL3196941 & 88810 & 5.483 & 4.9619 & TST & & \\
\hline HEMBL3192389 & 88810 & 6.38299 & 999999999 & & 5.7466 & \\
\hline CHEMBL1365260 & 688810 & 5.13299 & 999999999 & & & \\
\hline CHEMBL1443368 & 688810 & 4.833 & 5.0471 & TRN & & \\
\hline HEMBL1347452 & 588810 & 4.73300 & 000000000 & 005 & 5.1052 & \\
\hline HEMBL3197265 & 88810 & 5.63299 & 999999999 & & 5.4 & \\
\hline CHEMBL1582818 & 688810 & 6.03299 & 999999999 & 995 & 55 & \\
\hline CHEMBL1410688 & 688810 & 4.583 & 4.6545 & TRN & & \\
\hline HEMBL1450423 & 688810 & 5.78299 & 999999999 & 995 & 5.7225 & \\
\hline HEMBL1505997 & 588810 & 5.88299 & 999999999 & & 5.5656 & \\
\hline HEMBL1548886 & 88810 & 5.63299 & 999999999 & & 5.1399 & \\
\hline CHEMBL1340097 & 688810 & 6.03299 & 999999999 & 995 & 5.9807 & \\
\hline CHEMBL1314925 & 688810 & 4.883 & 4.8692 & TRN & & \\
\hline HEMBL1420203 & 688810 & 5.33299 & 999999999 & & & \\
\hline HEMBL1466092 & 688810 & 4.833 & 4.8043 & TRN & & \\
\hline HEMBL1551968 & 88810 & 4.783 & 5.4653 & TRN & & \\
\hline CHEMBL1441999 & 688810 & 4.73300 & 000000000 & 005 & & \\
\hline CHEMBL1 & 688810 & 5.483 & 5.6002 & TRN & & \\
\hline HEMBL1 & 688810 & 5.25 & 5.2837 & TRN & & \\
\hline HEMBL1 & 88810 & 4.633 & 5.2737 & TRN & & \\
\hline HEMBL1409606 & 810 & 5.083 & 4.9277 & TST & & \\
\hline CHEMBL 3190993 & 688810 & 5.33299 & 999999999 & & .5841 & \\
\hline CHEMBL1542574 & 688810 & 4.833 & 5.22 & TST & & \\
\hline CHEMBL1 & 688810 & 6.33299 & 999999999 & & 5.3706 & \\
\hline CHEMBL1571880 & 688810 & 5.683 & 5.5418 & TST & & \\
\hline HEMBL1527084 & 688810 & 4.883 & 5.4411 & TST & & \\
\hline CHEMBL1413209 & 688810 & 4.883 & 5.342000 & 00000 & 005 & \\
\hline CHEMBL1 & 688810 & 6.5 & 5.7037 & TST & & \\
\hline CHEMBL3 & 688810 & 5.38299 & 999999999 & & 5 & 1. \\
\hline CHEMBL1583635 & 688810 & 5.53299 & 999999999 & 995 & 5.0041 & $T$ \\
\hline CHEMBL1478339 & 688810 & 4.633 & 5.1377 & TRN & & \\
\hline CHEMBL1602715 & 688810 & 5.483 & 5.5918 & TRN & & \\
\hline CHEMBL1 & 688810 & 7.0329 & 6.1 & TRN & & \\
\hline CHEMBL 3 & 688810 & 5.033 & 4.7607 & TRN & & \\
\hline CHEMBL1348015 & 688810 & 5.183 & 5.2417 & TRN & & \\
\hline CHEMBL1432234 & 688810 & 4.73300 & 000000000 & 005 & 5.2441 & \\
\hline CHEMBL1488219 & 688810 & 4.933 & 5.3342 & TST & & \\
\hline CHEMBL 3193565 & 688810 & 5.7829 & 999999999 & 995 & 5.6654 & \\
\hline CHEMBL1482712 & 688810 & 4.683 & 5.0965 & TST & & \\
\hline CHEMBL1563895 & 688810 & 5.88299 & 999999999 & & צכבמס & II \\
\hline CHEMBL1530984 & 688810 & 5.53299 & 999999999 & 995 & 5.9322 & \\
\hline
\end{tabular}




\begin{tabular}{|c|c|c|c|c|c|c|}
\hline & & \multicolumn{5}{|c|}{ Supplemental Table s2.txt } \\
\hline CHEMBL1445781 & 688810 & 4.883 & 5.1994 & TRN & & \\
\hline CHEMBL1591367 & 688810 & 4.633 & 5.6634 & TRN & & \\
\hline CHEMBL1417428 & 688810 & 5.183 & 5.2225 & TST & & \\
\hline CHEMBL1568322 & 688810 & 5.983 & 6.1326 & TST & & \\
\hline CHEMBL1578264 & 688810 & \multicolumn{3}{|c|}{5.332999999999999} & 5.1921 & TRN \\
\hline CHEMBL1414845 & 688810 & 4.583 & 4.7253 & TRN & & \\
\hline CHEMBL1585171 & 688810 & 5.483 & 5.3586 & TRN & & \\
\hline CHEMBL1332598 & 688810 & 4.883 & 5.2517 & TRN & & \\
\hline CHEMBL1347925 & 688810 & 4.883 & 5.2869 & TRN & & \\
\hline CHEMBL1389343 & 688810 & \multicolumn{3}{|c|}{4.7330000000000005} & 4.9806 & TRN \\
\hline CHEMBL1585854 & 688810 & \multicolumn{3}{|c|}{5.382999999999999} & 5.439 & TRN \\
\hline CHEMBL1330558 & 688810 & 4.783 & 5.2339 & TRN & & \\
\hline CHEMBL1578232 & 688810 & 6.4829 & 5.6801 & TRN & & \\
\hline CHEMBL1453731 & 688810 & \multicolumn{3}{|c|}{5.7829999999999995} & 5.6263 & TRN \\
\hline CHEMBL1350768 & 688810 & 4.583 & 5.3853 & TST & & \\
\hline CHEMBL1498927 & 688810 & 4.833 & 5.2065 & TST & & \\
\hline CHEMBL1478464 & 688810 & 4.883 & 5.1199 & TRN & & \\
\hline CHEMBL1538317 & 688810 & 5.683 & 5.4202 & TST & & \\
\hline CHEMBL1403349 & 688810 & 4.783 & 5.3639 & TRN & & \\
\hline CHEMBL1381358 & 688810 & \multicolumn{3}{|c|}{5.832999999999999} & 6.2352 & TRN \\
\hline CHEMBL1479175 & 688810 & \multicolumn{3}{|c|}{5.7829999999999995} & 5.4068 & TRN \\
\hline CHEMBL1334276 & 688810 & \multicolumn{3}{|c|}{5.132999999999999} & 5.1122 & TRN \\
\hline CHEMBL1483479 & 688810 & 4.883 & 4.8213 & TRN & & \\
\hline CHEMBL3199915 & 688810 & 4.933 & 5.5143 & TST & & \\
\hline CHEMBL1544695 & 688810 & \multicolumn{3}{|c|}{6.082999999999999} & 5.5356 & TST \\
\hline CHEMBL1372828 & 688810 & 5.483 & 5.4649 & TRN & & \\
\hline CHEMBL1607469 & 688810 & \multicolumn{3}{|c|}{5.5329999999999995} & 5.3034 & TRN \\
\hline CHEMBL1397813 & 688810 & 4.583 & 5.3792 & TST & & \\
\hline CHEMBL1613210 & 688810 & \multicolumn{3}{|c|}{5.132999999999999} & 5.0 & TRN \\
\hline CHEMBL1253382 & 688810 & \multicolumn{3}{|c|}{4.7330000000000005} & 5.2327 & TRN \\
\hline CHEMBL3197275 & 688810 & 4.833 & 4.7779 & TRN & & \\
\hline CHEMBL1994635 & 688810 & 5.683 & 5.4811 & TST & & \\
\hline CHEMBL1494243 & 688810 & 4.633 & 5.4001 & TST & & \\
\hline CHEMBL1433457 & 688810 & 5.433 & 5.3124 & TRN & & \\
\hline CHEMBL1566003 & 688810 & \multicolumn{3}{|c|}{5.882999999999999} & 5.6709 & TRN \\
\hline CHEMBL1511843 & 688810 & \multicolumn{3}{|c|}{5.382999999999999} & 5.4165 & TRN \\
\hline CHEMBL1389956 & 688810 & 6.4829 & 5.5475 & TRN & & \\
\hline CHEMBL1399878 & 688810 & 6.9329 & 5.8148 & TRN & & \\
\hline CHEMBL1587643 & 688810 & 6.183 & 5.2775 & TST & & \\
\hline CHEMBL563919 & 688810 & 6.433 & 5.8724 & TRN & & \\
\hline CHEMBL1397899 & 688810 & 4.683 & 5.4556 & TRN & & \\
\hline CHEMBL1489340 & 688810 & 4.633 & 4.9769 & TRN & & \\
\hline CHEMBL1468435 & 688810 & \multicolumn{3}{|c|}{5.5329999999999995} & 5.2709 & TST \\
\hline CHEMBL1584917 & 688810 & \multicolumn{3}{|c|}{5.582999999999999} & 5.7296 & TST \\
\hline CHEMBL1410908 & 688810 & 5.733 & 5.7897 & TRN & & \\
\hline CHEMBL406557 & 688810 & 6.433 & 5.8489 & TRN & & \\
\hline CHEMBL1409781 & 688810 & 5.733 & 4.8988 & TST & & \\
\hline CHEMBL1564397 & 688810 & 5.733 & 5.3257 & TRN & & \\
\hline
\end{tabular}




\begin{tabular}{|c|c|c|c|c|c|c|}
\hline \multirow[b]{2}{*}{ CHEMBL3191284 } & \multicolumn{6}{|c|}{ 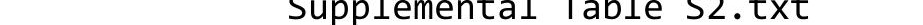 } \\
\hline & 688810 & 4.633 & 4.9319 & TRN & & \\
\hline CHEMBL1525900 & 688810 & \multicolumn{3}{|c|}{5.882999999999999} & 5.4138 & TRN \\
\hline CHEMBL1368465 & 688810 & 6.0 & 5.3601 & TRN & & \\
\hline CHEMBL1492668 & 688810 & 5.233 & 5.3109 & TRN & & \\
\hline CHEMBL 3213708 & 688810 & 4.783 & 5.1994 & TRN & & \\
\hline CHEMBL1301573 & 688810 & \multicolumn{3}{|c|}{5.5329999999999995} & 5.7477 & TST \\
\hline CHEMBL1407095 & 688810 & \multicolumn{3}{|c|}{5.882999999999999} & 5.7928 & \\
\hline CHEMBL1560210 & 688810 & \multicolumn{3}{|c|}{4.9830000000000005} & 5.2618 & TRN \\
\hline CHEMBL1490654 & 688810 & \multicolumn{3}{|c|}{5.332999999999999} & 5.3712 & $T$ \\
\hline CHEMBL1329750 & 688810 & 6.183 & 5.932 & TRN & & \\
\hline CHEMBL1425096 & 688810 & \multirow{2}{*}{\multicolumn{3}{|c|}{$\begin{array}{lll}4.883 & 5.1812 & \text { TRN } \\
5.2829999999999995\end{array}$}} & & \\
\hline CHEMBL1324408 & 688810 & & & & 5.6877 & 11 \\
\hline CHEMBL1571290 & 688810 & 6.0 & 4.8573 & TRN & & \\
\hline CHEMBL1545203 & 688810 & 5.033 & 6.1133 & TRN & & \\
\hline CHEMBL1548437 & 688810 & 5.183 & 5.5509 & TRN & & \\
\hline CHEMBL1424411 & 688810 & 6.983 & 5.4544 & TRN & & \\
\hline CHEMBL 3192257 & 688810 & 4.883 & 5.1529 & TST & & \\
\hline CHEMBL1600779 & 688810 & \multicolumn{3}{|c|}{4.9830000000000005} & 5.1681 & \\
\hline CHEMBL1469652 & 688810 & \multicolumn{3}{|c|}{5.332999999999999} & 5.1461 & \\
\hline CHEMBL1464105 & 688810 & 4.833 & 5.3435 & TRN & & \\
\hline CHEMBL1537211 & 688810 & \multicolumn{3}{|c|}{6.332999999999999} & 5.9022 & \\
\hline CHEMBL1601571 & 688810 & 4.883 & 5.3349 & TRN & & \\
\hline CHEMBL1412289 & 688810 & 5.683 & 5.9258 & TRN & & \\
\hline CHEMBL1402070 & 688810 & 5.183 & 4.8842 & TRN & & \\
\hline CHEMBL1513727 & 688810 & \multicolumn{3}{|c|}{5.632999999999999} & 6 & \\
\hline CHEMBL1445626 & 688810 & 4.783 & 5.8228 & TRN & & \\
\hline CHEMBL1336191 & 688810 & 4.883 & 5.2971 & TRN & & \\
\hline CHEMBL1571570 & 688810 & 5.683 & 5.4869 & TST & & \\
\hline CHEMBL1388529 & 688810 & 7.2328 & 5.479 & TRN & & \\
\hline CHEMBL1599803 & 688810 & \multicolumn{3}{|c|}{5.7829999999999995} & 65 & \\
\hline CHEMBL1363803 & 688810 & \multicolumn{3}{|c|}{5.132999999999999} & 5.5348 & \\
\hline CHEMBL1381599 & 688810 & 4.883 & 4.9262 & TST & & \\
\hline CHEMBL1304152 & 688810 & \multicolumn{3}{|c|}{5.832999999999999} & & TR \\
\hline CHEMBL1579261 & 688810 & \multicolumn{3}{|c|}{5.5329999999999995} & 5.7048 & \\
\hline CHEMBL1613213 & 688810 & \multicolumn{3}{|c|}{5.882999999999999} & 5 . & IT \\
\hline CHEMBL1493102 & 688810 & \multicolumn{3}{|c|}{4.7330000000000005} & 5.0926 & \\
\hline CHEMBL1389929 & 688810 & 5.233 & 5.6703 & TRN & & \\
\hline CHEMBL1368515 & 688810 & 5.483 & 5.1643 & TST & & \\
\hline CHEMBL1534315 & 688810 & \multicolumn{3}{|c|}{4.7330000000000005} & 4.8941 & $\mathrm{TS}$ \\
\hline CHEMBL 3191246 & 688810 & \multicolumn{3}{|c|}{4.7330000000000005} & 5.0684 & \\
\hline CHEMBL1424196 & 688810 & \multicolumn{3}{|c|}{6.2829999999999995} & 4.9695 & TRN \\
\hline CHEMBL1544002 & 688810 & 4.7330 & 0000000 & 005 & 5.1095 & \\
\hline CHEMBL1477875 & 688810 & 4.783 & 5.652 & TRN & & \\
\hline CHEMBL1383992 & 688810 & 4.933 & 5.5268 & TRN & & \\
\hline CHEMBL1566185 & 688810 & 4.9830 & $\partial 000000$ & 005 & 5.1658 & rRN \\
\hline CHEMBL1474710 & 688810 & 5.433 & 5.755 & TRN & & \\
\hline CHEMBL1585420 & 688810 & 5.6329 & 9999999 & & 5.2845 & TST \\
\hline CHEMBL1560379 & 688810 & 4.883 & 5.291 & TST & & \\
\hline
\end{tabular}




\begin{tabular}{|c|c|c|c|c|c|c|c|}
\hline \multicolumn{8}{|c|}{ oplemental Ta } \\
\hline CHEMBL1375009 & 688810 & 4.883 & 5.2416 & TST & & & \\
\hline CHEMBL1538749 & 688810 & 7.0329 & 6.0002 & TRN & & & \\
\hline CHEMBL1537480 & 688810 & 5.33299 & 99999999 & & 5.3204 & TST & \\
\hline CHEMBL1562245 & 688810 & 4.833 & 4.5636 & TST & & & \\
\hline CHEMBL 3199559 & 688810 & 4.833 & 4.8141 & TST & & & \\
\hline CHEMBL1531253 & 688810 & 5.033 & 5.402 & TST & & & \\
\hline CHEMBL1494587 & 688810 & 5.78299 & 999999995 & 995 & 5.25200 & 0000000001 & TRN \\
\hline CHEMBL 3192380 & 688810 & 4.933 & 5.3721 & TRN & & & \\
\hline CHEMBL1213905 & 688810 & 5.233 & 5.2433 & TRN & & & \\
\hline CHEMBL1562970 & 688810 & 4.833 & 5.0702 & TRN & & & \\
\hline CHEMBL1609470 & 688810 & 4.73300 & 000000006 & 005 & 5.3029 & TST & \\
\hline CHEMBL 2007276 & 688810 & 5.433 & 5.7236 & TRN & & & \\
\hline CHEMBL1583326 & 688810 & 4.833 & 5.3582 & TRN & & & \\
\hline CHEMBL1428157 & 688810 & 4.583 & 4.405 & TRN & & & \\
\hline CHEMBL1608084 & 688810 & 4.73300 & 000000006 & 005 & 4.873 & TST & \\
\hline CHEMBL1350057 & 688810 & 5.433 & 5.3666 & TRN & & & \\
\hline CHEMBL1308380 & 688810 & 5.13299 & 99999999؛ & & 5.141 & TRN & \\
\hline CHEMBL454746 & 688810 & 4.883 & 5.4679 & TRN & & & \\
\hline CHEMBL1417300 & 688810 & 5.433 & 5.0734 & TRN & & & \\
\hline CHEMBL1458102 & 688810 & 5.13299 & 999999995 & & 5.1149 & TST & \\
\hline CHEMBL1539077 & 688810 & 5.233 & 5.0963 & TRN & & & \\
\hline CHEMBL1368803 & 688810 & 5.083 & 5.4865 & TRN & & & \\
\hline CHEMBL1301732 & 688810 & 5.683 & 5.5034 & TST & & & \\
\hline CHEMBL1537984 & 688810 & 4.883 & 5.3245 & TRN & & & \\
\hline CHEMBL1498170 & 688810 & 5.733 & 5.3615 & TST & & & \\
\hline CHEMBL1551795 & 688810 & 5.13299 & 999999999 & & 5.0576 & TST & \\
\hline CHEMBL1552341 & 688810 & 4.73300 & 000000000 & 005 & 4.8505 & TST & \\
\hline CHEMBL1561625 & 688810 & 5.63299 & 999999999 & & 4.959 & TRN & \\
\hline CHEMBL1579339 & 688810 & 6.13299 & 999999999 & & 6.3171 & TRN & \\
\hline CHEMBL 3196214 & 688810 & 4.933 & 5.2038 & TST & & & \\
\hline CHEMBL1324632 & 688810 & 4.583 & 5.1885 & TRN & & & \\
\hline CHEMBL1595986 & 688810 & 5.88299 & 999999999 & & 5.831 & TRN & \\
\hline CHEMBL1395832 & 688810 & 4.633 & 5.0885 & TST & & & \\
\hline CHEMBL1585483 & 688810 & 4.98300 & 000000000 & 005 & 5.2513 & TRN & \\
\hline CHEMBL1361980 & 688810 & 4.783 & 5.5338 & TST & & & \\
\hline CHEMBL1311284 & 688810 & 4.883 & 5.5098 & TRN & & & \\
\hline CHEMBL1329109 & 688810 & 4.783 & 5.2092 & TST & & & \\
\hline CHEMBL1518922 & 688810 & 5.28299 & 999999999 & 995 & 5.1821 & TRN & \\
\hline CHEMBL1429512 & 688810 & 4.833 & 5.3779 & TRN & & & \\
\hline CHEMBL1462208 & 688810 & 4.73300 & 000000000 & 005 & 4.9934 & TST & \\
\hline CHEMBL1357384 & 688810 & 5.083 & 5.3393 & TRN & & & \\
\hline CHEMBL 3145064 & 688810 & 5.63299 & 999999999 & & 5.5725 & TST & \\
\hline CHEMBL1481531 & 688810 & 4.98300 & 000000000 & 005 & 5.2157 & TRN & \\
\hline CHEMBL1303984 & 688810 & 5.083 & 4.9292 & TRN & & & \\
\hline CHEMBL1557501 & 688810 & 5.683 & 5.3718 & TRN & & & \\
\hline CHEMBL1342380 & 688810 & 4.783 & 4.8389 & TRN & & & \\
\hline CHEMBL1496413 & 688810 & 6.433 & 5.5121 & TRN & & & \\
\hline CHEMBL1576347 & 688810 & 4.833 & 5.2146 & TRN & & & \\
\hline
\end{tabular}




\begin{tabular}{|c|c|c|c|c|c|c|}
\hline \multirow[b]{2}{*}{ CHEMBL1346617 } & \multirow[b]{2}{*}{688810} & \multicolumn{5}{|c|}{ Supplemental Table S2.txt } \\
\hline & & 4.933 & \multicolumn{4}{|c|}{5.1795 TRN } \\
\hline CHEMBL1429887 & 688810 & \multicolumn{3}{|c|}{5.132999999999999} & \multirow{2}{*}{5.4845} & \multirow[t]{2}{*}{ TRN } \\
\hline CHEMBL1441790 & 688810 & 5.183 & 5.1702 & TRN & & \\
\hline CHEMBL1584953 & 688810 & 5.433 & \multicolumn{3}{|c|}{5.5089999999999995} & \\
\hline CHEMBL1369287 & 688810 & 4.783 & 4.9615 & TRN & & \\
\hline CHEMBL1441990 & 688810 & 4.933 & 5.2287 & TRN & & \\
\hline CHEMBL1311636 & 688810 & \multicolumn{3}{|c|}{4.7330000000000005} & 4.988 & \\
\hline CHEMBL 3195986 & 688810 & 4.883 & 5.6038 & TST & & \\
\hline CHEMBL1545407 & 688810 & 5.083 & 5.3463 & TRN & & \\
\hline CHEMBL1518348 & 688810 & \multicolumn{3}{|c|}{5.132999999999999} & 5.4107 & \\
\hline CHEMBL1507070 & 688810 & 4.633 & 4.8568 & TST & & \\
\hline CHEMBL1602029 & 688810 & 4.833 & 5.5804 & TST & & \\
\hline HEMBL1419887 & 688810 & 5.083 & \multicolumn{3}{|c|}{5.843999999999999} & \\
\hline CHEMBL1555279 & 688810 & \multicolumn{3}{|c|}{5.882999999999999} & 5.1432 & \\
\hline CHEMBL1971760 & 688810 & 5.483 & 6.5338 & TST & & \\
\hline CHEMBL1335903 & 688810 & 4.783 & 5.5785 & TRN & & \\
\hline CHEMBL1307244 & 688810 & 5.983 & 6.1631 & TRN & & \\
\hline CHEMBL 31 & 688810 & \multicolumn{3}{|c|}{5.5329999999999995} & 5.4959 & \\
\hline CHEMBL14 & 688810 & 4.783 & \multicolumn{3}{|c|}{5.162999999999999} & \\
\hline CHEMBL1594042 & 688810 & 7.0329 & 5.8528 & TRN & & \\
\hline CHEMBL1395688 & 688810 & 4.783 & 5.0596 & TRN & & \\
\hline CHEMBL1340587 & 688810 & 4.583 & 5.1485 & TRN & & \\
\hline CHEMBL1 & 688810 & 5.233 & 4.8943 & TST & & \\
\hline CHEMBL13 & 688810 & \multicolumn{3}{|c|}{5.882999999999999} & 5648 & \\
\hline CHEMBL1557988 & 688810 & 5.483 & 5.5509 & TRN & & \\
\hline CHEMBL1606043 & 688810 & \multicolumn{3}{|c|}{5.132999999999999} & 418 & \\
\hline CHEMBL 3192210 & 688810 & 5.933 & 6.3012 & TRN & & \\
\hline CHEMBL1 & 688810 & 4.783 & 5.4493 & TRN & & \\
\hline CHEMBL1419880 & 688810 & \multicolumn{3}{|c|}{6.332999999999999} & 5.7602 & \\
\hline CHEMBL 3197479 & 688810 & \multicolumn{3}{|c|}{5.882999999999999} & 5.7931 & \\
\hline CHEMBL 3197781 & 688810 & 4.683 & 4.8678 & TRN & & \\
\hline CHEMBL1 & 688810 & 7.1831 & 5.5721 & TRN & & \\
\hline CHEMBL1 & 688810 & 5.183 & 5.2923 & TST & & \\
\hline CHEMBL1456683 & 688810 & \multicolumn{3}{|c|}{6.332999999999999} & 5.4027 & \\
\hline CHEMBL1383199 & 688810 & 4.783 & 4.9316 & TRN & & \\
\hline CHEMBL1489483 & 688810 & \multicolumn{3}{|c|}{4.7330000000000005} & 5.4334 & \\
\hline CHEMBL1 & 688810 & 4.833 & 5.2391 & TRN & & \\
\hline CHEMBL13 & 688810 & \multicolumn{3}{|c|}{ 5.382999999999999 } & 5.3415 & \\
\hline CHEMBL1322345 & 688810 & 4.883 & 5.7819 & TRN & & \\
\hline CHEMBL1565232 & 688810 & 4.833 & 5.4088 & TRN & & \\
\hline CHEMBL1501787 & 688810 & 5.13299 & 999999999 & & 5.1625 & \\
\hline CHEMBL1322995 & 688810 & 6.0 & 4.8463 & TRN & & \\
\hline CHEMBL1563230 & 688810 & 5.38299 & 999999999 & & 5.3854 & \\
\hline CHEMBL1306040 & 688810 & 4.833 & 5.1262 & TST & & \\
\hline CHEMBL1346252 & 688810 & 5.033 & 5.2109 & TRN & & \\
\hline CHEMBL1362464 & 688810 & 4.933 & 5.2536 & TRN & & \\
\hline CHEMBL1553273 & 688810 & 4.633 & 4.8064 & TST & & \\
\hline CHEMBL329872 & 688810 & 5.83299 & 999999999 & & 5.5575 & \\
\hline
\end{tabular}




\begin{tabular}{|c|c|c|c|c|c|c|c|}
\hline \multicolumn{7}{|c|}{ Supplemental Table S2.txt } & \\
\hline CHEMBL1605100 & 688810 & \multicolumn{3}{|c|}{5.5329999999999995} & 4.9729 & TRN & \\
\hline CHEMBL1417191 & 688810 & \multicolumn{3}{|c|}{5.132999999999999} & 4.9979 & TRN & \\
\hline CHEMBL1977087 & 688810 & \multicolumn{3}{|c|}{4.9830000000000005} & 4.9138 & TST & \\
\hline CHEMBL1496907 & 688810 & 4.783 & 4.9947 & TRN & & & \\
\hline CHEMBL1450807 & 688810 & \multicolumn{3}{|c|}{5.132999999999999} & 4.9665 & TST & \\
\hline CHEMBL1430895 & 688810 & 4.633 & 4.8257 & TRN & & & \\
\hline CHEMBL3192960 & 688810 & 4.833 & 5.1408 & TRN & & & \\
\hline CHEMBL1449988 & 688810 & 4.933 & 5.2859 & TRN & & & \\
\hline CHEMBL1399689 & 688810 & 4.933 & 4.9875 & TST & & & \\
\hline CHEMBL1356932 & 688810 & \multicolumn{3}{|c|}{5.132999999999999} & 5.5657 & TRN & \\
\hline CHEMBL1374755 & 688810 & \multicolumn{3}{|c|}{5.132999999999999} & 5.4149 & TRN & \\
\hline CHEMBL1595125 & 688810 & 4.783 & 5.1306 & TRN & & & \\
\hline CHEMBL1611426 & 688810 & \multicolumn{3}{|c|}{5.5329999999999995} & 5.2173 & TRN & \\
\hline CHEMBL1331718 & 688810 & 4.783 & 5.4691 & TRN & & & \\
\hline CHEMBL1392650 & 688810 & 5.433 & 5.3145 & TRN & & & \\
\hline CHEMBL1393813 & 688810 & 5.433 & 5.4635 & TRN & & & \\
\hline CHEMBL1387022 & 688810 & \multicolumn{3}{|c|}{ 5. 382999999999999} & 5.5886 & TRN & \\
\hline CHEMBL1324794 & 688810 & 4.833 & 5.2676 & TRN & & & \\
\hline CHEMBL1971120 & 688810 & 4.833 & 4.9493 & TST & & & \\
\hline CHEMBL1303687 & 688810 & \multicolumn{3}{|c|}{5.7829999999999995} & 5.4467 & TRN & \\
\hline CHEMBL1310682 & 688810 & \multicolumn{3}{|c|}{5.332999999999999} & 4.9763 & TRN & \\
\hline CHEMBL1336325 & 688810 & 4.883 & 4.6607 & TST & & & \\
\hline CHEMBL1315713 & 688810 & \multicolumn{3}{|c|}{5.382999999999999} & 5.199 & TRN & \\
\hline CHEMBL1345787 & 688810 & \multicolumn{3}{|c|}{6.0329999999999995} & 5.8511 & TRN & \\
\hline CHEMBL1499792 & 688810 & \multicolumn{3}{|c|}{5.132999999999999} & 5.2062 & TST & \\
\hline CHEMBL1482689 & 688810 & \multicolumn{3}{|c|}{5.2829999999999995} & 4.9226 & TRN & \\
\hline CHEMBL1438927 & 688810 & \multicolumn{3}{|c|}{5.632999999999999} & 5.2803 & TRN & \\
\hline CHEMBL1580472 & 688810 & 4.933 & 5.1323 & TRN & & & \\
\hline CHEMBL1455735 & 688810 & \multicolumn{3}{|c|}{4.7330000000000005} & 4.9358 & TRN & \\
\hline CHEMBL 3195626 & 688810 & 4.783 & 5.29 & TST & & & \\
\hline CHEMBL1342574 & 688810 & 4.633 & 5.1352 & TST & & & \\
\hline CHEMBL1427856 & 688810 & 4.883 & 5.3343 & TST & & & \\
\hline CHEMBL1547204 & 688810 & \multicolumn{3}{|c|}{5.7829999999999995} & 5.6863 & TST & \\
\hline CHEMBL1607684 & 688810 & \multicolumn{3}{|c|}{5.132999999999999} & 4.8057 & TRN & \\
\hline CHEMBL1554533 & 688810 & 4.833 & 5.4222 & TRN & & & \\
\hline CHEMBL1410121 & 688810 & 4.933 & 5.0574 & TRN & & & \\
\hline CHEMBL 3197324 & 688810 & 5.3829 & 99999999 & & 5.1755 & TRN & \\
\hline CHEMBL 3194264 & 688810 & 5.3829 & 99999999 & & 5.0416 & TRN & \\
\hline CHEMBL1429164 & 688810 & 5.3329 & 99999999 & & 5.166 & TRN & \\
\hline CHEMBL1595771 & 688810 & 4.7330 & 00000000 & 005 & 4.7352 & TRN & \\
\hline CHEMBL1307371 & 688810 & 5.3329 & 99999999 & & 5.53100 & 0000000001 & TRN \\
\hline CHEMBL1418679 & 688810 & 5.683 & 5.5644 & TRN & & & \\
\hline CHEMBL1543201 & 688810 & 4.883 & 5.1012 & TRN & & & \\
\hline CHEMBL1332174 & 688810 & 4.833 & 5.1606 & TST & & & \\
\hline CHEMBL1489221 & 688810 & 5.3829 & 99999999 & & 5.6197 & TRN & \\
\hline CHEMBL 3189662 & 688810 & 5.6329 & 99999999 & & 5.1017 & TRN & \\
\hline CHEMBL1384519 & 688810 & 5.183 & 5.3532 & TRN & & & \\
\hline CHEMBL1392502 & 688810 & 4.883 & 5.0395 & TRN & & & \\
\hline
\end{tabular}




\begin{tabular}{|c|c|c|c|c|c|c|c|}
\hline \multicolumn{7}{|c|}{ Supplemental Table S2.txt } & \\
\hline CHEMBL1416739 & 688810 & \multicolumn{3}{|c|}{4.7330000000000005} & 5.2003 & TST & \\
\hline CHEMBL1533373 & 688810 & 5.233 & 5.5538 & TRN & & & \\
\hline CHEMBL1306851 & 688810 & 4.883 & 5.0664 & TRN & & & \\
\hline CHEMBL1299363 & 688810 & 5.433 & 5.1202 & TST & & & \\
\hline CHEMBL1356286 & 688810 & 5.483 & 5.1919 & TRN & & & \\
\hline CHEMBL1479026 & 688810 & 4.833 & 5.0756 & TRN & & & \\
\hline CHEMBL1398721 & 688810 & 4.783 & 4.6752 & TRN & & & \\
\hline CHEMBL1392177 & 688810 & 5.733 & 5.1506 & TRN & & & \\
\hline CHEMBL1322846 & 688810 & \multicolumn{3}{|c|}{5.5329999999999995} & 5.6624 & TRN & \\
\hline CHEMBL1572074 & 688810 & 5.183 & 5.2211 & TRN & & & \\
\hline CHEMBL1607948 & 688810 & 4.583 & 5.2373 & TRN & & & \\
\hline CHEMBL1979455 & 688810 & 5.683 & 5.3551 & TRN & & & \\
\hline CHEMBL1419330 & 688810 & 4.883 & 5.0341 & TST & & & \\
\hline CHEMBL1497555 & 688810 & 5.733 & 5.4882 & TRN & & & \\
\hline CHEMBL1424068 & 688810 & \multicolumn{3}{|c|}{4.7330000000000005} & 5.1705 & TRN & \\
\hline CHEMBL1984628 & 688810 & 5.483 & 5.5272 & TRN & & & \\
\hline CHEMBL1423377 & 688810 & 7.3325 & 6.018 & TRN & & & \\
\hline CHEMBL3211002 & 688810 & 4.933 & 5.1108 & TRN & & & \\
\hline CHEMBL1401652 & 688810 & \multicolumn{3}{|c|}{5.832999999999999} & 6.3059 & TRN & \\
\hline CHEMBL1353454 & 688810 & 5.733 & 5.4479 & TRN & & & \\
\hline CHEMBL1492763 & 688810 & 6.433 & 5.2789 & TRN & & & \\
\hline CHEMBL1556051 & 688810 & 4.883 & 5.4519 & TRN & & & \\
\hline CHEMBL1355049 & 688810 & \multicolumn{3}{|c|}{5.5329999999999995} & 5.0699 & TRN & \\
\hline CHEMBL1434414 & 688810 & \multicolumn{3}{|c|}{5.132999999999999} & 5.0479 & TRN & \\
\hline CHEMBL1587756 & 688810 & 5.683 & 5.7896 & TRN & & & \\
\hline CHEMBL1595804 & 688810 & 6.4829 & \multicolumn{3}{|c|}{5.367000000000001} & TRN & \\
\hline CHEMBL1336616 & 688810 & 5.083 & 5.3203 & TRN & & & \\
\hline CHEMBL587856 & 688810 & 4.783 & 5.6638 & TST & & & \\
\hline CHEMBL 3190820 & 688810 & 4.833 & 5.3498 & TRN & & & \\
\hline CHEMBL 1400729 & 688810 & 6.683 & \multicolumn{3}{|c|}{5.337999999999999} & TRN & \\
\hline CHEMBL 3197478 & 688810 & \multicolumn{3}{|c|}{5.5329999999999995} & 5.1928 & TRN & \\
\hline CHEMBL1602226 & 688810 & \multicolumn{3}{|c|}{5.332999999999999} & 5.0302 & TRN & \\
\hline CHEMBL 3193216 & 688810 & 4.783 & 5.2545 & TST & & & \\
\hline CHEMBL1567026 & 688810 & \multicolumn{3}{|c|}{6.5329999999999995} & 5.8781 & TRN & \\
\hline CHEMBL1435387 & 688810 & 5.483 & 5.5488 & TRN & & & \\
\hline CHEMBL1452706 & 688810 & 4.783 & 5.9716 & TST & & & \\
\hline CHEMBL1470617 & 688810 & 5.033 & 5.8228 & TRN & & & \\
\hline CHEMBL1408969 & 688810 & \multicolumn{3}{|c|}{6.382999999999999} & 5.8569 & TRN & \\
\hline CHEMBL 3190047 & 688810 & \multicolumn{3}{|c|}{5.132999999999999} & 5.251 & TRN & \\
\hline CHEMBL 3198914 & 688810 & 4.583 & 5.2031 & TRN & & & \\
\hline CHEMBL1585677 & 688810 & 4.933 & 5.4386 & TST & & & \\
\hline CHEMBL1369425 & 688810 & 4.833 & 4.7485 & TRN & & & \\
\hline CHEMBL1556421 & 688810 & \multicolumn{3}{|c|}{6.0329999999999995} & 5.78299 & 99999999995 & TRN \\
\hline CHEMBL1473238 & 688810 & 4.933 & 4.9169 & TRN & & & \\
\hline CHEMBL1348357 & 688810 & \multicolumn{3}{|c|}{5.382999999999999} & 4.8216 & TRN & \\
\hline CHEMBL1335957 & 688810 & 5.083 & 5.2418 & TRN & & & \\
\hline CHEMBL1559668 & 688810 & \multicolumn{3}{|c|}{4.7330000000000005} & 5.1715 & TST & \\
\hline CHEMBL1561745 & 688810 & 4.833 & 5.1669 & TST & & & \\
\hline
\end{tabular}




\begin{tabular}{|c|c|c|c|c|c|c|c|}
\hline \multirow{3}{*}{$\begin{array}{l}\text { CHEMBL1360191 } \\
\text { CHEMBL1476462 }\end{array}$} & & \\
\hline & 688810 & 6.0 & 4.8414 & TRN & & & \\
\hline & 688810 & \multicolumn{3}{|c|}{4.7330000000000005} & 4.8716 & TRN & \\
\hline CHEMBL1548527 & 688810 & 5.033 & 5.3141 & TST & & & \\
\hline CHEMBL3212718 & 688810 & 6.7331 & 4.9543 & TST & & & \\
\hline CHEMBL1478992 & 688810 & 5.683 & 5.6348 & TRN & & & \\
\hline CHEMBL1376768 & 688810 & 4.783 & 5.2144 & TRN & & & \\
\hline CHEMBL1594294 & 688810 & 4.883 & 5.0811 & TRN & & & \\
\hline CHEMBL143703 & 688810 & 5.233 & 5.9268 & TRN & & & \\
\hline CHEMBL1426594 & 688810 & 5.483 & 5.4531 & TRN & & & \\
\hline CHEMBL1519738 & 688810 & \multicolumn{3}{|c|}{4.7330000000000005} & 5.1825 & TRN & \\
\hline CHEMBL1330568 & 688810 & \multicolumn{3}{|c|}{6.382999999999999} & \multicolumn{2}{|c|}{5.252000000000001} & TST \\
\hline CHEMBL1582488 & 688810 & \multicolumn{3}{|c|}{5.382999999999999} & 5.3777 & TRN & \\
\hline CHEMBL1561557 & 688810 & \multicolumn{3}{|c|}{5.382999999999999} & 5.2184 & TRN & \\
\hline CHEMBL1544089 & 688810 & 4.883 & 5.0077 & TRN & & & \\
\hline CHEMBL1401795 & 688810 & 4.933 & 4.9139 & TST & & & \\
\hline CHEMBL1353314 & 688810 & 4.883 & 5.2931 & TRN & & & \\
\hline CHEMBL1377385 & 688810 & 6.4829 & 5.3595 & TRN & & & \\
\hline CHEMBL1447532 & 688810 & 5.083 & 5.1186 & TRN & & & \\
\hline CHEMBL1600151 & 688810 & 4.583 & 5.1005 & TRN & & & \\
\hline CHEMBL1474157 & 688810 & \multicolumn{3}{|c|}{5.132999999999999} & 5.3616 & TST & \\
\hline CHEMBL 3210380 & 688810 & 4.833 & 5.4737 & TRN & & & \\
\hline CHEMBL1602059 & 688810 & \multicolumn{3}{|c|}{4.7330000000000005} & \multicolumn{2}{|c|}{5.122000000000001} & TRN \\
\hline CHEMBL1353153 & 688810 & \multicolumn{3}{|c|}{4.9830000000000005} & 4.9428 & TST & \\
\hline CHEMBL1577230 & 688810 & 5.8 & 4.9782 & TRN & & & \\
\hline CHEMBL333889 & 688810 & \multicolumn{3}{|c|}{6.5329999999999995} & 6.1389 & TRN & \\
\hline CHEMBL1544923 & 688810 & 5.683 & 5.246 & TRN & & & \\
\hline CHEMBL1393727 & 688810 & \multicolumn{3}{|c|}{6.382999999999999} & \multicolumn{2}{|c|}{5.7620000000000005} & TRN \\
\hline CHEMBL1319618 & 688810 & 4.783 & 4.6186 & TRN & & & \\
\hline CHEMBL1545149 & 688810 & \multicolumn{3}{|c|}{5.2829999999999995} & 5.2846 & TRN & \\
\hline CHEMBL3191820 & 688810 & \multicolumn{3}{|c|}{4.7330000000000005} & 5.4113 & TRN & \\
\hline CHEMBL3209742 & 688810 & \multicolumn{3}{|c|}{4.7330000000000005} & 5.3626 & TRN & \\
\hline CHEMBL1415921 & 688810 & 4.833 & 5.4119 & TRN & & & \\
\hline CHEMBL1379223 & 688810 & 4.783 & 5.2649 & TRN & & & \\
\hline CHEMBL1489022 & 688810 & 5.433 & 5.2788 & TRN & & & \\
\hline CHEMBL1362588 & 688810 & 4.883 & 4.7871 & TRN & & & \\
\hline CHEMBL1397599 & 688810 & 4.783 & 5.1385 & TRN & & & \\
\hline CHEMBL1304065 & 688810 & 4.633 & 4.9266 & TRN & & & \\
\hline CHEMBL1567378 & 688810 & 4.833 & 5.3418 & TST & & & \\
\hline CHEMBL1335963 & 688810 & 4.883 & 5.2564 & TRN & & & \\
\hline CHEMBL1444023 & 688810 & \multicolumn{3}{|c|}{5.582999999999999} & 5.5637 & TRN & \\
\hline CHEMBL1429759 & 688810 & \multicolumn{3}{|c|}{5.382999999999999} & 5.4054 & TRN & \\
\hline CHEMBL1568465 & 688810 & 5.933 & 5.5688 & TRN & & & \\
\hline CHEMBL1380914 & 688810 & 4.883 & 4.9926 & TRN & & & \\
\hline CHEMBL1409293 & 688810 & 4.633 & 4.8509 & TRN & & & \\
\hline CHEMBL1611371 & 688810 & 4.833 & 4.8019 & TRN & & & \\
\hline CHEMBL1483754 & 688810 & 5.733 & 5.1816 & TST & & & \\
\hline CHEMBL1398695 & 688810 & 4.73300 & 20000000 & 005 & 4.6853 & TST & \\
\hline CHEMBL1369993 & 688810 & 4.933 & 5.1465 & TRN & & & \\
\hline
\end{tabular}




\begin{tabular}{|c|c|c|c|c|c|c|c|}
\hline \multicolumn{8}{|c|}{ Supplemental Table s2.txt } \\
\hline CHEMBL1363490 & 688810 & 5.183 & 5.0758 & TRN & & & \\
\hline CHEMBL1308937 & 688810 & 4.833 & 4.6895 & TRN & & & \\
\hline CHEMBL464859 & 688810 & 7.9318 & 5.8327 & TRN & & & \\
\hline CHEMBL1548347 & 688810 & 4.783 & 5.3846 & TRN & & & \\
\hline CHEMBL1511833 & 688810 & 4.833 & 4.8489 & TRN & & & \\
\hline CHEMBL1327018 & 688810 & 5.183 & 5.1707 & TRN & & & \\
\hline CHEMBL1568555 & 688810 & \multicolumn{3}{|c|}{5.5329999999999995} & 5.5462 & TST & \\
\hline CHEMBL1604035 & 688810 & 4.783 & 5.0695 & TRN & & & \\
\hline CHEMBL1320706 & 688810 & \multicolumn{3}{|c|}{5.132999999999999} & 5.4269 & TRN & \\
\hline CHEMBL3209652 & 688810 & \multicolumn{3}{|c|}{5.832999999999999} & 5.4241 & TRN & \\
\hline CHEMBL1454686 & 688810 & \multicolumn{3}{|c|}{4.7330000000000005} & 5.3945 & TRN & \\
\hline CHEMBL1517625 & 688810 & \multicolumn{3}{|c|}{4.9830000000000005} & 4.5841 & TRN & \\
\hline CHEMBL1503192 & 688810 & 5.433 & 5.0849 & TRN & & & \\
\hline CHEMBL1570623 & 688810 & \multicolumn{3}{|c|}{5.332999999999999} & 5.2274 & TRN & \\
\hline CHEMBL1344547 & 688810 & \multicolumn{3}{|c|}{4.7330000000000005} & 4.8854 & TRN & \\
\hline CHEMBL1531688 & 688810 & 5.983 & 5.426 & TRN & & & \\
\hline CHEMBL1485358 & 688810 & 6.8831 & 5.6273 & TRN & & & \\
\hline CHEMBL486569 & 688810 & 4.933 & 6.1442 & TRN & & & \\
\hline CHEMBL1325243 & 688810 & 6.4829 & 5.7508 & TRN & & & \\
\hline CHEMBL1312037 & 688810 & \multicolumn{3}{|c|}{4.7330000000000005} & 4.7063 & TST & \\
\hline CHEMBL1568813 & 688810 & \multicolumn{3}{|c|}{5.5329999999999995} & 4.981 & TST & \\
\hline CHEMBL1385433 & 688810 & 4.633 & 4.727 & TST & & & \\
\hline CHEMBL1428284 & 688810 & 4.833 & 5.3644 & TRN & & & \\
\hline CHEMBL1989922 & 688810 & \multicolumn{3}{|c|}{5.882999999999999} & 5.7234 & TRN & \\
\hline CHEMBL1330199 & 688810 & \multicolumn{3}{|c|}{4.7330000000000005} & 5.3443 & TRN & \\
\hline CHEMBL1364402 & 688810 & \multicolumn{3}{|c|}{5.832999999999999} & 5.3782 & TRN & \\
\hline CHEMBL1528015 & 688810 & 5.733 & 5.7306 & TRN & & & \\
\hline CHEMBL1542742 & 688810 & 5.683 & 5.0942 & TRN & & & \\
\hline CHEMBL 3190291 & 688810 & 4.833 & 5.1797 & TRN & & & \\
\hline CHEMBL1571984 & 688810 & 6.0 & 5.5783 & TRN & & & \\
\hline CHEMBL1315463 & 688810 & 4.633 & 4.8459 & TRN & & & \\
\hline CHEMBL1590260 & 688810 & \multicolumn{3}{|c|}{5.832999999999999} & \multicolumn{2}{|c|}{5.672000000000001} & TRN \\
\hline CHEMBL1561927 & 688810 & 4.683 & 5.2548 & TRN & & & \\
\hline CHEMBL1412505 & 688810 & 5.433 & 4.9757 & TRN & & & \\
\hline CHEMBL445184 & 688810 & 6.4829 & 5.8384 & TRN & & & \\
\hline CHEMBL1360631 & 688810 & 5.033 & 5.4996 & TRN & & & \\
\hline CHEMBL1530379 & 688810 & \multicolumn{3}{|c|}{6.7829999999999995} & 6.2422 & TRN & \\
\hline CHEMBL1597228 & 688810 & \multicolumn{3}{|c|}{4.7330000000000005} & 5.3385 & TRN & \\
\hline CHEMBL1313592 & 688810 & 4.583 & 4.9397 & TRN & & & \\
\hline CHEMBL1544548 & 688810 & 5.733 & 5.7691 & TST & & & \\
\hline CHEMBL1516492 & 688810 & \multicolumn{3}{|c|}{6.0329999999999995} & \multicolumn{2}{|c|}{6.117000000000001} & TRN \\
\hline CHEMBL1341281 & 688810 & 4.883 & 4.9803 & TST & & & \\
\hline CHEMBL1520214 & 688810 & 4.833 & 4.7299 & TRN & & & \\
\hline CHEMBL1458062 & 688810 & 4.583 & 4.9073 & TRN & & & \\
\hline CHEMBL3189898 & 688810 & 5.033 & 5.2425 & TRN & & & \\
\hline CHEMBL1450911 & 688810 & \multicolumn{3}{|c|}{6.582999999999999} & 5.5595 & TRN & \\
\hline CHEMBL1404312 & 688810 & 4.683 & 5.1208 & TST & & & \\
\hline CHEMBL1546261 & 688810 & 4.883 & 5.184 & TRN & & & \\
\hline
\end{tabular}




\begin{tabular}{|c|c|c|c|c|c|c|}
\hline & & & oplemen & al & s2.txt & \\
\hline CHEMBL1448469 & 688810 & 6.3329 & 79999999 & & 5.8609 & TRN \\
\hline CHEMBL1482443 & 688810 & 5.7829 & 99999999 & 995 & 5.7285 & TRN \\
\hline CHEMBL1360318 & 688810 & 4.9830 & 00000000 & 005 & 5.4168 & TRN \\
\hline CHEMBL1572746 & 688810 & 6.3829 & 99999999 & & 5.1464 & TST \\
\hline CHEMBL1485121 & 688810 & 4.683 & 5.0244 & TRN & & \\
\hline CHEMBL1612973 & 688810 & 4.883 & 5.3389 & TRN & & \\
\hline CHEMBL1580941 & 688810 & 5.6329 & 99999999 & & 5.2761 & TST \\
\hline CHEMBL1597758 & 688810 & 5.033 & 5.5568 & TST & & \\
\hline CHEMBL1979558 & 688810 & 5.233 & 5.3857 & TST & & \\
\hline CHEMBL1299480 & 688810 & 4.783 & 5.3937 & TRN & & \\
\hline CHEMBL3213942 & 688810 & 4.633 & 5.1267 & TRN & & \\
\hline CHEMBL1553424 & 688810 & 4.833 & 4.7821 & TRN & & \\
\hline CHEMBL1431475 & 688810 & 4.833 & 4.5396 & TST & & \\
\hline CHEMBL1326467 & 688810 & 6.6329 & 99999999 & & 5.53 & TRN \\
\hline CHEMBL1316261 & 688810 & 5.183 & 5.905 & TRN & & \\
\hline CHEMBL1376244 & 688810 & 6.5829 & 79999999 & & 5.7965 & TRN \\
\hline CHEMBL1344200 & 688810 & 4.7330 & 00000000 & 005 & 5.1835 & TST \\
\hline CHEMBL1332013 & 688810 & 6.0 & 5.5375 & TRN & & \\
\hline CHEMBL1612632 & 688810 & 4.9830 & 00000000 & 005 & 5.3734 & TRN \\
\hline CHEMBL1460810 & 688810 & 5.033 & 4.8865 & TST & & \\
\hline CHEMBL1474270 & 688810 & 4.683 & 4.9947 & TRN & & \\
\hline CHEMBL1556284 & 688810 & 5.85 & 5.5476 & TRN & & \\
\hline CHEMBL1313588 & 688810 & 5.3829 & 99999999 & & 5.8603 & TRN \\
\hline CHEMBL1525940 & 688810 & 5.233 & 5.4105 & TST & & \\
\hline CHEMBL1377820 & 688810 & 5.483 & 5.4211 & TST & & \\
\hline CHEMBL1437888 & 688810 & 4.633 & 5.1234 & TRN & & \\
\hline CHEMBL1335018 & 688810 & 5.083 & 5.3714 & TST & & \\
\hline CHEMBL1388894 & 688810 & 4.833 & 5.7075 & TRN & & \\
\hline CHEMBL1357093 & 688810 & 5.483 & 5.3483 & TST & & \\
\hline CHEMBL1602788 & 688810 & 6.4829 & 6.4288 & TRN & & \\
\hline CHEMBL1518285 & 688810 & 5.033 & 5.0372 & TRN & & \\
\hline CHEMBL1442590 & 688810 & 5.5329 & 99999999 & 995 & 5.3888 & TRN \\
\hline CHEMBL1448284 & 688810 & 5.233 & 4.9496 & TRN & & \\
\hline CHEMBL1536318 & 688810 & 5.733 & 5.4278 & TRN & & \\
\hline CHEMBL1478916 & 688810 & 6.3329 & 99999999 & & 5.5032 & TRN \\
\hline CHEMBL1548743 & 688810 & 5.2829 & 79999999 & 995 & 5.0674 & TRN \\
\hline CHEMBL1569404 & 688810 & 4.933 & 5.1711 & TRN & & \\
\hline CHEMBL1544369 & 688810 & 5.683 & 5.66700 & 00006 & & TRN \\
\hline CHEMBL1383128 & 688810 & 6.1329 & 99999999 & & 5.4405 & TST \\
\hline CHEMBL1490060 & 688810 & 6.0829 & 99999999 & & 5.7569 & TRN \\
\hline CHEMBL1524829 & 688810 & 5.083 & 5.3103 & TRN & & \\
\hline CHEMBL1438919 & 688810 & 5.033 & 5.2513 & TRN & & \\
\hline CHEMBL1598214 & 688810 & 4.933 & 5.07600 & 00006 & 005 & TRN \\
\hline CHEMBL1509336 & 688810 & 6.5329 & 99999999 & 995 & 5.9388 & TRN \\
\hline CHEMBL1376412 & 688810 & 5.433 & 5.4288 & TRN & & \\
\hline CHEMBL1411497 & 688810 & 4.783 & 5.2909 & TRN & & \\
\hline CHEMBL1382191 & 688810 & 6.183 & 5.472 & TST & & \\
\hline CHEMBL1479172 & 688810 & 6.3829 & 79999999 & & 5.1749 & TST \\
\hline
\end{tabular}




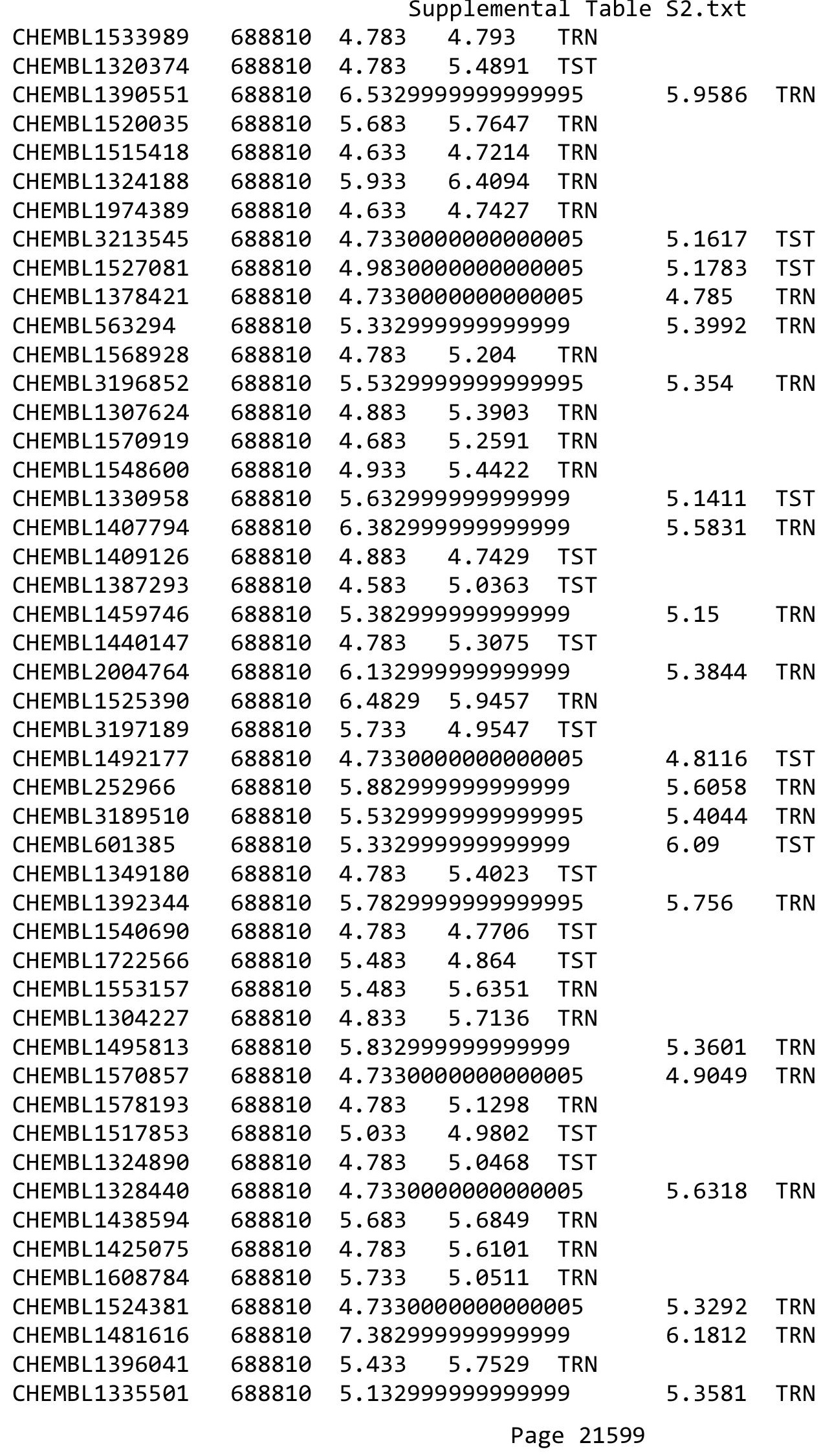




\begin{tabular}{|c|c|c|c|c|c|c|}
\hline \multirow[b]{2}{*}{ CHEMBL1468379 } & \\
\hline & 688810 & 4.933 & 5.3498 & TST & & \\
\hline CHEMBL1367148 & 688810 & 4.783 & 5.0408 & TST & & \\
\hline CHEMBL1485714 & 688810 & 4.833 & 4.8042 & TST & & \\
\hline CHEMBL1353350 & 688810 & 4.7330 & 00000000 & 005 & 5.659 & ונו \\
\hline CHEMBL1586605 & 688810 & 5.1329 & 99999999 & & 4.9233 & TRN \\
\hline CHEMBL1345909 & 688810 & 4.833 & 5.093 & TRN & & \\
\hline CHEMBL1992486 & 688810 & 5.3329 & 99999999 & & 5.0462 & \\
\hline CHEMBL1604281 & 688810 & 4.683 & 5.375 & TRN & & \\
\hline CHEMBL1525300 & 688810 & 6.8329 & 99999999 & & 5.9581 & \\
\hline CHEMBL3210321 & 688810 & 6.1329 & 99999999 & & 5.5711 & \\
\hline CHEMBL3194186 & 688810 & 5.5829 & 99999999 & & 5.4458 & \\
\hline CHEMBL1570276 & 688810 & 5.183 & 5.5479 & TRN & & \\
\hline CHEMBL3198010 & 688810 & 4.9830 & 00000000 & 005 & 5.3111 & \\
\hline CHEMBL1340287 & 688810 & 5.033 & 4.9944 & TRN & & \\
\hline CHEMBL1401582 & 688810 & 4.7330 & 00000000 & 005 & 4.7056 & \\
\hline CHEMBL1423711 & 688810 & 5.083 & 4.7621 & TST & & \\
\hline CHEMBL1501423 & 688810 & 5.733 & 5.2373 & TST & & \\
\hline CHEMBL1320375 & 688810 & 4.683 & 5.2042 & TRN & & \\
\hline CHEMBL1372573 & 688810 & 5.7829 & 99999999 & 995 & 5.3307 & \\
\hline CHEMBL1402985 & 688810 & 5.2829 & 99999999 & 995 & 5.4246 & \\
\hline CHEMBL1304498 & 688810 & 4.683 & 5.1666 & TRN & & \\
\hline CHEMBL1547064 & 688810 & 5.3329 & 99999999 & & 5.6162 & TRN \\
\hline CHEMBL1388229 & 688810 & 5.1329 & 99999999 & & 4.9742 & \\
\hline CHEMBL1501724 & 688810 & 6.183 & 5.2396 & TRN & & \\
\hline CHEMBL1373722 & 688810 & 5.1329 & 99999999 & & 5.7578 & Tro \\
\hline CHEMBL3191808 & 688810 & 5.5829 & 99999999 & & 5.1424 & \\
\hline CHEMBL3189622 & 688810 & 4.883 & 4.9448 & TRN & & \\
\hline CHEMBL1362331 & 688810 & 4.883 & 5.0758 & TST & & \\
\hline CHEMBL1558810 & 688810 & 4.7330 & 00000000 & 005 & 5.2028 & ונו \\
\hline CHEMBL1347156 & 688810 & 5.3329 & 99999999 & & 5.4824 & TRN \\
\hline CHEMBL1415834 & 688810 & 5.3329 & 99999999 & & 5.3132 & TRN \\
\hline CHEMBL3194305 & 688810 & 5.983 & 5.3852 & TRN & & \\
\hline CHEMBL1579932 & 688810 & 5.6329 & 99999999 & & 5.4218 & 11 \\
\hline CHEMBL1506805 & 688810 & 4.7330 & 00000000 & 005 & 4.9473 & \\
\hline CHEMBL3191680 & 688810 & 4.883 & 5.351 & TRN & & \\
\hline CHEMBL1452995 & 688810 & 4.783 & 5.3251 & TRN & & \\
\hline CHEMBL3196309 & 688810 & 6.433 & 6.001 & TRN & & \\
\hline CHEMBL1508827 & 688810 & 4.833 & 5.0676 & TST & & \\
\hline CHEMBL1303160 & 688810 & 4.833 & 5.5829 & TRN & & \\
\hline CHEMBL1510732 & 688810 & 4.783 & 5.4237 & TRN & & \\
\hline CHEMBL1357490 & 688810 & 4.583 & 4.6931 & TRN & & \\
\hline CHEMBL1460565 & 688810 & 6.0329 & 99999999 & 995 & 5.1221 & ונו \\
\hline CHEMBL1426363 & 688810 & 5.1329 & 99999999 & & 5.1235 & $-\pi$ \\
\hline CHEMBL1585733 & 688810 & 5.1329 & 99999999 & & 5.7985 & \\
\hline CHEMBL1332123 & 688810 & 4.783 & 5.0633 & TRN & & \\
\hline CHEMBL1434307 & 688810 & 4.7330 & 00000000 & 005 & 4.8639 & TKIV \\
\hline CHEMBL1347065 & 688810 & 4.7330 & 00000000 & 005 & 5.0772 & $\mathrm{TR}$ \\
\hline CHEMBL3191094 & 688810 & 5.733 & 5.5554 & TRN & & \\
\hline
\end{tabular}




\begin{tabular}{|c|c|c|c|c|c|c|}
\hline \multirow[b]{2}{*}{ CHEMBL1400531 } & \multicolumn{6}{|c|}{ Supplemental Table S2.txt } \\
\hline & 688810 & 5.233 & 5.7604 & TRN & & \\
\hline CHEMBL1353712 & 688810 & 5.233 & 5.6703 & TST & & \\
\hline CHEMBL1449911 & 688810 & 5.983 & 5.50706 & 00006 & & TRN \\
\hline CHEMBL1583703 & 688810 & 4.683 & 5.598 & TRN & & \\
\hline CHEMBL 3213886 & 688810 & 5.033 & 5.0153 & TRN & & \\
\hline CHEMBL1538366 & 688810 & 5.1329 & 99999999 & & 5.6557 & TRN \\
\hline CHEMBL1581700 & 688810 & 5.183 & 4.7559 & TRN & & \\
\hline CHEMBL1501745 & 688810 & 4.933 & 5.2306 & TRN & & \\
\hline CHEMBL1417295 & 688810 & 4.833 & 4.9609 & TRN & & \\
\hline CHEMBL1609921 & 688810 & 4.7330 & 00000006 & 005 & 5.5766 & TRN \\
\hline CHEMBL1547068 & 688810 & 4.7330 & $\partial 000000 €$ & 005 & 4.8097 & TST \\
\hline CHEMBL1543258 & 688810 & 5.8329 & 99999999 & & 5.1525 & \\
\hline CHEMBL1407779 & 688810 & 6.9329 & 5.6565 & TRN & & \\
\hline CHEMBL1411783 & 688810 & 4.833 & 5.3634 & TST & & \\
\hline CHEMBL1414226 & 688810 & 4.833 & 4.8894 & TRN & & \\
\hline CHEMBL1497102 & 688810 & 5.5329 & 99999999 & 995 & 5.9572 & \\
\hline CHEMBL1589812 & 688810 & 4.833 & 5.2609 & TRN & & \\
\hline CHEMBL1534173 & 688810 & 6.1329 & 99999999 & & 5.4168 & \\
\hline CHEMBL1475346 & 688810 & 5.733 & 5.2637 & TST & & \\
\hline CHEMBL1371891 & 688810 & 4.883 & 5.063 & TRN & & \\
\hline CHEMBL1364432 & 688810 & 6.233 & 5.4826 & TRN & & \\
\hline CHEMBL3197239 & 688810 & 5.183 & 5.3505 & TRN & & \\
\hline CHEMBL1470958 & 688810 & 5.433 & 5.2551 & TRN & & \\
\hline CHEMBL1483402 & 688810 & 4.9830 & $0000000 e$ & 005 & 5.3177 & $\mathrm{TF}$ \\
\hline CHEMBL1378710 & 688810 & 4.933 & 5.6951 & TRN & & \\
\hline CHEMBL1330508 & 688810 & 5.083 & 5.0701 & TRN & & \\
\hline CHEMBL1594544 & 688810 & 5.933 & 5.7139 & TRN & & \\
\hline CHEMBL1520198 & 688810 & 5.7829 & 99999999 & 995 & 5.3954 & \\
\hline CHEMBL 3208916 & 688810 & 5.083 & 5.2921 & TRN & & \\
\hline CHEMBL1356290 & 688810 & 5.2829 & 99999999 & 995 & .0372 & TC \\
\hline CHEMBL1422119 & 688810 & 6.8329 & 99999999 & & 4.9874 & TST \\
\hline CHEMBL1469730 & 688810 & 5.7829 & 99999999 & 995 & 5.7088 & \\
\hline CHEMBL1587385 & 688810 & 5.033 & 5.2685 & TRN & & \\
\hline CHEMBL1484314 & 688810 & 4.7330 & 20000000 & 005 & 5.3052 & \\
\hline CHEMBL1360698 & 688810 & 4.783 & 5.2851 & TRN & & \\
\hline CHEMBL1523079 & 688810 & 4.683 & 4.7014 & TST & & \\
\hline CHEMBL1569064 & 688810 & 5.683 & 5.1714 & TRN & & \\
\hline CHEMBL1964664 & 688810 & 5.433 & 5.3678 & TRN & & \\
\hline CHEMBL1504282 & 688810 & 4.833 & 4.9585 & TRN & & \\
\hline CHEMBL1529438 & 688810 & 4.783 & 5.3179 & TST & & \\
\hline CHEMBL593254 & 688810 & 4.683 & 5.0755 & TRN & & \\
\hline CHEMBL1471693 & 688810 & 5.183 & 5.404 & TRN & & \\
\hline CHEMBL3193310 & 688810 & 5.8829 & 99999999 & & 5.0442 & TRN \\
\hline CHEMBL1396642 & 688810 & 4.9830 & $\partial 000000 €$ & 005 & 5.0056 & TRN \\
\hline CHEMBL3207919 & 688810 & 5.3829 & 99999999 & & 5.4158 & TS \\
\hline CHEMBL1545578 & 688810 & 5.733 & 5.4075 & TRN & & \\
\hline CHEMBL1373122 & 688810 & 4.833 & 5.29799 & 99999 & & \\
\hline CHEMBL1084955 & 688810 & 5.1329 & 99999999 & & 5.6306 & \\
\hline
\end{tabular}




\begin{tabular}{|c|c|c|c|c|c|c|c|}
\hline \multicolumn{8}{|c|}{3} \\
\hline CHEMBL1470059 & 688810 & 4.933 & 5.0853 & TRN & & & \\
\hline CHEMBL1514039 & 688810 & 4.833 & 5.2523 & TST & & & \\
\hline CHEMBL1333719 & 688810 & 4.933 & 5.4113 & TRN & & & \\
\hline CHEMBL1608540 & 688810 & 6.28299 & 99999999 & 995 & 5.5688 & TRN & \\
\hline CHEMBL1558842 & 688810 & 4.833 & 5.2545 & TST & & & \\
\hline CHEMBL1370667 & 688810 & 5.83299 & 99999999 & & 5.2332 & TRN & \\
\hline CHEMBL1453959 & 688810 & 5.433 & 5.5923 & TRN & & & \\
\hline CHEMBL1346294 & 688810 & 4.883 & 5.3689 & TRN & & & \\
\hline CHEMBL1366037 & 688810 & 5.78299 & 99999999 & 995 & 5.5525 & TRN & \\
\hline CHEMBL1548624 & 688810 & 4.73300 & 00000000 & 005 & 5.2762 & TRN & \\
\hline CHEMBL1468942 & 688810 & 5.683 & 5.6005 & TRN & & & \\
\hline CHEMBL1380030 & 688810 & 4.73300 & 00000000 & 005 & 5.0819 & TRN & \\
\hline CHEMBL1524240 & 688810 & 5.53299 & 99999999 & 995 & 5.1397 & TRN & \\
\hline CHEMBL1369217 & 688810 & 5.033 & 5.5469 & TRN & & & \\
\hline CHEMBL1455402 & 688810 & 5.13299 & 99999999 & & 5.021 & TRN & \\
\hline CHEMBL1496231 & 688810 & 5.88299 & 99999999 & & 4.876 & TST & \\
\hline CHEMBL1515577 & 688810 & 5.88299 & 99999999 & & 5.6142 & TRN & \\
\hline CHEMBL1559135 & 688810 & 5.53299 & 99999999 & 995 & 5.175 & TRN & \\
\hline CHEMBL1393260 & 688810 & 6.38299 & 99999999 & & 5.1763 & TST & \\
\hline CHEMBL1567745 & 688810 & 5.483 & 5.6529 & TRN & & & \\
\hline CHEMBL1346179 & 688810 & 4.633 & 4.6344 & TST & & & \\
\hline CHEMBL1497825 & 688810 & 6.33299 & 99999999 & & 5.7344 & TRN & \\
\hline CHEMBL1448456 & 688810 & 5.28299 & 99999999 & 995 & 5.3137 & TRN & \\
\hline CHEMBL1405349 & 688810 & 5.233 & 5.0178 & TST & & & \\
\hline CHEMBL1359902 & 688810 & 4.73300 & 00000000 & 005 & 5.1791 & TST & \\
\hline CHEMBL1574539 & 688810 & 5.983 & 5.9315 & TRN & & & \\
\hline CHEMBL1485825 & 688810 & 4.783 & 5.1195 & TRN & & & \\
\hline CHEMBL1567567 & 688810 & 4.73300 & 00000000 & 005 & 5.345 & TRN & \\
\hline CHEMBL1606694 & 688810 & 4.783 & 5.0403 & TRN & & & \\
\hline CHEMBL1543774 & 688810 & 4.933 & 5.0621 & TRN & & & \\
\hline CHEMBL1311943 & 688810 & 4.933 & 5.3547 & TRN & & & \\
\hline CHEMBL3213557 & 688810 & 5.233 & 5.2042 & TST & & & \\
\hline CHEMBL1407688 & 688810 & 4.833 & 4.9485 & TRN & & & \\
\hline CHEMBL1587299 & 688810 & 5.033 & 5.3574 & TRN & & & \\
\hline CHEMBL1457955 & 688810 & 4.833 & 5.0034 & TRN & & & \\
\hline CHEMBL1544967 & 688810 & 6.28299 & 99999999 & 995 & 5.4531 & TRN & \\
\hline CHEMBL546344 & 688810 & 7.1331 & 5.8277 & TRN & & & \\
\hline CHEMBL1604042 & 688810 & 5.13299 & 99999999 & & 5.3281 & TRN & \\
\hline CHEMBL1485628 & 688810 & 4.98300 & 00000000 & 005 & 5.0139 & 9999999999 & TRN \\
\hline CHEMBL1365563 & 688810 & 4.683 & 4.6516 & TST & & & \\
\hline CHEMBL 3194660 & 688810 & 4.883 & 5.1523 & TST & & & \\
\hline CHEMBL1584502 & 688810 & 5.233 & 4.3021 & TST & & & \\
\hline CHEMBL1344912 & 688810 & 4.633 & 4.9321 & TRN & & & \\
\hline CHEMBL1383856 & 688810 & 6.45 & 5.1726 & TRN & & & \\
\hline CHEMBL1356728 & 688810 & 6.183 & 5.5537 & TRN & & & \\
\hline CHEMBL1571116 & 688810 & 5.033 & 5.3688 & TRN & & & \\
\hline CHEMBL1423345 & 688810 & 4.783 & 5.6395 & TRN & & & \\
\hline CHEMBL1401316 & 688810 & 4.833 & 5.3159 & TRN & & & \\
\hline
\end{tabular}




\begin{tabular}{|c|c|c|c|c|c|c|}
\hline \multirow[b]{2}{*}{ CHEMBL1351973 } & \multirow[b]{2}{*}{688810} & \multicolumn{5}{|c|}{ Supplemental Table S2.txt } \\
\hline & & 6.183 & 5.4923 & TST & & \\
\hline CHEMBL1444221 & 688810 & \multicolumn{3}{|c|}{5.632999999999999} & 5.1506 & 1 \\
\hline CHEMBL1350733 & 688810 & 5.033 & 4.9312 & TRN & & \\
\hline CHEMBL1368639 & 688810 & \multicolumn{3}{|c|}{4.9830000000000005} & 5.1465 & $\mathrm{~T}$ \\
\hline CHEMBL1478542 & 688810 & \multicolumn{3}{|c|}{4.7330000000000005} & 5.0879 & \\
\hline CHEMBL1436966 & 688810 & 4.633 & 5.3478 & TRN & & \\
\hline CHEMBL1435324 & 688810 & \multicolumn{3}{|c|}{5.5329999999999995} & 9434 & \\
\hline CHEMBL 3210983 & 688810 & \multicolumn{3}{|c|}{6.5329999999999995} & 5.7558 & \\
\hline CHEMBL1530630 & 688810 & 4.783 & 5.6359 & TST & & \\
\hline CHEMBL1485010 & 688810 & \multicolumn{3}{|c|}{5.5329999999999995} & 5.0178 & \\
\hline CHEMBL1522192 & 688810 & 4.883 & 5.2901 & TRN & & \\
\hline CHEMBL1470120 & 688810 & \multirow{2}{*}{\multicolumn{3}{|c|}{$\begin{array}{l}5.483 \quad 5.1583 \quad \text { IKIV } \\
5.632999999999999\end{array}$}} & & \\
\hline CHEMBL1505482 & 688810 & & & & 5.4924 & \\
\hline CHEMBL1419093 & 688810 & 4.783 & 4.9594 & TST & & \\
\hline CHEMBL1484658 & 688810 & \multicolumn{3}{|c|}{4.9830000000000005} & 5.3088 & \\
\hline CHEMBL1534496 & 688810 & 6.9329 & 5.5712 & TRN & & \\
\hline CHEMBL1419870 & 688810 & \multicolumn{3}{|c|}{5.132999999999999} & 1 & \\
\hline CHEMBL1588561 & 688810 & 5.183 & 5.5151 & TRN & & \\
\hline CHEMBL1 & 688810 & 4.883 & 5.1155 & TRN & & \\
\hline CHEMBL1490034 & 688810 & 5.683 & 5.0124 & TRN & & \\
\hline CHEMBL1591810 & 688810 & \multicolumn{3}{|c|}{4.7330000000000005} & 433 & \\
\hline CHEMBL1487709 & 688810 & 5.483 & 5.2314 & TST & & \\
\hline CHEMBL1323824 & 688810 & \multirow{2}{*}{\multicolumn{3}{|c|}{ 6.5329999999999995 }} & & \\
\hline CHEMBL1603253 & 688810 & & & & 5.5995 & \\
\hline CHEMBL1317919 & 688810 & 4.633 & 4.6635 & TRN & & \\
\hline CHEMBL1472104 & 688810 & \multicolumn{3}{|c|}{5.382999999999999} & 8.200 & \\
\hline CHEMBL1312767 & 688810 & 5.033 & 5.3392 & TST & & \\
\hline CHEMBL15 & 688810 & 5.183 & 5.3016 & TRN & & \\
\hline CHEMBL1302762 & 688810 & 5.683 & 5.3543 & TRN & & \\
\hline CHEMBL1543215 & 688810 & 5.433 & 5.3198 & TRN & & \\
\hline CHEMBL1412033 & 688810 & 5.083 & 5.0684 & TRN & & \\
\hline CHEMBL: & 688810 & 4.883 & 4.6858 & TST & & \\
\hline CHEMBL16 & 688810 & 5.183 & 5.3656 & TRN & & \\
\hline CHEMBL1585831 & 688810 & 5.083 & 5.5576 & TRN & & \\
\hline CHEMBL493863 & 688810 & 5.233 & 5.1456 & TST & & \\
\hline CHEMBL1554554 & 688810 & \multicolumn{3}{|c|}{5.382999999999999} & 5.1056 & \\
\hline CHEMBL15 & 688810 & 4.583 & 4.7336 & TRN & & \\
\hline CHEMBL1573665 & 688810 & \multirow{2}{*}{\multicolumn{3}{|c|}{$\begin{array}{l}3.033 \text { 5.112/ TRIN } \\
6.332999999999999\end{array}$}} & & \\
\hline CHEMBL1335851 & 688810 & & & & 5.6796 & \\
\hline CHEMBL379179 & 688810 & 6.8831 & 6.1575 & TRN & & \\
\hline CHEMBL1584006 & 688810 & 4.833 & 4.9759 & TRN & & \\
\hline CHEMBL1377303 & 688810 & 6.233 & 5.7334 & TRN & & \\
\hline CHEMBL1433155 & 688810 & \multicolumn{3}{|c|}{6.5329999999999995} & 5.8961 & TR \\
\hline CHEMBL1465552 & 688810 & 5.183 & 5.8336 & TRN & & \\
\hline CHEMBL1345550 & 688810 & 4.883 & 5.1069 & TRN & & \\
\hline CHEMBL1552652 & 688810 & \multicolumn{3}{|c|}{5.832999999999999} & 4.7798 & \\
\hline CHEMBL120734 & 688810 & \multicolumn{3}{|c|}{5.632999999999999} & 6.3933 & \\
\hline CHEMBL1306267 & 688810 & 5.5329 & 99999999 & 995 & 5.8292 & \\
\hline
\end{tabular}




\begin{tabular}{|c|c|c|c|c|c|c|}
\hline \multirow{3}{*}{$\begin{array}{l}\text { CHEMBL1326817 } \\
\text { CHEMBL1980959 }\end{array}$} & \multirow{3}{*}{$\begin{array}{l}688810 \\
688810\end{array}$} & \multicolumn{5}{|c|}{ Supplemental Table S2.txt } \\
\hline & & \multicolumn{3}{|c|}{5.332999999999999} & 5.2 & TR \\
\hline & & 4.833 & 5.1081 & TST & & \\
\hline CHEMBL1498744 & 688810 & 5.183 & 5.4811 & TRN & & \\
\hline CHEMBL1324892 & 688810 & 5.683 & 5.7253 & TRN & & \\
\hline CHEMBL1472246 & 588810 & 5.433 & 5.2914 & TRN & & \\
\hline CHEMBL1341870 & 688810 & 6.0 & 5.149 & TRN & & \\
\hline CHEMBL465980 & 688810 & \multicolumn{3}{|c|}{6.132999999999999} & 5.7494 & TRIV \\
\hline CHEMBL1432524 & 688810 & \multicolumn{3}{|c|}{5.882999999999999} & 5.4026 & \\
\hline CHEMBL1340487 & 688810 & 4.583 & 5.2083 & TRN & & \\
\hline CHEMBL1347436 & 688810 & \multicolumn{3}{|c|}{6.2829999999999995} & 4.8944 & In \\
\hline CHEMBL1353543 & 688810 & 4.833 & 5.3135 & TRN & & \\
\hline CHEMBL1483039 & 688810 & 4.883 & 5.0037 & TRN & & \\
\hline CHEMBL1499966 & 688810 & 5.233 & 5.3954 & TRN & & \\
\hline CHEMBL1585400 & 688810 & \multicolumn{3}{|c|}{7.082999999999999} & 5.8036 & TP \\
\hline CHEMBL1310221 & 688810 & \multicolumn{3}{|c|}{5.332999999999999} & 5.4612 & \\
\hline CHEMBL1316753 & 688810 & \multicolumn{3}{|c|}{5.632999999999999} & 5.6311 & \\
\hline CHEMBL1 & 688810 & 4.683 & 5.0679 & TRN & & \\
\hline CHEMBL15 & 688810 & \multicolumn{3}{|c|}{4.7330000000000005} & 5.28 & II \\
\hline CHEMBL1402669 & 688810 & 4.783 & 5.1017 & TRN & & \\
\hline CHEMBL1448199 & 688810 & \multicolumn{3}{|c|}{4.7330000000000005} & 4.9509 & TP \\
\hline CHEMBL1599625 & 688810 & \multicolumn{3}{|c|}{5.882999999999999} & 5.5694 & \\
\hline CHEMBL & 688 & 5.683 & 5.0996 & TRN & & \\
\hline CHEMBL & 688810 & 4.833 & 4.9739 & TST & & \\
\hline CHEMBL & 688810 & 4.783 & 5.2424 & TRN & & \\
\hline CHEMBL1540081 & 688810 & \multicolumn{3}{|c|}{5.132999999999999} & 1615 & $\mathrm{TI}$ \\
\hline CHEMBL1507066 & 688810 & 4.833 & 5.3263 & TRN & & \\
\hline CHEME & $68 \varepsilon$ & \multirow{2}{*}{\multicolumn{3}{|c|}{$\begin{array}{l}5.0 \quad 4.9 / 8 \\
5.2829999999999995\end{array}$}} & & \\
\hline CHEMBL1 & 688810 & & & & 5.1152 & $\mathrm{~T}$ \\
\hline CHEMBL1361424 & 688810 & 5.233 & 5.773 & TRN & & \\
\hline CHEMBL1466555 & 688810 & 4.833 & 5.2341 & TRN & & \\
\hline CHEMBL1350809 & 688810 & 5.483 & 5.4178 & TRN & & \\
\hline CHEME & 10 & 4.583 & 4.9824 & TRN & & \\
\hline CHEMBL1 & 688 & \multicolumn{3}{|c|}{5.882999999999999} & 5.6278 & \\
\hline CHEMBL1503390 & 688810 & \multicolumn{3}{|c|}{5.132999999999999} & & \\
\hline CHEMBL 3194097 & 688810 & 5.733 & 5.2021 & TRN & & \\
\hline CHEMBL1475180 & 688 & 4. & 4.9164 & TRN & & \\
\hline CHEMBL & 688810 & 4.833 & 5.54 & TST & & \\
\hline CHEMBL1425162 & 688810 & 4.883 & 5.2008 & TRN & & \\
\hline CHEMBL1605239 & 688810 & \multicolumn{3}{|c|}{4.7330000000000005} & 5.5323 & TS \\
\hline CHEMBL1575937 & 688810 & \multicolumn{3}{|c|}{6.5329999999999995} & 5.869 & \\
\hline CHEMBL1549411 & 688810 & \multicolumn{3}{|c|}{4.7330000000000005} & 5.3876 & $\mathrm{TR}$ \\
\hline CHEMBL 2094789 & 688810 & \multicolumn{3}{|c|}{5.832999999999999} & 5.7152 & $\mathrm{TR}$ \\
\hline CHEMBL1500770 & 688810 & 4.7336 & 00000000 & 005 & 5.414 & $\mathrm{TR}$ \\
\hline CHEMBL1587583 & 688810 & 6.4825 & 5.9727 & TRN & & \\
\hline CHEMBL1529033 & 688810 & 5.5829 & 99999999 & & & \\
\hline CHEMBL1610690 & 688810 & 4.9836 & 0000000 & 005 & 5.3187 & \\
\hline CHEMBL1464228 & 688810 & 6.2829 & 99999999 & 995 & 5.8987 & $\mathrm{TR}$ \\
\hline CHEMBL1461748 & 688810 & 4.7336 & 00000000 & 005 & 5.2196 & TRI \\
\hline
\end{tabular}




\begin{tabular}{|c|c|c|c|c|c|c|}
\hline \multirow{3}{*}{$\begin{array}{l}\text { CHEMBL1348741 } \\
\text { CHEMBL1382110 }\end{array}$} & \multicolumn{6}{|c|}{ Supplemental Table S2.txt } \\
\hline & 688810 & \multicolumn{4}{|c|}{6.382999999999999} & TRA \\
\hline & 688810 & 5.083 & 4.9425 & TST & & \\
\hline CHEMBL1524484 & 688810 & \multicolumn{3}{|c|}{5.882999999999999} & 6.6991 & TRN \\
\hline CHEMBL1420064 & 588810 & \multicolumn{3}{|c|}{5.7829999999999995} & 5.3848 & \\
\hline CHEMBL1605081 & 588810 & \multicolumn{3}{|c|}{5.132999999999999} & 5.2834 & \\
\hline CHEMBL1536140 & 688810 & \multicolumn{3}{|c|}{4.7330000000000005} & 5.1085 & \\
\hline CHEMBL1484528 & 688810 & 6.433 & 5.6053 & TRN & & \\
\hline CHEMBL1529079 & 688810 & \multicolumn{3}{|c|}{5.382999999999999} & 5.3949 & \\
\hline CHEMBL1428415 & 688810 & 6.0 & 5.3086 & TRN & & \\
\hline CHEMBL1585928 & 688810 & 5.183 & 4.9147 & TST & & \\
\hline CHEMBL1329035 & 688810 & \multicolumn{3}{|c|}{6.082999999999999} & 5.6764 & \\
\hline CHEMBL1466932 & 688810 & 4.833 & 5.0284 & TST & & \\
\hline CHEMBL1319584 & 688810 & \multirow{2}{*}{\multicolumn{3}{|c|}{$\begin{array}{ll}5.683 & 5.5122 \\
6.082999999999999\end{array}$}} & & \\
\hline CHEMBL1970422 & 688810 & & & & 5.7695 & \\
\hline CHEMBL1512787 & 688810 & 4.633 & 5.1442 & TRN & & \\
\hline CHEMBL148 & $68 \varepsilon$ & & 5.2 & TRN & & \\
\hline CHEMBL143 & 688 & 5 . & 4.5785 & TRN & & \\
\hline CHEMBL1593185 & 688810 & \multicolumn{3}{|c|}{4.9830000000000005} & 5.1126 & \\
\hline CHEMBL1568167 & 688810 & 5.983 & 5.8865 & TRN & & \\
\hline CHEMBL1474958 & 688 & 4.583 & 5.1478 & TST & & \\
\hline CHEMBL144 & 688 & \multicolumn{3}{|c|}{5.332999999999999} & $323>$ & \\
\hline CHEMBL1 & 688 & 6.9329 & 5.5816 & TRN & & \\
\hline CHEMBL1606582 & 688810 & 4.883 & 4.6964 & TRN & & \\
\hline CHEMBL1480605 & 688810 & \multicolumn{3}{|c|}{6.132999999999999} & 5 . & TRN \\
\hline CHEMBL1408173 & 688810 & \multicolumn{3}{|c|}{6.332999999999999} & 5.4645 & \\
\hline CHEMBL1 & 688 & 4.933 & 5.2769 & TRN & & \\
\hline CHEMBL158 & 688 & 4. & 5.0392 & TRN & & \\
\hline CHEMBL1348007 & 688 & 4.633 & 5.3133 & TST & & \\
\hline CHEMBL3189333 & 688810 & \multicolumn{3}{|c|}{5.132999999999999} & 4.8827 & 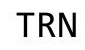 \\
\hline CHEMBL1550646 & 688810 & 4.783 & 5.197 & TST & & \\
\hline CHEMBL1 & 688 & \multicolumn{3}{|c|}{5.7829999999999995} & 5.2332 & 1 \\
\hline CHEMBL1461773 & 688 & 5.083 & 5.36 & TRN & & \\
\hline CHEMBL1479102 & 688810 & \multirow{2}{*}{\multicolumn{3}{|c|}{ 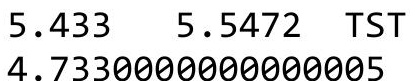 }} & & \\
\hline CHEMBL3189326 & 688810 & & & & 4.5977 & $12-8$ \\
\hline CHEMBL1489938 & 688810 & \multicolumn{3}{|c|}{$\begin{array}{l}4.7330000000000005 \\
4.883 \quad 5.073 \quad \text { TRN }\end{array}$} & & \\
\hline CHEMBL: & 688 & 5.083 & 5.35 & TRN & & \\
\hline CHEMBL1604734 & 688810 & \multicolumn{3}{|c|}{4.7330000000000005} & 4.9771 & $\mathrm{TI}$ \\
\hline CHEMBL1505964 & 688810 & 4.633 & 4.7225 & TST & & \\
\hline CHEMBL3192314 & 688810 & \multicolumn{3}{|c|}{6.332999999999999} & $3.481 /$ & 11 \\
\hline CHEMBL 1 & 688 & 4.833 & 5.2165 & TST & & \\
\hline CHEMBL1570609 & 688810 & \multicolumn{3}{|c|}{4.7330000000000005} & 5.0028 & $T$ \\
\hline CHEMBL3189492 & 688810 & 6.4829 & 5.9013 & TRN & & \\
\hline CHEMBL3212802 & 688810 & 6.0329 & 99999999 & 995 & 5.6246 & TRN \\
\hline CHEMBL1586476 & 688810 & 6.0329 & 99999999 & 995 & 5.6902 & TP \\
\hline CHEMBL1308151 & 688810 & 5.1329 & 99999999 & & 5.7203 & TST \\
\hline CHEMBL1559028 & 688810 & 4.783 & 5.5646 & TST & & \\
\hline CHEMBL1335610 & 688810 & 4.633 & 4.6437 & TRN & & \\
\hline CHEMBL1333405 & 688810 & 4.783 & 4.8731 & TST & & \\
\hline
\end{tabular}




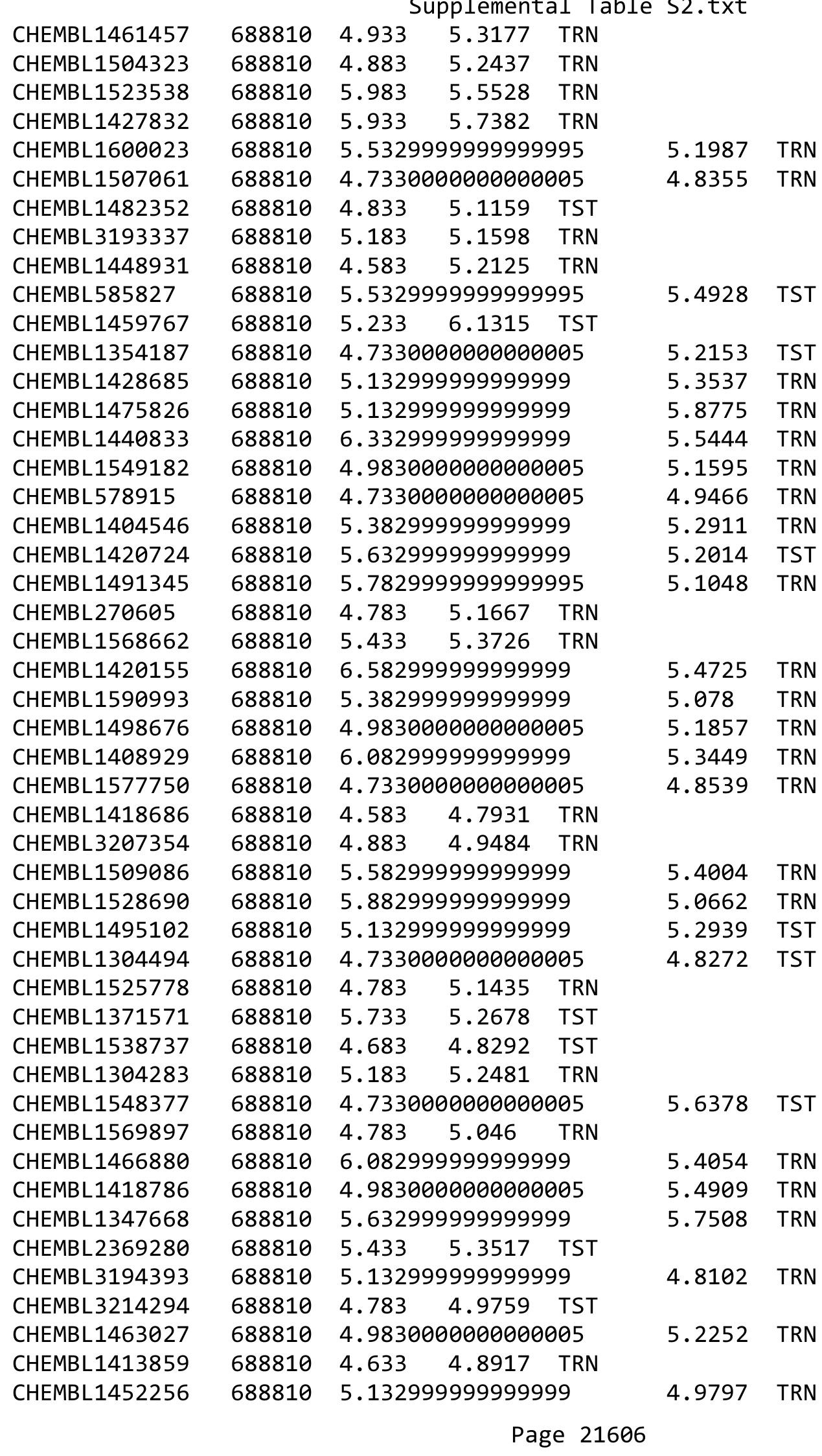




\begin{tabular}{|c|c|c|c|c|c|c|}
\hline \multirow[b]{2}{*}{ CHEMBL1329616 } & \multicolumn{6}{|c|}{ oplemental la } \\
\hline & 688810 & 5.033 & 4.928 & TRN & & \\
\hline CHEMBL1567934 & 688810 & 5.483 & 5.1721 & TST & & \\
\hline CHEMBL1469579 & 688810 & 4.833 & 5.5739 & TRN & & \\
\hline CHEMBL1343422 & 688810 & 4.783 & 5.0172 & TRN & & \\
\hline CHEMBL1332999 & 688810 & \multicolumn{3}{|c|}{5.2829999999999995} & 4.8888 & TST \\
\hline CHEMBL1461711 & 688810 & 6.683 & 5.1071 & TST & & \\
\hline CHEMBL1307475 & 688810 & 5.483 & 5.595 & TRN & & \\
\hline CHEMBL1441808 & 688810 & 5.683 & 5.4504 & TRN & & \\
\hline CHEMBL1467999 & 688810 & 5.183 & 4.9204 & TRN & & \\
\hline CHEMBL1481558 & 688810 & 5.733 & 5.3846 & TRN & & \\
\hline CHEMBL1530352 & 688810 & \multicolumn{3}{|c|}{5.332999999999999} & 5.2629 & TST \\
\hline CHEMBL1309655 & 688810 & \multicolumn{3}{|c|}{5.632999999999999} & 4.9761 & TRN \\
\hline CHEMBL1389924 & 688810 & \multicolumn{3}{|c|}{4.7330000000000005} & 5.2049 & TST \\
\hline CHEMBL1334384 & 688810 & \multicolumn{3}{|c|}{5.5329999999999995} & 5.1108 & TRN \\
\hline CHEMBL1562795 & 688810 & 6.683 & 5.2702 & TST & & \\
\hline CHEMBL1611344 & 688810 & 4.583 & 4.982 & TST & & \\
\hline CHEMBL1563741 & 688810 & 5.033 & 5.2104 & TRN & & \\
\hline CHEMBL1529633 & 688810 & \multicolumn{3}{|c|}{5.5329999999999995} & 5.4992 & TRN \\
\hline CHEMBL1463691 & 688810 & 5.083 & 5.6954 & TST & & \\
\hline CHEMBL1333361 & 688810 & 4.783 & 5.0187 & TST & & \\
\hline CHEMBL1517532 & 688810 & 5.983 & 5.6524 & TRN & & \\
\hline CHEMBL3211664 & 688810 & 4.683 & 5.2871 & TST & & \\
\hline CHEMBL1450510 & 688810 & \multicolumn{3}{|c|}{4.7330000000000005} & 5.2096 & TRN \\
\hline CHEMBL1557307 & 688810 & 4.933 & 5.6073 & TST & & \\
\hline CHEMBL1303798 & 688810 & 7.1331 & 5.949 & TST & & \\
\hline CHEMBL1564980 & 688810 & \multicolumn{3}{|c|}{6.0329999999999995} & 5.8067 & TRN \\
\hline CHEMBL469058 & 688810 & 4.933 & 5.1737 & TRN & & \\
\hline CHEMBL1418939 & 688810 & 5.233 & 5.1652 & TRN & & \\
\hline CHEMBL1315300 & 688810 & \multicolumn{3}{|c|}{4.9830000000000005} & 5.2024 & TST \\
\hline CHEMBL1556184 & 688810 & 5.433 & 5.0694 & TST & & \\
\hline CHEMBL1517034 & 688810 & 5.233 & 4.9542 & TRN & & \\
\hline CHEMBL1563249 & 688810 & 4.833 & 5.6511 & TRN & & \\
\hline CHEMBL1346125 & 688810 & 5.733 & 5.6968 & TRN & & \\
\hline CHEMBL1603438 & 688810 & 4.883 & 5.4188 & TRN & & \\
\hline CHEMBL1448611 & 688810 & \multicolumn{3}{|c|}{6.332999999999999} & 5.6813 & TST \\
\hline CHEMBL1590419 & 688810 & 4.883 & 4.9829 & TRN & & \\
\hline CHEMBL1409903 & 688810 & 5.083 & 5.0641 & TST & & \\
\hline CHEMBL1332610 & 688810 & \multicolumn{3}{|c|}{5.632999999999999} & 5.5199 & TRN \\
\hline CHEMBL1480189 & 688810 & 4.683 & 4.9947 & TRN & & \\
\hline CHEMBL3195943 & 688810 & 4.783 & 4.7759 & TRN & & \\
\hline CHEMBL1472274 & 688810 & \multicolumn{3}{|c|}{5.332999999999999} & 5.0903 & TRN \\
\hline CHEMBL1593330 & 688810 & \multicolumn{3}{|c|}{4.7330000000000005} & 5.1898 & TRN \\
\hline CHEMBL1436476 & 688810 & \multicolumn{3}{|c|}{4.9830000000000005} & 5.362 & TRN \\
\hline CHEMBL1408276 & 688810 & \multicolumn{3}{|c|}{5.582999999999999} & 6.0902 & TRN \\
\hline CHEMBL3196384 & 688810 & 4.883 & 5.3578 & TST & & \\
\hline CHEMBL1606816 & 688810 & \multicolumn{3}{|c|}{4.7330000000000005} & 5.0683 & TRN \\
\hline CHEMBL1414267 & 688810 & 4.883 & 4.9005 & TRN & & \\
\hline CHEMBL1322399 & 688810 & 4.783 & 4.9673 & TST & & \\
\hline
\end{tabular}




\begin{tabular}{|c|c|c|c|c|c|c|}
\hline \multirow[b]{2}{*}{ CHEMBL1592962 } & \multicolumn{6}{|c|}{ Lement } \\
\hline & 688810 & 4.583 & 4.9601 & TRN & & \\
\hline CHEMBL1528880 & 688810 & 4.633 & 5.0957 & TST & & \\
\hline CHEMBL1467974 & 688810 & 4.633 & 4.9164 & TRN & & \\
\hline CHEMBL1539282 & 688810 & 4.833 & 5.0464 & TRN & & \\
\hline CHEMBL1531392 & 688810 & \multicolumn{3}{|c|}{5.882999999999999} & 5.3356 & \\
\hline CHEMBL1437157 & 688810 & 4.633 & 5.0481 & TRN & & \\
\hline CHEMBL1339131 & 688810 & \multicolumn{3}{|c|}{5.332999999999999} & 5.2055 & II \\
\hline CHEMBL1519305 & 688810 & 5.183 & 5.3896 & TRN & & \\
\hline CHEMBL1380514 & 688810 & \multicolumn{3}{|c|}{6.382999999999999} & 5.5139 & \\
\hline CHEMBL1320670 & 688810 & 4.783 & 5.2462 & TST & & \\
\hline CHEMBL1455337 & 688810 & 4.633 & 5.1944 & TRN & & \\
\hline CHEMBL1318060 & 688810 & 8.4318 & 6.1163 & TRN & & \\
\hline CHEMBL1502481 & 688810 & \multicolumn{3}{|c|}{5.832999999999999} & 5.3561 & \\
\hline CHEMBL1497438 & 688810 & \multicolumn{3}{|c|}{5.7829999999999995} & 5.4732 & ומנו \\
\hline CHEMBL1224757 & 688810 & \multicolumn{3}{|c|}{5.382999999999999} & 5.2152 & TRN \\
\hline CHEMBL1431210 & 688810 & \multicolumn{3}{|c|}{5.632999999999999} & 5.7048 & TRN \\
\hline CHEMBL1383783 & 688810 & \multicolumn{3}{|c|}{5.332999999999999} & 4.8152 & \\
\hline CHEMBL3207915 & 688810 & 5.183 & 5.0109 & TST & & \\
\hline CHEMBL1365632 & 688810 & 4.883 & 5.4799 & TST & & \\
\hline CHEMBL1555087 & 688810 & \multicolumn{3}{|c|}{4.7330000000000005} & 5.0031 & Thiv \\
\hline CHEMBL1517635 & 688810 & \multicolumn{3}{|c|}{4.7330000000000005} & 5.0629 & \\
\hline CHEMBL1457665 & 688810 & 6.4829 & 5.2519 & TRN & & \\
\hline CHEMBL1453149 & 688810 & 4.633 & 4.6172 & TRN & & \\
\hline CHEMBL1409167 & 688810 & 5.033 & 5.1514 & TRN & & \\
\hline CHEMBL1431272 & 688810 & \multicolumn{3}{|c|}{5.332999999999999} & 4.9237 & \\
\hline CHEMBL1322034 & 688810 & 5.733 & 5.3976 & TRN & & \\
\hline CHEMBL 3190070 & 688810 & \multicolumn{3}{|c|}{5.382999999999999} & 5.6739 & $\mathrm{TP}$ \\
\hline CHEMBL1528144 & 688810 & 5.183 & 5.4096 & TRN & & \\
\hline CHEMBL1384106 & 688 & 5.033 & 5.1417 & TST & & \\
\hline CHEMBL 3211086 & 688810 & \multicolumn{3}{|c|}{5.132999999999999} & 5.1204 & \\
\hline CHEMBL1968064 & 688810 & \multicolumn{3}{|c|}{5.832999999999999} & 5.0333 & TRN \\
\hline CHEMBL1406264 & 688810 & 4.783 & 5.0758 & TRN & & \\
\hline CHEMBL1369483 & 688810 & 5.983 & 5.8762 & TRN & & \\
\hline CHEMBL3195856 & 688 & 5.683 & 5.6762 & TST & & \\
\hline CHEMBL1509871 & 688810 & \multicolumn{3}{|c|}{4.7330000000000005} & 5.0289 & TS \\
\hline CHEMBL1531638 & 688810 & 4.783 & 5.2807 & TRN & & \\
\hline CHEMBL1525000 & 688810 & 4.783 & 5.4233 & TST & & \\
\hline CHEMBL1972436 & 688810 & \multicolumn{3}{|c|}{5.632999999999999} & 5.6506 & TST \\
\hline CHEMBL1606602 & 688810 & \multicolumn{3}{|c|}{5.7829999999999995} & & \\
\hline CHEMBL1458688 & 688810 & 6.7331 & 5.9221 & TRN & & \\
\hline CHEMBL1493902 & 688810 & 5.733 & 5.2853 & TRN & & \\
\hline CHEMBL1323000 & 688810 & 4.633 & 4.8659 & TRN & & \\
\hline CHEMBL1602953 & 688810 & 4.833 & 4.9865 & TRN & & \\
\hline CHEMBL1375921 & 688810 & 4.933 & 5.1828 & TRN & & \\
\hline CHEMBL1317983 & 688810 & 4.783 & 4.9657 & TST & & \\
\hline CHEMBL1583199 & 688810 & 5.183 & 5.4914 & TST & & \\
\hline CHEMBL1095276 & 688810 & 6.2829 & 99999999 & 995 & 6.1558 & TKIV \\
\hline CHEMBL1321659 & 688810 & 5.1329 & 99999999 & & 5.3333 & \\
\hline
\end{tabular}




\begin{tabular}{|c|c|c|c|c|c|c|}
\hline & & \multicolumn{5}{|c|}{ Supplemental Table S2.txt } \\
\hline CHEMBL1524528 & 688810 & 5.183 & 5.6233 & TST & & \\
\hline CHEMBL 3190251 & 688810 & \multicolumn{3}{|c|}{5.582999999999999} & 5.8606 & TRN \\
\hline CHEMBL3194913 & 688810 & \multicolumn{3}{|c|}{5.5329999999999995} & 5.3628 & TRN \\
\hline CHEMBL1471700 & 688810 & \multicolumn{3}{|c|}{6.132999999999999} & 5.7116 & TST \\
\hline CHEMBL1486585 & 688810 & \multicolumn{3}{|c|}{5.832999999999999} & 5.7799 & TRN \\
\hline CHEMBL1578341 & 688810 & 4.833 & 4.8196 & TRN & & \\
\hline CHEMBL1599230 & 688810 & 4.833 & 5.4746 & TRN & & \\
\hline CHEMBL1513133 & 688810 & 4.783 & 5.6856 & TRN & & \\
\hline CHEMBL1401648 & 688810 & 5.933 & 5.2222 & TRN & & \\
\hline CHEMBL1503484 & 688810 & 4.933 & 5.2117 & TRN & & \\
\hline CHEMBL1473504 & 688810 & 4.633 & 5.1851 & TST & & \\
\hline CHEMBL1351018 & 688810 & \multicolumn{3}{|c|}{5.7829999999999995} & 153 & $\mathrm{TH}$ \\
\hline CHEMBL1519501 & 688810 & 4.833 & 5.7794 & TRN & & \\
\hline CHEMBL1413504 & 688810 & 4.833 & 4.8014 & TRN & & \\
\hline CHEMBL1559239 & 688810 & 5.433 & 5.8084 & TRN & & \\
\hline CHEMBL1583644 & 688810 & 5.083 & 5.1459 & TRN & & \\
\hline CHEMBL1533415 & 688810 & 4.833 & 4.9631 & TRN & & \\
\hline CHEMBL1563323 & 688810 & \multicolumn{3}{|c|}{4.9830000000000005} & 1 & \\
\hline CHEMBL159 & 688810 & 4.833 & 5.4985 & TRN & & \\
\hline CHEMBL1343221 & 688810 & 4.883 & 5.1081 & TRN & & \\
\hline CHEMBL3195175 & 688810 & \multicolumn{3}{|c|}{6.5329999999999995} & 6.4879 & TP \\
\hline CHEMBL1503169 & 688810 & 4.683 & 5.0514 & TST & & \\
\hline CHEMBL1 & 688 & 4.683 & 5.0191 & TRN & & \\
\hline CHEMBL13 & 688810 & \multicolumn{3}{|c|}{5.5329999999999995} & 4.8486 & TRI \\
\hline CHEMBL1378700 & 688810 & 5.233 & 4.9612 & TRN & & \\
\hline CHEMBL1343689 & 688810 & 6.4829 & 6.2154 & TRN & & \\
\hline CHEMBL1323898 & 688810 & 5.483 & 5.0356 & TRN & & \\
\hline CHEMBL1 & 688 & \multicolumn{3}{|c|}{5.132999999999999} & 5.0283 & Ts \\
\hline CHEMBL1374512 & 688810 & 5.183 & 5.2959 & TRN & & \\
\hline CHEMBL1547851 & 688810 & 5.433 & 5.4163 & TRN & & \\
\hline CHEMBL1398124 & 688810 & 4.783 & 5.2519 & TST & & \\
\hline CHEMBL1607973 & 688810 & \multicolumn{3}{|c|}{4.9830000000000005} & 151 & TRN \\
\hline CHEMBL1 & 688810 & \multicolumn{3}{|c|}{6.582999999999999} & 5. & TRN \\
\hline CHEMBL1333830 & 688810 & 5.233 & 5.1736 & TST & & \\
\hline CHEMBL1405593 & 688810 & \multicolumn{3}{|c|}{5.832999999999999} & 5.5973 & $\mathrm{TR}$ \\
\hline CHEMBL1313273 & 688810 & 5.433 & 5.4529 & TRN & & \\
\hline CHEMBL1572867 & 688810 & & & TRN & & \\
\hline CHEMBL13 & 688810 & \multicolumn{3}{|c|}{4.7330000000000005} & 5.5175 & TP \\
\hline CHEMBL1426720 & 688810 & 5.683 & 5.3659 & TRN & & \\
\hline CHEMBL1325709 & 688810 & 5.233 & 5.479 & TRN & & \\
\hline CHEMBL1309912 & 688810 & \multicolumn{3}{|c|}{4.9830000000000005} & 5.0487 & TRN \\
\hline CHEMBL1418232 & 688810 & \multicolumn{3}{|c|}{4.7330000000000005} & 4.9251 & TST \\
\hline CHEMBL1333049 & 688810 & \multicolumn{3}{|c|}{6.832999999999999} & 5.4902 & TRN \\
\hline CHEMBL1540120 & 688810 & \multicolumn{3}{|c|}{5.882999999999999} & 5.5452 & TRN \\
\hline CHEMBL1402345 & 688810 & 4.783 & 5.1339 & TST & & \\
\hline CHEMBL1333443 & 688810 & 5.683 & 5.4441 & TRN & & \\
\hline CHEMBL1605940 & 688810 & \multicolumn{3}{|c|}{5.5329999999999995} & 5.6541 & TRN \\
\hline CHEMBL1563821 & 688810 & \multicolumn{3}{|c|}{6.0329999999999995} & 6.0584 & \\
\hline
\end{tabular}




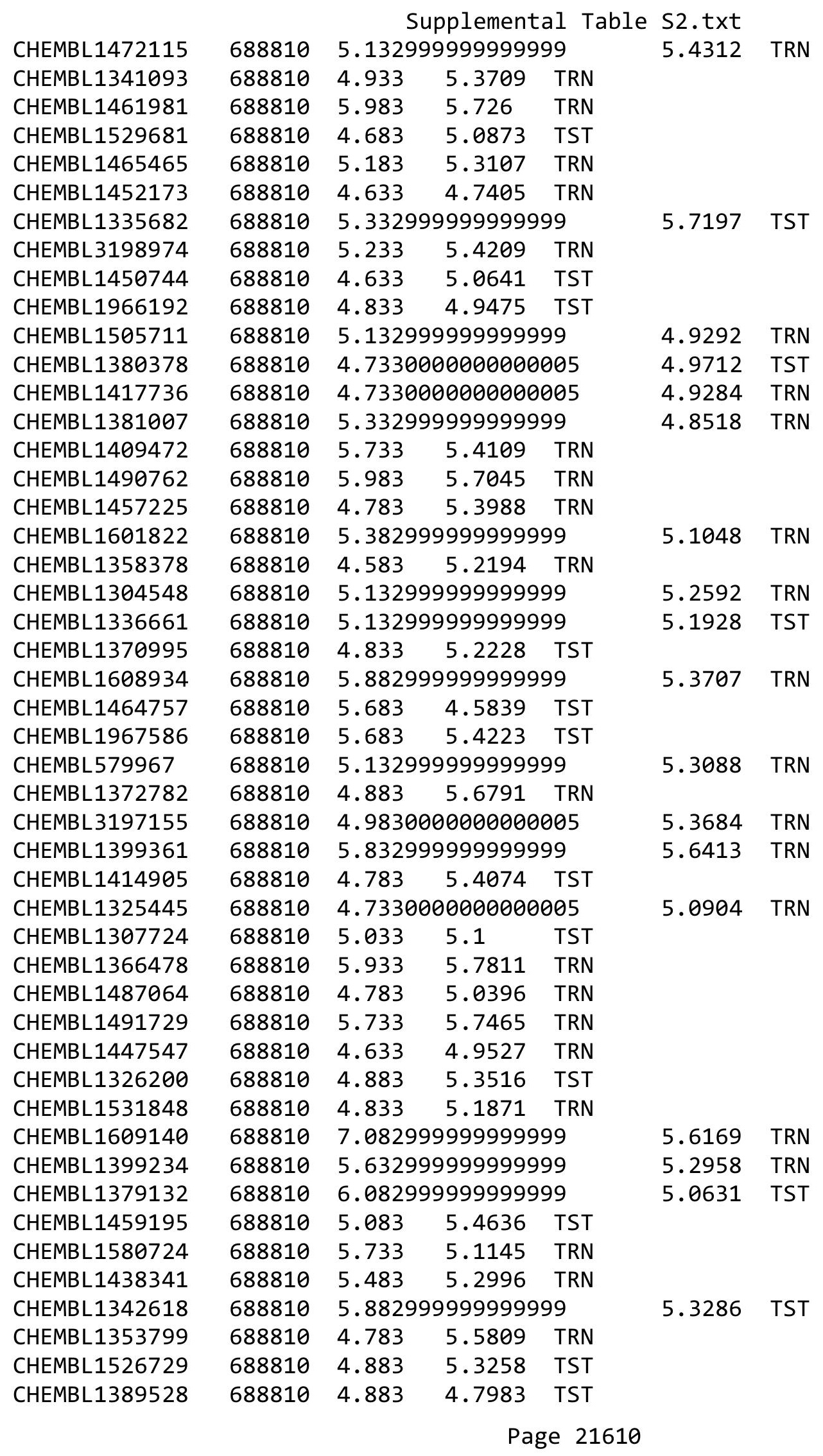




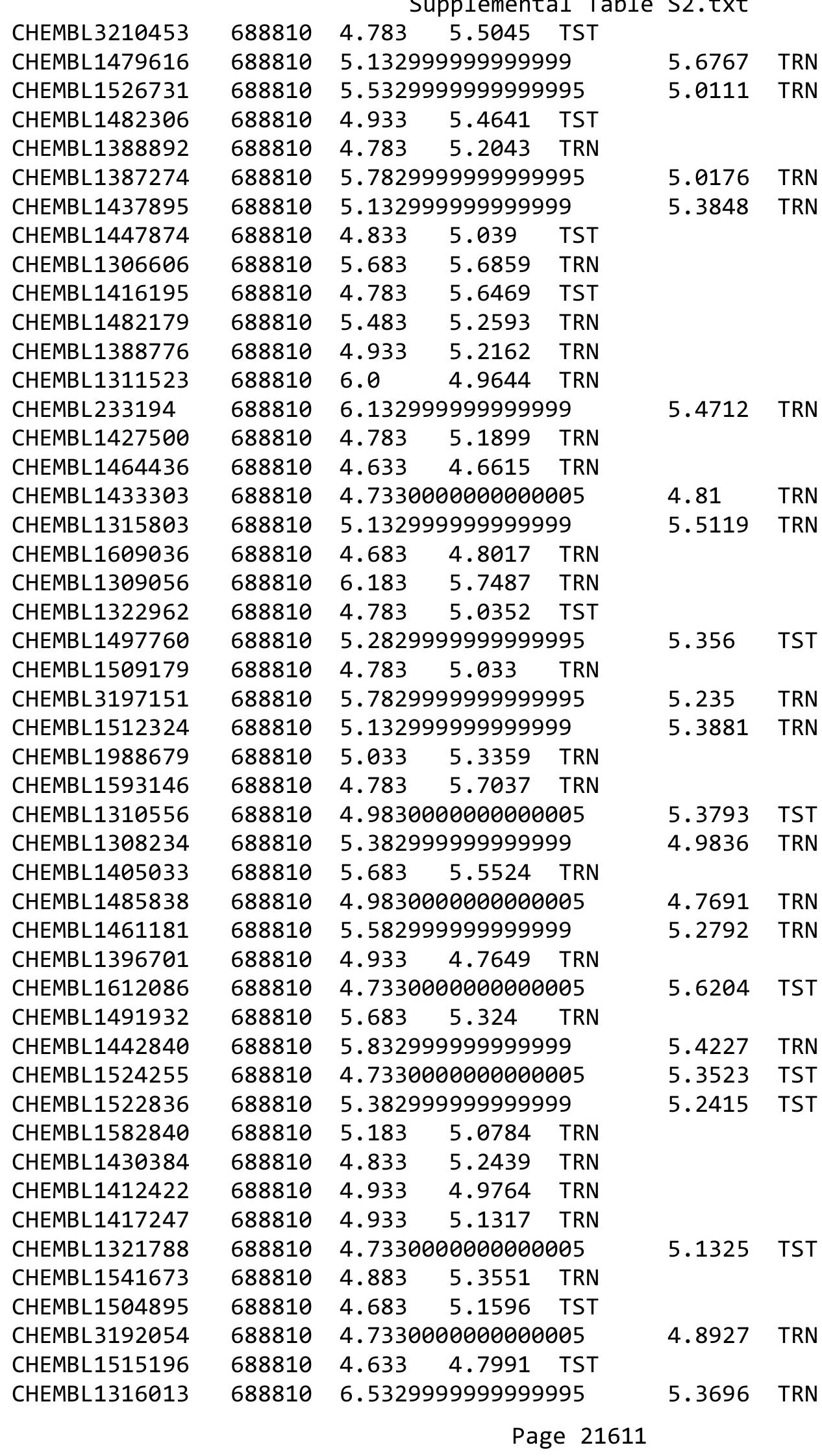




\begin{tabular}{|c|c|c|c|c|c|c|c|}
\hline \multicolumn{7}{|c|}{ Supplemental Table S2.txt } & \\
\hline CHEMBL1409543 & 688810 & \multicolumn{3}{|c|}{4.7330000000000005} & 5.0771 & TRN & \\
\hline CHEMBL1350239 & 688810 & 4.933 & 5.1562 & TRN & & & \\
\hline CHEMBL1338769 & 688810 & \multicolumn{3}{|c|}{4.7330000000000005} & 5.3844 & TRN & \\
\hline CHEMBL3209249 & 688810 & 5.183 & 5.2354 & TST & & & \\
\hline CHEMBL1463574 & 688810 & 5.183 & 5.3091 & TST & & & \\
\hline CHEMBL1432018 & 688810 & \multicolumn{3}{|c|}{6.332999999999999} & 5.2976 & TRN & \\
\hline CHEMBL1367707 & 688810 & 4.883 & 5.1943 & TST & & & \\
\hline CHEMBL1485306 & 688810 & 4.933 & 5.1588 & TRN & & & \\
\hline CHEMBL1530084 & 688810 & 5.983 & 5.7399 & TRN & & & \\
\hline CHEMBL582073 & 688810 & 6.0 & 5.6797 & TRN & & & \\
\hline CHEMBL1509227 & 688810 & 5.733 & 5.4116 & TRN & & & \\
\hline CHEMBL1420157 & 688810 & \multicolumn{3}{|c|}{4.9830000000000005} & 4.93 & TST & \\
\hline CHEMBL1436273 & 688810 & \multicolumn{3}{|c|}{5.582999999999999} & 5.3313 & TRN & \\
\hline CHEMBL1606307 & 688810 & \multicolumn{3}{|c|}{5.7829999999999995} & 5.5283 & TRN & \\
\hline CHEMBL1502567 & 688810 & \multicolumn{3}{|c|}{4.7330000000000005} & 5.471 & TRN & \\
\hline CHEMBL1546106 & 688810 & 4.783 & 5.5496 & TRN & & & \\
\hline CHEMBL1395072 & 688810 & 4.633 & 4.9779 & TRN & & & \\
\hline CHEMBL1334460 & 688810 & \multicolumn{3}{|c|}{5.2829999999999995} & 5.0839 & TST & \\
\hline CHEMBL1512380 & 688810 & \multicolumn{3}{|c|}{5.882999999999999} & 5.1623 & TST & \\
\hline CHEMBL1541291 & 688810 & \multicolumn{3}{|c|}{5.632999999999999} & 5.4021 & TRN & \\
\hline CHEMBL3194402 & 688810 & \multicolumn{3}{|c|}{5.5329999999999995} & 5.2895 & TRN & \\
\hline CHEMBL1321104 & 688810 & \multicolumn{3}{|c|}{5.832999999999999} & 5.6201 & TRN & \\
\hline CHEMBL3192397 & 688810 & \multicolumn{3}{|c|}{5.5329999999999995} & \multicolumn{2}{|c|}{5.1979999999999995} & TRN \\
\hline CHEMBL1587596 & 688810 & \multicolumn{3}{|c|}{5.2829999999999995} & 5.271 & TRN & \\
\hline CHEMBL1462831 & 688810 & 4.883 & 5.0426 & TRN & & & \\
\hline CHEMBL1575293 & 688810 & 4.883 & 4.8246 & TRN & & & \\
\hline CHEMBL1425061 & 688810 & 4.833 & 5.1634 & TRN & & & \\
\hline CHEMBL1608900 & 688810 & \multicolumn{3}{|c|}{5.132999999999999} & 5.4216 & TRN & \\
\hline CHEMBL 2000122 & 688810 & \multicolumn{3}{|c|}{6.5329999999999995} & 5.7866 & TRN & \\
\hline CHEMBL1463134 & 688810 & 4.583 & 5.153 & TST & & & \\
\hline CHEMBL1433153 & 688810 & \multicolumn{3}{|c|}{5.632999999999999} & \multicolumn{2}{|c|}{5.3420000000000005} & TRN \\
\hline CHEMBL1443669 & 688810 & 4.833 & 5.0616 & TST & & & \\
\hline CHEMBL1492432 & 688810 & 5.683 & 5.5753 & TRN & & & \\
\hline CHEMBL1482400 & 688810 & 4.883 & 5.3309 & TRN & & & \\
\hline CHEMBL1305475 & 688810 & \multicolumn{3}{|c|}{6.0329999999999995} & 6.9844 & TRN & \\
\hline CHEMBL1473734 & 688810 & 4.7330 & 00000000 & 005 & 5.0029 & TRN & \\
\hline CHEMBL1475756 & 688810 & 4.7330 & 00000000 & 005 & 5.0295 & TRN & \\
\hline CHEMBL 3185655 & 688810 & 6.8831 & 5.8431 & TST & & & \\
\hline CHEMBL1497763 & 688810 & 5.033 & 5.5271 & TRN & & & \\
\hline CHEMBL1456543 & 688810 & 5.433 & 5.6289 & TRN & & & \\
\hline CHEMBL1330723 & 688810 & 6.3329 & 99999999 & & 5.3871 & TRN & \\
\hline CHEMBL 3208247 & 688810 & 5.3329 & 99999999 & & 5.6241 & TRN & \\
\hline CHEMBL1361491 & 688810 & 5.3829 & 99999999 & & 5.0279 & TST & \\
\hline CHEMBL1469054 & 688810 & 5.1329 & 99999999 & & 5.3813 & TRN & \\
\hline CHEMBL600895 & 688810 & 5.183 & 5.7054 & TRN & & & \\
\hline CHEMBL1480916 & 688810 & 5.7829 & 99999999 & 995 & 5.5032 & TRN & \\
\hline CHEMBL1495119 & 688810 & 6.7829 & 99999999 & 995 & 5.9169 & TRN & \\
\hline CHEMBL600773 & 688810 & 5.3329 & 99999999 & & 5.2143 & TRN & \\
\hline
\end{tabular}




\begin{tabular}{|c|c|c|c|c|c|c|}
\hline CHEMBL1335522 & 688810 & 4.633 & 5.0972 & TST & & \\
\hline CHEMBL1593579 & 688810 & \multicolumn{3}{|c|}{6.382999999999999} & 5.1861 & TRN \\
\hline CHEMBL1571062 & 688810 & \multicolumn{3}{|c|}{5.632999999999999} & 5.4835 & \\
\hline CHEMBL1329307 & 688810 & 4.783 & 5.5232 & TRN & & \\
\hline CHEMBL1559802 & 588810 & 5.983 & 5.0962 & TRN & & \\
\hline CHEMBL1589689 & 588810 & 4.883 & 5.2545 & TST & & \\
\hline CHEMBL1554673 & 88810 & 5.433 & 5.2602 & TRN & & \\
\hline CHEMBL 3193879 & 688810 & 6.233 & 5.3342 & TRN & & \\
\hline CHEMBL1399711 & 688810 & \multicolumn{3}{|c|}{4.9830000000000005} & 5.6741 & TRN \\
\hline CHEMBL1311573 & 588810 & \multicolumn{3}{|c|}{4.7330000000000005} & 5.3958 & \\
\hline CHEMBL1381612 & 688810 & \multicolumn{3}{|c|}{4.9830000000000005} & 4.8889 & \\
\hline CHEMBL1524357 & 688810 & 4.633 & 4.9352 & TST & & \\
\hline CHEMBL1409229 & 688810 & 4.883 & 5.2037 & TRN & & \\
\hline CHEMBL1500395 & 688810 & \multicolumn{3}{|c|}{5.5329999999999995} & 5.6717 & \\
\hline CHEMBL1382033 & 688810 & \multicolumn{3}{|c|}{5.582999999999999} & & \\
\hline CHEMBL1414939 & 688810 & 5.183 & 5.2718 & TST & & \\
\hline HEMBL1491098 & 688810 & \multicolumn{3}{|c|}{4.7330000000000005} & 5.3848 & TRN \\
\hline HEMBL1509929 & 688810 & \multicolumn{3}{|c|}{5.882999999999999} & 319 & \\
\hline HEMBL1428625 & 688810 & \multicolumn{3}{|c|}{6.082999999999999} & 5.1905 & \\
\hline CHEMBL1339663 & 688810 & \multicolumn{3}{|c|}{4.7330000000000005} & 4.9549 & 13 \\
\hline CHEMBL1608816 & 688810 & \multicolumn{3}{|c|}{5.2829999999999995} & 266 & \\
\hline CHEMBL1466841 & 688810 & 5.183 & 5.2465 & TST & & \\
\hline CHEMBL1476313 & 688810 & 5.033 & 4.8816 & TRN & & \\
\hline CHEMBL1404241 & 688810 & 5.733 & 5.3112 & TRN & & \\
\hline CHEMBL1608477 & 688810 & \multicolumn{3}{|c|}{5.332999999999999} & $\partial 2$ & \\
\hline CHEMBL1444116 & 688810 & 5.233 & 5.4479 & TRN & & \\
\hline CHEMBL & 688810 & 5.183 & 5. & TRN & & \\
\hline CHEMBL: & 688810 & 5.683 & 5.3897 & TRN & & \\
\hline CHEMBL1555002 & 688810 & 5.183 & 5.6971 & TRN & & \\
\hline CHEMBL1299459 & 688810 & 4.883 & 5.3292 & TRN & & \\
\hline CHEMBL1477409 & 688810 & \multicolumn{3}{|c|}{4.7330000000000005} & & \\
\hline CHEMBL1344611 & 688810 & \multicolumn{3}{|c|}{5.632999999999999} & & \\
\hline CHEMBL1503361 & 688810 & \multicolumn{3}{|c|}{4.7330000000000005} & 5.2644 & \\
\hline CHEMBL1352295 & 688810 & 5.683 & 5.1535 & TRN & & \\
\hline CHEMBL 3192279 & 688810 & \multicolumn{3}{|c|}{5.7829999999999995} & 5.0758 & \\
\hline CHEMBL & 810 & 5.683 & 5.4477 & TRN & & \\
\hline CHEMBL1529647 & 810 & \multirow{2}{*}{\multicolumn{3}{|c|}{$\begin{array}{lr}6.183 & 5.4667 \\
5.582999999999999\end{array}$}} & & \\
\hline CHEMBL1475049 & 688810 & & & & 5.8091 & \\
\hline CHEMBL1546765 & 688810 & \multicolumn{3}{|c|}{$4.783 \quad 5.2724$ TRN } & & \\
\hline CHEMBL1522699 & 688810 & \multicolumn{3}{|c|}{6.2829999999999995} & 191 & TR \\
\hline CHEMBL 2001582 & 688810 & \multicolumn{3}{|c|}{5.2829999999999995} & & \\
\hline CHEMBL1381351 & 688810 & \multicolumn{3}{|c|}{4.7330000000000005} & 5.6801 & $\mathrm{TR}$ \\
\hline CHEMBL1598805 & 688810 & 5.8329 & 99999999 & & 5.3934 & TRA \\
\hline CHEMBL1583914 & 688810 & 5.6329 & 99999999 & & 5.2316 & \\
\hline CHEMBL1371383 & 688810 & 5.4 & 5.4566 & TRN & & \\
\hline CHEMBL1381395 & 688810 & 5.532 & 99999999 & 995 & 5.1722 & \\
\hline CHEMBL1412825 & 688810 & 6.3329 & 99999999 & & 5.3134 & \\
\hline CHEMBL1317145 & 688810 & 5.3329 & 99999999 & & 5.0045 & ס \\
\hline
\end{tabular}




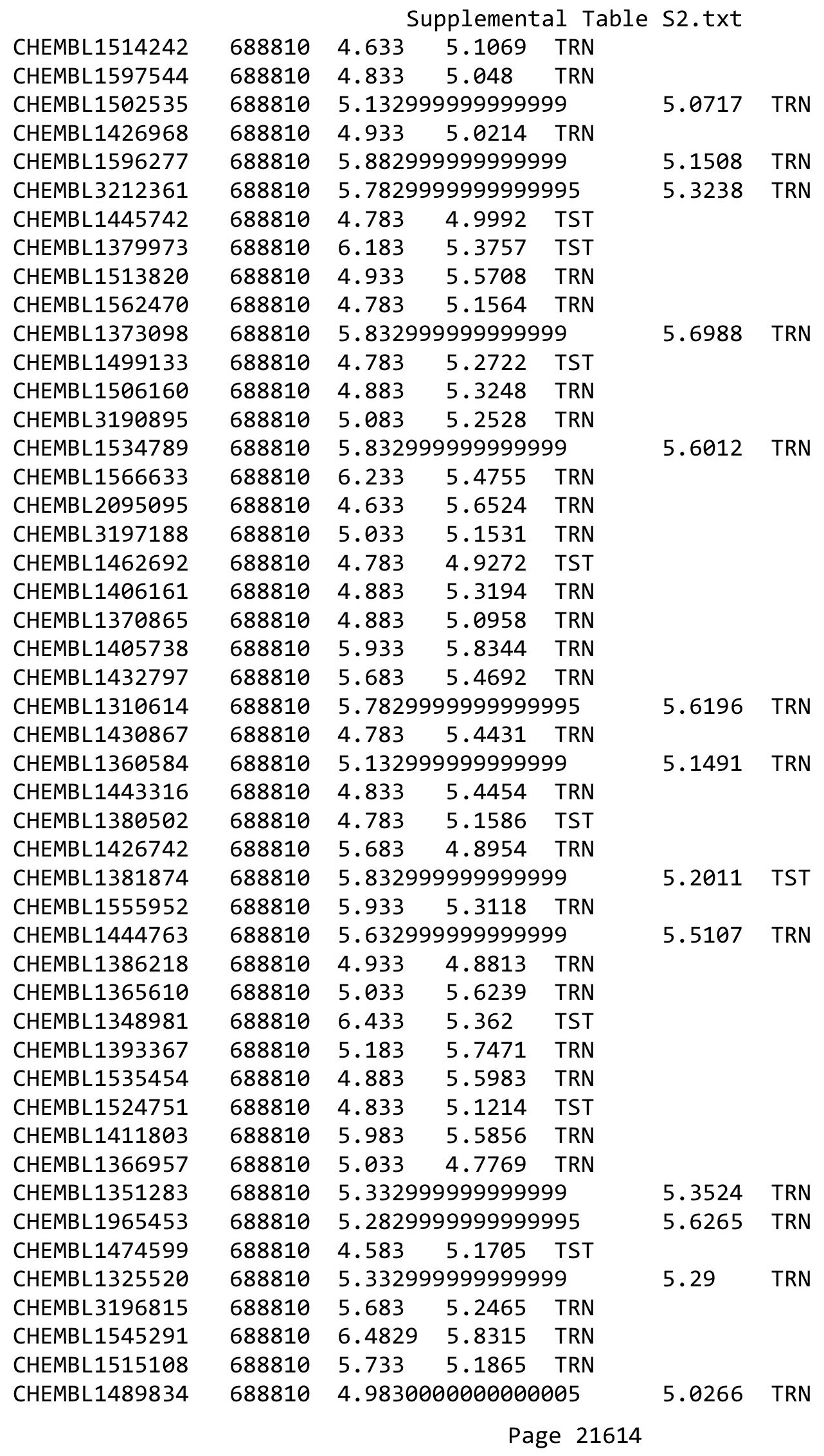




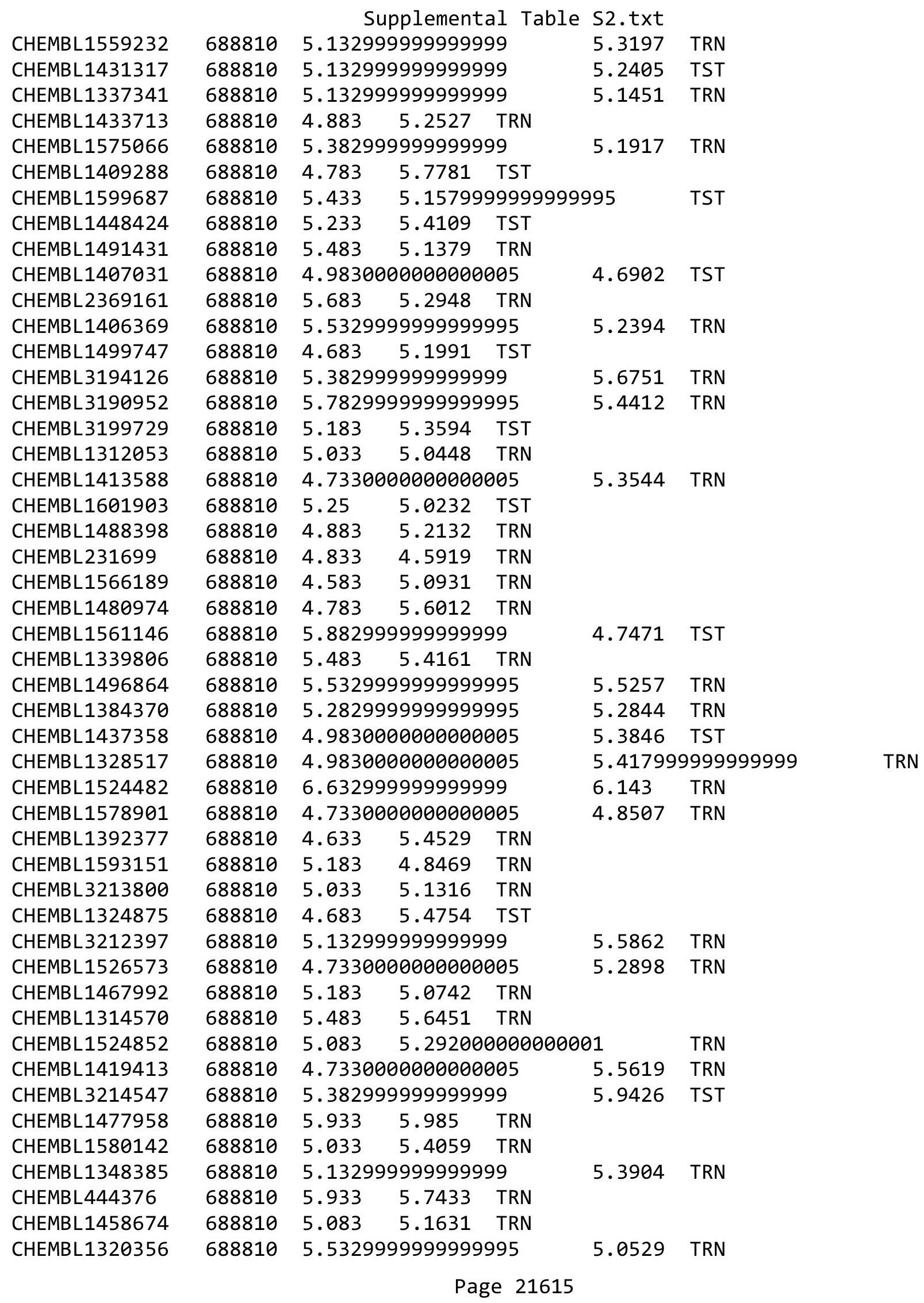




\begin{tabular}{|c|c|c|c|c|c|c|}
\hline \multirow[b]{2}{*}{ CHEMBL1337443 } & \multirow[b]{2}{*}{688810} & \multicolumn{5}{|c|}{ Supplemental Table S2.txt } \\
\hline & & \multicolumn{2}{|c|}{$3 \quad 5.2841$} & TRN & & \\
\hline CHEMBL1423762 & 688810 & 4.933 & 5.7279 & TRN & & \\
\hline CHEMBL1469517 & 688810 & \multicolumn{3}{|c|}{6.2829999999999995} & 5.1349 & TRN \\
\hline CHEMBL1434759 & 688810 & 4.683 & 5.2042 & TRN & & \\
\hline CHEMBL3195725 & 688810 & 4.933 & 4.8828 & TST & & \\
\hline CHEMBL1539778 & 688810 & 4.633 & 4.8486 & TST & & \\
\hline CHEMBL1313500 & 688810 & 4.933 & 5.153 & TRN & & \\
\hline CHEMBL1603047 & 688810 & \multicolumn{3}{|c|}{6.832999999999999} & 6.225 & TRN \\
\hline CHEMBL387618 & 688810 & \multicolumn{3}{|c|}{5.882999999999999} & 5.9882 & TRN \\
\hline CHEMBL1302596 & 688810 & 5.183 & 5.4171 & TRN & & \\
\hline CHEMBL1608433 & 688810 & 4.633 & 4.5657 & TST & & \\
\hline CHEMBL1509759 & 688810 & \multicolumn{3}{|c|}{5.382999999999999} & 5.4527 & TRN \\
\hline CHEMBL1331787 & 688810 & 6.0 & 5.8635 & TRN & & \\
\hline CHEMBL1370744 & 688810 & 4.933 & 5.1783 & TRN & & \\
\hline CHEMBL1552003 & 688810 & 5.733 & 5.6207 & TRN & & \\
\hline CHEMBL1431047 & 688810 & 4.883 & 5.1838 & TST & & \\
\hline CHEMBL1409618 & 688810 & \multicolumn{3}{|c|}{5.632999999999999} & 5.5241 & TRN \\
\hline CHEMBL1418889 & 688810 & 4.633 & 5.2454 & TRN & & \\
\hline CHEMBL1520301 & 688810 & \multicolumn{3}{|c|}{5.332999999999999} & 5.1156 & TRN \\
\hline CHEMBL601146 & 688810 & 6.0 & 5.3896 & TRN & & \\
\hline CHEMBL1368274 & 688810 & 5.183 & 5.3961 & TRN & & \\
\hline CHEMBL1482518 & 688810 & \multicolumn{3}{|c|}{4.7330000000000005} & 5.1656 & TRN \\
\hline CHEMBL1334903 & 688810 & 5.433 & 4.8844 & TST & & \\
\hline CHEMBL1368377 & 688810 & \multicolumn{3}{|c|}{5.2829999999999995} & 5.1704 & TRN \\
\hline CHEMBL1496406 & 688810 & 4.833 & 4.9365 & TST & & \\
\hline CHEMBL1412175 & 688810 & 4.933 & 5.1022 & TRN & & \\
\hline CHEMBL1415516 & 688810 & 5.8 & 5.8643 & TRN & & \\
\hline CHEMBL1392742 & 688810 & \multicolumn{3}{|c|}{5.382999999999999} & 5.0075 & TRN \\
\hline CHEMBL1415899 & 688810 & 5.083 & 5.5505 & TRN & & \\
\hline CHEMBL1308878 & 688810 & 5.683 & 5.2491 & TST & & \\
\hline CHEMBL1526072 & 688810 & 4.833 & 4.9223 & TRN & & \\
\hline CHEMBL1497932 & 688810 & 6.433 & 5.6821 & TRN & & \\
\hline CHEMBL1592795 & 688810 & 5.033 & 5.1188 & TRN & & \\
\hline CHEMBL3189304 & 688810 & 4.683 & 4.8149 & TST & & \\
\hline CHEMBL1362990 & 688810 & 4.783 & 4.7061 & TRN & & \\
\hline CHEMBL1362107 & 688810 & 4.633 & 4.8207 & TST & & \\
\hline CHEMBL1431252 & 688810 & \multicolumn{3}{|c|}{5.582999999999999} & 5.2334 & TRN \\
\hline CHEMBL1307910 & 688810 & 6.233 & 6.2621 & TRN & & \\
\hline CHEMBL1407088 & 688810 & 5.9 & 5.6271 & TRN & & \\
\hline CHEMBL1433083 & 688810 & 4.883 & 5.4813 & TST & & \\
\hline CHEMBL1334265 & 688810 & 4.833 & 4.9026 & TRN & & \\
\hline CHEMBL1481939 & 688810 & 5.233 & 5.3134 & TRN & & \\
\hline CHEMBL1416356 & 688810 & 4.683 & 5.4278 & TST & & \\
\hline CHEMBL1400463 & 688810 & \multicolumn{3}{|c|}{5.132999999999999} & 4.9446 & TRN \\
\hline CHEMBL1965298 & 688810 & 6.4829 & 6.2827 & TRN & & \\
\hline CHEMBL1553242 & 688810 & 5.083 & 5.657 & TRN & & \\
\hline CHEMBL1416270 & 688810 & 5.983 & 5.2259 & TRN & & \\
\hline CHEMBL1430160 & 688810 & 5.033 & 4.825 & TRN & & \\
\hline
\end{tabular}




\begin{tabular}{|c|c|c|c|c|c|c|c|}
\hline \multirow[b]{2}{*}{ CHEMBL1403523 } & & \\
\hline & 688810 & 4.633 & 4.7979 & TST & & & \\
\hline CHEMBL1362180 & 688810 & 4.883 & 5.2474 & TRN & & & \\
\hline CHEMBL1463573 & 688810 & 4.7330 & 00000000 & 005 & 5.032 & TST & \\
\hline CHEMBL1427218 & 688810 & 6.3829 & 99999999 & & 5.8618 & TRN & \\
\hline CHEMBL1340986 & 688810 & 4.883 & 5.2255 & TST & & & \\
\hline CHEMBL1413108 & 688810 & 5.033 & 5.2349 & TRN & & & \\
\hline CHEMBL1325704 & 688810 & 4.833 & 4.9012 & TRN & & & \\
\hline CHEMBL1349317 & 688810 & 5.5329 & 99999999 & 995 & 5.3104 & TRN & \\
\hline CHEMBL1570135 & 688810 & 4.583 & 4.7825 & TRN & & & \\
\hline CHEMBL1987894 & 688810 & 5.3329 & 99999999 & & 5.3432 & TRN & \\
\hline CHEMBL1350251 & 688810 & 6.0329 & 99999999 & 995 & 5.4264 & TST & \\
\hline CHEMBL1534459 & 688810 & 6.3329 & 99999999 & & 5.7278 & TRN & \\
\hline CHEMBL1351022 & 688810 & 5.8329 & 99999999 & & 5.4398 & TRN & \\
\hline CHEMBL1530166 & 688810 & 4.833 & 4.9475 & TRN & & & \\
\hline CHEMBL1473506 & 688810 & 5.1329 & 99999999 & & 5.6857 & TRN & \\
\hline CHEMBL1359195 & 688810 & 5.1329 & 99999999 & & 5.3796 & TRN & \\
\hline CHEMBL1466616 & 688810 & 4.683 & 5.3191 & TRN & & & \\
\hline CHEMBL 2000529 & 688810 & 6.183 & 5.6927 & TRN & & & \\
\hline CHEMBL1491417 & 688810 & 4.883 & 5.1704 & TRN & & & \\
\hline CHEMBL1582417 & 688810 & 4.933 & 5.4495 & TRN & & & \\
\hline CHEMBL 3190323 & 688810 & 4.783 & 5.2527 & TRN & & & \\
\hline CHEMBL1328681 & 688810 & 5.2829 & 99999999 & 995 & 5.1248 & TRN & \\
\hline CHEMBL1572176 & 688810 & 4.783 & 4.8573 & TST & & & \\
\hline CHEMBL1337996 & 688810 & 4.9830 & 00000000 & 005 & 5.2661 & TST & \\
\hline CHEMBL3213898 & 688810 & 4.833 & 5.1102 & TST & & & \\
\hline CHEMBL1467785 & 688810 & 4.633 & 5.1713 & TST & & & \\
\hline CHEMBL1561171 & 688810 & 5.233 & 5.6244 & TRN & & & \\
\hline CHEMBL1482798 & 688810 & 4.783 & 4.8974 & TST & & & \\
\hline CHEMBL1423935 & 688810 & 5.433 & 5.1671 & TRN & & & \\
\hline CHEMBL1479329 & 688810 & 4.7330 & 00000000 & 005 & 5.1658 & TRN & \\
\hline CHEMBL1379247 & 688810 & 4.933 & 5.2652 & TRN & & & \\
\hline CHEMBL1588641 & 688810 & 5.8329 & 99999999 & & 5.1893 & TRN & \\
\hline CHEMBL1489657 & 688810 & 5.033 & 5.2382 & TRN & & & \\
\hline CHEMBL1575715 & 688810 & 4.783 & 4.9103 & TRN & & & \\
\hline CHEMBL1352649 & 688810 & 5.183 & 5.0631 & TST & & & \\
\hline CHEMBL1556542 & 688810 & 6.2829 & 99999999 & 995 & 5.092 & TRN & \\
\hline CHEMBL1374129 & 688810 & 4.783 & 5.2766 & TRN & & & \\
\hline CHEMBL1548899 & 688810 & 6.2829 & 99999999 & 995 & 5.2360 & 0000000001 & TST \\
\hline CHEMBL1302780 & 688810 & 5.2829 & 99999999 & 995 & 4.9711 & TRN & \\
\hline CHEMBL1429406 & 688810 & 5.183 & 5.6411 & TRN & & & \\
\hline CHEMBL1321305 & 688810 & 6.3329 & 99999999 & & 5.0977 & TRN & \\
\hline CHEMBL1533668 & 688810 & 5.233 & 5.2426 & TST & & & \\
\hline CHEMBL3208941 & 688810 & 5.683 & 5.1623 & TRN & & & \\
\hline CHEMBL1505080 & 688810 & 4.883 & 5.6028 & TRN & & & \\
\hline CHEMBL1597766 & 688810 & 4.9830 & 00000000 & 005 & 5.1486 & TST & \\
\hline CHEMBL1492932 & 688810 & 5.5329 & 199999999 & 995 & 5.5251 & TRN & \\
\hline CHEMBL1325076 & 688810 & 4.683 & 4.9807 & TRN & & & \\
\hline CHEMBL1427511 & 688810 & 6.0329 & 99999999 & 995 & 5.2928 & TST & \\
\hline
\end{tabular}




\begin{tabular}{|c|c|c|c|c|c|c|}
\hline & & \multicolumn{5}{|c|}{ Supplemental Table S2.txt } \\
\hline CHEMBL1308989 & 688810 & 4.783 & 5.0634 & TRN & & \\
\hline CHEMBL1488133 & 688810 & 6.4829 & 5.4452 & TST & & \\
\hline CHEMBL1527899 & 688810 & 6.38299 & 999999999 & & 5.4676 & 10 \\
\hline CHEMBL1500721 & 688810 & 4.583 & 5.188 & TRN & & \\
\hline CHEMBL1308009 & 688810 & 4.883 & 5.1412 & TRN & & \\
\hline CHEMBL1450880 & 688810 & 4.783 & 5.5642 & TRN & & \\
\hline CHEMBL1569719 & 688810 & 5.13299 & 999999999 & & 5.1333 & this \\
\hline CHEMBL1576941 & 688810 & 4.633 & 4.9321 & TRN & & \\
\hline CHEMBL1427232 & 688810 & 5.28299 & 999999999 & 995 & 4.8924 & TST \\
\hline CHEMBL1538718 & 688810 & 5.233 & 5.7747 & TRN & & \\
\hline CHEMBL1486546 & 688810 & 5.183 & 5.0436 & TRN & & \\
\hline CHEMBL 3191809 & 688810 & 5.083 & 5.5518 & TRN & & \\
\hline CHEMBL1463724 & 688810 & 4.98300 & 000000006 & 005 & 5.1531 & \\
\hline CHEMBL1526782 & 688810 & 4.883 & 5.3415 & TST & & \\
\hline CHEMBL1560105 & 688810 & 4.833 & 5.3946 & TRN & & \\
\hline CHEMBL1367180 & 688810 & 5.083 & 5.6566 & TRN & & \\
\hline CHEMBL1373816 & 688810 & 5.083 & 5.3033 & TRN & & \\
\hline CHEMBL1525839 & 688810 & 4.683 & 5.3795 & TRN & & \\
\hline CHEMBL1387487 & 688810 & 5.433 & 5.3967 & TRN & & \\
\hline CHEMBL1308947 & 688810 & 5.733 & 6.0499 & TRN & & \\
\hline CHEMBL1382028 & 688810 & 6.78299 & 999999999 & 995 & 2 & \\
\hline CHEMBL1424548 & 688810 & 5.033 & 5.2054 & TRN & & \\
\hline CHEMBL 3192108 & 688810 & 7.3325 & 6.7491 & TRN & & \\
\hline CHEMBL 3192813 & 688810 & 5.033 & $5.16100 e$ & 000000000 & 305 & \\
\hline CHEMBL1484297 & 688810 & 4.883 & 5.2956 & TST & & \\
\hline CHEMBL1336269 & 688810 & 5.683 & 5.365 & TRN & & \\
\hline CHEMBL 3196374 & 688810 & 4.583 & 5.5471 & TRN & & \\
\hline CHEMBL1585145 & 688810 & 6.28299 & 999999999 & 995 & 5.4277 & \\
\hline CHEMBL 3193319 & 688810 & 4.73300 & 000000000 & 005 & 5.6069 & \\
\hline CHEMBL1438924 & 688810 & 5.233 & 4.8607 & TST & & \\
\hline CHEMBL1379943 & 688810 & 6.53299 & 999999999 & 995 & 5.601 & \\
\hline CHEMBL1501871 & 688810 & 4.783 & 5.0389 & TST & & \\
\hline CHEMBL1992801 & 688810 & 5.53299 & 999999999 & 995 & 5.7101 & \\
\hline CHEMBL1457039 & 688810 & 4.98300 & 000000000 & 005 & 5.2565 & \\
\hline CHEMBL1451375 & 688810 & 5.58299 & 999999999 & & 5.0459 & TRN \\
\hline CHEMBL1545068 & 688810 & 5.83299 & 999999999 & & 5.4378 & $\mathrm{TP}$ \\
\hline CHEMBL 3211191 & 688810 & 5.083 & 5.4363 & TRN & & \\
\hline CHEMBL1460956 & 688810 & 4.883 & 5.4605 & TRN & & \\
\hline CHEMBL1584646 & 688810 & 4.783 & 4.9561 & TST & & \\
\hline CHEMBL1395443 & 688810 & 5.033 & 5.2384 & TRN & & \\
\hline CHEMBL 3195922 & 688810 & 4.98300 & 000000000 & 005 & 5.3781 & \\
\hline CHEMBL1543522 & 688810 & 4.783 & 5.2307 & TRN & & \\
\hline CHEMBL1604245 & 688810 & 5.233 & 6.2589 & TRN & & \\
\hline CHEMBL 3213422 & 688810 & 5.733 & 5.0948 & TRN & & \\
\hline CHEMBL1348714 & 688810 & 4.883 & 5.6213 & TST & & \\
\hline CHEMBL1389817 & 688810 & 5.38299 & 999999999 & 99 & 5.9494 & IRI \\
\hline CHEMBL 1406600 & 688810 & 4.583 & 5.1945 & TRN & & \\
\hline CHEMBL1567795 & 688810 & 5.483 & 5.7313 & TRN & & \\
\hline
\end{tabular}




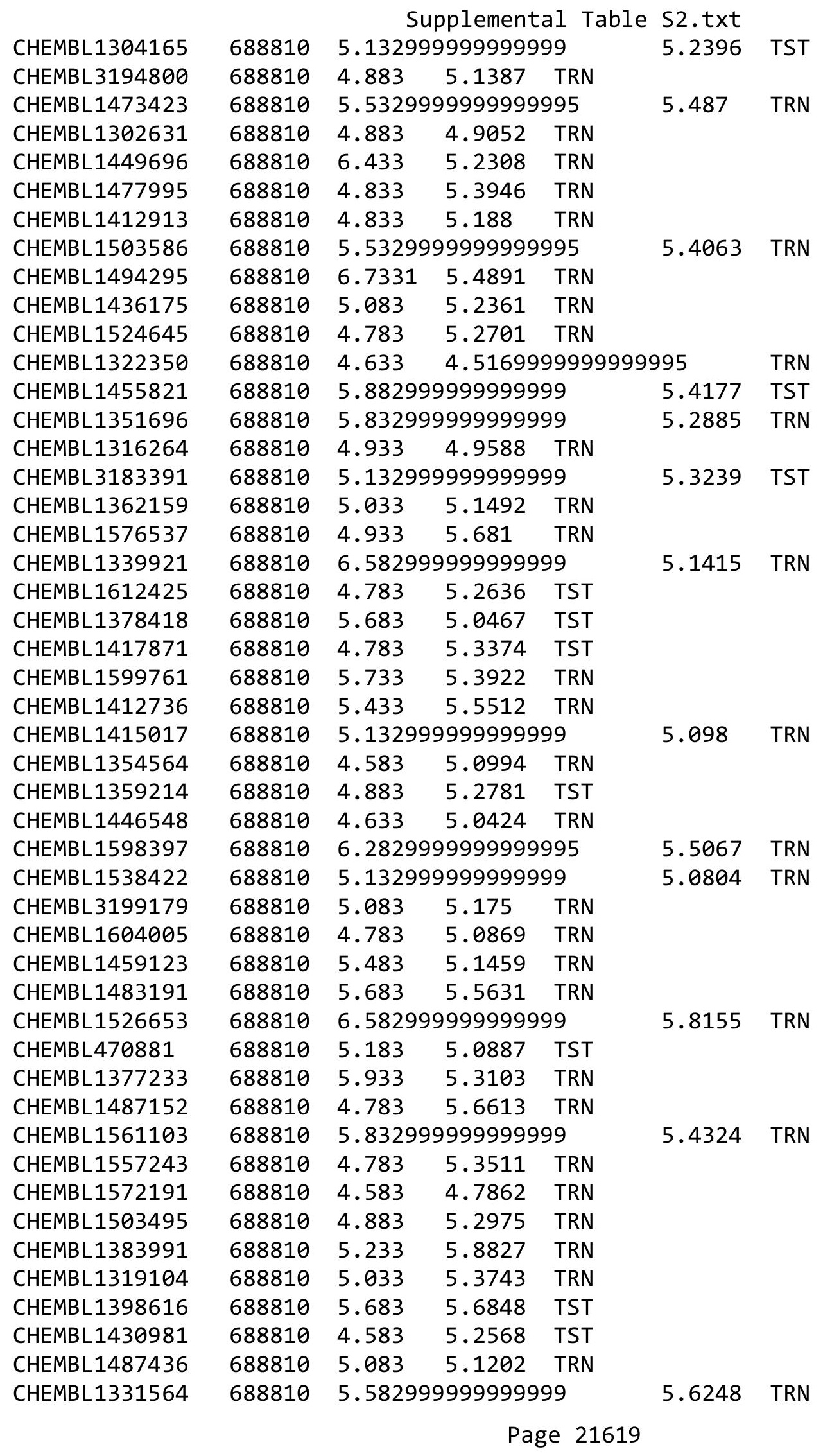




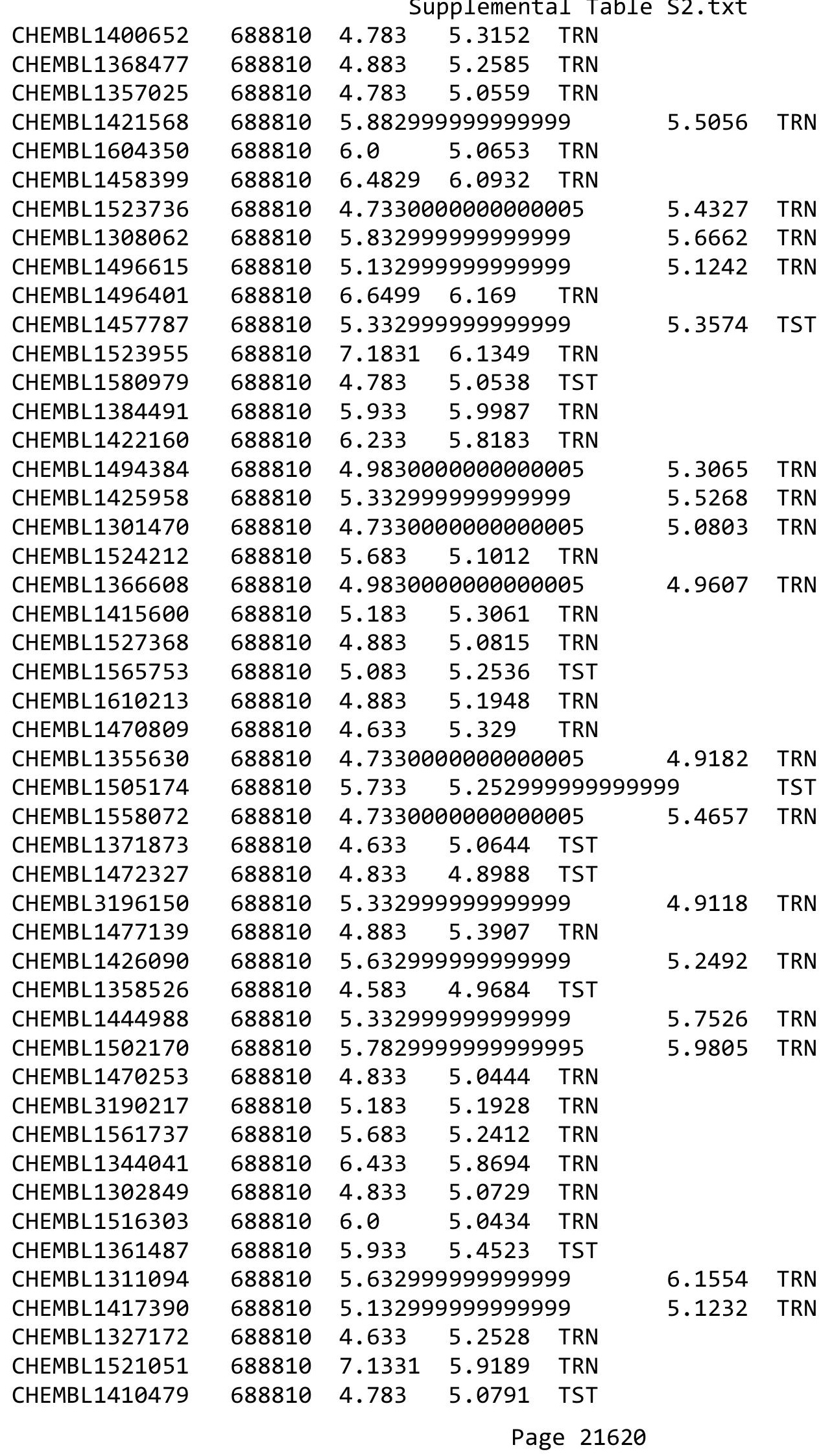




\begin{tabular}{|c|c|c|c|c|c|c|c|}
\hline \multirow[b]{2}{*}{ CHEMBL1322828 } & & \\
\hline & 688810 & 6.4829 & 5.9388 & TRN & & & \\
\hline CHEMBL1570718 & 688810 & \multicolumn{3}{|c|}{5.132999999999999} & 5.2559 & TRN & \\
\hline CHEMBL1372032 & 688810 & \multicolumn{3}{|c|}{4.9830000000000005} & 5.1306 & TRN & \\
\hline CHEMBL1368829 & 688810 & 5.183 & 5.2605 & TRN & & & \\
\hline CHEMBL1458814 & 688810 & 5.183 & 5.0836 & TRN & & & \\
\hline CHEMBL1999571 & 688810 & 4.833 & 5.1601 & TRN & & & \\
\hline CHEMBL1348597 & 688810 & 5.083 & 5.745 & TST & & & \\
\hline CHEMBL1380406 & 688810 & 4.633 & 5.1559 & TRN & & & \\
\hline CHEMBL1334083 & 688810 & 6.183 & 5.12 & TRN & & & \\
\hline CHEMBL1441614 & 688810 & 5.933 & 5.124 & TRN & & & \\
\hline CHEMBL 3196753 & 688810 & 4.933 & 5.3319 & TRN & & & \\
\hline CHEMBL1375246 & 688810 & 5.183 & 5.3699 & TRN & & & \\
\hline CHEMBL1550103 & 688810 & 5.183 & 4.9238 & TRN & & & \\
\hline CHEMBL1504556 & 688810 & 4.783 & 5.0546 & TRN & & & \\
\hline CHEMBL1416076 & 688810 & 4.583 & 5.7395 & TRN & & & \\
\hline CHEMBL 2005721 & 688810 & 4.633 & 5.0731 & TST & & & \\
\hline CHEMBL1483967 & 688810 & 4.633 & 5.1403 & TRN & & & \\
\hline CHEMBL104916 & 688810 & 4.933 & 5.1962 & TRN & & & \\
\hline CHEMBL1371655 & 688810 & 5.433 & 5.3842 & TST & & & \\
\hline CHEMBL1371614 & 688810 & 4.783 & 5.1787 & TRN & & & \\
\hline CHEMBL1331428 & 688810 & 4.783 & 4.9597 & TRN & & & \\
\hline CHEMBL1365585 & 688810 & 5.6329 & 99999999 & & 4.9197 & TRN & \\
\hline CHEMBL1975457 & 688810 & 4.9 & 5.6496 & TRN & & & \\
\hline CHEMBL573627 & 688810 & 5.1329 & 99999999 & & 5.3319 & TST & \\
\hline CHEMBL1450952 & 688810 & 5.2829 & 99999999 & 995 & 5.1501 & TRN & \\
\hline CHEMBL1311572 & 688810 & 4.583 & 5.2552 & TST & & & \\
\hline CHEMBL1559928 & 688810 & 4.883 & 5.2816 & TRN & & & \\
\hline CHEMBL1300450 & 688810 & 4.833 & 5.1645 & TRN & & & \\
\hline CHEMBL1366712 & 688810 & 6.0 & 6.1749 & TRN & & & \\
\hline CHEMBL1896260 & 688810 & 5.5329 & 99999999 & 995 & 5.0287 & TRN & \\
\hline CHEMBL1365902 & 688810 & 4.583 & 4.8391 & TRN & & & \\
\hline CHEMBL1486451 & 688810 & 5.8829 & 99999999 & & 5.2884 & TRN & \\
\hline CHEMBL1573916 & 688810 & 6.3329 & 99999999 & & 5.8434 & TRN & \\
\hline CHEMBL1587531 & 688810 & 4.833 & 5.4009 & TRN & & & \\
\hline CHEMBL1503951 & 688810 & 4.833 & 4.9102 & TST & & & \\
\hline CHEMBL1508054 & 688810 & 5.1329 & 99999999 & & 5.2459 & TST & \\
\hline CHEMBL1465328 & 688810 & 4.883 & 5.2542 & TRN & & & \\
\hline CHEMBL1414655 & 688810 & 4.7330 & $\partial 000000 €$ & 005 & 5.5415 & TRN & \\
\hline CHEMBL1608086 & 688810 & 5.483 & 5.3495 & TRN & & & \\
\hline CHEMBL1525146 & 688810 & 6.2829 & 99999999 & 995 & 5.9597 & TRN & \\
\hline CHEMBL1324768 & 688810 & 5.3829 & 99999999 & & 4.9865 & TRN & \\
\hline CHEMBL1290249 & 688810 & 4.883 & 4.6729 & TRN & & & \\
\hline CHEMBL1438499 & 688810 & 4.9830 & $\partial 0000006$ & 005 & $5.6110 e$ & 0000000001 & TST \\
\hline CHEMBL1539856 & 688810 & 5.2829 & 99999999 & 995 & 4.7605 & TRN & \\
\hline CHEMBL1472809 & 688810 & 4.833 & 5.23 & TST & & & \\
\hline CHEMBL1529530 & 688810 & 6.0 & 5.4248 & TRN & & & \\
\hline CHEMBL1320841 & 688810 & 5.8329 & 99999999 & & 5.405 & TRN & \\
\hline CHEMBL1529021 & 688810 & 4.833 & 5.2432 & TST & & & \\
\hline
\end{tabular}




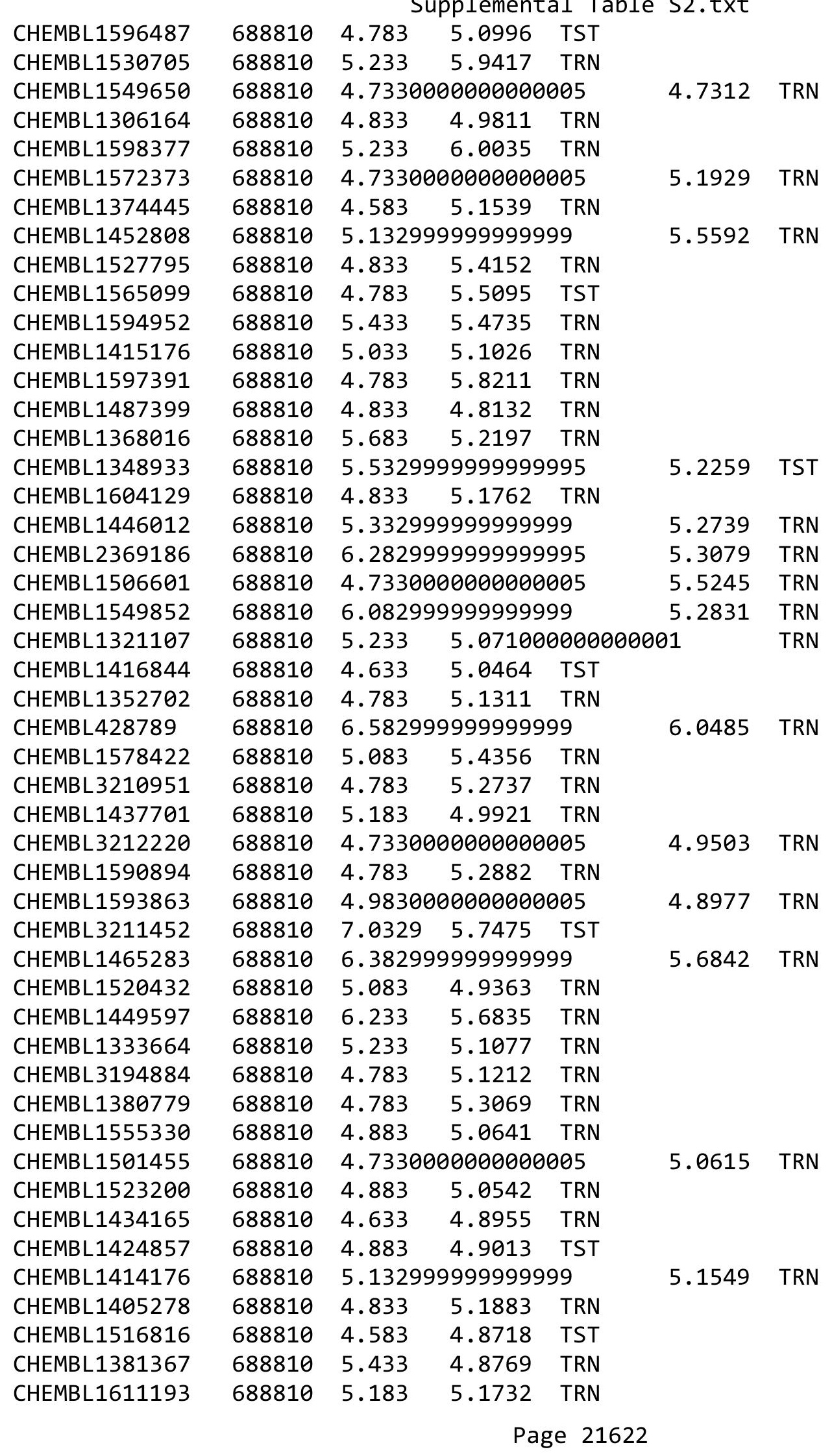




\begin{tabular}{|c|c|c|c|c|c|c|}
\hline & \multicolumn{5}{|c|}{. } \\
\hline CHEMBL1546586 & 688810 & 4.883 & 4.9372 & TRN & & \\
\hline CHEMBL1306157 & 688810 & \multicolumn{3}{|c|}{4.9830000000000005} & 5.2381 & TRN \\
\hline CHEMBL1566762 & 688810 & 5.083 & 5.2876 & TRN & & \\
\hline CHEMBL1469732 & 688810 & \multicolumn{3}{|c|}{5.132999999999999} & 5.5892 & TRN \\
\hline CHEMBL1314638 & 688810 & \multicolumn{3}{|c|}{4.7330000000000005} & 5.2067 & TRN \\
\hline CHEMBL1585614 & 688810 & 5.233 & 5.0898 & TST & & \\
\hline CHEMBL1309162 & 688810 & 7.1831 & 6.2417 & TRN & & \\
\hline CHEMBL1563839 & 688810 & \multicolumn{3}{|c|}{4.9830000000000005} & 4.9308 & TRN \\
\hline CHEMBL1385195 & 688810 & 5.433 & 5.5614 & TRN & & \\
\hline CHEMBL1556516 & 688810 & \multicolumn{3}{|c|}{5.632999999999999} & 5.4471 & TRN \\
\hline CHEMBL1586735 & 688810 & \multicolumn{3}{|c|}{5.5329999999999995} & 4.9654 & TRN \\
\hline CHEMBL 3194845 & 688810 & 4.933 & 5.5234 & TST & & \\
\hline CHEMBL1457407 & 688810 & 6.4829 & 5.6421 & TRN & & \\
\hline CHEMBL1372245 & 688810 & \multicolumn{3}{|c|}{5.7829999999999995} & 5.6939 & TRN \\
\hline CHEMBL1446596 & 688810 & 5.733 & 5.2439 & TRN & & \\
\hline CHEMBL 2002444 & 688810 & \multirow{2}{*}{\multicolumn{3}{|c|}{$\begin{array}{l}4.933 \text { I.4385 IS I I } \\
5.132999999999999\end{array}$}} & & \\
\hline CHEMBL1484368 & 688810 & & & & 5.3351 & TRN \\
\hline CHEMBL1309295 & 688810 & 4.583 & 4.97 & TRN & & \\
\hline CHEMBL1460167 & 688810 & 4.633 & 4.9247 & TRN & & \\
\hline CHEMBL1387463 & 688810 & \multicolumn{3}{|c|}{6.382999999999999} & 5.007 & TRN \\
\hline CHEMBL1392700 & 688810 & 5.083 & 5.17 & TST & & \\
\hline CHEMBL1546623 & 688810 & 5.733 & 5.8313 & TRN & & \\
\hline CHEMBL1376788 & 688810 & \multicolumn{3}{|c|}{5.2829999999999995} & 5.1844 & TRN \\
\hline CHEMBL456446 & 688810 & \multicolumn{3}{|c|}{5.632999999999999} & 5.2953 & TRN \\
\hline CHEMBL1369873 & 688810 & \multicolumn{3}{|c|}{4.7330000000000005} & 5.0379 & TRN \\
\hline CHEMBL1986725 & 688810 & \multicolumn{3}{|c|}{6.132999999999999} & 5.3555 & TRN \\
\hline CHEMBL1456669 & 688810 & 5.933 & 5.1508 & TRN & & \\
\hline CHEMBL171279 & 688810 & 4.683 & 4.9878 & TRN & & \\
\hline CHEMBL1586379 & 688810 & \multicolumn{3}{|c|}{5.382999999999999} & 4.8597 & TST \\
\hline CHEMBL1319763 & 688810 & 4.833 & 5.4652 & TRN & & \\
\hline CHEMBL1302598 & 688810 & \multicolumn{3}{|c|}{5.882999999999999} & 5.4923 & TRN \\
\hline CHEMBL1569394 & 688810 & 5.183 & 5.5068 & TRN & & \\
\hline CHEMBL1491496 & 688810 & \multicolumn{3}{|c|}{6.132999999999999} & 5.666 & TRN \\
\hline CHEMBL1395197 & 688810 & \multicolumn{3}{|c|}{6.2829999999999995} & 5.9206 & TRN \\
\hline CHEMBL1388102 & 688810 & \multicolumn{3}{|c|}{5.332999999999999} & 5.5538 & TRN \\
\hline CHEMBL1463171 & 688810 & 6.433 & 5.9213 & TRN & & \\
\hline CHEMBL1337129 & 688810 & 4.833 & 4.961 & TRN & & \\
\hline CHEMBL1461925 & 688810 & 4.933 & 5.3527 & TRN & & \\
\hline CHEMBL3194169 & 688810 & 4.783 & 5.0799 & TRN & & \\
\hline CHEMBL599307 & 688810 & 4.833 & 4.9084 & TST & & \\
\hline CHEMBL1558607 & 688810 & 5.33299 & 79999999 & & 5.4339 & TRN \\
\hline CHEMBL 3193843 & 688810 & 5.83299 & 79999999 & & 5.0676 & TRN \\
\hline CHEMBL1308610 & 688810 & 5.83299 & 99999999 & & 5.4686 & TRN \\
\hline CHEMBL1588245 & 688810 & 4.833 & 4.831 & TST & & \\
\hline CHEMBL1337497 & 688810 & 4.833 & 5.1704 & TRN & & \\
\hline CHEMBL1393143 & 688810 & 5.83299 & 79999999 & & 5.7104 & TRN \\
\hline CHEMBL1311730 & 688810 & 5.38299 & 99999999 & & 5.4778 & TRN \\
\hline CHEMBL1398582 & 688810 & 4.583 & 5.6188 & TRN & & \\
\hline
\end{tabular}




\begin{tabular}{|c|c|c|c|c|c|c|}
\hline & & & pplement & al Ta & $52 . t x t$ & \\
\hline CHEMBL1465675 & 688810 & 4.783 & 5.6832 & TRN & & \\
\hline CHEMBL1604992 & 688810 & 4.7330 & 00000000 & 005 & 5.2726 & TST \\
\hline CHEMBL1574688 & 688810 & 5.8829 & 99999999 & 99 & 5.4028 & TRN \\
\hline CHEMBL1595616 & 688810 & 5.033 & 5.1059 & TRN & & \\
\hline CHEMBL1447208 & 688810 & 5.433 & 5.3469 & TRN & & \\
\hline CHEMBL1511065 & 688810 & 6.2829 & 99999999 & 995 & 5.0816 & TRN \\
\hline CHEMBL1388073 & 688810 & 5.1329 & 99999999 & 99 & 5.4753 & TRN \\
\hline CHEMBL1495014 & 688810 & 5.183 & 5.307 & TRN & & \\
\hline CHEMBL1374323 & 688810 & 4.783 & 4.5702 & TST & & \\
\hline CHEMBL1405339 & 688810 & 4.833 & 5.30200 & 00000 & 005 & TST \\
\hline CHEMBL1313771 & 688810 & 4.883 & 5.1921 & TRN & & \\
\hline CHEMBL1463112 & 688810 & 6.3829 & 99999999 & 99 & 6.2093 & TRN \\
\hline CHEMBL1514744 & 688810 & 5.433 & 4.748 & TST & & \\
\hline CHEMBL1573062 & 688810 & 4.883 & 5.2322 & TST & & \\
\hline CHEMBL1531964 & 688810 & 4.633 & 4.9076 & TST & & \\
\hline CHEMBL1564313 & 688810 & 5.8329 & 99999999 & & 5.9538 & TST \\
\hline CHEMBL1607713 & 688810 & 6.433 & 5.621 & TRN & & \\
\hline CHEMBL1500910 & 688810 & 4.7330 & 00000000 & 005 & 5.1736 & TRN \\
\hline CHEMBL1608890 & 688810 & 4.883 & 5.0987 & TST & & \\
\hline CHEMBL1572651 & 688810 & 5.683 & 4.9738 & TST & & \\
\hline CHEMBL1602084 & 688810 & 4.9830 & 00000000 & 005 & 4.6981 & TST \\
\hline CHEMBL1398770 & 688810 & 5.733 & 5.5608 & TRN & & \\
\hline CHEMBL1360758 & 688810 & 5.2829 & 99999999 & 995 & 5.2851 & TRN \\
\hline CHEMBL1379069 & 688810 & 5.183 & 5.4151 & TRN & & \\
\hline CHEMBL3192922 & 688810 & 5.433 & 4.6971 & TST & & \\
\hline CHEMBL1578495 & 688810 & 6.183 & 5.8447 & TRN & & \\
\hline CHEMBL1565714 & 688810 & 4.783 & 4.8884 & TRN & & \\
\hline CHEMBL1524669 & 688810 & 4.883 & 4.9949 & TRN & & \\
\hline CHEMBL1320210 & 688810 & 5.5329 & 99999999 & 995 & 5.2506 & TRN \\
\hline CHEMBL1527724 & 688810 & 4.783 & 5.1252 & TRN & & \\
\hline CHEMBL3193790 & 688810 & 5.2829 & 99999999 & 995 & 5.449 & TRN \\
\hline CHEMBL1311266 & 688810 & 4.7330 & 00000000 & 005 & 5.3313 & TRN \\
\hline CHEMBL1330038 & 688810 & 5.033 & 4.7665 & TRN & & \\
\hline CHEMBL1499028 & 688810 & 5.483 & 5.4048 & TRN & & \\
\hline CHEMBL1526732 & 688810 & 4.883 & 5.0708 & TRN & & \\
\hline CHEMBL1423674 & 688810 & 4.783 & 4.7316 & TRN & & \\
\hline CHEMBL1345313 & 688810 & 4.783 & 5.1042 & TRN & & \\
\hline CHEMBL1460464 & 688810 & 5.183 & 5.1825 & TST & & \\
\hline CHEMBL1599027 & 688810 & 4.783 & 5.1693 & TRN & & \\
\hline CHEMBL1536391 & 688810 & 5.8829 & 99999999 & & 5.5614 & TRN \\
\hline CHEMBL1402216 & 688810 & 5.7829 & 99999999 & 995 & 5.0281 & TRN \\
\hline CHEMBL1440127 & 688810 & 5.183 & 5.0774 & TRN & & \\
\hline CHEMBL3197304 & 688810 & 6.3329 & 99999999 & 99 & 5.5594 & TRN \\
\hline CHEMBL1447489 & 688810 & 4.783 & 5.1415 & TRN & & \\
\hline CHEMBL1543317 & 688810 & 5.733 & 4.9466 & TRN & & \\
\hline CHEMBL1505683 & 688810 & 5.033 & 5.1115 & TRN & & \\
\hline CHEMBL1533676 & 688810 & 4.833 & 5.2906 & TST & & \\
\hline CHEMBL1583944 & 688810 & 4.833 & 4.8224 & TST & & \\
\hline
\end{tabular}




\begin{tabular}{|c|c|c|c|c|c|c|}
\hline \multicolumn{7}{|c|}{ Supplemental Table S2.txt } \\
\hline CHEMBL1572894 & 688810 & 5.083 & 5.4752 & TRN & & \\
\hline CHEMBL1569012 & 688810 & 5.983 & 5.6203 & TRN & & \\
\hline CHEMBL1464497 & 688810 & 5.85 & 5.3283 & TRN & & \\
\hline CHEMBL1361506 & 688810 & 5.233 & 5.3438 & TRN & & \\
\hline CHEMBL1336496 & 688810 & \multicolumn{3}{|c|}{6.332999999999999} & 6.0093 & TRN \\
\hline CHEMBL1552800 & 688810 & \multicolumn{3}{|c|}{5.132999999999999} & 4.7448 & TRN \\
\hline CHEMBL1489440 & 688810 & 5.683 & 5.6207 & TRN & & \\
\hline CHEMBL1313164 & 688810 & 4.833 & 4.8281 & TST & & \\
\hline CHEMBL1585185 & 688810 & 4.583 & 4.5526 & TRN & & \\
\hline CHEMBL1432072 & 688810 & \multicolumn{3}{|c|}{5.2829999999999995} & 5.0149 & TRN \\
\hline CHEMBL1446128 & 688810 & \multicolumn{3}{|c|}{5.882999999999999} & 5.5023 & TRN \\
\hline CHEMBL1550561 & 688810 & \multicolumn{3}{|c|}{4.7330000000000005} & 5.2934 & \\
\hline CHEMBL1431605 & 688810 & 4.883 & 4.9726 & TRN & & \\
\hline CHEMBL1301679 & 688810 & \multicolumn{3}{|c|}{4.7330000000000005} & 5.3819 & \\
\hline CHEMBL1323961 & 688810 & 5.683 & 5.1742 & TST & & \\
\hline CHEMBL1476269 & 688810 & 5.733 & 5.4148 & TRN & & \\
\hline CHEMBL1444977 & 688810 & 5.033 & 5.5816 & TRN & & \\
\hline CHEMBL1970117 & 688810 & 4.883 & 5.1217 & TRN & & \\
\hline CHEMBL1532227 & 688810 & \multicolumn{3}{|c|}{5.7829999999999995} & 5.9452 & TRN \\
\hline CHEMBL1447563 & 688810 & \multicolumn{3}{|c|}{5.132999999999999} & 5.3811 & \\
\hline CHEMBL1354568 & 688810 & 4.683 & 4.8578 & TRN & & \\
\hline CHEMBL1539913 & 688810 & 6.4829 & 5.3782 & TST & & \\
\hline CHEMBL1465114 & 688810 & 6.0 & 5.0105 & TRN & & \\
\hline CHEMBL1367886 & $68 \varepsilon$ & 5.233 & 5.4271 & TST & & \\
\hline CHEMBL1576273 & 688810 & \multicolumn{3}{|c|}{6.082999999999999} & 5.8643 & TR \\
\hline CHEMBL1416511 & 688810 & 4.833 & 5.3868 & TRN & & \\
\hline CHEMBL1403123 & 688810 & \multicolumn{3}{|c|}{5.7829999999999995} & 5.5114 & TRN \\
\hline CHEMBL1566802 & 688810 & \multicolumn{3}{|c|}{6.632999999999999} & 4.9746 & TST \\
\hline CHEMBL1417743 & 688810 & \multicolumn{3}{|c|}{4.9830000000000005} & 4.9846 & \\
\hline CHEMBL1453937 & 688810 & 5.433 & 5.1253 & TRN & & \\
\hline CHEMBL1523928 & 688810 & 4.783 & 5.0805 & TRN & & \\
\hline CHEMBL1445067 & 688810 & 6.183 & 5.7184 & TRN & & \\
\hline CHEMBL1427272 & 688810 & 4.783 & 5.0815 & TST & & \\
\hline CHEMBL1492115 & 688810 & \multicolumn{3}{|c|}{5.832999999999999} & 5.1859 & T1 \\
\hline CHEMBL1579394 & 688810 & 5.183 & 5.0547 & TST & & \\
\hline CHEMBL1596995 & 688810 & \multicolumn{3}{|c|}{5.632999999999999} & 5.7695 & TRN \\
\hline CHEMBL1487676 & 688810 & \multicolumn{3}{|c|}{4.9830000000000005} & 5.1809 & TST \\
\hline CHEMBL1351479 & 688810 & \multicolumn{3}{|c|}{4.7330000000000005} & 5.5372 & TST \\
\hline CHEMBL1385767 & 688810 & \multicolumn{3}{|c|}{4.7330000000000005} & 5.3631 & TS \\
\hline CHEMBL1352342 & 688810 & 4.833 & 4.9539 & TRN & & \\
\hline CHEMBL1553776 & 688810 & 4.933 & 5.4136 & TST & & \\
\hline CHEMBL1332800 & 688810 & \multicolumn{3}{|c|}{5.582999999999999} & 5.4126 & TRIV \\
\hline CHEMBL1413765 & 688810 & \multicolumn{3}{|c|}{4.7330000000000005} & 5.4081 & \\
\hline CHEMBL1504786 & 688810 & \multicolumn{3}{|c|}{5.2829999999999995} & 5.6233 & TST \\
\hline CHEMBL1524709 & 688810 & 4.73300 & 20000000 & 005 & 5.3231 & TRN \\
\hline CHEMBL1366848 & 688810 & 5.183 & 5.1837 & TRN & & \\
\hline CHEMBL1472300 & 688810 & 7.1831 & 5.9735 & TRN & & \\
\hline CHEMBL1612169 & 688810 & 4.833 & 5.1189 & TST & & \\
\hline
\end{tabular}




\begin{tabular}{|c|c|c|c|c|c|c|c|}
\hline & & & & & & & \\
\hline CHEMBL3194273 & 688810 & 7.0329 & 5.973 & TRN & & & \\
\hline CHEMBL1345801 & 688810 & 4.73300 & 000000006 & 005 & 5.3045 & TRN & \\
\hline CHEMBL1374854 & 688810 & 5.733 & 5.454 & TST & & & \\
\hline CHEMBL1550616 & 688810 & 5.88299 & 999999995 & & 5.2828 & TST & \\
\hline CHEMBL1548929 & 688810 & 5.483 & 5.6471 & TRN & & & \\
\hline CHEMBL1475005 & 688810 & 4.883 & 5.1011 & TST & & & \\
\hline CHEMBL1363917 & 688810 & 6.53299 & 999999999 & 995 & 5.6335 & TRN & \\
\hline CHEMBL1481224 & 688810 & 4.633 & 5.1768 & TRN & & & \\
\hline CHEMBL1424490 & 688810 & 6.683 & 5.7275 & TRN & & & \\
\hline CHEMBL1386330 & 688810 & 5.38299 & 999999995 & & 5.1976 & TRN & \\
\hline CHEMBL1321507 & 688810 & 5.83299 & 999999995 & & 5.652 & TRN & \\
\hline CHEMBL3197489 & 688810 & 4.633 & 4.6699 & TST & & & \\
\hline CHEMBL1468400 & 688810 & 5.13299 & 999999999 & & 5.3862 & TRN & \\
\hline CHEMBL 3190481 & 688810 & 5.183 & 4.998 & TRN & & & \\
\hline CHEMBL1603568 & 688810 & 5.13299 & 999999995 & & 5.3216 & TRN & \\
\hline CHEMBL1467277 & 688810 & 4.783 & 5.2267 & TRN & & & \\
\hline CHEMBL1439309 & 688810 & 4.583 & 5.1221 & TST & & & \\
\hline CHEMBL1612606 & 688810 & 7.08299 & 999999995 & & 5.9084 & TRN & \\
\hline CHEMBL1418683 & 688810 & 4.933 & 4.8653 & TST & & & \\
\hline CHEMBL1573333 & 688810 & 5.033 & 5.5708 & TRN & & & \\
\hline CHEMBL1569920 & 688810 & 5.683 & 5.3719 & TRN & & & \\
\hline CHEMBL1365239 & 688810 & 6.183 & 5.9514 & TRN & & & \\
\hline CHEMBL1447964 & 688810 & 5.28299 & 999999995 & 995 & 4.9683 & TRN & \\
\hline CHEMBL3192372 & 688810 & 5.58299 & 999999995 & & 5.377999 & 9999999999 & TRN \\
\hline CHEMBL1501694 & 688810 & 6.9329 & 6.5352 & TRN & & & \\
\hline CHEMBL1304586 & 688810 & 4.85 & 4.7189 & TST & & & \\
\hline CHEMBL1607281 & 688810 & 5.33299 & 999999999 & & 4.8898 & TRN & \\
\hline CHEMBL 2000380 & 688810 & 6.28299 & 999999995 & 995 & 5.8304 & TRN & \\
\hline CHEMBL1394513 & 688810 & 4.583 & 4.6358 & TST & & & \\
\hline CHEMBL1535491 & 688810 & 5.63299 & 999999995 & & 5.4028 & TRN & \\
\hline CHEMBL1499320 & 688810 & 4.633 & 5.5558 & TRN & & & \\
\hline CHEMBL3213109 & 688810 & 4.98300 & 000000006 & 005 & 5.1978 & TST & \\
\hline CHEMBL3196280 & 688810 & 5.683 & 5.1617 & TRN & & & \\
\hline CHEMBL1540575 & 688810 & 5.733 & 4.9075 & TRN & & & \\
\hline CHEMBL 1450782 & 688810 & 4.73300 & 00000000 & 005 & 4.8871 & TRN & \\
\hline CHEMBL1525320 & 688810 & 5.033 & 5.502006 & 000000000 & $\partial 1$ & TRN & \\
\hline CHEMBL1306441 & 688810 & 4.783 & 5.0848 & TRN & & & \\
\hline CHEMBL1449172 & 688810 & 6.33299 & 999999999 & & 5.7097 & TRN & \\
\hline CHEMBL1448943 & 688810 & 5.933 & 5.6126 & TRN & & & \\
\hline CHEMBL1383138 & 688810 & 5.13299 & 999999995 & & 5.4872 & TRN & \\
\hline CHEMBL1341981 & 688810 & 4.633 & 5.0585 & TRN & & & \\
\hline CHEMBL1556273 & 688810 & 4.583 & 5.0368 & TST & & & \\
\hline CHEMBL1569984 & 688810 & 7.08299 & 999999999 & & 5.8711 & TRN & \\
\hline CHEMBL3213754 & 688810 & 5.88299 & 999999995 & & 5.5741 & TST & \\
\hline CHEMBL1440416 & 688810 & 6.0 & 5.5398 & TRN & & & \\
\hline CHEMBL1366142 & 688810 & 4.583 & 5.3455 & TRN & & & \\
\hline CHEMBL1452832 & 688810 & 6.28299 & 999999995 & 995 & 5.7769 & TRN & \\
\hline CHEMBL1495183 & 688810 & 5.983 & 5.5819 & TST & & & \\
\hline
\end{tabular}




\begin{tabular}{|c|c|c|c|c|c|c|}
\hline \multicolumn{7}{|c|}{ Supplemental Table S2.txt } \\
\hline CHEMBL1600874 & 688810 & 4.933 & 5.022 & TST & & \\
\hline CHEMBL1578342 & 688810 & 5.233 & 5.4086 & TRN & & \\
\hline CHEMBL1505415 & 688810 & 5.433 & 5.039 & TRN & & \\
\hline CHEMBL1411079 & 688810 & 4.683 & 5.0318 & TRN & & \\
\hline CHEMBL1442562 & 688810 & 4.783 & 5.0976 & TRN & & \\
\hline CHEMBL1440303 & 688810 & \multicolumn{3}{|c|}{4.9830000000000005} & 4.9933 & TRN \\
\hline CHEMBL1588110 & 688810 & 5.433 & 5.4748 & TRN & & \\
\hline CHEMBL1433066 & 688810 & 4.833 & 5.2971 & TST & & \\
\hline CHEMBL1510805 & 688810 & 5.183 & 5.1367 & TRN & & \\
\hline CHEMBL1994877 & 688810 & \multicolumn{3}{|c|}{5.5329999999999995} & 4.8996 & TST \\
\hline CHEMBL1333430 & 688810 & 5.2 & 5.4106 & TRN & & \\
\hline CHEMBL1509103 & 688810 & 4.583 & 5.0486 & TST & & \\
\hline CHEMBL1439852 & 688810 & \multicolumn{3}{|c|}{5.7829999999999995} & 5.0631 & TRN \\
\hline CHEMBL1462001 & 688810 & 4.933 & 5.3807 & TST & & \\
\hline CHEMBL1583161 & 688810 & \multicolumn{3}{|c|}{5.132999999999999} & 4.8023 & TRN \\
\hline CHEMBL1601470 & 688810 & 5.733 & 5.1727 & TRN & & \\
\hline CHEMBL1377188 & 688810 & \multicolumn{3}{|c|}{5.5329999999999995} & \multicolumn{2}{|c|}{5.132000000000001} \\
\hline CHEMBL1547542 & 688810 & 4.833 & 5.2815 & TST & & \\
\hline CHEMBL1458403 & 688810 & 4.783 & 4.7949 & TST & & \\
\hline CHEMBL1576245 & 688810 & \multicolumn{3}{|c|}{4.7330000000000005} & 5.0431 & TRN \\
\hline CHEMBL3189217 & 688810 & 5.083 & \multicolumn{3}{|c|}{4.8180000000000005} & TRN \\
\hline CHEMBL1582510 & 688810 & \multicolumn{3}{|c|}{6.332999999999999} & 5.7036 & TRN \\
\hline CHEMBL1550768 & 688810 & \multicolumn{3}{|c|}{6.0329999999999995} & 5.5114 & TRN \\
\hline CHEMBL1384273 & 688810 & 4.833 & 5.2811 & TRN & & \\
\hline CHEMBL1587832 & 688810 & \multicolumn{3}{|c|}{5.332999999999999} & 5.7485 & TRN \\
\hline CHEMBL1513844 & 688810 & \multicolumn{3}{|c|}{4.9830000000000005} & 4.9272 & TST \\
\hline CHEMBL1547827 & 688810 & 4.933 & 5.3614 & TRN & & \\
\hline CHEMBL1596898 & 688810 & 4.883 & 5.5252 & TST & & \\
\hline CHEMBL1535551 & 688810 & \multicolumn{3}{|c|}{5.132999999999999} & 5.1181 & TST \\
\hline CHEMBL1362017 & 688810 & 5.233 & 4.673 & TRN & & \\
\hline CHEMBL1595206 & 688810 & \multicolumn{3}{|c|}{5.582999999999999} & 5.4563 & TRN \\
\hline CHEMBL1361185 & 688810 & 5.083 & 5.0925 & TRN & & \\
\hline CHEMBL1516711 & 688810 & 4.883 & 5.3359 & TRN & & \\
\hline CHEMBL1443037 & 688810 & \multicolumn{3}{|c|}{5.7829999999999995} & 5.3797 & TRN \\
\hline CHEMBL1347732 & 688810 & \multicolumn{3}{|c|}{4.9830000000000005} & 4.988 & TRN \\
\hline CHEMBL1576816 & 688810 & \multicolumn{3}{|c|}{5.832999999999999} & 5.4055 & TRN \\
\hline CHEMBL1564007 & 688810 & \multicolumn{3}{|c|}{4.7330000000000005} & 4.9853 & TRN \\
\hline CHEMBL1344163 & 688810 & \multicolumn{3}{|c|}{5.2829999999999995} & 5.2371 & TRN \\
\hline CHEMBL1414540 & 688810 & 5.233 & 5.2841 & TRN & & \\
\hline CHEMBL1374335 & 688810 & 4.833 & 5.1068 & TRN & & \\
\hline CHEMBL1569378 & 688810 & 5.683 & 5.1716 & TRN & & \\
\hline CHEMBL1424655 & 688810 & 4.683 & 5.4139 & TST & & \\
\hline CHEMBL1408390 & 688810 & 5.083 & 5.1409 & TRN & & \\
\hline CHEMBL1454593 & 688810 & \multicolumn{3}{|c|}{5.132999999999999} & 4.9815 & TRN \\
\hline CHEMBL1403097 & 688810 & 5.3829 & 999999999 & & 5.2342 & TRN \\
\hline CHEMBL1392307 & 688810 & 5.183 & 5.4893 & TRN & & \\
\hline CHEMBL1396723 & 688810 & 4.783 & 5.1361 & TRN & & \\
\hline CHEMBL1329016 & 688810 & 4.583 & 4.9515 & TRN & & \\
\hline
\end{tabular}




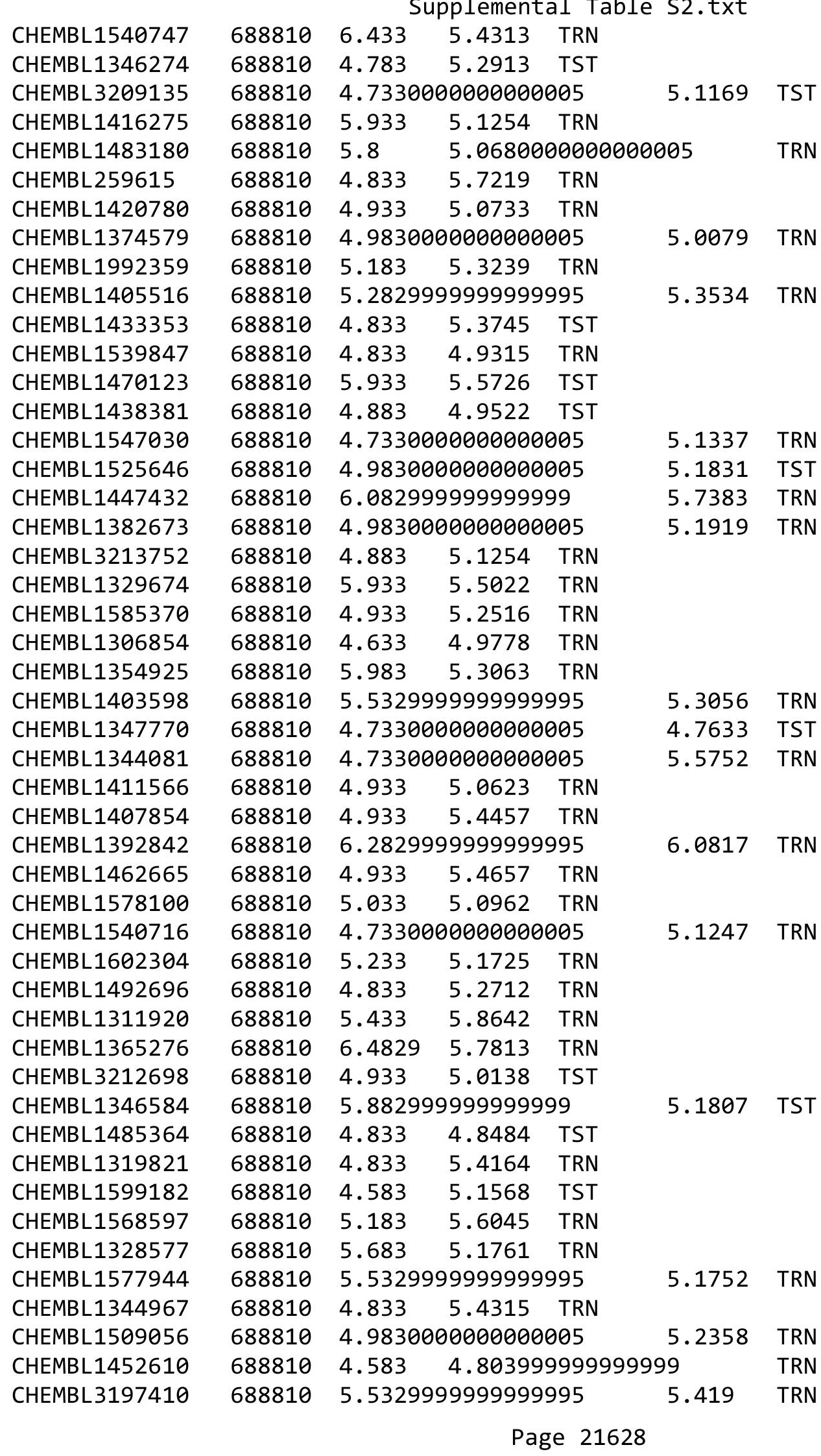




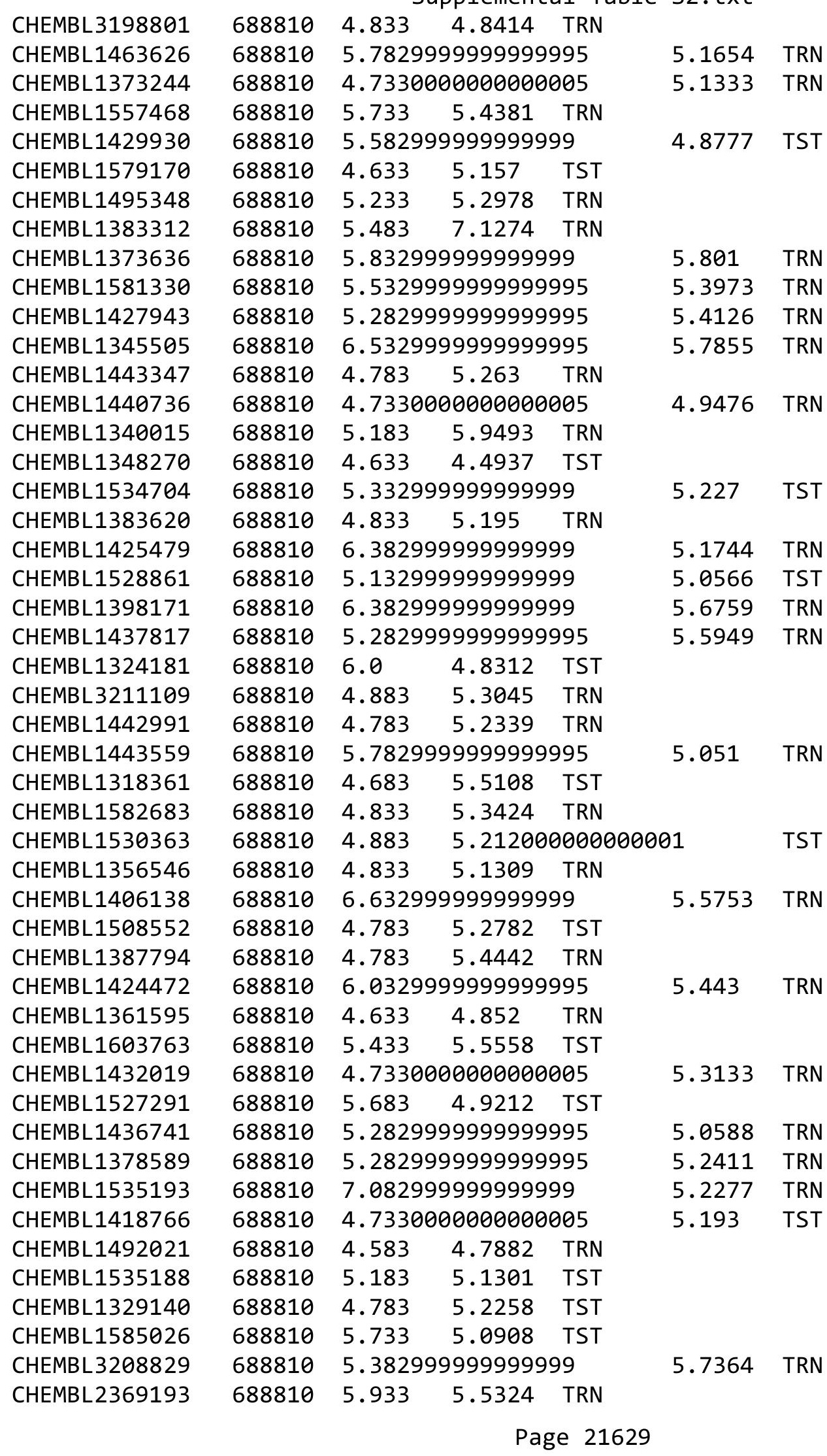




\begin{tabular}{|c|c|c|c|c|c|c|c|}
\hline \multirow[b]{2}{*}{ CHEMBL1496528 } & \multicolumn{6}{|c|}{ 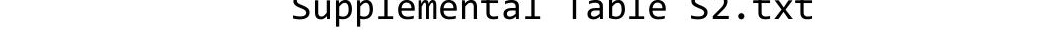 } & \\
\hline & 688810 & 5.933 & 5.7841 & TRN & & & \\
\hline CHEMBL1386245 & 688810 & 4.683 & 5.1596 & TRN & & & \\
\hline CHEMBL3195889 & 688810 & 6.3329 & 999999999 & & 5.5286 & TRN & \\
\hline CHEMBL1476170 & 688810 & 4.633 & 5.3412 & TST & & & \\
\hline CHEMBL1350929 & 688810 & 5.733 & 6.3397 & TRN & & & \\
\hline CHEMBL1481981 & 688810 & 4.9830 & 000000006 & 005 & 5.26 & TST & \\
\hline CHEMBL1456353 & 688810 & 5.8829 & 999999999 & & 5.974 & TRN & \\
\hline CHEMBL1406396 & 688810 & 5.1329 & 999999999 & & 5.077 & TST & \\
\hline CHEMBL1456468 & 688810 & 5.6329 & 999999995 & & 5.2257 & TRN & \\
\hline CHEMBL1527007 & 688810 & 5.933 & 5.5257 & TRN & & & \\
\hline CHEMBL1356019 & 688810 & 4.833 & 5.3529 & TST & & & \\
\hline CHEMBL1540336 & 688810 & 5.083 & 5.1528 & TST & & & \\
\hline CHEMBL1450449 & 688810 & 4.833 & 5.2526 & TRN & & & \\
\hline CHEMBL1500180 & 688810 & 4.933 & 4.9966 & TRN & & & \\
\hline CHEMBL1426411 & 688810 & 4.633 & 4.9914 & TST & & & \\
\hline CHEMBL1397810 & 688810 & 5.5329 & 999999995 & 995 & 5.7294 & TRN & \\
\hline CHEMBL1304106 & 688810 & 4.7330 & 000000006 & 005 & 4.8106 & TST & \\
\hline CHEMBL1363997 & 688810 & 4.7330 & 000000006 & 005 & 5.0747 & TRN & \\
\hline CHEMBL1609538 & 688810 & 5.3329 & 999999995 & & 5.4346 & TRN & \\
\hline CHEMBL3212849 & 688810 & 4.7330 & 00000000 & 005 & 5.3086 & TRN & \\
\hline CHEMBL1453589 & 688810 & 4.7330 & 000000006 & 005 & 5.0235 & TRN & \\
\hline CHEMBL1471426 & 688810 & 6.183 & 5.651 & TRN & & & \\
\hline CHEMBL1429485 & 688810 & 4.7330 & 000000006 & 005 & 5.279 & TRN & \\
\hline CHEMBL1577036 & 688810 & 5.033 & 5.8454 & TRN & & & \\
\hline CHEMBL1404107 & 688810 & 6.0829 & 999999995 & & 5.5336 & TRN & \\
\hline CHEMBL1581425 & 688810 & 4.633 & 4.9723 & TST & & & \\
\hline CHEMBL1302139 & 688810 & 4.633 & 5.2808 & TST & & & \\
\hline CHEMBL1431189 & 688810 & 5.3329 & 999999999 & & 5.0518 & TRN & \\
\hline CHEMBL1483819 & 688810 & 4.833 & 5.2129 & TST & & & \\
\hline CHEMBL1503130 & 688810 & 4.833 & 5.1359 & TRN & & & \\
\hline CHEMBL1555618 & 688810 & 5.5829 & 99999999 & & 4.6842 & TST & \\
\hline CHEMBL1457192 & 688810 & 5.733 & 5.3753 & TRN & & & \\
\hline CHEMBL1597749 & 688810 & 4.833 & 5.0528 & TST & & & \\
\hline CHEMBL1580803 & 688810 & 4.7330 & 000000006 & 005 & 5.2648 & TRN & \\
\hline CHEMBL1437695 & 688810 & 5.083 & 5.5731 & TRN & & & \\
\hline CHEMBL1566929 & 688810 & 4.883 & 4.9805 & TRN & & & \\
\hline CHEMBL1379303 & 688810 & 5.083 & 5.5914 & TRN & & & \\
\hline CHEMBL1300911 & 688810 & 4.833 & 4.9013 & TST & & & \\
\hline CHEMBL1307810 & 688810 & 4.583 & 4.887 & TST & & & \\
\hline CHEMBL1531731 & 688810 & 5.6329 & 999999999 & & 5.2520 & 0000000001 & TRN \\
\hline CHEMBL1530994 & 688810 & 5.233 & 5.0957 & TRN & & & \\
\hline CHEMBL1574449 & 688810 & 4.833 & 5.2466 & TRN & & & \\
\hline CHEMBL1423028 & 688810 & 4.933 & 5.1698 & TST & & & \\
\hline CHEMBL1349459 & 688810 & 4.7330 & 00000000 & 005 & 5.093 & TST & \\
\hline CHEMBL3193265 & 688810 & 5.2829 & 999999999 & 995 & 5.2494 & TRN & \\
\hline CHEMBL1610793 & 688810 & 4.633 & 5.2278 & TRN & & & \\
\hline CHEMBL1467245 & 688810 & 6.1329 & 999999999 & & 5.6124 & TRN & \\
\hline CHEMBL1484329 & 688810 & 4.783 & 5.0607 & TST & & & \\
\hline
\end{tabular}




\begin{tabular}{|c|c|c|c|c|c|c|}
\hline \multirow[b]{2}{*}{ CHEMBL1317551 } & \multirow[b]{2}{*}{688810} & \multicolumn{5}{|c|}{ Supplemental Table S2.txt } \\
\hline & & 4.633 & 4.8106 & TRN & & \\
\hline CHEMBL1363291 & 688810 & \multicolumn{3}{|c|}{5.832999999999999} & 5.9904 & TRN \\
\hline CHEMBL1379449 & 688810 & \multicolumn{3}{|c|}{5.382999999999999} & 5.0942 & TST \\
\hline CHEMBL1353642 & 688810 & 5.033 & 4.8321 & TRN & & \\
\hline CHEMBL3190795 & 688810 & \multicolumn{3}{|c|}{6.382999999999999} & 5.1737 & TST \\
\hline CHEMBL1600114 & 688810 & \multicolumn{3}{|c|}{5.632999999999999} & 5.5451 & TRN \\
\hline CHEMBL1302101 & 688810 & 4.833 & 5.0074 & TRN & & \\
\hline CHEMBL1319945 & 688810 & \multicolumn{3}{|c|}{4.9830000000000005} & 5.5294 & TST \\
\hline CHEMBL3195935 & 688810 & 4.933 & 5.0023 & TST & & \\
\hline CHEMBL1612466 & 688810 & \multicolumn{3}{|c|}{5.132999999999999} & 5.0318 & TRN \\
\hline CHEMBL3190885 & 688810 & \multicolumn{3}{|c|}{5.382999999999999} & 5.5588 & TST \\
\hline CHEMBL1542819 & 688810 & 5.483 & 4.9961 & TRN & & \\
\hline CHEMBL3197901 & 688810 & \multicolumn{3}{|c|}{5.2829999999999995} & 5.2429 & TRN \\
\hline CHEMBL193772 & 688810 & \multicolumn{3}{|c|}{4.7330000000000005} & 5.0014 & TST \\
\hline CHEMBL1362855 & 688810 & 4.633 & 4.9239 & TRN & & \\
\hline CHEMBL1599736 & 688810 & 4.833 & 5.1912 & TRN & & \\
\hline CHEMBL1489123 & 688810 & \multicolumn{3}{|c|}{4.7330000000000005} & 5.6972 & TRN \\
\hline CHEMBL1409639 & 688810 & \multicolumn{3}{|c|}{5.2829999999999995} & 5.2742 & TRN \\
\hline CHEMBL1569494 & 688810 & 4.833 & 5.1173 & TRN & & \\
\hline CHEMBL1429841 & 688810 & 5.483 & 6.0771 & TRN & & \\
\hline CHEMBL1541339 & 688810 & 5.933 & 5.2529 & TST & & \\
\hline CHEMBL1534733 & 688810 & 5.033 & 5.3121 & TST & & \\
\hline CHEMBL 378903 & 688810 & 5.433 & 5.3586 & TRN & & \\
\hline CHEMBL1458292 & 688810 & 4.783 & 5.2787 & TRN & & \\
\hline CHEMBL1445962 & 688810 & 4.583 & 4.7657 & TST & & \\
\hline CHEMBL3197750 & 688810 & 5.433 & 5.5219 & TRN & & \\
\hline CHEMBL7747 & 688810 & 4.933 & 5.5324 & TRN & & \\
\hline CHEMBL1449261 & 688810 & \multicolumn{3}{|c|}{5.132999999999999} & 5.1025 & TST \\
\hline CHEMBL1511183 & 688810 & \multicolumn{3}{|c|}{4.7330000000000005} & 5.3708 & TRN \\
\hline CHEMBL1501764 & 688810 & \multicolumn{3}{|c|}{4.7330000000000005} & 4.9136 & TST \\
\hline CHEMBL1510883 & 688810 & \multicolumn{3}{|c|}{5.382999999999999} & 5.8096 & TRN \\
\hline CHEMBL1329995 & 688810 & \multicolumn{3}{|c|}{4.7330000000000005} & 5.1703 & TST \\
\hline CHEMBL1479491 & 688810 & 4.833 & 4.8834 & TST & & \\
\hline CHEMBL1469136 & 688810 & \multicolumn{3}{|c|}{4.9830000000000005} & 5.1439 & TRN \\
\hline CHEMBL1459638 & 688810 & 5.033 & 5.3403 & TRN & & \\
\hline CHEMBL1346286 & 688810 & 4.783 & 5.2011 & TRN & & \\
\hline CHEMBL1517132 & 688810 & 6.183 & 5.8204 & TRN & & \\
\hline CHEMBL1405940 & 688810 & \multicolumn{3}{|c|}{6.382999999999999} & 5.7151 & TRN \\
\hline CHEMBL3208246 & 688810 & 4.9836 & 00000000 & 005 & 5.043 & TST \\
\hline CHEMBL1592703 & 688810 & 5.2829 & 99999999 & 995 & 5.7367 & TST \\
\hline CHEMBL1348787 & 688810 & 4.833 & 5.3084 & TRN & & \\
\hline CHEMBL1470598 & 688810 & 6.0829 & 99999999 & 99 & 5.5204 & TRN \\
\hline CHEMBL1344989 & 688810 & 4.833 & 5.0899 & TRN & & \\
\hline CHEMBL1565344 & 688810 & 4.833 & 5.1845 & TST & & \\
\hline CHEMBL1575504 & 688810 & 4.833 & 5.8496 & TRN & & \\
\hline CHEMBL1585609 & 688810 & 5.3320 & 99999999 & & 4.8591 & TST \\
\hline CHEMBL1595015 & 688810 & 4.683 & 5.2165 & TRN & & \\
\hline CHEMBL3194515 & 688810 & 5.033 & 4.9375 & TRN & & \\
\hline
\end{tabular}




\begin{tabular}{|c|c|c|c|c|c|c|}
\hline \multirow{3}{*}{$\begin{array}{l}\text { CHEMBL1551152 } \\
\text { CHEMBL1410798 }\end{array}$} & \multirow{3}{*}{$\begin{array}{l}688810 \\
688810\end{array}$} & \multicolumn{4}{|c|}{ Supplemental Table S2.txt } & \multirow{2}{*}{ TST } \\
\hline & & \multicolumn{3}{|c|}{5.132999999999999} & 5.0475 & \\
\hline & & 5.183 & 5.3466 & TRN & & \\
\hline CHEMBL3198374 & 688810 & 4.833 & 5.1444 & TRN & & \\
\hline CHEMBL3196655 & 688810 & \multicolumn{3}{|c|}{5.332999999999999} & 5.1911 & TRN \\
\hline CHEMBL570470 & 688810 & \multicolumn{3}{|c|}{6.332999999999999} & 5.5022 & TRN \\
\hline CHEMBL1398382 & 688810 & 4.633 & 4.9081 & TRN & & \\
\hline CHEMBL1563642 & 688810 & \multicolumn{3}{|c|}{5.632999999999999} & 5.5277 & TRN \\
\hline CHEMBL1460071 & 688810 & 4.783 & 5.2058 & TRN & & \\
\hline CHEMBL1365045 & 688810 & 4.833 & 4.8055 & TRN & & \\
\hline CHEMBL1441056 & 688810 & 4.683 & 4.8173 & TRN & & \\
\hline CHEMBL1316024 & 688810 & 4.883 & 5.1455 & TRN & & \\
\hline CHEMBL1481930 & 688810 & 5.733 & 5.5216 & TRN & & \\
\hline CHEMBL1593138 & 688810 & 4.633 & 5.331 & TRN & & \\
\hline CHEMBL1482883 & 688810 & \multicolumn{3}{|c|}{4.7330000000000005} & 5.1344 & TRN \\
\hline CHEMBL 234978 & 688810 & \multicolumn{3}{|c|}{5.382999999999999} & 5.3023 & TRN \\
\hline CHEMBL1391065 & 688810 & \multicolumn{3}{|c|}{6.332999999999999} & 6.255 & TRN \\
\hline CHEMBL3197896 & 688810 & 5.083 & 5.2724 & TRN & & \\
\hline CHEMBL1301723 & 688810 & \multicolumn{3}{|c|}{5.332999999999999} & 5.2994 & TRN \\
\hline CHEMBL1316140 & 688810 & 5.733 & 5.5235 & TRN & & \\
\hline CHEMBL1561202 & 688810 & \multicolumn{3}{|c|}{5.2829999999999995} & 4.772 & TRN \\
\hline CHEMBL1557660 & 688810 & 6.183 & 5.3023 & TST & & \\
\hline CHEMBL1429300 & 688810 & \multicolumn{3}{|c|}{6.332999999999999} & 5.29 & TRN \\
\hline CHEMBL1422034 & 688810 & 4.783 & 5.3068 & TRN & & \\
\hline CHEMBL1567527 & 688810 & 4.883 & 4.7941 & TST & & \\
\hline CHEMBL1446060 & 688810 & 4.833 & 5.1917 & TST & & \\
\hline CHEMBL1505457 & 688810 & \multicolumn{3}{|c|}{5.132999999999999} & 5.4001 & TRN \\
\hline CHEMBL1345197 & 688810 & 4.883 & 5.4563 & TRN & & \\
\hline CHEMBL1427485 & 688810 & 4.933 & 5.0168 & TRN & & \\
\hline CHEMBL1442526 & 688810 & \multicolumn{3}{|c|}{4.7330000000000005} & 5.0005 & TST \\
\hline CHEMBL1322285 & 688810 & \multicolumn{3}{|c|}{4.9830000000000005} & 5.4097 & TRN \\
\hline CHEMBL1592927 & 688810 & \multicolumn{3}{|c|}{5.582999999999999} & 5.4269 & TRN \\
\hline CHEMBL 2000039 & 688810 & 4.783 & 5.4561 & TRN & & \\
\hline CHEMBL1444081 & 688810 & 4.833 & 5.0654 & TRN & & \\
\hline CHEMBL1315431 & 688810 & \multicolumn{3}{|c|}{5.7829999999999995} & 5.1901 & TRN \\
\hline CHEMBL1492208 & 688810 & \multicolumn{3}{|c|}{5.332999999999999} & 5.8476 & TST \\
\hline CHEMBL1413081 & 688810 & 4.833 & 5.033 & TRN & & \\
\hline CHEMBL1307716 & 688810 & 4.833 & 5.2076 & TST & & \\
\hline CHEMBL1581129 & 688810 & \multicolumn{3}{|c|}{6.2829999999999995} & 4.9086 & TRN \\
\hline CHEMBL1506272 & 688810 & 4.9836 & 00000000 & 205 & 5.7056 & TRN \\
\hline CHEMBL1506252 & 688810 & 5.7829 & 99999999 & 995 & 5.0948 & TRN \\
\hline CHEMBL1990093 & 688810 & 5.6329 & 99999999 & & 5.7736 & TRN \\
\hline CHEMBL398765 & 688810 & 5.183 & 5.4133 & TRN & & \\
\hline CHEMBL1413082 & 688810 & 5.6329 & 99999999 & & 5.4743 & TRN \\
\hline CHEMBL1557334 & 688810 & 6.183 & 5.4491 & TRN & & \\
\hline CHEMBL1453117 & 688810 & 5.683 & 5.6396 & TRN & & \\
\hline CHEMBL1493396 & 688810 & 5.3329 & 99999999 & 99 & 5.11 & TRN \\
\hline CHEMBL1445290 & 688810 & 4.883 & 4.8778 & TRN & & \\
\hline CHEMBL1401950 & 688810 & 5.433 & 5.1089 & TST & & \\
\hline
\end{tabular}




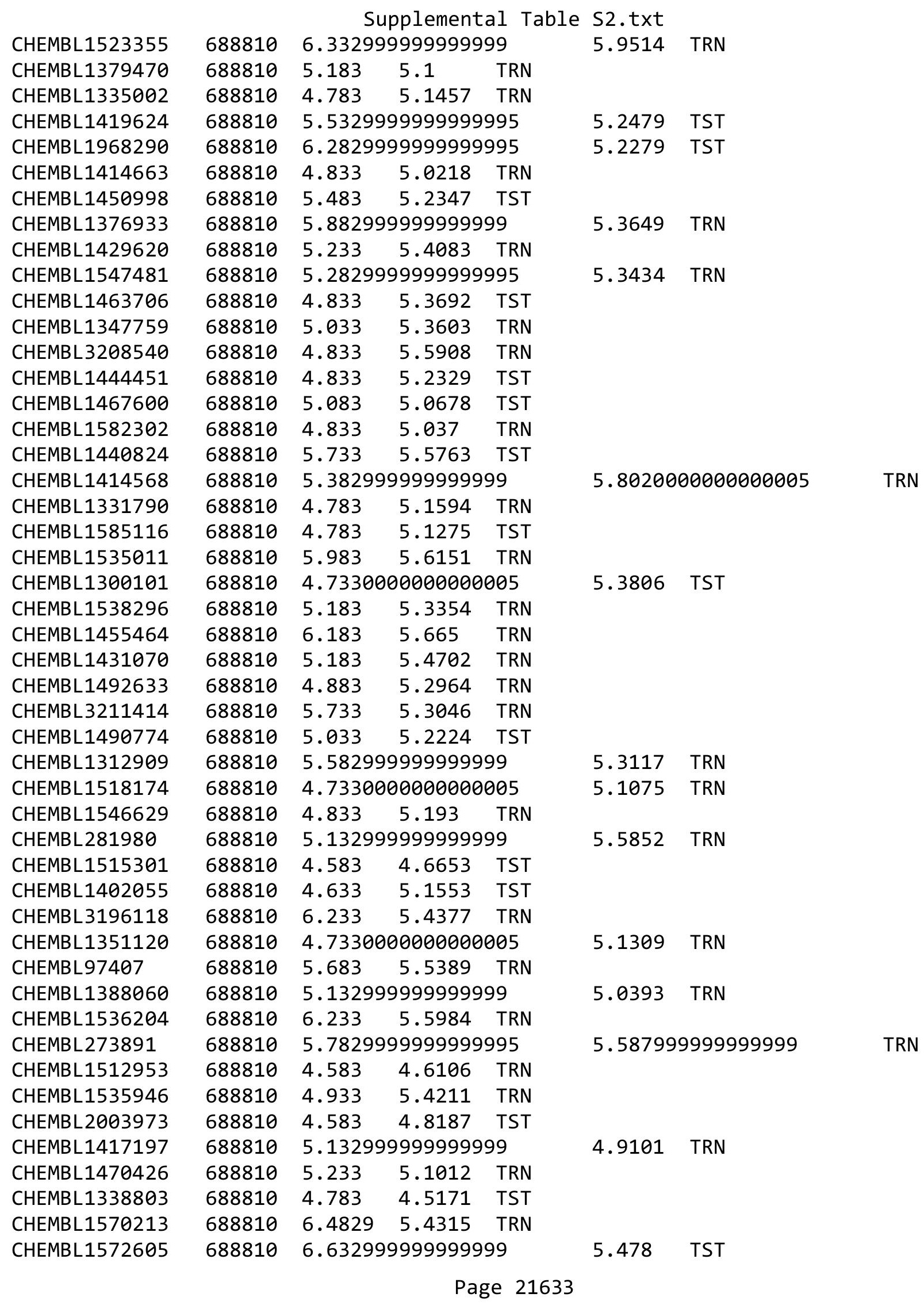




\begin{tabular}{|c|c|c|c|c|c|c|}
\hline \multirow[b]{2}{*}{ CHEMBL1558806 } & \multicolumn{6}{|c|}{ 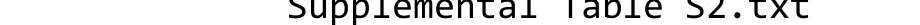 } \\
\hline & 688810 & 5.233 & 5.3716 & TRN & & \\
\hline CHEMBL1347628 & 688810 & 4.633 & 5.4156 & TRN & & \\
\hline CHEMBL1596326 & 688810 & 5.3829 & 99999999 & & 5.2383 & TRN \\
\hline CHEMBL1556906 & 688810 & 5.433 & 4.8178 & TST & & \\
\hline CHEMBL 2006757 & 688810 & 5.933 & 5.86299 & 9999 & 995 & TRN \\
\hline CHEMBL1565001 & 688810 & 4.7330 & 00000000 & 005 & 5.142 & TRN \\
\hline CHEMBL1980031 & 688810 & 5.483 & 5.2965 & TRN & & \\
\hline CHEMBL1459473 & 688810 & 4.7330 & 00000000 & 005 & 5.0411 & TRN \\
\hline CHEMBL1390409 & 688810 & 4.883 & 5.6247 & TRN & & \\
\hline CHEMBL1468158 & 688810 & 5.2829 & 99999999 & 995 & 4.8192 & IST \\
\hline CHEMBL1589508 & 688810 & 4.9830 & 00000000 & 005 & 5.2375 & \\
\hline CHEMBL1330686 & 688810 & 4.683 & 4.9215 & TRN & & \\
\hline CHEMBL1338975 & 688810 & 4.783 & 5.2655 & TST & & \\
\hline CHEMBL1495355 & 688810 & 5.3329 & 99999999 & & 5.2482 & TRIV \\
\hline CHEMBL1428108 & 688810 & 6.3829 & 99999999 & & 5.8004 & \\
\hline CHEMBL1355273 & 688810 & 5.083 & 6.0 & TRN & & \\
\hline CHEMBL 1476179 & 688810 & 5.433 & 5.6841 & TRN & & \\
\hline CHEMBL1406757 & 688810 & 5.1329 & 99999999 & & 5.3103 & TRN \\
\hline CHEMBL1361637 & 688810 & 5.2829 & 99999999 & 995 & 5.1643 & TST \\
\hline CHEMBL1411887 & 688810 & 5.5329 & 99999999 & 995 & 5.2744 & \\
\hline CHEMBL1445899 & 688810 & 4.933 & 4.3494 & TST & & \\
\hline CHEMBL1421212 & 688810 & 4.633 & 4.8767 & TST & & \\
\hline CHEMBL1613627 & 688810 & 6.5829 & 99999999 & & 6.0656 & $\mathrm{~T}$ \\
\hline CHEMBL1448321 & 688810 & 4.833 & 4.6589 & TRN & & \\
\hline CHEMBL1597102 & 688810 & 5.3829 & 999999995 & & 4.9983 & \\
\hline CHEMBL 3198511 & 688810 & 5.683 & 5.5252 & TST & & \\
\hline CHEMBL1318423 & 688810 & 4.633 & 5.125 & TST & & \\
\hline CHEMBL1349551 & 688810 & 5.183 & 5.3941 & TRN & & \\
\hline CHEMBL 3208881 & 688810 & 4.783 & 5.4163 & TST & & \\
\hline CHEMBL1522709 & 688810 & 4.583 & 5.2048 & TST & & \\
\hline CHEMBL 3193804 & 688810 & 5.033 & 5.3299 & TRN & & \\
\hline CHEMBL 3197848 & 688810 & 4.883 & 4.908 & TRN & & \\
\hline CHEMBL1574638 & 688810 & 4.583 & 4.5466 & TST & & \\
\hline CHEMBL1541539 & 688810 & 6.2829 & 99999999 & 995 & 5.4156 & \\
\hline CHEMBL1492944 & 688810 & 4.833 & 5.1588 & TRN & & \\
\hline CHEMBL1515400 & 688810 & 6.3329 & 99999999 & & 5.6163 & TRN \\
\hline CHEMBL 1532243 & 688810 & 4.7330 & 00000000 & 005 & 5.007 & TST \\
\hline CHEMBL1459215 & 688810 & 5.5329 & 999999999 & 995 & 5.3769 & TRN \\
\hline CHEMBL1462933 & 688810 & 4.833 & 4.9119 & TST & & \\
\hline CHEMBL1520639 & 688810 & 5.3329 & 99999999 & & 5.8198 & $\mathrm{NIN}$ \\
\hline CHEMBL 3196521 & 688810 & 5.7829 & 99999999 & 995 & 5.6539 & \\
\hline CHEMBL 1324046 & 688810 & 4.9830 & 00000000 & 005 & 5.1924 & TRN \\
\hline CHEMBL1431995 & 688810 & 6.5829 & 99999999 & & 5.8205 & TRN \\
\hline CHEMBL1500690 & 688810 & 5.5329 & 99999999 & 995 & 5.1786 & 列 \\
\hline CHEMBL1337435 & 688810 & 4.883 & 5.0455 & TRN & & \\
\hline CHEMBL1362424 & 688810 & 5.6329 & 99999999 & 99 & .0523 & TRN \\
\hline CHEMBL 1415851 & 688810 & 4.783 & 5.4746 & TST & & \\
\hline CHEMBL1444540 & 688810 & 4.833 & 4.9804 & TST & & \\
\hline
\end{tabular}




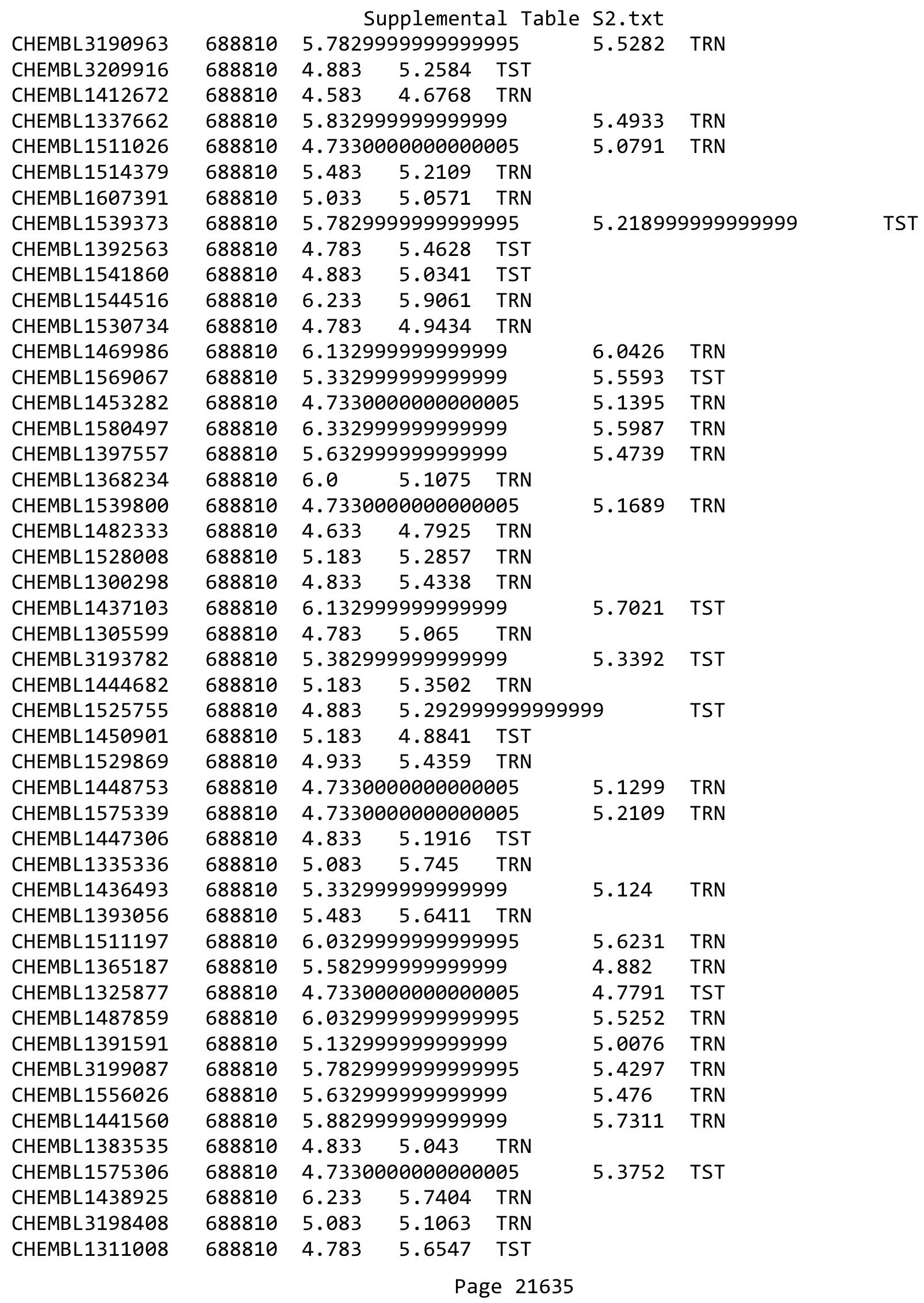




\begin{tabular}{|c|c|c|c|c|c|c|}
\hline & & \multicolumn{4}{|c|}{ Supplemental Table s2.txt } & \\
\hline CHEMBL1469417 & 688810 & $5.58299 \mathrm{c}$ & 999999999 & & 5.524 & TRN \\
\hline CHEMBL1351384 & 688810 & 5.483 & \multicolumn{3}{|c|}{5.202999999999999} & TRN \\
\hline CHEMBL1476816 & 688810 & \multicolumn{3}{|c|}{5.632999999999999} & 5.697 & TRN \\
\hline CHEMBL1477136 & 688810 & 4.633 & 5.3655 & TRN & & \\
\hline CHEMBL1532870 & 688810 & \multicolumn{3}{|c|}{4.9830000000000005} & 5.114 & TRN \\
\hline CHEMBL 256042 & 688810 & 4.783 & 5.2433 & TRN & & \\
\hline CHEMBL1545565 & 688810 & \multicolumn{3}{|c|}{5.132999999999999} & 5.3257 & TRN \\
\hline CHEMBL1371043 & 688810 & \multicolumn{3}{|c|}{4.9830000000000005} & 4.9882 & TRN \\
\hline CHEMBL1542955 & 688810 & 4.933 & 5.3617 & TRN & & \\
\hline CHEMBL1414522 & 688810 & 5.5 & 4.9354 & TRN & & \\
\hline CHEMBL1392992 & 688810 & \multicolumn{3}{|c|}{5.832999999999999} & 5.6009 & TRN \\
\hline CHEMBL1541214 & 688810 & 5.033 & \multicolumn{3}{|c|}{5.337999999999999} & TST \\
\hline CHEMBL3209077 & 688810 & 4.783 & 5.4331 & TRN & & \\
\hline CHEMBL1547504 & 688810 & \multicolumn{3}{|c|}{5.132999999999999} & 5.7074 & TRN \\
\hline CHEMBL1311630 & 688810 & \multicolumn{3}{|c|}{5.132999999999999} & 4.9995 & TRN \\
\hline CHEMBL1596742 & 688810 & 5.733 & 5.4905 & TRN & & \\
\hline CHEMBL 3198630 & 688810 & \multicolumn{3}{|c|}{5.832999999999999} & 5.3659 & TRN \\
\hline CHEMBL1567017 & 688810 & \multicolumn{3}{|c|}{5.7829999999999995} & 5.1936 & TRN \\
\hline CHEMBL1502133 & 688810 & 6.9329 & 6.019 & TRN & & \\
\hline CHEMBL1558769 & 688810 & 4.883 & 5.568 & TRN & & \\
\hline CHEMBL1299288 & 688810 & \multicolumn{3}{|c|}{6.5329999999999995} & 6.0086 & TRN \\
\hline CHEMBL1402598 & 688810 & 5.483 & 5.4276 & TST & & \\
\hline CHEMBL1466855 & 688810 & 5.733 & 5.2798 & TRN & & \\
\hline CHEMBL1479393 & 688810 & 4.633 & 4.7766 & TRN & & \\
\hline CHEMBL1381328 & 688810 & 5.683 & 5.6709 & TST & & \\
\hline CHEMBL1481543 & 688810 & \multicolumn{3}{|c|}{5.632999999999999} & 6.0187 & TRN \\
\hline CHEMBL1334555 & 688810 & \multicolumn{3}{|c|}{4.7330000000000005} & 5.3851 & TST \\
\hline CHEMBL1299663 & 688810 & 5.083 & 5.3685 & TST & & \\
\hline CHEMBL1568147 & 688810 & \multicolumn{3}{|c|}{5.382999999999999} & 5.477 & TRN \\
\hline CHEMBL1576725 & 688810 & 4.783 & 5.5404 & TRN & & \\
\hline CHEMBL601968 & 688810 & 5.683 & 5.2011 & TRN & & \\
\hline CHEMBL1606948 & 688810 & 4.633 & 4.825 & TRN & & \\
\hline CHEMBL1378489 & 688810 & 4.633 & 4.9671 & TST & & \\
\hline CHEMBL1465878 & 688810 & 4.683 & 5.0759 & TRN & & \\
\hline CHEMBL1384832 & 688810 & 6.683 & 6.2584 & TRN & & \\
\hline CHEMBL1388738 & 688810 & 6.683 & 5.8314 & TRN & & \\
\hline CHEMBL1612551 & 688810 & \multicolumn{3}{|c|}{5.332999999999999} & 5.4302 & TST \\
\hline CHEMBL1504269 & 688810 & 5.033 & 5.2131 & TRN & & \\
\hline CHEMBL1592708 & 688810 & 7.1831 & 5.6013 & TRN & & \\
\hline CHEMBL3191933 & 688810 & \multicolumn{3}{|c|}{5.832999999999999} & 5.6665 & TRN \\
\hline CHEMBL1573211 & 688810 & 5.433 & 5.7549 & TRN & & \\
\hline CHEMBL1374897 & 688810 & 4.783 & 5.1731 & TRN & & \\
\hline CHEMBL1543959 & 688810 & 4.783 & \multicolumn{3}{|c|}{5.412999999999999} & TRN \\
\hline CHEMBL1300977 & 688810 & \multicolumn{3}{|c|}{5.5329999999999995} & 5.1577 & TRN \\
\hline CHEMBL3209279 & 688810 & \multicolumn{3}{|c|}{5.7829999999999995} & 5.4681 & TRN \\
\hline CHEMBL1313521 & 688810 & 4.733006 & 000000000 & 005 & 4.9208 & TRN \\
\hline CHEMBL1595492 & 688810 & 5.483 & 5.8084 & TRN & & \\
\hline CHEMBL1362055 & 688810 & 6.183 & 5.2109 & TST & & \\
\hline
\end{tabular}




\begin{tabular}{|c|c|c|c|c|c|c|}
\hline \multirow{3}{*}{$\begin{array}{l}\text { CHEMBL1313940 } \\
\text { CHEMBL1361822 }\end{array}$} & \multirow{3}{*}{$\begin{array}{l}688810 \\
688810\end{array}$} & \multicolumn{5}{|c|}{ Supplemental Table S2.txt } \\
\hline & & \multicolumn{3}{|c|}{6.2829999999999995} & \multirow{2}{*}{5.6989} & \multirow{2}{*}{ TRA } \\
\hline & & 4.683 & 5.2405 & TST & & \\
\hline CHEMBL1447977 & 688810 & \multicolumn{3}{|c|}{5.132999999999999} & 5.1735 & TRN \\
\hline CHEMBL1325273 & 688810 & 5.083 & 5.4364 & TRN & & \\
\hline CHEMBL1337808 & 688810 & 5.433 & 5.2049 & TRN & & \\
\hline CHEMBL1372312 & 688810 & 4.883 & 5.0888 & TRN & & \\
\hline CHEMBL1394882 & 688810 & 4.833 & 4.9609 & TRN & & \\
\hline CHEMBL1601059 & 688810 & 4.683 & 5.2109 & TRN & & \\
\hline CHEMBL1988339 & 688810 & \multicolumn{3}{|c|}{5.382999999999999} & 5.2786 & TRN \\
\hline CHEMBL1555900 & 688810 & \multicolumn{3}{|c|}{4.7330000000000005} & 4.633 & TRN \\
\hline CHEMBL3198697 & 688810 & 5.183 & 5.4255 & TST & & \\
\hline CHEMBL154762 & 688810 & 4.833 & 5.4756 & TRN & & \\
\hline CHEMBL1364224 & 688810 & 5.733 & \multicolumn{3}{|c|}{5.877000000000001} & TRN \\
\hline CHEMBL1491251 & 688810 & 5.233 & 5.84 & TRN & & \\
\hline CHEMBL1480464 & 688810 & 4.783 & 4.7762 & TRN & & \\
\hline CHEMBL1427517 & 688810 & 5.433 & 5.4234 & TST & & \\
\hline CHEMBL1594327 & 688810 & \multicolumn{3}{|c|}{5.132999999999999} & 4.7873 & TRN \\
\hline CHEMBL1608632 & 688810 & \multicolumn{3}{|c|}{4.7330000000000005} & 5.0842 & TST \\
\hline CHEMBL1578499 & 688810 & 5.733 & 5.4663 & TRN & & \\
\hline CHEMBL1299374 & 688810 & \multicolumn{3}{|c|}{4.7330000000000005} & 4.8697 & TRN \\
\hline CHEMBL1347504 & 688810 & \multicolumn{3}{|c|}{5.882999999999999} & 5.9843 & TRN \\
\hline CHEMBL1370292 & 688810 & 5.683 & 5.1143 & TRN & & \\
\hline CHEMBL1503172 & 688810 & 6.183 & 6.1161 & TRN & & \\
\hline CHEMBL1328415 & 688810 & 4.883 & 5.0251 & TST & & \\
\hline CHEMBL1530472 & 688810 & 5.033 & 4.9873 & TRN & & \\
\hline CHEMBL1966499 & 688810 & 5.233 & 5.1102 & TST & & \\
\hline CHEMBL1319633 & 688810 & \multicolumn{3}{|c|}{5.882999999999999} & 5.7796 & TRN \\
\hline CHEMBL1306118 & 688810 & 5.733 & 4.971 & TST & & \\
\hline CHEMBL1596655 & 688810 & 4.833 & 5.0966 & TST & & \\
\hline CHEMBL1500771 & 688810 & 4.883 & 5.4734 & TST & & \\
\hline CHEMBL1518774 & 688810 & 6.4829 & 5.9757 & TRN & & \\
\hline CHEMBL1389625 & 688810 & 4.883 & 5.2028 & TRN & & \\
\hline CHEMBL1524793 & 688810 & 4.633 & 4.9266 & TST & & \\
\hline CHEMBL1413208 & 688810 & 5.083 & 4.8733 & TRN & & \\
\hline CHEMBL1475720 & 688810 & 5.033 & 4.8275 & TRN & & \\
\hline CHEMBL1382087 & 688810 & \multicolumn{3}{|c|}{6.332999999999999} & 5.987 & TRN \\
\hline CHEMBL1335850 & 688810 & 4.583 & 4.7149 & TST & & \\
\hline CHEMBL1591021 & 688810 & 4.883 & 5.0747 & TRN & & \\
\hline CHEMBL1612465 & 688810 & \multicolumn{3}{|c|}{5.7829999999999995} & 5.5562 & TRN \\
\hline CHEMBL1327106 & 688810 & \multicolumn{3}{|c|}{5.382999999999999} & 5.0729 & TST \\
\hline CHEMBL1337726 & 688810 & \multicolumn{3}{|c|}{5.2829999999999995} & 4.8219 & TST \\
\hline CHEMBL1537321 & 688810 & 5.183 & 5.2362 & TRN & & \\
\hline CHEMBL1372209 & 688810 & 4.783 & 4.9924 & TST & & \\
\hline CHEMBL1314817 & 688810 & 4.633 & 4.9018 & TST & & \\
\hline CHEMBL1365359 & 688810 & \multicolumn{3}{|c|}{5.382999999999999} & 5.4768 & TRN \\
\hline CHEMBL1432707 & 688810 & \multicolumn{3}{|c|}{5.132999999999999} & 4.6471 & TST \\
\hline CHEMBL1383569 & 688810 & 6.2829 & 99999999 & 995 & 5.6331 & TRN \\
\hline CHEMBL1454811 & 688810 & 4.883 & 4.9019 & TST & & \\
\hline
\end{tabular}




\begin{tabular}{|c|c|c|c|c|c|c|c|}
\hline \multicolumn{8}{|c|}{ supk } \\
\hline CHEMBL1516258 & 688810 & 4.783 & 5.0787 & TST & & & \\
\hline CHEMBL1487635 & 688810 & 4.783 & 5.1551 & TRN & & & \\
\hline CHEMBL1563222 & 688810 & 5.28299 & 99999999 & 995 & 5.2782 & TRN & \\
\hline CHEMBL1491373 & 688810 & 5.083 & 5.1802 & TRN & & & \\
\hline CHEMBL1434695 & 688810 & 5.183 & 5.3806 & TRN & & & \\
\hline CHEMBL3193098 & 688810 & 6.28299 & 99999999 & 995 & 5.9395 & TRN & \\
\hline CHEMBL1605956 & 688810 & 4.883 & 4.6933 & TRN & & & \\
\hline CHEMBL1340675 & 688810 & 5.483 & 5.369 & TST & & & \\
\hline CHEMBL1326469 & 688810 & 5.033 & 5.7435 & TRN & & & \\
\hline CHEMBL3199794 & 688810 & 6.53299 & 99999999 & 995 & 6.1924 & TRN & \\
\hline CHEMBL1387331 & 688810 & 5.733 & 5.5252 & TRN & & & \\
\hline CHEMBL1410403 & 688810 & 4.73300 & 00000000 & 005 & 5.03100 & 0000000001 & TRN \\
\hline CHEMBL1370676 & 688810 & 6.38299 & 99999999 & & 5.3581 & TRN & \\
\hline CHEMBL1498996 & 688810 & 5.13299 & 99999999 & & 4.9158 & TRN & \\
\hline CHEMBL1353524 & 688810 & 4.783 & 5.0807 & TST & & & \\
\hline CHEMBL1584379 & 688810 & 6.4829 & 5.9315 & TRN & & & \\
\hline CHEMBL1429574 & 688810 & 6.33299 & 99999999 & & 5.8 & TST & \\
\hline CHEMBL3196008 & 688810 & 6.183 & 5.6232 & TRN & & & \\
\hline CHEMBL1500868 & 688810 & 6.63299 & 99999999 & 99 & 5.8761 & TRN & \\
\hline CHEMBL1520374 & 688810 & 5.933 & 5.4107 & TRN & & & \\
\hline CHEMBL1418598 & 688810 & 4.583 & 5.3401 & TRN & & & \\
\hline CHEMBL1541727 & 688810 & 5.083 & 5.1858 & TRN & & & \\
\hline CHEMBL1520839 & 688810 & 4.98300 & 00000000 & 005 & 5.1492 & TRN & \\
\hline CHEMBL1368561 & 688810 & 6.7331 & 6.0953 & TRN & & & \\
\hline CHEMBL1552343 & 688810 & 4.883 & 5.7235 & TRN & & & \\
\hline CHEMBL1409196 & 688810 & 4.833 & 5.0094 & TST & & & \\
\hline CHEMBL1364205 & 688810 & 6.03299 & 99999999 & 995 & 5.7288 & TRN & \\
\hline CHEMBL1330768 & 688810 & 5.483 & 5.0596 & TRN & & & \\
\hline CHEMBL1434958 & 688810 & 5.983 & 5.3838 & TRN & & & \\
\hline CHEMBL1536024 & 688810 & 4.783 & 4.8869 & TRN & & & \\
\hline CHEMBL1338352 & 688810 & 4.883 & 5.3449 & TRN & & & \\
\hline CHEMBL1495025 & 688810 & 6.28299 & 99999999 & 995 & 5.574 & TST & \\
\hline CHEMBL1482750 & 688810 & 5.233 & 5.0016 & TST & & & \\
\hline CHEMBL1409766 & 688810 & 5.13299 & 99999999 & & 5.3544 & TRN & \\
\hline CHEMBL1592716 & 688810 & 4.583 & 5.1679 & TST & & & \\
\hline CHEMBL1572805 & 688810 & 4.633 & 5.3912 & TRN & & & \\
\hline CHEMBL3210545 & 688810 & 4.833 & 4.9781 & TST & & & \\
\hline CHEMBL1581463 & 688810 & 5.733 & 5.3299 & TST & & & \\
\hline CHEMBL1383050 & 688810 & 5.33299 & 99999999 & & 5.2163 & TRN & \\
\hline CHEMBL1588832 & 688810 & 4.783 & 5.1063 & TRN & & & \\
\hline CHEMBL1552547 & 688810 & 7.1331 & 5.523 & TST & & & \\
\hline CHEMBL1370581 & 688810 & 4.933 & 4.9473 & TRN & & & \\
\hline CHEMBL1390015 & 688810 & 5.033 & 5.1778 & TST & & & \\
\hline CHEMBL1361343 & 688810 & 4.883 & 5.3213 & TRN & & & \\
\hline CHEMBL1565578 & 688810 & 5.433 & 5.1714 & TST & & & \\
\hline CHEMBL1525704 & 688810 & 4.73300 & 00000000 & 005 & 4.9363 & TST & \\
\hline CHEMBL193747 & 688810 & 5.033 & 5.1816 & TRN & & & \\
\hline CHEMBL1405685 & 688810 & 5.733 & 4.6768 & TRN & & & \\
\hline
\end{tabular}




\begin{tabular}{|c|c|c|c|c|c|c|}
\hline \multirow[b]{2}{*}{ CHEMBL1381255 } & \multicolumn{6}{|c|}{ Supplemental Table S2.txt } \\
\hline & 688810 & 4.833 & 5.4639 & TRN & & \\
\hline CHEMBL1458725 & 688810 & 5.033 & 4.8077 & TST & & \\
\hline CHEMBL1556389 & 688810 & 4.7330 & 00000000 & 005 & 4.762 & (7) \\
\hline CHEMBL1502721 & 688810 & 5.5329 & 99999999 & 995 & 5.6781 & TRN \\
\hline CHEMBL3190150 & 688810 & 5.1329 & 99999999 & 99 & 5.3172 & \\
\hline CHEMBL1569259 & 688810 & 6.233 & 5.8992 & TRN & & \\
\hline CHEMBL1408254 & 688810 & 4.9830 & 00000000 & 005 & 5.0589 & \\
\hline CHEMBL3199410 & 688810 & 5.233 & 5.1689 & TRN & & \\
\hline CHEMBL1375539 & 688810 & 4.633 & 4.6642 & TST & & \\
\hline CHEMBL1592109 & 688810 & 4.583 & 5.1692 & TRN & & \\
\hline CHEMBL1447359 & 688810 & 6.233 & 5.4717 & TRN & & \\
\hline CHEMBL1329024 & 688810 & 5.1329 & 99999999 & & 5.6035 & \\
\hline CHEMBL1408041 & 688810 & 4.933 & 5.6517 & TRN & & \\
\hline CHEMBL1602354 & 688810 & 6.3829 & 99999999 & & 5.5076 & 1 \\
\hline CHEMBL1472058 & 688810 & 4.933 & 5.2833 & TRN & & \\
\hline CHEMBL1540130 & 688810 & 6.3829 & 99999999 & & 5.4876 & \\
\hline CHEMBL1733605 & 688810 & 4.833 & 5.2667 & TRN & & \\
\hline CHEMBL1326237 & 688810 & 4.783 & 4.9605 & TRN & & \\
\hline CHEMBL1351399 & 688810 & 6.433 & 5.6147 & TRN & & \\
\hline CHEMBL1464312 & 688810 & 4.683 & 4.7738 & TST & & \\
\hline CHEMBL1418302 & 688810 & 4.933 & 5.2394 & TST & & \\
\hline CHEMBL3211620 & 688810 & 6.683 & 6.1165 & TRN & & \\
\hline CHEMBL1539834 & 688810 & 5.2829 & 99999999 & 995 & 5.6928 & TRN \\
\hline CHEMBL1541328 & 688810 & 5.8329 & 99999999 & & 5.6541 & \\
\hline CHEMBL1520753 & 688810 & 5.433 & 5.3081 & TRN & & \\
\hline CHEMBL584883 & 688810 & 6.0 & 5.0545 & TRN & & \\
\hline CHEMBL1299379 & 688810 & 4.883 & 5.4204 & TRN & & \\
\hline CHEMBL1352061 & 688810 & 5.433 & 4.9122 & TST & & \\
\hline CHEMBL3194664 & 688810 & 5.3829 & 99999999 & & 5.4942 & TST \\
\hline CHEMBL1455643 & 688810 & 5.1329 & 99999999 & & 5.4875 & TRN \\
\hline CHEMBL3212280 & 688810 & 4.883 & 5.0706 & TRN & & \\
\hline CHEMBL1406991 & 688810 & 4.7330 & 20000000 & 005 & 5.8529 & 12 \\
\hline CHEMBL1600886 & 688810 & 4.633 & 5.2694 & TST & & \\
\hline CHEMBL1497732 & 688810 & 5.5329 & 99999999 & 995 & 5.5335 & $\mathrm{TP}$ \\
\hline CHEMBL1390460 & 688810 & 5.483 & 5.136 & TRN & & \\
\hline CHEMBL1465089 & 688810 & 4.683 & 5.1419 & TRN & & \\
\hline CHEMBL1570812 & 688810 & 5.8829 & 99999999 & & 5.1456 & ISI \\
\hline CHEMBL1342883 & 688810 & 6.0829 & 99999999 & & 5.1138 & TST \\
\hline CHEMBL1353774 & 688810 & 5.183 & 5.4251 & TRN & & \\
\hline CHEMBL1372701 & 688810 & 5.6329 & э9999999 & 99 & 5.4255 & $\mathrm{~T}$ \\
\hline CHEMBL1596248 & 688810 & 5.933 & 5.8186 & TRN & & \\
\hline CHEMBL1557674 & 688810 & 5.7829 & 99999999 & 995 & 5.4256 & ris \\
\hline CHEMBL1341999 & 688810 & 4.633 & 4.6955 & TRN & & \\
\hline CHEMBL1377850 & 688810 & 5.933 & 6.0879 & TRN & & \\
\hline CHEMBL1480124 & 688810 & 4.933 & 5.0547 & TST & & \\
\hline CHEMBL1461570 & 688810 & 4.933 & 5.1835 & TRN & & \\
\hline CHEMBL1423993 & 688810 & 4.833 & 5.1869 & TRN & & \\
\hline CHEMBL1605613 & 688810 & 6.2829 & 79999999 & 95 & 5.6951 & IIn \\
\hline
\end{tabular}




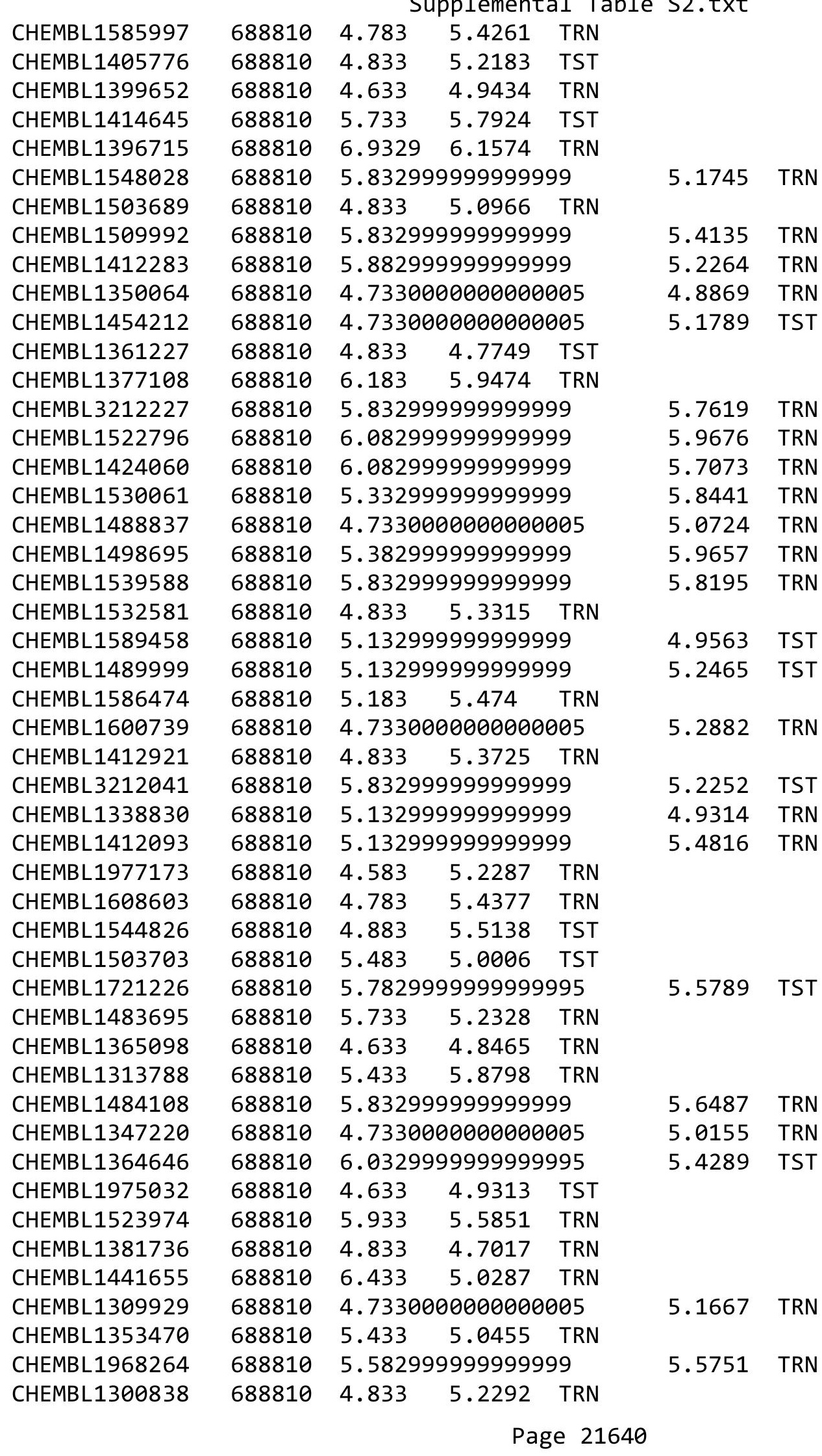




\begin{tabular}{|c|c|c|c|c|c|c|}
\hline \multirow[b]{2}{*}{ CHEMBL1534503 } & \multirow[b]{2}{*}{688810} & \multicolumn{5}{|c|}{ Supplemental Table S2.txt } \\
\hline & & 4.583 & 4.4797 & TRN & & \\
\hline CHEMBL1604345 & 688810 & 4.683 & 4.6779 & TST & & \\
\hline CHEMBL1516445 & 688810 & 4.833 & 5.1116 & TRN & & \\
\hline CHEMBL1449466 & 688810 & \multicolumn{3}{|c|}{5.5329999999999995} & \multirow[t]{3}{*}{5.2362} & \multirow[t]{3}{*}{ TRN } \\
\hline CHEMBL1530341 & 688810 & 5.483 & 5.8108 & TRN & & \\
\hline CHEMBL1439833 & 688810 & 5.033 & 5.7221 & TRN & & \\
\hline CHEMBL1562906 & 688810 & \multicolumn{3}{|c|}{4.7330000000000005} & \multirow[t]{4}{*}{4.8141} & \multirow[t]{4}{*}{ TRN } \\
\hline CHEMBL1605182 & 688810 & 4.833 & 4.9809 & TRN & & \\
\hline CHEMBL1420828 & 688810 & 5.083 & 5.403 & TRN & & \\
\hline CHEMBL1469710 & 688810 & 4.633 & 4.8077 & TRN & & \\
\hline CHEMBL1495645 & 688810 & \multicolumn{3}{|c|}{5.2829999999999995} & \multirow{6}{*}{5.9382} & \multirow[t]{6}{*}{ TRA } \\
\hline CHEMBL1563164 & 688810 & 5.25 & 5.2616 & TRN & & \\
\hline CHEMBL1451743 & 688810 & 4.683 & 5.1007 & TRN & & \\
\hline CHEMBL1453975 & 688810 & 4.833 & 5.3806 & TST & & \\
\hline CHEMBL1473261 & 688810 & 5.683 & 5.4149 & TRN & & \\
\hline CHEMBL373909 & 688810 & 5.733 & 5.1686 & TRN & & \\
\hline CHEMBL1583045 & 688810 & \multicolumn{3}{|c|}{4.7330000000000005} & \multirow[t]{2}{*}{5.5419} & \multirow[t]{2}{*}{ TST } \\
\hline CHEMBL1417750 & 688810 & 4.933 & 5.5101 & TRN & & \\
\hline CHEMBL1499823 & 688810 & \multicolumn{3}{|c|}{5.882999999999999} & 5.5055 & TST \\
\hline CHEMBL1472095 & 688810 & \multicolumn{3}{|c|}{5.132999999999999} & 5.3451 & TST \\
\hline CHEMBL602763 & 688810 & \multicolumn{3}{|c|}{5.5329999999999995} & 4.992 & TRN \\
\hline CHEMBL1598230 & 688810 & 4.583 & 5.8004 & TRN & & \\
\hline CHEMBL1318619 & 688810 & \multicolumn{3}{|c|}{4.9830000000000005} & \multirow[t]{3}{*}{5.0525} & \multirow[t]{3}{*}{ TRA } \\
\hline CHEMBL1365865 & 688810 & 5.233 & 4.8399 & TST & & \\
\hline CHEMBL1992286 & 688810 & 5.083 & 5.6732 & TRN & & \\
\hline CHEMBL1409485 & 688810 & 4.9836 & 0000000 & 005 & 5.0759 & TST \\
\hline CHEMBL1338209 & 688810 & 4.883 & 5.1086 & TRN & & \\
\hline CHEMBL1359037 & 688810 & 4.7336 & 0000000 & 005 & 5.1627 & TRN \\
\hline CHEMBL1476006 & 688810 & 4.633 & 4.9543 & TST & & \\
\hline CHEMBL1362715 & 688810 & 4.9836 & 0000000 & 005 & 4.8922 & TRN \\
\hline CHEMBL1547092 & 688810 & 4.7336 & 0000000 & 005 & 5.1552 & TST \\
\hline CHEMBL1496791 & 688810 & 5.733 & 5.5516 & TRN & & \\
\hline CHEMBL1306731 & 688810 & 4.933 & 5.2283 & TST & & \\
\hline CHEMBL1571963 & 688810 & 4.9836 & 0000000 & 005 & 5.0545 & TST \\
\hline CHEMBL1506308 & 688810 & 4.883 & 5.2432 & TRN & & \\
\hline CHEMBL1475230 & 688810 & 5.183 & 4.7288 & TST & & \\
\hline CHEMBL1463239 & 688810 & 5.6329 & 99999995 & & 5.5087 & TRN \\
\hline CHEMBL1446764 & 688810 & 4.783 & 5.1165 & TST & & \\
\hline CHEMBL1413583 & 688810 & 4.833 & 5.6646 & TRN & & \\
\hline CHEMBL1429695 & 688810 & 4.833 & 5.1855 & TRN & & \\
\hline CHEMBL1406465 & 688810 & 4.783 & 4.6828 & TRN & & \\
\hline CHEMBL 2000577 & 688810 & 4.7336 & 0000000 & 005 & 5.4151 & TRN \\
\hline CHEMBL1401696 & 688810 & 5.483 & 5.206 & TST & & \\
\hline CHEMBL1495443 & 688810 & 5.233 & 5.2281 & TST & & \\
\hline CHEMBL 3208538 & 688810 & 4.7336 & 0000000 & 005 & 5.2797 & TRN \\
\hline CHEMBL1378287 & 688810 & 4.633 & 5.0725 & TST & & \\
\hline CHEMBL1396133 & 688810 & 4.583 & 4.9362 & TRN & & \\
\hline CHEMBL1545088 & 688810 & 5.8329 & 9999999 & & 5.5145 & TRN \\
\hline & & & & & & \\
\hline
\end{tabular}




\begin{tabular}{|c|c|c|c|c|c|c|}
\hline \multirow[b]{2}{*}{ CHEMBL1596661 } & \multicolumn{6}{|c|}{ pplemental Ta } \\
\hline & 688810 & 4.783 & 5.4277 & TRN & & \\
\hline CHEMBL1459348 & 688810 & 4.833 & 5.3406 & TRN & & \\
\hline CHEMBL1312630 & 688810 & \multicolumn{3}{|c|}{5.882999999999999} & 5.8057 & TRN \\
\hline CHEMBL1382431 & 688810 & \multicolumn{3}{|c|}{4.7330000000000005} & 4.9974 & TRN \\
\hline CHEMBL1516985 & 688810 & \multicolumn{3}{|c|}{5.5329999999999995} & 5.3955 & TRN \\
\hline CHEMBL1513774 & 688810 & 4.633 & 4.7787 & TRN & & \\
\hline CHEMBL1372624 & 688810 & 4.883 & 5.2575 & TRN & & \\
\hline CHEMBL1450527 & 688810 & 5.433 & 5.7192 & TRN & & \\
\hline CHEMBL1593939 & 688810 & 4.633 & 4.7843 & TRN & & \\
\hline CHEMBL1335597 & 688810 & 6.233 & 6.1751 & TRN & & \\
\hline CHEMBL1355804 & 688810 & 4.583 & 4.9382 & TST & & \\
\hline CHEMBL1313911 & 688810 & 5.433 & 4.9379 & TRN & & \\
\hline CHEMBL1423675 & 688810 & 4.783 & 4.8385 & TST & & \\
\hline CHEMBL1562029 & 688810 & 5.083 & 5.3621 & TRN & & \\
\hline CHEMBL1493893 & 688810 & \multicolumn{3}{|c|}{5.2829999999999995} & 4.9744 & \\
\hline CHEMBL1609965 & 688810 & 5.183 & 5.0979 & TST & & \\
\hline CHEMBL1354976 & 688810 & 4.633 & 4.8963 & TRN & & \\
\hline CHEMBL1311136 & 688810 & \multicolumn{3}{|c|}{5.382999999999999} & 4.8864 & \\
\hline CHEMBL1364450 & 688810 & \multicolumn{3}{|c|}{5.7829999999999995} & 5.8021 & \\
\hline CHEMBL1301055 & 688810 & 5.733 & 5.7551 & TRN & & \\
\hline CHEMBL1541577 & 688810 & \multicolumn{3}{|c|}{5.2829999999999995} & 5.4044 & $1 / \mathrm{K}$ \\
\hline CHEMBL1405828 & 688810 & 4.683 & 5.1168 & TST & & \\
\hline CHEMBL1347563 & 688810 & 5.733 & 5.3085 & TRN & & \\
\hline CHEMBL1554759 & 688810 & \multicolumn{3}{|c|}{5.382999999999999} & 5.5425 & \\
\hline CHEMBL1418193 & 688810 & 4.833 & 5.4478 & TRN & & \\
\hline CHEMBL 3189373 & 688810 & \multicolumn{3}{|c|}{4.7330000000000005} & 5.2397 & \\
\hline CHEMBL1361802 & 688810 & 5.033 & 5.362 & TST & & \\
\hline CHEMBL1531943 & 688810 & 4.95 & 5.6997 & TRN & & \\
\hline CHEMBL1492865 & 688810 & \multicolumn{3}{|c|}{4.7330000000000005} & 5.2535 & TRN \\
\hline CHEMBL604311 & 688810 & 5.083 & 5.2705 & TRN & & \\
\hline CHEMBL1394769 & 688810 & 4.583 & 4.5377 & TRN & & \\
\hline CHEMBL42178 & 688810 & 6.4829 & 5.4902 & TRN & & \\
\hline CHEMBL1567005 & 688810 & \multicolumn{3}{|c|}{5.132999999999999} & 11 & \\
\hline CHEMBL1597960 & 688810 & \multicolumn{3}{|c|}{5.2829999999999995} & & \\
\hline CHEMBL1472468 & 688810 & 4.833 & 5.5359 & TST & & \\
\hline CHEMBL1416128 & 688810 & 4.933 & 5.1436 & TRN & & \\
\hline CHEMBL1405794 & 688810 & 4.583 & 5.0672 & TRN & & \\
\hline CHEMBL 1500220 & 688810 & 5.483 & 5.3898 & TRN & & \\
\hline CHEMBL1421196 & 688810 & 5.233 & 5.2054 & TRN & & \\
\hline CHEMBL1418201 & 688810 & \multicolumn{3}{|c|}{5.832999999999999} & 6.0415 & TRN \\
\hline CHEMBL1560239 & 688810 & 4.783 & 5.2467 & TRN & & \\
\hline CHEMBL1423807 & 688810 & 5.033 & 5.3589 & TRN & & \\
\hline CHEMBL3199254 & 688810 & 4.833 & 5.25 & TRN & & \\
\hline CHEMBL1496257 & 688810 & 4.783 & 4.8056 & TRN & & \\
\hline CHEMBL 3196846 & 688810 & \multicolumn{3}{|c|}{6.0329999999999995} & 6.0841 & Tाराण \\
\hline CHEMBL1494086 & 688810 & \multicolumn{3}{|c|}{5.2829999999999995} & 5.6139 & 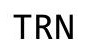 \\
\hline CHEMBL 3190596 & 688810 & 5.733 & 5.4967 & TRN & & \\
\hline CHEMBL1513066 & 688810 & 5.083 & 5.3278 & TRN & & \\
\hline
\end{tabular}




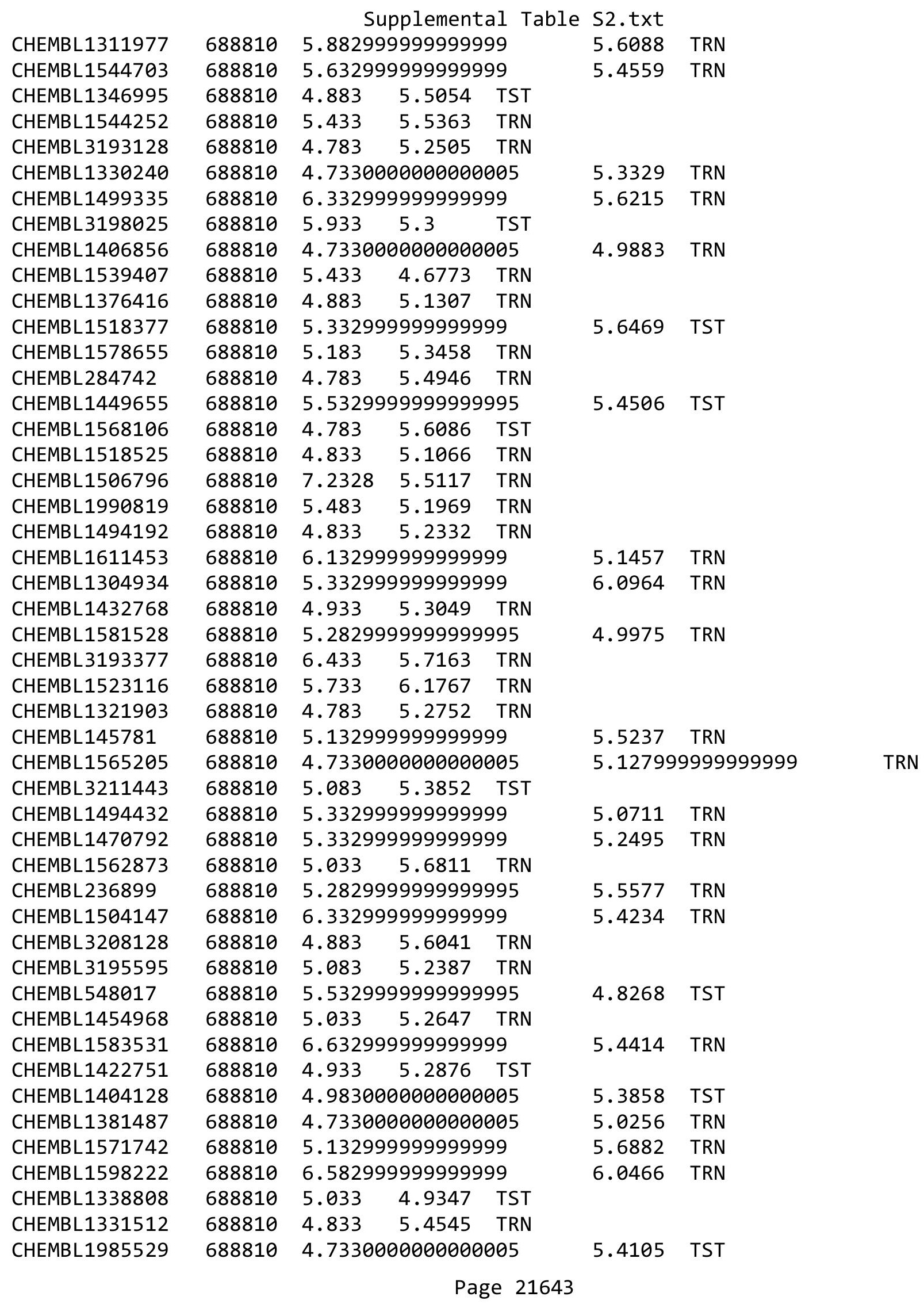




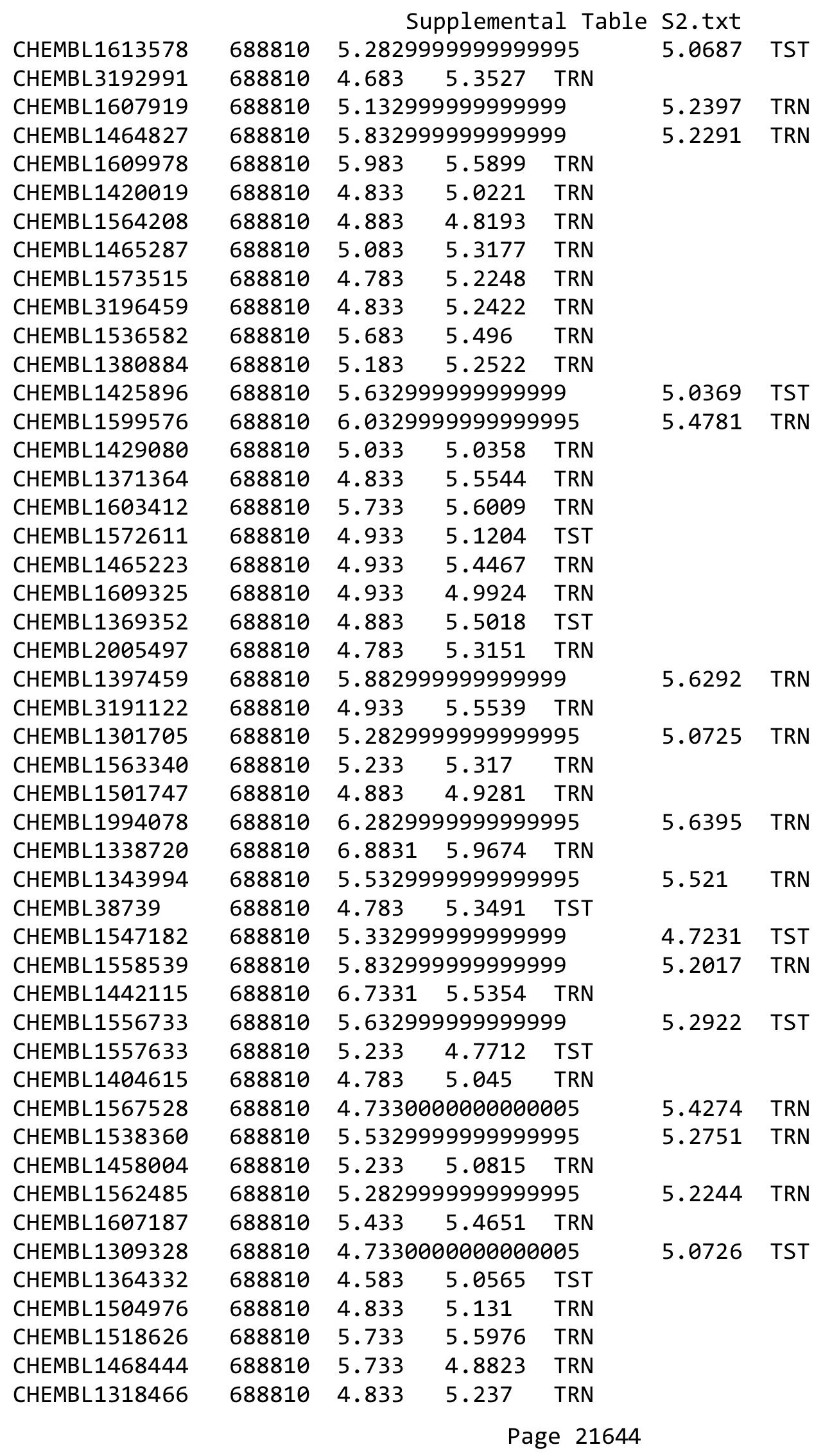




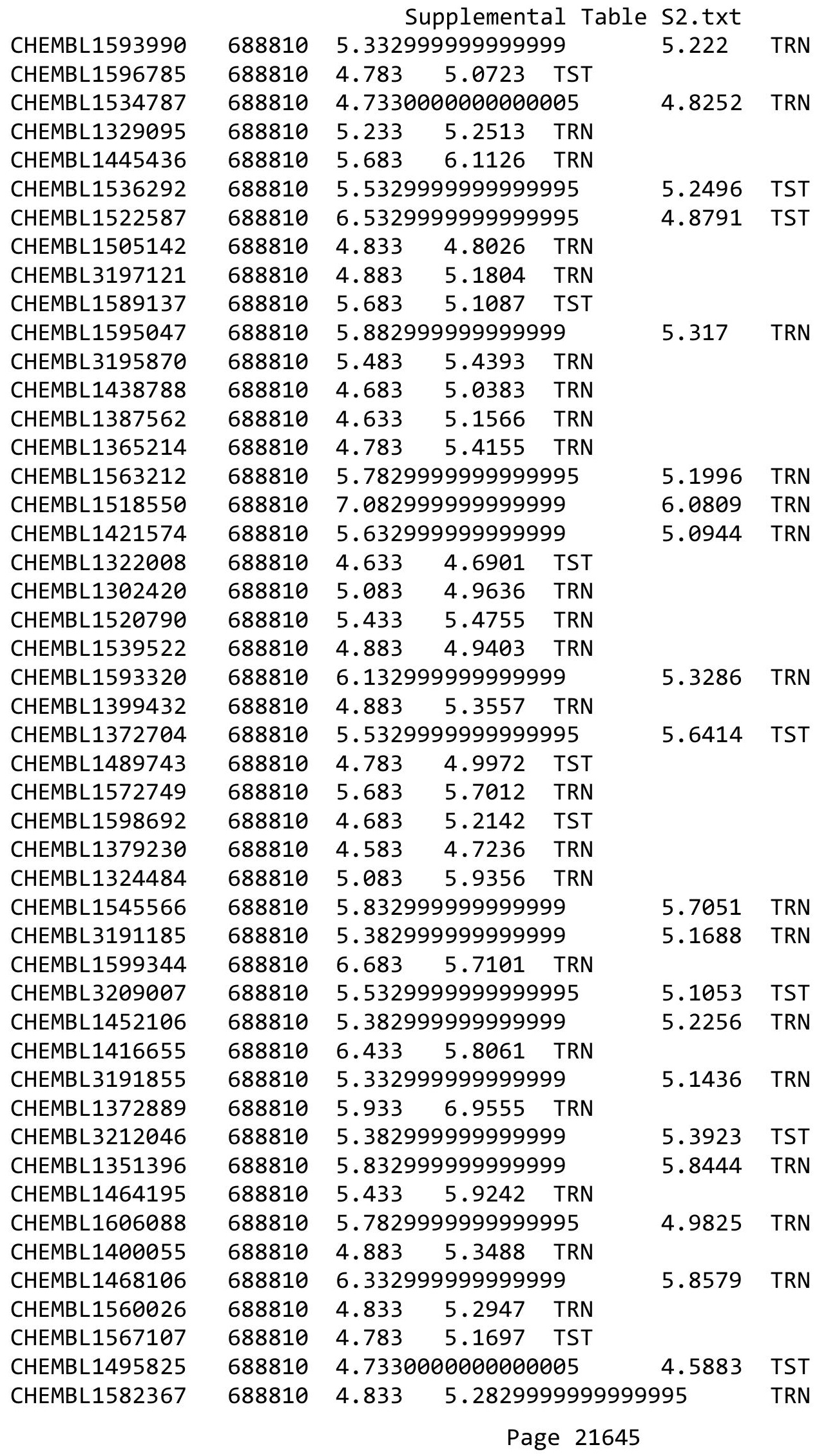




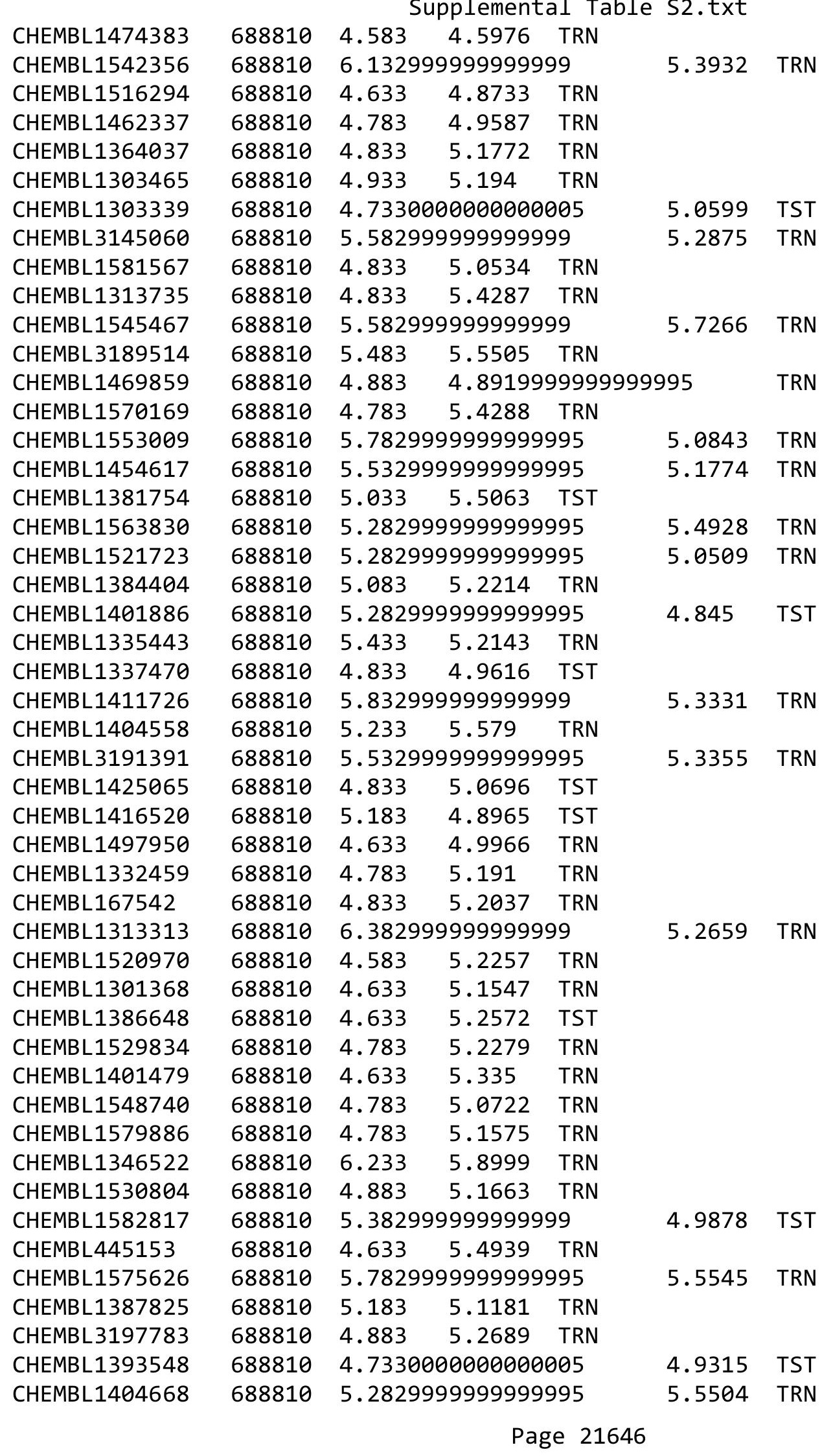




\begin{tabular}{|c|c|c|c|c|c|c|c|}
\hline \multicolumn{7}{|c|}{ Supplemental Table S2.txt } & \\
\hline CHEMBL1418596 & 688810 & 5.683 & 5.0635 & TST & & & \\
\hline CHEMBL1319027 & 688810 & 5.3829 & 99999999 & & 5.5627 & TRN & \\
\hline CHEMBL1574530 & 688810 & 4.683 & 5.6537 & TRN & & & \\
\hline CHEMBL1567827 & 688810 & 4.633 & 5.3103 & TRN & & & \\
\hline CHEMBL1515232 & 688810 & 6.433 & 5.3894 & TRN & & & \\
\hline CHEMBL1575409 & 688810 & 4.783 & 4.9646 & TRN & & & \\
\hline CHEMBL1500052 & 688810 & 4.883 & 4.994 & TST & & & \\
\hline CHEMBL1576127 & 688810 & 4.7330 & 00000000 & 005 & 4.9314 & TRN & \\
\hline CHEMBL1573618 & 688810 & 4.7330 & 00000000 & 005 & 4.9964 & TRN & \\
\hline CHEMBL1365055 & 688810 & 4.833 & 5.2608 & TRN & & & \\
\hline CHEMBL1417172 & 688810 & 6.6329 & 99999999 & & 5.6187 & TRN & \\
\hline CHEMBL1466696 & 688810 & 4.7330 & 00000000 & 005 & 5.1545 & TST & \\
\hline CHEMBL1340259 & 688810 & 5.483 & 5.0062 & TRN & & & \\
\hline CHEMBL1372677 & 688810 & 4.933 & 5.2803 & TST & & & \\
\hline CHEMBL1433404 & 688810 & 4.783 & 5.2206 & TRN & & & \\
\hline CHEMBL1486500 & 688810 & 4.583 & 5.0039 & TRN & & & \\
\hline CHEMBL1382367 & 688810 & 4.933 & 5.13899 & 999999999 & & TRN & \\
\hline CHEMBL1313217 & 688810 & 4.833 & 5.4043 & TRN & & & \\
\hline CHEMBL1325967 & 688810 & 5.8329 & 99999999 & & 5.8577 & TRN & \\
\hline CHEMBL 1493772 & 688810 & 4.933 & 4.9786 & TRN & & & \\
\hline CHEMBL1439006 & 688810 & 6.5829 & 99999999 & & 5.87799 & 9999999999 & TRN \\
\hline CHEMBL1881714 & 688810 & 5.183 & 5.4082 & TRN & & & \\
\hline CHEMBL1609950 & 688810 & 5.733 & 5.6676 & TRN & & & \\
\hline CHEMBL482604 & 688810 & 4.833 & 5.2612 & TRN & & & \\
\hline CHEMBL1536255 & 688810 & 5.6329 & 99999999 & & 5.3931 & TST & \\
\hline CHEMBL1582132 & 688810 & 6.233 & 5.7264 & TRN & & & \\
\hline CHEMBL1389275 & 688810 & 5.033 & 5.0685 & TST & & & \\
\hline CHEMBL1612172 & 688810 & 5.233 & 5.1458 & TRN & & & \\
\hline CHEMBL3196276 & 688810 & 4.783 & 5.2554 & TRN & & & \\
\hline CHEMBL1489055 & 688810 & 5.1329 & 99999999 & & 5.2292 & TRN & \\
\hline CHEMBL1491587 & 688810 & 5.483 & 5.4359 & TRN & & & \\
\hline CHEMBL 3145375 & 688810 & 5.933 & 5.4832 & TRN & & & \\
\hline CHEMBL1321603 & 688810 & 5.6329 & 99999999 & & 5.8077 & TRN & \\
\hline CHEMBL1408704 & 688810 & 4.7330 & 00000000 & 005 & 5.2327 & TRN & \\
\hline CHEMBL1470760 & 688810 & 5.3329 & 99999999 & & 5.4072 & TST & \\
\hline CHEMBL3197056 & 688810 & 5.1329 & 99999999 & & 5.3358 & TRN & \\
\hline CHEMBL1382355 & 688810 & 5.933 & 5.4084 & TRN & & & \\
\hline CHEMBL1394393 & 688810 & 5.083 & 4.9723 & TRN & & & \\
\hline CHEMBL1526866 & 688810 & 4.783 & 5.5539 & TRN & & & \\
\hline CHEMBL1415734 & 688810 & 4.883 & 5.6334 & TRN & & & \\
\hline CHEMBL1461129 & 688810 & 5.683 & 5.3663 & TRN & & & \\
\hline CHEMBL1301452 & 688810 & 4.933 & 5.1937 & TST & & & \\
\hline CHEMBL1474009 & 688810 & 5.6329 & 99999999 & & 5.5329 & TRN & \\
\hline CHEMBL1299352 & 688810 & 4.633 & 5.4928 & TST & & & \\
\hline CHEMBL1604999 & 688810 & 5.933 & 5.2897 & TRN & & & \\
\hline CHEMBL1456393 & 688810 & 6.433 & 5.7729 & TRN & & & \\
\hline CHEMBL1518077 & 688810 & 5.033 & 5.0575 & TRN & & & \\
\hline CHEMBL1382944 & 688810 & 5.8329 & 99999999 & & 5.5207 & TRN & \\
\hline
\end{tabular}




\begin{tabular}{|c|c|c|c|c|c|c|}
\hline \multicolumn{7}{|c|}{ Supplemental Table S2.txt } \\
\hline CHEMBL1359442 & 688810 & 5.733 & 5.6389 & TRN & & \\
\hline CHEMBL1595487 & 688810 & 5.683 & 5.4846 & TRN & & \\
\hline CHEMBL 3193831 & 688810 & 5.733 & 5.2415 & TRN & & \\
\hline CHEMBL 3212097 & 688810 & 4.9830 & 00000000 & 005 & 5.2222 & TRN \\
\hline CHEMBL1608670 & 688810 & 4.9830 & 00000000 & 005 & 5.4104 & TRN \\
\hline CHEMBL1341731 & 688810 & 4.833 & 5.4311 & TRN & & \\
\hline CHEMBL1441041 & 688810 & 5.7829 & 99999999 & 995 & 5.5183 & 15 \\
\hline CHEMBL1523644 & 688810 & 5.083 & 5.3131 & TST & & \\
\hline CHEMBL 3209790 & 688810 & 4.7330 & 00000000 & 005 & 4.9846 & \\
\hline CHEMBL 3207708 & 688810 & 4.933 & 4.9318 & TST & & \\
\hline CHEMBL1588715 & 688810 & 4.883 & 5.2018 & TRN & & \\
\hline CHEMBL1337282 & 688810 & 6.183 & 5.4157 & TRN & & \\
\hline CHEMBL1333893 & 688810 & 5.033 & 5.2346 & TRN & & \\
\hline CHEMBL1587792 & 688810 & 4.833 & 5.2823 & TRN & & \\
\hline CHEMBL1574935 & 688810 & 6.233 & 5.7362 & TRN & & \\
\hline CHEMBL1600675 & 688810 & 5.083 & 5.2943 & TRN & & \\
\hline CHEMBL1549097 & 688810 & 6.0 & 5.4601 & TRN & & \\
\hline CHEMBL 3212446 & 688810 & 5.8329 & 99999999 & & 5.3843 & \\
\hline CHEMBL1439210 & 688810 & 5.2829 & 99999999 & 995 & 5.3767 & \\
\hline CHEMBL1354578 & 688810 & 5.733 & 5.01 & TST & & \\
\hline CHEMBL1374727 & 688810 & 5.8829 & 99999999 & & 5.7358 & TRIV \\
\hline CHEMBL1974510 & 688810 & 5.083 & 5.2374 & TRN & & \\
\hline CHEMBL1381292 & 688810 & 5.033 & 4.9502 & TRN & & \\
\hline CHEMBL 3191640 & 688810 & 6.6329 & 99999999 & & 5.544 & \\
\hline CHEMBL1321911 & 688810 & 5.1329 & 99999999 & & 5.0065 & \\
\hline CHEMBL 3207579 & 688810 & 5.183 & 5.1665 & TRN & & \\
\hline CHEMBL1325776 & 688810 & 5.2829 & 99999999 & 995 & 5.0648 & TRN \\
\hline CHEMBL1392719 & 688810 & 4.7330 & 20000000 & 005 & 5.0344 & \\
\hline CHEMBL1544408 & 688810 & 4.7330 & $\partial 0000000$ & 005 & 5.2806 & \\
\hline CHEMBL1376118 & 688810 & 5.733 & 6.0456 & TRN & & \\
\hline CHEMBL1360735 & 688810 & 4.583 & 5.0754 & TRN & & \\
\hline CHEMBL587849 & 688810 & 4.783 & 5.3038 & TST & & \\
\hline CHEMBL1426909 & 688810 & 4.583 & 5.5545 & TRN & & \\
\hline CHEMBL 3193723 & 688810 & 5.033 & 5.2135 & TRN & & \\
\hline CHEMBL1537402 & 688810 & 4.9830 & 00000000 & 005 & 5.1698 & TRN \\
\hline CHEMBL1346318 & 688810 & 5.183 & 5.4298 & TST & & \\
\hline CHEMBL 3212483 & 688810 & 5.1329 & 99999999 & & 4.6827 & \\
\hline CHEMBL1593841 & 688810 & 4.783 & 5.0668 & TRN & & \\
\hline CHEMBL1428456 & 688810 & 5.8829 & 99999999 & & 5.7324 & TRN \\
\hline CHEMBL1481061 & 688810 & 4.633 & 5.1343 & TST & & \\
\hline CHEMBL 3190315 & 688810 & 5.8329 & 99999999 & & 5.3477 & TST \\
\hline CHEMBL1370890 & 688810 & 5.3829 & 99999999 & & 5.1077 & TRN \\
\hline CHEMBL1332594 & 688810 & 4.833 & 4.9811 & TRN & & \\
\hline CHEMBL1365533 & 688810 & 4.883 & 5.1405 & TST & & \\
\hline CHEMBL1555770 & 688810 & 4.9830 & 20000000 & 005 & 5.433 & ונדו \\
\hline CHEMBL1494580 & 688810 & 5.1329 & 99999999 & & 4.9455 & TRN \\
\hline CHEMBL1569574 & 688810 & 5.233 & 5.7172 & TRN & & \\
\hline CHEMBL1414080 & 688810 & 4.883 & 5.4692 & TST & & \\
\hline
\end{tabular}




\begin{tabular}{|c|c|c|c|c|c|c|}
\hline \multirow{3}{*}{$\begin{array}{l}\text { CHEMBL1576158 } \\
\text { CHEMBL1456823 }\end{array}$} & \multirow{3}{*}{$\begin{array}{l}688810 \\
688810\end{array}$} & \multicolumn{4}{|c|}{ Supplemental Table S2.txt } & \multirow{2}{*}{ TRN } \\
\hline & & \multicolumn{3}{|c|}{6.0329999999999995} & 5.7034 & \\
\hline & & 4.833 & 4.6397 & TRN & & \\
\hline CHEMBL1423760 & 688810 & 4.883 & 5.2636 & TRN & & \\
\hline CHEMBL1576626 & 688810 & 4.783 & 5.3725 & TRN & & \\
\hline CHEMBL145021 & 688810 & 4.783 & 5.2251 & TRN & & \\
\hline CHEMBL1341482 & 688810 & 4.95 & 5.1554 & TRN & & \\
\hline CHEMBL3213337 & 688810 & 4.833 & 5.3877 & TST & & \\
\hline CHEMBL1388147 & 688810 & 4.933 & 5.0543 & TRN & & \\
\hline CHEMBL1565906 & 688810 & 5.433 & 5.5129 & TRN & & \\
\hline CHEMBL1446106 & 688810 & 5.233 & 5.4901 & TRN & & \\
\hline CHEMBL1530498 & 688810 & \multicolumn{3}{|c|}{4.9830000000000005} & 5.3385 & TRN \\
\hline CHEMBL1310617 & 688810 & \multicolumn{3}{|c|}{5.882999999999999} & 5.7727 & TST \\
\hline CHEMBL1446371 & 688810 & 5.733 & 5.5243 & TRN & & \\
\hline CHEMBL1576774 & 688810 & \multicolumn{3}{|c|}{6.132999999999999} & 5.8015 & TRN \\
\hline CHEMBL3191871 & 688810 & 5.183 & 6.4489 & TRN & & \\
\hline CHEMBL1500769 & 688810 & 4.833 & 5.0524 & TRN & & \\
\hline CHEMBL1547420 & 688810 & 5.733 & 5.3992 & TRN & & \\
\hline CHEMBL1597432 & 688810 & \multicolumn{3}{|c|}{6.632999999999999} & 5.2655 & TRN \\
\hline CHEMBL1587224 & 688810 & 5.183 & 5.6277 & TRN & & \\
\hline CHEMBL1561136 & 688810 & \multicolumn{3}{|c|}{5.332999999999999} & 4.803 & TRN \\
\hline CHEMBL1977678 & 688810 & 5.483 & 5.4689 & TRN & & \\
\hline CHEMBL1425246 & 688810 & \multicolumn{3}{|c|}{5.132999999999999} & 5.365 & TRN \\
\hline CHEMBL1462220 & 688810 & \multicolumn{3}{|c|}{5.7829999999999995} & 5.098 & TRN \\
\hline CHEMBL1375227 & 688810 & \multicolumn{3}{|c|}{5.7829999999999995} & 5.919 & TRN \\
\hline CHEMBL1549645 & 688810 & 4.783 & 5.1741 & TRN & & \\
\hline CHEMBL1466865 & 688810 & 5.083 & 5.1302 & TRN & & \\
\hline CHEMBL1391048 & 688810 & \multicolumn{3}{|c|}{5.5329999999999995} & 5.2886 & TST \\
\hline CHEMBL1487501 & 688810 & \multicolumn{3}{|c|}{5.632999999999999} & 5.495 & TRN \\
\hline CHEMBL1964407 & 688810 & 4.783 & 4.907 & TST & & \\
\hline CHEMBL1513092 & 688810 & \multicolumn{3}{|c|}{5.2829999999999995} & 5.4417 & TST \\
\hline CHEMBL1395471 & 688810 & \multicolumn{3}{|c|}{5.5329999999999995} & 5.0608 & TRN \\
\hline CHEMBL1998566 & 688810 & 4.583 & 5.2301 & TRN & & \\
\hline CHEMBL1403439 & 688810 & \multirow{2}{*}{\multicolumn{3}{|c|}{$\begin{array}{ll}5.183 & 5.2347 \\
5.2829999999999995\end{array}$}} & & \\
\hline CHEMBL1423626 & 688810 & & & & 5.1447 & TST \\
\hline CHEMBL1389832 & 688810 & 5.183 & 4.802 & TST & & \\
\hline CHEMBL1413507 & 688810 & 4.9 & 5.5119 & TST & & \\
\hline CHEMBL1356301 & 688810 & 4.833 & 5.2251 & TST & & \\
\hline CHEMBL1440603 & 688810 & 4.833 & 4.7853 & TRN & & \\
\hline CHEMBL1598248 & 688810 & 4.833 & 5.3211 & TRN & & \\
\hline CHEMBL1409420 & 688810 & \multicolumn{3}{|c|}{5.882999999999999} & 5.5397 & TRN \\
\hline CHEMBL1333433 & 688810 & 4.683 & 4.9585 & TRN & & \\
\hline CHEMBL1383407 & 688810 & \multicolumn{3}{|c|}{5.132999999999999} & 5.086 & TRN \\
\hline CHEMBL1418818 & 688810 & 5.183 & 5.5176 & TRN & & \\
\hline CHEMBL1419191 & 688810 & \multicolumn{3}{|c|}{5.132999999999999} & 5.3346 & TST \\
\hline CHEMBL1337217 & 688810 & 4.933 & 5.187 & TRN & & \\
\hline CHEMBL1332626 & 688810 & 6.983 & 5.8738 & TRN & & \\
\hline CHEMBL1394378 & 688810 & 5.933 & 5.051 & TRN & & \\
\hline CHEMBL 2006611 & 688810 & 4.633 & 5.0465 & TRN & & \\
\hline
\end{tabular}




\begin{tabular}{|c|c|c|c|c|c|c|}
\hline \multirow[b]{2}{*}{ CHEMBL1378879 } & \multicolumn{6}{|c|}{ I } \\
\hline & 688810 & 4.783 & 5.3543 & TRN & & \\
\hline CHEMBL1565498 & 688810 & 4.583 & 5.2636 & TST & & \\
\hline CHEMBL1445251 & 688810 & 5.483 & 5.5235 & TRN & & \\
\hline CHEMBL1395020 & 688810 & 4.833 & 5.7124 & TRN & & \\
\hline CHEMBL1319446 & 688810 & 4.783 & 5.0708 & TRN & & \\
\hline CHEMBL1532879 & 688810 & 4.833 & 4.9649 & TRN & & \\
\hline CHEMBL3214280 & 688810 & \multicolumn{3}{|c|}{6.0329999999999995} & 5.5462 & TST \\
\hline CHEMBL3210309 & 688810 & 4.783 & 5.2215 & TRN & & \\
\hline CHEMBL1476423 & 688810 & 4.633 & 5.1469 & TST & & \\
\hline CHEMBL1566701 & 688810 & \multicolumn{3}{|c|}{4.7330000000000005} & 4.9816 & TST \\
\hline CHEMBL1605052 & 688810 & 4.633 & 4.6536 & TRN & & \\
\hline CHEMBL3194594 & 688810 & 5.083 & 4.9908 & TRN & & \\
\hline CHEMBL1571075 & 688810 & 4.833 & 5.087 & TRN & & \\
\hline CHEMBL1309006 & 688810 & \multicolumn{3}{|c|}{5.132999999999999} & 5.0581 & TRN \\
\hline CHEMBL3193976 & 688810 & \multicolumn{3}{|c|}{4.7330000000000005} & 5.6464 & TRN \\
\hline CHEMBL 3211998 & 688810 & 4.583 & 5.6918 & TRN & & \\
\hline CHEMBL187801 & 688810 & \multicolumn{3}{|c|}{5.132999999999999} & 5.3594 & TST \\
\hline CHEMBL1482261 & 688810 & \multicolumn{3}{|c|}{4.7330000000000005} & 5.1955 & TST \\
\hline CHEMBL1992834 & 688810 & \multicolumn{3}{|c|}{5.132999999999999} & 5.2184 & TRN \\
\hline CHEMBL1413585 & 688810 & 4.783 & 5.1991 & TRN & & \\
\hline CHEMBL1400512 & 688810 & 4.833 & 5.3296 & TST & & \\
\hline CHEMBL1509299 & 688810 & \multicolumn{3}{|c|}{4.9830000000000005} & 4.8662 & TST \\
\hline CHEMBL1551089 & 688810 & 4.583 & 4.9606 & TRN & & \\
\hline CHEMBL1573176 & 688810 & \multicolumn{3}{|c|}{4.9830000000000005} & 4.8476 & TRN \\
\hline CHEMBL1461001 & 688810 & \multicolumn{3}{|c|}{5.382999999999999} & 5.041 & TRN \\
\hline CHEMBL1479537 & 688810 & 5.483 & \multicolumn{3}{|c|}{5.4270000000000005} & TRN \\
\hline CHEMBL3208905 & 688810 & 5.183 & 5.2244 & TRN & & \\
\hline CHEMBL1501737 & 688810 & 4.783 & 5.0552 & TRN & & \\
\hline CHEMBL1365022 & 688810 & 5.483 & 5.3634 & TRN & & \\
\hline CHEMBL1508620 & 688810 & \multicolumn{3}{|c|}{5.7829999999999995} & 5.6948 & TRN \\
\hline CHEMBL1442755 & 688810 & 5.083 & 5.3613 & TRN & & \\
\hline CHEMBL1582822 & 688810 & \multicolumn{3}{|c|}{5.2829999999999995} & 5.2505 & TST \\
\hline CHEMBL1518934 & 688810 & \multicolumn{3}{|c|}{4.7330000000000005} & 4.8845 & TRN \\
\hline CHEMBL1312300 & 688810 & 4.783 & 5.5975 & TRN & & \\
\hline CHEMBL1492074 & 688810 & 4.833 & 4.8998 & TRN & & \\
\hline CHEMBL1414795 & 688810 & 4.783 & 4.8274 & TST & & \\
\hline CHEMBL1544445 & 688810 & 5.933 & 5.2658 & TST & & \\
\hline CHEMBL1383541 & 688810 & 5.683 & 6.0661 & TRN & & \\
\hline CHEMBL1605970 & 688810 & \multicolumn{3}{|c|}{4.7330000000000005} & 4.7464 & TRN \\
\hline CHEMBL1389604 & 688810 & \multicolumn{3}{|c|}{4.7330000000000005} & 4.7907 & TRN \\
\hline CHEMBL1414853 & 688810 & \multicolumn{3}{|c|}{5.382999999999999} & 5.0985 & TST \\
\hline CHEMBL592552 & 688810 & \multicolumn{3}{|c|}{4.9830000000000005} & 5.0382 & TRN \\
\hline CHEMBL449690 & 688810 & 4.633 & 5.1257 & TST & & \\
\hline CHEMBL1326141 & 688810 & 5.483 & 5.7996 & TRN & & \\
\hline CHEMBL1498612 & 688810 & 5.033 & 5.0521 & TRN & & \\
\hline CHEMBL1405567 & 688810 & \multicolumn{3}{|c|}{5.632999999999999} & 5.6348 & TRN \\
\hline CHEMBL1540107 & 688810 & 5.683 & 5.7182 & TRN & & \\
\hline CHEMBL1305960 & 688810 & 4.833 & 4.4481 & TRN & & \\
\hline
\end{tabular}




\begin{tabular}{|c|c|c|c|c|c|c|c|}
\hline \multirow[b]{2}{*}{ CHEMBL3196959 } & & \\
\hline & 688810 & 6.4829 & 5.5859 & TRN & & & \\
\hline CHEMBL1439477 & 688810 & 5.933 & 5.7877 & TRN & & & \\
\hline CHEMBL1348464 & 688810 & 5.33299 & 99999999 & & 5.4814 & TRN & \\
\hline CHEMBL3199098 & 688810 & 5.58299 & 99999999 & & 5.5737 & TRN & \\
\hline CHEMBL1303283 & 688810 & 6.53299 & 99999999 & 995 & 5.7761 & TRN & \\
\hline CHEMBL1486245 & 688810 & 6.233 & 5.4377 & TRN & & & \\
\hline CHEMBL1534197 & 688810 & 5.733 & 5.6376 & TRN & & & \\
\hline CHEMBL1457298 & 688810 & 5.033 & 4.8707 & TRN & & & \\
\hline CHEMBL1442681 & 688810 & 5.88299 & 99999999 & & 5.8577 & TRN & \\
\hline CHEMBL1455963 & 688810 & 5.433 & 5.1152 & TRN & & & \\
\hline CHEMBL1598834 & 688810 & 4.833 & 4.9134 & TRN & & & \\
\hline CHEMBL1392259 & 688810 & 5.13299 & 99999999 & & 5.5822 & TRN & \\
\hline CHEMBL1611556 & 688810 & 4.933 & 5.1787 & TRN & & & \\
\hline CHEMBL1564345 & 688810 & 4.883 & 5.2842 & TRN & & & \\
\hline CHEMBL1471361 & 688810 & 5.083 & 5.1372 & TRN & & & \\
\hline CHEMBL 1605026 & 688810 & 5.28299 & 99999999 & 995 & 5.2181 & TRN & \\
\hline CHEMBL1350332 & 688810 & 6.13299 & 99999999 & & 5.7991 & TRN & \\
\hline CHEMBL1443064 & 688810 & 5.13299 & 99999999 & & 5.5669 & TRN & \\
\hline CHEMBL1507089 & 688810 & 4.883 & 5.4694 & TRN & & & \\
\hline CHEMBL1981454 & 688810 & 5.183 & 5.4499 & TRN & & & \\
\hline CHEMBL1343224 & 688810 & 6.33299 & 99999999 & & 5.9086 & TRN & \\
\hline CHEMBL1460407 & 688810 & 4.73300 & 00000000 & 005 & 5.5645 & TRN & \\
\hline CHEMBL1610870 & 688810 & 5.483 & 4.9849 & TRN & & & \\
\hline CHEMBL1311280 & 688810 & 5.13299 & 99999999 & & 5.4618 & TST & \\
\hline CHEMBL1358264 & 688810 & 4.583 & 4.809 & TRN & & & \\
\hline CHEMBL3209944 & 688810 & 5.233 & 5.3657 & TRN & & & \\
\hline CHEMBL1486422 & 688810 & 4.633 & 5.4923 & TRN & & & \\
\hline CHEMBL1477565 & 688810 & 4.933 & 4.9979 & TRN & & & \\
\hline CHEMBL1465437 & 688810 & 5.13299 & 99999999 & & 5.61799 & 9999999999 & TRN \\
\hline CHEMBL1505364 & 688810 & 4.73300 & 00000000 & 005 & 5.7929 & TRN & \\
\hline CHEMBL1481499 & 688810 & 5.53299 & 99999999 & 995 & 5.3516 & TRN & \\
\hline CHEMBL1487067 & 688810 & 4.883 & 4.8352 & TST & & & \\
\hline CHEMBL 1454450 & 688810 & 4.98300 & 00000000 & 005 & 5.2509 & TRN & \\
\hline CHEMBL1481111 & 688810 & 4.73300 & 00000000 & 005 & 5.0985 & TST & \\
\hline CHEMBL1569935 & 688810 & 4.883 & 5.1997 & TRN & & & \\
\hline CHEMBL590397 & 688810 & 4.783 & 5.2324 & TRN & & & \\
\hline CHEMBL1419663 & 688810 & 4.73300 & 00000000 & 005 & 5.3549 & TST & \\
\hline CHEMBL1407512 & 688810 & 6.38299 & 99999999 & & 5.5518 & TRN & \\
\hline CHEMBL1338432 & 688810 & 5.58299 & 99999999 & & 5.0823 & TRN & \\
\hline CHEMBL1364931 & 688810 & 4.933 & 5.2172 & TRN & & & \\
\hline CHEMBL1396506 & 688810 & 4.683 & 5.0885 & TST & & & \\
\hline CHEMBL 3208962 & 688810 & 6.33299 & 99999999 & & 5.7731 & TRN & \\
\hline CHEMBL1311052 & 688810 & 4.833 & 4.8613 & TRN & & & \\
\hline CHEMBL1465096 & 688810 & 4.633 & 4.9422 & TRN & & & \\
\hline CHEMBL1508229 & 688810 & 4.833 & 5.2708 & TST & & & \\
\hline CHEMBL1422229 & 688810 & 4.783 & 5.289 & TRN & & & \\
\hline CHEMBL1401951 & 688810 & 4.683 & 5.0876 & TST & & & \\
\hline CHEMBL1364562 & 688810 & 4.833 & 5.1565 & TST & & & \\
\hline
\end{tabular}




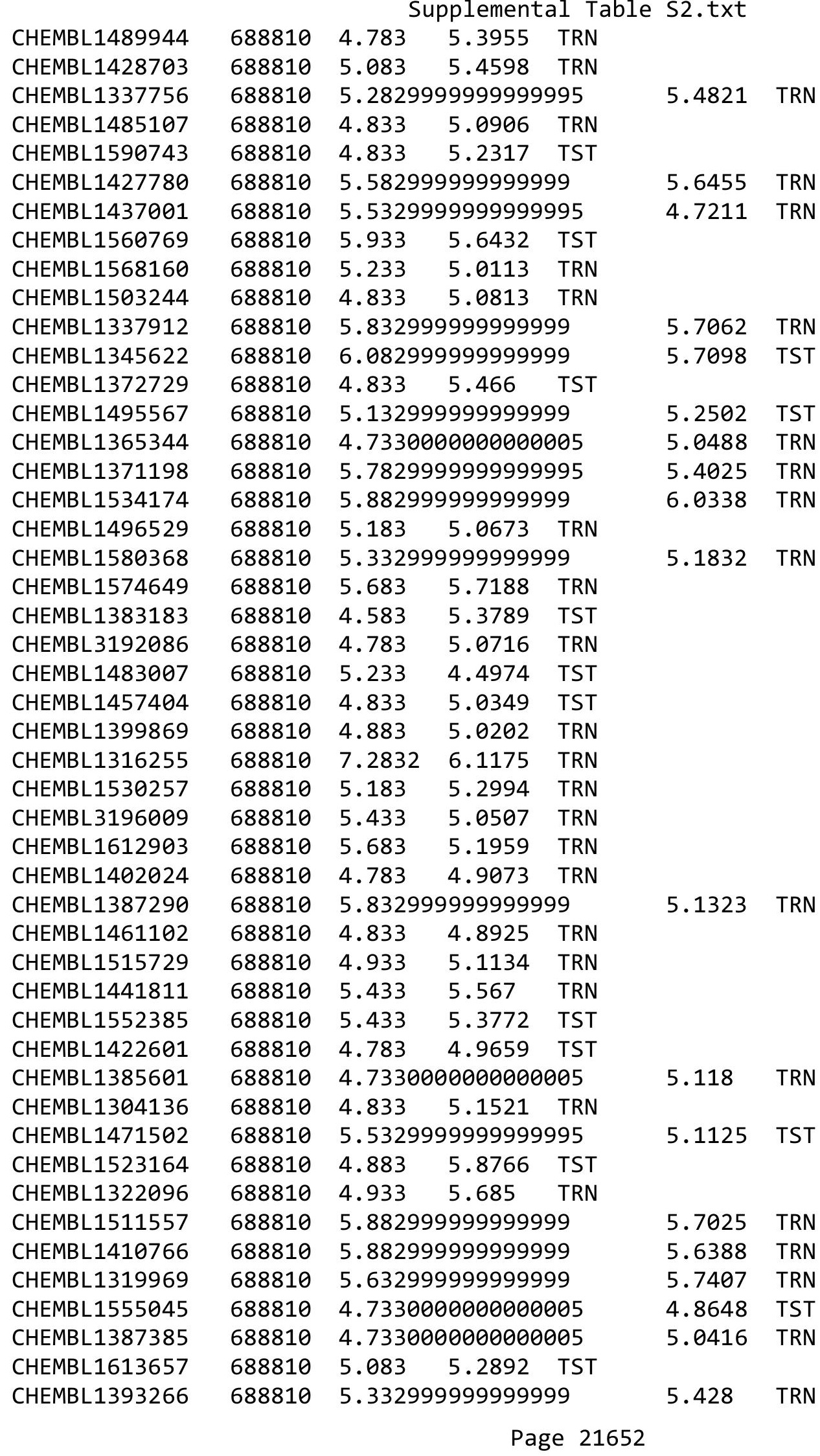




\begin{tabular}{|c|c|c|c|c|c|c|}
\hline & & & & & & \\
\hline CHEMBL1610631 & 688810 & 4.783 & 5.2731 & TST & & \\
\hline CHEMBL1590549 & 688810 & 4.583 & 5.0978 & TST & & \\
\hline CHEMBL1568925 & 688810 & 4.583 & 4.6864 & TRN & & \\
\hline CHEMBL1301785 & 588810 & 4.783 & 5.2602 & TRN & & \\
\hline CHEMBL1358705 & 688810 & 5.6329 & 9999999 & & 5.4214 & TRN \\
\hline CHEMBL1366374 & 688810 & 5.5829 & 9999999 & & 5.1931 & TST \\
\hline CHEMBL1596656 & 688810 & 6.0329 & 9999999 & 995 & 5.7945 & TRN \\
\hline CHEMBL1325601 & 688810 & 5.5329 & 9999999 & 995 & 5.3094 & \\
\hline CHEMBL1607974 & 688810 & 4.933 & 5.0819 & TRN & & \\
\hline CHEMBL1451955 & 688810 & 4.883 & 5.447 & TRN & & \\
\hline CHEMBL1580340 & 688810 & 5.233 & 5.9102 & TRN & & \\
\hline CHEMBL1534577 & 688810 & 6.183 & 5.7662 & TRN & & \\
\hline CHEMBL1355755 & 688810 & 6.433 & 6.1408 & TRN & & \\
\hline CHEMBL1433868 & 688810 & 4.7330 & 0000000 & 005 & 164 & \\
\hline CHEMBL1489033 & 688810 & 4.683 & 5.1555 & TST & & \\
\hline CHEMBL1515212 & 688810 & 4.9830 & 0000000 & 005 & 5.0738 & TRN \\
\hline CHEMBL1382656 & 688810 & 6.1329 & 9999999 & & 5.8 & \\
\hline CHEMBL1385987 & 688810 & 5.6329 & 9999999 & & 5.1597 & \\
\hline CHEMBL1609927 & 688810 & 4.833 & 5.3096 & TRN & & \\
\hline CHEMBL1333339 & 688810 & 6.433 & 5.7998 & TRN & & \\
\hline CHEMBL1500060 & 688810 & 6.3329 & 9999999 & & 5.8827 & INIV \\
\hline CHEMBL1491849 & 688810 & 6.0329 & 9999999 & 995 & 5.8097 & TRN \\
\hline CHEMBL1610839 & 688810 & 5.183 & 5.4434 & TRN & & \\
\hline CHEMBL1552723 & 688810 & 7.1331 & 5.53 & TRN & & \\
\hline CHEMBL1485664 & 688810 & 5.1329 & 9999999 & & 5.2432 & \\
\hline CHEMBL1567607 & 688810 & 5.683 & 5.9039 & TRN & & \\
\hline CHEMBL1550188 & 688810 & 4.883 & 4.9025 & TRN & & \\
\hline CHEMBL1506442 & 688810 & 4.883 & 5.1284 & TRN & & \\
\hline CHEMBL1495537 & 688810 & 5.8829 & 9999999 & & 5.6945 & TRN \\
\hline CHEMBL 3214527 & 688810 & 4.9830 & 0000000 & 005 & 5.3062 & TS \\
\hline CHEMBL1371638 & 688810 & 4.833 & 5.0105 & TRN & & \\
\hline CHEMBL1565401 & 688810 & 6.5829 & 9999999 & & 5.9347 & TST \\
\hline CHEMBL1406367 & 688810 & 5.6329 & 9999999 & & 5.0092 & TRN \\
\hline CHEMBL 3197240 & 688810 & 5.3329 & 9999999 & & 5.0848 & TR \\
\hline CHEMBL1338530 & 688810 & 4.633 & 5.2126 & TST & & \\
\hline CHEMBL3210634 & 688810 & 6.0829 & 9999999 & & 5.2 & TRN \\
\hline CHEMBL3214466 & 688810 & 5.8329 & 9999999 & & 5.3049 & TRN \\
\hline CHEMBL1968522 & 688810 & 4.833 & 5.0961 & TRN & & \\
\hline CHEMBL1484245 & 688810 & 4.883 & 5.2707 & TST & & \\
\hline CHEMBL1409988 & 688810 & 4.7330 & 0000000 & 05 & & INIV \\
\hline CHEMBL1440507 & 688810 & 4.7330 & 0000000 & 005 & 4.8114 & TST \\
\hline CHEMBL 3189936 & 688810 & 5.2829 & 9999999 & 995 & 5.3128 & TRN \\
\hline CHEMBL1521976 & 688810 & 4.833 & 5.1882 & TRN & & \\
\hline CHEMBL1583094 & 688810 & 4.7330 & 0000000 & 005 & 5.2137 & . \\
\hline CHEMBL 3192804 & 688810 & 4.583 & 5.1108 & TRN & & \\
\hline CHEMBL 3190036 & 688810 & 5.2829 & 9999999 & & 4.7316 & Trov \\
\hline CHEMBL1353805 & 688810 & 6.6329 & 9999999 & & 5.7958 & TRN \\
\hline CHEMBL1526249 & 688810 & 6.5829 & 9999999 & & 6.0083 & TRA \\
\hline
\end{tabular}




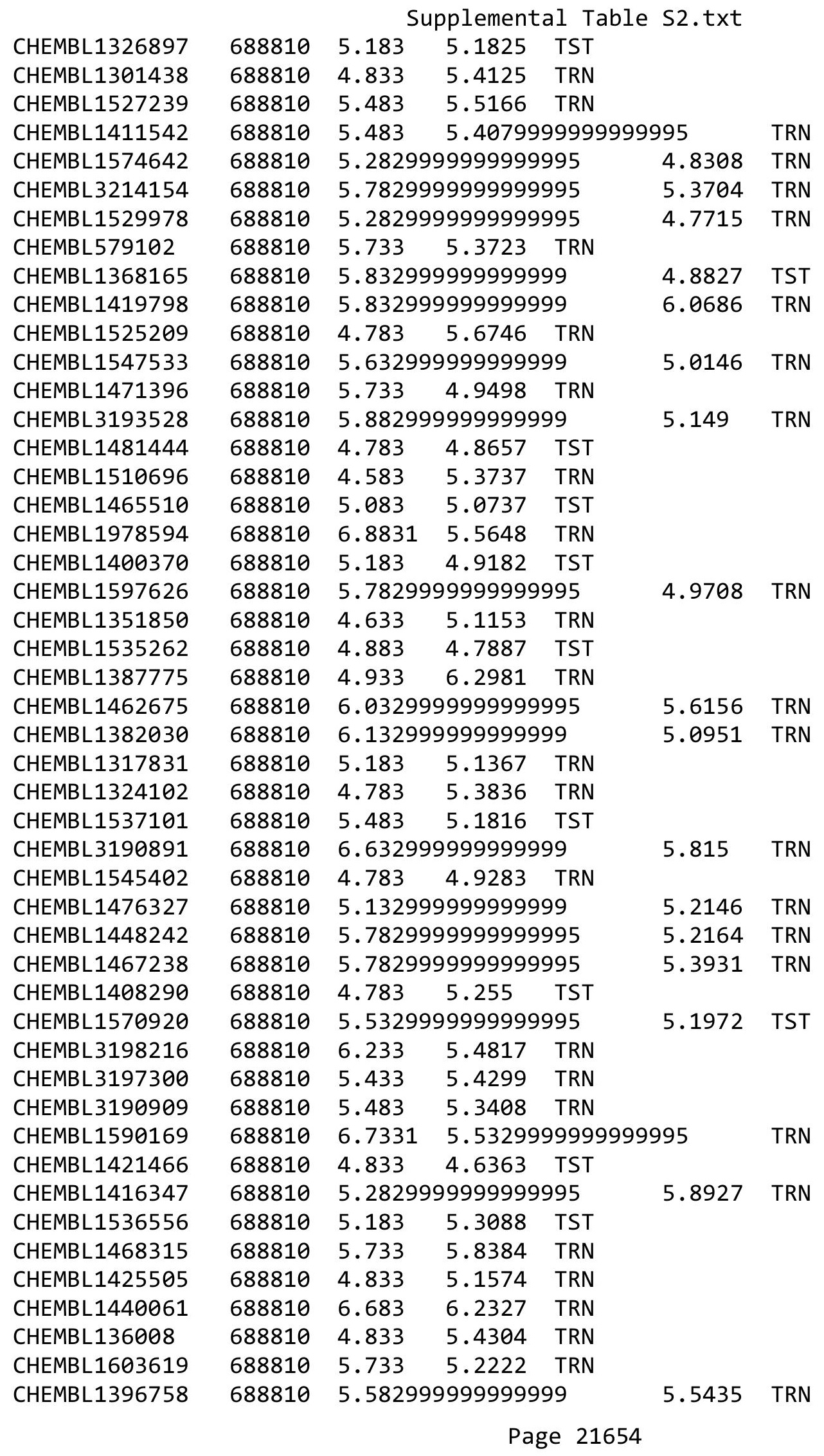




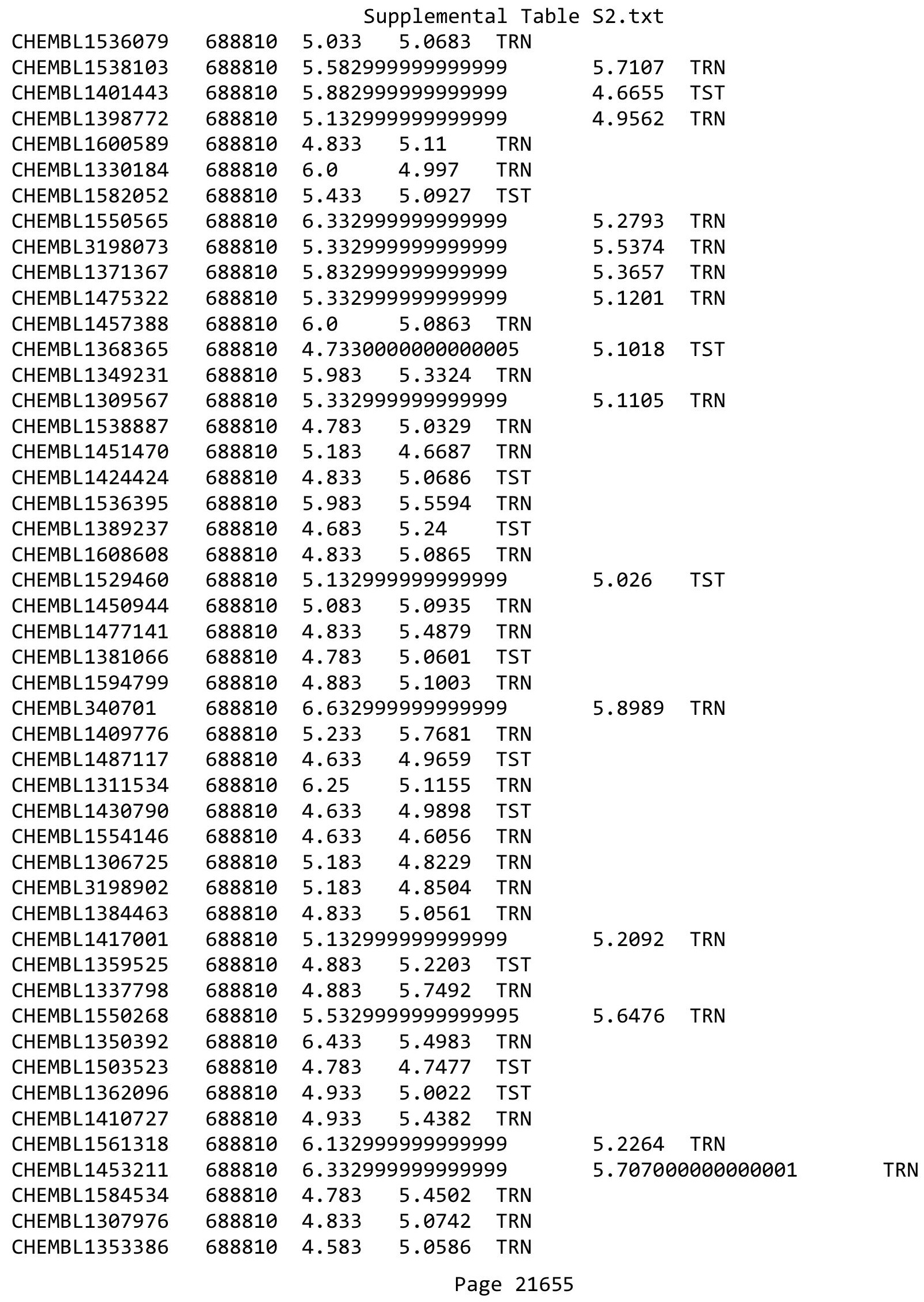




\begin{tabular}{|c|c|c|c|c|c|c|}
\hline \multicolumn{7}{|c|}{ Supplemental Table S2.txt } \\
\hline CHEMBL1603399 & 688810 & 5.483 & \multicolumn{3}{|c|}{5.587000000000001} & \multirow{2}{*}{$\begin{array}{l}\text { TRN } \\
\text { TRN }\end{array}$} \\
\hline CHEMBL1352960 & 688810 & \multicolumn{3}{|c|}{6.082999999999999} & 5.3959 & \\
\hline CHEMBL3195817 & 688810 & 4.783 & 5.1733 & TRN & & \\
\hline CHEMBL1359404 & 688810 & \multicolumn{3}{|c|}{6.332999999999999} & 5.5579 & TRN \\
\hline CHEMBL1609931 & 688810 & \multicolumn{3}{|c|}{4.7330000000000005} & 5.2351 & TRN \\
\hline CHEMBL1410093 & 688810 & 4.833 & 6.1291 & TRN & & \\
\hline CHEMBL1603127 & 688810 & 4.883 & 5.0528 & TST & & \\
\hline CHEMBL1586553 & 688810 & 5.683 & 5.9321 & TRN & & \\
\hline CHEMBL1543680 & 688810 & \multicolumn{3}{|c|}{5.2829999999999995} & 5.0129 & TRN \\
\hline CHEMBL1565242 & 688810 & \multicolumn{3}{|c|}{5.832999999999999} & 5.5679 & TRN \\
\hline CHEMBL3214532 & 688810 & 5.683 & 5.4318 & TRN & & \\
\hline CHEMBL1409468 & 688810 & \multicolumn{3}{|c|}{5.882999999999999} & 5.6664 & TRN \\
\hline CHEMBL1601275 & 688810 & \multicolumn{3}{|c|}{6.132999999999999} & 5.2788 & TRN \\
\hline CHEMBL1303494 & 688810 & \multicolumn{3}{|c|}{5.7829999999999995} & 5.2064 & TRN \\
\hline CHEMBL1488408 & 688810 & 4.883 & 4.9908 & TST & & \\
\hline CHEMBL1468774 & 688810 & 5.65 & \multicolumn{3}{|c|}{5.337000000000001} & TST \\
\hline CHEMBL3191691 & 688810 & \multicolumn{4}{|c|}{4.7330000000000005} & TST \\
\hline CHEMBL1390049 & 688810 & \multicolumn{3}{|c|}{5.582999999999999} & 5.6919 & TST \\
\hline CHEMBL1530612 & 688810 & 4.783 & 5.1618 & TRN & & \\
\hline CHEMBL1420163 & 688810 & 4.583 & \multicolumn{3}{|c|}{4.8919999999999995} & TRN \\
\hline CHEMBL1580699 & 688810 & 5.033 & 5.3108 & TST & & \\
\hline CHEMBL1526250 & 688810 & 4.883 & \multirow{2}{*}{\multicolumn{3}{|c|}{$\begin{array}{l}5.1894 \text { TRN } \\
4.6339999999999995\end{array}$}} & \\
\hline CHEMBL1610227 & 688810 & 4.633 & & & & TST \\
\hline CHEMBL1570142 & 688810 & 6.233 & 5.5159 & TRN & & \\
\hline CHEMBL1322261 & 688810 & 5.13299 & 999999999 & & 5.4135 & TRN \\
\hline CHEMBL1325808 & 688810 & \multicolumn{3}{|c|}{6.2829999999999995} & 5.3166 & TRN \\
\hline CHEMBL3190834 & 688810 & \multicolumn{3}{|c|}{5.832999999999999} & 5.4729 & TST \\
\hline CHEMBL1985680 & 688810 & 6.183 & 5.7152 & TRN & & \\
\hline CHEMBL1463018 & 688810 & \multicolumn{3}{|c|}{5.632999999999999} & 5.2719 & TRN \\
\hline CHEMBL1366158 & 688810 & \multicolumn{3}{|c|}{6.332999999999999} & 5.6262 & TRN \\
\hline CHEMBL1371392 & 688810 & 4.73300 & 000000000 & 005 & 4.9407 & TST \\
\hline CHEMBL1501462 & 688810 & 5.53299 & 999999999 & 995 & 5.1333 & TST \\
\hline CHEMBL1365319 & 688810 & 5.033 & 5.6555 & TRN & & \\
\hline CHEMBL1489131 & 688810 & 4.583 & 5.1103 & TST & & \\
\hline CHEMBL1403706 & 688810 & 5.033 & 5.1627 & TRN & & \\
\hline CHEMBL3192847 & 688810 & 5.083 & 5.2128 & TRN & & \\
\hline CHEMBL1587940 & 688810 & 4.73300 & 000000000 & 005 & 5.3105 & TRN \\
\hline CHEMBL1471030 & 688810 & 6.183 & 5.6519 & TRN & & \\
\hline CHEMBL1397770 & 688810 & 4.833 & 5.6346 & TRN & & \\
\hline CHEMBL1471914 & 688810 & 4.933 & 5.0521 & TRN & & \\
\hline CHEMBL1398497 & 688810 & 6.28299 & 999999999 & 995 & 5.6809 & TRN \\
\hline CHEMBL1464920 & 688810 & 4.783 & 5.5468 & TRN & & \\
\hline CHEMBL1483403 & 688810 & 4.933 & 5.1427 & TST & & \\
\hline CHEMBL1430893 & 688810 & 5.6 & 5.1249 & TRN & & \\
\hline CHEMBL1460740 & 688810 & 4.833 & 5.3996 & TST & & \\
\hline CHEMBL1431305 & 688810 & 4.73300 & 000000000 & 005 & 4.93199 & 99999999995 \\
\hline CHEMBL1359848 & 688810 & 4.73300 & 000000000 & 005 & 5.4073 & TST \\
\hline CHEMBL1443755 & 688810 & 5.183 & 5.3201 & TRN & & \\
\hline
\end{tabular}




\begin{tabular}{|c|c|c|c|c|c|c|}
\hline & & \multicolumn{5}{|c|}{ Supplemental Table s2.txt } \\
\hline CHEMBL 3213412 & 688810 & 4.833 & 5.0934 & TRN & & \\
\hline CHEMBL1327364 & 688810 & 4.883 & 5.4978 & TRN & & \\
\hline CHEMBL1306079 & 688810 & 4.633 & 4.7081 & TST & & \\
\hline CHEMBL1306949 & 688810 & 5.733 & 5.42 & TRN & & \\
\hline CHEMBL1587495 & 688810 & 5.483 & 5.3064 & TRN & & \\
\hline CHEMBL1365696 & 688810 & 4.633 & 5.1173 & TRN & & \\
\hline CHEMBL1514426 & 688810 & 5.483 & 5.7478 & TRN & & \\
\hline CHEMBL1461600 & 688810 & 5.733 & 5.5205 & TST & & \\
\hline CHEMBL1543248 & 688810 & 5.183 & 5.0942 & TST & & \\
\hline CHEMBL1337415 & 688810 & 4.933 & 5.0534 & TST & & \\
\hline CHEMBL1345632 & 688810 & 5.483 & 5.7425 & TST & & \\
\hline CHEMBL 3193573 & 688810 & 4.583 & 5.0137 & TST & & \\
\hline CHEMBL1603311 & 688810 & \multicolumn{3}{|c|}{4.7330000000000005} & 4.9581 & \\
\hline CHEMBL1611892 & 688810 & 4.833 & 5.4815 & TST & & \\
\hline CHEMBL 285819 & 688810 & 6.9329 & 6.1811 & TRN & & \\
\hline CHEMBL3195267 & 688810 & 4.783 & 5.3127 & TRN & & \\
\hline CHEMBL1551401 & 688810 & \multicolumn{3}{|c|}{6.0329999999999995} & 5.1205 & TRN \\
\hline CHEMBL1372066 & 688810 & \multicolumn{3}{|c|}{5.632999999999999} & 5.716 & TRN \\
\hline CHEMBL1605143 & 688810 & \multicolumn{3}{|c|}{4.9830000000000005} & 5.1049 & TRN \\
\hline CHEMBL1429228 & 688810 & \multicolumn{3}{|c|}{4.9830000000000005} & 5.0644 & TRN \\
\hline CHEMBL1489253 & 688810 & 4.683 & 5.0307 & TRN & & \\
\hline CHEMBL1575228 & 688810 & \multicolumn{3}{|c|}{6.2829999999999995} & 5.4146 & \\
\hline CHEMBL1300862 & 688810 & 5.033 & 5.3948 & TRN & & \\
\hline CHEMBL1442076 & 688810 & \multicolumn{3}{|c|}{4.7330000000000005} & 5.1627 & $\mathrm{TR}$ \\
\hline CHEMBL1381755 & 688810 & 5.683 & 5.4988 & TRN & & \\
\hline CHEMBL1439150 & 688810 & 4.783 & 4.7438 & TRN & & \\
\hline CHEMBL1367866 & 688810 & 4.783 & 4.6065 & TST & & \\
\hline CHEMBL1306695 & 688810 & 5.233 & 5.416 & TRN & & \\
\hline CHEMBL1420382 & 688810 & \multicolumn{3}{|c|}{5.332999999999999} & 5.0747 & TST \\
\hline CHEMBL1607584 & 688810 & \multicolumn{3}{|c|}{4.7330000000000005} & 5.0761 & TST \\
\hline CHEMBL1498285 & 688810 & 4.633 & 5.0457 & TST & & \\
\hline CHEMBL1300372 & 688810 & 5.233 & 5.5419 & TRN & & \\
\hline CHEMBL1510543 & 688810 & 4.633 & 4.9542 & TST & & \\
\hline CHEMBL1334030 & 688810 & \multicolumn{3}{|c|}{6.332999999999999} & 5.615 & $\mathrm{TR}$ \\
\hline CHEMBL1604194 & 688810 & 4.783 & 5.4328 & TRN & & \\
\hline CHEMBL1382054 & 688810 & \multicolumn{3}{|c|}{6.2829999999999995} & 5.4616 & TRN \\
\hline CHEMBL1601150 & 688810 & 4.883 & 5.2074 & TST & & \\
\hline CHEMBL1623028 & 688810 & \multicolumn{3}{|c|}{6.132999999999999} & 5.7698 & TRN \\
\hline CHEMBL1534021 & 688810 & \multicolumn{3}{|c|}{5.132999999999999} & 5.4354 & TRN \\
\hline CHEMBL1373226 & 688810 & 4.883 & 5.1457 & TST & & \\
\hline CHEMBL1372320 & 688810 & \multicolumn{3}{|c|}{5.132999999999999} & 5.1859 & $1 \mathrm{~K}$ \\
\hline CHEMBL1535520 & 688810 & 4.833 & 4.7809 & TST & & \\
\hline CHEMBL1564822 & 688810 & 5.183 & 5.0098 & TST & & \\
\hline CHEMBL1531929 & 688810 & \multicolumn{3}{|c|}{5.5329999999999995} & 5.5452 & TाN \\
\hline CHEMBL1595847 & 688810 & \multicolumn{3}{|c|}{5.132999999999999} & 5.1143 & $\mathrm{TR}$ \\
\hline CHEMBL1417596 & 688810 & 5.483 & 5.4838 & TRN & & \\
\hline CHEMBL1488093 & 688810 & 5.683 & 5.7889 & TRN & & \\
\hline CHEMBL1313648 & 688810 & \multicolumn{3}{|c|}{5.7829999999999995} & 5.6481 & 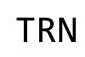 \\
\hline
\end{tabular}




\begin{tabular}{|c|c|c|c|c|c|c|c|}
\hline \multirow[b]{2}{*}{ CHEMBL3189518 } & & \\
\hline & 688810 & 5.733 & 5.4254 & TRN & & & \\
\hline CHEMBL1316968 & 688810 & 4.933 & 5.3228 & TRN & & & \\
\hline CHEMBL1558765 & 688810 & 5.1329 & 99999999 & & 4.869 & TRN & \\
\hline CHEMBL1377522 & 688810 & 4.833 & 5.4959 & TST & & & \\
\hline CHEMBL1577150 & 688810 & 4.883 & 5.1174 & TRN & & & \\
\hline CHEMBL1565809 & 688810 & 5.8829 & 99999999 & & 5.1418 & TRN & \\
\hline CHEMBL3199470 & 688810 & 5.7829 & 99999999 & 995 & 5.2302 & TRN & \\
\hline CHEMBL1323991 & 688810 & 5.5829 & 99999999 & & 5.4776 & TRN & \\
\hline CHEMBL1364277 & 688810 & 4.833 & 4.9081 & TST & & & \\
\hline CHEMBL1426922 & 688810 & 6.2829 & 99999999 & 995 & 5.7504 & TRN & \\
\hline CHEMBL1356215 & 688810 & 5.2829 & 99999999 & 995 & 5.3177 & TRN & \\
\hline CHEMBL1344790 & 688810 & 5.5329 & 99999999 & 995 & 5.6954 & TRN & \\
\hline CHEMBL1416310 & 688810 & 4.833 & 5.2714 & TRN & & & \\
\hline CHEMBL1339307 & 688810 & 5.2829 & 99999999 & 995 & 5.5921 & TRN & \\
\hline CHEMBL1575603 & 688810 & 4.833 & 4.8923 & TRN & & & \\
\hline CHEMBL1411023 & 688810 & 5.1329 & 99999999 & & 4.9071 & TST & \\
\hline CHEMBL1563190 & 688810 & 4.583 & 5.0496 & TRN & & & \\
\hline CHEMBL3189761 & 688810 & 5.233 & 5.3249 & TRN & & & \\
\hline CHEMBL1345519 & 688810 & 5.433 & 5.4975 & TRN & & & \\
\hline CHEMBL1334273 & 688810 & 5.233 & 5.3375 & TRN & & & \\
\hline CHEMBL1222386 & 688810 & 5.5329 & 99999999 & 995 & 5.4277 & TRN & \\
\hline CHEMBL1584740 & 688810 & 4.783 & 5.129 & TRN & & & \\
\hline CHEMBL1375000 & 688810 & 4.833 & 5.511 & TRN & & & \\
\hline CHEMBL1540371 & 688810 & 6.1329 & 99999999 & & 5.1394 & TST & \\
\hline CHEMBL1401137 & 688810 & 5.933 & 5.805 & TRN & & & \\
\hline CHEMBL1337987 & 688810 & 4.883 & 5.1161 & TRN & & & \\
\hline CHEMBL1396536 & 688810 & 4.633 & 4.9339 & TRN & & & \\
\hline CHEMBL1526637 & 688810 & 5.933 & 5.8994 & TRN & & & \\
\hline CHEMBL1477651 & 688810 & 5.2829 & 99999999 & 995 & 5.1158 & TRN & \\
\hline CHEMBL1580910 & 688810 & 4.7330 & 00000000 & 005 & 4.7459 & TST & \\
\hline CHEMBL1522953 & 688810 & 4.783 & 4.7253 & TRN & & & \\
\hline CHEMBL 3213502 & 688810 & 5.683 & 5.2744 & TRN & & & \\
\hline CHEMBL1610636 & 688810 & 6.983 & 6.2888 & TRN & & & \\
\hline CHEMBL1334550 & 688810 & 6.0 & 4.6315 & TRN & & & \\
\hline CHEMBL1609354 & 688810 & 5.933 & 5.4608 & TRN & & & \\
\hline CHEMBL1393221 & 688810 & 5.983 & 5.7169 & TRN & & & \\
\hline CHEMBL3208587 & 688810 & 5.983 & 5.2432 & TRN & & & \\
\hline CHEMBL1585034 & 688810 & 5.1329 & 99999999 & & 5.4855 & TRN & \\
\hline CHEMBL1487222 & 688810 & 5.033 & 5.3045 & TST & & & \\
\hline CHEMBL147514 & 688810 & 5.033 & 4.7965 & TST & & & \\
\hline CHEMBL1358894 & 688810 & 4.933 & 5.2454 & TRN & & & \\
\hline CHEMBL1565189 & 688810 & 4.9830 & 00000000 & 005 & 5.1825 & TST & \\
\hline CHEMBL1546195 & 688810 & 4.9830 & 00000000 & 005 & 5.80200 & 00000000005 & TRN \\
\hline CHEMBL1577226 & 688810 & 4.833 & 5.0073 & TRN & & & \\
\hline CHEMBL1318943 & 688810 & 4.583 & 4.8978 & TST & & & \\
\hline CHEMBL1342147 & 688810 & 5.1329 & 99999999 & & 6.1529 & TRN & \\
\hline CHEMBL1417654 & 688810 & 5.7829 & 99999999 & 995 & 5.0145 & TRN & \\
\hline CHEMBL1559014 & 688810 & 5.083 & 5.4619 & TRN & & & \\
\hline
\end{tabular}




\begin{tabular}{|c|c|c|c|c|c|c|}
\hline CHEMBL1324036 & 688810 & 4.933 & 5.1574 & TRN & & \\
\hline CHEMBL1405539 & 688810 & \multicolumn{3}{|c|}{4.7330000000000005} & 5.1838 & \\
\hline CHEMBL1381918 & 688810 & 5.933 & 5.7462 & TRN & & \\
\hline HEMBL1476790 & 88810 & 4.633 & 4.9001 & TRN & & \\
\hline CHEMBL1531555 & 88810 & \multicolumn{3}{|c|}{5.5329999999999995} & 5.5701 & \\
\hline CHEMBL1407168 & 588810 & \multicolumn{3}{|c|}{5.832999999999999} & 5.2464 & \\
\hline CHEMBL1610235 & 588810 & \multicolumn{3}{|c|}{5.2829999999999995} & 4.8 & \\
\hline HEMBL1971376 & 88810 & 4.883 & 5.0466 & TRN & & \\
\hline HEMBL3212546 & 88810 & 4.883 & 4.798 & TRN & & \\
\hline CHEMBL1423409 & 88810 & 6.433 & 6.0202 & TRN & & \\
\hline CHEMBL1537436 & 688810 & \multicolumn{3}{|c|}{6.2829999999999995} & 6.0067 & \\
\hline CHEMBL1544979 & 688810 & 4.883 & 4.902 & TRN & & \\
\hline HEMBL1595685 & 88810 & 4.95 & 5.6965 & TRN & & \\
\hline HEMBL1586035 & 88810 & \multicolumn{3}{|c|}{5.7829999999999995} & 8 & \\
\hline CHEMBL1444219 & 688810 & \multicolumn{3}{|c|}{5.2829999999999995} & & \\
\hline HEMBL1547207 & 688810 & 4.583 & 5.1495 & TRN & & \\
\hline HEMBL1369691 & 688810 & \multicolumn{3}{|c|}{6.7829999999999995} & 5.4688 & \\
\hline HEMBL1594484 & 88810 & 5.933 & 5.4851 & TRN & & \\
\hline CHEMBL1323490 & 688810 & \multicolumn{3}{|c|}{6.582999999999999} & 9 & \\
\hline CHEMBL1447004 & 688810 & 5.15 & 4.9514 & TRN & & \\
\hline HEMBL1343475 & 8810 & 4.783 & 5.1915 & TRN & & \\
\hline HEMBL1577430 & 810 & 5.733 & 5.1863 & TRN & & \\
\hline HEMBL1579236 & 88810 & 4.85 & 5.3892 & TRN & & \\
\hline CHEMBL1407036 & 688810 & \multicolumn{3}{|c|}{5.382999999999999} & & \\
\hline CHEMBL1589914 & 688810 & \multicolumn{3}{|c|}{5.382999999999999} & & \\
\hline CHEMBL1320319 & 688810 & 5.983 & 5.2117 & TST & & \\
\hline CHEMBL1387610 & 688810 & \multicolumn{3}{|c|}{5.332999999999999} & 339 & \\
\hline HEMBL1332925 & 688810 & 5.683 & 5.2599 & TST & & \\
\hline CHEMBL 3193974 & 688810 & \multicolumn{3}{|c|}{5.632999999999999} & 5.4386 & \\
\hline CHEMBLI & 688810 & 6.983 & 5.3574 & TST & & \\
\hline CHEMBL1 & 688810 & \multicolumn{3}{|c|}{6.082999999999999} & 5.1599 & \\
\hline CHEMBL1379976 & 688810 & 6.983 & 5.9998 & TRN & & \\
\hline CHEMBL1388983 & 688810 & \multirow{2}{*}{\multicolumn{3}{|c|}{$\begin{array}{lll}4.883 & 5.5828 & \text { TRN } \\
5.2829999999999995\end{array}$}} & & \\
\hline CHEMBL1371203 & 688810 & & & & 5.7577 & \\
\hline CHEMBL] & 688810 & 4.583 & 5.274 & TRN & & \\
\hline CHEMBL1985797 & 688810 & \multicolumn{3}{|c|}{5.132999999999999} & 926 & \\
\hline CHEMBL1579951 & 688810 & \multicolumn{3}{|c|}{4.7330000000000005} & & \\
\hline CHEMBL1303116 & 688810 & \multicolumn{3}{|c|}{4.9830000000000005} & 5. & \\
\hline CHEMBL1537047 & 688810 & 4.633 & \multicolumn{3}{|c|}{5.156000000000001} & \\
\hline CHEMBL1510582 & 688810 & 4.883 & 4.5069 & TRN & & \\
\hline CHEMBL1375130 & 688810 & \multicolumn{3}{|c|}{5.632999999999999} & 5.0079 & \\
\hline CHEMBL1377833 & 688810 & 4.883 & 5.5335 & TRN & & \\
\hline CHEMBL1341593 & 688810 & \multicolumn{3}{|c|}{4.7330000000000005} & 5.286 & \\
\hline CHEMBL1514145 & 688810 & 4.583 & 4.817 & TST & & \\
\hline CHEMBL1496428 & 688810 & 4.833 & \multicolumn{3}{|c|}{4.6610000000000005} & \\
\hline CHEMBL1393568 & 688810 & 4.633 & 5.088 & TRN & & \\
\hline CHEMBL1430053 & 688810 & 6.5829 & 999999999 & & & \\
\hline CHEMBL1546139 & 688810 & 4.7330 & 2000000 & 005 & 4.544 & \\
\hline
\end{tabular}




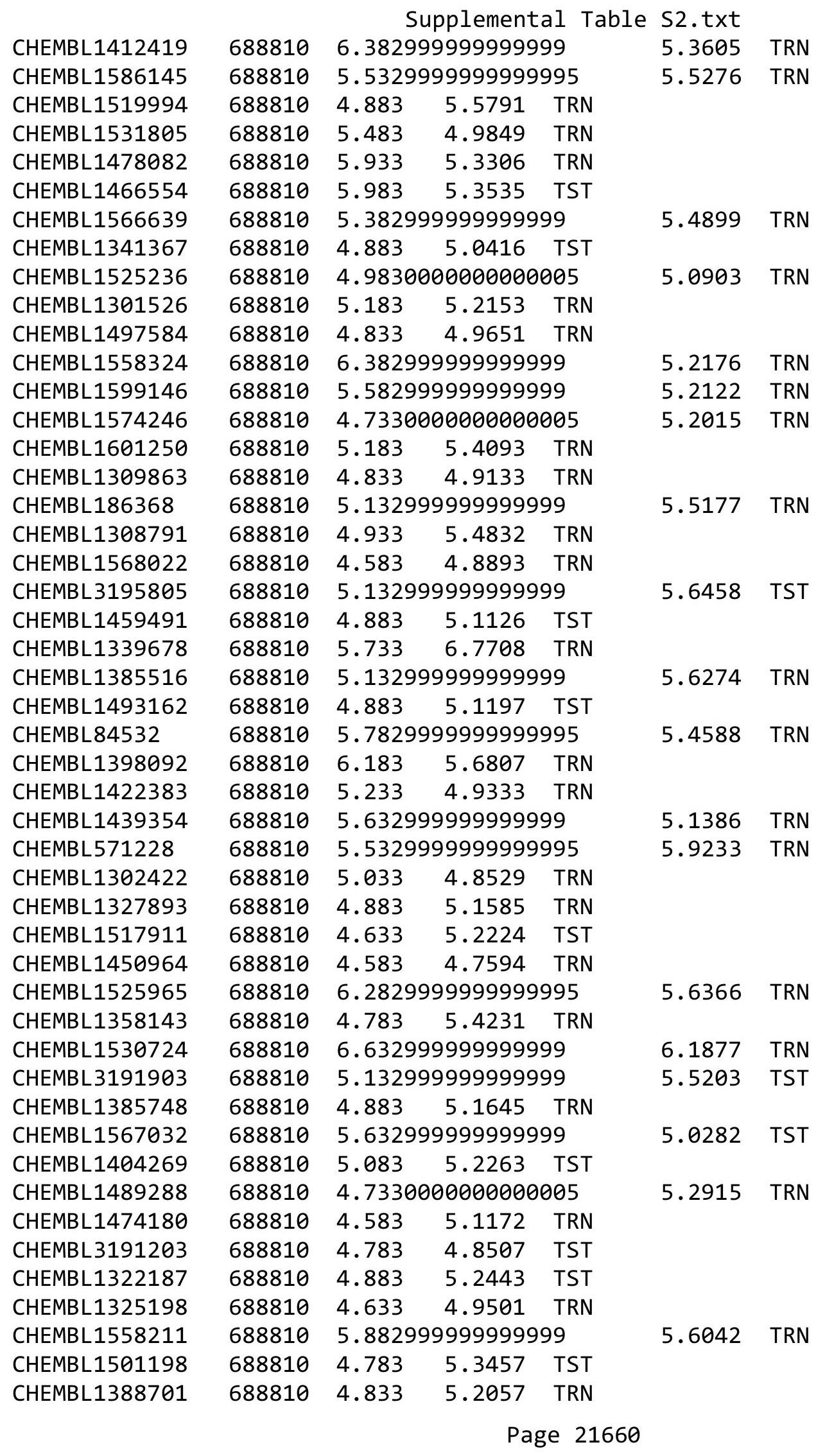




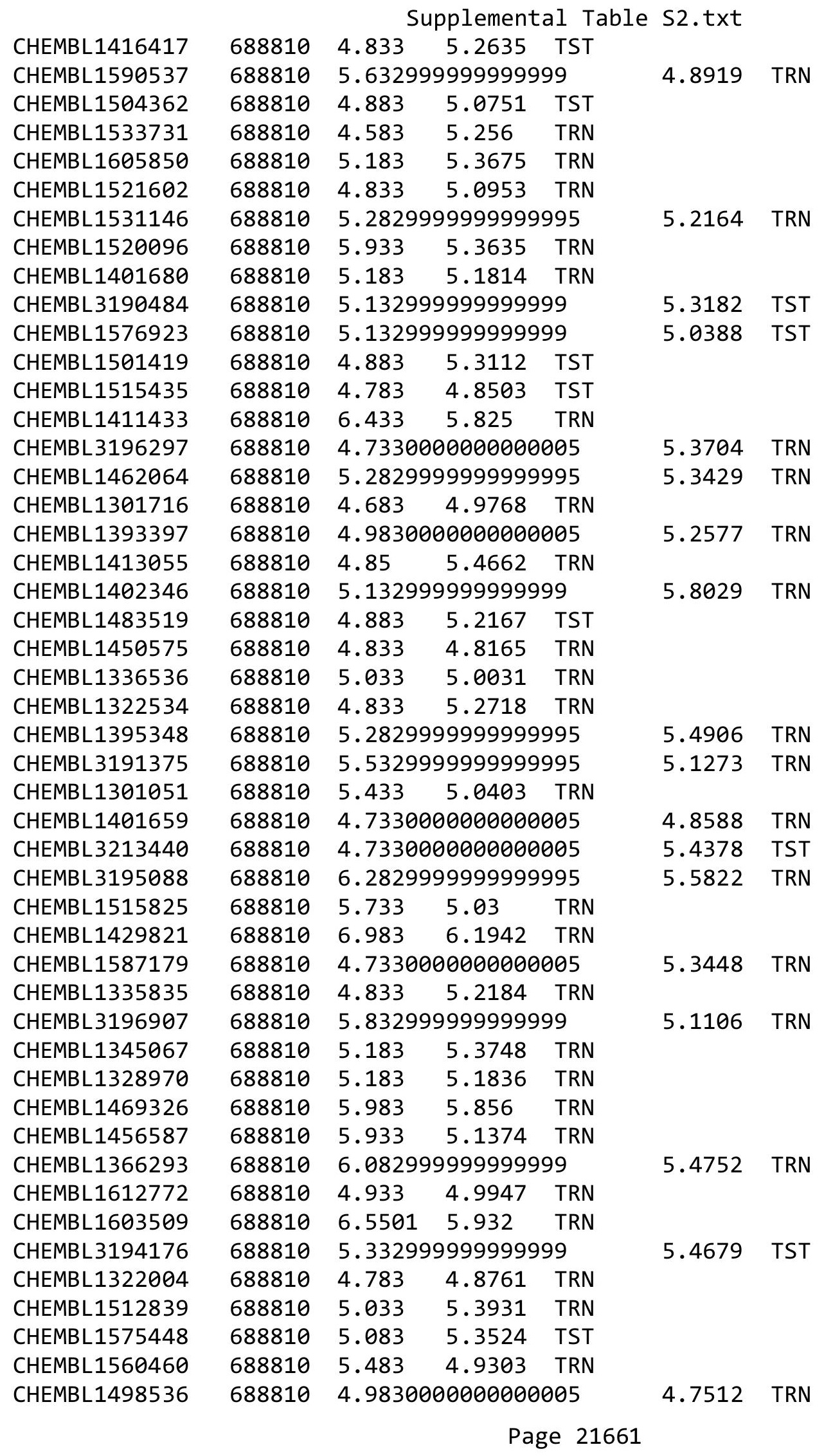




\begin{tabular}{|c|c|c|c|c|c|c|c|}
\hline \multicolumn{7}{|c|}{ Supplemental Table S2.txt } & \\
\hline CHEMBL1366360 & 688810 & 4.633 & \multicolumn{3}{|c|}{4.593999999999999} & \multirow[t]{2}{*}{ TRN } & \\
\hline CHEMBL1501273 & 688810 & 4.683 & 5.1501 & TST & & & \\
\hline CHEMBL1612748 & 688810 & 4.783 & 4.9388 & TRN & & & \\
\hline CHEMBL1345325 & 688810 & \multicolumn{3}{|c|}{4.7330000000000005} & 5.149 & TRN & \\
\hline CHEMBL1320453 & 688810 & 5.433 & 6.1734 & TRN & & & \\
\hline CHEMBL1565717 & 688810 & 5.933 & 5.6405 & TRN & & & \\
\hline CHEMBL1604192 & 688810 & 5.683 & 5.5665 & TRN & & & \\
\hline CHEMBL1564362 & 688810 & 4.633 & 5.1824 & TST & & & \\
\hline CHEMBL1548970 & 688810 & \multicolumn{3}{|c|}{5.2829999999999995} & 5.0313 & TRN & \\
\hline CHEMBL1468514 & 688810 & 5.033 & 5.8839 & TST & & & \\
\hline CHEMBL1347538 & 688810 & \multicolumn{3}{|c|}{4.7330000000000005} & 5.3442 & TRN & \\
\hline CHEMBL1382599 & 688810 & 5.483 & 4.9648 & TST & & & \\
\hline CHEMBL1302199 & 688810 & 5.933 & 5.1116 & TRN & & & \\
\hline CHEMBL1456630 & 688810 & \multicolumn{3}{|c|}{5.5329999999999995} & 5.5811 & TRN & \\
\hline CHEMBL1386503 & 688810 & 4.833 & 5.395 & TST & & & \\
\hline CHEMBL1390214 & 688810 & 4.933 & 4.9382 & TRN & & & \\
\hline CHEMBL1587018 & 688810 & 4.783 & 5.8459 & TST & & & \\
\hline CHEMBL1599864 & 688810 & 5.483 & 5.2189 & TRN & & & \\
\hline CHEMBL1566578 & 688810 & 4.783 & 4.8258 & TRN & & & \\
\hline CHEMBL3193464 & 688810 & \multicolumn{3}{|c|}{4.7330000000000005} & 5.1531 & TRN & \\
\hline CHEMBL1510128 & 688810 & \multicolumn{3}{|c|}{5.5329999999999995} & 5.5246 & TRN & \\
\hline CHEMBL1498999 & 688810 & 7.2328 & 5.8166 & TRN & & & \\
\hline CHEMBL1474507 & 688810 & 4.683 & 5.5607 & TRN & & & \\
\hline CHEMBL510349 & 688810 & 4.783 & 5.7947 & TRN & & & \\
\hline CHEMBL1312088 & 688810 & 5.433 & 5.3333 & TRN & & & \\
\hline CHEMBL1516537 & 688810 & \multicolumn{3}{|c|}{6.0329999999999995} & 5.3574 & TRN & \\
\hline CHEMBL1399248 & 688810 & \multicolumn{3}{|c|}{4.7330000000000005} & 4.9577 & TRN & \\
\hline CHEMBL1563639 & 688810 & 4.833 & 5.1414 & TRN & & & \\
\hline CHEMBL1453476 & 688810 & 5.483 & 5.5046 & TRN & & & \\
\hline CHEMBL1319967 & 688810 & 4.833 & 4.7951 & TRN & & & \\
\hline CHEMBL1411507 & 688810 & 4.833 & 4.8933 & TRN & & & \\
\hline CHEMBL1388563 & 688810 & 4.783 & 4.9407 & TRN & & & \\
\hline CHEMBL1380174 & 688810 & \multicolumn{3}{|c|}{4.7330000000000005} & 5.206 & TST & \\
\hline CHEMBL1554400 & 688810 & \multicolumn{3}{|c|}{5.582999999999999} & 6.306 & TRN & \\
\hline CHEMBL1465858 & 688810 & \multicolumn{3}{|c|}{5.332999999999999} & 5.0348 & TST & \\
\hline CHEMBL3198450 & 688810 & 5.433 & 5.3897 & TRN & & & \\
\hline CHEMBL1579808 & 688810 & \multicolumn{3}{|c|}{5.332999999999999} & 5.6749 & TST & \\
\hline CHEMBL1460748 & 688810 & \multicolumn{3}{|c|}{4.7330000000000005} & 4.6457 & TST & \\
\hline CHEMBL1510669 & 688810 & \multicolumn{3}{|c|}{6.332999999999999} & 5.36100 & 0000000001 & TRN \\
\hline CHEMBL1482802 & 688810 & 5.683 & 5.0345 & TRN & & & \\
\hline CHEMBL1397479 & 688810 & 4.883 & 4.9753 & TRN & & & \\
\hline CHEMBL1404524 & 688810 & \multicolumn{3}{|c|}{4.9830000000000005} & 5.1583 & TST & \\
\hline CHEMBL1301889 & 688810 & \multicolumn{3}{|c|}{6.0329999999999995} & 5.6588 & TRN & \\
\hline CHEMBL1585207 & 688810 & 4.833 & 5.1289 & TST & & & \\
\hline CHEMBL 3196827 & 688810 & \multicolumn{3}{|c|}{6.332999999999999} & 5.6523 & TRN & \\
\hline CHEMBL1989090 & 688810 & \multicolumn{3}{|c|}{5.332999999999999} & 5.9316 & TRN & \\
\hline CHEMBL1487764 & 688810 & 5.183 & 5.1675 & TRN & & & \\
\hline CHEMBL1395993 & 688810 & 5.78299 & 99999999 & 995 & 5.6647 & TRN & \\
\hline
\end{tabular}




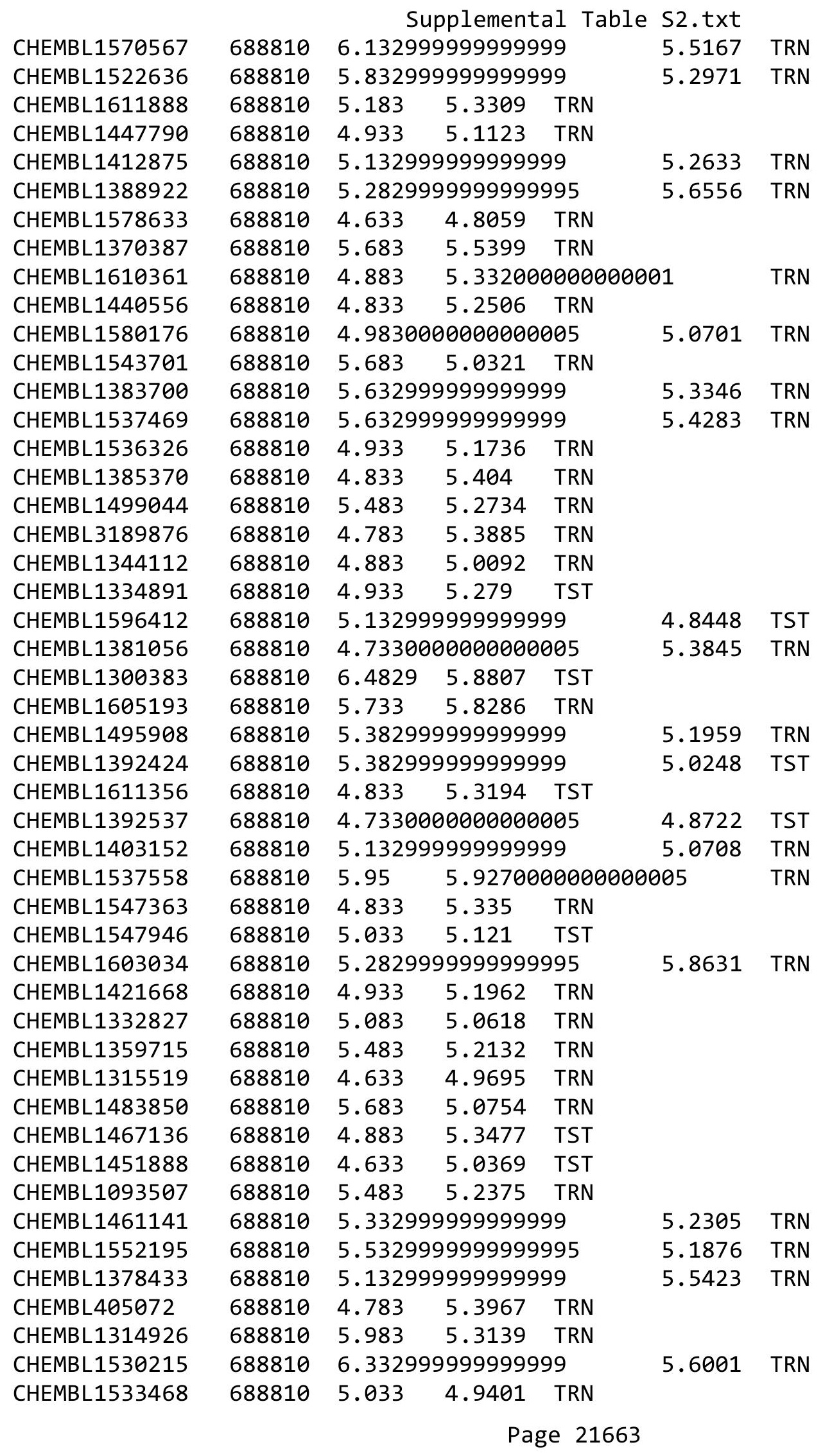




\begin{tabular}{|c|c|c|c|c|c|c|}
\hline \multirow[b]{2}{*}{ CHEMBL1578300 } & \\
\hline & 688810 & 5.083 & 5.6017 & TST & & \\
\hline CHEMBL 3197123 & 688810 & 5.433 & 5.6126 & TST & & \\
\hline CHEMBL1567136 & 688810 & \multicolumn{3}{|c|}{5.132999999999999} & 5.3987 & TRN \\
\hline CHEMBL1435099 & 688810 & \multicolumn{3}{|c|}{5.882999999999999} & 5.7264 & \\
\hline CHEMBL1388103 & 688810 & 4.883 & 5.4063 & TRN & & \\
\hline CHEMBL1481513 & 688810 & \multicolumn{3}{|c|}{4.7330000000000005} & 5.3371 & IRIV \\
\hline CHEMBL1971532 & 688810 & \multicolumn{3}{|c|}{5.382999999999999} & 5.3073 & \\
\hline CHEMBL1559554 & 688810 & 4.783 & 5.2921 & TRN & & \\
\hline CHEMBL1350432 & 688810 & 4.783 & 5.109 & TST & & \\
\hline CHEMBL1386117 & 688810 & 4.833 & 5.0301 & TST & & \\
\hline CHEMBL 3213278 & 688810 & 4.783 & 5.1176 & TST & & \\
\hline CHEMBL1584666 & 688810 & \multicolumn{3}{|c|}{5.2829999999999995} & 5.6465 & \\
\hline CHEMBL 3195001 & 688810 & 5.683 & 5.4835 & TRN & & \\
\hline CHEMBL1444791 & 688810 & 5.683 & 5.7395 & TRN & & \\
\hline CHEMBL1373549 & 688810 & 6.183 & 5.778 & TRN & & \\
\hline CHEMBL1301371 & 688810 & \multicolumn{3}{|c|}{4.9830000000000005} & 4.9719 & \\
\hline CHEMBL 1464723 & 688810 & 4.783 & 4.8304 & TST & & \\
\hline CHEMBL1556810 & 688810 & 4.933 & 5.1059 & TRN & & \\
\hline CHEMBL 1470513 & 688810 & 4.683 & 5.5882 & TRN & & \\
\hline CHEMBL1557083 & 688810 & 6.4829 & \multicolumn{3}{|c|}{5.412000000000001} & \\
\hline CHEMBL1557136 & 688810 & 4.783 & 5.5344 & TRN & & \\
\hline CHEMBL 2002274 & 688810 & 4.833 & 5.2187 & TRN & & \\
\hline CHEMBL1513114 & 688810 & 6.183 & 6.1323 & TRN & & \\
\hline CHEMBL1413306 & 688810 & \multicolumn{3}{|c|}{4.9830000000000005} & 5.621 & \\
\hline CHEMBL 1563700 & 688810 & \multicolumn{3}{|c|}{5.7829999999999995} & 5.0616 & \\
\hline CHEMBL1371377 & 688810 & \multicolumn{3}{|c|}{5.382999999999999} & 5.3191 & \\
\hline CHEMBL 1483768 & 688810 & 5.233 & 4.894 & TRN & & \\
\hline CHEMBL1524678 & 688810 & 4.633 & 4.65 & TST & & \\
\hline CHEMBL1346118 & 688810 & 6.7331 & 5.7644 & TRN & & \\
\hline CHEMBL1442518 & 688810 & 4.883 & 5.0827 & TRN & & \\
\hline CHEMBL1494105 & 688810 & \multicolumn{3}{|c|}{5.5329999999999995} & 5.1755 & \\
\hline CHEMBL1465644 & 688810 & 4.833 & 5.1409 & TST & & \\
\hline CHEMBL1419354 & 688810 & 4.783 & 5.6794 & TST & & \\
\hline CHEMBL568092 & 688810 & 5.933 & 5.5758 & TRN & & \\
\hline CHEMBL1354026 & 688810 & \multicolumn{3}{|c|}{4.7330000000000005} & 5.1393 & \\
\hline CHEMBL1445415 & 688810 & 4.783 & 5.1651 & TRN & & \\
\hline CHEMBL 1470064 & 688810 & 4.783 & 4.9764 & TRN & & \\
\hline CHEMBL 3212365 & 688810 & \multicolumn{3}{|c|}{5.2829999999999995} & 5.1166 & \\
\hline CHEMBL1531684 & 688810 & \multicolumn{3}{|c|}{5.132999999999999} & 4.8771 & \\
\hline CHEMBL 3196526 & 688810 & \multicolumn{3}{|c|}{5.882999999999999} & 5.4915 & \\
\hline CHEMBL1389940 & 688810 & 4.833 & 5.4818 & TRN & & \\
\hline CHEMBL1561067 & 688810 & \multicolumn{3}{|c|}{5.382999999999999} & 4.6739 & TST \\
\hline CHEMBL1313535 & 688810 & 4.883 & 5.3724 & TRN & & \\
\hline CHEMBL1612732 & 688810 & \multicolumn{3}{|c|}{5.7829999999999995} & 6.0366 & $\mathrm{TR}$ \\
\hline CHEMBL1579704 & 688810 & 5.933 & 5.7684 & TRN & & \\
\hline CHEMBL 1589858 & 688810 & 5.683 & 5.5941 & TRN & & \\
\hline CHEMBL1452690 & 688810 & 4.933 & 5.3198 & TST & & \\
\hline CHEMBL1361046 & 688810 & 5.483 & 5.5248 & TRN & & \\
\hline
\end{tabular}




\begin{tabular}{|c|c|c|c|c|c|c|c|}
\hline \multirow[b]{2}{*}{ CHEMBL1604550 } & \multicolumn{6}{|c|}{ Supplemental Table S2.txt } & \\
\hline & 688810 & 5.683 & 5.4917 & \multicolumn{3}{|c|}{ TRN } & \\
\hline CHEMBL1364286 & 688810 & 4.85 & 5.5256 & \multicolumn{4}{|l|}{ TST } \\
\hline CHEMBL1546940 & 688810 & \multicolumn{3}{|c|}{6.132999999999999} & \multicolumn{2}{|c|}{5.662000000000001} & TST \\
\hline CHEMBL1474765 & 688810 & 5.433 & 5.9243 & TRN & & & \\
\hline CHEMBL1349622 & 688810 & 4.783 & 5.2602 & TST & & & \\
\hline CHEMBL 1470450 & 688810 & \multicolumn{3}{|c|}{4.9830000000000005} & 4.9656 & TRN & \\
\hline CHEMBL1300605 & 688810 & 5.983 & 5.4025 & TRN & & & \\
\hline CHEMBL1401943 & 688810 & \multicolumn{3}{|c|}{4.9830000000000005} & 5.3781 & TRN & \\
\hline CHEMBL1512141 & 688810 & 4.783 & 5.5282 & TRN & & & \\
\hline CHEMBL1511301 & 688810 & 4.783 & 5.1712 & TRN & & & \\
\hline CHEMBL1556196 & 688810 & 4.833 & 5.0149 & TRN & & & \\
\hline CHEMBL1607487 & 688810 & 4.783 & 5.2983 & TST & & & \\
\hline CHEMBL1488449 & 688810 & \multicolumn{3}{|c|}{5.132999999999999} & 5.1749 & TRN & \\
\hline CHEMBL1585521 & 688810 & \multicolumn{3}{|c|}{5.832999999999999} & 5.6858 & TRN & \\
\hline CHEMBL1491869 & 688810 & \multicolumn{3}{|c|}{5.882999999999999} & 5.5202 & TRN & \\
\hline CHEMBL1573578 & 688810 & 5.433 & 5.4854 & TRN & & & \\
\hline CHEMBL1505902 & 688810 & 4.633 & 4.9007 & TST & & & \\
\hline CHEMBL1598482 & 688810 & \multicolumn{3}{|c|}{6.2829999999999995} & 5.2506 & TRN & \\
\hline CHEMBL1349337 & 688810 & \multicolumn{3}{|c|}{4.7330000000000005} & 5.1369 & TRN & \\
\hline CHEMBL1488502 & 688810 & 5.933 & 5.0018 & TRN & & & \\
\hline CHEMBL1308839 & 688810 & 4.783 & 5.0827 & TRN & & & \\
\hline CHEMBL1449808 & 688810 & \multicolumn{3}{|c|}{5.882999999999999} & 5.8312 & TRN & \\
\hline CHEMBL1335017 & 688810 & \multicolumn{3}{|c|}{4.7330000000000005} & 5.3354 & TRN & \\
\hline CHEMBL1455421 & 688810 & 4.633 & 5.053 & TRN & & & \\
\hline CHEMBL1429364 & 688810 & \multirow{2}{*}{\multicolumn{3}{|c|}{$\begin{array}{lcc}4.833 & 5.1753 & \text { TRN } \\
5.132999999999999\end{array}$}} & & & \\
\hline CHEMBL1472221 & 688810 & & & & 4.8381 & TRN & \\
\hline CHEMBL1352298 & 688810 & 4.833 & 5.5663 & TRN & & & \\
\hline CHEMBL1876078 & 688810 & 6.233 & 5.1333 & TRN & & & \\
\hline CHEMBL1305603 & 688810 & 4.933 & 5.1497 & TST & & & \\
\hline CHEMBL 2369241 & 688810 & 5.483 & 5.4945 & TRN & & & \\
\hline CHEMBL3194019 & 688810 & 4.783 & 5.3082 & TST & & & \\
\hline CHEMBL1370589 & 688810 & 4.883 & 5.045 & TRN & & & \\
\hline CHEMBL1552880 & 688810 & 4.633 & 4.7115 & TST & & & \\
\hline CHEMBL1446575 & 688810 & 5.2829 & 99999999 & 995 & 5.2931 & TRN & \\
\hline CHEMBL1439360 & 688810 & 4.9830 & j000000e & 005 & 4.9034 & TRN & \\
\hline CHEMBL1549154 & 688810 & 4.783 & 4.9754 & TRN & & & \\
\hline CHEMBL1376192 & 688810 & 5.6329 & 99999999 & & 5.2542 & TRN & \\
\hline CHEMBL1457810 & 688810 & 4.7330 & j000000e & 005 & 5.2608 & TRN & \\
\hline CHEMBL1552464 & 688810 & 4.633 & 4.7523 & TRN & & & \\
\hline CHEMBL1384576 & 688810 & 6.3329 & 99999999 & & 5.3359 & TRN & \\
\hline CHEMBL1469415 & 688810 & 5.5329 & 99999999 & 995 & 5.0724 & TST & \\
\hline CHEMBL1434089 & 688810 & 5.483 & 4.8723 & TRN & & & \\
\hline CHEMBL1314398 & 688810 & 5.233 & 5.7458 & TRN & & & \\
\hline CHEMBL1532403 & 688810 & 5.3829 & 99999999 & & 5.4461 & TST & \\
\hline CHEMBL1489817 & 688810 & 5.933 & 5.3739 & TRN & & & \\
\hline CHEMBL1336722 & 688810 & 5.733 & 5.0078 & TRN & & & \\
\hline CHEMBL1421553 & 688810 & 6.3329 & 99999999 & & 5.5368 & TRN & \\
\hline CHEMBL1441626 & 688810 & 5.1329 & 99999999 & & 5.9765 & TRN & \\
\hline & & & & 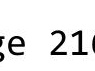 & & & \\
\hline
\end{tabular}




\begin{tabular}{|c|c|c|c|c|c|c|}
\hline \multirow[b]{2}{*}{ CHEMBL192984 } & \multicolumn{6}{|c|}{ supplemental } \\
\hline & 688810 & 7.1831 & 5.9862 & TRN & & \\
\hline CHEMBL1508330 & 688810 & 4.833 & 4.8181 & TST & & \\
\hline CHEMBL1484410 & 688810 & 5.58299 & 99999999 & & 5.3578 & TRN \\
\hline CHEMBL1401828 & 688810 & 5.83299 & 99999999 & & 5.3443 & TRN \\
\hline CHEMBL1457482 & 688810 & 4.73300 & $\partial 0000000$ & 005 & 5.2274 & TRN \\
\hline CHEMBL1327001 & 688810 & 5.53299 & 99999999 & 995 & 5.7691 & TRN \\
\hline CHEMBL1383967 & 688810 & 5.983 & 5.8322 & TRN & & \\
\hline CHEMBL1439379 & 688810 & 5.58299 & 99999999 & & 5.5393 & TRN \\
\hline CHEMBL1397569 & 688810 & 4.633 & 4.8591 & TRN & & \\
\hline CHEMBL1338313 & 688810 & 4.883 & 5.2571 & TRN & & \\
\hline CHEMBL1469288 & 688810 & 4.633 & 5.2522 & TRN & & \\
\hline CHEMBL1492532 & 688810 & 6.9329 & 5.8701 & TRN & & \\
\hline CHEMBL1461574 & 688810 & 4.833 & 5.2185 & TST & & \\
\hline CHEMBL3188020 & 688810 & 5.13299 & 99999999 & & 5.1677 & TRN \\
\hline CHEMBL1306619 & 688810 & 5.033 & 5.3874 & TRN & & \\
\hline CHEMBL1330640 & 688810 & 4.633 & 5.0668 & TST & & \\
\hline CHEMBL3193665 & 688810 & 5.63299 & 99999999 & & 6.1218 & TRN \\
\hline CHEMBL1320504 & 688810 & 6.38299 & 99999999 & & 5.3062 & TRN \\
\hline CHEMBL1467839 & 688810 & 5.733 & 5.279 & TRN & & \\
\hline CHEMBL1376685 & 688810 & 5.05 & 5.3487 & TST & & \\
\hline CHEMBL3194357 & 688810 & 6.9329 & 6.6592 & TRN & & \\
\hline CHEMBL1458147 & 688810 & 5.33299 & 99999999 & & 5.1465 & TRN \\
\hline CHEMBL1410532 & 688810 & 5.63299 & 99999999 & & 5.8179 & TRN \\
\hline CHEMBL1586566 & 688810 & 5.183 & 5.5078 & TRN & & \\
\hline CHEMBL1372980 & 688810 & 4.933 & 5.3855 & TRN & & \\
\hline CHEMBL1542502 & 688810 & 4.783 & 5.3003 & TRN & & \\
\hline CHEMBL1542598 & 688810 & 5.683 & 5.4525 & TRN & & \\
\hline CHEMBL1385152 & 688810 & 4.98300 & 20000000 & 005 & 5.2402 & TRN \\
\hline CHEMBL1595294 & 688810 & 4.633 & 5.0108 & TST & & \\
\hline CHEMBL1520777 & 688810 & 5.083 & 5.1747 & TRN & & \\
\hline CHEMBL1458187 & 688810 & 5.88299 & 99999999 & & 4.6118 & TST \\
\hline CHEMBL1518624 & 688810 & 6.28299 & 99999999 & 995 & 5.3093 & TRN \\
\hline CHEMBL1483875 & 688810 & 5.433 & 5.2161 & TRN & & \\
\hline CHEMBL1553124 & 688810 & 4.583 & 5.1244 & TRN & & \\
\hline CHEMBL1545922 & 688810 & 4.833 & 5.3122 & TRN & & \\
\hline CHEMBL1512398 & 688810 & 5.28299 & 99999999 & 995 & 5.7198 & TRN \\
\hline CHEMBL1447771 & 688810 & 5.083 & 5.4681 & TST & & \\
\hline CHEMBL1340462 & 688810 & 5.683 & 5.3288 & TRN & & \\
\hline CHEMBL1369135 & 688810 & 4.783 & 5.4974 & TST & & \\
\hline CHEMBL1600694 & 688810 & 4.933 & 5.1151 & TST & & \\
\hline CHEMBL1609032 & 688810 & 4.73300 & 00000000 & 005 & 5.1941 & TST \\
\hline CHEMBL1327256 & 688810 & 4.833 & 5.2711 & TST & & \\
\hline CHEMBL1489104 & 688810 & 5.63299 & 99999999 & & 5.0645 & TRN \\
\hline CHEMBL1540071 & 688810 & 5.78299 & 99999999 & 995 & 5.1704 & TRN \\
\hline CHEMBL1405071 & 688810 & 4.833 & 5.3174 & TRN & & \\
\hline CHEMBL1502937 & 688810 & 4.583 & 5.0998 & TRN & & \\
\hline CHEMBL1356364 & 688810 & 4.783 & 5.1707 & TRN & & \\
\hline CHEMBL1304708 & 688810 & 4.833 & 4.7795 & TRN & & \\
\hline
\end{tabular}




\begin{tabular}{|c|c|c|c|c|c|c|}
\hline \multirow[b]{2}{*}{ CHEMBL1598916 } & \multirow[b]{2}{*}{688810} & \multicolumn{5}{|c|}{ Supplemental Table S2.txt } \\
\hline & & \multicolumn{3}{|c|}{$\begin{array}{lll}4.883 & 5.0225 & \text { TRN }\end{array}$} & & \\
\hline CHEMBL1382789 & 688810 & \multicolumn{3}{|c|}{5.5329999999999995} & 5.5772 & $\mathrm{~T}$ \\
\hline CHEMBL1336350 & 688810 & 4.933 & 5.2814 & TST & & \\
\hline CHEMBL1394400 & 688810 & 4.783 & 5.2942 & TRN & & \\
\hline CHEMBL1396285 & 688810 & 4.583 & 4.9126 & TST & & \\
\hline CHEMBL1489749 & 688810 & 4.933 & 5.3098 & TRN & & \\
\hline CHEMBL1552163 & 688810 & \multicolumn{3}{|c|}{5.5329999999999995} & 5.3964 & \\
\hline CHEMBL1370293 & 688810 & \multicolumn{3}{|c|}{6.582999999999999} & 5.5907 & \\
\hline CHEMBL1301307 & 688810 & \multicolumn{3}{|c|}{5.582999999999999} & 5.593 & \\
\hline CHEMBL1401839 & 688810 & 4.833 & 5.1862 & TRN & & \\
\hline CHEMBL1362220 & 688810 & \multicolumn{3}{|c|}{$6.233 \quad 5.3575 \quad$ TRN } & & \\
\hline CHEMBL1600964 & 688810 & \multicolumn{3}{|c|}{5.5329999999999995} & 5.295 & \\
\hline CHEMBL1565391 & 688810 & 4.633 & 4.8673 & TST & & \\
\hline CHEMBL 3195220 & 688810 & \multicolumn{3}{|c|}{4.7330000000000005} & 4.9479 & \\
\hline CHEMBL1380687 & 688810 & \multicolumn{3}{|c|}{5.5329999999999995} & 5.1748 & \\
\hline CHEMBL1424379 & 688810 & 4.783 & 5.1354 & TRN & & \\
\hline CHEMBL1497808 & 688810 & 5.733 & 5.3365 & TRN & & \\
\hline CHEMBL1308027 & 688810 & 6.983 & 5.8569 & TRN & & \\
\hline CHEMBL13 & 688810 & 5.733 & 5.4937 & TRN & & \\
\hline CHEMBL1403707 & 688810 & \multicolumn{3}{|c|}{6.2829999999999995} & 5.487 & \\
\hline CHEMBL1451762 & 688810 & 5.483 & 5.5036 & TRN & & \\
\hline CHEMBL1566519 & 688810 & \multicolumn{3}{|c|}{5.2829999999999995} & 5 & \\
\hline CHEMBL1337254 & 688810 & 5.083 & 5.1326 & TRN & & \\
\hline CHEMBL1 & 688810 & 5.233 & 5.3919 & TRN & & \\
\hline CHEMBL1486729 & 688810 & \multicolumn{3}{|c|}{4.7330000000000005} & 5.0985 & \\
\hline CHEMBL1520276 & 688810 & \multicolumn{3}{|c|}{4.7330000000000005} & & \\
\hline CHEMBL1311267 & 688810 & 5.183 & 4.9061 & TRN & & \\
\hline CHEMBL1 & 688810 & 5.033 & 5.5568 & TRN & & \\
\hline CHEMBL1407912 & 688810 & 5.733 & 5.5995 & TRN & & \\
\hline CHEMBL1431286 & 688810 & 4.783 & 4.7458 & TST & & \\
\hline CHEMBL3214029 & 688810 & \multicolumn{3}{|c|}{4.7330000000000005} & 4.9027 & \\
\hline CHEMBL1510646 & 688810 & 7.3325 & 6.1535 & TRN & & \\
\hline CHEMBL1 & 688810 & \multicolumn{3}{|c|}{5.632999999999999} & 5.31 & \\
\hline CHEMBL1562304 & 688810 & 4.633 & 4.524 & TST & & \\
\hline CHEMBL1493736 & 688810 & 4.833 & 5.3017 & TST & & \\
\hline CHEMBL1410200 & 688810 & 5.733 & 5.4488 & TRN & & \\
\hline CHEMBL1439513 & 688810 & \multicolumn{3}{|c|}{5.832999999999999} & 5.0687 & TI \\
\hline CHEMBL1483678 & 688810 & \multicolumn{3}{|c|}{4.9830000000000005} & 5.5254 & \\
\hline CHEMBL1429527 & 688810 & 5.033 & 5.1487 & TRN & & \\
\hline CHEMBL1527038 & 688810 & \multicolumn{3}{|c|}{5.7829999999999995} & 5.6435 & TI \\
\hline CHEMBL1403844 & 688810 & 4.783 & 5.0492 & TRN & & \\
\hline CHEMBL1405155 & 688810 & 4.633 & 4.8209 & TST & & \\
\hline CHEMBL1606467 & 688810 & 4.783 & 5.17 & TRN & & \\
\hline CHEMBL1510681 & 688810 & 5.5329 & 99999999 & 995 & 5.3385 & TR \\
\hline CHEMBL3190008 & 688810 & 5.183 & 5.1175 & TST & & \\
\hline CHEMBL1501255 & 688810 & 5.7829 & 99999999 & 995 & & $\mathrm{I}$ \\
\hline CHEMBL1312320 & 688810 & 5.6329 & 99999999 & & 5.3189 & TST \\
\hline CHEMBL1527207 & 688810 & 4.9830 & 00000000 & 005 & 5.1588 & TRN \\
\hline
\end{tabular}




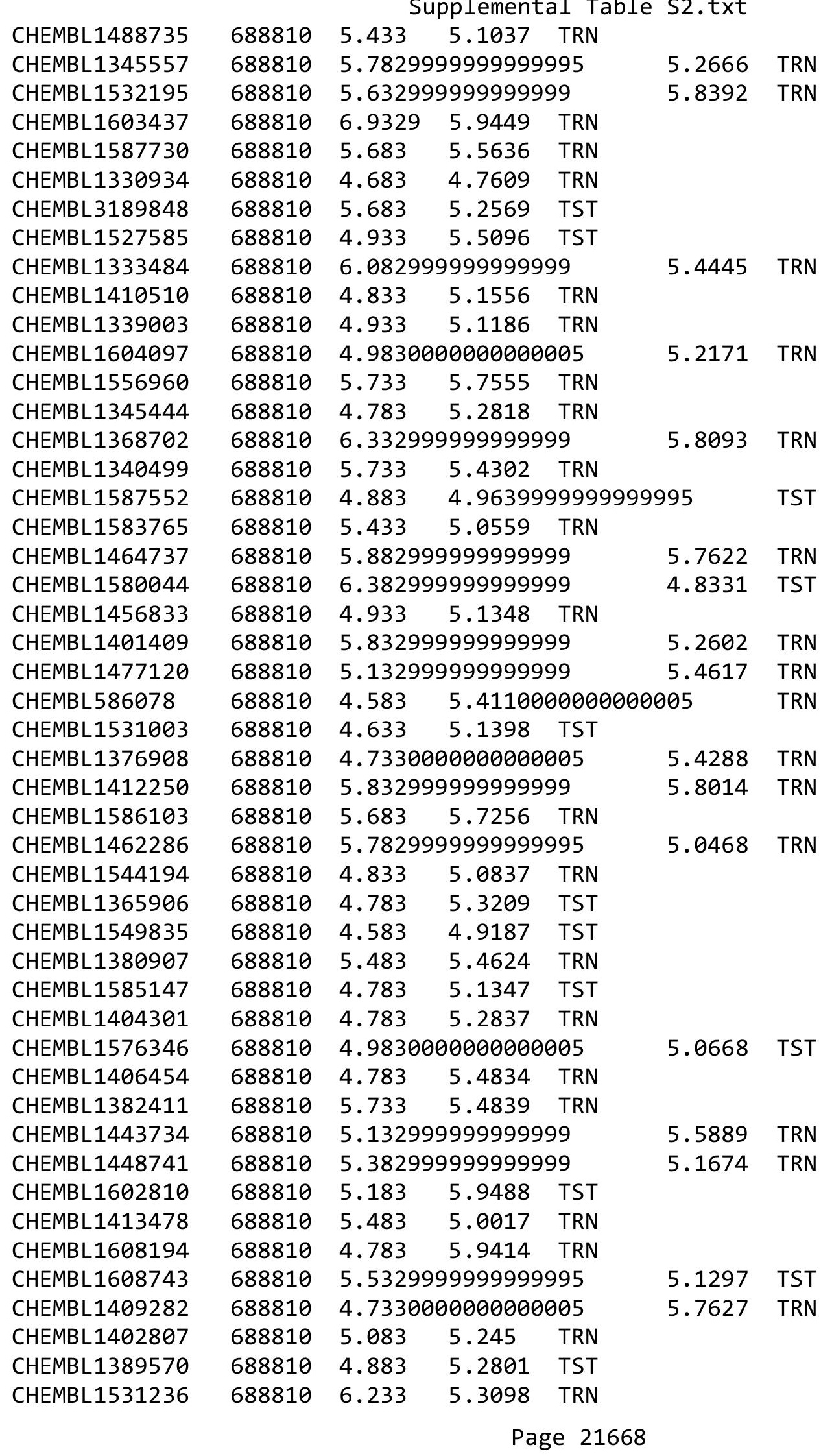




\begin{tabular}{|c|c|c|c|c|c|c|c|}
\hline \multicolumn{8}{|c|}{ 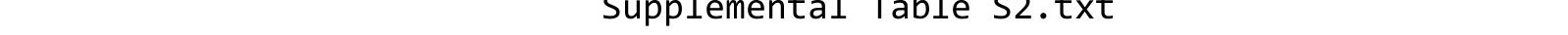 } \\
\hline CHEMBL1535810 & 688810 & 6.4829 & 5.8125 & TRN & & & \\
\hline CHEMBL1611408 & 688810 & 4.683 & 4.9761 & TRN & & & \\
\hline CHEMBL1325754 & 688810 & \multicolumn{3}{|c|}{4.7330000000000005} & 5.1773 & TRN & \\
\hline CHEMBL1550078 & 688810 & \multicolumn{3}{|c|}{5.382999999999999} & 5.9209 & TRN & \\
\hline CHEMBL1370483 & 688810 & \multicolumn{3}{|c|}{5.2829999999999995} & 5.1121 & TRN & \\
\hline CHEMBL1453691 & 688810 & \multicolumn{3}{|c|}{6.082999999999999} & 5.2975 & TRN & \\
\hline CHEMBL 1474788 & 688810 & 4.783 & 5.0405 & TRN & & & \\
\hline CHEMBL1476023 & 688810 & 5.233 & 5.0945 & TRN & & & \\
\hline CHEMBL1412874 & 688810 & \multicolumn{3}{|c|}{5.2829999999999995} & 4.7932 & TRN & \\
\hline CHEMBL1538024 & 688810 & \multicolumn{3}{|c|}{5.132999999999999} & 5.4123 & TRN & \\
\hline CHEMBL1532098 & 688810 & 5.233 & 4.9311 & TRN & & & \\
\hline CHEMBL1544818 & 688810 & 6.183 & 5.3121 & TST & & & \\
\hline CHEMBL1596486 & 688810 & \multicolumn{3}{|c|}{6.2829999999999995} & 5.6421 & TRN & \\
\hline CHEMBL1487951 & 688810 & \multicolumn{3}{|c|}{5.7829999999999995} & 4.9565 & TST & \\
\hline CHEMBL1453869 & 688810 & 4.883 & 5.0924 & TST & & & \\
\hline CHEMBL1352586 & 688810 & 4.633 & 4.7706 & TRN & & & \\
\hline CHEMBL1441246 & 688810 & 5.083 & 5.2541 & TRN & & & \\
\hline CHEMBL 388823 & 688810 & \multicolumn{3}{|c|}{6.082999999999999} & 5.8338 & TST & \\
\hline CHEMBL1506670 & 688810 & 5.233 & 5.5662 & TST & & & \\
\hline CHEMBL1445986 & 688810 & 4.833 & 5.0623 & TRN & & & \\
\hline CHEMBL1998334 & 688810 & \multicolumn{3}{|c|}{5.132999999999999} & 5.3981 & TRN & \\
\hline CHEMBL1299268 & 688810 & 5.483 & 5.5507 & TRN & & & \\
\hline CHEMBL1569967 & 688810 & \multicolumn{3}{|c|}{6.382999999999999} & \multicolumn{2}{|c|}{6.082999999999999} & TRN \\
\hline CHEMBL1568968 & 688810 & 6.433 & 6.104 & TRN & & & \\
\hline CHEMBL1431608 & 688810 & 5.083 & 5.2832 & TST & & & \\
\hline CHEMBL1318601 & 688810 & 5.033 & 5.4827 & TRN & & & \\
\hline CHEMBL1514079 & 688810 & \multicolumn{3}{|c|}{5.882999999999999} & 5.3072 & TRN & \\
\hline CHEMBL3208894 & 688810 & 5.683 & 5.3318 & TRN & & & \\
\hline CHEMBL1557649 & 688810 & \multicolumn{3}{|c|}{5.7829999999999995} & 5.1612 & TRN & \\
\hline CHEMBL3196485 & 688810 & 4.783 & 5.4974 & TRN & & & \\
\hline CHEMBL1595787 & 688810 & \multicolumn{3}{|c|}{5.132999999999999} & 5.268 & TRN & \\
\hline CHEMBL1567229 & 688810 & \multicolumn{3}{|c|}{4.7330000000000005} & 5.265 & TRN & \\
\hline CHEMBL1381735 & 688810 & \multicolumn{3}{|c|}{4.9830000000000005} & 5.1483 & TRN & \\
\hline CHEMBL1514165 & 688810 & 5.233 & 5.59 & TRN & & & \\
\hline CHEMBL1407154 & 688810 & \multicolumn{3}{|c|}{5.132999999999999} & 5.2916 & TRN & \\
\hline CHEMBL10050 & 688810 & 5.733 & 5.5164 & TRN & & & \\
\hline CHEMBL1477459 & 688810 & 4.683 & 5.3867 & TRN & & & \\
\hline CHEMBL1567593 & 688810 & 8.4318 & 5.6394 & TRN & & & \\
\hline CHEMBL1539053 & 688810 & 4.783 & 5.1992 & TRN & & & \\
\hline CHEMBL1474792 & 688810 & 4.883 & 4.9586 & TST & & & \\
\hline CHEMBL1603303 & 688810 & 5.433 & 4.8409 & TRN & & & \\
\hline CHEMBL3199090 & 688810 & 5.083 & 5.5724 & TRN & & & \\
\hline CHEMBL1384542 & 688810 & \multicolumn{3}{|c|}{4.7330000000000005} & 5.1368 & TRN & \\
\hline CHEMBL1500258 & 688810 & 5.683 & 5.287000 & 000000000 & & TRN & \\
\hline CHEMBL1376134 & 688810 & \multicolumn{3}{|c|}{5.2829999999999995} & 5.2834 & TRN & \\
\hline CHEMBL1611013 & 688810 & 4.633 & 4.7852 & TST & & & \\
\hline CHEMBL1604215 & 688810 & 4.783 & 5.2522 & TRN & & & \\
\hline CHEMBL1517606 & 688810 & 5.683 & 5.7003 & TRN & & & \\
\hline
\end{tabular}




\begin{tabular}{|c|c|c|c|c|c|c|}
\hline & & \multicolumn{4}{|c|}{ Supplemental Table S2.txt } & \\
\hline CHEMBL1564360 & 688810 & \multicolumn{3}{|c|}{5.582999999999999} & 5.3646 & TRN \\
\hline CHEMBL1520549 & 688810 & \multicolumn{3}{|c|}{4.7330000000000005} & 5.3319 & TST \\
\hline CHEMBL1452763 & 688810 & \multicolumn{3}{|c|}{5.132999999999999} & 5.2387 & \\
\hline CHEMBL1567687 & 688810 & 4.783 & 5.3288 & TRN & & \\
\hline CHEMBL1346753 & 688810 & 5.733 & 5.4506 & TST & & \\
\hline CHEMBL1358751 & 688810 & 5.083 & 5.3948 & TST & & \\
\hline CHEMBL1473661 & 688810 & 4.883 & 4.8065 & TST & & \\
\hline CHEMBL1547326 & 688810 & 4.833 & 5.0916 & TRN & & \\
\hline CHEMBL1464024 & 688810 & \multicolumn{3}{|c|}{5.382999999999999} & 5.1442 & \\
\hline CHEMBL1439399 & 688810 & 4.783 & 5.4603 & TRN & & \\
\hline CHEMBL1409883 & 688810 & 5.033 & 5.1234 & TRN & & \\
\hline CHEMBL1402869 & 688810 & 4.633 & 4.8375 & TRN & & \\
\hline CHEMBL1534289 & 688810 & \multicolumn{3}{|c|}{5.132999999999999} & 5.3119 & \\
\hline CHEMBL1486501 & 688810 & 4.783 & 5.0952 & TRN & & \\
\hline CHEMBL1551305 & 688810 & 4.783 & 4.7672 & TRN & & \\
\hline CHEMBL1443503 & 688810 & 4.933 & 5.4133 & TRN & & \\
\hline CHEMBL1317848 & 688810 & 4.933 & 4.691 & TST & & \\
\hline CHEMBL1361016 & 688810 & \multicolumn{3}{|c|}{6.582999999999999} & 5.4603 & $\mathrm{TI}$ \\
\hline CHEMBL1525541 & 688810 & \multicolumn{3}{|c|}{5.832999999999999} & 5.527 & \\
\hline CHEMBL1474411 & 688810 & \multicolumn{3}{|c|}{4.7330000000000005} & 5.4198 & TST \\
\hline CHEMBL1396168 & 688810 & \multicolumn{3}{|c|}{4.7330000000000005} & 4.9626 & TRN \\
\hline CHEMBL1376167 & 688810 & \multicolumn{3}{|c|}{5.832999999999999} & 5.7678 & \\
\hline CHEMBL1602472 & 688810 & 4.833 & 5.3094 & TRN & & \\
\hline CHEMBL1587613 & 688810 & 5.083 & 5.274 & TRN & & \\
\hline CHEMBL1542524 & 688810 & 4.783 & 4.8958 & TRN & & \\
\hline CHEMBL1549354 & 688810 & 4.883 & 5.3969 & TRN & & \\
\hline CHEMBL1 & 688 & 6.433 & 5.8306 & TRN & & \\
\hline CHEMBL3212549 & 688810 & \multicolumn{3}{|c|}{5.132999999999999} & 5.2203 & TST \\
\hline CHEMBL1587485 & 688810 & \multicolumn{3}{|c|}{4.7330000000000005} & 5.2928 & TRN \\
\hline CHEMBL 285932 & 688810 & 4.583 & 5.4933 & TST & & \\
\hline CHEMBL1301295 & 688810 & \multirow{2}{*}{\multicolumn{3}{|c|}{5.5329999999999995}} & & \\
\hline CHEMBL1447882 & 688810 & & & & 5.49 & $\mathrm{~T}$ \\
\hline CHEMBL3193454 & 688810 & 4.783 & 5.1328 & TRN & & \\
\hline CHEMBL1557711 & 688810 & 4.783 & 5.1452 & TRN & & \\
\hline CHEMBL1499016 & 688810 & \multicolumn{3}{|c|}{4.7330000000000005} & 5.5049 & TRN \\
\hline CHEMBL1992918 & 688810 & \multicolumn{3}{|c|}{5.2829999999999995} & 5.3165 & \\
\hline CHEMBL1486039 & 688810 & 4.883 & 5.7482 & TRN & & \\
\hline CHEMBL1594678 & 688810 & \multicolumn{3}{|c|}{5.632999999999999} & 5.1389 & TS \\
\hline CHEMBL1928483 & 688810 & 5.033 & 5.5084 & TRN & & \\
\hline CHEMBL1568650 & 688810 & 4.783 & 5.3786 & TRN & & \\
\hline CHEMBL1478975 & 688810 & \multicolumn{3}{|c|}{5.7829999999999995} & 5.6074 & $1 \mathrm{NT}$ \\
\hline CHEMBL587801 & 688810 & \multicolumn{3}{|c|}{5.332999999999999} & 5.477 & TST \\
\hline CHEMBL1492814 & 688810 & \multicolumn{3}{|c|}{5.5329999999999995} & 5.3442 & TRN \\
\hline CHEMBL1515549 & 688810 & 4.633 & 5.1303 & TST & & \\
\hline CHEMBL1451916 & 688810 & 5.483 & 5.2618 & TRN & & \\
\hline CHEMBL1389467 & 688810 & 4.883 & 5.3446 & TRN & & \\
\hline CHEMBL1358788 & 688810 & 6.183 & 5.0926 & TST & & \\
\hline CHEMBL1475398 & 688810 & 4.833 & 5.0294 & TRN & & \\
\hline
\end{tabular}




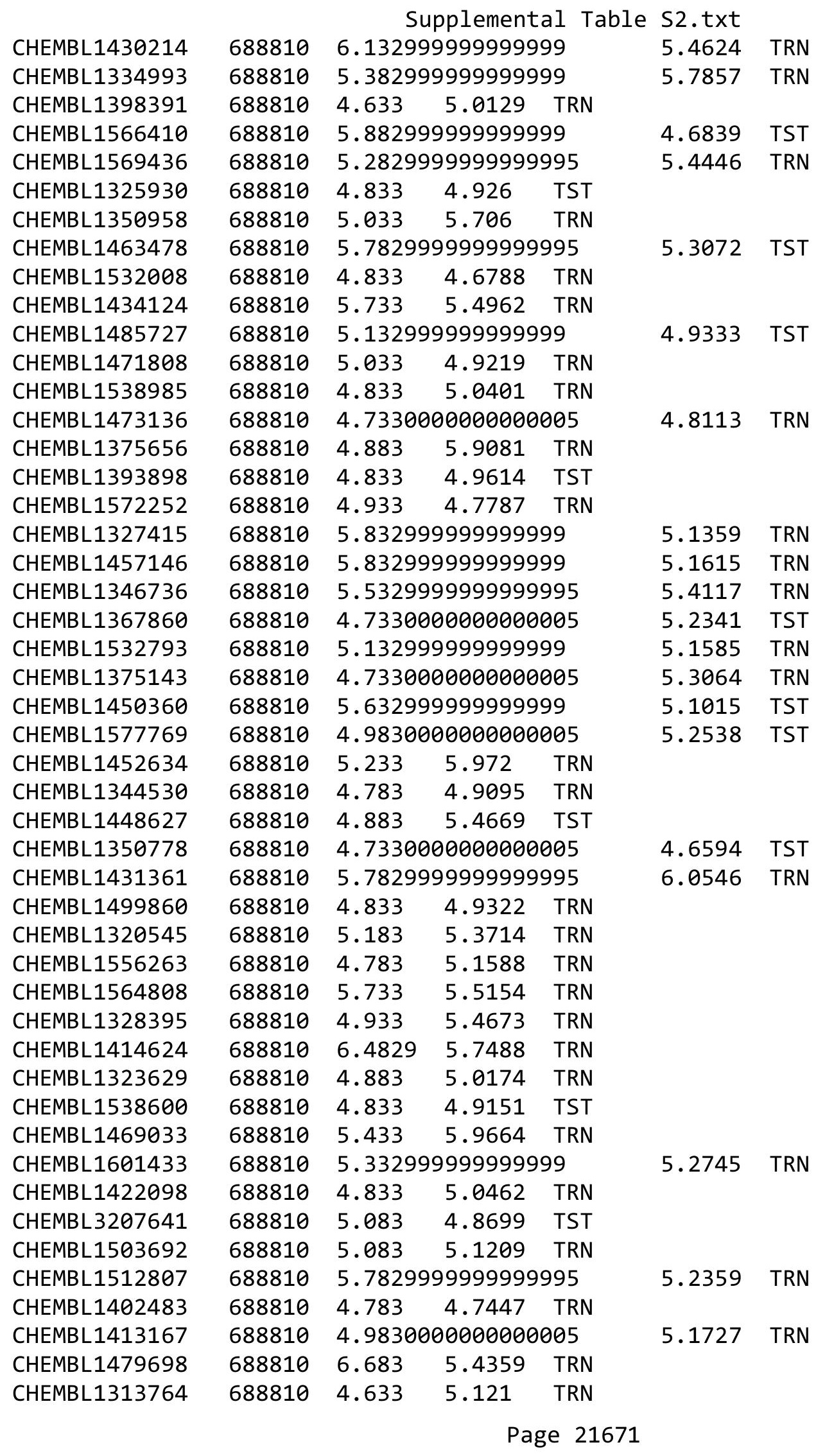




\begin{tabular}{|c|c|c|c|c|c|c|}
\hline \multirow{3}{*}{$\begin{array}{l}\text { CHEMBL1427152 } \\
\text { CHEMBL1354810 }\end{array}$} & \multirow{3}{*}{$\begin{array}{l}688810 \\
688810\end{array}$} & \multicolumn{4}{|c|}{ Supplemental Table S2.txt } & \multirow{2}{*}{ TRN } \\
\hline & & \multicolumn{3}{|c|}{4.7330000000000005} & 4.9328 & \\
\hline & & 4.783 & 5.2965 & TRN & & \\
\hline CHEMBL1348445 & 688810 & 5.683 & 5.7693 & TRN & & \\
\hline CHEMBL1522072 & 688810 & 4.833 & 4.8704 & TRN & & \\
\hline CHEMBL1425038 & 688810 & 4.833 & 5.0963 & TRN & & \\
\hline CHEMBL1340925 & 688810 & \multicolumn{3}{|c|}{6.5329999999999995} & 5.5396 & TST \\
\hline CHEMBL1403094 & 688810 & 4.783 & 5.2446 & TRN & & \\
\hline CHEMBL1439109 & 688810 & 4.633 & 4.9238 & TRN & & \\
\hline CHEMBL518797 & 688810 & \multicolumn{3}{|c|}{4.7330000000000005} & 4.8748 & TST \\
\hline CHEMBL1351248 & 688810 & \multicolumn{3}{|c|}{6.382999999999999} & 5.6526 & TRN \\
\hline CHEMBL3209766 & 688810 & \multicolumn{3}{|c|}{6.582999999999999} & 5.8351 & TRN \\
\hline CHEMBL1537527 & 688810 & 4.783 & 5.0046 & TRN & & \\
\hline CHEMBL1439047 & 688810 & & & TRN & & \\
\hline CHEMBL1496792 & 688810 & \multicolumn{3}{|c|}{4.7330000000000005} & 4.8062 & TRN \\
\hline CHEMBL1330164 & 688810 & 4.883 & 5.691 & TRN & & \\
\hline CHEMBL1464315 & 688810 & 4.883 & 5.2901 & TRN & & \\
\hline CHEMBL1339909 & 688810 & 4.883 & 5.0296 & TRN & & \\
\hline CHEMBL1378608 & 688810 & \multicolumn{3}{|c|}{5.382999999999999} & 5.5493 & TRN \\
\hline CHEMBL1488782 & 688810 & \multicolumn{3}{|c|}{5.132999999999999} & 5.1408 & TRA \\
\hline CHEMBL3199873 & 688810 & 4.833 & 5.151 & TRN & & \\
\hline CHEMBL1486673 & 688810 & 5.083 & 5.0621 & TST & & \\
\hline CHEMBL3192572 & 688810 & 4.933 & 4.9824 & TRN & & \\
\hline CHEMBL1517942 & 688810 & \multicolumn{3}{|c|}{4.9830000000000005} & 4.8601 & TST \\
\hline CHEMBL1504067 & 688810 & 5.733 & 5.6421 & TRN & & \\
\hline CHEMBL1490721 & 688810 & \multicolumn{3}{|c|}{5.5329999999999995} & 5.4123 & TRN \\
\hline CHEMBL3190918 & 688810 & \multicolumn{3}{|c|}{5.2829999999999995} & 4.7936 & TRN \\
\hline CHEMBL1539655 & 688810 & 4.583 & 4.8975 & TRN & & \\
\hline CHEMBL1565058 & 688810 & \multicolumn{3}{|c|}{5.132999999999999} & 5.3468 & TRA \\
\hline CHEMBL1348745 & 688810 & 5.433 & 5.3559 & TRN & & \\
\hline CHEMBL1398282 & 688810 & \multicolumn{3}{|c|}{6.082999999999999} & 5.3863 & TRN \\
\hline CHEMBL1327098 & 688810 & 5.683 & 5.2706 & TRN & & \\
\hline CHEMBL 375673 & 688810 & \multicolumn{3}{|c|}{4.7330000000000005} & 5.2933 & TST \\
\hline CHEMBL1493022 & 688810 & 4.833 & 5.5101 & TRN & & \\
\hline CHEMBL1399783 & 688810 & 4.95 & 5.0028 & TRN & & \\
\hline CHEMBL1432743 & 688810 & \multicolumn{3}{|c|}{5.632999999999999} & 5.1084 & TRN \\
\hline CHEMBL1408090 & 688810 & \multicolumn{3}{|c|}{4.9830000000000005} & 5.5854 & TRN \\
\hline CHEMBL1319858 & 688810 & 4.583 & 4.7455 & TST & & \\
\hline CHEMBL1546102 & 688810 & \multicolumn{3}{|c|}{4.7330000000000005} & 5.5409 & TRN \\
\hline CHEMBL1590686 & 688810 & 4.583 & 5.1052 & TRN & & \\
\hline CHEMBL1488010 & 688810 & 4.7330 & 00000000 & 005 & 5.4521 & TST \\
\hline CHEMBL1506503 & 688810 & 7.0329 & 6.4494 & TRN & & \\
\hline CHEMBL603020 & 688810 & 4.883 & 4.8755 & TRN & & \\
\hline CHEMBL3195498 & 688810 & 5.933 & 5.2342 & TRN & & \\
\hline CHEMBL1445238 & 688810 & 4.9830 & 00000000 & 005 & 5.0407 & TRN \\
\hline CHEMBL1607392 & 688810 & 4.633 & 4.9025 & TRN & & \\
\hline CHEMBL1613264 & 688810 & 5.5329 & 99999999 & 995 & 5.2996 & TST \\
\hline CHEMBL1487684 & 688810 & 4.833 & 5.1384 & TRN & & \\
\hline CHEMBL1408108 & 688810 & 5.033 & 5.1796 & TST & & \\
\hline
\end{tabular}




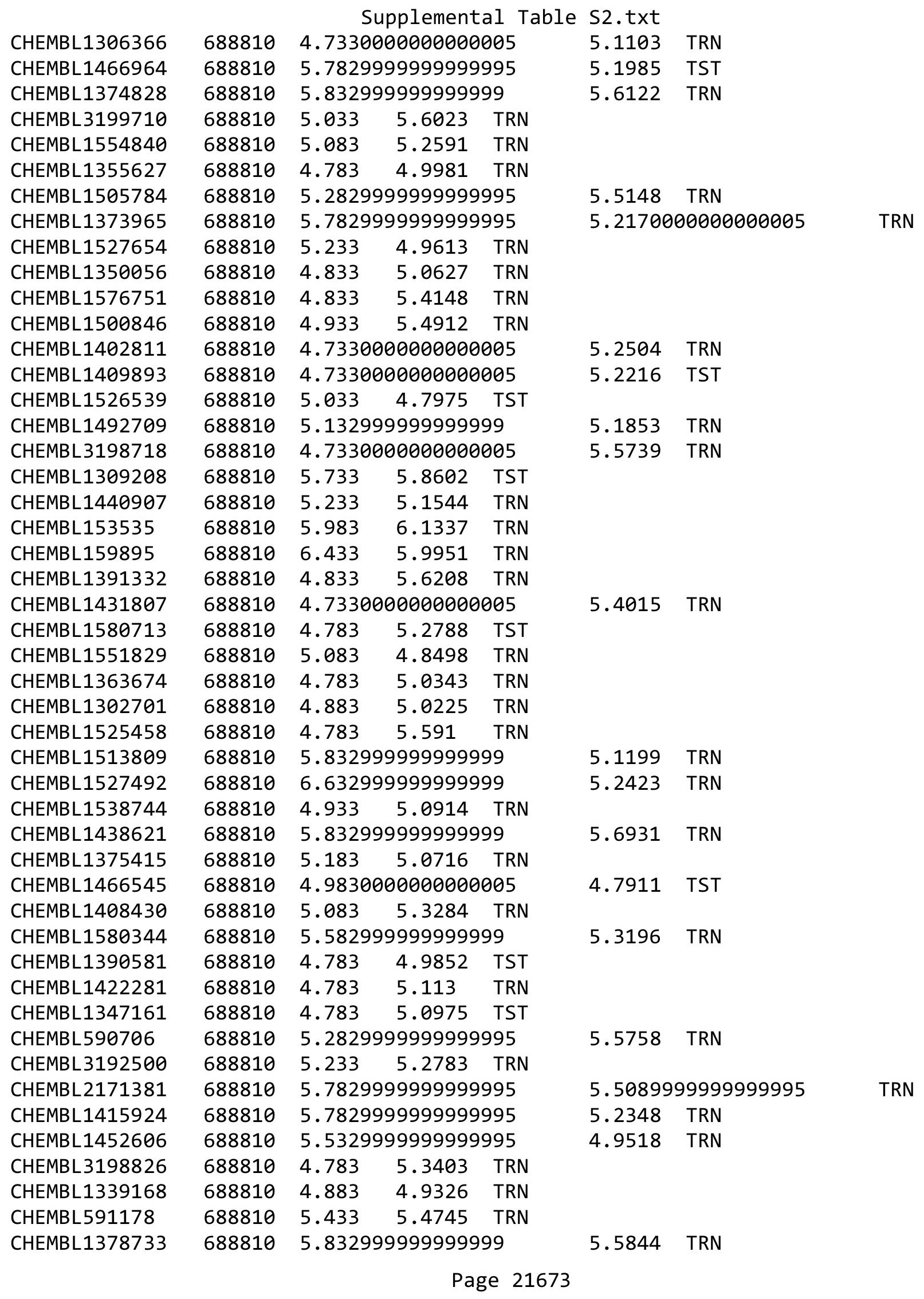




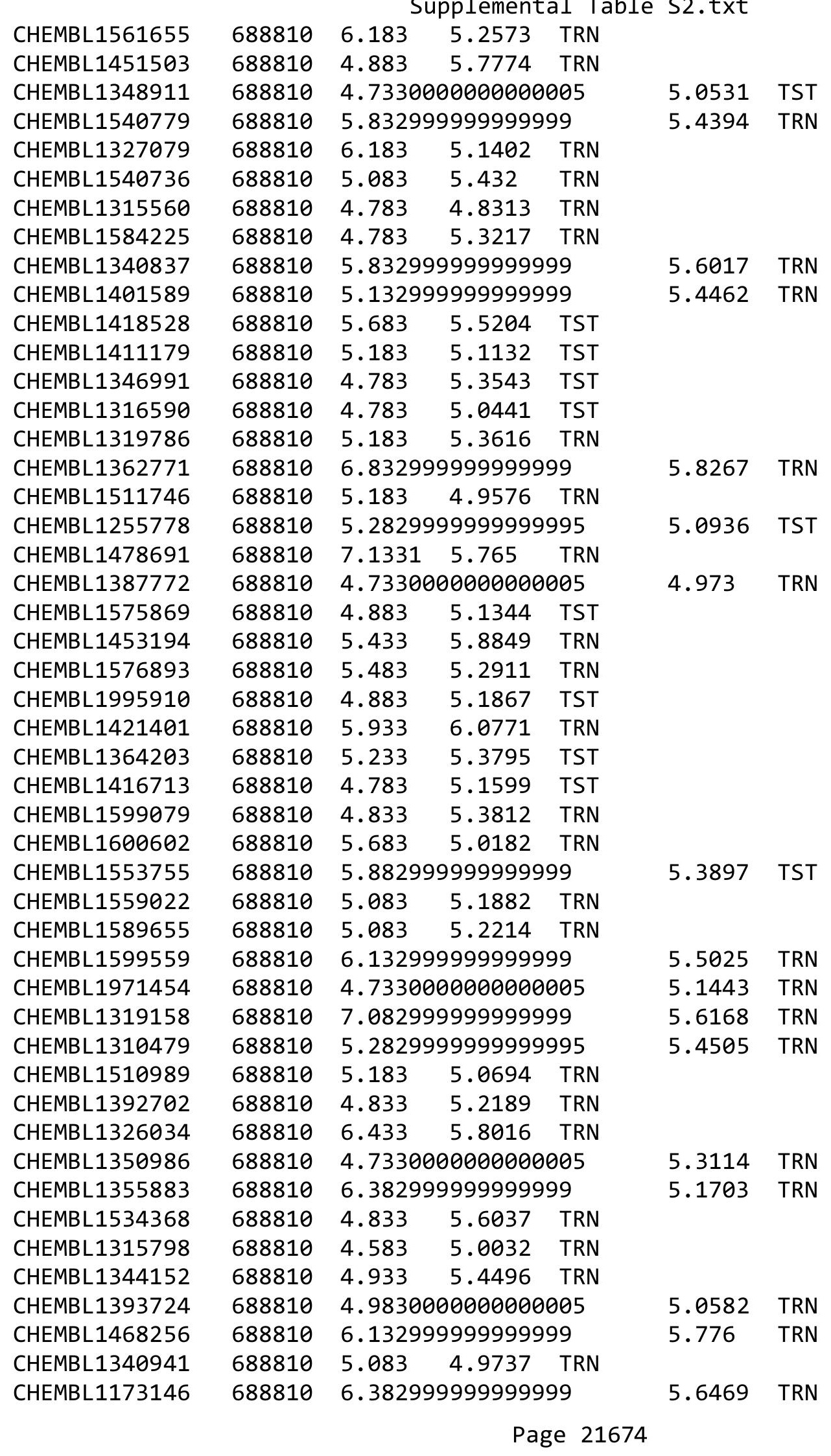




\begin{tabular}{|c|c|c|c|c|c|c|}
\hline \multirow{3}{*}{$\begin{array}{l}\text { CHEMBL1390789 } \\
\text { CHEMBL1342143 }\end{array}$} & & \multicolumn{5}{|c|}{ Supplemental Table S2.txt } \\
\hline & 688810 & \multicolumn{3}{|c|}{5.5329999999999995} & \multirow[t]{7}{*}{6.0814} & \multirow[t]{2}{*}{ TRN } \\
\hline & 688810 & 5.183 & 5.3031 & TST & & \\
\hline CHEMBL1481085 & 688810 & 4.633 & 4.444 & TRN & & \\
\hline CHEMBL1577140 & 688810 & 5.683 & 5.4353 & TRN & & \\
\hline CHEMBL1444082 & 688810 & 4.783 & 5.7301 & TRN & & \\
\hline CHEMBL1322056 & 688810 & 4.783 & 4.9297 & TRN & & \\
\hline CHEMBL1601827 & 688810 & 4.883 & 5.3066 & TRN & & \\
\hline CHEMBL1543337 & 688810 & \multicolumn{3}{|c|}{5.832999999999999} & 6.2411 & \\
\hline CHEMBL1390721 & 688810 & 4.883 & 5.216 & TRN & & \\
\hline CHEMBL1544530 & 688810 & \multicolumn{3}{|c|}{5.132999999999999} & 5.4806 & \\
\hline CHEMBL1396557 & 688810 & 5.683 & 5.3904 & TRN & & \\
\hline CHEMBL1495299 & 688810 & 4.633 & 5.0046 & TRN & & \\
\hline CHEMBL1418312 & 688810 & 4.883 & 5.1318 & TRN & & \\
\hline CHEMBL1993037 & 688810 & \multicolumn{3}{|c|}{5.382999999999999} & 5.4092 & \\
\hline CHEMBL1485560 & 688810 & 6.0 & 4.6695 & TRN & & \\
\hline CHEMBL1405928 & 688810 & 5.083 & 5.2281 & TRN & & \\
\hline CHEMBL1405816 & 688810 & \multicolumn{3}{|c|}{5.382999999999999} & 4.8 & \\
\hline CHEMBL1532172 & 688810 & 4.833 & \multicolumn{3}{|c|}{5.1579999999999995} & \\
\hline CHEMBL1567363 & 688810 & 5.233 & 5.3689 & TRN & & \\
\hline CHEMBL1347295 & 688810 & 4.633 & 4.8318 & TRN & & \\
\hline CHEMBL1525233 & 688810 & \multicolumn{3}{|c|}{4.7330000000000005} & 5.3041 & \\
\hline CHEMBL3191009 & 688810 & 5.233 & 5.1282 & TRN & & \\
\hline CHEMBL1338502 & 688810 & 5.683 & 6.1404 & TRN & & \\
\hline CHEMBL1586992 & 688810 & 4.833 & 5.2887 & TRN & & \\
\hline CHEMBL1367779 & 688810 & 4.833 & 5.1261 & TST & & \\
\hline CHEMBL1389690 & 688810 & \multicolumn{3}{|c|}{5.382999999999999} & 5.6015 & \\
\hline CHEMBL1465609 & 688810 & 4.683 & 4.9515 & TRN & & \\
\hline CHEMBL1331773 & 688810 & 4.633 & 5.1109 & TST & & \\
\hline CHEMBL1300831 & 688810 & \multicolumn{3}{|c|}{4.7330000000000005} & 5.1648 & TRN \\
\hline CHEMBL1534933 & 688810 & \multicolumn{3}{|c|}{5.132999999999999} & 5.0164 & \\
\hline CHEMBL1527254 & 688810 & 4.883 & 5.5093 & TRN & & \\
\hline CHEMBL1536196 & 688810 & 4.633 & 4.8561 & TST & & \\
\hline CHEMBL1489184 & 688810 & \multicolumn{3}{|c|}{6.582999999999999} & 5.7198 & $\mathrm{~T}$ \\
\hline CHEMBL1448972 & 688810 & 5.233 & 4.8931 & TST & & \\
\hline CHEMBL1374157 & 688810 & 5.733 & 5.2036 & TRN & & \\
\hline CHEMBL1541557 & 688810 & \multicolumn{3}{|c|}{5.132999999999999} & 5.0904 & \\
\hline CHEMBL567422 & 688810 & 5.233 & 4.9252 & TST & & \\
\hline CHEMBL1601779 & 688810 & \multicolumn{3}{|c|}{6.132999999999999} & 5.4953 & \\
\hline CHEMBL1491243 & 688810 & 4.683 & 4.6851 & TRN & & \\
\hline CHEMBL1339546 & 688810 & 4.833 & 4.9312 & TST & & \\
\hline CHEMBL1452811 & 688810 & \multicolumn{3}{|c|}{6.2829999999999995} & 5.6958 & 110 \\
\hline CHEMBL3195417 & 688810 & \multicolumn{3}{|c|}{5.882999999999999} & 5.1012 & \\
\hline CHEMBL1509571 & 688810 & 4.833 & 5.3645 & TST & & \\
\hline CHEMBL1493127 & 688810 & 4.883 & 5.0821 & TRN & & \\
\hline CHEMBL1533359 & 688810 & 4.783 & 5.2187 & TRN & & \\
\hline CHEMBL1596633 & 688810 & 4.783 & 5.2213 & TRN & & \\
\hline CHEMBL1389751 & 688810 & 5.083 & 5.0649 & TRN & & \\
\hline CHEMBL1345753 & 688810 & 4.783 & 5.3625 & TST & & \\
\hline
\end{tabular}




\begin{tabular}{|c|c|c|c|c|c|c|}
\hline \multirow[b]{2}{*}{ CHEMBL1462664 } & \multirow[b]{2}{*}{688810} & \multicolumn{5}{|c|}{ Iemental Ia } \\
\hline & & 4.783 & 5.1946 & TRN & & \\
\hline CHEMBL1425309 & 688810 & \multicolumn{3}{|c|}{6.382999999999999} & 5.3649 & TRN \\
\hline CHEMBL1358032 & 688810 & 4.583 & 5.069 & TRN & & \\
\hline CHEMBL1553674 & 688810 & 4.933 & 5.0845 & TRN & & \\
\hline CHEMBL1604369 & 688810 & 5.683 & 5.6578 & TST & & \\
\hline CHEMBL3211051 & 688810 & 4.783 & 5.0743 & TST & & \\
\hline CHEMBL3199642 & 688810 & 5.483 & 5.2701 & TRN & & \\
\hline CHEMBL1527158 & 688810 & 5.433 & 5.74 & TRN & & \\
\hline CHEMBL1329031 & 688810 & 4.633 & 4.7375 & TRN & & \\
\hline CHEMBL1513116 & 688810 & 5.233 & 5.0323 & TST & & \\
\hline CHEMBL1519652 & 688810 & 5.183 & 5.3764 & TRN & & \\
\hline CHEMBL1544685 & 688810 & 5.033 & 6.4717 & TRN & & \\
\hline CHEMBL1449120 & 688810 & 4.783 & 5.4182 & TRN & & \\
\hline CHEMBL1479800 & 688810 & \multicolumn{3}{|c|}{4.9830000000000005} & 4.8542 & TRN \\
\hline CHEMBL1553656 & 688810 & 4.683 & 4.7637 & TRN & & \\
\hline CHEMBL1499935 & 688810 & 4.933 & 5.1495 & TRN & & \\
\hline CHEMBL3199247 & 688810 & \multicolumn{3}{|c|}{5.2829999999999995} & 5.3744 & TST \\
\hline CHEMBL1400338 & 688810 & 5.183 & 5.2679 & TRN & & \\
\hline CHEMBL415506 & 688810 & \multicolumn{3}{|c|}{5.7829999999999995} & 5.3211 & TRN \\
\hline CHEMBL1445871 & 688810 & 6.4829 & 5.9954 & TRN & & \\
\hline CHEMBL1447262 & 688810 & 5.483 & 4.7264 & TRN & & \\
\hline CHEMBL1335085 & 688810 & \multicolumn{3}{|c|}{4.9830000000000005} & 5.3695 & TRN \\
\hline CHEMBL1449892 & 688810 & \multicolumn{3}{|c|}{4.9830000000000005} & 5.47 & TRN \\
\hline CHEMBL3211423 & 688810 & 4.883 & 5.3929 & TST & & \\
\hline CHEMBL1365310 & 688810 & 4.933 & 5.1174 & TST & & \\
\hline CHEMBL1446583 & 688810 & 5.433 & 5.2346 & TRN & & \\
\hline CHEMBL1571682 & 688810 & 4.883 & 5.0014 & TST & & \\
\hline CHEMBL1311367 & 688810 & \multicolumn{3}{|c|}{5.132999999999999} & 5.1154 & TST \\
\hline CHEMBL1405979 & 688810 & 4.833 & 5.2544 & TRN & & \\
\hline CHEMBL1366346 & 688810 & 5.033 & 5.3897 & TRN & & \\
\hline CHEMBL1431436 & 688810 & \multicolumn{3}{|c|}{5.132999999999999} & 5.1937 & TRN \\
\hline CHEMBL1438886 & 688810 & 5.183 & 5.0022 & TST & & \\
\hline CHEMBL1608312 & 688810 & 5.183 & 5.4433 & TRN & & \\
\hline CHEMBL598885 & 688810 & 8.4318 & 5.9666 & TRN & & \\
\hline CHEMBL1530426 & 688810 & \multicolumn{3}{|c|}{5.5329999999999995} & 5.7994 & TRN \\
\hline CHEMBL3195514 & 688810 & 5.083 & 4.9065 & TRN & & \\
\hline CHEMBL1385919 & 688810 & 5.183 & 4.9997 & TRN & & \\
\hline CHEMBL3193264 & 688810 & 4.883 & 5.1687 & TRN & & \\
\hline CHEMBL1462710 & 688810 & \multicolumn{3}{|c|}{5.332999999999999} & 5.6642 & TST \\
\hline CHEMBL1360566 & 688810 & 5.733 & 5.5304 & TRN & & \\
\hline CHEMBL1543482 & 688810 & 5.083 & 5.4029 & TST & & \\
\hline CHEMBL3198626 & 688810 & \multicolumn{3}{|c|}{4.7330000000000005} & 5.0798 & TRN \\
\hline CHEMBL1448310 & 688810 & 4.683 & 5.3515 & TST & & \\
\hline CHEMBL1580883 & 688810 & 5.433 & \multicolumn{3}{|c|}{5.2989999999999995} & TRN \\
\hline CHEMBL1493757 & 688810 & \multicolumn{3}{|c|}{6.7829999999999995} & 5.4821 & TRN \\
\hline CHEMBL 3194065 & 688810 & \multicolumn{3}{|c|}{5.332999999999999} & 5.476 & TRN \\
\hline CHEMBL1427443 & 688810 & 5.483 & 5.2334 & TST & & \\
\hline CHEMBL1698464 & 688810 & 5.233 & 5.2574 & TRN & & \\
\hline
\end{tabular}




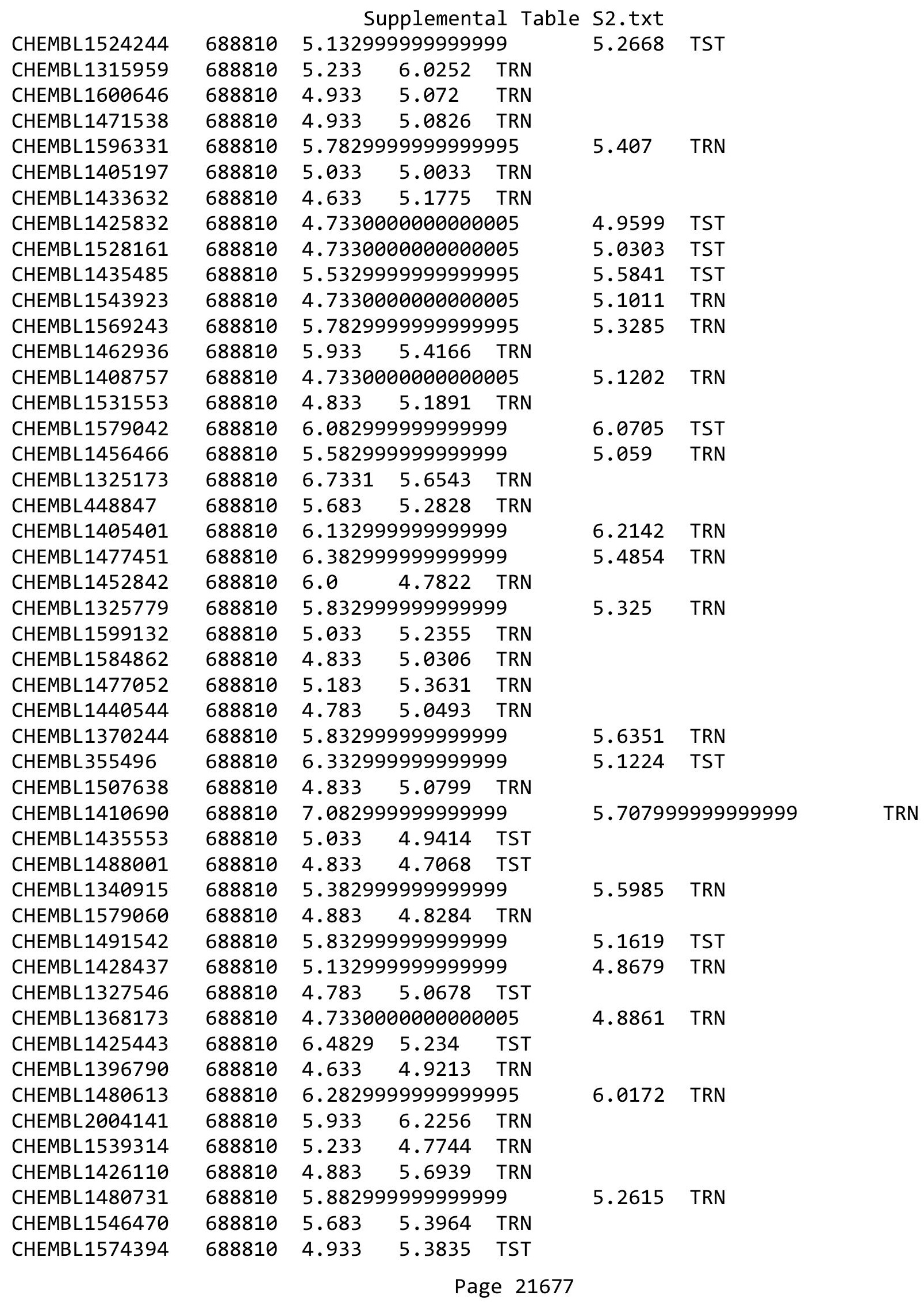




\begin{tabular}{|c|c|c|c|c|c|c|c|}
\hline \multirow[b]{2}{*}{ CHEMBL1489744 } & \multicolumn{6}{|c|}{ Supplemental Table s2.txt } & \\
\hline & 688810 & \multicolumn{3}{|c|}{6.382999999999999} & 5.484 & TRN & \\
\hline CHEMBL1545002 & 688810 & \multicolumn{3}{|c|}{5.7829999999999995} & \multicolumn{2}{|c|}{5.502000000000001} & TRN \\
\hline CHEMBL1454216 & 688810 & 7.1831 & 5.2607 & TRN & & & \\
\hline CHEMBL3208093 & 688810 & 4.933 & 5.5493 & TRN & & & \\
\hline CHEMBL1527186 & 688810 & \multicolumn{3}{|c|}{6.582999999999999} & 6.0877 & TRN & \\
\hline CHEMBL1253586 & 688810 & \multicolumn{3}{|c|}{5.382999999999999} & 5.3664 & TST & \\
\hline CHEMBL1484821 & 688810 & 5.433 & 5.1588 & TRN & & & \\
\hline CHEMBL1426350 & 688810 & \multicolumn{3}{|c|}{4.7330000000000005} & 5.1509 & TRN & \\
\hline CHEMBL1328639 & 688810 & \multicolumn{3}{|c|}{5.632999999999999} & 5.0404 & TRN & \\
\hline CHEMBL51931 & 688810 & \multicolumn{3}{|c|}{5.5329999999999995} & 5.3831 & TST & \\
\hline CHEMBL1583989 & 688810 & \multicolumn{3}{|c|}{5.2829999999999995} & 5.5462 & TRN & \\
\hline CHEMBL1409319 & 688810 & 5.733 & 5.4492 & TRN & & & \\
\hline CHEMBL1600162 & 688810 & 4.833 & 4.9869 & TRN & & & \\
\hline CHEMBL1561296 & 688810 & \multicolumn{3}{|c|}{5.5329999999999995} & 5.317 & TRN & \\
\hline CHEMBL1436356 & 688810 & 4.583 & 5.0105 & TST & & & \\
\hline CHEMBL1386984 & 688810 & 4.783 & 5.3295 & TST & & & \\
\hline CHEMBL1416304 & 688810 & 4.783 & 5.3985 & TRN & & & \\
\hline CHEMBL1490066 & 688810 & 4.933 & 5.2543 & TRN & & & \\
\hline CHEMBL1556113 & 688810 & \multicolumn{3}{|c|}{5.132999999999999} & \multicolumn{2}{|c|}{4.9430000000000005} & TRN \\
\hline CHEMBL1304445 & 688810 & 4.9 & 4.9939 & TST & & & \\
\hline CHEMBL1515065 & 688810 & 6.433 & 5.5567 & TRN & & & \\
\hline CHEMBL1432007 & 688810 & 6.433 & 5.7309 & TRN & & & \\
\hline CHEMBL1457303 & 688810 & 6.4829 & 5.7891 & TRN & & & \\
\hline CHEMBL1336288 & 688810 & 4.783 & 5.2232 & TRN & & & \\
\hline CHEMBL1335825 & 688810 & 4.783 & 5.2377 & TST & & & \\
\hline CHEMBL1300736 & 688810 & \multicolumn{3}{|c|}{5.332999999999999} & 5.2143 & TRN & \\
\hline CHEMBL1452114 & 688810 & 4.783 & 5.0528 & TRN & & & \\
\hline CHEMBL1611840 & 688810 & \multicolumn{3}{|c|}{5.5329999999999995} & 5.1502 & TST & \\
\hline CHEMBL1318311 & 688810 & 4.583 & 4.9714 & TRN & & & \\
\hline CHEMBL1513687 & 688810 & 4.633 & 4.9215 & TRN & & & \\
\hline CHEMBL1392817 & 688810 & \multicolumn{3}{|c|}{5.7829999999999995} & 5.6495 & TRN & \\
\hline CHEMBL1463953 & 688810 & \multicolumn{3}{|c|}{4.7330000000000005} & 5.4489 & TRN & \\
\hline CHEMBL1383189 & 688810 & 5.683 & 5.2901 & TRN & & & \\
\hline CHEMBL1597510 & 688810 & 5.483 & 4.9374 & TRN & & & \\
\hline CHEMBL1531984 & 688810 & 4.833 & 5.7287 & TRN & & & \\
\hline CHEMBL3199547 & 688810 & 5.083 & 5.5185 & TRN & & & \\
\hline CHEMBL1391443 & 688810 & 5.933 & 5.36799 & 9999 & 99 & TRN & \\
\hline CHEMBL1401821 & 688810 & 4.73300 & 00000006 & 005 & 4.8611 & TRN & \\
\hline CHEMBL1522334 & 688810 & 5.183 & 5.5685 & TRN & & & \\
\hline CHEMBL1546509 & 688810 & 5.033 & 5.1094 & TRN & & & \\
\hline CHEMBL1404071 & 688810 & 5.733 & 5.0694 & TST & & & \\
\hline CHEMBL1428565 & 688810 & 6.33299 & 9999999 & & 5.388 & TST & \\
\hline CHEMBL 2002162 & 688810 & 5.28299 & 9999999 & 995 & 5.506 & TST & \\
\hline CHEMBL1520005 & 688810 & 6.63299 & 99999995 & & 5.50799 & 9999999999 & TRN \\
\hline CHEMBL1336113 & 688810 & 5.683 & 5.1422 & TST & & & \\
\hline CHEMBL1362370 & 688810 & 6.78299 & 99999995 & 995 & 5.8084 & TRN & \\
\hline CHEMBL1591234 & 688810 & 4.73300 & 00000006 & 005 & 5.1622 & TRN & \\
\hline CHEMBL1529350 & 688810 & 5.183 & 5.3418 & TRN & & & \\
\hline
\end{tabular}




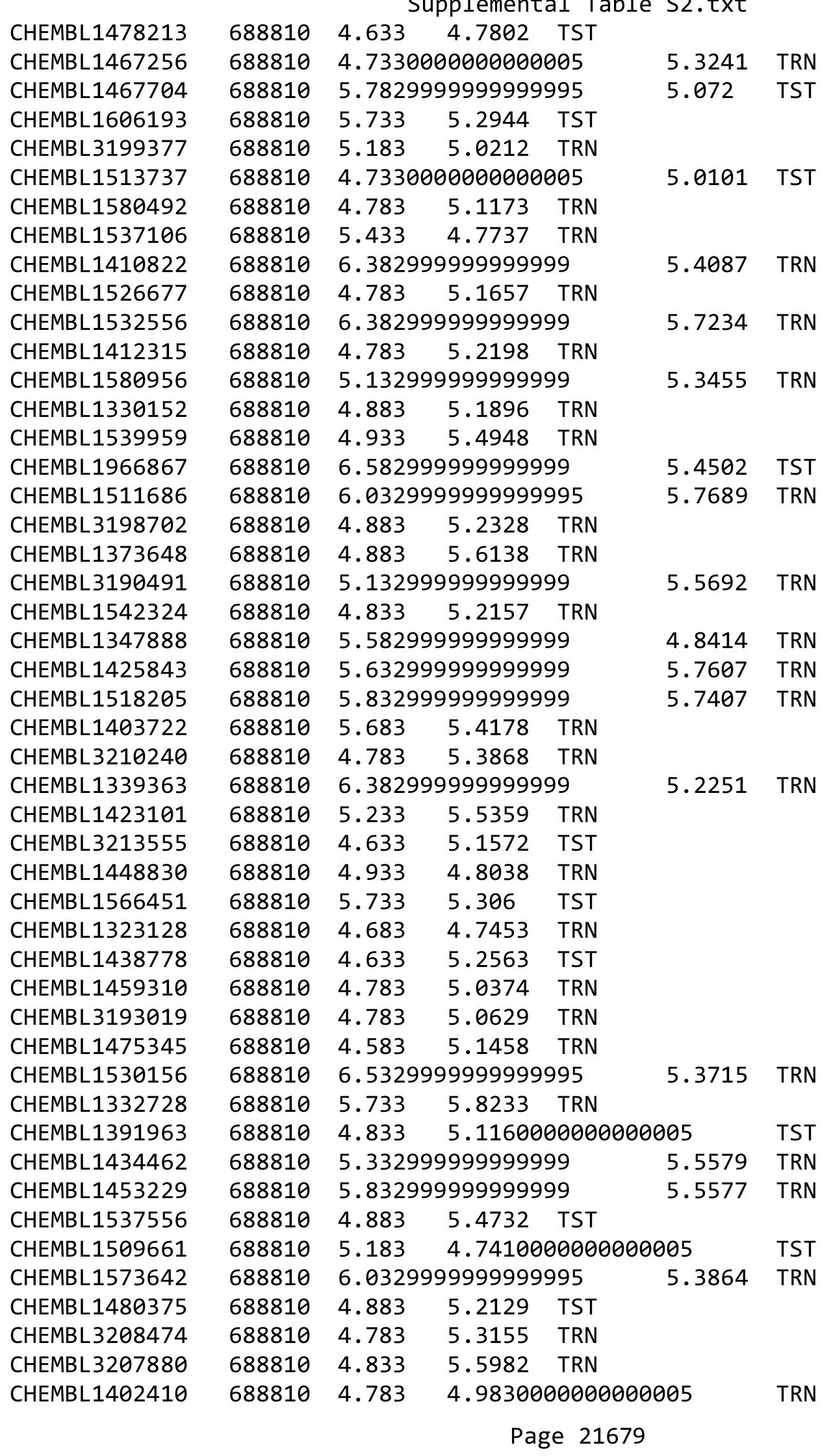




\begin{tabular}{|c|c|c|c|c|c|c|}
\hline \multicolumn{7}{|l|}{ 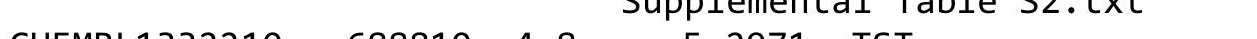 } \\
\hline CHEMBL1332210 & 688810 & 4.8 & 5.2971 & TST & & \\
\hline CHEMBL1538895 & 688810 & \multicolumn{3}{|c|}{6.332999999999999} & 5.4457 & TRN \\
\hline CHEMBL1575231 & 688810 & \multicolumn{3}{|c|}{ 5.332999999999999 } & 5.0965 & TRN \\
\hline CHEMBL1403294 & 688810 & 5.683 & 5.1835 & TRN & & \\
\hline CHEMBL1525719 & 688810 & 4.633 & 4.9754 & TRN & & \\
\hline CHEMBL1555793 & 688810 & \multicolumn{3}{|c|}{5.832999999999999} & 5.3804 & 1 \\
\hline CHEMBL1546726 & 688810 & 5.233 & 5.0773 & TRN & & \\
\hline CHEMBL1300074 & 688810 & 5.683 & 5.6229 & TRN & & \\
\hline CHEMBL1559721 & 688810 & 5.183 & 5.0257 & TST & & \\
\hline CHEMBL1517288 & 688810 & 4.933 & 5.4199 & TST & & \\
\hline CHEMBL522140 & 688810 & 4.783 & 5.1603 & TRN & & \\
\hline CHEMBL1488260 & 688810 & \multicolumn{3}{|c|}{5.132999999999999} & 5.3991 & \\
\hline CHEMBL1421720 & 688810 & 5.683 & 5.2879 & TRN & & \\
\hline CHEMBL1504701 & 688810 & \multicolumn{3}{|c|}{6.082999999999999} & 6.0944 & TR \\
\hline CHEMBL1416718 & 688810 & 4.883 & 5.0567 & TRN & & \\
\hline CHEMBL1381035 & 688810 & 4.633 & 5.0327 & TST & & \\
\hline CHEMBL1307461 & 688810 & 4.883 & 4.9809 & TRN & & \\
\hline CHEMBL1601207 & 688810 & 5.433 & 5.4276 & TRN & & \\
\hline CHEMBL1361692 & 688810 & 5.233 & 5.2101 & TRN & & \\
\hline CHEMBL1368427 & 688810 & 4.783 & \multicolumn{3}{|c|}{5.162000000000001} & \\
\hline CHEMBL1447762 & 688810 & 4.633 & 4.8124 & TST & & \\
\hline CHEMBL1410235 & 688810 & 5.483 & 5.7722 & TRN & & \\
\hline CHEMBL1458448 & 688810 & 4.783 & 5.2317 & TST & & \\
\hline CHEMBL1425956 & 688810 & 4.9 & 5.0979 & TRN & & \\
\hline CHEMBL1304655 & 688810 & \multicolumn{3}{|c|}{4.7330000000000005} & 183 & \\
\hline CHEMBL1170087 & 688810 & 5.683 & 5.1784 & TRN & & \\
\hline CHEMBL1559181 & 688810 & \multicolumn{3}{|c|}{5.632999999999999} & 5.4168 & \\
\hline CHEMBL1496925 & 688810 & 5.683 & 5.2383 & TST & & \\
\hline CHEMBL1531419 & 688810 & \multicolumn{3}{|c|}{4.7330000000000005} & 5.1801 & $\mathrm{TP}$ \\
\hline CHEMBL1535900 & 688810 & 5.183 & 5.6324 & TST & & \\
\hline CHEMBL1414933 & 688810 & 4.833 & 5.3294 & TRN & & \\
\hline CHEMBL1523967 & 688810 & \multicolumn{3}{|c|}{5.7829999999999995} & 5.1252 & TS \\
\hline CHEMBL1173570 & 688810 & 4.583 & 5.0483 & TRN & & \\
\hline CHEMBL1335863 & 688810 & \multicolumn{3}{|c|}{6.632999999999999} & 5.5982 & TRN \\
\hline CHEMBL1370159 & 688810 & \multicolumn{3}{|c|}{4.7330000000000005} & 5.2203 & TS \\
\hline CHEMBL1533153 & 688810 & 5.733 & \multicolumn{3}{|c|}{5.8660000000000005} & \\
\hline CHEMBL1351823 & 688810 & 4.633 & 4.3318 & TST & & \\
\hline CHEMBL1589249 & 688810 & \multicolumn{3}{|c|}{4.7330000000000005} & 5.0843 & TST \\
\hline CHEMBL1482356 & 688810 & \multicolumn{3}{|c|}{5.832999999999999} & 5.3795 & TST \\
\hline CHEMBL1334840 & 688810 & 4.783 & 4.8185 & TST & & \\
\hline CHEMBL1311838 & 688810 & \multicolumn{3}{|c|}{5.2829999999999995} & 5.415 & $1 \pi$ \\
\hline CHEMBL1549748 & 688810 & \multicolumn{3}{|c|}{6.5329999999999995} & 5.9645 & $T P_{1}-1$ \\
\hline CHEMBL1441530 & 688810 & 4.783 & 5.065 & TST & & \\
\hline CHEMBL1428795 & 688810 & 5.033 & 5.0675 & TRN & & \\
\hline CHEMBL1435486 & 688810 & \multicolumn{3}{|c|}{5.632999999999999} & 5.5711 & ובנו \\
\hline CHEMBL1467031 & 688810 & 5.683 & 5.0534 & TRN & & \\
\hline CHEMBL1552352 & 688810 & \multirow{2}{*}{\multicolumn{3}{|c|}{$\begin{array}{l}4.933 \quad 5.6391 \\
5.2829999999999995\end{array}$}} & & \\
\hline CHEMBL1389982 & 688810 & & & & 5.2258 & J \\
\hline
\end{tabular}




\begin{tabular}{|c|c|c|c|c|c|c|}
\hline & \multicolumn{5}{|c|}{ oplemental T } \\
\hline CHEMBL1575729 & 688810 & 5.233 & 5.0186 & TRN & & \\
\hline CHEMBL1326952 & 688810 & 4.73300 & 000000006 & 005 & 4.511 & TS \\
\hline CHEMBL1317889 & 688810 & 5.733 & 5.2469 & TRN & & \\
\hline CHEMBL1342287 & 688810 & 7.1331 & 5.8586 & TRN & & \\
\hline CHEMBL1470841 & 688810 & 4.783 & 5.0884 & TRN & & \\
\hline CHEMBL1586531 & 688810 & 5.083 & 5.013999 & 99999 & 99 & \\
\hline CHEMBL 3189651 & 688810 & 5.13299 & 999999999 & & 4.9817 & \\
\hline CHEMBL1317653 & 688810 & 4.633 & 4.9799 & TRN & & \\
\hline CHEMBL1494713 & 688810 & 4.833 & 4.8603 & TRN & & \\
\hline CHEMBL1439523 & 688810 & 4.98300 & 000000000 & 005 & 5.0078 & \\
\hline CHEMBL1449916 & 688810 & 6.433 & 6.0241 & TRN & & \\
\hline CHEMBL1476225 & 688810 & 5.13299 & 999999999 & & 5.1646 & \\
\hline CHEMBL1531774 & 688810 & 5.033 & 5.4331 & TRN & & \\
\hline CHEMBL1491213 & 688810 & 5.13299 & 999999999 & & 5.144 & \\
\hline CHEMBL1307715 & 688810 & 4.98300 & 000000006 & 005 & 4.9602 & \\
\hline CHEMBL 3213505 & 688810 & 4.98300 & 000000006 & 005 & 5.2811 & \\
\hline CHEMBL1306534 & 688810 & 6.4829 & 5.5487 & TRN & & \\
\hline CHEMBL 3195228 & 688810 & 5.53299 & 999999999 & 995 & 2 & \\
\hline CHEMBL1306900 & 688810 & 4.833 & 4.3217 & TRN & & \\
\hline CHEMBL1331087 & 688810 & 4.783 & 5.0801 & TRN & & \\
\hline CHEMBL1423661 & 688810 & 5.183 & 5.0941 & TST & & \\
\hline CHEMBL1526724 & 688810 & 6.433 & 5.9163 & TRN & & \\
\hline CHEMBL1339720 & 688810 & 5.183 & 5.5454 & TRN & & \\
\hline CHEMBL1408482 & 688810 & 4.783 & 5.2839 & TRN & & \\
\hline CHEMBL1580750 & 688810 & 5.13299 & 999999999 & & 4.7745 & \\
\hline CHEMBL1489461 & 688810 & 5.483 & 5.4846 & TRN & & \\
\hline CHEMBL1366133 & 688810 & 5.13299 & 999999999 & & 5.3126 & $\mathrm{TP}$ \\
\hline CHEMBL 3213955 & 688810 & 4.73300 & 000000000 & 005 & 5.2449 & \\
\hline CHEMBL1583496 & 688810 & 6.233 & 5.5316 & TRN & & \\
\hline CHEMBL1557437 & 688810 & 6.03299 & 999999999 & 995 & 5.3903 & 151 \\
\hline CHEMBL1591942 & 688810 & 4.633 & 4.5788 & TST & & \\
\hline CHEMBL1499032 & 688810 & 4.73300 & 000000000 & 005 & 4.921 & TR \\
\hline CHEMBL1478644 & 688810 & 6.433 & 6.1012 & TRN & & \\
\hline CHEMBL1412659 & 688810 & 4.933 & 5.2688 & TRN & & \\
\hline CHEMBL1566477 & 688810 & 4.833 & 4.8647 & TST & & \\
\hline CHEMBL1337583 & 688810 & 6.58299 & 999999999 & & 5.447 & TRN \\
\hline CHEMBL1304647 & 688810 & 5.28299 & 999999999 & 995 & 5.4453 & \\
\hline CHEMBL1589394 & 688810 & 4.833 & 5.4506 & TRN & & \\
\hline CHEMBL1490828 & 688810 & 4.73300 & 000000000 & 005 & 5.2844 & I RIN \\
\hline CHEMBL 3196948 & 688810 & 5.53299 & 999999999 & 995 & 5.7381 & TRN \\
\hline CHEMBL 3193795 & 688810 & 6.9329 & 6.5009 & TRN & & \\
\hline CHEMBL1472583 & 688810 & 5.28299 & 999999999 & 995 & 5.1806 & 15 \\
\hline CHEMBL1558218 & 688810 & 5.733 & 4.751 & TRN & & \\
\hline CHEMBL1504634 & 688810 & 4.683 & 5.3353 & TRN & & \\
\hline CHEMBL1313891 & 688810 & 5.683 & 6.1 & TRN & & \\
\hline CHEMBL1529296 & 688810 & 5.083 & 5.5444 & TRN & & \\
\hline CHEMBL1394526 & 688810 & 4.833 & 5.4974 & TST & & \\
\hline CHEMBL1447313 & 688810 & 4.783 & 5.2978 & TRN & & \\
\hline
\end{tabular}




\begin{tabular}{|c|c|c|c|c|c|c|}
\hline \multirow{3}{*}{$\begin{array}{l}\text { CHEMBL1450116 } \\
\text { CHEMBL1332955 }\end{array}$} & \multicolumn{6}{|c|}{ Supplemental Table s2.txt } \\
\hline & 688810 & \multicolumn{4}{|c|}{6.082999999999999} & TRN \\
\hline & 688810 & \multicolumn{3}{|c|}{5.332999999999999} & 4.8656 & TST \\
\hline CHEMBL3194330 & 688810 & 4.783 & 4.9665 & TRN & & \\
\hline CHEMBL1461634 & 688810 & 4.933 & 5.0059 & TRN & & \\
\hline CHEMBL595700 & 688810 & 4.633 & 5.0735 & TRN & & \\
\hline CHEMBL1545542 & 688810 & 7.2328 & 5.8762 & TRN & & \\
\hline CHEMBL1335757 & 688810 & 4.933 & 5.2482 & TRN & & \\
\hline CHEMBL1528455 & 688810 & \multicolumn{3}{|c|}{5.132999999999999} & 5.2301 & TST \\
\hline CHEMBL1377737 & 688810 & 5.983 & 5.4633 & TRN & & \\
\hline CHEMBL3210154 & 688810 & \multicolumn{3}{|c|}{5.5329999999999995} & 5.0619 & TRN \\
\hline CHEMBL1495002 & 688810 & 5.183 & 5.4875 & TRN & & \\
\hline CHEMBL452337 & 688810 & 5.033 & 5.4233 & TRN & & \\
\hline CHEMBL3207651 & 688810 & 4.833 & 5.0925 & TRN & & \\
\hline CHEMBL1516979 & 688810 & 4.883 & 5.1415 & TST & & \\
\hline CHEMBL1322058 & 688810 & \multicolumn{3}{|c|}{5.332999999999999} & 5.4485 & TRN \\
\hline CHEMBL3191362 & 688810 & 5.433 & 5.7147 & TST & & \\
\hline CHEMBL1418518 & 688810 & 6.8831 & 5.6651 & TRN & & \\
\hline CHEMBL1566770 & 688810 & 4.933 & \multicolumn{3}{|c|}{5.337000000000001} & TRN \\
\hline CHEMBL1458471 & 688810 & 5.183 & 4.9578 & TRN & & \\
\hline CHEMBL1488108 & 688810 & \multicolumn{3}{|c|}{5.632999999999999} & 5.638 & TST \\
\hline CHEMBL1490171 & 688810 & 4.833 & 5.0478 & TRN & & \\
\hline CHEMBL1504045 & 688810 & \multicolumn{3}{|c|}{4.7330000000000005} & 5.0524 & TRN \\
\hline CHEMBL 3213344 & 688810 & \multicolumn{3}{|c|}{5.2829999999999995} & 5.1036 & TRN \\
\hline CHEMBL3194521 & 688810 & \multicolumn{3}{|c|}{6.632999999999999} & 6.0572 & TRN \\
\hline CHEMBL1436326 & 688810 & \multicolumn{3}{|c|}{6.332999999999999} & 5.5847 & TRN \\
\hline CHEMBL1335581 & 688810 & \multicolumn{3}{|c|}{5.582999999999999} & 5.2493 & TST \\
\hline CHEMBL1570371 & 688810 & 5.033 & 6.1237 & TRN & & \\
\hline CHEMBL1401402 & 688810 & \multicolumn{3}{|c|}{5.582999999999999} & 5.1776 & TRN \\
\hline CHEMBL1395943 & 688810 & \multicolumn{3}{|c|}{5.832999999999999} & 5.4874 & TRN \\
\hline CHEMBL1588572 & 688810 & 5.433 & 5.8536 & TRN & & \\
\hline CHEMBL3197612 & 688810 & \multirow{2}{*}{\multicolumn{3}{|c|}{$\begin{array}{l}4.183 \quad 5.28 / 9 \text { TRN } \\
5.632999999999999\end{array}$}} & & \\
\hline CHEMBL1425200 & 688810 & & & & 5.1794 & TST \\
\hline CHEMBL1341938 & 688810 & 6.433 & 5.182 & TRN & & \\
\hline CHEMBL1485025 & 688810 & \multicolumn{3}{|c|}{4.7330000000000005} & 5.3303 & TRN \\
\hline CHEMBL1532568 & 688810 & 6.183 & 5.666 & TRN & & \\
\hline CHEMBL1361489 & 688810 & \multicolumn{3}{|c|}{6.0329999999999995} & 5.7743 & TRN \\
\hline CHEMBL1457410 & 688810 & 4.783 & 5.3139 & TRN & & \\
\hline CHEMBL1423902 & 688810 & \multicolumn{3}{|c|}{4.9830000000000005} & 5.4748 & TST \\
\hline CHEMBL1964833 & 688810 & 5.483 & 4.9574 & TRN & & \\
\hline CHEMBL1608600 & 688810 & 5.033 & \multicolumn{3}{|c|}{5.4079999999999995} & TRN \\
\hline CHEMBL1299208 & 688810 & 5.28299 & 99999999 & 995 & 5.9524 & TRN \\
\hline CHEMBL 2003149 & 688810 & 6.33299 & 99999999 & & 5.2938 & TST \\
\hline CHEMBL1537592 & 688810 & 4.833 & 5.0086 & TRN & & \\
\hline CHEMBL1551186 & 688810 & 6.9329 & 5.5746 & TRN & & \\
\hline CHEMBL1319198 & 688810 & 4.883 & 5.2512 & TST & & \\
\hline CHEMBL1500925 & 688810 & 5.183 & 5.1647 & TST & & \\
\hline CHEMBL1521327 & 688810 & 5.933 & 5.3843 & TRN & & \\
\hline CHEMBL1394905 & 688810 & 4.98300 & 00000000 & 05 & 5.1314 & TRN \\
\hline
\end{tabular}




\begin{tabular}{|c|c|c|c|c|c|c|}
\hline & & \multicolumn{4}{|c|}{ Supplemental Table S2.txt } & \multirow[b]{2}{*}{ TST } \\
\hline CHEMBL1548099 & 688810 & 4.9830 & 00000000 & 005 & 4.9364 & \\
\hline CHEMBL1345525 & 688810 & 4.783 & 5.5877 & TRN & & \\
\hline CHEMBL241987 & 688810 & \multicolumn{3}{|c|}{5.332999999999999} & 5.1566 & TST \\
\hline CHEMBL1371225 & 688810 & 5.483 & 5.6869 & TRN & & \\
\hline CHEMBL1464329 & 688810 & \multicolumn{3}{|c|}{4.7330000000000005} & 5.114 & TRN \\
\hline CHEMBL1523013 & 688810 & 5.233 & 5.2544 & TRN & & \\
\hline CHEMBL1442683 & 688810 & 5.183 & 5.4686 & TRN & & \\
\hline CHEMBL1422140 & 688810 & \multicolumn{3}{|c|}{5.132999999999999} & 5.2311 & TRN \\
\hline CHEMBL1393407 & 688810 & 4.783 & 4.8815 & TRN & & \\
\hline CHEMBL1419190 & 688810 & 5.033 & 5.1812 & TST & & \\
\hline CHEMBL1502692 & 688810 & \multicolumn{3}{|c|}{5.332999999999999} & 4.9976 & TST \\
\hline CHEMBL1613418 & 688810 & 4.583 & 5.0498 & TRN & & \\
\hline CHEMBL1515343 & 688810 & 5.183 & 5.3925 & TRN & & \\
\hline CHEMBL1503287 & 688810 & 5.033 & 5.1292 & TST & & \\
\hline CHEMBL475627 & 688810 & 7.0329 & 6.0341 & TRN & & \\
\hline CHEMBL1599964 & 688810 & 4.633 & 5.4161 & TRN & & \\
\hline CHEMBL1485166 & 688810 & \multicolumn{3}{|c|}{4.7330000000000005} & 5.0023 & TST \\
\hline CHEMBL1373823 & 688810 & \multicolumn{3}{|c|}{5.2829999999999995} & 5.0519 & TRN \\
\hline CHEMBL1437858 & 688810 & 4.883 & 5.3811 & TRN & & \\
\hline CHEMBL1562447 & 688810 & 4.783 & 4.8274 & TRN & & \\
\hline CHEMBL1378439 & 688810 & 4.933 & 5.2272 & TRN & & \\
\hline CHEMBL1407916 & 688810 & \multicolumn{3}{|c|}{5.132999999999999} & 5.2369 & TRN \\
\hline CHEMBL1306726 & 688810 & 4.883 & 5.2186 & TRN & & \\
\hline CHEMBL1483183 & 688810 & \multicolumn{3}{|c|}{4.7330000000000005} & 5.0833 & TRN \\
\hline CHEMBL1333000 & 688810 & \multicolumn{3}{|c|}{4.7330000000000005} & 5.0994 & TST \\
\hline CHEMBL1498894 & 688810 & 6.183 & 5.2055 & TRN & & \\
\hline CHEMBL1979843 & 688810 & 5.433 & 5.5883 & TRN & & \\
\hline CHEMBL1510086 & 688810 & \multicolumn{3}{|c|}{5.7829999999999995} & 5.6355 & TRN \\
\hline CHEMBL1339310 & 688810 & 5.233 & 5.0984 & TRN & & \\
\hline CHEMBL1429558 & 688810 & 5.483 & 5.355 & TRN & & \\
\hline CHEMBL1530557 & 688810 & 4.933 & 4.5968 & TRN & & \\
\hline CHEMBL1450629 & 688810 & 5.083 & 4.9334 & TST & & \\
\hline CHEMBL1490718 & 688810 & 5.683 & 5.568 & TRN & & \\
\hline CHEMBL1593500 & 688810 & \multicolumn{3}{|c|}{5.2829999999999995} & 4.9502 & TRN \\
\hline CHEMBL1489007 & 688810 & 5.083 & 4.9223 & TST & & \\
\hline CHEMBL1305890 & 688810 & \multicolumn{3}{|c|}{6.0329999999999995} & 5.3262 & TRN \\
\hline CHEMBL1326908 & 688810 & 4.783 & 5.1081 & TRN & & \\
\hline CHEMBL1535516 & 688810 & 5.183 & 5.4894 & TRN & & \\
\hline CHEMBL1308318 & 688810 & 5.033 & 5.6993 & TST & & \\
\hline CHEMBL1599157 & 688810 & 4.883 & 4.9985 & TST & & \\
\hline CHEMBL1425853 & 688810 & 5.433 & 5.0352 & TRN & & \\
\hline CHEMBL1556925 & 688810 & 5.483 & 5.8442 & TRN & & \\
\hline CHEMBL1974640 & 688810 & 5.933 & 5.3698 & TRN & & \\
\hline CHEMBL3212619 & 688810 & 5.083 & 5.513 & TST & & \\
\hline CHEMBL1345082 & 688810 & 5.733 & 5.3315 & TRN & & \\
\hline CHEMBL1588926 & 688810 & \multicolumn{3}{|c|}{5.7829999999999995} & 5.7805 & TRN \\
\hline CHEMBL1547795 & 688810 & \multicolumn{3}{|c|}{5.2829999999999995} & 5.395 & TRN \\
\hline CHEMBL1374508 & 688810 & 4.783 & 5.2052 & TRN & & \\
\hline
\end{tabular}




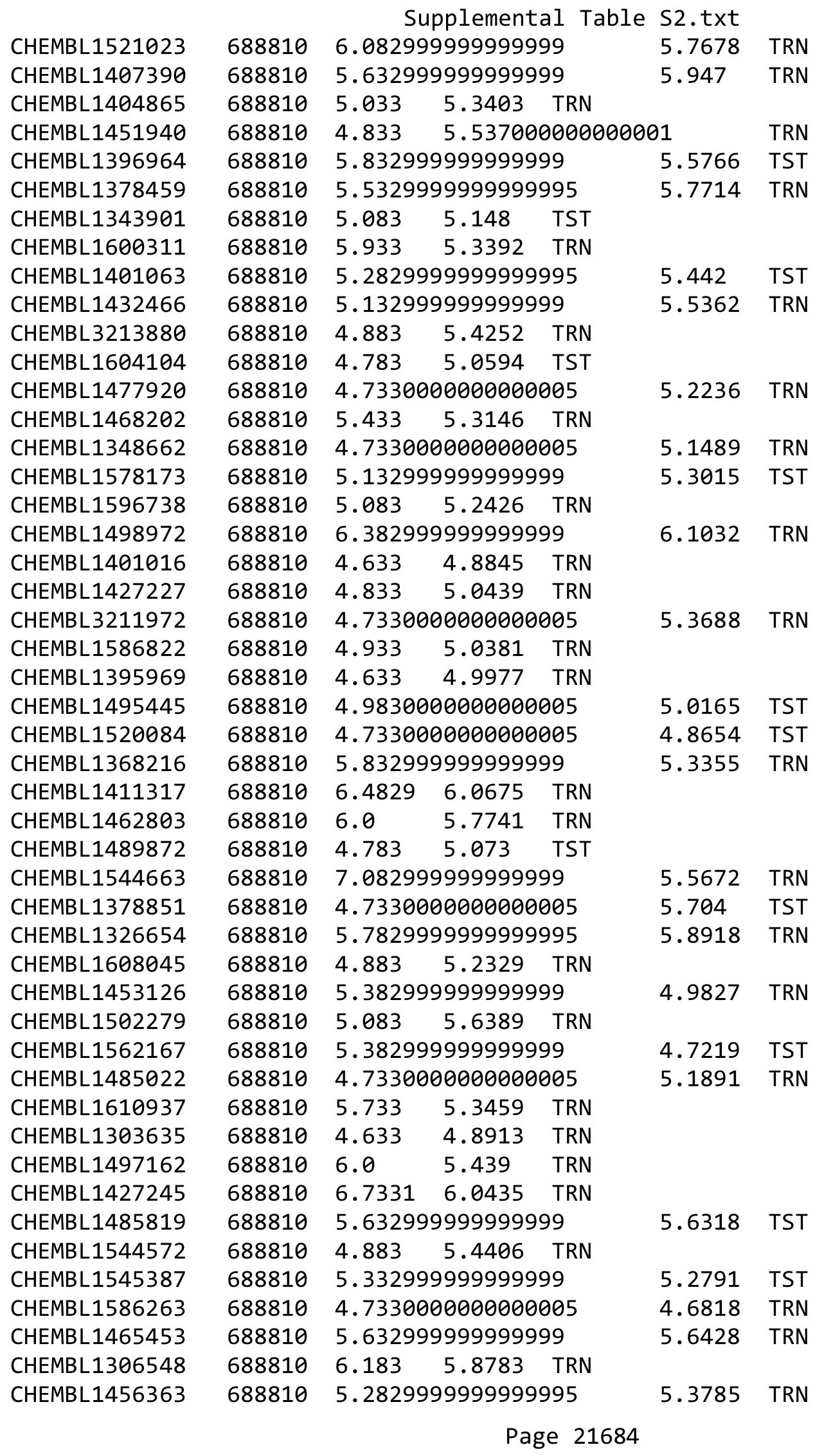




\begin{tabular}{|c|c|c|c|c|c|c|}
\hline CHEMBL1525127 & 688810 & 5.0 & 5.2695 & TRN & & \\
\hline CHEMBL 3189861 & 688810 & \multicolumn{3}{|c|}{5.332999999999999} & 5.2586 & \\
\hline CHEMBL1326256 & 688810 & 5.433 & 4.7743 & TST & & \\
\hline CHEMBL1307498 & 688810 & 4.783 & 5.4291 & TRN & & \\
\hline CHEMBL 3199295 & 688810 & \multicolumn{3}{|c|}{4.9830000000000005} & 5.3961 & \\
\hline CHEMBL1458284 & 688810 & 4.783 & 5.1248 & TST & & \\
\hline CHEMBL1353843 & 688810 & 5.083 & 5.7477 & TST & & \\
\hline CHEMBL1584304 & 688810 & \multicolumn{3}{|c|}{5.132999999999999} & 5.5484 & \\
\hline CHEMBL1522986 & 688810 & 4.833 & 5.2882 & TST & & \\
\hline CHEMBL1344871 & 688810 & \multicolumn{3}{|c|}{5.7829999999999995} & 5.1186 & \\
\hline CHEMBL1371014 & 688810 & 6.0 & 5.8221 & TRN & & \\
\hline CHEMBL1321474 & 688810 & 5.183 & 5.0777 & TRN & & \\
\hline CHEMBL1501125 & 688810 & 6.233 & 5.3072 & TRN & & \\
\hline CHEMBL1339589 & 688810 & 4.833 & 5.4458 & TRN & & \\
\hline CHEMBL1334565 & 688810 & 4.883 & 5.1835 & TST & & \\
\hline CHEMBL1487320 & 688810 & \multicolumn{3}{|c|}{4.7330000000000005} & 5.1 & \\
\hline CHEMBL 3191275 & 688810 & 4.883 & 5.1475 & TRN & & \\
\hline CHEMBL1333299 & 688810 & 5.183 & 5.2053 & TRN & & \\
\hline CHEMBL1443624 & 688810 & 4.833 & 5.6275 & TRN & & \\
\hline CHEMBL1602496 & 688810 & \multicolumn{3}{|c|}{4.9830000000000005} & 5.3889 & \\
\hline CHEMBL1419580 & 688810 & 4.783 & 5.1473 & TRN & & \\
\hline CHEMBL1597210 & 688810 & \multicolumn{3}{|c|}{5.332999999999999} & 5.0756 & \\
\hline CHEMBL1442813 & 688810 & \multicolumn{3}{|c|}{6.332999999999999} & 5.803 & \\
\hline CHEMBL 3194630 & 688810 & \multicolumn{3}{|c|}{5.132999999999999} & & \\
\hline CHEMBL1399631 & 688810 & 6.233 & 5.4284 & TRN & & \\
\hline CHEMBL1601174 & 688810 & \multicolumn{3}{|c|}{4.7330000000000005} & 5.249 & \\
\hline CHEMBL1527850 & 688810 & 5.683 & 5.2542 & TRN & & \\
\hline CHEMBL1538265 & 688810 & 4.883 & 4.9922 & TRN & & \\
\hline CHEMBL1553494 & 688810 & 5.083 & 4.9448 & TRN & & \\
\hline CHEMBL1343113 & 688810 & \multicolumn{3}{|c|}{4.7330000000000005} & $3.1 / 42$ & \\
\hline CHEMBL565486 & 688810 & \multicolumn{3}{|c|}{5.832999999999999} & 5.4646 & \\
\hline CHEMBL1350943 & 688810 & \multicolumn{3}{|c|}{5.882999999999999} & 5.2238 & \\
\hline CHEMBL1479779 & 688810 & 5.933 & 5.3241 & TST & & \\
\hline CHEMBL 3210480 & 688810 & \multicolumn{3}{|c|}{4.7330000000000005} & 5.2963 & \\
\hline CHEMBL1491999 & 688810 & 4.833 & 4.8995 & TST & & \\
\hline CHEMBL1422468 & 688810 & \multicolumn{3}{|c|}{5.332999999999999} & 5.1372 & \\
\hline CHEMBL1544938 & 688810 & 4.933 & 5.2189 & TRN & & \\
\hline CHEMBL1545180 & 688810 & 4.783 & 5.4325 & TRN & & \\
\hline CHEMBL1301586 & 688810 & \multicolumn{3}{|c|}{5.5329999999999995} & 5.4828 & \\
\hline CHEMBL1519059 & 688810 & 5.9 & 5.5964 & TRN & & \\
\hline CHEMBL 3190270 & 688810 & \multicolumn{3}{|c|}{6.382999999999999} & 5.2178 & \\
\hline CHEMBL1354315 & 688810 & \multicolumn{3}{|c|}{5.382999999999999} & 5.2451 & \\
\hline CHEMBL104728 & 688810 & \multicolumn{3}{|c|}{5.5329999999999995} & 5.5022 & \\
\hline CHEMBL1613274 & 688810 & 4.833 & 5.1165 & TRN & & \\
\hline CHEMBL1434714 & 688810 & \multicolumn{3}{|c|}{6.332999999999999} & 5.7127 & \\
\hline CHEMBL1558220 & 688810 & \multicolumn{3}{|c|}{4.7330000000000005} & 5.3936 & \\
\hline CHEMBL1424408 & 688810 & 4.883 & 4.7354 & TRN & & \\
\hline CHEMBL1376997 & 688810 & 4.883 & 5.0947 & TRN & & \\
\hline
\end{tabular}




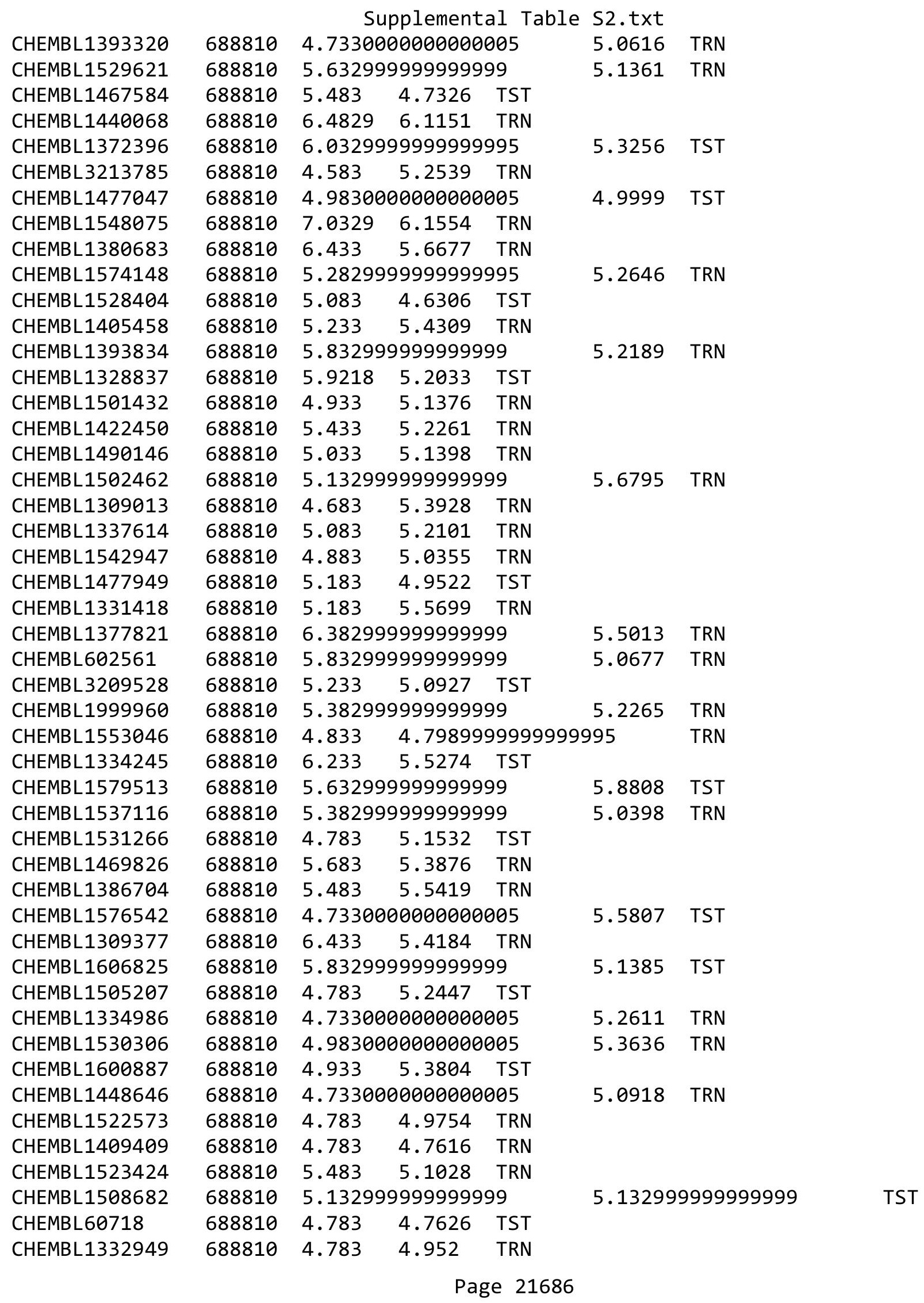




\begin{tabular}{|c|c|c|c|c|c|c|}
\hline \multirow{3}{*}{$\begin{array}{l}\text { CHEMBL1307499 } \\
\text { CHEMBL1356314 }\end{array}$} & & \multicolumn{5}{|c|}{ Supplemental Table S2.txt } \\
\hline & 688810 & 4.883 & \multicolumn{3}{|c|}{5.377000000000001} & \multirow[t]{2}{*}{ TRN } \\
\hline & 688810 & 4.883 & 4.8213 & TST & & \\
\hline CHEMBL1384998 & 688810 & 5.733 & 5.441 & TST & & \\
\hline CHEMBL3190702 & 688810 & 5.033 & 5.4531 & TRN & & \\
\hline CHEMBL265686 & 688810 & \multicolumn{3}{|c|}{5.632999999999999} & 6.9014 & TRN \\
\hline CHEMBL1482621 & 688810 & \multicolumn{3}{|c|}{5.132999999999999} & 5.5432 & \\
\hline CHEMBL1413197 & 688810 & 4.833 & 5.0809 & TRN & & \\
\hline CHEMBL1362438 & 688810 & \multicolumn{3}{|c|}{4.9830000000000005} & 4.9218 & TP \\
\hline CHEMBL1496240 & 688810 & \multicolumn{3}{|c|}{4.7330000000000005} & 4.675 & \\
\hline CHEMBL1529258 & 688810 & 5.483 & 5.5833 & TST & & \\
\hline CHEMBL1388639 & 688810 & 4.633 & 5.073 & TRN & & \\
\hline CHEMBL 3190095 & 688810 & 4.833 & 5.37 & TST & & \\
\hline CHEMBL1 & 688810 & 4.783 & 5.2085 & TRN & & \\
\hline CHEMBL1591417 & 688810 & 5.983 & 4.9073 & TST & & \\
\hline CHEMBL1336370 & 688810 & 4.583 & 5.0505 & TRN & & \\
\hline CHEMBL1368684 & 688810 & 6.0 & 5.4756 & TRN & & \\
\hline CHEMBL578487 & 688810 & \multicolumn{3}{|c|}{5.7829999999999995} & 156 & \\
\hline CHEMBL1 & 688810 & 4.783 & 5.3027 & TRN & & \\
\hline CHEMBL13 & 688810 & \multicolumn{3}{|c|}{5.5329999999999995} & 5.2308 & TRN \\
\hline CHEMBL1416917 & 688810 & \multicolumn{3}{|c|}{5.5329999999999995} & 5.5574 & \\
\hline CHEMBL1544083 & 688810 & 5.733 & 5.3109 & TRN & & \\
\hline CHEMBL1603678 & 688810 & \multicolumn{3}{|c|}{5.7829999999999995} & 5.5651 & \\
\hline CHEMBL1505651 & 688810 & \multicolumn{3}{|c|}{4.7330000000000005} & 5.2297 & TRN \\
\hline CHEMBL1423879 & 688810 & \multicolumn{3}{|c|}{6.632999999999999} & 5.5783 & TRN \\
\hline CHEMBL1501444 & 688810 & 4.683 & 5.1811 & TST & & \\
\hline CHEMBL1314972 & 688810 & 5.183 & 5.0676 & TRN & & \\
\hline CHEMBL13 & 688810 & \multicolumn{3}{|c|}{5.132999999999999} & 5.0537 & \\
\hline CHEMBL14 & 688810 & \multicolumn{3}{|c|}{5.832999999999999} & 5.2949 & \\
\hline CHEMBL 1474837 & 688810 & 4.883 & 4.8087 & TRN & & \\
\hline CHEMBL1405760 & 688810 & \multicolumn{3}{|c|}{4.7330000000000005} & 4.9864 & TP \\
\hline CHEMBL1435313 & 688810 & 7.3325 & 5.4006 & TST & & \\
\hline CHEMBL1 & 688810 & & 5.8525 & TRN & & \\
\hline CHEMBL1 & 688810 & 5. & 5.3555 & TRN & & \\
\hline CHEMBL1 & 688810 & 5.683 & 5.7123 & TST & & \\
\hline CHEMBL1389153 & 688810 & 5.733 & \multicolumn{3}{|c|}{5.257000000000001} & TRN \\
\hline CHEMBL1440699 & 688810 & \multicolumn{3}{|c|}{6.382999999999999} & 5.0566 & \\
\hline CHEMBL145 & 688810 & 5.683 & 5.4169 & TST & & \\
\hline CHEMBL1346635 & 688810 & \multicolumn{3}{|c|}{5.2829999999999995} & 5.055 & TST \\
\hline CHEMBL1588946 & 688810 & \multicolumn{3}{|c|}{5.332999999999999} & 5.2978 & TRN \\
\hline CHEMBL1351639 & 688810 & 5.5329 & 99999999 & 995 & 5.3753 & TRN \\
\hline CHEMBL1510116 & 688810 & 6.4829 & 5.6512 & TRN & & \\
\hline CHEMBL1403829 & 688810 & 4.583 & 4.9036 & TRN & & \\
\hline CHEMBL1492794 & 688810 & 5.933 & 5.6695 & TRN & & \\
\hline CHEMBL1353400 & 688810 & 5.083 & 5.1451 & TRN & & \\
\hline CHEMBL1600194 & 688810 & 5.183 & 5.5362 & TRN & & \\
\hline CHEMBL1555400 & 688810 & 4.833 & 5.1935 & TRN & & \\
\hline CHEMBL1463057 & 688810 & 5.6329 & 99999999 & & 5.1722 & 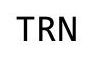 \\
\hline CHEMBL1390782 & 688810 & 5.6329 & 99999999 & & 5.1073 & \\
\hline
\end{tabular}




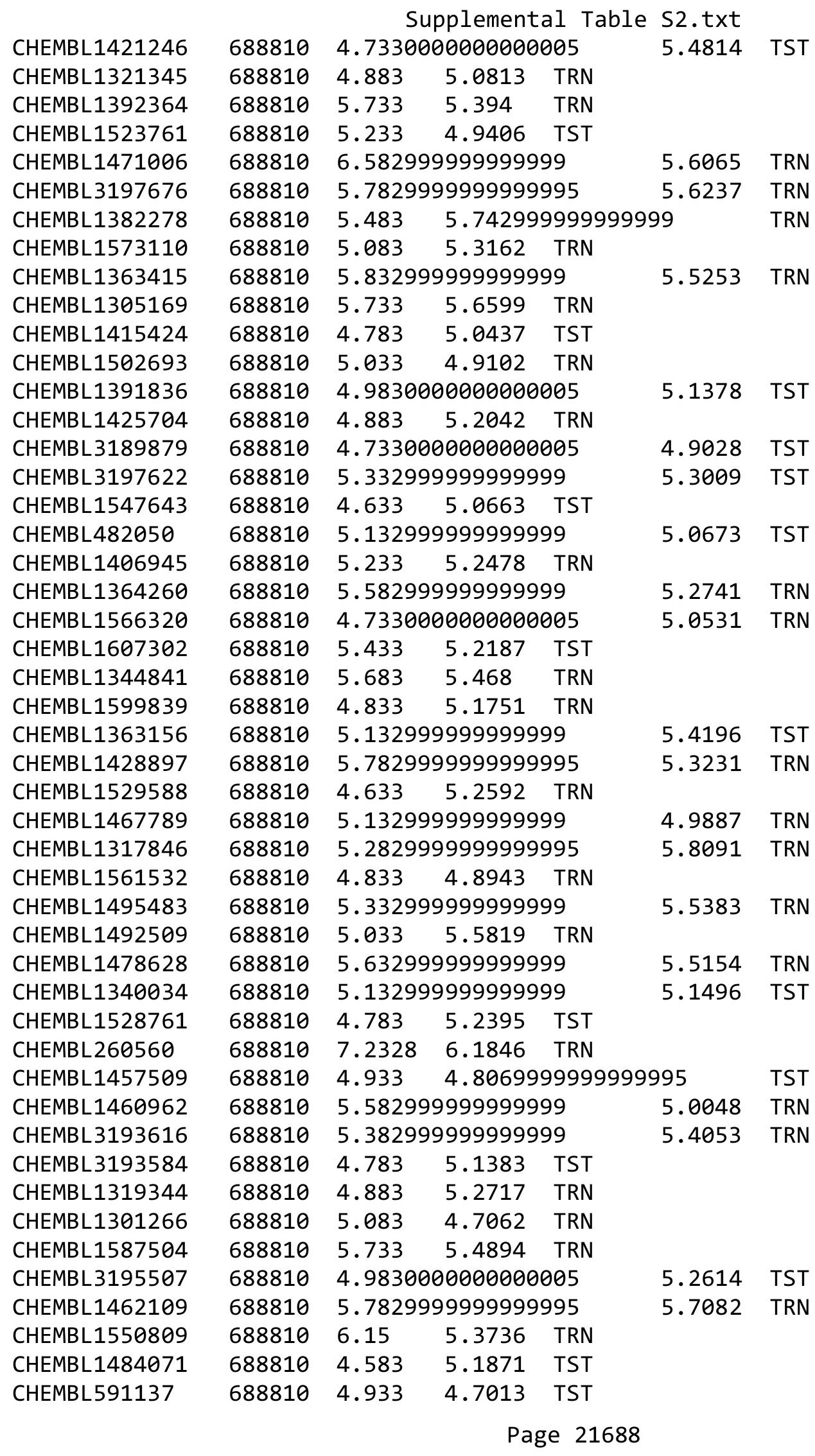




\begin{tabular}{|c|c|c|c|c|c|c|}
\hline CHEMBL1369569 & 688810 & 5.983 & 5.9973 & TRN & & \\
\hline CHEMBL1445355 & 688810 & \multicolumn{3}{|c|}{5.132999999999999} & 4.9074 & \\
\hline CHEMBL1564542 & 688810 & 4.633 & 4.7474 & TRN & & \\
\hline CHEMBL1328159 & 588810 & 6.233 & 5.6326 & TRN & & \\
\hline CHEMBL1546619 & 588810 & \multicolumn{3}{|c|}{5.132999999999999} & 5.0484 & \\
\hline CHEMBL1527046 & 588810 & 4.933 & 4.9725 & TRN & & \\
\hline CHEMBL1592745 & 688810 & \multicolumn{3}{|c|}{6.0329999999999995} & 5.5278 & \\
\hline CHEMBL1493793 & 688810 & 4.833 & 5.4225 & TRN & & \\
\hline CHEMBL1476915 & 588810 & 4.583 & 5.0448 & TRN & & \\
\hline CHEMBL1613710 & 588810 & 4.783 & 5.1593 & TRN & & \\
\hline HEMBL1585906 & 588810 & 5.033 & 5.7028 & TRN & & \\
\hline CHEMBL1464645 & 688810 & \multicolumn{3}{|c|}{5.5329999999999995} & 6.5002 & \\
\hline CHEMBL1422097 & 688810 & 5.683 & 5.8318 & TRN & & \\
\hline CHEMBL1395035 & 688810 & \multicolumn{3}{|c|}{5.382999999999999} & 009 & \\
\hline CHEMBL1360998 & 688810 & 4.833 & 5.0464 & TST & & \\
\hline HEMBL14 & 688810 & \multicolumn{3}{|c|}{5.2829999999999995} & 5.3281 & \\
\hline CHEMBLI & 688810 & \multicolumn{3}{|c|}{5.5329999999999995} & & \\
\hline CHEMBL13 & 688810 & 4.883 & 5.629 & TRN & & \\
\hline CHEMBL1422039 & 688810 & \multicolumn{3}{|c|}{4.7330000000000005} & 7 & \\
\hline CHEMBL14 & 688810 & 4.883 & 5.3876 & TRN & & \\
\hline HEMBL1 & 688810 & \multicolumn{3}{|c|}{5.5329999999999995} & 5.316 & \\
\hline CHEMBL: & 688810 & 4.783 & 5.3635 & TRN & & \\
\hline CHEMBL14 & 688810 & \multicolumn{3}{|c|}{5.2829999999999995} & 5.9091 & \\
\hline CHEMBL1437588 & 688810 & 5.033 & 5.3336 & TRN & & \\
\hline CHEMBL15 & 688810 & 4.583 & 5.2032 & TST & & \\
\hline CHEMBL] & 688810 & \multicolumn{3}{|c|}{5.132999999999999} & 5.3343 & \\
\hline CHEMBL: & 688810 & 5.083 & 5.2892 & TST & & \\
\hline HEMBL 1 & 688810 & 6.433 & 5.9367 & TRN & & \\
\hline CHEMBL1321135 & 688810 & \multicolumn{3}{|c|}{4.7330000000000005} & 5.0888 & \\
\hline CHEMBL1520465 & 688810 & 4.633 & 5.0182 & TST & & \\
\hline CHEMBL: & 688810 & 5.733 & 5. & TRN & & \\
\hline CHEMBL: & 10 & 5.683 & 5.5971 & TRN & & \\
\hline CHEMBL1414199 & 688810 & \multicolumn{3}{|c|}{5.882999999999999} & 5.0816 & \\
\hline CHEMBL1548867 & 688810 & 5.4 & 5.5278 & TRN & & \\
\hline CHEMBL16 & 688810 & \multicolumn{3}{|c|}{4.7330000000000005} & 676 & \\
\hline CHEMBL & 688810 & \multicolumn{3}{|c|}{5.632999999999999} & 4.9883 & \\
\hline CHEMBL1413345 & 688810 & 4.583 & 4.99 & TST & & \\
\hline CHEMBL1443326 & 688810 & \multicolumn{3}{|c|}{5.2829999999999995} & 5.6393 & \\
\hline CHEMBL1561920 & 688810 & 4.883 & 4.9912 & TST & & \\
\hline CHEMBL1 & 688 & 4.633 & 5.7067 & TRN & & \\
\hline CHEMBL13 & 688810 & \multicolumn{3}{|c|}{4.7330000000000005} & 4.8631 & \\
\hline CHEMBL1308460 & 688810 & \multicolumn{3}{|c|}{5.7829999999999995} & 5.4324 & \\
\hline CHEMBL1332685 & 688810 & \multicolumn{3}{|c|}{5.382999999999999} & 4.8498 & \\
\hline CHEMBL1510229 & 688810 & 5.483 & 5.4644 & TRN & & \\
\hline CHEMBL1309011 & 688810 & \multicolumn{3}{|c|}{6.082999999999999} & 5.7584 & \\
\hline CHEMBL1303734 & 688810 & 4.783 & 5.2473 & TS & & \\
\hline CHEMBL1430506 & 688810 & \multicolumn{3}{|c|}{5.882999999999999} & 5.3033 & \\
\hline CHEMBL1477846 & 688810 & \multicolumn{3}{|c|}{6.632999999999999} & 6.1443 & \\
\hline
\end{tabular}




\begin{tabular}{|c|c|c|c|c|c|c|}
\hline \multicolumn{7}{|c|}{ plemental } \\
\hline CHEMBL1550168 & 688810 & 5.05 & 4.7525 & TST & & \\
\hline CHEMBL1341711 & 688810 & \multicolumn{3}{|c|}{5.7829999999999995} & 5.1556 & TRN \\
\hline CHEMBL1324999 & 688810 & 5.733 & 5.4865 & TRN & & \\
\hline CHEMBL1299682 & 688810 & 5.033 & 5.2153 & TRN & & \\
\hline CHEMBL1402230 & 688810 & 4.833 & 5.3214 & TST & & \\
\hline CHEMBL1479351 & 688810 & 4.583 & 5.1063 & TRN & & \\
\hline CHEMBL118009 & 688810 & \multicolumn{3}{|c|}{6.582999999999999} & 5.6108 & TRN \\
\hline CHEMBL1559992 & 688810 & \multicolumn{3}{|c|}{4.7330000000000005} & 4.8508 & \\
\hline CHEMBL1591598 & 688810 & 5.083 & 5.43 & TRN & & \\
\hline CHEMBL1314888 & 688810 & 4.833 & 5.1039 & TRN & & \\
\hline CHEMBL1381714 & 688810 & 4.833 & 5.1865 & TST & & \\
\hline CHEMBL1435149 & 688810 & 5.733 & 5.7015 & TRN & & \\
\hline CHEMBL1351135 & 688810 & 4.933 & 5.3632 & TST & & \\
\hline CHEMBL1348326 & 688810 & \multicolumn{3}{|c|}{5.632999999999999} & 5.6039 & \\
\hline CHEMBL 3195363 & 688810 & 5.033 & 5.1738 & TST & & \\
\hline CHEMBL1458043 & 688810 & 4.683 & 4.9838 & TST & & \\
\hline CHEMBL1385388 & 688810 & 4.583 & 4.6869 & TRN & & \\
\hline CHEMBL1971185 & 688810 & \multicolumn{3}{|c|}{5.132999999999999} & 5.1696 & \\
\hline CHEMBL1404733 & 688810 & 5.483 & 5.3788 & TRN & & \\
\hline CHEMBL1591915 & 688810 & 5.733 & 5.7139 & TRN & & \\
\hline CHEMBL1577530 & 688810 & \multicolumn{3}{|c|}{4.7330000000000005} & 5.6765 & \\
\hline CHEMBL1453291 & 688810 & 4.933 & 5.4194 & TRN & & \\
\hline CHEMBL1372591 & 688810 & 4.833 & 4.6969 & TRN & & \\
\hline CHEMBL1579046 & 688810 & \multicolumn{3}{|c|}{5.2829999999999995} & 331 & \\
\hline CHEMBL1569945 & 688810 & \multicolumn{3}{|c|}{5.132999999999999} & 5.7863 & \\
\hline CHEMBL 3197063 & 688810 & \multicolumn{3}{|c|}{6.0329999999999995} & 5.8075 & \\
\hline CHEMBL1558433 & 688810 & 6.233 & 5.6708 & TRN & & \\
\hline CHEMBL348436 & 688810 & 4.933 & 5.5775 & TRN & & \\
\hline CHEMBL1360261 & 688810 & \multicolumn{3}{|c|}{4.7330000000000005} & 5.1298 & \\
\hline CHEMBL1486630 & 688810 & 4.783 & 5.1497 & TRN & & \\
\hline CHEMBL 3211797 & 688810 & 5.183 & 4.8919 & TRN & & \\
\hline CHEMBL1431659 & 688810 & 5.683 & 5.5658 & TRN & & \\
\hline CHEMBL1405602 & 688810 & 4.883 & 5.2573 & TRN & & \\
\hline CHEMBL1410498 & 688810 & 4.583 & 5.0123 & TST & & \\
\hline CHEMBL1498830 & 688810 & 4.883 & 5.3262 & TRN & & \\
\hline CHEMBL1575749 & 688810 & \multicolumn{3}{|c|}{6.132999999999999} & 5.8939 & \\
\hline CHEMBL1373294 & 688810 & \multicolumn{3}{|c|}{6.5329999999999995} & 5.7458 & \\
\hline CHEMBL1502192 & 688810 & 6.683 & 6.6255 & TRN & & \\
\hline CHEMBL1350624 & 688810 & 4.95 & 5.6396 & TST & & \\
\hline CHEMBL 3196161 & 688810 & \multicolumn{3}{|c|}{5.832999999999999} & 5.2618 & TRN \\
\hline CHEMBL1554111 & 688810 & 5.733 & 5.5511 & TRN & & \\
\hline CHEMBL1413057 & 688810 & 5.233 & 5.4596 & TRN & & \\
\hline CHEMBL1472806 & 688810 & 4.583 & 5.1016 & TST & & \\
\hline CHEMBL1532863 & 688810 & 4.683 & 5.2458 & TRN & & \\
\hline CHEMBL1379530 & 688810 & \multicolumn{3}{|c|}{5.7829999999999995} & 5.7076 & \\
\hline CHEMBL536008 & 688810 & 4.683 & 5.0779 & TST & & \\
\hline CHEMBL1540387 & 688810 & 4.783 & 5.0929 & TRN & & \\
\hline CHEMBL1460435 & 688810 & 5.733 & 5.17 & TST & & \\
\hline
\end{tabular}




\begin{tabular}{|c|c|c|c|c|c|c|c|}
\hline \multicolumn{7}{|c|}{ oplemental Ia } & \\
\hline CHEMBL1444581 & 688810 & 4.833 & 4.8591 & TST & & & \\
\hline CHEMBL1373635 & 688810 & 4.783 & 5.3826 & TRN & & & \\
\hline CHEMBL3194500 & 688810 & 5.983 & 5.5791 & TRN & & & \\
\hline CHEMBL1409630 & 688810 & 6.38299 & 999999995 & & 5.5077 & TRN & \\
\hline CHEMBL1540036 & 688810 & 4.583 & 5.1237 & TST & & & \\
\hline CHEMBL1538438 & 688810 & 5.033 & 5.1169 & TRN & & & \\
\hline CHEMBL1308093 & 688810 & 4.933 & 4.8256 & TRN & & & \\
\hline CHEMBL1613412 & 688810 & 6.13299 & 999999999 & & 5.7183 & TRN & \\
\hline CHEMBL1420742 & 688810 & 4.633 & 4.834 & TRN & & & \\
\hline CHEMBL1461303 & 688810 & $4.7330 e$ & 000000006 & 005 & 5.0616 & TRN & \\
\hline CHEMBL1299868 & 688810 & 6.183 & 5.5044 & TST & & & \\
\hline CHEMBL1303288 & 688810 & 5.033 & 5.0945 & TRN & & & \\
\hline CHEMBL47875 & 688810 & 6.433 & 6.1579 & TRN & & & \\
\hline CHEMBL1519387 & 688810 & 5.63299 & 999999995 & & 5.813 & TRN & \\
\hline CHEMBL120089 & 688810 & 5.033 & 5.3963 & TRN & & & \\
\hline CHEMBL1309573 & 688810 & 6.983 & 6.3809 & TRN & & & \\
\hline CHEMBL1569383 & 688810 & $4.7330 e$ & 000000006 & 005 & 5.3657 & TST & \\
\hline CHEMBL1502027 & 688810 & 4.883 & 5.2568 & TST & & & \\
\hline CHEMBL1411646 & 688810 & 5.28299 & 999999995 & 995 & 5.1031 & TRN & \\
\hline CHEMBL3192519 & 688810 & 4.833 & 5.1682 & TRN & & & \\
\hline CHEMBL1362564 & 688810 & 4.633 & 4.8836 & TRN & & & \\
\hline CHEMBL1482382 & 688810 & 4.883 & 5.5108 & TRN & & & \\
\hline CHEMBL1396824 & 688810 & 5.33299 & 999999999 & & 4.9894 & TST & \\
\hline CHEMBL1538408 & 688810 & 4.883 & 4.9978 & TST & & & \\
\hline CHEMBL1426215 & 688810 & 5.233 & 5.4367 & TST & & & \\
\hline CHEMBL3207816 & 688810 & 4.883 & 5.6978 & TRN & & & \\
\hline CHEMBL1489356 & 688810 & 4.783 & 5.3234 & TRN & & & \\
\hline CHEMBL1539263 & 688810 & 4.933 & 5.4307 & TST & & & \\
\hline CHEMBL1405249 & 688810 & 4.933 & 5.0174 & TST & & & \\
\hline CHEMBL1510259 & 688810 & 4.783 & 5.0435 & TST & & & \\
\hline CHEMBL1387181 & 688810 & 5.13299 & 99999999 & & 5.3253 & TRN & \\
\hline CHEMBL1500414 & 688810 & 5.483 & 5.551 & TST & & & \\
\hline CHEMBL1567832 & 688810 & 5.88299 & 999999999 & & 5.7288 & TRN & \\
\hline CHEMBL1527400 & 688810 & 5.13299 & 99999999 & & 6.6298 & TRN & \\
\hline CHEMBL3195472 & 688810 & 4.933 & 5.22 & TST & & & \\
\hline CHEMBL1426867 & 688810 & 5.733 & 5.4118 & TRN & & & \\
\hline CHEMBL1593516 & 688810 & 4.633 & 4.8655 & TST & & & \\
\hline CHEMBL1537553 & 688810 & 4.683 & 4.9965 & TST & & & \\
\hline CHEMBL1370394 & 688810 & 6.53299 & 999999995 & 995 & 5.4279 & TRN & \\
\hline CHEMBL1368098 & 688810 & 6.33299 & 999999999 & & 5.7965 & TRN & \\
\hline CHEMBL1581915 & 688810 & 5.38299 & 999999995 & & 5.57799 & 9999999999 & TRN \\
\hline CHEMBL1402878 & 688810 & 4.933 & 5.0385 & TRN & & & \\
\hline CHEMBL1547177 & 688810 & 4.833 & 5.1205 & TST & & & \\
\hline CHEMBL1554860 & 688810 & 4.73300 & 00000000 & 005 & 4.8038 & TRN & \\
\hline CHEMBL1499856 & 688810 & 5.88299 & 999999999 & & 5.7809 & TRN & \\
\hline CHEMBL1492007 & 688810 & 4.833 & 5.4636 & TRN & & & \\
\hline CHEMBL1454641 & 688810 & 4.583 & 5.0957 & TST & & & \\
\hline CHEMBL1427428 & 688810 & 5.13299 & 999999995 & & 5.4784 & TRN & \\
\hline
\end{tabular}




\begin{tabular}{|c|c|c|c|c|c|c|}
\hline \multicolumn{7}{|c|}{ Supplemental Table S2.txt } \\
\hline CHEMBL1369567 & 688810 & \multicolumn{3}{|c|}{5.132999999999999} & 5.4096 & TST \\
\hline CHEMBL1332933 & 688810 & \multicolumn{3}{|c|}{4.7330000000000005} & 4.7271 & TRN \\
\hline CHEMBL1464276 & 688810 & 6.233 & 5.7659 & TRN & & \\
\hline CHEMBL1579648 & 688810 & 4.833 & 5.0141 & TRN & & \\
\hline CHEMBL1502550 & 688810 & 4.633 & 5.2277 & TST & & \\
\hline CHEMBL1522033 & 688810 & 4.833 & 4.9432 & TRN & & \\
\hline CHEMBL1528444 & 688810 & 5.233 & 5.4678 & TRN & & \\
\hline CHEMBL1493662 & 688810 & 4.883 & 4.7798 & TRN & & \\
\hline CHEMBL 3194300 & 688810 & 4.833 & 5.5141 & TRN & & \\
\hline CHEMBL1583778 & 688810 & 4.783 & 5.597 & TST & & \\
\hline CHEMBL1515378 & 688810 & \multicolumn{3}{|c|}{4.9830000000000005} & 5.185 & TRN \\
\hline CHEMBL1407079 & 688810 & \multicolumn{3}{|c|}{5.632999999999999} & 5.1077 & TRN \\
\hline CHEMBL 309848 & 688810 & \multicolumn{3}{|c|}{5.132999999999999} & 5.2034 & TRN \\
\hline CHEMBL1417436 & 688810 & \multicolumn{3}{|c|}{5.332999999999999} & 5.3835 & TRN \\
\hline CHEMBL1307213 & 688810 & \multicolumn{3}{|c|}{4.9830000000000005} & 5.2235 & TRN \\
\hline CHEMBL1590707 & 688810 & 4.633 & 5.0104 & TST & & \\
\hline CHEMBL1607687 & 688810 & \multicolumn{3}{|c|}{5.132999999999999} & 5.37 & TRN \\
\hline CHEMBL1332961 & 688810 & 4.783 & 5.274 & TRN & & \\
\hline CHEMBL1305388 & 688810 & 5.233 & 5.7353 & TRN & & \\
\hline CHEMBL1349859 & 688810 & 5.5 & 5.3953 & TST & & \\
\hline CHEMBL1599751 & 688810 & 4.933 & 4.9841 & TRN & & \\
\hline CHEMBL1526755 & 688810 & 4.933 & 5.2379 & TST & & \\
\hline CHEMBL1513833 & 688810 & \multicolumn{3}{|c|}{5.332999999999999} & 5.4333 & TRN \\
\hline CHEMBL1601345 & 688810 & 4.783 & 5.1227 & TRN & & \\
\hline CHEMBL 3212087 & 688810 & 4.833 & 5.0102 & TST & & \\
\hline CHEMBL1473089 & 688810 & 4.633 & \multicolumn{3}{|c|}{5.0889999999999995} & TRN \\
\hline CHEMBL1465958 & 688810 & 4.783 & 5.1441 & TRN & & \\
\hline CHEMBL1453953 & 688810 & \multicolumn{3}{|c|}{6.2829999999999995} & 5.7 & TRN \\
\hline CHEMBL1333771 & 688810 & 5.733 & 5.3458 & TRN & & \\
\hline CHEMBL1415958 & 688810 & \multicolumn{3}{|c|}{5.382999999999999} & 6.0073 & TST \\
\hline CHEMBL 3198962 & 688810 & 5.083 & 5.4656 & TRN & & \\
\hline CHEMBL 3213826 & 688810 & \multicolumn{3}{|c|}{5.132999999999999} & 5.46899 & 9999999999 \\
\hline CHEMBL 1520312 & 688810 & \multicolumn{3}{|c|}{5.5329999999999995} & 5.3185 & TRN \\
\hline CHEMBL1451488 & 688810 & 5.083 & 4.9555 & TRN & & \\
\hline CHEMBL1386326 & 688810 & \multicolumn{3}{|c|}{4.9830000000000005} & 5.2175 & TRN \\
\hline CHEMBL1378863 & 688810 & \multicolumn{3}{|c|}{7.382999999999999} & 5.4434 & TRN \\
\hline CHEMBL 3208732 & 688810 & 6.433 & 5.4073 & TRN & & \\
\hline CHEMBL1332494 & 688810 & 5.733 & 5.1599 & TRN & & \\
\hline CHEMBL1492020 & 688810 & \multicolumn{3}{|c|}{5.632999999999999} & 5.4548 & TRN \\
\hline CHEMBL 2369252 & 688810 & \multicolumn{3}{|c|}{6.5329999999999995} & 5.6771 & TRN \\
\hline CHEMBL1481516 & 688810 & \multicolumn{3}{|c|}{5.132999999999999} & 5.1335 & TRN \\
\hline CHEMBL1322812 & 688810 & \multicolumn{3}{|c|}{5.7829999999999995} & 4.9947 & TRN \\
\hline CHEMBL1574958 & 688810 & 5.683 & 4.9974 & TST & & \\
\hline CHEMBL3207511 & 688810 & 4.883 & 5.2124 & TST & & \\
\hline CHEMBL1360553 & 688810 & 4.883 & 4.9475 & TST & & \\
\hline CHEMBL1598069 & 688810 & 4.633 & 4.835 & TST & & \\
\hline CHEMBL1604339 & 688810 & 4.883 & 5.0809 & TRN & & \\
\hline CHEMBL1352153 & 688810 & 5.033 & 5.1068 & TRN & & \\
\hline
\end{tabular}




\begin{tabular}{|c|c|c|c|c|c|c|c|}
\hline \multirow[b]{2}{*}{ CHEMBL1536960 } & \multicolumn{6}{|c|}{ pplemental Ia } & \\
\hline & 688810 & 5.083 & 5.4728 & TRN & & & \\
\hline CHEMBL1360225 & 688810 & \multicolumn{3}{|c|}{5.832999999999999} & 5.6146 & TRN & \\
\hline CHEMBL1319580 & 688810 & \multicolumn{3}{|c|}{4.7330000000000005} & \multicolumn{2}{|c|}{5.218999999999999} & TRN \\
\hline CHEMBL1370888 & 688810 & \multicolumn{3}{|c|}{4.7330000000000005} & 4.9614 & TST & \\
\hline CHEMBL1351116 & 688810 & 4.833 & 5.2679 & TST & & & \\
\hline CHEMBL1504227 & 688810 & 5.483 & 5.2838 & TRN & & & \\
\hline CHEMBL 1425542 & 688810 & \multicolumn{3}{|c|}{5.882999999999999} & 5.5467 & TRN & \\
\hline CHEMBL1455054 & 688810 & 4.783 & 5.2846 & TRN & & & \\
\hline CHEMBL1269508 & 688810 & \multicolumn{3}{|c|}{6.332999999999999} & 5.4051 & TRN & \\
\hline CHEMBL1364683 & 688810 & 5.733 & 5.043 & TRN & & & \\
\hline CHEMBL1417602 & 688810 & 4.833 & 5.2318 & TRN & & & \\
\hline CHEMBL3194197 & 688810 & \multicolumn{3}{|c|}{4.7330000000000005} & 5.7594 & TRN & \\
\hline CHEMBL1489921 & 688810 & \multicolumn{3}{|c|}{5.382999999999999} & 5.5511 & TRN & \\
\hline CHEMBL1486925 & 688810 & 4.883 & 4.9421 & TRN & & & \\
\hline CHEMBL1456585 & 688810 & 4.633 & 5.0555 & TRN & & & \\
\hline CHEMBL1492852 & 688810 & 4.783 & 4.942 & TRN & & & \\
\hline CHEMBL1546789 & 688810 & 4.833 & 5.0764 & TRN & & & \\
\hline CHEMBL1358089 & 688810 & 5.433 & 5.4161 & TRN & & & \\
\hline CHEMBL1501636 & 688810 & \multicolumn{3}{|c|}{4.7330000000000005} & 5.1149 & TRN & \\
\hline CHEMBL1358598 & 688810 & \multicolumn{3}{|c|}{5.132999999999999} & 5.4738 & TRN & \\
\hline CHEMBL1323478 & 688810 & \multicolumn{3}{|c|}{5.132999999999999} & 5.1457 & TRN & \\
\hline CHEMBL1459149 & 688810 & 4.833 & 5.4526 & TST & & & \\
\hline CHEMBL1566468 & 688810 & 4.933 & 5.0391 & TRN & & & \\
\hline CHEMBL1564546 & 688810 & \multicolumn{3}{|c|}{5.632999999999999} & 5.5045 & TRN & \\
\hline CHEMBL1533857 & 688810 & 4.633 & 5.4041 & TRN & & & \\
\hline CHEMBL1323218 & 688810 & 5.733 & 5.4602 & TST & & & \\
\hline CHEMBL1595607 & 688810 & 4.833 & 5.013 & TRN & & & \\
\hline CHEMBL1402378 & 688810 & 4.883 & 4.7967 & TRN & & & \\
\hline CHEMBL3198711 & 688810 & 4.933 & 5.2864 & TST & & & \\
\hline CHEMBL1463885 & 688810 & 4.883 & 4.9513 & TRN & & & \\
\hline CHEMBL1413264 & 688810 & \multicolumn{3}{|c|}{5.7829999999999995} & 5.4785 & TRN & \\
\hline CHEMBL1498386 & 688810 & 4.783 & 5.3707 & TST & & & \\
\hline CHEMBL1595659 & 688810 & 4.783 & 5.473 & TRN & & & \\
\hline CHEMBL3192821 & 688810 & 5.083 & \multicolumn{3}{|c|}{5.502999999999999} & TRN & \\
\hline CHEMBL1549599 & 688810 & 4.833 & 5.0093 & TST & & & \\
\hline CHEMBL1525769 & 688810 & 5.083 & 5.3369 & TRN & & & \\
\hline CHEMBL1360114 & 688810 & 4.933 & 4.9014 & TRN & & & \\
\hline CHEMBL1462433 & 688810 & 4.783 & \multicolumn{3}{|c|}{5.257999999999999} & TST & \\
\hline CHEMBL1604094 & 688810 & \multicolumn{3}{|c|}{4.7330000000000005} & 4.8372 & TRN & \\
\hline CHEMBL1576203 & 688810 & \multicolumn{3}{|c|}{5.132999999999999} & 5.4549 & TST & \\
\hline CHEMBL3199594 & 688810 & 4.883 & \multicolumn{3}{|c|}{4.9030000000000005} & TRN & \\
\hline CHEMBL 3145369 & 688810 & 4.833 & 5.8413 & TRN & & & \\
\hline CHEMBL1312115 & 688810 & 5.183 & 5.0287 & TST & & & \\
\hline CHEMBL1410285 & 688810 & 5.083 & 6.0064 & TRN & & & \\
\hline CHEMBL1319687 & 688810 & 5.933 & 5.3957 & TRN & & & \\
\hline CHEMBL1513594 & 688810 & 5.033 & 5.7878 & TRN & & & \\
\hline CHEMBL1392667 & 688810 & 5.3829 & 99999999 & & 5.1884 & TRN & \\
\hline CHEMBL1353362 & 688810 & 6.1329 & 99999999 & & 5.4463 & TRN & \\
\hline
\end{tabular}




\begin{tabular}{|c|c|c|c|c|c|c|}
\hline & & \multicolumn{5}{|c|}{ Supplemental Table s2.txt } \\
\hline CHEMBL1407632 & 688810 & 5.733 & 5.2615 & TRN & & \\
\hline CHEMBL1543654 & 688810 & 4.583 & 5.0707 & TRN & & \\
\hline CHEMBL1973921 & 688810 & 5.733 & 6.1656 & TRN & & \\
\hline CHEMBL1399316 & 688810 & 5.983 & 5.5681 & TRN & & \\
\hline CHEMBL1367851 & 688810 & 4.583 & 5.3256 & TST & & \\
\hline CHEMBL366884 & 688810 & 5.683 & 5.0993 & TRN & & \\
\hline CHEMBL1325873 & 688810 & 5.683 & 5.5629 & TRN & & \\
\hline CHEMBL1302998 & 688810 & \multicolumn{3}{|c|}{5.132999999999999} & 5.437 & TST \\
\hline CHEMBL1371794 & 688810 & \multicolumn{3}{|c|}{5.2829999999999995} & 4.9148 & TRN \\
\hline CHEMBL1496125 & 688810 & \multicolumn{3}{|c|}{5.132999999999999} & 5.76 & TST \\
\hline CHEMBL1604890 & 688810 & \multicolumn{3}{|c|}{4.7330000000000005} & 5.0747 & TRN \\
\hline CHEMBL1385343 & 688810 & \multicolumn{3}{|c|}{4.9830000000000005} & 5.5919 & \\
\hline CHEMBL1441328 & 688810 & 5.183 & 5.4544 & TST & & \\
\hline CHEMBL1505064 & 688810 & \multirow{2}{*}{\multicolumn{3}{|c|}{$\begin{array}{l}5.683 \quad 5.0669 \\
5.5329999999999995\end{array}$}} & & \\
\hline CHEMBL1570908 & 688810 & & & & 5.3511 & T- \\
\hline CHEMBL1449485 & 688810 & 4.933 & 5.2789 & TRN & & \\
\hline CHEMBL1520903 & 688810 & 4.883 & 5.2387 & TRN & & \\
\hline CHEMBL1508788 & 688810 & \multicolumn{3}{|c|}{5.382999999999999} & 5.4182 & \\
\hline CHEMBL1550582 & 688810 & 5.983 & 5.4241 & TRN & & \\
\hline CHEMBL1578340 & 688810 & 4.783 & 5.0477 & TRN & & \\
\hline CHEMBL1441374 & 688810 & \multicolumn{3}{|c|}{5.332999999999999} & 438 & \\
\hline CHEMBL1500142 & 688810 & 4.633 & 5.3978 & TST & & \\
\hline CHEMBL1344013 & 688810 & \multicolumn{3}{|c|}{4.7330000000000005} & 4.9654 & TRN \\
\hline CHEMBL1312232 & 688810 & \multicolumn{3}{|c|}{4.7330000000000005} & 5.115 & \\
\hline CHEMBL1541290 & 688810 & 4.883 & 5.2284 & TST & & \\
\hline CHEMBL1482271 & 688810 & \multirow{2}{*}{\multicolumn{3}{|c|}{$\begin{array}{lcc}6.183 & 5.791 & \text { TRN } \\
5.2829999999999995\end{array}$}} & & \\
\hline CHEMBL222646 & 688810 & & & & 5.7857 & 17 \\
\hline CHEMBL3189573 & 688810 & 4.783 & 5.4796 & TRN & & \\
\hline CHEMBL1510400 & 688810 & 6.183 & 5.4164 & TST & & \\
\hline CHEMBL3196957 & 688810 & 5.183 & 5.093 & TST & & \\
\hline CHEMBL1462768 & 688810 & 5.733 & 5.5384 & TRN & & \\
\hline CHEMBL1543836 & 688810 & 4.583 & 4.3613 & TST & & \\
\hline CHEMBL1384526 & 688810 & \multicolumn{3}{|c|}{6.0329999999999995} & 5.3903 & TR \\
\hline CHEMBL1566677 & 688810 & 4.933 & 5.0072 & TRN & & \\
\hline CHEMBL1388101 & 688810 & 5.683 & 5.2816 & TRN & & \\
\hline CHEMBL1529638 & 688810 & \multicolumn{3}{|c|}{4.7330000000000005} & 5.1002 & נI \\
\hline CHEMBL1351651 & 688810 & 5.683 & 5.4437 & TRN & & \\
\hline CHEMBL1594492 & 688810 & 4.883 & 5.1795 & TST & & \\
\hline CHEMBL1317672 & 688810 & \multicolumn{3}{|c|}{5.5329999999999995} & 5.6139 & \\
\hline CHEMBL1450254 & 688810 & \multicolumn{3}{|c|}{5.7829999999999995} & 5.6393 & \\
\hline CHEMBL1473521 & 688810 & 4.833 & 5.3224 & TST & & \\
\hline CHEMBL1322010 & 688810 & \multicolumn{3}{|c|}{5.832999999999999} & 5.8928 & $n$ \\
\hline CHEMBL582286 & 688810 & 4.633 & 5.3777 & TRN & & \\
\hline CHEMBL1480003 & 688810 & 6.183 & 5.6398 & TRN & & \\
\hline CHEMBL585622 & 688810 & 4.633 & 4.8027 & TRN & & \\
\hline CHEMBL1612646 & 688810 & 5.033 & 4.9133 & TRN & & \\
\hline CHEMBL1518054 & 688810 & 5.733 & 5.6474 & TRN & & \\
\hline CHEMBL1504281 & 688810 & 5.433 & 5.0804 & TST & & \\
\hline
\end{tabular}




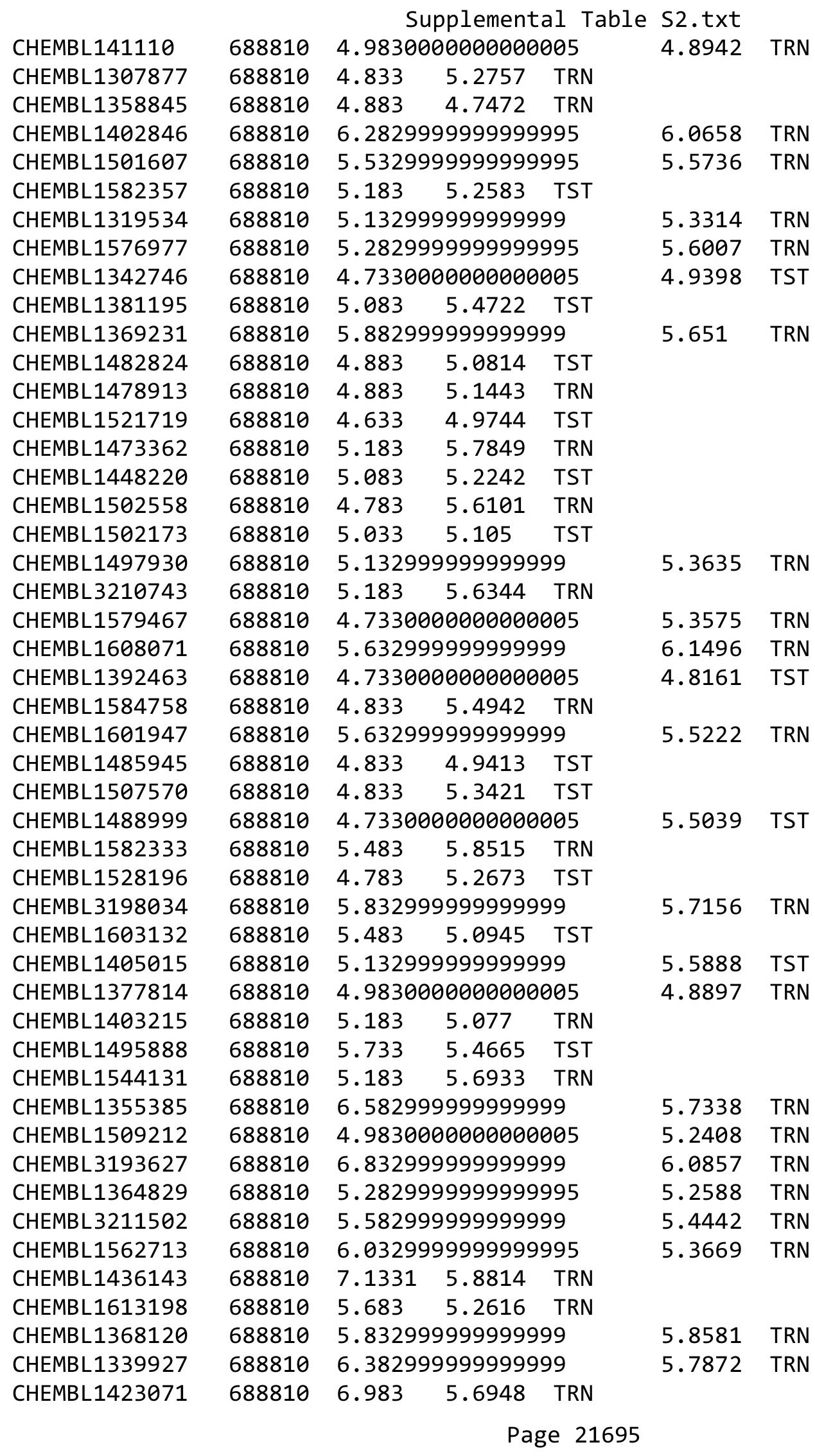




\begin{tabular}{|c|c|c|c|c|c|c|c|}
\hline \multicolumn{8}{|c|}{ Supplemental Table S2 } \\
\hline CHEMBL1471351 & 688810 & 4.633 & 4.8291 & TRN & & & \\
\hline CHEMBL3195270 & 688810 & 5.13299 & 99999999 & & 5.0626 & TRN & \\
\hline CHEMBL1552060 & 688810 & 4.783 & 5.0493 & TRN & & & \\
\hline CHEMBL1173141 & 688810 & 4.783 & 5.3404 & TRN & & & \\
\hline CHEMBL580891 & 688810 & 5.433 & 5.3983 & TRN & & & \\
\hline CHEMBL1528478 & 688810 & 4.783 & 4.7385 & TST & & & \\
\hline CHEMBL1428673 & 688810 & 6.183 & 5.6048 & TRN & & & \\
\hline CHEMBL1453452 & 688810 & 5.28299 & 99999999 & 995 & 5.0419 & TST & \\
\hline CHEMBL1320898 & 688810 & 5.433 & 5.2905 & TRN & & & \\
\hline CHEMBL1397890 & 688810 & 4.583 & 4.6291 & TRN & & & \\
\hline CHEMBL1342556 & 688810 & 5.78299 & 99999999 & 995 & 5.6046 & TST & \\
\hline CHEMBL1590942 & 688810 & 5.83299 & 99999999 & & 5.4499 & TRN & \\
\hline CHEMBL1335318 & 688810 & 5.683 & 5.5633 & TST & & & \\
\hline CHEMBL1447151 & 688810 & 4.783 & 5.0659 & TRN & & & \\
\hline CHEMBL1464928 & 688810 & 5.233 & 5.2953 & TST & & & \\
\hline CHEMBL1491894 & 688810 & 5.733 & 5.7426 & TST & & & \\
\hline CHEMBL1554596 & 688810 & 4.633 & 5.1768 & TST & & & \\
\hline CHEMBL1561385 & 688810 & 5.53299 & 99999999 & 995 & 5.9484 & TST & \\
\hline CHEMBL1306293 & 688810 & 4.583 & 4.9633 & TST & & & \\
\hline CHEMBL1362392 & 688810 & 5.933 & 5.0696 & TST & & & \\
\hline CHEMBL1528314 & 688810 & 4.833 & 4.8082 & TRN & & & \\
\hline CHEMBL1527295 & 688810 & 4.73300 & 00000000 & 005 & 5.4153 & TST & \\
\hline CHEMBL1351769 & 688810 & 6.28299 & 99999999 & 995 & 5.79799 & 9999999999 & TRN \\
\hline CHEMBL1580007 & 688810 & 5.483 & 5.3996 & TRN & & & \\
\hline CHEMBL1529046 & 688810 & 6.03299 & 999999999 & 995 & 5.6988 & TRN & \\
\hline CHEMBL 2005998 & 688810 & 4.683 & 5.6311 & TST & & & \\
\hline CHEMBL1450616 & 688810 & 4.933 & 5.1023 & TRN & & & \\
\hline CHEMBL1342977 & 688810 & 4.833 & 5.3209 & TRN & & & \\
\hline CHEMBL3207736 & 688810 & 5.28299 & 999999999 & 995 & 5.0052 & TRN & \\
\hline CHEMBL1465768 & 688810 & 5.083 & 4.9778 & TRN & & & \\
\hline CHEMBL1565917 & 688810 & 5.13299 & 999999999 & & 5.2396 & TRN & \\
\hline CHEMBL1537692 & 688810 & 4.883 & 5.0316 & TRN & & & \\
\hline CHEMBL1533343 & 688810 & 6.58299 & 999999999 & & 5.9575 & TRN & \\
\hline CHEMBL1342894 & 688810 & 5.78299 & 999999999 & 995 & 5.8626 & TST & \\
\hline CHEMBL1467054 & 688810 & 4.833 & 5.0281 & TST & & & \\
\hline CHEMBL1324818 & 688810 & 5.38299 & 999999999 & & 4.8677 & TST & \\
\hline CHEMBL1379890 & 688810 & 5.53299 & 999999999 & 995 & 5.3867 & TST & \\
\hline CHEMBL1481484 & 688810 & 4.833 & 4.9797 & TRN & & & \\
\hline CHEMBL1587927 & 688810 & 5.83299 & 999999999 & & 5.9235 & TRN & \\
\hline CHEMBL1427175 & 688810 & 5.683 & 5.0079 & TRN & & & \\
\hline CHEMBL3193229 & 688810 & 6.9329 & 5.5706 & TRN & & & \\
\hline CHEMBL1465980 & 688810 & 6.983 & 5.9762 & TRN & & & \\
\hline CHEMBL1430237 & 688810 & 4.73300 & 000000000 & 005 & 4.9741 & TST & \\
\hline CHEMBL1376511 & 688810 & 5.33299 & 999999999 & & 5.1792 & TRN & \\
\hline CHEMBL1577983 & 688810 & 5.483 & 4.9432 & TRN & & & \\
\hline CHEMBL1385866 & 688810 & 4.883 & 5.3375 & TRN & & & \\
\hline CHEMBL1472128 & 688810 & 6.28299 & 999999999 & 995 & 5.2918 & TRN & \\
\hline CHEMBL1333738 & 688810 & 5.233 & 5.5725 & TRN & & & \\
\hline
\end{tabular}




\begin{tabular}{|c|c|c|c|c|c|c|c|}
\hline \multicolumn{7}{|c|}{ Supplemental Table S2.txt } & \\
\hline CHEMBL1529701 & 688810 & 4.933 & 4.9291 & TRN & & & \\
\hline CHEMBL1589168 & 688810 & 4.683 & 4.798 & TST & & & \\
\hline CHEMBL1967041 & 688810 & 4.783 & 4.9135 & TST & & & \\
\hline CHEMBL1358869 & 688810 & 4.933 & 5.1545 & TRN & & & \\
\hline CHEMBL 1357020 & 688810 & 4.783 & 5.0635 & TRN & & & \\
\hline CHEMBL1359529 & 688810 & \multicolumn{3}{|c|}{6.082999999999999} & 5.4043 & TRN & \\
\hline CHEMBL1597057 & 688810 & 4.783 & 5.0498 & TST & & & \\
\hline CHEMBL1383395 & 688810 & 5.683 & 5.0962 & TST & & & \\
\hline CHEMBL1550592 & 688810 & 4.883 & 5.1757 & TRN & & & \\
\hline CHEMBL1603856 & 688810 & 6.433 & 5.6576 & TRN & & & \\
\hline CHEMBL1333767 & 688810 & 4.633 & 4.795 & TRN & & & \\
\hline CHEMBL1507533 & 688810 & 4.833 & 5.2452 & TRN & & & \\
\hline CHEMBL1367683 & 688810 & 5.183 & 5.2551 & TST & & & \\
\hline CHEMBL1341816 & 688810 & 6.683 & 6.0451 & TRN & & & \\
\hline CHEMBL1214525 & 688810 & 6.2 & 5.6076 & TRN & & & \\
\hline CHEMBL1421266 & 688810 & 5.733 & 5.3141 & TRN & & & \\
\hline CHEMBL1587534 & 688810 & 6.183 & 5.7864 & TRN & & & \\
\hline CHEMBL1446338 & 688810 & \multicolumn{3}{|c|}{5.382999999999999} & 5.3873 & TRN & \\
\hline CHEMBL1327277 & 688810 & 4.933 & 5.2965 & TRN & & & \\
\hline CHEMBL1409187 & 688810 & 5.233 & 5.0939 & TST & & & \\
\hline CHEMBL1331106 & 688810 & 4.883 & 5.3419 & TRN & & & \\
\hline CHEMBL1468838 & 688810 & \multicolumn{3}{|c|}{4.7330000000000005} & 5.2093 & TRN & \\
\hline CHEMBL1536020 & 688810 & 5.083 & 5.6408 & TRN & & & \\
\hline CHEMBL1458805 & 688810 & 4.633 & 4.9182 & TRN & & & \\
\hline CHEMBL3197889 & 688810 & 4.933 & 4.9512 & TRN & & & \\
\hline CHEMBL1381396 & 688810 & \multicolumn{3}{|c|}{5.882999999999999} & 5.5587 & TST & \\
\hline CHEMBL1583585 & 688810 & 5.683 & 5.7998 & TST & & & \\
\hline CHEMBL1461883 & 688810 & 5.233 & 5.3475 & TST & & & \\
\hline CHEMBL1605629 & 688810 & \multicolumn{3}{|c|}{5.7829999999999995} & 5.7649 & TRN & \\
\hline CHEMBL1465127 & 688810 & \multicolumn{3}{|c|}{5.5329999999999995} & 5.38700 & 00000000005 & TRN \\
\hline CHEMBL1391415 & 688810 & 4.833 & 5.0723 & TRN & & & \\
\hline CHEMBL1574741 & 688810 & \multicolumn{3}{|c|}{5.132999999999999} & 5.1973 & TRN & \\
\hline CHEMBL3212892 & 688810 & 4.633 & 5.1231 & TST & & & \\
\hline CHEMBL1602896 & 688810 & 5.433 & 5.4538 & TRN & & & \\
\hline CHEMBL1416956 & 688810 & 4.783 & 4.9588 & TRN & & & \\
\hline CHEMBL527677 & 688810 & 4.833 & 5.3113 & TRN & & & \\
\hline CHEMBL1447451 & 688810 & 5.183 & 5.3557 & TRN & & & \\
\hline CHEMBL1545159 & 688810 & \multicolumn{3}{|c|}{4.7330000000000005} & 4.7019 & TRN & \\
\hline CHEMBL1377231 & 688810 & \multicolumn{3}{|c|}{6.382999999999999} & 5.8146 & TRN & \\
\hline CHEMBL1570954 & 688810 & 4.633 & 4.935 & TRN & & & \\
\hline CHEMBL1575233 & 688810 & \multicolumn{3}{|c|}{6.082999999999999} & 5.1012 & TST & \\
\hline CHEMBL1525488 & 688810 & \multicolumn{3}{|c|}{5.2829999999999995} & 5.7881 & TRN & \\
\hline CHEMBL1377784 & 688810 & \multicolumn{3}{|c|}{6.082999999999999} & 5.8907 & TRN & \\
\hline CHEMBL1438294 & 688810 & \multicolumn{3}{|c|}{5.832999999999999} & 5.9711 & TRN & \\
\hline CHEMBL1577730 & 688810 & 5.033 & 5.4201 & TST & & & \\
\hline CHEMBL1305668 & 688810 & 4.783 & 5.1304 & TST & & & \\
\hline CHEMBL1508402 & 688810 & 4.833 & 4.9618 & TST & & & \\
\hline CHEMBL1558021 & 688810 & 5.233 & 4.6782 & TRN & & & \\
\hline
\end{tabular}




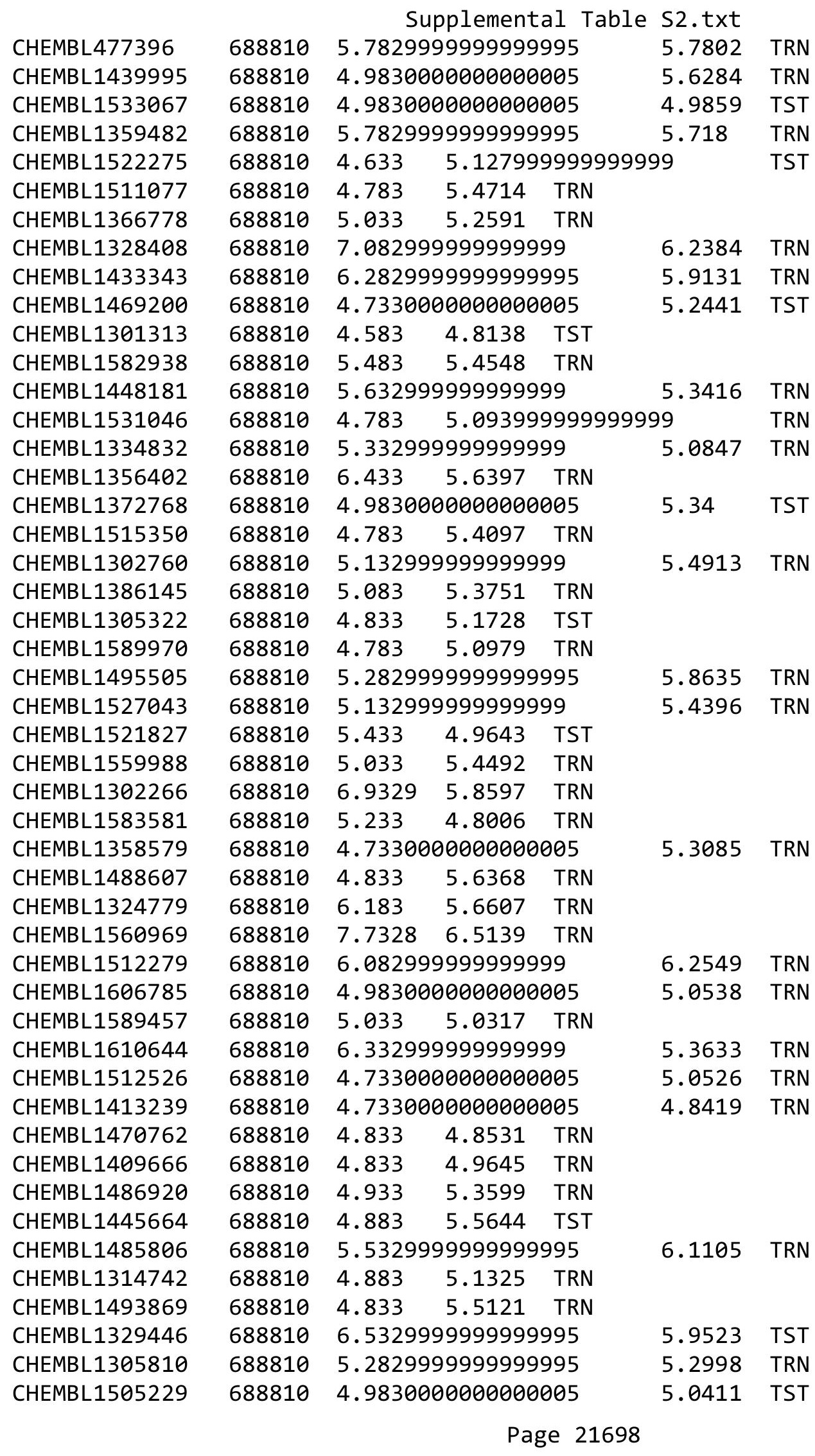




\begin{tabular}{|c|c|c|c|c|c|c|}
\hline & & \multicolumn{4}{|c|}{ Supplemental Table s2.txt } & \\
\hline CHEMBL1587952 & 688810 & \multicolumn{3}{|c|}{5.7829999999999995} & 5.4076 & TST \\
\hline CHEMBL1504374 & 688810 & \multicolumn{3}{|c|}{4.7330000000000005} & 5.4073 & TRN \\
\hline CHEMBL1478972 & 688810 & 5.483 & 4.8984 & TST & & \\
\hline CHEMBL1564369 & 688810 & 4.933 & 5.2544 & TRN & & \\
\hline CHEMBL1396785 & 688810 & \multicolumn{3}{|c|}{5.582999999999999} & 5.4594 & TRN \\
\hline CHEMBL1472778 & 688810 & \multicolumn{3}{|c|}{6.332999999999999} & 5.2313 & TRN \\
\hline CHEMBL1401424 & 688810 & 5.033 & 5.566 & TST & & \\
\hline CHEMBL1435576 & 688810 & 4.783 & 4.6477 & TRN & & \\
\hline CHEMBL1546886 & 688810 & 5.183 & 5.1726 & TRN & & \\
\hline CHEMBL1303263 & 688810 & 5.033 & 4.7249 & TST & & \\
\hline CHEMBL1308120 & 688810 & 4.883 & 5.3231 & TST & & \\
\hline CHEMBL1488228 & 688810 & \multicolumn{3}{|c|}{5.5329999999999995} & 5.2112 & TRN \\
\hline CHEMBL1447936 & 688810 & 5.733 & 5.3834 & TRN & & \\
\hline CHEMBL1299767 & 688810 & 4.883 & 5.1926 & TRN & & \\
\hline CHEMBL 252901 & 688810 & \multicolumn{3}{|c|}{5.5329999999999995} & 5.0087 & TRN \\
\hline CHEMBL1421407 & 688810 & 4.633 & 5.0955 & TST & & \\
\hline CHEMBL1582741 & 688810 & \multicolumn{3}{|c|}{5.332999999999999} & 5.0722 & TRN \\
\hline CHEMBL1428295 & 688810 & 5.183 & 5.567 & TRN & & \\
\hline CHEMBL1341951 & 688810 & 4.933 & 5.1045 & TRN & & \\
\hline CHEMBL1544797 & 688810 & \multicolumn{3}{|c|}{5.332999999999999} & 4.9539 & TRN \\
\hline CHEMBL3207828 & 688810 & \multicolumn{3}{|c|}{5.382999999999999} & 5.2084 & TRN \\
\hline CHEMBL1500986 & 688810 & \multicolumn{3}{|c|}{7.082999999999999} & 5.5166 & TRN \\
\hline CHEMBL1419445 & 688810 & \multicolumn{3}{|c|}{5.832999999999999} & 5.5433 & TRN \\
\hline CHEMBL1410762 & 688810 & 5.733 & 4.9543 & TRN & & \\
\hline CHEMBL1324351 & 688810 & 5.483 & 5.4978 & TRN & & \\
\hline CHEMBL1476639 & 688810 & \multicolumn{3}{|c|}{6.0329999999999995} & 5.3801 & TRN \\
\hline CHEMBL1413662 & 688810 & 5.933 & 5.7491 & TRN & & \\
\hline CHEMBL1524360 & 688810 & \multicolumn{3}{|c|}{5.832999999999999} & 5.7342 & TRN \\
\hline CHEMBL1502956 & 688810 & \multicolumn{3}{|c|}{5.632999999999999} & 5.4814 & TRN \\
\hline CHEMBL1322267 & 688810 & \multicolumn{3}{|c|}{4.7330000000000005} & 5.165 & TRN \\
\hline CHEMBL1343364 & 688810 & \multicolumn{3}{|c|}{5.832999999999999} & 5.4915 & TRN \\
\hline CHEMBL1391486 & 688810 & 5.033 & 5.7297 & TRN & & \\
\hline CHEMBL1348895 & 688810 & \multicolumn{3}{|c|}{5.632999999999999} & 5.1499 & TRN \\
\hline CHEMBL1476588 & 688810 & \multicolumn{3}{|c|}{5.7829999999999995} & 5.7425 & TRN \\
\hline CHEMBL1599411 & 688810 & 5.933 & 5.7266 & TST & & \\
\hline CHEMBL1498083 & 688810 & 5.733 & 5.5786 & TST & & \\
\hline CHEMBL1333087 & 688810 & 6.0 & 5.1915 & TRN & & \\
\hline CHEMBL1499355 & 688810 & 4.783 & 5.4143 & TST & & \\
\hline CHEMBL1445639 & 688810 & \multicolumn{3}{|c|}{5.882999999999999} & 5.6097 & TRN \\
\hline CHEMBL1458019 & 688810 & 4.933 & 5.0879 & TST & & \\
\hline CHEMBL3214515 & 688810 & 6.0 & 5.7853 & TRN & & \\
\hline CHEMBL 3189578 & 688810 & 5.183 & 5.3298 & TRN & & \\
\hline CHEMBL1510389 & 688810 & \multicolumn{3}{|c|}{5.5329999999999995} & 6.5317 & TRN \\
\hline CHEMBL1338787 & 688810 & 4.883 & 5.1028 & TRN & & \\
\hline CHEMBL1434338 & 688810 & 5.7829 & 99999999 & 995 & 5.5775 & TRN \\
\hline CHEMBL1299349 & 688810 & 5.033 & 5.275 & TRN & & \\
\hline CHEMBL1387655 & 688810 & 4.933 & 5.41299 & 99999 & & ST \\
\hline CHEMBL1411687 & 688810 & 5.5 & 5.7958 & TRN & & \\
\hline
\end{tabular}




\begin{tabular}{|c|c|c|c|c|c|c|}
\hline & & \multicolumn{4}{|c|}{ Supplemental Table S2.txt } & \\
\hline CHEMBL1323978 & 688810 & \multicolumn{3}{|c|}{7.082999999999999} & 5.7175 & TRN \\
\hline CHEMBL3195445 & 688810 & \multicolumn{3}{|c|}{6.832999999999999} & 5.3558 & \\
\hline CHEMBL142652 & 688810 & \multicolumn{3}{|c|}{5.332999999999999} & 5.1423 & \\
\hline CHEMBL365374 & 688810 & 4.633 & 5.1673 & TRN & & \\
\hline CHEMBL1469897 & 688810 & \multicolumn{3}{|c|}{5.132999999999999} & 5.1878 & \\
\hline CHEMBL1461478 & 688810 & 4.883 & 5.5522 & TRN & & \\
\hline CHEMBL1568589 & 688810 & \multicolumn{3}{|c|}{5.132999999999999} & 4.893 & \\
\hline CHEMBL1513803 & 688810 & 4.883 & 4.9995 & TST & & \\
\hline CHEMBL1524763 & 688810 & 6.4829 & 6.3086 & TRN & & \\
\hline CHEMBL3190063 & 688810 & 4.833 & 5.4165 & TST & & \\
\hline CHEMBL1547884 & 688810 & 5.083 & 5.1114 & TRN & & \\
\hline CHEMBL1448282 & 688810 & \multicolumn{3}{|c|}{5.132999999999999} & 5.6833 & \\
\hline CHEMBL1382833 & 688810 & \multicolumn{3}{|c|}{5.7829999999999995} & 5.4322 & \\
\hline CHEMBL1479618 & 688810 & \multicolumn{3}{|c|}{5.332999999999999} & 5.5746 & \\
\hline CHEMBL1532623 & 688810 & 6.433 & 5.1487 & TRN & & \\
\hline CHEMBL1502841 & 688810 & \multicolumn{3}{|c|}{4.7330000000000005} & 4.8966 & \\
\hline CHEMBL1401264 & 688810 & 5.933 & 5.7088 & TST & & \\
\hline CHEMBL1460323 & 688810 & \multicolumn{3}{|c|}{5.382999999999999} & 5.2338 & \\
\hline CHEMBL1336947 & 688810 & 4.833 & 5.3793 & TRN & & \\
\hline CHEMBL1383057 & 688810 & \multicolumn{3}{|c|}{4.7330000000000005} & 5.9067 & \\
\hline CHEMBL454580 & 688810 & 4.633 & 5.4043 & TST & & \\
\hline CHEMBL1547005 & 688810 & \multicolumn{3}{|c|}{5.382999999999999} & 6 & \\
\hline CHEMBL1299353 & 688810 & 4.833 & 5.2316 & TST & & \\
\hline CHEMBL1463660 & 688810 & \multicolumn{3}{|c|}{5.332999999999999} & 5.0722 & $\mathrm{~T}$ \\
\hline CHEMBL1459374 & 688810 & 4.783 & 4.9157 & TST & & \\
\hline CHEMBL1404713 & 688810 & \multicolumn{3}{|c|}{5.132999999999999} & 5.2994 & \\
\hline CHEMBL3 & 688810 & 4.683 & 5.0066 & TRN & & \\
\hline CHEMBL1339437 & 688810 & 4.833 & 5.0498 & TST & & \\
\hline CHEMBL1572149 & 688810 & \multicolumn{3}{|c|}{4.7330000000000005} & 5.597 & $\mathrm{TI}$ \\
\hline CHEMBL1547714 & 688810 & 5.733 & 5.5146 & TRN & & \\
\hline CHEMBL3211716 & 688810 & 5.683 & 5.2389 & TRN & & \\
\hline CHEMBL1 & 688810 & 4.833 & 4.8301 & TST & & \\
\hline CHEMBL1337337 & 688810 & \multicolumn{3}{|c|}{5.382999999999999} & 5.2236 & TRN \\
\hline CHEMBL1460352 & 688810 & \multicolumn{3}{|c|}{5.2829999999999995} & 5.9047 & TRN \\
\hline CHEMBL582507 & 688810 & 5.733 & 5.9416 & TRN & & \\
\hline CHEMBL1435751 & 688810 & 4.633 & 5.5612 & TRN & & \\
\hline CHEMBL1463491 & 688810 & 4.583 & 4.8779 & TST & & \\
\hline CHEMBL1440308 & 688810 & 5.083 & 4.9429 & TRN & & \\
\hline CHEMBL1583977 & 688810 & 4.833 & 5.0398 & TRN & & \\
\hline CHEMBL1406791 & 688810 & 5.183 & 5.3183 & TRN & & \\
\hline CHEMBL1318742 & 688810 & 4.933 & 5.011 & TST & & \\
\hline CHEMBL1505918 & 688810 & \multicolumn{3}{|c|}{4.9830000000000005} & 4.9574 & $T$ \\
\hline CHEMBL1577299 & 688810 & 4.833 & 5.1477 & TRN & & \\
\hline CHEMBL1383227 & 688810 & 4.883 & 5.17 & TST & & \\
\hline CHEMBL1361996 & 688810 & 4.783 & 5.6726 & TRN & & \\
\hline CHEMBL1535032 & 688810 & 4.783 & 4.8208 & TST & & \\
\hline CHEMBL1472126 & 688810 & 4.783 & 4.8716 & TRN & & \\
\hline CHEMBL1330740 & 688810 & 6.0 & 5.092 & TST & & \\
\hline
\end{tabular}




\begin{tabular}{|c|c|c|c|c|c|c|}
\hline \multicolumn{7}{|c|}{ Supplemental Table S2.txt } \\
\hline CHEMBL1328281 & 688810 & 4.883 & 5.0301 & TST & & \\
\hline CHEMBL1421546 & 688810 & 5.083 & 5.2408 & TRN & & \\
\hline CHEMBL1429021 & 688810 & 5.683 & 5.4623 & TRN & & \\
\hline CHEMBL1536287 & 688810 & 5.683 & 5.2483 & TRN & & \\
\hline CHEMBL1498022 & 688810 & 4.883 & 5.2521 & TST & & \\
\hline CHEMBL1425768 & 688810 & 4.883 & 4.8854 & TST & & \\
\hline CHEMBL1353601 & 688810 & \multicolumn{3}{|c|}{4.9830000000000005} & 5.3515 & TST \\
\hline CHEMBL1477456 & 688810 & 4.633 & 4.8574 & TST & & \\
\hline CHEMBL1452998 & 688810 & \multicolumn{3}{|c|}{5.7829999999999995} & 5.1255 & TRN \\
\hline CHEMBL1359742 & 688810 & 5.683 & 5.4096 & TRN & & \\
\hline CHEMBL1473898 & 688810 & 4.783 & 5.4571 & TRN & & \\
\hline CHEMBL1435904 & 688810 & \multicolumn{3}{|c|}{5.832999999999999} & 5.4956 & TRN \\
\hline CHEMBL1592789 & 688810 & 4.583 & 5.1869 & TST & & \\
\hline CHEMBL1348062 & 688810 & \multicolumn{3}{|c|}{4.9830000000000005} & 5.5505 & 11 \\
\hline CHEMBL1435458 & 688810 & 5.483 & 5.0431 & TRN & & \\
\hline CHEMBL3194991 & 688810 & \multicolumn{3}{|c|}{6.2829999999999995} & 5.9185 & TRN \\
\hline CHEMBL1415760 & 688810 & 4.883 & 4.8891 & TRN & & \\
\hline CHEMBL1399459 & 688810 & 5.683 & 5.0477 & TRN & & \\
\hline CHEMBL1309027 & 688810 & 5.683 & 5.6738 & TRN & & \\
\hline CHEMBL1594659 & 688810 & \multicolumn{3}{|c|}{4.9830000000000005} & 5.0417 & TRN \\
\hline CHEMBL1439686 & 688810 & 4.883 & 5.3716 & TRN & & \\
\hline CHEMBL1555566 & 688810 & 4.633 & 5.0344 & TRN & & \\
\hline CHEMBL1364058 & 688810 & \multicolumn{3}{|c|}{5.332999999999999} & 5.6701 & $\mathrm{TP}$ \\
\hline CHEMBL1338749 & 688810 & 4.583 & 5.1215 & TRN & & \\
\hline CHEMBL1591656 & 688810 & 5.433 & 5.6545 & TRN & & \\
\hline CHEMBL1544409 & 688810 & \multicolumn{3}{|c|}{5.332999999999999} & 5.0505 & TR \\
\hline CHEMBL1516413 & 688810 & 4.783 & 5.5485 & TRN & & \\
\hline CHEMBL1387020 & 688810 & 5.483 & 5.1888 & TRN & & \\
\hline CHEMBL1594582 & 688810 & 4.633 & 4.9288 & TST & & \\
\hline CHEMBL1473326 & 688810 & \multicolumn{3}{|c|}{5.382999999999999} & 5.2426 & TR \\
\hline CHEMBL1388672 & 688810 & 4.833 & 5.1236 & TST & & \\
\hline CHEMBL1454011 & 688810 & 4.833 & 5.3157 & TST & & \\
\hline CHEMBL 3192579 & 688810 & \multicolumn{3}{|c|}{4.7330000000000005} & & \\
\hline CHEMBL 3190454 & 688810 & \multicolumn{3}{|c|}{6.082999999999999} & 5.6163 & I KIV \\
\hline CHEMBL1483449 & 688810 & \multicolumn{3}{|c|}{5.132999999999999} & 5.4192 & TRN \\
\hline CHEMBL1418583 & 688810 & 4.783 & 5.4345 & TRN & & \\
\hline CHEMBL1370224 & 688810 & 6.9329 & 5.2898 & TRN & & \\
\hline CHEMBL1393809 & 688810 & 5.183 & 5.4119 & TRN & & \\
\hline CHEMBL1498039 & 688810 & 4.883 & 5.0781 & TRN & & \\
\hline CHEMBL 3199408 & 688810 & \multicolumn{3}{|c|}{4.9830000000000005} & 5.1593 & TST \\
\hline CHEMBL1507312 & 688810 & \multicolumn{3}{|c|}{4.9830000000000005} & 5.171 & TPA \\
\hline CHEMBL1485220 & 688810 & 4.833 & 5.2688 & TST & & \\
\hline CHEMBL1417360 & 688810 & \multicolumn{3}{|c|}{6.382999999999999} & 5.8255 & Triv \\
\hline CHEMBL1378767 & 688810 & \multicolumn{3}{|c|}{5.332999999999999} & 5.2553 & TST \\
\hline CHEMBL226187 & 688810 & \multicolumn{3}{|c|}{5.832999999999999} & 5.6515 & TRN \\
\hline CHEMBL1447448 & 688810 & 6.233 & 5.8943 & TRN & & \\
\hline CHEMBL1608996 & 688810 & 4.783 & 5.1121 & TST & & \\
\hline CHEMBL1414917 & 688810 & 4.883 & 5.4339 & TST & & \\
\hline
\end{tabular}




\begin{tabular}{|c|c|c|c|c|c|c|}
\hline \multirow[b]{2}{*}{ CHEMBL1587433 } & \multicolumn{6}{|c|}{ oplemental Ta } \\
\hline & 688810 & 5.683 & 5.1434 & TST & & \\
\hline CHEMBL1568788 & 688810 & 5.233 & 4.6849 & TRN & & \\
\hline CHEMBL1322183 & 688810 & 5.2829 & 9999999 & 995 & 5.1128 & TRN \\
\hline CHEMBL1344603 & 688810 & 4.7330 & 00000006 & 005 & 5.8803 & TRN \\
\hline CHEMBL1427865 & 688810 & 5.733 & 4.8347 & TRN & & \\
\hline CHEMBL1312684 & 688810 & 6.5329 & 99999999 & 995 & 5.3484 & TST \\
\hline CHEMBL1341109 & 688810 & 5.2829 & 99999999 & 995 & 5.1289 & \\
\hline CHEMBL1439624 & 688810 & 5.683 & 5.3407 & TRN & & \\
\hline CHEMBL1559401 & 688810 & 4.633 & 5.1516 & TRN & & \\
\hline CHEMBL1516768 & 688810 & 4.833 & 5.0906 & TRN & & \\
\hline CHEMBL1420843 & 688810 & 5.3829 & 99999999 & & 5.4833 & TRN \\
\hline CHEMBL1572980 & 688810 & 5.2829 & 99999999 & 995 & 5.4522 & TRN \\
\hline CHEMBL1576438 & 688810 & 4.7330 & 00000000 & 005 & 5.5724 & \\
\hline CHEMBL1351040 & 688810 & 5.683 & 5.4295 & TRN & & \\
\hline CHEMBL 3208387 & 688810 & 6.233 & 5.1706 & TRN & & \\
\hline CHEMBL1369677 & 688810 & 4.7330 & $0000000 €$ & 005 & 4.8916 & \\
\hline CHEMBL1900850 & 688810 & 5.933 & 5.8587 & TST & & \\
\hline CHEMBL1396872 & 688810 & 5.2829 & 9999999 & 995 & 607 & \\
\hline CHEMBL1420595 & 688810 & 4.833 & 5.3318 & TST & & \\
\hline CHEMBL3189799 & 688810 & 4.933 & 5.2359 & TST & & \\
\hline CHEMBL1392552 & 688810 & 5.183 & 5.3054 & TST & & \\
\hline CHEMBL1315059 & 688810 & 5.683 & 5.5129 & TRN & & \\
\hline CHEMBL1452208 & 688810 & 6.433 & 5.9156 & TRN & & \\
\hline CHEMBL1595172 & 688810 & 5.183 & 5.4613 & TRN & & \\
\hline CHEMBL1358623 & 688810 & 7.3829 & 9999999 & & 5.8589 & \\
\hline CHEMBL 3208285 & 688810 & 5.7829 & 99999999 & 995 & 5.0997 & TRN \\
\hline CHEMBL1445116 & 688810 & 5.983 & 5.6827 & TRN & & \\
\hline CHEMBL1474666 & 688810 & 4.783 & 4.9291 & TRN & & \\
\hline CHEMBL1540564 & 688810 & 4.833 & 4.8252 & TRN & & \\
\hline CHEMBL1425889 & 688810 & 6.1329 & 9999999 & & 5.2019 & TRN \\
\hline CHEMBL1549607 & 688810 & 4.783 & 5.0671 & TST & & \\
\hline CHEMBL1480989 & 688810 & 5.483 & 5.3649 & TST & & \\
\hline CHEMBL1494158 & 688810 & 4.683 & 5.3046 & TRN & & \\
\hline CHEMBL1565328 & 688810 & 5.6329 & 99999999 & & 5.4189 & 11 \\
\hline CHEMBL1979665 & 688810 & 5.083 & 5.0504 & TRN & & \\
\hline CHEMBL1546231 & 688810 & 5.3329 & 99999999 & & 5.2469 & TRN \\
\hline CHEMBL1302365 & 688810 & 5.5329 & 99999999 & 995 & 5.1981 & \\
\hline CHEMBL1362964 & 688810 & 6.683 & 5.8901 & TRN & & \\
\hline CHEMBL1610579 & 688810 & 4.933 & 4.9313 & TST & & \\
\hline CHEMBL1551519 & 688810 & 5.683 & 4.8739 & TRN & & \\
\hline CHEMBL1450406 & 688810 & 4.883 & 5.3243 & TRN & & \\
\hline CHEMBL1407268 & 688810 & 4.883 & 5.8053 & TRN & & \\
\hline CHEMBL3198067 & 688810 & 5.733 & 5.9062 & TRN & & \\
\hline CHEMBL598903 & 688810 & 4.583 & 5.0265 & TST & & \\
\hline CHEMBL1536233 & 688810 & 4.933 & 5.0985 & TST & & \\
\hline CHEMBL1519311 & 688810 & 5.483 & 5.6144 & TST & & \\
\hline CHEMBL1445297 & 688810 & 6.8329 & 99999999 & & 5.56 & RIV \\
\hline CHEMBL1452783 & 688810 & 5.1329 & 99999999 & & 5.0402 & \\
\hline
\end{tabular}




\begin{tabular}{|c|c|c|c|c|c|c|}
\hline \multirow{3}{*}{$\begin{array}{l}\text { CHEMBL1346564 } \\
\text { CHEMBL3209487 }\end{array}$} & & \multicolumn{5}{|c|}{ Supplemental Table S2.txt } \\
\hline & 688810 & \multicolumn{4}{|c|}{5.582999999999999} & \multirow{2}{*}{ TRN } \\
\hline & 688810 & 4.833 & 5.3466 & TST & & \\
\hline CHEMBL1404569 & 688810 & \multicolumn{3}{|c|}{5.832999999999999} & 5.341 & TRN \\
\hline CHEMBL1326358 & 688810 & \multicolumn{3}{|c|}{5.7829999999999995} & 5.4816 & TRN \\
\hline CHEMBL1578635 & 688810 & \multicolumn{3}{|c|}{4.9830000000000005} & 4.8955 & TRN \\
\hline CHEMBL1530795 & 688810 & 5.183 & 5.0952 & TRN & & \\
\hline CHEMBL1380100 & 688810 & 5.983 & 5.8199 & TRN & & \\
\hline CHEMBL1455088 & 688810 & \multicolumn{3}{|c|}{4.7330000000000005} & 5.1483 & TRN \\
\hline CHEMBL1464514 & 688810 & 5.683 & 5.2936 & TRN & & \\
\hline CHEMBL1467114 & 688810 & 5.233 & 5.3401 & TRN & & \\
\hline CHEMBL1589382 & 688810 & 4.833 & 4.9172 & TST & & \\
\hline CHEMBL1523417 & 688810 & 4.883 & 4.636 & TST & & \\
\hline CHEMBL1369448 & 688810 & 4.883 & 5.2028 & TRN & & \\
\hline CHEMBL428064 & 688810 & 5.183 & 5.4574 & TST & & \\
\hline CHEMBL1450259 & 688810 & 4.883 & 5.2513 & TRN & & \\
\hline CHEMBL1496258 & 688810 & 4.683 & 5.1982 & TRN & & \\
\hline CHEMBL1472360 & 688810 & \multicolumn{3}{|c|}{4.7330000000000005} & 5.0749 & TST \\
\hline CHEMBL1318628 & 688810 & 4.933 & 5.4046 & TST & & \\
\hline CHEMBL1432801 & 688810 & 5.733 & 5.4239 & TRN & & \\
\hline CHEMBL1608578 & 688810 & 4.933 & 5.6872 & TRN & & \\
\hline CHEMBL 1475647 & 688810 & 4.833 & 5.2896 & TST & & \\
\hline CHEMBL1356144 & 688810 & 4.683 & 4.8167 & TRN & & \\
\hline CHEMBL1479116 & 688810 & 5.033 & 5.0891 & TRN & & \\
\hline CHEMBL1541334 & 688810 & \multicolumn{3}{|c|}{6.332999999999999} & 5.9864 & TRN \\
\hline CHEMBL1530192 & 688810 & 4.833 & 5.6037 & TRN & & \\
\hline CHEMBL1502706 & 688810 & \multicolumn{3}{|c|}{5.2829999999999995} & 5.1149 & TRN \\
\hline CHEMBL1433260 & 688810 & 6.983 & 6.2819 & TRN & & \\
\hline CHEMBL1338053 & 688810 & 4.933 & 5.3773 & TRN & & \\
\hline CHEMBL1542481 & 688810 & 5.433 & 5.0553 & TRN & & \\
\hline CHEMBL1363376 & 688810 & 5.983 & 6.4538 & TRN & & \\
\hline CHEMBL1331007 & 688810 & \multicolumn{3}{|c|}{6.132999999999999} & 5.3956 & TRN \\
\hline CHEMBL1531697 & 688810 & 5.933 & 5.2889 & TRN & & \\
\hline CHEMBL1423968 & 688810 & \multicolumn{3}{|c|}{4.9830000000000005} & 5.477 & TRN \\
\hline CHEMBL1970453 & 688810 & 4.883 & 5.2661 & TRN & & \\
\hline CHEMBL1341393 & 688810 & \multicolumn{3}{|c|}{5.132999999999999} & 5.5671 & TRN \\
\hline CHEMBL1435190 & 688810 & 5.033 & 5.6419 & TRN & & \\
\hline CHEMBL1399108 & 688810 & \multirow{2}{*}{\multicolumn{3}{|c|}{4.9830000000000005}} & & \\
\hline CHEMBL1410343 & 688810 & & & & 4.9521 & TRN \\
\hline CHEMBL1983034 & 688810 & 6.233 & 5.5026 & TST & & \\
\hline CHEMBL1322304 & 688810 & 4.583 & 5.1145 & TST & & \\
\hline CHEMBL1462556 & 688810 & 5.933 & 5.7088 & TRN & & \\
\hline CHEMBL1380577 & 688810 & 4.683 & \multicolumn{3}{|c|}{5.672000000000001} & TRN \\
\hline CHEMBL1478988 & 688810 & 4.883 & 4.942 & TRN & & \\
\hline CHEMBL1524799 & 688810 & \multicolumn{3}{|c|}{5.7829999999999995} & 5.4522 & TST \\
\hline CHEMBL1477280 & 688810 & 5.233 & 5.6453 & TRN & & \\
\hline CHEMBL1371648 & 688810 & \multicolumn{3}{|c|}{5.332999999999999} & 5.8708 & TRN \\
\hline CHEMBL1533835 & 688810 & \multicolumn{3}{|c|}{4.7330000000000005} & 5.8087 & TRN \\
\hline CHEMBL1360949 & 688810 & 4.783 & 5.4117 & TRN & & \\
\hline
\end{tabular}




\begin{tabular}{|c|c|c|c|c|c|c|}
\hline \multirow[b]{2}{*}{ CHEMBL1391094 } & \multirow[b]{2}{*}{688810} & \multicolumn{5}{|c|}{ Supplemental Table s2.txt } \\
\hline & & 4.583 & 5.1437 & TRN & & \\
\hline CHEMBL1355018 & 688810 & \multicolumn{3}{|c|}{5.132999999999999} & 5.7747 & TRN \\
\hline CHEMBL1483842 & 688810 & \multicolumn{3}{|c|}{4.7330000000000005} & 5.4244 & TRN \\
\hline CHEMBL1380535 & 688810 & \multicolumn{3}{|c|}{6.332999999999999} & 6.1669 & TRN \\
\hline CHEMBL1404519 & 688810 & 4.883 & 4.9604 & TRN & & \\
\hline CHEMBL1396184 & 688810 & 7.0329 & 4.7316 & TRN & & \\
\hline CHEMBL1564978 & 688810 & \multicolumn{3}{|c|}{5.132999999999999} & 5.4235 & TRN \\
\hline CHEMBL1460296 & 688810 & 6.433 & 5.8042 & TRN & & \\
\hline CHEMBL1335169 & 688810 & \multicolumn{3}{|c|}{5.132999999999999} & 5.4778 & TRN \\
\hline CHEMBL1531925 & 688810 & \multicolumn{3}{|c|}{6.132999999999999} & 5.5565 & TRN \\
\hline CHEMBL1396669 & 688810 & 5.033 & 5.0317 & TST & & \\
\hline CHEMBL1333752 & 688810 & \multirow{2}{*}{\multicolumn{3}{|c|}{ 5.382999999999999 }} & & \\
\hline CHEMBL1529064 & 688810 & & & & 5.8353 & TRN \\
\hline CHEMBL1318818 & 688810 & 5.083 & 4.9951 & TRN & & \\
\hline CHEMBL1583414 & 688810 & \multicolumn{3}{|c|}{5.832999999999999} & 6.0466 & TRN \\
\hline CHEMBL1322727 & 688810 & \multicolumn{3}{|c|}{5.132999999999999} & 5.2983 & TRN \\
\hline CHEMBL1457273 & 688810 & 4.883 & 5.3419 & TRN & & \\
\hline CHEMBL1492738 & 688810 & 6.7331 & 5.7004 & TRN & & \\
\hline CHEMBL1456339 & 688810 & 4.933 & 4.8488 & TRN & & \\
\hline CHEMBL1490031 & 688810 & 5.083 & 5.0472 & TRN & & \\
\hline CHEMBL602206 & 688810 & 4.783 & 5.1674 & TST & & \\
\hline CHEMBL1449486 & 688810 & 4.783 & 5.1835 & TRN & & \\
\hline CHEMBL1304486 & 688810 & \multicolumn{3}{|c|}{5.132999999999999} & 4.8659 & TRN \\
\hline CHEMBL1404894 & 688810 & 5.083 & 5.8187 & TRN & & \\
\hline CHEMBL1528414 & 688810 & \multicolumn{3}{|c|}{6.2829999999999995} & 5.9037 & TRN \\
\hline CHEMBL1358028 & 688810 & 5.433 & 5.3658 & TRN & & \\
\hline CHEMBL3189975 & 688810 & 5.483 & 5.4886 & TRN & & \\
\hline CHEMBL1374184 & 688810 & 5.033 & 5.3386 & TRN & & \\
\hline CHEMBL1381473 & 688810 & 6.433 & 5.5333 & TRN & & \\
\hline CHEMBL1401837 & 688810 & \multicolumn{3}{|c|}{6.332999999999999} & 5.8651 & TRN \\
\hline CHEMBL1619418 & 688810 & \multicolumn{3}{|c|}{4.7330000000000005} & 5.082 & TRN \\
\hline CHEMBL1548449 & 688810 & \multicolumn{3}{|c|}{5.882999999999999} & 5.7706 & TRN \\
\hline CHEMBL1542941 & 688810 & 4.833 & 5.364 & TST & & \\
\hline CHEMBL1456696 & 688810 & \multicolumn{3}{|c|}{5.5329999999999995} & 5.6324 & TRN \\
\hline CHEMBL1502964 & 688810 & 5.183 & 5.3227 & TRN & & \\
\hline CHEMBL1575421 & 688810 & 4.683 & 5.3493 & TST & & \\
\hline CHEMBL1509087 & 688810 & 4.833 & 5.1236 & TST & & \\
\hline CHEMBL1789993 & 688810 & \multicolumn{3}{|c|}{5.382999999999999} & 5.1136 & TST \\
\hline CHEMBL1538546 & 688810 & \multicolumn{3}{|c|}{5.2829999999999995} & 5.4143 & TRN \\
\hline CHEMBL1513139 & 688810 & 4.633 & 4.8284 & TRN & & \\
\hline CHEMBL1319980 & 688810 & 5.983 & 5.1078 & TRN & & \\
\hline CHEMBL1421261 & 688810 & 4.833 & 5.1657 & TRN & & \\
\hline CHEMBL1481139 & 688810 & \multicolumn{3}{|c|}{5.332999999999999} & 5.1814 & TRN \\
\hline CHEMBL1516381 & 688810 & 5.63299 & 99999999 & & 5.228 & TRN \\
\hline CHEMBL1564883 & 688810 & 5.483 & 5.5716 & TRN & & \\
\hline CHEMBL1306086 & 688810 & 5.483 & 4.958 & TST & & \\
\hline CHEMBL1468270 & 688810 & 5.733 & 5.5963 & TRN & & \\
\hline CHEMBL1593722 & 688810 & 5.83299 & 99999999 & & 5.5259 & T \\
\hline & & & & & & \\
\hline
\end{tabular}




\begin{tabular}{|c|c|c|c|c|c|c|}
\hline \multirow{3}{*}{$\begin{array}{l}\text { CHEMBL } 1497566 \\
\text { CHEMBL1455776 }\end{array}$} & & \multicolumn{5}{|c|}{ Supplemental Table S2.txt } \\
\hline & 688810 & \multicolumn{3}{|c|}{5.132999999999999} & 4.8929 & TST \\
\hline & 688810 & 5.233 & 5.3312 & TRN & & \\
\hline CHEMBL1587744 & 688810 & 5.433 & \multicolumn{3}{|c|}{5.877999999999999} & TRN \\
\hline CHEMBL1586323 & 688810 & \multicolumn{3}{|c|}{5.132999999999999} & 5.0867 & TRN \\
\hline CHEMBL1580114 & 688810 & 4.583 & 5.3322 & TRN & & \\
\hline CHEMBL1320281 & 688810 & 6.433 & 5.3367 & TST & & \\
\hline CHEMBL1585752 & 688810 & \multicolumn{3}{|c|}{5.5329999999999995} & 5.1751 & TRN \\
\hline CHEMBL1452406 & 688810 & 6.183 & 5.2693 & TRN & & \\
\hline CHEMBL1523301 & 688810 & \multicolumn{3}{|c|}{5.2829999999999995} & 5.4521 & TRN \\
\hline CHEMBL1610477 & 688810 & 4.883 & 5.221 & TST & & \\
\hline CHEMBL1488586 & 688810 & 7.0329 & 5.7981 & TRN & & \\
\hline CHEMBL3213231 & 688810 & \multicolumn{3}{|c|}{4.9830000000000005} & 4.8166 & TST \\
\hline CHEMBL1536994 & 688810 & 5.733 & 5.2718 & TRN & & \\
\hline CHEMBL1529010 & 688810 & 4.883 & 5.2834 & TRN & & \\
\hline CHEMBL1361040 & 688810 & 4.933 & 4.8812 & TST & & \\
\hline CHEMBL1477453 & 688810 & 5.433 & 5.4739 & TRN & & \\
\hline CHEMBL1458200 & 688810 & 4.833 & 5.8384 & TRN & & \\
\hline CHEMBL1998521 & 688810 & 7.0329 & 6.0421 & TRN & & \\
\hline CHEMBL1484714 & 688810 & 4.883 & 5.7957 & TRN & & \\
\hline CHEMBL1453914 & 688810 & 5.733 & 5.3548 & TRN & & \\
\hline CHEMBL1349906 & 688810 & 5.683 & 5.7933 & TRN & & \\
\hline CHEMBL1306640 & 688810 & 5.233 & 5.0481 & TST & & \\
\hline CHEMBL1433116 & 688810 & \multicolumn{3}{|c|}{5.7829999999999995} & 5.2783 & TRN \\
\hline CHEMBL1537364 & 688810 & 5.233 & 5.1285 & TRN & & \\
\hline CHEMBL1557617 & 688810 & \multicolumn{3}{|c|}{5.382999999999999} & 5.3005 & TST \\
\hline CHEMBL1492017 & 688810 & 5.083 & 5.0979 & TST & & \\
\hline CHEMBL1312763 & 688810 & 5.733 & 5.521 & TRN & & \\
\hline CHEMBL3193017 & 688810 & 5.483 & 5.2776 & TRN & & \\
\hline CHEMBL1493273 & 688810 & 5.433 & \multicolumn{3}{|c|}{5.406000000000001} & TRN \\
\hline CHEMBL1526482 & 688810 & 5.483 & 5.2243 & TRN & & \\
\hline CHEMBL1410469 & 688810 & 5.433 & 5.2564 & TRN & & \\
\hline CHEMBL1470721 & 688810 & 4.883 & 5.3543 & TST & & \\
\hline CHEMBL1303058 & 688810 & 4.883 & 5.3955 & TRN & & \\
\hline CHEMBL1447231 & 688810 & 4.883 & 4.8287 & TRN & & \\
\hline CHEMBL1335000 & 688810 & 4.833 & 5.2367 & TST & & \\
\hline CHEMBL1387945 & 688810 & 5.433 & 5.9297 & TRN & & \\
\hline CHEMBL1313683 & 688810 & 6.433 & 5.6151 & TRN & & \\
\hline CHEMBL 1412210 & 688810 & 4.883 & 5.0345 & TRN & & \\
\hline CHEMBL1476878 & 688810 & 4.833 & 5.1121 & TST & & \\
\hline CHEMBL165 & 688810 & \multicolumn{3}{|c|}{5.382999999999999} & 5.6585 & TST \\
\hline CHEMBL 1605780 & 688810 & \multicolumn{3}{|c|}{5.132999999999999} & 5.0625 & TST \\
\hline CHEMBL1557494 & 688810 & \multicolumn{3}{|c|}{5.2829999999999995} & 5.4445 & TRN \\
\hline CHEMBL1576009 & 688810 & 6.233 & 5.6565 & TRN & & \\
\hline CHEMBL1312902 & 688810 & 4.883 & 5.0579 & TRN & & \\
\hline CHEMBL1372995 & 688810 & \multicolumn{3}{|c|}{4.9830000000000005} & 5.2952 & TST \\
\hline CHEMBL1480241 & 688810 & 4.783 & 4.9405 & TRN & & \\
\hline CHEMBL1434265 & 688810 & 5.183 & 5.0853 & TRN & & \\
\hline \multirow[t]{2}{*}{ CHEMBL3208972 } & 688810 & 4.783 & 5.1579 & TRN & & \\
\hline & & \multicolumn{4}{|c|}{ Page 21705} & \\
\hline
\end{tabular}




\begin{tabular}{|c|c|c|c|c|c|c|c|}
\hline \multirow[b]{2}{*}{ CHEMBL1515537 } & & \\
\hline & 688810 & 5.733 & 5.6191 & TRN & & & \\
\hline CHEMBL1533437 & 688810 & 5.88299 & 999999999 & & 5.3132 & TRN & \\
\hline CHEMBL1387640 & 688810 & 4.783 & \multicolumn{3}{|c|}{5.218999999999999} & TRN & \\
\hline CHEMBL1550104 & 688810 & 5.733 & 5.399 & \multicolumn{2}{|l|}{ TRN } & & \\
\hline CHEMBL1516470 & 688810 & 4.833 & 5.0653 & \multicolumn{2}{|l|}{ TST } & & \\
\hline CHEMBL1310277 & 688810 & \multicolumn{3}{|c|}{4.7330000000000005} & 5.2154 & TRN & \\
\hline CHEMBL1603031 & 688810 & \multicolumn{3}{|c|}{5.332999999999999} & 5.0126 & TRN & \\
\hline CHEMBL1392898 & 688810 & \multicolumn{3}{|c|}{4.7330000000000005} & 4.9768 & TRN & \\
\hline CHEMBL1555188 & 688810 & \multicolumn{3}{|c|}{4.7330000000000005} & 5.0561 & TRN & \\
\hline CHEMBL1431566 & 688810 & \multicolumn{3}{|c|}{5.882999999999999} & 6.1083 & TRN & \\
\hline CHEMBL1384068 & 688810 & 4.933 & 5.0244 & TRN & & & \\
\hline CHEMBL1330067 & 688810 & \multicolumn{3}{|c|}{6.382999999999999} & 5.4071 & TRN & \\
\hline CHEMBL1458893 & 688810 & 4.583 & \multicolumn{3}{|c|}{5.111000000000001} & TRN & \\
\hline CHEMBL1599601 & 688810 & \multicolumn{3}{|c|}{5.882999999999999} & 5.5729 & TRN & \\
\hline CHEMBL1454365 & 688810 & 5.733 & 5.4001 & TRN & & & \\
\hline CHEMBL1482003 & 688810 & 4.783 & 5.1864 & TRN & & & \\
\hline CHEMBL1979747 & 688810 & 4.633 & \multicolumn{3}{|c|}{5.468999999999999} & TRN & \\
\hline CHEMBL1442632 & 688810 & 5.433 & 5.3109 & TRN & & & \\
\hline CHEMBL1371750 & 688810 & 4.833 & 5.1619 & TRN & & & \\
\hline CHEMBL1992517 & 688810 & 4.783 & 5.3559 & TRN & & & \\
\hline CHEMBL3211678 & 688810 & 4.783 & 5.1892 & TST & & & \\
\hline CHEMBL 3214216 & 688810 & 5.433 & 5.5529 & TRN & & & \\
\hline CHEMBL1441814 & 688810 & \multicolumn{3}{|c|}{5.832999999999999} & 5.6115 & TRN & \\
\hline CHEMBL1343306 & 688810 & 4.883 & 5.0551 & TRN & & & \\
\hline CHEMBL1401958 & 688810 & 4.783 & 5.2351 & TST & & & \\
\hline CHEMBL1527187 & 688810 & \multicolumn{3}{|c|}{6.132999999999999} & 5.7792 & TRN & \\
\hline CHEMBL1373729 & 688810 & 4.933 & 4.9582 & TRN & & & \\
\hline CHEMBL1418304 & 688810 & 4.783 & 4.9754 & TRN & & & \\
\hline CHEMBL1605445 & 688810 & 5.233 & 5.6059 & TRN & & & \\
\hline CHEMBL1306971 & 688810 & \multicolumn{3}{|c|}{4.9830000000000005} & 5.8432 & TRN & \\
\hline CHEMBL1495579 & 688810 & \multicolumn{3}{|c|}{4.7330000000000005} & 5.33799 & 9999999999 & TST \\
\hline CHEMBL1407714 & 688810 & 5.233 & 5.1158 & TRN & & & \\
\hline CHEMBL1501825 & 688810 & 4.833 & 4.8355 & TRN & & & \\
\hline CHEMBL1576600 & 688810 & \multicolumn{3}{|c|}{6.332999999999999} & 5.9424 & TRN & \\
\hline CHEMBL1570464 & 688810 & 5.683 & 5.7679 & TRN & & & \\
\hline CHEMBL1997899 & 688810 & 7.2328 & 5.7286 & TST & & & \\
\hline CHEMBL1352208 & 688810 & 4.833 & 4.919 & TRN & & & \\
\hline CHEMBL1484327 & 688810 & \multicolumn{3}{|c|}{4.7330000000000005} & 5.6152 & TRN & \\
\hline CHEMBL1525849 & 688810 & 5.183 & 5.5535 & TRN & & & \\
\hline CHEMBL1584480 & 688810 & 5.183 & 5.2877 & TST & & & \\
\hline CHEMBL1348502 & 688810 & 4.883 & 5.2483 & TRN & & & \\
\hline CHEMBL1374178 & 688810 & 4.783 & 5.3393 & TRN & & & \\
\hline CHEMBL1469101 & 688810 & 4.73300 & 000000000 & 205 & 5.1252 & TST & \\
\hline CHEMBL1329383 & 688810 & 4.883 & 5.184 & TRN & & & \\
\hline CHEMBL1603779 & 688810 & 5.78299 & 999999999 & 995 & 5.7554 & TRN & \\
\hline CHEMBL1565008 & 688810 & 4.933 & 5.1123 & TRN & & & \\
\hline CHEMBL1507520 & 688810 & 6.233 & 5.6371 & TRN & & & \\
\hline CHEMBL1399170 & 688810 & 5.083 & 4.8492 & TRN & & & \\
\hline
\end{tabular}




\begin{tabular}{|c|c|c|c|c|c|c|}
\hline \multirow[b]{2}{*}{ CHEMBL1376212 } & \multirow[b]{2}{*}{688810} & \\
\hline & & 5.433 & 5.3594 & TRN & & \\
\hline CHEMBL1610364 & 688810 & 5.233 & 5.3513 & TRN & & \\
\hline CHEMBL1349146 & 688810 & 5.733 & 5.5925 & TST & & \\
\hline CHEMBL1362398 & 688810 & 5.233 & 5.3157 & TRN & & \\
\hline CHEMBL1417189 & 688810 & 4.933 & 4.9097 & TRN & & \\
\hline CHEMBL1326918 & 688810 & \multicolumn{3}{|c|}{5.2829999999999995} & 5.4473 & \\
\hline CHEMBL1339058 & 688810 & 5.183 & 5.0099 & TST & & \\
\hline CHEMBL1402683 & 688810 & \multicolumn{3}{|c|}{5.832999999999999} & 5.4668 & \\
\hline CHEMBL586602 & 688810 & \multicolumn{3}{|c|}{6.082999999999999} & 5.6434 & \\
\hline CHEMBL1340133 & 688810 & 4.833 & 5.4288 & TST & & \\
\hline CHEMBL1528120 & 688810 & \multicolumn{3}{|c|}{6.632999999999999} & 5.2727 & \\
\hline CHEMBL1482364 & 688810 & 5.033 & 5.2834 & TRN & & \\
\hline CHEMBL1352498 & 688810 & 5.683 & 5.7614 & TRN & & \\
\hline CHEMBL1526423 & 688810 & \multicolumn{3}{|c|}{4.7330000000000005} & 5.0043 & \\
\hline CHEMBL1476320 & 688810 & \multicolumn{3}{|c|}{4.7330000000000005} & 5.2359 & \\
\hline CHEMBL1517823 & 688810 & 4.833 & 5.3195 & TST & & \\
\hline CHEMBL1598830 & 688810 & \multicolumn{3}{|c|}{4.7330000000000005} & 5.121 & \\
\hline CHEMBL 3197310 & 688810 & 5.683 & \multicolumn{3}{|c|}{5.4239999999999995} & \\
\hline CHEMBL1537082 & 688810 & 4.783 & 5.6042 & TST & & \\
\hline CHEMBL 1557850 & 688810 & \multicolumn{3}{|c|}{5.882999999999999} & 5.4249 & \\
\hline CHEMBL1364157 & 688810 & \multicolumn{3}{|c|}{6.2829999999999995} & 85 & \\
\hline CHEMBL1534545 & 688810 & 4.583 & 5.1055 & TST & & \\
\hline CHEMBL 3208459 & 688810 & 5.483 & 5.1674 & TST & & \\
\hline CHEMBL1497091 & 688810 & \multicolumn{3}{|c|}{5.382999999999999} & 5 & \\
\hline CHEMBL1569446 & 688810 & \multicolumn{3}{|c|}{5.5329999999999995} & 5.4184 & \\
\hline CHEMBL1533711 & 688810 & 6.8831 & 5.9899 & TRN & & \\
\hline CHEMBL1566313 & 688810 & 5.483 & 5.2461 & TRN & & \\
\hline CHEMBL 3196522 & 688810 & 4.933 & 4.9534 & TST & & \\
\hline CHEMBL1355065 & 688810 & 5.233 & 5.3423 & TST & & \\
\hline CHEMBL1368052 & 688810 & \multicolumn{3}{|c|}{5.5329999999999995} & 5175 & \\
\hline CHEMBL1328688 & 688810 & \multicolumn{3}{|c|}{5.132999999999999} & 4.9826 & \\
\hline CHEMBL1509768 & 688810 & 4.883 & 5.1043 & TST & & \\
\hline CHEMBL1584467 & 688810 & \multicolumn{3}{|c|}{5.582999999999999} & 5.3644 & \\
\hline CHEMBL1473239 & 688810 & 4.783 & 5.3392 & TRN & & \\
\hline CHEMBL1369728 & 688810 & \multicolumn{3}{|c|}{5.382999999999999} & 5.5015 & \\
\hline CHEMBL1561827 & 688810 & 4.883 & 5.1833 & TST & & \\
\hline CHEMBL 1483414 & 688810 & 6.983 & \multicolumn{3}{|c|}{5.827999999999999} & \\
\hline CHEMBL1328499 & 688810 & 4.633 & 5.0244 & TST & & \\
\hline CHEMBL1546328 & 688810 & 4.883 & 4.9796 & TST & & \\
\hline CHEMBL514204 & 688810 & 5.1329 & 999999999 & & 6.2173 & \\
\hline CHEMBL1990959 & 688810 & 5.733 & 5.6836 & TRN & & \\
\hline CHEMBL 1579155 & 688810 & 5.233 & 5.3956 & TST & & \\
\hline CHEMBL 1403030 & 688810 & 5.983 & 4.8688 & TRN & & \\
\hline CHEMBL 1428180 & 688810 & 6.0329 & 999999999 & 995 & 5.7316 & \\
\hline CHEMBL1326819 & 688810 & 4.783 & 4.7748 & TRN & & \\
\hline CHEMBL1531309 & 688810 & 5.3329 & 999999999 & & 5.0855 & \\
\hline CHEMBL 1405633 & 688810 & 5.8829 & 999999999 & & 5.6018 & TRN \\
\hline CHEMBL1532732 & 688810 & 6.433 & 6.053999 & 9999999 & & K \\
\hline & & & & & & \\
\hline
\end{tabular}




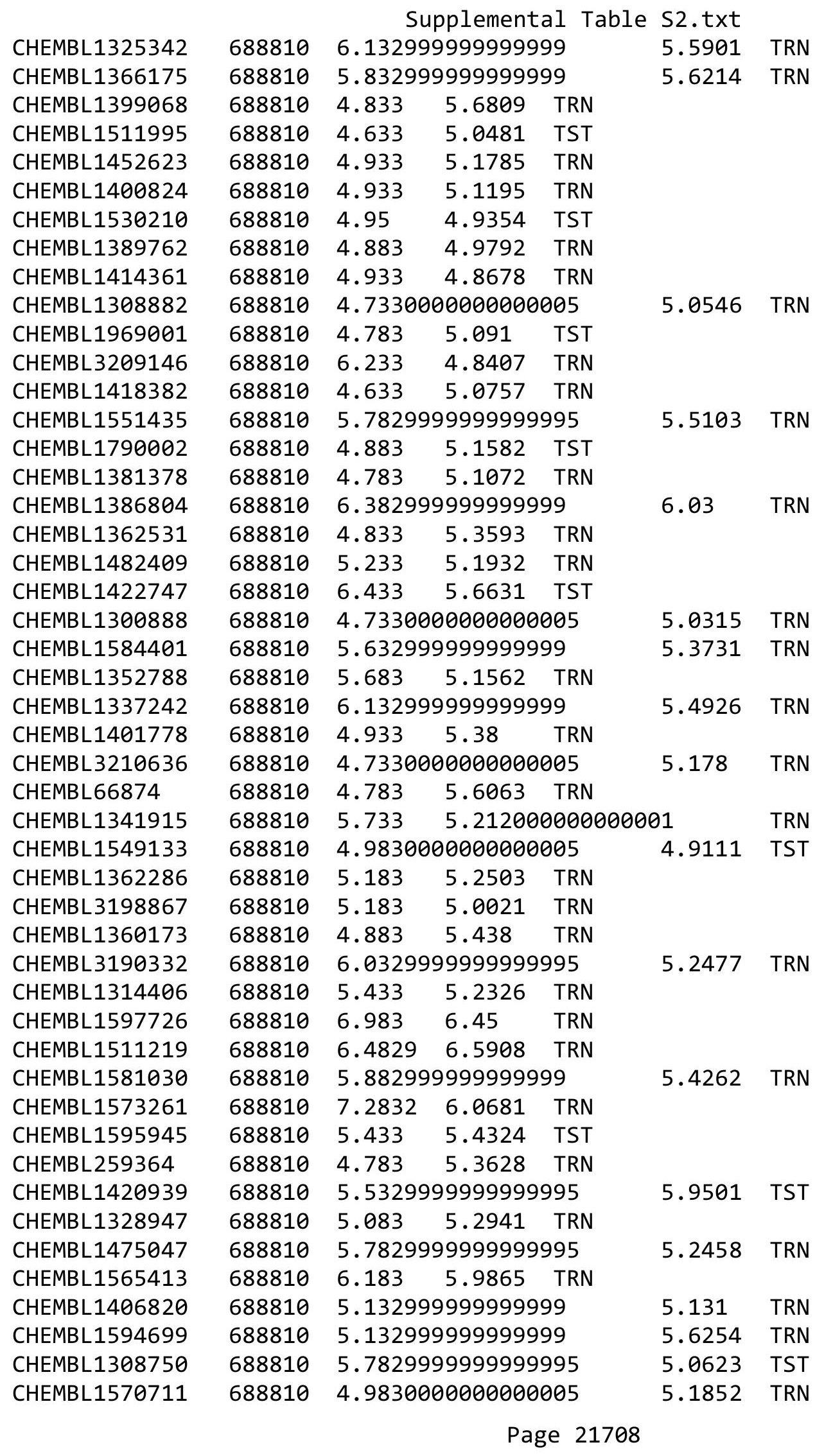




\begin{tabular}{|c|c|c|c|c|c|c|}
\hline & & & pplement & - & s2.txt & \\
\hline CHEMBL1406113 & 688810 & 4.7336 & 00000000 & 005 & 5.4991 & TRN \\
\hline CHEMBL1531352 & 688810 & 5.183 & 5.5711 & TRN & & \\
\hline CHEMBL1567968 & 688810 & 4.883 & 4.9637 & TRN & & \\
\hline CHEMBL1507557 & 688810 & 4.783 & 4.9652 & TRN & & \\
\hline CHEMBL1412094 & 688810 & 5.9 & 5.2821 & TRN & & \\
\hline CHEMBL1387801 & 688810 & 4.7336 & 00000000 & 005 & 5.2878 & TRN \\
\hline CHEMBL1300800 & 688810 & 4.883 & 5.1685 & TRN & & \\
\hline CHEMBL1403202 & 688810 & 5.183 & 5.1567 & TST & & \\
\hline CHEMBL3191336 & 688810 & 5.3329 & 99999999 & & 5.0678 & TRN \\
\hline CHEMBL1522706 & 688810 & 4.883 & 5.2428 & TRN & & \\
\hline CHEMBL1502431 & 688810 & 4.7336 & 00000000 & 005 & 5.0971 & TST \\
\hline CHEMBL1522237 & 688810 & 5.033 & 5.2217 & TRN & & \\
\hline CHEMBL1430300 & 688810 & 4.833 & 4.6915 & TST & & \\
\hline CHEMBL1367596 & 688810 & 4.633 & 5.2964 & TST & & \\
\hline CHEMBL1302115 & 688810 & 4.7336 & 00000000 & 005 & 4.9646 & TRN \\
\hline CHEMBL1415694 & 688810 & 5.683 & 5.7899 & TRN & & \\
\hline CHEMBL1407542 & 688810 & 4.833 & 5.3758 & TRN & & \\
\hline CHEMBL1324600 & 688810 & 5.8320 & 99999999 & & 5.9189 & TRN \\
\hline CHEMBL1341124 & 688810 & 5.183 & 5.3502 & TST & & \\
\hline CHEMBL1489623 & 688810 & 4.783 & 5.3303 & TRN & & \\
\hline CHEMBL3145378 & 688810 & 4.633 & 5.7238 & TST & & \\
\hline CHEMBL1456751 & 688810 & 5.5329 & 99999999 & 995 & 5.8176 & TRN \\
\hline CHEMBL1463278 & 688810 & 4.7336 & 00000000 & 005 & 5.5219 & TRN \\
\hline CHEMBL3199144 & 688810 & 4.783 & 5.5664 & TRN & & \\
\hline CHEMBL1474099 & 688810 & 6.1329 & 99999999 & & 5.3244 & TST \\
\hline CHEMBL1406144 & 688810 & 5.483 & 4.8475 & TST & & \\
\hline CHEMBL1589657 & 688810 & 4.883 & 5.0886 & TST & & \\
\hline CHEMBL1343407 & 688810 & 5.1329 & 99999999 & & 5.6124 & TRN \\
\hline CHEMBL1386322 & 688810 & 6.8329 & 99999999 & & 5.7643 & TRN \\
\hline CHEMBL1407458 & 688810 & 4.833 & 5.3464 & TRN & & \\
\hline CHEMBL3191575 & 688810 & 4.833 & 5.6446 & TRN & & \\
\hline CHEMBL1509594 & 688810 & 5.033 & 4.6826 & TST & & \\
\hline CHEMBL1501135 & 688810 & 4.583 & 5.1014 & TST & & \\
\hline CHEMBL1462541 & 688810 & 4.9836 & 00000000 & 005 & 5.515 & TST \\
\hline CHEMBL1441588 & 688810 & 4.9836 & 00000000 & 005 & 5.0554 & TST \\
\hline CHEMBL1468469 & 688810 & 5.5329 & 99999999 & 995 & 5.604 & TRN \\
\hline CHEMBL1609939 & 688810 & 4.7336 & 00000000 & 005 & 5.1148 & TRN \\
\hline CHEMBL1604037 & 688810 & 4.7336 & 00000000 & 005 & 5.3857 & TRN \\
\hline CHEMBL1416923 & 688810 & 5.183 & 5.3217 & TST & & \\
\hline CHEMBL1599309 & 688810 & 4.9836 & 00000000 & 005 & 5.045 & TRN \\
\hline CHEMBL1460688 & 688810 & 4.833 & 5.0732 & TRN & & \\
\hline CHEMBL1973571 & 688810 & 6.5829 & 99999999 & & 5.631 & TRN \\
\hline CHEMBL1355741 & 688810 & 4.683 & 5.1283 & TRN & & \\
\hline CHEMBL1425452 & 688810 & 4.783 & 5.0691 & TRN & & \\
\hline CHEMBL1468307 & 688810 & 5.483 & 5.6936 & TRN & & \\
\hline CHEMBL1384373 & 688810 & 4.633 & 5.2514 & TST & & \\
\hline CHEMBL1422352 & 688810 & 5.233 & 5.3903 & TRN & & \\
\hline CHEMBL1986898 & 688810 & 4.9836 & 00000000 & 005 & 5.3808 & TRN \\
\hline
\end{tabular}




\begin{tabular}{|c|c|c|c|c|c|c|c|}
\hline \multicolumn{8}{|c|}{ Supplemental Table S2.txt } \\
\hline CHEMBL1346510 & 688810 & 5.683 & 5.6054 & TST & & & \\
\hline CHEMBL1299786 & 688810 & 5.933 & 5.3496 & TST & & & \\
\hline CHEMBL1459239 & 688810 & 4.783 & 5.4456 & TST & & & \\
\hline CHEMBL1598696 & 688810 & \multicolumn{3}{|c|}{6.582999999999999} & 6.1616 & TST & \\
\hline CHEMBL1457165 & 688810 & \multicolumn{3}{|c|}{6.2829999999999995} & 5.3361 & TST & \\
\hline CHEMBL1611624 & 688810 & \multicolumn{3}{|c|}{4.9830000000000005} & \multicolumn{2}{|c|}{5.6979999999999995} & TRN \\
\hline CHEMBL591598 & 688810 & 6.9329 & 5.7051 & TRN & & & \\
\hline CHEMBL1462848 & 688810 & 7.2328 & 5.983 & TRN & & & \\
\hline CHEMBL1393983 & 688810 & 5.983 & 5.9241 & TRN & & & \\
\hline CHEMBL1356499 & 688810 & 5.083 & 5.3211 & TRN & & & \\
\hline CHEMBL1442645 & 688810 & 4.833 & 5.1072 & TST & & & \\
\hline CHEMBL1450249 & 688810 & 6.233 & 5.8836 & TRN & & & \\
\hline CHEMBL1559202 & 688810 & \multicolumn{3}{|c|}{4.7330000000000005} & 5.2912 & TST & \\
\hline CHEMBL1560756 & 688810 & 4.633 & 5.0164 & TST & & & \\
\hline CHEMBL1592108 & 688810 & 6.4829 & 5.5563 & TRN & & & \\
\hline CHEMBL1368040 & 688810 & 4.633 & 4.9093 & TRN & & & \\
\hline CHEMBL3212771 & 688810 & 5.733 & 5.2877 & TRN & & & \\
\hline CHEMBL1603149 & 688810 & 4.783 & 4.9071 & TST & & & \\
\hline CHEMBL1401187 & 688810 & \multicolumn{3}{|c|}{5.2829999999999995} & 5.3788 & TRN & \\
\hline CHEMBL 3208674 & 688810 & 4.683 & 5.1324 & TST & & & \\
\hline CHEMBL1542576 & 688810 & \multicolumn{3}{|c|}{6.5329999999999995} & 5.8281 & TRN & \\
\hline CHEMBL1461275 & 688810 & \multicolumn{3}{|c|}{6.0329999999999995} & 5.2439 & TRN & \\
\hline CHEMBL1308343 & 688810 & 4.833 & 4.9945 & TRN & & & \\
\hline CHEMBL1484741 & 688810 & 5.083 & 5.2166 & TST & & & \\
\hline CHEMBL1305480 & 688810 & 4.833 & 5.2632 & TST & & & \\
\hline CHEMBL1437035 & 688810 & \multicolumn{3}{|c|}{5.132999999999999} & 6.5017 & TRN & \\
\hline CHEMBL1479255 & 688810 & \multicolumn{3}{|c|}{6.082999999999999} & 5.3939 & TRN & \\
\hline CHEMBL1520996 & 688810 & 5.483 & 4.7456 & TRN & & & \\
\hline CHEMBL1313240 & 688810 & & & TRN & & & \\
\hline CHEMBL1527992 & 688810 & \multicolumn{3}{|c|}{ 6.5329999999999995 } & 6.1282 & TST & \\
\hline CHEMBL1488906 & 688810 & 5.183 & 5.2628 & TRN & & & \\
\hline CHEMBL1414871 & 688810 & \multicolumn{3}{|c|}{5.2829999999999995} & 4.978 & TRN & \\
\hline CHEMBL1492132 & 688810 & 4.783 & 5.1546 & TRN & & & \\
\hline CHEMBL1532668 & 688810 & 4.883 & 5.0661 & TRN & & & \\
\hline CHEMBL1607497 & 688810 & 5.933 & 5.6045 & TRN & & & \\
\hline CHEMBL1522007 & 688810 & 5.233 & 5.3841 & TST & & & \\
\hline CHEMBL1338666 & 688810 & \multicolumn{3}{|c|}{4.7330000000000005} & 5.3132 & TRN & \\
\hline CHEMBL1553596 & 688810 & 4.783 & 5.084 & TST & & & \\
\hline CHEMBL1398990 & 688810 & 4.933 & 4.8183 & TST & & & \\
\hline CHEMBL1564478 & 688810 & 5.733 & 5.5156 & TRN & & & \\
\hline CHEMBL1502217 & 688810 & 4.633 & 5.0779 & TST & & & \\
\hline CHEMBL 213017 & 688810 & 4.783 & 5.5082 & TST & & & \\
\hline CHEMBL1591505 & 688810 & \multicolumn{3}{|c|}{5.832999999999999} & 5.4926 & TRN & \\
\hline CHEMBL1462106 & 688810 & 4.783 & 4.958 & TRN & & & \\
\hline CHEMBL1401545 & 688810 & 6.183 & 5.7712 & TRN & & & \\
\hline CHEMBL1598740 & 688810 & 4.883 & 4.97 & TST & & & \\
\hline CHEMBL3210117 & 688810 & \multicolumn{3}{|c|}{5.382999999999999} & 5.2915 & TST & \\
\hline CHEMBL1349392 & 688810 & 5.933 & 5.2048 & TRN & & & \\
\hline
\end{tabular}




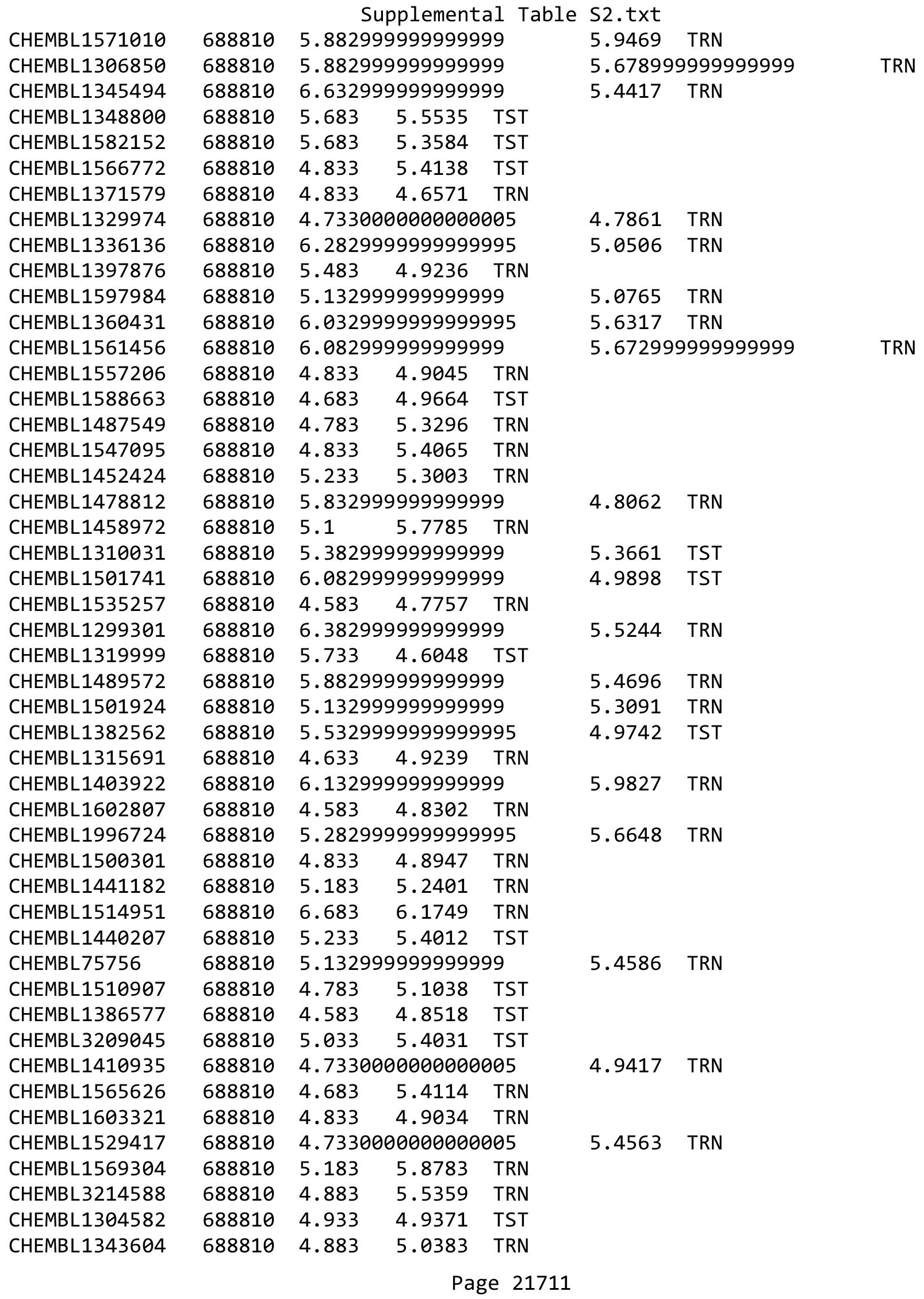




\begin{tabular}{|c|c|c|c|c|c|c|}
\hline & & & ppremert & & & \\
\hline CHEMBL1347493 & 688810 & 5.733 & 5.4527 & TRN & & \\
\hline CHEMBL3191591 & 688810 & 5.433 & 5.2694 & TRN & & \\
\hline CHEMBL1515803 & 688810 & 5.933 & 5.7929 & TRN & & \\
\hline CHEMBL1450386 & 688810 & 7.08299 & 99999999 & 99 & 6.3249 & TRN \\
\hline CHEMBL1350043 & 688810 & 5.683 & 5.7377 & TST & & \\
\hline CHEMBL1494823 & 688810 & 4.783 & 5.0878 & TRN & & \\
\hline CHEMBL1385051 & 688810 & 4.833 & 5.1626 & TRN & & \\
\hline CHEMBL1438100 & 688810 & 6.28299 & 99999999 & 995 & 5.6496 & TRN \\
\hline CHEMBL1471303 & 688810 & 4.883 & 5.2602 & TRN & & \\
\hline CHEMBL1409534 & 688810 & 4.783 & 4.9958 & TRN & & \\
\hline CHEMBL1374746 & 688810 & 6.4829 & 5.8819 & TST & & \\
\hline CHEMBL1306377 & 688810 & 5.033 & 4.7377 & TRN & & \\
\hline CHEMBL1327779 & 688810 & 4.783 & 4.9245 & TRN & & \\
\hline CHEMBL1415363 & 688810 & 5.933 & 5.7829 & TRN & & \\
\hline CHEMBL1518833 & 688810 & 5.38299 & 99999999 & & 5.4331 & TRN \\
\hline CHEMBL1535555 & 688810 & 4.98300 & 00000000 & 005 & 4.9843 & TRN \\
\hline CHEMBL3190999 & 688810 & 4.783 & 4.9897 & TRN & & \\
\hline CHEMBL1400527 & 688810 & 5.033 & 5.1347 & TRN & & \\
\hline CHEMBL1383544 & 688810 & 4.98300 & 00000000 & 005 & 5.1645 & TRN \\
\hline CHEMBL1422740 & 688810 & 5.38299 & 99999999 & & 5.5158 & TRN \\
\hline CHEMBL1525887 & 688810 & 4.833 & 5.1612 & TRN & & \\
\hline CHEMBL 3214545 & 688810 & 5.13299 & 99999999 & & 5.3766 & TRN \\
\hline CHEMBL3198951 & 688810 & 5.483 & 5.5205 & TRN & & \\
\hline CHEMBL148072 & 688810 & 4.98300 & 00000000 & 005 & 5.1916 & TST \\
\hline CHEMBL1976567 & 688810 & 4.783 & 4.8013 & TRN & & \\
\hline CHEMBL1419469 & 688810 & 4.633 & 5.0218 & TST & & \\
\hline CHEMBL1568441 & 688810 & 5.233 & 5.505 & TRN & & \\
\hline CHEMBL1429373 & 688810 & 4.783 & 5.3889 & TRN & & \\
\hline CHEMBL1612899 & 688810 & 5.683 & 5.3599 & TRN & & \\
\hline CHEMBL1444105 & 688810 & 4.833 & 5.0389 & TRN & & \\
\hline CHEMBL1479657 & 688810 & 6.7331 & 5.67 & TRN & & \\
\hline CHEMBL3196226 & 688810 & 6.183 & 5.3016 & TRN & & \\
\hline CHEMBL1308313 & 688810 & 4.633 & 5.3618 & TST & & \\
\hline CHEMBL1401901 & 688810 & 5.083 & 5.0999 & TRN & & \\
\hline CHEMBL1577968 & 688810 & 4.98300 & $\partial 0000000$ & 005 & 5.0933 & TRN \\
\hline CHEMBL1550318 & 688810 & 5.33299 & 99999999 & & 4.8934 & TRN \\
\hline CHEMBL1412371 & 688810 & 5.53299 & 99999999 & 995 & 5.2631 & TRN \\
\hline CHEMBL1481567 & 688810 & 4.583 & 4.8813 & TRN & & \\
\hline CHEMBL1448453 & 688810 & 6.38299 & 99999999 & & 5.3437 & TRN \\
\hline CHEMBL1548695 & 688810 & 4.73300 & $\partial 0000000$ & 005 & 4.9428 & TRN \\
\hline CHEMBL1343248 & 688810 & 7.2832 & 5.9679 & TRN & & \\
\hline CHEMBL1529147 & 688810 & 4.683 & 5.2383 & TST & & \\
\hline CHEMBL1527075 & 688810 & 4.933 & 5.2898 & TRN & & \\
\hline CHEMBL1403396 & 688810 & 5.83299 & 99999999 & & 5.4735 & TRN \\
\hline CHEMBL1353733 & 688810 & 5.38299 & 99999999 & & 5.8175 & TRN \\
\hline CHEMBL1422482 & 688810 & 5.38299 & 99999999 & & 5.6321 & TST \\
\hline CHEMBL1427740 & 688810 & 5.683 & 5.6526 & TST & & \\
\hline CHEMBL1561754 & 688810 & 6.45 & 5.4075 & TRN & & \\
\hline
\end{tabular}




\begin{tabular}{|c|c|c|c|c|c|c|}
\hline \multirow[b]{2}{*}{ CHEMBL1502501 } & \\
\hline & 688810 & 5.033 & 5.3967 & TRN & & \\
\hline CHEMBL1489742 & 688810 & 4.883 & 5.0057 & TRN & & \\
\hline CHEMBL1352829 & 688810 & 4.783 & 5.4515 & TRN & & \\
\hline CHEMBL1461741 & 688810 & 5.683 & 5.3851 & TRN & & \\
\hline CHEMBL1530743 & 688810 & \multicolumn{3}{|c|}{5.632999999999999} & 5.7027 & TRN \\
\hline CHEMBL 3212709 & 688810 & 4.833 & 5.0877 & TRN & & \\
\hline CHEMBL 1385323 & 688810 & 4.883 & 4.5712 & TRN & & \\
\hline CHEMBL1381938 & 688810 & 5.0 & 5.0868 & TRN & & \\
\hline CHEMBL1494683 & 688810 & \multicolumn{3}{|c|}{4.7330000000000005} & 5.433 & TRN \\
\hline CHEMBL1466250 & 688810 & \multicolumn{3}{|c|}{5.832999999999999} & 5.4753 & \\
\hline CHEMBL1565709 & 688810 & 4.783 & 5.181 & TRN & & \\
\hline CHEMBL1500088 & 688810 & 4.833 & 5.1445 & TRN & & \\
\hline CHEMBL1582477 & 688810 & 5.983 & 5.291 & TRN & & \\
\hline CHEMBL1588516 & 688810 & \multicolumn{3}{|c|}{5.132999999999999} & 5.2501 & \\
\hline CHEMBL1586442 & 688810 & 5.033 & 5.3346 & TST & & \\
\hline CHEMBL1576023 & 688810 & \multicolumn{3}{|c|}{4.7330000000000005} & 5.3878 & . \\
\hline CHEMBL1309857 & 688810 & \multicolumn{3}{|c|}{5.882999999999999} & 5.2119 & \\
\hline CHEMBL1317158 & 688810 & 4.783 & 5.0198 & TRN & & \\
\hline CHEMBL1437252 & 688810 & \multicolumn{3}{|c|}{6.082999999999999} & 5.9109 & \\
\hline CHEMBL1503935 & 688810 & 4.633 & 5.0654 & TST & & \\
\hline CHEMBL 3192725 & 688810 & 4.783 & 5.3481 & TRN & & \\
\hline CHEMBL1505472 & 688810 & 5.683 & 5.1961 & TRN & & \\
\hline CHEMBL1610981 & 688810 & 4.783 & 5.166 & TRN & & \\
\hline CHEMBL1331554 & 688810 & 4.833 & 5.3644 & TRN & & \\
\hline CHEMBL1509287 & 688810 & \multicolumn{3}{|c|}{4.9830000000000005} & 5.5862 & \\
\hline CHEMBL1322708 & 688810 & \multicolumn{3}{|c|}{6.332999999999999} & 5.7334 & TRN \\
\hline CHEMBL1386416 & 688810 & \multicolumn{3}{|c|}{5.832999999999999} & 5.7054 & \\
\hline CHEMBL1567671 & 688810 & 5.233 & 5.0214 & TST & & \\
\hline CHEMBL 1470018 & 688810 & \multicolumn{3}{|c|}{5.7829999999999995} & 5.3979 & TRN \\
\hline CHEMBL 583378 & 688810 & \multicolumn{3}{|c|}{5.7829999999999995} & 5.9056 & TRN \\
\hline CHEMBL1452191 & 688810 & \multicolumn{3}{|c|}{5.5329999999999995} & 5.354 & TST \\
\hline CHEMBL1532899 & 688810 & \multicolumn{3}{|c|}{4.9830000000000005} & 5.0911 & TST \\
\hline CHEMBL1590348 & 688810 & 4.833 & 5.1025 & TRN & & \\
\hline CHEMBL1439283 & 688810 & \multicolumn{3}{|c|}{4.9830000000000005} & 5.3758 & TRIV \\
\hline CHEMBL 1446980 & 688810 & \multicolumn{3}{|c|}{5.2829999999999995} & 4.8352 & TST \\
\hline CHEMBL1383915 & 688810 & 6.8831 & \multicolumn{3}{|c|}{6.236000000000001} & . \\
\hline CHEMBL 1454778 & 688810 & 4.833 & 4.9178 & TRN & & \\
\hline CHEMBL1581674 & 688810 & 4.583 & 4.8162 & TRN & & \\
\hline CHEMBL1592941 & 688810 & 4.783 & 4.9027 & TRN & & \\
\hline CHEMBL1500304 & 688810 & 4.783 & 5.0909 & TRN & & \\
\hline CHEMBL1516729 & 688810 & 4.933 & 5.6414 & TRN & & \\
\hline CHEMBL 1561820 & 688810 & 5.683 & 5.1421 & TRN & & \\
\hline CHEMBL 3213057 & 688810 & 4.783 & 5.2804 & TRN & & \\
\hline CHEMBL1601695 & 688810 & 4.633 & 4.917 & TRN & & \\
\hline CHEMBL1521352 & 688810 & 4.933 & 5.3391 & TRN & & \\
\hline CHEMBL1604066 & 688810 & 5.1329 & 99999999 & & 4.9195 & TRN \\
\hline CHEMBL 1275611 & 688810 & 4.7330 & 00000006 & 005 & 5.3031 & TRN \\
\hline CHEMBL1466906 & 688810 & 4.833 & 5.0448 & TST & & \\
\hline
\end{tabular}




\begin{tabular}{|c|c|c|c|c|c|c|}
\hline & & \multicolumn{5}{|c|}{ Supplemental Table s2.txt } \\
\hline CHEMBL1568488 & 688810 & \multicolumn{3}{|c|}{6.082999999999999} & 5.5729 & TRN \\
\hline CHEMBL1488002 & 688810 & \multicolumn{3}{|c|}{5.2829999999999995} & 5.3637 & TRN \\
\hline CHEMBL1505510 & 688810 & \multicolumn{3}{|c|}{5.832999999999999} & 5.6705 & TRN \\
\hline CHEMBL3190092 & 688810 & 5.033 & 4.8829 & TST & & \\
\hline CHEMBL1490962 & 688810 & 4.783 & 5.4731 & TRN & & \\
\hline CHEMBL3196620 & 688810 & \multicolumn{3}{|c|}{6.332999999999999} & 5.4442 & TRN \\
\hline CHEMBL1467200 & 688810 & \multicolumn{3}{|c|}{5.832999999999999} & 5.3062 & TRN \\
\hline CHEMBL1398590 & 688810 & 4.883 & 5.6227 & TRN & & \\
\hline CHEMBL1471769 & 688810 & 4.883 & 5.1091 & TRN & & \\
\hline CHEMBL1340442 & 688810 & \multicolumn{3}{|c|}{6.832999999999999} & 5.3215 & TST \\
\hline CHEMBL1334319 & 688810 & 4.783 & 5.6361 & TRN & & \\
\hline CHEMBL1581139 & 688810 & 5.983 & 5.3686 & TRN & & \\
\hline CHEMBL3208847 & 688810 & 7.3325 & 5.9643 & TST & & \\
\hline CHEMBL1561538 & 688810 & \multicolumn{3}{|c|}{5.132999999999999} & 5.3434 & TRN \\
\hline CHEMBL1586635 & 688810 & 4.833 & 5.2714 & TRN & & \\
\hline CHEMBL1409782 & 688810 & \multicolumn{3}{|c|}{5.132999999999999} & 5.6178 & TRN \\
\hline CHEMBL1338941 & 688810 & 5.083 & 5.4602 & TRN & & \\
\hline CHEMBL1355234 & 688810 & \multicolumn{3}{|c|}{5.5329999999999995} & 5.5096 & TRN \\
\hline CHEMBL1511680 & 688810 & 4.883 & \multicolumn{3}{|c|}{4.861000000000001} & TRN \\
\hline CHEMBL1325945 & 688810 & 5.033 & 4.9876 & TRN & & \\
\hline CHEMBL 270297 & 688810 & \multicolumn{3}{|c|}{5.882999999999999} & 5.5651 & TRN \\
\hline CHEMBL3199238 & 688810 & \multicolumn{3}{|c|}{5.132999999999999} & 5.0945 & TST \\
\hline CHEMBL1404229 & 688810 & \multicolumn{3}{|c|}{4.7330000000000005} & 4.8582 & TRN \\
\hline CHEMBL1471399 & 688810 & \multicolumn{3}{|c|}{5.332999999999999} & 5.1837 & TRN \\
\hline CHEMBL1565047 & 688810 & \multicolumn{3}{|c|}{6.382999999999999} & 6.0118 & TRN \\
\hline CHEMBL1606256 & 688810 & \multicolumn{3}{|c|}{4.7330000000000005} & 5.233 & TRN \\
\hline CHEMBL1392355 & 688810 & 5.733 & 5.2162 & TST & & \\
\hline CHEMBL1531495 & 688810 & \multirow{2}{*}{\multicolumn{3}{|c|}{$\begin{array}{lc}5.233 & 5.6233 \text { TRN } \\
4.7330000000000005\end{array}$}} & & \\
\hline CHEMBL1526187 & 688810 & & & & 5.5438 & TRN \\
\hline CHEMBL1560434 & 688810 & 4.883 & 5.794 & TST & & \\
\hline CHEMBL1465677 & 688810 & \multicolumn{3}{|c|}{4.7330000000000005} & 5.3502 & TRN \\
\hline CHEMBL1478650 & 688810 & 4.95 & 5.1651 & TRN & & \\
\hline CHEMBL1328077 & 688810 & 4.633 & 4.9873 & TRN & & \\
\hline CHEMBL1458176 & 688810 & 5.083 & 5.0871 & TST & & \\
\hline CHEMBL1349832 & 688810 & \multicolumn{3}{|c|}{4.9830000000000005} & 5.3369 & TRN \\
\hline CHEMBL1432115 & 688810 & 4.783 & 5.4779 & TST & & \\
\hline CHEMBL1312393 & 688810 & 4.783 & 5.1321 & TST & & \\
\hline CHEMBL1979383 & 688810 & \multicolumn{3}{|c|}{6.332999999999999} & 5.9724 & TRN \\
\hline CHEMBL1485857 & 688810 & 5.083 & 4.9626 & TST & & \\
\hline CHEMBL3197608 & 688810 & 4.783 & 5.7067 & TRN & & \\
\hline CHEMBL1341668 & 688810 & 5.433 & 5.7032 & TRN & & \\
\hline CHEMBL3197351 & 688810 & 5.483 & 5.1107 & TRN & & \\
\hline CHEMBL1575124 & 688810 & 7.2832 & 6.3586 & TRN & & \\
\hline CHEMBL1512687 & 688810 & 4.633 & 4.7917 & TRN & & \\
\hline CHEMBL1423463 & 688810 & 5.2829 & 99999999 & 995 & 4.7932 & TST \\
\hline CHEMBL1431440 & 688810 & $4.9830 €$ & 00000000 & 005 & 5.62 & TRN \\
\hline CHEMBL1547631 & 688810 & 5.183 & 5.2458 & TRN & & \\
\hline CHEMBL1423811 & 688810 & 5.683 & 5.3295 & TRN & & \\
\hline
\end{tabular}




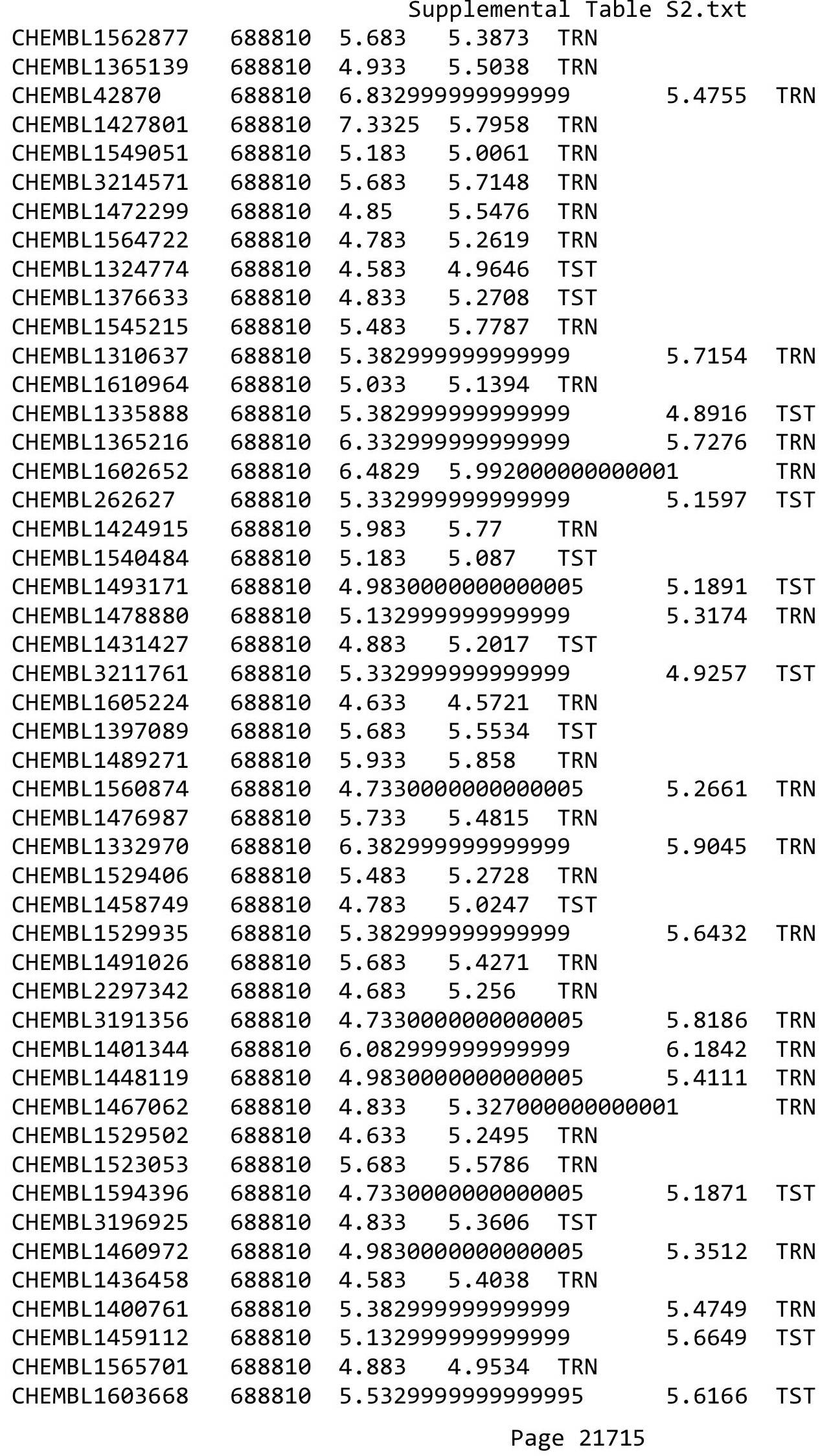




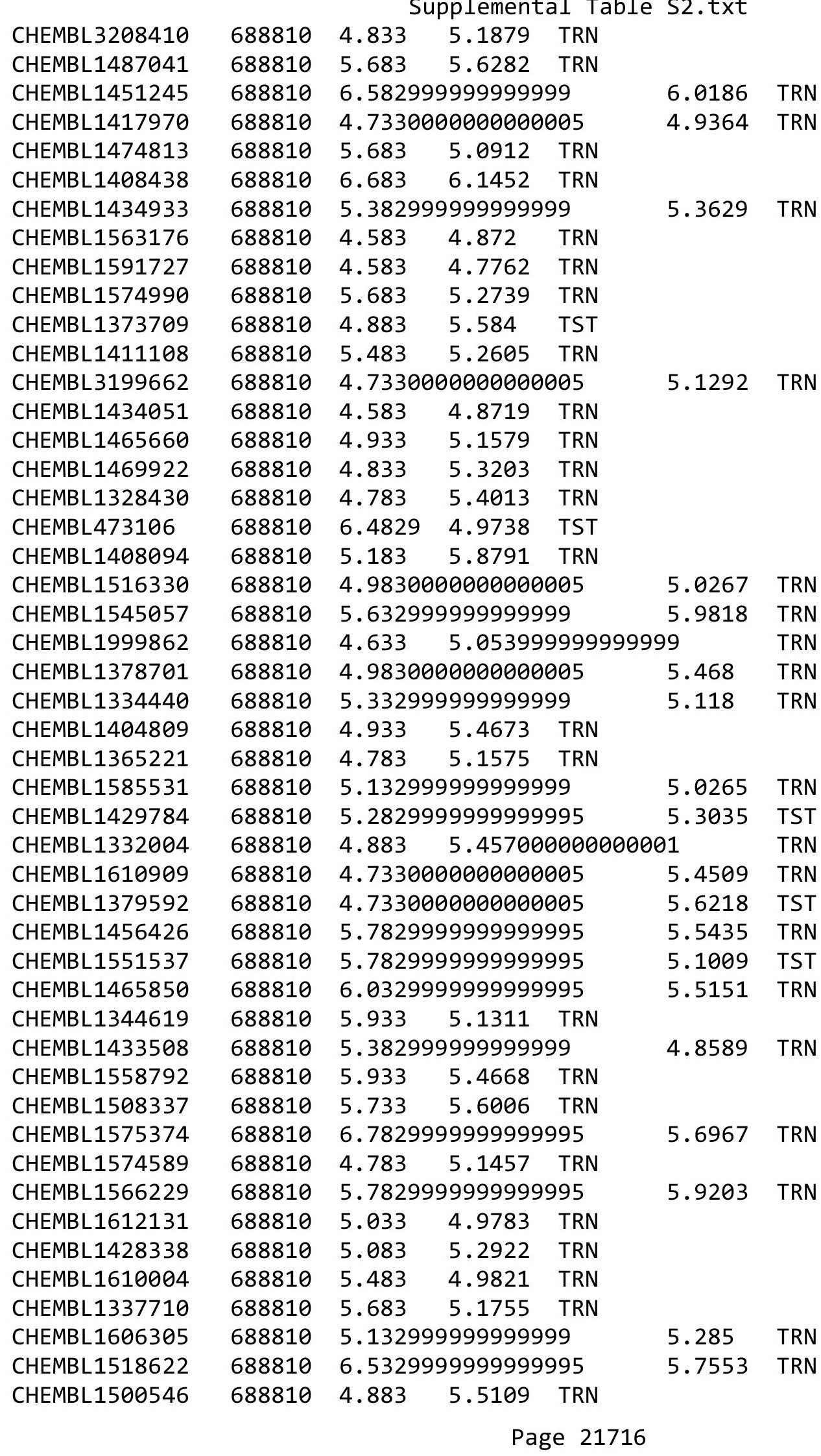




\begin{tabular}{|c|c|c|c|c|c|c|c|}
\hline \multicolumn{8}{|c|}{ Supplemental Table S2.txt } \\
\hline CHEMBL1480031 & 688810 & 5.033 & 5.6456 & TRN & & & \\
\hline CHEMBL1478639 & 688810 & 6.4829 & 5.4586 & TST & & & \\
\hline CHEMBL1542793 & 688810 & 4.633 & 5.4165 & TRN & & & \\
\hline CHEMBL1604852 & 688810 & 4.683 & 4.9328 & TST & & & \\
\hline CHEMBL1386457 & 688810 & \multicolumn{3}{|c|}{5.882999999999999} & 5.8004 & TRN & \\
\hline CHEMBL1438635 & 688810 & \multicolumn{3}{|c|}{4.7330000000000005} & \multicolumn{2}{|c|}{5.167999999999999} & TRN \\
\hline CHEMBL1344225 & 688810 & 6.183 & 5.4542 & TRN & & & \\
\hline CHEMBL1321373 & 688810 & 4.833 & 5.4197 & TRN & & & \\
\hline CHEMBL1547952 & 688810 & \multicolumn{3}{|c|}{5.332999999999999} & 5.3312 & TST & \\
\hline CHEMBL260624 & 688810 & 5.183 & 5.3222 & TRN & & & \\
\hline CHEMBL1535241 & 688810 & \multicolumn{3}{|c|}{6.082999999999999} & 5.1289 & TST & \\
\hline CHEMBL 2236983 & 688810 & 4.933 & 5.3242 & TRN & & & \\
\hline CHEMBL52347 & 688810 & \multicolumn{3}{|c|}{4.9830000000000005} & 5.4347 & TST & \\
\hline CHEMBL1550899 & 688810 & 4.633 & 4.4228 & TRN & & & \\
\hline CHEMBL1371531 & 688810 & \multicolumn{3}{|c|}{4.9830000000000005} & 5.098 & TRN & \\
\hline CHEMBL1299756 & 688810 & 5.733 & 5.5344 & TRN & & & \\
\hline CHEMBL1320593 & 688810 & \multicolumn{3}{|c|}{6.832999999999999} & 5.3138 & TRN & \\
\hline CHEMBL1365324 & 688810 & 4.783 & 5.2019 & TRN & & & \\
\hline CHEMBL1538435 & 688810 & \multicolumn{3}{|c|}{5.332999999999999} & 6.0296 & TRN & \\
\hline CHEMBL1366491 & 688810 & \multicolumn{3}{|c|}{4.9830000000000005} & 4.8883 & TRN & \\
\hline CHEMBL1474052 & 688810 & 4.883 & 4.9052 & TRN & & & \\
\hline CHEMBL1466479 & 688810 & \multicolumn{3}{|c|}{5.132999999999999} & 5.1422 & TRN & \\
\hline CHEMBL1527772 & 688810 & \multicolumn{3}{|c|}{4.9830000000000005} & \multicolumn{2}{|c|}{5.122999999999999} & TRN \\
\hline CHEMBL 3190198 & 688810 & 4.833 & 5.4927 & TRN & & & \\
\hline CHEMBL1486795 & 688810 & 4.833 & 5.2864 & TRN & & & \\
\hline CHEMBL1386658 & 688810 & 5.683 & 5.8947 & TRN & & & \\
\hline CHEMBL1488923 & 688810 & 5.933 & 5.88357 & TRN & & & \\
\hline CHEMBL1349374 & 688810 & 6.8831 & 6.1893 & TRN & & & \\
\hline CHEMBL1578728 & 688810 & 4.783 & 4.9092 & TST & & & \\
\hline CHEMBL1396290 & 688810 & 4.683 & 5.2453 & TRN & & & \\
\hline CHEMBL1518652 & 688810 & \multicolumn{3}{|c|}{5.132999999999999} & 5.1042 & TST & \\
\hline CHEMBL3198492 & 688810 & 6.183 & 5.3024 & TRN & & & \\
\hline CHEMBL1408441 & 688810 & \multicolumn{3}{|c|}{6.132999999999999} & 5.3743 & TST & \\
\hline CHEMBL1560184 & 688810 & 4.833 & 4.78597 & TST & & & \\
\hline CHEMBL1313826 & 688810 & \multicolumn{3}{|c|}{5.132999999999999} & 4.7449 & TRN & \\
\hline CHEMBL1547987 & 688810 & 4.783 & \multicolumn{3}{|c|}{5.707999999999999} & TRN & \\
\hline CHEMBL3195305 & 688810 & 4.883 & 5.2272 & TST & & & \\
\hline CHEMBL1541655 & 688810 & 4.783 & 5.1673 & TRN & & & \\
\hline CHEMBL1404190 & 688810 & \multicolumn{3}{|c|}{5.832999999999999} & 5.4076 & TRN & \\
\hline CHEMBL1578952 & 688810 & \multicolumn{3}{|c|}{5.832999999999999} & 5.8181 & TRN & \\
\hline CHEMBL1345614 & 688810 & 4.833 & 4.88647 & TRN & & & \\
\hline CHEMBL1313745 & 688810 & \multicolumn{3}{|c|}{4.9830000000000005} & 5.7561 & TRN & \\
\hline CHEMBL1575028 & 688810 & 5.63299 & 999999999 & & 5.2848 & TRN & \\
\hline CHEMBL1544288 & 688810 & 5.033 & 5.1834 & TST & & & \\
\hline CHEMBL1420258 & 688810 & 4.683 & 4.7797 & TRN & & & \\
\hline CHEMBL1372678 & 688810 & 4.933 & 4.9326 & TRN & & & \\
\hline CHEMBL1365422 & 688810 & 4.833 & 5.1585 & TRN & & & \\
\hline CHEMBL600315 & 688810 & 5.53299 & 999999999 & 995 & 5.1973 & TST & \\
\hline
\end{tabular}




\begin{tabular}{|c|c|c|c|c|c|c|}
\hline \multirow[b]{2}{*}{ CHEMBL1604413 } & \multirow[b]{2}{*}{688810} & \multicolumn{5}{|c|}{ Supplemental Table s2.txt } \\
\hline & & \multicolumn{3}{|c|}{35.1536 TRN } & & \\
\hline CHEMBL1347687 & 688810 & 7.2328 & 5.9132 & TRN & & \\
\hline CHEMBL1559844 & 688810 & \multicolumn{3}{|c|}{4.7330000000000005} & 5.4417 & TST \\
\hline CHEMBL1581235 & 688810 & 4.883 & 5.0401 & TST & & \\
\hline CHEMBL1445723 & 688810 & \multicolumn{3}{|c|}{6.332999999999999} & 5.4708 & TRN \\
\hline CHEMBL1403162 & 688810 & 5.733 & 5.6266 & TST & & \\
\hline CHEMBL1480571 & 688810 & \multicolumn{3}{|c|}{4.7330000000000005} & 4.9196 & TRN \\
\hline CHEMBL3191437 & 688810 & \multicolumn{3}{|c|}{6.632999999999999} & 5.4417 & TRN \\
\hline CHEMBL1309441 & 688810 & 4.683 & 5.1579 & TRN & & \\
\hline CHEMBL1535902 & 688810 & \multicolumn{3}{|c|}{5.382999999999999} & 5.3738 & TRN \\
\hline CHEMBL1468672 & 688810 & 5.233 & 5.6652 & TST & & \\
\hline CHEMBL578944 & 688810 & \multicolumn{3}{|c|}{5.5329999999999995} & 4.7661 & TST \\
\hline CHEMBL1552686 & 688810 & \multicolumn{3}{|c|}{4.7330000000000005} & 5.5773 & TRN \\
\hline CHEMBL1303184 & 688810 & \multicolumn{3}{|c|}{5.5329999999999995} & 5.3907 & TRN \\
\hline CHEMBL1424928 & 688810 & 5.483 & 5.0657 & TRN & & \\
\hline CHEMBL1561507 & 688810 & 5.683 & 5.6072 & TRN & & \\
\hline CHEMBL1332103 & 688810 & 4.883 & 5.0036 & TRN & & \\
\hline CHEMBL1531933 & 688810 & 5.033 & 5.2618 & TRN & & \\
\hline CHEMBL1583405 & 688810 & 4.833 & 5.0177 & TRN & & \\
\hline CHEMBL591412 & 688810 & \multicolumn{3}{|c|}{5.332999999999999} & 5.4049 & TRN \\
\hline CHEMBL1387193 & 688810 & 5.733 & 5.256 & TST & & \\
\hline CHEMBL1210920 & 688810 & 5.033 & 5.1268 & TRN & & \\
\hline CHEMBL1585216 & 688810 & 5.733 & 5.7136 & TRN & & \\
\hline CHEMBL1610180 & 688810 & 5.183 & \multicolumn{3}{|c|}{4.5569999999999995} & TST \\
\hline CHEMBL1594911 & 688810 & 5.483 & 5.4964 & TRN & & \\
\hline CHEMBL1456462 & 688810 & 4.883 & 5.3769 & TRN & & \\
\hline CHEMBL1517712 & 688810 & \multicolumn{3}{|c|}{5.132999999999999} & 4.9478 & TRN \\
\hline CHEMBL1517054 & 688810 & 4.833 & 4.9268 & TRN & & \\
\hline CHEMBL1309608 & 688810 & 4.633 & 4.8505 & TRN & & \\
\hline CHEMBL1437231 & 688810 & 5.033 & 5.1378 & TST & & \\
\hline CHEMBL1360419 & 688810 & 5.083 & 5.6522 & TRN & & \\
\hline CHEMBL1356838 & 688810 & \multicolumn{3}{|c|}{5.7829999999999995} & 5.5467 & TRN \\
\hline CHEMBL1411567 & 688810 & \multicolumn{3}{|c|}{5.132999999999999} & 5.4451 & TRN \\
\hline CHEMBL1474675 & 688810 & \multicolumn{3}{|c|}{6.132999999999999} & 5.9216 & TRN \\
\hline CHEMBL1422078 & 688810 & 4.833 & 6.0562 & TRN & & \\
\hline CHEMBL1345986 & 688810 & 4.883 & 4.8874 & TRN & & \\
\hline CHEMBL1430373 & 688810 & 4.833 & 5.0354 & TST & & \\
\hline CHEMBL1555009 & 688810 & \multicolumn{3}{|c|}{5.132999999999999} & 5.5025 & TRN \\
\hline CHEMBL1366300 & 688810 & 5.433 & 5.0853 & TRN & & \\
\hline CHEMBL1348430 & 688810 & 5.933 & 5.197 & TRN & & \\
\hline CHEMBL1502945 & 688810 & 4.683 & 5.1209 & TST & & \\
\hline CHEMBL1539876 & 688810 & 6.233 & 5.3902 & TST & & \\
\hline CHEMBL1427724 & 688810 & 4.783 & 5.2215 & TRN & & \\
\hline CHEMBL3193751 & 688810 & 5.183 & 5.3199 & TST & & \\
\hline CHEMBL1522989 & 688810 & 6.183 & 5.9514 & TRN & & \\
\hline CHEMBL1341886 & 688810 & 4.783 & 5.0755 & TRN & & \\
\hline CHEMBL1556126 & 688810 & 4.783 & 5.0006 & TRN & & \\
\hline \multirow[t]{2}{*}{ CHEMBL1302815 } & 688810 & 4.73300 & 00000000 & 005 & 5.2525 & TRN \\
\hline & & & & 217 & & \\
\hline
\end{tabular}




\begin{tabular}{|c|c|c|c|c|c|c|c|}
\hline \multicolumn{8}{|c|}{ Supplemental Ta } \\
\hline CHEMBL1436262 & 688810 & 5.433 & 5.0306 & TRN & & & \\
\hline CHEMBL1420487 & 688810 & 5.28299 & 999999995 & 995 & 5.2696 & TRN & \\
\hline CHEMBL1498693 & 688810 & 4.633 & 4.742 & TST & & & \\
\hline CHEMBL1577773 & 688810 & 6.183 & 5.9234 & TRN & & & \\
\hline CHEMBL1313298 & 688810 & 5.233 & 5.3823 & TRN & & & \\
\hline CHEMBL1409107 & 688810 & 4.73300 & 000000006 & 005 & 5.3732 & TST & \\
\hline CHEMBL1467407 & 688810 & 4.98300 & 000000006 & 005 & 4.7431 & TRN & \\
\hline CHEMBL1377224 & 688810 & 6.4829 & 5.7163 & TRN & & & \\
\hline CHEMBL1301119 & 688810 & 4.783 & 4.7612 & TST & & & \\
\hline CHEMBL1528342 & 688810 & 7.2328 & 5.9107 & TRN & & & \\
\hline CHEMBL1339789 & 688810 & 5.083 & 5.5706 & TRN & & & \\
\hline CHEMBL1577844 & 688810 & 5.13299 & 99999999؛ & & 5.5832 & TST & \\
\hline CHEMBL1455205 & 688810 & 5.78299 & 999999995 & 995 & 5.50799 & 9999999999 & TST \\
\hline CHEMBL589238 & 688810 & 5.983 & 5.3894 & TST & & & \\
\hline CHEMBL3198531 & 688810 & 5.13299 & 999999995 & & 5.6419 & TRN & \\
\hline CHEMBL1374156 & 688810 & 6.433 & 5.5366 & TRN & & & \\
\hline CHEMBL1335844 & 688810 & 5.33299 & 99999999؛ & & 5.1355 & TRN & \\
\hline CHEMBL1329798 & 688810 & 7.3325 & 6.7151 & TRN & & & \\
\hline CHEMBL1967431 & 688810 & 6.1 & 5.371 & TST & & & \\
\hline CHEMBL1565884 & 688810 & 4.883 & 5.164 & TRN & & & \\
\hline CHEMBL1407150 & 688810 & 5.53299 & 999999995 & 995 & 5.5568 & TRN & \\
\hline CHEMBL1491777 & 688810 & 5.58299 & 99999999؛ & & 5.102 & TRN & \\
\hline CHEMBL1376919 & 688810 & 6.38299 & 99999999s & & 5.693 & TRN & \\
\hline CHEMBL596633 & 688810 & 4.583 & 4.7001 & TST & & & \\
\hline CHEMBL1585187 & 688810 & 5.88299 & 999999999 & & 5.6635 & TRN & \\
\hline CHEMBL1442212 & 688810 & 5.683 & 5.6049 & TST & & & \\
\hline CHEMBL1426681 & 688810 & 5.683 & 5.5602 & TRN & & & \\
\hline CHEMBL1579916 & 688810 & 4.833 & 5.2254 & TST & & & \\
\hline CHEMBL1329650 & 688810 & 7.08299 & 999999999 & & 6.2469 & TRN & \\
\hline CHEMBL1320387 & 688810 & 4.633 & 4.8363 & TRN & & & \\
\hline CHEMBL1560076 & 688810 & 5.683 & 5.5783 & TRN & & & \\
\hline CHEMBL1546932 & 688810 & 4.683 & 5.2238 & TRN & & & \\
\hline CHEMBL1442049 & 688810 & 4.783 & 5.2108 & TRN & & & \\
\hline CHEMBL1493131 & 688810 & 5.38299 & 999999999 & & 5.2665 & TST & \\
\hline CHEMBL3209328 & 688810 & 4.73300 & 000000000 & 005 & 5.033 & TRN & \\
\hline CHEMBL1405264 & 688810 & 5.13299 & 999999999 & & 5.4826 & TRN & \\
\hline CHEMBL1321255 & 688810 & 6.433 & 5.6638 & TRN & & & \\
\hline CHEMBL1549310 & 688810 & 7.3325 & 6.0608 & TRN & & & \\
\hline CHEMBL1404287 & 688810 & 5.183 & 5.2178 & TST & & & \\
\hline CHEMBL1338774 & 688810 & 5.483 & 5.5515 & TST & & & \\
\hline CHEMBL1992346 & 688810 & 6.183 & 5.8457 & TRN & & & \\
\hline CHEMBL178531 & 688810 & 6.03299 & 999999999 & 995 & 4.9765 & TRN & \\
\hline CHEMBL1337589 & 688810 & 4.73300 & 000000000 & 005 & 5.3983 & TRN & \\
\hline CHEMBL1401535 & 688810 & 4.883 & 5.3537 & TST & & & \\
\hline CHEMBL1334968 & 688810 & 4.883 & 5.5656 & TRN & & & \\
\hline CHEMBL1309785 & 688810 & 4.833 & 5.3387 & TRN & & & \\
\hline CHEMBL3199262 & 688810 & 6.33299 & 999999999 & & 5.6777 & TST & \\
\hline CHEMBL1362291 & 688810 & 4.933 & 5.3645 & TRN & & & \\
\hline
\end{tabular}




\begin{tabular}{|c|c|c|c|c|c|c|}
\hline \multirow[b]{2}{*}{ CHEMBL1997543 } & & \multicolumn{5}{|c|}{ Supplemental Table s2.txt } \\
\hline & 688810 & 5.733 & 5.053 & TST & & \\
\hline CHEMBL1509927 & 688810 & \multicolumn{3}{|c|}{5.632999999999999} & 5.5738 & TRN \\
\hline CHEMBL1523140 & 688810 & 5.683 & 5.7535 & TRN & & \\
\hline CHEMBL1443206 & 688810 & 4.933 & 4.9882 & TRN & & \\
\hline CHEMBL1425521 & 688810 & 5.033 & 4.7151 & TST & & \\
\hline CHEMBL1539464 & 688810 & 4.933 & 5.3721 & TRN & & \\
\hline CHEMBL1395480 & 688810 & 5.183 & 5.3483 & TRN & & \\
\hline CHEMBL1525544 & 688810 & 4.833 & 5.2487 & TRN & & \\
\hline CHEMBL1511784 & 688810 & \multicolumn{3}{|c|}{4.7330000000000005} & 5.2355 & TRN \\
\hline CHEMBL1489760 & 688810 & 5.083 & 5.2054 & TRN & & \\
\hline CHEMBL1441816 & 688810 & \multicolumn{3}{|c|}{5.7829999999999995} & 5.1723 & TRN \\
\hline CHEMBL1602665 & 688810 & 4.883 & 5.2429 & TST & & \\
\hline CHEMBL1356864 & 688810 & \multicolumn{3}{|c|}{4.7330000000000005} & 4.915 & TRN \\
\hline CHEMBL1519727 & 688810 & 5.683 & 5.3955 & TRN & & \\
\hline CHEMBL1496139 & 688810 & \multicolumn{3}{|c|}{5.2829999999999995} & 4.8409 & TRN \\
\hline CHEMBL1362153 & 688810 & \multicolumn{3}{|c|}{6.632999999999999} & 5.6038 & TRN \\
\hline CHEMBL1995336 & 688810 & \multicolumn{3}{|c|}{5.832999999999999} & 5.2172 & TRN \\
\hline CHEMBL1368179 & 688810 & 4.933 & 5.3028 & TRN & & \\
\hline CHEMBL1516860 & 688810 & 4.683 & 5.0211 & TRN & & \\
\hline CHEMBL1721986 & 688810 & \multicolumn{3}{|c|}{5.332999999999999} & 5.3049 & TRN \\
\hline CHEMBL1438250 & 688810 & 4.683 & 5.0784 & TRN & & \\
\hline CHEMBL1305998 & 688810 & 5.183 & 5.0944 & TST & & \\
\hline CHEMBL1303390 & 688810 & 5.683 & 5.1503 & TRN & & \\
\hline CHEMBL1405585 & 688810 & 5.15 & 5.0103 & TRN & & \\
\hline CHEMBL1410647 & 688810 & \multicolumn{3}{|c|}{6.582999999999999} & 5.8393 & TRN \\
\hline CHEMBL1436369 & 688810 & 4.883 & 5.5269 & TRN & & \\
\hline CHEMBL1461591 & 688810 & \multicolumn{3}{|c|}{4.7330000000000005} & 5.3998 & TRN \\
\hline CHEMBL1368397 & 688810 & 4.783 & 5.0813 & TST & & \\
\hline CHEMBL1400357 & 688810 & 5.5 & 5.5832 & TRN & & \\
\hline CHEMBL1533357 & 688810 & 4.683 & 5.0921 & TST & & \\
\hline CHEMBL1479892 & 688810 & 4.883 & 5.8572 & TRN & & \\
\hline CHEMBL1435049 & 688810 & 5.033 & 5.61100 & 000000000 & & TST \\
\hline CHEMBL3195278 & 688810 & 5.483 & 5.0002 & TRN & & \\
\hline CHEMBL3211648 & 688810 & 4.883 & 5.5769 & TRN & & \\
\hline CHEMBL1369507 & 688810 & 4.883 & 5.4484 & TRN & & \\
\hline CHEMBL1484963 & 688810 & \multicolumn{3}{|c|}{5.132999999999999} & 5.1739 & TRN \\
\hline CHEMBL1303173 & 688810 & 4.933 & 5.8962 & TRN & & \\
\hline CHEMBL1570688 & 688810 & 5.233 & 5.0596 & TRN & & \\
\hline CHEMBL1300345 & 688810 & \multicolumn{3}{|c|}{5.632999999999999} & 4.8555 & TRN \\
\hline CHEMBL1413384 & 688810 & \multicolumn{3}{|c|}{5.382999999999999} & 5.1159 & TST \\
\hline CHEMBL1330311 & 688810 & 5.183 & 5.3736 & TST & & \\
\hline CHEMBL1510981 & 688810 & 4.633 & 4.9013 & TST & & \\
\hline CHEMBL3192044 & 688810 & 4.683 & 5.1156 & TRN & & \\
\hline CHEMBL1429762 & 688810 & 5.033 & 5.4364 & TST & & \\
\hline CHEMBL1577318 & 688810 & \multicolumn{3}{|c|}{5.5329999999999995} & 5.7566 & TST \\
\hline CHEMBL1309143 & 688810 & 4.783 & 5.2104 & TST & & \\
\hline CHEMBL1380651 & 688810 & 5.233 & 5.3318 & TRN & & \\
\hline CHEMBL1423084 & 688810 & 4.783 & 5.4381 & TST & & \\
\hline
\end{tabular}




\begin{tabular}{|c|c|c|c|c|c|c|}
\hline \multirow[b]{2}{*}{ CHEMBL1526551 } & \multicolumn{6}{|c|}{-ircas } \\
\hline & 688810 & 5.183 & 5.4241 & TST & & \\
\hline CHEMBL1500800 & 688810 & 5.933 & 4.8839 & TST & & \\
\hline CHEMBL1422405 & 688810 & 5.6329 & 999999999 & & 5.266 & TRN \\
\hline CHEMBL1531260 & 688810 & 5.8829 & 999999999 & & 5.1696 & \\
\hline CHEMBL1344397 & 688810 & 4.783 & 5.0786 & TRN & & \\
\hline CHEMBL1555803 & 688810 & 5.8829 & 999999999 & & 5.8168 & \\
\hline CHEMBL1431091 & 688810 & 5.083 & 5.4119 & TRN & & \\
\hline CHEMBL1497972 & 688810 & 4.7330 & 000000000 & 005 & 5.2147 & \\
\hline CHEMBL1558927 & 688810 & 4.883 & 5.1749 & TST & & \\
\hline CHEMBL1529654 & 688810 & 5.733 & 5.4114 & TRN & & \\
\hline CHEMBL1507712 & 688810 & 4.933 & 4.9761 & TST & & \\
\hline CHEMBL1556014 & 688810 & 5.3829 & 999999999 & & 5.0612 & \\
\hline CHEMBL1586511 & 688810 & 5.183 & 4.946000 & 00006 & $\partial 1$ & \\
\hline CHEMBL1378477 & 688810 & 5.7829 & 999999999 & 995 & 5.1665 & \\
\hline CHEMBL1554709 & 688810 & 4.633 & 4.9603 & TST & & \\
\hline CHEMBL1534798 & 688810 & 5.433 & 5.2395 & TRN & & \\
\hline CHEMBL1363637 & 688810 & 5.033 & 5.1048 & TRN & & \\
\hline CHEMBL1501095 & 688810 & 4.7330 & 000000000 & 005 & 5.1802 & \\
\hline CHEMBL1363346 & 688810 & 5.1329 & 999999999 & & 5.6254 & \\
\hline CHEMBL1339800 & 688810 & 5.7829 & 999999999 & 995 & 5.6192 & TRN \\
\hline CHEMBL1321943 & 688810 & 5.3829 & 999999999 & & 5. & \\
\hline CHEMBL1397448 & 688810 & 5.183 & 5.22 & TRN & & \\
\hline CHEMBL1486934 & 688810 & 4.833 & 4.8815 & TRN & & \\
\hline CHEMBL1597433 & 688810 & 5.5829 & 999999999 & & 51 & \\
\hline CHEMBL 1442123 & 688810 & 5.7829 & 999999999 & 995 & 5.669 & \\
\hline CHEMBL1433692 & 688810 & 6.983 & 5.867000 & 00006 & & \\
\hline CHEMBL1587515 & 688810 & 4.783 & 5.1499 & TST & & \\
\hline CHEMBL1412630 & 688810 & 5.6329 & 999999999 & & 5.1533 & $\mathrm{~T}$ \\
\hline CHEMBL1429642 & 688810 & 4.833 & 4.8687 & TST & & \\
\hline CHEMBL1503720 & 688810 & 6.3829 & 999999999 & & 04 & \\
\hline CHEMBL1582825 & 688810 & 6.3829 & 9999 & & 5.4646 & \\
\hline CHEMBL1416229 & 688810 & 5.683 & 5.0842 & TST & & \\
\hline CHEMBL1593522 & 688810 & 4.783 & 5.263999 & 99999 & & \\
\hline CHEMBL1595221 & 688810 & 4.783 & 4.633999 & 99999 & 995 & \\
\hline CHEMBL1324560 & 688810 & 5.183 & 5.7245 & TRN & & \\
\hline CHEMBL1470321 & 688810 & 4.7330 & 000000000 & 005 & 5.0653 & $\mathrm{TR}$ \\
\hline CHEMBL 3190726 & 688810 & 5.233 & 5.676 & TRN & & \\
\hline CHEMBL1540267 & 688810 & 4.933 & 5.088 & TST & & \\
\hline CHEMBL1562762 & 688810 & 5.8829 & 999999999 & & 5.3833 & In \\
\hline CHEMBL1315048 & 688810 & 5.183 & 5.7109 & TRN & & \\
\hline CHEMBL1388947 & 688810 & 4.633 & 5.2042 & TST & & \\
\hline CHEMBL1536489 & 688810 & 4.933 & 5.121 & TRN & & \\
\hline CHEMBL1437043 & 688810 & 5.1329 & 999999999 & & 5.2451 & TS \\
\hline CHEMBL1490111 & 688810 & 4.833 & 5.3351 & TRN & & \\
\hline CHEMBL 1446574 & 688810 & 5.5329 & 999999999 & 995 & 5.9489 & \\
\hline CHEMBL1566510 & 688810 & 4.633 & 5.1832 & TRN & & \\
\hline CHEMBL1304356 & 688810 & 4.9830 & 000000000 & 005 & 5.9905 & 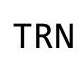 \\
\hline CHEMBL1344538 & 688810 & 4.883 & 5.3717 & TRN & & \\
\hline
\end{tabular}




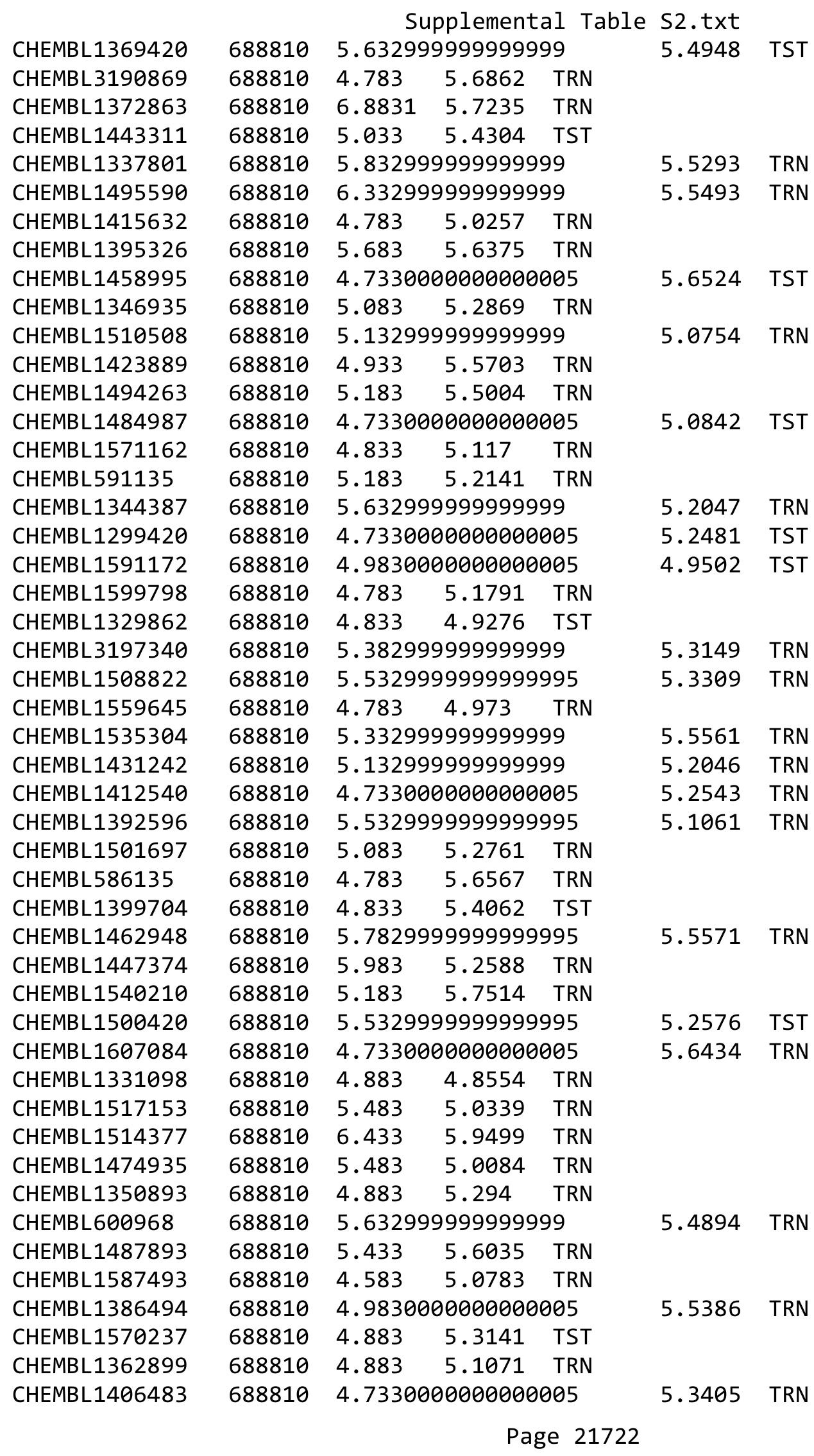




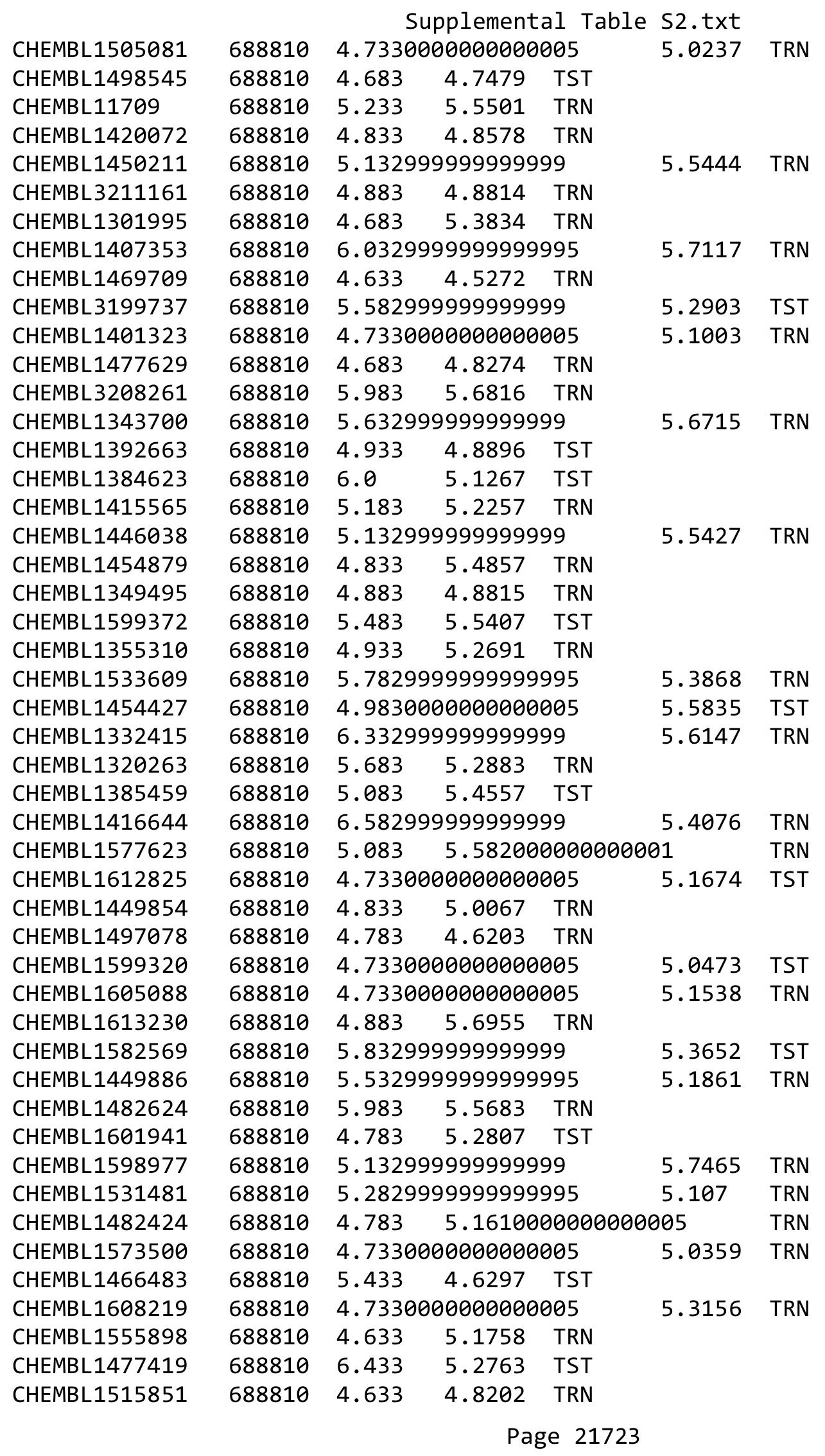




\begin{tabular}{|c|c|c|c|c|c|c|c|}
\hline & & & & & & & \\
\hline CHEMBL1481387 & 688810 & 4.783 & 5.2056 & TRN & & & \\
\hline CHEMBL1559529 & 688810 & 6.03299 & 999999995 & 995 & 5.9571 & TRN & \\
\hline CHEMBL1585110 & 688810 & 5.63299 & 99999999 & & 5.4986 & TRN & \\
\hline CHEMBL1506173 & 688810 & 4.833 & 5.2152 & TRN & & & \\
\hline CHEMBL1417148 & 688810 & 4.783 & 4.9775 & TST & & & \\
\hline CHEMBL1427228 & 688810 & 5.53299 & 999999995 & 995 & 5.7109 & TST & \\
\hline CHEMBL1579437 & 688810 & 4.833 & 4.8426 & TRN & & & \\
\hline CHEMBL1486984 & 688810 & 5.58299 & 99999999 & & 5.4397 & TRN & \\
\hline CHEMBL3193124 & 688810 & 5.13299 & 999999999 & & 5.3391 & TRN & \\
\hline CHEMBL3194292 & 688810 & 4.783 & 5.2441 & TRN & & & \\
\hline CHEMBL1330019 & 688810 & 6.233 & 5.9648 & TRN & & & \\
\hline CHEMBL1333047 & 688810 & 6.53299 & 999999995 & 995 & 5.0015 & TRN & \\
\hline CHEMBL1991441 & 688810 & 5.483 & 5.3099 & TST & & & \\
\hline CHEMBL1427640 & 688810 & 5.983 & 5.2499 & TRN & & & \\
\hline CHEMBL1453437 & 688810 & 4.883 & 4.7702 & TST & & & \\
\hline CHEMBL1997450 & 688810 & 5.183 & 5.7905 & TRN & & & \\
\hline CHEMBL1595123 & 688810 & 5.83299 & 99999999 & & 5.4564 & TRN & \\
\hline CHEMBL1518080 & 688810 & 6.183 & 5.6992 & TST & & & \\
\hline CHEMBL1463349 & 688810 & 5.733 & 6.0139 & TRN & & & \\
\hline CHEMBL1588495 & 688810 & 6.4829 & 5.4793 & TST & & & \\
\hline CHEMBL1567475 & 688810 & 4.583 & 5.2641 & TRN & & & \\
\hline CHEMBL1966114 & 688810 & 4.73300 & 000000006 & 005 & 5.0686 & TST & \\
\hline CHEMBL476598 & 688810 & 4.883 & 5.3775 & TRN & & & \\
\hline CHEMBL1313660 & 688810 & 5.58299 & 99999999s & & 5.6995 & TRN & \\
\hline CHEMBL1490293 & 688810 & 6.03299 & 999999995 & 995 & 6.1363 & TRN & \\
\hline CHEMBL1379283 & 688810 & 4.833 & 5.1873 & TRN & & & \\
\hline CHEMBL1516542 & 688810 & 6.83299 & 99999999 & & 6.2797 & TST & \\
\hline CHEMBL1401359 & 688810 & 5.28299 & 999999995 & 995 & 5.4208 & TRN & \\
\hline CHEMBL1490229 & 688810 & 4.633 & 4.7582 & TRN & & & \\
\hline CHEMBL1444150 & 688810 & 5.683 & 5.6045 & TRN & & & \\
\hline CHEMBL338474 & 688810 & 5.88299 & 99999999s & & 5.6817 & TRN & \\
\hline CHEMBL1438609 & 688810 & 4.98300 & 000000006 & 005 & 5.147 & TRN & \\
\hline CHEMBL1601421 & 688810 & 5.033 & 5.0666 & TRN & & & \\
\hline CHEMBL1430531 & 688810 & 4.883 & $4.98300 e$ & 00000000 & $\partial 05$ & TRN & \\
\hline CHEMBL1418104 & 688810 & 5.433 & 5.8197 & TRN & & & \\
\hline CHEMBL1334263 & 688810 & 4.933 & 4.5785 & TRN & & & \\
\hline CHEMBL1528633 & 688810 & 4.783 & 4.9383 & TRN & & & \\
\hline CHEMBL1545478 & 688810 & 6.13299 & 99999999 & & 5.3917 & TRN & \\
\hline CHEMBL1597249 & 688810 & 5.033 & 5.2725 & TRN & & & \\
\hline CHEMBL1605815 & 688810 & 4.73300 & 000000006 & 005 & 4.5992 & TRN & \\
\hline CHEMBL1552191 & 688810 & 4.833 & 5.2741 & TST & & & \\
\hline CHEMBL1570661 & 688810 & 5.78299 & 999999995 & 995 & 5.6008 & TST & \\
\hline CHEMBL 1606586 & 688810 & 4.633 & 4.6849 & TRN & & & \\
\hline CHEMBL1598792 & 688810 & 4.73300 & 000000006 & 005 & 5.46700 & 00000000005 & TRN \\
\hline CHEMBL1518957 & 688810 & 5.733 & 5.5212 & TRN & & & \\
\hline CHEMBL1429905 & 688810 & 4.933 & 4.9417 & TRN & & & \\
\hline CHEMBL1600092 & 688810 & 4.73300 & 000000006 & 005 & 5.0669 & TST & \\
\hline CHEMBL1347879 & 688810 & 5.25 & 5.2149 & TRN & & & \\
\hline
\end{tabular}




\begin{tabular}{|c|c|c|c|c|c|c|}
\hline \multirow[b]{2}{*}{ CHEMBL1445570 } & \multicolumn{6}{|c|}{ Supplemental Table S2.txt } \\
\hline & 688810 & 833 & 5.0651 & TRN & & \\
\hline CHEMBL1300552 & 688810 & \multicolumn{3}{|c|}{4.9830000000000005} & 5.0243 & TRN \\
\hline CHEMBL1326615 & 688810 & \multicolumn{3}{|c|}{5.332999999999999} & 5.7478 & \\
\hline CHEMBL492468 & 688810 & 5.083 & 5.1199 & TRN & & \\
\hline CHEMBL1433143 & 588810 & \multicolumn{3}{|c|}{5.5329999999999995} & 5.0289 & \\
\hline CHEMBL3212959 & 688810 & \multicolumn{3}{|c|}{5.582999999999999} & 5.1106 & \\
\hline CHEMBL3209370 & 688810 & 4.783 & 5.0004 & TRN & & \\
\hline CHEMBL1321138 & 688810 & 5.683 & 5.2513 & TRN & & \\
\hline CHEMBL1446331 & 688810 & \multicolumn{3}{|c|}{5.132999999999999} & 5.7943 & \\
\hline CHEMBL1350956 & 688810 & \multicolumn{3}{|c|}{5.832999999999999} & 5.2756 & \\
\hline CHEMBL1455190 & 688810 & \multicolumn{3}{|c|}{5.132999999999999} & 5.3087 & \\
\hline CHEMBL1606520 & 688810 & \multicolumn{3}{|c|}{6.382999999999999} & 5.1939 & \\
\hline CHEMBL1301234 & 688810 & 4.883 & 5.1291 & TRN & & \\
\hline CHEMBL1599396 & 688810 & \multicolumn{3}{|c|}{5.2829999999999995} & 5.4932 & \\
\hline CHEMBL 3195471 & 688810 & \multicolumn{3}{|c|}{5.632999999999999} & 5.7244 & \\
\hline CHEMBL1355020 & 688810 & 4.783 & 5.4741 & TRN & & \\
\hline CHEMBL142 & 688810 & 4.833 & 5.2501 & TRN & & \\
\hline CHEMBL1460273 & 688810 & 4.583 & 5.1708 & TRN & & \\
\hline CHEMBL1322198 & 688810 & 4.833 & 5.2938 & TRN & & \\
\hline CHEMBL1310148 & 688810 & \multicolumn{3}{|c|}{5.382999999999999} & 5 & \\
\hline CHEMBL1 & 688 & 4.583 & 5.3624 & TST & & \\
\hline CHEMBL 1 & 688810 & 4. & 4.8335 & TRN & & \\
\hline CHEMBL1379768 & 688810 & 4.883 & 5.0293 & TST & & \\
\hline CHEMBL1338834 & 688810 & \multicolumn{3}{|c|}{4.7330000000000005} & 1853 & \\
\hline CHEMBL1493071 & 688810 & \multicolumn{3}{|c|}{4.7330000000000005} & 5.2698 & \\
\hline CHEMBL136 & 688810 & \multicolumn{3}{|c|}{5.882999999999999} & 142 & \\
\hline CHEMBL3197758 & 688810 & \multicolumn{3}{|c|}{4.9830000000000005} & 5.0689 & \\
\hline CHEMBL3191475 & 688810 & 5.033 & 5.6809 & TRN & & \\
\hline CHEMBL1372356 & 688810 & \multirow{2}{*}{\multicolumn{3}{|c|}{$\begin{array}{lr}4.833 & 4.9952 \\
4.9830000000000005\end{array}$}} & & \\
\hline CHEMBL1594644 & 688810 & & & & 5.504 & \\
\hline CHEMBL1 & 688810 & \multicolumn{3}{|c|}{5.2829999999999995} & 4.6321 & \\
\hline CHEMBL1422386 & 688810 & 5.033 & 5.7128 & TST & & \\
\hline CHEMBL578636 & 688810 & \multicolumn{3}{|c|}{5.382999999999999} & 5.4041 & TP \\
\hline CHEMBL1320449 & 688810 & \multicolumn{3}{|c|}{5.332999999999999} & 5.2603 & \\
\hline CHEMBL1595449 & 688810 & 4.783 & 5.181 & TRN & & \\
\hline CHEMBL1 & 688810 & 5.183 & 5.1509 & TRN & & \\
\hline CHEMBL1420308 & 688810 & 5.683 & 5.3392 & TRN & & \\
\hline CHEMBL1393258 & 688810 & 4.783 & 5.0716 & TST & & \\
\hline CHEMBL1567220 & 688810 & 6.3329 & 99999999 & & 5.4255 & \\
\hline CHEMBL1529092 & 688810 & 6.3329 & 99999999 & & 5.5467 & \\
\hline CHEMBL1439048 & 688810 & 4.933 & 5.1134 & TRN & & \\
\hline CHEMBL1360031 & 688810 & 4.833 & 5.7887 & TST & & \\
\hline CHEMBL1428629 & 688810 & 6.0829 & 99999999 & & 5.9538 & \\
\hline CHEMBL1603926 & 688810 & 4.933 & 5.3689 & TRN & & \\
\hline CHEMBL1980744 & 688810 & 6.433 & 5.0605 & TST & & \\
\hline CHEMBL1512621 & 688810 & 5.8329 & 99999999 & & 5.4007 & . \\
\hline CHEMBL1401366 & 688810 & 4.7330 & 00000000 & 005 & 5.1806 & $\mathrm{TR}$ \\
\hline CHEMBL1534143 & 688810 & 6.2829 & 99999999 & 995 & 5.6646 & \\
\hline
\end{tabular}




\begin{tabular}{|c|c|c|c|c|c|c|}
\hline \multicolumn{7}{|c|}{ Supplemental Table S2.txt } \\
\hline CHEMBL1388233 & 688810 & 6.233 & 5.6251 & TRN & & \\
\hline CHEMBL1453868 & 688810 & 4.883 & 5.0595 & TRN & & \\
\hline CHEMBL 3190508 & 688810 & 4.833 & 5.1628 & TRN & & \\
\hline CHEMBL69631 & 688810 & \multicolumn{3}{|c|}{4.7330000000000005} & 5.2012 & TR \\
\hline CHEMBL1417665 & 688810 & 4.783 & 5.1961 & TRN & & \\
\hline CHEMBL1410509 & 688810 & \multicolumn{3}{|c|}{4.9830000000000005} & 5.3223 & TRN \\
\hline CHEMBL1489312 & 688810 & \multicolumn{3}{|c|}{5.382999999999999} & 5.0284 & \\
\hline CHEMBL1551969 & 688810 & 4.683 & 5.1968 & TST & & \\
\hline CHEMBL1376590 & 688810 & 5.233 & 4.9742 & TRN & & \\
\hline CHEMBL1523728 & 688810 & 5.933 & 5.5005 & TRN & & \\
\hline CHEMBL 3193340 & 688810 & 5.433 & 5.1847 & TST & & \\
\hline CHEMBL1557062 & 688810 & \multicolumn{3}{|c|}{ 5. 382999999999999} & 5.5282 & \\
\hline CHEMBL1335641 & 688810 & 4.683 & 5.3551 & TST & & \\
\hline CHEMBL1313956 & 688810 & 5.083 & 5.1792 & TRN & & \\
\hline CHEMBL1364105 & 688810 & \multicolumn{3}{|c|}{4.7330000000000005} & 5.0927 & \\
\hline CHEMBL1427035 & 688810 & 5.233 & 5.1451 & TRN & & \\
\hline CHEMBL1494027 & 688810 & \multicolumn{3}{|c|}{5.132999999999999} & 5.343 & \\
\hline CHEMBL1462650 & 688810 & 4.683 & 5.4597 & TRN & & \\
\hline CHEMBL 3209998 & 688810 & \multicolumn{3}{|c|}{4.7330000000000005} & 5.4939 & \\
\hline CHEMBL1369108 & 688810 & \multicolumn{3}{|c|}{4.7330000000000005} & 5.1595 & \\
\hline CHEMBL1342754 & 688810 & 4.883 & 5.3962 & TRN & & \\
\hline CHEMBL 3195508 & 688810 & 4.833 & 5.1857 & TRN & & \\
\hline CHEMBL1605782 & 688810 & 4.633 & 5.0594 & TRN & & \\
\hline CHEMBL1380360 & $68 \varepsilon$ & 4.883 & 5.2484 & TST & & \\
\hline CHEMBL1398104 & 688810 & 4.883 & 5.0776 & TRN & & \\
\hline CHEMBL 3198031 & 688810 & 5.733 & 5.4388 & TRN & & \\
\hline CHEMBL1429935 & 688810 & \multicolumn{3}{|c|}{4.7330000000000005} & 5.5624 & \\
\hline CHEMBL1358777 & 688810 & 4.883 & 5.2407 & TST & & \\
\hline CHEMBL1312907 & 688810 & 5.183 & 5.3869 & TRN & & \\
\hline CHEMBL1467678 & 688810 & 5.183 & 4.928 & TST & & \\
\hline CHEMBL1464100 & 688810 & 6.183 & 6.0316 & TRN & & \\
\hline CHEMBL1391973 & 688810 & \multicolumn{3}{|c|}{6.132999999999999} & 6.2747 & TRN \\
\hline CHEMBL1526362 & 688810 & 5.183 & 5.372000 & 300 & 31 & \\
\hline CHEMBL13 & 688810 & \multicolumn{3}{|c|}{5.832999999999999} & 5.6084 & \\
\hline CHEMBL1339776 & 688810 & 5.683 & 5.1777 & TRN & & \\
\hline CHEMBL1476665 & 688810 & \multicolumn{3}{|c|}{5.132999999999999} & 5.0312 & 13 \\
\hline CHEMBL1526934 & 688810 & 5.733 & 5.5722 & TST & & \\
\hline CHEMBL1444739 & 688810 & 4.783 & 5.0486 & TRN & & \\
\hline CHEMBL 3194248 & 688810 & 7.2832 & 6.1873 & TRN & & \\
\hline CHEMBL1546781 & 688810 & \multicolumn{3}{|c|}{6.0329999999999995} & 5.6157 & TR \\
\hline CHEMBL1311241 & 688810 & 4.833 & 4.9631 & TRN & & \\
\hline CHEMBL1523027 & 688810 & 4.783 & 4.8188 & TST & & \\
\hline CHEMBL1358732 & 688810 & 4.933 & 4.9172 & TST & & \\
\hline CHEMBL1361514 & 688810 & \multicolumn{3}{|c|}{5.832999999999999} & 5.7444 & T \\
\hline CHEMBL1568007 & 688810 & 4.633 & 4.9315 & TRN & & \\
\hline CHEMBL1319227 & 688810 & 5.083 & 5.1396 & TRN & & \\
\hline CHEMBL1338809 & 688810 & 5.733 & 5.3801 & TRN & & \\
\hline CHEMBL1334327 & 688810 & \multicolumn{3}{|c|}{5.832999999999999} & 5.1726 & \\
\hline
\end{tabular}




\begin{tabular}{|c|c|c|c|c|c|c|}
\hline & & \multicolumn{5}{|c|}{ ter. } \\
\hline CHEMBL1358433 & 688810 & 4.833 & 4.757 & TRN & & \\
\hline CHEMBL1336286 & 688810 & 4.833 & 4.8434 & TST & & \\
\hline CHEMBL1300082 & 688810 & 5.78299 & 99999999 & 995 & 5.6273 & TRN \\
\hline CHEMBL1573858 & 688810 & 4.883 & 5.3717 & TST & & \\
\hline CHEMBL1478403 & 688810 & 5.78299 & 99999999 & 995 & 5.4534 & TRN \\
\hline CHEMBL1412848 & 688810 & 5.28299 & 99999999 & 995 & 4.9954 & TST \\
\hline CHEMBL1549167 & 688810 & 4.73300 & 00000000 & 005 & 5.5289 & TRN \\
\hline CHEMBL1405922 & 688810 & 4.633 & 4.8451 & TST & & \\
\hline CHEMBL3212541 & 688810 & 5.53299 & 99999999 & 995 & 5.2874 & ThN \\
\hline CHEMBL1383220 & 688810 & 5.683 & 5.4484 & TST & & \\
\hline CHEMBL1469728 & 688810 & 4.73300 & 00000000 & 005 & 4.8509 & TRN \\
\hline CHEMBL1607194 & 688810 & 6.38299 & 99999999 & 99 & 5.7227 & TRN \\
\hline CHEMBL1600000 & 688810 & 6.33299 & 99999999 & 99 & 5.2534 & TRN \\
\hline CHEMBL3209036 & 688810 & 6.33299 & 99999999 & & 5.7317 & TRN \\
\hline CHEMBL1433899 & 688810 & 4.633 & 4.6554 & TST & & \\
\hline CHEMBL1325949 & 688810 & 5.683 & 5.3192 & TRN & & \\
\hline CHEMBL1432453 & 688810 & 4.633 & 5.2558 & TST & & \\
\hline CHEMBL1301278 & 688810 & 4.583 & 4.5789 & TST & & \\
\hline CHEMBL1610646 & 688810 & 5.233 & 5.1383 & TRN & & \\
\hline CHEMBL1477437 & 688810 & 4.98300 & 00000000 & 005 & 5.0083 & TRN \\
\hline CHEMBL1323818 & 688810 & 6.58299 & 99999999 & & 5.5295 & \\
\hline CHEMBL1434115 & 688810 & 4.883 & 5.0307 & TRN & & \\
\hline CHEMBL1362340 & 688810 & 5.483 & 5.3748 & TRN & & \\
\hline CHEMBL1519616 & 688810 & 4.73300 & 00000000 & 005 & 391 & $\mathrm{~T}$ \\
\hline CHEMBL1492168 & 688810 & 4.75 & 5.1352 & TRN & & \\
\hline CHEMBL1416916 & 688810 & 4.73300 & 00000000 & 005 & נ. & \\
\hline CHEMBL1357748 & 688810 & 4.633 & 5.0366 & TRN & & \\
\hline CHEMBL1359443 & 688810 & 4.73300 & 00000000 & 005 & 5.0634 & TST \\
\hline CHEMBL1448867 & 688810 & 6.233 & 5.6172 & TRN & & \\
\hline CHEMBL1508842 & 688810 & 5.083 & 5.5218 & TRN & & \\
\hline CHEMBL1442017 & 688810 & 4.98300 & 00000000 & 005 & 5.3235 & TST \\
\hline CHEMBL1343438 & 688810 & 5.13299 & 99999999 & & 5.0954 & TRN \\
\hline CHEMBL1343771 & 688810 & 6.53299 & 99999999 & 995 & 5.979 & TRN \\
\hline CHEMBL3214587 & 688810 & 4.783 & 5.1535 & TST & & \\
\hline CHEMBL1482096 & 688810 & 5.183 & 5.2682 & TRN & & \\
\hline CHEMBL1392803 & 688810 & 5.33299 & 99999999 & & 5.249 & $\mathrm{~T}$ \\
\hline CHEMBL1566908 & 688810 & 5.183 & 5.2873 & TRN & & \\
\hline CHEMBL1544709 & 688810 & 4.73300 & 00000000 & 005 & 809 & $\mathrm{~T}$ \\
\hline CHEMBL1359275 & 688810 & 4.883 & 5.1827 & TST & & \\
\hline CHEMBL1466445 & 688810 & 5.13299 & 99999999 & & 4.8257 & TST \\
\hline CHEMBL1599858 & 688810 & 5.28299 & 99999999 & 995 & 5.0173 & TRN \\
\hline CHEMBL1429948 & 688810 & 5.483 & 5.7707 & TRN & & \\
\hline CHEMBL1466288 & 688810 & 5.683 & 4.8375 & TST & & \\
\hline CHEMBL3193057 & 688810 & 5.13299 & 99999999 & & 5.1458 & 13 \\
\hline CHEMBL1534743 & 688810 & 4.633 & 4.9785 & TST & & \\
\hline CHEMBL1608358 & 688810 & 5.63299 & 99999999 & & 5.1955 & TST \\
\hline CHEMBL1403370 & 688810 & 5.58299 & 99999999 & & 5.2791 & TRN \\
\hline CHEMBL1407741 & 688810 & 6.433 & 5.8055 & TRN & & \\
\hline
\end{tabular}




\begin{tabular}{|c|c|c|c|c|c|c|}
\hline \multirow[b]{2}{*}{ CHEMBL1590196 } & \multicolumn{6}{|c|}{ plemental T } \\
\hline & 688810 & 4.783 & 5.4495 & TRN & & \\
\hline CHEMBL1607640 & 688810 & 4.583 & 4.4773 & TST & & \\
\hline CHEMBL1543489 & 688810 & 5.183 & 5.1652 & TRN & & \\
\hline CHEMBL1501310 & 688810 & \multicolumn{3}{|c|}{4.7330000000000005} & 4.8994 & TRN \\
\hline CHEMBL1405412 & 688810 & 4.883 & 5.2252 & TRN & & \\
\hline CHEMBL1357330 & 688810 & 5.233 & 5.0127 & TST & & \\
\hline CHEMBL1407890 & 688810 & 4.783 & 5.0213 & TRN & & \\
\hline CHEMBL1559957 & 688810 & \multicolumn{3}{|c|}{6.132999999999999} & 5.2305 & TST \\
\hline CHEMBL1346297 & 688810 & \multicolumn{3}{|c|}{5.132999999999999} & 4.8771 & TST \\
\hline CHEMBL1529815 & 688810 & 5.233 & 5.2435 & TST & & \\
\hline CHEMBL1502787 & 688810 & \multicolumn{3}{|c|}{5.2829999999999995} & 5.5792 & TRN \\
\hline CHEMBL1432275 & 688810 & \multicolumn{3}{|c|}{5.132999999999999} & 4.7561 & \\
\hline CHEMBL1517971 & 688810 & 4.933 & 5.2898 & TRN & & \\
\hline CHEMBL1375931 & 688810 & \multicolumn{3}{|c|}{6.082999999999999} & 5.7431 & \\
\hline CHEMBL1363939 & 688810 & \multicolumn{3}{|c|}{4.9830000000000005} & & \\
\hline CHEMBL1331218 & 688810 & 5.233 & 5.2422 & TRN & & \\
\hline CHEMBL1340124 & 688810 & \multicolumn{3}{|c|}{4.9830000000000005} & 5.6096 & TST \\
\hline CHEMBL1573961 & 688810 & \multicolumn{3}{|c|}{5.5329999999999995} & 5.3772 & TST \\
\hline CHEMBL1443863 & 688810 & 4.833 & 5.2162 & TRN & & \\
\hline CHEMBL1431318 & 688 & \multirow{2}{*}{\multicolumn{3}{|c|}{$\begin{array}{ll}5.433 & 5.2 / 4 \\
6.132999999999999\end{array}$}} & & \\
\hline CHEMBL1411900 & 688810 & & & & 5.2595 & TST \\
\hline CHEMBL1590733 & 688810 & 4.933 & 5.1427 & TRN & & \\
\hline CHEMBL1581465 & 688810 & 6.4829 & 5.522 & TRN & & \\
\hline CHEMBL136 & $68 \varepsilon$ & 5.683 & 5.16 & TRN & & \\
\hline CHEMBL1592684 & 688810 & \multicolumn{3}{|c|}{6.332999999999999} & 5.7087 & TRN \\
\hline CHEMBL1437363 & 688810 & \multicolumn{3}{|c|}{4.7330000000000005} & 5.3826 & TRN \\
\hline CHEMBL3193349 & 688810 & \multicolumn{3}{|c|}{5.882999999999999} & 5.6397 & TRN \\
\hline CHEMBL1456203 & 688810 & 4.833 & 5.0074 & TRN & & \\
\hline CHEMBL135 & 688810 & \multirow{2}{*}{\multicolumn{3}{|c|}{$\begin{array}{lcc}4.883 & 5.102 & \text { TP } \\
5.132999999999999\end{array}$}} & & \\
\hline CHEMBL1430035 & 688810 & & & & 5.1354 & TRA \\
\hline CHEMBL1558672 & 688810 & 4.833 & 5.1689 & TRN & & \\
\hline CHEMBL1306502 & 688810 & \multirow{2}{*}{\multicolumn{3}{|c|}{$\begin{array}{l}6.93295 .3478 \quad \text { TRN } \\
6.382999999999999\end{array}$}} & & \\
\hline CHEMBL1421948 & 688810 & & & & 5.3607 & $\mathrm{~T}_{\mathrm{K}}$ \\
\hline CHEMBL137 & 688810 & \multicolumn{3}{|c|}{$\begin{array}{lll}4.933 & 4.9218 & \text { TRN }\end{array}$} & & \\
\hline CHEMBL1542691 & 688810 & 5.683 & 5.8647 & TRN & & \\
\hline CHEMBL1400142 & 688810 & 4.833 & 5.0661 & TRN & & \\
\hline CHEMBL601751 & 688810 & 5.733 & 5.6708 & TRN & & \\
\hline CHEMBL 1426676 & 688810 & 4.783 & 5.0054 & TRN & & \\
\hline CHEMBL1429980 & 688810 & \multicolumn{3}{|c|}{6.582999999999999} & 5.5105 & TR \\
\hline CHEMBL1402249 & 688810 & 4.783 & 4.9857 & TRN & & \\
\hline CHEMBL1308624 & 688810 & \multirow{2}{*}{\multicolumn{3}{|c|}{$\begin{array}{lc}4.933 & 5.4712 \\
4.7330000000000005\end{array}$}} & & \\
\hline CHEMBL1483312 & 688810 & & & & 5.0616 & 13 \\
\hline CHEMBL1452107 & 688810 & \multicolumn{3}{|c|}{$4.833 \quad 5.1956$ TRN } & & \\
\hline CHEMBL1569729 & 688810 & 4.7330 & 00000000 & 005 & 4.8946 & TRN \\
\hline CHEMBL1426512 & 688810 & 5.1329 & 99999999 & & 5.2076 & TST \\
\hline CHEMBL1538404 & 688810 & 4.7330 & 00000000 & 005 & 5.3001 & TRN \\
\hline CHEMBL1578576 & 688810 & 4.933 & 5.3191 & TRN & & \\
\hline CHEMBL1353318 & 688810 & 5.433 & 5.0895 & TST & & \\
\hline
\end{tabular}




\begin{tabular}{|c|c|c|c|c|c|}
\hline & & \multicolumn{4}{|c|}{ Supplemental Table s2.txt } \\
\hline CHEMBL1376732 & 688810 & \multicolumn{2}{|c|}{5.2829999999999995} & 5.0672 & TRN \\
\hline CHEMBL1490123 & 688810 & \multicolumn{2}{|c|}{5.2829999999999995} & 5.35 & TST \\
\hline CHEMBL1352810 & 688810 & \multicolumn{2}{|l|}{5.832999999999999} & 5.369 & TRN \\
\hline CHEMBL565269 & 688810 & \multicolumn{2}{|c|}{5.7829999999999995} & 5.3636 & TRN \\
\hline CHEMBL3207771 & 688810 & 4.8673 & TST & & \\
\hline CHEMBL1492957 & 688810 & \multicolumn{2}{|c|}{5.582999999999999} & 5.4263 & TRN \\
\hline CHEMBL1558450 & 688810 & 5.8461 & TRN & & \\
\hline CHEMBL1557205 & 688810 & 5.275 & TRN & & \\
\hline CHEMBL1376487 & 688810 & \multicolumn{2}{|c|}{5.632999999999999} & 5.3631 & TRN \\
\hline CHEMBL1454183 & 688810 & \multicolumn{2}{|l|}{5.632999999999999} & 4.8765 & TST \\
\hline CHEMBL1549103 & 688810 & \multicolumn{2}{|l|}{5.882999999999999} & 5.6045 & TRN \\
\hline CHEMBL1503070 & 688810 & 4.6125 & TRN & & \\
\hline CHEMBL1478307 & 688810 & \multicolumn{2}{|c|}{5.132999999999999} & 5.4017 & TRN \\
\hline CHEMBL1989225 & 688810 & $7.2832 \quad 5.8478$ & TRN & & \\
\hline CHEMBL1594371 & 688810 & 5.1432 & TRN & & \\
\hline CHEMBL1405765 & 688810 & \multicolumn{2}{|c|}{5.7829999999999995} & 5.3801 & TRN \\
\hline CHEMBL1613237 & 688810 & 4.543 & TRN & & \\
\hline CHEMBL1388273 & 688810 & \multicolumn{2}{|c|}{5.5329999999999995} & 4.8855 & TRN \\
\hline CHEMBL1540365 & 688810 & \multicolumn{2}{|c|}{5.132999999999999} & 5.5583 & TRN \\
\hline CHEMBL1518900 & 688810 & 5.4023 & TRN & & \\
\hline CHEMBL1342888 & 688810 & \multicolumn{2}{|c|}{5.632999999999999} & 5.3071 & TST \\
\hline CHEMBL1565737 & 688810 & \multicolumn{2}{|l|}{5.832999999999999} & 5.224 & TRN \\
\hline CHEMBL1418955 & 688810 & \multicolumn{2}{|l|}{5.882999999999999} & 5.659 & TRN \\
\hline CHEMBL1453858 & 688810 & \multicolumn{2}{|c|}{5.5329999999999995} & 5.5181 & TRN \\
\hline CHEMBL1600374 & 688810 & 5.0988 & TRN & & \\
\hline CHEMBL1330532 & 688810 & 4.888 & TRN & & \\
\hline CHEMBL1531998 & 688810 & 5.0998 & TRN & & \\
\hline CHEMBL1350032 & 688810 & \multicolumn{2}{|c|}{5.332999999999999} & 5.5828 & TRN \\
\hline CHEMBL3195760 & 688810 & 6.0218 & TRN & & \\
\hline CHEMBL1368910 & 688810 & 6.2475 & TRN & & \\
\hline CHEMBL1606091 & 688810 & \multicolumn{2}{|c|}{5.2829999999999995} & 5.0871 & TRN \\
\hline CHEMBL1490887 & 688810 & 5.0099 & TST & & \\
\hline CHEMBL1401918 & 688810 & 4.9275 & TRN & & \\
\hline CHEMBL1471168 & 688810 & 5.5257 & TRN & & \\
\hline CHEMBL1507394 & 688810 & \multicolumn{2}{|l|}{6.082999999999999} & 5.0625 & TST \\
\hline CHEMBL1379600 & 688810 & 4.6918 & TRN & & \\
\hline CHEMBL1474183 & 688810 & \multicolumn{2}{|l|}{5.382999999999999} & 5.3807 & TRN \\
\hline CHEMBL1448213 & 688810 & $6.7331 \quad 5.8711$ & TRN & & \\
\hline CHEMBL1546379 & 688810 & 5.475 & TRN & & \\
\hline CHEMBL1334691 & 688810 & \multicolumn{2}{|c|}{6.0329999999999995} & 5.6741 & TRN \\
\hline CHEMBL1338450 & 688810 & 4.9496 & TRN & & \\
\hline CHEMBL1341557 & 688810 & 4.93199 & 999999999 & 995 & TRN \\
\hline CHEMBL1543937 & 688810 & 4.9635 & TRN & & \\
\hline CHEMBL1548814 & 688810 & 5.8829999999999 & & 5.6352 & TRN \\
\hline CHEMBL1520589 & 688810 & 5.2124 & TST & & \\
\hline CHEMBL1490478 & 688810 & 6.73316 .0903 & TRN & & \\
\hline CHEMBL1582770 & 688810 & 5.1919 & TRN & & \\
\hline CHEMBL1539969 & 688810 & 5.1419 & TRN & & \\
\hline
\end{tabular}




\begin{tabular}{|c|c|c|c|c|c|c|c|}
\hline \multicolumn{8}{|c|}{ S2.txt } \\
\hline CHEMBL1484017 & 688810 & 4.783 & 5.1978 & TRN & & & \\
\hline CHEMBL1582740 & 688810 & 5.183 & 5.7428 & TRN & & & \\
\hline CHEMBL1450943 & 688810 & 5.733 & 5.8019 & TRN & & & \\
\hline CHEMBL1328614 & 688810 & 5.233 & 5.4097 & TST & & & \\
\hline CHEMBL1501660 & 688810 & \multicolumn{3}{|c|}{5.132999999999999} & 5.1086 & TRN & \\
\hline CHEMBL1518971 & 688810 & \multicolumn{3}{|c|}{6.5329999999999995} & 5.121 & TRN & \\
\hline CHEMBL1568030 & 688810 & 5.033 & 5.6779 & TRN & & & \\
\hline CHEMBL1406653 & 688810 & 4.833 & 5.4182 & TRN & & & \\
\hline CHEMBL 3212664 & 688810 & \multicolumn{3}{|c|}{5.132999999999999} & 5.5533 & TRN & \\
\hline CHEMBL1348691 & 688810 & \multicolumn{3}{|c|}{5.7829999999999995} & 5.4346 & TRN & \\
\hline CHEMBL1516327 & 688810 & 4.583 & 5.0513 & TST & & & \\
\hline CHEMBL1563127 & 688810 & 4.783 & 5.3469 & TRN & & & \\
\hline CHEMBL3196573 & 688810 & \multicolumn{3}{|c|}{5.5329999999999995} & 5.2487 & TRN & \\
\hline CHEMBL1605698 & 688810 & 4.633 & 5.2158 & TRN & & & \\
\hline CHEMBL1530343 & 688810 & 5.183 & 5.3115 & TST & & & \\
\hline CHEMBL1371236 & 688810 & 4.833 & 5.1917 & TRN & & & \\
\hline CHEMBL1573186 & 688810 & 4.633 & 5.9379 & TRN & & & \\
\hline CHEMBL1577325 & 688810 & \multicolumn{3}{|c|}{4.7330000000000005} & \multicolumn{2}{|c|}{5.2410000000000005} & TRN \\
\hline CHEMBL1347792 & 688810 & 4.783 & 5.2967 & TRN & & & \\
\hline CHEMBL1327628 & 688810 & 4.783 & 5.2669 & TRN & & & \\
\hline CHEMBL1588982 & 688810 & 5.483 & 5.657 & TRN & & & \\
\hline CHEMBL1340381 & 688810 & 4.833 & 4.65 & TRN & & & \\
\hline CHEMBL1359020 & 688810 & 5.083 & 5.1632 & TRN & & & \\
\hline CHEMBL1439717 & 688810 & \multicolumn{3}{|c|}{5.832999999999999} & 5.5439 & TRN & \\
\hline CHEMBL1380676 & 688810 & \multicolumn{3}{|c|}{6.382999999999999} & 5.5836 & TRN & \\
\hline CHEMBL1531349 & 688810 & \multicolumn{3}{|c|}{4.9830000000000005} & 4.9537 & TST & \\
\hline CHEMBL1440215 & 688810 & \multicolumn{3}{|c|}{5.832999999999999} & 5.4694 & TRN & \\
\hline CHEMBL1403442 & 688810 & 5.683 & 5.1746 & TRN & & & \\
\hline CHEMBL1463480 & 688810 & \multicolumn{3}{|c|}{5.332999999999999} & 5.2036 & TRN & \\
\hline CHEMBL1569410 & 688810 & 4.583 & 5.3213 & TST & & & \\
\hline CHEMBL1586732 & 688810 & 6.9329 & 5.7088 & TRN & & & \\
\hline CHEMBL1427138 & 688810 & 5.683 & 5.3123 & TRN & & & \\
\hline CHEMBL1405661 & 688810 & \multicolumn{3}{|c|}{5.2829999999999995} & 5.261 & TRN & \\
\hline CHEMBL1339676 & 688810 & 4.833 & 4.7782 & TST & & & \\
\hline CHEMBL 3211378 & 688810 & 5.483 & 5.4295 & TRN & & & \\
\hline CHEMBL1523445 & 688810 & \multicolumn{3}{|c|}{4.7330000000000005} & 5.1481 & TRN & \\
\hline CHEMBL1580592 & 688810 & 5.933 & 5.9614 & TRN & & & \\
\hline CHEMBL1486390 & 688810 & \multicolumn{3}{|c|}{6.0329999999999995} & 6.0326 & TRN & \\
\hline CHEMBL1391972 & 688810 & 7.3325 & 6.2644 & TRN & & & \\
\hline CHEMBL1402415 & 688810 & 4.783 & 5.0489 & TRN & & & \\
\hline CHEMBL1387571 & 688810 & \multicolumn{3}{|c|}{5.5329999999999995} & 5.4049 & TRN & \\
\hline CHEMBL1434537 & 688810 & 4.633 & 4.8066 & TST & & & \\
\hline CHEMBL1595502 & 688810 & 5.433 & 4.9989 & TRN & & & \\
\hline CHEMBL1436312 & 688810 & 4.833 & 5.2553 & TST & & & \\
\hline CHEMBL3190622 & 688810 & 4.883 & 5.3433 & TRN & & & \\
\hline CHEMBL1502802 & 688810 & 4.833 & 4.9219 & TRN & & & \\
\hline CHEMBL3193434 & 688810 & \multicolumn{3}{|c|}{5.632999999999999} & 5.2733 & TRN & \\
\hline CHEMBL1382069 & 688810 & 4.883 & 5.1988 & TST & & & \\
\hline
\end{tabular}




\begin{tabular}{|c|c|c|c|c|c|c|}
\hline \multicolumn{7}{|c|}{ Supplemental Table S2.txt } \\
\hline CHEMBL1533209 & 688810 & \multicolumn{3}{|c|}{4.7330000000000005} & 5.3547 & TST \\
\hline CHEMBL1470495 & 688810 & \multicolumn{3}{|c|}{6.582999999999999} & 5.8285 & TRN \\
\hline CHEMBL1448592 & 688810 & \multicolumn{3}{|c|}{5.5329999999999995} & 5.3071 & TRN \\
\hline CHEMBL1542876 & 688810 & \multicolumn{3}{|c|}{6.582999999999999} & 5.0446 & TRN \\
\hline CHEMBL1568934 & 688810 & 4.633 & 4.9279 & TRN & & \\
\hline CHEMBL1374788 & 688810 & 4.933 & 4.6149 & TST & & \\
\hline CHEMBL1445073 & 688810 & \multicolumn{3}{|c|}{5.5329999999999995} & 5.4171 & TRN \\
\hline CHEMBL1603485 & 688810 & 5.733 & 5.2624 & TST & & \\
\hline CHEMBL511995 & 688810 & 4.833 & 5.039 & TRN & & \\
\hline CHEMBL1470381 & 688810 & \multicolumn{3}{|c|}{6.632999999999999} & 5.9953 & TRN \\
\hline CHEMBL1474810 & 688810 & 5.933 & 5.5252 & TRN & & \\
\hline CHEMBL1435507 & 688810 & 4.783 & 5.5054 & TRN & & \\
\hline CHEMBL1585372 & 688810 & \multicolumn{3}{|c|}{5.7829999999999995} & 5.5275 & TRN \\
\hline CHEMBL1424038 & 688810 & \multicolumn{3}{|c|}{4.7330000000000005} & 5.5972 & TRN \\
\hline CHEMBL1597379 & 688810 & 5.033 & 5.023 & TRN & & \\
\hline CHEMBL1406463 & 688810 & \multicolumn{3}{|c|}{4.7330000000000005} & 5.2089 & TRN \\
\hline CHEMBL1306419 & 688810 & \multicolumn{3}{|c|}{5.132999999999999} & 5.3246 & TRN \\
\hline CHEMBL1480761 & 688810 & 6.8831 & 5.7135 & TRN & & \\
\hline CHEMBL1529148 & 688810 & 5.733 & 6.0671 & TRN & & \\
\hline CHEMBL1417528 & 688810 & 4.883 & 5.2407 & TRN & & \\
\hline CHEMBL 3207526 & 688810 & \multicolumn{3}{|c|}{5.7829999999999995} & 5.522 & TRN \\
\hline CHEMBL1549243 & 688810 & \multicolumn{3}{|c|}{6.332999999999999} & 5.0483 & TRN \\
\hline CHEMBL1561336 & 688810 & \multicolumn{3}{|c|}{5.5329999999999995} & 5.2865 & TRN \\
\hline CHEMBL1605447 & 688810 & 4.883 & 4.9251 & TRN & & \\
\hline CHEMBL1563525 & 688810 & \multicolumn{3}{|c|}{ 4.883 5.4557 TRN } & & \\
\hline CHEMBL1432683 & 688810 & \multicolumn{3}{|c|}{5.5329999999999995} & 5.1159 & TRN \\
\hline CHEMBL3193139 & 688810 & 4.783 & 5.443 & TRN & & \\
\hline CHEMBL1542537 & 688810 & 4.583 & 5.1427 & TST & & \\
\hline CHEMBL1603832 & 688810 & 4.833 & 5.0516 & TST & & \\
\hline CHEMBL1417174 & 688810 & 5.483 & 5.4669 & TRN & & \\
\hline CHEMBL1373164 & 688810 & 4.783 & 5.3285 & TRN & & \\
\hline CHEMBL3195927 & 688810 & 4.633 & 5.1147 & TRN & & \\
\hline CHEMBL1397875 & 688810 & 6.683 & 4.8971 & TST & & \\
\hline CHEMBL1365174 & 688810 & \multicolumn{3}{|c|}{4.7330000000000005} & 4.9709 & TRN \\
\hline CHEMBL1516274 & 688810 & 4.583 & 4.7111 & TRN & & \\
\hline CHEMBL1386546 & 688810 & 4.933 & 5.5123 & TRN & & \\
\hline CHEMBL1434576 & 688810 & 4.583 & 5.0443 & TRN & & \\
\hline CHEMBL1385376 & 688810 & \multicolumn{3}{|c|}{5.882999999999999} & 5.2649 & TRN \\
\hline CHEMBL1460952 & 688810 & 4.833 & 5.1037 & TRN & & \\
\hline CHEMBL1465915 & 688810 & \multicolumn{3}{|c|}{5.882999999999999} & 5.9383 & TRN \\
\hline CHEMBL1994211 & 688810 & \multicolumn{3}{|c|}{5.7829999999999995} & 5.3732 & TRN \\
\hline CHEMBL1352487 & 688810 & 4.833 & 5.1274 & TST & & \\
\hline CHEMBL 1425080 & 688810 & \multicolumn{3}{|c|}{6.2829999999999995} & 6.1807 & TST \\
\hline CHEMBL1449828 & 688810 & 5.683 & 5.4469 & TRN & & \\
\hline CHEMBL1529777 & 688810 & 5.683 & 5.53799 & 99999 & & TST \\
\hline CHEMBL1416734 & 688810 & 4.933 & 5.0069 & TST & & \\
\hline CHEMBL1332913 & 688810 & 4.7330 & 00000000 & 005 & 4.968 & 9999999999 \\
\hline CHEMBL1481284 & 688810 & 5.1329 & 99999999 & & 5.1936 & TRN \\
\hline
\end{tabular}




\begin{tabular}{|c|c|c|c|c|c|c|}
\hline \multirow[b]{2}{*}{ CHEMBL1383327 } & \\
\hline & 688810 & 6.183 & 5.6598 & TRN & & \\
\hline CHEMBL1474674 & 688810 & 5.733 & 4.9946 & TST & & \\
\hline CHEMBL1429248 & 688810 & 4.833 & 5.25 & TST & & \\
\hline CHEMBL1475490 & 688810 & 4.933 & 5.2386 & TRN & & \\
\hline CHEMBL1535104 & 688810 & 4.783 & 5.218 & TRN & & \\
\hline CHEMBL1494390 & 688810 & 4.633 & 4.8962 & TRN & & \\
\hline CHEMBL1516925 & 688810 & 5.933 & 5.5683 & TRN & & \\
\hline CHEMBL1354622 & 688810 & 5.433 & 5.4876 & TRN & & \\
\hline CHEMBL1355003 & 688810 & 4.883 & 4.9029 & TRN & & \\
\hline CHEMBL1413901 & 688810 & 7.1831 & 5.94799 & 99999 & 995 & $T$ \\
\hline CHEMBL 3214032 & 688810 & 4.933 & 5.2212 & TRN & & \\
\hline CHEMBL3189906 & 688810 & 5.3329 & 99999999 & & 5.5987 & TRN \\
\hline CHEMBL1384158 & 688810 & 5.3829 & 99999999 & & 5.4076 & \\
\hline CHEMBL1607928 & 688810 & 6.3329 & 99999999 & & 5.8461 & TRN \\
\hline CHEMBL3189406 & 688810 & 5.5329 & 99999999 & 995 & 4.9885 & \\
\hline CHEMBL1319948 & 688810 & 5.033 & 5.2784 & TRN & & \\
\hline CHEMBL1587804 & 688810 & 5.3829 & 99999999 & & 4.8695 & TRN \\
\hline CHEMBL1589860 & 688810 & 4.7330 & 00000000 & 005 & 4.709 & \\
\hline CHEMBL1333489 & 688810 & 4.883 & 5.1959 & TRN & & \\
\hline CHEMBL1585747 & 688810 & 5.733 & 5.2573 & TRN & & \\
\hline CHEMBL1568905 & 688810 & 5.5329 & 99999999 & 995 & 5.7494 & TST \\
\hline CHEMBL3209105 & 688810 & 6.5829 & 99999999 & & 5.395 & TRN \\
\hline CHEMBL209699 & 688810 & 5.5329 & 99999999 & 995 & 5.6659 & TRN \\
\hline CHEMBL3189599 & 688810 & 4.833 & 4.8985 & TST & & \\
\hline CHEMBL1386433 & 688810 & 5.683 & 5.2636 & TST & & \\
\hline CHEMBL1336041 & 688810 & 4.783 & 5.4943 & TRN & & \\
\hline CHEMBL1322185 & 688810 & 5.8829 & 99999999 & & 5.5811 & TP \\
\hline CHEMBL1388684 & 688810 & 5.733 & 4.746 & TRN & & \\
\hline CHEMBL600336 & 688810 & 6.2829 & 99999999 & 995 & 5.9385 & TRTV \\
\hline CHEMBL1395731 & 688810 & 5.8329 & 99999999 & & 5.1698 & TRN \\
\hline CHEMBL1431283 & 688810 & 6.183 & 5.2354 & TRN & & \\
\hline CHEMBL1443812 & 688810 & 7.1331 & 6.0108 & TRN & & \\
\hline CHEMBL1420184 & 688810 & 5.8829 & 99999999 & & 5.6148 & TRN \\
\hline CHEMBL1412533 & 688810 & 5.183 & 5.3191 & TRN & & \\
\hline CHEMBL1589018 & 688810 & 4.883 & 4.9977 & TRN & & \\
\hline CHEMBL1513105 & 688810 & 6.683 & 5.5231 & TRN & & \\
\hline CHEMBL1386558 & 688810 & 5.683 & 5.0912 & TRN & & \\
\hline CHEMBL1354671 & 688810 & 4.583 & 4.9555 & TST & & \\
\hline CHEMBL3193236 & 688810 & 4.683 & 5.2145 & TST & & \\
\hline CHEMBL1357098 & 688810 & 6.3829 & 99999999 & & 5.6023 & TRN \\
\hline CHEMBL1458846 & 688810 & 6.3329 & 79999999 & & 5.2794 & TRN \\
\hline CHEMBL1594953 & 688810 & 5.183 & 5.6482 & TRN & & \\
\hline CHEMBL1434035 & 688810 & 5.3829 & 99999999 & & 5.4963 & TRN \\
\hline CHEMBL1561214 & 688810 & 5.1329 & 79999999 & & 4.9142 & $T C T$ \\
\hline CHEMBL3189317 & 688810 & 4.883 & 5.2036 & TRN & & \\
\hline CHEMBL1343267 & 688810 & 5.3829 & 99999999 & & 5.0759 & TRN \\
\hline CHEMBL3196623 & 688810 & 5.5329 & 99999999 & 995 & 5.3396 & TRN \\
\hline CHEMBL1598180 & 688810 & 5.933 & 5.7706 & TST & & \\
\hline
\end{tabular}




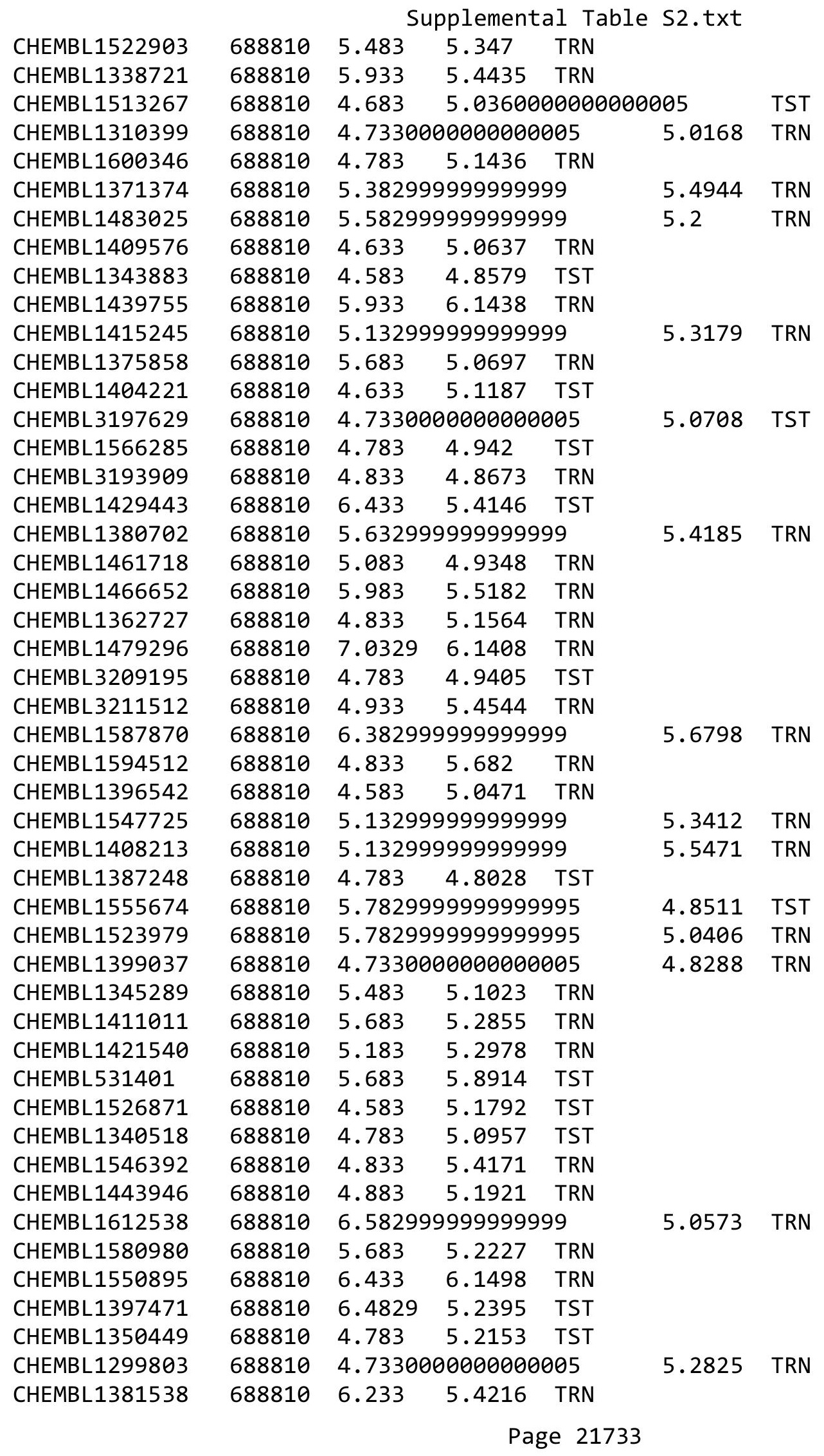




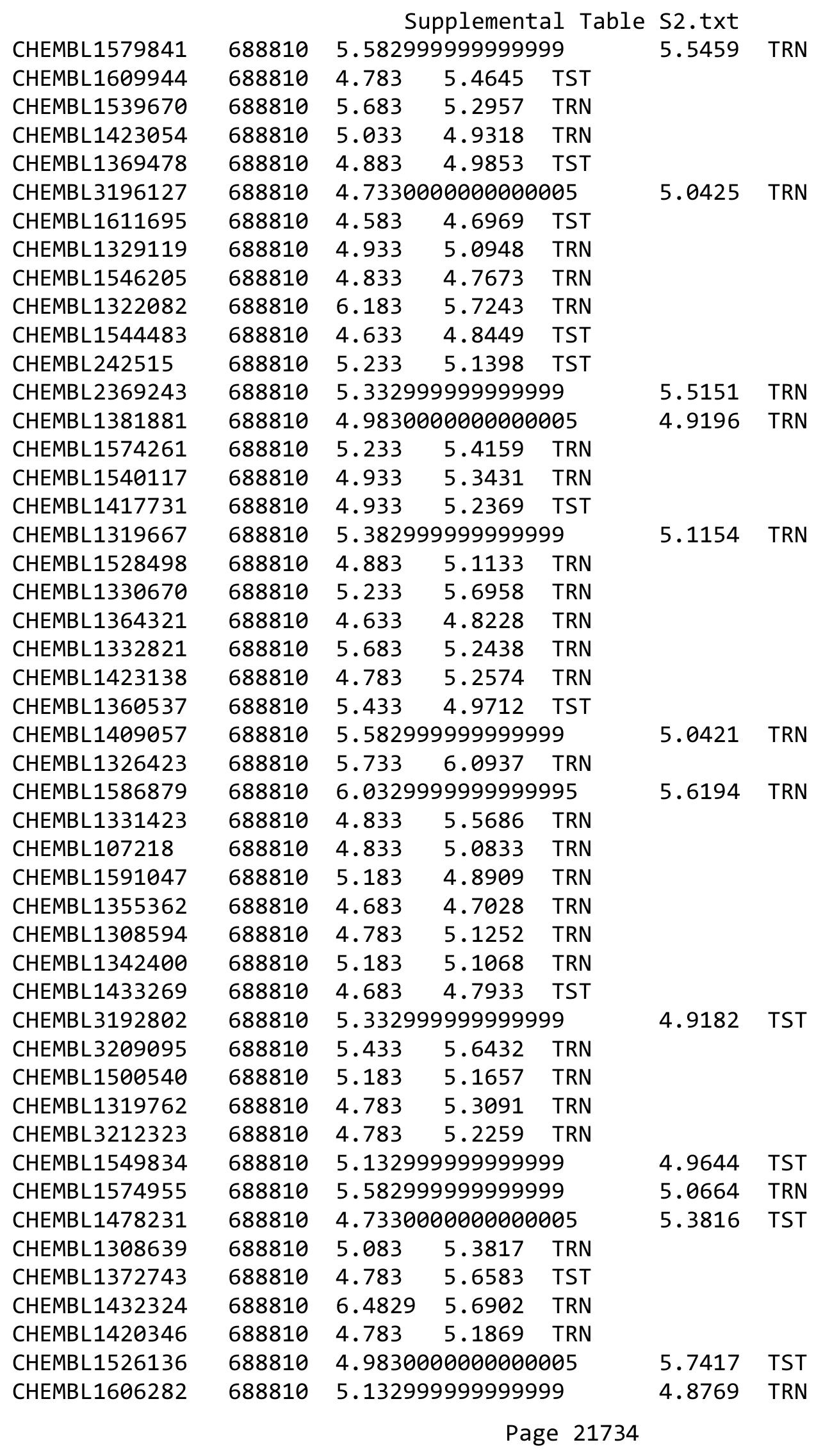




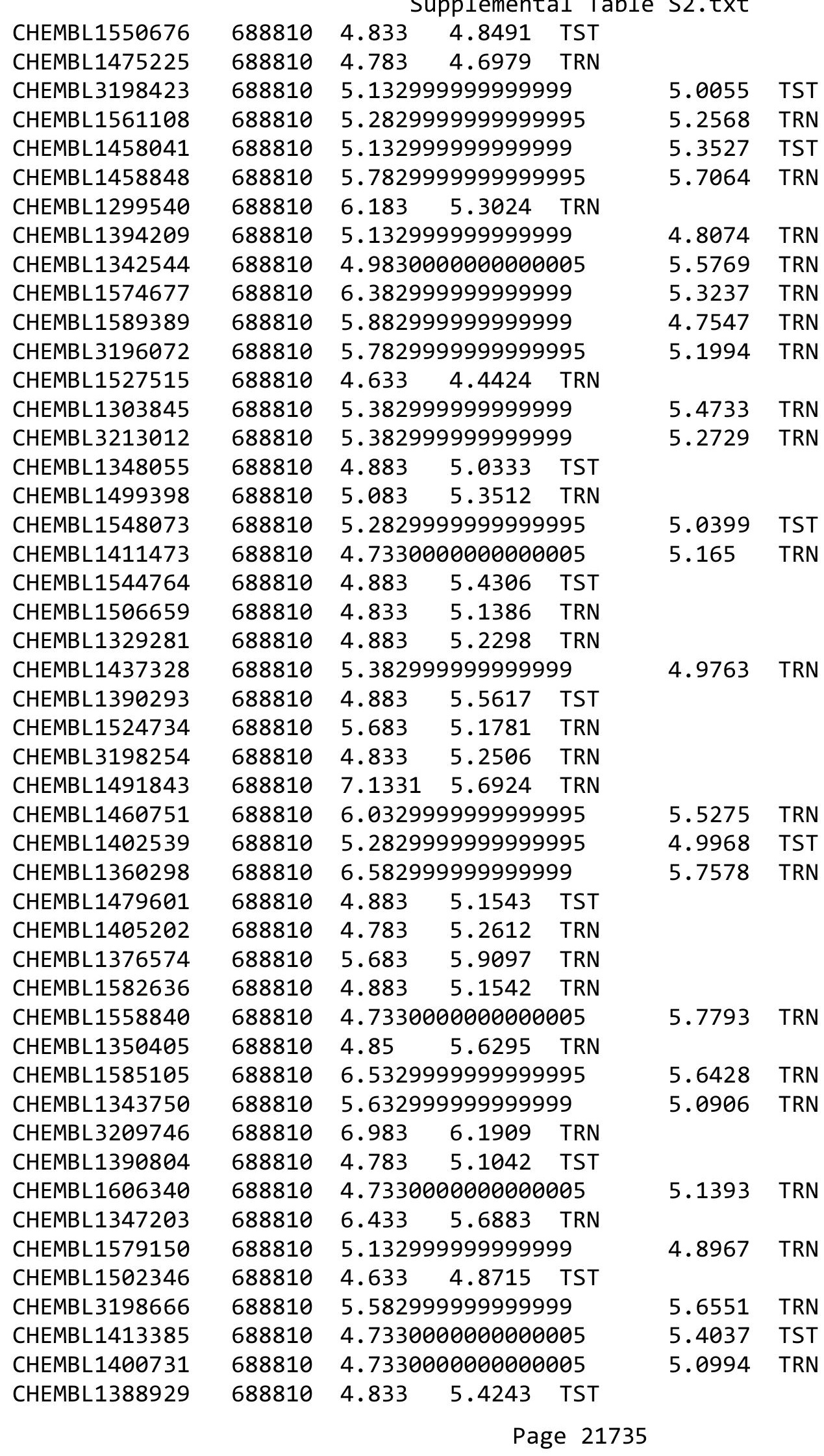




\begin{tabular}{|c|c|c|c|c|c|c|}
\hline \multirow[b]{2}{*}{ CHEMBL1492459 } & & \multicolumn{5}{|c|}{ Supplemental Table S2.txt } \\
\hline & 688810 & 5.933 & 5.8233 & TRN & & \\
\hline CHEMBL1598800 & 688810 & \multicolumn{3}{|c|}{5.5329999999999995} & 5.235 & TS \\
\hline CHEMBL1519020 & 688810 & 4.583 & 5.0986 & TST & & \\
\hline CHEMBL1454516 & 688810 & 4.783 & 5.19 & TRN & & \\
\hline CHEMBL1379749 & 688810 & 4.583 & 4.9437 & TRN & & \\
\hline CHEMBL 1475786 & 688810 & \multicolumn{3}{|c|}{5.882999999999999} & 5.553 & \\
\hline CHEMBL1421315 & 688810 & \multicolumn{3}{|c|}{5.832999999999999} & 5.9494 & \\
\hline CHEMBL1455166 & 688810 & 5.033 & 5.1211 & TST & & \\
\hline CHEMBL1521335 & 688810 & 4.783 & & TRN & & \\
\hline CHEMBL1515818 & 688810 & \multicolumn{3}{|c|}{6.0329999999999995} & 5.5257 & \\
\hline CHEMBL1462764 & 688810 & 4.783 & 5.0688 & TST & & \\
\hline CHEMBL1352168 & 688810 & \multicolumn{3}{|c|}{4.7330000000000005} & 5.5247 & \\
\hline CHEMBL1330852 & 688810 & 4.783 & 5.6763 & TRN & & \\
\hline CHEMBL1439808 & 688810 & 5.483 & 5.3534 & TRN & & \\
\hline CHEMBL1549026 & 688810 & 4.883 & 5.0955 & TRN & & \\
\hline CHEMBL1327227 & 688810 & 5.083 & 4.9734 & TST & & \\
\hline CHEMBL1417725 & 688810 & 4.883 & 4.9146 & TRN & & \\
\hline CHEMBL1308783 & 688810 & 4.633 & 5.0966 & TST & & \\
\hline CHEMBL1444917 & 688810 & \multicolumn{3}{|c|}{4.9830000000000005} & 5.4911 & $\mathrm{~T}$ \\
\hline CHEMBL1325485 & 688810 & \multicolumn{3}{|c|}{4.9830000000000005} & 5.3602 & \\
\hline CHEMBL1406781 & 688810 & 4.833 & 5.2754 & TST & & \\
\hline CHEMBL1559656 & 688810 & \multicolumn{3}{|c|}{4.7330000000000005} & 5.3569 & \\
\hline CHEMBL1548608 & 688810 & 4.633 & 5.2916 & TST & & \\
\hline CHEMBL1375425 & 688810 & 5.433 & 5.3187 & TRN & & \\
\hline CHEMBL455284 & 688810 & 7.5834 & 6.296 & TST & & \\
\hline CHEMBL1543240 & 688810 & 5.3 & 5.2124 & TRN & & \\
\hline CHEMBL1577977 & 688810 & \multicolumn{3}{|c|}{6.382999999999999} & 5.2644 & 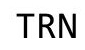 \\
\hline CHEMBL1461497 & 688810 & 5.0 & 4.8225 & TST & & \\
\hline CHEMBL601184 & 688810 & 4.583 & 5.3407 & TRN & & \\
\hline CHEMBL3211353 & 688810 & 5.683 & 5.2508 & TRN & & \\
\hline CHEMBL1602267 & 688810 & \multicolumn{3}{|c|}{5.5329999999999995} & 5.0435 & \\
\hline CHEMBL1494629 & 688810 & 4.883 & 4.9078 & TRN & & \\
\hline CHEMBL1400965 & 688810 & 5.983 & 5.5497 & TRN & & \\
\hline CHEMBL1602865 & 688810 & 5.083 & 5.4871 & TRN & & \\
\hline CHEMBL1569667 & 688810 & \multicolumn{3}{|c|}{5.632999999999999} & 4.862 & \\
\hline CHEMBL1979106 & 688810 & 4.833 & 5.0969 & TRN & & \\
\hline CHEMBL1311383 & 688810 & \multicolumn{3}{|c|}{4.9830000000000005} & 5.0803 & TRIV \\
\hline CHEMBL1518032 & 688810 & \multicolumn{3}{|c|}{6.2829999999999995} & 5.8656 & TST \\
\hline CHEMBL 3190427 & 688810 & \multicolumn{3}{|c|}{4.7330000000000005} & 5.2732 & TRN \\
\hline CHEMBL1346134 & 688810 & 4.783 & 5.4153 & TRN & & \\
\hline CHEMBL1332010 & 688810 & 6.0 & 5.0113 & TRN & & \\
\hline CHEMBL 3196378 & 688810 & 5.933 & 5.7673 & TRN & & \\
\hline CHEMBL1377340 & 688810 & 4.883 & 4.8809 & TRN & & \\
\hline CHEMBL1369237 & 688810 & \multicolumn{3}{|c|}{6.382999999999999} & 5.4273 & N \\
\hline CHEMBL1320522 & 688810 & 5.233 & 5.3586 & TRN & & \\
\hline CHEMBL1466106 & 688810 & 4.833 & 4.9305 & TRN & & \\
\hline CHEMBL1346504 & 688810 & \multicolumn{3}{|c|}{5.332999999999999} & 5.3282 & Tार \\
\hline CHEMBL1544656 & 688810 & \multicolumn{3}{|c|}{4.7330000000000005} & 5.9935 & TRN \\
\hline
\end{tabular}




\begin{tabular}{|c|c|c|c|c|c|c|}
\hline & & \multicolumn{4}{|c|}{ Supplemental Table S2.txt } & \\
\hline CHEMBL1380739 & 688810 & \multicolumn{3}{|c|}{4.7330000000000005} & 4.8857 & $\mathrm{TR}$ \\
\hline CHEMBL1560088 & 688810 & \multicolumn{3}{|c|}{4.7330000000000005} & 5.6095 & \\
\hline CHEMBL478825 & 688810 & \multicolumn{3}{|c|}{5.332999999999999} & 5.4952 & \\
\hline CHEMBL3211166 & 688810 & 5.183 & 5.1241 & TST & & \\
\hline CHEMBL1599358 & 688810 & \multicolumn{3}{|c|}{5.582999999999999} & 5.2207 & \\
\hline CHEMBL485690 & 688810 & 4.833 & 5.7537 & TST & & \\
\hline CHEMBL1591655 & 688810 & 4.883 & 5.4644 & TRN & & \\
\hline CHEMBL1444538 & 688810 & \multicolumn{3}{|c|}{5.382999999999999} & 5.176 & \\
\hline CHEMBL1514888 & 688810 & \multicolumn{3}{|c|}{6.332999999999999} & 5.768 & \\
\hline CHEMBL1452605 & 688810 & \multicolumn{3}{|c|}{5.132999999999999} & 5.3794 & \\
\hline CHEMBL1609199 & 688810 & 5.933 & 5.6926 & TRN & & \\
\hline CHEMBL1439817 & 688810 & 4.833 & 5.385 & TRN & & \\
\hline CHEMBL1580953 & 688810 & \multicolumn{3}{|c|}{6.332999999999999} & 5.5388 & 1. \\
\hline CHEMBL1304389 & 688810 & 6.433 & 5.8138 & TRN & & \\
\hline CHEMBL1455387 & 688810 & 5.183 & 5.6269 & TRN & & \\
\hline CHEMBL1599256 & 688810 & 6.183 & 5.7361 & TRN & & \\
\hline CHEMBL1449065 & 688810 & 4.833 & 5.5581 & TRN & & \\
\hline CHEMBL1356927 & 688810 & \multicolumn{3}{|c|}{4.9830000000000005} & 5.7551 & \\
\hline CHEMBL1475359 & 688810 & 4.633 & 4.6963 & TRN & & \\
\hline CHEMBL1582803 & 688810 & 5.183 & 5.141 & TST & & \\
\hline CHEMBL1463854 & 688810 & 5.083 & 5.2938 & TRN & & \\
\hline CHEMBL1 & 688 & 4.833 & 5.862 & TST & & \\
\hline CHEMBL1256364 & 688810 & 5.683 & 5.6039 & TST & & \\
\hline CHEMBL1515038 & 688810 & \multicolumn{3}{|c|}{5.7829999999999995} & 5.5281 & $\mathrm{TH}$ \\
\hline CHEMBL1334289 & 688810 & 4.783 & 5.2026 & TRN & & \\
\hline CHEMBL1395780 & 688810 & 4.583 & 5.2816 & TST & & \\
\hline CHEMBL1 & 688810 & \multicolumn{3}{|c|}{5.832999999999999} & 5.5168 & \\
\hline CHEMBL1 & 688810 & 4.833 & 5.7354 & TST & & \\
\hline CHEMBL1300536 & 688810 & \multicolumn{3}{|c|}{4.7330000000000005} & 5.4836 & $\mathrm{~T}$ \\
\hline CHEMBL1549602 & 688810 & 5.233 & 5.2182 & TRN & & \\
\hline CHEMBL1550247 & 688810 & 5.433 & 5.7606 & TRN & & \\
\hline CHEMB & 688810 & 5.083 & 5.1487 & TRN & & \\
\hline CHEMB & 688 & 4.783 & 4.8764 & TRN & & \\
\hline CHEMBL1587054 & 688810 & 4.933 & 5.5227 & TRN & & \\
\hline CHEMBL1356650 & 688810 & 5.233 & 5.4926 & TRN & & \\
\hline CHEMBL1345290 & 688 & 4.833 & 5.0629 & TRN & & \\
\hline CHEMBL3197801 & 688810 & 6.233 & \multicolumn{3}{|c|}{5.2410000000000005} & TRN \\
\hline CHEMBL1341894 & 688810 & \multicolumn{3}{|c|}{4.7330000000000005} & 5.0904 & TRN \\
\hline CHEMBL1566106 & 688810 & 6.5 & 6.1906 & TRN & & \\
\hline CHEMBL1336513 & 688810 & 5.483 & 5.4379 & TRN & & \\
\hline CHEMBL1594896 & 688810 & 4.633 & 5.0083 & TRN & & \\
\hline CHEMBL1367146 & 688810 & \multicolumn{3}{|c|}{4.7330000000000005} & 5.3512 & 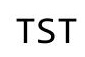 \\
\hline CHEMBL1352019 & 688810 & 5.083 & 5.2565 & TRN & & \\
\hline CHEMBL1411344 & 688810 & \multicolumn{3}{|c|}{4.7330000000000005} & 4.9283 & r \\
\hline CHEMBL1514650 & 688810 & 5.233 & 5.2618 & TRN & & \\
\hline CHEMBL1581738 & 688810 & 5.083 & 4.9112 & TRN & & \\
\hline CHEMBL1343271 & 688810 & \multicolumn{3}{|c|}{5.882999999999999} & 3.4201 & IRI \\
\hline CHEMBL1425016 & 688810 & 5.083 & 5.2152 & TST & & \\
\hline
\end{tabular}




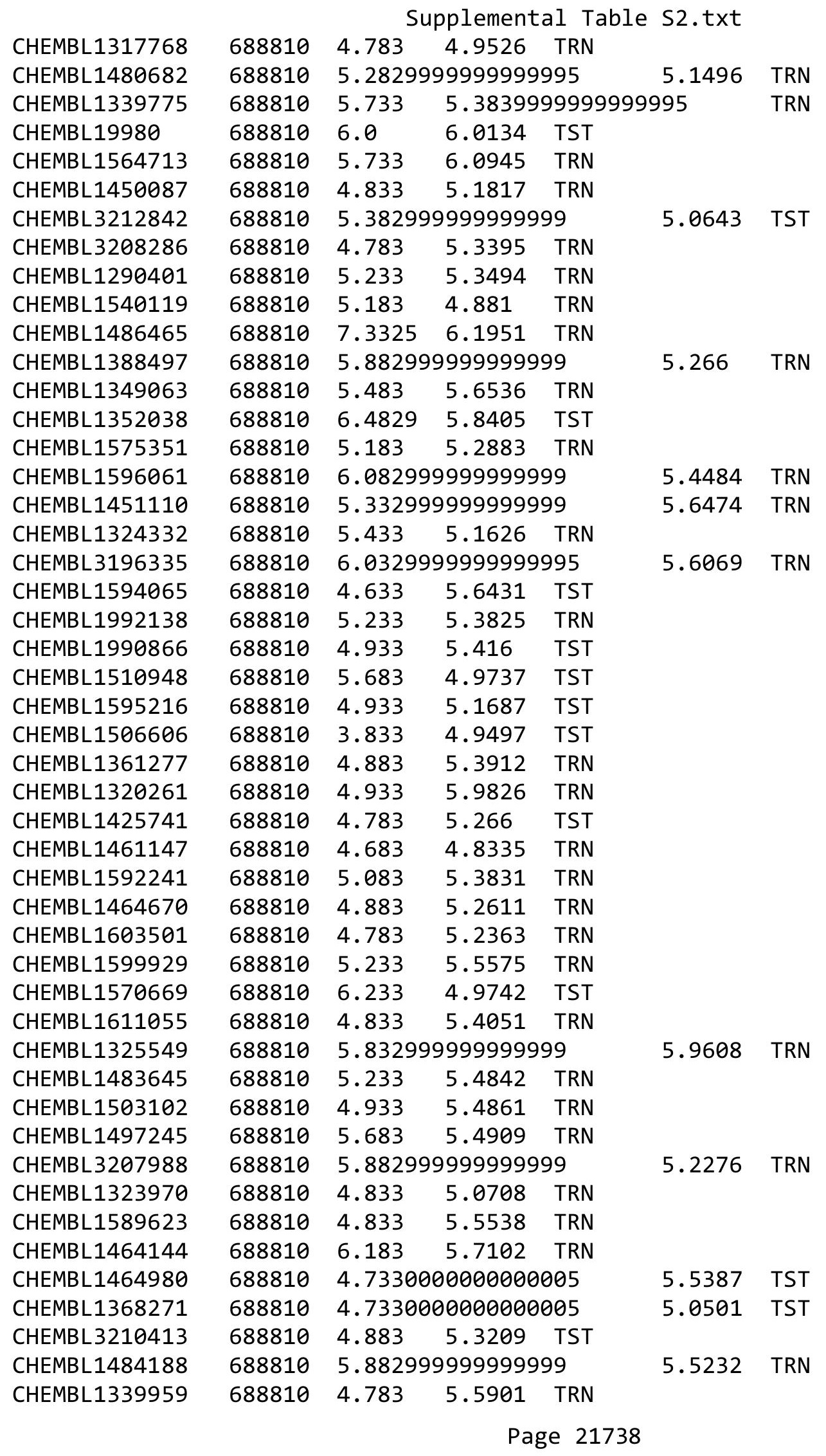




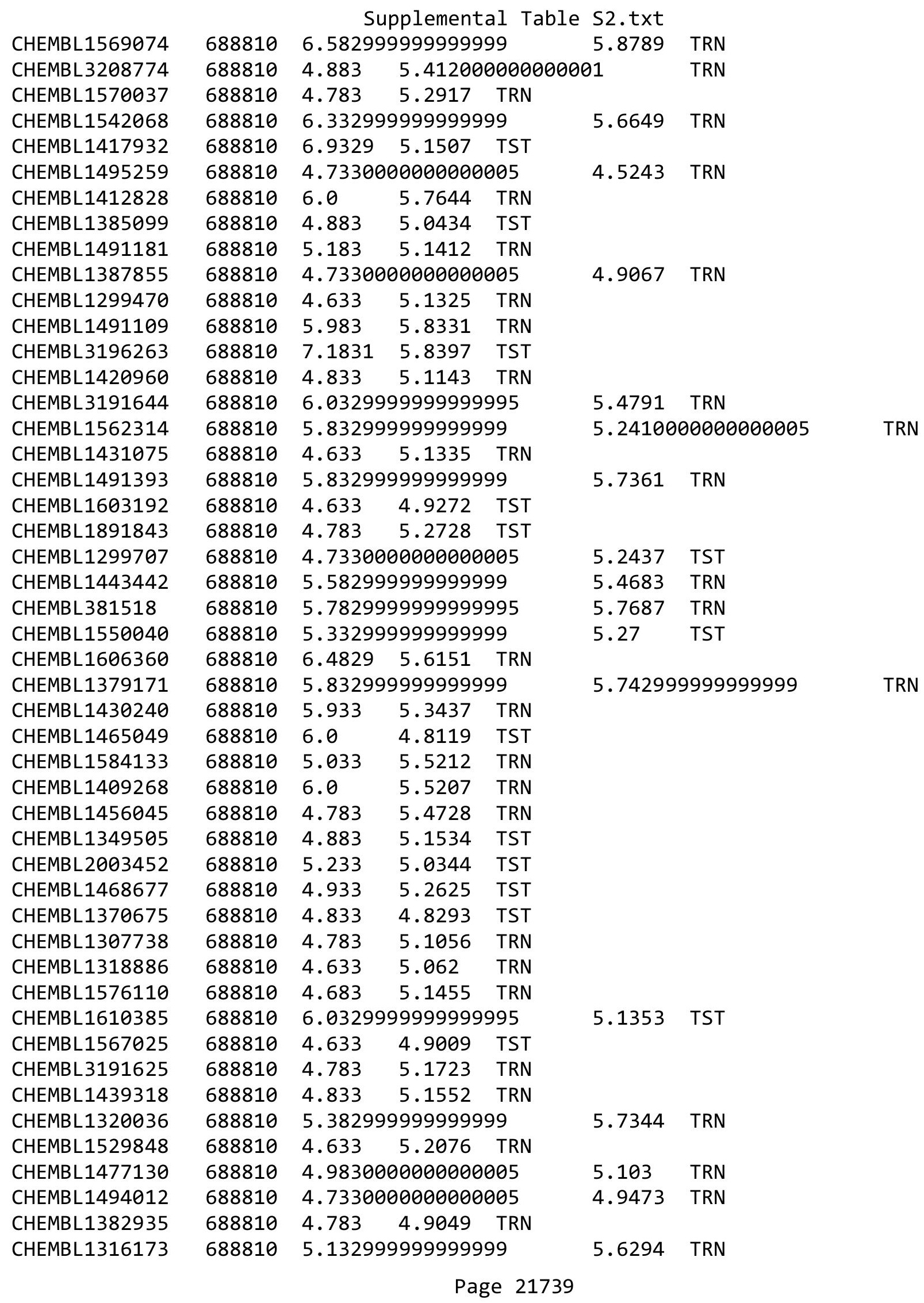




\begin{tabular}{|c|c|c|c|c|c|c|}
\hline \multirow{3}{*}{$\begin{array}{l}\text { CHEMBL1539660 } \\
\text { CHEMBL1301287 }\end{array}$} & \multirow{3}{*}{$\begin{array}{l}688810 \\
688810\end{array}$} & \multicolumn{5}{|c|}{ Supplemental Table S2.txt } \\
\hline & & \multicolumn{3}{|c|}{5.132999999999999} & \multirow{3}{*}{5.6973} & \multirow[t]{3}{*}{ TRN } \\
\hline & & 6.433 & 5.2828 & TRN & & \\
\hline CHEMBL1555356 & 688810 & 5.233 & 5.24 & TRN & & \\
\hline CHEMBL1612792 & 688810 & \multicolumn{3}{|c|}{4.9830000000000005} & 5.403 & TRN \\
\hline CHEMBL1552056 & 688810 & \multicolumn{3}{|c|}{4.7330000000000005} & 4.9158 & TST \\
\hline CHEMBL1474736 & 688810 & 4.783 & 5.0192 & TRN & & \\
\hline CHEMBL1587080 & 688810 & 4.783 & 5.2853 & TST & & \\
\hline CHEMBL1387110 & 688810 & 4.633 & 5.8772 & TRN & & \\
\hline CHEMBL1409980 & 688810 & \multicolumn{3}{|c|}{4.7330000000000005} & 5.0554 & TST \\
\hline CHEMBL1603928 & 688810 & 4.933 & 5.3473 & TST & & \\
\hline CHEMBL1474419 & 688810 & 5.083 & 5.2568 & TRN & & \\
\hline CHEMBL1340393 & 688810 & 4.833 & 5.1545 & TRN & & \\
\hline CHEMBL1454489 & 688810 & 4.933 & 5.1387 & TRN & & \\
\hline CHEMBL1570180 & 688810 & 4.783 & 5.1256 & TRN & & \\
\hline CHEMBL1490748 & 688810 & 4.883 & 4.8474 & TST & & \\
\hline CHEMBL3194507 & 688810 & \multicolumn{3}{|c|}{5.132999999999999} & 5.0092 & TST \\
\hline CHEMBL1331391 & 688810 & 5.433 & 5.5673 & TRN & & \\
\hline CHEMBL1494059 & 688810 & 5.683 & 5.7363 & TRN & & \\
\hline CHEMBL1411919 & 688810 & \multicolumn{3}{|c|}{5.632999999999999} & 5.8877 & TRN \\
\hline CHEMBL1483840 & 688810 & 4.833 & 5.1423 & TST & & \\
\hline CHEMBL1457887 & 688810 & 4.833 & 5.3597 & TRN & & \\
\hline CHEMBL1446788 & 688810 & \multicolumn{3}{|c|}{5.5329999999999995} & 5.421 & TST \\
\hline CHEMBL1471016 & 688810 & \multicolumn{3}{|c|}{6.332999999999999} & 5.5907 & TRN \\
\hline CHEMBL1610821 & 688810 & 5.933 & \multicolumn{3}{|c|}{5.712000000000001} & TRN \\
\hline CHEMBL1396220 & 688810 & 4.933 & 4.9969 & TST & & \\
\hline CHEMBL1482955 & 688810 & \multicolumn{3}{|c|}{5.382999999999999} & 5.5432 & TRN \\
\hline CHEMBL1445987 & 688810 & \multicolumn{3}{|c|}{4.9830000000000005} & 5.0953 & TST \\
\hline CHEMBL1307593 & 688810 & 4.783 & 5.1052 & TRN & & \\
\hline CHEMBL1580204 & 688810 & 5.183 & 5.5662 & TRN & & \\
\hline CHEMBL1341666 & 688810 & \multicolumn{3}{|c|}{5.7829999999999995} & 5.5263 & TRN \\
\hline CHEMBL1445232 & 688810 & 4.583 & 4.5632 & TRN & & \\
\hline CHEMBL1541948 & 688810 & \multicolumn{3}{|c|}{6.082999999999999} & 5.8943 & TST \\
\hline CHEMBL1422265 & 688810 & 6.233 & 5.6864 & TRN & & \\
\hline CHEMBL1466715 & 688810 & \multicolumn{3}{|c|}{5.132999999999999} & 5.2597 & TRN \\
\hline CHEMBL1409275 & 688810 & 5.033 & 5.3844 & TRN & & \\
\hline CHEMBL1401167 & 688810 & 4.783 & 5.3073 & TRN & & \\
\hline CHEMBL1530335 & 688810 & \multicolumn{3}{|c|}{4.7330000000000005} & 5.2863 & TRN \\
\hline CHEMBL3199449 & 688810 & 4.883 & 5.2632 & TRN & & \\
\hline CHEMBL1426162 & 688810 & 4.833 & 5.2392 & TST & & \\
\hline CHEMBL1401945 & 688810 & \multicolumn{3}{|c|}{6.382999999999999} & 5.4616 & TST \\
\hline CHEMBL1389578 & 688810 & 4.883 & 5.3405 & TRN & & \\
\hline CHEMBL1301035 & 688810 & 4.783 & 5.1136 & TST & & \\
\hline CHEMBL1331092 & 688810 & 4.683 & 5.2268 & TRN & & \\
\hline CHEMBL1359027 & 688810 & 4.783 & 5.1789 & TRN & & \\
\hline CHEMBL1430116 & 688810 & 4.933 & 5.192 & TRN & & \\
\hline CHEMBL1568268 & 688810 & 4.883 & 5.1577 & TRN & & \\
\hline CHEMBL1558608 & 688810 & 4.783 & 5.2592 & TRN & & \\
\hline CHEMBL1302493 & 688810 & 5.3329 & 99999999 & & 4.8837 & TST \\
\hline
\end{tabular}




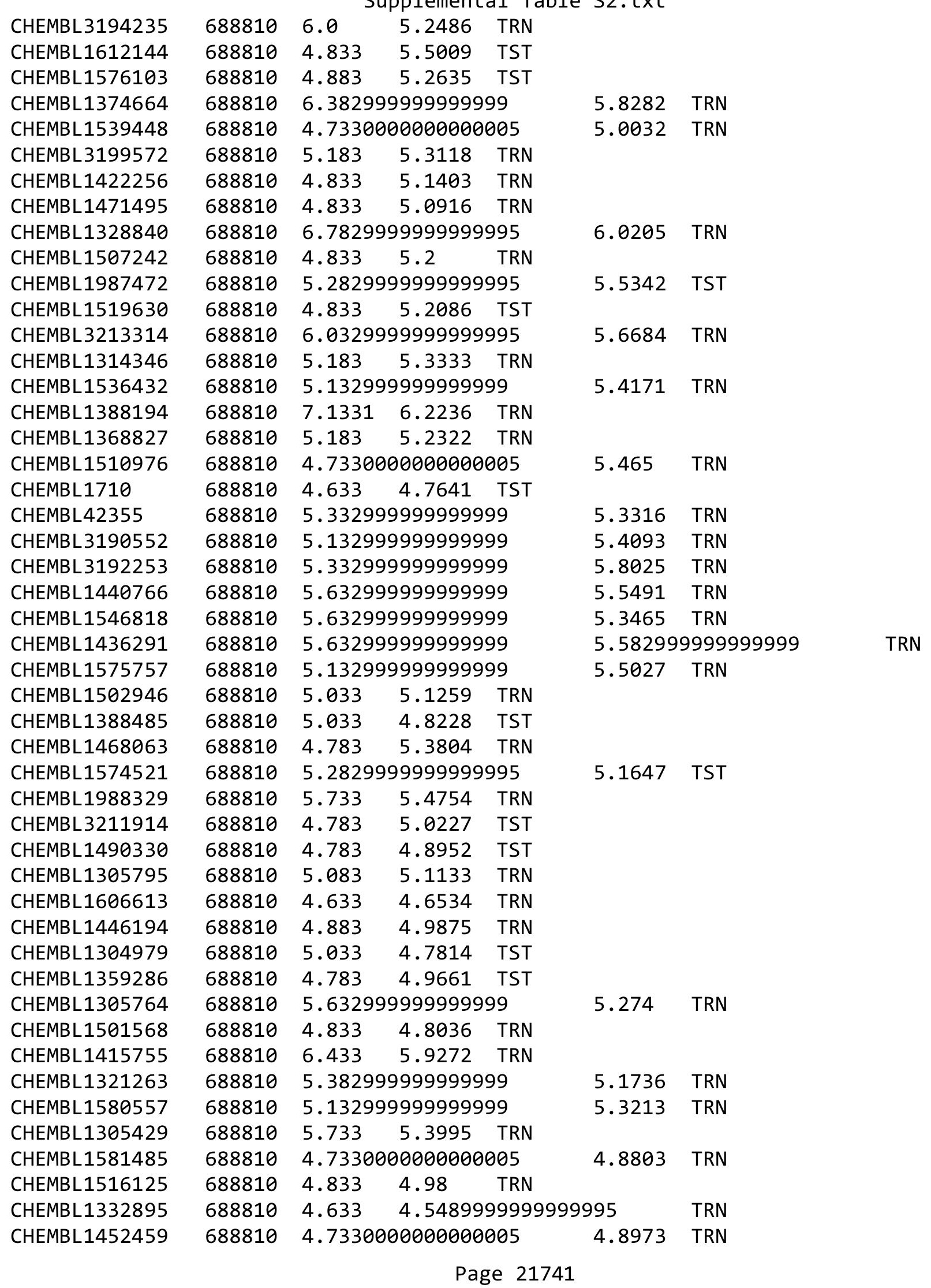




\begin{tabular}{|c|c|c|c|c|c|c|c|}
\hline \multirow{2}{*}{ CHEMBL1529158 } & \multicolumn{6}{|c|}{ oplemental Ta } & \\
\hline & 688810 & 4.883 & 4.8711 & TST & & & \\
\hline CHEMBL1349636 & 688810 & \multicolumn{3}{|c|}{5.382999999999999} & 5.3155 & TST & \\
\hline CHEMBL3198142 & 688810 & \multicolumn{3}{|c|}{4.7330000000000005} & 4.8297 & TST & \\
\hline CHEMBL1309184 & 688810 & 5.183 & 5.2976 & TRN & & & \\
\hline CHEMBL1526216 & 688810 & 4.95 & 5.5071 & TRN & & & \\
\hline CHEMBL1590770 & 688810 & \multicolumn{3}{|c|}{5.832999999999999} & 5.4637 & TRN & \\
\hline CHEMBL1306342 & 688810 & \multicolumn{3}{|c|}{4.7330000000000005} & 4.9266 & TST & \\
\hline CHEMBL1493472 & 688810 & \multicolumn{3}{|c|}{6.2829999999999995} & 5.3148 & TRN & \\
\hline CHEMBL 3427333 & 688810 & 4.883 & 5.1255 & TRN & & & \\
\hline CHEMBL1407298 & 688810 & 4.883 & 5.1005 & TRN & & & \\
\hline CHEMBL1517697 & 688810 & 4.833 & 5.06 & TRN & & & \\
\hline CHEMBL1518747 & 688810 & \multicolumn{3}{|c|}{4.7330000000000005} & 5.2108 & TRN & \\
\hline CHEMBL1544103 & 688810 & \multicolumn{3}{|c|}{5.582999999999999} & 5.2001 & TRN & \\
\hline CHEMBL1576095 & 688810 & \multicolumn{3}{|c|}{5.832999999999999} & 5.2464 & TRN & \\
\hline CHEMBL1342150 & 688810 & \multicolumn{3}{|c|}{5.382999999999999} & 5.3826 & TRN & \\
\hline CHEMBL1570569 & 688810 & 4.933 & 5.4568 & TRN & & & \\
\hline CHEMBL1438472 & 688810 & \multicolumn{3}{|c|}{6.2829999999999995} & 5.9291 & TRN & \\
\hline CHEMBL1497812 & 688810 & 4.583 & 5.1213 & TST & & & \\
\hline CHEMBL1353851 & 688810 & \multicolumn{3}{|c|}{5.132999999999999} & \multicolumn{2}{|c|}{5.5120000000000005} & TRN \\
\hline CHEMBL1574888 & 688810 & 5.683 & 5.5566 & TRN & & & \\
\hline CHEMBL1592987 & 688810 & \multicolumn{3}{|c|}{4.7330000000000005} & 5.0203 & TRN & \\
\hline CHEMBL1319525 & 688810 & 4.933 & 5.5783 & TST & & & \\
\hline CHEMBL1434990 & 688810 & \multicolumn{3}{|c|}{5.5329999999999995} & 5.9698 & TRN & \\
\hline CHEMBL1970836 & 688810 & 4.833 & 5.4108 & TST & & & \\
\hline CHEMBL1308224 & 688810 & 4.783 & 4.3597 & TST & & & \\
\hline CHEMBL1517442 & 688810 & 4.933 & 5.1369 & TRN & & & \\
\hline CHEMBL3198026 & 688810 & 4.833 & 5.3613 & TRN & & & \\
\hline CHEMBL1334350 & 688810 & 5.433 & 4.8505 & TRN & & & \\
\hline CHEMBL1436610 & 688810 & \multicolumn{3}{|c|}{5.882999999999999} & 5.4366 & TRN & \\
\hline CHEMBL1337035 & 688810 & 6.4829 & 5.31 & TST & & & \\
\hline CHEMBL1534748 & 688810 & 6.0 & 5.5811 & TRN & & & \\
\hline CHEMBL1480119 & 688810 & 4.833 & 5.0259 & TRN & & & \\
\hline CHEMBL1475922 & 688810 & 5.733 & 5.6334 & TRN & & & \\
\hline CHEMBL1300159 & 688810 & 5.083 & 5.1494 & TRN & & & \\
\hline CHEMBL1538677 & 688810 & 6.683 & 5.7812 & TRN & & & \\
\hline CHEMBL1392445 & 688810 & 5.683 & 5.2362 & TST & & & \\
\hline CHEMBL3211251 & 688810 & \multicolumn{3}{|c|}{4.7330000000000005} & 5.4153 & TRN & \\
\hline CHEMBL1421811 & 688810 & \multicolumn{3}{|c|}{5.7829999999999995} & 5.8145 & TRN & \\
\hline CHEMBL 3210543 & 688810 & 5.033 & 5.3564 & TRN & & & \\
\hline CHEMBL1512069 & 688810 & \multirow{2}{*}{\multicolumn{3}{|c|}{$\begin{array}{l}4.833 \quad 5.0212 \text { TRN } \\
5.632999999999999\end{array}$}} & & & \\
\hline CHEMBL1330457 & 688810 & & & & 5.3145 & TST & \\
\hline CHEMBL1472821 & 688810 & 4.583 & 5.0034 & TST & & & \\
\hline CHEMBL1467324 & 688810 & \multicolumn{3}{|c|}{5.132999999999999} & 5.4661 & TRN & \\
\hline CHEMBL1312568 & 688810 & 5.033 & 6.1173 & TRN & & & \\
\hline CHEMBL1550861 & 688810 & 5.8329 & 99999999 & & 5.2845 & TST & \\
\hline CHEMBL1501521 & 688810 & 5.2829 & 99999999 & 995 & 5.9101 & TRN & \\
\hline CHEMBL1554517 & 688810 & 5.8329 & 99999999 & & 5.1058 & TST & \\
\hline CHEMBL1338768 & 688810 & 4.7330 & 00000000 & 005 & 5.2029 & TRN & \\
\hline
\end{tabular}




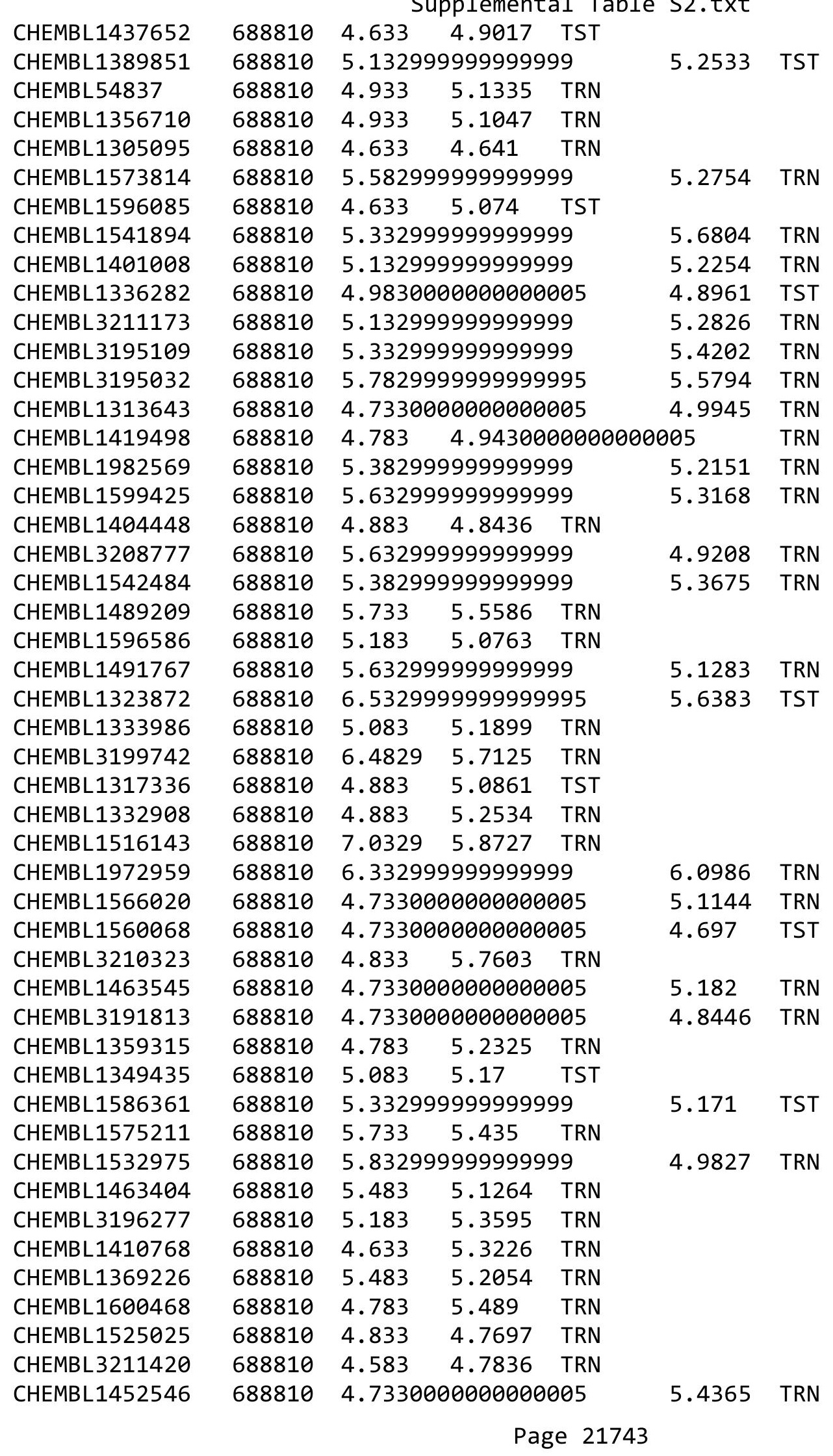




\begin{tabular}{|c|c|c|c|c|c|c|}
\hline CHEMBL1327298 & 688810 & \multicolumn{4}{|c|}{ Supplemental Table S2.txt } & TST \\
\hline CHEMBL3210407 & 688810 & 4.833 & 5.3862 & TRN & & \\
\hline CHEMBL1463161 & 688810 & 5.733 & 5.4306 & TRN & & \\
\hline CHEMBL1541652 & 688810 & 5.733 & 5.2724 & TST & & \\
\hline CHEMBL1562950 & 688810 & 4.783 & 4.9461 & TRN & & \\
\hline CHEMBL3193734 & 688810 & 4.783 & 5.1355 & TST & & \\
\hline CHEMBL1367972 & 688810 & 4.783 & 4.8234 & TST & & \\
\hline CHEMBL1522657 & 688810 & 5.683 & 5.6789 & TRN & & \\
\hline CHEMBL1531725 & 688810 & \multicolumn{3}{|c|}{4.9830000000000005} & 4.8735 & TST \\
\hline CHEMBL1306610 & 688810 & 5.683 & 4.8483 & TST & & \\
\hline CHEMBL1311421 & 688810 & 5.983 & 5.2314 & TRN & & \\
\hline CHEMBL 899 & 688810 & \multicolumn{3}{|c|}{5.632999999999999} & 5.1181 & \\
\hline CHEMBL1545127 & 688810 & 4.883 & 5.4101 & TRN & & \\
\hline CHEMBL1301015 & 688810 & 4.883 & 5.4251 & TRN & & \\
\hline CHEMBL1557595 & 688810 & 5.733 & 5.4432 & TRN & & \\
\hline CHEMBL1572968 & 688810 & 5.683 & 5.3157 & TRN & & \\
\hline CHEMBL1376718 & 688810 & 4.633 & 4.8438 & TST & & \\
\hline CHEMBL1550961 & 688810 & 4.783 & 5.075 & TST & & \\
\hline CHEMBL1545406 & 688810 & 5.733 & 5.2562 & TRN & & \\
\hline CHEMBL1479215 & 688810 & \multicolumn{3}{|c|}{5.2829999999999995} & 5.0998 & TRN \\
\hline CHEMBL1416060 & 688810 & \multicolumn{3}{|c|}{4.7330000000000005} & 5.1915 & TRN \\
\hline CHEMBL1486711 & 688810 & \multicolumn{3}{|c|}{6.2829999999999995} & 5.4405 & \\
\hline CHEMBL1572363 & 688810 & 5.733 & 5.1943 & TRN & & \\
\hline CHEMBL3194013 & 688810 & 7.3325 & 5.8931 & TRN & & \\
\hline CHEMBL1439430 & 688810 & 4.933 & 5.5205 & TRN & & \\
\hline CHEMBL1427219 & 688810 & 5.033 & 5.2116 & TRN & & \\
\hline CHEMBL1550107 & 688810 & 5.0 & 5.0061 & TRN & & \\
\hline CHEMBL1569211 & 688810 & \multicolumn{3}{|c|}{5.332999999999999} & 5.5403 & \\
\hline CHEMBL1581634 & 688810 & \multicolumn{3}{|c|}{4.9830000000000005} & 5.4243 & TRN \\
\hline CHEMBL1598581 & 688810 & \multicolumn{3}{|c|}{6.632999999999999} & 5.9441 & TRN \\
\hline CHEMBL1571136 & 688810 & \multicolumn{3}{|c|}{4.7330000000000005} & 5.1606 & \\
\hline CHEMBL1574280 & 688810 & 4.583 & 5.4739 & TST & & \\
\hline CHEMBL3189468 & 688810 & \multicolumn{3}{|c|}{5.132999999999999} & 5.7265 & TRN \\
\hline CHEMBL1438254 & 688810 & \multicolumn{3}{|c|}{4.9830000000000005} & 5.2779 & TRN \\
\hline CHEMBL1483544 & 688810 & 4.783 & 5.2147 & TST & & \\
\hline CHEMBL1452022 & 688810 & 5.483 & 5.9524 & TRN & & \\
\hline CHEMBL1602030 & 688810 & 4.833 & 4.914 & TST & & \\
\hline CHEMBL1387196 & 688810 & 4.833 & 5.2213 & TRN & & \\
\hline CHEMBL1407676 & 688810 & 5.733 & 5.4052 & TRN & & \\
\hline CHEMBL1354452 & 688810 & 4.783 & 5.6889 & TST & & \\
\hline CHEMBL1425218 & 688810 & 4.833 & 4.5332 & TST & & \\
\hline CHEMBL3198327 & 688810 & 4.933 & 5.5038 & TRN & & \\
\hline CHEMBL600090 & 688810 & 5.033 & 5.0814 & TRN & & \\
\hline CHEMBL1495848 & 688810 & 4.683 & 4.7216 & TST & & \\
\hline CHEMBL1457402 & 688810 & 5.483 & 5.8977 & TRN & & \\
\hline CHEMBL1405315 & 688810 & 5.183 & 5.2472 & TRN & & \\
\hline CHEMBL1452993 & 688810 & 4.933 & 5.0556 & TRN & & \\
\hline CHEMBL1329221 & 688810 & 6.3329 & (9999999 & & 5.2941 & J \\
\hline
\end{tabular}




\begin{tabular}{|c|c|c|c|c|c|c|}
\hline \multirow{3}{*}{$\begin{array}{l}\text { CHEMBL1514409 } \\
\text { CHEMBL1511655 }\end{array}$} & \multirow{3}{*}{$\begin{array}{l}688810 \\
688810\end{array}$} & \multicolumn{5}{|c|}{ Supplemental Table S2.txt } \\
\hline & & \multicolumn{3}{|c|}{6.632999999999999} & \multirow[t]{3}{*}{5.3193} & \multirow[t]{2}{*}{ TRN } \\
\hline & & 4.833 & 5.5268 & TRN & & \\
\hline CHEMBL1415206 & 688810 & 4.683 & 5.0165 & TST & & \\
\hline CHEMBL1492918 & 688810 & \multicolumn{3}{|c|}{6.5329999999999995} & 5.6639 & 11 \\
\hline CHEMBL1525289 & 688810 & 4.783 & 4.8922 & TRN & & \\
\hline CHEMBL1361926 & 688810 & \multicolumn{3}{|c|}{5.5329999999999995} & 5.2444 & \\
\hline CHEMBL1404262 & 688810 & 5.033 & 5.0505 & TRN & & \\
\hline CHEMBL3193031 & 688810 & 4.683 & 5.2353 & TRN & & \\
\hline CHEMBL1435667 & 588810 & 4.583 & 5.4266 & TST & & \\
\hline CHEMBL1497719 & 688810 & \multicolumn{3}{|c|}{4.9830000000000005} & 5.2568 & \\
\hline CHEMBL1446966 & 688810 & 7.1331 & 6.0306 & TRN & & \\
\hline CHEMBL3198412 & 688810 & 6.683 & 5.6085 & TST & & \\
\hline CHEMBL1526993 & 688810 & \multicolumn{3}{|c|}{4.9830000000000005} & 5.2003 & TP \\
\hline CHEMBL3191837 & 688810 & 5.083 & 5.4469 & TRN & & \\
\hline CHEMBL1431764 & 688810 & 4.783 & 5.1762 & TRN & & \\
\hline CHEMBL1312443 & 688 & 5.683 & 5.4519 & TRN & & \\
\hline CHEMBL151 & 688 & \multicolumn{3}{|c|}{6.082999999999999} & 5.1172 & $\mathrm{TS}$ \\
\hline CHEMBL1366850 & 688810 & 4.633 & 4.7047 & TST & & \\
\hline CHEMBL1386967 & 688810 & 5.433 & 5.3102 & TRN & & \\
\hline CHEMBL1556683 & 688810 & 4.833 & 4.6333 & TRN & & \\
\hline CHEMBL1: & 688 & \multicolumn{3}{|c|}{5.132999999999999} & 5.2387 & TRN \\
\hline CHEMBL1392447 & 688810 & \multicolumn{3}{|c|}{6.382999999999999} & 5.4493 & \\
\hline CHEMBL3189415 & 688810 & \multicolumn{3}{|c|}{5.582999999999999} & 4.6973 & TST \\
\hline CHEMBL1335126 & 688810 & \multicolumn{3}{|c|}{5.5329999999999995} & 663 & TRN \\
\hline CHEMBL1527091 & 688810 & \multicolumn{3}{|c|}{5.632999999999999} & 5.4649 & \\
\hline CHEMBL15 & $688 \varepsilon$ & 4.633 & 4.9469 & TRN & & \\
\hline CHEMBL1601920 & 688 & 4.833 & 5.2999 & TST & & \\
\hline CHEMBL1304209 & 688810 & 4. & 5.4119 & TST & & \\
\hline CHEMBL1609798 & 688810 & 5.2 & 5.349 & TRN & & \\
\hline CHEMBL1535952 & 688810 & 4.8 & 5.2792 & TST & & \\
\hline CHEMBL13 & 688 & 5.233 & 5.0355 & TST & & \\
\hline CHEMBL1485101 & 688810 & \multicolumn{3}{|c|}{6.7829999999999995} & 5.8438 & TRN \\
\hline CHEMBL1389975 & 688810 & \multicolumn{3}{|c|}{5.7829999999999995} & 5.9623 & ס \\
\hline CHEMBL1588726 & 688810 & 5.933 & 5.1841 & TRN & & \\
\hline CHEMBL15 & 688 & 4.883 & 4.8251 & TST & & \\
\hline CHEMBL1598561 & 688810 & \multicolumn{3}{|c|}{4.7330000000000005} & 4.777 & $\mathrm{TH}$ \\
\hline CHEMBL3190687 & 688810 & 4.583 & 5.136 & TRN & & \\
\hline CHEMBL1488237 & 688810 & 4.883 & 5.0607 & TRN & & \\
\hline CHEMBL1517195 & 688810 & 4.783 & 5.2501 & TRN & & \\
\hline CHEMBL1441118 & 688 & 4.933 & 5.5501 & TRN & & \\
\hline CHEMBL1490252 & 688810 & 5.733 & 5.5192 & TRN & & \\
\hline CHEMBL1368106 & 688810 & 4.933 & 5.6007 & TRN & & \\
\hline CHEMBL1349611 & 688810 & \multicolumn{3}{|c|}{5.2829999999999995} & 5.6408 & \\
\hline CHEMBL1319729 & 688810 & \multicolumn{3}{|c|}{5.132999999999999} & 5.2119 & \\
\hline CHEMBL1612653 & 688810 & 5.683 & 5.2169 & TRN & & \\
\hline CHEMBL2005198 & 688810 & 4.833 & 5.2329 & TRN & & \\
\hline CHEMBL1372525 & 688810 & 6.03299 & 99999999 & 995 & 5.6548 & 11 \\
\hline CHEMBL1591202 & 688810 & 5.13299 & 99999999 & & 5.6384 & \\
\hline
\end{tabular}




\begin{tabular}{|c|c|c|c|c|c|c|}
\hline \multirow[b]{2}{*}{ CHEMBL1454606 } & \multirow[b]{2}{*}{688810} & \multicolumn{5}{|c|}{ Supplemental Table S2.txt } \\
\hline & & \multicolumn{3}{|c|}{$\begin{array}{l}\text { Supplemental Ta } \\
3 \quad 5.404 \text { TRN }\end{array}$} & s2.txt & \\
\hline CHEMBL3199346 & 688810 & 5.083 & 5.22 & TRN & & \\
\hline CHEMBL1513442 & 688810 & 4.583 & 4.618 & TRN & & \\
\hline CHEMBL1530523 & 688810 & \multicolumn{3}{|c|}{6.0329999999999995} & 5.7183 & \\
\hline CHEMBL1561504 & 688810 & 4.783 & 5.3684 & TRN & & \\
\hline CHEMBL1401434 & 688810 & 4.783 & 5.1768 & TST & & \\
\hline CHEMBL1554245 & 688810 & 4.633 & 5.2846 & TRN & & \\
\hline CHEMBL1432894 & 688810 & 4.783 & 5.0958 & TST & & \\
\hline CHEMBL1402079 & 688810 & \multicolumn{3}{|c|}{4.7330000000000005} & 5.1564 & TST \\
\hline CHEMBL1392461 & 688810 & 4.783 & 5.2022 & TST & & \\
\hline CHEMBL1419009 & 688810 & \multicolumn{3}{|c|}{5.5329999999999995} & 5.0602 & ThN \\
\hline CHEMBL1404118 & 688810 & \multicolumn{3}{|c|}{6.332999999999999} & 4.9317 & \\
\hline CHEMBL1385232 & 688810 & \multicolumn{3}{|c|}{4.7330000000000005} & 5.1143 & \\
\hline CHEMBL1521960 & 688810 & \multicolumn{3}{|c|}{6.2829999999999995} & 5.4879 & \\
\hline CHEMBL1433211 & 688810 & 5.033 & 4.9907 & TRN & & \\
\hline CHEMBL 3210221 & 688810 & 4.883 & 5.3258 & TST & & \\
\hline CHEMBL1409463 & 688810 & 4.833 & 5.2397 & TRN & & \\
\hline CHEMBL1538625 & 688810 & \multicolumn{3}{|c|}{5.132999999999999} & 5.4917 & \\
\hline CHEMBL14 & 688810 & 4.683 & 5.2036 & TST & & \\
\hline CHEMBL1516663 & 688810 & 4.583 & 5.4568 & TST & & \\
\hline CHEMBL1437704 & 688810 & \multicolumn{3}{|c|}{5.5329999999999995} & 5.3614 & \\
\hline CHEMBL1591111 & 688810 & \multicolumn{3}{|c|}{4.7330000000000005} & 4.7573 & \\
\hline CHEMBL19€ & 688810 & \multicolumn{3}{|c|}{4.9830000000000005} & 5.3192 & \\
\hline CHEMBL14 & 688810 & 4.883 & 5.024 & TRN & & \\
\hline CHEMBL1589981 & 688810 & \multicolumn{3}{|c|}{5.132999999999999} & 5.8328 & $\mathrm{TI}$ \\
\hline CHEMBL1483408 & 688810 & 4.783 & 5.0304 & TRN & & \\
\hline CHEMBL1466206 & 688810 & \multicolumn{3}{|c|}{6.382999999999999} & .4045 & \\
\hline CHEMBL14 & 688810 & \multicolumn{3}{|c|}{6.582999999999999} & 5.4894 & \\
\hline CHEMBL1303177 & 688810 & 5.683 & 5.4046 & TST & & \\
\hline CHEMBL1432287 & 688810 & \multicolumn{3}{|c|}{6.382999999999999} & 5.6315 & TRN \\
\hline CHEMBL1310704 & 688810 & \multicolumn{3}{|c|}{4.9830000000000005} & 5.0806 & \\
\hline CHEMBL1513061 & 688810 & \multicolumn{3}{|c|}{5.632999999999999} & 5.1337 & \\
\hline CHEMBL13. & 688810 & 4.7336 & 0000000 & 005 & 4.6625 & \\
\hline CHEMBL1356586 & 688810 & 4.633 & 4.8318 & TRN & & \\
\hline CHEMBL1551484 & 688810 & 4.833 & 5.0123 & TRN & & \\
\hline CHEMBL1548164 & 688810 & 5.183 & 5.3099 & TRN & & \\
\hline CHEMBL13 & 688810 & 4.9836 & 00000006 & 005 & 5.1425 & ThN \\
\hline CHEMBL1305680 & 688810 & 5.1325 & 999999 & & 5.3435 & TRN \\
\hline CHEMBL1586846 & 688810 & 5.832 & 9999999 & & 5.7135 & TRN \\
\hline CHEMBL1534905 & 688810 & 4.9836 & 0000000 & 005 & 5.0479 & TRN \\
\hline CHEMBL1571615 & 688810 & 5.132 & 99999995 & & 5.8463 & \\
\hline CHEMBL3192153 & 688810 & 5.733 & 4.7552 & TRN & & \\
\hline CHEMBL1562079 & 688810 & 5.183 & 6.1284 & TRN & & \\
\hline CHEMBL1606532 & 688810 & 4.883 & 4.7318 & TST & & \\
\hline CHEMBL1578888 & 688810 & 5.632 & 99999995 & & 5.7649 & TKN \\
\hline CHEMBL3191967 & 688810 & $6.782 \mathrm{~s}$ & 99999995 & 995 & 5.9279 & $-\pi$ \\
\hline CHEMBL1574154 & 688810 & 5.132 & 9999999 & & 5.151 & 促 \\
\hline CHEMBL1559427 & 688810 & 4.9836 & 0000000 & 005 & 4.9122 & \\
\hline
\end{tabular}




\begin{tabular}{|c|c|c|c|c|c|c|}
\hline \multicolumn{7}{|c|}{ Supplemental Table S2.txt } \\
\hline CHEMBL1304601 & 688810 & \multicolumn{3}{|c|}{4.7330000000000005} & 5.6491 & TRN \\
\hline CHEMBL1507028 & 688810 & 5.233 & 5.3496 & TRN & & \\
\hline CHEMBL1515703 & 688810 & \multicolumn{3}{|c|}{4.7330000000000005} & 4.8744 & TRN \\
\hline CHEMBL1529450 & 688810 & 4.933 & 6.2143 & TRN & & \\
\hline CHEMBL1420450 & 688810 & \multicolumn{3}{|c|}{5.132999999999999} & 4.9237 & TRN \\
\hline CHEMBL1489617 & 688810 & \multicolumn{3}{|c|}{5.332999999999999} & 5.4276 & TRN \\
\hline CHEMBL1503635 & 688810 & 4.633 & 4.8587 & TST & & \\
\hline CHEMBL1315574 & 688810 & 5.233 & 6.0683 & TRN & & \\
\hline CHEMBL1399521 & 688810 & \multicolumn{3}{|c|}{5.632999999999999} & 5.1094 & TRN \\
\hline CHEMBL1365226 & 688810 & 4.783 & 5.0203 & TST & & \\
\hline CHEMBL1406194 & 688810 & 4.633 & 5.3457 & TRN & & \\
\hline CHEMBL1375371 & 688810 & 5.433 & 5.1711 & TST & & \\
\hline CHEMBL1612673 & 688810 & \multicolumn{3}{|c|}{5.882999999999999} & 5.4054 & TRN \\
\hline CHEMBL1564416 & 688810 & \multicolumn{3}{|c|}{6.2829999999999995} & 5.5157 & TRN \\
\hline CHEMBL1571459 & 688810 & \multicolumn{3}{|c|}{6.0329999999999995} & 5.2453 & TRN \\
\hline CHEMBL1403424 & 688810 & \multicolumn{3}{|c|}{5.2829999999999995} & 5.28100 & 0000000001 \\
\hline CHEMBL1449707 & 688810 & \multicolumn{3}{|c|}{5.832999999999999} & 5.3215 & TST \\
\hline CHEMBL1444426 & 688810 & 4.883 & 5.0337 & TRN & & \\
\hline CHEMBL1570390 & 688810 & 4.683 & 4.8954 & TST & & \\
\hline CHEMBL1402185 & 688810 & 5.183 & 5.4964 & TRN & & \\
\hline CHEMBL1321450 & 688810 & 6.7331 & 6.2798 & TRN & & \\
\hline CHEMBL1536629 & 688810 & 4.783 & 4.6741 & TST & & \\
\hline CHEMBL1464666 & 688810 & 5.683 & 5.4634 & TRN & & \\
\hline CHEMBL1336550 & 688810 & 5.433 & 5.4562 & TRN & & \\
\hline CHEMBL3211541 & 688810 & 4.783 & 5.4501 & TRN & & \\
\hline CHEMBL 3190035 & 688810 & 5.733 & 5.1463 & TST & & \\
\hline CHEMBL 1602567 & 688810 & \multicolumn{3}{|c|}{5.2829999999999995} & 5.989 & TRN \\
\hline CHEMBL1372424 & 688810 & 4.833 & 5.0577 & TRN & & \\
\hline CHEMBL1396001 & 688810 & 4.883 & 5.2452 & TRN & & \\
\hline CHEMBL 3192188 & 688810 & 4.933 & 5.0554 & TRN & & \\
\hline CHEMBL1492914 & 688810 & 4.783 & 5.05399 & 999999999 & 99 & TST \\
\hline CHEMBL1517238 & 688810 & \multicolumn{3}{|c|}{5.132999999999999} & 5.0101 & TRN \\
\hline CHEMBL1384671 & 688810 & 5.483 & 5.2533 & TST & & \\
\hline CHEMBL1353463 & 688810 & \multicolumn{3}{|c|}{5.132999999999999} & 5.5752 & TRN \\
\hline CHEMBL1415218 & 688810 & 5.183 & 5.1906 & TRN & & \\
\hline CHEMBL1362868 & 688810 & 4.833 & 4.9407 & TST & & \\
\hline CHEMBL1569856 & 688810 & \multicolumn{3}{|c|}{4.7330000000000005} & 5.1129 & TST \\
\hline CHEMBL1362825 & 688810 & 4.633 & 4.8247 & TRN & & \\
\hline CHEMBL1352240 & 688810 & \multicolumn{3}{|c|}{5.2829999999999995} & 5.0739 & TST \\
\hline CHEMBL1519587 & 688810 & \multicolumn{3}{|c|}{5.5329999999999995} & 4.7601 & TRN \\
\hline CHEMBL1555000 & 688810 & 4.783 & 5.5958 & TRN & & \\
\hline CHEMBL1374953 & 688810 & 4.833 & 4.8414 & TRN & & \\
\hline CHEMBL1324559 & 688810 & 7.1831 & 5.9939 & TRN & & \\
\hline CHEMBL1377129 & 688810 & 4.883 & 5.0918 & TST & & \\
\hline CHEMBL3197570 & 688810 & 5.733 & 5.5049 & TST & & \\
\hline CHEMBL1451617 & 688810 & \multicolumn{3}{|c|}{6.382999999999999} & 5.8741 & TRN \\
\hline CHEMBL1577782 & 688810 & 5.033 & 5.0589 & TRN & & \\
\hline CHEMBL1559669 & 688810 & 5.733 & 5.5212 & TRN & & \\
\hline
\end{tabular}




\begin{tabular}{|c|c|c|c|c|c|c|}
\hline & & \multicolumn{5}{|c|}{ Supplemental Table s2.txt } \\
\hline CHEMBL1444863 & 688810 & 4.883 & 5.0187 & TRN & & \\
\hline CHEMBL1420730 & 688810 & 4.833 & 5.1773 & TRN & & \\
\hline CHEMBL1393222 & 688810 & 5.083 & 5.0009 & TST & & \\
\hline CHEMBL1606973 & 688810 & \multicolumn{3}{|c|}{5.382999999999999} & 5.2871 & TRN \\
\hline CHEMBL1390302 & 688810 & \multicolumn{3}{|c|}{5.382999999999999} & 5.5116 & TRN \\
\hline CHEMBL1600598 & 688810 & \multicolumn{3}{|c|}{5.632999999999999} & 5.6624 & TRN \\
\hline CHEMBL1609792 & 688810 & 6.433 & 5.7684 & TRN & & \\
\hline CHEMBL1521562 & 688810 & \multicolumn{3}{|c|}{5.632999999999999} & 5.4856 & TRN \\
\hline CHEMBL1454063 & 688810 & 5.733 & 5.3272 & TRN & & \\
\hline CHEMBL1467985 & 688810 & 5.183 & 5.2989 & TRN & & \\
\hline CHEMBL1483215 & 688810 & 4.883 & 5.3855 & TRN & & \\
\hline CHEMBL1564710 & 688810 & \multicolumn{3}{|c|}{4.7330000000000005} & 5.2969 & TRN \\
\hline CHEMBL1393496 & 688810 & 5.233 & 5.0658 & TRN & & \\
\hline CHEMBL1432127 & 688810 & 5.483 & 5.1193 & TRN & & \\
\hline CHEMBL1332491 & 688810 & 5.983 & 5.4886 & TRN & & \\
\hline CHEMBL1356053 & 688810 & \multicolumn{3}{|c|}{5.382999999999999} & 4.8628 & TST \\
\hline CHEMBL1318793 & 688810 & \multicolumn{3}{|c|}{5.882999999999999} & 5.3351 & TRN \\
\hline CHEMBL1411970 & 688810 & 4.583 & 5.0341 & TRN & & \\
\hline CHEMBL1334219 & 688810 & 4.583 & 5.2655 & TST & & \\
\hline CHEMBL1303471 & 688810 & \multicolumn{3}{|c|}{5.132999999999999} & 5.4873 & TST \\
\hline CHEMBL1496902 & 688810 & 4.833 & 5.3302 & TRN & & \\
\hline CHEMBL1353287 & 688810 & 4.783 & 5.1365 & TRN & & \\
\hline CHEMBL1403604 & 688810 & \multicolumn{3}{|c|}{5.382999999999999} & 5.1415 & TRN \\
\hline CHEMBL1361693 & 688810 & 5.683 & 5.5444 & TRN & & \\
\hline CHEMBL1342090 & 688810 & 5.033 & 5.2038 & TRN & & \\
\hline CHEMBL1564326 & 688810 & 5.733 & 5.7904 & TRN & & \\
\hline CHEMBL1361994 & 688810 & \multicolumn{3}{|c|}{6.582999999999999} & 5.7915 & TST \\
\hline CHEMBL1456371 & 688810 & 4.833 & 4.9909 & TST & & \\
\hline CHEMBL1465311 & 688810 & \multicolumn{3}{|c|}{4.7330000000000005} & 5.3027 & TRN \\
\hline CHEMBL1519234 & 688810 & 4.683 & 5.1234 & TRN & & \\
\hline CHEMBL1487567 & 688810 & 4.583 & 4.92899 & 999999999 & & TST \\
\hline CHEMBL1432642 & 688810 & 4.633 & 5.0868 & TRN & & \\
\hline CHEMBL1598707 & 688810 & 4.833 & 5.7818 & TRN & & \\
\hline CHEMBL1405288 & 688810 & 5.183 & 5.3347 & TST & & \\
\hline CHEMBL1300493 & 688810 & \multicolumn{3}{|c|}{6.582999999999999} & 6.1382 & TRN \\
\hline CHEMBL1485687 & 688810 & \multicolumn{3}{|c|}{4.7330000000000005} & 5.3013 & TST \\
\hline CHEMBL1443655 & 688810 & 4.833 & 4.7601 & TRN & & \\
\hline CHEMBL1523501 & 688810 & \multicolumn{3}{|c|}{6.632999999999999} & 5.8661 & TRN \\
\hline CHEMBL1549591 & 688810 & 4.783 & 5.2637 & TRN & & \\
\hline CHEMBL1572082 & 688810 & 5.433 & 5.0284 & TRN & & \\
\hline CHEMBL3192001 & 688810 & \multicolumn{3}{|c|}{5.2829999999999995} & 5.0709 & TRN \\
\hline CHEMBL1505937 & 688810 & 7.0329 & 6.0915 & TRN & & \\
\hline CHEMBL1306017 & 688810 & 4.883 & 5.2642 & TRN & & \\
\hline CHEMBL1493385 & 688810 & 5.683 & 5.0517 & TRN & & \\
\hline CHEMBL1608480 & 688810 & 4.783 & 5.6042 & TRN & & \\
\hline CHEMBL1359492 & 688810 & 4.883 & 5.5294 & TRN & & \\
\hline CHEMBL3209413 & 688810 & 5.033 & 5.2364 & TRN & & \\
\hline CHEMBL1407924 & 688810 & 4.783 & 5.1983 & TRN & & \\
\hline
\end{tabular}




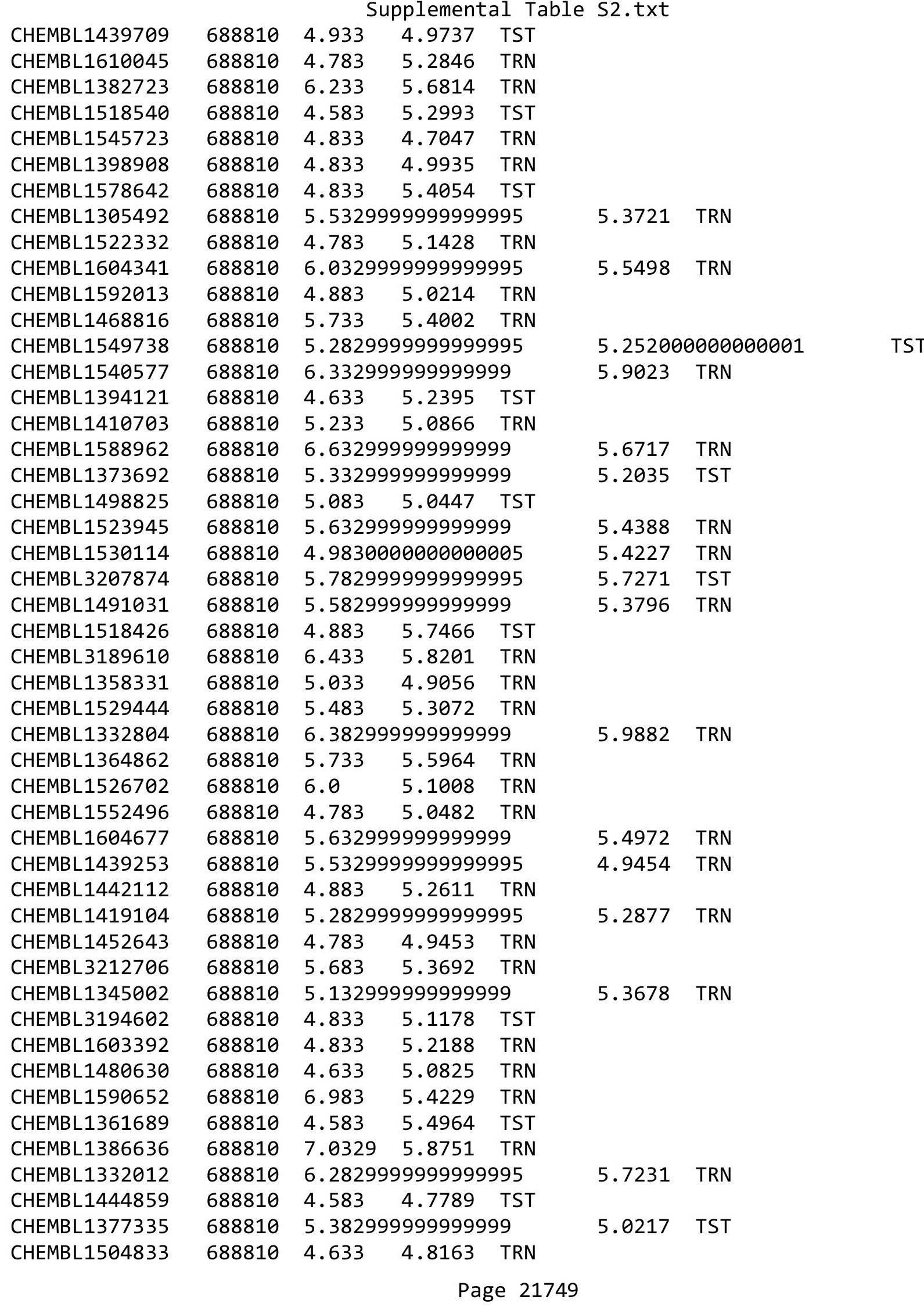




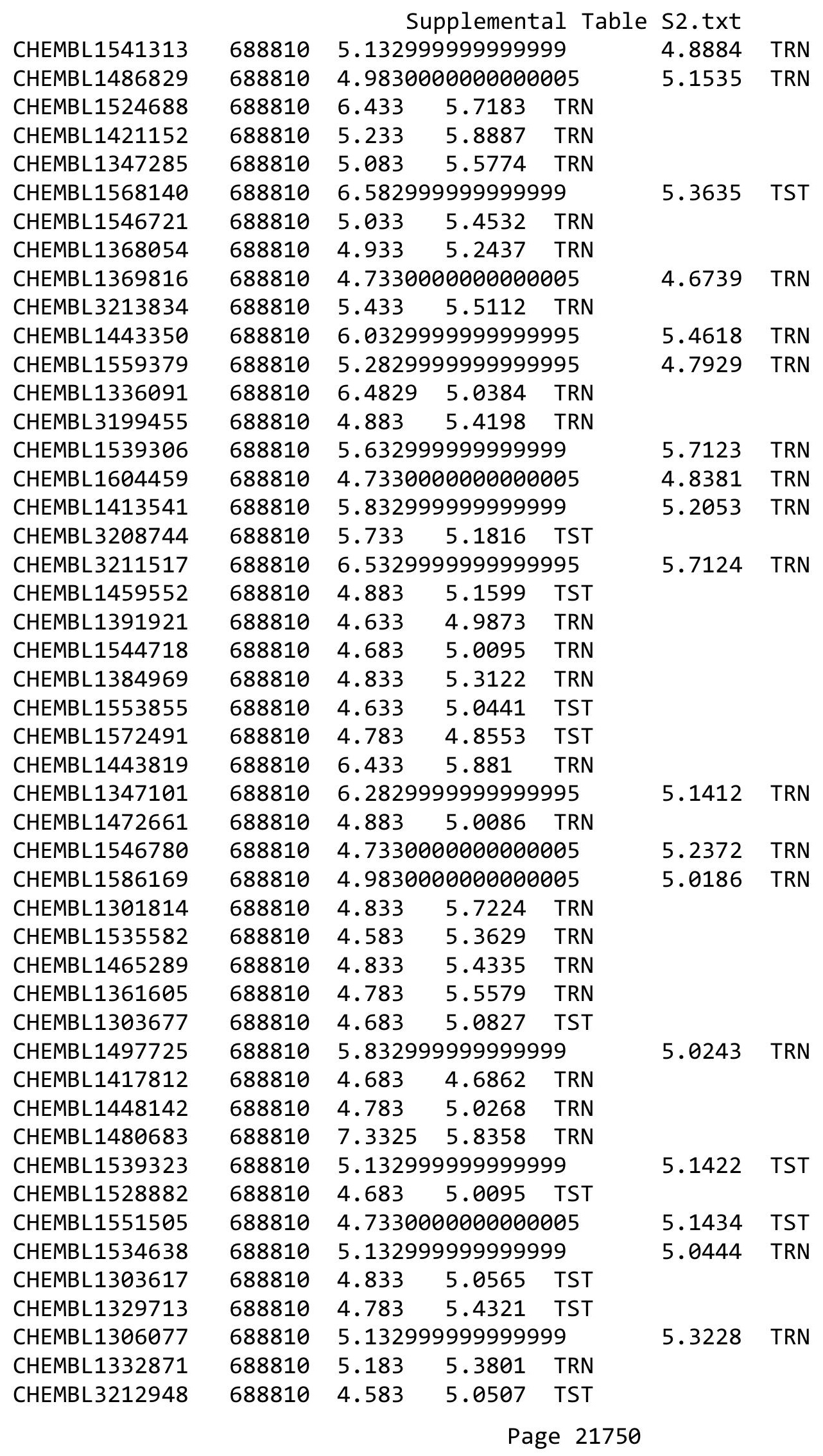




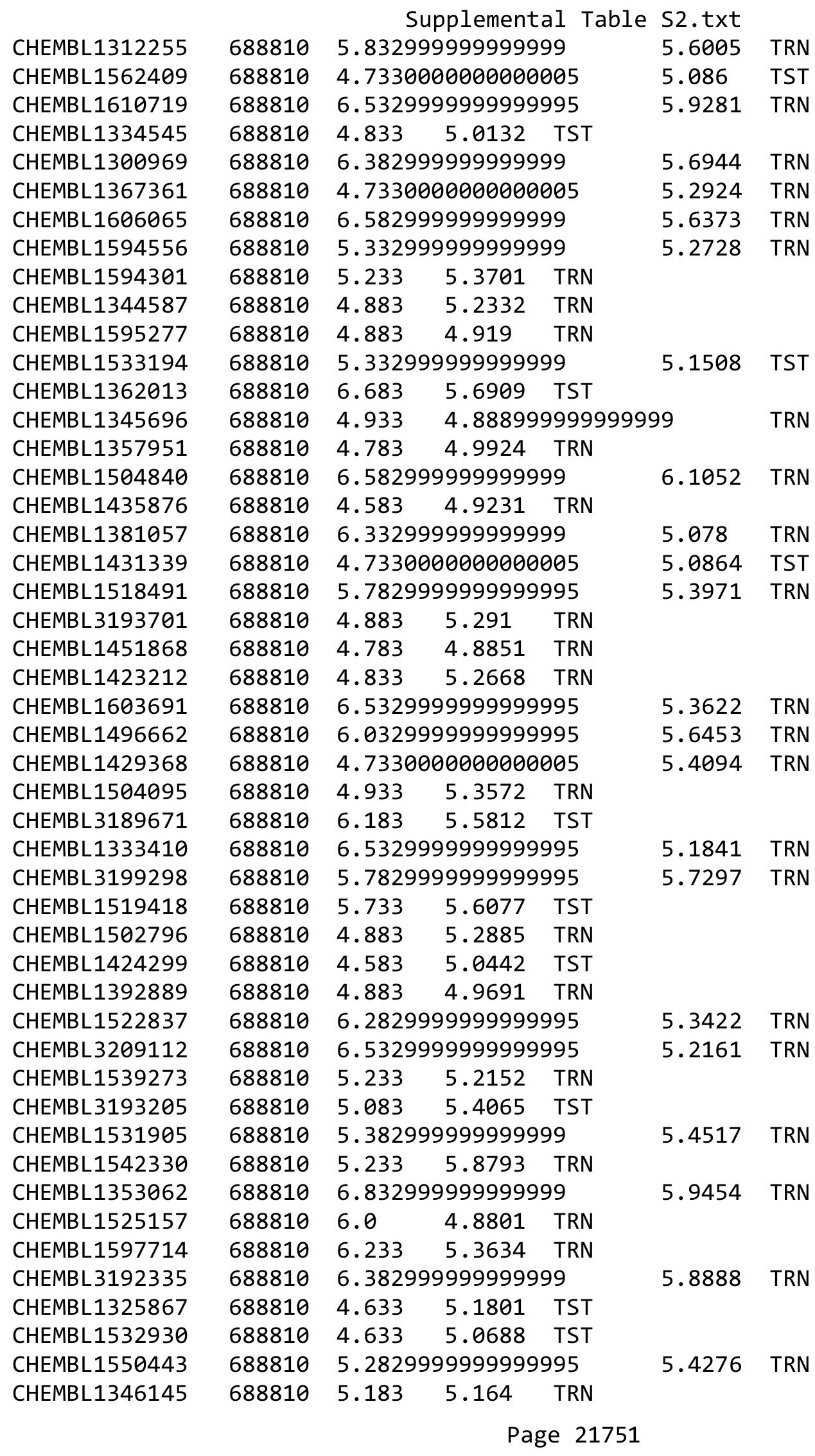




\begin{tabular}{|c|c|c|c|c|c|c|}
\hline \multirow[b]{2}{*}{ CHEMBL1422949 } & \multicolumn{6}{|c|}{ Supplemental Table S2.txt } \\
\hline & 688810 & 5.183 & 5.3727 & TRN & & \\
\hline CHEMBL1609339 & 688810 & 4.883 & 5.451000 & 30000 & 305 & 10 \\
\hline CHEMBL1336396 & 688810 & 4.883 & 5.1032 & TST & & \\
\hline CHEMBL1448265 & 688810 & 4.73300 & 000000000 & 305 & 5.1805 & \\
\hline CHEMBL1328862 & 688810 & 5.13299 & 999999999 & & 5.5533 & \\
\hline CHEMBL1361922 & 688810 & 6.683 & 6.4524 & TRN & & \\
\hline CHEMBL1542854 & 688810 & 5.53299 & 999999999 & 995 & 5.6384 & \\
\hline CHEMBL1454434 & 688810 & 4.783 & 5.2998 & TRN & & \\
\hline CHEMBL1413981 & 688810 & 4.98300 & 000000000 & 305 & 5.3809 & \\
\hline CHEMBL1541656 & 688810 & 4.683 & 4.8914 & TST & & \\
\hline CHEMBL1328660 & 688810 & 5.88299 & 999999999 & & 5.0804 & \\
\hline CHEMBL1407627 & 688810 & 4.633 & 4.698 & TRN & & \\
\hline CHEMBL1479458 & 688810 & 4.783 & 4.9657 & TRN & & \\
\hline CHEMBL531710 & 688810 & 6.8831 & 5.8638 & TRN & & \\
\hline CHEMBL1523699 & 688810 & 4.833 & 5.0434 & TRN & & \\
\hline CHEMBL 3210574 & 688810 & 6.28299 & 999999999 & 995 & 5.3537 & \\
\hline CHEMBL1416349 & 688810 & 5.33299 & 999999999 & & 4.7631 & \\
\hline CHEMBL1421759 & 688810 & 4.833 & 5.0951 & TST & & \\
\hline CHEMBL1389263 & 688810 & 4.783 & 5.206 & TST & & \\
\hline CHEMBL1509879 & 688810 & 4.833 & 5.1075 & TRN & & \\
\hline CHEMBL1480093 & 688810 & 4.98300 & 000000000 & 305 & 801 & \\
\hline CHEMBL 3191007 & 688810 & 4.783 & 4.8979 & TST & & \\
\hline CHEMBL1388208 & 688810 & 4.683 & 5.0044 & TST & & \\
\hline CHEMBL1414261 & 688810 & 4.833 & 5.4312 & TRN & & \\
\hline CHEMBL1341130 & 688810 & 4.883 & 5.0906 & TST & & \\
\hline CHEMBL3209299 & 688810 & 4.583 & 5.3724 & TRN & & \\
\hline CHEMBL1608068 & 688810 & 5.58299 & 999999999 & & 4.6318 & \\
\hline CHEMBL1557161 & 688810 & 5.13299 & 999999999 & & 4.9964 & \\
\hline CHEMBL1501634 & 688810 & 5.033 & 4.8764 & TRN & & \\
\hline CHEMBL1536260 & 688810 & 5.033 & 5.1069 & TRN & & \\
\hline CHEMBL1545349 & 688810 & 5.38299 & 999999999 & & 5.0182 & \\
\hline CHEMBL1592917 & 688810 & 4.633 & 4.9805 & TRN & & \\
\hline CHEMBL1369358 & 688810 & 5.83299 & 999999999 & & 5.5025 & \\
\hline CHEMBL1354555 & 688810 & 5.183 & 5.5347 & TRN & & \\
\hline CHEMBL1476992 & 688810 & 4.583 & 5.0113 & TRN & & \\
\hline CHEMBL 3192360 & 688810 & 5.13299 & 999999999 & 99 & 4.9645 & \\
\hline CHEMBL 3198998 & 688810 & 5.433 & 5.4841 & TRN & & \\
\hline CHEMBL1501064 & 688810 & 6.433 & 5.5417 & TRN & & \\
\hline CHEMBL1419454 & 688810 & 5.233 & 4.8365 & TRN & & \\
\hline CHEMBL1473242 & 688810 & 5.733 & 5.411000 & 0000 & 305 & \\
\hline CHEMBL1517741 & 688810 & 5.433 & 5.416 & TRN & & \\
\hline CHEMBL1505212 & 688810 & 5.78299 & 999999999 & 995 & 5.4049 & \\
\hline CHEMBL1606047 & 688810 & 5.683 & 5.3851 & TRN & & \\
\hline CHEMBL1536821 & 688810 & 4.933 & 5.2 & TST & & \\
\hline CHEMBL1338689 & 688810 & 5.233 & 5.3027 & TRN & & \\
\hline CHEMBL1476311 & 688810 & 5.78299 & 999999999 & 995 & 5.355 & \\
\hline CHEMBL1349604 & 688810 & 5.933 & 5.4375 & TRN & & \\
\hline CHEMBL1463624 & 688810 & 6.433 & 5.2068 & TRN & & \\
\hline
\end{tabular}




\begin{tabular}{|c|c|c|c|c|c|c|}
\hline \multirow{2}{*}{ CHEMBL1420003 } & \multirow{3}{*}{$\begin{array}{l}688810 \\
688810\end{array}$} & \multicolumn{5}{|c|}{ Supplemental Table s2.txt } \\
\hline & & \multicolumn{3}{|c|}{4.7330000000000005} & \multirow[t]{2}{*}{5.215} & \multirow[t]{2}{*}{ TRN } \\
\hline CHEMBL1999900 & & 5.933 & 5.7639 & TST & & \\
\hline CHEMBL1610702 & 688810 & \multicolumn{3}{|c|}{5.7829999999999995} & 6.1093 & This \\
\hline CHEMBL1403657 & 588810 & \multicolumn{3}{|c|}{5.632999999999999} & 5.31 & \\
\hline CHEMBL1563099 & 688810 & \multicolumn{3}{|c|}{6.382999999999999} & 5.4371 & \\
\hline CHEMBL1595408 & 688810 & 5.733 & 5.6421 & TRN & & \\
\hline CHEMBL1375572 & 588810 & \multicolumn{3}{|c|}{4.9830000000000005} & 5.1537 & TST \\
\hline CHEMBL1491944 & 688810 & \multicolumn{3}{|c|}{6.382999999999999} & 5.61 & \\
\hline CHEMBL1365620 & 688810 & 5.183 & 5.3783 & TRN & & \\
\hline CHEMBL1517940 & 688810 & \multicolumn{3}{|c|}{5.582999999999999} & 5.1171 & TRN \\
\hline CHEMBL1384000 & 588810 & \multicolumn{3}{|c|}{4.7330000000000005} & 5.065 & \\
\hline CHEMBL1381495 & 688810 & 4.783 & 5.3914 & TST & & \\
\hline CHEMBL1467225 & 688810 & 4.633 & 4.8783 & TST & & \\
\hline CHEMBL1403939 & 588810 & 5.083 & 4.8293 & TRN & & \\
\hline CHEMBL3190911 & 588810 & 5.233 & 5.3256 & TST & & \\
\hline HEMBL1535436 & 588810 & \multicolumn{3}{|c|}{6.082999999999999} & 5.5258 & TRN \\
\hline CHEMBL1562224 & 688810 & \multicolumn{3}{|c|}{4.7330000000000005} & & \\
\hline CHEMBL14 & 688810 & 4.783 & 5.1163 & TRN & & \\
\hline HEMBL1 & 688810 & \multirow{2}{*}{\multicolumn{3}{|c|}{$\begin{array}{l}4.633 \\
4.7330000000000005\end{array}$}} & & \\
\hline CHEMBL3190258 & 688810 & & & & 5.1957 & $1 / \mathrm{K}$ \\
\hline CHEMBL1549158 & 688810 & 4.883 & 4.9208 & TRN & & \\
\hline CHEMBL1470446 & 688810 & & 5.063 & TST & & \\
\hline CHEMBL] & 688 & 4.633 & 4.7543 & TRN & & \\
\hline CHEMBL13: & 688810 & \multicolumn{3}{|c|}{4.7330000000000005} & 5.1197 & $\mathrm{~T}$ \\
\hline CHEMBL1560901 & 688810 & 4.933 & 5.1545 & TRN & & \\
\hline CHEMBL1383475 & 688810 & \multicolumn{3}{|c|}{5.882999999999999} & 5.4079 & TST \\
\hline CHEMBL1488034 & 688810 & \multicolumn{3}{|c|}{5.382999999999999} & 5.3801 & \\
\hline CHEMBL] & 688 & 4.833 & 4.8551 & TST & & \\
\hline CHEMBL19 & 10 & \multirow{2}{*}{\multicolumn{3}{|c|}{ 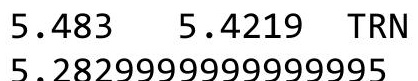 }} & & \\
\hline CHEMBL3209281 & 688810 & & & & 569 & TR \\
\hline CHEMBL1431651 & 688810 & \multicolumn{3}{|c|}{$4.833 \quad 5.1859 \quad$ TRN } & & \\
\hline CHEMBL1405405 & 688810 & 5.2829 & 99999999 & 995 & 5.2336 & 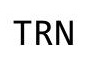 \\
\hline CHEMBL & 688 & 4.833 & 5.2274 & TST & & \\
\hline CHEMBL1411758 & 688810 & 5.5829 & 99999999 & & 4.9751 & TRN \\
\hline CHEMBL1378056 & 688810 & 4.7330 & 20000000 & 005 & 5.178 & TRN \\
\hline CHEMBL3209300 & 688810 & 5.3329 & 99999999 & & 5.5458 & TR \\
\hline CHEMBL 3210292 & 688810 & 4.883 & 5.3306 & TRN & & \\
\hline CHEMBL & 688 & 5.033 & 5.2895 & TRN & & \\
\hline CHEMBL1483226 & 688810 & 6.0829 & 99999999 & & 5.4877 & TRN \\
\hline CHEMBL1537781 & 688810 & 6.5829 & 99999999 & & 6.0387 & $\mathrm{TR}$ \\
\hline CHEMBL1451732 & 688810 & 5.233 & 5.3755 & TST & & \\
\hline CHEMBL1466147 & 688810 & 5.733 & 5.9955 & TRN & & \\
\hline CHEMBL1494792 & 688810 & 5.6329 & 99999999 & & 5.525 & TRN \\
\hline CHEMBL3191383 & 688810 & 5.5329 & 99999999 & 995 & 5.4337 & $T C T$ \\
\hline CHEMBL1321054 & 688810 & 5.733 & 5.1824 & TRN & & \\
\hline CHEMBL1386881 & 688810 & 4.633 & 4.7495 & TRN & & \\
\hline CHEMBL1440751 & 688810 & 5.183 & 4.9297 & TRN & & \\
\hline CHEMBL1528829 & 688810 & 5.3329 & 99999999 & & 5.1459 & 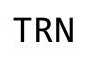 \\
\hline
\end{tabular}




\begin{tabular}{|c|c|c|c|c|c|c|}
\hline \multirow[b]{2}{*}{ CHEMBL1452933 } & & \multicolumn{5}{|c|}{ Supplemental Table S2.txt } \\
\hline & 688810 & 5.483 & \multicolumn{3}{|c|}{5.906000000000001} & TRN \\
\hline CHEMBL1312290 & 688810 & \multicolumn{3}{|c|}{5.332999999999999} & 5.1541 & TST \\
\hline CHEMBL241608 & 688810 & \multicolumn{3}{|c|}{5.832999999999999} & 5.6273 & TRN \\
\hline CHEMBL3198373 & 688810 & \multicolumn{3}{|c|}{6.332999999999999} & 5.4262 & \\
\hline CHEMBL1490067 & 688810 & 4.783 & 5.1951 & TRN & & \\
\hline CHEMBL1415918 & 588810 & 4.883 & 4.993 & TST & & \\
\hline CHEMBL1495817 & 588810 & .933 & 5.1744 & TRN & & \\
\hline CHEMBL1522042 & 688810 & \multicolumn{3}{|c|}{5.2829999999999995} & 5.428 & TR \\
\hline CHEMBL1599863 & 688810 & \multicolumn{3}{|c|}{6.2829999999999995} & 5.3528 & \\
\hline CHEMBL1361085 & 688810 & 5.083 & 5.3398 & TRN & & \\
\hline CHEMBL1594810 & 688810 & 5.483 & 5.5947 & TRN & & \\
\hline CHEMBL1490377 & 688810 & \multicolumn{3}{|c|}{6.332999999999999} & 2419 & \\
\hline CHEMBL1597030 & 688810 & 4.783 & 5.2237 & TRN & & \\
\hline CHEMBL1472925 & 688810 & 6.8831 & 6.3372 & TRN & & \\
\hline CHEMBL1489567 & 688810 & \multicolumn{3}{|c|}{6.632999999999999} & 5.4077 & \\
\hline CHEMBL1552413 & 688810 & 4.783 & 5.0343 & TRN & & \\
\hline CHEMBL3190181 & 688810 & \multicolumn{3}{|c|}{5.332999999999999} & 033 & \\
\hline CHEMBL1 & 688810 & 4.883 & 5.2604 & TRN & & \\
\hline CHEMBL1 & 688810 & 4.683 & 4.8567 & TRN & & \\
\hline CHEMBL 3198788 & 688810 & \multicolumn{3}{|c|}{5.832999999999999} & 4654 & \\
\hline CHEMBL1566735 & 688810 & 4.933 & 5.2983 & TRN & & \\
\hline CHEMBL1407489 & 688810 & \multicolumn{3}{|c|}{6.5329999999999995} & 5.2703 & \\
\hline CHEMBL1 & 688810 & 4.683 & 4.9417 & TST & & \\
\hline CHEMBL1 & 688810 & 325 & 5.8411 & TST & & \\
\hline CHEMBL1340266 & 688810 & 5.7 & 5.8106 & TST & & \\
\hline CHEMBL1357166 & 688810 & & 4.86 & TRN & & \\
\hline CHEMBL1 & 688810 & $4 . \varepsilon$ & 5.1288 & TST & & \\
\hline CHEMBL1 & 688810 & 5.2 & 5.3216 & TRN & & \\
\hline CHEMBL & 688810 & 5.083 & 5.4366 & TRN & & \\
\hline CHEMBL1453812 & 688810 & \multicolumn{3}{|c|}{5.5329999999999995} & 5.4112 & TP \\
\hline CHEMBL1429579 & 688810 & 4.883 & 4.8643 & TRN & & \\
\hline CHEMBL: & 688810 & & 5.2532 & TST & & \\
\hline CHEMBL 2 & 688810 & 4.833 & 5.4817 & TRN & & \\
\hline CHEMBL1497097 & 688810 & \multicolumn{3}{|c|}{5.5329999999999995} & 5.5648 & TR \\
\hline CHEMBL1414254 & 688810 & \multicolumn{3}{|c|}{5.832999999999999} & 5.5214 & \\
\hline CHEMBL1570079 & 688810 & 5.033 & 5.434 & TRN & & \\
\hline CHEMBL15 & 688810 & 5.033 & 4.8846 & TRN & & \\
\hline CHEMBL3196616 & 688810 & \multicolumn{3}{|c|}{5.832999999999999} & 5.5989 & $\mathrm{TI}$ \\
\hline CHEMBL1377269 & 688810 & 4.883 & 5.113 & TRN & & \\
\hline CHEMBL1531778 & 688810 & \multicolumn{3}{|c|}{5.832999999999999} & 5.7879 & TR \\
\hline CHEMBL1602151 & 688810 & \multicolumn{3}{|c|}{5.582999999999999} & 5.2815 & \\
\hline CHEMBL1384167 & 688810 & \multicolumn{3}{|c|}{5.5329999999999995} & 5.3321 & \\
\hline CHEMBL1494376 & 688810 & 4.933 & 5.6227 & TRN & & \\
\hline CHEMBL1412155 & 688810 & \multicolumn{3}{|c|}{4.7330000000000005} & 5.0192 & \\
\hline CHEMBL1333766 & 688810 & 6.3329 & 99999999 & & 5.7554 & \\
\hline CHEMBL1493656 & 688810 & 5.3329 & 99999999 & & 5.2018 & \\
\hline CHEMBL3198860 & 688810 & 6.3329 & 99999999 & & 5.309 & \\
\hline CHEMBL1528034 & 688810 & 4.7330 & 00000000 & & 5.3661 & \\
\hline
\end{tabular}




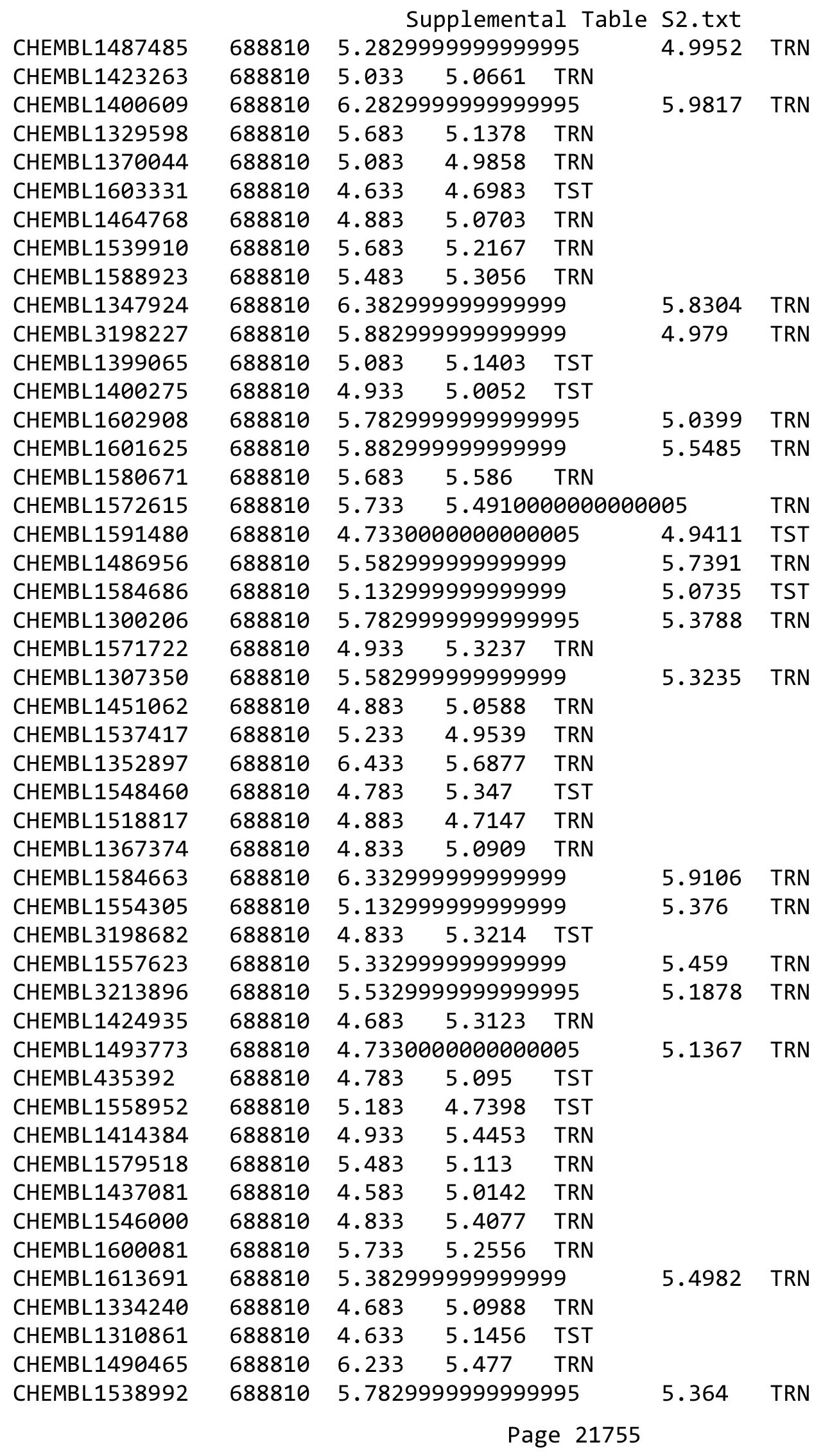




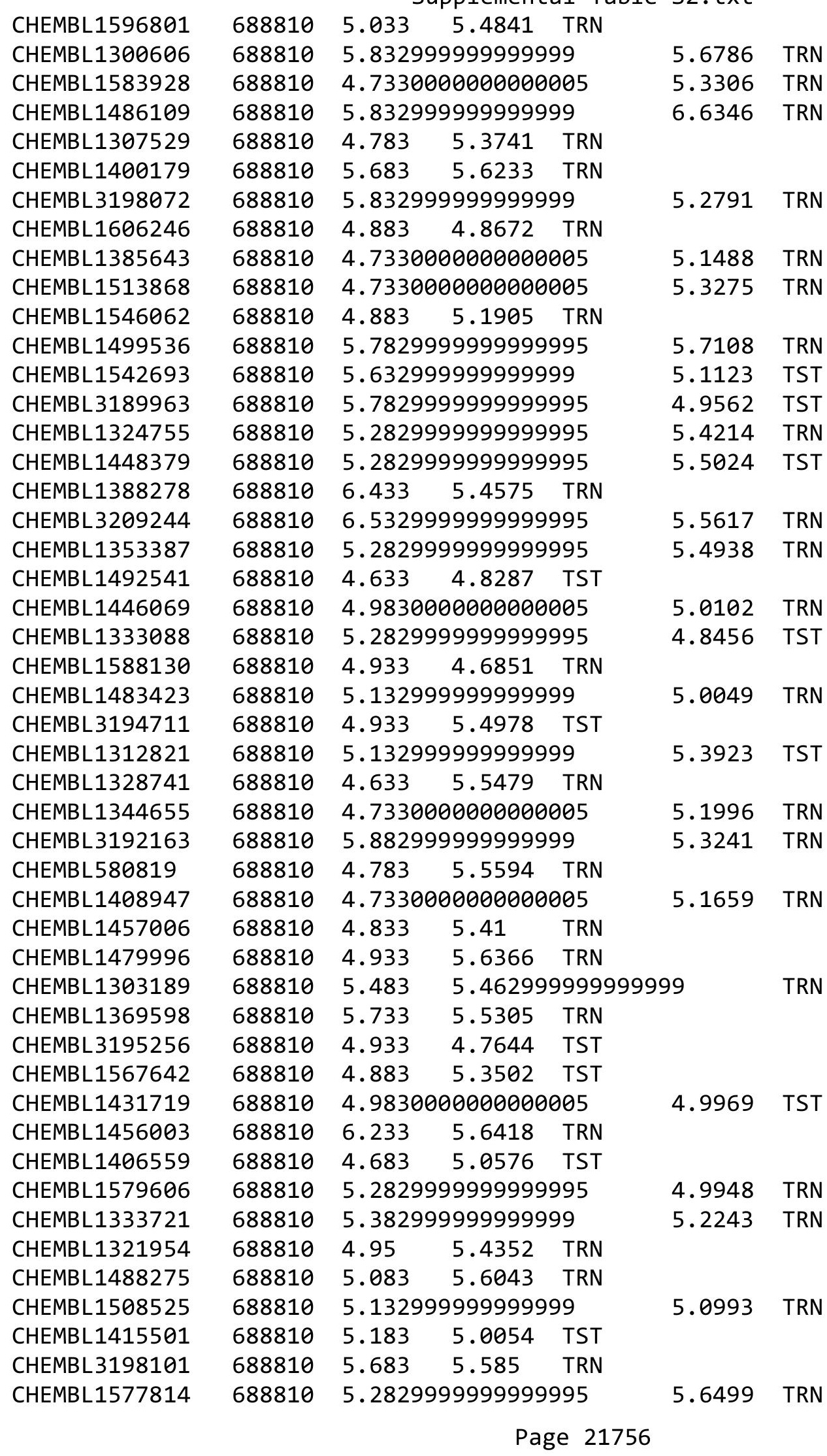




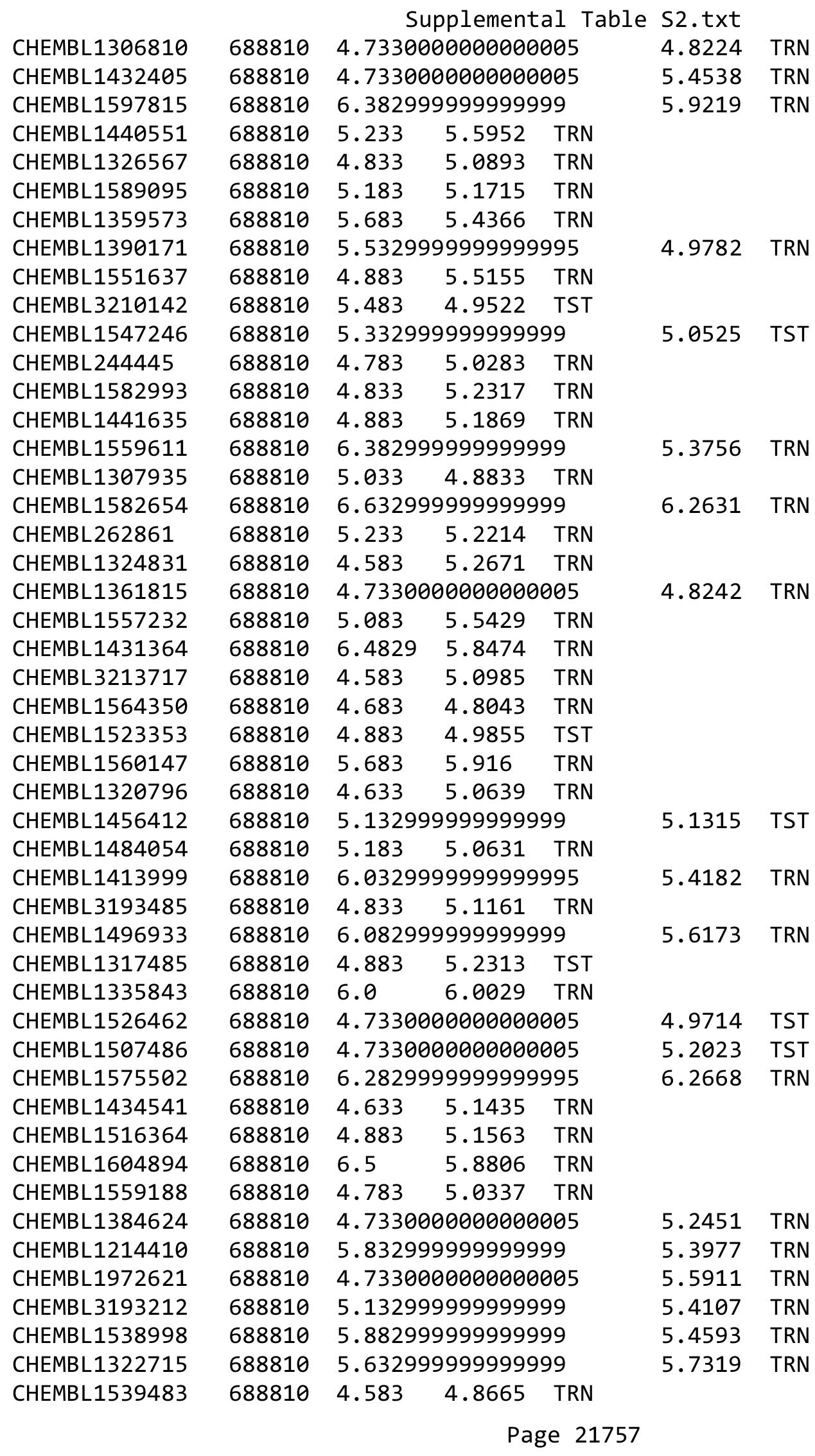




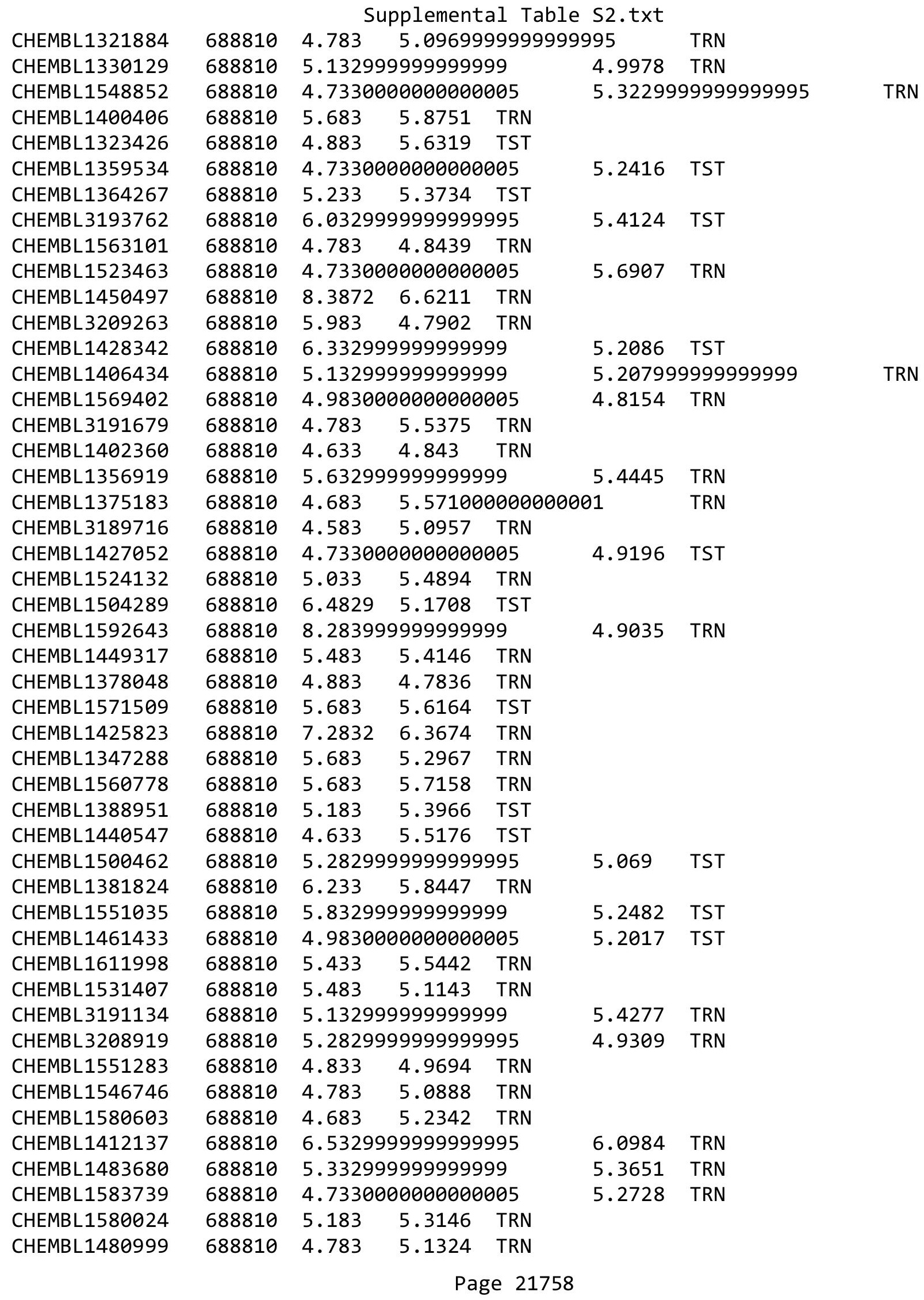




\begin{tabular}{|c|c|c|c|c|c|c|}
\hline \multirow[b]{2}{*}{ CHEMBL1400351 } & \multirow[b]{2}{*}{688810} & \multicolumn{5}{|c|}{ Supplemental Table s2.txt } \\
\hline & & 6.7331 & 5.6969 & TRN & & \\
\hline CHEMBL1336439 & 688810 & 4.583 & 5.0459 & TST & & \\
\hline CHEMBL1381097 & 688810 & 5.183 & 5.2978 & TST & & \\
\hline CHEMBL1596302 & 688810 & \multicolumn{3}{|c|}{5.332999999999999} & 5.5431 & TRN \\
\hline CHEMBL1463270 & 688810 & 4.833 & 5.1081 & TRN & & \\
\hline CHEMBL1306338 & 688810 & 4.883 & 5.2403 & TRN & & \\
\hline CHEMBL1407798 & 688810 & 4.583 & 4.9564 & TST & & \\
\hline CHEMBL1556570 & 688810 & 4.633 & 4.8974 & TRN & & \\
\hline CHEMBL1608841 & 688810 & 4.883 & 5.2697 & TRN & & \\
\hline CHEMBL1465441 & 688810 & \multicolumn{3}{|c|}{5.5329999999999995} & 4.9865 & TST \\
\hline CHEMBL1516772 & 688810 & 4.783 & 4.8124 & TRN & & \\
\hline CHEMBL1421254 & 688810 & \multicolumn{3}{|c|}{5.382999999999999} & 5.0899 & TST \\
\hline CHEMBL1542812 & 688810 & 4.833 & 5.0884 & TRN & & \\
\hline CHEMBL3194325 & 688810 & \multicolumn{3}{|c|}{5.7829999999999995} & 5.3741 & TRN \\
\hline CHEMBL1553712 & 688810 & 4.783 & 4.5515 & TRN & & \\
\hline CHEMBL1584634 & 688810 & \multicolumn{3}{|c|}{5.832999999999999} & 5.5802 & TRN \\
\hline CHEMBL1460321 & 688810 & 5.433 & 5.475 & TRN & & \\
\hline CHEMBL1402875 & 688810 & \multicolumn{3}{|c|}{5.2829999999999995} & 5.2309 & TRN \\
\hline CHEMBL3199437 & 688810 & 5.183 & 5.2671 & TRN & & \\
\hline CHEMBL1574660 & 688810 & 4.783 & 5.015 & TST & & \\
\hline CHEMBL1466824 & 688810 & 5.433 & 5.1928 & TRN & & \\
\hline CHEMBL1579644 & 688810 & 5.233 & 4.7048 & TRN & & \\
\hline CHEMBL1471107 & 688810 & 4.833 & 5.3537 & TRN & & \\
\hline CHEMBL1541659 & 688810 & 4.683 & 5.007 & TRN & & \\
\hline CHEMBL1511689 & 688810 & 5.083 & 5.0883 & TRN & & \\
\hline CHEMBL1609641 & 688810 & \multicolumn{3}{|c|}{5.632999999999999} & 5.2396 & TRN \\
\hline CHEMBL1426816 & 688810 & \multicolumn{3}{|c|}{5.332999999999999} & 5.1517 & TST \\
\hline CHEMBL1442418 & 688810 & \multicolumn{3}{|c|}{4.7330000000000005} & 4.8612 & TST \\
\hline CHEMBL1463088 & 688810 & \multicolumn{3}{|c|}{6.582999999999999} & 5.8681 & TRN \\
\hline CHEMBL1596341 & 688810 & 4.883 & 5.0557 & TRN & & \\
\hline CHEMBL1485375 & 688810 & \multicolumn{3}{|c|}{5.2829999999999995} & 5.4643 & TRN \\
\hline CHEMBL1504690 & 688810 & \multicolumn{3}{|c|}{5.132999999999999} & 5.0578 & TRN \\
\hline CHEMBL 3207793 & 688810 & \multicolumn{3}{|c|}{5.382999999999999} & 5.1258 & TRN \\
\hline CHEMBL1465884 & 688810 & 5.683 & 5.3101 & TRN & & \\
\hline CHEMBL1379777 & 688810 & 4.833 & 5.0493 & TRN & & \\
\hline CHEMBL3213469 & 688810 & 4.783 & 5.0952 & TRN & & \\
\hline CHEMBL1447161 & 688810 & \multicolumn{3}{|c|}{4.7330000000000005} & 5.1089 & TRN \\
\hline CHEMBL1331907 & 688810 & \multicolumn{3}{|c|}{5.132999999999999} & 5.2707 & TRN \\
\hline CHEMBL1438232 & 688810 & \multicolumn{3}{|c|}{5.5329999999999995} & 5.6059 & TRN \\
\hline CHEMBL1399406 & 688810 & 6.4829 & 5.3179 & TRN & & \\
\hline CHEMBL1317724 & 688810 & \multirow{2}{*}{\multicolumn{3}{|c|}{$\begin{array}{lcc}4.583 & 5.5344 \\
5.132999999999999\end{array}$}} & & \\
\hline CHEMBL1340397 & 688810 & & & & 5.4391 & TST \\
\hline CHEMBL1501576 & 688810 & 4.683 & 4.9037 & TRN & & \\
\hline CHEMBL1340089 & 688810 & 5.233 & 5.2429 & TRN & & \\
\hline CHEMBL1542710 & 688810 & 4.933 & 5.3379 & TRN & & \\
\hline CHEMBL1528485 & 688810 & 4.833 & 5.1048 & TST & & \\
\hline CHEMBL1344800 & 688810 & 4.883 & 5.2441 & TRN & & \\
\hline CHEMBL1545910 & 688810 & 4.783 & 4.9109 & TRN & & \\
\hline
\end{tabular}




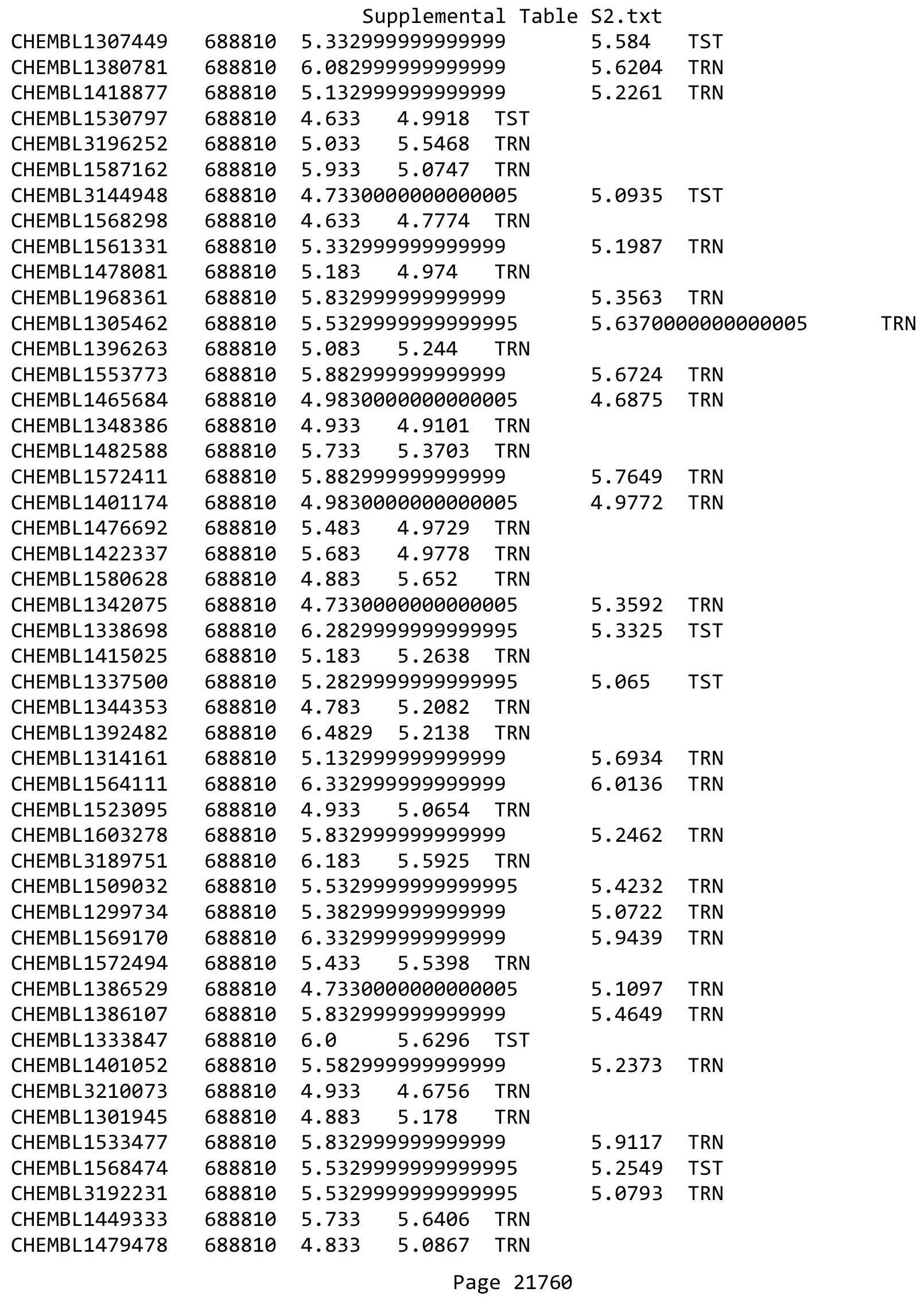




\begin{tabular}{|c|c|c|c|c|c|c|c|}
\hline \multicolumn{7}{|c|}{ Supplemental Table s2.txt } & \\
\hline CHEMBL1300174 & 688810 & \multicolumn{3}{|c|}{4.7330000000000005} & 4.9775 & TST & \\
\hline CHEMBL3193416 & 688810 & \multicolumn{3}{|c|}{5.882999999999999} & 5.3326 & TRN & \\
\hline CHEMBL1994523 & 688810 & \multicolumn{3}{|c|}{5.832999999999999} & 4.97 & TRN & \\
\hline CHEMBL1301557 & 688810 & 4.583 & 5.4298 & TST & & & \\
\hline CHEMBL1457941 & 688810 & \multicolumn{3}{|c|}{6.382999999999999} & 6.0504 & TRN & \\
\hline CHEMBL1603067 & 688810 & 5.683 & 5.4663 & TRN & & & \\
\hline CHEMBL1587766 & 688810 & \multicolumn{3}{|c|}{5.132999999999999} & \multicolumn{2}{|c|}{5.0569999999999995} & TST \\
\hline CHEMBL1478035 & 688810 & \multicolumn{3}{|c|}{5.632999999999999} & 5.5435 & TRN & \\
\hline CHEMBL1483475 & 688810 & 4.633 & \multicolumn{3}{|c|}{5.2589999999999995} & TST & \\
\hline CHEMBL1491646 & 688810 & 4.833 & 5.4068 & TRN & & & \\
\hline CHEMBL1401004 & 688810 & 4.883 & 4.9972 & TRN & & & \\
\hline CHEMBL1332930 & 688810 & 5.0 & 5.4282 & TST & & & \\
\hline CHEMBL1345973 & 688810 & \multicolumn{3}{|c|}{4.9830000000000005} & 5.2087 & TRN & \\
\hline CHEMBL1595100 & 688810 & \multicolumn{3}{|c|}{6.2829999999999995} & 5.46 & TRN & \\
\hline CHEMBL1491094 & 688810 & 5.933 & 5.5943 & TRN & & & \\
\hline CHEMBL1524514 & 688810 & \multicolumn{3}{|c|}{4.9830000000000005} & 5.0943 & TRN & \\
\hline CHEMBL3211451 & 688810 & \multicolumn{3}{|c|}{5.132999999999999} & 4.8031 & TRN & \\
\hline CHEMBL3190512 & 688810 & 4.783 & 5.2325 & TRN & & & \\
\hline CHEMBL1390863 & 688810 & 6.4829 & 5.5741 & TRN & & & \\
\hline CHEMBL579420 & 688810 & 4.633 & 5.0912 & TST & & & \\
\hline CHEMBL1569008 & 688810 & 4.783 & 5.0226 & TRN & & & \\
\hline CHEMBL1428054 & 688810 & \multicolumn{3}{|c|}{5.5329999999999995} & 6.26 & TRN & \\
\hline CHEMBL1545447 & 688810 & 4.933 & 5.1552 & TST & & & \\
\hline CHEMBL1561290 & 688810 & \multicolumn{3}{|c|}{4.9830000000000005} & 5.394 & TRN & \\
\hline CHEMBL1541090 & 688810 & 6.183 & 5.5104 & TST & & & \\
\hline CHEMBL1543726 & 688810 & 4.833 & 5.2563 & TRN & & & \\
\hline CHEMBL1505462 & 688810 & \multicolumn{3}{|c|}{4.7330000000000005} & 5.3968 & TRN & \\
\hline CHEMBL1566734 & 688810 & 5.233 & 4.8298 & TRN & & & \\
\hline CHEMBL1302779 & 688810 & 6.683 & 6.0936 & TRN & & & \\
\hline CHEMBL1459255 & 688810 & 5.183 & 4.9756 & TRN & & & \\
\hline CHEMBL1403354 & 688810 & 6.233 & 5.7477 & TRN & & & \\
\hline CHEMBL1383644 & 688810 & 5.183 & \multicolumn{3}{|c|}{5.406000000000001} & TST & \\
\hline CHEMBL1565949 & 688810 & 4.783 & 5.1559 & TRN & & & \\
\hline CHEMBL1429995 & 688810 & \multicolumn{3}{|c|}{5.5329999999999995} & 5.3408 & TRN & \\
\hline CHEMBL1351765 & 688810 & \multicolumn{3}{|c|}{4.9830000000000005} & 4.7831 & TRN & \\
\hline CHEMBL1304147 & 688810 & 4.783 & 5.0026 & TRN & & & \\
\hline CHEMBL1544377 & 688810 & \multicolumn{3}{|c|}{6.332999999999999} & 5.4488 & TRN & \\
\hline CHEMBL1455781 & 688810 & 4.633 & 5.1356 & TRN & & & \\
\hline CHEMBL1429594 & 688810 & 4.833 & 6.0842 & TRN & & & \\
\hline CHEMBL1458537 & 688810 & 4.833 & 5.2697 & TRN & & & \\
\hline CHEMBL1572989 & 688810 & \multicolumn{3}{|c|}{5.5329999999999995} & 5.6822 & TRN & \\
\hline CHEMBL1334210 & 688810 & 6.33299 & 99999999 & & 5.8123 & TRN & \\
\hline CHEMBL1580034 & 688810 & 4.783 & 5.6189 & TST & & & \\
\hline CHEMBL1309607 & 688810 & 6.183 & 6.13299 & 999999999 & 99 & TRN & \\
\hline CHEMBL1558095 & 688810 & 4.73300 & 00000000 & 005 & 5.7609 & TRN & \\
\hline CHEMBL1491495 & 688810 & 4.73300 & 00000000 & 005 & 5.3795 & TRN & \\
\hline CHEMBL1600937 & 688810 & 4.583 & 4.9082 & TRN & & & \\
\hline CHEMBL1364280 & 688810 & 4.73300 & 00000000 & 005 & 5.2451 & TRN & \\
\hline
\end{tabular}




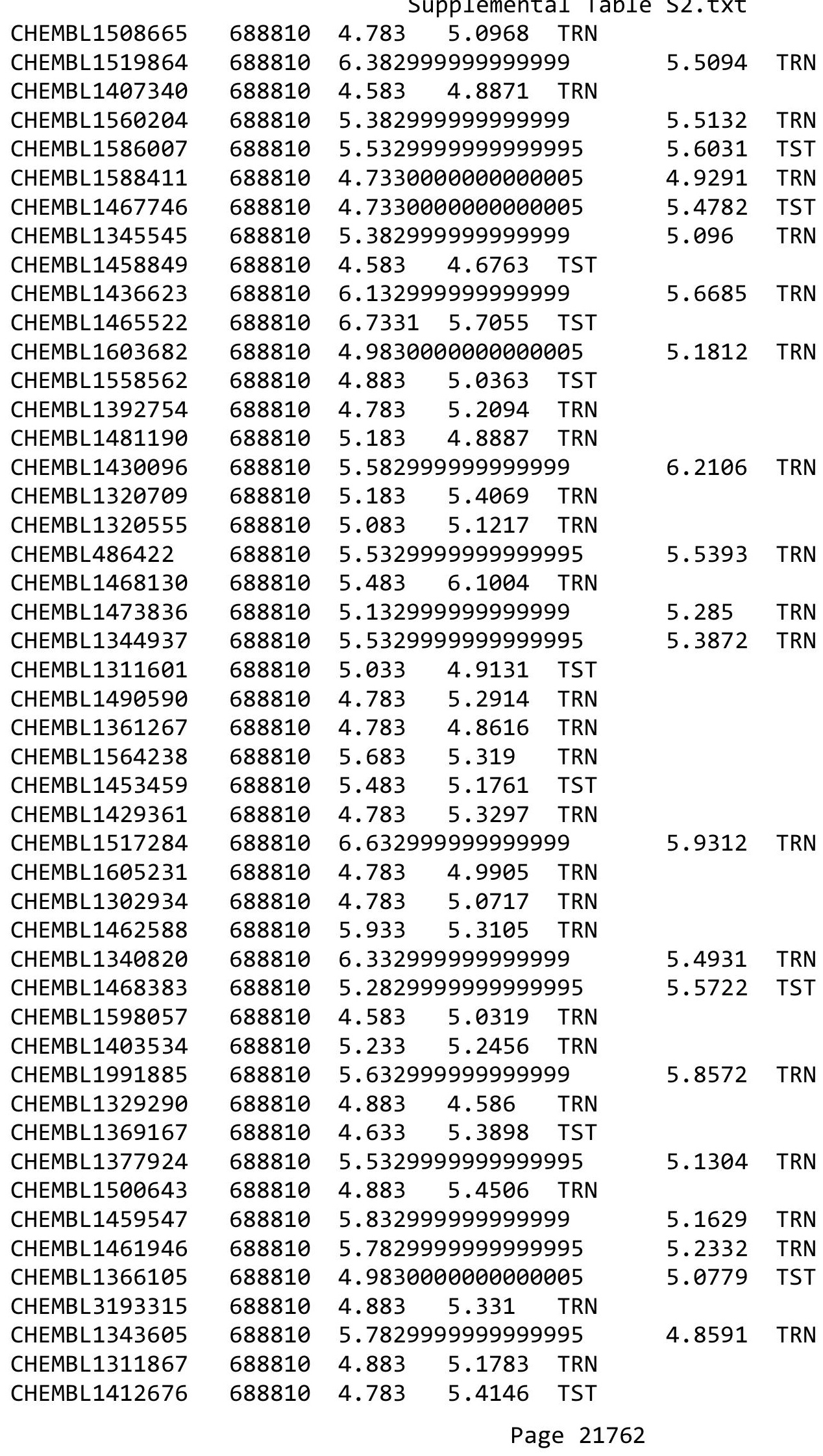




\begin{tabular}{|c|c|c|c|c|c|c|}
\hline \multirow{3}{*}{$\begin{array}{l}\text { CHEMBL1600395 } \\
\text { CHEMBL1535546 }\end{array}$} & \multicolumn{6}{|c|}{ Supplemental Table S2.txt } \\
\hline & 688810 & \multicolumn{3}{|c|}{5.2829999999999995} & 5.1468 & TRN \\
\hline & 688810 & 4.833 & 5.3052 & TRN & & \\
\hline CHEMBL1604322 & 688810 & 6.233 & 6.0699 & TRN & & \\
\hline CHEMBL1389689 & 688810 & 4.883 & 5.2436 & TST & & \\
\hline CHEMBL1344873 & 688810 & 4.933 & 4.968 & TRN & & \\
\hline CHEMBL1436218 & 688810 & 5.183 & 5.1809 & TRN & & \\
\hline CHEMBL1537930 & 688810 & 5.733 & 5.4305 & TRN & & \\
\hline CHEMBL3195779 & 688810 & 7.2328 & 6.4985 & TRN & & \\
\hline CHEMBL1376795 & 688810 & 5.733 & 5.1323 & TRN & & \\
\hline CHEMBL1496651 & 688810 & 4.933 & 5.8081 & TRN & & \\
\hline CHEMBL1579926 & 688810 & 5.183 & 5.3308 & TRN & & \\
\hline CHEMBL1398007 & 688810 & 4.783 & 5.6628 & TST & & \\
\hline CHEMBL1429832 & 688810 & 5.183 & 5.7098 & TRN & & \\
\hline CHEMBL1467444 & 688810 & 4.783 & 5.5772 & TRN & & \\
\hline CHEMBL1531028 & 688810 & 4.833 & 4.6478 & TRN & & \\
\hline CHEMBL1550411 & 688810 & \multicolumn{3}{|c|}{4.7330000000000005} & 5.3301 & TST \\
\hline CHEMBL1348721 & 688810 & \multicolumn{3}{|c|}{6.382999999999999} & 5.2873 & TST \\
\hline CHEMBL1395912 & 688810 & \multicolumn{3}{|c|}{6.082999999999999} & 5.9156 & TRN \\
\hline CHEMBL1336848 & 688810 & 6.233 & 5.5698 & TST & & \\
\hline CHEMBL1484637 & 688810 & 4.683 & 5.8468 & TRN & & \\
\hline CHEMBL1308917 & 688810 & 4.833 & 5.2427 & TST & & \\
\hline CHEMBL1609409 & 688810 & 4.783 & 5.1609 & TST & & \\
\hline CHEMBL1601487 & 688810 & 5.183 & 5.0438 & TRN & & \\
\hline CHEMBL1424864 & 688810 & 5.733 & 5.3715 & TST & & \\
\hline CHEMBL1487026 & 688810 & \multicolumn{3}{|c|}{5.5329999999999995} & 5.6082 & TRN \\
\hline CHEMBL1557386 & 688810 & \multicolumn{3}{|c|}{5.832999999999999} & 5.2487 & TRN \\
\hline CHEMBL1426015 & 688810 & \multirow{2}{*}{\multicolumn{3}{|c|}{$\begin{array}{ll}4.683 & 5.411000000 \\
4.7330000000000005\end{array}$}} & 005 & TRN \\
\hline CHEMBL1408887 & 688810 & & & & 4.9175 & TST \\
\hline CHEMBL1414311 & 688810 & \multicolumn{3}{|c|}{$\begin{array}{l}4.7330000000000005 \\
5.233 \quad 4.7165 \quad \text { TRN }\end{array}$} & & \\
\hline CHEMBL1302377 & 688810 & 4.833 & 5.4817 & TRN & & \\
\hline CHEMBL1536491 & 688810 & 4.633 & 4.9916 & TRN & & \\
\hline CHEMBL19032 & 688810 & 4.883 & 5.4426 & TST & & \\
\hline CHEMBL1368891 & 688810 & 4.883 & 5.1509 & TST & & \\
\hline CHEMBL1532153 & 688810 & \multicolumn{3}{|c|}{5.132999999999999} & 5.3466 & TRN \\
\hline CHEMBL1405247 & 688810 & 5.033 & 5.5522 & TRN & & \\
\hline CHEMBL1401768 & 688810 & \multicolumn{3}{|c|}{5.2829999999999995} & 5.4652 & TRN \\
\hline CHEMBL1364234 & 688810 & \multicolumn{3}{|c|}{5.632999999999999} & 5.0445 & TRN \\
\hline CHEMBL1513252 & 688810 & 4.633 & 5.2471 & TRN & & \\
\hline CHEMBL1579736 & 688810 & 4.683 & 4.881 & TRN & & \\
\hline CHEMBL1379154 & 688810 & 5.683 & 5.1198 & TRN & & \\
\hline CHEMBL1338683 & 688810 & 5.483 & 5.303 & TRN & & \\
\hline CHEMBL1502863 & 688810 & \multicolumn{3}{|c|}{5.7829999999999995} & 5.4244 & TRN \\
\hline CHEMBL3199492 & 688810 & 4.833 & 5.4645 & TST & & \\
\hline CHEMBL1609996 & 688810 & 5.483 & 5.3157 & TRN & & \\
\hline CHEMBL1452463 & 688810 & \multicolumn{3}{|c|}{6.082999999999999} & 5.5562 & TRN \\
\hline CHEMBL1550543 & 688810 & 4.933 & 5.3904 & TRN & & \\
\hline CHEMBL1545590 & 688810 & 5.233 & \multicolumn{3}{|c|}{5.6339999999999995} & TRN \\
\hline CHEMBL3190098 & 688810 & \multicolumn{3}{|c|}{4.7330000000000005} & 5.7163 & TRN \\
\hline
\end{tabular}




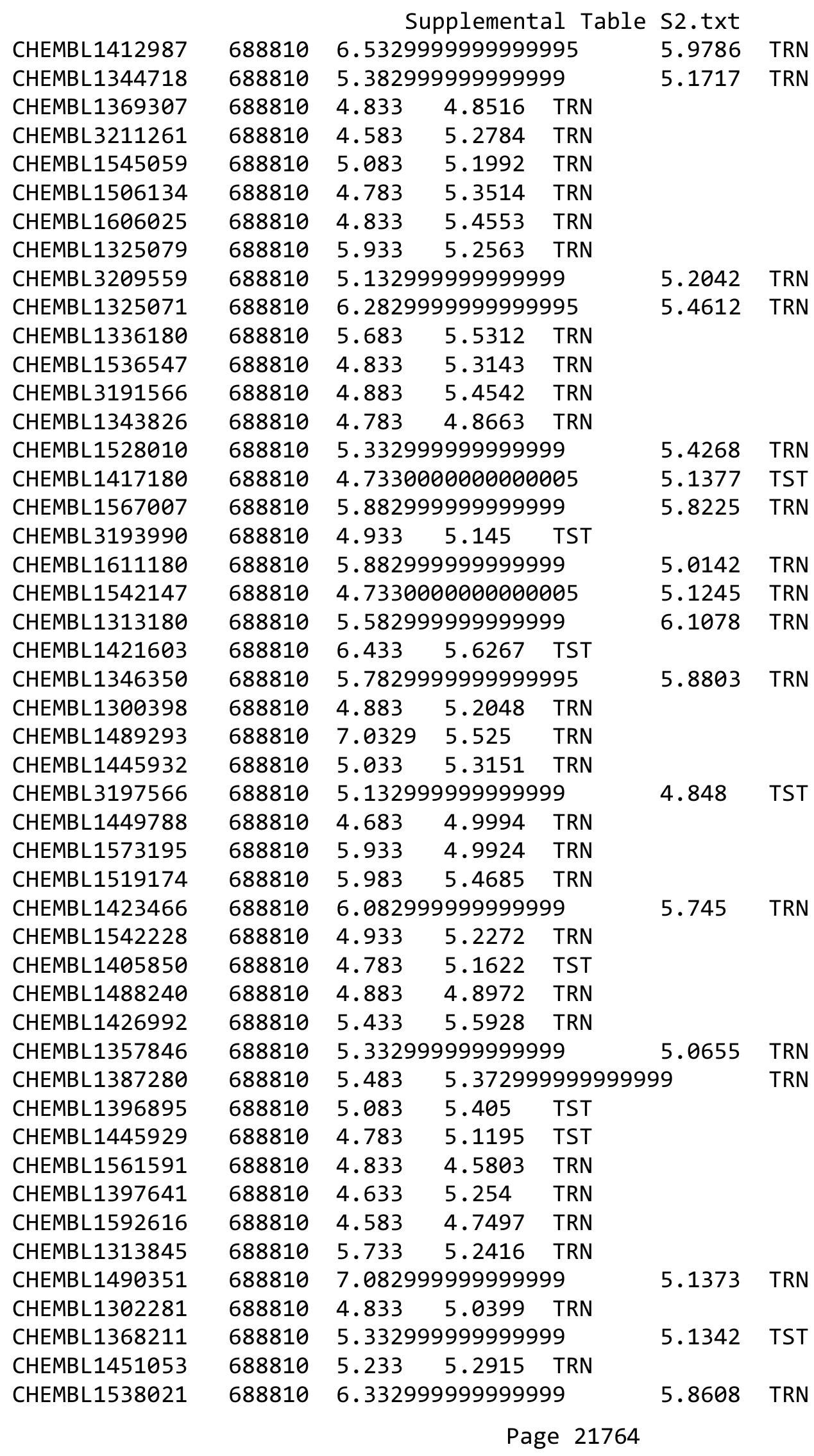




\begin{tabular}{|c|c|c|c|c|c|c|}
\hline \multirow[b]{2}{*}{ CHEMBL1454378 } & \multicolumn{6}{|c|}{ Supplemental Table S2.txt } \\
\hline & 688810 & 5.683 & 5.2552 & TRN & & \\
\hline CHEMBL1349863 & 688810 & 5.033 & 6.0571 & TRN & & \\
\hline CHEMBL1436095 & 688810 & 4.883 & 5.3069 & TST & & \\
\hline CHEMBL1577201 & 688810 & 5.733 & 5.2798 & TRN & & \\
\hline CHEMBL1524710 & 688810 & 4.633 & 5.1825 & TST & & \\
\hline CHEMBL1396103 & 688810 & 5.733 & 5.4601 & TST & & \\
\hline CHEMBL 3198145 & 688810 & 4.783 & 5.0024 & TRN & & \\
\hline CHEMBL1439772 & 688810 & \multicolumn{3}{|c|}{5.132999999999999} & 5.8644 & TRN \\
\hline CHEMBL1512359 & 688810 & 4.933 & 5.7871 & TST & & \\
\hline CHEMBL1421036 & 688810 & 5.233 & 5.0323 & TRN & & \\
\hline CHEMBL 3212230 & 688810 & 5.183 & 5.1095 & TST & & \\
\hline CHEMBL3208997 & 688810 & \multicolumn{3}{|c|}{5.382999999999999} & 5.1002 & TRN \\
\hline CHEMBL1491717 & 688810 & 4.833 & 5.0099 & TRN & & \\
\hline CHEMBL1404163 & 688810 & \multicolumn{3}{|c|}{5.7829999999999995} & 5.7191 & TRN \\
\hline CHEMBL1601182 & 688810 & 4.833 & 5.1542 & TRN & & \\
\hline CHEMBL1476963 & 688810 & 4.933 & 5.1154 & TRN & & \\
\hline CHEMBL1359587 & 688810 & \multicolumn{3}{|c|}{5.382999999999999} & 5.6906 & TRN \\
\hline CHEMBL1592648 & 688810 & 4.933 & 5.0687 & TRN & & \\
\hline CHEMBL1439347 & 688810 & \multicolumn{3}{|c|}{6.0329999999999995} & 5.1965 & TRN \\
\hline CHEMBL1482681 & 688810 & 4.633 & 5.0905 & TST & & \\
\hline CHEMBL3208515 & 688810 & 4.883 & 5.1919 & TRN & & \\
\hline CHEMBL1381584 & 688810 & \multicolumn{3}{|c|}{6.082999999999999} & 5.6791 & TST \\
\hline CHEMBL3208987 & 688810 & 5.183 & 5.5254 & TRN & & \\
\hline CHEMBL1558529 & 688810 & 4.833 & 5.2746 & TRN & & \\
\hline CHEMBL1508793 & 688810 & 4.883 & 5.1417 & TST & & \\
\hline CHEMBL1342395 & 688810 & 4.883 & 4.853 & TRN & & \\
\hline CHEMBL1306090 & 688810 & 5.683 & 5.4671 & TRN & & \\
\hline CHEMBL1573230 & 688810 & \multicolumn{3}{|c|}{4.7330000000000005} & 4.7531 & TST \\
\hline CHEMBL1318268 & 688810 & \multicolumn{3}{|c|}{4.7330000000000005} & 5.2352 & TRN \\
\hline CHEMBL1344317 & 688810 & \multicolumn{3}{|c|}{4.7330000000000005} & 5.2952 & TRN \\
\hline CHEMBL1514367 & 688810 & 4.633 & 5.0821 & TRN & & \\
\hline CHEMBL1376620 & 688810 & 4.783 & 5.3406 & TST & & \\
\hline CHEMBL1549001 & 688810 & \multicolumn{3}{|c|}{5.632999999999999} & 5.3088 & TST \\
\hline CHEMBL1476215 & 688810 & 6.9329 & 5.3401 & TRN & & \\
\hline CHEMBL1599938 & 688810 & 4.783 & 5.2589 & TRN & & \\
\hline CHEMBL1303968 & 688810 & 4.833 & 5.1406 & TRN & & \\
\hline CHEMBL1439576 & 688810 & 5.433 & 5.3667 & TRN & & \\
\hline CHEMBL1386689 & 688810 & 7.2832 & \multicolumn{3}{|c|}{5.382999999999999} & TRN \\
\hline CHEMBL1401755 & 688810 & \multicolumn{3}{|c|}{4.7330000000000005} & 5.6005 & TRN \\
\hline CHEMBL585374 & 688810 & 4.783 & 5.3503 & TRN & & \\
\hline CHEMBL1389360 & 688810 & 4.783 & \multicolumn{3}{|c|}{5.696000000000001} & TRN \\
\hline CHEMBL85321 & 688810 & 5.233 & 5.0781 & TST & & \\
\hline CHEMBL1578936 & 688810 & 4.783 & 5.2161 & TST & & \\
\hline CHEMBL494255 & 688810 & \multicolumn{3}{|c|}{5.332999999999999} & 5.2809 & TRN \\
\hline CHEMBL1300133 & 688810 & \multicolumn{3}{|c|}{4.7330000000000005} & 5.1245 & TRN \\
\hline CHEMBL1463220 & 688810 & \multirow{2}{*}{\multicolumn{3}{|c|}{$\begin{array}{l}4.91100000000000 \\
9999999995\end{array}$}} & 05 & TRN \\
\hline CHEMBL1413680 & 688810 & & & & 5.4617 & TST \\
\hline \multirow[t]{2}{*}{ CHEMBL1389396 } & 688810 & 4.783 & 5.1595 & TRN & & \\
\hline & & \multicolumn{5}{|c|}{ Page 21765} \\
\hline
\end{tabular}




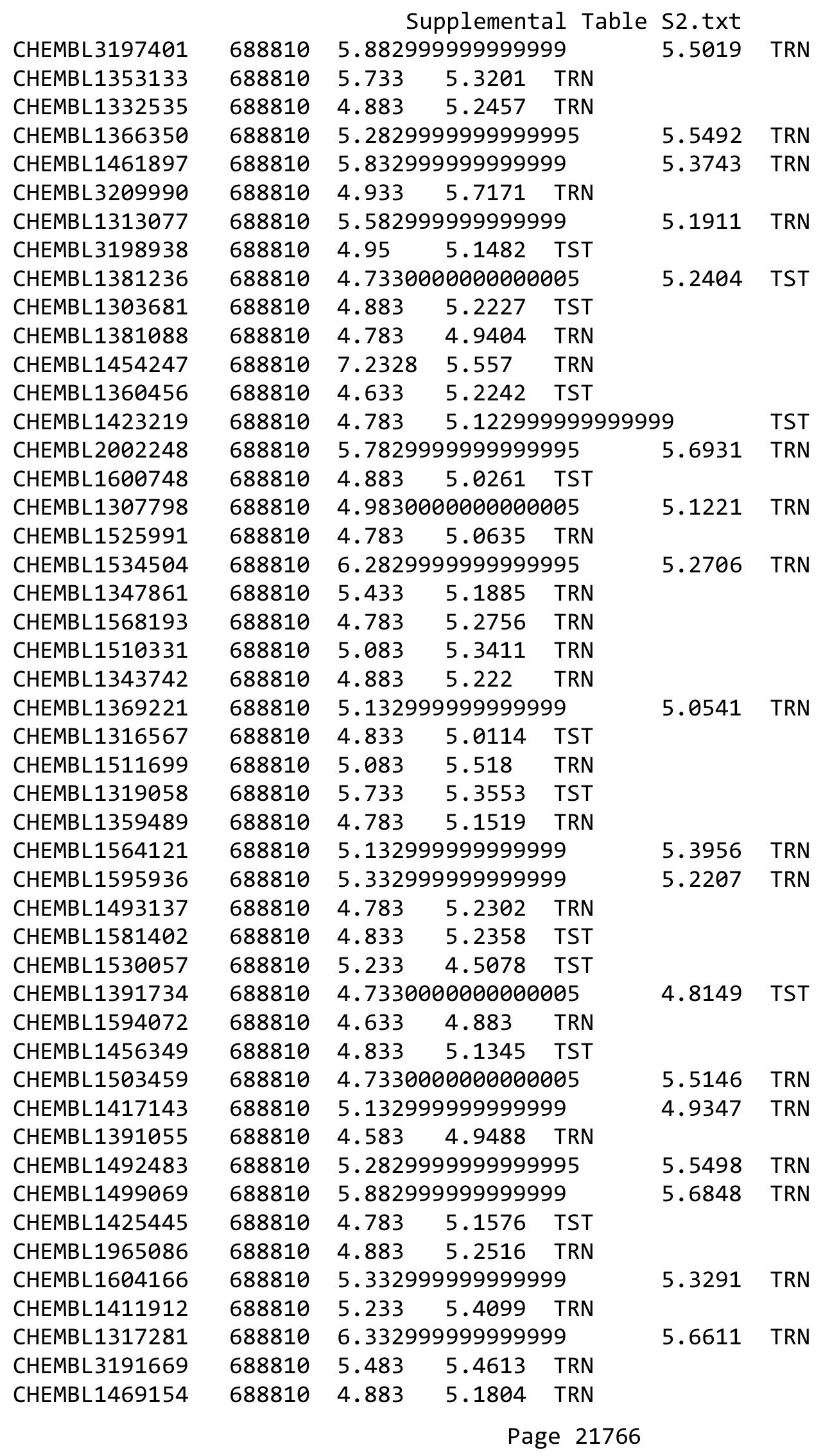




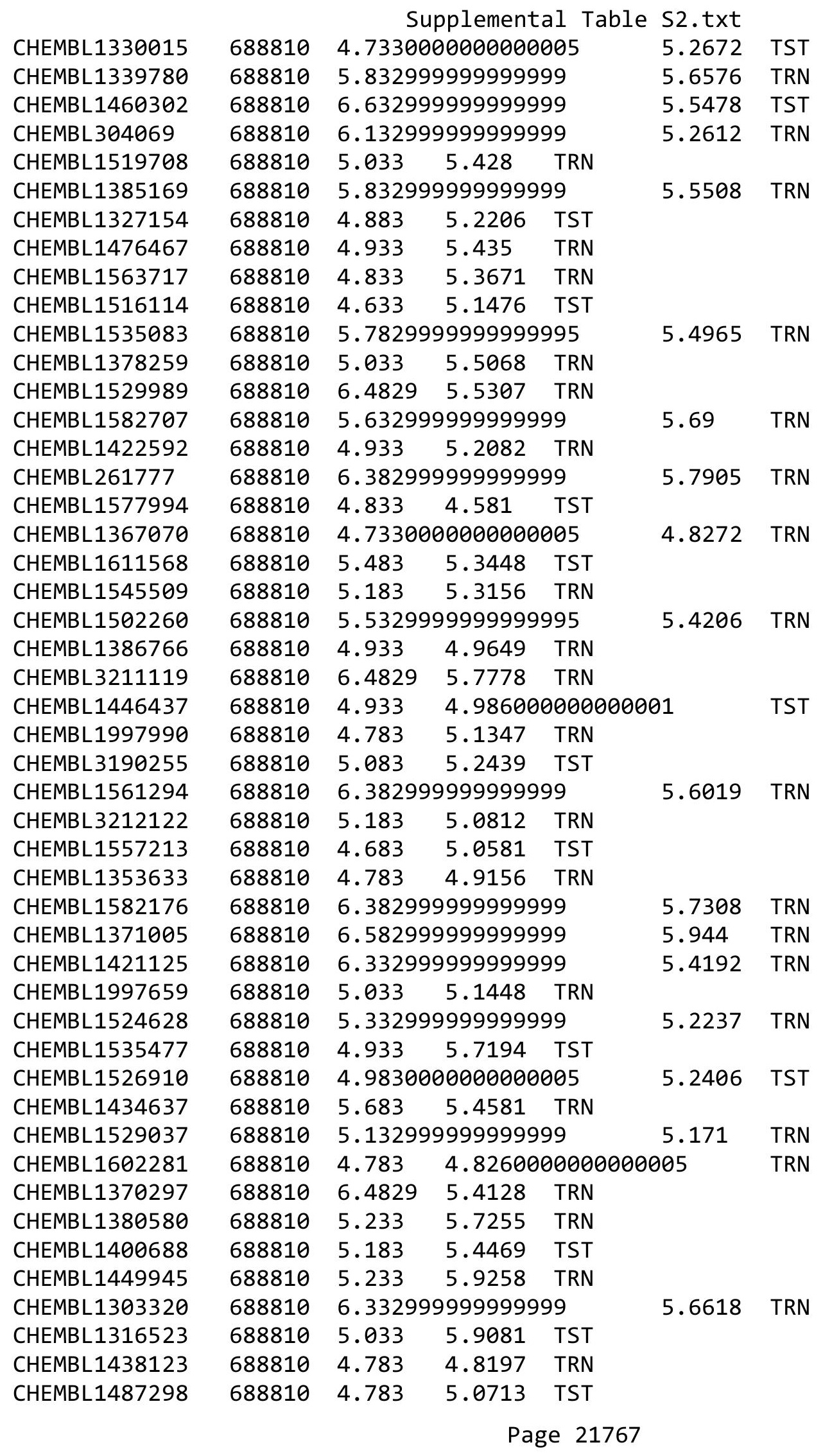




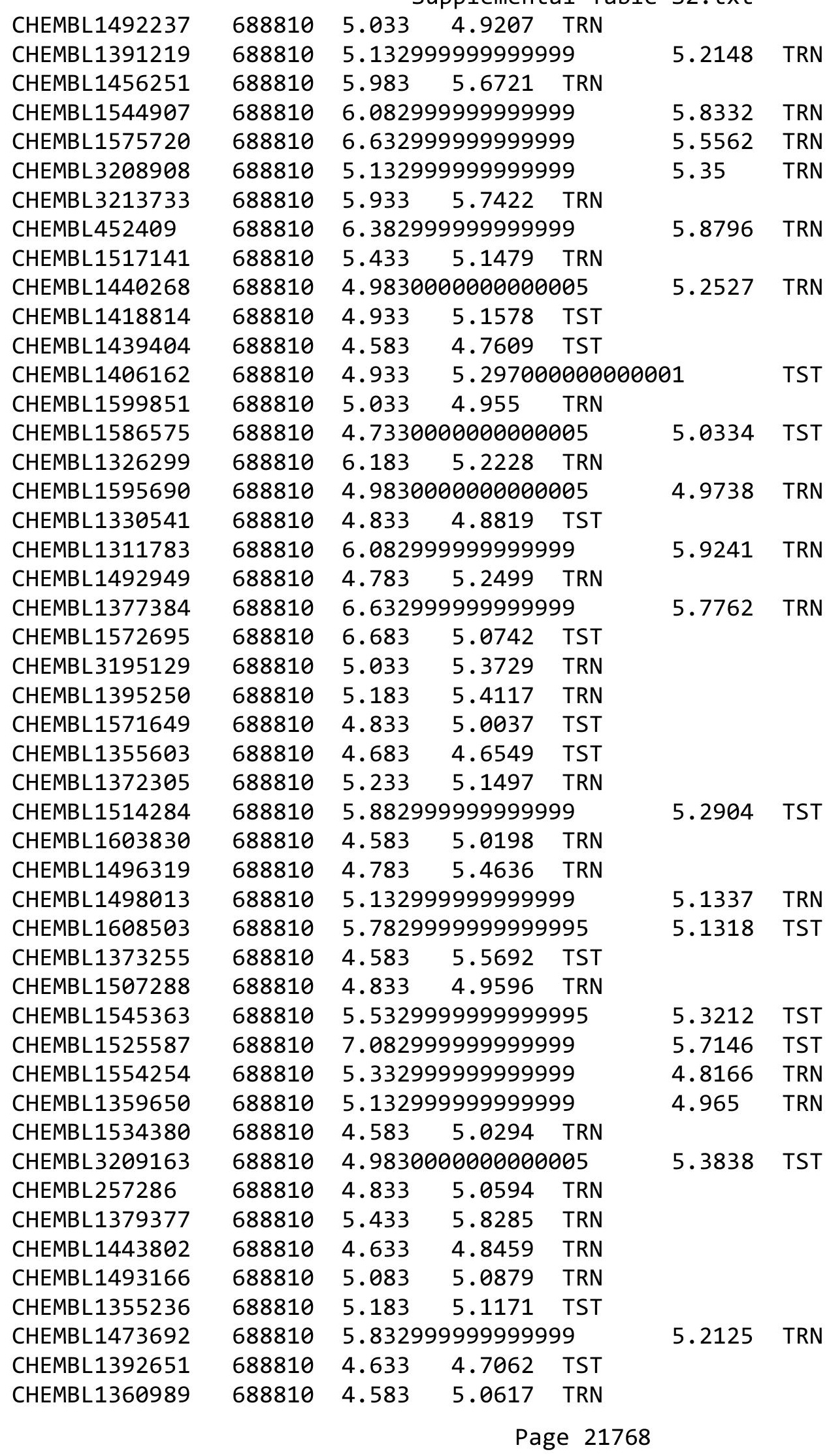




\begin{tabular}{|c|c|c|c|c|c|c|}
\hline & & \multicolumn{5}{|c|}{ Supplemental Table S2.txt } \\
\hline CHEMBL1375907 & 688810 & 5.183 & 5.0649 & TRN & & \\
\hline CHEMBL1476787 & 688810 & 6.4829 & 6.0563 & TRN & & \\
\hline CHEMBL1507708 & 588810 & 4.833 & 4.9043 & TRN & & \\
\hline CHEMBL1371774 & 688810 & 4.633 & 4.7003 & TRN & & \\
\hline CHEMBL1471515 & 688810 & \multicolumn{3}{|c|}{6.082999999999999} & 5.3083 & TRN \\
\hline CHEMBL1535159 & 688810 & 4.783 & 5.1538 & TRN & & \\
\hline CHEMBL3189331 & 688810 & 5.183 & 5.2713 & TRN & & \\
\hline CHEMBL1407319 & 88810 & 4.933 & 5.3098 & TRN & & \\
\hline CHEMBL1479567 & 688810 & 4.833 & 5.4804 & TRN & & \\
\hline CHEMBL3209070 & 688810 & \multicolumn{3}{|c|}{5.132999999999999} & 5.3228 & TRN \\
\hline CHEMBL1502516 & 688810 & \multicolumn{3}{|c|}{4.7330000000000005} & 5.5724 & \\
\hline CHEMBL579143 & 688810 & 4.933 & 4.7063 & TRN & & \\
\hline CHEMBL1593799 & 688810 & \multicolumn{3}{|c|}{4.7330000000000005} & 4.6543 & \\
\hline CHEMBL1353771 & 688810 & 5.683 & 5.2802 & TRN & & \\
\hline CHEMBL1560506 & 688810 & \multicolumn{3}{|c|}{4.7330000000000005} & 4.868 & ובנו \\
\hline CHEMBL1442514 & 688810 & 4.883 & 5.0049 & TRN & & \\
\hline CHEMBL1358256 & 688810 & \multicolumn{3}{|c|}{5.132999999999999} & 5.2248 & TRN \\
\hline CHEMBL1449119 & 688810 & \multicolumn{3}{|c|}{5.332999999999999} & & \\
\hline CHEMBL1571014 & 688810 & 4.833 & 5.2825 & TRN & & \\
\hline CHEMBL1499436 & 688810 & 4.633 & 5.5383 & TST & & \\
\hline CHEMBL1420243 & 688810 & \multicolumn{3}{|c|}{6.7829999999999995} & 6 & TRN \\
\hline CHEMBL1575621 & 688810 & \multicolumn{3}{|c|}{4.7330000000000005} & 372 & TKIV \\
\hline CHEMBL1368806 & 688810 & \multicolumn{3}{|c|}{6.582999999999999} & 5.1583 & TRN \\
\hline CHEMBL1385288 & 688810 & 5.183 & 5.5106 & TST & & \\
\hline CHEMBL1485788 & 688810 & \multicolumn{3}{|c|}{$5.933 \quad 5.5203 \quad$ TRN } & & \\
\hline CHEMBL1344216 & 688810 & \multicolumn{3}{|c|}{5.832999999999999} & כני & \\
\hline CHEMBL1 & 688810 & 5.183 & 4.8199 & TST & & \\
\hline CHEMBL1 & 688810 & \multicolumn{3}{|c|}{6.382999999999999} & 6.0611 & SI \\
\hline CHEMBL1565113 & 688810 & 5.483 & 5.7716 & TRN & & \\
\hline CHEMBL3212894 & 688810 & 5.233 & 5.3657 & TST & & \\
\hline CHEMBL1462363 & 688810 & 5.9 & 5.4724 & TRN & & \\
\hline CHEMBL1 & 688 & \multicolumn{3}{|c|}{4.7330000000000005} & & ונכו \\
\hline CHEMBL19 & 688810 & \multicolumn{3}{|c|}{5.5329999999999995} & 5.5232 & TST \\
\hline CHEMBL1422830 & 688810 & 4.783 & 5.1155 & TRN & & \\
\hline CHEMBL1527857 & 688810 & \multicolumn{3}{|c|}{6.5329999999999995} & & TRN \\
\hline CHEMBL1570797 & 688810 & \multicolumn{3}{|c|}{4.7330000000000005} & 4.4221 & \\
\hline CHEMBL1 & 688 & & 5.4033 & TST & & \\
\hline CHEMBL14 & 688810 & 5.683 & 5.4872 & TRN & & \\
\hline CHEMBL1392056 & 688810 & 5.683 & 4.79 & TST & & \\
\hline CHEMBL1452079 & 688810 & 5.983 & 5.6243 & TRN & & \\
\hline CHEMBL1347211 & 688810 & \multicolumn{3}{|c|}{4.9830000000000005} & & TRN \\
\hline CHEMBL1484439 & 688810 & 5.983 & \multicolumn{3}{|c|}{5.486000000000001} & \\
\hline CHEMBL1568521 & 688810 & 4.783 & 5.2614 & TST & & \\
\hline CHEMBL1561748 & 688810 & \multicolumn{3}{|c|}{5.7829999999999995} & 5.2484 & נו \\
\hline CHEMBL1574585 & 688810 & 4.683 & 5.1163 & TST & & \\
\hline CHEMBL1462755 & 688810 & 4.833 & 5.0482 & TST & & \\
\hline CHEMBL 3194947 & 688810 & 5.28299 & 99999999 & 995 & 5.5433 & 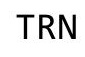 \\
\hline CHEMBL1966612 & 688810 & 5.63299 & 99999999 & & 5.2073 & \\
\hline
\end{tabular}




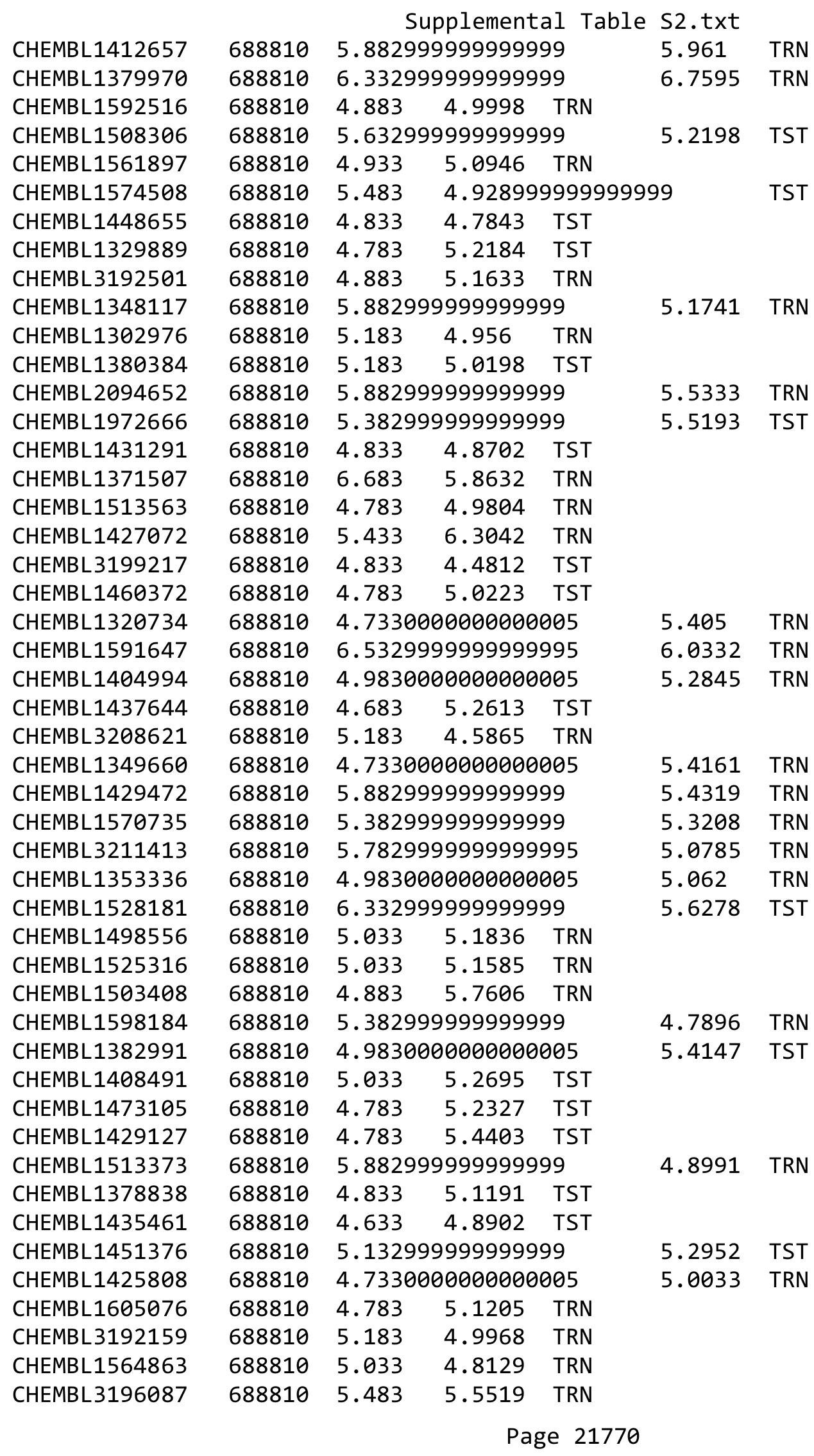




\begin{tabular}{|c|c|c|c|c|c|c|}
\hline & \multicolumn{5}{|c|}{ pplemental T } \\
\hline CHEMBL1395702 & 688810 & 4.633 & 4.9667 & TST & & \\
\hline CHEMBL1585050 & 688810 & 5.5829 & 999999999 & & 5.574 & TRI \\
\hline CHEMBL1357810 & 688810 & 4.633 & 4.9244 & TRN & & \\
\hline CHEMBL1575731 & 688810 & 4.7330 & 00000000 & 005 & 5.4232 & \\
\hline CHEMBL1442243 & 688810 & 5.3329 & 999999999 & & 5.1823 & \\
\hline CHEMBL1325846 & 688810 & 4.933 & 5.4841 & TRN & & \\
\hline CHEMBL1977978 & 688810 & 5.483 & 5.7296 & TRN & & \\
\hline CHEMBL1324130 & 688810 & 5.5329 & 999999999 & 995 & 5.5546 & \\
\hline CHEMBL2369261 & 688810 & 5.8329 & 999999999 & & 5.6573 & \\
\hline CHEMBL3213102 & 688810 & 6.6329 & 999999999 & & 6.0887 & \\
\hline CHEMBL1412908 & 688810 & 6.1329 & 999999999 & & 5.8804 & \\
\hline CHEMBL1372639 & 688810 & 5.2829 & 999999999 & 995 & 5.2089 & \\
\hline CHEMBL1391286 & 688810 & 4.883 & 4.774 & TRN & & \\
\hline CHEMBL67376 & 688810 & 5.3329 & 999999999 & & 5.4391 & \\
\hline CHEMBL1470195 & 688810 & 5.5329 & 999999999 & 995 & 5.2224 & \\
\hline CHEMBL1350897 & 688810 & 5.2829 & 999999999 & 995 & 4.8055 & \\
\hline CHEMBL1387525 & 688810 & 5.5829 & 999999999 & & 5.3839 & \\
\hline CHEMBL1328353 & 688810 & 5.1329 & 999999999 & & 4.9115 & \\
\hline CHEMBL1562496 & 688810 & 6.683 & 5.9494 & TRN & & \\
\hline CHEMBL1482184 & 688810 & 4.783 & 5.1801 & TST & & \\
\hline CHEMBL1571314 & 688810 & 5.5829 & 999999999 & & 5.5545 & \\
\hline CHEMBL1540638 & 688810 & 5.183 & 5.43 & TRN & & \\
\hline CHEMBL1479595 & 688810 & 5.483 & 5.3305 & TST & & \\
\hline CHEMBL1088589 & 688810 & 5.733 & 5.6741 & TST & & \\
\hline CHEMBL538430 & 688810 & 5.483 & 5.1848 & TRN & & \\
\hline CHEMBL1572719 & 688810 & 5.1329 & 999999999 & & 4.8577 & $\mathrm{Tr}$ \\
\hline CHEMBL1516075 & 688810 & 4.883 & 5.7233 & TST & & \\
\hline CHEMBL1492268 & 688810 & 6.0 & 4.9831 & TRN & & \\
\hline CHEMBL1434134 & 688810 & 4.73306 & 00000000 & 005 & 5.1013 & \\
\hline CHEMBL1597435 & 688810 & 4.783 & 5.1172 & TRN & & \\
\hline CHEMBL1381841 & 688810 & 4.933 & 4.8802 & TRN & & \\
\hline CHEMBL1550909 & 688810 & 5.13299 & 999999999 & & 5.3175 & \\
\hline CHEMBL1512059 & 688810 & 4.783 & 5.3243 & TRN & & \\
\hline CHEMBL1369518 & 688810 & 5.53299 & 999999999 & 995 & 5.8631 & \\
\hline CHEMBL1440969 & 688810 & 5.083 & 5.4222 & TRN & & \\
\hline CHEMBL1565349 & 688810 & 5.28299 & 999999999 & 995 & 5.0438 & TRN \\
\hline CHEMBL1385747 & 688810 & 5.8829 & 999999999 & & 5.4832 & \\
\hline CHEMBL1522250 & 688810 & 4.833 & 5.3915 & TST & & \\
\hline CHEMBL1473949 & 688810 & 5.38299 & 999999999 & & 4.9642 & I RIN \\
\hline CHEMBL1346166 & 688810 & 5.1329 & 999999999 & & 5.4579 & TRN \\
\hline CHEMBL1400443 & 688810 & 4.783 & 5.5362 & TRN & & \\
\hline CHEMBL1557849 & 688810 & 6.0 & 5.2039 & TRN & & \\
\hline CHEMBL1418320 & 688810 & 5.083 & 5.3177 & TRN & & \\
\hline CHEMBL1402065 & 688810 & 4.883 & 5.0541 & TRN & & \\
\hline CHEMBL1499152 & 688810 & 6.8329 & 999999999 & & 5.8384 & TRN \\
\hline CHEMBL1327783 & 688810 & 4.833 & 5.1138 & TRN & & \\
\hline CHEMBL 3197007 & 688810 & 4.933 & 5.4326 & TRN & & \\
\hline CHEMBL1416527 & 688810 & 4.883 & 5.0807 & TRN & & \\
\hline
\end{tabular}




\begin{tabular}{|c|c|c|c|c|c|c|}
\hline \multirow{2}{*}{\multicolumn{2}{|c|}{ CHEMBL1393189 }} & \\
\hline & 688810 & \multirow{2}{*}{\multicolumn{3}{|c|}{5.632999999999999}} & & \\
\hline CHEMBL 3191757 & 688810 & & & & 5.3264 & $\mathrm{TR}$ \\
\hline CHEMBL1429188 & 688810 & 4.833 & 5.2043 & TRN & & \\
\hline CHEMBL1580852 & 688810 & 4.883 & 5.3936 & TRN & & \\
\hline CHEMBL1382907 & 688810 & \multicolumn{3}{|c|}{4.7330000000000005} & 5.1815 & TRN \\
\hline CHEMBL1541522 & 688810 & \multicolumn{3}{|c|}{4.9830000000000005} & 5.5351 & \\
\hline CHEMBL1347250 & 688810 & 5.933 & 5.2625 & TRN & & \\
\hline CHEMBL 3214023 & 688810 & 4.583 & 4.5907 & TRN & & \\
\hline CHEMBL1412585 & 688810 & \multicolumn{3}{|c|}{5.7829999999999995} & 5.2187 & \\
\hline CHEMBL1606085 & 688810 & 5.683 & 5.3433 & TRN & & \\
\hline CHEMBL1380586 & 688810 & 5.683 & 5.3285 & TRN & & \\
\hline CHEMBL1597836 & 688810 & \multicolumn{3}{|c|}{5.132999999999999} & 5.1545 & \\
\hline CHEMBL1559853 & 688810 & 5.733 & 5.7466 & TRN & & \\
\hline CHEMBL1564873 & 688810 & 4.933 & 5.5305 & TRN & & \\
\hline CHEMBL1457096 & 688810 & 5.083 & 6.0028 & TRN & & \\
\hline CHEMBL 3191840 & 688810 & \multicolumn{3}{|c|}{4.7330000000000005} & 5.3422 & \\
\hline CHEMBL1604007 & 688810 & \multicolumn{3}{|c|}{ 5.382999999999999 } & 4.9563 & \\
\hline CHEMBL1518684 & 688810 & \multicolumn{3}{|c|}{5.332999999999999} & 5.4996 & \\
\hline CHEMBL 3212624 & 688810 & \multicolumn{3}{|c|}{6.382999999999999} & 5.5542 & \\
\hline CHEMBL1522934 & 688810 & 5.233 & 5.5871 & TRN & & \\
\hline CHEMBL1478089 & 688810 & \multicolumn{3}{|c|}{5.132999999999999} & 4938 & \\
\hline CHEMBL1454515 & 688810 & \multicolumn{3}{|c|}{5.882999999999999} & 164 & \\
\hline CHEMBL1542961 & 688810 & 4.933 & 5.3314 & TRN & & \\
\hline CHEMBL1555066 & 688810 & \multicolumn{3}{|c|}{5.132999999999999} & 5.9701 & \\
\hline CHEMBL1304398 & 688810 & \multicolumn{3}{|c|}{6.5329999999999995} & 398 & \\
\hline CHEMBL1471836 & 688810 & \multicolumn{3}{|c|}{5.7829999999999995} & 34 & \\
\hline CHEMBL1527907 & 688810 & 4.633 & 5.0621 & TRN & & \\
\hline CHEMBL1311848 & 688810 & \multirow{2}{*}{\multicolumn{3}{|c|}{$\begin{array}{lcc}5.183 & 5.4553 & \text { TRN } \\
4.7330000000000005\end{array}$}} & & \\
\hline CHEMBL1349088 & 688810 & & & & 5.5661 & $T$ \\
\hline CHEMBL1342447 & 688810 & \multicolumn{3}{|c|}{$\begin{array}{lll}5.683 & 6.09 & \text { TRN }\end{array}$} & & \\
\hline CHEMBL1605583 & 688810 & 5.183 & 5.1211 & TST & & \\
\hline CHEMBL 3212424 & 688810 & \multicolumn{3}{|c|}{5.632999999999999} & 5.0658 & \\
\hline CHEMBL1349389 & 688810 & \multicolumn{3}{|c|}{5.832999999999999} & 5.1018 & \\
\hline CHEMBL1450689 & 688810 & \multicolumn{3}{|c|}{5.2829999999999995} & 4.8064 & \\
\hline CHEMBL1553922 & 688810 & 4.583 & 5.099 & TST & & \\
\hline CHEMBL1581754 & 688810 & 5.183 & 4.9794 & TRN & & \\
\hline CHEMBL1976777 & 688810 & 5.183 & 5.0112 & TST & & \\
\hline CHEMBL1562180 & 688810 & 4.7330 & 2000000e & 005 & 5.1145 & \\
\hline CHEMBL1340829 & 688810 & 5.2829 & 99999999 & 995 & 4.7734 & \\
\hline CHEMBL1496375 & 688810 & 4.933 & 5.5232 & TRN & & \\
\hline CHEMBL1383228 & 688810 & 4.633 & 4.7367 & TST & & \\
\hline CHEMBL1394980 & 688810 & 4.583 & 5.0546 & TRN & & \\
\hline CHEMBL1531428 & 688810 & 4.833 & 5.2726 & TRN & & \\
\hline CHEMBL 3197279 & 688810 & 4.583 & 5.5229 & TST & & \\
\hline CHEMBL1424763 & 688810 & 5.483 & 5.2459 & TRN & & \\
\hline CHEMBL1446121 & 688810 & 4.833 & 5.0125 & TST & & \\
\hline CHEMBL1383585 & 688810 & 5.683 & 5.6939 & TRN & & \\
\hline CHEMBL1383973 & 688810 & 5.3329 & 99999999 & & 5.2303 & \\
\hline
\end{tabular}




\begin{tabular}{|c|c|c|c|c|c|c|c|}
\hline \multicolumn{8}{|c|}{ Supplemental Ta } \\
\hline CHEMBL1409165 & 688810 & 4.833 & 5.2171 & TRN & & & \\
\hline CHEMBL1529259 & 688810 & 5.28299 & 99999999 & 995 & 5.3341 & TRN & \\
\hline CHEMBL1309526 & 688810 & 5.38299 & 99999999 & 99 & 5.4016 & TST & \\
\hline CHEMBL3212249 & 688810 & 4.73300 & 00000006 & 005 & 5.42 & TRN & \\
\hline CHEMBL1403468 & 688810 & 5.183 & 5.2673 & TST & & & \\
\hline CHEMBL1553969 & 688810 & 4.833 & 5.3259 & TST & & & \\
\hline CHEMBL1321017 & 688810 & 5.28299 & 99999999 & 995 & 5.7634 & TRN & \\
\hline CHEMBL1392623 & 688810 & 5.63299 & 99999999 & 99 & 5.9364 & TRN & \\
\hline CHEMBL1440474 & 688810 & 5.733 & 5.4141 & TRN & & & \\
\hline CHEMBL1588078 & 688810 & 4.883 & 4.6762 & TST & & & \\
\hline CHEMBL1513972 & 688810 & 4.633 & 4.8939 & TST & & & \\
\hline CHEMBL1501843 & 688810 & 5.33299 & 99999999 & 99 & 4.9168 & TRN & \\
\hline CHEMBL3196353 & 688810 & $4.7330 e$ & 00000006 & 005 & 4.7441 & TRN & \\
\hline CHEMBL1349269 & 688810 & 5.233 & 5.0872 & TST & & & \\
\hline CHEMBL1588310 & 688810 & 4.883 & 5.0959 & TRN & & & \\
\hline CHEMBL1591415 & 688810 & 5.88299 & 99999999 & 99 & 5.7325 & TST & \\
\hline CHEMBL1548306 & 688810 & 4.683 & 5.2675 & TRN & & & \\
\hline CHEMBL1589238 & 688810 & 5.033 & 5.0456 & TRN & & & \\
\hline CHEMBL1467905 & 688810 & 4.883 & 4.877 & TRN & & & \\
\hline CHEMBL1549657 & 688810 & 4.833 & 4.9211 & TRN & & & \\
\hline CHEMBL1453996 & 688810 & 5.63299 & 99999999 & & $7.1670 €$ & 0000000001 & TST \\
\hline CHEMBL1403138 & 688810 & 4.783 & 4.8634 & TRN & & & \\
\hline CHEMBL1527377 & 688810 & 5.683 & 5.3514 & TRN & & & \\
\hline CHEMBL3212380 & 688810 & 5.33299 & 99999995 & & 4.8576 & TRN & \\
\hline CHEMBL1571541 & 688810 & 5.33299 & 99999995 & & 5.697 & TRN & \\
\hline CHEMBL1363251 & 688810 & 4.73300 & 0000000 & 005 & 5.0756 & TRN & \\
\hline CHEMBL1497472 & 688810 & 5.53299 & 99999999 & 995 & 4.8855 & TRN & \\
\hline CHEMBL1572885 & 688810 & 5.083 & 5.4833 & TRN & & & \\
\hline CHEMBL1328918 & 688810 & 4.883 & 5.3896 & TRN & & & \\
\hline CHEMBL1373256 & 688810 & 6.38299 & 99999995 & & 5.6711 & TRN & \\
\hline CHEMBL1312602 & 688810 & $4.9830 e$ & 0000000 & 005 & 5.0226 & TST & \\
\hline CHEMBL1429927 & 688810 & 4.883 & 5.2697 & TRN & & & \\
\hline CHEMBL1581270 & 688810 & 6.28299 & 99999999 & 995 & 5.9916 & TRN & \\
\hline CHEMBL1593915 & 688810 & 4.783 & 5.079 & TRN & & & \\
\hline CHEMBL1349693 & 688810 & 5.083 & 5.0555 & TRN & & & \\
\hline CHEMBL1364984 & 688810 & 4.833 & 5.176 & TRN & & & \\
\hline CHEMBL3194460 & 688810 & 4.933 & 5.3925 & TST & & & \\
\hline CHEMBL1469829 & 688810 & 6.13299 & 99999999 & & 5.5559 & TST & \\
\hline CHEMBL1605916 & 688810 & 4.833 & 5.465 & TST & & & \\
\hline CHEMBL1373732 & 688810 & 5.233 & 4.8655 & TST & & & \\
\hline CHEMBL3191571 & 688810 & 6.433 & 5.8719 & TRN & & & \\
\hline CHEMBL1494844 & 688810 & 5.083 & 5.4184 & TRN & & & \\
\hline CHEMBL1556966 & 688810 & 6.7331 & 5.9105 & TST & & & \\
\hline CHEMBL1518557 & 688810 & 4.633 & 4.7523 & TST & & & \\
\hline CHEMBL1315071 & 688810 & 5.433 & 5.2049 & TST & & & \\
\hline CHEMBL1435570 & 688810 & 4.783 & 5.7985 & TST & & & \\
\hline CHEMBL1380822 & 688810 & 5.33299 & 9999999s & & 5.6329 & TRN & \\
\hline CHEMBL1438555 & 688810 & 5.13299 & 99999995 & & 5.7055 & TRN & \\
\hline
\end{tabular}




\begin{tabular}{|c|c|c|c|c|c|c|}
\hline & & & pplement & al la & $32.0 \times 2$ & \\
\hline CHEMBL1365398 & 688810 & 5.233 & 4.8893 & TRN & & \\
\hline CHEMBL1592154 & 688810 & 4.9836 & $\partial 000000 e$ & 005 & 5.4389 & TRN \\
\hline CHEMBL1449642 & 688810 & 5.233 & 5.064 & TRN & & \\
\hline CHEMBL1613723 & 688810 & 4.583 & 4.9971 & TST & & \\
\hline CHEMBL1449578 & 688810 & 4.9836 & j000000e & 005 & 4.9843 & TRN \\
\hline CHEMBL1596190 & 688810 & 6.6329 & 99999999 & & 5.3323 & TRN \\
\hline CHEMBL1351173 & 688810 & 5.3329 & 99999999 & 99 & 5.6393 & TST \\
\hline CHEMBL1300465 & 688810 & 4.883 & 5.2999 & TRN & & \\
\hline CHEMBL1524445 & 688810 & 4.7336 & 00000000 & 005 & 5.2202 & TRN \\
\hline CHEMBL1303553 & 688810 & 6.2829 & 99999999 & 995 & 5.3099 & TST \\
\hline CHEMBL1461605 & 688810 & 5.183 & 5.0455 & TRN & & \\
\hline CHEMBL1580812 & 688810 & 5.433 & 5.715 & TRN & & \\
\hline CHEMBL 297548 & 688810 & 4.633 & 5.2413 & TRN & & \\
\hline CHEMBL1497507 & 688810 & 4.833 & 4.9965 & TRN & & \\
\hline CHEMBL1340694 & 688810 & 4.633 & 4.7505 & TRN & & \\
\hline CHEMBL1383581 & 688810 & 4.783 & 5.4861 & TRN & & \\
\hline CHEMBL1486073 & 688810 & 4.7336 & g000000e & 005 & 5.0967 & TRN \\
\hline CHEMBL1475814 & 688810 & 4.583 & 4.959 & TST & & \\
\hline CHEMBL1591217 & 688810 & 5.083 & 5.0956 & TST & & \\
\hline CHEMBL1465659 & 688810 & 5.683 & 5.5506 & TST & & \\
\hline CHEMBL1367354 & 688810 & 5.3329 & 99999999 & & 5.2474 & TRN \\
\hline CHEMBL1487786 & 688810 & 6.433 & 5.4733 & TRN & & \\
\hline CHEMBL1499631 & 688810 & 4.7336 & j000000e & 005 & 5.4802 & TST \\
\hline CHEMBL1455411 & 688810 & 4.633 & 5.4668 & TRN & & \\
\hline CHEMBL1386302 & 688810 & 6.183 & 5.0656 & TRN & & \\
\hline CHEMBL1572372 & 688810 & 4.933 & 6.3214 & TRN & & \\
\hline CHEMBL1545171 & 688810 & 4.833 & 4.9577 & TRN & & \\
\hline CHEMBL1607199 & 688810 & 4.7336 & 2000000e & 005 & 4.9365 & TRN \\
\hline CHEMBL1544340 & 688810 & 5.7820 & 99999999 & 995 & 5.3379 & TRN \\
\hline CHEMBL1307792 & 688810 & 5.233 & 5.3661 & TST & & \\
\hline CHEMBL 3207375 & 688810 & 5.733 & 5.3391 & TRN & & \\
\hline CHEMBL1609987 & 688810 & 5.183 & 5.3011 & TRN & & \\
\hline CHEMBL1524339 & 688810 & 6.3829 & 99999999 & & 5.9072 & TRN \\
\hline CHEMBL1328528 & 688810 & $5.882 \mathrm{C}$ & 99999999 & & 5.3754 & TRN \\
\hline CHEMBL1590304 & 688810 & 4.783 & 4.5569 & TRN & & \\
\hline CHEMBL600485 & 688810 & 4.883 & 5.3907 & TRN & & \\
\hline CHEMBL175296 & 688810 & 4.833 & 5.3344 & TRN & & \\
\hline CHEMBL1559250 & 688810 & 4.7336 & j000000e & 005 & 4.7508 & TST \\
\hline CHEMBL1332711 & 688810 & 4.7336 & j000000e & 005 & 5.7899 & TRN \\
\hline CHEMBL1505217 & 688810 & 5.233 & 5.5611 & TRN & & \\
\hline CHEMBL1464595 & 688810 & 5.5320 & 99999999 & 995 & 5.1354 & TST \\
\hline CHEMBL1322698 & 688810 & 5.1329 & 99999999 & & 5.1898 & TST \\
\hline CHEMBL1490742 & 688810 & 4.883 & 5.2244 & TRN & & \\
\hline CHEMBL1606709 & 688810 & 6.8325 & 99999999 & & 5.9622 & TRN \\
\hline CHEMBL3197109 & 688810 & 5.2829 & 99999999 & 995 & 5.9636 & TRN \\
\hline CHEMBL 3214581 & 688810 & 4.833 & 4.9778 & TRN & & \\
\hline CHEMBL1462209 & 688810 & 5.983 & 5.8997 & TRN & & \\
\hline CHEMBL1310082 & 688810 & 4.783 & 4.9169 & TRN & & \\
\hline
\end{tabular}




\begin{tabular}{|c|c|c|c|c|c|c|}
\hline \multirow[b]{2}{*}{ CHEMBL1318298 } & \multicolumn{6}{|c|}{ Supplemental Table S2.txt } \\
\hline & 688810 & 4.583 & 5.0686 & TST & & \\
\hline CHEMBL1324125 & 688810 & 5.683 & 5.3501 & TST & & \\
\hline CHEMBL1327424 & 688810 & 5.083 & 5.9467 & TRN & & \\
\hline CHEMBL1368644 & 688810 & 5.483 & 5.1837 & TRN & & \\
\hline CHEMBL1603967 & 688810 & \multicolumn{3}{|c|}{5.582999999999999} & 5.2355 & TRN \\
\hline CHEMBL1593484 & 688810 & \multicolumn{3}{|c|}{4.7330000000000005} & 5.2845 & \\
\hline CHEMBL1470436 & 688810 & \multicolumn{3}{|c|}{5.632999999999999} & 5.4122 & \\
\hline CHEMBL512749 & 688810 & 5.033 & 5.9621 & TRN & & \\
\hline CHEMBL1517002 & 688810 & 6.4829 & 5.4635 & TRN & & \\
\hline CHEMBL3190694 & 688810 & \multicolumn{3}{|c|}{5.2829999999999995} & 5.4111 & \\
\hline CHEMBL1315572 & 688810 & 4.583 & 5.1028 & TRN & & \\
\hline CHEMBL1592831 & 688810 & 4.833 & \multicolumn{3}{|c|}{5.242999999999999} & \\
\hline CHEMBL1446120 & 688810 & \multicolumn{3}{|c|}{4.7330000000000005} & 5.1863 & \\
\hline CHEMBL1537967 & 688810 & 6.233 & 5.5627 & TRN & & \\
\hline CHEMBL1504003 & 688810 & 4.783 & 5.4955 & TRN & & \\
\hline CHEMBL3192095 & 688810 & 4.783 & 5.7655 & TRN & & \\
\hline CHEMBL1560581 & 688810 & 4.883 & 5.3279 & TRN & & \\
\hline CHEMBL1370719 & 688810 & \multicolumn{3}{|c|}{5.332999999999999} & 5.4533 & \\
\hline CHEMBL1374141 & 688810 & 4.783 & 4.9097 & TST & & \\
\hline CHEMBL1596719 & 688810 & \multicolumn{3}{|c|}{6.832999999999999} & 6.2298 & \\
\hline CHEMBL1577049 & 688810 & 4.883 & 5.2452 & TRN & & \\
\hline CHEMBL1359371 & 688810 & 4.833 & 5.4434 & TRN & & \\
\hline CHEMBL1315928 & 688810 & 4.583 & 5.2246 & TRN & & \\
\hline CHEMBL1313086 & 688810 & \multicolumn{3}{|c|}{5.5329999999999995} & 5.5442 & TRN \\
\hline CHEMBL1565640 & 688810 & \multicolumn{3}{|c|}{4.7330000000000005} & 5.5043 & \\
\hline CHEMBL1525369 & 688810 & \multicolumn{3}{|c|}{5.382999999999999} & 5.2482 & \\
\hline CHEMBL1304029 & 688810 & \multicolumn{3}{|c|}{5.832999999999999} & 447 & \\
\hline CHEMBL1500933 & 688810 & 4.783 & 4.9529 & TST & & \\
\hline CHEMBL1613234 & 688810 & 4.833 & 5.3631 & TRN & & \\
\hline CHEMBL1497967 & 688810 & 5.083 & 4.95 & TST & & \\
\hline CHEMBL1367082 & 688810 & 5.033 & 5.0336 & TST & & \\
\hline CHEMBL3199330 & 688810 & 5.083 & 5.4213 & TRN & & \\
\hline CHEMBL1317698 & 688810 & \multicolumn{3}{|c|}{5.132999999999999} & 4.8941 & $\mathrm{TI}$ \\
\hline CHEMBL1341848 & 688810 & 5.233 & 5.2656 & TRN & & \\
\hline CHEMBL1394916 & 688810 & 5.733 & 5.4567 & TRN & & \\
\hline CHEMBL1427323 & 688810 & \multicolumn{3}{|c|}{4.7330000000000005} & 4.8776 & $\pi$ \\
\hline CHEMBL1494088 & 688810 & 5.183 & 5.3798 & TRN & & \\
\hline CHEMBL1565520 & 688810 & 4.633 & 4.6819 & TRN & & \\
\hline CHEMBL3191397 & 688810 & 5.083 & 5.3516 & TRN & & \\
\hline CHEMBL1337594 & 688810 & \multicolumn{3}{|c|}{5.132999999999999} & 5.3284 & SIS \\
\hline CHEMBL1570697 & 688810 & 4.783 & 5.3166 & TRN & & \\
\hline CHEMBL1565928 & 688810 & 4.583 & 5.2747 & TRN & & \\
\hline CHEMBL1307905 & 688810 & 4.933 & 5.3109 & TRN & & \\
\hline CHEMBL1472031 & 688810 & 4.783 & 5.1302 & TST & & \\
\hline CHEMBL1605111 & 688810 & \multicolumn{3}{|c|}{5.632999999999999} & 5.5 & . \\
\hline CHEMBL3213932 & 688810 & \multicolumn{3}{|c|}{4.7330000000000005} & 4.8865 & \\
\hline CHEMBL1310338 & 688810 & 6.683 & 5.9536 & TRN & & \\
\hline CHEMBL1449156 & 688810 & \multicolumn{3}{|c|}{6.132999999999999} & 5.2886 & 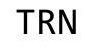 \\
\hline
\end{tabular}




\begin{tabular}{|c|c|c|c|c|c|c|}
\hline \multirow{3}{*}{$\begin{array}{l}\text { CHEMBL1504595 } \\
\text { CHEMBL1605931 }\end{array}$} & \multirow{3}{*}{$\begin{array}{l}688810 \\
688810\end{array}$} & \multicolumn{5}{|c|}{ Supplemental Table S2.txt } \\
\hline & & \multicolumn{3}{|c|}{4.9830000000000005} & 5.4942 & TST \\
\hline & & 4.95 & 5.3025 & TRN & & \\
\hline CHEMBL1395609 & 688810 & 5.233 & 5.3899 & TST & & \\
\hline CHEMBL 3197947 & 688810 & \multicolumn{3}{|c|}{5.2829999999999995} & 5.0992 & \\
\hline CHEMBL1548774 & 688810 & 5.683 & 5.3637 & TRN & & \\
\hline CHEMBL1424355 & 688810 & 5.733 & \multicolumn{3}{|c|}{5.867999999999999} & \\
\hline CHEMBL1532203 & 688810 & 5.683 & 6.0441 & TRN & & \\
\hline CHEMBL1463053 & 688810 & 4.933 & 5.0286 & TRN & & \\
\hline CHEMBL1419822 & 688810 & 4.933 & 5.1678 & TRN & & \\
\hline CHEMBL1416497 & 688810 & 4.683 & 4.7304 & TRN & & \\
\hline CHEMBL579640 & 688810 & 4.883 & 5.2478 & TST & & \\
\hline CHEMBL3209151 & 688810 & \multicolumn{3}{|c|}{5.7829999999999995} & 5.0149 & \\
\hline CHEMBL1503485 & 688810 & 6.233 & 5.3894 & TST & & \\
\hline CHEMBL1336871 & 688810 & \multicolumn{3}{|c|}{5.2829999999999995} & 4.9085 & \\
\hline CHEMBL405317 & 688810 & \multicolumn{3}{|c|}{5.832999999999999} & 6.9854 & \\
\hline CHEMBL1484672 & 688810 & 5.55 & 4.8701 & TST & & \\
\hline CHEMBL15 & 688810 & 5.233 & 5.7271 & TRN & & \\
\hline CHEMBL1538689 & 688810 & \multicolumn{3}{|c|}{6.332999999999999} & 5.5388 & \\
\hline CHEMBL 2006390 & 688810 & 4.933 & 5.2937 & TST & & \\
\hline CHEMBL1357904 & 688810 & \multicolumn{3}{|c|}{5.582999999999999} & 4.8803 & \\
\hline CHEMBL1525496 & 688810 & 5.033 & 5.1288 & TRN & & \\
\hline CHEMBL: & 688810 & \multicolumn{3}{|c|}{5.5329999999999995} & • & \\
\hline CHEMBL1462073 & 688810 & 4.783 & 5.0059 & TRN & & \\
\hline CHEMBL1330052 & 688810 & 5.083 & 5.155 & TRN & & \\
\hline CHEMBL1471474 & 688810 & \multicolumn{3}{|c|}{5.5329999999999995} & 7696 & \\
\hline CHEMBL1558333 & 688810 & 4.933 & 5.2897 & TST & & \\
\hline CHEMB & 688 & 5.183 & 5.6511 & TST & & \\
\hline CHEMBL1557524 & 688810 & 4.583 & 4.9754 & TRN & & \\
\hline CHEMBL1546043 & 688810 & \multicolumn{3}{|c|}{5.382999999999999} & 5.1805 & \\
\hline CHEMBL1419163 & 688810 & 5.933 & 5.4158 & TRN & & \\
\hline CHEMBL1356308 & 688 & \multicolumn{3}{|c|}{5.332999999999999} & 34 & \\
\hline CHEMB & 688 & \multicolumn{3}{|c|}{5.5329999999999995} & & \\
\hline CHEMBL] & 688810 & 4.683 & 5.0328 & TST & & \\
\hline CHEMBL1544962 & 688810 & 6.433 & 6.0111 & TRN & & \\
\hline CHEMBL1589624 & 688810 & 5.733 & 5.5061 & TRN & & \\
\hline CHEMBL13 & 688810 & \multicolumn{3}{|c|}{6.2829999999999995} & 5.5596 & \\
\hline CHEMBL15 & 688810 & 4.883 & 5.1314 & TRN & & \\
\hline CHEMBL1356752 & 688810 & 4.833 & 5.1307 & TRN & & \\
\hline CHEMBL1442871 & 688810 & 5.083 & 5.4876 & TRN & & \\
\hline CHEMBL1461786 & 688810 & 5.933 & 5.5238 & TRN & & \\
\hline CHEMBL1570326 & 688810 & 5.233 & 5.166 & TST & & \\
\hline CHEMBL1517460 & 688810 & 5.683 & 5.3568 & TRN & & \\
\hline CHEMBL1505147 & 688810 & 4.933 & 5.3505 & TRN & & \\
\hline CHEMBL1336911 & 688810 & 5.433 & 4.7358 & TRN & & \\
\hline CHEMBL1485264 & 688810 & \multicolumn{3}{|c|}{5.382999999999999} & 4. & \\
\hline CHEMBL1442210 & 688810 & \multicolumn{3}{|c|}{5.132999999999999} & 4.9192 & \\
\hline CHEMBL1480962 & 688810 & 4.933 & 5.0791 & TR & & \\
\hline CHEMBL1343458 & 688810 & \multicolumn{3}{|c|}{6.332999999999999} & 6.6028 & \\
\hline
\end{tabular}




\begin{tabular}{|c|c|c|c|c|c|c|c|}
\hline \multirow[b]{2}{*}{ CHEMBL1496182 } & \multicolumn{6}{|c|}{ tist } & \\
\hline & 688810 & 5.733 & 5.6399 & TRN & & & \\
\hline CHEMBL3198812 & 688810 & 4.633 & 4.8254 & TRN & & & \\
\hline CHEMBL276139 & 688810 & 4.583 & 5.1756 & TST & & & \\
\hline CHEMBL1497776 & 688810 & \multicolumn{3}{|c|}{5.132999999999999} & 5.0747 & TRN & \\
\hline CHEMBL1500842 & 688810 & \multicolumn{3}{|c|}{4.7330000000000005} & 4.7965 & TST & \\
\hline CHEMBL1566838 & 688810 & \multicolumn{3}{|c|}{6.5329999999999995} & 5.7291 & TRN & \\
\hline CHEMBL1439014 & 688810 & 5.233 & 5.5161 & TRN & & & \\
\hline CHEMBL3195584 & 688810 & \multicolumn{3}{|c|}{5.832999999999999} & \multicolumn{2}{|c|}{5.577000000000001} & TRN \\
\hline CHEMBL1455746 & 688810 & 4.883 & 5.2505 & TRN & & & \\
\hline CHEMBL1605488 & 688810 & 6.233 & 5.2665 & TRN & & & \\
\hline CHEMBL3193099 & 688810 & \multicolumn{3}{|c|}{4.7330000000000005} & 5.0471 & TST & \\
\hline CHEMBL1366593 & 688810 & \multicolumn{3}{|c|}{4.7330000000000005} & 5.0079 & TRN & \\
\hline CHEMBL3210907 & 688810 & 5.233 & 5.449 & TST & & & \\
\hline CHEMBL1442636 & 688810 & \multicolumn{3}{|c|}{4.7330000000000005} & 5.105 & TRN & \\
\hline CHEMBL1412039 & 688810 & 5.433 & 4.9204 & TRN & & & \\
\hline CHEMBL1574529 & 688810 & 4.883 & 4.9351 & TRN & & & \\
\hline CHEMBL1459368 & 688810 & \multicolumn{3}{|c|}{5.132999999999999} & 5.6595 & TRN & \\
\hline CHEMBL1465010 & 688810 & \multicolumn{3}{|c|}{4.7330000000000005} & 5.6265 & TRN & \\
\hline CHEMBL1585621 & 688810 & 5.233 & 5.303 & TST & & & \\
\hline CHEMBL1552807 & 688810 & \multicolumn{3}{|c|}{5.582999999999999} & 5.8509 & TST & \\
\hline CHEMBL1556435 & 688810 & 4.883 & 4.9691 & TRN & & & \\
\hline CHEMBL1487914 & 688810 & \multicolumn{3}{|c|}{5.582999999999999} & 5.1665 & TRN & \\
\hline CHEMBL1389022 & 688810 & 4.883 & 5.1508 & TRN & & & \\
\hline CHEMBL1495094 & 688810 & 4.633 & 4.7182 & TRN & & & \\
\hline CHEMBL1450777 & 688810 & 5.033 & 5.1909 & TRN & & & \\
\hline CHEMBL1399876 & 688810 & 4.883 & 5.7281 & TRN & & & \\
\hline CHEMBL1571636 & 688810 & \multicolumn{3}{|c|}{5.332999999999999} & 5.1241 & TST & \\
\hline CHEMBL1613363 & 688810 & \multicolumn{3}{|c|}{5.5329999999999995} & 5.8721 & TRN & \\
\hline CHEMBL191015 & 688810 & \multicolumn{3}{|c|}{6.382999999999999} & 5.8983 & TRN & \\
\hline CHEMBL1531156 & 688810 & 4.783 & 5.1649 & TST & & & \\
\hline CHEMBL1325114 & 688810 & \multicolumn{3}{|c|}{5.132999999999999} & 5.4838 & TRN & \\
\hline CHEMBL1439020 & 688810 & \multicolumn{3}{|c|}{5.582999999999999} & 5.1021 & TRN & \\
\hline CHEMBL1324255 & 688810 & \multicolumn{3}{|c|}{5.132999999999999} & 5.4602 & TRN & \\
\hline CHEMBL1424269 & 688810 & 5.8329 & 999999995 & & 5.1567 & TST & \\
\hline CHEMBL3195684 & 688810 & 5.2829 & 999999995 & 995 & 5.0088 & TRN & \\
\hline CHEMBL1361569 & 688810 & 5.433 & 5.5532 & TRN & & & \\
\hline CHEMBL156040 & 688810 & 5.7829 & 999999999 & 995 & 5.5177 & TRN & \\
\hline CHEMBL1405504 & 688810 & 5.2829 & 999999995 & 995 & 5.3987 & TRN & \\
\hline CHEMBL1415376 & 688810 & 4.883 & 4.9103 & TRN & & & \\
\hline CHEMBL1213910 & 688810 & 4.883 & 5.0076 & TRN & & & \\
\hline CHEMBL3207491 & 688810 & 5.7829 & 999999995 & 995 & 5.5309 & TRN & \\
\hline CHEMBL1538275 & 688810 & 4.7330 & 00000000 & 005 & 4.7949 & TRN & \\
\hline CHEMBL3208435 & 688810 & 4.833 & 5.3824 & TRN & & & \\
\hline CHEMBL1313001 & 688810 & 4.783 & 5.4455 & TST & & & \\
\hline CHEMBL1549111 & 688810 & 4.7330 & 000000006 & 005 & 5.4418 & TST & \\
\hline CHEMBL1333599 & 688810 & 4.833 & 5.046 & TRN & & & \\
\hline CHEMBL1541515 & 688810 & 5.7829 & 999999995 & 995 & 5.6786 & TRN & \\
\hline CHEMBL1553394 & 688810 & 5.233 & 4.9877 & TRN & & & \\
\hline
\end{tabular}




\begin{tabular}{|c|c|c|c|c|c|c|}
\hline \multirow{3}{*}{$\begin{array}{l}\text { CHEMBL } 1377608 \\
\text { CHEMBL44 }\end{array}$} & \multirow{3}{*}{$\begin{array}{l}688810 \\
688810\end{array}$} & \multicolumn{5}{|c|}{ Supplemental Table S2.txt } \\
\hline & & \multicolumn{3}{|c|}{5.382999999999999} & \multirow[t]{8}{*}{5.0484} & \multirow[t]{2}{*}{ TST } \\
\hline & & 5.683 & 5.6847 & TRN & & \\
\hline CHEMBL1517521 & 688810 & 5.033 & 5.5239 & TRN & & \\
\hline CHEMBL1454884 & 688810 & 4.933 & 5.3048 & TST & & \\
\hline CHEMBL1525271 & 688810 & 5.433 & 5.7518 & TRN & & \\
\hline CHEMBL1606211 & 688810 & 4.933 & 5.0516 & TRN & & \\
\hline CHEMBL1474926 & 688810 & 4.633 & 5.3793 & TST & & \\
\hline CHEMBL1317643 & 688810 & 4.633 & 5.2425 & TRN & & \\
\hline CHEMBL1523697 & 688810 & \multicolumn{3}{|c|}{5.2829999999999995} & \multirow{4}{*}{5.8106} & \\
\hline CHEMBL1370889 & 688810 & 4.883 & 4.8061 & TRN & & \\
\hline CHEMBL3197251 & 688810 & 6.7331 & 5.8552 & TRN & & \\
\hline CHEMBL1322602 & 688810 & 6.433 & 5.7818 & TRN & & \\
\hline CHEMBL1335130 & 688810 & \multicolumn{3}{|c|}{5.882999999999999} & \multirow[t]{3}{*}{5.4546} & \\
\hline CHEMBL1567943 & 688810 & 4.883 & 5.1002 & TST & & \\
\hline CHEMBL1357296 & 688810 & 4.633 & 5.336 & TST & & \\
\hline CHEMBL1399516 & 688810 & \multicolumn{3}{|c|}{5.2829999999999995} & \multirow{4}{*}{5.2431} & \\
\hline CHEMBL1595724 & 688810 & 4.633 & 5.0134 & TST & & \\
\hline CHEMBL1370349 & 688810 & 5.083 & 5.3091 & TRN & & \\
\hline CHEMBL1376305 & 688810 & 5.683 & 5.5263 & TST & & \\
\hline CHEMBL1337036 & 688810 & \multicolumn{3}{|c|}{5.382999999999999} & 4.9742 & \\
\hline CHEMBL1387734 & 688810 & 5.183 & 5.4708 & TRN & & \\
\hline CHEMBL1348794 & 688810 & \multicolumn{3}{|c|}{5.382999999999999} & 5.5913 & 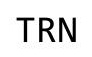 \\
\hline CHEMBL1531595 & 688810 & \multicolumn{3}{|c|}{5.132999999999999} & 5.5202 & \\
\hline CHEMBL1605898 & 688810 & \multicolumn{3}{|c|}{4.7330000000000005} & 4.9966 & TRN \\
\hline CHEMBL1455877 & 688810 & \multicolumn{3}{|c|}{5.332999999999999} & & \\
\hline CHEMBL1516149 & 688810 & 4.683 & 5.6067 & TRN & & \\
\hline CHEMBL & 688810 & 4.783 & 5.3263 & TST & & \\
\hline CHEMBL1561348 & 688810 & 5.933 & 5.5144 & TRN & & \\
\hline CHEMBL3211809 & 688810 & \multicolumn{3}{|c|}{6.2829999999999995} & 5.3279 & $\mathrm{TH}$ \\
\hline CHEMBL1523741 & 688810 & 5.183 & 5.0707 & TRN & & \\
\hline CHEMBL1335855 & 688810 & 4.933 & 5.8079 & TRN & & \\
\hline CHEMBL14 & 688810 & 5.733 & 5.3472 & TRN & & \\
\hline CHEMBL1414355 & 688810 & \multicolumn{3}{|c|}{5.132999999999999} & 5.4194 & \\
\hline CHEMBL 3211025 & 688810 & \multicolumn{3}{|c|}{5.132999999999999} & & \\
\hline CHEMBL1602686 & 688810 & 4.933 & 5.1322 & TRN & & \\
\hline CHEMBL1578170 & 688810 & \multirow{2}{*}{\multicolumn{3}{|c|}{4.9830000000000005}} & & \\
\hline CHEMBL1336442 & 688810 & & & & 4.6545 & \\
\hline CHEMBL1500604 & 688810 & 4.933 & 5.1106 & TST & & \\
\hline CHEMBL3198294 & 688810 & 6.0829 & 9999999 & & 5.5557 & TR \\
\hline CHEMBL1440193 & 688810 & 5.433 & 5.0355 & TRN & & \\
\hline CHEMBL1612215 & 688810 & 4.583 & 5.393 & TST & & \\
\hline CHEMBL1467868 & 688810 & 4.783 & 5.1114 & TST & & \\
\hline CHEMBL587836 & 688810 & 4.833 & 5.2178 & TRN & & \\
\hline CHEMBL3211498 & 688810 & 4.9830 & 00000006 & 205 & 5.222 & \\
\hline CHEMBL1590015 & 688810 & 5.183 & 5.2223 & TRN & & \\
\hline CHEMBL1388768 & 688810 & 5.8329 & 99999995 & & 5.4868 & \\
\hline CHEMBL1395851 & 688810 & 4.783 & 5.4092 & TRN & & \\
\hline CHEMBL1481347 & 688810 & 5.8329 & 9999999 & & 5.5366 & $\mathrm{NI}$ \\
\hline
\end{tabular}


CHEMBL1335246

CHEMBL1507436

CHEMBL1599868

CHEMBL 1323340

CHEMBL3197259

CHEMBL1546367

CHEMBL1502125

CHEMBL1507170

CHEMBL1417099

CHEMBL1392322

CHEMBL1600781

CHEMBL1413941

CHEMBL1305967

CHEMBL1554426

CHEMBL1413480

CHEMBL1560216

CHEMBL 3189770

CHEMBL1602144

CHEMBL1585755

CHEMBL1380218

CHEMBL1384101

CHEMBL1500537

CHEMBL1371511

CHEMBL1571328

CHEMBL1370563

CHEMBL1352266

CHEMBL1562946

CHEMBL1613659

CHEMBL1362034

CHEMBL1466055

CHEMBL1597099

CHEMBL1440037

CHEMBL1588685

CHEMBL1545364

CHEMBL1531367

CHEMBL1499514

CHEMBL1510398

CHEMBL1385092

CHEMBL1516891

CHEMBL1574899

CHEMBL1491581

CHEMBL1451193

CHEMBL1535816

CHEMBL1427257

CHEMBL1553980

CHEMBL1581554

CHEMBL 3199431

CHEMBL1539956
Supplemental Table S2.txt

$\begin{array}{llllll}688810 & 4.883 & 4.9138 & \text { TST } & & \\ 688810 & 4.933 & 5.7412 & \text { TRN } & & \\ 688810 & 4.7330000000000005 & 5.2867 & \text { TST } \\ 688810 & 5.483 & 5.6475 \text { TRN } & & \\ 688810 & 5.332999999999999 & 5.6121 & \text { TST } \\ 688810 & 5.183 \quad 5.1184 \text { TRN } & & \\ 688810 & 4.9830000000000005 & 5.0387 & \text { TST }\end{array}$

$\begin{array}{lllll}688810 & 4.783 & 5.242999999999999 & \text { TRN }\end{array}$

688810

688810

688810

688810

688810

688810

688810

688810

688810

688810

688810

688810

688810

688810

688810

688810

688810

688810

688810

688810

688810

688810

688810

688810

688810

688810

688810

688810

688810

688810

688810

688810

688810

688810

688810

688810

688810

688810

688810

688810

$5.433 \quad 5.2711$ TRN

4.7330000000000005

$5.683 \quad 5.6597 \quad$ TRN

$5.183 \quad 5.1947$ TRN

$4.583 \quad 5.3643$ TRN

4.9335 .2115 TRN

5.4335 .1858 TRN

4.8335 .3482 TRN

$4.633 \quad 5.1669$ TRN

4.7330000000000005

$6.683 \quad 5.4007$ TRN

4.9335 .1187 TRN

$\begin{array}{lll}5.483 & 5.611000000000001 & \text { TRN }\end{array}$

$5.233 \quad 5.6134$ TRN

$4.7330000000000005 \quad 5.3411$ TRN

$5.083 \quad 5.3906$ TRN

$4.933 \quad 5.2347$ TST

$4.883 \quad 5.0986$ TRN

$4.883 \quad 5.2609$ TRN

5.382999999999999

4.9706 TRN

5.0114 TRN

4.7330000000000005

$5.933 \quad 5.0483$ TRN

$4.783 \quad 5.5601$ TRN

5.332999999999999

5.382999999999999

$5.233 \quad 5.4391$ TRN

5.382999999999999

4.7834 .9618 TRN

$5.983 \quad 5.6138$ TRN

5.7829999999999995

4.9830000000000005

5.2898 TRN

5.3939 TRN

$\begin{array}{lll}5.033 & 4.9974 & \text { TRN }\end{array}$

$5.083 \quad 5.0945$ TRN

4.9830000000000005

4.7330000000000005

$4.883 \quad 5.1684$ TST

$5.183 \quad 5.3834$ TRN

4.7834 .9951 TRN

4.7330000000000005

5.0165 TRN
5.2119 TRN

5.0102 TRN

5.5323 TRN

5.5614 TRN

5.0501 TRN

5.2469 TST

5.0312 TRN
TST 


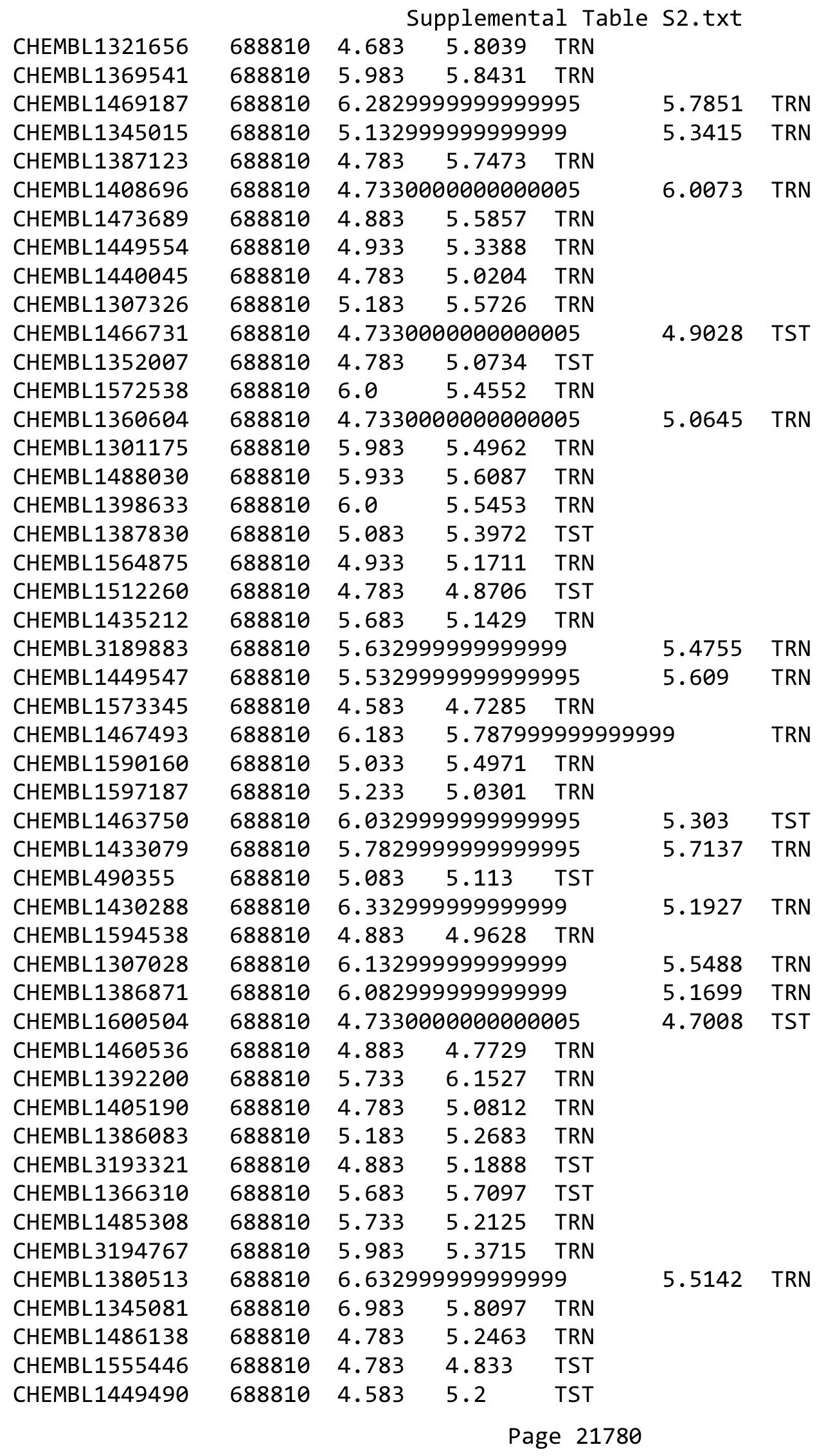




\begin{tabular}{|c|c|c|c|c|c|c|}
\hline & & \multicolumn{5}{|c|}{ Supplemental Table S2.txt } \\
\hline CHEMBL1336520 & 688810 & 6.28299 & 999999999 & 995 & 5.2445 & TRN \\
\hline HEMBL1340977 & 588810 & 4.73300 & 000000000 & 305 & 5.1356 & \\
\hline CHEMBL1580272 & 688810 & 4.783 & \multicolumn{3}{|c|}{5.167000000000001} & \\
\hline CHEMBL3199430 & 688810 & 4.783 & 5.4677 & TST & & \\
\hline CHEMBL1383719 & 688810 & \multicolumn{3}{|c|}{4.7330000000000005} & 5.2326 & \\
\hline CHEMBL1500498 & 588810 & 4.833 & 5.0787 & TRN & & \\
\hline HEMBL1507679 & 88810 & 4.683 & 5.1506 & TRN & & \\
\hline HEMBL1467921 & 688810 & \multicolumn{3}{|c|}{5.832999999999999} & 5.5515 & TRN \\
\hline CHEMBL1463272 & 688810 & \multicolumn{3}{|c|}{5.7829999999999995} & 5.7626 & \\
\hline CHEMBL1326967 & 688810 & 7.1331 & 6.5139 & TRN & & \\
\hline HEMBL1420139 & 688810 & 5.683 & 5.6688 & TRN & & \\
\hline CHEMBL1340364 & 688810 & \multicolumn{3}{|c|}{4.7330000000000005} & 4.9445 & \\
\hline CHEMBL13 & 688810 & 4.783 & 5.0858 & TRN & & \\
\hline CHEMBL1496447 & 688810 & \multicolumn{3}{|c|}{4.9830000000000005} & $3.1 \angle 1$ & \\
\hline HEMBL1510645 & 688810 & 4.633 & 5.1936 & TST & & \\
\hline HEMBL1515073 & 688810 & 4.883 & 5.2222 & TST & & \\
\hline CHEMBL15 & 688810 & 4.783 & 5.0642 & TRN & & \\
\hline HEMBL1 & 688810 & \multicolumn{3}{|c|}{4.7330000000000005} & 5.0598 & \\
\hline CHEMBL1597898 & 688810 & 4.833 & 5.6359 & TRN & & \\
\hline HEMBL1341339 & 688810 & \multicolumn{3}{|c|}{5.332999999999999} & 4.8119 & \\
\hline CHEMBL1459929 & 688810 & \multicolumn{3}{|c|}{6.382999999999999} & 5.6645 & \\
\hline CHEMBL1 & 688810 & 4.633 & 4.7246 & TRN & & \\
\hline HEMBL1 & 688810 & \multicolumn{3}{|c|}{5.5329999999999995} & 5.4584 & \\
\hline CHEMBL2369248 & 310 & \multicolumn{3}{|c|}{4.7330000000000005} & 5.2161 & \\
\hline CHEMBL1535147 & 688810 & 4.833 & \multicolumn{3}{|c|}{5.132999999999999} & \\
\hline CHEMBL1309228 & 688810 & \multicolumn{3}{|c|}{4.7330000000000005} & 4.8743 & \\
\hline HEMBL13 & 688810 & \multicolumn{3}{|c|}{5.132999999999999} & 5.2593 & \\
\hline CHEMBL15 & 688810 & \multicolumn{3}{|c|}{5.332999999999999} & 5.307 & \\
\hline CHEMBL1610987 & 310 & 4.783 & 4.6597 & TST & & \\
\hline CHEMBL1390450 & 688810 & \multicolumn{3}{|c|}{5.882999999999999} & 5.59 & \\
\hline CHEMBL1486587 & 688810 & 5.983 & 5.683 & $\mathrm{TR}$ & & \\
\hline CHEMBL2 & 688810 & \multicolumn{3}{|c|}{5.132999999999999} & 4118 & \\
\hline CHEMBL & 10 & 5.483 & 5.5204 & TRN & & \\
\hline CHEMBL1472062 & 10 & 5.083 & 5.4403 & TRN & & \\
\hline CHEMBL1360295 & 688810 & 7.1331 & 5.9412 & TRN & & \\
\hline CHEMBL1327923 & 688810 & \multicolumn{3}{|c|}{5.132999999999999} & $3.1 / 12$ & \\
\hline CHEMBL & 310 & \multicolumn{3}{|c|}{6.7829999999999995} & & \\
\hline CHEMBL & 10 & 4.633 & 5.0904 & TRN & & \\
\hline CHEMBL1417967 & 688810 & 5.733 & 5.7701 & TST & & \\
\hline CHEMBL1418869 & 688810 & 4.783 & 4.8752 & TRN & & \\
\hline CHEMBL1387187 & 688810 & 4.883 & 5.2847 & TRN & & \\
\hline CHEMBL1522276 & 688810 & 4.583 & 5.1438 & TRN & & \\
\hline CHEMBL3208686 & 688810 & \multicolumn{3}{|c|}{4.7330000000000005} & 5.4915 & TRN \\
\hline CHEMBL1341379 & 688810 & 4.783 & 5.1738 & TST & & \\
\hline CHEMBL1995481 & 688810 & 6.33299 & 999999999 & & 5.3398 & . \\
\hline CHEMBL1401584 & 688810 & 4.883 & 5.1787 & TST & & \\
\hline CHEMBL1592530 & 688810 & 4.583 & 5.0567 & TRN & & \\
\hline CHEMBL1364999 & 688810 & 5.233 & 5.285 & TST & & \\
\hline
\end{tabular}




\begin{tabular}{|c|c|c|c|c|c|c|}
\hline \multirow{3}{*}{$\begin{array}{l}\text { CHEMBL1369926 } \\
\text { CHEMBL1351441 }\end{array}$} & \multirow{3}{*}{$\begin{array}{l}688810 \\
688810\end{array}$} & \multicolumn{5}{|c|}{ Supplemental Table s2.txt } \\
\hline & & \multicolumn{3}{|c|}{6.2829999999999995} & \multirow{2}{*}{5.7453} & \multirow{2}{*}{ TRA } \\
\hline & & 4.933 & 5.4008 & TST & & \\
\hline CHEMBL1380805 & 688810 & \multicolumn{3}{|c|}{5.7829999999999995} & 6.0232 & TRN \\
\hline CHEMBL1493296 & 688810 & \multicolumn{3}{|c|}{5.132999999999999} & 5.245 & TRN \\
\hline CHEMBL1448038 & 688810 & \multicolumn{3}{|c|}{5.132999999999999} & 5.6148 & TRN \\
\hline CHEMBL1457070 & 688810 & \multicolumn{3}{|c|}{5.7829999999999995} & 5.3284 & TRN \\
\hline CHEMBL1347812 & 688810 & 4.833 & 5.157 & TRN & & \\
\hline CHEMBL1470939 & 688810 & \multicolumn{3}{|c|}{4.9830000000000005} & 5.7111 & TST \\
\hline CHEMBL1518138 & 688810 & 6.233 & 5.2852 & TRN & & \\
\hline CHEMBL1509913 & 688810 & 4.783 & 5.1743 & TST & & \\
\hline CHEMBL1515175 & 688810 & 5.233 & 5.1958 & TRN & & \\
\hline CHEMBL1362846 & 688810 & 5.033 & 5.0584 & TRN & & \\
\hline CHEMBL1459446 & 688810 & 4.833 & 4.9579 & TRN & & \\
\hline CHEMBL1971267 & 688810 & \multicolumn{3}{|c|}{6.632999999999999} & 5.4611 & TRN \\
\hline CHEMBL1463567 & 688810 & 5.033 & 5.5549 & TRN & & \\
\hline CHEMBL1569866 & 688810 & 4.933 & 4.7601 & TRN & & \\
\hline CHEMBL1342383 & 688810 & 5.233 & 5.6348 & TST & & \\
\hline CHEMBL1507539 & 688810 & 4.783 & 5.4503 & TST & & \\
\hline CHEMBL1588100 & 688810 & 4.933 & 5.3675 & TRN & & \\
\hline CHEMBL 3197824 & 688810 & 5.183 & 5.6779 & TRN & & \\
\hline CHEMBL1471104 & 688810 & 5.683 & 5.1651 & TST & & \\
\hline CHEMBL1535172 & 688810 & 5.233 & 5.7945 & TRN & & \\
\hline CHEMBL1487451 & 688810 & 5.433 & 5.5765 & TRN & & \\
\hline CHEMBL1325673 & 688810 & \multicolumn{3}{|c|}{6.2829999999999995} & 5.6627 & TRN \\
\hline CHEMBL 3210770 & 688810 & 5.933 & 5.3899 & TRN & & \\
\hline CHEMBL1601374 & 688810 & \multicolumn{3}{|c|}{4.7330000000000005} & 5.3686 & TRN \\
\hline CHEMBL3199007 & 688810 & \multicolumn{3}{|c|}{5.2829999999999995} & 5.2927 & TST \\
\hline CHEMBL1330933 & 688810 & \multicolumn{3}{|c|}{6.332999999999999} & 5.6303 & TRN \\
\hline CHEMBL1550553 & 688810 & 4.783 & 5.1647 & TST & & \\
\hline CHEMBL1351542 & 688810 & 5.483 & 4.9192 & TST & & \\
\hline CHEMBL1494328 & 688810 & \multicolumn{3}{|c|}{5.832999999999999} & 5.3095 & TRN \\
\hline CHEMBL1590210 & 688810 & 4.783 & 5.0958 & TST & & \\
\hline CHEMBL1601919 & 688810 & 4.833 & 5.2569 & TRN & & \\
\hline CHEMBL1545399 & 688810 & 4.933 & 4.9272 & TST & & \\
\hline CHEMBL1509051 & 688810 & 5.433 & 5.2902 & TST & & \\
\hline CHEMBL1486576 & 688810 & 4.633 & 5.6304 & TST & & \\
\hline CHEMBL1575588 & 688810 & \multicolumn{3}{|c|}{5.582999999999999} & 5.0326 & TST \\
\hline CHEMBL1410778 & 688810 & \multicolumn{3}{|c|}{5.2829999999999995} & 4.7452 & TST \\
\hline CHEMBL1350976 & 688810 & 4.833 & 4.9159 & TST & & \\
\hline CHEMBL1559862 & 688810 & \multicolumn{3}{|c|}{$\begin{array}{lll}4.683 & 4.9675 & \text { TST }\end{array}$} & & \\
\hline CHEMBL1435821 & 688810 & \multicolumn{3}{|c|}{4.9830000000000005} & 5.1941 & TRN \\
\hline CHEMBL1577289 & 688810 & 5.483 & 5.0352 & TST & & \\
\hline CHEMBL1534196 & 688810 & 5.5829 & 99999999 & & 5.1491 & TRN \\
\hline CHEMBL1347876 & 688810 & 4.7330 & 00000000 & 005 & 5.0218 & TST \\
\hline CHEMBL1472791 & 688810 & 5.083 & 5.3238 & TRN & & \\
\hline CHEMBL1390612 & 688810 & 4.583 & 5.3379 & TST & & \\
\hline CHEMBL1533287 & 688810 & 4.883 & 4.9876 & TRN & & \\
\hline CHEMBL1480069 & 688810 & 4.9830 & 00000000 & 005 & 5.2998 & TRN \\
\hline
\end{tabular}




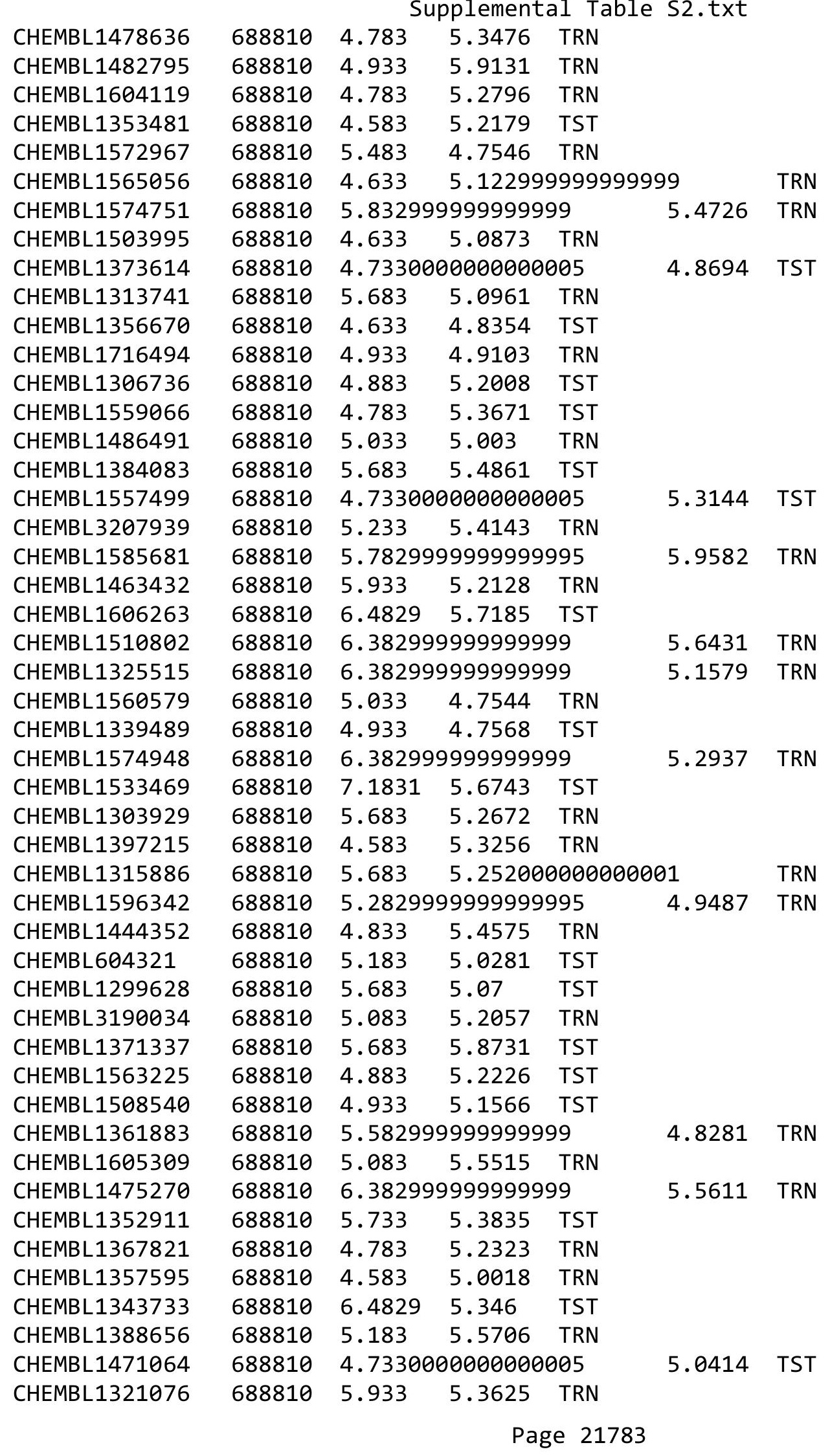




\begin{tabular}{|c|c|c|c|c|c|c|}
\hline \multirow{3}{*}{$\begin{array}{l}\text { CHEMBL1498118 } \\
\text { CHEMBL3191888 }\end{array}$} & & \multicolumn{5}{|c|}{ Supplemental Table S2.txt } \\
\hline & 688810 & \multicolumn{3}{|c|}{5.7829999999999995} & 5.3151 & TRN \\
\hline & 688810 & 5.983 & 5.1403 & TRN & & \\
\hline CHEMBL1355632 & 688810 & 4.833 & 4.897 & TRN & & \\
\hline CHEMBL1339694 & 688810 & \multicolumn{3}{|c|}{5.332999999999999} & 5.3071 & TRN \\
\hline CHEMBL1536587 & 688810 & 4.933 & 5.0358 & TST & & \\
\hline CHEMBL 2005944 & 688810 & \multicolumn{3}{|c|}{5.132999999999999} & 5.6851 & TRN \\
\hline CHEMBL1592590 & 688810 & \multicolumn{3}{|c|}{4.7330000000000005} & 5.0459 & TRN \\
\hline CHEMBL1420437 & 688810 & 4.833 & 5.0022 & TRN & & \\
\hline CHEMBL1559982 & 688810 & 5.683 & 5.6318 & TST & & \\
\hline CHEMBL1356867 & 688810 & 5.683 & 5.6368 & TRN & & \\
\hline CHEMBL1547530 & 688810 & 4.933 & 4.8862 & TST & & \\
\hline CHEMBL1324465 & 688810 & 5.683 & 5.4332 & TRN & & \\
\hline CHEMBL1343958 & 688810 & 4.783 & 5.2389 & TST & & \\
\hline CHEMBL1487834 & 688810 & 4.833 & 5.005 & TRN & & \\
\hline CHEMBL1587813 & 688810 & 4.883 & 4.8877 & TRN & & \\
\hline CHEMBL1560550 & 688810 & \multicolumn{3}{|c|}{6.632999999999999} & 6.0057 & TRN \\
\hline CHEMBL1302906 & 688810 & \multicolumn{3}{|c|}{6.132999999999999} & 5.0409 & TRN \\
\hline CHEMBL1385607 & 688810 & \multicolumn{3}{|c|}{4.9830000000000005} & 5.1395 & TRN \\
\hline CHEMBL1299972 & 688810 & \multicolumn{3}{|c|}{5.832999999999999} & 5.682 & TRN \\
\hline CHEMBL1400522 & 688810 & 4.783 & 5.1164 & TST & & \\
\hline CHEMBL1328190 & 688810 & 4.783 & 4.7311 & TRN & & \\
\hline CHEMBL1305047 & 688810 & 5.183 & 5.2489 & TRN & & \\
\hline CHEMBL1560735 & 688810 & 4.783 & 5.0868 & TRN & & \\
\hline CHEMBL1432104 & 688810 & 5.483 & 5.4516 & TRN & & \\
\hline CHEMBL1588452 & 688810 & 6.183 & 5.4626 & TRN & & \\
\hline CHEMBL1347555 & 688810 & 5.483 & 5.2414 & TRN & & \\
\hline CHEMBL1474350 & 688810 & \multicolumn{3}{|c|}{4.7330000000000005} & 5.5268 & TRN \\
\hline CHEMBL1407945 & 688810 & 5.733 & 5.4346 & TRN & & \\
\hline CHEMBL1578775 & 688810 & 4.783 & 5.1281 & TRN & & \\
\hline CHEMBL1429159 & 688810 & 5.033 & 5.1197 & TST & & \\
\hline CHEMBL1525751 & 688810 & 5.233 & 5.6715 & TRN & & \\
\hline CHEMBL1347716 & 688810 & 4.783 & 4.9004 & TST & & \\
\hline CHEMBL1546520 & 688810 & 6.183 & 5.855 & TRN & & \\
\hline CHEMBL1300899 & 688810 & 5.733 & 5.3082 & TST & & \\
\hline CHEMBL1993029 & 688810 & \multicolumn{3}{|c|}{6.632999999999999} & 5.8969 & TRN \\
\hline CHEMBL1553865 & 688810 & 4.883 & 4.8445 & TRN & & \\
\hline CHEMBL1368971 & 688810 & 4.833 & 5.4066 & TRN & & \\
\hline CHEMBL1532472 & 688810 & \multicolumn{3}{|c|}{5.832999999999999} & 5.8737 & TRN \\
\hline CHEMBL1445427 & 688810 & \multicolumn{3}{|c|}{6.082999999999999} & 5.5076 & TST \\
\hline CHEMBL1304004 & 688810 & \multicolumn{3}{|c|}{6.332999999999999} & 5.853 & TRN \\
\hline CHEMBL3209609 & 688810 & 4.883 & 5.2206 & TRN & & \\
\hline CHEMBL1331120 & 688810 & 5.733 & 6.0659 & TRN & & \\
\hline CHEMBL1327326 & 688810 & 5.083 & 5.4025 & TRN & & \\
\hline CHEMBL3213741 & 688810 & \multicolumn{3}{|c|}{6.332999999999999} & 5.7977 & TRN \\
\hline CHEMBL1525425 & 688810 & \multicolumn{3}{|c|}{5.132999999999999} & 5.3589 & TRN \\
\hline CHEMBL1487322 & 688810 & \multicolumn{3}{|c|}{6.132999999999999} & 5.2353 & TRN \\
\hline CHEMBL1321751 & 688810 & 5.233 & 5.6335 & TRN & & \\
\hline CHEMBL1354512 & 688810 & 4.633 & 5.0525 & TRN & & \\
\hline
\end{tabular}




\begin{tabular}{|c|c|c|c|c|c|c|c|}
\hline \multicolumn{8}{|c|}{ 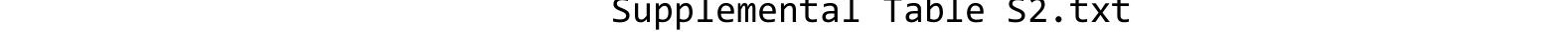 } \\
\hline CHEMBL1498679 & 688810 & 5.733 & 5.0206 & TRN & & & \\
\hline CHEMBL1340433 & 688810 & 5.683 & 5.12 & TRN & & & \\
\hline CHEMBL3198964 & 688810 & 7.1331 & 5.372999 & 999999999 & & TRN & \\
\hline CHEMBL1599895 & 688810 & 6.7331 & 5.7853 & TRN & & & \\
\hline CHEMBL1529203 & 688810 & 4.583 & 5.0951 & TRN & & & \\
\hline CHEMBL1451348 & 688810 & 5.13299 & 999999999 & & 4.9346 & TRN & \\
\hline CHEMBL1430944 & 688810 & 5.083 & 5.6829 & TRN & & & \\
\hline CHEMBL1485800 & 688810 & 4.633 & 5.4227 & TRN & & & \\
\hline CHEMBL1568027 & 688810 & 5.13299 & 999999995 & & 5.4145 & TST & \\
\hline CHEMBL1401599 & 688810 & 4.98300 & 000000006 & 005 & 5.1005 & TRN & \\
\hline CHEMBL1311787 & 688810 & 4.883 & 5.4945 & TST & & & \\
\hline CHEMBL1408523 & 688810 & 5.233 & 5.1376 & TRN & & & \\
\hline CHEMBL1509487 & 688810 & 6.28299 & 99999999 & 995 & 5.0455 & TRN & \\
\hline CHEMBL1414723 & 688810 & 5.733 & 5.7959 & TRN & & & \\
\hline CHEMBL1420422 & 688810 & 5.083 & 5.1528 & TRN & & & \\
\hline CHEMBL1593016 & 688810 & 5.683 & 5.2726 & TRN & & & \\
\hline CHEMBL1503659 & 688810 & 5.33299 & 999999999 & & 6.20299 & 9999999999 & TRN \\
\hline CHEMBL1359879 & 688810 & 5.983 & 5.5981 & TRN & & & \\
\hline CHEMBL 1437740 & 688810 & 4.583 & 4.9137 & TRN & & & \\
\hline CHEMBL1413886 & 688810 & 5.78299 & 999999995 & 995 & 5.0958 & TRN & \\
\hline CHEMBL1531806 & 688810 & 5.933 & 5.841 & TRN & & & \\
\hline CHEMBL1411712 & 688810 & 5.683 & 5.483 & TRN & & & \\
\hline CHEMBL1499615 & 688810 & 4.883 & 5.1488 & TRN & & & \\
\hline CHEMBL1586492 & 688810 & 5.78299 & 999999995 & 995 & 5.95 & TRN & \\
\hline CHEMBL1382022 & 688810 & 4.583 & 4.5616 & TRN & & & \\
\hline CHEMBL380184 & 688810 & 5.683 & 5.5503 & TRN & & & \\
\hline CHEMBL574954 & 688810 & 5.13299 & 999999999 & & 5.4871 & TRN & \\
\hline CHEMBL1460456 & 688810 & 4.683 & 5.4086 & TRN & & & \\
\hline CHEMBL1320020 & 688810 & 4.73300 & 000000000 & 005 & 4.9692 & TST & \\
\hline CHEMBL599102 & 688810 & 4.833 & 5.1338 & TRN & & & \\
\hline CHEMBL1403905 & 688810 & 4.633 & 4.7312 & TST & & & \\
\hline CHEMBL1452003 & 688810 & 5.28299 & 999999999 & 995 & 5.42899 & 9999999999 & TRN \\
\hline CHEMBL1481132 & 688810 & 4.633 & 5.2057 & TRN & & & \\
\hline CHEMBL1494624 & 688810 & 5.78299 & 999999999 & 995 & 5.6157 & TRN & \\
\hline CHEMBL1454103 & 688810 & 5.033 & 5.0829 & TST & & & \\
\hline CHEMBL1532583 & 688810 & 5.483 & 5.0071 & TRN & & & \\
\hline CHEMBL1385511 & 688810 & 4.883 & 5.4401 & TST & & & \\
\hline CHEMBL1319810 & 688810 & 5.13299 & 999999999 & & 5.8021 & TRN & \\
\hline CHEMBL1456768 & 688810 & 4.833 & 5.0477 & TRN & & & \\
\hline CHEMBL3193178 & 688810 & 4.933 & 5.2574 & TRN & & & \\
\hline CHEMBL3198108 & 688810 & 5.433 & 5.3461 & TST & & & \\
\hline CHEMBL1409532 & 688810 & 5.38299 & 999999999 & & 4.8692 & TRN & \\
\hline CHEMBL1975216 & 688810 & 5.483 & 5.0995 & TST & & & \\
\hline CHEMBL1550863 & 688810 & 5.28299 & 999999999 & 995 & 5.3421 & TRN & \\
\hline CHEMBL1358857 & 688810 & 4.73300 & 000000000 & 005 & 4.8398 & TRN & \\
\hline CHEMBL1320819 & 688810 & 5.13299 & 999999999 & & 5.2651 & TRN & \\
\hline CHEMBL1420901 & 688810 & 4.933 & 5.1866 & TRN & & & \\
\hline CHEMBL1453572 & 688810 & 4.833 & 5.6074 & TRN & & & \\
\hline
\end{tabular}




\begin{tabular}{|c|c|c|c|c|c|c|}
\hline \multirow[b]{2}{*}{ CHEMBL1397512 } & \\
\hline & 688810 & 4.833 & 5.0922 & TST & & \\
\hline CHEMBL1336549 & 688810 & 4.783 & 5.0936 & TRN & & \\
\hline CHEMBL1399050 & 688810 & $4.9830 e$ & 00000000 & 005 & 5.4955 & TRN \\
\hline CHEMBL 3199386 & 688810 & 4.933 & 5.1383 & TST & & \\
\hline CHEMBL1361801 & 688810 & 5.13299 & 99999999 & 99 & 5.074 & TST \\
\hline CHEMBL1423238 & 688810 & 5.683 & 4.9699 & TST & & \\
\hline CHEMBL1512003 & 688810 & $4.9830 e$ & 00000000 & 005 & 5.2656 & וכו \\
\hline CHEMBL 3207345 & 688810 & 4.783 & 5.5488 & TRN & & \\
\hline CHEMBL1353544 & 688810 & 5.033 & 5.22 & TST & & \\
\hline CHEMBL1366627 & 688810 & 4.683 & 5.8239 & TRN & & \\
\hline CHEMBL1606409 & 688810 & 4.833 & 5.1634 & TRN & & \\
\hline CHEMBL1543465 & 688810 & 4.833 & 4.9076 & TRN & & \\
\hline CHEMBL1599375 & 688810 & 4.783 & 5.4531 & TRN & & \\
\hline CHEMBL1299300 & 688810 & 5.1329 & 99999999 & & 4.7879 & . \\
\hline CHEMBL1584143 & 688810 & $4.7330 e$ & 00000000 & 005 & 4.9367 & \\
\hline CHEMBL1484663 & 688810 & 4.683 & 5.5531 & TRN & & \\
\hline CHEMBL1412393 & 688810 & 5.233 & 5.1425 & TRN & & \\
\hline CHEMBL1305626 & 688810 & 4.783 & 5.8149 & TRN & & \\
\hline CHEMBL1320175 & 688810 & 5.083 & 5.45100 & 00000 & 205 & \\
\hline CHEMBL1442877 & 688810 & 4.683 & 5.2219 & TST & & \\
\hline CHEMBL1563171 & 688810 & 5.733 & 5.6877 & TRN & & \\
\hline CHEMBL1392431 & 688810 & $4.7330 e$ & 00000000 & 005 & 5.3274 & \\
\hline CHEMBL1326464 & 688810 & 5.933 & 5.7907 & TST & & \\
\hline CHEMBL1393321 & 688810 & 6.03299 & 99999999 & 995 & 5.4527 & \\
\hline CHEMBL1583053 & 688810 & $4.7330 e$ & 00000000 & 005 & 5.1155 & \\
\hline CHEMBL1521301 & 688810 & 6.03299 & 99999999 & 995 & 5.4787 & $\mathrm{Tr}$ \\
\hline CHEMBL1302837 & 688810 & 5.183 & 5.2895 & TRN & & \\
\hline CHEMBL1442846 & 688810 & 5.183 & 5.1753 & TST & & \\
\hline CHEMBL1411585 & 688810 & 4.783 & 5.1761 & TRN & & \\
\hline CHEMBL1371675 & 688810 & 4.833 & 5.3294 & TRN & & \\
\hline CHEMBL1358134 & 688810 & $4.9830 €$ & 00000000 & 005 & 5.1778 & \\
\hline CHEMBL1321322 & 688810 & 5.13299 & 99999999 & & 5.0495 & $1 \mathrm{~T}$ \\
\hline CHEMBL1466214 & 688810 & 5.3329 & 99999999 & & 5.4009 & \\
\hline CHEMBL1520402 & 688810 & 5.733 & 5.2452 & TRN & & \\
\hline CHEMBL1562006 & 688810 & 5.7 & 5.1762 & TRN & & \\
\hline CHEMBL1329479 & 688810 & 5.33299 & 99999999 & & 5.0038 & TST \\
\hline CHEMBL1396804 & 688810 & 4.883 & 4.7501 & TRN & & \\
\hline CHEMBL1411520 & 688810 & 4.73306 & 00000000 & & 5.2943 & \\
\hline CHEMBL1310154 & 688810 & 5.683 & 5.4505 & TST & & \\
\hline CHEMBL1965911 & 688810 & 4.833 & 5.0187 & TRN & & \\
\hline CHEMBL1480085 & 688810 & 4.583 & 5.1115 & TST & & \\
\hline CHEMBL1558877 & 688810 & 4.583 & 4.8978 & TRN & & \\
\hline CHEMBL1552838 & 688810 & 5.78299 & 99999999 & 995 & 5.138 & \\
\hline CHEMBL1348171 & 688810 & 5.83299 & 99999999 & & 5.5156 & \\
\hline CHEMBL1421232 & 688810 & 6.1329 & 99999999 & & 5.8965 & TRN \\
\hline CHEMBL1557712 & 688810 & 5.13299 & 99999999 & & 5.0474 & 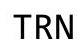 \\
\hline CHEMBL3191668 & 688810 & 8.1805 & 5.3608 & TRN & & \\
\hline CHEMBL1524727 & 688810 & 4.833 & 5.1094 & TRN & & \\
\hline
\end{tabular}




\begin{tabular}{|c|c|c|c|c|c|c|}
\hline \multirow[b]{2}{*}{ CHEMBL1519812 } & \multicolumn{6}{|c|}{ ement? } \\
\hline & 688810 & 4.783 & 5.3822 & TST & & \\
\hline CHEMBL1376582 & 688810 & 4.783 & 5.0928 & TRN & & \\
\hline CHEMBL1382410 & 688810 & 5.28299 & 999999999 & 995 & 5.7303 & this \\
\hline CHEMBL1452601 & 688810 & 4.633 & 4.8823 & TRN & & \\
\hline CHEMBL1513644 & 688810 & 4.73300 & 000000000 & 305 & 5.5431 & \\
\hline CHEMBL1429268 & 688810 & 5.733 & 5.3641 & TRN & & \\
\hline CHEMBL1407161 & 688810 & 4.583 & 4.8873 & TRN & & \\
\hline CHEMBL1427736 & 688810 & 5.033 & 5.8992 & TRN & & \\
\hline CHEMBL1487614 & 688810 & 4.633 & 5.0931 & TST & & \\
\hline CHEMBL1327342 & 688810 & 5.183 & 5.2228 & TRN & & \\
\hline CHEMBL 3191874 & 688810 & 4.583 & 5.82 & TRN & & \\
\hline CHEMBL1433072 & 688810 & 4.73300 & 000000000 & 305 & 5.3103 & \\
\hline CHEMBL1364801 & 688810 & 4.883 & 5.4487 & TST & & \\
\hline CHEMBL566531 & 688810 & 4.73300 & 000000000 & 305 & 5.0422 & \\
\hline CHEMBL1356715 & 688810 & 5.53299 & 999999999 & 995 & & \\
\hline CHEMBL1402422 & 688810 & 5.033 & 5.101 & TST & & \\
\hline CHEMBL1496465 & 688810 & 4.783 & 5.2684 & TRN & & \\
\hline CHEMBL1570612 & 688810 & 5.28299 & 999999999 & 995 & 202 & \\
\hline CHEMBL1330314 & 688810 & 5.28299 & 999999999 & 995 & 5.6864 & \\
\hline CHEMBL1425205 & 688810 & 4.783 & 4.8302 & TRN & & \\
\hline CHEMBL1442502 & 688810 & 6.33299 & 999999999 & & 5.6935 & \\
\hline CHEMBL1463470 & 688810 & 5.683 & 5.1912 & TRN & & \\
\hline CHEMBL1558889 & 688810 & 5.33299 & 999999999 & & 3 & \\
\hline CHEMBL1430994 & 688810 & 5.083 & 5.3792 & TRN & & \\
\hline CHEMBL1585624 & 688810 & 5.53299 & 999999999 & 995 & 5.3325 & \\
\hline CHEMBL1420677 & 688810 & 5.13299 & 999999999 & & 5.2288 & \\
\hline CHEMBL1422237 & 688810 & 4.783 & 5.523 & TRN & & \\
\hline CHEMBL1595440 & 688810 & 4.783 & 5.5063 & TRN & & \\
\hline CHEMBL1595525 & 688810 & 4.73300 & 000000000 & 305 & 5.4672 & \\
\hline CHEMBL1564080 & 688810 & 6.53299 & 999999999 & 995 & 5.5481 & \\
\hline CHEMBL1430820 & 688810 & 5.88299 & 999999999 & & 5.544 & $\mathrm{TI}$ \\
\hline CHEMBL 3189663 & 688810 & 5.683 & 5.1383 & TRN & & \\
\hline CHEMBL1508637 & 688810 & 5.83299 & 999999999 & & 5.3654 & \\
\hline CHEMBL 2 & 688810 & 4.583 & 5.1977 & TRN & & \\
\hline CHEMBL1527527 & 688810 & 4.883 & 5.6624 & TRN & & \\
\hline CHEMBL 3198107 & 688810 & 4.883 & 4.3874 & TST & & \\
\hline CHEMBL1528309 & 688810 & 5.233 & 5.632000 & 0000 & $\partial 1$ & \\
\hline CHEMBL 1582476 & 688810 & 5.33299 & 999999999 & & 5.2 & \\
\hline CHEMBL1423806 & 688810 & 4.98300 & 000000000 & 305 & 5.4655 & \\
\hline CHEMBL1549877 & 688810 & 5.28299 & 999999999 & 995 & 5.1489 & . \\
\hline CHEMBL1332994 & 688810 & 5.483 & 5.3374 & TRN & & \\
\hline CHEMBL 3195103 & 688810 & 4.73300 & 000000000 & 305 & 5.4124 & IN \\
\hline CHEMBL1528436 & 688810 & 6.183 & 5.7929 & TRN & & \\
\hline CHEMBL1529932 & 688810 & 5.983 & 5.7483 & TRN & & \\
\hline CHEMBL 3199584 & 688810 & 4.583 & 5.1809 & TRN & & \\
\hline CHEMBL 3199093 & 688810 & 6.13299 & 999999999 & & 5.9831 & In \\
\hline CHEMBL1610894 & 688810 & 6.4829 & 6.026 & TRN & & \\
\hline CHEMBL1394869 & 688810 & 4.833 & 5.0085 & TST & & \\
\hline
\end{tabular}




\begin{tabular}{|c|c|c|c|c|c|c|}
\hline \multicolumn{7}{|c|}{ Supplemental Table S2.txt } \\
\hline CHEMBL1609492 & 688810 & \multicolumn{3}{|c|}{5.832999999999999} & 4.9732 & TRN \\
\hline CHEMBL1403645 & 688810 & \multicolumn{3}{|c|}{5.332999999999999} & 5.5153 & TST \\
\hline CHEMBL1420265 & 688810 & 5.683 & 5.5996 & TRN & & \\
\hline CHEMBL1321622 & 688810 & 5.183 & 5.4506 & TRN & & \\
\hline CHEMBL1409243 & 688810 & \multicolumn{3}{|c|}{5.7829999999999995} & 5.066 & TRN \\
\hline CHEMBL1449009 & 688810 & \multicolumn{3}{|c|}{5.632999999999999} & 5.2621 & TRN \\
\hline CHEMBL1576502 & 688810 & 5.483 & 4.9379 & TRN & & \\
\hline CHEMBL1385982 & 688810 & 4.833 & 5.73 & TST & & \\
\hline CHEMBL1474590 & 688810 & 4.633 & 4.8223 & TRN & & \\
\hline CHEMBL1359835 & 688810 & 4.783 & 5.3262 & TRN & & \\
\hline CHEMBL1486356 & 688810 & \multicolumn{3}{|c|}{4.7330000000000005} & 5.1097 & TRN \\
\hline CHEMBL1537846 & 688810 & 4.833 & 5.4094 & TST & & \\
\hline CHEMBL1312974 & 688810 & 4.783 & 5.4728 & TST & & \\
\hline CHEMBL1574298 & 688810 & \multicolumn{3}{|c|}{5.832999999999999} & 5.671 & TRN \\
\hline CHEMBL1301544 & 688810 & 4.883 & 5.0161 & TST & & \\
\hline CHEMBL1498562 & 688810 & \multicolumn{3}{|c|}{5.632999999999999} & 5.7798 & TRN \\
\hline CHEMBL3210921 & 688810 & 5.183 & 5.5238 & TRN & & \\
\hline CHEMBL317172 & 688810 & \multicolumn{3}{|c|}{5.132999999999999} & 5.1628 & TST \\
\hline CHEMBL1398047 & 688810 & \multicolumn{3}{|c|}{6.632999999999999} & 5.7639 & TRN \\
\hline CHEMBL1519962 & 688810 & 5.483 & 5.4767 & TRN & & \\
\hline CHEMBL1523036 & 688810 & 5.233 & \multicolumn{3}{|c|}{5.6739999999999995} & TRN \\
\hline CHEMBL1529225 & 688810 & 4.783 & 4.6984 & TRN & & \\
\hline CHEMBL300389 & 688810 & 6.683 & 6.1368 & TST & & \\
\hline CHEMBL1578229 & 688810 & 4.783 & 4.7571 & TRN & & \\
\hline CHEMBL486094 & 688810 & 4.883 & 5.0338 & TRN & & \\
\hline CHEMBL1553965 & 688810 & \multicolumn{3}{|c|}{5.332999999999999} & 5.5657 & TST \\
\hline CHEMBL1590049 & 688810 & 6.4829 & 5.6204 & TRN & & \\
\hline CHEMBL1585599 & 688810 & 4.833 & 5.3142 & TST & & \\
\hline CHEMBL1432780 & 688810 & \multicolumn{3}{|c|}{5.7829999999999995} & 5.2454 & TRN \\
\hline CHEMBL1608402 & 688810 & 5.033 & 5.0891 & TST & & \\
\hline CHEMBL1534441 & 688810 & 6.683 & 5.7581 & TRN & & \\
\hline CHEMBL1535665 & 688810 & 5.233 & 4.8248 & TST & & \\
\hline CHEMBL3195200 & 688810 & \multicolumn{3}{|c|}{6.632999999999999} & 5.4539 & TRN \\
\hline CHEMBL1439864 & 688810 & \multicolumn{3}{|c|}{4.7330000000000005} & 5.0225 & TST \\
\hline CHEMBL1333193 & 688810 & \multicolumn{3}{|c|}{4.7330000000000005} & 5.1366 & TRN \\
\hline CHEMBL1435214 & 688810 & \multicolumn{3}{|c|}{4.9830000000000005} & 5.5485 & TST \\
\hline CHEMBL1599704 & 688810 & \multicolumn{3}{|c|}{5.632999999999999} & 5.4608 & TRN \\
\hline CHEMBL1439295 & 688810 & 6.233 & 5.4488 & TRN & & \\
\hline CHEMBL1443936 & 688810 & 5.433 & 6.189 & TRN & & \\
\hline CHEMBL1491971 & 688810 & \multicolumn{3}{|c|}{5.5329999999999995} & 5.1717 & TRN \\
\hline CHEMBL1395126 & 688810 & 5.433 & \multicolumn{3}{|c|}{5.542999999999999} & TST \\
\hline CHEMBL1515438 & 688810 & 6.983 & 5.7404 & TRN & & \\
\hline CHEMBL1315580 & 688810 & \multicolumn{3}{|c|}{5.7829999999999995} & $5.4060 e$ & 0000000001 \\
\hline CHEMBL1391071 & 688810 & 5.733 & 5.3616 & TRN & & \\
\hline CHEMBL1467841 & 688810 & 6.0829 & 99999999 & & 5.3756 & TRN \\
\hline CHEMBL1434258 & 688810 & 5.8829 & 99999999 & & 5.8407 & TRN \\
\hline CHEMBL1476765 & 688810 & 5.083 & 5.7338 & TRN & & \\
\hline CHEMBL1465908 & 688810 & 5.233 & 5.941 & TRN & & \\
\hline
\end{tabular}




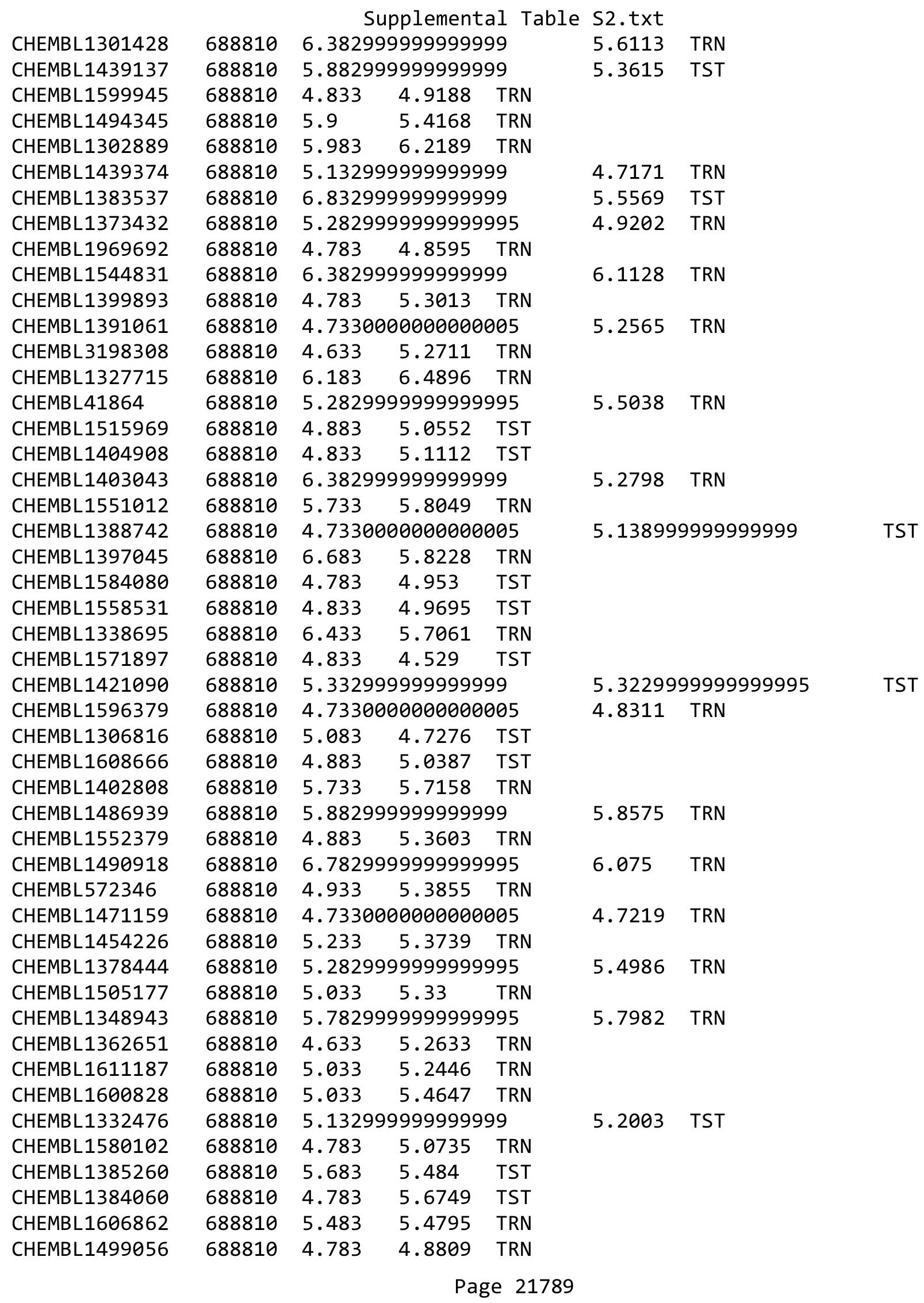




\begin{tabular}{|c|c|c|c|c|c|c|c|}
\hline \multicolumn{8}{|c|}{ Supplemental Table S2.txt } \\
\hline CHEMBL3211864 & 688810 & 4.783 & 4.9489 & TRN & & & \\
\hline CHEMBL1391343 & 688810 & 4.883 & 4.9677 & TRN & & & \\
\hline CHEMBL3196622 & 688810 & 6.183 & 5.8527 & TRN & & & \\
\hline CHEMBL1421103 & 688810 & 4.783 & 5.0155 & TST & & & \\
\hline CHEMBL1299297 & 688810 & \multicolumn{3}{|c|}{5.382999999999999} & 5.2481 & TST & \\
\hline CHEMBL379099 & 688810 & 4.583 & 5.3685 & TRN & & & \\
\hline CHEMBL1479974 & 688810 & \multicolumn{3}{|c|}{6.5329999999999995} & 5.749 & TRN & \\
\hline CHEMBL1311643 & 688810 & 5.233 & 5.6698 & TRN & & & \\
\hline CHEMBL1600373 & 688810 & 4.883 & 5.4588 & TRN & & & \\
\hline CHEMBL1541714 & 688810 & 4.783 & 5.0421 & TRN & & & \\
\hline CHEMBL1468734 & 688810 & \multicolumn{3}{|c|}{4.7330000000000005} & 5.1169 & TRN & \\
\hline CHEMBL1407140 & 688810 & 4.583 & 5.5455 & TRN & & & \\
\hline CHEMBL1500091 & 688810 & 5.983 & 5.2077 & TRN & & & \\
\hline CHEMBL1492648 & 688810 & 4.633 & 5.1421 & TRN & & & \\
\hline CHEMBL1537509 & 688810 & 5.033 & 4.6847 & TST & & & \\
\hline CHEMBL1451655 & 688810 & 4.783 & 5.2087 & TRN & & & \\
\hline CHEMBL1529921 & 688810 & 4.933 & 5.0279 & TRN & & & \\
\hline CHEMBL1398099 & 688810 & 5.933 & 5.8455 & TRN & & & \\
\hline CHEMBL119769 & 688810 & 6.683 & 6.0029 & TRN & & & \\
\hline CHEMBL1531722 & 688810 & 4.883 & 5.1793 & TRN & & & \\
\hline CHEMBL1517665 & 688810 & 5.483 & 5.3345 & TRN & & & \\
\hline CHEMBL1332943 & 688810 & \multicolumn{3}{|c|}{4.7330000000000005} & 5.0269 & TST & \\
\hline CHEMBL1599989 & 688810 & 5.483 & 5.2041 & TRN & & & \\
\hline CHEMBL1328213 & 688810 & 4.633 & 5.3294 & TST & & & \\
\hline CHEMBL1307100 & 688810 & 4.683 & 5.0562 & TRN & & & \\
\hline CHEMBL1450402 & 688810 & 4.883 & 5.269 & TRN & & & \\
\hline CHEMBL1326021 & 688810 & \multicolumn{3}{|c|}{5.132999999999999} & \multicolumn{2}{|c|}{5.343999999999999} & TST \\
\hline CHEMBL1610032 & 688810 & 5.483 & 5.7571 & TRN & & & \\
\hline CHEMBL1429585 & 688810 & 5.183 & 5.4293 & TRN & & & \\
\hline CHEMBL1561248 & 688810 & \multicolumn{3}{|c|}{6.632999999999999} & 5.6153 & TRN & \\
\hline CHEMBL1603382 & 688810 & \multicolumn{3}{|c|}{4.9830000000000005} & 5.1816 & TRN & \\
\hline CHEMBL1437449 & 688810 & 4.933 & 5.0696 & TRN & & & \\
\hline CHEMBL1303198 & 688810 & 4.883 & 5.5617 & TRN & & & \\
\hline CHEMBL1550670 & 688810 & \multicolumn{3}{|c|}{4.7330000000000005} & 5.0181 & TST & \\
\hline CHEMBL1421941 & 688810 & \multicolumn{3}{|c|}{5.132999999999999} & 5.9933 & TRN & \\
\hline CHEMBL1549805 & 688810 & 4.883 & 4.9352 & TRN & & & \\
\hline CHEMBL1321593 & 688810 & 6.9329 & 5.9748 & TRN & & & \\
\hline CHEMBL1457974 & 688810 & 4.783 & 4.7354 & TST & & & \\
\hline CHEMBL1605075 & 688810 & \multicolumn{3}{|c|}{4.9830000000000005} & 5.3641 & TST & \\
\hline CHEMBL578523 & 688810 & 4.633 & 5.3015 & TST & & & \\
\hline CHEMBL1393594 & 688810 & \multicolumn{3}{|c|}{5.7829999999999995} & 5.6016 & TRN & \\
\hline CHEMBL1453532 & 688810 & 4.883 & \multicolumn{3}{|c|}{4.9830000000000005} & TRN & \\
\hline CHEMBL1464721 & 688810 & 4.633 & 5.7372 & TRN & & & \\
\hline CHEMBL1545955 & 688810 & \multicolumn{3}{|c|}{6.632999999999999} & 5.4516 & TRN & \\
\hline CHEMBL1485405 & 688810 & 4.783 & 4.9819 & TRN & & & \\
\hline CHEMBL 3194251 & 688810 & \multicolumn{3}{|c|}{5.332999999999999} & 5.0589 & TRN & \\
\hline CHEMBL1322920 & 688810 & 4.783 & 5.1063 & TRN & & & \\
\hline CHEMBL1408078 & 688810 & 4.833 & 5.2134 & TRN & & & \\
\hline
\end{tabular}




\begin{tabular}{|c|c|c|c|c|c|c|c|}
\hline \multirow[b]{2}{*}{ CHEMBL1410134 } & & \\
\hline & 688810 & 5.233 & 5.0374 & TST & & & \\
\hline CHEMBL1429517 & 688810 & \multicolumn{3}{|c|}{5.132999999999999} & \multirow{4}{*}{5.54} & \multirow[t]{4}{*}{ TRN } & \\
\hline CHEMBL1569546 & 688810 & 5.733 & 5.5229 & TRN & & & \\
\hline CHEMBL1512098 & 688810 & 4.933 & 5.1933 & TRN & & & \\
\hline CHEMBL 3192242 & 688810 & 4.783 & 5.1686 & TRN & & & \\
\hline CHEMBL1532512 & 688810 & \multicolumn{3}{|c|}{5.632999999999999} & 5.3484 & TRN & \\
\hline CHEMBL1600513 & 688810 & 4.633 & 5.0116 & TRN & & & \\
\hline CHEMBL1300355 & 688810 & 4.883 & 4.9859 & TRN & & & \\
\hline CHEMBL3192353 & 688810 & \multicolumn{3}{|c|}{4.7330000000000005} & 5.3219 & TRN & \\
\hline CHEMBL1459958 & 688810 & 4.633 & 4.9929 & TST & & & \\
\hline CHEMBL1511095 & 688810 & \multicolumn{3}{|c|}{4.7330000000000005} & 5.0609 & TRN & \\
\hline CHEMBL1304397 & 688810 & \multicolumn{3}{|c|}{5.7829999999999995} & 5.436 & TRN & \\
\hline CHEMBL1342739 & 688810 & 7.2328 & 6.09 & TRN & & & \\
\hline CHEMBL1312690 & 688810 & 4.783 & 4.9199 & TST & & & \\
\hline CHEMBL1611812 & 688810 & \multicolumn{3}{|c|}{5.5329999999999995} & 5.6087 & TRN & \\
\hline CHEMBL1490308 & 688810 & 4.783 & 5.1814 & TRN & & & \\
\hline CHEMBL 2006503 & 688810 & 4.833 & 5.4367 & TRN & & & \\
\hline CHEMBL1511483 & 688810 & \multicolumn{3}{|c|}{4.7330000000000005} & 5.3259 & TST & \\
\hline CHEMBL3212018 & 688810 & \multicolumn{3}{|c|}{4.7330000000000005} & 4.529 & TST & \\
\hline CHEMBL1434318 & 688810 & 5.183 & 5.2773 & TRN & & & \\
\hline CHEMBL1433046 & 688810 & 5.183 & 5.8015 & TRN & & & \\
\hline CHEMBL1375955 & 688810 & 4.833 & 4.9858 & TRN & & & \\
\hline CHEMBL1333382 & 688810 & 4.833 & 5.229 & TRN & & & \\
\hline CHEMBL1470349 & 688810 & 4.883 & 5.0736 & TRN & & & \\
\hline CHEMBL1416732 & 688810 & 5.233 & 5.1503 & TST & & & \\
\hline CHEMBL1413946 & 688810 & 4.933 & 5.4018 & TRN & & & \\
\hline CHEMBL 3197915 & 688810 & \multicolumn{3}{|c|}{4.7330000000000005} & 5.1883 & TRN & \\
\hline CHEMBL1592948 & 688810 & 5.083 & 4.9263 & TRN & & & \\
\hline CHEMBL1974521 & 688810 & 5.433 & 5.2576 & TRN & & & \\
\hline CHEMBL1378510 & 688810 & \multicolumn{3}{|c|}{5.332999999999999} & 5.1412 & TST & \\
\hline CHEMBL1324718 & 688810 & 4.883 & 5.2513 & TRN & & & \\
\hline CHEMBL1347459 & 688810 & 5.733 & 5.3282 & TRN & & & \\
\hline CHEMBL1363390 & 688810 & 5.683 & 5.5096 & TRN & & & \\
\hline CHEMBL1592787 & 688810 & 5.733 & 4.9816 & TRN & & & \\
\hline CHEMBL1346456 & 688810 & 4.633 & 5.3709 & TST & & & \\
\hline CHEMBL1531533 & 688810 & \multicolumn{3}{|c|}{5.582999999999999} & 5.7342 & TST & \\
\hline CHEMBL1388751 & 688810 & 5.433 & 5.3947 & TRN & & & \\
\hline CHEMBL1585843 & 688810 & 4.883 & 5.1726 & TRN & & & \\
\hline CHEMBL1604966 & 688810 & \multicolumn{3}{|c|}{5.5329999999999995} & 5.946006 & 0000000001 & TRN \\
\hline CHEMBL1485265 & 688810 & 6.433 & 5.5391 & TRN & & & \\
\hline CHEMBL1368818 & 688810 & 6.183 & 5.775 & TRN & & & \\
\hline CHEMBL1336013 & 688810 & 5.183 & 4.9826 & TRN & & & \\
\hline CHEMBL1313750 & 688810 & 5.233 & 5.5364 & TST & & & \\
\hline CHEMBL1529612 & 688810 & \multicolumn{3}{|c|}{6.0329999999999995} & 5.8938 & TRN & \\
\hline CHEMBL1411211 & 688810 & 5.083 & 5.1828 & TRN & & & \\
\hline CHEMBL1469911 & 688810 & 4.783 & 5.1573 & TRN & & & \\
\hline CHEMBL1390287 & 688810 & 4.783 & 5.0072 & TST & & & \\
\hline CHEMBL1394539 & 688810 & \multicolumn{3}{|c|}{6.132999999999999} & 5.6583 & TRN & \\
\hline
\end{tabular}




\begin{tabular}{|c|c|c|c|c|c|c|}
\hline & & \multicolumn{5}{|c|}{ Supplemental Table S2.txt } \\
\hline CHEMBL1564923 & 688810 & 4.583 & 5.5636 & TRN & & \\
\hline CHEMBL3190032 & 688810 & \multicolumn{3}{|c|}{4.7330000000000005} & 5.3645 & TST \\
\hline CHEMBL1372804 & 688810 & \multicolumn{3}{|c|}{5.2829999999999995} & 5.2416 & TRN \\
\hline CHEMBL1348506 & 688810 & \multicolumn{3}{|c|}{5.2829999999999995} & 5.3006 & TRN \\
\hline CHEMBL1372857 & 688810 & \multicolumn{3}{|c|}{5.832999999999999} & 4.9525 & TRN \\
\hline CHEMBL1405075 & 688810 & 4.883 & 5.3583 & TST & & \\
\hline CHEMBL1299997 & 688810 & 4.783 & 5.4543 & TST & & \\
\hline CHEMBL1578411 & 688810 & 5.483 & 5.1145 & TRN & & \\
\hline CHEMBL1565015 & 688810 & \multicolumn{3}{|c|}{5.832999999999999} & 5.7403 & TRN \\
\hline CHEMBL1477078 & 688810 & 4.683 & 5.2711 & TRN & & \\
\hline CHEMBL1992547 & 688810 & 4.833 & 5.3167 & TRN & & \\
\hline CHEMBL1531357 & 688810 & 4.683 & 4.8532 & TST & & \\
\hline CHEMBL1602966 & 688810 & 5.183 & 5.1333 & TST & & \\
\hline CHEMBL1477325 & 688810 & 5.033 & 5.113 & TRN & & \\
\hline CHEMBL1493074 & 688810 & 4.833 & 5.3147 & TST & & \\
\hline CHEMBL1436318 & 688810 & \multicolumn{3}{|c|}{5.2829999999999995} & 5.7862 & TRN \\
\hline CHEMBL1573328 & 688810 & \multicolumn{3}{|c|}{4.7330000000000005} & 5.1093 & TRN \\
\hline CHEMBL3198969 & 688810 & 4.883 & 4.9015 & TRN & & \\
\hline CHEMBL1572594 & 688810 & 4.783 & 5.319 & TST & & \\
\hline CHEMBL1462192 & 688810 & 5.683 & 5.2615 & TRN & & \\
\hline CHEMBL1484163 & 688810 & 4.783 & 4.98 & TRN & & \\
\hline CHEMBL52682 & 688810 & 4.633 & 4.6822 & TRN & & \\
\hline CHEMBL1503613 & 688810 & 6.4829 & 5.5729 & TRN & & \\
\hline CHEMBL3196745 & 688810 & 5.033 & 5.5315 & TRN & & \\
\hline CHEMBL1320392 & 688810 & 5.033 & 5.0681 & TRN & & \\
\hline CHEMBL1596218 & 688810 & 5.683 & 5.3225 & TRN & & \\
\hline CHEMBL1595194 & 688810 & \multicolumn{3}{|c|}{5.582999999999999} & 5.4507 & TRN \\
\hline CHEMBL1338265 & 688810 & 4.883 & 4.7707 & TRN & & \\
\hline CHEMBL1448258 & 688810 & 5.083 & 5.1841 & TRN & & \\
\hline CHEMBL1471402 & 688810 & 4.783 & \multicolumn{3}{|c|}{5.1160000000000005} & TST \\
\hline CHEMBL1435790 & 688810 & 5.233 & 5.3028 & TRN & & \\
\hline CHEMBL1564403 & 688810 & 4.833 & 5.0664 & TRN & & \\
\hline CHEMBL1299668 & 688810 & 4.833 & 5.335 & TRN & & \\
\hline CHEMBL1438614 & 688810 & \multicolumn{3}{|c|}{7.082999999999999} & 5.4757 & TST \\
\hline CHEMBL1531920 & 688810 & 4.583 & 5.1249 & TRN & & \\
\hline CHEMBL1367347 & 688810 & 4.633 & 5.2833 & TRN & & \\
\hline CHEMBL1530621 & 688810 & 5.183 & 5.2266 & TRN & & \\
\hline CHEMBL1604707 & 688810 & 5.433 & 5.4553 & TRN & & \\
\hline CHEMBL1448339 & 688810 & 4.783 & 4.8832 & TST & & \\
\hline CHEMBL1309378 & 688810 & 6.183 & 5.7692 & TRN & & \\
\hline CHEMBL1493258 & 688810 & 5.183 & 5.1355 & TRN & & \\
\hline CHEMBL3214385 & 688810 & \multicolumn{3}{|c|}{4.7330000000000005} & 5.0061 & TRN \\
\hline CHEMBL1306132 & 688810 & \multicolumn{3}{|c|}{4.9830000000000005} & 6.2956 & TST \\
\hline CHEMBL1327258 & 688810 & 4.783 & 4.7498 & TRN & & \\
\hline CHEMBL1402000 & 688810 & 5.7 & 5.1431 & TRN & & \\
\hline CHEMBL1539980 & 688810 & \multicolumn{3}{|c|}{5.132999999999999} & 6.0797 & TRN \\
\hline CHEMBL1352181 & 688810 & 4.783 & 5.3511 & TRN & & \\
\hline CHEMBL1609811 & 688810 & 5.433 & 5.4625 & TRN & & \\
\hline
\end{tabular}




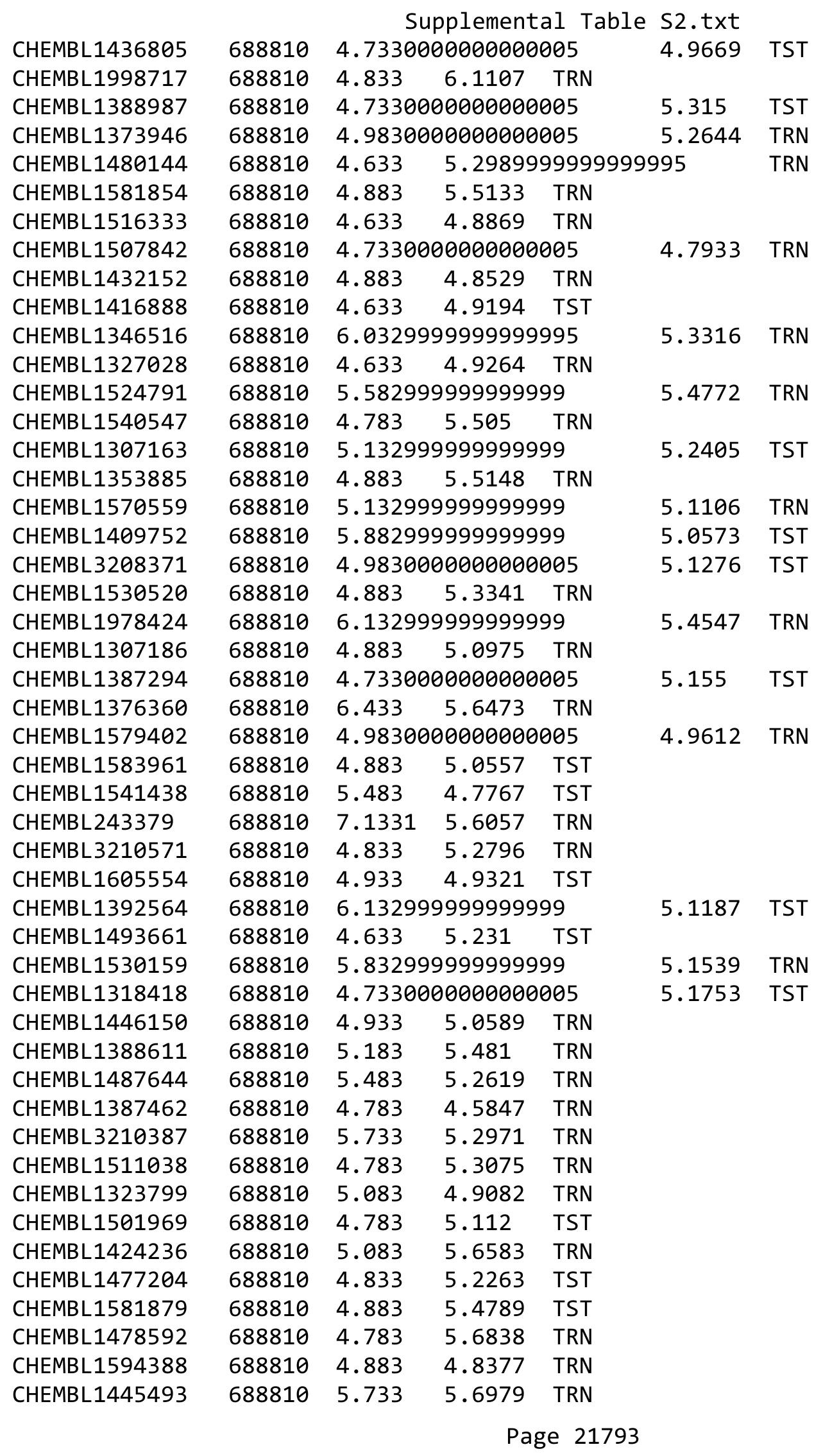




\begin{tabular}{|c|c|c|c|c|c|c|}
\hline \multirow[b]{2}{*}{ CHEMBL1443790 } & \multicolumn{6}{|c|}{ Supplemental Table S2.txt } \\
\hline & 688810 & 4.783 & 5.0506 & TRN & & \\
\hline CHEMBL1425892 & 688810 & \multicolumn{3}{|c|}{5.382999999999999} & 5.5294 & $\mathrm{~T}$ \\
\hline CHEMBL1477578 & 688810 & \multicolumn{3}{|c|}{4.7330000000000005} & 5.1914 & \\
\hline CHEMBL1375998 & 688810 & 4.633 & 5.1213 & TRN & & \\
\hline CHEMBL1498133 & 688810 & \multicolumn{3}{|c|}{5.2829999999999995} & 5.4103 & $\mathrm{~T}$ \\
\hline CHEMBL1565448 & 688810 & \multicolumn{3}{|c|}{4.7330000000000005} & 5.1799 & \\
\hline CHEMBL1401524 & 688810 & 4.583 & 5.0851 & TRN & & \\
\hline CHEMBL1372247 & 688810 & 5.483 & 5.4887 & TRN & & \\
\hline CHEMBL1497634 & 688810 & 5.733 & 5.3738 & TRN & & \\
\hline CHEMBL1586649 & 688810 & 5.933 & 5.0161 & TRN & & \\
\hline CHEMBL1334136 & 688810 & 6.233 & 6.1752 & TRN & & \\
\hline CHEMBL1496717 & 688810 & \multicolumn{3}{|c|}{4.7330000000000005} & 5.3639 & \\
\hline CHEMBL1393041 & 688810 & \multicolumn{3}{|c|}{4.9830000000000005} & 5349 & \\
\hline CHEMBL1363188 & 688810 & 4.583 & \multicolumn{3}{|c|}{5.0569999999999995} & \\
\hline CHEMBL3208395 & 688810 & \multirow{2}{*}{$\begin{array}{l}4.783 \\
5.183\end{array}$} & 5.1092 & TRN & & \\
\hline CHEMBL1510935 & 688810 & & 5.506 & TRN & & \\
\hline CHEMBL1420098 & 688810 & \multicolumn{3}{|c|}{5.7829999999999995} & 612 & \\
\hline CHEMBL31S & 688810 & 4.933 & 5.4093 & TRN & & \\
\hline CHEMBL1 & 688810 & 4.833 & 5.317 & TRN & & \\
\hline CHEMBL 2369215 & 688810 & 4.783 & 5.142 & TST & & \\
\hline CHEMBL1901606 & 688810 & 4.633 & 5.2079 & TRN & & \\
\hline CHEMBL1374956 & 688810 & \multicolumn{3}{|c|}{5.632999999999999} & 5.4838 & \\
\hline CHEMBL15 & 688810 & \multicolumn{3}{|c|}{6.332999999999999} & 5.5736 & \\
\hline CHEMBL6: & 688810 & \multicolumn{3}{|c|}{6.132999999999999} & 5.733 & \\
\hline CHEMBL1353298 & 688810 & \multicolumn{3}{|c|}{5.132999999999999} & & \\
\hline CHEMBL162609 & 688810 & 6.233 & 6.0004 & TST & & \\
\hline CHEMBL 3193248 & 688810 & 4.783 & 5.1629 & TRN & & \\
\hline CHEMBL1 & 688810 & 6.433 & 5.8844 & TRN & & \\
\hline CHEMBL1339435 & 688810 & 5.033 & 5.3824 & TRN & & \\
\hline CHEMBL489340 & 688810 & 4.883 & 5.3658 & TRN & & \\
\hline CHEMBL1440598 & 688810 & 4.583 & 5.641 & TST & & \\
\hline CHEMBL1535823 & 688810 & 4.633 & 5.1252 & TRN & & \\
\hline CHEMBL1 & 688810 & 5.233 & 5.1733 & TRN & & \\
\hline CHEMBL1613243 & 688810 & \multicolumn{3}{|c|}{4.7330000000000005} & 5.1753 & $\mathrm{TI}$ \\
\hline CHEMBL1568981 & 688810 & 5.8 & 5.5235 & TRN & & \\
\hline CHEMBL1605913 & 688810 & \multicolumn{3}{|c|}{5.832999999999999} & 5.4044 & \\
\hline CHEMBL1 & 688810 & 6.9329 & 5.7151 & TRN & & \\
\hline CHEMBL1 & 688810 & \multirow{2}{*}{\multicolumn{3}{|c|}{$\begin{array}{lrr}4.783 & 6.1527 & \text { TST } \\
5.2829999999999995\end{array}$}} & & \\
\hline CHEMBL1559671 & 688810 & & & & 5.5983 & $\mathrm{~T}$ \\
\hline CHEMBL1490048 & 688810 & \multicolumn{3}{|c|}{$4.833 \quad 5.0217$ TRN } & & \\
\hline CHEMBL1488035 & 688810 & 4.583 & 5.345 & TRN & & \\
\hline CHEMBL1578022 & 688810 & \multicolumn{3}{|c|}{5.132999999999999} & 4.8795 & r \\
\hline CHEMBL1599778 & 688810 & 6.4829 & 6.1061 & TRN & & \\
\hline CHEMBL1586887 & 688810 & 4.7330 & 0000000 & 005 & 5.1344 & $\mathrm{~T}$ \\
\hline CHEMBL1388470 & 688810 & 5.083 & 5.2726 & TST & & \\
\hline CHEMBL564201 & 688810 & 6.0829 & 99999995 & & 5.7394 & TST \\
\hline CHEMBL1435939 & 688810 & 5.083 & 5.1434 & TRN & & \\
\hline CHEMBL1384582 & 688810 & 5.8329 & 9999999 & & 5.7596 & \\
\hline
\end{tabular}


Supplemental Table S2.txt

\begin{tabular}{|c|c|c|c|c|c|c|c|}
\hline CHEMBL1582553 & 688810 & 4.883 & \multicolumn{3}{|c|}{5.452000000000001} & \multicolumn{2}{|l|}{ TRN } \\
\hline CHEMBL1576130 & 688810 & 4.783 & 5.0641 & TST & & & \\
\hline CHEMBL1567904 & 688810 & 4.833 & 4.8737 & TRN & & & \\
\hline CHEMBL1312691 & 688810 & 4.833 & 5.5084 & TST & & & \\
\hline CHEMBL1476042 & 688810 & 4.783 & 4.94 & TRN & & & \\
\hline CHEMBL1503834 & 688810 & 4.583 & 5.5107 & TST & & & \\
\hline CHEMBL3190295 & 688810 & 6.183 & 5.4381 & TRN & & & \\
\hline CHEMBL1465998 & 688810 & 4.883 & 5.2541 & TRN & & & \\
\hline CHEMBL1494524 & 688810 & 5.183 & 5.5705 & TRN & & & \\
\hline CHEMBL578515 & 688810 & 4.633 & 4.9468 & TRN & & & \\
\hline CHEMBL1513607 & 688810 & 4.783 & 4.8916 & TST & & & \\
\hline CHEMBL1467837 & 688810 & \multicolumn{3}{|c|}{5.382999999999999} & 5.2794 & TST & \\
\hline CHEMBL3189986 & 688810 & 4.833 & 5.1798 & TST & & & \\
\hline CHEMBL585656 & 688810 & 4.883 & 4.922 & TST & & & \\
\hline CHEMBL1600990 & 688810 & 4.783 & 4.6415 & TST & & & \\
\hline CHEMBL1521145 & 688810 & \multicolumn{3}{|c|}{5.382999999999999} & 5.5636 & TRN & \\
\hline CHEMBL1369972 & 688810 & 4.933 & 5.1951 & TRN & & & \\
\hline CHEMBL1565290 & 688810 & \multicolumn{3}{|c|}{4.7330000000000005} & 5.2372 & TST & \\
\hline CHEMBL1371656 & 688810 & \multicolumn{3}{|c|}{6.382999999999999} & 4.9721 & TRN & \\
\hline CHEMBL1345922 & 688810 & 4.783 & 5.2316 & TRN & & & \\
\hline CHEMBL1592999 & 688810 & 6.433 & 5.5999 & TRN & & & \\
\hline CHEMBL3210608 & 688810 & \multicolumn{3}{|c|}{6.332999999999999} & \multicolumn{2}{|c|}{5.053999999999999} & TRN \\
\hline CHEMBL1608662 & 688810 & 5.733 & 5.4379 & TRN & & & \\
\hline CHEMBL1342214 & 688810 & 5.183 & 4.9944 & TRN & & & \\
\hline CHEMBL1429800 & 688810 & 5.183 & 4.93 & TRN & & & \\
\hline CHEMBL1429134 & 688810 & 4.783 & 5.1333 & TRN & & & \\
\hline CHEMBL3193372 & 688810 & \multicolumn{3}{|c|}{4.7330000000000005} & 5.1171 & TRN & \\
\hline CHEMBL1543182 & 688810 & \multicolumn{3}{|c|}{6.332999999999999} & 5.5291 & TRN & \\
\hline CHEMBL1358182 & 688810 & 4.583 & 5.4754 & TRN & & & \\
\hline CHEMBL1323624 & 688810 & \multicolumn{3}{|c|}{5.132999999999999} & 5.0819 & TRN & \\
\hline CHEMBL1482499 & 688810 & 4.833 & 5.6173 & TRN & & & \\
\hline CHEMBL1542245 & 688810 & \multicolumn{3}{|c|}{4.9830000000000005} & 5.3156 & TRN & \\
\hline CHEMBL1559727 & 688810 & \multicolumn{3}{|c|}{4.9830000000000005} & 4.9851 & TRN & \\
\hline CHEMBL1413556 & 688810 & 6.7331 & 5.7625 & TST & & & \\
\hline CHEMBL1408675 & 688810 & 4.933 & 5.5617 & TRN & & & \\
\hline CHEMBL1372094 & 688810 & \multicolumn{3}{|c|}{5.7829999999999995} & 5.9987 & TRN & \\
\hline CHEMBL1386296 & 688810 & \multicolumn{3}{|c|}{5.7829999999999995} & 4.8965 & TRN & \\
\hline CHEMBL1362628 & 688810 & 5.083 & 4.7371 & TST & & & \\
\hline CHEMBL1504592 & 688810 & 6.233 & 5.3132 & TST & & & \\
\hline CHEMBL1342609 & 688810 & \multicolumn{3}{|c|}{5.7829999999999995} & 5.2738 & TRN & \\
\hline CHEMBL1311856 & 688810 & \multicolumn{3}{|c|}{6.332999999999999} & 5.75899 & 99999999995 & TRN \\
\hline CHEMBL1558691 & 688810 & 6.183 & 5.2551 & TRN & & & \\
\hline CHEMBL1413424 & 688810 & 5.033 & 5.307 & TRN & & & \\
\hline CHEMBL1337017 & 688810 & \multicolumn{3}{|c|}{4.7330000000000005} & 4.9905 & TST & \\
\hline CHEMBL1339328 & 688810 & 5.183 & 4.9803 & TST & & & \\
\hline CHEMBL1585842 & 688810 & 5.083 & 5.5408 & TRN & & & \\
\hline CHEMBL1421441 & 688810 & 4.633 & 4.7726 & TRN & & & \\
\hline CHEMBL448245 & 688810 & 5.2829 & 99999999 & 995 & 5.6239 & TST & \\
\hline
\end{tabular}




\begin{tabular}{|c|c|c|c|c|c|c|c|}
\hline \multicolumn{8}{|c|}{ 年 } \\
\hline CHEMBL1432213 & 688810 & 6.233 & 5.4701 & TRN & & & \\
\hline CHEMBL1311769 & 688810 & 4.833 & 5.1174 & TST & & & \\
\hline CHEMBL1552501 & 688810 & 4.73300 & 00000000 & 005 & 5.2791 & TRN & \\
\hline CHEMBL1575768 & 688810 & 5.83299 & 999999995 & & 5.2731 & TRN & \\
\hline CHEMBL1496313 & 688810 & 4.833 & 4.9488 & TST & & & \\
\hline CHEMBL1444341 & 688810 & 4.883 & 5.3521 & TST & & & \\
\hline CHEMBL1358366 & 688810 & 5.083 & 5.3644 & TRN & & & \\
\hline CHEMBL1469144 & 688810 & 4.883 & 5.1794 & TST & & & \\
\hline CHEMBL1547711 & 688810 & 5.683 & 5.7606 & TRN & & & \\
\hline CHEMBL3207492 & 688810 & 4.73300 & 000000006 & 005 & 5.2209 & TRN & \\
\hline CHEMBL1514428 & 688810 & 4.583 & 4.8736 & TRN & & & \\
\hline CHEMBL1365705 & 688810 & 5.88299 & 999999999 & & 5.8543 & TRN & \\
\hline CHEMBL1349341 & 688810 & 5.0 & 5.2047 & TST & & & \\
\hline CHEMBL1385545 & 688810 & 5.88299 & 999999995 & & 5.1973 & TST & \\
\hline CHEMBL 237253 & 688810 & 5.933 & 5.6225 & TRN & & & \\
\hline CHEMBL1549533 & 688810 & 4.833 & 5.0337 & TST & & & \\
\hline CHEMBL1338049 & 688810 & 4.933 & 5.1149 & TST & & & \\
\hline CHEMBL1337084 & 688810 & 5.58299 & 999999995 & & 5.3173 & TRN & \\
\hline CHEMBL1969515 & 688810 & 4.98300 & 000000006 & 005 & 5.12799 & 9999999999 & TRN \\
\hline CHEMBL1519056 & 688810 & 5.78299 & 999999995 & 995 & 5.4849 & TRN & \\
\hline CHEMBL1404130 & 688810 & 4.633 & 5.1878 & TST & & & \\
\hline CHEMBL1459869 & 688810 & 4.73300 & 000000006 & 005 & 5.2865 & TRN & \\
\hline CHEMBL1493792 & 688810 & 4.783 & 5.1757 & TST & & & \\
\hline CHEMBL1403826 & 688810 & 4.933 & 5.0654 & TST & & & \\
\hline CHEMBL1508905 & 688810 & 4.933 & 5.5776 & TRN & & & \\
\hline CHEMBL1500941 & 688810 & 5.233 & 5.29 & TRN & & & \\
\hline CHEMBL3191969 & 688810 & 5.38299 & 999999999 & & 5.7176 & TST & \\
\hline CHEMBL1332825 & 688810 & 5.033 & 5.2529 & TST & & & \\
\hline CHEMBL1398613 & 688810 & 5.433 & 5.5385 & TST & & & \\
\hline CHEMBL1502201 & 688810 & 5.433 & 5.5567 & TRN & & & \\
\hline CHEMBL1545241 & 688810 & 5.13299 & 999999999 & & 5.1905 & TRN & \\
\hline CHEMBL1518707 & 688810 & 7.0329 & 5.3002 & TRN & & & \\
\hline CHEMBL1512314 & 688810 & 5.033 & 5.3924 & TRN & & & \\
\hline CHEMBL1606790 & 688810 & 5.78299 & 999999995 & 995 & 5.6459 & TRN & \\
\hline CHEMBL1571971 & 688810 & 6.0 & 5.5607 & TRN & & & \\
\hline CHEMBL1576565 & 688810 & 4.933 & 5.1992 & TST & & & \\
\hline CHEMBL1417487 & 688810 & 4.933 & 4.8391 & TRN & & & \\
\hline CHEMBL1440637 & 688810 & 5.13299 & 999999999 & & 5.0036 & TRN & \\
\hline CHEMBL1429140 & 688810 & 5.683 & 4.8445 & TRN & & & \\
\hline CHEMBL1461506 & 688810 & 6.28299 & 999999995 & 995 & 6.2513 & TRN & \\
\hline CHEMBL1508851 & 688810 & 4.833 & 5.0047 & TST & & & \\
\hline CHEMBL1458298 & 688810 & 4.883 & 5.2914 & TRN & & & \\
\hline CHEMBL1549229 & 688810 & 4.98300 & 000000006 & 005 & 5.4783 & TST & \\
\hline CHEMBL1335678 & 688810 & 6.38299 & 999999995 & & 5.6184 & TRN & \\
\hline CHEMBL1302894 & 688810 & 4.933 & 5.0221 & TST & & & \\
\hline CHEMBL1568762 & 688810 & 4.783 & 5.6104 & TRN & & & \\
\hline CHEMBL1484568 & 688810 & 4.98300 & 000000006 & 005 & 5.005 & TRN & \\
\hline CHEMBL1593166 & 688810 & 6.33299 & 999999995 & & 5.7449 & TRN & \\
\hline
\end{tabular}




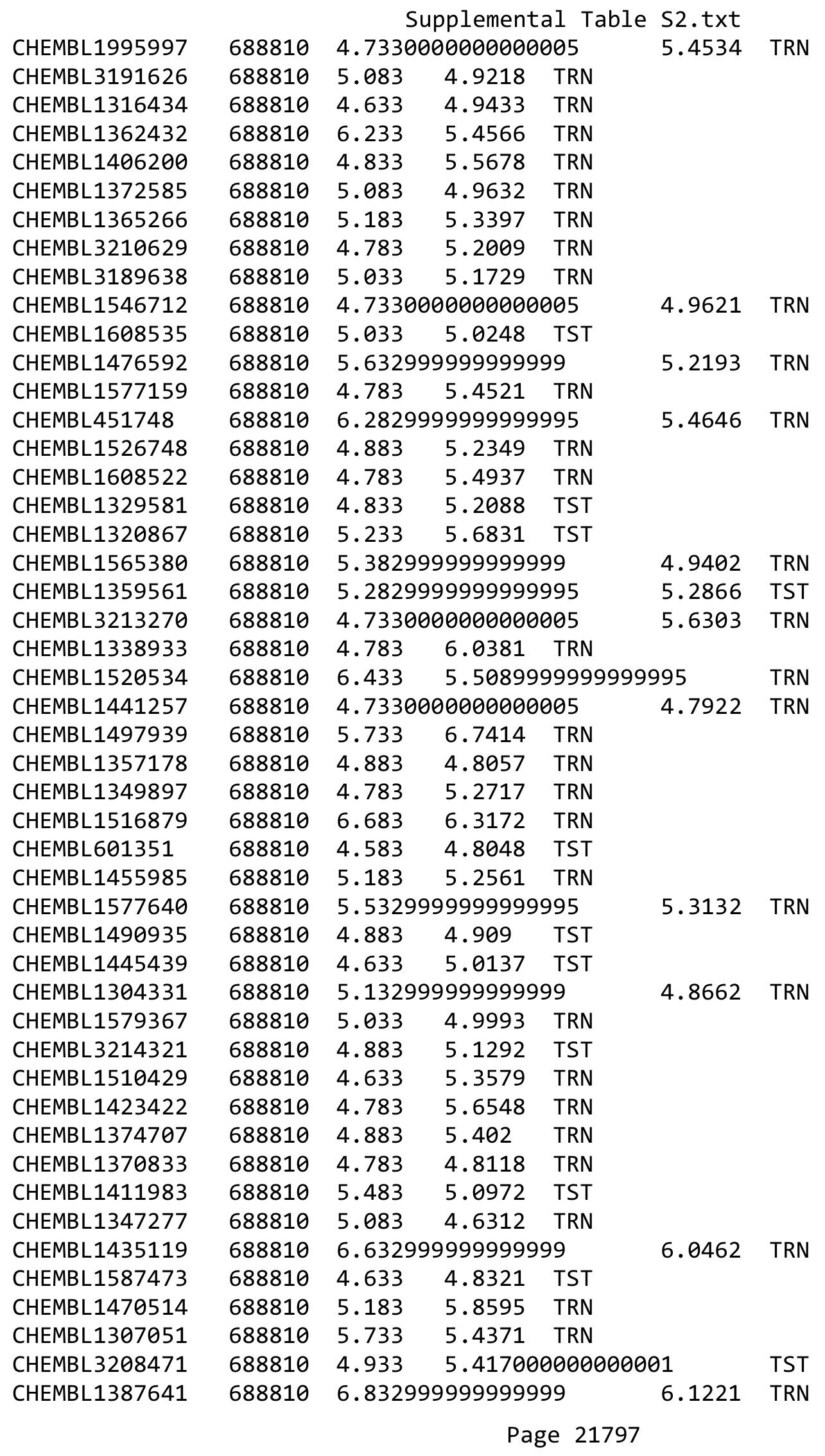




\begin{tabular}{|c|c|c|c|c|c|c|}
\hline & & & pplement & al & s2.txt & \\
\hline CHEMBL1485578 & 688810 & 4.9836 & 0000000 & 005 & 4.9389 & TST \\
\hline CHEMBL1558038 & 688810 & 4.633 & 5.2623 & TRN & & \\
\hline CHEMBL1438308 & 688810 & $5.282 \mathrm{C}$ & $9999999 \leq$ & 995 & 5.2094 & TST \\
\hline CHEMBL1373467 & 688810 & 4.833 & 5.5077 & TST & & \\
\hline CHEMBL3209582 & 688810 & 5.733 & 5.5751 & TRN & & \\
\hline CHEMBL1994685 & 688810 & 5.083 & 5.1901 & TST & & \\
\hline CHEMBL1449569 & 688810 & 5.1329 & 99999995 & & 5.4866 & TRN \\
\hline CHEMBL1489311 & 688810 & 4.7336 & 0000000 & 005 & 5.1103 & TRN \\
\hline CHEMBL 3198171 & 688810 & 4.783 & 5.5269 & TRN & & \\
\hline CHEMBL 2004056 & 688810 & 4.633 & 4.9877 & TST & & \\
\hline CHEMBL1551630 & 688810 & 5.433 & 5.33206 & 00006 & 01 & TRN \\
\hline CHEMBL3196489 & 688810 & 5.8820 & 9999999 & & 5.2073 & TRN \\
\hline CHEMBL1418191 & 688810 & 4.583 & 4.8448 & TRN & & \\
\hline CHEMBL1449424 & 688810 & 5.733 & 5.5258 & TRN & & \\
\hline CHEMBL1562114 & 688810 & 5.1325 & 9999999 & & 4.7421 & TRN \\
\hline CHEMBL1336148 & 688810 & 5.8329 & 9999999 & & 5.7743 & TRN \\
\hline CHEMBL1592591 & 688810 & 4.783 & 4.8264 & TRN & & \\
\hline CHEMBL1362789 & 688810 & 4.783 & 5.1675 & TRN & & \\
\hline CHEMBL1499507 & 688810 & 5.183 & 4.9638 & TRN & & \\
\hline CHEMBL1531841 & 688810 & 4.633 & 4.3633 & TST & & \\
\hline CHEMBL1421583 & 688810 & 4.783 & 5.9817 & TRN & & \\
\hline CHEMBL1582111 & 688810 & 5.433 & 5.5086 & TST & & \\
\hline CHEMBL1386790 & 688810 & 4.783 & 5.4037 & TST & & \\
\hline CHEMBL3210249 & 688810 & 4.7336 & 00000006 & 005 & 0968 & TRN \\
\hline CHEMBL1353244 & 688810 & 5.683 & 5.6332 & TRN & & \\
\hline CHEMBL1318618 & 688810 & 5.233 & 5.348 & TRN & & \\
\hline CHEMBL1518827 & 688810 & 4.7336 & 0000000 & 005 & 5.4308 & TRN \\
\hline CHEMBL1360416 & 688810 & 5.8829 & 99999995 & & 5.8523 & TRN \\
\hline CHEMBL1526172 & 688810 & 4.7336 & 0000000 & 005 & 5.0958 & TST \\
\hline CHEMBL1578485 & 688810 & 4.833 & 5.318 & TST & & \\
\hline CHEMBL1531113 & 688810 & 5.683 & 5.4921 & TRN & & \\
\hline CHEMBL1490250 & 688810 & 5.683 & 5.2506 & TST & & \\
\hline CHEMBL1330522 & 688810 & 4.883 & 5.0213 & TST & & \\
\hline CHEMBL1300329 & 688810 & 4.883 & 5.2297 & TRN & & \\
\hline CHEMBL1313939 & 688810 & 5.233 & 5.5139 & TRN & & \\
\hline CHEMBL1331322 & 688810 & 4.633 & 5.1678 & TRN & & \\
\hline CHEMBL1548613 & 688810 & 6.1329 & 99999995 & & 6.3808 & TST \\
\hline CHEMBL1480179 & 688810 & 6.983 & 5.4872 & TST & & \\
\hline CHEMBL1317703 & 688810 & 4.883 & 5.2691 & TRN & & \\
\hline CHEMBL1324646 & 688810 & 4.883 & 5.2055 & TRN & & \\
\hline CHEMBL1607406 & 688810 & 4.783 & 4.8364 & TRN & & \\
\hline CHEMBL1436848 & 688810 & 5.933 & 5.1395 & TRN & & \\
\hline CHEMBL1386612 & 688810 & 4.7336 & 00000006 & 005 & 5.0186 & TRN \\
\hline CHEMBL1493353 & 688810 & 4.933 & 5.3684 & TST & & \\
\hline CHEMBL1306237 & 688810 & 5.183 & 5.8512 & TRN & & \\
\hline CHEMBL1529837 & 688810 & 5.433 & 5.5687 & TRN & & \\
\hline CHEMBL1377488 & 688810 & 5.2829 & 9999999 & 995 & 5.7411 & TST \\
\hline CHEMBL1404363 & 688810 & 4.783 & 5.6669 & TST & & \\
\hline
\end{tabular}




\begin{tabular}{|c|c|c|c|c|c|c|c|}
\hline \multicolumn{8}{|c|}{ Supplemental Ta } \\
\hline CHEMBL1538238 & 688810 & 4.833 & 4.9209 & TRN & & & \\
\hline CHEMBL1569144 & 688810 & 4.783 & 5.1404 & TRN & & & \\
\hline CHEMBL1329937 & 688810 & 5.28299 & 999999999 & 995 & 4.9099 & TRN & \\
\hline CHEMBL3192849 & 688810 & 4.73300 & 000000000 & 05 & 5.2672 & TRN & \\
\hline CHEMBL1554542 & 688810 & 5.88299 & 999999999 & & 5.5188 & TRN & \\
\hline CHEMBL1434713 & 688810 & 4.833 & 5.0538 & TST & & & \\
\hline CHEMBL1464486 & 688810 & 4.73300 & 000000000 & 005 & 4.7448 & TRN & \\
\hline CHEMBL1337160 & 688810 & 4.933 & 5.3823 & TRN & & & \\
\hline CHEMBL1544834 & 688810 & 5.483 & 5.0172 & TRN & & & \\
\hline CHEMBL3207295 & 688810 & 4.783 & 5.0659 & TST & & & \\
\hline CHEMBL1427061 & 688810 & 5.733 & 5.5303 & TST & & & \\
\hline CHEMBL1354673 & 688810 & 6.08299 & 999999999 & & 5.71 & TRN & \\
\hline CHEMBL1300405 & 688810 & 4.833 & 4.9581 & TST & & & \\
\hline CHEMBL1379224 & 688810 & 5.733 & 5.64 & TRN & & & \\
\hline CHEMBL1611106 & 688810 & 4.833 & 4.8604 & TST & & & \\
\hline CHEMBL3193067 & 688810 & 4.883 & 5.0073 & TRN & & & \\
\hline CHEMBL1440238 & 688810 & 5.95 & 5.5108 & TRN & & & \\
\hline CHEMBL1380733 & 688810 & 5.683 & 5.3128 & TRN & & & \\
\hline CHEMBL1331356 & 688810 & 5.033 & 4.8999 & TST & & & \\
\hline CHEMBL1525597 & 688810 & 5.13299 & 999999999 & & 5.2071 & TRN & \\
\hline CHEMBL1488450 & 688810 & 5.733 & 5.0228 & TST & & & \\
\hline CHEMBL1426546 & 688810 & 5.83299 & 999999999 & & $5.4970 e$ & 0000000001 & TRN \\
\hline CHEMBL1388065 & 688810 & 4.833 & 5.301 & TRN & & & \\
\hline CHEMBL1565933 & 688810 & 4.73300 & 000000000 & 005 & 5.3939 & TRN & \\
\hline CHEMBL1409330 & 688810 & 5.483 & 5.393 & TRN & & & \\
\hline CHEMBL1572715 & 688810 & 6.433 & 5.4404 & TRN & & & \\
\hline CHEMBL1591996 & 688810 & 4.73300 & 000000000 & 005 & 5.0625 & TRN & \\
\hline CHEMBL3211125 & 688810 & 4.783 & 5.0888 & TRN & & & \\
\hline CHEMBL1425439 & 688810 & 4.783 & 4.9859 & TRN & & & \\
\hline CHEMBL3196362 & 688810 & 4.883 & 5.6765 & TRN & & & \\
\hline CHEMBL1328521 & 688810 & 4.883 & 5.0178 & TRN & & & \\
\hline CHEMBL1508512 & 688810 & 5.63299 & 999999999 & & 5.1714 & TRN & \\
\hline CHEMBL1353727 & 688810 & 4.98300 & 000000000 & 005 & 5.1689 & TRN & \\
\hline CHEMBL1482663 & 688810 & 5.53299 & 999999999 & 995 & 5.5299 & TST & \\
\hline CHEMBL1611026 & 688810 & 4.633 & 4.6029 & TST & & & \\
\hline CHEMBL1311979 & 688810 & 4.783 & 5.4837 & TST & & & \\
\hline CHEMBL1407778 & 688810 & 5.63299 & 999999999 & & $5.3320 e$ & 0000000001 & TRN \\
\hline CHEMBL1516915 & 688810 & 5.033 & 4.649 & TST & & & \\
\hline CHEMBL1479901 & 688810 & 4.783 & 5.1364 & TST & & & \\
\hline CHEMBL 3192838 & 688810 & 5.78299 & 999999999 & 995 & 5.2198 & TRN & \\
\hline CHEMBL1354625 & 688810 & 4.633 & 4.7087 & TRN & & & \\
\hline CHEMBL1410745 & 688810 & 5.38299 & 999999999 & & 5.2456 & TST & \\
\hline CHEMBL1402324 & 688810 & 5.033 & 5.0927 & TRN & & & \\
\hline CHEMBL1370834 & 688810 & 5.183 & 5.6225 & TRN & & & \\
\hline CHEMBL1593226 & 688810 & 4.633 & 5.0129 & TRN & & & \\
\hline CHEMBL1420361 & 688810 & 5.33299 & 999999999 & & 5.1327 & TRN & \\
\hline CHEMBL1395876 & 688810 & 4.633 & 4.9055 & TRN & & & \\
\hline CHEMBL1424911 & 688810 & 5.183 & 5.3516 & TRN & & & \\
\hline
\end{tabular}




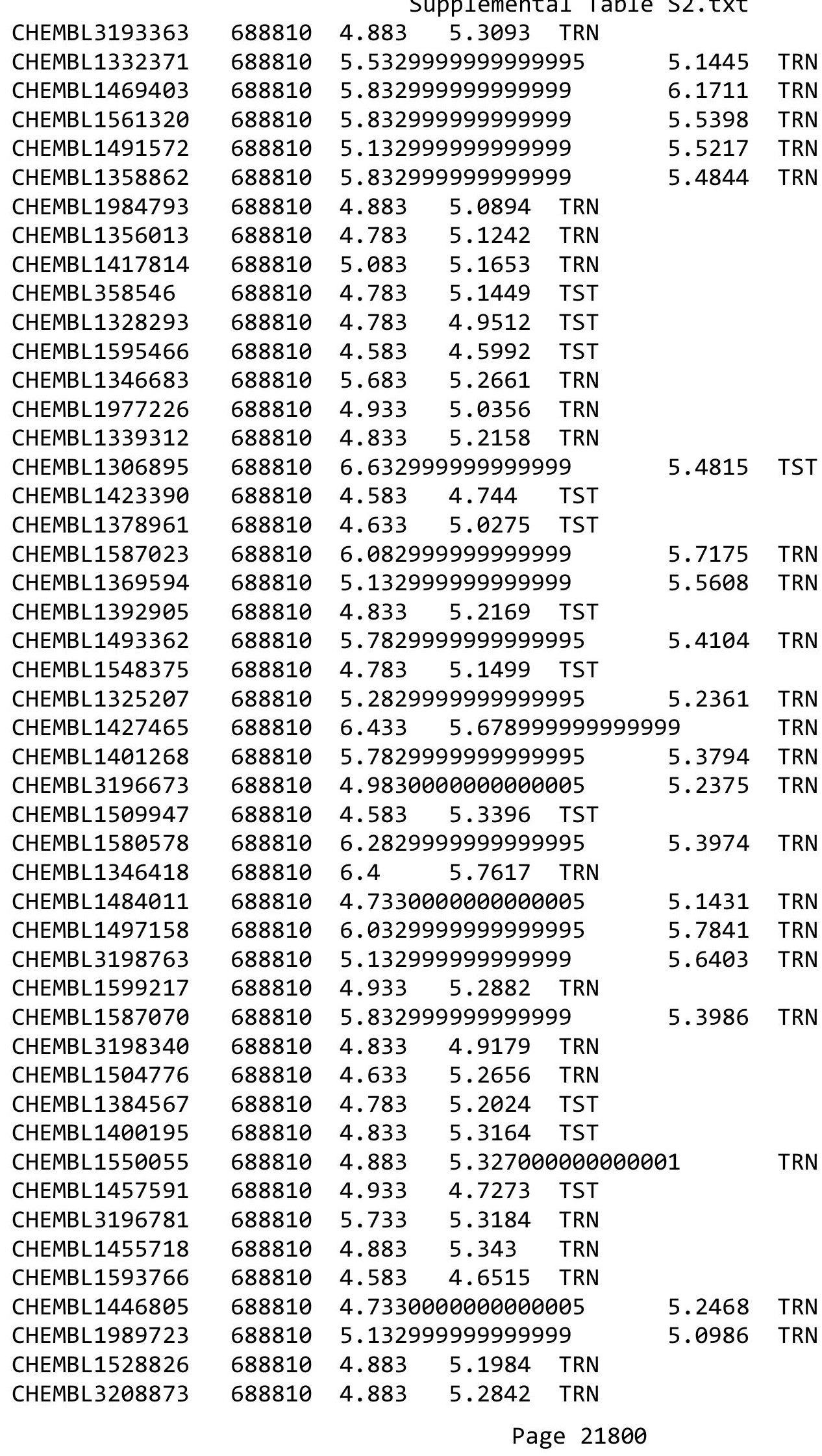




\begin{tabular}{|c|c|c|c|c|c|c|}
\hline & & & ICILa & & & \\
\hline CHEMBL1344539 & 688810 & 5.683 & 5.3961 & TRN & & \\
\hline CHEMBL3190349 & 688810 & 4.783 & 4.986000 & 000000000 & & TST \\
\hline CHEMBL1552153 & 688810 & 5.332999 & 999999999 & & 5.0724 & TRN \\
\hline CHEMBL1585767 & 688810 & 4.633 & 5.137000 & 000000000 & 05 & TST \\
\hline CHEMBL1429817 & 688810 & 4.683 & 4.9548 & TRN & & \\
\hline CHEMBL1610968 & 688810 & 5.483 & 5.2306 & TRN & & \\
\hline CHEMBL1564302 & 688810 & 5.733 & 5.1025 & TST & & \\
\hline CHEMBL1542492 & 688810 & 4.783 & 5.3407 & TST & & \\
\hline CHEMBL1388509 & 688810 & 4.833 & 5.6565 & TST & & \\
\hline CHEMBL1597459 & 688810 & 4.833 & 5.0146 & TST & & \\
\hline CHEMBL1535096 & 688810 & 6.0 & 4.9439 & TRN & & \\
\hline CHEMBL3199205 & 688810 & 5.183 & 5.0478 & TRN & & \\
\hline CHEMBL3210546 & 688810 & 4.783 & 5.3736 & TST & & \\
\hline CHEMBL1453260 & 688810 & 4.733006 & 000000000 & 205 & 4.703 & TRN \\
\hline CHEMBL1515192 & 688810 & 5.282990 & 999999999 & 995 & 5.2125 & TRN \\
\hline CHEMBL 3213784 & 688810 & 5.882999 & 999999999 & & 5.271 & TST \\
\hline CHEMBL1604973 & 688810 & 5.183 & 5.3076 & TRN & & \\
\hline CHEMBL1501110 & 688810 & 5.582999 & 999999999 & & 5.3327 & TRN \\
\hline CHEMBL1498773 & 688810 & 5.483 & 5.1432 & TST & & \\
\hline CHEMBL3190373 & 688810 & 6.132999 & 999999999 & & 5.4056 & TRN \\
\hline CHEMBL1493701 & 688810 & 5.483 & 4.9771 & TST & & \\
\hline CHEMBL1503342 & 688810 & 6.13299 & 999999999 & & 4.8209 & TST \\
\hline CHEMBL1392776 & 688810 & 6.4829 & 5.5188 & TRN & & \\
\hline CHEMBL1573706 & 688810 & 4.933 & 5.0571 & TRN & & \\
\hline CHEMBL1594868 & 688810 & 5.683 & 5.7038 & TRN & & \\
\hline CHEMBL1483431 & 688810 & 4.733006 & 000000000 & 205 & 4.9861 & TRN \\
\hline CHEMBL1392473 & 688810 & 5.532999 & 999999999 & 995 & 5.4172 & TRN \\
\hline CHEMBL533082 & 688810 & 5.233 & 5.1602 & TST & & \\
\hline CHEMBL1489383 & 688810 & 5.332999 & 999999999 & & 4.9254 & TST \\
\hline CHEMBL1428001 & 688810 & 5.33299 & 999999999 & & 5.3869 & TST \\
\hline CHEMBL1322074 & 688810 & 4.883 & 5.3095 & TRN & & \\
\hline CHEMBL1428644 & 688810 & 6.433 & 5.9151 & TRN & & \\
\hline CHEMBL1594268 & 688810 & 4.633 & 5.2763 & TRN & & \\
\hline CHEMBL1424300 & 688810 & 5.332999 & 999999999 & & 5.8289 & TRN \\
\hline CHEMBL1477676 & 688810 & 6.282999 & 999999999 & 995 & 5.9189 & TRN \\
\hline CHEMBL1341898 & 688810 & 5.683 & 5.2707 & TRN & & \\
\hline CHEMBL1325319 & 688810 & 5.282999 & 999999999 & 995 & 5.3504 & TRN \\
\hline CHEMBL3195657 & 688810 & 7.3325 & 6.9033 & TRN & & \\
\hline CHEMBL1542043 & 688810 & 5.083 & 5.4812 & TRN & & \\
\hline CHEMBL1976111 & 688810 & 4.933 & 4.7735 & TST & & \\
\hline CHEMBL1490314 & 688810 & 4.733006 & 000000000 & 205 & 5.2627 & TST \\
\hline CHEMBL1597292 & 688810 & 4.783 & 4.9774 & TST & & \\
\hline CHEMBL1447402 & 688810 & 5.033 & 4.8162 & TST & & \\
\hline CHEMBL1560119 & 688810 & 4.783 & 5.0486 & TRN & & \\
\hline CHEMBL1318074 & 688810 & 4.783 & 5.0885 & TRN & & \\
\hline CHEMBL3190052 & 688810 & 5.183 & 5.3535 & TST & & \\
\hline CHEMBL1588895 & 688810 & 4.883 & 4.876 & TRN & & \\
\hline CHEMBL1320917 & 688810 & 7.0329 & 5.9734 & TRN & & \\
\hline
\end{tabular}




\begin{tabular}{|c|c|c|c|c|c|c|}
\hline \multirow{2}{*}{\multicolumn{2}{|c|}{ CHEMPI 1302295}} & \\
\hline & 688810 & \multirow{2}{*}{\multicolumn{3}{|c|}{5.382999999999999}} & & \\
\hline CHEMBL1334701 & 688810 & & & & 5.5011 & $\mathrm{Tr}$ \\
\hline CHEMBL1491683 & 688810 & 4.933 & 5.2234 & TRN & & \\
\hline CHEMBL1415579 & 688810 & 5.233 & 4.9795 & TRN & & \\
\hline CHEMBL1446080 & 688810 & \multicolumn{3}{|c|}{4.7330000000000005} & 5.1486 & \\
\hline CHEMBL1446828 & 688810 & \multicolumn{3}{|c|}{6.082999999999999} & 5.5086 & \\
\hline CHEMBL1374535 & 688810 & 5.983 & 5.8776 & TRN & & \\
\hline CHEMBL 3190456 & 688810 & 6.233 & 5.3939 & TRN & & \\
\hline CHEMBL1363196 & 688810 & \multicolumn{3}{|c|}{4.9830000000000005} & 4.9367 & \\
\hline CHEMBL1493178 & 688810 & 6.233 & 5.9235 & TRN & & \\
\hline CHEMBL 3209462 & 688810 & 5.683 & 5.2013 & TRN & & \\
\hline CHEMBL1340332 & 688810 & \multicolumn{3}{|c|}{6.332999999999999} & 5.5518 & \\
\hline CHEMBL1558388 & 688810 & 5.233 & 5.8057 & TRN & & \\
\hline CHEMBL1545287 & 688810 & \multicolumn{3}{|c|}{4.7330000000000005} & 4.9083 & \\
\hline CHEMBL1515461 & 688810 & 4.783 & 4.9708 & TRN & & \\
\hline CHEMBL1496854 & 688810 & \multicolumn{3}{|c|}{6.582999999999999} & 586 & \\
\hline CHEMBL 3208543 & 688810 & 4.783 & 5.3995 & TST & & \\
\hline CHEMBL518575 & 688810 & 5.683 & 5.5726 & TST & & \\
\hline CHEMBL 3213101 & 688810 & 6.233 & 5.5873 & TRN & & \\
\hline CHEMBL1577439 & 688810 & 4.883 & 5.0747 & TST & & \\
\hline CHEMBL 3192474 & 688810 & \multicolumn{3}{|c|}{4.7330000000000005} & 4.9335 & \\
\hline CHEMBL1304898 & 688810 & 4.783 & 5.8835 & TST & & \\
\hline CHEMBL1610782 & 688810 & 4.783 & 5.1026 & TRN & & \\
\hline CHEMBL1584098 & 688810 & \multicolumn{3}{|c|}{4.9830000000000005} & 5.1562 & \\
\hline CHEMBL1588075 & 688810 & \multicolumn{3}{|c|}{4.7330000000000005} & & \\
\hline CHEMBL1422619 & 688810 & 5.683 & 5.2068 & TST & & \\
\hline CHEMBL1319574 & 688810 & \multicolumn{3}{|c|}{4.7330000000000005} & 4.8873 & \\
\hline CHEMBL1360351 & 688810 & \multicolumn{3}{|c|}{5.382999999999999} & 5.2607 & \\
\hline CHEMBL1611125 & 688810 & \multicolumn{3}{|c|}{5.832999999999999} & 5.3937 & \\
\hline CHEMBL1099177 & 688810 & 6.183 & 5.8662 & TRN & & \\
\hline CHEMBL1511472 & 688810 & 4.833 & 5.2535 & TRN & & \\
\hline CHEMBL1319698 & 688810 & 4.783 & 5.5619 & TRN & & \\
\hline CHEMBL1416206 & 688810 & 4.833 & 5.2998 & TRN & & \\
\hline CHEMBL1359927 & 688810 & 4.783 & 5.341 & TRN & & \\
\hline CHEMBL1449372 & 688810 & \multicolumn{3}{|c|}{4.7330000000000005} & 503 & \\
\hline CHEMBL1 & 688810 & \multicolumn{3}{|c|}{5.2829999999999995} & 47 & \\
\hline CHEMBL1596978 & 688810 & \multicolumn{3}{|c|}{4.9830000000000005} & 4.9844 & \\
\hline CHEMBL1582563 & 688810 & \multicolumn{3}{|c|}{5.132999999999999} & 5.7121 & \\
\hline CHEMBL1357752 & 688810 & \multicolumn{3}{|c|}{5.632999999999999} & 5.7687 & \\
\hline CHEMBL233119 & 688810 & 6.433 & 5.8498 & TRN & & \\
\hline CHEMBL1309749 & 688810 & 5.483 & 5.065 & TRN & & \\
\hline CHEMBL1599290 & 688810 & 7.1331 & 6.0485 & TRN & & \\
\hline CHEMBL1311868 & 688810 & 4.883 & 5.0671 & TST & & \\
\hline CHEMBL1323955 & 688810 & 6.2829 & 99999999 & 995 & 5.2586 & \\
\hline CHEMBL1426565 & 688810 & 4.583 & 4.8103 & TST & & \\
\hline CHEMBL1530893 & 688810 & 5.983 & 5.54200 & 00000 & & \\
\hline CHEMBL 2004511 & 688810 & 4.833 & 4.9457 & TRN & & \\
\hline CHEMBL1497340 & 688810 & 5.6329 & 99999999 & & 5.1313 & \\
\hline
\end{tabular}




\begin{tabular}{|c|c|c|c|c|c|c|}
\hline \multirow[b]{2}{*}{ CHEMBL1462003 } & \multirow[b]{2}{*}{688810} & \multicolumn{5}{|c|}{ Supplemental Table S2.txt } \\
\hline & & \multicolumn{3}{|c|}{$4.633 \quad 5.1462$ TRN } & & \multirow{5}{*}{ TST } \\
\hline CHEMBL1494916 & 688810 & 5.083 & 5.2307 & TRN & \multirow{4}{*}{5.2154} & \\
\hline CHEMBL1542790 & 688810 & \multicolumn{3}{|c|}{4.7330000000000005} & & \\
\hline CHEMBL1429236 & 688810 & 5.983 & 5.5806 & TRN & & \\
\hline CHEMBL1374040 & 688810 & 4.933 & 5.1672 & TRN & & \\
\hline CHEMBL1372087 & 688810 & \multicolumn{3}{|c|}{5.7829999999999995} & 5.4621 & TRN \\
\hline CHEMBL1465619 & 688810 & 4.883 & 4.8622 & TRN & & \\
\hline CHEMBL1456654 & 688810 & \multicolumn{3}{|c|}{5.7829999999999995} & 5.7237 & TRN \\
\hline CHEMBL 3189245 & 688810 & 4.583 & 5.8412 & TRN & & \\
\hline CHEMBL1332600 & 688810 & \multicolumn{3}{|c|}{5.832999999999999} & 5.3669 & TRN \\
\hline CHEMBL3210705 & 688810 & \multicolumn{3}{|c|}{4.7330000000000005} & 5.2243 & TRN \\
\hline CHEMBL1474305 & 688810 & 4.833 & 4.9127 & TRN & & \\
\hline CHEMBL1537123 & 688810 & 4.633 & 5.113 & TST & & \\
\hline CHEMBL1533919 & 688810 & 6.233 & 5.2381 & TRN & & \\
\hline CHEMBL1534390 & 688810 & \multicolumn{3}{|c|}{4.7330000000000005} & 5.2475 & TRN \\
\hline CHEMBL1598748 & 688810 & 4.933 & 5.0307 & TRN & & \\
\hline CHEMBL348267 & 688810 & 4.783 & 5.6703 & TRN & & \\
\hline CHEMBL1531859 & 688810 & 4.833 & 5.0522 & TRN & & \\
\hline CHEMBL1412108 & 688810 & \multicolumn{3}{|c|}{5.7829999999999995} & 5.801 & TRN \\
\hline CHEMBL1491210 & 688810 & 6.433 & 5.8208 & TRN & & \\
\hline CHEMBL1384417 & 688810 & 4.933 & 5.0031 & TRN & & \\
\hline CHEMBL1534302 & 688810 & \multicolumn{3}{|c|}{4.9830000000000005} & 5.3764 & TST \\
\hline CHEMBL1387835 & 688810 & 4.633 & 5.0325 & TST & & \\
\hline CHEMBL1500948 & 688810 & 5.433 & 5.0177 & TST & & \\
\hline CHEMBL1419524 & 688810 & 5.733 & 5.1767 & TRN & & \\
\hline CHEMBL1561349 & 688810 & \multicolumn{3}{|c|}{4.7330000000000005} & 4.6154 & TRN \\
\hline CHEMBL1342890 & 688810 & 4.783 & 4.9532 & TST & & \\
\hline CHEMBL1509854 & 688810 & 5.483 & 5.4331 & TRN & & \\
\hline CHEMBL3191597 & 688810 & 5.433 & 5.2247 & TRN & & \\
\hline CHEMBL1417573 & 688810 & \multicolumn{3}{|c|}{6.2829999999999995} & 5.3942 & TRN \\
\hline CHEMBL1560679 & 688810 & \multicolumn{3}{|c|}{6.0329999999999995} & 5.3156 & TST \\
\hline CHEMBL1519558 & 688810 & \multicolumn{3}{|c|}{5.332999999999999} & 5.3003 & TRN \\
\hline CHEMBL1348406 & 688810 & \multicolumn{3}{|c|}{5.7829999999999995} & 5.5346 & TST \\
\hline CHEMBL1580032 & 688810 & 5.033 & \multicolumn{3}{|c|}{4.9830000000000005} & TRN \\
\hline CHEMBL1308212 & 688810 & 4.933 & 5.0107 & TST & & \\
\hline CHEMBL1613467 & 688810 & \multicolumn{3}{|c|}{5.832999999999999} & 4.9732 & TRN \\
\hline CHEMBL3211095 & 688810 & 5.033 & 5.1238 & TST & & \\
\hline CHEMBL1464689 & 688810 & 6.183 & 5.1283 & TRN & & \\
\hline CHEMBL1482661 & 688810 & 5.1329 & 99999999 & & 5.5321 & TRN \\
\hline CHEMBL1416773 & 688810 & 5.6329 & 99999999 & & 5.4691 & TRN \\
\hline CHEMBL1457456 & 688810 & 5.033 & 5.2737 & TRN & & \\
\hline CHEMBL1571934 & 688810 & 4.7330 & 00000000 & 005 & 4.5381 & TST \\
\hline CHEMBL1415141 & 688810 & 6.3329 & 99999999 & & 5.7613 & TRN \\
\hline CHEMBL19954 & 688810 & 5.5329 & 99999999 & 995 & 5.2501 & TST \\
\hline CHEMBL1376193 & 688810 & 4.883 & 5.0523 & TRN & & \\
\hline CHEMBL1403148 & 688810 & 5.083 & 4.8989 & TRN & & \\
\hline CHEMBL1502358 & 688810 & 4.633 & 5.3028 & TST & & \\
\hline CHEMBL1572503 & 688810 & 5.5829 & 99999999 & & 5.6037 & TRN \\
\hline
\end{tabular}




\begin{tabular}{|c|c|c|c|c|c|c|}
\hline \multirow[b]{2}{*}{ CHEMBL1330046 } & \multirow[b]{2}{*}{688810} & \multicolumn{5}{|c|}{ Supplemental Table S2.txt } \\
\hline & & 6.233 & 5.4307 & TRN & & \\
\hline CHEMBL1463128 & 688810 & 5.83299 & 99999999 & & 5.7182 & TRN \\
\hline CHEMBL1416262 & 688810 & 5.78299 & 99999999 & 995 & 5.9896 & TRN \\
\hline CHEMBL 3208182 & 688810 & 5.83299 & 99999999 & 99 & 5.415 & TRN \\
\hline CHEMBL1320907 & 688810 & 4.783 & 5.1947 & TRN & & \\
\hline CHEMBL1423612 & 688810 & 4.73300 & 20000000 & 005 & 5.119 & TRN \\
\hline CHEMBL1607610 & 688810 & 4.683 & 5.1106 & TRN & & \\
\hline CHEMBL1610312 & 688810 & 6.183 & 5.8216 & TRN & & \\
\hline CHEMBL1368727 & 688810 & 4.933 & 5.182 & TRN & & \\
\hline CHEMBL1379238 & 688810 & 5.33299 & 99999999 & & 5.2837 & TRN \\
\hline CHEMBL1432474 & 688810 & 5.183 & 5.0332 & TRN & & \\
\hline CHEMBL1319194 & 688810 & 5.28299 & 99999999 & 995 & 4.7515 & TRN \\
\hline CHEMBL1541549 & 688810 & 5.83299 & 99999999 & & 5.1622 & TRN \\
\hline CHEMBL1373344 & 688810 & 5.53299 & 99999999 & 995 & 5.1698 & TST \\
\hline CHEMBL1403668 & 688810 & 5.033 & 5.4951 & TST & & \\
\hline CHEMBL1331777 & 688810 & 4.583 & 4.8 & TRN & & \\
\hline CHEMBL1354621 & 688810 & 5.433 & 5.3818 & TRN & & \\
\hline CHEMBL1457830 & 688810 & 4.833 & 5.4139 & TRN & & \\
\hline CHEMBL3195992 & 688810 & 6.08299 & 99999999 & & 5.5181 & TRN \\
\hline CHEMBL1414465 & 688810 & 5.433 & 5.2962 & TST & & \\
\hline CHEMBL1415524 & 688810 & 4.98300 & 00000000 & 005 & 5.303 & TST \\
\hline CHEMBL1609096 & 688810 & 6.08299 & 99999999 & & 4.9554 & TST \\
\hline CHEMBL1467987 & 688810 & 5.63299 & 99999999 & & 5.4344 & TRN \\
\hline CHEMBL1445373 & 688810 & 5.13299 & 99999999 & & 5.0978 & TRN \\
\hline CHEMBL1981357 & 688810 & 5.183 & 5.6473 & TST & & \\
\hline CHEMBL3213162 & 688810 & 4.783 & 4.9905 & TRN & & \\
\hline CHEMBL1977983 & 688810 & 4.883 & 5.2023 & TRN & & \\
\hline CHEMBL1439125 & 688810 & 4.73300 & $\partial 0000000$ & 005 & 5.2218 & TRN \\
\hline CHEMBL1303604 & 688810 & 7.0329 & 6.3914 & TRN & & \\
\hline CHEMBL1607184 & 688810 & 5.083 & 5.3745 & TST & & \\
\hline CHEMBL1448922 & 688810 & 5.33299 & 99999999 & 99 & 5.4717 & TRN \\
\hline CHEMBL1458622 & 688810 & 5.733 & 5.5108 & TRN & & \\
\hline CHEMBL1497836 & 688810 & 4.883 & 5.4252 & TRN & & \\
\hline CHEMBL1356999 & 688810 & 4.783 & 5.0581 & TRN & & \\
\hline CHEMBL3193443 & 688810 & 5.683 & 5.1493 & TRN & & \\
\hline CHEMBL1493929 & 688810 & 4.73300 & 30000000 & 005 & 5.1399 & TRN \\
\hline CHEMBL45152 & 688810 & 4.883 & 5.2908 & TST & & \\
\hline CHEMBL528165 & 688810 & 5.433 & 5.3019 & TST & & \\
\hline CHEMBL1380877 & 688810 & 5.033 & 5.4979 & TRN & & \\
\hline CHEMBL504256 & 688810 & 4.633 & 4.9371 & TST & & \\
\hline CHEMBL1328297 & 688810 & 4.833 & 5.6403 & TRN & & \\
\hline CHEMBL1523568 & 688810 & 4.633 & 4.9607 & TRN & & \\
\hline CHEMBL1407344 & 688810 & 4.833 & 5.5079 & TRN & & \\
\hline CHEMBL1486766 & 688810 & 6.08299 & 99999999 & & 5.9953 & TRN \\
\hline CHEMBL1489719 & 688810 & 4.883 & 5.2865 & TRN & & \\
\hline CHEMBL1529957 & 688810 & 5.483 & 5.3077 & TRN & & \\
\hline CHEMBL1470332 & 688810 & 4.683 & 4.9627 & TST & & \\
\hline CHEMBL3189447 & 688810 & 6.233 & 5.8169 & TRN & & \\
\hline
\end{tabular}




\begin{tabular}{|c|c|c|c|c|c|c|c|}
\hline \multirow[b]{2}{*}{ CHEMBL1539485 } & \multicolumn{6}{|c|}{ Supplemental Table S2.txt } & \\
\hline & 688810 & 5.683 & \multicolumn{3}{|c|}{5.6979999999999995} & \multirow[t]{2}{*}{ TRN } & \\
\hline CHEMBL3209353 & 688810 & 4.833 & 5.3143 & TRN & & & \\
\hline CHEMBL1444507 & 688810 & 4.7330000000000005 & \multicolumn{2}{|c|}{00000000005} & 4.9201 & \multicolumn{2}{|l|}{ TRN } \\
\hline CHEMBL3197851 & 688810 & \multicolumn{3}{|c|}{5.382999999999999} & 5.3224 & \multicolumn{2}{|l|}{ TST } \\
\hline CHEMBL1469748 & 688810 & 5.683 & 5.4626 & TRN & & & \\
\hline CHEMBL1560956 & 688810 & \multicolumn{3}{|c|}{4.9830000000000005} & 4.71899 & 9999999999 & TRN \\
\hline CHEMBL1427829 & 688810 & \multicolumn{3}{|c|}{5.332999999999999} & 5.5215 & TRN & \\
\hline CHEMBL1426797 & 688810 & \multicolumn{3}{|c|}{6.382999999999999} & 5.5201 & TRN & \\
\hline CHEMBL1609323 & 688810 & 4.933 & 5.0546 & TRN & & & \\
\hline CHEMBL1582736 & 688810 & 4.933 & 4.9252 & TST & & & \\
\hline CHEMBL1451080 & 688810 & \multicolumn{3}{|c|}{6.0329999999999995} & 5.7071 & TRN & \\
\hline CHEMBL1490118 & 688810 & \multicolumn{3}{|c|}{4.7330000000000005} & 5.1028 & TRN & \\
\hline CHEMBL1372505 & 688810 & \multicolumn{3}{|c|}{5.2829999999999995} & 5.4975 & TRN & \\
\hline CHEMBL1350409 & 688810 & \multicolumn{3}{|c|}{5.132999999999999} & 4.9909 & TRN & \\
\hline CHEMBL112610 & 688810 & 5.183 & 6.0112 & TRN & & & \\
\hline CHEMBL3199393 & 688810 & 5.733 & & TRN & & & \\
\hline CHEMBL1571772 & 688810 & \multicolumn{3}{|c|}{4.7330000000000005} & 5.1898 & TRN & \\
\hline CHEMBL1388193 & 688810 & 4.883 & 4.9927 & TRN & & & \\
\hline CHEMBL1580164 & 688810 & \multicolumn{3}{|c|}{5.5329999999999995} & 5.5618 & TRN & \\
\hline CHEMBL1984155 & 688810 & \multicolumn{3}{|c|}{5.832999999999999} & 5.5152 & TRN & \\
\hline CHEMBL1513058 & 688810 & 4.883 & 5.0355 & TST & & & \\
\hline CHEMBL1514320 & 688810 & \multirow{2}{*}{\multicolumn{3}{|c|}{$\begin{array}{lcc}6.4829 & 5.767 & \text { TRN } \\
4.7330000000000005\end{array}$}} & & & \\
\hline CHEMBL1520838 & 688810 & & & & 4.9895 & TST & \\
\hline CHEMBL1450286 & 688810 & 5.483 & 5.1943 & TRN & & & \\
\hline CHEMBL1349559 & 688810 & 6.233 & 5.1601 & TRN & & & \\
\hline CHEMBL1601439 & 688810 & 6.0 & 5.3064 & TRN & & & \\
\hline CHEMBL1560925 & 688810 & 4.583 & 4.886 & TST & & & \\
\hline CHEMBL1321829 & 688810 & 4.73300 & 000000000 & 005 & 5.1043 & TST & \\
\hline CHEMBL1401432 & 688810 & 5.183 & 5.0889 & TRN & & & \\
\hline CHEMBL3198939 & 688810 & 6.83299 & 999999999 & & 6.2197 & TRN & \\
\hline CHEMBL1492624 & 688810 & 4.883 & 5.102 & TST & & & \\
\hline CHEMBL1525858 & 688810 & 4.833 & 5.3439 & TST & & & \\
\hline CHEMBL1536695 & 688810 & 4.933 & 5.161000 & 00000 & 005 & TRN & \\
\hline CHEMBL1497366 & 688810 & 6.0 & 5.4109 & TRN & & & \\
\hline CHEMBL1518753 & 688810 & 5.88299 & 999999999 & & 5.1372 & TST & \\
\hline CHEMBL1552931 & 688810 & 4.73300 & 000000000 & 005 & 5.3619 & TRN & \\
\hline CHEMBL1436656 & 688810 & 5.033 & 5.706 & TRN & & & \\
\hline CHEMBL1387222 & 688810 & 4.73300 & 000000000 & 005 & 5.357 & TST & \\
\hline CHEMBL1564748 & 688810 & 5.13299 & 999999999 & & 5.3794 & TRN & \\
\hline CHEMBL1369889 & 688810 & 4.833 & 5.0028 & TRN & & & \\
\hline CHEMBL1451600 & 688810 & 5.38299 & 999999999 & & 4.8684 & TRN & \\
\hline CHEMBL 2000686 & 688810 & 4.73300 & 000000000 & 005 & 4.6961 & TST & \\
\hline CHEMBL1487816 & 688810 & 5.33299 & 999999999 & & 5.4231 & TRN & \\
\hline CHEMBL1563048 & 688810 & 4.783 & 4.8939 & TST & & & \\
\hline CHEMBL1408876 & 688810 & 4.633 & 4.8637 & TST & & & \\
\hline CHEMBL3209042 & 688810 & 5.78299 & 999999999 & 995 & 5.12 & TRN & \\
\hline CHEMBL1437262 & 688810 & 4.883 & 5.1262 & TRN & & & \\
\hline CHEMBL1495759 & 688810 & 5.78299 & 999999999 & 995 & 5.0199 & TST & \\
\hline
\end{tabular}




\begin{tabular}{|c|c|c|c|c|c|c|}
\hline \multirow[b]{2}{*}{ CHEMBL1324115 } & \multicolumn{6}{|c|}{ 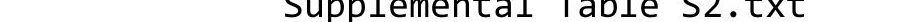 } \\
\hline & 688810 & 4.583 & 4.9638 & TRN & & \\
\hline CHEMBL191750 & 688810 & 5.033 & 5.1964 & TRN & & \\
\hline CHEMBL1424048 & 688810 & 5.8829 & 99999999 & 99 & 5.593 & TRN \\
\hline CHEMBL3196921 & 688810 & 5.6329 & 99999999 & 99 & 5.2896 & TST \\
\hline CHEMBL1325806 & 688810 & 5.233 & 5.2826 & TST & & \\
\hline CHEMBL580076 & 688810 & 4.883 & 5.1249 & TRN & & \\
\hline CHEMBL1467180 & 688810 & 5.1329 & 99999999 & & 5.085 & TRN \\
\hline CHEMBL1477352 & 688810 & 4.7330 & 00000000 & 005 & 5.0219 & TRN \\
\hline CHEMBL1498043 & 688810 & 4.633 & 4.9348 & TRN & & \\
\hline CHEMBL90846 & 688810 & 4.833 & 5.99100 & 0000 & 005 & TRN \\
\hline CHEMBL 242946 & 688810 & 5.3829 & 99999999 & & 5.4208 & TRN \\
\hline CHEMBL1346236 & 688810 & 5.5329 & 99999999 & 995 & 5.6617 & TRN \\
\hline CHEMBL1494703 & 688810 & 4.783 & 5.5439 & TRN & & \\
\hline CHEMBL1437680 & 688810 & 4.633 & 4.8735 & TRN & & \\
\hline CHEMBL1454503 & 688810 & 4.7330 & 20000000 & 005 & 5.5345 & TST \\
\hline CHEMBL1607263 & 688810 & 4.783 & 4.88399 & 9999 & 995 & TRN \\
\hline CHEMBL1326315 & 688810 & 6.6329 & 99999999 & & 5.6804 & TST \\
\hline CHEMBL1593953 & 688810 & 6.0829 & 99999999 & & 5.0356 & TRN \\
\hline CHEMBL1413159 & 688810 & 5.5829 & 99999999 & & 5.0926 & TRN \\
\hline CHEMBL1450753 & 688810 & 6.683 & 6.171 & TRN & & \\
\hline CHEMBL1434810 & 688810 & 5.3329 & 99999999 & & 4.9224 & TRN \\
\hline CHEMBL1566884 & 688810 & 4.7330 & 30000000 & 005 & 4.8571 & TRN \\
\hline CHEMBL1523441 & 688810 & 5.1329 & 99999999 & & 5.8414 & TRN \\
\hline CHEMBL1369305 & 688810 & 4.683 & 5.6093 & TST & & \\
\hline CHEMBL3195398 & 688810 & 4.883 & 5.2915 & TST & & \\
\hline CHEMBL1459083 & 688810 & 5.933 & 5.2264 & TST & & \\
\hline CHEMBL1379424 & 688810 & 5.033 & 5.3009 & TRN & & \\
\hline CHEMBL1435018 & 688810 & 4.9830 & 20000000 & 005 & 5.0928 & TRN \\
\hline CHEMBL1416585 & 688810 & 4.883 & 5.3511 & TRN & & \\
\hline CHEMBL587247 & 688810 & 4.7330 & 00000000 & 005 & 5.1617 & TRN \\
\hline CHEMBL1520063 & 688810 & 4.783 & 4.7575 & TRN & & \\
\hline CHEMBL1301786 & 688810 & 4.783 & 5.2926 & TST & & \\
\hline CHEMBL1468329 & 688810 & 5.6329 & 99999999 & & 5.8551 & TRN \\
\hline CHEMBL1402664 & 688810 & 5.983 & 5.7651 & TRN & & \\
\hline CHEMBL1556231 & 688810 & 4.7330 & $\partial 0000000$ & 005 & 5.3286 & TRN \\
\hline CHEMBL1591388 & 688810 & 4.7330 & 00000000 & 005 & 4.9773 & TRN \\
\hline CHEMBL1327474 & 688810 & 6.183 & 5.9083 & TRN & & \\
\hline CHEMBL1321689 & 688810 & 4.883 & 5.2929 & TRN & & \\
\hline CHEMBL3195006 & 688810 & 5.483 & 5.4805 & TRN & & \\
\hline CHEMBL1449896 & 688810 & 5.433 & 5.98600 & 0000 & & TRN \\
\hline CHEMBL1342393 & 688810 & 4.7330 & $\partial 0000000$ & 005 & 4.9162 & TST \\
\hline CHEMBL1401735 & 688810 & 4.783 & 5.6143 & TRN & & \\
\hline CHEMBL1311087 & 688810 & 5.8329 & 99999999 & & 5.6248 & TRN \\
\hline CHEMBL1391064 & 688810 & 5.2829 & 99999999 & 995 & 5.4297 & TST \\
\hline CHEMBL1473380 & 688810 & 4.883 & 5.2488 & TRN & & \\
\hline CHEMBL1417809 & 688810 & 4.783 & 5.5281 & TRN & & \\
\hline CHEMBL1439902 & 688810 & 5.033 & 5.4858 & TST & & \\
\hline CHEMBL1359387 & 688810 & 5.9 & 5.1138 & TRN & & \\
\hline
\end{tabular}




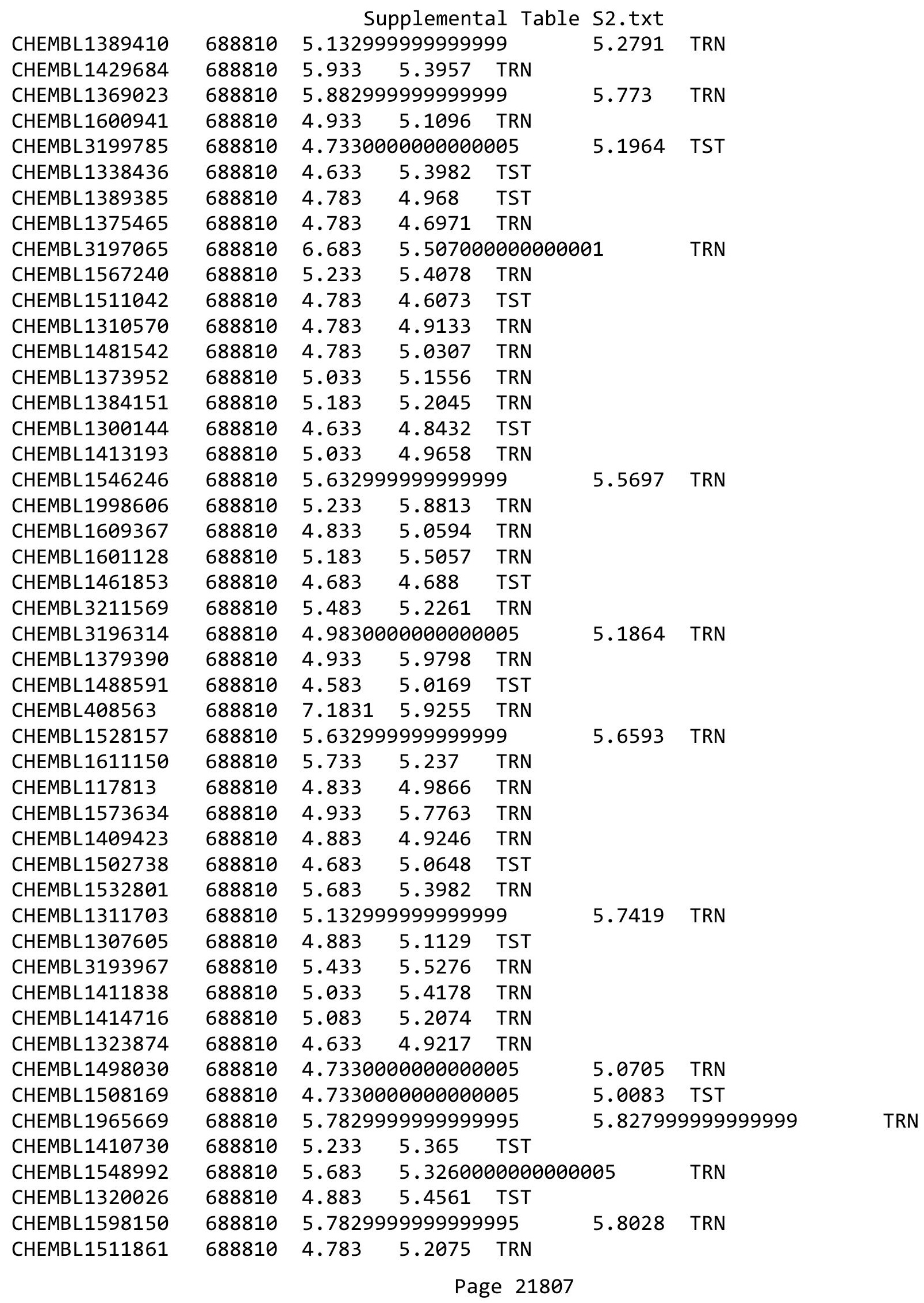




\begin{tabular}{|c|c|c|c|c|c|c|}
\hline \multirow[b]{2}{*}{ CHEMBL608109 } & \multirow[b]{2}{*}{688810} & \multicolumn{5}{|c|}{ Supplemental Table S2.txt } \\
\hline & & \multicolumn{3}{|c|}{$4.683 \quad 5.4454$ TRN } & & \\
\hline CHEMBL1529083 & 688810 & 4.683 & 5.1555 & TRN & & \\
\hline CHEMBL1542722 & 688810 & \multicolumn{3}{|c|}{4.7330000000000005} & 5.2825 & TST \\
\hline CHEMBL50207 & 688810 & \multicolumn{3}{|c|}{4.7330000000000005} & 5.2917 & TST \\
\hline CHEMBL1586840 & 688810 & 4.883 & 5.0353 & TRN & & \\
\hline CHEMBL1358960 & 688810 & 5.483 & 5.2957 & TRN & & \\
\hline CHEMBL1354826 & 688810 & \multicolumn{3}{|c|}{4.7330000000000005} & 4.9344 & TST \\
\hline CHEMBL1418311 & 688810 & 4.583 & 4.4513 & TST & & \\
\hline CHEMBL1526853 & 688810 & \multicolumn{3}{|c|}{5.882999999999999} & 5.4214 & TRN \\
\hline CHEMBL1366523 & 688810 & 5.733 & 5.68 & TRN & & \\
\hline CHEMBL1369565 & 688810 & 5.233 & 5.278 & TST & & \\
\hline CHEMBL1438970 & 688810 & 4.833 & 5.3199 & TRN & & \\
\hline CHEMBL1439244 & 688810 & \multicolumn{3}{|c|}{6.632999999999999} & 6.1043 & TRA \\
\hline CHEMBL1611182 & 688810 & \multicolumn{3}{|c|}{5.2829999999999995} & 4.6737 & TRN \\
\hline CHEMBL1379756 & 688810 & 4.933 & 5.3568 & TRN & & \\
\hline CHEMBL1451236 & 688810 & 4.933 & 5.4344 & TRN & & \\
\hline CHEMBL1309315 & 688810 & 4.883 & 5.8703 & TST & & \\
\hline CHEMBL1462518 & 688810 & \multicolumn{3}{|c|}{5.632999999999999} & 5.3251 & TST \\
\hline CHEMBL1432063 & 688810 & \multicolumn{3}{|c|}{5.332999999999999} & 5.1241 & TRA \\
\hline CHEMBL1348179 & 688810 & 5.733 & 5.8981 & TST & & \\
\hline CHEMBL3195082 & 688810 & \multicolumn{3}{|c|}{5.5329999999999995} & 5.5412 & TRN \\
\hline CHEMBL1524072 & 688810 & 5.033 & 5.7762 & TRN & & \\
\hline CHEMBL1535059 & 688810 & 5.233 & 5.7405 & TRN & & \\
\hline CHEMBL1340511 & 688810 & 5.083 & 5.0743 & TRN & & \\
\hline CHEMBL1386360 & 688810 & 5.183 & 5.4302 & TRN & & \\
\hline CHEMBL1589109 & 688810 & \multicolumn{3}{|c|}{4.7330000000000005} & 5.2411 & TRN \\
\hline CHEMBL1334323 & 688810 & \multicolumn{3}{|c|}{4.7330000000000005} & 5.2324 & TST \\
\hline CHEMBL1610697 & 688810 & 4.933 & 4.9233 & TRN & & \\
\hline CHEMBL1373093 & 688810 & \multicolumn{3}{|c|}{5.7829999999999995} & 4.9295 & TRN \\
\hline CHEMBL1361456 & 688810 & \multicolumn{3}{|c|}{5.382999999999999} & 5.3566 & TRN \\
\hline CHEMBL1597636 & 688810 & 5.433 & 5.7317 & TRN & & \\
\hline CHEMBL1384565 & 688810 & 5.233 & 5.2332 & TRN & & \\
\hline CHEMBL1330037 & 688810 & 6.0 & 4.9501 & TRN & & \\
\hline CHEMBL1423174 & 688810 & 5.233 & 5.1755 & TRN & & \\
\hline CHEMBL1574509 & 688810 & \multicolumn{3}{|c|}{5.832999999999999} & 5.4778 & TRA \\
\hline CHEMBL1480100 & 688810 & 4.833 & 4.9397 & TST & & \\
\hline CHEMBL1550612 & 688810 & 5.683 & 5.3546 & TRN & & \\
\hline CHEMBL1554870 & 688810 & \multicolumn{3}{|c|}{4.7330000000000005} & 4.9386 & TRN \\
\hline CHEMBL1483288 & 688810 & \multicolumn{3}{|c|}{5.632999999999999} & 5.676 & TRA \\
\hline CHEMBL1498938 & 688810 & 4.833 & 5.044 & TST & & \\
\hline CHEMBL1516657 & 688810 & 5.983 & 5.0699 & TRN & & \\
\hline CHEMBL1515169 & 688810 & 4.633 & 4.9195 & TRN & & \\
\hline CHEMBL1488300 & 688810 & \multicolumn{3}{|c|}{5.132999999999999} & 5.2262 & TRN \\
\hline CHEMBL3209306 & 688810 & 5.6329 & 7999999 & & 5.2651 & TRA \\
\hline CHEMBL1436487 & 688810 & 4.883 & 5.2798 & TRN & & \\
\hline CHEMBL1556399 & 688810 & 5.683 & 4.9967 & TRN & & \\
\hline CHEMBL1571160 & 688810 & 6.3829 & 7999999 & 99 & 5.1268 & TRA \\
\hline CHEMBL1578404 & 688810 & 5.033 & 5.6458 & TRN & & \\
\hline
\end{tabular}




\begin{tabular}{|c|c|c|c|c|c|c|c|}
\hline \multicolumn{7}{|c|}{ Supplemental Table S2.txt } & \\
\hline CHEMBL1413937 & 688810 & \multicolumn{3}{|c|}{4.7330000000000005} & 5.3966 & TRN & \\
\hline CHEMBL1338059 & 688810 & 4.783 & 5.4206 & TRN & & & \\
\hline CHEMBL1464277 & 688810 & 4.833 & 5.0056 & TRN & & & \\
\hline CHEMBL1996752 & 688810 & \multicolumn{3}{|c|}{5.2829999999999995} & 5.9405 & TRN & \\
\hline CHEMBL1569671 & 688810 & 5.733 & \multicolumn{3}{|c|}{5.1339999999999995} & TST & \\
\hline CHEMBL1368999 & 688810 & 4.633 & 4.5927 & TST & & & \\
\hline CHEMBL3197681 & 688810 & 6.983 & \multicolumn{3}{|c|}{5.957999999999999} & TRN & \\
\hline CHEMBL1590533 & 688810 & 7.3325 & 5.8332 & TRN & & & \\
\hline CHEMBL1332868 & 688810 & 4.883 & 5.3936 & TST & & & \\
\hline CHEMBL1493626 & 688810 & 4.633 & 4.8963 & TRN & & & \\
\hline CHEMBL1513025 & 688810 & 5.233 & 5.7524 & TRN & & & \\
\hline CHEMBL 2007403 & 688810 & \multicolumn{3}{|c|}{5.7829999999999995} & 5.8839 & TRN & \\
\hline CHEMBL1322922 & 688810 & 4.9 & 5.1982 & TRN & & & \\
\hline CHEMBL1529752 & 688810 & 4.833 & \multicolumn{3}{|c|}{5.497000000000001} & TRN & \\
\hline CHEMBL123 & 688810 & 5.183 & 5.3403 & TST & & & \\
\hline CHEMBL1607801 & 688810 & 6.233 & \multicolumn{3}{|c|}{6.2829999999999995} & TRN & \\
\hline CHEMBL1453870 & 688810 & 4.933 & 5.4234 & TRN & & & \\
\hline CHEMBL1305734 & 688810 & 4.833 & 4.9373 & TRN & & & \\
\hline CHEMBL1534986 & 688810 & 4.633 & 5.0408 & TRN & & & \\
\hline CHEMBL1482930 & 688810 & \multicolumn{3}{|c|}{5.132999999999999} & 4.6482 & TRN & \\
\hline CHEMBL1361727 & 688810 & 4.783 & 5.2019 & TRN & & & \\
\hline CHEMBL1559227 & 688810 & 4.933 & 4.7517 & TRN & & & \\
\hline CHEMBL3210802 & 688810 & 4.783 & 5.0433 & TST & & & \\
\hline CHEMBL1400093 & 688810 & \multicolumn{3}{|c|}{5.832999999999999} & 5.0874 & TRN & \\
\hline CHEMBL1457356 & 688810 & 6.433 & 5.2286 & TRN & & & \\
\hline CHEMBL1445231 & 688810 & \multicolumn{3}{|c|}{5.7829999999999995} & 5.4787 & TRN & \\
\hline CHEMBL1466712 & 688810 & \multicolumn{3}{|c|}{5.382999999999999} & 5.188 & TRN & \\
\hline CHEMBL1317709 & 688810 & 4.683 & 4.8469 & TRN & & & \\
\hline CHEMBL1489114 & 688810 & 4.783 & 5.4545 & TRN & & & \\
\hline CHEMBL1306743 & 688810 & 4.933 & 4.6571 & TRN & & & \\
\hline CHEMBL1579844 & 688810 & 5.433 & 5.5504 & TRN & & & \\
\hline CHEMBL1546332 & 688810 & \multicolumn{3}{|c|}{6.382999999999999} & 5.2278 & TRN & \\
\hline CHEMBL1589841 & 688810 & 4.833 & 5.0726 & TRN & & & \\
\hline CHEMBL1547086 & 688810 & 4.783 & 4.9507 & TRN & & & \\
\hline CHEMBL1378313 & 688810 & 4.833 & 5.092 & TRN & & & \\
\hline CHEMBL1467016 & 688810 & 5.683 & 5.5563 & TRN & & & \\
\hline CHEMBL1532578 & 688810 & 4.583 & 5.1107 & TRN & & & \\
\hline CHEMBL1366676 & 688810 & 5.933 & 5.5125 & TRN & & & \\
\hline CHEMBL1322815 & 688810 & 4.883 & 5.1736 & TRN & & & \\
\hline CHEMBL3192131 & 688810 & 7.3325 & 6.5552 & TRN & & & \\
\hline CHEMBL1613359 & 688810 & \multicolumn{3}{|c|}{4.7330000000000005} & 5.2772 & TRN & \\
\hline CHEMBL 3208383 & 688810 & \multicolumn{3}{|c|}{5.332999999999999} & 5.428999 & 9999999999 & TRN \\
\hline CHEMBL1509760 & 688810 & 4.833 & 4.9911 & TRN & & & \\
\hline CHEMBL1516833 & 688810 & 4.783 & 5.2265 & TRN & & & \\
\hline CHEMBL1352618 & 688810 & 5.733 & 5.5162 & TRN & & & \\
\hline CHEMBL1526647 & 688810 & \multicolumn{3}{|c|}{ 5.382999999999999 } & 5.3295 & TRN & \\
\hline CHEMBL1581617 & 688810 & 4.933 & 4.922 & TRN & & & \\
\hline CHEMBL1598564 & 688810 & \multicolumn{3}{|c|}{4.9830000000000005} & 4.9266 & TRN & \\
\hline
\end{tabular}




\begin{tabular}{|c|c|c|c|c|c|c|}
\hline \multirow{3}{*}{$\begin{array}{l}\text { CHEMBL1328359 } \\
\text { CHEMBL1359483 }\end{array}$} & \multirow{3}{*}{$\begin{array}{l}688810 \\
688810\end{array}$} & \multicolumn{5}{|c|}{ Supplemental Table S2.txt } \\
\hline & & \multicolumn{3}{|c|}{4.7330000000000005} & \multirow{3}{*}{5.0397} & \multirow[t]{3}{*}{ TRN } \\
\hline & & 5.683 & 4.9228 & TRN & & \\
\hline CHEMBL3210192 & 688810 & 5.483 & 4.9126 & TRN & & \\
\hline CHEMBL1415059 & 688810 & \multicolumn{3}{|c|}{4.9830000000000005} & \multirow[t]{3}{*}{5.0315} & \multirow[t]{3}{*}{ TRN } \\
\hline CHEMBL1465060 & 688810 & 6.233 & 5.1003 & TRN & & \\
\hline CHEMBL1464256 & 688810 & 5.683 & 4.976 & TRN & & \\
\hline CHEMBL3192055 & 688810 & \multicolumn{3}{|c|}{5.332999999999999} & \multirow[t]{5}{*}{5.2347} & \multirow[t]{5}{*}{ TRN } \\
\hline CHEMBL1353573 & 688810 & 5.033 & 4.8595 & TRN & & \\
\hline CHEMBL1350671 & 688810 & 4.783 & 5.0809 & TST & & \\
\hline CHEMBL1421026 & 688810 & 5.183 & 5.2751 & TRN & & \\
\hline CHEMBL1446678 & 688810 & 4.633 & 4.9435 & TST & & \\
\hline CHEMBL1555726 & 688810 & \multicolumn{3}{|c|}{4.9830000000000005} & \multirow[t]{5}{*}{5.2763} & \multirow[t]{5}{*}{ TRN } \\
\hline CHEMBL1510022 & 688810 & 5.683 & 5.8114 & TRN & & \\
\hline CHEMBL1551155 & 688810 & 4.633 & 5.1869 & TRN & & \\
\hline CHEMBL1501003 & 688810 & 4.783 & 5.15 & TRN & & \\
\hline CHEMBL3197335 & 688810 & 5.233 & 5.4202 & TRN & & \\
\hline CHEMBL3208369 & 688810 & \multicolumn{3}{|c|}{5.5329999999999995} & 5.7368 & TRN \\
\hline CHEMBL1475164 & 688810 & \multicolumn{3}{|c|}{5.2829999999999995} & 5.3612 & TRN \\
\hline CHEMBL1495873 & 688810 & 5.183 & 5.6245 & TRN & & \\
\hline CHEMBL1503082 & 688810 & 5.433 & 5.5861 & TRN & & \\
\hline CHEMBL1377731 & 688810 & \multicolumn{3}{|c|}{5.132999999999999} & 4.9199 & TST \\
\hline CHEMBL1420610 & 688810 & \multicolumn{3}{|c|}{6.2829999999999995} & 6.105 & TRN \\
\hline CHEMBL1316226 & 688810 & \multicolumn{3}{|c|}{6.132999999999999} & 5.6531 & TRA \\
\hline CHEMBL1379831 & 688810 & \multicolumn{3}{|c|}{4.9830000000000005} & 5.1076 & TRN \\
\hline CHEMBL 3198481 & 688810 & 5.483 & 5.1151 & TST & & \\
\hline CHEMBL1988210 & 688810 & 5.1329 & 9999999 & & 5.4962 & TST \\
\hline CHEMBL1369555 & 688810 & 4.933 & 5.2723 & TRN & & \\
\hline CHEMBL1420069 & 688810 & 5.183 & 5.3042 & TRN & & \\
\hline CHEMBL1442695 & 688810 & 4.633 & 4.7717 & TRN & & \\
\hline CHEMBL1565696 & 688810 & 6.983 & 5.2076 & TRN & & \\
\hline CHEMBL1383401 & 688810 & 5.733 & 6.0746 & TRN & & \\
\hline CHEMBL1491697 & 688810 & 4.7336 & 0000000 & 005 & 4.3265 & TRN \\
\hline CHEMBL1607346 & 688810 & 5.683 & 5.3156 & TRN & & \\
\hline CHEMBL1587285 & 688810 & 6.4825 & 5.5769 & TST & & \\
\hline CHEMBL1490876 & 688810 & 5.2829 & 9999999 & 995 & 5.2167 & TST \\
\hline CHEMBL1543691 & 688810 & 6.3829 & 9999999 & & 5.6727 & TRN \\
\hline CHEMBL3191771 & 688810 & 6.3829 & 9999999 & & 5.4713 & TRN \\
\hline CHEMBL530636 & 688810 & 5.7829 & 9999999 & 995 & 6.1326 & TRN \\
\hline CHEMBL1390388 & 688810 & 6.433 & 5.6354 & TRN & & \\
\hline CHEMBL1418950 & 688810 & 5.483 & 4.8204 & TRN & & \\
\hline CHEMBL1437506 & 688810 & 5.483 & 5.1231 & TRN & & \\
\hline CHEMBL1379386 & 688810 & 4.933 & 5.2627 & TRN & & \\
\hline CHEMBL1591292 & 688810 & 5.733 & 5.1042 & TRN & & \\
\hline CHEMBL1542701 & 688810 & 4.7336 & 0000000 & 005 & 4.8768 & TRN \\
\hline CHEMBL1596866 & 688810 & 4.7336 & 3000000 & 005 & 4.9975 & TRN \\
\hline CHEMBL1562411 & 688810 & 5.7829 & 9999999 & 995 & 5.5862 & TRA \\
\hline CHEMBL1415143 & 688810 & 4.833 & 5.1314 & TRN & & \\
\hline CHEMBL1531227 & 688810 & 4.833 & 5.1847 & TST & & \\
\hline
\end{tabular}




\begin{tabular}{|c|c|c|c|c|c|c|}
\hline \multirow[b]{2}{*}{ CHEMBL1382265 } & \multirow[b]{2}{*}{688810} & \multicolumn{5}{|c|}{ Supplemental Table s2.txt } \\
\hline & & 4.583 & 4.9026 & TRN & & \\
\hline CHEMBL1371653 & 688810 & \multicolumn{3}{|c|}{4.9830000000000005} & 5.2277 & TRN \\
\hline CHEMBL1567317 & 688810 & 7.0329 & 5.6599 & TRN & & \\
\hline CHEMBL1398939 & 688810 & 5.233 & 5.1207 & TRN & & \\
\hline CHEMBL1409076 & 688810 & 4.783 & 4.9113 & TRN & & \\
\hline CHEMBL1364726 & 688810 & 4.933 & 5.2182 & TRN & & \\
\hline CHEMBL1416863 & 688810 & \multicolumn{3}{|c|}{4.7330000000000005} & 4.81 & TST \\
\hline CHEMBL1412182 & 688810 & \multicolumn{3}{|c|}{5.382999999999999} & 5.5305 & TRN \\
\hline CHEMBL3192148 & 688810 & \multicolumn{3}{|c|}{5.582999999999999} & 5.0755 & TRN \\
\hline CHEMBL1310980 & 688810 & 5.983 & 5.5201 & TRN & & \\
\hline CHEMBL1997568 & 688810 & 5.983 & 5.8731 & TRN & & \\
\hline CHEMBL1310810 & 688810 & \multicolumn{3}{|c|}{4.7330000000000005} & 5.4254 & TST \\
\hline CHEMBL3196367 & 688810 & 7.0329 & 5.4007 & TST & & \\
\hline CHEMBL1313912 & 688810 & \multicolumn{3}{|c|}{4.9830000000000005} & 5.2823 & TRN \\
\hline CHEMBL1315442 & 688810 & 4.633 & 4.456 & TST & & \\
\hline CHEMBL1487273 & 688810 & \multicolumn{3}{|c|}{4.7330000000000005} & 5.6327 & TRN \\
\hline CHEMBL1408207 & 688810 & 4.883 & 5.3082 & TST & & \\
\hline CHEMBL1487173 & 688810 & \multicolumn{3}{|c|}{5.7829999999999995} & 5.182 & TST \\
\hline CHEMBL1300812 & 688810 & 5.683 & 5.5936 & TRN & & \\
\hline CHEMBL1543615 & 688810 & \multicolumn{3}{|c|}{5.5329999999999995} & 5.3086 & TRN \\
\hline CHEMBL1582363 & 688810 & 4.783 & 5.2073 & TRN & & \\
\hline CHEMBL3198708 & 688810 & 4.933 & 5.0699 & TRN & & \\
\hline CHEMBL1986151 & 688810 & 5.233 & 5.5054 & TRN & & \\
\hline CHEMBL1367734 & 688810 & 4.933 & 5.1213 & TRN & & \\
\hline CHEMBL1536438 & 688810 & \multicolumn{3}{|c|}{4.9830000000000005} & 5.2385 & TRN \\
\hline CHEMBL1538266 & 688810 & \multicolumn{3}{|c|}{5.382999999999999} & 5.092 & TRN \\
\hline CHEMBL1588487 & 688810 & \multicolumn{3}{|c|}{4.7330000000000005} & 5.2708 & TRN \\
\hline CHEMBL1392415 & 688810 & 4.883 & 5.1803 & TRN & & \\
\hline CHEMBL1508710 & 688810 & 4.933 & 5.0811 & TRN & & \\
\hline CHEMBL1447852 & 688810 & 4.833 & 5.4817 & TRN & & \\
\hline CHEMBL1316871 & 688810 & \multicolumn{3}{|c|}{5.2829999999999995} & 5.1071 & TRN \\
\hline CHEMBL1339239 & 688810 & 4.883 & 4.9903 & TRN & & \\
\hline CHEMBL1517323 & 688810 & \multicolumn{3}{|c|}{6.2829999999999995} & 5.2882 & TRN \\
\hline CHEMBL601742 & 688810 & 4.633 & 4.7735 & TRN & & \\
\hline CHEMBL1468250 & 688810 & 4.833 & 5.404 & TRN & & \\
\hline CHEMBL1376048 & 688810 & 5.483 & 5.3333 & TST & & \\
\hline CHEMBL1432640 & 688810 & 5.233 & 5.4053 & TRN & & \\
\hline CHEMBL1604301 & 688810 & \multicolumn{3}{|c|}{4.9830000000000005} & 5.2471 & TRN \\
\hline CHEMBL1556013 & 688810 & 5.183 & 5.0375 & TRN & & \\
\hline CHEMBL1575309 & 688810 & 5.083 & 5.3049 & TRN & & \\
\hline CHEMBL1525999 & 688810 & 4.783 & 5.0746 & TRN & & \\
\hline CHEMBL1583827 & 688810 & \multicolumn{3}{|c|}{4.7330000000000005} & 5.2286 & TRN \\
\hline CHEMBL3212574 & 688810 & 4.833 & 4.9184 & TRN & & \\
\hline CHEMBL1602085 & 688810 & 7.1831 & 6.4652 & TRN & & \\
\hline CHEMBL1593752 & 688810 & 4.783 & 5.2651 & TRN & & \\
\hline CHEMBL 214321 & 688810 & \multicolumn{3}{|c|}{5.382999999999999} & 5.6401 & TRN \\
\hline CHEMBL1589873 & 688810 & 4.883 & 4.7763 & TRN & & \\
\hline CHEMBL1517400 & 688810 & 5.083 & 4.9784 & TRN & & \\
\hline
\end{tabular}




\begin{tabular}{|c|c|c|c|c|c|c|c|}
\hline \multirow{3}{*}{$\begin{array}{l}\text { CHEMBL1385132 } \\
\text { CHEMBL1393669 }\end{array}$} & & & & & & & \\
\hline & 688810 & 5.033 & 5.4964 & TRN & & & \\
\hline & 688810 & \multicolumn{3}{|c|}{5.882999999999999} & 5.1977 & TRN & \\
\hline CHEMBL1339128 & 688810 & 4.783 & 4.891 & TRN & & & \\
\hline CHEMBL1525889 & 688810 & 4.933 & 4.7728 & TST & & & \\
\hline CHEMBL1589790 & 688810 & \multicolumn{3}{|c|}{5.5329999999999995} & 5.7243 & TRN & \\
\hline CHEMBL1398581 & 688810 & \multicolumn{3}{|c|}{4.7330000000000005} & 5.1588 & TRN & \\
\hline CHEMBL1369635 & 688810 & \multicolumn{3}{|c|}{5.132999999999999} & 5.1769 & TRN & \\
\hline CHEMBL1514254 & 688810 & 5.083 & 4.9236 & TRN & & & \\
\hline CHEMBL1452521 & 688810 & \multicolumn{3}{|c|}{5.832999999999999} & 5.8021 & TRN & \\
\hline CHEMBL1511502 & 688810 & \multicolumn{3}{|c|}{6.332999999999999} & 5.95200 & $\partial 000000001$ & TRN \\
\hline CHEMBL1457648 & 688810 & \multicolumn{3}{|c|}{4.7330000000000005} & 5.2399 & TRN & \\
\hline CHEMBL572339 & 688810 & \multicolumn{3}{|c|}{4.7330000000000005} & 5.4549 & TRN & \\
\hline CHEMBL1596681 & 688810 & 5.933 & 5.5366 & TRN & & & \\
\hline CHEMBL1520703 & 688810 & \multicolumn{3}{|c|}{5.832999999999999} & 5.6691 & TRN & \\
\hline CHEMBL1591414 & 688810 & 4.883 & 5.2781 & TRN & & & \\
\hline CHEMBL1601638 & 688810 & 4.833 & 5.2471 & TRN & & & \\
\hline CHEMBL1303246 & 688810 & 5.083 & 5.2137 & TRN & & & \\
\hline CHEMBL584442 & 688810 & \multicolumn{3}{|c|}{5.832999999999999} & \multicolumn{2}{|c|}{5.457000000000001} & TRN \\
\hline CHEMBL1431773 & 688810 & \multicolumn{3}{|c|}{4.9830000000000005} & 5.0007 & TST & \\
\hline CHEMBL1347600 & 688810 & 5.733 & 5.5092 & TRN & & & \\
\hline CHEMBL1436804 & 688810 & 4.633 & 4.7911 & TRN & & & \\
\hline CHEMBL1606172 & 688810 & \multicolumn{3}{|c|}{5.2829999999999995} & 5.204 & TRN & \\
\hline CHEMBL 3190662 & 688810 & \multicolumn{3}{|c|}{5.132999999999999} & 5.0453 & TST & \\
\hline CHEMBL1610120 & 688810 & 6.433 & 5.7063 & TRN & & & \\
\hline CHEMBL1567082 & 688810 & 5.233 & 5.3189 & TST & & & \\
\hline CHEMBL1308467 & 688810 & 5.033 & 5.3283 & TRN & & & \\
\hline CHEMBL1550740 & 688810 & 6.8831 & 5.5891 & TRN & & & \\
\hline CHEMBL1549175 & 688810 & 4.633 & 5.1953 & TRN & & & \\
\hline CHEMBL1567467 & 688810 & 4.633 & 4.7411 & TRN & & & \\
\hline CHEMBL1383088 & 688810 & \multicolumn{3}{|c|}{6.382999999999999} & 5.5554 & TST & \\
\hline CHEMBL1427365 & 688810 & \multicolumn{3}{|c|}{4.7330000000000005} & 5.3274 & TST & \\
\hline CHEMBL1374574 & 688810 & 4.883 & 5.0846 & TST & & & \\
\hline CHEMBL1361135 & 688810 & \multicolumn{3}{|c|}{5.2829999999999995} & 4.6242 & TRN & \\
\hline CHEMBL1353664 & 688810 & 4.633 & 5.1329 & TRN & & & \\
\hline CHEMBL1479295 & 688810 & 5.733 & 5.4278 & TRN & & & \\
\hline CHEMBL1483243 & 688810 & 4.883 & 5.3209 & TRN & & & \\
\hline CHEMBL1299957 & 688810 & 5.233 & 5.2748 & TST & & & \\
\hline CHEMBL1478356 & 688810 & \multicolumn{3}{|c|}{5.582999999999999} & 5.8819 & TRN & \\
\hline CHEMBL1402105 & 688810 & 5.63299 & 999999999 & & 5.1927 & TST & \\
\hline CHEMBL1602548 & 688810 & 4.85 & 5.4799 & TRN & & & \\
\hline CHEMBL1589425 & 688810 & 4.633 & 4.8997 & TST & & & \\
\hline CHEMBL1309798 & 688810 & 5.33299 & 999999999 & & 5.5262 & TRN & \\
\hline CHEMBL1446032 & 688810 & 5.13299 & 999999999 & & 5.7446 & TRN & \\
\hline CHEMBL1326590 & 688810 & 4.833 & 5.1696 & TRN & & & \\
\hline CHEMBL3190334 & 688810 & 6.9329 & 5.8624 & TRN & & & \\
\hline CHEMBL1533591 & 688810 & 5.83299 & 999999999 & & 4.9536 & TRN & \\
\hline CHEMBL1424724 & 688810 & 4.683 & 4.9983 & TST & & & \\
\hline CHEMBL1355265 & 688810 & 4.633 & 5.0003 & TST & & & \\
\hline
\end{tabular}




\begin{tabular}{|c|c|c|c|c|c|c|}
\hline \multirow{3}{*}{$\begin{array}{l}\text { CHEMBL1401162 } \\
\text { CHEMBL1402668 }\end{array}$} & \multirow{3}{*}{$\begin{array}{l}688810 \\
688810\end{array}$} & \multicolumn{5}{|c|}{ Supplemental Table S2.txt } \\
\hline & & \multicolumn{3}{|c|}{5.7829999999999995} & \multirow{2}{*}{5.8806} & \multirow{2}{*}{ TRN } \\
\hline & & 4.633 & 5.256 & TRN & & \\
\hline CHEMBL1404345 & 688810 & \multicolumn{3}{|c|}{6.132999999999999} & 5.0899 & TRN \\
\hline CHEMBL3190851 & 688810 & 5.183 & 5.6832 & TRN & & \\
\hline CHEMBL1333876 & 688810 & \multicolumn{3}{|c|}{6.332999999999999} & 5.6299 & TRN \\
\hline CHEMBL1458067 & 688810 & 5.233 & 5.6199 & TRN & & \\
\hline CHEMBL1371460 & 688810 & 5.483 & 5.7231 & TRN & & \\
\hline CHEMBL1337395 & 688810 & \multicolumn{3}{|c|}{5.832999999999999} & 5.5595 & TRN \\
\hline CHEMBL1372802 & 688810 & \multicolumn{3}{|c|}{6.0329999999999995} & 5.4546 & TRN \\
\hline CHEMBL1414729 & 688810 & \multicolumn{3}{|c|}{6.382999999999999} & 5.1043 & TRN \\
\hline CHEMBL1403068 & 688810 & 4.883 & 5.4361 & TST & & \\
\hline CHEMBL1503864 & 688810 & 4.933 & 5.3731 & TST & & \\
\hline CHEMBL1594366 & 688810 & \multicolumn{3}{|c|}{4.7330000000000005} & 5.144 & TRN \\
\hline CHEMBL1583847 & 688810 & \multicolumn{3}{|c|}{6.582999999999999} & 5.1074 & TRN \\
\hline CHEMBL1468360 & 688810 & \multicolumn{3}{|c|}{6.2829999999999995} & 5.6584 & TRN \\
\hline CHEMBL1483814 & 688810 & 6.233 & 6.1061 & TRN & & \\
\hline CHEMBL1421615 & 688810 & \multicolumn{3}{|c|}{5.582999999999999} & 5.2532 & TRN \\
\hline CHEMBL3208479 & 688810 & \multicolumn{3}{|c|}{5.382999999999999} & 5.6365 & TRN \\
\hline CHEMBL551604 & 688810 & 5.683 & 5.3598 & TRN & & \\
\hline CHEMBL1438498 & 688810 & 5.433 & 5.5669 & TRN & & \\
\hline CHEMBL1585377 & 688810 & 4.933 & 4.7155 & TRN & & \\
\hline CHEMBL1581188 & 688810 & \multicolumn{3}{|c|}{5.382999999999999} & 5.6998 & TRN \\
\hline CHEMBL1310184 & 688810 & 5.183 & 5.5908 & TRN & & \\
\hline CHEMBL1550600 & 688810 & 4.633 & 5.2033 & TST & & \\
\hline CHEMBL1508216 & 688810 & 5.983 & 5.4456 & TRN & & \\
\hline CHEMBL3191062 & 688810 & \multicolumn{3}{|c|}{6.5329999999999995} & 5.7325 & TRN \\
\hline CHEMBL1578302 & 688810 & 5.933 & 5.8484 & TRN & & \\
\hline CHEMBL1342798 & 688810 & \multicolumn{3}{|c|}{6.7829999999999995} & 5.7604 & TRN \\
\hline CHEMBL1382123 & 688810 & \multicolumn{3}{|c|}{5.2829999999999995} & 5.2015 & TRN \\
\hline CHEMBL1512727 & 688810 & 5.483 & 4.9441 & TRN & & \\
\hline CHEMBL1325006 & 688810 & 4.833 & 5.4913 & TRN & & \\
\hline CHEMBL1507972 & 688810 & 5.433 & 5.5891 & TRN & & \\
\hline CHEMBL1418306 & 688810 & 4.633 & 4.9985 & TST & & \\
\hline CHEMBL1556303 & 688810 & \multicolumn{3}{|c|}{4.9830000000000005} & 4.7389 & TRN \\
\hline CHEMBL1482740 & 688810 & 5.78299 & 99999999 & 995 & 5.2203 & TST \\
\hline CHEMBL1522952 & 688810 & 5.13299 & 99999999 & & 4.9712 & TRN \\
\hline CHEMBL1466488 & 688810 & 4.633 & 4.9519 & TRN & & \\
\hline CHEMBL1475099 & 688810 & 4.633 & 5.1 & TST & & \\
\hline CHEMBL1545984 & 688810 & 7.1831 & 5.4577 & TST & & \\
\hline CHEMBL1525394 & 688810 & 4.783 & 5.2069 & TST & & \\
\hline CHEMBL1377682 & 688810 & 4.833 & 4.487 & TRN & & \\
\hline CHEMBL1412215 & 688810 & 5.53299 & 99999999 & 995 & 5.6057 & TRN \\
\hline CHEMBL1338501 & 688810 & 5.33299 & 99999999 & & 5.4884 & TRN \\
\hline CHEMBL1602511 & 688810 & 4.98300 & 00000000 & 205 & 4.57 & TRN \\
\hline CHEMBL1351908 & 688810 & 4.933 & 6.8469 & TRN & & \\
\hline CHEMBL1366623 & 688810 & 4.883 & 5.5158 & TST & & \\
\hline CHEMBL1606131 & 688810 & 5.233 & 4.8438 & TST & & \\
\hline CHEMBL3192367 & 688810 & 4.933 & 5.3342 & TRN & & \\
\hline
\end{tabular}




\begin{tabular}{|c|c|c|c|c|c|c|c|}
\hline \multicolumn{7}{|c|}{ Supplemental Table S2.txt } & \\
\hline CHEMBL1349571 & 688810 & 4.833 & 5.1965 & TRN & & & \\
\hline CHEMBL1596924 & 688810 & 4.7330 & 00000000 & 005 & 4.8909 & TRN & \\
\hline CHEMBL1442742 & 688810 & 4.833 & 5.003 & TST & & & \\
\hline CHEMBL1411259 & 688810 & 4.7330 & 00000000 & 005 & 5.0396 & TST & \\
\hline CHEMBL1498608 & 688810 & 5.033 & 5.5437 & TRN & & & \\
\hline CHEMBL1436890 & 688810 & 5.033 & 5.3922 & TRN & & & \\
\hline CHEMBL1393161 & 688810 & 5.7829 & 99999999 & 995 & 5.2339 & TRN & \\
\hline CHEMBL1527622 & 688810 & 4.783 & 4.9764 & TST & & & \\
\hline CHEMBL1361161 & 688810 & 4.783 & 5.1765 & TRN & & & \\
\hline CHEMBL1458167 & 688810 & 5.1329 & 99999999 & & 5.1698 & TRN & \\
\hline CHEMBL 3190577 & 688810 & 5.183 & 5.7085 & TST & & & \\
\hline CHEMBL1468087 & 688810 & 4.7330 & 00000000 & 005 & 5.224 & TST & \\
\hline CHEMBL1318405 & 688810 & 4.9830 & 00000000 & 005 & 4.8229 & TST & \\
\hline CHEMBL1349723 & 688810 & 5.033 & 5.3662 & TST & & & \\
\hline CHEMBL1550291 & 688810 & 4.783 & 5.2138 & TRN & & & \\
\hline CHEMBL1380819 & 688810 & 4.933 & 5.4623 & TRN & & & \\
\hline CHEMBL1427920 & 688810 & 4.933 & 4.947 & TST & & & \\
\hline CHEMBL1602947 & 688810 & 5.083 & 5.2627 & TRN & & & \\
\hline CHEMBL3213584 & 688810 & 5.733 & 5.1081 & TRN & & & \\
\hline CHEMBL1511243 & 688810 & 5.5329 & 99999999 & 995 & 5.3891 & TRN & \\
\hline CHEMBL1374097 & 688810 & 6.7829 & 99999999 & 995 & 5.7122 & TRN & \\
\hline CHEMBL1429094 & 688810 & 5.483 & 5.3525 & TRN & & & \\
\hline CHEMBL1330233 & 688810 & 4.7330 & 00000000 & 005 & 5.1969 & TRN & \\
\hline CHEMBL1464799 & 688810 & 5.3829 & 99999999 & & 5.2261 & TRN & \\
\hline CHEMBL1558850 & 688810 & 5.8329 & 99999999 & & 5.9134 & TRN & \\
\hline CHEMBL1575750 & 688810 & 4.7330 & 00000000 & 005 & 5.3524 & TRN & \\
\hline CHEMBL1433548 & 688810 & 4.833 & 5.2869 & TST & & & \\
\hline CHEMBL1534141 & 688810 & 4.7330 & 00000000 & 005 & 5.0012 & TRN & \\
\hline CHEMBL1537255 & 688810 & 4.7330 & 00000000 & 005 & 5.0936 & TST & \\
\hline CHEMBL1349724 & 688810 & 5.183 & 4.8145 & TST & & & \\
\hline CHEMBL1303170 & 688810 & 4.683 & 4.989 & TRN & & & \\
\hline CHEMBL1587051 & 688810 & 4.883 & 5.1751 & TRN & & & \\
\hline CHEMBL1517192 & 688810 & 5.3829 & 99999999 & & 5.079 & TRN & \\
\hline CHEMBL1526584 & 688810 & 4.833 & 4.9802 & TRN & & & \\
\hline CHEMBL1305698 & 688810 & 5.683 & 5.50899 & 999999999 & 995 & TRN & \\
\hline CHEMBL1373404 & 688810 & 6.0 & 5.4617 & TRN & & & \\
\hline CHEMBL1409218 & 688810 & 5.8829 & 99999999 & & 5.392 & TRN & \\
\hline CHEMBL1426366 & 688810 & 5.033 & 5.9626 & TRN & & & \\
\hline CHEMBL1458129 & 688810 & 5.033 & 5.4186 & TST & & & \\
\hline CHEMBL1529274 & 688810 & 5.183 & 5.1533 & TRN & & & \\
\hline CHEMBL1421878 & 688810 & 6.0829 & 99999999 & & 5.91799 & 9999999999 & TRN \\
\hline CHEMBL1417483 & 688810 & 4.833 & 5.0439 & TRN & & & \\
\hline CHEMBL3211877 & 688810 & 4.633 & 5.2976 & TRN & & & \\
\hline CHEMBL598204 & 688810 & 5.1329 & 99999999 & & 5.6477 & TST & \\
\hline CHEMBL1525742 & 688810 & 4.833 & 5.2576 & TRN & & & \\
\hline CHEMBL1575523 & 688810 & 4.783 & 4.9596 & TST & & & \\
\hline CHEMBL1444302 & 688810 & 6.233 & 5.9236 & TRN & & & \\
\hline CHEMBL1599332 & 688810 & 4.7330 & 00000000 & 005 & 5.20299 & 9999999999 & TRN \\
\hline
\end{tabular}




\begin{tabular}{|c|c|c|c|c|c|c|}
\hline \multirow{3}{*}{$\begin{array}{l}\text { CHEMBL1536762 } \\
\text { CHEMBL1577171 }\end{array}$} & \multicolumn{6}{|c|}{ Supplemental Table S2.txt } \\
\hline & 688810 & \multicolumn{3}{|c|}{5.132999999999999} & 5.0629 & $\mathrm{TH}$ \\
\hline & 688810 & 5.933 & 6.034 & TRN & & \\
\hline CHEMBL1304903 & 688810 & 4.583 & 5.6161 & TST & & \\
\hline CHEMBL1586935 & 588810 & \multicolumn{3}{|c|}{5.2829999999999995} & 5.3229 & TRN \\
\hline CHEMBL1539470 & 688810 & \multicolumn{3}{|c|}{4.7330000000000005} & 5.1827 & \\
\hline CHEMBL1585799 & 688810 & 5.683 & 5.4366 & TRN & & \\
\hline CHEMBL3199392 & 688810 & 4.833 & 5.1787 & TRN & & \\
\hline CHEMBL1988883 & 588810 & 6.683 & 5.4587 & TRN & & \\
\hline CHEMBL1348941 & 88810 & 5.683 & 5.4481 & TRN & & \\
\hline CHEMBL1330131 & 688810 & 5.683 & 5.4937 & TST & & \\
\hline CHEMBL1331928 & 688810 & \multicolumn{3}{|c|}{5.332999999999999} & 5.5399 & TRN \\
\hline CHEMBL1545876 & 688810 & 5.733 & \multicolumn{3}{|c|}{5.492999999999999} & \\
\hline CHEMBL1582978 & 688810 & 5.183 & 4.9635 & TRN & & \\
\hline CHEMBL1536188 & 688810 & \multicolumn{3}{|c|}{4.7330000000000005} & 2668 & \\
\hline CHEMBL211692 & 688810 & 4.833 & 4.9864 & TRN & & \\
\hline CHEMBL1 & 688810 & \multicolumn{3}{|c|}{5.632999999999999} & .6951 & \\
\hline CHEMBL1 & 688810 & 6.183 & 5.9569 & TRN & & \\
\hline CHEMBL1339120 & 688810 & \multicolumn{3}{|c|}{5.7829999999999995} & 5.3186 & \\
\hline CHEMBL1428047 & 688810 & 4.783 & 4.6951 & TRN & & \\
\hline CHEMBL1586155 & 688810 & \multicolumn{3}{|c|}{4.7330000000000005} & 5.4239 & \\
\hline HEMBL3 & 688 & \multicolumn{3}{|c|}{4.7330000000000005} & 4.9965 & \\
\hline CHEMBL197 & 688810 & \multicolumn{3}{|c|}{4.7330000000000005} & 5.4919 & \\
\hline CHEMBL3190582 & 688810 & 4.683 & 4.9208 & TRN & & \\
\hline CHEMBL1491053 & 688810 & \multicolumn{3}{|c|}{4.9830000000000005} & 8 & \\
\hline CHEMBL1306034 & 688810 & \multicolumn{3}{|c|}{5.382999999999999} & 5.1607 & \\
\hline CHEMBL1 & 688 & 5.683 & 5.7712 & TRN & & \\
\hline CHEMBL1391623 & 688 & \multicolumn{3}{|c|}{5.132999999999999} & 5.4228 & \\
\hline CHEMBL3195811 & 688810 & \multicolumn{3}{|c|}{5.132999999999999} & 5.5177 & \\
\hline CHEMBL1303003 & 688810 & \multicolumn{3}{|c|}{5.832999999999999} & 5.6122 & \\
\hline CHEMBL1394681 & 688810 & \multicolumn{3}{|c|}{5.332999999999999} & 988 & . \\
\hline CHEMBL1 & 688 & \multicolumn{3}{|c|}{5.582999999999999} & 5.1976 & \\
\hline CHEMBL14€ & 688810 & 4.883 & 5.4537 & TST & & \\
\hline CHEMBL1547102 & 688810 & 4.883 & 5.4728 & TRN & & \\
\hline CHEMBL1553189 & 688810 & \multicolumn{3}{|c|}{4.7330000000000005} & 946 & \\
\hline CHEMBL1 & 688 & 5.2829 & 99999999 & 995 & & T \\
\hline CHEMBL13 & 688810 & 5.7829 & 99999999 & 995 & 5.8151 & TR \\
\hline CHEMBL1348679 & 688810 & 4.933 & 5.0078 & TRN & & \\
\hline CHEMBL1411203 & 688810 & 5.033 & 4.93 & TRN & & \\
\hline CHEMBL1521694 & 688810 & 5 . & 5.4299 & TRN & & \\
\hline CHEMBL1 & 688 & & $4 . \varepsilon$ & TRN & & \\
\hline CHEMBL1593664 & 688810 & 4.933 & 5.5967 & TRN & & \\
\hline CHEMBL3211710 & 688810 & 4.783 & 5.1766 & TRN & & \\
\hline CHEMBL1303302 & 688810 & & 5.0281 & TST & & \\
\hline CHEMBL1528094 & 688810 & 4.583 & 5.1557 & TRN & & \\
\hline CHEMBL3194035 & 688810 & 4.9836 & $000000 t$ & 005 & & . \\
\hline CHEMBL1382917 & 688810 & 5.8325 & 9999999 & & 6.309 & \\
\hline CHEMBL1304625 & 688810 & 5.3329 & 9999999 & & 4.8475 & $\mathrm{TR}$ \\
\hline CHEMBL1540719 & 688810 & 5.3329 & 99999995 & & 6.1542 & $\mathrm{TR}$ \\
\hline
\end{tabular}




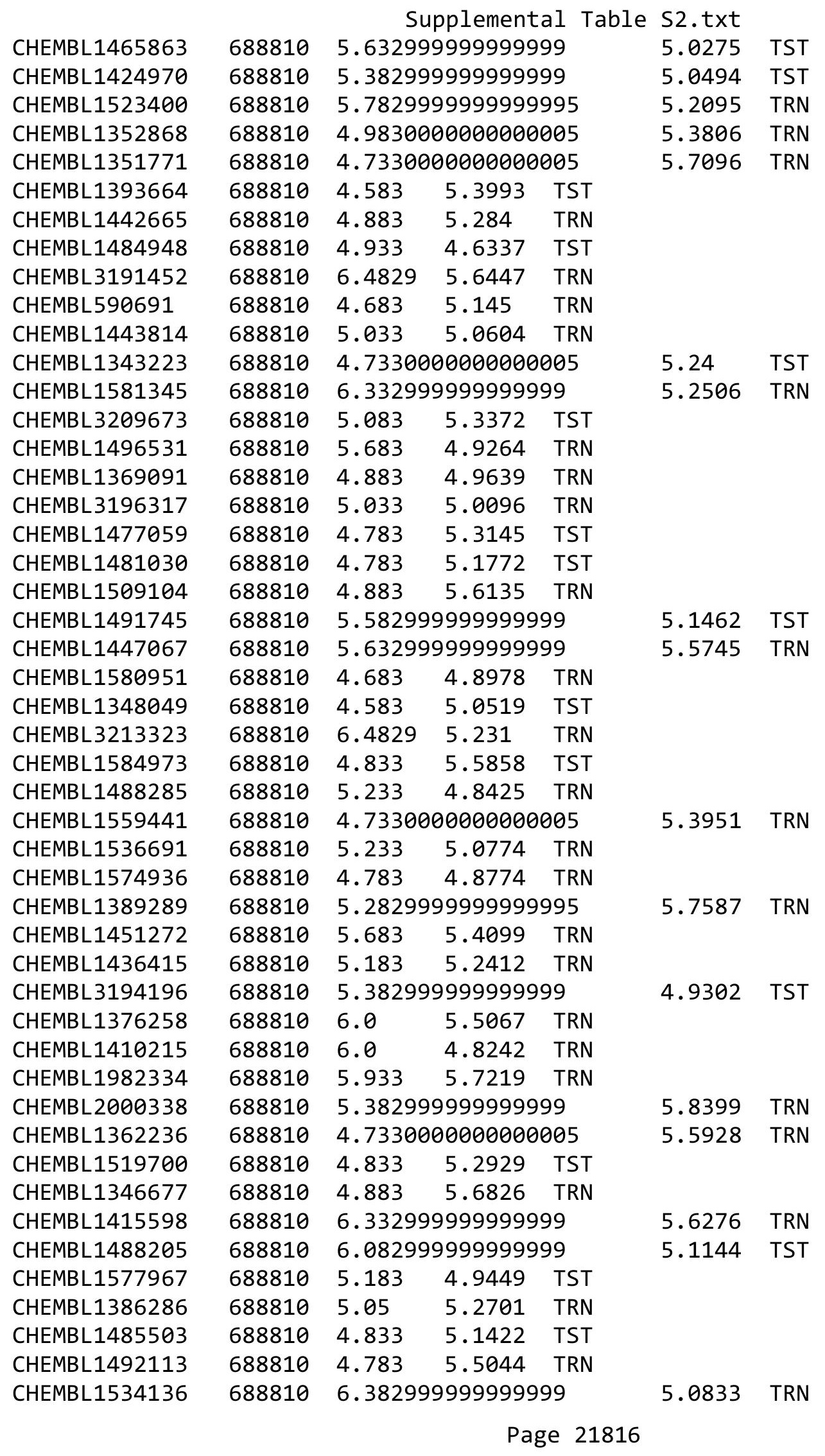




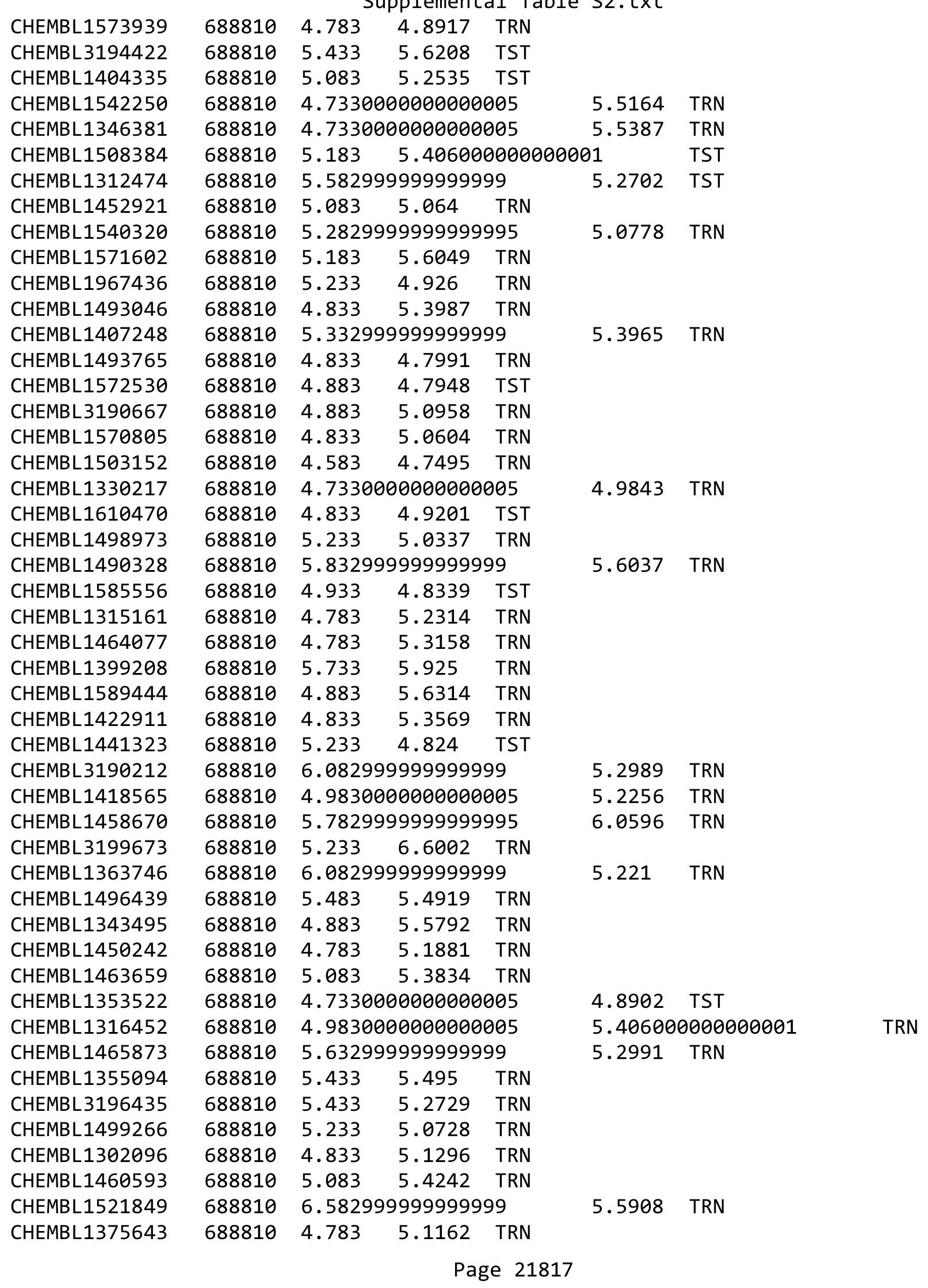




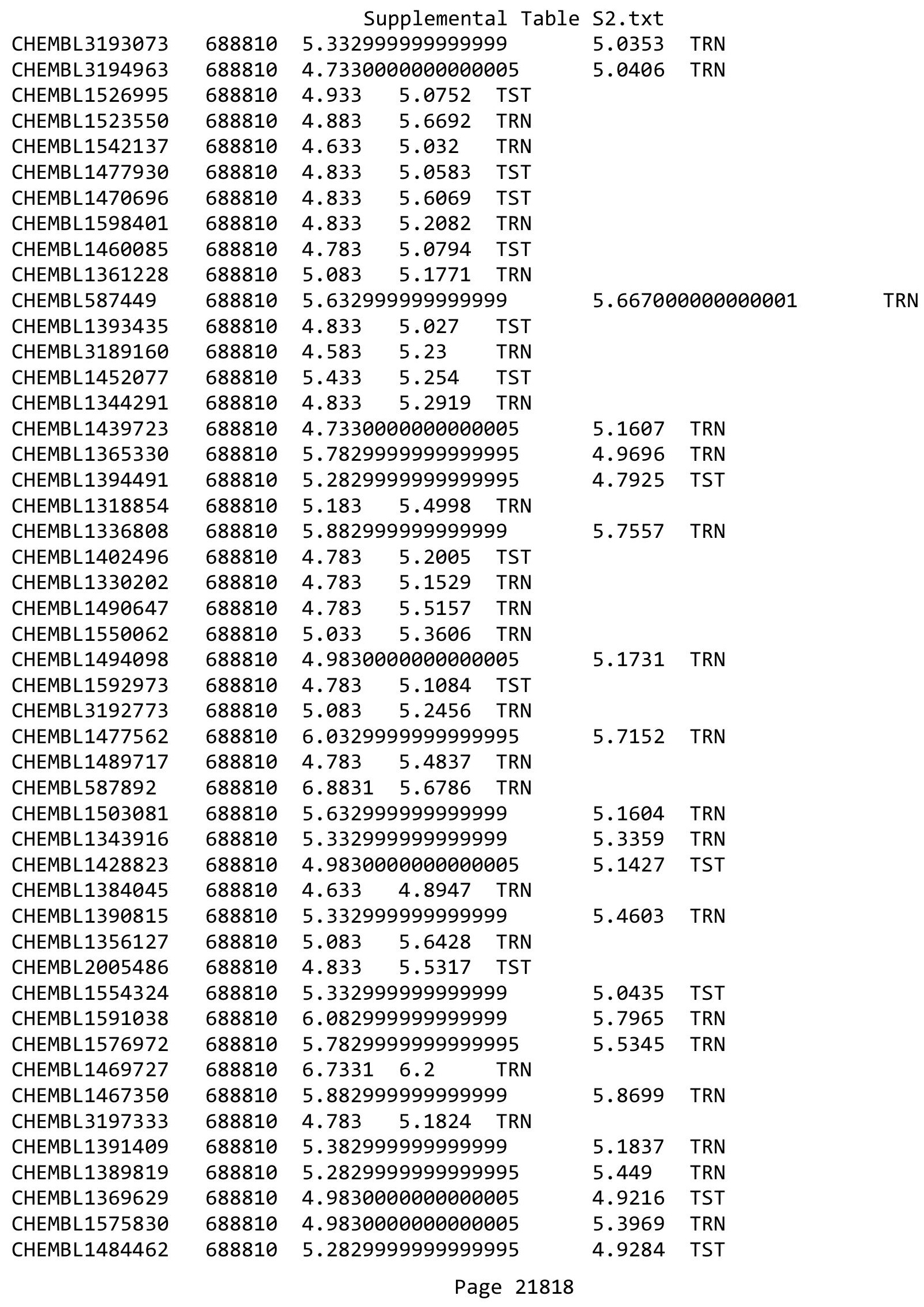




\begin{tabular}{|c|c|c|c|c|c|c|c|}
\hline \multicolumn{7}{|c|}{ oplemental Ia } & \\
\hline CHEMBL1536874 & 688810 & 5.033 & 5.0418 & TST & & & \\
\hline CHEMBL1336237 & 688810 & 6.433 & 5.5517 & TRN & & & \\
\hline CHEMBL1504881 & 688810 & 4.73300 & 00000000 & 005 & 5.4814 & TRN & \\
\hline CHEMBL1431755 & 688810 & 4.783 & 4.8012 & TST & & & \\
\hline CHEMBL1454996 & 688810 & 6.38299 & 99999999 & & 6.0261 & TRN & \\
\hline CHEMBL 3199713 & 688810 & 4.883 & 5.904 & TRN & & & \\
\hline CHEMBL1563428 & 688810 & 4.833 & 5.6319 & TRN & & & \\
\hline CHEMBL1414843 & 688810 & 4.833 & 5.449 & TRN & & & \\
\hline CHEMBL1392265 & 688810 & 4.783 & 5.3921 & TST & & & \\
\hline CHEMBL1403689 & 688810 & 4.583 & 5.0214 & TST & & & \\
\hline CHEMBL69003 & 688810 & 4.783 & 4.7735 & TST & & & \\
\hline CHEMBL1586371 & 688810 & 5.88299 & 99999999 & & 4.7782 & TST & \\
\hline CHEMBL1517662 & 688810 & 4.783 & 4.8347 & TST & & & \\
\hline CHEMBL1534924 & 688810 & 5.88299 & 99999999 & & 5.8815 & TST & \\
\hline CHEMBL1546270 & 688810 & 4.583 & 4.8257 & TST & & & \\
\hline CHEMBL1457369 & 688810 & 4.933 & 5.0213 & TRN & & & \\
\hline CHEMBL1345312 & 688810 & 4.783 & 5.8379 & TRN & & & \\
\hline CHEMBL1560830 & 688810 & 4.783 & 4.7289 & TRN & & & \\
\hline CHEMBL1398569 & 688810 & 4.933 & 4.9884 & TRN & & & \\
\hline CHEMBL1432569 & 688810 & 4.73300 & 00000000 & 005 & 4.8367 & TRN & \\
\hline CHEMBL1304583 & 688810 & 6.233 & 5.9334 & TRN & & & \\
\hline CHEMBL1574463 & 688810 & 5.183 & 4.938 & TST & & & \\
\hline CHEMBL1334778 & 688810 & 5.88299 & 99999999 & & 5.3228 & TST & \\
\hline CHEMBL1471266 & 688810 & 5.13299 & 99999999 & & 5.2749 & TRN & \\
\hline CHEMBL1566635 & 688810 & 5.733 & 5.6262 & TRN & & & \\
\hline CHEMBL1458785 & 688810 & 5.88299 & 99999999 & & 5.2818 & TRN & \\
\hline CHEMBL1597789 & 688810 & 5.183 & 5.0705 & TRN & & & \\
\hline CHEMBL1408287 & 688810 & 6.433 & 5.9645 & TRN & & & \\
\hline CHEMBL1437451 & 688810 & 5.63299 & 99999999 & & 5.6271 & TRN & \\
\hline CHEMBL1590615 & 688810 & 4.633 & 4.7734 & TST & & & \\
\hline CHEMBL 3193556 & 688810 & 4.833 & 5.2856 & TRN & & & \\
\hline CHEMBL1593820 & 688810 & 4.73300 & 00000000 & 005 & 5.3271 & TRN & \\
\hline CHEMBL 2002465 & 688810 & 5.13299 & 99999999 & & 5.028000 & 00000000005 & TST \\
\hline CHEMBL1601721 & 688810 & 7.08299 & 99999999 & & 5.7542 & TRN & \\
\hline CHEMBL1530434 & 688810 & 6.53299 & 99999999 & 995 & 5.3984 & TRN & \\
\hline CHEMBL1433837 & 688810 & 4.833 & 5.0931 & TST & & & \\
\hline CHEMBL1305994 & 688810 & 4.98300 & 00000000 & 005 & 5.0328 & TRN & \\
\hline CHEMBL1422295 & 688810 & 4.783 & 5.3058 & TRN & & & \\
\hline CHEMBL1458414 & 688810 & 5.233 & 5.1231 & TRN & & & \\
\hline CHEMBL1518154 & 688810 & 6.4829 & 5.7535 & TST & & & \\
\hline CHEMBL1455616 & 688810 & 5.33299 & 999999995 & & 5.1751 & TST & \\
\hline CHEMBL3109023 & 688810 & 4.583 & 4.9797 & TRN & & & \\
\hline CHEMBL1464056 & 688810 & 5.233 & 5.2488 & TRN & & & \\
\hline CHEMBL1380787 & 688810 & 5.183 & 5.0522 & TRN & & & \\
\hline CHEMBL 3211218 & 688810 & 5.683 & 5.1798 & TRN & & & \\
\hline CHEMBL 3211915 & 688810 & 4.783 & 5.3762 & TRN & & & \\
\hline CHEMBL1399633 & 688810 & 4.833 & 4.9435 & TRN & & & \\
\hline CHEMBL 3209214 & 688810 & 4.98300 & 00000000 & 005 & 5.2192 & TRN & \\
\hline
\end{tabular}




\begin{tabular}{|c|c|c|c|c|c|c|}
\hline \multirow{3}{*}{$\begin{array}{l}\text { CHEMBL1579332 } \\
\text { CHEMBL1510307 }\end{array}$} & \multirow{3}{*}{$\begin{array}{l}688810 \\
688810\end{array}$} & \multicolumn{4}{|c|}{ Supplemental Table S2.txt } & \multirow{2}{*}{ TST } \\
\hline & & \multicolumn{3}{|c|}{5.632999999999999} & 5.3117 & \\
\hline & & 4.783 & 5.6393 & TRN & & \\
\hline CHEMBL1301355 & 688810 & 4.583 & 5.1087 & TST & & \\
\hline CHEMBL1319384 & 688810 & 5.983 & 5.4181 & TRN & & \\
\hline CHEMBL1369054 & 688810 & \multicolumn{3}{|c|}{4.7330000000000005} & 5.2104 & TST \\
\hline CHEMBL1323928 & 688810 & 4.783 & 5.1512 & TRN & & \\
\hline CHEMBL1443948 & 688810 & 5.7 & 4.96 & TRN & & \\
\hline CHEMBL1580321 & 688810 & 5.083 & 5.7383 & TRN & & \\
\hline CHEMBL1563552 & 688810 & 4.583 & 5.1316 & TRN & & \\
\hline CHEMBL1462968 & 688810 & 4.583 & 4.9254 & TRN & & \\
\hline CHEMBL1319015 & 688810 & 4.633 & 4.9611 & TRN & & \\
\hline CHEMBL1415337 & 688810 & 4.833 & 5.0259 & TST & & \\
\hline CHEMBL1355470 & 688810 & 4.883 & 4.8168 & TST & & \\
\hline CHEMBL1388896 & 688810 & \multicolumn{3}{|c|}{4.7330000000000005} & 5.2773 & TRN \\
\hline CHEMBL1438725 & 688810 & 5.733 & 5.7262 & TRN & & \\
\hline CHEMBL1505109 & 688810 & \multicolumn{3}{|c|}{5.582999999999999} & 5.0775 & TRN \\
\hline CHEMBL1323670 & 688810 & 4.783 & 5.3634 & TST & & \\
\hline CHEMBL1457606 & 688810 & 5.083 & \multicolumn{3}{|c|}{5.292000000000001} & TRN \\
\hline CHEMBL1564356 & 688810 & 5.683 & 5.3665 & TRN & & \\
\hline CHEMBL1581971 & 688810 & 4.783 & 5.0557 & TRN & & \\
\hline CHEMBL1365435 & 688810 & \multicolumn{3}{|c|}{5.2829999999999995} & 4.6923 & TRN \\
\hline CHEMBL1470749 & 688810 & 5.733 & 5.7717 & TRN & & \\
\hline CHEMBL1334062 & 688810 & 4.633 & 5.1406 & TRN & & \\
\hline CHEMBL1387546 & 688810 & 5.433 & 5.5505 & TRN & & \\
\hline CHEMBL1539521 & 688810 & 4.883 & 5.3908 & TRN & & \\
\hline CHEMBL1564465 & 688810 & 7.0329 & 5.7508 & TRN & & \\
\hline CHEMBL1354129 & 688810 & \multicolumn{3}{|c|}{4.7330000000000005} & 5.1432 & TST \\
\hline CHEMBL1387933 & 688810 & \multicolumn{3}{|c|}{5.2829999999999995} & 5.4724 & TRN \\
\hline CHEMBL1537338 & 688810 & \multicolumn{3}{|c|}{5.382999999999999} & 5.2148 & TRN \\
\hline CHEMBL1343701 & 688810 & 4.783 & 5.2596 & TRN & & \\
\hline CHEMBL1323722 & 688810 & 5.683 & 5.2091 & TRN & & \\
\hline CHEMBL1553370 & 688810 & \multicolumn{3}{|c|}{5.7829999999999995} & 5.3036 & TRN \\
\hline CHEMBL1483846 & 688810 & \multicolumn{3}{|c|}{4.7330000000000005} & 5.0422 & TRN \\
\hline CHEMBL 3145371 & 688810 & \multicolumn{3}{|c|}{4.7330000000000005} & 5.4531 & TRN \\
\hline CHEMBL1428858 & 688810 & 4.833 & 5.46 & TST & & \\
\hline CHEMBL1552486 & 688810 & \multicolumn{3}{|c|}{5.882999999999999} & 4.8513 & TST \\
\hline CHEMBL1339466 & 688810 & 5.183 & 5.8418 & TRN & & \\
\hline CHEMBL1483163 & 688810 & \multicolumn{3}{|c|}{5.7829999999999995} & 5.7592 & TRN \\
\hline CHEMBL1603136 & 688810 & 4.833 & 5.3584 & TRN & & \\
\hline CHEMBL1414482 & 688810 & \multicolumn{3}{|c|}{4.9830000000000005} & 5.0415 & TRN \\
\hline CHEMBL1551471 & 688810 & 4.783 & 5.3227 & TST & & \\
\hline CHEMBL1605430 & 688810 & 6.433 & 5.4812 & TST & & \\
\hline CHEMBL1408725 & 688810 & 4.683 & 4.8376 & TRN & & \\
\hline CHEMBL1520092 & 688810 & \multicolumn{3}{|c|}{5.7829999999999995} & 5.8298 & TRN \\
\hline CHEMBL1455610 & 688810 & \multicolumn{3}{|c|}{5.332999999999999} & 5.2073 & TRN \\
\hline CHEMBL1349825 & 688810 & 5.683 & 5.7549 & TRN & & \\
\hline CHEMBL1394275 & 688810 & 5.183 & 5.365 & TRN & & \\
\hline CHEMBL492091 & 688810 & 5.733 & 5.5478 & TRN & & \\
\hline
\end{tabular}




\begin{tabular}{|c|c|c|c|c|c|c|}
\hline \multirow[b]{2}{*}{ CHEMBL1380161 } & \multicolumn{6}{|c|}{ pplemental T } \\
\hline & 688810 & 6.183 & 5.9703 & TRN & & \\
\hline CHEMBL 3192116 & 688810 & 5.033 & 5.4019 & TRN & & \\
\hline CHEMBL1460316 & 688810 & \multicolumn{3}{|c|}{6.332999999999999} & 5.6971 & TRN \\
\hline CHEMBL1531188 & 688810 & \multicolumn{3}{|c|}{4.7330000000000005} & 4.9875 & \\
\hline CHEMBL1346084 & 688810 & 5.233 & 4.8107 & TST & & \\
\hline CHEMBL1317655 & 688810 & 4.583 & 5.0175 & TRN & & \\
\hline CHEMBL1328661 & 688810 & \multicolumn{3}{|c|}{4.7330000000000005} & 5.3849 & TI \\
\hline CHEMBL1414389 & 688810 & 5.033 & 5.0635 & TRN & & \\
\hline CHEMBL1548699 & 688810 & 4.833 & 5.1742 & TST & & \\
\hline CHEMBL1413169 & 688810 & \multicolumn{3}{|c|}{5.832999999999999} & 5.8532 & \\
\hline CHEMBL1577745 & 688810 & 4.633 & 5.0136 & TRN & & \\
\hline CHEMBL1549398 & 688810 & 5.733 & 5.9505 & TRN & & \\
\hline CHEMBL1610566 & 688810 & \multicolumn{3}{|c|}{6.582999999999999} & 5.8583 & \\
\hline CHEMBL68442 & 688810 & \multicolumn{3}{|c|}{5.632999999999999} & 5.0576 & \\
\hline CHEMBL1371871 & 688810 & 4.833 & 4.9083 & TST & & \\
\hline CHEMBL1328624 & 688810 & \multicolumn{3}{|c|}{6.332999999999999} & 5.4017 & \\
\hline CHEMBL1399973 & 688810 & \multicolumn{3}{|c|}{5.832999999999999} & 5.6474 & \\
\hline CHEMBL 3192706 & 688810 & 4.933 & 5.2906 & TRN & & \\
\hline CHEMBL1541915 & 688810 & \multicolumn{3}{|c|}{5.382999999999999} & 5.4962 & \\
\hline CHEMBL1483474 & 688810 & \multicolumn{3}{|c|}{5.332999999999999} & 5.5349 & \\
\hline CHEMBL1302337 & 688810 & 5.983 & 6.1466 & TRN & & \\
\hline CHEMBL1540205 & 688810 & \multicolumn{3}{|c|}{5.332999999999999} & 5.3777 & \\
\hline CHEMBL1611874 & 688810 & 5.083 & 5.2071 & TRN & & \\
\hline CHEMBL1595352 & 688810 & 5.433 & 5.1744 & TRN & & \\
\hline CHEMBL1343639 & 688810 & 4.783 & 4.9425 & TRN & & \\
\hline CHEMBL1402439 & 688810 & 6.983 & 6.053 & TRN & & \\
\hline CHEMBL1538056 & 688810 & 6.4829 & 5.8477 & TRN & & \\
\hline CHEMBL1326838 & 688810 & 4.883 & 5.0232 & TRN & & \\
\hline CHEMBL1353455 & 688810 & 5.183 & 6.016 & TST & & \\
\hline CHEMBL1510369 & 688810 & 6.233 & 4.8742 & TRN & & \\
\hline CHEMBL1548556 & 688810 & 4.883 & 5.2966 & TRN & & \\
\hline CHEMBL1506637 & 688810 & \multicolumn{3}{|c|}{4.7330000000000005} & 4.9737 & TR \\
\hline CHEMBL1322287 & 688810 & \multicolumn{3}{|c|}{5.332999999999999} & 5.3155 & \\
\hline CHEMBL1576946 & 688810 & 5.033 & 4.9801 & TST & & \\
\hline CHEMBL1516004 & 688810 & 4.783 & 6.0382 & TRN & & \\
\hline CHEMBL1421436 & 688810 & 5.183 & 5.6312 & TST & & \\
\hline CHEMBL1406696 & 688810 & 4.883 & 4.9216 & TST & & \\
\hline CHEMBL1597828 & 688810 & 5.483 & 5.0297 & TRN & & \\
\hline CHEMBL1435310 & 688810 & 4.783 & 4.8633 & TRN & & \\
\hline CHEMBL1322576 & 688810 & 4.9830 & 00000000 & 005 & 5.1066 & TRN \\
\hline CHEMBL1549472 & 688810 & 6.0329 & 99999999 & 995 & 5.2167 & TRN \\
\hline CHEMBL1487784 & 688810 & 5.8329 & 99999999 & & 5.7141 & \\
\hline CHEMBL1441319 & 688810 & 5.983 & 5.645 & TRN & & \\
\hline CHEMBL1080171 & 688810 & 5.3829 & 99999999 & & 5.2348 & (2010 \\
\hline CHEMBL1432696 & 688810 & 5.8829 & 99999999 & & 5.5871 & $\pi$ \\
\hline CHEMBL1303147 & 688810 & 4.883 & 5.2687 & TRN & & \\
\hline CHEMBL1379619 & 688810 & 4.833 & 5.3065 & TRN & & \\
\hline CHEMBL1500543 & 688810 & 6.6329 & 99999999 & & 6.1074 & \\
\hline
\end{tabular}




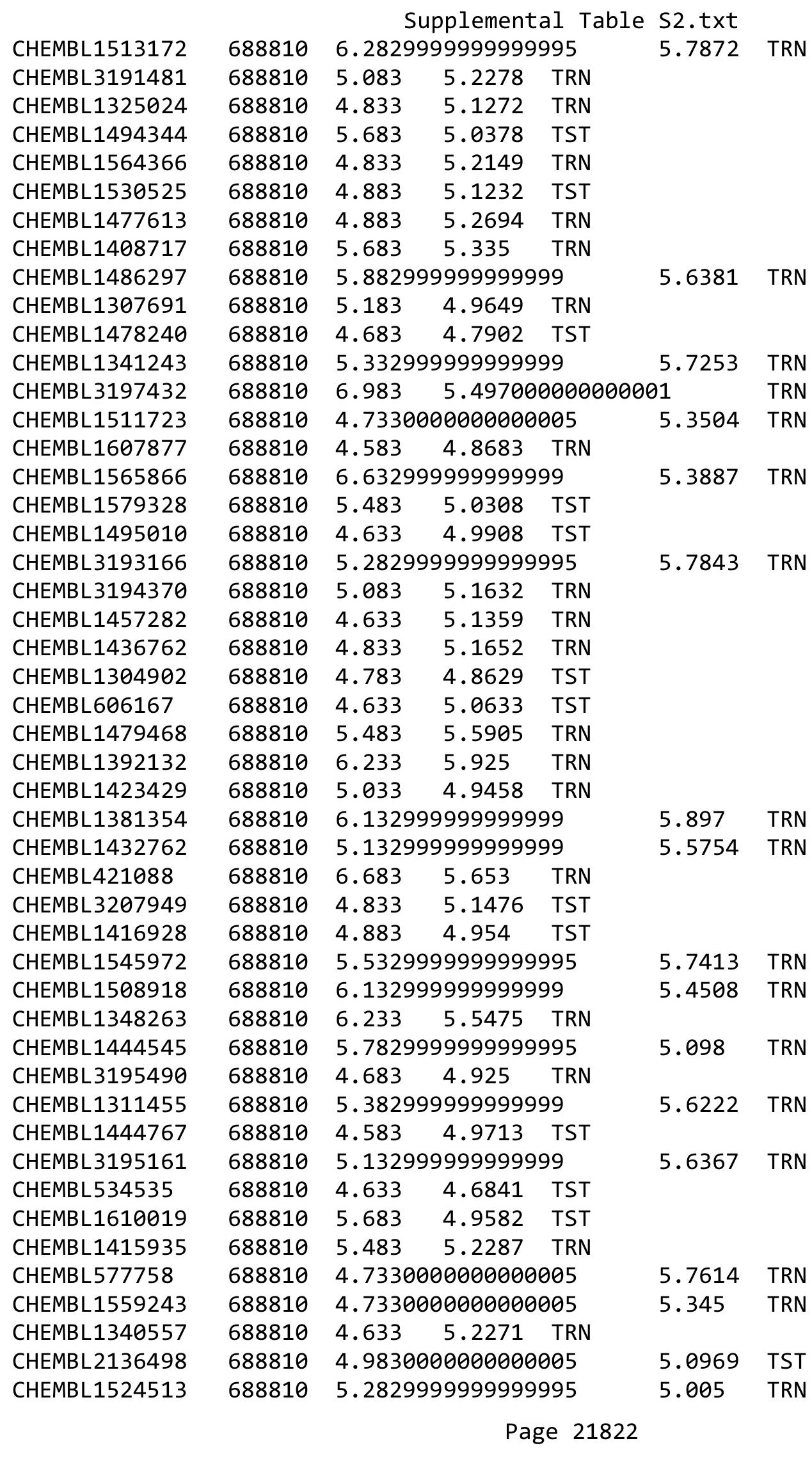




\begin{tabular}{|c|c|c|c|c|c|c|c|}
\hline \multirow{3}{*}{$\begin{array}{l}\text { CHEMBL1454918 } \\
\text { CHEMBL3191439 }\end{array}$} & \multicolumn{5}{|c|}{ Supplemental Table s2.txt } & \multirow{2}{*}{ TRN } & \\
\hline & 688810 & \multicolumn{3}{|c|}{4.9830000000000005} & 5.0426 & & \\
\hline & 688810 & 4.783 & 5.1935 & TRN & & & \\
\hline CHEMBL3191170 & 688810 & 5.433 & 6.1068 & TRN & & & \\
\hline CHEMBL1407549 & 688810 & 4.783 & 5.121 & TRN & & & \\
\hline CHEMBL1346780 & 688810 & 4.633 & 5.2572 & TST & & & \\
\hline CHEMBL 3195413 & 688810 & 5.033 & 5.0298 & TST & & & \\
\hline CHEMBL1542383 & 688810 & 4.783 & 5.0056 & TRN & & & \\
\hline CHEMBL1413781 & 688810 & 5.483 & 5.3652 & TRN & & & \\
\hline CHEMBL1563202 & 688810 & 4.833 & 4.9274 & TRN & & & \\
\hline CHEMBL1403302 & 688810 & 5.183 & 5.5666 & TRN & & & \\
\hline CHEMBL1552452 & 688810 & 4.933 & 5.1447 & TRN & & & \\
\hline CHEMBL1572158 & 688810 & \multicolumn{3}{|c|}{4.9830000000000005} & 4.8615 & TRN & \\
\hline CHEMBL1378600 & 688810 & 5.733 & 4.9233 & TRN & & & \\
\hline CHEMBL1978607 & 688810 & \multicolumn{3}{|c|}{5.582999999999999} & 5.6185 & TST & \\
\hline CHEMBL1579924 & 688810 & \multicolumn{3}{|c|}{5.332999999999999} & 5.1917 & TST & \\
\hline CHEMBL233302 & 688810 & 5.9 & 5.3005 & TRN & & & \\
\hline CHEMBL1450593 & 688810 & \multicolumn{3}{|c|}{5.2829999999999995} & 4.7359 & TRN & \\
\hline CHEMBL1524533 & 688810 & 5.983 & 5.8403 & TST & & & \\
\hline CHEMBL1337903 & 688810 & \multicolumn{3}{|c|}{5.882999999999999} & 5.473 & TRN & \\
\hline CHEMBL 3207847 & 688810 & 4.933 & 5.231 & TRN & & & \\
\hline CHEMBL1503294 & 688810 & 4.883 & 5.8217 & TRN & & & \\
\hline CHEMBL1326434 & 688810 & 4.833 & 5.5387 & TRN & & & \\
\hline CHEMBL1416387 & 688810 & \multicolumn{3}{|c|}{6.082999999999999} & 5.6084 & TRN & \\
\hline CHEMBL1340962 & 688810 & 4.633 & 4.9534 & TST & & & \\
\hline CHEMBL1504204 & 688810 & 4.833 & 4.9282 & TST & & & \\
\hline CHEMBL1325553 & 688810 & \multicolumn{3}{|c|}{5.332999999999999} & 5.504 & TRN & \\
\hline CHEMBL1309430 & 688810 & \multicolumn{3}{|c|}{5.632999999999999} & 4.8147 & TST & \\
\hline CHEMBL1513835 & 688810 & \multicolumn{3}{|c|}{6.632999999999999} & 5.4615 & TRN & \\
\hline CHEMBL1440746 & 688810 & 4.633 & 5.3726 & TST & & & \\
\hline CHEMBL1508105 & 688810 & 4.833 & 5.4552 & TRN & & & \\
\hline CHEMBL1378699 & 688810 & 5.483 & 5.0478 & TRN & & & \\
\hline CHEMBL1494302 & 688810 & \multicolumn{3}{|c|}{4.9830000000000005} & 5.0324 & TRN & \\
\hline CHEMBL1964439 & 688810 & \multicolumn{3}{|c|}{5.7829999999999995} & 5.29299 & 9999999999 & TST \\
\hline CHEMBL1340076 & 688810 & \multicolumn{3}{|c|}{5.132999999999999} & 4.7842 & TST & \\
\hline CHEMBL1411342 & 688810 & 4.833 & 5.2159 & TST & & & \\
\hline CHEMBL1378551 & 688810 & \multirow{2}{*}{\multicolumn{3}{|c|}{$\begin{array}{lll}5.033 & 5.1292 & \text { TRN } \\
5.2829999999999995\end{array}$}} & & & \\
\hline CHEMBL1575543 & 688810 & & & & 5.2049 & TRN & \\
\hline CHEMBL1474085 & 688810 & 4.633 & 5.4769 & TST & & & \\
\hline CHEMBL1465063 & 688810 & \multicolumn{3}{|c|}{5.832999999999999} & 5.7083 & TRN & \\
\hline CHEMBL1378986 & 688810 & 5.233 & 5.4093 & TRN & & & \\
\hline CHEMBL1390155 & 688810 & \multicolumn{3}{|c|}{5.332999999999999} & 5.0609 & TST & \\
\hline CHEMBL1381333 & 688810 & 4.633 & 4.9889 & TST & & & \\
\hline CHEMBL1541744 & 688810 & 6.683 & 5.9597 & TRN & & & \\
\hline CHEMBL1433741 & 688810 & 4.633 & 5.0874 & TRN & & & \\
\hline CHEMBL1533584 & 688810 & 5.083 & 5.279 & TRN & & & \\
\hline CHEMBL1535988 & 688810 & \multicolumn{3}{|c|}{6.382999999999999} & 5.3098 & TRN & \\
\hline CHEMBL1604431 & 688810 & 6.3829 & 9999999 & & 5.6186 & TRN & \\
\hline CHEMBL1501691 & 688810 & 4.7330 & 0000000 & 005 & 5.3968 & TRN & \\
\hline
\end{tabular}




\begin{tabular}{|c|c|c|c|c|c|c|c|}
\hline \multicolumn{8}{|c|}{ Supplemental Table S2.txt } \\
\hline CHEMBL1340292 & 688810 & 4.783 & 4.9962 & TRN & & & \\
\hline CHEMBL1438075 & 688810 & 5.433 & 5.2536 & TST & & & \\
\hline CHEMBL1498988 & 688810 & 4.783 & 4.5033 & TST & & & \\
\hline CHEMBL1372039 & 688810 & 7.0329 & 5.9393 & TRN & & & \\
\hline CHEMBL3198985 & 688810 & 6.4829 & 5.6198 & TST & & & \\
\hline CHEMBL1576566 & 688810 & 4.583 & 4.5482 & TST & & & \\
\hline CHEMBL1307696 & 688810 & 4.633 & 4.8554 & TST & & & \\
\hline CHEMBL1312636 & 688810 & 4.783 & 5.1961 & TRN & & & \\
\hline CHEMBL 241858 & 688810 & 5.183 & 4.8014 & TRN & & & \\
\hline CHEMBL1314881 & 688810 & 5.183 & 4.967 & TRN & & & \\
\hline CHEMBL1325991 & 688810 & 5.033 & 5.2873 & TRN & & & \\
\hline CHEMBL1450831 & 688810 & \multicolumn{3}{|c|}{5.832999999999999} & 5.6185 & TRN & \\
\hline CHEMBL1374845 & 688810 & 5.683 & 5.3139 & TRN & & & \\
\hline CHEMBL463175 & 688810 & 5.183 & 4.9544 & TST & & & \\
\hline CHEMBL1467672 & 688810 & 4.783 & 5.5723 & TST & & & \\
\hline CHEMBL1370495 & 688810 & 4.883 & 5.1229 & TST & & & \\
\hline CHEMBL1506154 & 688810 & 4.833 & 5.216 & TRN & & & \\
\hline CHEMBL602969 & 688810 & 4.883 & 5.2067 & TST & & & \\
\hline CHEMBL1325132 & 688810 & 4.783 & 5.3477 & TRN & & & \\
\hline CHEMBL1478832 & 688810 & 4.783 & 5.1157 & TRN & & & \\
\hline CHEMBL1523520 & 688810 & \multicolumn{3}{|c|}{6.082999999999999} & \multicolumn{2}{|c|}{5.292999999999999} & TST \\
\hline CHEMBL1553461 & 688810 & \multicolumn{3}{|c|}{5.832999999999999} & \multicolumn{2}{|c|}{5.617999999999999} & TRN \\
\hline CHEMBL1367872 & 688810 & 5.683 & 5.2622 & TST & & & \\
\hline CHEMBL1586285 & 688810 & 4.583 & 5.0949 & TST & & & \\
\hline CHEMBL1439189 & 688810 & 4.583 & 5.3648 & TST & & & \\
\hline CHEMBL1557288 & 688810 & \multicolumn{3}{|c|}{5.7829999999999995} & 6.255 & TRN & \\
\hline CHEMBL1302399 & 688810 & 5.183 & 4.7594 & TST & & & \\
\hline CHEMBL602828 & 688810 & \multicolumn{3}{|c|}{5.582999999999999} & 5.1794 & TST & \\
\hline CHEMBL1517953 & 688810 & \multicolumn{3}{|c|}{5.132999999999999} & 5.0966 & TRN & \\
\hline CHEMBL1170069 & 688810 & 5.683 & 5.2312 & TRN & & & \\
\hline CHEMBL597251 & 688810 & 4.633 & 4.6561 & TST & & & \\
\hline CHEMBL1391864 & 688810 & \multicolumn{3}{|c|}{5.132999999999999} & 5.5314 & TRN & \\
\hline CHEMBL1530809 & 688810 & 4.783 & 4.9725 & TRN & & & \\
\hline CHEMBL1429540 & 688810 & 5.683 & 5.6363 & TRN & & & \\
\hline CHEMBL1390868 & 688810 & 7.0329 & 5.893 & TST & & & \\
\hline CHEMBL1473497 & 688810 & 5.733 & 5.4814 & TRN & & & \\
\hline CHEMBL1448295 & 688810 & 5.033 & 5.0243 & TRN & & & \\
\hline CHEMBL1574031 & 688810 & 4.633 & 5.4194 & TST & & & \\
\hline CHEMBL1584061 & 688810 & 4.783 & 5.106 & TRN & & & \\
\hline CHEMBL1554715 & 688810 & 4.583 & 5.1692 & TST & & & \\
\hline CHEMBL3197153 & 688810 & \multicolumn{3}{|c|}{4.9830000000000005} & 5.1251 & TST & \\
\hline CHEMBL1405521 & 688810 & 5.233 & 5.2974 & TRN & & & \\
\hline CHEMBL1530988 & 688810 & 4.633 & 4.8294 & TRN & & & \\
\hline CHEMBL1372359 & 688810 & 5.983 & 5.8008 & TRN & & & \\
\hline CHEMBL1424485 & 688810 & 5.033 & 5.36 & TRN & & & \\
\hline CHEMBL577662 & 688810 & \multicolumn{3}{|c|}{5.7829999999999995} & 5.6516 & TRN & \\
\hline CHEMBL1364287 & 688810 & \multicolumn{3}{|c|}{5.2829999999999995} & 5.2064 & TST & \\
\hline CHEMBL1523058 & 688810 & 4.783 & 4.9793 & TRN & & & \\
\hline
\end{tabular}




\begin{tabular}{|c|c|c|c|c|c|c|c|}
\hline \multicolumn{7}{|c|}{ Supplemental Table S2.txt } & \\
\hline CHEMBL1368933 & 688810 & \multicolumn{3}{|c|}{5.2829999999999995} & 6.0256 & TRN & \\
\hline CHEMBL1494073 & 688810 & \multicolumn{3}{|c|}{5.832999999999999} & 5.3469 & TRN & \\
\hline CHEMBL1501303 & 688810 & 5.433 & 4.7016 & TST & & & \\
\hline CHEMBL1568346 & 688810 & \multicolumn{3}{|c|}{6.382999999999999} & 5.8156 & TRN & \\
\hline CHEMBL1581997 & 688810 & 5.183 & 5.2626 & TRN & & & \\
\hline CHEMBL1420629 & 688810 & \multicolumn{3}{|c|}{5.582999999999999} & 5.2173 & TRN & \\
\hline CHEMBL3195883 & 688810 & \multicolumn{3}{|c|}{6.582999999999999} & 5.5476 & TRN & \\
\hline CHEMBL1543650 & 688810 & 4.833 & 5.0446 & TRN & & & \\
\hline CHEMBL1299603 & 688810 & 5.233 & 5.4129 & TST & & & \\
\hline CHEMBL1480310 & 688810 & 5.933 & 5.595 & TRN & & & \\
\hline CHEMBL3191350 & 688810 & \multicolumn{3}{|c|}{6.2829999999999995} & 5.0626 & TRN & \\
\hline CHEMBL1461392 & 688810 & 4.833 & 5.3 & TST & & & \\
\hline CHEMBL1468420 & 688810 & \multicolumn{3}{|c|}{5.882999999999999} & 5.8415 & TRN & \\
\hline CHEMBL1435820 & 688810 & 4.583 & 4.763 & TST & & & \\
\hline CHEMBL1597541 & 688810 & \multicolumn{3}{|c|}{4.7330000000000005} & 5.7073 & TRN & \\
\hline CHEMBL1346338 & 688810 & 6.0 & 5.9754 & TRN & & & \\
\hline CHEMBL1378422 & 688810 & \multicolumn{3}{|c|}{5.5329999999999995} & 5.6657 & TRN & \\
\hline CHEMBL1555321 & 688810 & 4.583 & 5.3413 & TRN & & & \\
\hline CHEMBL1534410 & 688810 & \multicolumn{3}{|c|}{5.132999999999999} & 5.0705 & TRN & \\
\hline CHEMBL1439278 & 688810 & 4.833 & 5.056 & TST & & & \\
\hline CHEMBL1512759 & 688810 & 4.583 & 5.2351 & TRN & & & \\
\hline CHEMBL1420875 & 688810 & \multicolumn{3}{|c|}{4.7330000000000005} & 5.2495 & TRN & \\
\hline CHEMBL3195853 & 688810 & 4.883 & 5.11 & TST & & & \\
\hline CHEMBL1324717 & 688810 & 5.083 & 5.1503 & TRN & & & \\
\hline CHEMBL1305092 & 688810 & \multicolumn{3}{|c|}{5.132999999999999} & \multicolumn{3}{|c|}{5.0680000000000005} \\
\hline CHEMBL1438681 & 688810 & \multicolumn{3}{|c|}{4.7330000000000005} & 5.2037 & TST & \\
\hline CHEMBL3214033 & 688810 & 5.233 & 5.2573 & TST & & & \\
\hline CHEMBL1613404 & 688810 & 4.783 & 5.1225 & TRN & & & \\
\hline CHEMBL1390665 & 688810 & 4.783 & 5.5999 & TST & & & \\
\hline CHEMBL 2005423 & 688810 & 6.0 & 5.3084 & TRN & & & \\
\hline CHEMBL1458533 & 688810 & \multicolumn{3}{|c|}{4.7330000000000005} & 5.2863 & TRN & \\
\hline CHEMBL1499207 & 688810 & 5.683 & 5.5537 & TRN & & & \\
\hline CHEMBL1303963 & 688810 & 5.033 & 5.5865 & TRN & & & \\
\hline CHEMBL1424968 & 688810 & 5.183 & 5.6903 & TRN & & & \\
\hline CHEMBL1497868 & 688810 & 5.183 & 5.0601 & TRN & & & \\
\hline CHEMBL1516936 & 688810 & \multicolumn{3}{|c|}{5.382999999999999} & 5.3293 & TRN & \\
\hline CHEMBL1590286 & 688810 & \multicolumn{3}{|c|}{6.332999999999999} & 5.2877 & TRN & \\
\hline CHEMBL1450164 & 688810 & 4.683 & 5.5205 & TRN & & & \\
\hline CHEMBL1528733 & 688810 & \multicolumn{3}{|c|}{5.132999999999999} & 5.1866 & TRN & \\
\hline CHEMBL1460869 & 688810 & 7.0329 & 5.8549 & TRN & & & \\
\hline CHEMBL1470538 & 688810 & \multicolumn{3}{|c|}{6.582999999999999} & 6.3607 & TRN & \\
\hline CHEMBL1535610 & 688810 & \multicolumn{3}{|c|}{5.632999999999999} & 5.53100 & 0000000001 & TRN \\
\hline CHEMBL1440135 & 688810 & 5.183 & 5.207999 & 999999999 & 99 & TRN & \\
\hline CHEMBL1484487 & 688810 & 5.28299 & 999999999 & 995 & 4.9669 & TST & \\
\hline CHEMBL1415226 & 688810 & 4.833 & 5.2785 & TRN & & & \\
\hline CHEMBL1301862 & 688810 & 4.833 & 4.8385 & TRN & & & \\
\hline CHEMBL1319873 & 688810 & 6.4829 & 5.7487 & TRN & & & \\
\hline CHEMBL1535129 & 688810 & 5.63299 & 999999999 & & 5.0588 & TRN & \\
\hline
\end{tabular}




\begin{tabular}{|c|c|c|c|c|c|c|c|}
\hline \multicolumn{7}{|c|}{ Supplemental Table S2.txt } & \\
\hline CHEMBL1309458 & 688810 & 4.633 & 5.3832 & TRN & & & \\
\hline CHEMBL1604837 & 688810 & 5.33299 & 99999999 & & 5.4135 & TRN & \\
\hline CHEMBL1352349 & 688810 & 5.13299 & 99999999 & & 5.0536 & TST & \\
\hline CHEMBL1571315 & 688810 & 6.53299 & 99999999 & 995 & 6.1361 & TRN & \\
\hline CHEMBL1341123 & 688810 & 5.63299 & 99999999 & & 5.2352 & TRN & \\
\hline CHEMBL1505300 & 688810 & 6.33299 & 99999999 & & 5.3074 & TRN & \\
\hline CHEMBL1571296 & 688810 & 4.883 & 4.8457 & TST & & & \\
\hline CHEMBL1526874 & 688810 & 5.63299 & 99999999 & & 5.38299 & 9999999999 & TRN \\
\hline CHEMBL1538138 & 688810 & 5.78299 & 99999999 & 995 & 5.0604 & TST & \\
\hline CHEMBL1304103 & 688810 & 6.38299 & 99999999 & & 5.4994 & TST & \\
\hline CHEMBL1555213 & 688810 & 4.833 & 5.0504 & TRN & & & \\
\hline CHEMBL3197767 & 688810 & 5.433 & 5.6442 & TRN & & & \\
\hline CHEMBL1506193 & 688810 & 4.633 & 4.9796 & TRN & & & \\
\hline CHEMBL1356222 & 688810 & 4.633 & 5.1475 & TST & & & \\
\hline CHEMBL1398925 & 688810 & 6.53299 & 99999999 & 995 & 5.5164 & TRN & \\
\hline CHEMBL 3208028 & 688810 & 5.433 & 5.3807 & TST & & & \\
\hline CHEMBL1543752 & 688810 & 4.633 & 4.7046 & TST & & & \\
\hline CHEMBL153505 & 688810 & 4.883 & 5.8649 & TRN & & & \\
\hline CHEMBL1415932 & 688810 & 4.73300 & 00000000 & 005 & 5.1504 & TRN & \\
\hline CHEMBL490324 & 688810 & 4.633 & 5.0652 & TRN & & & \\
\hline CHEMBL1572430 & 688810 & 4.783 & 5.2633 & TST & & & \\
\hline CHEMBL1399315 & 688810 & 5.183 & 5.3691 & TRN & & & \\
\hline CHEMBL1543513 & 688810 & 5.483 & 5.6411 & TRN & & & \\
\hline CHEMBL1610601 & 688810 & 5.78299 & 99999999 & 995 & 5.46 & TRN & \\
\hline CHEMBL1588318 & 688810 & 4.933 & 4.9894 & TRN & & & \\
\hline CHEMBL1524971 & 688810 & 4.683 & 5.0765 & TST & & & \\
\hline CHEMBL1485333 & 688810 & 4.73300 & 00000000 & 005 & 5.0423 & TRN & \\
\hline CHEMBL1443924 & 688810 & 4.783 & 5.1513 & TRN & & & \\
\hline CHEMBL1420711 & 688810 & 5.083 & 5.1744 & TRN & & & \\
\hline CHEMBL1527656 & 688810 & 6.33299 & 99999999s & & 5.5063 & TRN & \\
\hline CHEMBL3213996 & 688810 & 4.683 & 5.1989 & TST & & & \\
\hline CHEMBL1489425 & 688810 & 5.53299 & 99999999 & 995 & 4.9029 & TRN & \\
\hline CHEMBL1404741 & 688810 & 4.783 & 5.1556 & TRN & & & \\
\hline CHEMBL1964776 & 688810 & 5.53299 & 99999999 & 995 & 5.3458 & TRN & \\
\hline CHEMBL1546121 & 688810 & 5.233 & 5.2113 & TRN & & & \\
\hline CHEMBL1597668 & 688810 & 5.38299 & 99999999 & 99 & 5.2829 & TRN & \\
\hline CHEMBL1587067 & 688810 & 4.883 & 4.9957 & TRN & & & \\
\hline CHEMBL1511667 & 688810 & 4.98300 & 00000000 & 005 & 5.3204 & TST & \\
\hline CHEMBL1421503 & 688810 & 4.683 & 5.0541 & TST & & & \\
\hline CHEMBL1339521 & 688810 & 5.88299 & 99999999 & 99 & 5.0033 & TRN & \\
\hline CHEMBL3195196 & 688810 & 5.683 & 5.3622 & TST & & & \\
\hline CHEMBL1384350 & 688810 & 4.73300 & 00000000 & 005 & 5.0263 & TRN & \\
\hline CHEMBL1462983 & 688810 & 5.433 & 5.4477 & TRN & & & \\
\hline CHEMBL530291 & 688810 & 5.933 & 5.5366 & TRN & & & \\
\hline CHEMBL1376274 & 688810 & 4.683 & 5.1594 & TST & & & \\
\hline CHEMBL1397179 & 688810 & 5.78299 & 999999995 & 995 & 5.2341 & TRN & \\
\hline CHEMBL1994935 & 688810 & 4.583 & 5.1539 & TRN & & & \\
\hline CHEMBL1333386 & 688810 & 5.983 & 5.5001 & TST & & & \\
\hline
\end{tabular}




\begin{tabular}{|c|c|c|c|c|c|c|}
\hline & & \multicolumn{5}{|c|}{ Supplemental Table s2.txt } \\
\hline CHEMBL1458733 & 688810 & 4.833 & 4.961 & TRN & & \\
\hline CHEMBL1550862 & 688810 & 4.583 & 5.2741 & TRN & & \\
\hline CHEMBL1358035 & 688810 & 5.683 & 5.1892 & TRN & & \\
\hline CHEMBL1593031 & 688810 & 4.783 & 4.7621 & TRN & & \\
\hline CHEMBL1516547 & 688810 & 4.683 & 5.3865 & TRN & & \\
\hline CHEMBL1470468 & 688810 & 5.033 & 5.3568 & TRN & & \\
\hline CHEMBL1406586 & 688810 & 4.883 & 5.3909 & TST & & \\
\hline CHEMBL1587886 & 688810 & 4.883 & 5.438 & TRN & & \\
\hline CHEMBL1349087 & 688810 & \multicolumn{3}{|c|}{4.7330000000000005} & 5.0153 & $\mathrm{~T}$ \\
\hline CHEMBL1524383 & 688810 & 4.883 & 5.2853 & TRN & & \\
\hline CHEMBL1340838 & 688810 & 6.183 & \multicolumn{3}{|c|}{5.6610000000000005} & \\
\hline CHEMBL10276 & 688810 & \multicolumn{3}{|c|}{5.132999999999999} & 5.5625 & \\
\hline CHEMBL3194826 & 688810 & 7.2832 & 5.6513 & TRN & & \\
\hline CHEMBL1607208 & 688810 & \multicolumn{3}{|c|}{5.7829999999999995} & 6.0591 & TRN \\
\hline CHEMBL1603813 & 688810 & \multicolumn{3}{|c|}{5.7829999999999995} & 5.4916 & \\
\hline CHEMBL1327858 & 688810 & 6.183 & 5.2816 & TRN & & \\
\hline CHEMBL1385182 & 688810 & 5.183 & 5.6507 & TRN & & \\
\hline CHEMBL156 & 688810 & 5.483 & 5.3086 & TRN & & \\
\hline CHEMBL1472038 & 688810 & \multicolumn{3}{|c|}{5.2829999999999995} & 5.2308 & $\mathrm{TS}$ \\
\hline CHEMBL1607462 & 688810 & 4.883 & 5.0316 & TRN & & \\
\hline CHEMBL1450526 & 688810 & 5.933 & 5.4044 & TRN & & \\
\hline CHEMBL1372541 & 688810 & 4.783 & 4.7131 & TST & & \\
\hline CHEMBL1496534 & 688810 & \multicolumn{3}{|c|}{5.382999999999999} & 5.1511 & \\
\hline CHEMBL1312919 & 688810 & 4.883 & 5.0904 & TRN & & \\
\hline CHEMBL1313945 & 688810 & \multicolumn{3}{|c|}{5.332999999999999} & 5.3806 & TP \\
\hline CHEMBL1448630 & 688810 & 4.783 & 4.8566 & TRN & & \\
\hline CHEMBL1514496 & 688810 & 4.783 & 5.1176 & TRN & & \\
\hline CHEMBL1397296 & 688810 & \multicolumn{3}{|c|}{4.9830000000000005} & 5.4848 & TRN \\
\hline CHEMBL1370861 & 688810 & \multicolumn{3}{|c|}{5.632999999999999} & 5.599 & TRN \\
\hline CHEMBL1331257 & 688810 & \multicolumn{3}{|c|}{5.132999999999999} & 5.6136 & TRN \\
\hline CHEMBL1340673 & 688810 & \multicolumn{3}{|c|}{5.882999999999999} & 5.2117 & \\
\hline CHEMBL16 & 688810 & & 5.4315 & TST & & \\
\hline CHEMBL13 & 688810 & & & TST & & \\
\hline CHEMBL3207763 & 688810 & \multicolumn{3}{|c|}{4.7330000000000005} & 5.4691 & $\mathrm{TR}$ \\
\hline CHEMBL1991311 & 688810 & 5.433 & 5.2831 & TRN & & \\
\hline CHEMBL1372913 & 688810 & & 4.7158 & TRN & & \\
\hline CHEMBL1448504 & 688810 & & 5.2327 & TRN & & \\
\hline CHEMBL484663 & 688810 & 5.233 & 5.5749 & TRN & & \\
\hline CHEMBL1499003 & 688810 & 4.783 & 4.863 & TST & & \\
\hline CHEMBL1466707 & 688810 & 6.4829 & 5.2423 & TRN & & \\
\hline CHEMBL1466286 & 688810 & \multicolumn{3}{|c|}{4.9830000000000005} & & TRN \\
\hline CHEMBL3194597 & 688810 & \multicolumn{3}{|c|}{5.132999999999999} & 4.9403 & I RN \\
\hline CHEMBL1384581 & 688810 & 4.883 & 5.4067 & TRN & & \\
\hline CHEMBL1486744 & 688810 & \multicolumn{3}{|c|}{4.7330000000000005} & 4.7754 & TST \\
\hline CHEMBL1508931 & 688810 & \multicolumn{3}{|c|}{5.132999999999999} & 5.7042 & TRN \\
\hline CHEMBL1335133 & 688810 & \multicolumn{3}{|c|}{5.632999999999999} & 5.535 & 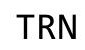 \\
\hline CHEMBL1525468 & 688810 & 5.933 & 5.5607 & TRN & & \\
\hline CHEMBL1576288 & 688810 & \multicolumn{3}{|c|}{4.9830000000000005} & 5.1165 & . \\
\hline
\end{tabular}




\begin{tabular}{|c|c|c|c|c|c|c|}
\hline \multirow[b]{2}{*}{ CHEMBL1560628 } & \multicolumn{6}{|c|}{ Supplemental Tak } \\
\hline & 688810 & 5.233 & 5.6327 & TST & & \\
\hline CHEMBL1328325 & 688810 & 4.633 & 5.012 & TRN & & \\
\hline CHEMBL1557119 & 688810 & 5.53299 & 999999999 & 995 & 4.9993 & 10 \\
\hline CHEMBL1366101 & 688810 & 4.833 & 5.1919 & TRN & & \\
\hline CHEMBL1502000 & 688810 & 4.633 & 5.1852 & TST & & \\
\hline CHEMBL1397162 & 688810 & 4.833 & 5.4495 & TRN & & \\
\hline CHEMBL1573623 & 688810 & 5.13299 & 999999999 & & 5.1239 & 10 \\
\hline CHEMBL1433869 & 688810 & 4.833 & 5.4627 & TST & & \\
\hline CHEMBL1454136 & 688810 & 5.0 & 5.2106 & TST & & \\
\hline CHEMBL1542660 & 688810 & 5.683 & 5.1929 & TRN & & \\
\hline CHEMBL1573259 & 688810 & 5.733 & 5.0858 & TRN & & \\
\hline CHEMBL1315149 & 688810 & 6.08299 & 999999999 & & 5.4733 & \\
\hline CHEMBL1546452 & 688810 & 5.58299 & 999999999 & & 5.0081 & \\
\hline CHEMBL1591534 & 688810 & 4.633 & 4.9874 & TST & & \\
\hline CHEMBL1335541 & 688810 & 4.583 & 5.1671 & TRN & & \\
\hline CHEMBL1607932 & 688810 & 5.28299 & 999999999 & 995 & 5.9817 & \\
\hline CHEMBL1557191 & 688810 & 6.4829 & 6.1284 & TRN & & \\
\hline CHEMBL1579421 & 688810 & 5.53299 & 999999999 & 995 & 498 & \\
\hline CHEMBL1477350 & 688810 & 4.883 & 5.4164 & TRN & & \\
\hline CHEMBL1560206 & 688810 & 5.683 & 5.411000 & 0000 & 205 & \\
\hline CHEMBL1427595 & 688810 & 5.63299 & 999999999 & & 5.4963 & \\
\hline CHEMBL1582518 & 688810 & 4.783 & 5.4171 & TST & & \\
\hline CHEMBL1428116 & 688810 & 6.233 & 5.6052 & TRN & & \\
\hline CHEMBL1493983 & 688 & 5.13299 & 999999999 & & 5.159 & \\
\hline CHEMBL1582317 & 688810 & 4.73300 & 000000000 & 305 & 5.0108 & \\
\hline CHEMBL1299332 & 688810 & 4.98300 & 000000000 & 305 & 5.2437 & \\
\hline CHEMBL1387688 & 688810 & 4.833 & 5.1267 & TRN & & \\
\hline CHEMBL1524276 & 688810 & 6.38299 & 999999999 & & 8 & \\
\hline CHEMBL1537475 & 688810 & 4.833 & 5.1407 & TRN & & \\
\hline CHEMBL1435418 & 688810 & 4.783 & 5.0651 & TRN & & \\
\hline CHEMBL1307360 & 688810 & 5.13299 & 999999999 & & 4.7924 & \\
\hline CHEMBL1501215 & 688810 & 4.833 & 4.4512 & TRN & & \\
\hline CHEMBL1309882 & 688810 & 4.933 & 5.1023 & TRN & & \\
\hline CHEMBL1538442 & 688810 & 6.38299 & 999999999 & & 5.9102 & TRN \\
\hline CHEMBL 3193739 & 688810 & 4.683 & 5.343999 & 99999 & 99 & \\
\hline CHEMBL1556606 & 688810 & 6.5 & 5.4778 & TRN & & \\
\hline CHEMBL1593888 & 688810 & 5.33299 & 999999999 & & 5.2381 & 10 \\
\hline CHEMBL1565956 & 688810 & 4.883 & 4.9361 & TRN & & \\
\hline CHEMBL1416569 & 688810 & 4.583 & 5.1781 & TRN & & \\
\hline CHEMBL1486922 & 688810 & 6.4829 & 5.3805 & TRN & & \\
\hline CHEMBL1423639 & 688810 & 5.483 & 4.9516 & TRN & & \\
\hline CHEMBL1594488 & 688810 & 5.13299 & 999999999 & & 5.4462 & \\
\hline CHEMBL1442882 & & 4.633 & 5.5671 & TST & & \\
\hline CHEMBL1389716 & 688810 & 4.783 & 5.0289 & TRN & & \\
\hline CHEMBL1328781 & 688810 & 4.73300 & 000000000 & 005 & 5.4227 & TRN \\
\hline CHEMBL1334787 & 688810 & 4.883 & 5.6475 & TRN & & \\
\hline CHEMBL1494594 & 688810 & 4.73300 & 000000000 & 305 & 5.6416 & T \\
\hline CHEMBL1413922 & 688810 & 4.783 & 5.1747 & TRN & & \\
\hline
\end{tabular}




\begin{tabular}{|c|c|c|c|c|c|c|}
\hline \multirow[b]{2}{*}{ CHEMBL3197130 } & \multicolumn{6}{|c|}{ Supplemental Table S2.txt } \\
\hline & 688810 & 5.683 & 5.5675 & TRN & & \\
\hline CHEMBL1536418 & 688810 & 5.38299 & 99999999 & & 5.6944 & TST \\
\hline CHEMBL1516735 & 688810 & 4.98300 & 0000000 & 005 & 5.3409 & TRN \\
\hline CHEMBL1426556 & 688810 & 4.98300 & 00000006 & 005 & 4.9798 & TRN \\
\hline CHEMBL1534284 & 688810 & 4.783 & 5.4986 & TRN & & \\
\hline CHEMBL1563174 & 688810 & 4.783 & 5.0866 & TRN & & \\
\hline CHEMBL1562587 & 688810 & 4.783 & 5.3095 & TRN & & \\
\hline CHEMBL1324113 & 688810 & 6.183 & 5.5063 & TRN & & \\
\hline CHEMBL1573719 & 688810 & 4.833 & 5.1243 & TST & & \\
\hline CHEMBL1451273 & 688810 & 4.833 & 5.2367 & TRN & & \\
\hline CHEMBL1427621 & 688810 & 6.433 & 6.1297 & TRN & & \\
\hline CHEMBL1336046 & 688810 & 7.08299 & 99999999 & & 5.5312 & TRN \\
\hline CHEMBL1452128 & 688810 & 5.75 & 5.6278 & TRN & & \\
\hline CHEMBL1433075 & 688810 & 4.883 & 5.2708 & TST & & \\
\hline CHEMBL1438324 & 688810 & 5.83299 & 9999999 & & 5.2445 & TRN \\
\hline CHEMBL1512633 & 688810 & 4.633 & 5.1789 & 999999999 & 99 & TRN \\
\hline CHEMBL1313978 & 688810 & 4.833 & 4.711 & TRN & & \\
\hline CHEMBL1539288 & 688810 & 5.083 & 5.2592 & TRN & & \\
\hline CHEMBL1320107 & 688810 & 5.88299 & 9999999 & & 5.4515 & TRN \\
\hline CHEMBL1365801 & 688810 & 4.783 & 5.559 & TRN & & \\
\hline CHEMBL1324098 & 688810 & 6.433 & 5.8894 & TRN & & \\
\hline CHEMBL3211775 & 688810 & 6.03299 & 99999995 & 995 & 5.3899 & TRN \\
\hline CHEMBL1393610 & 688810 & 5.233 & 5.1821 & TRN & & \\
\hline CHEMBL1343506 & 688810 & 4.783 & 5.0129 & TST & & \\
\hline CHEMBL1417704 & 688810 & 4.783 & 4.93 & TRN & & \\
\hline CHEMBL1390331 & 688810 & 4.633 & 4.9893 & TST & & \\
\hline CHEMBL1586545 & 688810 & 4.833 & 5.3275 & TST & & \\
\hline CHEMBL1507345 & 688810 & 4.583 & 4.6062 & TST & & \\
\hline CHEMBL1612555 & 688810 & 5.183 & 5.185 & TST & & \\
\hline CHEMBL1478962 & 688810 & 5.033 & 5.5304 & TRN & & \\
\hline CHEMBL1492491 & 688810 & 5.183 & 5.3501 & TRN & & \\
\hline CHEMBL1367758 & 688810 & 5.033 & 5.3412 & TST & & \\
\hline CHEMBL3193547 & 688810 & 5.733 & 5.7825 & TRN & & \\
\hline CHEMBL1488263 & 688810 & 5.733 & 5.4652 & TRN & & \\
\hline CHEMBL1570231 & 688810 & 4.73300 & 0000000 & 005 & 5.1434 & TRN \\
\hline CHEMBL1388949 & 688810 & 4.73300 & 0000000 & 005 & 4.8677 & TRN \\
\hline CHEMBL1604296 & 688810 & 5.88299 & 9999999 & & 5.3686 & TST \\
\hline CHEMBL1330890 & 688810 & 5.88299 & 9999999 & & 5.8047 & TRN \\
\hline CHEMBL1361124 & 688810 & 5.483 & 5.1138 & TRN & & \\
\hline CHEMBL1525678 & 688810 & 6.183 & 6.0564 & TRN & & \\
\hline CHEMBL1414926 & 688810 & 5.78299 & 99999995 & 995 & 5.8616 & TRN \\
\hline CHEMBL1551118 & 688810 & 4.783 & 5.1785 & TST & & \\
\hline CHEMBL1400666 & 688810 & 4.73300 & 0000000 & 005 & 5.0477 & TST \\
\hline CHEMBL1301273 & 688810 & 4.833 & 4.9418 & TRN & & \\
\hline CHEMBL1392388 & 688810 & 4.883 & 5.2223 & TRN & & \\
\hline CHEMBL1453273 & 688810 & 5.78299 & 99999995 & 995 & 5.3687 & TRN \\
\hline CHEMBL1448375 & 688810 & 4.833 & 5.6151 & TRN & & \\
\hline CHEMBL1343837 & 688810 & 7.1831 & 4.8197 & TST & & \\
\hline
\end{tabular}

Page 21829 


\begin{tabular}{|c|c|c|c|c|c|c|}
\hline \multirow[b]{2}{*}{ CHEMBL1343710 } & & \multicolumn{5}{|c|}{ Supplemental Table S2.txt } \\
\hline & 688810 & 4.833 & 4.9093 & TST & & \\
\hline CHEMBL1416641 & 688810 & 4.933 & 4.9472 & TRN & & \\
\hline CHEMBL 3211290 & 688810 & 5.033 & 5.4038 & TRN & & \\
\hline CHEMBL3211118 & 688810 & 4.833 & 5.0887 & TRN & & \\
\hline CHEMBL1599131 & 688810 & 4.883 & 5.2807 & TRN & & \\
\hline CHEMBL1308010 & 688810 & 5.683 & 5.124 & TRN & & \\
\hline CHEMBL1362403 & 688810 & \multicolumn{3}{|c|}{5.132999999999999} & 5.393 & TRN \\
\hline CHEMBL1554107 & 688810 & 5.683 & 5.6076 & TRN & & \\
\hline CHEMBL1607327 & 688810 & 4.933 & 4.795 & TRN & & \\
\hline CHEMBL1539867 & 688810 & \multicolumn{3}{|c|}{5.132999999999999} & 5.4338 & TRN \\
\hline CHEMBL1411257 & 688810 & 6.95 & 5.9184 & TRN & & \\
\hline CHEMBL1428191 & 688810 & 4.783 & 5.4715 & TRN & & \\
\hline CHEMBL1398662 & 688810 & 4.883 & 5.3526 & TRN & & \\
\hline CHEMBL1546134 & 688810 & 4.633 & 5.062 & TST & & \\
\hline CHEMBL1563333 & 688810 & 5.183 & 5.3084 & TRN & & \\
\hline CHEMBL1996068 & 688810 & \multicolumn{3}{|c|}{6.5329999999999995} & 6.2627 & TST \\
\hline CHEMBL1457961 & 688810 & \multicolumn{3}{|c|}{6.5329999999999995} & 5.3466 & TST \\
\hline CHEMBL1442520 & 688810 & 5.5 & 5.2456 & TRN & & \\
\hline CHEMBL1579879 & 688810 & 4.933 & 5.2834 & TST & & \\
\hline CHEMBL1593110 & 688810 & 4.633 & 4.7863 & TST & & \\
\hline CHEMBL1529404 & 688810 & 7.3325 & 5.8001 & TRN & & \\
\hline CHEMBL1600245 & 688810 & 6.0 & 4.6973 & TRN & & \\
\hline CHEMBL1416100 & 688810 & 4.883 & 5.2053 & TRN & & \\
\hline CHEMBL1302707 & 688810 & \multicolumn{3}{|c|}{5.832999999999999} & 5.5477 & TRN \\
\hline CHEMBL1356910 & 688810 & 5.083 & 5.0182 & TRN & & \\
\hline CHEMBL1164527 & 688810 & \multicolumn{3}{|c|}{5.7829999999999995} & 5.1781 & TRN \\
\hline CHEMBL1517873 & 688810 & 4.583 & 4.7772 & TRN & & \\
\hline CHEMBL1364202 & 688810 & \multicolumn{3}{|c|}{6.5329999999999995} & 5.4618 & TRN \\
\hline CHEMBL1359959 & 688810 & 4.883 & 5.5659 & TRN & & \\
\hline CHEMBL1375468 & 688810 & \multicolumn{3}{|c|}{6.382999999999999} & 5.4994 & TST \\
\hline CHEMBL1984688 & 688810 & 5.483 & 5.7361 & TRN & & \\
\hline CHEMBL3194068 & 688810 & 5.983 & 5.2139 & TRN & & \\
\hline CHEMBL1471008 & 688810 & 4.933 & 5.1388 & TRN & & \\
\hline CHEMBL1509462 & 688810 & \multicolumn{3}{|c|}{5.132999999999999} & 5.9641 & TRN \\
\hline CHEMBL1417929 & 688810 & 5.183 & 5.2858 & TST & & \\
\hline CHEMBL1377669 & 688810 & 5.233 & 5.2603 & TRN & & \\
\hline CHEMBL1319599 & 688810 & 4.833 & 5.1229 & TRN & & \\
\hline CHEMBL1344395 & 688810 & 4.783 & 5.2708 & TRN & & \\
\hline CHEMBL1401476 & 688810 & 4.633 & 5.1247 & TRN & & \\
\hline CHEMBL3199133 & 688810 & 4.883 & 5.0446 & TST & & \\
\hline CHEMBL1313744 & 688810 & 5.083 & 5.2411 & TRN & & \\
\hline CHEMBL140 & 688810 & 4.633 & 5.1148 & TRN & & \\
\hline CHEMBL1608267 & 688810 & \multicolumn{3}{|c|}{5.7829999999999995} & 5.7302 & TST \\
\hline CHEMBL1537712 & 688810 & \multicolumn{3}{|c|}{4.7330000000000005} & 5.1779 & TST \\
\hline CHEMBL1547209 & 688810 & 4.883 & 4.9867 & TRN & & \\
\hline CHEMBL1347053 & 688810 & \multicolumn{3}{|c|}{5.2829999999999995} & 5.5511 & TRN \\
\hline CHEMBL1539395 & 688810 & 4.633 & 4.7133 & TRN & & \\
\hline CHEMBL1312387 & 688810 & 4.833 & 5.5202 & TRN & & \\
\hline
\end{tabular}




\begin{tabular}{|c|c|c|c|c|c|c|}
\hline \multirow{3}{*}{$\begin{array}{l}\text { CHEMBL1519607 } \\
\text { CHEMBL1369302 }\end{array}$} & \multirow{3}{*}{$\begin{array}{l}688810 \\
688810\end{array}$} & \multicolumn{5}{|c|}{ Supplemental Table S2.txt } \\
\hline & & \multicolumn{3}{|c|}{4.7330000000000005} & \multirow[t]{3}{*}{5.3614} & \multirow[t]{3}{*}{ TRN } \\
\hline & & 4.883 & 5.7244 & TRN & & \\
\hline CHEMBL1304407 & 688810 & 4.783 & 5.0379 & TST & & \\
\hline CHEMBL1352800 & 688810 & \multicolumn{3}{|c|}{4.7330000000000005} & 5.1386 & $T$ \\
\hline CHEMBL1370166 & 688810 & 6.433 & 5.6782 & TRN & & \\
\hline CHEMBL1490955 & 688810 & \multicolumn{3}{|c|}{5.5329999999999995} & 5.5061 & \\
\hline CHEMBL1369196 & 688810 & 5.683 & 5.8172 & TRN & & \\
\hline CHEMBL1408552 & 688810 & 4.833 & 5.2158 & TRN & & \\
\hline CHEMBL1463371 & 688810 & \multicolumn{3}{|c|}{6.082999999999999} & 5.8972 & In \\
\hline CHEMBL 3192844 & 688810 & 5.233 & 5.1897 & TRN & & \\
\hline CHEMBL1357262 & 688810 & 4.833 & 4.9958 & TST & & \\
\hline CHEMBL 3213180 & 688810 & 5.183 & 5.4603 & TST & & \\
\hline CHEMBL3210737 & 688810 & 4.783 & 4.9989 & TRN & & \\
\hline CHEMBL1459479 & 688810 & 4.783 & 5.3139 & TRN & & \\
\hline CHEMBL1371376 & 688 & 5.183 & 5.2302 & TRN & & \\
\hline CHEMBL1 & 688 & \multicolumn{3}{|c|}{5.882999999999999} & 5.3748 & . \\
\hline CHEMBL15 & 688 & \multicolumn{3}{|c|}{4.9830000000000005} & 271 & \\
\hline CHEMBL1606429 & 688810 & 4.933 & 5.2508 & TST & & \\
\hline CHEMBL1436598 & 688810 & \multirow{2}{*}{\multicolumn{3}{|c|}{$\begin{array}{lll}4.633 & 4.7415 & \text { TRN } \\
5.332999999999999\end{array}$}} & & \\
\hline CHEMBL1375315 & 688810 & & & & 8 & \\
\hline CHEMBL1 & 688 & 4.833 & 5.0941 & TRN & & \\
\hline CHEMBL 1 & 688 & \multirow{2}{*}{\multicolumn{3}{|c|}{$\begin{array}{l}5.233 \quad 4.988 \text { ISI } \\
5.382999999999999\end{array}$}} & & \\
\hline CHEMBL1305181 & 688810 & & & & 5091 & $\mathrm{TI}$ \\
\hline CHEMBL162783 & 688810 & 5.183 & 4.85 & TST & & \\
\hline CHEMBL1411494 & 688810 & \multicolumn{3}{|c|}{6.382999999999999} & שוםדים & \\
\hline CHEMBL & 688 & 5.733 & 5.3283 & TRN & & \\
\hline CHEMBL: & 688 & & & TRN & & \\
\hline CHEMBL1533085 & 688810 & \multicolumn{3}{|c|}{4.7330000000000005} & 1842 & $T$ \\
\hline CHEMBL1347655 & 688810 & 5.683 & 5.2052 & TST & & \\
\hline CHEMBL13 & 688810 & \multicolumn{3}{|c|}{5.2829999999999995} & (3.574 & \\
\hline CHEMBL1 & $68 \varepsilon$ & 5.183 & 5.3343 & TRN & & \\
\hline CHEMBL1 & 688 & 4. & 5.1614 & TRN & & \\
\hline CHEMBL1348144 & 688810 & 6.6 & 5.7396 & TRN & & \\
\hline CHEMBL1536258 & 688810 & 5.683 & 5.7925 & TST & & \\
\hline CHEMBL3 & 688 & \multicolumn{3}{|c|}{5.2829999999999995} & $3.4 / 50$ & \\
\hline CHEMBL1374910 & 688 & 5.483 & 5.1706 & TRN & & \\
\hline CHEMBL1413771 & 688810 & 4.633 & 5.6721 & TST & & \\
\hline CHEMBL1343345 & 688810 & \multicolumn{3}{|c|}{5.582999999999999} & 5.9674 & TP \\
\hline CHEMBL1427335 & 688810 & \multicolumn{3}{|c|}{4.7330000000000005} & 5.7515 & \\
\hline CHEMBL13 & 688 & 4.883 & 5.1442 & TRN & & \\
\hline CHEMBL1573688 & 688810 & \multicolumn{3}{|c|}{5.2829999999999995} & 4.8408 & $T s$ \\
\hline CHEMBL1514827 & 688810 & 4.833 & 5.0327 & TRN & & \\
\hline CHEMBL1458979 & 688810 & \multicolumn{3}{|c|}{ 5. 382999999999999} & 5.1401 & $1 \pi$ \\
\hline CHEMBL1481296 & 688810 & & 4.4223 & TRN & & \\
\hline CHEMBL1395322 & 688810 & 5.5329 & 99999999 & 995 & & . \\
\hline CHEMBL1365725 & 688810 & 4.9836 & 00000000 & 005 & 5.2308 & TST \\
\hline CHEMBL1449789 & 688810 & 5.5329 & 99999999 & 995 & 5.1423 & TRN \\
\hline CHEMBL1572753 & 688810 & 5.3325 & 99999999 & & 5.495 & \\
\hline
\end{tabular}




\begin{tabular}{|c|c|c|c|c|c|c|}
\hline & & & pplemen & l Table & s2.txt & \\
\hline CHEMBL1566311 & 688810 & 5.3329 & 9999999 & & 5.5939 & TRA \\
\hline CHEMBL1537466 & 688810 & 4.833 & 5.1551 & TST & & \\
\hline CHEMBL1535576 & 688810 & 5.233 & 4.8179 & TRN & & \\
\hline CHEMBL1534381 & 688810 & 4.833 & 5.2878 & TST & & \\
\hline CHEMBL1362824 & 688810 & 5.7829 & 9999999 & 995 & 5.0118 & TRN \\
\hline CHEMBL530499 & 688810 & 5.5329 & 9999999 & 995 & 5.6387 & TRA \\
\hline CHEMBL3195230 & 688810 & 4.7330 & 0000000 & 005 & 5.3379 & TRN \\
\hline CHEMBL1474556 & 688810 & 4.583 & 4.9607 & TRN & & \\
\hline CHEMBL1336090 & 688810 & 5.733 & 5.0473 & TST & & \\
\hline CHEMBL1494161 & 688810 & 4.783 & 5.1161 & TRN & & \\
\hline CHEMBL1361967 & 688810 & 4.633 & 4.8535 & TST & & \\
\hline CHEMBL1424288 & 688810 & 5.2829 & 9999999 & 995 & 5.7219 & TRN \\
\hline CHEMBL241862 & 688810 & 5.1329 & 99999995 & & 5.3905 & TRA \\
\hline CHEMBL1414608 & 688810 & 4.9830 & 0000000 & 005 & 4.9904 & TST \\
\hline CHEMBL1455819 & 688810 & 5.083 & 5.6312 & TRN & & \\
\hline CHEMBL1339614 & 688810 & 5.233 & 5.4099 & TRN & & \\
\hline CHEMBL1547458 & 688810 & 4.783 & 5.176 & TRN & & \\
\hline CHEMBL1583785 & 688810 & 6.1329 & 99999995 & & 5.2602 & TRN \\
\hline CHEMBL1439118 & 688810 & 4.683 & 5.0545 & TRN & & \\
\hline CHEMBL1415785 & 688810 & 4.633 & 4.8331 & TRN & & \\
\hline CHEMBL 3190571 & 688810 & 5.733 & 5.0135 & TST & & \\
\hline CHEMBL1323085 & 688810 & 4.883 & 5.5454 & TRN & & \\
\hline CHEMBL1412319 & 688810 & 6.1 & 5.8241 & TRN & & \\
\hline CHEMBL1579233 & 688810 & 4.7330 & 00000006 & 005 & 5.5329 & TRN \\
\hline CHEMBL1541461 & 688810 & 4.883 & 4.8612 & TRN & & \\
\hline CHEMBL1323133 & 688810 & 5.7829 & 9999999 & 995 & 5.8729 & TST \\
\hline CHEMBL1372920 & 688810 & 4.783 & 5.2004 & TST & & \\
\hline CHEMBL1397514 & 688810 & 5.433 & 5.0505 & TST & & \\
\hline CHEMBL1364360 & 688810 & 4.7330 & 0000000 & 005 & 5.2669 & TRA \\
\hline CHEMBL433680 & 688810 & 8.3372 & 6.29799 & 999999999 & 99 & TST \\
\hline CHEMBL35962 & 688810 & 4.783 & 5.3498 & TST & & \\
\hline CHEMBL1571716 & 688810 & 4.783 & 4.5963 & TRN & & \\
\hline CHEMBL1319658 & 688810 & 5.233 & 5.1272 & TRN & & \\
\hline CHEMBL1370883 & 688810 & 5.3829 & 99999995 & & 5.4084 & TRA \\
\hline CHEMBL1393126 & 688810 & 6.683 & 5.2185 & TRN & & \\
\hline CHEMBL1472112 & 688810 & 4.7330 & 0000000 & 005 & 5.1323 & TRA \\
\hline CHEMBL1511238 & 688810 & 4.9830 & 0000000 & 005 & 5.4541 & TST \\
\hline CHEMBL1555079 & 688810 & 4.883 & 5.2003 & TRN & & \\
\hline CHEMBL1487466 & 688810 & 5.8329 & 99999995 & & 5.9407 & TRN \\
\hline CHEMBL1366749 & 688810 & 4.783 & 5.4883 & TRN & & \\
\hline CHEMBL1381270 & 688810 & 5.3829 & 9999999 & & 5.36 & TRA \\
\hline CHEMBL1378724 & 688810 & 5.7829 & 9999999 & 995 & 5.1708 & TRN \\
\hline CHEMBL1368371 & 688810 & 4.583 & 4.6844 & TRN & & \\
\hline CHEMBL1341400 & 688810 & 4.633 & 4.8183 & TRN & & \\
\hline CHEMBL1321538 & 688810 & 4.633 & 4.7588 & TST & & \\
\hline CHEMBL1567722 & 688810 & 5.1329 & 9999999 & & 5.4974 & TST \\
\hline CHEMBL1597076 & 688810 & 6.3329 & 9999999 & & 5.7782 & TRN \\
\hline CHEMBL1353591 & 688810 & 5.933 & 5.3663 & TRN & & \\
\hline
\end{tabular}




\begin{tabular}{|c|c|c|c|c|c|c|c|}
\hline \multicolumn{7}{|c|}{ Supplemental Table S2.txt } & \\
\hline CHEMBL1332644 & 688810 & \multicolumn{3}{|c|}{4.7330000000000005} & 5.45 & TRN & \\
\hline CHEMBL1352636 & 688810 & \multicolumn{3}{|c|}{5.382999999999999} & 5.6798 & TRN & \\
\hline CHEMBL1516355 & 688810 & \multicolumn{3}{|c|}{5.332999999999999} & 5.5489 & TRN & \\
\hline CHEMBL1440300 & 688810 & 5.433 & 5.3488 & TRN & & & \\
\hline CHEMBL1507129 & 688810 & \multicolumn{3}{|c|}{6.082999999999999} & \multicolumn{2}{|c|}{5.7410000000000005} & TRN \\
\hline CHEMBL1494249 & 688810 & \multicolumn{3}{|c|}{5.632999999999999} & 5.7717 & TRN & \\
\hline CHEMBL1552784 & 688810 & 6.433 & 5.0898 & TST & & & \\
\hline CHEMBL1532354 & 688810 & 4.933 & 4.9918 & TRN & & & \\
\hline CHEMBL1378580 & 688810 & \multicolumn{3}{|c|}{5.332999999999999} & 5.5623 & TST & \\
\hline CHEMBL1395520 & 688810 & 4.933 & 5.3541 & TRN & & & \\
\hline CHEMBL1306573 & 688810 & 4.883 & 5.0637 & TST & & & \\
\hline CHEMBL1565562 & 688810 & 5.233 & 5.5619 & TRN & & & \\
\hline CHEMBL1498085 & 688810 & \multicolumn{3}{|c|}{5.7829999999999995} & 5.581 & TRN & \\
\hline CHEMBL1511768 & 688810 & 4.583 & 5.1908 & TRN & & & \\
\hline CHEMBL1343256 & 688810 & \multicolumn{3}{|c|}{4.7330000000000005} & 5.3134 & TRN & \\
\hline CHEMBL1447078 & 688810 & 5.683 & 5.6134 & TST & & & \\
\hline CHEMBL1343697 & 688810 & \multicolumn{3}{|c|}{6.082999999999999} & 6.1081 & TST & \\
\hline CHEMBL1440156 & 688810 & \multicolumn{3}{|c|}{6.132999999999999} & 5.5284 & TRN & \\
\hline CHEMBL1527840 & 688810 & 5.083 & 5.0021 & TRN & & & \\
\hline CHEMBL1531634 & 688810 & \multicolumn{3}{|c|}{6.0329999999999995} & 5.892 & TRN & \\
\hline CHEMBL1470229 & 688810 & 4.933 & 5.2882 & TST & & & \\
\hline CHEMBL1401392 & 688810 & 4.783 & 5.6218 & TRN & & & \\
\hline CHEMBL1503238 & 688810 & \multicolumn{3}{|c|}{6.582999999999999} & 5.2611 & TRN & \\
\hline CHEMBL1547767 & 688810 & 5.183 & 5.3725 & TRN & & & \\
\hline CHEMBL1313115 & 688810 & \multicolumn{3}{|c|}{4.7330000000000005} & 5.3314 & TST & \\
\hline CHEMBL1392107 & 688810 & 4.583 & 5.1785 & TST & & & \\
\hline CHEMBL3209305 & 688810 & 4.883 & 5.3364 & TRN & & & \\
\hline CHEMBL1336531 & 688810 & 5.733 & 5.9253 & TRN & & & \\
\hline CHEMBL1502801 & 688810 & 4.783 & 5.2516 & TRN & & & \\
\hline CHEMBL1501596 & 688810 & 5.683 & 5.1528 & TST & & & \\
\hline CHEMBL1382144 & 688810 & 4.883 & 5.018 & TRN & & & \\
\hline CHEMBL1304589 & 688810 & \multicolumn{3}{|c|}{5.132999999999999} & 5.0978 & TRN & \\
\hline CHEMBL1574263 & 688810 & 4.633 & 4.939 & TRN & & & \\
\hline CHEMBL1428407 & 688810 & 4.683 & 4.681 & TRN & & & \\
\hline CHEMBL1432066 & 688810 & 4.833 & 5.1732 & TRN & & & \\
\hline CHEMBL1577491 & 688810 & \multicolumn{3}{|c|}{5.832999999999999} & 5.5701 & TRN & \\
\hline CHEMBL1489639 & 688810 & 5.183 & 5.8697 & TRN & & & \\
\hline CHEMBL1440691 & 688810 & 4.783 & 4.8299 & TST & & & \\
\hline CHEMBL1493139 & 688810 & 4.633 & 4.633 & TRN & & & \\
\hline CHEMBL1522285 & 688810 & 5.183 & 5.1272 & TRN & & & \\
\hline CHEMBL1579477 & 688810 & 4.783 & 4.9403 & TRN & & & \\
\hline CHEMBL1532072 & 688810 & \multicolumn{3}{|c|}{4.7330000000000005} & 5.2484 & TRN & \\
\hline CHEMBL1549946 & 688810 & 4.583 & 5.1932 & TST & & & \\
\hline CHEMBL1498582 & 688810 & 5.083 & 5.0228 & TRN & & & \\
\hline CHEMBL1539747 & 688810 & \multicolumn{3}{|c|}{5.332999999999999} & 5.1969 & TST & \\
\hline CHEMBL1335818 & 688810 & \multicolumn{3}{|c|}{5.7829999999999995} & 5.3218 & TRN & \\
\hline CHEMBL1534625 & 688810 & 4.833 & 4.971 & TRN & & & \\
\hline CHEMBL1564034 & 688810 & 5.033 & 5.135 & TRN & & & \\
\hline
\end{tabular}




\begin{tabular}{|c|c|c|c|c|c|c|}
\hline \multirow[b]{2}{*}{ CHEMBL3192214 } & \multirow[b]{2}{*}{688810} & \multicolumn{5}{|c|}{ Supplemental Table S2.txt } \\
\hline & & \multicolumn{3}{|c|}{$6.183 \quad 5.9338$ TST } & & \\
\hline CHEMBL1504208 & 688810 & 4.85 & 5.2177 & TST & & \\
\hline CHEMBL162347 & 688810 & \multicolumn{3}{|c|}{5.132999999999999} & 4.9416 & TRN \\
\hline CHEMBL1448722 & 688810 & 5.183 & 5.6346 & TRN & & \\
\hline CHEMBL1436431 & 688810 & 4.883 & 5.0525 & TRN & & \\
\hline CHEMBL1305892 & 688810 & 4.883 & 5.1642 & TRN & & \\
\hline CHEMBL3194093 & 688810 & 5.033 & 5.6023 & TRN & & \\
\hline CHEMBL1333859 & 688810 & 6.233 & 5.6711 & TRN & & \\
\hline CHEMBL1546928 & 688810 & \multicolumn{3}{|c|}{5.332999999999999} & 5.1968 & TRN \\
\hline CHEMBL1601485 & 688810 & 4.833 & 5.4703 & TRN & & \\
\hline CHEMBL1535960 & 688810 & 4.833 & 5.2134 & TRN & & \\
\hline CHEMBL1539406 & 688810 & 4.933 & 5.4656 & TRN & & \\
\hline CHEMBL1541614 & 688810 & 5.683 & 5.2052 & TST & & \\
\hline CHEMBL1450679 & 688810 & 4.783 & 4.7268 & TST & & \\
\hline CHEMBL3199539 & 688810 & \multicolumn{3}{|c|}{5.582999999999999} & 5.3399 & TRN \\
\hline CHEMBL1524783 & 688810 & \multicolumn{3}{|c|}{5.632999999999999} & 5.5561 & TRN \\
\hline CHEMBL1538620 & 688810 & 5.083 & 5.4828 & TRN & & \\
\hline CHEMBL1548614 & 688810 & 5.033 & 5.6155 & TST & & \\
\hline CHEMBL1305673 & 688810 & 4.783 & 4.7825 & TRN & & \\
\hline CHEMBL1560217 & 688810 & \multicolumn{3}{|c|}{4.7330000000000005} & 4.8476 & TRN \\
\hline CHEMBL1335831 & 688810 & 4.633 & 5.0663 & TRN & & \\
\hline CHEMBL1322794 & 688810 & 4.683 & 5.2197 & TRN & & \\
\hline CHEMBL1394849 & 688810 & \multicolumn{3}{|c|}{4.7330000000000005} & 5.0319 & TRN \\
\hline CHEMBL3209654 & 688810 & 5.733 & 5.513 & TST & & \\
\hline CHEMBL1549784 & 688810 & \multicolumn{3}{|c|}{5.332999999999999} & 4.9272 & TRN \\
\hline CHEMBL1519633 & 688810 & \multicolumn{3}{|c|}{5.7829999999999995} & 5.9029 & TST \\
\hline CHEMBL1332808 & 688810 & 4.683 & 4.9832 & TST & & \\
\hline CHEMBL1393560 & 688810 & 5.233 & 5.1474 & TRN & & \\
\hline CHEMBL1491893 & 688810 & 5.033 & 4.9945 & TRN & & \\
\hline CHEMBL1543241 & 688810 & 4.833 & 5.4035 & TST & & \\
\hline CHEMBL490592 & 688810 & \multicolumn{3}{|c|}{6.382999999999999} & 5.5913 & TRN \\
\hline CHEMBL 3210035 & 688810 & 4.783 & 5.1142 & TRN & & \\
\hline CHEMBL1480646 & 688810 & 6.233 & 5.7149 & TRN & & \\
\hline CHEMBL1469487 & 688810 & 4.833 & 5.3573 & TRN & & \\
\hline CHEMBL1553974 & 688810 & 6.433 & 5.7521 & TRN & & \\
\hline CHEMBL1508783 & 688810 & 4.783 & 5.178 & TST & & \\
\hline CHEMBL1613479 & 688810 & \multicolumn{3}{|c|}{6.582999999999999} & 6.1196 & TRN \\
\hline CHEMBL1309788 & 688810 & \multicolumn{3}{|c|}{5.832999999999999} & 5.8988 & TRN \\
\hline CHEMBL1583473 & 688810 & \multicolumn{3}{|c|}{5.832999999999999} & 5.2346 & TRN \\
\hline CHEMBL1373690 & 688810 & 4.883 & 5.1353 & TRN & & \\
\hline CHEMBL1490323 & 688810 & 5.683 & 5.2705 & TRN & & \\
\hline CHEMBL1325494 & 688810 & 4.633 & 5.0822 & TRN & & \\
\hline CHEMBL1381372 & 688810 & \multicolumn{3}{|c|}{5.2829999999999995} & 5.3634 & TRN \\
\hline CHEMBL1300249 & 688810 & \multicolumn{3}{|c|}{6.582999999999999} & 5.7225 & TRN \\
\hline CHEMBL1305239 & 688810 & 6.433 & 6.16206 & 0000 & 01 & TRN \\
\hline CHEMBL 274070 & 688810 & \multicolumn{3}{|c|}{5.882999999999999} & 6.1513 & TST \\
\hline CHEMBL1564239 & 688810 & 4.833 & 4.5796 & TRN & & \\
\hline CHEMBL1589058 & 688810 & 5.083 & 4.9066 & TRN & & \\
\hline
\end{tabular}




\begin{tabular}{|c|c|c|c|c|c|c|}
\hline \multirow[b]{2}{*}{ CHEMBL1340976 } & \multicolumn{6}{|c|}{ Supplemental Table S2.txt } \\
\hline & 688810 & 4.883 & 5.0599 & TRN & & \\
\hline CHEMBL1347881 & 688810 & 4.833 & 5.026 & TRN & & \\
\hline CHEMBL1480059 & 688810 & 4.883 & 5.1099 & TST & & \\
\hline CHEMBL1570475 & 688810 & 5.9 & 5.3949 & TRN & & \\
\hline CHEMBL3199843 & 688810 & 5.033 & 5.0738 & TRN & & \\
\hline CHEMBL1477957 & 688810 & 5.083 & 5.7292 & TRN & & \\
\hline CHEMBL1312792 & 688810 & 5.083 & 5.3352 & TRN & & \\
\hline CHEMBL1520360 & 688810 & 4.833 & 5.3834 & TRN & & \\
\hline CHEMBL1486796 & 688810 & \multicolumn{3}{|c|}{5.832999999999999} & 6.0362 & TRN \\
\hline CHEMBL1523118 & 688810 & \multicolumn{3}{|c|}{5.882999999999999} & 5.8867 & TRN \\
\hline CHEMBL1315956 & 688810 & 4.783 & 5.1119 & TRN & & \\
\hline CHEMBL1534728 & 688810 & \multicolumn{3}{|c|}{6.382999999999999} & 5.5997 & TRN \\
\hline CHEMBL1579301 & 688810 & 4.883 & 5.0497 & TRN & & \\
\hline CHEMBL1305213 & 688810 & \multicolumn{3}{|c|}{5.332999999999999} & 5.1276 & TRN \\
\hline CHEMBL1503175 & 688810 & \multicolumn{3}{|c|}{5.132999999999999} & 5.5002 & TRN \\
\hline CHEMBL1561490 & 688810 & \multicolumn{3}{|c|}{4.7330000000000005} & 5.4346 & TRN \\
\hline CHEMBL1521367 & 688810 & 5.183 & 5.1715 & TRN & & \\
\hline CHEMBL1433545 & 688810 & 4.633 & 5.0188 & TST & & \\
\hline CHEMBL1564717 & 688810 & 5.983 & 5.2167 & TRN & & \\
\hline CHEMBL1388711 & 688810 & 4.933 & 5.539 & TRN & & \\
\hline CHEMBL3191138 & 688810 & \multicolumn{3}{|c|}{5.132999999999999} & 4.8785 & TRN \\
\hline CHEMBL1403254 & 688810 & \multicolumn{3}{|c|}{5.382999999999999} & 5.0984 & TST \\
\hline CHEMBL3199810 & 688810 & \multicolumn{3}{|c|}{4.7330000000000005} & 5.4007 & TRN \\
\hline CHEMBL1497698 & 688810 & \multicolumn{3}{|c|}{5.132999999999999} & 5.447 & TRN \\
\hline CHEMBL1512055 & 688810 & 4.783 & 4.8672 & TRN & & \\
\hline CHEMBL1470185 & 688810 & 4.633 & 5.1942 & TST & & \\
\hline CHEMBL1373992 & 688810 & 4.633 & 4.644 & TST & & \\
\hline CHEMBL1384771 & 688810 & 5.483 & 5.1655 & TST & & \\
\hline CHEMBL1303419 & 688810 & \multicolumn{3}{|c|}{4.9830000000000005} & 5.2768 & TST \\
\hline CHEMBL1582020 & 688810 & 4.883 & 5.1138 & TRN & & \\
\hline CHEMBL1451878 & 688810 & 4.633 & 5.1543 & TST & & \\
\hline CHEMBL 3208241 & 688810 & 4.583 & 5.5029 & TRN & & \\
\hline CHEMBL1443180 & 688810 & 4.833 & 4.9567 & TRN & & \\
\hline CHEMBL 3194104 & 688810 & 5.083 & 5.3174 & TRN & & \\
\hline CHEMBL1391920 & 688810 & \multicolumn{3}{|c|}{5.5329999999999995} & 5.57 & TST \\
\hline CHEMBL1529606 & 688810 & 4.783 & 5.1549 & TRN & & \\
\hline CHEMBL1584271 & 688810 & 5.183 & 5.6336 & TRN & & \\
\hline CHEMBL1594234 & 688810 & 4.833 & 4.9716 & TST & & \\
\hline CHEMBL1595789 & 688810 & 4.833 & 5.4104 & TST & & \\
\hline CHEMBL1516899 & 688810 & 4.933 & 4.7101 & TRN & & \\
\hline CHEMBL1521122 & 688810 & 5.433 & 5.4527 & TST & & \\
\hline CHEMBL1398002 & 688810 & \multicolumn{3}{|c|}{5.2829999999999995} & 5.4856 & TRN \\
\hline CHEMBL1367089 & 688810 & \multicolumn{3}{|c|}{5.132999999999999} & 4.7911 & TST \\
\hline CHEMBL1425146 & 688810 & 4.833 & 4.9352 & TRN & & \\
\hline CHEMBL1341127 & 688810 & 5.183 & 5.04899 & 99999 & 995 & TRN \\
\hline CHEMBL1549574 & 688810 & 4.683 & 5.0179 & TST & & \\
\hline CHEMBL1344118 & 688810 & 4.783 & 4.8749 & TRN & & \\
\hline \multirow[t]{2}{*}{ CHEMBL1453005 } & 688810 & \multicolumn{3}{|c|}{5.132999999999999} & 5.319 & TST \\
\hline & & \multicolumn{5}{|c|}{ Page 21835} \\
\hline
\end{tabular}




\begin{tabular}{|c|c|c|c|c|c|c|}
\hline \multirow[b]{2}{*}{ CHEMBL1301647 } & \multicolumn{6}{|c|}{ 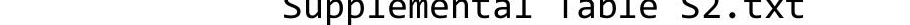 } \\
\hline & 688810 & 4.633 & 5.2708 & TST & & \\
\hline CHEMBL1514727 & 688810 & 4.783 & 5.2539 & TST & & \\
\hline CHEMBL1364520 & 688810 & 4.783 & 5.2113 & TRN & & \\
\hline CHEMBL1471578 & 688810 & \multicolumn{3}{|c|}{5.832999999999999} & 5.4074 & TRN \\
\hline CHEMBL 3190273 & 688810 & \multicolumn{3}{|c|}{5.332999999999999} & 5.6685 & \\
\hline CHEMBL1339070 & 688810 & 4.783 & 5.146 & TRN & & \\
\hline CHEMBL1333982 & 688810 & \multicolumn{3}{|c|}{4.7330000000000005} & 5.4597 & 1. \\
\hline CHEMBL1483193 & 688810 & 6.7331 & 5.7235 & TRN & & \\
\hline CHEMBL1517325 & 688810 & \multicolumn{3}{|c|}{5.2829999999999995} & 5.6951 & \\
\hline CHEMBL1534683 & 688810 & \multicolumn{3}{|c|}{6.332999999999999} & 5.4726 & \\
\hline CHEMBL1577459 & 688810 & \multicolumn{3}{|c|}{5.882999999999999} & 5.0256 & \\
\hline CHEMBL1370219 & 688810 & 5.683 & 5.3869 & TRN & & \\
\hline CHEMBL1359181 & 688810 & 4.633 & 5.3376 & TST & & \\
\hline CHEMBL1543582 & 688810 & \multicolumn{3}{|c|}{5.832999999999999} & 4.9208 & \\
\hline CHEMBL1343821 & 688810 & 5.233 & 5.3174 & TRN & & \\
\hline CHEMBL1535901 & 688810 & \multicolumn{3}{|c|}{4.7330000000000005} & 4.9944 & \\
\hline CHEMBL1382203 & 688810 & \multicolumn{3}{|c|}{6.332999999999999} & 5.8443 & \\
\hline CHEMBL1515135 & 688810 & 4.633 & 4.9505 & TRN & & \\
\hline CHEMBL1586443 & 688810 & 4.933 & 5.5193 & TRN & & \\
\hline CHEMBL1330417 & 688810 & 6.9329 & 6.2866 & TRN & & \\
\hline CHEMBL1586767 & 688810 & \multicolumn{3}{|c|}{4.7330000000000005} & 5.8162 & $1 K \mathrm{KI}$ \\
\hline CHEMBL 3189172 & 688810 & \multicolumn{3}{|c|}{4.7330000000000005} & 5.2266 & \\
\hline CHEMBL1379020 & 688810 & 5.183 & 4.8245 & TST & & \\
\hline CHEMBL 1550330 & 688810 & \multicolumn{3}{|c|}{5.382999999999999} & 5594 & \\
\hline CHEMBL 2369298 & 688810 & \multicolumn{3}{|c|}{5.832999999999999} & 5.3951 & \\
\hline CHEMBL1444884 & 688810 & \multicolumn{3}{|c|}{6.082999999999999} & 5.7977 & \\
\hline CHEMBL1311425 & 688810 & 4.833 & 5.3048 & TST & & \\
\hline CHEMBL1447068 & 688810 & 5.933 & 4.9136 & TRN & & \\
\hline CHEMBL1313947 & 688810 & 4.833 & 5.0345 & TRN & & \\
\hline CHEMBL 3197863 & 688810 & \multicolumn{3}{|c|}{4.9830000000000005} & 5.2246 & זות \\
\hline CHEMBL1347743 & 688810 & \multicolumn{3}{|c|}{6.2829999999999995} & 5.1696 & \\
\hline CHEMBL1364195 & 688810 & \multicolumn{3}{|c|}{5.5329999999999995} & 5.4968 & \\
\hline CHEMBL1525953 & 688810 & 5.433 & 5.7126 & TRN & & \\
\hline CHEMBL1495882 & 688810 & \multicolumn{3}{|c|}{4.7330000000000005} & 5.131 & \\
\hline CHEMBL1327867 & 688810 & 4.833 & 5.4397 & TRN & & \\
\hline CHEMBL13 & 688810 & \multicolumn{3}{|c|}{6.082999999999999} & 5.4044 & \\
\hline CHEMBL1590929 & 688810 & 4.583 & 5.2301 & TST & & \\
\hline CHEMBL1465706 & 688810 & 5.5329 & 99999999 & 995 & & TNTr \\
\hline CHEMBL1354522 & 688810 & 5.1329 & 99999999 & & 5.3626 & \\
\hline CHEMBL1967273 & 688810 & 5.683 & 5.5576 & TRN & & \\
\hline CHEMBL15 & 688810 & 5.933 & 5.568 & TRN & & \\
\hline CHEMBL 1406664 & 688810 & 5.8329 & 99999999 & & 5.3622 & TRN \\
\hline CHEMBL1386551 & 688810 & 4.9830 & 00000000 & 005 & 5.3664 & $\mathrm{TR}$ \\
\hline CHEMBL1597225 & 688810 & 4.783 & 5.0995 & TRN & & \\
\hline CHEMBL 3209536 & 688810 & 4.833 & 5.038 & TRN & & \\
\hline CHEMBL 3213937 & 688810 & 4.883 & 5.1349 & TRN & & \\
\hline CHEMBL1524754 & 688810 & 4.783 & 5.3274 & TST & & \\
\hline CHEMBL1332770 & 688810 & 5.1329 & 99999999 & & 5.6037 & Ih \\
\hline
\end{tabular}




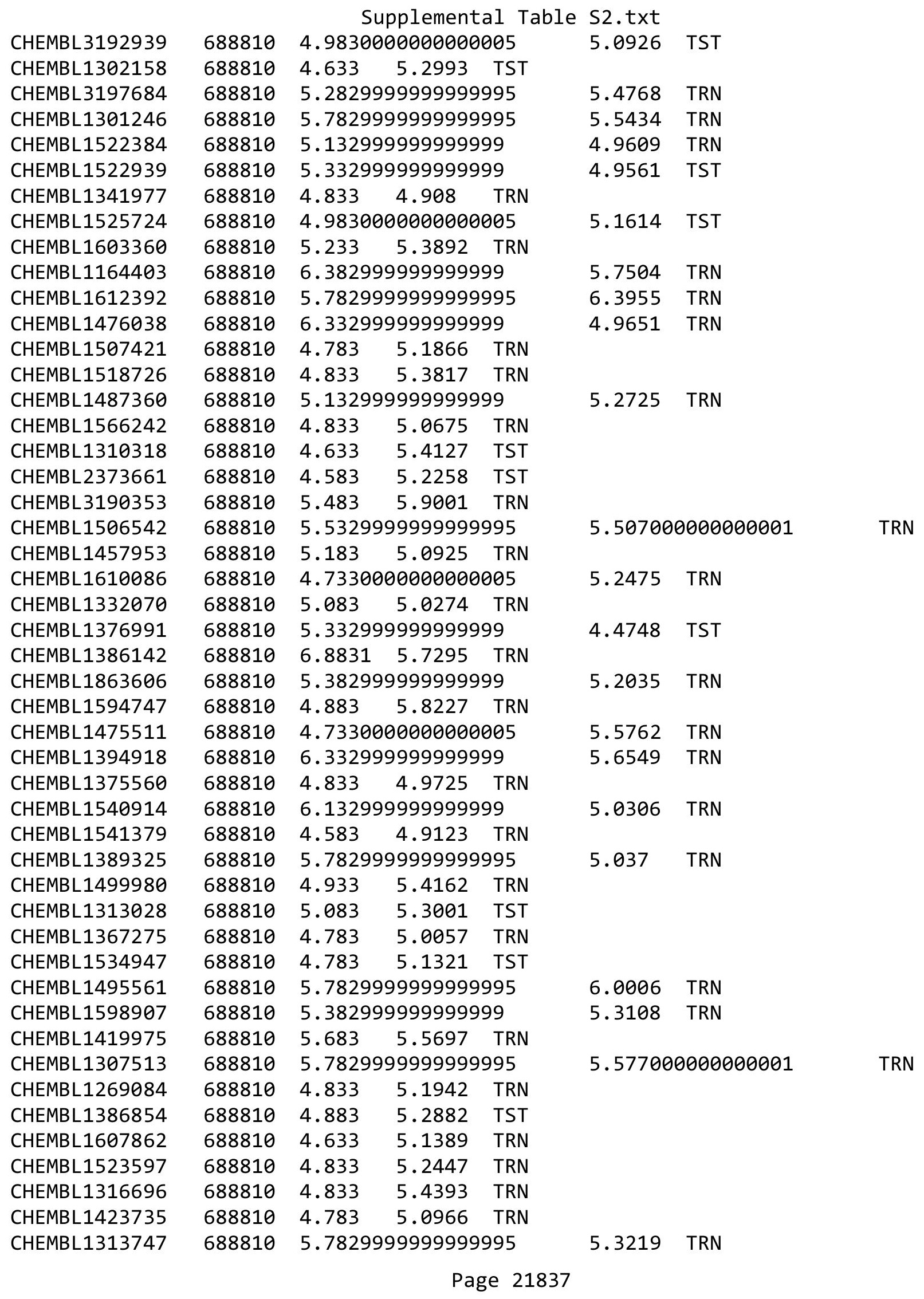




\begin{tabular}{|c|c|c|c|c|c|c|}
\hline & & & & & & \\
\hline CHEMBL 3209096 & 688810 & 5.733 & 5.5631 & TRN & & \\
\hline CHEMBL1435758 & 688810 & 4.583 & 5.2432 & TST & & \\
\hline CHEMBL1605715 & 688810 & 4.583 & 4.7544 & TST & & \\
\hline CHEMBL1425605 & 688810 & \multicolumn{3}{|c|}{4.7330000000000005} & 5.3427 & $\mathrm{Tr}$ \\
\hline CHEMBL1577599 & 688810 & \multicolumn{3}{|c|}{5.132999999999999} & 5.4568 & \\
\hline CHEMBL1538197 & 688810 & 4.833 & 5.1104 & TRN & & \\
\hline CHEMBL1457951 & 688810 & 4.883 & 5.1812 & TST & & \\
\hline CHEMBL1375648 & 688810 & \multicolumn{3}{|c|}{5.332999999999999} & 5.7667 & \\
\hline CHEMBL600121 & 688810 & \multicolumn{3}{|c|}{5.5329999999999995} & 5.1542 & \\
\hline CHEMBL1560684 & 688810 & \multicolumn{3}{|c|}{6.0329999999999995} & 5.5132 & \\
\hline CHEMBL1490734 & 688810 & 5.683 & 5.8496 & TST & & \\
\hline CHEMBL1416946 & 688810 & \multicolumn{3}{|c|}{5.882999999999999} & 5.1736 & \\
\hline CHEMBL1386715 & 688810 & 4.783 & 5.2311 & TST & & \\
\hline CHEMBL1443597 & 688810 & 5.183 & 5.224 & TRN & & \\
\hline CHEMBL 3199692 & 688810 & 4.883 & 5.2121 & TRN & & \\
\hline CHEMBL1501845 & 688810 & \multicolumn{3}{|c|}{5.2829999999999995} & 5.2909 & \\
\hline CHEMBL1593442 & 688810 & \multicolumn{3}{|c|}{5.5329999999999995} & 5.5736 & \\
\hline CHEMBL1363228 & 688810 & \multicolumn{3}{|c|}{6.382999999999999} & 5.4234 & \\
\hline CHEMBL1496294 & 688810 & 4.883 & 5.2611 & TRN & & \\
\hline CHEMBL1387096 & 688810 & \multicolumn{3}{|c|}{4.7330000000000005} & 5.2326 & \\
\hline CHEMBL1514498 & 688810 & 4.583 & 4.515 & TRN & & \\
\hline CHEMBL1971142 & 688810 & \multicolumn{3}{|c|}{5.632999999999999} & 6.6448 & \\
\hline CHEMBL1602859 & 688810 & \multicolumn{3}{|c|}{5.7829999999999995} & 5.4134 & \\
\hline CHEMBL1590665 & 688810 & \multicolumn{3}{|c|}{5.5329999999999995} & 5.5724 & \\
\hline CHEMBL1429722 & 688810 & \multicolumn{3}{|c|}{6.132999999999999} & 5.3535 & \\
\hline CHEMBL 3210176 & 688810 & 5.483 & 5.6971 & TRN & & \\
\hline CHEMBL1324243 & 688810 & 4.583 & 4.8834 & TST & & \\
\hline CHEMBL1424457 & 688810 & 4.783 & 5.1246 & TRN & & \\
\hline CHEMBL1594537 & 688810 & 5.483 & 5.0364 & TRN & & \\
\hline CHEMBL1411369 & 688810 & 5.483 & 5.6066 & TRN & & \\
\hline CHEMBL1348219 & 688810 & 5.683 & 4.9565 & TRN & & \\
\hline CHEMBL1376059 & 688810 & 4.883 & 5.3262 & TST & & \\
\hline CHEMBL1512514 & 688810 & \multicolumn{3}{|c|}{4.7330000000000005} & 5.6505 & \\
\hline CHEMBL1332194 & 688810 & \multicolumn{3}{|c|}{5.632999999999999} & 5.2751 & \\
\hline CHEMBL 3210557 & 688810 & \multicolumn{3}{|c|}{4.7330000000000005} & 5.2857 & \\
\hline CHEMBL1582928 & 688810 & 4.883 & 5.3205 & TRN & & \\
\hline CHEMBL 1500140 & 688810 & 5.233 & 5.2141 & TRN & & \\
\hline CHEMBL1459113 & 688810 & \multicolumn{3}{|c|}{4.7330000000000005} & 4.9476 & \\
\hline CHEMBL 3197115 & 688810 & \multicolumn{3}{|c|}{5.832999999999999} & 5.5887 & \\
\hline CHEMBL1364712 & 688810 & 5.483 & 5.7339 & TRN & & \\
\hline CHEMBL1511860 & 688810 & \multicolumn{3}{|c|}{5.332999999999999} & 5.5231 & $T$ \\
\hline CHEMBL 3198249 & 688810 & 5.083 & 5.1368 & TRN & & \\
\hline CHEMBL1358535 & 688810 & 4.583 & 5.0187 & TRN & & \\
\hline CHEMBL 3145373 & 688810 & 5.7829 & 99999999 & 995 & 5.5271 & \\
\hline CHEMBL1564295 & 688810 & 6.3829 & 99999999 & & 5.5131 & \\
\hline CHEMBL1514160 & 688810 & 4.583 & 4.663 & TRN & & \\
\hline CHEMBL1381595 & 688810 & 4.9830 & 00000000 & 005 & 5.5321 & $T$ \\
\hline CHEMBL1388017 & 688810 & 4.783 & 5.1313 & TRN & & \\
\hline
\end{tabular}




\begin{tabular}{|c|c|c|c|c|c|c|c|}
\hline \multirow[b]{2}{*}{ CHEMBL1564611 } & \multicolumn{6}{|c|}{ oplemental Table } & \\
\hline & 688810 & 4.85 & 5.1779 & TRN & & & \\
\hline CHEMBL1369614 & 688810 & 4.73300 & 00000000 & 005 & 5.1504 & TST & \\
\hline CHEMBL3190559 & 688810 & 4.883 & 5.1606 & TRN & & & \\
\hline CHEMBL1501113 & 688810 & 5.63299 & 99999999 & & 4.7423 & TRN & \\
\hline CHEMBL1547862 & 688810 & 4.583 & 5.0913 & TST & & & \\
\hline CHEMBL3194261 & 688810 & 5.733 & 5.4282 & TRN & & & \\
\hline CHEMBL1450905 & 688810 & 5.53299 & 99999999 & 995 & 5.6699 & TRN & \\
\hline CHEMBL1433539 & 688810 & 5.233 & 5.8658 & TRN & & & \\
\hline CHEMBL1307707 & 688810 & 5.33299 & 99999999 & & 5.8724 & TRN & \\
\hline CHEMBL1560308 & 688810 & 4.73300 & 00000000 & 005 & 4.7786 & TST & \\
\hline CHEMBL1440725 & 688810 & 5.28299 & 99999999 & 995 & 5.2269 & TRN & \\
\hline CHEMBL1589176 & 688810 & 5.033 & 5.28100 & 000000000 & & TRN & \\
\hline CHEMBL1608274 & 688810 & 4.73300 & 00000000 & 005 & 5.1219 & TRN & \\
\hline CHEMBL1415227 & 688810 & 5.33299 & 99999999 & & 5.0987 & TRN & \\
\hline CHEMBL1327470 & 688810 & 4.833 & 5.2132 & TST & & & \\
\hline CHEMBL1398307 & 688810 & 5.933 & 5.2448 & TRN & & & \\
\hline CHEMBL3211520 & 688810 & 5.28299 & 99999999 & 995 & 5.4061 & TRN & \\
\hline CHEMBL1548167 & 688810 & 5.733 & 5.7247 & TRN & & & \\
\hline CHEMBL1456058 & 688810 & 5.63299 & 99999999 & & 5.29799 & 9999999999 & TRN \\
\hline CHEMBL1443898 & 688810 & 4.783 & 4.7656 & TST & & & \\
\hline CHEMBL1436159 & 688810 & 5.38299 & 99999999 & & 5.6902 & TRN & \\
\hline CHEMBL1550039 & 688810 & 4.98300 & 00000000 & 005 & 5.1063 & TRN & \\
\hline CHEMBL1456282 & 688810 & 5.083 & 5.1173 & TRN & & & \\
\hline CHEMBL1608757 & 688810 & 4.833 & 4.9716 & TST & & & \\
\hline CHEMBL1349758 & 688810 & 5.083 & 4.9315 & TRN & & & \\
\hline CHEMBL1406040 & 688810 & 5.53299 & 99999999 & 995 & 5.4563 & TRN & \\
\hline CHEMBL1345845 & 688810 & 6.13299 & 99999999 & & 5.4939 & TRN & \\
\hline CHEMBL1479139 & 688810 & 5.683 & 5.1104 & TRN & & & \\
\hline CHEMBL1389553 & 688810 & 4.783 & 5.4111 & TRN & & & \\
\hline CHEMBL1471489 & 688810 & 5.33299 & 99999999 & & 5.3142 & TRN & \\
\hline CHEMBL1348215 & 688810 & 4.833 & 4.8115 & TST & & & \\
\hline CHEMBL1505173 & 688810 & 5.28299 & 99999999 & 995 & 5.371 & TRN & \\
\hline CHEMBL1608727 & 688810 & 5.88299 & 99999999 & & 5.0635 & TST & \\
\hline CHEMBL1315579 & 688810 & 4.833 & 5.0058 & TRN & & & \\
\hline CHEMBL1504572 & 688810 & 4.73300 & 00000000 & 005 & 5.0567 & TRN & \\
\hline CHEMBL1339519 & 688810 & 5.88299 & 99999999 & 99 & 5.3191 & TST & \\
\hline CHEMBL1502199 & 688810 & 4.633 & 5.0557 & TST & & & \\
\hline CHEMBL1558056 & 688810 & 4.833 & 5.4014 & TRN & & & \\
\hline CHEMBL1451903 & 688810 & 4.833 & 5.199 & TRN & & & \\
\hline CHEMBL1358220 & 688810 & 4.683 & 4.9444 & TRN & & & \\
\hline CHEMBL3192114 & 688810 & 4.783 & 5.1606 & TST & & & \\
\hline CHEMBL1422056 & 688810 & 6.0 & 5.3574 & TST & & & \\
\hline CHEMBL1354798 & 688810 & 4.833 & 5.0577 & TRN & & & \\
\hline CHEMBL1333225 & 688810 & 5.683 & 5.6103 & TRN & & & \\
\hline CHEMBL510929 & 688810 & 6.28299 & 99999999 & 995 & 5.9898 & TRN & \\
\hline CHEMBL3198532 & 688810 & 4.783 & 4.9164 & TST & & & \\
\hline CHEMBL1603181 & 688810 & 5.933 & 5.2873 & TRN & & & \\
\hline CHEMBL1406720 & 688810 & 4.833 & 4.8436 & TRN & & & \\
\hline
\end{tabular}




\begin{tabular}{|c|c|c|c|c|c|c|}
\hline \multirow[b]{2}{*}{ CHEMBL1474500 } & & \multicolumn{5}{|c|}{ Supplemental Table S2.txt } \\
\hline & 688810 & 6.233 & 5.2454 & TRN & & \\
\hline CHEMBL1377656 & 688810 & 4.833 & 5.0271 & TST & & \\
\hline CHEMBL1303720 & 688810 & 5.683 & 5.3276 & TST & & \\
\hline CHEMBL1568261 & 688810 & \multicolumn{3}{|c|}{5.5329999999999995} & 5.008 & $\mathrm{TP}$ \\
\hline CHEMBL1300237 & 688810 & 5.733 & 5.8906 & TRN & & \\
\hline CHEMBL1591733 & 688810 & 5.033 & 5.1391 & TRN & & \\
\hline CHEMBL1304595 & 688810 & 5.233 & 5.1451 & TST & & \\
\hline CHEMBL1473832 & 688810 & \multicolumn{3}{|c|}{5.832999999999999} & 5.4695 & \\
\hline CHEMBL1384160 & 688810 & 5.733 & 5.4218 & TRN & & \\
\hline CHEMBL1424944 & 688810 & 5.083 & 4.7808 & TRN & & \\
\hline CHEMBL1501987 & 688810 & \multicolumn{3}{|c|}{4.7330000000000005} & 5.3706 & \\
\hline CHEMBL 3145365 & 688810 & 5.433 & $5.3544 \quad T$ & TRN & & \\
\hline CHEMBL1977007 & 688810 & \multicolumn{3}{|c|}{6.332999999999999} & 5.3539 & \\
\hline CHEMBL1514269 & 688810 & 4.883 & $5.0285 \quad T$ & TRN & & \\
\hline CHEMBL1524133 & 688810 & 5.483 & 5.4795 & TRN & & \\
\hline CHEMBL1480389 & 688810 & \multicolumn{3}{|c|}{ 5.332999999999999 } & 5.5976 & \\
\hline CHEMBL1561093 & 688810 & 5.233 & $5.2814 \quad T$ & TRN & & \\
\hline CHEMBL1431006 & 688810 & \multicolumn{3}{|c|}{5.132999999999999} & 4.9464 & \\
\hline CHEMBL 3211390 & 688810 & 4.783 & $5.0278 \quad T$ & TRN & & \\
\hline CHEMBL1335011 & 688810 & 4.883 & $4.9602 \quad T$ & TRN & & \\
\hline CHEMBL1385377 & 688810 & \multicolumn{3}{|c|}{5.132999999999999} & 5.2243 & \\
\hline CHEMBL1379264 & 688810 & \multicolumn{3}{|c|}{4.7330000000000005} & 5.2045 & \\
\hline CHEMBL1605979 & 688810 & 4.933 & 5.354 & TRN & & \\
\hline CHEMBL1604090 & 688810 & 4.633 & $4.4418 \quad T$ & TST & & \\
\hline CHEMBL1378232 & 688810 & \multicolumn{3}{|c|}{5.832999999999999} & 6.4383 & \\
\hline CHEMBL1494685 & 688810 & \multicolumn{3}{|c|}{6.0329999999999995} & & \\
\hline CHEMBL1452568 & 688810 & 4.833 & 4.7465 & TRN & & \\
\hline CHEMBL1599860 & 688810 & 4.583 & $4.9869 \quad T$ & TRN & & \\
\hline CHEMBL1314210 & 688810 & 5.033 & 5.16 & TST & & \\
\hline CHEMBL1441499 & 688810 & \multicolumn{3}{|c|}{5.832999999999999} & 5.5606 & \\
\hline CHEMBL1310341 & 688810 & 4.883 & $6.0478 \quad T$ & TRN & & \\
\hline CHEMBL1440093 & 688810 & 5.183 & 5.2218 & TRN & & \\
\hline CHEMBL1483381 & 688810 & 4.783 & $4.8863 \quad T$ & TST & & \\
\hline CHEMBL1317516 & 688810 & 5.483 & 4.8363 & TRN & & \\
\hline CHEMBL1419364 & 688810 & \multicolumn{3}{|c|}{5.382999999999999} & & \\
\hline CHEMBL3211092 & 688810 & \multicolumn{3}{|c|}{6.332999999999999} & 5.4369 & \\
\hline CHEMBL 14 & 688810 & \multicolumn{3}{|c|}{4.7330000000000005} & 5.1957 & \\
\hline CHEMBL1507935 & 688810 & 5.433 & 4.918 & TRN & & \\
\hline CHEMBL1560430 & 688810 & \multicolumn{3}{|c|}{5.332999999999999} & 5.621 & \\
\hline CHEMBL1399158 & 688810 & 4.783 & 4.8623 & TST & & \\
\hline CHEMBL1391287 & 688810 & \multicolumn{3}{|c|}{5.332999999999999} & 5.5557 & Th \\
\hline CHEMBL1303952 & 688810 & 4.783 & $4.9498 \quad T$ & TRN & & \\
\hline CHEMBL1315621 & 688810 & 4.883 & 5.1039 & TRN & & \\
\hline CHEMBL 3210931 & 688810 & 5.233 & 5.204 & TRN & & \\
\hline CHEMBL 3213036 & 688810 & \multicolumn{3}{|c|}{5.332999999999999} & 5.36 & $\mathrm{~T}$ \\
\hline CHEMBL1300423 & 688810 & 4.783 & $5.3074 \quad T$ & TRN & & \\
\hline CHEMBL1578377 & 688810 & 4.783 & $4.9547 \quad T$ & TRN & & \\
\hline CHEMBL1564670 & 688810 & 5.6329 & 9999999999 & & 4.9715 & \\
\hline
\end{tabular}




\begin{tabular}{|c|c|c|c|c|c|c|c|}
\hline \multicolumn{7}{|c|}{ Supplemental Table S2.txt } & \\
\hline CHEMBL 3192461 & 688810 & \multicolumn{3}{|c|}{5.7829999999999995} & 5.2122 & TST & \\
\hline CHEMBL1305561 & 688810 & 5.183 & 4.7993 & TRN & & & \\
\hline CHEMBL1345529 & 688810 & \multicolumn{3}{|c|}{4.7330000000000005} & 4.8716 & TST & \\
\hline CHEMBL1545015 & 688810 & 4.783 & 4.8759 & TRN & & & \\
\hline CHEMBL1397396 & 688810 & 4.633 & 4.7215 & TRN & & & \\
\hline CHEMBL 3189461 & 688810 & 5.233 & 5.2051 & TRN & & & \\
\hline CHEMBL1514421 & 688810 & 5.683 & 5.0899 & TRN & & & \\
\hline CHEMBL1513239 & 688810 & 4.833 & 4.9406 & TRN & & & \\
\hline CHEMBL1363806 & 688810 & \multicolumn{3}{|c|}{5.2829999999999995} & 5.2449 & TST & \\
\hline CHEMBL1411330 & 688810 & 6.233 & 5.9575 & TRN & & & \\
\hline CHEMBL1495849 & 688810 & 6.15 & 5.9665 & TRN & & & \\
\hline CHEMBL1600867 & 688810 & 6.9329 & 5.2047 & TRN & & & \\
\hline CHEMBL1608495 & 688810 & 4.783 & 5.4084 & TRN & & & \\
\hline CHEMBL1323331 & 688810 & 5.183 & 4.7066 & TRN & & & \\
\hline CHEMBL1323491 & 688810 & 6.4829 & 5.8563 & TST & & & \\
\hline CHEMBL1425227 & 688810 & \multicolumn{3}{|c|}{5.2829999999999995} & 5.0982 & TRN & \\
\hline CHEMBL1364467 & 688810 & 4.883 & 5.4494 & TRN & & & \\
\hline CHEMBL1991779 & 688810 & 7.0329 & 5.8679 & TRN & & & \\
\hline CHEMBL1376384 & 688810 & 5.683 & 4.9392 & TST & & & \\
\hline CHEMBL1323859 & 688810 & 4.633 & 5.5593 & TRN & & & \\
\hline CHEMBL1553193 & 688810 & \multicolumn{3}{|c|}{5.132999999999999} & 5.1123 & TRN & \\
\hline CHEMBL1450967 & 688810 & 5.483 & 5.0582 & TRN & & & \\
\hline CHEMBL3198796 & 688810 & \multicolumn{3}{|c|}{5.882999999999999} & 5.29799 & 9999999999 & TRN \\
\hline CHEMBL1549837 & 688810 & \multicolumn{3}{|c|}{5.132999999999999} & 5.1061 & TRN & \\
\hline CHEMBL1306817 & 688810 & \multicolumn{3}{|c|}{5.382999999999999} & 5.3232 & TRN & \\
\hline CHEMBL608673 & 688810 & \multicolumn{3}{|c|}{4.7330000000000005} & 5.0148 & TRN & \\
\hline CHEMBL1482872 & 688810 & \multicolumn{3}{|c|}{5.832999999999999} & 5.9243 & TRN & \\
\hline CHEMBL1585773 & 688810 & \multicolumn{3}{|c|}{6.5329999999999995} & 5.3563 & TRN & \\
\hline CHEMBL1538854 & 688810 & \multicolumn{3}{|c|}{6.2829999999999995} & 6.1946 & TRN & \\
\hline CHEMBL1345170 & 688810 & 5.433 & 5.4391 & TST & & & \\
\hline CHEMBL1316122 & 688810 & 4.583 & 4.8404 & TRN & & & \\
\hline CHEMBL1583953 & 688810 & \multicolumn{3}{|c|}{4.9830000000000005} & 5.4338 & TRN & \\
\hline CHEMBL1376879 & 688810 & 5.683 & 5.1778 & TRN & & & \\
\hline CHEMBL1576415 & 688810 & \multicolumn{3}{|c|}{4.7330000000000005} & 5.1374 & TRN & \\
\hline CHEMBL1356020 & 688810 & 4.633 & 5.0173 & TRN & & & \\
\hline CHEMBL1565771 & 688810 & 4.933 & 4.5907 & TRN & & & \\
\hline CHEMBL1579138 & 688810 & 5.183 & 4.8636 & TST & & & \\
\hline CHEMBL 1402936 & 688810 & \multicolumn{3}{|c|}{5.7829999999999995} & 5.6809 & TRN & \\
\hline CHEMBL1975473 & 688810 & \multicolumn{3}{|c|}{5.332999999999999} & 5.4154 & TST & \\
\hline CHEMBL1436697 & 688810 & \multicolumn{3}{|c|}{5.7829999999999995} & 5.4204 & TRN & \\
\hline CHEMBL1329407 & 688810 & \multicolumn{3}{|c|}{4.7330000000000005} & 5.2044 & TRN & \\
\hline CHEMBL1385668 & 688810 & \multicolumn{3}{|c|}{4.7330000000000005} & 5.2662 & TRN & \\
\hline CHEMBL1589640 & 688810 & 6.0 & 5.5014 & TRN & & & \\
\hline CHEMBL1374547 & 688810 & 5.433 & 5.5505 & TRN & & & \\
\hline CHEMBL1539929 & 688810 & 4.883 & 5.3457 & TRN & & & \\
\hline CHEMBL1428467 & 688810 & 4.833 & 5.2196 & TRN & & & \\
\hline CHEMBL1346543 & 688810 & 4.933 & 5.7026 & TRN & & & \\
\hline CHEMBL1550164 & 688810 & 4.783 & 4.9395 & TRN & & & \\
\hline
\end{tabular}




\begin{tabular}{|c|c|c|c|c|c|c|}
\hline \multirow[b]{2}{*}{ CHEMBL1591337 } & \multirow[b]{2}{*}{688810} & \multicolumn{5}{|c|}{ Supplemental Table S2.txt } \\
\hline & & 4.633 & 5.2973 & TST & & \\
\hline CHEMBL1455115 & 688810 & \multicolumn{3}{|c|}{5.132999999999999} & 5.3003 & TRN \\
\hline CHEMBL1421698 & 688810 & 4.883 & 5.2375 & TRN & & \\
\hline CHEMBL1427349 & 688810 & \multicolumn{3}{|c|}{5.7829999999999995} & 5.1368 & TRN \\
\hline CHEMBL1426651 & 688810 & \multicolumn{3}{|c|}{6.2829999999999995} & 5.4917 & TRN \\
\hline CHEMBL1524038 & 688810 & 5.733 & 5.5616 & TRN & & \\
\hline CHEMBL1403250 & 688810 & 6.7331 & 5.3436 & TRN & & \\
\hline CHEMBL1420018 & 688810 & \multicolumn{3}{|c|}{5.132999999999999} & 5.3008 & TRN \\
\hline CHEMBL1387597 & 688810 & 4.883 & 5.5703 & TRN & & \\
\hline CHEMBL1327159 & 688810 & 4.933 & 5.3827 & TST & & \\
\hline CHEMBL1355153 & 688810 & \multicolumn{3}{|c|}{4.9830000000000005} & 4.8668 & TRN \\
\hline CHEMBL1527546 & 688810 & \multicolumn{3}{|c|}{5.332999999999999} & 5.003 & TST \\
\hline CHEMBL1401239 & 688810 & \multicolumn{3}{|c|}{4.7330000000000005} & 5.3799 & TRN \\
\hline CHEMBL1414667 & 688810 & 4.883 & 5.0255 & TST & & \\
\hline CHEMBL1411528 & 688810 & \multicolumn{3}{|c|}{4.7330000000000005} & 4.9407 & TRN \\
\hline CHEMBL1506861 & 688810 & \multicolumn{3}{|c|}{4.7330000000000005} & 5.08 & TRN \\
\hline CHEMBL1394852 & 688810 & 4.883 & 5.0054 & TRN & & \\
\hline CHEMBL1372307 & 688810 & \multicolumn{3}{|c|}{6.582999999999999} & 5.5508 & TRN \\
\hline CHEMBL1995550 & 688810 & 4.633 & 5.4825 & TST & & \\
\hline CHEMBL1438512 & 688810 & 7.0329 & 5.9989 & TRN & & \\
\hline CHEMBL1345587 & 688810 & 4.833 & 5.1737 & TRN & & \\
\hline CHEMBL1429874 & 688810 & \multicolumn{3}{|c|}{5.332999999999999} & 5.2234 & TRN \\
\hline CHEMBL1448649 & 688810 & 4.833 & 5.2087 & TRN & & \\
\hline CHEMBL1412660 & 688810 & 5.683 & 5.0922 & TRN & & \\
\hline CHEMBL1493946 & 688810 & 4.833 & 5.1883 & TRN & & \\
\hline CHEMBL1471716 & 688810 & 4.783 & 5.39 & TRN & & \\
\hline CHEMBL1447731 & 688810 & 5.033 & 5.3248 & TRN & & \\
\hline CHEMBL1403950 & 688810 & \multicolumn{3}{|c|}{5.5329999999999995} & 5.3469 & TRN \\
\hline CHEMBL1456614 & 688810 & 4.783 & 5.6223 & TRN & & \\
\hline CHEMBL3198304 & 688810 & 5.933 & 5.4522 & TRN & & \\
\hline CHEMBL1383974 & 688810 & 4.833 & 5.3672 & TRN & & \\
\hline CHEMBL1572156 & 688810 & \multicolumn{3}{|c|}{5.882999999999999} & 5.7283 & TRN \\
\hline CHEMBL1605827 & 688810 & 4.883 & 5.0829 & TRN & & \\
\hline CHEMBL1437430 & 688810 & 4.633 & 4.7302 & TST & & \\
\hline CHEMBL1595208 & 688810 & 4.783 & 4.9944 & TRN & & \\
\hline CHEMBL1552522 & 688810 & 5.083 & 5.349 & TRN & & \\
\hline CHEMBL1389983 & 688810 & 4.833 & 5.3378 & TRN & & \\
\hline CHEMBL1513779 & 688810 & 4.833 & 4.6105 & TST & & \\
\hline CHEMBL1513086 & 688810 & 5.033 & 5.2044 & TRN & & \\
\hline CHEMBL1406674 & 688810 & 5.083 & 5.3862 & TST & & \\
\hline CHEMBL 2004241 & 688810 & 4.683 & \multicolumn{3}{|c|}{5.321000000000001} & TST \\
\hline CHEMBL1461721 & 688810 & 4.783 & 5.3096 & TST & & \\
\hline CHEMBL1599723 & 688810 & 4.583 & 5.3025 & TST & & \\
\hline CHEMBL1464966 & 688810 & 5.683 & 5.553 & TST & & \\
\hline CHEMBL1510845 & 688810 & \multicolumn{3}{|c|}{4.7330000000000005} & 5.2076 & TST \\
\hline CHEMBL1512806 & 688810 & 4.933 & 5.3485 & TRN & & \\
\hline CHEMBL1516855 & 688810 & 5.733 & 5.5897 & TRN & & \\
\hline CHEMBL1610042 & 688810 & 5.183 & 5.1526 & TRN & & \\
\hline
\end{tabular}




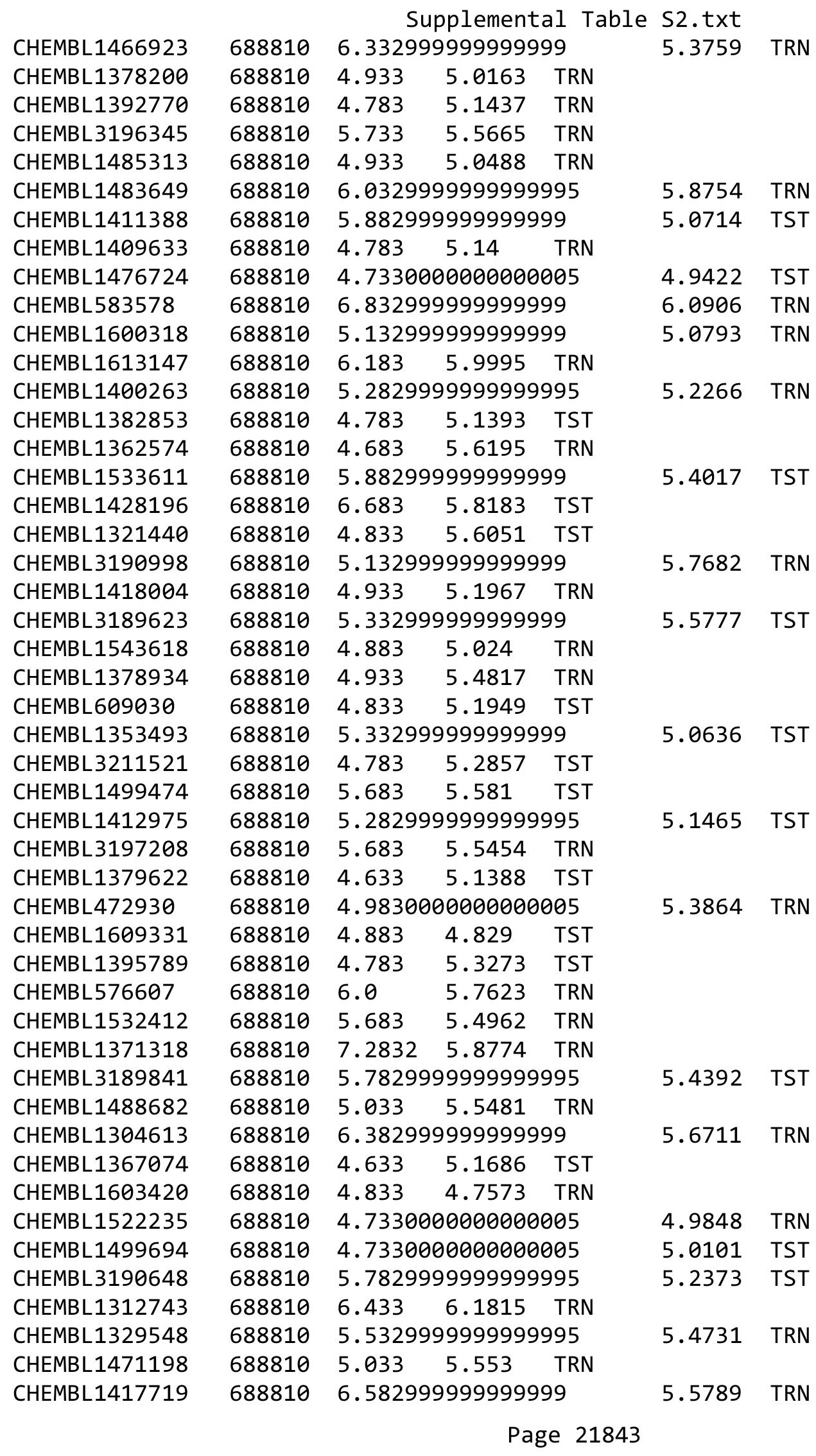




\begin{tabular}{|c|c|c|c|c|c|c|}
\hline & & \multicolumn{5}{|c|}{ Supplemental Table S2.txt } \\
\hline CHEMBL1384146 & 688810 & \multicolumn{3}{|c|}{5.382999999999999} & 5.7483 & TRN \\
\hline CHEMBL 3190871 & 688810 & 4.783 & 5.1834 & TRN & & \\
\hline CHEMBL234378 & 688810 & \multicolumn{3}{|c|}{7.082999999999999} & 6.2376 & TRN \\
\hline CHEMBL1580912 & 688810 & \multicolumn{3}{|c|}{4.7330000000000005} & 5.1663 & TRN \\
\hline CHEMBL1310979 & 688810 & 4.883 & 5.6224 & TRN & & \\
\hline CHEMBL1589526 & 688810 & 5.183 & 5.1993 & TRN & & \\
\hline CHEMBL3197532 & 688810 & 4.633 & 4.9221 & TRN & & \\
\hline CHEMBL1495283 & 688810 & 4.783 & 5.3178 & TRN & & \\
\hline CHEMBL1604071 & 688810 & \multicolumn{3}{|c|}{4.7330000000000005} & 5.4203 & TRN \\
\hline CHEMBL3210577 & 688810 & \multicolumn{3}{|c|}{5.5329999999999995} & 5.0974 & TST \\
\hline CHEMBL1540051 & 688810 & \multicolumn{3}{|c|}{6.2829999999999995} & 5.6046 & TRN \\
\hline CHEMBL1451362 & 688810 & 5.933 & 5.6319 & TRN & & \\
\hline CHEMBL1588256 & 688810 & 4.783 & 4.6362 & TRN & & \\
\hline CHEMBL1165229 & 688810 & 4.833 & 5.1913 & TRN & & \\
\hline CHEMBL1344186 & 688810 & 5.183 & 5.0306 & TRN & & \\
\hline CHEMBL1422087 & 688810 & \multicolumn{3}{|c|}{5.832999999999999} & 5.2115 & TST \\
\hline CHEMBL1987483 & 688810 & 5.033 & 4.8033 & TRN & & \\
\hline CHEMBL1480534 & 688810 & \multicolumn{3}{|c|}{5.832999999999999} & 5.6802 & TRN \\
\hline CHEMBL3192631 & 688810 & 4.833 & 5.1977 & TRN & & \\
\hline CHEMBL1364368 & 688810 & 4.883 & 5.2002 & TST & & \\
\hline CHEMBL1338979 & 688810 & 4.883 & 4.9807 & TRN & & \\
\hline CHEMBL1374870 & 688810 & \multicolumn{3}{|c|}{5.832999999999999} & 5.699 & TRN \\
\hline CHEMBL1534574 & 688810 & 5.033 & \multicolumn{3}{|c|}{5.787999999999999} & TRN \\
\hline CHEMBL1467432 & 688810 & 4.833 & 5.0899 & TRN & & \\
\hline CHEMBL1326613 & 688810 & \multicolumn{3}{|c|}{5.332999999999999} & 6.1101 & TRN \\
\hline CHEMBL1581665 & 688810 & \multicolumn{3}{|c|}{5.132999999999999} & 5.0542 & TRN \\
\hline CHEMBL1400068 & 688810 & 4.933 & 5.1492 & TRN & & \\
\hline CHEMBL1404986 & 688810 & \multicolumn{3}{|c|}{5.882999999999999} & 5.6537 & TRN \\
\hline CHEMBL1444328 & 688810 & 4.883 & 5.1991 & TST & & \\
\hline CHEMBL1534726 & 688810 & \multicolumn{3}{|c|}{4.7330000000000005} & 5.0798 & TST \\
\hline CHEMBL1490608 & 688810 & \multicolumn{3}{|c|}{5.132999999999999} & 4.5904 & TRN \\
\hline CHEMBL1555162 & 688810 & 5.033 & 5.1721 & TRN & & \\
\hline CHEMBL1376254 & 688810 & \multicolumn{3}{|c|}{5.2829999999999995} & 5.5152 & TST \\
\hline CHEMBL1359641 & 688810 & 4.833 & 5.2631 & TST & & \\
\hline CHEMBL1450732 & 688810 & 4.833 & 5.5245 & TST & & \\
\hline CHEMBL1518539 & 688810 & 4.833 & 5.1381 & TRN & & \\
\hline CHEMBL1386646 & 688810 & 5.233 & 5.4703 & TRN & & \\
\hline CHEMBL1333515 & 688810 & 6.4829 & 5.6328 & TRN & & \\
\hline CHEMBL3211735 & 688810 & 4.833 & 5.126 & TRN & & \\
\hline CHEMBL1428990 & 688810 & \multicolumn{3}{|c|}{5.7829999999999995} & 4.8586 & TRN \\
\hline CHEMBL1499800 & 688810 & 4.883 & 4.9326 & TRN & & \\
\hline CHEMBL1571450 & 688810 & 4.783 & 5.0628 & TRN & & \\
\hline CHEMBL1340302 & 688810 & 4.633 & 4.9193 & TRN & & \\
\hline CHEMBL1572146 & 688810 & \multicolumn{3}{|c|}{5.332999999999999} & 5.5141 & TRN \\
\hline CHEMBL1567895 & 688810 & 5.183 & 5.6498 & TRN & & \\
\hline CHEMBL3213939 & 688810 & 5.683 & 5.5461 & TRN & & \\
\hline CHEMBL1521159 & 688810 & 4.883 & \multicolumn{3}{|c|}{5.212000000000001} & TRN \\
\hline CHEMBL505057 & 688810 & 5.183 & 5.2358 & TRN & & \\
\hline
\end{tabular}




\begin{tabular}{|c|c|c|c|c|c|c|c|}
\hline \multirow{3}{*}{$\begin{array}{l}\text { CHEMBL1466240 } \\
\text { CHEMBL1489071 }\end{array}$} & & \\
\hline & 688810 & 5.033 & 5.4173 & TRN & & & \\
\hline & 688810 & \multicolumn{3}{|c|}{5.5329999999999995} & 5.5204 & TRN & \\
\hline CHEMBL1413633 & 688810 & 5.083 & 5.3053 & TRN & & & \\
\hline CHEMBL1408473 & 688810 & \multicolumn{3}{|c|}{5.2829999999999995} & 4.9109 & TRN & \\
\hline CHEMBL3192362 & 688810 & \multicolumn{3}{|c|}{6.582999999999999} & 5.7661 & TRN & \\
\hline CHEMBL1309627 & 688810 & \multicolumn{3}{|c|}{4.7330000000000005} & 5.3391 & TRN & \\
\hline CHEMBL1447684 & 688810 & \multicolumn{3}{|c|}{4.7330000000000005} & 5.5797 & TRN & \\
\hline CHEMBL3189437 & 688810 & 4.783 & 5.2009 & TRN & & & \\
\hline CHEMBL1555846 & 688810 & 6.183 & 5.1186 & TRN & & & \\
\hline CHEMBL1444680 & 688810 & 4.833 & 4.9815 & TRN & & & \\
\hline CHEMBL1506259 & 688810 & 4.783 & \multicolumn{3}{|c|}{5.297999999999999} & TRN & \\
\hline CHEMBL1367503 & 688810 & 4.833 & 5.9274 & TRN & & & \\
\hline CHEMBL1484137 & 688810 & 4.783 & 5.1614 & TST & & & \\
\hline CHEMBL1612197 & 688810 & 4.883 & 5.0459 & TST & & & \\
\hline CHEMBL1365929 & 688810 & 4.783 & 5.3273 & TRN & & & \\
\hline CHEMBL1506926 & 688810 & 5.233 & 6.2253 & TRN & & & \\
\hline CHEMBL1389236 & 688810 & 6.433 & 5.7209 & TRN & & & \\
\hline CHEMBL3208332 & 688810 & \multicolumn{3}{|c|}{5.5329999999999995} & 5.4265 & TRN & \\
\hline CHEMBL1518745 & 688810 & 5.033 & 5.5825 & TST & & & \\
\hline CHEMBL1309602 & 688810 & \multicolumn{3}{|c|}{4.9830000000000005} & 5.0478 & TRN & \\
\hline CHEMBL1584503 & 688810 & 4.833 & 4.9651 & TST & & & \\
\hline CHEMBL1330874 & 688810 & 5.483 & 6.057 & TRN & & & \\
\hline CHEMBL1410843 & 688810 & \multicolumn{3}{|c|}{4.7330000000000005} & 5.0462 & TRN & \\
\hline CHEMBL3198076 & 688810 & 4.833 & 5.1479 & TRN & & & \\
\hline CHEMBL1586404 & 688810 & 4.633 & 4.8342 & TST & & & \\
\hline CHEMBL1469032 & 688810 & 5.483 & 5.9026 & TRN & & & \\
\hline CHEMBL1528926 & 688810 & 5.483 & 5.5813 & TST & & & \\
\hline CHEMBL1330734 & 688810 & 4.883 & 4.998 & TRN & & & \\
\hline CHEMBL1613062 & 688810 & \multicolumn{3}{|c|}{4.7330000000000005} & 5.4236 & TRN & \\
\hline CHEMBL1543361 & 688810 & \multicolumn{3}{|c|}{5.882999999999999} & 5.6476 & TRN & \\
\hline CHEMBL1377970 & 688810 & 5.183 & 5.4262 & TRN & & & \\
\hline CHEMBL1326191 & 688810 & \multicolumn{3}{|c|}{5.332999999999999} & 5.3973 & TRN & \\
\hline CHEMBL1339208 & 688810 & 4.633 & 4.816 & TRN & & & \\
\hline CHEMBL1587121 & 688810 & 7.1831 & 5.2017 & TRN & & & \\
\hline CHEMBL3192307 & 688810 & 6.683 & 6.0501 & TRN & & & \\
\hline CHEMBL1516388 & 688810 & 5.483 & 5.5258 & TST & & & \\
\hline CHEMBL1581632 & 688810 & 5.033 & 5.3582 & TRN & & & \\
\hline CHEMBL1551288 & 688810 & \multicolumn{3}{|c|}{5.7829999999999995} & \multicolumn{2}{|c|}{5.053999999999999} & TST \\
\hline CHEMBL1401065 & 688810 & \multicolumn{3}{|c|}{4.7330000000000005} & 5.0301 & TRN & \\
\hline CHEMBL1557436 & 688810 & 4.783 & 5.2322 & TST & & & \\
\hline CHEMBL1332131 & 688810 & 4.833 & 5.8011 & TRN & & & \\
\hline CHEMBL1573657 & 688810 & 5.733 & 5.2633 & TRN & & & \\
\hline CHEMBL1490260 & 688810 & 4.783 & 5.3755 & TST & & & \\
\hline CHEMBL1308329 & 688810 & 4.783 & 4.8437 & TST & & & \\
\hline CHEMBL1465153 & 688810 & \multicolumn{3}{|c|}{5.582999999999999} & 5.4215 & TRN & \\
\hline CHEMBL1576399 & 688810 & \multicolumn{3}{|c|}{5.882999999999999} & 5.3542 & TRN & \\
\hline CHEMBL3199263 & 688810 & 5.733 & 5.0202 & TST & & & \\
\hline CHEMBL1345888 & 688810 & 5.483 & 5.41 & TRN & & & \\
\hline
\end{tabular}




\begin{tabular}{|c|c|c|c|c|c|c|}
\hline \multirow[b]{2}{*}{ CHEMBL1457453 } & \multirow[b]{2}{*}{688810} & \multicolumn{5}{|c|}{ Supplemental Table s2.txt } \\
\hline & & \multicolumn{3}{|c|}{$5.683 \quad 5.4564$ TRN } & & \\
\hline CHEMBL 3213011 & 688810 & 4.833 & 5.0187 & TRN & & \\
\hline CHEMBL3189243 & 688810 & \multicolumn{3}{|c|}{4.7330000000000005} & \multirow[t]{4}{*}{5.2465} & \multirow[t]{4}{*}{ TRN } \\
\hline CHEMBL1483966 & 688810 & 4.883 & 5.4849 & TRN & & \\
\hline CHEMBL1569862 & 688810 & 6.233 & 5.5316 & TRN & & \\
\hline CHEMBL1605871 & 688810 & 4.633 & 5.7664 & TRN & & \\
\hline CHEMBL1606385 & 688810 & \multicolumn{3}{|c|}{6.0329999999999995} & 5.811 & TRN \\
\hline CHEMBL1472013 & 688810 & 4.583 & 5.256 & TST & & \\
\hline CHEMBL568419 & 688810 & \multicolumn{3}{|c|}{5.332999999999999} & 5.9036 & TRN \\
\hline CHEMBL1524347 & 688810 & 5.683 & 5.6768 & TRN & & \\
\hline CHEMBL1362993 & 688810 & 4.833 & 5.3422 & TRN & & \\
\hline CHEMBL1325658 & 688810 & 6.9329 & 5.9375 & TRN & & \\
\hline CHEMBL1434180 & 688810 & 4.583 & 4.7029 & TRN & & \\
\hline CHEMBL1486960 & 688810 & 4.783 & 5.3521 & TRN & & \\
\hline CHEMBL1597569 & 688810 & \multicolumn{3}{|c|}{5.832999999999999} & 5.4281 & TRN \\
\hline CHEMBL1976304 & 688810 & 4.683 & 4.85 & TST & & \\
\hline CHEMBL1327912 & 688810 & \multicolumn{3}{|c|}{4.7330000000000005} & 5.0975 & TRN \\
\hline CHEMBL1532518 & 688810 & 4.833 & 5.6463 & TRN & & \\
\hline CHEMBL1352356 & 688810 & 4.783 & 4.9928 & TST & & \\
\hline CHEMBL1587805 & 688810 & \multicolumn{3}{|c|}{5.832999999999999} & 5.4502 & TST \\
\hline CHEMBL1571647 & 688810 & \multicolumn{3}{|c|}{5.132999999999999} & 5.9443 & TRN \\
\hline CHEMBL3190197 & 688810 & \multicolumn{3}{|c|}{5.132999999999999} & 4.7869 & TRN \\
\hline CHEMBL1344315 & 688810 & 5.083 & 5.3258 & TRN & & \\
\hline CHEMBL 3196227 & 688810 & \multicolumn{3}{|c|}{5.882999999999999} & 5.7047 & TRN \\
\hline CHEMBL1535829 & 688810 & 4.833 & 5.1074 & TST & & \\
\hline CHEMBL1553839 & 688810 & 4.583 & 5.0779 & TST & & \\
\hline CHEMBL1301332 & 688810 & 5.083 & 5.1578 & TRN & & \\
\hline CHEMBL1965587 & 688810 & \multicolumn{3}{|c|}{6.332999999999999} & 5.5605 & TRN \\
\hline CHEMBL1507930 & 688810 & 5.933 & 5.4293 & TRN & & \\
\hline CHEMBL1519452 & 688810 & 5.033 & 5.4127 & TRN & & \\
\hline CHEMBL1377067 & 688810 & \multicolumn{3}{|c|}{6.582999999999999} & 5.3856 & TRN \\
\hline CHEMBL1388469 & 688810 & 4.883 & 4.6757 & TRN & & \\
\hline CHEMBL1404458 & 688810 & 5.733 & 6.015 & TRN & & \\
\hline CHEMBL1990214 & 688810 & \multicolumn{3}{|c|}{6.332999999999999} & 5.7662 & TRN \\
\hline CHEMBL1608872 & 688810 & \multicolumn{3}{|c|}{4.7330000000000005} & 5.556 & TRN \\
\hline CHEMBL1302891 & 688810 & \multicolumn{3}{|c|}{5.882999999999999} & 6.0362 & TRN \\
\hline CHEMBL1571982 & 688810 & 4.583 & 5.0125 & TRN & & \\
\hline CHEMBL1387669 & 688810 & \multicolumn{3}{|c|}{4.7330000000000005} & 5.3256 & TRN \\
\hline CHEMBL1470289 & 688810 & 4.833 & 5.1519 & TRN & & \\
\hline CHEMBL1575747 & 688810 & 4.833 & 5.1474 & TRN & & \\
\hline CHEMBL1414244 & 688810 & 5.1329 & 99999999 & & 5.2517 & TRN \\
\hline CHEMBL1325574 & 688810 & 4.9830 & $\partial 0000000$ & 005 & 5.2548 & TRN \\
\hline CHEMBL1362146 & 688810 & 4.833 & 5.5283 & TRN & & \\
\hline CHEMBL 2004776 & 688810 & 4.633 & 5.0346 & TST & & \\
\hline CHEMBL1581902 & 688810 & 4.783 & 5.2777 & TRN & & \\
\hline CHEMBL1489005 & 688810 & 4.833 & 5.3426 & TRN & & \\
\hline CHEMBL1472101 & 688810 & 5.733 & 5.6079 & TRN & & \\
\hline CHEMBL1534635 & 688810 & 4.883 & 5.0293 & TST & & \\
\hline
\end{tabular}




\begin{tabular}{|c|c|c|c|c|c|c|c|}
\hline \multicolumn{7}{|c|}{ Supplemental Table S2.txt } & \\
\hline CHEMBL1512285 & 688810 & \multicolumn{3}{|c|}{5.632999999999999} & 5.2356 & TST & \\
\hline CHEMBL116569 & 688810 & 6.0 & 5.6046 & TRN & & & \\
\hline CHEMBL1375852 & 688810 & 4.633 & 5.1338 & TST & & & \\
\hline CHEMBL1575411 & 688810 & \multicolumn{3}{|c|}{6.132999999999999} & 5.459 & TRN & \\
\hline CHEMBL1493577 & 688810 & \multicolumn{3}{|c|}{6.382999999999999} & 5.6687 & TRN & \\
\hline CHEMBL1564522 & 688810 & \multicolumn{3}{|c|}{5.332999999999999} & 5.033 & TRN & \\
\hline CHEMBL3199686 & 688810 & \multicolumn{3}{|c|}{4.7330000000000005} & 4.9644 & TRN & \\
\hline CHEMBL1382550 & 688810 & \multicolumn{3}{|c|}{5.632999999999999} & 5.5425 & TRN & \\
\hline CHEMBL1350679 & 688810 & \multicolumn{3}{|c|}{4.7330000000000005} & 5.1561 & TRN & \\
\hline CHEMBL1431765 & 688810 & 4.933 & 5.1185 & TRN & & & \\
\hline CHEMBL1326180 & 688810 & 4.633 & 5.0396 & TST & & & \\
\hline CHEMBL1313338 & 688810 & 5.033 & 4.9771 & TST & & & \\
\hline CHEMBL1536708 & 688810 & \multicolumn{3}{|c|}{5.382999999999999} & 5.7001 & TRN & \\
\hline CHEMBL1448185 & 688810 & \multicolumn{3}{|c|}{4.7330000000000005} & 5.2136 & TRN & \\
\hline CHEMBL1304079 & 688810 & \multicolumn{3}{|c|}{5.2829999999999995} & 5.4088 & TRN & \\
\hline CHEMBL1353405 & 688810 & 4.833 & 5.2746 & TST & & & \\
\hline CHEMBL 2170108 & 688810 & \multirow{2}{*}{\multicolumn{3}{|c|}{$\begin{array}{lll}4.833 & 5.0383 \\
5.2829999999999995\end{array}$}} & & & \\
\hline CHEMBL1353989 & 688810 & & & & 5.7812 & TRN & \\
\hline CHEMBL1478602 & 688810 & 4.633 & 4.8821 & TRN & & & \\
\hline CHEMBL460518 & 688810 & \multicolumn{3}{|c|}{6.0329999999999995} & 5.7247 & TRN & \\
\hline CHEMBL1319859 & 688810 & \multicolumn{3}{|c|}{5.2829999999999995} & 4.7935 & TRN & \\
\hline CHEMBL1510561 & 688810 & 4.683 & 5.2508 & TRN & & & \\
\hline CHEMBL1309138 & 688810 & \multicolumn{3}{|c|}{5.5329999999999995} & 5.1877 & TRN & \\
\hline CHEMBL560073 & 688810 & 4.933 & 4.8811 & TRN & & & \\
\hline CHEMBL1553346 & 688810 & 5.033 & 4.8171 & TRN & & & \\
\hline CHEMBL3193833 & 688810 & 4.933 & 5.4157 & TRN & & & \\
\hline CHEMBL1329747 & 688810 & \multicolumn{3}{|c|}{5.382999999999999} & 5.2352 & TST & \\
\hline CHEMBL1571312 & 688810 & \multicolumn{3}{|c|}{4.7330000000000005} & 5.425 & TRN & \\
\hline CHEMBL 1353732 & 688810 & 5.233 & 5.4777 & TRN & & & \\
\hline CHEMBL1520393 & 688810 & \multicolumn{3}{|c|}{5.882999999999999} & \multicolumn{2}{|c|}{5.6610000000000005} & TRN \\
\hline CHEMBL1558094 & 688810 & 5.083 & 5.2623 & TRN & & & \\
\hline CHEMBL3195978 & 688810 & 5.183 & 5.4628 & TRN & & & \\
\hline CHEMBL1566781 & 688810 & \multicolumn{3}{|c|}{6.7829999999999995} & 5.9898 & TRN & \\
\hline CHEMBL1388677 & 688810 & \multicolumn{3}{|c|}{4.7330000000000005} & 5.1878 & TRN & \\
\hline CHEMBL1300302 & 688810 & 5.183 & 4.7998 & TRN & & & \\
\hline CHEMBL1548859 & 688810 & 4.7336 & 20000000 & 205 & 5.2360 & 0000000001 & TST \\
\hline CHEMBL1431832 & 688810 & 4.933 & 5.5512 & TRN & & & \\
\hline CHEMBL1300445 & 688810 & 5.233 & 5.1406 & TRN & & & \\
\hline CHEMBL1589781 & 688810 & $5.582 \mathrm{C}$ & 99999999 & & 5.6276 & TRN & \\
\hline CHEMBL1353266 & 688810 & 5.7825 & 99999999 & 995 & 5.3339 & TRN & \\
\hline CHEMBL1317527 & 688810 & 4.833 & 5.2682 & TRN & & & \\
\hline CHEMBL1546325 & 688810 & 5.532 & 99999999 & 995 & 5.4696 & TRN & \\
\hline CHEMBL1388292 & 688810 & 6.0325 & 99999999 & 995 & 5.5006 & TRN & \\
\hline CHEMBL1488810 & 688810 & $5.582 \mathrm{~s}$ & 99999999 & & 5.4358 & TRN & \\
\hline CHEMBL1458514 & 688810 & 5.282 & 99999999 & 995 & 5.3553 & TRN & \\
\hline CHEMBL1520222 & 688810 & 4.933 & 5.4006 & TRN & & & \\
\hline CHEMBL1331282 & 688810 & 4.833 & 5.3914 & TST & & & \\
\hline CHEMBL1448605 & 688810 & 5.632 & 99999999 & & 5.5836 & TST & \\
\hline
\end{tabular}




\begin{tabular}{|c|c|c|c|c|c|c|}
\hline & & \multicolumn{5}{|c|}{ Supplemental Table s2.txt } \\
\hline CHEMBL1887153 & 688810 & 5.683 & 5.5677 & TST & & \\
\hline CHEMBL3191914 & 688810 & 6.9329 & 5.3219 & TRN & & \\
\hline CHEMBL1458796 & 688810 & 5.183 & 4.8714 & TRN & & \\
\hline CHEMBL1983323 & 688810 & \multicolumn{3}{|c|}{6.332999999999999} & 5.5953 & TRN \\
\hline CHEMBL1603235 & 688810 & 4.883 & 5.0569 & TRN & & \\
\hline CHEMBL1415109 & 688810 & 4.783 & 5.0215 & TRN & & \\
\hline CHEMBL1528460 & 688810 & \multicolumn{3}{|c|}{5.882999999999999} & 5.3176 & TRN \\
\hline CHEMBL1329235 & 688810 & \multicolumn{3}{|c|}{5.2829999999999995} & 5.7887 & TRN \\
\hline CHEMBL3199016 & 688810 & \multicolumn{3}{|c|}{6.0329999999999995} & 6.0621 & TRN \\
\hline CHEMBL1987798 & 688810 & \multicolumn{3}{|c|}{5.832999999999999} & 6.3708 & TRN \\
\hline CHEMBL1348139 & 688810 & 5.683 & 5.1669 & TRN & & \\
\hline CHEMBL3195857 & 688810 & 5.183 & 5.3445 & TRN & & \\
\hline CHEMBL3197649 & 688810 & \multicolumn{3}{|c|}{5.382999999999999} & 5.147 & TRN \\
\hline CHEMBL1542584 & 688810 & 4.783 & 5.4907 & TRN & & \\
\hline CHEMBL1382405 & 688810 & 5.033 & 5.3459 & TRN & & \\
\hline CHEMBL1408146 & 688810 & \multicolumn{3}{|c|}{5.632999999999999} & 5.0566 & TRN \\
\hline CHEMBL1602759 & 688810 & 5.483 & 5.31 & TST & & \\
\hline CHEMBL1302196 & 688810 & 4.833 & 4.8961 & TRN & & \\
\hline CHEMBL1307327 & 688810 & 5.483 & 5.4582 & TRN & & \\
\hline CHEMBL3191307 & 688810 & 7.1831 & 5.4906 & TRN & & \\
\hline CHEMBL1532997 & 688810 & 4.833 & 5.4432 & TST & & \\
\hline CHEMBL1427279 & 688810 & 5.733 & \multicolumn{3}{|c|}{6.247000000000001} & TRN \\
\hline CHEMBL1418423 & 688810 & 5.033 & 4.8698 & TST & & \\
\hline CHEMBL1578017 & 688810 & 5.733 & 5.3382 & TRN & & \\
\hline CHEMBL17201 & 688810 & 4.683 & 5.3331 & TRN & & \\
\hline CHEMBL1378909 & 688810 & 5.233 & 5.0572 & TRN & & \\
\hline CHEMBL1503273 & 688810 & 5.233 & 5.4233 & TRN & & \\
\hline CHEMBL1486728 & 688810 & \multicolumn{3}{|c|}{6.082999999999999} & 5.7084 & TRN \\
\hline CHEMBL1428779 & 688810 & 4.783 & 5.1213 & TST & & \\
\hline CHEMBL236615 & 688810 & 5.433 & 5.8577 & TST & & \\
\hline CHEMBL3193883 & 688810 & 5.183 & 5.2759 & TST & & \\
\hline CHEMBL1604150 & 688810 & \multicolumn{3}{|c|}{4.9830000000000005} & 5.1922 & TRN \\
\hline CHEMBL1524345 & 688810 & 4.683 & 5.5883 & TRN & & \\
\hline CHEMBL1304773 & 688810 & 5.233 & 5.0092 & TRN & & \\
\hline CHEMBL1325039 & 688810 & 4.583 & 4.6456 & TST & & \\
\hline CHEMBL589507 & 688810 & \multicolumn{3}{|c|}{5.5329999999999995} & 5.6696 & TRN \\
\hline CHEMBL1412640 & 688810 & 4.783 & 5.3158 & TRN & & \\
\hline CHEMBL1369337 & 688810 & \multicolumn{3}{|c|}{4.7330000000000005} & 5.4671 & TST \\
\hline CHEMBL1310409 & 688810 & 5.683 & 5.2994 & TRN & & \\
\hline CHEMBL1587615 & 688810 & 4.783 & 5.1443 & TST & & \\
\hline CHEMBL1557044 & 688810 & 4.833 & 5.8487 & TRN & & \\
\hline CHEMBL1450961 & 688810 & 4.883 & 5.3348 & TST & & \\
\hline CHEMBL1412359 & 688810 & 4.833 & 4.815 & TRN & & \\
\hline CHEMBL1327780 & 688810 & 5.733 & 5.8851 & TRN & & \\
\hline CHEMBL1314849 & 688810 & \multicolumn{3}{|c|}{5.882999999999999} & 5.1299 & TRN \\
\hline CHEMBL1604747 & 688810 & 4.783 & 5.3766 & TRN & & \\
\hline CHEMBL1513301 & 688810 & 4.833 & 5.3715 & TRN & & \\
\hline CHEMBL1499893 & 688810 & 5.083 & 4.7555 & TRN & & \\
\hline
\end{tabular}




\begin{tabular}{|c|c|c|c|c|c|c|}
\hline & & \multicolumn{4}{|c|}{ Supplemental Table s2.txt } & \\
\hline CHEMBL 3189943 & 688810 & \multicolumn{3}{|c|}{6.332999999999999} & 5.6967 & TRN \\
\hline CHEMBL1538234 & 688810 & \multicolumn{3}{|c|}{5.2829999999999995} & 5.0817 & TRN \\
\hline CHEMBL1609565 & 688810 & 5.033 & 4.9536 & TRN & & \\
\hline CHEMBL1470647 & 688810 & \multicolumn{3}{|c|}{6.332999999999999} & 5.6168 & TRN \\
\hline CHEMBL1494264 & 688810 & 4.833 & 4.8666 & TST & & \\
\hline CHEMBL1374367 & 688810 & 7.2328 & 6.1094 & TRN & & \\
\hline CHEMBL1590202 & 688810 & \multicolumn{3}{|c|}{5.7829999999999995} & 5.0466 & TRN \\
\hline CHEMBL1599104 & 688810 & \multicolumn{3}{|c|}{5.7829999999999995} & 5.2804 & TRN \\
\hline CHEMBL1450563 & 688810 & \multicolumn{3}{|c|}{4.7330000000000005} & 5.0603 & TRN \\
\hline CHEMBL1416856 & 688810 & 5.033 & 5.0819 & TST & & \\
\hline CHEMBL1455243 & 688810 & 4.883 & 5.3786 & TRN & & \\
\hline CHEMBL1560667 & 688810 & \multicolumn{3}{|c|}{5.2829999999999995} & 5.5912 & TRN \\
\hline CHEMBL1533198 & 688810 & \multicolumn{3}{|c|}{6.0329999999999995} & 5.0208 & TRN \\
\hline CHEMBL1383800 & 688810 & 4.933 & 5.0216 & TRN & & \\
\hline CHEMBL585221 & 688810 & 4.783 & 5.5322 & TST & & \\
\hline CHEMBL1334307 & 688810 & \multicolumn{3}{|c|}{6.382999999999999} & 5.0742 & TST \\
\hline CHEMBL1503900 & 688810 & \multicolumn{3}{|c|}{6.382999999999999} & 5.4748 & TRN \\
\hline CHEMBL1502434 & 688810 & \multicolumn{3}{|c|}{4.9830000000000005} & 5.1608 & TST \\
\hline CHEMBL1346662 & 688810 & 4.783 & 5.2079 & TST & & \\
\hline CHEMBL1976161 & 688810 & \multicolumn{3}{|c|}{5.832999999999999} & 5.4154 & TRN \\
\hline CHEMBL1609787 & 688810 & 5.933 & 5.4413 & TRN & & \\
\hline CHEMBL1369469 & 688810 & 4.883 & 4.8563 & TRN & & \\
\hline CHEMBL1477502 & 688810 & 4.833 & \multicolumn{3}{|c|}{5.0089999999999995} & TRN \\
\hline CHEMBL1361020 & 688810 & 4.833 & 5.4616 & TST & & \\
\hline CHEMBL1317170 & 688810 & 4.583 & 4.7979 & TRN & & \\
\hline CHEMBL1503930 & 688810 & 6.433 & 5.8988 & TRN & & \\
\hline CHEMBL1594986 & 688810 & 4.683 & 5.2381 & TRN & & \\
\hline CHEMBL1476287 & 688810 & \multicolumn{3}{|c|}{6.5329999999999995} & 5.7335 & TRN \\
\hline CHEMBL1424062 & 688810 & 5.433 & 5.2245 & TRN & & \\
\hline CHEMBL1385464 & 688810 & 4.883 & 5.7674 & TRN & & \\
\hline CHEMBL1531233 & 688810 & 7.1331 & 5.8076 & TRN & & \\
\hline CHEMBL1490884 & 688810 & 4.783 & 5.1566 & TRN & & \\
\hline CHEMBL1549361 & 688810 & 5.683 & 5.4971 & TRN & & \\
\hline CHEMBL1545826 & 688810 & 5.733 & 4.9827 & TRN & & \\
\hline CHEMBL1404414 & 688810 & 6.183 & 5.8961 & TRN & & \\
\hline CHEMBL1448700 & 688810 & \multicolumn{3}{|c|}{4.9830000000000005} & 5.2471 & TST \\
\hline CHEMBL1426583 & 688810 & 4.883 & 5.2998 & TRN & & \\
\hline CHEMBL1981539 & 688810 & 4.833 & 4.8642 & TST & & \\
\hline CHEMBL1381446 & 688810 & \multicolumn{3}{|c|}{5.7829999999999995} & 5.4841 & TRN \\
\hline CHEMBL1494400 & 688810 & \multicolumn{3}{|c|}{4.7330000000000005} & 5.1064 & TRN \\
\hline CHEMBL1500521 & 688810 & 4.833 & 5.2582 & TRN & & \\
\hline CHEMBL1407926 & 688810 & 4.833 & 5.3932 & TST & & \\
\hline CHEMBL1256749 & 688810 & 4.633 & 5.0343 & TST & & \\
\hline CHEMBL1586053 & 688810 & \multicolumn{3}{|c|}{6.332999999999999} & 5.6159 & TRN \\
\hline CHEMBL1330614 & 688810 & 5.183 & 5.3408 & TRN & & \\
\hline CHEMBL1448047 & 688810 & 5.483 & 5.1522 & TRN & & \\
\hline CHEMBL1397626 & 688810 & 4.783 & 4.8252 & TRN & & \\
\hline CHEMBL1560825 & 688810 & 4.883 & 5.3042 & TST & & \\
\hline
\end{tabular}




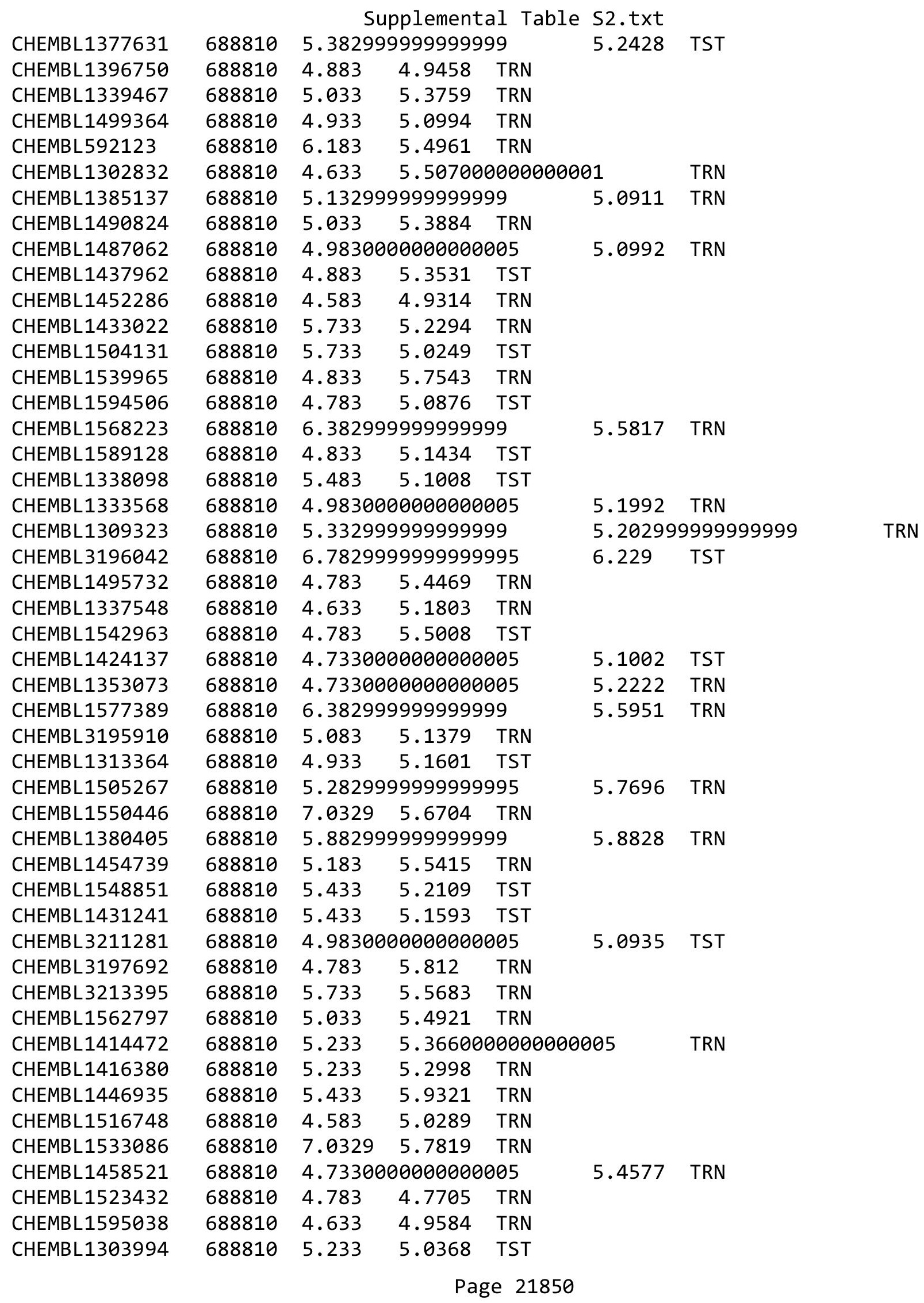




\begin{tabular}{|c|c|c|c|c|c|c|}
\hline & & & & \multirow{3}{*}{5.3133} & \multirow[b]{3}{*}{ TRN } \\
\hline CHEMBL1608424 & 688810 & \multirow{2}{*}{\multicolumn{3}{|c|}{$\begin{array}{lcc}4.833 & 5.3093 & \text { TST } \\
4.9830000000000005\end{array}$}} & & \\
\hline CHEMBL1521629 & 688810 & & & & & \\
\hline CHEMBL1318021 & 688810 & 5.083 & 4.8761 & TRN & & \\
\hline CHEMBL1354507 & 88810 & 4.783 & 4.8805 & TRN & & \\
\hline CHEMBL1602962 & 688810 & \multicolumn{3}{|c|}{5.2829999999999995} & 5.2758 & \\
\hline CHEMBL1385368 & 688810 & 5.433 & 5.2538 & TRN & & \\
\hline CHEMBL1452616 & 688810 & 4.933 & 5.2001 & TRN & & \\
\hline CHEMBL1412015 & 688810 & \multicolumn{3}{|c|}{5.7829999999999995} & 5.2964 & \\
\hline CHEMBL 1574218 & 688810 & 4.833 & 4.9137 & TST & & \\
\hline CHEMBL1567692 & 688810 & \multicolumn{3}{|c|}{6.082999999999999} & 5.4887 & \\
\hline CHEMBL1605203 & 688810 & 4.833 & 4.9795 & TRN & & \\
\hline CHEMBL1416824 & 688810 & \multicolumn{3}{|c|}{5.632999999999999} & 5.5953 & \\
\hline CHEMBL 3199417 & 688810 & 5.433 & \multicolumn{3}{|c|}{5.0489999999999995} & \\
\hline CHEMBL1601787 & 688810 & 4.833 & 4.9543 & TRN & & \\
\hline HEMBL1571696 & 688810 & 5.033 & 4.9651 & TRN & & \\
\hline CHEMBL1321657 & 688810 & 5.033 & 5.3288 & TRN & & \\
\hline CHEMBL1970135 & 688810 & 7.1331 & 6.3336 & TRN & & \\
\hline CHEMBL1556762 & 688810 & 4.783 & 5.4614 & TST & & \\
\hline CHEMBL1526855 & 688810 & 4.833 & 4.9396 & TST & & \\
\hline HEMBL1594576 & 688810 & 4.933 & 4.5944 & TRN & & \\
\hline CHEMBL1320874 & 688810 & \multicolumn{3}{|c|}{6.7829999999999995} & 5.6005 & \\
\hline CHEMBL1612046 & 688810 & \multicolumn{3}{|c|}{5.2829999999999995} & 5 . & \\
\hline CHEMBL1417353 & 688810 & 4.583 & 5.1607 & TRN & & \\
\hline CHEMBL1542889 & 688810 & 6.433 & 5.9241 & TRN & & \\
\hline HEMBL1501755 & 688810 & 4.583 & 4.4619 & TRN & & \\
\hline CHEMBL1605528 & 688810 & \multicolumn{3}{|c|}{5.882999999999999} & 5.5153 & \\
\hline CHEMBL1600720 & 688810 & \multicolumn{3}{|c|}{5.7829999999999995} & 5.6617 & \\
\hline CHEMBL1328952 & 688810 & \multicolumn{3}{|c|}{6.332999999999999} & 6.0055 & \\
\hline CHEMBL1353549 & 688810 & 4.783 & 5.2546 & TRN & & \\
\hline CHEMBL1613042 & 688810 & 5.483 & 5.3641 & TST & & \\
\hline CHEMBL1482673 & 688810 & 6.433 & 5.3639 & TRN & & \\
\hline CHEMBL1546458 & 688810 & \multicolumn{3}{|c|}{6.2829999999999995} & 5.4184 & \\
\hline CHEMBL1604484 & 688810 & 5.733 & 5.228 & TST & & \\
\hline CHEMBL1347505 & 688810 & \multicolumn{3}{|c|}{5.132999999999999} & 5.3621 & \\
\hline CHEMBL1 & 688810 & 5.483 & 5.4244 & TST & & \\
\hline CHEMBL1403877 & 688810 & \multicolumn{3}{|c|}{5.382999999999999} & 5.7923 & \\
\hline CHEMBL580609 & 688810 & 5.433 & 5.1131 & TRN & & \\
\hline CHEMBL 206483 & 688810 & 4.583 & 5.2654 & TRN & & \\
\hline CHEMBL1460250 & 688810 & \multicolumn{3}{|c|}{5.2829999999999995} & 5.3211 & \\
\hline CHEMBL1317412 & 688810 & 4.933 & 5.3066 & TRN & & \\
\hline CHEMBL1567836 & 688810 & \multicolumn{3}{|c|}{5.2829999999999995} & 5.5119 & \\
\hline CHEMBL1333418 & 688810 & 4.783 & 4.8488 & TRN & & \\
\hline CHEMBL 206778 & 688810 & 5.083 & 5.1944 & TRN & & \\
\hline CHEMBL1350145 & 688810 & \multicolumn{3}{|c|}{4.7330000000000005} & 5.3059 & \\
\hline CHEMBL1538973 & 688810 & 6.0 & 5.8872 & TRN & & \\
\hline CHEMBL1523069 & 688810 & 5.33299 & 999999999 & & 5.3637 & \\
\hline CHEMBL1421448 & 688810 & 5.13299 & 999999999 & & 5.4438 & \\
\hline CHEMBL1429665 & 688810 & 4.783 & 4.7784 & TRN & & \\
\hline
\end{tabular}




\begin{tabular}{|c|c|c|c|c|c|c|}
\hline \multirow[b]{2}{*}{ CHEMBL1325413 } & \multirow[b]{2}{*}{688810} & \multicolumn{5}{|c|}{ Supplemental Table S2.txt } \\
\hline & & 5.433 & 5.857 & TRN & & \\
\hline CHEMBL1521164 & 688810 & \multicolumn{3}{|c|}{5.582999999999999} & 5.1875 & TRN \\
\hline CHEMBL1477229 & 688810 & \multicolumn{3}{|c|}{4.7330000000000005} & 5.0312 & TST \\
\hline CHEMBL1506017 & 688810 & 5.033 & 5.5025 & TRN & & \\
\hline CHEMBL1441974 & 688810 & 4.883 & 5.0794 & TST & & \\
\hline CHEMBL446827 & 688810 & \multicolumn{3}{|c|}{5.2829999999999995} & 4.859 & TRN \\
\hline CHEMBL1604103 & 688810 & 5.733 & 5.6112 & TRN & & \\
\hline CHEMBL1484397 & 688810 & \multicolumn{3}{|c|}{5.382999999999999} & 5.4258 & TRN \\
\hline CHEMBL1303062 & 688810 & 5.083 & 5.0854 & TRN & & \\
\hline CHEMBL1321860 & 688810 & 4.933 & 5.0954 & TRN & & \\
\hline CHEMBL1594643 & 688810 & \multicolumn{3}{|c|}{5.332999999999999} & 5.0497 & TRN \\
\hline CHEMBL1601031 & 688810 & 6.233 & 5.1112 & TST & & \\
\hline CHEMBL1317596 & 688810 & \multicolumn{3}{|c|}{4.9830000000000005} & 4.7528 & TRN \\
\hline CHEMBL1478953 & 688810 & 4.633 & 4.8764 & TRN & & \\
\hline CHEMBL1553427 & 688810 & \multicolumn{3}{|c|}{5.832999999999999} & 5.5689 & TRN \\
\hline CHEMBL1357215 & 688810 & 5.683 & 5.0341 & TRN & & \\
\hline CHEMBL1467491 & 688810 & \multirow{2}{*}{\multicolumn{3}{|c|}{4.7330000000000005}} & & \\
\hline CHEMBL486078 & 688810 & & & & 5.1343 & TRN \\
\hline CHEMBL1424541 & 688810 & 5.183 & 5.1906 & TRN & & \\
\hline CHEMBL1409542 & 688810 & \multicolumn{3}{|c|}{4.7330000000000005} & 5.1861 & TRN \\
\hline CHEMBL1517210 & 688810 & \multicolumn{3}{|c|}{5.5329999999999995} & 5.4087 & TRN \\
\hline CHEMBL1500344 & 688810 & \multicolumn{3}{|c|}{4.7330000000000005} & 5.1965 & TRN \\
\hline CHEMBL1349122 & 688810 & 4.783 & 5.1807 & TST & & \\
\hline CHEMBL1302492 & 688810 & \multirow{2}{*}{\multicolumn{3}{|c|}{$\begin{array}{lcc}4.833 & 5.1306 & \text { TST } \\
4.7330000000000005\end{array}$}} & & \\
\hline CHEMBL1543194 & 688810 & & & & 5.1549 & TRN \\
\hline CHEMBL1613411 & 688810 & \multicolumn{2}{|c|}{4.7330000000000005} & TRN & & \\
\hline CHEMBL3213078 & 688810 & 4.883 & 5.1251 & TST & & \\
\hline CHEMBL1336874 & 688810 & 5.183 & 5.5597 & TRN & & \\
\hline CHEMBL1533634 & 688810 & 5.933 & 5.607 & TRN & & \\
\hline CHEMBL1523998 & 688810 & 5.933 & 5.0831 & TST & & \\
\hline CHEMBL1389725 & 688810 & 4.783 & 5.1158 & TRN & & \\
\hline CHEMBL1505324 & 688810 & 5.483 & 5.3779 & TRN & & \\
\hline CHEMBL1363932 & 688810 & 4.883 & 5.2338 & TST & & \\
\hline CHEMBL1541182 & 688810 & 6.433 & 5.7878 & TRN & & \\
\hline CHEMBL1574059 & 688810 & \multicolumn{3}{|c|}{5.332999999999999} & 5.7328 & TRN \\
\hline CHEMBL1475635 & 688810 & \multicolumn{3}{|c|}{4.7330000000000005} & 5.2305 & TRN \\
\hline CHEMBL1409407 & 688810 & \multicolumn{3}{|c|}{5.2829999999999995} & 5.2476 & TST \\
\hline CHEMBL1499803 & 688810 & \multicolumn{3}{|c|}{5.882999999999999} & 5.4117 & TRN \\
\hline CHEMBL1404179 & 688810 & \multicolumn{3}{|c|}{5.132999999999999} & 5.7357 & TRN \\
\hline CHEMBL1416951 & 688810 & 5.733 & 5.558 & TRN & & \\
\hline CHEMBL3189421 & 688810 & 4.783 & 4.9788 & TRN & & \\
\hline CHEMBL1492451 & 688810 & 4.7336 & 00000000 & 005 & 5.2801 & TST \\
\hline CHEMBL1565989 & 688810 & 4.933 & 5.3711 & TST & & \\
\hline CHEMBL1312337 & 688810 & 4.833 & 5.1107 & TRN & & \\
\hline CHEMBL1485680 & 688810 & 5.083 & 5.5111 & TRN & & \\
\hline CHEMBL1571631 & 688810 & 6.0325 & 99999999 & 995 & 5.6071 & TRN \\
\hline CHEMBL1396977 & 688810 & 5.1325 & 99999999 & & 6.0075 & TRN \\
\hline CHEMBL1573912 & 688810 & 4.7336 & 00000000 & 005 & 5.1749 & TST \\
\hline & & & & & & \\
\hline
\end{tabular}




\begin{tabular}{|c|c|c|c|c|c|c|c|}
\hline \multicolumn{8}{|c|}{ Supplemental Table s2.txt } \\
\hline CHEMBL1473678 & 688810 & 4.633 & 5.1628 & TRN & & & \\
\hline CHEMBL1479324 & 688810 & 4.883 & 5.1709 & TRN & & & \\
\hline CHEMBL3191217 & 688810 & 6.183 & 5.9183 & TRN & & & \\
\hline CHEMBL 2004449 & 688810 & \multicolumn{3}{|c|}{6.7829999999999995} & \multicolumn{3}{|c|}{5.9166 TRN } \\
\hline CHEMBL1496195 & 688810 & \multicolumn{3}{|c|}{5.7829999999999995} & \multicolumn{2}{|c|}{6.178999999999999} & TRN \\
\hline CHEMBL1422015 & 688810 & \multicolumn{3}{|c|}{5.5329999999999995} & 5.4166 & TRN & \\
\hline CHEMBL1466675 & 688810 & 5.683 & 5.159 & TRN & & & \\
\hline CHEMBL1577562 & 688810 & \multicolumn{3}{|c|}{5.5329999999999995} & 5.5841 & TRN & \\
\hline CHEMBL1313722 & 688810 & 6.0 & 4.4976 & TST & & & \\
\hline CHEMBL3208898 & 688810 & 4.783 & 5.394 & TRN & & & \\
\hline CHEMBL1545245 & 688810 & 5.233 & 5.2303 & TST & & & \\
\hline CHEMBL1556786 & 688810 & 7.1331 & 5.9409 & TRN & & & \\
\hline CHEMBL1301453 & 688810 & \multicolumn{3}{|c|}{4.7330000000000005} & 4.7734 & TST & \\
\hline CHEMBL 3211158 & 688810 & 5.683 & 6.1597 & TRN & & & \\
\hline CHEMBL1337663 & 688810 & 5.183 & 5.29899 & 999999999 & 995 & TRN & \\
\hline CHEMBL1554101 & 688810 & 4.583 & 5.2195 & TRN & & & \\
\hline CHEMBL1501288 & 688810 & 5.483 & 5.4172 & TST & & & \\
\hline CHEMBL1491862 & 688810 & 4.783 & 5.1328 & TRN & & & \\
\hline CHEMBL1507868 & 688810 & \multicolumn{3}{|c|}{5.332999999999999} & 5.3661 & TRN & \\
\hline CHEMBL1411391 & 688810 & 5.683 & 5.2197 & TRN & & & \\
\hline CHEMBL1481638 & 688810 & 4.933 & 5.5611 & TRN & & & \\
\hline CHEMBL1486025 & 688810 & 5.25 & 5.4073 & TRN & & & \\
\hline CHEMBL1328189 & 688810 & 4.583 & 5.3005 & TRN & & & \\
\hline CHEMBL3191054 & 688810 & 4.933 & 5.0706 & TST & & & \\
\hline CHEMBL3211551 & 688810 & 4.633 & 5.4537 & TST & & & \\
\hline CHEMBL1494672 & 688810 & 4.933 & 5.5717 & TST & & & \\
\hline CHEMBL1419219 & 688810 & \multicolumn{3}{|c|}{6.382999999999999} & 6.0302 & TRN & \\
\hline CHEMBL1310104 & 688810 & 5.083 & 4.9367 & TST & & & \\
\hline CHEMBL1559011 & 688810 & 4.833 & 5.7358 & TRN & & & \\
\hline CHEMBL1399455 & 688810 & 4.933 & 5.1708 & TRN & & & \\
\hline CHEMBL1301591 & 688810 & 4.833 & 5.5718 & TRN & & & \\
\hline CHEMBL1596571 & 688810 & \multicolumn{3}{|c|}{4.7330000000000005} & 5.2995 & TST & \\
\hline CHEMBL1345947 & 688810 & 5.683 & 5.2493 & TRN & & & \\
\hline CHEMBL1567111 & 688810 & 4.933 & 5.5913 & TST & & & \\
\hline CHEMBL1499955 & 688810 & \multicolumn{3}{|c|}{4.7330000000000005} & \multicolumn{2}{|c|}{4.928999999999999} & TRN \\
\hline CHEMBL1484953 & 688810 & 5.183 & 4.931 & TRN & & & \\
\hline CHEMBL1443657 & 688810 & 4.633 & 4.7308 & TST & & & \\
\hline CHEMBL3194782 & 688810 & 4.883 & 5.5798 & TST & & & \\
\hline CHEMBL1329009 & 688810 & \multicolumn{3}{|c|}{5.832999999999999} & \multicolumn{2}{|c|}{5.4479999999999995} & TST \\
\hline CHEMBL1391475 & 688810 & \multirow{2}{*}{\multicolumn{3}{|c|}{$\begin{array}{l}4.7330000000000005 \\
5.5329999999999995\end{array}$}} & 5.4856 & TST & \\
\hline CHEMBL1305282 & 688810 & & & & 5.6211 & TRN & \\
\hline CHEMBL1328299 & 688810 & 5.7 & 5.4532 & TRN & & & \\
\hline CHEMBL1429992 & 688810 & 4.783 & 5.0896 & TRN & & & \\
\hline CHEMBL3199631 & 688810 & 4.783 & 5.6441 & TRN & & & \\
\hline CHEMBL1478847 & 688810 & 4.883 & 4.9744 & TRN & & & \\
\hline CHEMBL1502747 & 688810 & 5.683 & 5.7475 & TRN & & & \\
\hline CHEMBL1510392 & 688810 & 4.783 & 5.0703 & TRN & & & \\
\hline CHEMBL1501931 & 688810 & 4.883 & 4.9516 & TST & & & \\
\hline
\end{tabular}




\begin{tabular}{|c|c|c|c|c|c|c|}
\hline & & & pplement & al la & $32.0 \times 2$ & \\
\hline CHEMBL16312 & 688810 & 5.233 & 5.7814 & TRN & & \\
\hline CHEMBL1316551 & 688810 & 5.33299 & 99999999 & 99 & 5.2927 & TST \\
\hline CHEMBL1449349 & 688810 & 4.98300 & 00000000 & 005 & 5.1588 & TRN \\
\hline CHEMBL1588285 & 688810 & 5.933 & 5.4527 & TST & & \\
\hline CHEMBL1478262 & 688810 & 5.78299 & 99999999 & 995 & 5.2422 & TRN \\
\hline CHEMBL1606557 & 688810 & 4.73300 & 00000000 & 005 & 4.7604 & TRN \\
\hline CHEMBL1520039 & 688810 & 4.783 & 5.1 & TRN & & \\
\hline CHEMBL1521425 & 688810 & 4.683 & 4.9911 & TRN & & \\
\hline CHEMBL1529882 & 688810 & 5.83299 & 99999999 & & 5.4835 & TRN \\
\hline CHEMBL1535053 & 688810 & 5.483 & 4.9117 & TRN & & \\
\hline CHEMBL3192913 & 688810 & 6.03299 & 99999999 & 995 & 5.6177 & TRN \\
\hline CHEMBL1545690 & 688810 & 4.883 & 5.1836 & TST & & \\
\hline CHEMBL1392157 & 688810 & 4.98300 & 20000000 & 005 & 5.4669 & TRN \\
\hline CHEMBL1499437 & 688810 & 4.73300 & 00000000 & 005 & 5.4651 & TRN \\
\hline CHEMBL1442242 & 688810 & 4.73300 & 00000000 & 005 & 4.8733 & TRN \\
\hline CHEMBL3192082 & 688810 & 5.13299 & 99999999 & 99 & 5.295 & TRN \\
\hline CHEMBL1353514 & 688810 & 4.73300 & 20000000 & 005 & 4.9199 & TRN \\
\hline CHEMBL1469931 & 688810 & 4.783 & 5.2234 & TST & & \\
\hline CHEMBL1428274 & 688810 & 4.633 & 5.194 & TST & & \\
\hline CHEMBL1502544 & 688810 & 6.63299 & 99999999 & & 5.6416 & TRN \\
\hline CHEMBL1476717 & 688810 & 4.933 & 5.3622 & TRN & & \\
\hline CHEMBL1509778 & 688810 & 5.483 & 5.7194 & TRN & & \\
\hline CHEMBL1548869 & 688810 & 4.633 & 5.7425 & TRN & & \\
\hline CHEMBL578890 & 688810 & 4.633 & 5.1548 & TRN & & \\
\hline CHEMBL2005079 & 688810 & 5.033 & 5.7397 & TST & & \\
\hline CHEMBL1518603 & 688810 & 5.683 & 5.3177 & TRN & & \\
\hline CHEMBL1339871 & 688810 & 6.63299 & 99999999 & & 5.7906 & TRN \\
\hline CHEMBL1402332 & 688810 & 6.0 & 4.7746 & TRN & & \\
\hline CHEMBL1353319 & 688810 & 4.933 & 4.9204 & TST & & \\
\hline CHEMBL3189604 & 688810 & 4.883 & 5.1667 & TRN & & \\
\hline CHEMBL1522343 & 688810 & 4.833 & 4.9058 & TST & & \\
\hline CHEMBL3213317 & 688810 & 5.78299 & 99999999 & 995 & 5.1544 & TRN \\
\hline CHEMBL1331465 & 688810 & 4.883 & 5.5607 & TRN & & \\
\hline CHEMBL1301861 & 688810 & 5.433 & 5.0477 & TRN & & \\
\hline CHEMBL3193579 & 688810 & 4.583 & 5.3743 & TRN & & \\
\hline CHEMBL1586427 & 688810 & 5.78299 & 99999999 & 995 & 5.5338 & TST \\
\hline CHEMBL1479666 & 688810 & 5.13299 & 99999999 & & 5.1951 & TRN \\
\hline CHEMBL1353698 & 688810 & 4.98300 & 20000000 & 005 & 5.3734 & TRN \\
\hline CHEMBL1444290 & 688810 & 4.73300 & 00000000 & 005 & 4.9804 & TRN \\
\hline CHEMBL1446899 & 688810 & 4.783 & 5.029 & TRN & & \\
\hline CHEMBL1551327 & 688810 & 4.833 & 4.8285 & TRN & & \\
\hline CHEMBL1414503 & 688810 & 5.733 & 5.4198 & TRN & & \\
\hline CHEMBL1461612 & 688810 & 4.833 & 5.1677 & TST & & \\
\hline CHEMBL1349408 & 688810 & 5.58299 & 99999999 & & 5.3077 & TST \\
\hline CHEMBL1603011 & 688810 & 4.73300 & 30000000 & 005 & 5.4096 & TRN \\
\hline CHEMBL1302809 & 688810 & 4.933 & 5.4348 & TST & & \\
\hline CHEMBL1582665 & 688810 & 7.2328 & 6.2176 & TRN & & \\
\hline CHEMBL1446163 & 688810 & 4.833 & 5.5028 & TRN & & \\
\hline
\end{tabular}




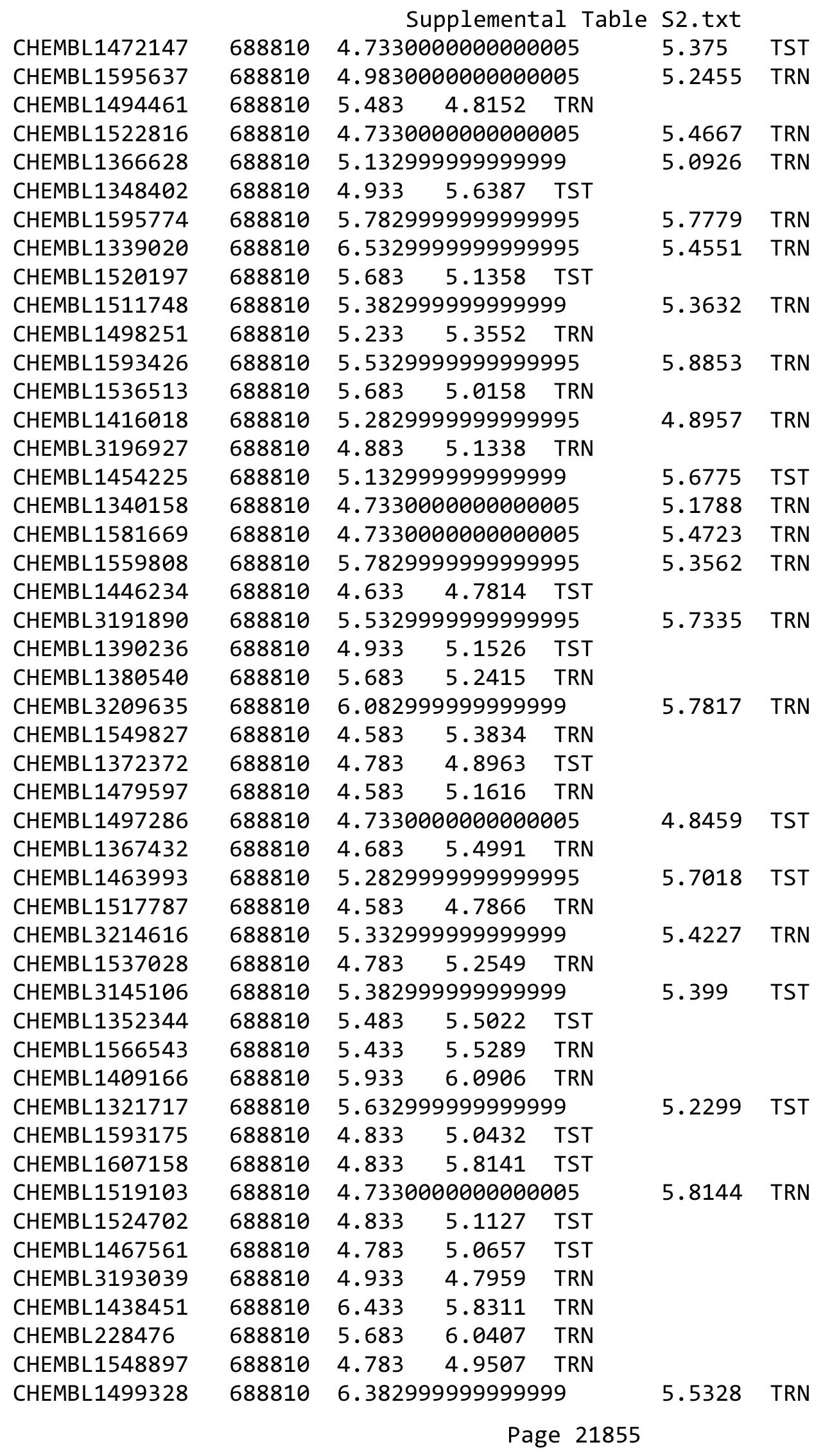




\begin{tabular}{|c|c|c|c|c|c|c|}
\hline \multirow{3}{*}{$\begin{array}{l}\text { CHEMBL1377778 } \\
\text { CHEMBL1582411 }\end{array}$} & \multicolumn{5}{|c|}{ Supplemental Table S2.txt } & \multirow[b]{2}{*}{ TRN } \\
\hline & 688810 & \multicolumn{3}{|c|}{5.2829999999999995} & \multirow[t]{2}{*}{5.6916} & \\
\hline & 688810 & 4.933 & 5.3821 & TST & & \\
\hline CHEMBL1488229 & 688810 & \multicolumn{3}{|c|}{6.0329999999999995} & 5.5234 & TRN \\
\hline CHEMBL1609144 & 688810 & 5.033 & 4.923 & TRN & & \\
\hline CHEMBL1546374 & 688810 & \multicolumn{3}{|c|}{5.7829999999999995} & 5.5831 & TST \\
\hline CHEMBL1505738 & 688810 & 5.183 & 5.0671 & TRN & & \\
\hline CHEMBL3208320 & 688810 & 4.933 & 4.9581 & TST & & \\
\hline CHEMBL1353663 & 688810 & \multicolumn{3}{|c|}{6.2829999999999995} & 5.7027 & TRN \\
\hline CHEMBL1587181 & 688810 & 4.883 & 4.7376 & TST & & \\
\hline CHEMBL1372050 & 688810 & 6.233 & 5.7269 & TRN & & \\
\hline CHEMBL1455867 & 688810 & \multicolumn{3}{|c|}{5.832999999999999} & 5.5235 & TRN \\
\hline CHEMBL1406441 & 688810 & 5.983 & 5.6829 & TRN & & \\
\hline CHEMBL3192440 & 688810 & 4.783 & 5.1679 & TRN & & \\
\hline CHEMBL1521680 & 688810 & 5.983 & 5.7474 & TRN & & \\
\hline CHEMBL1452620 & 688810 & \multicolumn{3}{|c|}{4.7330000000000005} & 5.3027 & TRN \\
\hline CHEMBL1513214 & 688810 & 4.583 & 4.8006 & TRN & & \\
\hline CHEMBL1386779 & 688810 & \multicolumn{3}{|c|}{6.132999999999999} & \multicolumn{2}{|c|}{5.7379999999999995} \\
\hline CHEMBL1569176 & 688810 & \multicolumn{3}{|c|}{5.7829999999999995} & 5.1954 & TST \\
\hline CHEMBL1511217 & 688810 & 6.183 & 5.0401 & TRN & & \\
\hline CHEMBL1498258 & 688810 & 4.883 & 4.9181 & TRN & & \\
\hline CHEMBL3196671 & 688810 & \multicolumn{3}{|c|}{4.9830000000000005} & 5.1634 & TRN \\
\hline CHEMBL1430056 & 688810 & 5.233 & 5.2513 & TRN & & \\
\hline CHEMBL1308108 & 688810 & \multicolumn{3}{|c|}{4.7330000000000005} & 5.2514 & TRN \\
\hline CHEMBL1392208 & 688810 & 5.45 & 5.439 & TRN & & \\
\hline CHEMBL1607804 & 688810 & 5.683 & 5.4527 & TRN & & \\
\hline CHEMBL1554253 & 688810 & 4.883 & 5.0296 & TRN & & \\
\hline CHEMBL1363769 & 688810 & \multicolumn{3}{|c|}{5.5329999999999995} & 5.0421 & TRN \\
\hline CHEMBL1341853 & 688810 & 5.433 & 4.868 & TST & & \\
\hline CHEMBL1610255 & 688810 & 5.033 & 5.0639 & TRN & & \\
\hline CHEMBL1540929 & 688810 & \multicolumn{3}{|c|}{5.582999999999999} & 5.2085 & TRN \\
\hline CHEMBL1602701 & 688810 & 5.483 & 5.0015 & TRN & & \\
\hline CHEMBL1543238 & 688810 & \multicolumn{3}{|c|}{5.332999999999999} & 6.5808 & TRN \\
\hline CHEMBL1406761 & 688810 & \multicolumn{3}{|c|}{5.132999999999999} & 5.0578 & TRN \\
\hline CHEMBL1466749 & 688810 & \multicolumn{3}{|c|}{5.2829999999999995} & 5.2441 & TRN \\
\hline CHEMBL1583823 & 688810 & \multicolumn{3}{|c|}{4.7330000000000005} & 5.1413 & TRN \\
\hline CHEMBL1555923 & 688810 & 5.433 & 5.3709 & TRN & & \\
\hline CHEMBL1352160 & 688810 & & 5.2641 & TRN & & \\
\hline CHEMBL1553089 & 688810 & 5.83299 & 99999999 & & 5.0194 & TRN \\
\hline CHEMBL1517444 & 688810 & 4.883 & 5.1888 & TST & & \\
\hline CHEMBL1578879 & 688810 & 6.53299 & 99999999 & 995 & 5.9639 & TRN \\
\hline CHEMBL1347404 & 688810 & 5.13299 & 99999999 & & 5.4158 & TRN \\
\hline CHEMBL1563193 & 688810 & 5.233 & 5.5874 & TRN & & \\
\hline CHEMBL1556429 & 688810 & 4.883 & 5.5231 & TRN & & \\
\hline CHEMBL1412954 & 688810 & 5.83299 & 99999999 & 99 & 5.0806 & TRN \\
\hline CHEMBL1516572 & 688810 & 5.233 & 5.1537 & TRN & & \\
\hline CHEMBL1425629 & 688810 & 5.53299 & 99999999 & 995 & 5.1714 & TRN \\
\hline CHEMBL1526740 & 688810 & 4.883 & 5.4287 & TRN & & \\
\hline CHEMBL1321432 & 688810 & 4.933 & 5.62299 & 999999999 & & TRN \\
\hline
\end{tabular}




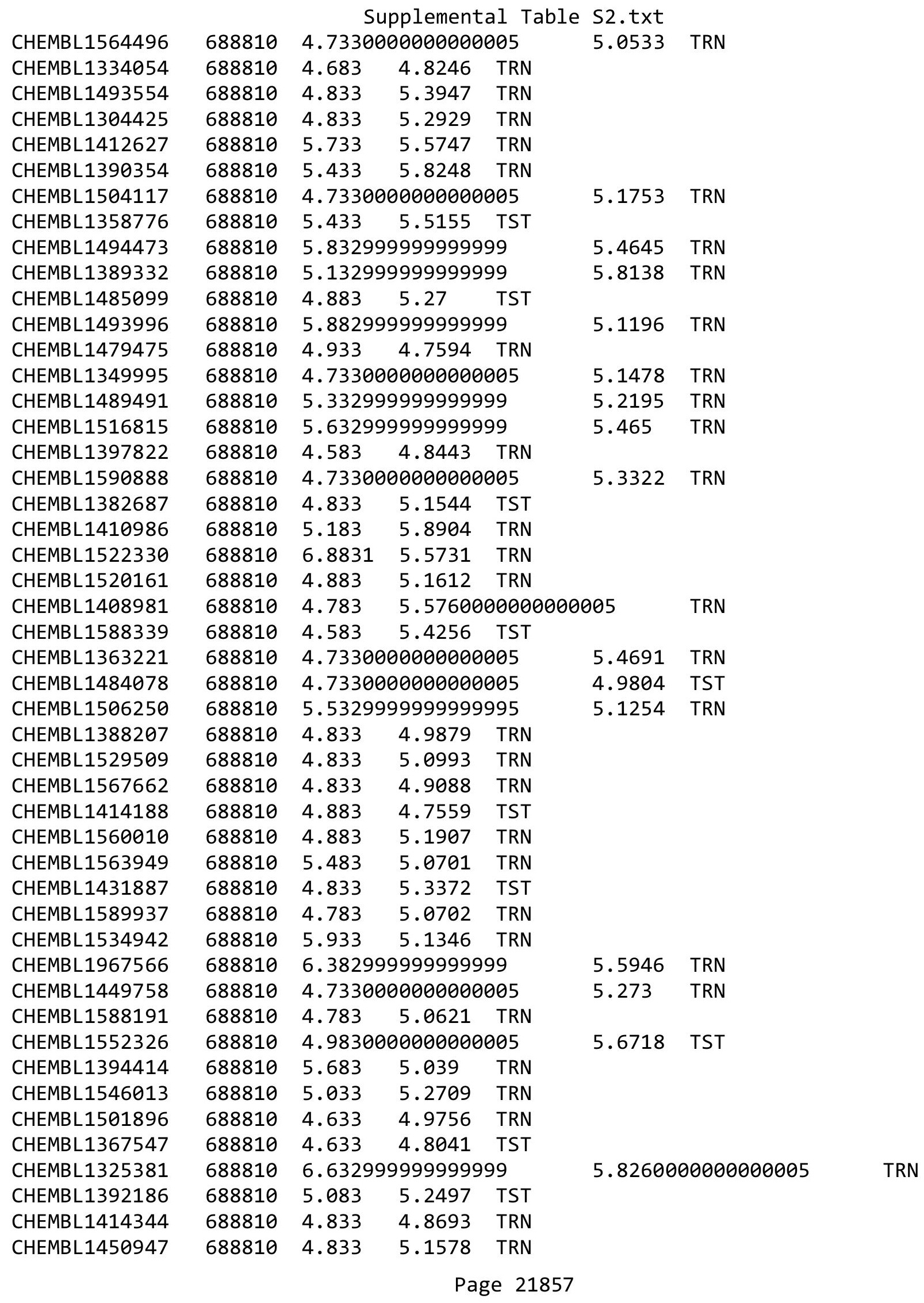




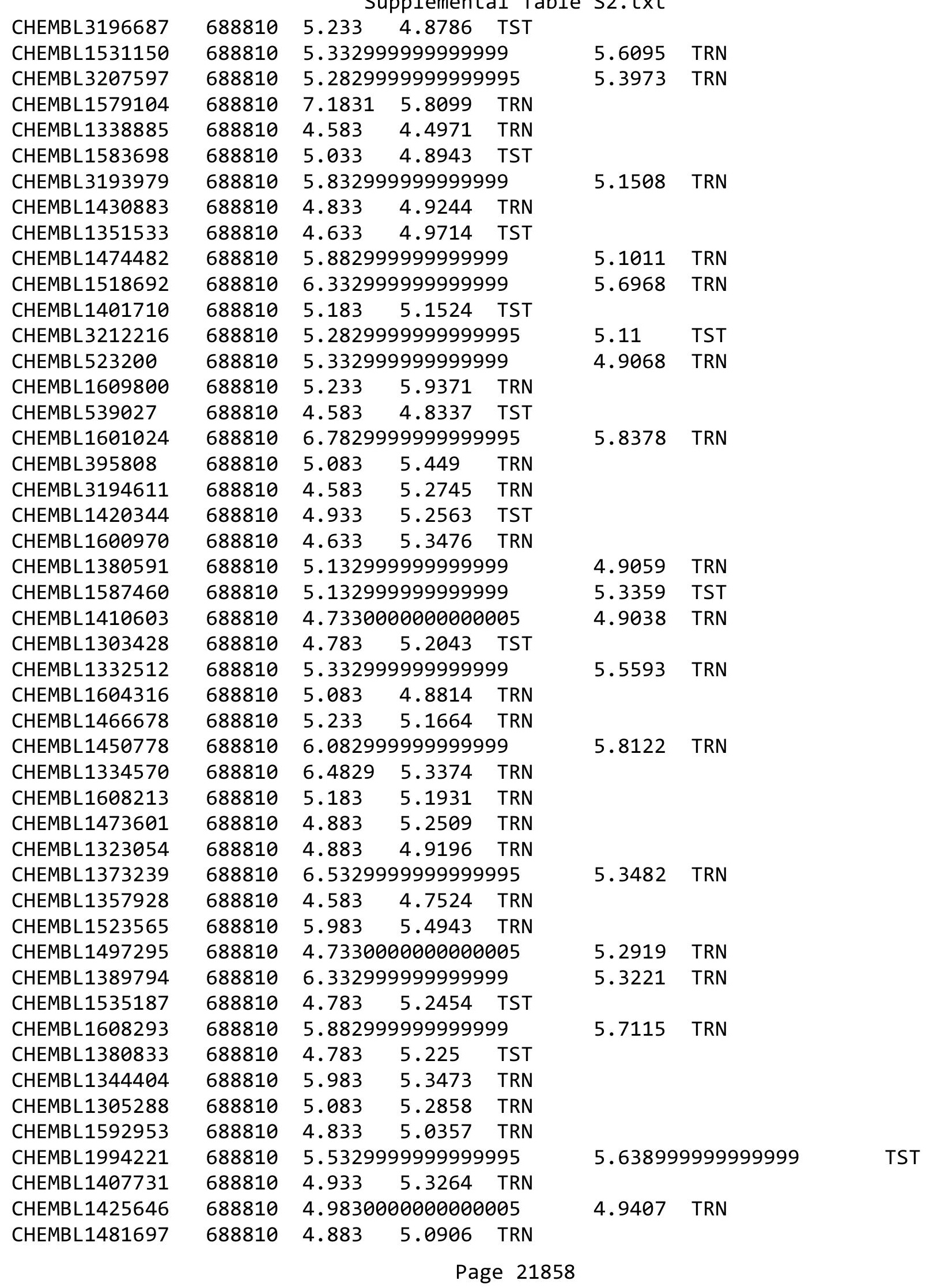




\begin{tabular}{|c|c|c|c|c|c|c|c|}
\hline \multicolumn{8}{|c|}{ Supplemental Table S2.txt } \\
\hline CHEMBL1493060 & 688810 & 4.783 & 4.7775 & TRN & & & \\
\hline CHEMBL1511314 & 688810 & 5.083 & 5.2356 & TRN & & & \\
\hline CHEMBL1528986 & 688810 & 4.783 & 5.7066 & TRN & & & \\
\hline CHEMBL1481795 & 688810 & 4.833 & 5.7928 & TST & & & \\
\hline CHEMBL1382288 & 688810 & 6.183 & 5.5082 & TRN & & & \\
\hline CHEMBL1305530 & 688810 & 4.883 & 5.0422 & TST & & & \\
\hline CHEMBL1305415 & 688810 & 5.183 & 5.426 & TST & & & \\
\hline CHEMBL1572929 & 688810 & 5.433 & 5.4449 & TRN & & & \\
\hline CHEMBL1428758 & 688810 & 4.783 & 4.8714 & TRN & & & \\
\hline CHEMBL1448637 & 688810 & \multicolumn{3}{|c|}{5.382999999999999} & 5.6022 & TRN & \\
\hline CHEMBL1476812 & 688810 & \multicolumn{3}{|c|}{4.7330000000000005} & 4.9223 & TRN & \\
\hline CHEMBL1497430 & 688810 & \multicolumn{3}{|c|}{5.832999999999999} & 5.4945 & TRN & \\
\hline CHEMBL1366941 & 688810 & \multicolumn{3}{|c|}{6.382999999999999} & 5.131 & TRN & \\
\hline CHEMBL1373092 & 688810 & 4.683 & 4.8357 & TRN & & & \\
\hline CHEMBL1575201 & 688810 & 5.183 & 5.5852 & TRN & & & \\
\hline CHEMBL1391054 & 688810 & \multicolumn{3}{|c|}{4.7330000000000005} & 5.1794 & TRN & \\
\hline CHEMBL1478551 & 688810 & 4.833 & 5.118 & TRN & & & \\
\hline CHEMBL1308359 & 688810 & 4.933 & 5.3569 & TRN & & & \\
\hline CHEMBL1344763 & 688810 & 4.633 & 5.4823 & TRN & & & \\
\hline CHEMBL1380874 & 688810 & \multicolumn{3}{|c|}{4.7330000000000005} & 5.1237 & TRN & \\
\hline CHEMBL1595747 & 688810 & \multicolumn{3}{|c|}{6.7829999999999995} & 5.4114 & TRN & \\
\hline CHEMBL1562836 & 688810 & 4.833 & 5.1915 & TRN & & & \\
\hline CHEMBL1370183 & 688810 & 4.583 & 4.8851 & TRN & & & \\
\hline CHEMBL1461376 & 688810 & 4.783 & 4.96 & TRN & & & \\
\hline CHEMBL1465554 & 688810 & 4.583 & 4.9367 & TRN & & & \\
\hline CHEMBL1422329 & 688810 & \multicolumn{3}{|c|}{6.2829999999999995} & 5.7044 & TRN & \\
\hline CHEMBL1989372 & 688810 & 6.183 & 6.0657 & TRN & & & \\
\hline CHEMBL3199616 & 688810 & 4.883 & 5.0649 & TRN & & & \\
\hline CHEMBL1424822 & 688810 & \multicolumn{3}{|c|}{5.832999999999999} & \multirow{2}{*}{\multicolumn{2}{|c|}{5.372999999999999}} & TST \\
\hline CHEMBL1548674 & 688810 & 4.783 & 5.2975 & TRN & & & \\
\hline CHEMBL1391266 & 688810 & \multicolumn{3}{|c|}{5.882999999999999} & 5.1927 & TRN & \\
\hline CHEMBL1551941 & 688810 & \multicolumn{3}{|c|}{4.7330000000000005} & 4.8205 & TRN & \\
\hline CHEMBL1338706 & 688810 & 4.883 & 5.3568 & TST & & & \\
\hline CHEMBL1303102 & 688810 & 5.483 & 5.2732 & TRN & & & \\
\hline CHEMBL1507205 & 688810 & 4.783 & 5.7596 & TST & & & \\
\hline CHEMBL1330331 & 688810 & \multicolumn{3}{|c|}{6.132999999999999} & 5.3149 & TRN & \\
\hline CHEMBL1558676 & 688810 & 4.9 & 5.2241 & TST & & & \\
\hline CHEMBL1393551 & 688810 & \multirow{2}{*}{\multicolumn{3}{|c|}{ 5.632999999999999 }} & & & \\
\hline CHEMBL1440520 & 688810 & & & & 5.9008 & TRN & \\
\hline CHEMBL1349139 & 688810 & 4.933 & 5.1596 & TRN & & & \\
\hline CHEMBL1436429 & 688810 & 4.583 & 5.0507 & TRN & & & \\
\hline CHEMBL1405497 & 688810 & 4.933 & 5.1205 & TRN & & & \\
\hline CHEMBL1575371 & 688810 & 4.683 & 5.2918 & TRN & & & \\
\hline CHEMBL1476194 & 688810 & 4.583 & 4.6576 & TRN & & & \\
\hline CHEMBL1364845 & 688810 & \multicolumn{3}{|c|}{5.2829999999999995} & 5.5867 & TRN & \\
\hline CHEMBL1379858 & 688810 & 5.183 & 5.1362 & TRN & & & \\
\hline CHEMBL3195204 & 688810 & 5.483 & 5.4988 & TRN & & & \\
\hline CHEMBL1328321 & 688810 & 4.633 & 5.4073 & TRN & & & \\
\hline
\end{tabular}




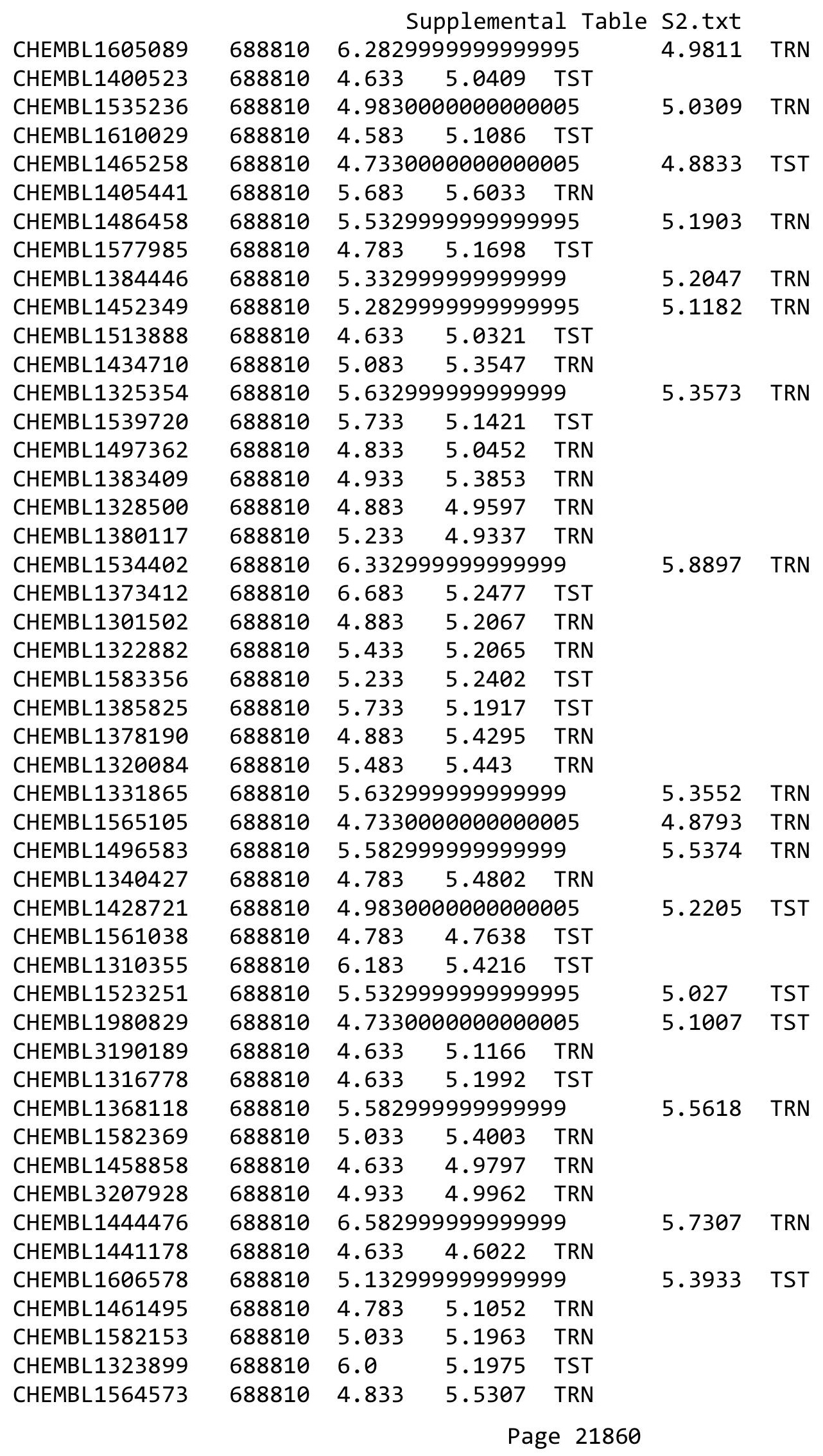




\begin{tabular}{|c|c|c|c|c|c|c|}
\hline & & \multicolumn{5}{|c|}{ Supplemental Table s2.txt } \\
\hline CHEMBL1535519 & 688810 & 5.233 & 5.7764 & TRN & & \\
\hline CHEMBL1967031 & 688810 & 7.1831 & 5.7109 & TRN & & \\
\hline CHEMBL1561797 & 688810 & 6.63299 & 999999999 & 99 & 5.7874 & T1 \\
\hline CHEMBL1316782 & 688810 & 4.583 & 4.9437 & TST & & \\
\hline CHEMBL1445924 & 688810 & 4.73300 & 000000000 & 005 & 4.9648 & \\
\hline CHEMBL1564250 & 688810 & 5.233 & 5.4429 & TST & & \\
\hline CHEMBL1400852 & 688810 & 4.73300 & 000000006 & 005 & 5.3379 & \\
\hline CHEMBL1613284 & 688810 & 5.13299 & 999999999 & 99 & 5.1273 & \\
\hline CHEMBL1571703 & 688810 & 5.733 & 4.9042 & TRN & & \\
\hline CHEMBL1312917 & 688810 & 5.033 & 4.7279 & TRN & & \\
\hline CHEMBL1515302 & 688810 & 4.98300 & 000000006 & 005 & 5.0136 & \\
\hline CHEMBL1426536 & 688810 & 5.733 & 5.7821 & TRN & & \\
\hline CHEMBL1583952 & 688810 & 5.433 & 5.5208 & TRN & & \\
\hline CHEMBL1458590 & 688810 & 5.13299 & 999999999 & & 3.45 & \\
\hline CHEMBL1410128 & 688810 & 5.78299 & 999999999 & 995 & 5.5587 & \\
\hline CHEMBL1447193 & 688810 & 5.233 & 5.146 & TRN & & \\
\hline CHEMBL1391983 & 688810 & 5.183 & 4.9352 & TRN & & \\
\hline CHEMBL1580401 & 688810 & 4.683 & 5.6027 & TST & & \\
\hline CHEMBL1300674 & 688810 & 4.933 & 5.3013 & TRN & & \\
\hline CHEMBL1424478 & 688810 & 5.53299 & 999999999 & 995 & 5.2404 & \\
\hline CHEMBL1346027 & 688810 & 5.28299 & 999999999 & 995 & 5.2368 & \\
\hline CHEMBL1520939 & 688810 & 5.78299 & 999999999 & 995 & 5.6795 & \\
\hline CHEMBL1562027 & 688810 & 4.833 & 5.3592 & TRN & & \\
\hline CHEMBL1540905 & $68 \varepsilon$ & 4.833 & 5.2451 & TST & & \\
\hline CHEMBL1493865 & 688810 & 4.783 & 5.157999 & 999999 & 995 & \\
\hline CHEMBL1560408 & 688810 & 4.783 & 5.17 & TST & & \\
\hline CHEMBL1569643 & 688810 & 6.433 & 5.8267 & TRN & & \\
\hline CHEMBL1371559 & 688810 & 4.583 & 5.1725 & TST & & \\
\hline CHEMBL1586872 & 688810 & 5.28299 & 999999999 & 995 & 5.2268 & \\
\hline CHEMBL1426107 & 688810 & 6.78299 & 999999999 & 995 & 5.8296 & \\
\hline CHEMBL1557640 & 688810 & 4.633 & 4.9774 & TST & & \\
\hline CHEMBL1305920 & 688810 & 4.73300 & 000000000 & 005 & 5.0364 & \\
\hline CHEMBL1591041 & 688810 & 4.783 & 4.9318 & TRN & & \\
\hline CHEMBL1594984 & 688810 & 5.88299 & 999999999 & & 5.4923 & II \\
\hline CHEMBL1327226 & 688810 & 4.73300 & 000000000 & 005 & 5.2359 & \\
\hline CHEMBL1511433 & 688810 & 4.833 & 5.2679 & TRN & & \\
\hline CHEMBL1447246 & 688810 & 4.783 & 4.7161 & TRN & & \\
\hline CHEMBL1555437 & 688810 & 5.033 & 5.1135 & TST & & \\
\hline CHEMBL1575512 & 688810 & 4.883 & 5.2783 & TST & & \\
\hline CHEMBL 3198507 & 688810 & 5.683 & 5.6916 & TRN & & \\
\hline CHEMBL1391837 & 688810 & 5.13299 & 999999999 & & 5.0476 & $T 0$ \\
\hline CHEMBL1489582 & 688810 & 4.933 & 5.0703 & TST & & \\
\hline CHEMBL3190653 & 688810 & 6.983 & 6.1752 & TRN & & \\
\hline CHEMBL1543297 & 688810 & 4.73300 & 000000000 & 005 & 5.3623 & \\
\hline CHEMBL1568694 & 688810 & 4.933 & 5.3435 & TST & & \\
\hline CHEMBL 3212392 & 688810 & 5.13299 & 999999999 & & 5.1653 & \\
\hline CHEMBL1547325 & 688810 & 4.833 & 5.0765 & TRN & & \\
\hline CHEMBL1339707 & 688810 & 6.08299 & 999999999 & 99 & 5.4941 & \\
\hline
\end{tabular}




\begin{tabular}{|c|c|c|c|c|c|c|}
\hline \multicolumn{7}{|c|}{ Supplemental Table S2.txt } \\
\hline CHEMBL1495321 & 688810 & 4.933 & \multicolumn{3}{|c|}{5.093999999999999} & TRN \\
\hline CHEMBL1361913 & 688810 & 4.833 & 4.9852 & TST & & \\
\hline CHEMBL1523375 & 688810 & \multicolumn{3}{|c|}{6.2829999999999995} & 5.487 & TRN \\
\hline CHEMBL1465489 & 688810 & 4.883 & 5.4221 & TRN & & \\
\hline CHEMBL1548996 & 688810 & 4.783 & 5.2015 & TST & & \\
\hline CHEMBL1332674 & 688810 & 4.783 & 5.0109 & TRN & & \\
\hline CHEMBL3199104 & 688810 & \multicolumn{3}{|c|}{5.632999999999999} & 5.5645 & TRN \\
\hline CHEMBL1308510 & 688810 & 4.883 & 5.1473 & TRN & & \\
\hline CHEMBL1306775 & 688810 & 5.183 & 5.6642 & TRN & & \\
\hline CHEMBL1406632 & 688810 & 4.783 & 5.2945 & TST & & \\
\hline CHEMBL1466899 & 688810 & \multicolumn{3}{|c|}{6.332999999999999} & 5.875 & TRN \\
\hline CHEMBL1421022 & 688810 & \multicolumn{3}{|c|}{6.0329999999999995} & 5.1017 & TRN \\
\hline CHEMBL1576663 & 688810 & \multicolumn{3}{|c|}{5.332999999999999} & 5.2583 & TRN \\
\hline CHEMBL1507389 & 688810 & 6.4829 & 5.4406 & TRN & & \\
\hline CHEMBL1406911 & 688810 & 4.933 & 5.4654 & TRN & & \\
\hline CHEMBL1353396 & 688810 & \multicolumn{3}{|c|}{6.2829999999999995} & 5.7558 & TRN \\
\hline CHEMBL1321292 & 688810 & 5.683 & 5.0891 & TRN & & \\
\hline CHEMBL3196538 & 688810 & 6.183 & 5.6759 & TST & & \\
\hline CHEMBL1442118 & 688810 & 5.033 & 5.1014 & TST & & \\
\hline CHEMBL1602694 & 688810 & \multicolumn{3}{|c|}{5.5329999999999995} & 5.2693 & TRN \\
\hline CHEMBL1411818 & 688810 & 5.083 & 5.705 & TRN & & \\
\hline CHEMBL 2002046 & 688810 & 5.033 & 5.0095 & TST & & \\
\hline CHEMBL1523369 & 688810 & 6.433 & 5.3194 & TST & & \\
\hline CHEMBL1464317 & 688810 & \multicolumn{3}{|c|}{5.382999999999999} & 4.8112 & TST \\
\hline CHEMBL1400143 & 688810 & 6.433 & 6.1373 & TRN & & \\
\hline CHEMBL1475937 & 688810 & \multicolumn{3}{|c|}{5.5329999999999995} & 5.0144 & TRN \\
\hline CHEMBL1446039 & 688810 & \multicolumn{3}{|c|}{6.332999999999999} & 6.0317 & TRN \\
\hline CHEMBL1603553 & 688810 & \multicolumn{3}{|c|}{6.132999999999999} & 5.7951 & TRN \\
\hline CHEMBL1415528 & 688810 & \multicolumn{3}{|c|}{4.9830000000000005} & 5.3453 & TST \\
\hline CHEMBL1563725 & 688810 & \multicolumn{3}{|c|}{6.132999999999999} & 5.2524 & TRN \\
\hline CHEMBL1494905 & 688810 & \multicolumn{3}{|c|}{6.332999999999999} & 5.0701 & TRN \\
\hline CHEMBL1363938 & 688810 & \multicolumn{3}{|c|}{5.7829999999999995} & 5.3152 & TRN \\
\hline CHEMBL1580053 & 688810 & 4.933 & 4.9704 & TRN & & \\
\hline CHEMBL1339341 & 688810 & 5.733 & \multicolumn{3}{|c|}{5.236000000000001} & TRN \\
\hline CHEMBL1492119 & 688810 & \multicolumn{3}{|c|}{5.5329999999999995} & 6.0911 & TRN \\
\hline CHEMBL1533576 & 688810 & 4.783 & 5.48600 & 0000000001 & & TST \\
\hline CHEMBL 1499053 & 688810 & \multicolumn{3}{|c|}{4.7330000000000005} & 5.66700 & 0000000001 \\
\hline CHEMBL1474843 & 688810 & \multicolumn{3}{|c|}{5.332999999999999} & 5.9663 & TRN \\
\hline CHEMBL1483900 & 688810 & 4.833 & 4.9457 & TRN & & \\
\hline CHEMBL1388137 & 688810 & \multirow{2}{*}{\multicolumn{3}{|c|}{$\begin{array}{l}5.033 \\
4.9830000000000005\end{array}$}} & & \\
\hline CHEMBL1571190 & 688810 & & & & 5.3073 & TST \\
\hline CHEMBL1315971 & 688810 & 5.033 & 4.842 & TRN & & \\
\hline CHEMBL1541308 & 688810 & 4.783 & 5.4258 & TRN & & \\
\hline CHEMBL1973785 & 688810 & 4.883 & 5.2912 & TRN & & \\
\hline CHEMBL1372333 & 688810 & 6.78299 & 99999999 & 995 & 6.0476 & TRN \\
\hline CHEMBL1531589 & 688810 & 4.583 & 4.9598 & TST & & \\
\hline CHEMBL1459475 & 688810 & 4.73300 & 00000000 & 005 & 4.9782 & TST \\
\hline
\end{tabular}




\begin{tabular}{|c|c|c|c|c|c|c|c|}
\hline CHEMBL1433882 & 688810 & 4.583 & 4.9133 & TRN & & & \\
\hline CHEMBL1570928 & 688810 & \multicolumn{3}{|c|}{5.132999999999999} & 4.9925 & TRN & \\
\hline CHEMBL3212329 & 688810 & 4.633 & 5.4855 & TRN & & & \\
\hline CHEMBL1330799 & 688810 & 4.883 & 5.859 & TRN & & & \\
\hline CHEMBL1392604 & 688810 & 4.883 & 5.1727 & TST & & & \\
\hline CHEMBL1552543 & 688810 & \multicolumn{3}{|c|}{5.332999999999999} & 5.3196 & TRN & \\
\hline CHEMBL1317227 & 688810 & 4.783 & 5.2522 & TST & & & \\
\hline CHEMBL1485287 & 688810 & 5.683 & 5.472 & TRN & & & \\
\hline CHEMBL1377126 & 688810 & \multicolumn{3}{|c|}{5.132999999999999} & 5.4214 & TRN & \\
\hline CHEMBL1585578 & 688810 & 4.783 & 5.4405 & TST & & & \\
\hline CHEMBL1438836 & 688810 & 5.733 & 5.6461 & TRN & & & \\
\hline CHEMBL1309260 & 688810 & \multicolumn{3}{|c|}{6.832999999999999} & 5.8335 & TRN & \\
\hline CHEMBL1536914 & 688810 & 5.183 & 5.3761 & TRN & & & \\
\hline CHEMBL1352987 & 688810 & 5.983 & 5.5785 & TRN & & & \\
\hline CHEMBL1459865 & 688810 & \multicolumn{3}{|c|}{4.7330000000000005} & 5.5091 & TRN & \\
\hline CHEMBL1374433 & 688810 & 5.733 & 5.7716 & TST & & & \\
\hline CHEMBL1322844 & 688810 & 5.483 & 5.2787 & TRN & & & \\
\hline CHEMBL1359029 & 688810 & \multicolumn{3}{|c|}{6.632999999999999} & 5.6025 & TRN & \\
\hline CHEMBL3195227 & 688810 & 4.833 & 5.1046 & TRN & & & \\
\hline CHEMBL1503751 & 688810 & 5.433 & 5.3251 & TRN & & & \\
\hline CHEMBL1453235 & 688810 & \multicolumn{3}{|c|}{6.082999999999999} & 5.2806 & TRN & \\
\hline CHEMBL1492524 & 688810 & \multicolumn{3}{|c|}{6.7829999999999995} & 5.9338 & TRN & \\
\hline CHEMBL1561605 & 688810 & 4.883 & 5.4526 & TRN & & & \\
\hline CHEMBL1970537 & 688810 & \multicolumn{3}{|c|}{4.7330000000000005} & 5.3421 & TST & \\
\hline CHEMBL1324064 & 688810 & 5.033 & 4.9905 & TRN & & & \\
\hline CHEMBL1606306 & 688810 & \multicolumn{3}{|c|}{6.082999999999999} & 5.4609 & TRN & \\
\hline CHEMBL1502791 & 688810 & \multicolumn{3}{|c|}{4.7330000000000005} & 5.1374 & TST & \\
\hline CHEMBL1500630 & 688810 & 4.783 & 5.3474 & TRN & & & \\
\hline CHEMBL1439411 & 688810 & 4.783 & 4.896 & TST & & & \\
\hline CHEMBL3198516 & 688810 & \multicolumn{3}{|c|}{4.7330000000000005} & 5.1478 & TST & \\
\hline CHEMBL1373897 & 688810 & \multicolumn{3}{|c|}{5.882999999999999} & 5.4211 & TRN & \\
\hline CHEMBL1488437 & 688810 & 5.183 & 5.4121 & TRN & & & \\
\hline CHEMBL1496958 & 688810 & 5.083 & 5.1757 & TRN & & & \\
\hline CHEMBL3211273 & 688810 & \multicolumn{3}{|c|}{5.7829999999999995} & 5.2966 & TRN & \\
\hline CHEMBL1449615 & 688810 & 5.933 & 5.4428 & TRN & & & \\
\hline CHEMBL1307787 & 688810 & \multicolumn{3}{|c|}{5.832999999999999} & 5.0755 & TRN & \\
\hline CHEMBL1447419 & 688810 & \multicolumn{3}{|c|}{6.0329999999999995} & 5.6061 & TRN & \\
\hline CHEMBL1612818 & 688810 & 4.833 & 5.129 & TRN & & & \\
\hline CHEMBL1342357 & 688810 & 4.633 & 5.2968 & TST & & & \\
\hline CHEMBL1325980 & 688810 & 6.0 & 5.8788 & TRN & & & \\
\hline CHEMBL1523461 & 688810 & 5.933 & 5.5233 & TRN & & & \\
\hline CHEMBL1334799 & 688810 & \multicolumn{3}{|c|}{5.7829999999999995} & 5.4579 & 9999999999 & TRN \\
\hline CHEMBL1360879 & 688810 & 5.933 & 5.391 & TRN & & & \\
\hline CHEMBL1466726 & 688810 & \multicolumn{3}{|c|}{4.7330000000000005} & 4.9426 & TRN & \\
\hline CHEMBL1303991 & 688810 & 4.883 & 5.0363 & TRN & & & \\
\hline CHEMBL1498788 & 688810 & \multirow{2}{*}{\multicolumn{3}{|c|}{$\begin{array}{ll}5.233 & 5.5074 \\
5.7829999999999995\end{array}$}} & & & \\
\hline CHEMBL1499883 & 688810 & & & & 6.0198 & TRN & \\
\hline CHEMBL1478779 & 688810 & 4.883 & 5.1928 & TST & & & \\
\hline
\end{tabular}




\begin{tabular}{|c|c|c|c|c|c|c|}
\hline \multirow[b]{2}{*}{ CHEMBL1332698 } & \multicolumn{6}{|c|}{ Supplemental Table S2.txt } \\
\hline & 688810 & 4.683 & 5.1936 & TST & & \\
\hline CHEMBL1504497 & 688810 & 4.883 & 4.9285 & TST & & \\
\hline CHEMBL1383777 & 688810 & 5.483 & 5.1432 & TST & & \\
\hline CHEMBL1319419 & 688810 & 4.633 & 4.8154 & TRN & & \\
\hline CHEMBL1455399 & 688810 & 4.883 & 5.6258 & TRN & & \\
\hline CHEMBL1319122 & 688810 & 4.683 & 5.5103 & TRN & & \\
\hline CHEMBL1358973 & 688810 & \multicolumn{3}{|c|}{6.0329999999999995} & 5.3271 & $\mathrm{~T}$ \\
\hline CHEMBL3194760 & 688810 & 5.683 & 5.2443 & TST & & \\
\hline CHEMBL3207312 & 688810 & 4.883 & 5.1341 & TRN & & \\
\hline CHEMBL1448593 & 688810 & 4.583 & 5.1025 & TRN & & \\
\hline CHEMBL1458559 & 688810 & 5.0 & 5.0247 & TST & & \\
\hline CHEMBL1437979 & 688810 & 4.883 & 5.0888 & TRN & & \\
\hline CHEMBL1488645 & 688810 & \multicolumn{3}{|c|}{4.7330000000000005} & 4.8792 & \\
\hline CHEMBL1397129 & 688810 & 4.883 & 5.1383 & TST & & \\
\hline CHEMBL1347976 & 688810 & 4.883 & 5.3383 & TST & & \\
\hline CHEMBL1340418 & 688810 & 4.833 & 5.0485 & TST & & \\
\hline CHEMBL1558198 & 688810 & \multicolumn{3}{|c|}{5.5329999999999995} & 5.4337 & TRN \\
\hline CHEMBL160012 & 688810 & \multicolumn{3}{|c|}{4.7330000000000005} & 5.5984 & \\
\hline CHEMBL1584232 & 688810 & 6.233 & 5.4246 & TRN & & \\
\hline CHEMBL3192523 & 688810 & 4.933 & 5.2033 & TST & & \\
\hline CHEMBL1389853 & 688810 & \multicolumn{3}{|c|}{6.132999999999999} & 5.2609 & \\
\hline CHEMBL1332237 & 688810 & \multicolumn{3}{|c|}{4.7330000000000005} & 5.2519 & \\
\hline CHEMBL1425269 & 688810 & 5.683 & 5.1576 & TST & & \\
\hline CHEMBL1552590 & 688810 & 4.833 & 5.5827 & TST & & \\
\hline CHEMBL1301226 & 688810 & 4.883 & 5.035 & TRN & & \\
\hline CHEMBL1460817 & 688810 & 4.683 & 4.9643 & TST & & \\
\hline CHEMBL1329138 & 688810 & \multicolumn{3}{|c|}{5.382999999999999} & 5.749 & $\mathrm{TI}$ \\
\hline CHEMBL1468133 & 688810 & 5.033 & 5.0427 & TRN & & \\
\hline CHEMBL1416472 & 688810 & \multicolumn{3}{|c|}{4.7330000000000005} & 5.5152 & TRN \\
\hline CHEMBL1518778 & 688810 & \multicolumn{3}{|c|}{4.7330000000000005} & 5.3202 & \\
\hline CHEMBL1532083 & 688810 & 4.883 & 4.9215 & TRN & & \\
\hline CHEMBL1478590 & 688810 & 4.833 & 5.1189 & TRN & & \\
\hline CHEMBL1461955 & 688810 & 4.583 & 5.0474 & TST & & \\
\hline CHEMBL1432008 & 688810 & \multicolumn{3}{|c|}{5.5329999999999995} & 5.45 & TाTा \\
\hline CHEMBL1435446 & 688810 & \multicolumn{3}{|c|}{5.5329999999999995} & 5.2245 & TRN \\
\hline CHEMBL1607990 & 688810 & \multicolumn{3}{|c|}{5.132999999999999} & 5.2119 & TP \\
\hline CHEMBL1413357 & 688810 & 4.783 & 4.8003 & TST & & \\
\hline CHEMBL1461800 & 688810 & \multicolumn{3}{|c|}{5.332999999999999} & 5.1472 & TR \\
\hline CHEMBL1611138 & 688810 & 4.933 & 5.2903 & TRN & & \\
\hline CHEMBL1613005 & 688810 & 4.933 & 4.9942 & TST & & \\
\hline CHEMBL1466874 & 688810 & \multicolumn{3}{|c|}{6.132999999999999} & 5.5346 & $\mathrm{~T}$ \\
\hline CHEMBL1310496 & 688810 & 6.4829 & 6.0139 & TRN & & \\
\hline CHEMBL1530393 & 688810 & 4.833 & 5.7444 & TRN & & \\
\hline CHEMBL1370490 & 688810 & \multicolumn{3}{|c|}{7.082999999999999} & 6.1395 & TRI \\
\hline CHEMBL1572993 & 688810 & 6.433 & 5.5191 & TRN & & \\
\hline CHEMBL1405570 & 688810 & 4.833 & 5.5275 & TRN & & \\
\hline CHEMBL1594316 & 688810 & \multicolumn{3}{|c|}{6.5329999999999995} & 6.4019 & TRN \\
\hline CHEMBL1372680 & 688810 & \multicolumn{3}{|c|}{4.7330000000000005} & 4.9661 & 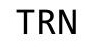 \\
\hline
\end{tabular}




\begin{tabular}{|c|c|c|c|c|c|c|c|}
\hline \multirow[b]{2}{*}{ CHEMBL1613323 } & & \\
\hline & 688810 & 5.483 & 5.0955 & TRN & & & \\
\hline CHEMBL1320357 & 688810 & 6.2829 & 99999999 & 995 & 5.3969 & TRN & \\
\hline CHEMBL1351128 & 688810 & 5.3329 & 99999999 & & 5.4999 & TST & \\
\hline CHEMBL1584247 & 688810 & 4.7330 & 00000000 & 005 & 5.0373 & TRN & \\
\hline CHEMBL1359423 & 688810 & 4.7330 & 00000000 & 005 & 5.1163 & TRN & \\
\hline CHEMBL1312361 & 688810 & 4.633 & 4.9471 & TRN & & & \\
\hline CHEMBL1300792 & 688810 & 5.5829 & 99999999 & & 5.5238 & TRN & \\
\hline CHEMBL1526938 & 688810 & 5.5329 & 99999999 & 995 & 5.3335 & TRN & \\
\hline CHEMBL1500427 & 688810 & 5.1329 & 99999999 & & 5.7178 & TRN & \\
\hline CHEMBL1313386 & 688810 & 4.883 & 5.7509 & TRN & & & \\
\hline CHEMBL1392674 & 688810 & 5.733 & 5.3327 & TST & & & \\
\hline CHEMBL268559 & 688810 & 4.783 & 5.3968 & TRN & & & \\
\hline CHEMBL1550351 & 688810 & 5.1329 & 99999999 & & 5.9639 & TRN & \\
\hline CHEMBL1343783 & 688810 & 5.183 & 4.7139 & TRN & & & \\
\hline CHEMBL1305705 & 688810 & 4.633 & 5.5493 & TST & & & \\
\hline CHEMBL1351610 & 688810 & 5.8829 & 99999999 & & 5.32 & TRN & \\
\hline CHEMBL1385904 & 688810 & 6.2829 & 99999999 & 995 & 5.6342 & TST & \\
\hline CHEMBL1343615 & 688810 & 4.7330 & 00000000 & 005 & 4.6757 & TRN & \\
\hline CHEMBL3209601 & 688810 & 4.833 & 5.0098 & TRN & & & \\
\hline CHEMBL1393722 & 688810 & 4.7330 & 00000000 & 005 & 5.2069 & TRN & \\
\hline CHEMBL1498639 & 688810 & 6.8831 & 5.9622 & TRN & & & \\
\hline CHEMBL1493461 & 688810 & 5.183 & 5.291 & TRN & & & \\
\hline CHEMBL1570804 & 688810 & 5.983 & 5.2874 & TST & & & \\
\hline CHEMBL1390196 & 688810 & 5.683 & 4.8619 & TST & & & \\
\hline CHEMBL1404052 & 688810 & 6.4829 & 5.2633 & TST & & & \\
\hline CHEMBL1437698 & 688810 & 4.7330 & 00000000 & 005 & 4.9901 & TST & \\
\hline CHEMBL1307050 & 688810 & 5.233 & 5.4378 & TRN & & & \\
\hline CHEMBL 292785 & 688810 & 6.183 & 5.6979 & TRN & & & \\
\hline CHEMBL3191685 & 688810 & 5.1329 & 99999999 & & 5.4419 & TRN & \\
\hline CHEMBL1412539 & 688810 & 5.8329 & 99999999 & & 5.5957 & TRN & \\
\hline CHEMBL3207836 & 688810 & 4.833 & 5.3265 & TRN & & & \\
\hline CHEMBL1438256 & 688810 & 5.5329 & 99999999 & 995 & 5.5760 & 30000000005 & TRN \\
\hline CHEMBL1467383 & 688810 & 4.633 & 5.0769 & TRN & & & \\
\hline CHEMBL1419108 & 688810 & 5.05 & 5.5391 & TRN & & & \\
\hline CHEMBL1388252 & 688810 & 6.183 & 5.8618 & TRN & & & \\
\hline CHEMBL1589029 & 688810 & 5.5829 & 99999999 & & 5.6127 & TRN & \\
\hline CHEMBL1348026 & 688810 & 4.583 & 4.9188 & TRN & & & \\
\hline CHEMBL1438503 & 688810 & 5.6329 & 99999999 & & 5.2419 & TRN & \\
\hline CHEMBL1531389 & 688810 & 5.183 & 4.9264 & TRN & & & \\
\hline CHEMBL1453473 & 688810 & 5.2829 & 99999999 & 995 & 5.6031 & TST & \\
\hline CHEMBL1429327 & 688810 & 5.1329 & 99999999 & & 5.4404 & TRN & \\
\hline CHEMBL1585980 & 688810 & 6.4829 & 5.6063 & TRN & & & \\
\hline CHEMBL1342771 & 688810 & 4.783 & 5.2675 & TST & & & \\
\hline CHEMBL1478645 & 688810 & 5.8829 & 99999999 & & 5.6765 & TRN & \\
\hline CHEMBL1524395 & 688810 & 5.033 & 5.1251 & TST & & & \\
\hline CHEMBL1320578 & 688810 & 4.883 & 5.3126 & TRN & & & \\
\hline CHEMBL1418908 & 688810 & 5.433 & 5.6094 & TST & & & \\
\hline CHEMBL1322635 & 688810 & 5.8329 & 99999999 & & 5.6202 & TRN & \\
\hline
\end{tabular}




\begin{tabular}{|c|c|c|c|c|c|c|}
\hline \multirow[b]{2}{*}{ CHEMBL1433891 } & \multirow[b]{2}{*}{688810} & \\
\hline & & 4.883 & 5.0718 & TRN & & \\
\hline CHEMBL1388559 & 688810 & \multicolumn{3}{|c|}{6.2829999999999995} & 4.909 & TST \\
\hline CHEMBL1445547 & 688810 & \multicolumn{3}{|c|}{5.832999999999999} & 5.3654 & \\
\hline CHEMBL1382510 & 688810 & 4.883 & 4.9577 & TRN & & \\
\hline CHEMBL1301074 & 688810 & \multicolumn{3}{|c|}{6.0329999999999995} & 5.8229 & \\
\hline CHEMBL1451237 & 688810 & \multicolumn{3}{|c|}{5.2829999999999995} & 5.1939 & \\
\hline CHEMBL1427109 & 688810 & 4.883 & 5.0112 & TST & & \\
\hline CHEMBL1504426 & 688810 & 6.7331 & 5.8372 & TRN & & \\
\hline CHEMBL1437350 & 688810 & \multicolumn{3}{|c|}{ 5.382999999999999 } & 5.0102 & \\
\hline CHEMBL1451105 & 688810 & \multicolumn{3}{|c|}{6.5329999999999995} & 5.5777 & \\
\hline CHEMBL1335930 & 688810 & 5.183 & 5.731 & TRN & & \\
\hline CHEMBL1505192 & 688810 & 5.233 & 5.1366 & TRN & & \\
\hline CHEMBL1333878 & 688810 & 5.033 & 5.2989 & TST & & \\
\hline CHEMBL1505197 & 688810 & 4.583 & 5.0066 & TST & & \\
\hline CHEMBL1362327 & 688810 & 6.233 & 5.5987 & TRN & & \\
\hline CHEMBL1304128 & 688810 & \multicolumn{3}{|c|}{4.7330000000000005} & 5.1096 & \\
\hline CHEMBL1337569 & 688810 & \multicolumn{3}{|c|}{5.632999999999999} & 5.481 & \\
\hline CHEMBL1393529 & 688810 & \multicolumn{3}{|c|}{4.9830000000000005} & 5.0123 & \\
\hline CHEMBL1500507 & 688810 & 4.833 & 5.3238 & TRN & & \\
\hline CHEMBL1602608 & 688810 & \multicolumn{3}{|c|}{5.5329999999999995} & 5.7933 & \\
\hline CHEMBL1346944 & 688810 & 4.883 & 4.9461 & TRN & & \\
\hline CHEMBL1327068 & 688810 & \multirow{2}{*}{\multicolumn{3}{|c|}{$\begin{array}{l}5.483 \quad 5.2202 \text { IS I } \\
5.332999999999999\end{array}$}} & & \\
\hline CHEMBL1524205 & 688810 & & & & 4485 & \\
\hline CHEMBL1537737 & 688810 & 5.683 & 5.4665 & TRN & & \\
\hline CHEMBL1563561 & 688810 & \multicolumn{3}{|c|}{4.7330000000000005} & 5.081 & \\
\hline CHEMBL1588056 & 688810 & \multicolumn{3}{|c|}{5.332999999999999} & 5.5689 & \\
\hline CHEMBL1381193 & 688810 & \multicolumn{3}{|c|}{5.7829999999999995} & 5.5669 & \\
\hline CHEMBL1519284 & 688810 & 4.833 & 5.3019 & TRN & & \\
\hline CHEMBL1357447 & 688810 & \multicolumn{3}{|c|}{ 4.883 4.7203 TRN } & & \\
\hline CHEMBL1426718 & 688810 & \multicolumn{3}{|c|}{5.632999999999999} & 3 & \\
\hline CHEMBL1436728 & 688810 & 5.733 & 5.4695 & TRN & & \\
\hline CHEMBL1489521 & 688810 & \multicolumn{3}{|c|}{4.9830000000000005} & 5.4452 & \\
\hline CHEMBL1382437 & 688810 & 4.833 & 5.0621 & TST & & \\
\hline CHEMBL1591210 & 688810 & \multicolumn{3}{|c|}{5.2829999999999995} & 4.6659 & \\
\hline CHEMBL15 & 688 & 4.833 & 5.4564 & TRN & & \\
\hline CHEMBL3199355 & 688810 & 6.13299 & 999999999 & & 5.6919 & \\
\hline CHEMBL1404649 & 688810 & 5.083 & 5.1146 & TRN & & \\
\hline CHEMBL 3208032 & 688810 & 5.63299 & 999999999 & & 5.3872 & \\
\hline CHEMBL1524385 & 688810 & 4.933 & 5.5219 & TRN & & \\
\hline CHEMBL3211285 & 688810 & 5.78299 & 999999999 & 995 & 4.9723 & \\
\hline CHEMBL1314202 & 688810 & 5.083 & 5.0658 & TRN & & \\
\hline CHEMBL1307660 & 688810 & 5.483 & 5.3054 & TRN & & \\
\hline CHEMBL590184 & 688810 & 5.38299 & 999999999 & & 5.6243 & \\
\hline CHEMBL1518066 & 688810 & 5.78299 & 999999999 & 995 & 4.982 & \\
\hline CHEMBL1368683 & 688810 & 5.983 & 5.1866 & TRN & & \\
\hline CHEMBL1565151 & 688810 & 4.783 & 5.1953 & TST & & \\
\hline CHEMBL 3189265 & 688810 & 4.883 & 5.3077 & TRN & & \\
\hline CHEMBL1323536 & 688810 & 4.73306 & 000000000 & 005 & 4.5845 & \\
\hline
\end{tabular}




\begin{tabular}{|c|c|c|c|c|c|c|}
\hline \multirow{3}{*}{$\begin{array}{l}\text { CHEMBL1596465 } \\
\text { CHEMBL1541067 }\end{array}$} & \multicolumn{6}{|c|}{ Supplemental Table S2.txt } \\
\hline & 688810 & \multicolumn{3}{|c|}{4.7330000000000005} & 5.1737 & TST \\
\hline & 688810 & 5.733 & 5.5237 & TRN & & \\
\hline CHEMBL1383319 & 688810 & \multicolumn{3}{|c|}{5.132999999999999} & 5.5408 & $\mathrm{TI}$ \\
\hline CHEMBL1537574 & 588810 & \multicolumn{3}{|c|}{4.7330000000000005} & 5.2435 & TST \\
\hline CHEMBL1378171 & 688810 & \multicolumn{3}{|c|}{4.9830000000000005} & 5.7647 & \\
\hline CHEMBL3191677 & 688810 & 4.883 & 5.415 & TST & & \\
\hline CHEMBL1367195 & 688810 & 4.833 & 5.1174 & TRN & & \\
\hline CHEMBL1573978 & 688810 & 5.683 & 5.8111 & TST & & \\
\hline CHEMBL1548889 & 688810 & \multicolumn{3}{|c|}{4.7330000000000005} & 5.584 & \\
\hline CHEMBL1347638 & 688810 & 4.933 & 4.8952 & TRN & & \\
\hline CHEMBL1600438 & 688810 & \multicolumn{3}{|c|}{5.882999999999999} & 5.4479 & $T$ \\
\hline CHEMBL1380103 & 688810 & 5.233 & 5.1919 & TRN & & \\
\hline CHEMBL1489933 & 688810 & \multicolumn{3}{|c|}{5.382999999999999} & 5.1471 & $T$ \\
\hline CHEMBL1404506 & 688810 & 5.433 & 5.229 & TRN & & \\
\hline CHEMBL1476044 & 688810 & \multicolumn{3}{|c|}{5.2829999999999995} & 5.105 & $\mathrm{TI}$ \\
\hline CHEMBL3208165 & 688810 & \multicolumn{3}{|c|}{4.7330000000000005} & 5.1151 & TRN \\
\hline CHEMBL14 & 688 & \multicolumn{3}{|c|}{5.832999999999999} & 5.6928 & TST \\
\hline CHEMBL1448810 & 688810 & \multicolumn{3}{|c|}{4.7330000000000005} & 5.0327 & TRN \\
\hline CHEMBL1442800 & 688810 & 5.083 & 5.075 & TRN & & \\
\hline CHEMBL1337087 & 688810 & 5.233 & 5.6125 & TRN & & \\
\hline CHEMBL15 & 688 & 5.683 & 5.2795 & TRN & & \\
\hline CHEMBL1475371 & 688 & 4.883 & 5.3358 & TRN & & \\
\hline CHEMBL3196561 & 688810 & 5.733 & 5.6976 & TST & & \\
\hline CHEMBL1448090 & 688810 & 4.833 & 5.4013 & TST & & \\
\hline CHEMBL132 & 688810 & 4.8 & 5.091 & TRN & & \\
\hline CHEMBL13 & 688 & 6.9 & 5.1936 & TRN & & \\
\hline CHEMBL127066 & 688810 & 4.783 & 5.5862 & TRN & & \\
\hline CHEMBL1336470 & 688 & 5.9 & 5.8749 & TRN & & \\
\hline CHEMBL1548865 & 688810 & 5.483 & 5.6061 & TRN & & \\
\hline CHEMBL1422327 & 688810 & \multicolumn{3}{|c|}{5.2829999999999995} & 5.0219 & \\
\hline CHEMBL154 & 688 & 4.783 & 5.0716 & TRN & & \\
\hline CHEMBL1309107 & 688810 & 4.783 & 5.4714 & TST & & \\
\hline CHEMBL600100 & 688810 & 5.233 & 5.4865 & TRN & & \\
\hline CHEMBL1599830 & 688810 & 4.583 & 4.7992 & TST & & \\
\hline CHEMBL15 & 68 & & 5.3291 & TRN & & \\
\hline CHEMBL 1 & 688 & 4.833 & 5.1975 & TST & & \\
\hline CHEMBL1599486 & 688810 & \multicolumn{3}{|c|}{5.332999999999999} & 5.8637 & $\mathrm{TR}$ \\
\hline CHEMBL1305605 & 688810 & \multicolumn{3}{|c|}{6.382999999999999} & 5.9754 & TP \\
\hline CHEMBL1431850 & 688810 & \multicolumn{3}{|c|}{4.7330000000000005} & 5.0741 & $\mathrm{TS}$ \\
\hline CHEMBL1300326 & 688810 & \multicolumn{3}{|c|}{4.7330000000000005} & 5.312 & \\
\hline CHEMBL3211326 & 688810 & 6.183 & 5.2802 & TRN & & \\
\hline CHEMBL1497878 & 688810 & 5.733 & 5.5853 & TRN & & \\
\hline CHEMBL3197380 & 688810 & 4.833 & 5.2687 & TRN & & \\
\hline CHEMBL1387787 & 688810 & \multicolumn{3}{|c|}{4.9830000000000005} & 203 & $\mathrm{~T}$ \\
\hline CHEMBL1353881 & 688810 & \multicolumn{3}{|c|}{5.132999999999999} & 4.9394 & \\
\hline CHEMBL1440829 & 688810 & 5.433 & 5.7439 & TRN & & \\
\hline CHEMBL3199694 & 688810 & \multicolumn{3}{|c|}{5.5329999999999995} & 5.3158 & 11 \\
\hline CHEMBL2369223 & 688810 & 5.7829 & 99999999 & 995 & 5.3263 & \\
\hline
\end{tabular}




\begin{tabular}{|c|c|c|c|c|c|c|}
\hline & & \multicolumn{5}{|c|}{ Supplemental Table S2.txt } \\
\hline CHEMBL1579931 & 688810 & \multicolumn{3}{|c|}{4.9830000000000005} & 222 & \\
\hline CHEMBL475541 & 688810 & 4.933 & 5.0178 & TRN & & \\
\hline CHEMBL1531845 & 688810 & 4.833 & 5.3412 & TRN & & \\
\hline CHEMBL1462895 & 588810 & 4.783 & 4.9839 & TRN & & \\
\hline CHEMBL1383781 & 588810 & \multicolumn{3}{|c|}{6.2829999999999995} & 5.9452 & \\
\hline CHEMBL1539277 & 688810 & 5.683 & 5.3457 & TRN & & \\
\hline CHEMBL1494925 & 688810 & \multicolumn{3}{|c|}{4.7330000000000005} & 5.3178 & \\
\hline CHEMBL1309783 & 688810 & 5.233 & 5.0929 & TRN & & \\
\hline CHEMBL1489803 & 688810 & 6.233 & 5.4511 & TRN & & \\
\hline CHEMBL1338443 & 88810 & 5.033 & 5.2522 & TRN & & \\
\hline CHEMBL1454673 & 688810 & \multicolumn{3}{|c|}{5.132999999999999} & 5.1328 & \\
\hline HEMBL1408825 & 688810 & \multicolumn{3}{|c|}{4.7330000000000005} & 4.9549 & \\
\hline CHEMBL1363732 & 688810 & 4.933 & 5.2273 & TST & & \\
\hline CHEMBL1513762 & 688810 & \multicolumn{3}{|c|}{6.382999999999999} & 5.4036 & \\
\hline CHEMBL1390471 & 688810 & 4.583 & 4.4506 & TRN & & \\
\hline CHEMBL 3 & 688810 & 5.183 & 5.4674 & TRN & & \\
\hline HEMBL3 & 688 & \multicolumn{3}{|c|}{4.7330000000000005} & 5.3977 & \\
\hline CHEMBL & 688810 & 4.783 & \multicolumn{3}{|c|}{5.486000000000001} & \\
\hline CHEMBL1588780 & 688810 & 6.433 & 6.0243 & TRN & & \\
\hline CHEMBL1536341 & 688810 & 6.8831 & 5.7394 & TRN & & \\
\hline CHEMBL1491158 & 688810 & \multicolumn{3}{|c|}{4.9830000000000005} & 5.6238 & \\
\hline HEMBL: & 688 & \multicolumn{3}{|c|}{6.7829999999999995} & 93 & \\
\hline CHEMBL & 688810 & 4.783 & 5.4958 & TRN & & \\
\hline CHEMBL3210865 & 688810 & \multicolumn{3}{|c|}{5.332999999999999} & 485 & \\
\hline CHEMBL1299230 & 688810 & 4.933 & 5.3937 & TST & & \\
\hline CHEMBL1523356 & 688 & 6.8831 & 5.6652 & TRN & & \\
\hline HEME & 10 & \multicolumn{3}{|c|}{6.2829999999999995} & 5.3075 & \\
\hline CHEMB & 688 & \multicolumn{3}{|c|}{5.632999999999999} & 5.5907 & \\
\hline CHEMBL 3190207 & 688810 & \multicolumn{3}{|c|}{5.382999999999999} & 5.6697 & \\
\hline CHEMBL1546317 & 688810 & 5.683 & 5.0808 & TR & & \\
\hline CHEMBL1540821 & 688 & \multicolumn{3}{|c|}{5.382999999999999} & 5.5041 & \\
\hline CHEME & 688 & 5.033 & 5.0443 & TRN & & \\
\hline CHEME & $68 \varepsilon$ & 4.883 & 4.9509 & TST & & \\
\hline CHEMBL1378884 & 688810 & \multicolumn{3}{|c|}{5.2829999999999995} & 5.0053 & \\
\hline CHEMBL1426196 & 688810 & 4.783 & 4.7911 & TRN & & \\
\hline CHEMBL1 & 688 & \multicolumn{3}{|c|}{4.7330000000000005} & 5.8329 & \\
\hline CHEMB & 688 & 4.833 & 5.0996 & TRN & & \\
\hline CHEMBL 1443120 & 688810 & \multicolumn{3}{|c|}{5.882999999999999} & 5.2403 & \\
\hline CHEMBL1317201 & 688810 & 5.483 & 5.0521 & TRN & & \\
\hline CHEMBL1454480 & 688810 & \multicolumn{3}{|c|}{5.7829999999999995} & 5.2154 & \\
\hline CHEMBL1314810 & 688810 & 5.233 & 5.2151 & TRN & & \\
\hline CHEMBL1350275 & 688810 & \multicolumn{3}{|c|}{4.7330000000000005} & 4.670 & \\
\hline CHEMBL1520615 & 688810 & 4.783 & 5.1498 & TST & & \\
\hline CHEMBL1370897 & 688810 & 5.78299 & 99999999 & 995 & 5.6234 & 11 \\
\hline CHEMBL1482901 & 688810 & 6.58299 & 99999999 & & 5.3248 & \\
\hline CHEMBL1359381 & 688810 & 5.033 & 4.8369 & TST & & \\
\hline CHEMBL1331006 & 688810 & 5.233 & 4.9383 & TRN & & \\
\hline CHEMBL1353954 & 688810 & 5.083 & 5.5133 & TRN & & \\
\hline
\end{tabular}




\begin{tabular}{|c|c|c|c|c|c|c|c|}
\hline \multicolumn{7}{|c|}{ Supplemental Table S2.txt } & \\
\hline CHEMBL474749 & 688810 & 4.833 & 5.6887 & TRN & & & \\
\hline CHEMBL1410792 & 688810 & 6.4829 & 5.9831 & TRN & & & \\
\hline CHEMBL3189370 & 688810 & 4.883 & 5.1071 & TRN & & & \\
\hline CHEMBL1603053 & 688810 & 6.233 & 5.2214 & TRN & & & \\
\hline CHEMBL1973122 & 688810 & \multicolumn{3}{|c|}{4.7330000000000005} & 4.856 & TST & \\
\hline CHEMBL1331348 & 688810 & 4.883 & 4.9522 & TST & & & \\
\hline CHEMBL1360177 & 688810 & 4.833 & 5.0529 & TST & & & \\
\hline CHEMBL1418885 & 688810 & 4.883 & 4.9724 & TRN & & & \\
\hline CHEMBL1414005 & 688810 & 5.983 & 5.4502 & TRN & & & \\
\hline CHEMBL1368413 & 688810 & \multicolumn{3}{|c|}{5.332999999999999} & 5.1488 & TRN & \\
\hline CHEMBL1315551 & 688810 & \multicolumn{3}{|c|}{5.332999999999999} & 5.4351 & TRN & \\
\hline CHEMBL1462498 & 688810 & 4.833 & 5.2266 & TST & & & \\
\hline CHEMBL1583837 & 688810 & \multicolumn{3}{|c|}{6.582999999999999} & 5.9123 & TST & \\
\hline CHEMBL1392845 & 688810 & \multicolumn{3}{|c|}{5.882999999999999} & 5.4729 & TRN & \\
\hline CHEMBL1714669 & 688810 & 6.433 & \multicolumn{3}{|c|}{5.547999999999999} & TST & \\
\hline CHEMBL1349626 & 688810 & 5.433 & 5.0144 & TRN & & & \\
\hline CHEMBL1441685 & 688810 & 6.7331 & 6.2056 & TST & & & \\
\hline CHEMBL1346909 & 688810 & 4.783 & 5.3403 & TST & & & \\
\hline CHEMBL1374009 & 688810 & 7.2832 & 6.1109 & TRN & & & \\
\hline CHEMBL 2003485 & 688810 & 4.933 & 5.0617 & TRN & & & \\
\hline CHEMBL1325470 & 688810 & 6.0 & 5.4031 & TRN & & & \\
\hline CHEMBL3189760 & 688810 & 5.733 & 5.32299 & 999999999 & 995 & TRN & \\
\hline CHEMBL1461321 & 688810 & 5.183 & 5.9836 & TRN & & & \\
\hline CHEMBL1531201 & 688810 & \multicolumn{3}{|c|}{5.132999999999999} & \multicolumn{2}{|c|}{4.9510000000000005} & TST \\
\hline CHEMBL144472 & 688810 & \multicolumn{3}{|c|}{6.5329999999999995} & 5.4826 & TST & \\
\hline CHEMBL1349908 & 688810 & \multicolumn{3}{|c|}{5.132999999999999} & 5.72 & TRN & \\
\hline CHEMBL1410079 & 688810 & \multicolumn{3}{|c|}{5.582999999999999} & 5.7656 & TRN & \\
\hline CHEMBL1349067 & 688810 & 6.233 & 6.0462 & TRN & & & \\
\hline CHEMBL1584414 & 688810 & 4.933 & 5.3276 & TRN & & & \\
\hline CHEMBL1444860 & 688810 & 4.783 & 5.2102 & TST & & & \\
\hline CHEMBL1424903 & 688810 & \multicolumn{3}{|c|}{4.7330000000000005} & 5.3003 & TRN & \\
\hline CHEMBL1466598 & 688810 & \multicolumn{3}{|c|}{4.9830000000000005} & 4.7744 & TST & \\
\hline CHEMBL1477342 & 688810 & 4.833 & 5.5263 & TRN & & & \\
\hline CHEMBL1533372 & 688810 & 5.983 & 5.4135 & TRN & & & \\
\hline CHEMBL1568095 & 688810 & 4.633 & 5.6955 & TRN & & & \\
\hline CHEMBL1572788 & 688810 & \multicolumn{3}{|c|}{6.332999999999999} & 5.9062 & TRN & \\
\hline CHEMBL1523082 & 688810 & \multicolumn{3}{|c|}{4.7330000000000005} & 4.9707 & TRN & \\
\hline CHEMBL1594900 & 688810 & 4.883 & 5.4085 & TST & & & \\
\hline CHEMBL1440359 & 688810 & \multicolumn{3}{|c|}{4.7330000000000005} & 5.0536 & TRN & \\
\hline CHEMBL1341020 & 688810 & 5.683 & 5.5128 & TRN & & & \\
\hline CHEMBL1341317 & 688810 & 4.783 & 5.1282 & TRN & & & \\
\hline CHEMBL3209997 & 688810 & 4.833 & 5.0883 & TRN & & & \\
\hline CHEMBL1326704 & 688810 & 4.783 & 5.0886 & TRN & & & \\
\hline CHEMBL1393380 & 688810 & 4.883 & 5.3652 & TRN & & & \\
\hline CHEMBL1593491 & 688810 & \multicolumn{3}{|c|}{5.132999999999999} & 5.0397 & TRN & \\
\hline CHEMBL1443994 & 688810 & \multicolumn{3}{|c|}{5.132999999999999} & 5.1909 & TRN & \\
\hline CHEMBL1400808 & 688810 & 5.983 & 5.7245 & TRN & & & \\
\hline CHEMBL1547314 & 688810 & 5.083 & 5.5734 & TRN & & & \\
\hline
\end{tabular}




\begin{tabular}{|c|c|c|c|c|c|c|}
\hline \multirow[b]{2}{*}{ CHEMBL1440090 } & \multicolumn{6}{|c|}{ Supplemental Table S2.txt } \\
\hline & 688810 & 4.883 & 5.3988 & TRN & & \\
\hline CHEMBL1313706 & 688810 & 5.733 & 5.5378 & TST & & \\
\hline CHEMBL1426551 & 688810 & 5.7829 & 99999999 & 995 & 5.4125 & TRN \\
\hline CHEMBL1429633 & 688810 & 5.7829 & 99999999 & 995 & 5.1007 & TRN \\
\hline CHEMBL3199234 & 688810 & 4.833 & 5.4361 & TRN & & \\
\hline CHEMBL536166 & 688810 & 5.433 & 5.6434 & TRN & & \\
\hline CHEMBL1572378 & 688810 & 5.683 & 5.046 & TRN & & \\
\hline CHEMBL1613483 & 688810 & 5.5329 & 99999999 & 995 & 5.7598 & TRN \\
\hline CHEMBL1338156 & 688810 & 5.6329 & 99999999 & & 5.2668 & TST \\
\hline CHEMBL1315140 & 688810 & 4.633 & 5.2736 & TRN & & \\
\hline CHEMBL1493474 & 688810 & 5.983 & 5.6662 & TRN & & \\
\hline CHEMBL1338072 & 688810 & 4.833 & 4.8847 & TRN & & \\
\hline CHEMBL1348126 & 688810 & 5.1329 & 99999999 & & 5.3095 & TRN \\
\hline CHEMBL1993070 & 688810 & 6.7829 & 99999999 & 995 & 5.6769 & \\
\hline CHEMBL1316725 & 688810 & 4.633 & 5.1762 & TRN & & \\
\hline CHEMBL1447111 & 688810 & 6.5329 & 99999999 & 995 & 7487 & \\
\hline CHEMBL1451816 & 688810 & 5.083 & 5.4843 & TRN & & \\
\hline CHEMBL1592404 & 688810 & 5.183 & 5.3086 & TST & & \\
\hline CHEMBL1395521 & 688810 & 6.4829 & 5.7811 & TRN & & \\
\hline CHEMBL1446330 & 688810 & 4.833 & 5.2635 & TRN & & \\
\hline CHEMBL1605334 & 688810 & 4.833 & 5.216 & TRN & & \\
\hline CHEMBL1981002 & 688810 & 4.833 & 4.9763 & TST & & \\
\hline CHEMBL1451144 & 688810 & 4.783 & 5.7022 & TRN & & \\
\hline CHEMBL1504424 & 688810 & 6.433 & 5.6964 & TRN & & \\
\hline CHEMBL1606511 & 688810 & 4.633 & 5.3019 & TST & & \\
\hline CHEMBL1570709 & 688810 & 4.933 & 4.9894 & TST & & \\
\hline CHEMBL1496765 & 688810 & 4.583 & 4.8472 & TRN & & \\
\hline CHEMBL1370295 & 688810 & 5.6329 & 99999999 & & 5.0246 & \\
\hline CHEMBL1369655 & 688810 & 5.483 & 5.5441 & TRN & & \\
\hline CHEMBL1412457 & 688810 & 4.783 & 5.2303 & TRN & & \\
\hline CHEMBL1587276 & 688810 & 4.833 & 5.2443 & TRN & & \\
\hline CHEMBL1446545 & 688810 & 4.783 & 5.5626 & TST & & \\
\hline CHEMBL1355541 & 688810 & 4.583 & 5.7942 & TST & & \\
\hline CHEMBL1995948 & 688810 & 5.233 & 5.3026 & TST & & \\
\hline CHEMBL1421815 & 688810 & 4.633 & 5.2578 & TST & & \\
\hline CHEMBL1410344 & 688810 & 4.783 & 5.074 & TRN & & \\
\hline CHEMBL1989298 & 688810 & 5.8329 & 79999999 & & 5.4103 & \\
\hline CHEMBL1409255 & 688810 & 4.883 & 5.0888 & TRN & & \\
\hline CHEMBL1481234 & 688810 & 4.933 & 4.7865 & TST & & \\
\hline CHEMBL1552204 & 688810 & 4.633 & 5.6157 & TRN & & \\
\hline CHEMBL1510618 & 688810 & 4.783 & 5.0316 & TRN & & \\
\hline CHEMBL3193399 & 688810 & 4.783 & 5.3802 & TRN & & \\
\hline CHEMBL1571004 & 688810 & 5.433 & 5.2669 & TRN & & \\
\hline CHEMBL1349964 & 688810 & 5.6329 & 9999999 & & 5.8081 & th \\
\hline CHEMBL1531846 & 688810 & 5.033 & 5.7329 & TST & & \\
\hline CHEMBL1330368 & 688810 & 6.0 & 5.3211 & TRN & & \\
\hline CHEMBL1392070 & 688810 & 5.6329 & 9999999 & & 5.227 & \\
\hline CHEMBL1222382 & 688810 & 5.6329 & 9999999 & & 5.4023 & \\
\hline
\end{tabular}




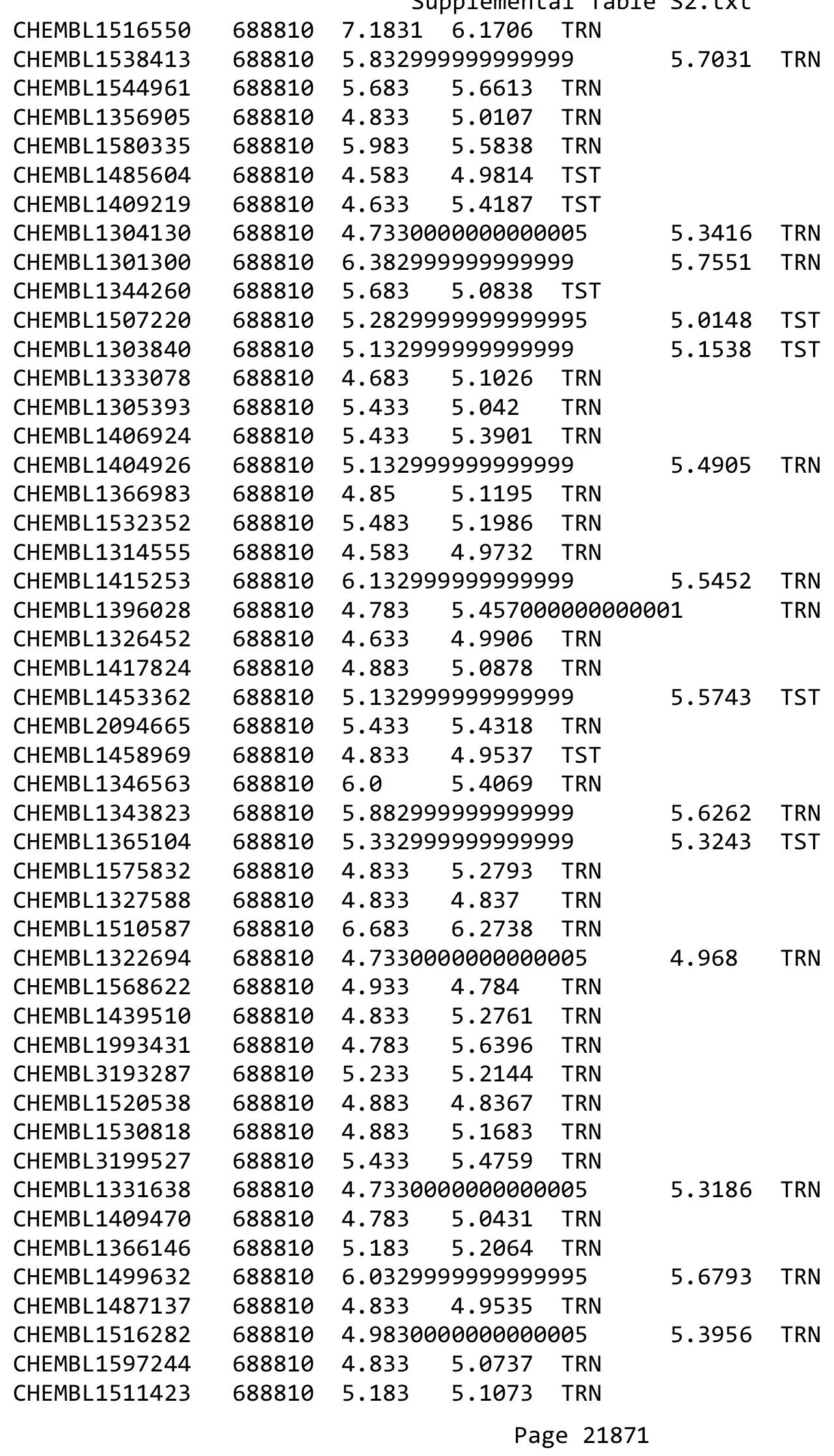




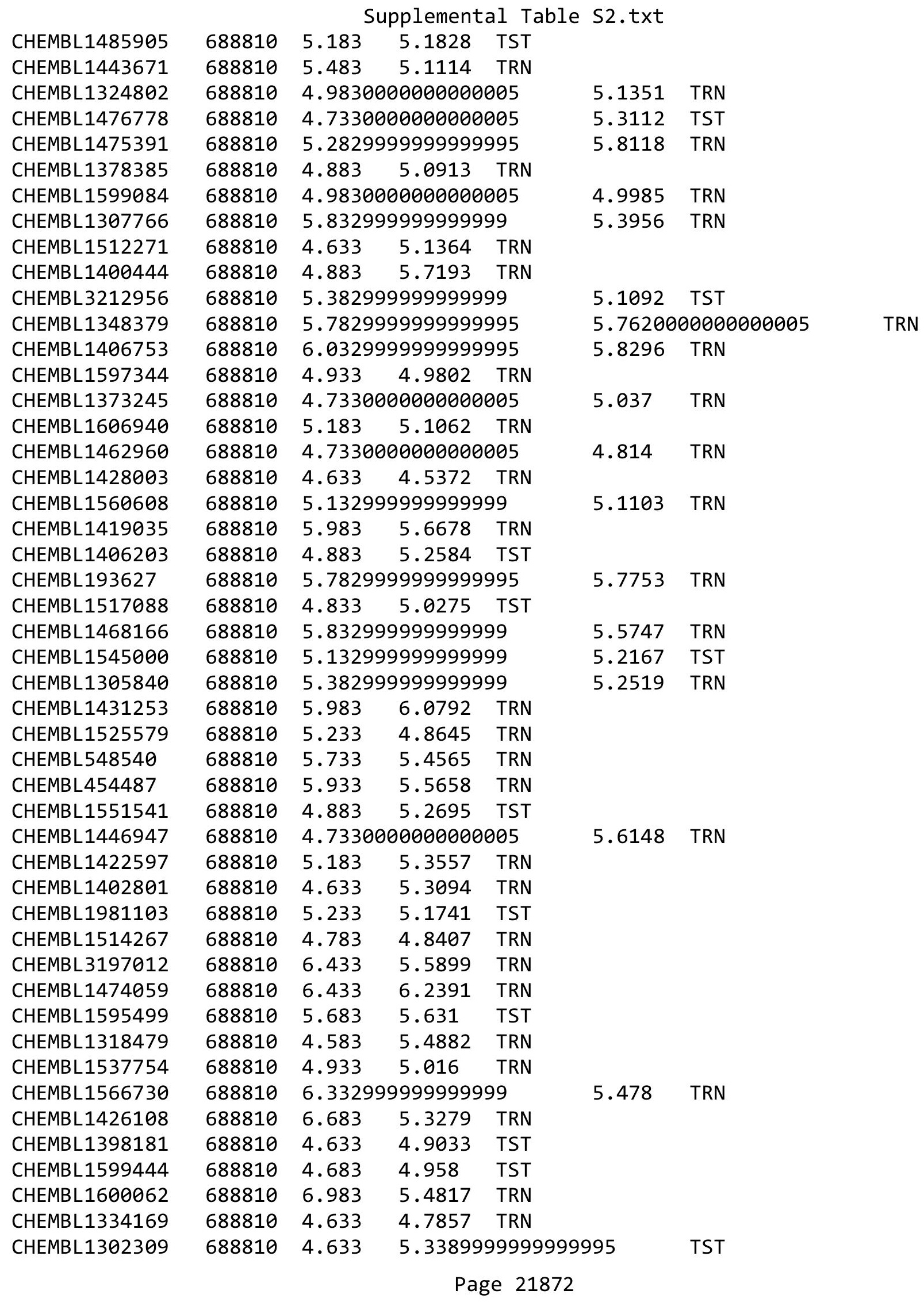




\begin{tabular}{|c|c|c|c|c|c|c|c|}
\hline \multicolumn{8}{|c|}{ Supplemental Table S2.txt } \\
\hline CHEMBL3212972 & 688810 & 4.783 & 5.2591 & TRN & & & \\
\hline CHEMBL1390139 & 688810 & 4.783 & 4.876 & TRN & & & \\
\hline CHEMBL1984052 & 688810 & 5.8329 & 999999995 & & 5.5802 & TRN & \\
\hline CHEMBL1588678 & 688810 & 5.433 & 5.4095 & TRN & & & \\
\hline CHEMBL1349921 & 688810 & 5.3329 & 999999999 & & 5.2134 & TRN & \\
\hline CHEMBL1580362 & 688810 & 5.733 & 5.4509 & TRN & & & \\
\hline CHEMBL1306030 & 688810 & 4.683 & 5.1003 & TST & & & \\
\hline CHEMBL1371956 & 688810 & 4.933 & 5.3217 & TRN & & & \\
\hline CHEMBL3196997 & 688810 & 5.933 & 5.6087 & TRN & & & \\
\hline CHEMBL1609713 & 688810 & 4.7330 & 000000006 & 005 & 5.0903 & TRN & \\
\hline CHEMBL1533618 & 688810 & 5.233 & 5.0207 & TRN & & & \\
\hline CHEMBL1336476 & 688810 & 4.883 & 4.9682 & TRN & & & \\
\hline CHEMBL1424581 & 688810 & 4.7330 & 00000000 & 005 & 5.1306 & TRN & \\
\hline CHEMBL1498040 & 688810 & 4.783 & 5.2758 & TRN & & & \\
\hline CHEMBL1531885 & 688810 & 4.7330 & 00000000 & 005 & 5.0969 & TRN & \\
\hline CHEMBL 2007297 & 688810 & 4.883 & 5.5917 & TRN & & & \\
\hline CHEMBL1354557 & 688810 & 5.083 & 5.5188 & TRN & & & \\
\hline CHEMBL1413230 & 688810 & 4.7330 & 00000000 & 005 & 5.2579 & TST & \\
\hline CHEMBL1336860 & 688810 & 5.8329 & 99999999 & & 5.5491 & TRN & \\
\hline CHEMBL1509308 & 688810 & 4.9830 & 00000000 & 005 & 5.40799 & 99999999995 & TRN \\
\hline CHEMBL1498995 & 688810 & 4.933 & 5.5114 & TRN & & & \\
\hline CHEMBL3213267 & 688810 & 5.5829 & 999999995 & & 5.0962 & TRN & \\
\hline CHEMBL1610222 & 688810 & 4.833 & 5.2016 & TRN & & & \\
\hline CHEMBL1604748 & 688810 & 6.1329 & 99999999 & & 5.9088 & TST & \\
\hline CHEMBL1458316 & 688810 & 4.883 & 5.0239 & TRN & & & \\
\hline CHEMBL1367869 & 688810 & 4.683 & 4.8376 & TRN & & & \\
\hline CHEMBL1528828 & 688810 & 5.5329 & 999999995 & 995 & 5.1928 & TRN & \\
\hline CHEMBL1438177 & 688810 & 6.0 & 4.9387 & TRN & & & \\
\hline CHEMBL1556276 & 688810 & 5.183 & 5.2453 & TST & & & \\
\hline CHEMBL1570692 & 688810 & 6.1329 & 999999995 & & 5.7207 & TRN & \\
\hline CHEMBL1362330 & 688810 & 4.9830 & 000000006 & 005 & 5.471 & TRN & \\
\hline CHEMBL3191948 & 688810 & 4.7330 & 00000000 & 005 & 5.3598 & TRN & \\
\hline CHEMBL1592872 & 688810 & 5.433 & 5.7702 & TRN & & & \\
\hline CHEMBL1588575 & 688810 & 5.983 & 5.511 & TRN & & & \\
\hline CHEMBL1573242 & 688810 & 4.633 & 5.3124 & TRN & & & \\
\hline CHEMBL1532402 & 688810 & 4.7330 & 000000006 & 005 & 4.8379 & TRN & \\
\hline CHEMBL 1370512 & 688810 & 4.833 & 5.0925 & TRN & & & \\
\hline CHEMBL1440254 & 688810 & 4.833 & 5.4261 & TRN & & & \\
\hline CHEMBL1507963 & 688810 & 4.783 & 5.7077 & TRN & & & \\
\hline CHEMBL1424561 & 688810 & 4.883 & 5.0206 & TRN & & & \\
\hline CHEMBL1487113 & 688810 & 5.5829 & 999999999 & & 4.9213 & TRN & \\
\hline CHEMBL1405899 & 688810 & 4.783 & 5.5131 & TRN & & & \\
\hline CHEMBL1327719 & 688810 & 5.1329 & 999999999 & & 5.3358 & TRN & \\
\hline CHEMBL1388231 & 688810 & 4.833 & 5.4169 & TRN & & & \\
\hline CHEMBL1387969 & 688810 & 5.483 & 4.9123 & TRN & & & \\
\hline CHEMBL1546836 & 688810 & 5.8329 & 999999999 & & 5.5506 & TRN & \\
\hline CHEMBL1304658 & 688810 & 5.183 & 4.9784 & TRN & & & \\
\hline CHEMBL592068 & 688810 & 5.3829 & 999999999 & & 5.3714 & TRN & \\
\hline
\end{tabular}




\begin{tabular}{|c|c|c|c|c|c|c|c|}
\hline \multicolumn{8}{|c|}{ 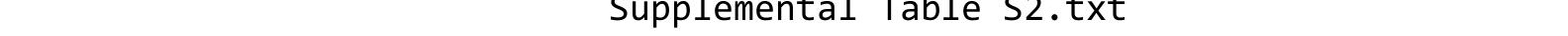 } \\
\hline CHEMBL1353760 & 688810 & 4.633 & 4.8157 & TRN & & & \\
\hline CHEMBL1528976 & 688810 & 4.783 & 5.1206 & TRN & & & \\
\hline CHEMBL1358797 & 688810 & \multicolumn{3}{|c|}{5.332999999999999} & 5.2748 & TRN & \\
\hline CHEMBL1464009 & 688810 & 4.833 & 5.3685 & TST & & & \\
\hline CHEMBL1362224 & 688810 & \multicolumn{3}{|c|}{4.9830000000000005} & 5.1634 & TRN & \\
\hline CHEMBL1339222 & 688810 & 5.233 & \multicolumn{3}{|c|}{5.763999999999999} & TRN & \\
\hline CHEMBL1307267 & 688810 & 4.783 & 5.6981 & TRN & & & \\
\hline CHEMBL1494181 & 688810 & \multicolumn{3}{|c|}{6.582999999999999} & \multicolumn{2}{|c|}{5.7829999999999995} & TRN \\
\hline CHEMBL1404146 & 688810 & 5.233 & 5.8227 & TRN & & & \\
\hline CHEMBL1557047 & 688810 & 4.833 & 4.926 & TRN & & & \\
\hline CHEMBL1595161 & 688810 & 4.633 & 4.9233 & TST & & & \\
\hline CHEMBL1327094 & 688810 & 4.583 & 5.4269 & TST & & & \\
\hline CHEMBL1575652 & 688810 & 4.833 & 5.2821 & TST & & & \\
\hline CHEMBL 3208740 & 688810 & 4.933 & 4.7462 & TST & & & \\
\hline CHEMBL1372397 & 688810 & 5.033 & 5.0184 & TRN & & & \\
\hline CHEMBL1524797 & 688810 & \multicolumn{3}{|c|}{4.7330000000000005} & 5.4037 & TST & \\
\hline CHEMBL1304449 & 688810 & \multicolumn{3}{|c|}{5.7829999999999995} & 5.7519 & TRN & \\
\hline CHEMBL1572931 & 688810 & 7.1831 & 5.8653 & TRN & & & \\
\hline CHEMBL1511147 & 688810 & 5.28299 & 99999999 & 995 & 5.5001 & TST & \\
\hline CHEMBL1439446 & 688810 & 4.833 & 5.5772 & TRN & & & \\
\hline CHEMBL1486715 & 688810 & 5.733 & 5.4517 & TRN & & & \\
\hline CHEMBL1347685 & 688810 & 4.933 & 5.1747 & TRN & & & \\
\hline CHEMBL1442585 & 688810 & \multicolumn{3}{|c|}{5.882999999999999} & 5.8065 & TRN & \\
\hline CHEMBL1400111 & 688810 & \multicolumn{3}{|c|}{4.7330000000000005} & 5.0208 & TST & \\
\hline CHEMBL1584517 & 688810 & 4.833 & 5.4049 & TRN & & & \\
\hline CHEMBL1374602 & 688810 & 4.833 & 5.5125 & TRN & & & \\
\hline CHEMBL1365768 & 688810 & \multicolumn{3}{|c|}{6.5329999999999995} & 5.9498 & TRN & \\
\hline CHEMBL1539416 & 688810 & 6.4829 & 5.3249 & TRN & & & \\
\hline CHEMBL1409224 & 688810 & 4.783 & 4.8969 & TRN & & & \\
\hline CHEMBL 3199849 & 688810 & \multicolumn{3}{|c|}{6.2829999999999995} & 5.6037 & TRN & \\
\hline CHEMBL1387929 & 688810 & \multicolumn{3}{|c|}{7.082999999999999} & 5.6503 & TRN & \\
\hline CHEMBL1446951 & 688810 & 6.183 & 5.4732 & TST & & & \\
\hline CHEMBL1515952 & 688810 & \multicolumn{3}{|c|}{5.132999999999999} & 5.6476 & TRN & \\
\hline CHEMBL1305496 & 688810 & 4.933 & 5.1621 & TRN & & & \\
\hline CHEMBL1521892 & 688810 & 4.783 & 4.8076 & TRN & & & \\
\hline CHEMBL1396428 & 688810 & 4.783 & 5.1112 & TST & & & \\
\hline CHEMBL1460129 & 688810 & 4.933 & 5.2563 & TRN & & & \\
\hline CHEMBL1484754 & 688810 & \multicolumn{3}{|c|}{5.2829999999999995} & 5.226 & TST & \\
\hline CHEMBL1448638 & 688810 & \multicolumn{3}{|c|}{4.7330000000000005} & 5.1102 & TRN & \\
\hline CHEMBL 1380222 & 688810 & \multicolumn{3}{|c|}{4.7330000000000005} & 5.3593 & TRN & \\
\hline CHEMBL1551325 & 688810 & \multicolumn{3}{|c|}{5.132999999999999} & 5.3866 & TST & \\
\hline CHEMBL1479973 & 688810 & \multicolumn{3}{|c|}{6.5329999999999995} & 5.6677 & TRN & \\
\hline CHEMBL1373043 & 688810 & \multicolumn{3}{|c|}{6.132999999999999} & 5.5616 & TRN & \\
\hline CHEMBL1573574 & 688810 & 4.833 & 5.2413 & TST & & & \\
\hline CHEMBL1390335 & 688810 & 5.183 & 5.599 & TST & & & \\
\hline CHEMBL1488160 & 688810 & 6.233 & 5.4095 & TRN & & & \\
\hline CHEMBL1324509 & 688810 & 4.633 & 4.9196 & TST & & & \\
\hline CHEMBL1328025 & 688810 & 4.933 & 6.068 & TRN & & & \\
\hline
\end{tabular}




\begin{tabular}{|c|c|c|c|c|c|c|}
\hline & & & oplement & al Table & s2.txt & \\
\hline CHEMBL1410165 & 688810 & 4.73300 & 30000000 & 005 & 5.0798 & TRN \\
\hline CHEMBL1431928 & 688810 & 4.73300 & 00000000 & 005 & 5.0235 & TRN \\
\hline CHEMBL1405021 & 688810 & 5.83299 & 99999999 & & 5.2823 & TRN \\
\hline CHEMBL1316301 & 688810 & 7.3325 & 5.8405 & TRN & & \\
\hline CHEMBL1556970 & 688810 & 5.733 & 5.3855 & TRN & & \\
\hline CHEMBL3190480 & 688810 & 4.583 & 4.9729 & TRN & & \\
\hline CHEMBL1360613 & 688810 & 5.63299 & 99999999 & & 5.4018 & TRN \\
\hline CHEMBL1553419 & 688810 & 5.683 & 5.5572 & TRN & & \\
\hline CHEMBL1372586 & 688810 & 5.183 & 5.1421 & TST & & \\
\hline CHEMBL1585632 & 688810 & 5.78299 & э9999999 & 995 & 5.6226 & TRN \\
\hline CHEMBL1366470 & 688810 & 6.0 & 5.7531 & TRN & & \\
\hline CHEMBL489 & 688810 & 4.833 & 4.89199 & 999999999 & 995 & TST \\
\hline CHEMBL1343732 & 688810 & 4.783 & 5.0665 & TST & & \\
\hline CHEMBL1362763 & 688810 & 4.73300 & 00000000 & 005 & 5.3309 & TST \\
\hline CHEMBL3197216 & 688810 & 5.33299 & 99999999 & & 5.0791 & TST \\
\hline CHEMBL1356109 & 688810 & 4.633 & 5.0816 & TRN & & \\
\hline CHEMBL1502056 & 688810 & 4.73300 & 00000000 & 005 & 5.3711 & TRN \\
\hline CHEMBL1556168 & 688810 & 5.083 & 4.8689 & TRN & & \\
\hline CHEMBL1301155 & 688810 & 5.78299 & 99999999 & 995 & 5.6732 & TRN \\
\hline CHEMBL1428400 & 688810 & 4.933 & 5.3593 & TRN & & \\
\hline CHEMBL1547570 & 688810 & 7.0329 & 5.89 & TRN & & \\
\hline CHEMBL1577902 & 688810 & 6.433 & 5.6747 & TRN & & \\
\hline CHEMBL1371865 & 688810 & 6.183 & 5.5409 & TST & & \\
\hline CHEMBL1569716 & 688810 & 4.783 & 5.2875 & TRN & & \\
\hline CHEMBL1512097 & 688810 & 4.683 & 4.7723 & TST & & \\
\hline CHEMBL1398684 & 688810 & 4.783 & 5.4089 & TRN & & \\
\hline CHEMBL1300982 & 688810 & 4.883 & 5.3321 & TRN & & \\
\hline CHEMBL1501105 & 688810 & 5.63299 & 99999999 & & 5.5607 & TRN \\
\hline CHEMBL1347890 & 688810 & 4.883 & 4.8121 & TST & & \\
\hline CHEMBL1581521 & 688810 & 5.733 & 5.3931 & TRN & & \\
\hline CHEMBL3197522 & 688810 & 5.58299 & 79999999 & & 5.0101 & TRN \\
\hline CHEMBL1507729 & 688810 & 4.783 & 4.6265 & TRN & & \\
\hline CHEMBL1550634 & 688810 & 4.833 & 5.2592 & TRN & & \\
\hline CHEMBL1375790 & 688810 & 5.183 & 5.595 & TRN & & \\
\hline CHEMBL3189897 & 688810 & 5.983 & 5.3991 & TRN & & \\
\hline CHEMBL1562664 & 688810 & 5.983 & 5.5758 & TRN & & \\
\hline CHEMBL1510310 & 688810 & 4.883 & 5.4671 & TST & & \\
\hline CHEMBL3190260 & 688810 & 5.683 & 5.8175 & TRN & & \\
\hline CHEMBL3212543 & 688810 & 5.733 & 5.5807 & TST & & \\
\hline CHEMBL1575019 & 688810 & 4.783 & 4.8821 & TRN & & \\
\hline CHEMBL1582841 & 688810 & 5.33299 & 79999999 & & 5.0615 & TRN \\
\hline CHEMBL1418531 & 688810 & 4.883 & 5.5488 & TRN & & \\
\hline CHEMBL1405281 & 688810 & 4.633 & 4.8875 & TRN & & \\
\hline CHEMBL1391277 & 688810 & 4.833 & 5.0532 & TRN & & \\
\hline CHEMBL1433040 & 688810 & 5.433 & 5.7037 & TRN & & \\
\hline CHEMBL3189395 & 688810 & 4.73300 & 20000000 & 005 & 4.8756 & TRN \\
\hline CHEMBL1569682 & 688810 & 4.933 & 5.0634 & TRN & & \\
\hline CHEMBL1519429 & 688810 & 5.033 & 5.8411 & TST & & \\
\hline
\end{tabular}




\begin{tabular}{|c|c|c|c|c|c|c|}
\hline & & \multicolumn{4}{|c|}{ Supplemental Table s2.txt } & \\
\hline CHEMBL1375185 & 688810 & \multicolumn{3}{|c|}{4.7330000000000005} & 5.0979 & TRN \\
\hline CHEMBL1563480 & 688810 & \multicolumn{3}{|c|}{5.2829999999999995} & 4.6872 & TRN \\
\hline CHEMBL1572558 & 688810 & \multicolumn{3}{|c|}{5.382999999999999} & 5.1654 & TST \\
\hline CHEMBL1467876 & 688810 & 6.433 & 5.6669 & TRN & & \\
\hline CHEMBL1544147 & 688810 & 4.833 & 5.4632 & TRN & & \\
\hline CHEMBL1598821 & 688810 & 4.883 & 5.0992 & TRN & & \\
\hline CHEMBL1359235 & 688810 & 5.183 & 5.3655 & TRN & & \\
\hline CHEMBL3192898 & 688810 & 4.583 & 5.3219 & TRN & & \\
\hline CHEMBL1547039 & 688810 & 5.233 & 5.1606 & TRN & & \\
\hline CHEMBL1511024 & 688810 & \multicolumn{3}{|c|}{5.882999999999999} & 5.4637 & TRN \\
\hline CHEMBL1583108 & 688810 & \multicolumn{3}{|c|}{5.5329999999999995} & 5.2287 & TRN \\
\hline CHEMBL1372155 & 688810 & \multicolumn{3}{|c|}{5.5329999999999995} & 5.5243 & TRN \\
\hline CHEMBL1367274 & 688810 & 4.883 & 5.2185 & TRN & & \\
\hline CHEMBL399632 & 688810 & 4.683 & 5.279 & TST & & \\
\hline CHEMBL1447544 & 688810 & 4.883 & 5.2332 & TRN & & \\
\hline CHEMBL1378507 & 688810 & 4.883 & 5.2289 & TST & & \\
\hline CHEMBL1377370 & 688810 & 4.783 & 5.5216 & TRN & & \\
\hline CHEMBL 3207781 & 688810 & 4.883 & 5.2233 & TRN & & \\
\hline CHEMBL1390832 & 688810 & \multicolumn{3}{|c|}{4.7330000000000005} & 4.9581 & TST \\
\hline CHEMBL1533282 & 688810 & 4.933 & 5.6115 & TRN & & \\
\hline CHEMBL1581808 & 688810 & 4.883 & 4.3822 & TRN & & \\
\hline CHEMBL1428397 & 688810 & \multicolumn{3}{|c|}{5.882999999999999} & 5.5529 & TST \\
\hline CHEMBL1546600 & 688810 & \multicolumn{3}{|c|}{5.5329999999999995} & 5.6153 & TRN \\
\hline CHEMBL3211005 & 688810 & \multicolumn{3}{|c|}{5.132999999999999} & 5.3887 & TRN \\
\hline CHEMBL1460449 & 688810 & \multicolumn{3}{|c|}{4.7330000000000005} & 4.9331 & TRN \\
\hline CHEMBL1604705 & 688810 & 4.683 & 4.8903 & TRN & & \\
\hline CHEMBL1329099 & 688810 & \multirow{2}{*}{\multicolumn{3}{|c|}{4.7330000000000005}} & & \\
\hline CHEMBL1501680 & 688810 & & & & 4.9951 & TRN \\
\hline CHEMBL1333282 & 688810 & 6.233 & 5.8397 & TRN & & \\
\hline CHEMBL2004918 & 688810 & \multicolumn{3}{|c|}{5.832999999999999} & 5.6029 & TRN \\
\hline CHEMBL1386821 & 688810 & 4.833 & 5.1048 & TRN & & \\
\hline CHEMBL1368198 & 688810 & \multicolumn{3}{|c|}{4.7330000000000005} & 5.4281 & TST \\
\hline CHEMBL1520048 & 688810 & 5.033 & 4.9836 & TRN & & \\
\hline CHEMBL3189881 & 688810 & 4.883 & 5.3306 & TRN & & \\
\hline CHEMBL1573511 & 688810 & 6.433 & 5.4974 & TRN & & \\
\hline CHEMBL1575010 & 688810 & \multicolumn{3}{|c|}{4.7330000000000005} & 5.482 & TST \\
\hline CHEMBL1431324 & 688810 & 5.483 & 5.3937 & TST & & \\
\hline CHEMBL 1453828 & 688810 & \multirow{2}{*}{\multicolumn{3}{|c|}{$\begin{array}{l}\text { b.183 } 5.4469 \text { IRN } \\
6.582999999999999\end{array}$}} & & \\
\hline CHEMBL1351678 & 688810 & & & & 5.0601 & TST \\
\hline CHEMBL1373898 & 688810 & 5.933 & 5.294 & TRN & & \\
\hline CHEMBL1409817 & 688810 & \multirow{2}{*}{\multicolumn{3}{|c|}{$\begin{array}{l}6.93295 .5184 \text { TRN } \\
4.7330000000000005\end{array}$}} & & \\
\hline CHEMBL1607286 & 688810 & & & & 5.2828 & TST \\
\hline CHEMBL1485354 & 688810 & 6.0 & 5.6446 & TRN & & \\
\hline CHEMBL1428788 & 688810 & 5.183 & 5.1818 & TST & & \\
\hline CHEMBL1515322 & 688810 & \multicolumn{3}{|c|}{5.7829999999999995} & 5.0616 & TRN \\
\hline CHEMBL1603038 & 688810 & 6.183 & 5.8717 & TRN & & \\
\hline CHEMBL1428462 & 688810 & 5.033 & 4.9807 & TST & & \\
\hline CHEMBL1503365 & 688810 & 5.733 & 5.2844 & TST & & \\
\hline
\end{tabular}




\begin{tabular}{|c|c|c|c|c|c|c|c|}
\hline \multicolumn{8}{|c|}{ Supplemental Table S2.txt } \\
\hline CHEMBL 3214609 & 688810 & 4.883 & 5.3972 & TRN & & & \\
\hline CHEMBL1458840 & 688810 & 4.633 & 4.6352 & TST & & & \\
\hline CHEMBL1428862 & 688810 & 4.633 & 5.2934 & TRN & & & \\
\hline CHEMBL1485273 & 688810 & 4.883 & 5.0828 & TST & & & \\
\hline CHEMBL1522279 & 688810 & 4.933 & 5.8294 & TRN & & & \\
\hline CHEMBL1548535 & 688810 & 4.583 & 4.966 & TRN & & & \\
\hline CHEMBL1348807 & 688810 & \multicolumn{3}{|c|}{5.7829999999999995} & 5.2965 & TRN & \\
\hline CHEMBL1331814 & 688810 & \multicolumn{3}{|c|}{4.9830000000000005} & 4.933 & TRN & \\
\hline CHEMBL1307057 & 688810 & \multicolumn{3}{|c|}{4.7330000000000005} & \multicolumn{2}{|c|}{5.053999999999999} & TRN \\
\hline CHEMBL1580449 & 688810 & 4.933 & 5.1701 & TST & & & \\
\hline CHEMBL1346014 & 688810 & 5.733 & 5.3573 & TRN & & & \\
\hline CHEMBL1459178 & 688810 & 4.833 & 5.0683 & TRN & & & \\
\hline CHEMBL1539762 & 688810 & \multicolumn{3}{|c|}{5.582999999999999} & \multicolumn{2}{|c|}{5.446000000000001} & TRN \\
\hline CHEMBL1547988 & 688810 & 4.783 & 5.0078 & TRN & & & \\
\hline CHEMBL1475867 & 688810 & \multicolumn{3}{|c|}{5.132999999999999} & 5.3528 & TRN & \\
\hline CHEMBL1313081 & 688810 & 4.783 & 4.6918 & TST & & & \\
\hline CHEMBL1500583 & 688810 & \multicolumn{3}{|c|}{5.132999999999999} & 5.2782 & TST & \\
\hline CHEMBL1410567 & 688810 & 5.683 & 5.7843 & TRN & & & \\
\hline CHEMBL1447844 & 688810 & \multicolumn{3}{|c|}{5.2829999999999995} & 5.4411 & TRN & \\
\hline CHEMBL3189508 & 688810 & \multicolumn{3}{|c|}{5.2829999999999995} & 5.2722 & TST & \\
\hline CHEMBL1391045 & 688810 & 5.083 & 5.4522 & TRN & & & \\
\hline CHEMBL1335952 & 688810 & 5.65 & 5.1534 & TRN & & & \\
\hline CHEMBL1487727 & 688810 & 4.883 & 5.296 & TST & & & \\
\hline CHEMBL1600827 & 688810 & 4.633 & 5.4026 & TRN & & & \\
\hline CHEMBL1556952 & 688810 & 5.683 & 5.2233 & TST & & & \\
\hline CHEMBL1511941 & 688810 & 4.633 & 5.1738 & TST & & & \\
\hline CHEMBL1588629 & 688810 & 4.783 & 4.931 & TRN & & & \\
\hline CHEMBL1607516 & 688810 & 4.833 & 5.2863 & TRN & & & \\
\hline CHEMBL1457952 & 688810 & \multicolumn{3}{|c|}{4.7330000000000005} & 5.311 & TRN & \\
\hline CHEMBL1494579 & 688810 & 4.633 & 5.0344 & TRN & & & \\
\hline CHEMBL1557045 & 688810 & \multicolumn{3}{|c|}{5.382999999999999} & 5.2244 & TRN & \\
\hline CHEMBL1374829 & 688810 & 5.083 & 5.2337 & TRN & & & \\
\hline CHEMBL1319483 & 688810 & \multirow{2}{*}{\multicolumn{3}{|c|}{$\begin{array}{ll}5.183 & 5.353 \\
4.7330000000000005\end{array}$}} & & & \\
\hline CHEMBL1964628 & 688810 & & & & 4.9061 & TRN & \\
\hline CHEMBL1339073 & 688810 & 4.783 & 5.7264 & TRN & & & \\
\hline CHEMBL1488930 & 688810 & 4.933 & 5.4464 & TRN & & & \\
\hline CHEMBL1441217 & 688810 & \multicolumn{3}{|c|}{5.132999999999999} & 4.8559 & TRN & \\
\hline CHEMBL1563187 & 688810 & \multicolumn{3}{|c|}{6.082999999999999} & 5.7134 & TRN & \\
\hline CHEMBL1402526 & 688810 & \multicolumn{3}{|c|}{5.632999999999999} & 5.1946 & TRN & \\
\hline CHEMBL 3191149 & 688810 & 4.783 & 5.006 & TRN & & & \\
\hline CHEMBL1442085 & 688810 & \multicolumn{3}{|c|}{5.382999999999999} & 5.1902 & TRN & \\
\hline CHEMBL1520223 & 688810 & 5.083 & 5.2058 & TRN & & & \\
\hline CHEMBL 2007318 & 688810 & 4.833 & 5.2203 & TRN & & & \\
\hline CHEMBL3190106 & 688810 & 5.233 & 5.3061 & TRN & & & \\
\hline CHEMBL1461038 & 688810 & 5.183 & 5.1367 & TRN & & & \\
\hline CHEMBL1443383 & 688810 & \multicolumn{3}{|c|}{5.832999999999999} & 5.6089 & TST & \\
\hline CHEMBL1393224 & 688810 & \multicolumn{3}{|c|}{4.7330000000000005} & 4.9263 & TRN & \\
\hline CHEMBL1525533 & 688810 & \multicolumn{3}{|c|}{5.632999999999999} & 5.2568 & TRN & \\
\hline
\end{tabular}




\begin{tabular}{|c|c|c|c|c|c|c|}
\hline & & \multicolumn{5}{|c|}{ Supplemental Table s2.txt } \\
\hline CHEMBL1570542 & 688810 & 5.683 & 5.5626 & TRN & & \\
\hline CHEMBL1563594 & 688810 & 5.083 & 5.2458 & TRN & & \\
\hline CHEMBL1377500 & 688810 & \multicolumn{3}{|c|}{5.382999999999999} & 5.4073 & TRN \\
\hline CHEMBL1538585 & 688810 & \multicolumn{3}{|c|}{5.2829999999999995} & 5.7036 & TRN \\
\hline CHEMBL1560962 & 688810 & 4.633 & 4.9417 & TST & & \\
\hline CHEMBL1507537 & 688810 & 5.433 & 5.3697 & TRN & & \\
\hline CHEMBL1468810 & 688810 & 5.033 & 5.0774 & TRN & & \\
\hline CHEMBL1423995 & 688810 & \multicolumn{3}{|c|}{5.132999999999999} & 5.2913 & TRN \\
\hline CHEMBL1441505 & 688810 & \multicolumn{3}{|c|}{5.7829999999999995} & 5.36 & TRN \\
\hline CHEMBL1403300 & 688810 & 4.783 & 4.9635 & TRN & & \\
\hline CHEMBL1574096 & 688810 & 4.633 & 5.1253 & TST & & \\
\hline CHEMBL1320410 & 688810 & 5.083 & 5.0498 & TRN & & \\
\hline CHEMBL1461679 & 688810 & 4.633 & 5.4167 & TST & & \\
\hline CHEMBL1346587 & 688810 & 4.633 & 4.7512 & TST & & \\
\hline CHEMBL1479242 & 688810 & \multicolumn{3}{|c|}{6.632999999999999} & 5.5937 & TRN \\
\hline CHEMBL1600656 & 688810 & 4.883 & 5.018 & TRN & & \\
\hline CHEMBL1520332 & 688810 & \multicolumn{3}{|c|}{5.2829999999999995} & 5.3421 & TRN \\
\hline CHEMBL1454987 & 688810 & 4.783 & 4.8769 & TRN & & \\
\hline CHEMBL1396869 & 688810 & 4.633 & 5.2856 & TRN & & \\
\hline CHEMBL1554476 & 688810 & \multicolumn{3}{|c|}{5.332999999999999} & 5.1143 & TRN \\
\hline CHEMBL1510094 & 688810 & 6.183 & 5.4424 & TRN & & \\
\hline CHEMBL1333630 & 688810 & 6.433 & 5.315 & TRN & & \\
\hline CHEMBL1456777 & 688810 & 4.783 & 5.0567 & TRN & & \\
\hline CHEMBL1568395 & 688810 & 4.933 & 5.3951 & TRN & & \\
\hline CHEMBL1317711 & 688810 & 5.683 & 5.0128 & TRN & & \\
\hline CHEMBL1461026 & 688810 & 4.833 & 5.3101 & TST & & \\
\hline CHEMBL1403074 & 688810 & \multicolumn{3}{|c|}{5.132999999999999} & 5.4412 & TST \\
\hline CHEMBL1503780 & 688810 & \multicolumn{3}{|c|}{6.582999999999999} & 6.2736 & TRN \\
\hline CHEMBL1309923 & 688810 & \multicolumn{3}{|c|}{5.5329999999999995} & 5.2785 & TRN \\
\hline CHEMBL1330726 & 688810 & 4.933 & 4.6128 & TRN & & \\
\hline CHEMBL1450060 & 688810 & 4.583 & 5.2606 & TRN & & \\
\hline CHEMBL1329829 & 688810 & 7.0329 & 5.7508 & TRN & & \\
\hline CHEMBL1441148 & 688810 & 5.983 & 5.6178 & TRN & & \\
\hline CHEMBL1448626 & 688810 & 4.883 & 5.0903 & TRN & & \\
\hline CHEMBL1967184 & 688810 & \multicolumn{3}{|c|}{5.2829999999999995} & 5.0192 & TST \\
\hline CHEMBL1522344 & 688810 & \multicolumn{3}{|c|}{5.2829999999999995} & 5.8397 & TRN \\
\hline CHEMBL1505546 & 688810 & \multicolumn{3}{|c|}{4.7330000000000005} & 5.0995 & TRN \\
\hline CHEMBL1412223 & 688810 & 5.983 & 5.7732 & TRN & & \\
\hline CHEMBL1353922 & 688810 & \multicolumn{3}{|c|}{5.7829999999999995} & 5.4859 & TRN \\
\hline CHEMBL1348366 & 688810 & \multicolumn{3}{|c|}{5.132999999999999} & 5.5758 & TRN \\
\hline CHEMBL1493664 & 688810 & 5.933 & 5.4535 & TST & & \\
\hline CHEMBL1345360 & 688810 & 4.833 & 5.3578 & TST & & \\
\hline CHEMBL1592615 & 688810 & 4.833 & 5.0263 & TRN & & \\
\hline CHEMBL1367079 & 688810 & 4.933 & 5.0247 & TRN & & \\
\hline CHEMBL3190751 & 688810 & 6.233 & 5.5256 & TRN & & \\
\hline CHEMBL1380934 & 688810 & 4.783 & 5.1755 & TRN & & \\
\hline CHEMBL1376242 & 688810 & 5.4 & 5.2268 & TRN & & \\
\hline CHEMBL1375138 & 688810 & 4.783 & 5.2524 & TRN & & \\
\hline
\end{tabular}




\begin{tabular}{|c|c|c|c|c|c|c|c|}
\hline \multirow[b]{2}{*}{ CHEMBL1389833 } & \multicolumn{6}{|c|}{ Supplemental Table S2.txt } & \\
\hline & 688810 & 5.733 & 5.7193 & TRN & & & \\
\hline CHEMBL3145119 & 688810 & 4.98300 & 00000000 & 005 & 4.9262 & TRN & \\
\hline CHEMBL1579396 & 688810 & 5.433 & 5.8075 & TRN & & & \\
\hline CHEMBL1604451 & 688810 & 5.33299 & 99999999 & 99 & 5.36600 & 00000000005 & TST \\
\hline CHEMBL1589288 & 688810 & 4.933 & 5.2149 & TST & & & \\
\hline CHEMBL1464424 & 688810 & 7.2328 & 5.8924 & TRN & & & \\
\hline CHEMBL1547370 & 688810 & 5.183 & 5.3586 & TRN & & & \\
\hline CHEMBL1565238 & 688810 & 4.633 & 5.4381 & TRN & & & \\
\hline CHEMBL1425388 & 688810 & 4.833 & 5.1379 & TST & & & \\
\hline CHEMBL1362869 & 688810 & 5.88299 & 99999999 & & 5.6624 & TRN & \\
\hline CHEMBL1326455 & 688810 & 6.433 & 5.7604 & TST & & & \\
\hline CHEMBL1467414 & 688810 & 4.633 & 5.3664 & TST & & & \\
\hline CHEMBL1454243 & 688810 & 4.833 & 5.16200 & 000000000 & & TRN & \\
\hline CHEMBL1362260 & 688810 & 5.63299 & 99999999 & & 5.6761 & TST & \\
\hline CHEMBL3197076 & 688810 & 5.83299 & 99999999 & & 5.0515 & TST & \\
\hline CHEMBL465226 & 688810 & 4.583 & 5.2295 & TST & & & \\
\hline CHEMBL1387718 & 688810 & 4.783 & 5.4261 & TRN & & & \\
\hline CHEMBL1388824 & 688810 & 4.98300 & 00000000 & 005 & 5.2517 & TST & \\
\hline CHEMBL1545737 & 688810 & 4.73300 & 00000000 & 005 & 5.0463 & TRN & \\
\hline CHEMBL1604637 & 688810 & 4.883 & 5.6244 & TRN & & & \\
\hline CHEMBL1445389 & 688810 & 4.883 & 5.4716 & TST & & & \\
\hline CHEMBL1305030 & 688810 & 4.583 & 5.0774 & TST & & & \\
\hline CHEMBL1518721 & 688810 & 5.433 & 5.6143 & TRN & & & \\
\hline CHEMBL1370454 & 688810 & 5.433 & 5.9676 & TRN & & & \\
\hline CHEMBL1463365 & 688810 & 5.083 & 4.9068 & TRN & & & \\
\hline CHEMBL1523337 & 688810 & 5.63299 & 79999999 & & 4.7242 & TRN & \\
\hline CHEMBL1397639 & 688810 & 4.73300 & 00000000 & 005 & 4.961 & TRN & \\
\hline CHEMBL1597290 & 688810 & 6.38299 & 99999999 & & 5.5613 & TRN & \\
\hline CHEMBL1600230 & 688810 & 5.033 & 5.2481 & TRN & & & \\
\hline CHEMBL1568554 & 688810 & 5.78299 & 99999999 & 995 & 5.3553 & TRN & \\
\hline CHEMBL1524838 & 688810 & 4.933 & 5.255 & TRN & & & \\
\hline CHEMBL1524529 & 688810 & 4.783 & 4.958 & TRN & & & \\
\hline CHEMBL1450055 & 688810 & 4.883 & 5.1465 & TRN & & & \\
\hline CHEMBL1370267 & 688810 & 4.883 & 5.3842 & TRN & & & \\
\hline CHEMBL1548211 & 688810 & 6.38299 & 99999999 & & 5.1311 & TRN & \\
\hline CHEMBL3191619 & 688810 & 5.933 & 5.2136 & TRN & & & \\
\hline CHEMBL1482958 & 688810 & 5.33299 & 99999999 & & 5.4426 & TRN & \\
\hline CHEMBL1508715 & 688810 & 6.33299 & 79999999 & & 5.5676 & TRN & \\
\hline CHEMBL1435512 & 688810 & 5.53299 & 79999999 & 995 & 5.2804 & TRN & \\
\hline CHEMBL1352111 & 688810 & 4.883 & 4.9236 & TRN & & & \\
\hline CHEMBL3209857 & 688810 & 5.983 & 5.893 & TRN & & & \\
\hline CHEMBL1590986 & 688810 & 4.633 & 5.0615 & TST & & & \\
\hline CHEMBL3194985 & 688810 & 5.88299 & 99999999 & & 5.2 & TRN & \\
\hline CHEMBL1331628 & 688810 & 4.73300 & 00000000 & 005 & 4.855 & TRN & \\
\hline CHEMBL1522641 & 688810 & 4.833 & 5.0459 & TRN & & & \\
\hline CHEMBL 275391 & 688810 & 5.183 & 5.4122 & TRN & & & \\
\hline CHEMBL1341855 & 688810 & 4.833 & 4.9608 & TRN & & & \\
\hline CHEMBL1562638 & 688810 & 5.083 & 5.3155 & TRN & & & \\
\hline
\end{tabular}




\begin{tabular}{|c|c|c|c|c|c|c|}
\hline \multirow{3}{*}{$\begin{array}{l}\text { CHEMBL1442711 } \\
\text { CHEMBL1496970 }\end{array}$} & \multirow{3}{*}{$\begin{array}{l}688810 \\
688810\end{array}$} & \multicolumn{5}{|c|}{ Supplemental Table S2.txt } \\
\hline & & \multicolumn{3}{|c|}{5.132999999999999} & 5.4307 & TST \\
\hline & & 5.083 & 5.3709 & TRN & & \\
\hline CHEMBL1384387 & 688810 & 4.633 & 4.8997 & TST & & \\
\hline CHEMBL1487636 & 688810 & \multicolumn{3}{|c|}{4.7330000000000005} & 5.2501 & TRN \\
\hline CHEMBL1495910 & 688810 & \multicolumn{3}{|c|}{5.132999999999999} & 5.3789 & TRN \\
\hline CHEMBL1337151 & 688810 & 4.883 & 4.8817 & TRN & & \\
\hline CHEMBL3195974 & 688810 & 5.683 & 5.3128 & TRN & & \\
\hline CHEMBL1481301 & 688810 & 4.783 & 5.5647 & TRN & & \\
\hline CHEMBL1600510 & 688810 & 5.033 & 5.3118 & TRN & & \\
\hline CHEMBL1570117 & 688810 & 5.183 & 5.5139 & TRN & & \\
\hline CHEMBL1401811 & 688810 & 4.833 & 4.8791 & TST & & \\
\hline CHEMBL1515852 & 688810 & \multicolumn{3}{|c|}{4.9830000000000005} & 4.8928 & TRN \\
\hline CHEMBL1611573 & 688810 & 4.683 & 5.4834 & TST & & \\
\hline CHEMBL1490744 & 688810 & 5.033 & 5.4304 & TRN & & \\
\hline CHEMBL1445137 & 688810 & \multicolumn{3}{|c|}{5.132999999999999} & 5.3417 & TRN \\
\hline CHEMBL1569408 & 688810 & \multicolumn{3}{|c|}{6.632999999999999} & 5.3284 & TST \\
\hline CHEMBL1579064 & 688810 & 5.733 & 5.7582 & TRN & & \\
\hline CHEMBL 3198372 & 688810 & \multicolumn{3}{|c|}{4.7330000000000005} & 5.2182 & TRN \\
\hline CHEMBL1593084 & 688810 & 4.583 & 5.246 & TRN & & \\
\hline CHEMBL1438577 & 688810 & 4.933 & 5.0097 & TRN & & \\
\hline CHEMBL1536531 & 688810 & 5.483 & 5.191 & TRN & & \\
\hline CHEMBL1530506 & 688810 & \multicolumn{3}{|c|}{4.9830000000000005} & 4.935 & TRN \\
\hline CHEMBL1496860 & 688810 & 4.883 & 4.9253 & TRN & & \\
\hline CHEMBL1594897 & 688810 & \multicolumn{3}{|c|}{5.832999999999999} & 5.7593 & TRN \\
\hline CHEMBL1393019 & 688810 & \multicolumn{3}{|c|}{4.7330000000000005} & 5.2137 & TRN \\
\hline CHEMBL1380303 & 688810 & 5.433 & 5.8275 & TRN & & \\
\hline CHEMBL1386706 & 688810 & \multicolumn{3}{|c|}{5.882999999999999} & 5.5587 & TRN \\
\hline CHEMBL1465899 & 688810 & 4.583 & 4.6676 & TRN & & \\
\hline CHEMBL1384957 & 688810 & \multirow{2}{*}{\multicolumn{3}{|c|}{$\begin{array}{lll}4.933 & 4.7936 & \text { TRN } \\
6.5329999999999995\end{array}$}} & & \\
\hline CHEMBL1536545 & 688810 & & & & 5.4313 & TST \\
\hline CHEMBL1547051 & 688810 & 6.233 & 5.7257 & TRN & & \\
\hline CHEMBL1332534 & 688810 & \multirow{2}{*}{\multicolumn{3}{|c|}{$\begin{array}{lr}4.833 & 5.3478 \text { TRN } \\
5.7829999999999995\end{array}$}} & & \\
\hline CHEMBL3196102 & 688810 & & & 5.7829999999999995 & 5.8362 & TRN \\
\hline CHEMBL1491847 & 688810 & 4.833 & 5.1079 & TRN & & \\
\hline CHEMBL1397788 & 688810 & 4.833 & 5.7625 & TRN & & \\
\hline CHEMBL1549081 & 688810 & 4.783 & 5.5577 & TRN & & \\
\hline CHEMBL1586136 & 688810 & 5.183 & 4.8094 & TST & & \\
\hline CHEMBL1342757 & 688810 & 5.183 & 5.234 & TRN & & \\
\hline CHEMBL1536588 & 688810 & 4.633 & 5.2009 & TRN & & \\
\hline CHEMBL1446909 & 688810 & 5.483 & 5.3957 & TRN & & \\
\hline CHEMBL3198260 & 688810 & 6.0 & 4.8521 & TRN & & \\
\hline CHEMBL3199653 & 688810 & \multicolumn{3}{|c|}{4.7330000000000005} & 5.1547 & TRN \\
\hline CHEMBL1310043 & 688810 & 4.783 & 4.9344 & TRN & & \\
\hline CHEMBL1339547 & 688810 & \multicolumn{3}{|c|}{4.9830000000000005} & 5.3538 & TRN \\
\hline CHEMBL1514691 & 688810 & \multicolumn{3}{|c|}{4.9830000000000005} & 6.0441 & TST \\
\hline CHEMBL1317050 & 688810 & 4.583 & 5.1697 & TRN & & \\
\hline CHEMBL1552505 & 688810 & 6.9329 & 5.5296 & TRN & & \\
\hline CHEMBL 3195720 & 688810 & 4.583 & 5.0609 & TRN & & \\
\hline
\end{tabular}




\begin{tabular}{|c|c|c|c|c|c|c|}
\hline \multicolumn{7}{|c|}{ oplemental Ta } \\
\hline CHEMBL1517433 & 688810 & 5.083 & 5.4141 & TRN & & \\
\hline CHEMBL1325412 & 688810 & 5.433 & 5.3005 & TRN & & \\
\hline CHEMBL1430594 & 688810 & 4.883 & 5.4155 & TST & & \\
\hline CHEMBL1409236 & 688810 & 4.783 & 5.0279 & TRN & & \\
\hline CHEMBL1384739 & 688810 & 5.183 & 5.5294 & TRN & & \\
\hline CHEMBL1377552 & 688810 & \multicolumn{3}{|c|}{5.332999999999999} & 5.4792 & $\mathrm{TP}$ \\
\hline CHEMBL1510311 & 688810 & 5.183 & 5.4141 & TRN & & \\
\hline CHEMBL1609660 & 688810 & \multicolumn{3}{|c|}{4.7330000000000005} & 5.1149 & \\
\hline CHEMBL1516199 & 688810 & \multicolumn{3}{|c|}{5.7829999999999995} & 5.2967 & \\
\hline CHEMBL1578433 & 688810 & 4.783 & 5.1878 & TRN & & \\
\hline CHEMBL3190078 & 688810 & \multicolumn{3}{|c|}{5.382999999999999} & 5.3563 & \\
\hline CHEMBL1412074 & 688810 & 5.183 & 5.2451 & TRN & & \\
\hline CHEMBL1488813 & 688810 & \multicolumn{3}{|c|}{5.2829999999999995} & 5.3179 & \\
\hline CHEMBL1523486 & 688810 & \multicolumn{3}{|c|}{4.7330000000000005} & 4.9132 & \\
\hline CHEMBL1541000 & 688810 & \multicolumn{3}{|c|}{6.382999999999999} & 5.8116 & \\
\hline CHEMBL1577925 & 688810 & \multicolumn{3}{|c|}{4.9830000000000005} & 5.0965 & \\
\hline CHEMBL 2000196 & 688810 & \multicolumn{3}{|c|}{5.5329999999999995} & 5.4984 & \\
\hline CHEMBL1465938 & 688810 & \multicolumn{3}{|c|}{4.7330000000000005} & 4.8092 & \\
\hline CHEMBL1340845 & 688810 & \multicolumn{3}{|c|}{6.5329999999999995} & 5.7757 & \\
\hline CHEMBL1525901 & 688810 & \multicolumn{3}{|c|}{5.832999999999999} & 6.2379 & \\
\hline CHEMBL 3191378 & 688810 & \multicolumn{3}{|c|}{5.7829999999999995} & 5.0415 & \\
\hline CHEMBL1377687 & 688810 & 6.233 & 5.5403 & TRN & & \\
\hline CHEMBL1599656 & 688810 & 5.083 & 4.7984 & TST & & \\
\hline CHEMBL 22062 & 688810 & 5.183 & 5.1882 & TRN & & \\
\hline CHEMBL1345 & 688810 & 4.783 & 5.0802 & TRN & & \\
\hline CHEMBL1342128 & 688810 & 4.9 & 5.2854 & TRN & & \\
\hline CHEMBL1423291 & 688810 & \multicolumn{3}{|c|}{4.9830000000000005} & 5.4235 & \\
\hline CHEMBL1998302 & 688810 & 4.833 & 5.4769 & TRN & & \\
\hline CHEMBL1323279 & 688810 & \multicolumn{3}{|c|}{5.7829999999999995} & 5.9054 & \\
\hline CHEMBL1454995 & 688810 & \multicolumn{3}{|c|}{4.9830000000000005} & 5.3268 & \\
\hline CHEMBL1410615 & 688810 & 5.233 & 5.2951 & TST & & \\
\hline CHEMBL1364908 & 688810 & \multirow{2}{*}{\multicolumn{3}{|c|}{$\begin{array}{ll}5.183 & 5.1431 \\
5.132999999999999\end{array}$}} & & \\
\hline CHEMBL1557844 & 688810 & & & & 4.9374 & \\
\hline CHEMBL1523981 & 688810 & \multicolumn{3}{|c|}{$\begin{array}{lll}4.933 & 5.0953 & \text { TST }\end{array}$} & & \\
\hline CHEMBL1470993 & 688810 & 5.683 & 5.4959 & TRN & & \\
\hline CHEMBL1465699 & 688810 & 5.233 & 5.7147 & TRN & & \\
\hline CHEMBL1444799 & 688810 & 4.783 & 5.0414 & TRN & & \\
\hline CHEMBL1374043 & 688810 & \multicolumn{3}{|c|}{5.632999999999999} & 5.3611 & \\
\hline CHEMBL1496033 & 688810 & 4.783 & 5.2025 & TRN & & \\
\hline CHEMBL1534661 & 688810 & \multirow{2}{*}{\multicolumn{3}{|c|}{$\begin{array}{lrr}4.883 & 5.2048 & \text { TR } \\
6.082999999999999\end{array}$}} & & \\
\hline CHEMBL1493206 & 688810 & & & & 5.2236 & \\
\hline CHEMBL1308373 & 688810 & 4.783 & 5.5182 & TRN & & \\
\hline CHEMBL1495375 & 688810 & 5.8829 & 9999999 & & & \\
\hline CHEMBL1454651 & 688810 & 5.8329 & 99999999 & & 5.4028 & \\
\hline CHEMBL1518968 & 688810 & 5.083 & 4.9442 & TST & & \\
\hline CHEMBL1376504 & 688810 & 4.833 & 5.1714 & TST & & \\
\hline CHEMBL1376804 & 688810 & 5.6329 & 99999999 & & 5.3298 & I RIV \\
\hline CHEMBL1602384 & 688810 & 5.1329 & 99999999 & & 5.4768 & \\
\hline
\end{tabular}




\begin{tabular}{|c|c|c|c|c|c|c|}
\hline & & \multicolumn{5}{|c|}{ Supplemental Table S2.txt } \\
\hline CHEMBL1592350 & 688810 & 5.183 & 5.0814 & TRN & & \\
\hline CHEMBL1355537 & 688810 & 4.883 & 6.1857 & TRN & & \\
\hline CHEMBL1550249 & 688810 & 5.083 & 4.9094 & TRN & & \\
\hline CHEMBL1328629 & 688810 & 4.883 & 5.2854 & TST & & \\
\hline CHEMBL1576059 & 688810 & 5.683 & 5.2041 & TRN & & \\
\hline CHEMBL1464294 & 688810 & 5.183 & 5.4018 & TRN & & \\
\hline CHEMBL1412708 & 688810 & 4.833 & 4.9573 & TRN & & \\
\hline CHEMBL1363246 & 688810 & \multicolumn{3}{|c|}{5.882999999999999} & 5.3089 & \\
\hline CHEMBL1303953 & 688810 & 4.833 & 5.0733 & TRN & & \\
\hline CHEMBL452153 & 688810 & 4.783 & 5.8681 & TRN & & \\
\hline CHEMBL 3197637 & 688810 & 4.683 & 4.7981 & TRN & & \\
\hline CHEMBL1558465 & 688810 & \multicolumn{3}{|c|}{4.7330000000000005} & 4.9224 & \\
\hline CHEMBL3190376 & 688810 & 4.583 & 5.4827 & TRN & & \\
\hline CHEMBL1303718 & 688810 & 4.833 & 5.117 & TRN & & \\
\hline CHEMBL3195086 & 688810 & \multicolumn{3}{|c|}{5.7829999999999995} & 5.5499 & 11 \\
\hline CHEMBL1570361 & 688810 & 4.933 & 5.1339 & TRN & & \\
\hline CHEMBL1396894 & 688810 & \multicolumn{3}{|c|}{4.9830000000000005} & 4.7378 & \\
\hline CHEMBL1306153 & 688810 & 4.783 & 5.5604 & TST & & \\
\hline CHEMBL1368631 & 688810 & 4.833 & 5.7267 & TRN & & \\
\hline CHEMBL1521083 & 688810 & \multicolumn{3}{|c|}{4.9830000000000005} & 4.9153 & $\mathrm{TH}$ \\
\hline CHEMBL1552571 & 688810 & 5.733 & 5.3281 & TRN & & \\
\hline CHEMBL1453927 & 688810 & 4.883 & 5.1137 & TRN & & \\
\hline CHEMBL1444157 & 688810 & 5.683 & 5.3241 & TRN & & \\
\hline CHEMBL1311771 & 688810 & \multicolumn{3}{|c|}{6.382999999999999} & 5.9314 & $\mathrm{TI}$ \\
\hline CHEMBL1606217 & 688810 & 4.833 & 5.2535 & TST & & \\
\hline CHEMBL1508982 & 688810 & 5.233 & 5.8456 & TRN & & \\
\hline CHEMBL3197836 & 688810 & 5.433 & 5.5886 & TRN & & \\
\hline CHEMBL1412695 & 688810 & 6.983 & 5.6884 & TRN & & \\
\hline CHEMBL1427014 & 688810 & \multicolumn{3}{|c|}{5.582999999999999} & 5.3671 & $\mathrm{TI}$ \\
\hline CHEMBL1442075 & 688810 & 4.633 & 5.24 & TRN & & \\
\hline CHEMBL1375352 & 688810 & 4.583 & 4.9261 & TRN & & \\
\hline CHEMBL1304704 & 688810 & \multicolumn{3}{|c|}{5.2829999999999995} & 5.0426 & I K \\
\hline CHEMBL1522518 & 688810 & \multicolumn{3}{|c|}{5.132999999999999} & 4.9987 & TRN \\
\hline CHEMBL3189624 & 688810 & 4.683 & 4.7828 & TST & & \\
\hline CHEMBL1546323 & 688810 & 4.833 & 4.9537 & TST & & \\
\hline CHEMBL1507042 & 688810 & 5.483 & 5.5209 & TRN & & \\
\hline CHEMBL1433500 & 688810 & 4.783 & 5.4357 & TST & & \\
\hline CHEMBL1562493 & 688810 & 4.833 & 5.5131 & TRN & & \\
\hline CHEMBL1467025 & 688810 & \multicolumn{3}{|c|}{5.832999999999999} & 5.4758 & $\mathrm{TR}$ \\
\hline CHEMBL1432027 & 688810 & 5.083 & 5.5211 & TRN & & \\
\hline CHEMBL1539679 & 688810 & 4.783 & 5.0039 & TRN & & \\
\hline CHEMBL1984639 & 688810 & \multicolumn{3}{|c|}{6.382999999999999} & 5.6635 & TST \\
\hline CHEMBL3194008 & 688810 & 6.883 & 5.4795 & TRN & & \\
\hline CHEMBL1347782 & 688810 & \multicolumn{3}{|c|}{4.7330000000000005} & 4.5178 & TRI \\
\hline CHEMBL1345305 & 688810 & 5.033 & 5.3483 & TRN & & \\
\hline CHEMBL399121 & 688810 & 4.783 & 4.5842 & TST & & \\
\hline CHEMBL1545244 & 688810 & \multicolumn{3}{|c|}{5.132999999999999} & 5.3306 & ונמו \\
\hline CHEMBL1303864 & 688810 & \multicolumn{3}{|c|}{5.882999999999999} & 5.2901 & \\
\hline
\end{tabular}




\begin{tabular}{|c|c|c|c|c|c|c|}
\hline & & \multicolumn{5}{|c|}{ Supplemental Table S2.txt } \\
\hline CHEMBL1975525 & 688810 & 6.183 & 5.3432 & TRN & & \\
\hline CHEMBL1592216 & 688810 & 6.4829 & 5.7295 & TRN & & \\
\hline CHEMBL1416153 & 688810 & 4.883 & 5.0378 & TRN & & \\
\hline CHEMBL1577058 & 688810 & 4.833 & 4.7252 & TRN & & \\
\hline CHEMBL1302618 & 688810 & 5.033 & 5.5876 & TRN & & \\
\hline CHEMBL1389438 & 688810 & 6.183 & 5.393 & TRN & & \\
\hline CHEMBL1364731 & 688810 & 4.833 & 5.4068 & TRN & & \\
\hline CHEMBL1604016 & 688810 & 5.683 & 5.3611 & TRN & & \\
\hline CHEMBL1389196 & 688810 & 4.833 & 4.9642 & TST & & \\
\hline CHEMBL1341432 & 688810 & 4.883 & 4.7855 & TRN & & \\
\hline CHEMBL1392850 & 688810 & \multicolumn{3}{|c|}{6.132999999999999} & 4.9368 & TRN \\
\hline CHEMBL1372137 & 688810 & 5.733 & 5.2766 & TRN & & \\
\hline CHEMBL1587363 & 688810 & 4.933 & 5.1452 & TRN & & \\
\hline CHEMBL1489455 & 688810 & 4.883 & 5.1993 & TST & & \\
\hline CHEMBL1425537 & 688810 & \multicolumn{3}{|c|}{5.382999999999999} & 5.3074 & TRN \\
\hline CHEMBL1355038 & 688810 & 4.633 & 4.9852 & TRN & & \\
\hline CHEMBL1312838 & 688810 & 5.683 & 5.4673 & TRN & & \\
\hline CHEMBL1312720 & 688810 & 6.4829 & 5.4021 & TRN & & \\
\hline CHEMBL1571094 & 688810 & \multicolumn{3}{|c|}{4.9830000000000005} & 4.9685 & TRN \\
\hline CHEMBL1546823 & 688810 & \multicolumn{3}{|c|}{4.7330000000000005} & 4.7002 & TST \\
\hline CHEMBL1309110 & 688810 & 4.883 & 5.2453 & TRN & & \\
\hline CHEMBL1320192 & 688810 & 4.833 & 5.226 & TRN & & \\
\hline CHEMBL1400851 & 688810 & \multicolumn{3}{|c|}{5.332999999999999} & 5.3843 & TRN \\
\hline CHEMBL1381377 & 688810 & 6.433 & 5.5711 & TRN & & \\
\hline CHEMBL391351 & 688810 & 5.483 & 5.6216 & TRN & & \\
\hline CHEMBL1406139 & 688810 & \multicolumn{3}{|c|}{4.7330000000000005} & 4.9713 & TRN \\
\hline CHEMBL1504716 & 688810 & \multicolumn{3}{|c|}{4.9830000000000005} & 4.7947 & TST \\
\hline CHEMBL3192747 & 688810 & 4.783 & 4.9423 & TST & & \\
\hline CHEMBL1323408 & 688810 & \multicolumn{3}{|c|}{6.082999999999999} & 5.2682 & TRN \\
\hline CHEMBL1501761 & 688810 & 4.583 & 5.532 & TRN & & \\
\hline CHEMBL1480234 & 688810 & 4.933 & \multicolumn{3}{|c|}{5.7170000000000005} & TST \\
\hline CHEMBL1601249 & 688810 & \multicolumn{3}{|c|}{5.2829999999999995} & 5.1139 & TRN \\
\hline CHEMBL1364627 & 688810 & 4.783 & 4.9147 & TST & & \\
\hline CHEMBL1367327 & 688810 & \multicolumn{3}{|c|}{6.332999999999999} & 5.9597 & TRN \\
\hline CHEMBL1441479 & 688810 & 4.933 & 5.1917 & TRN & & \\
\hline CHEMBL1383842 & 688810 & 6.183 & 5.5082 & TRN & & \\
\hline CHEMBL1389436 & 688810 & 4.833 & 5.3654 & TST & & \\
\hline CHEMBL1360292 & 688810 & 4.783 & 5.0252 & TST & & \\
\hline CHEMBL1563036 & 688810 & 4.833 & 5.0565 & TST & & \\
\hline CHEMBL1308619 & 688810 & 4.783 & 5.1762 & TRN & & \\
\hline CHEMBL1598287 & 688810 & 5.733 & 5.3596 & TRN & & \\
\hline CHEMBL1431451 & 688810 & 4.883 & 5.6922 & TRN & & \\
\hline CHEMBL1313856 & 688810 & 5.083 & 5.2683 & TST & & \\
\hline CHEMBL1517382 & 688810 & \multicolumn{3}{|c|}{6.582999999999999} & 4.8351 & TST \\
\hline CHEMBL1338958 & 688810 & 4.633 & 4.8641 & TRN & & \\
\hline CHEMBL1473454 & 688810 & \multicolumn{3}{|c|}{5.132999999999999} & 5.5078 & TRN \\
\hline CHEMBL1344339 & 688810 & 4.633 & 5.1468 & TST & & \\
\hline CHEMBL1520043 & 688810 & 5.083 & 5.1742 & TRN & & \\
\hline
\end{tabular}




\begin{tabular}{|c|c|c|c|c|c|c|c|}
\hline \multicolumn{8}{|c|}{ Supplemental Table s2.txt } \\
\hline CHEMBL1415300 & 688810 & 4.883 & 5.2732 & TRN & & & \\
\hline CHEMBL1579152 & 688810 & 5.233 & 5.3345 & TRN & & & \\
\hline CHEMBL1533117 & 688810 & \multicolumn{3}{|c|}{5.382999999999999} & 5.4185 & TRN & \\
\hline CHEMBL1338307 & 688810 & \multicolumn{3}{|c|}{5.882999999999999} & 5.118 & TST & \\
\hline CHEMBL1394797 & 688810 & 4.883 & 5.1984 & TRN & & & \\
\hline CHEMBL1523672 & 688810 & \multicolumn{3}{|c|}{5.132999999999999} & 4.9528 & TRN & \\
\hline CHEMBL1436372 & 688810 & \multicolumn{3}{|c|}{5.882999999999999} & 5.3763 & TRN & \\
\hline CHEMBL1340448 & 688810 & \multicolumn{3}{|c|}{5.582999999999999} & 5.4745 & TST & \\
\hline CHEMBL1371088 & 688810 & \multicolumn{3}{|c|}{5.632999999999999} & 5.7464 & TRN & \\
\hline CHEMBL1370337 & 688810 & \multicolumn{3}{|c|}{5.132999999999999} & 4.8983 & TRN & \\
\hline CHEMBL1610041 & 688810 & 4.783 & 4.98 & TRN & & & \\
\hline CHEMBL1430215 & 688810 & 4.883 & 5.1787 & TRN & & & \\
\hline CHEMBL399249 & 688810 & 4.783 & 4.7387 & TRN & & & \\
\hline CHEMBL1323427 & 688810 & \multicolumn{3}{|c|}{5.132999999999999} & 5.1611 & TRN & \\
\hline CHEMBL1343670 & 688810 & 4.783 & 4.9879 & TRN & & & \\
\hline CHEMBL1525073 & 688810 & \multicolumn{3}{|c|}{5.382999999999999} & 4.8949 & TRN & \\
\hline CHEMBL1537782 & 688810 & 6.433 & 5.6615 & TRN & & & \\
\hline CHEMBL1520311 & 688810 & 4.783 & 5.3131 & TRN & & & \\
\hline CHEMBL1465725 & 688810 & 6.233 & 5.0888 & TRN & & & \\
\hline CHEMBL1430953 & 688810 & \multicolumn{3}{|c|}{5.132999999999999} & 4.9753 & TST & \\
\hline CHEMBL1302039 & 688810 & 4.783 & 5.1864 & TRN & & & \\
\hline CHEMBL1411383 & 688810 & 6.0 & 5.0553 & TRN & & & \\
\hline CHEMBL1399667 & 688810 & 5.183 & 5.7436 & TRN & & & \\
\hline CHEMBL1592201 & 688810 & 5.733 & 5.7979 & TRN & & & \\
\hline CHEMBL3195188 & 688810 & 4.883 & 5.6912 & TRN & & & \\
\hline CHEMBL1451256 & 688810 & \multicolumn{3}{|c|}{6.0329999999999995} & 5.8671 & TRN & \\
\hline CHEMBL1436522 & 688810 & 5.033 & 5.0181 & TRN & & & \\
\hline CHEMBL1333044 & 688810 & 5.433 & & TRN & & & \\
\hline CHEMBL1371059 & 688810 & \multicolumn{3}{|c|}{6.2829999999999995} & 5.22 & TRN & \\
\hline CHEMBL1599341 & 688810 & 4.783 & 4.824 & TRN & & & \\
\hline CHEMBL1540761 & 688810 & \multicolumn{3}{|c|}{5.7829999999999995} & 5.8828 & TST & \\
\hline CHEMBL1402920 & 688810 & 4.633 & 4.9875 & TST & & & \\
\hline CHEMBL1588543 & 688810 & 4.783 & 5.2005 & TRN & & & \\
\hline CHEMBL1436229 & 688810 & 4.883 & 4.856 & TST & & & \\
\hline CHEMBL1585921 & 688810 & \multicolumn{3}{|c|}{4.9830000000000005} & 4.7931 & TRN & \\
\hline CHEMBL1495192 & 688810 & 4.633 & 5.1299 & TRN & & & \\
\hline CHEMBL3194031 & 688810 & 4.883 & 5.3583 & TST & & & \\
\hline CHEMBL1436358 & 688810 & 4.833 & 5.5883 & TRN & & & \\
\hline CHEMBL1430598 & 688810 & \multicolumn{3}{|c|}{5.632999999999999} & \multicolumn{2}{|c|}{5.696000000000001} & TRN \\
\hline CHEMBL1433895 & 688810 & 6.233 & 5.6078 & TRN & & & \\
\hline CHEMBL1449236 & 688810 & 4.833 & \multicolumn{3}{|c|}{4.9910000000000005} & TRN & \\
\hline CHEMBL1347188 & 688810 & \multicolumn{3}{|c|}{5.332999999999999} & 5.5341 & TST & \\
\hline CHEMBL1398720 & 688810 & 5.033 & 5.4893 & TRN & & & \\
\hline CHEMBL1343966 & 688810 & 4.833 & 4.9787 & TRN & & & \\
\hline CHEMBL1443234 & 688810 & 5.083 & 5.3435 & TRN & & & \\
\hline CHEMBL 3212098 & 688810 & 5.183 & 5.5001 & TST & & & \\
\hline CHEMBL1317366 & 688810 & 5.183 & 5.50200 & 000000000 & & TRN & \\
\hline CHEMBL1509293 & 688810 & 5.233 & 5.2 & TRN & & & \\
\hline
\end{tabular}




\begin{tabular}{|c|c|c|c|c|c|c|}
\hline & & \multicolumn{5}{|c|}{ Supplemental Table S2.txt } \\
\hline CHEMBL1502876 & 688810 & 5.183 & 5.2008 & TRN & & \\
\hline CHEMBL1410943 & 688810 & 4.933 & 5.3226 & TST & & \\
\hline CHEMBL1405448 & 88810 & .583 & 4.7877 & TST & & \\
\hline CHEMBL1598743 & 688810 & \multicolumn{3}{|c|}{6.832999999999999} & 6.1905 & TRN \\
\hline CHEMBL1379740 & 688810 & \multicolumn{3}{|c|}{6.7829999999999995} & 5.6517 & TST \\
\hline CHEMBL1510804 & 688810 & 6.433 & 5.5825 & TRN & & \\
\hline CHEMBL1590714 & 688810 & \multicolumn{3}{|c|}{6.382999999999999} & 5.8394 & IIV \\
\hline CHEMBL1581488 & 688810 & \multicolumn{3}{|c|}{5.332999999999999} & 5.5589 & TRN \\
\hline CHEMBL1362346 & 688810 & \multicolumn{3}{|c|}{4.7330000000000005} & 5.1333 & \\
\hline CHEMBL1398976 & 688810 & 4.633 & 5.4151 & TRN & & \\
\hline CHEMBL1432745 & 688810 & \multicolumn{3}{|c|}{6.382999999999999} & 5.5602 & $1 \mathrm{NI}$ \\
\hline CHEMBL1425297 & 688810 & 5.683 & 5.2018 & TRN & & \\
\hline CHEMBL1443709 & 688810 & 4.933 & 5.119 & TRN & & \\
\hline CHEMBL1527228 & 688810 & 5.683 & 5.5662 & TRN & & \\
\hline CHEMBL1324969 & 688810 & 5.033 & 5.483 & TRN & & \\
\hline CHEMBL1528305 & 688810 & 4.883 & 5.7134 & TRN & & \\
\hline CHEMBL1374900 & 688810 & 5.233 & 5.2949 & TRN & & \\
\hline CHEMBL16 & 688810 & 4.883 & 5.2496 & TRN & & \\
\hline CHEMBL14 & 688810 & 4.883 & 5.4144 & TRN & & \\
\hline CHEMBL1361810 & 688810 & 5.733 & 5.4455 & TRN & & \\
\hline CHEMBL1434829 & 688810 & 5.483 & 5.0266 & TRN & & \\
\hline CHEMBL1524134 & 688810 & \multicolumn{3}{|c|}{6.0329999999999995} & 277 & \\
\hline CHEMBL15 & 688810 & 4.883 & 5.3314 & TST & & \\
\hline CHEMBL15 & 688810 & \multicolumn{3}{|c|}{5.832999999999999} & 6.1461 & TRN \\
\hline CHEMBL1600862 & 688810 & 4.683 & \multicolumn{3}{|c|}{5.0969999999999995} & TRN \\
\hline CHEMBL1375280 & 688810 & \multicolumn{3}{|c|}{5.7829999999999995} & 5.5 & TRN \\
\hline CHEMBL19 & 688810 & \multicolumn{3}{|c|}{5.7829999999999995} & & TST \\
\hline CHEMBL1 & 688810 & \multicolumn{3}{|c|}{6.332999999999999} & & TST \\
\hline CHEMBL1345300 & 688810 & 5.483 & 5.4899 & TRN & & \\
\hline CHEMBL1459878 & 688810 & 5.033 & 5.4334 & TRN & & \\
\hline CHEMBL1567431 & 688810 & \multicolumn{3}{|c|}{4.7330000000000005} & & TST \\
\hline CHEMBL1 & 688810 & \multicolumn{3}{|c|}{4.9830000000000005} & & TST \\
\hline CHEMBL3 & 688810 & \multicolumn{3}{|c|}{5.132999999999999} & 5.315 & TRN \\
\hline CHEMBL1435750 & 688810 & 4.783 & 5.0627 & TRN & & \\
\hline CHEMBL1453237 & 688810 & 4.9 & 5.6588 & TST & & \\
\hline CHEMBL1447992 & 688810 & 4.833 & 4.8721 & TRN & & \\
\hline CHEMBL1 & 688810 & \multicolumn{3}{|c|}{6.082999999999999} & 5.1657 & it \\
\hline CHEMBL13 & 688810 & 4.883 & 5.1725 & TRN & & \\
\hline CHEMBL585769 & 688810 & \multicolumn{3}{|c|}{6.0329999999999995} & & TRN \\
\hline CHEMBL1326723 & 688810 & \multicolumn{3}{|c|}{5.582999999999999} & & TRN \\
\hline CHEMBL1309497 & 688810 & \multicolumn{3}{|c|}{5.632999999999999} & 5.7619 & TP \\
\hline CHEMBL1458318 & 688810 & 5.233 & 5.2286 & TST & & \\
\hline CHEMBL1439954 & 688810 & \multicolumn{3}{|c|}{5.832999999999999} & 6.0072 & TRN \\
\hline CHEMBL1590089 & 688810 & 5.2829 & 99999999 & 995 & 4.7541 & TST \\
\hline CHEMBL1355558 & 688810 & 5.3329 & 99999999 & & 5.1217 & TRN \\
\hline CHEMBL1540337 & 688810 & 4.783 & 5.1963 & TRN & & \\
\hline CHEMBL1535601 & 688810 & 4.7330 & 00000000 & 005 & 5.6243 & כ \\
\hline CHEMBL1517447 & 688810 & 5.183 & 4.9156 & TRN & & \\
\hline
\end{tabular}




\begin{tabular}{|c|c|c|c|c|c|c|}
\hline \multirow{4}{*}{$\begin{array}{l}\text { CHEMBL } 3196551 \\
\text { CHEMBL1514742 } \\
\text { CHEMBL1607924 }\end{array}$} & \multirow[b]{2}{*}{688810} & \multicolumn{5}{|c|}{ Supplemental Table S2.txt } \\
\hline & & 5.233 & \multicolumn{3}{|c|}{5.5360000000000005} & TST \\
\hline & 688810 & 4.883 & \multicolumn{3}{|c|}{5.236000000000001} & TST \\
\hline & 688810 & 4.833 & 5.425 & TRN & & \\
\hline CHEMBL1338805 & 688810 & 5.083 & 4.9641 & TRN & & \\
\hline CHEMBL1596726 & 688810 & \multicolumn{3}{|c|}{5.832999999999999} & 5.6814 & TRN \\
\hline CHEMBL1319818 & 688810 & \multicolumn{3}{|c|}{4.9830000000000005} & 5.6441 & \\
\hline CHEMBL1574311 & 688810 & 4.833 & 5.2668 & TRN & & \\
\hline HEMBL1397743 & 588810 & 5.733 & 5.2635 & TST & & \\
\hline CHEMBL1366506 & 688810 & 5.033 & 5.2943 & TRN & & \\
\hline CHEMBL601137 & 588810 & 5.033 & 5.4433 & TST & & \\
\hline CHEMBL1556111 & 88810 & 4.783 & 5.4688 & TRN & & \\
\hline CHEMBL3213193 & 688810 & 4.783 & 5.0423 & TRN & & \\
\hline CHEMBL1498051 & 588810 & 5.483 & 5.3809 & TRN & & \\
\hline CHEMBL1599636 & 688810 & \multicolumn{3}{|c|}{5.2829999999999995} & 5.254 & TST \\
\hline CHEMBL1580230 & 688810 & \multicolumn{3}{|c|}{4.7330000000000005} & 4.9424 & \\
\hline CHEMBL1497166 & 688810 & 5.033 & 5.0112 & TRN & & \\
\hline CHEMBL1340788 & 688810 & \multicolumn{3}{|c|}{4.9830000000000005} & 5.4978 & \\
\hline CHEMBL1461524 & 688810 & 4.683 & 5.7274 & TRN & & \\
\hline HEMBL1482928 & 688810 & 4.783 & 5.1199 & TST & & \\
\hline HEMBL1377073 & 688810 & \multicolumn{3}{|c|}{4.9830000000000005} & 5.275 & TRN \\
\hline CHEMBL1580040 & 688810 & \multicolumn{3}{|c|}{6.082999999999999} & & \\
\hline CHEMBL1571635 & 688810 & 4.933 & 4.9888 & TRN & & \\
\hline CHEMBL1609228 & 688810 & 4.883 & 5.069 & TRN & & \\
\hline CHEMBL1429254 & 688810 & 4.783 & 5.2888 & TRN & & \\
\hline CHEMBL1546597 & 688810 & \multicolumn{3}{|c|}{4.7330000000000005} & 5.2409 & $\mathrm{TP}$ \\
\hline CHEMBL1361116 & 688810 & 6.0 & 5.8915 & TRN & & \\
\hline CHEMBL1366395 & 688810 & 4.783 & 5.6389 & TST & & \\
\hline CHEMBL1496969 & 688810 & 4.933 & 5.5275 & TST & & \\
\hline CHEMBL1505153 & 688810 & \multicolumn{3}{|c|}{5.2829999999999995} & 5.5177 & TRN \\
\hline CHEMBL1589345 & 688810 & \multicolumn{3}{|c|}{5.2829999999999995} & 4.9038 & $\mathrm{TP}$ \\
\hline CHEMBL1566808 & 688810 & 4.883 & 4.7229 & TRN & & \\
\hline CHEMBL1359521 & 688810 & 6 . & 6.4132 & TRN & & \\
\hline CHEMBL151946 & 688810 & 5.083 & 5.1416 & TST & & \\
\hline CHEMBL1585146 & 688810 & \multicolumn{3}{|c|}{4.7330000000000005} & 5.3166 & $\mathrm{TR}$ \\
\hline CHEMBL1533799 & 688810 & 4.583 & 4.8982 & TST & & \\
\hline CHEMBL1518056 & 688810 & \multicolumn{3}{|c|}{5.132999999999999} & 5.0428 & $1 \mathrm{~K}$ \\
\hline CHEMBL1530142 & 688810 & 4.833 & 4.9982 & TRN & & \\
\hline CHEMBL1324156 & 688810 & 4.883 & 5.4977 & TST & & \\
\hline CHEMBL1511526 & 688810 & 4.583 & 4.7819 & TRN & & \\
\hline CHEMBL1321410 & 688810 & \multicolumn{3}{|c|}{6.382999999999999} & 5.7487 & 17 \\
\hline CHEMBL1518990 & 688810 & \multicolumn{3}{|c|}{4.9830000000000005} & 5.2285 & $\mathrm{TH}$ \\
\hline CHEMBL1378735 & 688810 & 5.033 & 4.9314 & TRN & & \\
\hline CHEMBL3198218 & 688810 & \multicolumn{3}{|c|}{5.132999999999999} & 5.2967 & 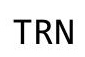 \\
\hline CHEMBL1422320 & 688810 & 5.933 & 5.3638 & TRN & & \\
\hline CHEMBL1502702 & 688810 & 5.683 & 5.5443 & TRN & & \\
\hline CHEMBL1559489 & 688810 & \multicolumn{3}{|c|}{5.382999999999999} & 545 & TST \\
\hline CHEMBL1316250 & 688810 & 5.332 & 999999 & & 4.9773 & rs \\
\hline CHEMBL1452852 & 688810 & 5.733 & 5.5131 & TR & & \\
\hline
\end{tabular}




\begin{tabular}{|c|c|c|c|c|c|c|c|}
\hline \multicolumn{8}{|c|}{ 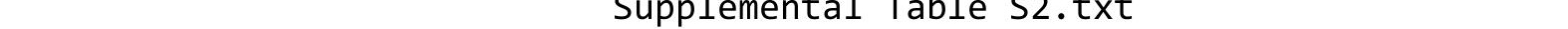 } \\
\hline CHEMBL1434205 & 688810 & 4.783 & 5.1998 & TRN & & & \\
\hline CHEMBL452241 & 688810 & 4.783 & 5.2782 & TRN & & & \\
\hline CHEMBL1461798 & 688810 & 4.883 & 5.3626 & TRN & & & \\
\hline CHEMBL1579136 & 688810 & 4.883 & 5.4898 & TRN & & & \\
\hline CHEMBL1563597 & 688810 & 6.0 & 5.6207 & TRN & & & \\
\hline CHEMBL1424776 & 688810 & 5.6329 & 99999995 & & 5.7528 & TRN & \\
\hline CHEMBL1572758 & 688810 & 5.483 & $5.7410 €$ & 000000000 & 005 & TRN & \\
\hline CHEMBL1330960 & 688810 & 5.733 & 5.544 & TRN & & & \\
\hline CHEMBL1462346 & 688810 & 4.7330 & 0000000 & 005 & 5.419 & TST & \\
\hline CHEMBL1323863 & 688810 & 5.433 & 5.1848 & TRN & & & \\
\hline CHEMBL1542862 & 688810 & 5.3829 & 9999999 & 99 & 4.94 & TRN & \\
\hline CHEMBL1599090 & 688810 & 5.183 & 5.8965 & TRN & & & \\
\hline CHEMBL1978103 & 688810 & 5.483 & 5.4794 & TRN & & & \\
\hline CHEMBL1595696 & 688810 & 5.5329 & 9999999 & 995 & 5.6441 & TRN & \\
\hline CHEMBL1327408 & 688810 & 5.5329 & 99999999 & 995 & 5.40799 & 99999999995 & TRN \\
\hline CHEMBL1454279 & 688810 & 5.7829 & 99999995 & 995 & 5.4431 & TRN & \\
\hline CHEMBL1453794 & 688810 & 5.183 & 5.2851 & TRN & & & \\
\hline CHEMBL1532937 & 688810 & 4.833 & 5.1424 & TRN & & & \\
\hline CHEMBL1522556 & 688810 & 4.9830 & 0000000 & 005 & 5.25799 & 9999999999 & TRN \\
\hline CHEMBL1509282 & 688810 & 5.033 & 4.8638 & TRN & & & \\
\hline CHEMBL3192555 & 688810 & 5.233 & 5.5259 & TRN & & & \\
\hline CHEMBL1307170 & 688810 & 5.7829 & 99999995 & 995 & 5.2483 & TRN & \\
\hline CHEMBL1542287 & 688810 & 4.7330 & 0000000 & 005 & 5.2474 & TST & \\
\hline CHEMBL1591057 & 688810 & 5.3829 & 99999995 & & 5.2487 & TRN & \\
\hline CHEMBL1444483 & 688810 & 5.183 & 5.2586 & TRN & & & \\
\hline CHEMBL1527634 & 688810 & 5.2829 & 9999999 & 995 & 5.0665 & TRN & \\
\hline CHEMBL1524929 & 688810 & 6.433 & 6.2685 & TRN & & & \\
\hline CHEMBL1507938 & 688810 & 5.083 & 5.3367 & TRN & & & \\
\hline CHEMBL1466936 & 688810 & 5.3829 & 99999990 & & 5.9844 & TRN & \\
\hline CHEMBL1521681 & 688810 & 6.6329 & 99999999 & & 5.3531 & TST & \\
\hline CHEMBL1437686 & 688810 & 4.633 & 5.1123 & TST & & & \\
\hline CHEMBL1607514 & 688810 & 5.033 & 5.1714 & TST & & & \\
\hline CHEMBL1525249 & 688810 & 5.2829 & 9999999s & 995 & 4.9754 & TRN & \\
\hline CHEMBL1421737 & 688810 & 5.1329 & 99999995 & & 5.3613 & TRN & \\
\hline CHEMBL1420835 & 688810 & 5.433 & 4.8232 & TRN & & & \\
\hline CHEMBL1362720 & 688810 & 4.683 & 4.7784 & TRN & & & \\
\hline CHEMBL3211707 & 688810 & 5.1329 & 99999999 & 99 & 4.9423 & TST & \\
\hline CHEMBL1577483 & 688810 & 4.783 & 5.2112 & TRN & & & \\
\hline CHEMBL1343686 & 688810 & 4.933 & 4.8875 & TRN & & & \\
\hline CHEMBL1423203 & 688810 & 5.6329 & 99999999 & 99 & 5.6964 & TRN & \\
\hline CHEMBL1378618 & 688810 & 4.783 & 5.2072 & TRN & & & \\
\hline CHEMBL1608209 & 688810 & 4.633 & 4.5745 & TRN & & & \\
\hline CHEMBL1389606 & 688810 & 5.033 & 5.317 & TRN & & & \\
\hline CHEMBL1354549 & 688810 & 4.7330 & 0000000 & 005 & 5.0829 & TRN & \\
\hline CHEMBL1441311 & 688810 & 4.833 & 5.0369 & TRN & & & \\
\hline CHEMBL1311849 & 688810 & 5.483 & 5.2334 & TRN & & & \\
\hline CHEMBL1425447 & 688810 & 4.833 & 5.1214 & TRN & & & \\
\hline CHEMBL1503034 & 688810 & 4.583 & 5.4804 & TRN & & & \\
\hline
\end{tabular}




\begin{tabular}{|c|c|c|c|c|c|c|}
\hline & \multicolumn{5}{|c|}{ revilits } \\
\hline CHEMBL3213066 & 688810 & 4.783 & 5.2999 & TST & & \\
\hline CHEMBL1583933 & 688810 & \multicolumn{3}{|c|}{4.7330000000000005} & 4.9869 & TRN \\
\hline CHEMBL1599542 & 688810 & 5.233 & 5.3925 & TRN & & \\
\hline CHEMBL1469281 & 688810 & 4.633 & 4.5847 & TRN & & \\
\hline CHEMBL1505044 & 688810 & 4.583 & 5.2912 & TST & & \\
\hline CHEMBL1307915 & 688810 & \multicolumn{3}{|c|}{5.2829999999999995} & 5.1645 & TST \\
\hline CHEMBL1387277 & 688810 & 5.433 & 5.6979 & TRN & & \\
\hline CHEMBL1354694 & 688810 & 6.183 & 5.6329 & TRN & & \\
\hline CHEMBL1480121 & 688810 & 4.783 & 5.8665 & TRN & & \\
\hline CHEMBL1345630 & 688810 & \multicolumn{3}{|c|}{5.7829999999999995} & 5.0187 & TST \\
\hline CHEMBL1527175 & 688810 & \multicolumn{3}{|c|}{5.832999999999999} & 5.9075 & \\
\hline CHEMBL1605918 & 688810 & 4.883 & 4.9523 & TRN & & \\
\hline CHEMBL1449015 & 688810 & 4.883 & 4.9336 & TRN & & \\
\hline CHEMBL1596690 & 688810 & \multicolumn{3}{|c|}{4.7330000000000005} & 5.0142 & Thro \\
\hline CHEMBL1513226 & 688810 & \multicolumn{3}{|c|}{4.9830000000000005} & 4.7556 & rRN \\
\hline CHEMBL1437484 & 688810 & \multicolumn{3}{|c|}{5.832999999999999} & 5.0536 & \\
\hline CHEMBL1549911 & 688810 & 5.683 & 4.8714 & TRN & & \\
\hline CHEMBL1331516 & 688810 & 4.783 & 5.2889 & TST & & \\
\hline CHEMBL1488279 & 688810 & 4.833 & 5.1655 & TRN & & \\
\hline CHEMBL1499490 & 688810 & \multicolumn{3}{|c|}{4.9830000000000005} & 976 & \\
\hline CHEMBL1585332 & 688810 & 4.783 & 4.9142 & TRN & & \\
\hline CHEMBL1451772 & 688810 & 5.933 & 5.2668 & TRN & & \\
\hline CHEMBL1556343 & 688810 & 4.883 & 5.3766 & TST & & \\
\hline CHEMBL1542408 & 688810 & \multicolumn{3}{|c|}{4.9830000000000005} & 5.2077 & \\
\hline CHEMBL1434157 & 688810 & \multicolumn{3}{|c|}{5.632999999999999} & 4.9726 & TST \\
\hline CHEMBL1484400 & 688810 & \multicolumn{3}{|c|}{4.7330000000000005} & 5.2109 & \\
\hline CHEMBL1358319 & 688810 & 5.683 & 5.3061 & TRN & & \\
\hline CHEMBL1600932 & 688810 & 4.833 & 5.1576 & TRN & & \\
\hline CHEMBL 1442508 & 688810 & 5.733 & 4.6325 & TRN & & \\
\hline CHEMBL1421708 & 688810 & 5.083 & 5.3944 & TRN & & \\
\hline CHEMBL1507959 & 688810 & 4.783 & 4.743 & TRN & & \\
\hline CHEMBL1313646 & 688810 & 5.683 & 5.3366 & TST & & \\
\hline CHEMBL 34137 & 688810 & \multicolumn{3}{|c|}{6.2829999999999995} & 5.5412 & TRN \\
\hline CHEMBL1468601 & 688810 & \multicolumn{3}{|c|}{4.7330000000000005} & 5.9936 & \\
\hline CHEMBL1559820 & 688810 & 5.933 & 5.5886 & TRN & & \\
\hline CHEMBL1508749 & 688810 & \multirow{2}{*}{\multicolumn{3}{|c|}{$\begin{array}{lcc}4.883 & 5.65 & \text { TST } \\
4.7330000000000005\end{array}$}} & & \\
\hline CHEMBL1596411 & 688810 & & & & 4.7876 & $T$ \\
\hline CHEMBL1332724 & 688810 & \multicolumn{3}{|c|}{$\begin{array}{l}4.7330000000000005 \\
5.033 \quad 5.4287 \quad \text { TRN }\end{array}$} & & \\
\hline CHEMBL3207456 & 688810 & 5.033 & 5.8279 & TRN & & \\
\hline CHEMBL3192873 & 688810 & \multicolumn{3}{|c|}{7.082999999999999} & 5.8513 & $\mathrm{TR}$ \\
\hline CHEMBL1306935 & 688810 & \multicolumn{3}{|c|}{4.7330000000000005} & 5.308 & \\
\hline CHEMBL3208453 & 688810 & 4.833 & 5.5567 & TST & & \\
\hline CHEMBL1572597 & 688810 & 6.233 & 5.794 & TST & & \\
\hline CHEMBL1540373 & 688810 & 4.833 & 5.5738 & TRN & & \\
\hline CHEMBL1467157 & 688810 & 6.433 & 5.4122 & TRN & & \\
\hline CHEMBL1598901 & 688810 & 4.633 & 5.0637 & TST & & \\
\hline CHEMBL1393502 & 688810 & 5.7829 & 99999999 & 995 & 5.7713 & Tn \\
\hline CHEMBL1299417 & 688810 & 4.883 & 5.6118 & TRN & & \\
\hline
\end{tabular}




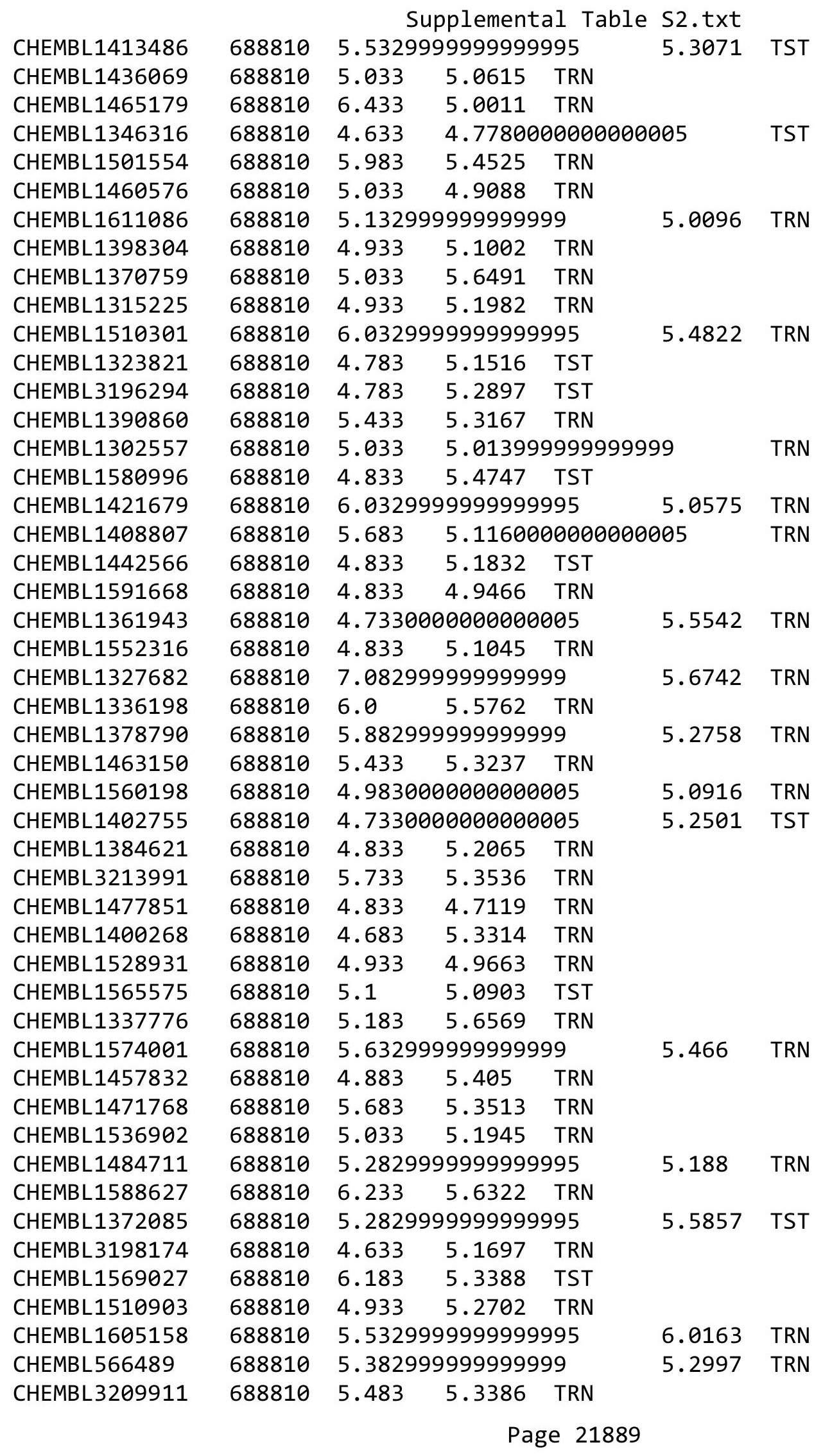




\begin{tabular}{|c|c|c|c|c|c|c|c|}
\hline & & & & & & & \\
\hline CHEMBL1446929 & 688810 & 4.833 & 5.1451 & TST & & & \\
\hline CHEMBL1406256 & 688810 & 4.73306 & 00000000 & 005 & 5.0416 & TRN & \\
\hline CHEMBL1486376 & 688810 & 4.783 & 5.0972 & TRN & & & \\
\hline CHEMBL1965444 & 688810 & 4.833 & 5.4459 & TRN & & & \\
\hline CHEMBL1424295 & 688810 & 4.783 & 5.3293 & TST & & & \\
\hline CHEMBL1304009 & 688810 & 6.78299 & 99999999 & 995 & 5.8393 & TRN & \\
\hline CHEMBL1391470 & 688810 & 5.183 & 4.8952 & TRN & & & \\
\hline CHEMBL1470687 & 688810 & 5.483 & 5.1318 & TRN & & & \\
\hline CHEMBL1549664 & 688810 & 5.733 & 5.5112 & TRN & & & \\
\hline CHEMBL1417969 & 688810 & 5.3829 & 99999999 & & 5.272 & TST & \\
\hline CHEMBL1445997 & 688810 & 5.083 & 5.1031 & TST & & & \\
\hline CHEMBL1605885 & 688810 & 5.13299 & 99999999 & & 5.4481 & TRN & \\
\hline CHEMBL1428158 & 688810 & 5.433 & 5.3996 & TRN & & & \\
\hline CHEMBL1309580 & 688810 & 5.983 & 5.4242 & TRN & & & \\
\hline CHEMBL1383855 & 688810 & 4.883 & 5.164 & TRN & & & \\
\hline CHEMBL1454209 & 688810 & 5.5829 & 99999999 & & 5.01 & TRN & \\
\hline CHEMBL1426367 & 688810 & 4.783 & 4.7914 & TST & & & \\
\hline CHEMBL1345046 & 688810 & 6.0329 & 99999999 & 995 & 5.7068 & TRN & \\
\hline CHEMBL1605598 & 688810 & 4.833 & 4.9325 & TRN & & & \\
\hline CHEMBL1428313 & 688810 & 5.183 & 5.6273 & TRN & & & \\
\hline CHEMBL1347437 & 688810 & 5.7829 & 99999999 & 995 & 5.4294 & TRN & \\
\hline CHEMBL1319768 & 688810 & 5.083 & 5.8679 & TRN & & & \\
\hline CHEMBL1407667 & 688810 & 5.8329 & 99999999 & & 5.5393 & TST & \\
\hline CHEMBL1476100 & 688810 & 4.783 & 4.9245 & TRN & & & \\
\hline CHEMBL1436423 & 688810 & 4.633 & 5.2799 & TRN & & & \\
\hline CHEMBL1586224 & 688810 & 5.8329 & 99999999 & & 5.6306 & TRN & \\
\hline CHEMBL3190842 & 688810 & 4.73306 & 00000000 & 005 & 5.2511 & TRN & \\
\hline CHEMBL 1430784 & 688810 & 4.783 & 5.8006 & TRN & & & \\
\hline CHEMBL1409100 & 688810 & 4.98306 & 00000000 & 005 & 5.0634 & TRN & \\
\hline CHEMBL1332957 & 688810 & 5.1329 & 99999999 & & 5.3720 & 0000000001 & TRN \\
\hline CHEMBL1465861 & 688810 & 5.983 & 5.4525 & TRN & & & \\
\hline CHEMBL1402159 & 688810 & 5.483 & 5.3651 & TRN & & & \\
\hline CHEMBL 1444294 & 688810 & 4.633 & 5.149 & TST & & & \\
\hline CHEMBL1612852 & 688810 & 5.183 & 5.075 & TRN & & & \\
\hline CHEMBL3208878 & 688810 & 5.3829 & 99999999 & & 5.1946 & TRN & \\
\hline CHEMBL1356689 & 688810 & 5.8829 & 99999999 & & 5.7341 & TRN & \\
\hline CHEMBL1376949 & 688810 & 6.3329 & 99999999 & & 5.7987 & TRN & \\
\hline CHEMBL1522504 & 688810 & 4.933 & 5.6409 & TRN & & & \\
\hline CHEMBL1471710 & 688810 & 6.683 & 5.6001 & TRN & & & \\
\hline CHEMBL1581581 & 688810 & 4.7330 & 00000000 & 005 & 5.2231 & TRN & \\
\hline CHEMBL1609337 & 688810 & 4.73306 & 00000000 & 005 & 4.9805 & TST & \\
\hline CHEMBL1511072 & 688810 & 4.933 & 5.3331 & TRN & & & \\
\hline CHEMBL1499877 & 688810 & 6.0829 & 99999999 & & 5.2142 & TST & \\
\hline CHEMBL1521136 & 688810 & 6.3329 & 99999999 & & 6.0785 & TRN & \\
\hline CHEMBL1355466 & 688810 & 6.0 & 4.8307 & TST & & & \\
\hline CHEMBL1374155 & 688810 & 4.583 & 5.0087 & TRN & & & \\
\hline CHEMBL1328819 & 688810 & 6.683 & 5.7314 & TRN & & & \\
\hline CHEMBL1382154 & 688810 & 6.0329 & 99999999 & 995 & 5.1153 & TRN & \\
\hline
\end{tabular}




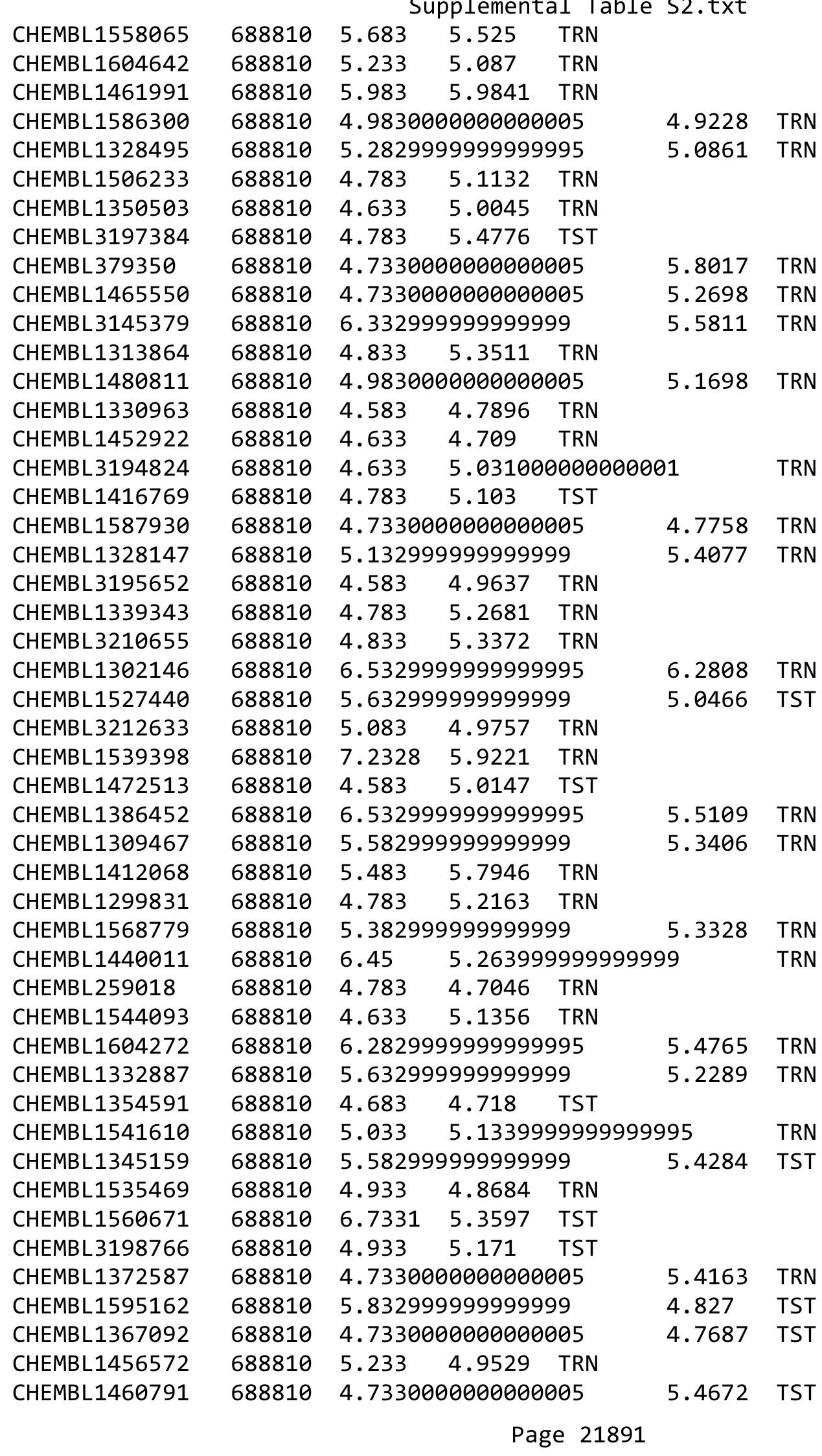




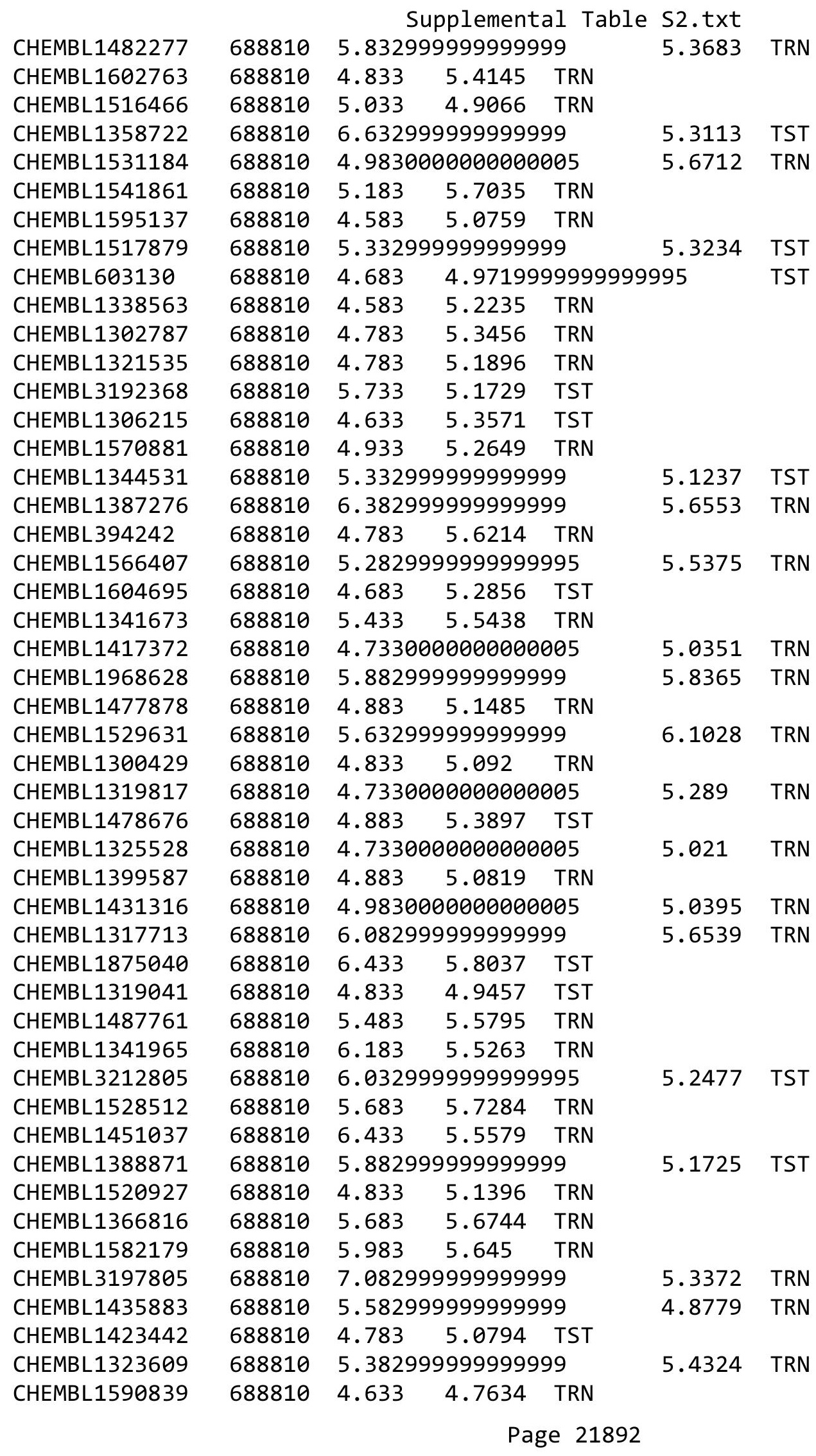




\begin{tabular}{|c|c|c|c|c|c|c|c|}
\hline \multirow[b]{2}{*}{ CHEMBL1528467 } & \multicolumn{6}{|c|}{ pptemerisede } & \\
\hline & 688810 & 5.483 & 5.1278 & TST & & & \\
\hline CHEMBL1308979 & 688810 & 4.783 & 5.0177 & TRN & & & \\
\hline CHEMBL1363112 & 688810 & 4.683 & 4.8111 & TRN & & & \\
\hline CHEMBL1500303 & 688810 & 6.38299 & 999999995 & & 5.6354 & TRN & \\
\hline CHEMBL1320297 & 688810 & 4.783 & 4.9509 & TRN & & & \\
\hline CHEMBL1336921 & 688810 & 4.833 & 5.1697 & TST & & & \\
\hline CHEMBL1505940 & 688810 & 5.78299 & 999999999 & 995 & 5.2507 & TRN & \\
\hline CHEMBL1494468 & 688810 & 5.183 & 5.4103 & TRN & & & \\
\hline CHEMBL1323258 & 688810 & 5.183 & 5.1176 & TRN & & & \\
\hline CHEMBL1520126 & 688810 & 5.78299 & 999999995 & 995 & 5.0777 & TRN & \\
\hline CHEMBL1477090 & 688810 & 5.13299 & 999999999 & & 5.4527 & TST & \\
\hline CHEMBL1497193 & 688810 & 4.833 & 5.4553 & TRN & & & \\
\hline CHEMBL1377726 & 688810 & 5.083 & 5.1069 & TRN & & & \\
\hline CHEMBL1422182 & 688810 & 5.033 & 4.8646 & TRN & & & \\
\hline CHEMBL2369158 & 688810 & 5.233 & 5.3809 & TRN & & & \\
\hline CHEMBL1490017 & 688810 & 6.4829 & 5.8498 & TRN & & & \\
\hline CHEMBL1314609 & 688810 & 4.833 & 4.6998 & TRN & & & \\
\hline CHEMBL1303620 & 688810 & 5.733 & 6.1511 & TRN & & & \\
\hline CHEMBL1304354 & 688810 & 5.13299 & 999999995 & & 5.1907 & TRN & \\
\hline CHEMBL1541277 & 688810 & 5.683 & 5.3034 & TRN & & & \\
\hline CHEMBL1428508 & 688810 & 5.233 & 5.0746 & TRN & & & \\
\hline CHEMBL1372269 & 688810 & 4.883 & 4.7323 & TST & & & \\
\hline CHEMBL1565912 & 688810 & 5.53299 & 999999999 & 995 & 5.1785 & TST & \\
\hline CHEMBL1426300 & 688810 & 5.683 & 5.7436 & TRN & & & \\
\hline CHEMBL1486569 & 688810 & 4.583 & 5.6185 & TST & & & \\
\hline CHEMBL1344988 & 688810 & 4.933 & 5.0335 & TST & & & \\
\hline CHEMBL1560273 & 688810 & 4.583 & 5.0981 & TST & & & \\
\hline CHEMBL1420838 & 688810 & 6.28299 & 999999999 & 995 & 5.5091 & TRN & \\
\hline CHEMBL1305968 & 688810 & 5.88299 & 99999999 & & 5.4679 & TRN & \\
\hline CHEMBL1491957 & 688810 & 6.683 & 5.3694 & TRN & & & \\
\hline CHEMBL1533535 & 688810 & 6.28299 & 99999999 & 995 & 5.4529 & 9999999999 & TRN \\
\hline CHEMBL1601636 & 688810 & 5.13299 & 999999995 & & 5.3758 & TRN & \\
\hline CHEMBL1512544 & 688810 & 5.033 & 4.6154 & TRN & & & \\
\hline CHEMBL1597429 & 688810 & 4.73300 & 000000006 & 005 & 5.4627 & TRN & \\
\hline CHEMBL1386377 & 688810 & 5.83299 & 999999995 & & 5.6903 & TRN & \\
\hline CHEMBL1494178 & 688810 & 5.78299 & 99999999 & 995 & 5.3973 & TRN & \\
\hline CHEMBL1334252 & 688810 & 5.183 & 5.2533 & TRN & & & \\
\hline CHEMBL1582375 & 688810 & 5.483 & 5.8595 & TRN & & & \\
\hline CHEMBL1569685 & 688810 & 5.083 & 5.4442 & TRN & & & \\
\hline CHEMBL3194638 & 688810 & 4.683 & 5.5113 & TST & & & \\
\hline CHEMBL1314527 & 688810 & 4.683 & 4.8499 & TRN & & & \\
\hline CHEMBL1527947 & 688810 & 4.783 & 5.2825 & TST & & & \\
\hline CHEMBL1321880 & 688810 & 5.033 & 5.1141 & TRN & & & \\
\hline CHEMBL1543243 & 688810 & 4.98300 & 00000000 & 005 & 5.5804 & TRN & \\
\hline CHEMBL1499905 & 688810 & 5.83299 & 999999999 & & 5.9219 & TRN & \\
\hline CHEMBL1534571 & 688810 & 4.933 & 5.1698 & TST & & & \\
\hline CHEMBL1349632 & 688810 & 5.683 & 5.0628 & TRN & & & \\
\hline CHEMBL1328302 & 688810 & 6.83299 & 999999995 & & 6.2333 & TRN & \\
\hline
\end{tabular}




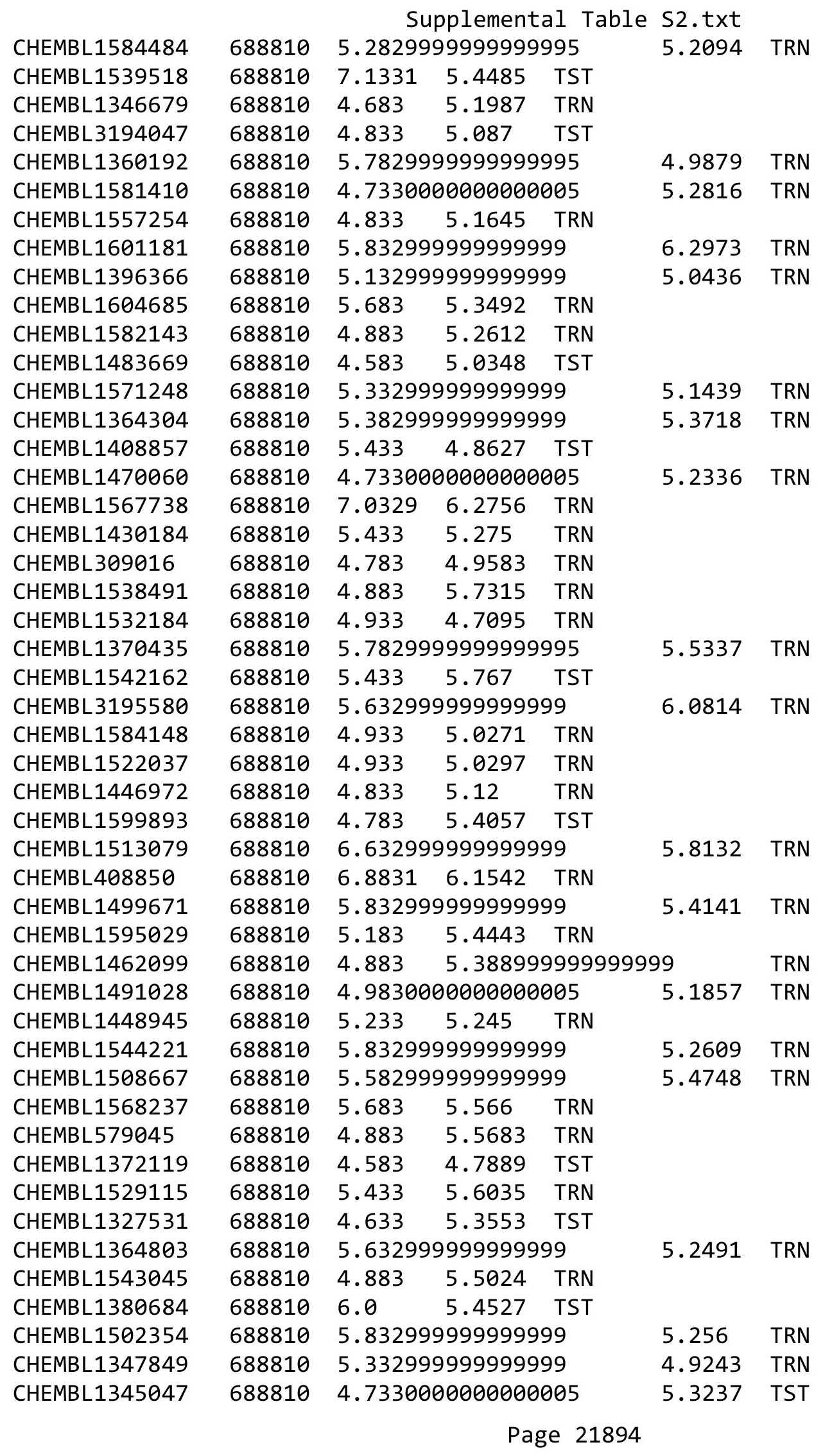




\begin{tabular}{|c|c|c|c|c|c|c|c|}
\hline \multicolumn{7}{|c|}{ Supplemental Table S2.txt } & \\
\hline CHEMBL1408581 & 688810 & 6.03299 & 99999999 & 995 & 5.7163 & TRN & \\
\hline CHEMBL 2005117 & 688810 & 4.833 & 4.747 & TRN & & & \\
\hline CHEMBL1569816 & 688810 & 6.38299 & 99999999 & & 5.6256 & TRN & \\
\hline CHEMBL1493646 & 688810 & 6.83299 & 99999999 & 99 & 5.3753 & TRN & \\
\hline CHEMBL1612355 & 688810 & 4.933 & 5.1379 & TST & & & \\
\hline CHEMBL1487433 & 688810 & 5.033 & 4.9486 & TRN & & & \\
\hline CHEMBL1334008 & 688810 & 5.78299 & 99999999 & 995 & 5.28299 & 99999999995 & TRN \\
\hline CHEMBL1384857 & 688810 & 5.88299 & 99999999 & & 5.07 & TRN & \\
\hline CHEMBL1488059 & 688810 & 4.633 & 5.1689 & TST & & & \\
\hline CHEMBL1428641 & 688810 & 4.783 & 5.5473 & TRN & & & \\
\hline CHEMBL1488346 & 688810 & 4.98300 & 00000000 & 005 & 5.1853 & TST & \\
\hline CHEMBL1483280 & 688810 & 5.183 & 4.6749 & TRN & & & \\
\hline CHEMBL1483297 & 688810 & 4.683 & 5.4482 & TRN & & & \\
\hline CHEMBL1309946 & 688810 & 6.683 & 5.5947 & TRN & & & \\
\hline CHEMBL1303892 & 688810 & 6.433 & 5.5495 & TRN & & & \\
\hline CHEMBL1386788 & 688810 & 5.13299 & 99999999 & & 5.3822 & TRN & \\
\hline CHEMBL1444103 & 688810 & 5.233 & 5.5961 & TST & & & \\
\hline CHEMBL1358435 & 688810 & 5.63299 & 99999999 & & 5.1162 & TRN & \\
\hline CHEMBL1490738 & 688810 & 5.78299 & 99999999 & 995 & 5.3689 & TRN & \\
\hline CHEMBL1333890 & 688810 & 4.783 & 5.1343 & TST & & & \\
\hline CHEMBL1413576 & 688810 & 5.58299 & 99999999 & & 5.2173 & TST & \\
\hline CHEMBL1459094 & 688810 & 5.083 & 5.21700 & 000000000 & 205 & TRN & \\
\hline CHEMBL1364072 & 688810 & 4.883 & 5.1469 & TST & & & \\
\hline CHEMBL1498361 & 688810 & 5.083 & 5.3386 & TST & & & \\
\hline CHEMBL1353510 & 688810 & 5.78299 & 99999999 & 995 & 5.7887 & TRN & \\
\hline CHEMBL1539118 & 688810 & 4.683 & 5.6538 & TST & & & \\
\hline CHEMBL1508789 & 688810 & 5.733 & 5.1485 & TRN & & & \\
\hline CHEMBL1305912 & 688810 & 4.98300 & 00000000 & 005 & 5.2305 & TRN & \\
\hline CHEMBL1573994 & 688810 & 5.33299 & 99999999 & & 6.4938 & TRN & \\
\hline CHEMBL1364386 & 688810 & 5.083 & 5.4817 & TST & & & \\
\hline CHEMBL1389243 & 688810 & 5.033 & 5.0246 & TST & & & \\
\hline CHEMBL1496409 & 688810 & 5.033 & 5.0815 & TRN & & & \\
\hline CHEMBL1526122 & 688810 & 4.883 & 4.9488 & TRN & & & \\
\hline CHEMBL1536264 & 688810 & 5.033 & 4.9718 & TRN & & & \\
\hline CHEMBL1340145 & 688810 & 4.683 & 5.0546 & TRN & & & \\
\hline CHEMBL1377690 & 688810 & 5.28299 & 99999999 & 995 & 4.9882 & TST & \\
\hline CHEMBL1444822 & 688810 & 6.38299 & 99999999 & & 6.2853 & TRN & \\
\hline CHEMBL1349215 & 688810 & 5.033 & 5.3395 & TRN & & & \\
\hline CHEMBL3196106 & 688810 & 5.083 & 5.33899 & 999999999 & 995 & TRN & \\
\hline CHEMBL1350361 & 688810 & 5.033 & 5.0803 & TRN & & & \\
\hline CHEMBL1479078 & 688810 & 4.833 & 4.8013 & TRN & & & \\
\hline CHEMBL1436395 & 688810 & 4.833 & 5.1384 & TRN & & & \\
\hline CHEMBL1365748 & 688810 & 5.28299 & 99999999 & 995 & 5.3322 & TRN & \\
\hline CHEMBL1565972 & 688810 & 5.683 & 5.1164 & TST & & & \\
\hline CHEMBL1590338 & 688810 & 4.933 & 4.9685 & TRN & & & \\
\hline CHEMBL1316098 & 688810 & 5.78299 & 99999999 & 995 & 5.5166 & TRN & \\
\hline CHEMBL1421468 & 688810 & 4.73300 & 00000000 & 005 & 4.9624 & TRN & \\
\hline CHEMBL1410494 & 688810 & 4.633 & 5.4028 & TRN & & & \\
\hline
\end{tabular}




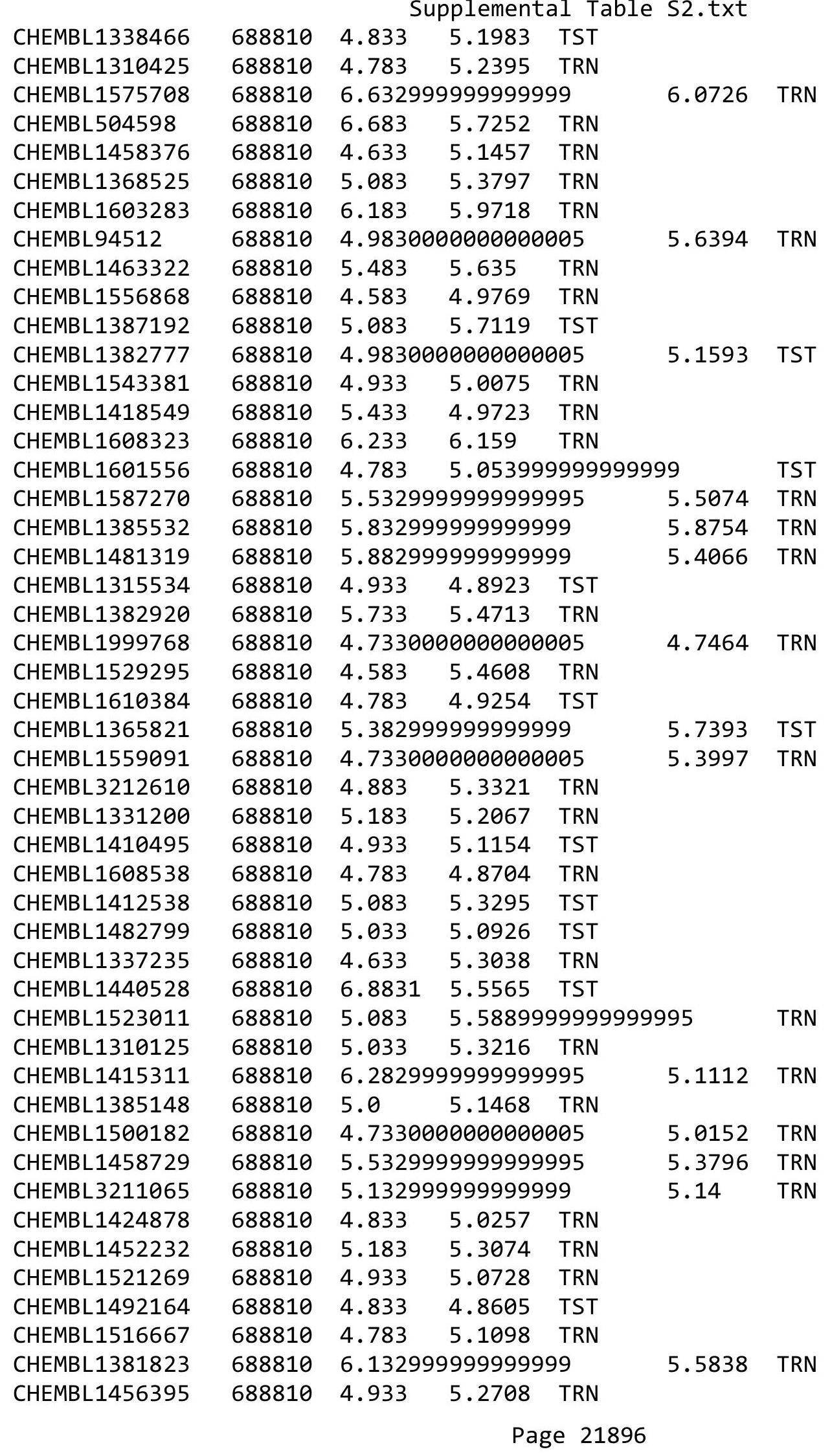




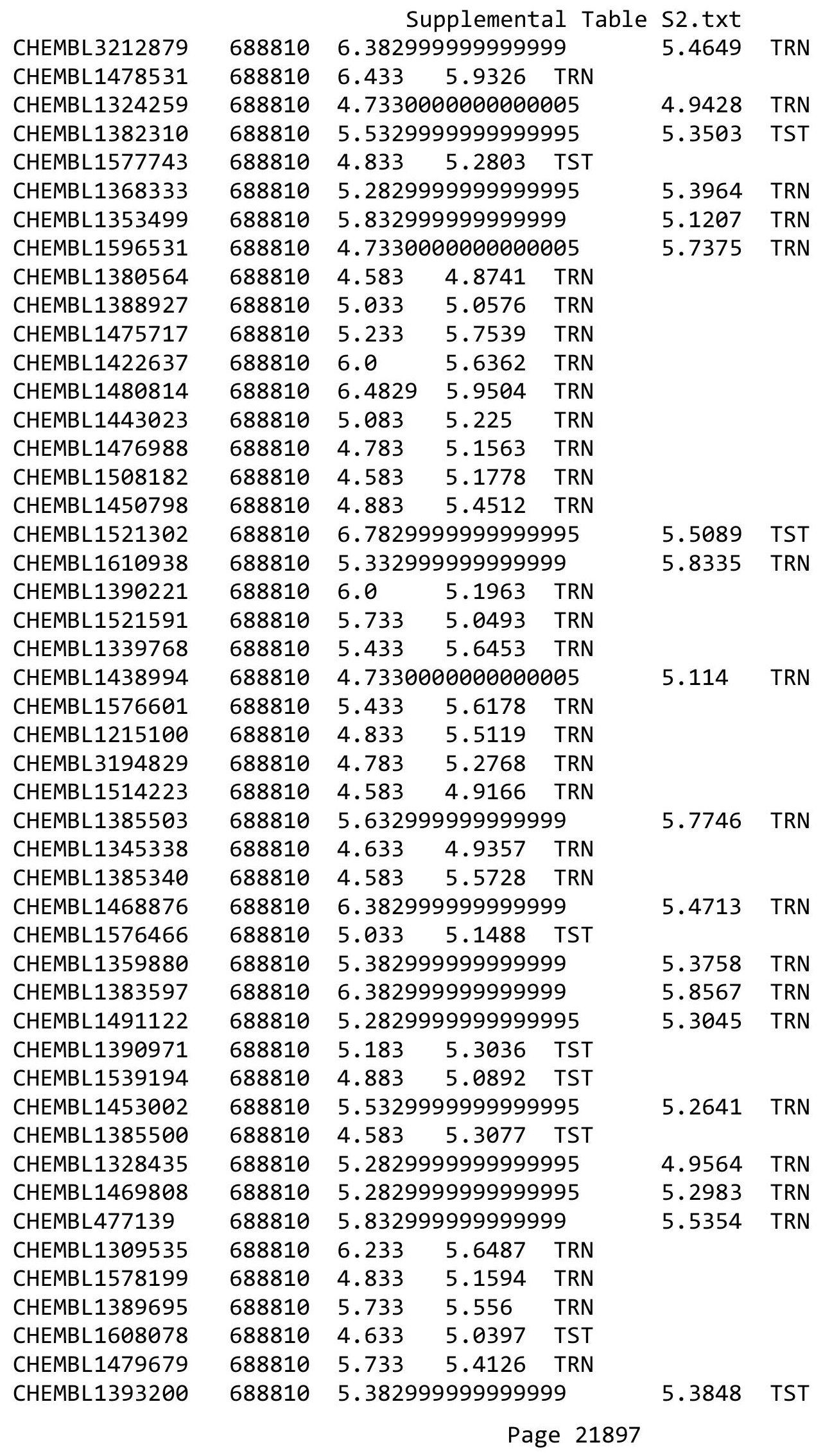




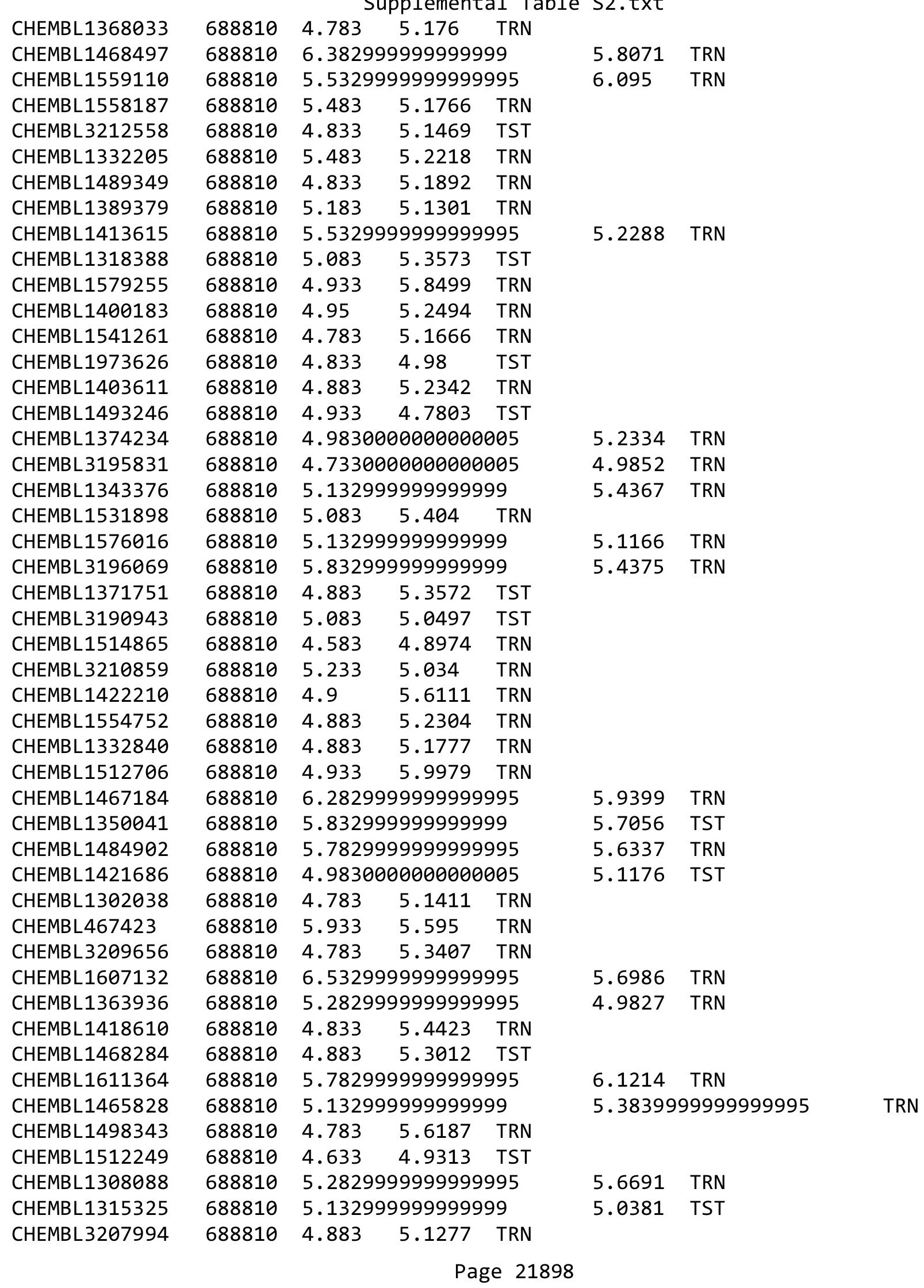




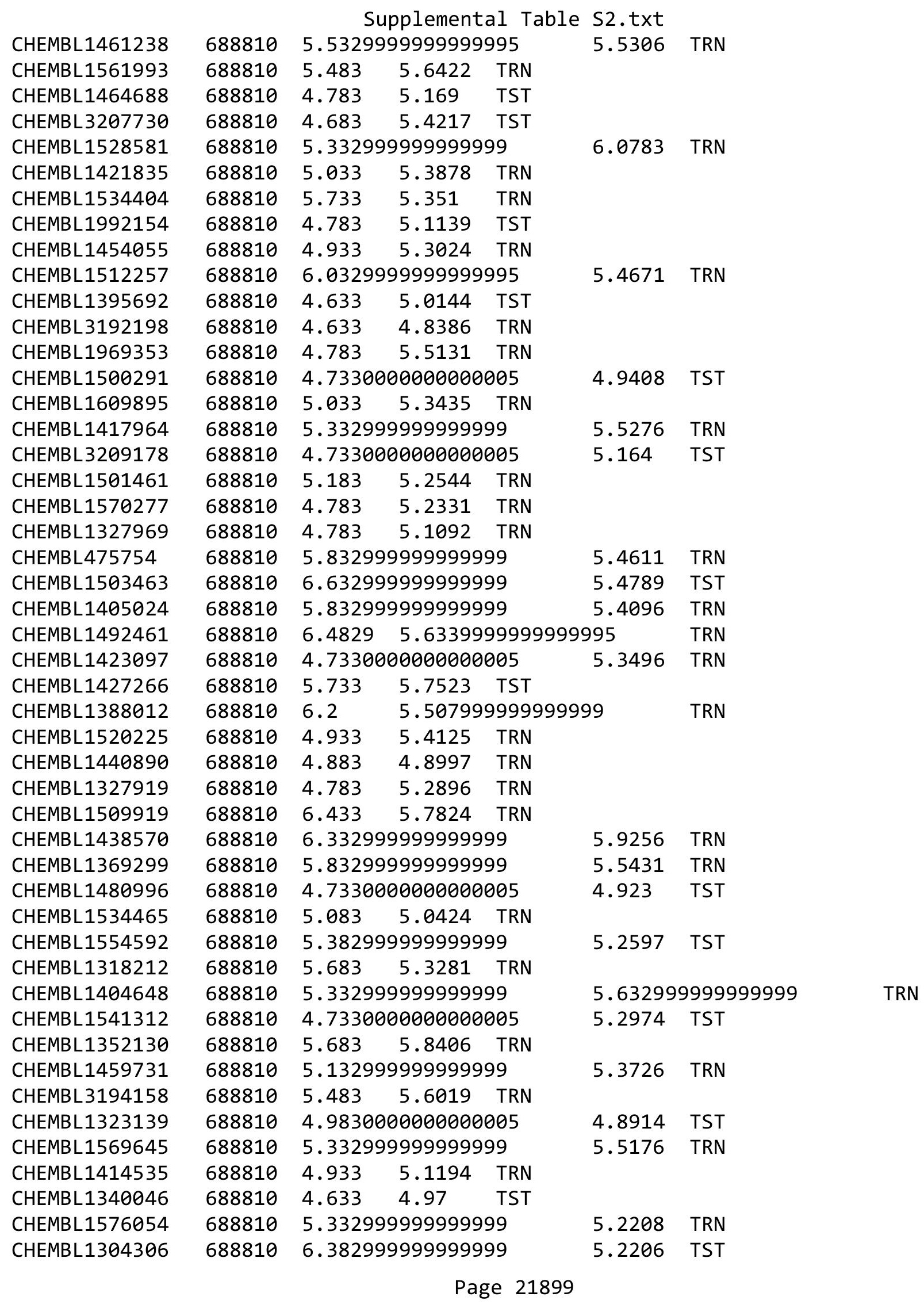




\begin{tabular}{|c|c|c|c|c|c|c|c|}
\hline \multirow[b]{2}{*}{ CHEMBL1303595 } & \multicolumn{6}{|c|}{ Supplemental Ta } & \\
\hline & 688810 & 4.683 & 5.4072 & TRN & & & \\
\hline CHEMBL1586181 & 688810 & 4.783 & 5.5064 & TRN & & & \\
\hline CHEMBL1484232 & 688810 & 4.783 & 5.3489 & TRN & & & \\
\hline CHEMBL1478914 & 688810 & 6.4829 & 5.7451 & TRN & & & \\
\hline CHEMBL1308668 & 688810 & \multicolumn{3}{|c|}{5.882999999999999} & 5.7622 & TRN & \\
\hline CHEMBL1366652 & 688810 & 4.933 & 5.2441 & TRN & & & \\
\hline CHEMBL1610170 & 688810 & 5.033 & 5.1063 & TRN & & & \\
\hline CHEMBL1494349 & 688810 & \multicolumn{3}{|c|}{5.332999999999999} & 5.184 & TRN & \\
\hline CHEMBL1511313 & 688810 & 4.883 & 5.1699 & TRN & & & \\
\hline CHEMBL1597343 & 688810 & 5.183 & 4.874 & TRN & & & \\
\hline CHEMBL1402386 & 688810 & \multicolumn{3}{|c|}{6.332999999999999} & 6.0487 & TRN & \\
\hline CHEMBL1454201 & 688810 & 5.683 & 5.2141 & TRN & & & \\
\hline CHEMBL1329212 & 688810 & 4.933 & 5.0197 & TRN & & & \\
\hline CHEMBL 3199331 & 688810 & 6.4829 & 5.104 & TRN & & & \\
\hline CHEMBL453974 & 688810 & 5.933 & 5.3388 & TST & & & \\
\hline CHEMBL1374950 & 688810 & \multicolumn{3}{|c|}{5.882999999999999} & 5.3994 & TRN & \\
\hline CHEMBL1327542 & 688810 & \multicolumn{3}{|c|}{4.7330000000000005} & 5.3227 & TST & \\
\hline CHEMBL1521868 & 688810 & \multicolumn{3}{|c|}{4.9830000000000005} & 5.0348 & TRN & \\
\hline CHEMBL1449093 & 688810 & \multicolumn{3}{|c|}{5.382999999999999} & 5.0859 & TRN & \\
\hline CHEMBL1439533 & 688810 & 4.683 & 4.8735 & TRN & & & \\
\hline CHEMBL1495180 & 688810 & \multicolumn{3}{|c|}{5.332999999999999} & 5.4274 & TRN & \\
\hline CHEMBL1500013 & 688810 & 4.833 & 5.7987 & TRN & & & \\
\hline CHEMBL1451206 & 688810 & 5.183 & 5.2179 & TRN & & & \\
\hline CHEMBL1495345 & 688810 & 5.733 & 5.0387 & TRN & & & \\
\hline CHEMBL1502843 & 688810 & 5.183 & 5.0048 & TRN & & & \\
\hline CHEMBL1451460 & 688810 & \multicolumn{3}{|c|}{4.7330000000000005} & 4.9932 & TRN & \\
\hline CHEMBL1594015 & 688810 & 5.733 & 5.5545 & TRN & & & \\
\hline CHEMBL 3190828 & 688810 & 5.233 & 5.2392 & TST & & & \\
\hline CHEMBL1338463 & 688810 & \multicolumn{3}{|c|}{6.132999999999999} & 5.9186 & TRN & \\
\hline CHEMBL1603158 & 688810 & \multicolumn{3}{|c|}{4.7330000000000005} & 4.9526 & TRN & \\
\hline CHEMBL1352992 & 688810 & \multicolumn{3}{|c|}{5.632999999999999} & 4.9658 & TRN & \\
\hline CHEMBL1349371 & 688810 & 4.933 & 4.7789 & TST & & & \\
\hline CHEMBL1490409 & 688810 & 4.633 & & TRN & & & \\
\hline CHEMBL1311291 & 688810 & \multicolumn{3}{|c|}{5.132999999999999} & 4.8458 & TRN & \\
\hline CHEMBL1382162 & 688810 & 4.783 & 4.9993 & TRN & & & \\
\hline CHEMBL1542936 & 688810 & 4.833 & 4.5394 & TRN & & & \\
\hline CHEMBL1996922 & 688810 & 5.983 & 5.6365 & TRN & & & \\
\hline CHEMBL1309395 & 688810 & 6.183 & 5.625 & TRN & & & \\
\hline CHEMBL259103 & 688810 & \multicolumn{3}{|c|}{6.832999999999999} & \multicolumn{2}{|c|}{6.5360000000000005} & TRN \\
\hline CHEMBL1332154 & 688810 & 5.683 & 5.1474 & TRN & & & \\
\hline CHEMBL1508393 & 688810 & \multicolumn{3}{|c|}{4.7330000000000005} & 5.0919 & TRN & \\
\hline CHEMBL1510572 & 688810 & \multicolumn{3}{|c|}{5.632999999999999} & 5.6842 & TRN & \\
\hline CHEMBL 1555048 & 688810 & 4.833 & 5.0452 & TST & & & \\
\hline CHEMBL1558285 & 688810 & \multicolumn{3}{|c|}{6.132999999999999} & 5.5007 & TST & \\
\hline CHEMBL 3198982 & 688810 & \multicolumn{3}{|c|}{5.332999999999999} & 5.1884 & TST & \\
\hline CHEMBL1965415 & 688810 & 5.83299 & 99999999 & & 5.4775 & TRN & \\
\hline CHEMBL1387991 & 688810 & 5.63299 & 99999999 & & 5.6475 & TRN & \\
\hline CHEMBL1508884 & 688810 & 5.13299 & 99999999 & & 5.3711 & TRN & \\
\hline
\end{tabular}




\begin{tabular}{|c|c|c|c|c|c|c|}
\hline & & & pplementa & al Table & s2.txt & \\
\hline CHEMBL1470658 & 688810 & 5.13299 & 99999999 & & 5.1901 & TRN \\
\hline CHEMBL1462272 & 688810 & 4.833 & 5.4698 & TRN & & \\
\hline CHEMBL1476355 & 688810 & 4.73300 & 00000000 & 005 & 5.2526 & TRN \\
\hline CHEMBL1597753 & 688810 & 4.933 & 5.0168 & TRN & & \\
\hline CHEMBL1536427 & 688810 & 5.38299 & 99999999 & & 5.3476 & TRN \\
\hline CHEMBL1376214 & 688810 & 4.583 & 5.17399 & 999999999 & 995 & TRN \\
\hline CHEMBL1413283 & 688810 & 5.28299 & 99999999 & 995 & 5.5831 & TST \\
\hline CHEMBL1352801 & 688810 & 7.2832 & 5.8218 & TRN & & \\
\hline CHEMBL1540031 & 688810 & 4.683 & 5.5146 & TRN & & \\
\hline CHEMBL1473804 & 688810 & 5.433 & 4.8198 & TRN & & \\
\hline CHEMBL3212647 & 688810 & 4.98300 & 200000006 & 005 & 5.1305 & TRN \\
\hline CHEMBL1339226 & 688810 & 4.73300 & $00000000 t$ & 005 & 4.7079 & TST \\
\hline CHEMBL1545125 & 688810 & 4.833 & 5.3426 & TRN & & \\
\hline CHEMBL1361694 & 688810 & 5.13299 & 99999999 & & 5.1324 & TST \\
\hline CHEMBL1328454 & 688810 & 5.033 & 5.4476 & TRN & & \\
\hline CHEMBL1399793 & 688810 & 4.583 & 5.317 & TRN & & \\
\hline CHEMBL1527764 & 688810 & 4.933 & 5.1972 & TRN & & \\
\hline CHEMBL1350776 & 688810 & 4.933 & 4.8209 & TRN & & \\
\hline CHEMBL1572844 & 688810 & 6.08299 & 99999999 & & 5.4837 & TRN \\
\hline CHEMBL3195225 & 688810 & 5.033 & 5.7362 & TRN & & \\
\hline CHEMBL1489962 & 688810 & 4.783 & 5.1747 & TST & & \\
\hline CHEMBL1508045 & 688810 & 5.083 & 5.0098 & TRN & & \\
\hline CHEMBL1609009 & 688810 & 4.933 & 4.9571 & TST & & \\
\hline CHEMBL3207658 & 688810 & 5.033 & 5.2891 & TRN & & \\
\hline CHEMBL1331716 & 688810 & 5.28299 & 99999999 & 995 & 4.6718 & TST \\
\hline CHEMBL1437560 & 688810 & 4.633 & 4.7526 & TST & & \\
\hline CHEMBL1367139 & 688810 & 4.783 & 4.979 & TRN & & \\
\hline CHEMBL3195878 & 688810 & 5.38299 & 99999999 & & 5.2138 & TRN \\
\hline CHEMBL1348114 & 688810 & 4.833 & 5.1881 & TRN & & \\
\hline CHEMBL1607518 & 688810 & 4.833 & 4.8742 & TRN & & \\
\hline CHEMBL3210575 & 688810 & 5.733 & 5.651 & TRN & & \\
\hline CHEMBL1517530 & 688810 & 5.183 & 5.5043 & TRN & & \\
\hline CHEMBL1513162 & 688810 & 5.78299 & 99999999 & 995 & 5.4093 & TRN \\
\hline CHEMBL1390294 & 688810 & 6.33299 & 99999999 & & 5.5281 & TRN \\
\hline CHEMBL1361127 & 688810 & 5.53299 & 99999999 & 995 & 5.4813 & TRN \\
\hline CHEMBL3209641 & 688810 & 5.083 & 4.907 & TST & & \\
\hline CHEMBL1447809 & 688810 & 5.233 & 5.3092 & TRN & & \\
\hline CHEMBL3190739 & 688810 & 4.833 & 4.8289 & TST & & \\
\hline CHEMBL1473363 & 688810 & 4.883 & 5.001 & TRN & & \\
\hline CHEMBL1375292 & 688810 & 5.28299 & 99999999 & 995 & 5.4132 & TRN \\
\hline CHEMBL1341462 & 688810 & 5.083 & 4.9361 & TST & & \\
\hline CHEMBL1508424 & 688810 & 6.4829 & 5.2334 & TRN & & \\
\hline CHEMBL1324894 & 688810 & 5.433 & 5.5516 & TRN & & \\
\hline CHEMBL1489928 & 688810 & 4.883 & 5.0458 & TRN & & \\
\hline CHEMBL1459908 & 688810 & 5.933 & 5.7728 & TRN & & \\
\hline CHEMBL1376945 & 688810 & 6.33299 & 99999999 & 99 & 4.8569 & TST \\
\hline CHEMBL1300898 & 688810 & 4.783 & 4.9311 & TRN & & \\
\hline CHEMBL1447104 & 688810 & 4.633 & 4.9111 & TRN & & \\
\hline
\end{tabular}




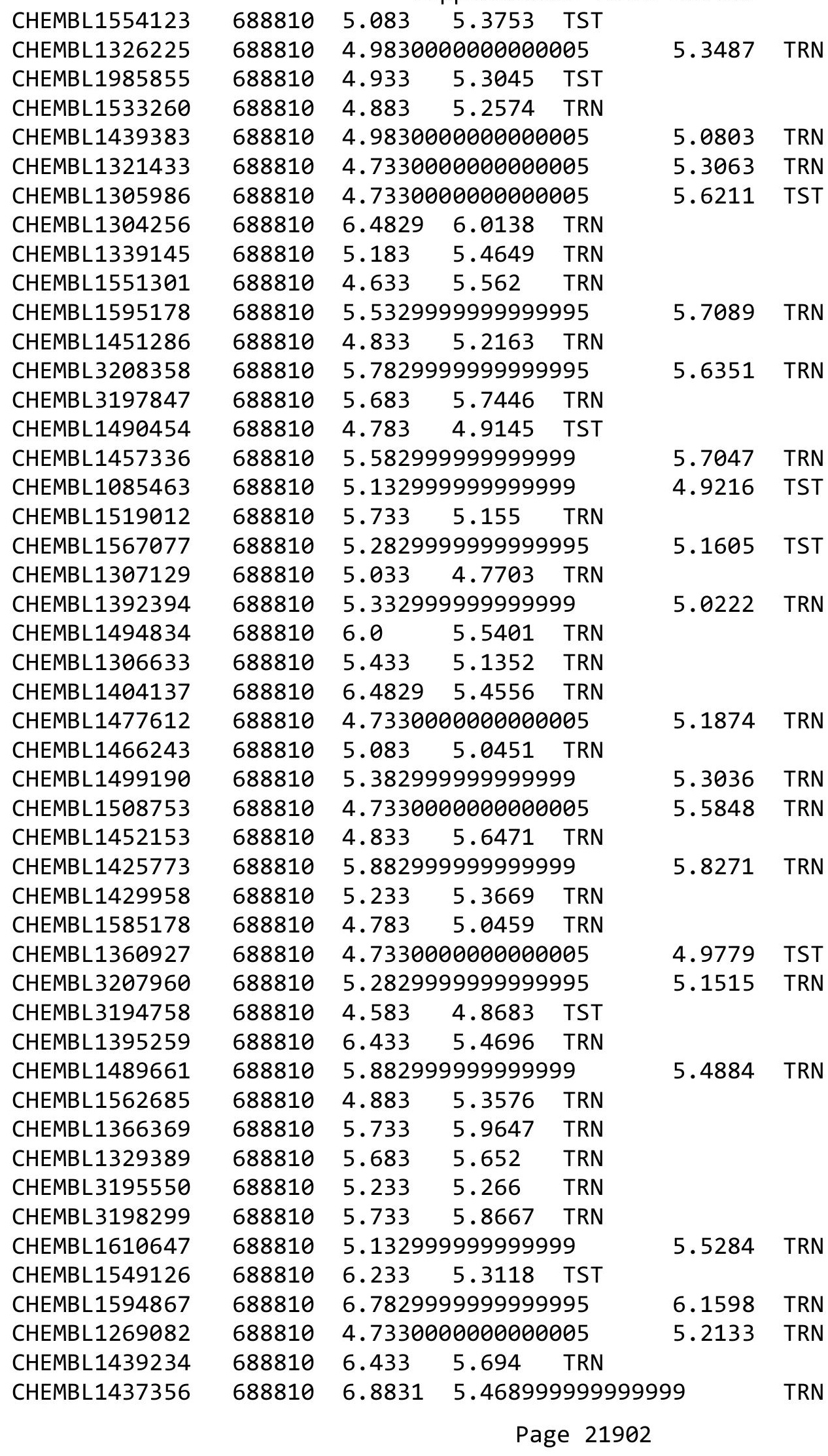




\begin{tabular}{|c|c|c|c|c|c|c|}
\hline & & \multicolumn{5}{|c|}{ Supplemental Table s2.txt } \\
\hline CHEMBL1370781 & 688810 & 4.883 & 4.7873 & TST & & \\
\hline CHEMBL1495292 & 688810 & 4.833 & 5.1269 & TRN & & \\
\hline CHEMBL1306323 & 688810 & 7.3325 & 5.8447 & TRN & & \\
\hline CHEMBL1315721 & 688810 & 7.8827 & 6.1859 & TRN & & \\
\hline CHEMBL1372932 & 688810 & \multicolumn{3}{|c|}{6.2829999999999995} & 5.5112 & TRN \\
\hline CHEMBL1605163 & 688810 & 6.183 & 5.4875 & TRN & & \\
\hline CHEMBL1452651 & 688810 & 4.833 & 5.1906 & TRN & & \\
\hline CHEMBL3191945 & 688810 & 4.783 & 5.0099 & TRN & & \\
\hline CHEMBL1526596 & 688810 & 4.933 & 5.2357 & TRN & & \\
\hline CHEMBL1361154 & 688810 & 5.033 & 5.3248 & TRN & & \\
\hline CHEMBL1370985 & 688810 & 4.833 & 5.1089 & TRN & & \\
\hline CHEMBL1444181 & 688810 & \multicolumn{3}{|c|}{5.332999999999999} & 5.5924 & TRN \\
\hline CHEMBL1317725 & 688810 & 4.633 & 5.353 & TST & & \\
\hline CHEMBL1367313 & 688810 & 6.433 & 5.6267 & TRN & & \\
\hline CHEMBL1502220 & 688810 & 5.683 & 5.7688 & TRN & & \\
\hline CHEMBL1347531 & 688810 & \multicolumn{3}{|c|}{6.332999999999999} & 4.9671 & TST \\
\hline CHEMBL1382257 & 688810 & 4.883 & 5.3105 & TRN & & \\
\hline CHEMBL1527223 & 688810 & 5.083 & 5.3229 & TRN & & \\
\hline CHEMBL1442915 & 688810 & \multicolumn{3}{|c|}{6.582999999999999} & 5.7605 & TRN \\
\hline CHEMBL1417800 & 688810 & 5.733 & 4.9389 & TRN & & \\
\hline CHEMBL1455189 & 688810 & 5.683 & 5.33 & TST & & \\
\hline CHEMBL3210095 & 688810 & \multicolumn{3}{|c|}{6.0329999999999995} & 5.3519 & TST \\
\hline CHEMBL1312263 & 688810 & 5.183 & 5.574 & TRN & & \\
\hline CHEMBL1327265 & 688810 & \multicolumn{3}{|c|}{4.9830000000000005} & 5.2828 & TRN \\
\hline CHEMBL1443086 & 688810 & 6.0 & 5.4523 & TRN & & \\
\hline CHEMBL1563317 & 688810 & 4.783 & 5.0307 & TRN & & \\
\hline CHEMBL1524779 & 688810 & 5.083 & 5.1682 & TST & & \\
\hline CHEMBL1428254 & 688810 & \multicolumn{3}{|c|}{5.132999999999999} & 5.0198 & TST \\
\hline CHEMBL1484975 & 688810 & 4.883 & \multicolumn{3}{|c|}{5.4239999999999995} & TRN \\
\hline CHEMBL1502716 & 688810 & \multicolumn{3}{|c|}{5.882999999999999} & 5.3755 & TRN \\
\hline CHEMBL1311602 & 688810 & \multicolumn{3}{|c|}{5.332999999999999} & 4.8923 & TRN \\
\hline CHEMBL1499479 & 688810 & \multicolumn{3}{|c|}{5.2829999999999995} & 5.2408 & TRN \\
\hline CHEMBL1483945 & 688810 & \multicolumn{3}{|c|}{4.7330000000000005} & 4.8407 & TRN \\
\hline CHEMBL1431536 & 688810 & 5.183 & 5.4778 & TRN & & \\
\hline CHEMBL1452032 & 688810 & 4.933 & 5.4651 & TRN & & \\
\hline CHEMBL3196606 & 688810 & 5.683 & 5.1801 & TRN & & \\
\hline CHEMBL1335779 & 688810 & 5.483 & 5.0062 & TRN & & \\
\hline CHEMBL1452136 & 688810 & 4.683 & 4.9938 & TST & & \\
\hline CHEMBL1344803 & 688810 & 5.183 & 5.6012 & TRN & & \\
\hline CHEMBL3194331 & 688810 & 4.933 & 5.0978 & TRN & & \\
\hline CHEMBL1351290 & 688810 & 5.083 & 4.8515 & TST & & \\
\hline CHEMBL1578822 & 688810 & 4.883 & 5.0748 & TRN & & \\
\hline CHEMBL1570047 & 688810 & \multicolumn{3}{|c|}{6.0329999999999995} & 5.7896 & TRN \\
\hline CHEMBL1564332 & 688810 & \multicolumn{3}{|c|}{5.882999999999999} & 5.9494 & TRN \\
\hline CHEMBL1404765 & 688810 & 5.683 & 5.566 & TRN & & \\
\hline CHEMBL1488913 & 688810 & 4.783 & 5.2252 & TST & & \\
\hline CHEMBL1527304 & 688810 & 4.583 & 5.5907 & TST & & \\
\hline CHEMBL1590189 & 688810 & 5.733 & 5.6643 & TRN & & \\
\hline
\end{tabular}




\begin{tabular}{|c|c|c|c|c|c|c|c|}
\hline \multicolumn{7}{|c|}{ Supplemental Table S2.txt } & \\
\hline CHEMBL1424065 & 688810 & \multicolumn{3}{|c|}{7.082999999999999} & 6.4575 & TRN & \\
\hline CHEMBL1531764 & 688810 & 5.733 & 5.6262 & TST & & & \\
\hline CHEMBL1566881 & 688810 & 5.483 & 5.6827 & TRN & & & \\
\hline CHEMBL1533529 & 688810 & 4.783 & 4.923 & TRN & & & \\
\hline CHEMBL1302741 & 688810 & \multicolumn{3}{|c|}{5.882999999999999} & 5.9782 & TST & \\
\hline CHEMBL1389566 & 688810 & \multicolumn{3}{|c|}{5.7829999999999995} & 5.3742 & TRN & \\
\hline CHEMBL1566434 & 688810 & 6.7331 & 5.9456 & TRN & & & \\
\hline CHEMBL1430707 & 688810 & \multicolumn{3}{|c|}{5.382999999999999} & 5.4362 & TRN & \\
\hline CHEMBL1420701 & 688810 & \multicolumn{3}{|c|}{4.9830000000000005} & 5.1686 & TRN & \\
\hline CHEMBL1431688 & 688810 & \multicolumn{3}{|c|}{6.132999999999999} & 5.9128 & TRN & \\
\hline CHEMBL1517512 & 688810 & \multicolumn{3}{|c|}{5.582999999999999} & 5.1493 & TRN & \\
\hline CHEMBL1455992 & 688810 & 6.433 & 5.6041 & TRN & & & \\
\hline CHEMBL1431996 & 688810 & 5.083 & 5.2227 & TRN & & & \\
\hline CHEMBL1474707 & 688810 & 4.783 & 4.9198 & TRN & & & \\
\hline CHEMBL1478826 & 688810 & \multicolumn{3}{|c|}{5.382999999999999} & 5.4024 & TRN & \\
\hline CHEMBL 3192856 & 688810 & \multicolumn{3}{|c|}{5.5329999999999995} & 5.9072 & TRN & \\
\hline CHEMBL1355805 & 688810 & 4.583 & 5.069 & TST & & & \\
\hline CHEMBL1456437 & 688810 & \multicolumn{3}{|c|}{6.832999999999999} & 6.0927 & TRN & \\
\hline CHEMBL1542737 & 688810 & 5.033 & 5.1394 & TRN & & & \\
\hline CHEMBL1431679 & 688810 & \multicolumn{3}{|c|}{6.382999999999999} & 5.3323 & TRN & \\
\hline CHEMBL1327504 & 688810 & \multicolumn{3}{|c|}{5.882999999999999} & 5.38200 & 0000000001 & TRN \\
\hline CHEMBL1494324 & 688810 & 5.983 & 5.3408 & TRN & & & \\
\hline CHEMBL1324518 & 688810 & 4.883 & 4.8991 & TRN & & & \\
\hline CHEMBL1564777 & 688810 & \multicolumn{3}{|c|}{6.0329999999999995} & 5.6388 & TRN & \\
\hline CHEMBL1596723 & 688810 & \multicolumn{3}{|c|}{5.632999999999999} & 5.527 & TST & \\
\hline CHEMBL1431572 & 688810 & 4.933 & 4.9166 & TRN & & & \\
\hline CHEMBL1373064 & 688810 & \multicolumn{3}{|c|}{5.382999999999999} & 5.5886 & TRN & \\
\hline CHEMBL 1472660 & 688810 & \multicolumn{3}{|c|}{5.2829999999999995} & 5.2806 & TRN & \\
\hline CHEMBL1404392 & 688810 & 5.433 & 5.8529 & TRN & & & \\
\hline CHEMBL1412529 & 688810 & 5.483 & 5.309 & TRN & & & \\
\hline CHEMBL1557027 & 688810 & 5.683 & 4.8819 & TST & & & \\
\hline CHEMBL1436447 & 688810 & 4.933 & 5.2169 & TRN & & & \\
\hline CHEMBL1351751 & 688810 & 4.933 & 5.126 & TRN & & & \\
\hline CHEMBL1583020 & 688810 & 4.683 & 5.2727 & TRN & & & \\
\hline CHEMBL1442379 & 688810 & 4.783 & 5.9062 & TRN & & & \\
\hline CHEMBL1600901 & 688810 & \multicolumn{3}{|c|}{6.582999999999999} & 5.9679 & TST & \\
\hline CHEMBL1414770 & 688810 & 4.933 & 5.0885 & TRN & & & \\
\hline CHEMBL1457058 & 688810 & 7.1331 & 5.8153 & TRN & & & \\
\hline CHEMBL1378914 & 688810 & \multicolumn{3}{|c|}{5.7829999999999995} & 5.6115 & TRN & \\
\hline CHEMBL1405617 & 688810 & 4.833 & 5.3789 & TRN & & & \\
\hline CHEMBL 1605025 & 688810 & 6.183 & 5.7111 & TST & & & \\
\hline CHEMBL1553265 & 688810 & 7.1331 & 6.1898 & TRN & & & \\
\hline CHEMBL1573627 & 688810 & \multicolumn{3}{|c|}{4.7330000000000005} & 5.3664 & TST & \\
\hline CHEMBL3198633 & 688810 & \multicolumn{3}{|c|}{6.332999999999999} & 5.974 & TST & \\
\hline CHEMBL1344582 & 688810 & 7.0329 & 6.3883 & TRN & & & \\
\hline CHEMBL1580491 & 688810 & 5.183 & 4.9081 & TRN & & & \\
\hline CHEMBL1570720 & 688810 & 5.183 & 5.5479 & TRN & & & \\
\hline CHEMBL1325056 & 688810 & 5.7829 & 99999999 & 995 & 5.231 & TRN & \\
\hline
\end{tabular}




\begin{tabular}{|c|c|c|c|c|c|c|}
\hline \multirow{3}{*}{$\begin{array}{l}\text { CHEMBL1420463 } \\
\text { CHEMBL3195483 }\end{array}$} & \multirow{3}{*}{$\begin{array}{l}688810 \\
688810\end{array}$} & \multicolumn{5}{|c|}{ Supplemental Table S2.txt } \\
\hline & & \multicolumn{3}{|c|}{4.9830000000000005} & \multirow[t]{4}{*}{5.6585} & \multirow[t]{4}{*}{ TRN } \\
\hline & & 4.783 & 5.4606 & TRN & & \\
\hline CHEMBL1553321 & 688810 & 4.633 & 5.2719 & TRN & & \\
\hline CHEMBL1390330 & 688810 & 5.083 & 5.6244 & TRN & & \\
\hline CHEMBL1583892 & 688810 & \multicolumn{3}{|c|}{5.332999999999999} & 4.6041 & \\
\hline CHEMBL1554048 & 688810 & 4.933 & 4.794 & TRN & & \\
\hline CHEMBL1973226 & 688810 & \multicolumn{3}{|c|}{6.5329999999999995} & 5.5827 & \\
\hline CHEMBL1476991 & 688810 & 4.633 & 4.9847 & TRN & & \\
\hline CHEMBL1502514 & 688810 & 5.183 & 5.1426 & TST & & \\
\hline CHEMBL1386092 & 688810 & \multicolumn{3}{|c|}{5.332999999999999} & 5.0446 & \\
\hline CHEMBL1432983 & 688810 & 4.883 & 5.2192 & TRN & & \\
\hline CHEMBL1478741 & 688810 & \multicolumn{3}{|c|}{5.632999999999999} & 5.9214 & \\
\hline CHEMBL3191858 & 688810 & 4.783 & 5.2055 & TRN & & \\
\hline CHEMBL1585657 & 688810 & \multicolumn{3}{|c|}{4.9830000000000005} & 5.4402 & \\
\hline CHEMBL3214002 & 688810 & 4.9 & 5.6717 & TST & & \\
\hline CHEMBL3191311 & 688810 & \multicolumn{3}{|c|}{5.882999999999999} & 5.095 & \\
\hline HEMBL1 & 688810 & \multicolumn{3}{|c|}{4.9830000000000005} & & \\
\hline CHEMBL1 & 688810 & 5.183 & 5.2094 & TRN & & \\
\hline CHEMBL1469662 & 688810 & \multicolumn{3}{|c|}{5.882999999999999} & 5.7166 & \\
\hline CHEMBL1544322 & 688810 & 5.683 & 5.1437 & TRN & & \\
\hline CHEMBL1581626 & 688810 & 4.833 & 5.7354 & TST & & \\
\hline HEMB & 688 & \multicolumn{3}{|c|}{6.332999999999999} & 6.0279 & \\
\hline CHEMBL & 688810 & 4.833 & 5.6754 & TRN & & \\
\hline CHEMBL1612099 & 688810 & \multicolumn{3}{|c|}{4.7330000000000005} & 5.0177 & \\
\hline CHEMBL1425523 & 688810 & 4.883 & 4.9906 & TRN & & \\
\hline CHEMBL3191477 & 688810 & 5.183 & 5.3219 & TST & & \\
\hline CHEME & 688 & \multicolumn{3}{|c|}{6.0329999999999995} & 5.9463 & \\
\hline CHEME & 688810 & 4.783 & 4.9416 & TST & & \\
\hline CHEMBL1421980 & 688810 & \multicolumn{3}{|c|}{6.132999999999999} & 5.7797 & $\mathrm{~T}$ \\
\hline CHEMBL3209143 & 688810 & \multicolumn{3}{|c|}{5.832999999999999} & 5.2878 & \\
\hline CHEMBL1424888 & 688810 & \multicolumn{3}{|c|}{5.7829999999999995} & 5.0885 & \\
\hline CHEME & 688 & 5.183 & 4.9315 & TRN & & \\
\hline CHEMB & 688 & \multicolumn{3}{|c|}{6.2829999999999995} & 5.4321 & \\
\hline CHEMBL1501454 & 688810 & 5.083 & 5.1023 & TRN & & \\
\hline CHEMBL1977424 & 688810 & 6.683 & 5.8251 & TRN & & \\
\hline CHEMBL: & 688 & 4.7336 & 00000000 & 205 & & 11 \\
\hline CHEMB & 688810 & 6.0825 & 99999999 & & & \\
\hline CHEMBL: & 688810 & 4.933 & 5.7042 & TRN & & \\
\hline CHEMBL1494500 & 688810 & 4.883 & 5.042 & TRN & & \\
\hline CHEMBL1597792 & 688810 & 4.883 & 5.1351 & TRN & & \\
\hline CHEMBL1448355 & 688810 & 4.633 & 4.7998 & TRN & & \\
\hline CHEMBL1608921 & 688810 & 5.183 & 5.1951 & TRN & & \\
\hline CHEMBL591522 & 688810 & 4.7336 & 00000000 & 205 & 5.6733 & \\
\hline CHEMBL1411739 & 688810 & 5.5329 & 99999999 & 995 & 4.8972 & \\
\hline CHEMBL1611819 & 688810 & 4.833 & 4.885 & TST & & \\
\hline CHEMBL1498514 & 688810 & 4.9836 & 00000000 & 205 & 5.0811 & \\
\hline CHEMBL1438772 & 688810 & 5.1320 & 99999999 & & 5.2685 & \\
\hline CHEMBL1332178 & 688810 & 4.683 & 4.8598 & TRN & & \\
\hline
\end{tabular}




\begin{tabular}{|c|c|c|c|c|c|c|c|}
\hline \multicolumn{7}{|c|}{ Supplemental Table S2.txt } & \\
\hline CHEMBL1523083 & 688810 & 5.033 & 5.1646 & TRN & & & \\
\hline CHEMBL1354660 & 688810 & 4.73300 & 00000000 & 005 & 5.2222 & TRN & \\
\hline CHEMBL1498393 & 688810 & 5.033 & 4.9033 & TRN & & & \\
\hline CHEMBL1604969 & 688810 & 4.883 & 5.1843 & TRN & & & \\
\hline CHEMBL1371110 & 688810 & 6.13299 & 99999999 & 99 & 5.2435 & TST & \\
\hline CHEMBL1975620 & 688810 & 4.73300 & 00000000 & 005 & 5.1204 & TRN & \\
\hline CHEMBL3197885 & 688810 & 6.63299 & 99999999 & 99 & 5.4942 & TRN & \\
\hline CHEMBL1606820 & 688810 & 5.933 & 5.4635 & TRN & & & \\
\hline CHEMBL1367421 & 688810 & 5.78299 & 99999999 & 995 & 4.9796 & TST & \\
\hline CHEMBL1381673 & 688810 & 4.633 & 4.8822 & TRN & & & \\
\hline CHEMBL 3198651 & 688810 & 5.733 & 5.7502 & TRN & & & \\
\hline CHEMBL1482351 & 688810 & 4.933 & 4.7329 & TRN & & & \\
\hline CHEMBL3213363 & 688810 & 4.833 & 5.21899 & 99999999 & & TRN & \\
\hline CHEMBL1531086 & 688810 & 5.0 & 4.9618 & TRN & & & \\
\hline CHEMBL1343176 & 688810 & 5.38299 & 99999999 & 99 & 5.3537 & TST & \\
\hline CHEMBL 89671 & 688810 & 5.483 & 6.1052 & TRN & & & \\
\hline CHEMBL1509200 & 688810 & 4.833 & 5.3486 & TRN & & & \\
\hline CHEMBL1600176 & 688810 & 5.083 & 5.4719 & TRN & & & \\
\hline CHEMBL1456355 & 688810 & 4.883 & 5.5622 & TST & & & \\
\hline CHEMBL1375627 & 688810 & 4.783 & 5.0648 & TST & & & \\
\hline CHEMBL1527814 & 688810 & 5.28299 & 99999999 & 995 & 5.3287 & TRN & \\
\hline CHEMBL1400744 & 688810 & 5.13299 & 99999999 & 99 & 5.3062 & TRN & \\
\hline CHEMBL1446759 & 688810 & 6.233 & 5.1292 & TRN & & & \\
\hline CHEMBL1330663 & 688810 & 5.13299 & 99999999 & 99 & 5.03100 & 0000000001 & TRN \\
\hline CHEMBL1551114 & 688810 & 4.883 & 5.2083 & TRN & & & \\
\hline CHEMBL1489287 & 688810 & 5.733 & 5.6819 & TRN & & & \\
\hline CHEMBL1314841 & 688810 & 7.1831 & 6.0728 & TRN & & & \\
\hline CHEMBL1511858 & 688810 & 5.933 & 5.2727 & TRN & & & \\
\hline CHEMBL1343394 & 688810 & 5.83299 & 99999999 & & 5.8789 & TRN & \\
\hline CHEMBL1612840 & 688810 & 5.083 & 5.0667 & TST & & & \\
\hline CHEMBL1440181 & 688810 & 5.683 & 5.2285 & TST & & & \\
\hline CHEMBL1586959 & 688810 & 5.033 & 4.8549 & TRN & & & \\
\hline CHEMBL1466462 & 688810 & 5.53299 & 99999999 & 995 & 5.899 & TRN & \\
\hline CHEMBL1326124 & 688810 & 5.683 & 5.4517 & TRN & & & \\
\hline CHEMBL1380300 & 688810 & 4.633 & 4.7914 & TRN & & & \\
\hline CHEMBL1610395 & 688810 & 5.683 & 5.4813 & TST & & & \\
\hline CHEMBL1939691 & 688810 & 5.13299 & 99999999 & & 5.1924 & TRN & \\
\hline CHEMBL1561548 & 688810 & 5.83299 & 99999999 & & 5.2978 & TST & \\
\hline CHEMBL1542703 & 688810 & 4.783 & 5.1623 & TRN & & & \\
\hline CHEMBL1517614 & 688810 & 6.13299 & 99999999 & & 5.4042 & TRN & \\
\hline CHEMBL1547111 & 688810 & 5.28299 & 99999999 & 995 & 5.3576 & TRN & \\
\hline CHEMBL1569063 & 688810 & 4.583 & 4.8772 & TRN & & & \\
\hline CHEMBL1400780 & 688810 & 5.233 & 5.4618 & TRN & & & \\
\hline CHEMBL1451492 & 688810 & 6.28299 & 99999999 & 995 & 5.4962 & TRN & \\
\hline CHEMBL1429710 & 688810 & 6.63299 & 99999999 & & 5.4835 & TRN & \\
\hline CHEMBL3194787 & 688810 & 4.833 & 5.3476 & TRN & & & \\
\hline CHEMBL1326938 & 688810 & 5.28299 & 99999999 & 995 & 5.0953 & TRN & \\
\hline CHEMBL1463363 & 688810 & 6.03299 & 99999999 & 995 & 5.419 & TRN & \\
\hline
\end{tabular}




\begin{tabular}{|c|c|c|c|c|c|c|c|}
\hline & & & pplement & al Table & s2.txt & & \\
\hline CHEMBL1999965 & 688810 & 5.5329 & 99999999 & 995 & 5.2435 & TRN & \\
\hline CHEMBL1394010 & 688810 & 4.883 & 5.1488 & TST & & & \\
\hline CHEMBL1477925 & 688810 & 5.033 & 4.9694 & TST & & & \\
\hline CHEMBL1600037 & 688810 & 4.9830 & 00000000 & 005 & 5.1331 & TRN & \\
\hline CHEMBL1349012 & 688810 & 6.0329 & 99999999 & 995 & 5.86600 & 00000000005 & TRN \\
\hline CHEMBL1455196 & 688810 & 4.933 & 4.8372 & TST & & & \\
\hline CHEMBL 3213602 & 688810 & 4.683 & 5.2522 & TRN & & & \\
\hline CHEMBL1455397 & 688810 & 4.833 & 5.4357 & TRN & & & \\
\hline CHEMBL1415796 & 688810 & 5.433 & 5.2966 & TRN & & & \\
\hline CHEMBL1561718 & 688810 & 6.8329 & 99999999 & & 5.7871 & TST & \\
\hline CHEMBL473162 & 688810 & 5.8829 & 99999999 & & 6.199 & TRN & \\
\hline CHEMBL3193405 & 688810 & 7.3325 & 5.8791 & TRN & & & \\
\hline CHEMBL1509359 & 688810 & 4.7330 & 00000000 & 005 & 5.5118 & TRN & \\
\hline CHEMBL1593098 & 688810 & 5.483 & 5.1709 & TRN & & & \\
\hline CHEMBL1402321 & 688810 & 5.183 & 5.022 & TRN & & & \\
\hline CHEMBL1484561 & 688810 & 5.733 & 5.3624 & TRN & & & \\
\hline CHEMBL1361333 & 688810 & 5.183 & 5.16799 & 999999999 & & TRN & \\
\hline CHEMBL1486877 & 688810 & 5.733 & 5.6448 & TRN & & & \\
\hline CHEMBL1363037 & 688810 & 4.933 & 5.0713 & TRN & & & \\
\hline CHEMBL 3197270 & 688810 & 6.2829 & 99999999 & 995 & 5.8764 & TRN & \\
\hline CHEMBL1577306 & 688810 & 5.5329 & 99999999 & 995 & 5.1768 & TRN & \\
\hline CHEMBL1444711 & 688810 & 4.783 & 4.9112 & TRN & & & \\
\hline CHEMBL1546255 & 688810 & 4.933 & 4.854 & TRN & & & \\
\hline CHEMBL1448671 & 688810 & 5.6329 & 99999999 & & 5.2366 & TRN & \\
\hline CHEMBL1540413 & 688810 & 4.783 & 5.3358 & TRN & & & \\
\hline CHEMBL1476760 & 688810 & 4.883 & 5.0843 & TRN & & & \\
\hline CHEMBL1423379 & 688810 & 4.7330 & 00000000 & 005 & 5.1308 & TRN & \\
\hline CHEMBL1550455 & 688810 & 4.683 & 5.5008 & TST & & & \\
\hline CHEMBL1456921 & 688810 & 4.583 & 4.5273 & TRN & & & \\
\hline CHEMBL1519276 & 688810 & 6.0 & 5.211 & TRN & & & \\
\hline CHEMBL1411199 & 688810 & 4.7330 & 00000000 & 005 & 5.0901 & TRN & \\
\hline CHEMBL 2141886 & 688810 & 5.8829 & 99999999 & & 5.2044 & TST & \\
\hline CHEMBL1593502 & 688810 & 5.433 & 5.4551 & TRN & & & \\
\hline CHEMBL1386603 & 688810 & 4.883 & 5.2255 & TRN & & & \\
\hline CHEMBL1408101 & 688810 & 5.983 & 5.3418 & TRN & & & \\
\hline CHEMBL1569936 & 688810 & 4.583 & 4.8723 & TST & & & \\
\hline CHEMBL1379729 & 688810 & 5.8829 & 99999999 & & 5.5219 & TRN & \\
\hline CHEMBL1381855 & 688810 & 5.6329 & 99999999 & & 5.6115 & TRN & \\
\hline CHEMBL3190668 & 688810 & 6.233 & 5.2971 & TRN & & & \\
\hline CHEMBL1490856 & 688810 & 5.433 & 5.2871 & TRN & & & \\
\hline CHEMBL1407850 & 688810 & 6.0 & 5.7012 & TRN & & & \\
\hline CHEMBL1463210 & 688810 & 5.1329 & 99999999 & & 5.2005 & TRN & \\
\hline CHEMBL1463875 & 688810 & 4.683 & 6.0266 & TRN & & & \\
\hline CHEMBL3196904 & 688810 & 5.3329 & 99999999 & 99 & 5.0933 & TRN & \\
\hline CHEMBL1353081 & 688810 & 5.183 & 5.0333 & TRN & & & \\
\hline CHEMBL 3189853 & 688810 & 5.733 & 5.1407 & TRN & & & \\
\hline CHEMBL1601580 & 688810 & 5.733 & 5.4719 & TRN & & & \\
\hline CHEMBL1301784 & 688810 & 5.233 & 5.0257 & TRN & & & \\
\hline
\end{tabular}




\begin{tabular}{|c|c|c|c|c|c|c|}
\hline CHEMBL1590803 & 688810 & 5.933 & 5.3725 & TRN & & \\
\hline CHEMBL1351520 & 688810 & 4.933 & 5.9827 & TRN & & \\
\hline CHEMBL1463718 & 688810 & \multicolumn{3}{|c|}{5.132999999999999} & 4.8883 & TR \\
\hline CHEMBL1510212 & 588810 & 5.183 & 5.1789 & TRN & & \\
\hline CHEMBL1531715 & 88810 & 5.033 & 5.1065 & TST & & \\
\hline CHEMBL1509112 & 88810 & 5.683 & 5.6549 & TRN & & \\
\hline CHEMBL1374640 & 688810 & \multicolumn{3}{|c|}{4.9830000000000005} & 5.1838 & $\mathrm{TR}$ \\
\hline CHEMBL1429791 & 688810 & \multicolumn{3}{|c|}{4.7330000000000005} & & \\
\hline HEMBL1519307 & 88810 & 4.683 & 5.5219 & TRN & & \\
\hline CHEMBL1445787 & 88810 & 4.633 & 5.2535 & TST & & \\
\hline CHEMBL1333094 & 688810 & \multicolumn{3}{|c|}{4.7330000000000005} & 5.1177 & \\
\hline CHEMBL1579474 & 688810 & \multicolumn{3}{|c|}{5.2829999999999995} & & \\
\hline CHEMBL1338542 & 688810 & 4.883 & 5.3709 & TRN & & \\
\hline HEMBL1562186 & 688810 & 4.933 & 5.2218 & TST & & \\
\hline HEMBL1308936 & 588810 & 5.033 & 4.6349 & TST & & \\
\hline CHEMBL1 & 688810 & 4.883 & 5.2995 & TST & & \\
\hline CHEMBL1 & 688810 & \multicolumn{3}{|c|}{6.132999999999999} & & \\
\hline CHEMBL1 & 688810 & 5.183 & 4.8486 & TST & & \\
\hline HEMBL1 & 688810 & 4.783 & 5.2788 & TRN & & \\
\hline HEMBL1 & 688810 & 4.833 & 5.1751 & TST & & \\
\hline CHEMBL1 & 688810 & 5.033 & 5.5963 & TRN & & \\
\hline CHEMBL: & 688810 & \multicolumn{3}{|c|}{4.7330000000000005} & 5.4988 & \\
\hline CHEMBL1 & 688810 & \multicolumn{3}{|c|}{5.2829999999999995} & 33 & \\
\hline HEMBL13 & 688810 & 4.933 & 5.2302 & TRN & & \\
\hline CHEMBL1385535 & 688810 & \multicolumn{3}{|c|}{4.7330000000000005} & 5.2 & \\
\hline CHEMBL1519487 & 688810 & 4.783 & \multicolumn{3}{|c|}{5.0969999999999995} & \\
\hline CHEMBL: & 688810 & 5.933 & 4.8907 & TRN & & \\
\hline HEMBL: & 688810 & \multicolumn{3}{|c|}{5.832999999999999} & 6 & \\
\hline CHEMBL1325105 & 688810 & \multicolumn{3}{|c|}{5.332999999999999} & & \\
\hline CHEMBL1337578 & 688810 & 6.4829 & 5.5226 & $\mathrm{TR}$ & & \\
\hline CHEMBL14 & 688810 & \multicolumn{3}{|c|}{5.132999999999999} & 3 & \\
\hline CHEMBL: & 688810 & 4.633 & 5.0246 & TRN & & \\
\hline CHEMBL & 688810 & \multicolumn{3}{|c|}{5.5329999999999995} & 5.3958 & $T$ \\
\hline HEMBL1 & 688810 & 4.633 & 4.8734 & TRN & & \\
\hline HEMBL1460591 & 688810 & 5.483 & 5.0787 & TRN & & \\
\hline CHEMBL & 688810 & \multicolumn{3}{|c|}{5.2829999999999995} & 5.4477 & $1 \mathrm{RI}$ \\
\hline CHEMBL & 688810 & 5.483 & 5.4824 & TRN & & \\
\hline CHEMBL1 & 688810 & 6.183 & 5.8982 & TRN & & \\
\hline CHEMBL1372760 & 688810 & 6.4829 & 5.843 & TRN & & \\
\hline CHEMBL13 & 688810 & 4.583 & 5.0058 & TRN & & \\
\hline CHEMBL1524049 & 688810 & 4.783 & 5.4774 & TST & & \\
\hline CHEMBL1991440 & 688810 & \multicolumn{3}{|c|}{5.332999999999999} & 4.9332 & TRI \\
\hline CHEMBL1410569 & 688810 & \multicolumn{3}{|c|}{5.5329999999999995} & 5.1712 & TR \\
\hline CHEMBL1452746 & 688810 & 4.833 & 5.0979 & TST & & \\
\hline CHEMBL1322116 & 688810 & 5.683 & 5.2317 & TRN & & \\
\hline CHEMBL1341101 & 688810 & \multicolumn{3}{|c|}{4.7330000000000005} & 4.7243 & \\
\hline CHEMBL1461131 & 688810 & \multicolumn{3}{|c|}{5.5329999999999995} & 5.3123 & \\
\hline CHEMBL1333732 & 688810 & \multicolumn{3}{|c|}{5.332999999999999} & 5.7631 & \\
\hline
\end{tabular}




\begin{tabular}{|c|c|c|c|c|c|c|}
\hline \multirow{3}{*}{$\begin{array}{l}\text { CHEMBL1469489 } \\
\text { CHEMBL1544320 }\end{array}$} & \multirow{3}{*}{$\begin{array}{l}688810 \\
688810\end{array}$} & \multicolumn{5}{|c|}{ Supplemental Table S2.txt } \\
\hline & & \multicolumn{3}{|c|}{4.9830000000000005} & \multirow[t]{5}{*}{5.1815} & \multirow[t]{5}{*}{ TRN } \\
\hline & & 4.683 & 5.0725 & TRN & & \\
\hline CHEMBL1570080 & 688810 & 6.0 & 5.0984 & TRN & & \\
\hline CHEMBL 3195238 & 688810 & 5.183 & 5.5866 & TRN & & \\
\hline CHEMBL1318302 & 88810 & 4.683 & 5.3316 & TRN & & \\
\hline CHEMBL1608010 & 688810 & \multicolumn{3}{|c|}{6.382999999999999} & 5.907 & \\
\hline CHEMBL1475593 & 688810 & 4.783 & 5.09 & TRN & & \\
\hline CHEMBL1461532 & 688810 & \multicolumn{3}{|c|}{5.382999999999999} & 5.381 & 1 \\
\hline CHEMBL1352113 & 688810 & 4.833 & 5.5854 & TST & & \\
\hline CHEMBL1326663 & 688810 & 5.483 & \multicolumn{3}{|c|}{5.377999999999999} & I TाN \\
\hline CHEMBL600008 & 688810 & \multicolumn{3}{|c|}{5.132999999999999} & 5.2222 & TST \\
\hline CHEMBL1447271 & 688810 & \multicolumn{3}{|c|}{6.2829999999999995} & 5.1526 & \\
\hline CHEMBL1558205 & 688810 & \multicolumn{3}{|c|}{4.9830000000000005} & 4.9142 & \\
\hline CHEMBL3193066 & 688810 & 5.083 & 5.4204 & TRN & & \\
\hline CHEMBL1406597 & 688810 & 5.683 & 5.8113 & TRN & & \\
\hline CHEMBL1428357 & 688810 & 4.883 & 4.8716 & TRN & & \\
\hline CHEMBL1 & 688 & 5.983 & 5.4319 & TRN & & \\
\hline CHEMBL196 & 688810 & \multicolumn{3}{|c|}{5.132999999999999} & 5.8609 & \\
\hline CHEMBL1454819 & 688810 & 4.633 & 4.9026 & TRN & & \\
\hline CHEMBL1317049 & 688810 & 4.783 & 5.2377 & TRN & & \\
\hline CHEMBL1307647 & 688810 & 5.083 & 5.0187 & TRN & & \\
\hline HEMBL: & 688 & \multicolumn{3}{|c|}{4.7330000000000005} & -01 & \\
\hline CHEMBL & 688810 & 4.883 & 5.7113 & TRN & & \\
\hline HEMBL1579102 & 688810 & 5.183 & 5.4808 & TRN & & \\
\hline CHEMBL1328215 & 688810 & 4.583 & 4.9807 & TST & & \\
\hline CHEMBL1570807 & 688810 & \multicolumn{3}{|c|}{5.7829999999999995} & 5.1614 & \\
\hline CHEME & $68 \varepsilon$ & 5.083 & 5.6134 & TST & & \\
\hline CHEMB & 688810 & \multicolumn{3}{|c|}{5.832999999999999} & 6.0375 & $\mathrm{~T}$ \\
\hline CHEMBL1312444 & 688810 & 4.683 & 5.5081 & TRN & & \\
\hline CHEMBL1544832 & 688810 & 5.433 & 5.5691 & TST & & \\
\hline CHEMBL3190347 & 688 & 4.833 & 5.2172 & TST & & \\
\hline CHEME & 688 & \multicolumn{3}{|c|}{6.0329999999999995} & 5.7429 & TP \\
\hline CHEMB & 688 & 5.433 & \multicolumn{3}{|c|}{5.3260000000000005} & \\
\hline CHEMBL1528127 & 688810 & 4.883 & 5.3272 & TRN & & \\
\hline CHEMBL3213419 & 688810 & 7.0329 & 5.2709 & TRN & & \\
\hline CHEMBL: & & 5.983 & 5.6509 & TRN & & \\
\hline CHEMB & 688 & \multicolumn{3}{|c|}{6.5329999999999995} & 5.3472 & TP \\
\hline CHEMBL1463218 & 688810 & \multicolumn{3}{|c|}{5.632999999999999} & 5.0522 & \\
\hline CHEMBL1379797 & 688810 & 4.883 & 5.3408 & TRN & & \\
\hline CHEMBL1577676 & 688810 & 4.783 & 4.4875 & TRN & & \\
\hline CHEMBL1361148 & 688810 & 5.033 & 5.102 & TRN & & \\
\hline CHEMBL1390470 & 688810 & 4.833 & 5.1796 & TST & & \\
\hline CHEMBL1445650 & 688810 & 4.833 & 5.3195 & TRN & & \\
\hline CHEMBL1364185 & 688810 & \multicolumn{3}{|c|}{5.132999999999999} & 5.5145 & $T$ \\
\hline CHEMBL1518283 & 688810 & 4.783 & 5.3098 & TST & & \\
\hline CHEMBL1590402 & 688810 & 4.7330 & 00000000 & 005 & 4.9079 & \\
\hline CHEMBL1550167 & 688810 & 6.0829 & 99999999 & & 5.6286 & TS \\
\hline CHEMBL1505469 & 688810 & 5.8329 & 99999999 & & 5.3797 & 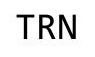 \\
\hline
\end{tabular}




\begin{tabular}{|c|c|c|c|c|c|c|}
\hline \multirow{3}{*}{$\begin{array}{l}\text { CHEMBL1428076 } \\
\text { CHEMBL1971634 }\end{array}$} & \multirow{3}{*}{$\begin{array}{l}688810 \\
688810\end{array}$} & \multicolumn{4}{|c|}{ Supplemental Table S2.txt } & \multirow{2}{*}{ TST } \\
\hline & & \multicolumn{3}{|c|}{5.832999999999999} & 5.7518 & \\
\hline & & 4.633 & 5.5285 & TRN & & \\
\hline CHEMBL1445758 & 688810 & 4.583 & 5.322 & TRN & & \\
\hline CHEMBL1457342 & 688810 & 5.083 & 5.1646 & TRN & & \\
\hline CHEMBL1373057 & 688810 & 5.683 & 5.474 & TST & & \\
\hline CHEMBL1493505 & 688810 & 5.433 & \multicolumn{3}{|c|}{5.337999999999999} & TST \\
\hline CHEMBL1477057 & 688810 & \multicolumn{3}{|c|}{6.382999999999999} & 5.9007 & TRN \\
\hline CHEMBL1355134 & 688810 & 4.833 & 4.9657 & TRN & & \\
\hline CHEMBL1371920 & 688810 & \multicolumn{3}{|c|}{4.7330000000000005} & 4.9342 & TRN \\
\hline CHEMBL1323281 & 688810 & 4.833 & 5.1813 & TRN & & \\
\hline CHEMBL1505809 & 688810 & 6.683 & 5.4197 & TST & & \\
\hline CHEMBL1578432 & 688810 & \multicolumn{3}{|c|}{6.582999999999999} & 5.7861 & TRN \\
\hline CHEMBL1455349 & 688810 & 6.9329 & 5.9336 & TRN & & \\
\hline CHEMBL1993173 & 688810 & \multicolumn{3}{|c|}{4.7330000000000005} & 5.6426 & TRN \\
\hline CHEMBL1406543 & 688810 & 5.083 & 5.7577 & TRN & & \\
\hline CHEMBL1596022 & 688810 & 4.633 & 5.0978 & TRN & & \\
\hline CHEMBL3194073 & 688810 & \multicolumn{3}{|c|}{5.132999999999999} & 5.2471 & TRN \\
\hline CHEMBL1400478 & 688810 & 5.033 & 5.4043 & TRN & & \\
\hline CHEMBL1341008 & 688810 & 4.683 & 4.9039 & TST & & \\
\hline CHEMBL1556052 & 688810 & 4.883 & \multicolumn{3}{|c|}{5.138999999999999} & TRN \\
\hline CHEMBL1370601 & 688810 & \multicolumn{3}{|c|}{5.132999999999999} & 5.1139 & TRN \\
\hline CHEMBL1365356 & 688810 & 4.883 & 5.3757 & TRN & & \\
\hline CHEMBL1351568 & 688810 & 5.683 & 5.0747 & TST & & \\
\hline CHEMBL3191175 & 688810 & 4.883 & 5.1147 & TRN & & \\
\hline CHEMBL1995078 & 688810 & 5.433 & 5.2203 & TRN & & \\
\hline CHEMBL1313327 & 688810 & 4.783 & 5.6514 & TST & & \\
\hline CHEMBL1562796 & 688810 & \multicolumn{3}{|c|}{4.7330000000000005} & 5.1422 & TRN \\
\hline CHEMBL1579773 & 688810 & 6.4829 & 5.5332 & TRN & & \\
\hline CHEMBL1507274 & 688810 & 6.8831 & 5.8849 & TRN & & \\
\hline CHEMBL1513003 & 688810 & 5.183 & 4.841 & TST & & \\
\hline CHEMBL1587526 & 688810 & 4.633 & 4.9338 & TST & & \\
\hline CHEMBL1495100 & 688810 & \multicolumn{3}{|c|}{4.7330000000000005} & 5.7023 & TRN \\
\hline CHEMBL1505977 & 688810 & \multicolumn{3}{|c|}{5.132999999999999} & 5.3661 & TRN \\
\hline CHEMBL1395405 & 688810 & 4.583 & 5.5707 & TRN & & \\
\hline CHEMBL1362188 & 688810 & \multicolumn{3}{|c|}{6.332999999999999} & 5.2648 & TRN \\
\hline CHEMBL1386313 & 688810 & 5.183 & 5.0884 & TRN & & \\
\hline CHEMBL1400174 & 688810 & \multicolumn{3}{|c|}{5.5329999999999995} & 5.8841 & TRN \\
\hline CHEMBL1320008 & 688810 & \multicolumn{3}{|c|}{6.2829999999999995} & 5.0389 & TRN \\
\hline CHEMBL1426766 & 688810 & \multicolumn{3}{|c|}{4.9830000000000005} & 5.1908 & TRN \\
\hline CHEMBL1386701 & 688810 & 5.0 & 4.7567 & TRN & & \\
\hline CHEMBL1438038 & 688810 & & & & & \\
\hline CHEMBL1369240 & 688810 & \multicolumn{3}{|c|}{4.7330000000000005} & 5.069 & TRN \\
\hline CHEMBL1524446 & 688810 & 4.683 & 4.9487 & TST & & \\
\hline CHEMBL1609109 & 688810 & 5.183 & 4.9402 & TRN & & \\
\hline CHEMBL3208406 & 688810 & 4.683 & 5.0278 & TST & & \\
\hline CHEMBL1407128 & 688810 & 4.783 & 4.8862 & TRN & & \\
\hline CHEMBL1573986 & 688810 & 5.033 & 5.6214 & TRN & & \\
\hline CHEMBL3213871 & 688810 & 5.083 & 5.3379 & 9999 & & TRN \\
\hline & & & & & & \\
\hline
\end{tabular}




\begin{tabular}{|c|c|c|c|c|c|c|c|}
\hline \\
\hline CHEMBL1369047 & 688810 & 5.033 & 5.2811 & TRN & & & \\
\hline CHEMBL1601294 & 688810 & 4.883 & 5.3747 & TRN & & & \\
\hline CHEMBL1472311 & 688810 & 5.233 & 5.7545 & TRN & & & \\
\hline CHEMBL1557010 & 688810 & \multicolumn{3}{|c|}{4.7330000000000005} & 5.7057 & TST & \\
\hline CHEMBL1503529 & 688810 & \multicolumn{3}{|c|}{4.7330000000000005} & 5.2922 & TST & \\
\hline CHEMBL1517391 & 688810 & 4.883 & 5.5033 & TRN & & & \\
\hline CHEMBL1578012 & 688810 & 6.183 & 5.8155 & TRN & & & \\
\hline CHEMBL1310721 & 688810 & \multicolumn{3}{|c|}{5.7829999999999995} & 5.5029 & TRN & \\
\hline CHEMBL1395319 & 688810 & \multicolumn{3}{|c|}{6.332999999999999} & 5.8611 & TRN & \\
\hline CHEMBL1536037 & 688810 & 5.733 & 4.6429 & TRN & & & \\
\hline CHEMBL1580686 & 688810 & 5.033 & 5.2931 & TRN & & & \\
\hline CHEMBL1449308 & 688810 & \multicolumn{3}{|c|}{4.7330000000000005} & 5.5135 & TRN & \\
\hline CHEMBL1885024 & 688810 & 4.583 & 5.3017 & TRN & & & \\
\hline CHEMBL1487870 & 688810 & 4.883 & 5.2768 & TRN & & & \\
\hline CHEMBL1323634 & 688810 & \multicolumn{3}{|c|}{6.082999999999999} & \multicolumn{2}{|c|}{5.468999999999999} & TRN \\
\hline CHEMBL1528535 & 688810 & 4.783 & 5.4103 & TRN & & & \\
\hline CHEMBL1450979 & 688810 & 5.233 & 5.5469 & TRN & & & \\
\hline CHEMBL1366634 & 688810 & \multicolumn{3}{|c|}{4.9830000000000005} & 5.0528 & TRN & \\
\hline CHEMBL1486028 & 688810 & \multicolumn{3}{|c|}{5.632999999999999} & 5.481 & TRN & \\
\hline CHEMBL1434543 & 688810 & \multicolumn{3}{|c|}{4.7330000000000005} & 5.0008 & TRN & \\
\hline CHEMBL1437922 & 688810 & 4.783 & 4.9542 & TRN & & & \\
\hline CHEMBL1368862 & 688810 & 4.633 & 5.3001 & TST & & & \\
\hline CHEMBL1365439 & 688810 & 5.083 & 5.3233 & TRN & & & \\
\hline CHEMBL1314384 & 688810 & \multicolumn{3}{|c|}{5.132999999999999} & 4.9488 & TRN & \\
\hline CHEMBL1306782 & 688810 & \multicolumn{3}{|c|}{6.0329999999999995} & 5.4983 & TRN & \\
\hline CHEMBL1504959 & 688810 & 5.083 & 5.2429 & TRN & & & \\
\hline CHEMBL1497019 & 688810 & \multicolumn{3}{|c|}{5.832999999999999} & 6.7004 & TRN & \\
\hline CHEMBL1300766 & 688810 & 5.733 & 5.6468 & TST & & & \\
\hline CHEMBL1404678 & 688810 & 5.733 & 5.2007 & TRN & & & \\
\hline CHEMBL1445242 & 688810 & 5.733 & 5.2011 & TRN & & & \\
\hline CHEMBL1584429 & 688810 & \multicolumn{3}{|c|}{5.132999999999999} & 5.2277 & TST & \\
\hline CHEMBL3212304 & 688810 & \multicolumn{3}{|c|}{5.5329999999999995} & 5.6364 & TST & \\
\hline CHEMBL1420313 & 688810 & 4.833 & 5.004 & TRN & & & \\
\hline CHEMBL1451031 & 688810 & 4.783 & 4.9825 & TRN & & & \\
\hline CHEMBL1456271 & 688810 & \multicolumn{3}{|c|}{6.632999999999999} & 6.0088 & TRN & \\
\hline CHEMBL1308321 & 688810 & 7.032 & 6.1963 & TRN & & & \\
\hline CHEMBL1547965 & 688810 & \multicolumn{3}{|c|}{4.7330000000000005} & 5.5798 & TRN & \\
\hline CHEMBL1343828 & 688810 & 5.033 & 5.1976 & TRN & & & \\
\hline CHEMBL1552483 & 688810 & 4.583 & 5.1157 & TRN & & & \\
\hline CHEMBL1598445 & 688810 & 6.233 & 6.1764 & TRN & & & \\
\hline CHEMBL1319703 & 688810 & \multicolumn{3}{|c|}{6.332999999999999} & 5.8796 & TRN & \\
\hline CHEMBL1428811 & 688810 & 5.233 & 4.9286 & TRN & & & \\
\hline CHEMBL1579321 & 688810 & 4.833 & 5.5134 & TRN & & & \\
\hline CHEMBL1474691 & 688810 & 4.583 & 5.0854 & TRN & & & \\
\hline CHEMBL1591226 & 688810 & 5.933 & 5.3851 & TRN & & & \\
\hline CHEMBL1370414 & 688810 & 5.183 & 4.9315 & TRN & & & \\
\hline CHEMBL1415983 & 688810 & 5.033 & 4.9504 & TRN & & & \\
\hline CHEMBL1503423 & 688810 & 4.783 & 5.0399 & TRN & & & \\
\hline
\end{tabular}




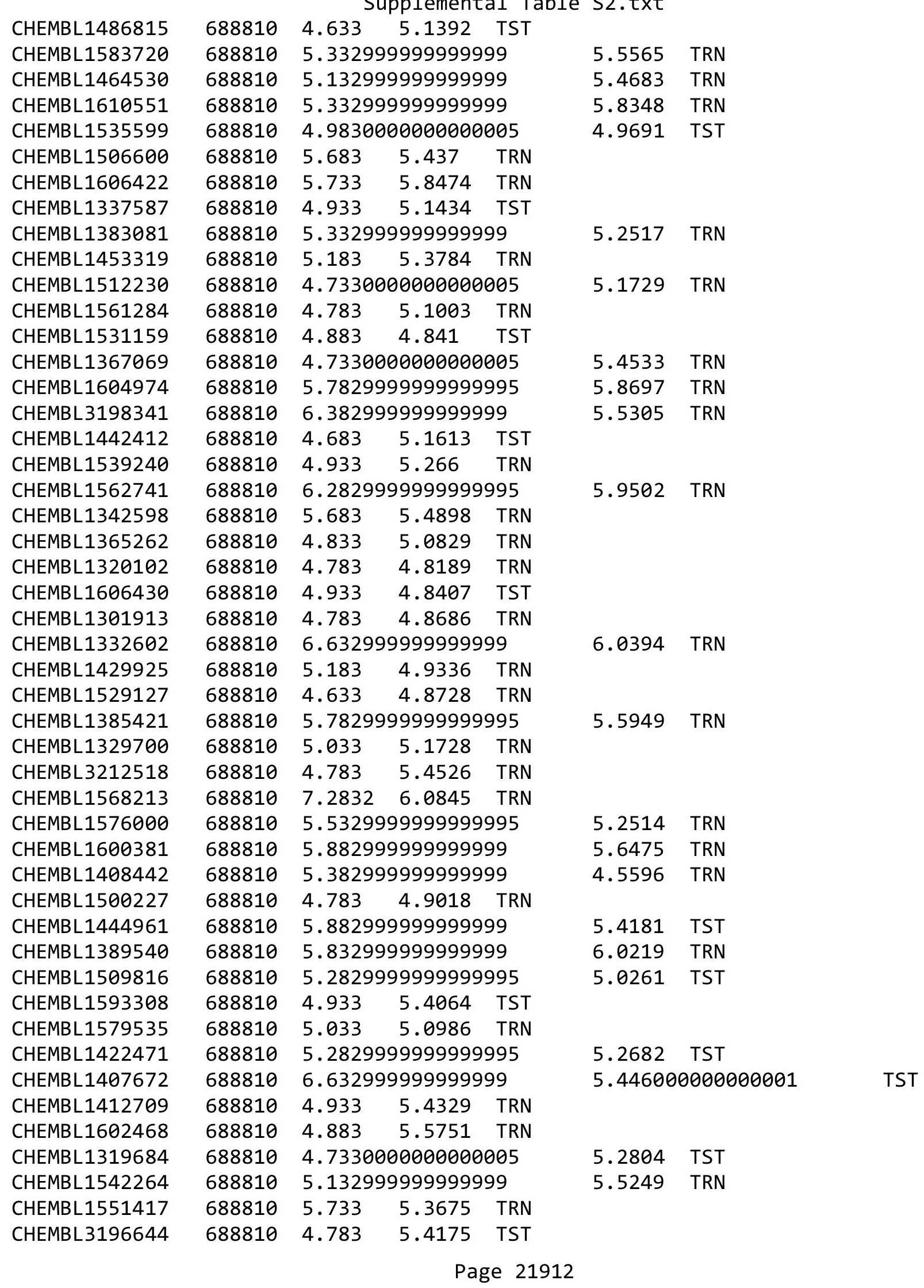




\begin{tabular}{|c|c|c|c|c|c|c|}
\hline \multirow[b]{2}{*}{ CHEMBL 3210025} & \multicolumn{6}{|c|}{ S } \\
\hline & 688810 & 6.233 & 5.5903 & TRN & & \\
\hline CHEMBL1440188 & 688810 & 6.4829 & 6.1423 & TRN & & \\
\hline CHEMBL1432339 & 688810 & 4.683 & 5.0646 & TRN & & \\
\hline CHEMBL1578145 & 688810 & \multicolumn{3}{|c|}{5.632999999999999} & 5.3485 & TRN \\
\hline CHEMBL301507 & 688810 & 5.433 & 5.5186 & TRN & & \\
\hline CHEMBL1515437 & 688810 & 4.783 & 4.9759 & TST & & \\
\hline CHEMBL1477988 & 688810 & \multicolumn{3}{|c|}{5.332999999999999} & 5.0391 & TRN \\
\hline CHEMBL412603 & 688810 & \multicolumn{3}{|c|}{5.832999999999999} & 5.3144 & TRN \\
\hline CHEMBL1471090 & 688810 & 5.033 & 5.2109 & TRN & & \\
\hline CHEMBL1549543 & 688810 & \multicolumn{3}{|c|}{4.9830000000000005} & 5.3609 & TRN \\
\hline CHEMBL1559310 & 688810 & 4.933 & 5.3673 & TRN & & \\
\hline CHEMBL1471383 & 688810 & 6.7331 & 5.4221 & TRN & & \\
\hline CHEMBL1525631 & 688810 & 5.033 & 5.3525 & TRN & & \\
\hline CHEMBL1593119 & 688810 & \multicolumn{3}{|c|}{5.132999999999999} & 5.0863 & TRN \\
\hline CHEMBL1489839 & 688810 & \multicolumn{3}{|c|}{4.7330000000000005} & 4.8056 & TRN \\
\hline CHEMBL1552586 & 688810 & 4.783 & 5.4957 & TST & & \\
\hline CHEMBL3192865 & 688810 & \multicolumn{3}{|c|}{4.9830000000000005} & 5.3751 & TRN \\
\hline CHEMBL1523814 & 688810 & \multicolumn{3}{|c|}{4.7330000000000005} & 5.4727 & TRN \\
\hline CHEMBL1576166 & 688810 & 7.1331 & 6.4221 & TRN & & \\
\hline CHEMBL 2006634 & 688810 & \multirow{2}{*}{\multicolumn{3}{|c|}{$\begin{array}{l}4.383 \text { 5.196/ IRIN } \\
5.332999999999999\end{array}$}} & & \\
\hline CHEMBL 3196279 & 688810 & & & & 5.1823 & TRN \\
\hline CHEMBL1365070 & 688810 & 5.433 & 5.5697 & TST & & \\
\hline CHEMBL1569287 & 688810 & 5.433 & 5.1534 & TRN & & \\
\hline CHEMBL3193507 & 688810 & 5.233 & 5.2784 & TRN & & \\
\hline CHEMBL1310201 & 688810 & \multicolumn{3}{|c|}{5.382999999999999} & 5.4187 & TRN \\
\hline CHEMBL1381322 & 688810 & 7.1331 & \multicolumn{3}{|c|}{6.1610000000000005} & TRN \\
\hline CHEMBL1445828 & 688810 & 5.233 & 5.1871 & TRN & & \\
\hline CHEMBL1613473 & 688810 & \multicolumn{3}{|c|}{4.7330000000000005} & 5.4929 & TRN \\
\hline CHEMBL1312192 & 688810 & 4.883 & 5.0768 & TST & & \\
\hline CHEMBL1307972 & 688810 & \multicolumn{3}{|c|}{5.832999999999999} & 5.1339 & TRN \\
\hline CHEMBL1441738 & 688810 & \multicolumn{3}{|c|}{5.332999999999999} & 5.51 & TST \\
\hline CHEMBL1523739 & 688810 & 5.433 & 5.4949 & TST & & \\
\hline CHEMBL1395924 & 688810 & 4.783 & 5.0834 & TRN & & \\
\hline CHEMBL1564084 & 688810 & \multicolumn{3}{|c|}{5.632999999999999} & 5.3261 & TRN \\
\hline CHEMBL1587454 & 688810 & 4.783 & 5.0248 & TRN & & \\
\hline CHEMBL1472423 & 688810 & 4.933 & 5.5182 & TST & & \\
\hline CHEMBL3194312 & 688810 & 4.783 & 5.2065 & TRN & & \\
\hline CHEMBL1442404 & 688810 & \multicolumn{3}{|c|}{5.832999999999999} & 5.2239 & TRN \\
\hline CHEMBL1433255 & 688810 & \multicolumn{3}{|c|}{6.7829999999999995} & 5.7631 & TRN \\
\hline CHEMBL1378124 & 688810 & 4.833 & 4.9599 & TRN & & \\
\hline CHEMBL1359093 & 688810 & 5.083 & 5.1504 & TST & & \\
\hline CHEMBL1353250 & 688810 & 4.783 & 5.2997 & TRN & & \\
\hline CHEMBL1416710 & 688810 & 4.783 & 5.3607 & TRN & & \\
\hline CHEMBL1601730 & 688810 & 5.083 & 5.5556 & TST & & \\
\hline CHEMBL1542918 & 688810 & 5.033 & 5.6421 & TRN & & \\
\hline CHEMBL1557096 & 688810 & \multicolumn{3}{|c|}{5.132999999999999} & 4.8355 & TRN \\
\hline CHEMBL1304330 & 688810 & 6.183 & 4.981 & TRN & & \\
\hline CHEMBL591519 & 688810 & 4.883 & 5.3037 & TRN & & \\
\hline
\end{tabular}




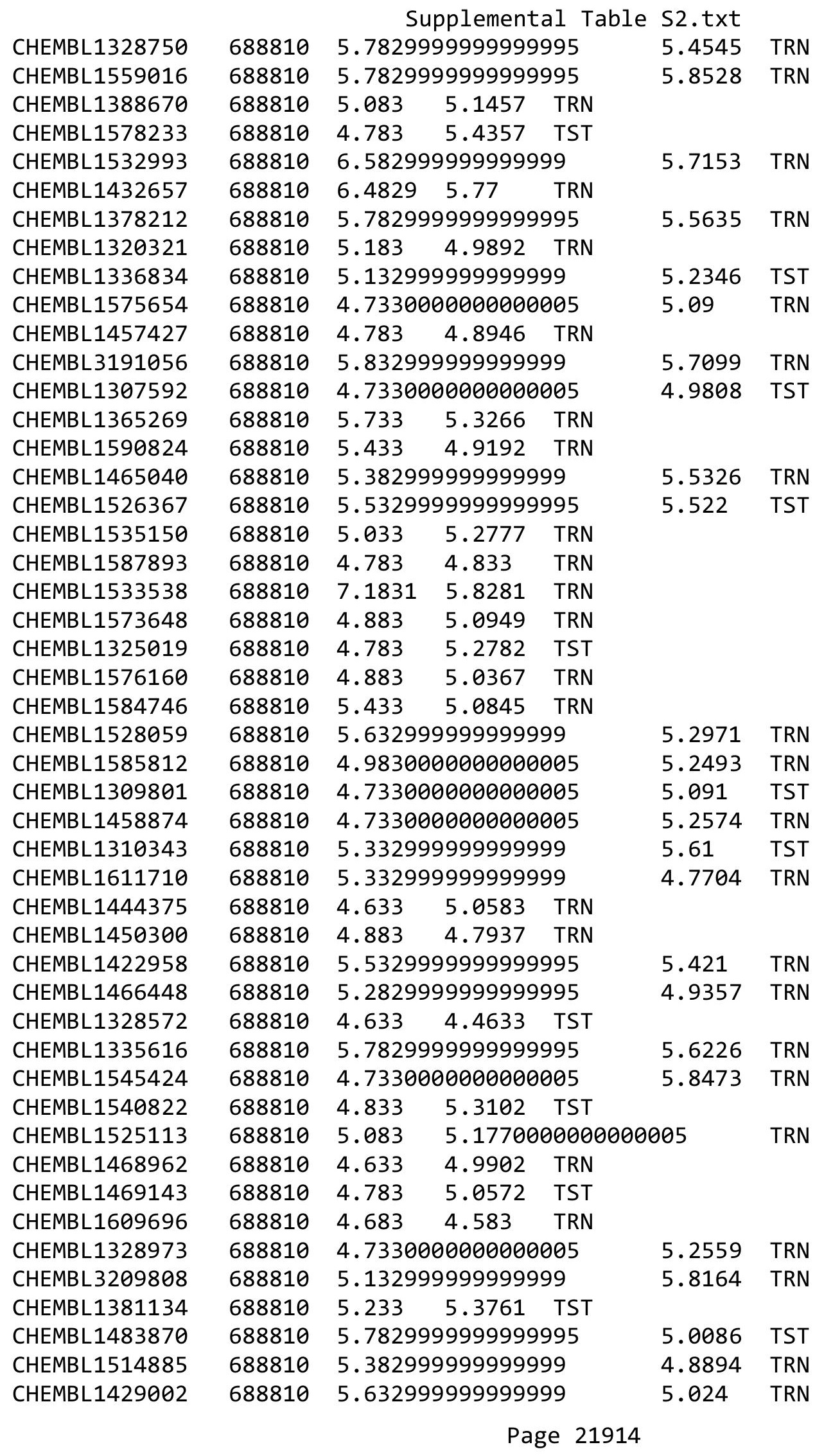




\begin{tabular}{|c|c|c|c|c|c|c|}
\hline \multirow[b]{2}{*}{ CHEMBL1451784 } & \multirow[b]{2}{*}{688810} & \multicolumn{5}{|c|}{ Supplemental Table S2.txt } \\
\hline & & 4.883 & 5.2511 & TRN & & \\
\hline CHEMBL1488548 & 688810 & 5.13299 & 99999999 & & 5.3785 & TRN \\
\hline CHEMBL1504728 & 688810 & 5.33299 & 99999999 & 99 & 5.1715 & TRN \\
\hline CHEMBL1399080 & 688810 & 4.833 & 5.5223 & TST & & \\
\hline CHEMBL1415473 & 688810 & 4.73300 & 20000000 & 005 & 5.3781 & TST \\
\hline CHEMBL1524792 & 688810 & 4.883 & 5.1086 & TST & & \\
\hline CHEMBL1357996 & 688810 & 5.83299 & 99999999 & & 5.5641 & TRN \\
\hline CHEMBL1582368 & 688810 & 5.683 & 5.8938 & TRN & & \\
\hline CHEMBL1465137 & 688810 & 5.78299 & 99999999 & 995 & 5.9119 & TST \\
\hline CHEMBL1303489 & 688810 & 4.633 & 4.4788 & TRN & & \\
\hline CHEMBL1439787 & 688810 & 6.683 & 5.4399 & TRN & & \\
\hline CHEMBL1311351 & 688810 & 6.08299 & 99999999 & & 5.4198 & TST \\
\hline CHEMBL1568877 & 688810 & 5.933 & 5.3664 & TRN & & \\
\hline CHEMBL1351793 & 688810 & 4.933 & 5.0728 & TST & & \\
\hline CHEMBL1364743 & 688810 & 5.28299 & 99999999 & 995 & 5.5806 & TRN \\
\hline CHEMBL3195773 & 688810 & 4.783 & 5.26200 & 000000000 & 05 & TRN \\
\hline CHEMBL1300882 & 688810 & 5.13299 & 99999999 & & 5.4502 & TRN \\
\hline CHEMBL1604799 & 688810 & 6.03299 & 99999999 & 995 & 5.1723 & TRN \\
\hline CHEMBL1313894 & 688810 & 4.683 & 5.0176 & TRN & & \\
\hline CHEMBL1595151 & 688810 & 4.783 & 5.3139 & TRN & & \\
\hline CHEMBL1422621 & 688810 & 5.58299 & 99999999 & & 5.1567 & TST \\
\hline CHEMBL1380158 & 688810 & 5.433 & 5.5611 & TRN & & \\
\hline CHEMBL1413075 & 688810 & 7.08299 & 99999999 & & 5.8628 & TRN \\
\hline CHEMBL1547670 & 688810 & 5.183 & 5.0807 & TRN & & \\
\hline CHEMBL1492947 & 688810 & 4.783 & 4.9872 & TST & & \\
\hline CHEMBL1386813 & 688810 & 4.783 & 5.2938 & TRN & & \\
\hline CHEMBL1317520 & 688810 & 6.28299 & 99999999 & 995 & 5.5442 & TRN \\
\hline CHEMBL1452577 & 688810 & 4.73300 & $\partial 0000000$ & 005 & 5.4487 & TST \\
\hline CHEMBL1517045 & 688810 & 5.183 & 5.5746 & TST & & \\
\hline CHEMBL1410519 & 688810 & 4.833 & 5.1016 & TRN & & \\
\hline CHEMBL1343377 & 688810 & 4.933 & 5.6144 & TST & & \\
\hline CHEMBL1965973 & 688810 & 5.733 & 5.813 & TST & & \\
\hline CHEMBL1544272 & 688810 & 5.733 & 5.3051 & TRN & & \\
\hline CHEMBL1426910 & 688810 & 5.733 & 5.2988 & TRN & & \\
\hline CHEMBL3196736 & 688810 & 5.183 & 5.3462 & TST & & \\
\hline CHEMBL3144916 & 688810 & 5.183 & 5.5693 & TST & & \\
\hline CHEMBL1447723 & 688810 & 5.233 & 5.692 & TRN & & \\
\hline CHEMBL1445381 & 688810 & 4.783 & 5.2779 & TRN & & \\
\hline CHEMBL1484968 & 688810 & 6.78299 & 99999999 & 995 & 5.5676 & TRN \\
\hline CHEMBL1326990 & 688810 & 4.633 & 4.8476 & TRN & & \\
\hline CHEMBL1592723 & 688810 & 4.633 & 4.5919 & TRN & & \\
\hline CHEMBL202366 & 688810 & 6.233 & 5.9286 & TRN & & \\
\hline CHEMBL114249 & 688810 & 5.83299 & 99999999 & & 6.3005 & TRN \\
\hline CHEMBL1556327 & 688810 & 5.683 & 5.7955 & TRN & & \\
\hline CHEMBL1347951 & 688810 & 4.73300 & 00000000 & 005 & 4.8428 & TRN \\
\hline CHEMBL3191921 & 688810 & 7.0329 & 5.5953 & TRN & & \\
\hline CHEMBL585222 & 688810 & 5.233 & 5.3115 & TRN & & \\
\hline CHEMBL1431131 & 688810 & 5.483 & 5.3935 & TRN & & \\
\hline
\end{tabular}




\begin{tabular}{|c|c|c|c|c|c|c|}
\hline \multirow[b]{2}{*}{ CHEMBL1598483 } & \multirow[b]{2}{*}{688810} & \multicolumn{5}{|c|}{ Supplemental Table S2.txt } \\
\hline & & 4.633 & 5.7844 & TST & & \\
\hline CHEMBL1374458 & 688810 & \multicolumn{3}{|c|}{5.832999999999999} & 5.6673 & TRN \\
\hline CHEMBL1584763 & 688810 & \multicolumn{3}{|c|}{5.5329999999999995} & 5.664 & TRN \\
\hline CHEMBL1573954 & 688810 & 5.183 & 5.1753 & TRN & & \\
\hline CHEMBL1448223 & 688810 & \multicolumn{3}{|c|}{6.2829999999999995} & 5.6656 & TRN \\
\hline CHEMBL1303501 & 688810 & \multicolumn{3}{|c|}{6.132999999999999} & 6.1349 & TRN \\
\hline CHEMBL3212469 & 688810 & 5.083 & 5.1634 & TRN & & \\
\hline CHEMBL1362679 & 688810 & 5.183 & 5.1484 & TRN & & \\
\hline CHEMBL1363308 & 688810 & \multicolumn{3}{|c|}{5.832999999999999} & 5.2301 & TRN \\
\hline CHEMBL1492507 & 688810 & 5.733 & 5.0778 & TRN & & \\
\hline CHEMBL1471069 & 688810 & \multicolumn{3}{|c|}{5.882999999999999} & 5.6248 & TRN \\
\hline CHEMBL1393674 & 688810 & 5.733 & 5.3821 & TST & & \\
\hline CHEMBL1458275 & 688810 & \multicolumn{3}{|c|}{4.9830000000000005} & 5.0639 & TST \\
\hline CHEMBL1518871 & 688810 & 4.633 & 4.7219 & TRN & & \\
\hline CHEMBL1603775 & 688810 & 4.933 & 4.9281 & TRN & & \\
\hline CHEMBL1526189 & 688810 & 6.233 & 6.0059 & TST & & \\
\hline CHEMBL1519018 & 688810 & 4.833 & 5.0179 & TST & & \\
\hline CHEMBL1568411 & 688810 & 5.233 & 5.6894 & TRN & & \\
\hline CHEMBL1391035 & 688810 & 5.683 & 5.3084 & TRN & & \\
\hline CHEMBL1367801 & 688810 & 4.783 & 4.7625 & TRN & & \\
\hline CHEMBL1399401 & 688810 & 4.583 & 4.6628 & TST & & \\
\hline CHEMBL1502502 & 688810 & 5.733 & 5.048 & TST & & \\
\hline CHEMBL1601122 & 688810 & \multicolumn{3}{|c|}{6.632999999999999} & 5.9924 & TRN \\
\hline CHEMBL1545641 & 688810 & 4.883 & 5.1033 & TRN & & \\
\hline CHEMBL1565757 & 688810 & \multicolumn{3}{|c|}{$\begin{array}{lll}5.483 & 5.7423 & \text { TST }\end{array}$} & & \\
\hline CHEMBL1387365 & 688810 & \multicolumn{3}{|c|}{5.632999999999999} & 5.7893 & TRN \\
\hline CHEMBL1513547 & 688810 & 5.733 & 5.3135 & TRN & & \\
\hline CHEMBL1449155 & 688810 & & & TST & & \\
\hline CHEMBL1313979 & 688810 & \multicolumn{3}{|c|}{6.632999999999999} & 5.5832 & TRN \\
\hline CHEMBL1481374 & 688810 & 4.833 & 4.9411 & TRN & & \\
\hline CHEMBL1347497 & 688810 & 4.583 & 4.8194 & TST & & \\
\hline CHEMBL1604871 & 688810 & 4.833 & \multicolumn{3}{|c|}{5.332000000000001} & ISI \\
\hline CHEMBL1440781 & 688810 & \multicolumn{3}{|c|}{6.832999999999999} & 5.6302 & TST \\
\hline CHEMBL1326968 & 688810 & 5.683 & 5.2299 & TRN & & \\
\hline CHEMBL1496187 & 688810 & 4.583 & 5.3968 & TST & & \\
\hline CHEMBL1413323 & 688810 & 5.933 & 5.2952 & TRN & & \\
\hline CHEMBL1466087 & 688810 & \multicolumn{3}{|c|}{6.832999999999999} & 5.9668 & TRN \\
\hline CHEMBL1323198 & 688810 & 4.833 & 5.169 & TRN & & \\
\hline CHEMBL1560487 & 688810 & 6.183 & 5.7342 & TRN & & \\
\hline CHEMBL1397668 & 688810 & 4.883 & 4.9535 & TRN & & \\
\hline CHEMBL1427823 & 688810 & 5.433 & 5.6185 & TRN & & \\
\hline CHEMBL1323968 & 688810 & 7.1331 & 6.189 & TRN & & \\
\hline CHEMBL1491357 & 688810 & 4.783 & 5.1204 & TRN & & \\
\hline CHEMBL1371452 & 688810 & 4.683 & 5.1886 & TRN & & \\
\hline CHEMBL125970 & 688810 & \multicolumn{3}{|c|}{6.582999999999999} & 5.84 & TRN \\
\hline CHEMBL1370087 & 688810 & \multicolumn{3}{|c|}{6.2829999999999995} & 5.8033 & TRN \\
\hline CHEMBL1360340 & 688810 & 5.733 & 5.0371 & TRN & & \\
\hline \multirow[t]{2}{*}{ CHEMBL1344507 } & 688810 & \multicolumn{3}{|c|}{5.632999999999999} & 5.7082 & TRN \\
\hline & & & & & & \\
\hline
\end{tabular}




\begin{tabular}{|c|c|c|c|c|c|c|}
\hline & & & & & & \\
\hline CHEMBL1443817 & 688810 & 4.783 & 5.1737 TRN & & & \\
\hline CHEMBL1367675 & 688810 & 6.183 & 5.9053 TRN & & & \\
\hline CHEMBL1456392 & 688810 & 5.183 & 5.2718 & & & \\
\hline CHEMBL1360480 & 688810 & 4.98300 & 00000000005 & 5.2689 & TST & \\
\hline CHEMBL1524930 & 688810 & 5.233 & 5.4349 TRN & & & \\
\hline CHEMBL1437965 & 688810 & 5.63299 & 9999999999 & 5.5385 & TRN & \\
\hline CHEMBL1381350 & 688810 & 4.933 & 4.9327 TRN & & & \\
\hline CHEMBL1547932 & 688810 & 5.38299 & 9999999999 & 5.2527 & TRN & \\
\hline CHEMBL1327920 & 688810 & 4.883 & 5.3187 TRN & & & \\
\hline CHEMBL1213831 & 688810 & 6.53299 & 99999999995 & 5.766 & TRN & \\
\hline CHEMBL1572485 & 688810 & 4.683 & 5.0903 TRN & & & \\
\hline CHEMBL1540306 & 688810 & 5.13299 & 9999999999 & 5.6856 & TRN & \\
\hline CHEMBL1592230 & 688810 & 5.483 & 5.1055 TST & & & \\
\hline CHEMBL3192388 & 688810 & 4.73300 & 00000000005 & 5.4645 & TST & \\
\hline CHEMBL1306966 & 688810 & 6.28299 & 99999999995 & 5.6075 & TRN & \\
\hline CHEMBL1304556 & 688810 & 5.13299 & 9999999999 & 5.6696 & TRN & \\
\hline CHEMBL1462962 & 688810 & 4.683 & 5.0509 TST & & & \\
\hline CHEMBL1425684 & 688810 & 5.28299 & 99999999995 & 5.1817 & TRN & \\
\hline CHEMBL1546603 & 688810 & 4.73300 & 00000000005 & 4.8709 & TRN & \\
\hline CHEMBL1437963 & 688810 & 5.38299 & 9999999999 & 5.1979 & TRN & \\
\hline CHEMBL1610763 & 688810 & 5.033 & 5.2411 TRN & & & \\
\hline CHEMBL1307842 & 688810 & 4.98300 & 00000000005 & 5.5295 & TST & \\
\hline CHEMBL1391631 & 688810 & 5.933 & 4.6168 TST & & & \\
\hline CHEMBL1452351 & 688810 & 5.83299 & 9999999999 & 5.0324 & TRN & \\
\hline CHEMBL1471201 & 688810 & 5.683 & 5.9179 TRN & & & \\
\hline CHEMBL1376174 & 688810 & 4.833 & 5.3532 TST & & & \\
\hline CHEMBL1471899 & 688810 & 5.13299 & 9999999999 & 6.2382 & TST & \\
\hline CHEMBL1346550 & 688810 & 5.13299 & 9999999999 & 5.2627 & TST & \\
\hline CHEMBL1533806 & 688810 & 4.633 & 5.6141 TST & & & \\
\hline CHEMBL1569337 & 688810 & 4.73300 & 00000000005 & 5.4318 & TRN & \\
\hline CHEMBL1391348 & 688810 & 4.883 & 5.0661 TRN & & & \\
\hline CHEMBL1336976 & 688810 & 5.38299 & 9999999999 & 5.295 & TRN & \\
\hline CHEMBL1602082 & 688810 & 4.783 & 4.9884 TRN & & & \\
\hline CHEMBL1324670 & 688810 & 5.38299 & 9999999999 & 5.477 & TRN & \\
\hline CHEMBL 2003086 & 688810 & 5.13299 & 9999999999 & 5.3695 & TRN & \\
\hline CHEMBL1555342 & 688810 & 5.78299 & 99999999995 & 5.6381 & TRN & \\
\hline CHEMBL1432784 & 688810 & 4.633 & 5.1813 TRN & & & \\
\hline CHEMBL1460115 & 688810 & 4.98300 & 00000000005 & 5.5978 & TRN & \\
\hline CHEMBL1305307 & 688810 & 4.683 & 5.4142 TST & & & \\
\hline CHEMBL1311663 & 688810 & 4.883 & 5.1775 TST & & & \\
\hline CHEMBL1366238 & 688810 & 4.73300 & 00000000005 & 5.24299 & 9999999999 & TST \\
\hline CHEMBL1573088 & 688810 & 5.483 & 5.2318 TRN & & & \\
\hline CHEMBL1416089 & 688810 & 6.0 & 5.3833 & & & \\
\hline CHEMBL3194739 & 688810 & 6.83299 & 9999999999 & 6.3773 & TRN & \\
\hline CHEMBL1550934 & 688810 & 5.733 & 5.3468 TST & & & \\
\hline CHEMBL1584803 & 688810 & 6.78299 & 99999999995 & 5.6742 & TRN & \\
\hline CHEMBL1579278 & 688810 & 4.933 & 5.1924 TST & & & \\
\hline CHEMBL1438582 & 688810 & 5.033 & 4.9356 TRN & & & \\
\hline
\end{tabular}




\begin{tabular}{|c|c|c|c|c|c|c|}
\hline \multirow[b]{2}{*}{ CHEMBL1413640 } & \multicolumn{6}{|c|}{ penter } \\
\hline & 688810 & 4.783 & 5.3047 & TRN & & \\
\hline CHEMBL 3189629 & 688810 & \multicolumn{3}{|c|}{5.832999999999999} & 5.6435 & TRN \\
\hline CHEMBL1524524 & 688810 & \multicolumn{3}{|c|}{5.832999999999999} & 5.5545 & TRN \\
\hline CHEMBL1367397 & 688810 & \multicolumn{3}{|c|}{4.9830000000000005} & 5.3584 & \\
\hline CHEMBL1317531 & 688810 & 5.033 & 5.01 & TST & & \\
\hline CHEMBL1600963 & 688810 & 4.783 & 4.7074 & TRN & & \\
\hline CHEMBL1504089 & 688810 & 6.183 & 5.6923 & TRN & & \\
\hline CHEMBL3194151 & 688810 & 5.183 & 5.3172 & TRN & & \\
\hline CHEMBL1465214 & 688810 & \multicolumn{3}{|c|}{4.9830000000000005} & 5.063 & TRN \\
\hline CHEMBL476668 & 688810 & \multicolumn{3}{|c|}{5.382999999999999} & 5.1292 & TRN \\
\hline CHEMBL1507181 & 688810 & \multicolumn{3}{|c|}{6.5329999999999995} & 5.2724 & \\
\hline CHEMBL1587831 & 688810 & 4.583 & 5.1832 & TST & & \\
\hline CHEMBL1583201 & 688810 & \multicolumn{3}{|c|}{$\begin{array}{llll}5.433 & 4.7075 & \text { TRN }\end{array}$} & & \\
\hline CHEMBL1420408 & 688810 & \multicolumn{3}{|c|}{4.7330000000000005} & 826 & \\
\hline CHEMBL1319101 & 688810 & 5.033 & 5.2963 & TRN & & \\
\hline CHEMBL1980308 & 688810 & \multicolumn{3}{|c|}{5.7829999999999995} & 5.5198 & \\
\hline CHEMBL1438758 & 688810 & 4.933 & 6.2398 & TRN & & \\
\hline CHEMBL1310644 & 688810 & 4.633 & 5.1275 & TRN & & \\
\hline CHEMBL1491164 & 688810 & 4.683 & 5.1707 & TRN & & \\
\hline CHEMBL1487833 & 688810 & 6.433 & 5.2697 & TRN & & \\
\hline CHEMBL1472817 & 688810 & \multicolumn{3}{|c|}{6.7829999999999995} & 5.8807 & TRN \\
\hline CHEMBL1415838 & 688810 & \multicolumn{3}{|c|}{6.632999999999999} & 6.2113 & TRN \\
\hline CHEMBL1385704 & 688810 & 5.033 & 5.0977 & TRN & & \\
\hline CHEMBL 2369291 & 688810 & 5.483 & \multicolumn{3}{|c|}{5.4239999999999995} & TST \\
\hline CHEMBL1366736 & 688810 & \multicolumn{3}{|c|}{5.382999999999999} & 5.2185 & \\
\hline CHEMBL1550224 & 688810 & 4.583 & 5.2583 & TST & & \\
\hline CHEMBL1443693 & 688810 & 5.233 & 4.7175 & TRN & & \\
\hline CHEMBL1462426 & 688810 & 5.483 & 5.5402 & TRN & & \\
\hline CHEMBL1583619 & 688810 & 4.783 & 5.3375 & TRN & & \\
\hline CHEMBL1391428 & 688810 & 4.783 & 5.2369 & TRN & & \\
\hline CHEMBL1577781 & 688810 & \multicolumn{3}{|c|}{4.7330000000000005} & 5.5218 & TRN \\
\hline CHEMBL1445254 & 688810 & \multicolumn{3}{|c|}{6.582999999999999} & 5.7944 & TRN \\
\hline CHEMBL1314633 & 688810 & \multicolumn{3}{|c|}{5.132999999999999} & 5.4356 & TS \\
\hline CHEMBL1549419 & 688810 & 4.633 & 5.3085 & TST & & \\
\hline CHEMBL15 & 688810 & 5.083 & 5.4498 & TRN & & \\
\hline CHEMBL1511172 & 688810 & 5.483 & 5.2317 & TRN & & \\
\hline CHEMBL1539179 & 688810 & 4.783 & 5.0674 & TST & & \\
\hline CHEMBL1536425 & 688810 & \multicolumn{3}{|c|}{6.132999999999999} & 4.9919 & TRN \\
\hline CHEMBL1514189 & 688810 & \multicolumn{3}{|c|}{5.582999999999999} & 5.0439 & \\
\hline CHEMBL1463695 & 688810 & \multicolumn{3}{|c|}{5.5329999999999995} & 5.3507 & ונדו \\
\hline CHEMBL1528991 & 688810 & 5.2829 & 9999999 & 995 & 5.0858 & TRN \\
\hline CHEMBL1417064 & 688810 & 6.5829 & 99999999 & & 6.2315 & TRN \\
\hline CHEMBL1441577 & 688810 & 4.883 & 5.5903 & TRN & & \\
\hline CHEMBL1540122 & 688810 & 5.933 & 5.8411 & TRN & & \\
\hline CHEMBL1606349 & 688810 & 5.6329 & 99999999 & & 5.1186 & IIn \\
\hline CHEMBL1401553 & 688810 & 5.6329 & 99999999 & & 5.5288 & TRI \\
\hline CHEMBL1366740 & 688810 & 4.9830 & 2000000e & 005 & 5.0937 & $\mathrm{TR}$ \\
\hline CHEMBL1549529 & 688810 & 5.433 & 6.0098 & TRN & & \\
\hline
\end{tabular}




\begin{tabular}{|c|c|c|c|c|c|c|}
\hline \multirow{3}{*}{$\begin{array}{l}\text { CHEMBL } 3209468 \\
\text { CHEMBL1308687 }\end{array}$} & \multicolumn{6}{|c|}{ Supplemental Table S2.txt } \\
\hline & 688810 & \multicolumn{4}{|c|}{5.132999999999999} & TST \\
\hline & 688810 & 4.583 & 5.1165 & TRN & & \\
\hline CHEMBL1341628 & 688810 & \multicolumn{3}{|c|}{5.2829999999999995} & 5.0238 & $\mathrm{TI}$ \\
\hline CHEMBL 3212613 & 588810 & \multicolumn{3}{|c|}{4.7330000000000005} & 5.3336 & \\
\hline CHEMBL1606534 & 588810 & \multicolumn{3}{|c|}{5.7829999999999995} & 5.399 & \\
\hline CHEMBL1454521 & 688810 & \multicolumn{3}{|c|}{5.132999999999999} & 5.5154 & \\
\hline CHEMBL1981541 & 688810 & 5.433 & 5.7077 & TST & & \\
\hline CHEMBL1322179 & 688810 & 5.983 & 5.0709 & TRN & & \\
\hline CHEMBL1348498 & 88810 & 5.483 & 5.4188 & TRN & & \\
\hline CHEMBL1352627 & 688810 & \multicolumn{3}{|c|}{4.7330000000000005} & 5.0519 & \\
\hline CHEMBL1548590 & 688810 & 4.683 & 4.7835 & TST & & \\
\hline CHEMBL1594536 & 688810 & 4.783 & 4.7899 & TRN & & \\
\hline CHEMBL1310290 & 688810 & \multicolumn{3}{|c|}{5.132999999999999} & 5.0615 & \\
\hline CHEMBL1589875 & 688810 & 4.633 & 5.0028 & TRN & & \\
\hline CHEMBL1389729 & 688 & 4.833 & 5.0459 & TRN & & \\
\hline CHEMBL153 & 688 & \multicolumn{3}{|c|}{5.7829999999999995} & 5.47 & TST \\
\hline CHEMBL145 & 688 & \multicolumn{3}{|c|}{5.132999999999999} & 5.035 & \\
\hline CHEMBL3208254 & 688810 & \multicolumn{3}{|c|}{4.9830000000000005} & 5.3777 & \\
\hline CHEMBL1357614 & 688810 & 4.933 & 5.2332 & TST & & \\
\hline CHEMBL1547469 & 688810 & \multicolumn{3}{|c|}{6.0329999999999995} & 5.3058 & \\
\hline CHEMBL1 & 688 & 4.783 & 5.1858 & TRN & & \\
\hline CHEMBL 1 & 688 & 4.933 & 4.6353 & TRN & & \\
\hline CHEMBL1610936 & 688810 & \multicolumn{3}{|c|}{4.9830000000000005} & 5.4272 & $\mathrm{~T}$ \\
\hline CHEMBL1462130 & 688810 & \multicolumn{3}{|c|}{4.9830000000000005} & & \\
\hline CHEMBL1511029 & 688 & 5.233 & 5.5153 & TRN & & \\
\hline CHEMBL136 & 688 & \multicolumn{3}{|c|}{4.7330000000000005} & 3.1203 & 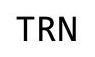 \\
\hline CHEMBL1411175 & 688 & 5.233 & 5.6437 & TRN & & \\
\hline CHEMBL1468229 & 688 & 4. & 5.30 & TRN & & \\
\hline CHEMBL1379343 & 688810 & 4.6 & 5.0102 & TST & & \\
\hline CHEMBL1568413 & 688 & & 5.0 & TRN & & \\
\hline CHEMBL & 0 & 4. & 5.0 & TST & & \\
\hline CHEMBL1584460 & $68 \varepsilon$ & 5.75 & 5.5617 & TRN & & \\
\hline CHEMBL1317272 & 688810 & \multicolumn{3}{|c|}{5.132999999999999} & 5.7065 & $T$ \\
\hline CHEMBL1608009 & 688810 & 6.45 & 5.1815 & TRN & & \\
\hline CHEMBL1 & 68 & & 5.3 & TRN & & \\
\hline CHEMBL 1 & $68 \varepsilon$ & 6.0 & 5.2764 & TRN & & \\
\hline CHEMBL1326637 & 688810 & \multicolumn{3}{|c|}{6.382999999999999} & 5.4888 & \\
\hline CHEMBL1382185 & 688810 & 4.833 & 5.1627 & TRN & & \\
\hline CHEMBL3194415 & 688810 & \multirow{2}{*}{\multicolumn{3}{|c|}{$\begin{array}{ll}5.033 & 5.1813 \\
4.9830000000000005\end{array}$}} & & \\
\hline CHEMBL1 & 688 & & & & 5.5966 & \\
\hline CHEMBL1325217 & 688810 & \multicolumn{3}{|c|}{$\begin{array}{lll}5.683 & 5.013\end{array}$} & & \\
\hline CHEMBL1545709 & 688810 & 5.733 & 5.4917 & TST & & \\
\hline CHEMBL299228 & 688810 & \multicolumn{3}{|c|}{ 4.633 4.9791 TRN } & & \\
\hline CHEMBL1517753 & 688810 & 5.3329 & 99999999 & & 5.4609 & TR \\
\hline CHEMBL1536068 & 688810 & 4.833 & 5.4246 & TRN & & \\
\hline CHEMBL1373565 & 688810 & 5.1329 & 99999999 & & 5.4217 & TRN \\
\hline CHEMBL1309690 & 688810 & 5.1329 & 99999999 & & 5.6636 & $\mathrm{TR}$ \\
\hline CHEMBL1526574 & 688810 & 4.7336 & 00000000 & 005 & 5.0613 & $\mathrm{TR}$ \\
\hline
\end{tabular}




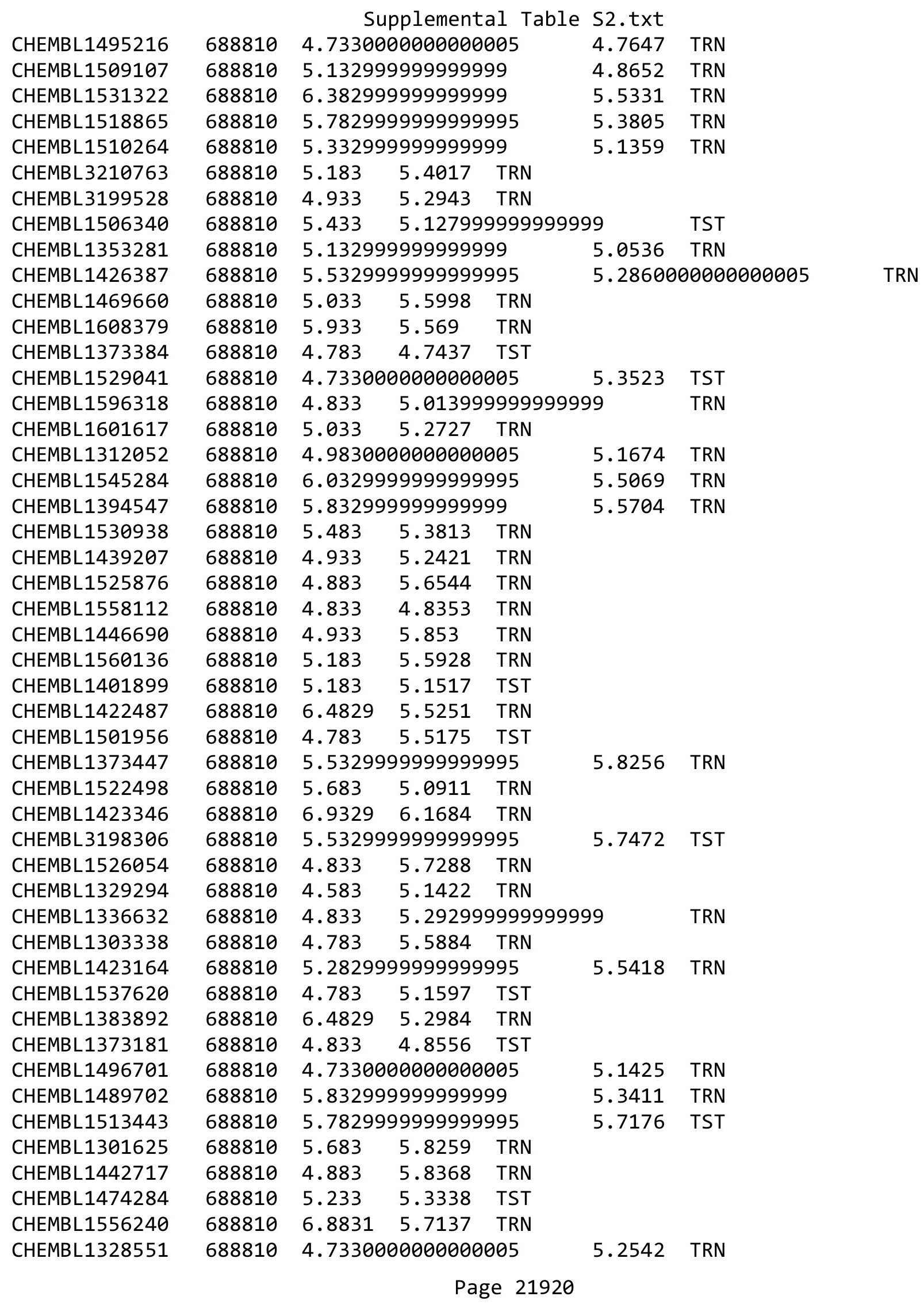




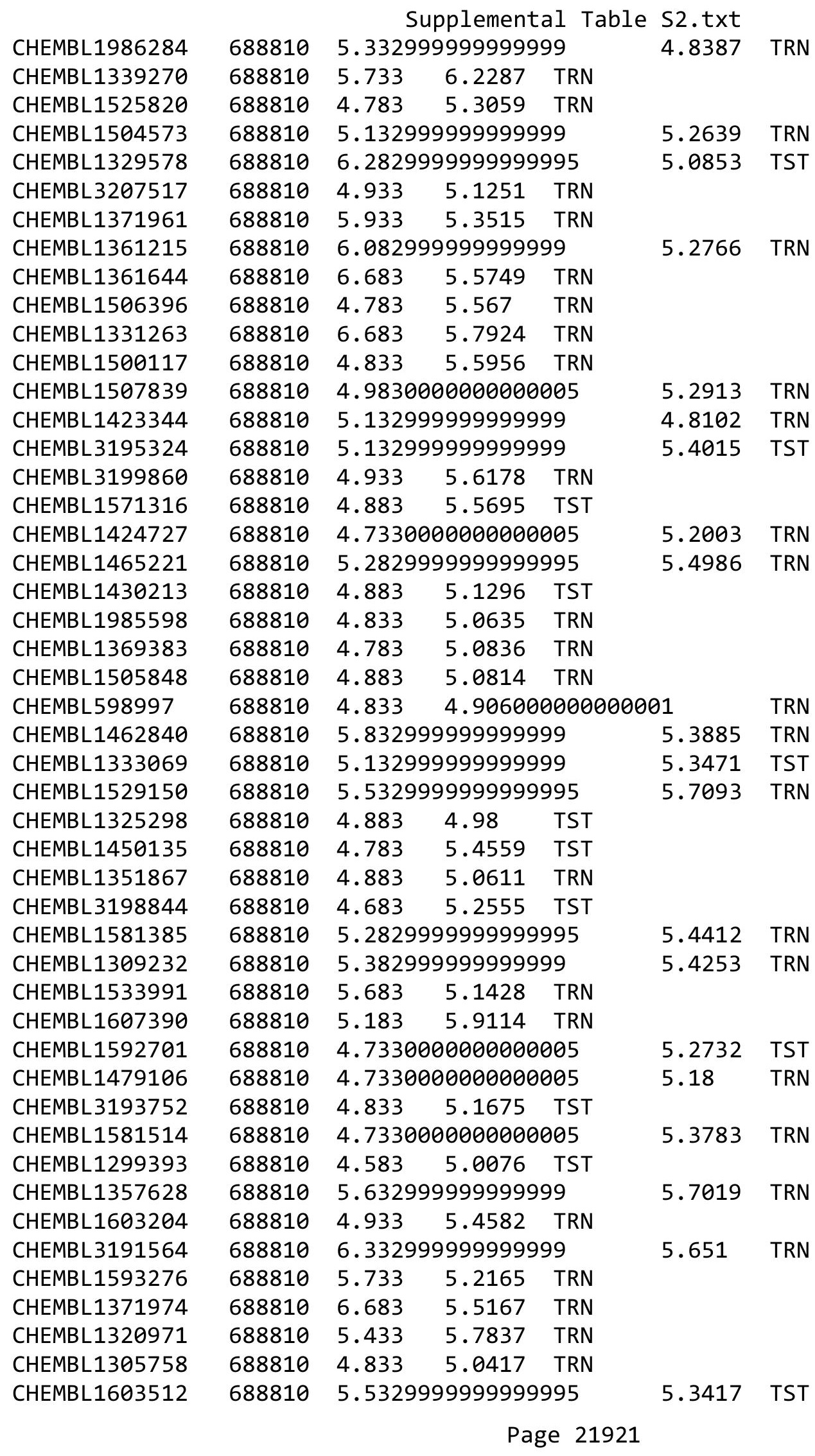




\begin{tabular}{|c|c|c|c|c|c|c|}
\hline \multirow[b]{2}{*}{ CHEMBL1502512 } & \multirow{2}{*}{688810} & \\
\hline & & \multirow{2}{*}{\multicolumn{3}{|c|}{$\begin{array}{l}4.833 \quad 5.2983 \text { ISI } \\
5.582999999999999\end{array}$}} & \multirow{3}{*}{5.4906} & \multirow[b]{2}{*}{ TRN } \\
\hline CHEMBL1328084 & 688810 & & & & & \\
\hline CHEMBL1586641 & 688810 & 4.683 & 5.5021 & TRN & & \\
\hline CHEMBL1305556 & 688810 & 4.833 & 5.0253 & TRN & & \\
\hline CHEMBL1542546 & 688810 & \multicolumn{3}{|c|}{5.332999999999999} & 5.6893 & TST \\
\hline CHEMBL1432320 & 688810 & 4.883 & 4.9191 & TRN & & \\
\hline CHEMBL1351829 & 688810 & \multicolumn{3}{|c|}{4.7330000000000005} & 5.3003 & \\
\hline CHEMBL1429016 & 688810 & 4.833 & 4.945 & TRN & & \\
\hline CHEMBL1582891 & 688810 & \multicolumn{3}{|c|}{5.7829999999999995} & 5.6454 & \\
\hline CHEMBL1611046 & 688810 & \multicolumn{3}{|c|}{6.132999999999999} & 5.7583 & \\
\hline CHEMBL1521627 & 688810 & \multicolumn{3}{|c|}{4.7330000000000005} & 5.0479 & \\
\hline CHEMBL1313410 & 688810 & 4.633 & 5.4161 & TST & & \\
\hline CHEMBL1558563 & 688810 & 5.483 & 5.4708 & TST & & \\
\hline CHEMBL1454039 & 688810 & \multicolumn{3}{|c|}{5.7829999999999995} & 5.5187 & \\
\hline CHEMBL1362510 & 688810 & 6.433 & 5.5463 & TRN & & \\
\hline CHEMBL1595601 & 688810 & \multicolumn{3}{|c|}{5.832999999999999} & 5.3427 & \\
\hline CHEMBL224844 & 688810 & \multicolumn{3}{|c|}{5.332999999999999} & 6.0475 & \\
\hline CHEMBL1554993 & 688810 & 4.883 & 4.9025 & TRN & & \\
\hline CHEMBL1423814 & 688810 & \multicolumn{3}{|c|}{4.7330000000000005} & 828 & \\
\hline CHEMBL1395238 & 688810 & 4.883 & 5.3257 & TRN & & \\
\hline CHEMBL1327547 & 688810 & \multicolumn{3}{|c|}{5.832999999999999} & 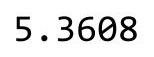 & \\
\hline CHEMBL1431019 & 688810 & 4.633 & 5.5211 & TRN & & \\
\hline CHEMBL1356980 & 688810 & 5.483 & 5.0675 & TRN & & \\
\hline CHEMBL1575456 & 688810 & \multicolumn{3}{|c|}{5.632999999999999} & 5 & \\
\hline CHEMBL1411044 & 688810 & \multicolumn{3}{|c|}{5.632999999999999} & 5.2869 & \\
\hline CHEMBL1310563 & 688810 & \multicolumn{3}{|c|}{ 5. 382999999999999} & 5.5326 & \\
\hline CHEMBL1579670 & 688810 & \multicolumn{3}{|c|}{5.882999999999999} & 5.9188 & \\
\hline CHEMBL1606549 & 688810 & 5.933 & 5.5523 & TRN & & \\
\hline CHEMBL1554385 & 688810 & \multicolumn{3}{|c|}{ 5.332999999999999 } & 4.7065 & \\
\hline CHEMBL1478222 & 688810 & 4.583 & 4.9008 & TST & & \\
\hline CHEMBL13 & 688810 & 5.78299 & 999999999 & 995 & 4.8613 & \\
\hline CHEMBL1387786 & 688810 & 4.783 & 5.8168 & TRN & & \\
\hline CHEMBL1366641 & 688810 & 5.033 & 5.1394 & TRN & & \\
\hline CHEMBL1538019 & 688810 & 5.183 & 5.111000 & 30000 & & \\
\hline CHEMBL1605565 & 688 & 5.53299 & 999999999 & 995 & 5.6752 & \\
\hline CHEMBL1540883 & 688810 & 4.933 & 4.8679 & TST & & \\
\hline CHEMBL1574879 & 688810 & 5.933 & 5.611000 & 0000 & & \\
\hline CHEMBL1480104 & 688810 & 5.38299 & 999999999 & 99 & 5.1194 & \\
\hline CHEMBL1600241 & 688810 & 4.883 & 5.6772 & TRN & & \\
\hline CHEMBL14 & 688 & 4.833 & 5.3 & TST & & \\
\hline CHEMBL1389268 & 688810 & 5.033 & 5.4213 & TRN & & \\
\hline CHEMBL 3213960 & 688810 & 6.58299 & 999999999 & & 5.3867 & \\
\hline CHEMBL1552344 & 688810 & 5.183 & 5.013 & TST & & \\
\hline CHEMBL1532931 & 688810 & 6.8831 & 5. & TRN & & \\
\hline CHEMBL1598285 & 688810 & 5.683 & 5.2882 & TRN & & \\
\hline CHEMBL 3211368 & 688810 & 5.33299 & 999999999 & & 5.4803 & \\
\hline CHEMBL1549568 & 688810 & 6.38299 & 999999999 & & 5.558 & \\
\hline CHEMBL1380654 & 688810 & 4.833 & 5.0478 & TRN & & \\
\hline
\end{tabular}




\begin{tabular}{|c|c|c|c|c|c|c|}
\hline & & \multicolumn{4}{|c|}{ Supplemental Table S2.txt } & \\
\hline CHEMBL1540417 & 688810 & $5.78299 \mathrm{c}$ & 99999999 & 995 & 5.8412 & TST \\
\hline CHEMBL1508896 & 688810 & 4.833 & \multicolumn{3}{|c|}{4.9910000000000005} & TST \\
\hline CHEMBL1439751 & 688810 & \multicolumn{3}{|c|}{5.7829999999999995} & 5.7664 & TRN \\
\hline CHEMBL1431650 & 688810 & 4.683 & 5.1291 & TRN & & \\
\hline CHEMBL1434160 & 688810 & \multicolumn{3}{|c|}{5.332999999999999} & 4.9893 & TRN \\
\hline CHEMBL1419769 & 688810 & \multicolumn{3}{|c|}{5.632999999999999} & 5.2467 & TRN \\
\hline CHEMBL1471683 & 688810 & \multicolumn{3}{|c|}{6.2829999999999995} & 5.5 & TRN \\
\hline CHEMBL1385338 & 688810 & 5.433 & 4.9375 & TRN & & \\
\hline CHEMBL1421200 & 688810 & 4.933 & 4.902 & TRN & & \\
\hline CHEMBL1379833 & 688810 & \multicolumn{3}{|c|}{4.7330000000000005} & 4.7464 & TRN \\
\hline CHEMBL1596406 & 688810 & 7.1831 & 6.1443 & TRN & & \\
\hline CHEMBL1517035 & 688810 & \multicolumn{3}{|c|}{4.7330000000000005} & 4.9996 & TRN \\
\hline CHEMBL1512130 & 688810 & 4.583 & 5.0354 & TRN & & \\
\hline CHEMBL1565671 & 688810 & \multicolumn{3}{|c|}{5.582999999999999} & 5.5148 & TRN \\
\hline CHEMBL3196004 & 688810 & 5.733 & 5.2307 & TRN & & \\
\hline CHEMBL3210463 & 688810 & 4.683 & 4.9854 & TST & & \\
\hline CHEMBL1380937 & 688810 & \multicolumn{3}{|c|}{5.5329999999999995} & 5.09 & TRN \\
\hline CHEMBL3211542 & 688810 & 4.883 & 5.1237 & TRN & & \\
\hline CHEMBL1578551 & 688810 & 4.933 & 5.1498 & TST & & \\
\hline CHEMBL1554040 & 688810 & 4.583 & 5.1892 & TRN & & \\
\hline CHEMBL1601211 & 688810 & \multicolumn{3}{|c|}{4.7330000000000005} & 5.2073 & TRN \\
\hline CHEMBL1331598 & 688810 & 4.633 & 4.9424 & TRN & & \\
\hline CHEMBL1341788 & 688810 & 5.433 & 5.5076 & TRN & & \\
\hline CHEMBL1541632 & 688810 & 5.033 & 5.5188 & TST & & \\
\hline CHEMBL1508154 & 688810 & \multicolumn{3}{|c|}{5.132999999999999} & 4.9561 & TRN \\
\hline CHEMBL1468869 & 688810 & \multicolumn{3}{|c|}{5.132999999999999} & 5.6599 & TRN \\
\hline CHEMBL1343671 & 688810 & 5.433 & 5.5625 & TRN & & \\
\hline CHEMBL 3210160 & 688810 & 5.733 & 5.3448 & TRN & & \\
\hline CHEMBL1595444 & 688810 & 4.683 & 5.0149 & TRN & & \\
\hline CHEMBL1468040 & 688810 & 5.433 & 4.9373 & TRN & & \\
\hline CHEMBL1587523 & 688810 & 4.783 & 5.3697 & TST & & \\
\hline CHEMBL1429019 & 688810 & \multicolumn{3}{|c|}{5.332999999999999} & 5.3215 & TST \\
\hline CHEMBL1301778 & 688810 & \multicolumn{3}{|c|}{4.7330000000000005} & 4.895 & TST \\
\hline CHEMBL1571395 & 688810 & \multicolumn{3}{|c|}{4.7330000000000005} & 5.0711 & TST \\
\hline CHEMBL1449750 & 688810 & \multicolumn{3}{|c|}{6.132999999999999} & 5.5626 & TRN \\
\hline CHEMBL1388508 & 688810 & 6.433 & 5.8762 & TRN & & \\
\hline CHEMBL1613308 & 688810 & \multirow{2}{*}{\multicolumn{3}{|c|}{$\begin{array}{ll}5.683 & 5.65 / 5 \\
4.9830000000000005\end{array}$}} & & \\
\hline CHEMBL1467219 & 688810 & & & & 5.4335 & TRN \\
\hline CHEMBL1568731 & 688810 & 4.883 & 5.4033 & TRN & & \\
\hline CHEMBL1469212 & 688810 & \multicolumn{3}{|c|}{5.132999999999999} & 5.0657 & TRN \\
\hline CHEMBL1535087 & 688810 & 5.733 & \multicolumn{3}{|c|}{5.8839999999999995} & TRN \\
\hline CHEMBL1301513 & 688810 & 4.883 & 5.2036 & TRN & & \\
\hline CHEMBL1577086 & 688810 & 4.683 & 5.4609 & TST & & \\
\hline CHEMBL1353184 & 688810 & \multicolumn{3}{|c|}{5.7829999999999995} & 5.9202 & TRN \\
\hline CHEMBL1405619 & 688810 & 5.483 & 5.2577 & TRN & & \\
\hline CHEMBL 3189745 & 688810 & 4.833 & 5.1926 & TRN & & \\
\hline CHEMBL1547217 & 688810 & 6.9329 & 6.1888 & TRN & & \\
\hline CHEMBL1445652 & 688810 & 5.233 & 5.561 & TRN & & \\
\hline
\end{tabular}




\begin{tabular}{|c|c|c|c|c|c|c|}
\hline \multirow[b]{2}{*}{ CHEMBL1316863 } & \multicolumn{6}{|c|}{ supplementa1 I } \\
\hline & 688810 & 4.633 & 5.1263 & TST & & \\
\hline CHEMBL1450251 & 688810 & 5.933 & 5.4278 & TST & & \\
\hline CHEMBL1375477 & 688810 & 5.28299 & 99999999 & 995 & 5.2991 & TST \\
\hline CHEMBL1410311 & 688810 & 4.883 & 5.4636 & TST & & \\
\hline CHEMBL1348092 & 688810 & 6.33299 & 99999999 & & 5.0452 & TRN \\
\hline CHEMBL1441292 & 688810 & 5.433 & 5.1509 & TRN & & \\
\hline CHEMBL1475149 & 688810 & 5.13299 & 99999999 & & 5.4451 & TRN \\
\hline CHEMBL1470728 & 688810 & 5.33299 & 99999999 & & 5.3689 & TST \\
\hline CHEMBL1330294 & 688810 & 4.633 & 4.9269 & TRN & & \\
\hline CHEMBL1306977 & 688810 & 5.63299 & 99999999 & & 5.9554 & TRN \\
\hline CHEMBL1379799 & 688810 & 5.83299 & 99999999 & & 5.402 & TRN \\
\hline CHEMBL1403111 & 688810 & 4.98300 & 20000000 & 005 & 5.3986 & TRN \\
\hline CHEMBL1533159 & 688810 & 4.933 & 5.5966 & TST & & \\
\hline CHEMBL1415793 & 688810 & 5.33299 & 99999999 & & 5.8841 & TRN \\
\hline CHEMBL1542620 & 688810 & 4.833 & 4.8378 & TRN & & \\
\hline CHEMBL1344677 & 688810 & 8.3872 & 6.3062 & TST & & \\
\hline CHEMBL1333191 & 688810 & 4.833 & 5.0936 & TRN & & \\
\hline CHEMBL1352023 & 688810 & 6.233 & 5.6473 & TRN & & \\
\hline CHEMBL1387254 & 688810 & 4.933 & 5.4889 & TRN & & \\
\hline CHEMBL1422074 & 688810 & 4.73300 & j0000000 & 005 & 5.4694 & TRN \\
\hline CHEMBL1508819 & 688810 & 6.33299 & 99999999 & & 5.5362 & TRN \\
\hline CHEMBL3209535 & 688810 & 4.833 & 5.0103 & TRN & & \\
\hline CHEMBL3195186 & 688810 & 6.03299 & 99999999 & 995 & 5.1357 & TRN \\
\hline CHEMBL1462938 & 688810 & 6.83299 & 99999999 & & 5.455 & TST \\
\hline CHEMBL1381324 & 688810 & 4.833 & 5.5606 & TRN & & \\
\hline CHEMBL1312363 & 688810 & 5.33299 & 99999999 & & 5.3535 & TST \\
\hline CHEMBL1576113 & 688810 & 5.38299 & 99999999 & & 5.5086 & TST \\
\hline CHEMBL1466684 & 688810 & 4.883 & 5.5818 & TST & & \\
\hline CHEMBL1612112 & 688810 & 4.833 & 4.9206 & TST & & \\
\hline CHEMBL1311339 & 688810 & 4.98300 & g0000000 & 005 & 5.6626 & TST \\
\hline CHEMBL1374706 & 688810 & 5.483 & 5.5617 & TRN & & \\
\hline CHEMBL1425614 & 688810 & 6.0 & 5.5498 & TRN & & \\
\hline CHEMBL1313318 & 688810 & 5.38299 & 99999999 & & 5.3881 & TRN \\
\hline CHEMBL1529111 & 688810 & 5.78299 & 99999999 & 995 & 5.2444 & TRN \\
\hline CHEMBL1584427 & 688810 & 5.183 & 5.4939 & TRN & & \\
\hline CHEMBL1509000 & 688810 & 5.88299 & 99999999 & & 5.4047 & TRN \\
\hline CHEMBL1561361 & 688810 & 5.13299 & 99999999 & & 5.0257 & TST \\
\hline CHEMBL1467583 & 688810 & 5.683 & 5.0609 & TRN & & \\
\hline CHEMBL1390067 & 688810 & 5.53299 & 99999999 & 995 & 5.5746 & TRN \\
\hline CHEMBL1526346 & 688810 & 4.933 & 4.9061 & TST & & \\
\hline CHEMBL1418943 & 688810 & 5.433 & 5.0613 & TST & & \\
\hline CHEMBL1541242 & 688810 & 4.98300 & j0000000 & 005 & 5.4695 & TRN \\
\hline CHEMBL1505090 & 688810 & 5.58299 & 99999999 & & 5.4459 & TRN \\
\hline CHEMBL492116 & 688810 & 5.483 & 5.0573 & TRN & & \\
\hline CHEMBL1596982 & 688810 & 5.38299 & 99999999 & & 5.8177 & TRN \\
\hline CHEMBL1472841 & 688810 & 4.98300 & 00000000 & 005 & 4.9197 & TRN \\
\hline CHEMBL1497953 & 688810 & 4.783 & 4.8475 & TST & & \\
\hline CHEMBL3210573 & 688810 & 5.233 & 5.2885 & TRN & & \\
\hline
\end{tabular}




\begin{tabular}{|c|c|c|c|c|c|c|}
\hline \multirow[b]{2}{*}{ CHEMBL486706 } & \multicolumn{6}{|c|}{ oplemental Ta } \\
\hline & 688810 & 5.033 & 5.2064 & TST & & \\
\hline CHEMBL1502879 & 688810 & 4.783 & 5.1195 & TRN & & \\
\hline CHEMBL 3194245 & 688810 & 4.883 & 5.3644 & TRN & & \\
\hline CHEMBL1303748 & 688810 & 5.5329 & 99999999 & 995 & 5.1298 & TRN \\
\hline CHEMBL1470326 & 688810 & 4.783 & 4.8481 & TRN & & \\
\hline CHEMBL1553105 & 688810 & 5.7829 & 99999999 & 995 & 5.5257 & $\mathrm{TP}$ \\
\hline CHEMBL1332928 & 688810 & 7.2328 & 6.2852 & TST & & \\
\hline CHEMBL1570977 & 688810 & 5.5329 & 99999999 & 995 & 5.2696 & \\
\hline CHEMBL1535788 & 688810 & 5.7829 & 99999999 & 995 & 5.4534 & \\
\hline CHEMBL1371237 & 688810 & 5.983 & 5.6733 & TRN & & \\
\hline CHEMBL1460982 & 688810 & 4.783 & 5.1157 & TRN & & \\
\hline CHEMBL 223453 & 688810 & 4.833 & 5.2531 & TRN & & \\
\hline CHEMBL1465410 & 688810 & 4.783 & 5.2604 & TST & & \\
\hline CHEMBL 3207538 & 688810 & 5.483 & 5.2174 & TRN & & \\
\hline CHEMBL1427254 & 688810 & 5.5329 & 99999999 & 995 & 5.0511 & \\
\hline CHEMBL1562810 & 688810 & 4.883 & 5.3994 & TRN & & \\
\hline CHEMBL1429687 & 688810 & 4.633 & 4.9527 & TRN & & \\
\hline CHEMBL1578021 & 688810 & 4.7330 & 00000000 & 005 & 5.255 & \\
\hline CHEMBL1320043 & 688810 & 4.883 & 5.3323 & TST & & \\
\hline CHEMBL1409138 & 688810 & 4.833 & 5.3925 & TRN & & \\
\hline CHEMBL1563513 & 688810 & 6.0329 & 99999999 & 995 & 5.3447 & \\
\hline CHEMBL1335423 & 688810 & 5.8829 & 99999999 & & 5.0306 & \\
\hline CHEMBL1314410 & 688810 & 4.633 & 5.09 & TRN & & \\
\hline CHEMBL1586895 & 688810 & 4.7330 & 00000000 & 005 & 5.0579 & \\
\hline CHEMBL1303094 & 688810 & 4.7330 & 00000000 & 005 & 5.3447 & \\
\hline CHEMBL1518055 & 688810 & 5.033 & 5.3415 & TRN & & \\
\hline CHEMBL1337634 & 688810 & 5.683 & 5.6508 & TRN & & \\
\hline CHEMBL1433561 & 688810 & 5.8829 & 99999999 & & 5.3823 & \\
\hline CHEMBL1497012 & 688810 & 6.3829 & 99999999 & & 5.6278 & \\
\hline CHEMBL1370978 & 688810 & 5.033 & 5.2657 & TRN & & \\
\hline CHEMBL1353747 & 688810 & 4.933 & 5.4472 & TRN & & \\
\hline CHEMBL1603537 & 688810 & 4.883 & 4.9563 & TST & & \\
\hline CHEMBL1495625 & 688810 & 5.1329 & 99999999 & & 1 & \\
\hline CHEMBL1338662 & 688810 & 5.3829 & 99999999 & & & \\
\hline CHEMBL1546132 & 688810 & 5.733 & 5.5737 & TST & & \\
\hline CHEMBL1381867 & 688810 & 4.883 & 5.1667 & TST & & \\
\hline CHEMBL1385217 & 688810 & 6.183 & 5.5302 & TST & & \\
\hline CHEMBL1391887 & 688810 & 4.9830 & 20000000 & 005 & 5.2399 & . \\
\hline CHEMBL1530261 & 688810 & 5.083 & 5.1105 & TRN & & \\
\hline CHEMBL1506690 & 688810 & 5.233 & 5.4375 & TRN & & \\
\hline CHEMBL1550917 & 688810 & 4.783 & 4.9056 & TRN & & \\
\hline CHEMBL1441851 & 688810 & 4.783 & 5.0464 & TST & & \\
\hline CHEMBL1384976 & 688810 & 6.0329 & 99999999 & 995 & 5.2358 & \\
\hline CHEMBL1982868 & 688810 & 4.783 & 5.0253 & TST & & \\
\hline CHEMBL1518128 & 688810 & 6.0829 & 99999999 & & 5.7609 & Tाराण \\
\hline CHEMBL1400597 & 688810 & 5.3829 & 99999999 & & 4.937 & TRN \\
\hline CHEMBL1609358 & 688810 & 4.933 & 5.5294 & TRN & & \\
\hline CHEMBL1428354 & 688810 & 4.883 & 4.7208 & TRN & & \\
\hline
\end{tabular}




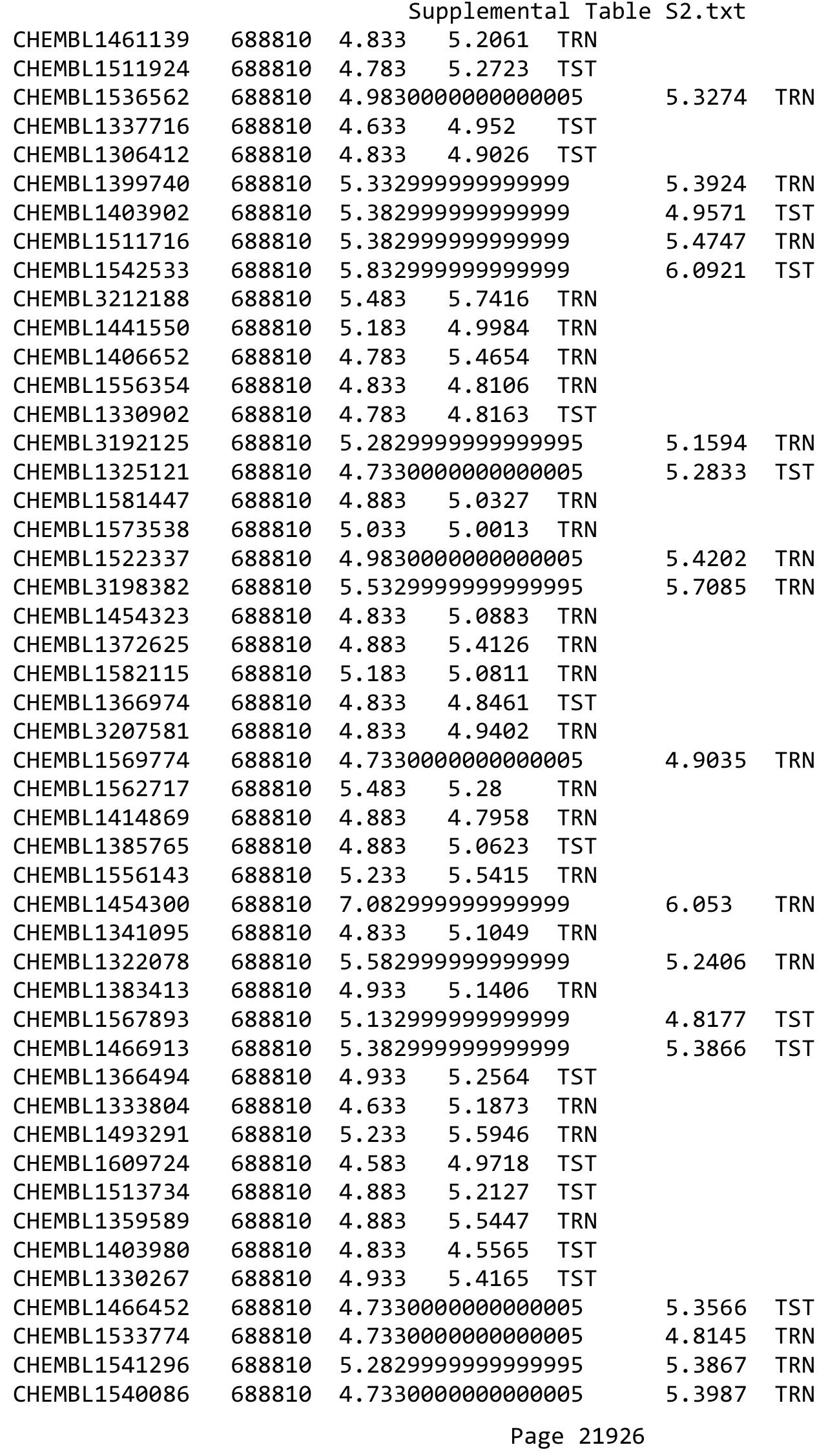




\begin{tabular}{|c|c|c|c|c|c|c|}
\hline \multirow{3}{*}{$\begin{array}{l}\text { CHEMBL1437146 } \\
\text { CHEMBL3194854 }\end{array}$} & \multirow{3}{*}{$\begin{array}{l}688810 \\
688810\end{array}$} & \multicolumn{5}{|c|}{ Supplemental Table S2.txt } \\
\hline & & \multicolumn{4}{|c|}{$5.7829999999999995 \quad 5.2631$} & \multirow{2}{*}{ TRA } \\
\hline & & 6.183 & 5.3824 & TRN & & \\
\hline CHEMBL1401721 & 688810 & \multicolumn{3}{|c|}{4.7330000000000005} & 5.058 & TST \\
\hline CHEMBL1557056 & 688810 & 4.933 & 5.2757 & TRN & & \\
\hline CHEMBL1390671 & 688810 & 5.733 & 5.6029 & TRN & & \\
\hline CHEMBL1509922 & 688810 & \multicolumn{3}{|c|}{4.9830000000000005} & 5.0239 & TRN \\
\hline CHEMBL1472643 & 688810 & 4.583 & 4.8312 & TST & & \\
\hline CHEMBL3199170 & 688810 & \multicolumn{3}{|c|}{5.832999999999999} & 5.7013 & TRN \\
\hline CHEMBL1595663 & 688810 & \multicolumn{3}{|c|}{5.632999999999999} & 5.3747 & TRN \\
\hline CHEMBL1995152 & 688810 & 4.583 & 5.2631 & TRN & & \\
\hline CHEMBL1405252 & 688810 & 4.883 & 5.1606 & TRN & & \\
\hline CHEMBL1415532 & 688810 & \multicolumn{3}{|c|}{6.0329999999999995} & 6.004 & TRN \\
\hline CHEMBL1322970 & 688810 & \multicolumn{3}{|c|}{4.7330000000000005} & 5.4089 & TRN \\
\hline CHEMBL3214013 & 688810 & 5.183 & 4.9088 & TRN & & \\
\hline CHEMBL1489794 & 688810 & 5.233 & 5.6505 & TRN & & \\
\hline CHEMBL1428294 & 688810 & \multicolumn{3}{|c|}{4.7330000000000005} & 5.5066 & TST \\
\hline CHEMBL3213515 & 688810 & \multicolumn{3}{|c|}{5.882999999999999} & 5.4927 & TST \\
\hline CHEMBL1511132 & 688810 & 4.883 & 5.007 & TRN & & \\
\hline CHEMBL1416558 & 688810 & 4.883 & 5.0766 & TRN & & \\
\hline CHEMBL1321668 & 688810 & \multicolumn{3}{|c|}{5.832999999999999} & 5.725 & TRN \\
\hline CHEMBL1582309 & 688810 & \multicolumn{3}{|c|}{5.832999999999999} & 5.3818 & TRN \\
\hline CHEMBL1601466 & 688810 & 4.933 & 5.0034 & TST & & \\
\hline CHEMBL1435594 & 688810 & 5.733 & 5.4414 & TRN & & \\
\hline CHEMBL1417112 & 688810 & \multicolumn{3}{|c|}{6.632999999999999} & 6.3125 & TRN \\
\hline CHEMBL1499649 & 688810 & \multicolumn{3}{|c|}{5.7829999999999995} & 5.641 & TRN \\
\hline CHEMBL1434701 & 688810 & \multicolumn{3}{|c|}{5.7829999999999995} & 5.7648 & TRN \\
\hline CHEMBL1384923 & 688810 & 4.933 & 5.2592 & TRN & & \\
\hline CHEMBL1348920 & 688810 & 4.833 & 5.3051 & TST & & \\
\hline CHEMBL1498836 & 688810 & 6.4829 & 5.815 & TRN & & \\
\hline CHEMBL1598419 & 688810 & 6.45 & 5.2204 & TST & & \\
\hline CHEMBL1517151 & 688810 & 4.783 & 5.325 & TRN & & \\
\hline CHEMBL1469798 & 688810 & 5.233 & 5.3172 & TRN & & \\
\hline CHEMBL1306343 & 688810 & 5.033 & 5.3743 & TRN & & \\
\hline CHEMBL1444261 & 688810 & \multicolumn{3}{|c|}{5.132999999999999} & 5.2101 & TRN \\
\hline CHEMBL1535290 & 688810 & 5.483 & 5.3419 & TRN & & \\
\hline CHEMBL1517759 & 688810 & 4.883 & 4.9745 & TST & & \\
\hline CHEMBL1465520 & 688810 & \multicolumn{3}{|c|}{4.7330000000000005} & 5.2507 & TRN \\
\hline CHEMBL1423533 & 688810 & 4.783 & 5.2334 & TST & & \\
\hline CHEMBL1469755 & 688810 & 5.183 & 5.1976 & TRN & & \\
\hline CHEMBL1506877 & 688810 & 4.833 & 4.9365 & TRN & & \\
\hline CHEMBL1580889 & 688810 & 4.783 & 4.909 & TRN & & \\
\hline CHEMBL1416154 & 688810 & 4.783 & 5.5769 & TRN & & \\
\hline CHEMBL1343103 & 688810 & \multicolumn{3}{|c|}{5.332999999999999} & 5.4977 & TST \\
\hline CHEMBL1591651 & 688810 & 4.583 & 5.0837 & TST & & \\
\hline CHEMBL1448296 & 688810 & 5.033 & 5.419 & TRN & & \\
\hline CHEMBL1479872 & 688810 & 5.1329 & 99999999 & & 5.0375 & TRN \\
\hline CHEMBL1444579 & 688810 & 4.783 & 5.0751 & TST & & \\
\hline CHEMBL1545433 & 688810 & 5.183 & 5.3731 & TRN & & \\
\hline
\end{tabular}




\begin{tabular}{|c|c|c|c|c|c|c|c|}
\hline CHEMBL1353187 & 688810 & 4.833 & 5.4529 & TST & \multirow{2}{*}{\multicolumn{2}{|c|}{5.4479999999999995}} & \\
\hline CHEMBL1510704 & 688810 & 5.38299 & 99999999 & & & & TRN \\
\hline CHEMBL1518520 & 688810 & 5.233 & 5.3991 & TRN & & & \\
\hline CHEMBL1530216 & 688810 & $4.7330 e$ & 00000000 & 005 & 5.3413 & TRN & \\
\hline CHEMBL1490766 & 688810 & 4.583 & 5.3425 & TRN & & & \\
\hline CHEMBL1611003 & 688810 & 5.33299 & 99999999 & & 5.6051 & TRN & \\
\hline CHEMBL 2007190 & 688810 & 5.38299 & 99999999 & 99 & 5.1773 & TRN & \\
\hline CHEMBL1390361 & 688810 & 5.13299 & 99999999 & 99 & 5.1892 & TRN & \\
\hline CHEMBL1427185 & 688810 & 4.633 & 4.7269 & TST & & & \\
\hline CHEMBL1516044 & 688810 & 4.633 & 4.8734 & TRN & & & \\
\hline CHEMBL3192212 & 688810 & 5.83299 & 99999999 & & 5.3036 & TRN & \\
\hline CHEMBL1532707 & 688810 & 6.03299 & 99999999 & 995 & 5.5015 & TST & \\
\hline CHEMBL1592678 & 688810 & 4.633 & 5.1152 & TRN & & & \\
\hline CHEMBL3196691 & 688810 & 4.73300 & 00000000 & 005 & 5.8691 & TRN & \\
\hline CHEMBL1532349 & 688810 & 5.233 & 5.2077 & TRN & & & \\
\hline CHEMBL1565240 & 688810 & $4.9830 e$ & 00000000 & 005 & 5.1626 & TST & \\
\hline CHEMBL1398836 & 688810 & 5.78299 & 99999999 & 995 & 6.2495 & TRN & \\
\hline CHEMBL199194 & 688810 & 5.233 & 5.9354 & TST & & & \\
\hline CHEMBL1607865 & 688810 & 6.183 & 5.8643 & TRN & & & \\
\hline CHEMBL3197126 & 688810 & 5.53299 & 99999999 & 995 & 5.2525 & TRN & \\
\hline CHEMBL1362680 & 688810 & 5.083 & 5.63299 & 999999999 & 99 & TST & \\
\hline CHEMBL1379918 & 688810 & 5.58299 & 99999999 & & 5.1487 & TRN & \\
\hline CHEMBL1311991 & 688810 & 5.58299 & 99999999 & & 5.1078 & TRN & \\
\hline CHEMBL1582062 & 688810 & 4.783 & 5.4129 & TRN & & & \\
\hline CHEMBL1482032 & 688810 & $4.7330 e$ & 00000000 & 005 & 5.2326 & TRN & \\
\hline CHEMBL1559461 & 688810 & 6.83299 & 99999999 & & 6.0197 & TRN & \\
\hline CHEMBL1601935 & 688810 & 4.833 & 5.2022 & TST & & & \\
\hline CHEMBL3211325 & 688810 & 5.63299 & 99999999 & & 5.3221 & TRN & \\
\hline CHEMBL3189230 & 688810 & 5.38299 & 99999999 & & 5.3429 & TRN & \\
\hline CHEMBL1611002 & 688810 & 5.233 & 5.9518 & TRN & & & \\
\hline CHEMBL1406859 & 688810 & 5.53299 & 99999999 & 995 & 5.5515 & TRN & \\
\hline CHEMBL1300601 & 688810 & 4.883 & 4.7714 & TST & & & \\
\hline CHEMBL 2369262 & 688810 & 4.883 & 5.1712 & TRN & & & \\
\hline CHEMBL1421305 & 688810 & 4.783 & 4.931 & TST & & & \\
\hline CHEMBL1369283 & 688810 & 4.783 & 5.0498 & TRN & & & \\
\hline CHEMBL1382564 & 688810 & 4.833 & 5.6039 & TRN & & & \\
\hline CHEMBL1471728 & 688810 & 5.733 & 5.4276 & TRN & & & \\
\hline CHEMBL1564174 & 688810 & 5.78299 & 99999999 & 995 & 5.57100 & 0000000001 & TRN \\
\hline CHEMBL3197450 & 688810 & 4.783 & 5.1759 & TRN & & & \\
\hline CHEMBL1359925 & 688810 & 6.0 & 5.8829 & TRN & & & \\
\hline CHEMBL1454662 & 688810 & 4.85 & 5.3605 & TST & & & \\
\hline CHEMBL1307120 & 688810 & 5.78299 & 99999999 & 995 & 5.1941 & TRN & \\
\hline CHEMBL1516887 & 688810 & 5.483 & 5.2886 & TRN & & & \\
\hline CHEMBL3192930 & 688810 & $4.9830 e$ & 00000000 & 005 & 5.2302 & TRN & \\
\hline CHEMBL1967005 & 688810 & 6.183 & 5.4741 & TRN & & & \\
\hline CHEMBL3190603 & 688810 & $4.7330 e$ & 00000000 & 005 & 5.2737 & TST & \\
\hline CHEMBL1328362 & 688810 & 4.73300 & 00000000 & 005 & 5.2285 & TRN & \\
\hline CHEMBL1460848 & 688810 & 5.53299 & 99999999 & 995 & 5.4493 & TRN & \\
\hline
\end{tabular}




\begin{tabular}{|c|c|c|c|c|c|c|c|}
\hline \multicolumn{7}{|c|}{ Supplemental Table S2.txt } & \\
\hline CHEMBL1582298 & 688810 & \multicolumn{3}{|c|}{5.132999999999999} & 5.1673 & TRN & \\
\hline CHEMBL1453905 & 688810 & \multicolumn{3}{|c|}{6.082999999999999} & 5.7063 & TRN & \\
\hline CHEMBL3198106 & 688810 & 4.783 & 5.0067 & TST & & & \\
\hline CHEMBL1539001 & 688810 & 4.783 & 5.6757 & TRN & & & \\
\hline CHEMBL1578206 & 688810 & 4.783 & 5.3616 & TRN & & & \\
\hline CHEMBL1351525 & 688810 & \multicolumn{3}{|c|}{5.132999999999999} & 5.6891 & TRN & \\
\hline CHEMBL1371213 & 688810 & \multicolumn{3}{|c|}{4.7330000000000005} & \multicolumn{2}{|c|}{5.361000000000001} & TRN \\
\hline CHEMBL1571455 & 688810 & 4.833 & 4.7849 & TRN & & & \\
\hline CHEMBL 3193441 & 688810 & 5.433 & 4.9128 & TRN & & & \\
\hline CHEMBL1430941 & 688810 & 5.483 & 5.5444 & TRN & & & \\
\hline CHEMBL1483161 & 688810 & 4.633 & 5.1742 & TST & & & \\
\hline CHEMBL1526810 & 688810 & 5.733 & 5.5918 & TRN & & & \\
\hline CHEMBL1411659 & 688810 & 5.683 & 5.4043 & TRN & & & \\
\hline CHEMBL1312795 & 688810 & 4.633 & 4.9888 & TST & & & \\
\hline CHEMBL1427507 & 688810 & 4.783 & 4.9429 & TRN & & & \\
\hline CHEMBL1453175 & 688810 & \multicolumn{3}{|c|}{4.7330000000000005} & 5.6217 & TRN & \\
\hline CHEMBL1533253 & 688810 & 6.683 & 5.6311 & TRN & & & \\
\hline CHEMBL1304553 & 688810 & \multicolumn{3}{|c|}{5.632999999999999} & 5.3355 & TST & \\
\hline CHEMBL1468327 & 688810 & 5.933 & 5.2105 & TST & & & \\
\hline CHEMBL1525407 & 688810 & \multicolumn{3}{|c|}{5.132999999999999} & 5.8356 & TRN & \\
\hline CHEMBL1428197 & 688810 & 4.833 & 5.0987 & TRN & & & \\
\hline CHEMBL1372813 & 688810 & 4.85 & 5.0429 & TRN & & & \\
\hline CHEMBL1349959 & 688810 & 6.4829 & 5.1279 & TRN & & & \\
\hline CHEMBL1577682 & 688810 & 4.783 & 5.4041 & TRN & & & \\
\hline CHEMBL1379389 & 688810 & 5.933 & 6.0662 & TRN & & & \\
\hline CHEMBL1438026 & 688810 & \multicolumn{3}{|c|}{5.132999999999999} & 5.3878 & TRN & \\
\hline CHEMBL1492533 & 688810 & \multicolumn{3}{|c|}{6.582999999999999} & 5.6256 & TRN & \\
\hline CHEMBL1451846 & 688810 & 5.033 & 5.0656 & TRN & & & \\
\hline CHEMBL1446233 & 688810 & \multicolumn{3}{|c|}{5.382999999999999} & 5.2623 & TRN & \\
\hline CHEMBL3144987 & 688810 & 4.833 & 5.3363 & TST & & & \\
\hline CHEMBL1492945 & 688810 & & & TRN & & & \\
\hline CHEMBL1407281 & 688810 & \multicolumn{3}{|c|}{5.332999999999999} & 4.7672 & TRN & \\
\hline CHEMBL1428129 & 688810 & 5.083 & 5.1495 & TST & & & \\
\hline CHEMBL1474988 & 688810 & \multicolumn{3}{|c|}{4.7330000000000005} & 5.3489 & TRN & \\
\hline CHEMBL1489517 & 688810 & 4.783 & 5.1626 & TRN & & & \\
\hline CHEMBL1318705 & 688810 & 4.883 & 5.1873 & TST & & & \\
\hline CHEMBL3197772 & 688810 & 4.783 & 5.2267 & TST & & & \\
\hline CHEMBL1402325 & 688810 & 4.833 & 4.9617 & TRN & & & \\
\hline CHEMBL1332866 & 688810 & 5.033 & 5.092 & TRN & & & \\
\hline CHEMBL1473885 & 688810 & \multicolumn{3}{|c|}{4.9830000000000005} & 5.0898 & TRN & \\
\hline CHEMBL1451402 & 688810 & \multicolumn{3}{|c|}{5.7829999999999995} & 5.3117 & TRN & \\
\hline CHEMBL1440817 & 688810 & 4.783 & 4.6172 & TST & & & \\
\hline CHEMBL1400375 & 688810 & 4.883 & 5.2902 & TST & & & \\
\hline CHEMBL1519243 & 688810 & 4.883 & 5.0303 & TST & & & \\
\hline CHEMBL1515504 & 688810 & 6.433 & 5.3444 & TRN & & & \\
\hline CHEMBL 3190267 & 688810 & 5.2829 & 99999999 & 995 & 5.1757 & TRN & \\
\hline CHEMBL1594642 & 688810 & 4.9830 & 00000000 & 005 & 5.3009 & TRN & \\
\hline CHEMBL1512692 & 688810 & 4.633 & 4.9454 & TRN & & & \\
\hline
\end{tabular}




\begin{tabular}{|c|c|c|c|c|c|c|}
\hline & \multicolumn{5}{|c|}{ 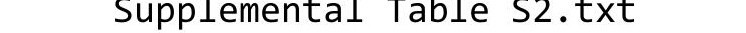 } \\
\hline CHEMBL1313232 & 688810 & 5.733 & 5.2307 & TRN & & \\
\hline CHEMBL1306597 & 688810 & \multicolumn{3}{|c|}{ 5.332999999999999 } & 5.9121 & TR \\
\hline CHEMBL1338157 & 688810 & 6.233 & 5.5868 & TRN & & \\
\hline CHEMBL1453439 & 688810 & \multicolumn{3}{|c|}{5.382999999999999} & 5.2453 & \\
\hline CHEMBL1583909 & 688810 & \multicolumn{3}{|c|}{5.582999999999999} & 5.0868 & \\
\hline CHEMBL1586127 & 688810 & 4.933 & 5.1116 & TRN & & \\
\hline CHEMBL 3210804 & 688810 & \multicolumn{3}{|c|}{5.2829999999999995} & 5.1653 & \\
\hline CHEMBL1465435 & 688810 & 4.833 & 5.3541 & TRN & & \\
\hline CHEMBL1329279 & 688810 & 4.783 & 4.8799 & TRN & & \\
\hline CHEMBL 3194882 & 688810 & 4.833 & 5.2405 & TRN & & \\
\hline CHEMBL1455900 & 688810 & 4.583 & 4.8794 & TRN & & \\
\hline CHEMBL1415914 & 688810 & 4.783 & 5.1 & TRN & & \\
\hline CHEMBL1548136 & 688810 & \multicolumn{3}{|c|}{6.332999999999999} & 4.9304 & \\
\hline CHEMBL1485820 & 688810 & 5.083 & 5.3023 & TRN & & \\
\hline CHEMBL15 & 688810 & 4.833 & 4.982 & TRN & & \\
\hline CHEMBL1559463 & 688810 & \multicolumn{3}{|c|}{5.132999999999999} & 5.5119 & \\
\hline CHEMBL3190652 & 688810 & 5.733 & 5.596 & TRN & & \\
\hline CHEMBL578061 & 688810 & \multicolumn{3}{|c|}{6.132999999999999} & 5.3744 & \\
\hline CHEMBL1361800 & 688810 & \multicolumn{3}{|c|}{6.2829999999999995} & & \\
\hline CHEMBL14 & 688810 & 4.833 & 5.3794 & TST & & \\
\hline CHEMBL1299633 & 688810 & 4.833 & 5.5694 & TST & & \\
\hline CHEMBL1576523 & 688810 & 4.883 & 4.9857 & TRN & & \\
\hline CHEMBL1429488 & 688810 & 4.783 & 5.2523 & TRN & & \\
\hline CHEMBL1583762 & 688810 & 5.433 & 5.4363 & TST & & \\
\hline CHEMBL1 & 688810 & 4.933 & 5.2228 & TRN & & \\
\hline CHEMBL130 & 688810 & \multicolumn{3}{|c|}{5.5329999999999995} & 2984 & \\
\hline CHEMBL1423617 & 688810 & \multicolumn{3}{|c|}{5.382999999999999} & 5.5687 & \\
\hline CHEMBL1989260 & 688810 & \multicolumn{3}{|c|}{5.832999999999999} & 5.4536 & \\
\hline CHEMBL1991234 & 688810 & \multicolumn{3}{|c|}{5.382999999999999} & 5.2207 & \\
\hline CHEMBL1214404 & 688810 & 4.883 & 5.596 & TRN & & \\
\hline CHEMBL1424697 & 688810 & \multicolumn{3}{|c|}{4.9830000000000005} & 5.5738 & \\
\hline CHEMBL1319867 & 688810 & \multicolumn{3}{|c|}{4.7330000000000005} & & $\mathrm{TH}$ \\
\hline CHEMBL1607299 & 688810 & 4.833 & 5.1652 & TRN & & \\
\hline CHEMBL1302363 & 688810 & \multirow{2}{*}{\multicolumn{3}{|c|}{$\begin{array}{lcc}4.783 & 5.4696 & \text { TRN } \\
4.7330000000000005\end{array}$}} & & \\
\hline CHEMBL1409623 & 688810 & & & & 5.1619 & \\
\hline CHEMBL1370196 & 688810 & \multicolumn{3}{|c|}{$\begin{array}{l}4.7330000000000005 \\
5.183 \quad 5.0976 \text { TRN }\end{array}$} & & \\
\hline CHEMBL1513560 & 688810 & 5.483 & 5.1158 & TRN & & \\
\hline CHEMBL1531641 & 688810 & \multicolumn{3}{|c|}{4.9830000000000005} & 5.5536 & \\
\hline CHEMBL1476200 & 688810 & 4.633 & 4.9825 & TST & & \\
\hline CHEMBL1523081 & 688810 & 5.733 & \multicolumn{3}{|c|}{5.1579999999999995} & \\
\hline CHEMBL1466315 & 688810 & 4.783 & 5.4571 & TST & & \\
\hline CHEMBL1424477 & 688810 & \multicolumn{3}{|c|}{4.7330000000000005} & 5.7315 & T. \\
\hline CHEMBL1994838 & 688810 & 5.5829 & 99999999 & & 5.2416 & \\
\hline CHEMBL1467635 & 688810 & 5.083 & 5.3174 & TRN & & \\
\hline CHEMBL1517536 & 688810 & 6.233 & 5.8044 & TRN & & \\
\hline CHEMBL1397725 & 688810 & 5.933 & 5.5261 & TRN & & \\
\hline CHEMBL1346440 & 688810 & 4.7330 & 00000000 & 005 & 5.5313 & RIV \\
\hline CHEMBL1430984 & 688810 & 4.7330 & 00000000 & 05 & 5.4047 & \\
\hline
\end{tabular}




\begin{tabular}{|c|c|c|c|c|c|c|}
\hline \multirow[b]{2}{*}{ CHEMBL1487979 } & \multicolumn{6}{|c|}{ splemental T } \\
\hline & 688810 & 5.183 & 5.4177 & TRN & & \\
\hline CHEMBL1301776 & 688810 & 5.6329 & 99999995 & & 5.8852 & TRN \\
\hline CHEMBL1488667 & 688810 & 5.5329 & 99999995 & 995 & 5.5955 & TRN \\
\hline CHEMBL1442507 & 688810 & 5.8329 & 9999999 & 99 & 5.7082 & TRN \\
\hline CHEMBL 236897 & 688810 & 5.683 & 6.027 & TRN & & \\
\hline CHEMBL 1467033 & 688810 & 5.483 & 5.2168 & TRN & & \\
\hline CHEMBL1589385 & 688810 & 5.3329 & 99999995 & & 5.4052 & זות \\
\hline CHEMBL1609797 & 688810 & 4.583 & 5.1738 & TRN & & \\
\hline CHEMBL1573586 & 688810 & 5.2829 & 9999999 & 995 & 5.5003 & TST \\
\hline CHEMBL1516076 & 688810 & 4.583 & 5.0827 & TRN & & \\
\hline CHEMBL1496833 & 688810 & 5.6329 & 99999995 & & 5.3968 & TRN \\
\hline CHEMBL1322854 & 688810 & 5.1329 & 99999995 & & 5.3812 & TRN \\
\hline CHEMBL1353660 & 688810 & 4.783 & 5.3203 & TRN & & \\
\hline CHEMBL1529687 & 688810 & 4.833 & 5.1427 & TRN & & \\
\hline CHEMBL1369769 & 688810 & 4.883 & 5.2604 & TRN & & \\
\hline CHEMBL1558697 & 688810 & 4.883 & 5.2247 & TRN & & \\
\hline CHEMBL1314557 & 688810 & 5.033 & 5.1214 & TST & & \\
\hline CHEMBL1433319 & 688810 & 5.2829 & 99999995 & 995 & 5.3856 & TRN \\
\hline CHEMBL1485651 & 688810 & 6.3825 & 9999999 & & 5.5304 & \\
\hline CHEMBL1361858 & 688810 & 5.083 & 5.5296 & TRN & & \\
\hline CHEMBL1599915 & 688810 & 5.083 & 5.8796 & TRN & & \\
\hline CHEMBL1534664 & 688810 & 4.933 & 5.9444 & TRN & & \\
\hline CHEMBL1383281 & 688810 & 4.883 & 6.0127 & TRN & & \\
\hline CHEMBL1502016 & 688810 & 5.233 & 5.0798 & TST & & \\
\hline CHEMBL1524050 & 688810 & 4.7336 & 00000006 & 005 & 5.3548 & TST \\
\hline CHEMBL1550510 & 688810 & 5.1329 & 9999999 & & 5.3852 & TST \\
\hline CHEMBL1493725 & 688810 & 6.1329 & 99999995 & & 5.874 & TRN \\
\hline CHEMBL1608301 & 688810 & 6.983 & 6.1365 & TRN & & \\
\hline CHEMBL1393714 & 688810 & 5.933 & 5.7718 & TRN & & \\
\hline CHEMBL1445456 & 688810 & 5.3820 & 9999999 & & 5.2503 & TRA \\
\hline CHEMBL1543865 & 688810 & 4.583 & 5.3081 & TRN & & \\
\hline CHEMBL1557832 & 688810 & 4.933 & 4.7397 & TRN & & \\
\hline CHEMBL1582063 & 688810 & 4.783 & 5.0979 & TRN & & \\
\hline CHEMBL1448914 & 688810 & 4.7336 & 0000000 & 005 & 5.3666 & I RIN \\
\hline CHEMBL1520712 & 688810 & 4.9836 & 0000000 & 005 & 4.8795 & TRN \\
\hline CHEMBL1606486 & 688810 & 5.233 & 5.6426 & TRN & & \\
\hline CHEMBL1457617 & 688810 & 5.233 & 5.4441 & TRN & & \\
\hline CHEMBL1564494 & 688810 & 5.033 & 4.81 & TRN & & \\
\hline CHEMBL1546240 & 688810 & 5.6325 & 9999999 & & 5.7088 & TRN \\
\hline CHEMBL1999069 & 688810 & 4.7336 & 0000000 & 005 & 6.2447 & TRN \\
\hline CHEMBL1546072 & 688810 & 4.7336 & 0000000 & 005 & 4.823 & TST \\
\hline CHEMBL1414932 & 688810 & 6.0829 & 99999995 & & 5.6782 & TRN \\
\hline CHEMBL1337724 & 688810 & 5.733 & 5.6825 & TRN & & \\
\hline CHEMBL1611383 & 688810 & 5.6325 & 9999999 & & 5.4998 & rRN \\
\hline CHEMBL1556838 & 688810 & 4.633 & 5.4075 & TST & & \\
\hline CHEMBL1533108 & 688810 & 5.3829 & 9999999 & & 5.7202 & I RIN \\
\hline CHEMBL1533920 & 688810 & 5.1329 & 9999999 & & 5.0351 & TST \\
\hline CHEMBL1525949 & 688810 & 4.783 & 5.1059 & TRN & & \\
\hline
\end{tabular}




\begin{tabular}{|c|c|c|c|c|c|c|c|}
\hline & & & pplement & al Table & s2.txt & & \\
\hline CHEMBL1506291 & 688810 & 4.98300 & 00000000 & 005 & 4.6705 & TST & \\
\hline CHEMBL1407262 & 688810 & 4.783 & 5.586 & TRN & & & \\
\hline CHEMBL1461287 & 688810 & 6.7331 & 5.8051 & TRN & & & \\
\hline CHEMBL1466714 & 688810 & 5.733 & 5.6474 & TRN & & & \\
\hline CHEMBL1360064 & 688810 & 5.733 & 5.4403 & TST & & & \\
\hline CHEMBL1440441 & 688810 & 5.58299 & 99999999 & & 5.6367 & TRN & \\
\hline CHEMBL1366236 & 688810 & 5.58299 & 99999999 & & 5.5731 & TRN & \\
\hline CHEMBL3210364 & 688810 & 4.633 & 5.3698 & TST & & & \\
\hline CHEMBL1575184 & 688810 & 5.433 & 5.5426 & TST & & & \\
\hline CHEMBL1363889 & 688810 & 5.13299 & 99999999 & & 5.2269 & TRN & \\
\hline CHEMBL1359912 & 688810 & 4.883 & 4.7232 & TRN & & & \\
\hline CHEMBL1385287 & 688810 & 4.783 & 5.5811 & TRN & & & \\
\hline CHEMBL1441980 & 688810 & 5.13299 & 99999999 & & 5.1951 & TRN & \\
\hline CHEMBL1574726 & 688810 & 5.53299 & 99999999 & 995 & 5.1167 & TRN & \\
\hline CHEMBL1578053 & 688810 & 6.53299 & 99999999 & 995 & 5.957006 & 0000000001 & TRN \\
\hline CHEMBL1410610 & 688810 & 5.83299 & 99999999 & & 5.6823 & TRN & \\
\hline CHEMBL1390572 & 688810 & 5.083 & 4.744 & TRN & & & \\
\hline CHEMBL1610184 & 688810 & 5.233 & 5.2689 & TST & & & \\
\hline CHEMBL1481849 & 688810 & 4.633 & 4.8047 & TRN & & & \\
\hline CHEMBL1516746 & 688810 & 5.28299 & 99999999 & 995 & 4.9832 & TRN & \\
\hline CHEMBL 3207610 & 688810 & 5.78299 & 99999999 & 995 & 5.4637 & TRN & \\
\hline CHEMBL1468323 & 688810 & 7.38299 & 99999999 & & 6.6488 & TRN & \\
\hline CHEMBL1306554 & 688810 & 5.683 & 5.2509 & TRN & & & \\
\hline CHEMBL1330322 & 688810 & 5.78299 & 99999999 & 995 & 5.2213 & TST & \\
\hline CHEMBL1411784 & 688810 & 6.683 & 5.4128 & TRN & & & \\
\hline CHEMBL1409825 & 688810 & 5.083 & 5.2478 & TST & & & \\
\hline CHEMBL1492959 & 688810 & 6.28299 & 99999999 & 995 & 6.0025 & TST & \\
\hline CHEMBL 1481074 & 688810 & 5.033 & 5.0384 & TST & & & \\
\hline CHEMBL3198798 & 688810 & 5.13299 & 99999999 & & 5.0403 & TST & \\
\hline CHEMBL3190362 & 688810 & 5.483 & 5.2686 & TRN & & & \\
\hline CHEMBL1510156 & 688810 & 4.783 & 4.9347 & TST & & & \\
\hline CHEMBL1430269 & 688810 & 5.733 & 5.379 & TRN & & & \\
\hline CHEMBL1574687 & 688810 & 4.933 & 5.1405 & TRN & & & \\
\hline CHEMBL1305281 & 688810 & 5.28299 & 99999999 & 995 & 4.9773 & TRN & \\
\hline CHEMBL 272945 & 688810 & 5.183 & 5.114 & TRN & & & \\
\hline CHEMBL1305154 & 688810 & 5.183 & 5.0458 & TRN & & & \\
\hline CHEMBL1355715 & 688810 & 4.98300 & 00000000 & 005 & 5.5533 & TST & \\
\hline CHEMBL1991303 & 688810 & 4.73300 & 00000000 & 005 & 5.5518 & TRN & \\
\hline CHEMBL1556148 & 688810 & 4.98300 & 00000000 & 005 & 5.12 & TRN & \\
\hline CHEMBL1598518 & 688810 & 4.633 & 5.0003 & TRN & & & \\
\hline CHEMBL1412555 & 688810 & 4.883 & 5.4289 & TRN & & & \\
\hline CHEMBL3198645 & 688810 & 4.833 & 4.992 & TRN & & & \\
\hline CHEMBL1451966 & 688810 & 6.38299 & 99999999 & & 5.0795 & TST & \\
\hline CHEMBL1598823 & 688810 & 4.833 & 5.1547 & TRN & & & \\
\hline CHEMBL3191795 & 688810 & 4.933 & 4.7518 & TRN & & & \\
\hline CHEMBL3211554 & 688810 & 6.4829 & 5.5448 & TST & & & \\
\hline CHEMBL1467230 & 688810 & 4.833 & 4.9249 & TRN & & & \\
\hline CHEMBL 3198665 & 688810 & 5.38299 & 99999999 & & 5.5979 & TST & \\
\hline
\end{tabular}




\begin{tabular}{|c|c|c|c|c|c|c|c|}
\hline \multirow{3}{*}{$\begin{array}{l}\text { CHEMBL1498960 } \\
\text { CHEMBL1584111 }\end{array}$} & & \\
\hline & 688810 & 6.433 & 5.66 & TRN & & & \\
\hline & 688810 & \multicolumn{3}{|c|}{5.7829999999999995} & 5.3318 & TRN & \\
\hline CHEMBL1487883 & 688810 & 6.233 & 5.9584 & TRN & & & \\
\hline CHEMBL1469483 & 688810 & 4.933 & 5.1125 & TST & & & \\
\hline CHEMBL1476037 & 688810 & \multicolumn{3}{|c|}{5.332999999999999} & 5.6462 & TRN & \\
\hline CHEMBL1470839 & 688810 & \multicolumn{3}{|c|}{5.832999999999999} & 5.2221 & TRN & \\
\hline CHEMBL1556122 & 688810 & \multicolumn{3}{|c|}{4.7330000000000005} & 5.4915 & TRN & \\
\hline CHEMBL1513934 & 688810 & 6.433 & 5.3372 & TRN & & & \\
\hline CHEMBL1565736 & 688810 & \multicolumn{3}{|c|}{5.832999999999999} & 5.5566 & TRN & \\
\hline CHEMBL1334922 & 688810 & \multicolumn{3}{|c|}{4.9830000000000005} & 4.882 & TRN & \\
\hline CHEMBL1574506 & 688810 & 4.883 & 5.1125 & TRN & & & \\
\hline CHEMBL1596322 & 688810 & 4.633 & 4.9615 & TST & & & \\
\hline CHEMBL1428929 & 688810 & 4.833 & 5.2481 & TRN & & & \\
\hline CHEMBL1414989 & 688810 & \multicolumn{3}{|c|}{5.882999999999999} & \multicolumn{2}{|c|}{5.757000000000001} & TRN \\
\hline CHEMBL1383594 & 688810 & 5.233 & 5.7037 & TRN & & & \\
\hline CHEMBL1516157 & 688810 & 5.183 & 5.2821 & TRN & & & \\
\hline CHEMBL3214307 & 688810 & \multicolumn{3}{|c|}{4.7330000000000005} & 5.1514 & TRN & \\
\hline CHEMBL1480809 & 688810 & \multicolumn{3}{|c|}{5.2829999999999995} & 5.4891 & TRN & \\
\hline CHEMBL3195387 & 688810 & 4.883 & 5.2389 & TRN & & & \\
\hline CHEMBL1407865 & 688810 & 4.683 & 4.8371 & TST & & & \\
\hline CHEMBL1462070 & 688810 & 5.483 & \multicolumn{3}{|c|}{5.537999999999999} & TST & \\
\hline CHEMBL1355221 & 688810 & \multicolumn{3}{|c|}{5.132999999999999} & 5.1937 & TRN & \\
\hline CHEMBL1504139 & 688810 & 4.833 & 5.0435 & TST & & & \\
\hline CHEMBL 3198324 & 688810 & 4.883 & 5.3288 & TRN & & & \\
\hline CHEMBL1554727 & 688810 & 6.233 & 5.3295 & TRN & & & \\
\hline CHEMBL1476747 & 688810 & \multicolumn{3}{|c|}{4.7330000000000005} & 5.1521 & TST & \\
\hline CHEMBL1981344 & 688810 & \multicolumn{3}{|c|}{5.832999999999999} & 5.6588 & TRN & \\
\hline CHEMBL1497650 & 688810 & 4.783 & 5.7781 & TST & & & \\
\hline CHEMBL1477222 & 688810 & 5.233 & 5.6588 & TRN & & & \\
\hline CHEMBL1558461 & 688810 & 4.833 & 4.8258 & TRN & & & \\
\hline CHEMBL1362372 & 688810 & \multicolumn{3}{|c|}{4.7330000000000005} & 5.3089 & TRN & \\
\hline CHEMBL1506780 & 688810 & \multicolumn{3}{|c|}{6.382999999999999} & 5.5966 & TRN & \\
\hline CHEMBL1509368 & 688810 & 4.883 & \multicolumn{3}{|c|}{5.4879999999999995} & TRN & \\
\hline CHEMBL1502712 & 688810 & \multicolumn{3}{|c|}{4.7330000000000005} & 4.6861 & TST & \\
\hline CHEMBL1439091 & 688810 & 5.183 & 5.5696 & TRN & & & \\
\hline CHEMBL1318984 & 688810 & 4.833 & 5.1346 & TRN & & & \\
\hline CHEMBL1305309 & 688810 & 4.883 & 5.1022 & TST & & & \\
\hline CHEMBL1373336 & 688810 & 4.833 & 5.6232 & TRN & & & \\
\hline CHEMBL1448427 & 688810 & 4.7330 & 00000006 & 005 & 5.1878 & TRN & \\
\hline CHEMBL1359984 & 688810 & 4.9830 & 00000006 & 005 & 5.428 & TST & \\
\hline CHEMBL1593692 & 688810 & 6.983 & 5.7952 & TRN & & & \\
\hline CHEMBL1451791 & 688810 & 6.433 & 6.2437 & TRN & & & \\
\hline CHEMBL1583578 & 688810 & 4.933 & 5.1349 & TRN & & & \\
\hline CHEMBL1391312 & 688810 & 4.883 & 5.2582 & TRN & & & \\
\hline CHEMBL1327816 & 688810 & 4.633 & 5.1001 & TRN & & & \\
\hline CHEMBL1429186 & 688810 & 4.833 & $4.9110 €$ & 0000 & 005 & TRN & \\
\hline CHEMBL1498985 & 688810 & 5.683 & 5.2334 & TRN & & & \\
\hline CHEMBL1602800 & 688810 & 5.183 & 4.737 & TRN & & & \\
\hline
\end{tabular}




\begin{tabular}{|c|c|c|c|c|c|c|}
\hline & & \multicolumn{4}{|c|}{ Supplemental Table S2.txt } & \\
\hline CHEMBL1362566 & 688810 & \multicolumn{3}{|c|}{5.382999999999999} & 4.5815 & TRN \\
\hline CHEMBL1468981 & 688810 & \multicolumn{3}{|c|}{4.7330000000000005} & 4.8659 & TRN \\
\hline CHEMBL1569357 & 688810 & 5.55 & 5.4402 & TRN & & \\
\hline CHEMBL1324867 & 688810 & \multicolumn{3}{|c|}{5.2829999999999995} & 5.171 & TST \\
\hline CHEMBL1494370 & 688810 & 4.833 & 5.1328 & TST & & \\
\hline CHEMBL1322336 & 688810 & 5.433 & 5.1516 & TRN & & \\
\hline CHEMBL1304741 & 688810 & 4.933 & 4.8946 & TST & & \\
\hline CHEMBL1524148 & 688810 & 5.483 & 5.0699 & TRN & & \\
\hline CHEMBL1535762 & 688810 & 4.783 & 5.5117 & TRN & & \\
\hline CHEMBL1516666 & 688810 & \multicolumn{3}{|c|}{6.082999999999999} & 5.4037 & TRN \\
\hline CHEMBL1482373 & 688810 & 4.683 & 5.0868 & TRN & & \\
\hline CHEMBL1394912 & 688810 & 5.083 & 5.4255 & TRN & & \\
\hline CHEMBL1351967 & 688810 & 5.433 & 5.5348 & TRN & & \\
\hline CHEMBL1523248 & 688810 & 5.483 & 5.7625 & TST & & \\
\hline CHEMBL 293776 & 688810 & \multicolumn{3}{|c|}{5.632999999999999} & 5.5788 & TRN \\
\hline CHEMBL1302118 & 688810 & 5.183 & 5.3616 & TRN & & \\
\hline CHEMBL1324787 & 688810 & 7.1331 & 5.7459 & TRN & & \\
\hline CHEMBL1308236 & 688810 & 4.833 & 5.5117 & TRN & & \\
\hline CHEMBL1523114 & 688810 & \multicolumn{3}{|c|}{5.5329999999999995} & 5.8473 & TRN \\
\hline CHEMBL1353194 & 688810 & 6.0 & 5.0228 & TRN & & \\
\hline CHEMBL 3213367 & 688810 & \multicolumn{3}{|c|}{4.9830000000000005} & 5.2424 & TRN \\
\hline CHEMBL3210076 & 688810 & \multicolumn{3}{|c|}{5.582999999999999} & 5.0481 & TST \\
\hline CHEMBL1578479 & 688810 & 4.883 & 5.0332 & TRN & & \\
\hline CHEMBL1487314 & 688810 & 4.783 & 5.4802 & TRN & & \\
\hline CHEMBL1594910 & 688810 & 5.683 & 5.6291 & TRN & & \\
\hline CHEMBL3193035 & 688810 & \multicolumn{3}{|c|}{4.9830000000000005} & 5.5852 & TRN \\
\hline CHEMBL1470314 & 688810 & 4.633 & 5.4523 & TST & & \\
\hline CHEMBL1431743 & 688810 & \multicolumn{3}{|c|}{5.382999999999999} & 5.1698 & TST \\
\hline CHEMBL1489593 & 688810 & \multicolumn{3}{|c|}{4.9830000000000005} & 5.1449 & TST \\
\hline CHEMBL1387450 & 688810 & \multicolumn{3}{|c|}{5.132999999999999} & 5.1519 & TRN \\
\hline CHEMBL1491335 & 688810 & 4.933 & 5.215 & TRN & & \\
\hline CHEMBL1548354 & 688810 & 4.833 & 5.2375 & TRN & & \\
\hline CHEMBL1339672 & 688810 & \multicolumn{3}{|c|}{5.332999999999999} & 5.472 & TRN \\
\hline CHEMBL1370437 & 688810 & \multicolumn{3}{|c|}{6.382999999999999} & 5.7727 & TRN \\
\hline CHEMBL1469222 & 688810 & \multicolumn{3}{|c|}{6.132999999999999} & 5.7003 & TRN \\
\hline CHEMBL1577173 & 688810 & 5.483 & 5.7193 & TRN & & \\
\hline CHEMBL1571017 & 688810 & \multirow{2}{*}{\multicolumn{3}{|c|}{6.0329999999999995}} & & \\
\hline CHEMBL1340457 & 688810 & & & & 5.4454 & TRN \\
\hline CHEMBL1605873 & 688810 & 4.833 & 5.1285 & TRN & & \\
\hline CHEMBL1375822 & 688810 & 4.833 & 6.1076 & TRN & & \\
\hline CHEMBL1388079 & 688810 & 5.933 & 5.1748 & TRN & & \\
\hline CHEMBL1430391 & 688810 & 4.883 & 5.7009 & TST & & \\
\hline CHEMBL3211653 & 688810 & \multicolumn{3}{|c|}{4.9830000000000005} & 5.2339 & TRN \\
\hline CHEMBL1510489 & 688810 & 4.883 & 4.8259 & TRN & & \\
\hline CHEMBL1397315 & 688810 & 4.833 & 5.3938 & TST & & \\
\hline CHEMBL1422678 & 688810 & 6.0 & 6.0499 & TRN & & \\
\hline CHEMBL1579754 & 688810 & 6.433 & 5.7211 & TRN & & \\
\hline CHEMBL1526628 & 688810 & 6.9329 & 5.5714 & TRN & & \\
\hline
\end{tabular}




\begin{tabular}{|c|c|c|c|c|c|c|c|}
\hline \multicolumn{8}{|c|}{ Supplemental Ta } \\
\hline CHEMBL1388773 & 688810 & 4.783 & 5.1598 & TRN & & & \\
\hline CHEMBL3191171 & 688810 & 6.983 & 5.5575 & TRN & & & \\
\hline CHEMBL1578044 & 688810 & \multicolumn{3}{|c|}{4.7330000000000005} & \multicolumn{2}{|c|}{5.0169999999999995} & TRN \\
\hline CHEMBL1461757 & 688810 & 5.483 & 5.3484 & TRN & & & \\
\hline CHEMBL1429910 & 688810 & 5.033 & 4.9629 & TRN & & & \\
\hline CHEMBL1338372 & 688810 & 4.633 & 5.0245 & TST & & & \\
\hline CHEMBL1534889 & 688810 & 4.633 & 4.7078 & TRN & & & \\
\hline CHEMBL1363210 & 688810 & 6.433 & 5.6796 & TRN & & & \\
\hline CHEMBL1553037 & 688810 & 4.683 & 4.975 & TST & & & \\
\hline CHEMBL1529847 & 688810 & 4.833 & 4.562 & TST & & & \\
\hline CHEMBL1505395 & 688810 & 5.233 & 5.2287 & TRN & & & \\
\hline CHEMBL1325324 & 688810 & 5.733 & 5.261 & TST & & & \\
\hline CHEMBL1557485 & 688810 & \multicolumn{3}{|c|}{4.7330000000000005} & 4.9768 & TST & \\
\hline CHEMBL1370262 & 688810 & 4.783 & 5.1004 & TRN & & & \\
\hline CHEMBL1587630 & 688810 & 5.483 & 5.1987 & TST & & & \\
\hline CHEMBL1325892 & 688810 & \multicolumn{3}{|c|}{4.7330000000000005} & 5.6785 & TRN & \\
\hline CHEMBL1479866 & 688810 & \multicolumn{3}{|c|}{4.7330000000000005} & 4.8353 & TRN & \\
\hline CHEMBL1461585 & 688810 & 4.833 & 4.7925 & TRN & & & \\
\hline CHEMBL3209902 & 688810 & 5.033 & 5.1645 & TRN & & & \\
\hline CHEMBL1380493 & 688810 & 5.433 & 5.3518 & TRN & & & \\
\hline CHEMBL1484385 & 688810 & \multicolumn{3}{|c|}{5.2829999999999995} & 5.0055 & TRN & \\
\hline CHEMBL1606351 & 688810 & \multicolumn{3}{|c|}{6.332999999999999} & 5.5446 & TRN & \\
\hline CHEMBL1436367 & 688810 & \multicolumn{3}{|c|}{5.132999999999999} & 5.528 & TRN & \\
\hline CHEMBL1521031 & 688810 & 4.883 & 5.4087 & TST & & & \\
\hline CHEMBL1456179 & 688810 & 6.0 & 5.5685 & TRN & & & \\
\hline CHEMBL1568951 & 688810 & \multicolumn{3}{|c|}{5.382999999999999} & 5.5253 & TRN & \\
\hline CHEMBL1342938 & 688810 & \multicolumn{3}{|c|}{5.2829999999999995} & 5.1085 & TST & \\
\hline CHEMBL1565635 & 688810 & \multicolumn{3}{|c|}{5.582999999999999} & 5.2947 & TST & \\
\hline CHEMBL1367375 & 688810 & \multicolumn{3}{|c|}{5.7829999999999995} & 5.2867 & TRN & \\
\hline CHEMBL1565909 & 688810 & \multicolumn{3}{|c|}{6.382999999999999} & 5.6425 & TRN & \\
\hline CHEMBL1538690 & 688810 & 4.883 & 4.8273 & TST & & & \\
\hline CHEMBL1557948 & 688810 & 6.183 & 5.6733 & TRN & & & \\
\hline CHEMBL1310435 & 688810 & 6.4829 & 5.6026 & TRN & & & \\
\hline CHEMBL3194804 & 688810 & \multicolumn{3}{|c|}{4.7330000000000005} & 5.4241 & TRN & \\
\hline CHEMBL1466104 & 688810 & 5.933 & 5.3832 & TRN & & & \\
\hline CHEMBL1392570 & 688810 & \multicolumn{3}{|c|}{5.132999999999999} & 6.1209 & TRN & \\
\hline CHEMBL1594990 & 688810 & 4.783 & 5.1182 & TST & & & \\
\hline CHEMBL1452108 & 688810 & 6.0 & 4.9921 & TRN & & & \\
\hline CHEMBL1436282 & 688810 & \multicolumn{3}{|c|}{4.7330000000000005} & 5.3268 & TST & \\
\hline CHEMBL1509230 & 688810 & \multicolumn{3}{|c|}{5.7829999999999995} & 5.7641 & TRN & \\
\hline CHEMBL1332684 & 688810 & 5.483 & 5.2864 & TST & & & \\
\hline CHEMBL3194361 & 688810 & \multicolumn{3}{|c|}{6.382999999999999} & 5.8891 & TRN & \\
\hline CHEMBL1407247 & 688810 & 4.783 & 4.9013 & TRN & & & \\
\hline CHEMBL1530452 & 688810 & 5.233 & 4.8332 & TRN & & & \\
\hline CHEMBL3194516 & 688810 & 5.933 & 5.6157 & TRN & & & \\
\hline CHEMBL1468783 & 688810 & 6.4829 & 5.5715 & TRN & & & \\
\hline CHEMBL1516032 & 688810 & 5.183 & 4.9772 & TRN & & & \\
\hline CHEMBL1437193 & 688810 & 5.983 & 5.3903 & TST & & & \\
\hline
\end{tabular}




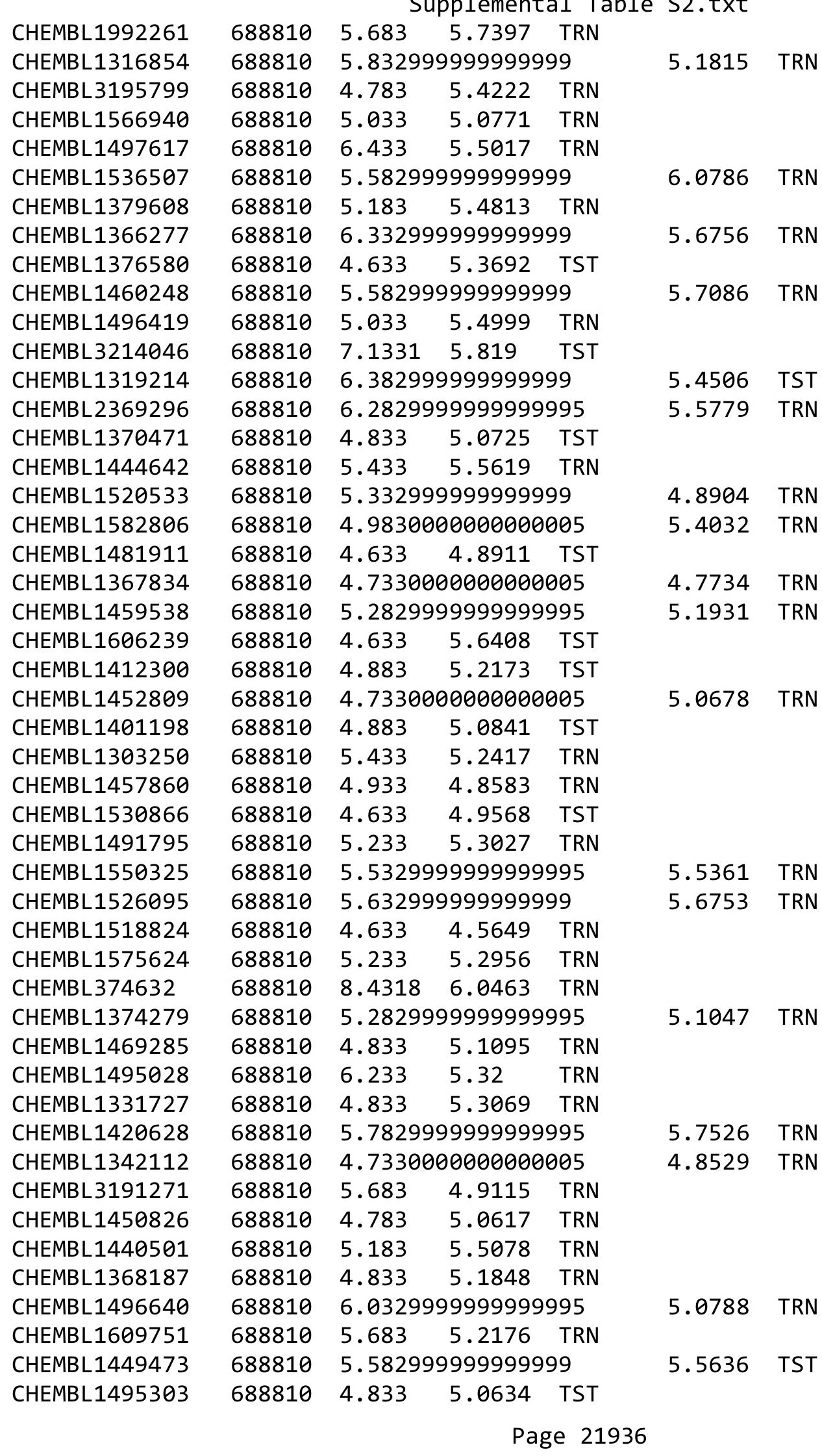




\begin{tabular}{|c|c|c|c|c|c|c|c|}
\hline \multicolumn{8}{|c|}{ PPमеmет } \\
\hline CHEMBL1579279 & 688810 & 4.783 & 5.1993 & TRN & & & \\
\hline CHEMBL1541650 & 688810 & 4.783 & 5.1686 & TRN & & & \\
\hline CHEMBL1313488 & 688810 & 5.233 & 5.4898 & TRN & & & \\
\hline CHEMBL1342793 & 688810 & 4.783 & 5.0376 & TST & & & \\
\hline CHEMBL1526499 & 688810 & \multicolumn{3}{|c|}{6.582999999999999} & 6.3587 & TRN & \\
\hline CHEMBL1464864 & 688810 & 5.233 & 5.078 & TST & & & \\
\hline CHEMBL1434522 & 688810 & 5.233 & 4.5895 & TRN & & & \\
\hline CHEMBL1425166 & 688810 & 4.633 & 4.5876 & TST & & & \\
\hline CHEMBL1376588 & 688810 & 4.783 & 5.1801 & TRN & & & \\
\hline CHEMBL1432332 & 688810 & \multicolumn{3}{|c|}{5.5329999999999995} & 5.0077 & TRN & \\
\hline CHEMBL1980889 & 688810 & 5.233 & 5.433 & TRN & & & \\
\hline CHEMBL1583945 & 688810 & 4.683 & 5.0433 & TST & & & \\
\hline CHEMBL1320882 & 688810 & 5.433 & 5.0201 & TRN & & & \\
\hline CHEMBL1405095 & 688810 & 5.233 & 5.609 & TRN & & & \\
\hline CHEMBL1498466 & 688810 & 4.883 & 5.01399 & 999999999 & & TRN & \\
\hline CHEMBL1452214 & 688810 & 5.983 & 5.8974 & TRN & & & \\
\hline CHEMBL1561900 & 688810 & 5.033 & 5.131 & TRN & & & \\
\hline CHEMBL1512973 & 688810 & \multicolumn{3}{|c|}{4.7330000000000005} & 5.0942 & TRN & \\
\hline CHEMBL1518282 & 688810 & 6.183 & \multicolumn{3}{|c|}{5.242999999999999} & TRN & \\
\hline CHEMBL1336057 & 688810 & 5.233 & 5.1203 & TRN & & & \\
\hline CHEMBL1468908 & 688810 & 5.483 & 5.2265 & TST & & & \\
\hline CHEMBL1525342 & 688810 & 6.0 & 5.5388 & TST & & & \\
\hline CHEMBL1490369 & 688810 & 4.933 & 5.1026 & TRN & & & \\
\hline CHEMBL1427212 & 688810 & 5.183 & 5.1433 & TST & & & \\
\hline CHEMBL1590842 & 688810 & 4.783 & 5.0482 & TRN & & & \\
\hline CHEMBL1554365 & 688810 & \multicolumn{3}{|c|}{6.382999999999999} & 5.1305 & TRN & \\
\hline CHEMBL1451648 & 688810 & \multicolumn{3}{|c|}{5.632999999999999} & 5.4804 & TRN & \\
\hline CHEMBL610198 & 688810 & \multicolumn{3}{|c|}{5.2829999999999995} & 5.25899 & 99999999995 & TRN \\
\hline CHEMBL1389740 & 688810 & 4.783 & 5.1738 & TST & & & \\
\hline CHEMBL1352234 & 688810 & 4.783 & 5.2144 & TRN & & & \\
\hline CHEMBL1408733 & 688810 & 4.833 & 4.9413 & TRN & & & \\
\hline CHEMBL1339111 & 688810 & 5.933 & 5.3737 & TST & & & \\
\hline CHEMBL1511456 & 688810 & \multicolumn{3}{|c|}{5.882999999999999} & 5.5148 & TRN & \\
\hline CHEMBL1521225 & 688810 & 5.033 & 4.97 & TRN & & & \\
\hline CHEMBL1568658 & 688810 & 4.583 & 4.7107 & TST & & & \\
\hline CHEMBL1327977 & 688810 & 5.483 & 5.4225 & TST & & & \\
\hline CHEMBL1402459 & 688810 & 5.183 & 5.5715 & TRN & & & \\
\hline CHEMBL1502183 & 688810 & \multicolumn{3}{|c|}{6.582999999999999} & 5.8021 & TRN & \\
\hline CHEMBL1507560 & 688810 & \multicolumn{3}{|c|}{5.832999999999999} & 5.4069 & TRN & \\
\hline CHEMBL3210997 & 688810 & 5.733 & 5.2276 & TRN & & & \\
\hline CHEMBL1570935 & 688810 & \multicolumn{3}{|c|}{5.382999999999999} & 5.4043 & TRN & \\
\hline CHEMBL1329375 & 688810 & \multicolumn{3}{|c|}{5.5329999999999995} & 5.637006 & 00000000005 & TRN \\
\hline CHEMBL 1307556 & 688810 & \multicolumn{3}{|c|}{4.9830000000000005} & 5.7286 & TRN & \\
\hline CHEMBL1571775 & 688810 & \multicolumn{3}{|c|}{5.832999999999999} & 5.6372 & TRN & \\
\hline CHEMBL1455034 & 688810 & \multicolumn{3}{|c|}{4.9830000000000005} & 5.0188 & TST & \\
\hline CHEMBL1340122 & 688810 & 4.633 & 4.9541 & TRN & & & \\
\hline CHEMBL1398221 & 688810 & 6.983 & 5.1428 & TRN & & & \\
\hline CHEMBL1365428 & 688810 & 4.883 & 5.1184 & TRN & & & \\
\hline
\end{tabular}




\begin{tabular}{|c|c|c|c|c|c|c|}
\hline & & & oplement & al Table & s2.txt & \\
\hline CHEMBL1455144 & 688810 & 5.5829 & 79999999 & & 5.0008 & TRN \\
\hline CHEMBL1484168 & 688810 & 5.1329 & 79999999 & & 4.7694 & TRN \\
\hline CHEMBL1597693 & 688810 & 4.883 & 5.3731 & TRN & & \\
\hline CHEMBL1429220 & 688810 & 4.7330 & 00000000 & 005 & 5.1649 & TST \\
\hline CHEMBL1395590 & 688810 & 5.683 & 5.8688 & TRN & & \\
\hline CHEMBL1500316 & 688810 & 4.683 & 4.9867 & TST & & \\
\hline CHEMBL1551125 & 688810 & 4.583 & 5.2555 & TRN & & \\
\hline CHEMBL1486602 & 688810 & 4.783 & 5.1212 & TST & & \\
\hline CHEMBL3212560 & 688810 & 5.8329 & 99999999 & 99 & 5.4343 & TRN \\
\hline CHEMBL1588983 & 688810 & 5.183 & 5.2257 & TST & & \\
\hline CHEMBL1481000 & 688810 & 4.633 & 5.05699 & 999999999 & 995 & TST \\
\hline CHEMBL3190220 & 688810 & 4.783 & 4.9431 & TST & & \\
\hline CHEMBL1299889 & 688810 & 4.933 & 4.9305 & TST & & \\
\hline CHEMBL1513918 & 688810 & 5.733 & 5.1055 & TRN & & \\
\hline CHEMBL1513165 & 688810 & 5.2829 & 99999999 & 995 & 5.0703 & TRN \\
\hline CHEMBL2311905 & 688810 & 5.1329 & 99999999 & 99 & 5.1921 & TRN \\
\hline CHEMBL1437818 & 688810 & 5.683 & 5.2434 & TRN & & \\
\hline CHEMBL1365034 & 688810 & 4.833 & 5.0998 & TRN & & \\
\hline CHEMBL1485516 & 688810 & 5.2829 & 99999999 & 995 & 5.4958 & TRN \\
\hline CHEMBL1487869 & 688810 & 5.733 & 5.853 & TRN & & \\
\hline CHEMBL1327357 & 688810 & 4.633 & 4.9621 & TST & & \\
\hline CHEMBL1557400 & 688810 & 4.783 & 5.1516 & TRN & & \\
\hline CHEMBL3192246 & 688810 & 5.183 & 5.3327 & TRN & & \\
\hline CHEMBL1384933 & 688810 & 4.833 & 5.0964 & TRN & & \\
\hline CHEMBL1505519 & 688810 & 7.2328 & 5.6412 & TRN & & \\
\hline CHEMBL1385302 & 688810 & 5.3329 & 99999999 & 99 & 5.1166 & TRN \\
\hline CHEMBL1432053 & 688810 & 5.183 & 5.4953 & TST & & \\
\hline CHEMBL1492568 & 688810 & 6.233 & 5.2234 & TRN & & \\
\hline CHEMBL1595786 & 688810 & 4.633 & 4.7929 & TST & & \\
\hline CHEMBL1374957 & 688810 & 4.833 & 5.0377 & TRN & & \\
\hline CHEMBL1494316 & 688810 & 4.883 & 5.5292 & TRN & & \\
\hline CHEMBL1418839 & 688810 & 5.7829 & 99999999 & 995 & 5.2709 & TRN \\
\hline CHEMBL1603173 & 688810 & 4.583 & 4.957 & TRN & & \\
\hline CHEMBL3145037 & 688810 & 4.833 & 5.6217 & TST & & \\
\hline CHEMBL1599189 & 688810 & 4.833 & 5.2841 & TRN & & \\
\hline CHEMBL3190816 & 688810 & 6.5329 & 99999999 & 995 & 5.2781 & TRN \\
\hline CHEMBL1533450 & 688810 & 4.633 & 4.6524 & TRN & & \\
\hline CHEMBL1610388 & 688810 & 6.683 & 5.5302 & TRN & & \\
\hline CHEMBL1343705 & 688810 & 5.1329 & 99999995 & 99 & 5.1125 & TRN \\
\hline CHEMBL1406032 & 688810 & 5.683 & 5.3648 & TRN & & \\
\hline CHEMBL1406731 & 688810 & 4.883 & 5.4183 & TRN & & \\
\hline CHEMBL1386911 & 688810 & 5.183 & 5.1297 & TRN & & \\
\hline CHEMBL1611067 & 688810 & 5.8329 & 99999995 & 99 & 5.4783 & TRN \\
\hline CHEMBL1372286 & 688810 & 5.433 & 5.436 & TRN & & \\
\hline CHEMBL1311387 & 688810 & 4.783 & 5.3156 & TST & & \\
\hline CHEMBL3193204 & 688810 & 4.633 & 5.0762 & TST & & \\
\hline CHEMBL1488150 & 688810 & 4.633 & 4.7739 & TRN & & \\
\hline CHEMBL1387968 & 688810 & 4.833 & 5.688 & TRN & & \\
\hline
\end{tabular}




\begin{tabular}{|c|c|c|c|c|c|c|}
\hline \multicolumn{7}{|c|}{ Supplemental Table S2.txt } \\
\hline CHEMBL1322033 & 688810 & 4.833 & 5.0735 & TST & & \\
\hline CHEMBL1373305 & 688810 & 4.883 & 5.4484 & TRN & & \\
\hline CHEMBL3209083 & 688810 & 5.183 & 5.0442 & TRN & & \\
\hline CHEMBL1344923 & 688810 & 4.883 & 5.8503 & TRN & & \\
\hline CHEMBL1564120 & 688810 & 5.033 & 5.7053 & TRN & & \\
\hline CHEMBL1603857 & 688810 & 5.483 & 6.3064 & TRN & & \\
\hline CHEMBL1975622 & 688810 & 4.933 & 5.2642 & TRN & & \\
\hline CHEMBL1304993 & 688810 & \multicolumn{3}{|c|}{5.2829999999999995} & 5.2471 & \\
\hline CHEMBL1431718 & 688810 & 5.433 & 5.3332 & TRN & & \\
\hline CHEMBL1540903 & 688810 & \multicolumn{3}{|c|}{4.9830000000000005} & 5.2298 & 1. \\
\hline CHEMBL3192729 & 688810 & 4.933 & 5.4434 & TRN & & \\
\hline CHEMBL1491625 & 688810 & 4.583 & 4.8931 & TRN & & \\
\hline CHEMBL1534555 & 688810 & \multicolumn{3}{|c|}{4.7330000000000005} & 5.2214 & \\
\hline CHEMBL1578805 & 688810 & 5.183 & 5.0128 & TRN & & \\
\hline CHEMBL1453994 & 688810 & 5.733 & 5.8887 & TRN & & \\
\hline CHEMBL1977867 & 688810 & \multicolumn{3}{|c|}{5.632999999999999} & 4.8378 & \\
\hline CHEMBL1530707 & 688810 & 4.633 & 4.9392 & TST & & \\
\hline CHEMBL1311983 & 688810 & 5.033 & 5.0765 & TST & & \\
\hline CHEMBL1374691 & 688810 & 5.733 & 5.7572 & TST & & \\
\hline CHEMBL3194911 & 688810 & \multicolumn{3}{|c|}{4.7330000000000005} & 5.0384 & TRN \\
\hline CHEMBL1348392 & 688810 & \multicolumn{3}{|c|}{4.7330000000000005} & 4.8735 & \\
\hline CHEMBL1444921 & 688810 & \multicolumn{3}{|c|}{5.2829999999999995} & 5.2908 & \\
\hline CHEMBL1470702 & 688810 & 5.433 & 5.3783 & TST & & \\
\hline CHEMBL1306558 & 688810 & 5.433 & 5.1692 & TRN & & \\
\hline CHEMBL3189689 & 688810 & \multicolumn{3}{|c|}{5.382999999999999} & 5.1524 & TST \\
\hline CHEMBL1522885 & 688810 & \multicolumn{3}{|c|}{5.882999999999999} & 5.9531 & TRN \\
\hline CHEMBL1498728 & 688810 & \multicolumn{3}{|c|}{6.5329999999999995} & 5.669 & \\
\hline CHEMBL1555729 & 688810 & 6.183 & 5.7865 & TRN & & \\
\hline CHEMBL1546642 & 688810 & 4.85 & 4.85 & TRN & & \\
\hline CHEMBL1375958 & 688810 & 5.433 & 5.1122 & TRN & & \\
\hline CHEMBL1490272 & 688810 & 5.083 & 4.8467 & TRN & & \\
\hline CHEMBL1490104 & 688810 & 6.233 & 5.945 & TRN & & \\
\hline CHEMBL 3198334 & 688810 & \multicolumn{3}{|c|}{5.2829999999999995} & 5.3772 & $\mathrm{~T}$ \\
\hline CHEMBL1319282 & 688810 & 5.483 & 5.015 & TST & & \\
\hline CHEMBL1443791 & 688810 & \multicolumn{3}{|c|}{4.9830000000000005} & 5.0906 & \\
\hline CHEMBL1553916 & 688810 & 4.833 & 4.9939 & TRN & & \\
\hline CHEMBL1401453 & 688810 & 4.833 & \multicolumn{3}{|c|}{5.507000000000001} & (1) \\
\hline CHEMBL1413987 & 688810 & \multicolumn{3}{|c|}{6.0329999999999995} & 5.6417 & TRN \\
\hline CHEMBL1383378 & 688810 & 5.733 & 5.6589 & TRN & & \\
\hline CHEMBL1358429 & 688810 & 4.783 & 5.1035 & TRN & & \\
\hline CHEMBL1522324 & 688810 & \multicolumn{3}{|c|}{4.7330000000000005} & 5.5039 & 11 \\
\hline CHEMBL1531435 & 688810 & \multicolumn{3}{|c|}{5.132999999999999} & 5.2691 & \\
\hline CHEMBL1582886 & 688810 & 4.833 & 5.2538 & TRN & & \\
\hline CHEMBL1462381 & 688810 & \multicolumn{3}{|c|}{5.832999999999999} & 5.8552 & , \\
\hline CHEMBL1427959 & 688810 & 7.1331 & 6.1598 & TRN & & \\
\hline CHEMBL1409203 & 688810 & 5.233 & 5.1088 & TRN & & \\
\hline CHEMBL1429121 & 688810 & 4.783 & 5.4915 & TRN & & \\
\hline CHEMBL1472832 & 688810 & 4.583 & 5.3877 & TRN & & \\
\hline
\end{tabular}




\begin{tabular}{|c|c|c|c|c|c|c|}
\hline & & \multicolumn{4}{|c|}{ Supplemental Table s2.txt } & \\
\hline CHEMBL1545767 & 688810 & \multicolumn{3}{|c|}{5.132999999999999} & 6.1297 & TRN \\
\hline CHEMBL1495372 & 688810 & 5.183 & 5.007 & TRN & & \\
\hline CHEMBL1507362 & 688810 & 4.783 & 5.1308 & TRN & & \\
\hline CHEMBL1418245 & 688810 & 5.183 & 4.7585 & TRN & & \\
\hline CHEMBL1441454 & 688810 & 6.683 & 5.7873 & TRN & & \\
\hline CHEMBL1515152 & 688810 & 4.633 & 5.1179 & TRN & & \\
\hline CHEMBL3198547 & 688810 & 4.783 & 4.8307 & TST & & \\
\hline CHEMBL1331181 & 688810 & 7.1831 & 5.468 & TRN & & \\
\hline CHEMBL1501374 & 688810 & \multicolumn{3}{|c|}{6.832999999999999} & 5.9 & TRN \\
\hline CHEMBL1366987 & 688810 & 5.433 & 4.848 & TST & & \\
\hline CHEMBL1300476 & 688810 & \multicolumn{3}{|c|}{5.382999999999999} & 6.0453 & TRN \\
\hline CHEMBL1367525 & 688810 & \multicolumn{3}{|c|}{4.7330000000000005} & 5.4225 & TRN \\
\hline CHEMBL1475763 & 688810 & \multicolumn{3}{|c|}{5.332999999999999} & 5.2668 & TRN \\
\hline CHEMBL1432218 & 688810 & 5.233 & 5.8103 & TRN & & \\
\hline CHEMBL1419680 & 688810 & \multicolumn{3}{|c|}{5.382999999999999} & 5.7421 & TRN \\
\hline CHEMBL1521974 & 688810 & 5.183 & \multicolumn{3}{|c|}{5.787999999999999} & TRN \\
\hline CHEMBL1584789 & 688810 & \multicolumn{3}{|c|}{5.2829999999999995} & 4.8964 & TST \\
\hline CHEMBL1397993 & 688810 & \multicolumn{3}{|c|}{5.2829999999999995} & 5.2259 & TRN \\
\hline CHEMBL1398217 & 688810 & 4.633 & 5.5479 & TST & & \\
\hline CHEMBL1584190 & 688810 & 5.683 & 5.641 & TRN & & \\
\hline CHEMBL1477199 & 688810 & 4.883 & 5.1463 & TST & & \\
\hline CHEMBL1558243 & 688810 & \multicolumn{3}{|c|}{5.7829999999999995} & 5.4431 & TST \\
\hline CHEMBL 3199275 & 688810 & 5.483 & 5.1911 & TRN & & \\
\hline CHEMBL1368059 & 688810 & 5.933 & 5.8841 & TRN & & \\
\hline CHEMBL1499934 & 688810 & \multicolumn{3}{|c|}{5.882999999999999} & 5.1784 & TRN \\
\hline CHEMBL3189978 & 688810 & \multicolumn{3}{|c|}{4.7330000000000005} & 5.1355 & TST \\
\hline CHEMBL1584684 & 688810 & \multicolumn{3}{|c|}{5.7829999999999995} & 6.19 & TRN \\
\hline CHEMBL1536961 & 688810 & \multicolumn{3}{|c|}{6.382999999999999} & 5.2719 & TRN \\
\hline CHEMBL1525906 & 688810 & \multicolumn{3}{|c|}{5.132999999999999} & 5.4344 & TRN \\
\hline CHEMBL1385387 & 688810 & 4.583 & 5.2971 & TST & & \\
\hline CHEMBL1460595 & 688810 & 7.3325 & 6.0501 & TRN & & \\
\hline CHEMBL1456527 & 688810 & \multicolumn{3}{|c|}{4.9830000000000005} & 5.5109 & TST \\
\hline CHEMBL1359125 & 688810 & 5.433 & 5.4069 & TRN & & \\
\hline CHEMBL1423162 & 688810 & 4.883 & 5.0797 & TRN & & \\
\hline CHEMBL1362278 & 688810 & 4.633 & 4.9962 & TST & & \\
\hline CHEMBL1488592 & 688810 & 5.733 & 5.2353 & TRN & & \\
\hline CHEMBL1342055 & 688810 & 5.233 & 5.3848 & TRN & & \\
\hline CHEMBL3194755 & 688810 & \multicolumn{3}{|c|}{4.9830000000000005} & 5.3612 & TRN \\
\hline CHEMBL1402934 & 688810 & 5.183 & 5.2317 & TRN & & \\
\hline CHEMBL3197569 & 688810 & \multicolumn{3}{|c|}{4.7330000000000005} & 5.1045 & TST \\
\hline CHEMBL1318869 & 688810 & 4.633 & 4.7737 & TRN & & \\
\hline CHEMBL1496462 & 688810 & 6.183 & 5.1886 & TRN & & \\
\hline CHEMBL3211385 & 688810 & \multicolumn{3}{|c|}{5.5329999999999995} & 5.0934 & TRN \\
\hline CHEMBL1497694 & 688810 & 5.683 & 5.1781 & TRN & & \\
\hline CHEMBL1446070 & 688810 & 4.633 & 5.1816 & TRN & & \\
\hline CHEMBL1535532 & 688810 & 4.833 & 5.0545 & TST & & \\
\hline CHEMBL1565794 & 688810 & 4.883 & 5.1046 & TRN & & \\
\hline CHEMBL3194959 & 688810 & 4.833 & 5.0549 & TRN & & \\
\hline
\end{tabular}




\begin{tabular}{|c|c|c|c|c|c|c|c|}
\hline \multicolumn{8}{|c|}{ Supplemental Table S2.txt } \\
\hline CHEMBL1529636 & 688810 & 5.683 & 5.1884 & TST & & & \\
\hline CHEMBL1586396 & 688810 & \multicolumn{3}{|c|}{5.132999999999999} & 5.1869 & TRN & \\
\hline CHEMBL1546223 & 688810 & 4.883 & 4.8491 & TST & & & \\
\hline CHEMBL1588653 & 688810 & \multicolumn{3}{|c|}{4.7330000000000005} & 5.0819 & TST & \\
\hline CHEMBL3191295 & 688810 & \multicolumn{3}{|c|}{5.5329999999999995} & 5.59 & TRN & \\
\hline CHEMBL1330492 & 688810 & \multicolumn{3}{|c|}{5.132999999999999} & 5.1198 & TRN & \\
\hline CHEMBL1384103 & 688810 & 5.433 & 5.3445 & TRN & & & \\
\hline CHEMBL1587734 & 688810 & \multicolumn{3}{|c|}{5.582999999999999} & \multicolumn{2}{|c|}{5.297999999999999} & TRN \\
\hline CHEMBL1320636 & 688810 & 4.933 & 5.1448 & TST & & & \\
\hline CHEMBL1458746 & 688810 & 5.083 & 5.2754 & TRN & & & \\
\hline CHEMBL1592150 & 688810 & 4.633 & 5.2109 & TRN & & & \\
\hline CHEMBL1301753 & 688810 & \multicolumn{3}{|c|}{5.2829999999999995} & 5.5422 & TRN & \\
\hline CHEMBL3199175 & 688810 & 4.883 & 5.4393 & TRN & & & \\
\hline CHEMBL3190435 & 688810 & 5.433 & 5.7451 & TRN & & & \\
\hline CHEMBL1303571 & 688810 & 5.033 & 4.9467 & TRN & & & \\
\hline CHEMBL3211849 & 688810 & 4.883 & 5.6862 & TST & & & \\
\hline CHEMBL1537944 & 688810 & 5.033 & 5.0663 & TST & & & \\
\hline CHEMBL1420922 & 688810 & \multicolumn{3}{|c|}{5.7829999999999995} & 5.6363 & TRN & \\
\hline CHEMBL1344059 & 688810 & 4.633 & 4.8515 & TST & & & \\
\hline CHEMBL1534262 & 688810 & \multicolumn{3}{|c|}{5.2829999999999995} & 5.3412 & TRN & \\
\hline CHEMBL1531755 & 688810 & \multicolumn{3}{|c|}{5.7829999999999995} & 6.0007 & TRN & \\
\hline CHEMBL1349002 & 688810 & 5.233 & 5.6142 & TST & & & \\
\hline CHEMBL1389377 & 688810 & 4.783 & 5.1446 & TRN & & & \\
\hline CHEMBL1480056 & 688810 & \multicolumn{3}{|c|}{6.382999999999999} & 6.4255 & TRN & \\
\hline CHEMBL1332117 & 688810 & 5.933 & 5.2993 & TRN & & & \\
\hline CHEMBL1589334 & 688810 & 5.683 & 6.0773 & TRN & & & \\
\hline CHEMBL1357267 & 688810 & \multicolumn{3}{|c|}{5.132999999999999} & 5.2867 & TRN & \\
\hline CHEMBL1405013 & 688810 & 4.883 & 4.9978 & TST & & & \\
\hline CHEMBL1412891 & 688810 & 4.633 & 5.0976 & TRN & & & \\
\hline CHEMBL1335244 & 688810 & \multicolumn{3}{|c|}{4.7330000000000005} & 5.3243 & TRN & \\
\hline CHEMBL1541828 & 688810 & 4.633 & 5.2957 & TRN & & & \\
\hline CHEMBL1317687 & 688810 & 5.233 & 4.8758 & TRN & & & \\
\hline CHEMBL1463939 & 688810 & 5.433 & 5.5719 & TRN & & & \\
\hline CHEMBL1442927 & 688810 & \multicolumn{3}{|c|}{6.2829999999999995} & 5.4602 & TRN & \\
\hline CHEMBL1558144 & 688810 & 4.683 & 4.8449 & TRN & & & \\
\hline CHEMBL1339905 & 688810 & \multicolumn{3}{|c|}{6.2829999999999995} & 5.3975 & TRN & \\
\hline CHEMBL1446253 & 688810 & 4.833 & 5.284 & TRN & & & \\
\hline CHEMBL586031 & 688810 & 5.483 & 5.1735 & TRN & & & \\
\hline CHEMBL1612542 & 688810 & 5.683 & 5.25899 & 999999999 & 995 & TRN & \\
\hline CHEMBL1575177 & 688810 & 4.833 & 5.2463 & TRN & & & \\
\hline CHEMBL1503205 & 688810 & 4.933 & 5.1835 & TRN & & & \\
\hline CHEMBL1522438 & 688810 & \multicolumn{3}{|c|}{6.0329999999999995} & \multicolumn{2}{|c|}{5.617999999999999} & TRN \\
\hline CHEMBL1313849 & 688810 & \multicolumn{3}{|c|}{5.132999999999999} & 5.035 & TST & \\
\hline CHEMBL1598706 & 688810 & 6.183 & 5.3382 & TST & & & \\
\hline CHEMBL1463686 & 688810 & 5.733 & 5.94 & TRN & & & \\
\hline CHEMBL1538470 & 688810 & 5.083 & 5.4686 & TRN & & & \\
\hline CHEMBL1442002 & 688810 & 4.683 & 4.9816 & TRN & & & \\
\hline CHEMBL1584557 & 688810 & 7.2328 & 5.9273 & TRN & & & \\
\hline
\end{tabular}

Page 21941 


\begin{tabular}{|c|c|c|c|c|c|c|c|}
\hline \multirow[b]{2}{*}{ CHEMBL3198258 } & \multicolumn{6}{|c|}{ 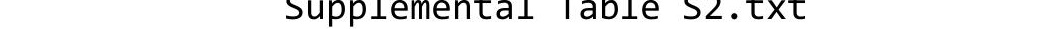 } & \\
\hline & 688810 & 5.233 & 5.3526 & TRN & & & \\
\hline CHEMBL486817 & 688810 & 4.883 & 5.2204 & TST & & & \\
\hline CHEMBL1611997 & 688810 & 4.883 & 4.945 & TRN & & & \\
\hline CHEMBL1351385 & 688810 & 4.633 & 4.5498 & TRN & & & \\
\hline CHEMBL1579988 & 688810 & 5.2829 & 99999999 & 995 & 4.998 & TRN & \\
\hline CHEMBL1382867 & 688810 & 5.1329 & 99999999 & & 5.8823 & TRN & \\
\hline CHEMBL1356820 & 688810 & 4.583 & 4.914 & TRN & & & \\
\hline CHEMBL1570466 & 688810 & 5.933 & 4.9393 & TST & & & \\
\hline CHEMBL1600446 & 688810 & 4.883 & 4.9527 & TST & & & \\
\hline CHEMBL1377872 & 688810 & 6.58299 & 99999999 & & 5.6639 & TRN & \\
\hline CHEMBL1595855 & 688810 & 4.783 & 5.2468 & TRN & & & \\
\hline CHEMBL1338162 & 688810 & 4.933 & 4.7818 & TRN & & & \\
\hline CHEMBL1409896 & 688810 & 4.783 & 4.8758 & TRN & & & \\
\hline CHEMBL1568171 & 688810 & 5.8329 & 99999999 & & 5.3938 & TRN & \\
\hline CHEMBL1530203 & 688810 & 6.4829 & 5.9834 & TRN & & & \\
\hline CHEMBL1581958 & 688810 & 4.73306 & 00000000 & 005 & 5.1744 & TRN & \\
\hline CHEMBL1361785 & 688810 & 5.3829 & 99999999 & & 5.1055 & TRN & \\
\hline CHEMBL1558637 & 688810 & 5.683 & 5.2993 & TRN & & & \\
\hline CHEMBL1993627 & 688810 & 7.1831 & 5.6391 & TRN & & & \\
\hline CHEMBL1594558 & 688810 & 5.983 & 5.4776 & TRN & & & \\
\hline CHEMBL1338340 & 688810 & 4.783 & 5.2074 & TST & & & \\
\hline CHEMBL1546709 & 688810 & 6.433 & 5.9454 & TRN & & & \\
\hline CHEMBL3193959 & 688810 & 5.233 & 5.4874 & TRN & & & \\
\hline CHEMBL1304031 & 688810 & 5.1329 & 99999999 & & 5.2489 & TRN & \\
\hline CHEMBL1391557 & 688810 & 4.783 & 4.9933 & TRN & & & \\
\hline CHEMBL1608990 & 688810 & 4.98306 & 00000000 & 005 & 5.5502 & TRN & \\
\hline CHEMBL3191734 & 688810 & 6.1329 & 99999999 & & 5.2931 & TRN & \\
\hline CHEMBL3199578 & 688810 & 5.1329 & 99999999 & & 5.54700 & 0000000001 & TRN \\
\hline CHEMBL1471189 & 688810 & $4.9830 e$ & 00000000 & 005 & 5.4524 & TST & \\
\hline CHEMBL1562618 & 688810 & 4.73306 & 00000000 & 005 & 4.7849 & TST & \\
\hline CHEMBL1565774 & 688810 & 6.2829 & 99999999 & 995 & 5.5312 & TRN & \\
\hline CHEMBL1424887 & 688810 & 5.5329 & 99999999 & 995 & 5.4314 & TRN & \\
\hline CHEMBL1312428 & 688810 & 5.3829 & 99999999 & & 5.3771 & TRN & \\
\hline CHEMBL1508721 & 688810 & 5.8329 & 99999999 & & 5.3869 & TRN & \\
\hline CHEMBL1338658 & 688810 & 6.0329 & 99999999 & 995 & 5.4234 & TRN & \\
\hline CHEMBL1597956 & 688810 & 4.883 & 5.7974 & TST & & & \\
\hline CHEMBL1361452 & 688810 & 6.433 & 5.7619 & TRN & & & \\
\hline CHEMBL1588029 & 688810 & 4.783 & 5.1807 & TST & & & \\
\hline CHEMBL1567985 & 688810 & 6.8329 & 99999999 & & 5.6778 & TRN & \\
\hline CHEMBL1343363 & 688810 & 4.583 & 5.1263 & TST & & & \\
\hline CHEMBL1611896 & 688810 & 6.4829 & 6.0482 & TRN & & & \\
\hline CHEMBL3189921 & 688810 & 4.833 & 4.7673 & TST & & & \\
\hline CHEMBL1386640 & 688810 & 5.233 & 5.7571 & TST & & & \\
\hline CHEMBL1583690 & 688810 & 5.433 & 5.0689 & TRN & & & \\
\hline CHEMBL1563033 & 688810 & $4.7330 e$ & 00000000 & 005 & 5.0888 & TRN & \\
\hline CHEMBL1355379 & 688810 & 6.2829 & 99999999 & 995 & 5.6124 & TRN & \\
\hline CHEMBL1436250 & 688810 & 4.583 & 5.3249 & TRN & & & \\
\hline CHEMBL1310825 & 688810 & 5.683 & 5.313 & TST & & & \\
\hline
\end{tabular}




\begin{tabular}{|c|c|c|c|c|c|c|c|}
\hline \multirow{3}{*}{$\begin{array}{l}\text { CHEMBL1474627 } \\
\text { CHEMBL1533740 }\end{array}$} & & \\
\hline & 688810 & 6.683 & 5.3585 & TRN & & & \\
\hline & 688810 & 5.88299 & 99999999 & & 5.70299 & 9999999999 & TRN \\
\hline CHEMBL1373501 & 688810 & 5.433 & 5.0126 & TST & & & \\
\hline CHEMBL1362848 & 688810 & 4.833 & 5.42899 & 999999999 & & TRN & \\
\hline CHEMBL1537087 & 688810 & 5.083 & 4.914 & TRN & & & \\
\hline CHEMBL1429192 & 688810 & 5.233 & 5.2101 & TRN & & & \\
\hline CHEMBL1501219 & 688810 & 4.783 & 5.1675 & TRN & & & \\
\hline CHEMBL1457401 & 688810 & 4.933 & 5.0827 & TRN & & & \\
\hline CHEMBL1587205 & 688810 & 4.683 & 5.2759 & TST & & & \\
\hline CHEMBL1439909 & 688810 & 6.8831 & 6.2217 & TRN & & & \\
\hline CHEMBL1376578 & 688810 & 5.13299 & 99999999 & & 4.7821 & TST & \\
\hline CHEMBL1444828 & 688810 & 4.833 & 5.4258 & TRN & & & \\
\hline CHEMBL1611082 & 688810 & 4.883 & 5.278 & TST & & & \\
\hline CHEMBL1326874 & 688810 & 6.183 & 5.0676 & TRN & & & \\
\hline CHEMBL1357910 & 688810 & 5.83299 & 99999999 & & 5.159 & TRN & \\
\hline CHEMBL1562579 & 688810 & 4.933 & 5.1826 & TST & & & \\
\hline CHEMBL1452714 & 688810 & 5.88299 & 99999999 & 99 & 5.37799 & 9999999999 & TRN \\
\hline CHEMBL1397236 & 688810 & 4.683 & 4.8547 & TRN & & & \\
\hline CHEMBL1418081 & 688810 & 5.683 & 5.3237 & TRN & & & \\
\hline CHEMBL1604163 & 688810 & 6.183 & 5.9668 & TRN & & & \\
\hline CHEMBL1423607 & 688810 & 5.78299 & 99999999 & 995 & 5.8084 & TRN & \\
\hline CHEMBL1440713 & 688810 & 5.183 & 5.3615 & TRN & & & \\
\hline CHEMBL 3192493 & 688810 & 5.78299 & 99999999 & 995 & 5.0459 & TST & \\
\hline CHEMBL1492936 & 688810 & 5.433 & 5.49799 & 999999999 & & TRN & \\
\hline CHEMBL1405255 & 688810 & 5.28299 & 99999999 & 995 & 4.6718 & TST & \\
\hline CHEMBL1437373 & 688810 & 4.73300 & 00000000 & 005 & 5.2287 & TRN & \\
\hline CHEMBL1564834 & 688810 & 7.3325 & 5.7233 & TRN & & & \\
\hline CHEMBL1343279 & 688810 & 4.883 & 5.2882 & TRN & & & \\
\hline CHEMBL589479 & 688810 & 4.833 & 5.3206 & TRN & & & \\
\hline CHEMBL1491887 & 688810 & 4.583 & 4.9494 & TRN & & & \\
\hline CHEMBL3194239 & 688810 & 5.58299 & 99999999 & & 5.307 & TRN & \\
\hline CHEMBL1375708 & 688810 & 4.583 & 5.1017 & TRN & & & \\
\hline CHEMBL1355115 & 688810 & 5.13299 & 99999999 & & 5.3164 & TRN & \\
\hline CHEMBL3197106 & 688810 & 5.13299 & 99999999 & & 5.33799 & 9999999999 & TRN \\
\hline CHEMBL1982774 & 688810 & 6.4829 & 5.8094 & TRN & & & \\
\hline CHEMBL1471848 & 688810 & 4.883 & 5.23600 & 000000000 & & TST & \\
\hline CHEMBL1600616 & 688810 & 4.583 & 4.9402 & TRN & & & \\
\hline CHEMBL1527006 & 688810 & 5.233 & 5.1441 & TRN & & & \\
\hline CHEMBL1507978 & 688810 & 4.833 & 5.2944 & TRN & & & \\
\hline CHEMBL1381977 & 688810 & 5.033 & 5.6342 & TRN & & & \\
\hline CHEMBL1520356 & 688810 & 6.433 & 5.4998 & TST & & & \\
\hline CHEMBL1507744 & 688810 & 6.08299 & 99999999 & & 5.3768 & TRN & \\
\hline CHEMBL1516270 & 688810 & 4.933 & 5.0058 & TRN & & & \\
\hline CHEMBL1422720 & 688810 & 4.633 & 4.7971 & TST & & & \\
\hline CHEMBL1345199 & 688810 & 4.783 & 5.5794 & TRN & & & \\
\hline CHEMBL1469152 & 688810 & 5.983 & 5.1509 & TRN & & & \\
\hline CHEMBL1393595 & 688810 & 5.183 & 4.9601 & TRN & & & \\
\hline CHEMBL1503790 & 688810 & 4.783 & 5.0884 & TRN & & & \\
\hline
\end{tabular}




\begin{tabular}{|c|c|c|c|c|c|c|c|}
\hline \multicolumn{8}{|c|}{ Supplemental Ta } \\
\hline CHEMBL1303307 & 688810 & 5.683 & 5.3476 & TRN & & & \\
\hline CHEMBL1595930 & 688810 & 5.083 & 4.9451 & TRN & & & \\
\hline CHEMBL1401587 & 688810 & 4.833 & 5.1392 & TRN & & & \\
\hline CHEMBL1567359 & 688810 & 5.433 & 5.1559 & TRN & & & \\
\hline CHEMBL1526333 & 688810 & 4.633 & 5.3183 & TST & & & \\
\hline CHEMBL1320313 & 688810 & 4.783 & 5.0482 & TRN & & & \\
\hline CHEMBL1574604 & 688810 & 5.28299 & 99999999 & 995 & 5.7879 & 9999999999 & TRN \\
\hline CHEMBL1336277 & 688810 & 5.433 & 6.2243 & TST & & & \\
\hline CHEMBL1479449 & 688810 & 5.83299 & 99999999 & 99 & 5.4839 & TRN & \\
\hline CHEMBL1549360 & 688810 & 4.783 & 4.9762 & TRN & & & \\
\hline CHEMBL1543524 & 688810 & 4.633 & 5.1163 & TRN & & & \\
\hline CHEMBL1584476 & 688810 & 5.78299 & 99999999 & 995 & 5.614 & TRN & \\
\hline CHEMBL1546461 & 688810 & 5.183 & 5.5948 & TST & & & \\
\hline CHEMBL1438978 & 688810 & 5.13299 & 99999999 & 99 & 5.0189 & TST & \\
\hline CHEMBL1331555 & 688810 & 4.833 & 5.1246 & TRN & & & \\
\hline CHEMBL582473 & 688810 & 5.733 & 4.9066 & TRN & & & \\
\hline CHEMBL1548253 & 688810 & 4.883 & 4.9597 & TST & & & \\
\hline CHEMBL539507 & 688810 & 5.13299 & 99999999 & & 4.9436 & TRN & \\
\hline CHEMBL1389287 & 688810 & 4.833 & 5.2712 & TRN & & & \\
\hline CHEMBL1441921 & 688810 & 5.53299 & 99999999 & 995 & 5.5134 & TRN & \\
\hline CHEMBL1493559 & 688810 & 4.883 & 5.3439 & TRN & & & \\
\hline CHEMBL 2005671 & 688810 & 4.833 & 5.3289 & TRN & & & \\
\hline CHEMBL1430297 & 688810 & 4.833 & 4.9808 & TST & & & \\
\hline CHEMBL3193797 & 688810 & 5.033 & 5.2843 & TRN & & & \\
\hline CHEMBL1990793 & 688810 & 5.33299 & 99999999 & & 5.2484 & TRN & \\
\hline CHEMBL1424398 & 688810 & 4.633 & 5.0316 & TRN & & & \\
\hline CHEMBL1417496 & 688810 & 4.783 & 4.5217 & TST & & & \\
\hline CHEMBL1412802 & 688810 & 4.883 & 5.6775 & TST & & & \\
\hline CHEMBL1457140 & 688810 & 5.183 & 5.2425 & TRN & & & \\
\hline CHEMBL1504686 & 688810 & 4.933 & 5.0958 & TRN & & & \\
\hline CHEMBL1411498 & 688810 & 4.73300 & 00000000 & 005 & 5.2304 & TST & \\
\hline CHEMBL1609595 & 688810 & 6.433 & 5.6169 & TRN & & & \\
\hline CHEMBL1402097 & 688810 & 5.83299 & 99999999 & & 5.4175 & TRN & \\
\hline CHEMBL1359565 & 688810 & 5.83299 & 99999999 & & 5.4345 & TRN & \\
\hline CHEMBL1393283 & 688810 & 4.633 & 4.9924 & TST & & & \\
\hline CHEMBL1572905 & 688810 & 4.883 & 5.4471 & TRN & & & \\
\hline CHEMBL316796 & 688810 & 4.98300 & 00000000 & 005 & 5.4928 & TRN & \\
\hline CHEMBL1989426 & 688810 & 5.683 & 5.3992 & TST & & & \\
\hline CHEMBL1367340 & 688810 & 5.58299 & 999999999 & 99 & 5.0166 & TRN & \\
\hline CHEMBL1461176 & 688810 & 5.033 & 4.8115 & TST & & & \\
\hline CHEMBL1531911 & 688810 & 5.3 & 5.6419 & TRN & & & \\
\hline CHEMBL1505806 & 688810 & 4.783 & 5.5605 & TRN & & & \\
\hline CHEMBL1603384 & 688810 & 5.53299 & 999999999 & 995 & 5.8370 & 0000000001 & TRN \\
\hline CHEMBL1357497 & 688810 & 5.183 & 5.4878 & TRN & & & \\
\hline CHEMBL1398350 & 688810 & 6.183 & 5.3846 & TRN & & & \\
\hline CHEMBL1553208 & 688810 & 5.433 & 4.8972 & TRN & & & \\
\hline CHEMBL3199906 & 688810 & 4.783 & 4.9952 & TRN & & & \\
\hline CHEMBL1327828 & 688810 & 5.183 & 5.7889 & TRN & & & \\
\hline
\end{tabular}




\begin{tabular}{|c|c|c|c|c|c|c|}
\hline \multicolumn{7}{|c|}{ Supplemental Table S2.txt } \\
\hline CHEMBL1500290 & 688810 & \multicolumn{3}{|c|}{5.132999999999999} & 5.0211 & TRN \\
\hline CHEMBL1423803 & 688810 & 4.783 & 4.853 & TST & & \\
\hline CHEMBL1503313 & 688810 & \multicolumn{3}{|c|}{5.582999999999999} & 5.4368 & TRN \\
\hline CHEMBL1483332 & 688810 & 4.833 & 4.9781 & TRN & & \\
\hline CHEMBL580918 & 688810 & 5.983 & 5.6434 & TRN & & \\
\hline CHEMBL1487921 & 688810 & 4.783 & 5.0978 & TRN & & \\
\hline CHEMBL1303165 & 688810 & 5.033 & 5.1088 & TST & & \\
\hline CHEMBL1571804 & 688810 & \multicolumn{3}{|c|}{5.882999999999999} & 5.487 & TRN \\
\hline CHEMBL1595410 & 688810 & 4.833 & 5.1058 & TRN & & \\
\hline CHEMBL1379916 & 688810 & 4.683 & 5.276 & TST & & \\
\hline CHEMBL1545689 & 688810 & \multicolumn{3}{|c|}{5.5329999999999995} & 5.159 & TST \\
\hline CHEMBL1603839 & 688810 & \multicolumn{3}{|c|}{4.9830000000000005} & 5.2681 & TRN \\
\hline CHEMBL1592855 & 688810 & \multicolumn{3}{|c|}{5.332999999999999} & 5.7702 & TRN \\
\hline CHEMBL1586663 & 688810 & 4.883 & 5.1292 & TRN & & \\
\hline CHEMBL1604797 & 688810 & 4.683 & 4.9235 & TST & & \\
\hline CHEMBL1506511 & 688810 & 4.85 & 5.2645 & TRN & & \\
\hline CHEMBL1447950 & 688810 & 4.933 & 4.8653 & TST & & \\
\hline CHEMBL1521791 & 688810 & 5.433 & 5.1632 & TST & & \\
\hline CHEMBL1593252 & 688810 & 6.433 & 5.5515 & TRN & & \\
\hline CHEMBL1393402 & 688810 & 5.733 & 5.8256 & TRN & & \\
\hline CHEMBL1586509 & 688810 & \multicolumn{3}{|c|}{6.082999999999999} & 5.5058 & TRN \\
\hline CHEMBL548619 & 688810 & \multicolumn{3}{|c|}{5.832999999999999} & 5.5758 & TRN \\
\hline CHEMBL177754 & 688810 & 5.483 & 5.0313 & TRN & & \\
\hline CHEMBL1320886 & 688810 & 4.783 & 5.1711 & TST & & \\
\hline CHEMBL1528627 & 688810 & 4.883 & 4.6744 & TST & & \\
\hline CHEMBL1514491 & 688810 & 4.783 & 5.2353 & TRN & & \\
\hline CHEMBL1488200 & 688810 & 6.233 & 5.49 & TRN & & \\
\hline CHEMBL1452139 & 688810 & 6.9329 & 5.2851 & TST & & \\
\hline CHEMBL 3207968 & 688810 & \multicolumn{3}{|c|}{6.382999999999999} & 5.5657 & TST \\
\hline CHEMBL1322817 & 688810 & \multicolumn{3}{|c|}{4.7330000000000005} & 4.8134 & TRN \\
\hline CHEMBL1582854 & 688810 & \multicolumn{3}{|c|}{6.382999999999999} & 5.7895 & TST \\
\hline CHEMBL1607103 & 688810 & 4.95 & 5.1382 & TRN & & \\
\hline CHEMBL1376466 & 688810 & 4.833 & 5.1296 & TRN & & \\
\hline CHEMBL1332126 & 688810 & 4.633 & 4.8232 & TST & & \\
\hline CHEMBL 3199142 & 688810 & 5.733 & 5.1897 & TRN & & \\
\hline CHEMBL1506750 & 688810 & 6.0 & 5.0805 & TRN & & \\
\hline CHEMBL1972143 & 688810 & 5.683 & 5.2521 & TST & & \\
\hline CHEMBL1371477 & 688810 & \multicolumn{3}{|c|}{5.132999999999999} & 5.0576 & TRN \\
\hline CHEMBL1412123 & 688810 & \multicolumn{3}{|c|}{6.132999999999999} & 5.7229 & TRN \\
\hline CHEMBL1472885 & 688810 & 4.833 & 5.769 & TRN & & \\
\hline CHEMBL 3193610 & 688810 & 5.033 & 5.1237 & TST & & \\
\hline CHEMBL1560791 & 688810 & 5.483 & 5.2362 & TRN & & \\
\hline CHEMBL1429863 & 688810 & 4.933 & 5.1854 & TRN & & \\
\hline CHEMBL 1408440 & 688810 & \multicolumn{3}{|c|}{5.582999999999999} & 5.1282 & TRN \\
\hline CHEMBL1338713 & 688810 & 5.733 & 5.3109 & TRN & & \\
\hline CHEMBL1307919 & 688810 & \multicolumn{3}{|c|}{5.632999999999999} & 5.90799 & 99999999995 \\
\hline CHEMBL1411325 & 688810 & 4.783 & 5.0026 & TRN & & \\
\hline CHEMBL1517405 & 688810 & 5.183 & 5.5631 & TRN & & \\
\hline
\end{tabular}




\begin{tabular}{|c|c|c|c|c|c|c|}
\hline \multirow[b]{2}{*}{ CHEMBL1315812 } & \multicolumn{6}{|c|}{ Supplemental Table S2.txt } \\
\hline & 688810 & 4.583 & 4.8881 & TRN & & \\
\hline CHEMBL1496103 & 688810 & 4.583 & 4.9441 & TRN & & \\
\hline CHEMBL1591817 & 688810 & 4.783 & 4.9687 & TRN & & \\
\hline CHEMBL1584036 & 688810 & 5.3329 & 99999999 & 99 & 5.0189 & TST \\
\hline CHEMBL600313 & 688810 & 5.233 & 4.9896 & TST & & \\
\hline CHEMBL1588237 & 688810 & 4.933 & 5.3092 & TRN & & \\
\hline CHEMBL1520565 & 688810 & 5.733 & 5.2609 & TRN & & \\
\hline CHEMBL1369424 & 688810 & 5.483 & 5.2855 & TST & & \\
\hline CHEMBL1477524 & 688810 & 5.683 & 5.29299 & 999999999 & & TRN \\
\hline CHEMBL1533593 & 688810 & 5.7829 & 99999999 & 995 & 4.9649 & TRN \\
\hline CHEMBL1393739 & 688810 & 6.0829 & 99999999 & & 5.5233 & TRN \\
\hline CHEMBL1607979 & 688810 & 5.6329 & 99999999 & & 5.4463 & TRN \\
\hline CHEMBL1390369 & 688810 & 6.6329 & 99999999 & & 5.8416 & TRN \\
\hline CHEMBL3195549 & 688810 & 4.783 & 4.9639 & TRN & & \\
\hline CHEMBL398095 & 688810 & 4.933 & 5.1222 & TRN & & \\
\hline CHEMBL1380353 & 688810 & 4.833 & 5.4275 & TST & & \\
\hline CHEMBL1496095 & 688810 & 4.583 & 4.7629 & TST & & \\
\hline CHEMBL1316936 & 688810 & 5.8329 & 99999999 & & 5.3327 & TRN \\
\hline CHEMBL1484736 & 688810 & 5.5329 & 99999999 & 995 & 5.5142 & TST \\
\hline CHEMBL1324340 & 688810 & 4.883 & 4.86100 & 000000000 & & TST \\
\hline CHEMBL1330655 & 688810 & 5.8329 & 99999999 & & 5.6856 & TRN \\
\hline CHEMBL1464002 & 688810 & 4.783 & 5.1051 & TST & & \\
\hline CHEMBL601140 & 688810 & 4.7330 & 00000000 & 005 & 5.0279 & TRN \\
\hline CHEMBL1441555 & 688810 & 4.633 & 5.1966 & TRN & & \\
\hline CHEMBL1417097 & 688810 & 4.883 & 4.8657 & TRN & & \\
\hline CHEMBL1438752 & 688810 & 4.933 & 5.2944 & TRN & & \\
\hline CHEMBL 3210088 & 688810 & 7.0329 & 5.7203 & TRN & & \\
\hline CHEMBL1575926 & 688810 & 6.433 & 6.3219 & TRN & & \\
\hline CHEMBL 3212261 & 688810 & 5.433 & 5.3526 & TST & & \\
\hline CHEMBL1564613 & 688810 & 4.833 & 5.54299 & 999999999 & & TRN \\
\hline CHEMBL1493953 & 688810 & 4.833 & 4.8658 & TRN & & \\
\hline CHEMBL1355214 & 688810 & 5.983 & 5.9084 & TRN & & \\
\hline CHEMBL1462391 & 688810 & 5.433 & 5.353 & TST & & \\
\hline CHEMBL1413940 & 688810 & 4.583 & 5.1273 & TRN & & \\
\hline CHEMBL1526253 & 688810 & 4.783 & 5.1878 & TRN & & \\
\hline CHEMBL1409569 & 688810 & 6.4829 & 5.5196 & TRN & & \\
\hline CHEMBL1327888 & 688810 & 5.1329 & 99999999 & & 5.1693 & TRN \\
\hline CHEMBL1333831 & 688810 & 6.3829 & 99999999 & & 6.1172 & TRN \\
\hline CHEMBL1557474 & 688810 & 5.1329 & 99999999 & & 5.5427 & TRN \\
\hline CHEMBL1985343 & 688810 & 4.9830 & 00000000 & 005 & 5.2941 & TRN \\
\hline CHEMBL1540570 & 688810 & 5.983 & 5.1905 & TST & & \\
\hline CHEMBL1454113 & 688810 & 5.8329 & 99999999 & & 5.209 & TST \\
\hline CHEMBL3210433 & 688810 & 4.833 & 5.1911 & TRN & & \\
\hline CHEMBL1428992 & 688810 & 5.6329 & 99999999 & & 5.1381 & TST \\
\hline CHEMBL1330757 & 688810 & 4.7330 & 00000000 & 005 & 5.5757 & TRN \\
\hline CHEMBL1301125 & 688810 & 5.3829 & 99999999 & & 5.5073 & TST \\
\hline CHEMBL591404 & 688810 & 4.683 & 4.7411 & TRN & & \\
\hline CHEMBL1327005 & 688810 & 6.233 & 6.2373 & TRN & & \\
\hline
\end{tabular}




\begin{tabular}{|c|c|c|c|c|c|c|}
\hline \multirow[b]{2}{*}{ CHEMBL1416174 } & & \multicolumn{5}{|c|}{ Supplemental Table S2.txt } \\
\hline & 688810 & 4.933 & 5.4649 & TRN & & \\
\hline CHEMBL1339746 & 688810 & 4.883 & 5.4357 & TST & & \\
\hline CHEMBL1371184 & 688810 & 4.783 & 4.918 & TRN & & \\
\hline CHEMBL1579022 & 688810 & \multicolumn{3}{|c|}{4.7330000000000005} & 4.8909 & TST \\
\hline CHEMBL1313647 & 688810 & \multicolumn{3}{|c|}{5.5329999999999995} & 5.312 & TRN \\
\hline CHEMBL204914 & 688810 & 4.633 & 4.997 & TST & & \\
\hline CHEMBL1319537 & 688810 & 4.633 & 5.0023 & TRN & & \\
\hline CHEMBL1340530 & 688810 & \multicolumn{3}{|c|}{5.832999999999999} & 5.3804 & TRN \\
\hline CHEMBL1577188 & 688810 & 5.433 & 5.3419 & TST & & \\
\hline CHEMBL1521676 & 688810 & 5.083 & 5.4694 & TRN & & \\
\hline CHEMBL1379536 & 688810 & 4.883 & 5.2267 & TRN & & \\
\hline CHEMBL1406920 & 688810 & 4.783 & 5.0702 & TRN & & \\
\hline CHEMBL1581831 & 688810 & 4.883 & 5.1067 & TRN & & \\
\hline CHEMBL1571121 & 688810 & 4.783 & 5.144 & TRN & & \\
\hline CHEMBL1578993 & 688810 & 5.683 & 4.7334 & TRN & & \\
\hline CHEMBL1345948 & 688810 & 5.033 & 5.3291 & TRN & & \\
\hline CHEMBL1332878 & 688810 & 7.0329 & 5.335 & TRN & & \\
\hline CHEMBL1543276 & 688810 & 6.8831 & 5.8945 & TRN & & \\
\hline CHEMBL1354646 & 688810 & 4.633 & 5.03 & TRN & & \\
\hline CHEMBL1444606 & 688810 & 4.933 & 5.3917 & TST & & \\
\hline CHEMBL1612636 & 688810 & 5.733 & 5.5515 & TRN & & \\
\hline CHEMBL1352189 & 688810 & \multicolumn{3}{|c|}{4.7330000000000005} & 5.1031 & TRN \\
\hline CHEMBL 3195070 & 688810 & 4.783 & 5.445 & TRN & & \\
\hline CHEMBL1534724 & 688810 & 5.483 & 5.1275 & TRN & & \\
\hline CHEMBL1502364 & 688810 & 5.233 & 5.272 & TST & & \\
\hline CHEMBL1517169 & 688810 & 4.783 & 5.4705 & TRN & & \\
\hline CHEMBL3209474 & 688810 & 5.733 & 5.4931 & TST & & \\
\hline CHEMBL1312914 & 688810 & 5.233 & 5.1312 & TST & & \\
\hline CHEMBL1352850 & 688810 & 4.783 & 5.175 & TST & & \\
\hline CHEMBL602150 & 688810 & \multicolumn{3}{|c|}{5.332999999999999} & 5.0519 & TRN \\
\hline CHEMBL1530528 & 688810 & \multicolumn{3}{|c|}{5.632999999999999} & 5.3675 & TST \\
\hline CHEMBL1574623 & 688810 & 4.783 & 4.7589 & TRN & & \\
\hline CHEMBL1396099 & 688810 & \multicolumn{3}{|c|}{5.332999999999999} & 4.8857 & TST \\
\hline CHEMBL1569437 & 688810 & \multicolumn{3}{|c|}{5.332999999999999} & 4.9946 & TRN \\
\hline CHEMBL1422611 & 688810 & 4.783 & 4.7156 & TST & & \\
\hline CHEMBL1315894 & 688810 & 4.783 & 5.1126 & TRN & & \\
\hline CHEMBL1556677 & 688810 & \multicolumn{3}{|c|}{5.7829999999999995} & 5.0838 & TRN \\
\hline CHEMBL3197909 & 688810 & 5.083 & 5.1032 & TST & & \\
\hline CHEMBL1425271 & 688810 & & 5.1966 & TRN & & \\
\hline CHEMBL1550047 & 688810 & \multicolumn{3}{|c|}{5.332999999999999} & 5.2387 & TRN \\
\hline CHEMBL1382651 & 688810 & 5.233 & 5.5315 & TRN & & \\
\hline CHEMBL1362914 & 688810 & 4.933 & 4.752 & TST & & \\
\hline CHEMBL1492777 & 688810 & 4.833 & 5.1999 & TRN & & \\
\hline CHEMBL1530020 & 688810 & 7.0329 & 5.814 & TRN & & \\
\hline CHEMBL1524020 & 688810 & \multicolumn{3}{|c|}{6.2829999999999995} & 6.0261 & TRN \\
\hline CHEMBL1381257 & 688810 & \multicolumn{3}{|c|}{4.7330000000000005} & 5.1685 & TST \\
\hline CHEMBL1308969 & 688810 & \multicolumn{3}{|c|}{4.7330000000000005} & 5.6192 & TST \\
\hline CHEMBL1467015 & 688810 & 5.033 & 5.0538 & TRN & & \\
\hline
\end{tabular}




\begin{tabular}{|c|c|c|c|c|c|c|c|}
\hline \multicolumn{8}{|c|}{ Supplemental Table S2.txt } \\
\hline CHEMBL1522762 & 688810 & 4.683 & 5.0328 & TST & & & \\
\hline CHEMBL1578880 & 688810 & 5.483 & 5.1829 & TRN & & & \\
\hline CHEMBL514612 & 688810 & 5.933 & 5.6875 & TRN & & & \\
\hline CHEMBL1592618 & 688810 & 6.28299 & 99999999 & 995 & 5.2905 & TRN & \\
\hline CHEMBL1538167 & 688810 & 5.233 & 5.1091 & TRN & & & \\
\hline CHEMBL1429609 & 688810 & 4.883 & 5.3147 & TST & & & \\
\hline CHEMBL1573375 & 688810 & 4.883 & 5.5041 & TST & & & \\
\hline CHEMBL1613684 & 688810 & 5.38299 & 99999999 & & 5.2993 & TRN & \\
\hline CHEMBL1574587 & 688810 & 6.78299 & 99999999 & 995 & 5.7711 & TST & \\
\hline CHEMBL3196677 & 688810 & 4.73300 & 00000000 & 005 & 5.1044 & TRN & \\
\hline CHEMBL375966 & 688810 & 5.78299 & 99999999 & 995 & 5.8368 & TRN & \\
\hline CHEMBL1459930 & 688810 & 6.0 & 5.2506 & TRN & & & \\
\hline CHEMBL1405373 & 688810 & 5.83299 & 99999999 & & 5.5171 & TRN & \\
\hline CHEMBL1393761 & 688810 & 4.783 & 5.075 & TRN & & & \\
\hline CHEMBL3190509 & 688810 & 5.183 & 5.1658 & TST & & & \\
\hline CHEMBL 1364610 & 688810 & 5.233 & 5.1718 & TST & & & \\
\hline CHEMBL1418770 & 688810 & 4.73300 & 00000000 & 005 & 5.3227 & TST & \\
\hline CHEMBL1450275 & 688810 & 4.883 & 5.2061 & TST & & & \\
\hline CHEMBL1426835 & 688810 & 4.833 & 5.3377 & TRN & & & \\
\hline CHEMBL3199028 & 688810 & 4.883 & 5.3347 & TRN & & & \\
\hline CHEMBL1421199 & 688810 & 6.7331 & 5.33899 & 999999999 & 995 & TST & \\
\hline CHEMBL1481525 & 688810 & 4.833 & 4.6229 & TST & & & \\
\hline CHEMBL1451906 & 688810 & 5.38299 & 99999999 & & 5.1854 & TRN & \\
\hline CHEMBL1354681 & 688810 & 4.73300 & 00000000 & 005 & 5.1042 & TRN & \\
\hline CHEMBL1509310 & 688810 & 4.73300 & 00000000 & 005 & 5.0646 & TRN & \\
\hline CHEMBL1241371 & 688810 & 5.433 & 5.6491 & TRN & & & \\
\hline CHEMBL3208465 & 688810 & 4.883 & 5.5178 & TRN & & & \\
\hline CHEMBL1612481 & 688810 & 5.53299 & 99999999 & 995 & 5.63200 & 0000000001 & TRN \\
\hline CHEMBL1323776 & 688810 & 4.883 & 5.1792 & TRN & & & \\
\hline CHEMBL1481372 & 688810 & 4.833 & 5.1797 & TRN & & & \\
\hline CHEMBL1303740 & 688810 & 4.783 & 5.3676 & TRN & & & \\
\hline CHEMBL1438877 & 688810 & 4.633 & 5.0961 & TST & & & \\
\hline CHEMBL1473602 & 688810 & 5.233 & 5.1748 & TRN & & & \\
\hline CHEMBL1503772 & 688810 & 5.033 & 5.0323 & TST & & & \\
\hline CHEMBL1519535 & 688810 & 4.783 & 4.8821 & TST & & & \\
\hline CHEMBL1976236 & 688810 & 5.83299 & 99999999 & & 5.5095 & TST & \\
\hline CHEMBL1379163 & 688810 & 5.683 & 5.4591 & TRN & & & \\
\hline CHEMBL1538283 & 688810 & 5.083 & 5.0597 & TRN & & & \\
\hline CHEMBL1587607 & 688810 & 4.833 & 5.4889 & TRN & & & \\
\hline CHEMBL1319613 & 688810 & 5.13299 & 99999999 & & 5.6901 & TRN & \\
\hline CHEMBL1470161 & 688810 & 4.883 & 5.1301 & TRN & & & \\
\hline CHEMBL1558030 & 688810 & 5.53299 & 99999999 & 995 & 5.5422 & TRN & \\
\hline CHEMBL1330079 & 688810 & 5.083 & 5.3504 & TRN & & & \\
\hline CHEMBL1498622 & 688810 & 5.13299 & 99999999 & & 5.0969 & TRN & \\
\hline CHEMBL1339702 & 688810 & 6.28299 & 99999999 & 995 & 5.8519 & TRN & \\
\hline CHEMBL1331222 & 688810 & 4.783 & 5.2437 & TRN & & & \\
\hline CHEMBL1532452 & 688810 & 4.783 & 5.0105 & TST & & & \\
\hline CHEMBL1341509 & 688810 & 6.28299 & 99999999 & 995 & 5.7958 & TRN & \\
\hline
\end{tabular}




\begin{tabular}{|c|c|c|c|c|c|c|}
\hline \multicolumn{7}{|c|}{ plement } \\
\hline CHEMBL1414490 & 688810 & 6.0 & 489 & TRN & & \\
\hline CHEMBL1591040 & 688810 & \multicolumn{3}{|c|}{4.9830000000000005} & 5.4334 & TRN \\
\hline CHEMBL1489428 & 688810 & \multicolumn{3}{|c|}{5.132999999999999} & 5.5016 & TRN \\
\hline CHEMBL1455689 & 688810 & \multicolumn{3}{|c|}{5.832999999999999} & 5.5246 & \\
\hline CHEMBL1392635 & 688810 & \multicolumn{3}{|c|}{5.382999999999999} & 5.2959 & \\
\hline CHEMBL 3189632 & 688810 & \multicolumn{3}{|c|}{4.9830000000000005} & 5.1805 & \\
\hline CHEMBL1330282 & 688810 & 5.683 & 5.4664 & TRN & & \\
\hline CHEMBL1453866 & 688810 & 4.783 & 5.4055 & TRN & & \\
\hline CHEMBL1557587 & 688810 & 5.483 & 5.008 & TRN & & \\
\hline CHEMBL40004 & 688810 & 4.883 & 5.315 & TRN & & \\
\hline CHEMBL1470789 & 688810 & 4.783 & 4.9603 & TST & & \\
\hline CHEMBL1499277 & 688810 & \multicolumn{3}{|c|}{5.7829999999999995} & 5.2506 & \\
\hline CHEMBL1985987 & 688810 & 5.683 & 4.8242 & TRN & & \\
\hline CHEMBL1214345 & 688810 & 5.683 & 5.6149 & TRN & & \\
\hline CHEMBL1600852 & 688810 & \multicolumn{3}{|c|}{4.9830000000000005} & 4.9047 & \\
\hline CHEMBL1468394 & 688810 & \multicolumn{3}{|c|}{5.382999999999999} & 5.688 & \\
\hline CHEMBL1385348 & 688810 & 5.183 & 5.5898 & TRN & & \\
\hline CHEMBL1381579 & 688810 & \multicolumn{3}{|c|}{4.7330000000000005} & 711 & \\
\hline CHEMBL1312205 & 688810 & 4.933 & 5.2714 & TRN & & \\
\hline CHEMBL1542118 & 688810 & 4.783 & 5.6192 & TRN & & \\
\hline CHEMBL1554981 & 688810 & 4.633 & 5.0829 & TST & & \\
\hline CHEMBL1319820 & 688810 & 4.933 & 5.3361 & TRN & & \\
\hline CHEMBL1605420 & 688810 & 5.083 & 5.3867 & TST & & \\
\hline CHEMBL1314853 & 688810 & 4.633 & 5.0105 & TRN & & \\
\hline CHEMBL4 & 688810 & 7.1831 & 6.3466 & TRN & & \\
\hline CHEMBL 3190711 & 688810 & \multicolumn{3}{|c|}{5.632999999999999} & 899 & \\
\hline CHEMBL1435457 & 688810 & \multicolumn{3}{|c|}{4.7330000000000005} & 5.148 & \\
\hline CHEMBL1408634 & 688810 & \multicolumn{3}{|c|}{5.132999999999999} & 4.8456 & TF \\
\hline CHEMBL1385411 & 688810 & 5.233 & \multicolumn{3}{|c|}{5.9270000000000005} & \\
\hline CHEMBL1314184 & 688810 & 6.183 & 5.7647 & TRN & & \\
\hline CHEMBL1550117 & 688810 & 4.833 & 5.0578 & TRN & & \\
\hline CHEMBL1568458 & 688810 & 6.0 & 5.4523 & TRN & & \\
\hline CHEMBL1578434 & 688810 & \multicolumn{3}{|c|}{4.7330000000000005} & 5.2 & \\
\hline CHEMBL1410491 & 688810 & 4.833 & 5.3542 & TST & & \\
\hline CHEMBL1353110 & 688810 & 4.633 & 4.8526 & TRN & & \\
\hline CHEMBL1321213 & 688810 & \multicolumn{3}{|c|}{5.882999999999999} & 5.3073 & $\mathrm{Tr}$ \\
\hline CHEMBL1327694 & 688810 & 8.5376 & 5.4968 & TST & & \\
\hline CHEMBL552178 & 688810 & 5.233 & 5.0871 & TRN & & \\
\hline CHEMBL1367191 & 688810 & 6.233 & 5.7766 & TRN & & \\
\hline CHEMBL1305452 & 688810 & 4.783 & 5.9606 & TST & & \\
\hline CHEMBL1529425 & 688810 & \multicolumn{3}{|c|}{5.2829999999999995} & 5.2006 & \\
\hline CHEMBL1491655 & 688810 & 5.433 & 4.984 & TST & & \\
\hline CHEMBL1328132 & 688810 & \multicolumn{3}{|c|}{5.132999999999999} & 4.8558 & TRN \\
\hline CHEMBL1345143 & 688810 & \multicolumn{3}{|c|}{6.5329999999999995} & 5.2547 & 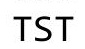 \\
\hline CHEMBL400585 & 688810 & \multicolumn{3}{|c|}{5.582999999999999} & 5.5068 & \\
\hline CHEMBL1534447 & 688810 & 5.083 & 5.1688 & TRN & & \\
\hline CHEMBL1337593 & 688810 & \multicolumn{3}{|c|}{5.2829999999999995} & 5.8723 & In \\
\hline CHEMBL1597093 & 688810 & 5.083 & 5.0818 & TRN & & \\
\hline
\end{tabular}




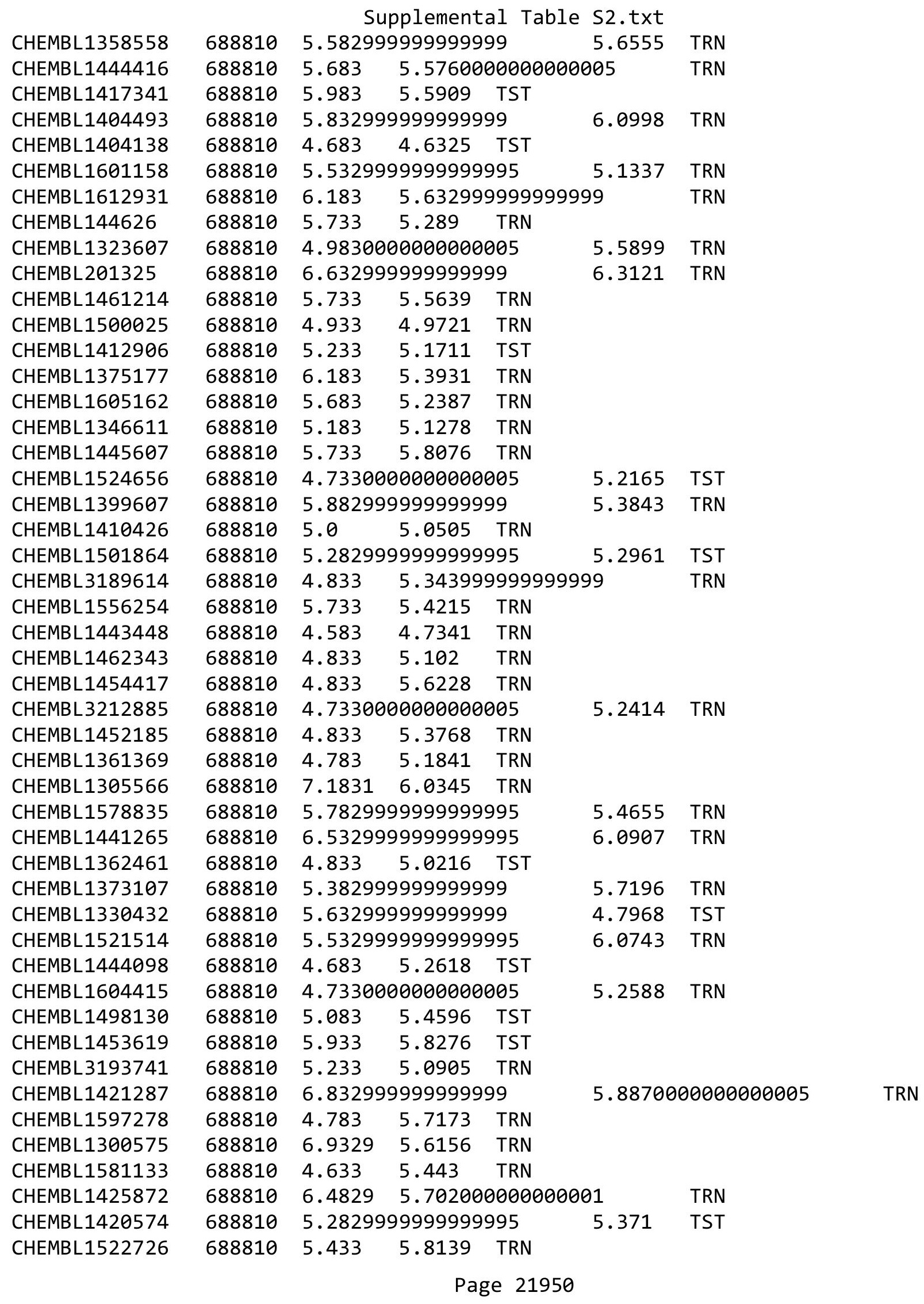




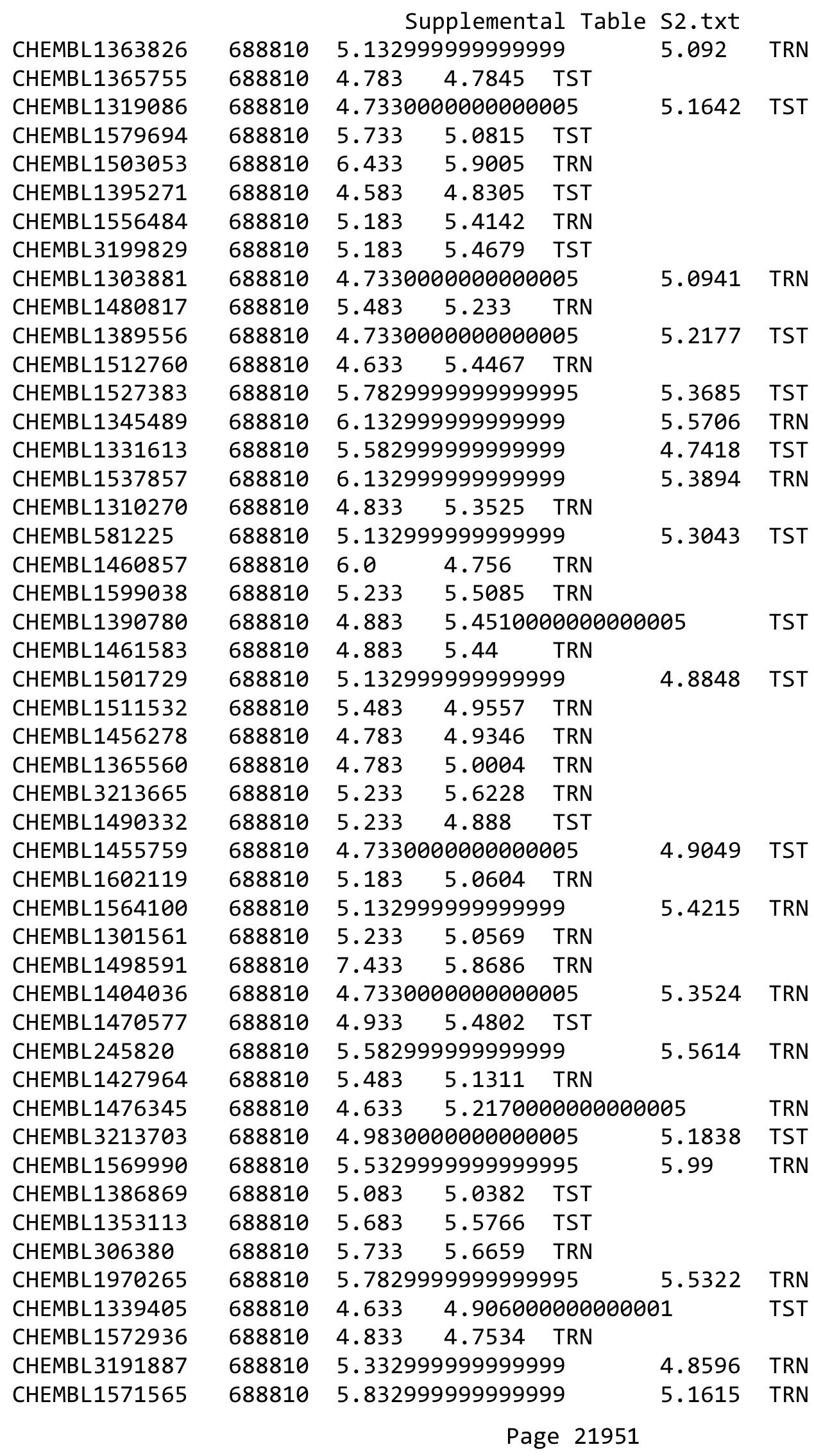




\begin{tabular}{|c|c|c|c|c|c|c|}
\hline \multirow[b]{2}{*}{ CHEMBL 3212292} & \multirow[b]{2}{*}{688810} & \\
\hline & & 5.483 & 5.0274 & TST & & \\
\hline CHEMBL1478296 & 688810 & \multicolumn{3}{|c|}{4.7330000000000005} & 5.2234 & TST \\
\hline CHEMBL1471529 & 688810 & \multicolumn{3}{|c|}{5.5329999999999995} & 5.3184 & \\
\hline CHEMBL1340713 & 688810 & 5.233 & 4.8941 & TST & & \\
\hline CHEMBL1406828 & 688810 & 5.033 & 5.3443 & TRN & & \\
\hline CHEMBL1303391 & 688810 & 5.083 & 5.1376 & TRN & & \\
\hline CHEMBL1585298 & 688810 & 4.783 & 5.0467 & TRN & & \\
\hline CHEMBL1609175 & 688810 & \multicolumn{3}{|c|}{5.132999999999999} & 5.2283 & \\
\hline CHEMBL1322755 & 688810 & 4.833 & 5.3683 & TRN & & \\
\hline CHEMBL1521125 & 688810 & 4.783 & 4.8883 & TST & & \\
\hline CHEMBL1448844 & 688810 & 5.433 & 5.2863 & TRN & & \\
\hline CHEMBL1335489 & 688810 & 6.9329 & 5.9946 & TRN & & \\
\hline CHEMBL1419289 & 688810 & \multicolumn{3}{|c|}{5.582999999999999} & 5.2777 & \\
\hline CHEMBL1569407 & 688810 & 5.183 & 5.5085 & TRN & & \\
\hline CHEMBL1510242 & 688810 & \multicolumn{3}{|c|}{5.332999999999999} & 5.0454 & \\
\hline CHEMBL1540211 & 688810 & \multicolumn{3}{|c|}{4.7330000000000005} & 4.947 & \\
\hline CHEMBL1511813 & 688810 & 4.833 & 5.3262 & TST & & \\
\hline CHEMBL1421807 & 688810 & \multicolumn{3}{|c|}{5.5329999999999995} & 5.5459 & \\
\hline CHEMBL1479386 & 688810 & 5.933 & 5.0697 & TRN & & \\
\hline CHEMBL1418430 & 688810 & 4.833 & 5.0558 & TRN & & \\
\hline CHEMBL1473619 & 688810 & 5.033 & 4.9934 & TST & & \\
\hline CHEMBL1317524 & 688810 & \multicolumn{3}{|c|}{5.382999999999999} & 5.4164 & \\
\hline CHEMBL1442500 & 688810 & \multicolumn{3}{|c|}{5.382999999999999} & 5.5962 & \\
\hline CHEMBL1499489 & 688810 & \multicolumn{3}{|c|}{6.0329999999999995} & 5.5898 & \\
\hline CHEMBL1501734 & 688810 & \multicolumn{3}{|c|}{5.632999999999999} & 5.4269 & \\
\hline CHEMBL1381634 & 688810 & \multicolumn{3}{|c|}{5.2829999999999995} & 5.3499 & \\
\hline CHEMBL1465736 & 688810 & \multicolumn{3}{|c|}{5.882999999999999} & 5.5903 & \\
\hline CHEMBL1993565 & 688810 & \multicolumn{3}{|c|}{5.2829999999999995} & 4.7462 & \\
\hline CHEMBL1580432 & 688810 & \multicolumn{3}{|c|}{4.9830000000000005} & 4.6746 & \\
\hline CHEMBL1408818 & 688810 & 4.783 & 5.303 & TRN & & \\
\hline CHEMBL1608314 & 688810 & 4.683 & 5.1347 & TRN & & \\
\hline CHEMBL1473022 & 688810 & 4.933 & 5.1859 & TRN & & \\
\hline CHEMBL1493633 & 688810 & 4.633 & 5.0164 & TST & & \\
\hline CHEMBL1498481 & 688810 & 5.683 & 5.2519 & TRN & & \\
\hline CHEMBL3193439 & 688810 & 4.933 & 5.0036 & TRN & & \\
\hline CHEMBL1404858 & 688810 & 5.233 & 5.5736 & TRN & & \\
\hline CHEMBL1489205 & 688810 & 4.833 & 5.3132 & TRN & & \\
\hline CHEMBL 3195772 & 688810 & 5.033 & 4.9716 & TST & & \\
\hline CHEMBL1311793 & 688810 & 5.183 & 5.476 & TRN & & \\
\hline CHEMBL1406436 & 688810 & 4.833 & 4.7111 & TRN & & \\
\hline CHEMBL1537329 & 688810 & 5.8329 & 7999999 & & 5.4681 & \\
\hline CHEMBL1517869 & 688810 & 5.733 & 5.3598 & TRN & & \\
\hline CHEMBL476190 & 688810 & 5.183 & 5.1903 & TST & & \\
\hline CHEMBL1328746 & 688810 & 4.9830 & 3000000 & 005 & 5.2122 & \\
\hline CHEMBL1575746 & 688810 & 4.933 & 5.1984 & TRN & & \\
\hline CHEMBL1484882 & 688810 & 4.933 & 5.206 & TRN & & \\
\hline CHEMBL1401381 & 688810 & 4.9830 & 000000 & 005 & 5.0384 & . \\
\hline CHEMBL1407085 & 688810 & 4.933 & 5.1852 & TRN & & \\
\hline
\end{tabular}




\begin{tabular}{|c|c|c|c|c|c|c|}
\hline \multirow{3}{*}{$\begin{array}{l}\text { CHEMBL1315269 } \\
\text { CHEMBL1540700 }\end{array}$} & \multirow{3}{*}{$\begin{array}{l}688810 \\
688810\end{array}$} & \multicolumn{5}{|c|}{ Supplemental Table S2.txt } \\
\hline & & \multicolumn{3}{|c|}{5.332999999999999} & \multirow[t]{2}{*}{5.0187} & \multirow[t]{2}{*}{ TRN } \\
\hline & & 4.783 & 5.4149 & TRN & & \\
\hline CHEMBL1351997 & 688810 & \multicolumn{3}{|c|}{5.382999999999999} & \multirow[t]{3}{*}{5.0759} & \\
\hline CHEMBL1586886 & 688810 & 4.633 & 5.1012 & TST & & \\
\hline CHEMBL1590010 & 588810 & 4.583 & 4.5362 & TRN & & \\
\hline CHEMBL1538778 & 688810 & \multicolumn{3}{|c|}{5.132999999999999} & \multirow[t]{3}{*}{4.9356} & \\
\hline CHEMBL1410571 & 688810 & 4.833 & 5.4691 & TRN & & \\
\hline CHEMBL1339679 & 688810 & 4.783 & 5.3765 & TRN & & \\
\hline CHEMBL1508155 & 688810 & \multicolumn{3}{|c|}{4.7330000000000005} & 5.0508 & \\
\hline CHEMBL1569621 & 688810 & 6.433 & 5.91 & TRN & & \\
\hline CHEMBL3192530 & 688810 & \multicolumn{3}{|c|}{4.9830000000000005} & 4.9915 & \\
\hline CHEMBL2369275 & 688810 & 4.583 & 5.2274 & TRN & & \\
\hline CHEMBL1478485 & 688810 & \multicolumn{3}{|c|}{5.132999999999999} & 5.1794 & \\
\hline CHEMBL1526193 & 688810 & 4.833 & 5.4014 & TRN & & \\
\hline CHEMBL1340958 & 688810 & \multicolumn{3}{|c|}{4.7330000000000005} & 5.2723 & \\
\hline CHEMBL1504438 & 688810 & 6.983 & 5.5749 & TRN & & \\
\hline HEMBL1320653 & 688810 & \multicolumn{3}{|c|}{4.9830000000000005} & 5.2022 & \\
\hline CHEMBL1583650 & 688810 & \multicolumn{3}{|c|}{6.5329999999999995} & 5.8186 & \\
\hline CHEMBL1325178 & 688810 & \multicolumn{3}{|c|}{5.7829999999999995} & 5.4443 & \\
\hline CHEMBL3195095 & 688810 & 4.783 & 5.2864 & TRN & & \\
\hline CHEMBL 1321350 & 688810 & 5.083 & 5.1997 & TST & & \\
\hline HEMBL & 688 & \multicolumn{3}{|c|}{5.2829999999999995} & 5 & \\
\hline CHEMBL: & 688810 & 5.683 & 5.2556 & TRN & & \\
\hline CHEMBL3191599 & 688810 & 4.933 & 5.4565 & TRN & & \\
\hline CHEMBL1389613 & 688810 & 5.683 & 5.0396 & TST & & \\
\hline CHEMBL1388817 & 688810 & \multicolumn{3}{|c|}{5.5329999999999995} & 5.6486 & \\
\hline CHEMB & 688 & \multicolumn{3}{|c|}{4.9830000000000005} & 5.4796 & \\
\hline CHEMBL & 688810 & 5.933 & 5.5098 & TRN & & \\
\hline CHEMBL1411617 & 688810 & \multicolumn{3}{|c|}{5.2829999999999995} & 5.8197 & \\
\hline CHEMBL1607817 & 688810 & 5.6329 & 99999999 & & 5.2246 & \\
\hline CHEMBL234583 & 688810 & 6.433 & 5.9773 & TRN & & \\
\hline CHEMB & 688 & 5.8329 & 99999 & & 5.6291 & \\
\hline CHEMB & 688810 & 4.783 & 4.6694 & TRN & & \\
\hline CHEMBL1563898 & 688810 & 4.783 & 5.1989 & TST & & \\
\hline CHEMBL1415519 & 688810 & 5.083 & 5.3333 & TST & & \\
\hline CHEMBL1606451 & 688 & 5 . & 5.3129 & TRN & & \\
\hline CHEMB & 688810 & 4.633 & 4.9561 & TRN & & \\
\hline CHEMBL1 & 688810 & 4.583 & 5.1399 & TRN & & \\
\hline CHEMBL1500961 & 688810 & 5.3829 & 99999999 & & 5.2863 & \\
\hline CHEMBL1329097 & 688810 & 5.3329 & 99999999 & & 4.8911 & \\
\hline CHEMBL1444565 & 688810 & 5.5329 & 99999999 & 995 & 5.3024 & \\
\hline CHEMBL1603125 & 688810 & 5.183 & 5.1395 & TRN & & \\
\hline CHEMBL1500474 & 688810 & 5.933 & 5.1891 & TRN & & \\
\hline CHEMBL1595727 & 688810 & 6.0329 & 99999999 & 995 & 5.2779 & \\
\hline CHEMBL1570824 & 688810 & 5.683 & 5.282 & TRN & & \\
\hline CHEMBL1332909 & 688810 & 5.683 & 5.5201 & TRN & & \\
\hline CHEMBL3195060 & 688810 & 5.433 & 5.2217 & TRN & & \\
\hline CHEMBL1463435 & 688810 & 6.7829 & 99999999 & 995 & 5.7776 & \\
\hline
\end{tabular}




\begin{tabular}{|c|c|c|c|c|c|c|c|}
\hline \multicolumn{8}{|c|}{ 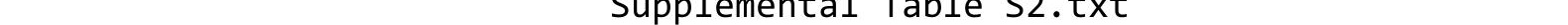 } \\
\hline CHEMBL1429466 & 688810 & 4.933 & 5.6957 & TRN & & & \\
\hline CHEMBL1977473 & 688810 & 4.783 & 5.1175 & TST & & & \\
\hline CHEMBL1575487 & 688810 & 4.633 & 5.2589 & TST & & & \\
\hline CHEMBL1452029 & 688810 & 5.083 & 5.0115 & TRN & & & \\
\hline CHEMBL1559133 & 688810 & 5.433 & 5.1114 & TST & & & \\
\hline CHEMBL1543899 & 688810 & 4.633 & 4.9677 & TST & & & \\
\hline CHEMBL1420295 & 688810 & \multicolumn{3}{|c|}{5.5329999999999995} & 4.9294 & TRN & \\
\hline CHEMBL1506996 & 688810 & 4.783 & 5.3837 & TRN & & & \\
\hline CHEMBL1555359 & 688810 & 5.733 & 5.4685 & TRN & & & \\
\hline CHEMBL1548007 & 688810 & 5.083 & 5.386 & TRN & & & \\
\hline CHEMBL1326791 & 688810 & \multicolumn{3}{|c|}{4.7330000000000005} & 4.9167 & TST & \\
\hline CHEMBL1396485 & 688810 & \multicolumn{3}{|c|}{5.632999999999999} & 5.9308 & TRN & \\
\hline CHEMBL 3213893 & 688810 & 5.683 & 5.6291 & TST & & & \\
\hline CHEMBL1484454 & 688810 & \multicolumn{3}{|c|}{6.332999999999999} & 6.1734 & TRN & \\
\hline CHEMBL1413793 & 688810 & \multicolumn{3}{|c|}{5.5329999999999995} & 5.5786 & TRN & \\
\hline CHEMBL1409053 & 688810 & 6.233 & 5.3071 & TRN & & & \\
\hline CHEMBL1592366 & 688810 & \multicolumn{3}{|c|}{5.632999999999999} & \multicolumn{2}{|c|}{5.172000000000001} & TRN \\
\hline CHEMBL1520843 & 688810 & \multirow{2}{*}{\multicolumn{3}{|c|}{$\begin{array}{l}5.132999999999999 \\
4.7330000000000005\end{array}$}} & 5.5461 & TRN & \\
\hline CHEMBL1610996 & 688810 & & & & 5.61299 & 99999999995 & TRN \\
\hline CHEMBL1595763 & 688810 & 4.583 & 5.3684 & TST & & & \\
\hline CHEMBL1392852 & 688810 & 5.033 & 5.0261 & TRN & & & \\
\hline CHEMBL 3208632 & 688810 & \multicolumn{3}{|c|}{6.332999999999999} & 5.0627 & TST & \\
\hline CHEMBL1472197 & 688810 & \multicolumn{3}{|c|}{5.882999999999999} & 5.3437 & TST & \\
\hline CHEMBL 3214630 & 688810 & 4.783 & 5.125 & TST & & & \\
\hline CHEMBL1383436 & 688810 & 5.483 & 5.2926 & TRN & & & \\
\hline CHEMBL1531037 & 688810 & \multicolumn{3}{|c|}{5.7829999999999995} & 5.7474 & TRN & \\
\hline CHEMBL1997288 & 688810 & 4.783 & 4.9346 & TRN & & & \\
\hline CHEMBL1386094 & 688810 & \multicolumn{3}{|c|}{5.382999999999999} & 5.0539 & TRN & \\
\hline CHEMBL1360015 & 688810 & \multicolumn{3}{|c|}{4.7330000000000005} & 5.0611 & TRN & \\
\hline CHEMBL1423729 & 688810 & 5.083 & 5.9576 & TRN & & & \\
\hline CHEMBL1325231 & 688810 & & & TRN & & & \\
\hline CHEMBL1409398 & 688810 & \multicolumn{3}{|c|}{5.2829999999999995} & 5.1949 & TST & \\
\hline CHEMBL1458511 & 688810 & 4.833 & 5.5198 & TRN & & & \\
\hline CHEMBL1409305 & 688810 & 5.083 & 4.8587 & TST & & & \\
\hline CHEMBL1372459 & 688810 & 4.783 & 5.1229 & TRN & & & \\
\hline CHEMBL1383315 & 688810 & \multicolumn{3}{|c|}{5.132999999999999} & 5.0228 & TST & \\
\hline CHEMBL1597833 & 688810 & \multicolumn{3}{|c|}{4.9830000000000005} & 5.6289 & TRN & \\
\hline CHEMBL1401001 & 688810 & \multicolumn{3}{|c|}{5.132999999999999} & 5.6022 & TRN & \\
\hline CHEMBL1449964 & 688810 & 5.683 & 5.2127 & TRN & & & \\
\hline CHEMBL1376293 & 688810 & 4.783 & 4.8483 & TRN & & & \\
\hline CHEMBL1454222 & 688810 & \multicolumn{3}{|c|}{5.7829999999999995} & 5.3306 & TRN & \\
\hline CHEMBL1604696 & 688810 & 6.433 & 5.7887 & TRN & & & \\
\hline CHEMBL1586168 & 688810 & 5.433 & 5.0486 & TRN & & & \\
\hline CHEMBL3209853 & 688810 & 5.733 & 5.255 & TRN & & & \\
\hline CHEMBL1419688 & 688810 & 6.183 & 5.4167 & TST & & & \\
\hline CHEMBL1317812 & 688810 & 4.583 & 4.8057 & TRN & & & \\
\hline CHEMBL1566609 & 688810 & 4.583 & 5.1856 & TRN & & & \\
\hline CHEMBL1579260 & 688810 & 5.033 & 5.3159 & TRN & & & \\
\hline
\end{tabular}




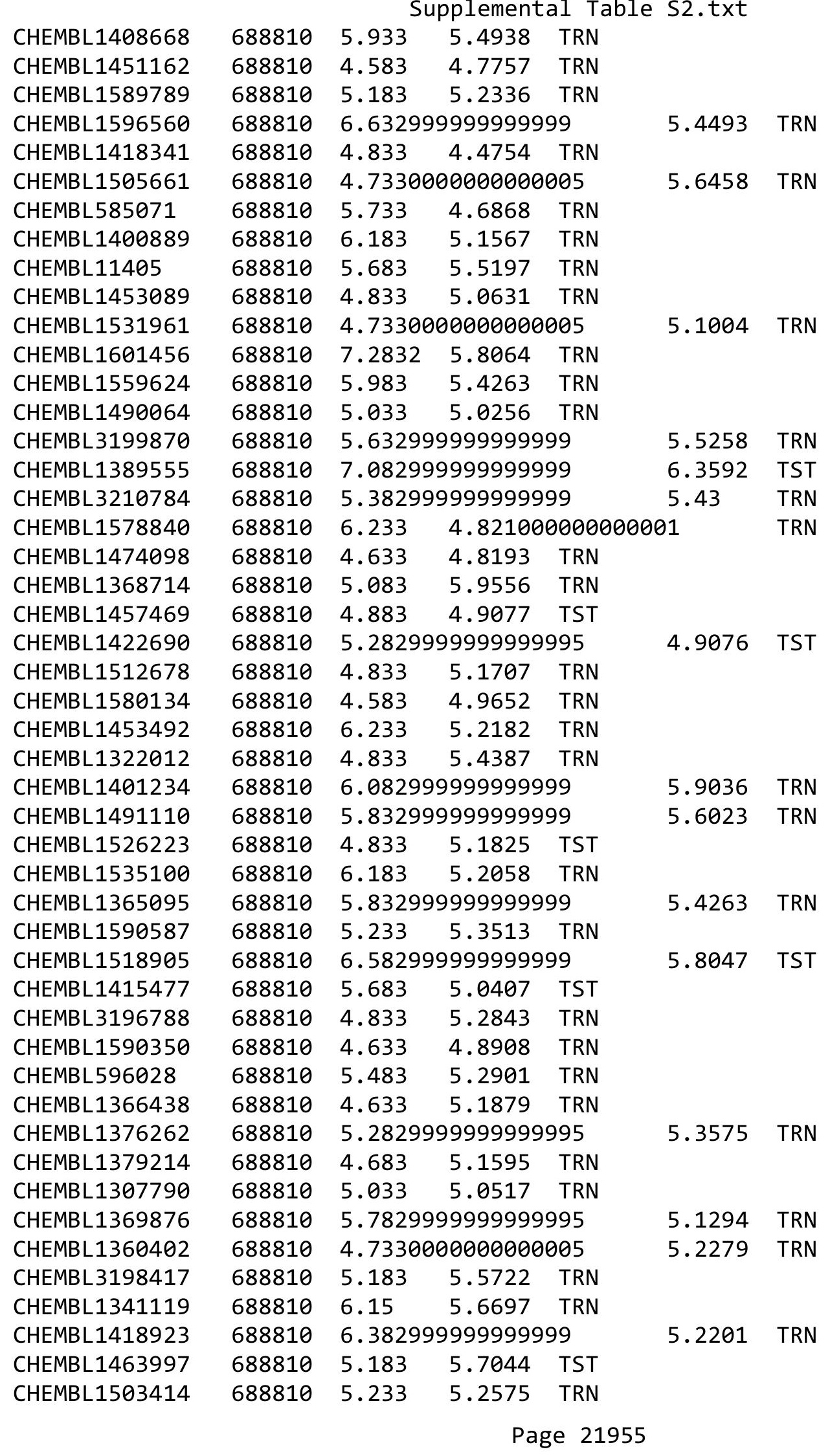




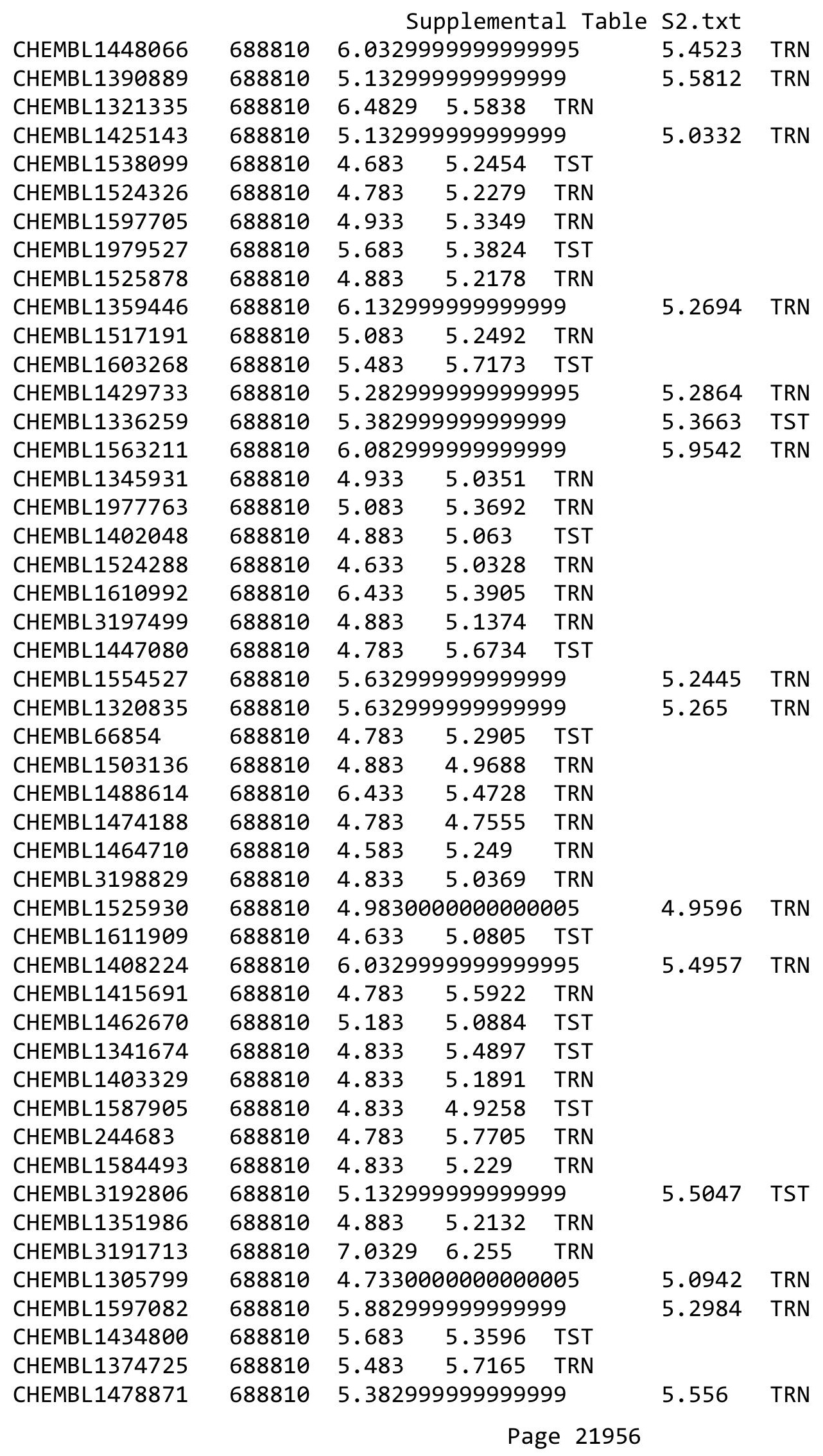




\begin{tabular}{|c|c|c|c|c|c|c|}
\hline & & \multicolumn{5}{|c|}{ Supplemental Table s2.txt } \\
\hline CHEMBL1353015 & 688810 & 4.833 & 4.7924 & TRN & & \\
\hline CHEMBL1469912 & 688810 & 5.733 & 4.9566 & TST & & \\
\hline CHEMBL1498228 & 688810 & 4.783 & 5.5035 & TRN & & \\
\hline CHEMBL1340582 & 688810 & 5.183 & 5.6722 & TRN & & \\
\hline CHEMBL1409552 & 688810 & 4.883 & 5.2268 & TRN & & \\
\hline CHEMBL1309733 & 688810 & 4.683 & 4.6893 & TST & & \\
\hline CHEMBL3213348 & 688810 & \multicolumn{3}{|c|}{5.332999999999999} & 5.3361 & TRN \\
\hline CHEMBL1488703 & 688810 & \multicolumn{3}{|c|}{5.132999999999999} & 5.4752 & TRN \\
\hline CHEMBL1565422 & 688810 & 5.483 & 5.1798 & TRN & & \\
\hline CHEMBL1425102 & 688810 & 6.233 & 5.199 & TST & & \\
\hline CHEMBL1313738 & 688810 & \multicolumn{3}{|c|}{5.832999999999999} & 5.7685 & TRN \\
\hline CHEMBL1341325 & 688810 & 4.833 & 5.3746 & TRN & & \\
\hline CHEMBL1324157 & 688810 & \multicolumn{3}{|c|}{5.582999999999999} & 5.5009 & TRN \\
\hline CHEMBL1411545 & 688810 & \multicolumn{3}{|c|}{5.7829999999999995} & 5.686 & TRN \\
\hline CHEMBL1999700 & 688810 & \multicolumn{3}{|c|}{5.7829999999999995} & 5.6446 & TRN \\
\hline CHEMBL1390650 & 688810 & \multicolumn{3}{|c|}{6.7829999999999995} & 5.9043 & TRN \\
\hline CHEMBL1551707 & 688810 & \multicolumn{3}{|c|}{5.832999999999999} & 5.0801 & TRN \\
\hline CHEMBL1585361 & 688810 & \multicolumn{3}{|c|}{4.7330000000000005} & 4.7669 & TST \\
\hline CHEMBL1506065 & 688810 & 5.683 & 5.9464 & TRN & & \\
\hline CHEMBL469424 & 688810 & 4.933 & 4.9032 & TST & & \\
\hline CHEMBL1418121 & 688810 & \multicolumn{3}{|c|}{5.632999999999999} & 5.3298 & TRN \\
\hline CHEMBL1345019 & 688810 & \multicolumn{3}{|c|}{4.7330000000000005} & 5.0599 & TRN \\
\hline CHEMBL1317989 & 688810 & 4.633 & 5.3369 & TRN & & \\
\hline CHEMBL1409644 & 688810 & \multicolumn{3}{|c|}{4.7330000000000005} & 5.1207 & TST \\
\hline CHEMBL227881 & 688810 & \multicolumn{3}{|c|}{5.832999999999999} & 5.4698 & TRN \\
\hline CHEMBL1424687 & 688810 & \multicolumn{3}{|c|}{4.7330000000000005} & 5.2187 & TRN \\
\hline CHEMBL1486395 & 688810 & 4.883 & 5.2876 & TRN & & \\
\hline CHEMBL1363474 & 688810 & \multirow{2}{*}{\multicolumn{3}{|c|}{$\begin{array}{lll}4.933 & 5.419 & \text { TRN } \\
5.632999999999999\end{array}$}} & & \\
\hline CHEMBL1486620 & 688810 & & & & 5.581 & TRN \\
\hline CHEMBL1450942 & 688810 & 4.883 & 5.3517 & TRN & & \\
\hline CHEMBL1505427 & 688810 & \multicolumn{3}{|c|}{$\begin{array}{lll}5.683 & 5.4806 & \text { TRN }\end{array}$} & & \\
\hline CHEMBL1527570 & 688810 & \multirow{2}{*}{\multicolumn{3}{|c|}{$\begin{array}{l}5.2829999999999995 \\
4.883 \quad 4.7739 \text { TRN }\end{array}$}} & 5.5874 & TRN \\
\hline CHEMBL1601781 & 688810 & & & & & \\
\hline CHEMBL1310806 & 688810 & \multicolumn{3}{|c|}{4.7330000000000005} & 5.1977 & TST \\
\hline CHEMBL1612935 & 688810 & 5.683 & 5.688 & TRN & & \\
\hline CHEMBL1577702 & 688810 & 4.833 & 4.9578 & TRN & & \\
\hline CHEMBL1424483 & 688810 & 5.083 & 4.8967 & TRN & & \\
\hline CHEMBL1540231 & 688810 & 4.633 & 4.341 & TST & & \\
\hline CHEMBL1561191 & 688810 & \multicolumn{3}{|c|}{4.7330000000000005} & 5.4716 & TRN \\
\hline CHEMBL472839 & 688810 & 5.433 & 5.6828 & TRN & & \\
\hline CHEMBL1399453 & 688810 & \multicolumn{3}{|c|}{6.132999999999999} & 5.2326 & TRN \\
\hline CHEMBL1434212 & 688810 & 4.833 & 5.2329 & TST & & \\
\hline CHEMBL1544838 & 688810 & 4.783 & 5.0733 & TST & & \\
\hline CHEMBL1520121 & 688810 & 6.3829 & 99999999 & & 5.8418 & TRN \\
\hline CHEMBL1586425 & 688810 & 5.433 & 4.8117 & TRN & & \\
\hline CHEMBL1447829 & 688810 & 4.633 & 5.2098 & TRN & & \\
\hline CHEMBL1500421 & 688810 & 6.233 & 5.7387 & TRN & & \\
\hline CHEMBL1408098 & 688810 & 4.833 & 5.4078 & TRN & & \\
\hline
\end{tabular}




\begin{tabular}{|c|c|c|c|c|c|c|c|}
\hline \multirow[b]{2}{*}{ CHEMBL472929 } & \multicolumn{6}{|c|}{ 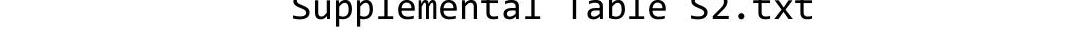 } & \\
\hline & 688810 & 6.4829 & 5.9316 & TRN & & & \\
\hline CHEMBL1302089 & 688810 & 5.983 & 5.1752 & TRN & & & \\
\hline CHEMBL1992088 & 688810 & 4.73300 & 00000000 & 005 & 5.1379 & TRN & \\
\hline CHEMBL1372313 & 688810 & 4.833 & 5.0658 & TST & & & \\
\hline CHEMBL1344214 & 688810 & 4.833 & 5.0803 & TRN & & & \\
\hline CHEMBL1450168 & 688810 & 5.38299 & 99999999 & & 5.636 & TRN & \\
\hline CHEMBL1522846 & 688810 & 4.883 & 5.154 & TST & & & \\
\hline CHEMBL1389047 & 688810 & 5.433 & 5.8147 & TRN & & & \\
\hline CHEMBL1542428 & 688810 & 5.483 & 5.182 & TRN & & & \\
\hline CHEMBL1540682 & 688810 & 5.58299 & 99999999 & & 5.2196 & TST & \\
\hline CHEMBL1451769 & 688810 & 6.28299 & 99999999 & 995 & 5.8361 & TRN & \\
\hline CHEMBL3192181 & 688810 & 5.28299 & 99999999 & 995 & 5.5888 & TRN & \\
\hline CHEMBL1515160 & 688810 & 4.583 & 5.0709 & TRN & & & \\
\hline CHEMBL600734 & 688810 & 5.033 & 5.0204 & TST & & & \\
\hline CHEMBL1991888 & 688810 & 4.633 & 4.8566 & TST & & & \\
\hline CHEMBL1371993 & 688810 & 4.73300 & 00000000 & 005 & 5.4455 & TST & \\
\hline CHEMBL1607159 & 688810 & 6.183 & 5.8737 & TRN & & & \\
\hline CHEMBL1585055 & 688810 & 5.983 & 6.0708 & TRN & & & \\
\hline CHEMBL1540114 & 688810 & 5.53299 & 99999999 & 995 & 5.2107 & TRN & \\
\hline CHEMBL1385654 & 688810 & 4.883 & 4.881 & TRN & & & \\
\hline CHEMBL1448037 & 688810 & 5.58299 & 99999999 & & 5.5833 & TRN & \\
\hline CHEMBL1548916 & 688810 & 5.733 & 5.7018 & TRN & & & \\
\hline CHEMBL1996833 & 688810 & 5.733 & 5.605 & TRN & & & \\
\hline CHEMBL1346290 & 688810 & 4.833 & 5.3306 & TST & & & \\
\hline CHEMBL1500367 & 688810 & 4.883 & 5.2455 & TRN & & & \\
\hline CHEMBL1378956 & 688810 & 4.833 & 4.9176 & TRN & & & \\
\hline CHEMBL1471524 & 688810 & 4.98300 & 00000000 & 005 & 5.5520 & 00000000005 & TST \\
\hline CHEMBL1591131 & 688810 & 5.38299 & 99999999 & & 5.4383 & TRN & \\
\hline CHEMBL3194491 & 688810 & 4.933 & 5.0949 & TRN & & & \\
\hline CHEMBL1999551 & 688810 & 4.583 & 5.5689 & TRN & & & \\
\hline CHEMBL1376611 & 688810 & 6.33299 & 99999999 & & 5.4529 & 9999999999 & TRN \\
\hline CHEMBL1566684 & 688810 & 4.73300 & 00000000 & 005 & 4.9599 & TST & \\
\hline CHEMBL1589772 & 688810 & 4.783 & 5.3428 & TRN & & & \\
\hline CHEMBL1317677 & 688810 & 4.98300 & 00000000 & 005 & 5.0742 & TST & \\
\hline CHEMBL3198709 & 688810 & 5.13299 & 99999999 & & 5.7157 & TRN & \\
\hline CHEMBL1563500 & 688810 & 7.0329 & 5.4085 & TRN & & & \\
\hline CHEMBL1551472 & 688810 & 5.733 & 5.5645 & TRN & & & \\
\hline CHEMBL1417723 & 688810 & 4.633 & 5.1227 & TRN & & & \\
\hline CHEMBL1313436 & 688810 & 6.433 & 5.8014 & TRN & & & \\
\hline CHEMBL1981570 & 688810 & 5.233 & 5.8759 & TRN & & & \\
\hline CHEMBL600034 & 688810 & 5.78299 & 99999999 & 995 & 5.5710 & 0000000001 & TRN \\
\hline CHEMBL1361268 & 688810 & 6.28299 & 99999999 & 995 & 5.5377 & TRN & \\
\hline CHEMBL1588511 & 688810 & 5.78299 & 99999999 & 995 & 5.9676 & TRN & \\
\hline CHEMBL1429317 & 688810 & 4.783 & 5.1942 & TRN & & & \\
\hline CHEMBL1500923 & 688810 & 7.2328 & 6.6892 & TRN & & & \\
\hline CHEMBL1453314 & 688810 & 6.08299 & 99999999 & & 4.8301 & TST & \\
\hline CHEMBL1546266 & 688810 & 5.88299 & 99999999 & & 5.1123 & TRN & \\
\hline CHEMBL1567560 & 688810 & 5.683 & 5.3177 & TRN & & & \\
\hline
\end{tabular}




\begin{tabular}{|c|c|c|c|c|c|c|}
\hline & & & pptemer & 等 & & \\
\hline CHEMBL1581319 & 688810 & 4.783 & 5.4201 & TRN & & \\
\hline CHEMBL3198173 & 688810 & 4.783 & 4.6778 & TRN & & \\
\hline CHEMBL1314830 & 688810 & 5.183 & 5.0193 & TST & & \\
\hline CHEMBL1609498 & 688810 & 5.8329 & 99999999 & 99 & 5.8763 & TRN \\
\hline CHEMBL1394243 & 688810 & 4.633 & 5.2117 & TRN & & \\
\hline CHEMBL1577228 & 688810 & 5.8329 & 99999999 & 99 & 5.4282 & TRN \\
\hline CHEMBL1564792 & 688810 & 6.3329 & 99999999 & 99 & 5.9037 & TRN \\
\hline CHEMBL3189872 & 688810 & 6.2829 & 99999999 & 995 & 5.3129 & TRN \\
\hline CHEMBL3192269 & 688810 & 5.233 & 5.1709 & TRN & & \\
\hline CHEMBL1437734 & 688810 & 5.183 & 4.8421 & TRN & & \\
\hline CHEMBL1498372 & 688810 & 4.783 & 5.5767 & TST & & \\
\hline CHEMBL1334187 & 688810 & 5.1329 & 99999999 & 99 & 5.289 & TRN \\
\hline CHEMBL1566498 & 688810 & 6.0 & 5.9612 & TRN & & \\
\hline CHEMBL1580838 & 688810 & 5.5329 & 99999999 & 995 & 5.3895 & TRN \\
\hline CHEMBL1354016 & 688810 & 5.3329 & 99999999 & 99 & 5.6531 & TRN \\
\hline CHEMBL1377507 & 688810 & 7.3829 & 99999999 & 99 & 5.1353 & TST \\
\hline CHEMBL1570242 & 688810 & 5.233 & 5.4317 & TST & & \\
\hline CHEMBL3192850 & 688810 & 4.633 & 5.7537 & TRN & & \\
\hline CHEMBL1456323 & 688810 & 4.833 & 5.6379 & TST & & \\
\hline CHEMBL1482053 & 688810 & 5.233 & 4.9436 & TST & & \\
\hline CHEMBL1594554 & 688810 & 6.1329 & 99999999 & 99 & 5.4368 & TRN \\
\hline CHEMBL1551400 & 688810 & 5.683 & 5.7183 & TRN & & \\
\hline CHEMBL1510039 & 688810 & 4.9830 & 00000000 & 005 & 5.2331 & TRN \\
\hline CHEMBL1362448 & 688810 & 4.883 & 5.5629 & TST & & \\
\hline CHEMBL1536621 & 688810 & 5.2829 & 99999999 & 995 & 5.3808 & TRN \\
\hline CHEMBL1462713 & 688810 & 6.6329 & 99999999 & & 5.7349 & TRN \\
\hline CHEMBL1520528 & 688810 & 4.933 & 5.2715 & TRN & & \\
\hline CHEMBL1537619 & 688810 & 6.433 & 5.5957 & TRN & & \\
\hline CHEMBL1335644 & 688810 & 5.6329 & 99999999 & & 5.3569 & TRN \\
\hline CHEMBL1534915 & 688810 & 6.233 & 5.6485 & TST & & \\
\hline CHEMBL1989110 & 688810 & 5.183 & 4.8283 & TRN & & \\
\hline CHEMBL1392956 & 688810 & 4.7330 & 00000000 & 005 & 5.2859 & TRN \\
\hline CHEMBL1454916 & 688810 & 4.933 & 5.4317 & TRN & & \\
\hline CHEMBL1994683 & 688810 & 5.8829 & 99999999 & & 5.9224 & TRN \\
\hline CHEMBL1598732 & 688810 & 5.733 & 5.1556 & TST & & \\
\hline CHEMBL1358604 & 688810 & 4.683 & 4.9402 & TST & & \\
\hline CHEMBL1554004 & 688810 & 4.833 & 5.2524 & TST & & \\
\hline CHEMBL1542161 & 688810 & 5.083 & 5.2641 & TST & & \\
\hline CHEMBL1559251 & 688810 & 5.5329 & 99999999 & 995 & 6.3476 & TRN \\
\hline CHEMBL3199613 & 688810 & 6.5329 & 99999999 & 995 & 5.3619 & TRN \\
\hline CHEMBL3193478 & 688810 & 4.833 & 4.8129 & TST & & \\
\hline CHEMBL1399134 & 688810 & 6.683 & 5.3586 & TRN & & \\
\hline CHEMBL3213188 & 688810 & 4.9830 & 00000000 & 005 & 5.2428 & TRN \\
\hline CHEMBL1390469 & 688810 & 4.933 & 4.8136 & TST & & \\
\hline CHEMBL1605104 & 688810 & 5.5329 & 99999999 & 995 & 5.6397 & TRN \\
\hline CHEMBL3194259 & 688810 & 6.2829 & 99999999 & 995 & 5.4952 & TRN \\
\hline CHEMBL1575514 & 688810 & 4.933 & 5.4884 & TRN & & \\
\hline CHEMBL1531041 & 688810 & 5.683 & 5.6426 & TRN & & \\
\hline
\end{tabular}




\begin{tabular}{|c|c|c|c|c|c|c|c|}
\hline \multirow[b]{2}{*}{ CHEMBL1343476 } & \multicolumn{6}{|c|}{ 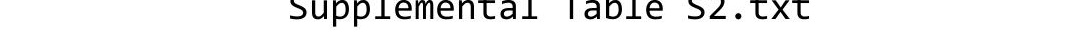 } & \\
\hline & 688810 & 5.483 & 5.5733 & TRN & & & \\
\hline CHEMBL 3198155 & 688810 & 5.433 & 5.0396 & TRN & & & \\
\hline CHEMBL1603335 & 688810 & 4.633 & 4.9265 & TST & & & \\
\hline CHEMBL1497597 & 688810 & 4.633 & 4.6248 & TRN & & & \\
\hline CHEMBL1354427 & 688810 & 4.883 & 5.4531 & TST & & & \\
\hline CHEMBL1498966 & 688810 & \multicolumn{3}{|c|}{6.0329999999999995} & 5.4726 & TST & \\
\hline CHEMBL1471132 & 688810 & 4.883 & 5.2201 & TRN & & & \\
\hline CHEMBL1524310 & 688810 & \multicolumn{3}{|c|}{5.832999999999999} & 5.2162 & TST & \\
\hline CHEMBL1593290 & 688810 & \multicolumn{3}{|c|}{5.382999999999999} & 5.3608 & TRN & \\
\hline CHEMBL1465527 & 688810 & \multicolumn{3}{|c|}{5.582999999999999} & 5.21700 & $\partial 0000000005$ & TST \\
\hline CHEMBL1301725 & 688810 & \multicolumn{3}{|c|}{5.7829999999999995} & 5.1036 & TRN & \\
\hline CHEMBL1454258 & 688810 & 5.183 & 5.1676 & TRN & & & \\
\hline CHEMBL1487993 & 688810 & \multicolumn{3}{|c|}{4.7330000000000005} & 4.8908 & TRN & \\
\hline CHEMBL1625031 & 688810 & 4.683 & 4.7329 & TRN & & & \\
\hline CHEMBL1396837 & 688810 & 6.183 & 5.2844 & TST & & & \\
\hline CHEMBL1581143 & 688810 & 4.833 & 5.4804 & TRN & & & \\
\hline CHEMBL1500438 & 688810 & 4.783 & 5.1964 & TRN & & & \\
\hline CHEMBL1536104 & 688810 & 5.733 & 5.9504 & TRN & & & \\
\hline CHEMBL1586373 & 688810 & \multicolumn{3}{|c|}{5.882999999999999} & 5.5128 & TRN & \\
\hline CHEMBL1511523 & 688810 & \multicolumn{3}{|c|}{6.332999999999999} & 4.976 & TST & \\
\hline CHEMBL 3196708 & 688810 & \multicolumn{3}{|c|}{4.7330000000000005} & 5.2292 & TRN & \\
\hline CHEMBL 3211684 & 688810 & \multicolumn{3}{|c|}{4.7330000000000005} & 5.4176 & TST & \\
\hline CHEMBL1517036 & 688810 & \multicolumn{3}{|c|}{5.2829999999999995} & 5.2134 & TRN & \\
\hline CHEMBL1543735 & 688810 & 5.233 & 5.2275 & TST & & & \\
\hline CHEMBL1402896 & 688810 & 4.833 & 5.4766 & TRN & & & \\
\hline CHEMBL1597921 & 688810 & \multicolumn{3}{|c|}{6.332999999999999} & 5.7622 & TRN & \\
\hline CHEMBL3191696 & 688810 & 4.883 & 5.3374 & TRN & & & \\
\hline CHEMBL 3198245 & 688810 & 4.933 & 5.48799 & 999999999 & 95 & TST & \\
\hline CHEMBL1299527 & 688810 & 4.683 & 5.2418 & TRN & & & \\
\hline CHEMBL1578086 & 688810 & 4.883 & 4.8404 & TRN & & & \\
\hline CHEMBL 3195397 & 688810 & \multicolumn{3}{|c|}{6.5329999999999995} & \multicolumn{2}{|c|}{5.3839999999999995} & TRN \\
\hline CHEMBL1582213 & 688810 & \multicolumn{3}{|c|}{4.9830000000000005} & 4.7408 & TST & \\
\hline CHEMBL1369899 & 688810 & 4.683 & 4.8355 & TRN & & & \\
\hline CHEMBL1561614 & 688810 & 4.833 & 4.9404 & TRN & & & \\
\hline CHEMBL 2006856 & 688810 & 5.733 & 5.1039 & TRN & & & \\
\hline CHEMBL1403977 & 688810 & 4.783 & 5.2641 & TRN & & & \\
\hline CHEMBL1362599 & 688810 & 4.783 & 5.0914 & TRN & & & \\
\hline CHEMBL1485879 & 688810 & 4.783 & 5.1163 & TST & & & \\
\hline CHEMBL1412795 & 688810 & 6.7331 & 5.8757 & TRN & & & \\
\hline CHEMBL1553430 & 688810 & \multicolumn{3}{|c|}{5.132999999999999} & 5.1681 & TRN & \\
\hline CHEMBL1471962 & 688810 & 5.683 & 4.9698 & TRN & & & \\
\hline CHEMBL1465006 & 688810 & 6.433 & 5.7506 & TRN & & & \\
\hline CHEMBL1602306 & 688810 & \multicolumn{3}{|c|}{4.7330000000000005} & 4.9933 & TRN & \\
\hline CHEMBL1518278 & 688810 & 5.733 & 5.6447 & TRN & & & \\
\hline CHEMBL1560957 & 688810 & 4.783 & 5.3449 & TRN & & & \\
\hline CHEMBL1410388 & 688810 & \multicolumn{3}{|c|}{5.832999999999999} & 5.3254 & TRN & \\
\hline CHEMBL1442155 & 688810 & 5.183 & 5.3782 & TST & & & \\
\hline CHEMBL1549430 & 688810 & 6.2 & 5.6918 & TRN & & & \\
\hline
\end{tabular}




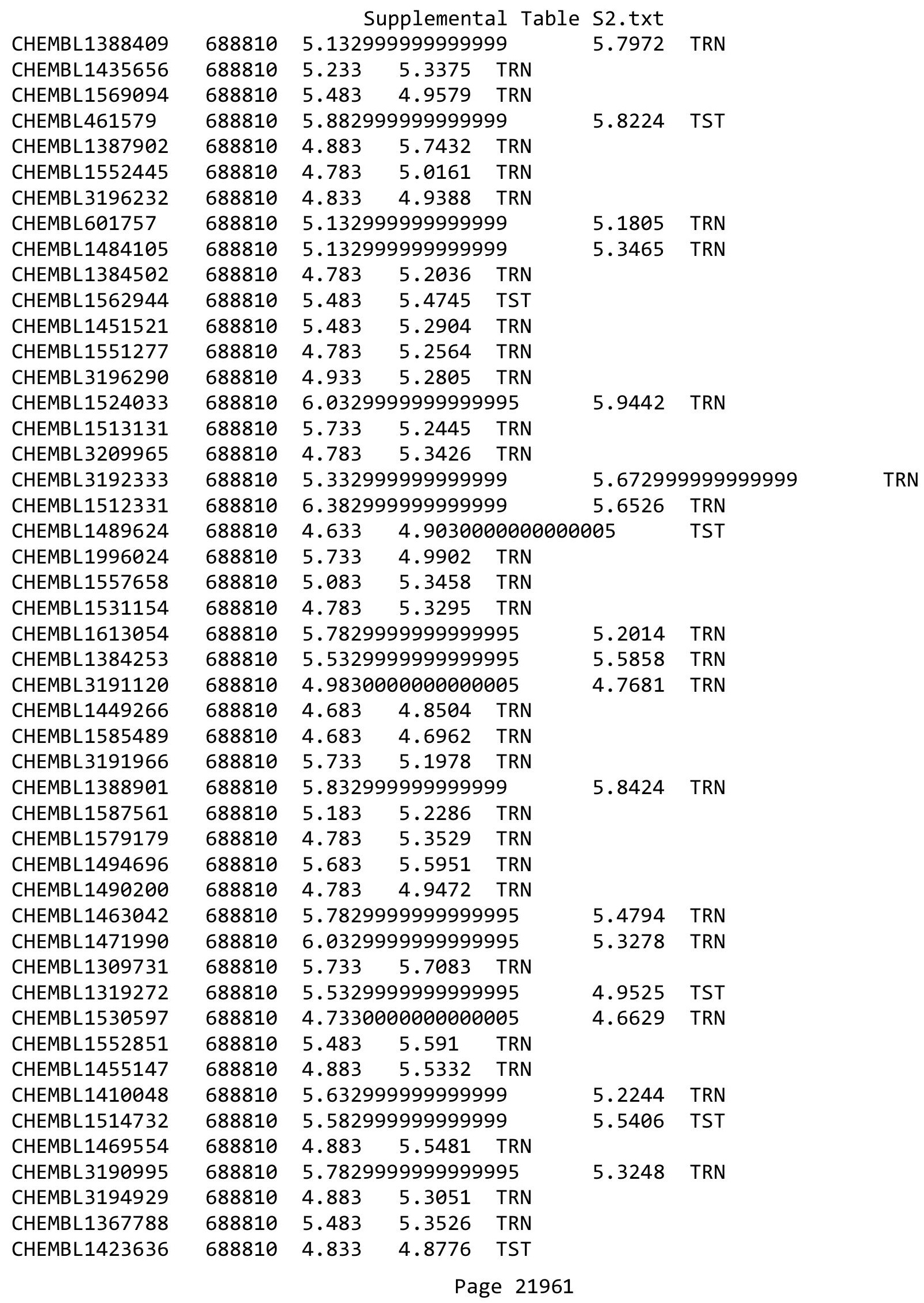




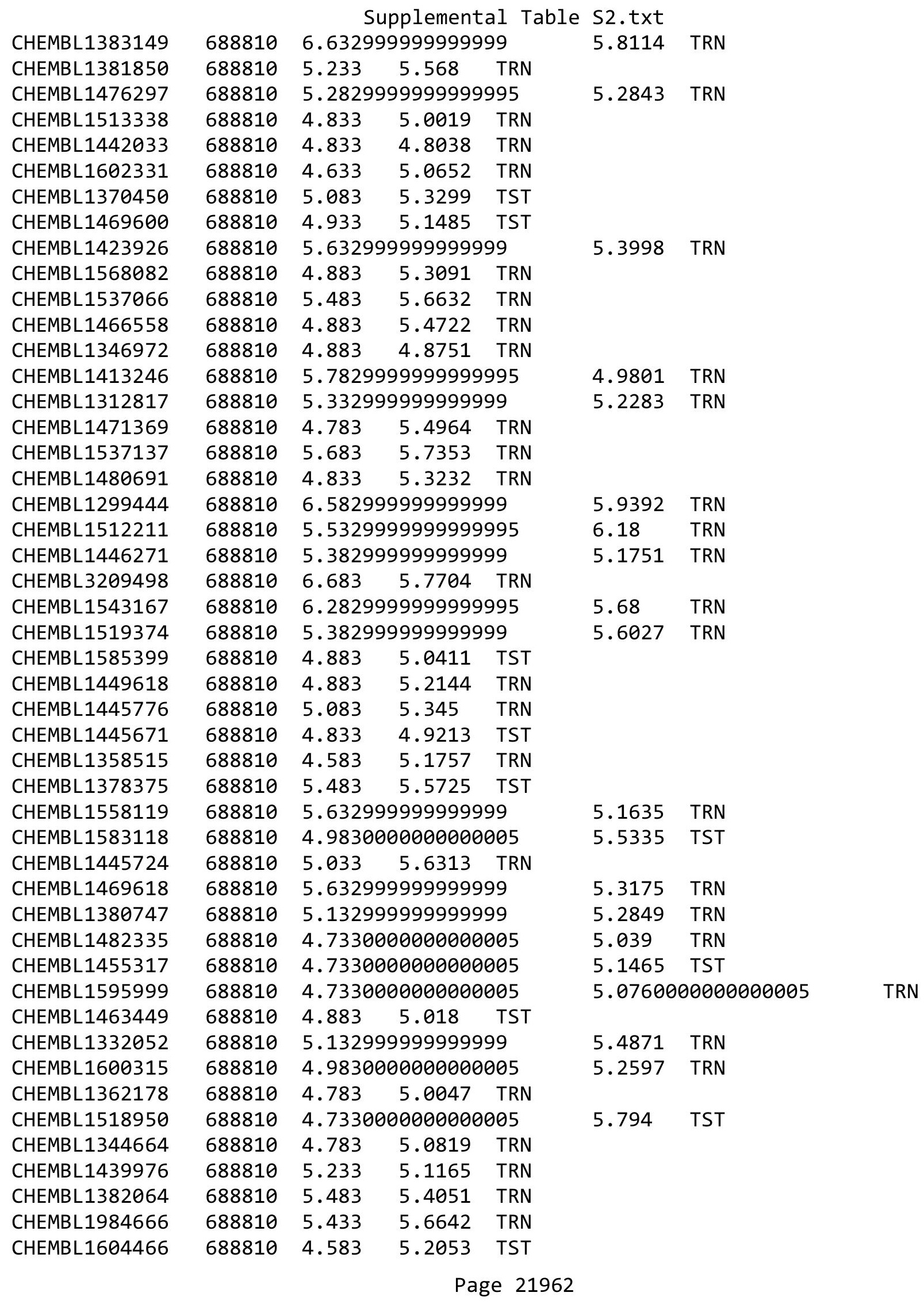




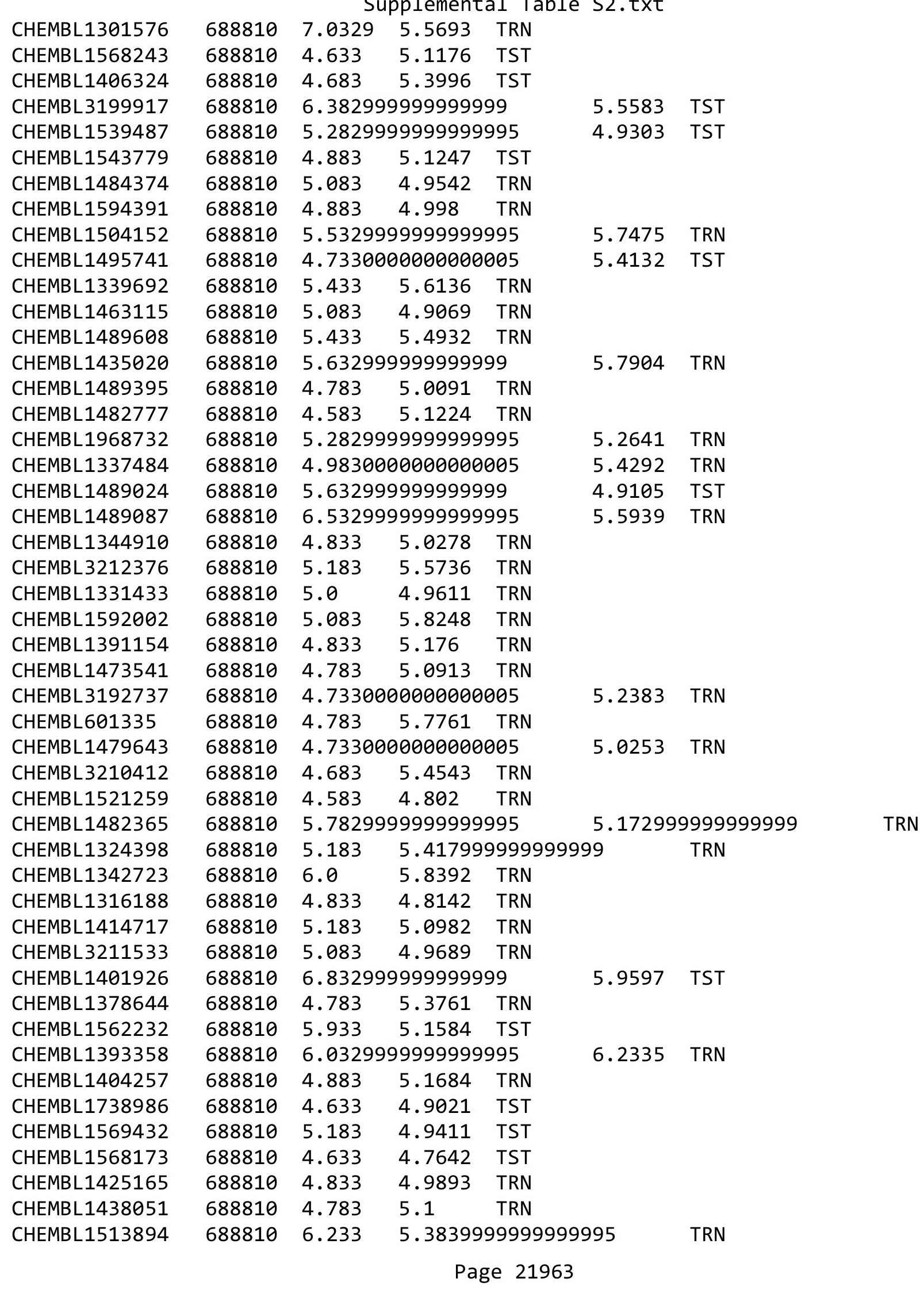




\begin{tabular}{|c|c|c|c|c|c|c|c|}
\hline \multirow[b]{2}{*}{ CHEMBL1412105 } & & \\
\hline & 688810 & 5.683 & 5.4898 & TRN & & & \\
\hline CHEMBL1326439 & 688810 & 4.783 & 5.4096 & TRN & & & \\
\hline CHEMBL1372204 & 688810 & 6.8329 & 99999999 & & 5.7618 & TRN & \\
\hline CHEMBL1391533 & 688810 & 5.8329 & 99999999 & & 5.73 & TRN & \\
\hline CHEMBL1556239 & 688810 & 4.933 & 4.9618 & TST & & & \\
\hline CHEMBL1520607 & 688810 & 5.2829 & 99999999 & 995 & 5.371 & TRN & \\
\hline CHEMBL 3207434 & 688810 & 4.7330 & 00000000 & 005 & 5.1465 & TST & \\
\hline CHEMBL1543015 & 688810 & 5.683 & 5.3619 & TRN & & & \\
\hline CHEMBL1499688 & 688810 & 6.3829 & 99999999 & & 5.4975 & TRN & \\
\hline CHEMBL1558727 & 688810 & 6.9329 & 5.6859 & TRN & & & \\
\hline CHEMBL1324762 & 688810 & 5.1329 & 99999999 & & 5.6702 & TRN & \\
\hline CHEMBL1341802 & 688810 & 5.5329 & 99999999 & 995 & 5.3696 & TRN & \\
\hline CHEMBL1435583 & 688810 & 4.7330 & 00000000 & 005 & 5.2879 & TRN & \\
\hline CHEMBL1316615 & 688810 & 4.583 & 4.8067 & TRN & & & \\
\hline CHEMBL1452421 & 688810 & 5.233 & 5.2271 & TRN & & & \\
\hline CHEMBL1437722 & 688810 & 4.683 & 4.6675 & TRN & & & \\
\hline CHEMBL1495892 & 688810 & 4.933 & 5.3193 & TRN & & & \\
\hline CHEMBL1321519 & 688810 & 5.2829 & 99999999 & 995 & 5.7464 & TRN & \\
\hline CHEMBL1556848 & 688810 & 6.183 & 5.4566 & TRN & & & \\
\hline CHEMBL1428935 & 688810 & 5.3329 & 99999999 & & 5.2668 & TRN & \\
\hline CHEMBL1410758 & 688810 & 5.233 & 5.263 & TRN & & & \\
\hline CHEMBL 3193268 & 688810 & 5.183 & 4.9703 & TRN & & & \\
\hline CHEMBL1414992 & 688810 & 4.783 & 4.9547 & TRN & & & \\
\hline CHEMBL1492519 & 688810 & 4.7330 & 00000000 & 005 & 5.1353 & TST & \\
\hline CHEMBL7724 & 688810 & 6.183 & 5.9002 & TRN & & & \\
\hline CHEMBL1609518 & 688810 & 5.7829 & 99999999 & 995 & 5.6118 & TRN & \\
\hline CHEMBL1569085 & 688810 & 5.233 & 5.38899 & 999999999 & 99 & TRN & \\
\hline CHEMBL1315978 & 688810 & 5.3329 & 99999999 & & 5.8331 & TRN & \\
\hline CHEMBL1480820 & 688810 & 5.6329 & 99999999 & & 5.135 & TRN & \\
\hline CHEMBL1567172 & 688810 & 6.683 & 5.9939 & TRN & & & \\
\hline CHEMBL1385216 & 688810 & 4.883 & 5.3781 & TRN & & & \\
\hline CHEMBL1598426 & 688810 & 5.2829 & 99999999 & 995 & 5.4767 & TST & \\
\hline CHEMBL1613709 & 688810 & 5.033 & 5.1556 & TRN & & & \\
\hline CHEMBL1604076 & 688810 & 4.783 & 5.2697 & TRN & & & \\
\hline CHEMBL1416283 & 688810 & 4.7330 & 00000000 & 005 & 4.8851 & TRN & \\
\hline CHEMBL1972435 & 688810 & 4.833 & 4.823 & TRN & & & \\
\hline CHEMBL1508938 & 688810 & 5.483 & 5.4192 & TRN & & & \\
\hline CHEMBL1537385 & 688810 & 5.733 & 5.7368 & TRN & & & \\
\hline CHEMBL489940 & 688810 & 5.5329 & 99999999 & 995 & 5.2392 & TST & \\
\hline CHEMBL1232179 & 688810 & 5.1329 & 99999999 & & 4.9242 & TRN & \\
\hline CHEMBL 3198120 & 688810 & 4.783 & 5.1384 & TRN & & & \\
\hline CHEMBL1441326 & 688810 & 5.3829 & 99999999 & & 5.55200 & 00000000005 & TST \\
\hline CHEMBL1603017 & 688810 & 6.2829 & 99999999 & 995 & 5.0896 & TRN & \\
\hline CHEMBL1546933 & 688810 & 5.183 & 5.3142 & TST & & & \\
\hline CHEMBL1401242 & 688810 & 6.683 & 6.2674 & TRN & & & \\
\hline CHEMBL1535225 & 688810 & 7.2328 & 6.2115 & TRN & & & \\
\hline CHEMBL1534411 & 688810 & 5.683 & 5.5514 & TRN & & & \\
\hline CHEMBL1368611 & 688810 & 5.2829 & 99999999 & 995 & 5.0713 & TRN & \\
\hline
\end{tabular}




\begin{tabular}{|c|c|c|c|c|c|c|c|}
\hline \multicolumn{7}{|c|}{ Supplemental Table S2.txt } & \\
\hline CHEMBL1518265 & 688810 & \multicolumn{3}{|c|}{4.7330000000000005} & 5.8413 & TRN & \\
\hline CHEMBL1438118 & 688810 & \multicolumn{3}{|c|}{5.132999999999999} & 5.3877 & TST & \\
\hline CHEMBL1310383 & 688810 & \multicolumn{3}{|c|}{4.7330000000000005} & 4.8747 & TST & \\
\hline CHEMBL1593285 & 688810 & 4.783 & 4.7448 & TRN & & & \\
\hline CHEMBL1387401 & 688810 & \multicolumn{3}{|c|}{5.132999999999999} & 5.1108 & TST & \\
\hline CHEMBL1601285 & 688810 & 5.233 & 5.2804 & TRN & & & \\
\hline CHEMBL1437960 & 688810 & 5.433 & 5.5359 & TRN & & & \\
\hline CHEMBL1612016 & 688810 & 4.583 & 5.0656 & TST & & & \\
\hline CHEMBL1446827 & 688810 & 7.0329 & 5.96 & TRN & & & \\
\hline CHEMBL1412237 & 688810 & 4.633 & 5.2685 & TRN & & & \\
\hline CHEMBL1381427 & 688810 & 4.783 & 4.9147 & TRN & & & \\
\hline CHEMBL1393872 & 688810 & 5.733 & 5.4005 & TRN & & & \\
\hline CHEMBL1433733 & 688810 & \multicolumn{3}{|c|}{4.7330000000000005} & 5.2147 & TST & \\
\hline CHEMBL1334801 & 688810 & 4.883 & 4.6347 & TRN & & & \\
\hline CHEMBL1365990 & 688810 & \multicolumn{3}{|c|}{4.7330000000000005} & 4.7944 & TST & \\
\hline CHEMBL1444305 & 688810 & \multicolumn{3}{|c|}{4.7330000000000005} & 5.0815 & TRN & \\
\hline CHEMBL1390703 & 688810 & 5.683 & 5.9459 & TRN & & & \\
\hline CHEMBL1534349 & 688810 & 5.733 & 5.1996 & TRN & & & \\
\hline CHEMBL 3189851 & 688810 & 4.883 & 5.2463 & TST & & & \\
\hline CHEMBL1505015 & 688810 & 4.783 & 4.9336 & TRN & & & \\
\hline CHEMBL1506498 & 688810 & \multicolumn{3}{|c|}{5.332999999999999} & 5.1123 & TST & \\
\hline CHEMBL1606607 & 688810 & \multicolumn{3}{|c|}{6.632999999999999} & 5.1621 & TRN & \\
\hline CHEMBL 1405400 & 688810 & \multicolumn{3}{|c|}{5.5329999999999995} & 5.7171 & TRN & \\
\hline CHEMBL1344285 & 688810 & \multicolumn{3}{|c|}{4.7330000000000005} & 4.9899 & TRN & \\
\hline CHEMBL1511747 & 688810 & 5.433 & 5.2929 & TRN & & & \\
\hline CHEMBL1409994 & 688810 & \multicolumn{3}{|c|}{5.332999999999999} & 5.5735 & TRN & \\
\hline CHEMBL1502723 & 688810 & 4.783 & 5.1718 & TST & & & \\
\hline CHEMBL1992651 & 688810 & 5.033 & 5.4448 & TRN & & & \\
\hline CHEMBL1359760 & 688810 & 6.4829 & 5.2902 & TRN & & & \\
\hline CHEMBL 3211751 & 688810 & 5.683 & 4.8563 & TRN & & & \\
\hline CHEMBL1413986 & 688810 & 5.983 & 5.434 & TRN & & & \\
\hline CHEMBL1574120 & 688810 & \multicolumn{3}{|c|}{5.832999999999999} & 5.4162 & TRN & \\
\hline CHEMBL3198941 & 688810 & 5.733 & 5.2792 & TRN & & & \\
\hline CHEMBL1303711 & 688810 & \multicolumn{3}{|c|}{4.9830000000000005} & 5.2996 & TRN & \\
\hline CHEMBL1391744 & 688810 & 5.233 & 5.218 & TRN & & & \\
\hline CHEMBL1336903 & 688810 & 5.033 & 5.0639 & TRN & & & \\
\hline CHEMBL1456197 & 688810 & \multicolumn{3}{|c|}{4.9830000000000005} & 6.0335 & TRN & \\
\hline CHEMBL392680 & 688810 & 4.933 & 5.1239 & TRN & & & \\
\hline CHEMBL1335770 & 688810 & 4.833 & 5.27 & TST & & & \\
\hline CHEMBL1573969 & 688810 & 4.583 & 4.8664 & TRN & & & \\
\hline CHEMBL1509395 & 688810 & 4.783 & 5.1555 & TST & & & \\
\hline CHEMBL1997059 & 688810 & \multicolumn{3}{|c|}{5.7829999999999995} & 5.49200 & 0000000001 & TST \\
\hline CHEMBL1486005 & 688810 & 5.683 & 5.4828 & TRN & & & \\
\hline CHEMBL1481023 & 688810 & 4.833 & 5.5725 & TST & & & \\
\hline CHEMBL1420728 & 688810 & \multicolumn{3}{|c|}{4.7330000000000005} & 5.0231 & TST & \\
\hline CHEMBL1608341 & 688810 & 5.083 & 4.7377 & TST & & & \\
\hline CHEMBL1347339 & 688810 & 4.833 & 5.3461 & TST & & & \\
\hline CHEMBL1589310 & 688810 & 5.733 & 4.9625 & TST & & & \\
\hline
\end{tabular}




\begin{tabular}{|c|c|c|c|c|c|c|}
\hline \multirow[b]{2}{*}{ CHEMBL1503604 } & \multirow[b]{2}{*}{688810} & \multicolumn{5}{|c|}{ Supplemental Table S2.txt } \\
\hline & & 4.583 & 5.0564 & TRN & & \\
\hline CHEMBL1424024 & 688810 & 5.83299 & 99999999 & & 5.6852 & TRN \\
\hline CHEMBL1322521 & 688810 & 5.63299 & 99999999 & 99 & 5.2887 & TRN \\
\hline CHEMBL1557451 & 688810 & 5.38299 & 99999999 & 99 & 5.972 & TRN \\
\hline CHEMBL1599820 & 688810 & 5.233 & 4.9731 & TRN & & \\
\hline CHEMBL1487632 & 688810 & 5.33299 & 99999999 & & 5.3126 & TRN \\
\hline CHEMBL1429418 & 688810 & 4.883 & 4.5584 & TRN & & \\
\hline CHEMBL1510937 & 688810 & 6.13299 & 99999999 & 99 & 5.6236 & TST \\
\hline CHEMBL1469016 & 688810 & 4.833 & 5.2034 & TRN & & \\
\hline CHEMBL1303712 & 688810 & 4.833 & 5.1172 & TRN & & \\
\hline CHEMBL1349481 & 688810 & 4.783 & 5.2658 & TRN & & \\
\hline CHEMBL1439094 & 688810 & 4.883 & 5.2274 & TRN & & \\
\hline CHEMBL1340593 & 688810 & 4.783 & 5.365 & TST & & \\
\hline CHEMBL488140 & 688810 & 6.03299 & 99999999 & 995 & 5.5767 & TRN \\
\hline CHEMBL583351 & 688810 & 5.033 & 5.6083 & TRN & & \\
\hline CHEMBL1598769 & 688810 & 5.233 & 6.2203 & TRN & & \\
\hline CHEMBL1316581 & 688810 & 5.033 & 4.9359 & TST & & \\
\hline CHEMBL1499520 & 688810 & 5.63299 & 99999999 & & 5.8329 & TRN \\
\hline CHEMBL1572857 & 688810 & 5.033 & 5.1582 & TRN & & \\
\hline CHEMBL1377341 & 688810 & 6.33299 & 99999999 & & 5.1002 & TRN \\
\hline CHEMBL1477760 & 688810 & 5.433 & 5.3034 & TST & & \\
\hline CHEMBL1376769 & 688810 & 4.883 & 5.318 & TRN & & \\
\hline CHEMBL1358581 & 688810 & 5.933 & 5.8801 & TRN & & \\
\hline CHEMBL1391417 & 688810 & 4.633 & 4.9154 & TST & & \\
\hline CHEMBL1538274 & 688810 & 4.833 & 5.074 & TRN & & \\
\hline CHEMBL1385839 & 688810 & 4.883 & 5.0547 & TRN & & \\
\hline CHEMBL1522895 & 688810 & 5.33299 & 99999999 & & 5.4765 & TRN \\
\hline CHEMBL3194656 & 688810 & 4.633 & 5.4397 & TRN & & \\
\hline CHEMBL1437584 & 688810 & 5.933 & 5.3987 & TRN & & \\
\hline CHEMBL1350120 & 688810 & 6.4829 & 6.0557 & TRN & & \\
\hline CHEMBL1410357 & 688810 & 5.683 & 5.6798 & TRN & & \\
\hline CHEMBL1336405 & 688810 & 4.783 & 5.1983 & TRN & & \\
\hline CHEMBL1494309 & 688810 & 5.733 & 5.131 & TRN & & \\
\hline CHEMBL1305938 & 688810 & 4.833 & 5.3439 & TST & & \\
\hline CHEMBL1347491 & 688810 & 6.58299 & 99999999 & & 5.7546 & TRN \\
\hline CHEMBL1487952 & 688810 & 4.783 & 5.1212 & TRN & & \\
\hline CHEMBL1300471 & 688810 & 5.33299 & 99999999 & & 5.1969 & TRN \\
\hline CHEMBL3196204 & 688810 & 6.7331 & 5.5024 & TRN & & \\
\hline CHEMBL1571123 & 688810 & 5.38299 & 99999999 & & 5.1833 & TRN \\
\hline CHEMBL1411123 & 688810 & 5.433 & 5.5796 & TRN & & \\
\hline CHEMBL1518147 & 688810 & 5.38299 & 99999999 & & 5.0772 & TST \\
\hline CHEMBL1334807 & 688810 & 5.13299 & 99999999 & & 5.0557 & TRN \\
\hline CHEMBL1453269 & 688810 & 4.73300 & 20000000 & 005 & 5.2155 & TRN \\
\hline CHEMBL1449470 & 688810 & 4.73300 & 00000000 & 005 & 5.185 & TRN \\
\hline CHEMBL3193118 & 688810 & 5.933 & 5.6676 & TRN & & \\
\hline CHEMBL1575279 & 688810 & 4.933 & 5.1674 & TRN & & \\
\hline CHEMBL1559430 & 688810 & 5.083 & 5.5943 & TRN & & \\
\hline CHEMBL1564785 & 688810 & 5.233 & 5.2392 & TST & & \\
\hline
\end{tabular}




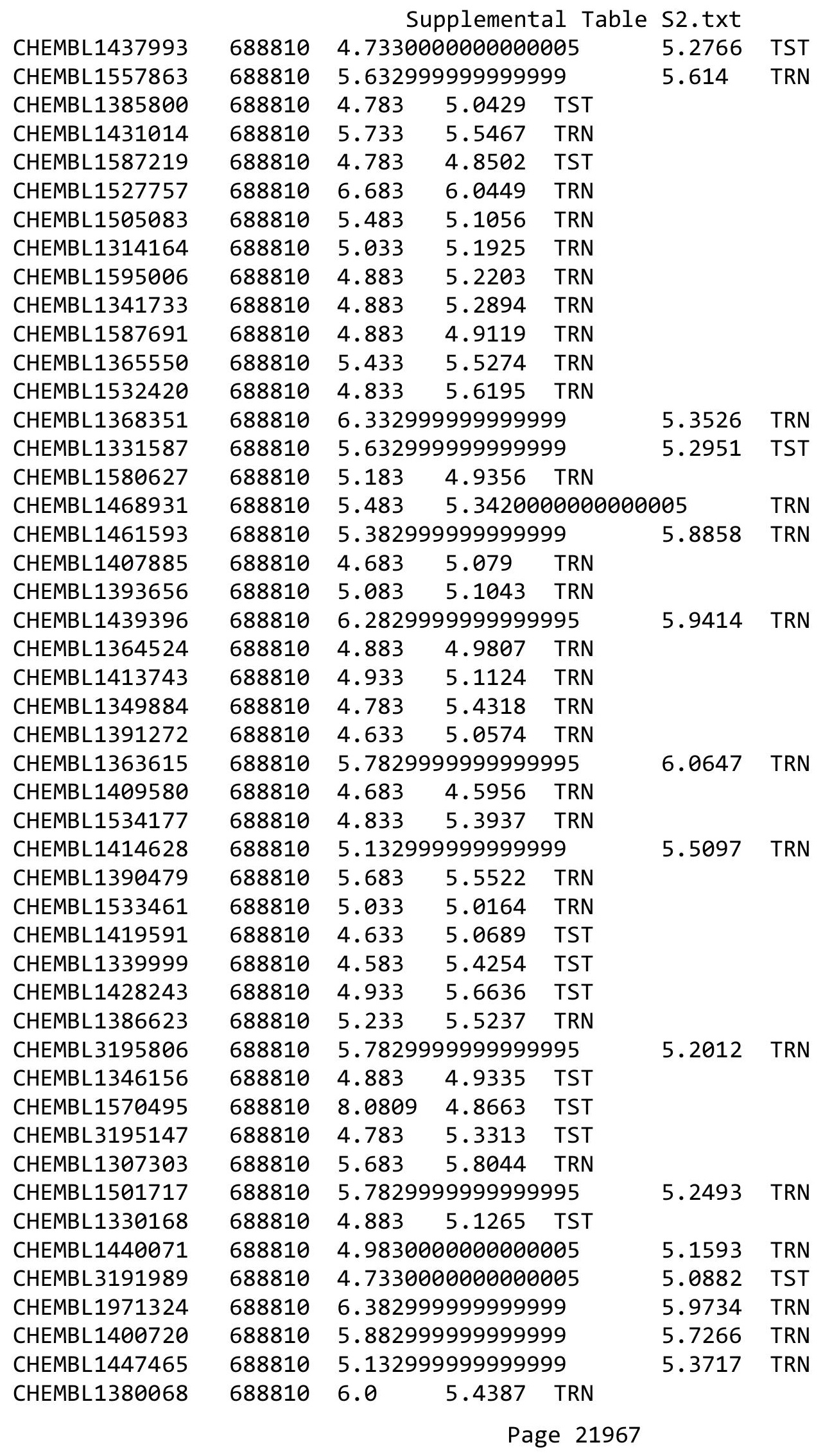




\begin{tabular}{|c|c|c|c|c|c|c|c|}
\hline \multirow{2}{*}{ CHEMBL1310999 } & \multicolumn{6}{|c|}{ Supplemental Table S2.txt } & \\
\hline & 688810 & \multicolumn{3}{|c|}{6.382999999999999} & 5.7209 & TRN & \\
\hline CHEMBL3210193 & 688810 & 4.783 & 5.4079 & TRN & & & \\
\hline CHEMBL1429878 & 688810 & 4.683 & 4.9551 & TST & & & \\
\hline CHEMBL1596222 & 688810 & 4.883 & 5.2693 & TRN & & & \\
\hline CHEMBL1426502 & 688810 & 4.933 & 5.3456 & TST & & & \\
\hline CHEMBL3214346 & 688810 & 4.833 & 5.0814 & TRN & & & \\
\hline CHEMBL1531997 & 688810 & \multicolumn{3}{|c|}{4.7330000000000005} & 5.1032 & TRN & \\
\hline CHEMBL1579380 & 688810 & \multicolumn{3}{|c|}{5.582999999999999} & 5.7825 & TRN & \\
\hline CHEMBL1585637 & 688810 & \multicolumn{3}{|c|}{5.7829999999999995} & 5.1865 & TRN & \\
\hline CHEMBL1507540 & 688810 & \multicolumn{3}{|c|}{5.632999999999999} & 5.5332 & TRN & \\
\hline CHEMBL1437508 & 688810 & \multicolumn{3}{|c|}{4.9830000000000005} & 5.3782 & TRN & \\
\hline CHEMBL1491946 & 688810 & \multicolumn{3}{|c|}{5.382999999999999} & 5.1211 & TRN & \\
\hline CHEMBL1374692 & 688810 & \multicolumn{3}{|c|}{5.382999999999999} & 5.3779 & TRN & \\
\hline CHEMBL1325619 & 688810 & \multicolumn{3}{|c|}{4.7330000000000005} & 5.1367 & TRN & \\
\hline CHEMBL1534252 & 688810 & 4.833 & \multicolumn{3}{|c|}{5.9110000000000005} & TRN & \\
\hline CHEMBL1431758 & 688810 & \multicolumn{4}{|c|}{6.0329999999999995} & TRN & \\
\hline CHEMBL1489739 & 688810 & \multicolumn{3}{|c|}{4.7330000000000005} & \multicolumn{2}{|c|}{5.1610000000000005} & TRN \\
\hline CHEMBL1452467 & 688810 & \multicolumn{3}{|c|}{5.5329999999999995} & 5.3994 & TRN & \\
\hline CHEMBL1613425 & 688810 & \multicolumn{3}{|c|}{4.7330000000000005} & 4.9816 & TST & \\
\hline CHEMBL1406314 & 688810 & 5.483 & 5.2542 & TRN & & & \\
\hline CHEMBL1361413 & 688810 & 5.55 & 5.1448 & TRN & & & \\
\hline CHEMBL1345420 & 688810 & 4.783 & 5.0363 & TRN & & & \\
\hline CHEMBL1344489 & 688810 & 5.483 & \multicolumn{3}{|c|}{5.327000000000001} & TRN & \\
\hline CHEMBL1523901 & 688810 & \multicolumn{3}{|c|}{4.7330000000000005} & 4.9777 & TRN & \\
\hline CHEMBL1547916 & 688810 & 4.833 & 5.3344 & TST & & & \\
\hline CHEMBL3189944 & 688810 & 5.033 & 5.2542 & TRN & & & \\
\hline CHEMBL1570398 & 688810 & \multicolumn{3}{|c|}{5.382999999999999} & 5.2637 & TST & \\
\hline CHEMBL1377322 & 688810 & \multicolumn{3}{|c|}{5.5329999999999995} & 5.3996 & TRN & \\
\hline CHEMBL1342613 & 688810 & 4.783 & 5.0896 & TRN & & & \\
\hline CHEMBL1331285 & 688810 & 4.883 & 5.3558 & TRN & & & \\
\hline CHEMBL1349795 & 688810 & 5.183 & 5.0343 & TST & & & \\
\hline CHEMBL1489939 & 688810 & 5.8329 & 99999995 & & 5.0073 & TRN & \\
\hline CHEMBL1518412 & 688810 & 6.5829 & 99999999 & & 5.7906 & TRN & \\
\hline CHEMBL1556012 & 688810 & 4.933 & 5.0167 & TRN & & & \\
\hline CHEMBL1410436 & 688810 & 5.1329 & 99999999 & & 5.0782 & TRN & \\
\hline CHEMBL1530374 & 688810 & 5.5329 & 9999999 & 995 & 5.2706 & TRN & \\
\hline CHEMBL 1432528 & 688810 & 4.783 & 5.29799 & 9999 & & TRN & \\
\hline CHEMBL1579959 & 688810 & 4.7330 & 00000006 & 005 & 5.3612 & TRN & \\
\hline CHEMBL1323146 & 688810 & 5.1329 & 99999995 & & 5.4974 & TRN & \\
\hline CHEMBL1374378 & 688810 & 5.233 & 5.335 & TRN & & & \\
\hline CHEMBL1335003 & 688810 & 4.633 & 4.7706 & TST & & & \\
\hline CHEMBL1302928 & 688810 & 5.033 & 4.8403 & TRN & & & \\
\hline CHEMBL1329597 & 688810 & 4.583 & 5.0733 & TST & & & \\
\hline CHEMBL1451669 & 688810 & 4.833 & 5.1686 & TRN & & & \\
\hline CHEMBL3191656 & 688810 & 4.7330 & 00000006 & 005 & 5.2511 & TRN & \\
\hline CHEMBL1399900 & 688810 & 4.783 & 5.0827 & TRN & & & \\
\hline CHEMBL3192130 & 688810 & 4.883 & 4.9969 & TRN & & & \\
\hline CHEMBL3207390 & 688810 & 4.933 & 5.4242 & TRN & & & \\
\hline
\end{tabular}




\begin{tabular}{|c|c|c|c|c|c|c|c|}
\hline CHEMBL1594046 & 688810 & 6.9329 & 5.6885 & TRN & & & \\
\hline CHEMBL1491948 & 688810 & 4.783 & 5.2125 & TRN & & & \\
\hline CHEMBL1302028 & 688810 & 4.933 & 4.5938 & TRN & & & \\
\hline CHEMBL1394182 & 688810 & 4.883 & 5.0256 & TRN & & & \\
\hline CHEMBL1514871 & 688810 & 5.83299 & 999999999 & & 5.2871 & TRN & \\
\hline CHEMBL3209647 & 688810 & 5.733 & 4.9992 & TRN & & & \\
\hline CHEMBL1389669 & 688810 & 6.7331 & 5.9827 & TST & & & \\
\hline CHEMBL1351907 & 688810 & 5.33299 & 999999999 & & 5.4116 & TST & \\
\hline CHEMBL1541843 & 688810 & 5.28299 & 999999999 & 995 & 5.1224 & TRN & \\
\hline CHEMBL1408324 & 688810 & 4.73300 & 000000006 & 005 & 4.9197 & TRN & \\
\hline CHEMBL1448466 & 688810 & 5.83299 & 999999995 & & 5.7162 & TRN & \\
\hline CHEMBL1430341 & 688810 & 4.73300 & 00000000 & 005 & 5.0641 & TRN & \\
\hline CHEMBL3196777 & 688810 & 5.58299 & 999999999 & & 5.4968 & TRN & \\
\hline CHEMBL3207419 & 688810 & 4.98300 & 000000000 & 005 & 5.1827 & TRN & \\
\hline CHEMBL1351881 & 688810 & 5.183 & 5.2895 & TRN & & & \\
\hline CHEMBL1579271 & 688810 & 5.13299 & 999999999 & & 5.7026 & TRN & \\
\hline CHEMBL1402051 & 688810 & 5.88299 & 999999999 & & 5.4943 & TRN & \\
\hline CHEMBL1461285 & 688810 & 5.38299 & 999999999 & & 5.8286 & TRN & \\
\hline CHEMBL1608347 & 688810 & 5.33299 & 999999999 & & 5.595 & TST & \\
\hline CHEMBL1501354 & 688810 & 4.73300 & 000000000 & 005 & 5.479 & TST & \\
\hline CHEMBL1403855 & 688810 & 4.633 & 5.0376 & TRN & & & \\
\hline CHEMBL1411904 & 688810 & 5.63299 & 999999999 & & 5.5808 & TRN & \\
\hline CHEMBL1418212 & 688810 & 4.783 & 5.1668 & TRN & & & \\
\hline CHEMBL1411776 & 688810 & 4.73300 & 000000000 & 005 & 5.1452 & TRN & \\
\hline CHEMBL1419597 & 688810 & 6.0 & 5.4632 & TRN & & & \\
\hline CHEMBL1378111 & 688810 & 5.033 & 5.0065 & TST & & & \\
\hline CHEMBL1417082 & 688810 & 4.73300 & 000000000 & 005 & 4.9506 & TRN & \\
\hline CHEMBL1968327 & 688810 & 5.933 & 5.4215 & TRN & & & \\
\hline CHEMBL1315497 & 688810 & 4.783 & 5.2394 & TRN & & & \\
\hline CHEMBL1497127 & 688810 & 5.28299 & 999999999 & 995 & 5.3193 & TRN & \\
\hline CHEMBL1420759 & 688810 & 6.38299 & 999999999 & & 5.9652 & TRN & \\
\hline CHEMBL1444473 & 688810 & 4.683 & 4.9367 & TRN & & & \\
\hline CHEMBL1543332 & 688810 & 5.083 & 4.9917 & TRN & & & \\
\hline CHEMBL1503907 & 688810 & 5.13299 & 999999999 & & 5.4957 & TRN & \\
\hline CHEMBL1551293 & 688810 & 6.13299 & 999999999 & & 5.78100 & 2000000001 & TRN \\
\hline CHEMBL1509452 & 688810 & 5.933 & 5.6936 & TRN & & & \\
\hline CHEMBL59026 & 688810 & 4.783 & 4.9341 & TRN & & & \\
\hline CHEMBL1418013 & 688810 & 7.3325 & 5.9681 & TRN & & & \\
\hline CHEMBL1566239 & 688810 & 4.883 & 5.2487 & TRN & & & \\
\hline CHEMBL1994973 & 688810 & 4.73300 & 000000000 & 005 & 5.062 & TRN & \\
\hline CHEMBL1363307 & 688810 & 4.583 & 4.7545 & TRN & & & \\
\hline CHEMBL1407272 & 688810 & 7.1831 & 5.733 & TRN & & & \\
\hline CHEMBL1572935 & 688810 & 6.08299 & 999999999 & & 5.3951 & TRN & \\
\hline CHEMBL1567962 & 688810 & 4.833 & 5.351 & TRN & & & \\
\hline CHEMBL1529876 & 688810 & 6.28299 & 999999999 & 995 & 5.2752 & TST & \\
\hline CHEMBL1415756 & 688810 & 6.183 & 5.64 & TRN & & & \\
\hline CHEMBL1416660 & 688810 & 5.38299 & 999999999 & & 5.4887 & TRN & \\
\hline CHEMBL3190822 & 688810 & 4.833 & 5.116000 & 000000000 & 205 & TST & \\
\hline
\end{tabular}




\begin{tabular}{|c|c|c|c|c|c|c|}
\hline & & \multicolumn{5}{|c|}{ Supplemental Table s2.txt } \\
\hline CHEMBL1610448 & 688810 & 4.783 & 5.2596 & TRN & & \\
\hline CHEMBL1315170 & 688810 & 4.9836 & 000000000 & 305 & 4.8471 & TRN \\
\hline CHEMBL1539968 & 688810 & 4.783 & 5.608 & TRN & & \\
\hline CHEMBL228527 & 688810 & 4.783 & 5.4364 & TRN & & \\
\hline CHEMBL1499853 & 688810 & 5.033 & 5.3467 & TST & & \\
\hline CHEMBL1338826 & 688810 & 4.933 & 5.3941 & TRN & & \\
\hline CHEMBL1559722 & 688810 & 4.883 & 5.2253 & TRN & & \\
\hline CHEMBL1338928 & 688810 & 5.083 & 5.2784 & TST & & \\
\hline CHEMBL1510925 & 688810 & 5.6329 & 999999999 & & 5.6558 & TRN \\
\hline CHEMBL1401986 & 688810 & 4.783 & 5.1954 & TST & & \\
\hline CHEMBL1450768 & 688810 & 6.0829 & 999999999 & 99 & 4.9712 & זענו \\
\hline CHEMBL1368993 & 688810 & 5.083 & 5.6029 & TRN & & \\
\hline CHEMBL1563733 & 688810 & 4.883 & 5.1895 & TRN & & \\
\hline CHEMBL 3199872 & 688810 & 5.1329 & 999999999 & & 5.1821 & $T$ \\
\hline CHEMBL1410893 & 688810 & 4.683 & 5.0132 & TST & & \\
\hline CHEMBL 3213005 & 688810 & 5.3829 & 999999999 & & 5.7664 & TRIV \\
\hline CHEMBL1440039 & 688810 & 5.033 & 5.7322 & TRN & & \\
\hline CHEMBL1454141 & 688810 & 6.0825 & 999999999 & & 5.5264 & $\mathrm{Tl}$ \\
\hline CHEMBL1558327 & 688810 & 4.833 & 5.9281 & TRN & & \\
\hline CHEMBL1504338 & 688810 & 4.883 & 5.1049 & TRN & & \\
\hline CHEMBL1301331 & 688810 & 5.6329 & 999999999 & & 5.1483 & TST \\
\hline CHEMBL1600848 & 688810 & 5.683 & 5.6194 & TRN & & \\
\hline CHEMBL1300772 & 688810 & 4.783 & 5.5577 & TRN & & \\
\hline CHEMBL1364400 & 688810 & 5.233 & 5.3152 & TRN & & \\
\hline CHEMBL1320219 & 688810 & 5.233 & 5.4102 & TRN & & \\
\hline CHEMBL3191265 & 688810 & 7.1331 & 5.4393 & TRN & & \\
\hline CHEMBL1337527 & 688810 & 6.6329 & 999999999 & & 5.68 & TR \\
\hline CHEMBL 3191896 & 688810 & 5.033 & 5.5954 & TST & & \\
\hline CHEMBL1339433 & 688810 & 5.683 & 4.5667 & TRN & & \\
\hline CHEMBL1612898 & 688810 & 4.683 & 5.1316 & TST & & \\
\hline CHEMBL1608241 & 688810 & 4.833 & 4.9797 & TRN & & \\
\hline CHEMBL1540611 & 688810 & 4.883 & 5.0795 & TRN & & \\
\hline CHEMBL1475973 & 688810 & 4.7336 & 000000000 & 005 & 5.4982 & 11 \\
\hline CHEMBL1597227 & 688810 & 4.933 & 5.2164 & TRN & & \\
\hline CHEMBL 3197211 & 688810 & 4.783 & 5.2528 & TRN & & \\
\hline CHEMBL1527599 & 688810 & 5.683 & 5.6116 & TRN & & \\
\hline CHEMBL1307112 & 688810 & 4.783 & 5.4359 & TRN & & \\
\hline CHEMBL1350339 & 688810 & 6.5829 & 999999999 & & 5.1985 & TRIV \\
\hline CHEMBL1310717 & 688810 & 6.1325 & 999999999 & & 5.6934 & TP \\
\hline CHEMBL1320969 & 688810 & 5.083 & 5.1949 & TST & & \\
\hline CHEMBL1557529 & 688810 & 4.833 & 5.2995 & TST & & \\
\hline CHEMBL1449522 & 688810 & 4.883 & 5.1694 & TRN & & \\
\hline CHEMBL1386396 & 688810 & 5.683 & 5.2111 & TRN & & \\
\hline CHEMBL1553895 & 688810 & 4.9836 & 000000000 & 305 & 5.4662 & TRN \\
\hline CHEMBL1376505 & 688810 & 5.983 & 5.3716 & TRN & & \\
\hline CHEMBL1511488 & 688810 & 4.883 & 5.2772 & TST & & \\
\hline CHEMBL1568933 & 688810 & 5.5829 & 999999999 & 99 & 5.6149 & ונדו \\
\hline CHEMBL1357243 & 688810 & 5.183 & 4.9493 & TST & & \\
\hline
\end{tabular}




\begin{tabular}{|c|c|c|c|c|c|c|}
\hline & \multicolumn{5}{|c|}{ oplemental Table } \\
\hline CHEMBL1470207 & 688810 & 4.683 & 5.0197 & TRN & & \\
\hline CHEMBL1592342 & 688810 & 6.63299 & 99999999 & 99 & 5.9139 & TRI \\
\hline CHEMBL1547825 & 688810 & 7.1831 & 5.6171 & TRN & & \\
\hline CHEMBL1349080 & 688810 & 5.63299 & 99999999 & 99 & 5.5642 & \\
\hline CHEMBL3193392 & 688810 & 4.683 & 5.2533 & TRN & & \\
\hline CHEMBL 2234807 & 688810 & 4.98300 & 00000000 & 005 & 5.1149 & $T$ \\
\hline CHEMBL1482497 & 688810 & 4.783 & 4.9025 & TRN & & \\
\hline CHEMBL1450337 & 688810 & 4.883 & 5.3214 & TRN & & \\
\hline CHEMBL 3198850 & 688810 & 4.73300 & 00000000 & 005 & 4.8736 & \\
\hline CHEMBL1407861 & 688810 & 4.833 & 4.8936 & TRN & & \\
\hline CHEMBL1528049 & 688810 & 5.733 & 5.2531 & TRN & & \\
\hline CHEMBL1590278 & 688810 & 5.28299 & 99999999 & 995 & 5.3647 & \\
\hline CHEMBL1387325 & 688810 & 5.483 & 5.5709 & TRN & & \\
\hline CHEMBL1535506 & 688810 & 5.083 & 5.2344 & TRN & & \\
\hline CHEMBL1451781 & 688810 & 4.73300 & 00000000 & 005 & 5.1181 & \\
\hline CHEMBL1419436 & 688810 & 4.783 & $5.41200 t$ & 0000000001 & 01 & \\
\hline CHEMBL1532177 & 688810 & 5.183 & 5.2532 & TRN & & \\
\hline CHEMBL1334962 & 688810 & 5.483 & 5.2936 & TRN & & \\
\hline CHEMBL1491500 & 688810 & 4.933 & 5.2289 & TRN & & \\
\hline CHEMBL 3211717 & 688810 & 4.883 & 5.1027 & TRN & & \\
\hline CHEMBL1524006 & 688810 & 4.98300 & 00000000 & 005 & 5.1616 & \\
\hline CHEMBL1428900 & 688810 & 4.73300 & 00000000 & 005 & 5.5652 & \\
\hline CHEMBL1341991 & 688810 & 4.73300 & 00000000 & 005 & 5.5358 & TST \\
\hline CHEMBL1339717 & 688810 & 5.53299 & 99999999 & 995 & 5.638 & \\
\hline CHEMBL1584991 & 688810 & 5.83299 & 99999999 & & 5.2567 & \\
\hline CHEMBL1307506 & 688810 & 6.9329 & 5.2592 & TST & & \\
\hline CHEMBL1496177 & 688810 & 5.183 & 5.1116 & TST & & \\
\hline CHEMBL1369755 & 688810 & 4.783 & 5.2085 & TRN & & \\
\hline CHEMBL1442316 & 688810 & 5.58299 & 99999999 & & 5.9524 & \\
\hline CHEMBL1591179 & 688810 & 4.583 & 5.4755 & TST & & \\
\hline CHEMBL1496748 & 688810 & 5.933 & 5.8094 & TRN & & \\
\hline CHEMBL1584676 & 688810 & 4.883 & 5.0986 & TST & & \\
\hline CHEMBL1329825 & 688810 & 4.633 & 4.8694 & TRN & & \\
\hline CHEMBL1462769 & 688810 & 5.483 & 5.3753 & TST & & \\
\hline CHEMBL1982441 & 688810 & 7.08299 & 99999999 & & 5.5583 & TR \\
\hline CHEMBL1422674 & 688810 & 4.833 & 5.1957 & TRN & & \\
\hline CHEMBL1503016 & 688810 & 6.183 & 5.5936 & TRN & & \\
\hline CHEMBL1521773 & 688810 & 4.783 & 5.3922 & TRN & & \\
\hline CHEMBL1458423 & 688810 & 4.933 & 5.4455 & TST & & \\
\hline CHEMBL 3210908 & 688810 & 6.433 & 5.7759 & TRN & & \\
\hline CHEMBL1560192 & 688810 & 5.483 & 5.6433 & TST & & \\
\hline CHEMBL1426337 & 688810 & 5.233 & 5.4756 & TST & & \\
\hline CHEMBL1392025 & 688810 & 4.833 & 4.9034 & TRN & & \\
\hline CHEMBL1525198 & 688810 & 5.733 & 5.6672 & TRN & & \\
\hline CHEMBL1364983 & 688810 & 5.033 & 5.322 & TRN & & \\
\hline CHEMBL1323988 & 688810 & 5.733 & 5.5837 & TST & & \\
\hline CHEMBL1995156 & 688810 & 6.78299 & 99999999 & 995 & 6.0922 & \\
\hline CHEMBL 2094573 & 688810 & 5.483 & 5.3302 & TRN & & \\
\hline
\end{tabular}




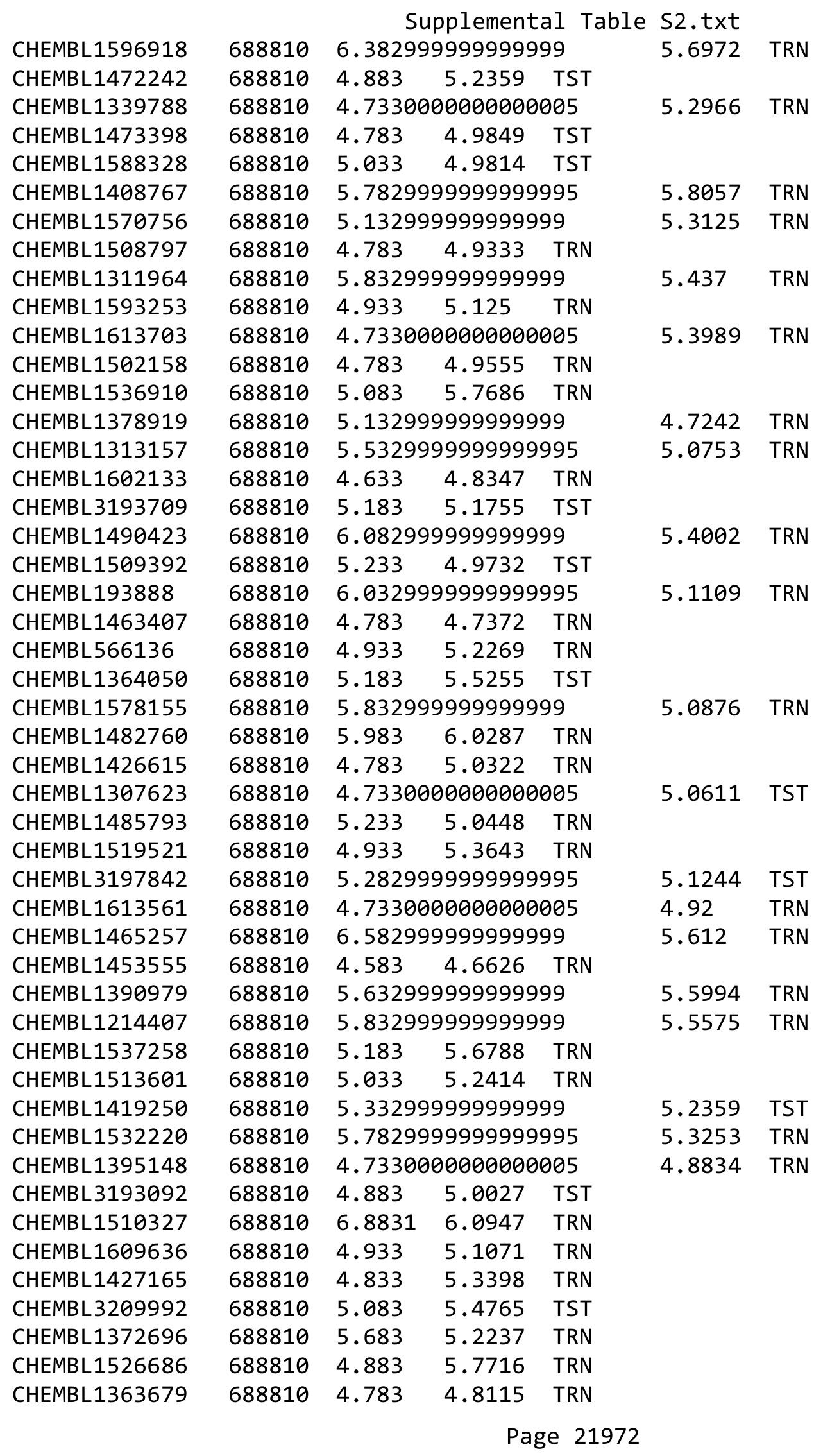




\begin{tabular}{|c|c|c|c|c|c|c|}
\hline & & & pplement & al Table & s2.txt & \\
\hline CHEMBL1406726 & 688810 & 6.28299 & 99999999 & 995 & 5.6053 & TRN \\
\hline CHEMBL1587114 & 688810 & 5.733 & 5.4378 & TST & & \\
\hline CHEMBL1499061 & 688810 & 4.73300 & 00000000 & 005 & 5.37 & TST \\
\hline CHEMBL1442317 & 688810 & 5.63299 & 99999999 & & 5.1458 & TST \\
\hline CHEMBL1333464 & 688810 & 5.83299 & 99999999 & & 5.1037 & TST \\
\hline CHEMBL1421422 & 688810 & 4.98300 & 20000000 & 005 & 5.2978 & TST \\
\hline CHEMBL1386152 & 688810 & 5.13299 & 99999999 & & 5.0442 & TRN \\
\hline CHEMBL1463447 & 688810 & 5.88299 & 99999999 & & 5.8269 & TRN \\
\hline CHEMBL1572095 & 688810 & 4.783 & 5.3389 & TST & & \\
\hline CHEMBL3145114 & 688810 & 6.53299 & 99999999 & 995 & 5.4791 & TRN \\
\hline CHEMBL1389756 & 688810 & 4.883 & 5.3085 & TRN & & \\
\hline CHEMBL1396455 & 688810 & 4.583 & 4.5154 & TRN & & \\
\hline CHEMBL1381251 & 688810 & 5.88299 & 99999999 & & 5.5339 & TRN \\
\hline CHEMBL3145048 & 688810 & 7.5834 & 5.5081 & TRN & & \\
\hline CHEMBL1312341 & 688810 & 5.083 & 5.1993 & TRN & & \\
\hline CHEMBL1517000 & 688810 & 6.4829 & 6.0492 & TRN & & \\
\hline CHEMBL1554912 & 688810 & 4.583 & 5.0489 & TRN & & \\
\hline CHEMBL1593418 & 688810 & 4.98300 & 20000000 & 005 & 4.8097 & TRN \\
\hline CHEMBL1363582 & 688810 & 5.183 & 5.20299 & 999999999 & 99 & TRN \\
\hline CHEMBL1479454 & 688810 & 6.0 & 5.0277 & TRN & & \\
\hline CHEMBL1334674 & 688810 & 7.1331 & 5.763 & TRN & & \\
\hline CHEMBL1450725 & 688810 & 5.433 & 5.4863 & TRN & & \\
\hline CHEMBL1561182 & 688810 & 4.73300 & 20000000 & 005 & 4.7289 & TRN \\
\hline CHEMBL3197673 & 688810 & 5.53299 & 99999999 & 995 & 4.7755 & TRN \\
\hline CHEMBL1458314 & 688810 & 4.783 & 5.0338 & TRN & & \\
\hline CHEMBL1452615 & 688810 & 4.933 & 5.3072 & TRN & & \\
\hline CHEMBL1345334 & 688810 & 5.78299 & 99999999 & 995 & 5.3167 & TRN \\
\hline CHEMBL1569302 & 688810 & 4.933 & 5.3206 & TRN & & \\
\hline CHEMBL1529852 & 688810 & 4.883 & 5.0265 & TRN & & \\
\hline CHEMBL1315007 & 688810 & 5.083 & 5.6484 & TRN & & \\
\hline CHEMBL1429813 & 688810 & 5.13299 & 99999999 & & 5.1989 & TST \\
\hline CHEMBL 2436520 & 688810 & 6.08299 & 99999999 & & 5.4833 & TRN \\
\hline CHEMBL1517525 & 688810 & 5.38299 & 99999999 & & 5.2167 & TRN \\
\hline CHEMBL1476353 & 688810 & 4.783 & 4.6167 & TRN & & \\
\hline CHEMBL1400017 & 688810 & 6.28299 & 99999999 & 995 & 5.7398 & TRN \\
\hline CHEMBL1459826 & 688810 & 4.783 & 5.3758 & TST & & \\
\hline CHEMBL1303456 & 688810 & 4.833 & 5.3735 & TRN & & \\
\hline CHEMBL1447607 & 688810 & 4.833 & 5.077 & TRN & & \\
\hline CHEMBL1550661 & 688810 & 5.033 & 5.1836 & TST & & \\
\hline CHEMBL1315044 & 688810 & 5.483 & 5.2887 & TRN & & \\
\hline CHEMBL1369045 & 688810 & 5.63299 & 99999999 & & 5.6933 & TRN \\
\hline CHEMBL1337752 & 688810 & 7.0329 & 5.4495 & TST & & \\
\hline CHEMBL1595361 & 688810 & 4.833 & 5.2159 & TRN & & \\
\hline CHEMBL1530714 & 688810 & 5.033 & 5.0097 & TST & & \\
\hline CHEMBL1443553 & 688810 & 4.933 & 5.209 & TRN & & \\
\hline CHEMBL1327117 & 688810 & 5.083 & 5.3773 & TRN & & \\
\hline CHEMBL1555990 & 688810 & 4.833 & 4.9273 & TRN & & \\
\hline CHEMBL1407606 & 688810 & 5.78299 & 99999999 & 995 & 4.8091 & TRN \\
\hline
\end{tabular}




\begin{tabular}{|c|c|c|c|c|c|c|}
\hline \multirow[b]{2}{*}{ CHEMBL1329594 } & & \multicolumn{5}{|c|}{ Supplemental Table S2.txt } \\
\hline & 688810 & 4.633 & 4.8744 & TRN & & \\
\hline CHEMBL1574625 & 688810 & 4.783 & 5.1578 & TST & & \\
\hline CHEMBL1374522 & 688810 & 5.183 & 4.8972 & TST & & \\
\hline CHEMBL1400240 & 688810 & \multicolumn{3}{|c|}{4.7330000000000005} & 5.3441 & TST \\
\hline CHEMBL1305364 & 688810 & \multicolumn{3}{|c|}{4.7330000000000005} & 5.0169 & TRN \\
\hline CHEMBL 3210082 & 688810 & \multicolumn{3}{|c|}{5.132999999999999} & 5.865 & TRN \\
\hline CHEMBL1466730 & 688810 & 5.183 & 5.4343 & TST & & \\
\hline CHEMBL1537008 & 688810 & \multicolumn{3}{|c|}{6.832999999999999} & 5.6914 & TRN \\
\hline CHEMBL1505118 & 688810 & 4.783 & 4.9206 & TST & & \\
\hline CHEMBL1379511 & 688810 & 4.833 & 6.3447 & TRN & & \\
\hline CHEMBL1381954 & 688810 & 5.233 & 5.2627 & TRN & & \\
\hline CHEMBL1542110 & 688810 & 5.183 & 5.7185 & TRN & & \\
\hline CHEMBL1383514 & 688810 & 4.833 & 5.5555 & TST & & \\
\hline CHEMBL1326428 & 688810 & \multicolumn{3}{|c|}{5.382999999999999} & 5.4241 & TRN \\
\hline CHEMBL1560201 & 688810 & 4.783 & 4.9365 & TRN & & \\
\hline CHEMBL1369014 & 688810 & 4.633 & 5.3257 & TST & & \\
\hline CHEMBL1984523 & 688810 & \multicolumn{3}{|c|}{5.2829999999999995} & 4.9737 & TST \\
\hline CHEMBL 2004657 & 688810 & \multicolumn{3}{|c|}{4.7330000000000005} & 5.2751 & TRN \\
\hline CHEMBL1520597 & 688810 & 4.933 & 5.1294 & TST & & \\
\hline CHEMBL1530113 & 688810 & \multicolumn{3}{|c|}{5.632999999999999} & 5.4867 & TST \\
\hline CHEMBL1372027 & 688810 & 4.883 & 5.1078 & TST & & \\
\hline CHEMBL1309113 & 688810 & 4.833 & 5.2575 & TRN & & \\
\hline CHEMBL1535064 & 688810 & 5.183 & 5.495 & TST & & \\
\hline CHEMBL3209670 & 688810 & 4.833 & 5.4615 & TRN & & \\
\hline CHEMBL1445663 & 688810 & 5.083 & 4.9492 & TRN & & \\
\hline CHEMBL1601812 & 688810 & \multicolumn{3}{|c|}{5.832999999999999} & 5.7562 & TRN \\
\hline CHEMBL1502012 & 688810 & 5.483 & 5.8982 & TST & & \\
\hline CHEMBL1445486 & 688810 & 6.9329 & 5.9189 & TRN & & \\
\hline CHEMBL1336900 & 688810 & 4.933 & 5.2209 & TST & & \\
\hline CHEMBL1451347 & 688810 & \multicolumn{3}{|c|}{5.832999999999999} & 4.9986 & TRN \\
\hline CHEMBL1607591 & 688810 & \multicolumn{3}{|c|}{6.632999999999999} & 5.7616 & TRN \\
\hline CHEMBL1418342 & 688810 & 5.083 & 5.7782 & TRN & & \\
\hline CHEMBL2369217 & 688810 & 6.433 & 5.6166 & TRN & & \\
\hline CHEMBL3211870 & 688810 & 5.933 & 5.7165 & TRN & & \\
\hline CHEMBL1527869 & 688810 & 6.8831 & 5.454 & TRN & & \\
\hline CHEMBL1401895 & 688810 & 4.783 & 5.1504 & TRN & & \\
\hline CHEMBL1486374 & 688810 & 5.083 & 5.4234 & TRN & & \\
\hline CHEMBL1408294 & 688810 & 4.783 & 4.723 & TRN & & \\
\hline CHEMBL1449786 & 688810 & 5.58299 & 99999999 & & 4.9213 & TRN \\
\hline CHEMBL1514232 & 688810 & 5.28299 & 99999999 & 995 & 5.0224 & TRN \\
\hline CHEMBL1458171 & 688810 & 4.73300 & 00000000 & 005 & 5.4804 & TRN \\
\hline CHEMBL3196066 & 688810 & 5.33299 & 99999999 & & 5.419 & TRN \\
\hline CHEMBL1534466 & 688810 & 5.78299 & 99999999 & 995 & 5.4301 & TRN \\
\hline CHEMBL1373910 & 688810 & 5.28299 & 99999999 & 995 & 5.6006 & TRN \\
\hline CHEMBL1365850 & 688810 & 6.4 & 5.7189 & TRN & & \\
\hline CHEMBL3193855 & 688810 & 5.63299 & 99999999 & & 5.3684 & TRN \\
\hline CHEMBL1414767 & 688810 & 5.53299 & 99999999 & 995 & 5.2038 & TRN \\
\hline CHEMBL1324392 & 688810 & 4.883 & 5.3112 & TRN & & \\
\hline
\end{tabular}




\begin{tabular}{|c|c|c|c|c|c|c|c|}
\hline \multirow[b]{2}{*}{ CHEMBL402053 } & \multicolumn{6}{|c|}{ Supplemental Table S2.txt } & \\
\hline & 688810 & 4.833 & 5.077 & TRN & & & \\
\hline CHEMBL1373577 & 688810 & 5.58299 & 99999999 & & $5.3610 \ell$ & 0000000001 & TRN \\
\hline CHEMBL1306137 & 688810 & 5.033 & 5.6976 & TRN & & & \\
\hline CHEMBL1346114 & 688810 & 6.33299 & 99999999 & 99 & 5.7332 & TRN & \\
\hline CHEMBL1498284 & 688810 & 4.883 & 5.4264 & TST & & & \\
\hline CHEMBL1309059 & 688810 & 5.233 & 5.3677 & TST & & & \\
\hline CHEMBL1580091 & 688810 & 5.183 & 5.3511 & TRN & & & \\
\hline CHEMBL1508357 & 688810 & 6.183 & 5.1925 & TST & & & \\
\hline CHEMBL1458369 & 688810 & 4.783 & 5.675 & TRN & & & \\
\hline CHEMBL1494072 & 688810 & 4.783 & 5.1692 & TRN & & & \\
\hline CHEMBL1410309 & 688810 & 4.833 & 4.7901 & TRN & & & \\
\hline CHEMBL1505520 & 688810 & 4.783 & 5.2747 & TST & & & \\
\hline CHEMBL1486568 & 688810 & 4.883 & 5.4241 & TRN & & & \\
\hline CHEMBL1300086 & 688810 & 4.833 & 5.3993 & TST & & & \\
\hline CHEMBL1349786 & 688810 & 4.73300 & 00000000 & 005 & 5.3603 & TRN & \\
\hline CHEMBL1398356 & 688810 & 4.583 & 5.1058 & TST & & & \\
\hline CHEMBL1502047 & 688810 & 5.933 & 5.5613 & TST & & & \\
\hline CHEMBL1394511 & 688810 & 4.833 & 4.8944 & TRN & & & \\
\hline CHEMBL1544929 & 688810 & 5.183 & 5.4949 & TRN & & & \\
\hline CHEMBL1527435 & 688810 & 6.0 & 5.6538 & TRN & & & \\
\hline CHEMBL1970272 & 688810 & 4.73300 & 00000000 & 005 & 5.2316 & TST & \\
\hline CHEMBL1528469 & 688810 & 4.633 & 5.3787 & TST & & & \\
\hline CHEMBL1414202 & 688810 & 4.883 & 5.0964 & TRN & & & \\
\hline CHEMBL1423074 & 688810 & 4.783 & 5.1569 & TST & & & \\
\hline CHEMBL1514762 & 688810 & 5.13299 & 99999999 & & 5.4421 & TRN & \\
\hline CHEMBL1578866 & 688810 & 5.13299 & 99999999 & & 5.2127 & TST & \\
\hline CHEMBL1323984 & 688810 & 4.73300 & 00000000 & 005 & 4.7874 & TRN & \\
\hline CHEMBL1355328 & 688810 & 5.13299 & 99999999 & & 5.5494 & TRN & \\
\hline CHEMBL1601310 & 688810 & 4.783 & 4.8818 & TST & & & \\
\hline CHEMBL1399758 & 688810 & 5.78299 & 99999999 & 995 & 5.4970 & 0000000001 & TRN \\
\hline CHEMBL1518199 & 688810 & 4.883 & 5.053 & TRN & & & \\
\hline CHEMBL1478817 & 688810 & 5.88299 & 99999999 & & 5.4672 & TRN & \\
\hline CHEMBL1337152 & 688810 & 5.28299 & 99999999 & 995 & 5.5821 & TRN & \\
\hline CHEMBL1584229 & 688810 & 4.583 & 4.8824 & TST & & & \\
\hline CHEMBL3212552 & 688810 & 4.783 & 5.0206 & TST & & & \\
\hline CHEMBL1373923 & 688810 & 4.883 & 5.1034 & TST & & & \\
\hline CHEMBL1591887 & 688810 & 5.28299 & 99999999 & 995 & 5.1834 & TST & \\
\hline CHEMBL1610332 & 688810 & 4.933 & 5.6021 & TRN & & & \\
\hline CHEMBL1310491 & 688810 & 5.13299 & 99999999 & & 5.192 & TRN & \\
\hline CHEMBL1388039 & 688810 & 6.4829 & 5.3468 & TST & & & \\
\hline CHEMBL1566901 & 688810 & 6.0 & 5.7919 & TRN & & & \\
\hline CHEMBL1474024 & 688810 & 4.633 & 5.2138 & TRN & & & \\
\hline CHEMBL1438047 & 688810 & 5.63299 & 99999999 & & 5.5064 & TST & \\
\hline CHEMBL1393911 & 688810 & 4.98300 & 00000000 & 005 & 5.1579 & TRN & \\
\hline CHEMBL1339785 & 688810 & 5.53299 & 99999999 & 995 & 5.099 & TST & \\
\hline CHEMBL1578546 & 688810 & 4.883 & 5.2794 & TRN & & & \\
\hline CHEMBL1428061 & 688810 & 4.73300 & 00000000 & 005 & 5.0181 & TST & \\
\hline CHEMBL1413516 & 688810 & 4.783 & 5.2772 & TRN & & & \\
\hline
\end{tabular}




\begin{tabular}{|c|c|c|c|c|c|c|}
\hline \multirow{3}{*}{$\begin{array}{l}\text { CHEMBL1398967 } \\
\text { CHEMBL1423419 }\end{array}$} & \multirow{3}{*}{$\begin{array}{l}688810 \\
688810\end{array}$} & \multicolumn{4}{|c|}{ Supplemental Table S2.txt } & \multirow{3}{*}{ TRN } \\
\hline & & \multicolumn{3}{|c|}{5.832999999999999} & \multirow[t]{5}{*}{5.4396} & \\
\hline & & 4.633 & 5.3416 & TST & & \\
\hline CHEMBL1356913 & 688810 & 4.683 & 5.3332 & TRN & & \\
\hline CHEMBL1574431 & 588810 & 6.433 & 5.7762 & TRN & & \\
\hline CHEMBL1428056 & 588810 & 4.783 & 5.0805 & TRN & & \\
\hline CHEMBL1434953 & 688810 & \multicolumn{3}{|c|}{5.5329999999999995} & 5.1433 & \\
\hline CHEMBL1560399 & 688810 & 5.083 & 5.3579 & TRN & & \\
\hline CHEMBL1333149 & 688810 & \multicolumn{3}{|c|}{5.382999999999999} & 5.4878 & \\
\hline CHEMBL1319119 & 688810 & 4.833 & 5.0534 & TRN & & \\
\hline CHEMBL1415900 & 688810 & 4.783 & 5.2795 & TRN & & \\
\hline CHEMBL3191488 & 688810 & \multicolumn{3}{|c|}{5.882999999999999} & 5.4289 & \\
\hline CHEMBL1470599 & 688810 & \multicolumn{3}{|c|}{5.882999999999999} & 5.5281 & \\
\hline CHEMBL1464206 & 688810 & 5.183 & 5.1154 & TRN & & \\
\hline CHEMBL1418630 & 688810 & 4.683 & 5.2459 & TRN & & \\
\hline CHEMBL1541170 & 688810 & \multicolumn{3}{|c|}{5.382999999999999} & 5.3214 & \\
\hline CHEMBL140 & 688 & \multicolumn{3}{|c|}{5.582999999999999} & & \\
\hline CHEMBL130 & 688 & 6.183 & 5.5846 & TST & & \\
\hline CHEMBL1599076 & 688810 & \multicolumn{3}{|c|}{5.5329999999999995} & 5.7423 & \\
\hline CHEMBL1586951 & 688810 & 5.183 & 5.5939 & TRN & & \\
\hline CHEMBL1566835 & 688 & 4.833 & 5.0288 & TST & & \\
\hline CHEMBL13 & 688 & \multicolumn{3}{|c|}{6.132999999999999} & 103 & \\
\hline CHEMBL14€ & 688 & \multicolumn{3}{|c|}{6.0329999999999995} & 5 . & \\
\hline CHEMBL1541584 & 688810 & 6.433 & 5.1682 & TRN & & \\
\hline CHEMBL1480187 & 688810 & \multicolumn{3}{|c|}{5.2829999999999995} & 34 & \\
\hline CHEMBL1419271 & 688810 & 4.833 & 5.1598 & TRN & & \\
\hline CHEMBL 1 & 688 & 4 & 4.9 & TST & & \\
\hline CHEMBL1324742 & 688 & 4. & 4.9925 & TRN & & \\
\hline CHEMBL1558310 & 688810 & 5.083 & 5.6221 & TRN & & \\
\hline CHEMBL1562727 & 688810 & 4.833 & 5.2472 & TRN & & \\
\hline CHEMBL1389857 & 688810 & \multicolumn{3}{|c|}{5.832999999999999} & 5.8436 & \\
\hline CHEMBL: & 688 & 5.433 & 5.3815 & TRN & & \\
\hline CHEMBL & 688 & 4.783 & 5.2191 & TRN & & \\
\hline CHEMBL1351338 & 688810 & 5.733 & 5.4454 & TRN & & \\
\hline CHEMBL1584144 & 688810 & \multicolumn{3}{|c|}{5.332999999999999} & 5.6789 & \\
\hline CHEMBL139250 & 688810 & \multicolumn{3}{|c|}{5.332999999999999} & 5.3977 & \\
\hline CHEMBL: & 688 & 5.433 & 5.3875 & TST & & \\
\hline CHEMBL1309091 & 688810 & 5.733 & \multicolumn{3}{|c|}{5.4879999999999995} & \\
\hline CHEMBL3195881 & 688810 & 5.683 & 5.1009 & TST & & \\
\hline CHEMBL1375392 & 688810 & \multicolumn{3}{|c|}{4.7330000000000005} & 5.0562 & \\
\hline CHEMBL1399985 & 688810 & 5.132 & 99999999 & & 5.3626 & \\
\hline CHEMBL1354352 & 688810 & 5.483 & 5.029 & TRN & & \\
\hline CHEMBL1457498 & 688810 & 4.883 & 5.041 & TST & & \\
\hline CHEMBL1409161 & 688810 & 4.683 & 5.131 & TRN & & \\
\hline CHEMBL1323278 & 688810 & 4.7336 & 00000000 & 005 & 5.0012 & \\
\hline CHEMBL1341186 & 688810 & 4.933 & 5.1979 & TST & & \\
\hline CHEMBL1373867 & 688810 & 6.0825 & 99999999 & & 5.688 & \\
\hline CHEMBL3189334 & 688810 & 4.583 & 5.0732 & TRN & & \\
\hline CHEMBL1429293 & 688810 & 5.532 & 9999999 & 95 & 5.3335 & \\
\hline
\end{tabular}




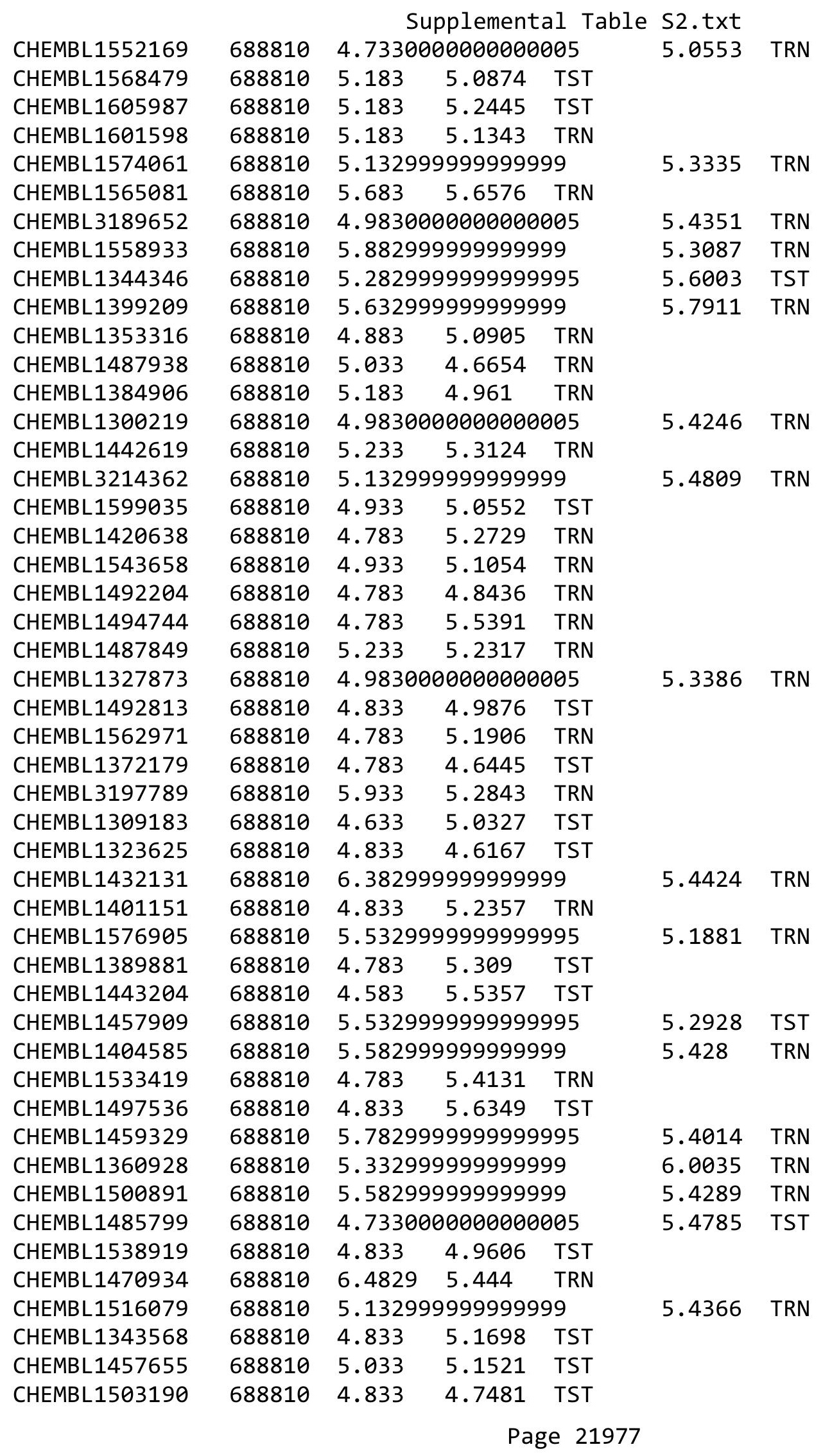




\begin{tabular}{|c|c|c|c|c|c|c|}
\hline \multirow{2}{*}{ CHEMBL1537340 } & \multicolumn{6}{|c|}{ Supplemental Table S2.txt } \\
\hline & 688810 & \multicolumn{3}{|c|}{4.7330000000000005} & 4.8583 & TST \\
\hline CHEMBL370256 & 688810 & \multicolumn{3}{|c|}{5.332999999999999} & 5.2834 & \\
\hline CHEMBL1323165 & 688810 & \multicolumn{3}{|c|}{5.5329999999999995} & 4.9942 & \\
\hline CHEMBL1499852 & 688810 & \multicolumn{3}{|c|}{5.7829999999999995} & 5.0539 & \\
\hline CHEMBL1387720 & 688810 & 4.833 & 4.7089 & TRN & & \\
\hline CHEMBL1483252 & 688810 & 5.483 & 5.1052 & TST & & \\
\hline CHEMBL1371282 & 688810 & \multicolumn{3}{|c|}{5.832999999999999} & 5.3722 & \\
\hline CHEMBL1517233 & 688810 & 5.933 & 5.3434 & TRN & & \\
\hline CHEMBL1588752 & 688810 & \multicolumn{3}{|c|}{4.9830000000000005} & 5.1666 & TST \\
\hline CHEMBL1372672 & 688810 & \multicolumn{3}{|c|}{4.7330000000000005} & 5.5207 & \\
\hline CHEMBL1555982 & 688810 & 5.983 & 5.8767 & TRN & & \\
\hline CHEMBL1398739 & 688810 & 5.033 & 5.1002 & TRN & & \\
\hline CHEMBL1423997 & 688810 & 4.85 & 4.9137 & TRN & & \\
\hline CHEMBL65063 & 688810 & 4.783 & 5.8696 & TRN & & \\
\hline CHEMBL1371447 & 688810 & 4.933 & 5.6037 & TRN & & \\
\hline CHEMBL3197167 & 688810 & 5.483 & 5.0875 & TRN & & \\
\hline CHEMBL1550941 & 688810 & 4.883 & 5.4994 & TST & & \\
\hline CHEMBL1480311 & 688810 & 4.833 & 5.0456 & TRN & & \\
\hline CHEMBL1541721 & 688810 & 5.183 & 5.4647 & TRN & & \\
\hline CHEMBL1608407 & 688810 & 5.7829 & 99999995 & 995 & 5.1444 & \\
\hline CHEMBL3193180 & 688810 & 5.3829 & 99999999 & & 4.9707 & \\
\hline CHEMBL1 & 688810 & 4.683 & 5.5955 & TRN & & \\
\hline CHEMBL1331497 & 688810 & 5.183 & 5.2138 & TRN & & \\
\hline CHEMBL1510552 & 688810 & 4.833 & 5.1641 & TRN & & \\
\hline CHEMBL1422312 & 688810 & 5.5829 & 99999995 & & 5.5104 & \\
\hline CHEMBL1471867 & 688810 & 4.933 & 5.4753 & TRN & & \\
\hline CHEMBL14 & 688810 & 5.6329 & 9999999 & & 5.5486 & \\
\hline CHEMBL1515830 & 688810 & 4.783 & 4.8791 & TRN & & \\
\hline CHEMBL1341390 & 688810 & 5.8829 & 99999999 & & 5.7397 & TP \\
\hline CHEMBL1516246 & 688810 & 4.7330 & 0000000 & 205 & 4.8984 & \\
\hline CHEMBL1606976 & 688810 & 5.38 & 99999995 & & 5.1459 & TRN \\
\hline CHEMBL1468150 & 688810 & 4.7330 & 0000000 & 205 & 5.2577 & \\
\hline CHEMBL1446390 & 688810 & 4.883 & 5.0318 & TRN & & \\
\hline CHEMBL1431048 & 688810 & 4.933 & 5.5568 & TST & & \\
\hline CHEMBL1502306 & 688810 & 5.3329 & 99999995 & & 5.4463 & \\
\hline CHEMBL1470633 & 688810 & 5.28 & 999999 & 995 & 5.1937 & $\mathrm{TS}$ \\
\hline CHEMBL1972090 & 688810 & 6.6329 & 9999 & & 5.7343 & TRN \\
\hline CHEMBL1402502 & 688810 & 5.2829 & 9999999 & 995 & 4.7266 & \\
\hline CHEMBL1543078 & 688810 & 4.933 & 5.3825 & TRN & & \\
\hline CHEMBL1354268 & 688810 & 6.183 & 5.3598 & TRN & & \\
\hline CHEMBL1561545 & 688810 & 5.233 & 5.5538 & TRN & & \\
\hline CHEMBL1456255 & 688810 & 5.433 & 5.5945 & TRN & & \\
\hline CHEMBL1434871 & 688810 & 4.583 & 5.0819 & TST & & \\
\hline CHEMBL1446849 & 688810 & 5.7829 & 9999999 & 995 & 5.1747 & TR \\
\hline CHEMBL65 & 688810 & 6.983 & 5.9515 & TST & & \\
\hline CHEMBL1369378 & 688810 & 4.9830 & 00000006 & 205 & 5.3996 & \\
\hline CHEMBL1497784 & 688810 & 6.7331 & 5.7023 & TRN & & \\
\hline CHEMBL1342441 & 688810 & 5.8329 & 9999999 & & 5.3767 & $\mathrm{n}$ \\
\hline
\end{tabular}




\begin{tabular}{|c|c|c|c|c|c|c|}
\hline \multirow{3}{*}{$\begin{array}{l}\text { CHEMBL1596076 } \\
\text { CHEMBL1495242 }\end{array}$} & & \multicolumn{5}{|c|}{ Supplemental Table s2.txt } \\
\hline & 688810 & \multicolumn{3}{|c|}{5.2829999999999995} & \multirow{3}{*}{5.2681} & \multirow{3}{*}{ TRN } \\
\hline & 688810 & 4.833 & 5.4005 & TST & & \\
\hline CHEMBL1349101 & 688810 & 5.483 & 5.2017 & TST & & \\
\hline CHEMBL1404397 & 688810 & \multicolumn{3}{|c|}{6.082999999999999} & 5.7783 & TRN \\
\hline CHEMBL1577197 & 688810 & 4.783 & 5.2579 & TRN & & \\
\hline CHEMBL1436130 & 688810 & 5.033 & 5.0491 & TRN & & \\
\hline CHEMBL260028 & 688810 & \multicolumn{3}{|c|}{6.832999999999999} & 6.5133 & TRN \\
\hline CHEMBL1393476 & 688810 & 5.033 & 5.0699 & TST & & \\
\hline CHEMBL3196278 & 688810 & \multicolumn{3}{|c|}{5.132999999999999} & 5.2745 & TRN \\
\hline CHEMBL1559455 & 688810 & 4.783 & 4.9383 & TRN & & \\
\hline CHEMBL1389053 & 688810 & 4.833 & 5.6436 & TST & & \\
\hline CHEMBL3194699 & 688810 & 5.033 & 4.7735 & TST & & \\
\hline CHEMBL1567058 & 688810 & \multicolumn{3}{|c|}{4.7330000000000005} & 5.5345 & TRN \\
\hline CHEMBL1441858 & 688810 & \multicolumn{3}{|c|}{5.832999999999999} & 5.6148 & TRN \\
\hline CHEMBL1535335 & 688810 & 4.933 & 5.1222 & TRN & & \\
\hline CHEMBL1371877 & 688810 & 5.483 & 5.2992 & TST & & \\
\hline CHEMBL1341706 & 688810 & 4.883 & 5.0783 & TRN & & \\
\hline CHEMBL1345786 & 688810 & 5.033 & 5.2018 & TST & & \\
\hline CHEMBL3212955 & 688810 & \multicolumn{3}{|c|}{4.7330000000000005} & 5.441 & TRN \\
\hline CHEMBL1365162 & 688810 & \multicolumn{3}{|c|}{6.382999999999999} & 5.4518 & TRN \\
\hline CHEMBL1559811 & 688810 & 6.183 & 5.34200 & 00006 & 005 & TRN \\
\hline CHEMBL1488250 & 688810 & \multicolumn{3}{|c|}{6.382999999999999} & 5.8754 & TRN \\
\hline CHEMBL1419183 & 688810 & 4.783 & 5.3293 & TST & & \\
\hline CHEMBL3193775 & 688810 & \multicolumn{3}{|c|}{4.9830000000000005} & 5.1757 & TRN \\
\hline CHEMBL1306126 & 688810 & 5.483 & 5.3704 & TRN & & \\
\hline CHEMBL1360809 & 688810 & 4.583 & 5.3216 & TRN & & \\
\hline CHEMBL1567428 & 688810 & \multicolumn{3}{|c|}{6.132999999999999} & 5.6332 & TRN \\
\hline CHEMBL1316382 & 688810 & \multicolumn{3}{|c|}{5.832999999999999} & 5.4913 & TRN \\
\hline CHEMBL1409279 & 688810 & \multicolumn{3}{|c|}{5.7829999999999995} & 4.9641 & TRN \\
\hline CHEMBL1542993 & 688810 & 4.783 & 6.1219 & TST & & \\
\hline CHEMBL1468909 & 688810 & 5.233 & 5.0161 & TRN & & \\
\hline CHEMBL1486418 & 688810 & 5.733 & 5.279 & TRN & & \\
\hline CHEMBL1304996 & 688810 & 4.933 & 6.1477 & TRN & & \\
\hline CHEMBL1567973 & 688810 & 4.683 & 5.0154 & TST & & \\
\hline CHEMBL1579313 & 688810 & 4.783 & 4.9413 & TRN & & \\
\hline CHEMBL1592612 & 688810 & \multicolumn{3}{|c|}{5.2829999999999995} & 5.0735 & TST \\
\hline CHEMBL3190025 & 688810 & 5.233 & 5.2556 & TRN & & \\
\hline CHEMBL1401752 & 688810 & 5.183 & 5.1447 & TRN & & \\
\hline CHEMBL1329152 & 688810 & 5.1 & 5.2344 & TRN & & \\
\hline CHEMBL1385573 & 688810 & \multicolumn{3}{|c|}{7.082999999999999} & 5.9857 & TRN \\
\hline CHEMBL1503324 & 688810 & 4.833 & 4.7384 & TST & & \\
\hline CHEMBL1321361 & 688810 & \multirow{2}{*}{\multicolumn{3}{|c|}{$\begin{array}{ll}5.233 & 5.7352 \\
5.132999999999999\end{array}$}} & & \\
\hline CHEMBL1385158 & 688810 & & & & 5.5115 & TRN \\
\hline CHEMBL1322645 & 688810 & 6.0 & 4.7064 & TRN & & \\
\hline CHEMBL1431211 & 688810 & 6.233 & 4.6912 & TRN & & \\
\hline CHEMBL1463498 & 688810 & 5.683 & 5.5609 & TRN & & \\
\hline CHEMBL1559885 & 688810 & \multicolumn{3}{|c|}{5.2829999999999995} & .1482 & TST \\
\hline CHEMBL1524742 & 688810 & 4.783 & 5.3012 & TRN & & \\
\hline
\end{tabular}




\begin{tabular}{|c|c|c|c|c|c|c|}
\hline & \multicolumn{5}{|c|}{ I Table } \\
\hline CHEMBL1370681 & 688810 & 4.633 & 4.7683 & TRN & & \\
\hline CHEMBL1459298 & 688810 & 4.9830 & $0000000 €$ & 005 & 4.9248 & TST \\
\hline CHEMBL 209410 & 688810 & 5.8829 & 9999999 & & 5.99299 & \\
\hline CHEMBL1348318 & 688810 & 4.7330 & 00000000 & 005 & 5.2649 & \\
\hline CHEMBL1522980 & 688810 & 5.2829 & 9999999 & 995 & 4.6405 & \\
\hline CHEMBL 1476414 & 688810 & 4.583 & 4.9529 & TRN & & \\
\hline CHEMBL1573103 & 688810 & 4.833 & 5.2239 & TRN & & \\
\hline CHEMBL 3199038 & 688810 & 4.7330 & 00000006 & 005 & 5.4459 & \\
\hline CHEMBL1575152 & 688810 & 5.5329 & 9999999 & 995 & 5.2769 & \\
\hline CHEMBL1372681 & 688810 & 6.433 & 5.3897 & TRN & & \\
\hline CHEMBL1332642 & 688810 & 5.083 & 5.3553 & TRN & & \\
\hline CHEMBL1413671 & 688810 & 6.5829 & 99999999 & & 6.1134 & \\
\hline CHEMBL1300260 & 688810 & 5.233 & 5.65799 & 999999 & 995 & \\
\hline CHEMBL1372938 & 688810 & 4.883 & 5.5368 & TST & & \\
\hline CHEMBL1396127 & 688810 & 4.7330 & 00000006 & 005 & 4.9445 & \\
\hline CHEMBL1424553 & 688810 & 4.783 & 5.2371 & TRN & & \\
\hline CHEMBL1508180 & 688810 & 5.5329 & 99999999 & 995 & 5.5063 & \\
\hline CHEMBL1402035 & 688810 & 4.7330 & 00000000 & 005 & 5.2319 & \\
\hline CHEMBL1425035 & 688810 & 5.1329 & 99999999 & & 5.4357 & \\
\hline CHEMBL1521261 & 688810 & 4.833 & 5.7079 & TST & & \\
\hline CHEMBL 259805 & 688810 & 5.1329 & 99999999 & & 6.3422 & \\
\hline CHEMBL1395970 & 688810 & 4.7330 & 2000000e & 005 & 4.9349 & \\
\hline CHEMBL1340027 & 688810 & 4.783 & 5.5383 & TST & & \\
\hline CHEMBL1354636 & 688810 & 4.833 & 5.0783 & TRN & & \\
\hline CHEMBL 3210230 & 688810 & 5.083 & 4.9369 & TST & & \\
\hline CHEMBL1398149 & 688810 & 6.7331 & 5.6592 & TRN & & \\
\hline CHEMBL1315110 & 688810 & 5.233 & 5.0289 & TRN & & \\
\hline CHEMBL1499500 & 688810 & 5.3329 & 99999999 & & 5.2578 & \\
\hline CHEMBL1398224 & 688810 & 4.583 & 5.1039 & TST & & \\
\hline CHEMBL1538208 & 688810 & 5.5329 & 99999999 & 995 & 5.6091 & \\
\hline CHEMBL1348874 & 688810 & 4.633 & 4.9288 & TRN & & \\
\hline CHEMBL1474763 & 688810 & 4.783 & 5.2565 & TRN & & \\
\hline CHEMBL1367439 & 688810 & 4.633 & 5.2982 & TST & & \\
\hline CHEMBL1548670 & 688810 & 5.083 & 5.6435 & TRN & & \\
\hline CHEMBL1368138 & 688810 & 5.6329 & 99999999 & & 5.2853 & \\
\hline CHEMBL256202 & 688810 & 4.783 & 5.1239 & TST & & \\
\hline CHEMBL 3195906 & 688810 & 5.933 & 6.0145 & TRN & & \\
\hline CHEMBL1383204 & 688810 & 5.483 & 4.9702 & TRN & & \\
\hline CHEMBL1595375 & 688810 & 5.033 & 5.0534 & TRN & & \\
\hline CHEMBL1578482 & 688810 & 5.1329 & 99999999 & & 5.3184 & \\
\hline CHEMBL1558321 & 688810 & 5.033 & 5.1082 & TRN & & \\
\hline CHEMBL1557635 & 688810 & 4.683 & 5.3201 & TRN & & \\
\hline CHEMBL1470041 & 688810 & 4.9830 & 2000000e & 005 & & \\
\hline CHEMBL1474831 & 688810 & 4.7330 & 2000000e & 005 & 5.1973 & \\
\hline CHEMBL1484825 & 688810 & 5.933 & 5.7978 & TRN & & \\
\hline CHEMBL 3196859 & 688810 & 4.933 & 4.7339 & TRN & & \\
\hline CHEMBL1429775 & 688810 & 4.833 & 5.082 & TRN & & \\
\hline CHEMBL1540848 & 688810 & 6.433 & 5.4372 & TRN & & \\
\hline
\end{tabular}




\begin{tabular}{|c|c|c|c|c|c|c|}
\hline \multirow[b]{2}{*}{ CHEMBL1485947 } & \multicolumn{6}{|c|}{ pplemental Ta } \\
\hline & 688810 & 4.883 & 5.2627 & TRN & & \\
\hline CHEMBL1613307 & 688810 & 4.833 & 5.1609 & TRN & & \\
\hline CHEMBL1440541 & 688810 & 4.783 & 5.3449 & TRN & & \\
\hline CHEMBL1450536 & 688810 & 5.7829 & 999999999 & 995 & 5.9643 & TRN \\
\hline CHEMBL1609494 & 688810 & 5.233 & 5.3108 & TRN & & \\
\hline CHEMBL1478996 & 688810 & 6.5329 & 999999999 & 995 & 5.6035 & TRN \\
\hline CHEMBL 3196640 & 688810 & 4.833 & 5.0167 & TST & & \\
\hline CHEMBL1322983 & 688810 & 4.583 & 5.2431 & TRN & & \\
\hline CHEMBL1395301 & 688810 & 6.0329 & 999999999 & 995 & 5.2572 & TRN \\
\hline CHEMBL1519965 & 688810 & 6.0329 & 999999999 & 995 & & \\
\hline CHEMBL1357775 & 688810 & 4.883 & 4.9829 & TST & & \\
\hline CHEMBL388979 & 688810 & 4.683 & 4.8969 & TST & & \\
\hline CHEMBL1561904 & 688810 & 5.933 & 6.0855 & TRN & & \\
\hline CHEMBL1452937 & 688810 & 5.5329 & 999999999 & 995 & 5.6 & \\
\hline CHEMBL1432436 & 688810 & 4.883 & 5.1352 & TST & & \\
\hline CHEMBL1500499 & 688810 & 4.833 & 5.4626 & TST & & \\
\hline CHEMBL1480635 & 688810 & 5.933 & 5.2932 & TST & & \\
\hline CHEMBL1526203 & 688810 & 4.783 & 5.4549 & TRN & & \\
\hline CHEMBL1489093 & 688810 & 4.683 & 4.7359 & TRN & & \\
\hline CHEMBL1527580 & 688810 & 5.5329 & 999999999 & 995 & 5.4537 & Thiv \\
\hline CHEMBL1489649 & 688810 & 4.7330 & 000000000 & 005 & 5.0269 & \\
\hline CHEMBL 3194761 & 688810 & 5.683 & 5.3844 & TRN & & \\
\hline CHEMBL1359801 & 688810 & 4.7330 & 000000000 & 005 & 3 & \\
\hline CHEMBL1539488 & 688810 & 4.933 & 5.6721 & TRN & & \\
\hline CHEMBL1489960 & 688810 & 4.9830 & 000000000 & & 5.0334 & I KIV \\
\hline CHEMBL3210479 & 688810 & 4.633 & 5.1978 & TST & & \\
\hline CHEMBL1478578 & 688810 & 4.883 & 5.052 & TRN & & \\
\hline CHEMBL1608377 & 688810 & 4.95 & 5.3885 & TRN & & \\
\hline CHEMBL1350122 & 688810 & 4.783 & 4.8671 & TST & & \\
\hline CHEMBL 3197437 & 688810 & 4.933 & 4.9773 & TRN & & \\
\hline CHEMBL1491559 & 688810 & 5.183 & 5.3963 & TRN & & \\
\hline CHEMBL 2007227 & 688810 & 6.0829 & 999999999 & & 5.4387 & \\
\hline CHEMBL1419621 & 688810 & 5.933 & 5.5757 & TRN & & \\
\hline CHEMBL1590120 & 688810 & 4.583 & 4.9426 & TST & & \\
\hline CHEMBL1348405 & 688810 & 5.233 & 5.3826 & TRN & & \\
\hline CHEMBL1443834 & 688810 & 4.9830 & 000000000 & 205 & 5.2391 & TR \\
\hline CHEMBL1407114 & 688810 & 5.233 & 5.1766 & TST & & \\
\hline CHEMBL1600760 & 688810 & 5.233 & 4.9074 & TST & & \\
\hline CHEMBL1582709 & 688810 & 4.9830 & 000000000 & 205 & 5.2172 & TRN \\
\hline CHEMBL1540987 & 688810 & 4.833 & 5.3578 & TRN & & \\
\hline CHEMBL546170 & 688810 & 4.583 & 5.7468 & TST & & \\
\hline CHEMBL1504639 & 688810 & 4.7330 & 000000000 & 205 & 5.0981 & ובני \\
\hline CHEMBL1347104 & 688810 & 4.833 & 4.837 & TRN & & \\
\hline CHEMBL1304458 & 688810 & 4.683 & 5.3013 & TRN & & \\
\hline CHEMBL1454347 & 688810 & 4.783 & 5.0679 & TRN & & \\
\hline CHEMBL1405169 & 688810 & 4.833 & 5.332000 & 20000 & $\partial 1$ & I KIV \\
\hline CHEMBL1519211 & 688810 & 5.8829 & 999999999 & & 5.3942 & 1 \\
\hline CHEMBL1469960 & 688810 & 4.783 & 4.8762 & TRN & & \\
\hline
\end{tabular}




\begin{tabular}{|c|c|c|c|c|c|c|}
\hline \multirow[b]{2}{*}{ CHEMBL1366443 } & \multirow[b]{2}{*}{688810} & \multicolumn{5}{|c|}{ Supplemental Table S2.txt } \\
\hline & & \multirow{2}{*}{\multicolumn{3}{|c|}{$\begin{array}{ll}6.183 & 5.4409 \\
5.582999999999999\end{array}$}} & \multirow{2}{*}{5.5583} & \multirow[b]{2}{*}{ TRN } \\
\hline CHEMBL1387927 & 688810 & & & & & \\
\hline CHEMBL1476181 & 688810 & 6.0 & 4.8391 & TST & & \\
\hline CHEMBL1382331 & 688810 & 4.833 & 5.2686 & TST & & \\
\hline CHEMBL 1487960 & 688810 & 4.783 & 5.5749 & TRN & & \\
\hline CHEMBL1299209 & 688810 & \multicolumn{3}{|c|}{4.7330000000000005} & 5.1144 & TRN \\
\hline CHEMBL1385055 & 688810 & 5.183 & 4.9338 & TRN & & \\
\hline CHEMBL1325180 & 688810 & \multicolumn{3}{|c|}{4.7330000000000005} & 5.3795 & \\
\hline CHEMBL1498860 & 688810 & 4.783 & 4.8546 & TRN & & \\
\hline CHEMBL1338273 & 688810 & 4.833 & 4.987 & TRN & & \\
\hline CHEMBL 74930 & 688810 & \multicolumn{3}{|c|}{4.7330000000000005} & 5.2352 & TRN \\
\hline CHEMBL1507990 & 688810 & \multicolumn{3}{|c|}{4.7330000000000005} & 4.6084 & \\
\hline CHEMBL1465091 & 688810 & 5.433 & 5.215 & TRN & & \\
\hline CHEMBL1321426 & 688810 & \multirow{2}{*}{\multicolumn{3}{|c|}{$\begin{array}{lll}4.833 & 5.1211 & \text { IRIN } \\
6.0329999999999995\end{array}$}} & & \\
\hline CHEMBL1536630 & 688810 & & & & 5.6336 & In \\
\hline CHEMBL3207839 & 688810 & 5.733 & 5.2823 & TRN & & \\
\hline CHEMBL1498724 & 688810 & \multicolumn{3}{|c|}{6.5329999999999995} & 832 & TRN \\
\hline CHEMBL1378893 & 688810 & \multicolumn{3}{|c|}{5.382999999999999} & & \\
\hline CHEMBL 319 & 688810 & 5.233 & 5.1954 & TRN & & \\
\hline CHEMBL1574443 & 688810 & \multicolumn{3}{|c|}{5.582999999999999} & 259 & TRN \\
\hline CHEMBL1355854 & 688810 & \multicolumn{3}{|c|}{4.7330000000000005} & 4.6096 & \\
\hline CHEMBL1311146 & 688810 & 4.833 & 5.255 & TRN & & \\
\hline CHEMBL1 & 688 & \multicolumn{3}{|c|}{5.332999999999999} & & \\
\hline CHEMBL13: & 688810 & \multicolumn{3}{|c|}{6.0329999999999995} & 105 & TRN \\
\hline CHEMBL1583316 & 688810 & 5.083 & 5.5562 & TRN & & \\
\hline CHEMBL1352093 & 688810 & 4.783 & 5.164 & TRN & & \\
\hline CHEMBL1429082 & 688810 & \multicolumn{3}{|c|}{5.132999999999999} & & TRN \\
\hline CHEMBL & $68 \varepsilon$ & \multicolumn{3}{|c|}{5.582999999999999} & & \\
\hline CHEMBL15e & 688810 & 5.683 & 5.309 & TRN & & \\
\hline CHEMBL1580279 & 688810 & 5.083 & 5.0988 & TRN & & \\
\hline CHEMBL1516160 & 688810 & 4.783 & 4.9075 & TRN & & \\
\hline CHEMBL1329367 & 688810 & 6.433 & 5.7437 & TST & & \\
\hline CHEMBL1 & 688 & 5.6 & 5.4675 & TRN & & \\
\hline CHEMBL1329822 & 688 & 5.683 & 5.3174 & TST & & \\
\hline CHEMBL1474443 & 688810 & 4.833 & 4.8522 & TST & & \\
\hline CHEMBL1383007 & 688810 & 5.5329 & 99999999 & 995 & & TRN \\
\hline CHEMBL1582450 & 688810 & 5.33 & 9999999 & & 5.4311 & TRN \\
\hline CHEMBL1355716 & 688810 & 5.132 & 99999999 & & 5.5432 & TRN \\
\hline CHEMBL1990057 & 688810 & 5.5829 & 99999999 & & 5.3606 & TRN \\
\hline CHEMBL1313421 & 688810 & 4.833 & 5.2817 & TRN & & \\
\hline CHEMBL1445746 & 688810 & 5.2829 & 99999999 & 995 & & IRIN \\
\hline CHEMBL1529252 & 688810 & 4.983 & 00000000 & 005 & 5.149 & TR \\
\hline CHEMBL1372017 & 688810 & 5.782 & 99999999 & 995 & 5.6596 & TRN \\
\hline CHEMBL1380056 & 688810 & 5.8329 & 99999999 & & 5.2318 & TST \\
\hline CHEMBL1373446 & 688810 & 6.0829 & 99999999 & & 5.6545 & TRN \\
\hline CHEMBL3207845 & 688810 & 6.3829 & 99999999 & & 5.3544 & TRN \\
\hline CHEMBL1563707 & 688810 & 4.7330 & 00000000 & 005 & 5.2529 & TRN \\
\hline CHEMBL3194311 & 688810 & 5.1329 & 99999999 & & 5.3651 & TRN \\
\hline
\end{tabular}




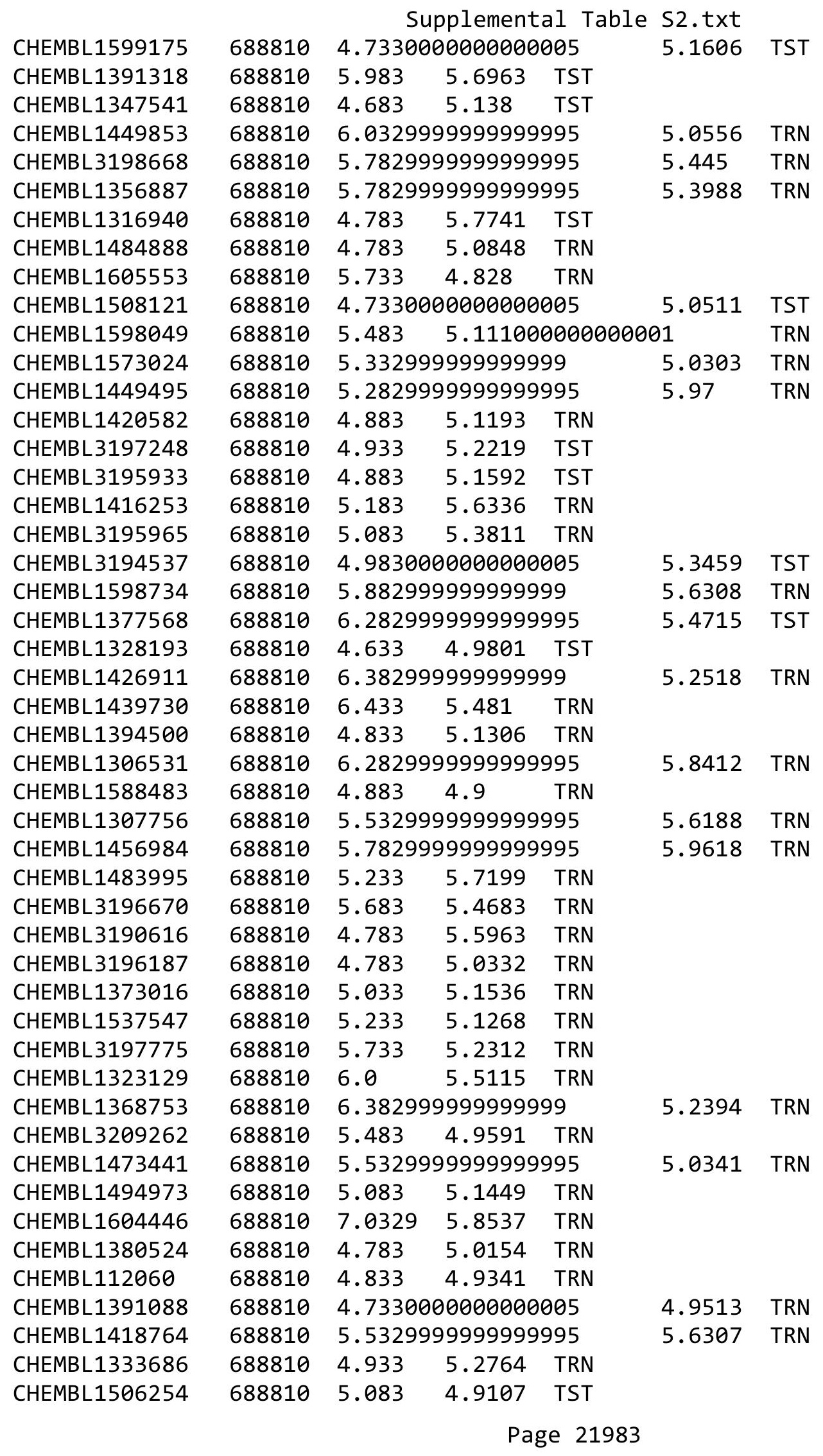




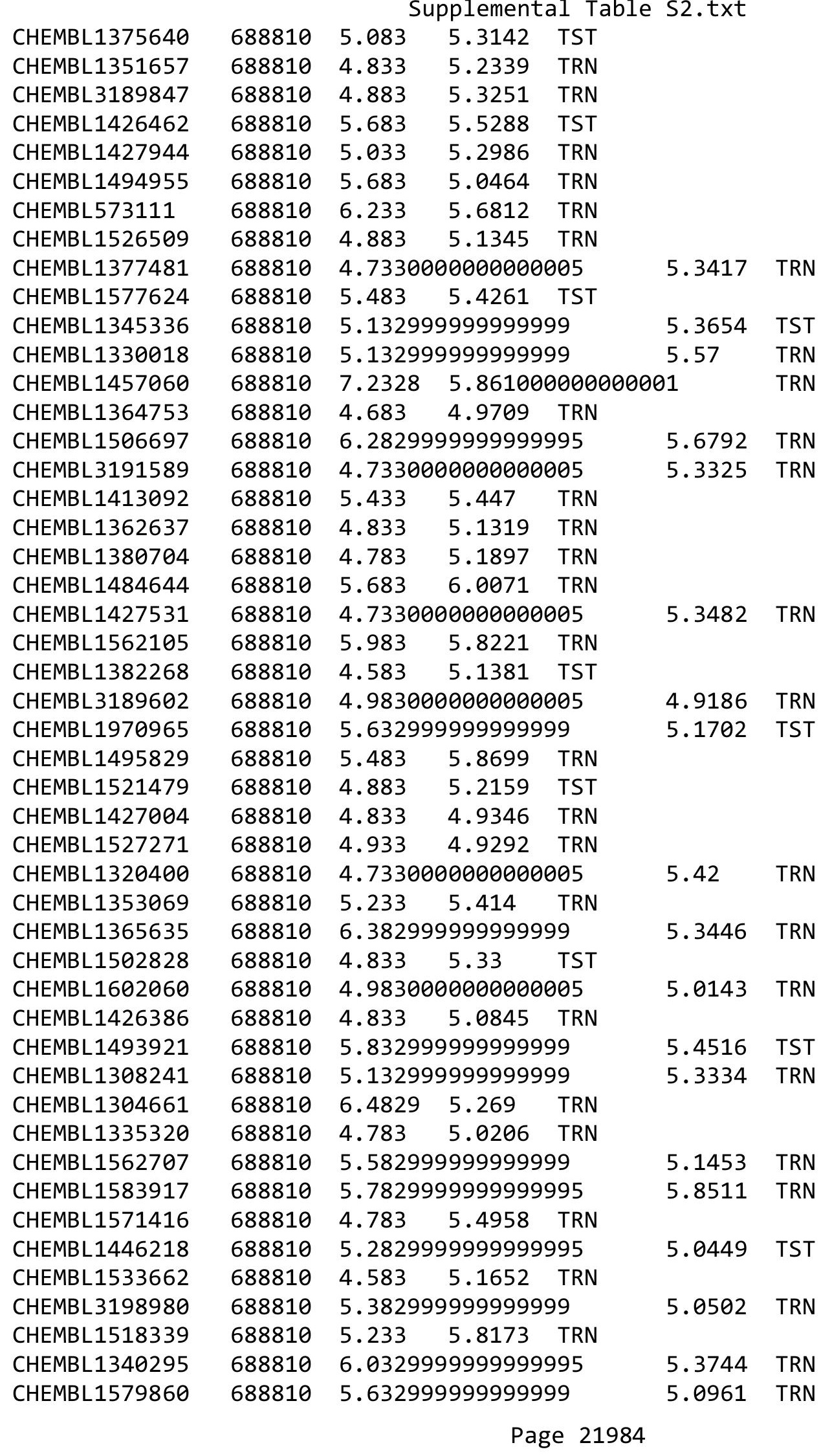




\begin{tabular}{|c|c|c|c|c|c|c|}
\hline CHEMBL1409822 & 688810 & \multicolumn{4}{|c|}{ Supplemental Table S2.txt } & TRN \\
\hline CHEMBL1382479 & 688810 & 6.0 & 5.3549 & TST & & \\
\hline CHEMBL1303272 & 688810 & 4.783 & 5.2838 & TST & & \\
\hline CHEMBL1569442 & 688810 & 5.733 & 6.0637 & TRN & & \\
\hline CHEMBL1360670 & 688810 & 5.083 & 5.372006 & 000000000 & $\partial 1$ & \\
\hline CHEMBL1524749 & 688810 & 4.73300 & 000000006 & 005 & 5.4278 & \\
\hline CHEMBL601110 & 688810 & 4.933 & 4.9504 & TRN & & \\
\hline CHEMBL 3208447 & 688810 & 5.033 & 5.4353 & TST & & \\
\hline CHEMBL1333530 & 688810 & 5.53299 & 99999999 & 995 & 4.8344 & \\
\hline CHEMBL1553475 & 688810 & 4.633 & 5.2484 & TRN & & \\
\hline CHEMBL3208946 & 688810 & 5.53299 & 99999999 & 995 & 5.3644 & \\
\hline CHEMBL1541305 & 688810 & 4.683 & 5.0855 & TST & & \\
\hline CHEMBL1528904 & 688810 & 4.833 & 5.0978 & TRN & & \\
\hline CHEMBL1491688 & 688810 & 4.73300 & 00000000 & 005 & 5.3402 & \\
\hline CHEMBL1582535 & 688810 & 6.03299 & 99999999 & 995 & 5.1467 & \\
\hline CHEMBL1317147 & 688810 & 5.683 & 5.5003 & TRN & & \\
\hline CHEMBL1477473 & 688810 & 5.983 & 5.7659 & TRN & & \\
\hline CHEMBL1469668 & 688810 & 5.78299 & 99999999 & 995 & 5.5583 & \\
\hline CHEMBL3196052 & 688810 & 4.833 & 5.2839 & TRN & & \\
\hline CHEMBL1336000 & 688810 & 4.73300 & 00000000 & 005 & 5.3609 & \\
\hline CHEMBL1352528 & 688810 & 6.433 & 5.7871 & TRN & & \\
\hline CHEMBL1565163 & 688810 & 5.733 & 5.3781 & TRN & & \\
\hline CHEMBL1465074 & 688810 & 6.05 & 5.9884 & TRN & & \\
\hline CHEMBL1519341 & 688810 & 4.583 & 4.737 & TRN & & \\
\hline CHEMBL1572130 & 688810 & 5.683 & 5.3263 & TRN & & \\
\hline CHEMBL1332672 & 688810 & 5.28299 & 99999999 & 995 & 5.1644 & \\
\hline CHEMBL1434706 & 688810 & 5.183 & 5.2471 & TRN & & \\
\hline CHEMBL1540770 & 688810 & 5.78299 & 99999999 & 995 & 5.5229 & \\
\hline CHEMBL1579718 & 688810 & 5.733 & 5.0079 & TST & & \\
\hline CHEMBL1395006 & 688810 & 4.98300 & 00000000 & 005 & 5.5917 & \\
\hline CHEMBL1518701 & 688810 & 4.883 & 5.3098 & TST & & \\
\hline CHEMBL 3194448 & 688810 & 5.233 & 5.0026 & TRN & & \\
\hline CHEMBL1482541 & 688810 & 5.733 & 5.6527 & TST & & \\
\hline CHEMBL1334777 & 688810 & 5.28299 & 99999999 & 995 & 5.687 & $T$ \\
\hline CHEMBL1415716 & 688810 & 5.733 & 4.8838 & TST & & \\
\hline CHEMBL1566179 & 688810 & 4.583 & 5.3138 & TST & & \\
\hline CHEMBL1357485 & 688810 & 5.733 & 5.4207 & TST & & \\
\hline CHEMBL3196450 & 688810 & 5.233 & 5.5352 & TRN & & \\
\hline CHEMBL1445765 & 688810 & 4.883 & 5.5821 & TRN & & \\
\hline CHEMBL1490874 & 688810 & 4.783 & 5.2437 & TRN & & \\
\hline CHEMBL1365939 & 688810 & 4.783 & 5.3961 & TST & & \\
\hline CHEMBL3196049 & 688810 & 4.933 & 4.9024 & TRN & & \\
\hline CHEMBL1304177 & 688810 & 5.233 & 5.3014 & TST & & \\
\hline CHEMBL1406373 & 688810 & 4.783 & 5.18 & TRN & & \\
\hline CHEMBL3196116 & 688810 & 4.833 & 5.3594 & TRN & & \\
\hline CHEMBL1440949 & 688810 & 5.183 & 5.5651 & TRN & & \\
\hline CHEMBL1530295 & 688810 & 6.0 & 4.9837 & TST & & \\
\hline CHEMBL1306805 & 688810 & 4.833 & 4.9571 & TRN & & \\
\hline
\end{tabular}




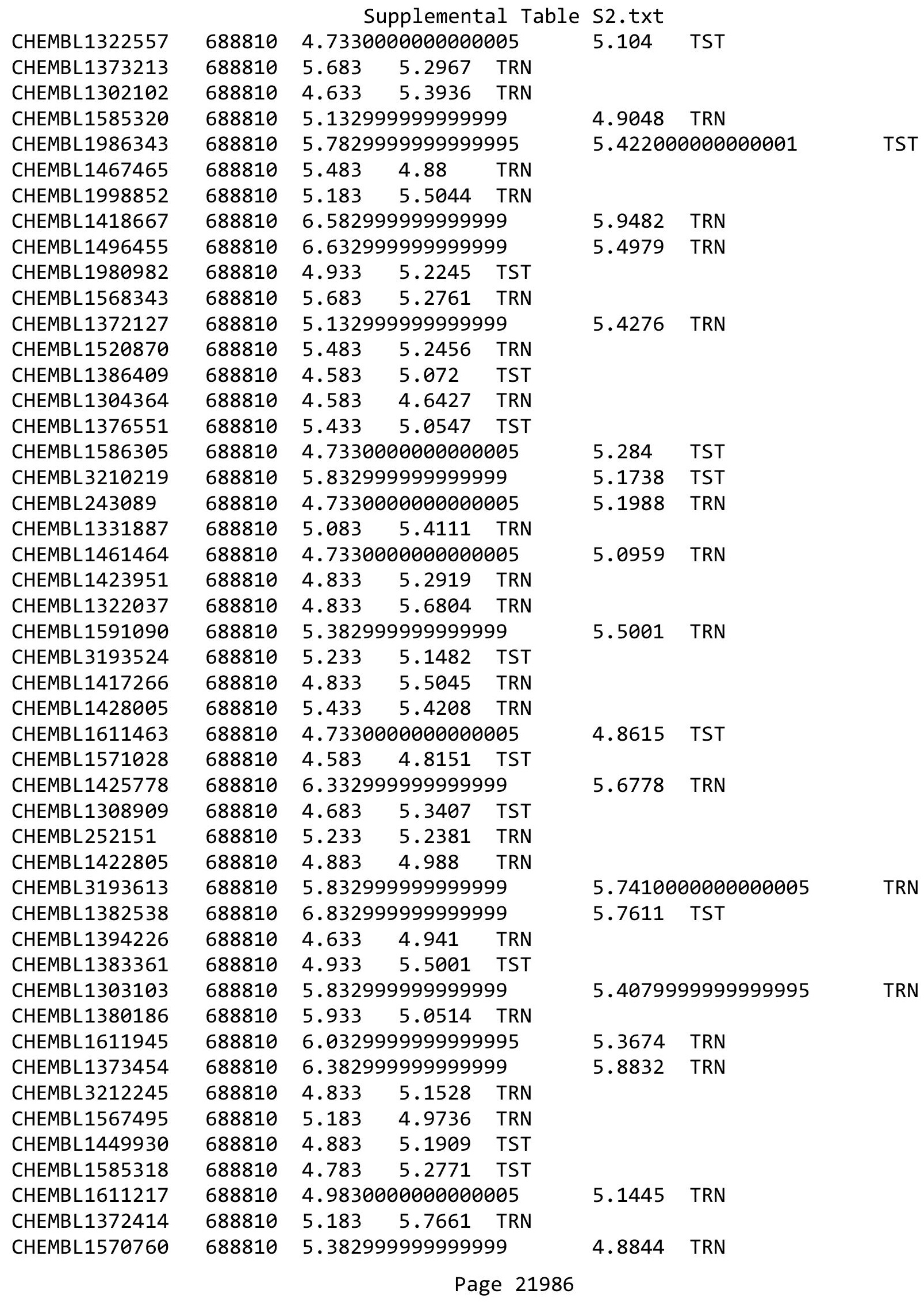




\begin{tabular}{|c|c|c|c|c|c|c|c|}
\hline \multicolumn{7}{|c|}{ S2.txt } & \\
\hline CHEMBL1386032 & 688810 & 4.783 & 5.5336 & TST & & & \\
\hline CHEMBL1540470 & 688810 & 4.783 & 5.2112 & TRN & & & \\
\hline CHEMBL1333417 & 688810 & 4.73300 & 000000006 & 005 & 5.3741 & TST & \\
\hline CHEMBL1354471 & 688810 & 5.483 & 4.9944 & TRN & & & \\
\hline CHEMBL1429509 & 688810 & 6.33299 & 99999999 & & 5.6857 & TRN & \\
\hline CHEMBL1582831 & 688810 & 5.33299 & 99999999 & & 5.1571 & TRN & \\
\hline CHEMBL1486982 & 688810 & 5.38299 & 999999999 & & 5.1413 & TRN & \\
\hline CHEMBL1334090 & 688810 & 6.9329 & 6.2573 & TRN & & & \\
\hline CHEMBL1421184 & 688810 & 4.683 & 4.6064 & TRN & & & \\
\hline CHEMBL3208079 & 688810 & 4.833 & 4.9907 & TRN & & & \\
\hline CHEMBL1537141 & 688810 & 6.33299 & 999999999 & & 5.4919 & TRN & \\
\hline CHEMBL1450393 & 688810 & 5.33299 & 999999999 & & 5.0798 & TST & \\
\hline CHEMBL1613656 & 688810 & 4.683 & 5.0938 & TRN & & & \\
\hline CHEMBL1481699 & 688810 & 4.833 & 5.2122 & TRN & & & \\
\hline CHEMBL1418614 & 688810 & 4.583 & 4.8909 & TST & & & \\
\hline CHEMBL1596095 & 688810 & 5.733 & 6.0515 & TRN & & & \\
\hline CHEMBL1523422 & 688810 & 5.38299 & 99999999 & & 5.1756 & TRN & \\
\hline CHEMBL1364837 & 688810 & 4.73300 & 000000006 & 005 & 5.16299 & 9999999999 & TST \\
\hline CHEMBL 3196924 & 688810 & 5.13299 & 999999999 & & 5.3645 & TRN & \\
\hline CHEMBL1565326 & 688810 & 5.733 & 4.9283 & TST & & & \\
\hline CHEMBL1585706 & 688810 & 4.583 & 4.8825 & TRN & & & \\
\hline CHEMBL1532611 & 688810 & 4.73300 & 000000006 & 005 & 5.1439 & TST & \\
\hline CHEMBL1435076 & 688810 & 5.433 & 5.8245 & TRN & & & \\
\hline CHEMBL1522808 & 688810 & 5.183 & 5.6212 & TRN & & & \\
\hline CHEMBL1589649 & 688810 & 4.883 & 5.2734 & TST & & & \\
\hline CHEMBL1571454 & 688810 & 4.933 & 5.2793 & TRN & & & \\
\hline CHEMBL1978671 & 688810 & 4.73300 & 000000006 & 005 & 5.0817 & TRN & \\
\hline CHEMBL1563106 & 688810 & 5.483 & 5.3858 & TST & & & \\
\hline CHEMBL1542279 & 688810 & 5.33299 & 999999999 & & 4.9133 & TST & \\
\hline CHEMBL1369050 & 688810 & 4.933 & 5.3616 & TRN & & & \\
\hline CHEMBL1341053 & 688810 & 5.483 & 5.4426 & TRN & & & \\
\hline CHEMBL1458074 & 688810 & 5.733 & 5.1419 & TRN & & & \\
\hline CHEMBL 3208705 & 688810 & 4.783 & 5.4221 & TRN & & & \\
\hline CHEMBL 3192363 & 688810 & 5.183 & 5.2147 & TRN & & & \\
\hline CHEMBL1331678 & 688810 & 5.733 & 5.1855 & TST & & & \\
\hline CHEMBL1303809 & 688810 & 5.38299 & 999999999 & 99 & 5.0751 & TRN & \\
\hline CHEMBL1399281 & 688810 & 5.933 & 5.5654 & TST & & & \\
\hline CHEMBL1339526 & 688810 & 4.933 & 5.1558 & TST & & & \\
\hline CHEMBL1595830 & 688810 & 4.833 & 4.8338 & TRN & & & \\
\hline CHEMBL1487345 & 688810 & 5.233 & 4.9397 & TST & & & \\
\hline CHEMBL1513122 & 688810 & 4.683 & 4.7219 & TST & & & \\
\hline CHEMBL1522743 & 688810 & 5.88299 & 999999995 & & 5.5281 & TRN & \\
\hline CHEMBL1591135 & 688810 & 5.683 & 5.2495 & TRN & & & \\
\hline CHEMBL1450458 & 688810 & 5.13299 & 999999999 & 99 & 5.0057 & TRN & \\
\hline CHEMBL1581994 & 688810 & 5.083 & 4.8962 & TRN & & & \\
\hline CHEMBL1324028 & 688810 & 4.783 & 5.0924 & TRN & & & \\
\hline CHEMBL1387283 & 688810 & 5.13299 & 99999999s & & 5.419 & TRN & \\
\hline CHEMBL1376882 & 688810 & 6.433 & 5.3841 & TRN & & & \\
\hline
\end{tabular}




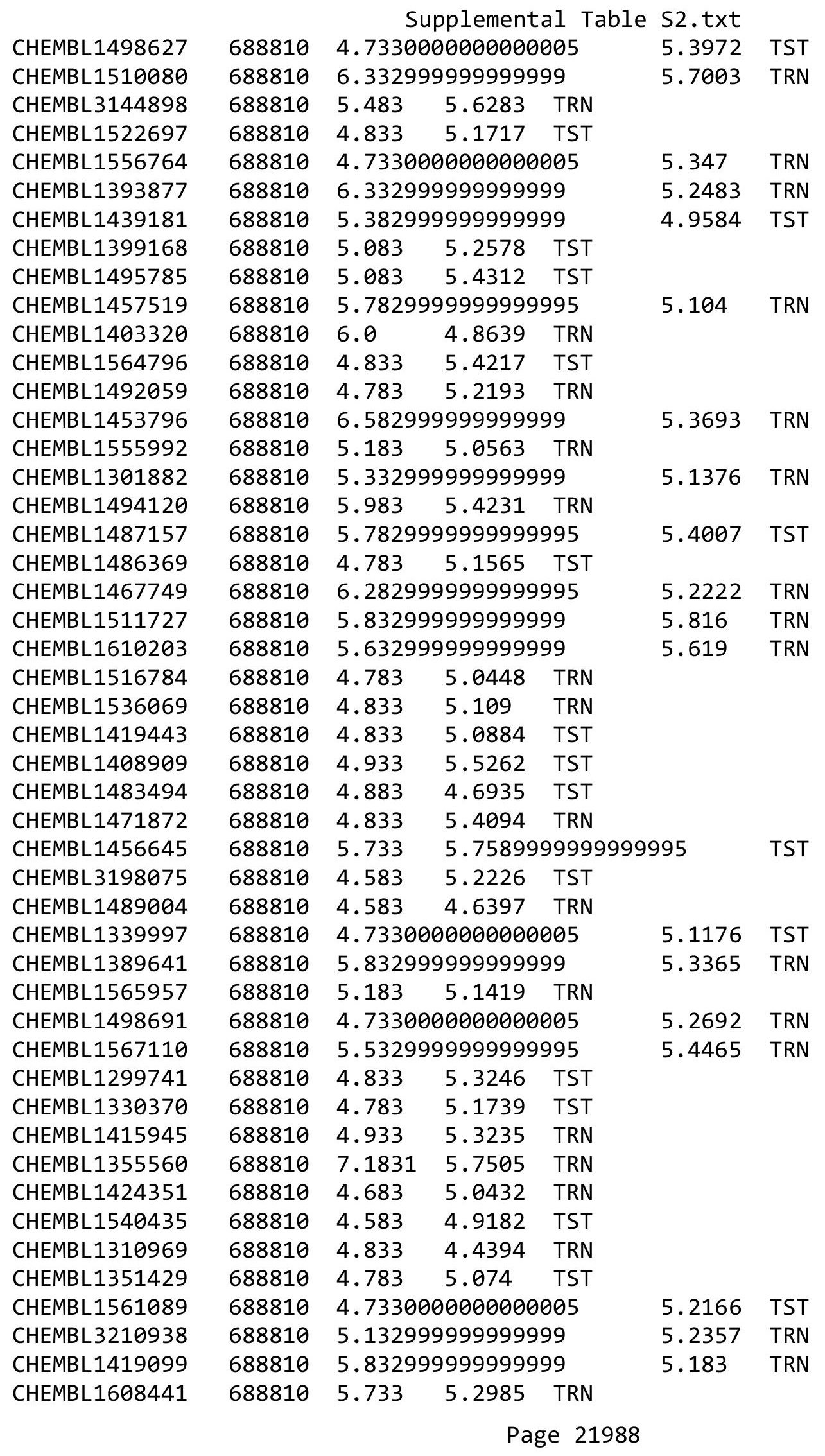




\begin{tabular}{|c|c|c|c|c|c|c|}
\hline \multirow[b]{2}{*}{ CHEMBL 3197994} & \multicolumn{6}{|c|}{ plemental Tá } \\
\hline & 688810 & 4.883 & 4.5892 & TST & & \\
\hline CHEMBL1385419 & 688810 & 4.933 & 5.2152 & TRN & & \\
\hline CHEMBL1410082 & 688810 & \multicolumn{3}{|c|}{4.7330000000000005} & 5.0664 & Tाт \\
\hline CHEMBL1392281 & 688810 & \multicolumn{3}{|c|}{5.882999999999999} & 5.3767 & \\
\hline CHEMBL1406698 & 688810 & \multicolumn{3}{|c|}{5.7829999999999995} & 5.2976 & \\
\hline CHEMBL1464476 & 688810 & 4.833 & 4.9659 & TRN & & \\
\hline CHEMBL1382661 & 688810 & 4.933 & 4.8144 & TST & & \\
\hline CHEMBL1564446 & 688810 & 4.783 & 4.9605 & TRN & & \\
\hline CHEMBL1603963 & 688810 & \multicolumn{3}{|c|}{6.332999999999999} & 5.317 & \\
\hline CHEMBL1318477 & 688810 & 4.633 & 5.2713 & TST & & \\
\hline CHEMBL1515814 & 688810 & \multicolumn{3}{|c|}{5.5329999999999995} & 5.2838 & \\
\hline CHEMBL1304922 & 688810 & \multicolumn{3}{|c|}{ 5.332999999999999 } & 5.3811 & \\
\hline CHEMBL1537425 & 688810 & 5.433 & 5.9817 & TRN & & \\
\hline CHEMBL1497779 & 688810 & \multicolumn{3}{|c|}{4.7330000000000005} & 5.53 & \\
\hline CHEMBL1605248 & 688810 & \multicolumn{3}{|c|}{5.5329999999999995} & & \\
\hline CHEMBL1579695 & 688810 & 5.933 & 5.9857 & TRN & & \\
\hline CHEMBL1336920 & 688810 & 7.3325 & 6.1276 & TRN & & \\
\hline CHEMBL1446397 & 688810 & 5.433 & 5.3694 & TRN & & \\
\hline CHEMBL1364620 & 688810 & 5.733 & 5.9571 & TRN & & \\
\hline CHEMBL31 & 688810 & \multicolumn{3}{|c|}{5.832999999999999} & 5.3646 & \\
\hline CHEMBL1318170 & 688810 & 5.183 & 5.1466 & TRN & & \\
\hline CHEMBL1611922 & 688810 & \multirow{2}{*}{\multicolumn{3}{|c|}{$\begin{array}{lcc}4.833 & 4.9321 & \text { TRN } \\
5.132999999999999\end{array}$}} & & \\
\hline CHEMBL1330591 & 688810 & & & & 5.1475 & \\
\hline CHEMBL15 & $68 \varepsilon$ & 4.833 & 5.2108 & TST & & \\
\hline CHEMBL1493691 & 68 & 4.633 & 5.0387 & TST & & \\
\hline CHEMBL1499327 & 688810 & \multicolumn{3}{|c|}{5.332999999999999} & 5.2057 & \\
\hline CHEMBL1323015 & 688810 & \multicolumn{3}{|c|}{6.0329999999999995} & 5.6308 & \\
\hline CHEMBL1471418 & 688810 & 4.633 & 4.5661 & TST & & \\
\hline CHEMBL 39 & 68 & 4.883 & 4.9169 & TRN & & \\
\hline CHEMBL1964967 & 688810 & 4.933 & 5.3336 & TRN & & \\
\hline CHEMBL1608927 & 688810 & \multicolumn{3}{|c|}{4.7330000000000005} & 5.1101 & $\mathrm{~T}$ \\
\hline CHEMBL1349387 & 688810 & 5.183 & 5.1438 & TRN & & \\
\hline CHEMBL1343627 & 688810 & \multicolumn{3}{|c|}{6.382999999999999} & 1 & \\
\hline CHEMBL14 & 688810 & \multicolumn{3}{|c|}{6.2829999999999995} & 5 . & \\
\hline CHEMBL1467006 & 688810 & 5.033 & 5.5413 & TRN & & \\
\hline CHEMBL1541973 & 688810 & \multicolumn{3}{|c|}{4.7330000000000005} & 4.9923 & \\
\hline CHEMBL1499620 & 688810 & 4.933 & 4.9165 & TRN & & \\
\hline CHEMBL1419051 & 688810 & \multicolumn{3}{|c|}{5.382999999999999} & 6.0547 & $1 \mathrm{~K}$ \\
\hline CHEMBL 3196396 & 688810 & 5.183 & 5.3828 & TRN & & \\
\hline CHEMBL1355069 & 688810 & 5.433 & 5.3087 & TRN & & \\
\hline CHEMBL1355423 & 688810 & 4.883 & 5.2067 & TST & & \\
\hline CHEMBL1303829 & 688810 & 4.833 & 5.1412 & TRN & & \\
\hline CHEMBL3195344 & 688810 & 4.633 & 5.1543 & TRN & & \\
\hline CHEMBL1570640 & 688810 & \multicolumn{3}{|c|}{4.7330000000000005} & 5.2171 & TRN \\
\hline CHEMBL1544611 & 688810 & 5.233 & 5.1973 & TRN & & \\
\hline CHEMBL 3214467 & 688810 & \multicolumn{3}{|c|}{5.382999999999999} & 5.0887 & 13 \\
\hline CHEMBL1445504 & 688810 & 5.78299 & 99999999 & 995 & 5.6219 & . \\
\hline CHEMBL1464608 & 688810 & 5.733 & 5.8625 & TRN & & \\
\hline
\end{tabular}




\begin{tabular}{|c|c|c|c|c|c|c|}
\hline \multirow[b]{2}{*}{ CHEMBL1604854 } & \multicolumn{6}{|c|}{ IEIIET } \\
\hline & 688810 & 4.783 & 5.2587 & TST & & \\
\hline CHEMBL1367248 & 688810 & 4.783 & 5.4869 & TST & & \\
\hline CHEMBL1368219 & 688810 & 5.983 & 5.401 & TRN & & \\
\hline CHEMBL1336748 & 688810 & 4.833 & 4.954 & TRN & & \\
\hline CHEMBL1613489 & 688810 & \multicolumn{3}{|c|}{5.382999999999999} & 5.3032 & TST \\
\hline CHEMBL588028 & 688810 & \multicolumn{3}{|c|}{5.132999999999999} & 5.185 & TRN \\
\hline CHEMBL1600888 & 688810 & \multicolumn{3}{|c|}{4.7330000000000005} & 4.9797 & \\
\hline CHEMBL1439220 & 688810 & 4.783 & 4.9082 & TRN & & \\
\hline CHEMBL 3210440 & 688810 & \multicolumn{3}{|c|}{5.2829999999999995} & 5.1823 & \\
\hline CHEMBL1306894 & 688810 & \multicolumn{3}{|c|}{5.7829999999999995} & 5.1975 & \\
\hline CHEMBL1453461 & 688810 & \multicolumn{3}{|c|}{4.7330000000000005} & 4.9509 & \\
\hline CHEMBL1340555 & 688810 & 6.233 & 5.8881 & TRN & & \\
\hline CHEMBL1499317 & 688810 & 4.833 & 4.8095 & TRN & & \\
\hline CHEMBL1339565 & 688810 & 4.633 & 4.7805 & TRN & & \\
\hline CHEMBL1 & 688810 & 7.1331 & 5.9242 & TRN & & \\
\hline CHEMBL150 & 688810 & \multicolumn{3}{|c|}{6.2829999999999995} & 5.3095 & 1. \\
\hline CHEMBL1478971 & 688810 & 4.833 & 5.1721 & TRN & & \\
\hline CHEMBL3195067 & 688810 & \multicolumn{3}{|c|}{4.7330000000000005} & 5.4837 & \\
\hline CHEMBL1478755 & 688810 & \multicolumn{3}{|c|}{5.5329999999999995} & 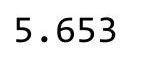 & \\
\hline CHEMBL1. & 688810 & 4.933 & 5.0686 & TRN & & \\
\hline CHEMBL1479529 & 688810 & \multicolumn{3}{|c|}{4.7330000000000005} & 5.2064 & $1 \mathrm{~K}$ \\
\hline CHEMBL1446527 & 688810 & 4.633 & 5.1863 & TRN & & \\
\hline CHEMBL1550829 & 688810 & \multicolumn{3}{|c|}{5.132999999999999} & 127 & $\mathrm{TI}$ \\
\hline CHEMBL1 & 688 & 4.833 & 5.1863 & TST & & \\
\hline CHEMBL1 & 688 & 4.783 & 5.4267 & TRN & & \\
\hline CHEMBL1459896 & 688 & 4.583 & 5.1419 & TST & & \\
\hline CHEMBL1532892 & 688810 & \multicolumn{3}{|c|}{4.9830000000000005} & 5.0457 & TR \\
\hline CHEMBL1555575 & 688810 & 4.833 & 5.2973 & TST & & \\
\hline CHEMBL1 & 688 & 5 . & 5.2875 & TST & & \\
\hline CHEMBL14€ & 688 & 5.183 & 5.2925 & TRN & & \\
\hline CHEMBL1443160 & 688 & 4.933 & 5.1596 & TRN & & \\
\hline CHEMBL1599947 & 688810 & 4.633 & 5.2245 & TST & & \\
\hline CHEMBL1390691 & 688810 & 5.083 & 5.0166 & TRN & & \\
\hline CHEMBL1 & 688 & 4.833 & 5.0928 & TRN & & \\
\hline CHEMBL1331376 & 688810 & \multicolumn{3}{|c|}{5.5329999999999995} & 5.1773 & TR \\
\hline CHEMBL1499202 & 688810 & 5.233 & 5.9678 & TST & & \\
\hline CHEMBL1429297 & 688810 & \multicolumn{3}{|c|}{4.9830000000000005} & 4.7498 & \\
\hline CHEMBL1366235 & 688810 & 4.933 & 4.6595 & TST & & \\
\hline CHEMBL1574559 & 688810 & & \multicolumn{3}{|c|}{5.5729999999999995} & ISI \\
\hline CHEMBL1455873 & 688810 & 4.583 & 4.9614 & TRN & & \\
\hline CHEMBL1519940 & 688810 & \multicolumn{3}{|c|}{5.132999999999999} & 4.7183 & TST \\
\hline CHEMBL1593184 & 688810 & \multicolumn{3}{|c|}{6.132999999999999} & 5.7905 & TR \\
\hline CHEMBL1365009 & 688810 & \multicolumn{3}{|c|}{5.582999999999999} & 5.1404 & \\
\hline CHEMBL1994510 & 688810 & \multicolumn{3}{|c|}{5.7829999999999995} & 5.5528 & IRN \\
\hline CHEMBL1459542 & 688810 & 4.7330 & 00000000 & 005 & 4.9665 & TRN \\
\hline CHEMBL1307682 & 688810 & 5.183 & 4.9115 & TRN & & \\
\hline CHEMBL1549267 & 688810 & 4.933 & 5.5743 & TRN & & \\
\hline CHEMBL1465840 & 688810 & 4.7330 & 00000000 & 005 & 5.1488 & \\
\hline
\end{tabular}




\begin{tabular}{|c|c|c|c|c|c|c|}
\hline \multicolumn{7}{|c|}{ Supplemental Table S2.txt } \\
\hline CHEMBL1422644 & 688810 & 5.233 & 5.5025 & TRN & & \\
\hline CHEMBL1411665 & 688810 & 6.683 & 5.6838 & TRN & & \\
\hline CHEMBL1331661 & 688810 & 5.733 & 5.4459 & TRN & & \\
\hline CHEMBL 3192901 & 688810 & 6.0 & 5.6022 & TRN & & \\
\hline CHEMBL1468863 & 688810 & \multicolumn{3}{|c|}{6.2829999999999995} & 5.7494 & $\mathrm{TP}$ \\
\hline CHEMBL1342328 & 688810 & 4.833 & 5.2795 & TST & & \\
\hline CHEMBL1550511 & 688810 & \multicolumn{3}{|c|}{5.5329999999999995} & 5.0053 & \\
\hline CHEMBL1536400 & 688810 & 6.433 & 4.7577 & TST & & \\
\hline CHEMBL1413454 & 688810 & \multicolumn{3}{|c|}{6.7829999999999995} & 5.9473 & \\
\hline CHEMBL472931 & 688810 & \multicolumn{3}{|c|}{5.382999999999999} & 5.3893 & \\
\hline CHEMBL317469 & 688810 & 5.083 & 5.4067 & TRN & & \\
\hline CHEMBL1313116 & 688810 & \multicolumn{3}{|c|}{5.582999999999999} & 5.5062 & \\
\hline CHEMBL1307181 & 688810 & 5.233 & 5.4812 & TST & & \\
\hline CHEMBL1536497 & 688810 & \multicolumn{3}{|c|}{5.832999999999999} & 5.9074 & \\
\hline CHEMBL3191946 & 688810 & 6.233 & 6.403 & TRN & & \\
\hline CHEMBL1549532 & 688810 & 4.783 & 5.0746 & TST & & \\
\hline CHEMBL1420703 & 688810 & \multicolumn{3}{|c|}{5.132999999999999} & 5.4318 & \\
\hline CHEMBL 3208511 & 688810 & \multicolumn{3}{|c|}{5.2829999999999995} & 5.1538 & \\
\hline CHEMBL1355548 & 688810 & 4.633 & 5.1328 & TRN & & \\
\hline CHEMBL1459864 & 688810 & 5.083 & 5.1538 & TRN & & \\
\hline CHEMBL1447159 & 688810 & 5.233 & 5.1589 & TRN & & \\
\hline CHEMBL1332558 & 688810 & \multicolumn{3}{|c|}{4.7330000000000005} & 5.7336 & \\
\hline CHEMBL1981286 & 688810 & 4.883 & 5.2234 & TRN & & \\
\hline CHEMBL1484597 & 688810 & 4.633 & 4.8873 & TST & & \\
\hline CHEMBL1411531 & 688810 & 4.583 & 4.7634 & TST & & \\
\hline CHEMBL1584752 & 688810 & 4.783 & 4.9092 & TRN & & \\
\hline CHEMBL1393647 & 688810 & 4.783 & 5.2776 & TRN & & \\
\hline CHEMBL15 & 688810 & \multicolumn{3}{|c|}{6.582999999999999} & 5.5459 & \\
\hline CHEMBL1531958 & 688810 & \multicolumn{3}{|c|}{5.632999999999999} & 5.6239 & \\
\hline CHEMBL1489337 & 688810 & 5.683 & 5.6695 & TRN & & \\
\hline CHEMBL1422646 & 688810 & \multicolumn{3}{|c|}{4.7330000000000005} & 5.0921 & \\
\hline CHEMBL1446116 & 688810 & 4.683 & 5.3099 & TRN & & \\
\hline CHEMBL 14 & 688810 & 4.783 & 5.4376 & TRN & & \\
\hline CHEMBL1416181 & 688810 & 4.783 & 5.4749 & TRN & & \\
\hline CHEMBL1384493 & 688810 & \multicolumn{3}{|c|}{5.832999999999999} & 5.2021 & \\
\hline CHEMBL1425131 & 688810 & \multicolumn{3}{|c|}{6.5329999999999995} & 5.8337 & \\
\hline CHEMBL13 & 688810 & 4.833 & 5.1898 & TRN & & \\
\hline CHEMBL1368519 & 688810 & \multicolumn{3}{|c|}{6.582999999999999} & 6.2972 & TH \\
\hline CHEMBL1465682 & 688810 & 4.883 & 5.1598 & TRN & & \\
\hline CHEMBL 3199125 & 688810 & 5.683 & 5.3024 & TRN & & \\
\hline CHEMBL1566141 & 688810 & 5.933 & 6.0638 & TRN & & \\
\hline CHEMBL1419973 & 688810 & \multicolumn{3}{|c|}{6.2829999999999995} & 5.4595 & I KIV \\
\hline CHEMBL1336098 & 688810 & \multicolumn{3}{|c|}{6.0329999999999995} & 5.5195 & TP \\
\hline CHEMBL1527652 & 688810 & \multicolumn{3}{|c|}{5.132999999999999} & 5.5889 & TRN \\
\hline CHEMBL1490481 & 688810 & \multicolumn{3}{|c|}{4.7330000000000005} & 5.2613 & TR \\
\hline CHEMBL1588233 & 688810 & 4.783 & 5.3521 & TST & & \\
\hline CHEMBL1465357 & 688810 & \multicolumn{3}{|c|}{5.7829999999999995} & 5.3816 & \\
\hline CHEMBL1449678 & 688810 & 4.883 & 5.0535 & TRN & & \\
\hline
\end{tabular}




\begin{tabular}{|c|c|c|c|c|c|c|}
\hline \multirow[b]{2}{*}{ CHEMBL1578827 } & \multicolumn{6}{|c|}{ suppretrer } \\
\hline & 688810 & 4.833 & 5.2906 & TRN & & \\
\hline CHEMBL1595566 & 688810 & 4.933 & 5.4007 & TRN & & \\
\hline CHEMBL 3199543 & 688810 & 5.483 & 5.2071 & TRN & & \\
\hline CHEMBL1423196 & 688810 & 4.883 & 5.1939 & TST & & \\
\hline CHEMBL1398648 & 688810 & 4.7330 & 000000006 & 005 & 5.0775 & TRN \\
\hline CHEMBL1412669 & 688810 & 5.183 & 5.4693 & TRN & & \\
\hline CHEMBL 2006762 & 688810 & 5.5329 & 999999999 & 995 & 5.4197 & $\mathrm{TP}$ \\
\hline CHEMBL1442186 & 688810 & 4.833 & 4.7917 & TST & & \\
\hline CHEMBL1316794 & 688810 & 4.833 & 4.9596 & TRN & & \\
\hline CHEMBL1487212 & 688810 & 5.233 & 4.9672 & TRN & & \\
\hline CHEMBL1368144 & 688810 & 5.683 & 5.6779 & TRN & & \\
\hline CHEMBL 3189439 & 688810 & 4.833 & 5.1591 & TST & & \\
\hline CHEMBL1524233 & 688810 & 4.583 & 4.816 & TRN & & \\
\hline CHEMBL1394298 & 688810 & 5.2829 & 999999999 & 995 & 4.9147 & IST \\
\hline CHEMBL1414566 & 688810 & 5.083 & 4.7474 & TRN & & \\
\hline CHEMBL1337412 & 688810 & 4.7330 & 000000006 & 005 & 5.0337 & TRN \\
\hline CHEMBL3198647 & 688810 & 5.1329 & 999999999 & & 5.4203 & TRN \\
\hline CHEMBL1393752 & 688810 & 5.8329 & 999999999 & & 4.9385 & TST \\
\hline CHEMBL1585373 & 688810 & 4.583 & 4.5191 & TRN & & \\
\hline CHEMBL 3193394 & 688810 & 4.9830 & 000000000 & 005 & 5.2855 & TR \\
\hline CHEMBL 3213172 & 688810 & 4.833 & 4.901 & TRN & & \\
\hline CHEMBL 1589863 & 688810 & 4.7330 & 000000000 & 005 & 5.1034 & TST \\
\hline CHEMBL1528536 & 688810 & 6.0 & 4.5607 & TRN & & \\
\hline CHEMBL1994148 & 688810 & 5.7829 & 999999999 & 995 & 5.2462 & $\mathrm{TP}$ \\
\hline CHEMBL1444756 & 688810 & 4.783 & 5.1065 & TRN & & \\
\hline CHEMBL1464103 & 688810 & 6.183 & 5.1166 & TRN & & \\
\hline CHEMBL1560101 & 688810 & 5.7829 & 999999999 & 995 & 6.0554 & TRN \\
\hline CHEMBL1513430 & 688810 & 5.7829 & 999999999 & 995 & 5.1198 & TRN \\
\hline CHEMBL1581859 & 688810 & 5.083 & 4.9603 & TRN & & \\
\hline CHEMBL 3199075 & 688810 & 5.683 & 5.4999 & TRN & & \\
\hline CHEMBL1460200 & 688810 & 5.2829 & 999999999 & 995 & 4.959 & 11 \\
\hline CHEMBL 1409118 & 688810 & 4.833 & 5.3058 & TRN & & \\
\hline CHEMBL1328504 & 688810 & 5.5329 & 999999999 & 995 & 5.8511 & TRN \\
\hline CHEMBL 3198318 & 688810 & 5.483 & 5.3432 & TRN & & \\
\hline CHEMBL1523413 & 688810 & 4.883 & 4.8442 & TRN & & \\
\hline CHEMBL1389427 & 688810 & 5.8329 & 999999999 & & 5.3537 & $\mathrm{TP}$ \\
\hline CHEMBL 1527672 & 688810 & 5.733 & 5.0492 & TRN & & \\
\hline CHEMBL1453788 & 688810 & 4.783 & 5.2932 & TRN & & \\
\hline CHEMBL1530857 & 688810 & 4.833 & 5.087 & TST & & \\
\hline CHEMBL1470965 & 688810 & 5.683 & 5.32 & TST & & \\
\hline CHEMBL1448612 & 688810 & 4.7330 & 000000000 & 005 & 5.1656 & TST \\
\hline CHEMBL 1306380 & 688810 & 5.7829 & 999999999 & 995 & 5.5191 & TRN \\
\hline CHEMBL 1453831 & 688810 & 5.3329 & 999999999 & & 5.1671 & TST \\
\hline CHEMBL1432977 & 688810 & 6.4829 & 6.0312 & TRN & & \\
\hline CHEMBL1516506 & 688810 & 4.583 & 5.1828 & TRN & & \\
\hline CHEMBL 1420789 & 688810 & 4.833 & 4.9052 & TST & & \\
\hline CHEMBL 1480539 & 688810 & 5.083 & 6.0448 & TRN & & \\
\hline CHEMBL1329210 & 688810 & 4.883 & 5.3104 & TRN & & \\
\hline
\end{tabular}




\begin{tabular}{|c|c|c|c|c|c|c|}
\hline \multicolumn{7}{|c|}{ Supplemental Table S2.txt } \\
\hline CHEMBL1448841 & 688810 & 4.933 & 5.5765 & TRN & & \\
\hline CHEMBL1410950 & 688810 & 5.183 & 5.0812 & TRN & & \\
\hline CHEMBL1527842 & 688810 & 4.883 & 5.4042 & TST & & \\
\hline CHEMBL1318128 & 688810 & 6.683 & 5.7963 & TRN & & \\
\hline CHEMBL1580319 & 688810 & 5.033 & 5.4159 & TST & & \\
\hline CHEMBL1390537 & 688810 & \multicolumn{3}{|c|}{4.7330000000000005} & 5.5778 & TST \\
\hline CHEMBL1351194 & 688810 & 4.783 & 5.153 & TST & & \\
\hline CHEMBL1323581 & 688810 & 5.683 & 5.0172 & TRN & & \\
\hline CHEMBL1456610 & 688810 & \multicolumn{3}{|c|}{4.7330000000000005} & 5.2884 & TRN \\
\hline CHEMBL1438487 & 688810 & \multicolumn{3}{|c|}{4.7330000000000005} & 4.9977 & TST \\
\hline CHEMBL1445361 & 688810 & \multicolumn{3}{|c|}{5.332999999999999} & 5.1158 & TST \\
\hline CHEMBL1303988 & 688810 & 5.933 & 5.4535 & TRN & & \\
\hline CHEMBL1565862 & 688810 & 5.433 & 5.6722 & TRN & & \\
\hline CHEMBL1548913 & 688810 & \multicolumn{3}{|c|}{4.7330000000000005} & 5.3858 & TRN \\
\hline CHEMBL1360867 & 688810 & 4.833 & 5.6106 & TRN & & \\
\hline CHEMBL1581570 & 688810 & \multicolumn{3}{|c|}{5.582999999999999} & \multicolumn{2}{|c|}{5.122000000000001} \\
\hline CHEMBL1561032 & 688810 & 5.733 & 5.439 & TRN & & \\
\hline CHEMBL1350195 & 688810 & \multicolumn{3}{|c|}{5.382999999999999} & 5.4861 & TRN \\
\hline CHEMBL1369270 & 688810 & \multicolumn{3}{|c|}{5.7829999999999995} & 5.3062 & TRN \\
\hline CHEMBL1537327 & 688810 & \multicolumn{3}{|c|}{5.332999999999999} & 5.2393 & TRN \\
\hline CHEMBL1549660 & 688810 & 4.783 & \multicolumn{3}{|c|}{4.8260000000000005} & TRN \\
\hline CHEMBL1330166 & 688810 & 5.233 & 5.3168 & TRN & & \\
\hline CHEMBL1485418 & 688810 & 4.933 & 6.0659 & TRN & & \\
\hline CHEMBL1453460 & 688810 & \multicolumn{3}{|c|}{6.382999999999999} & 5.8687 & TST \\
\hline CHEMBL1988541 & 688810 & 4.583 & 4.9492 & TRN & & \\
\hline CHEMBL1398572 & 688810 & 5.733 & 5.8939 & TRN & & \\
\hline CHEMBL1466197 & 688810 & 5.183 & 5.0664 & TRN & & \\
\hline CHEMBL1323838 & 688810 & 5.083 & 5.291 & TST & & \\
\hline CHEMBL1319900 & 688810 & \multicolumn{3}{|c|}{5.882999999999999} & 5.6668 & TRN \\
\hline CHEMBL1562193 & 688810 & 5.683 & 5.3513 & TRN & & \\
\hline CHEMBL1351842 & 688810 & \multicolumn{3}{|c|}{4.7330000000000005} & 5.2941 & TRN \\
\hline CHEMBL3195946 & 688810 & 5.983 & 5.8282 & TRN & & \\
\hline CHEMBL1492856 & 688810 & 5.183 & 5.8153 & TST & & \\
\hline CHEMBL1605142 & 688810 & 4.883 & 5.2235 & TRN & & \\
\hline CHEMBL1429857 & 688810 & \multicolumn{3}{|c|}{4.7330000000000005} & 5.1056 & TRN \\
\hline CHEMBL1355029 & 688810 & 4.633 & 5.4215 & TRN & & \\
\hline CHEMBL1422727 & 688810 & 6.9329 & 5.8221 & TRN & & \\
\hline CHEMBL1328606 & 688810 & 4.883 & \multicolumn{3}{|c|}{4.6930000000000005} & TRN \\
\hline CHEMBL1361537 & 688810 & \multicolumn{3}{|c|}{5.332999999999999} & 5.2504 & TRN \\
\hline CHEMBL1557921 & 688810 & \multicolumn{3}{|c|}{4.7330000000000005} & 5.0243 & TRN \\
\hline CHEMBL1343259 & 688810 & \multicolumn{3}{|c|}{4.7330000000000005} & 5.1145 & TST \\
\hline CHEMBL1556248 & 688810 & \multicolumn{3}{|c|}{5.5329999999999995} & 5.0267 & TRN \\
\hline CHEMBL1406419 & 688810 & 4.583 & 5.3756 & TST & & \\
\hline CHEMBL1483684 & 688810 & 5.2829 & 99999999 & 995 & 5.3587 & TST \\
\hline CHEMBL1442453 & 688810 & 4.9830 & 2000000e & 305 & 5.1707 & TRN \\
\hline CHEMBL1321897 & 688810 & 4.833 & 5.3925 & TRN & & \\
\hline CHEMBL1407708 & 688810 & 4.783 & 5.4097 & TST & & \\
\hline CHEMBL1448363 & 688810 & 5.233 & 5.0774 & TST & & \\
\hline
\end{tabular}




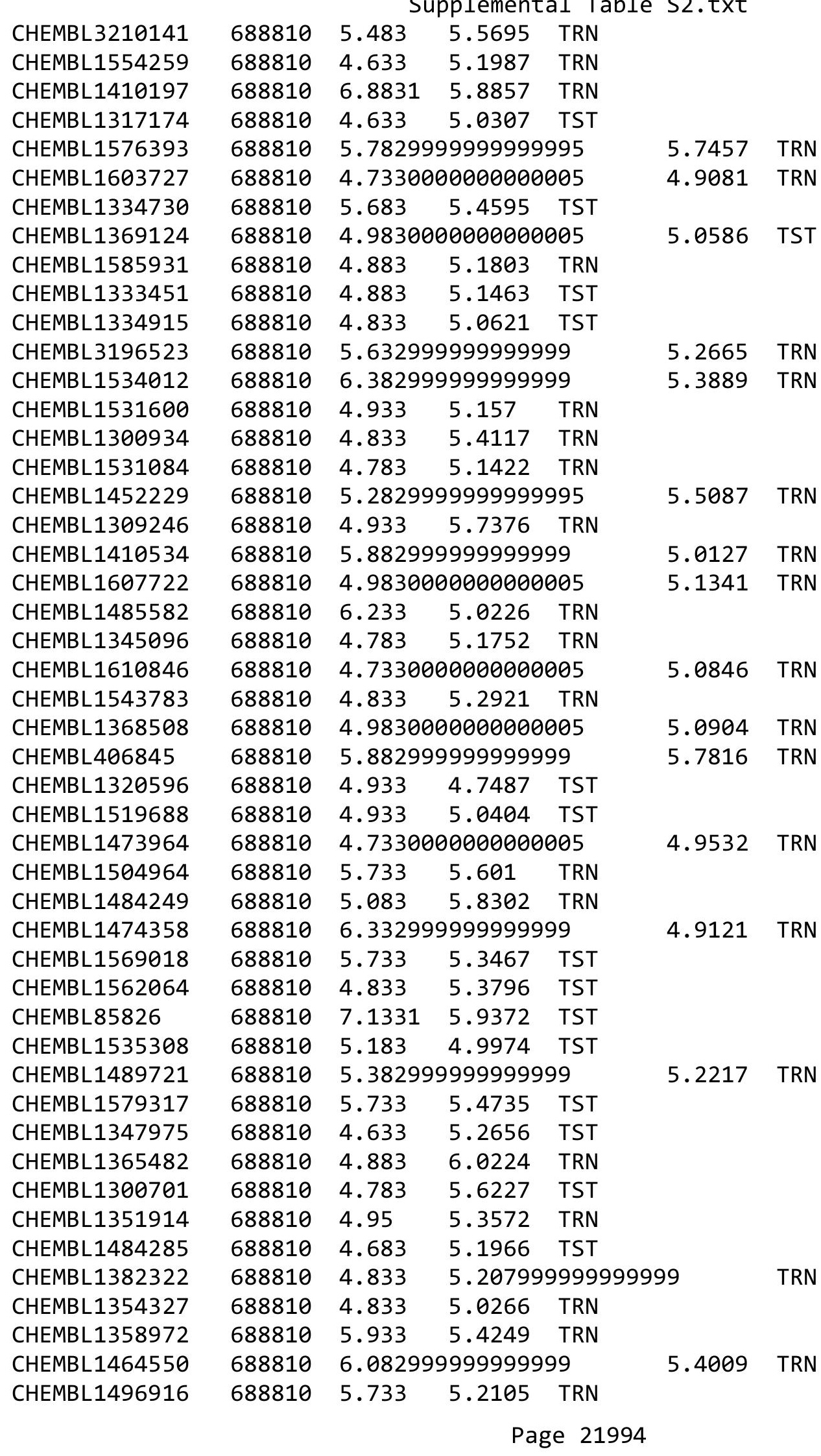




\begin{tabular}{|c|c|c|c|c|c|c|}
\hline & & \multicolumn{4}{|c|}{ Supplemental Table s2.txt } & \\
\hline CHEMBL3196361 & 688810 & \multicolumn{3}{|c|}{6.5329999999999995} & 5.8977 & $\mathrm{~T}$ \\
\hline CHEMBL1373066 & 688810 & 4.783 & 5.6201 & TRN & & \\
\hline CHEMBL1387710 & 688810 & 6.433 & 5.5551 & TST & & \\
\hline CHEMBL1399879 & 688810 & 4.783 & 5.5421 & TRN & & \\
\hline CHEMBL1464833 & 688810 & 5.433 & 5.4801 & TRN & & \\
\hline CHEMBL1559322 & 688810 & 5.433 & 5.5771 & TRN & & \\
\hline CHEMBL3197483 & 688810 & \multicolumn{3}{|c|}{5.582999999999999} & 5.4465 & \\
\hline CHEMBL1478310 & 688810 & 5.433 & 5.5255 & TST & & \\
\hline CHEMBL1558845 & 688810 & \multicolumn{3}{|c|}{5.132999999999999} & 5.4708 & \\
\hline CHEMBL1436234 & 688810 & \multicolumn{3}{|c|}{6.5329999999999995} & 6.0225 & \\
\hline CHEMBL1497853 & 688810 & 5.233 & 5.5514 & TRN & & \\
\hline CHEMBL1609596 & 688810 & 4.833 & 4.8919 & TRN & & \\
\hline CHEMBL1371816 & 688810 & 4.783 & 5.7992 & TRN & & \\
\hline CHEMBL1443740 & 688810 & 5.233 & 5.3052 & TRN & & \\
\hline CHEMBL599359 & 688810 & 4.783 & 5.1115 & TRN & & \\
\hline CHEMBL1403635 & 688810 & 6.433 & 5.4071 & TRN & & \\
\hline CHEMBL203946 & 688810 & 5.033 & 5.1417 & TRN & & \\
\hline CHEMBL1520523 & 688810 & 5.983 & 5.1746 & TRN & & \\
\hline CHEMBL1545410 & 688810 & 5.233 & 5.5331 & TRN & & \\
\hline CHEMBL1571393 & 688810 & 4.883 & 5.4115 & TRN & & \\
\hline CHEMBL1413087 & 688810 & \multicolumn{3}{|c|}{5.382999999999999} & 5.3829 & \\
\hline CHEMBL1406639 & 688810 & 5.433 & 4.669 & TST & & \\
\hline CHEMBL1450281 & 688810 & \multicolumn{3}{|c|}{4.7330000000000005} & 5.4876 & I Thiv \\
\hline CHEMBL1486332 & 688810 & 5.083 & 4.8881 & TST & & \\
\hline CHEMBL1328633 & 688810 & \multicolumn{3}{|c|}{4.7330000000000005} & 5.1793 & \\
\hline CHEMBL1562851 & 688810 & 4.783 & 5.1398 & TRN & & \\
\hline CHEMBL1421664 & 688810 & 5.483 & 5.8137 & TRN & & \\
\hline CHEMBL1302785 & 688810 & 5.233 & 5.0568 & TST & & \\
\hline CHEMBL3197262 & 688810 & 5.683 & 4.9313 & TRN & & \\
\hline CHEMBL1352257 & 688810 & 5.483 & 5.5166 & TRN & & \\
\hline CHEMBL1348395 & 688810 & 4.883 & 5.0564 & TRN & & \\
\hline CHEMBL1432038 & 688810 & 4.933 & 5.1101 & TRN & & \\
\hline CHEMBL1472108 & 688810 & 4.583 & 5.2067 & TRN & & \\
\hline CHEMBL1426035 & 688810 & 4.833 & 4.6965 & TST & & \\
\hline CHEMBL1326231 & 688810 & 5.083 & 5.8767 & TRN & & \\
\hline CHEMBL1590263 & 688810 & \multicolumn{3}{|c|}{4.9830000000000005} & 5.4702 & $\mathrm{TR}$ \\
\hline CHEMBL1532915 & 688810 & 4.633 & 4.524 & TST & & \\
\hline CHEMBL1371379 & 688810 & 4.883 & 5.3318 & TST & & \\
\hline CHEMBL1533114 & 688810 & 5.483 & 5.649 & TRN & & \\
\hline CHEMBL1583808 & 688810 & 5.183 & 5.6167 & TRN & & \\
\hline CHEMBL1607294 & 688810 & 4.833 & 4.9983 & TRN & & \\
\hline CHEMBL1346585 & 688810 & 6.683 & 6.0028 & TRN & & \\
\hline CHEMBL1159655 & 688810 & 4.583 & 4.6114 & TST & & \\
\hline CHEMBL1349784 & 688810 & 4.783 & \multicolumn{3}{|c|}{5.513999999999999} & \\
\hline CHEMBL1404400 & 688810 & 4.833 & 5.1941 & TRN & & \\
\hline CHEMBL1409185 & 688810 & \multicolumn{3}{|c|}{5.632999999999999} & 5.6799 & 18 \\
\hline CHEMBL1568522 & 688810 & \multicolumn{3}{|c|}{4.7330000000000005} & 5.1396 & TRN \\
\hline CHEMBL1453607 & 688810 & \multicolumn{3}{|c|}{5.7829999999999995} & 5.6042 & 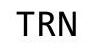 \\
\hline
\end{tabular}




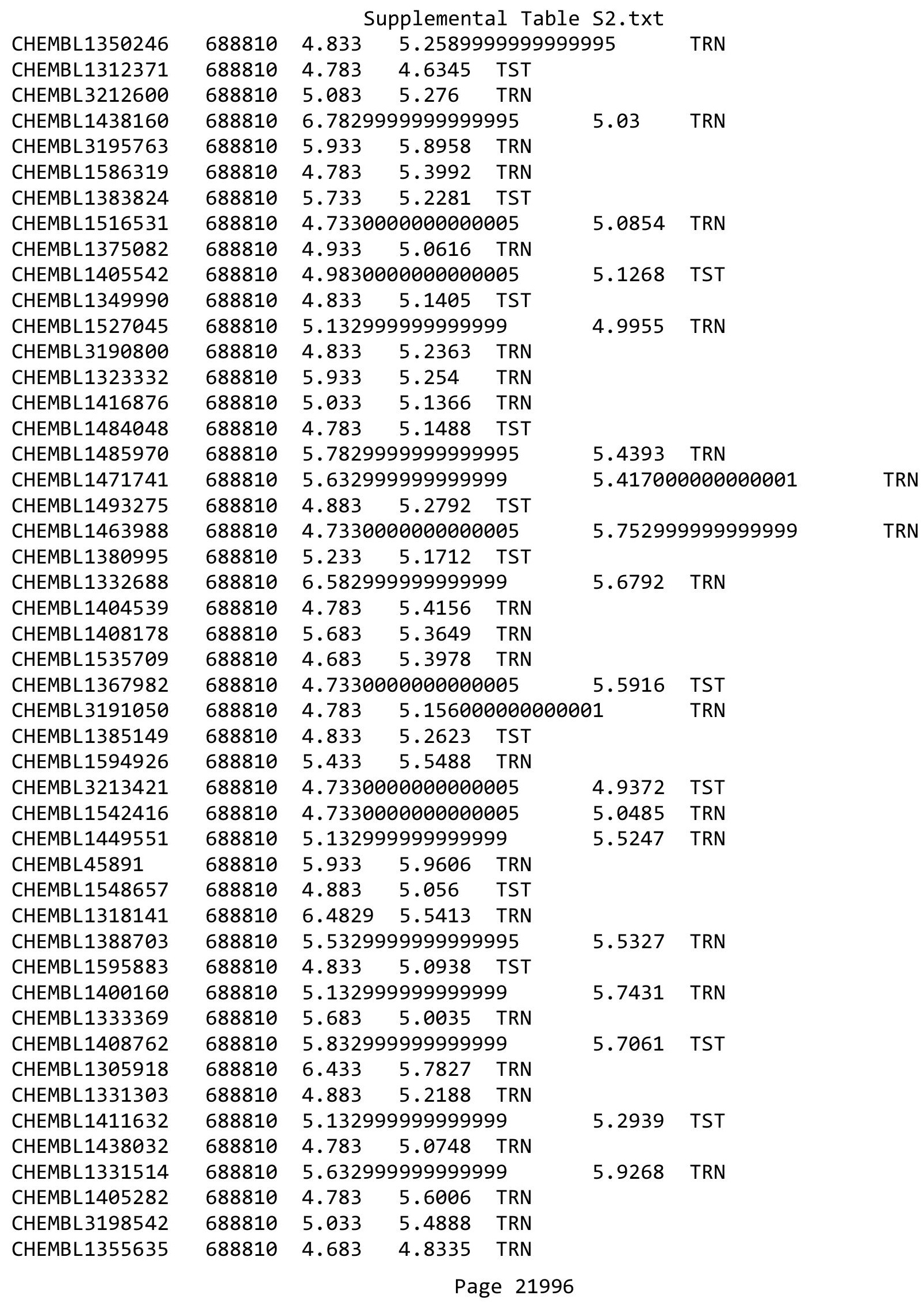




\begin{tabular}{|c|c|c|c|c|c|c|c|}
\hline \multicolumn{8}{|c|}{ Supplemental Ta } \\
\hline CHEMBL1470676 & 688810 & 7.2832 & 6.1312 & TRN & & & \\
\hline CHEMBL1379322 & 688810 & 5.83299 & 99999999 & & 5.9345 & TRN & \\
\hline CHEMBL1360237 & 688810 & 5.033 & 5.2208 & TRN & & & \\
\hline CHEMBL1417039 & 688810 & 5.28299 & 99999999 & 995 & 5.5202 & TRN & \\
\hline CHEMBL1313954 & 688810 & 5.13299 & 99999999 & 99 & 5.8133 & TRN & \\
\hline CHEMBL3192730 & 688810 & 5.083 & 5.1907 & TRN & & & \\
\hline CHEMBL1371479 & 688810 & 6.53299 & 99999999 & 995 & 6.1918 & TRN & \\
\hline CHEMBL1500193 & 688810 & 6.03299 & 99999999 & 995 & 5.6505 & TRN & \\
\hline CHEMBL1354123 & 688810 & 4.73300 & 00000000 & 005 & 5.4093 & TRN & \\
\hline CHEMBL1322716 & 688810 & 5.13299 & 99999999 & 99 & 5.103 & TRN & \\
\hline CHEMBL3197506 & 688810 & 5.13299 & 99999999 & & 5.3266 & TRN & \\
\hline CHEMBL1392924 & 688810 & 4.73300 & 00000000 & 005 & 5.0187 & TST & \\
\hline CHEMBL1443251 & 688810 & 5.083 & 5.3671 & TRN & & & \\
\hline CHEMBL1467194 & 688810 & 4.633 & 5.0995 & TST & & & \\
\hline CHEMBL1524352 & 688810 & 4.933 & 5.2259 & TRN & & & \\
\hline CHEMBL3210482 & 688810 & 4.583 & 5.0882 & TRN & & & \\
\hline CHEMBL515763 & 688810 & 4.73300 & 00000000 & 005 & 5.3725 & TRN & \\
\hline CHEMBL1333620 & 688810 & 4.73300 & 00000000 & 005 & 4.9291 & TST & \\
\hline CHEMBL1578924 & 688810 & 6.03299 & 99999999 & 995 & 5.26399 & 9999999999 & TRN \\
\hline CHEMBL1449204 & 688810 & 4.583 & 4.8927 & TRN & & & \\
\hline CHEMBL1602553 & 688810 & 6.33299 & 99999999 & 99 & 5.6145 & TST & \\
\hline CHEMBL1367757 & 688810 & 4.783 & 5.1263 & TRN & & & \\
\hline CHEMBL1342003 & 688810 & 4.783 & 5.0758 & TRN & & & \\
\hline CHEMBL602776 & 688810 & 4.883 & 5.1548 & TRN & & & \\
\hline CHEMBL 3189442 & 688810 & 6.78299 & 99999999 & 995 & 5.9074 & TRN & \\
\hline CHEMBL 1443570 & 688810 & 4.583 & 4.9667 & TRN & & & \\
\hline CHEMBL1417661 & 688810 & 4.883 & 5.8697 & TRN & & & \\
\hline CHEMBL1452179 & 688810 & 4.883 & 5.3665 & TRN & & & \\
\hline CHEMBL1449243 & 688810 & 6.683 & 5.2417 & TRN & & & \\
\hline CHEMBL1314758 & 688810 & 4.633 & 4.9115 & TST & & & \\
\hline CHEMBL236388 & 688810 & 4.73300 & 00000000 & 005 & 5.0146 & TRN & \\
\hline CHEMBL1370559 & 688810 & 4.933 & 5.2299 & TST & & & \\
\hline CHEMBL1593912 & 688810 & 6.13299 & 99999999 & & 5.8334 & TRN & \\
\hline CHEMBL1982107 & 688810 & 4.783 & 5.0022 & TRN & & & \\
\hline CHEMBL1484463 & 688810 & 4.883 & 4.7989 & TST & & & \\
\hline CHEMBL1583897 & 688810 & 5.183 & 5.2636 & TRN & & & \\
\hline CHEMBL1468936 & 688810 & 5.233 & 5.1772 & TRN & & & \\
\hline CHEMBL1596226 & 688810 & 4.683 & 5.0012 & TST & & & \\
\hline CHEMBL1468862 & 688810 & 4.833 & 5.1103 & TRN & & & \\
\hline CHEMBL1389366 & 688810 & 6.63299 & 99999999 & & 5.8872 & TRN & \\
\hline CHEMBL 3207987 & 688810 & 5.183 & 5.2916 & TST & & & \\
\hline CHEMBL1403009 & 688810 & 6.38299 & 99999999 & 99 & 5.4724 & TST & \\
\hline CHEMBL1457689 & 688810 & 4.73300 & 00000000 & 005 & 5.2446 & TRN & \\
\hline CHEMBL1501282 & 688810 & 5.733 & 5.4066 & TRN & & & \\
\hline CHEMBL1378203 & 688810 & 4.73300 & 00000000 & 005 & 5.2153 & TRN & \\
\hline CHEMBL3191410 & 688810 & 6.13299 & 99999999 & & 5.5381 & TRN & \\
\hline CHEMBL1424942 & 688810 & 5.083 & 5.7872 & TRN & & & \\
\hline CHEMBL1462882 & 688810 & 5.733 & 5.9998 & TRN & & & \\
\hline
\end{tabular}




\begin{tabular}{|c|c|c|c|c|c|c|}
\hline \multirow{3}{*}{$\begin{array}{l}\text { CHEMBL1332043 } \\
\text { CHEMBL1464521 }\end{array}$} & \multirow{3}{*}{$\begin{array}{l}688810 \\
688810\end{array}$} & \multicolumn{5}{|c|}{ Supplemental Table S2.txt } \\
\hline & & \multicolumn{3}{|c|}{5.5329999999999995} & \multirow[t]{5}{*}{5.3039} & \multirow[t]{5}{*}{ TRN } \\
\hline & & 5.683 & 5.5819 & TRN & & \\
\hline CHEMBL1428808 & 688810 & 4.633 & 4.9219 & TST & & \\
\hline CHEMBL1501853 & 688810 & 4.683 & 4.9202 & TRN & & \\
\hline CHEMBL1446192 & 588810 & 4.633 & 4.8618 & TRN & & \\
\hline CHEMBL1399297 & 688810 & \multicolumn{3}{|c|}{5.132999999999999} & \multirow{5}{*}{5.3219} & \multirow{5}{*}{ TRN } \\
\hline CHEMBL1455335 & 688810 & 4.783 & 5.3027 & TRN & & \\
\hline CHEMBL1599319 & 688810 & 5.483 & 5.2166 & TRN & & \\
\hline CHEMBL1371175 & 688810 & 5.733 & 5.3328 & TRN & & \\
\hline CHEMBL1397120 & 688810 & 5.933 & 5.6455 & TRN & & \\
\hline CHEMBL1577498 & 688810 & \multicolumn{3}{|c|}{6.0329999999999995} & \multirow[t]{3}{*}{5.5116} & \multirow[t]{3}{*}{ TRN } \\
\hline CHEMBL1336467 & 688810 & 5.083 & 4.8596 & TST & & \\
\hline CHEMBL1435403 & 688810 & 4.633 & 4.9276 & TST & & \\
\hline CHEMBL1573451 & 688810 & \multicolumn{3}{|c|}{4.7330000000000005} & 4.6129 & \\
\hline CHEMBL3210664 & 688810 & 4.783 & 5.1826 & TRN & & \\
\hline CHEMBL1575517 & 688810 & \multicolumn{3}{|c|}{5.832999999999999} & \multirow[t]{4}{*}{5.6449} & \multirow[t]{4}{*}{ TRN } \\
\hline CHEMBL3190139 & 688810 & 4.833 & 5.0067 & TRN & & \\
\hline CHEMBL1542067 & 688810 & 6.4829 & 5.7837 & TRN & & \\
\hline CHEMBL1486531 & 688810 & 6.4829 & 5.4267 & TRN & & \\
\hline CHEMBL1529558 & 688810 & \multicolumn{3}{|c|}{5.132999999999999} & \multirow[t]{2}{*}{5.4567} & \multirow[t]{2}{*}{ TRN } \\
\hline CHEMBL1503406 & 688810 & 4.883 & 4.6715 & TRN & & \\
\hline CHEMBL1449685 & 688810 & \multicolumn{3}{|c|}{5.2829999999999995} & 5.3608 & \\
\hline CHEMBL1345220 & 688810 & 5.933 & 4.9593 & TRN & & \\
\hline CHEMBL1536190 & 688810 & \multicolumn{3}{|c|}{7.082999999999999} & 5.6937 & \\
\hline CHEMBL1405210 & 688810 & 5.183 & 5.0544 & TRN & & \\
\hline CHEMBL1375456 & 688810 & 5.3829 & 99999999 & & 5.3864 & \\
\hline CHEMB & 688 & 6.683 & 5.8456 & TRN & & \\
\hline CHEMBL1423723 & 688810 & 6.1329 & 99999999 & & 5.3558 & \\
\hline CHEMBL3195212 & 688810 & 6.0829 & 99999999 & & 5.8285 & \\
\hline CHEMBL1328956 & 688810 & 6.9329 & 5.4246 & TRN & & \\
\hline CHEMBL1529860 & 688810 & & 5.805 & TRN & & \\
\hline CHEMB & 688 & 5.033 & 5.3259 & TRN & & \\
\hline CHEMBL1425753 & 688810 & 4.9830 & 00000000 & 005 & 5.4129 & \\
\hline CHEMBL1601807 & 688810 & 6.0329 & (99999999 & 995 & 5.4268 & $\mathrm{~T}$ \\
\hline CHEMBL1311739 & 688810 & 4.883 & 5.3478 & TRN & & \\
\hline CHEMBL1369698 & 688810 & 5.1329 & 99999999 & & 5.3188 & \\
\hline CHEMBL1557186 & 688810 & 5.683 & 5.046 & TRN & & \\
\hline CHEMBL1366838 & 688810 & 5.3329 & 99999999 & & 5.2204 & \\
\hline CHEMBL1542972 & 688810 & 5.5829 & 99999999 & & 5.1377 & TRN \\
\hline CHEMBL1495870 & 688810 & 5.5329 & 99999999 & 995 & 4.7315 & \\
\hline CHEMBL1402362 & 688810 & 5.933 & 5.1343 & TRN & & \\
\hline CHEMBL3209787 & 688810 & 4.833 & 5.1151 & TRN & & \\
\hline CHEMBL1570942 & 688810 & 4.9830 & 00000000 & 005 & 5.1102 & \\
\hline CHEMBL1359803 & 688810 & 4.933 & 5.5295 & TST & & \\
\hline CHEMBL1539430 & 688810 & 5.183 & 5.1472 & TST & & \\
\hline CHEMBL1329757 & 688810 & 5.3329 & 99999999 & & 5.1654 & \\
\hline CHEMBL1566148 & 688810 & 6.233 & 5.4851 & TRN & & \\
\hline CHEMBL1498292 & 688810 & 6.5329 & 99999999 & 995 & 6.1802 & III \\
\hline
\end{tabular}




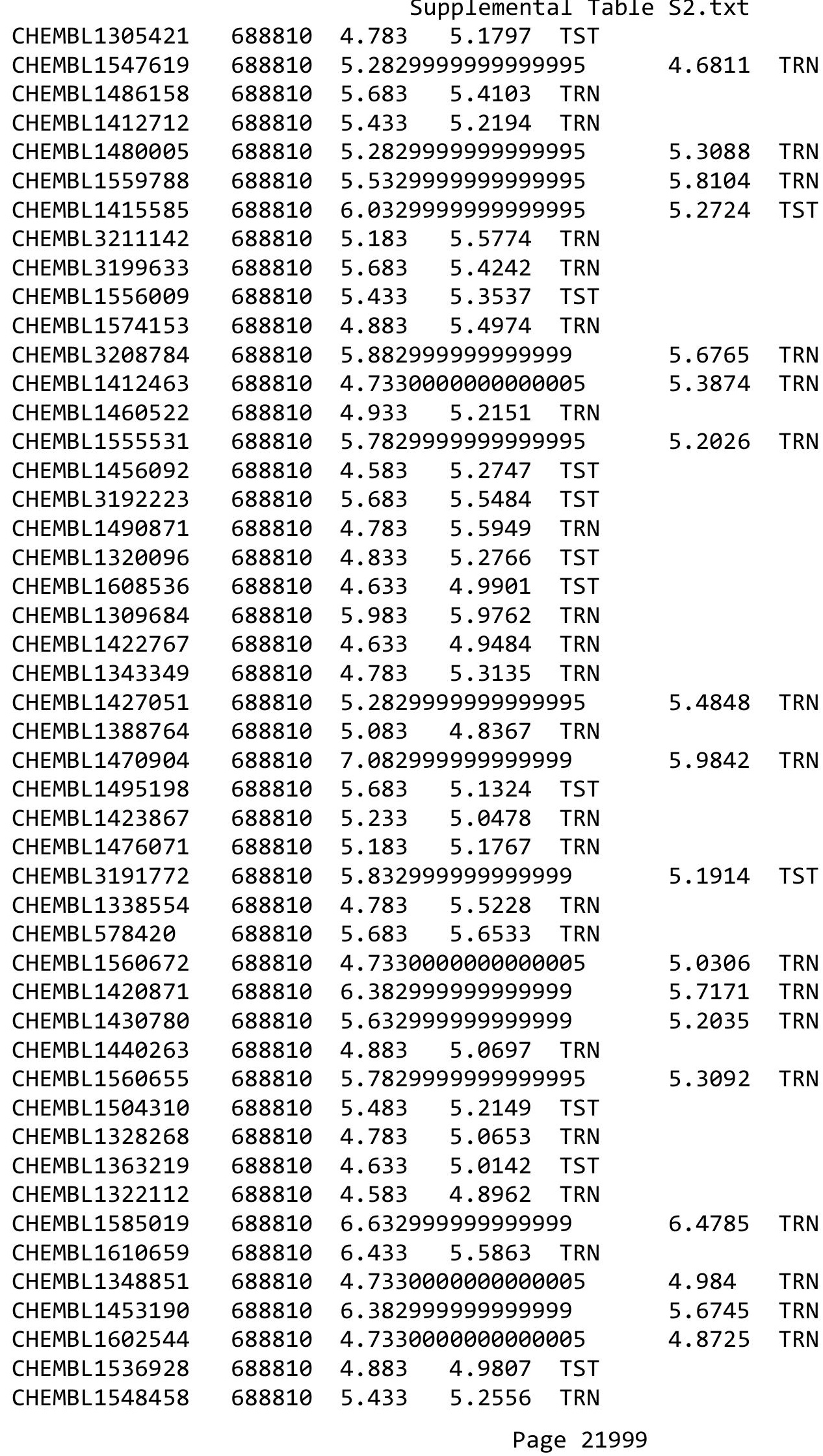




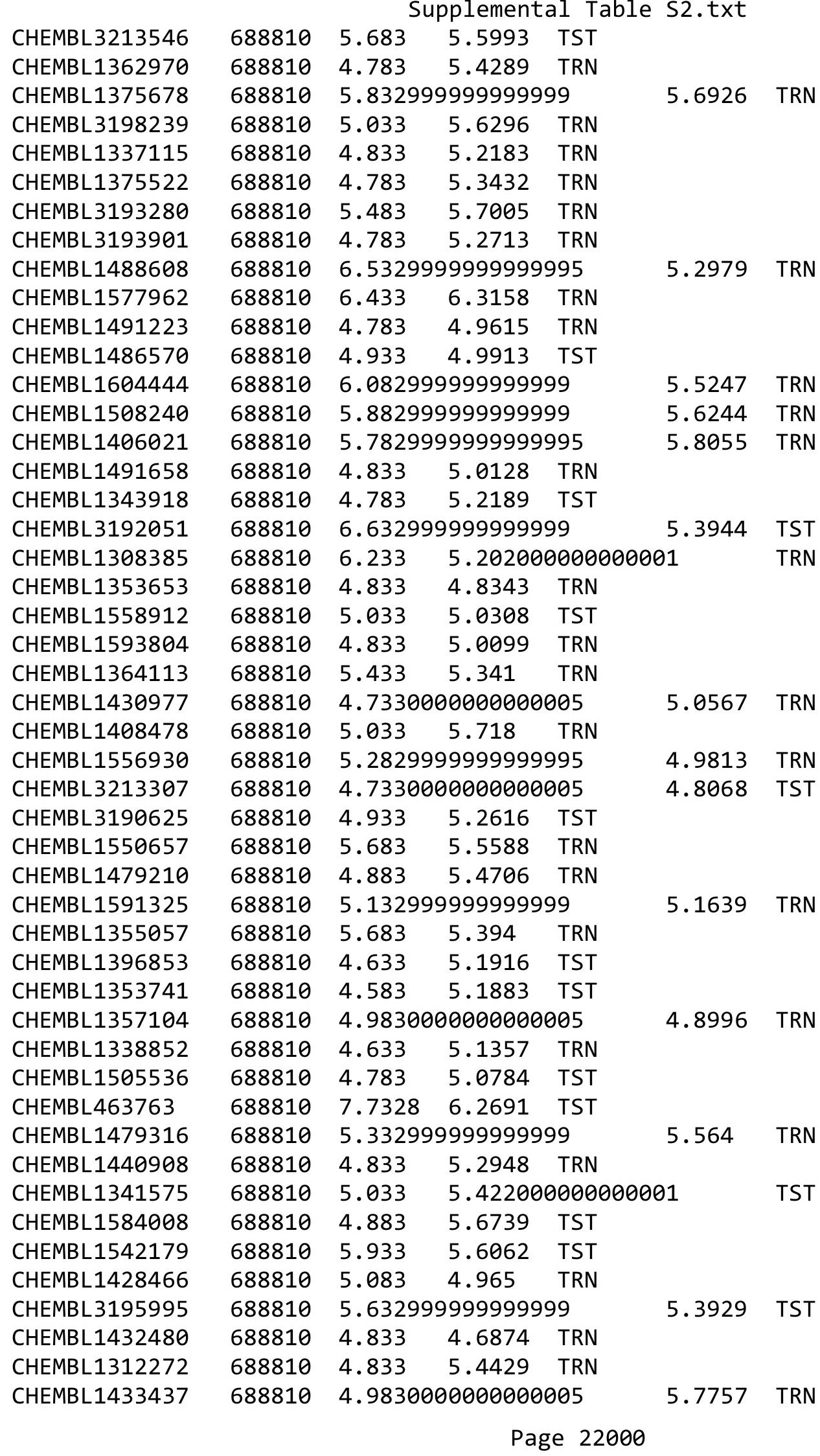




\begin{tabular}{|c|c|c|c|c|c|c|}
\hline \multirow[b]{2}{*}{ CHEMBL1299646 } & \multicolumn{6}{|c|}{ oplemental T } \\
\hline & 688810 & 5.033 & 5.2558 & TRN & & \\
\hline CHEMBL1366319 & 688810 & \multicolumn{3}{|c|}{ 5.332999999999999 } & 5.5388 & TRN \\
\hline CHEMBL1472798 & 688810 & \multicolumn{3}{|c|}{5.832999999999999} & 6.0395 & \\
\hline CHEMBL1372274 & 688810 & 5.033 & 5.1673 & TRN & & \\
\hline CHEMBL337821 & 688810 & 4.583 & 5.3968 & TRN & & \\
\hline CHEMBL1556179 & 688810 & 5.033 & 5.1738 & TRN & & \\
\hline CHEMBL1529749 & 688810 & 6.183 & 5.5926 & TST & & \\
\hline CHEMBL1414183 & 688810 & 5.733 & 5.267 & TRN & & \\
\hline CHEMBL1573883 & 688810 & \multicolumn{3}{|c|}{5.2829999999999995} & 6.1079 & \\
\hline CHEMBL1590795 & 688810 & 4.783 & 4.9176 & TRN & & \\
\hline CHEMBL1445209 & 688810 & 4.633 & 4.6988 & TST & & \\
\hline CHEMBL1454295 & 688810 & 4.933 & 4.9979 & TRN & & \\
\hline CHEMBL1480325 & 688810 & 4.783 & 5.0265 & TRN & & \\
\hline CHEMBL1542025 & 688810 & \multicolumn{3}{|c|}{6.7829999999999995} & 5.4846 & \\
\hline CHEMBL1327041 & 688810 & \multicolumn{3}{|c|}{4.7330000000000005} & 4.87 & \\
\hline CHEMBL1468662 & 688810 & \multicolumn{3}{|c|}{6.7829999999999995} & 5.449 & \\
\hline CHEMBL3195732 & 688810 & 5.733 & 5.6176 & TST & & \\
\hline CHEMBL1535734 & 688810 & \multirow{2}{*}{\multicolumn{3}{|c|}{ 6.2829999999999995 }} & & \\
\hline CHEMBL1327318 & 688810 & & & & 5.7372 & \\
\hline CHEMBL1557668 & 688810 & 5.933 & 5.311 & TRN & & \\
\hline CHEMBL 2005394 & 688810 & 5.433 & 5.602 & TRN & & \\
\hline CHEMBL1345379 & 688810 & \multicolumn{3}{|c|}{ 6.382999999999999 } & 5.6469 & \\
\hline CHEMBL1577291 & 688810 & \multicolumn{3}{|c|}{5.5329999999999995} & 5.6579 & \\
\hline CHEMBL1601073 & 688810 & 4.633 & 4.8185 & TRN & & \\
\hline CHEMBL1529103 & 688810 & 4.783 & 5.2907 & TRN & & \\
\hline CHEMBL1583879 & 688810 & 6.4829 & 5.7689 & TRN & & \\
\hline CHEMBL1597669 & 688810 & \multicolumn{3}{|c|}{6.5329999999999995} & 6.1717 & \\
\hline CHEMBL1599881 & 688810 & 4.883 & 5.4555 & TRN & & \\
\hline CHEMBL1985165 & 688810 & 5.033 & 5.5682 & TRN & & \\
\hline CHEMBL1410152 & 688810 & 5.733 & 5.1272 & TRN & & \\
\hline CHEMBL1424599 & 688810 & 5.083 & 4.8823 & TST & & \\
\hline CHEMBL1330446 & 688810 & \multicolumn{3}{|c|}{5.632999999999999} & 5.6209 & $\mathrm{TP}$ \\
\hline CHEMBL 2007021 & 688810 & \multicolumn{3}{|c|}{5.632999999999999} & 5.4799 & \\
\hline CHEMBL1381731 & 688810 & 5.483 & 4.9012 & TRN & & \\
\hline CHEMBL1575525 & 688810 & 5.183 & 5.5601 & TRN & & \\
\hline CHEMBL1404447 & 688810 & 5.683 & 5.1288 & TRN & & \\
\hline CHEMBL1300590 & 688810 & 4.833 & 5.3043 & TST & & \\
\hline CHEMBL1446172 & 688810 & 4.633 & 5.2439 & TRN & & \\
\hline CHEMBL1522918 & 688810 & \multicolumn{3}{|c|}{6.082999999999999} & 5.5733 & $\mathrm{Tr}$ \\
\hline CHEMBL1351039 & 688810 & 4.683 & 5.0853 & TRN & & \\
\hline CHEMBL1305041 & 688810 & 4.783 & 5.063 & TRN & & \\
\hline CHEMBL1345724 & 688810 & \multicolumn{3}{|c|}{6.2829999999999995} & 5.5076 & \\
\hline CHEMBL1610912 & 688810 & 4.683 & 4.7627 & TST & & \\
\hline CHEMBL1386418 & 688810 & \multicolumn{3}{|c|}{4.9830000000000005} & 4.9885 & TRN \\
\hline CHEMBL1390121 & 688810 & 5.033 & 5.2858 & TST & & \\
\hline CHEMBL1524371 & 688810 & \multicolumn{3}{|c|}{5.132999999999999} & 5.3631 & $1 \mathrm{n}$ \\
\hline CHEMBL1313423 & 688810 & 5.933 & 5.6808 & TRN & & \\
\hline CHEMBL1441181 & 688810 & 4.883 & 4.8382 & TRN & & \\
\hline
\end{tabular}




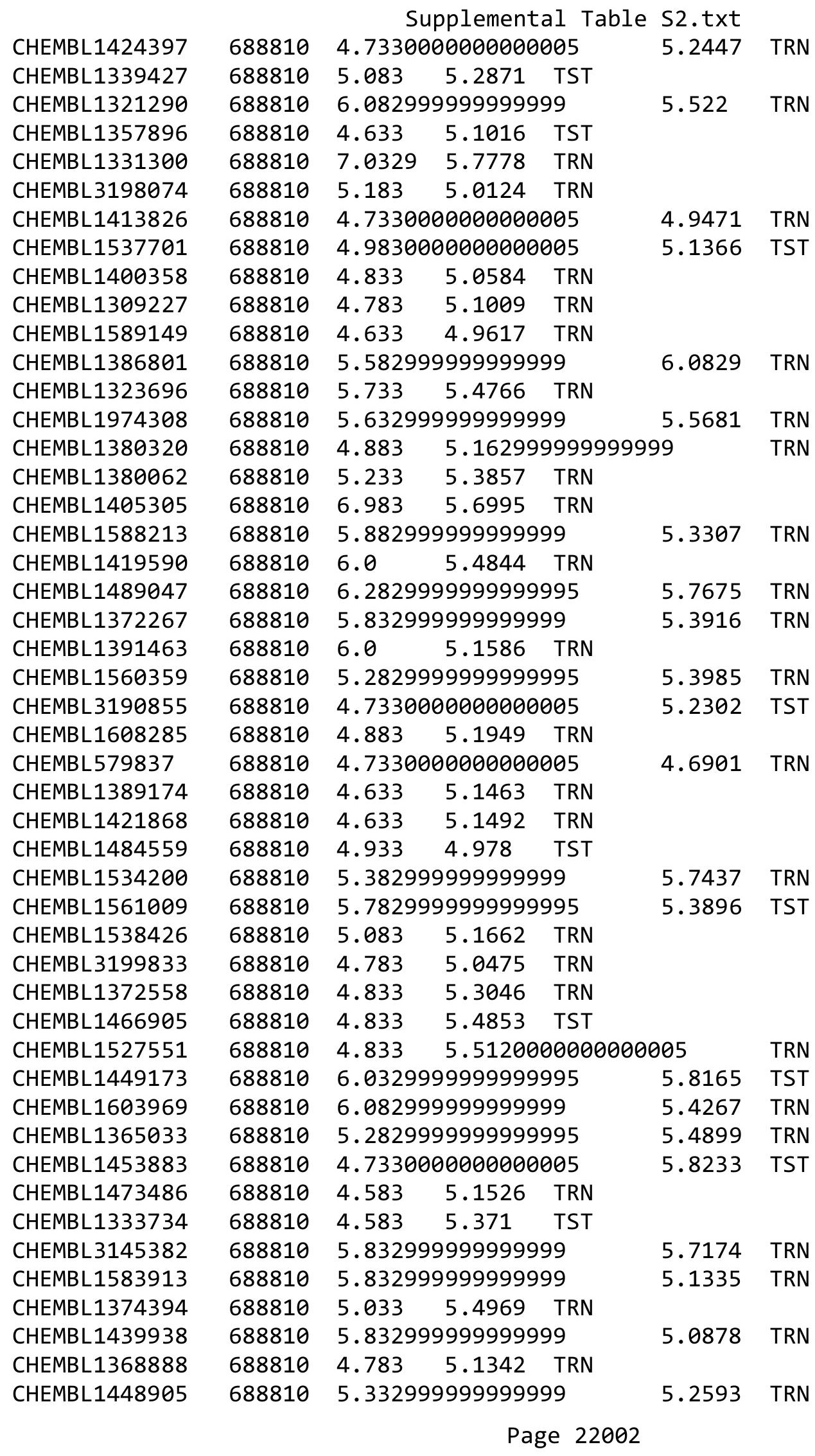




\begin{tabular}{|c|c|c|c|c|c|c|c|}
\hline \multicolumn{8}{|c|}{ Supplemental Table s2.txt } \\
\hline CHEMBL1593967 & 688810 & 4.783 & 5.0426 & TRN & & & \\
\hline CHEMBL1562819 & 688810 & 4.633 & 5.2562 & TRN & & & \\
\hline CHEMBL1564558 & 688810 & \multicolumn{3}{|c|}{5.2829999999999995} & 5.5705 & TRN & \\
\hline CHEMBL1346011 & 688810 & \multicolumn{3}{|c|}{4.7330000000000005} & 5.0859 & TRN & \\
\hline CHEMBL1425532 & 688810 & \multicolumn{3}{|c|}{5.132999999999999} & 4.9945 & TST & \\
\hline CHEMBL1502572 & 688810 & 5.033 & 5.24 & TRN & & & \\
\hline CHEMBL1590903 & 688810 & 4.783 & 5.1034 & TRN & & & \\
\hline CHEMBL1462784 & 688810 & 4.883 & 5.1148 & TRN & & & \\
\hline CHEMBL1383338 & 688810 & 4.783 & 5.0052 & TRN & & & \\
\hline CHEMBL1407839 & 688810 & \multicolumn{3}{|c|}{4.7330000000000005} & 4.9823 & TRN & \\
\hline CHEMBL1527966 & 688810 & 4.833 & 5.3658 & TRN & & & \\
\hline CHEMBL1472904 & 688810 & 4.583 & 5.029 & TRN & & & \\
\hline CHEMBL1601049 & 688810 & 4.883 & 5.2652 & TRN & & & \\
\hline CHEMBL1528097 & 688810 & 4.95 & 4.8169 & TRN & & & \\
\hline CHEMBL1601724 & 688810 & \multicolumn{3}{|c|}{5.7829999999999995} & 5.7057 & TRN & \\
\hline CHEMBL1303657 & 688810 & 4.683 & 4.6479 & TST & & & \\
\hline CHEMBL1334576 & 688810 & \multicolumn{3}{|c|}{5.2829999999999995} & 4.9916 & TRN & \\
\hline CHEMBL1481317 & 688810 & 4.583 & 4.6671 & TST & & & \\
\hline CHEMBL1511008 & 688810 & \multicolumn{3}{|c|}{5.882999999999999} & 6.0008 & TRN & \\
\hline CHEMBL1502977 & 688810 & \multicolumn{3}{|c|}{6.082999999999999} & 5.26200 & 00000000005 & TRN \\
\hline CHEMBL1378059 & 688810 & \multicolumn{3}{|c|}{4.7330000000000005} & 5.4132 & TRN & \\
\hline CHEMBL1479234 & 688810 & \multicolumn{3}{|c|}{4.7330000000000005} & 5.1462 & TRN & \\
\hline CHEMBL1535572 & 688810 & \multicolumn{3}{|c|}{5.332999999999999} & 5.2699 & TRN & \\
\hline CHEMBL1502980 & 688810 & 4.633 & 4.848 & TST & & & \\
\hline CHEMBL1356920 & 688810 & 4.833 & 4.8797 & TRN & & & \\
\hline CHEMBL1431385 & 688810 & 5.183 & 5.1143 & TRN & & & \\
\hline CHEMBL1593674 & 688810 & 4.633 & 4.4803 & TRN & & & \\
\hline CHEMBL1417192 & 688810 & \multicolumn{3}{|c|}{6.0329999999999995} & 5.7728 & TRN & \\
\hline CHEMBL1592398 & 688810 & 5.683 & 5.3053 & TRN & & & \\
\hline CHEMBL 2369292 & 688810 & \multicolumn{3}{|c|}{5.132999999999999} & 5.2199 & TRN & \\
\hline CHEMBL1331895 & 688810 & \multicolumn{3}{|c|}{6.7829999999999995} & 5.8003 & TST & \\
\hline CHEMBL1484073 & 688810 & \multicolumn{3}{|c|}{4.7330000000000005} & 4.8857 & TRN & \\
\hline CHEMBL1575165 & 688810 & \multicolumn{3}{|c|}{5.132999999999999} & 5.2703 & TRN & \\
\hline CHEMBL3194418 & 688810 & 5.733 & 5.6048 & TRN & & & \\
\hline CHEMBL1321672 & 688810 & 4.833 & 5.0776 & TRN & & & \\
\hline CHEMBL1504361 & 688810 & \multicolumn{3}{|c|}{4.9830000000000005} & 4.9529 & TRN & \\
\hline CHEMBL1462078 & 688810 & \multicolumn{3}{|c|}{5.382999999999999} & 5.0761 & TST & \\
\hline CHEMBL1397579 & 688810 & \multicolumn{3}{|c|}{4.7330000000000005} & 4.9969 & TRN & \\
\hline CHEMBL1607398 & 688810 & 4.833 & 5.5453 & TRN & & & \\
\hline CHEMBL1476950 & 688810 & \multicolumn{3}{|c|}{4.7330000000000005} & 5.0445 & TRN & \\
\hline CHEMBL1407983 & 688810 & 4.683 & 4.88 & TRN & & & \\
\hline CHEMBL1344501 & 688810 & 4.883 & 5.7235 & TRN & & & \\
\hline CHEMBL1436349 & 688810 & 5.183 & 5.2098 & TRN & & & \\
\hline CHEMBL1985575 & 688810 & 6.83299 & 99999999 & & 5.9513 & TRN & \\
\hline CHEMBL1552826 & 688810 & 5.183 & 4.5966 & TRN & & & \\
\hline CHEMBL1342148 & 688810 & 5.483 & 5.3765 & TRN & & & \\
\hline CHEMBL1472680 & 688810 & 4.833 & 4.9558 & TRN & & & \\
\hline CHEMBL1526056 & 688810 & 5.083 & 5.0289 & TST & & & \\
\hline
\end{tabular}




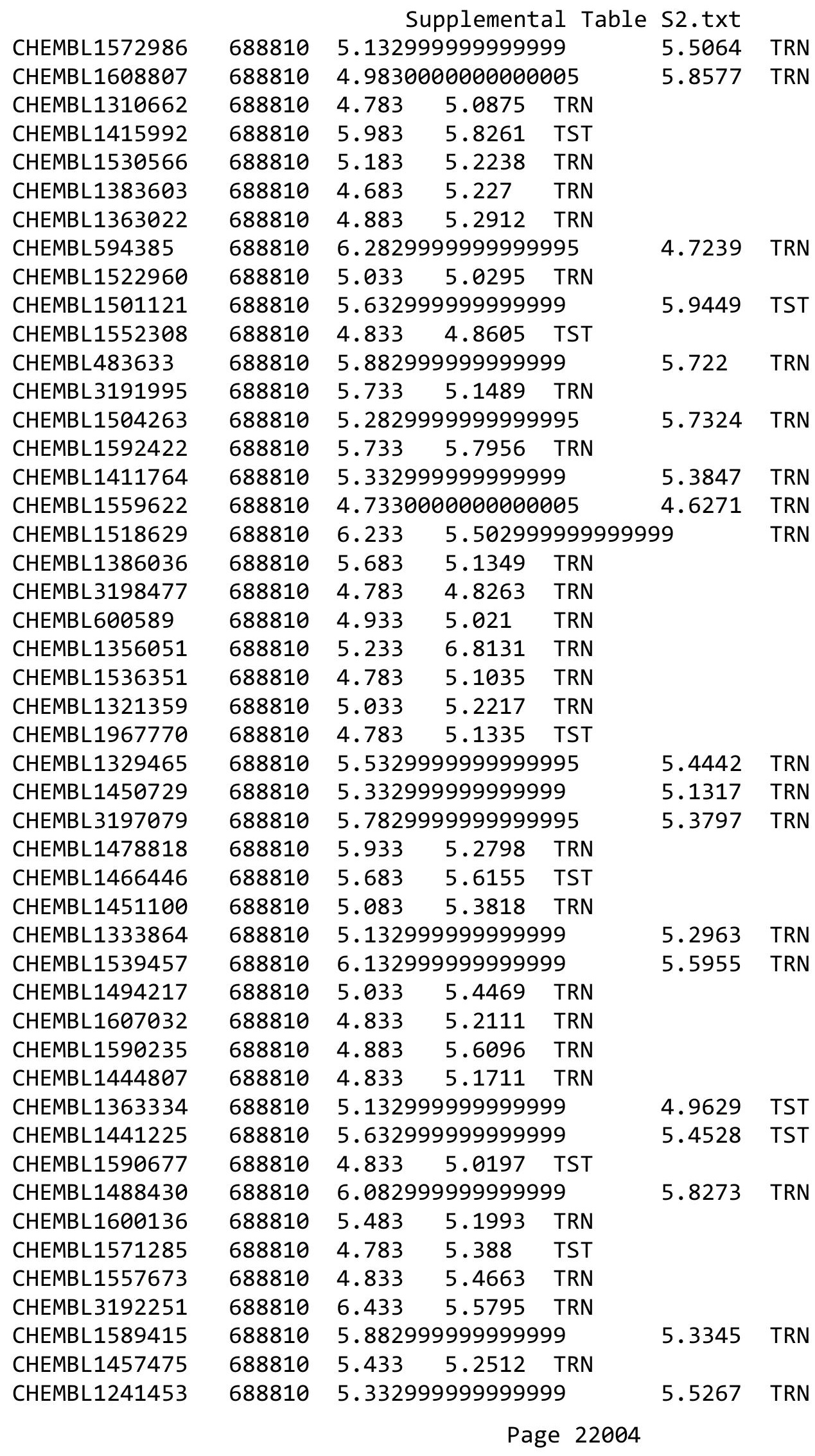




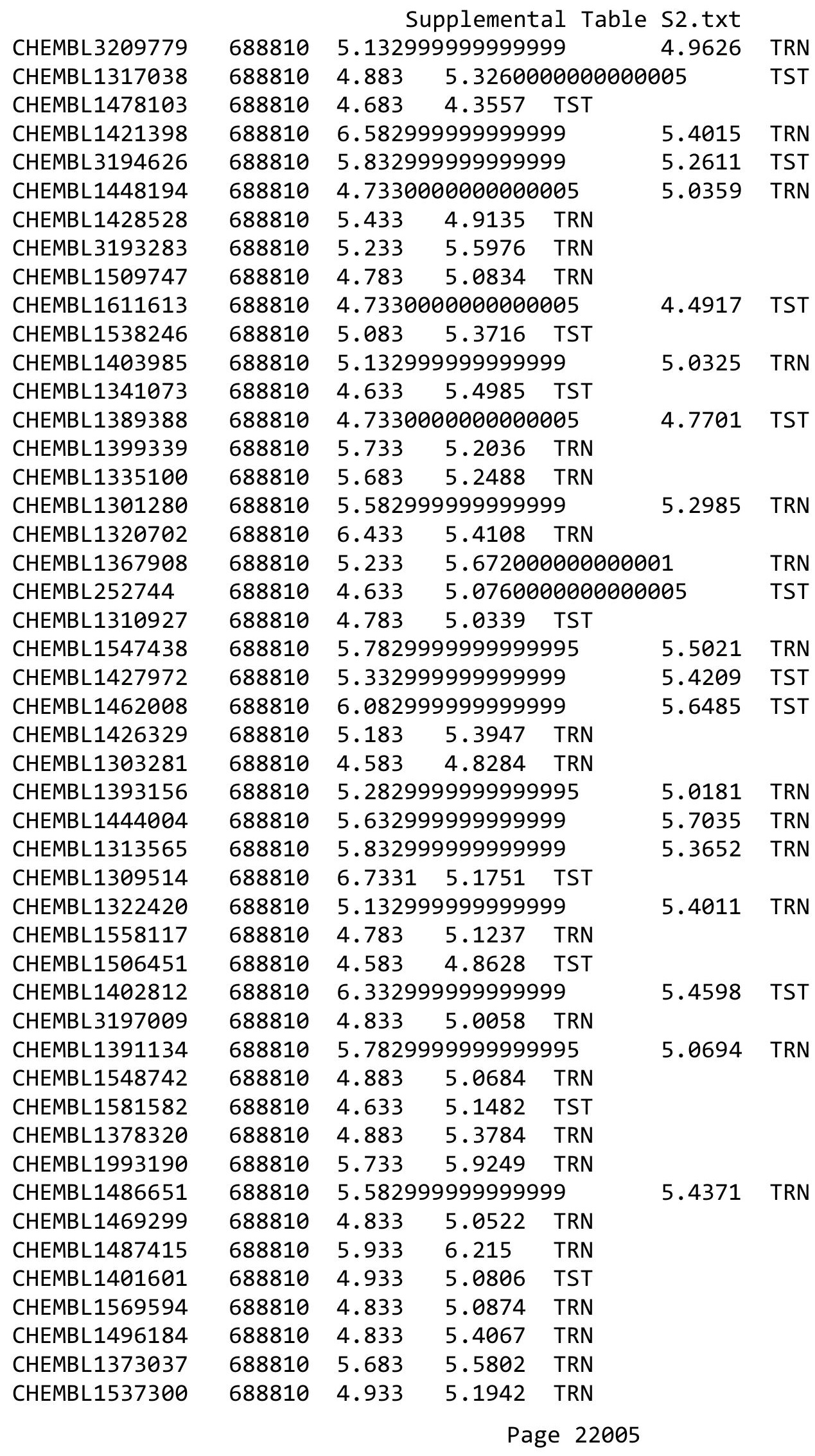




\begin{tabular}{|c|c|c|c|c|c|c|}
\hline \multirow{3}{*}{$\begin{array}{l}\text { CHEMBL1419935 } \\
\text { CHEMBL1569914 }\end{array}$} & \multirow{3}{*}{$\begin{array}{l}688810 \\
688810\end{array}$} & \multicolumn{5}{|c|}{ Supplemental Table S2.txt } \\
\hline & & \multicolumn{4}{|c|}{$6.0329999999999995 \quad 5.1257$} & \multirow{2}{*}{ TST } \\
\hline & & 5.733 & 5.7392 & TRN & & \\
\hline CHEMBL505670 & 688810 & \multicolumn{3}{|c|}{5.582999999999999} & 5.2 & TST \\
\hline CHEMBL1545247 & 688810 & \multicolumn{3}{|c|}{6.382999999999999} & 5.7935 & TRA \\
\hline CHEMBL1542516 & 688810 & \multicolumn{3}{|c|}{5.7829999999999995} & 5.3388 & TRN \\
\hline CHEMBL1346273 & 688810 & 4.833 & 5.09 & TST & & \\
\hline CHEMBL1410232 & 688810 & 5.733 & 5.6507 & TRN & & \\
\hline CHEMBL1966121 & 688810 & 6.4829 & 5.6075 & TRN & & \\
\hline CHEMBL1499014 & 688810 & 4.583 & 4.7786 & TST & & \\
\hline CHEMBL3214522 & 688810 & \multicolumn{3}{|c|}{5.332999999999999} & 5.6712 & TRN \\
\hline CHEMBL1585349 & 688810 & 5.033 & 5.654 & TRN & & \\
\hline CHEMBL1372612 & 688810 & 4.833 & 5.2663 & TRN & & \\
\hline CHEMBL1460004 & 688810 & \multicolumn{3}{|c|}{5.5329999999999995} & 5.1309 & TRN \\
\hline CHEMBL1427730 & 688810 & \multicolumn{3}{|c|}{5.832999999999999} & 5.5661 & TRA \\
\hline CHEMBL1310482 & 688810 & 4.833 & 5.314 & TST & & \\
\hline CHEMBL1430395 & 688810 & 4.783 & 5.3041 & TRN & & \\
\hline CHEMBL1461390 & 688810 & 4.783 & 5.4666 & TRN & & \\
\hline CHEMBL1546387 & 688810 & 4.783 & 5.0564 & TRN & & \\
\hline CHEMBL1563870 & 688810 & 5.033 & 5.0619 & TST & & \\
\hline CHEMBL1481066 & 688810 & 4.783 & 4.9278 & TRN & & \\
\hline CHEMBL3211215 & 688810 & \multicolumn{3}{|c|}{4.9830000000000005} & 4.9794 & TST \\
\hline CHEMBL1520803 & 688810 & \multicolumn{3}{|c|}{6.7829999999999995} & 5.4017 & TRN \\
\hline CHEMBL1358267 & 688810 & 5.933 & 5.4818 & TRN & & \\
\hline CHEMBL1528938 & 688810 & \multicolumn{3}{|c|}{5.332999999999999} & 5.6586 & TST \\
\hline CHEMBL1379195 & 688810 & 4.783 & 5.37 & TST & & \\
\hline CHEMBL1458059 & 688810 & 4.783 & 5.266 & TRN & & \\
\hline CHEMBL1492232 & 688810 & \multicolumn{3}{|c|}{5.2829999999999995} & 5.2648 & TST \\
\hline CHEMBL1362732 & 688810 & \multicolumn{3}{|c|}{4.9830000000000005} & 5.0987 & TRA \\
\hline CHEMBL1511552 & 688810 & 4.633 & 5.3078 & TST & & \\
\hline CHEMBL1319427 & 688810 & \multicolumn{3}{|c|}{5.382999999999999} & 5.2015 & TRN \\
\hline CHEMBL1339268 & 688810 & \multicolumn{3}{|c|}{5.882999999999999} & 5.1673 & TRA \\
\hline CHEMBL1457031 & 688810 & 5.183 & 5.2596 & TRN & & \\
\hline CHEMBL1312353 & 688810 & \multicolumn{3}{|c|}{4.7330000000000005} & 5.1673 & TST \\
\hline CHEMBL1440681 & 688810 & 4.883 & 5.2379 & TRN & & \\
\hline CHEMBL1313520 & 688810 & \multicolumn{3}{|c|}{6.332999999999999} & 5.8443 & TRN \\
\hline CHEMBL1336252 & 688810 & 4.883 & 5.2899 & TRN & & \\
\hline CHEMBL1514536 & 688810 & 4.783 & 4.6892 & TRN & & \\
\hline CHEMBL1609788 & 688810 & \multicolumn{3}{|c|}{5.382999999999999} & 5.1999 & TST \\
\hline CHEMBL1389810 & 688810 & 5.88299 & 99999999 & & 5.3373 & TRN \\
\hline CHEMBL1539807 & 688810 & 4.833 & 5.5305 & TRN & & \\
\hline CHEMBL1583692 & 688810 & 4.833 & 4.9665 & TST & & \\
\hline CHEMBL1366347 & 688810 & 5.13299 & 99999999 & & 6.4033 & TRN \\
\hline CHEMBL1518440 & 688810 & 5.53299 & 99999999 & 995 & 5.7154 & TRN \\
\hline CHEMBL1568412 & 688810 & 6.63299 & 99999999 & & 5.2104 & TST \\
\hline CHEMBL1326893 & 688810 & 4.833 & 5.1298 & TRN & & \\
\hline CHEMBL1404835 & 688810 & 5.38299 & 99999999 & & 5.7222 & TRA \\
\hline CHEMBL1371833 & 688810 & 4.783 & 5.5658 & TRN & & \\
\hline CHEMBL1547112 & 688810 & 5.733 & 5.159 & TST & & \\
\hline
\end{tabular}




\begin{tabular}{|c|c|c|c|c|c|c|}
\hline & & \multicolumn{4}{|c|}{ Supplemental Table S2.txt } & \\
\hline CHEMBL1210791 & 688810 & \multicolumn{4}{|c|}{5.332999999999999} & TRा \\
\hline CHEMBL1598405 & 688810 & \multicolumn{3}{|c|}{6.332999999999999} & 5.9348 & \\
\hline CHEMBL1501971 & 688810 & 5.483 & 5.7919 & TRN & & \\
\hline CHEMBL1544953 & 688810 & 5.233 & 5.2375 & TRN & & \\
\hline CHEMBL1612828 & 588810 & \multicolumn{3}{|c|}{5.2829999999999995} & 5.2197 & \\
\hline CHEMBL1436508 & 688810 & \multicolumn{3}{|c|}{6.132999999999999} & 5.2069 & \\
\hline CHEMBL1472363 & 688810 & \multicolumn{3}{|c|}{6.382999999999999} & 5.5958 & \\
\hline CHEMBL1501102 & 688810 & 4.833 & 5.2558 & TST & & \\
\hline CHEMBL1224755 & 688810 & 5.433 & 4.7911 & TST & & \\
\hline CHEMBL1380297 & 688810 & 4.783 & 5.3133 & TRN & & \\
\hline CHEMBL1532781 & 688810 & 5.233 & 5.1508 & TST & & \\
\hline CHEMBL1471040 & 688810 & 6.433 & 5.7393 & TRN & & \\
\hline CHEMBL1433189 & 688810 & 6.683 & 5.699 & TRN & & \\
\hline CHEMBL1538486 & 688810 & 5.083 & 5.1334 & TRN & & \\
\hline CHEMBL1570319 & 688810 & 4.633 & 5.0224 & TST & & \\
\hline CHEMBL1569948 & 688810 & 4.933 & 5.4646 & TRN & & \\
\hline CHEMBL138 & 688810 & 6.183 & 5.7111 & TRN & & \\
\hline CHEMBL1383299 & 688810 & \multicolumn{3}{|c|}{4.9830000000000005} & 5.4636 & \\
\hline CHEMBL1504601 & 688810 & \multicolumn{3}{|c|}{5.632999999999999} & 5.2135 & \\
\hline CHEMBL1320000 & 688810 & \multicolumn{3}{|c|}{5.832999999999999} & 5.8334 & \\
\hline CHEMBL1519603 & 688810 & 4.833 & 5.555 & TST & & \\
\hline CHEMBL15€ & 688810 & \multicolumn{3}{|c|}{5.132999999999999} & 5.2423 & \\
\hline CHEMBL1966298 & 688810 & \multicolumn{3}{|c|}{4.9830000000000005} & 5.3851 & \\
\hline CHEMBL1573250 & 688810 & 5.933 & 5.3643 & TST & & \\
\hline CHEMBL3212343 & 688810 & 5.233 & 5.1906 & TRN & & \\
\hline CHEMBL1308593 & 688810 & 5.483 & 5.3486 & TRN & & \\
\hline CHEMBL 32 & 688810 & \multicolumn{3}{|c|}{5.132999999999999} & 5.324 & \\
\hline CHEMBL3199348 & 688810 & 4.783 & 5.4881 & TRN & & \\
\hline CHEMBL1535003 & 688810 & 5.183 & 5.1578 & TRN & & \\
\hline CHEMBL1354689 & 688810 & \multicolumn{3}{|c|}{4.7330000000000005} & 5.5165 & \\
\hline CHEMBL1612470 & 688810 & \multicolumn{3}{|c|}{5.132999999999999} & 5.3229 & \\
\hline CHEMBL 1 & 688810 & 5.033 & 4.9668 & TRN & & \\
\hline CHEMBL1424574 & 688810 & \multicolumn{3}{|c|}{4.9830000000000005} & 4.5831 & \\
\hline CHEMBL1396252 & 688810 & 5.483 & 5.0662 & TRN & & \\
\hline CHEMBL1485951 & 688810 & \multicolumn{3}{|c|}{5.582999999999999} & 5.2745 & \\
\hline CHEMBL3191348 & 688810 & 5.683 & 4.8805 & TRN & & \\
\hline CHEMBL 1 & 688 & 5.983 & 5.5964 & TRN & & \\
\hline CHEMBL1594618 & 688810 & 4.783 & \multicolumn{3}{|c|}{5.093999999999999} & $\mathrm{TR}$ \\
\hline CHEMBL1420765 & 688810 & \multicolumn{3}{|c|}{4.7330000000000005} & 5.6352 & \\
\hline CHEMBL1592605 & 688810 & 4.583 & 5.0397 & TRN & & \\
\hline CHEMBL1530830 & 688810 & 4.783 & 5.2541 & TST & & \\
\hline CHEMBL1591878 & 688810 & 4.883 & 5.0602 & TST & & \\
\hline CHEMBL1546405 & 688810 & \multicolumn{3}{|c|}{6.632999999999999} & 5.6196 & TR \\
\hline CHEMBL1590790 & 688810 & \multicolumn{3}{|c|}{5.2829999999999995} & 5.4353 & \\
\hline CHEMBL1301921 & 688810 & \multicolumn{3}{|c|}{5.132999999999999} & 5.1745 & \\
\hline CHEMBL1374200 & 688810 & 6.7331 & 5.8468 & TRN & & \\
\hline CHEMBL1473922 & 688810 & 5.683 & 5.8137 & TRN & & \\
\hline CHEMBL1353630 & 688810 & 6.433 & 5.9396 & TRN & & \\
\hline
\end{tabular}




\begin{tabular}{|c|c|c|c|c|c|c|}
\hline \multirow[b]{2}{*}{ CHEMBL1317532 } & & \multicolumn{5}{|c|}{ al labıe } \\
\hline & 688810 & 5.083 & 5.1426 & TRN & & \\
\hline CHEMBL1325034 & 688810 & \multicolumn{3}{|c|}{5.2829999999999995} & 5.848 & TRN \\
\hline CHEMBL1200792 & 688810 & 4.633 & 4.8086 & TST & & \\
\hline CHEMBL1497875 & 688810 & 5.733 & 5.4591 & TRN & & \\
\hline CHEMBL1410697 & 688810 & 5.433 & 5.6548 & TST & & \\
\hline CHEMBL1332639 & 688810 & \multicolumn{3}{|c|}{5.332999999999999} & 4.5704 & $\mathrm{TP}$ \\
\hline CHEMBL1336702 & 688810 & 4.883 & 5.0073 & TRN & & \\
\hline CHEMBL1402138 & 688810 & 5.983 & 5.2746 & TRN & & \\
\hline CHEMBL1346531 & 688810 & \multicolumn{3}{|c|}{6.082999999999999} & 5.5519 & 11 \\
\hline CHEMBL1490467 & 688810 & 4.783 & 5.1042 & TRN & & \\
\hline CHEMBL1313266 & 688810 & 4.883 & 5.0985 & TRN & & \\
\hline CHEMBL1533104 & 688810 & 5.933 & 5.2238 & TRN & & \\
\hline CHEMBL1342729 & 688810 & 4.783 & 4.8391 & TST & & \\
\hline CHEMBL1406411 & 688810 & 5.233 & 5.6966 & TRN & & \\
\hline CHEMBL1534673 & 688810 & \multicolumn{3}{|c|}{5.2829999999999995} & 5.4596 & \\
\hline CHEMBL1493614 & 688810 & 6.433 & 5.6207 & TRN & & \\
\hline CHEMBL1469031 & 688810 & 4.883 & 5.2177 & TRN & & \\
\hline CHEMBL1545961 & 688810 & 5.233 & 5.2939 & TRN & & \\
\hline CHEMBL1393105 & 688810 & \multicolumn{3}{|c|}{6.382999999999999} & 5.5183 & \\
\hline CHEMBL1425678 & 688810 & 5.433 & 5.2362 & TRN & & \\
\hline CHEMBL1314431 & 688810 & 4.683 & 4.9814 & TRN & & \\
\hline CHEMBL1400881 & 688810 & 7.1331 & 5.5101 & TRN & & \\
\hline CHEMBL 3211008 & 688810 & 5.083 & 4.9148 & TRN & & \\
\hline CHEMBL1345580 & 688810 & 5.183 & 5.1034 & TRN & & \\
\hline CHEMBL1320437 & 688810 & 4.883 & 5.086 & TST & & \\
\hline CHEMBL1554039 & 688810 & 6.233 & 5.5675 & TST & & \\
\hline CHEMBL1520468 & 688810 & \multicolumn{3}{|c|}{4.7330000000000005} & 5.6585 & \\
\hline CHEMBL1454470 & 688810 & 4.783 & 5.3665 & TRN & & \\
\hline CHEMBL1512253 & 688810 & 4.933 & 4.8527 & TST & & \\
\hline CHEMBL 3193502 & 688810 & \multicolumn{3}{|c|}{4.7330000000000005} & 5.3565 & \\
\hline CHEMBL1540473 & 688810 & 5.233 & 5.1806 & TRN & & \\
\hline CHEMBL 3208980 & 688810 & 4.883 & 4.963999 & 999999999 & 995 & \\
\hline CHEMBL1534282 & 688810 & \multicolumn{3}{|c|}{5.332999999999999} & 5.2358 & \\
\hline CHEMBL1511445 & 688810 & 5.183 & 4.8996 & TRN & & \\
\hline CHEMBL1439562 & 688810 & 4.833 & 5.975 & TST & & \\
\hline CHEMBL1385690 & 688810 & 4.583 & 4.9397 & TST & & \\
\hline CHEMBL1979800 & 688810 & \multicolumn{3}{|c|}{5.2829999999999995} & 5.402 & \\
\hline CHEMBL1566031 & 688810 & \multicolumn{3}{|c|}{5.132999999999999} & 5.6553 & \\
\hline CHEMBL1576995 & 688810 & 4.783 & 4.9857 & TRN & & \\
\hline CHEMBL1554691 & 688810 & 5.933 & 5.46 & TRN & & \\
\hline CHEMBL1372880 & 688810 & 5.233 & 5.2699 & TST & & \\
\hline CHEMBL1593293 & 688810 & 7.0329 & 5.7251 & TRN & & \\
\hline CHEMBL1559040 & 688810 & \multicolumn{3}{|c|}{5.832999999999999} & 5.45 & \\
\hline CHEMBL1452866 & 688810 & 5.683 & 5.5233 & TRN & & \\
\hline CHEMBL1593403 & 688810 & 5.033 & 5.0132 & TRN & & \\
\hline CHEMBL1326037 & 688810 & 5.683 & 5.0322 & TRN & & \\
\hline CHEMBL1563905 & 688810 & 4.783 & 5.0381 & TRN & & \\
\hline CHEMBL1472261 & 688810 & 4.883 & 5.2036 & TRN & & \\
\hline
\end{tabular}




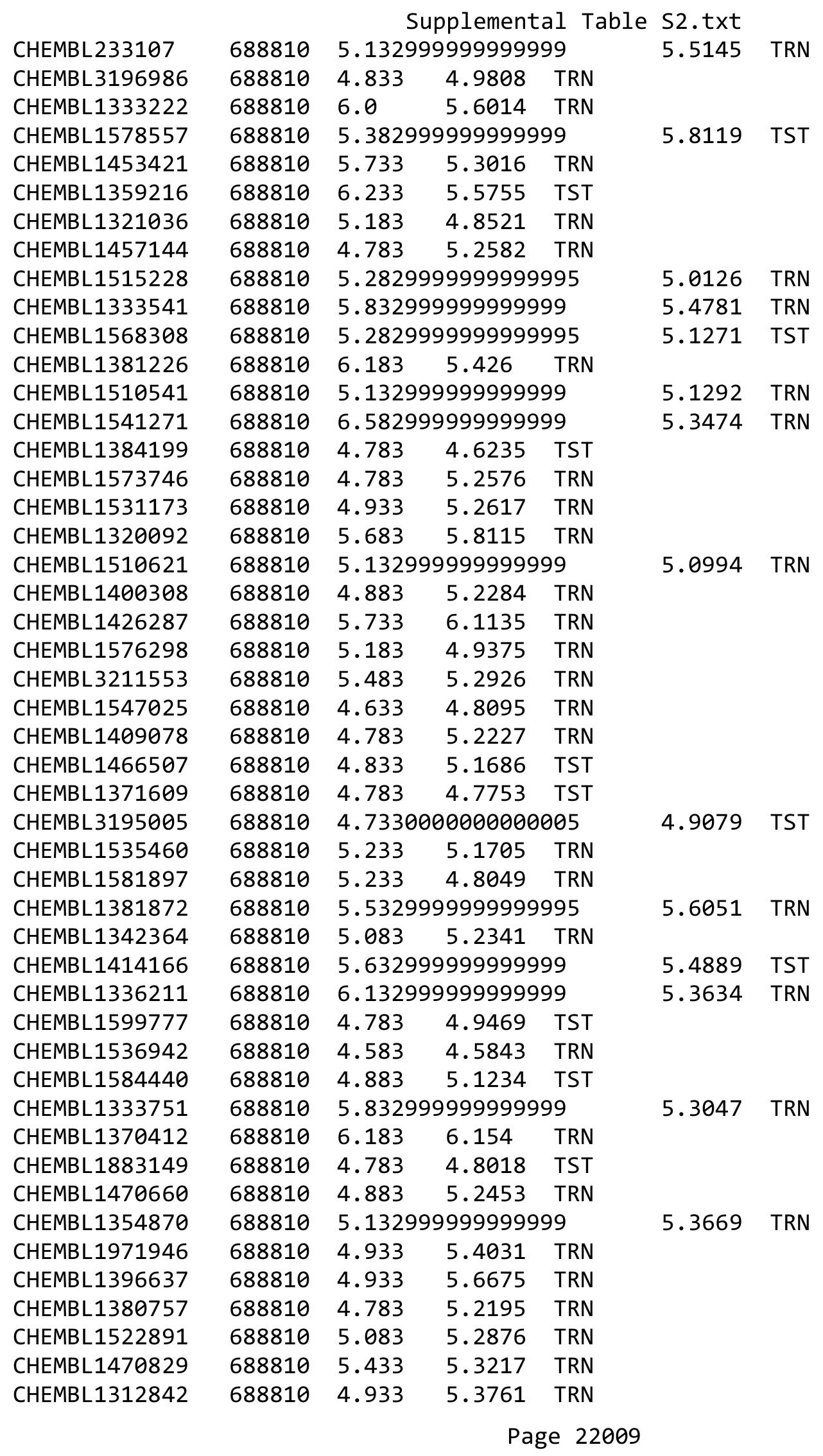




\begin{tabular}{|c|c|c|c|c|c|c|}
\hline & \\
\hline CHEMBL1327596 & 688810 & 4.583 & 5.3371 & TRN & & \\
\hline CHEMBL3207786 & 688810 & \multicolumn{3}{|c|}{5.5329999999999995} & 5.3267 & TST \\
\hline CHEMBL1613733 & 688810 & 5.083 & 4.8102 & TST & & \\
\hline CHEMBL 3190808 & 688810 & 4.783 & 5.1841 & TRN & & \\
\hline CHEMBL1518284 & 688810 & 4.783 & 4.7701 & TRN & & \\
\hline CHEMBL1421213 & 688810 & \multicolumn{3}{|c|}{5.382999999999999} & 4.9684 & TRN \\
\hline CHEMBL1352983 & 688810 & \multicolumn{3}{|c|}{5.7829999999999995} & 5.2995 & TST \\
\hline CHEMBL1478843 & 688810 & 4.583 & 5.3281 & TST & & \\
\hline CHEMBL1392774 & 688810 & 4.833 & 4.9971 & TRN & & \\
\hline CHEMBL1414737 & 688810 & 5.683 & \multicolumn{3}{|c|}{5.172000000000001} & TRN \\
\hline CHEMBL1431639 & 688810 & 4.833 & 5.0197 & TRN & & \\
\hline CHEMBL1486214 & 688810 & \multicolumn{3}{|c|}{5.582999999999999} & 4.7489 & TST \\
\hline CHEMBL1442969 & 688810 & 5.733 & 5.3503 & TRN & & \\
\hline CHEMBL3192028 & 688810 & 5.433 & 5.5253 & TRN & & \\
\hline CHEMBL1545890 & 688810 & 4.833 & 4.9748 & TRN & & \\
\hline CHEMBL1439384 & 688810 & 4.883 & 4.633 & TRN & & \\
\hline CHEMBL1555497 & 688810 & \multicolumn{3}{|c|}{5.382999999999999} & 5.6445 & TRN \\
\hline CHEMBL1562712 & 688810 & 6.8831 & 5.864 & TRN & & \\
\hline CHEMBL3208375 & 688810 & 5.483 & 5.0611 & TST & & \\
\hline CHEMBL1356974 & 688810 & 6.433 & 5.6675 & TRN & & \\
\hline CHEMBL1584938 & 688810 & \multicolumn{3}{|c|}{4.9830000000000005} & 4.9536 & TST \\
\hline CHEMBL1380797 & 688810 & 4.833 & 4.9188 & TRN & & \\
\hline CHEMBL1384550 & 688810 & 4.583 & 5.0157 & TST & & \\
\hline CHEMBL1545108 & 688810 & 5.183 & 4.7978 & TRN & & \\
\hline CHEMBL1356155 & 688810 & 4.633 & 4.9394 & TST & & \\
\hline CHEMBL1974506 & 688810 & 6.4829 & 5.8705 & TRN & & \\
\hline CHEMBL1338853 & 688810 & 5.7 & 5.9079 & TRN & & \\
\hline CHEMBL1312265 & 688810 & 5.683 & 5.4452 & TRN & & \\
\hline CHEMBL1450185 & 688810 & 5.183 & 5.2934 & TST & & \\
\hline CHEMBL1510373 & 688810 & 4.933 & 5.3456 & TST & & \\
\hline CHEMBL1379892 & 688810 & 6.433 & 5.9707 & TRN & & \\
\hline CHEMBL1593036 & 688810 & 4.933 & 5.5939 & TRN & & \\
\hline CHEMBL1591644 & 688810 & \multicolumn{3}{|c|}{5.832999999999999} & 5.4566 & TRN \\
\hline CHEMBL1581066 & 688810 & 6.433 & 5.6722 & TRN & & \\
\hline CHEMBL 1353750 & 688810 & 5.183 & 5.0095 & TST & & \\
\hline CHEMBL1389665 & 688810 & 4.833 & 5.2104 & TRN & & \\
\hline CHEMBL1469763 & 688810 & \multicolumn{3}{|c|}{5.2829999999999995} & 5.5361 & TRN \\
\hline CHEMBL1356298 & 688810 & \multicolumn{3}{|c|}{5.7829999999999995} & 5.706 & TST \\
\hline CHEMBL1366942 & 688810 & \multicolumn{3}{|c|}{5.632999999999999} & 5.7721 & TRN \\
\hline CHEMBL1444019 & 688810 & 4.933 & 4.8591 & TRN & & \\
\hline CHEMBL3197935 & 688810 & 4.883 & 4.9617 & TST & & \\
\hline CHEMBL1524052 & 688810 & \multicolumn{3}{|c|}{4.7330000000000005} & 4.7696 & TST \\
\hline CHEMBL1329631 & 688810 & 4.833 & 4.5647 & TRN & & \\
\hline CHEMBL1549233 & 688810 & 4.933 & 5.1683 & TRN & & \\
\hline CHEMBL3210855 & 688810 & 5.933 & 5.2278 & TRN & & \\
\hline CHEMBL3191747 & 688810 & 4.833 & 5.0084 & TRN & & \\
\hline CHEMBL1301356 & 688810 & \multicolumn{3}{|c|}{5.132999999999999} & 4.8065 & TRN \\
\hline CHEMBL1367246 & 688810 & 6.233 & 5.7173 & TRN & & \\
\hline
\end{tabular}




\begin{tabular}{|c|c|c|c|c|c|c|c|}
\hline \multicolumn{7}{|c|}{ Supplemental Table S2.txt } & \\
\hline CHEMBL1439933 & 688810 & \multicolumn{3}{|c|}{4.7330000000000005} & 4.8047 & TRN & \\
\hline CHEMBL1535564 & 688810 & 4.933 & 5.1448 & TRN & & & \\
\hline CHEMBL1583231 & 688810 & 5.183 & 5.5572 & TRN & & & \\
\hline CHEMBL1367587 & 688810 & 4.883 & 5.3713 & TST & & & \\
\hline CHEMBL3214007 & 688810 & \multicolumn{3}{|c|}{5.632999999999999} & 5.5216 & TRN & \\
\hline CHEMBL1482470 & 688810 & \multicolumn{3}{|c|}{5.2829999999999995} & 4.655 & TRN & \\
\hline CHEMBL1529620 & 688810 & 4.833 & 5.1361 & TRN & & & \\
\hline CHEMBL1535938 & 688810 & 4.933 & 5.1409 & TST & & & \\
\hline CHEMBL1581095 & 688810 & \multicolumn{3}{|c|}{5.332999999999999} & 5.4105 & TRN & \\
\hline CHEMBL1497197 & 688810 & 7.1331 & 6.1642 & TST & & & \\
\hline CHEMBL1439063 & 688810 & 4.633 & 4.9128 & TST & & & \\
\hline CHEMBL1457311 & 688810 & 5.183 & 5.8552 & TRN & & & \\
\hline CHEMBL1419519 & 688810 & \multicolumn{3}{|c|}{6.2829999999999995} & 5.4861 & TRN & \\
\hline CHEMBL3195432 & 688810 & \multicolumn{3}{|c|}{5.832999999999999} & 5.9476 & TRN & \\
\hline CHEMBL1548989 & 688810 & \multicolumn{3}{|c|}{4.7330000000000005} & 5.6839 & TST & \\
\hline CHEMBL1483253 & 688810 & 5.733 & 5.7441 & TRN & & & \\
\hline CHEMBL1602114 & 688810 & 4.783 & 5.1604 & TRN & & & \\
\hline CHEMBL1503657 & 688810 & \multicolumn{3}{|c|}{6.7829999999999995} & 5.5171 & TRN & \\
\hline CHEMBL1315085 & 688810 & 4.633 & 4.8979 & TST & & & \\
\hline CHEMBL 3214458 & 688810 & \multicolumn{3}{|c|}{4.7330000000000005} & 5.5036 & TST & \\
\hline CHEMBL1421793 & 688810 & \multicolumn{3}{|c|}{5.132999999999999} & 5.282 & TRN & \\
\hline CHEMBL1559299 & 688810 & 5.083 & 5.3404 & TST & & & \\
\hline CHEMBL1560848 & 688810 & 5.433 & 5.379 & TRN & & & \\
\hline CHEMBL1476322 & 688810 & 5.033 & 5.2212 & TST & & & \\
\hline CHEMBL 258549 & 688810 & \multicolumn{3}{|c|}{6.5329999999999995} & 5.5839 & TRN & \\
\hline CHEMBL1396361 & 688810 & \multicolumn{3}{|c|}{5.332999999999999} & 5.3861 & TST & \\
\hline CHEMBL1424772 & 688810 & 4.683 & 5.2499 & TRN & & & \\
\hline CHEMBL1463690 & 688810 & \multicolumn{3}{|c|}{5.332999999999999} & 5.7634 & TRN & \\
\hline CHEMBL1442407 & 688810 & \multicolumn{3}{|c|}{4.7330000000000005} & 4.97199 & 99999999995 & TRN \\
\hline CHEMBL1511561 & 688810 & 4.683 & 5.3552 & TRN & & & \\
\hline CHEMBL1333784 & 688810 & \multicolumn{3}{|c|}{5.7829999999999995} & 5.5266 & TRN & \\
\hline CHEMBL1310733 & 688810 & 4.833 & 5.3591 & TRN & & & \\
\hline CHEMBL1409702 & 688810 & 5.683 & 5.4663 & TRN & & & \\
\hline CHEMBL1463996 & 688810 & 4.783 & 4.7847 & TRN & & & \\
\hline CHEMBL1517909 & 688810 & 4.783 & 5.359 & TRN & & & \\
\hline CHEMBL1409513 & 688810 & 7.0329 & 5.7059 & TRN & & & \\
\hline CHEMBL451191 & 688810 & 4.783 & 5.5272 & TRN & & & \\
\hline CHEMBL1484441 & 688810 & \multicolumn{3}{|c|}{4.9830000000000005} & 5.0834 & TRN & \\
\hline CHEMBL1323296 & 688810 & 4.833 & 5.0346 & TRN & & & \\
\hline CHEMBL1562259 & 688810 & 5.183 & 5.3204 & TRN & & & \\
\hline CHEMBL319381 & 688810 & \multicolumn{3}{|c|}{5.7829999999999995} & 5.5584 & TRN & \\
\hline CHEMBL3190338 & 688810 & 4.833 & 5.178 & TST & & & \\
\hline CHEMBL1401528 & 688810 & \multicolumn{3}{|c|}{6.2829999999999995} & 5.0648 & TRN & \\
\hline CHEMBL1453946 & 688810 & \multicolumn{3}{|c|}{4.7330000000000005} & 4.852 & TRN & \\
\hline CHEMBL1578423 & 688810 & \multicolumn{3}{|c|}{5.332999999999999} & 5.62200 & 0000000001 & TRN \\
\hline CHEMBL1560215 & 688810 & 6.45 & 5.4337 & TRN & & & \\
\hline CHEMBL1334017 & 688810 & 4.683 & 5.3954 & TRN & & & \\
\hline CHEMBL3192183 & 688810 & 4.783 & 5.2579 & TRN & & & \\
\hline
\end{tabular}




\begin{tabular}{|c|c|c|c|c|c|}
\hline \multirow[b]{2}{*}{ CHEMBL 3198514} & \multicolumn{5}{|c|}{ oplemental Table } \\
\hline & 688810 & 4.633 & 5.0741 & & \\
\hline CHEMBL1307007 & 688810 & 4.833 & 5.20700 & & TRI \\
\hline CHEMBL1390519 & 688810 & 4.783 & 5.1126 & & \\
\hline CHEMBL1398398 & 688810 & 4.783 & 5.0742 & & \\
\hline CHEMBL1563081 & 688810 & 5.78299 & 99999999 & 5.1704 & TRN \\
\hline CHEMBL1548000 & 688810 & 5.33299 & 99999999 & 5.4771 & \\
\hline CHEMBL1387481 & 688810 & 4.783 & 4.8815 & & \\
\hline CHEMBL1527010 & 688810 & 6.4829 & 5.096 & & \\
\hline CHEMBL1571307 & 688810 & 5.733 & 5.4417 & & \\
\hline CHEMBL1545569 & 688810 & 5.13299 & 99999999 & 5.2351 & \\
\hline CHEMBL 1438833 & 688810 & 4.933 & 4.9358 & & \\
\hline CHEMBL 3214405 & 688810 & 5.733 & 5.0473 & & \\
\hline CHEMBL 3191889 & 688810 & 5.63299 & 99999999 & 5.2781 & \\
\hline CHEMBL1379678 & 688810 & 4.98300 & 00000000 & 4.8574 & \\
\hline CHEMBL1307777 & 688810 & 4.833 & 5.3635 & & \\
\hline CHEMBL1372465 & 688810 & 5.733 & 5.6192 & & \\
\hline CHEMBL1423851 & 688810 & 4.833 & 5.9574 & & \\
\hline CHEMBL1373924 & 688810 & 6.63299 & 99999999 & 1 & \\
\hline CHEMBL1570501 & 688810 & 5.483 & 5.4425 & & \\
\hline CHEMBL1345699 & 688810 & 4.783 & 5.1603 & & \\
\hline CHEMBL1299967 & 688810 & 4.583 & 5.0185 & & \\
\hline CHEMBL1488919 & 688810 & 5.183 & 5.5974 & & \\
\hline CHEMBL1589383 & 688810 & 4.783 & 5.518 & & \\
\hline CHEMBL1497379 & 688810 & 5.233 & 5.37 & & \\
\hline CHEMBL1381099 & 688810 & 4.73300 & 00000000 & 5.3558 & \\
\hline CHEMBL 3210839 & 688810 & 4.783 & 5.4939 & & \\
\hline CHEMBL1576674 & 688810 & 4.783 & 5.2951 & & \\
\hline CHEMBL1525749 & 688810 & 4.933 & 5.2769 & & \\
\hline CHEMBL1589539 & 688810 & 5.233 & 5.8154 & & \\
\hline CHEMBL1415155 & 688810 & 5.78299 & 99999999 & 5.5138 & \\
\hline CHEMBL1571018 & 688810 & 6.58299 & 99999999 & 6.1107 & TRN \\
\hline CHEMBL1537091 & 688810 & 5.13299 & 99999999 & 5.4735 & TPN \\
\hline CHEMBL1385068 & 688810 & 4.783 & 4.7711 & & \\
\hline CHEMBL3190936 & 688810 & 4.73300 & $\partial 0000000$ & 5.0589 & TRN \\
\hline CHEMBL1557639 & 688810 & 4.883 & 4.7705 & & \\
\hline CHEMBL1424531 & 688810 & 5.63299 & 99999999 & 5.1549 & TRN \\
\hline CHEMBL1570217 & 688810 & 6.28299 & 99999999 & 6.0649 & \\
\hline CHEMBL1567793 & 688810 & 5.433 & 5.9743 & & \\
\hline CHEMBL1357159 & 688810 & 5.63299 & 99999999 & 5.3592 & $\mathrm{~K}$ \\
\hline CHEMBL1542099 & 688810 & 7.0329 & 6.279 & & \\
\hline CHEMBL1379457 & 688810 & 5.683 & 5.6289 & & \\
\hline CHEMBL1352326 & 688810 & 5.733 & 5.6384 & & \\
\hline CHEMBL1502209 & 688810 & 6.233 & 5.2023 & & \\
\hline CHEMBL1510117 & 688810 & 5.083 & 5.6454 & & \\
\hline CHEMBL1361173 & 688810 & 6.433 & 5.0694 & & \\
\hline CHEMBL1387923 & 688810 & 4.833 & 5.4713 & & \\
\hline CHEMBL469362 & 688810 & 6.8831 & 5.7309 & & \\
\hline CHEMBL467590 & 688810 & 4.883 & 5.4013 & & \\
\hline
\end{tabular}




\begin{tabular}{|c|c|c|c|c|c|c|}
\hline \multirow{3}{*}{$\begin{array}{l}\text { CHEMBL1453006 } \\
\text { CHEMBL1353128 }\end{array}$} & \multicolumn{6}{|c|}{ Supplemental Table S2.txt } \\
\hline & 688810 & \multicolumn{3}{|c|}{5.7829999999999995} & \multirow[t]{3}{*}{5.7771} & \multirow[t]{3}{*}{ TRN } \\
\hline & 688810 & 5.683 & 5.4065 & TRN & & \\
\hline CHEMBL1527438 & 688810 & 5.083 & 5.2434 & TRN & & \\
\hline CHEMBL1449954 & 688810 & \multicolumn{3}{|c|}{5.7829999999999995} & 5.5182 & TRN \\
\hline CHEMBL1407401 & 688810 & 4.583 & 4.9923 & TRN & & \\
\hline CHEMBL1312289 & 688810 & \multicolumn{3}{|c|}{5.832999999999999} & 5.4249 & \\
\hline CHEMBL1467586 & 688810 & 4.633 & 5.2703 & TST & & \\
\hline CHEMBL1512520 & 688810 & \multicolumn{3}{|c|}{6.2829999999999995} & 5.5967 & TRN \\
\hline CHEMBL1450720 & 688810 & \multicolumn{3}{|c|}{6.5329999999999995} & 5.6389 & \\
\hline CHEMBL1596709 & 688810 & 5.933 & 5.322 & TRN & & \\
\hline CHEMBL1499494 & 688810 & 4.883 & 4.8643 & TST & & \\
\hline CHEMBL3214518 & 688810 & 4.833 & 5.7672 & TRN & & \\
\hline CHEMBL469976 & 688810 & \multicolumn{3}{|c|}{4.9830000000000005} & 5.3399 & \\
\hline CHEMBL1606344 & 688810 & 5.683 & 5.8686 & TRN & & \\
\hline CHEMBL1545093 & 688810 & 4.783 & 5.0198 & TST & & \\
\hline CHEMBL133 & 0 & 5.6 & 4.9 & TRN & & \\
\hline CHEMBL1 & 10 & 5 . & 5.559 & TST & & \\
\hline CHEMBL1570835 & 688 & 4.833 & 5.4483 & TRN & & \\
\hline CHEMBL3189188 & 688810 & 5.183 & 5.1397 & TRN & & \\
\hline CHEMBL1331686 & 688 & \multicolumn{3}{|c|}{6.332999999999999} & 4 & \\
\hline CHEMBL1 & $68 \varepsilon$ & 4.833 & 5.1811 & TST & & \\
\hline CHEMBL & 688 & 5.733 & 5.2891 & TST & & \\
\hline CHEMBL1393129 & 688810 & \multicolumn{3}{|c|}{5.132999999999999} & 6.3131 & Ts \\
\hline CHEMBL1345975 & 688810 & 4.833 & 5.534 & TRN & & \\
\hline CHEMBL1308391 & 688810 & \multicolumn{3}{|c|}{5.132999999999999} & .4853 & TRN \\
\hline CHEMBL1 & 10 & \multicolumn{3}{|c|}{6.382999999999999} & 983 & TRN \\
\hline CHEMBL15 & 688 & \multicolumn{3}{|c|}{5.132999999999999} & 5.8174 & \\
\hline CHEMBL1548353 & 688810 & \multicolumn{3}{|c|}{4.7330000000000005} & 5.0606 & TRN \\
\hline CHEMBL1315021 & 688810 & 4.583 & 4.7642 & TRN & & \\
\hline CHEMBL1421236 & 688810 & 4.683 & 5.2144 & TRN & & \\
\hline CHEMBL: & 10 & \multicolumn{3}{|c|}{6.132999999999999} & 557 & TST \\
\hline CHEMBL3 & $68 \varepsilon$ & \multicolumn{3}{|c|}{5.832999999999999} & 391 & TRN \\
\hline CHEMBL1498932 & 688810 & \multicolumn{3}{|c|}{5.832999999999999} & 5.7986 & $\mathrm{TH}$ \\
\hline CHEMBL1402054 & 688810 & 4.883 & 5.4035 & TRN & & \\
\hline CHEMBL2369169 & 688810 & & 5.2542 & TST & & \\
\hline CHEMBL: & $68 \varepsilon$ & 4.833 & 5.032 & TRN & & \\
\hline CHEMBL1 & 688 & \multicolumn{3}{|c|}{5.2829999999999995} & 5.0453 & TST \\
\hline CHEMBL1301112 & 688810 & 4.883 & \multicolumn{3}{|c|}{5.2620000000000005} & -7 \\
\hline CHEMBL1326164 & 688810 & 5.983 & 5.7062 & TRN & & \\
\hline CHEMBL1 & 688 & 4.783 & 5.1427 & TST & & \\
\hline CHEMBL3199086 & 688810 & 5.6329 & 99999999 & & 4.9228 & $T$ \\
\hline CHEMBL1425868 & 688810 & 5.233 & 5.393 & TRN & & \\
\hline CHEMBL1559204 & 688810 & 4.933 & 4.923 & TRN & & \\
\hline CHEMBL3210532 & 688810 & 5.183 & 5.1389 & TRN & & \\
\hline CHEMBL1543712 & 688810 & 5.8329 & 99999999 & & 5.6312 & TRN \\
\hline CHEMBL1322754 & 688810 & 5.233 & 5.17200 & 0000 & 01 & \\
\hline CHEMBL1310405 & 688810 & 4.783 & 5.1865 & TST & & \\
\hline CHEMBL1448104 & 688810 & 4.7330 & 00000000 & 05 & 4.9851 & RIN \\
\hline
\end{tabular}




\begin{tabular}{|c|c|c|c|c|c|c|}
\hline \multirow[b]{2}{*}{ CHEMBL1363703 } & \multirow[b]{2}{*}{688810} & \multicolumn{5}{|c|}{ Supplemental Table s2.txt } \\
\hline & & \multicolumn{3}{|c|}{$\begin{array}{lll}4.833 & 5.1714 & \text { TST }\end{array}$} & & \\
\hline CHEMBL3195108 & 688810 & 5.733 & 5.6308 & TRN & & \\
\hline CHEMBL1476803 & 688810 & \multicolumn{3}{|c|}{4.7330000000000005} & 4.7921 & TST \\
\hline CHEMBL1546279 & 688810 & 6.433 & 5.1481 & TRN & & \\
\hline CHEMBL1573488 & 688810 & 5.733 & 5.3861 & TRN & & \\
\hline CHEMBL1565953 & 688810 & 5.183 & 5.3396 & TRN & & \\
\hline CHEMBL2369304 & 688810 & \multicolumn{3}{|c|}{5.7829999999999995} & 5.2948 & TRN \\
\hline CHEMBL3190398 & 688810 & 5.183 & 5.3213 & TST & & \\
\hline CHEMBL1363079 & 688810 & \multicolumn{3}{|c|}{4.7330000000000005} & 5.3932 & TRN \\
\hline CHEMBL1512205 & 688810 & 4.833 & 4.9115 & TST & & \\
\hline CHEMBL1372986 & 688810 & 5.183 & 4.8488 & TRN & & \\
\hline CHEMBL3189405 & 688810 & \multicolumn{3}{|c|}{5.632999999999999} & 4.9845 & TST \\
\hline CHEMBL1336419 & 688810 & 4.833 & 5.1211 & TRN & & \\
\hline CHEMBL1528668 & 688810 & 7.2832 & 5.4481 & TRN & & \\
\hline CHEMBL1463990 & 688810 & 4.833 & 5.4308 & TST & & \\
\hline CHEMBL1312714 & 688810 & \multicolumn{3}{|c|}{4.7330000000000005} & 5.2741 & TST \\
\hline CHEMBL1582677 & 688810 & 4.833 & 5.1416 & TRN & & \\
\hline CHEMBL1169929 & 688810 & 4.833 & 5.1557 & TRN & & \\
\hline CHEMBL1345128 & 688810 & \multicolumn{3}{|c|}{5.5329999999999995} & 5.0029 & TRN \\
\hline CHEMBL1462733 & 688810 & 4.833 & 5.2517 & TST & & \\
\hline CHEMBL1556686 & 688810 & 4.933 & 5.8347 & TRN & & \\
\hline CHEMBL1299526 & 688810 & 5.433 & 4.8979 & TST & & \\
\hline CHEMBL1593251 & 688810 & 7.0329 & 6.166 & TRN & & \\
\hline CHEMBL1517198 & 688810 & \multicolumn{3}{|c|}{5.882999999999999} & 5.4037 & TRN \\
\hline CHEMBL1378837 & 688810 & 4.9 & 4.7343 & TRN & & \\
\hline CHEMBL1461119 & 688810 & 4.783 & 4.6595 & TRN & & \\
\hline CHEMBL1414223 & 688810 & \multicolumn{3}{|c|}{4.7330000000000005} & 4.9325 & TRN \\
\hline CHEMBL1473368 & 688810 & 5.433 & 5.2467 & TST & & \\
\hline CHEMBL1548237 & 688810 & \multicolumn{3}{|c|}{5.382999999999999} & 5.3299 & TRN \\
\hline CHEMBL1344961 & 688810 & 5.083 & 5.0233 & TRN & & \\
\hline CHEMBL1551312 & 688810 & 4.833 & 5.0097 & TRN & & \\
\hline CHEMBL1349759 & 688810 & 6.983 & 6.2305 & TRN & & \\
\hline CHEMBL1532607 & 688810 & 4.833 & 5.5284 & TRN & & \\
\hline CHEMBL1299787 & 688810 & 4.883 & 5.0236 & TRN & & \\
\hline CHEMBL1423133 & 688810 & \multicolumn{3}{|c|}{5.2829999999999995} & 5.1347 & TRN \\
\hline CHEMBL 240333 & 688810 & 5.233 & 5.8363 & TRN & & \\
\hline CHEMBL1328145 & 688810 & 6.983 & 5.8539 & TRN & & \\
\hline CHEMBL1547464 & 688810 & 5.983 & 5.5924 & TRN & & \\
\hline CHEMBL1337185 & 688810 & \multicolumn{3}{|c|}{4.7330000000000005} & 5.141 & TST \\
\hline CHEMBL1445548 & 688810 & 5.683 & 5.3263 & TRN & & \\
\hline CHEMBL3213083 & 688810 & \multicolumn{3}{|c|}{5.5329999999999995} & 5.2113 & TRN \\
\hline CHEMBL3213808 & 688810 & \multicolumn{3}{|c|}{5.5329999999999995} & 5.0144 & TRN \\
\hline CHEMBL1572882 & 688810 & 4.783 & 5.1542 & TST & & \\
\hline CHEMBL1451802 & 688810 & 4.883 & 4.919 & TRN & & \\
\hline CHEMBL1541251 & 688810 & 6.0 & 5.1091 & TRN & & \\
\hline CHEMBL1597288 & 688810 & 4.833 & 4.8419 & TRN & & \\
\hline CHEMBL1437412 & 688810 & 4.583 & 5.1433 & TRN & & \\
\hline CHEMBL1348802 & 688810 & 4.833 & 5.6275 & TRN & & \\
\hline
\end{tabular}




\begin{tabular}{|c|c|c|c|c|c|c|}
\hline \multirow[b]{2}{*}{ CHEMBL1588361 } & \multicolumn{6}{|c|}{ pplemental Ta } \\
\hline & 688810 & 4.783 & 5.1774 & TRN & & \\
\hline CHEMBL1366824 & 688810 & 5.433 & 5.3238 & TRN & & \\
\hline CHEMBL1303642 & 688810 & 4.883 & 5.1573 & TST & & \\
\hline CHEMBL1478997 & 688810 & \multicolumn{3}{|c|}{5.882999999999999} & 5.7076 & I KIV \\
\hline CHEMBL1350521 & 688810 & \multicolumn{3}{|c|}{4.7330000000000005} & 4.945 & TRN \\
\hline CHEMBL1492846 & 688810 & \multicolumn{3}{|c|}{5.132999999999999} & 5.0309 & \\
\hline CHEMBL 3213503 & 688810 & 5.183 & 4.9 & TST & & \\
\hline CHEMBL1595912 & 688810 & 4.633 & 5.1087 & TST & & \\
\hline CHEMBL1978564 & 688810 & 5.733 & 5.4869 & TRN & & \\
\hline CHEMBL1491632 & 688810 & 4.783 & 4.7434 & TST & & \\
\hline CHEMBL 3209761 & 688810 & \multicolumn{3}{|c|}{5.632999999999999} & 5.4452 & TRN \\
\hline CHEMBL1431747 & 688810 & \multicolumn{3}{|c|}{4.7330000000000005} & 5.1138 & \\
\hline CHEMBL118175 & 688810 & \multicolumn{3}{|c|}{4.7330000000000005} & 5.2662 & \\
\hline CHEMBL1422397 & 688810 & \multicolumn{3}{|c|}{4.9830000000000005} & 5.105 & \\
\hline CHEMBL1526372 & 688810 & 4.833 & 5.4033 & TRN & & \\
\hline CHEMBL1440152 & 688810 & 5.683 & 5.1485 & TST & & \\
\hline CHEMBL 3208298 & 688810 & 4.833 & 5.2864 & TRN & & \\
\hline CHEMBL 3194813 & 688810 & 4.883 & 5.2995 & TRN & & \\
\hline CHEMBL154 & 688 & 4.883 & 4.9795 & TRN & & \\
\hline CHEMBL1468103 & 688810 & \multicolumn{3}{|c|}{5.132999999999999} & 5.3611 & \\
\hline CHEMBL1601896 & 688810 & 5.233 & 5.1166 & TRN & & \\
\hline CHEMBL1431971 & 688810 & 4.683 & 5.1757 & TRN & & \\
\hline CHEMBL1538055 & 688810 & \multicolumn{3}{|c|}{4.7330000000000005} & 5.5634 & \\
\hline CHEMBL1495788 & $68 \varepsilon$ & 4.883 & 5.5169 & TRN & & \\
\hline CHEMBL1515130 & 688810 & \multicolumn{3}{|c|}{6.382999999999999} & 5.5236 & \\
\hline CHEMBL1418728 & 688810 & \multicolumn{3}{|c|}{5.132999999999999} & 5.2035 & \\
\hline CHEMBL1403994 & 688810 & \multicolumn{3}{|c|}{5.2829999999999995} & 4.9722 & TRN \\
\hline CHEMBL1541030 & 688810 & \multicolumn{3}{|c|}{4.7330000000000005} & 5.3527 & TRN \\
\hline CHEMBL1367297 & 688810 & \multicolumn{3}{|c|}{4.7330000000000005} & 5.2456 & \\
\hline CHEMBL1608383 & 688810 & 7.2832 & 5.7644 & TRN & & \\
\hline CHEMBL 3211613 & 688810 & 5.233 & 5.3738 & TRN & & \\
\hline CHEMBL 3195841 & 688810 & 7.1831 & 5.3464 & TRN & & \\
\hline CHEMBL1372194 & 688810 & 4.783 & 5.4558 & TST & & \\
\hline CHEMBL1523189 & 688810 & 4.633 & \multicolumn{3}{|c|}{5.132000000000001} & TST \\
\hline CHEMBL1976433 & 688810 & 4.833 & 5.2643 & TRN & & \\
\hline CHEMBL1411012 & 688810 & \multicolumn{3}{|c|}{5.132999999999999} & 5.2877 & TST \\
\hline CHEMBL 3196203 & 688810 & 4.833 & 5.3893 & TRN & & \\
\hline CHEMBL1367394 & 688810 & 6.0 & 4.8884 & TRN & & \\
\hline CHEMBL1501014 & $68 \varepsilon$ & 7.1331 & 5.5072 & TRN & & \\
\hline CHEMBL1337420 & 688810 & \multicolumn{3}{|c|}{4.7330000000000005} & 5.4165 & TRN \\
\hline CHEMBL1519597 & 688810 & 7.1331 & \multicolumn{3}{|c|}{5.8229999999999995} & TR \\
\hline CHEMBL1569441 & 688810 & 5.033 & 5.5267 & TRN & & \\
\hline CHEMBL1319647 & 688810 & 5.183 & 5.4249 & TST & & \\
\hline CHEMBL1583715 & 688810 & 5.033 & 4.6259 & TRN & & \\
\hline CHEMBL1466151 & 688810 & 5.733 & 5.2748 & TRN & & \\
\hline CHEMBL1547034 & 688810 & 4.783 & 5.6772 & TST & & \\
\hline CHEMBL1457931 & 688810 & \multicolumn{3}{|c|}{4.9830000000000005} & 5.4588 & In \\
\hline CHEMBL1443573 & 688810 & 4.583 & 5.0406 & TRN & & \\
\hline
\end{tabular}




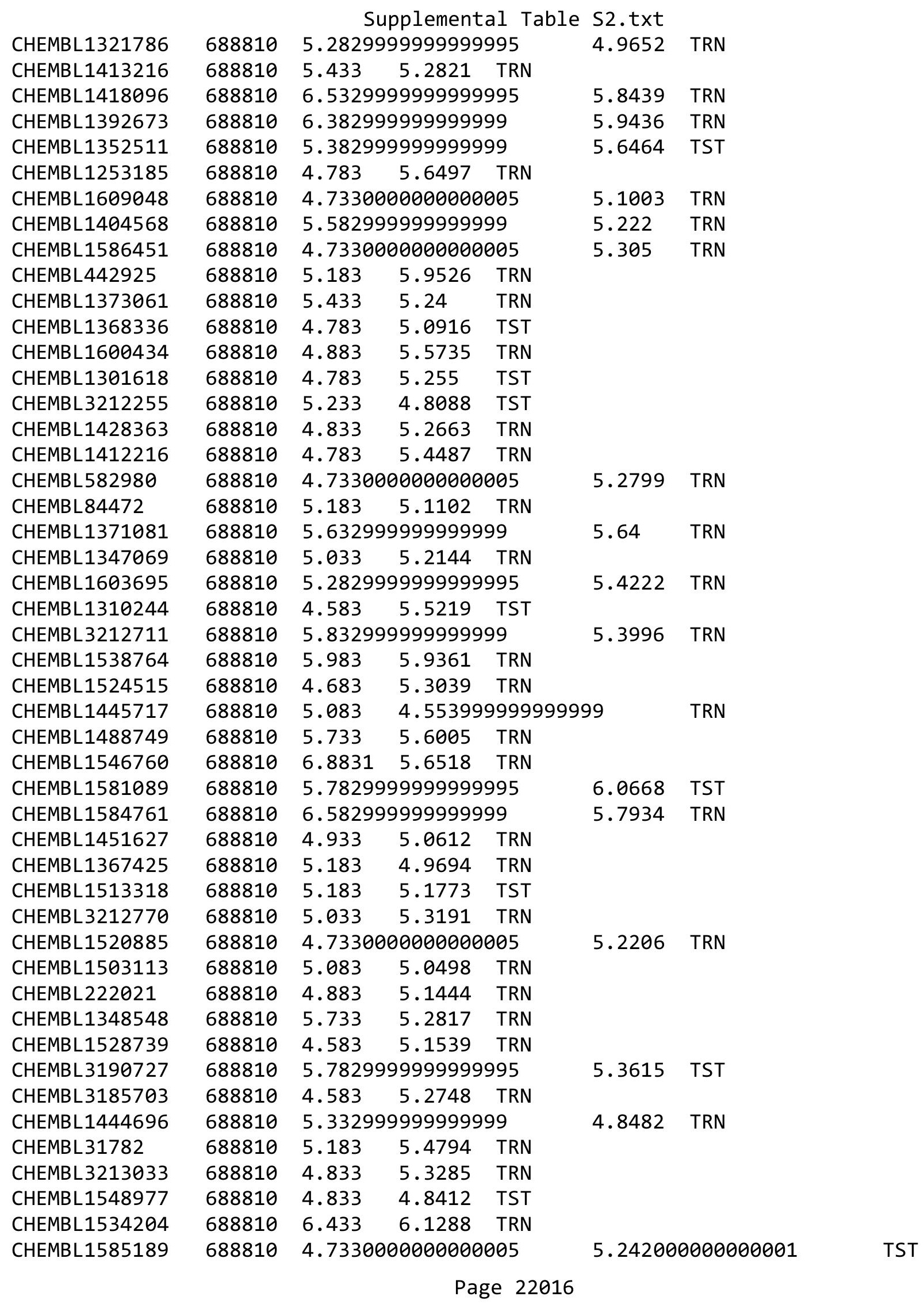




\begin{tabular}{|c|c|c|c|c|c|c|c|}
\hline \multicolumn{8}{|c|}{ Supplemental Table S2.txt } \\
\hline CHEMBL1498920 & 688810 & \multicolumn{3}{|c|}{4.7330000000000005} & 5.2438 & TRN & \\
\hline CHEMBL1442084 & 688810 & \multirow{2}{*}{\multicolumn{3}{|c|}{$\begin{array}{l}6.0329999999999995 \\
4.783 \quad 4.9124\end{array}$}} & 5.9717 & TRN & \\
\hline CHEMBL1510949 & 688810 & & & & & & \\
\hline CHEMBL1412478 & 688810 & \multicolumn{3}{|c|}{5.632999999999999} & 5.8842 & TRN & \\
\hline CHEMBL1337918 & 688810 & 5.683 & 4.9914 & TRN & & & \\
\hline CHEMBL1418012 & 688810 & \multicolumn{3}{|c|}{5.132999999999999} & \multicolumn{2}{|c|}{5.162999999999999} & TRN \\
\hline CHEMBL1512623 & 688810 & 4.633 & 5.1473 & TST & & & \\
\hline CHEMBL1527112 & 688810 & 5.033 & 5.1869 & TRN & & & \\
\hline CHEMBL1466078 & 688810 & 4.883 & 4.8763 & TRN & & & \\
\hline CHEMBL1375884 & 688810 & 4.833 & 5.0572 & TRN & & & \\
\hline CHEMBL1501910 & 688810 & \multicolumn{3}{|c|}{5.832999999999999} & 5.2452 & TRN & \\
\hline CHEMBL1400371 & 688810 & 4.783 & 4.9975 & TRN & & & \\
\hline CHEMBL1535526 & 688810 & \multicolumn{3}{|c|}{4.7330000000000005} & 5.4287 & TRN & \\
\hline CHEMBL1981797 & 688810 & \multicolumn{3}{|c|}{5.132999999999999} & 4.9084 & TRN & \\
\hline CHEMBL1538850 & 688810 & 4.633 & 5.0297 & TRN & & & \\
\hline CHEMBL1583133 & 688810 & \multicolumn{3}{|c|}{5.132999999999999} & 5.2795 & TRN & \\
\hline CHEMBL1536228 & 688810 & 5.233 & 5.6166 & TRN & & & \\
\hline CHEMBL1499864 & 688810 & \multicolumn{3}{|c|}{5.132999999999999} & 5.7593 & TRN & \\
\hline CHEMBL1596232 & 688810 & \multicolumn{3}{|c|}{4.7330000000000005} & 4.8356 & TRN & \\
\hline CHEMBL1506517 & 688810 & 4.833 & 4.8428 & TRN & & & \\
\hline CHEMBL1326386 & 688810 & 4.833 & 4.9554 & TRN & & & \\
\hline CHEMBL3191977 & 688810 & 5.683 & 5.6255 & TRN & & & \\
\hline CHEMBL1341399 & 688810 & 5.233 & 5.2782 & TST & & & \\
\hline CHEMBL1537720 & 688810 & 4.833 & 4.8067 & TRN & & & \\
\hline CHEMBL1352955 & 688810 & \multicolumn{3}{|c|}{6.5329999999999995} & 5.7069 & TRN & \\
\hline CHEMBL1475709 & 688810 & \multicolumn{3}{|c|}{4.7330000000000005} & 5.266 & TRN & \\
\hline CHEMBL1332362 & 688810 & 5.183 & 5.5309 & TRN & & & \\
\hline CHEMBL1511318 & 688810 & 4.833 & 5.1349 & TRN & & & \\
\hline CHEMBL3190259 & 688810 & \multicolumn{3}{|c|}{5.7829999999999995} & 5.1442 & TST & \\
\hline CHEMBL1544423 & 688810 & 4.633 & 5.1744 & TRN & & & \\
\hline CHEMBL1331469 & 688810 & 4.85 & 5.5376 & TRN & & & \\
\hline CHEMBL1307730 & 688810 & \multicolumn{3}{|c|}{5.632999999999999} & 5.1359 & TRN & \\
\hline CHEMBL1306666 & 688810 & 5.233 & 5.6265 & TRN & & & \\
\hline CHEMBL1431663 & 688810 & 5.183 & 5.4644 & TRN & & & \\
\hline CHEMBL1573025 & 688810 & \multicolumn{3}{|c|}{4.7330000000000005} & 5.0844 & TST & \\
\hline CHEMBL1413843 & 688810 & \multicolumn{3}{|c|}{5.2829999999999995} & 5.8444 & TRN & \\
\hline CHEMBL1545621 & 688810 & \multicolumn{3}{|c|}{5.2829999999999995} & 5.4443 & TRN & \\
\hline CHEMBL1317906 & 688810 & 5.083 & 5.7606 & TRN & & & \\
\hline CHEMBL1502389 & 688810 & \multicolumn{3}{|c|}{4.7330000000000005} & 5.1239 & TRN & \\
\hline CHEMBL1473495 & 688810 & 5.233 & 5.005 & TRN & & & \\
\hline CHEMBL1390836 & 688810 & \multicolumn{3}{|c|}{5.2829999999999995} & 5.1897 & TRN & \\
\hline CHEMBL1307081 & 688810 & 5.183 & 5.4249 & TRN & & & \\
\hline CHEMBL1383812 & 688810 & 4.7330 & 00000000 & 005 & 5.3066 & TST & \\
\hline CHEMBL1535828 & 688810 & 5.733 & 5.7681 & TRN & & & \\
\hline CHEMBL1385925 & 688810 & 4.683 & 5.5274 & TST & & & \\
\hline CHEMBL1531181 & 688810 & 4.633 & 5.074 & TRN & & & \\
\hline CHEMBL1534058 & 688810 & 4.883 & 4.8545 & TRN & & & \\
\hline CHEMBL1436048 & 688810 & 4.633 & 4.8677 & TST & & & \\
\hline
\end{tabular}




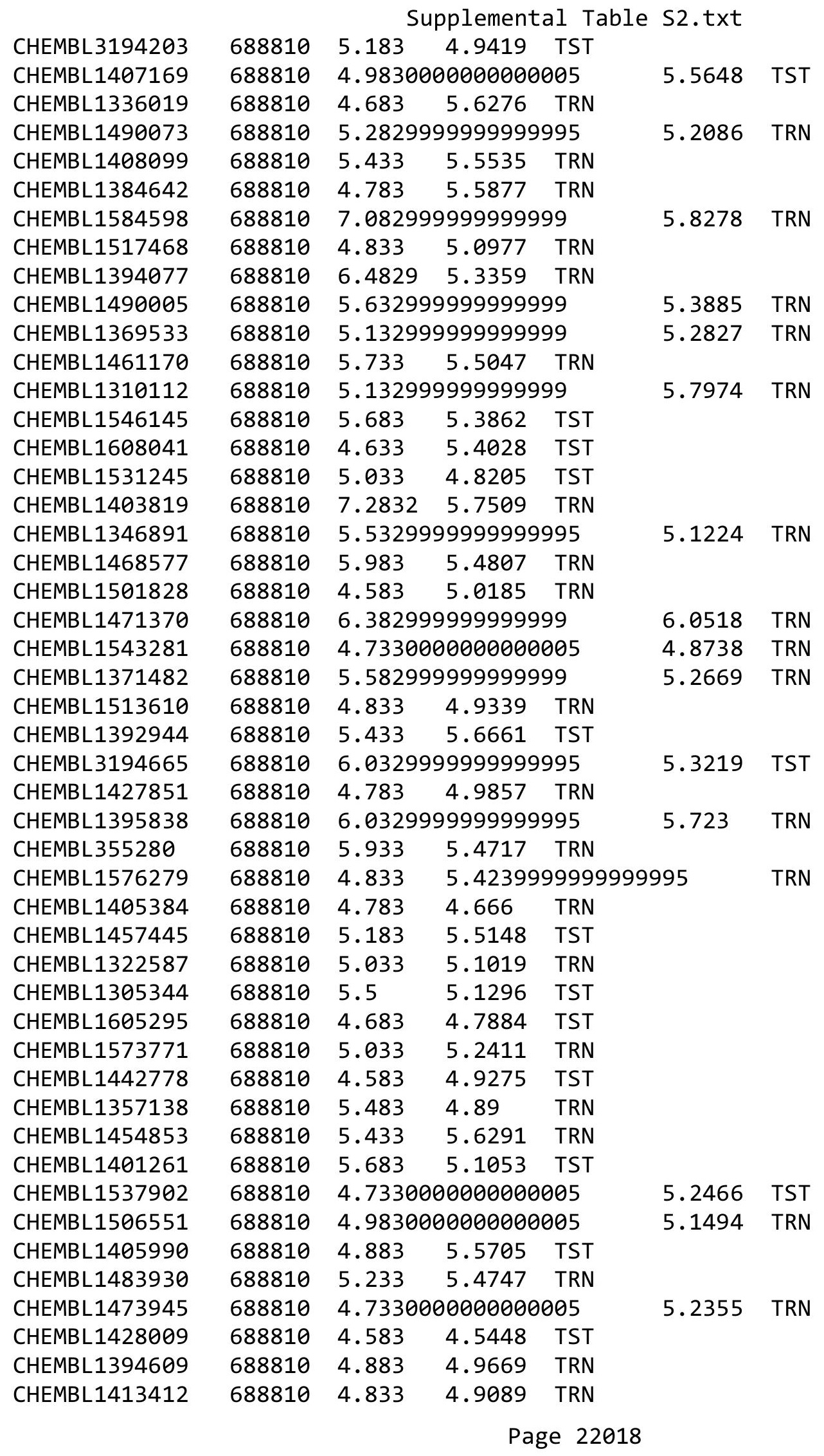




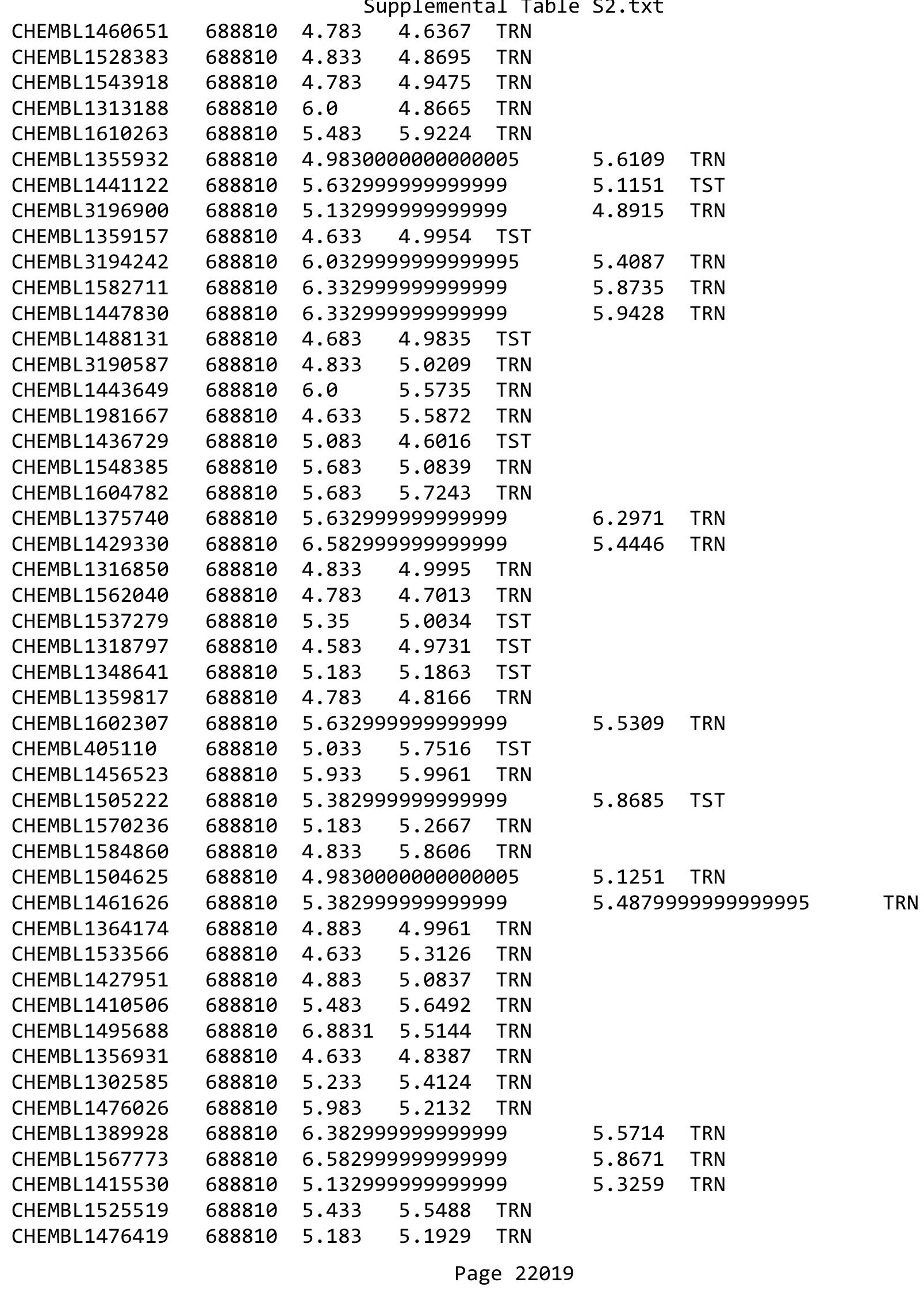




\begin{tabular}{|c|c|c|c|c|c|c|}
\hline \multirow[b]{2}{*}{ CHEMBL1321156 } & & \multicolumn{5}{|c|}{ Supplemental Table S2.txt } \\
\hline & 688810 & 5.983 & 5.3087 & TRN & & \\
\hline CHEMBL1454747 & 688810 & \multicolumn{3}{|c|}{6.082999999999999} & 5.6194 & 1 \\
\hline CHEMBL1320992 & 688810 & \multicolumn{3}{|c|}{5.2829999999999995} & 4.6713 & \\
\hline CHEMBL1516980 & 688810 & \multicolumn{3}{|c|}{4.7330000000000005} & 4.9258 & \\
\hline CHEMBL1539023 & 688810 & 4.783 & 5.1056 & TRN & & \\
\hline CHEMBL1490116 & 688810 & 5.183 & 5.1385 & TRN & & \\
\hline CHEMBL1450252 & 688810 & \multicolumn{3}{|c|}{4.7330000000000005} & 9407 & \\
\hline CHEMBL1569690 & 688810 & 6.0 & 5.706 & TRN & & \\
\hline CHEMBL3214351 & 688810 & \multirow{2}{*}{\multicolumn{3}{|c|}{$\begin{array}{lc}4.883 & 4.7258 \\
5.2829999999999995\end{array}$}} & & \\
\hline CHEMBL1390116 & 688810 & & & & 5.1468 & \\
\hline CHEMBL1411348 & 688810 & \multicolumn{3}{|c|}{$4.883 \quad 5.5322$ TRN } & & \\
\hline CHEMBL1434336 & 688810 & 4.833 & 5.3957 & TST & & \\
\hline CHEMBL1409629 & 688810 & \multicolumn{3}{|c|}{6.132999999999999} & 5.1811 & \\
\hline CHEMBL1589962 & 688810 & 5.183 & 5.5138 & TRN & & \\
\hline CHEMBL1323156 & 688810 & \multicolumn{3}{|c|}{4.7330000000000005} & 4.9864 & \\
\hline CHEMBL1590798 & 688810 & 4.633 & 4.8387 & TRN & & \\
\hline CHEMBL1366185 & 688810 & \multicolumn{3}{|c|}{4.9830000000000005} & 3877 & \\
\hline CHEMBL1383265 & 688810 & 5.233 & 5.1964 & TRN & & \\
\hline CHEMBL1 & 688810 & \multicolumn{3}{|c|}{4.7330000000000005} & 5.2063 & \\
\hline CHEMBL1364052 & 688810 & 5.933 & 4.9241 & TST & & \\
\hline CHEMBL1470997 & 688810 & \multicolumn{3}{|c|}{5.7829999999999995} & 417 & \\
\hline CHEMBL1995045 & 688810 & \multicolumn{3}{|c|}{6.132999999999999} & 5.3702 & \\
\hline CHEMBL1 & 688810 & 5.183 & 5.0019 & TRN & & \\
\hline CHEMBL1 & 688810 & \multicolumn{3}{|c|}{4.7330000000000005} & 0084 & \\
\hline CHEMBL1418493 & 688810 & \multicolumn{3}{|c|}{6.082999999999999} & 5.5946 & \\
\hline CHEMBL1530880 & 688810 & \multicolumn{3}{|c|}{5.382999999999999} & & \\
\hline CHEMBL 3192520 & 688810 & 4.783 & 5.2946 & TRN & & \\
\hline CHEMBL: & 688810 & \multicolumn{3}{|c|}{5.132999999999999} & 89 & IRIN \\
\hline CHEMBL1426866 & 688810 & \multicolumn{3}{|c|}{4.9830000000000005} & 42 & \\
\hline CHEMBL1584967 & 688810 & 4.633 & 4.9664 & TRN & & \\
\hline CHEMBL1550704 & 688810 & \multirow{2}{*}{\multicolumn{3}{|c|}{$\begin{array}{lll}6.4829 & 5.6641 & \text { TRN } \\
6.382999999999999\end{array}$}} & & \\
\hline CHEMBL1353561 & 688810 & & & & & I KIV \\
\hline CHEMBL1 & 688810 & \multicolumn{3}{|c|}{4.9830000000000005} & 4.6473 & \\
\hline CHEMBL3190453 & 688810 & 4.833 & 5.296 & TRN & & \\
\hline CHEMBL1547125 & 688810 & 5.083 & 5.3472 & TRN & & \\
\hline CHEMBL1332881 & 688810 & 4.883 & 5.2926 & TRN & & \\
\hline CHEMBL 1 & 688 & 5.433 & 5.3076 & TST & & \\
\hline CHEMBL1 & 688810 & $5.532 \mathrm{C}$ & 9999999 & 995 & 4.9087 & $\mathrm{TI}$ \\
\hline CHEMBL1406571 & 688810 & 6.233 & 5.3659 & TRN & & \\
\hline CHEMBL1506677 & 688810 & $5.132 \mathrm{c}$ & 9999999 & & & TP \\
\hline CHEMBL1558421 & 688810 & 5.2829 & 999999 & 995 & 4.6657 & $\mathrm{TI}$ \\
\hline CHEMBL1521736 & 688810 & 6.2829 & 9999999 & 995 & 5.5836 & \\
\hline CHEMBL1460252 & 688810 & 5.433 & 5.5866 & TST & & \\
\hline CHEMBL1308604 & 688810 & 4.783 & 4.8957 & TRN & & \\
\hline CHEMBL1320920 & 688810 & 5.683 & 5.3745 & TRN & & \\
\hline CHEMBL1560191 & 688810 & 5.5329 & 9999999 & 995 & 12 & $T$ \\
\hline CHEMBL3196123 & 688810 & $5.782 \mathrm{C}$ & 9999999 & 995 & 5.4538 & 110 \\
\hline CHEMBL1321646 & 688810 & $6.132 \mathrm{c}$ & 9999999 & & 5.1743 & \\
\hline & & & & & & \\
\hline
\end{tabular}




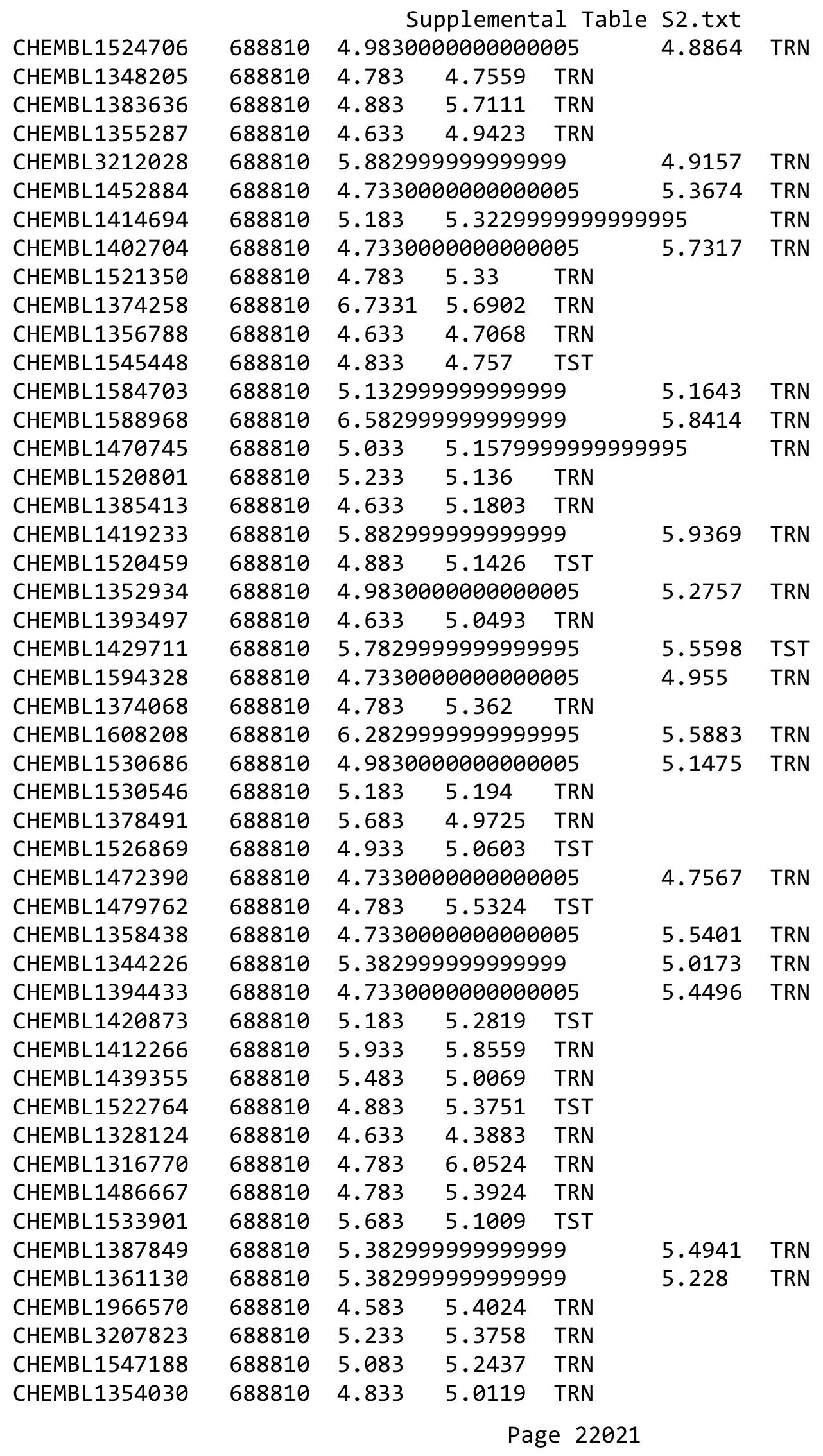




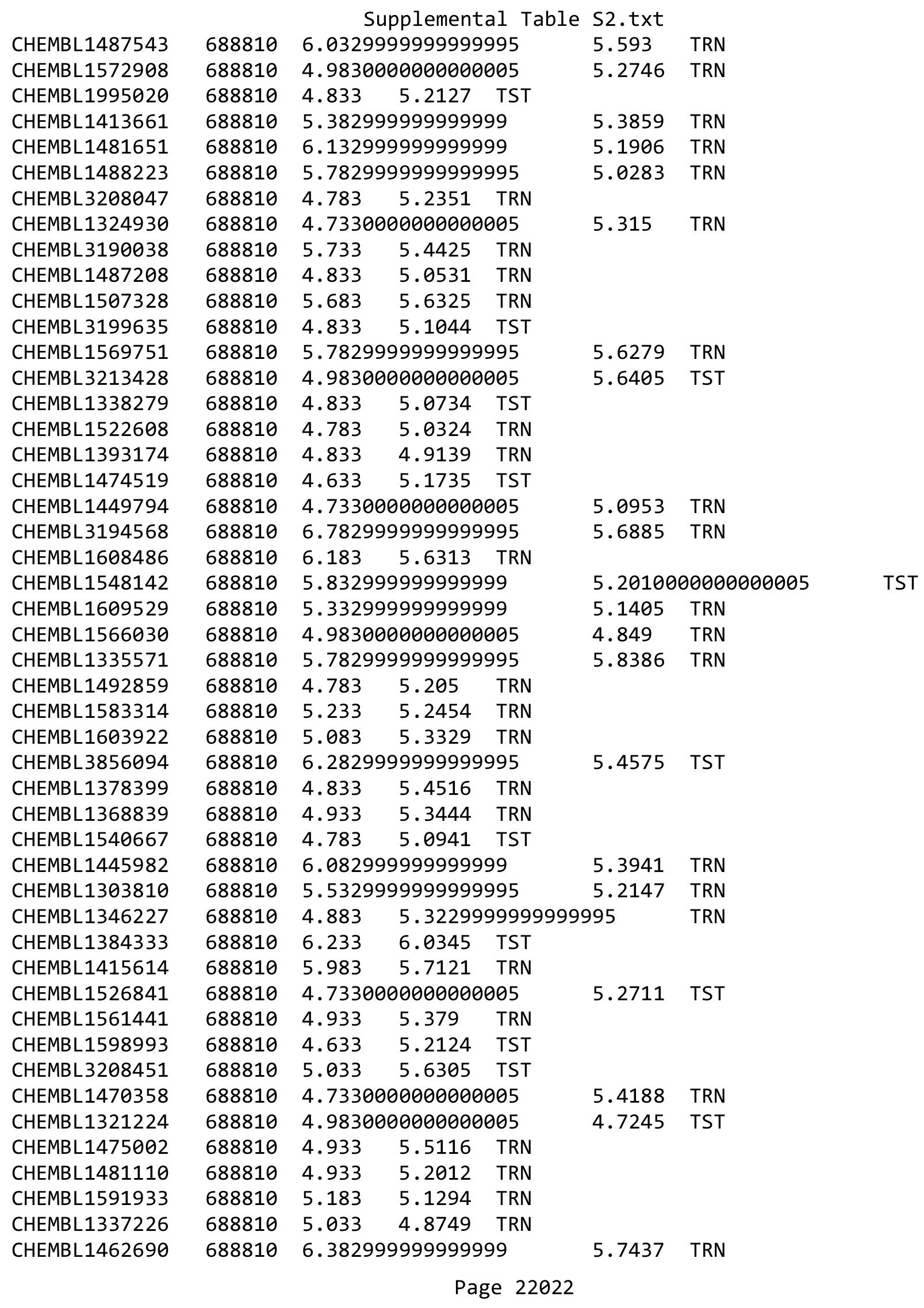




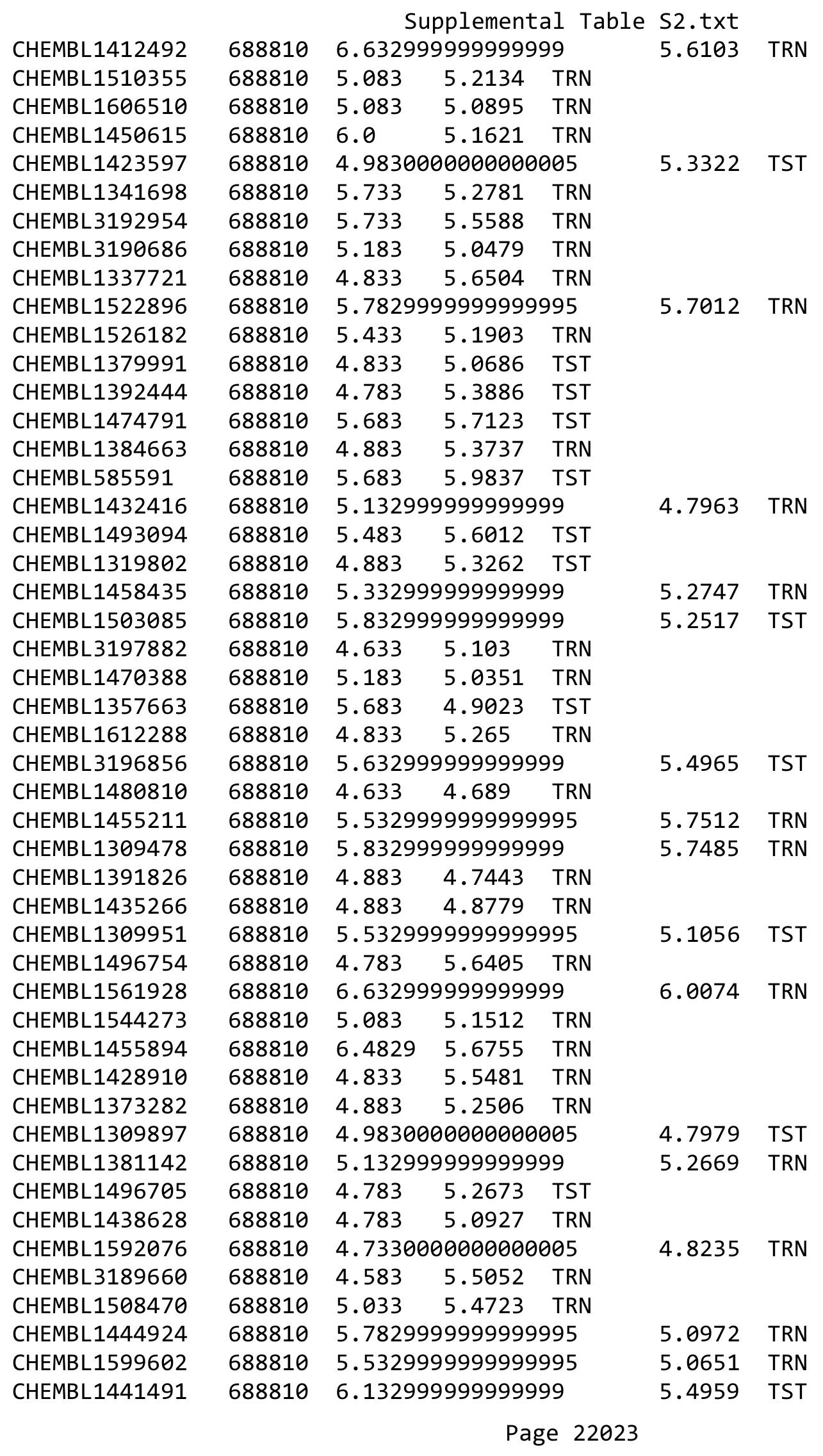




\begin{tabular}{|c|c|c|c|c|c|c|}
\hline \multirow[b]{2}{*}{ CHEMBL1368954 } & \multirow[b]{2}{*}{688810} & \multicolumn{5}{|c|}{ Supplemental Table S2.txt } \\
\hline & & 4.833 & 5.0717 & TRN & & \\
\hline CHEMBL1437602 & 688810 & \multicolumn{3}{|c|}{6.582999999999999} & 5.5053 & TRN \\
\hline CHEMBL1584235 & 688810 & 4.783 & 5.1852 & TRN & & \\
\hline CHEMBL1547557 & 688810 & 5.983 & 5.2423 & TRN & & \\
\hline CHEMBL 2002262 & 688810 & 4.583 & 5.3242 & TST & & \\
\hline CHEMBL1603760 & 688810 & 4.783 & 4.8324 & TRN & & \\
\hline CHEMBL3189267 & 688810 & \multicolumn{3}{|c|}{5.582999999999999} & 5.9204 & TRN \\
\hline CHEMBL1372535 & 688810 & \multicolumn{3}{|c|}{6.832999999999999} & 5.7462 & TRN \\
\hline CHEMBL1547166 & 688810 & \multicolumn{3}{|c|}{5.132999999999999} & 5.2301 & TRN \\
\hline CHEMBL1577759 & 688810 & \multicolumn{3}{|c|}{5.7829999999999995} & 4.9804 & TRN \\
\hline CHEMBL1347319 & 688810 & 4.95 & 4.8746 & TRN & & \\
\hline CHEMBL585502 & 688810 & \multicolumn{3}{|c|}{5.5329999999999995} & 5.8059 & TST \\
\hline CHEMBL496727 & 688810 & 6.683 & 5.3066 & TST & & \\
\hline CHEMBL1334622 & 688810 & \multirow{2}{*}{\multicolumn{3}{|c|}{$\begin{array}{ll}4.833 & 5.5727 \\
4.9830000000000005\end{array}$}} & & \\
\hline CHEMBL1478058 & 688810 & & & & 5.4314 & TRN \\
\hline CHEMBL1465999 & 688810 & 5.183 & 5.3588 & TRN & & \\
\hline CHEMBL1313907 & 688810 & 5.033 & 6.0331 & TRN & & \\
\hline CHEMBL1349291 & 688810 & \multicolumn{3}{|c|}{4.7330000000000005} & 4.9343 & TST \\
\hline CHEMBL1975988 & 688810 & \multicolumn{3}{|c|}{6.132999999999999} & 5.4195 & TST \\
\hline CHEMBL1385608 & 688810 & 4.633 & 5.4087 & TST & & \\
\hline CHEMBL1459468 & 688810 & \multicolumn{3}{|c|}{5.832999999999999} & 6.4196 & TRN \\
\hline CHEMBL1429226 & 688810 & 4.933 & 5.1157 & TRN & & \\
\hline CHEMBL1528792 & 688810 & 4.933 & 4.9742 & TRN & & \\
\hline CHEMBL1490787 & 688810 & 5.483 & 5.4595 & TRN & & \\
\hline CHEMBL1534506 & 688810 & 4.583 & 4.908 & TST & & \\
\hline CHEMBL1440197 & 688810 & 5.983 & 5.4711 & TRN & & \\
\hline CHEMBL1481793 & 688810 & \multicolumn{3}{|c|}{5.632999999999999} & 5.8957 & TRN \\
\hline CHEMBL1542806 & 688810 & \multicolumn{3}{|c|}{4.7330000000000005} & 5.5059 & TST \\
\hline CHEMBL1386853 & 688810 & 4.833 & 5.1474 & TRN & & \\
\hline CHEMBL1969293 & 688810 & \multicolumn{3}{|c|}{5.832999999999999} & 5.2635 & TRN \\
\hline CHEMBL1554125 & 688810 & 5.933 & 5.4695 & TRN & & \\
\hline CHEMBL3199416 & 688810 & 5.683 & 5.8708 & TST & & \\
\hline CHEMBL1570262 & 688810 & 6.9329 & 5.9509 & TRN & & \\
\hline CHEMBL588038 & 688810 & \multicolumn{3}{|c|}{5.2829999999999995} & 5.0783 & TST \\
\hline CHEMBL1335628 & 688810 & 6.05 & 5.0393 & TRN & & \\
\hline CHEMBL1309165 & 688810 & 5.483 & 5.5091 & TRN & & \\
\hline CHEMBL1417291 & 688810 & 4.783 & 4.9843 & TRN & & \\
\hline CHEMBL3193953 & 688810 & \multicolumn{3}{|c|}{4.7330000000000005} & 4.9442 & TRN \\
\hline CHEMBL1299411 & 688810 & 5.733 & 5.7541 & TRN & & \\
\hline CHEMBL1457581 & 688810 & 5.483 & 5.0191 & TST & & \\
\hline CHEMBL3192746 & 688810 & 4.883 & 4.9565 & TRN & & \\
\hline CHEMBL1506350 & 688810 & 5.183 & 4.9282 & TRN & & \\
\hline CHEMBL1601870 & 688810 & 5.183 & 5.065 & TRN & & \\
\hline CHEMBL1366594 & 688810 & 4.833 & 5.4819 & TST & & \\
\hline CHEMBL3194444 & 688810 & \multicolumn{3}{|c|}{5.5329999999999995} & 5.5322 & TRN \\
\hline CHEMBL1507676 & 688810 & 6.233 & 6.0675 & TRN & & \\
\hline CHEMBL1407228 & 688810 & 4.633 & 5.1684 & TST & & \\
\hline CHEMBL1404327 & 688810 & 7.1331 & 5.5848 & TRN & & \\
\hline
\end{tabular}




\begin{tabular}{|c|c|c|c|c|c|c|c|}
\hline \multicolumn{7}{|c|}{ Supplemental Table S2.txt } & \\
\hline CHEMBL1382924 & 688810 & \multicolumn{3}{|c|}{5.632999999999999} & 5.2773 & TRN & \\
\hline CHEMBL1341169 & 688810 & \multicolumn{3}{|c|}{5.5329999999999995} & 5.231 & TRN & \\
\hline CHEMBL1580737 & 688810 & 4.683 & 5.0121 & TST & & & \\
\hline CHEMBL1321809 & 688810 & 4.833 & 5.1992 & TRN & & & \\
\hline CHEMBL1583561 & 688810 & 5.183 & 5.4293 & TRN & & & \\
\hline CHEMBL1370884 & 688810 & \multicolumn{3}{|c|}{5.632999999999999} & 5.2582 & TST & \\
\hline CHEMBL1534814 & 688810 & 4.783 & 5.0079 & TRN & & & \\
\hline CHEMBL 3194285 & 688810 & 4.833 & 5.239 & TRN & & & \\
\hline CHEMBL 3214260 & 688810 & 4.933 & 5.3288 & TRN & & & \\
\hline CHEMBL1451121 & 688810 & 4.783 & 5.5888 & TRN & & & \\
\hline CHEMBL1476492 & 688810 & \multicolumn{3}{|c|}{5.132999999999999} & 4.8659 & TRN & \\
\hline CHEMBL1416804 & 688810 & 4.883 & 4.9974 & TST & & & \\
\hline CHEMBL1603013 & 688810 & 4.833 & 5.2836 & TRN & & & \\
\hline CHEMBL1442908 & 688810 & 4.583 & 4.7574 & TST & & & \\
\hline CHEMBL1588275 & 688810 & 4.683 & 5.2449 & TRN & & & \\
\hline CHEMBL1333952 & 688810 & 4.783 & 5.2293 & TST & & & \\
\hline CHEMBL1417724 & 688810 & 4.583 & \multicolumn{3}{|c|}{4.928999999999999} & TST & \\
\hline CHEMBL1352555 & 688810 & 4.633 & 5.2375 & TRN & & & \\
\hline CHEMBL1532550 & 688810 & \multicolumn{3}{|c|}{4.7330000000000005} & 5.0657 & TST & \\
\hline CHEMBL1475011 & 688810 & 4.783 & 5.4255 & TRN & & & \\
\hline CHEMBL 1487098 & 688810 & \multicolumn{3}{|c|}{5.832999999999999} & 5.0581 & TST & \\
\hline CHEMBL1387701 & 688810 & \multicolumn{3}{|c|}{5.132999999999999} & 4.8952 & TRN & \\
\hline CHEMBL1366672 & 688810 & \multicolumn{3}{|c|}{4.9830000000000005} & 4.9275 & TST & \\
\hline CHEMBL1430772 & 688810 & 4.583 & 5.0788 & TST & & & \\
\hline CHEMBL1602437 & 688810 & \multicolumn{3}{|c|}{6.082999999999999} & 5.7516 & TRN & \\
\hline CHEMBL573226 & 688810 & 4.683 & 5.3874 & TRN & & & \\
\hline CHEMBL1461688 & 688810 & 4.883 & 5.0272 & TST & & & \\
\hline CHEMBL1586171 & 688810 & 5.183 & 5.0424 & TRN & & & \\
\hline CHEMBL1422429 & 688810 & 5.933 & 5.9048 & TST & & & \\
\hline CHEMBL3194403 & 688810 & \multicolumn{3}{|c|}{5.382999999999999} & 5.2645 & TRN & \\
\hline CHEMBL1504239 & 688810 & \multicolumn{3}{|c|}{6.5329999999999995} & 5.5294 & TRN & \\
\hline CHEMBL1332882 & 688810 & \multicolumn{3}{|c|}{5.132999999999999} & 5.2488 & TST & \\
\hline CHEMBL1301188 & 688810 & 4.783 & 5.1838 & TRN & & & \\
\hline CHEMBL1463825 & 688810 & \multicolumn{3}{|c|}{5.7829999999999995} & 5.6451 & TRN & \\
\hline CHEMBL1465951 & 688810 & \multicolumn{3}{|c|}{4.7330000000000005} & 5.2829 & TST & \\
\hline CHEMBL1613033 & 688810 & 5.033 & 5.6748 & TRN & & & \\
\hline CHEMBL1334612 & 688810 & 5.433 & 5.8148 & TRN & & & \\
\hline CHEMBL1391694 & 688810 & \multicolumn{3}{|c|}{5.882999999999999} & 5.5429 & TRN & \\
\hline CHEMBL1432011 & 688810 & 5.033 & 5.4892 & TRN & & & \\
\hline CHEMBL1374108 & 688810 & \multicolumn{3}{|c|}{4.7330000000000005} & \multirow{2}{*}{\multicolumn{2}{|c|}{5.252000000000001}} & TST \\
\hline CHEMBL1352995 & 688810 & 4.583 & 5.3147 & TRN & & & \\
\hline CHEMBL1519414 & 688810 & 5.033 & 5.6468 & TRN & & & \\
\hline CHEMBL1330075 & 688810 & 4.883 & 4.8585 & TST & & & \\
\hline CHEMBL1305233 & 688810 & 7.1831 & 6.069 & TRN & & & \\
\hline CHEMBL1405292 & 688810 & 4.633 & 5.0271 & TRN & & & \\
\hline CHEMBL1585759 & 688810 & 5.983 & 5.5135 & TST & & & \\
\hline CHEMBL1559383 & 688810 & 4.633 & 4.9762 & TST & & & \\
\hline CHEMBL1414067 & 688810 & 5.3829 & 99999999 & & 5.6256 & TRN & \\
\hline
\end{tabular}




\begin{tabular}{|c|c|c|c|c|c|c|c|}
\hline \multicolumn{8}{|c|}{ Supplemental Table S2.txt } \\
\hline CHEMBL3211930 & 688810 & 5.683 & 5.4108 & TRN & & & \\
\hline CHEMBL1365841 & 688810 & 4.783 & 5.0784 & TST & & & \\
\hline CHEMBL1378420 & 688810 & \multicolumn{3}{|c|}{4.7330000000000005} & 4.8208 & TRN & \\
\hline CHEMBL1456023 & 688810 & 5.483 & 5.2939 & TRN & & & \\
\hline CHEMBL1537583 & 688810 & \multicolumn{3}{|c|}{5.132999999999999} & 5.3833 & TRN & \\
\hline CHEMBL1599640 & 688810 & 4.833 & 4.9719 & TRN & & & \\
\hline CHEMBL1554915 & 688810 & 5.183 & 5.1974 & TRN & & & \\
\hline CHEMBL1404522 & 688810 & 6.9329 & 5.5418 & TST & & & \\
\hline CHEMBL1527990 & 688810 & 4.833 & 5.2706 & TST & & & \\
\hline CHEMBL1506506 & 688810 & \multicolumn{3}{|c|}{6.332999999999999} & 5.6991 & TRN & \\
\hline CHEMBL1980103 & 688810 & \multicolumn{3}{|c|}{6.5329999999999995} & 5.9438 & TST & \\
\hline CHEMBL1492608 & 688810 & 5.433 & 5.4648 & TRN & & & \\
\hline CHEMBL1397116 & 688810 & 4.633 & 4.9778 & TRN & & & \\
\hline CHEMBL1419938 & 688810 & \multicolumn{3}{|c|}{6.382999999999999} & 5.1238 & TRN & \\
\hline CHEMBL1496052 & 688810 & 4.783 & 5.0619 & TRN & & & \\
\hline CHEMBL1339671 & 688810 & 6.0 & 5.654 & TRN & & & \\
\hline CHEMBL3196057 & 688810 & 5.683 & 5.2847 & TRN & & & \\
\hline CHEMBL1602164 & 688810 & 5.183 & 4.7704 & TRN & & & \\
\hline CHEMBL1514677 & 688810 & 7.3325 & 5.7365 & TRN & & & \\
\hline CHEMBL1550649 & 688810 & 4.783 & 5.1313 & TRN & & & \\
\hline CHEMBL1343033 & 688810 & 4.833 & 4.9545 & TRN & & & \\
\hline CHEMBL3194075 & 688810 & \multicolumn{3}{|c|}{5.632999999999999} & 5.3922 & TRN & \\
\hline CHEMBL1414577 & 688810 & \multicolumn{3}{|c|}{5.882999999999999} & 5.5382 & TRN & \\
\hline CHEMBL1577922 & 688810 & \multicolumn{3}{|c|}{5.632999999999999} & 5.55200 & 00000000005 & TRN \\
\hline CHEMBL1539863 & 688810 & \multicolumn{3}{|c|}{5.882999999999999} & 5.1879 & TRN & \\
\hline CHEMBL1596626 & 688810 & 4.783 & 5.2757 & TRN & & & \\
\hline CHEMBL1320589 & 688810 & 5.483 & 4.9492 & TRN & & & \\
\hline CHEMBL1444136 & 688810 & \multicolumn{3}{|c|}{5.632999999999999} & 5.4809 & TRN & \\
\hline CHEMBL1498014 & 688810 & 5.183 & 5.0726 & TRN & & & \\
\hline CHEMBL1468275 & 688810 & \multicolumn{3}{|c|}{5.332999999999999} & 5.4107 & TRN & \\
\hline CHEMBL1310722 & 688810 & \multicolumn{3}{|c|}{4.9830000000000005} & 5.2947 & TRN & \\
\hline CHEMBL1413491 & 688810 & 4.633 & 4.8535 & TRN & & & \\
\hline CHEMBL1333504 & 688810 & 5.683 & 5.4349 & TST & & & \\
\hline CHEMBL3192669 & 688810 & 4.833 & 5.0099 & TRN & & & \\
\hline CHEMBL1497410 & 688810 & 5.733 & 5.3123 & TST & & & \\
\hline CHEMBL3192394 & 688810 & \multicolumn{3}{|c|}{5.382999999999999} & 5.1115 & TRN & \\
\hline CHEMBL1392479 & 688810 & \multicolumn{3}{|c|}{4.9830000000000005} & 4.8517 & TRN & \\
\hline CHEMBL1590628 & 688810 & 4.583 & 4.8348 & TRN & & & \\
\hline CHEMBL1371882 & 688810 & 5.733 & 5.0755 & TRN & & & \\
\hline CHEMBL1580286 & 688810 & \multicolumn{3}{|c|}{4.7330000000000005} & 4.8237 & TRN & \\
\hline CHEMBL1415148 & 688810 & \multicolumn{3}{|c|}{5.632999999999999} & 5.20799 & 9999999999 & TST \\
\hline CHEMBL1532940 & 688810 & 5.083 & 4.9745 & TRN & & & \\
\hline CHEMBL1606984 & 688810 & \multirow{2}{*}{\multicolumn{3}{|c|}{$\begin{array}{l}5.435 \\
5.7829999999999995\end{array}$}} & & & \\
\hline CHEMBL601119 & 688810 & & & & 5.3425 & TRN & \\
\hline CHEMBL1973328 & 688810 & 4.833 & 5.3687 & TRN & & & \\
\hline CHEMBL1523621 & 688810 & \multicolumn{3}{|c|}{4.9830000000000005} & 4.8015 & TST & \\
\hline CHEMBL3210944 & 688810 & \multicolumn{3}{|c|}{4.9830000000000005} & 4.8397 & TRN & \\
\hline CHEMBL1536647 & 688810 & \multicolumn{3}{|c|}{5.832999999999999} & 5.6047 & TRN & \\
\hline
\end{tabular}




\begin{tabular}{|c|c|c|c|c|c|c|}
\hline CHEMBL1347251 & 688810 & 5.433 & 4.9481 & TRN & & \\
\hline CHEMBL1353226 & 688810 & \multicolumn{3}{|c|}{5.5329999999999995} & 5.4756 & \\
\hline CHEMBL1525220 & 688810 & 5.433 & 5.404 & TRN & & \\
\hline CHEMBL1544991 & 588810 & 4.833 & 5.1296 & TRN & & \\
\hline CHEMBL1587263 & 588810 & \multicolumn{3}{|c|}{5.582999999999999} & 5.6831 & \\
\hline CHEMBL1350077 & 688810 & \multicolumn{3}{|c|}{5.132999999999999} & 5.2405 & \\
\hline CHEMBL1969300 & 688810 & 4.633 & 5.4499 & TST & & \\
\hline CHEMBL1508499 & 688810 & \multicolumn{3}{|c|}{4.7330000000000005} & 5.0525 & \\
\hline CHEMBL1598233 & 688810 & \multicolumn{3}{|c|}{5.582999999999999} & 5.6401 & \\
\hline CHEMBL1407577 & 688810 & 5.683 & 5.7267 & TRN & & \\
\hline CHEMBL 3195199 & 688810 & \multicolumn{3}{|c|}{5.5329999999999995} & 5.461 & \\
\hline CHEMBL3197908 & 688810 & \multicolumn{3}{|c|}{4.9830000000000005} & 5.3706 & \\
\hline CHEMBL1329399 & 688810 & 4.833 & 5.0306 & TRN & & \\
\hline CHEMBL1341879 & 688810 & \multicolumn{3}{|c|}{6.2829999999999995} & 972 & \\
\hline CHEMBL1314741 & 688810 & 4.583 & 5.2804 & TRN & & \\
\hline CHEMBL1372159 & 688810 & \multicolumn{3}{|c|}{5.832999999999999} & 5. & \\
\hline CHEMBL1454799 & 688810 & 4.883 & 5.4635 & TRN & & \\
\hline CHEMBL1547792 & 688810 & \multicolumn{3}{|c|}{6.332999999999999} & 6.195 & \\
\hline CHEMBL1444539 & 688810 & 4.683 & 4.864 & TRN & & \\
\hline CHEMBL1383757 & 688810 & \multicolumn{3}{|c|}{4.9830000000000005} & & \\
\hline CHEMBL1588181 & 688810 & \multicolumn{3}{|c|}{5.5329999999999995} & & \\
\hline CHEMBL1475976 & 688810 & 4.883 & 4.8743 & TRN & & \\
\hline CHEMBL 3211699 & 688810 & 5.483 & 5.6756 & TST & & \\
\hline CHEMBL1514837 & 688810 & 4.633 & 5.0575 & TRN & & \\
\hline CHEMBL1533473 & 688810 & 5.083 & 5.2349 & TRN & & \\
\hline CHEMBL1583911 & 688810 & 4.883 & 5.3113 & TRN & & \\
\hline CHEMBL1485763 & 688810 & 4.583 & 5.5607 & TRN & & \\
\hline CHEMBL1573577 & 688810 & \multicolumn{3}{|c|}{5.2829999999999995} & 5.166 & \\
\hline CHEMBL1562575 & 688810 & 6.4829 & 6.4707 & TRN & & \\
\hline CHEMBL1607529 & 688810 & \multicolumn{3}{|c|}{4.9830000000000005} & 5.2437 & \\
\hline CHEMBL1529521 & 688810 & 5.733 & 5.7532 & TRN & & \\
\hline CHEMBL1593141 & 688810 & \multicolumn{3}{|c|}{6.582999999999999} & 5.6899 & \\
\hline CHEMBL1344238 & 688810 & \multicolumn{3}{|c|}{5.632999999999999} & 5.6701 & \\
\hline CHEMBL1606867 & 688810 & 4.583 & 4.6649 & TRN & & \\
\hline CHEMBL1432746 & 688810 & \multicolumn{3}{|c|}{4.7330000000000005} & 4.8363 & \\
\hline CHEMBL1530600 & 688810 & 4.883 & 4.7682 & TRN & & \\
\hline CHEMBL1478925 & 688810 & \multicolumn{3}{|c|}{5.332999999999999} & & \\
\hline CHEMBL1456623 & 688810 & \multicolumn{3}{|c|}{5.582999999999999} & 4.6724 & \\
\hline CHEMBL1399757 & 688810 & 4.783 & 5.1592 & TST & & \\
\hline CHEMBL1341278 & 688810 & \multicolumn{3}{|c|}{4.7330000000000005} & 5.5015 & \\
\hline CHEMBL1337753 & 688810 & 5.083 & 5.0035 & TRN & & \\
\hline CHEMBL1334717 & 688810 & 5.083 & 5.1393 & TRN & & \\
\hline CHEMBL1546321 & 688810 & 5.683 & 5.4201 & TRN & & \\
\hline CHEMBL1585607 & 688810 & 5.433 & 5.1066 & TRN & & \\
\hline CHEMBL1361702 & 688810 & 4.783 & 5.7543 & TRN & & \\
\hline CHEMBL1580834 & 688810 & 4.833 & 4.9622 & TRN & & \\
\hline CHEMBL1324885 & 688810 & \multicolumn{3}{|c|}{6.0329999999999995} & 5.1177 & \\
\hline CHEMBL1608066 & 688810 & 5.933 & 5.3904 & TRN & & \\
\hline
\end{tabular}




\begin{tabular}{|c|c|c|c|c|c|c|c|}
\hline & & & pplemen & l Table & s2.txt & & \\
\hline CHEMBL1559053 & 688810 & 5.13299 & 99999999 & & 5.2084 & TST & \\
\hline CHEMBL1301891 & 688810 & 4.933 & 5.2346 & TST & & & \\
\hline CHEMBL1306638 & 688810 & 6.8831 & 6.0359 & TRN & & & \\
\hline CHEMBL1393419 & 688810 & 4.583 & 5.0875 & TST & & & \\
\hline CHEMBL1418105 & 688810 & 4.73300 & 20000000 & 005 & 5.29799 & 9999999999 & TST \\
\hline CHEMBL1430255 & 688810 & 5.28299 & 99999999 & 995 & 5.1548 & TST & \\
\hline CHEMBL1488897 & 688810 & 5.13299 & 99999999 & & 5.5705 & TRN & \\
\hline CHEMBL1598631 & 688810 & 5.233 & 5.2933 & TST & & & \\
\hline CHEMBL1561133 & 688810 & 4.633 & 4.7152 & TST & & & \\
\hline CHEMBL1339289 & 688810 & 6.183 & 5.5904 & TST & & & \\
\hline CHEMBL1340682 & 688810 & 5.83299 & 99999999 & & 5.7743 & TRN & \\
\hline CHEMBL1591740 & 688810 & 5.53299 & 99999999 & 995 & 5.7733 & TRN & \\
\hline CHEMBL1422014 & 688810 & 5.53299 & 99999999 & 995 & 5.3386 & TRN & \\
\hline CHEMBL1303887 & 688810 & 5.78299 & 99999999 & 995 & 5.3715 & TST & \\
\hline CHEMBL1397171 & 688810 & 5.183 & 5.7278 & TRN & & & \\
\hline CHEMBL1372398 & 688810 & 4.73300 & 00000000 & 005 & 4.4599 & TST & \\
\hline CHEMBL1510092 & 688810 & 4.73300 & 20000000 & 005 & 5.0627 & TRN & \\
\hline CHEMBL1319565 & 688810 & 4.73300 & 20000000 & 005 & 5.4939 & TST & \\
\hline CHEMBL1338533 & 688810 & 6.28299 & 99999999 & 995 & 5.1896 & TRN & \\
\hline CHEMBL3212394 & 688810 & 4.833 & 5.1034 & TST & & & \\
\hline CHEMBL1406456 & 688810 & 4.933 & 5.6898 & TRN & & & \\
\hline CHEMBL1549208 & 688810 & 6.83299 & 99999999 & & 6.3059 & TRN & \\
\hline CHEMBL1375970 & 688810 & 4.583 & 4.5666 & TRN & & & \\
\hline CHEMBL1441538 & 688810 & 5.683 & 5.1879 & TRN & & & \\
\hline CHEMBL1391563 & 688810 & 5.78299 & 99999999 & 995 & 5.6454 & TRN & \\
\hline CHEMBL1565394 & 688810 & 5.933 & 6.1526 & TRN & & & \\
\hline CHEMBL1466963 & 688810 & 5.183 & 5.291 & TRN & & & \\
\hline CHEMBL1338322 & 688810 & 4.783 & 5.0946 & TRN & & & \\
\hline CHEMBL1384408 & 688810 & 4.73300 & 00000000 & 005 & 5.2614 & TRN & \\
\hline CHEMBL 3194193 & 688810 & 4.833 & 5.1603 & TRN & & & \\
\hline CHEMBL1313411 & 688810 & 5.733 & 5.2752 & TRN & & & \\
\hline CHEMBL1519611 & 688810 & 4.783 & 5.0889 & TRN & & & \\
\hline CHEMBL1376016 & 688810 & 4.783 & 4.8376 & TST & & & \\
\hline CHEMBL1535908 & 688810 & 4.683 & 4.6788 & TRN & & & \\
\hline CHEMBL1394116 & 688810 & 4.833 & 4.9937 & TRN & & & \\
\hline CHEMBL1611658 & 688810 & 4.833 & 4.8791 & TST & & & \\
\hline CHEMBL1347392 & 688810 & 5.933 & 5.5027 & TRN & & & \\
\hline CHEMBL 3199580 & 688810 & 5.83299 & 99999999 & & 5.8395 & TRN & \\
\hline CHEMBL1554119 & 688810 & 4.783 & 4.9314 & TRN & & & \\
\hline CHEMBL 3209378 & 688810 & 5.83299 & 99999999 & & 5.3257 & TRN & \\
\hline CHEMBL1351979 & 688810 & 4.73300 & 00000000 & 005 & 5.6701 & TRN & \\
\hline CHEMBL1575435 & 688810 & 5.483 & 5.25299 & 999999999 & & TRN & \\
\hline CHEMBL1410439 & 688810 & 6.233 & 5.3328 & TRN & & & \\
\hline CHEMBL1606826 & 688810 & 4.73300 & 00000000 & 005 & 5.1567 & TRN & \\
\hline CHEMBL 2001381 & 688810 & 4.73300 & 00000000 & 005 & 5.42299 & 9999999999 & RN \\
\hline CHEMBL 3194247 & 688810 & 5.733 & 5.6815 & TRN & & & \\
\hline CHEMBL1364512 & 688810 & 5.53299 & 99999999 & 995 & 5.3174 & TST & \\
\hline CHEMBL1429010 & 688810 & 4.783 & 5.3364 & TST & & & \\
\hline
\end{tabular}




\begin{tabular}{|c|c|c|c|c|c|c|}
\hline & \multicolumn{5}{|c|}{1 lable $\mathrm{S} 2 . \mathrm{t}$} \\
\hline CHEMBL1533549 & 688810 & 4.883 & 5.3971 & TRN & & \\
\hline CHEMBL1337240 & 688810 & \multicolumn{3}{|c|}{4.7330000000000005} & 5.4179 & TST \\
\hline CHEMBL1387436 & 688810 & 5.433 & 6.3376 & TRN & & \\
\hline CHEMBL1310737 & 688810 & 4.783 & 5.3656 & TRN & & \\
\hline CHEMBL1472350 & 688810 & 4.833 & 5.2169 & TST & & \\
\hline CHEMBL1349331 & 688810 & 5.733 & 5.3167 & TST & & \\
\hline CHEMBL1450676 & 688810 & \multicolumn{3}{|c|}{6.632999999999999} & 5.564 & $\mathrm{Tr}$ \\
\hline CHEMBL1548896 & 688810 & \multicolumn{3}{|c|}{5.132999999999999} & 5.2174 & \\
\hline CHEMBL1405830 & 688810 & 5.433 & 5.5543 & TRN & & \\
\hline CHEMBL1361147 & 688810 & 5.233 & 4.8604 & TRN & & \\
\hline CHEMBL1410454 & 688810 & \multicolumn{3}{|c|}{6.382999999999999} & 5.3157 & \\
\hline CHEMBL1488838 & 688810 & \multicolumn{3}{|c|}{5.132999999999999} & 5.0626 & \\
\hline CHEMBL1529024 & 688810 & 5.183 & 5.3565 & TRN & & \\
\hline CHEMBL1609599 & 688810 & \multicolumn{3}{|c|}{5.2829999999999995} & 5.3073 & \\
\hline CHEMBL1601731 & 688810 & 5.483 & 5.3522 & TRN & & \\
\hline CHEMBL1315150 & 688810 & 4.783 & 4.8111 & TRN & & \\
\hline CHEMBL1375658 & 688810 & \multicolumn{3}{|c|}{5.5329999999999995} & 5.6413 & \\
\hline CHEMBL1499544 & 688810 & 4.833 & 4.832 & TST & & \\
\hline CHEMBL1532511 & 688810 & 5.033 & 4.9794 & TRN & & \\
\hline CHEMBL1409488 & 688810 & 6.233 & 5.6734 & TRN & & \\
\hline CHEMBL1309549 & 688810 & 4.833 & 5.2185 & TRN & & \\
\hline CHEMBL1443564 & 688810 & 5.433 & 5.1515 & TRN & & \\
\hline CHEMBL1543446 & 688810 & 5.033 & 5.1965 & TRN & & \\
\hline CHEMBL1968322 & 688810 & 5.033 & 5.2368 & TRN & & \\
\hline CHEMBL1398258 & 688810 & 4.583 & 4.7797 & TRN & & \\
\hline CHEMBL1554207 & 688810 & 4.933 & 4.96 & TST & & \\
\hline CHEMBL1509413 & 688810 & 4.883 & 4.9328 & TST & & \\
\hline CHEMBL1317164 & 688810 & 4.833 & 4.9133 & TRN & & \\
\hline CHEMBL1439782 & 688810 & \multicolumn{3}{|c|}{5.132999999999999} & 5.6408 & \\
\hline CHEMBL1380537 & 688810 & 5.683 & 5.3284 & TRN & & \\
\hline CHEMBL1534561 & 688810 & \multicolumn{3}{|c|}{5.5329999999999995} & 5.7859 & \\
\hline CHEMBL1547191 & 688810 & 4.783 & 5.4807 & TRN & & \\
\hline CHEMBL1517387 & 688810 & 6.4829 & 5.9502 & TRN & & \\
\hline CHEMBL1489687 & 688810 & 6.0 & 5.7374 & TST & & \\
\hline CHEMBL1601364 & 688810 & \multicolumn{3}{|c|}{6.332999999999999} & 5.5941 & I RIN \\
\hline CHEMBL1531308 & 688810 & \multicolumn{3}{|c|}{5.132999999999999} & 5.2837 & \\
\hline CHEMBL1595695 & 688810 & 4.833 & 5.2155 & TRN & & \\
\hline CHEMBL 2001024 & 688810 & \multicolumn{3}{|c|}{5.2829999999999995} & 5.0922 & \\
\hline CHEMBL 1459140 & 688810 & 6.0 & 4.8967 & TRN & & \\
\hline CHEMBL 3189237 & 688810 & 4.683 & 4.9213 & TRN & & \\
\hline CHEMBL1354343 & 688810 & 4.783 & 5.0888 & TST & & \\
\hline CHEMBL1550386 & 688810 & 5.983 & 6.0999 & TRN & & \\
\hline CHEMBL1314857 & 688810 & 5.183 & 5.0808 & TRN & & \\
\hline CHEMBL1406081 & 688810 & \multicolumn{3}{|c|}{5.7829999999999995} & 5.5452 & \\
\hline CHEMBL1300188 & 688810 & 4.683 & 4.9601 & TRN & & \\
\hline CHEMBL1870966 & 688810 & 5.433 & 5.609 & TRN & & \\
\hline CHEMBL1576665 & 688810 & 4.683 & \multicolumn{3}{|c|}{5.207000000000001} & \\
\hline CHEMBL1390579 & 688810 & 4.783 & 5.1268 & TST & & \\
\hline
\end{tabular}




\begin{tabular}{|c|c|c|c|c|c|c|}
\hline \multirow[b]{2}{*}{ CHEMBL1456373 } & \multirow{2}{*}{688810} & \\
\hline & & \multirow{2}{*}{\multicolumn{3}{|c|}{$\begin{array}{lcc}4.583 & 4.9841 & \text { TST } \\
4.7330000000000005\end{array}$}} & & \\
\hline CHEMBL1413805 & 688810 & & & & 5.0321 & TR \\
\hline CHEMBL1376270 & 688810 & \multicolumn{3}{|c|}{5.582999999999999} & 5.801 & \\
\hline CHEMBL1375990 & 688810 & \multicolumn{3}{|c|}{5.132999999999999} & 4.9466 & \\
\hline CHEMBL1337714 & 688810 & \multicolumn{3}{|c|}{4.7330000000000005} & 5.0506 & \\
\hline CHEMBL1354245 & 688810 & \multicolumn{3}{|c|}{5.2829999999999995} & 5.268 & \\
\hline CHEMBL1332739 & 688810 & \multicolumn{3}{|c|}{4.7330000000000005} & 5.4588 & \\
\hline CHEMBL1497391 & 688810 & 6.433 & 5.7624 & TST & & \\
\hline CHEMBL1505703 & 688810 & \multicolumn{3}{|c|}{5.7829999999999995} & 5.5095 & \\
\hline CHEMBL1546450 & 688810 & \multicolumn{3}{|c|}{5.332999999999999} & 5.1948 & \\
\hline CHEMBL1347686 & 688810 & \multicolumn{3}{|c|}{5.582999999999999} & 5.6589 & \\
\hline CHEMBL1403363 & 688810 & 5.183 & 4.7842 & TRN & & \\
\hline CHEMBL1313719 & 688810 & \multicolumn{3}{|c|}{5.632999999999999} & 5.38 & \\
\hline CHEMBL1459630 & 688810 & 4.833 & 5.1439 & TRN & & \\
\hline CHEMBL1380764 & 688810 & 4.833 & 5.3246 & TRN & & \\
\hline CHEMBL1581016 & 688810 & \multicolumn{3}{|c|}{4.7330000000000005} & 5.4767 & \\
\hline CHEMBL15 & 688810 & \multicolumn{3}{|c|}{4.7330000000000005} & 5.1531 & \\
\hline CHEMBL1414704 & 688810 & 4.783 & 4.7417 & TST & & \\
\hline CHEMBL1483803 & 688810 & 4.633 & 5.3316 & TST & & \\
\hline CHEMBL1557315 & 688810 & \multicolumn{3}{|c|}{5.632999999999999} & 5.6631 & \\
\hline CHEMBL13 & 688810 & 4.633 & 4.713 & TST & & \\
\hline CHEMBL1555832 & 688810 & 4.833 & 4.9831 & TRN & & \\
\hline CHEMBL1575640 & 688810 & 4.783 & 5.1818 & TRN & & \\
\hline CHEMBL1511516 & 688810 & \multicolumn{3}{|c|}{4.7330000000000005} & 5.2095 & \\
\hline CHEMBL3196665 & 688810 & \multicolumn{3}{|c|}{5.882999999999999} & 5.3626 & \\
\hline CHEMBL13 & 688810 & 5.033 & 5.1909 & TST & & \\
\hline CHEMBL14 & 688810 & 4.883 & 4.9462 & TST & & \\
\hline CHEMBL1488385 & 688810 & 5.033 & 4.7834 & TRN & & \\
\hline CHEMBL3196515 & 688810 & 5.083 & 5.2293 & TST & & \\
\hline CHEMBL1556379 & 688810 & 4.783 & \multicolumn{3}{|c|}{5.3229999999999995} & \\
\hline CHEMBL1325267 & 688810 & 5.433 & 5.4718 & TRN & & \\
\hline CHEMBL1551502 & 688810 & 7.1331 & 5.8098 & TRN & & \\
\hline CHEMBL1577680 & 688810 & \multicolumn{3}{|c|}{6.2829999999999995} & 5.4311 & \\
\hline CHEMBL1358676 & 688810 & 4.633 & 4.9175 & TST & & \\
\hline CHEMBL1520989 & 688810 & 4.783 & 5.234 & TRN & & \\
\hline CHEMBL1516066 & 688810 & 7.2328 & 5.6112 & TRN & & \\
\hline CHEMBL1444379 & 688810 & 4.783 & 4.9319 & TRN & & \\
\hline CHEMBL1451559 & 688810 & \multicolumn{3}{|c|}{6.5329999999999995} & 5.9012 & \\
\hline CHEMBL1332275 & 688810 & 4.933 & 5.1381 & TRN & & \\
\hline CHEMBL1507474 & 688810 & 6.183 & 5.3279 & TRN & & \\
\hline CHEMBL1603821 & 688810 & 5.033 & 5.3672 & TRN & & \\
\hline CHEMBL259588 & 688810 & 4.783 & 5.5407 & TRN & & \\
\hline CHEMBL1497717 & 688810 & 4.633 & 4.9598 & TRN & & \\
\hline CHEMBL1531270 & 688810 & 4.73300 & 000000000 & 005 & 5.1042 & \\
\hline CHEMBL1477845 & 688810 & 4.883 & 4.9401 & TST & & \\
\hline CHEMBL1392887 & 688810 & 4.783 & 5.2341 & TRN & & \\
\hline CHEMBL3210972 & 688810 & 5.83299 & 999999999 & & 5.2319 & $1 \mathrm{KI}$ \\
\hline CHEMBL1535706 & 688810 & 4.783 & 5.2016 & TST & & \\
\hline
\end{tabular}




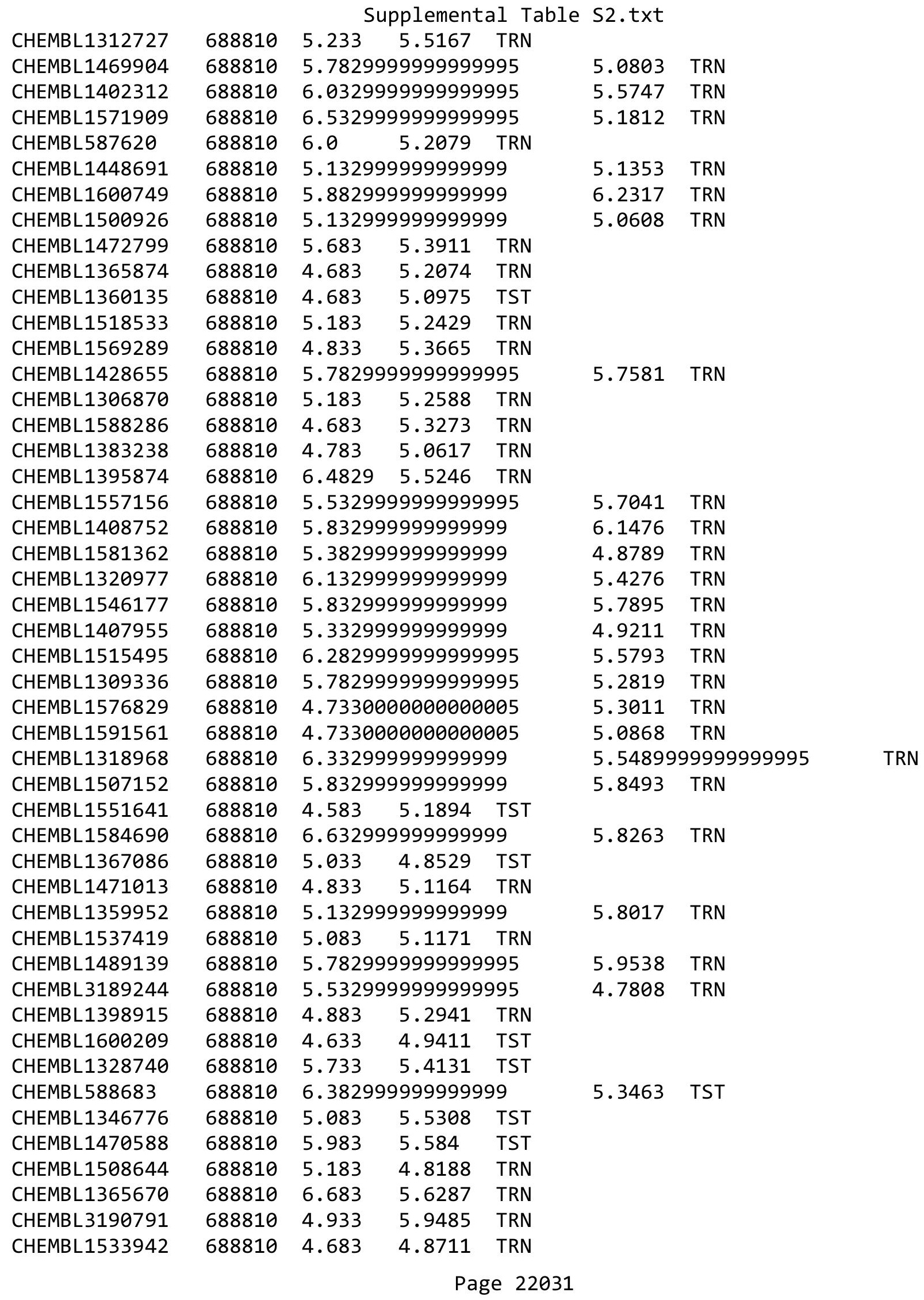




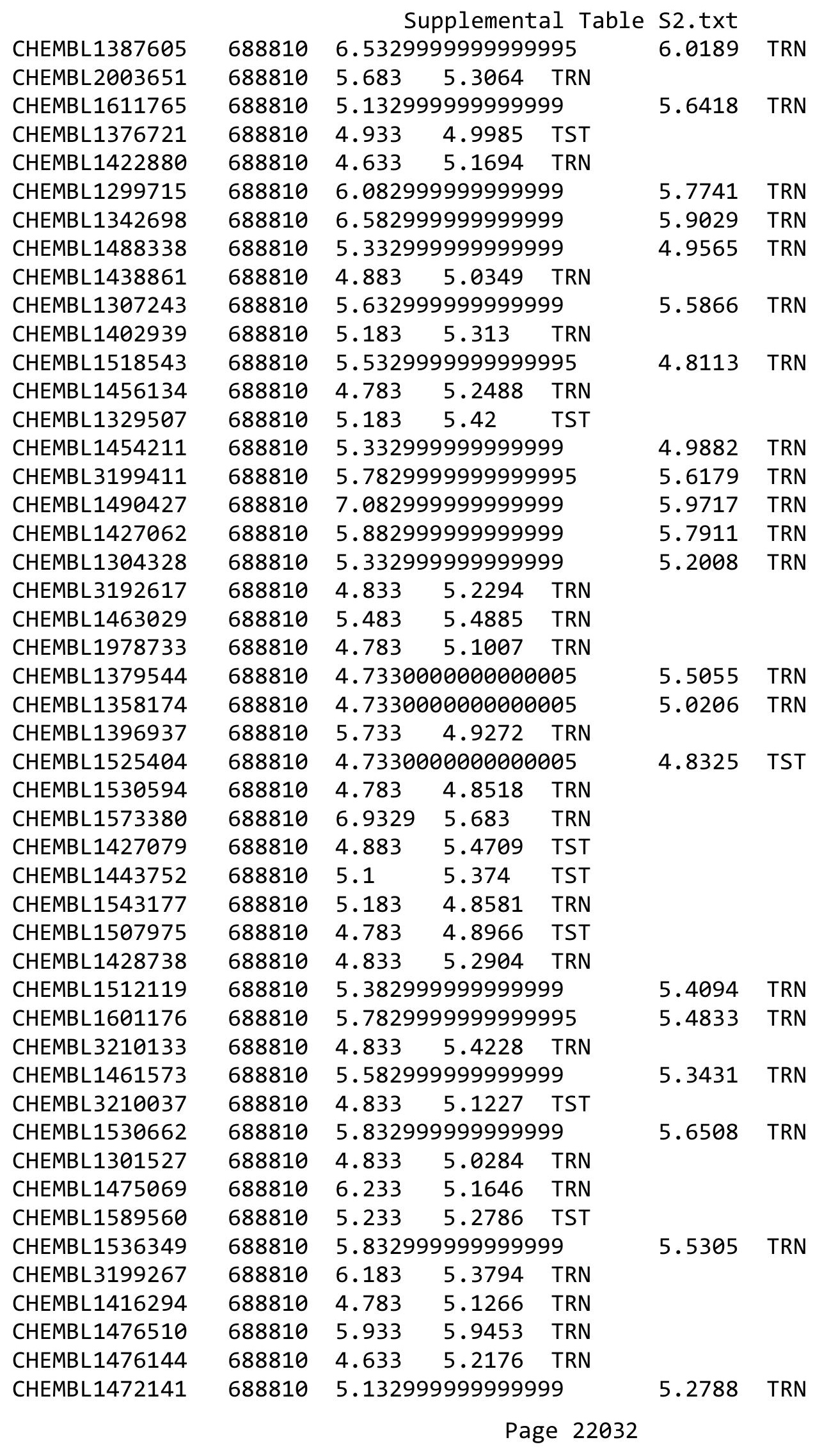




\begin{tabular}{|c|c|c|c|c|c|c|c|}
\hline \multicolumn{8}{|c|}{811} \\
\hline CHEMBL3193962 & 688810 & 4.883 & 5.3176 & TRN & & & \\
\hline CHEMBL1426415 & 688810 & 5.183 & 4.9283 & TST & & & \\
\hline CHEMBL1503841 & 688810 & 4.783 & 5.3384 & TRN & & & \\
\hline CHEMBL1531080 & 688810 & 5.683 & 5.3056 & TRN & & & \\
\hline CHEMBL1611902 & 688810 & 4.583 & 5.2916 & TST & & & \\
\hline CHEMBL1367759 & 688810 & 5.433 & 5.7977 & TST & & & \\
\hline CHEMBL1324468 & 688810 & $4.733 e$ & 00000006 & 005 & 5.4348 & TST & \\
\hline CHEMBL1518161 & 688810 & 6.0329 & 9999999 & 995 & 5.5898 & TRN & \\
\hline CHEMBL1336070 & 688810 & 5.733 & 5.4701 & TRN & & & \\
\hline CHEMBL1488090 & 688810 & 6.0329 & 99999999 & 995 & 5.4595 & TRN & \\
\hline CHEMBL1530896 & 688810 & 4.933 & 5.5657 & TRN & & & \\
\hline CHEMBL3210377 & 688810 & 6.3329 & 99999999 & & 6.03799 & 9999999999 & TRN \\
\hline CHEMBL1432495 & 688810 & $4.983 e$ & 0000000 & 005 & 5.711 & TRN & \\
\hline CHEMBL1525529 & 688810 & 5.983 & 5.7217 & TST & & & \\
\hline CHEMBL1407643 & 688810 & 5.5829 & 99999995 & & 5.59 & TST & \\
\hline CHEMBL1456019 & 688810 & $4.733 e$ & 00000006 & 005 & 5.1099 & TRN & \\
\hline CHEMBL1507785 & 688810 & 5.733 & 5.4404 & TRN & & & \\
\hline CHEMBL1528203 & 688810 & 5.733 & 5.0185 & TRN & & & \\
\hline CHEMBL3197411 & 688810 & 5.5329 & 99999990 & 995 & 5.5345 & TRN & \\
\hline CHEMBL1593469 & 688810 & 4.633 & 4.6743 & TRN & & & \\
\hline CHEMBL1372556 & 688810 & 5.8329 & 99999995 & & 5.1389 & TRN & \\
\hline CHEMBL1314497 & 688810 & 5.2829 & 9999999 & 995 & 5.6909 & TRN & \\
\hline CHEMBL3191230 & 688810 & 4.933 & 5.7024 & TRN & & & \\
\hline CHEMBL1327597 & 688810 & 5.033 & 5.1733 & TRN & & & \\
\hline CHEMBL1400981 & 688810 & 4.7336 & 00000006 & 005 & 4.9546 & TRN & \\
\hline CHEMBL1444991 & 688810 & 5.733 & 5.044 & TRN & & & \\
\hline CHEMBL414890 & 688810 & 5.233 & 5.3597 & TRN & & & \\
\hline CHEMBL1585127 & 688810 & 6.0 & 5.6232 & TRN & & & \\
\hline CHEMBL1448357 & 688810 & 5.5829 & 99999995 & & 5.3148 & TST & \\
\hline CHEMBL1535086 & 688810 & 4.583 & 5.0422 & TST & & & \\
\hline CHEMBL1302727 & 688810 & 4.85 & 5.2498 & TRN & & & \\
\hline CHEMBL1562077 & 688810 & $4.983 e$ & 00000006 & 005 & 5.3124 & TRN & \\
\hline CHEMBL1434091 & 688810 & 4.833 & 5.1641 & TRN & & & \\
\hline CHEMBL1593665 & 688810 & 4.783 & 5.187 & TST & & & \\
\hline CHEMBL 1483668 & 688810 & 5.5329 & 99999999 & 995 & 5.2953 & TRN & \\
\hline CHEMBL1411441 & 688810 & $4.733 e$ & 0000000 & 005 & 5.0906 & TRN & \\
\hline CHEMBL1534210 & 688810 & 5.1329 & 99999999 & & 5.1192 & TRN & \\
\hline CHEMBL1552139 & 688810 & $4.983 e$ & 00000006 & 005 & 5.126 & TST & \\
\hline CHEMBL1598190 & 688810 & 4.883 & 4.8577 & TST & & & \\
\hline CHEMBL 3207300 & 688810 & 5.8329 & 99999999 & & 5.4685 & TRN & \\
\hline CHEMBL1602754 & 688810 & 5.733 & 5.8632 & TRN & & & \\
\hline CHEMBL3189216 & 688810 & 4.883 & 5.6648 & TRN & & & \\
\hline CHEMBL1606634 & 688810 & 5.233 & 5.1292 & TST & & & \\
\hline CHEMBL1405969 & 688810 & 6.45 & 5.3747 & TST & & & \\
\hline CHEMBL 1374662 & 688810 & 5.683 & 4.9802 & TST & & & \\
\hline CHEMBL1388351 & 688810 & 6.433 & 5.4248 & TST & & & \\
\hline CHEMBL3191931 & 688810 & $4.733 e$ & 0000000 & 005 & 5.0027 & TRN & \\
\hline CHEMBL1462015 & 688810 & 5.8829 & 99999999 & & 5.3961 & TRN & \\
\hline
\end{tabular}




\begin{tabular}{|c|c|c|c|c|c|c|}
\hline CHEMBL3199779 & 688810 & 4.933 & 5.1786 & TRN & & \\
\hline CHEMBL1523703 & 688810 & \multicolumn{3}{|c|}{4.9830000000000005} & 5.4012 & TRN \\
\hline CHEMBL1520463 & 588810 & \multicolumn{3}{|c|}{5.332999999999999} & 5.0389 & TRN \\
\hline CHEMBL1478550 & 688810 & \multicolumn{3}{|c|}{4.7330000000000005} & 4.9498 & \\
\hline CHEMBL1475864 & 688810 & 4.883 & 5.5468 & TRN & & \\
\hline CHEMBL1511385 & 688810 & \multicolumn{3}{|c|}{5.7829999999999995} & 5.7448 & TI \\
\hline CHEMBL3198366 & 688810 & \multicolumn{3}{|c|}{4.7330000000000005} & 4.9523 & \\
\hline CHEMBL1378158 & 688810 & 4.583 & 4.9353 & TRN & & \\
\hline CHEMBL1321527 & 688810 & 4.683 & 5.2858 & TST & & \\
\hline CHEMBL1471750 & 688810 & 4.583 & 4.7433 & TST & & \\
\hline CHEMBL1576283 & 688810 & 4.933 & 4.9422 & TRN & & \\
\hline CHEMBL1538858 & 688810 & \multicolumn{3}{|c|}{5.2829999999999995} & 5.2969 & \\
\hline CHEMBL1573068 & 688810 & \multicolumn{3}{|c|}{5.332999999999999} & 4.8609 & \\
\hline CHEMBL1409802 & 688810 & \multicolumn{3}{|c|}{6.7829999999999995} & 5.9433 & \\
\hline CHEMBL1332324 & 688810 & 4.833 & 5.3027 & TRN & & \\
\hline CHEMBL 3211094 & 688810 & \multirow{2}{*}{\multicolumn{3}{|c|}{$\begin{array}{l}4.833 \\
6.082999999999999\end{array}$}} & & \\
\hline CHEMBL1332782 & 688810 & & & & 5.763 & \\
\hline CHEMBL1338413 & 688810 & 4.783 & 4.8349 & TRN & & \\
\hline CHEMBL1448008 & 688810 & 4.783 & 5.3098 & TST & & \\
\hline CHEMBL1449627 & 688810 & \multicolumn{3}{|c|}{5.882999999999999} & 109 & \\
\hline CHEMBL1518735 & 688810 & 4.633 & 4.922 & TRN & & \\
\hline CHEMBL 2369265 & 688810 & \multicolumn{3}{|c|}{4.9830000000000005} & 5.48 & \\
\hline CHEMBL1484460 & 688810 & 5.233 & 5.1513 & TST & & \\
\hline CHEMBL1580010 & 688810 & 4.883 & 5.1868 & TRN & & \\
\hline CHEMBL1408661 & 688810 & 5.483 & 5.4527 & TRN & & \\
\hline CHEMBL1411991 & 688810 & \multicolumn{3}{|c|}{5.2829999999999995} & 5.4823 & TR \\
\hline CHEMBL1417316 & 688810 & 4.783 & 4.9255 & TRN & & \\
\hline CHEMBL1335557 & 688810 & 6.433 & 5.2814 & TRN & & \\
\hline CHEMBL1302862 & 688810 & 6.433 & 5.7305 & TRN & & \\
\hline CHEMBL1530663 & 688810 & 4.933 & 5.4834 & TRN & & \\
\hline CHEMBL1592834 & 688810 & 5.983 & 5.5375 & TRN & & \\
\hline CHEMBL1495504 & 688810 & \multicolumn{3}{|c|}{6.082999999999999} & 5.5683 & $\mathrm{TI}$ \\
\hline CHEMBL1317083 & 688810 & \multicolumn{3}{|c|}{4.7330000000000005} & 5.2577 & \\
\hline CHEMBL1444064 & 688810 & \multicolumn{3}{|c|}{5.2829999999999995} & 5.2082 & \\
\hline CHEMBL1410219 & 688810 & 5.933 & 5.2753 & TRN & & \\
\hline CHEMBL 3190289 & 688810 & \multicolumn{3}{|c|}{4.7330000000000005} & 5.2648 & TS \\
\hline CHEMBL1589244 & 688810 & 5.433 & 5.6739 & TRN & & \\
\hline CHEMBL1488948 & 688810 & 5.183 & 5.0103 & TRN & & \\
\hline CHEMBL1340716 & 688810 & \multicolumn{3}{|c|}{5.7829999999999995} & 5.6858 & $1 \mathrm{~T}$ \\
\hline CHEMBL1359533 & 688810 & 4.783 & 5.0441 & TRN & & \\
\hline CHEMBL1301567 & 688810 & 4.833 & 5.3901 & TST & & \\
\hline CHEMBL 3209152 & 688810 & 5.183 & 5.0661 & TST & & \\
\hline CHEMBL1551944 & 688810 & 4.583 & 4.7212 & TRN & & \\
\hline CHEMBL1411935 & 688810 & \multicolumn{3}{|c|}{5.132999999999999} & 551 & RN \\
\hline CHEMBL1482765 & 688810 & \multicolumn{3}{|c|}{4.7330000000000005} & 5.3148 & \\
\hline CHEMBL1592544 & 688810 & \multicolumn{3}{|c|}{5.5329999999999995} & 5.3212 & $\pi$ \\
\hline CHEMBL1422806 & 688810 & 5.233 & 5.1577 & TST & & \\
\hline CHEMBL1326041 & 688810 & 5.683 & 5.0511 & TRN & & \\
\hline
\end{tabular}




\begin{tabular}{|c|c|c|c|c|c|c|}
\hline & & \multicolumn{5}{|c|}{ Supplemental Table s2.txt } \\
\hline CHEMBL1301158 & 688810 & \multicolumn{3}{|c|}{6.5329999999999995} & 5.9349 & TST \\
\hline CHEMBL1574136 & 688810 & \multicolumn{3}{|c|}{4.9830000000000005} & 5.114 & TRN \\
\hline CHEMBL3194634 & 688810 & 4.883 & 5.3308 & TST & & \\
\hline CHEMBL1361138 & 688810 & 4.933 & 5.0136 & TRN & & \\
\hline CHEMBL3198012 & 688810 & 4.933 & 5.3036 & TRN & & \\
\hline CHEMBL1493785 & 688810 & \multicolumn{3}{|c|}{6.582999999999999} & 5.7449 & TRN \\
\hline CHEMBL1524091 & 688810 & \multicolumn{3}{|c|}{4.7330000000000005} & 4.797 & TST \\
\hline CHEMBL1460106 & 688810 & 4.833 & 5.246 & TRN & & \\
\hline CHEMBL1435936 & 688810 & 4.783 & 5.0952 & TRN & & \\
\hline CHEMBL1544062 & 688810 & 5.483 & 5.6546 & TRN & & \\
\hline CHEMBL1506416 & 688810 & \multicolumn{3}{|c|}{5.382999999999999} & 4.942 & TRN \\
\hline CHEMBL1378535 & 688810 & \multicolumn{3}{|c|}{5.7829999999999995} & 5.5819 & TST \\
\hline CHEMBL1333561 & 688810 & 5.733 & 5.4123 & TRN & & \\
\hline CHEMBL1442136 & 688810 & 4.833 & 4.8407 & TST & & \\
\hline CHEMBL3196563 & 688810 & 5.183 & 5.407 & TRN & & \\
\hline CHEMBL1548220 & 688810 & \multicolumn{3}{|c|}{5.132999999999999} & 5.185 & TRN \\
\hline CHEMBL1323980 & 688810 & 4.783 & 5.4245 & TRN & & \\
\hline CHEMBL3213175 & 688810 & \multicolumn{3}{|c|}{5.132999999999999} & 5.2731 & TRN \\
\hline CHEMBL1512957 & 688810 & 4.783 & 5.419 & TRN & & \\
\hline CHEMBL1530719 & 688810 & 4.833 & 4.9232 & TRN & & \\
\hline CHEMBL1590926 & 688810 & 4.583 & 4.9064 & TRN & & \\
\hline CHEMBL3196711 & 688810 & 5.733 & 6.2209 & TRN & & \\
\hline CHEMBL1404393 & 688810 & 6.233 & 5.2211 & TRN & & \\
\hline CHEMBL1450922 & 688810 & \multicolumn{3}{|c|}{5.832999999999999} & 5.5513 & TRN \\
\hline CHEMBL1571228 & 688810 & 4.883 & 5.5116 & TST & & \\
\hline CHEMBL1553420 & 688810 & 4.933 & 5.2767 & TRN & & \\
\hline CHEMBL1433251 & 688810 & 4.883 & 5.1206 & TST & & \\
\hline CHEMBL1411688 & 688810 & 5.233 & 5.1797 & TRN & & \\
\hline CHEMBL1433112 & 688810 & 4.783 & 5.0731 & TRN & & \\
\hline CHEMBL1482344 & 688810 & 4.633 & 5.0999 & TST & & \\
\hline CHEMBL1345839 & 688810 & \multicolumn{3}{|c|}{4.7330000000000005} & 5.1746 & TRN \\
\hline CHEMBL1413177 & 688810 & \multicolumn{3}{|c|}{5.132999999999999} & 5.0036 & TRN \\
\hline CHEMBL1555689 & 688810 & \multicolumn{3}{|c|}{5.7829999999999995} & 5.5866 & TRN \\
\hline CHEMBL1411761 & 688810 & 4.933 & 5.7705 & TST & & \\
\hline CHEMBL1409622 & 688810 & 5.683 & 5.1985 & TRN & & \\
\hline CHEMBL1458548 & 688810 & \multicolumn{3}{|c|}{5.2829999999999995} & 4.8869 & TRN \\
\hline CHEMBL1460564 & 688810 & \multicolumn{3}{|c|}{6.082999999999999} & 5.709 & TRN \\
\hline CHEMBL1468717 & 688810 & 4.783 & 5.2939 & TRN & & \\
\hline CHEMBL1420122 & 688810 & 4.833 & 5.6785 & TST & & \\
\hline CHEMBL1440685 & 688810 & 4.683 & 5.1546 & TRN & & \\
\hline CHEMBL1542594 & 688810 & 5.033 & 5.1777 & TRN & & \\
\hline CHEMBL1329962 & 688810 & 4.633 & 5.1468 & TST & & \\
\hline CHEMBL 1468720 & 688810 & \multicolumn{3}{|c|}{6.632999999999999} & 6.0181 & TRN \\
\hline CHEMBL1486413 & 688810 & 6.0 & 5.5066 & TRN & & \\
\hline CHEMBL1468847 & 688810 & 4.883 & 4.9408 & TRN & & \\
\hline CHEMBL1574219 & 688810 & 4.633 & 4.9054 & TST & & \\
\hline CHEMBL3192956 & 688810 & 4.583 & 4.6378 & TRN & & \\
\hline CHEMBL1382693 & 688810 & 4.783 & 5.36 & TST & & \\
\hline
\end{tabular}




\begin{tabular}{|c|c|c|c|c|c|c|}
\hline \multicolumn{7}{|c|}{ 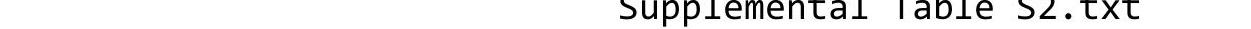 } \\
\hline CHEMBL1508255 & 688810 & 5.733 & 5.3541 & TRN & & \\
\hline CHEMBL1378574 & 688810 & 4.883 & 5.2986 & TRN & & \\
\hline CHEMBL1499773 & 688810 & 4.783 & 5.083 & TRN & & \\
\hline CHEMBL 3191183 & 688810 & 5.183 & 5.1715 & TRN & & \\
\hline CHEMBL1326849 & 688810 & 5.3329 & 99999999 & & 5.0937 & TR \\
\hline CHEMBL1381454 & 688810 & 5.683 & 5.4318 & TRN & & \\
\hline CHEMBL1513265 & 688810 & 4.7330 & 00000000 & 005 & 5.1939 & TST \\
\hline CHEMBL3213930 & 688810 & 6.2829 & 99999999 & 995 & 5.5946 & \\
\hline CHEMBL1545674 & 688810 & 5.1329 & 99999999 & 99 & 5.4247 & TRN \\
\hline CHEMBL 3196241 & 688810 & 5.8829 & 99999999 & 99 & 5.2629 & \\
\hline CHEMBL1467952 & 688810 & 5.1329 & 99999999 & 99 & 5.1109 & \\
\hline CHEMBL1567808 & 688810 & 4.633 & 4.8675 & TRN & & \\
\hline CHEMBL1462406 & 688810 & 5.1329 & 99999999 & 99 & 5.0141 & \\
\hline CHEMBL1559500 & 688810 & 6.433 & 5.9073 & TRN & & \\
\hline CHEMBL1390244 & 688810 & 5.8329 & 99999999 & & 5.7197 & \\
\hline CHEMBL1303663 & 688810 & 5.1329 & 99999999 & 99 & 5.4073 & \\
\hline CHEMBL1325839 & 688810 & 6.233 & 5.3386 & TRN & & \\
\hline CHEMBL1480238 & 688810 & 5.2829 & 99999999 & 995 & 6.2354 & \\
\hline CHEMBL1345391 & 688810 & 6.233 & 5.3753 & TRN & & \\
\hline CHEMBL1563037 & 688810 & 4.7330 & 00000000 & 005 & 072 & \\
\hline CHEMBL1609562 & 688810 & 5.683 & 5.5354 & TRN & & \\
\hline CHEMBL1482094 & 688810 & 4.933 & 5.2186 & TRN & & \\
\hline CHEMBL1493502 & 688810 & 5.033 & 5.1604 & TRN & & \\
\hline CHEMBL1339563 & 688810 & 5.8329 & 99999999 & & 5 & \\
\hline CHEMBL1578471 & 688810 & 4.9830 & 00000000 & 005 & 1 & \\
\hline CHEMBL1461903 & 688810 & 4.933 & 5.1884 & TRN & & \\
\hline CHEMBL1503644 & 688810 & 5.483 & 6.0969 & TRN & & \\
\hline CHEMBL1603924 & 688810 & 4.7330 & 00000000 & 005 & 5.0593 & \\
\hline CHEMBL1517624 & 688810 & 5.733 & 5.4603 & TRN & & \\
\hline CHEMBL1440683 & 688810 & 5.3829 & 99999999 & & 5.3925 & \\
\hline CHEMBL1381862 & 688810 & 4.783 & 5.3263 & TRN & & \\
\hline CHEMBL1571522 & 688810 & 4.683 & 5.2686 & TST & & \\
\hline CHEMBL1374723 & 688810 & 5.933 & 6.26 & TRN & & \\
\hline CHEMBL1403044 & 688810 & 4.933 & 5.4649 & TRN & & \\
\hline CHEMBL1556453 & 688810 & 5.3829 & 99999999 & & 4.9311 & ונכו \\
\hline CHEMBL1433928 & 688810 & 5.5829 & 99999999 & & 5.7639 & \\
\hline CHEMBL1473209 & 688810 & 5.733 & 4.9467 & TRN & & \\
\hline CHEMBL1480983 & 688810 & 5.433 & 4.9712 & TRN & & \\
\hline CHEMBL1577158 & 688810 & 5.233 & 5.2946 & TRN & & \\
\hline CHEMBL1319262 & 688810 & 4.783 & 5.3215 & TRN & & \\
\hline CHEMBL1326159 & 688810 & 5.5329 & 99999999 & 995 & 5.6186 & \\
\hline CHEMBL1533514 & 688810 & 5.083 & 5.6411 & TRN & & \\
\hline CHEMBL1595236 & 688810 & 5.1329 & 99999999 & & 5.5117 & \\
\hline CHEMBL1525009 & 688810 & 5.7829 & 99999999 & 995 & 5.5476 & \\
\hline CHEMBL1339742 & 688810 & 5.033 & 4.9743 & TRN & & \\
\hline CHEMBL1386464 & 688810 & 4.7330 & 00000000 & 005 & 4.8646 & \\
\hline CHEMBL1584153 & 688810 & 6.0 & 5.0623 & TRN & & \\
\hline CHEMBL1528246 & 688810 & 4.833 & 5.2479 & TRN & & \\
\hline
\end{tabular}




\begin{tabular}{|c|c|c|c|c|c|c|}
\hline & & \multicolumn{4}{|c|}{ Supplemental Table S2.txt } & \\
\hline CHEMBL1477147 & 688810 & \multicolumn{3}{|c|}{4.7330000000000005} & 5.1058 & TS \\
\hline CHEMBL1583300 & 688810 & \multicolumn{3}{|c|}{4.7330000000000005} & 5.1178 & \\
\hline CHEMBL1558549 & 688810 & 5.733 & 5.5656 & TRN & & \\
\hline CHEMBL3195289 & 688810 & 4.783 & 5.7388 & TRN & & \\
\hline CHEMBL1999648 & 688810 & 5.733 & 5.0688 & TST & & \\
\hline CHEMBL1316947 & 688810 & \multicolumn{3}{|c|}{5.332999999999999} & 5.4667 & \\
\hline CHEMBL1484321 & 688810 & 4.883 & 5.5278 & TST & & \\
\hline CHEMBL1381466 & 688810 & 5.483 & 5.0901 & TRN & & \\
\hline CHEMBL3214455 & 688810 & \multicolumn{3}{|c|}{5.632999999999999} & 6.106 & \\
\hline CHEMBL1490341 & 688810 & 4.833 & 5.5688 & TRN & & \\
\hline CHEMBL1540615 & 688810 & 4.833 & 4.94 & TRN & & \\
\hline CHEMBL1403324 & 688810 & 5.733 & 5.2298 & TRN & & \\
\hline CHEMBL1407825 & 688810 & \multicolumn{3}{|c|}{5.132999999999999} & 5.0039 & \\
\hline CHEMBL1391555 & 688810 & 5.033 & 5.3 & TRN & & \\
\hline CHEMBL1541455 & 688810 & 4.883 & 5.0127 & TRN & & \\
\hline CHEMBL1361429 & 688810 & 4.883 & 5.3224 & TRN & & \\
\hline CHEMBL1454395 & 688810 & \multicolumn{3}{|c|}{4.9830000000000005} & 5.2722 & \\
\hline CHEMBL1369984 & 688810 & 5.483 & 4.8828 & TST & & \\
\hline CHEMBL1465386 & 688810 & \multicolumn{3}{|c|}{5.132999999999999} & 5.789 & \\
\hline CHEMBL1313936 & 688810 & \multicolumn{3}{|c|}{6.632999999999999} & 6.0498 & \\
\hline CHEMBL1470281 & 688810 & 5.183 & 4.9438 & TST & & \\
\hline CHEMBL1349166 & 688810 & 4.833 & 5.2498 & TRN & & \\
\hline CHEMBL1363166 & 688810 & \multicolumn{3}{|c|}{6.2829999999999995} & 5.043 & \\
\hline CHEMBL 1423796 & 688810 & \multicolumn{3}{|c|}{5.582999999999999} & 5.5567 & \\
\hline CHEMBL1562572 & 688810 & 4.583 & 5.4541 & TRN & & \\
\hline CHEMBL1328010 & 688810 & 4.783 & 5.6891 & TRN & & \\
\hline CHEMBL15 & 688810 & 4.933 & 5.2558 & TRN & & \\
\hline CHEMBL1434310 & 688810 & 4.583 & 5.2442 & TRN & & \\
\hline CHEMBL1594945 & 688810 & \multicolumn{3}{|c|}{4.9830000000000005} & 5.0921 & $\mathrm{TH}$ \\
\hline CHEMBL1966679 & 688810 & \multicolumn{3}{|c|}{4.7330000000000005} & 5.1844 & \\
\hline CHEMBL1383468 & 688810 & 4.9 & 4.9386 & TRN & & \\
\hline CHEMBL13 & 688810 & \multicolumn{3}{|c|}{5.582999999999999} & 5.1927 & \\
\hline CHEMBL1348349 & 688810 & 4.883 & 5.0634 & TST & & \\
\hline CHEMBL1608805 & 688810 & 4.883 & 5.7471 & TRN & & \\
\hline CHEMBL1333474 & 688810 & \multicolumn{3}{|c|}{5.632999999999999} & 5.3085 & Th \\
\hline CHEMBL1426490 & 688810 & 6.0 & 5.2074 & TRN & & \\
\hline CHEMBL1490289 & 688810 & 5.933 & 5.7377 & TST & & \\
\hline CHEMBL 1407187 & 688810 & 4.783 & 5.1013 & TRN & & \\
\hline CHEMBL1532037 & 688810 & \multicolumn{3}{|c|}{6.132999999999999} & 5.6267 & TRN \\
\hline CHEMBL1455824 & 688810 & \multicolumn{3}{|c|}{5.7829999999999995} & 5.7993 & \\
\hline CHEMBL1477538 & 688810 & 4.783 & 5.0121 & TRN & & \\
\hline CHEMBL1525787 & 688810 & \multirow{2}{*}{\multicolumn{3}{|c|}{$\begin{array}{lll}5.083 & 5.6204 \\
4.7330000000000005\end{array}$}} & & \\
\hline CHEMBL1519953 & 688810 & & & & 4.7237 & TR \\
\hline CHEMBL1586201 & 688810 & 5.733 & 5.4786 & TRN & & \\
\hline CHEMBL1573553 & 688810 & 5.483 & 5.3156 & TRN & & \\
\hline CHEMBL3213953 & 688810 & 5.983 & 5.2023 & TRN & & \\
\hline CHEMBL1554002 & 688810 & 4.633 & 5.3847 & TRN & & \\
\hline CHEMBL1445134 & 688810 & 5.083 & 5.4094 & TRN & & \\
\hline
\end{tabular}




\begin{tabular}{|c|c|c|c|c|c|c|}
\hline & & \multicolumn{5}{|c|}{ Supplemental Table S2.txt } \\
\hline CHEMBL1451027 & 688810 & 5.183 & 5.223 & TRN & & \\
\hline CHEMBL1327169 & 688810 & 6.183 & 5.8443 & TRN & & \\
\hline CHEMBL1213769 & 688810 & 5.983 & 5.5433 & TRN & & \\
\hline CHEMBL1494863 & 688810 & 4.783 & 5.3862 & TRN & & \\
\hline CHEMBL171325 & 688810 & 5.983 & 5.4619 & TRN & & \\
\hline CHEMBL3189706 & 688810 & 5.733 & 5.0371 & TRN & & \\
\hline CHEMBL1494802 & 688810 & 4.783 & 5.6823 & TST & & \\
\hline CHEMBL1358754 & 688810 & 4.933 & 5.118 & TRN & & \\
\hline CHEMBL1535921 & 688810 & \multicolumn{3}{|c|}{6.832999999999999} & 5.9809 & TRN \\
\hline CHEMBL507237 & 688810 & 5.183 & 5.4128 & TST & & \\
\hline CHEMBL1306925 & 688810 & 4.783 & 5.0473 & TRN & & \\
\hline CHEMBL1350132 & 688810 & \multicolumn{3}{|c|}{4.9830000000000005} & 4.9586 & TST \\
\hline CHEMBL1366454 & 688810 & 4.783 & 5.2621 & TRN & & \\
\hline CHEMBL1590275 & 688810 & \multicolumn{3}{|c|}{5.2829999999999995} & 5.2509 & TRN \\
\hline CHEMBL1423438 & 688810 & \multicolumn{3}{|c|}{5.2829999999999995} & 5.3284 & TRN \\
\hline CHEMBL380979 & 688810 & \multicolumn{3}{|c|}{6.132999999999999} & 5.8079 & TRN \\
\hline CHEMBL1507374 & 688810 & \multicolumn{3}{|c|}{4.7330000000000005} & 5.4212 & TST \\
\hline CHEMBL1568669 & 688810 & 4.833 & 5.4692 & TRN & & \\
\hline CHEMBL1472773 & 688810 & 5.983 & 5.2591 & TST & & \\
\hline CHEMBL3194103 & 688810 & 6.4829 & 5.3534 & TRN & & \\
\hline CHEMBL1302966 & 688810 & 4.783 & 5.1644 & TST & & \\
\hline CHEMBL1493877 & 688810 & \multicolumn{3}{|c|}{5.132999999999999} & 4.7721 & TST \\
\hline CHEMBL1353711 & 688810 & \multicolumn{3}{|c|}{4.9830000000000005} & 5.0938 & TST \\
\hline CHEMBL1400840 & 688810 & \multicolumn{3}{|c|}{4.9830000000000005} & 5.4086 & TRN \\
\hline CHEMBL1964843 & 688810 & \multicolumn{3}{|c|}{5.582999999999999} & 5.6369 & TRN \\
\hline CHEMBL1371291 & 688810 & 4.883 & 5.2543 & TRN & & \\
\hline CHEMBL1431459 & 688810 & 4.783 & 5.0346 & TST & & \\
\hline CHEMBL1388390 & 688810 & \multicolumn{3}{|c|}{5.832999999999999} & 5.6145 & TRN \\
\hline CHEMBL1418392 & 688810 & \multicolumn{3}{|c|}{6.632999999999999} & 5.6925 & TRN \\
\hline CHEMBL1423002 & 688810 & 4.783 & 5.5121 & TST & & \\
\hline CHEMBL1472867 & 688810 & 7.2328 & \multicolumn{3}{|c|}{5.457000000000001} & TRN \\
\hline CHEMBL1528119 & 688810 & \multicolumn{3}{|c|}{6.332999999999999} & 5.4658 & TRN \\
\hline CHEMBL1574268 & 688810 & 4.783 & 5.151 & TRN & & \\
\hline CHEMBL1387822 & 688810 & 5.433 & 5.2645 & TRN & & \\
\hline CHEMBL1388370 & 688810 & 4.883 & 5.5092 & TST & & \\
\hline CHEMBL1488855 & 688810 & 5.683 & 5.8543 & TRN & & \\
\hline CHEMBL1579902 & 688810 & \multicolumn{3}{|c|}{6.632999999999999} & 5.5152 & TRN \\
\hline CHEMBL1389420 & 688810 & \multicolumn{3}{|c|}{4.9830000000000005} & 5.0419 & TRN \\
\hline CHEMBL1611957 & 688810 & 4.633 & 4.6094 & TRN & & \\
\hline CHEMBL3211782 & 688810 & 4.933 & 5.0894 & TRN & & \\
\hline CHEMBL1360255 & 688810 & 6.8831 & 5.6807 & TRN & & \\
\hline CHEMBL1374119 & 688810 & \multicolumn{3}{|c|}{4.7330000000000005} & 5.2929 & TST \\
\hline CHEMBL1505331 & 688810 & 4.783 & 5.2619 & TST & & \\
\hline CHEMBL1543907 & 688810 & \multirow{2}{*}{\multicolumn{2}{|c|}{$\begin{array}{lr}4.633 & 4.9576 \\
6.3329999999999\end{array}$}} & TRN & & \\
\hline CHEMBL1533353 & 688810 & & & 6.332999999999999 & 5.3511 & TRN \\
\hline CHEMBL1360487 & 688810 & 4.833 & 4.6999 & TST & & \\
\hline CHEMBL1368873 & 688810 & 4.933 & 5.047 & TRN & & \\
\hline CHEMBL1475597 & 688810 & 4.583 & 5.3652 & TST & & \\
\hline
\end{tabular}




\begin{tabular}{|c|c|c|c|c|c|c|}
\hline & & & & & & \\
\hline CHEMBL1506622 & 688810 & 5.483 & 5.4655 & TST & & \\
\hline CHEMBL1414405 & 688810 & 5.183 & 6.041 & TRN & & \\
\hline CHEMBL1380189 & 688810 & 5.0 & 5.5705 & TST & & \\
\hline CHEMBL1573636 & 688810 & 5.683 & 5.8768 & TRN & & \\
\hline CHEMBL1540145 & 688810 & 4.783 & 5.4579 & TST & & \\
\hline CHEMBL1341160 & 688810 & 4.883 & 5.0693 & TRN & & \\
\hline CHEMBL1310858 & 688810 & 5.183 & 5.5574 & TST & & \\
\hline CHEMBL1501579 & 688810 & 4.883 & 5.0646 & TRN & & \\
\hline CHEMBL1584059 & 688810 & \multicolumn{3}{|c|}{6.582999999999999} & 6.0091 & TRN \\
\hline CHEMBL1549201 & 688810 & 6.233 & 5.2782 & TST & & \\
\hline CHEMBL1381600 & 688810 & \multicolumn{3}{|c|}{5.332999999999999} & 5.5158 & \\
\hline CHEMBL1391644 & 688810 & 5.983 & 4.9698 & TRN & & \\
\hline CHEMBL1328961 & 688810 & 4.883 & 5.2964 & TRN & & \\
\hline CHEMBL1582448 & 688810 & 5.233 & 5.6246 & TRN & & \\
\hline CHEMBL 3190071 & 688810 & \multicolumn{3}{|c|}{5.882999999999999} & 5.0797 & TRN \\
\hline CHEMBL1347798 & 688810 & \multicolumn{3}{|c|}{5.382999999999999} & 5.3312 & \\
\hline CHEMBL1334123 & 688810 & 5.483 & 5.2139 & TRN & & \\
\hline CHEMBL1381239 & 688810 & 5.483 & 5.2551 & TRN & & \\
\hline CHEMBL 1470256 & 688810 & \multicolumn{3}{|c|}{5.582999999999999} & 5.359 & \\
\hline CHEMBL1613374 & 688810 & 5.683 & 5.8858 & TRN & & \\
\hline CHEMBL1502812 & 688810 & 4.683 & 5.1378 & TRN & & \\
\hline CHEMBL1472015 & 688810 & \multicolumn{3}{|c|}{5.2829999999999995} & 5.386 & TRN \\
\hline CHEMBL1385733 & 688810 & 4.883 & 5.2822 & TRN & & \\
\hline CHEMBL1529872 & 688810 & 4.833 & 4.9025 & TST & & \\
\hline CHEMBL1563822 & 688810 & 4.833 & 5.101 & TRN & & \\
\hline CHEMBL1383030 & 688810 & \multicolumn{3}{|c|}{5.5329999999999995} & 5.8928 & $1 \mathrm{~K}$ \\
\hline CHEMBL1391081 & 688810 & 4.833 & 5.0985 & TST & & \\
\hline CHEMBL1462686 & 688810 & 5.683 & 5.0651 & TST & & \\
\hline CHEMBL1464493 & 688810 & 5.733 & 5.1758 & TRN & & \\
\hline CHEMBL1333863 & 688810 & 4.583 & 5.4121 & TST & & \\
\hline CHEMBL1362945 & 688810 & \multicolumn{3}{|c|}{5.7829999999999995} & 5.4032 & $\mathrm{TH}$ \\
\hline CHEMBL1540471 & 688810 & 4.833 & 5.2018 & TRN & & \\
\hline CHEMBL 1977078 & 688810 & 5.183 & 5.2106 & TRN & & \\
\hline CHEMBL1582955 & 688810 & \multicolumn{3}{|c|}{5.132999999999999} & 5.2545 & \\
\hline CHEMBL 1447641 & 688810 & \multicolumn{3}{|c|}{4.7330000000000005} & 5.4041 & 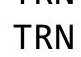 \\
\hline CHEMBL1583361 & 688810 & 5.183 & 5.0902 & TRN & & \\
\hline CHEMBL 1578075 & 688810 & 5.183 & 5.137006 & 000000000 & 305 & $T n$ \\
\hline CHEMBL1377477 & 688810 & 6.183 & 5.3426 & TRN & & \\
\hline CHEMBL1521903 & 688810 & 5.233 & 5.1803 & TRN & & \\
\hline CHEMBL1552275 & 688810 & \multicolumn{3}{|c|}{5.332999999999999} & 5.0278 & KIV \\
\hline CHEMBL1975997 & 688810 & \multicolumn{3}{|c|}{5.5329999999999995} & 5.7507 & 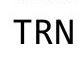 \\
\hline CHEMBL1376944 & 688810 & 4.783 & 5.1748 & TRN & & \\
\hline CHEMBL 3197509 & 688810 & 4.783 & 4.9479 & TST & & \\
\hline CHEMBL1300459 & 688810 & 4.683 & 5.1684 & TRN & & \\
\hline CHEMBL1565369 & 688810 & 4.833 & 5.4661 & TST & & \\
\hline CHEMBL 1452672 & 688810 & 6.4829 & 6.2578 & TRN & & \\
\hline CHEMBL1477262 & 688810 & 5.233 & 5.0702 & TST & & \\
\hline CHEMBL1411813 & 688810 & 4.833 & 5.1542 & TRN & & \\
\hline
\end{tabular}




\begin{tabular}{|c|c|c|c|c|c|c|}
\hline \multirow[b]{2}{*}{ CHEMBL1416617 } & \multirow[b]{2}{*}{688810} & \multicolumn{5}{|c|}{ Supplemental Table S2.txt } \\
\hline & & \multirow{2}{*}{\multicolumn{3}{|c|}{ 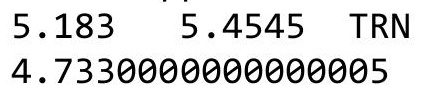 }} & & \\
\hline CHEMBL1403350 & 688810 & & & & 5.2489 & TRN \\
\hline CHEMBL1451855 & 688810 & \multicolumn{3}{|c|}{5.2829999999999995} & 5.4262 & TRN \\
\hline CHEMBL1497673 & 688810 & 5.45 & 5.0434 & TRN & & \\
\hline CHEMBL3209422 & 688810 & 5.233 & 4.9439 & TST & & \\
\hline CHEMBL1360149 & 688810 & 4.783 & 5.1496 & TRN & & \\
\hline CHEMBL1561286 & 688810 & \multicolumn{3}{|c|}{5.832999999999999} & 5.7765 & TST \\
\hline CHEMBL1609181 & 688810 & \multicolumn{3}{|c|}{6.082999999999999} & 5.5548 & TRN \\
\hline CHEMBL1415032 & 688810 & 5.033 & 5.3029 & TST & & \\
\hline CHEMBL1342873 & 688810 & \multicolumn{3}{|c|}{5.382999999999999} & 5.4085 & TRN \\
\hline CHEMBL1364988 & 688810 & 5.683 & 5.6471 & TRN & & \\
\hline CHEMBL3210308 & 688810 & 5.933 & 5.4034 & TRN & & \\
\hline CHEMBL1533360 & 688810 & 4.833 & 5.228 & TRN & & \\
\hline CHEMBL1604441 & 688810 & 6.183 & 4.9366 & TST & & \\
\hline CHEMBL1538035 & 688810 & 4.633 & 4.7652 & TRN & & \\
\hline CHEMBL1395100 & 688810 & 5.033 & 5.2878 & TST & & \\
\hline CHEMBL1499459 & 688810 & 4.833 & 5.2347 & TRN & & \\
\hline CHEMBL1465755 & 688810 & \multicolumn{3}{|c|}{4.9830000000000005} & 5.2027 & TRN \\
\hline CHEMBL1536129 & 688810 & 5.183 & 5.2026 & TRN & & \\
\hline CHEMBL1429204 & 688810 & \multicolumn{3}{|c|}{4.7330000000000005} & 5.2143 & TRN \\
\hline CHEMBL3198303 & 688810 & \multicolumn{3}{|c|}{6.0329999999999995} & 5.7318 & TRN \\
\hline CHEMBL1532631 & 688810 & 5.233 & 5.1759 & TST & & \\
\hline CHEMBL1330701 & 688810 & \multicolumn{3}{|c|}{$5.433 \quad 5.0692$} & & \\
\hline CHEMBL1990767 & 688810 & \multicolumn{3}{|c|}{5.132999999999999} & 5.2015 & TRN \\
\hline CHEMBL1431880 & 688810 & 4.883 & 5.0408 & TRN & & \\
\hline CHEMBL1370654 & 688810 & 4.783 & 5.0455 & TRN & & \\
\hline CHEMBL1611713 & 688810 & 6.683 & 6.0529 & TRN & & \\
\hline CHEMBL1356253 & 688810 & 4.883 & 4.9976 & TRN & & \\
\hline CHEMBL1462585 & 688810 & 4.583 & 5.3246 & TST & & \\
\hline CHEMBL1486502 & 688810 & 4.933 & 5.4871 & TST & & \\
\hline CHEMBL1529156 & 688810 & \multicolumn{3}{|c|}{6.332999999999999} & 6.0416 & TRN \\
\hline CHEMBL1438636 & 688810 & 5.233 & 4.8535 & TRN & & \\
\hline CHEMBL1407379 & 688810 & 4.783 & 5.308 & TST & & \\
\hline CHEMBL1353341 & 688810 & 4.883 & 4.7459 & TST & & \\
\hline CHEMBL1327678 & 688810 & 4.783 & 4.6832 & TRN & & \\
\hline CHEMBL1533100 & 688810 & 4.783 & 5.4578 & TST & & \\
\hline CHEMBL1538461 & 688810 & 5.083 & 5.2653 & TST & & \\
\hline CHEMBL1481451 & 688810 & 5.683 & 5.3106 & TST & & \\
\hline CHEMBL1613444 & 688810 & 4.833 & 5.6464 & TST & & \\
\hline CHEMBL1461891 & 688810 & 4.583 & 5.2812 & TST & & \\
\hline CHEMBL1593701 & 688810 & \multicolumn{3}{|c|}{4.7330000000000005} & 5.1193 & TST \\
\hline CHEMBL1389421 & 688810 & 4.833 & 5.2693 & TRN & & \\
\hline CHEMBL1582327 & 688810 & 4.933 & 4.9741 & TRN & & \\
\hline CHEMBL1493159 & 688810 & 4.883 & 5.6626 & TRN & & \\
\hline CHEMBL3209435 & 688810 & 4.833 & 4.92399 & 99999 & 995 & TST \\
\hline CHEMBL1550163 & 688810 & 4.833 & 5.1235 & TRN & & \\
\hline CHEMBL1487634 & 688810 & 4.583 & 4.5617 & TRN & & \\
\hline CHEMBL1529573 & 688810 & 4.783 & 4.8984 & TRN & & \\
\hline
\end{tabular}




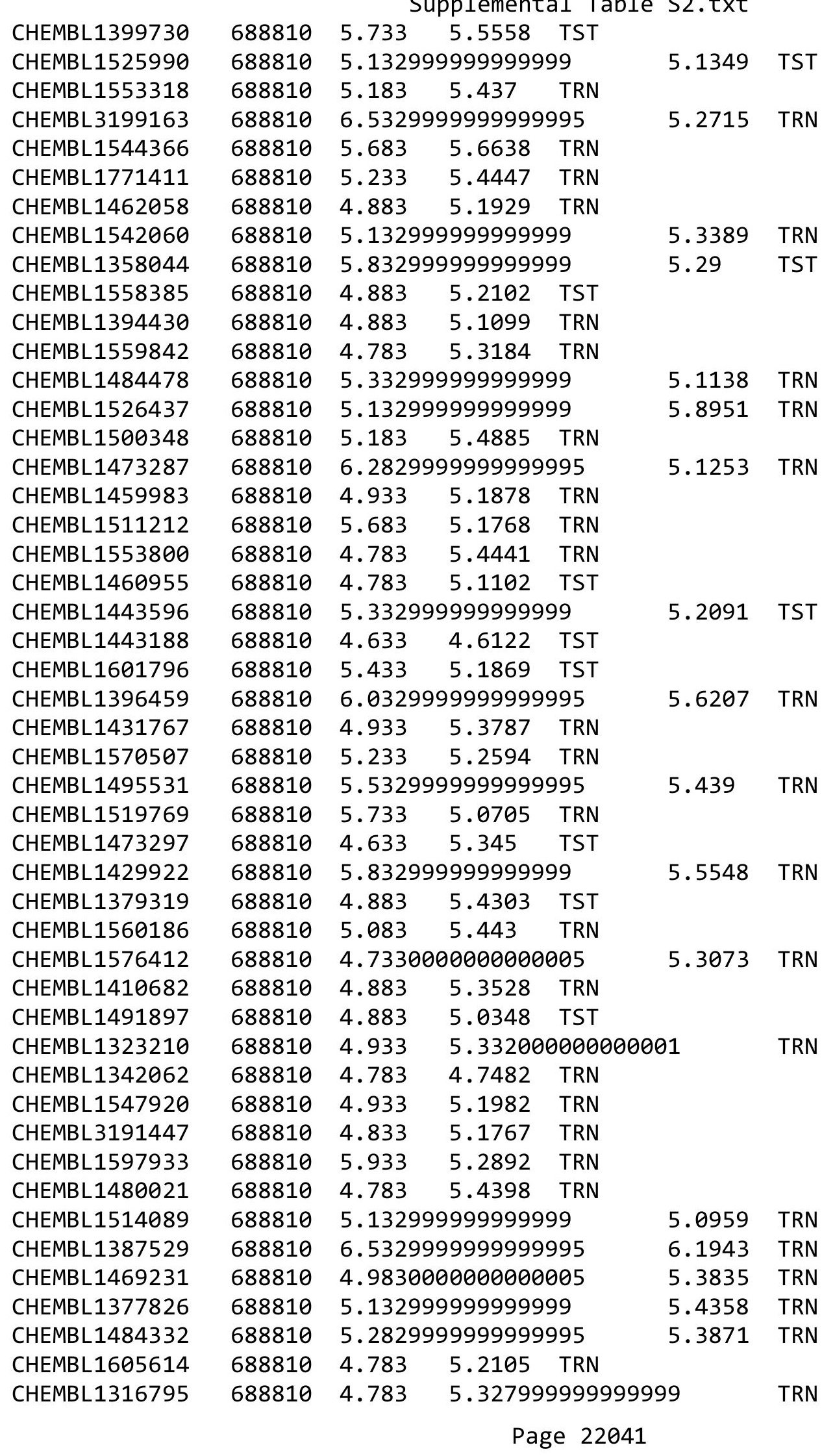




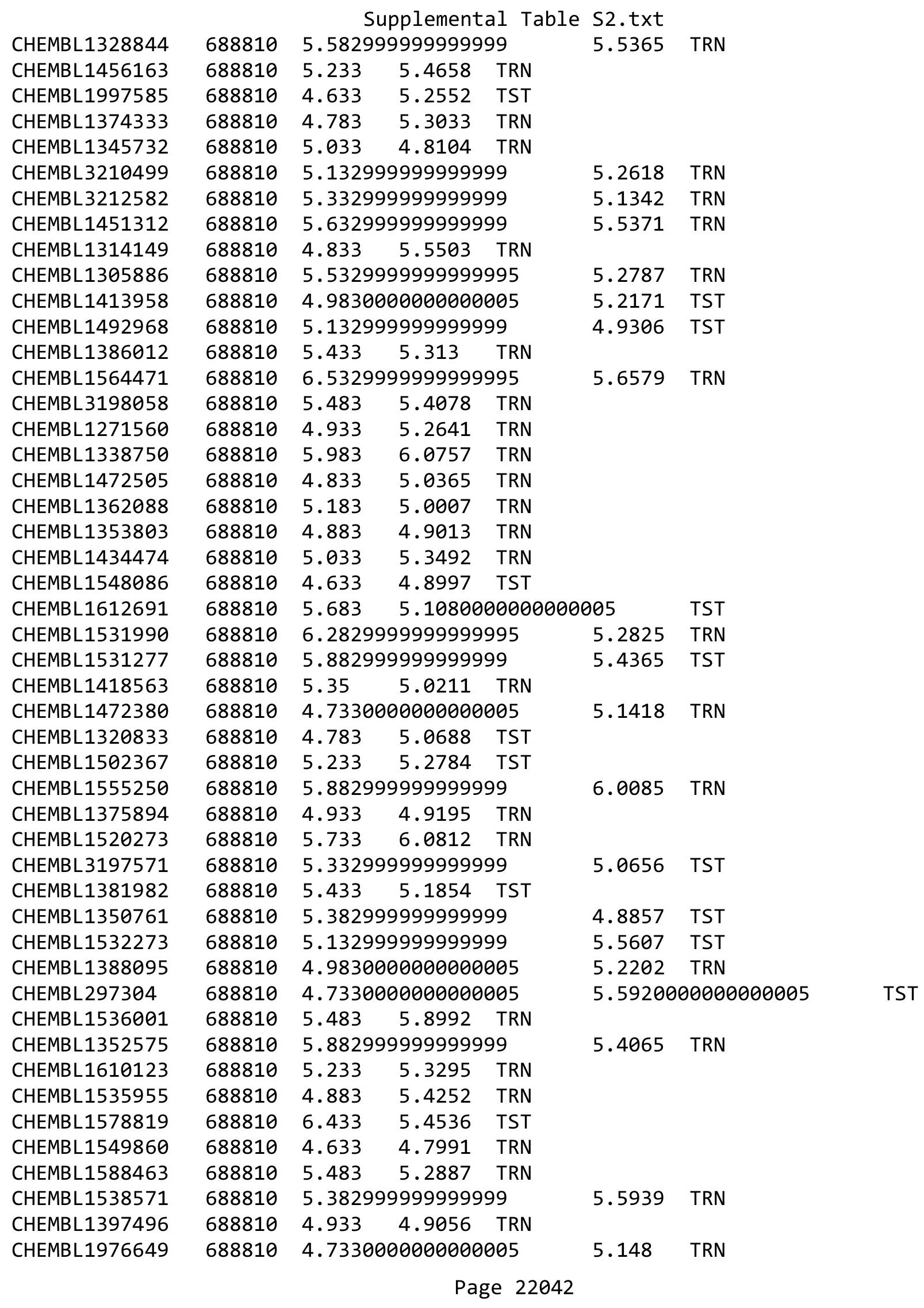




\begin{tabular}{|c|c|c|c|c|c|c|}
\hline & & \multicolumn{5}{|c|}{ Supplemental Table S2.txt } \\
\hline CHEMBL 3199500 & 688810 & 4.833 & 5.4301 & TST & & \\
\hline CHEMBL1545327 & 688810 & 4.783 & 4.7872 & TRN & & \\
\hline CHEMBL1564202 & 688810 & 5.233 & 4.9797 & TST & & \\
\hline CHEMBL1510913 & 688810 & 5.8329 & 999999999 & & 5.8589 & TRN \\
\hline CHEMBL1487593 & 688810 & 4.583 & 4.6672 & TRN & & \\
\hline CHEMBL1312941 & 688810 & 4.9830 & 000000000 & 305 & 5.1452 & TRN \\
\hline CHEMBL1508773 & 688810 & 4.833 & 5.0048 & TRN & & \\
\hline CHEMBL1497933 & 688810 & 5.1329 & 999999999 & 99 & 5.126 & \\
\hline CHEMBL1389843 & 688810 & 4.833 & 5.505 & TST & & \\
\hline CHEMBL1363949 & 688810 & 5.6329 & 999999999 & & 4.8394 & TR \\
\hline CHEMBL1511576 & 688810 & 5.183 & 5.104 & TRN & & \\
\hline CHEMBL1091028 & 688810 & 6.433 & 5.7577 & TRN & & \\
\hline CHEMBL1978279 & 688810 & 7.1831 & 5.6291 & TRN & & \\
\hline CHEMBL1524562 & 688810 & 4.833 & 5.2738 & TST & & \\
\hline CHEMBL1423728 & 688810 & 4.7330 & 000000000 & 305 & 5.079 & TRN \\
\hline CHEMBL1507986 & 688810 & 5.3829 & 999999999 & & 5.559 & N \\
\hline CHEMBL1320672 & 688810 & 6.433 & 5.1312 & TRN & & \\
\hline CHEMBL1426049 & 688810 & 4.933 & 5.0796 & TST & & \\
\hline CHEMBL1596663 & 688810 & 6.8329 & 999999999 & & 5.6596 & TRN \\
\hline CHEMBL1459373 & 688810 & 4.883 & 5.0438 & TRN & & \\
\hline CHEMBL1509905 & 688810 & 5.683 & 5.7578 & TRN & & \\
\hline CHEMBL1329938 & 688810 & 5.1329 & 999999999 & & 4.6 & \\
\hline CHEMBL1343769 & 688810 & 5.8829 & 999999999 & & 5.1352 & TST \\
\hline CHEMBL1507872 & 688810 & 5.483 & 5.1812 & TST & & \\
\hline CHEMBL1456847 & 688810 & 4.783 & 5.1549 & TRN & & \\
\hline CHEMBL1579416 & 688810 & 5.183 & 5.3709 & TRN & & \\
\hline CHEMBL1412192 & 688810 & 4.7330 & 000000000 & 305 & 4.9423 & \\
\hline CHEMBL1466167 & 688810 & 5.7829 & 999999999 & 995 & 5.7431 & TRN \\
\hline CHEMBL1504792 & 688810 & 4.9830 & 000000000 & 305 & 5.0584 & \\
\hline CHEMBL1569305 & 688810 & 6.0829 & 999999999 & & 5.7467 & TR \\
\hline CHEMBL1423628 & 688810 & 4.933 & 5.1872 & TRN & & \\
\hline CHEMBL1437881 & 688810 & 4.933 & 5.5813 & TRN & & \\
\hline CHEMBL1558989 & 688810 & 4.933 & 5.2911 & TRN & & \\
\hline CHEMBL 3211393 & 688810 & 4.833 & 5.1441 & TST & & \\
\hline CHEMBL69612 & 688810 & 4.9830 & 000000000 & 305 & 5.08 & \\
\hline CHEMBL1448670 & 688810 & 5.3829 & 999999999 & & 4.9933 & \\
\hline CHEMBL1593814 & 688810 & 4.583 & 4.8198 & TRN & & \\
\hline CHEMBL1449513 & 688810 & 5.7829 & 999999999 & 995 & 5.3647 & TRN \\
\hline CHEMBL 3191730 & 688810 & 5.933 & 5.8788 & TRN & & \\
\hline CHEMBL 3209207 & 688810 & 4.583 & 4.8524 & TST & & \\
\hline CHEMBL 3193256 & 688810 & 4.883 & 5.3576 & TRN & & \\
\hline CHEMBL1518677 & 688810 & 4.883 & 5.1074 & TRN & & \\
\hline CHEMBL1423461 & 688810 & 4.883 & 5.0124 & TRN & & \\
\hline CHEMBL1361740 & 688810 & 5.3329 & 999999999 & & 5.1651 & ונדו \\
\hline CHEMBL1340866 & 688810 & 4.9830 & 200000000 & 305 & 5.032 & TRN \\
\hline CHEMBL1483047 & 688810 & 4.783 & 4.9924 & TRN & & \\
\hline CHEMBL1432434 & 688810 & 6.2829 & 999999999 & 995 & 5.6371 & \\
\hline CHEMBL1468472 & 688810 & 4.833 & 5.5432 & TST & & \\
\hline
\end{tabular}




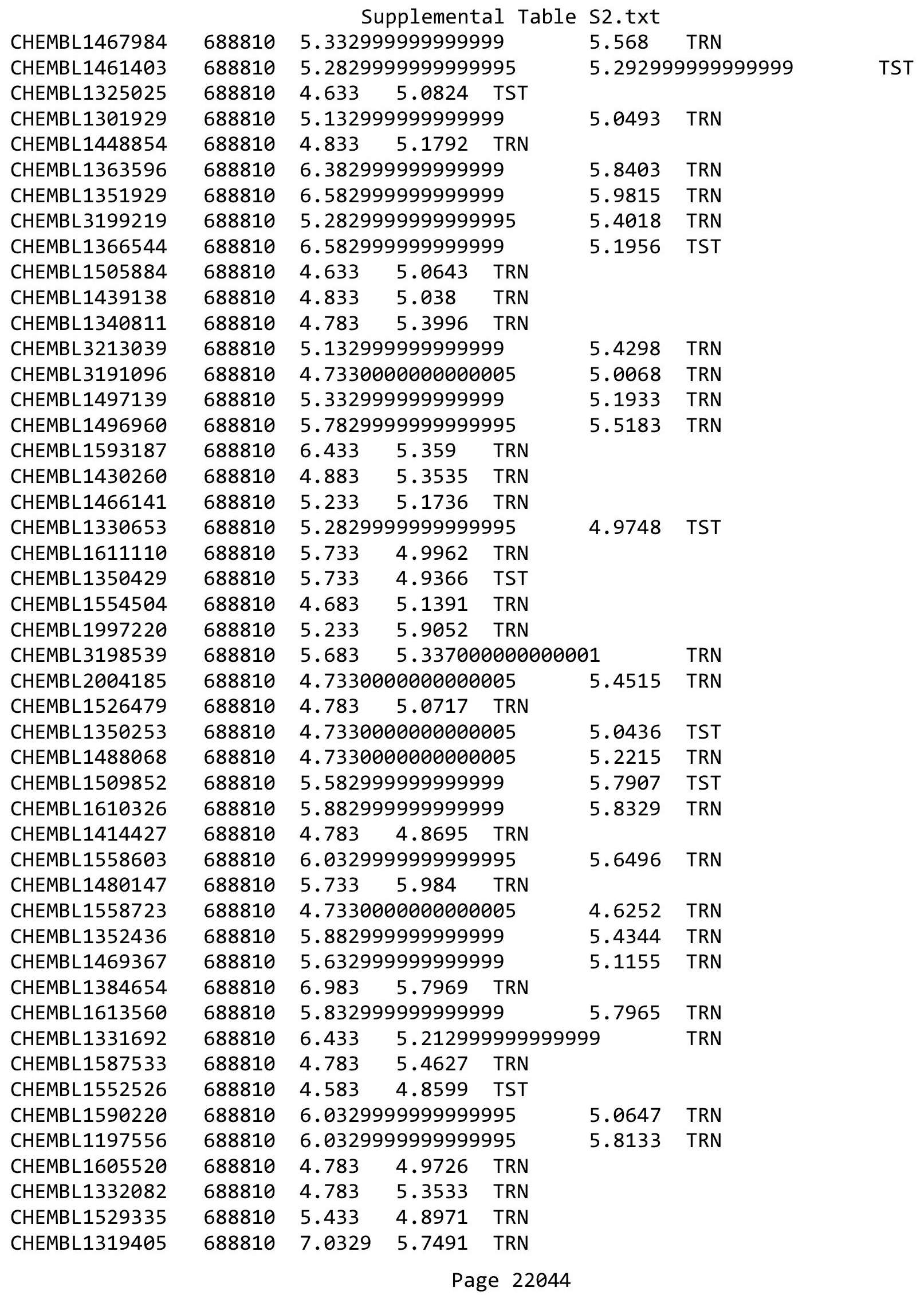




\begin{tabular}{|c|c|c|c|c|c|c|}
\hline \multirow{2}{*}{ CHEMBL1470236 } & \multicolumn{6}{|c|}{ Supplemental Table S2.txt } \\
\hline & 688810 & \multicolumn{4}{|c|}{6.382999999999999} & TST \\
\hline CHEMBL1471540 & 688810 & \multicolumn{3}{|c|}{6.0329999999999995} & 5.3121 & TRN \\
\hline CHEMBL1607304 & 688810 & \multicolumn{3}{|c|}{6.382999999999999} & 5.5005 & TRN \\
\hline CHEMBL1344426 & 688810 & 4.933 & 4.8465 & TST & & \\
\hline CHEMBL1495506 & 688810 & 5.183 & 5.3528 & TRN & & \\
\hline CHEMBL1577857 & 688810 & \multicolumn{3}{|c|}{6.7829999999999995} & 6.3502 & TRN \\
\hline CHEMBL1477425 & 688810 & 4.883 & 5.3414 & TST & & \\
\hline CHEMBL1449229 & 688810 & 4.883 & 5.6818 & TRN & & \\
\hline CHEMBL585439 & 688810 & \multicolumn{3}{|c|}{4.7330000000000005} & 4.7615 & TRN \\
\hline CHEMBL1502185 & 688810 & 6.183 & 5.3218 & TRN & & \\
\hline CHEMBL3193623 & 688810 & \multicolumn{3}{|c|}{6.632999999999999} & 6.0035 & TRN \\
\hline CHEMBL1511650 & 688810 & 4.783 & 5.3606 & TRN & & \\
\hline CHEMBL1440341 & 688810 & \multicolumn{3}{|c|}{5.882999999999999} & 5.5543 & TRN \\
\hline CHEMBL1486828 & 688810 & 6.0 & 5.3924 & TRN & & \\
\hline CHEMBL 3212450 & 688810 & \multicolumn{3}{|c|}{4.9830000000000005} & 5.3483 & TST \\
\hline CHEMBL1465434 & 688810 & \multicolumn{3}{|c|}{6.082999999999999} & 5.7728 & TRN \\
\hline CHEMBL1476167 & 688810 & 5.033 & 5.6692 & TRN & & \\
\hline CHEMBL1515189 & 688810 & \multicolumn{3}{|c|}{5.882999999999999} & 5.0568 & TST \\
\hline CHEMBL1529810 & 688810 & 5.083 & 5.4307 & TRN & & \\
\hline CHEMBL1459578 & 688810 & 4.583 & 5.3811 & TST & & \\
\hline CHEMBL1503754 & 688810 & 4.883 & 5.2553 & TRN & & \\
\hline CHEMBL1403095 & 688810 & 5.683 & 5.2026 & TRN & & \\
\hline CHEMBL1502936 & 688810 & \multicolumn{3}{|c|}{5.832999999999999} & 5.9096 & TRN \\
\hline CHEMBL1347487 & 688810 & \multicolumn{3}{|c|}{5.632999999999999} & 5.138 & TST \\
\hline CHEMBL1304131 & 688810 & 4.933 & 4.9903 & TST & & \\
\hline CHEMBL510132 & 688810 & \multicolumn{3}{|c|}{4.7330000000000005} & 5.2154 & TRN \\
\hline CHEMBL1339170 & 688810 & \multicolumn{3}{|c|}{4.7330000000000005} & 5.2684 & TRN \\
\hline CHEMBL1529039 & 688810 & 4.833 & 5.1904 & TRN & & \\
\hline CHEMBL1299745 & 688810 & 4.933 & 5.313 & TRN & & \\
\hline CHEMBL1320212 & 688810 & 4.783 & 5.1153 & TRN & & \\
\hline CHEMBL 3197533 & 688810 & 6.983 & 5.3508 & TRN & & \\
\hline CHEMBL1395678 & 688810 & 5.483 & 5.3413 & TRN & & \\
\hline CHEMBL1568301 & 688810 & 4.783 & 5.2605 & TRN & & \\
\hline CHEMBL1390385 & 688810 & 5.183 & 5.2812 & TRN & & \\
\hline CHEMBL1304092 & 688810 & 4.783 & 4.8161 & TRN & & \\
\hline CHEMBL1350287 & 688810 & 5.033 & 5.3987 & TRN & & \\
\hline CHEMBL71314 & 688810 & 4.783 & 5.2634 & TRN & & \\
\hline CHEMBL1418367 & 688810 & 5.532 & 99999999 & 995 & 5.2503 & TRN \\
\hline CHEMBL1558957 & 688810 & 4.633 & 5.1049 & TRN & & \\
\hline CHEMBL1387312 & 688810 & 4.783 & 5.6876 & TRN & & \\
\hline CHEMBL1457383 & 688810 & 4.783 & 4.6935 & TRN & & \\
\hline CHEMBL1369585 & 688810 & 4.633 & 4.8169 & TST & & \\
\hline CHEMBL3213759 & 688810 & 5.483 & 5.3042 & TST & & \\
\hline CHEMBL1538800 & 688810 & 4.783 & 5.1899 & TRN & & \\
\hline CHEMBL1516337 & 688810 & 5.233 & 5.6129 & TRN & & \\
\hline CHEMBL1981939 & 688810 & 4.933 & 5.3403 & TRN & & \\
\hline CHEMBL1498178 & 688810 & 5.933 & 5.7395 & TRN & & \\
\hline CHEMBL1496611 & 688810 & \multicolumn{3}{|c|}{6.382999999999999} & 5.8606 & TRN \\
\hline
\end{tabular}




\begin{tabular}{|c|c|c|c|c|c|c|}
\hline & & \multicolumn{5}{|c|}{ Supplemental Table S2.txt } \\
\hline CHEMBL1463172 & 688810 & 4.783 & 4.7739 & TST & & \\
\hline CHEMBL1367850 & 688810 & 4.883 & 5.5886 & TRN & & \\
\hline CHEMBL1412583 & 688810 & 4.883 & 5.1735 & TST & & \\
\hline CHEMBL1504077 & 688810 & 5.433 & 5.2063 & TRN & & \\
\hline CHEMBL3189645 & 688810 & 4.883 & 5.3958 & TST & & \\
\hline CHEMBL1482449 & 688810 & 5.733 & 5.8226 & TRN & & \\
\hline CHEMBL1537245 & 688810 & 4.783 & 5.1637 & TRN & & \\
\hline CHEMBL1347011 & 688810 & 6.433 & 5.8671 & TRN & & \\
\hline CHEMBL1542512 & 688810 & 4.833 & 4.8184 & TST & & \\
\hline CHEMBL1363756 & 688810 & 4.583 & 4.864 & TRN & & \\
\hline CHEMBL1384936 & 688810 & \multicolumn{3}{|c|}{4.7330000000000005} & 4.8891 & TRN \\
\hline CHEMBL1320211 & 688810 & 5.433 & 5.5465 & TRN & & \\
\hline CHEMBL1314271 & 688810 & 4.783 & 5.1466 & TST & & \\
\hline CHEMBL1985350 & 688810 & 4.633 & 4.9563 & TST & & \\
\hline CHEMBL1459759 & 688810 & 4.883 & 5.1523 & TRN & & \\
\hline CHEMBL1555979 & 688810 & \multicolumn{3}{|c|}{6.582999999999999} & 6.3702 & TRN \\
\hline CHEMBL1312674 & 688810 & \multicolumn{3}{|c|}{5.832999999999999} & 5.2351 & TST \\
\hline CHEMBL1480704 & 688810 & \multicolumn{3}{|c|}{6.132999999999999} & 5.2342 & TRN \\
\hline CHEMBL1586460 & 688810 & 6.433 & 5.6445 & TRN & & \\
\hline CHEMBL1456578 & 688810 & 4.933 & 5.279 & TRN & & \\
\hline CHEMBL1340407 & 688810 & 5.933 & 5.6538 & TRN & & \\
\hline CHEMBL1557974 & 688810 & \multicolumn{3}{|c|}{5.2829999999999995} & 5.7189 & TRN \\
\hline CHEMBL1565155 & 688810 & \multicolumn{3}{|c|}{5.132999999999999} & 5.1645 & TRN \\
\hline CHEMBL1311874 & 688810 & 4.833 & 5.3369 & TRN & & \\
\hline CHEMBL1401450 & 688810 & 4.783 & 5.2562 & TST & & \\
\hline CHEMBL3191821 & 688810 & 4.783 & 5.0673 & TST & & \\
\hline CHEMBL1477528 & 688810 & 5.033 & 4.9074 & TRN & & \\
\hline CHEMBL1359055 & 688810 & 4.783 & 5.1412 & TST & & \\
\hline CHEMBL1396329 & 688810 & 4.833 & 5.4782 & TRN & & \\
\hline CHEMBL1361242 & 688810 & \multicolumn{3}{|c|}{5.7829999999999995} & 5.6605 & TRN \\
\hline CHEMBL1609493 & 688810 & \multicolumn{3}{|c|}{4.7330000000000005} & 4.8902 & TRN \\
\hline CHEMBL1345709 & 688810 & 5.233 & 5.1255 & TST & & \\
\hline CHEMBL51085 & 688810 & 4.833 & 5.4763 & TST & & \\
\hline CHEMBL1528872 & 688810 & 5.433 & 4.8778 & TRN & & \\
\hline CHEMBL1395300 & 688810 & 4.633 & 4.7472 & TST & & \\
\hline CHEMBL1341995 & 688810 & 5.183 & 5.1035 & TRN & & \\
\hline CHEMBL1400589 & 688810 & 5.983 & 6.2666 & TRN & & \\
\hline CHEMBL1607515 & 688810 & \multicolumn{3}{|c|}{6.382999999999999} & 6.2628 & TRN \\
\hline CHEMBL1361072 & 688810 & \multicolumn{3}{|c|}{4.7330000000000005} & 4.3117 & TST \\
\hline CHEMBL1387868 & 688810 & 5.083 & 5.4699 & TRN & & \\
\hline CHEMBL1382250 & 688810 & 4.833 & 5.1545 & TRN & & \\
\hline CHEMBL1501169 & 688810 & 5.483 & 5.4806 & TST & & \\
\hline CHEMBL1422995 & 688810 & \multicolumn{3}{|c|}{4.9830000000000005} & 5.0657 & TRN \\
\hline CHEMBL1331362 & 688810 & \multicolumn{3}{|c|}{5.5329999999999995} & 5.2141 & TRN \\
\hline CHEMBL1533279 & 688810 & 4.783 & 5.1171 & TST & & \\
\hline CHEMBL1612916 & 688810 & \multicolumn{3}{|c|}{6.2829999999999995} & 4.9312 & TST \\
\hline CHEMBL1326083 & 688810 & 5.233 & 5.0623 & TST & & \\
\hline CHEMBL1326403 & 688810 & 4.583 & 4.3665 & TRN & & \\
\hline
\end{tabular}




\begin{tabular}{|c|c|c|c|c|c|c|c|}
\hline \multicolumn{7}{|c|}{ Supplemental Table S2.txt } & \\
\hline CHEMBL1300723 & 688810 & 6.9329 & 6.2531 & TRN & & & \\
\hline CHEMBL1600282 & 688810 & 4.833 & 5.4525 & TRN & & & \\
\hline CHEMBL1456099 & 688810 & 5.033 & 5.4917 & TRN & & & \\
\hline CHEMBL1602453 & 688810 & 4.783 & 5.1947 & TRN & & & \\
\hline CHEMBL1382006 & 688810 & 4.683 & 5.2385 & TRN & & & \\
\hline CHEMBL1403085 & 688810 & 5.033 & 5.0569 & TRN & & & \\
\hline CHEMBL1344529 & 688810 & 6.63299 & 99999999 & & 5.8969 & TRN & \\
\hline CHEMBL1419839 & 688810 & 5.683 & 6.2098 & TRN & & & \\
\hline CHEMBL1442134 & 688810 & 4.633 & 4.9911 & TST & & & \\
\hline CHEMBL1508071 & 688810 & 4.73300 & 00000000 & 005 & 5.3972 & TRN & \\
\hline CHEMBL1997837 & 688810 & 4.98300 & 00000000 & 005 & 5.4411 & TRN & \\
\hline CHEMBL3194833 & 688810 & 4.583 & 4.9897 & TRN & & & \\
\hline CHEMBL1583290 & 688810 & 5.483 & 5.0236 & TRN & & & \\
\hline CHEMBL1549247 & 688810 & 4.833 & 5.1607 & TRN & & & \\
\hline CHEMBL1478611 & 688810 & 4.833 & 5.3187 & TST & & & \\
\hline CHEMBL1490190 & 688810 & 5.13299 & 99999999 & & 5.374 & TRN & \\
\hline CHEMBL1397620 & 688810 & 5.28299 & 99999999 & 995 & 5.008 & TRN & \\
\hline CHEMBL3190328 & 688810 & 4.833 & 4.7661 & TRN & & & \\
\hline CHEMBL3191163 & 688810 & 4.683 & 5.2983 & TRN & & & \\
\hline CHEMBL1613064 & 688810 & 4.683 & 5.0187 & TST & & & \\
\hline CHEMBL1517894 & 688810 & 5.733 & 5.381 & TRN & & & \\
\hline CHEMBL1473009 & 688810 & 4.633 & 4.9411 & TRN & & & \\
\hline CHEMBL1322104 & 688810 & 5.83299 & 99999999 & & 5.5896 & TRN & \\
\hline CHEMBL1497828 & 688810 & 4.833 & 5.1813 & TRN & & & \\
\hline CHEMBL1477009 & 688810 & 4.633 & 5.07 & TRN & & & \\
\hline CHEMBL1490493 & 688810 & 5.483 & 5.6435 & TST & & & \\
\hline CHEMBL1241452 & 688810 & 5.13299 & 99999999 & & 5.5504 & TST & \\
\hline CHEMBL1506896 & 688810 & 4.98300 & 00000000 & 005 & 5.0848 & TRN & \\
\hline CHEMBL3212340 & 688810 & 4.833 & 5.0515 & TST & & & \\
\hline CHEMBL1412761 & 688810 & 6.03299 & 99999999 & 995 & 4.8849 & TRN & \\
\hline CHEMBL1335365 & 688810 & 5.28299 & 99999999 & 995 & 4.7526 & TRN & \\
\hline CHEMBL1529772 & 688810 & 4.883 & 5.2703 & TRN & & & \\
\hline CHEMBL1347256 & 688810 & 4.933 & 5.1691 & TRN & & & \\
\hline CHEMBL1602012 & 688810 & 5.13299 & 99999999 & & 5.0679 & TRN & \\
\hline CHEMBL1581233 & 688810 & 5.033 & 4.7269 & TST & & & \\
\hline CHEMBL1428789 & 688810 & 5.28299 & 99999999 & 995 & 4.9141 & TST & \\
\hline CHEMBL1422242 & 688810 & 5.083 & 5.3029 & TRN & & & \\
\hline CHEMBL1372530 & 688810 & 4.73300 & 00000000 & 005 & 5.3936 & TRN & \\
\hline CHEMBL1551318 & 688810 & 4.783 & 5.3735 & TST & & & \\
\hline CHEMBL1502830 & 688810 & 4.583 & 4.9358 & TST & & & \\
\hline CHEMBL1310000 & 688810 & 5.13299 & 99999999 & & 5.5029 & 9999999999 & TRN \\
\hline CHEMBL1319679 & 688810 & 6.7331 & 5.6973 & TRN & & & \\
\hline CHEMBL1531992 & 688810 & 5.683 & 5.7901 & TRN & & & \\
\hline CHEMBL1462179 & 688810 & 5.433 & 5.3867 & TRN & & & \\
\hline CHEMBL1382374 & 688810 & 5.88299 & 99999999 & & 5.0646 & TRN & \\
\hline CHEMBL3213483 & 688810 & 5.78299 & 99999999 & 995 & 5.5266 & TRN & \\
\hline CHEMBL1438948 & 688810 & 4.783 & 5.1367 & TRN & & & \\
\hline CHEMBL1555409 & 688810 & 5.28299 & 99999999 & 995 & 4.9998 & TRN & \\
\hline
\end{tabular}




\begin{tabular}{|c|c|c|c|c|c|c|}
\hline & & & 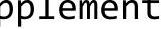 & & & \\
\hline CHEMBL1389335 & 688810 & 5.233 & 6.0004 & TRN & & \\
\hline CHEMBL1490730 & 688810 & 6.0 & 5.7029 & TRN & & \\
\hline CHEMBL1337718 & 688810 & 5.1329 & 99999999 & 99 & 5.4475 & TRN \\
\hline CHEMBL1393538 & 688810 & 4.7330 & 00000000 & 005 & 4.8787 & TRN \\
\hline CHEMBL1610831 & 688810 & 4.633 & 5.1187 & TST & & \\
\hline CHEMBL1546756 & 688810 & 4.933 & 5.0766 & TST & & \\
\hline CHEMBL1506330 & 688810 & 6.0829 & 99999999 & 99 & 5.6615 & TRN \\
\hline CHEMBL1373280 & 688810 & 4.7330 & 00000000 & 005 & 5.0585 & TRN \\
\hline CHEMBL1502184 & 688810 & 5.933 & 5.5834 & TRN & & \\
\hline CHEMBL1553519 & 688810 & 5.5329 & 99999999 & 995 & 5.3147 & TRN \\
\hline CHEMBL1558553 & 688810 & 5.6329 & 99999999 & 99 & 5.2554 & TRN \\
\hline CHEMBL1310663 & 688810 & 5.5329 & 99999999 & 995 & 5.3193 & TST \\
\hline CHEMBL1468996 & 688810 & 4.833 & 5.0776 & TRN & & \\
\hline CHEMBL1413003 & 688810 & 5.233 & 4.7366 & TRN & & \\
\hline CHEMBL1596046 & 688810 & 6.3829 & 99999999 & & 6.358 & TRN \\
\hline CHEMBL1478388 & 688810 & 5.733 & 5.5987 & TRN & & \\
\hline CHEMBL3190684 & 688810 & 4.583 & 5.6381 & TRN & & \\
\hline CHEMBL 3212830 & 688810 & 6.0 & 5.7079 & TRN & & \\
\hline CHEMBL1519034 & 688810 & 6.3329 & 99999999 & & 5.7635 & TRN \\
\hline CHEMBL1308129 & 688810 & 4.633 & 4.8629 & TST & & \\
\hline CHEMBL1338671 & 688810 & 5.183 & 5.3351 & TRN & & \\
\hline CHEMBL1344848 & 688810 & 6.8831 & 5.6961 & TRN & & \\
\hline CHEMBL1583323 & 688810 & 5.683 & 5.5669 & TRN & & \\
\hline CHEMBL1326292 & 688810 & 5.5829 & 99999999 & & 5.7023 & TRN \\
\hline CHEMBL1386344 & 688810 & 5.3329 & 99999999 & & 4.523 & TST \\
\hline CHEMBL1569626 & 688810 & 4.7330 & 00000000 & 005 & 5.5368 & TRN \\
\hline CHEMBL 2003831 & 688810 & 5.2829 & 99999999 & 995 & 5.3558 & TRN \\
\hline CHEMBL1432754 & 688810 & 4.783 & 4.88899 & 999999999 & 9 & TRN \\
\hline CHEMBL1377357 & 688810 & 4.7330 & 00000000 & 005 & 5.4339 & TRN \\
\hline CHEMBL1447750 & 688810 & 6.433 & 5.3485 & TRN & & \\
\hline CHEMBL1538692 & 688810 & 5.233 & 5.1858 & TRN & & \\
\hline CHEMBL1299674 & 688810 & 5.233 & 6.0008 & TRN & & \\
\hline CHEMBL3199473 & 688810 & 4.833 & 5.3517 & TRN & & \\
\hline CHEMBL1398960 & 688810 & 5.3829 & 99999999 & & 4.9398 & TRN \\
\hline CHEMBL1484995 & 688810 & 8.7959 & 5.362 & TST & & \\
\hline CHEMBL1407552 & 688810 & 6.5829 & 99999999 & & 5.7209 & TRN \\
\hline CHEMBL1342054 & 688810 & 4.7330 & 00000000 & 005 & 4.8759 & TRN \\
\hline CHEMBL1410600 & 688810 & 4.883 & 5.0774 & TRN & & \\
\hline CHEMBL1427698 & 688810 & 4.7330 & 00000000 & 005 & 5.2346 & TRN \\
\hline CHEMBL2311901 & 688810 & 5.3329 & 99999999 & & 5.0494 & TRN \\
\hline CHEMBL1356647 & 688810 & 6.0329 & 99999999 & 995 & 5.5635 & TRN \\
\hline CHEMBL1325021 & 688810 & 4.783 & 4.8371 & TRN & & \\
\hline CHEMBL1566827 & 688810 & 4.883 & 5.1693 & TRN & & \\
\hline CHEMBL1310761 & 688810 & 5.183 & 5.2632 & TRN & & \\
\hline CHEMBL1368024 & 688810 & 4.9830 & $\partial 0000000$ & 005 & 5.1278 & TRN \\
\hline CHEMBL1376008 & 688810 & 4.833 & 5.0812 & TST & & \\
\hline CHEMBL1362867 & 688810 & 4.833 & 5.0927 & TRN & & \\
\hline CHEMBL1529662 & 688810 & 4.783 & 5.2004 & TRN & & \\
\hline
\end{tabular}




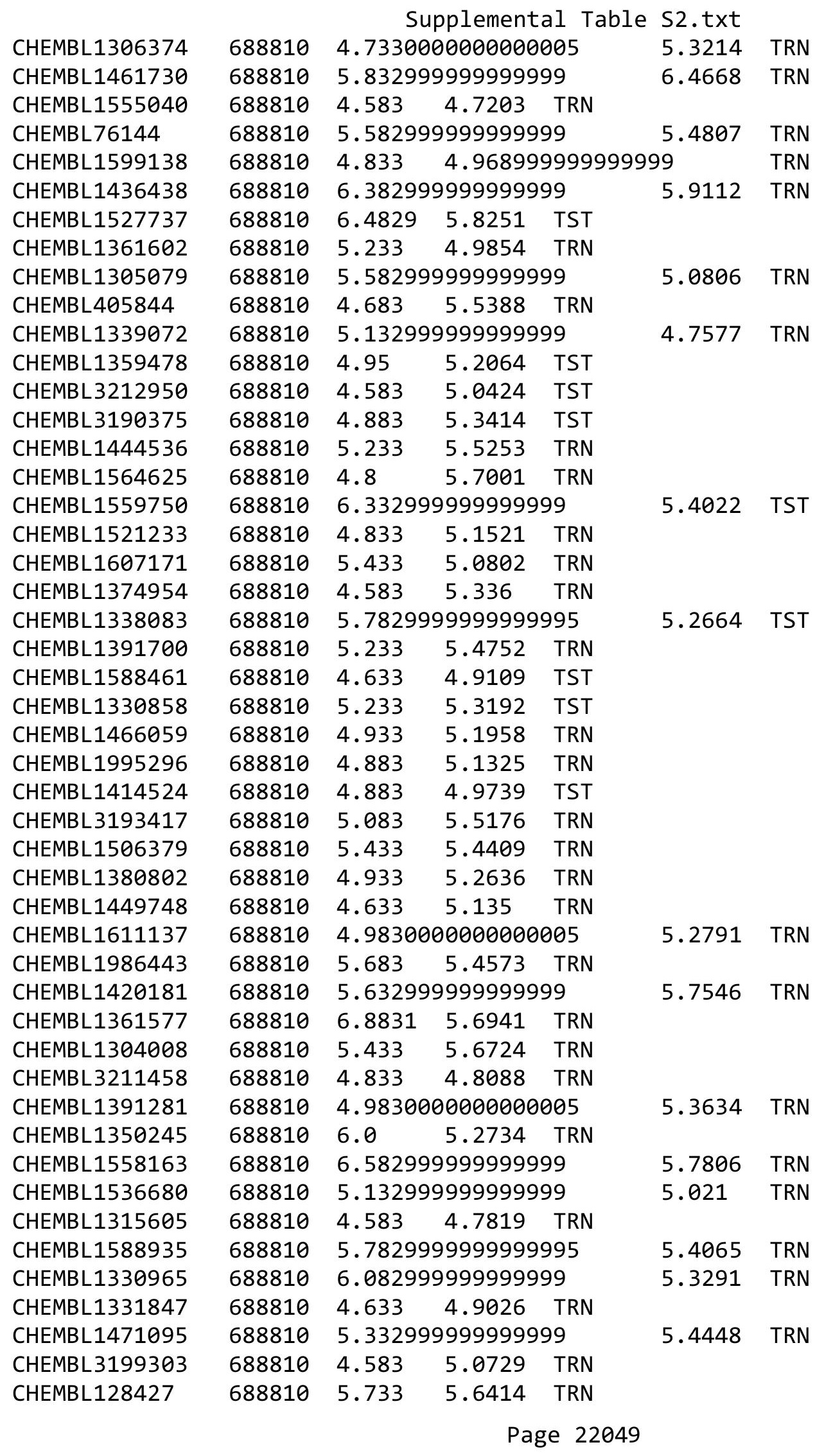




\begin{tabular}{|c|c|c|c|c|c|c|}
\hline \multirow[b]{2}{*}{ CHEMBL1432720 } & & \multicolumn{5}{|c|}{ Supplemental Table S2.txt } \\
\hline & 688810 & 4.783 & 4.849 & TRN & & \\
\hline CHEMBL1356996 & 688810 & 4.783 & 5.391 & TST & & \\
\hline CHEMBL1543762 & 688810 & 5.683 & 5.6471 & TRN & & \\
\hline CHEMBL1534478 & 688810 & 5.033 & 5.3863 & TST & & \\
\hline CHEMBL1443608 & 688810 & \multicolumn{3}{|c|}{5.332999999999999} & 5.2644 & TRN \\
\hline CHEMBL1576649 & 688810 & \multicolumn{3}{|c|}{5.882999999999999} & 5.6007 & TRN \\
\hline CHEMBL1429089 & 688810 & 4.833 & 5.0691 & TRN & & \\
\hline CHEMBL1487204 & 688810 & 4.833 & 5.7218 & TST & & \\
\hline CHEMBL602970 & 688810 & 5.733 & 5.7082 & TRN & & \\
\hline CHEMBL1428961 & 688810 & 5.733 & 5.682 & TRN & & \\
\hline CHEMBL3198735 & 688810 & 4.783 & 5.4177 & TRN & & \\
\hline CHEMBL1309290 & 688810 & 4.633 & 4.9384 & TST & & \\
\hline CHEMBL3195053 & 688810 & 4.833 & 5.3884 & TRN & & \\
\hline CHEMBL1305292 & 688810 & 4.633 & 5.1513 & TRN & & \\
\hline CHEMBL1549883 & 688810 & 4.683 & 4.6474 & TST & & \\
\hline CHEMBL1610124 & 688810 & 6.233 & 5.625 & TRN & & \\
\hline CHEMBL1485198 & 688810 & 4.583 & 5.2715 & TRN & & \\
\hline CHEMBL199868 & 688810 & \multicolumn{3}{|c|}{4.7330000000000005} & 5.6315 & TRN \\
\hline CHEMBL1472950 & 688810 & \multicolumn{3}{|c|}{4.9830000000000005} & 5.4333 & TRN \\
\hline CHEMBL365939 & 688810 & 5.183 & 5.3762 & TRN & & \\
\hline CHEMBL 2002818 & 688810 & \multicolumn{3}{|c|}{5.132999999999999} & 5.3108 & TRN \\
\hline CHEMBL3216654 & 688810 & 5.433 & 5.1572 & TST & & \\
\hline CHEMBL1499306 & 688810 & 5.433 & 5.2062 & TRN & & \\
\hline CHEMBL1567301 & 688810 & 4.783 & 4.9953 & TST & & \\
\hline CHEMBL1481264 & 688810 & \multicolumn{3}{|c|}{4.7330000000000005} & 5.1016 & TST \\
\hline CHEMBL1546773 & 688810 & 5.733 & 4.9734 & TRN & & \\
\hline CHEMBL1439235 & 688810 & 5.183 & 5.3454 & TRN & & \\
\hline CHEMBL1600758 & 688810 & 4.783 & 4.8802 & TRN & & \\
\hline CHEMBL1335795 & 688810 & 4.783 & 4.9746 & TST & & \\
\hline CHEMBL1610061 & 688810 & 4.883 & 5.4194 & TRN & & \\
\hline CHEMBL1361077 & 688810 & 4.633 & 5.2765 & TRN & & \\
\hline CHEMBL1445264 & 688810 & \multicolumn{3}{|c|}{5.7829999999999995} & 5.052 & TRN \\
\hline CHEMBL1419856 & 688810 & 4.883 & 4.996 & TRN & & \\
\hline CHEMBL1583285 & 688810 & \multicolumn{3}{|c|}{4.7330000000000005} & 5.1607 & TRN \\
\hline CHEMBL1533657 & 688810 & 6.4829 & 5.6178 & TRN & & \\
\hline CHEMBL1387736 & 688810 & 4.833 & 5.1032 & TRN & & \\
\hline CHEMBL1386099 & 688810 & 6.4829 & 5.7884 & TRN & & \\
\hline CHEMBL1454767 & 688810 & 5.083 & 4.9232 & TRN & & \\
\hline CHEMBL1503339 & 688810 & \multicolumn{3}{|c|}{5.882999999999999} & 5.3589 & TRN \\
\hline CHEMBL1351959 & 688810 & 4.833 & 5.2626 & TRN & & \\
\hline CHEMBL1610118 & 688810 & 6.183 & 5.0729 & TRN & & \\
\hline CHEMBL1467239 & 688810 & \multicolumn{3}{|c|}{5.7829999999999995} & 4.8817 & TRN \\
\hline CHEMBL1490671 & 688810 & 6.4829 & 6.0015 & TST & & \\
\hline CHEMBL1403203 & 688810 & \multicolumn{3}{|c|}{4.9830000000000005} & 5.4566 & TST \\
\hline CHEMBL1339090 & 688810 & 4.783 & 4.9243 & TST & & \\
\hline CHEMBL1322617 & 688810 & \multicolumn{3}{|c|}{4.7330000000000005} & 5.1829 & TST \\
\hline CHEMBL1541008 & 688810 & 4.883 & 5.822 & TST & & \\
\hline CHEMBL1374673 & 688810 & 5.0 & 5.2139 & TST & & \\
\hline
\end{tabular}




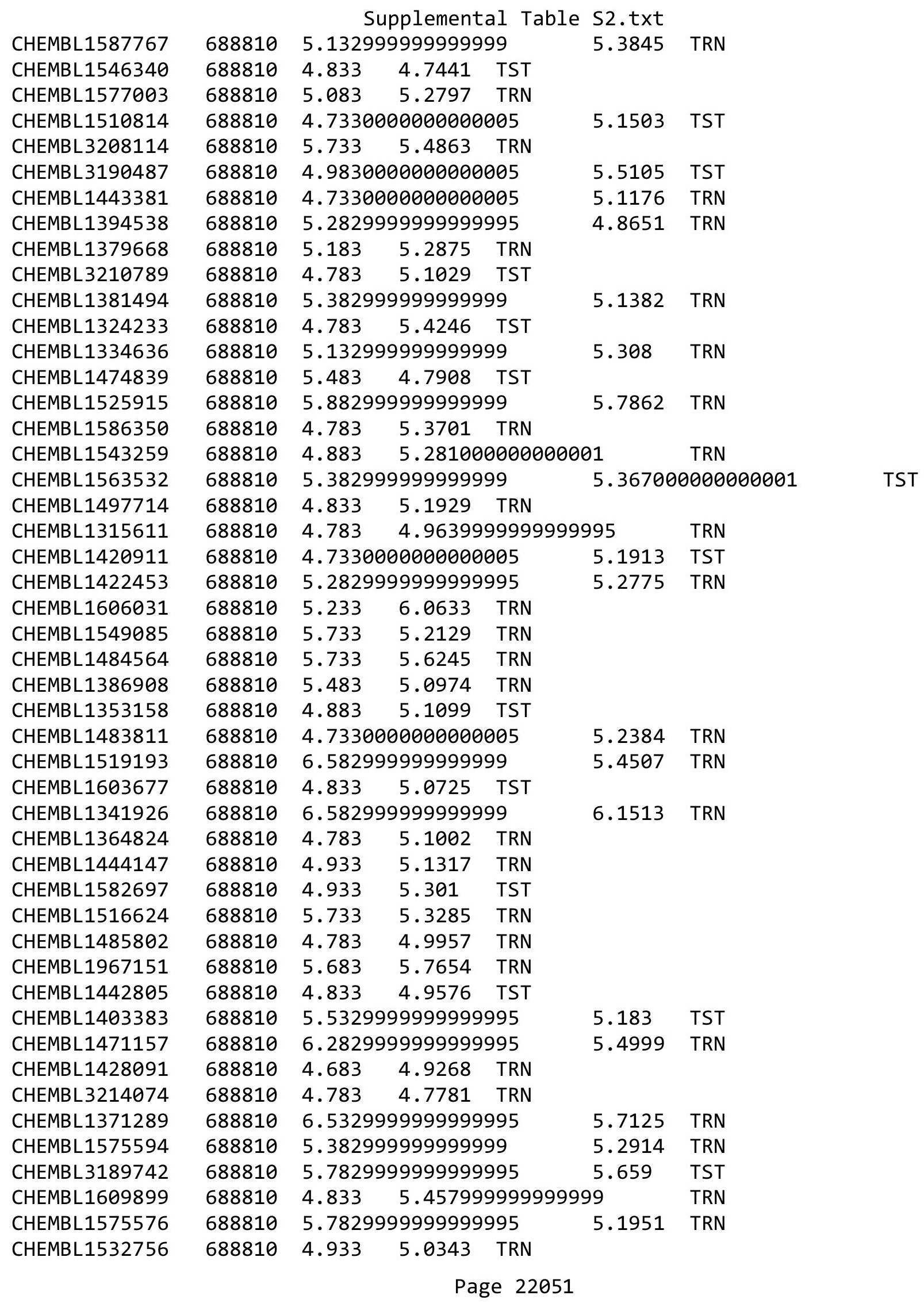




\begin{tabular}{|c|c|c|c|c|c|c|c|}
\hline \multicolumn{7}{|c|}{ Supplemental Table S2.txt } & \\
\hline CHEMBL1485463 & 688810 & 4.583 & \multicolumn{3}{|c|}{5.0969999999999995} & TRN & \\
\hline CHEMBL1308481 & 688810 & 4.833 & 4.9028 & TST & & & \\
\hline CHEMBL1429812 & 688810 & 4.783 & 5.3933 & TRN & & & \\
\hline CHEMBL1529007 & 688810 & \multicolumn{3}{|c|}{6.132999999999999} & \multicolumn{2}{|c|}{5.2829999999999995} & TRN \\
\hline CHEMBL1496410 & 688810 & \multicolumn{3}{|c|}{4.9830000000000005} & 4.9973 & TRN & \\
\hline CHEMBL 3194080 & 688810 & 4.833 & 5.4571 & TRN & & & \\
\hline CHEMBL1516339 & 688810 & 5.433 & 6.0708 & TRN & & & \\
\hline CHEMBL1319737 & 688810 & \multicolumn{3}{|c|}{5.882999999999999} & 5.164 & TRN & \\
\hline CHEMBL1309463 & 688810 & 4.833 & 4.718 & TRN & & & \\
\hline CHEMBL1524438 & 688810 & 5.233 & 4.7678 & TRN & & & \\
\hline CHEMBL 3212638 & 688810 & 4.883 & 5.3899 & TRN & & & \\
\hline CHEMBL1519620 & 688810 & 4.883 & 4.9801 & TST & & & \\
\hline CHEMBL1440284 & 688810 & 5.683 & 5.5155 & TRN & & & \\
\hline CHEMBL1436168 & 688810 & 5.733 & 5.2884 & TRN & & & \\
\hline CHEMBL1318630 & 688810 & 6.0 & 5.2242 & TST & & & \\
\hline CHEMBL 3213329 & 688810 & \multicolumn{3}{|c|}{5.832999999999999} & 5.1415 & TST & \\
\hline CHEMBL1588436 & 688810 & 4.883 & 5.0022 & TST & & & \\
\hline CHEMBL1420528 & 688810 & 5.983 & 5.2731 & TST & & & \\
\hline CHEMBL1490325 & 688810 & \multicolumn{3}{|c|}{5.332999999999999} & 5.0733 & TRN & \\
\hline CHEMBL1492780 & 688810 & \multicolumn{3}{|c|}{5.332999999999999} & 5.3518 & TRN & \\
\hline CHEMBL1585028 & 688810 & \multicolumn{3}{|c|}{5.5329999999999995} & 5.2869 & TRN & \\
\hline CHEMBL1604825 & 688810 & 4.833 & 5.0856 & TRN & & & \\
\hline CHEMBL1347974 & 688810 & \multicolumn{3}{|c|}{4.7330000000000005} & 5.1965 & TRN & \\
\hline CHEMBL1313121 & 688810 & 4.633 & \multicolumn{3}{|c|}{4.7219999999999995} & TRN & \\
\hline CHEMBL1361526 & 688810 & 5.733 & 5.3736 & TRN & & & \\
\hline CHEMBL1465969 & 688810 & 5.433 & 5.5107 & TRN & & & \\
\hline CHEMBL1509343 & 688810 & 4.683 & 5.2982 & TRN & & & \\
\hline CHEMBL1401707 & 688810 & \multicolumn{3}{|c|}{5.832999999999999} & 5.5512 & TRN & \\
\hline CHEMBL1579785 & 688810 & 4.833 & 5.0778 & TRN & & & \\
\hline CHEMBL3192027 & 688810 & \multicolumn{3}{|c|}{5.382999999999999} & 5.2311 & TRN & \\
\hline CHEMBL1312469 & 688810 & \multicolumn{3}{|c|}{4.9830000000000005} & 4.9745 & TRN & \\
\hline CHEMBL1463989 & 688810 & 6.233 & 5.1118 & TRN & & & \\
\hline CHEMBL1413509 & 688810 & 4.883 & 5.022 & TRN & & & \\
\hline CHEMBL1439341 & 688810 & 4.683 & 5.1905 & TRN & & & \\
\hline CHEMBL1353077 & 688810 & \multicolumn{3}{|c|}{4.7330000000000005} & 4.7082 & TRN & \\
\hline CHEMBL1495376 & 688810 & 6.7331 & 5.9585 & TRN & & & \\
\hline CHEMBL 3209333 & 688810 & 4.833 & 5.3306 & TST & & & \\
\hline CHEMBL 1582551 & 688810 & 4.633 & 5.3368 & TST & & & \\
\hline CHEMBL1329038 & 688810 & 4.783 & 4.82 & TRN & & & \\
\hline CHEMBL1341919 & 688810 & 4.783 & 5.1477 & TST & & & \\
\hline CHEMBL1303275 & 688810 & \multicolumn{3}{|c|}{4.7330000000000005} & 5.1322 & TST & \\
\hline CHEMBL1569154 & 688810 & 4.85 & 5.4239 & TRN & & & \\
\hline CHEMBL1349524 & 688810 & 4.933 & 5.0992 & TRN & & & \\
\hline CHEMBL1599794 & 688810 & 5.233 & 5.4386 & TST & & & \\
\hline CHEMBL1540432 & 688810 & \multicolumn{3}{|c|}{4.7330000000000005} & 5.2151 & TRN & \\
\hline CHEMBL1401550 & 688810 & 5.233 & 5.1437 & TRN & & & \\
\hline CHEMBL1412271 & 688810 & 5.233 & 4.9634 & TST & & & \\
\hline CHEMBL1506222 & 688810 & 5.933 & 5.4204 & TRN & & & \\
\hline
\end{tabular}




\begin{tabular}{|c|c|c|c|c|c|c|c|}
\hline \multicolumn{8}{|c|}{ pplemental Ta } \\
\hline CHEMBL1322766 & 688810 & 4.633 & 4.9022 & TRN & & & \\
\hline CHEMBL1392808 & 688810 & \multicolumn{3}{|c|}{5.7829999999999995} & 5.7902 & TRN & \\
\hline CHEMBL3189998 & 688810 & \multicolumn{3}{|c|}{5.132999999999999} & 5.2474 & TRN & \\
\hline CHEMBL1346860 & 688810 & 4.683 & 5.351 & TST & & & \\
\hline CHEMBL1483788 & 688810 & \multicolumn{3}{|c|}{4.7330000000000005} & 4.8101 & TST & \\
\hline CHEMBL1495706 & 688810 & \multicolumn{3}{|c|}{5.7829999999999995} & 5.0483 & TRN & \\
\hline CHEMBL1612398 & 688810 & 4.783 & 5.3221 & TST & & & \\
\hline CHEMBL1559323 & 688810 & \multicolumn{3}{|c|}{4.7330000000000005} & 5.2031 & TRN & \\
\hline CHEMBL1412674 & 688810 & \multicolumn{3}{|c|}{5.832999999999999} & 5.1022 & TST & \\
\hline CHEMBL1339347 & 688810 & 4.783 & 5.1072 & TRN & & & \\
\hline CHEMBL1347609 & 688810 & \multicolumn{3}{|c|}{5.132999999999999} & 5.312 & TRN & \\
\hline CHEMBL1567961 & 688810 & 5.183 & 5.1208 & TRN & & & \\
\hline CHEMBL3194933 & 688810 & 5.483 & 4.9386 & TST & & & \\
\hline CHEMBL1371987 & 688810 & \multicolumn{3}{|c|}{4.9830000000000005} & 5.3261 & TRN & \\
\hline CHEMBL1404174 & 688810 & 4.883 & 5.1136 & TRN & & & \\
\hline CHEMBL1514008 & 688810 & 4.583 & 4.9841 & TRN & & & \\
\hline CHEMBL1594726 & 688810 & \multicolumn{3}{|c|}{5.132999999999999} & 5.5712 & TRN & \\
\hline CHEMBL1488052 & 688810 & 4.833 & 4.9437 & TRN & & & \\
\hline CHEMBL1591345 & 688810 & 5.983 & 5.2244 & TRN & & & \\
\hline CHEMBL1402428 & 688810 & 4.833 & 4.8689 & TRN & & & \\
\hline CHEMBL3195823 & 688810 & 5.033 & 5.3894 & TRN & & & \\
\hline CHEMBL1509409 & 688810 & 5.433 & 5.0156 & TRN & & & \\
\hline CHEMBL1489148 & 688810 & 4.883 & 5.2951 & TRN & & & \\
\hline CHEMBL 3210363 & 688810 & 4.933 & 5.1924 & TRN & & & \\
\hline CHEMBL1594948 & 688810 & \multicolumn{3}{|c|}{5.7829999999999995} & \multicolumn{2}{|c|}{5.4110000000000005} & TRN \\
\hline CHEMBL1412416 & 688810 & \multicolumn{3}{|c|}{6.0329999999999995} & 5.6553 & TRN & \\
\hline CHEMBL1345315 & 688810 & 5.083 & 5.0113 & TRN & & & \\
\hline CHEMBL3194960 & 688810 & 4.933 & 4.8534 & TST & & & \\
\hline CHEMBL1524960 & 688810 & 4.833 & 4.9109 & TRN & & & \\
\hline CHEMBL1304631 & 688810 & \multicolumn{3}{|c|}{5.882999999999999} & 5.4984 & TRN & \\
\hline CHEMBL1530924 & 688810 & \multicolumn{3}{|c|}{5.882999999999999} & 5.4242 & TST & \\
\hline CHEMBL1454860 & 688810 & \multicolumn{3}{|c|}{5.5329999999999995} & 5.1234 & TRN & \\
\hline CHEMBL1302481 & 688810 & \multicolumn{3}{|c|}{4.7330000000000005} & 5.125 & TRN & \\
\hline CHEMBL1613002 & 688810 & 4.883 & 4.8545 & TST & & & \\
\hline CHEMBL1361718 & 688810 & \multicolumn{3}{|c|}{4.7330000000000005} & 5.2085 & TRN & \\
\hline CHEMBL1445702 & 688810 & \multicolumn{3}{|c|}{5.832999999999999} & 5.5617 & TRN & \\
\hline CHEMBL3190186 & 688810 & 4.833 & 4.9391 & TST & & & \\
\hline CHEMBL 1557380 & 688810 & 4.933 & 5.0566 & TRN & & & \\
\hline CHEMBL1320352 & 688810 & 5.933 & 5.3405 & TRN & & & \\
\hline CHEMBL344344 & 688810 & 4.783 & 5.0883 & TRN & & & \\
\hline CHEMBL1347057 & 688810 & \multicolumn{3}{|c|}{6.082999999999999} & 5.4668 & TRN & \\
\hline CHEMBL1307600 & 688810 & 4.833 & 5.4516 & TRN & & & \\
\hline CHEMBL1552375 & 688810 & 4.583 & 4.9449 & TST & & & \\
\hline CHEMBL1320247 & 688810 & 4.7330 & 0000000 & 005 & 5.4704 & TRN & \\
\hline CHEMBL1443777 & 688810 & 4.9830 & 0000000 & 005 & 5.5688 & TRN & \\
\hline CHEMBL1572293 & 688810 & 4.9830 & 0000000 & 005 & 5.1016 & TRN & \\
\hline CHEMBL1335515 & 688810 & 5.433 & 5.2828 & TRN & & & \\
\hline CHEMBL1357723 & 688810 & 4.9830 & 0000000 & 005 & 5.0503 & TRN & \\
\hline
\end{tabular}




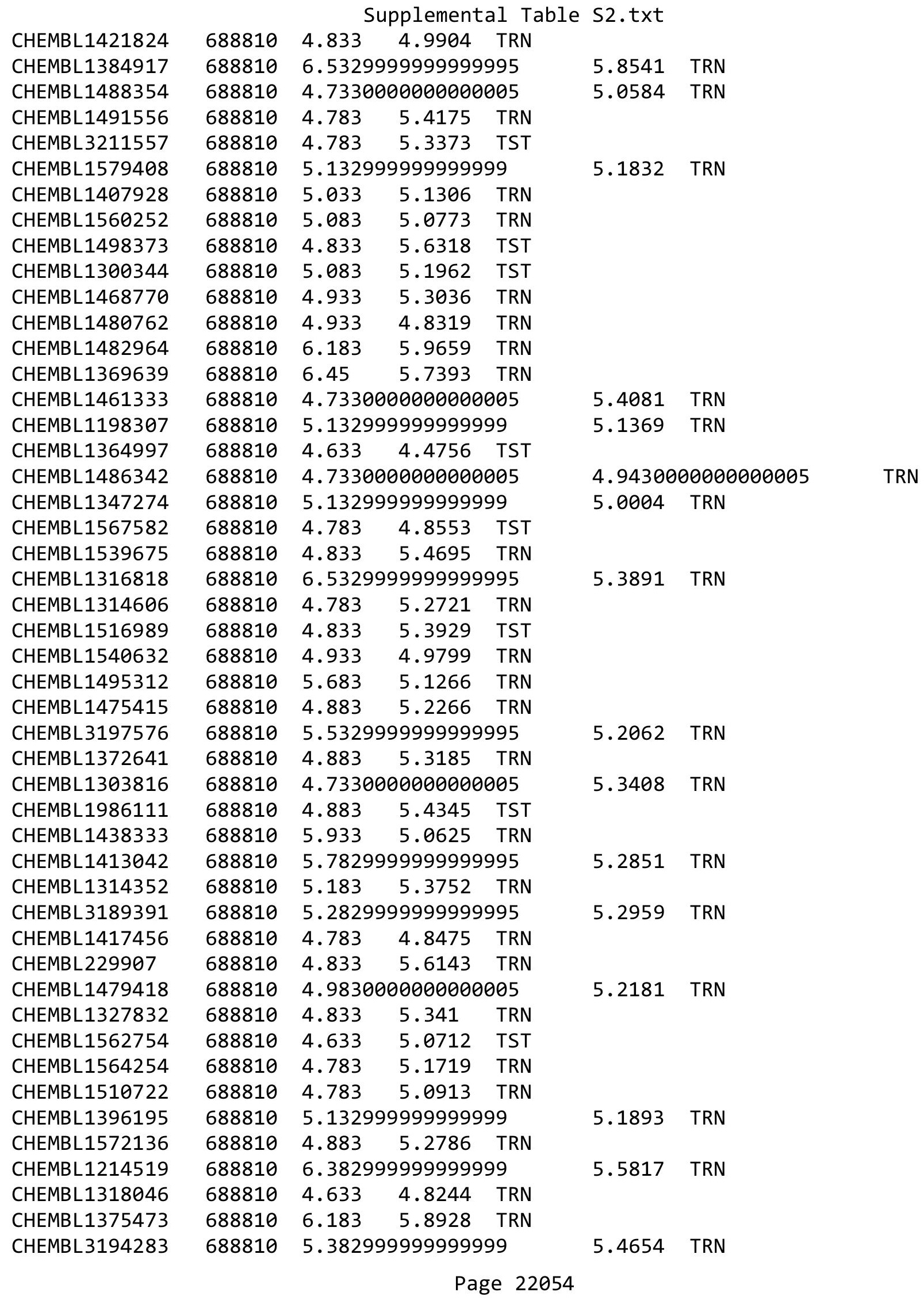




\begin{tabular}{|c|c|c|c|c|c|c|}
\hline \multirow[b]{2}{*}{ CHEMBL1329472 } & \multicolumn{6}{|c|}{ Supplemental Table S2.txt } \\
\hline & 688810 & 4.833 & 4.9594 & TRN & & \\
\hline CHEMBL1424267 & 688810 & 5.033 & 5.4175 & TRN & & \\
\hline CHEMBL1418909 & 688810 & 5.483 & 5.6803 & TRN & & \\
\hline CHEMBL1300777 & 688810 & \multicolumn{3}{|c|}{5.332999999999999} & 5.6622 & TS \\
\hline CHEMBL1501376 & 688810 & 4.583 & 5.2046 & TST & & \\
\hline CHEMBL1443062 & 688810 & 4.783 & 4.979 & TRN & & \\
\hline CHEMBL1415004 & 688810 & \multicolumn{3}{|c|}{5.132999999999999} & 4.9825 & \\
\hline CHEMBL1405435 & 688810 & 4.833 & 5.0898 & TRN & & \\
\hline CHEMBL1585511 & 688810 & 4.833 & 5.1689 & TRN & & \\
\hline CHEMBL1302565 & 688810 & 4.883 & 4.8635 & TRN & & \\
\hline CHEMBL3209382 & 688810 & 5.483 & 5.7812 & TST & & \\
\hline CHEMBL1400481 & 688810 & 4.633 & 4.8722 & TST & & \\
\hline CHEMBL1575022 & 688810 & \multicolumn{3}{|c|}{5.382999999999999} & 5.6953 & \\
\hline CHEMBL1325563 & 688810 & 6.4829 & 5.233 & TRN & & \\
\hline CHEMBL1512175 & 688810 & 4.883 & 4.8652 & TRN & & \\
\hline CHEMBL1390366 & 688810 & \multicolumn{3}{|c|}{5.2829999999999995} & 5,811 & \\
\hline CHEMBL1523920 & 688810 & 6.183 & 5.7065 & TRN & & \\
\hline CHEMBL1540694 & 688810 & \multicolumn{3}{|c|}{5.132999999999999} & 5.3566 & \\
\hline CHEMBL1571051 & 688810 & 5.183 & 4.8292 & TRN & & \\
\hline CHEMBL1403078 & 688810 & \multicolumn{3}{|c|}{6.0329999999999995} & 6.0604 & TS \\
\hline CHEMBL1465971 & 688810 & \multicolumn{3}{|c|}{5.132999999999999} & 5.3 & \\
\hline CHEMBL1592073 & 688810 & 4.633 & 5.0347 & TST & & \\
\hline CHEMBL1385837 & 688810 & \multicolumn{3}{|c|}{4.9830000000000005} & 5.1243 & \\
\hline CHEMBL1346838 & 688810 & \multicolumn{3}{|c|}{5.832999999999999} & 5.6574 & \\
\hline CHEMBL1497677 & 688810 & 5.183 & 5.0968 & TRN & & \\
\hline CHEMBL1414691 & 688810 & \multicolumn{3}{|c|}{4.9830000000000005} & 5.4279 & \\
\hline CHEMBL1591133 & 688810 & 4.783 & 4.7149 & TRN & & \\
\hline CHEMBL3191951 & 688810 & 4.633 & 5.58 & TRN & & \\
\hline CHEMBL1584340 & 688810 & 5.083 & 4.9995 & TRN & & \\
\hline CHEMBL1596624 & 688810 & 5.183 & 5.29799 & 99999 & 99 & TRN \\
\hline CHEMBL1321713 & 688810 & 4.633 & 5.1831 & TRN & & \\
\hline CHEMBL1468733 & 688810 & \multicolumn{3}{|c|}{6.382999999999999} & 5.8842 & TR \\
\hline CHEMBL1601900 & 688810 & 5.183 & 5.2372 & TRN & & \\
\hline CHEMBL1501547 & 688810 & \multicolumn{3}{|c|}{6.582999999999999} & 5.9049 & $\mathrm{TR}$ \\
\hline CHEMBL1485445 & 688810 & 4.683 & 4.6745 & TRN & & \\
\hline CHEMBL1346427 & 688810 & 4.833 & 5.426 & TRN & & \\
\hline CHEMBL1606927 & 688810 & 4.833 & 4.8964 & TRN & & \\
\hline CHEMBL1519546 & 688810 & 5.183 & 5.41 & TRN & & \\
\hline CHEMBL1535487 & 688810 & \multicolumn{3}{|c|}{5.2829999999999995} & 5.5413 & I N \\
\hline CHEMBL1551874 & 688810 & \multicolumn{3}{|c|}{6.082999999999999} & 5.4618 & 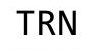 \\
\hline CHEMBL1563401 & 688810 & \multicolumn{3}{|c|}{5.882999999999999} & 5.619 & TRN \\
\hline CHEMBL1533199 & 688810 & \multicolumn{3}{|c|}{4.7330000000000005} & 5.1226 & TRN \\
\hline CHEMBL1370081 & 688810 & 4.883 & 5.2204 & TRN & & \\
\hline CHEMBL1613626 & 688810 & \multicolumn{3}{|c|}{5.132999999999999} & 5.5836 & TRN \\
\hline CHEMBL1322449 & 688810 & \multicolumn{3}{|c|}{4.7330000000000005} & 5.1872 & TS \\
\hline CHEMBL1598791 & 688810 & 4.833 & 5.4125 & TST & & \\
\hline CHEMBL1557225 & 688810 & 4.883 & 4.9658 & TRN & & \\
\hline CHEMBL3197565 & 688810 & 5.3329 & 79999999 & 99 & 5.5068 & 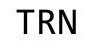 \\
\hline
\end{tabular}




\begin{tabular}{|c|c|c|c|c|c|c|}
\hline \multirow{3}{*}{$\begin{array}{l}\text { CHEMBL1465897 } \\
\text { CHEMBL3199775 }\end{array}$} & \multirow{3}{*}{$\begin{array}{l}688810 \\
688810\end{array}$} & \multicolumn{5}{|c|}{ Supplemental Table S2.txt } \\
\hline & & \multicolumn{4}{|c|}{5.212000000000001} & TST \\
\hline & & \multicolumn{3}{|c|}{5.582999999999999} & \multirow[t]{4}{*}{5.3473} & \\
\hline CHEMBL1563797 & 688810 & 4.933 & 5.1926 & TRN & & \\
\hline CHEMBL1604405 & 688810 & 5.083 & 4.9408 & TRN & & \\
\hline CHEMBL1343711 & 588810 & 5.083 & 4.8498 & TRN & & \\
\hline CHEMBL1341742 & 688810 & \multicolumn{3}{|c|}{5.832999999999999} & 5.3627 & \\
\hline CHEMBL1399255 & 688810 & 4.783 & 5.21 & TRN & & \\
\hline CHEMBL1393211 & 688810 & \multicolumn{3}{|c|}{5.7829999999999995} & 5.5296 & \\
\hline CHEMBL1600313 & 688810 & 4.833 & 5.2721 & TST & & \\
\hline CHEMBL1385089 & 688810 & 5.433 & 5.3304 & TST & & \\
\hline CHEMBL 3189288 & 688810 & 5.183 & 4.9631 & TST & & \\
\hline CHEMBL1608506 & 688810 & \multicolumn{3}{|c|}{5.632999999999999} & 091 & \\
\hline CHEMBL1567097 & 688810 & 7.2328 & 5.8448 & TST & & \\
\hline CHEMBL1575073 & 688810 & 4.783 & 5.0992 & TRN & & \\
\hline CHEMBL16e & 688810 & 6.433 & 5.8177 & TRN & & \\
\hline CHEMBL1609632 & 688810 & 5.733 & 5.0845 & TRN & & \\
\hline CHEMBL142 & 688810 & 6.233 & 6.1342 & TRN & & \\
\hline HEMBL14 & 688810 & \multicolumn{3}{|c|}{5.7829999999999995} & 5.6511 & TRN \\
\hline CHEMBL14 & 688810 & \multicolumn{3}{|c|}{5.382999999999999} & 5.1169 & TRN \\
\hline CHEMBL1378324 & 688810 & \multicolumn{3}{|c|}{6.382999999999999} & 5.4123 & TRN \\
\hline CHEMBL1611074 & 688810 & 5.233 & \multicolumn{3}{|c|}{5.372000000000001} & \\
\hline CHEMBL142 & 688810 & 5.183 & 5.3252 & TRN & & \\
\hline CHEMBL14 & 688810 & \multicolumn{3}{|c|}{6.382999999999999} & 4.9989 & \\
\hline CHEMBL13 & 688810 & 5.683 & 5.5206 & TRN & & \\
\hline CHEMBL1409609 & 688810 & \multicolumn{3}{|c|}{4.7330000000000005} & 5.6031 & TP \\
\hline CHEMBL1346933 & 688810 & \multicolumn{3}{|c|}{5.882999999999999} & & \\
\hline CHEMBL1 & 688810 & 6.183 & 5.4781 & TRN & & \\
\hline CHEMBL1 & 688810 & \multicolumn{3}{|c|}{6.132999999999999} & 156 & TRN \\
\hline CHEMBL1340551 & 688810 & \multicolumn{3}{|c|}{5.332999999999999} & 328 & \\
\hline CHEMBL1597854 & 688810 & 4.833 & 5.1367 & TRN & & \\
\hline CHEMBL1408414 & 688810 & 5.733 & 5.4107 & TRN & & \\
\hline CHEMBL3 & 688 & בכס.נ & 5.4918 & TST & & \\
\hline CHEMBL13 & 688810 & \multicolumn{3}{|c|}{5.832999999999999} & 5.4663 & $\mathrm{TH}$ \\
\hline CHEMBL1540795 & 688810 & 4.633 & 4.7482 & TST & & \\
\hline CHEMBL1322324 & 688810 & \multicolumn{3}{|c|}{4.7330000000000005} & 5.1157 & $T 0$ \\
\hline CHEMBL1426427 & 688810 & 5.483 & 5.2535 & TST & & \\
\hline CHEMBL1 & 688810 & & 5.1221 & TRN & & \\
\hline CHEMBL152 & 688810 & 5.233 & 5.3245 & TRN & & \\
\hline CHEMBL1986827 & 688810 & 4.783 & 5.1484 & TST & & \\
\hline CHEMBL1403741 & 688810 & \multicolumn{3}{|c|}{5.832999999999999} & & $\mathrm{TI}$ \\
\hline CHEMBL501358 & 688810 & 4.73300 & 20000000 & 005 & 5.2131 & $\mathrm{TS}$ \\
\hline CHEMBL1397831 & 688810 & 5.183 & 4.8001 & TST & & \\
\hline CHEMBL1348002 & 688810 & 5.83299 & 99999999 & & 5.3947 & TR \\
\hline CHEMBL1514278 & 688810 & 5.53299 & 99999999 & 995 & 5.0348 & 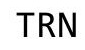 \\
\hline CHEMBL1325141 & 688810 & 4.583 & 4.8377 & TST & & \\
\hline CHEMBL1543734 & 688810 & 5.78299 & 99999999 & 995 & 5.5814 & \\
\hline CHEMBL1470568 & 688810 & 5.733 & 6.3367 & TRN & & \\
\hline CHEMBL1356896 & 688810 & 5.13299 & 99999999 & & 5.254 & \\
\hline
\end{tabular}




\begin{tabular}{|c|c|c|c|c|c|c|c|}
\hline \multicolumn{8}{|c|}{ oplemental Ia } \\
\hline CHEMBL3211529 & 688810 & 4.583 & 4.4765 & TRN & & & \\
\hline CHEMBL1451834 & 688810 & 6.683 & 5.7661 & TRN & & & \\
\hline CHEMBL1431355 & 688810 & 4.833 & 5.4117 & TRN & & & \\
\hline CHEMBL1989858 & 688810 & 5.233 & 4.8614 & TRN & & & \\
\hline CHEMBL1445489 & 688810 & 4.633 & 4.7072 & TRN & & & \\
\hline CHEMBL1300952 & 688810 & \multicolumn{3}{|c|}{5.832999999999999} & 5.0642 & TRN & \\
\hline CHEMBL3190384 & 688810 & 4.833 & 5.4049 & TRN & & & \\
\hline CHEMBL1420568 & 688810 & \multicolumn{3}{|c|}{6.082999999999999} & 5.2505 & TST & \\
\hline CHEMBL1406083 & 688810 & 4.933 & 5.0263 & TRN & & & \\
\hline CHEMBL1518665 & 688810 & 4.783 & 5.4965 & TST & & & \\
\hline CHEMBL1379301 & 688810 & 5.933 & 5.1605 & TRN & & & \\
\hline CHEMBL3195217 & 688810 & \multicolumn{3}{|c|}{6.2829999999999995} & 5.6983 & TRN & \\
\hline CHEMBL1323994 & 688810 & 5.483 & 5.3894 & TRN & & & \\
\hline CHEMBL1321696 & 688810 & \multicolumn{3}{|c|}{4.7330000000000005} & 4.7828 & TRN & \\
\hline CHEMBL1495170 & 688810 & \multicolumn{3}{|c|}{4.9830000000000005} & 5.426 & TST & \\
\hline CHEMBL1337906 & 688810 & 6.233 & 5.5659 & TST & & & \\
\hline CHEMBL1485334 & 688810 & 5.033 & 5.039 & TRN & & & \\
\hline CHEMBL3209987 & 688810 & 4.833 & 5.7219 & TST & & & \\
\hline CHEMBL1589612 & 688810 & \multicolumn{3}{|c|}{5.132999999999999} & 5.9263 & TRN & \\
\hline CHEMBL1542825 & 688810 & \multicolumn{3}{|c|}{4.7330000000000005} & 5.3603 & TST & \\
\hline CHEMBL1494406 & 688810 & 4.933 & 4.9663 & TRN & & & \\
\hline CHEMBL1604460 & 688810 & 5.233 & 5.1573 & TRN & & & \\
\hline CHEMBL1447186 & 688810 & \multicolumn{3}{|c|}{6.2829999999999995} & 5.9415 & TRN & \\
\hline CHEMBL1423497 & 688810 & \multicolumn{3}{|c|}{4.9830000000000005} & 5.608 & TRN & \\
\hline CHEMBL1570010 & 688810 & 4.783 & 4.795 & TRN & & & \\
\hline CHEMBL1303164 & 688810 & \multicolumn{3}{|c|}{4.7330000000000005} & 5.2265 & TRN & \\
\hline CHEMBL1419733 & 688810 & \multicolumn{3}{|c|}{5.5329999999999995} & 5.796 & TST & \\
\hline CHEMBL1521909 & 688810 & \multicolumn{3}{|c|}{4.9830000000000005} & 5.3023 & TRN & \\
\hline CHEMBL600334 & 688810 & 6.233 & 4.8391 & TRN & & & \\
\hline CHEMBL1545761 & 688810 & \multicolumn{3}{|c|}{5.832999999999999} & 4.7642 & TST & \\
\hline CHEMBL3196407 & 688810 & 4.583 & 5.7524 & TST & & & \\
\hline CHEMBL1492380 & 688810 & \multicolumn{3}{|c|}{4.7330000000000005} & 5.6789 & 9999999999 & TRN \\
\hline CHEMBL1598978 & 688810 & \multicolumn{3}{|c|}{5.132999999999999} & 5.1644 & TRN & \\
\hline CHEMBL1435100 & 688810 & \multicolumn{3}{|c|}{6.7829999999999995} & 5.3768 & TRN & \\
\hline CHEMBL1325748 & 688810 & 4.833 & 5.3451 & TRN & & & \\
\hline CHEMBL1381081 & 688810 & 4.833 & 4.9832 & TRN & & & \\
\hline CHEMBL1531190 & 688810 & 5.233 & 5.2346 & TRN & & & \\
\hline CHEMBL1437528 & 688810 & 5.183 & 4.8987 & TST & & & \\
\hline CHEMBL1412199 & 688810 & \multicolumn{3}{|c|}{5.382999999999999} & 5.317 & TRN & \\
\hline CHEMBL1487639 & 688810 & 4.783 & 5.4485 & TRN & & & \\
\hline CHEMBL 3198707 & 688810 & 5.733 & 5.17 & TST & & & \\
\hline CHEMBL1419771 & 688810 & \multicolumn{3}{|c|}{5.2829999999999995} & 5.2589 & 99999999995 & TRN \\
\hline CHEMBL1419866 & 688810 & \multicolumn{3}{|c|}{6.382999999999999} & 5.4497 & TRN & \\
\hline CHEMBL1312665 & 688810 & 5.983 & 5.5034 & TST & & & \\
\hline CHEMBL1483099 & 688810 & 4.783 & 5.7528 & TRN & & & \\
\hline CHEMBL1421652 & 688810 & 5.3329 & 99999999 & & 5.5394 & TRN & \\
\hline CHEMBL1421119 & 688810 & 5.733 & 5.3955 & TRN & & & \\
\hline CHEMBL1371093 & 688810 & 5.183 & 5.6807 & TRN & & & \\
\hline
\end{tabular}




\begin{tabular}{|c|c|c|c|c|c|c|}
\hline & \\
\hline CHEMBL 3197786 & 688810 & 4.583 & 5.1818 & TST & & \\
\hline CHEMBL1384228 & 688810 & \multicolumn{3}{|c|}{6.332999999999999} & 5.5167 & TRN \\
\hline CHEMBL1387899 & 688810 & 4.833 & 4.8507 & TRN & & \\
\hline CHEMBL1553483 & 688810 & \multicolumn{3}{|c|}{5.5329999999999995} & 5.8454 & TRN \\
\hline CHEMBL1539056 & 688810 & \multicolumn{3}{|c|}{5.582999999999999} & 4.9881 & \\
\hline CHEMBL1449118 & 688810 & 5.683 & 5.4751 & TRN & & \\
\hline CHEMBL1415430 & 688810 & 4.583 & \multicolumn{3}{|c|}{5.0089999999999995} & TST \\
\hline CHEMBL 3195736 & 688810 & 5.483 & 5.3374 & TRN & & \\
\hline CHEMBL1338117 & 688810 & 5.033 & 5.9138 & TRN & & \\
\hline CHEMBL1559717 & 688810 & 6.0 & 5.085 & TST & & \\
\hline CHEMBL1403279 & 688810 & 5.733 & 5.0952 & TRN & & \\
\hline CHEMBL 1568330 & 688810 & 6.433 & 5.4822 & TRN & & \\
\hline CHEMBL1507209 & 688810 & \multicolumn{3}{|c|}{5.832999999999999} & 5.5868 & \\
\hline CHEMBL1554164 & 688810 & \multicolumn{3}{|c|}{6.082999999999999} & 5.5847 & \\
\hline CHEMBL1601032 & 688810 & 6.233 & 5.3453 & TRN & & \\
\hline CHEMBL1372758 & 688810 & 4.883 & 5.3102 & TST & & \\
\hline CHEMBL1500271 & 688810 & \multicolumn{3}{|c|}{5.132999999999999} & 5.187 & \\
\hline CHEMBL1486199 & 688810 & 4.883 & 5.3239 & TRN & & \\
\hline CHEMBL1347084 & 688810 & \multicolumn{3}{|c|}{4.9830000000000005} & 3512 & \\
\hline CHEMBL1596101 & 688810 & \multicolumn{3}{|c|}{6.0329999999999995} & 5.9774 & \\
\hline CHEMBL 3196880 & 688810 & \multicolumn{3}{|c|}{5.582999999999999} & 5.449 & \\
\hline CHEMBL 1416490 & 688810 & 4.783 & 5.2885 & TRN & & \\
\hline CHEMBL1429724 & 688810 & \multicolumn{3}{|c|}{4.7330000000000005} & 4.8621 & \\
\hline CHEMBL1588672 & 688810 & 4.883 & 5.2597 & TRN & & \\
\hline CHEMBL1337023 & 688810 & 4.783 & 5.7066 & TRN & & \\
\hline CHEMBL1551240 & 688810 & 4.633 & 5.072 & TRN & & \\
\hline CHEMBL 1583256 & 688810 & \multicolumn{3}{|c|}{6.582999999999999} & 5.776 & $\mathrm{TP}$ \\
\hline CHEMBL1392771 & 688810 & 5.183 & 5.6326 & TST & & \\
\hline CHEMBL 3191983 & 688810 & 4.783 & 5.8924 & TRN & & \\
\hline CHEMBL1555101 & 688810 & 5.233 & 5.4322 & TRN & & \\
\hline CHEMBL1498428 & 688810 & 4.883 & 5.1074 & TST & & \\
\hline CHEMBL1345392 & 688810 & \multicolumn{3}{|c|}{6.0329999999999995} & 5.8235 & $\mathrm{TI}$ \\
\hline CHEMBL1472308 & 688810 & \multicolumn{3}{|c|}{5.632999999999999} & 4.6721 & N \\
\hline CHEMBL1533255 & 688810 & \multicolumn{3}{|c|}{5.832999999999999} & 5.2066 & TS \\
\hline CHEMBL 3196688 & 688810 & \multicolumn{3}{|c|}{5.382999999999999} & 4.5719 & 110 \\
\hline CHEMBL1448566 & 688810 & \multicolumn{3}{|c|}{4.7330000000000005} & 5.4189 & \\
\hline CHEMBL1514817 & 688810 & \multicolumn{3}{|c|}{5.132999999999999} & 4.7712 & TS \\
\hline CHEMBL1382658 & 688810 & \multicolumn{3}{|c|}{5.2829999999999995} & 6.1356 & 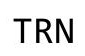 \\
\hline CHEMBL1431992 & 688810 & 4.783 & 5.1877 & TST & & \\
\hline CHEMBL 3195170 & 688810 & 4.783 & 4.9918 & TST & & \\
\hline CHEMBL1364051 & 688810 & 4.933 & 4.8482 & TRN & & \\
\hline CHEMBL 1371347 & 688810 & 5.183 & 4.8727 & TST & & \\
\hline CHEMBL1597334 & 688810 & 5.2829 & 99999999 & 995 & 5.5565 & \\
\hline CHEMBL 3208066 & 688810 & 5.3829 & 99999999 & & 5.1466 & \\
\hline CHEMBL1583665 & 688810 & 4.583 & 5.1066 & TRN & & \\
\hline CHEMBL1395894 & 688810 & 5.8329 & 99999999 & & 5.3549 & \\
\hline CHEMBL1300301 & 688810 & 5.8329 & 99999999 & & 5.4091 & \\
\hline CHEMBL1605209 & 688810 & 4.933 & 5.5349 & TST & & \\
\hline
\end{tabular}




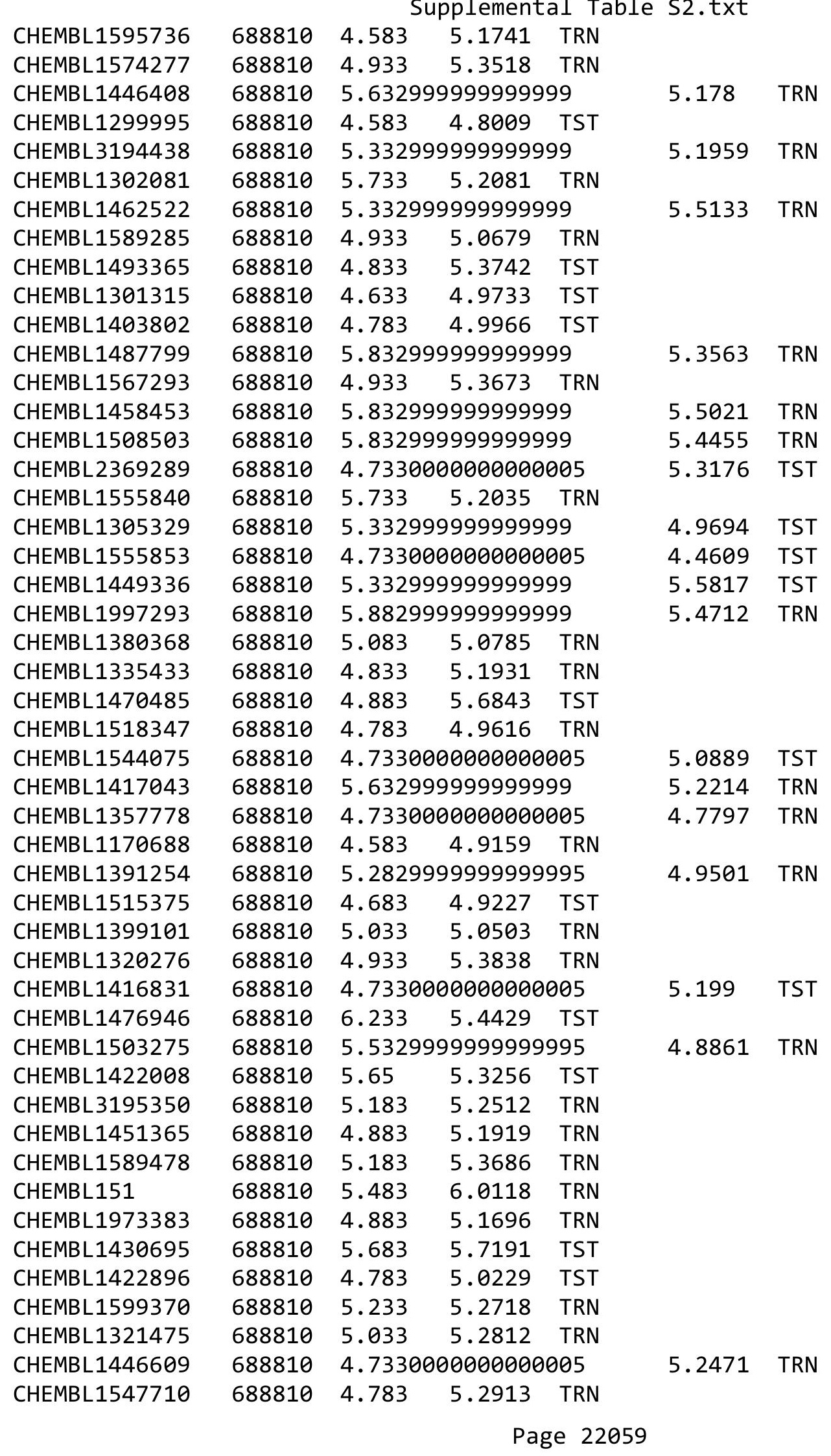




\begin{tabular}{|c|c|c|c|c|c|c|}
\hline \multirow[b]{2}{*}{ CHEMBL1558920 } & \multicolumn{6}{|c|}{ Supplemental Table S2.txt } \\
\hline & 688810 & 5.183 & 5.051 & TRN & & \\
\hline CHEMBL1541441 & 688810 & 4.833 & \multicolumn{3}{|c|}{4.946000000000001} & TST \\
\hline CHEMBL1526153 & 688810 & \multicolumn{3}{|c|}{5.132999999999999} & 4.9471 & TRN \\
\hline CHEMBL1530075 & 688810 & 4.833 & 4.9528 & TRN & & \\
\hline CHEMBL1305235 & 688810 & 4.883 & 5.1914 & TRN & & \\
\hline CHEMBL1543776 & 688810 & 4.633 & 5.3851 & TRN & & \\
\hline CHEMBL1986394 & 688810 & 4.883 & 5.45 & TRN & & \\
\hline CHEMBL1467843 & 688810 & 6.233 & \multicolumn{3}{|c|}{5.7589999999999995} & TRN \\
\hline CHEMBL1419997 & 688810 & \multicolumn{3}{|c|}{5.882999999999999} & 5.4412 & TRN \\
\hline CHEMBL1459189 & 688810 & 4.583 & 5.0308 & TRN & & \\
\hline CHEMBL1448343 & 688810 & 4.633 & 5.1433 & TST & & \\
\hline CHEMBL1490128 & 688810 & 4.833 & \multicolumn{3}{|c|}{5.2170000000000005} & TRN \\
\hline CHEMBL1333867 & 688810 & 6.0 & 5.4587 & TRN & & \\
\hline CHEMBL1521989 & 688810 & 4.583 & 4.9526 & TST & & \\
\hline CHEMBL1512401 & 688810 & 4.833 & 5.4441 & TRN & & \\
\hline CHEMBL1489256 & 688810 & 6.183 & 5.4759 & TRN & & \\
\hline CHEMBL1392030 & 688810 & 5.033 & 4.9953 & TRN & & \\
\hline CHEMBL1371568 & 688810 & \multicolumn{3}{|c|}{5.832999999999999} & 5.6059 & TRN \\
\hline CHEMBL1576382 & 688810 & 4.583 & 4.9113 & TRN & & \\
\hline CHEMBL1452981 & 688810 & \multicolumn{3}{|c|}{5.7829999999999995} & 5.3149 & TST \\
\hline CHEMBL579082 & 688810 & \multicolumn{3}{|c|}{4.7330000000000005} & 5.2536 & TST \\
\hline CHEMBL1422438 & 688810 & \multicolumn{3}{|c|}{5.132999999999999} & 5.1087 & TRN \\
\hline CHEMBL1579257 & 688810 & \multicolumn{3}{|c|}{5.382999999999999} & 5.2454 & TRN \\
\hline CHEMBL1507441 & 688810 & 4.633 & 4.8023 & TRN & & \\
\hline CHEMBL1607270 & 688810 & 5.183 & 5.4698 & TRN & & \\
\hline CHEMBL1552307 & 688810 & 4.883 & 5.0488 & TST & & \\
\hline CHEMBL1350682 & 688810 & 4.883 & 5.2751 & TRN & & \\
\hline CHEMBL1530042 & 688810 & 5.733 & 4.8884 & TRN & & \\
\hline CHEMBL1459393 & 688810 & \multicolumn{3}{|c|}{5.332999999999999} & 5.5366 & TRN \\
\hline CHEMBL3194581 & 688810 & 5.983 & 5.5176 & TRN & & \\
\hline CHEMBL1587295 & 688810 & 4.883 & 5.2151 & TRN & & \\
\hline CHEMBL1489384 & 688810 & 4.833 & 5.4298 & TST & & \\
\hline CHEMBL1487374 & 688810 & \multicolumn{3}{|c|}{5.7829999999999995} & 5.5628 & TRN \\
\hline CHEMBL1301351 & 688810 & 4.783 & 5.0802 & TRN & & \\
\hline CHEMBL1457573 & 688810 & \multicolumn{3}{|c|}{6.2829999999999995} & 5.4262 & TRN \\
\hline CHEMBL1460805 & 688810 & \multicolumn{3}{|c|}{4.7330000000000005} & 5.1571 & TST \\
\hline CHEMBL1547108 & 688810 & \multicolumn{3}{|c|}{5.2829999999999995} & 4.8944 & TRN \\
\hline CHEMBL1428447 & 688810 & \multicolumn{3}{|c|}{5.832999999999999} & 5.0389 & TRN \\
\hline CHEMBL3196933 & 688810 & \multicolumn{3}{|c|}{4.9830000000000005} & 5.1966 & TRN \\
\hline CHEMBL1327627 & 688810 & 4.633 & 5.0002 & TRN & & \\
\hline CHEMBL1505260 & 688810 & 5.233 & 5.245 & TRN & & \\
\hline CHEMBL1578675 & 688810 & 5.183 & 5.4331 & TRN & & \\
\hline CHEMBL1422215 & 688810 & 4.633 & 4.8786 & TST & & \\
\hline CHEMBL1450556 & 688810 & \multicolumn{3}{|c|}{5.132999999999999} & 5.3702 & TRN \\
\hline CHEMBL1424555 & 688810 & 5.733 & 5.6221 & TRN & & \\
\hline CHEMBL282234 & 688810 & \multicolumn{3}{|c|}{5.882999999999999} & 5.5214 & TRN \\
\hline CHEMBL1316927 & 688810 & 5.033 & 5.4346 & TST & & \\
\hline CHEMBL1315381 & 688810 & 5.2829 & 99999999 & 995 & 5.3642 & TRN \\
\hline
\end{tabular}




\begin{tabular}{|c|c|c|c|c|c|c|}
\hline \multirow[b]{2}{*}{ CHEMBL1419995 } & \multirow[b]{2}{*}{688810} & \multicolumn{5}{|c|}{ Supplemental Table s2.txt } \\
\hline & & 5.733 & 5.2559 & TRN & \multirow{5}{*}{4.9105} & \multirow{3}{*}{ TST } \\
\hline CHEMBL1446802 & 688810 & \multicolumn{3}{|c|}{4.7330000000000005} & & \\
\hline CHEMBL1608982 & 688810 & 4.633 & 5.0793 & TST & & \\
\hline CHEMBL1537954 & 688810 & 5.733 & 5.2333 & TST & & \\
\hline CHEMBL1562963 & 688810 & 5.033 & 5.9029 & TRN & & \\
\hline CHEMBL1350324 & 688810 & \multicolumn{3}{|c|}{5.832999999999999} & 4.9872 & TRN \\
\hline CHEMBL1474766 & 688810 & 4.633 & 4.685 & TRN & & \\
\hline CHEMBL1488781 & 688810 & \multicolumn{3}{|c|}{5.132999999999999} & 5.5435 & TRN \\
\hline CHEMBL1604622 & 688810 & 5.233 & 5.2938 & TRN & & \\
\hline CHEMBL1557179 & 688810 & 7.0329 & 6.0603 & TRN & & \\
\hline CHEMBL1428777 & 688810 & \multicolumn{3}{|c|}{5.132999999999999} & 5.1852 & TRN \\
\hline CHEMBL3189927 & 688810 & \multicolumn{3}{|c|}{5.132999999999999} & 5.2938 & TST \\
\hline CHEMBL1419714 & 688810 & 5.033 & \multicolumn{3}{|c|}{5.252999999999999} & TRN \\
\hline CHEMBL1411121 & 688810 & \multicolumn{3}{|c|}{6.2829999999999995} & 5.3485 & TST \\
\hline CHEMBL1982869 & 688810 & 4.833 & 5.5435 & TST & & \\
\hline CHEMBL1572342 & 688810 & 4.933 & 5.1984 & TRN & & \\
\hline CHEMBL1567899 & 688810 & 4.583 & 5.4017 & TRN & & \\
\hline CHEMBL1519809 & 688810 & 5.433 & 5.1173 & TRN & & \\
\hline CHEMBL1319241 & 688810 & 5.083 & 5.4267 & TST & & \\
\hline CHEMBL1599537 & 688810 & 4.833 & 5.371 & TST & & \\
\hline CHEMBL1306488 & 688810 & \multicolumn{3}{|c|}{5.832999999999999} & 5.0605 & TRN \\
\hline CHEMBL1566113 & 688810 & \multicolumn{3}{|c|}{4.9830000000000005} & 5.1696 & TST \\
\hline CHEMBL1380894 & 688810 & 5.483 & 5.2294 & TRN & & \\
\hline CHEMBL1345341 & 688810 & 5.433 & 5.9553 & TRN & & \\
\hline CHEMBL1457057 & 688810 & 6.4829 & 5.8537 & TST & & \\
\hline CHEMBL1400307 & 688810 & 4.783 & 4.9635 & TRN & & \\
\hline CHEMBL1733957 & 688810 & 4.783 & 4.7271 & TST & & \\
\hline CHEMBL1412369 & 688810 & 4.633 & 5.0731 & TST & & \\
\hline CHEMBL1495205 & 688810 & 4.883 & 4.8232 & TRN & & \\
\hline CHEMBL1310074 & 688810 & 4.833 & 5.3797 & TRN & & \\
\hline CHEMBL1511638 & 688810 & \multicolumn{3}{|c|}{5.132999999999999} & 5.087 & TRN \\
\hline CHEMBL1543685 & 688810 & 5.933 & 5.5581 & TST & & \\
\hline CHEMBL1393851 & 688810 & 5.733 & 4.8956 & TRN & & \\
\hline CHEMBL1489335 & 688810 & \multicolumn{3}{|c|}{6.582999999999999} & 5.8309 & TST \\
\hline CHEMBL1492231 & 688810 & 4.883 & 5.1491 & TRN & & \\
\hline CHEMBL1339465 & 688810 & \multicolumn{3}{|c|}{4.7330000000000005} & 5.0952 & TRN \\
\hline CHEMBL1332934 & 688810 & \multicolumn{3}{|c|}{5.5329999999999995} & 5.0024 & TRN \\
\hline CHEMBL1478512 & 688810 & 5.083 & 4.9126 & TRN & & \\
\hline CHEMBL3191244 & 688810 & 5.733 & 5.3922 & TRN & & \\
\hline CHEMBL1320060 & 688810 & 4.783 & 5.0937 & TRN & & \\
\hline CHEMBL3210723 & 688810 & \multicolumn{3}{|c|}{5.7829999999999995} & 5.4745 & TRN \\
\hline CHEMBL1609639 & 688810 & \multicolumn{3}{|c|}{5.132999999999999} & 5.1817 & TRN \\
\hline CHEMBL1602192 & 688810 & 5.083 & 5.3427 & TRN & & \\
\hline CHEMBL1350919 & 688810 & 4.933 & 5.1661 & TRN & & \\
\hline CHEMBL192293 & 688810 & 5.183 & 5.2969 & TRN & & \\
\hline CHEMBL 3198383 & 688810 & 4.783 & 5.2333 & TRN & & \\
\hline CHEMBL1501552 & 688810 & \multicolumn{3}{|c|}{4.7330000000000005} & 5.4753 & TRN \\
\hline CHEMBL1575397 & 688810 & 4.98300 & 00000000 & 005 & 5.2001 & TRN \\
\hline & & & & & & \\
\hline
\end{tabular}




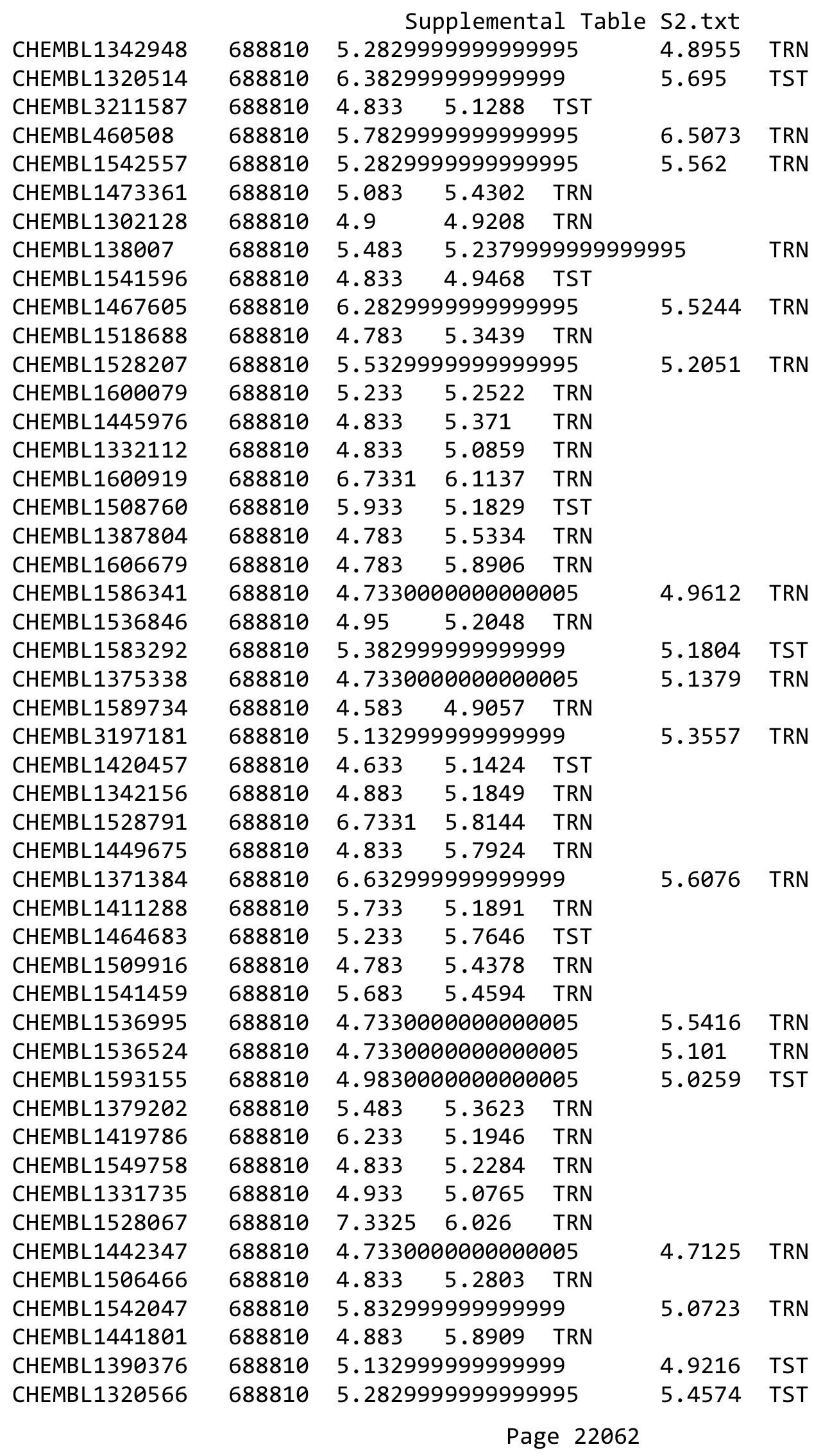




\begin{tabular}{|c|c|c|c|c|c|c|}
\hline \multirow[b]{2}{*}{ CHEMBL1585478 } & & \multicolumn{5}{|c|}{ pplemental Ta } \\
\hline & 688810 & 4.933 & 4.9133 & TST & & \\
\hline CHEMBL1504838 & 688810 & \multicolumn{3}{|c|}{5.132999999999999} & 4.9457 & TST \\
\hline CHEMBL580340 & 688810 & 4.883 & 4.7814 & TRN & & \\
\hline CHEMBL1482213 & 688810 & 4.933 & 4.8012 & TRN & & \\
\hline CHEMBL1458022 & 688810 & 5.483 & 5.3719 & TST & & \\
\hline CHEMBL1411151 & 688810 & 4.783 & 5.6078 & TRN & & \\
\hline CHEMBL1367179 & 688810 & 4.783 & 5.0406 & TRN & & \\
\hline CHEMBL1600508 & 688810 & \multicolumn{3}{|c|}{4.7330000000000005} & 5.0692 & TKIV \\
\hline CHEMBL1600587 & 688810 & 5.433 & 4.7297 & TRN & & \\
\hline CHEMBL3212294 & 688810 & 5.683 & 5.4323 & TRN & & \\
\hline CHEMBL1411637 & 688810 & \multicolumn{3}{|c|}{6.2829999999999995} & 5.2064 & \\
\hline CHEMBL1442344 & 688810 & 5.983 & 5.4252 & TRN & & \\
\hline CHEMBL1400318 & 688810 & 6.7331 & 5.7279 & TST & & \\
\hline CHEMBL3193890 & 688810 & \multicolumn{3}{|c|}{4.7330000000000005} & 5.1149 & \\
\hline CHEMBL3213941 & 688810 & 5.483 & 4.7995 & TST & & \\
\hline CHEMBL1328462 & 688810 & 6.0 & 4.4524 & TRN & & \\
\hline CHEMBL1504933 & 688810 & 4.783 & 5.5244 & TRN & & \\
\hline CHEMBL1531356 & 688810 & \multicolumn{3}{|c|}{4.7330000000000005} & 4.948 & $\mathrm{~T}$ \\
\hline CHEMBL1477560 & 688810 & \multicolumn{3}{|c|}{4.9830000000000005} & 5.1922 & \\
\hline CHEMBL1405432 & 688810 & 5.183 & 5.404 & TST & & \\
\hline CHEMBL1411805 & 688810 & 5.233 & 4.7353 & TRN & & \\
\hline CHEMBL1451129 & 688810 & 4.783 & 5.2097 & TST & & \\
\hline CHEMBL1329586 & 688810 & 5.233 & \multicolumn{3}{|c|}{5.127000000000001} & \\
\hline CHEMBL1422220 & 688810 & \multicolumn{3}{|c|}{5.2829999999999995} & 5.1778 & \\
\hline CHEMBL1545729 & 688810 & \multicolumn{3}{|c|}{6.2829999999999995} & 5.1437 & \\
\hline CHEMBL1967862 & 688810 & \multicolumn{3}{|c|}{4.7330000000000005} & 5.2957 & TST \\
\hline CHEMBL1571896 & 688810 & \multicolumn{3}{|c|}{5.382999999999999} & 4.9265 & \\
\hline CHEMBL1531326 & 688810 & 4.783 & 5.1264 & TRN & & \\
\hline CHEMBL15 & 10 & \multirow{2}{*}{\multicolumn{3}{|c|}{4.9830000000000005}} & & \\
\hline CHEMBL1367175 & 688810 & & & & 5.1881 & \\
\hline CHEMBL1560967 & 688810 & 5.183 & 5.3867 & TRN & & \\
\hline CHEMBL1560106 & 688810 & \multicolumn{3}{|c|}{6.382999999999999} & 5.1412 & 11 \\
\hline CHEMBL1600075 & 688810 & \multicolumn{3}{|c|}{4.9830000000000005} & 5.3936 & \\
\hline CHEMBL3198267 & 688810 & \multicolumn{3}{|c|}{5.382999999999999} & 5.3072 & \\
\hline CHEMBL1540446 & 688810 & 4.633 & 4.9145 & TRN & & \\
\hline CHEMBL1369081 & 688810 & 4.633 & 5.1035 & TST & & \\
\hline CHEMBL1472201 & 688810 & \multicolumn{3}{|c|}{ 5.332999999999999 } & 5.3711 & \\
\hline CHEMBL1426047 & 688810 & \multicolumn{3}{|c|}{5.2829999999999995} & 5.2355 & \\
\hline CHEMBL1315823 & 688810 & \multicolumn{3}{|c|}{6.332999999999999} & 5.4749 & \\
\hline CHEMBL1494639 & 688810 & 4.783 & 5.1744 & TRN & & \\
\hline CHEMBL1461939 & 688810 & 4.883 & 4.7764 & TST & & \\
\hline CHEMBL1347369 & 688810 & 4.633 & 4.7706 & TST & & \\
\hline CHEMBL3655174 & 1527735 & \multicolumn{3}{|c|}{5.821000000000001} & 5.8747 & n \\
\hline CHEMBL 3651349 & 1527735 & 5.0077 & 5.4155 & TRN & & \\
\hline CHEMBL 392107 & 1527735 & 4.0 & 4.8182 & TRN & & \\
\hline CHEMBL3655295 & 1527735 & 4.0 & 4.5429 & TRN & & \\
\hline CHEMBL3651352 & 1527735 & 5.6727 & 5.8045 & TRN & & \\
\hline CHEMBL3655113 & 1527735 & 5.4863 & 5.603 & TRN & & \\
\hline
\end{tabular}


Supplemental Table S2.txt

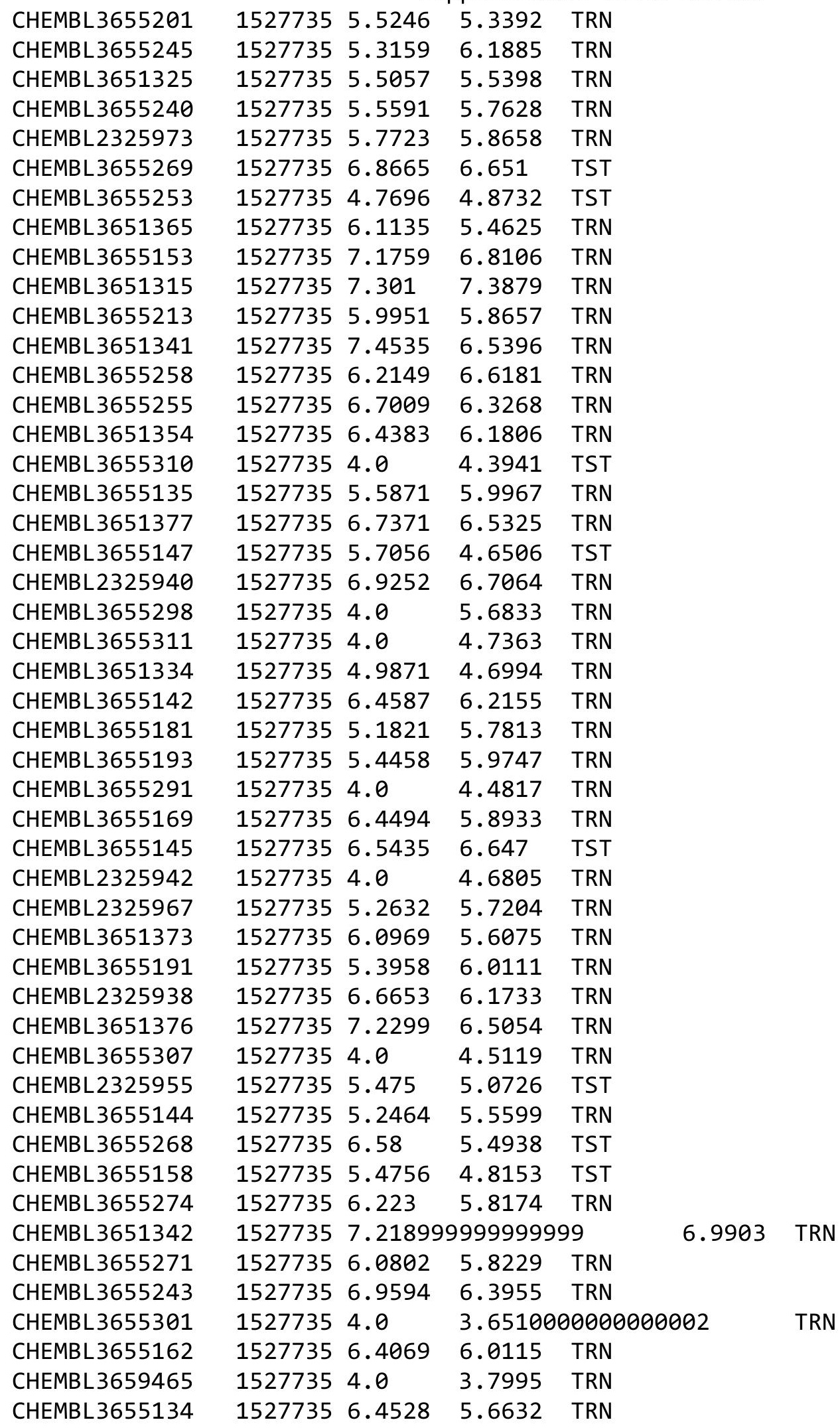

Page 22064 
Supplemental Table S2.txt

\begin{tabular}{|c|c|c|c|c|c|}
\hline CHEMBL 3655155 & 1527735 & 6.1696 & 5.8542 & TRN & \\
\hline CHEMBL 3651347 & 1527735 & 5.1213 & 5.3747 & TRN & \\
\hline CHEMBL 3655244 & 1527735 & 6.3329 & 6.147 & TRN & \\
\hline CHEMBL 3655251 & 1527735 & 5.9678 & 3.7631 & TST & \\
\hline CHEMBL 2325941 & 1527735 & 4.0 & 3.6862 & TRN & \\
\hline CHEMBL3651318 & 1527735 & 5.2573 & 5.375 & TRN & \\
\hline CHEMBL 3655302 & 1527735 & 4.0 & 3.7894 & TRN & \\
\hline CHEMBL 3651371 & 1527735 & 6.4949 & 5.7232 & TRN & \\
\hline CHEMBL 3655124 & 1527735 & 6.3207 & 6.1601 & TRN & \\
\hline CHEMBL 3655256 & 1527735 & 6.6647 & 5.8632 & TRN & \\
\hline CHEMBL 2325974 & 1527735 & 5.2019 & 5.7642 & TRN & \\
\hline CHEMBL 3655312 & 1527735 & 4.0 & 4.0365 & TRN & \\
\hline CHEMBL 3651375 & 1527735 & 5.1707 & 3.5419 & TST & \\
\hline CHEMBL 3651363 & 1527735 & 7.0 & 6.7969 & TRN & \\
\hline CHEMBL 3655207 & 1527735 & 5.7301 & 4.109 & TST & \\
\hline CHEMBL3655290 & 1527735 & 4.0 & 4.5249 & TRN & \\
\hline CHEMBL 3655224 & 1527735 & 6.2981 & 6.7115 & TRN & \\
\hline CHEMBL 3655284 & 1527735 & 4.0 & 5.0684 & TRN & \\
\hline CHEMBL2325970 & 1527735 & 5.7212 & 6.6118 & TRN & \\
\hline CHEMBL 3655281 & 1527735 & 4.0 & 5.4446 & TRN & \\
\hline CHEMBL 3655266 & 1527735 & 5.7756 & 5.9348 & TRN & \\
\hline CHEMBL 3655250 & 1527735 & 5.3277 & 4.5602 & TST & \\
\hline CHEMBL 2325945 & 1527735 & 6.4325 & 6.6091 & TRN & \\
\hline CHEMBL 3655165 & 1527735 & 5.7754 & 5.5299 & TST & \\
\hline CHEMBL 3655254 & 1527735 & 6.7547 & 6.7437 & TRN & \\
\hline CHEMBL 3655138 & 1527735 & 6.4067 & 6.3908 & TST & \\
\hline CHEMBL3655228 & 1527735 & 6.4841 & 6.978 & TRN & \\
\hline CHEMBL3655109 & 1527735 & 6.0499 & 6.3285 & TRN & \\
\hline CHEMBL 3655233 & 1527735 & 5.8688 & 6.4705 & TRN & \\
\hline CHEMBL 3651320 & 1527735 & 5.1641 & 5.9006 & TST & \\
\hline CHEMBL 3651340 & 1527735 & 6.7416 & 6.7884 & TRN & \\
\hline CHEMBL3651355 & 1527735 & 6.0689 & 6.2631 & TRN & \\
\hline CHEMBL3651374 & 1527735 & 5.2848 & 5.58799 & 9999999999 & TRN \\
\hline CHEMBL 3655189 & 1527735 & 5.3721 & 5.352 & TRN & \\
\hline CHEMBL 3655105 & 1527735 & 5.9189 & 5.6939 & TRN & \\
\hline CHEMBL3651366 & 1527735 & 5.1959 & 4.3911 & TRN & \\
\hline CHEMBL3651358 & 1527735 & 6.5016 & 6.0391 & TRN & \\
\hline CHEMBL3655300 & 1527735 & 4.0 & 3.8387 & TRN & \\
\hline CHEMBL 3655137 & 1527735 & 6.1868 & 6.2832 & TST & \\
\hline CHEMBL3655168 & 1527735 & 6.1561 & 5.6517 & TRN & \\
\hline CHEMBL 3651381 & 1527735 & 5.8357 & 5.3247 & TRN & \\
\hline CHEMBL 2325946 & 1527735 & 5.9734 & 6.2632 & TRN & \\
\hline CHEMBL3651350 & 1527735 & 5.5303 & 5.4933 & TST & \\
\hline CHEMBL 3655129 & 1527735 & 5.6657 & 6.1947 & TRN & \\
\hline CHEMBL 3655148 & 1527735 & 5.5659 & 5.7441 & TST & \\
\hline CHEMBL 3655237 & 1527735 & 6.9508 & 7.0295 & TRN & \\
\hline CHEMBL3651329 & 1527735 & 5.8699 & 5.3932 & TRN & \\
\hline CHEMBL3639541 & 1527735 & 5.3072 & 5.3654 & TST & \\
\hline
\end{tabular}


Supplemental Table S2.txt

\begin{tabular}{|c|c|c|c|c|}
\hline CHEMBL 3659468 & 1527735 & 4.0 & 5.3654 & TST \\
\hline CHEMBL 3655197 & 1527735 & 5.7098 & 5.5985 & TRN \\
\hline CHEMBL3651369 & 1527735 & 5.6289 & 5.1116 & TRN \\
\hline CHEMBL 3651345 & 1527735 & 6.6326 & 6.3599 & TRN \\
\hline CHEMBL 3655122 & 1527735 & 5.7254 & 5.4396 & TRN \\
\hline CHEMBL 3655198 & 1527735 & \multicolumn{3}{|c|}{5.132000000000001} \\
\hline CHEMBL 2325961 & 1527735 & 7.0214 & 6.1681 & TRN \\
\hline CHEMBL 3655106 & 1527735 & 5.1052 & 5.5299 & TRN \\
\hline CHEMBL 3655121 & 1527735 & 5.9796 & 6.6117 & TRN \\
\hline CHEMBL392788 & 1527735 & 4.9914 & 4.7452 & TRN \\
\hline CHEMBL 3655154 & 1527735 & 5.4403 & 6.01 & TST \\
\hline CHEMBL 3655118 & 1527735 & 5.2535 & 5.5877 & TRN \\
\hline CHEMBL 3655241 & 1527735 & 5.4966 & 5.5581 & TRN \\
\hline CHEMBL 3655119 & 1527735 & 6.1206 & 6.0009 & TRN \\
\hline CHEMBL 3651380 & 1527735 & 6.9408 & 6.2116 & TRN \\
\hline CHEMBL 3655223 & 1527735 & 7.1244 & 6.871 & TRN \\
\hline CHEMBL 3655280 & 1527735 & 6.3117 & 6.0282 & TRN \\
\hline CHEMBL 3655303 & 1527735 & 4.0 & 3.73199 & 99999999998 \\
\hline CHEMBL 2325954 & 1527735 & 7.0458 & 5.9603 & TRN \\
\hline CHEMBL 3655205 & 1527735 & 5.1515 & 3.1788 & TST \\
\hline CHEMBL 3655287 & 1527735 & 4.0 & 4.8005 & TRN \\
\hline CHEMBL 3651336 & 1527735 & 5.8554 & 5.409 & TST \\
\hline CHEMBL 3655238 & 1527735 & 6.5272 & 6.7685 & TRN \\
\hline CHEMBL 2325971 & 1527735 & 7.3125 & 6.2759 & TRN \\
\hline CHEMBL 3651344 & 1527735 & 5.7966 & 5.9182 & TRN \\
\hline CHEMBL 2325937 & 1527735 & 6.3451 & 5.5896 & TRN \\
\hline CHEMBL 3655211 & 1527735 & 6.1308 & 5.2257 & TST \\
\hline CHEMBL 3651367 & 1527735 & 6.6383 & 6.5957 & TRN \\
\hline CHEMBL 3651313 & 1527735 & 5.6492 & 6.6477 & TST \\
\hline CHEMBL 3651326 & 1527735 & 5.3747 & 6.0338 & TRN \\
\hline CHEMBL 2325947 & 1527735 & 7.1249 & 6.6371 & TRN \\
\hline CHEMBL 3655151 & 1527735 & 7.3575 & 6.1574 & TST \\
\hline CHEMBL3655120 & 1527735 & 6.3672 & 6.3213 & TRN \\
\hline CHEMBL 3655196 & 1527735 & 5.4804 & 5.7928 & TRN \\
\hline CHEMBL 3655226 & 1527735 & 6.0 & 6.71 & TRN \\
\hline CHEMBL 3655293 & 1527735 & 4.0 & 4.2224 & TST \\
\hline CHEMBL 3651323 & 1527735 & 5.7496 & 6.091 & TRN \\
\hline CHEMBL 3655163 & 1527735 & 6.0908 & 5.2824 & TST \\
\hline CHEMBL 3655149 & 1527735 & 6.1744 & 5.7288 & TST \\
\hline CHEMBL 3651311 & 1527735 & 5.6849 & 5.9976 & TRN \\
\hline CHEMBL 3651364 & 1527735 & 6.0 & 5.6113 & TRN \\
\hline CHEMBL 3651332 & 1527735 & 6.2526 & 6.6419 & TRN \\
\hline CHEMBL 3890029 & 1527735 & 4.0 & 3.7592 & TRN \\
\hline CHEMBL 3655247 & 1527735 & 7.301 & 7.176 & TRN \\
\hline CHEMBL 3651316 & 1527735 & 5.8149 & 6.1536 & TRN \\
\hline CHEMBL 3655185 & 1527735 & 5.4601 & 5.3705 & TRN \\
\hline CHEMBL 3655275 & 1527735 & 5.8649 & 6.2407 & TRN \\
\hline CHEMBL3651317 & 1527735 & 5.9403 & 5.8745 & TRN \\
\hline
\end{tabular}

Page 22066 
Supplemental Table S2.txt

\begin{tabular}{|c|c|c|c|c|}
\hline CHEMBL 3655139 & 1527735 & 6.7366 & 5.8833 & TST \\
\hline CHEMBL 3655114 & 1527735 & 5.166 & 4.8093 & TST \\
\hline CHEMBL 3655130 & 1527735 & 5.4206 & 6.103 & TRN \\
\hline CHEMBL 3651331 & 1527735 & 6.0011 & 5.7154 & TRN \\
\hline CHEMBL 3655112 & 1527735 & 6.6554 & 6.1234 & TRN \\
\hline CHEMBL 3655260 & 1527735 & 6.7062 & 5.7715 & TRN \\
\hline CHEMBL 2325964 & 1527735 & 6.9626 & 5.9946 & TRN \\
\hline CHEMBL 3651368 & 1527735 & 6.2596 & 6.1922 & TRN \\
\hline CHEMBL3655249 & 1527735 & 6.3527 & 6.0374 & TRN \\
\hline CHEMBL3655309 & 1527735 & 4.0 & 4.6199 & TST \\
\hline CHEMBL 3655126 & 1527735 & 6.2803 & 6.7787 & TRN \\
\hline CHEMBL 2325962 & 1527735 & 6.6144 & 5.6775 & TRN \\
\hline CHEMBL 2325958 & 1527735 & 6.8551 & 6.682 & TRN \\
\hline CHEMBL 3655305 & 1527735 & 4.0 & 4.4672 & TST \\
\hline CHEMBL 3651356 & 1527735 & 5.96 & 5.563 & TRN \\
\hline CHEMBL 3651386 & 1527735 & 5.38899 & 99999999 & 5.7725 \\
\hline CHEMBL3655277 & 1527735 & 5.9024 & 5.6238 & TRN \\
\hline CHEMBL 3655262 & 1527735 & 5.3857 & 5.4383 & TRN \\
\hline CHEMBL 3655215 & 1527735 & 5.7748 & 5.2816 & TRN \\
\hline CHEMBL 3655242 & 1527735 & 6.3665 & 5.9245 & TRN \\
\hline CHEMBL 3655187 & 1527735 & 5.481 & 4.4952 & TST \\
\hline CHEMBL 3655252 & 1527735 & 5.4568 & 4.1569 & TST \\
\hline CHEMBL 3655259 & 1527735 & 6.6959 & 6.0787 & TRN \\
\hline CHEMBL 3655289 & 1527735 & 4.0 & 4.3282 & TRN \\
\hline CHEMBL 3655276 & 1527735 & 6.2057 & 5.3016 & TRN \\
\hline CHEMBL 3655265 & 1527735 & 6.0273 & 6.2928 & TRN \\
\hline CHEMBL 3655273 & 1527735 & 6.0107 & 6.1093 & TRN \\
\hline CHEMBL 3651378 & 1527735 & 6.3382 & 6.1958 & TRN \\
\hline CHEMBL3655107 & 1527735 & 5.5809 & 5.4638 & TRN \\
\hline CHEMBL3655127 & 1527735 & 6.6631 & 6.4637 & TRN \\
\hline CHEMBL3655117 & 1527735 & 5.0692 & 5.0471 & TRN \\
\hline CHEMBL 3655222 & 1527735 & 6.6588 & 6.7294 & TRN \\
\hline CHEMBL 3655270 & 1527735 & 5.9109 & 6.4513 & TRN \\
\hline CHEMBL3655111 & 1527735 & 5.8198 & 6.0645 & TRN \\
\hline CHEMBL 3651338 & 1527735 & 6.2131 & 5.6486 & TST \\
\hline CHEMBL 3655160 & 1527735 & 6.7258 & 5.6573 & TST \\
\hline CHEMBL3655136 & 1527735 & 5.2236 & 6.2334 & TST \\
\hline CHEMBL3655279 & 1527735 & 5.6889 & 5.6075 & TRN \\
\hline CHEMBL 3651353 & 1527735 & 6.1998 & 5.6302 & TRN \\
\hline CHEMBL 3655175 & 1527735 & 5.2547 & \multicolumn{2}{|c|}{5.6610000000000005} \\
\hline CHEMBL3655166 & 1527735 & 5.3542 & 5.4072 & TST \\
\hline CHEMBL2325968 & 1527735 & 6.0464 & 5.8625 & TRN \\
\hline CHEMBL3651384 & 1527735 & 5.5951 & 5.4219 & TST \\
\hline CHEMBL 3655294 & 1527735 & 4.0 & 4.5262 & TRN \\
\hline CHEMBL2325965 & 1527735 & 6.6234 & 5.7405 & TRN \\
\hline CHEMBL2325960 & 1527735 & 7.0526 & 6.9447 & TRN \\
\hline CHEMBL 3639540 & 1527735 & 5.4337 & 5.6522 & TST \\
\hline CHEMBL 3655150 & 1527735 & 6.3686 & 5.4634 & TST \\
\hline
\end{tabular}




\begin{tabular}{|c|c|c|c|c|c|c|}
\hline \multicolumn{7}{|c|}{ Supplemental Table s2.txt } \\
\hline CHEMBL3655314 & 1527735 & 4.0 & 4.8116 & TRN & & \\
\hline CHEMBL3655299 & 1527735 & 4.0 & 3.7947 & TRN & & \\
\hline CHEMBL3651348 & 1527735 & 5.5553 & 5.9839 & TST & & \\
\hline CHEMBL2325963 & 1527735 & 6.132000 & 00000000 & 01 & 5.6683 & TRN \\
\hline CHEMBL 3655297 & 1527735 & 4.0 & 4.4944 & TRN & & \\
\hline CHEMBL2325957 & 1527735 & 6.308 & 6.4029 & TRN & & \\
\hline CHEMBL 3655177 & 1527735 & 5.1593 & 5.5492 & TRN & & \\
\hline CHEMBL3655216 & 1527735 & 5.4556 & 6.1065 & TRN & & \\
\hline CHEMBL 3655208 & 1527735 & 7.5229 & 6.8894 & TST & & \\
\hline CHEMBL3655190 & 1527735 & 5.3441 & 5.5679 & TRN & & \\
\hline CHEMBL 3655176 & 1527735 & 5.6639 & 5.1915 & TRN & & \\
\hline CHEMBL3655152 & 1527735 & 6.001 & 4.8667 & TST & & \\
\hline CHEMBL392106 & 1527735 & 4.0 & 4.3225 & TRN & & \\
\hline CHEMBL3651333 & 1527735 & 6.2067 & 5.2555 & TRN & & \\
\hline CHEMBL 3655264 & 1527735 & 5.9316 & 5.6038 & TRN & & \\
\hline CHEMBL 2325936 & 1527735 & 6.6312 & 5.9314 & TRN & & \\
\hline CHEMBL3655159 & 1527735 & 5.6441 & 5.7546 & TST & & \\
\hline CHEMBL3655316 & 1527735 & 4.0 & 5.7187 & TST & & \\
\hline CHEMBL 3655283 & 1527735 & 4.0 & 5.6726 & TST & & \\
\hline CHEMBL3655285 & 1527735 & 4.0 & 5.3923 & TRN & & \\
\hline CHEMBL3655203 & 1527735 & 5.3 & 3.8567 & TST & & \\
\hline CHEMBL 3655210 & 1527735 & 6.1805 & 5.5905 & TST & & \\
\hline CHEMBL3655133 & 1527735 & 5.4758 & 6.3272 & TST & & \\
\hline CHEMBL 3655188 & 1527735 & 5.0718 & 4.8577 & TRN & & \\
\hline CHEMBL3655186 & 1527735 & 5.4113 & 5.6121 & TRN & & \\
\hline CHEMBL3651310 & 1527735 & 7.0186 & 6.0671 & TST & & \\
\hline CHEMBL3651372 & 1527735 & 5.0996 & 5.305 & TRN & & \\
\hline CHEMBL 2325944 & 1527735 & 6.6588 & 6.4252 & TRN & & \\
\hline CHEMBL 3655261 & 1527735 & 5.7034 & 5.7021 & TRN & & \\
\hline CHEMBL3651324 & 1527735 & 5.1412 & 4.7618 & TRN & & \\
\hline CHEMBL3655282 & 1527735 & 4.0 & 4.8909 & TRN & & \\
\hline CHEMBL3651351 & 1527735 & 5.6393 & 5.5477 & TRN & & \\
\hline CHEMBL3655306 & 1527735 & 4.0 & 4.5793 & TRN & & \\
\hline CHEMBL3655157 & 1527735 & 5.5806 & 6.201006 & 0000000000 & 05 & TST \\
\hline CHEMBL3655170 & 1527735 & 5.9469 & 5.8594 & TRN & & \\
\hline CHEMBL 3655234 & 1527735 & 5.16 & 5.0693 & TRN & & \\
\hline CHEMBL3655212 & 1527735 & 6.1979 & 5.6589 & TRN & & \\
\hline CHEMBL3651314 & 1527735 & 6.8164 & 6.9708 & TRN & & \\
\hline CHEMBL3655179 & 1527735 & 5.2252 & 5.0615 & TRN & & \\
\hline CHEMBL3655296 & 1527735 & 4.0 & 5.7141 & TST & & \\
\hline CHEMBL3655183 & 1527735 & 6.0752 & 5.7131 & TRN & & \\
\hline CHEMBL 3655272 & 1527735 & 6.0983 & 5.7486 & TST & & \\
\hline CHEMBL3655257 & 1527735 & 6.393 & 6.3296 & TRN & & \\
\hline CHEMBL3655236 & 1527735 & 6.4437 & 6.0264 & TRN & & \\
\hline CHEMBL3651357 & 1527735 & 6.7251 & 6.3938 & TRN & & \\
\hline CHEMBL2325939 & 1527735 & 6.862999 & 79999999 & 995 & 6.5476 & TRN \\
\hline CHEMBL3655219 & 1527735 & 6.3979 & 6.7553 & TRN & & \\
\hline CHEMBL3651361 & 1527735 & 6.7423 & 6.546 & TRN & & \\
\hline
\end{tabular}




\begin{tabular}{|c|c|c|c|c|c|}
\hline CHEMBL3655161 & 1527735 & 5.41200 & $\begin{array}{l}\text { oplement } \\
\text { jo000000 }\end{array}$ & $\begin{array}{lr}\text { al } & \text { Table } \\
01 & 4.7935\end{array}$ & TST \\
\hline CHEMBL3651335 & 1527735 & 5.0445 & 5.2121 & TRN & \\
\hline CHEMBL3655292 & 1527735 & 4.0 & 4.6129 & TRN & \\
\hline CHEMBL3651379 & 1527735 & 6.7491 & 6.5831 & TRN & \\
\hline CHEMBL2325951 & 1527735 & 6.2419 & 6.1453 & TRN & \\
\hline CHEMBL3651337 & 1527735 & 5.1915 & 5.1892 & TRN & \\
\hline CHEMBL3659466 & 1527735 & 4.0 & 4.5571 & TRN & \\
\hline CHEMBL2325956 & 1527735 & 5.3882 & 4.7181 & TST & \\
\hline CHEMBL3651308 & 1527735 & 5.4293 & 5.4721 & TRN & \\
\hline CHEMBL3655315 & 1527735 & 4.0 & 4.5225 & TST & \\
\hline CHEMBL2325948 & 1527735 & 6.3238 & 6.2716 & TRN & \\
\hline CHEMBL 3655263 & 1527735 & 5.4885 & 4.8453 & TRN & \\
\hline CHEMBL3655156 & 1527735 & 6.9147 & 6.1893 & TST & \\
\hline CHEMBL3655313 & 1527735 & 4.0 & 5.6968 & TRN & \\
\hline CHEMBL 3655248 & 1527735 & 5.0022 & 4.1149 & TST & \\
\hline CHEMBL3651383 & 1527735 & 6.6155 & 7.0194 & TST & \\
\hline CHEMBL3651360 & 1527735 & 6.393 & 6.4716 & TRN & \\
\hline CHEMBL3651339 & 1527735 & 6.6876 & 6.985 & TST & \\
\hline CHEMBL3651322 & 1527735 & 6.0044 & 6.4571 & TST & \\
\hline CHEMBL3655192 & 1527735 & 5.4417 & 5.3131 & TRN & \\
\hline CHEMBL3655180 & 1527735 & 5.0255 & 5.7234 & TRN & \\
\hline CHEMBL 3655178 & 1527735 & 5.7622 & 6.1236 & TST & \\
\hline CHEMBL3655221 & 1527735 & 6.8136 & 6.5693 & TRN & \\
\hline CHEMBL3651305 & 1527735 & 6.005 & 6.7987 & TRN & \\
\hline CHEMBL3655125 & 1527735 & 6.3812 & 6.9149 & TRN & \\
\hline CHEMBL3655173 & 1527735 & 5.6653 & 5.7323 & TRN & \\
\hline CHEMBL3655204 & 1527735 & 5.1929 & 3.4946 & TST & \\
\hline CHEMBL3655195 & 1527735 & 5.4087 & 5.2935 & TRN & \\
\hline CHEMBL3655164 & 1527735 & 5.1627 & 6.709 & TST & \\
\hline CHEMBL2325949 & 1527735 & 6.4815 & 6.2668 & TRN & \\
\hline CHEMBL3655308 & 1527735 & 4.0 & \multicolumn{2}{|c|}{ 4.2669999999999995 } & \\
\hline CHEMBL 3655267 & 1527735 & 6.495 & 5.6591 & TRN & \\
\hline CHEMBL3655317 & 1527735 & 4.0 & 5.0456 & TST & \\
\hline CHEMBL3655167 & 1527735 & 5.732 & 6.6746 & TST & \\
\hline CHEMBL3659467 & 1527735 & 4.0 & 5.5467 & TST & \\
\hline CHEMBL3655206 & 1527735 & 5.931 & 4.9288 & TST & \\
\hline CHEMBL3651312 & 1527735 & 6.4815 & 6.1212 & TST & \\
\hline CHEMBL3655214 & 1527735 & 5.4811 & 5.6735 & TRN & \\
\hline CHEMBL3655116 & 1527735 & 5.2737 & 5.2713 & TST & \\
\hline CHEMBL 3655278 & 1527735 & 5.4198 & 4.7281 & TRN & \\
\hline CHEMBL2325959 & 1527735 & 6.9326 & 6.5807 & TRN & \\
\hline CHEMBL2325972 & 1527735 & 7.0555 & 6.3631 & TRN & \\
\hline CHEMBL3655123 & 1527735 & 6.4626 & 6.5267 & TRN & \\
\hline CHEMBL3655131 & 1527735 & 6.1367 & 5.5929 & TRN & \\
\hline CHEMBL 3655128 & 1527735 & 6.4554 & 6.3543 & TRN & \\
\hline CHEMBL 3655184 & 1527735 & 5.528 & 5.2258 & TRN & \\
\hline CHEMBL3655318 & 1527735 & 4.0 & 5.5779 & TRN & \\
\hline CHEMBL3655171 & 1527735 & 5.4116 & 5.7632 & TRN & \\
\hline
\end{tabular}

Page 22069 
Supplemental Table S2.txt

\begin{tabular}{|c|c|c|c|c|}
\hline CHEMBL 3651321 & 1527735 & 5.1558 & 5.5015 & TRN \\
\hline CHEMBL 3655202 & 1527735 & 5.6283 & 4.6264 & TST \\
\hline CHEMBL2325969 & 1527735 & 5.7285 & 6.3092 & TRN \\
\hline CHEMBL 3655246 & 1527735 & 7.433 & 7.1509 & TRN \\
\hline CHEMBL 3655140 & 1527735 & 6.0032 & 6.2273 & TST \\
\hline CHEMBL 3655286 & 1527735 & 4.0 & 5.3763 & TRN \\
\hline CHEMBL 3655288 & 1527735 & 4.0 & 4.4999 & TRN \\
\hline CHEMBL 3651307 & 1527735 & 6.6737 & 6.8395 & TRN \\
\hline CHEMBL 3651359 & 1527735 & 6.6923 & 6.7018 & TRN \\
\hline CHEMBL 3651328 & 1527735 & 6.0429 & 5.7422 & TRN \\
\hline CHEMBL 3655218 & 1527735 & 6.3967 & 7.0853 & TRN \\
\hline CHEMBL 3651370 & 1527735 & 5.0195 & 5.1434 & TST \\
\hline CHEMBL 2325966 & 1527735 & 5.4954 & 5.8746 & TRN \\
\hline CHEMBL 2325950 & 1527735 & 6.4195 & 5.4227 & TRN \\
\hline CHEMBL 3651319 & 1527735 & 5.3022 & 5.6568 & TST \\
\hline CHEMBL 3655132 & 1527735 & 6.5931 & 5.284 & TST \\
\hline CHEMBL 3655304 & 1527735 & 4.0 & 3.54 & TRN \\
\hline CHEMBL 3651382 & 1527735 & 5.7034 & 5.8295 & TRN \\
\hline CHEMBL 3655143 & 1527735 & 6.4746 & 5.8643 & TST \\
\hline CHEMBL 3651385 & 1527735 & 5.8327 & 5.5716 & TRN \\
\hline CHEMBL3655225 & 1527735 & 6.8579 & 6.4121 & TRN \\
\hline CHEMBL 3655239 & 1527735 & 6.166 & 5.3901 & TRN \\
\hline CHEMBL 3655194 & 1527735 & 4.9355 & 5.4534 & TRN \\
\hline CHEMBL3651309 & 1527735 & 6.4461 & 5.4918 & TST \\
\hline CHEMBL 245408 & 1527735 & 6.8303 & 6.5535 & TRN \\
\hline CHEMBL 3651343 & 1527735 & 6.2349 & 6.5574 & TRN \\
\hline CHEMBL 3655172 & 1527735 & 5.8478 & 5.2817 & TRN \\
\hline CHEMBL 3655235 & 1527735 & 5.7496 & 6.3732 & TRN \\
\hline CHEMBL3651306 & 1527735 & 6.5677 & 6.7823 & TRN \\
\hline CHEMBL 3655209 & 1527735 & 6.1938 & 4.6952 & TST \\
\hline CHEMBL 3659470 & 1527735 & 4.0 & 4.2752 & TRN \\
\hline CHEMBL 2325952 & 1527735 & 7.063 & 6.6093 & TRN \\
\hline CHEMBL 3655217 & 1527735 & 5.2611 & 5.136 & TRN \\
\hline CHEMBL 3655108 & 1527735 & 5.1634 & 4.4242 & TRN \\
\hline CHEMBL 3651330 & 1527735 & 5.9382 & 5.9342 & TRN \\
\hline CHEMBL 3655146 & 1527735 & 6.8386 & 6.2964 & TST \\
\hline CHEMBL3659469 & 1527735 & 4.0 & 6.1202 & TST \\
\hline CHEMBL3655199 & 1527735 & 5.3823 & 5.5526 & TRN \\
\hline CHEMBL 3655220 & 1527735 & 5.4962 & 5.3256 & TST \\
\hline CHEMBL 3655200 & 1527735 & 5.6556 & 5.8756 & TRN \\
\hline CHEMBL 3651362 & 1527735 & 5.7055 & 6.2805 & TRN \\
\hline CHEMBL 3651327 & 1527735 & 5.8178 & 5.7561 & TRN \\
\hline CHEMBL3655115 & 1527735 & 5.2528 & 4.7366 & TRN \\
\hline CHEMBL 3655182 & 1527735 & 4.891 & 5.382999 & 9999999999 \\
\hline CHEMBL 3655141 & 1527735 & 5.848 & 5.8272 & TST \\
\hline CHEMBL 3911537 & 1641607 & 5.0334 & 5.1337 & TRN \\
\hline CHEMBL 3923614 & 1641607 & 5.9666 & 5.859 & TRN \\
\hline CHEMBL3911716 & 1641607 & 6.7235 & 6.5209 & TRN \\
\hline
\end{tabular}

Page 22070 
Supplemental Table S2.txt

\begin{tabular}{|c|c|c|c|c|c|}
\hline CHEMBL3941301 & 1641607 & 6.2708 & 6.3662 & TRN & \\
\hline CHEMBL3983383 & 1641607 & 5.6655 & 6.2785 & TRN & \\
\hline CHEMBL3947194 & 1641607 & 6.9666 & 6.6749 & TRN & \\
\hline CHEMBL3977620 & 1641607 & 6.7328 & 6.4602 & TRN & \\
\hline CHEMBL 3952932 & 1641607 & 7.0862 & 6.6569 & TRN & \\
\hline CHEMBL3896695 & 1641607 & 6.6576 & 6.7822 & TRN & \\
\hline CHEMBL3923755 & 1641607 & 4.4672 & 4.8962 & TRN & \\
\hline CHEMBL3901213 & 1641607 & 6.1891 & 6.4057 & TRN & \\
\hline CHEMBL3924736 & 1641607 & 7.6021 & 7.4613 & TRN & \\
\hline CHEMBL 3964867 & 1641607 & 6.4389 & 5.6285 & TRN & \\
\hline CHEMBL3910123 & 1641607 & 4.5513 & 5.2265 & TRN & \\
\hline CHEMBL3972449 & 1641607 & 7.6383 & 8.1697 & TRN & \\
\hline CHEMBL3893462 & 1641607 & 6.8729 & 6.1748 & TRN & \\
\hline CHEMBL 3898614 & 1641607 & 6.4001 & 6.7872 & TRN & \\
\hline CHEMBL 3955347 & 1641607 & 6.0625 & 6.8748 & TRN & \\
\hline CHEMBL 3954200 & 1641607 & 6.7144 & 6.5631 & TRN & \\
\hline CHEMBL3963139 & 1641607 & 7.1871 & 6.6405 & TRN & \\
\hline CHEMBL3980484 & 1641607 & 8.699 & 8.2549 & TRN & \\
\hline CHEMBL 3973534 & 1641607 & 8.0458 & 7.741000 & 0000000005 & TST \\
\hline CHEMBL 3928341 & 1641607 & 5.0137 & 5.1112 & TRN & \\
\hline CHEMBL 3985492 & 1641607 & 7.4815 & 6.8384 & TRN & \\
\hline CHEMBL3900666 & 1641607 & 5.7375 & 5.3564 & TRN & \\
\hline CHEMBL3910292 & 1641607 & 6.4949 & 6.6111 & TRN & \\
\hline CHEMBL3933666 & 1641607 & 8.1549 & 6.8417 & TRN & \\
\hline CHEMBL3938050 & 1641607 & 4.7399 & 5.7264 & TRN & \\
\hline CHEMBL3932565 & 1641607 & 6.1096 & 5.7743 & TRN & \\
\hline CHEMBL3902315 & 1641607 & 6.0 & 6.1996 & TRN & \\
\hline CHEMBL3896381 & 1641607 & 6.7932 & 6.6816 & TRN & \\
\hline CHEMBL3922902 & 1641607 & 6.5867 & 6.3272 & TRN & \\
\hline CHEMBL3932733 & 1641607 & 5.8827 & 6.11 & TRN & \\
\hline CHEMBL3914734 & 1641607 & 5.4179 & 5.348 & TRN & \\
\hline CHEMBL3927854 & 1641607 & 6.3363 & 6.4623 & TST & \\
\hline CHEMBL3895844 & 1641607 & 7.8861 & 7.5148 & TRN & \\
\hline CHEMBL3918155 & 1641607 & 6.2848 & 5.8218 & TRN & \\
\hline CHEMBL3979124 & 1641607 & 6.7235 & 6.9972 & TRN & \\
\hline CHEMBL3951074 & 1641607 & 6.1733 & 7.0094 & TRN & \\
\hline CHEMBL3889501 & 1641607 & 5.1261 & 5.7068 & TRN & \\
\hline CHEMBL3986265 & 1641607 & 6.8386 & 6.3881 & TRN & \\
\hline CHEMBL3983988 & 1641607 & 7.0458 & 7.8634 & TRN & \\
\hline CHEMBL3975173 & 1641607 & 4.7905 & 5.6472 & TRN & \\
\hline CHEMBL 3948054 & 1641607 & 7.0088 & 6.0072 & TRN & \\
\hline CHEMBL3940148 & 1641607 & 6.5528 & 6.4325 & TRN & \\
\hline CHEMBL3984545 & 1641607 & 5.8539 & 5.511 & TRN & \\
\hline CHEMBL3966376 & 1641607 & 6.5017 & 6.4172 & TRN & \\
\hline CHEMBL3890833 & 1641607 & 5.2076 & 5.6018 & TST & \\
\hline CHEMBL 3944174 & 1641607 & 6.75700 & 100000000 & 6.2974 & TRN \\
\hline CHEMBL 3893396 & 1641607 & 5.6757 & 6.0747 & TRN & \\
\hline CHEMBL3953528 & 1641607 & 6.4248 & 5.0677 & TST & \\
\hline
\end{tabular}

Page 22071 
Supplemental Table S2.txt

\begin{tabular}{|c|c|c|c|c|c|}
\hline CHEMBL3932449 & 1641607 & 5.9666 & 5.9469 & TRN & \\
\hline CHEMBL3971961 & 1641607 & 6.3233 & 5.841 & TST & \\
\hline CHEMBL3967113 & 1641607 & 6.9747 & 6.9197 & TRN & \\
\hline CHEMBL3921841 & 1641607 & 5.4711 & 5.8596 & TRN & \\
\hline CHEMBL 3945804 & 1641607 & 5.3726 & 5.6511 & TST & \\
\hline CHEMBL3943102 & 1641607 & 6.1308 & 6.3101 & TRN & \\
\hline CHEMBL3900921 & 1641607 & 6.2403 & 7.0217 & TRN & \\
\hline CHEMBL3922557 & 1641607 & 5.341 & 5.4544 & TRN & \\
\hline CHEMBL3929412 & 1641607 & 5.7011 & 5.9069 & TST & \\
\hline CHEMBL3946217 & 1641607 & 6.5114 & 6.2504 & TRN & \\
\hline CHEMBL3922075 & 1641607 & 7.7447 & 7.8535 & TRN & \\
\hline CHEMBL3948402 & 1641607 & 6.3615 & 6.0358 & TRN & \\
\hline CHEMBL3917530 & 1641607 & 7.2676 & 6.965 & TRN & \\
\hline CHEMBL3906153 & 1641607 & 7.9586 & 6.8189 & TST & \\
\hline CHEMBL3910968 & 1641607 & 6.9872 & 6.7954 & TST & \\
\hline CHEMBL3904953 & 1641607 & 8.2218 & 8.1264 & TST & \\
\hline CHEMBL3932919 & 1641607 & 7.0915 & 6.4183 & TRN & \\
\hline CHEMBL3983509 & 1641607 & 9.0 & 8.1169 & TST & \\
\hline CHEMBL3947063 & 1641607 & \multicolumn{2}{|c|}{4.9830000000000005} & 5.0554 & TRN \\
\hline CHEMBL3919976 & 1641607 & 7.0706 & 7.1426 & TST & \\
\hline CHEMBL3944166 & 1641607 & 6.3143 & 6.5967 & TRN & \\
\hline CHEMBL 3892254 & 1641607 & 5.8297 & 5.25799 & 9999999999 & TRN \\
\hline CHEMBL3943893 & 1641607 & 7.1308 & 6.755 & TRN & \\
\hline CHEMBL3962473 & 1641607 & 6.433 & 5.3701 & TRN & \\
\hline CHEMBL 3960944 & 1641607 & 5.4045 & 6.4375 & TST & \\
\hline CHEMBL3909266 & 1641607 & 7.1367 & 7.5599 & TRN & \\
\hline CHEMBL3937329 & 1641607 & 7.9208 & 6.8937 & TST & \\
\hline CHEMBL3938206 & 1641607 & 6.6345 & 6.3491 & TST & \\
\hline CHEMBL 3895618 & 1641607 & 5.0931 & 5.4921 & TST & \\
\hline CHEMBL3891939 & 1641607 & 5.5817 & 6.2764 & TRN & \\
\hline CHEMBL3901075 & 1641607 & 5.8268 & 6.5657 & TST & \\
\hline CHEMBL3946857 & 1641607 & 4.9066 & 5.3512 & TRN & \\
\hline CHEMBL3919298 & 1641607 & \multicolumn{3}{|c|}{6.752000000000001} & TRN \\
\hline CHEMBL 3961254 & 1641607 & 6.3497 & 6.8191 & TRN & \\
\hline CHEMBL3922656 & 1641607 & 6.7932 & 6.4654 & TST & \\
\hline CHEMBL3928689 & 1641607 & 6.6676 & 6.8964 & TST & \\
\hline CHEMBL3972432 & 1641607 & 6.0 & 5.6895 & TST & \\
\hline CHEMBL3973408 & 1641607 & 7.1675 & 6.9604 & TRN & \\
\hline CHEMBL3977035 & 1641607 & 5.2976 & 5.4918 & TRN & \\
\hline CHEMBL3962126 & 1641607 & 6.9957 & 7.4735 & TRN & \\
\hline CHEMBL3948431 & 1641607 & 7.7212 & 7.4873 & TRN & \\
\hline CHEMBL3910370 & 1641607 & 7.1249 & 7.3534 & TST & \\
\hline CHEMBL3938762 & 1641607 & 6.3788 & 6.4927 & TRN & \\
\hline CHEMBL3911702 & 1641607 & 5.4157 & 6.1476 & TST & \\
\hline CHEMBL3981156 & 1641607 & 8.3979 & 8.0865 & TRN & \\
\hline CHEMBL3973335 & 1641607 & 6.8386 & 6.4742 & TST & \\
\hline CHEMBL 3916242 & 1641607 & 7.7696 & 6.9479 & TRN & \\
\hline CHEMBL 3890342 & 1641607 & 6.8153 & 6.9685 & TST & \\
\hline
\end{tabular}


Supplemental Table S2.txt

\begin{tabular}{|c|c|c|c|c|}
\hline 632 & & & & TRN \\
\hline HEMBL3913443 & 641607 & 5.7799 & 5.9637 & \\
\hline & 607 & & & \\
\hline 82 & 607 & & & \\
\hline IEMBL 3985734 & 541607 & & כ2 & \\
\hline IEMBL 3968526 & 641607 & 2924 & 7679 & \\
\hline EMBL3975536 & 607 & & 8903 & \\
\hline & 607 & & 6208 & \\
\hline EMBL3916740 & 607 & & .9215 & \\
\hline AEMBL2380893 & 58172 & & 4.6039 & \\
\hline AEMBL2381016 & 58172 & & 4305 & \\
\hline EMBL2380318 & 72 & & 8352 & \\
\hline 380917 & & & & \\
\hline IEMBL 2381037 & 72 & & .5295 & \\
\hline EMBL 2381014 & 172 & & 7173 & \\
\hline 889 & 72 & 9 & 5027 & \\
\hline IEMBL 2381008 & 72 & & 33 & \\
\hline IEMBL 2380882 & & & 996 & \\
\hline EMBL 2380896 & 72 & & 4.5275 & \\
\hline EMBL 2380911 & 72 & & 7723 & \\
\hline EMBL 2380909 & 72 & 4. & 4.6758 & \\
\hline EMBL2381024 & 72 & & 577 & \\
\hline EMBL 2380890 & 72 & & & \\
\hline 380895 & & & .8543 & \\
\hline$\partial 6$ & & & & \\
\hline EMBL2380920 & 72 & & . 2719 & RI \\
\hline EMBL2380899 & 72 & & .3908 & \\
\hline EMBL2380913 & & & & \\
\hline & & & & \\
\hline תר וסטזו & & & & \\
\hline EMBL2380919 & 72 & & 97 & RI \\
\hline MBL2380886 & & & 35 & RN \\
\hline & & & & TRN \\
\hline & & & & \\
\hline EMBL 2380924 & 72 & & 88 & $F$ \\
\hline 81018 & & & .2948 & R \\
\hline 3 & & & 45 & RI \\
\hline & & & 14 & IRN \\
\hline IEMBL 2380898 & 172 & & 4.4182 & S \\
\hline MBL 2381025 & 72 & & 3.7695 & $\mathrm{~s}$ \\
\hline EMBL2381033 & & & .5735 & $\mathrm{R}$ \\
\hline & & & 4.0292 & Nor \\
\hline EMBL2380922 & & & 5.6259 & RI \\
\hline MBL238092 & 8172 & & 6.2796 & $R$ \\
\hline 19 & & & 4.8692 & $\mathrm{~K}$ \\
\hline MBL 2380926 & & & 5.5986 & \\
\hline CHEMBL 23809 & & & 4.806 & \\
\hline CHEMBL2380907 & 958172 & 5.4685 & 5.0197 & \\
\hline
\end{tabular}

Page 22073 


\begin{tabular}{|c|c|c|c|c|c|}
\hline \multicolumn{6}{|c|}{ Supplemental Table S2.txt } \\
\hline CHEMBL2381041 & 958172 & 3.0 & 3.3457 & TRN & \\
\hline CHEMBL 2380885 & 958172 & 4.4698 & 4.0679 & TRN & \\
\hline CHEMBL2380902 & 958172 & 3.0 & 4.0997 & TST & \\
\hline CHEMBL2380897 & 958172 & 5.0 & 4.7181 & TST & \\
\hline CHEMBL2381043 & 958172 & 6.0 & 5.7158 & TRN & \\
\hline CHEMBL2381015 & 958172 & 4.8239 & 4.6017 & TRN & \\
\hline CHEMBL2381012 & 958172 & 6.0 & 5.1653 & TRN & \\
\hline CHEMBL 2381017 & 958172 & 4.3372 & 4.2399 & TRN & \\
\hline CHEMBL2380906 & 958172 & 5.4815 & 4.9562 & TRN & \\
\hline CHEMBL2380883 & 958172 & 4.5361 & 4.6385 & TST & \\
\hline CHEMBL2380900 & 958172 & 4.7852 & 4.4467 & TST & \\
\hline CHEMBL2380916 & 958172 & 4.8729 & 4.71 & TST & \\
\hline CHEMBL 2380891 & 958172 & 4.4609 & 4.4724 & TRN & \\
\hline CHEMBL2381034 & 958172 & 4.585 & 4.8908 & TRN & \\
\hline CHEMBL2380918 & 958172 & 4.684 & 4.7672 & TRN & \\
\hline CHEMBL2380901 & 958172 & 5.2111 & 4.8813 & TST & \\
\hline CHEMBL2380921 & 958172 & 5.0969 & 5.5475 & TRN & \\
\hline CHEMBL 2380894 & 958172 & 4.8996 & 4.724 & TRN & \\
\hline CHEMBL2381038 & 958172 & 5.0809 & 5.1413 & TRN & \\
\hline CHEMBL2380910 & 958172 & 5.0915 & 4.9059 & TRN & \\
\hline CHEMBL2380912 & 958172 & 5.2676 & 5.0572 & TRN & \\
\hline CHEMBL2381021 & 958172 & 4.3872 & 3.3235 & TRN & \\
\hline CHEMBL 2381013 & 958172 & 4.4202 & 4.5439 & TST & \\
\hline CHEMBL2381044 & 958172 & 3.0 & 3.5566 & TST & \\
\hline CHEMBL2380904 & 958172 & 4.2865 & 4.2107 & TST & \\
\hline CHEMBL1452056 & 1462660 & 5.0506 & 4.779 & TRN & \\
\hline CHEMBL302245 & 1462660 & 4.6757 & 4.5742 & TRN & \\
\hline CHEMBL3397112 & 1462660 & 4.5421 & 4.395 & TRN & \\
\hline CHEMBL1504404 & 1462660 & 4.5229 & 4.5071 & TRN & \\
\hline CHEMBL3397265 & 1462660 & 4.6799 & 4.5422 & TRN & \\
\hline CHEMBL3397236 & 1462660 & 4.567 & 3.91600 & 00000000004 & TRN \\
\hline CHEMBL3397241 & 1462660 & 3.0 & 4.5144 & TST & \\
\hline CHEMBL3397143 & 1462660 & 5.5376 & 5.5993 & TRN & \\
\hline CHEMBL3397228 & 1462660 & 4.0814 & 3.4544 & TRN & \\
\hline CHEMBL3397141 & 1462660 & 7.0 & 5.8826 & TST & \\
\hline CHEMBL3397263 & 1462660 & 4.4413 & 4.6062 & TRN & \\
\hline CHEMBL3397122 & 1462660 & 4.6716 & 4.8672 & TRN & \\
\hline CHEMBL3397109 & 1462660 & 4.5287 & 4.9653 & TST & \\
\hline CHEMBL3397113 & 1462660 & 4.3737 & 4.5959 & TST & \\
\hline CHEMBL1492174 & 1462660 & 4.8928 & 4.4567 & TRN & \\
\hline CHEMBL3397262 & 1462660 & 4.2984 & 4.1657 & TRN & \\
\hline CHEMBL3397118 & 1462660 & 4.1331 & 4.1894 & TST & \\
\hline CHEMBL3397131 & 1462660 & 4.3925 & 4.122 & TRN & \\
\hline CHEMBL3397244 & 1462660 & 5.5376 & 4.8462 & TRN & \\
\hline CHEMBL3397232 & 1462660 & 4.52 & 3.9515 & TRN & \\
\hline CHEMBL3397124 & 1462660 & 4.1302 & 4.41 & TRN & \\
\hline CHEMBL3397146 & 1462660 & 4.3686 & 3.9206 & TRN & \\
\hline CHEMBL3397261 & 1462660 & 4.1379 & 3.7634 & TRN & \\
\hline
\end{tabular}

Page 22074 
Supplemental Table S2.txt

\begin{tabular}{|c|c|c|c|c|}
\hline CHEMBL 3397147 & 1462660 & 4.4535 & 3.9515 & TRN \\
\hline CHEMBL3397135 & 1462660 & 4.5017 & 4.5483 & TRN \\
\hline CHEMBL3397255 & 1462660 & 5.585 & 5.0142 & TRN \\
\hline CHEMBL3397145 & 1462660 & 6.699 & 6.3308 & TRN \\
\hline CHEMBL3397239 & 1462660 & 4.5591 & 3.8931 & TRN \\
\hline CHEMBL3397251 & 1462660 & 4.556 & 5.0142 & TRN \\
\hline CHEMBL3397233 & 1462660 & 3.0 & 3.4544 & TRN \\
\hline CHEMBL3397140 & 1462660 & 6.0969 & 5.2329 & TST \\
\hline CHEMBL3397134 & 1462660 & 5.2076 & 4.6044 & TST \\
\hline CHEMBL3397117 & 1462660 & 4.7055 & 4.5668 & TRN \\
\hline CHEMBL3397142 & 1462660 & 5.7959 & 6.2108 & TRN \\
\hline CHEMBL3397115 & 1462660 & 4.4815 & 4.802 & TRN \\
\hline CHEMBL3397133 & 1462660 & 5.7212 & 4.7446 & TST \\
\hline CHEMBL3397252 & 1462660 & 4.6737 & 4.9577 & TRN \\
\hline CHEMBL3397111 & 1462660 & 4.618 & 4.7241 & TRN \\
\hline CHEMBL3397260 & 1462660 & 3.0 & 4.1231 & TRN \\
\hline CHEMBL3397242 & 1462660 & 4.4449 & 4.947 & TRN \\
\hline CHEMBL3397129 & 1462660 & 3.0 & 3.8894 & TRN \\
\hline CHEMBL3397114 & 1462660 & 4.382 & 4.6797 & TRN \\
\hline CHEMBL3397257 & 1462660 & 5.6576 & 5.8866 & TST \\
\hline CHEMBL 3397247 & 1462660 & 5.5376 & 5.1516 & TST \\
\hline CHEMBL3397230 & 1462660 & 4.0168 & 3.7998 & TRN \\
\hline CHEMBL3397256 & 1462660 & 5.8539 & 5.8159 & TRN \\
\hline CHEMBL3397235 & 1462660 & 4.5702 & 3.8931 & TRN \\
\hline CHEMBL3397125 & 1462660 & 3.0 & 3.8987 & TRN \\
\hline CHEMBL3397120 & 1462660 & 4.2774 & 4.6831 & TST \\
\hline CHEMBL3397116 & 1462660 & 4.6596 & 4.7272 & TST \\
\hline CHEMBL3397121 & 1462660 & 4.6073 & 4.7326 & TRN \\
\hline CHEMBL3397234 & 1462660 & 4.6676 & 4.0444 & TST \\
\hline CHEMBL3397237 & 1462660 & 4.5986 & 4.3608 & TRN \\
\hline CHEMBL3397267 & 1462660 & 5.1871 & 4.4055 & TST \\
\hline CHEMBL3397259 & 1462660 & 5.7212 & 5.44600 & 0000000001 \\
\hline CHEMBL3397136 & 1462660 & 4.5513 & 4.9333 & TRN \\
\hline CHEMBL3397240 & 1462660 & 4.6126 & 4.4212 & TRN \\
\hline CHEMBL3397132 & 1462660 & 4.6144 & 4.9413 & TRN \\
\hline CHEMBL3397110 & 1462660 & 4.5544 & 4.3381 & TST \\
\hline CHEMBL3397126 & 1462660 & 4.2373 & 4.5254 & TRN \\
\hline CHEMBL3397245 & 1462660 & 5.5376 & 5.5667 & TRN \\
\hline CHEMBL3397144 & 1462660 & 6.699 & 6.3929 & TRN \\
\hline CHEMBL3397246 & 1462660 & 5.5376 & 5.4277 & TRN \\
\hline CHEMBL 3397264 & 1462660 & 4.6108 & 4.7163 & TRN \\
\hline CHEMBL3397139 & 1462660 & 5.2441 & 4.681 & TST \\
\hline CHEMBL3397138 & 1462660 & 4.6536 & 4.8108 & TRN \\
\hline CHEMBL3397253 & 1462660 & 5.7959 & 5.7724 & TRN \\
\hline CHEMBL3397250 & 1462660 & 4.8327 & 5.1516 & TST \\
\hline CHEMBL3397229 & 1462660 & 4.1198 & 4.2183 & TRN \\
\hline CHEMBL3397243 & 1462660 & 5.6021 & 5.0703 & TRN \\
\hline CHEMBL3397249 & 1462660 & 4.1599 & 4.8462 & TRN \\
\hline
\end{tabular}

Page 22075 
Supplemental Table S2.txt

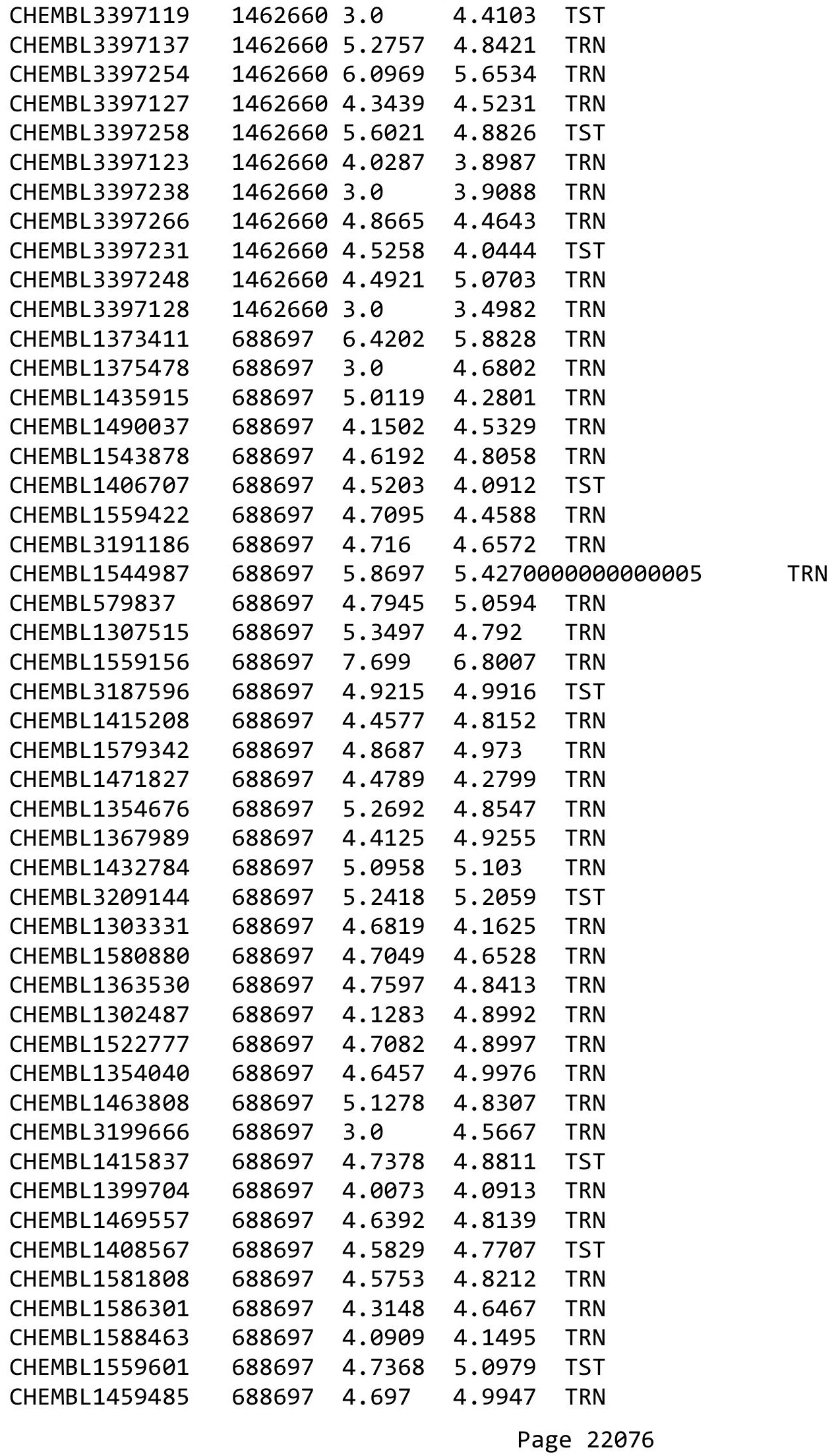




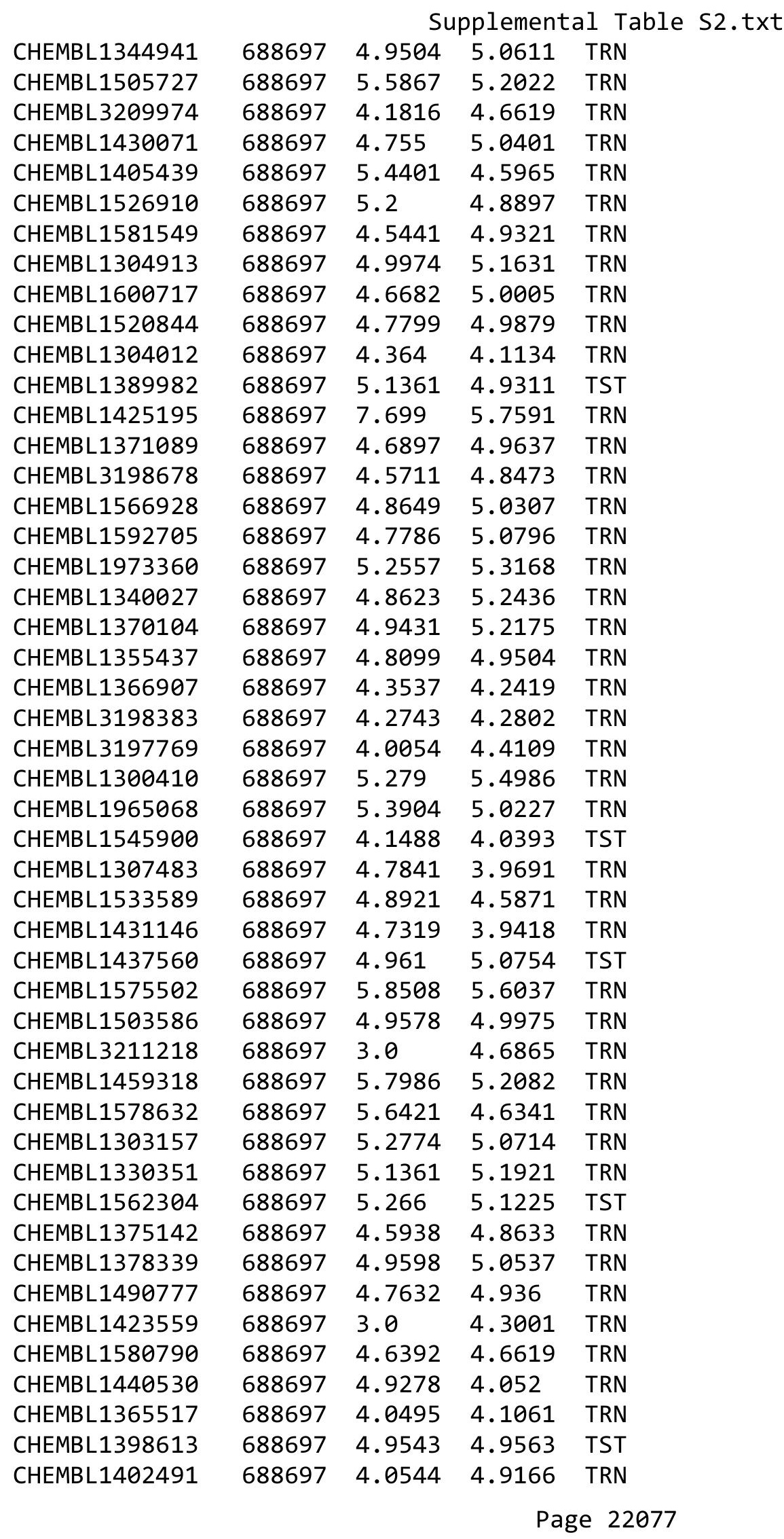




\begin{tabular}{|c|c|c|c|c|c|}
\hline \multirow[b]{2}{*}{ CHEMBL1364999 } & & \multicolumn{4}{|c|}{ Supplemental Table S2.txt } \\
\hline & 688697 & 5.2396 & 5.3320 & 0000000001 & TRN \\
\hline CHEMBL1556766 & 688697 & 4.1586 & 4.7387 & TRN & \\
\hline CHEMBL1558826 & 688697 & 5.8962 & 5.5903 & TST & \\
\hline CHEMBL1510023 & 688697 & 5.7282 & 5.4759 & TRN & \\
\hline CHEMBL1973332 & 688697 & 4.4141 & 4.7934 & TRN & \\
\hline CHEMBL1447262 & 688697 & 3.0 & 5.0454 & TRN & \\
\hline CHEMBL1332275 & 688697 & 4.2869 & 3.9427 & TRN & \\
\hline CHEMBL1383584 & 688697 & 5.1945 & 5.1684 & TRN & \\
\hline CHEMBL1465113 & 688697 & 4.3471 & 4.7661 & TRN & \\
\hline CHEMBL1427106 & 688697 & 4.5284 & 4.8398 & TRN & \\
\hline CHEMBL1375045 & 688697 & 4.5188 & 5.0055 & TRN & \\
\hline CHEMBL1568431 & 688697 & 4.5268 & 4.1543 & TRN & \\
\hline CHEMBL1522758 & 688697 & 5.1355 & 5.0758 & TRN & \\
\hline CHEMBL1594055 & 688697 & 5.9747 & 5.5614 & TST & \\
\hline CHEMBL1479657 & 688697 & 5.2907 & 5.0653 & TRN & \\
\hline CHEMBL 3198919 & 688697 & 4.0274 & 3.9267 & TRN & \\
\hline CHEMBL1350494 & 688697 & 4.3307 & 3.9932 & TRN & \\
\hline CHEMBL1528186 & 688697 & 4.6609 & 4.9749 & TRN & \\
\hline CHEMBL1497838 & 688697 & 5.8894 & 5.7562 & TRN & \\
\hline CHEMBL1584696 & 688697 & 5.2434 & 5.0517 & TRN & \\
\hline CHEMBL1489353 & 688697 & 4.2 & 4.138 & TRN & \\
\hline CHEMBL1310318 & 688697 & 4.7296 & 5.1043 & TST & \\
\hline CHEMBL1461050 & 688697 & 4.439 & 4.7569 & TRN & \\
\hline CHEMBL 3190934 & 688697 & 5.5452 & 5.2785 & TRN & \\
\hline CHEMBL1310481 & 688697 & 4.7729 & 4.3341 & TRN & \\
\hline CHEMBL1303293 & 688697 & 4.8854 & 4.0187 & TRN & \\
\hline CHEMBL1346092 & 688697 & 5.9172 & 5.3132 & TRN & \\
\hline CHEMBL1994401 & 688697 & 5.4157 & 5.4455 & TRN & \\
\hline CHEMBL1308461 & 688697 & 4.62 & 5.1106 & TRN & \\
\hline CHEMBL1462548 & 688697 & 4.119 & 4.677 & TRN & \\
\hline CHEMBL1589428 & 688697 & 5.9245 & 5.5988 & TRN & \\
\hline CHEMBL1434649 & 688697 & 4.5018 & 4.9461 & TRN & \\
\hline CHEMBL1421048 & 688697 & 4.1276 & 5.1854 & TRN & \\
\hline CHEMBL1575156 & 688697 & 4.6499 & 5.0206 & TST & \\
\hline CHEMBL1076559 & 688697 & 4.3674 & 4.0406 & TRN & \\
\hline CHEMBL1361116 & 688697 & 4.4648 & 4.0604 & TRN & \\
\hline CHEMBL3195501 & 688697 & 5.061 & 5.1926 & TRN & \\
\hline CHEMBL1385784 & 688697 & 5.7399 & 5.5928 & TRN & \\
\hline CHEMBL1557139 & 688697 & 5.6144 & 5.2731 & TRN & \\
\hline CHEMBL1557157 & 688697 & 4.0016 & 5.0009 & TRN & \\
\hline CHEMBL1546095 & 688697 & 4.1676 & 4.6704 & TRN & \\
\hline CHEMBL462576 & 688697 & 4.3303 & 4.9188 & TST & \\
\hline CHEMBL1607882 & 688697 & 6.1805 & 5.3505 & TRN & \\
\hline CHEMBL 3195975 & 688697 & 4.633 & 4.9966 & TST & \\
\hline CHEMBL1429343 & 688697 & 4.6251 & 4.9541 & TRN & \\
\hline CHEMBL1533597 & 688697 & 6.0132 & 5.0205 & TRN & \\
\hline CHEMBL1453076 & 688697 & 4.9519 & 5.0263 & TRN & \\
\hline CHEMBL1478065 & 688697 & 4.3554 & 4.8359 & TRN & \\
\hline
\end{tabular}




\begin{tabular}{|c|c|c|c|c|c|}
\hline & & \multicolumn{4}{|c|}{ Supplemental Table S2.txt } \\
\hline CHEMBL1393504 & 688697 & 4.3318 & 4.8602 & TRN & \\
\hline CHEMBL1348119 & 688697 & 6.0506 & 5.62 & TRN & \\
\hline CHEMBL1470131 & 688697 & 4.6275 & 4.2808 & TRN & \\
\hline CHEMBL172 & 688697 & 4.7409 & 5.0876 & TST & \\
\hline CHEMBL1393714 & 688697 & 5.1302 & 5.0206 & TRN & \\
\hline CHEMBL1391810 & 688697 & 5.2211 & 5.3303 & TRN & \\
\hline CHEMBL1409511 & 688697 & 4.8841 & 5.0071 & TRN & \\
\hline CHEMBL1456111 & 688697 & 5.2175 & 4.872 & TRN & \\
\hline CHEMBL1430882 & 688697 & 5.1972 & 5.3253 & TRN & \\
\hline CHEMBL1483112 & 688697 & 4.9914 & 4.9743 & TRN & \\
\hline CHEMBL1521646 & 688697 & 4.3345 & 4.3645 & TRN & \\
\hline CHEMBL590949 & 688697 & 4.7757 & 5.0624 & TRN & \\
\hline CHEMBL581152 & 688697 & 4.8617 & 5.0943 & TRN & \\
\hline CHEMBL1309280 & 688697 & 5.0017 & 5.0326 & TRN & \\
\hline CHEMBL1256686 & 688697 & 5.9586 & 5.4903 & TST & \\
\hline CHEMBL1372085 & 688697 & 4.9694 & 5.2638 & TRN & \\
\hline CHEMBL3195700 & 688697 & 4.9129 & 5.0557 & TRN & \\
\hline CHEMBL1386080 & 688697 & 4.4411 & 4.8572 & TRN & \\
\hline CHEMBL1987622 & 688697 & 5.9136 & 5.2858 & TRN & \\
\hline CHEMBL1539910 & 688697 & 5.341 & 5.4265 & TRN & \\
\hline CHEMBL1993662 & 688697 & 4. 3971 & 4.7512 & TRN & \\
\hline CHEMBL1515261 & 688697 & 4.2918 & 4.0749 & TRN & \\
\hline CHEMBL1563204 & 688697 & 4.4423 & 4.9882 & TRN & \\
\hline CHEMBL1561043 & 688697 & 4.4261 & 4.8607 & TRN & \\
\hline CHEMBL1397089 & 688697 & 4.8834 & 4.7919 & TST & \\
\hline CHEMBL1572129 & 688697 & 5.5935 & 5.5684 & TRN & \\
\hline CHEMBL1409443 & 688697 & 5.5272 & 5.52 & TRN & \\
\hline CHEMBL1542899 & 688697 & 6.4202 & 4.0485 & TRN & \\
\hline CHEMBL1372438 & 688697 & 4.0336 & 4.5605 & TRN & \\
\hline CHEMBL1314342 & 688697 & 6.2291 & 5.7152 & TRN & \\
\hline CHEMBL1546797 & 688697 & 4.8847 & 4.1018 & TRN & \\
\hline CHEMBL1348830 & 688697 & 4.2782 & 4.617 & TRN & \\
\hline CHEMBL1600447 & 688697 & 4.672 & $5.1270 e$ & 2000000001 & TRN \\
\hline CHEMBL1521164 & 688697 & 4.6126 & 4.6047 & TRN & \\
\hline CHEMBL1548060 & 688697 & 4.3667 & 4.0056 & TRN & \\
\hline CHEMBL1300370 & 688697 & 4.6326 & 4.7806 & TRN & \\
\hline CHEMBL1413988 & 688697 & 4.0981 & 4.1834 & TRN & \\
\hline CHEMBL1390303 & 688697 & 4.7562 & 4.6804 & TRN & \\
\hline CHEMBL1331851 & 688697 & 4.6245 & 4.9698 & TRN & \\
\hline CHEMBL1964793 & 688697 & 6.2291 & 5.4166 & TRN & \\
\hline CHEMBL1323274 & 688697 & 4.2529 & 4.6795 & TRN & \\
\hline CHEMBL1789993 & 688697 & 5.5528 & 5.4731 & TST & \\
\hline CHEMBL1585589 & 688697 & 4.2063 & 4.6414 & TST & \\
\hline CHEMBL1483215 & 688697 & 4.7557 & 4.953 & TRN & \\
\hline CHEMBL 489 & 688697 & 4.648 & 5.0304 & TRN & \\
\hline CHEMBL1407137 & 688697 & 4.0226 & 4.0377 & TRN & \\
\hline CHEMBL1460823 & 688697 & 4.2514 & 4.1154 & TRN & \\
\hline CHEMBL1564038 & 688697 & 4.5011 & 4.7793 & TRN & \\
\hline
\end{tabular}

Page 22079 


\begin{tabular}{|c|c|c|c|c|c|}
\hline & & \multicolumn{4}{|c|}{ Supplemental Table S2.txt } \\
\hline CHEMBL1363226 & 688697 & 4.0805 & 4.6245 & TST & \\
\hline CHEMBL1352171 & 688697 & 4.3288 & 4.0637 & TRN & \\
\hline CHEMBL1548354 & 688697 & 3.0 & 4.7751 & TRN & \\
\hline CHEMBL1612123 & 688697 & 4.0892 & 5.0133 & TRN & \\
\hline CHEMBL1527803 & 688697 & 4.6019 & 4.8136 & TRN & \\
\hline CHEMBL1421244 & 688697 & 5.1637 & 5.2445 & TRN & \\
\hline CHEMBL1510456 & 688697 & 4.6535 & 5.0819 & TRN & \\
\hline CHEMBL1498022 & 688697 & 4.9642 & 5.1941 & TST & \\
\hline CHEMBL1481135 & 688697 & 5.6144 & 5.4597 & TRN & \\
\hline CHEMBL1386467 & 688697 & 4.9 & 5.1276 & TRN & \\
\hline CHEMBL1539177 & 688697 & 4.9226 & 4.8916 & TRN & \\
\hline CHEMBL1503243 & 688697 & 4.8404 & 4.8689 & TRN & \\
\hline CHEMBL1496578 & 688697 & 4.7873 & 4.1536 & TRN & \\
\hline CHEMBL1582268 & 688697 & 4.1809 & 4.6079 & TRN & \\
\hline CHEMBL1336035 & 688697 & 4.4259 & 4.8745 & TRN & \\
\hline CHEMBL3196102 & 688697 & 3.0 & 4.8299 & TRN & \\
\hline CHEMBL1340213 & 688697 & 5.5186 & 5.2338 & TRN & \\
\hline CHEMBL1326491 & 688697 & 4.7359 & 4.7246 & TRN & \\
\hline CHEMBL1978623 & 688697 & 4.5375 & 4.7239 & TRN & \\
\hline CHEMBL1526067 & 688697 & 7.699 & 6.3225 & TRN & \\
\hline CHEMBL1585467 & 688697 & 3.0 & 4.6625 & TRN & \\
\hline CHEMBL3210810 & 688697 & \multicolumn{3}{|c|}{4.486000000000001} & 4.3152 \\
\hline CHEMBL1576407 & 688697 & 6.1427 & 6.0004 & TRN & \\
\hline CHEMBL1399212 & 688697 & 5.2581 & 5.2817 & TRN & \\
\hline CHEMBL1608593 & 688697 & 4.5173 & 4.9292 & TRN & \\
\hline CHEMBL1429179 & 688697 & 5.0106 & 4.6737 & TRN & \\
\hline CHEMBL1331995 & 688697 & 4.9481 & 5.0566 & TRN & \\
\hline CHEMBL1590377 & 688697 & 4.6782 & 4.8864 & TRN & \\
\hline CHEMBL1549599 & 688697 & 5.4101 & 5.2049 & TRN & \\
\hline CHEMBL1584509 & 688697 & 5.3019 & 5.0664 & TRN & \\
\hline CHEMBL1535055 & 688697 & 4.3843 & 4.3194 & TRN & \\
\hline CHEMBL1313588 & 688697 & 6.6778 & 4.8537 & TRN & \\
\hline CHEMBL1335703 & 688697 & 6.4318 & 4.8166 & TRN & \\
\hline CHEMBL1537149 & 688697 & 4.2728 & 4.1004 & TRN & \\
\hline CHEMBL3211067 & 688697 & 3.0 & 4.8976 & TRN & \\
\hline CHEMBL585656 & 688697 & 5.2343 & 5.2377 & TRN & \\
\hline CHEMBL1600169 & 688697 & 4.467 & 4.931 & TRN & \\
\hline CHEMBL1471344 & 688697 & 5.2336 & 5.1665 & TRN & \\
\hline CHEMBL1556306 & 688697 & 5.4342 & 5.4425 & TRN & \\
\hline CHEMBL1387328 & 688697 & 5.1481 & 4.9979 & TRN & \\
\hline CHEMBL1478525 & 688697 & 4.8608 & 4.8051 & TRN & \\
\hline CHEMBL3196266 & 688697 & 4.6519 & 4.945 & TRN & \\
\hline CHEMBL1594915 & 688697 & 4.7749 & 4.8853 & TRN & \\
\hline CHEMBL1376992 & 688697 & 4.1649 & 4.0834 & TRN & \\
\hline CHEMBL1583479 & 688697 & 4.5991 & 4.7958 & TST & \\
\hline CHEMBL1469980 & 688697 & 5.1469 & 4.5353 & TRN & \\
\hline CHEMBL1342553 & 688697 & 4.4218 & 4.8177 & TRN & \\
\hline CHEMBL1485349 & 688697 & 4.7342 & 4.9626 & TRN & \\
\hline
\end{tabular}

Page 22080 


\begin{tabular}{|c|c|c|c|c|c|}
\hline \multirow[b]{2}{*}{ CHEMBL1337445 } & \multicolumn{5}{|c|}{ supplemental } \\
\hline & 688697 & 4.3441 & 4.2017 & TRN & \\
\hline CHEMBL1559250 & 688697 & 5.8996 & 5.711 & TRN & \\
\hline CHEMBL1312315 & 688697 & 5.2041 & 4.9007 & TRN & \\
\hline CHEMBL1372467 & 688697 & 4.6423 & 5.0069 & TRN & \\
\hline CHEMBL1472327 & 688697 & 4.9523 & \multicolumn{2}{|c|}{5.257000000000001} & TST \\
\hline CHEMBL1384764 & 688697 & 4.6321 & 4.1032 & TRN & \\
\hline CHEMBL1306816 & 688697 & 4.9223 & 5.0666 & TRN & \\
\hline CHEMBL1326813 & 688697 & 5.2132 & 5.3206 & TRN & \\
\hline CHEMBL1426775 & 688697 & 3.0 & 4.9255 & TRN & \\
\hline CHEMBL1387564 & 688697 & 4.8681 & 4.7981 & TRN & \\
\hline CHEMBL1463750 & 688697 & 5.4698 & 4.8851 & TRN & \\
\hline CHEMBL1323072 & 688697 & 4.274 & 4.6893 & TRN & \\
\hline CHEMBL1353695 & 688697 & 4.5563 & 4.2809 & TRN & \\
\hline CHEMBL1520030 & 688697 & 5.0066 & 5.2907 & TRN & \\
\hline CHEMBL1311416 & 688697 & 5.983 & 5.0629 & TRN & \\
\hline CHEMBL1488012 & 688697 & 4.7891 & 4.0005 & TRN & \\
\hline CHEMBL1482389 & 688697 & 4.5227 & 4.9035 & TRN & \\
\hline CHEMBL1460452 & 688697 & 4.2784 & 4.1649 & TRN & \\
\hline CHEMBL1303443 & 688697 & 4.8614 & 5.0239 & TRN & \\
\hline CHEMBL1455542 & 688697 & 4.9531 & 4.4198 & TRN & \\
\hline CHEMBL1593484 & 688697 & 4.4546 & 4.7691 & TRN & \\
\hline CHEMBL579082 & 688697 & 4.9052 & 5.1172 & TRN & \\
\hline CHEMBL1601176 & 688697 & 4.5456 & 4.2103 & TRN & \\
\hline CHEMBL1505221 & 688697 & 5.3335 & 5.2782 & TST & \\
\hline CHEMBL1393773 & 688697 & 4.7156 & 4.9373 & TRN & \\
\hline CHEMBL3193608 & 688697 & 5.1018 & 5.0394 & TRN & \\
\hline CHEMBL1342495 & 688697 & 5.1979 & 5.0462 & TRN & \\
\hline CHEMBL1601374 & 688697 & 3.0 & 4.9284 & TST & \\
\hline CHEMBL1517264 & 688697 & 4.5336 & 4.1353 & TRN & \\
\hline CHEMBL1500119 & 688697 & 4.9187 & 4.9753 & TRN & \\
\hline CHEMBL1429042 & 688697 & 4.776 & 5.1176 & TRN & \\
\hline CHEMBL1437961 & 688697 & 3.0 & 4.6668 & TRN & \\
\hline CHEMBL11475 & 688697 & 5.0958 & 5.441 & TST & \\
\hline CHEMBL1333422 & 688697 & 4.3408 & 4.6959 & TRN & \\
\hline CHEMBL1573635 & 688697 & 4.9363 & 5.5835 & TRN & \\
\hline CHEMBL1336428 & 688697 & 5.0106 & 4.92399 & 99999999995 & TRN \\
\hline CHEMBL3199272 & 688697 & 5.4597 & 5.2492 & TRN & \\
\hline CHEMBL1990598 & 688697 & 4.7857 & 5.0438 & TRN & \\
\hline CHEMBL1586047 & 688697 & 4.4646 & 4.8624 & TRN & \\
\hline CHEMBL1316515 & 688697 & 5.3316 & 5.325 & TRN & \\
\hline CHEMBL1419591 & 688697 & 4.0982 & 4.1664 & TRN & \\
\hline CHEMBL1340684 & 688697 & 4.93 & 4.94600 & 0000000001 & TRN \\
\hline CHEMBL1501567 & 688697 & 5.9318 & 5.6003 & TRN & \\
\hline CHEMBL1384233 & 688697 & 4.4259 & 4.4347 & TST & \\
\hline CHEMBL1550600 & 688697 & 4.8831 & 4.0329 & TRN & \\
\hline CHEMBL1371896 & 688697 & 4.7199 & 4.9855 & TRN & \\
\hline CHEMBL1383937 & 688697 & 4.9289 & 5.0433 & TRN & \\
\hline CHEMBL1377490 & 688697 & 4.8368 & 4.84699 & 99999999995 & TRN \\
\hline & & & & 22081 & \\
\hline
\end{tabular}




\begin{tabular}{|c|c|c|c|c|c|c|}
\hline \multirow[b]{2}{*}{ CHEMBL1360206 } & & \multicolumn{5}{|c|}{ Supplemental Table S2.txt } \\
\hline & 688697 & 4.7212 & 4.2632 & TRN & & \\
\hline CHEMBL1991516 & 688697 & 4.1358 & 4.9294 & TRN & & \\
\hline CHEMBL1523542 & 688697 & $5.7620 e$ & 00000000 & 205 & 5.539 & TRN \\
\hline CHEMBL1349034 & 688697 & 5.1713 & 5.1007 & TRN & & \\
\hline CHEMBL1342907 & 688697 & 5.5482 & 5.2848 & TRN & & \\
\hline CHEMBL1557632 & 688697 & 7.699 & 5.9405 & TRN & & \\
\hline CHEMBL1469539 & 688697 & 4.9359 & 5.1175 & TRN & & \\
\hline CHEMBL1398363 & 688697 & 4.2899 & 4.2551 & TRN & & \\
\hline CHEMBL1592668 & 688697 & 4.0167 & 4.8233 & TRN & & \\
\hline CHEMBL1428194 & 688697 & $5.2020 e$ & 00000000 & & 5.3226 & TRN \\
\hline CHEMBL1488075 & 688697 & 5.9586 & 5.5086 & TRN & & \\
\hline CHEMBL1409148 & 688697 & 4.6133 & 4.7771 & TST & & \\
\hline CHEMBL1489026 & 688697 & 3.0 & 3.8291 & TRN & & \\
\hline CHEMBL1496386 & 688697 & 4.6912 & 4.2035 & TRN & & \\
\hline CHEMBL1437731 & 688697 & 4.1926 & 4.6463 & TRN & & \\
\hline CHEMBL1369287 & 688697 & 5.0506 & 5.3499 & TRN & & \\
\hline CHEMBL1407612 & 688697 & 4.7135 & 4.685 & TRN & & \\
\hline CHEMBL1460865 & 688697 & 5.6234 & 5.3511 & TRN & & \\
\hline CHEMBL3193504 & 688697 & 3.0 & 4.677 & TRN & & \\
\hline CHEMBL1492103 & 688697 & 4.6304 & 4.7606 & TRN & & \\
\hline CHEMBL1427913 & 688697 & 7.699 & 6.4286 & TRN & & \\
\hline CHEMBL1580037 & 688697 & 4.4519 & 4.1683 & TRN & & \\
\hline CHEMBL1310527 & 688697 & 4.5327 & 4.9939 & TRN & & \\
\hline CHEMBL1421112 & 688697 & 5.5272 & 5.0111 & TRN & & \\
\hline CHEMBL1547916 & 688697 & 5.4112 & 5.2979 & TRN & & \\
\hline CHEMBL1982484 & 688697 & 4.3398 & 4.3832 & TRN & & \\
\hline CHEMBL1310809 & 688697 & 4.2999 & 4.9405 & TRN & & \\
\hline CHEMBL1556891 & 688697 & 4.7387 & 5.0615 & TST & & \\
\hline CHEMBL1459918 & 688697 & 5.5317 & 4.913 & TRN & & \\
\hline CHEMBL1508591 & 688697 & 4.6124 & 4.1995 & TST & & \\
\hline CHEMBL1481318 & 688697 & 4.6358 & 4.9177 & TRN & & \\
\hline CHEMBL1469642 & 688697 & 4.1233 & 4.2117 & TRN & & \\
\hline CHEMBL1379929 & 688697 & 4.6415 & 4.4375 & TRN & & \\
\hline CHEMBL1459535 & 688697 & 5.1739 & 5.1371 & TRN & & \\
\hline CHEMBL1452158 & 688697 & 5.1457 & 5.2084 & TRN & & \\
\hline CHEMBL 2007227 & 688697 & 4.8726 & 4.2065 & TRN & & \\
\hline CHEMBL1393437 & 688697 & 3.0 & 4.8857 & TST & & \\
\hline CHEMBL1351922 & 688697 & 4.5213 & 4.2229 & TST & & \\
\hline CHEMBL1347533 & 688697 & 4.6306 & 4.8753 & TRN & & \\
\hline CHEMBL1470679 & 688697 & 5.6968 & 5.5055 & TRN & & \\
\hline CHEMBL1565391 & 688697 & 4.2685 & 4.5561 & TRN & & \\
\hline CHEMBL1541494 & 688697 & 4.5455 & 4.901 & TRN & & \\
\hline CHEMBL3196221 & 688697 & 4.9739 & 4.1123 & TRN & & \\
\hline CHEMBL1577085 & 688697 & 5.4559 & 5.2333 & TRN & & \\
\hline CHEMBL1986355 & 688697 & 4.9965 & 4.8735 & TRN & & \\
\hline CHEMBL1995152 & 688697 & 4.9622 & 5.0864 & TRN & & \\
\hline CHEMBL1970597 & 688697 & 5.5768 & 5.4415 & TRN & & \\
\hline CHEMBL1510905 & 688697 & 5.6308 & 5.5782 & TRN & & \\
\hline
\end{tabular}




\begin{tabular}{|c|c|c|c|c|c|}
\hline \multirow[b]{2}{*}{ CHEMBL1542076 } & \multirow{2}{*}{688697} & \\
\hline & & 4.3932 & 4.8468 & TRN & \\
\hline CHEMBL1335734 & 688697 & 4.7523 & 4.1746 & TRN & \\
\hline CHEMBL1343144 & 688697 & 5.8268 & 5.4365 & TRN & \\
\hline CHEMBL1512724 & 688697 & 4.3116 & 4.7493 & TRN & \\
\hline CHEMBL1389318 & 688697 & 4.6386 & 4.8903 & TST & \\
\hline CHEMBL1352919 & 688697 & 4.7768 & 4.3983 & TRN & \\
\hline CHEMBL1366648 & 688697 & 7.699 & 5.2268 & TRN & \\
\hline CHEMBL1256740 & 688697 & 4.6101 & 4.9867 & TST & \\
\hline CHEMBL1490367 & 688697 & 5.684 & 4.8649 & TRN & \\
\hline CHEMBL1342025 & 688697 & 3.0 & 4.3678 & TRN & \\
\hline CHEMBL3189154 & 688697 & 4.0909 & 4.2031 & TRN & \\
\hline CHEMBL3210464 & 688697 & 5.0851 & 4.8963 & TRN & \\
\hline CHEMBL1543899 & 688697 & 6.585 & 5.9067 & TST & \\
\hline CHEMBL1420417 & 688697 & 4.378 & 4.7834 & TRN & \\
\hline CHEMBL1593107 & 688697 & 4.5931 & 4.8509 & TRN & \\
\hline CHEMBL1365507 & 688697 & 4.7688 & 4.7943 & TRN & \\
\hline CHEMBL1521687 & 688697 & 4.0432 & 4.1481 & TRN & \\
\hline CHEMBL1422182 & 688697 & 5.9066 & 5.6033 & TRN & \\
\hline CHEMBL1512896 & 688697 & 4.9151 & 5.0117 & TRN & \\
\hline CHEMBL1571761 & 688697 & 5.1838 & 5.3897 & TRN & \\
\hline CHEMBL 1457570 & 688697 & 5.3468 & 5.3412 & TRN & \\
\hline CHEMBL1413395 & 688697 & 4.6323 & 4.8558 & TRN & \\
\hline CHEMBL1611662 & 688697 & 4.5133 & 4.3163 & TRN & \\
\hline CHEMBL1549682 & 688697 & 4.3382 & 4.8725 & TST & \\
\hline CHEMBL1611026 & 688697 & 4.6564 & 4.9371 & TRN & \\
\hline CHEMBL1370865 & 688697 & \multicolumn{3}{|c|}{5.2620000000000005} & TRN \\
\hline CHEMBL1538399 & 688697 & 4.5552 & \multicolumn{2}{|c|}{4.861000000000001} & TRN \\
\hline CHEMBL1585147 & 688697 & 4.4595 & 4.8866 & TRN & \\
\hline CHEMBL1302894 & 688697 & 4.3083 & 4.7363 & TRN & \\
\hline CHEMBL1392865 & 688697 & 5.7033 & 4.8235 & TRN & \\
\hline CHEMBL1399805 & 688697 & 4.6278 & 4.7673 & TRN & \\
\hline CHEMBL1368213 & 688697 & 7.699 & 6.2664 & TRN & \\
\hline CHEMBL1389509 & 688697 & 4.7261 & 5.0415 & TRN & \\
\hline CHEMBL1984120 & 688697 & 3.0 & 4.9887 & TRN & \\
\hline CHEMBL994 & 688697 & 5.0391 & 5.1616 & TST & \\
\hline CHEMBL1353047 & 688697 & 5.5513 & 5.0006 & TRN & \\
\hline CHEMBL1343853 & 688697 & 4.5464 & 4.0926 & TRN & \\
\hline CHEMBL1581275 & 688697 & 5.1169 & 4.5873 & TRN & \\
\hline CHEMBL1410066 & 688697 & 5.5452 & 5.2003 & TRN & \\
\hline CHEMBL1609009 & 688697 & 6.0088 & 5.527 & TRN & \\
\hline CHEMBL1467396 & 688697 & 4.7055 & 5.0859 & TST & \\
\hline CHEMBL1301556 & 688697 & 5.2916 & 5.3288 & TST & \\
\hline CHEMBL1431684 & 688697 & 5.6676 & 5.2479 & TRN & \\
\hline CHEMBL1513242 & 688697 & 4.6761 & 4.673 & TRN & \\
\hline CHEMBL1316573 & 688697 & 4.7828 & 5.1191 & TRN & \\
\hline CHEMBL1585273 & 688697 & 4.3258 & 4.7428 & TRN & \\
\hline CHEMBL1451716 & 688697 & 7.699 & 5.3732 & TRN & \\
\hline \multirow[t]{2}{*}{ CHEMBL1333929 } & 688697 & 4.6558 & 4.86600 & 00000000005 & TRN \\
\hline & & \multicolumn{3}{|c|}{ Page 22083} & \\
\hline
\end{tabular}


Supplemental Table S2.txt

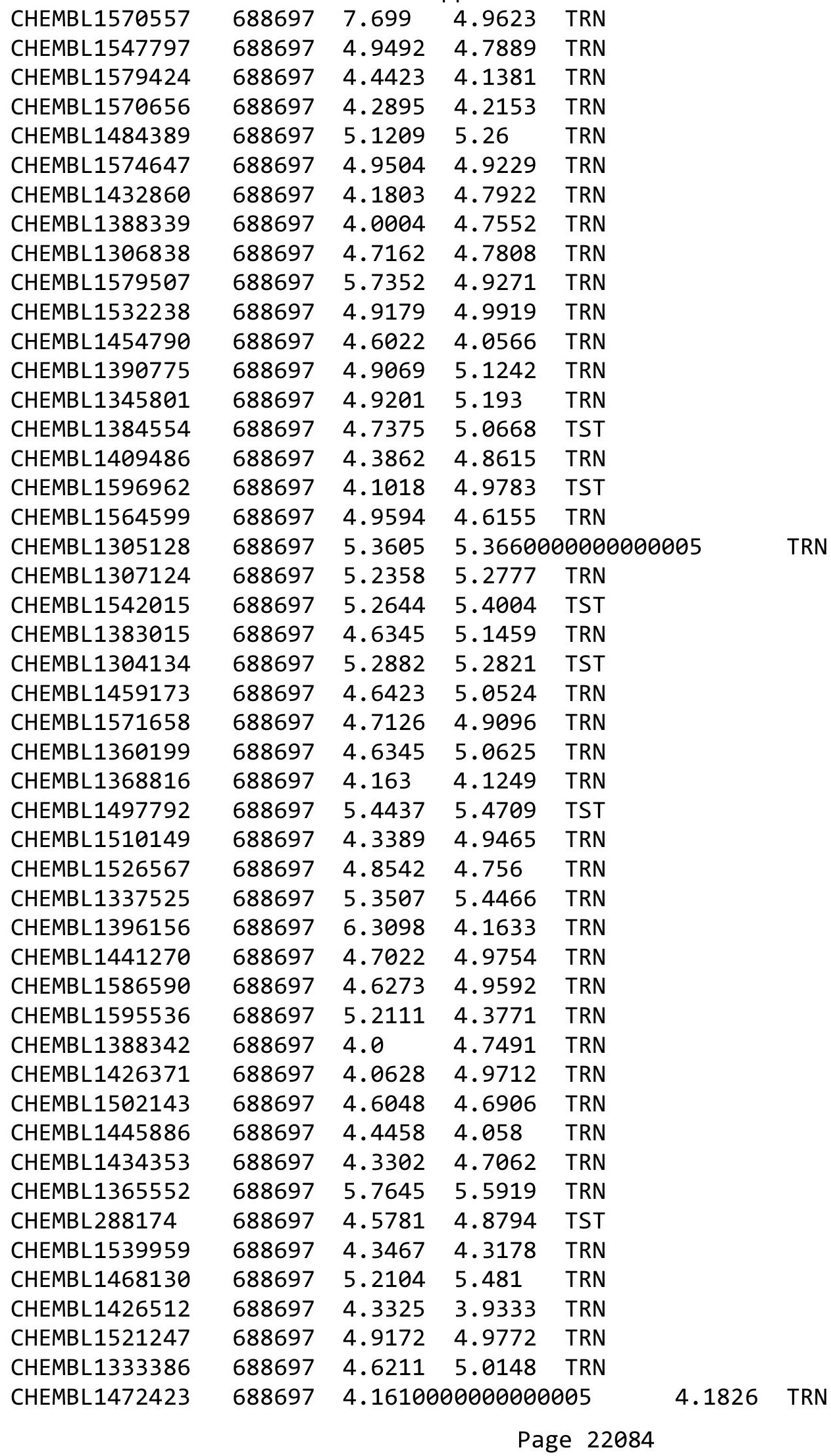




\begin{tabular}{|c|c|c|c|c|c|c|}
\hline & & \multicolumn{5}{|c|}{ Supplemental Table S2.txt } \\
\hline CHEMBL1533012 & 688697 & 4.5107 & 4.7657 & TRN & & \\
\hline CHEMBL1530587 & 688697 & \multicolumn{3}{|c|}{5.3420000000000005} & 5.1585 & TRN \\
\hline CHEMBL1543127 & 688697 & 6.3188 & 5.8362 & TRN & & \\
\hline CHEMBL1507759 & 688697 & 4.1252 & 4.1482 & TRN & & \\
\hline CHEMBL1381257 & 688697 & 4.9763 & 5.0323 & TRN & & \\
\hline CHEMBL1339273 & 688697 & 5.2125 & 5.3115 & TRN & & \\
\hline CHEMBL1586054 & 688697 & 4.6373 & 4.8222 & TRN & & \\
\hline CHEMBL1492922 & 688697 & 5.2048 & 4.613 & TST & & \\
\hline CHEMBL1482988 & 688697 & 7.699 & 5.4176 & TRN & & \\
\hline CHEMBL1369671 & 688697 & 7.699 & 6.0676 & TRN & & \\
\hline CHEMBL1607550 & 688697 & 4.6674 & 5.0345 & TRN & & \\
\hline CHEMBL604321 & 688697 & 4.9435 & 5.2805 & TRN & & \\
\hline CHEMBL1356472 & 688697 & 4.4903 & 4.9352 & TRN & & \\
\hline CHEMBL1527476 & 688697 & 4.3535 & 4.1542 & TRN & & \\
\hline CHEMBL1405092 & 688697 & \multicolumn{3}{|c|}{4.821000000000001} & 5.0861 & TRN \\
\hline CHEMBL1492896 & 688697 & 4.4178 & 3.9152 & TRN & & \\
\hline CHEMBL117966 & 688697 & 5.3799 & 5.5226 & TRN & & \\
\hline CHEMBL1594358 & 688697 & 5.2916 & 5.2587 & TRN & & \\
\hline CHEMBL1506459 & 688697 & 5.4815 & 5.3874 & TST & & \\
\hline CHEMBL1463698 & 688697 & 4.9594 & 4.9457 & TRN & & \\
\hline CHEMBL1412150 & 688697 & 7.699 & 5.7159 & TRN & & \\
\hline CHEMBL1562104 & 688697 & 5.8894 & 5.6259 & TRN & & \\
\hline CHEMBL1399127 & 688697 & 4.5473 & 4.362 & TST & & \\
\hline CHEMBL1608392 & 688697 & 5.0472 & 5.2169 & TRN & & \\
\hline CHEMBL1406804 & 688697 & 4.8668 & 5.0722 & TRN & & \\
\hline CHEMBL1469676 & 688697 & 6.0362 & 5.54700 & 0000000001 & & TRN \\
\hline CHEMBL1358375 & 688697 & 5.0931 & 4.8944 & TRN & & \\
\hline CHEMBL1469497 & 688697 & 4.2176 & 4.5405 & TST & & \\
\hline CHEMBL1409954 & 688697 & 4.3707 & 4.7575 & TRN & & \\
\hline CHEMBL1559953 & 688697 & 4.6855 & 4.9977 & TRN & & \\
\hline CHEMBL3212223 & 688697 & 4.0149 & 4.7496 & TRN & & \\
\hline CHEMBL1400960 & 688697 & 4.761 & 4.8865 & TRN & & \\
\hline CHEMBL1477319 & 688697 & 4.516 & 4.7636 & TRN & & \\
\hline CHEMBL1331872 & 688697 & 4.2803 & 4.7089 & TRN & & \\
\hline CHEMBL1459487 & 688697 & 4.6535 & 4.7056 & TRN & & \\
\hline CHEMBL1556481 & 688697 & 6.1192 & 5.5441 & TRN & & \\
\hline CHEMBL1494461 & 688697 & 4.5707 & 4.8481 & TRN & & \\
\hline CHEMBL1442080 & 688697 & 5.9788 & 5.4174 & TRN & & \\
\hline CHEMBL3214555 & 688697 & 5.9626 & 6.1865 & TRN & & \\
\hline CHEMBL1452379 & 688697 & 4.5424 & 4.7669 & TRN & & \\
\hline CHEMBL1506311 & 688697 & 4.522 & 4.9254 & TRN & & \\
\hline CHEMBL1302100 & 688697 & 4.7066 & 4.9226 & TRN & & \\
\hline CHEMBL1455633 & 688697 & 4.9851 & 5.3235 & TST & & \\
\hline CHEMBL1426722 & 688697 & 5.4584 & 5.2672 & TRN & & \\
\hline CHEMBL1400481 & 688697 & 4.8891 & 5.0265 & TST & & \\
\hline CHEMBL1403774 & 688697 & 5.1878 & 5.4108 & TRN & & \\
\hline CHEMBL1543250 & 688697 & 5.6556 & 4.4552 & TRN & & \\
\hline CHEMBL1477770 & 688697 & 5.1129 & 4.9883 & TRN & & \\
\hline
\end{tabular}




\begin{tabular}{|c|c|c|c|c|c|c|}
\hline & & \multicolumn{5}{|c|}{ Supplemental Table s2.txt } \\
\hline CHEMBL1413130 & 688697 & 4.6627 & 5.0365 & TRN & & \\
\hline CHEMBL3199825 & 688697 & 4.0493 & 4.0805 & TST & & \\
\hline CHEMBL1390496 & 688697 & 4.9755 & 4.9329 & TRN & & \\
\hline CHEMBL1423611 & 688697 & 4.7406 & 5.0489 & TRN & & \\
\hline CHEMBL1390546 & 688697 & 4.3714 & 4.8566 & TRN & & \\
\hline CHEMBL1358628 & 688697 & 4.3584 & 4.6629 & TRN & & \\
\hline CHEMBL1477154 & 688697 & 5.5467 & 5.4821 & TRN & & \\
\hline CHEMBL1382443 & 688697 & 4.2403 & 4.1034 & TRN & & \\
\hline CHEMBL1302215 & 688697 & 5.2132 & 5.1957 & TST & & \\
\hline CHEMBL1429160 & 688697 & 5.7645 & 5.2243 & TRN & & \\
\hline CHEMBL1383664 & 688697 & 5.4622 & 5.3131 & TRN & & \\
\hline CHEMBL1300881 & 688697 & 4.3629 & 4.8359 & TRN & & \\
\hline CHEMBL1459140 & 688697 & \multicolumn{3}{|c|}{5.821000000000001} & 5.5569 & TRN \\
\hline CHEMBL3193568 & 688697 & 4.6055 & 4.8674 & TRN & & \\
\hline CHEMBL1523817 & 688697 & 4.6774 & 4.9617 & TST & & \\
\hline CHEMBL1405645 & 688697 & 4.9792 & 5.1243 & TRN & & \\
\hline CHEMBL1529485 & 688697 & 4.0116 & 4.6722 & TRN & & \\
\hline CHEMBL1576940 & 688697 & 5.3536 & 5.1791 & TST & & \\
\hline CHEMBL1561085 & 688697 & 4.6686 & 4.9035 & TST & & \\
\hline CHEMBL1457690 & 688697 & 4.7865 & 4.841 & TRN & & \\
\hline CHEMBL1467427 & 688697 & 4.4209 & 4.5887 & TRN & & \\
\hline CHEMBL1441992 & 688697 & 4.235 & 4.6794 & TRN & & \\
\hline CHEMBL1354631 & 688697 & 4.6751 & 4.975 & TRN & & \\
\hline CHEMBL3211140 & 688697 & 4.4382 & 4.6125 & TRN & & \\
\hline CHEMBL1371706 & 688697 & 4.0283 & 4.7741 & TRN & & \\
\hline CHEMBL1538027 & 688697 & 3.0 & 4.9158 & TRN & & \\
\hline CHEMBL1342473 & 688697 & 5.5031 & 5.2998 & TRN & & \\
\hline CHEMBL90181 & 688697 & 4.919 & 5.2402 & TST & & \\
\hline CHEMBL528068 & 688697 & 4.6914 & 5.0229 & TRN & & \\
\hline CHEMBL1391463 & 688697 & 4.6602 & 5.1947 & TRN & & \\
\hline CHEMBL1592492 & 688697 & 7.699 & 6.1817 & TRN & & \\
\hline CHEMBL1444373 & 688697 & 4.6855 & 4.8717 & TRN & & \\
\hline CHEMBL1479550 & 688697 & 5.2097 & 5.2243 & TRN & & \\
\hline CHEMBL1582569 & 688697 & 4.8993 & 4.8858 & TRN & & \\
\hline CHEMBL1560366 & 688697 & 5.27 & 5.3293 & TRN & & \\
\hline CHEMBL1560460 & 688697 & 4.6944 & 4.7238 & TRN & & \\
\hline CHEMBL3199305 & 688697 & 4.5988 & 4.814 & TRN & & \\
\hline CHEMBL1510647 & 688697 & 4.4227 & 3.991 & TRN & & \\
\hline CHEMBL1603862 & 688697 & 4.5441 & 3.9722 & TRN & & \\
\hline CHEMBL1506397 & 688697 & 4.9927 & 5.2586 & TRN & & \\
\hline CHEMBL1405496 & 688697 & 5.9626 & 5.5185 & TRN & & \\
\hline CHEMBL1555926 & 688697 & 4.9274 & 4.7775 & TRN & & \\
\hline CHEMBL1574748 & 688697 & 4.4219 & 4.078 & TRN & & \\
\hline CHEMBL1541360 & 688697 & 4.4024 & 4.0199 & TRN & & \\
\hline CHEMBL1455662 & 688697 & 5.0595 & 4.4708 & TRN & & \\
\hline CHEMBL1606918 & 688697 & 4.0773 & 4.0084 & TST & & \\
\hline CHEMBL1423275 & 688697 & 4.7535 & 4.1877 & TRN & & \\
\hline \multirow[t]{2}{*}{ CHEMBL1987274 } & 688697 & \multicolumn{3}{|c|}{ 4.7139999999999995 } & 4.26 & TRN \\
\hline & & \multicolumn{5}{|c|}{ Page 22086} \\
\hline
\end{tabular}




\begin{tabular}{|c|c|c|c|c|c|c|}
\hline & & \multicolumn{5}{|c|}{ Supplemental Table S2.txt } \\
\hline CHEMBL1446181 & 688697 & 4.5494 & 4.1365 & TRN & & \\
\hline CHEMBL1607086 & 688697 & 5.0035 & 4.8652 & TRN & & \\
\hline CHEMBL1453809 & 688697 & 4.6383 & 4.8851 & TRN & & \\
\hline CHEMBL530682 & 688697 & 5.6536 & 5.2708 & TRN & & \\
\hline CHEMBL1533651 & 688697 & 4.6872 & 4.957 & TRN & & \\
\hline CHEMBL1433263 & 688697 & 6.1549 & 5.3721 & TST & & \\
\hline CHEMBL1383998 & 688697 & 4.6438 & 4.9852 & TRN & & \\
\hline CHEMBL1585923 & 688697 & 4.7899 & 4.8442 & TRN & & \\
\hline CHEMBL1479780 & 688697 & 4.4084 & 4.8047 & TRN & & \\
\hline CHEMBL1520551 & 688697 & 5.1186 & 5.2252 & TRN & & \\
\hline CHEMBL1452235 & 688697 & 5.091 & 5.3128 & TRN & & \\
\hline CHEMBL1471612 & 688697 & 4.0813 & 5.1201 & TRN & & \\
\hline CHEMBL1544423 & 688697 & 5.9747 & 5.6902 & TRN & & \\
\hline CHEMBL1339405 & 688697 & 4.5248 & 4.6891 & TRN & & \\
\hline CHEMBL1327172 & 688697 & 5.7852 & 5.5702 & TRN & & \\
\hline CHEMBL1434730 & 688697 & 4.8153 & 5.0595 & TRN & & \\
\hline CHEMBL1334809 & 688697 & 4.6521 & 5.0051 & TRN & & \\
\hline CHEMBL1531820 & 688697 & 4.6899 & 4.9228 & TRN & & \\
\hline CHEMBL1431312 & 688697 & 4.6708 & 4.1382 & TRN & & \\
\hline CHEMBL1426274 & 688697 & 4.3348 & 4.7925 & TRN & & \\
\hline CHEMBL1600533 & 688697 & 4.6566 & 4.8252 & TRN & & \\
\hline CHEMBL1602601 & 688697 & 5.9914 & 4.6903 & TRN & & \\
\hline CHEMBL 3198950 & 688697 & 4.2611 & 3.9087 & TRN & & \\
\hline CHEMBL1322923 & 688697 & 4.828 & 4.7513 & TST & & \\
\hline CHEMBL1576837 & 688697 & 4.71 & 4.9803 & TST & & \\
\hline CHEMBL1480783 & 688697 & 6.2291 & 5.5496 & TRN & & \\
\hline CHEMBL1413247 & 688697 & 5.3665 & 5.4349 & TRN & & \\
\hline CHEMBL1417614 & 688697 & 4.5938 & 4.6573 & TRN & & \\
\hline CHEMBL 2005545 & 688697 & 5.2211 & 5.1509 & TRN & & \\
\hline CHEMBL 1560575 & 688697 & 5.284 & 4.6051 & TRN & & \\
\hline CHEMBL1572280 & 688697 & 5.7305 & 5.5375 & TST & & \\
\hline CHEMBL1571944 & 688697 & 3.0 & 4.8191 & TST & & \\
\hline CHEMBL 3193196 & 688697 & 4.2542 & 4.8461 & TST & & \\
\hline CHEMBL1495124 & 688697 & 4.28600 & 300000006 & 005 & 4.8533 & TS \\
\hline CHEMBL1461279 & 688697 & 4.4242 & 4.8677 & TRN & & \\
\hline CHEMBL1310332 & 688697 & 4.6633 & 4.4174 & TST & & \\
\hline CHEMBL1451713 & 688697 & 5.75700 & 0000000 & 01 & 4.9667 & TRN \\
\hline CHEMBL1453673 & 688697 & 4.3136 & 4.6949 & TST & & \\
\hline CHEMBL1528618 & 688697 & 4.5124 & 4.9334 & TRN & & \\
\hline CHEMBL1334719 & 688697 & 5.2487 & 5.2913 & TRN & & \\
\hline CHEMBL 3191867 & 688697 & 5.1403 & 5.4047 & TRN & & \\
\hline CHEMBL 3193986 & 688697 & 4.4765 & 4.5486 & TST & & \\
\hline CHEMBL1502035 & 688697 & 7.699 & 5.0597 & TRN & & \\
\hline CHEMBL1460723 & 688697 & 4.0283 & 4.0359 & TRN & & \\
\hline CHEMBL1494654 & 688697 & 4.3672 & 4.8191 & TRN & & \\
\hline CHEMBL1430812 & 688697 & 5.7905 & 4.4671 & TRN & & \\
\hline CHEMBL 3193468 & 688697 & 5.5406 & 5.4221 & TRN & & \\
\hline CHEMBL1491010 & 688697 & 4.3336 & 4.7722 & TRN & & \\
\hline
\end{tabular}




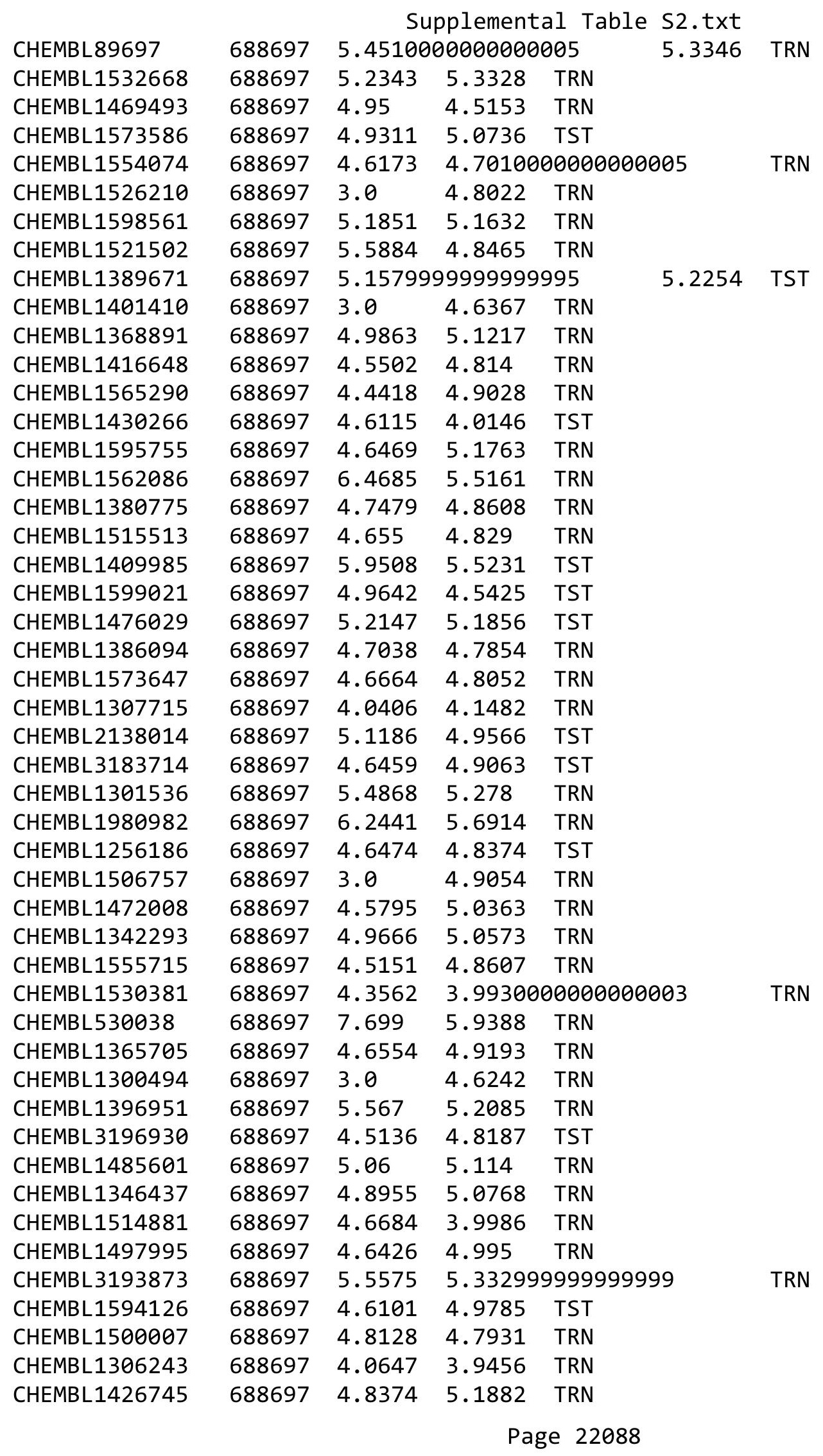




\begin{tabular}{|c|c|c|c|c|}
\hline \multicolumn{5}{|c|}{ Supplemental Table S2.txt } \\
\hline CHEMBL1549222 & 688697 & 4.93 & 4.9744 & TRN \\
\hline CHEMBL1347156 & 688697 & 4.8142 & 4.9859 & TRN \\
\hline CHEMBL1386048 & 688697 & 5.4949 & 5.4303 & TRN \\
\hline CHEMBL1344348 & 688697 & 5.5391 & 4.8488 & TRN \\
\hline CHEMBL1598631 & 688697 & 4.8952 & 5.0316 & TST \\
\hline CHEMBL1468953 & 688697 & 4.0961 & 4.8347 & TRN \\
\hline CHEMBL 3196538 & 688697 & 4.4462 & 4.609 & TRN \\
\hline CHEMBL1421481 & 688697 & 4.4562 & 4.8313 & TRN \\
\hline CHEMBL1478237 & 688697 & 7.699 & 6.881 & TRN \\
\hline CHEMBL1327702 & 688697 & 4.672 & 4.9566 & TRN \\
\hline CHEMBL 3196272 & 688697 & 4.6919 & 4.1411 & TRN \\
\hline CHEMBL1561576 & 688697 & 5.4389 & 5.2916 & TRN \\
\hline CHEMBL1399822 & 688697 & 4.2528 & 4.5825 & TRN \\
\hline CHEMBL1522198 & 688697 & 5.0937 & 4.7204 & TRN \\
\hline CHEMBL1232805 & 688697 & 5.3391 & 5.3495 & TST \\
\hline CHEMBL1320644 & 688697 & 3.0 & 4.667 & TRN \\
\hline CHEMBL1501376 & 688697 & 5.2823 & 4.2218 & TRN \\
\hline CHEMBL1375216 & 688697 & 4.0553 & 3.8702 & TRN \\
\hline CHEMBL 3213912 & 688697 & 4.0411 & 4.0291 & TRN \\
\hline CHEMBL1360965 & 688697 & 4.07 & 4.5441 & TRN \\
\hline CHEMBL1417731 & 688697 & 6.4437 & 5.9969 & TRN \\
\hline CHEMBL1484411 & 688697 & 4.7503 & 4.959 & TST \\
\hline CHEMBL1400824 & 688697 & 4.6366 & 4.8652 & TRN \\
\hline CHEMBL1970707 & 688697 & 5.5229 & 5.2949 & TRN \\
\hline CHEMBL1422720 & 688697 & 4.8965 & 5.0112 & TRN \\
\hline CHEMBL1607863 & 688697 & 4.453 & 4.3161 & TRN \\
\hline CHEMBL1331670 & 688697 & 4.6254 & 4.8566 & TRN \\
\hline CHEMBL1549103 & 688697 & 4.5645 & 4.1507 & TRN \\
\hline CHEMBL1576999 & 688697 & 5.9788 & 5.4117 & TRN \\
\hline CHEMBL1493220 & 688697 & 5.1791 & 5.0695 & TRN \\
\hline CHEMBL1201074 & 688697 & 4.7194 & 4.9893 & TST \\
\hline CHEMBL1520182 & 688697 & 4.6064 & 4.3656 & TST \\
\hline CHEMBL1458512 & 688697 & 5.6536 & 5.5316 & TRN \\
\hline CHEMBL1609437 & 688697 & 4.7212 & 5.063 & TRN \\
\hline CHEMBL1461370 & 688697 & 4.5678 & 4.2039 & TRN \\
\hline CHEMBL1465648 & 688697 & 4.4996 & 4.1947 & TRN \\
\hline CHEMBL1564658 & 688697 & 4.8066 & 4.2549 & TST \\
\hline CHEMBL1466340 & 688697 & 6.1079 & 5.6267 & TRN \\
\hline CHEMBL 3196069 & 688697 & 4.9169 & 4.8106 & TRN \\
\hline CHEMBL429095 & 688697 & 5.2175 & 5.1924 & TRN \\
\hline CHEMBL1522550 & 688697 & 4.6286 & 4.842 & TRN \\
\hline CHEMBL1566395 & 688697 & 4.8918 & 4.5867 & TRN \\
\hline CHEMBL1311547 & 688697 & 4.6478 & 4.4047 & TRN \\
\hline CHEMBL1972500 & 688697 & 4.73 & 4.8885 & TRN \\
\hline CHEMBL578487 & 688697 & 5.2757 & 5.2775 & TST \\
\hline CHEMBL1455925 & 688697 & 4.7069 & 4.329 & TRN \\
\hline CHEMBL1327677 & 688697 & 4.302 & 3.8108 & TRN \\
\hline CHEMBL1421212 & 688697 & 4.4919 & 4.8225 & TST \\
\hline
\end{tabular}


Supplemental Table S2.txt

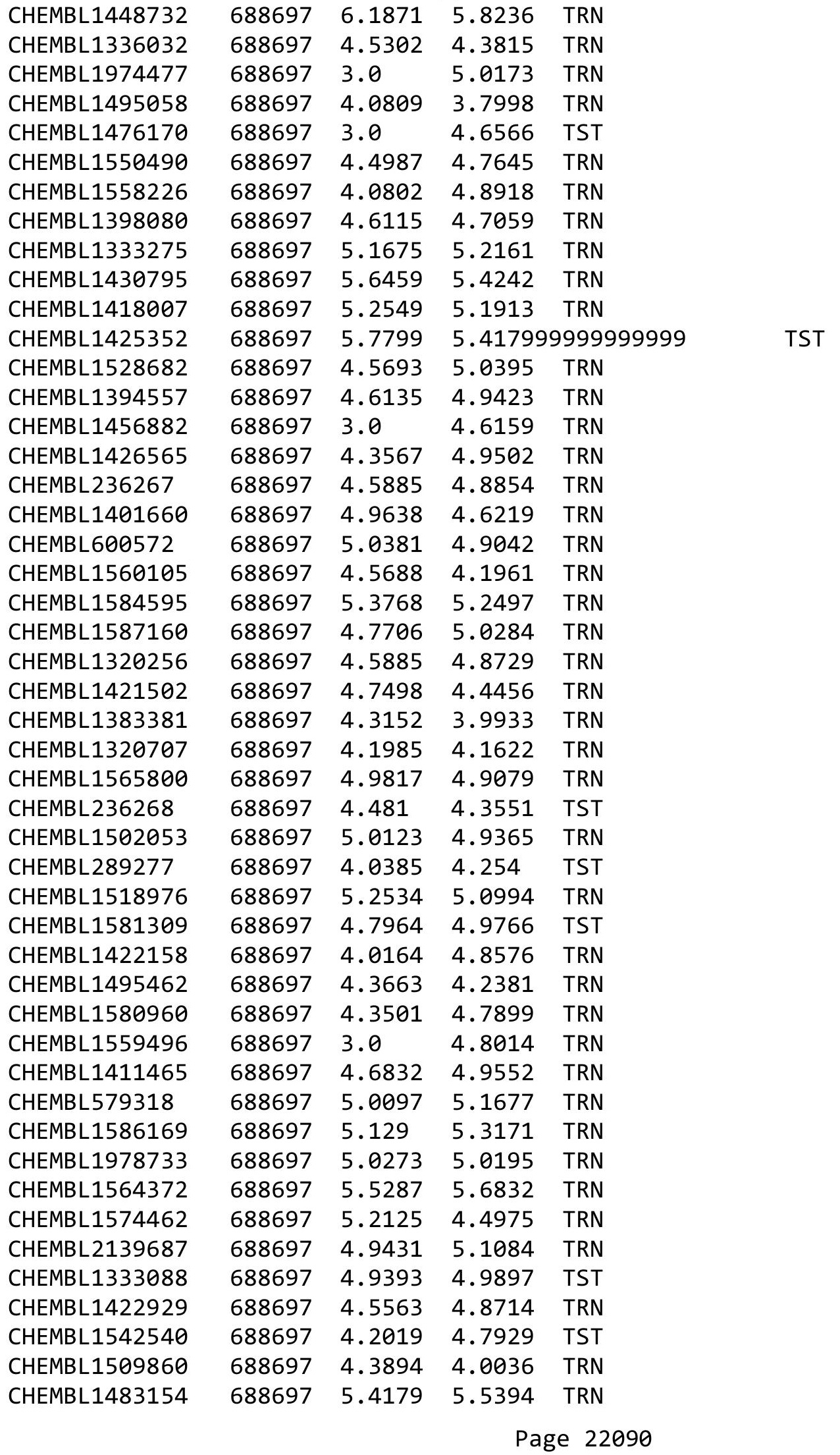




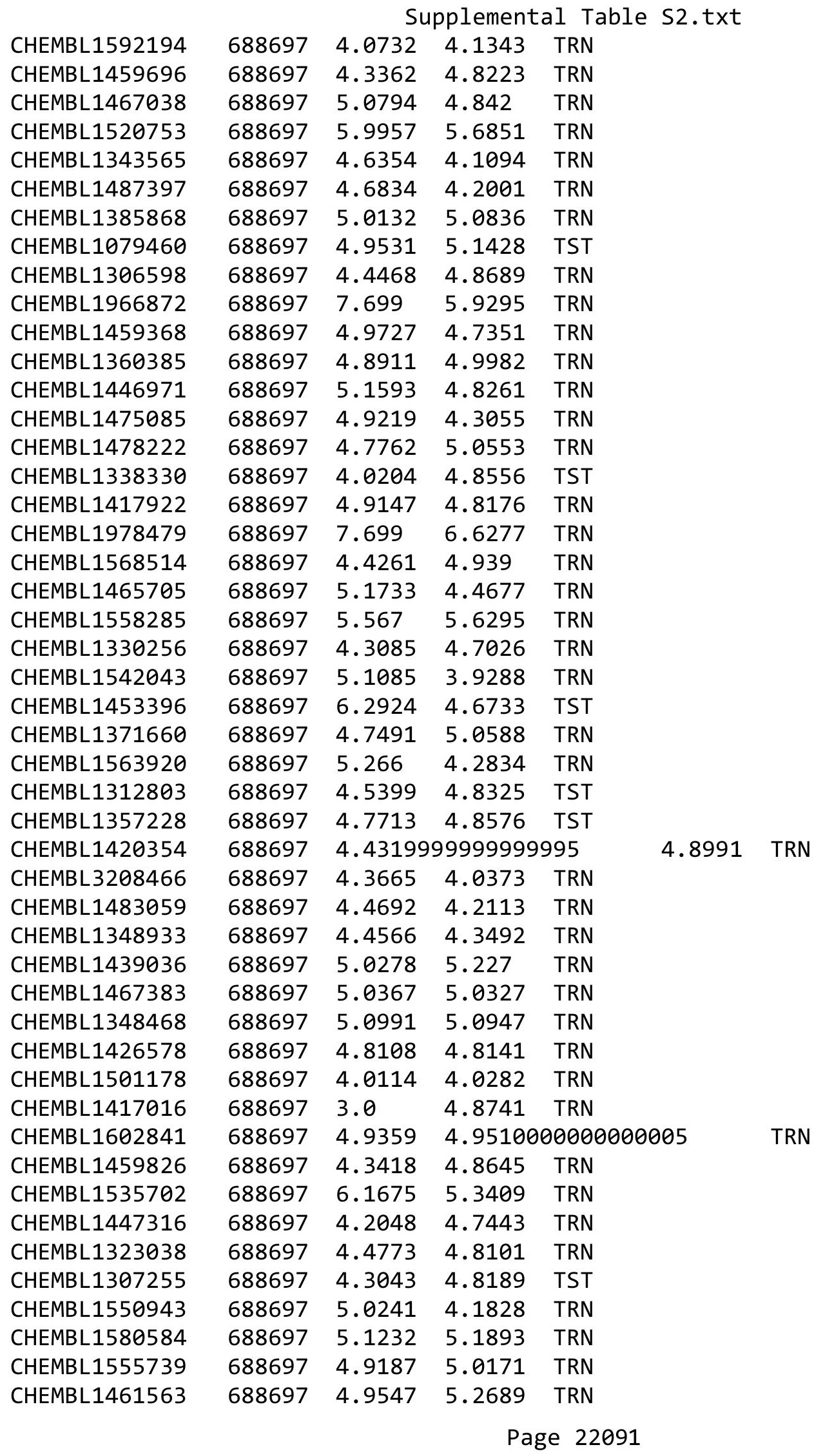




\begin{tabular}{|c|c|c|c|c|c|}
\hline \multicolumn{6}{|c|}{ Supplemental Table S2.txt } \\
\hline CHEMBL1601781 & 688697 & 4.756 & 5.1523 & TRN & \\
\hline CHEMBL1325558 & 688697 & 4.5369 & 4.2031 & TRN & \\
\hline CHEMBL1463659 & 688697 & 5.0438 & 5.2156 & TRN & \\
\hline CHEMBL1562079 & 688697 & 5.684 & 5.1134 & TRN & \\
\hline CHEMBL3195885 & 688697 & 5.2472 & 5.4143 & TST & \\
\hline CHEMBL1391424 & 688697 & 4.2099 & 4.7133 & TRN & \\
\hline CHEMBL1498258 & 688697 & 4.7948 & 5.0011 & TRN & \\
\hline CHEMBL1529766 & 688697 & 3.0 & 5.0037 & TST & \\
\hline CHEMBL1608333 & 688697 & 5.5317 & 5.3217 & TRN & \\
\hline CHEMBL1428563 & 688697 & 4.9176 & 5.1658 & TRN & \\
\hline CHEMBL1576490 & 688697 & 3.0 & 4.871 & TRN & \\
\hline CHEMBL1501549 & 688697 & 4.3395 & 4.7021 & TRN & \\
\hline CHEMBL1318919 & 688697 & 3.0 & 5.0756 & TRN & \\
\hline CHEMBL1392811 & 688697 & 4.9359 & 5.0614 & TST & \\
\hline CHEMBL3199084 & 688697 & 4.275 & 4.5499 & TRN & \\
\hline CHEMBL1548564 & 688697 & 4.3333 & 4.831 & TRN & \\
\hline CHEMBL1492432 & 688697 & 5.6383 & 5.2643 & TRN & \\
\hline CHEMBL1535532 & 688697 & 6.0362 & 5.4279 & TRN & \\
\hline CHEMBL1507666 & 688697 & 4.8477 & 4.1828 & TRN & \\
\hline CHEMBL1421862 & 688697 & 4.7552 & 5.0416 & TST & \\
\hline CHEMBL1539171 & 688697 & 5.0334 & 4.4274 & TRN & \\
\hline CHEMBL1608414 & 688697 & 3.0 & 4.7593 & TRN & \\
\hline CHEMBL1545088 & 688697 & 6.2147 & 4.8272 & TRN & \\
\hline CHEMBL1405174 & 688697 & 5.4112 & 5.4579 & TRN & \\
\hline CHEMBL3197105 & 688697 & 5.4168 & 5.5726 & TRN & \\
\hline CHEMBL1385701 & 688697 & 4.7416 & 5.051 & TRN & \\
\hline CHEMBL1468188 & 688697 & 4.495 & 4.8156 & TRN & \\
\hline CHEMBL1490799 & 688697 & 4.4503 & 4.7319 & TRN & \\
\hline CHEMBL1568335 & 688697 & 5.0778 & 4.9191 & TRN & \\
\hline CHEMBL1335669 & 688697 & 4.5036 & 4.9182 & TST & \\
\hline CHEMBL1442523 & 688697 & 4.6218 & 5.0284 & TRN & \\
\hline CHEMBL1482184 & 688697 & 4.8033 & 5.0116 & TST & \\
\hline CHEMBL503363 & 688697 & 5.3098 & 5.2414 & TRN & \\
\hline CHEMBL1575617 & 688697 & 3.0 & 4.5985 & TRN & \\
\hline CHEMBL1483224 & 688697 & 4.51399 & 999999999 & 4.8949 & TRN \\
\hline CHEMBL1307796 & 688697 & 4.5794 & $4.91100 e$ & 00000000005 & TRN \\
\hline CHEMBL1454334 & 688697 & 4.6258 & 4.9655 & TRN & \\
\hline CHEMBL1302576 & 688697 & 4.6187 & 4.1522 & TRN & \\
\hline CHEMBL1436062 & 688697 & 4.3393 & 3.839 & TRN & \\
\hline CHEMBL1331206 & 688697 & 4.3301 & 4.9335 & TRN & \\
\hline CHEMBL1560101 & 688697 & 4.5029 & 4.7924 & TRN & \\
\hline CHEMBL1524180 & 688697 & 6.1249 & 5.2893 & TRN & \\
\hline CHEMBL1376350 & 688697 & 4.4364 & 5.02 & TRN & \\
\hline CHEMBL1501186 & 688697 & 4.9404 & 5.0666 & TST & \\
\hline CHEMBL 1415172 & 688697 & 4.4633 & 4.9197 & TRN & \\
\hline CHEMBL1373625 & 688697 & 4.4634 & 4.2629 & TRN & \\
\hline CHEMBL1371841 & 688697 & 4.7066 & 4.8735 & TRN & \\
\hline CHEMBL1594001 & 688697 & 4.2313 & 4.1477 & TRN & \\
\hline
\end{tabular}

Page 22092 


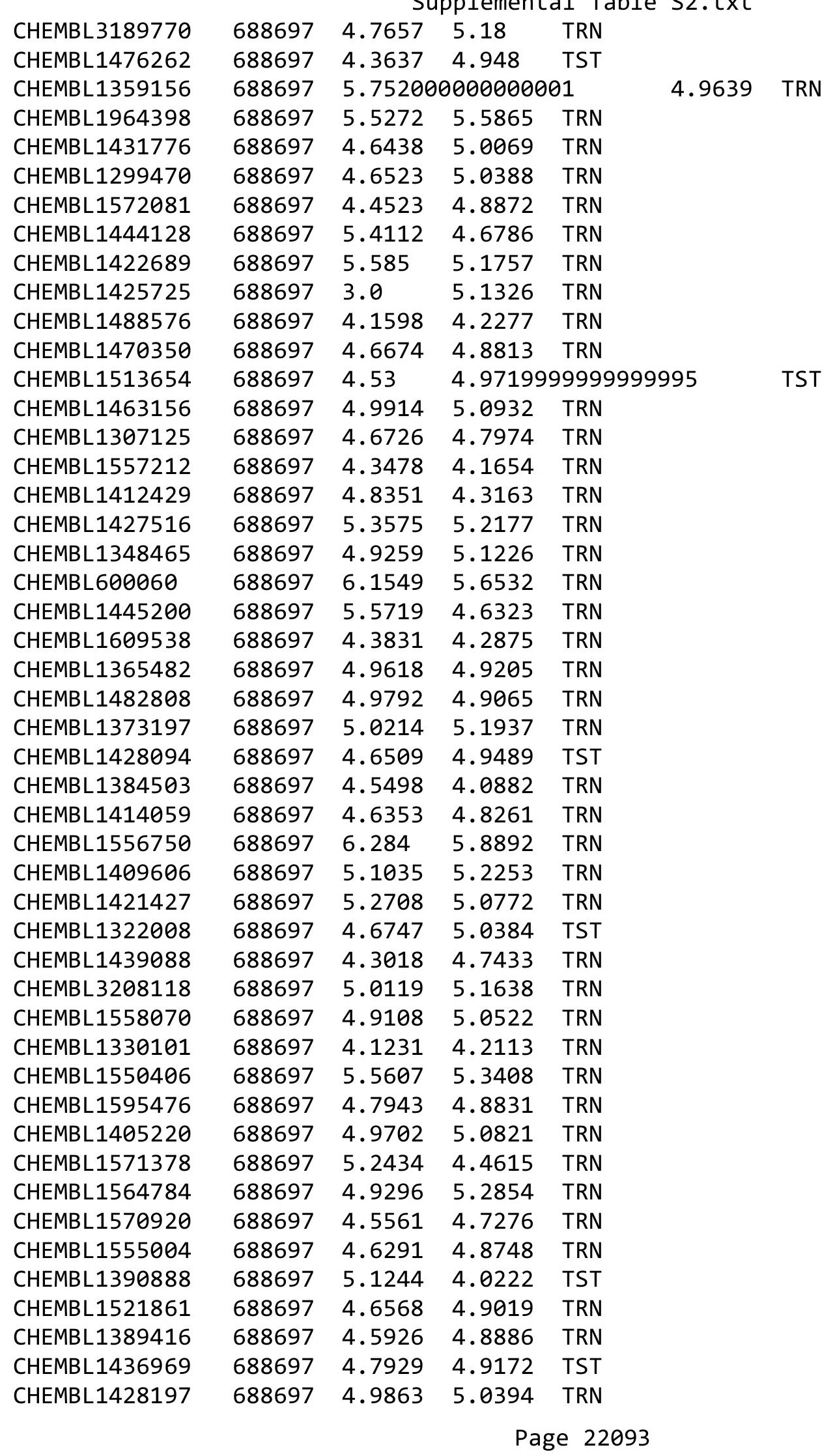




\begin{tabular}{|c|c|c|c|c|c|}
\hline \multicolumn{6}{|c|}{ Supplemental Table S2.txt } \\
\hline CHEMBL1458022 & 688697 & 5.224 & 5.1103 & TRN & \\
\hline CHEMBL1535752 & 688697 & 4.1432 & 4.0902 & TRN & \\
\hline CHEMBL598270 & 688697 & 4.6068 & 4.8571 & TRN & \\
\hline CHEMBL1422395 & 688697 & 4.8847 & 4.8606 & TST & \\
\hline CHEMBL3189714 & 688697 & 5.0985 & 5.2528 & TST & \\
\hline CHEMBL472437 & 688697 & 5.5171 & 5.2187 & TST & \\
\hline CHEMBL1470941 & 688697 & 4.9531 & 5.1926 & TRN & \\
\hline CHEMBL3195591 & 688697 & 6.1871 & 4.7131 & TRN & \\
\hline CHEMBL1485363 & 688697 & 4.7474 & 4.8315 & TRN & \\
\hline CHEMBL1376851 & 688697 & 5.0132 & 5.0853 & TRN & \\
\hline CHEMBL1607286 & 688697 & 4.6515 & 4.9179 & TRN & \\
\hline CHEMBL1444767 & 688697 & 4.988 & 5.2384 & TRN & \\
\hline CHEMBL1551228 & 688697 & 4.9066 & 5.1089 & TRN & \\
\hline CHEMBL1489131 & 688697 & 4.6451 & 5.0237 & TRN & \\
\hline CHEMBL1391654 & 688697 & 5.5272 & 5.0136 & TRN & \\
\hline CHEMBL1537101 & 688697 & 6.0362 & 5.6088 & TRN & \\
\hline CHEMBL1562280 & 688697 & 4.3876 & 5.0017 & TRN & \\
\hline CHEMBL3193181 & 688697 & 4.8413 & 5.1006 & TST & \\
\hline CHEMBL578512 & 688697 & 5.7799 & 5.5099 & TRN & \\
\hline CHEMBL1365734 & 688697 & 4.5977 & 4.9066 & TST & \\
\hline CHEMBL1322532 & 688697 & 4.3534 & 4.7156 & TRN & \\
\hline CHEMBL1353090 & 688697 & 4.3465 & 4.2456 & TRN & \\
\hline CHEMBL1584746 & 688697 & 4.522 & 4.7773 & TRN & \\
\hline CHEMBL1462257 & 688697 & 5.2832 & 5.0926 & TRN & \\
\hline CHEMBL1535546 & 688697 & 5.4935 & 5.3317 & TRN & \\
\hline CHEMBL1371353 & 688697 & 5.4089 & 5.285 & TRN & \\
\hline CHEMBL1451125 & 688697 & 4.9842 & 5.1287 & TRN & \\
\hline CHEMBL1566401 & 688697 & 4.3218 & 4.7932 & TRN & \\
\hline CHEMBL1399417 & 688697 & 4.8533 & 4.19300 & 00000000005 & TST \\
\hline CHEMBL1338747 & 688697 & 4.9884 & 5.1398 & TRN & \\
\hline CHEMBL1421517 & 688697 & 4.7196 & 4.942 & TRN & \\
\hline CHEMBL1333312 & 688697 & 4.3097 & 4.6502 & TRN & \\
\hline CHEMBL1604551 & 688697 & 4.9158 & 4.1632 & TRN & \\
\hline CHEMBL1313887 & 688697 & 4.7667 & 4.6287 & TRN & \\
\hline CHEMBL1428063 & 688697 & 4.0649 & 3.9458 & TRN & \\
\hline CHEMBL1409835 & 688697 & 4.7812 & 4.9346 & TST & \\
\hline CHEMBL1569917 & 688697 & 5.8297 & 5.9197 & TRN & \\
\hline CHEMBL1399232 & 688697 & 4.4707 & 4.9105 & TRN & \\
\hline CHEMBL3392078 & 688697 & 4.2463 & 4.6875 & TST & \\
\hline CHEMBL1469362 & 688697 & 4.3391 & 4.7119 & TRN & \\
\hline CHEMBL1359688 & 688697 & 6.1805 & 5.7247 & TRN & \\
\hline CHEMBL 2002849 & 688697 & 4.6178 & 5.0611 & TRN & \\
\hline CHEMBL1529827 & 688697 & 4.4715 & 4.9403 & TRN & \\
\hline CHEMBL1362206 & 688697 & 4.3267 & 4.0767 & TST & \\
\hline CHEMBL 3195813 & 688697 & 5.0246 & 5.1701 & TRN & \\
\hline CHEMBL1567119 & 688697 & 4.2805 & 4.0056 & TRN & \\
\hline CHEMBL1556134 & 688697 & 4.7181 & 4.8843 & TRN & \\
\hline CHEMBL1594650 & 688697 & 4.5624 & 4.3477 & TRN & \\
\hline
\end{tabular}

Page 22094 
Supplemental Table S2.txt

\begin{tabular}{|c|c|c|c|c|c|}
\hline CHEMBL1410618 & 688697 & 7.699 & 6.4138 & TRN & \\
\hline CHEMBL1982032 & 688697 & 7.699 & \multicolumn{2}{|c|}{5.6579999999999995} & TST \\
\hline CHEMBL1342485 & 688697 & 5.011 & 5.0596 & TST & \\
\hline CHEMBL1543733 & 688697 & 4.9431 & 5.05 & TRN & \\
\hline CHEMBL3194905 & 688697 & 4.9654 & \multicolumn{2}{|c|}{5.1770000000000005} & TRN \\
\hline CHEMBL1409491 & 688697 & 5.3575 & 5.0496 & TRN & \\
\hline CHEMBL1415890 & 688697 & 6.1675 & 4.6628 & TRN & \\
\hline CHEMBL1988120 & 688697 & 5.2269 & 5.3642 & TRN & \\
\hline CHEMBL 3194969 & 688697 & 5.3478 & 5.2421 & TRN & \\
\hline CHEMBL1354632 & 688697 & 5.02 & 5.043 & TRN & \\
\hline CHEMBL 3145205 & 688697 & 5.2565 & 4.1027 & TRN & \\
\hline CHEMBL1439184 & 688697 & 4.5406 & 4.9036 & TRN & \\
\hline CHEMBL1399035 & 688697 & 4.9169 & 5.0615 & TRN & \\
\hline CHEMBL1526703 & 688697 & 4.1157 & 4.0031 & TRN & \\
\hline CHEMBL3198662 & 688697 & 5.0195 & 5.1536 & TRN & \\
\hline CHEMBL1312788 & 688697 & 5.6882 & 5.5255 & TRN & \\
\hline CHEMBL1334115 & 688697 & 4.9626 & 4.8564 & TRN & \\
\hline CHEMBL563585 & 688697 & 5.0506 & 5.0121 & TRN & \\
\hline CHEMBL1550840 & 688697 & 4.2512 & 4.0924 & TRN & \\
\hline CHEMBL1449875 & 688697 & 4.7361 & 4.5113 & TRN & \\
\hline CHEMBL1305033 & 688697 & 3.0 & 4.8589 & TRN & \\
\hline CHEMBL1495265 & 688697 & 4.9508 & 4.3614 & TRN & \\
\hline CHEMBL1497430 & 688697 & 5.0788 & 5.1119 & TRN & \\
\hline CHEMBL1341756 & 688697 & 6.4089 & 5.8211 & TRN & \\
\hline CHEMBL1332327 & 688697 & 5.0269 & 5.0563 & TRN & \\
\hline CHEMBL1460323 & 688697 & 4.5535 & \multicolumn{2}{|c|}{4.9110000000000005} & TRN \\
\hline CHEMBL1445858 & 688697 & 4.4004 & 4.8241 & TRN & \\
\hline CHEMBL1563766 & 688697 & 4.9602 & 5.087 & TRN & \\
\hline CHEMBL1586241 & 688697 & 4.5751 & 4.7161 & TRN & \\
\hline CHEMBL1507180 & 688697 & 4.3047 & 4.1845 & TRN & \\
\hline CHEMBL1418496 & 688697 & 4.2507 & 3.8905 & TRN & \\
\hline CHEMBL3211808 & 688697 & 5.2336 & 4.8734 & TRN & \\
\hline CHEMBL1404407 & 688697 & 4.6323 & 5.0136 & TRN & \\
\hline CHEMBL1449042 & 688697 & 5.1029 & 5.0635 & TRN & \\
\hline CHEMBL1594567 & 688697 & 4.3756 & 4.706 & TRN & \\
\hline CHEMBL1188078 & 688697 & 4.8925 & 5.0621 & TRN & \\
\hline CHEMBL1965444 & 688697 & 4.3116 & 4.6378 & TRN & \\
\hline CHEMBL1502358 & 688697 & 5.2749 & 5.1816 & TST & \\
\hline CHEMBL1484144 & 688697 & 4.9462 & 4.575 & TRN & \\
\hline CHEMBL1470129 & 688697 & 4.1646 & 4.7419 & TRN & \\
\hline CHEMBL1423709 & 688697 & 4.6165 & 4.1851 & TRN & \\
\hline CHEMBL1521841 & 688697 & 4.6221 & 4.8646 & TST & \\
\hline CHEMBL1385350 & 688697 & 5.2007 & 5.1612 & TRN & \\
\hline CHEMBL1434681 & 688697 & 4.6726 & 4.7983 & TRN & \\
\hline CHEMBL 3197170 & 688697 & 4.6592 & 4.9054 & TRN & \\
\hline CHEMBL1358604 & 688697 & 4.6799 & 4.8538 & TRN & \\
\hline CHEMBL1338801 & 688697 & 4.6386 & 4.8113 & TRN & \\
\hline CHEMBL1979721 & 688697 & 4.6321 & 5.0587 & TRN & \\
\hline
\end{tabular}




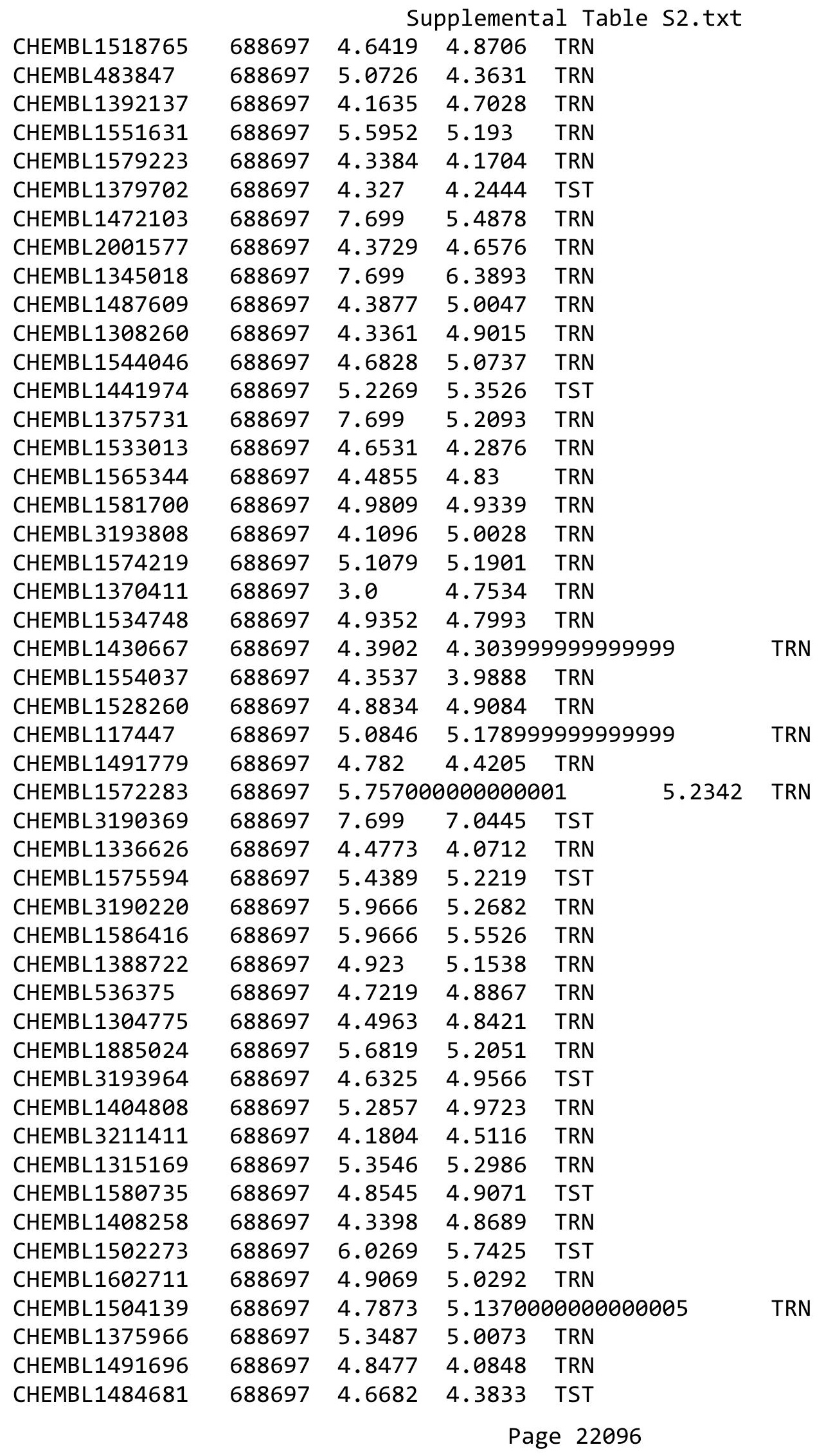




\begin{tabular}{|c|c|c|c|c|c|}
\hline & & \multicolumn{4}{|c|}{ Supplemental Table S2.txt } \\
\hline CHEMBL1441408 & 688697 & 4.5929 & 4.9018 & TRN & \\
\hline CHEMBL1476017 & 688697 & 6.1079 & 5.2397 & TRN & \\
\hline CHEMBL1510371 & 688697 & 4.8554 & 4.9991 & TRN & \\
\hline CHEMBL1497387 & 688697 & 4.3389 & 4.8985 & TRN & \\
\hline CHEMBL1417988 & 688697 & 4.8306 & 4.631 & TRN & \\
\hline CHEMBL1605956 & 688697 & 7.699 & 6.0472 & TRN & \\
\hline CHEMBL1546758 & 688697 & 4.6362 & 4.8077 & TRN & \\
\hline CHEMBL1516976 & 688697 & 4.6496 & 5.0439 & TRN & \\
\hline CHEMBL1484227 & 688697 & 4.8063 & 5.0764 & TRN & \\
\hline CHEMBL1385593 & 688697 & 4.3937 & 4.8828 & TRN & \\
\hline CHEMBL1981928 & 688697 & 4.0304 & 4.9884 & TRN & \\
\hline CHEMBL1313242 & 688697 & 4.8804 & 3.8383 & TRN & \\
\hline CHEMBL1505574 & 688697 & 4.8969 & 4.9825 & TRN & \\
\hline CHEMBL3198312 & 688697 & 4.1757 & 4.9344 & TRN & \\
\hline CHEMBL1568255 & 688697 & 4.1688 & 4.0807 & TST & \\
\hline CHEMBL1454529 & 688697 & 4.5354 & 4.7936 & TRN & \\
\hline CHEMBL1402664 & 688697 & 5.4306 & 5.4091 & TRN & \\
\hline CHEMBL1585527 & 688697 & 4.8523 & 4.9995 & TRN & \\
\hline CHEMBL 3194446 & 688697 & 4.037 & \multicolumn{2}{|c|}{5.031000000000001} & TRN \\
\hline CHEMBL1359780 & 688697 & 3.0 & 4.8385 & TST & \\
\hline CHEMBL 373481 & 688697 & 4.5896 & 4.7861 & TRN & \\
\hline CHEMBL1404454 & 688697 & 5.2612 & 5.0386 & TRN & \\
\hline CHEMBL1454414 & 688697 & 5.1146 & 4.3746 & TRN & \\
\hline CHEMBL1325258 & 688697 & \multicolumn{3}{|c|}{4.638999999999999} & TRN \\
\hline CHEMBL1986741 & 688697 & 4.3806 & 4.8154 & TRN & \\
\hline CHEMBL1337598 & 688697 & 4.0547 & 4.0932 & TST & \\
\hline CHEMBL1472145 & 688697 & 4.9136 & 5.2156 & TRN & \\
\hline CHEMBL1604153 & 688697 & 5.4179 & 4.9292 & TRN & \\
\hline CHEMBL1373255 & 688697 & 4.8216 & 3.9648 & TRN & \\
\hline CHEMBL1376799 & 688697 & 4.551 & 4.8283 & TRN & \\
\hline CHEMBL1424151 & 688697 & 4.0248 & 3.9706 & TRN & \\
\hline CHEMBL1543133 & 688697 & 4.0761 & 4.6414 & TST & \\
\hline CHEMBL1997543 & 688697 & 4.5511 & 5.0961 & TRN & \\
\hline CHEMBL1982308 & 688697 & 5.7799 & 5.79799 & 9999999999 & TRN \\
\hline CHEMBL1550330 & 688697 & 4.7491 & 4.3065 & TRN & \\
\hline CHEMBL1319750 & 688697 & 5.5376 & 5.4525 & TRN & \\
\hline CHEMBL1332821 & 688697 & 4.5675 & 4.0513 & TRN & \\
\hline CHEMBL1343697 & 688697 & 4.6287 & 4.8441 & TRN & \\
\hline CHEMBL1374480 & 688697 & 4.9801 & 5.1436 & TRN & \\
\hline CHEMBL1500855 & 688697 & 5.7773 & 5.3791 & TRN & \\
\hline CHEMBL1393399 & 688697 & 4.4268 & 4.8474 & TRN & \\
\hline CHEMBL1306490 & 688697 & 4.3579 & 4.4823 & TRN & \\
\hline CHEMBL1524101 & 688697 & 4.9292 & 5.0252 & TST & \\
\hline CHEMBL 388959 & 688697 & 4.6824 & 4.8605 & TRN & \\
\hline CHEMBL1550076 & 688697 & 7.699 & 6.5572 & TRN & \\
\hline CHEMBL1588559 & 688697 & 4.8827 & 5.1297 & TRN & \\
\hline CHEMBL1348813 & 688697 & 3.0 & 4.737 & TRN & \\
\hline CHEMBL1328824 & 688697 & 5.3028 & 5.1426 & TST & \\
\hline
\end{tabular}




\begin{tabular}{|c|c|c|c|c|c|c|}
\hline & & \multicolumn{5}{|c|}{ Supplemental Table S2.txt } \\
\hline CHEMBL1372112 & 688697 & 5.3251 & 5.2125 & TRN & & \\
\hline CHEMBL1398665 & 688697 & 5.9747 & 4.685 & TRN & & \\
\hline CHEMBL3197008 & 688697 & 4.4607 & 4.2973 & TRN & & \\
\hline CHEMBL1391269 & 688697 & 4.8586 & 4.5527 & TRN & & \\
\hline CHEMBL1533220 & 688697 & 4.67 & 5.0492 & TRN & & \\
\hline CHEMBL1555532 & 688697 & 4.8142 & 5.1009 & TRN & & \\
\hline CHEMBL1560784 & 688697 & 4.8941 & 5.1273 & TRN & & \\
\hline CHEMBL1412700 & 688697 & 5.7932 & 4.3072 & TRN & & \\
\hline CHEMBL1256132 & 688697 & 4.4044 & 5.01 & TST & & \\
\hline CHEMBL1606097 & 688697 & 4.6231 & 4.2681 & TRN & & \\
\hline CHEMBL1582440 & 688697 & 4.4743 & 4.6954 & TRN & & \\
\hline CHEMBL1971410 & 688697 & 3.0 & 4.9151 & TRN & & \\
\hline CHEMBL1333248 & 688697 & 5.2314 & 5.3236 & TRN & & \\
\hline CHEMBL1580940 & 688697 & 4.3492 & 4.9203 & TRN & & \\
\hline CHEMBL1563483 & 688697 & 5.8697 & 5.6614 & TST & & \\
\hline CHEMBL1304898 & 688697 & 4.8986 & 4.2866 & TRN & & \\
\hline CHEMBL1537958 & 688697 & 4.8788 & 4.8662 & TRN & & \\
\hline CHEMBL1345665 & 688697 & 4.2738 & 4.662 & TRN & & \\
\hline CHEMBL1476094 & 688697 & 4.6463 & 5.0331 & TST & & \\
\hline CHEMBL1378118 & 688697 & 5.2027 & 5.1064 & TRN & & \\
\hline CHEMBL1509758 & 688697 & 4.2803 & 4.6973 & TRN & & \\
\hline CHEMBL36654 & 688697 & 5.7799 & 5.5334 & TRN & & \\
\hline CHEMBL3212236 & 688697 & 4.5321 & 4.1009 & TRN & & \\
\hline CHEMBL1320267 & 688697 & 4.2807 & 4.54 & TRN & & \\
\hline CHEMBL1550591 & 688697 & 4.9931 & 5.0745 & TST & & \\
\hline CHEMBL1407017 & 688697 & 5.0362 & 5.246 & TRN & & \\
\hline CHEMBL1347479 & 688697 & 5.0878 & 5.0833 & TST & & \\
\hline CHEMBL1358582 & 688697 & 4.2686 & 4.2895 & TRN & & \\
\hline CHEMBL1519411 & 688697 & 4.9378 & 5.0656 & TRN & & \\
\hline CHEMBL1512404 & 688697 & 5.1068 & 4.5043 & TRN & & \\
\hline CHEMBL1586982 & 688697 & 7.699 & 5.2565 & TRN & & \\
\hline CHEMBL1446547 & 688697 & 3.0 & 4.2492 & TRN & & \\
\hline CHEMBL1439119 & 688697 & 5.9318 & 5.5707 & TRN & & \\
\hline CHEMBL1560649 & 688697 & 5.2291 & 4.3973 & TRN & & \\
\hline CHEMBL1567159 & 688697 & $4.5680 €$ & 00000000 & 005 & 4.8522 & TRN \\
\hline CHEMBL1320592 & 688697 & 4.3965 & 4.1712 & TRN & & \\
\hline CHEMBL1342388 & 688697 & 5.2314 & 5.4056 & TST & & \\
\hline CHEMBL1400856 & 688697 & 4.9638 & 5.1895 & TST & & \\
\hline CHEMBL1347108 & 688697 & 4.1651 & 4.6786 & TRN & & \\
\hline CHEMBL3193557 & 688697 & 4.3729 & 4.8646 & TRN & & \\
\hline CHEMBL1536587 & 688697 & 4.0016 & 4.7513 & TRN & & \\
\hline CHEMBL1613402 & 688697 & 4.8564 & 4.9772 & TRN & & \\
\hline CHEMBL1469854 & 688697 & 5.0061 & 4.5705 & TRN & & \\
\hline CHEMBL1412226 & 688697 & 5.3497 & 4.6538 & TRN & & \\
\hline CHEMBL1341524 & 688697 & 5.3605 & 5.3207 & TRN & & \\
\hline CHEMBL1608727 & 688697 & 4.7734 & 5.0438 & TRN & & \\
\hline CHEMBL1396393 & 688697 & 4.004 & 4.76399 & 9999999999 & & TRN \\
\hline CHEMBL1607203 & 688697 & 4.3174 & 4.899 & TRN & & \\
\hline
\end{tabular}


Supplemental Table S2.txt

\begin{tabular}{|c|c|c|c|c|c|}
\hline CHEMBL1422381 & 688697 & 5.1226 & 4.0281 & TRN & \\
\hline CHEMBL1313724 & 688697 & 4.4638 & 4.7755 & TRN & \\
\hline CHEMBL1433269 & 688697 & 5.2161 & 5.0611 & TST & \\
\hline CHEMBL1467326 & 688697 & 4.7071 & 4.9523 & TRN & \\
\hline CHEMBL1381793 & 688697 & 4.7744 & 4.8585 & TRN & \\
\hline CHEMBL3145174 & 688697 & 5.1555 & 5.0541 & TRN & \\
\hline CHEMBL1502109 & 688697 & 4.3391 & 4.9201 & TRN & \\
\hline CHEMBL1408593 & 688697 & 4.7734 & 4.825 & TST & \\
\hline CHEMBL1583579 & 688697 & 4.4577 & 4.8089 & TRN & \\
\hline CHEMBL3195226 & 688697 & 6.0362 & 5.7082 & TRN & \\
\hline CHEMBL3197521 & 688697 & 4.2185 & 4.8058 & TRN & \\
\hline CHEMBL1462070 & 688697 & 4.96899 & 999999995 & 5.0792 & TRN \\
\hline CHEMBL1374668 & 688697 & 4.8976 & 4.4437 & TRN & \\
\hline CHEMBL375781 & 688697 & 6.3098 & 5.7922 & TST & \\
\hline CHEMBL1344675 & 688697 & 4.3172 & 4.7192 & TRN & \\
\hline CHEMBL1465165 & 688697 & 4.5585 & 4.8821 & TRN & \\
\hline CHEMBL3195331 & 688697 & 4.3232 & 4.6953 & TRN & \\
\hline CHEMBL1365183 & 688697 & 4.6546 & 5.0371 & TST & \\
\hline CHEMBL1538786 & 688697 & 4.803 & 4.9869 & TRN & \\
\hline CHEMBL1503165 & 688697 & 4.6964 & 4.925 & TRN & \\
\hline CHEMBL1348638 & 688697 & 4.9007 & 4.2545 & TRN & \\
\hline CHEMBL1475498 & 688697 & 4.8931 & 4.5723 & TST & \\
\hline CHEMBL3190259 & 688697 & 4.9112 & 4.8502 & TST & \\
\hline CHEMBL599943 & 688697 & 4.7097 & 4.9758 & TRN & \\
\hline CHEMBL1563137 & 688697 & 4.3958 & 3.8807 & TRN & \\
\hline CHEMBL1351495 & 688697 & 4.595 & 4.779 & TRN & \\
\hline CHEMBL1312624 & 688697 & 4.607 & 4.923999 & 99999999995 & TRN \\
\hline CHEMBL1381450 & 688697 & 4.4046 & 4.8454 & TRN & \\
\hline CHEMBL3191202 & 688697 & 5.1487 & 5.2401 & TST & \\
\hline CHEMBL1509379 & 688697 & 6.0969 & 5.6502 & TRN & \\
\hline CHEMBL1417886 & 688697 & 5.8601 & 5.6591 & TRN & \\
\hline CHEMBL1544732 & 688697 & 5.0315 & 4.8966 & TRN & \\
\hline CHEMBL3210529 & 688697 & 4.3268 & 4.8212 & TRN & \\
\hline CHEMBL1496901 & 688697 & 4.0875 & 4.6496 & TRN & \\
\hline CHEMBL602969 & 688697 & 5.2218 & 5.2887 & TST & \\
\hline CHEMBL3198213 & 688697 & 4.7731 & 4.9469 & TST & \\
\hline CHEMBL1347298 & 688697 & 4.7233 & 4.0726 & TRN & \\
\hline CHEMBL1319374 & 688697 & 4.9136 & 5.038 & TRN & \\
\hline CHEMBL3145059 & 688697 & 4.7406 & 3.988 & TRN & \\
\hline CHEMBL1470728 & 688697 & 5.067 & 5.2861 & TST & \\
\hline CHEMBL1590743 & 688697 & 4.7445 & 4.9342 & TRN & \\
\hline CHEMBL1503907 & 688697 & 3.0 & 4.7877 & TRN & \\
\hline CHEMBL1367648 & 688697 & 3.0 & 4.5496 & TRN & \\
\hline CHEMBL259388 & 688697 & 4.3493 & 4.762 & TRN & \\
\hline CHEMBL1518440 & 688697 & 5.767 & 4.5267 & TRN & \\
\hline CHEMBL494668 & 688697 & \multicolumn{3}{|c|}{5.327000000000001} & TRN \\
\hline CHEMBL1550359 & 688697 & 4.1308 & 4.0031 & TRN & \\
\hline CHEMBL1612259 & 688697 & 3.0 & 4.4766 & TRN & \\
\hline
\end{tabular}


Supplemental Table S2.txt

\begin{tabular}{|c|c|c|c|c|}
\hline CHEMBL1322356 & 688697 & 4.631 & 4.7682 & TRN \\
\hline CHEMBL 3196232 & 688697 & 4.1227 & 4.6999 & TRN \\
\hline CHEMBL3195309 & 688697 & 4.8697 & 4.8978 & TRN \\
\hline CHEMBL1525222 & 688697 & 5.9666 & 5.6965 & TRN \\
\hline CHEMBL1420800 & 688697 & 4.1994 & 4.0966 & TRN \\
\hline CHEMBL1373992 & 688697 & 6.1805 & 5.8005 & TST \\
\hline CHEMBL1438956 & 688697 & 4.9602 & 4.9494 & TRN \\
\hline CHEMBL1484537 & 688697 & 4.8716 & 4.8731 & TRN \\
\hline CHEMBL1374306 & 688697 & 4.9743 & 4.922 & TRN \\
\hline CHEMBL1548022 & 688697 & 4.0016 & 5.0865 & TRN \\
\hline CHEMBL1348980 & 688697 & 4.3768 & 4.1438 & TRN \\
\hline CHEMBL1989453 & 688697 & 3.0 & 4.5084 & TRN \\
\hline CHEMBL1449173 & 688697 & 5.1707 & 5.1043 & TRN \\
\hline CHEMBL1322886 & 688697 & 5.4559 & 5.0431 & TRN \\
\hline CHEMBL1355039 & 688697 & 4.3881 & 4.643 & TRN \\
\hline CHEMBL1355537 & 688697 & 3.0 & 4.8528 & TRN \\
\hline CHEMBL1387887 & 688697 & 4.815 & 4.8465 & TRN \\
\hline CHEMBL1313206 & 688697 & 7.699 & 5.7233 & TRN \\
\hline CHEMBL1391340 & 688697 & 5.9318 & 5.6184 & TRN \\
\hline CHEMBL1546038 & 688697 & 6.0315 & 5.5054 & TRN \\
\hline CHEMBL1548703 & 688697 & 5.0074 & 4.9875 & TRN \\
\hline CHEMBL1995097 & 688697 & 4.9562 & 5.1954 & TRN \\
\hline CHEMBL443510 & 688697 & 4.5455 & 4.9506 & TRN \\
\hline CHEMBL1346860 & 688697 & 4.9038 & 4.8301 & TRN \\
\hline CHEMBL1368342 & 688697 & 5.5214 & 5.50899 & 99999999995 \\
\hline CHEMBL1582426 & 688697 & 5.8356 & 5.3763 & TRN \\
\hline CHEMBL1431850 & 688697 & 4.4559 & 4.0097 & TRN \\
\hline CHEMBL27811 & 688697 & 4.4901 & 4.8155 & TRN \\
\hline CHEMBL1592636 & 688697 & 4.8804 & 4.9945 & TRN \\
\hline CHEMBL1587075 & 688697 & 5.0325 & 5.0123 & TST \\
\hline CHEMBL1567688 & 688697 & 4.1049 & 4.6332 & TRN \\
\hline CHEMBL1414009 & 688697 & 4.6207 & 4.8552 & TST \\
\hline CHEMBL1600969 & 688697 & 4.2837 & 3.9528 & TRN \\
\hline CHEMBL1305678 & 688697 & 4.5563 & 4.2707 & TRN \\
\hline CHEMBL1511793 & 688697 & 4.3654 & 4.7711 & TRN \\
\hline CHEMBL 3196660 & 688697 & 3.0 & 4.9218 & TRN \\
\hline CHEMBL1433503 & 688697 & 4.8116 & 4.1718 & TRN \\
\hline CHEMBL1345622 & 688697 & 4.9179 & 4.2185 & TRN \\
\hline CHEMBL1407492 & 688697 & 6.4318 & 4.6035 & TRN \\
\hline CHEMBL1528781 & 688697 & 4.3784 & 4.7939 & TRN \\
\hline CHEMBL1359515 & 688697 & 4.3569 & 4.8345 & TRN \\
\hline CHEMBL 3191380 & 688697 & 5.4473 & 5.6706 & TRN \\
\hline CHEMBL1602754 & 688697 & 4.8444 & 4.4189 & TRN \\
\hline CHEMBL1337704 & 688697 & 4.4517 & 4.851 & TRN \\
\hline CHEMBL1586404 & 688697 & 4.6509 & 5.0165 & TRN \\
\hline CHEMBL1428883 & 688697 & 5.0301 & 5.0725 & TRN \\
\hline CHEMBL1537770 & 688697 & 4.6227 & 3.9844 & TRN \\
\hline CHEMBL1376674 & 688697 & 4.3856 & 3.9038 & TRN \\
\hline
\end{tabular}

Page 22100 
Supplemental Table S2.txt

\begin{tabular}{|c|c|c|c|c|}
\hline Th & & & & \\
\hline & 88697 & 5.3969 & 5.0582 & \\
\hline 10 & & & & \\
\hline AEMBL1 & 3697 & & & \\
\hline AEMBL1453960 & 697 & 862 & 1942 & \\
\hline HEMBL1389339 & 88697 & 2716 & 3032 & \\
\hline & 3697 & & & \\
\hline IFMR 130 & 697 & & & RN \\
\hline AEMBL1343969 & 88697 & & 7259 & \\
\hline AEMBL1539376 & 38697 & 26 & 3515 & \\
\hline HEMBL1596475 & 88697 & & 63 & \\
\hline IEMBL1573291 & 697 & 69 & 85 & \\
\hline AEMBL1543836 & & & & \\
\hline HEMBL1321725 & 88697 & 635 & 3174 & \\
\hline AEMBL3196585 & 697 & 11 & & \\
\hline AEMBL1340792 & 88697 & & 48 & \\
\hline HEMBL1999 & 8697 & & 56 & \\
\hline HEMBL1527 & 8697 & & & \\
\hline AEMBL1405 & 88697 & & & \\
\hline AEMBL3196 & 97 & & & \\
\hline AEMBLIS & 97 & & 03 & NIV \\
\hline HEMBL1492 & 97 & & 91 & 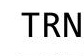 \\
\hline AEMBL136e & 97 & & & \\
\hline AEMBL1498565 & 88697 & & & \\
\hline AEMBL1333 & 97 & & & (3) \\
\hline AEMBL16 & 97 & & 52 & $\cdots$ \\
\hline AEMBL: & & & 57 & RN \\
\hline AFMBI 32 & 97 & & 992 & \\
\hline HEMBL15 & 88697 & & & I KIV \\
\hline HEMBL13591 & 38697 & & 073 & 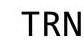 \\
\hline HEMBL1309 & 97 & & 351 & RIV \\
\hline HEMBL3 & & & 384 & ST \\
\hline $15 M P \mid 2$ & 97 & & 148 & RN \\
\hline AEMBL1372732 & & & 788 & IRN \\
\hline HEMBL1568905 & 88697 & & 633 & TRN \\
\hline HEMBL1561446 & 88697 & & & Miv \\
\hline HᄃMP I 1 & & & & \\
\hline HEMBL1538449 & & & 976 & TRN \\
\hline HEMBL1375823 & 88697 & & 917 & TRN \\
\hline HEMBL155846 & 88697 & & 1019 & $\Gamma \mathrm{RN}$ \\
\hline HEMBL1363 & 88697 & & 407 & $\Gamma \mathrm{RN}$ \\
\hline LHEMBL1445710 & 88697 & & & TRN \\
\hline HEMBL1577829 & 88697 & & 466 & RN \\
\hline AEMBL1406021 & 38697 & & 1689 & TRN \\
\hline HEMBL 1449 & 88697 & & 127 & RN \\
\hline HEMBL143 & 88697 & & 9183 & \\
\hline CHEMBL1520528 & 88697 & & 9675 & \\
\hline CHEMBL3197899 & 688697 & 4.4632 & 4.8268 & RN \\
\hline
\end{tabular}

Page 22101 


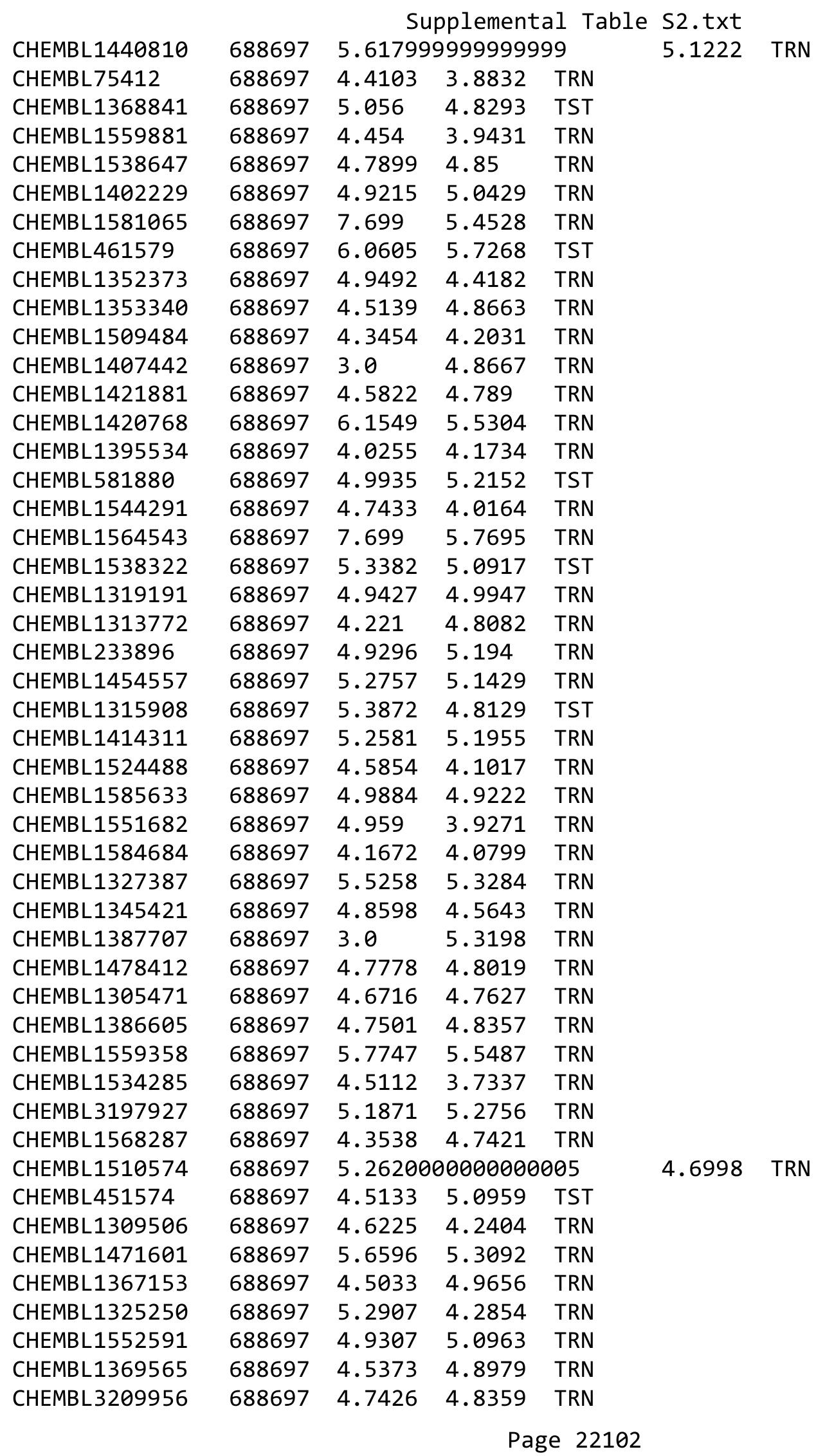




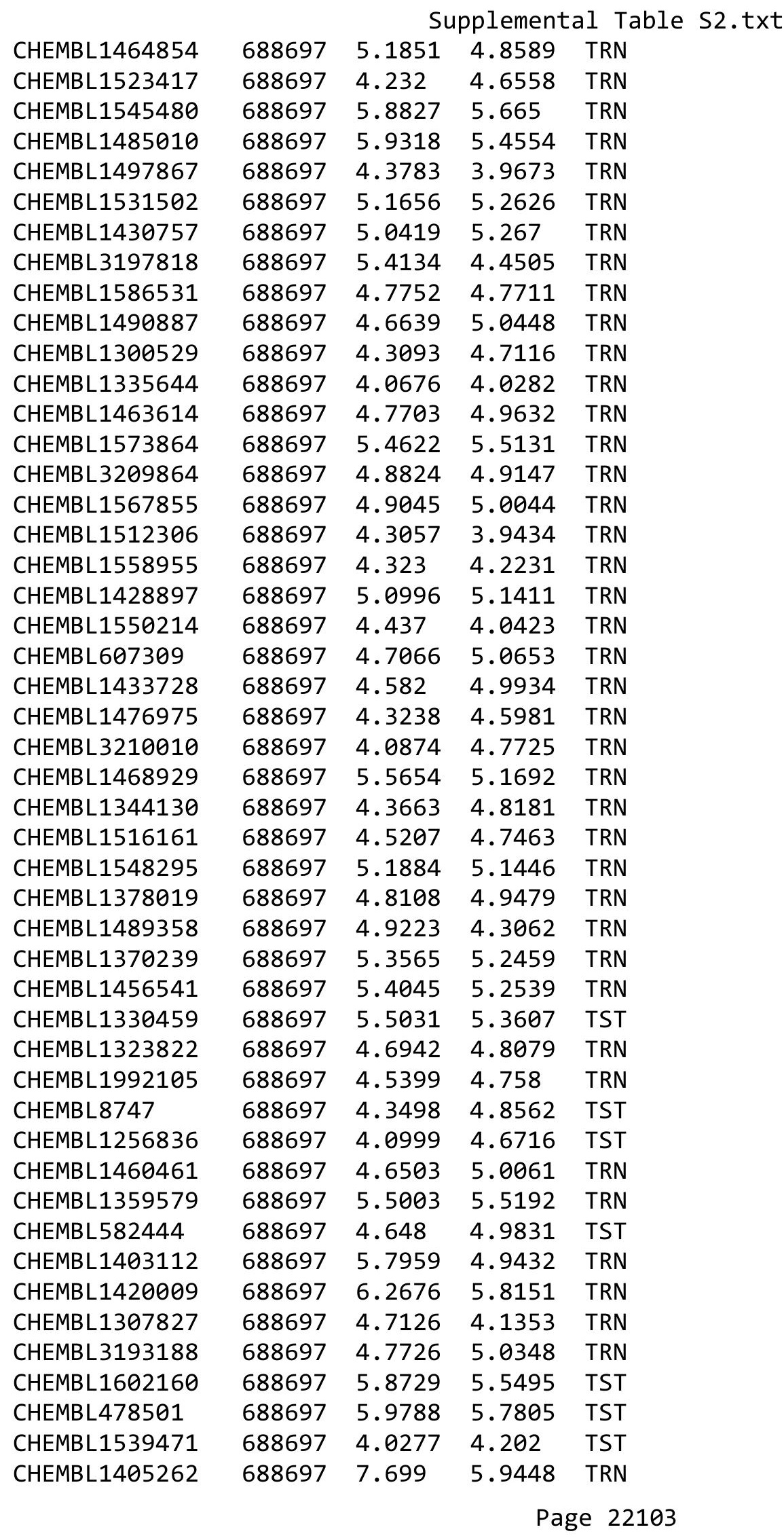




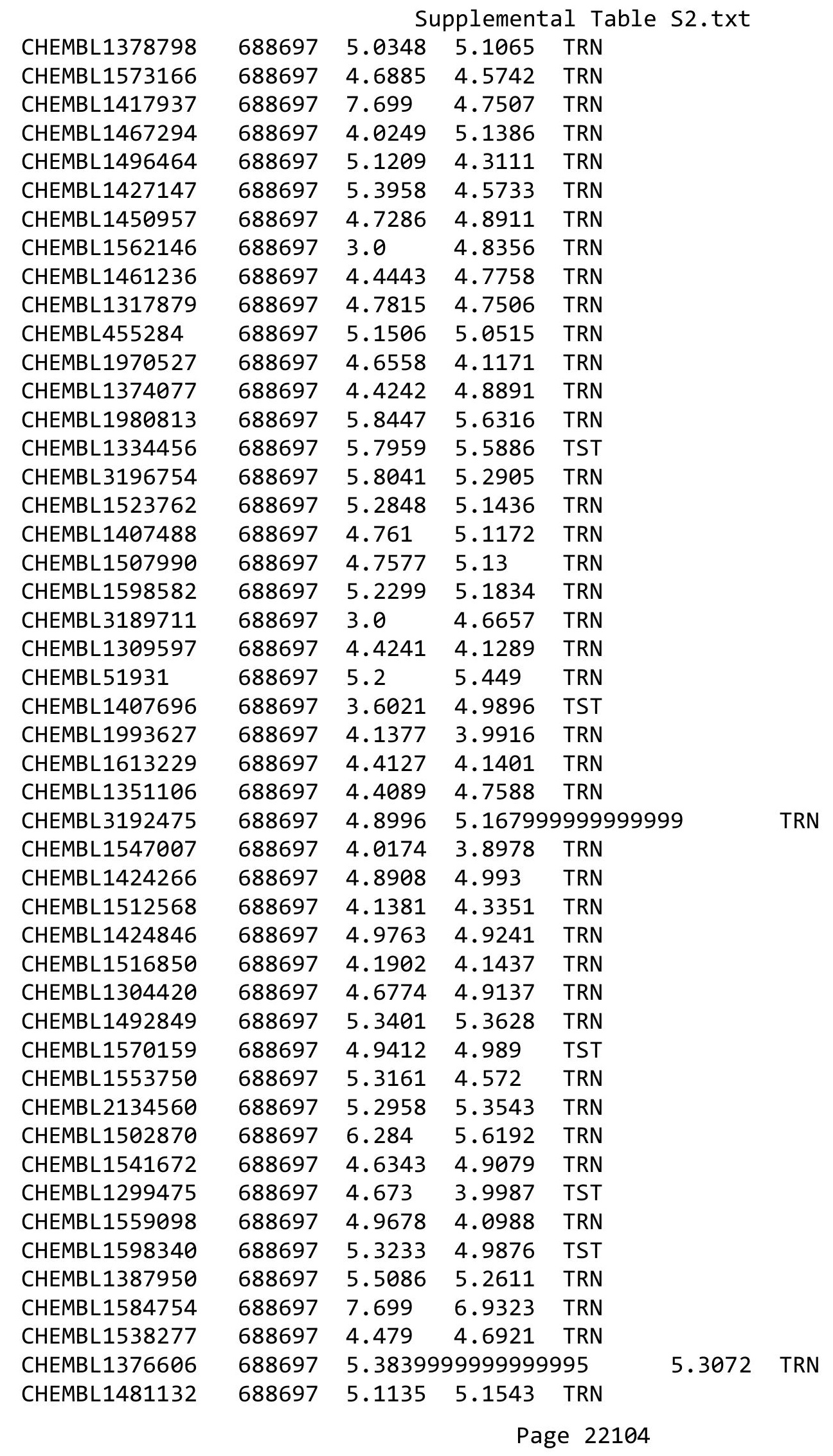


Supplemental Table S2.txt

\begin{tabular}{|c|c|c|c|c|}
\hline CHEMBL1353054 & 688697 & 5.9706 & 5.886 & TRN \\
\hline CHEMBL1473706 & 688697 & 4.6114 & 4.3461 & TRN \\
\hline CHEMBL1470502 & 688697 & 4.2179 & 4.7071 & TRN \\
\hline CHEMBL1586725 & 688697 & 5.091 & 4.8163 & TRN \\
\hline CHEMBL3192672 & 688697 & 5.6478 & 5.4717 & TRN \\
\hline CHEMBL1476797 & 688697 & 4.9686 & 4.3418 & TRN \\
\hline CHEMBL1390969 & 688697 & 4.0329 & 4.794 & TRN \\
\hline CHEMBL1972216 & 688697 & 5.4377 & 5.24200 & 0000000001 \\
\hline CHEMBL3193654 & 688697 & 3.0 & 4.9467 & TRN \\
\hline CHEMBL1504310 & 688697 & 4.3773 & 4.9047 & TST \\
\hline CHEMBL1495602 & 688697 & 4.5983 & 4.9341 & TST \\
\hline CHEMBL1581146 & 688697 & 4.0213 & 4.0185 & TRN \\
\hline CHEMBL1315069 & 688697 & 5.2636 & 5.0128 & TRN \\
\hline CHEMBL1353710 & 688697 & 4.8901 & 5.0209 & TRN \\
\hline CHEMBL1477242 & 688697 & 4.7802 & 4.9134 & TRN \\
\hline CHEMBL1559898 & 688697 & 4.3665 & 4.9234 & TST \\
\hline CHEMBL1332598 & 688697 & 4.1697 & 4.619 & TRN \\
\hline CHEMBL3212707 & 688697 & 5.1319 & 5.0264 & TST \\
\hline CHEMBL1487183 & 688697 & 5.4425 & 5.325 & TST \\
\hline CHEMBL1448940 & 688697 & 4.6362 & 4.9282 & TRN \\
\hline CHEMBL3192042 & 688697 & 4.8677 & 4.956 & TRN \\
\hline CHEMBL1399888 & 688697 & 3.0 & 4.7448 & TRN \\
\hline CHEMBL3191573 & 688697 & 4.6212 & 4.863 & TRN \\
\hline CHEMBL1550143 & 688697 & 4.6085 & 4.7822 & TRN \\
\hline CHEMBL1428009 & 688697 & 4.8362 & 5.0949 & TRN \\
\hline CHEMBL3192820 & 688697 & 4.4692 & 4.251 & TST \\
\hline CHEMBL1527324 & 688697 & 4.5789 & 5.0612 & TRN \\
\hline CHEMBL1332956 & 688697 & 4.6863 & 5.0366 & TST \\
\hline CHEMBL1489173 & 688697 & 5.3872 & 5.1811 & TRN \\
\hline CHEMBL1481343 & 688697 & 4.8342 & 4.3859 & TRN \\
\hline CHEMBL1463329 & 688697 & 4.5607 & 4.0692 & TRN \\
\hline CHEMBL1504710 & 688697 & 5.3546 & 5.2162 & TRN \\
\hline CHEMBL1966865 & 688697 & 7.699 & 4.6831 & TRN \\
\hline CHEMBL1430904 & 688697 & 4.8371 & 4.3981 & TRN \\
\hline CHEMBL1330578 & 688697 & 4.4991 & 4.9146 & TRN \\
\hline CHEMBL1458597 & 688697 & 4.016 & 4.7394 & TRN \\
\hline CHEMBL1511179 & 688697 & 7.699 & 5.6519 & TRN \\
\hline CHEMBL1527058 & 688697 & 5.0419 & 4.2975 & TRN \\
\hline CHEMBL1332165 & 688697 & 5.6615 & 5.4377 & TRN \\
\hline CHEMBL1359675 & 688697 & 4.4568 & 4.2701 & TRN \\
\hline CHEMBL1597655 & 688697 & 4.2112 & 4.28600 & 30000000005 \\
\hline CHEMBL1590201 & 688697 & 5.6968 & 5.4203 & TRN \\
\hline CHEMBL1597768 & 688697 & 4.4222 & 4.6757 & TRN \\
\hline CHEMBL1452546 & 688697 & 4.3467 & 4.7691 & TRN \\
\hline CHEMBL1485168 & 688697 & 7.699 & 5.4324 & TST \\
\hline CHEMBL1552626 & 688697 & 5.8508 & 5.5187 & TST \\
\hline CHEMBL1468518 & 688697 & 4.9059 & 4.9311 & TRN \\
\hline CHEMBL1434073 & 688697 & 5.8996 & 5.5239 & TRN \\
\hline
\end{tabular}

Page 22105 
Supplemental Table S2.txt

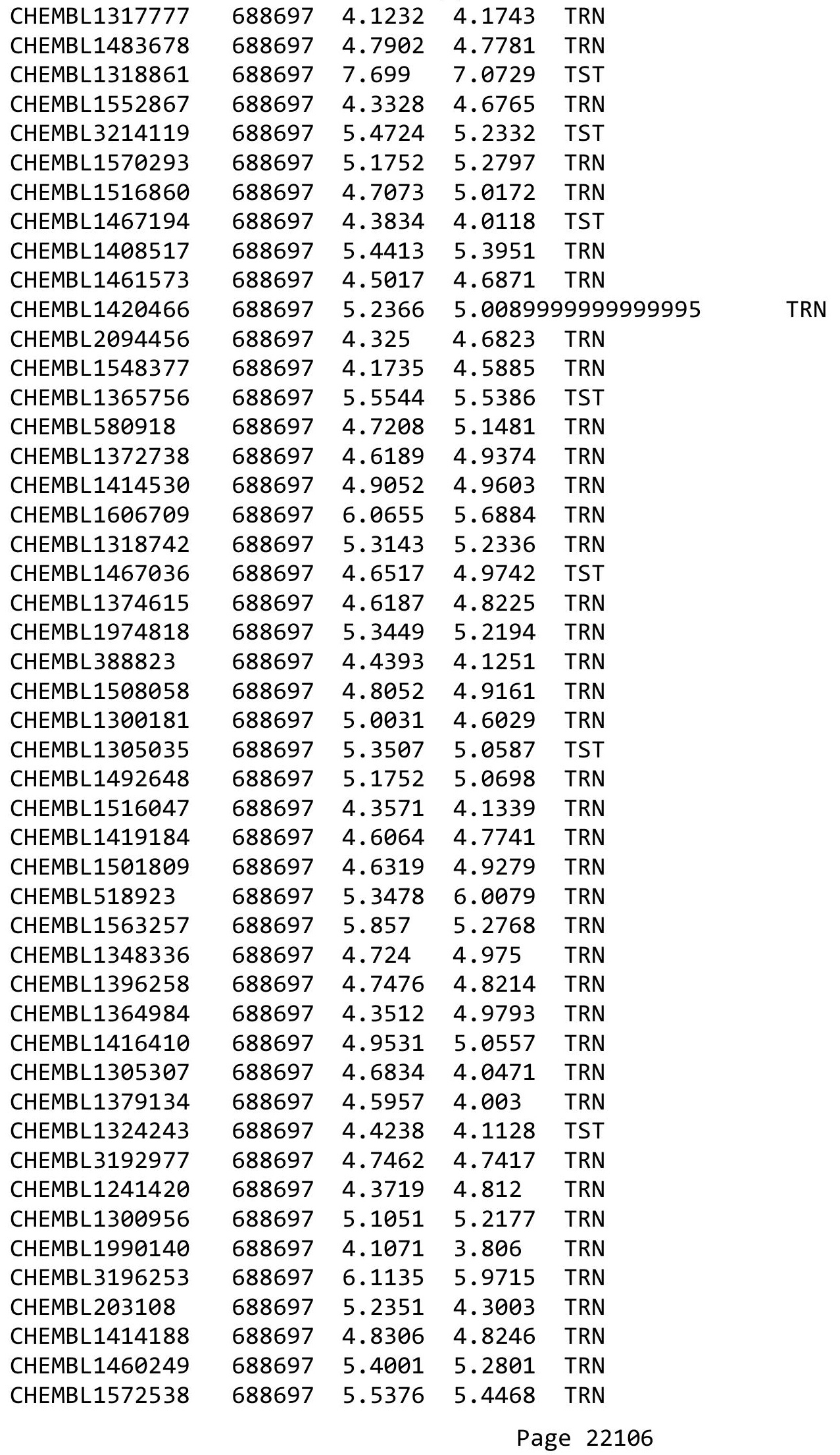




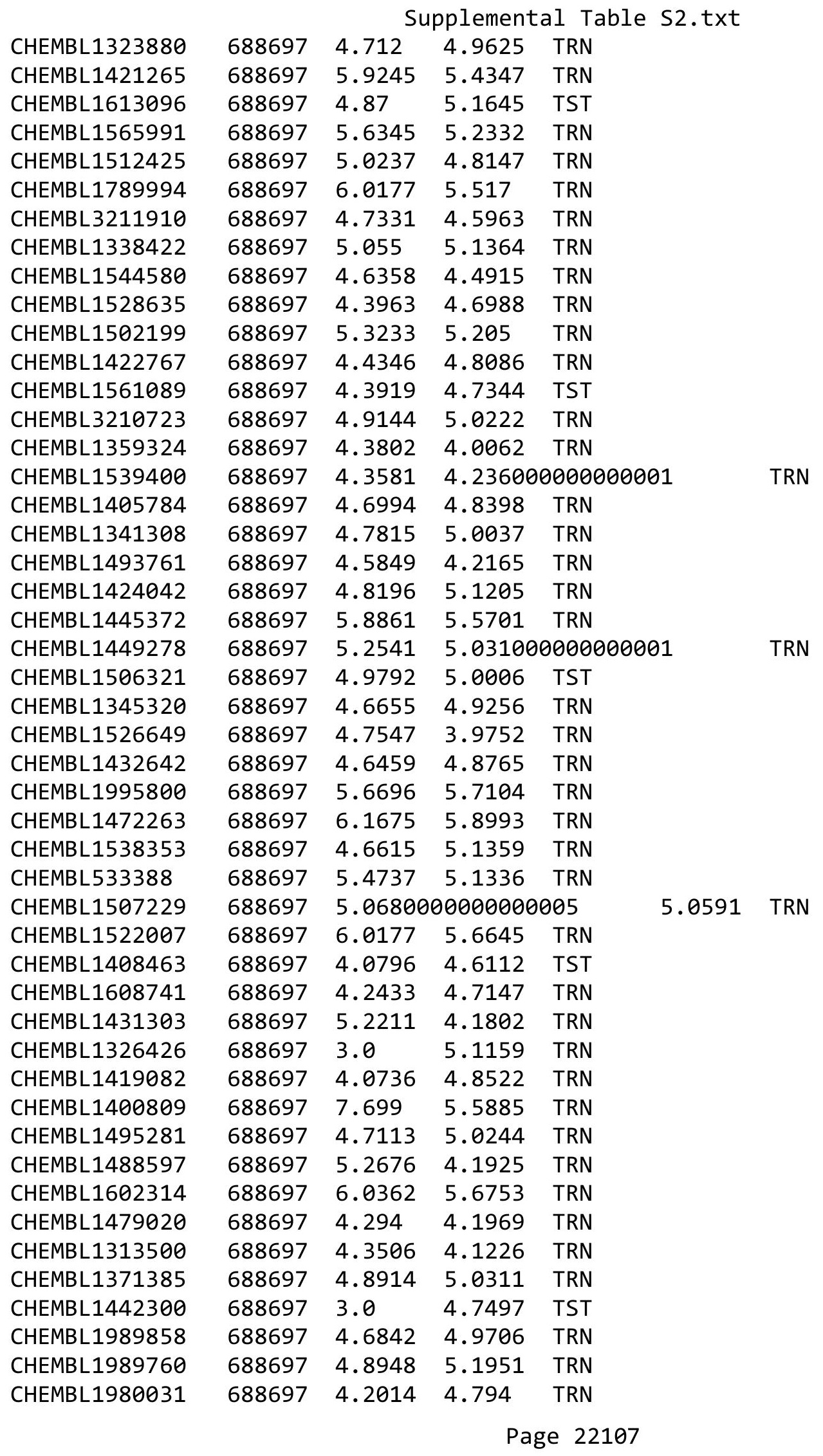




\begin{tabular}{|c|c|c|c|c|c|c|}
\hline & & \multicolumn{5}{|c|}{ Supplemental Table S2.txt } \\
\hline CHEMBL3193291 & 688697 & 4.6247 & 4.9928 & TRN & & \\
\hline CHEMBL1378668 & 688697 & 6.1367 & 5.8842 & TRN & & \\
\hline CHEMBL1319018 & 688697 & 4.5173 & 4.9335 & TRN & & \\
\hline CHEMBL1573650 & 688697 & 5.3458 & 4.6158 & TRN & & \\
\hline CHEMBL1457787 & 688697 & 5.5591 & 5.3664 & TRN & & \\
\hline CHEMBL1459216 & 688697 & 5.1267 & 4.0463 & TRN & & \\
\hline CHEMBL1339131 & 688697 & 5.5421 & 5.2538 & TRN & & \\
\hline CHEMBL1488976 & 688697 & 4.7445 & 4.9431 & TRN & & \\
\hline CHEMBL1558210 & 688697 & 5.2487 & 5.1527 & TRN & & \\
\hline CHEMBL1554131 & 688697 & 5.5719 & 5.4021 & TST & & \\
\hline CHEMBL1558865 & 688697 & 4.7029 & 4.9115 & TRN & & \\
\hline CHEMBL1574179 & 688697 & 5.3134 & 5.4739 & TST & & \\
\hline CHEMBL1432466 & 688697 & 5.1385 & 4.7819 & TRN & & \\
\hline CHEMBL1437516 & 688697 & 4.6356 & 4.9952 & TRN & & \\
\hline CHEMBL1378445 & 688697 & 4.6214 & \multicolumn{3}{|c|}{4.9430000000000005} & TRN \\
\hline CHEMBL1424036 & 688697 & 4.8668 & 5.0685 & TRN & & \\
\hline CHEMBL1340794 & 688697 & 5.1811 & 4.9548 & TST & & \\
\hline CHEMBL1530139 & 688697 & 4.3483 & 4.5933 & TRN & & \\
\hline CHEMBL1403209 & 688697 & 5.6345 & 5.4488 & TRN & & \\
\hline CHEMBL1611561 & 688697 & 4.0399 & 4.1354 & TRN & & \\
\hline CHEMBL1411355 & 688697 & 4.6759 & 4.8728 & TRN & & \\
\hline CHEMBL1425701 & 688697 & 4.5669 & 4.8513 & TRN & & \\
\hline CHEMBL1426748 & 688697 & 4.7673 & 5.0091 & TRN & & \\
\hline CHEMBL1361820 & 688697 & 4.8716 & 5.002 & TRN & & \\
\hline CHEMBL3213820 & 688697 & 4.3696 & 5.035 & TRN & & \\
\hline CHEMBL1515360 & 688697 & 5.2388 & 5.1949 & TRN & & \\
\hline CHEMBL3212193 & 688697 & 5.699 & 5.2097 & TRN & & \\
\hline CHEMBL1418039 & 688697 & \multicolumn{3}{|c|}{4.593999999999999} & 4.9578 & TRN \\
\hline CHEMBL1537065 & 688697 & 4.4715 & 5.0272 & TRN & & \\
\hline CHEMBL1472513 & 688697 & 4.9255 & 4.8625 & TRN & & \\
\hline CHEMBL3197639 & 688697 & 5.4056 & 5.2742 & TST & & \\
\hline CHEMBL410063 & 688697 & 4.3751 & 4.1877 & TST & & \\
\hline CHEMBL1546964 & 688697 & 4.5133 & 4.9896 & TRN & & \\
\hline CHEMBL1307988 & 688697 & 4.636 & 4.8894 & TRN & & \\
\hline CHEMBL1969867 & 688697 & 4.9097 & 4.9795 & TRN & & \\
\hline CHEMBL1362660 & 688697 & 5.3686 & 5.1003 & TRN & & \\
\hline CHEMBL1319850 & 688697 & 5.2464 & 5.3356 & TRN & & \\
\hline CHEMBL1428714 & 688697 & 4.9165 & 5.0362 & TST & & \\
\hline CHEMBL84472 & 688697 & 3.0 & 4.7677 & TRN & & \\
\hline CHEMBL1452948 & 688697 & 4.5274 & 5.0054 & TRN & & \\
\hline CHEMBL1498517 & 688697 & 5.4881 & 5.3169 & TRN & & \\
\hline CHEMBL1463626 & 688697 & 5.4711 & 5.4505 & TRN & & \\
\hline CHEMBL1606685 & 688697 & 6.0506 & 5.775 & TRN & & \\
\hline CHEMBL1383777 & 688697 & 5.2899 & 5.3798 & TST & & \\
\hline CHEMBL1330556 & 688697 & 5.1397 & 5.0737 & TRN & & \\
\hline CHEMBL1423404 & 688697 & 5.3188 & 5.1025 & TRN & & \\
\hline CHEMBL1459822 & 688697 & 5.0716 & 4.7439 & TRN & & \\
\hline CHEMBL1434912 & 688697 & 4.8592 & 5.1384 & TRN & & \\
\hline
\end{tabular}


Supplemental Table S2.txt

\begin{tabular}{|c|c|c|c|c|c|c|}
\hline CHEMBL1457697 & 688697 & 4.6803 & \multicolumn{3}{|c|}{4.9110000000000005} & \\
\hline CHEMBL1452303 & 688697 & 5.8153 & 5.4092 & TST & & \\
\hline CHEMBL1300700 & 688697 & 4.7047 & 4.9771 & TRN & & \\
\hline CHEMBL1407510 & 688697 & 4.4492 & 4.8116 & TRN & & \\
\hline CHEMBL1353346 & 688697 & 5.058 & 4.9012 & TRN & & \\
\hline CHEMBL1551370 & 688697 & 5.5935 & 5.5875 & TRN & & \\
\hline CHEMBL1369594 & 688697 & 4.6739 & 4.8611 & TRN & & \\
\hline CHEMBL1554497 & 688697 & 4.8979 & 5.1191 & TST & & \\
\hline CHEMBL1598829 & 688697 & 5.3233 & 5.4224 & TRN & & \\
\hline CHEMBL1565206 & 688697 & 4.0148 & 5.0057 & TRN & & \\
\hline CHEMBL1996343 & 688697 & 4.8114 & 4.3271 & TST & & \\
\hline CHEMBL1302885 & 688697 & 4.2635 & 4.6697 & TRN & & \\
\hline CHEMBL493691 & 688697 & 4.1676 & 4.15 & TRN & & \\
\hline CHEMBL1379181 & 688697 & 5.9172 & 4.5304 & TRN & & \\
\hline CHEMBL1516044 & 688697 & \multicolumn{3}{|c|}{4.9910000000000005} & 5.1706 & \\
\hline CHEMBL1340221 & 688697 & 5.9431 & 5.3229 & TRN & & \\
\hline CHEMBL2004193 & 688697 & 5.0438 & 5.0535 & TRN & & \\
\hline CHEMBL1981797 & 688697 & 5.8416 & 5.4536 & TRN & & \\
\hline CHEMBL 3191592 & 688697 & 4.9952 & 5.1532 & TRN & & \\
\hline CHEMBL1389533 & 688697 & 7.699 & 5.7917 & TST & & \\
\hline CHEMBL1599207 & 688697 & 7.699 & 4.837 & TRN & & \\
\hline CHEMBL1426455 & 688697 & 4.7406 & 4.8307 & TRN & & \\
\hline CHEMBL1341108 & 688697 & 4.4486 & 4.7295 & TRN & & \\
\hline CHEMBL1564523 & 688697 & 4.6499 & 4.9173 & TRN & & \\
\hline CHEMBL1415447 & 688697 & 4.1198 & 4.6076 & TST & & \\
\hline CHEMBL1503257 & 688697 & 7.699 & 5.0316 & TRN & & \\
\hline CHEMBL1585597 & 688697 & 4.7335 & 3.9574 & TRN & & \\
\hline CHEMBL 3199926 & 688697 & 4.3122 & 4.5417 & TRN & & \\
\hline CHEMBL1594452 & 688697 & 5.1675 & 5.1179 & TRN & & \\
\hline CHEMBL1526479 & 688697 & 5.0799 & 5.2895 & TRN & & \\
\hline CHEMBL1401091 & 688697 & 4.6325 & 4.8593 & TRN & & \\
\hline CHEMBL1303588 & 688697 & 5.0555 & 4.6872 & TRN & & \\
\hline CHEMBL1339324 & 688697 & 6.5229 & 5.7883 & TRN & & \\
\hline CHEMBL1395962 & 688697 & 4.1067 & 4.1881 & TST & & \\
\hline CHEMBL1449349 & 688697 & 5.8386 & 5.4134 & TRN & & \\
\hline CHEMBL1599566 & 688697 & 4.5849 & 4.9765 & TRN & & \\
\hline CHEMBL 3193118 & 688697 & 5.2197 & 5.3528 & TRN & & \\
\hline CHEMBL1497052 & 688697 & 5.2823 & 5.0703 & TRN & & \\
\hline CHEMBL1493982 & 688697 & 4.7324 & 4.8777 & TRN & & \\
\hline CHEMBL1336823 & 688697 & 4.7342 & 5.0418 & TST & & \\
\hline CHEMBL1999908 & 688697 & 4.2331 & 4.008 & TRN & & \\
\hline CHEMBL1610386 & 688697 & 4.8038 & 4.9898 & TRN & & \\
\hline CHEMBL1311886 & 688697 & 4.211 & 4.1666 & TRN & & \\
\hline CHEMBL589238 & 688697 & 4.6533 & 5.0811 & TRN & & \\
\hline CHEMBL1495859 & 688697 & 4.762 & 4.2239 & TRN & & \\
\hline CHEMBL 1467760 & 688697 & 6.4685 & 5.6118 & TRN & & \\
\hline CHEMBL1378456 & 688697 & 4.6064 & 4.8765 & TRN & & \\
\hline CHEMBL342995 & 688697 & 4.6419 & 4.9745 & TRN & & \\
\hline
\end{tabular}

Page 22109 


\begin{tabular}{|c|c|c|c|c|}
\hline \multicolumn{5}{|c|}{ Supplemental Table s2.txt } \\
\hline CHEMBL1554047 & 688697 & 5.2941 & 4.5244 & TRN \\
\hline CHEMBL1412012 & 688697 & 5.3002 & 4.8233 & TRN \\
\hline CHEMBL1600257 & 688697 & 4.4222 & 4.8637 & TRN \\
\hline CHEMBL1461822 & 688697 & 4.1834 & 4.0994 & TRN \\
\hline CHEMBL1589324 & 688697 & 4.3885 & 4.1081 & TRN \\
\hline CHEMBL1420061 & 688697 & 4.9112 & 4.9398 & TRN \\
\hline CHEMBL19954 & 688697 & 6.0506 & 5.5978 & TST \\
\hline CHEMBL1605435 & 688697 & 4.6615 & 4.978 & TRN \\
\hline CHEMBL1307757 & 688697 & 5.1141 & 5.0498 & TRN \\
\hline CHEMBL3212850 & 688697 & 4.644 & 4.9153 & TRN \\
\hline CHEMBL300389 & 688697 & 4.6819 & 4.6726 & TRN \\
\hline CHEMBL1598251 & 688697 & 4.6507 & 4.2326 & TST \\
\hline CHEMBL1422619 & 688697 & 4.4934 & 4.7726 & TRN \\
\hline CHEMBL3192253 & 688697 & 4.0827 & 4.7636 & TRN \\
\hline CHEMBL1429901 & 688697 & 4.934 & 5.0379 & TRN \\
\hline CHEMBL1415720 & 688697 & 4.3772 & 4.6771 & TST \\
\hline CHEMBL1443601 & 688697 & 4.1846 & 4.7535 & TRN \\
\hline CHEMBL 3213352 & 688697 & 5.0706 & 5.2675 & TRN \\
\hline CHEMBL 1420638 & 688697 & 4.6245 & 5.0655 & TRN \\
\hline CHEMBL3195773 & 688697 & 4.3642 & 4.7699 & TRN \\
\hline CHEMBL1431906 & 688697 & 4.9488 & 5.0033 & TRN \\
\hline CHEMBL3193150 & 688697 & 5.0867 & 4.976 & TRN \\
\hline CHEMBL1531536 & 688697 & 5.6459 & 5.0303 & TRN \\
\hline CHEMBL1565135 & 688697 & 5.0255 & 5.2098 & TRN \\
\hline CHEMBL1599905 & 688697 & 5.1662 & 5.1735 & TRN \\
\hline CHEMBL1517153 & 688697 & 4.3859 & 4.7734 & TRN \\
\hline CHEMBL1385443 & 688697 & 4.0662 & 4.7126 & TRN \\
\hline CHEMBL1975069 & 688697 & 5.1152 & 5.1938 & TST \\
\hline CHEMBL1582091 & 688697 & 4.923 & 4.9578 & TST \\
\hline CHEMBL1536883 & 688697 & 4.0076 & 3.9967 & TST \\
\hline CHEMBL1364242 & 688697 & 5.5171 & 5.3654 & TST \\
\hline CHEMBL 1488795 & 688697 & 4.2279 & 4.1352 & TST \\
\hline CHEMBL1995862 & 688697 & 4.7224 & 5.1644 & TST \\
\hline CHEMBL3193369 & 688697 & 3.0 & 4.7599 & TST \\
\hline CHEMBL1471737 & 688697 & 4.6117 & 4.7591 & TST \\
\hline CHEMBL1491929 & 688697 & 4.6334 & 4.8127 & TST \\
\hline CHEMBL3193510 & 688697 & 5.2284 & 5.2087 & TST \\
\hline CHEMBL1301368 & 688697 & 4.4614 & 4.0073 & TST \\
\hline CHEMBL1379656 & 688697 & 4.2233 & 4.1516 & TST \\
\hline CHEMBL1375577 & 688697 & 4.3295 & 4.6692 & TST \\
\hline CHEMBL1600649 & 688697 & 4.6625 & 4.8334 & TST \\
\hline CHEMBL1301994 & 688697 & 3.0 & 4.6156 & TST \\
\hline CHEMBL1497146 & 688697 & 4.1403 & 4.94 & TST \\
\hline CHEMBL 2369281 & 688697 & 4.1615 & 3.8754 & TST \\
\hline CHEMBL3190261 & 688697 & 5.1681 & 4.4263 & TST \\
\hline CHEMBL1320111 & 688697 & 4.8486 & 4.8951 & TST \\
\hline CHEMBL1353124 & 688697 & 5.2434 & 4.5669 & TST \\
\hline CHEMBL1976586 & 688697 & 5.3768 & 5.3196 & TST \\
\hline
\end{tabular}




\begin{tabular}{|c|c|c|c|c|c|}
\hline \multirow[b]{2}{*}{ CHEMBL1610008 } & \multicolumn{5}{|c|}{ supple } \\
\hline & 688697 & 4.7645 & 4.1994 & TST & \\
\hline CHEMBL1537810 & 688697 & 4.6891 & 4.6863 & TST & \\
\hline CHEMBL1613064 & 688697 & 4.1938 & 4.9298 & TST & \\
\hline CHEMBL1324755 & 688697 & 4.1566 & 4.8385 & TST & \\
\hline CHEMBL1423668 & 688697 & 5.71 & 5.6164 & TST & \\
\hline CHEMBL1381113 & 688697 & 4.957 & 5.2 & TST & \\
\hline CHEMBL1321578 & 688697 & 4.2152 & 4.7515 & TST & \\
\hline CHEMBL1515190 & 688697 & 4.3394 & 4.8082 & TST & \\
\hline CHEMBL1605089 & 688697 & 7.699 & 6.4377 & TST & \\
\hline CHEMBL1556582 & 688697 & 5.2381 & 5.2071 & TST & \\
\hline CHEMBL1599666 & 688697 & 4.4032 & 4.8141 & TST & \\
\hline CHEMBL1573869 & 688697 & 4.5707 & 4.939 & TST & \\
\hline CHEMBL1315950 & 688697 & 5.1694 & 5.3008 & TST & \\
\hline CHEMBL 3144979 & 688697 & 5.2541 & 5.0901 & TST & \\
\hline CHEMBL1581244 & 688697 & 4.8735 & 4.9456 & TST & \\
\hline CHEMBL1344225 & 688697 & 7.699 & 6.0341 & TST & \\
\hline CHEMBL1500199 & 688697 & 4.7387 & 4.4048 & TST & \\
\hline CHEMBL1537171 & 688697 & 4.0318 & 3.9562 & TST & \\
\hline CHEMBL1305987 & 688697 & 4.6684 & 4.1963 & TST & \\
\hline CHEMBL3213855 & 688697 & 4.3898 & 4.79899 & 99999999995 & TST \\
\hline CHEMBL1438983 & 688697 & 4.7713 & 5.0022 & TST & \\
\hline CHEMBL1315061 & 688697 & 5.2255 & 5.3039 & TST & \\
\hline CHEMBL1390784 & 688697 & 4.6985 & 4.8787 & TST & \\
\hline CHEMBL1607614 & 688697 & 4.1807 & 3.9626 & TST & \\
\hline CHEMBL1403980 & 688697 & 5.5575 & 5.114 & TST & \\
\hline CHEMBL393287 & 688697 & 4.0808 & 4.8347 & TST & \\
\hline CHEMBL1353226 & 688697 & 4.7817 & 4.3167 & TST & \\
\hline CHEMBL1594230 & 688697 & 5.8729 & 4.6579 & TST & \\
\hline CHEMBL1494293 & 688697 & 6.5528 & 4.3042 & TST & \\
\hline CHEMBL1519414 & 688697 & 4.2106 & 4.1117 & TST & \\
\hline CHEMBL1347285 & 688697 & 4.0048 & 4.8376 & TST & \\
\hline CHEMBL1509812 & 688697 & 4.5983 & 4.9192 & TST & \\
\hline CHEMBL1383181 & 688697 & 4.6872 & 4.0791 & TST & \\
\hline CHEMBL1383506 & 688697 & 5.5935 & 5.64 & TST & \\
\hline CHEMBL1353891 & 688697 & 5.2403 & 5.4786 & TST & \\
\hline CHEMBL1329396 & 688697 & 4.4533 & 4.8611 & TST & \\
\hline CHEMBL1327844 & 688697 & 5.1192 & $4.06800 t$ & 00000000005 & TST \\
\hline CHEMBL1340776 & 688697 & 6.4815 & 4.1638 & TST & \\
\hline CHEMBL1570468 & 688697 & 4.6349 & 4.2215 & TST & \\
\hline CHEMBL1462313 & 688697 & 5.2495 & 5.0644 & TST & \\
\hline CHEMBL1416483 & 688697 & 4.0656 & 4.0886 & TST & \\
\hline CHEMBL1309134 & 688697 & 5.0904 & 5.061 & TST & \\
\hline CHEMBL 3211304 & 688697 & 6.0132 & 5.3795 & TST & \\
\hline CHEMBL1502222 & 688697 & 4.1491 & 4.0607 & TST & \\
\hline CHEMBL1585327 & 688697 & 4.5854 & 4.2326 & TST & \\
\hline CHEMBL1429052 & 688697 & 4.9401 & 4.3179 & TST & \\
\hline CHEMBL1522050 & 688697 & 6.1805 & 5.2315 & TST & \\
\hline CHEMBL1412497 & 688697 & 4.9462 & 5.1672 & TST & \\
\hline & & & & 22111 & \\
\hline
\end{tabular}


Supplemental Table S2.txt

\begin{tabular}{|c|c|c|c|c|}
\hline th & & 722 & & \\
\hline H & 88697 & 5.1818 & 4.9967 & \\
\hline & 597 & & & \\
\hline HEMBL1 & & & & \\
\hline AEMBL1593516 & 697 & & & \\
\hline HEMBL1521681 & 88697 & 5702 & 5502 & \\
\hline HEMBL 320 & 8697 & & & \\
\hline IFMRI 13 & 697 & & & \\
\hline AEMBL139؟ & 88697 & & & \\
\hline HEMBL3199620 & 38697 & & .9504 & \\
\hline HEMBL1445640 & 88697 & & 8072 & \\
\hline IEMBL139 & 697 & & 741 & \\
\hline AEMBL150 & & & & \\
\hline AEMBL1567951 & 88697 & & 9907 & \\
\hline AEMBL3199642 & 697 & & & \\
\hline AEMBL1525781 & 88697 & & 39 & \\
\hline AEMBL135 & 697 & & & \\
\hline HEMBL198 & 97 & & & \\
\hline AEMBL3209176 & 88697 & & 4.8348 & \\
\hline AEMBL319 & 97 & & & \\
\hline HEMBL 14 & 97 & & 64 & \\
\hline AEMBL13 & 7 & & 32 & \\
\hline AEMBL13 & 97 & & 71 & \\
\hline 553 & 88697 & & & \\
\hline IEMBL14 & 97 & & & \\
\hline HEMBL15 & 97 & & 76 & \\
\hline HEMBL1 & & & 42 & \\
\hline AFMBI 14 & 97 & & 36 & \\
\hline AEMBL158 & 88697 & & & \\
\hline HEMBL13894 & 88697 & & & ГST \\
\hline HEMBL31 & 8697 & & & ST \\
\hline AEMBL & & & & \\
\hline 51 & 97 & & 06 & \\
\hline HEMBL1375555 & & & & \\
\hline HEMBL3198095 & 88697 & & 284 & TST \\
\hline JEMBL15 & 88697 & & 7279 & 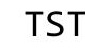 \\
\hline 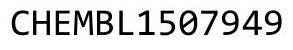 & & & 07 & \\
\hline HEMBL1: & & & & ST \\
\hline HEMBL1579339 & 88697 & & 5895 & ГST \\
\hline IEMBL156 & 88697 & & 327 & TS \\
\hline HEMBL147 & 88697 & & & \\
\hline HEMBL140 & & & & S \\
\hline HEMBL1270217 & 38697 & & 4668 & IST \\
\hline AEMBL1359762 & 88697 & 562 & 931 & is \\
\hline 1 & & & 0442 & \\
\hline HEMBL144 & 88697 & & .9109 & \\
\hline LHEMBL1492986 & 88697 & & .7269 & \\
\hline HEMBL1471431 & 688697 & 4.7226 & 5.0912 & ST \\
\hline
\end{tabular}

Page 22112 


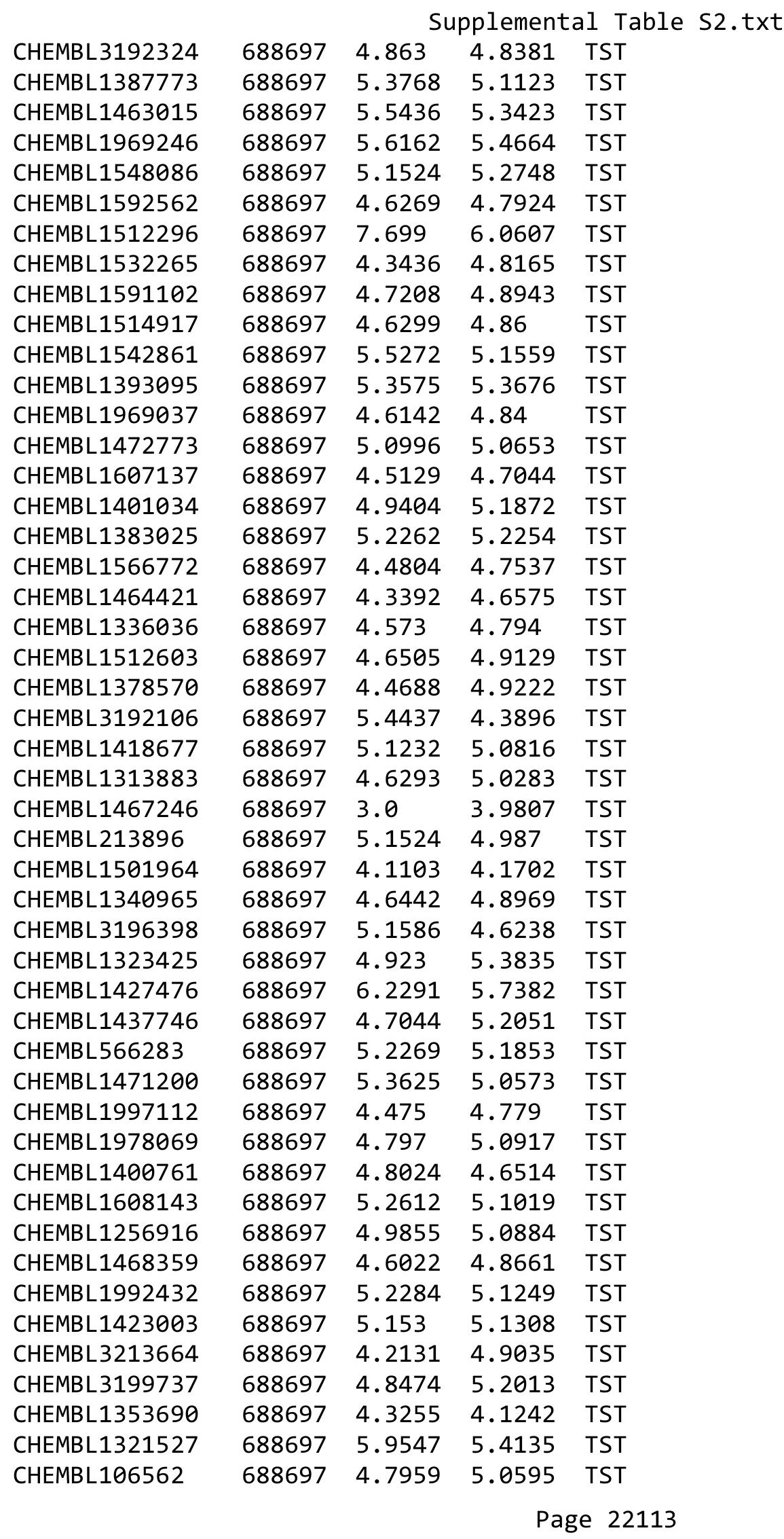




\begin{tabular}{|c|c|c|c|c|c|c|}
\hline & & \multicolumn{5}{|c|}{ Supplemental Table s2.txt } \\
\hline CHEMBL1582695 & 688697 & 4.9618 & 4.9898 & TST & & \\
\hline CHEMBL1428972 & 688697 & 4.9169 & 5.0582 & TST & & \\
\hline CHEMBL1310680 & 688697 & 4.9278 & 4.9439 & TST & & \\
\hline CHEMBL1413107 & 688697 & 4.4553 & 4.9536 & TST & & \\
\hline CHEMBL1329027 & 688697 & 4.3899 & 4.2676 & TST & & \\
\hline CHEMBL1478103 & 688697 & 4.7781 & 5.1243 & TST & & \\
\hline CHEMBL1299328 & 688697 & 5.5513 & 5.341 & TST & & \\
\hline CHEMBL528734 & 688697 & 4.045 & 4.808 & TST & & \\
\hline CHEMBL1536608 & 688697 & 4.3127 & 4.1981 & TST & & \\
\hline CHEMBL3189269 & 688697 & 3.0 & 4.8929 & TST & & \\
\hline CHEMBL1344838 & 688697 & 4.9759 & 4.2004 & TST & & \\
\hline CHEMBL1592917 & 688697 & 5.0991 & 5.3031 & TST & & \\
\hline CHEMBL1409714 & 688697 & 4.841 & 4.103 & TST & & \\
\hline CHEMBL1471993 & 688697 & 4.6609 & 5.002 & TST & & \\
\hline CHEMBL1360823 & 688697 & 4.6741 & 4.825 & TST & & \\
\hline CHEMBL1612019 & 688697 & 4.9893 & 4.7761 & TST & & \\
\hline CHEMBL563577 & 688697 & 4.301 & 4.7025 & TST & & \\
\hline CHEMBL1574691 & 688697 & 4.5635 & 5.0234 & TST & & \\
\hline CHEMBL1524824 & 688697 & 4.959 & 4.9831 & TST & & \\
\hline CHEMBL1570139 & 688697 & 4.988 & 5.2106 & TST & & \\
\hline CHEMBL1560530 & 688697 & 4.934 & 5.0156 & TST & & \\
\hline CHEMBL1449660 & 688697 & 4.104 & 4.8906 & TST & & \\
\hline CHEMBL1612260 & 688697 & 4.9531 & 5.1227 & TST & & \\
\hline CHEMBL1332079 & 688697 & 5.0711 & 5.2622 & TST & & \\
\hline CHEMBL395915 & 688697 & 3.0 & 5.0115 & TST & & \\
\hline CHEMBL1424729 & 688697 & 4.8359 & 5.3153 & TST & & \\
\hline CHEMBL1481814 & 688697 & 4.4264 & 4.8195 & TST & & \\
\hline CHEMBL3191975 & 688697 & 4.9133 & 4.8233 & TST & & \\
\hline CHEMBL1536935 & 688697 & 4.1299 & 4.5558 & TST & & \\
\hline CHEMBL1334065 & 688697 & 4.6319 & 5.1353 & TST & & \\
\hline CHEMBL1403554 & 688697 & 5.1739 & 4.5938 & TST & & \\
\hline CHEMBL1325300 & 688697 & 3.0 & 4.8465 & TST & & \\
\hline CHEMBL1499389 & 688697 & 5.4486 & 5.435 & TST & & \\
\hline CHEMBL1530087 & 688697 & 4.7508 & 5.0152 & TST & & \\
\hline CHEMBL1597716 & 688697 & 6.1549 & 5.6254 & TST & & \\
\hline CHEMBL1487590 & 688697 & 5.75200 & 30000000 & $\partial 1$ & 5.2212 & TST \\
\hline CHEMBL1496095 & 688697 & 4.0268 & 4.0555 & TST & & \\
\hline CHEMBL1381804 & 688697 & 4.4954 & 4.89 & TST & & \\
\hline CHEMBL1519146 & 688697 & 5.4425 & 5.4439 & TST & & \\
\hline CHEMBL1491019 & 688697 & 4.9208 & 5.025 & TST & & \\
\hline CHEMBL3196108 & 688697 & 4.7886 & 5.0109 & TST & & \\
\hline CHEMBL1506442 & 688697 & 5.301 & 5.6002 & TST & & \\
\hline CHEMBL 2000807 & 688697 & 4.4984 & 4.9748 & TST & & \\
\hline CHEMBL1411860 & 688697 & 4.4425 & 4.8439 & TST & & \\
\hline CHEMBL1594275 & 688697 & 4.42399 & 99999999 & 995 & 4.8157 & TST \\
\hline CHEMBL1597705 & 688697 & 6.0555 & 5.2396 & TST & & \\
\hline CHEMBL1443834 & 688697 & 4.3696 & 4.9314 & TST & & \\
\hline CHEMBL3191542 & 688697 & 4.3916 & 4.9381 & TST & & \\
\hline
\end{tabular}


Supplemental Table S2.txt

\begin{tabular}{|c|c|c|c|c|}
\hline $\mathrm{HEN}$ & 597 & 571 & 3.9579 & 列 \\
\hline HEMBL1598934 & 88697 & 5.0752 & 3.9733 & \\
\hline AFMRI 16 & 697 & & & \\
\hline AEMBL1 & 8697 & 528 & 45 & \\
\hline HEMBL1520465 & 38697 & 766 & & \\
\hline HEMBL1584066 & 88697 & 5.1605 & 2805 & \\
\hline HEMBL1399213 & 38697 & 731 & 3831 & \\
\hline AEMBL1538748 & 38697 & & & \\
\hline HEMBL3211062 & 88697 & 5361 & 1475 & \\
\hline HEMBL1556998 & 88697 & 229 & 4.8748 & \\
\hline HEMBL1499682 & 88697 & 3307 & 373 & \\
\hline AEMBL1505721 & 88697 & 878 & 312 & \\
\hline HEMBL142 & 38697 & & & \\
\hline HEMBL445311 & 88697 & 5353 & 4.939 & \\
\hline HEMBL1534019 & 88697 & 5.0 & & ST \\
\hline AEMBL1600494 & 88697 & 4.3944 & 91 & \\
\hline HEMBL1302962 & 88697 & 49 & 59 & \\
\hline HEMBL 143 & 88697 & 498 & & \\
\hline HEMBL3194493 & 88697 & 3.0 & 4.9591 & \\
\hline AEMBL567 & 88697 & & & \\
\hline HEMBL 263 & 697 & 57 & 59 & \\
\hline HEMBL135 & 97 & & & \\
\hline HEMBL139 & 88697 & 57 & & \\
\hline HEMBL1522544 & 88697 & 17 & & \\
\hline AEMBL1410670 & 88697 & & & (1 \\
\hline HEMBL1452821 & 88697 & & 26 & \\
\hline HEMBL15 & 97 & & & \\
\hline HEMBL1334260 & 88697 & 74 & 23 & ST \\
\hline HEMBL1334138 & 88697 & & & \\
\hline HEMBL1303785 & 88697 & & & ST \\
\hline HEMBL1460591 & 88697 & & & ST \\
\hline HEMBL1 & 97 & & 33 & ונכ \\
\hline HEMBL139 & 97 & 5 & 41 & ST \\
\hline HEMBL1397597 & 88697 & & 4 . & I \\
\hline HEMBL1509380 & 88697 & & 5.1655 & TST \\
\hline HEMBL 299642 & 9797 & & 7. & rRN \\
\hline HFMRI 3 & 97 & 9 & 9 . & RIV \\
\hline HEMBL41 & 9797 & & & RN \\
\hline HEMBL50402 & 9797 & 18 & 164 & TRN \\
\hline AEMBL13662 & 9797 & & & ST \\
\hline HEMBL 299210 & 9797 & 96 & 266 & \\
\hline CHEMBL50320 & & & & RN \\
\hline HEMBL 53587 & 69797 & 9208 & 8.8179 & RN \\
\hline HEMBL 292380 & 69797 & 301 & 9.0998 & TRN \\
\hline EMBL5 & & & 6.6946 & \\
\hline HEMBL 296383 & 59797 & & 8.9174 & \\
\hline CHEMBL299802 & 69797 & 8.4949 & 8.5981 & \\
\hline HEMBL301336 & 69797 & 7.7447 & 7.7468 & ГRN \\
\hline
\end{tabular}

Page 22115 


\begin{tabular}{|c|c|c|c|c|c|}
\hline \multicolumn{6}{|c|}{ Supplemental Table S2.txt } \\
\hline CHEMBL298501 & 69797 & 7.1308 & 7.0313 & TRN & \\
\hline CHEMBL 300951 & 69797 & 9.0757 & 9.0724 & TRN & \\
\hline CHEMBL52818 & 69797 & 6.8539 & 6.968 & TRN & \\
\hline CHEMBL55081 & 69797 & 6.2518 & 6.1778 & TRN & \\
\hline CHEMBL 301104 & 69797 & 5.0 & 5.0451 & TRN & \\
\hline CHEMBL298730 & 69797 & 5.0 & 5.0757 & TRN & \\
\hline CHEMBL296607 & 69797 & 9.1938 & 8.6506 & TRN & \\
\hline CHEMBL53529 & 69797 & 8.0969 & 8.0578 & TRN & \\
\hline CHEMBL 292462 & 69797 & 8.7696 & 8.7636 & TRN & \\
\hline CHEMBL 300018 & 69797 & 7.4089 & 7.4712 & TRN & \\
\hline CHEMBL299611 & 69797 & 9.4815 & 9.5692 & TRN & \\
\hline CHEMBL299882 & 69797 & 5.0 & 5.5288 & TRN & \\
\hline CHEMBL53729 & 69797 & 7.5376 & 7.3115 & TRN & \\
\hline CHEMBL52962 & 69797 & 5.0 & 5.05699 & 99999999995 & TRN \\
\hline CHEMBL445358 & 69797 & 6.7696 & 6.6887 & TRN & \\
\hline CHEMBL55450 & 69797 & 7.5229 & 7.4551 & TRN & \\
\hline CHEMBL300867 & 69797 & 6.7959 & 7.0288 & TRN & \\
\hline CHEMBL 273456 & 69797 & 7.0969 & 7.1982 & TRN & \\
\hline CHEMBL273680 & 69797 & 5.0 & 4.9806 & TST & \\
\hline CHEMBL 298386 & 69797 & 9.0555 & 9.1 & TRN & \\
\hline CHEMBL53528 & 69797 & 5.0 & 4.8481 & TRN & \\
\hline CHEMBL53238 & 69797 & 9.4202 & 9.4909 & TRN & \\
\hline CHEMBL 297717 & 69797 & 7.1427 & 6.8301 & TRN & \\
\hline CHEMBL299736 & 69797 & 7.7959 & 7.772 & TRN & \\
\hline CHEMBL54211 & 69797 & 5.0 & 4.9875 & TRN & \\
\hline CHEMBL52310 & 69797 & 7.8861 & 7.9057 & TRN & \\
\hline CHEMBL53642 & 69797 & 6.8861 & 6.9539 & TRN & \\
\hline CHEMBL 298760 & 69797 & 8.2924 & 8.615 & TRN & \\
\hline CHEMBL52014 & 69797 & 5.0 & 5.12700 & 0000000001 & TRN \\
\hline CHEMBL 299437 & 69797 & 7.5086 & 7.3944 & TRN & \\
\hline CHEMBL52696 & 69797 & 6.7696 & 6.8165 & TRN & \\
\hline CHEMBL441612 & 69797 & 8.3979 & 8.4527 & TRN & \\
\hline CHEMBL52030 & 69797 & 9.3979 & 7.5523 & TST & \\
\hline CHEMBL300497 & 69797 & 8.9586 & 9.0788 & TRN & \\
\hline CHEMBL 297481 & 69797 & 5.0 & 4.8044 & TRN & \\
\hline CHEMBL 300862 & 69797 & 9.4437 & 9.2599 & TST & \\
\hline CHEMBL300690 & 69797 & 6.6021 & 6.6797 & TST & \\
\hline CHEMBL 297958 & 69797 & 6.6198 & 5.0225 & TST & \\
\hline CHEMBL52672 & 69797 & 9.4815 & 8.5175 & TST & \\
\hline CHEMBL54859 & 69797 & 5.3188 & 6.5563 & TST & \\
\hline CHEMBL51911 & 69797 & 6.7959 & 6.9833 & TST & \\
\hline CHEMBL50581 & 69797 & 7.4202 & 7.4685 & TST & \\
\hline CHEMBL441978 & 69797 & 7.7212 & 7.6408 & TST & \\
\hline CHEMBL53977 & 69797 & 5.0 & 6.0177 & TST & \\
\hline CHEMBL 301063 & 69797 & 9.1308 & 9.174 & TST & \\
\hline CHEMBL 299995 & 69797 & 5.0 & 5.8268 & TST & \\
\hline CHEMBL 301181 & 69797 & 8.5686 & 8.5998 & TST & \\
\hline CHEMBL3216034 & 566781 & 5.6716 & 5.7395 & TRN & \\
\hline
\end{tabular}

Page 22116 


\begin{tabular}{|c|c|c|c|c|c|}
\hline \multicolumn{6}{|c|}{ Supplemental Table S2.txt } \\
\hline CHEMBL495012 & 566781 & 3.0 & 2.7241 & TRN & \\
\hline CHEMBL3216903 & 566781 & 4.7905 & 4.6403 & TRN & \\
\hline CHEMBL3215764 & 566781 & 6.5952 & 6.1057 & TRN & \\
\hline CHEMBL3216032 & 566781 & 5.3507 & 5.5748 & TRN & \\
\hline CHEMBL 3215763 & 566781 & 3.0 & 2.7739 & TRN & \\
\hline CHEMBL3216660 & 566781 & 5.1618 & 4.7977 & TRN & \\
\hline CHEMBL3216031 & 566781 & 5.5143 & 5.0312 & TRN & \\
\hline CHEMBL 3216427 & 566781 & 3.5406 & 5.0814 & TRN & \\
\hline CHEMBL 3215765 & 566781 & 3.8996 & 3.6919 & TRN & \\
\hline CHEMBL3216426 & 566781 & 5.8239 & 5.5276 & TRN & \\
\hline CHEMBL 3216425 & 566781 & 3.0 & 4.5596 & TST & \\
\hline CHEMBL3216902 & 566781 & 5.7055 & 5.3973 & TRN & \\
\hline CHEMBL3216894 & 566781 & 2.699 & 2.4984 & TRN & \\
\hline CHEMBL 3216435 & 566781 & 4.6198 & 4.9027 & TRN & \\
\hline CHEMBL3215578 & 566781 & 4.7144 & 4.7029 & TRN & \\
\hline CHEMBL3215569 & 566781 & 4.51 & 4.7634 & TRN & \\
\hline CHEMBL3216214 & 566781 & 4.8125 & 4.9096 & TRN & \\
\hline CHEMBL3217105 & 566781 & 4.6498 & 4.7809 & TRN & \\
\hline CHEMBL3216901 & 566781 & 4.9431 & 4.8196 & TRN & \\
\hline CHEMBL3215567 & 566781 & 3.0 & 3.0045 & TRN & \\
\hline CHEMBL3217107 & 566781 & 3.301 & 4.2028 & TRN & \\
\hline CHEMBL3216657 & 566781 & 4.6596 & 4.7809 & TRN & \\
\hline CHEMBL522874 & 566781 & 3.0 & 3.4865 & TST & \\
\hline CHEMBL3216424 & 566781 & 3.0 & 3.5926 & TST & \\
\hline CHEMBL494957 & 566781 & 5.2403 & 5.2227 & TRN & \\
\hline CHEMBL3215577 & 566781 & 4.5114 & 4.1313 & TRN & \\
\hline CHEMBL3216013 & 566781 & 4.5969 & 4.3256 & TST & \\
\hline CHEMBL3215766 & 566781 & 5.1481 & 4.5366 & TRN & \\
\hline CHEMBL 3216215 & 566781 & 5.6234 & 5.5844 & TRN & \\
\hline CHEMBL494956 & 566781 & 5.5575 & 5.1433 & TRN & \\
\hline CHEMBL492579 & 566781 & 6.2993 & 6.2581 & TRN & \\
\hline CHEMBL3215568 & 566781 & 3.0 & 3.0657 & TRN & \\
\hline CHEMBL3215771 & 566781 & 4.4191 & 4.6299 & TST & \\
\hline CHEMBL3216228 & 566781 & 4.8665 & 4.4015 & TRN & \\
\hline CHEMBL3216017 & 566781 & 4.2549 & 4.2588 & TRN & \\
\hline CHEMBL3216658 & 566781 & 5.8069 & 5.8669 & TST & \\
\hline CHEMBL3217109 & 566781 & 3.0 & 4.6115 & TST & \\
\hline CHEMBL3215782 & 566781 & 4.4609 & 4.5557 & TRN & \\
\hline CHEMBL3216016 & 566781 & 3.0 & 3.8266 & TRN & \\
\hline CHEMBL3216890 & 566781 & 4.279 & 4.46399 & 99999999995 & TRN \\
\hline CHEMBL 2360824 & 566781 & 5.9318 & 5.3597 & TST & \\
\hline CHEMBL935 & 566781 & 5.7375 & 5.3973 & TRN & \\
\hline CHEMBL3216225 & 566781 & 5.8386 & 5.6914 & TST & \\
\hline CHEMBL3216217 & 566781 & 4.7496 & 4.8496 & TRN & \\
\hline CHEMBL 3217108 & 566781 & 5.3288 & 5.1244 & TRN & \\
\hline CHEMBL3216423 & 566781 & 4.8239 & 5.0568 & TRN & \\
\hline CHEMBL3216670 & 566781 & 2.699 & 2.1999 & TST & \\
\hline CHEMBL3216891 & 566781 & 5.8962 & 5.3036 & TST & \\
\hline
\end{tabular}

Page 22117 


\begin{tabular}{|c|c|c|c|c|c|c|}
\hline CHEMBL3216662 & 566781 & \multicolumn{4}{|c|}{ Supplemental Table S2.txt } & TST \\
\hline CHEMBL 3216434 & 566781 & 5.5258 & 5.3222 & TRN & & \\
\hline CHEMBL3217113 & 566781 & 4.2832 & 4.9826 & TST & & \\
\hline CHEMBL3216030 & 566781 & 4.4401 & 4.5946 & TRN & & \\
\hline CHEMBL3216436 & 566781 & 4.2526 & 4.5667 & TST & & \\
\hline CHEMBL3215566 & 566781 & 5.4962 & 5.5844 & TRN & & \\
\hline CHEMBL3215565 & 566781 & 4.4034 & 4.4318 & TRN & & \\
\hline CHEMBL3216663 & 566781 & 4.4101 & 4.5873 & TRN & & \\
\hline CHEMBL3216033 & 566781 & 3.301 & 4.7838 & TST & & \\
\hline CHEMBL3216889 & 566781 & 4.9355 & 4.9096 & TRN & & \\
\hline CHEMBL3216216 & 566781 & 3.0 & 4.2733 & TST & & \\
\hline CHEMBL3217116 & 566781 & 5.2168 & 5.5729 & TRN & & \\
\hline CHEMBL3217106 & 566781 & 5.7258 & 5.6675 & TRN & & \\
\hline CHEMBL241924 & 446180 & 6.1612 & 6.0619 & TRN & & \\
\hline CHEMBL244235 & 446180 & 6.8539 & 6.9213 & TRN & & \\
\hline CHEMBL244964 & 446180 & 6.0 & 6.1879 & TRN & & \\
\hline CHEMBL244236 & 446180 & 7.0655 & 7.5606 & TRN & & \\
\hline CHEMBL397268 & 446180 & 6.8539 & 6.8698 & TRN & & \\
\hline CHEMBL394781 & 446180 & 7.284 & 7.2014 & TRN & & \\
\hline CHEMBL243150 & 446180 & 7.9586 & 7.9201 & TRN & & \\
\hline CHEMBL226764 & 446180 & 6.9208 & 6.3674 & TST & & \\
\hline CHEMBL242076 & 446180 & 4.301 & 4.1432 & TRN & & \\
\hline CHEMBL244754 & 446180 & 7.0 & 6.5076 & TRN & & \\
\hline CHEMBL 242924 & 446180 & 7.9208 & 8.0378 & TRN & & \\
\hline CHEMBL242353 & 446180 & 6.699 & 6.7687 & TRN & & \\
\hline CHEMBL 243151 & 446180 & 8.1549 & 7.9932 & TRN & & \\
\hline CHEMBL428215 & 446180 & 7.1487 & 6.4335 & TRN & & \\
\hline CHEMBL242139 & 446180 & 5.3979 & 6.0469 & TRN & & \\
\hline CHEMBL244904 & 446180 & 7.1549 & 7.1896 & TRN & & \\
\hline CHEMBL 242926 & 446180 & 8.3979 & 8.0041 & TRN & & \\
\hline CHEMBL242561 & 446180 & 7.5229 & 7.2272 & TRN & & \\
\hline CHEMBL243265 & 446180 & 7.6778 & 7.1427 & TRN & & \\
\hline CHEMBL394786 & 446180 & 7.4949 & 7.4846 & TRN & & \\
\hline CHEMBL 244520 & 446180 & 7.5229 & 7.1293 & TST & & \\
\hline CHEMBL 394782 & 446180 & 7.301 & 7.2671 & TST & & \\
\hline CHEMBL243655 & 446180 & 7.2076 & 7.17700 & 0000000000 & 05 & TRN \\
\hline CHEMBL389142 & 446180 & 7.2076 & 7.4126 & TRN & & \\
\hline CHEMBL243366 & 446180 & 7.4815 & 7.7598 & TRN & & \\
\hline CHEMBL430194 & 446180 & 7.301 & 7.2203 & TRN & & \\
\hline CHEMBL407451 & 446180 & 6.6576 & 6.405 & TST & & \\
\hline CHEMBL394536 & 446180 & 6.6021 & 6.8347 & TRN & & \\
\hline CHEMBL 394353 & 446180 & 7.6778 & 7.7314 & TRN & & \\
\hline CHEMBL389141 & 446180 & 6.75700 & 30000000 & 01 & 7.0732 & TST \\
\hline CHEMBL395819 & 446180 & 7.3565 & 7.7504 & TST & & \\
\hline CHEMBL 389331 & 446180 & 6.7447 & 6.9579 & TRN & & \\
\hline CHEMBL242609 & 446180 & 6.8861 & 6.8807 & TRN & & \\
\hline CHEMBL437708 & 446180 & 7.0706 & 5.8758 & TST & & \\
\hline CHEMBL243377 & 446180 & 7.699 & 7.9202 & TRN & & \\
\hline
\end{tabular}




\begin{tabular}{|c|c|c|c|c|c|}
\hline \multirow[b]{2}{*}{ CHEMBL389829 } & \multicolumn{5}{|c|}{ sирргепіеть } \\
\hline & 446180 & 7.8239 & 7.5599 & TRN & \\
\hline CHEMBL244700 & 446180 & 7.2147 & 7.0137 & TRN & \\
\hline CHEMBL244863 & 446180 & 7.7212 & 6.9841 & TST & \\
\hline CHEMBL216874 & 446180 & 8.0 & 6.893 & TST & \\
\hline CHEMBL389332 & 446180 & 6.8861 & 7.0364 & TRN & \\
\hline CHEMBL216389 & 446180 & 6.3565 & 6.2477 & TRN & \\
\hline CHEMBL244051 & 446180 & 6.1487 & 6.3822 & TRN & \\
\hline CHEMBL216683 & 446180 & 7.5229 & 7.1817 & TST & \\
\hline CHEMBL242137 & 446180 & 7.0 & 7.0166 & TRN & \\
\hline CHEMBL394610 & 446180 & 7.5528 & 8.0092 & TST & \\
\hline CHEMBL390225 & 446180 & 6.0 & 6.5398 & TRN & \\
\hline CHEMBL243365 & 446180 & 8.0969 & 7.7466 & TRN & \\
\hline CHEMBL394537 & 446180 & 7.3872 & 7.7172 & TRN & \\
\hline CHEMBL427698 & 446180 & 6.699 & 6.7067 & TRN & \\
\hline CHEMBL389566 & 446180 & 7.4318 & 7.3365 & TRN & \\
\hline CHEMBL244651 & 446180 & 7.2076 & 7.4158 & TST & \\
\hline CHEMBL428570 & 446180 & 7.1805 & 6.3666 & TST & \\
\hline CHEMBL400663 & 460657 & 3.5229 & 3.4194 & TRN & \\
\hline CHEMBL254227 & 460657 & 3.5229 & 3.6432 & TST & \\
\hline CHEMBL400542 & 460657 & 3.5229 & 3.63100 & 00000000002 & TRN \\
\hline CHEMBL252934 & 460657 & 5.983 & 5.4847 & TRN & \\
\hline CHEMBL399513 & 460657 & 3.5229 & 3.9191 & TST & \\
\hline CHEMBL400248 & 460657 & 3.5229 & 3.3551 & TRN & \\
\hline CHEMBL253611 & 460657 & 3.5229 & 3.3012 & TRN & \\
\hline CHEMBL 255087 & 460657 & 5.1141 & 5.3008 & TRN & \\
\hline CHEMBL253830 & 460657 & 3.5229 & 3.5368 & TRN & \\
\hline CHEMBL398311 & 460657 & 3.5229 & 3.6824 & TRN & \\
\hline CHEMBL399094 & 460657 & 4.752 & 3.1939 & TST & \\
\hline CHEMBL251973 & 460657 & 3.5229 & 3.3643 & TRN & \\
\hline CHEMBL398708 & 460657 & 3.5229 & 3.498 & TRN & \\
\hline CHEMBL252360 & 460657 & 4.6271 & 3.45899 & 99999999996 & TST \\
\hline CHEMBL252359 & 460657 & 3.5229 & 3.5364 & TRN & \\
\hline CHEMBL255038 & 460657 & 3.5229 & 3.6123 & TRN & \\
\hline CHEMBL252729 & 460657 & 3.5229 & 3.4532 & TRN & \\
\hline CHEMBL400522 & 460657 & 3.5229 & 3.5106 & TRN & \\
\hline CHEMBL254828 & 460657 & 3.5229 & 3.6787 & TRN & \\
\hline CHEMBL254618 & 460657 & 3.5229 & 3.6475 & TRN & \\
\hline CHEMBL402052 & 460657 & 4.7201 & 3.2109 & TST & \\
\hline CHEMBL254619 & 460657 & 3.5229 & 3.4672 & TRN & \\
\hline CHEMBL399026 & 460657 & 3.5229 & 3.4664 & TRN & \\
\hline CHEMBL399095 & 460657 & 3.5229 & 3.5132 & TRN & \\
\hline CHEMBL254617 & 460657 & 3.5229 & 3.6509 & TRN & \\
\hline CHEMBL252156 & 460657 & 3.5229 & 3.66899 & 99999999996 & TRN \\
\hline CHEMBL251923 & 460657 & 3.5229 & 3.6072 & TRN & \\
\hline CHEMBL400095 & 460657 & 3.5229 & 3.4583 & TRN & \\
\hline CHEMBL252121 & 460657 & 3.5229 & 3.5948 & TRN & \\
\hline CHEMBL252158 & 460657 & 3.5229 & 3.8672 & TST & \\
\hline CHEMBL429121 & 460657 & 3.5229 & 3.0256 & TST & \\
\hline & & & & 22119 & \\
\hline
\end{tabular}




\begin{tabular}{|c|c|c|c|c|c|}
\hline \multicolumn{6}{|c|}{ Supplemental Table S2.txt } \\
\hline CHEMBL255079 & 460657 & 3.5229 & 3.5631 & TRN & \\
\hline CHEMBL400096 & 460657 & 3.5229 & 3.425 & TRN & \\
\hline CHEMBL254827 & 460657 & 3.5229 & 3.4639 & TRN & \\
\hline CHEMBL252933 & 460657 & 3.5229 & 3.5319 & TRN & \\
\hline CHEMBL400454 & 460657 & 3.5229 & 3.5486 & TRN & \\
\hline CHEMBL253829 & 460657 & 3.5229 & 3.4389 & TRN & \\
\hline CHEMBL252363 & 460657 & 3.5229 & 3.6072 & TRN & \\
\hline CHEMBL252157 & 460657 & 3.5229 & 3.7078 & TRN & \\
\hline CHEMBL398505 & 460657 & 3.5229 & 3.6424 & TRN & \\
\hline CHEMBL436637 & 460657 & 3.5229 & 3.3769 & TRN & \\
\hline CHEMBL254412 & 460657 & 5.2652 & 5.3728 & TRN & \\
\hline CHEMBL255086 & 460657 & 3.5229 & 3.4664 & TRN & \\
\hline CHEMBL400664 & 460657 & 3.5229 & 3.4102 & TRN & \\
\hline CHEMBL255080 & 460657 & 3.5229 & 3.6983 & TRN & \\
\hline CHEMBL253831 & 460657 & 3.5229 & 3.5904 & TRN & \\
\hline CHEMBL252558 & 460657 & 3.5229 & 3.4749 & TRN & \\
\hline CHEMBL398504 & 460657 & 3.5229 & 3.616 & TRN & \\
\hline CHEMBL251959 & 460657 & 3.5229 & 3.3803 & TRN & \\
\hline CHEMBL398507 & 460657 & 3.5229 & 3.2551 & TST & \\
\hline CHEMBL400453 & 460657 & 3.5229 & 3.3657 & TST & \\
\hline CHEMBL400097 & 460657 & 3.5229 & 5.4756 & TST & \\
\hline CHEMBL252362 & 460657 & 3.5229 & 3.3602 & TST & \\
\hline CHEMBL400543 & 460657 & 3.5229 & 3.20600 & 00000000004 & TST \\
\hline CHEMBL399027 & 460657 & 3.5229 & 3.8669 & TST & \\
\hline CHEMBL252361 & 460657 & 3.5229 & 3.5762 & TST & \\
\hline CHEMBL400458 & 454312 & 6.5686 & 5.36700 & 0000000001 & TST \\
\hline CHEMBL395420 & 454312 & 5.2774 & 5.3147 & TRN & \\
\hline CHEMBL246059 & 454312 & 6.7447 & 5.5469 & TST & \\
\hline CHEMBL 247144 & 454312 & 5.7447 & 5.7469 & TRN & \\
\hline CHEMBL245886 & 454312 & 6.6021 & 6.5614 & TRN & \\
\hline CHEMBL245683 & 454312 & 5.7825 & 5.7946 & TRN & \\
\hline CHEMBL246091 & 454312 & 6.8239 & 5.989 & TST & \\
\hline CHEMBL247145 & 454312 & 5.279 & 5.2846 & TRN & \\
\hline CHEMBL 246934 & 454312 & 5.8356 & 5.8244 & TRN & \\
\hline CHEMBL246919 & 454312 & 5.6536 & 5.6546 & TRN & \\
\hline CHEMBL246921 & 454312 & 6.0506 & 6.1231 & TRN & \\
\hline CHEMBL 247350 & 454312 & 6.6198 & 6.5013 & TRN & \\
\hline CHEMBL394083 & 454312 & 5.9281 & 5.8937 & TRN & \\
\hline CHEMBL 395677 & 454312 & 5.1463 & 5.1198 & TRN & \\
\hline CHEMBL246085 & 454312 & 5.5229 & 5.5574 & TRN & \\
\hline CHEMBL245695 & 454312 & 4.7773 & 4.7562 & TRN & \\
\hline CHEMBL248152 & 454312 & 5.6326 & 5.6269 & TRN & \\
\hline CHEMBL395158 & 454312 & 6.2596 & 6.3064 & TRN & \\
\hline CHEMBL 396100 & 454312 & 6.6198 & 6.4928 & TRN & \\
\hline CHEMBL396699 & 454312 & 6.0506 & 6.0668 & TRN & \\
\hline CHEMBL248329 & 454312 & 5.1391 & 5.1605 & TRN & \\
\hline CHEMBL399020 & 454312 & 5.5143 & 5.1403 & TST & \\
\hline CHEMBL245675 & 454312 & 5.3536 & 5.3809 & TRN & \\
\hline
\end{tabular}


Supplemental Table S2.txt

\begin{tabular}{|c|c|c|c|c|}
\hline 853 & 454312 & .9666 & 5.9506 & TRN \\
\hline HEMBL 249694 & 454312 & 4.7773 & 4.7853 & \\
\hline HEMBL 394737 & 54312 & 6198 & 5617 & \\
\hline HEMBL 250931 & 312 & 5.1096 & 0673 & ה \\
\hline HEMBL 246689 & 454312 & 6.6198 & 6294 & \\
\hline HEMBL 245685 & 454312 & 5.9547 & 9409 & \\
\hline HEMBL 246938 & 454312 & 6.3468 & 6.3493 & \\
\hline HEMBL 245283 & 54312 & 2161 & .341 & \\
\hline HEMBL 247744 & 454312 & 5.2441 & 5.2499 & \\
\hline HEMBL397644 & 454312 & 4.7496 & 4.7631 & \\
\hline HEMBL 247549 & 454312 & 5.0706 & 5.0559 & \\
\hline HEMBL 247297 & 454312 & .3134 & 5.3553 & \\
\hline HEMBL 24 & 12 & 4.7773 & .7606 & RN \\
\hline HEMBL 245684 & 45 & 5.7212 & 5.4316 & \\
\hline HEMBL 248121 & 454312 & 6.6198 & 5.6913 & SI \\
\hline HEMBL394969 & 454312 & 2441 & 5.2531 & RIV \\
\hline HEMBL 251330 & 454312 & 318 & 5.4446 & NIV \\
\hline HEMBL42 & 45 & 41 & 5.7833 & RN \\
\hline HEMBL 24 & 45 & 6.0177 & 6.3826 & ST \\
\hline HEMBL393493 & 454 & 6.6021 & 6.399 & ST \\
\hline HEMBL 267380 & 454 & 18 & 4.7348 & SI \\
\hline HEMBL 247351 & 12 & .2924 & 5.3055 & RN \\
\hline HEMBL24 & 45 & 576 & 7251 & RN \\
\hline HEMBL 247126 & 45 & 5.585 & 5.1759 & ST \\
\hline HEMBL249491 & 45 & 544 & 4.365 & ST \\
\hline HEMBL 250915 & 454 & 43 & 4.5849 & TST \\
\hline HEMBL393042 & 454 & .6038 & 5.4471 & RN \\
\hline ZHEMBL39 & 45 & 4.7773 & 4.7789 & RN \\
\hline LHEMBL395474 & 45 & 468 & 6.4259 & RN \\
\hline HEMBL 246387 & 453 & 7.3372 & 7.4092 & RN \\
\hline HEMBL395160 & 52 & .6778 & 6.7207 & $\mathrm{RN}$ \\
\hline HEMBL396929 & 52 & 7.9586 & 8.0146 & RN \\
\hline CHEMBL394069 & 453 & 6.1675 & 6.1484 & RN \\
\hline CHEMBL395689 & 45 & 7.3188 & 7.4443 & TRN \\
\hline HEMBL245914 & 453152 & 6.041 & 6.0599 & TRN \\
\hline HEMBL 247176 & 52 & 7447 & 6.8236 & $\mathrm{RN}$ \\
\hline CHEMBL246161 & 453 & 7.0458 & 7.0393 & TRN \\
\hline CHEMBL 39 & & 7.2218 & 7.2249 & RN \\
\hline CHEMBL247979 & 453 & 7.9208 & 8.0456 & TRN \\
\hline CHEMBL 246386 & 453152 & 8.1549 & 8.0772 & TRN \\
\hline CHEMBL246183 & 52 & 969 & 8.0209 & RN \\
\hline CHEMBL245912 & 453152 & 7.8861 & 7.7577 & RN \\
\hline CHEMBL246177 & & 7.4089 & 7.4445 & TRN \\
\hline CHEMBL246182 & 453152 & 7.3768 & 7.4375 & TRN \\
\hline CHEMBL245757 & 453152 & 7.0809 & 7.1324 & RN \\
\hline CHEMBL427874 & 453152 & 4.0 & 3.9977 & \\
\hline CHEMBL392642 & 453152 & 8.301 & 8.3041 & RIN \\
\hline L247375 & 453152 & 5.3768 & 5.5877 & \\
\hline
\end{tabular}

Page 22121 


\begin{tabular}{|c|c|c|c|c|}
\hline & & & oplement & al $\mathrm{T}$ \\
\hline CHEMBL245977 & 453152 & 7.8239 & 7.7837 & TRN \\
\hline CHEMBL437941 & 453152 & 7.0706 & 7.1701 & TRN \\
\hline CHEMBL396370 & 453152 & 7.4559 & 7.3969 & TRN \\
\hline CHEMBL391753 & 453152 & 6.7959 & 6.7395 & TST \\
\hline CHEMBL 245783 & 453152 & 7.6576 & 7.6996 & TRN \\
\hline CHEMBL 246366 & 453152 & 6.3468 & 7.3 & TST \\
\hline CHEMBL 247377 & 453152 & 7.1135 & 7.1392 & TRN \\
\hline CHEMBL391754 & 453152 & 6.699 & 7.3709 & TST \\
\hline CHEMBL 245958 & 453152 & 6.6778 & 6.5864 & TRN \\
\hline CHEMBL391609 & 453152 & 7.0458 & 6.9297 & TRN \\
\hline CHEMBL 247177 & 453152 & 6.8861 & 6.7389 & TRN \\
\hline CHEMBL394114 & 453152 & 5.8239 & 5.8469 & TRN \\
\hline CHEMBL 246325 & 453152 & 5.6021 & 5.6306 & TRN \\
\hline CHEMBL391610 & 453152 & 7.2676 & 7.2164 & TRN \\
\hline CHEMBL397397 & 453152 & 6.5686 & 6.7223 & TRN \\
\hline CHEMBL 247573 & 453152 & 7.0269 & 6.8885 & TRN \\
\hline CHEMBL395690 & 453152 & 7.7696 & 7.6881 & TRN \\
\hline CHEMBL392261 & 453152 & 6.0 & 6.6299 & TST \\
\hline CHEMBL 246175 & 453152 & 8.301 & 8.2837 & TRN \\
\hline CHEMBL 247376 & 453152 & 6.1938 & 6.6979 & TST \\
\hline CHEMBL 245960 & 453152 & 4.9208 & 4.989 & TRN \\
\hline CHEMBL248183 & 453152 & 7.7447 & 7.7742 & TRN \\
\hline CHEMBL438669 & 453152 & 7.4089 & 7.3407 & TRN \\
\hline CHEMBL246184 & 453152 & 7.5686 & 7.5477 & TRN \\
\hline CHEMBL428405 & 453152 & 4.0 & 3.9813 & TRN \\
\hline CHEMBL 247572 & 453152 & 7.5086 & 6.8786 & TST \\
\hline CHEMBL246367 & 453152 & 6.9586 & 7.3 & TST \\
\hline CHEMBL 247571 & 453152 & 6.301 & 6.3436 & TRN \\
\hline CHEMBL246160 & 453152 & 7.2676 & 7.2401 & TRN \\
\hline CHEMBL 246365 & 453152 & 8.5229 & 8.6605 & TRN \\
\hline CHEMBL428751 & 453152 & 7.4685 & 7.3331 & TRN \\
\hline CHEMBL246972 & 453152 & 6.7696 & 6.2617 & TST \\
\hline CHEMBL 246121 & 453152 & 5.6576 & 6.2845 & TST \\
\hline CHEMBL391958 & 453152 & 4.0 & 7.4156 & TST \\
\hline CHEMBL394113 & 453152 & 6.3979 & 6.4122 & TST \\
\hline CHEMBL 245982 & 453152 & 7.0 & 7.2754 & TST \\
\hline CHEMBL246174 & 453152 & 8.2218 & 8.0411 & TST \\
\hline CHEMBL3930735 & 1641468 & 6.0 & 7.4256 & TRN \\
\hline CHEMBL3952836 & 1641468 & 6.0 & 7.7272 & TRN \\
\hline CHEMBL3926772 & 1641468 & 8.7986 & 8.2185 & TRN \\
\hline CHEMBL 3936266 & 1641468 & 6.9788 & 6.7441 & TST \\
\hline CHEMBL3977151 & 1641468 & 7.7825 & 7.6969 & TRN \\
\hline CHEMBL3959664 & 1641468 & 7.2351 & 7.4726 & TRN \\
\hline CHEMBL3980260 & 1641468 & 6.8697 & 6.7052 & TST \\
\hline CHEMBL3973273 & 1641468 & 6.9626 & 6.7846 & TRN \\
\hline CHEMBL3901317 & 1641468 & 6.8928 & 6.5204 & TRN \\
\hline CHEMBL 3919342 & 1641468 & 8.9066 & 8.5626 & TST \\
\hline CHEMBL 3893274 & 1641468 & 7.0287 & 6.9497 & TST \\
\hline
\end{tabular}

Page 22122 
Supplemental Table S2.txt

\begin{tabular}{|c|c|c|c|c|c|c|}
\hline CHEMBL3942126 & 1641468 & 8.684 & \multicolumn{2}{|c|}{7.792000000000001} & & TST \\
\hline CHEMBL3905017 & 1641468 & 6.8069 & 6.7254 & TRN & & \\
\hline CHEMBL3981302 & 1641468 & 4.9031 & 6.4491 & TRN & & \\
\hline CHEMBL 3889726 & 1641468 & 7.2269 & 6.4515 & TRN & & \\
\hline CHEMBL3951417 & 1641468 & 7.1397 & 7.8893 & TRN & & \\
\hline CHEMBL3979487 & 1641468 & 7.4078 & 7.5106 & TRN & & \\
\hline CHEMBL3973183 & 1641468 & 8.399 & 7.9136 & TRN & & \\
\hline CHEMBL3984572 & 1641468 & 8.2358 & 7.7178 & TRN & & \\
\hline CHEMBL3983593 & 1641468 & 7.8069 & 6.7938 & TST & & \\
\hline CHEMBL3928140 & 1641468 & 6.4377 & 6.9133 & TST & & \\
\hline CHEMBL3908226 & 1641468 & 6.4377 & 7.49 & TRN & & \\
\hline CHEMBL3907575 & 1641468 & 5.0 & 6.7077 & TST & & \\
\hline CHEMBL3969860 & 1641468 & 6.251 & 6.6064 & TRN & & \\
\hline CHEMBL3903096 & 1641468 & 6.9318 & 7.4481 & TRN & & \\
\hline CHEMBL 3902284 & 1641468 & 7.341 & 6.9757 & TRN & & \\
\hline CHEMBL3982191 & 1641468 & 8.7747 & 8.2104 & TRN & & \\
\hline CHEMBL3974058 & 1641468 & 7.1811 & 7.4222 & TRN & & \\
\hline CHEMBL3921438 & 1641468 & 7.8268 & 7.4195 & TRN & & \\
\hline CHEMBL3958422 & 1641468 & 8.5986 & 8.0675 & TRN & & \\
\hline CHEMBL3948524 & 1641468 & 8.1057 & 7.4536 & TRN & & \\
\hline CHEMBL3956067 & 1641468 & 8.0721 & 7.7957 & TRN & & \\
\hline CHEMBL3933870 & 1641468 & 7.4921 & 6.9869 & TRN & & \\
\hline CHEMBL3910038 & 1641468 & 7.3125 & 7.4721 & TRN & & \\
\hline CHEMBL3915390 & 1641468 & 7.1085 & 7.5132 & TRN & & \\
\hline CHEMBL3977555 & 1641468 & 8.1656 & 7.6855 & TRN & & \\
\hline CHEMBL3962361 & 1641468 & 7.1701 & 7.474 & TRN & & \\
\hline CHEMBL3919592 & 1641468 & 7.7471 & 6.94600 & 0000000001 & & TRN \\
\hline CHEMBL3944711 & 1641468 & 8.4191 & 8.24 & TRN & & \\
\hline CHEMBL3899313 & 1641468 & 7.6055 & 7.1016 & TST & & \\
\hline CHEMBL 3934748 & 1641468 & 6.1397 & 6.4061 & TRN & & \\
\hline CHEMBL3938960 & 1641468 & 8.0128 & 7.9308 & TRN & & \\
\hline CHEMBL3985246 & 1641468 & 7.9208 & 7.8478 & TRN & & \\
\hline CHEMBL3889810 & 1641468 & 6.0 & 7.1081 & TRN & & \\
\hline CHEMBL3903986 & 1641468 & 7.3354 & 7.3873 & TRN & & \\
\hline CHEMBL3900702 & 1641468 & 8.0044 & 7.3659 & TRN & & \\
\hline CHEMBL3975973 & 1641468 & 7.1669 & 7.0621 & TST & & \\
\hline CHEMBL3893678 & 1641468 & 7.82100 & 00000000 & $\partial 1$ & 7.6009 & TRN \\
\hline CHEMBL3905938 & 1641468 & 7.1273 & 6.3405 & TRN & & \\
\hline CHEMBL3951801 & 1641468 & 7.0376 & 6.4675 & TST & & \\
\hline CHEMBL3895275 & 1641468 & 5.8297 & 6.5549 & TST & & \\
\hline CHEMBL3957979 & 1641468 & 7.8297 & 7.5064 & TRN & & \\
\hline CHEMBL3968966 & 1641468 & 6.8416 & 7.0597 & TST & & \\
\hline CHEMBL3943137 & 1641468 & 7.5003 & 8.0717 & TRN & & \\
\hline CHEMBL3917334 & 1641468 & 7.45100 & 00000000 & 205 & 7.1746 & TR \\
\hline CHEMBL3972148 & 1641468 & 6.0 & 7.4203 & TRN & & \\
\hline CHEMBL3974901 & 1641468 & 6.0 & 7.7115 & TRN & & \\
\hline CHEMBL 3978418 & 1641468 & 8.0721 & 7.6027 & TST & & \\
\hline CHEMBL3983465 & 1641468 & 8.684 & 7.9185 & TRN & & \\
\hline
\end{tabular}




\begin{tabular}{|c|c|c|c|c|c|c|}
\hline \multicolumn{7}{|c|}{ Supplemental Table s2.txt } \\
\hline CHEMBL3916039 & 1641468 & 6.0 & 7.6419 & TRN & & \\
\hline CHEMBL3923906 & 1641468 & 7.6091 & 7.3927 & TRN & & \\
\hline CHEMBL3938095 & 1641468 & 7.7595 & 7.6299 & TRN & & \\
\hline CHEMBL 3903223 & 1641468 & 7.75700 & 000000000 & & 7.2898 & TRN \\
\hline CHEMBL3949058 & 1641468 & 5.9508 & 7.3585 & TRN & & \\
\hline CHEMBL3889878 & 1641468 & 7.75200 & 000000000 & & 7.2893 & TST \\
\hline CHEMBL 3943172 & 1641468 & 7.3635 & 7.4494 & TRN & & \\
\hline CHEMBL 3897163 & 1641468 & 7.7825 & 6.8864 & TRN & & \\
\hline CHEMBL3977946 & 1641468 & 7.9355 & 6.9855 & TRN & & \\
\hline CHEMBL3963786 & 1641468 & 6.3316 & 7.3774 & TRN & & \\
\hline CHEMBL3969053 & 1641468 & 6.0 & 7.7859 & TRN & & \\
\hline CHEMBL3938160 & 1641468 & 7.1152 & 7.187 & TRN & & \\
\hline CHEMBL3919929 & 1641468 & 7.5591 & 7.282 & TRN & & \\
\hline CHEMBL3986560 & 1641468 & 7.0747 & 7.6106 & TRN & & \\
\hline CHEMBL3976934 & 1641468 & 8.1238 & 7.8926 & TRN & & \\
\hline CHEMBL3986641 & 1641468 & 8.3851 & 7.3625 & TRN & & \\
\hline CHEMBL3891444 & 1641468 & 7.4921 & 7.3685 & TRN & & \\
\hline CHEMBL3901992 & 1641468 & 6.5513 & 7.0605 & TRN & & \\
\hline CHEMBL3922761 & 1641468 & 6.2612 & 6.801 & TST & & \\
\hline CHEMBL3935243 & 1641468 & 7.0491 & 7.5525 & TRN & & \\
\hline CHEMBL3983165 & 1641468 & 6.0 & 7.3531 & TST & & \\
\hline CHEMBL3942792 & 1641468 & 8.699 & 8.2963 & TRN & & \\
\hline CHEMBL3908572 & 1641468 & 5.8601 & 7.2577 & TRN & & \\
\hline CHEMBL3925757 & 1641468 & 7.9469 & 8.1009 & TRN & & \\
\hline CHEMBL3944248 & 1641468 & 7.7167 & 7.6245 & TRN & & \\
\hline CHEMBL3962655 & 1641468 & 7.2069 & 7.4344 & TST & & \\
\hline CHEMBL3968828 & 1641468 & 5.7773 & 6.0038 & TST & & \\
\hline CHEMBL3980399 & 1641468 & 6.0 & 7.9267 & TRN & & \\
\hline CHEMBL3921601 & 1641468 & 7.7747 & 7.5003 & TRN & & \\
\hline CHEMBL3941928 & 1641468 & 6.0762 & 6.6637 & TRN & & \\
\hline CHEMBL3934997 & 1641468 & 7.2798 & 8.107999 & 9999999999 & & TRN \\
\hline CHEMBL3972490 & 1641468 & 6.475 & 7.2481 & TRN & & \\
\hline CHEMBL3892918 & 1641468 & 6.4547 & 7.0192 & TRN & & \\
\hline CHEMBL 3985234 & 1641468 & 8.3716 & 8.1826 & TRN & & \\
\hline CHEMBL3892281 & 1641468 & 8.2048 & 7.5234 & TRN & & \\
\hline CHEMBL3893100 & 1641468 & 7.1688 & 7.2783 & TRN & & \\
\hline CHEMBL3966033 & 1641468 & 7.2 & 6.9313 & TRN & & \\
\hline CHEMBL3972460 & 1641468 & 8.5243 & 7.8983 & TRN & & \\
\hline CHEMBL3961119 & 1641468 & 6.6576 & 6.6306 & TST & & \\
\hline CHEMBL3922531 & 1641468 & 7.0357 & 7.6899 & TRN & & \\
\hline CHEMBL3892373 & 1641468 & 5.6696 & 6.4657 & TRN & & \\
\hline CHEMBL3903328 & 1641468 & 5.8356 & 6.3324 & TST & & \\
\hline CHEMBL3933558 & 1641468 & 7.71899 & 999999999 & & 7.4442 & TST \\
\hline CHEMBL3902477 & 1641468 & 8.5969 & 7.1693 & TRN & & \\
\hline CHEMBL3934232 & 1641468 & 6.8182 & 7.4487 & TST & & \\
\hline CHEMBL3891475 & 1641468 & 7.2765 & 7.3129 & TRN & & \\
\hline CHEMBL3937508 & 1641468 & 7.5513 & 7.5995 & TRN & & \\
\hline CHEMBL3930521 & 1641468 & 7.3904 & 6.9169 & TST & & \\
\hline
\end{tabular}


Supplemental Table S2.txt

\begin{tabular}{|c|c|c|c|c|c|}
\hline CHEMBL 3944884 & 1641468 & 6.8539 & 6.6589 & TST & \\
\hline CHEMBL 3920375 & 1641468 & 7.0846 & 7.5077 & TRN & \\
\hline CHEMBL3904757 & 1641468 & 7.6126 & 6.9778 & TRN & \\
\hline CHEMBL3972246 & 1641468 & 5.9245 & 6.4613 & TRN & \\
\hline CHEMBL3918187 & 1641468 & 7.7799 & 7.7113 & TRN & \\
\hline CHEMBL 3933632 & 1641468 & 8.7747 & 8.0172 & TRN & \\
\hline CHEMBL3985166 & 1641468 & 6.9626 & 7.3945 & TRN & \\
\hline CHEMBL 3978224 & 1641468 & 7.4634 & 7.1388 & TRN & \\
\hline CHEMBL3908809 & 1641468 & 7.062 & 7.175 & TST & \\
\hline CHEMBL3957075 & 1641468 & 7.9031 & 7.4089 & TRN & \\
\hline CHEMBL 3943562 & 1641468 & 7.0857 & 7.3585 & TRN & \\
\hline CHEMBL3910312 & 1641468 & 7.9431 & 6.7723 & TST & \\
\hline CHEMBL3949756 & 1641468 & 7.4559 & 6.5771 & TRN & \\
\hline CHEMBL3955806 & 1641468 & 5.9318 & 6.693 & TST & \\
\hline CHEMBL3900946 & 1641468 & 7.6517 & 7.6834 & TRN & \\
\hline CHEMBL 3956872 & 1641468 & \multicolumn{2}{|c|}{7.7620000000000005} & 7.6539 & TRN \\
\hline CHEMBL3922718 & 1641468 & 5.8861 & 7.324 & TST & \\
\hline CHEMBL3925853 & 1641468 & 6.6402 & 6.3932 & TRN & \\
\hline CHEMBL3912409 & 1641468 & 7.3045 & 7.2347 & TRN & \\
\hline CHEMBL3970948 & 1641468 & 7.6655 & 6.9706 & TST & \\
\hline CHEMBL3903507 & 1641468 & 8.4908 & 7.5083 & TST & \\
\hline CHEMBL3917207 & 1641468 & 7.9706 & 7.4798 & TST & \\
\hline CHEMBL 3986388 & 1641468 & 6.6198 & 6.4454 & TRN & \\
\hline CHEMBL 3939782 & 1641468 & 8.2 & 7.8141 & TRN & \\
\hline CHEMBL3910378 & 1641468 & 6.8539 & 6.4983 & TRN & \\
\hline CHEMBL3977811 & 1641468 & 7.8268 & 7.5433 & TRN & \\
\hline CHEMBL 3984924 & 1641468 & 6.6536 & 6.5858 & TST & \\
\hline CHEMBL3929376 & 1641468 & 6.7852 & 6.6801 & TST & \\
\hline CHEMBL 3891873 & 1641468 & 7.1319 & 7.46899 & & TRN \\
\hline CHEMBL3971849 & 1641468 & 7.4056 & 6.6533 & TRN & \\
\hline CHEMBL3893945 & 1641468 & 7.6234 & 7.5421 & TST & \\
\hline CHEMBL 3960840 & 1641468 & 7.857 & 7.8959 & TRN & \\
\hline CHEMBL 3894343 & 1641468 & 6.6478 & 6.7322 & TST & \\
\hline CHEMBL 3892542 & 1641468 & 8.1844 & 7.4906 & TRN & \\
\hline CHEMBL3969239 & 1641468 & 7.5702 & 6.65 & TRN & \\
\hline CHEMBL3975163 & 1641468 & 6.4559 & 7.46200 & 0000000001 & TRN \\
\hline CHEMBL3905852 & 1641468 & 7.5735 & 7.3752 & TRN & \\
\hline CHEMBL 3896602 & 1641468 & 7.1746 & 7.0322 & TST & \\
\hline CHEMBL3943589 & 1641468 & 5.2495 & 5.9225 & TST & \\
\hline CHEMBL3981515 & 1641468 & 7.7825 & 7.2392 & TRN & \\
\hline CHEMBL3975508 & 1641468 & 7.7878 & 6.3645 & TRN & \\
\hline CHEMBL3909597 & 1641468 & 7.0132 & 6.38700 & 00000000005 & TRN \\
\hline CHEMBL3924946 & 1641468 & 7.1169 & 6.9374 & TRN & \\
\hline CHEMBL 3908755 & 1641468 & 7.5391 & 7.4676 & TRN & \\
\hline CHEMBL 3982340 & 1641468 & 6.9508 & 7.602 & TRN & \\
\hline CHEMBL3980189 & 1641468 & 8.0205 & 7.5339 & TRN & \\
\hline CHEMBL3967193 & 1641468 & 6.4283 & 7.0472 & TRN & \\
\hline CHEMBL3960733 & 1641468 & 7.3028 & 7.0915 & TRN & \\
\hline
\end{tabular}

Page 22125 
Supplemental Table S2.txt

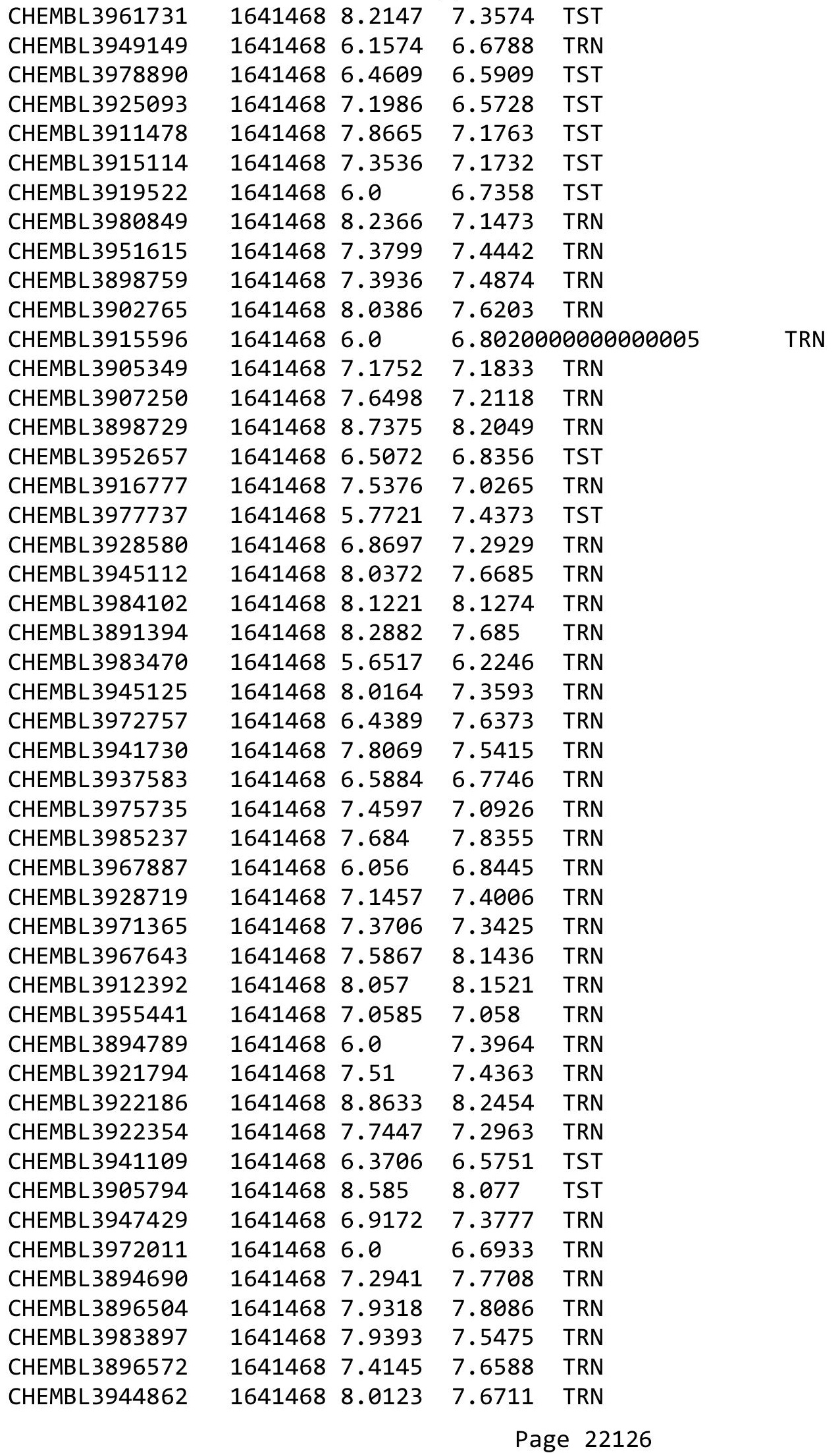


Supplemental Table S2.txt

\begin{tabular}{|c|c|c|c|c|c|}
\hline CHEMBL3901436 & 1641468 & 6.0 & 7.4966 & TRN & \\
\hline CHEMBL3974008 & 1641468 & 7.6716 & 7.6615 & TRN & \\
\hline CHEMBL3933376 & 1641468 & 6.5229 & 7.1254 & TRN & \\
\hline CHEMBL3918989 & 1641468 & 7.7471 & 7.1301 & TST & \\
\hline CHEMBL 3914601 & 1641468 & 7.8153 & 7.6851 & TST & \\
\hline CHEMBL3952556 & 1641468 & 6.3526 & 7.3704 & TRN & \\
\hline CHEMBL3908957 & 1641468 & 7.3686 & 6.5359 & TRN & \\
\hline CHEMBL3916082 & 1641468 & 7.6904 & 7.6625 & TRN & \\
\hline CHEMBL3899935 & 1641468 & 8.0615 & 7.689 & TRN & \\
\hline CHEMBL 3934267 & 1641468 & 8.2604 & 7.3687 & TRN & \\
\hline CHEMBL3896914 & 1641468 & 7.7352 & 7.4087 & TRN & \\
\hline CHEMBL3945530 & 1641468 & 7.5918 & 7.7798 & TRN & \\
\hline CHEMBL3906614 & 1641468 & 6.9914 & 6.6979 & TST & \\
\hline CHEMBL 3933187 & 1641468 & 7.9318 & 7.7113 & TRN & \\
\hline CHEMBL 3952200 & 1641468 & 6.5272 & 7.4205 & TST & \\
\hline CHEMBL3964455 & 1641468 & 6.8447 & 6.6183 & TRN & \\
\hline CHEMBL3965162 & 1641468 & 8.0737 & 8.1154 & TRN & \\
\hline CHEMBL3973325 & 1641468 & 6.0039 & 6.7588 & TST & \\
\hline CHEMBL 3944794 & 1641468 & 7.2676 & 7.2324 & TRN & \\
\hline CHEMBL3897061 & 1641468 & 8.0264 & 7.3594 & TRN & \\
\hline CHEMBL 3930470 & 1641468 & 8.2083 & 7.5688 & TRN & \\
\hline CHEMBL3967932 & 1641468 & 6.6968 & 6.2014 & TST & \\
\hline CHEMBL3931833 & 1641468 & 6.4225 & 6.8389 & TRN & \\
\hline CHEMBL3895892 & 1641468 & 6.08299 & 79999999 & 7.3366 & TRN \\
\hline CHEMBL3958710 & 1641468 & 8.3401 & 8.2125 & TRN & \\
\hline CHEMBL3959532 & 1641468 & 7.0218 & 7.3178 & TRN & \\
\hline CHEMBL3898216 & 1641468 & 6.7852 & 7.532 & TRN & \\
\hline CHEMBL3944157 & 1641468 & 7.8928 & 7.3685 & TRN & \\
\hline CHEMBL3912627 & 1641468 & 8.0958 & 7.3453 & TRN & \\
\hline CHEMBL3901166 & 1641468 & 6.3788 & 6.7765 & TRN & \\
\hline CHEMBL3962685 & 1641468 & 6.8861 & 6.6087 & TST & \\
\hline CHEMBL3961513 & 1641468 & 7.8125 & 7.6162 & TRN & \\
\hline CHEMBL3946294 & 1641468 & 5.8729 & 5.8695 & TST & \\
\hline CHEMBL 3899714 & 1641468 & 6.6655 & 6.2354 & TRN & \\
\hline CHEMBL 3986780 & 1641468 & 8.5186 & 7.6539 & TRN & \\
\hline CHEMBL3951556 & 1641468 & 6.4214 & 6.5426 & TRN & \\
\hline CHEMBL3979773 & 1641468 & 5.8386 & 5.7409 & TST & \\
\hline CHEMBL3910241 & 1641468 & 7.9355 & 7.2982 & TST & \\
\hline CHEMBL3901096 & 1641468 & 6.5129 & 6.6425 & TST & \\
\hline CHEMBL 3949223 & 1641468 & 7.4559 & 7.7305 & TRN & \\
\hline CHEMBL3981746 & 1641468 & 6.3468 & 6.8534 & TRN & \\
\hline CHEMBL3975713 & 1641468 & 7.4855 & 7.1213 & TST & \\
\hline CHEMBL3956278 & 1641468 & 7.1018 & 7.4173 & TRN & \\
\hline CHEMBL3918189 & 1641468 & 7.5735 & 7.3987 & TRN & \\
\hline CHEMBL3933642 & 1641468 & 7.6421 & 7.4034 & TRN & \\
\hline CHEMBL3972000 & 1641468 & 7.2526 & 7.15799 & э99999999995 & I RI \\
\hline CHEMBL 3972499 & 1641468 & 7.4145 & 7.2332 & TRN & \\
\hline CHEMBL3923512 & 1641468 & 8.1612 & 8.1828 & TRN & \\
\hline
\end{tabular}

Page 22127 
Supplemental Table S2.txt

\begin{tabular}{|c|c|c|c|c|c|}
\hline CHEMBL3946417 & 1641468 & 7.317 & 7.416 & TRN & \\
\hline CHEMBL3905620 & 1641468 & 8.0343 & 7.4164 & TRN & \\
\hline CHEMBL3928497 & 1641468 & 6.8327 & 6.7264 & TST & \\
\hline CHEMBL3946865 & 1641468 & 7.2097 & 7.3929 & TST & \\
\hline CHEMBL3966135 & 1641468 & 7.3363 & 7.4114 & TRN & \\
\hline CHEMBL3965508 & 1641468 & 7.3726 & 7.3116 & TRN & \\
\hline CHEMBL3934833 & 1641468 & 7.4283 & 6.249 & TST & \\
\hline CHEMBL3891076 & 1641468 & 6.6778 & 7.6037 & TRN & \\
\hline CHEMBL3969420 & 1641468 & 7.6308 & 7.6373 & TRN & \\
\hline CHEMBL3929130 & 1641468 & 7.266 & 6.7308 & TST & \\
\hline CHEMBL3935560 & 1641468 & 6.3526 & 6.2073 & TRN & \\
\hline CHEMBL3967728 & 1641468 & 6.6861 & 6.4184 & TST & \\
\hline CHEMBL3930530 & 1641468 & 6.7696 & 7.5963 & TRN & \\
\hline CHEMBL3912342 & 1641468 & 7.8928 & 7.5957 & TRN & \\
\hline CHEMBL3901453 & 1641468 & 7.8013 & 6.9124 & TRN & \\
\hline CHEMBL3954032 & 1641468 & 7.9788 & 7.8515 & TST & \\
\hline CHEMBL3983540 & 1641468 & 6.7077 & 7.3479 & TST & \\
\hline CHEMBL3893617 & 1641468 & 7.5607 & 7.4388 & TRN & \\
\hline CHEMBL3952739 & 1641468 & 7.857 & 7.4176 & TRN & \\
\hline CHEMBL3945095 & 1641468 & 6.1319 & 7.3413 & TRN & \\
\hline CHEMBL3936306 & 1641468 & 8.0762 & 7.3565 & TRN & \\
\hline CHEMBL3977432 & 1641468 & 6.8761 & 7.0155 & TRN & \\
\hline CHEMBL3917752 & 1641468 & 6.7235 & 6.6988 & TST & \\
\hline CHEMBL3961131 & 1641468 & 5.5017 & 6.5948 & TRN & \\
\hline CHEMBL3980309 & 1641468 & 7.6003 & 6.4462 & TRN & \\
\hline CHEMBL3953519 & 1641468 & 7.4123 & 7.1617 & TRN & \\
\hline CHEMBL3939727 & 1641468 & 7.3224 & 7.2744 & TRN & \\
\hline CHEMBL3948094 & 1641468 & 7.58 & 7.5424 & TST & \\
\hline CHEMBL3956084 & 1641468 & 6.0953 & 7.3857 & TRN & \\
\hline CHEMBL3903312 & 1641468 & 7.3747 & 7.5036 & TRN & \\
\hline CHEMBL3964416 & 1641468 & 7.6271 & 6.691 & TRN & \\
\hline CHEMBL3929527 & 1641468 & 8.4921 & 8.112 & TRN & \\
\hline CHEMBL3982613 & 1641468 & 7.2518 & 6.9053 & TRN & \\
\hline CHEMBL 3904508 & 1641468 & 7.4815 & 7.2432 & TRN & \\
\hline CHEMBL3905868 & 1641468 & 8.083 & \multicolumn{2}{|c|}{7.367999999999999} & TRN \\
\hline CHEMBL3940933 & 1641468 & 8.4461 & 7.6537 & TRN & \\
\hline CHEMBL3969804 & 1641468 & 7.9281 & 8.0562 & TST & \\
\hline CHEMBL3986010 & 1641468 & 6.0 & 7.6054 & TRN & \\
\hline CHEMBL3957123 & 1641468 & 6.2104 & 6.2532 & TST & \\
\hline CHEMBL3920507 & 1641468 & 6.5406 & \multicolumn{2}{|c|}{6.337999999999999} & TST \\
\hline CHEMBL3915599 & 1641468 & 7.5331 & 7.3668 & TRN & \\
\hline CHEMBL3971266 & 1641468 & 6.6778 & 7.0482 & TST & \\
\hline CHEMBL3893704 & 1641468 & 7.5575 & 7.5235 & TRN & \\
\hline CHEMBL3937735 & 1641468 & 7.6655 & 6.9293 & TRN & \\
\hline CHEMBL 3956842 & 1641468 & 8.1391 & 8.2122 & TRN & \\
\hline CHEMBL3912166 & 1641468 & 5.6289 & 6.0878 & TST & \\
\hline CHEMBL3923077 & 1641468 & 7.3565 & 6.5255 & TRN & \\
\hline CHEMBL3952169 & 1641468 & 6.51 & 6.4477 & TRN & \\
\hline
\end{tabular}


Supplemental Table S2.txt

\begin{tabular}{|c|c|c|c|c|c|}
\hline CHEMBL3897964 & 1641468 & 7.3883 & 7.4868 & TRN & \\
\hline CHEMBL3980425 & 1641468 & 8.1561 & 7.4499 & TRN & \\
\hline CHEMBL3932848 & 1641468 & 6.9208 & 6.4146 & TRN & \\
\hline CHEMBL3900608 & 1641468 & 7.9666 & 7.6739 & TRN & \\
\hline CHEMBL3950191 & 1641468 & 6.699 & 6.7036 & TRN & \\
\hline CHEMBL3960869 & 1641468 & 8.0516 & 7.4614 & TRN & \\
\hline CHEMBL3921226 & 1641468 & 6.4045 & 7.2991 & TRN & \\
\hline CHEMBL3973471 & 1641468 & 7.6556 & 7.367000 & 0000000001 & TST \\
\hline CHEMBL 3964707 & 1641468 & 7.9626 & 7.0723 & TRN & \\
\hline CHEMBL3895866 & 1641468 & 7.9586 & 7.4328 & TRN & \\
\hline CHEMBL 3946535 & 1641468 & 6.0731 & 7.1739 & TST & \\
\hline CHEMBL3963031 & 1641468 & 7.9747 & 7.5535 & TST & \\
\hline CHEMBL3909913 & 1641468 & 6.7471 & 7.3557 & TRN & \\
\hline CHEMBL 3955582 & 1641468 & 8.0195 & 7.4023 & TST & \\
\hline CHEMBL3978181 & 1641468 & 5.2487 & 6.5247 & TRN & \\
\hline CHEMBL 3906557 & 1641468 & 8.2644 & 7.8861 & TRN & \\
\hline CHEMBL3982299 & 1641468 & 8.0888 & 7.7995 & TRN & \\
\hline CHEMBL3919219 & 1641468 & 7.0297 & 7.2998 & TRN & \\
\hline CHEMBL3952161 & 1641468 & 7.5607 & 7.2956 & TST & \\
\hline CHEMBL3895565 & 1641468 & 7.1397 & 7.5095 & TRN & \\
\hline CHEMBL3896490 & 1641468 & 8.6308 & 8.2047 & TRN & \\
\hline CHEMBL3924546 & 1641468 & 8.3098 & 7.8274 & TRN & \\
\hline CHEMBL3907377 & 1641468 & 8.0013 & 8.1224 & TRN & \\
\hline CHEMBL 3984840 & 1641468 & 8.2336 & 7.9596 & TRN & \\
\hline CHEMBL 3977765 & 1641468 & 6.857 & 7.0412 & TRN & \\
\hline CHEMBL 3987158 & 1641468 & 7.1481 & 7.4527 & TRN & \\
\hline CHEMBL3983198 & 1641468 & 7.61799 & 999999999 & 7.2879 & \\
\hline CHEMBL3939791 & 1641468 & 7.4449 & 7.5578 & TRN & \\
\hline CHEMBL 3964070 & 1641468 & 7.4711 & 6.2963 & TRN & \\
\hline CHEMBL 3947327 & 1641468 & 6.0 & 7.5985 & TRN & \\
\hline CHEMBL 3931493 & 1641468 & 7.3645 & 6.6561 & TST & \\
\hline CHEMBL 3953984 & 1641468 & 8.0545 & 7.5415 & TRN & \\
\hline CHEMBL 3985582 & 1641468 & 7.644 & 7.0874 & TST & \\
\hline CHEMBL 3950385 & 1641468 & 8.2596 & 7.5163 & TRN & \\
\hline CHEMBL 3958052 & 1641468 & 8.2882 & 7.5894 & TRN & \\
\hline CHEMBL3901106 & 1641468 & 5.2434 & 6.567 & TRN & \\
\hline CHEMBL3915753 & 1641468 & 6.9136 & 6.699 & TRN & \\
\hline CHEMBL 3910146 & 1641468 & 6.7878 & 6.5985 & TST & \\
\hline CHEMBL 3896526 & 1641468 & 8.3799 & 7.8167 & TRN & \\
\hline CHEMBL3915476 & 1641468 & 8.3809 & 8.1463 & TRN & \\
\hline CHEMBL3911565 & 1641468 & 6.75700 & 000000000 & 7.4168 & T \\
\hline CHEMBL3940366 & 1641468 & 8.5302 & 7.0382 & TST & \\
\hline CHEMBL3890709 & 1641468 & 7.4949 & 7.5213 & TRN & \\
\hline CHEMBL 3933281 & 1641468 & 7.0731 & 7.5874 & TRN & \\
\hline CHEMBL3914852 & 1641468 & 6.9957 & 7.4532 & TRN & \\
\hline CHEMBL3969109 & 1641468 & 8.4034 & 7.6343 & TRN & \\
\hline CHEMBL 3896888 & 1641468 & 8.308 & 7.773 & TST & \\
\hline CHEMBL 3903441 & 1641468 & 7.6073 & 7.4778 & TRN & \\
\hline
\end{tabular}


Supplemental Table S2.txt

\begin{tabular}{|c|c|c|c|c|}
\hline CHEMBL 3920747 & 1641468 & 6.2388 & 7.3794 & TRN \\
\hline CHEMBL3916068 & 1641468 & 6.8665 & 7.4118 & TRN \\
\hline CHEMBL3938859 & 1641468 & 5.9136 & 7.4192 & TRN \\
\hline CHEMBL3943701 & 1641468 & 8.0283 & 8.0623 & TRN \\
\hline CHEMBL3953007 & 1641468 & 7.7375 & 7.7086 & TRN \\
\hline CHEMBL3910353 & 1641468 & 7.289 & 6.3636 & TST \\
\hline CHEMBL3980234 & 1641468 & 7.6556 & 7.2866 & TST \\
\hline CHEMBL3966908 & 1641468 & 8.5421 & 7.6899 & TRN \\
\hline CHEMBL 3894844 & 1641468 & 6.4622 & 7.0751 & TST \\
\hline CHEMBL3891439 & 1641468 & 7.3188 & \multicolumn{2}{|c|}{7.111000000000001} \\
\hline CHEMBL3916836 & 1641468 & 8.3036 & 8.0601 & TRN \\
\hline CHEMBL3967518 & 1641468 & 7.2168 & 7.2689 & TRN \\
\hline CHEMBL 3931418 & 1641468 & 7.5784 & 7.5483 & TRN \\
\hline CHEMBL 3930144 & 1641468 & 6.7905 & 6.9253 & TRN \\
\hline CHEMBL 3976087 & 1641468 & 6.0 & 7.7108 & TRN \\
\hline CHEMBL 3920749 & 1641468 & 8.1662 & 7.4757 & TRN \\
\hline CHEMBL3986842 & 1641468 & 7.0283 & 6.5672 & TST \\
\hline CHEMBL3939962 & 1641468 & 6.8894 & 7.5598 & TRN \\
\hline CHEMBL3922638 & 1641468 & 7.6696 & 7.539 & TRN \\
\hline CHEMBL3972992 & 1641468 & 8.1163 & 7.5745 & TST \\
\hline CHEMBL3901921 & 1641468 & 8.4737 & 8.1668 & TRN \\
\hline CHEMBL3933582 & 1641468 & 8.7721 & 8.331 & TRN \\
\hline CHEMBL 3894285 & 1641468 & 7.9281 & 8.0041 & TRN \\
\hline CHEMBL3918436 & 1641468 & 7.2069 & 6.8998 & TST \\
\hline CHEMBL3926103 & 1641468 & 7.251 & 7.4231 & TRN \\
\hline CHEMBL3974095 & 1641468 & 7.2733 & 7.146 & TST \\
\hline CHEMBL3969080 & 1641468 & 8.3089 & 6.8452 & TRN \\
\hline CHEMBL3969318 & 1641468 & 7.3893 & 7.3793 & TRN \\
\hline CHEMBL3919404 & 1641468 & 7.7878 & 7.7289 & TRN \\
\hline CHEMBL3970634 & 1641468 & 7.6882 & 7.0489 & TRN \\
\hline CHEMBL3909174 & 1641468 & 6.8125 & 7.3605 & TRN \\
\hline CHEMBL 3911751 & 1641468 & 7.5361 & 7.5214 & TRN \\
\hline CHEMBL 3982202 & 1641468 & 7.8297 & 7.1082 & TRN \\
\hline CHEMBL3961345 & 1641468 & 6.7011 & 6.6201 & TRN \\
\hline CHEMBL3895419 & 1641468 & 7.8894 & 7.3989 & TST \\
\hline CHEMBL3913732 & 1641468 & 8.0066 & 7.2474 & TRN \\
\hline CHEMBL 3917160 & 1641468 & 7.9245 & 7.4953 & TST \\
\hline CHEMBL3917598 & 1641468 & 8.4895 & 8.2351 & TRN \\
\hline CHEMBL3923959 & 1641468 & 7.8761 & 7.6418 & TRN \\
\hline CHEMBL3946447 & 1641468 & 6.4101 & 6.4615 & TRN \\
\hline CHEMBL3927300 & 1641468 & 7.6696 & 7.5723 & TRN \\
\hline CHEMBL 3985875 & 1641468 & 6.9666 & 7.478 & TRN \\
\hline CHEMBL 3894641 & 1641468 & 6.0 & 7.705 & TRN \\
\hline CHEMBL3977306 & 1641468 & 8.1612 & 7.3927 & TRN \\
\hline CHEMBL3915440 & 1641468 & 7.6055 & 7.4583 & TRN \\
\hline CHEMBL3954295 & 1641468 & 7.3799 & 6.9234 & TST \\
\hline CHEMBL 3937052 & 1641468 & 6.644 & 7.5209 & TRN \\
\hline CHEMBL 3898678 & 1641468 & 6.1261 & 6.5056 & TRN \\
\hline
\end{tabular}

Page 22130 
Supplemental Table S2.txt

\begin{tabular}{|c|c|c|c|c|c|c|}
\hline CHEMBL 3986386 & 1641468 & 7.0814 & 7.2495 & TST & & \\
\hline CHEMBL 3913477 & 1641468 & 6.1113 & 7.5457 & TST & & \\
\hline CHEMBL 3955004 & 1641468 & 8.1325 & 7.7351 & TST & & \\
\hline CHEMBL 3938089 & 1641468 & 8.2041 & 7.9689 & TRN & & \\
\hline CHEMBL 3970866 & 1641468 & 7.3565 & 7.3881 & TST & & \\
\hline CHEMBL 3971984 & 1641468 & 6.0 & 7.5888 & TRN & & \\
\hline CHEMBL 3900716 & 1641468 & 7.9957 & 8.2544 & TRN & & \\
\hline CHEMBL3936169 & 1641468 & 6.9136 & 7.5652 & TRN & & \\
\hline CHEMBL 3939694 & 1641468 & 7.6778 & 6.3631 & TST & & \\
\hline CHEMBL3947312 & 1641468 & 7.5376 & 6.5431 & TRN & & \\
\hline CHEMBL 3940527 & 1641468 & 8.4881 & 7.4336 & TST & & \\
\hline CHEMBL 3918406 & 1641468 & 8.0511 & 7.6139 & TST & & \\
\hline CHEMBL3911865 & 1641468 & 7.4225 & 6.9348 & TST & & \\
\hline CHEMBL 3947077 & 1641468 & 7.266 & 7.4672 & TST & & \\
\hline CHEMBL3948549 & 1641468 & 8.0996 & 7.7019 & TRN & & \\
\hline CHEMBL 3955567 & 1641468 & 6.699 & 7.4127 & TST & & \\
\hline CHEMBL3935595 & 1641468 & 5.8097 & 7.4871 & TRN & & \\
\hline CHEMBL 3917263 & 1641468 & 7.8239 & 7.3091 & TRN & & \\
\hline CHEMBL 3967908 & 1641468 & 8.3161 & 7.655 & TRN & & \\
\hline CHEMBL 3974520 & 1641468 & 7.5702 & 7.1731 & TRN & & \\
\hline CHEMBL 3894884 & 1641468 & 7.6478 & 6.7538 & TRN & & \\
\hline CHEMBL 3894793 & 1641468 & 7.71 & 7.153 & TST & & \\
\hline CHEMBL 3902147 & 1641468 & 6.3605 & 6.5695 & TST & & \\
\hline CHEMBL 3924584 & 1641468 & 7.2899 & 7.1833 & TRN & & \\
\hline CHEMBL 3925127 & 1641468 & 6.0 & 7.6086 & TRN & & \\
\hline CHEMBL 3929302 & 1641468 & 8.2774 & 7.8168 & TRN & & \\
\hline CHEMBL 3962339 & 1641468 & 8.6253 & 7.5004 & TST & & \\
\hline CHEMBL 3894167 & 1641468 & 8.4908 & 8.1689 & TRN & & \\
\hline CHEMBL3925973 & 1641468 & 7.2233 & 7.4718 & TRN & & \\
\hline CHEMBL 3901624 & 1641468 & 7.6073 & 6.3595 & TRN & & \\
\hline CHEMBL 3935764 & 1641468 & 7.7212 & 7.9145 & TRN & & \\
\hline CHEMBL 3923436 & 1641468 & \multicolumn{3}{|c|}{7.7620000000000005} & 7.3693 & TRN \\
\hline CHEMBL 3949607 & 1641468 & \multicolumn{3}{|c|}{7.821000000000001} & 7.5737 & TRN \\
\hline CHEMBL 3972622 & 1641468 & 8.0841 & 7.7999 & TST & & \\
\hline CHEMBL 3929748 & 1641468 & 8.3363 & 7.1838 & TRN & & \\
\hline CHEMBL 3933820 & 1641468 & 8.52 & 8.3485 & TRN & & \\
\hline CHEMBL 3930683 & 1641468 & 6.1314 & 6.2448 & TRN & & \\
\hline CHEMBL 3950055 & 1641468 & 7.3615 & 6.485 & TRN & & \\
\hline CHEMBL 3973049 & 1641468 & 6.9788 & 7.3464 & TRN & & \\
\hline CHEMBL 3908364 & 1641468 & \multicolumn{3}{|c|}{7.382999999999999} & 7.1385 & TST \\
\hline CHEMBL3897661 & 1641468 & 6.0 & 5.9632 & TST & & \\
\hline CHEMBL 3979553 & 1641468 & \multicolumn{3}{|c|}{8.062000000000001} & 7.7069 & TRN \\
\hline CHEMBL 3961415 & 1641468 & 8.4868 & 7.2519 & TST & & \\
\hline CHEMBL 3933718 & 1641468 & 8.6946 & 8.2561 & TRN & & \\
\hline CHEMBL 3963731 & 1641468 & 7.3429 & 7.0466 & TST & & \\
\hline CHEMBL 3944930 & 1641468 & 7.3675 & 6.3556 & TRN & & \\
\hline CHEMBL 3982547 & 1641468 & 7.8416 & 7.2352 & TRN & & \\
\hline CHEMBL3977501 & 1641468 & 7.8861 & 7.6328 & TRN & & \\
\hline
\end{tabular}

Page 22131 
Supplemental Table S2.txt

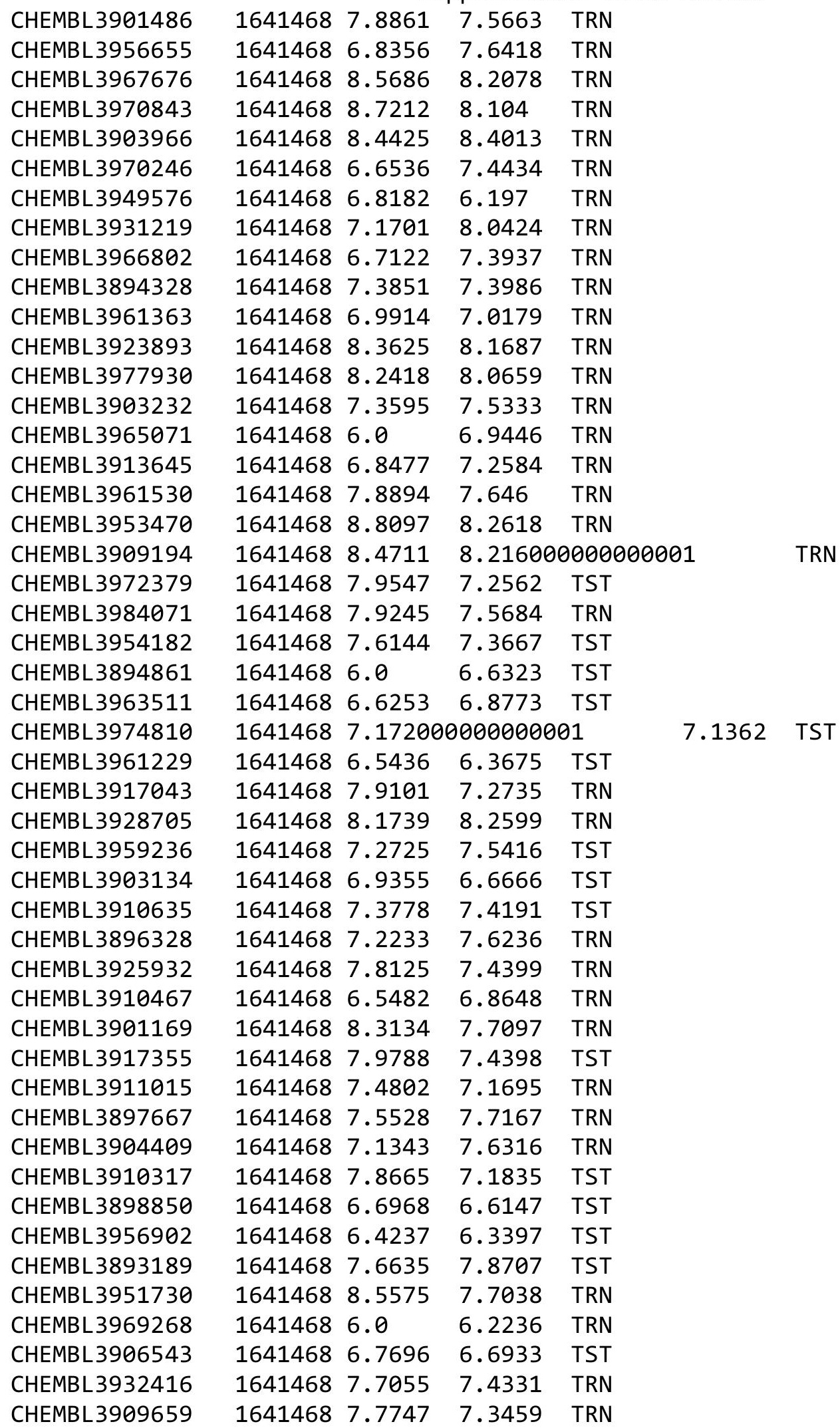

Page 22132 
Supplemental Table S2.txt

\begin{tabular}{|c|c|c|c|c|c|c|}
\hline CHEMBL 3938898 & 1641468 & 8.8239 & 8.2259 & TRN & & \\
\hline CHEMBL3963525 & 1641468 & 7.1439 & 6.8194 & TRN & & \\
\hline CHEMBL3937420 & 1641468 & 8.2449 & 7.5569 & TST & & \\
\hline CHEMBL3965636 & 1641468 & 8.4425 & 8.0931 & TRN & & \\
\hline CHEMBL3928187 & 1641468 & 8.3107 & 7.4983 & TRN & & \\
\hline CHEMBL3910840 & 1641468 & 8.821 & 7.9096 & TRN & & \\
\hline CHEMBL3953619 & 1641468 & 8.9136 & 7.9255 & TRN & & \\
\hline CHEMBL 3892205 & 1641468 & 7.5702 & 7.1867 & TRN & & \\
\hline CHEMBL 3974320 & 1641468 & 8.0737 & 8.2135 & TRN & & \\
\hline CHEMBL3966042 & 1641468 & 7.2204 & 7.1977 & TST & & \\
\hline CHEMBL3923253 & 1641468 & 7.9747 & 7.6423 & TRN & & \\
\hline CHEMBL3978411 & 1641468 & 8.0101 & 7.3847 & TRN & & \\
\hline CHEMBL3944747 & 1641468 & 7.2418 & 7.9015 & TRN & & \\
\hline CHEMBL 3984210 & 1641468 & 7.8297 & 7.4325 & TRN & & \\
\hline CHEMBL3945584 & 1641468 & 7.4101 & 7.5019 & TRN & & \\
\hline CHEMBL3956376 & 1641468 & 7.7352 & 7.6103 & TRN & & \\
\hline CHEMBL3906024 & 1641468 & 7.9281 & 7.7993 & TRN & & \\
\hline CHEMBL3905371 & 1641468 & 7.15799 & 99999999 & 995 & 7.1329 & TRN \\
\hline CHEMBL3939507 & 1641468 & 7.1838 & 6.4841 & TST & & \\
\hline CHEMBL3913274 & 1641468 & 7.9706 & 7.7679 & TRN & & \\
\hline CHEMBL3925548 & 1641468 & 7.2958 & 7.5268 & TRN & & \\
\hline CHEMBL3921130 & 1641468 & 8.5784 & 8.0315 & TRN & & \\
\hline CHEMBL3911084 & 1641468 & 5.7932 & 6.5048 & TRN & & \\
\hline CHEMBL3915514 & 1641468 & 7.5867 & 7.8309 & TRN & & \\
\hline CHEMBL3912156 & 1641468 & 7.0825 & 7.0941 & TRN & & \\
\hline CHEMBL3963471 & 1641468 & 8.2725 & 7.5378 & TST & & \\
\hline CHEMBL3966533 & 1641468 & 7.1838 & 7.0574 & TRN & & \\
\hline CHEMBL3965213 & 1641468 & 7.9469 & 7.3627 & TRN & & \\
\hline CHEMBL3918575 & 1641468 & 6.0 & 7.346 & TRN & & \\
\hline CHEMBL3910326 & 1641468 & 8.8041 & 7.2124 & TRN & & \\
\hline CHEMBL 3954274 & 1641468 & 7.52 & 7.0356 & TRN & & \\
\hline CHEMBL 3907983 & 1641468 & 7.1656 & 6.5366 & TST & & \\
\hline CHEMBL3895350 & 1641468 & 8.3002 & 8.0049 & TRN & & \\
\hline CHEMBL 3984343 & 1641468 & 7.6498 & 7.4811 & TRN & & \\
\hline CHEMBL3972705 & 1641468 & 6.6696 & 6.5464 & TST & & \\
\hline CHEMBL3959913 & 1641468 & 8.0706 & 7.7951 & TRN & & \\
\hline CHEMBL3921193 & 1641468 & 7.9281 & 8.0899 & TRN & & \\
\hline CHEMBL 3897694 & 1641468 & 8.0434 & 7.3636 & TRN & & \\
\hline CHEMBL3953866 & 1641468 & 6.3655 & 7.2492 & TRN & & \\
\hline CHEMBL 3945648 & 1641468 & 6.3215 & 7.5437 & TRN & & \\
\hline CHEMBL3943216 & 1641468 & 7.8182 & 7.6184 & TRN & & \\
\hline CHEMBL3976762 & 1641468 & 7.1152 & 7.5168 & TRN & & \\
\hline CHEMBL3920837 & 1641468 & 7.8996 & 7.1974 & TRN & & \\
\hline CHEMBL3897103 & 1641468 & 8.6364 & 8.032 & TRN & & \\
\hline CHEMBL3949693 & 1641468 & 8.1798 & 8.1837 & TRN & & \\
\hline CHEMBL3972994 & 1641468 & 7.8729 & 8.2053 & TRN & & \\
\hline CHEMBL3968700 & 1641468 & 6.8297 & 6.6412 & TST & & \\
\hline CHEMBL3921331 & 1641468 & 8.9872 & 8.1667 & TRN & & \\
\hline
\end{tabular}

Page 22133 
Supplemental Table S2.txt

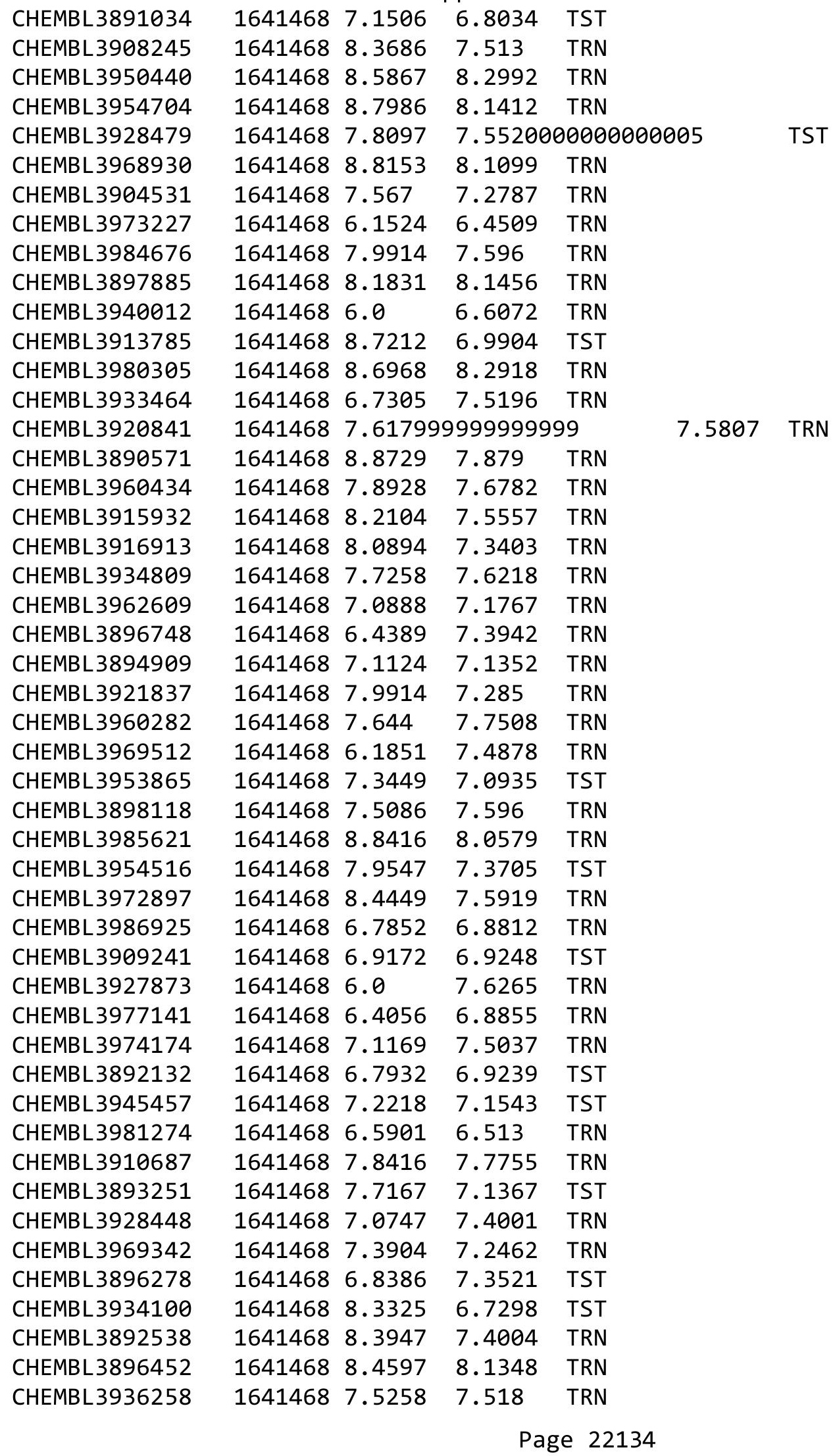


Supplemental Table S2.txt

\begin{tabular}{|c|c|c|c|c|c|}
\hline CHEMBL3899192 & 1641468 & 6.5751 & 7.4853 & TRN & \\
\hline CHEMBL 3936304 & 1641468 & 6.9626 & 6.3734 & TRN & \\
\hline CHEMBL3919961 & 1641468 & 6.0 & 8.2109 & TRN & \\
\hline CHEMBL 3895029 & 1641468 & 6.9547 & 7.4656 & TRN & \\
\hline CHEMBL3982392 & 1641468 & 7.3116 & 7.2305 & TRN & \\
\hline CHEMBL 3901932 & 1641468 & 8.317 & 8.1095 & TRN & \\
\hline CHEMBL 3907136 & 1641468 & 6.9547 & 7.4441 & TRN & \\
\hline CHEMBL 3968550 & 1641468 & 7.9788 & 7.7549 & TRN & \\
\hline CHEMBL 3898124 & 1641468 & 7.1864 & 6.3321 & TRN & \\
\hline CHEMBL 3971854 & 1641468 & 6.8665 & 7.0422 & TRN & \\
\hline CHEMBL 3945255 & 1641468 & 7.8665 & 6.9178 & TST & \\
\hline CHEMBL 3939421 & 1641468 & 7.4559 & 7.3662 & TST & \\
\hline CHEMBL 3925598 & 1641468 & 7.2027 & 7.3206 & TST & \\
\hline CHEMBL 3940548 & 1641468 & 7.1765 & 7.0421 & TST & \\
\hline CHEMBL 3932411 & 1641468 & 8.0022 & 7.6678 & TRN & \\
\hline CHEMBL 3952120 & 1641468 & 7.6234 & 7.6314 & TRN & \\
\hline CHEMBL 3924514 & 1641468 & 7.08299 & 799999999 & 99 & 7.5877 \\
\hline CHEMBL 3939488 & 1641468 & 7.3279 & 7.6361 & TRN & \\
\hline CHEMBL 3904788 & 1641468 & 7.4976 & 7.4034 & TST & \\
\hline CHEMBL 3966221 & 1641468 & 7.4763 & 7.4066 & TRN & \\
\hline CHEMBL 3978272 & 1641468 & 7.3799 & 6.6032 & TST & \\
\hline CHEMBL3925699 & 1641468 & 7.2725 & 7.2679 & TRN & \\
\hline CHEMBL 3955387 & 1641468 & 7.9957 & 8.2689 & TRN & \\
\hline CHEMBL 3921946 & 1641468 & 7.7375 & 7.6253 & TRN & \\
\hline CHEMBL 3967580 & 1641468 & 6.4248 & 6.4044 & TRN & \\
\hline CHEMBL 3891178 & 1641468 & 6.8996 & 7.4071 & TRN & \\
\hline CHEMBL 3906469 & 1641468 & 7.1713 & 7.1872 & TRN & \\
\hline CHEMBL 3927934 & 1641468 & 7.2358 & 7.1259 & TRN & \\
\hline CHEMBL 3978962 & 1641468 & 7.0311 & 7.5195 & TRN & \\
\hline CHEMBL 3914368 & 1641468 & 8.719 & 8.1146 & TRN & \\
\hline CHEMBL 3906297 & 1641468 & 7.2314 & 7.4012 & TRN & \\
\hline CHEMBL 3940269 & 1641468 & 7.1273 & 6.6369 & TRN & \\
\hline CHEMBL 3915518 & 1641468 & 6.7033 & 6.6676 & TST & \\
\hline CHEMBL 3973962 & 1641468 & 8.6757 & 8.1209 & TRN & \\
\hline CHEMBL 3967478 & 1641468 & 8.6596 & 8.2243 & TRN & \\
\hline CHEMBL3951375 & 1641468 & 7.9355 & 6.5614 & TRN & \\
\hline CHEMBL 3941682 & 1641468 & 8.1284 & 7.7425 & TRN & \\
\hline CHEMBL 3916971 & 1641468 & 8.8041 & 7.9684 & TRN & \\
\hline CHEMBL 3896552 & 1641468 & 7.0083 & 7.5456 & TRN & \\
\hline CHEMBL 3973581 & 1641468 & 8.15 & 7.9478 & TRN & \\
\hline CHEMBL 3971990 & 1641468 & 7.1746 & 7.4632 & TRN & \\
\hline CHEMBL 3971687 & 1641468 & 8.5302 & 8.1738 & TRN & \\
\hline CHEMBL 3905827 & 1641468 & 7.0814 & 7.7856 & TRN & \\
\hline CHEMBL 3951685 & 1641468 & 8.3098 & 7.5598 & TRN & \\
\hline CHEMBL 3921522 & 1641468 & 7.3188 & 7.1959 & TRN & \\
\hline CHEMBL 3923017 & 1641468 & 7.1911 & 6.9344 & TST & \\
\hline CHEMBL 3953649 & 1641468 & 8.1273 & 7.4698 & TRN & \\
\hline CHEMBL 3916026 & 1641468 & 6.0 & 7.522 & TRN & \\
\hline
\end{tabular}


Supplemental Table S2.txt

\begin{tabular}{|c|c|c|c|c|}
\hline CHEMBL3916589 & 1641468 & 6.0 & 6.4596 & TRN \\
\hline CHEMBL3982231 & 1641468 & 7.5528 & 7.4433 & TRN \\
\hline CHEMBL3979429 & 1641468 & 7.1662 & 7.0536 & TST \\
\hline CHEMBL3966358 & 1641468 & 7.1062 & 6.9027 & TRN \\
\hline CHEMBL 3917797 & 1641468 & 8.3116 & 7.9102 & TRN \\
\hline CHEMBL3985379 & 1641468 & 7.9355 & 7.4726 & TRN \\
\hline CHEMBL3927332 & 1641468 & 8.4841 & 8.003 & TRN \\
\hline CHEMBL3981513 & 1641468 & 8.3778 & 7.6415 & TRN \\
\hline CHEMBL3986521 & 1641468 & 7.24799 & 79999999 & 6.7837 \\
\hline CHEMBL3920094 & 1641468 & 6.8665 & 7.4401 & TRN \\
\hline CHEMBL 3934277 & 1641468 & 7.2411 & 7.2425 & TRN \\
\hline CHEMBL3941769 & 1641468 & 7.4001 & 7.4905 & TST \\
\hline CHEMBL3952797 & 1641468 & 6.295 & 6.6808 & TST \\
\hline CHEMBL3968071 & 1641468 & 8.1612 & 7.3957 & TRN \\
\hline CHEMBL3977909 & 1641468 & 7.6799 & 7.6783 & TRN \\
\hline CHEMBL 3919283 & 1641468 & 7.4622 & 7.4814 & TST \\
\hline CHEMBL3986094 & 1641468 & 7.1129 & 7.5905 & TST \\
\hline CHEMBL3947219 & 1641468 & 7.2147 & 6.3062 & TST \\
\hline CHEMBL3907281 & 1641468 & 8.4012 & 8.1138 & TRN \\
\hline CHEMBL3924935 & 1641468 & 8.0168 & 7.6268 & TRN \\
\hline CHEMBL3908363 & 1641468 & 7.2343 & 6.3814 & TRN \\
\hline CHEMBL3974621 & 1641468 & 6.9245 & 7.2739 & TRN \\
\hline CHEMBL3893557 & 1641468 & 7.1051 & 6.5539 & TST \\
\hline CHEMBL3942612 & 1641468 & 7.5986 & 7.3148 & TRN \\
\hline CHEMBL 3948127 & 1641468 & 7.2495 & 6.9718 & TST \\
\hline CHEMBL3942877 & 1641468 & 6.7696 & 7.4485 & TRN \\
\hline CHEMBL3893308 & 1641468 & 6.5513 & 6.2468 & TST \\
\hline CHEMBL3967630 & 1641468 & 8.3507 & 7.541 & TST \\
\hline CHEMBL3933941 & 1641468 & 7.068 & 6.3765 & TRN \\
\hline CHEMBL3889566 & 1641468 & 7.857 & 7.5203 & TRN \\
\hline CHEMBL3937013 & 1641468 & 8.0804 & 8.0895 & TRN \\
\hline CHEMBL3926032 & 1641468 & 7.2197 & 6.7605 & TST \\
\hline CHEMBL3893668 & 1641468 & 8.3516 & 7.0709 & TST \\
\hline CHEMBL3932762 & 1641468 & 6.4789 & 7.5201 & TRN \\
\hline CHEMBL3927701 & 1641468 & 7.2168 & 7.3421 & TRN \\
\hline CHEMBL3942911 & 1641468 & 7.295 & 6.8993 & TST \\
\hline CHEMBL3911528 & 1641468 & 7.4855 & 7.3671 & TRN \\
\hline CHEMBL3977379 & 1641468 & 6.0 & 7.1651 & TRN \\
\hline CHEMBL3986968 & 1641468 & 8.2351 & 7.5267 & TRN \\
\hline CHEMBL 3894493 & 1641468 & 6.8996 & 6.6709 & TST \\
\hline CHEMBL3970432 & 1641468 & 4.9031 & 6.5039 & TRN \\
\hline CHEMBL3946957 & 1641468 & 7.7167 & 7.28700 & 0000000001 \\
\hline CHEMBL3956724 & 1641468 & 7.3516 & 7.5041 & TST \\
\hline CHEMBL3972815 & 1641468 & 8.8182 & 8.1518 & TRN \\
\hline CHEMBL3912659 & 1641468 & 7.4685 & 7.3181 & TRN \\
\hline CHEMBL3947298 & 1641468 & 6.6968 & 6.9231 & TST \\
\hline CHEMBL3968933 & 1641468 & 7.1308 & 6.4205 & TRN \\
\hline CHEMBL3929954 & 1641468 & 6.0 & 7.6536 & TRN \\
\hline
\end{tabular}


Supplemental Table S2.txt

\begin{tabular}{|c|c|c|c|c|c|}
\hline CHEMBL 3916321 & 1641468 & 7.3382 & 7.4364 & TRN & \\
\hline CHEMBL 3916648 & 1641468 & 6.0 & 6.8829 & TST & \\
\hline CHEMBL3963038 & 1641468 & 8.0367 & 7.5685 & TRN & \\
\hline CHEMBL 3977867 & 1641468 & 7.3507 & 7.5648 & TRN & \\
\hline CHEMBL3985904 & 1641468 & 6.6498 & 7.34399 & 9999999999 & TRN \\
\hline CHEMBL3929951 & 1641468 & 7.3233 & 6.523 & TRN & \\
\hline CHEMBL 3889922 & 1641468 & 7.4572 & 7.4348 & TRN & \\
\hline CHEMBL3959969 & 1641468 & 6.9469 & 7.2219 & TRN & \\
\hline CHEMBL3959738 & 1641468 & 7.8794 & 7.5746 & TRN & \\
\hline CHEMBL3900104 & 1641468 & 6.0 & 7.7002 & TRN & \\
\hline CHEMBL3986540 & 1641468 & 6.9031 & 6.5829 & TST & \\
\hline CHEMBL 3928984 & 1641468 & 7.9431 & 7.6421 & TRN & \\
\hline CHEMBL 3895584 & 1641468 & 8.1273 & 8.0549 & TRN & \\
\hline CHEMBL 3904748 & 1641468 & 6.0 & 7.5487 & TRN & \\
\hline CHEMBL 3921826 & 1641468 & 8.6925 & 7.865 & TRN & \\
\hline CHEMBL3926076 & 1641468 & 6.4841 & 7.1233 & TRN & \\
\hline CHEMBL 3958262 & 1641468 & 8.2848 & 7.9977 & TRN & \\
\hline CHEMBL 3911374 & 1641468 & 8.5157 & 8.3097 & TRN & \\
\hline CHEMBL 3970357 & 1641468 & 8.1791 & 7.7807 & TST & \\
\hline CHEMBL3926671 & 1641468 & 5.6345 & 7.5003 & TRN & \\
\hline CHEMBL 3983731 & 1641468 & 6.0 & 6.8126 & TRN & \\
\hline CHEMBL3925333 & 1641468 & 6.0 & 7.5175 & TRN & \\
\hline CHEMBL3932831 & 1641468 & 8.0237 & 8.0394 & TRN & \\
\hline CHEMBL3899713 & 1641468 & 7.9318 & 7.4744 & TST & \\
\hline CHEMBL3913656 & 1641468 & 8.5129 & 7.597 & TRN & \\
\hline CHEMBL 3924387 & 1641468 & 6.9957 & 7.4236 & TRN & \\
\hline CHEMBL 3903024 & 1641468 & 6.4841 & 6.8829 & TST & \\
\hline CHEMBL3943241 & 1641468 & 7.3152 & 7.4335 & TRN & \\
\hline CHEMBL3896997 & 1641468 & 7.8447 & 7.0591 & TRN & \\
\hline CHEMBL 3948053 & 1641468 & 7.4949 & 7.3159 & TST & \\
\hline CHEMBL 3938168 & 1641468 & 6.0 & 7.5045 & TRN & \\
\hline CHEMBL 3923569 & 1641468 & 8.1198 & 7.4846 & TRN & \\
\hline CHEMBL3907811 & 1641468 & 8.0969 & 8.1334 & TRN & \\
\hline CHEMBL 3924747 & 1641468 & 6.2226 & 6.4554 & TRN & \\
\hline CHEMBL 3906020 & 1641468 & \multicolumn{3}{|c|}{5.3420000000000005} & TST \\
\hline CHEMBL 3930756 & 1641468 & 8.0052 & 7.2944 & TST & \\
\hline CHEMBL 3949050 & 1641468 & 5.5817 & 6.5587 & TRN & \\
\hline CHEMBL3915525 & 1641468 & 6.9626 & 7.5766 & TRN & \\
\hline CHEMBL3936706 & 1641468 & 5.8041 & 7.3552 & TRN & \\
\hline CHEMBL3897744 & 1641468 & 6.5406 & 7.4728 & TRN & \\
\hline CHEMBL3959908 & 1641468 & 7.2741 & 7.0947 & TRN & \\
\hline CHEMBL 3941834 & 1641468 & 7.8827 & 7.6348 & TRN & \\
\hline CHEMBL 3943244 & 1641468 & 8.382 & 8.1582 & TRN & \\
\hline CHEMBL 3943678 & 1641468 & 6.4134 & 7.7158 & TRN & \\
\hline CHEMBL3949798 & 1641468 & 7.4547 & 7.3166 & TRN & \\
\hline CHEMBL 3916354 & 1641468 & 8.2358 & 8.1884 & TRN & \\
\hline CHEMBL 3944962 & 1641468 & 6.6536 & 7.3451 & TRN & \\
\hline CHEMBL3899353 & 1641468 & 7.1146 & 7.097 & TRN & \\
\hline
\end{tabular}


Supplemental Table S2.txt

\begin{tabular}{|c|c|c|c|c|}
\hline CHEMBL3922772 & 1641468 & 8.6421 & 8.2398 & TRN \\
\hline CHEMBL3945245 & 1641468 & 7.6308 & 7.5907 & TRN \\
\hline CHEMBL3943777 & 1641468 & 8.684 & 7.6543 & TRN \\
\hline CHEMBL3907391 & 1641468 & 8.7986 & 8.3764 & TRN \\
\hline CHEMBL3903221 & 1641468 & 6.9431 & 7.4186 & TRN \\
\hline CHEMBL3959243 & 1641468 & 8.1308 & 7.6067 & TRN \\
\hline CHEMBL3970696 & 1641468 & 8.0862 & 6.5507 & TST \\
\hline CHEMBL3948230 & 1641468 & 8.0565 & 7.5404 & TRN \\
\hline CHEMBL3969935 & 1641468 & 7.5834 & 7.3708 & TST \\
\hline CHEMBL3937777 & 1641468 & 6.4191 & 6.6531 & TST \\
\hline CHEMBL3933919 & 1641468 & 6.6737 & 7.4053 & TRN \\
\hline CHEMBL3978279 & 1641468 & 6.0137 & 7.2928 & TRN \\
\hline CHEMBL3972980 & 1641468 & 8.6536 & 8.2258 & TRN \\
\hline CHEMBL3955956 & 1641468 & 6.5575 & 6.5545 & TRN \\
\hline CHEMBL3931915 & 1641468 & 8.3429 & 7.7854 & TRN \\
\hline CHEMBL3971263 & 1641468 & 7.7212 & 7.3038 & TST \\
\hline CHEMBL3929837 & 1641468 & 7.1079 & 7.1857 & TRN \\
\hline CHEMBL3909982 & 1641468 & 7.9547 & 7.5588 & TRN \\
\hline CHEMBL3975809 & 1641468 & 7.5702 & 6.8301 & TRN \\
\hline CHEMBL3921821 & 1641468 & 7.2132 & 7.1691 & TRN \\
\hline CHEMBL3914786 & 1641468 & 7.382999 & 99999999 & 6.957999999999999 \\
\hline CHEMBL3964496 & 1641468 & 7.7447 & 7.1933 & ences \\
\hline CHEMBL3959810 & 1641468 & 7.5528 & 7.4443 & TRN \\
\hline CHEMBL3960365 & 1641468 & 7.7399 & 7.2157 & TST \\
\hline CHEMBL3947744 & 1641468 & 7.3288 & 7.4313 & TST \\
\hline CHEMBL3940652 & 1641468 & 5.7352 & 7.3788 & TRN \\
\hline CHEMBL3911470 & 1641468 & 8.4522 & 7.5176 & TRN \\
\hline CHEMBL3893765 & 1641468 & 8.3134 & 7.6379 & TRN \\
\hline CHEMBL 3974546 & 1641468 & 7.1618 & 7.316 & TRN \\
\hline CHEMBL3906668 & 1641468 & 6.5654 & 6.2335 & TST \\
\hline CHEMBL3958649 & 1641468 & 7.4685 & 7.626 & TRN \\
\hline CHEMBL3895229 & 1641468 & 7.3497 & 7.0115 & TRN \\
\hline CHEMBL3921576 & 1641468 & 7.0742 & 6.8343 & TRN \\
\hline CHEMBL3939923 & 1641468 & 8.1681 & 7.61700 & 3000000001 \\
\hline CHEMBL3912714 & 1641468 & 7.4067 & 6.7794 & TRN \\
\hline CHEMBL3931298 & 1641468 & 7.6498 & 7.2485 & TST \\
\hline CHEMBL3902199 & 1641468 & 7.6946 & 7.1752 & TRN \\
\hline CHEMBL3942975 & 1641468 & 7.7932 & 7.5658 & TRN \\
\hline CHEMBL3956607 & 1641468 & 8.5272 & 8.1352 & TRN \\
\hline CHEMBL3977199 & 1641468 & 6.8928 & 7.0217 & TST \\
\hline CHEMBL3937529 & 1641468 & 6.7011 & 6.9967 & TST \\
\hline CHEMBL3931373 & 1641468 & 7.9281 & 6.6159 & TST \\
\hline CHEMBL3920931 & 1641468 & 7.7595 & 7.3768 & TRN \\
\hline CHEMBL3966103 & 1641468 & 6.0031 & 7.4762 & TRN \\
\hline CHEMBL3951298 & 1641468 & 6.6904 & 6.7581 & TRN \\
\hline CHEMBL3909366 & 1641468 & 6.7825 & 6.8676 & TRN \\
\hline CHEMBL3962036 & 1641468 & 6.7721 & 7.0895 & TRN \\
\hline CHEMBL3984187 & 1641468 & 6.7144 & 7.5119 & TST \\
\hline
\end{tabular}


Supplemental Table S2.txt

\begin{tabular}{|c|c|c|c|c|c|}
\hline CHEMBL3927387 & 1641468 & 5.2612 & 6.4564 & TRN & \\
\hline CHEMBL 3911447 & 1641468 & 6.8697 & \multicolumn{2}{|c|}{7.502999999999999} & TRN \\
\hline CHEMBL 3915480 & 1641468 & 8.2534 & 7.3821 & TST & \\
\hline CHEMBL 3891646 & 1641468 & 7.2262 & 6.9398 & TST & \\
\hline CHEMBL3903773 & 1641468 & 7.5901 & 7.4698 & TST & \\
\hline CHEMBL3966992 & 1641468 & 5.9469 & 6.5235 & TST & \\
\hline CHEMBL 3922300 & 1641468 & 7.6757 & \multicolumn{2}{|c|}{7.9479999999999995} & TRN \\
\hline CHEMBL 3978341 & 1641468 & 7.0348 & 7.4095 & TRN & \\
\hline CHEMBL 3898142 & 1641468 & 7.2495 & 7.4689 & TST & \\
\hline CHEMBL3906958 & 1641468 & 6.0 & 7.5028 & TRN & \\
\hline CHEMBL 3918778 & 1641468 & 7.6234 & 7.3708 & TRN & \\
\hline CHEMBL 3918373 & 1641468 & 8.4685 & 7.8194 & TRN & \\
\hline CHEMBL3932798 & 1641468 & 7.2034 & 7.5302 & TST & \\
\hline CHEMBL 3966202 & 1641468 & 6.1746 & 7.4241 & TRN & \\
\hline CHEMBL3977919 & 1641468 & 7.6696 & 6.5082 & TRN & \\
\hline CHEMBL3933184 & 1641468 & 5.7645 & 7.2579 & TRN & \\
\hline CHEMBL3895157 & 1641468 & 7.2449 & 7.3578 & TRN & \\
\hline CHEMBL3906982 & 1641468 & 8.3585 & 7.6248 & TST & \\
\hline CHEMBL 3939552 & 1641468 & 8.2464 & 7.7344 & TRN & \\
\hline CHEMBL 3977854 & 1641468 & 8.4868 & \multicolumn{2}{|c|}{8.197000000000001} & TRN \\
\hline CHEMBL 3943984 & 1641468 & 7.8794 & 7.528 & TRN & \\
\hline CHEMBL3940377 & 1641468 & 8.52 & 7.2653 & TST & \\
\hline CHEMBL3966863 & 1641468 & 7.9031 & 7.5981 & TRN & \\
\hline CHEMBL 3930561 & 1641468 & 7.4237 & 7.6739 & TRN & \\
\hline CHEMBL 3957315 & 1641468 & 8.5768 & 7.1836 & TRN & \\
\hline CHEMBL 3908987 & 1641468 & 7.9136 & 7.4584 & TRN & \\
\hline CHEMBL 3892947 & 1641468 & 8.3116 & 8.2176 & TRN & \\
\hline CHEMBL3917682 & 1641468 & 7.644 & 7.1501 & TRN & \\
\hline CHEMBL 3911329 & 1641468 & 8.1778 & 8.217 & TRN & \\
\hline CHEMBL3905266 & 1641468 & 6.8996 & 7.4811 & TRN & \\
\hline CHEMBL 3911973 & 1641468 & 7.5751 & 7.3804 & TRN & \\
\hline CHEMBL3982479 & 1641468 & 5.2472 & 6.6155 & TRN & \\
\hline CHEMBL3937701 & 1641468 & 8.2457 & 7.71 & TRN & \\
\hline CHEMBL 3894499 & 1641468 & 8.3565 & 7.6158 & TRN & \\
\hline CHEMBL3931034 & 1641468 & 8.2314 & 8.096 & TRN & \\
\hline CHEMBL 3892464 & 1641468 & 7.5686 & 7.4652 & TRN & \\
\hline CHEMBL3920134 & 1641468 & 8.4976 & 8.0267 & TRN & \\
\hline CHEMBL3934028 & 1641468 & 8.0799 & \multicolumn{2}{|c|}{7.736000000000001} & TRN \\
\hline CHEMBL3959684 & 1641468 & 6.4271 & 6.636 & TST & \\
\hline CHEMBL3986490 & 1641468 & 7.5421 & 7.0888 & TST & \\
\hline CHEMBL3920722 & 1641468 & 6.4976 & 7.4158 & TRN & \\
\hline CHEMBL3950709 & 1641468 & 7.8928 & 7.5496 & TRN & \\
\hline CHEMBL3972869 & 1641468 & 8.7645 & 7.6566 & TRN & \\
\hline CHEMBL 3978862 & 1641468 & 7.4168 & 7.4452 & TRN & \\
\hline CHEMBL3890164 & 1641468 & 7.3298 & 7.817 & TRN & \\
\hline CHEMBL3954276 & 1641468 & 6.8601 & 7.1078 & TRN & \\
\hline CHEMBL3944052 & 1641468 & 7.5361 & 7.496 & TRN & \\
\hline CHEMBL3957676 & 1641468 & 6.475 & 7.3799 & TRN & \\
\hline
\end{tabular}


Supplemental Table S2.txt

\begin{tabular}{|c|c|c|c|c|c|}
\hline CHEMBL3930855 & 1641468 & 8.0372 & 7.5186 & TRN & \\
\hline CHEMBL3902590 & 1641468 & 8.5258 & 7.7737 & TST & \\
\hline CHEMBL3916340 & 1641468 & 7.3072 & 7.4421 & TRN & \\
\hline CHEMBL3962776 & 1641468 & 7.6556 & 7.6828 & TRN & \\
\hline CHEMBL3912285 & 1641468 & 5.7496 & 7.4722 & TRN & \\
\hline CHEMBL3904586 & 1641468 & 6.0 & 7.4546 & TRN & \\
\hline CHEMBL3981429 & 1641468 & 7.1415 & 7.4063 & TRN & \\
\hline CHEMBL3910358 & 1641468 & 6.9914 & 7.4897 & TST & \\
\hline CHEMBL3960632 & 1641468 & 7.3487 & 7.0443 & TRN & \\
\hline CHEMBL3960879 & 1641468 & 7.7545 & 7.3973 & TRN & \\
\hline CHEMBL3896775 & 1641468 & 7.3936 & 7.0129 & TST & \\
\hline CHEMBL3975643 & 1641468 & 7.2848 & 6.6621 & TRN & \\
\hline CHEMBL3908666 & 1641468 & 7.71 & 7.7801 & TRN & \\
\hline CHEMBL3947040 & 1641468 & 7.6234 & 7.33700 & $\partial 000000001$ & TRN \\
\hline CHEMBL3945792 & 1641468 & 6.0 & 7.5098 & TRN & \\
\hline CHEMBL3982113 & 1641468 & 7.1331 & 6.7396 & TST & \\
\hline CHEMBL3970920 & 1641468 & 6.9066 & 7.4767 & TRN & \\
\hline CHEMBL3909907 & 1641468 & 8.2328 & 7.4616 & TRN & \\
\hline CHEMBL3922987 & 1641468 & 8.0141 & 7.7306 & TRN & \\
\hline CHEMBL3970983 & 1641468 & 7.983 & 7.6858 & TRN & \\
\hline CHEMBL3938585 & 1641468 & 7.7258 & 7.3579 & TRN & \\
\hline CHEMBL3947098 & 1641468 & 5.8069 & 6.4794 & TRN & \\
\hline CHEMBL3914047 & 1641468 & 8.6517 & 7.9766 & TRN & \\
\hline CHEMBL3892516 & 1641468 & 5.8508 & 6.8771 & TST & \\
\hline CHEMBL3961132 & 1641468 & 5.5243 & 6.4779 & TRN & \\
\hline CHEMBL3891452 & 1641468 & 7.5768 & 6.9444 & TRN & \\
\hline CHEMBL3919541 & 1641468 & 7.3439 & 7.3969 & TRN & \\
\hline CHEMBL3918177 & 1641468 & 7.057 & 6.4401 & TST & \\
\hline CHEMBL3893420 & 1641468 & 8.6968 & 7.7753 & TST & \\
\hline CHEMBL3952799 & 1641468 & 7.2168 & 7.0439 & TRN & \\
\hline CHEMBL3922681 & 1641468 & 7.1169 & 7.4362 & TST & \\
\hline CHEMBL 3950529 & 1641468 & 7.4789 & 7.4666 & TRN & \\
\hline CHEMBL3982604 & 1641468 & 7.7545 & 7.5402 & TST & \\
\hline CHEMBL3986657 & 1641468 & \multicolumn{3}{|c|}{6.757000000000001} & TST \\
\hline CHEMBL3923245 & 1641468 & 7.3372 & 6.6228 & TST & \\
\hline CHEMBL3958216 & 1641468 & 7.4841 & 7.4685 & TRN & \\
\hline CHEMBL3937602 & 1641468 & 6.6402 & 7.5334 & TRN & \\
\hline CHEMBL3909761 & 1641468 & 5.9172 & 6.7389 & TST & \\
\hline CHEMBL3944741 & 1641468 & 8.6925 & 8.2352 & TRN & \\
\hline CHEMBL3900360 & 1641468 & 7.644 & 7.1737 & TRN & \\
\hline CHEMBL3981575 & 1641468 & 7.3152 & 7.0419 & TST & \\
\hline CHEMBL3969024 & 1641468 & 7.2 & 6.9957 & TST & \\
\hline CHEMBL3948557 & 1641468 & 6.3969 & 7.5046 & TRN & \\
\hline CHEMBL3964742 & 1641468 & 8.3188 & 8.1633 & TST & \\
\hline CHEMBL3976440 & 1641468 & 6.5607 & 6.4873 & TST & \\
\hline CHEMBL 3940248 & 1641468 & 7.1713 & 7.4667 & TRN & \\
\hline CHEMBL3928454 & 1641468 & 7.8665 & 7.7172 & TRN & \\
\hline CHEMBL3962347 & 1641468 & 8.6556 & 6.9269 & TST & \\
\hline
\end{tabular}


Supplemental Table S2.txt

\begin{tabular}{|c|c|c|c|c|c|}
\hline CHEMBL3961878 & 1641468 & 7.5884 & 6.68 & TRN & \\
\hline CHEMBL3960965 & 1641468 & 7.2125 & 6.9749 & TRN & \\
\hline CHEMBL3894564 & 1641468 & 6.8962 & 7.4938 & TRN & \\
\hline CHEMBL3906370 & 1641468 & 7.1397 & 7.5906 & TRN & \\
\hline CHEMBL3963129 & 1641468 & 8.2 & 8.2138 & TRN & \\
\hline CHEMBL3945215 & 1641468 & 7.7825 & 7.1944 & TRN & \\
\hline CHEMBL3904179 & 1641468 & 8.1107 & 8.1197 & TRN & \\
\hline CHEMBL3969296 & 1641468 & 6.0 & 7.1822 & TRN & \\
\hline CHEMBL3890822 & 1641468 & 7.3298 & 7.0802 & TRN & \\
\hline CHEMBL3957986 & 1641468 & 6.153 & $7.04200 t$ & 0000000001 & TRN \\
\hline CHEMBL3915945 & 1641468 & 7.9469 & 7.6887 & TST & \\
\hline CHEMBL3980534 & 1641468 & 6.9031 & 7.5233 & TRN & \\
\hline CHEMBL3915351 & 1641468 & 8.2388 & 7.6186 & TRN & \\
\hline CHEMBL3936773 & 1641468 & 7.8447 & 7.593 & TRN & \\
\hline CHEMBL3961147 & 1641468 & 8.2612 & 7.9074 & TRN & \\
\hline CHEMBL3906840 & 1641468 & 7.213999 & 79999999 & 7.2168 & TST \\
\hline CHEMBL3949581 & 1641468 & 7.2255 & 6.6042 & TST & \\
\hline CHEMBL3968091 & 1641468 & 7.0701 & 7.205 & TRN & \\
\hline CHEMBL3937043 & 1641468 & 7.7423 & 7.447999 & 79999999995 & TRN \\
\hline CHEMBL3917107 & 1641468 & 7.2518 & 6.0965 & TST & \\
\hline CHEMBL3898618 & 1641468 & 7.857 & 7.6829 & TRN & \\
\hline CHEMBL3914763 & 1641468 & 7.6778 & 7.6305 & TRN & \\
\hline CHEMBL3903924 & 1641468 & 8.4353 & 7.7871 & TRN & \\
\hline CHEMBL3984583 & 1641468 & 5.6778 & 6.5025 & TRN & \\
\hline CHEMBL3975148 & 1641468 & 7.4437 & 6.5645 & TST & \\
\hline CHEMBL3982642 & 1641468 & 8.1805 & 7.6563 & TST & \\
\hline CHEMBL3904279 & 1641468 & 7.3089 & 7.4045 & TRN & \\
\hline CHEMBL3906272 & 1641468 & 7.5376 & 7.6453 & TRN & \\
\hline CHEMBL3904100 & 1641468 & 6.6517 & 6.675 & TST & \\
\hline CHEMBL3985383 & 1641468 & 6.9747 & 7.0664 & TST & \\
\hline CHEMBL3946192 & 1641468 & 6.9957 & 6.9796 & TRN & \\
\hline CHEMBL3930259 & 1641468 & 7.8327 & 6.8365 & TRN & \\
\hline CHEMBL3896930 & 1641468 & 8.2062 & 7.3706 & TRN & \\
\hline CHEMBL3891831 & 1641468 & 6.0 & 8.0422 & TRN & \\
\hline CHEMBL3952999 & 1641468 & 7.7033 & 7.5366 & TRN & \\
\hline CHEMBL3907888 & 1641468 & 7.6498 & 7.2797 & TST & \\
\hline CHEMBL3892278 & 1641468 & 7.8861 & 7.4707 & TRN & \\
\hline CHEMBL3891164 & 1641468 & 6.4841 & 6.7111 & TST & \\
\hline CHEMBL3890856 & 1641468 & 7.8297 & 7.7935 & TRN & \\
\hline CHEMBL3915838 & 1641468 & 7.6882 & 6.8988 & TST & \\
\hline CHEMBL3914619 & 1641468 & 8.8697 & 8.1769 & TRN & \\
\hline CHEMBL3904105 & 1641468 & 7.6144 & 7.5424 & TRN & \\
\hline CHEMBL3940862 & 1641468 & 8.6576 & 7.6014 & TRN & \\
\hline CHEMBL3913742 & 1641468 & 6.0 & 7.5365 & TRN & \\
\hline CHEMBL3935701 & 1641468 & 8.5528 & 8.2828 & TRN & \\
\hline CHEMBL3980353 & 1641468 & 7.3915 & 7.9545 & TRN & \\
\hline CHEMBL3902530 & 1641468 & 7.3116 & 6.5914 & TST & \\
\hline CHEMBL3915002 & 1641468 & 8.342 & 8.0984 & TRN & \\
\hline
\end{tabular}


Supplemental Table S2.txt

\begin{tabular}{|c|c|c|c|c|}
\hline CHEMBL3938162 & 1641468 & 7.0545 & 6.6492 & TST \\
\hline CHEMBL3966538 & 1641468 & 7.51 & 6.8502 & TRN \\
\hline CHEMBL3953369 & 1641468 & 8.1232 & 7.3703 & TRN \\
\hline CHEMBL 3957100 & 1641468 & 7.7696 & 7.8114 & TST \\
\hline CHEMBL 3940814 & 1641468 & 8.1221 & 6.9433 & TST \\
\hline CHEMBL3961929 & 1641468 & 7.4425 & 7.5902 & TRN \\
\hline CHEMBL3947703 & 1641468 & 7.1586 & 7.4412 & TRN \\
\hline CHEMBL 3942358 & 1641468 & 6.8861 & 7.1349 & TRN \\
\hline CHEMBL3911697 & 1641468 & 6.4672 & 6.6495 & TST \\
\hline CHEMBL3966612 & 1641468 & 7.475 & 7.622006 & 000000001 \\
\hline CHEMBL3968099 & 1641468 & 7.9547 & 7.3823 & TRN \\
\hline CHEMBL3912258 & 1641468 & 6.7212 & 7.3346 & TRN \\
\hline CHEMBL3937299 & 1641468 & 7.3747 & 7.2598 & TST \\
\hline CHEMBL3980546 & 1641468 & 6.2628 & 6.9587 & TRN \\
\hline CHEMBL3963853 & 1641468 & 7.6055 & 7.5615 & TRN \\
\hline CHEMBL 3952740 & 1641468 & 6.6326 & 7.5363 & TRN \\
\hline CHEMBL3946058 & 1641468 & 7.4001 & 6.6147 & TST \\
\hline CHEMBL3900162 & 1641468 & 7.0132 & 6.9712 & TST \\
\hline CHEMBL3900854 & 1641468 & 8.2328 & 7.4215 & TRN \\
\hline CHEMBL3977664 & 1641468 & 6.0 & 6.3036 & TST \\
\hline CHEMBL 3934824 & 1641468 & 6.5607 & 6.7166 & TST \\
\hline CHEMBL3911820 & 1641468 & 6.0 & 7.5266 & TRN \\
\hline CHEMBL3918841 & 1641468 & 7.5751 & 7.4412 & TRN \\
\hline CHEMBL3979639 & 1641468 & 8.0395 & 6.5954 & TST \\
\hline CHEMBL 3930880 & 1641468 & 7.9586 & 7.2501 & TRN \\
\hline CHEMBL 3932814 & 1641468 & 7.6345 & 7.664 & TRN \\
\hline CHEMBL3915143 & 1641468 & 7.3116 & 7.3759 & TRN \\
\hline CHEMBL3954943 & 1641468 & 8.4449 & 7.7266 & TRN \\
\hline CHEMBL 3889844 & 1641468 & 7.9914 & 7.6201 & TRN \\
\hline CHEMBL 3944257 & 1641468 & 7.3516 & 7.6917 & TRN \\
\hline CHEMBL 3895284 & 1641468 & 6.9172 & 7.2015 & TRN \\
\hline CHEMBL3979820 & 1641468 & 6.4776 & 6.9396 & TST \\
\hline CHEMBL 3894706 & 1641468 & 5.8327 & 7.4812 & TRN \\
\hline CHEMBL 3928844 & 1641468 & 6.0 & 7.3654 & TRN \\
\hline CHEMBL3939865 & 1641468 & 8.2211 & 8.1769 & TRN \\
\hline CHEMBL3930391 & 1641468 & 7.8996 & 7.7558 & TRN \\
\hline CHEMBL 3944863 & 1641468 & 7.5654 & 7.6358 & TRN \\
\hline CHEMBL3906160 & 1641468 & 8.6126 & 8.23899 & (999999999 \\
\hline CHEMBL3916084 & 1641468 & 8.3063 & 7.5536 & TRN \\
\hline CHEMBL3946262 & 1641468 & 8.0516 & 7.7333 & TRN \\
\hline CHEMBL 3924470 & 1641468 & 8.8268 & 8.2138 & TRN \\
\hline CHEMBL3963742 & 1641468 & 6.0 & 7.6771 & TRN \\
\hline CHEMBL3906171 & 1641468 & 8.1325 & 7.5624 & TST \\
\hline CHEMBL3924856 & 1641468 & 8.0141 & 7.3982 & TRN \\
\hline CHEMBL 3928852 & 1641468 & 7.1085 & 6.9987 & TRN \\
\hline CHEMBL 3977590 & 1641468 & 8.2336 & 7.6541 & TST \\
\hline CHEMBL3940458 & 1641468 & 7.4067 & 7.4609 & TRN \\
\hline CHEMBL 3913420 & 1641468 & 8.3487 & 8.082 & TRN \\
\hline
\end{tabular}

Page 22142 
Supplemental Table S2.txt

\begin{tabular}{|c|c|c|c|c|c|c|}
\hline CHEMBL 3982210 & 1641468 & 7.7167 & 7.2223 & TRN & & \\
\hline CHEMBL3951369 & 1641468 & 8.6073 & 8.2587 & TRN & & \\
\hline CHEMBL3921001 & 1641468 & 8.5272 & 8.164 & TRN & & \\
\hline CHEMBL 3958858 & 1641468 & 6.0 & 7.2634 & TRN & & \\
\hline CHEMBL 3984524 & 1641468 & 5.7033 & 6.0593 & TST & & \\
\hline CHEMBL3953541 & 1641468 & 7.5287 & 7.2203 & TRN & & \\
\hline CHEMBL 3985574 & 1641468 & 7.38299 & 999999999 & 99 & 7.505 & TRN \\
\hline CHEMBL3919991 & 1641468 & 6.0 & 7.1094 & TRN & & \\
\hline CHEMBL 3958028 & 1641468 & 8.1101 & 7.8288 & TST & & \\
\hline CHEMBL3974194 & 1641468 & 7.0443 & 6.6043 & TST & & \\
\hline CHEMBL3937973 & 1641468 & 7.61799 & 799999999 & 99 & 7.4169 & TST \\
\hline CHEMBL 3982530 & 1641468 & 7.5452 & 7.4989 & TRN & & \\
\hline CHEMBL3953923 & 1641468 & 7.9747 & 7.4727 & TST & & \\
\hline CHEMBL 3903719 & 1641468 & 7.3107 & 7.4211 & TRN & & \\
\hline CHEMBL3951887 & 1641468 & 8.2277 & 7.4524 & TRN & & \\
\hline CHEMBL3925656 & 1641906 & 9.2147 & 8.9175 & TRN & & \\
\hline CHEMBL3983799 & 1641906 & 6.3904 & 7.8595 & TST & & \\
\hline CHEMBL 3974646 & 1641906 & 8.2291 & 8.2023 & TRN & & \\
\hline CHEMBL 3965563 & 1641906 & 8.8539 & 8.7536 & TRN & & \\
\hline CHEMBL3928715 & 1641906 & 9.8861 & 9.1022 & TST & & \\
\hline CHEMBL3911815 & 1641906 & 8.5686 & 8.4203 & TRN & & \\
\hline CHEMBL 3958664 & 1641906 & 9.5528 & 9.3504 & TRN & & \\
\hline CHEMBL 3945414 & 1641906 & 7.7212 & 8.2403 & TST & & \\
\hline CHEMBL3973656 & 1641906 & 9.3979 & 9.1535 & TST & & \\
\hline CHEMBL 3928009 & 1641906 & 8.0969 & 7.8844 & TRN & & \\
\hline CHEMBL3956477 & 1641906 & 7.7696 & 7.9882 & TRN & & \\
\hline CHEMBL3972113 & 1641906 & 8.1675 & 8.0801 & TRN & & \\
\hline CHEMBL 3933183 & 1641906 & 8.3279 & 8.1739 & TST & & \\
\hline CHEMBL 3913108 & 1641906 & 8.8861 & 8.9746 & TRN & & \\
\hline CHEMBL 3979544 & 1641906 & 8.9208 & 8.8612 & TRN & & \\
\hline CHEMBL 3922184 & 1641906 & 8.9586 & 8.5504 & TRN & & \\
\hline CHEMBL 3979020 & 1641906 & 7.9586 & 8.1113 & TRN & & \\
\hline CHEMBL 3980148 & 1641906 & 8.0223 & 8.2598 & TRN & & \\
\hline CHEMBL3978105 & 1641906 & 7.2007 & 7.4683 & TRN & & \\
\hline CHEMBL 3910729 & 1641906 & 8.4685 & 8.5617 & TRN & & \\
\hline CHEMBL 3945114 & 1641906 & 9.2147 & 9.4531 & TRN & & \\
\hline CHEMBL3979959 & 1641906 & 8.6576 & 8.1763 & TST & & \\
\hline CHEMBL 3968636 & 1641906 & 7.7212 & 7.4341 & TRN & & \\
\hline CHEMBL 3973158 & 1641906 & 8.6021 & 9.0724 & TRN & & \\
\hline CHEMBL 3917672 & 1641906 & 9.699 & 9.5003 & TRN & & \\
\hline CHEMBL3950441 & 1641906 & 9.3098 & 8.9736 & TRN & & \\
\hline CHEMBL3935613 & 1641906 & 8.0655 & 8.2531 & TRN & & \\
\hline CHEMBL 3926635 & 1641906 & 8.8861 & 9.0435 & TRN & & \\
\hline CHEMBL 3984948 & 1641906 & 8.3979 & 8.2576 & TRN & & \\
\hline CHEMBL 3925703 & 1641906 & 8.8239 & 8.7897 & TRN & & \\
\hline CHEMBL3912079 & 1641906 & 7.6576 & 7.5854 & TRN & & \\
\hline CHEMBL3928401 & 1641906 & 7.585 & 8.2688 & TRN & & \\
\hline CHEMBL3978011 & 1641906 & 7.8861 & 8.1266 & TRN & & \\
\hline
\end{tabular}

Page 22143 
Supplemental Table S2.txt

\begin{tabular}{|c|c|c|c|c|}
\hline 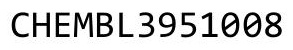 & & & & \\
\hline HEN & 906 & 9.9208 & & \\
\hline HEMBL 3907291 & 641906 & 9.585 & 375 & \\
\hline HEMBL3891048 & 641906 & 7.5686 & 3618 & \\
\hline & & 8.9208 & & \\
\hline 310 & 906 & 8.5086 & 355 & \\
\hline AEMBL3959432 & 641906 & 1249 & 9964 & \\
\hline HEMBL3904064 & 641906 & 4949 & .3212 & \\
\hline AEMBL3927371 & 906 & 4089 & 2186 & \\
\hline 594 & 06 & 3539 & 2003 & \\
\hline 848 & 06 & 872 & 4341 & \\
\hline HEMBL3971023 & 906 & 5576 & 7.4885 & \\
\hline AEMBL3966142 & 906 & 249 & 7.3762 & \\
\hline HEMBL396 & 26 & 59 & 3555 & \\
\hline 174 & 06 & 862 & 905 & \\
\hline HEMBL 397 & & 518 & 4265 & \\
\hline AEMBL3905171 & 906 & 9.1308 & 8.2332 & \\
\hline HEMBL 391 & 906 & 249 & 1256 & \\
\hline 37 & 96 & 92 & 3387 & \\
\hline 15 & 6 & 1871 & .174 & \\
\hline 01 & 06 & 528 & 9.218 & \\
\hline HEMBL3940312 & 906 & 366 & 7.9552 & \\
\hline HEMBL397 & 06 & 007 & 3167 & \\
\hline 59 & 6 & 86 & 3421 & \\
\hline 86 & & 86 & 2018 & \\
\hline 25 & & 68 & 5362 & \\
\hline L39 & 906 & 706 & 0832 & \\
\hline AEMBL392 & & & & \\
\hline AEMBL39 & 06 & 6 & 9546 & RN \\
\hline 50 & 26 & & 471 & \\
\hline 47 & 36 & 18 & 1706 & \\
\hline HEMBL395 & & & 8435 & RN \\
\hline AEMBL3981776 & & & 5699 & RN \\
\hline HEMBL392 & 06 & 969 & 531 & $5 \mathrm{~T}$ \\
\hline 96 & 6 & 86 & 359 & RN \\
\hline 92 & & 76 & 784 & . \\
\hline HEMBL3948975 & 906 & 192 & 9232 & RN \\
\hline AEMBL 3937405 & & 208 & & RN \\
\hline AEMBL3 & 06 & 706 & 925 & ST \\
\hline 9 & & 72 & 428 & TIIV \\
\hline & & 212 & 74 & RN \\
\hline AEMBL3894028 & 906 & 7.5229 & 7.3909 & RN \\
\hline AEMBL398 & & 586 & 3073 & $\mathrm{~N}$ \\
\hline HEMBL 39 & & & 735 & זיר \\
\hline & & & 8.2593 & \\
\hline HEMBL391 & & 696 & 7.9389 & ST \\
\hline-3907196 & 61100 & 4559 & 9.2765 & $\mathrm{~N}$ \\
\hline CHEMBL 3910763 & 16419 & 8.4089 & 8.5402 & \\
\hline
\end{tabular}

Page 22144 
Supplemental Table S2.txt

\begin{tabular}{|c|c|c|c|c|}
\hline להם & 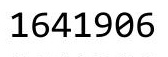 & & 2157 & \\
\hline AEMBL3947591 & 641906 & 9.0315 & 6567 & \\
\hline HEMBL3911279 & 641906 & 7447 & 6703 & \\
\hline L3893152 & 641906 & 8.6778 & 6968 & \\
\hline HEMBL3982900 & 641906 & 9.0 & 7923 & \\
\hline AEMBL3955116 & 641906 & $\partial 915$ & 1592 & \\
\hline AEMBL3982758 & 641906 & .6576 & .5354 & \\
\hline AEMBL3941063 & 641906 & 8.1549 & 3188 & \\
\hline AEMBL3965650 & 641906 & 458 & 381 & \\
\hline AEMBL3945472 & 641906 & & & \\
\hline AEMBL3971107 & 641906 & 7.3372 & 7.48 & \\
\hline AEMBL3899933 & 641906 & 8.8861 & 3915 & \\
\hline AEMBL3911235 & 906 & 57 & & \\
\hline HEMBL39] & 906 & 007 & & \\
\hline AEMBL 39 & 906 & & & \\
\hline AEMBL3963280 & 641906 & 447 & & \\
\hline AEMBL3889666 & 906 & 15 & 74 & \\
\hline AEMBL3978899 & 906 & 96 & 58 & \\
\hline 324 & 906 & 49 & & \\
\hline 334 & 906 & & & \\
\hline L3896266 & 641906 & 098 & 292 & \\
\hline AEMBL3947970 & 906 & 8 . & & \\
\hline AEMBL39 & 906 & $\partial 2$ & 661 & \\
\hline HEMBL3 & 6 & 69 & 771 & \\
\hline 390 & 06 & & 669 & \\
\hline 584 & 906 & 7. & 302 & \\
\hline JEMBL 39 & 106 & & & \\
\hline IEMBL39 & 906 & 12 & 95 & \\
\hline 146 & 0 & 37 & 79 & \\
\hline 424 & 906 & 21 & & \\
\hline L3895138 & 906 & & & \\
\hline AEMBL3983761 & 906 & 8. & 39 & \\
\hline AEMBL39 & 906 & 8. & 96 & \\
\hline AFMRI 36 & 26 & 8 & 86 & \\
\hline 87 & 26 & 8. & 76 & \\
\hline AEMBL3896762 & 641906 & 8.6198 & 16 & \\
\hline AEMBL3905446 & 641906 & 9.5376 & 263 & \\
\hline 536 & & & 888 & \\
\hline 2 & & & 83 & \\
\hline HEMBL3932062 & & & 521 & ST \\
\hline HEMBL3909918 & 641906 & 9.5528 & 4517 & $\mathrm{R}$ \\
\hline AEMBL 39 & 906 & 8. & 726 & \\
\hline HEMBL3979842 & & 9 . & 61 & \\
\hline CHEMBL3431726 & & & & \\
\hline AEMBL3431719 & 1479043 & 3.0 & 2.8455 & RN \\
\hline AEMBL3431631 & 479043 & 3.0 & 3.2559 & \\
\hline-3431883 & & & & \\
\hline HEMPI 2121015 & 17091 & & 2.7402 & \\
\hline
\end{tabular}

Page 22145 


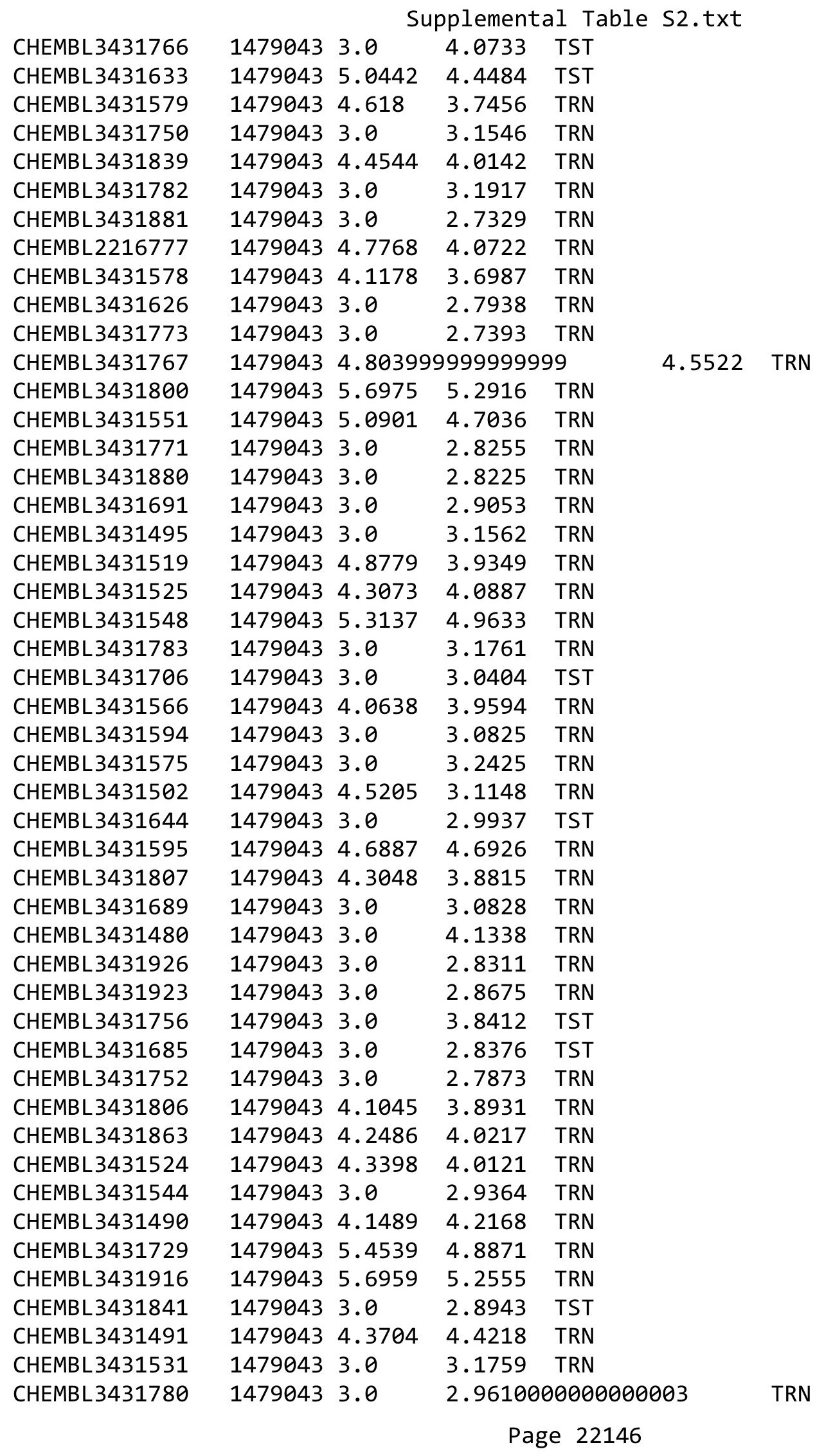


Supplemental Table S2.txt

\begin{tabular}{|c|c|c|c|c|}
\hline CHEMBL3431649 & 1479043 & 3.0 & 2.7384 & TRN \\
\hline HEMBL 3431473 & 1479043 & 3.0 & 3.5562 & \\
\hline AEMBL3431921 & 479043 & 3.0 & 9004 & \\
\hline HEMBL3431893 & 479043 & 3.0 & 5395 & \\
\hline HEMBL3431907 & 479043 & 4.6398 & 1983 & \\
\hline HEMBL3431824 & 479043 & 3.0 & 7304 & \\
\hline HEMBL3431657 & 479043 & 3.0 & .9774 & \\
\hline AEMBL3431754 & 479043 & 3.0 & .7604 & DN \\
\hline HEMBL3431906 & 479043 & 3.0 & .0689 & \\
\hline HEMBL3431678 & 479043 & 3.0 & .792 & \\
\hline HEMBL3431509 & 479043 & 3.0 & 9097 & \\
\hline HEMBL3 & .479043 & 3.0 & 4172 & \\
\hline HEMBL3431497 & 1479043 & 3.0 & 2.9201 & \\
\hline HEMBL3431648 & 479043 & 3.0 & .7515 & \\
\hline HEMBL3431770 & 479043 & 3.0 & .054 & \\
\hline AEMBL3. & 479043 & 3.0 & 3219 & \\
\hline HEMBL3 & 479043 & 3.0 & 553 & \\
\hline HEMBL3 & .479043 & 3.0 & 2.813 & \\
\hline AEMBL3431654 & 9043 & 3.0 & 9832 & RN \\
\hline HEMBL3431785 & 479043 & 3.0 & 38 & TST \\
\hline HEMBL3 & 1479043 & 3.0 & 818 & RN \\
\hline HEMBL & 9043 & 4.55 & & \\
\hline HEMBL3 & 479043 & 4.2822 & 2571 & RN \\
\hline HEMBL3 & 9043 & 3.0 & 7194 & RN \\
\hline HEMBL3 3 & 479043 & 3.0 & 5161 & RN \\
\hline HEMBL3 & 79043 & 3.0 & 265 & 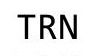 \\
\hline HEMBL & 43 & 3.0 & 78 & RN \\
\hline HEMBL & 3 & 3.0 & 3798 & RN \\
\hline HEMBL3 & 3 & 3.0 & 277 & TRN \\
\hline HEMBL3 3 & 479043 & 3.0 & 0342 & TST \\
\hline HEMBL3 & 479043 & 3.0 & 284 & וזנ \\
\hline HEMBL & 3 & 3.0 & 745 & \\
\hline HEMBL & & 3.0 & 3604 & $\mathrm{RN}$ \\
\hline HEMBL3 & L479043 & 3.0 & 3356 & $\Gamma R$ \\
\hline AEMBL3 & 479043 & 5.18 & 5756 & TRN \\
\hline HEMBL3 & 1479043 & 5.0 & 408 & . \\
\hline CHEMBL3 & 43 & 4 & 21 & RN \\
\hline CHEMBL 3 & 1479043 & 3.0 & 2.9507 & ST \\
\hline HEMBL3 3 & 1479043 & 5.1307 & 3943 & TRN \\
\hline JEMBL3 & 9043 & 3.0 & 285 & TRN \\
\hline CHEMBL 3 & 1479043 & 3.0 & 3.5568 & \\
\hline CHEMBL3L & 1479043 & 3.0 & 2.7487 & $\mathrm{RN}$ \\
\hline CHEMBL3L & 1479043 & 4.9768 & 4.7186 & $\mathrm{RN}$ \\
\hline CHEMBL3 & 1479043 & 5.1865 & 4.9392 & $\mathrm{RI}$ \\
\hline CHEMBL 3 & 1479043 & 5.1903 & 4.5877 & \\
\hline CHEMBL 3431635 & 1479043 & 3.0 & 2.7846 & \\
\hline CHEMBL3431897 & 1479043 & 5.01 & 4.7994 & \\
\hline CHEMBL3431609 & 1479043 & 4.2437 & 3.5886 & \\
\hline
\end{tabular}

Page 22147 
Supplemental Table S2.txt

\begin{tabular}{|c|c|c|c|c|}
\hline CHEMBL3431877 & 1479043 & 3.0 & 3.6303 & TRN \\
\hline CHEMBL3431487 & 1479043 & 3.0 & 3.9506 & TRN \\
\hline CHEMBL3431788 & 1479043 & 4.6829 & 4.3019 & TRN \\
\hline CHEMBL3431763 & 1479043 & 4.4276 & 4.644 & TRN \\
\hline CHEMBL 3431861 & 1479043 & 5.1821 & 4.3572 & TRN \\
\hline CHEMBL3431647 & 1479043 & 4.7805 & 4.6344 & TRN \\
\hline CHEMBL 3431507 & 1479043 & 3.0 & 2.7082 & TST \\
\hline CHEMBL 3431882 & 1479043 & 3.0 & 2.7498 & TRN \\
\hline CHEMBL3431915 & 1479043 & 5.3637 & 5.1587 & TRN \\
\hline CHEMBL 3431582 & 1479043 & 4.2015 & 3.6805 & TRN \\
\hline CHEMBL 3431870 & 1479043 & 4.0992 & 3.1146 & TRN \\
\hline CHEMBL 3431829 & 1479043 & 4.5666 & 4.0917 & TRN \\
\hline CHEMBL 3431857 & 1479043 & 3.0 & 3.7244 & TRN \\
\hline CHEMBL 3431751 & 1479043 & 3.0 & 4.3285 & TRN \\
\hline CHEMBL 3431605 & 1479043 & 6.4624 & 5.3125 & TRN \\
\hline CHEMBL3431692 & 1479043 & 5.4314 & 4.9295 & TRN \\
\hline CHEMBL 3431701 & 1479043 & 3.0 & 3.0127 & TRN \\
\hline CHEMBL 3431664 & 1479043 & 3.0 & 2.95399 & 99999999997 \\
\hline CHEMBL 3431511 & 1479043 & 3.0 & 2.8643 & TRN \\
\hline CHEMBL3431825 & 1479043 & 4.1705 & 3.4985 & TRN \\
\hline CHEMBL 3431690 & 1479043 & 3.0 & 2.9225 & TRN \\
\hline CHEMBL3431564 & 1479043 & 3.0 & 3.286 & TST \\
\hline CHEMBL 3431461 & 1479043 & 3.0 & 2.7293 & TRN \\
\hline CHEMBL 3431478 & 1479043 & 5.7317 & 4.6589 & TRN \\
\hline CHEMBL3431669 & 1479043 & 3.0 & 2.8683 & TST \\
\hline CHEMBL 3431887 & 1479043 & 3.0 & 2.74300 & 0000000003 \\
\hline CHEMBL 3431602 & 1479043 & 6.1648 & 5.435 & TRN \\
\hline CHEMBL 3431868 & 1479043 & 4.0543 & 3.7663 & TRN \\
\hline CHEMBL 3431730 & 1479043 & 5.7943 & 5.129 & TRN \\
\hline CHEMBL 3431514 & 1479043 & 3.0 & 3.5646 & TST \\
\hline CHEMBL 3431889 & 1479043 & 3.0 & 2.8589 & TRN \\
\hline CHEMBL3431559 & 1479043 & 3.0 & 3.5266 & TRN \\
\hline CHEMBL3431765 & 1479043 & 4.9757 & 4.6796 & TRN \\
\hline CHEMBL 3431867 & 1479043 & 3.0 & 2.9175 & TRN \\
\hline CHEMBL 3431843 & 1479043 & 5.3625 & 4.6854 & TST \\
\hline CHEMBL3431522 & 1479043 & 5.9713 & 4.6189 & TST \\
\hline CHEMBL3431527 & 1479043 & 4.4002 & 3.7961 & TRN \\
\hline CHEMBL3431896 & 1479043 & 4.9782 & 4.8914 & TRN \\
\hline CHEMBL 3431515 & 1479043 & 4.4232 & 3.8872 & TRN \\
\hline CHEMBL3431537 & 1479043 & 4.8241 & 3.6159 & TRN \\
\hline CHEMBL 3431483 & 1479043 & 3.0 & 3.6931 & TRN \\
\hline CHEMBL 3431797 & 1479043 & 3.0 & 2.7245 & TST \\
\hline CHEMBL3431688 & 1479043 & 3.0 & 3.7016 & TRN \\
\hline CHEMBL 3431542 & 1479043 & 4.7172 & 3.8207 & TRN \\
\hline CHEMBL 3431804 & 1479043 & 3.0 & 3.2776 & TRN \\
\hline CHEMBL 3431693 & 1479043 & 3.0 & 3.4054 & TST \\
\hline CHEMBL 3431735 & 1479043 & 6.3049 & 5.2861 & TRN \\
\hline CHEMBL 3431725 & 1479043 & 3.0 & 3.1668 & TST \\
\hline
\end{tabular}




\begin{tabular}{|c|c|c|c|c|c|}
\hline \multicolumn{6}{|c|}{ Supplemental Table S2.txt } \\
\hline CHEMBL 3431718 & 1479043 & 3.0 & 2.807 & TRN & \\
\hline CHEMBL3431581 & 1479043 & 3.0 & 3.6967 & TRN & \\
\hline CHEMBL3431694 & 1479043 & 5.1647 & 4.4728 & TST & \\
\hline CHEMBL 3431665 & 1479043 & 3.0 & 3.8378 & TRN & \\
\hline CHEMBL3431666 & 1479043 & 4.1011 & 4.2313 & TRN & \\
\hline CHEMBL 3431493 & 1479043 & 3.0 & 3.9828 & TRN & \\
\hline CHEMBL3431533 & 1479043 & 3.0 & 2.9197 & TST & \\
\hline CHEMBL3431506 & 1479043 & 4.5518 & 4.24 & TST & \\
\hline CHEMBL3431496 & 1479043 & 4.1973 & 3.9427 & TRN & \\
\hline CHEMBL3431540 & 1479043 & 4.2718 & 3.9209 & TRN & \\
\hline CHEMBL 3431749 & 1479043 & 3.0 & 3.0094 & TRN & \\
\hline CHEMBL 3431468 & 1479043 & 3.0 & 2.9746 & TRN & \\
\hline CHEMBL 3431742 & 1479043 & 3.0 & 3.7223 & TST & \\
\hline CHEMBL3431539 & 1479043 & 3.0 & 3.5376 & TST & \\
\hline CHEMBL3431928 & 1479043 & 3.0 & 2.8103 & TRN & \\
\hline CHEMBL3431671 & 1479043 & 3.0 & 2.78899 & 99999999997 & TST \\
\hline CHEMBL3431481 & 1479043 & 3.0 & 3.9844 & TRN & \\
\hline CHEMBL 3431552 & 1479043 & 4.992 & 4.6981 & TRN & \\
\hline CHEMBL3431521 & 1479043 & 3.0 & 4.0141 & TST & \\
\hline CHEMBL3431732 & 1479043 & 4.3408 & 4.725 & TST & \\
\hline CHEMBL3431530 & 1479043 & 4.0818 & 3.9256 & TRN & \\
\hline CHEMBL3431832 & 1479043 & 3.0 & 2.9124 & TRN & \\
\hline CHEMBL 3431818 & 1479043 & 3.0 & 2.7417 & TST & \\
\hline CHEMBL3431748 & 1479043 & 3.0 & 3.0661 & TRN & \\
\hline CHEMBL 3431769 & 1479043 & 3.0 & 3.7782 & TRN & \\
\hline CHEMBL3431908 & 1479043 & 3.0 & 3.2761 & TRN & \\
\hline CHEMBL 3431768 & 1479043 & 3.0 & 2.9142 & TST & \\
\hline CHEMBL 3431840 & 1479043 & 3.0 & 3.0457 & TST & \\
\hline CHEMBL3431859 & 1479043 & 4.1235 & 4.0002 & TRN & \\
\hline CHEMBL3431761 & 1479043 & 3.0 & 3.6939 & TRN & \\
\hline CHEMBL 3431489 & 1479043 & 3.0 & 3.1713 & TRN & \\
\hline CHEMBL 3431494 & 1479043 & 4.0461 & 3.9946 & TRN & \\
\hline CHEMBL 3431572 & 1479043 & 4.4539 & 3.7745 & TRN & \\
\hline CHEMBL3431645 & 1479043 & 3.0 & 3.2304 & TRN & \\
\hline CHEMBL3431630 & 1479043 & 5.1885 & 4.9354 & TST & \\
\hline CHEMBL3431672 & 1479043 & 3.0 & 2.91 & TRN & \\
\hline CHEMBL3431580 & 1479043 & 4.0883 & 3.3574 & TST & \\
\hline CHEMBL 3431821 & 1479043 & 3.0 & 2.7511 & TRN & \\
\hline CHEMBL3431717 & 1479043 & 3.0 & 2.89600 & 00000000004 & TRN \\
\hline CHEMBL3431467 & 1479043 & 3.0 & 2.9334 & TRN & \\
\hline CHEMBL3431553 & 1479043 & 3.0 & 3.4381 & TRN & \\
\hline CHEMBL3431736 & 1479043 & 6.2686 & 5.3066 & TST & \\
\hline CHEMBL3431662 & 1479043 & 3.0 & 2.6912 & TST & \\
\hline CHEMBL3431696 & 1479043 & 3.0 & 3.9973 & TST & \\
\hline CHEMBL3431836 & 1479043 & 3.0 & 2.7171 & TRN & \\
\hline CHEMBL3431779 & 1479043 & 3.0 & 2.708 & TST & \\
\hline CHEMBL 3431475 & 1479043 & 3.0 & 3.8138 & TRN & \\
\hline CHEMBL3431629 & 1479043 & 5.4836 & 4.6981 & TST & \\
\hline
\end{tabular}


Supplemental Table S2.txt

\begin{tabular}{|c|c|c|c|c|c|}
\hline CHEMBL3431661 & 1479043 & 3.0 & 2.9277 & TRN & \\
\hline CHEMBL 3431747 & 1479043 & 3.0 & 3.772 & TRN & \\
\hline CHEMBL3431541 & 1479043 & 3.0 & 3.0319 & TST & \\
\hline CHEMBL3431721 & 1479043 & 3.0 & 3.3798 & TRN & \\
\hline CHEMBL3431573 & 1479043 & 4.6315 & 4.59 & TRN & \\
\hline CHEMBL3431904 & 1479043 & 3.0 & 4.0407 & TRN & \\
\hline CHEMBL3431642 & 1479043 & 5.6023 & 4.8161 & TRN & \\
\hline CHEMBL3431793 & 1479043 & 5.5817 & 4.9005 & TST & \\
\hline CHEMBL3431777 & 1479043 & 6.5367 & 5.1598 & TST & \\
\hline CHEMBL3431918 & 1479043 & 5.2814 & 4.7951 & TRN & \\
\hline CHEMBL3431570 & 1479043 & 4.1333 & 3.6339 & TRN & \\
\hline CHEMBL3431733 & 1479043 & 5.5453 & 5.004 & TST & \\
\hline CHEMBL3431592 & 1479043 & 4.0522 & 3.034 & TRN & \\
\hline CHEMBL3431574 & 1479043 & 4.6787 & 4.5562 & TRN & \\
\hline CHEMBL3431681 & 1479043 & 3.0 & 2.8374 & TST & \\
\hline CHEMBL3431924 & 1479043 & 3.0 & 2.7562 & TRN & \\
\hline CHEMBL3431658 & 1479043 & 3.0 & 3.7587 & TST & \\
\hline CHEMBL3431612 & 1479043 & 4.3326 & 4.229 & TRN & \\
\hline CHEMBL3431848 & 1479043 & 3.0 & 4.4744 & TRN & \\
\hline CHEMBL3431466 & 1479043 & 3.0 & 3.6705 & TRN & \\
\hline CHEMBL3431784 & 1479043 & 3.0 & 2.7812 & TST & \\
\hline CHEMBL 3431743 & 1479043 & 4.2417 & 3.8988 & TST & \\
\hline CHEMBL3431492 & 1479043 & 3.0 & 3.9353 & TRN & \\
\hline CHEMBL3431643 & 1479043 & 4.4736 & 3.9647 & TRN & \\
\hline CHEMBL3431505 & 1479043 & 3.0 & 2.8804 & TRN & \\
\hline CHEMBL3431710 & 1479043 & 3.0 & 3.5298 & TST & \\
\hline CHEMBL3431764 & 1479043 & 5.0438 & 4.8184 & TRN & \\
\hline CHEMBL3431828 & 1479043 & 3.0 & 2.7461 & TRN & \\
\hline CHEMBL3431619 & 1479043 & 3.0 & 3.0754 & TRN & \\
\hline CHEMBL 2216779 & 1479043 & 5.1067 & 4.9072 & TRN & \\
\hline CHEMBL3431831 & 1479043 & 3.0 & 2.7568 & TRN & \\
\hline CHEMBL3431621 & 1479043 & 3.0 & 2.7537 & TRN & \\
\hline CHEMBL3431535 & 1479043 & 5.5444 & 4.6743 & TRN & \\
\hline CHEMBL3431700 & 1479043 & 3.0 & 3.4052 & TRN & \\
\hline CHEMBL3431879 & 1479043 & 3.0 & 2.9058 & TRN & \\
\hline CHEMBL3431686 & 1479043 & 3.0 & 2.8843 & TST & \\
\hline CHEMBL3431653 & 1479043 & 3.0 & 3.9841 & TRN & \\
\hline CHEMBL3431656 & 1479043 & 3.0 & 3.1562 & TST & \\
\hline CHEMBL3431534 & 1479043 & 3.0 & 2.8923 & TRN & \\
\hline CHEMBL3431913 & 1479043 & $5.2410 e$ & 0000000 & 005 & 4.9118 \\
\hline CHEMBL3431787 & 1479043 & 3.0 & 2.7607 & TRN & \\
\hline CHEMBL3431513 & 1479043 & 3.0 & 2.9379 & TST & \\
\hline CHEMBL3431873 & 1479043 & 3.0 & 3.2209 & TRN & \\
\hline CHEMBL3431702 & 1479043 & 3.0 & 3.1176 & TRN & \\
\hline CHEMBL3431853 & 1479043 & 3.0 & 3.6832 & TRN & \\
\hline CHEMBL3431850 & 1479043 & 4.3685 & 4.7121 & TRN & \\
\hline CHEMBL3431809 & 1479043 & 3.0 & 3.0007 & TRN & \\
\hline CHEMBL3431781 & 1479043 & 3.0 & 2.8062 & TST & \\
\hline
\end{tabular}


Supplemental Table S2.txt

\begin{tabular}{|c|c|c|c|c|c|}
\hline CHEMBL 2216774 & 1479043 & 4.5129 & \multicolumn{2}{|c|}{4.2330000000000005} & TRN \\
\hline CHEMBL3431851 & 1479043 & 3.0 & 4.2511 & TRN & \\
\hline CHEMBL3431927 & 1479043 & 3.0 & 2.8794 & TRN & \\
\hline CHEMBL 3431814 & 1479043 & 3.0 & 2.7309 & TRN & \\
\hline CHEMBL3431709 & 1479043 & 4.1061 & 3.7566 & TST & \\
\hline CHEMBL 3431673 & 1479043 & 3.0 & 3.5052 & TRN & \\
\hline CHEMBL3431528 & 1479043 & 3.0 & 3.0858 & TRN & \\
\hline CHEMBL3431634 & 1479043 & 3.0 & 2.8023 & TRN & \\
\hline CHEMBL3431895 & 1479043 & 3.0 & 4.4111 & TRN & \\
\hline CHEMBL3431722 & 1479043 & 3.0 & 2.8633 & TRN & \\
\hline CHEMBL3431902 & 1479043 & 3.0 & 4.0429 & TRN & \\
\hline CHEMBL3431846 & 1479043 & 3.0 & 3.0015 & TRN & \\
\hline CHEMBL3431628 & 1479043 & 5.5732 & 4.9626 & TST & \\
\hline CHEMBL3431776 & 1479043 & 6.0173 & 4.8767 & TST & \\
\hline CHEMBL3431919 & 1479043 & 5.291 & 4.5706 & TRN & \\
\hline CHEMBL3431488 & 1479043 & 3.0 & 4.0626 & TRN & \\
\hline CHEMBL3431682 & 1479043 & 3.0 & 3.4069 & TST & \\
\hline CHEMBL3431639 & 1479043 & 4.3846 & 3.7196 & TST & \\
\hline CHEMBL3431758 & 1479043 & 3.0 & 2.9968 & TRN & \\
\hline CHEMBL3431796 & 1479043 & 3.0 & \multicolumn{2}{|c|}{4.8260000000000005} & TST \\
\hline CHEMBL3431465 & 1479043 & 3.0 & \multicolumn{2}{|c|}{ 3.6239999999999997 } & TRN \\
\hline CHEMBL3431517 & 1479043 & 3.0 & 3.2091 & TRN & \\
\hline CHEMBL3431695 & 1479043 & 3.0 & 3.1015 & TST & \\
\hline CHEMBL3431905 & 1479043 & 3.0 & 4.1199 & TRN & \\
\hline CHEMBL3431716 & 1479043 & 3.0 & 3.8662 & TRN & \\
\hline CHEMBL3431545 & 1479043 & 4.3673 & 3.779 & TRN & \\
\hline CHEMBL3431876 & 1479043 & 3.0 & 4.1074 & TRN & \\
\hline CHEMBL3431615 & 1479043 & 3.0 & 3.1142 & TRN & \\
\hline CHEMBL3431697 & 1479043 & 3.0 & 3.699 & TST & \\
\hline CHEMBL3431565 & 1479043 & 4.2108 & 4.0098 & TRN & \\
\hline CHEMBL3431734 & 1479043 & 5.5728 & 4.9877 & TST & \\
\hline CHEMBL3431667 & 1479043 & 5.1177 & 4.1114 & TRN & \\
\hline CHEMBL3431911 & 1479043 & 3.0 & 3.1386 & TST & \\
\hline CHEMBL3431727 & 1479043 & 3.0 & 2.6901 & TRN & \\
\hline CHEMBL3431469 & 1479043 & 3.0 & 2.9652 & TRN & \\
\hline CHEMBL3431698 & 1479043 & 4.4468 & 4.0872 & TST & \\
\hline CHEMBL3431739 & 1479043 & 6.1542 & 5.3333 & TST & \\
\hline CHEMBL3431774 & 1479043 & 5.4749 & 5.0536 & TST & \\
\hline CHEMBL3431914 & 1479043 & 4.5496 & 4.9128 & TRN & \\
\hline CHEMBL3431838 & 1479043 & 3.0 & 2.7272 & TRN & \\
\hline CHEMBL3431760 & 1479043 & 3.0 & \multicolumn{2}{|c|}{3.7310000000000003} & TRN \\
\hline CHEMBL3431477 & 1479043 & 3.0 & 3.1791 & TRN & \\
\hline CHEMBL3431775 & 1479043 & 5.5829 & 4.9073 & TST & \\
\hline CHEMBL3431894 & 1479043 & 5.6742 & \multicolumn{2}{|c|}{4.8660000000000005} & TRN \\
\hline CHEMBL3431874 & 1479043 & 3.0 & 2.9414 & TRN & \\
\hline CHEMBL3431546 & 1479043 & 4.1416 & 4.2869 & TRN & \\
\hline CHEMBL3431586 & 1479043 & 3.0 & 3.75 & TST & \\
\hline CHEMBL3431762 & 1479043 & 3.0 & 2.9875 & TST & \\
\hline
\end{tabular}


Supplemental Table S2.txt

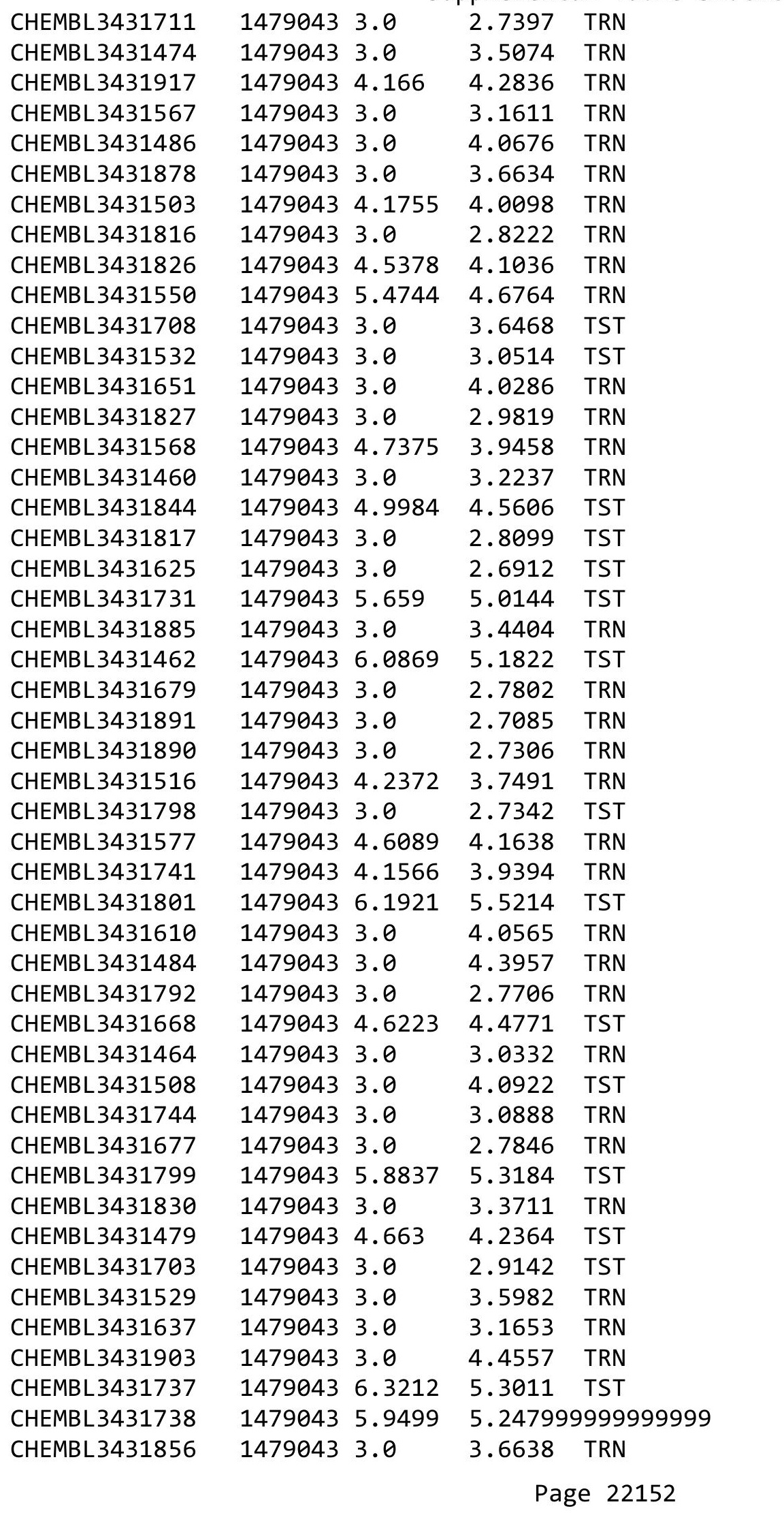


Supplemental Table S2.txt

\begin{tabular}{|c|c|c|c|c|c|}
\hline CHEMBL3431823 & 1479043 & 3.0 & 2.7848 & TST & \\
\hline CHEMBL3431819 & 1479043 & 3.0 & 3.4909 & TRN & \\
\hline CHEMBL3431558 & 1479043 & 4.029 & 3.7054 & TRN & \\
\hline CHEMBL3431753 & 1479043 & 3.0 & 2.8007 & TRN & \\
\hline CHEMBL3431871 & 1479043 & 3.0 & 2.9979 & TST & \\
\hline CHEMBL3431620 & 1479043 & 4.0252 & 3.6843 & TRN & \\
\hline CHEMBL3431712 & 1479043 & 3.0 & 2.8786 & TRN & \\
\hline CHEMBL3431547 & 1479043 & 4.6478 & 4.2532 & TRN & \\
\hline CHEMBL3431892 & 1479043 & 3.0 & 3.8232 & TRN & \\
\hline CHEMBL3431470 & 1479043 & 3.0 & 2.7419 & TRN & \\
\hline CHEMBL 3431714 & 1479043 & 4.2314 & 4.16 & TRN & \\
\hline CHEMBL 3431740 & 1479043 & 3.0 & 2.6945 & TST & \\
\hline CHEMBL3431587 & 1479043 & 4.7969 & 4.5094 & TRN & \\
\hline CHEMBL3431576 & 1479043 & 3.0 & 3.2205 & TRN & \\
\hline CHEMBL3431500 & 1479043 & 3.0 & $2.91300 t$ & 00000000003 & TRN \\
\hline CHEMBL3431471 & 1479043 & 3.0 & 2.7232 & TRN & \\
\hline CHEMBL3431875 & 1479043 & 3.0 & 3.0981 & TRN & \\
\hline CHEMBL3431920 & 1479043 & 3.0 & 3.5732 & TRN & \\
\hline CHEMBL3431680 & 1479043 & 3.0 & 2.9437 & TRN & \\
\hline CHEMBL3431556 & 1479043 & 3.0 & 2.9219 & TRN & \\
\hline CHEMBL3431636 & 1479043 & 3.0 & 3.0874 & TST & \\
\hline CHEMBL3431854 & 1479043 & 3.0 & 3.8266 & TRN & \\
\hline CHEMBL3431925 & 1479043 & 3.0 & 2.74 & TRN & \\
\hline CHEMBL3431659 & 1479043 & 4.255 & 4.3912 & TRN & \\
\hline CHEMBL3431884 & 1479043 & 3.0 & 2.8664 & TRN & \\
\hline CHEMBL3431655 & 1479043 & 3.0 & 3.8952 & TRN & \\
\hline CHEMBL3431583 & 1479043 & 4.1267 & 3.7833 & TRN & \\
\hline CHEMBL3431536 & 1479043 & 4.4366 & 4.0999 & TRN & \\
\hline CHEMBL3431778 & 1479043 & 5.895 & 5.136 & TST & \\
\hline CHEMBL3431622 & 1479043 & 3.0 & 2.842 & TRN & \\
\hline CHEMBL3431705 & 1479043 & 3.0 & 2.9616 & TST & \\
\hline CHEMBL3431810 & 1479043 & 4.5009 & 4.0697 & TRN & \\
\hline CHEMBL3431898 & 1479043 & 5.4111 & 5.0794 & TRN & \\
\hline CHEMBL3431852 & 1479043 & 3.0 & 3.1278 & TRN & \\
\hline CHEMBL3431501 & 1479043 & 3.0 & 3.167 & TRN & \\
\hline CHEMBL3431614 & 1479043 & 3.0 & 2.9649 & TRN & \\
\hline CHEMBL3431675 & 1479043 & 3.0 & 2.9039 & TRN & \\
\hline CHEMBL3431772 & 1479043 & 3.0 & 3.8673 & TRN & \\
\hline CHEMBL3431811 & 1479043 & 4.7086 & 4.7187 & TST & \\
\hline CHEMBL3431864 & 1479043 & 3.0 & 3.1516 & TRN & \\
\hline CHEMBL3431723 & 1479043 & 3.0 & 2.9449 & TST & \\
\hline CHEMBL3431555 & 1479043 & 4.3723 & 4.5664 & TST & \\
\hline CHEMBL3431860 & 1479043 & 3.0 & 3.0496 & TRN & \\
\hline CHEMBL3431638 & 1479043 & 3.0 & 2.718 & TRN & \\
\hline CHEMBL3431472 & 1479043 & 3.0 & 3.4354 & TRN & \\
\hline CHEMBL3431660 & 1479043 & 3.0 & 3.911 & TRN & \\
\hline CHEMBL3431603 & 1479043 & 3.0 & 4.215 & TRN & \\
\hline CHEMBL3431791 & 1479043 & 3.0 & 2.7649 & TRN & \\
\hline
\end{tabular}


Supplemental Table S2.txt

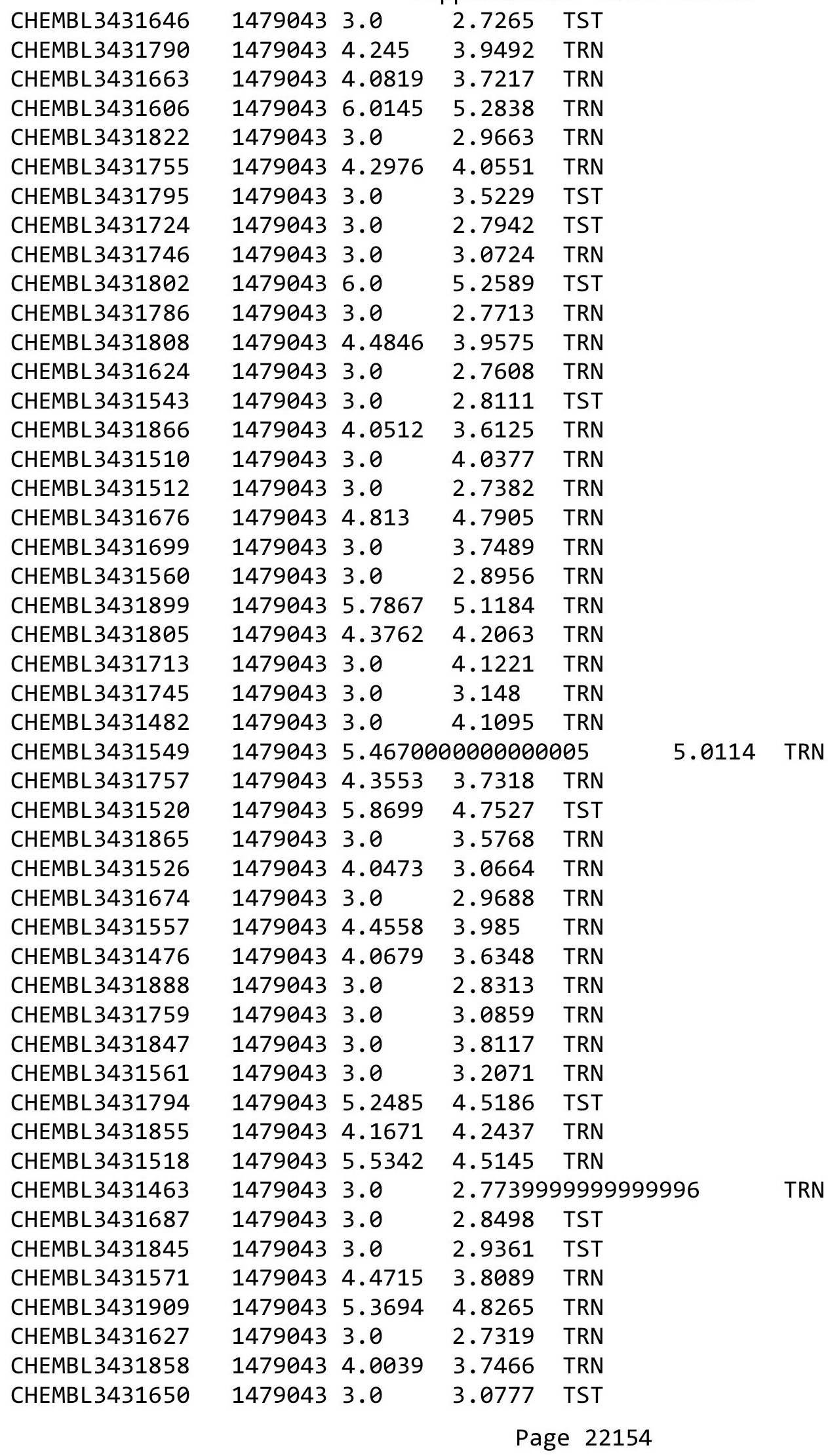




$$
\text { Supplemental Table S2.txt }
$$

\begin{tabular}{|c|c|c|c|c|c|}
\hline CHEMBL3431569 & 1479043 & 4.1546 & 3.8469 & TRN & \\
\hline CHEMBL3431670 & 1479043 & 3.0 & 3.8564 & TRN & \\
\hline CHEMBL3431842 & 1479043 & 3.0 & 2.8746 & TST & \\
\hline CHEMBL3431835 & 1479043 & 3.0 & 2.8658 & TRN & \\
\hline CHEMBL3431715 & 1479043 & 3.0 & 3.1344 & TRN & \\
\hline CHEMBL3431538 & 1479043 & 3.0 & 2.8655 & TST & \\
\hline CHEMBL3431640 & 1479043 & 3.0 & 3.083 & TRN & \\
\hline CHEMBL3946595 & 1640610 & 3.0 & 4.6842 & TRN & \\
\hline CHEMBL 3974524 & 1640610 & 5.4949 & 5.2879 & TRN & \\
\hline CHEMBL3962837 & 1640610 & 8.301 & 8.0934 & TRN & \\
\hline CHEMBL3960569 & 1640610 & 4.7932 & 5.4618 & TRN & \\
\hline CHEMBL3948316 & 1640610 & 6.301 & 5.6511 & TRN & \\
\hline CHEMBL3901049 & 1640610 & 7.5229 & 7.1275 & TRN & \\
\hline CHEMBL 3948596 & 1640610 & 6.0 & 6.615 & TST & \\
\hline CHEMBL3975892 & 1640610 & 5.0223 & 4.8348 & TRN & \\
\hline CHEMBL3956613 & 1640610 & 8.3979 & 7.6926 & TRN & \\
\hline CHEMBL3951353 & 1640610 & 5.0 & 5.1926 & TRN & \\
\hline CHEMBL3918116 & 1640610 & 5.0 & 5.3738 & TRN & \\
\hline CHEMBL3920645 & 1640610 & 8.301 & 8.0545 & TRN & \\
\hline CHEMBL3964038 & 1640610 & 8.2218 & 7.6879 & TRN & \\
\hline CHEMBL3959131 & 1640610 & 7.6021 & 8.8573 & TST & \\
\hline CHEMBL3973157 & 1640610 & 5.9586 & 5.91299 & 9999999999 & TRN \\
\hline CHEMBL3943510 & 1640610 & 5.7696 & 5.5769 & TRN & \\
\hline CHEMBL 3940755 & 1640610 & 4.4634 & 5.1584 & TRN & \\
\hline CHEMBL3917856 & 1640610 & 4.98300 & 000000006 & 4.7363 & TRN \\
\hline CHEMBL3892644 & 1640610 & 8.5229 & 8.4093 & TRN & \\
\hline CHEMBL 3958292 & 1640610 & 6.9208 & 6.603 & TRN & \\
\hline CHEMBL3984237 & 1640610 & 7.9586 & 7.7505 & TRN & \\
\hline CHEMBL3896631 & 1640610 & 6.0 & 5.7005 & TRN & \\
\hline CHEMBL3955939 & 1640610 & 5.0 & 6.3993 & TRN & \\
\hline CHEMBL3896186 & 1640610 & 5.8539 & 5.4959 & TRN & \\
\hline CHEMBL 3972505 & 1640610 & 4.5702 & 6.0813 & TST & \\
\hline CHEMBL3922363 & 1640610 & 6.3468 & 5.9489 & TRN & \\
\hline CHEMBL 3972032 & 1640610 & 4.1798 & 4.9271 & TRN & \\
\hline CHEMBL3358112 & 1640610 & 7.7959 & 7.483 & TRN & \\
\hline CHEMBL3919528 & 1640610 & 4.279 & 4.891 & TRN & \\
\hline CHEMBL 3963287 & 1640610 & 7.699 & 7.6313 & TRN & \\
\hline CHEMBL3962021 & 1640610 & 8.2218 & 8.5101 & TRN & \\
\hline CHEMBL 3976191 & 1640610 & 6.7905 & 7.4478 & TRN & \\
\hline CHEMBL3962167 & 1640610 & 5.8239 & 5.5063 & TRN & \\
\hline CHEMBL3941256 & 1640610 & 5.8539 & 5.4702 & TRN & \\
\hline CHEMBL 3967171 & 1640610 & 8.2218 & 7.8057 & TRN & \\
\hline CHEMBL3925626 & 1640610 & 6.4437 & 5.1521 & TRN & \\
\hline CHEMBL 3900540 & 1640610 & 4.9172 & 5.1549 & TRN & \\
\hline CHEMBL3983207 & 1640610 & 5.699 & 5.8901 & TRN & \\
\hline CHEMBL3926019 & 1640610 & 5.3279 & 4.8208 & TRN & \\
\hline CHEMBL3965395 & 1640610 & 7.7959 & 9.6408 & TST & \\
\hline CHEMBL3910013 & 1640610 & 5.3468 & 5.153 & TRN & \\
\hline
\end{tabular}


Supplemental Table S2.txt

\begin{tabular}{|c|c|c|c|c|c|}
\hline CHEMBL 3357703 & 1640610 & 8.5229 & 8.9573 & TST & \\
\hline CHEMBL3961717 & 1640610 & 5.8861 & 6.2361 & TRN & \\
\hline CHEMBL3910690 & 1640610 & 6.0655 & 5.5679 & TRN & \\
\hline CHEMBL 3939644 & 1640610 & 8.0 & 8.0449 & TRN & \\
\hline CHEMBL3901668 & 1640610 & 7.9586 & 8.8114 & TRN & \\
\hline CHEMBL3982534 & 1640610 & 4.2924 & 4.1725 & TST & \\
\hline CHEMBL3960648 & 1640610 & 7.699 & 6.5644 & TRN & \\
\hline CHEMBL3943401 & 1640610 & 3.0 & 3.8958 & TRN & \\
\hline CHEMBL 3947389 & 1640610 & 5.3768 & 5.8725 & TRN & \\
\hline CHEMBL3895183 & 1640610 & 3.0 & 4.2692 & TST & \\
\hline CHEMBL3918165 & 1640610 & 8.301 & 8.0859 & TRN & \\
\hline CHEMBL3932603 & 1640610 & 6.3665 & 6.2021 & TRN & \\
\hline CHEMBL3919591 & 1640610 & 5.6021 & 4.9519 & TRN & \\
\hline CHEMBL3911002 & 1640610 & 8.0969 & 8.3283 & TRN & \\
\hline CHEMBL3961187 & 1640610 & 8.3979 & 8.8858 & TRN & \\
\hline CHEMBL3973037 & 1640610 & 7.301 & 8.8649 & TST & \\
\hline CHEMBL3932240 & 1640610 & 5.5686 & 5.9576 & TRN & \\
\hline CHEMBL 3899113 & 1640610 & 6.0 & 6.4686 & TRN & \\
\hline CHEMBL 3984926 & 1640610 & 6.0132 & 5.6909 & TRN & \\
\hline CHEMBL3973658 & 1640610 & 6.6778 & 6.247000 & 2000000001 & TRN \\
\hline CHEMBL 3924944 & 1640610 & 6.7696 & 6.4961 & TRN & \\
\hline CHEMBL3918312 & 1640610 & 5.0 & 4.9676 & TRN & \\
\hline CHEMBL3908790 & 1640610 & 4.699 & 4.4485 & TST & \\
\hline CHEMBL 3938379 & 1640610 & 5.2218 & 5.7469 & TRN & \\
\hline CHEMBL3921898 & 1640610 & 5.7212 & 5.6097 & TRN & \\
\hline CHEMBL 3925632 & 1640610 & 8.3979 & 8.6741 & TRN & \\
\hline CHEMBL3935742 & 1640610 & 6.1739 & 6.1109 & TRN & \\
\hline CHEMBL3977065 & 1640610 & 6.4437 & 6.1289 & TRN & \\
\hline CHEMBL 3955664 & 1640610 & 8.5229 & 7.09 & TRN & \\
\hline CHEMBL3982330 & 1640610 & 3.9101 & 5.1272 & TST & \\
\hline CHEMBL 3932827 & 1640610 & 5.2518 & 4.866000 & 00000000005 & TRN \\
\hline CHEMBL3966960 & 1640610 & 6.0 & 5.5456 & TRN & \\
\hline CHEMBL 3895423 & 1640610 & 3.0 & 3.6834 & TST & \\
\hline CHEMBL3960699 & 1640610 & 8.3979 & 9.1382 & TRN & \\
\hline CHEMBL3939608 & 1640610 & 7.9208 & 8.1188 & TRN & \\
\hline CHEMBL 3976624 & 1640610 & 7.1135 & 7.2897 & TRN & \\
\hline CHEMBL3980324 & 1640610 & 6.0 & 6.5511 & TRN & \\
\hline CHEMBL3952070 & 1640610 & 8.5229 & 8.0995 & TRN & \\
\hline CHEMBL 3949204 & 1640610 & 5.6778 & 4.3129 & TRN & \\
\hline CHEMBL3899985 & 1640610 & 5.5528 & 5.6145 & TRN & \\
\hline CHEMBL 3937505 & 1640610 & 5.7447 & 5.8832 & TRN & \\
\hline CHEMBL3956897 & 1640610 & 8.301 & 9.2952 & TRN & \\
\hline CHEMBL3358111 & 1640610 & 8.699 & 8.8129 & TRN & \\
\hline CHEMBL 3946709 & 1640610 & 7.0706 & 8.0459 & TRN & \\
\hline CHEMBL3925406 & 1640610 & 4.9547 & 4.601 & TRN & \\
\hline CHEMBL 3924900 & 1640610 & 5.1938 & 5.4749 & TRN & \\
\hline CHEMBL3925688 & 1640610 & 8.5229 & 8.2532 & TRN & \\
\hline CHEMBL 3925635 & 1640610 & 5.0969 & 4.6344 & TRN & \\
\hline
\end{tabular}


Supplemental Table S2.txt

\begin{tabular}{|c|c|c|c|c|c|}
\hline CHEMBL3961560 & 1640610 & 7.3979 & 7.5472 & TRN & \\
\hline CHEMBL3897905 & 1640610 & 9.0 & 8.1125 & TRN & \\
\hline CHEMBL3983910 & 1640610 & 5.699 & 5.4309 & TRN & \\
\hline CHEMBL 3924504 & 1640610 & 8.301 & 7.6233 & TST & \\
\hline CHEMBL3977548 & 1640610 & 7.9586 & 7.6105 & TRN & \\
\hline CHEMBL3959227 & 1640610 & 6.0 & 6.6718 & TRN & \\
\hline CHEMBL3931275 & 1640610 & 3.0 & 5.1309 & TST & \\
\hline CHEMBL3963401 & 1640610 & 6.0 & 5.1062 & TRN & \\
\hline CHEMBL 3918876 & 1640610 & 7.5686 & 6.7131 & TRN & \\
\hline CHEMBL3972938 & 1640610 & 6.0177 & 5.7019 & TRN & \\
\hline CHEMBL3936245 & 1640610 & 7.585 & 6.9938 & TRN & \\
\hline CHEMBL3927779 & 1640610 & 8.5229 & 7.8996 & TRN & \\
\hline CHEMBL3929834 & 1640610 & 5.3979 & 5.0525 & TRN & \\
\hline CHEMBL 3932409 & 1640610 & 6.8539 & 6.4169 & TRN & \\
\hline CHEMBL3902698 & 1640610 & 4.2076 & 5.1416 & TRN & \\
\hline CHEMBL3946575 & 1640610 & 4.0223 & 3.3852 & TST & \\
\hline CHEMBL3938106 & 1640610 & 5.8539 & 6.865 & TRN & \\
\hline CHEMBL3941368 & 1640610 & 5.1612 & 5.1484 & TRN & \\
\hline CHEMBL3965476 & 1640610 & 6.041 & 4.3707 & TRN & \\
\hline CHEMBL3913730 & 1640610 & 8.301 & 8.4906 & TRN & \\
\hline CHEMBL3977084 & 1640610 & 6.0458 & 6.2992 & TRN & \\
\hline CHEMBL3958873 & 1640610 & 8.5229 & 8.0921 & TRN & \\
\hline CHEMBL3983187 & 1640610 & 4.1612 & 6.1982 & TST & \\
\hline CHEMBL3978128 & 1640610 & 6.1192 & 4.6174 & TRN & \\
\hline CHEMBL3924481 & 1640610 & 5.7959 & 5.4661 & TST & \\
\hline CHEMBL 3907454 & 1640610 & 5.4815 & 4.6046 & TRN & \\
\hline CHEMBL3358115 & 1640610 & 8.5229 & 8.547 & TRN & \\
\hline CHEMBL3936941 & 1640610 & 6.4685 & 6.9866 & TRN & \\
\hline CHEMBL3959734 & 1640610 & 6.5686 & 6.2549 & TRN & \\
\hline CHEMBL3974136 & 1640610 & 6.4437 & 5.8613 & TST & \\
\hline CHEMBL3970518 & 1640610 & 5.9666 & 5.4817 & TRN & \\
\hline CHEMBL3916124 & 1640610 & 9.0 & 8.7477 & TRN & \\
\hline CHEMBL3901961 & 1640610 & 7.0 & 6.9916 & TST & \\
\hline CHEMBL3961420 & 1640610 & 5.284 & $4.60800 t$ & 00000000005 & TRN \\
\hline CHEMBL3909390 & 1640610 & 4.3556 & 4.2164 & TST & \\
\hline CHEMBL3890782 & 1640610 & 8.2218 & 7.7792 & TRN & \\
\hline CHEMBL 3982653 & 1640610 & 7.1549 & 6.2722 & TRN & \\
\hline CHEMBL3961995 & 1640610 & 5.9586 & 5.5325 & TRN & \\
\hline CHEMBL3935642 & 1640610 & 7.699 & 7.1081 & TRN & \\
\hline CHEMBL3970815 & 1640610 & 5.8239 & 4.5693 & TST & \\
\hline CHEMBL3895470 & 1640610 & 6.0 & 5.8641 & TRN & \\
\hline CHEMBL 3890054 & 1640610 & 4.5229 & 3.8449 & TST & \\
\hline CHEMBL3931388 & 1640610 & 8.5229 & 8.6891 & TRN & \\
\hline CHEMBL 3895572 & 1640610 & 8.0 & 7.7689 & TRN & \\
\hline CHEMBL3972803 & 1640610 & 4.3979 & 6.2755 & TRN & \\
\hline CHEMBL3904089 & 1640610 & 8.699 & 8.7 & TRN & \\
\hline CHEMBL3912318 & 1640610 & 8.5229 & 9.0293 & TRN & \\
\hline CHEMBL3941157 & 1640610 & 8.3979 & 8.8183 & TRN & \\
\hline
\end{tabular}


Supplemental Table S2.txt

\begin{tabular}{|c|c|c|c|c|}
\hline . & $\partial 610$ & & & \\
\hline & 640610 & 7.7959 & & \\
\hline 99 & & & & \\
\hline AEMBL 393 & 0610 & & & \\
\hline AEMBL3958811 & 640610 & 8.0 & 2597 & \\
\hline HEMBL3947935 & 640610 & 6.0555 & 6357 & \\
\hline 92 & 510 & & 817 & \\
\hline EMPI 390 & 610 & & & \\
\hline HEMBL392 & 640610 & 8.0 & 5803 & \\
\hline HEMBL396 & 640610 & 8.0 & 8824 & \\
\hline AEMBL394 & 640610 & 8.04 & 8406 & \\
\hline IEMBL39 & 510 & & & \\
\hline AEMBL3: & & & & \\
\hline HEMBL 39 & 640610 & & 5458 & \\
\hline AEMBL396 & 610 & & 196 & \\
\hline AEMBL392 & 10 & 58 & 35 & \\
\hline AEMBL39 & 10 & & 78 & \\
\hline AEMBL39 & & & & \\
\hline HEMBL39 & 640610 & & 8.4978 & \\
\hline AEMBL39 & 610 & 7. & & \\
\hline HEIMBLSS & 10 & 5 & 68 & RIN \\
\hline AEMBL3S & 20 & & 35 & RN \\
\hline HEMBL3S & 10 & & & \\
\hline 512 & 610 & & & \\
\hline AEMBL39 & & & & ISI \\
\hline HEMBL3S & 10 & & 1004 & I RN \\
\hline HEMBL3 & 10 & & 949 & וד \\
\hline HFMBI 36 & 10 & & 38 & \\
\hline HEMBL 39 & & & & $\ln$ \\
\hline HEMBL 398 & 10 & 8.5229 & & 15 \\
\hline HEMBL39 & 10 & 3 & 305 & RN \\
\hline HEMBL; & & & & RN \\
\hline AFMP & 10 & 6 & 96 & TRN \\
\hline HEMBL389 & & & & $\mathrm{IR}$ \\
\hline HEMBL3931524 & 510 & & 818 & TST \\
\hline HEMBL39 & 10 & & 473 & TRN \\
\hline HFMRI 3 & 10 & & 76 & RN \\
\hline HEMBL3 & & 8.0969 & 8.4139 & ГST \\
\hline HEMBL 391 & 610 & 3. & 233 & $\Gamma \mathrm{RN}$ \\
\hline HEMBL 396 & 10 & & 61 & TRN \\
\hline HEMBL 393 & 10 & & 308 & \\
\hline HEMBL 392 & & & & NIV \\
\hline HEMBL395 & 610 & 6.9208 & 417 & RN \\
\hline HEMBL389 & 640610 & 8.5229 & 5691 & TR \\
\hline MBL39 & & & & \\
\hline HEMBL 39 & 10 & .5702 & 4964 & \\
\hline CHEMBL 392 & & 4.3768 & .9572 & \\
\hline CHEMBL3893567 & 1640610 & 8.2218 & 8.5463 & \\
\hline
\end{tabular}

Page 22158 
Supplemental Table S2.txt

\begin{tabular}{|c|c|c|c|c|}
\hline 307 & 640610 & & & TR \\
\hline HEMBL3921265 & 640610 & & 6.7812 & \\
\hline & 610 & & & \\
\hline 204 & 610 & & & \\
\hline 53755 & 640610 & 3.0 & & \\
\hline IEMBL 3909209 & 640610 & 6.0 & 393 & \\
\hline EMBL3968535 & 610 & & & \\
\hline 512 & 610 & & & \\
\hline EMBL3932214 & 640610 & & & \\
\hline AEMBL3942893 & 640610 & 7.5528 & & \\
\hline AEMBL3935267 & 640610 & 8.1549 & J & \\
\hline EMBL3908370 & 610 & 49 & 54 & \\
\hline 3587 & 510 & & & \\
\hline IEMBL 3934303 & 610 & 5.7696 & & \\
\hline IEMBL3933420 & 640610 & 7.7447 & & \\
\hline IEMBL 3946640 & 610 & & 58 & \\
\hline IEMBL3358114 & 510 & . & & \\
\hline IEMBL 3902674 & 510 & & & \\
\hline IEMBL 3900986 & 610 & 6 & & \\
\hline 357701 & 610 & & & \\
\hline IEMBL 3980541 & 610 & 6 & & \\
\hline EMBL3900805 & 10 & ה כמ & & \\
\hline EMBL3954901 & 10 & & & \\
\hline 131 & 510 & 2147 & & \\
\hline 750 & 10 & & & \\
\hline MBL 3929549 & 510 & 5 & 59 & $\mathrm{RI}$ \\
\hline 3653 & 10 & 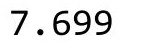 & & \\
\hline 559 & 10 & & & \\
\hline & 510 & & & \\
\hline EMBL3 & 10 & & & \\
\hline MBL 3904856 & 610 & 5.22 & & RI \\
\hline 5099 & 10 & & & . \\
\hline 917 & 10 & & & \\
\hline & & & & \\
\hline IEMBL 3946377 & 610 & 5.4202 & 22 & RI \\
\hline MBL3900458 & 510 & & & $\mathrm{R}$ \\
\hline 2 & 10 & - & & \\
\hline & 10 & & & RN \\
\hline IEMBL3968621 & 640610 & 5.585 & & RI \\
\hline MBL3971768 & 610 & 2 & & $\mathrm{R}$ \\
\hline MBL3937436 & 610 & 33 & & \\
\hline & 610 & & & \\
\hline MBL3930017 & 610 & 5.2076 & 768 & RI \\
\hline MBL3953146 & 640610 & 8.5229 & 326 & $\mathrm{R}$ \\
\hline 97 & 610 & & & \\
\hline MBL3917083 & 640610 & 401 & & \\
\hline CHEMBL3358120 & 640610 & 8.699 & 9.554 & \\
\hline CHEMBL3975680 & 1640610 & 4.3215 & 5.6898 & \\
\hline
\end{tabular}

Page 22159 
Supplemental Table S2.txt

\begin{tabular}{|c|c|c|c|c|}
\hline & & & & \\
\hline HEMBL 3936253 & 640610 & 6.0 & & \\
\hline HEMBL3 & 610 & & & \\
\hline 09 & 610 & 8601 & & \\
\hline 8850 & 610 & & & \\
\hline AEMBL3891533 & 640610 & 3.0 & 888 & 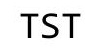 \\
\hline AEMBL3911634 & 640610 & 8.3979 & 953 & \\
\hline HEMBL3963025 & 510 & & & \\
\hline 393 & 610 & .3372 & 618 & 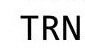 \\
\hline IEMBL: & 610 & .5229 & & $C T$ \\
\hline AEMBL3919250 & 640610 & 6.0 & .9737 & $\mathrm{~N}$ \\
\hline AEMBL3918266 & 610 & & 221 & \\
\hline HEMBL3982847 & 10 & & & \\
\hline 353 & 10 & .69 & & RN \\
\hline 504 & 10 & 8.3979 & & \\
\hline IEMBL: & 610 & 7.2007 & 503 & ST \\
\hline HEMBL3 & 10 & 6.6778 & & ST \\
\hline HEMBL3 & 10 & & & RIV \\
\hline AEMBL & 10 & 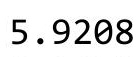 & & $\mathrm{RN}$ \\
\hline 3235 & 10 & 458 & & TST \\
\hline IEMBL & 510 & & 162 & ST \\
\hline IEMBL39 & 10 & 7.72 & & 1 \\
\hline AEMBL: & 10 & 8 & & ST \\
\hline 608 & 10 & 979 & 77 & RN \\
\hline 950 & 10 & 8.0 & 981 & RRN \\
\hline 4202 & 10 & 5 & & RN \\
\hline IEMBL39 & 10 & & & SST \\
\hline 9829 & 10 & & & RN \\
\hline 907 & 10 & & & TST \\
\hline 173 & 10 & 47 & & TRN \\
\hline IEMBL: & 10 & 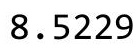 & & TST \\
\hline AEMBL3 & 10 & 6.0655 & & rRN \\
\hline 348 & 10 & & & IST \\
\hline 66 & 10 & & & TRN \\
\hline 4991 & 10 & 7.85 & & rRN \\
\hline AEMBL; & 10 & & & TRN \\
\hline HEMBL] & 510 & & & TST \\
\hline & & 8 & & rRN \\
\hline 212 & 10 & & & TST \\
\hline HEMBL & 610 & 7.61 & 502 & TST \\
\hline AMBL3 & 610 & 7.82 & 532 & rRN \\
\hline 383 & 610 & - & & RN \\
\hline & & & 87 & SST \\
\hline CHEMBL: & 610 & 4.2403 & & rRN \\
\hline CHEMBL 3904229 & 640610 & 5.301 & 6.3528 & rRN \\
\hline HEMBL3935499 & 640610 & 7.301 & 532 & TST \\
\hline CHEMI & & & & TST \\
\hline CHEMBL390414 & L640610 & $-\pi$ & 8.5972 & I RI \\
\hline
\end{tabular}

Page 22160 
Supplemental Table S2.txt

\begin{tabular}{|c|c|c|c|c|c|}
\hline CHEMBL3928322 & 1640610 & 8.0458 & 7.9949 & TRN & \\
\hline CHEMBL 3955480 & 1640610 & 8.301 & 7.3448 & TRN & \\
\hline CHEMBL3982140 & 1640610 & 5.0315 & 5.01 & TRN & \\
\hline CHEMBL 3902870 & 1640610 & 4.8665 & 5.2104 & TRN & \\
\hline CHEMBL3919987 & 1640610 & 5.1805 & 5.4355 & TST & \\
\hline CHEMBL3943528 & 1640610 & 6.1192 & 7.30399 & 999999999 & TRN \\
\hline CHEMBL3900435 & 1640610 & 4.4559 & 6.1137 & TRN & \\
\hline CHEMBL3948239 & 1640610 & 8.0458 & 7.7135 & TRN & \\
\hline CHEMBL3898559 & 1640610 & 4.7328 & 5.3751 & TST & \\
\hline CHEMBL3946215 & 1640610 & 7.3468 & 6.9376 & TRN & \\
\hline CHEMBL3911128 & 1640610 & 6.2147 & 6.6638 & TRN & \\
\hline CHEMBL3897356 & 1640610 & 5.6198 & 6.0972 & TRN & \\
\hline CHEMBL3890420 & 1640610 & 8.0969 & 7.4679 & TRN & \\
\hline CHEMBL3986633 & 1640610 & 8.0 & 7.1636 & TRN & \\
\hline CHEMBL3896984 & 1640610 & 8.5229 & 8.4035 & TST & \\
\hline CHEMBL3919930 & 1640610 & 4.7144 & 3.9326 & TRN & \\
\hline CHEMBL3940545 & 1640610 & 5.2441 & 4.5971 & TRN & \\
\hline CHEMBL3985114 & 1640610 & 9.0 & 7.9374 & TRN & \\
\hline CHEMBL3898035 & 1640610 & 8.301 & 6.9031 & TRN & \\
\hline CHEMBL3950436 & 1640610 & 7.7959 & 7.6215 & TST & \\
\hline CHEMBL3945163 & 1640610 & 7.3979 & 7.0676 & TST & \\
\hline CHEMBL3912803 & 1640610 & 8.2218 & 8.0331 & TRN & \\
\hline CHEMBL3945105 & 1640610 & 5.0044 & 5.3003 & TRN & \\
\hline CHEMBL3904240 & 1640610 & 6.2596 & 4.7635 & TRN & \\
\hline CHEMBL3961299 & 1640610 & 4.3799 & 5.0914 & TST & \\
\hline CHEMBL3969385 & 1640610 & 8.0 & 7.1896 & TRN & \\
\hline CHEMBL3923289 & 1640610 & 8.5229 & 9.0309 & TRN & \\
\hline CHEMBL3927295 & 1640610 & 5.6778 & 5.9566 & TST & \\
\hline CHEMBL3980911 & 1640610 & 5.5528 & \multicolumn{2}{|c|}{5.372999999999999} & TRN \\
\hline CHEMBL3906429 & 1640610 & 4.9318 & 5.2245 & TRN & \\
\hline CHEMBL3938637 & 1640610 & 4.0506 & 5.1572 & TRN & \\
\hline CHEMBL 3905029 & 1640610 & 6.1487 & 6.27 & TRN & \\
\hline CHEMBL3979203 & 1640610 & 8.2218 & 8.6091 & TRN & \\
\hline CHEMBL3942939 & 1640610 & 8.5229 & 7.8562 & TRN & \\
\hline CHEMBL3909950 & 1640610 & 5.0315 & 5.9377 & TST & \\
\hline CHEMBL3952060 & 1640610 & 5.0088 & 4.6811 & TRN & \\
\hline CHEMBL3983994 & 1640610 & 6.9586 & 7.6858 & TRN & \\
\hline CHEMBL3896505 & 1640610 & 4.4949 & 5.5024 & TST & \\
\hline CHEMBL3962947 & 1640610 & 6.3188 & 6.2362 & TRN & \\
\hline CHEMBL3952375 & 1640610 & 7.2218 & 8.0108 & TRN & \\
\hline CHEMBL3974152 & 1640610 & 4.9318 & 5.4529 & TST & \\
\hline CHEMBL3932225 & 1640610 & 8.2218 & 7.3941 & TRN & \\
\hline CHEMBL3937220 & 1640610 & 6.0 & 6.3834 & TRN & \\
\hline CHEMBL3944346 & 1640610 & 5.1308 & 5.5045 & TST & \\
\hline CHEMBL3949990 & 1640610 & 5.1427 & 6.1081 & TRN & \\
\hline CHEMBL3944999 & 1640610 & 8.2218 & 7.9509 & TRN & \\
\hline CHEMBL3953532 & 1640610 & 6.1739 & 5.2392 & TRN & \\
\hline CHEMBL3913358 & 1640610 & 8.0969 & 7.5823 & TRN & \\
\hline
\end{tabular}

Page 22161 
Supplemental Table S2.txt

\begin{tabular}{|c|c|c|c|c|}
\hline CHEMBL 3923265 & 1640610 & 7.8539 & 8.1014 & TST \\
\hline CHEMBL 3955348 & 1640610 & 4.3516 & 4.9406 & TRN \\
\hline CHEMBL3965646 & 1640610 & 5.5686 & 5.0452 & TRN \\
\hline CHEMBL3980953 & 1640610 & 5.3565 & 6.1432 & TRN \\
\hline CHEMBL3970773 & 1640610 & 5.0555 & 5.3419 & TST \\
\hline CHEMBL3933171 & 1640610 & 8.301 & 8.0444 & TRN \\
\hline CHEMBL3357705 & 1640610 & 7.699 & 7.9405 & TST \\
\hline CHEMBL3357706 & 1640610 & 8.5229 & 8.168 & TST \\
\hline CHEMBL3930914 & 1640610 & 6.301 & 5.8335 & TST \\
\hline CHEMBL3974010 & 1640610 & 8.1549 & 7.7252 & TRN \\
\hline CHEMBL 3895030 & 1640610 & 3.0 & 5.5481 & TST \\
\hline CHEMBL3986941 & 1640610 & 7.8539 & 7.9459 & TST \\
\hline CHEMBL 3949774 & 1640610 & 5.9586 & 6.1467 & TRN \\
\hline CHEMBL3903426 & 1640610 & 5.7212 & 5.0656 & TRN \\
\hline CHEMBL3971269 & 1640610 & 8.1549 & 8.1233 & TRN \\
\hline CHEMBL3891116 & 1640610 & 4.3768 & 4.6435 & TRN \\
\hline CHEMBL3892722 & 1640610 & 4.5467 & 4.2226 & TRN \\
\hline CHEMBL3926050 & 1640610 & 7.0458 & 7.4478 & TST \\
\hline CHEMBL3976043 & 1640610 & 6.0605 & 5.2206 & TST \\
\hline CHEMBL 3946900 & 1640610 & 8.699 & 9.1767 & TST \\
\hline CHEMBL3938568 & 1640610 & 4.1226 & 4.9554 & TST \\
\hline CHEMBL3939340 & 1640610 & 5.4559 & 4.8344 & TRN \\
\hline CHEMBL 3931602 & 1640610 & 5.6021 & 4.8138 & TRN \\
\hline CHEMBL3955412 & 1640610 & 7.2676 & 7.5098 & TST \\
\hline CHEMBL3899218 & 1640610 & 6.7696 & 6.7812 & TST \\
\hline CHEMBL3933999 & 1640610 & 5.4685 & 5.3513 & TST \\
\hline CHEMBL 3892014 & 1640610 & 5.0969 & 4.8891 & TRN \\
\hline CHEMBL 3357702 & 1640610 & 8.5229 & 9.5527 & TST \\
\hline CHEMBL3948370 & 1640610 & 6.585 & 6.816 & TST \\
\hline CHEMBL3893957 & 1640610 & 4.9066 & 5.7502 & TRN \\
\hline CHEMBL3932878 & 1640610 & 8.3979 & 8.9565 & TST \\
\hline CHEMBL3913305 & 1640610 & 8.3979 & 7.902 & TRN \\
\hline CHEMBL3967798 & 1640610 & 6.0 & 5.9948 & TRN \\
\hline CHEMBL3959082 & 1640610 & 3.0 & 3.9657 & TRN \\
\hline CHEMBL3969455 & 1640610 & 5.2757 & 5.0977 & TST \\
\hline CHEMBL3901983 & 1640610 & 6.7959 & 6.7897 & TRN \\
\hline CHEMBL3958400 & 1640610 & 8.0 & 9.5711 & TST \\
\hline CHEMBL3934524 & 1640610 & 6.6383 & 7.2312 & TRN \\
\hline CHEMBL3919507 & 1640610 & 4.8928 & 5.8872 & TRN \\
\hline CHEMBL3949210 & 1640610 & 5.4949 & 5.9617 & TST \\
\hline CHEMBL 3937674 & 1640610 & 7.7959 & 7.9009 & TST \\
\hline CHEMBL3962497 & 1640610 & 3.0 & 3.93399 & 99999999997 \\
\hline CHEMBL 3952832 & 1640610 & 3.0 & 4.1386 & TRN \\
\hline CHEMBL3917062 & 1640610 & 7.7696 & 8.09799 & 9999999999 \\
\hline CHEMBL3986162 & 1640610 & 4.9508 & 5.255 & TRN \\
\hline CHEMBL3941233 & 1640610 & 4.7696 & 4.8988 & TRN \\
\hline CHEMBL3956840 & 1640610 & 5.0757 & 4.5573 & TRN \\
\hline CHEMBL3916788 & 1640610 & 4.9245 & 6.2419 & TRN \\
\hline
\end{tabular}


Supplemental Table S2.txt

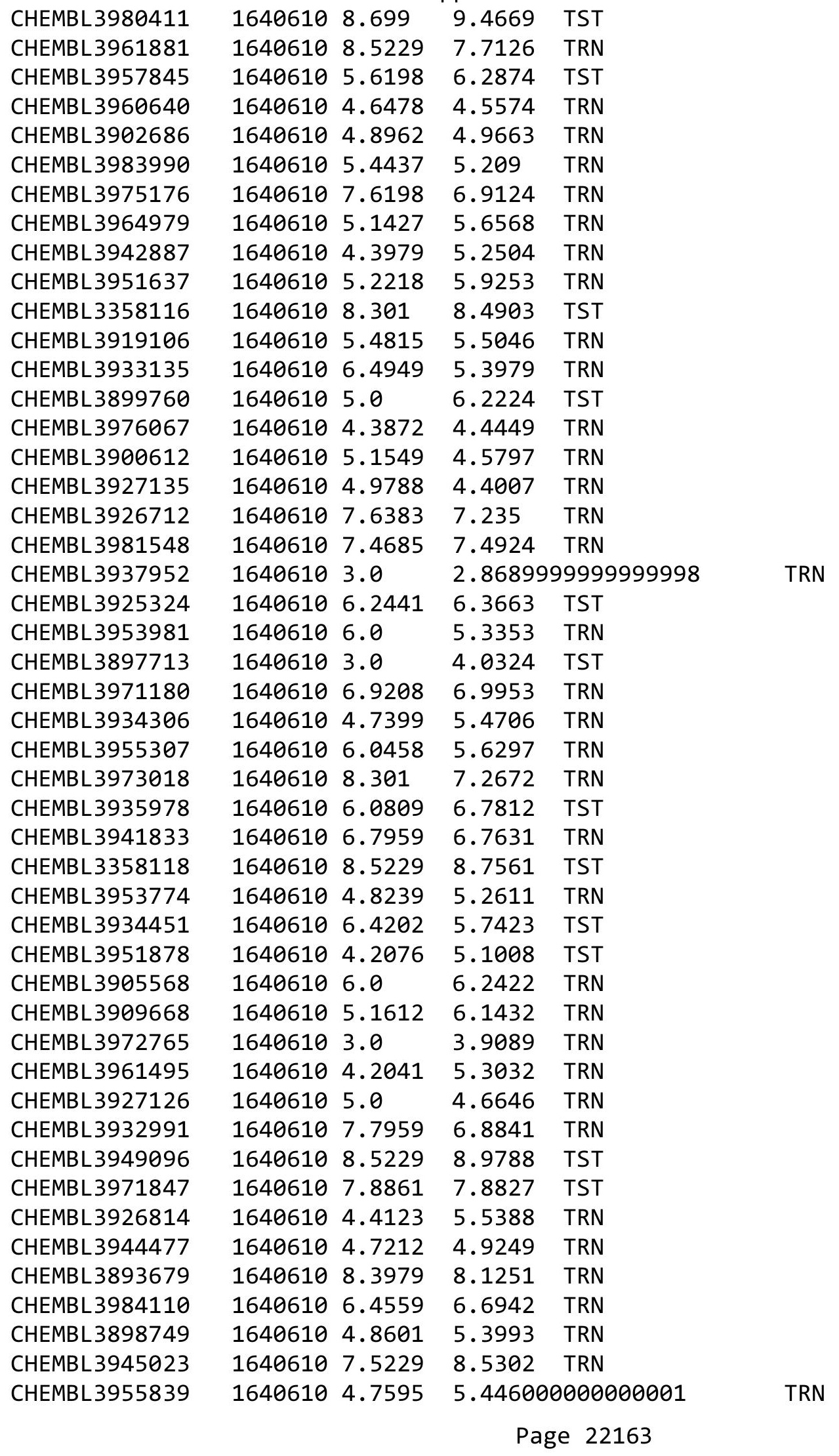


Supplemental Table S2.txt

\begin{tabular}{|c|c|c|c|c|c|}
\hline CHEMBL3958329 & 1640610 & 5.0969 & 5.1687 & TRN & \\
\hline CHEMBL3952154 & 1640610 & 6.1024 & 5.4718 & TRN & \\
\hline CHEMBL3939534 & 1640610 & 4.5513 & 5.4253 & TST & \\
\hline CHEMBL3924293 & 1640610 & 8.0 & 8.0977 & TRN & \\
\hline CHEMBL3975663 & 1640610 & 7.6021 & 7.6673 & TRN & \\
\hline CHEMBL3980267 & 1640610 & 6.0953 & 5.8038 & TRN & \\
\hline CHEMBL3944355 & 1640610 & 4.6326 & 5.4914 & TST & \\
\hline CHEMBL3901661 & 1640610 & 5.6198 & 5.069 & TRN & \\
\hline CHEMBL3969027 & 1640610 & 6.699 & 6.7112 & TRN & \\
\hline CHEMBL3893295 & 1640610 & 8.699 & 8.4854 & TRN & \\
\hline CHEMBL3906451 & 1640610 & 4.5935 & 4.9462 & TRN & \\
\hline CHEMBL3969457 & 1640610 & 5.0 & 6.59399 & 9999999999 & TST \\
\hline CHEMBL3958423 & 1640610 & 4.1221 & 4.6276 & TRN & \\
\hline CHEMBL3949844 & 1640610 & 5.9586 & 5.7633 & TRN & \\
\hline CHEMBL3358119 & 1640610 & 8.699 & 9.7458 & TST & \\
\hline CHEMBL3969777 & 1640610 & 3.0 & 4.6218 & TRN & \\
\hline CHEMBL3902418 & 1640610 & 4.3565 & 5.2007 & TRN & \\
\hline CHEMBL3931957 & 1640610 & 7.699 & 6.9364 & TRN & \\
\hline CHEMBL3933151 & 1640610 & 5.7959 & 5.8332 & TRN & \\
\hline CHEMBL3936759 & 1640610 & 7.5376 & 7.4478 & TST & \\
\hline CHEMBL3979069 & 1640610 & 7.9586 & 8.8266 & TST & \\
\hline CHEMBL3975446 & 1640610 & 6.0 & 5.7003 & TRN & \\
\hline CHEMBL3905924 & 1640610 & 7.585 & 6.9249 & TRN & \\
\hline CHEMBL3962527 & 1640610 & 4.9281 & 4.2029 & TRN & \\
\hline CHEMBL3959452 & 1640610 & 6.5157 & 7.0221 & TRN & \\
\hline CHEMBL3981815 & 1640610 & 4.8697 & 5.4411 & TRN & \\
\hline CHEMBL3358109 & 1640610 & 7.7212 & 7.8326 & TST & \\
\hline CHEMBL3903782 & 1640610 & 7.6021 & 8.2466 & TST & \\
\hline CHEMBL3933288 & 1640610 & 5.3665 & 5.5131 & TRN & \\
\hline CHEMBL3939158 & 1640610 & 6.4685 & 6.2811 & TRN & \\
\hline CHEMBL3966586 & 1640610 & 5.585 & 6.2626 & TRN & \\
\hline CHEMBL3955388 & 1640610 & 5.3188 & 5.49 & TRN & \\
\hline CHEMBL3908890 & 1640610 & 8.3979 & 8.8248 & TST & \\
\hline CHEMBL3969274 & 1640610 & 4.2218 & 5.442 & TRN & \\
\hline CHEMBL3889636 & 1640610 & 4.2104 & 4.94600 & 0000000001 & TRN \\
\hline CHEMBL3941930 & 1640610 & 9.0 & 9.2704 & TRN & \\
\hline CHEMBL3978902 & 1640610 & 4.684 & 5.0864 & TRN & \\
\hline CHEMBL3955516 & 1640610 & 6.1487 & 6.1544 & TRN & \\
\hline CHEMBL3958608 & 1640610 & 5.6198 & 4.6604 & TRN & \\
\hline CHEMBL3925041 & 1640610 & 5.0132 & 5.3303 & TRN & \\
\hline CHEMBL3937813 & 1640610 & 8.3979 & 9.1285 & TST & \\
\hline CHEMBL3905259 & 1640610 & 5.2291 & 5.2583 & TRN & \\
\hline CHEMBL3358113 & 1640610 & 8.699 & 8.8019 & TST & \\
\hline CHEMBL3933932 & 1640610 & 8.0 & 7.0306 & TRN & \\
\hline CHEMBL3895306 & 1640610 & 6.2147 & 5.6095 & TST & \\
\hline CHEMBL3924294 & 1640610 & 8.2218 & 8.0685 & TRN & \\
\hline CHEMBL3957045 & 1640610 & 5.3098 & 5.699 & TST & \\
\hline CHEMBL3909978 & 1640610 & 8.0 & 8.5714 & TRN & \\
\hline
\end{tabular}


Supplemental Table S2.txt

\begin{tabular}{|c|c|c|c|c|}
\hline CHEMBL 3983449 & 1640610 & 3.0 & 4.8545 & TRN \\
\hline CHEMBL 3898264 & 1640610 & 7.699 & 7.7516 & TST \\
\hline CHEMBL3958662 & 1640610 & 4.158 & 5.3221 & TRN \\
\hline CHEMBL 3920791 & 1640610 & 6.0 & 6.5753 & TRN \\
\hline CHEMBL3964159 & 1640610 & 8.5229 & 8.83 & TRN \\
\hline CHEMBL 3977595 & 1640610 & 7.1549 & 7.5886 & TRN \\
\hline CHEMBL3358121 & 1640610 & 8.5229 & 9.0513 & TST \\
\hline CHEMBL 3935150 & 1640610 & 7.9208 & 7.606 & TST \\
\hline CHEMBL 3959497 & 1640610 & 7.2676 & 6.3161 & TRN \\
\hline CHEMBL3912225 & 1640610 & 4.3872 & 5.1204 & TRN \\
\hline CHEMBL 3949901 & 1640610 & 8.699 & 8.5306 & TST \\
\hline CHEMBL 3910519 & 1640610 & 6.1612 & 7.0436 & TRN \\
\hline CHEMBL 3891297 & 1640610 & 9.0 & 8.9619 & TRN \\
\hline CHEMBL3913151 & 1640610 & 8.2218 & 7.9748 & TRN \\
\hline CHEMBL3982976 & 1640610 & 5.2366 & 4.9793 & TST \\
\hline CHEMBL 3943332 & 1640610 & 3.0 & 3.0149 & TRN \\
\hline CHEMBL 3974878 & 1640610 & 4.5229 & 4.4392 & TRN \\
\hline CHEMBL 3934898 & 1640610 & 4.3224 & 4.82 & TRN \\
\hline CHEMBL 3972560 & 1640610 & 3.0 & 5.5384 & TRN \\
\hline CHEMBL3935391 & 1640610 & 5.6198 & 6.2515 & TST \\
\hline CHEMBL 3902777 & 1640610 & 6.0809 & 5.5222 & TRN \\
\hline CHEMBL3933939 & 1640610 & 5.3468 & 4.7786 & TST \\
\hline CHEMBL 3903865 & 1640610 & 6.7399 & 6.8685 & TRN \\
\hline CHEMBL 3981031 & 1640610 & 5.699 & 6.1191 & TRN \\
\hline CHEMBL 3950378 & 1640610 & 3.0 & 3.5183 & TRN \\
\hline CHEMBL 3973144 & 1640610 & 7.5229 & 6.9316 & TRN \\
\hline CHEMBL 3950779 & 1640610 & 6.0362 & 7.2873 & TST \\
\hline CHEMBL 3934422 & 1640610 & 6.4949 & 5.9167 & TRN \\
\hline CHEMBL 3918421 & 1640610 & 5.6383 & 5.2431 & TRN \\
\hline CHEMBL 3942889 & 1640610 & 7.3665 & 7.2016 & TRN \\
\hline CHEMBL 3702626 & 1642001 & 4.0 & 4.2955 & TRN \\
\hline CHEMBL3945632 & 1642001 & 4.0 & 4.2995 & TRN \\
\hline CHEMBL 3702637 & 1642001 & 4.0 & 3.7412 & TRN \\
\hline CHEMBL 3702631 & 1642001 & 4.0 & 4.2298 & TRN \\
\hline CHEMBL 3702641 & 1642001 & 4.0 & 4.1943 & TRN \\
\hline CHEMBL 3702604 & 1642001 & 7.3872 & 7.5571 & TRN \\
\hline CHEMBL 3702611 & 1642001 & 5.9281 & 5.6553 & TRN \\
\hline CHEMBL3702635 & 1642001 & 4.0 & 4.0399 & TRN \\
\hline CHEMBL 3702642 & 1642001 & 5.1965 & 6.2652 & TRN \\
\hline CHEMBL 3964894 & 1642001 & 4.0 & 3.8915 & TRN \\
\hline CHEMBL3931989 & 1642001 & 4.0 & 3.7747 & TRN \\
\hline CHEMBL3979459 & 1642001 & 4.0 & 4.026 & TRN \\
\hline CHEMBL3702617 & 1642001 & 6.5129 & 7.2939 & TST \\
\hline CHEMBL 3702640 & 1642001 & 4.0 & 3.9178 & TRN \\
\hline CHEMBL 3644559 & 1642001 & 6.6383 & 6.805 & TRN \\
\hline CHEMBL 3985794 & 1642001 & 4.0 & 4.0099 & TRN \\
\hline CHEMBL 3644548 & 1642001 & 4.0 & 3.9528 & TST \\
\hline CHEMBL 3644555 & 1642001 & 8.0969 & 6.824 & TST \\
\hline
\end{tabular}


Supplemental Table S2.txt

\begin{tabular}{|c|c|c|c|c|}
\hline 518 & 642001 & 5.6716 & 6.4404 & \\
\hline & 642001 & 4.0 & 246 & \\
\hline 7 & 001 & 4.0 & & \\
\hline IEMBL3 & 642001 & 6.8268 & & \\
\hline AEMBL 3702630 & 642001 & 4.0 & 474 & \\
\hline AEMBL & $\partial 01$ & 5.6576 & 693 & \\
\hline 29 & 001 & 4.0 & & \\
\hline IEMBL & $\partial 01$ & 4.0 & & \\
\hline AEMBL3949537 & 1642001 & 4.0 & & \\
\hline AEMBL3 & 642001 & 7.5686 & 22 & \\
\hline 95 & $\partial 01$ & 4.0 & & \\
\hline 44 & $\partial 01$ & 6.2336 & & \\
\hline HEME & $\partial 01$ & 4.0 & & \\
\hline AEMBL: & 1642001 & 7.9208 & & \\
\hline AEMBL & 001 & 4.0 & & \\
\hline 6 & $\partial 01$ & 6.43 & & \\
\hline 1 & 01 & 5.0 & & \\
\hline IEME & 16 & 4.0 & & \\
\hline 38 & 001 & 4.0 & & \\
\hline 9 & $\partial 1$ & 4.0 & & \\
\hline 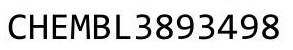 & 16 & 6. & & \\
\hline 1 & & & & \\
\hline 5 & 16 & 7.7 & & \\
\hline 69 & $\partial 01$ & & & \\
\hline 1 & & 5. & & \\
\hline 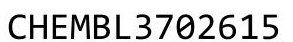 & $\partial 1$ & 4. & & \\
\hline 3 & & 4.0 & & \\
\hline 0 & 16 & 7.5086 & & \\
\hline & $\partial 1$ & 5.0 & & \\
\hline 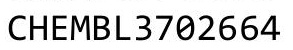 & 01 & 7.76 & & \\
\hline & 01 & 6.3 & & \\
\hline & 1 & 4.0 & & \\
\hline & 16 & 6 & & \\
\hline & & 7.56 & & \\
\hline 605 & & 7.9208 & & \\
\hline & & 0. & & \\
\hline $\mathrm{CH}$ & 1 & 4.0 & & \\
\hline & & 7.26 & & \\
\hline CHEMBL & 1642001 & 6.9431 & & \\
\hline & $\partial 01$ & 7.8 & & \\
\hline $\mathrm{CH}$ & 16 & 6.2472 & & \\
\hline CHEMB & 001 & 7.1739 & & \\
\hline CHEMBL & 001 & 5.6718 & & \\
\hline AEMBL & 1642001 & 7.9586 & 48 & \\
\hline 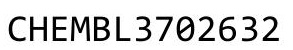 & 1642001 & 4.0 & & \\
\hline CHEME & 1642001 & 4.0 & & \\
\hline & 1642001 & 7.65 & 7.684 & \\
\hline CHEMBL3932718 & 1642001 & .0 & 3.8591 & \\
\hline
\end{tabular}

Page 22166 


\begin{tabular}{|c|c|c|c|c|}
\hline \multicolumn{5}{|c|}{ Supplemental Table S2.txt } \\
\hline CHEMBL3702628 & 1642001 & 4.0 & 3.9969 & TRN \\
\hline CHEMBL3702606 & 1642001 & 6.1062 & 6.151 & TRN \\
\hline CHEMBL3702608 & 1642001 & 6.8386 & 6.9772 & TRN \\
\hline CHEMBL3644552 & 1642001 & 7.4089 & 7.0642 & TST \\
\hline CHEMBL3644546 & 1642001 & 4.0 & 3.8816 & TST \\
\hline CHEMBL3644557 & 1642001 & 6.6576 & 6.6189 & TST \\
\hline CHEMBL3702633 & 1642001 & 4.0 & 3.9285 & TRN \\
\hline CHEMBL3702622 & 1642001 & 4.0 & 3.9826 & TRN \\
\hline CHEMBL3942265 & 1642001 & 4.0 & 3.9206 & TRN \\
\hline CHEMBL3977676 & 1642001 & 5.0 & 4.9875 & TRN \\
\hline CHEMBL3644549 & 1642001 & 5.0 & 3.1579 & TST \\
\hline CHEMBL3986876 & 1642001 & 4.0 & 3.5914 & TST \\
\hline CHEMBL3702625 & 1642001 & 4.0 & 4.0867 & TRN \\
\hline CHEMBL3702602 & 1642001 & 7.9208 & 7.2823 & TRN \\
\hline CHEMBL3702627 & 1642001 & 4.0 & 3.8867 & TRN \\
\hline CHEMBL3644550 & 1642001 & 6.5114 & 6.9674 & TST \\
\hline CHEMBL3702662 & 1642001 & 7.5686 & 7.5028 & TRN \\
\hline CHEMBL3702666 & 1642001 & 6.983 & 7.0451 & TRN \\
\hline CHEMBL 3644558 & 1642001 & 7.3098 & 6.8797 & TST \\
\hline CHEMBL3702614 & 1642001 & 4.0 & 3.943 & TRN \\
\hline CHEMBL179065 & 304894 & 6.9066 & 7.2464 & TRN \\
\hline CHEMBL369732 & 304894 & 6.2366 & 5.1954 & TRN \\
\hline CHEMBL181282 & 304894 & 5.4685 & 4.4127 & TRN \\
\hline CHEMBL359824 & 304894 & 4.4815 & 3.8795 & TRN \\
\hline CHEMBL179898 & 304894 & 6.6576 & 5.4523 & TRN \\
\hline CHEMBL360689 & 304894 & 4.301 & 4.8588 & TRN \\
\hline CHEMBL361347 & 304894 & 6.8539 & 5.4143 & TRN \\
\hline CHEMBL180740 & 304894 & 3.301 & 5.2721 & TRN \\
\hline CHEMBL301612 & 304894 & 5.585 & 5.2284 & TRN \\
\hline CHEMBL178510 & 304894 & 7.1612 & 6.5876 & TST \\
\hline CHEMBL369296 & 304894 & 6.6021 & 6.3903 & TRN \\
\hline CHEMBL180810 & 304894 & 5.7212 & 5.3331 & TRN \\
\hline CHEMBL180316 & 304894 & 6.585 & 7.1553 & TRN \\
\hline CHEMBL360698 & 304894 & 3.301 & 4.8831 & TRN \\
\hline CHEMBL362402 & 304894 & 6.3872 & 4.9425 & TRN \\
\hline CHEMBL181733 & 304894 & 5.6198 & 5.3092 & TRN \\
\hline CHEMBL180290 & 304894 & 4.9586 & 4.4299 & TRN \\
\hline CHEMBL360544 & 304894 & 4.5686 & 5.1467 & TRN \\
\hline CHEMBL181871 & 304894 & 4.3872 & 4.4465 & TRN \\
\hline CHEMBL180673 & 304894 & 3.301 & 3.9658 & TRN \\
\hline CHEMBL180821 & 304894 & 6.2676 & 5.675 & TST \\
\hline CHEMBL433559 & 304894 & 6.7212 & 7.0551 & TRN \\
\hline CHEMBL181095 & 304894 & 6.0044 & 5.8336 & TST \\
\hline CHEMBL181982 & 304894 & 5.4318 & 5.1483 & TRN \\
\hline CHEMBL434907 & 304894 & 5.8239 & 5.6175 & TRN \\
\hline CHEMBL181233 & 304894 & 7.1308 & 5.4831 & TRN \\
\hline CHEMBL182044 & 304894 & 5.4949 & 5.5122 & TRN \\
\hline CHEMBL113070 & 304894 & 7.4949 & 6.9295 & TRN \\
\hline
\end{tabular}




\begin{tabular}{|c|c|c|c|c|c|}
\hline \multicolumn{6}{|c|}{ Supplemental Table S2.txt } \\
\hline CHEMBL360672 & 304894 & 3.301 & 4.3009 & TRN & \\
\hline CHEMBL359732 & 304894 & 3.301 & 4.3984 & TST & \\
\hline CHEMBL181822 & 304894 & 4.5086 & 5.3808 & TRN & \\
\hline CHEMBL181476 & 304894 & 5.585 & 5.1264 & TRN & \\
\hline CHEMBL180401 & 304894 & 3.301 & 4.2284 & TRN & \\
\hline CHEMBL362862 & 304894 & 7.0223 & 7.4785 & TRN & \\
\hline CHEMBL362692 & 304894 & 6.8477 & 7.4243 & TRN & \\
\hline CHEMBL178439 & 304894 & 6.0 & 5.1663 & TRN & \\
\hline CHEMBL178122 & 304894 & 5.4437 & 5.3423 & TRN & \\
\hline CHEMBL360799 & 304894 & 6.3872 & 4.7873 & TST & \\
\hline CHEMBL178758 & 304894 & 6.9208 & 6.7464 & TST & \\
\hline CHEMBL180794 & 304894 & 5.9208 & 4.7114 & TST & \\
\hline CHEMBL540206 & 304894 & 7.0969 & 6.4286 & TST & \\
\hline CHEMBL181314 & 304894 & 7.3979 & 6.5089 & TST & \\
\hline CHEMBL181423 & 304894 & 6.8239 & 6.4133 & TST & \\
\hline CHEMBL180149 & 304894 & 5.3468 & 5.0788 & TRN & \\
\hline CHEMBL181285 & 304894 & 7.0655 & 6.41799 & 9999999999 & TST \\
\hline CHEMBL180448 & 304894 & 3.301 & 4.0479 & TRN & \\
\hline CHEMBL179806 & 304894 & 5.0655 & 5.5654 & TRN & \\
\hline CHEMBL181017 & 304894 & 6.2596 & 5.4707 & TST & \\
\hline CHEMBL362005 & 304894 & 5.0655 & 5.0099 & TRN & \\
\hline CHEMBL360225 & 304894 & 3.301 & 4.9331 & TRN & \\
\hline CHEMBL359898 & 304894 & 6.0044 & 4.9427 & TRN & \\
\hline CHEMBL 366922 & 304894 & 7.3979 & 6.4703 & TST & \\
\hline CHEMBL435732 & 304894 & 7.0458 & 6.6576 & TST & \\
\hline CHEMBL425873 & 304894 & 5.0132 & 4.9211 & TRN & \\
\hline CHEMBL180035 & 304894 & 5.4559 & 5.4412 & TRN & \\
\hline CHEMBL361574 & 304894 & 3.301 & 4.0892 & TRN & \\
\hline CHEMBL 386814 & 407359 & 3.6345 & 3.5698 & TRN & \\
\hline CHEMBL217488 & 407359 & 2.301 & 3.1335 & TRN & \\
\hline CHEMBL433949 & 407359 & 4.7852 & 4.0965 & TRN & \\
\hline CHEMBL216341 & 407359 & 3.7423 & 3.5342 & TST & \\
\hline CHEMBL178215 & 407359 & 3.3335 & 4.1556 & TRN & \\
\hline CHEMBL362614 & 407359 & 4.2441 & 4.2802 & TRN & \\
\hline CHEMBL428667 & 407359 & 2.301 & 3.2268 & TRN & \\
\hline CHEMBL213917 & 407359 & 3.4202 & 3.6646 & TST & \\
\hline CHEMBL384251 & 407359 & 3.6861 & 3.7209 & TRN & \\
\hline CHEMBL384379 & 407359 & 4.0177 & 3.7203 & TRN & \\
\hline CHEMBL 214460 & 407359 & 3.8182 & 3.1864 & TRN & \\
\hline CHEMBL180866 & 407359 & 3.6108 & 3.1615 & TRN & \\
\hline CHEMBL386190 & 407359 & 2.301 & 3.252 & TRN & \\
\hline CHEMBL180048 & 407359 & 2.699 & 3.1574 & TRN & \\
\hline CHEMBL182052 & 407359 & 4.0458 & 3.7305 & TST & \\
\hline CHEMBL386519 & 407359 & 4.0555 & 3.8409 & TST & \\
\hline CHEMBL217621 & 407359 & 3.3098 & 3.1568 & TRN & \\
\hline CHEMBL384798 & 407359 & 3.6144 & 3.5905 & TST & \\
\hline CHEMBL214459 & 407359 & 4.1024 & 3.485 & TRN & \\
\hline CHEMBL217146 & 407359 & 3.5072 & 3.6809 & TRN & \\
\hline
\end{tabular}




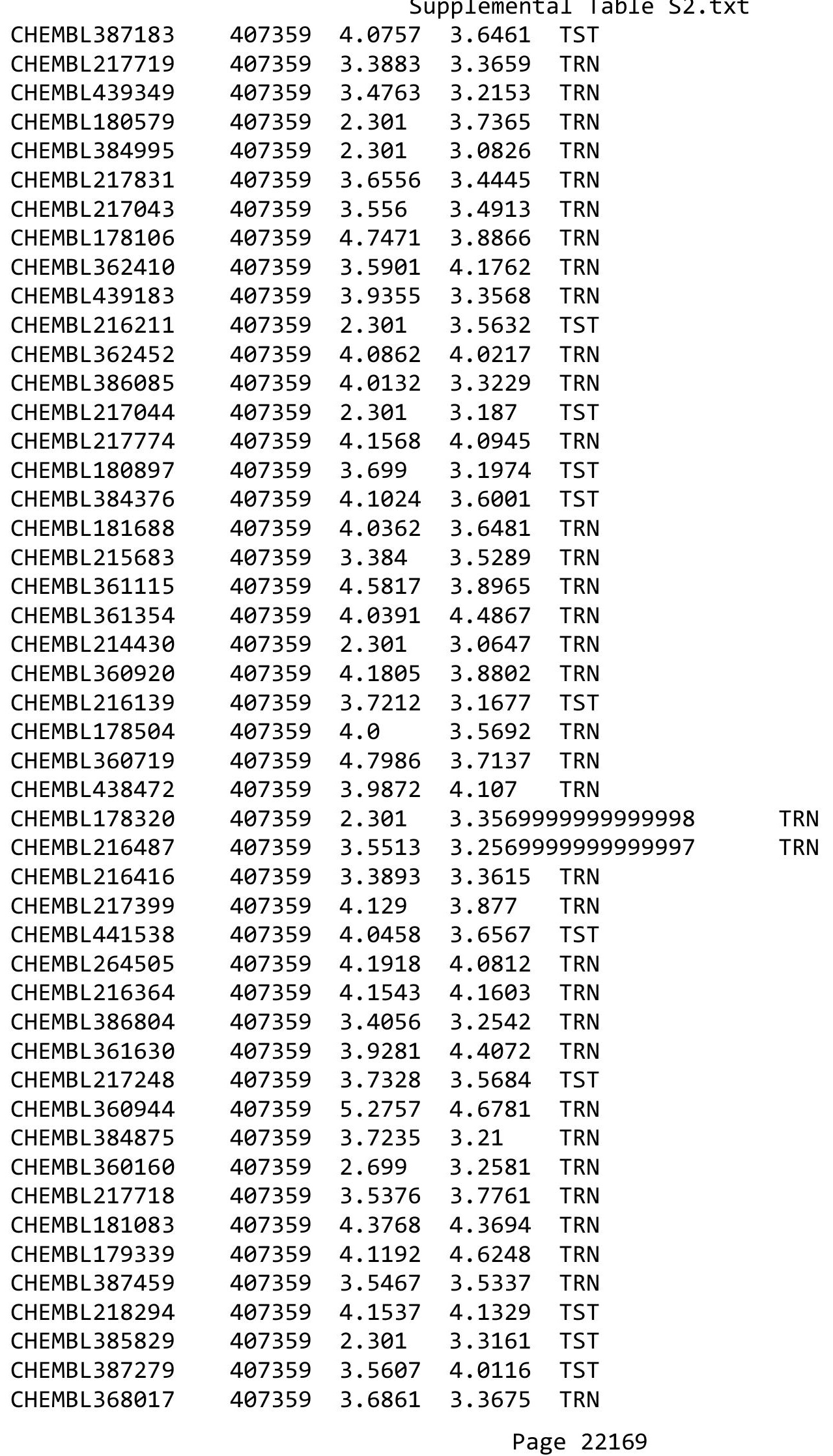




\begin{tabular}{|c|c|c|c|c|c|c|}
\hline & & \multicolumn{5}{|c|}{ Supplemental Table S2.txt } \\
\hline CHEMBL179114 & 407359 & 4.1549 & \multicolumn{3}{|c|}{3.5780000000000003} & TS \\
\hline CHEMBL 217054 & 407359 & 3.3575 & 3.1996 & TRN & & \\
\hline CHEMBL438289 & 407359 & 2.301 & 3.1839 & TRN & & \\
\hline CHEMBL437916 & 407359 & 3.4815 & 3.3821 & TRN & & \\
\hline CHEMBL426784 & 407359 & 3.5058 & 3.9101 & TRN & & \\
\hline CHEMBL 360141 & 407359 & 4.8416 & 3.8177 & TRN & & \\
\hline CHEMBL 384464 & 407359 & 4.1549 & 3.4554 & TRN & & \\
\hline CHEMBL 385387 & 407359 & 3.5017 & 3.1911 & TRN & & \\
\hline CHEMBL 214180 & 407359 & 3.719 & 3.3533 & TST & & \\
\hline CHEMBL424731 & 407359 & 4.1079 & 3.5565 & TST & & \\
\hline CHEMBL 385219 & 407359 & 3.64399 & 99999999 & 997 & 3.5147 & \\
\hline CHEMBL180862 & 407359 & 4.0044 & 4.147 & TRN & & \\
\hline CHEMBL 213918 & 407359 & 3.5467 & 3.1109 & TRN & & \\
\hline CHEMBL 214623 & 407359 & 3.9872 & 3.7019 & TST & & \\
\hline CHEMBL 216358 & 407359 & 3.4522 & 3.4006 & TST & & \\
\hline CHEMBL 217884 & 407359 & 3.4622 & 3.1302 & TRN & & \\
\hline CHEMBL 361345 & 407359 & 3.7282 & 4.4175 & TRN & & \\
\hline CHEMBL 386911 & 407359 & 2.301 & 3.2551 & TRN & & \\
\hline CHEMBL 385595 & 407359 & 3.3224 & 3.5701 & TRN & & \\
\hline CHEMBL 214545 & 407359 & 4.2366 & 3.5364 & TRN & & \\
\hline CHEMBL179549 & 407359 & 4.5686 & 4.28 & TRN & & \\
\hline CHEMBL 387225 & 407359 & 3.4868 & 3.5781 & TST & & \\
\hline CHEMBL216799 & 407359 & 3.6696 & 3.932 & TRN & & \\
\hline CHEMBL 3973365 & 1640370 & 6.0 & 6.5212 & TRN & & \\
\hline CHEMBL3902359 & 1640370 & 5.2076 & 5.6817 & TRN & & \\
\hline CHEMBL3939035 & 1640370 & 7.0555 & 6.608 & TRN & & \\
\hline CHEMBL3977864 & 1640370 & 7.0223 & 6.6124 & TRN & & \\
\hline CHEMBL3911151 & 1640370 & 5.8539 & 5.8191 & TRN & & \\
\hline CHEMBL 3929251 & 1640370 & 6.8861 & 6.4857 & TRN & & \\
\hline CHEMBL 3937347 & 1640370 & 5.8861 & 5.7252 & TST & & \\
\hline CHEMBL 3984824 & 1640370 & 6.0 & 6.3465 & TRN & & \\
\hline CHEMBL 3952467 & 1640370 & 6.0757 & 5.8941 & TRN & & \\
\hline CHEMBL 3948304 & 1640370 & 6.0 & 6.1081 & TRN & & \\
\hline CHEMBL 3894536 & 1640370 & 6.8539 & 5.7292 & TST & & \\
\hline CHEMBL3981499 & 1640370 & 6.0 & 6.2894 & TRN & & \\
\hline CHEMBL 3933618 & 1640370 & 6.0 & 6.1755 & TST & & \\
\hline CHEMBL 3898025 & 1640370 & 6.0809 & 6.3144 & TRN & & \\
\hline CHEMBL 3976449 & 1640370 & 6.0 & 5.8265 & TRN & & \\
\hline CHEMBL 3936472 & 1640370 & 5.9208 & 6.3244 & TRN & & \\
\hline CHEMBL 3940615 & 1640370 & 6.2757 & 6.2306 & TRN & & \\
\hline CHEMBL3910175 & 1640370 & 6.0 & 6.3864 & TRN & & \\
\hline CHEMBL3963647 & 1640370 & 4.699 & 5.7077 & TRN & & \\
\hline CHEMBL3941589 & 1640370 & 6.1367 & 6.1557 & TRN & & \\
\hline CHEMBL 3909319 & 1640370 & 7.1192 & 6.3365 & TRN & & \\
\hline CHEMBL 3890653 & 1640370 & 6.0 & 5.7795 & TRN & & \\
\hline CHEMBL 3926207 & 1640370 & 6.0 & 6.3051 & TRN & & \\
\hline CHEMBL3914349 & 1640370 & 6.6021 & 5.8179 & TRN & & \\
\hline CHEMBL3899950 & 1640370 & 6.0 & 6.178 & TRN & & \\
\hline
\end{tabular}




\begin{tabular}{|c|c|c|c|c|c|}
\hline \multicolumn{6}{|c|}{ Supplemental Table S2.txt } \\
\hline CHEMBL3906752 & 1640370 & 6.0 & 6.5402 & TRN & \\
\hline CHEMBL 3967664 & 1640370 & 6.0 & 6.2976 & TRN & \\
\hline CHEMBL3982967 & 1640370 & 5.699 & 5.7169 & TRN & \\
\hline CHEMBL3985626 & 1640370 & 6.2218 & 5.8221 & TRN & \\
\hline CHEMBL3890733 & 1640370 & 6.0 & 5.8265 & TRN & \\
\hline CHEMBL3913762 & 1640370 & 7.0088 & 6.7044 & TRN & \\
\hline CHEMBL3892211 & 1640370 & 6.0 & 6.4888 & TRN & \\
\hline CHEMBL3939896 & 1640370 & 6.8239 & 5.7539 & TST & \\
\hline CHEMBL3906691 & 1640370 & 6.0 & 5.6637 & TRN & \\
\hline CHEMBL3913088 & 1640370 & 6.8861 & 5.7199 & TST & \\
\hline CHEMBL3965410 & 1640370 & 5.9208 & 5.6622 & TST & \\
\hline CHEMBL3956188 & 1640370 & 7.1871 & 6.5675 & TST & \\
\hline CHEMBL3964012 & 1640370 & 6.0862 & 5.8282 & TST & \\
\hline CHEMBL3929397 & 1640370 & 6.5686 & 6.1342 & TRN & \\
\hline CHEMBL3934917 & 1640370 & 5.8539 & 6.5517 & TRN & \\
\hline CHEMBL3984845 & 1640370 & 6.0 & 5.8075 & TRN & \\
\hline CHEMBL3896551 & 1640370 & 6.6198 & 6.0773 & TRN & \\
\hline CHEMBL 3958097 & 1640370 & 6.0 & 6.2031 & TRN & \\
\hline CHEMBL 3899418 & 1640370 & 6.0 & 6.1993 & TRN & \\
\hline CHEMBL3926036 & 1640370 & 6.0757 & 5.8077 & TRN & \\
\hline CHEMBL3912179 & 1640370 & 6.0 & 5.8679 & TRN & \\
\hline CHEMBL3981226 & 1640370 & 5.7959 & 5.8483 & TRN & \\
\hline CHEMBL3969212 & 1640370 & 6.2007 & 5.9778 & TRN & \\
\hline CHEMBL3931011 & 1640370 & 6.0 & 6.33 & TST & \\
\hline CHEMBL3946503 & 1640370 & 6.3098 & 5.7911 & TST & \\
\hline CHEMBL3911123 & 1640370 & 6.0 & 5.5923 & TRN & \\
\hline CHEMBL3960760 & 1640370 & 6.5686 & 6.3203 & TST & \\
\hline CHEMBL3892496 & 1640370 & 6.7696 & 6.5553 & TRN & \\
\hline CHEMBL3903601 & 1640370 & 5.7959 & 5.8095 & TST & \\
\hline CHEMBL3904366 & 1640370 & 5.3565 & 5.9148 & TRN & \\
\hline CHEMBL 3891731 & 1640370 & 6.0 & 6.0494 & TRN & \\
\hline CHEMBL3944178 & 1640370 & 6.0 & 5.9769 & TRN & \\
\hline CHEMBL3947896 & 1640370 & 5.6198 & 5.8072 & TRN & \\
\hline CHEMBL3918649 & 1640370 & 6.1487 & 6.2146 & TRN & \\
\hline CHEMBL3916848 & 1640370 & 6.301 & 6.0265 & TRN & \\
\hline CHEMBL3919438 & 1640370 & 5.6198 & 6.2279 & TRN & \\
\hline CHEMBL3899051 & 1640370 & 6.0 & 5.9837 & TRN & \\
\hline CHEMBL3971424 & 1640370 & 5.4559 & 5.6386 & TRN & \\
\hline CHEMBL3920809 & 1640370 & 7.4202 & 6.8639 & TRN & \\
\hline CHEMBL3949511 & 1640370 & 6.0 & 6.3392 & TRN & \\
\hline CHEMBL3934131 & 1640370 & 7.3279 & 6.5677 & TRN & \\
\hline CHEMBL3938239 & 1640370 & 6.0 & 5.9225 & TRN & \\
\hline CHEMBL3982263 & 1640370 & 6.7959 & 6.1727 & TST & \\
\hline CHEMBL3932695 & 1640370 & 6.0 & 6.2054 & TST & \\
\hline CHEMBL3951231 & 1640370 & 6.0 & 6.62299 & 9999999999 & TRN \\
\hline CHEMBL3945533 & 1640370 & 6.0 & 6.3553 & TST & \\
\hline CHEMBL3973032 & 1640370 & 6.3872 & 5.546 & TST & \\
\hline CHEMBL3899773 & 1640370 & 6.699 & 6.4444 & TRN & \\
\hline
\end{tabular}


Supplemental Table S2.txt

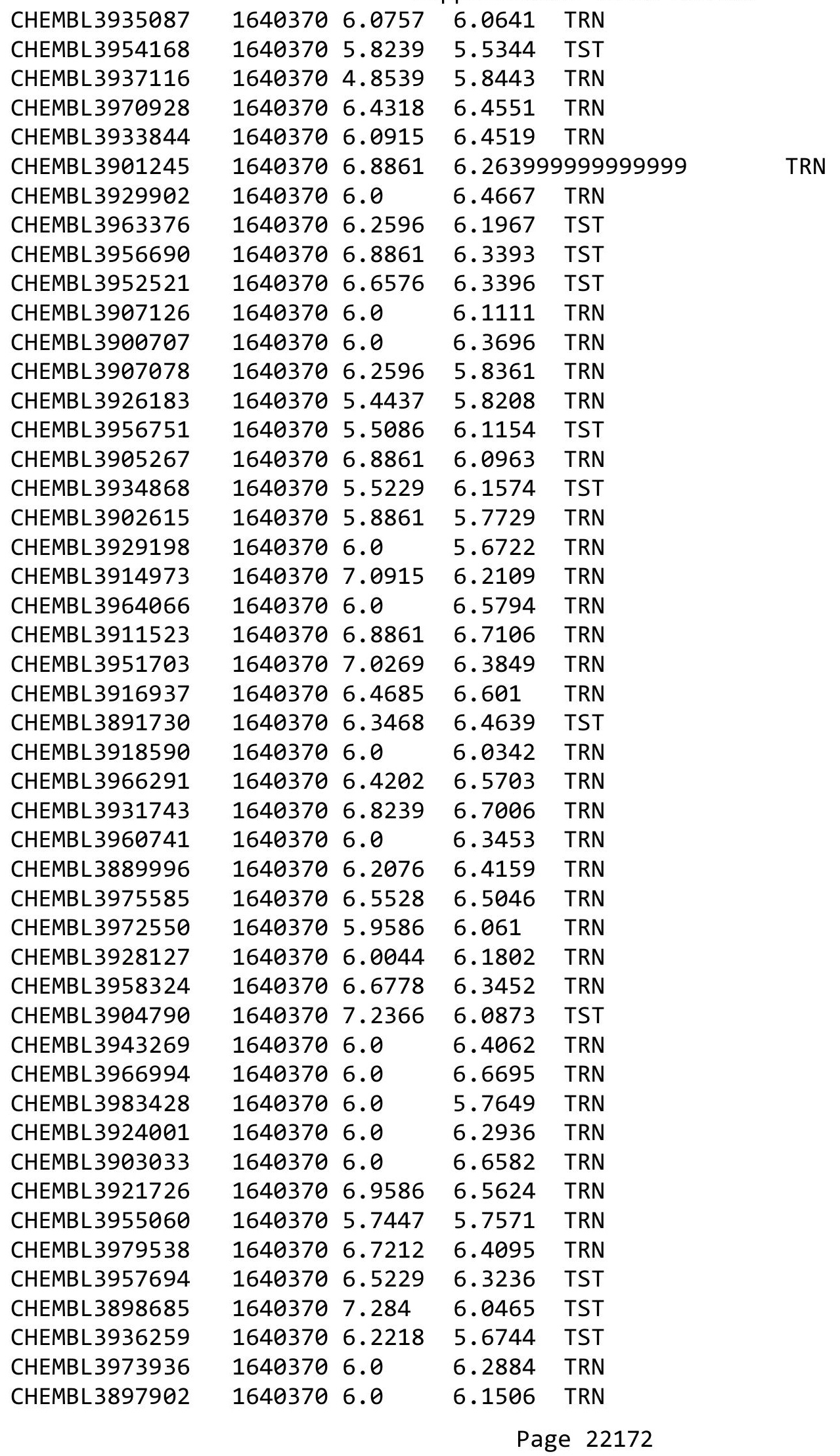


Supplemental Table S2.txt

\begin{tabular}{|c|c|c|c|c|}
\hline CHEMBL3890647 & 1640370 & 6.0 & 5.8013 & TRN \\
\hline CHEMBL3940332 & 1640370 & 7.0706 & 6.7155 & TRN \\
\hline CHEMBL3906915 & 1640370 & 7.1079 & 6.2322 & TRN \\
\hline CHEMBL3930623 & 1640370 & 6.1308 & 6.2098 & TRN \\
\hline CHEMBL3906583 & 1640370 & 6.0 & 5.8562 & TRN \\
\hline CHEMBL3963880 & 1640370 & 6.6778 & 6.2897 & TST \\
\hline CHEMBL3980332 & 1640370 & 6.4089 & 5.9865 & TRN \\
\hline CHEMBL3890363 & 1640370 & 6.7447 & 6.3084 & TST \\
\hline CHEMBL3917029 & 1640370 & 7.1938 & 5.7152 & TST \\
\hline CHEMBL3970366 & 1640370 & 6.1487 & 5.7444 & TST \\
\hline CHEMBL3948601 & 1640370 & 6.8539 & 6.5383 & TRN \\
\hline CHEMBL3890454 & 1640370 & 6.0 & 6.2974 & TRN \\
\hline CHEMBL3976241 & 1640370 & 6.3279 & 5.9555 & TST \\
\hline CHEMBL3919349 & 1640370 & 6.8239 & 6.3437 & TRN \\
\hline CHEMBL3910231 & 1640370 & 7.4437 & 6.5772 & TRN \\
\hline CHEMBL3983219 & 1640370 & 6.4949 & 5.6191 & TST \\
\hline CHEMBL3949671 & 1640370 & 6.1135 & 6.4028 & TRN \\
\hline CHEMBL3925751 & 1640370 & 6.1367 & 5.9907 & TRN \\
\hline CHEMBL3952434 & 1640370 & 7.2518 & 6.7956 & TRN \\
\hline CHEMBL3931772 & 1640370 & 5.9586 & 5.9199 & TRN \\
\hline CHEMBL3892318 & 1640370 & 6.2291 & 5.9207 & TRN \\
\hline CHEMBL3892629 & 1640370 & 6.5086 & 6.3202 & TRN \\
\hline CHEMBL3892178 & 1640370 & 5.9208 & 6.3286 & TRN \\
\hline CHEMBL3978584 & 1640370 & 5.6383 & 5.9973 & TST \\
\hline CHEMBL3950818 & 1640370 & 6.5229 & 6.2878 & TRN \\
\hline CHEMBL3963654 & 1640370 & 5.3372 & 5.8353 & TST \\
\hline CHEMBL3926211 & 1640370 & 5.9586 & 6.4711 & TRN \\
\hline CHEMBL3961181 & 1640370 & 5.6021 & 5.9005 & TRN \\
\hline CHEMBL3968572 & 1640370 & 7.2007 & 6.649 & TST \\
\hline CHEMBL 3974911 & 1640370 & 6.0 & 5.9674 & TRN \\
\hline CHEMBL3923426 & 1640370 & 6.0809 & 5.9424 & TRN \\
\hline CHEMBL 3923588 & 1640370 & 4.8539 & 5.8065 & TRN \\
\hline CHEMBL3944576 & 1640370 & 4.8861 & 5.5764 & TRN \\
\hline CHEMBL3927077 & 1640370 & 6.0 & 5.8811 & TRN \\
\hline CHEMBL3968783 & 1640370 & 6.0 & 6.0524 & TST \\
\hline CHEMBL3983845 & 1640370 & 6.0 & 6.0073 & TRN \\
\hline CHEMBL 3940128 & 1640370 & 6.0 & 6.3222 & TST \\
\hline CHEMBL3980899 & 1640370 & 6.9586 & 6.2469 & TST \\
\hline CHEMBL3900590 & 1640370 & 5.5686 & 5.6008 & TST \\
\hline CHEMBL3982904 & 1640370 & 6.0 & 5.5804 & TST \\
\hline CHEMBL1964290 & 809252 & 4.8 & 5.6776 & TRN \\
\hline CHEMBL213505 & 809252 & 6.3 & 5.2782 & TRN \\
\hline CHEMBL1987034 & 809252 & 6.2 & 7.1641 & TRN \\
\hline CHEMBL1993941 & 809252 & 4.8 & 5.9813 & TRN \\
\hline CHEMBL1980435 & 809252 & 6.5 & 6.9076 & TRN \\
\hline CHEMBL377383 & 809252 & 4.8 & 4.8 & TRN \\
\hline CHEMBL 2005886 & 809252 & 6.9 & 6.6927 & TRN \\
\hline CHEMBL481491 & 809252 & 4.8 & 5.3193 & TST \\
\hline
\end{tabular}




\begin{tabular}{|c|c|c|c|c|c|}
\hline \multicolumn{6}{|c|}{ Supplemental Table S2.txt } \\
\hline CHEMBL1973142 & 809252 & 4.8 & 4.8853 & TRN & \\
\hline CHEMBL1973145 & 809252 & 4.8 & 5.0007 & TRN & \\
\hline CHEMBL1982924 & 809252 & 5.9 & 5.6189 & TRN & \\
\hline CHEMBL 2005936 & 809252 & 4.8 & 5.8215 & TRN & \\
\hline CHEMBL1807515 & 809252 & 6.9 & 7.3931 & TRN & \\
\hline CHEMBL1971141 & 809252 & 4.8 & 4.8279 & TRN & \\
\hline CHEMBL1995813 & 809252 & 7.0 & 7.2811 & TRN & \\
\hline CHEMBL206236 & 809252 & 4.8 & 5.034 & TRN & \\
\hline CHEMBL244378 & 809252 & 4.8 & 6.6581 & TRN & \\
\hline CHEMBL 2001957 & 809252 & 4.8 & 4.6353 & TRN & \\
\hline CHEMBL1969372 & 809252 & 4.8 & 4.6731 & TRN & \\
\hline CHEMBL1993413 & 809252 & 7.5 & 6.1261 & TRN & \\
\hline CHEMBL1986943 & 809252 & 8.3 & 7.706 & TRN & \\
\hline CHEMBL 2006263 & 809252 & 5.9 & 5.2012 & TST & \\
\hline CHEMBL1993584 & 809252 & 4.8 & 5.2808 & TRN & \\
\hline CHEMBL1986263 & 809252 & 4.9 & 5.6102 & TRN & \\
\hline CHEMBL 2000114 & 809252 & 5.8 & 5.2638 & TRN & \\
\hline CHEMBL210618 & 809252 & 4.8 & 4.6713 & TRN & \\
\hline CHEMBL1971172 & 809252 & 7.8 & 7.1944 & TRN & \\
\hline CHEMBL1975647 & 809252 & 5.9 & 4.59699 & 99999999995 & TRN \\
\hline CHEMBL1968380 & 809252 & 6.6 & 5.5451 & TRN & \\
\hline CHEMBL1964644 & 809252 & 4.8 & 4.7713 & TRN & \\
\hline CHEMBL1981782 & 809252 & 4.8 & 5.3692 & TRN & \\
\hline CHEMBL1977681 & 809252 & 6.7 & 5.5551 & TRN & \\
\hline CHEMBL1970142 & 809252 & 4.8 & 5.4029 & TRN & \\
\hline CHEMBL1990912 & 809252 & 4.8 & 4.5254 & TRN & \\
\hline CHEMBL1988163 & 809252 & 6.0 & 6.4818 & TRN & \\
\hline CHEMBL2006493 & 809252 & 4.8 & 4.9398 & TST & \\
\hline CHEMBL1983449 & 809252 & 4.8 & 5.2974 & TRN & \\
\hline CHEMBL1992323 & 809252 & 4.8 & 4.9722 & TRN & \\
\hline CHEMBL1969735 & 809252 & 4.8 & 4.7164 & TRN & \\
\hline CHEMBL 2002649 & 809252 & 6.4 & 5.6872 & TRN & \\
\hline CHEMBL1983589 & 809252 & 8.3 & 7.4532 & TRN & \\
\hline CHEMBL 2005718 & 809252 & 9.0 & 7.3151 & TRN & \\
\hline CHEMBL1994321 & 809252 & 6.1 & 5.7601 & TRN & \\
\hline CHEMBL1997129 & 809252 & 6.4 & 6.0325 & TRN & \\
\hline CHEMBL 2000508 & 809252 & 4.8 & 4.6902 & TRN & \\
\hline CHEMBL1971694 & 809252 & 4.8 & 5.0948 & TST & \\
\hline CHEMBL 2001547 & 809252 & 4.8 & 4.7252 & TRN & \\
\hline CHEMBL 210928 & 809252 & 4.8 & 4.7693 & TRN & \\
\hline CHEMBL1986603 & 809252 & 4.8 & 4.91 & TST & \\
\hline CHEMBL1977148 & 809252 & 4.8 & 5.2466 & TRN & \\
\hline CHEMBL 2003286 & 809252 & 4.8 & 5.3612 & TRN & \\
\hline CHEMBL1992306 & 809252 & 4.8 & 5.0733 & TRN & \\
\hline CHEMBL2002165 & 809252 & 5.9 & 6.28299 & 99999999995 & TRN \\
\hline CHEMBL206382 & 809252 & 4.8 & 4.8924 & TRN & \\
\hline CHEMBL1998585 & 809252 & 6.6 & 6.1816 & TRN & \\
\hline CHEMBL127898 & 809252 & 4.8 & 5.3885 & TST & \\
\hline
\end{tabular}




\begin{tabular}{|c|c|c|c|c|}
\hline & & & pplement & 0 \\
\hline CHEMBL519697 & 809252 & 4.8 & 5.3271 & TST \\
\hline CHEMBL 2004934 & 809252 & 4.8 & 4.7617 & TRN \\
\hline CHEMBL1975128 & 809252 & 6.4 & 6.3237 & TRN \\
\hline CHEMBL 2001485 & 809252 & 6.2 & 5.5555 & TRN \\
\hline CHEMBL1966425 & 809252 & 5.9 & 5.4887 & TRN \\
\hline CHEMBL1984363 & 809252 & 4.8 & 5.1087 & TRN \\
\hline CHEMBL1978099 & 809252 & 4.8 & 5.8836 & TRN \\
\hline CHEMBL1988608 & 809252 & 4.8 & 5.3188 & TRN \\
\hline CHEMBL184847 & 809252 & 4.8 & 4.9009 & TRN \\
\hline CHEMBL1984367 & 809252 & 6.1 & 5.3046 & TRN \\
\hline CHEMBL1985723 & 809252 & 8.2 & 7.4037 & TRN \\
\hline CHEMBL226898 & 809252 & 7.8 & 7.3785 & TRN \\
\hline CHEMBL1982563 & 809252 & 4.8 & 4.7012 & TRN \\
\hline CHEMBL539474 & 809252 & 6.1 & 5.495 & TST \\
\hline CHEMBL575824 & 809252 & 4.8 & 5.2736 & TRN \\
\hline CHEMBL1988387 & 809252 & 7.0 & 6.0056 & TRN \\
\hline CHEMBL1977128 & 809252 & 6.8 & 6.8942 & TRN \\
\hline CHEMBL1989708 & 809252 & 4.8 & 5.9496 & TRN \\
\hline CHEMBL1990288 & 809252 & 4.8 & 4.8445 & TRN \\
\hline CHEMBL1970074 & 809252 & 4.8 & 5.0762 & TRN \\
\hline CHEMBL1986970 & 809252 & 5.9 & 5.2484 & TRN \\
\hline CHEMBL1958401 & 809252 & 4.8 & 5.0898 & TRN \\
\hline CHEMBL 2003456 & 809252 & 4.8 & 5.1827 & TRN \\
\hline CHEMBL1966816 & 809252 & 4.8 & 4.6891 & TRN \\
\hline CHEMBL1972584 & 809252 & 6.6 & 5.8856 & TRN \\
\hline CHEMBL2002992 & 809252 & 4.8 & 5.4051 & TRN \\
\hline CHEMBL560813 & 809252 & 4.8 & 4.8713 & TRN \\
\hline CHEMBL1968791 & 809252 & 6.2 & 5.6849 & TRN \\
\hline CHEMBL1971186 & 809252 & 4.8 & 4.7838 & TRN \\
\hline CHEMBL 2003482 & 809252 & 4.8 & 4.6531 & TRN \\
\hline CHEMBL1973211 & 809252 & 6.1 & 5.8728 & TRN \\
\hline CHEMBL1984700 & 809252 & 4.8 & 4.7284 & TRN \\
\hline CHEMBL1998953 & 809252 & 7.2 & 6.2394 & TRN \\
\hline CHEMBL1972125 & 809252 & 4.9 & 5.0537 & TRN \\
\hline CHEMBL1976134 & 809252 & 5.8 & 5.535 & TRN \\
\hline CHEMBL1965131 & 809252 & 4.8 & 4.9107 & TRN \\
\hline CHEMBL1972158 & 809252 & 6.3 & 6.2009 & TRN \\
\hline CHEMBL1979855 & 809252 & 4.8 & 5.0238 & TRN \\
\hline CHEMBL1970340 & 809252 & 4.8 & 4.849 & TRN \\
\hline CHEMBL 2005186 & 809252 & 4.8 & 5.1165 & TRN \\
\hline CHEMBL 2006450 & 809252 & 4.7 & 5.9858 & TRN \\
\hline CHEMBL1975534 & 809252 & 5.9 & 5.1992 & TRN \\
\hline CHEMBL1993424 & 809252 & 4.8 & 5.7849 & TRN \\
\hline CHEMBL1966703 & 809252 & 4.8 & 4.7713 & TST \\
\hline CHEMBL1969561 & 809252 & 4.8 & 5.2741 & TRN \\
\hline CHEMBL1975121 & 809252 & 4.8 & 4.5986 & TRN \\
\hline CHEMBL1997023 & 809252 & 4.8 & 5.5737 & TST \\
\hline CHEMBL1964687 & 809252 & 4.8 & 5.6133 & TRN \\
\hline
\end{tabular}




\begin{tabular}{|c|c|c|c|c|c|}
\hline \\
\hline CHEMBL1971943 & 809252 & 6.0 & 5.5626 & TRN & \\
\hline CHEMBL1974254 & 809252 & 4.8 & 5.6748 & TRN & \\
\hline CHEMBL1988537 & 809252 & 4.8 & 5.3435 & TST & \\
\hline CHEMBL1969049 & 809252 & 4.8 & 4.8481 & TRN & \\
\hline CHEMBL 2005828 & 809252 & 4.8 & 5.0896 & TRN & \\
\hline CHEMBL1998611 & 809252 & 4.8 & 5.082 & TRN & \\
\hline CHEMBL1975900 & 809252 & 4.8 & 5.3736 & TRN & \\
\hline CHEMBL255822 & 809252 & 4.8 & 5.483 & TRN & \\
\hline CHEMBL1972221 & 809252 & 4.8 & 4.5336 & TRN & \\
\hline CHEMBL 2006778 & 809252 & 4.8 & 5.7435 & TRN & \\
\hline CHEMBL378627 & 809252 & 4.8 & 4.79899 & 99999999995 & TRN \\
\hline CHEMBL1996979 & 809252 & 6.2 & 5.8464 & TRN & \\
\hline CHEMBL1997025 & 809252 & 6.7 & 4.8075 & TRN & \\
\hline CHEMBL1968406 & 809252 & 6.0 & 5.6413 & TRN & \\
\hline CHEMBL1984274 & 809252 & 5.8 & 5.5219 & TST & \\
\hline CHEMBL1998545 & 809252 & 4.8 & 4.7324 & TRN & \\
\hline CHEMBL1986869 & 809252 & 4.8 & 4.8872 & TRN & \\
\hline CHEMBL1682558 & 809252 & 4.8 & 5.0027 & TRN & \\
\hline CHEMBL1990496 & 809252 & 4.8 & 5.0732 & TRN & \\
\hline CHEMBL 2002479 & 809252 & 7.1 & 5.8968 & TRN & \\
\hline CHEMBL1967094 & 809252 & 6.7 & 5.561 & TRN & \\
\hline CHEMBL 2003341 & 809252 & 4.8 & 4.8545 & TRN & \\
\hline CHEMBL1982992 & 809252 & 4.8 & 4.7207 & TRN & \\
\hline CHEMBL1999590 & 809252 & 4.8 & 5.0178 & TST & \\
\hline CHEMBL1981079 & 809252 & 4.8 & 5.609 & TRN & \\
\hline CHEMBL1978166 & 809252 & 4.7 & 5.9599 & TRN & \\
\hline CHEMBL1980489 & 809252 & 4.8 & 5.3357 & TRN & \\
\hline CHEMBL1967116 & 809252 & 6.2 & 5.8797 & TRN & \\
\hline CHEMBL 2000832 & 809252 & 6.1 & 5.1561 & TRN & \\
\hline CHEMBL1970709 & 809252 & 4.8 & 4.912 & TRN & \\
\hline CHEMBL1965660 & 809252 & 4.8 & 5.8712 & TRN & \\
\hline CHEMBL1998112 & 809252 & 4.8 & 5.2149 & TRN & \\
\hline CHEMBL1972290 & 809252 & 8.7 & 7.4726 & TRN & \\
\hline CHEMBL1969126 & 809252 & 4.8 & 4.7997 & TRN & \\
\hline CHEMBL1980896 & 809252 & 4.8 & 4.9442 & TRN & \\
\hline CHEMBL1970104 & 809252 & 6.3 & 5.8918 & TRN & \\
\hline CHEMBL1991429 & 809252 & 6.0 & 5.2337 & TRN & \\
\hline CHEMBL1964777 & 809252 & 6.0 & 5.1094 & TST & \\
\hline CHEMBL1971149 & 809252 & 4.8 & 4.768 & TRN & \\
\hline CHEMBL1999714 & 809252 & 4.8 & 4.7864 & TRN & \\
\hline CHEMBL1994040 & 809252 & 4.8 & 4.84 & TRN & \\
\hline CHEMBL 388978 & 809252 & 9.5 & 7.6562 & TST & \\
\hline CHEMBL1984548 & 809252 & 8.9 & 7.4072 & TRN & \\
\hline CHEMBL579246 & 809252 & 6.2 & 5.6691 & TRN & \\
\hline CHEMBL398951 & 809252 & 7.1 & 5.6767 & TRN & \\
\hline CHEMBL1982506 & 809252 & 4.8 & 4.8666 & TST & \\
\hline CHEMBL 2004716 & 809252 & 7.2 & 6.4763 & TRN & \\
\hline CHEMBL1968127 & 809252 & 4.8 & 4.7131 & TRN & \\
\hline
\end{tabular}




\begin{tabular}{|c|c|c|c|c|c|}
\hline \multicolumn{6}{|c|}{ Supplemental Table S2.txt } \\
\hline CHEMBL1975233 & 809252 & 4.8 & 4.7656 & TRN & \\
\hline CHEMBL1985406 & 809252 & 4.8 & 4.6484 & TRN & \\
\hline CHEMBL 207400 & 809252 & 4.8 & 4.7518 & TST & \\
\hline CHEMBL 2000894 & 809252 & 4.8 & 4.888 & TST & \\
\hline CHEMBL1982135 & 809252 & 4.8 & 5.0155 & TRN & \\
\hline CHEMBL1976090 & 809252 & 5.8 & 5.4867 & TRN & \\
\hline CHEMBL1993243 & 809252 & 4.8 & 5.525 & TRN & \\
\hline CHEMBL1992922 & 809252 & 6.0 & 5.8854 & TRN & \\
\hline CHEMBL 2004771 & 809252 & 4.8 & 5.0237 & TRN & \\
\hline CHEMBL1997597 & 809252 & 4.8 & 4.9788 & TRN & \\
\hline CHEMBL1969537 & 809252 & 5.8 & 5.6097 & TST & \\
\hline CHEMBL1976093 & 809252 & 4.8 & 4.6576 & TRN & \\
\hline CHEMBL1975256 & 809252 & 4.8 & 4.9337 & TST & \\
\hline CHEMBL508928 & 809252 & 6.2 & 5.2994 & TRN & \\
\hline CHEMBL1991356 & 809252 & 4.8 & 4.9001 & TST & \\
\hline CHEMBL 2004892 & 809252 & 4.8 & 5.2189 & TRN & \\
\hline CHEMBL116070 & 809252 & 4.8 & 5.0376 & TST & \\
\hline CHEMBL1970314 & 809252 & 4.8 & 4.8989 & TRN & \\
\hline CHEMBL 2004871 & 809252 & 4.8 & 4.842 & TRN & \\
\hline CHEMBL 2004872 & 809252 & 4.8 & 4.743 & TRN & \\
\hline CHEMBL1969879 & 809252 & 4.8 & 5.0157 & TRN & \\
\hline CHEMBL1981720 & 809252 & 4.8 & 4.4408 & TRN & \\
\hline CHEMBL419932 & 809252 & 4.8 & 5.5307 & TRN & \\
\hline CHEMBL262433 & 809252 & 6.5 & 5.2896 & TRN & \\
\hline CHEMBL 306380 & 809252 & 4.8 & 5.27 & TRN & \\
\hline CHEMBL1966722 & 809252 & 4.8 & 5.58200 & 0000000001 & TST \\
\hline CHEMBL1983595 & 809252 & 6.4 & 6.8605 & TRN & \\
\hline CHEMBL1975500 & 809252 & 4.8 & 5.0363 & TRN & \\
\hline CHEMBL394619 & 809252 & 4.8 & 5.246 & TRN & \\
\hline CHEMBL1996831 & 809252 & 4.8 & 5.1156 & TST & \\
\hline CHEMBL411903 & 809252 & 7.0 & 5.5832 & TRN & \\
\hline CHEMBL1980253 & 809252 & 7.7 & 7.1979 & TRN & \\
\hline CHEMBL1965988 & 809252 & 6.8 & 5.8839 & TRN & \\
\hline CHEMBL418203 & 809252 & 4.7 & 4.8884 & TST & \\
\hline CHEMBL1989646 & 809252 & 4.8 & 5.9449 & TRN & \\
\hline CHEMBL225519 & 809252 & 4.8 & 5.5033 & TRN & \\
\hline CHEMBL1978200 & 809252 & 4.8 & 4.6663 & TRN & \\
\hline CHEMBL1970522 & 809252 & 4.8 & 5.4287 & TRN & \\
\hline CHEMBL1964692 & 809252 & 6.2 & 5.0816 & TRN & \\
\hline CHEMBL1996931 & 809252 & 4.8 & 4.7467 & TRN & \\
\hline CHEMBL1964413 & 809252 & 4.8 & 5.1047 & TRN & \\
\hline CHEMBL1973483 & 809252 & 4.8 & 4.8683 & TRN & \\
\hline CHEMBL1998470 & 809252 & 6.9 & 6.36799 & 9999999999 & TRN \\
\hline CHEMBL1997340 & 809252 & 4.8 & 4.9989 & TRN & \\
\hline CHEMBL1994669 & 809252 & 8.8 & 7.523 & TRN & \\
\hline CHEMBL1522508 & 809252 & 4.8 & 4.6475 & TRN & \\
\hline CHEMBL1989474 & 809252 & 4.8 & 4.8639 & TRN & \\
\hline CHEMBL1090360 & 809252 & 4.8 & 5.1299 & TRN & \\
\hline
\end{tabular}




\begin{tabular}{|c|c|c|c|c|c|}
\hline \\
\hline CHEMBL210887 & 809252 & 4.8 & 4.8136 & TST & \\
\hline CHEMBL458997 & 809252 & 6.5 & 6.4304 & TRN & \\
\hline CHEMBL1971021 & 809252 & 4.8 & 4.6926 & TRN & \\
\hline CHEMBL 227271 & 809252 & 6.6 & 7.4713 & TRN & \\
\hline CHEMBL583144 & 809252 & 4.8 & 5.2726 & TRN & \\
\hline CHEMBL1974310 & 809252 & 6.1 & 5.0984 & TST & \\
\hline CHEMBL1982660 & 809252 & 4.8 & 4.7147 & TRN & \\
\hline CHEMBL1994693 & 809252 & 6.4 & 5.3169 & TRN & \\
\hline CHEMBL1982957 & 809252 & 6.4 & 6.3995 & TRN & \\
\hline CHEMBL1725279 & 809252 & 6.4 & 5.7126 & TST & \\
\hline CHEMBL1975138 & 809252 & 6.7 & 5.1188 & TST & \\
\hline CHEMBL424872 & 809252 & 4.7 & 4.7437 & TRN & \\
\hline CHEMBL412142 & 809252 & 4.8 & 5.119 & TST & \\
\hline CHEMBL1980704 & 809252 & 4.8 & 5.1595 & TST & \\
\hline CHEMBL 2003271 & 809252 & 4.8 & 5.1084 & TRN & \\
\hline CHEMBL1966808 & 809252 & 4.8 & 5.4947 & TST & \\
\hline CHEMBL2004447 & 809252 & 4.8 & 4.9771 & TST & \\
\hline CHEMBL1992231 & 809252 & 7.1 & 6.1411 & TRN & \\
\hline CHEMBL1983111 & 809252 & 6.7 & 6.9437 & TST & \\
\hline CHEMBL1973860 & 809252 & 4.8 & 4.8341 & TRN & \\
\hline CHEMBL 260135 & 809252 & 4.8 & 4.6018 & TRN & \\
\hline CHEMBL 220241 & 809252 & 4.8 & 6.2234 & TRN & \\
\hline CHEMBL 2004544 & 809252 & 5.8 & 5.3181 & TST & \\
\hline CHEMBL1982610 & 809252 & 4.8 & 4.8245 & TST & \\
\hline CHEMBL1999496 & 809252 & 4.8 & 4.9847 & TRN & \\
\hline CHEMBL1988300 & 809252 & 4.8 & 5.1596 & TRN & \\
\hline CHEMBL1991078 & 809252 & 6.4 & 7.0795 & TRN & \\
\hline CHEMBL1987359 & 809252 & 4.8 & 4.869 & TST & \\
\hline CHEMBL1994438 & 809252 & 8.8 & 7.3359 & TRN & \\
\hline CHEMBL1969502 & 809252 & 4.8 & 5.5214 & TST & \\
\hline CHEMBL1682553 & 809252 & 4.8 & 5.1088 & TRN & \\
\hline CHEMBL1983963 & 809252 & 4.8 & 5.2628 & TRN & \\
\hline CHEMBL1997764 & 809252 & 5.8 & $5.5920 e$ & 00000000005 & TRN \\
\hline CHEMBL1985092 & 809252 & 6.2 & 5.6809 & TRN & \\
\hline CHEMBL1981410 & 809252 & 6.2 & 5.1618 & TRN & \\
\hline CHEMBL1996234 & 809252 & 4.8 & 5.3017 & TRN & \\
\hline CHEMBL1991434 & 809252 & 4.8 & 5.0195 & TST & \\
\hline CHEMBL1967544 & 809252 & 6.4 & 5.4044 & TRN & \\
\hline CHEMBL 223367 & 809252 & 6.6 & 5.8549 & TST & \\
\hline CHEMBL340384 & 809252 & 5.9 & 5.4328 & TST & \\
\hline CHEMBL1969151 & 809252 & 8.5 & 7.5634 & TRN & \\
\hline CHEMBL1996587 & 809252 & 4.8 & 4.845 & TRN & \\
\hline CHEMBL1964804 & 809252 & 4.8 & 4.7156 & TRN & \\
\hline CHEMBL443962 & 809252 & 4.8 & 4.805 & TST & \\
\hline CHEMBL 2000354 & 809252 & 6.0 & 5.4797 & TRN & \\
\hline CHEMBL1965507 & 809252 & 7.1 & 5.8013 & TRN & \\
\hline CHEMBL 274064 & 809252 & 6.1 & 4.9074 & TRN & \\
\hline CHEMBL1967564 & 809252 & 4.8 & 4.3603 & TRN & \\
\hline
\end{tabular}




\begin{tabular}{|c|c|c|c|c|c|}
\hline \multicolumn{6}{|c|}{ Supplemental Table s2.txt } \\
\hline CHEMBL592030 & 809252 & 6.6 & 6.9942 & TST & \\
\hline CHEMBL 2000071 & 809252 & 5.9 & 5.9556 & TRN & \\
\hline CHEMBL1979176 & 809252 & 4.8 & 4.7364 & TRN & \\
\hline CHEMBL 2002613 & 809252 & 6.1 & 6.9169 & TRN & \\
\hline CHEMBL 2000408 & 809252 & 4.8 & 4.7169 & TRN & \\
\hline CHEMBL248757 & 809252 & 6.7 & 5.67 & TST & \\
\hline CHEMBL1978014 & 809252 & 4.8 & 5.0383 & TRN & \\
\hline CHEMBL1994538 & 809252 & 4.8 & 4.4568 & TRN & \\
\hline CHEMBL1975490 & 809252 & 6.4 & 5.476 & TRN & \\
\hline CHEMBL1964444 & 809252 & 4.8 & 4.6056 & TRN & \\
\hline CHEMBL1986139 & 809252 & 4.8 & 4.6478 & TRN & \\
\hline CHEMBL1980540 & 809252 & 4.8 & 4.7065 & TRN & \\
\hline CHEMBL278041 & 809252 & 4.7 & 4.7046 & TRN & \\
\hline CHEMBL1979883 & 809252 & 6.0 & 5.9085 & TRN & \\
\hline CHEMBL1984162 & 809252 & 8.4 & 6.8518 & TRN & \\
\hline CHEMBL1998432 & 809252 & 8.9 & 7.6004 & TRN & \\
\hline CHEMBL491758 & 809252 & 4.8 & 5.48799 & 99999999995 & TRN \\
\hline CHEMBL549730 & 809252 & 4.8 & 5.62200 & 0000000001 & TRN \\
\hline CHEMBL1970189 & 809252 & 4.8 & 5.0165 & TST & \\
\hline CHEMBL1996791 & 809252 & 4.8 & 5.0345 & TRN & \\
\hline CHEMBL371206 & 809252 & 4.8 & 5.5075 & TRN & \\
\hline CHEMBL1974664 & 809252 & 4.8 & 4.8915 & TST & \\
\hline CHEMBL406845 & 809252 & 6.2 & 5.1474 & TRN & \\
\hline CHEMBL1974288 & 809252 & 4.8 & 4.8269 & TRN & \\
\hline CHEMBL196363 & 809252 & 6.2 & 5.7531 & TRN & \\
\hline CHEMBL1190711 & 809252 & 4.8 & 4.8636 & TRN & \\
\hline CHEMBL1968705 & 809252 & 4.8 & 5.2875 & TRN & \\
\hline CHEMBL404367 & 809252 & 4.8 & 4.9203 & TRN & \\
\hline CHEMBL1966343 & 809252 & 5.8 & 5.7042 & TRN & \\
\hline CHEMBL1967887 & 809252 & 6.3 & 5.7189 & TRN & \\
\hline CHEMBL 2000568 & 809252 & 4.8 & 5.2819 & TRN & \\
\hline CHEMBL 2000335 & 809252 & 6.9 & 6.0702 & TRN & \\
\hline CHEMBL1988717 & 809252 & 4.8 & 5.1209 & TRN & \\
\hline CHEMBL1974328 & 809252 & 5.0 & 6.7611 & TRN & \\
\hline CHEMBL509032 & 809252 & 6.8 & 6.8311 & TRN & \\
\hline CHEMBL243298 & 809252 & 5.9 & 6.1553 & TRN & \\
\hline CHEMBL1973808 & 809252 & 4.8 & 4.8095 & TRN & \\
\hline CHEMBL 2000429 & 809252 & 4.8 & 4.6724 & TRN & \\
\hline CHEMBL1972576 & 809252 & 5.8 & 5.9261 & TRN & \\
\hline CHEMBL1990254 & 809252 & 4.8 & 4.8242 & TRN & \\
\hline CHEMBL1992342 & 809252 & 4.8 & 5.0518 & TRN & \\
\hline CHEMBL1988173 & 809252 & 4.8 & 5.612 & TST & \\
\hline CHEMBL1966204 & 809252 & 7.3 & 7.0138 & TRN & \\
\hline CHEMBL1989805 & 809252 & 6.0 & 5.231 & TST & \\
\hline CHEMBL1965423 & 809252 & 4.8 & 4.6153 & TRN & \\
\hline CHEMBL1983025 & 809252 & 6.4 & 5.7145 & TRN & \\
\hline CHEMBL205415 & 809252 & 4.8 & 5.6191 & TRN & \\
\hline CHEMBL1977135 & 809252 & 4.8 & 4.7678 & TRN & \\
\hline
\end{tabular}




\begin{tabular}{|c|c|c|c|c|}
\hline & & & & al la \\
\hline CHEMBL2001920 & 809252 & 6.2 & 5.8224 & TRN \\
\hline CHEMBL1241473 & 809252 & 7.4 & 7.3263 & TRN \\
\hline CHEMBL1978448 & 809252 & 6.7 & 5.3593 & TST \\
\hline CHEMBL 2001257 & 809252 & 4.8 & 5.824 & TRN \\
\hline CHEMBL1992536 & 809252 & 4.8 & 4.9503 & TRN \\
\hline CHEMBL1992740 & 809252 & 4.8 & 4.4638 & TRN \\
\hline CHEMBL439340 & 809252 & 4.8 & 5.0556 & TRN \\
\hline CHEMBL2006188 & 809252 & 4.8 & 5.091 & TRN \\
\hline CHEMBL1967531 & 809252 & 4.8 & 5.7825 & TRN \\
\hline CHEMBL1973893 & 809252 & 4.8 & 4.5291 & TRN \\
\hline CHEMBL1970913 & 809252 & 4.8 & 4.4176 & TRN \\
\hline CHEMBL1997534 & 809252 & 4.8 & 4.9998 & TRN \\
\hline CHEMBL1996500 & 809252 & 4.8 & 4.5908 & TRN \\
\hline CHEMBL1985095 & 809252 & 4.8 & 6.3288 & TST \\
\hline CHEMBL1682540 & 809252 & 4.8 & 4.8437 & TRN \\
\hline CHEMBL1976420 & 809252 & 4.8 & 5.3785 & TST \\
\hline CHEMBL1994864 & 809252 & 4.8 & 5.2783 & TRN \\
\hline CHEMBL 2002446 & 809252 & 7.2 & 5.2417 & TRN \\
\hline CHEMBL497151 & 809252 & 6.3 & 5.9038 & TST \\
\hline CHEMBL246970 & 809252 & 4.8 & 5.3288 & TRN \\
\hline CHEMBL340921 & 809252 & 6.0 & 4.934 & TST \\
\hline CHEMBL1999718 & 809252 & 4.8 & 4.8227 & TRN \\
\hline CHEMBL1987073 & 809252 & 7.3 & 6.8028 & TRN \\
\hline CHEMBL1276446 & 809252 & 8.2 & 6.7613 & TST \\
\hline CHEMBL1977346 & 809252 & 4.8 & 4.9212 & TRN \\
\hline CHEMBL1971649 & 809252 & 4.8 & 4.7207 & TRN \\
\hline CHEMBL 2006439 & 809252 & 6.5 & 6.7114 & TRN \\
\hline CHEMBL1969190 & 809252 & 4.8 & 5.5041 & TRN \\
\hline CHEMBL1973937 & 809252 & 4.8 & 5.4612 & TRN \\
\hline CHEMBL1991674 & 809252 & 6.7 & 7.3586 & TRN \\
\hline CHEMBL1982711 & 809252 & 6.1 & 6.2076 & TRN \\
\hline CHEMBL 2007044 & 809252 & 7.3 & 5.5168 & TRN \\
\hline CHEMBL1994241 & 809252 & 5.8 & 5.6325 & TST \\
\hline CHEMBL 223460 & 809252 & 6.3 & 5.666 & TST \\
\hline CHEMBL1998829 & 809252 & 4.8 & 5.3067 & TRN \\
\hline CHEMBL50894 & 809252 & 4.8 & 5.556 & TST \\
\hline CHEMBL1988838 & 809252 & 5.9 & 6.3457 & TRN \\
\hline CHEMBL1981725 & 809252 & 4.8 & 6.2979 & TRN \\
\hline CHEMBL1982753 & 809252 & 6.4 & 5.8251 & TRN \\
\hline CHEMBL1972346 & 809252 & 7.1 & 5.57799 & 9999999999 \\
\hline CHEMBL1982866 & 809252 & 4.8 & 4.8887 & TRN \\
\hline CHEMBL1979933 & 809252 & 6.1 & 6.1218 & TRN \\
\hline CHEMBL1965570 & 809252 & 4.8 & 5.69 & TRN \\
\hline CHEMBL 2007592 & 809252 & 4.8 & 5.0375 & TST \\
\hline CHEMBL1976936 & 809252 & 7.6 & 7.3612 & TRN \\
\hline CHEMBL210963 & 809252 & 4.8 & 4.7315 & TRN \\
\hline CHEMBL1082440 & 809252 & 4.8 & 5.3889 & TST \\
\hline CHEMBL1614705 & 809252 & 4.8 & 4.9294 & TRN \\
\hline
\end{tabular}




\begin{tabular}{|c|c|c|c|c|c|}
\hline \multicolumn{6}{|c|}{ Supplemental Table S2.txt } \\
\hline CHEMBL1984633 & 809252 & 4.8 & 4.8881 & TRN & \\
\hline CHEMBL1965845 & 809252 & 4.8 & 5.8304 & TRN & \\
\hline CHEMBL 2006715 & 809252 & 5.9 & 5.5288 & TRN & \\
\hline CHEMBL1986597 & 809252 & 4.8 & 4.9079 & TRN & \\
\hline CHEMBL1990482 & 809252 & 4.8 & 4.9639 & TRN & \\
\hline CHEMBL1990904 & 809252 & 4.8 & 4.8749 & TRN & \\
\hline CHEMBL1987448 & 809252 & 8.3 & 6.978 & TRN & \\
\hline CHEMBL 2005475 & 809252 & 7.1 & 5.9913 & TRN & \\
\hline CHEMBL402846 & 809252 & 4.8 & 4.9138 & TRN & \\
\hline CHEMBL183844 & 809252 & 4.8 & 4.7483 & TRN & \\
\hline CHEMBL1997349 & 809252 & 6.0 & 5.1113 & TST & \\
\hline CHEMBL220057 & 809252 & 4.8 & 5.2799 & TRN & \\
\hline CHEMBL1682545 & 809252 & 4.8 & 4.8906 & TRN & \\
\hline CHEMBL 383541 & 809252 & 4.8 & 5.33899 & 99999999995 & TRN \\
\hline CHEMBL 2001224 & 809252 & 4.8 & 4.9397 & TRN & \\
\hline CHEMBL10 & 809252 & 4.7 & 4.7891 & TRN & \\
\hline CHEMBL1976732 & 809252 & 4.8 & 5.1945 & TRN & \\
\hline CHEMBL 2005216 & 809252 & 7.6 & 7.4009 & TRN & \\
\hline CHEMBL1964937 & 809252 & 5.8 & 5.7589 & TRN & \\
\hline CHEMBL1969506 & 809252 & 4.8 & 5.0404 & TRN & \\
\hline CHEMBL1980163 & 809252 & 4.8 & 4.8235 & TRN & \\
\hline CHEMBL2005899 & 809252 & 4.8 & 5.5597 & TRN & \\
\hline CHEMBL1682552 & 809252 & 4.8 & 5.0321 & TRN & \\
\hline CHEMBL229799 & 809252 & 7.1 & 7.7815 & TRN & \\
\hline CHEMBL105739 & 809252 & 4.8 & 5.7934 & TRN & \\
\hline CHEMBL379300 & 809252 & 6.5 & 6.8904 & TRN & \\
\hline CHEMBL1973720 & 809252 & 8.5 & 7.715 & TRN & \\
\hline CHEMBL1969523 & 809252 & 7.3 & 6.0678 & TRN & \\
\hline CHEMBL1986781 & 809252 & 4.8 & 4.8226 & TRN & \\
\hline CHEMBL526133 & 809252 & 4.8 & 5.3942 & TRN & \\
\hline CHEMBL387971 & 809252 & 6.4 & 5.0804 & TRN & \\
\hline CHEMBL1979057 & 809252 & 6.6 & 5.1314 & TRN & \\
\hline CHEMBL1999428 & 809252 & 4.8 & 4.6994 & TRN & \\
\hline CHEMBL1967560 & 809252 & 4.8 & 5.1333 & TRN & \\
\hline CHEMBL 211378 & 809252 & 4.8 & 4.95 & TRN & \\
\hline CHEMBL1516890 & 809252 & 4.8 & 5.5962 & TRN & \\
\hline CHEMBL1982465 & 809252 & 6.2 & 5.689 & TRN & \\
\hline CHEMBL 2001751 & 809252 & 8.3 & 7.0994 & TRN & \\
\hline CHEMBL 2003420 & 809252 & 4.8 & 5.1159 & TRN & \\
\hline CHEMBL1984586 & 809252 & 4.8 & 5.1765 & TRN & \\
\hline CHEMBL1972659 & 809252 & 4.8 & 4.8563 & TST & \\
\hline CHEMBL 272453 & 809252 & 4.8 & 5.1392 & TRN & \\
\hline CHEMBL1970217 & 809252 & 4.8 & 4.6866 & TRN & \\
\hline CHEMBL 2005528 & 809252 & 4.8 & 4.926 & TST & \\
\hline CHEMBL185569 & 809252 & 5.9 & 4.7164 & TRN & \\
\hline CHEMBL1969843 & 809252 & 4.8 & 5.034 & TRN & \\
\hline CHEMBL 2007002 & 809252 & 4.8 & 4.9533 & TRN & \\
\hline CHEMBL1987007 & 809252 & 6.5 & 5.4399 & TRN & \\
\hline
\end{tabular}




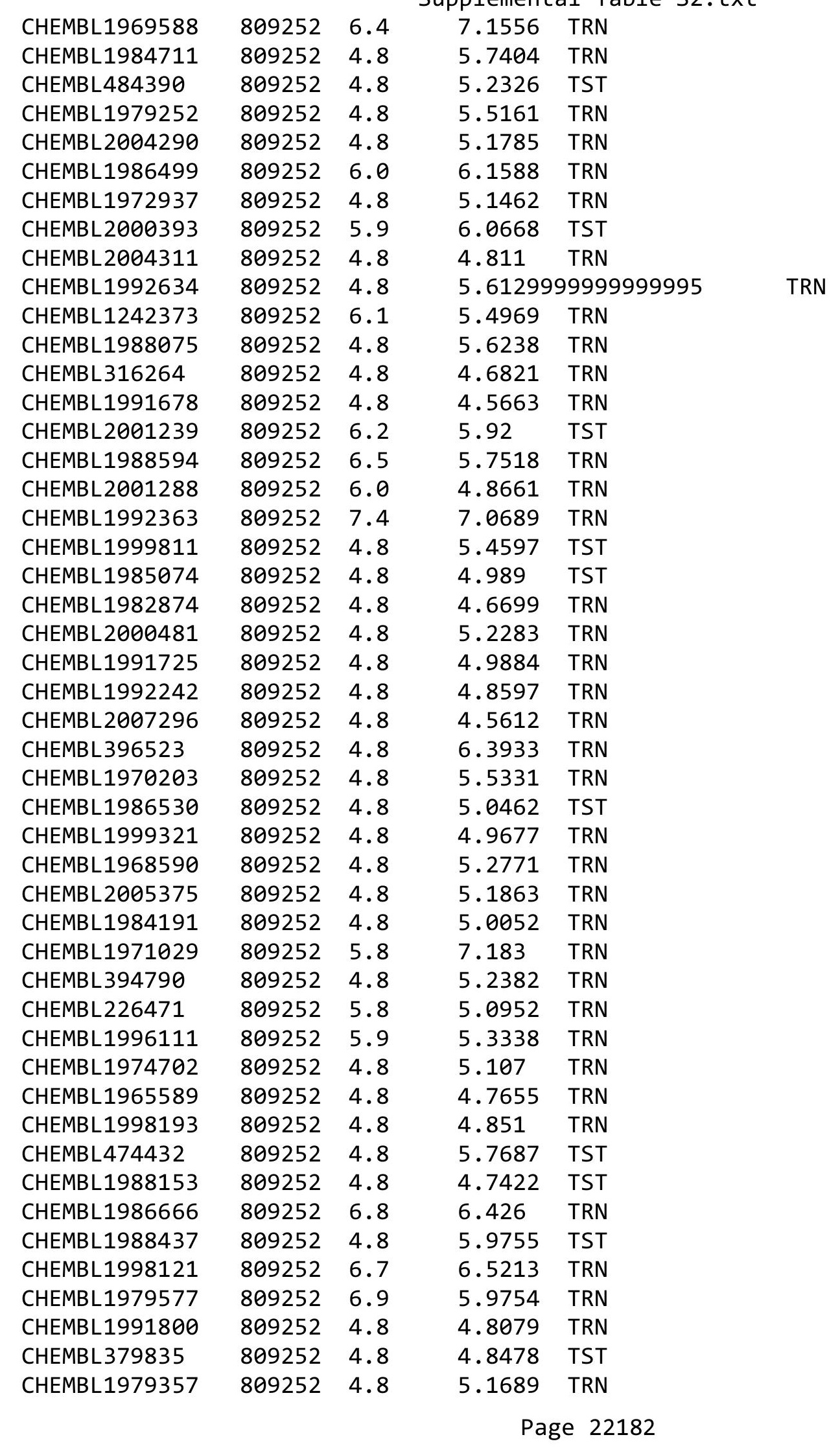




\begin{tabular}{|c|c|c|c|c|c|}
\hline \\
\hline CHEMBL1996817 & 809252 & 6.3 & 6.3664 & TRN & \\
\hline CHEMBL468280 & 809252 & 4.8 & 4.9424 & TST & \\
\hline CHEMBL1990884 & 809252 & 4.8 & 5.1033 & TRN & \\
\hline CHEMBL3109278 & 809252 & 4.9 & 6.6716 & TRN & \\
\hline CHEMBL 256835 & 809252 & 4.8 & 4.8266 & TRN & \\
\hline CHEMBL1980142 & 809252 & 4.8 & 4.6783 & TRN & \\
\hline CHEMBL41783 & 809252 & 4.8 & 4.3005 & TRN & \\
\hline CHEMBL2006276 & 809252 & 4.8 & 4.9042 & TRN & \\
\hline CHEMBL191003 & 809252 & 6.2 & 5.8201 & TRN & \\
\hline CHEMBL271381 & 809252 & 4.8 & 5.3834 & TRN & \\
\hline CHEMBL 2006785 & 809252 & 4.8 & 4.9025 & TRN & \\
\hline CHEMBL1982466 & 809252 & 4.8 & 5.4837 & TRN & \\
\hline CHEMBL1995740 & 809252 & 4.8 & 4.8757 & TRN & \\
\hline CHEMBL1990162 & 809252 & 6.9 & 6.8961 & TRN & \\
\hline CHEMBL234085 & 809252 & 5.2 & 5.2957 & TRN & \\
\hline CHEMBL1995832 & 809252 & 4.8 & 4.654 & TRN & \\
\hline CHEMBL1969042 & 809252 & 6.0 & 5.5032 & TRN & \\
\hline CHEMBL 2000345 & 809252 & 5.9 & 5.976 & TST & \\
\hline CHEMBL1999931 & 809252 & 6.4 & 7.2416 & TRN & \\
\hline CHEMBL 2007064 & 809252 & 4.8 & 6.0004 & TRN & \\
\hline CHEMBL1981047 & 809252 & 6.1 & 6.2258 & TST & \\
\hline CHEMBL229968 & 809252 & 6.7 & 7.5851 & TRN & \\
\hline CHEMBL1976240 & 809252 & 4.8 & 4.8865 & TRN & \\
\hline CHEMBL1979093 & 809252 & 4.8 & 5.5412 & TRN & \\
\hline CHEMBL1968151 & 809252 & 4.8 & 5.3108 & TST & \\
\hline CHEMBL1987009 & 809252 & 7.0 & 5.8638 & TRN & \\
\hline CHEMBL379218 & 809252 & 6.2 & 6.968 & TRN & \\
\hline CHEMBL2003817 & 809252 & 4.8 & 4.5236 & TRN & \\
\hline CHEMBL1994830 & 809252 & 4.8 & 4.5875 & TST & \\
\hline CHEMBL226403 & 809252 & 4.9 & 5.2501 & TRN & \\
\hline CHEMBL2005631 & 809252 & 5.8 & 5.8062 & TRN & \\
\hline CHEMBL1994938 & 809252 & 4.8 & $5.7010 e$ & 00000000005 & TRN \\
\hline CHEMBL1977223 & 809252 & 5.9 & 5.7671 & TRN & \\
\hline CHEMBL1825138 & 809252 & 4.8 & 5.4118 & TST & \\
\hline CHEMBL1236126 & 809252 & 4.8 & 4.7509 & TST & \\
\hline CHEMBL1966279 & 809252 & 4.8 & 5.2088 & TRN & \\
\hline CHEMBL1997846 & 809252 & 6.5 & 6.9968 & TRN & \\
\hline CHEMBL2004419 & 809252 & 4.8 & 4.7069 & TRN & \\
\hline CHEMBL1995811 & 809252 & 6.4 & 6.4421 & TRN & \\
\hline CHEMBL1972489 & 809252 & 4.8 & 4.7923 & TRN & \\
\hline CHEMBL1994074 & 809252 & 6.3 & 5.1664 & TRN & \\
\hline CHEMBL1992937 & 809252 & 5.8 & 5.1599 & TST & \\
\hline CHEMBL1972119 & 809252 & 4.8 & 4.8063 & TST & \\
\hline CHEMBL1090356 & 809252 & 4.8 & 5.1663 & TST & \\
\hline CHEMBL95692 & 809252 & 4.8 & 4.8342 & TST & \\
\hline CHEMBL1986328 & 809252 & 4.8 & 5.2718 & TST & \\
\hline CHEMBL1976455 & 809252 & 4.8 & 4.3621 & TST & \\
\hline CHEMBL1983923 & 809252 & 4.8 & 6.4216 & TST & \\
\hline & & & & 22183 & \\
\hline
\end{tabular}




\begin{tabular}{|c|c|c|c|c|c|}
\hline \multicolumn{6}{|c|}{ Supplemental Table S2.txt } \\
\hline CHEMBL1983534 & 809252 & 4.8 & 4.6819 & TST & \\
\hline CHEMBL1982361 & 809252 & 4.8 & 5.8131 & TST & \\
\hline CHEMBL1982122 & 809252 & 4.8 & 4.852 & TST & \\
\hline CHEMBL 2000801 & 809252 & 4.8 & 4.8965 & TST & \\
\hline CHEMBL1999112 & 809252 & 4.8 & 5.0898 & TST & \\
\hline CHEMBL1682546 & 809252 & 4.8 & 4.848 & TST & \\
\hline CHEMBL1991395 & 809252 & 4.8 & 4.6529 & TST & \\
\hline CHEMBL1971245 & 809252 & 4.8 & 5.2876 & TST & \\
\hline CHEMBL1972142 & 809252 & 4.8 & 5.15600 & 0000000001 & TST \\
\hline CHEMBL1966514 & 809252 & 4.8 & 5.5196 & TST & \\
\hline CHEMBL 2003638 & 809252 & 4.8 & 6.9754 & TST & \\
\hline CHEMBL1996066 & 809252 & 4.8 & 4.8472 & TST & \\
\hline CHEMBL1993722 & 809252 & 4.8 & 5.0415 & TST & \\
\hline CHEMBL1979970 & 809252 & 4.8 & 4.2025 & TST & \\
\hline CHEMBL1375640 & 809252 & 4.8 & 5.2309 & TST & \\
\hline CHEMBL249282 & 809252 & 6.2 & 5.6385 & TST & \\
\hline CHEMBL 2006237 & 809252 & 4.8 & 4.8685 & TST & \\
\hline CHEMBL1967720 & 809252 & 4.8 & 6.1989 & TST & \\
\hline CHEMBL1572266 & 809252 & 4.8 & 5.0216 & TST & \\
\hline CHEMBL1969755 & 809252 & 4.8 & 4.8585 & TST & \\
\hline CHEMBL1979516 & 809252 & 4.8 & 5.8011 & TST & \\
\hline CHEMBL1991138 & 809252 & 4.8 & 5.0116 & TST & \\
\hline CHEMBL1605605 & 809252 & 4.8 & 4.7214 & TST & \\
\hline CHEMBL1989029 & 809252 & 4.8 & 5.1716 & TST & \\
\hline CHEMBL392642 & 809252 & 4.8 & 5.3041 & TST & \\
\hline CHEMBL514499 & 809252 & 6.8 & 5.4663 & TST & \\
\hline CHEMBL1965631 & 809252 & 4.8 & 5.4424 & TST & \\
\hline CHEMBL1980144 & 809252 & 4.8 & 5.6287 & TST & \\
\hline CHEMBL1991188 & 809252 & 4.8 & 4.849 & TST & \\
\hline CHEMBL1972849 & 809252 & 4.8 & 4.8821 & TST & \\
\hline CHEMBL377408 & 809252 & 6.8 & 4.94300 & 00000000005 & TST \\
\hline CHEMBL231209 & 809252 & 4.8 & 5.1182 & TST & \\
\hline CHEMBL1976220 & 809252 & 4.8 & 5.2243 & TST & \\
\hline CHEMBL1997617 & 809252 & 6.4 & 6.1379 & TST & \\
\hline CHEMBL259922 & 809252 & 4.8 & 4.8673 & TST & \\
\hline CHEMBL1982383 & 809252 & 4.8 & 4.7711 & TST & \\
\hline CHEMBL1969301 & 809252 & 4.8 & 5.3762 & TST & \\
\hline CHEMBL17370 & 809252 & 4.8 & 4.8611 & TST & \\
\hline CHEMBL1987910 & 809252 & 4.8 & 4.8601 & TST & \\
\hline CHEMBL1983932 & 809252 & 4.8 & 4.8836 & TST & \\
\hline CHEMBL1997822 & 809252 & 4.8 & 5.0348 & TST & \\
\hline CHEMBL1991285 & 809252 & 4.8 & 4.9688 & TST & \\
\hline CHEMBL1984038 & 809252 & 4.7 & 4.8768 & TST & \\
\hline CHEMBL 243088 & 809252 & 4.8 & 6.3488 & TST & \\
\hline CHEMBL1993661 & 809252 & 7.0 & 7.5802 & TST & \\
\hline CHEMBL1974416 & 809252 & 5.9 & 5.8205 & TST & \\
\hline CHEMBL1997872 & 809252 & 4.8 & 4.9769 & TST & \\
\hline CHEMBL3126910 & 1294969 & 3.699 & 3.7379 & TRN & \\
\hline
\end{tabular}


Supplemental Table S2.txt

\begin{tabular}{|c|c|c|c|c|c|}
\hline CHEMBL 3126875 & 1294969 & 4.7747 & 4.3218 & TRN & \\
\hline CHEMBL 3126883 & 1294969 & 3.699 & 3.8305 & TRN & \\
\hline CHEMBL3127050 & 1294969 & 5.4881 & 5.3591 & TRN & \\
\hline CHEMBL 3126867 & 1294969 & 3.699 & 3.9353 & TRN & \\
\hline CHEMBL3126911 & 1294969 & 5.2557 & 4.9438 & TRN & \\
\hline CHEMBL3126885 & 1294969 & 3.699 & 3.6223 & TRN & \\
\hline CHEMBL 3124960 & 1294969 & 3.699 & 3.9725 & TRN & \\
\hline CHEMBL 3127059 & 1294969 & 3.699 & 3.7219 & TRN & \\
\hline CHEMBL3126878 & 1294969 & 3.699 & 4.0361 & TRN & \\
\hline CHEMBL3126894 & 1294969 & 3.699 & 3.9235 & TRN & \\
\hline CHEMBL3127057 & 1294969 & 5.1118 & 4.1802 & TST & \\
\hline CHEMBL3126887 & 1294969 & 3.699 & 3.4775 & TRN & \\
\hline CHEMBL 3127058 & 1294969 & \multicolumn{2}{|c|}{4.821000000000001} & 5.2204 & TRN \\
\hline CHEMBL 3126865 & 1294969 & 5.9547 & 4.7917 & TST & \\
\hline CHEMBL3127049 & 1294969 & 6.6778 & 6.7499 & TRN & \\
\hline CHEMBL1814768 & 1294969 & 7.699 & 7.5573 & TRN & \\
\hline CHEMBL3126892 & 1294969 & 3.699 & 3.8931 & TRN & \\
\hline CHEMBL 3126876 & 1294969 & 4.7375 & 4.2885 & TRN & \\
\hline CHEMBL3127062 & 1294969 & 3.699 & 3.4704 & TRN & \\
\hline CHEMBL3126913 & 1294969 & 3.699 & 3.9363 & TRN & \\
\hline CHEMBL3126915 & 1294969 & 3.699 & 4.92 & TST & \\
\hline CHEMBL3126893 & 1294969 & 3.699 & 3.8567 & TRN & \\
\hline CHEMBL 3126884 & 1294969 & 3.699 & 3.2704 & TRN & \\
\hline CHEMBL319177 & 1294969 & 3.699 & 3.2217 & TST & \\
\hline CHEMBL3126881 & 1294969 & 3.699 & 4.01699 & 99999999995 & TRN \\
\hline CHEMBL3126901 & 1294969 & 3.699 & 3.8453 & TRN & \\
\hline CHEMBL3126897 & 1294969 & 3.699 & 4.1507 & TST & \\
\hline CHEMBL 3127047 & 1294969 & 6.4202 & 4.8448 & TST & \\
\hline CHEMBL3127067 & 1294969 & 5.2076 & 5.3136 & TRN & \\
\hline CHEMBL3126880 & 1294969 & 4.8386 & 4.6059 & TRN & \\
\hline CHEMBL3126899 & 1294969 & 5.8928 & 5.9751 & TRN & \\
\hline CHEMBL3126891 & 1294969 & 3.699 & 3.9832 & TRN & \\
\hline CHEMBL 3127065 & 1294969 & 6.4202 & 6.4017 & TRN & \\
\hline CHEMBL3126902 & 1294969 & 3.699 & 4.1579 & TRN & \\
\hline CHEMBL3127055 & 1294969 & 7.1549 & 6.3273 & TST & \\
\hline CHEMBL3127066 & 1294969 & 5.5498 & 5.3882 & TRN & \\
\hline CHEMBL3126900 & 1294969 & 4.8268 & 4.3844 & TRN & \\
\hline CHEMBL 3127061 & 1294969 & 3.699 & 3.5804 & TRN & \\
\hline CHEMBL3127052 & 1294969 & 3.699 & 3.8879 & TRN & \\
\hline CHEMBL 3126909 & 1294969 & 3.699 & 3.9634 & TRN & \\
\hline CHEMBL3127051 & 1294969 & 3.699 & 3.8986 & TRN & \\
\hline CHEMBL3126872 & 1294969 & 3.699 & 3.8648 & TST & \\
\hline CHEMBL3127053 & 1294969 & 3.699 & 3.6103 & TRN & \\
\hline CHEMBL403715 & 1294969 & 3.699 & 3.6943 & TST & \\
\hline CHEMBL 3126896 & 1294969 & 5.4828 & 4.2565 & TST & \\
\hline CHEMBL3127045 & 1294969 & 3.699 & 3.6404 & TRN & \\
\hline CHEMBL 3126877 & 1294969 & 3.699 & 3.9855 & TRN & \\
\hline CHEMBL3126879 & 1294969 & 4.7496 & 4.3839 & TRN & \\
\hline
\end{tabular}

Page 22185 


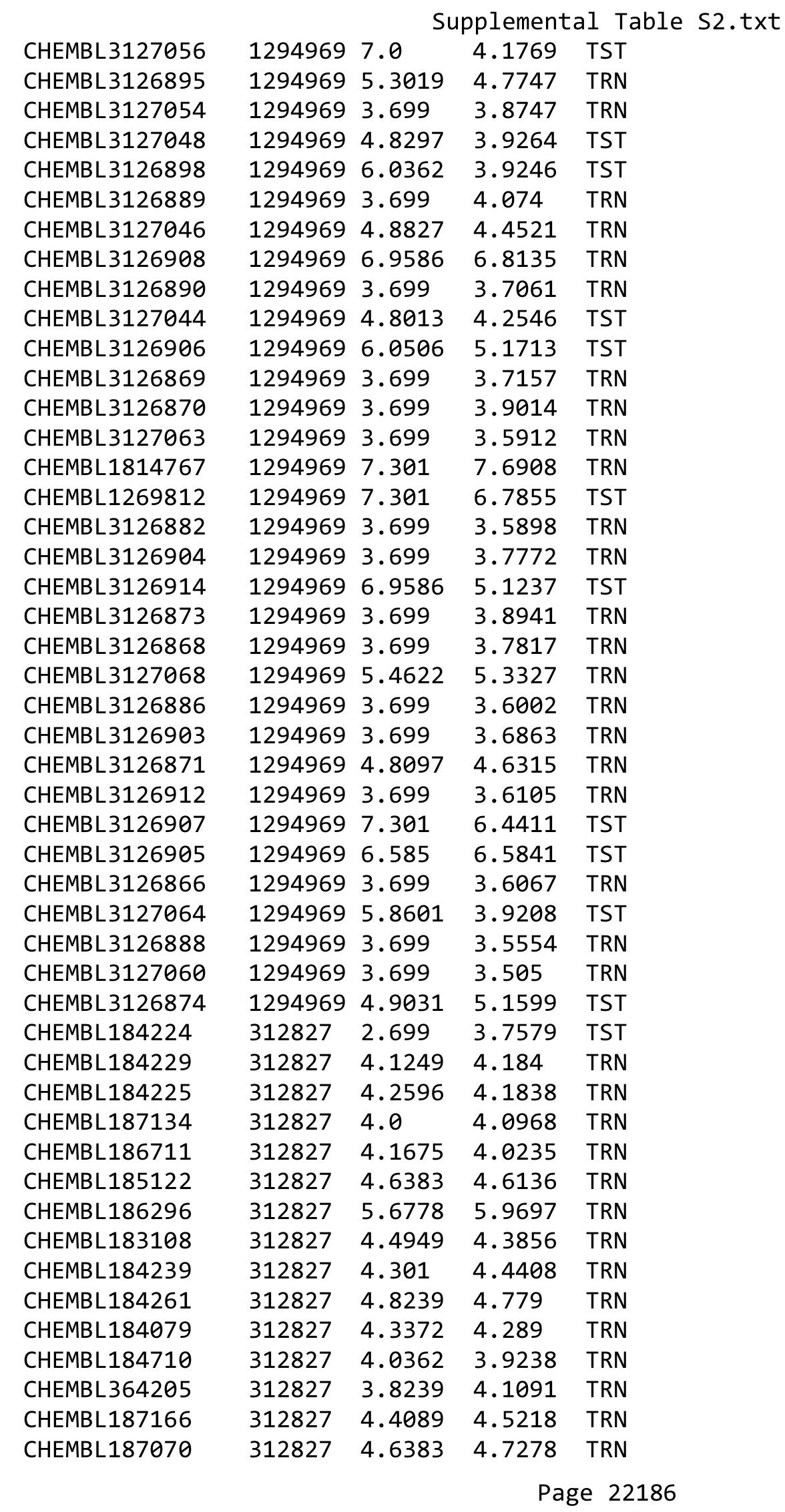


Supplemental Table S2.txt

\begin{tabular}{|c|c|c|c|c|}
\hline CHEMBL 360203 & 12827 & 4.3098 & 4.3533 & TRN \\
\hline CHEMBL187332 & 312827 & 4.0862 & 4.1876 & TRN \\
\hline HEMBL187036 & 12827 & 4.8861 & 9441 & $2 \mathrm{~N}$ \\
\hline HEMBL 363014 & 12827 & 3768 & 1325 & \\
\hline HEMBL185377 & 12827 & 5.0044 & 5.1946 & TRN \\
\hline HEMBL185422 & 12827 & 4.7959 & 4.6102 & \\
\hline HEMBL184208 & 12827 & 4.7212 & 5.0584 & IRN \\
\hline HEMBL186869 & 12827 & 4.4685 & 4.2567 & CT \\
\hline HEMBL366110 & 312827 & 5.1192 & 4.8103 & IRN \\
\hline HEMBL434543 & 12827 & 4.6383 & 4.6631 & TRN \\
\hline CHEMBL187182 & 12827 & 3.983 & 3.9407 & \\
\hline HEMBL184675 & 12827 & 4.6383 & 4.2932 & IST \\
\hline HEMBL184763 & 12827 & 4.4559 & 4.6004 & 「RN \\
\hline HEMBL183634 & 12827 & 4.2676 & 4.1618 & TRN \\
\hline HEMBL187241 & 12827 & 2.699 & 3.912 & TST \\
\hline CHEMBL184518 & 12827 & 4.4202 & 4.3548 & I KIV \\
\hline HEMBL187026 & 12827 & 4.6383 & 4.5207 & TRN \\
\hline HEMBL 360423 & 12827 & 4.4559 & 4.84 & TST \\
\hline HEMBL187533 & 12827 & 2.699 & 2.903 & TST \\
\hline HEMBL187218 & 12827 & 269 & 183 & TST \\
\hline HEMBL186556 & 12827 & 208 & 4.8145 & I RIN \\
\hline HEMBL3 & 12827 & 021 & 5797 & TRN \\
\hline HEMBL188070 & 12827 & 4.0969 & 4.0189 & TRN \\
\hline HEMBL184321 & 12827 & 376 & 3.3966 & TST \\
\hline CHEMBL 363221 & 12827 & 177 & 4.1319 & TRN \\
\hline HEMBL186587 & 12827 & & 2028 & TST \\
\hline HEMBL1 & 12827 & & 355 & TST \\
\hline CHEMBL186982 & 12827 & 4.0862 & 3.8969 & TRN \\
\hline HEMBL187078 & 12827 & 132 & 4.1732 & TRN \\
\hline HEMBL184517 & 12827 & 4.6021 & 3.4893 & TST \\
\hline HEMBL187011 & 12827 & 861 & 3895 & TST \\
\hline CHEMBL1 & 27 & 99 & 475 & TRN \\
\hline CHEMBL 366330 & & 4.2147 & 4.2556 & TRN \\
\hline HEMBL184485 & 12827 & 2.699 & 2.9791 & TRN \\
\hline HEMBL184137 & 12827 & 2.699 & 3.5708 & TST \\
\hline HEMBL184095 & 12827 & 99 & 5919 & TRN \\
\hline CHEMBL1 & 12827 & 198 & 4.7475 & TRN \\
\hline CHEMBL184322 & 312827 & 5.0915 & 5.0354 & TRN \\
\hline CHEMBL515829 & 40741 & 5.9859 & 5.9861 & TRN \\
\hline CHEMBL475308 & 40741 & 4.8146 & 4.776 & TRN \\
\hline CHEMBL511161 & 540741 & 807 & 5.8874 & TRN \\
\hline CHEMBL511162 & 540741 & 5.8931 & 5.8813 & TRN \\
\hline CHEMBL457244 & 540741 & 6.0565 & 6.1016 & TRN \\
\hline CHEMBL474687 & 40741 & 5853 & 6505 & TRN \\
\hline CHEMBL4 & 5407 & 5 & 5.8709 & IRIV \\
\hline CHEMBL474096 & 540741 & 5.4036 & 5.3712 & KIV \\
\hline CHEMBL518325 & 540741 & 6.02 & 6.028 & 「RN \\
\hline CHEMBL515091 & 540741 & 5.7918 & 5.6466 & IRN \\
\hline
\end{tabular}

Page 22187 


\begin{tabular}{|c|c|c|c|c|c|c|}
\hline & & \multicolumn{5}{|c|}{ Supplemental Table S2.txt } \\
\hline CHEMBL457451 & 540741 & 6.0429 & 5.9587 & TRN & & \\
\hline CHEMBL240215 & 540741 & 5.78700 & 000000006 & $\partial 1$ & 6.9402 & TST \\
\hline CHEMBL475497 & 540741 & 4.2148 & 4.235 & TRN & & \\
\hline CHEMBL517167 & 540741 & 5.644 & 6.9108 & TST & & \\
\hline CHEMBL516077 & 540741 & 3.9134 & 3.8985 & TRN & & \\
\hline CHEMBL464192 & 540741 & 5.4981 & 5.5693 & TRN & & \\
\hline CHEMBL473280 & 540741 & 5.5258 & 5.5276 & TRN & & \\
\hline CHEMBL517265 & 540741 & 5.9446 & 5.9466 & TRN & & \\
\hline CHEMBL475094 & 540741 & 5.5995 & 5.5979 & TRN & & \\
\hline CHEMBL473278 & 540741 & 5.5408 & 5.5227 & TRN & & \\
\hline CHEMBL501088 & 540741 & 5.8139 & 5.8244 & TRN & & \\
\hline CHEMBL510201 & 540741 & 4.4802 & 5.8554 & TST & & \\
\hline CHEMBL510745 & 540741 & 6.1198 & 5.9888 & TRN & & \\
\hline CHEMBL473884 & 540741 & 5.2509 & 5.2163 & TRN & & \\
\hline CHEMBL240657 & 540741 & 4.4215 & 5.5721 & TST & & \\
\hline CHEMBL516187 & 540741 & 5.9739 & 5.9832 & TRN & & \\
\hline CHEMBL471262 & 540741 & 5.5082 & 5.5424 & TRN & & \\
\hline CHEMBL514463 & 540741 & 5.7097 & 5.726 & TRN & & \\
\hline CHEMBL475096 & 540741 & 6.0615 & 6.0891 & TRN & & \\
\hline CHEMBL472867 & 540741 & 7.4949 & 7.4855 & TRN & & \\
\hline CHEMBL473279 & 540741 & 5.7442 & 5.744 & TRN & & \\
\hline CHEMBL511649 & 540741 & 6.0996 & 6.1237 & TRN & & \\
\hline CHEMBL514606 & 540741 & 4.2261 & 4.2307 & TRN & & \\
\hline CHEMBL514965 & 540741 & 4.3436 & 4.3123 & TRN & & \\
\hline CHEMBL456225 & 540741 & 5.8167 & 5.9594 & TRN & & \\
\hline CHEMBL515901 & 540741 & 5.0857 & 4.9631 & TRN & & \\
\hline CHEMBL472086 & 540741 & 5.2991 & 5.2987 & TRN & & \\
\hline CHEMBL474092 & 540741 & 5.6786 & 5.8333 & TRN & & \\
\hline CHEMBL473904 & 540741 & 6.2692 & 6.8445 & TST & & \\
\hline CHEMBL516024 & 540741 & 4.5378 & 4.53 & TRN & & \\
\hline CHEMBL472676 & 540741 & 5.0404 & 5.654 & TST & & \\
\hline CHEMBL473898 & 540741 & 5.9122 & 5.8803 & TRN & & \\
\hline CHEMBL515554 & 540741 & 3.728 & 3.79 & TRN & & \\
\hline CHEMBL471880 & 540741 & 6.05399 & 99999999 & 99 & 6.0566 & TI \\
\hline CHEMBL475310 & 540741 & 6.4248 & 7.0287 & TST & & \\
\hline CHEMBL474283 & 540741 & 5.5786 & 5.6341 & TRN & & \\
\hline CHEMBL241272 & 540741 & 3.8228 & 5.4565 & TST & & \\
\hline CHEMBL514662 & 540741 & 6.2874 & 6.9371 & TST & & \\
\hline CHEMBL473272 & 540741 & 5.6308 & 5.6208 & TRN & & \\
\hline CHEMBL239822 & 540741 & 5.7471 & 5.8981 & TST & & \\
\hline CHEMBL464191 & 540741 & 5.6232 & 5.6351 & TRN & & \\
\hline CHEMBL473701 & 540741 & 6.4214 & 6.3315 & TST & & \\
\hline CHEMBL472677 & 540741 & 5.2666 & 5.3088 & TRN & & \\
\hline CHEMBL471882 & 540741 & 5.7713 & 5.7749 & TRN & & \\
\hline CHEMBL515142 & 540741 & 5.7757 & 6.6226 & TST & & \\
\hline CHEMBL474091 & 540741 & 4.635 & 4.6867 & TRN & & \\
\hline CHEMBL475707 & 540741 & 5.9666 & 6.7201 & TST & & \\
\hline CHEMBL515575 & 540741 & 5.585 & 5.5862 & TRN & & \\
\hline
\end{tabular}




\begin{tabular}{|c|c|c|c|c|c|c|}
\hline & & \multicolumn{5}{|c|}{ Supplemental Table S2.txt } \\
\hline CHEMBL516389 & 540741 & 6.4318 & 7.1319 & TST & & \\
\hline CHEMBL473700 & 540741 & 6.062 & 6.9869 & TST & & \\
\hline CHEMBL460636 & 540741 & 6.0301 & 6.0301 & TRN & & \\
\hline CHEMBL475496 & 540741 & 3.7166 & 3.7067 & TRN & & \\
\hline CHEMBL499169 & 540741 & 5.3226 & 5.2954 & TRN & & \\
\hline CHEMBL474708 & 540741 & 4.3563 & 4.3868 & TRN & & \\
\hline CHEMBL473068 & 540741 & 6.2381 & 6.2116 & TRN & & \\
\hline CHEMBL514489 & 540741 & 5.2996 & 5.8262 & TST & & \\
\hline CHEMBL472669 & 540741 & 6.3516 & 7.2619 & TST & & \\
\hline CHEMBL 3937237 & 1528828 & 7.3401 & 7.6713 & TRN & & \\
\hline CHEMBL 3892035 & 1528828 & 7.2403 & 7.7415 & TST & & \\
\hline CHEMBL 3948732 & 1528828 & 8.7696 & 8.0033 & TRN & & \\
\hline CHEMBL 3962546 & 1528828 & 7.7235 & 7.7876 & TST & & \\
\hline CHEMBL3700941 & 1528828 & 8.6576 & 8.5888 & TST & & \\
\hline CHEMBL 3968228 & 1528828 & 8.585 & 8.0129 & TRN & & \\
\hline CHEMBL 3930639 & 1528828 & 7.5935 & 7.8556 & TRN & & \\
\hline CHEMBL 3895994 & 1528828 & 7.0391 & 7.8629 & TRN & & \\
\hline CHEMBL 3704369 & 1528828 & 7.1107 & 7.8906 & TRN & & \\
\hline CHEMBL 3972351 & 1528828 & 8.2366 & 8.2411 & TRN & & \\
\hline CHEMBL3700981 & 1528828 & 7.4056 & 7.9299 & TRN & & \\
\hline CHEMBL 3700980 & 1528828 & 8.5376 & 8.427 & TST & & \\
\hline CHEMBL 3969002 & 1528828 & 8.6021 & 7.9477 & TRN & & \\
\hline CHEMBL 3704385 & 1528828 & 8.28399 & 99999999 & 99 & 8.2344 & TST \\
\hline CHEMBL 3907198 & 1528828 & 8.8539 & 7.9913 & TRN & & \\
\hline CHEMBL 3704376 & 1528828 & 8.5686 & 8.6077 & TRN & & \\
\hline CHEMBL3900186 & 1528828 & 8.2076 & 7.6613 & TST & & \\
\hline CHEMBL 3704393 & 1528828 & 8.2147 & 8.2398 & TRN & & \\
\hline CHEMBL 3941753 & 1528828 & 8.5528 & 7.6616 & TST & & \\
\hline CHEMBL3942021 & 1528828 & 8.2218 & 8.052 & TST & & \\
\hline CHEMBL 3704371 & 1528828 & 7.7282 & 7.8587 & TRN & & \\
\hline CHEMBL3936068 & 1528828 & 7.0947 & 7.9709 & TRN & & \\
\hline CHEMBL 3977823 & 1528828 & 7.4191 & 7.6411 & TST & & \\
\hline CHEMBL 3700949 & 1528828 & 7.6498 & 7.8737 & TRN & & \\
\hline CHEMBL 3904630 & 1528828 & 7.8386 & 7.941 & TRN & & \\
\hline CHEMBL3700951 & 1528828 & 7.1284 & 7.8677 & TRN & & \\
\hline CHEMBL3924212 & 1528828 & 9.0 & 8.0747 & TST & & \\
\hline CHEMBL 3700902 & 1528828 & 7.6308 & 7.8039 & TRN & & \\
\hline CHEMBL 3700911 & 1528828 & 8.4685 & 8.4005 & TRN & & \\
\hline CHEMBL 3704372 & 1528828 & 8.6021 & 8.5609 & TRN & & \\
\hline CHEMBL 3700982 & 1528828 & 8.4437 & 8.4276 & TRN & & \\
\hline CHEMBL3704380 & 1528828 & 8.5686 & 8.6699 & TST & & \\
\hline CHEMBL 3700909 & 1528828 & 8.4318 & 8.3124 & TRN & & \\
\hline CHEMBL 3950274 & 1528828 & 8.585 & 8.1464 & TRN & & \\
\hline CHEMBL 3700947 & 1528828 & 7.6799 & 8.1438 & TRN & & \\
\hline CHEMBL 3704388 & 1528828 & 8.2924 & 8.2579 & TST & & \\
\hline CHEMBL 3704373 & 1528828 & 8.4949 & 8.7348 & TRN & & \\
\hline CHEMBL 3704377 & 1528828 & 8.4437 & 8.6659 & TRN & & \\
\hline CHEMBL 3973447 & 1528828 & 8.2218 & 8.0334 & TRN & & \\
\hline
\end{tabular}


Supplemental Table S2.txt

\begin{tabular}{|c|c|c|c|c|c|c|}
\hline CHEMBL3948513 & 1528828 & 7.5129 & 7.7911 & TRN & & \\
\hline CHEMBL3958016 & 1528828 & 8.0506 & 7.7705 & TST & & \\
\hline CHEMBL3700907 & 1528828 & 8.7696 & 8.3271 & TRN & & \\
\hline CHEMBL 3704379 & 1528828 & 8.585 & 8.6668 & TRN & & \\
\hline CHEMBL3957786 & 1528828 & 8.4202 & 7.649 & TST & & \\
\hline CHEMBL 3976820 & 1528828 & 7.71899 & 999999999 & 99 & 7.6941 & TRN \\
\hline CHEMBL3965865 & 1528828 & 8.4089 & 7.6719 & TST & & \\
\hline CHEMBL 3704375 & 1528828 & 8.6383 & 8.6718 & TRN & & \\
\hline CHEMBL3903508 & 1528828 & 8.2596 & 7.7454 & TRN & & \\
\hline CHEMBL3903222 & 1528828 & 8.1612 & 7.7932 & TRN & & \\
\hline CHEMBL3700955 & 1528828 & 8.2676 & 8.0892 & TRN & & \\
\hline CHEMBL3963686 & 1528828 & 7.8539 & 7.7495 & TST & & \\
\hline CHEMBL3901066 & 1528828 & 7.6364 & 7.6543 & TRN & & \\
\hline CHEMBL3897659 & 1528828 & 7.6737 & 7.6972 & TRN & & \\
\hline CHEMBL 3704378 & 1528828 & 8.6021 & 8.6701 & TRN & & \\
\hline CHEMBL3979318 & 1528828 & 7.02 & 7.6238 & TRN & & \\
\hline CHEMBL 3700924 & 1528828 & 8.7959 & 8.2513 & TRN & & \\
\hline CHEMBL 3700974 & 1528828 & 8.585 & 8.4636 & TRN & & \\
\hline CHEMBL3939691 & 1528828 & 8.5086 & 7.6773 & TST & & \\
\hline CHEMBL 3704383 & 1528828 & 8.6021 & 8.6133 & TRN & & \\
\hline CHEMBL 3958978 & 1528828 & 8.2147 & 8.0838 & TRN & & \\
\hline CHEMBL 3893546 & 1528828 & 8.5376 & 7.8425 & TRN & & \\
\hline CHEMBL 3704370 & 1528828 & 8.1079 & 8.4268 & TRN & & \\
\hline CHEMBL 3700983 & 1528828 & 8.2366 & 8.4148 & TRN & & \\
\hline CHEMBL 3937444 & 1528828 & 8.0458 & 7.6611 & TST & & \\
\hline CHEMBL 3979345 & 1528828 & 7.3478 & 7.9284 & TRN & & \\
\hline CHEMBL 3982009 & 1528828 & 7.9031 & 7.9536 & TRN & & \\
\hline CHEMBL3932499 & 1528828 & 8.0132 & 7.6542 & TRN & & \\
\hline CHEMBL 3952546 & 1528828 & 7.8153 & 7.7924 & TRN & & \\
\hline CHEMBL 3939271 & 1528828 & 8.9208 & 8.0812 & TST & & \\
\hline CHEMBL 3912452 & 1528828 & 8.7212 & 7.9692 & TRN & & \\
\hline CHEMBL 3981323 & 1528828 & 7.4559 & 7.6776 & TST & & \\
\hline CHEMBL 3893513 & 1528828 & 7.6819 & 7.9354 & TRN & & \\
\hline CHEMBL3945005 & 1528828 & 8.3979 & 8.0625 & TRN & & \\
\hline CHEMBL3704397 & 1528828 & 8.1427 & 8.3547 & TRN & & \\
\hline CHEMBL3953797 & 1528828 & 7.9788 & 7.6795 & TST & & \\
\hline CHEMBL 3978629 & 1528828 & 8.5086 & 7.7462 & TRN & & \\
\hline CHEMBL3923553 & 1528828 & 8.0223 & 7.9356 & TST & & \\
\hline CHEMBL 3700945 & 1528828 & 8.0555 & 7.9422 & TRN & & \\
\hline CHEMBL 3977303 & 1528828 & 7.4202 & 7.7866 & TRN & & \\
\hline CHEMBL 3956038 & 1528828 & 7.9031 & 8.0474 & TRN & & \\
\hline CHEMBL3955054 & 1528828 & 8.0223 & 7.8451 & TRN & & \\
\hline CHEMBL 3933149 & 1528828 & 8.6778 & 8.0637 & TRN & & \\
\hline CHEMBL 3704374 & 1528828 & 8.4559 & 8.6 & TRN & & \\
\hline CHEMBL3700939 & 1528828 & 7.7496 & 8.1312 & TRN & & \\
\hline CHEMBL 3700917 & 1528828 & 8.7696 & 8.3571 & TRN & & \\
\hline CHEMBL 3962543 & 1528828 & 7.0241 & 7.8237 & TRN & & \\
\hline CHEMBL3704395 & 1528828 & 8.1871 & 8.0096 & TRN & & \\
\hline
\end{tabular}

Page 22190 
Supplemental Table S2.txt

\begin{tabular}{|c|c|c|c|c|c|}
\hline CHEMBL 3985978 & 1528828 & 8.2441 & 7.6342 & TRN & \\
\hline CHEMBL 3951470 & 1528828 & 9.0458 & 8.0514 & TST & \\
\hline CHEMBL3704381 & 1528828 & 8.585 & 8.7082 & TRN & \\
\hline CHEMBL 3893695 & 1528828 & 7.6498 & 7.6118 & TRN & \\
\hline CHEMBL 3967553 & 1528828 & 7.3458 & 7.7937 & TRN & \\
\hline CHEMBL3960621 & 1528828 & 7.4763 & 8.0175 & TST & \\
\hline CHEMBL 3700940 & 1528828 & 8.5528 & 8.5838 & TRN & \\
\hline CHEMBL 3700978 & 1528828 & 8.6383 & 8.4872 & TRN & \\
\hline CHEMBL3913564 & 1528828 & 7.9393 & 8.0999 & TRN & \\
\hline CHEMBL3681189 & 1528484 & 7.8356 & 8.0968 & TRN & \\
\hline CHEMBL 2331668 & 1528484 & 9.6144 & 9.5581 & TRN & \\
\hline CHEMBL3681059 & 1528484 & 7.5751 & 8.1427 & TST & \\
\hline CHEMBL 2331663 & 1528484 & 9.0747 & 8.9512 & TRN & \\
\hline CHEMBL3681149 & 1528484 & 6.2557 & 6.191 & TRN & \\
\hline CHEMBL 3681138 & 1528484 & 7.5544 & 7.4211 & TRN & \\
\hline CHEMBL3681118 & 1528484 & 7.2976 & 7.4952 & TRN & \\
\hline CHEMBL3681083 & 1528484 & 8.1113 & 8.138 & TRN & \\
\hline CHEMBL 3681093 & 1528484 & 7.0101 & 7.1447 & TRN & \\
\hline CHEMBL 3681080 & 1528484 & 7.7496 & 7.7704 & TRN & \\
\hline CHEMBL 3681094 & 1528484 & 7.9431 & 8.1688 & TRN & \\
\hline CHEMBL 3681070 & 1528484 & 8.3089 & 8.3635 & TRN & \\
\hline CHEMBL3681123 & 1528484 & 9.3526 & 9.3549 & TRN & \\
\hline CHEMBL 3681174 & 1528484 & 8.7055 & 8.3598 & TST & \\
\hline CHEMBL3681133 & 1528484 & 8.0168 & 8.0473 & TRN & \\
\hline CHEMBL 3681077 & 1528484 & 8.0737 & 7.4369 & TST & \\
\hline CHEMBL 3681057 & 1528484 & 8.3307 & 7.7301 & TST & \\
\hline CHEMBL3681177 & 1528484 & 9.1818 & \multicolumn{2}{|c|}{9.062999999999999} & TRN \\
\hline CHEMBL 3681079 & 1528484 & \multicolumn{3}{|c|}{8.857000000000001} & TRN \\
\hline CHEMBL 3681143 & 1528484 & 7.7282 & 7.8612 & TRN & \\
\hline CHEMBL 3681142 & 1528484 & 8.6402 & 8.8465 & TRN & \\
\hline CHEMBL 3681169 & 1528484 & 8.317 & 8.0112 & TST & \\
\hline CHEMBL 3681081 & 1528484 & 7.9747 & 8.3622 & TRN & \\
\hline CHEMBL 3681180 & 1528484 & 7.8416 & 7.4701 & TST & \\
\hline CHEMBL 3681078 & 1528484 & 8.6696 & 8.5593 & TRN & \\
\hline CHEMBL 3681068 & 1528484 & 8.1024 & 8.096 & TRN & \\
\hline CHEMBL 3681170 & 1528484 & 6.3546 & 7.2983 & TST & \\
\hline CHEMBL 3681082 & 1528484 & 8.4789 & 8.6323 & TRN & \\
\hline CHEMBL 3681187 & 1528484 & 8.7122 & 8.4562 & TRN & \\
\hline CHEMBL3681069 & 1528484 & 7.9066 & 7.9115 & TRN & \\
\hline CHEMBL3681071 & 1528484 & 8.3936 & 8.3868 & TRN & \\
\hline CHEMBL 2331667 & 1528484 & 8.8729 & 8.2061 & TST & \\
\hline CHEMBL3681099 & 1528484 & 7.7352 & 7.8095 & TRN & \\
\hline CHEMBL3681054 & 1528484 & 8.6799 & 8.2476 & TST & \\
\hline CHEMBL3681073 & 1528484 & \multicolumn{3}{|c|}{8.466000000000001} & TRN \\
\hline CHEMBL 3681139 & 1528484 & 8.1073 & 8.0061 & TRN & \\
\hline CHEMBL 3681122 & 1528484 & 8.5214 & 8.5397 & TRN & \\
\hline CHEMBL 2331661 & 1528484 & 8.5784 & 8.5307 & TRN & \\
\hline CHEMBL3681116 & 1528484 & 7.5986 & 7.624 & TRN & \\
\hline
\end{tabular}


Supplemental Table S2.txt

\begin{tabular}{|c|c|c|c|c|c|c|}
\hline CHEMBL 3681171 & 1528484 & 8.3344 & 8.3625 & TST & & \\
\hline CHEMBL 3681130 & 1528484 & 7.8962 & 8.2112 & TRN & & \\
\hline CHEMBL 3681072 & 1528484 & 8.3125 & 8.3309 & TRN & & \\
\hline CHEMBL 3681098 & 1528484 & 8.5986 & 8.7983 & TRN & & \\
\hline CHEMBL3681084 & 1528484 & 8.0195 & 8.0323 & TRN & & \\
\hline CHEMBL3681076 & 1528484 & 8.3098 & 8.2567 & TRN & & \\
\hline CHEMBL 3681153 & 1528484 & 8.4425 & 8.4865 & TRN & & \\
\hline CHEMBL2331662 & 1528484 & 8.6326 & 8.6285 & TRN & & \\
\hline CHEMBL 3681186 & 1528484 & 6.4584 & 8.101 & TST & & \\
\hline CHEMBL3681106 & 1528484 & 7.3969 & 8.0059 & TRN & & \\
\hline CHEMBL 3681067 & 1528484 & 8.09100 & 000000000 & $\partial 1$ & 8.0983 & TRN \\
\hline CHEMBL3681055 & 1528484 & 7.5702 & 7.6105 & TST & & \\
\hline CHEMBL 2331658 & 1528484 & 8.327 & 8.186 & TRN & & \\
\hline CHEMBL 3681108 & 1528484 & 8.8508 & 8.8019 & TRN & & \\
\hline CHEMBL 2331664 & 1528484 & 8.8508 & 8.8894 & TRN & & \\
\hline CHEMBL 3681063 & 1528484 & 7.3958 & 7.0804 & TST & & \\
\hline CHEMBL3681137 & 1528484 & 8.1221 & 8.1277 & TRN & & \\
\hline CHEMBL 3681126 & 1528484 & 8.7645 & 8.2116 & TRN & & \\
\hline CHEMBL 3681160 & 1528484 & 9.3936 & 7.9498 & TST & & \\
\hline CHEMBL3681119 & 1528484 & 8.0752 & 7.8653 & TRN & & \\
\hline CHEMBL3681100 & 1528484 & 7.8539 & 7.7301 & TRN & & \\
\hline CHEMBL2331669 & 1528484 & 8.58 & 8.4196 & TST & & \\
\hline CHEMBL 3681085 & 1528484 & 8.7959 & 8.4714 & TRN & & \\
\hline CHEMBL 3681075 & 1528484 & 8.0123 & 7.9922 & TRN & & \\
\hline CHEMBL 3681176 & 1528484 & 9.4908 & 9.8569 & TRN & & \\
\hline CHEMBL3681147 & 1528484 & 7.8041 & 7.7838 & TRN & & \\
\hline CHEMBL 3681134 & 1528484 & 7.3546 & 7.3858 & TRN & & \\
\hline CHEMBL2331659 & 1528484 & 8.699 & 8.6483 & TRN & & \\
\hline CHEMBL3681190 & 1528484 & 8.0701 & 8.1275 & TRN & & \\
\hline CHEMBL 3681127 & 1528484 & 8.1925 & 7.9103 & TRN & & \\
\hline CHEMBL 3681064 & 1528484 & 7.6676 & 7.8942 & TST & & \\
\hline CHEMBL 3681092 & 1528484 & 7.9031 & 7.8173 & TRN & & \\
\hline CHEMBL 3681165 & 1528484 & 9.5243 & 9.4632 & TRN & & \\
\hline CHEMBL 3681154 & 1528484 & 9.4815 & 9.5002 & TRN & & \\
\hline CHEMBL 3681087 & 1528484 & 8.0975 & 8.3668 & TRN & & \\
\hline CHEMBL2331665 & 1528484 & 7.7328 & 8.0868 & TRN & & \\
\hline CHEMBL3681091 & 1528484 & 7.8729 & 7.9162 & TRN & & \\
\hline CHEMBL 3681058 & 1528484 & 8.0443 & 8.5406 & TST & & \\
\hline CHEMBL 3681135 & 1528484 & 8.2147 & 8.1423 & TRN & & \\
\hline CHEMBL 3639799 & 1528484 & 8.0448 & 8.1816 & TRN & & \\
\hline CHEMBL3681113 & 1528484 & 8.3458 & 7.8857 & TRN & & \\
\hline CHEMBL3681191 & 1528484 & 7.9872 & 7.8366 & TRN & & \\
\hline CHEMBL 3681103 & 1528484 & 9.6904 & 9.6442 & TRN & & \\
\hline CHEMBL 3681188 & 1528484 & \multicolumn{3}{|c|}{8.466000000000001} & 8.3551 & TRN \\
\hline CHEMBL 3681101 & 1528484 & 7.1355 & 7.0155 & TRN & & \\
\hline CHEMBL 3681097 & 1528484 & 7.9172 & 8.007 & TRN & & \\
\hline CHEMBL 3681173 & 1528484 & 8.7721 & 8.5827 & TST & & \\
\hline CHEMBL3681125 & 1528484 & 8.9872 & 9.0303 & TRN & & \\
\hline
\end{tabular}

Page 22192 
Supplemental Table S2.txt

\begin{tabular}{|c|c|c|c|c|c|}
\hline CHEMBL 3681168 & 1528484 & 7.4522 & 7.5513 & TRN & \\
\hline CHEMBL3681066 & 1528484 & 7.9066 & 7.6212 & TST & \\
\hline CHEMBL3681096 & 1528484 & 8.2328 & \multicolumn{2}{|c|}{8.357000000000001} & TRN \\
\hline CHEMBL3681109 & 1528484 & 8.9281 & 8.5742 & TRN & \\
\hline CHEMBL3681056 & 1528484 & 8.3706 & 8.2424 & TST & \\
\hline CHEMBL 3681105 & 1528484 & 8.1439 & 8.0702 & TRN & \\
\hline CHEMBL 3681148 & 1528484 & 7.3002 & 7.2301 & TRN & \\
\hline CHEMBL 3681175 & 1528484 & 9.618 & 9.7756 & TRN & \\
\hline CHEMBL3681115 & 1528484 & 7.8761 & 7.8102 & TRN & \\
\hline CHEMBL3681172 & 1528484 & 8.752 & 8.5209 & TST & \\
\hline CHEMBL 3681140 & 1528484 & 8.7595 & 8.8866 & TRN & \\
\hline CHEMBL 3681167 & 1528484 & 8.6925 & 8.7317 & TRN & \\
\hline CHEMBL3639800 & 1528484 & 7.9914 & 8.0521 & TRN & \\
\hline CHEMBL 3681121 & 1528484 & 8.7645 & 8.6447 & TRN & \\
\hline CHEMBL3681132 & 1528484 & 8.0921 & 8.064 & TRN & \\
\hline CHEMBL3681146 & 1528484 & 6.6655 & 6.5956 & TRN & \\
\hline CHEMBL3681114 & 1528484 & 8.0477 & 8.1452 & TRN & \\
\hline CHEMBL3681150 & 1528484 & 6.6402 & 6.9456 & TRN & \\
\hline CHEMBL3681129 & 1528484 & 7.1409 & 7.4556 & TRN & \\
\hline CHEMBL3681074 & 1528484 & 8.3665 & 8.3908 & TRN & \\
\hline CHEMBL3681152 & 1528484 & 6.9788 & 7.0623 & TRN & \\
\hline CHEMBL 3681124 & 1528484 & 8.4535 & 7.9987 & TRN & \\
\hline CHEMBL3681155 & 1528484 & 7.2503 & 8.1422 & TST & \\
\hline CHEMBL 3681088 & 1528484 & 7.8761 & 7.9449 & TRN & \\
\hline CHEMBL 3681166 & 1528484 & 8.7496 & 8.7838 & TRN & \\
\hline CHEMBL3681181 & 1528484 & 6.5638 & 7.2927 & TST & \\
\hline CHEMBL 3681151 & 1528484 & 6.1798 & 6.1376 & TRN & \\
\hline CHEMBL3681110 & 1528484 & 8.4828 & 8.6987 & TRN & \\
\hline CHEMBL 3681095 & 1528484 & 9.0851 & 8.6587 & TRN & \\
\hline CHEMBL 3681131 & 1528484 & 8.3585 & 8.2354 & TRN & \\
\hline CHEMBL2331666 & 1528484 & 9.4237 & 9.1672 & TRN & \\
\hline CHEMBL 3681136 & 1528484 & 8.9469 & 8.9581 & TRN & \\
\hline CHEMBL 3681184 & 1528484 & 7.556 & 7.5759 & TST & \\
\hline CHEMBL 3681111 & 1528484 & 8.4157 & 8.2233 & TRN & \\
\hline CHEMBL 3681182 & 1528484 & 9.4449 & 9.3199 & TRN & \\
\hline CHEMBL3681158 & 1528484 & 8.0164 & 8.0161 & TST & \\
\hline CHEMBL3681159 & 1528484 & 8.1555 & 8.8662 & TST & \\
\hline CHEMBL 3681102 & 1528484 & 7.7545 & 7.9834 & TRN & \\
\hline CHEMBL3681060 & 1528484 & 8.8125 & 8.0688 & TST & \\
\hline CHEMBL 3681161 & 1528484 & 8.1765 & 7.4493 & TST & \\
\hline CHEMBL 3681183 & 1528484 & 9.9318 & 9.7137 & TRN & \\
\hline CHEMBL3681062 & 1528484 & 7.8097 & 7.4924 & TST & \\
\hline CHEMBL3681112 & 1528484 & 8.9747 & 9.0351 & TRN & \\
\hline CHEMBL3681141 & 1528484 & 7.6576 & 7.5031 & TRN & \\
\hline CHEMBL3681145 & 1528484 & 7.3261 & 7.1696 & TRN & \\
\hline CHEMBL3681117 & 1528484 & 8.4271 & 8.3683 & TRN & \\
\hline CHEMBL 3681104 & 1528484 & 8.1945 & 8.456 & TRN & \\
\hline CHEMBL 3681090 & 1528484 & 7.9957 & 8.0377 & TRN & \\
\hline
\end{tabular}

Page 22193 
Supplemental Table S2.txt

\begin{tabular}{|c|c|c|c|c|}
\hline HEMB & 528484 & 8.4776 & 8.4717 & בו \\
\hline HEMBL3681089 & 528484 & 8.4202 & 8.6146 & \\
\hline 179 & 28484 & 464 & 3435 & \\
\hline AEMBL3681178 & 28484 & & & \\
\hline AEMBL3681086 & 528484 & 8.1421 & 9599 & \\
\hline HEMBL3681065 & 528484 & 8.1851 & 9816 & \\
\hline HEMBL 368 & 528484 & & 1275 & \\
\hline HEMBL147 & 288277 & & 255 & \\
\hline HEMBL3115121 & 288277 & 5. & .0445 & \\
\hline HEMBL3115131 & 288277 & 3.0 & 6444 & \\
\hline HEMBL3115118 & 288277 & 3.0 & .7488 & \\
\hline AEMBL & 277 & 6. & 0457 & \\
\hline HEMBL31 & 277 & & .5823 & \\
\hline HEMBL1727453 & 288277 & 3 . & 9195 & \\
\hline HEMBL1349252 & & & 4.1076 & \\
\hline HEMBL1 & 1 & & 9421 & \\
\hline HEMBL3 & & & 132 & \\
\hline HEMBL3: & 277 & & & \\
\hline HEMBL 311 & 277 & 3. & 7209 & \\
\hline HEMBL311 & & & 3.7833 & \\
\hline HEMBL3 & 1 & & 3575 & RN \\
\hline HEMBL & & & 184 & \\
\hline AEMBL 3 & & & 1154 & \\
\hline HEMBL3 & & & 1523 & \\
\hline HEMBL311 & 77 & 3 & 5.0642 & I RIN \\
\hline HEMBL1. & 1 & & 2383 & ST \\
\hline HEMBL 3 & & & 237 & $\mathrm{RN}$ \\
\hline HEME & & & 3.8241 & \\
\hline HEMBL 311 & & 3 & 3722 & IST \\
\hline HEMBL311: & 77 & 4. & 9365 & TRN \\
\hline HEMBL311 & & & 594 & RN \\
\hline HFM & & & 28 & RN \\
\hline ح & & & & $\mathrm{RN}$ \\
\hline HEMBL 311 & & & 9625 & ГST \\
\hline HEMBL311: & & 4. & 3381 & RN \\
\hline HEMP 12 & 1 & 3 & 65 & ST \\
\hline 5 & & & 07 & RN \\
\hline HEMBL311 & & 3 . & 3.5048 & TRN \\
\hline HEMBL3 & & 3. & 653 & $\Gamma R$ \\
\hline 8 & & & 435 & RN \\
\hline HEMBL3 & & & & TRN \\
\hline HEMBL3 & & 3. & 9918 & RN \\
\hline HEMBL1363800 & & 4. & 9469 & TST \\
\hline HEMBL 311 & 1 & & & TR \\
\hline and & & & & \\
\hline HEMBL311 & & & 3.8457 & \\
\hline CHEMBL311 & 277 & 3.0 & 3.7853 & \\
\hline CHEMBL3115159 & 1288277 & 5.6778 & 4.9739 & \\
\hline
\end{tabular}

Page 22194 
Supplemental Table S2.txt

\begin{tabular}{|c|c|c|c|c|}
\hline CHEMBL 3115154 & 1288277 & 3.0 & 3.8048 & TST \\
\hline CHEMBL3115137 & 1288277 & 5.8239 & 5.1385 & TRN \\
\hline CHEMBL3115152 & 1288277 & 3.0 & 3.8291 & TST \\
\hline CHEMBL3115138 & 1288277 & 5.699 & 4.7983 & TRN \\
\hline CHEMBL3115130 & 1288277 & 3.0 & 4.0877 & TST \\
\hline CHEMBL 3115160 & 1288277 & 5.3279 & 4.062 & TST \\
\hline CHEMBL3115143 & 1288277 & 4.4318 & 5.2075 & TRN \\
\hline CHEMBL3115119 & 1288277 & 6.2757 & 5.001 & TRN \\
\hline CHEMBL 3115141 & 1288277 & 5.2007 & 5.2479 & TRN \\
\hline CHEMBL3115133 & 1288277 & 3.0 & 3.7949 & TRN \\
\hline CHEMBL 3115147 & 1288277 & 3.0 & 3.9941 & TRN \\
\hline CHEMBL3115125 & 1288277 & 4.7212 & 3.8396 & TRN \\
\hline CHEMBL 3115126 & 1288277 & 4.3565 & 3.88199 & 99999999997 \\
\hline CHEMBL1098771 & 632481 & 6.1238 & 6.7228 & TRN \\
\hline CHEMBL1094831 & 632481 & 7.2596 & 6.1954 & TST \\
\hline CHEMBL1094501 & 632481 & 7.2366 & 6.6476 & TST \\
\hline CHEMBL1098450 & 632481 & 6.6946 & 6.9916 & TST \\
\hline CHEMBL1097807 & 632481 & 7.2676 & 7.1623 & TRN \\
\hline CHEMBL1096788 & 632481 & 6.7305 & 6.4749 & TRN \\
\hline CHEMBL1097528 & 632481 & 4.0 & 5.4615 & TST \\
\hline CHEMBL1094503 & 632481 & 8.0 & 7.4854 & TST \\
\hline CHEMBL1098200 & 632481 & 6.699 & 6.6052 & TRN \\
\hline CHEMBL1096787 & 632481 & 6.0044 & 5.7365 & TRN \\
\hline CHEMBL1097801 & 632481 & 7.0223 & 6.572 & TRN \\
\hline CHEMBL1096873 & 632481 & 7.9586 & 8.1057 & TRN \\
\hline CHEMBL1097802 & 632481 & 5.8496 & 6.0592 & TRN \\
\hline CHEMBL1098143 & 632481 & 7.3279 & 7.1562 & TRN \\
\hline CHEMBL1094213 & 632481 & 6.9508 & 6.9657 & TRN \\
\hline CHEMBL1095152 & 632481 & 7.4685 & 7.5429 & TRN \\
\hline CHEMBL1095995 & 632481 & 7.4318 & 7.4485 & TRN \\
\hline CHEMBL1097537 & 632481 & 6.9066 & 7.1924 & TRN \\
\hline CHEMBL1097182 & 632481 & 6.8447 & 6.5771 & TRN \\
\hline CHEMBL1094192 & 632481 & 7.3279 & 6.9433 & TRN \\
\hline CHEMBL1098811 & 632481 & 6.9136 & 6.7521 & TRN \\
\hline CHEMBL1094193 & 632481 & 6.2336 & 6.7161 & TST \\
\hline CHEMBL1098449 & 632481 & 6.9872 & 6.9875 & TST \\
\hline CHEMBL1097803 & 632481 & 6.4647 & 6.5783 & TRN \\
\hline CHEMBL1094248 & 632481 & 6.2007 & 6.2548 & TST \\
\hline CHEMBL1094885 & 632481 & 6.6478 & 6.7451 & TRN \\
\hline CHEMBL1094834 & 632481 & 6.4597 & 6.7446 & TST \\
\hline CHEMBL1098356 & 632481 & 4.0 & 5.4285 & TST \\
\hline CHEMBL1094247 & 632481 & 6.4486 & 6.7749 & TRN \\
\hline CHEMBL1098203 & 632481 & 6.8297 & 6.5074 & TRN \\
\hline CHEMBL1098447 & 632481 & 6.9914 & 7.343 & TRN \\
\hline CHEMBL1097103 & 632481 & 7.1739 & 7.0994 & TRN \\
\hline CHEMBL1098202 & 632481 & 6.6498 & 6.2125 & TRN \\
\hline CHEMBL1097529 & 632481 & 6.3893 & 6.6365 & TRN \\
\hline CHEMBL1098448 & 632481 & 6.8327 & 7.0415 & TRN \\
\hline
\end{tabular}

Page 22195 
Supplemental Table S2.txt

\begin{tabular}{|c|c|c|c|c|c|}
\hline CHEMBL1098013 & 632481 & 6.699 & 6.5918 & TRN & \\
\hline CHEMBL1097535 & 632481 & 7.1427 & 7.1952 & TRN & \\
\hline CHEMBL1096872 & 632481 & 7.7212 & 8.1026 & TRN & \\
\hline CHEMBL1097809 & 632481 & 7.5086 & 7.4187 & TRN & \\
\hline CHEMBL1098770 & 632481 & 6.7328 & 6.6645 & TRN & \\
\hline CHEMBL1096340 & 632481 & 4.0 & 4.2879 & TRN & \\
\hline CHEMBL1096541 & 632481 & 6.0339 & 6.4762 & TST & \\
\hline CHEMBL1094502 & 632481 & 6.5498 & 6.7607 & TST & \\
\hline CHEMBL1094699 & 632481 & 6.5867 & 6.3083 & TRN & \\
\hline CHEMBL1096478 & 632481 & 6.6003 & 6.73 & TRN & \\
\hline CHEMBL1096676 & 632481 & 7.2366 & 6.9458 & TRN & \\
\hline CHEMBL1098144 & 632481 & 6.9747 & 7.2435 & TRN & \\
\hline CHEMBL1095153 & 632481 & 6.9586 & 6.8841 & TRN & \\
\hline CHEMBL1097808 & 632481 & 7.4559 & 6.9681 & TRN & \\
\hline CHEMBL1096542 & 632481 & 5.7411 & \multicolumn{2}{|c|}{6.537000000000001} & TST \\
\hline CHEMBL1098201 & 632481 & 6.6968 & 6.4384 & TRN & \\
\hline CHEMBL1097800 & 632481 & 7.0088 & 7.0209 & TRN & \\
\hline CHEMBL1095987 & 632481 & 5.9076 & 6.2544 & TRN & \\
\hline CHEMBL1099016 & 632481 & 4.0 & 4.4362 & TST & \\
\hline CHEMBL1098772 & 632481 & 6.3526 & 6.3428 & TRN & \\
\hline CHEMBL1097526 & 632481 & 5.1903 & 5.4507 & TST & \\
\hline CHEMBL1097183 & 632481 & 5.0639 & 5.46 & TRN & \\
\hline CHEMBL1094246 & 632481 & 6.058 & 6.3403 & TRN & \\
\hline CHEMBL1096786 & 632481 & 7.2076 & 6.9456 & TRN & \\
\hline CHEMBL1098142 & 632481 & 7.1079 & 7.0317 & TRN & \\
\hline CHEMBL1094491 & 632481 & 6.3197 & 6.4737 & TST & \\
\hline CHEMBL1097536 & 632481 & 6.7471 & 6.6423 & TRN & \\
\hline CHEMBL1098484 & 632481 & 5.9838 & 6.3985 & TRN & \\
\hline CHEMBL1097527 & 632481 & 4.0 & 5.5721 & TST & \\
\hline CHEMBL1098467 & 632481 & 6.8125 & 6.6997 & TRN & \\
\hline CHEMBL1097843 & 632481 & 6.9914 & 6.9402 & TRN & \\
\hline CHEMBL1241945 & 654928 & 6.1778 & 6.8042 & TRN & \\
\hline CHEMBL1241484 & 654928 & 8.2596 & 7.9509 & TRN & \\
\hline CHEMBL1242199 & 654928 & 7.6198 & 7.4688 & TRN & \\
\hline CHEMBL1241679 & 654928 & 4.7696 & 4.6072 & TRN & \\
\hline CHEMBL1241674 & 654928 & 5.4437 & 5.8459 & TST & \\
\hline CHEMBL1241271 & 654928 & 6.6326 & 6.7736 & TRN & \\
\hline CHEMBL1242377 & 654928 & 7.8539 & 7.4987 & TRN & \\
\hline CHEMBL1241491 & 654928 & 6.0491 & 6.1393 & TRN & \\
\hline CHEMBL1241944 & 654928 & 5.9586 & 6.0704 & TRN & \\
\hline CHEMBL1242118 & 654928 & 5.6576 & 4.8803 & TRN & \\
\hline CHEMBL1242030 & 654928 & 4.9586 & 4.8717 & TRN & \\
\hline CHEMBL1241683 & 654928 & 5.4202 & 5.8099 & TRN & \\
\hline CHEMBL1242666 & 654928 & 4.9208 & 5.7874 & TRN & \\
\hline CHEMBL1242385 & 654928 & 6.0883 & 6.444 & TRN & \\
\hline CHEMBL1242290 & 654928 & 5.3872 & 5.6336 & TRN & \\
\hline CHEMBL1242109 & 654928 & 6.7959 & 7.1932 & TRN & \\
\hline CHEMBL1241439 & 654928 & 5.3468 & 4.9994 & TST & \\
\hline
\end{tabular}


Supplemental Table S2.txt

\begin{tabular}{|c|c|c|c|c|c|}
\hline CHEMBL1241773 & 654928 & 5.699 & 4.9008 & TRN & \\
\hline CHEMBL1241863 & 654928 & 4.4559 & 4.141 & TRN & \\
\hline CHEMBL1242203 & 654928 & 5.3979 & 5.8842 & TRN & \\
\hline CHEMBL1241684 & 654928 & 4.301 & 5.0606 & TST & \\
\hline CHEMBL1242202 & 654928 & 7.1675 & 7.4689 & TRN & \\
\hline CHEMBL1241950 & 654928 & 5.5229 & 5.2168 & TRN & \\
\hline CHEMBL1241767 & 654928 & 4.7696 & \multicolumn{2}{|c|}{3.7760000000000002} & TST \\
\hline CHEMBL1241858 & 654928 & 5.1007 & 5.3155 & TRN & \\
\hline CHEMBL1242381 & 654928 & 6.0 & 5.4548 & TRN & \\
\hline CHEMBL1242207 & 654928 & 4.9208 & 4.9613 & TRN & \\
\hline CHEMBL1242289 & 654928 & 6.2161 & 6.221 & TRN & \\
\hline CHEMBL1242208 & 654928 & 5.6778 & 5.1136 & TRN & \\
\hline CHEMBL1242572 & 654928 & 6.8539 & 6.7971 & TRN & \\
\hline CHEMBL1242848 & 654928 & 6.6819 & 6.3949 & TRN & \\
\hline CHEMBL1233882 & 654928 & 6.8539 & 6.6265 & TRN & \\
\hline CHEMBL1242386 & 654928 & 6.3028 & 6.6306 & TRN & \\
\hline CHEMBL1241587 & 654928 & 5.284 & 5.1268 & TST & \\
\hline CHEMBL1242754 & 654928 & 6.0 & 5.6546 & TRN & \\
\hline CHEMBL1241578 & 654928 & 7.6778 & 7.8493 & TRN & \\
\hline CHEMBL1241270 & 654928 & 6.2518 & 6.041 & TST & \\
\hline CHEMBL1242477 & 654928 & 6.9586 & 6.9139 & TRN & \\
\hline CHEMBL1241680 & 654928 & 5.4685 & 5.1585 & TRN & \\
\hline CHEMBL1241864 & 654928 & 4.0 & 3.958 & TRN & \\
\hline CHEMBL1241490 & 654928 & 6.2692 & 5.9156 & TRN & \\
\hline CHEMBL1242665 & 654928 & 4.8539 & 4.2937 & TST & \\
\hline CHEMBL1241677 & 654928 & 6.2967 & 6.92899 & 9999999999 & TRN \\
\hline CHEMBL1242294 & 654928 & 6.5302 & 6.8943 & TRN & \\
\hline CHEMBL1241676 & 654928 & 8.9208 & 8.6633 & TRN & \\
\hline CHEMBL1242111 & 654928 & 7.2007 & 6.949 & TST & \\
\hline CHEMBL1240553 & 654928 & 6.0 & 6.0876 & TRN & \\
\hline CHEMBL1242758 & 654928 & 5.6576 & 6.2047 & TST & \\
\hline CHEMBL1241391 & 654928 & 4.301 & 4.122 & TRN & \\
\hline CHEMBL1241861 & 654928 & 5.8861 & 5.4003 & TRN & \\
\hline CHEMBL1242755 & 654928 & 6.1198 & 5.887006 & 00000000005 & TRN \\
\hline CHEMBL1233881 & 654928 & 6.4685 & 6.3918 & TRN & \\
\hline CHEMBL1242113 & 654928 & 6.752006 & 00000000 & 6.4831 & TRN \\
\hline CHEMBL1242115 & 654928 & 5.4949 & 4.8853 & TST & \\
\hline CHEMBL1242750 & 654928 & 7.1739 & 7.4337 & TRN & \\
\hline CHEMBL1242852 & 654928 & 6.2782 & 6.1542 & TRN & \\
\hline CHEMBL1242286 & 654928 & 6.4962 & 6.45299 & 9999999999 & TRN \\
\hline CHEMBL1241390 & 654928 & 4.4949 & 4.4482 & TRN & \\
\hline CHEMBL1242751 & 654928 & 4.9508 & 5.6022 & TRN & \\
\hline CHEMBL1241946 & 654928 & 4.7959 & 4.8929 & TRN & \\
\hline CHEMBL1242469 & 654928 & 6.0164 & 6.1511 & TST & \\
\hline CHEMBL1242027 & 654928 & 5.6021 & 6.1484 & TRN & \\
\hline CHEMBL1242659 & 654928 & 5.2182 & 5.2484 & TRN & \\
\hline CHEMBL1242471 & 654928 & 5.2111 & 3.948 & TST & \\
\hline CHEMBL1242288 & 654928 & 5.6882 & 5.7744 & TRN & \\
\hline
\end{tabular}




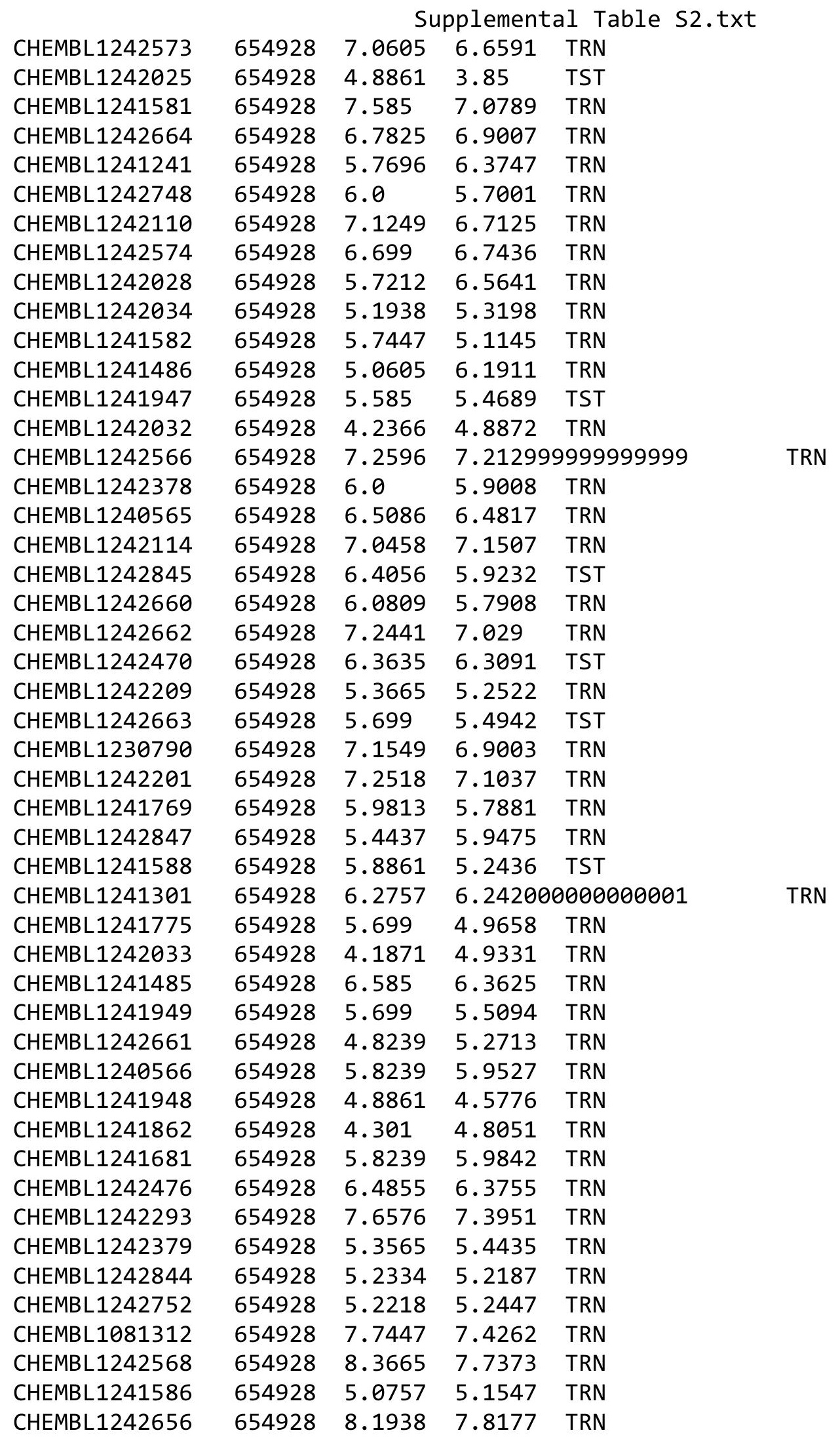

Page 22198 
Supplemental Table S2.txt

\begin{tabular}{|c|c|c|c|c|}
\hline CHEMBL1242384 & 654928 & 6.1612 & 6.2268 & TRN \\
\hline CHEMBL1242112 & 654928 & 5.8239 & 5.8867 & TRN \\
\hline CHEMBL1241300 & 654928 & 6.1057 & 5.6018 & TST \\
\hline CHEMBL1241859 & 654928 & 5.3468 & 5.8603 & TRN \\
\hline CHEMBL1241583 & 654928 & 4.301 & 4.9972 & TRN \\
\hline CHEMBL1241774 & 654928 & 5.6576 & 5.6125 & TRN \\
\hline CHEMBL1241482 & 654928 & 6.24799 & 79999999 & 5.556 \\
\hline CHEMBL1242031 & 654928 & 4.9586 & 5.0624 & TRN \\
\hline CHEMBL1240554 & 654928 & 6.0706 & 5.8961 & TRN \\
\hline CHEMBL1242200 & 654928 & 5.8239 & 6.0829 & TRN \\
\hline CHEMBL1240545 & 654928 & 5.1024 & 5.1066 & TRN \\
\hline CHEMBL1241860 & 654928 & 6.1624 & 5.9198 & TRN \\
\hline CHEMBL1242757 & 654928 & 5.585 & 5.8653 & TST \\
\hline CHEMBL1242198 & 654928 & 7.284 & 7.07799 & 9999999999 \\
\hline CHEMBL1242287 & 654928 & 7.6383 & 7.5298 & TRN \\
\hline CHEMBL1242285 & 654928 & 7.585 & 7.2107 & TRN \\
\hline CHEMBL1241492 & 654928 & 4.8861 & 4.9644 & TRN \\
\hline CHEMBL1241776 & 654928 & 6.4841 & 6.1281 & TRN \\
\hline CHEMBL1241771 & 654928 & 5.301 & 4.8984 & TRN \\
\hline CHEMBL1242472 & 654928 & 5.6778 & 5.7727 & TRN \\
\hline CHEMBL1242846 & 654928 & 5.9245 & 5.9142 & TST \\
\hline CHEMBL1241772 & 654928 & 4.301 & 4.4389 & TRN \\
\hline CHEMBL1242376 & 654928 & 7.3468 & 7.407 & TRN \\
\hline CHEMBL1242119 & 654928 & 5.699 & 5.6018 & TRN \\
\hline CHEMBL1242295 & 654928 & 6.6308 & 7.2066 & TRN \\
\hline CHEMBL1242753 & 654928 & 4.1871 & 4.5008 & TRN \\
\hline CHEMBL1234815 & 654928 & 5.9208 & 5.6238 & TRN \\
\hline CHEMBL1242475 & 654928 & 6.3288 & 6.4261 & TRN \\
\hline CHEMBL1242026 & 654928 & 7.5086 & 7.7106 & TST \\
\hline CHEMBL1242024 & 654928 & 7.1549 & 7.1388 & TST \\
\hline CHEMBL1241483 & 654928 & 6.2534 & 6.29899 & 99999999995 \\
\hline CHEMBL1241682 & 654928 & 5.2924 & 5.2925 & TST \\
\hline CHEMBL1241487 & 654928 & 6.9469 & 6.5751 & TST \\
\hline CHEMBL1242567 & 654928 & 6.5331 & 6.5218 & TST \\
\hline CHEMBL1242117 & 654928 & 4.0 & 4.3316 & TST \\
\hline CHEMBL1241299 & 654928 & 6.9626 & 7.1178 & TST \\
\hline CHEMBL1242029 & 654928 & 5.7696 & 5.5799 & TST \\
\hline CHEMBL1241943 & 654928 & 5.8928 & 5.9661 & TST \\
\hline CHEMBL1241770 & 654928 & 7.0862 & 6.2648 & TST \\
\hline CHEMBL1242756 & 654928 & 4.0 & 5.4608 & TST \\
\hline CHEMBL1242853 & 654928 & 6.0362 & 5.4674 & TST \\
\hline CHEMBL1241675 & 654928 & 4.8861 & 4.7457 & TST \\
\hline CHEMBL1242657 & 654928 & 6.0 & 5.6327 & TST \\
\hline CHEMBL1241481 & 654928 & 10.0 & 6.5732 & TST \\
\hline CHEMBL1241580 & 654928 & 7.4949 & 7.8806 & TST \\
\hline CHEMBL1242569 & 654928 & 4.8356 & 4.4081 & TST \\
\hline CHEMBL 2164110 & 860056 & 5.4202 & 5.4102 & TRN \\
\hline CHEMBL2164093 & 860056 & 4.0 & 5.3772 & TST \\
\hline
\end{tabular}




\begin{tabular}{|c|c|c|c|c|c|}
\hline & & \multicolumn{4}{|c|}{ Supplemental Table S2.txt } \\
\hline CHEMBL 2164088 & 860056 & 6.0605 & 6.0388 & TRN & \\
\hline CHEMBL 2164114 & 860056 & 6.585 & 6.5833 & TRN & \\
\hline CHEMBL2164092 & 860056 & 6.3872 & 5.7394 & TST & \\
\hline CHEMBL 2164115 & 860056 & 6.6778 & 6.6728 & TRN & \\
\hline CHEMBL 2164116 & 860056 & 5.6696 & 5.6666 & TRN & \\
\hline CHEMBL 2164087 & 860056 & 6.3665 & 6.3703 & TRN & \\
\hline CHEMBL 2164448 & 860056 & 4.0 & 3.2832 & TST & \\
\hline CHEMBL2163735 & 860056 & 7.301 & 7.305 & TRN & \\
\hline CHEMBL 2164111 & 860056 & 7.1549 & 7.1384 & TRN & \\
\hline CHEMBL2164122 & 860056 & 7.3979 & 7.4035 & TRN & \\
\hline CHEMBL 2164449 & 860056 & 6.6198 & 6.6526 & TRN & \\
\hline CHEMBL 2163738 & 860056 & 6.3372 & 6.3374 & TRN & \\
\hline CHEMBL 2164090 & 860056 & 4.0 & 5.61799 & 9999999999 & TST \\
\hline CHEMBL 2164085 & 860056 & 5.7959 & 5.7944 & TRN & \\
\hline CHEMBL 2164118 & 860056 & 4.0 & 4.0011 & TRN & \\
\hline CHEMBL 2164102 & 860056 & 4.0 & 3.9987 & TRN & \\
\hline CHEMBL 2164123 & 860056 & 4.0 & 3.6144 & TST & \\
\hline CHEMBL 2163737 & 860056 & 4.0 & 3.9969 & TRN & \\
\hline CHEMBL 2164084 & 860056 & 5.8239 & 5.8237 & TRN & \\
\hline CHEMBL 2164095 & 860056 & 4.0 & 5.6268 & TST & \\
\hline CHEMBL 2164096 & 860056 & 4.0 & 5.3298 & TST & \\
\hline CHEMBL 2163736 & 860056 & 6.6383 & 6.6522 & TRN & \\
\hline CHEMBL 2164080 & 860056 & 5.9031 & 5.9123 & TRN & \\
\hline CHEMBL 2164113 & 860056 & 7.0458 & 7.0409 & TRN & \\
\hline CHEMBL251686 & 860056 & 8.2007 & 0.9946 & TST & \\
\hline CHEMBL 2164121 & 860056 & 7.5229 & 7.5413 & TRN & \\
\hline CHEMBL 2164089 & 860056 & 5.9318 & 5.5557 & TST & \\
\hline CHEMBL 2164082 & 860056 & 5.7447 & 5.7531 & TRN & \\
\hline CHEMBL 2164098 & 860056 & 5.2366 & 6.3406 & TST & \\
\hline CHEMBL 2164094 & 860056 & 7.5229 & 5.6705 & TST & \\
\hline CHEMBL 2164083 & 860056 & 5.3872 & 5.3884 & TRN & \\
\hline CHEMBL2164106 & 860056 & 5.4559 & 5.4447 & TRN & \\
\hline CHEMBL 2163734 & 860056 & 4.0 & 4.007 & TRN & \\
\hline CHEMBL 2164079 & 860056 & 6.1427 & 6.1377 & TRN & \\
\hline CHEMBL 2164103 & 860056 & 6.9586 & 6.9741 & TRN & \\
\hline CHEMBL 2164120 & 860056 & 7.301 & 7.2641 & TRN & \\
\hline CHEMBL2164104 & 860056 & 6.4089 & 6.3982 & TRN & \\
\hline CHEMBL 2164112 & 860056 & 5.7959 & 5.7956 & TRN & \\
\hline CHEMBL 2164078 & 860056 & 6.1549 & 6.1449 & TRN & \\
\hline CHEMBL 2164107 & 860056 & 7.301 & 7.3051 & TRN & \\
\hline CHEMBL 2164105 & 860056 & 5.2757 & 5.29299 & 9999999999 & TRN \\
\hline CHEMBL 2164091 & 860056 & 5.3872 & 4.7916 & TST & \\
\hline CHEMBL 2164086 & 860056 & 5.585 & 5.5576 & TRN & \\
\hline CHEMBL 2164119 & 860056 & 4.0 & 4.0105 & TRN & \\
\hline CHEMBL 2164108 & 860056 & 4.0 & 4.0022 & TRN & \\
\hline CHEMBL 2164081 & 860056 & 5.2757 & 5.2779 & TRN & \\
\hline CHEMBL 2164097 & 860056 & 5.1871 & 6.0538 & TST & \\
\hline CHEMBL 2164109 & 860056 & 6.9208 & 6.9343 & TRN & \\
\hline
\end{tabular}




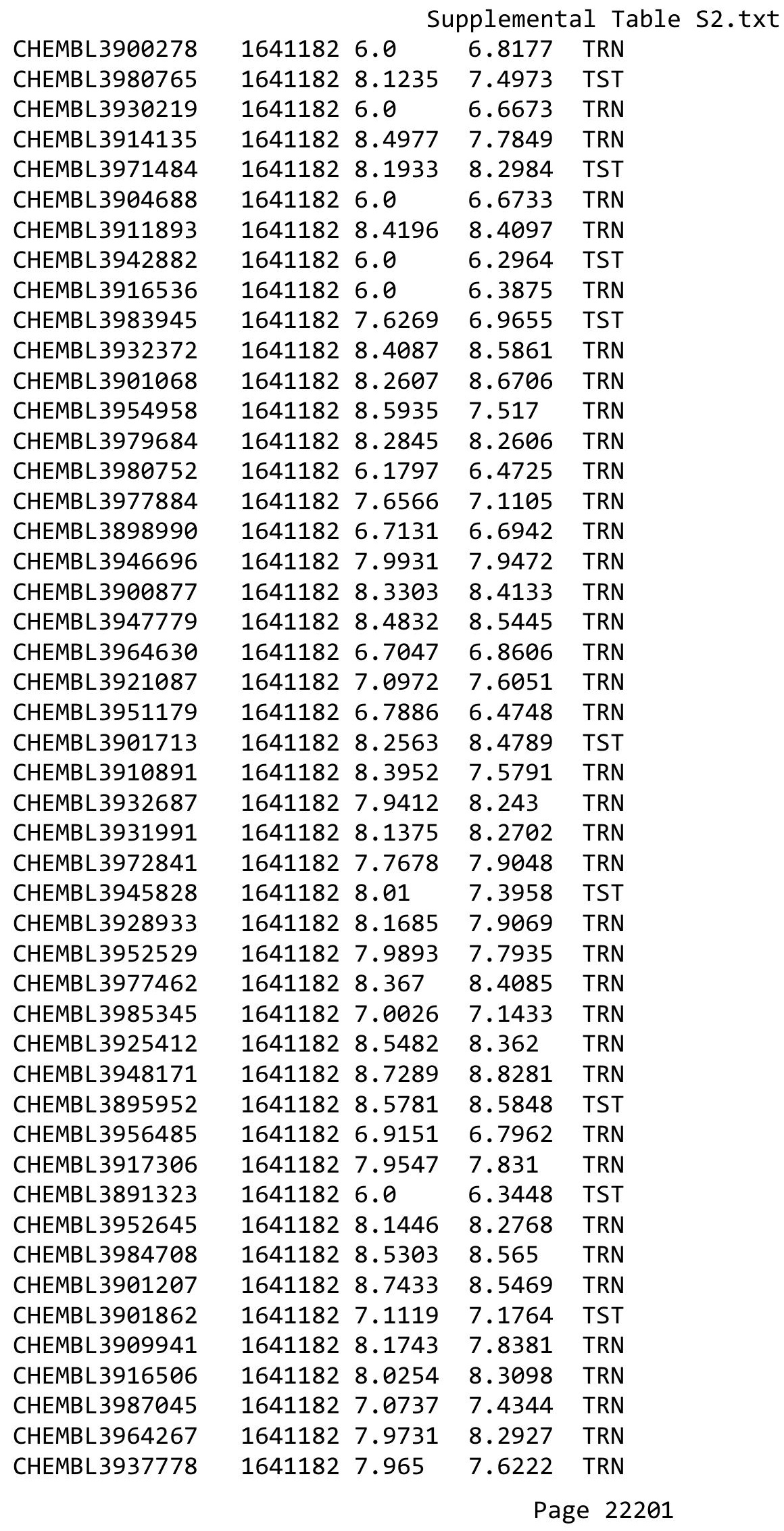


Supplemental Table S2.txt

\begin{tabular}{|c|c|c|c|c|c|}
\hline CHEMBL3909768 & 1641182 & 8.0416 & 7.8158 & TRN & \\
\hline CHEMBL3967409 & 1641182 & 8.2935 & 8.4261 & TRN & \\
\hline CHEMBL3935437 & 1641182 & 8.0008 & \multicolumn{2}{|c|}{8.232000000000001} & TRN \\
\hline CHEMBL3954719 & 1641182 & 7.2812 & 7.2273 & TRN & \\
\hline CHEMBL 3923062 & 1641182 & 8.4026 & 8.0268 & TRN & \\
\hline CHEMBL 3964172 & 1641182 & 8.0632 & 8.4942 & TRN & \\
\hline CHEMBL3941278 & 1641182 & 6.8884 & 6.6735 & TRN & \\
\hline CHEMBL 3898085 & 1641182 & 7.8099 & 8.0799 & TRN & \\
\hline CHEMBL3916832 & 1641182 & 7.4643 & 6.9814 & TRN & \\
\hline CHEMBL3922375 & 1641182 & 8.6385 & 8.408 & TRN & \\
\hline CHEMBL 3936821 & 1641182 & 8.5549 & 7.9482 & TRN & \\
\hline CHEMBL3917905 & 1641182 & 6.5287 & 6.1291 & TRN & \\
\hline CHEMBL3970019 & 1641182 & 8.3333 & 8.1157 & TRN & \\
\hline CHEMBL3966448 & 1641182 & 7.9722 & 8.0362 & TRN & \\
\hline CHEMBL3919958 & 1641182 & 7.8468 & \multicolumn{2}{|c|}{8.056000000000001} & TRN \\
\hline CHEMBL 3963380 & 1641182 & 7.6139 & 7.6691 & TRN & \\
\hline CHEMBL3976190 & 1641182 & 6.0 & 6.4516 & TST & \\
\hline CHEMBL3975918 & 1641182 & 7.7825 & 7.9802 & TRN & \\
\hline CHEMBL3954156 & 1641182 & 8.3319 & 8.1042 & TST & \\
\hline CHEMBL3939908 & 1641182 & 8.0596 & 8.4606 & TST & \\
\hline CHEMBL 3937875 & 1641182 & 8.1369 & 8.1235 & TST & \\
\hline CHEMBL3919141 & 1641182 & 7.7245 & 7.7152 & TST & \\
\hline CHEMBL 3895519 & 1641182 & 8.4317 & 8.7551 & TRN & \\
\hline CHEMBL 3904284 & 1641182 & 7.0799 & 7.0598 & TST & \\
\hline CHEMBL3972307 & 1641182 & 8.4032 & 8.0451 & TST & \\
\hline CHEMBL 3893835 & 1641182 & 8.484 & 8.4632 & TRN & \\
\hline CHEMBL3955411 & 1641182 & 6.0 & 6.6164 & TRN & \\
\hline CHEMBL 3891570 & 1641182 & 7.5053 & 7.7088 & TST & \\
\hline CHEMBL3908585 & 1641182 & 7.4703 & 7.1111 & TST & \\
\hline CHEMBL3895909 & 1641182 & 7.3747 & 7.4113 & TST & \\
\hline CHEMBL3947746 & 1641182 & 7.7688 & 7.6093 & TST & \\
\hline CHEMBL3974839 & 1641182 & 8.0348 & 7.5382 & TRN & \\
\hline CHEMBL 3937501 & 1641182 & 8.5938 & 8.4952 & TRN & \\
\hline CHEMBL3986737 & 1641182 & 7.8356 & 7.7357 & TST & \\
\hline CHEMBL 3931431 & 1640707 & 7.0 & 6.4948 & TRN & \\
\hline CHEMBL3948588 & 1640707 & 7.0 & 7.3646 & TRN & \\
\hline CHEMBL3971655 & 1640707 & 7.0 & 7.0296 & TRN & \\
\hline CHEMBL 3894435 & 1640707 & 7.0 & 7.2527 & TRN & \\
\hline CHEMBL3926919 & 1640707 & 8.0 & 6.99799 & 9999999999 & TRN \\
\hline CHEMBL3976316 & 1640707 & 8.0 & 8.3692 & TST & \\
\hline CHEMBL3936975 & 1640707 & 7.0 & 7.3543 & TRN & \\
\hline CHEMBL 3586509 & 1640707 & 8.0 & 7.806 & TST & \\
\hline CHEMBL3950362 & 1640707 & 7.0 & 7.0956 & TRN & \\
\hline CHEMBL 3898528 & 1640707 & 8.0 & 7.3231 & TST & \\
\hline CHEMBL 3899909 & 1640707 & 8.0 & 7.8365 & TRN & \\
\hline CHEMBL3920053 & 1640707 & 7.0 & 6.7671 & TRN & \\
\hline CHEMBL3964132 & 1640707 & 8.0 & 6.7091 & TST & \\
\hline CHEMBL3906601 & 1640707 & 8.0 & 7.5706 & TRN & \\
\hline
\end{tabular}




\begin{tabular}{|c|c|c|c|c|c|}
\hline & & & & & \\
\hline CHEMBL3899446 & 1640707 & 8.0 & 7.9704 & TRN & \\
\hline CHEMBL3898449 & 1640707 & 7.0 & 7.4933 & TST & \\
\hline CHEMBL3914393 & 1640707 & 7.0 & 7.2844 & TRN & \\
\hline CHEMBL3958620 & 1640707 & 7.0 & 7.28 & TRN & \\
\hline CHEMBL3586508 & 1640707 & 8.0 & 8.5102 & TST & \\
\hline CHEMBL3909327 & 1640707 & 8.0 & 7.51 & TRN & \\
\hline CHEMBL3978540 & 1640707 & 7.0 & 7.5235 & TST & \\
\hline CHEMBL3893657 & 1640707 & 7.0 & 6.9982 & TRN & \\
\hline CHEMBL3976249 & 1640707 & 7.0 & 6.3907 & TRN & \\
\hline CHEMBL 3900252 & 1640707 & 8.0 & 7.04899 & 99999999995 & TRN \\
\hline CHEMBL 3892745 & 1640707 & 7.0 & 7.3681 & TRN & \\
\hline CHEMBL3932829 & 1640707 & 7.0 & 7.1101 & TST & \\
\hline CHEMBL3971526 & 1640707 & 5.0 & 6.6426 & TST & \\
\hline CHEMBL 3912320 & 1640707 & 7.0 & 7.0715 & TRN & \\
\hline CHEMBL 3962404 & 1640707 & 8.0 & 8.061 & TST & \\
\hline CHEMBL3974894 & 1640707 & 7.0 & 7.4161 & TRN & \\
\hline CHEMBL3586496 & 1640707 & 7.0 & 6.8098 & TST & \\
\hline CHEMBL 3972442 & 1640707 & 7.0 & 6.7277 & TRN & \\
\hline CHEMBL3933496 & 1640707 & 7.0 & 7.5472 & TST & \\
\hline CHEMBL3586500 & 1640707 & 7.0 & 6.4141 & TST & \\
\hline CHEMBL3909398 & 1640707 & 7.0 & 6.3056 & TRN & \\
\hline CHEMBL 3980194 & 1640707 & 8.0 & 7.489 & TRN & \\
\hline CHEMBL 3586484 & 1640707 & 7.0 & 7.3504 & TST & \\
\hline CHEMBL3917215 & 1640707 & 7.0 & 7.2035 & TRN & \\
\hline CHEMBL3908966 & 1640707 & 8.0 & 7.895 & TRN & \\
\hline CHEMBL3931124 & 1640707 & 8.0 & 8.1864 & TRN & \\
\hline CHEMBL3586506 & 1640707 & 8.0 & 7.645 & TST & \\
\hline CHEMBL3952633 & 1640707 & 8.0 & 7.9647 & TRN & \\
\hline CHEMBL3974126 & 1640707 & 7.0 & 7.3185 & TRN & \\
\hline CHEMBL 3982787 & 1640707 & 7.0 & 6.795 & TST & \\
\hline CHEMBL3892790 & 1640707 & 8.0 & 7.3282 & TRN & \\
\hline CHEMBL3920277 & 1640707 & 8.0 & 7.3501 & TRN & \\
\hline CHEMBL 3957369 & 1640707 & 7.0 & 6.5844 & TRN & \\
\hline CHEMBL3955427 & 1640707 & 8.0 & 7.2551 & TST & \\
\hline CHEMBL 3918899 & 1640707 & 8.0 & 7.2853 & TRN & \\
\hline CHEMBL3952402 & 1640707 & 8.0 & 8.1881 & TRN & \\
\hline CHEMBL 3912286 & 1640707 & 8.0 & 7.517 & TRN & \\
\hline CHEMBL 3943129 & 1640707 & 7.0 & 7.3594 & TRN & \\
\hline CHEMBL 3894394 & 1640707 & 8.0 & 8.0723 & TRN & \\
\hline CHEMBL3931326 & 1640707 & 7.0 & 7.3637 & TRN & \\
\hline CHEMBL3890937 & 1640707 & 8.0 & 7.5294 & TRN & \\
\hline CHEMBL 3908634 & 1640707 & 8.0 & 7.7345 & TRN & \\
\hline CHEMBL 3960442 & 1640707 & 8.0 & 7.8724 & TRN & \\
\hline CHEMBL3921734 & 1640707 & 7.0 & 7.1912 & TRN & \\
\hline CHEMBL 3918974 & 1640707 & 8.0 & 8.4013 & TRN & \\
\hline CHEMBL3909061 & 1640707 & 5.0 & 7.3301 & TRN & \\
\hline CHEMBL3936996 & 1640707 & 8.0 & 7.638 & TRN & \\
\hline CHEMBL3979995 & 1640707 & 7.0 & 6.6753 & TRN & \\
\hline & & & & 22203 & \\
\hline
\end{tabular}




\begin{tabular}{|c|c|c|c|c|}
\hline \\
\hline CHEMBL3981799 & 1640707 & 7.0 & 7.0724 & TRN \\
\hline CHEMBL 3946350 & 1640707 & 7.0 & 6.8653 & TRN \\
\hline CHEMBL 3933431 & 1640707 & 8.0 & 7.5519 & TRN \\
\hline CHEMBL3918603 & 1640707 & 8.0 & 7.2797 & TRN \\
\hline CHEMBL 3894449 & 1640707 & 8.0 & 7.3612 & TRN \\
\hline CHEMBL3899780 & 1640707 & 7.0 & 6.6683 & TRN \\
\hline CHEMBL 3958291 & 1640707 & 7.0 & 6.8611 & TRN \\
\hline CHEMBL3586511 & 1640707 & 8.0 & 7.2873 & TST \\
\hline CHEMBL 3894869 & 1640707 & 7.0 & 6.876 & TRN \\
\hline CHEMBL3963677 & 1640707 & 7.0 & 7.1148 & TRN \\
\hline CHEMBL 3940487 & 1640707 & 8.0 & 6.9598 & TRN \\
\hline CHEMBL 3936900 & 1640707 & 8.0 & 7.6183 & TRN \\
\hline CHEMBL 3972693 & 1640707 & 7.0 & 7.2032 & TRN \\
\hline CHEMBL 3925181 & 1640707 & 7.0 & 6.9324 & TRN \\
\hline CHEMBL3586501 & 1640707 & 8.0 & 7.0011 & TST \\
\hline CHEMBL3920512 & 1640707 & 8.0 & 7.7803 & TRN \\
\hline CHEMBL3901086 & 1640707 & 8.0 & 7.8181 & TRN \\
\hline CHEMBL3926115 & 1640707 & 7.0 & 7.2102 & TRN \\
\hline CHEMBL3948951 & 1640707 & 7.0 & 7.1693 & TRN \\
\hline CHEMBL 3934835 & 1640707 & 7.0 & 7.3123 & TRN \\
\hline CHEMBL3931420 & 1640707 & 7.0 & 7.6887 & TRN \\
\hline CHEMBL3586499 & 1640707 & 7.0 & 6.5688 & TST \\
\hline CHEMBL3913498 & 1640707 & 7.0 & 7.4263 & TRN \\
\hline CHEMBL3949661 & 1640707 & 8.0 & 7.1227 & TRN \\
\hline CHEMBL3964623 & 1640707 & 8.0 & 7.6959 & TST \\
\hline CHEMBL3889905 & 1640707 & 8.0 & 7.6329 & TRN \\
\hline CHEMBL 3927390 & 1640707 & 8.0 & 8.2846 & TRN \\
\hline CHEMBL3968759 & 1640707 & 8.0 & 8.1487 & TST \\
\hline CHEMBL 3951282 & 1640707 & 8.0 & 7.6633 & TRN \\
\hline CHEMBL3960718 & 1640707 & 8.0 & 7.32299 & 99999999995 \\
\hline CHEMBL3956292 & 1640707 & 7.0 & 7.4248 & TST \\
\hline CHEMBL 3897686 & 1640707 & 8.0 & 7.54 & TRN \\
\hline CHEMBL3938166 & 1640707 & 7.0 & 6.8517 & TRN \\
\hline CHEMBL 3970676 & 1640707 & 7.0 & 6.5278 & TRN \\
\hline CHEMBL 3897856 & 1640707 & 7.0 & 6.8383 & TRN \\
\hline CHEMBL3978837 & 1640707 & 7.0 & 6.4745 & TRN \\
\hline CHEMBL 3910472 & 1640707 & 8.0 & 7.9832 & TRN \\
\hline CHEMBL3968371 & 1640707 & 8.0 & 7.4794 & TRN \\
\hline CHEMBL 3928721 & 1640707 & 8.0 & 7.2306 & TRN \\
\hline CHEMBL3963633 & 1640707 & 7.0 & 6.5687 & TRN \\
\hline CHEMBL3586492 & 1640707 & 7.0 & 6.9689 & TST \\
\hline CHEMBL3909526 & 1640707 & 7.0 & 7.2493 & TRN \\
\hline CHEMBL3900908 & 1640707 & 7.0 & 6.7196 & TRN \\
\hline CHEMBL3912316 & 1640707 & 8.0 & 7.9214 & TRN \\
\hline CHEMBL 3982170 & 1640707 & 7.0 & 6.33 & TST \\
\hline CHEMBL3897604 & 1640707 & 7.0 & 7.6482 & TRN \\
\hline CHEMBL 3986973 & 1640707 & 5.0 & 6.021 & TRN \\
\hline CHEMBL3899478 & 1640707 & 7.0 & 7.5545 & TRN \\
\hline
\end{tabular}




\begin{tabular}{|c|c|c|c|c|c|}
\hline \multirow[b]{2}{*}{ CHEMBL3936809 } & \multirow{2}{*}{\multicolumn{2}{|c|}{16407078.0}} & \\
\hline & & & 8.1426 & TRN & \\
\hline CHEMBL3954582 & 1640707 & 8.0 & 7.5763 & TST & \\
\hline CHEMBL3921515 & 1640707 & 7.0 & 6.8911 & TRN & \\
\hline CHEMBL3923780 & 1640707 & 7.0 & \multicolumn{2}{|c|}{6.9270000000000005} & TRN \\
\hline CHEMBL3958433 & 1640707 & 8.0 & 7.8218 & TRN & \\
\hline CHEMBL3953368 & 1640707 & 8.0 & 8.1128 & TRN & \\
\hline CHEMBL3897519 & 1640707 & 7.0 & 7.47 & TRN & \\
\hline CHEMBL3937404 & 1640707 & 8.0 & 7.9947 & TRN & \\
\hline CHEMBL3951493 & 1640707 & 7.0 & 7.1054 & TRN & \\
\hline CHEMBL3937335 & 1640707 & 7.0 & 6.2256 & TRN & \\
\hline CHEMBL 3954648 & 1640707 & 8.0 & 8.2929 & TRN & \\
\hline CHEMBL3586490 & 1640707 & 7.0 & 6.6289 & TST & \\
\hline CHEMBL3955922 & 1640707 & 7.0 & 7.21 & TRN & \\
\hline CHEMBL3973551 & 1640707 & 7.0 & 7.4283 & TRN & \\
\hline CHEMBL3924317 & 1640707 & 8.0 & 7.9194 & TRN & \\
\hline CHEMBL3909042 & 1640707 & 7.0 & 6.9469 & TRN & \\
\hline CHEMBL3949312 & 1640707 & 7.0 & 6.8713 & TRN & \\
\hline CHEMBL3943605 & 1640707 & 7.0 & 7.5318 & TRN & \\
\hline CHEMBL3922099 & 1640707 & 7.0 & 7.5104 & TRN & \\
\hline CHEMBL3909063 & 1640707 & 8.0 & 7.7946 & TRN & \\
\hline CHEMBL3981292 & 1640707 & 5.0 & 6.7193 & TRN & \\
\hline CHEMBL3986993 & 1640707 & 7.0 & 6.9854 & TRN & \\
\hline CHEMBL3904807 & 1640707 & 8.0 & 7.7198 & TRN & \\
\hline CHEMBL3975374 & 1640707 & 8.0 & \multicolumn{2}{|c|}{7.7170000000000005} & TRN \\
\hline CHEMBL 3894857 & 1640707 & 8.0 & 6.9963 & TRN & \\
\hline CHEMBL3961753 & 1640707 & 8.0 & 7.3966 & TRN & \\
\hline CHEMBL3903671 & 1640707 & 8.0 & 6.6625 & TRN & \\
\hline CHEMBL3901110 & 1640707 & 8.0 & 7.3422 & TST & \\
\hline CHEMBL3933937 & 1640707 & 5.0 & 6.4919 & TRN & \\
\hline CHEMBL3981649 & 1640707 & 8.0 & 7.2757 & TRN & \\
\hline CHEMBL3892596 & 1640707 & 8.0 & 7.5751 & TRN & \\
\hline CHEMBL3945811 & 1640707 & 7.0 & 6.8011 & TRN & \\
\hline CHEMBL3915439 & 1640707 & 8.0 & 7.4294 & TRN & \\
\hline CHEMBL3972360 & 1640707 & 8.0 & \multicolumn{2}{|c|}{7.372000000000001} & TRN \\
\hline CHEMBL3936608 & 1640707 & 7.0 & 7.0762 & TRN & \\
\hline CHEMBL3938085 & 1640707 & 5.0 & 6.4539 & TRN & \\
\hline CHEMBL3946723 & 1640707 & 7.0 & 7.3223 & TRN & \\
\hline CHEMBL3978471 & 1640707 & 7.0 & 6.6378 & TRN & \\
\hline CHEMBL3899809 & 1640707 & 8.0 & 7.7368 & TRN & \\
\hline CHEMBL3966782 & 1640707 & 8.0 & 7.3545 & TRN & \\
\hline CHEMBL3908856 & 1640707 & 8.0 & 8.4481 & TRN & \\
\hline CHEMBL 3892202 & 1640707 & 8.0 & 7.4953 & TRN & \\
\hline CHEMBL3894436 & 1640707 & 7.0 & 6.4128 & TRN & \\
\hline CHEMBL3962393 & 1640707 & 8.0 & 7.8182 & TRN & \\
\hline CHEMBL3940677 & 1640707 & 7.0 & 6.8346 & TRN & \\
\hline CHEMBL3972016 & 1640707 & 8.0 & 7.8211 & TRN & \\
\hline CHEMBL3963318 & 1640707 & 8.0 & 8.1563 & TST & \\
\hline \multirow[t]{2}{*}{ CHEMBL3975182 } & 1640707 & 8.0 & 6.8957 & TRN & \\
\hline & & & \multicolumn{2}{|c|}{ Page 22205} & \\
\hline
\end{tabular}




\begin{tabular}{|c|c|c|c|c|}
\hline & & & ement & al Ta \\
\hline CHEMBL3912499 & 1640707 & 5.0 & 6.4694 & TRN \\
\hline CHEMBL3942465 & 1640707 & 7.0 & 7.1521 & TRN \\
\hline CHEMBL3950375 & 1640707 & 8.0 & 8.6121 & TRN \\
\hline CHEMBL3985571 & 1640707 & 7.0 & 6.8888 & TRN \\
\hline CHEMBL3948096 & 1640707 & 5.0 & 7.3066 & TRN \\
\hline CHEMBL3900598 & 1640707 & 7.0 & 7.1211 & TRN \\
\hline CHEMBL3899414 & 1640707 & 8.0 & 7.3502 & TRN \\
\hline CHEMBL3900405 & 1640707 & 5.0 & 6.6761 & TRN \\
\hline CHEMBL3983691 & 1640707 & 5.0 & 6.2309 & TRN \\
\hline CHEMBL3936851 & 1640707 & 7.0 & 7.0656 & TRN \\
\hline CHEMBL3890904 & 1640707 & 7.0 & 7.1964 & TRN \\
\hline CHEMBL3962169 & 1640707 & 8.0 & 7.5701 & TRN \\
\hline CHEMBL3586495 & 1640707 & 8.0 & 7.2137 & TST \\
\hline CHEMBL 3942826 & 1640707 & 7.0 & 6.4152 & TRN \\
\hline CHEMBL3929117 & 1640707 & 8.0 & 7.1859 & TRN \\
\hline CHEMBL3909465 & 1640707 & 8.0 & 8.2573 & TRN \\
\hline CHEMBL3909414 & 1640707 & 7.0 & 6.5742 & TST \\
\hline CHEMBL3906519 & 1640707 & 8.0 & 7.4466 & TRN \\
\hline CHEMBL3957973 & 1640707 & 7.0 & 7.1227 & TRN \\
\hline CHEMBL3897735 & 1640707 & 8.0 & 7.0001 & TRN \\
\hline CHEMBL3586510 & 1640707 & 8.0 & 7.2888 & TST \\
\hline CHEMBL3894089 & 1640707 & 7.0 & 7.4703 & TRN \\
\hline CHEMBL3897625 & 1640707 & 7.0 & 6.6683 & TRN \\
\hline CHEMBL 3898670 & 1640707 & 8.0 & 7.2485 & TRN \\
\hline CHEMBL3968683 & 1640707 & 8.0 & 7.4773 & TRN \\
\hline CHEMBL3974589 & 1640707 & 7.0 & 7.0432 & TRN \\
\hline CHEMBL3906006 & 1640707 & 7.0 & 7.6343 & TRN \\
\hline CHEMBL3909014 & 1640707 & 8.0 & 8.0317 & TRN \\
\hline CHEMBL3926793 & 1640707 & 5.0 & 6.1572 & TRN \\
\hline CHEMBL 3972075 & 1640707 & 8.0 & 7.5501 & TRN \\
\hline CHEMBL3980882 & 1640707 & 8.0 & 7.6755 & TRN \\
\hline CHEMBL3906627 & 1640707 & 7.0 & 7.0928 & TRN \\
\hline CHEMBL3934570 & 1640707 & 7.0 & 7.1355 & TRN \\
\hline CHEMBL3951256 & 1640707 & 8.0 & 7.9017 & TST \\
\hline CHEMBL 3920200 & 1640707 & 8.0 & 7.5482 & TRN \\
\hline CHEMBL3967389 & 1640707 & 7.0 & 7.3357 & TRN \\
\hline CHEMBL3981196 & 1640707 & 8.0 & 8.0819 & TRN \\
\hline CHEMBL3904526 & 1640707 & 5.0 & 6.603 & TRN \\
\hline CHEMBL3938253 & 1640707 & 8.0 & 7.7455 & TRN \\
\hline CHEMBL 3940314 & 1640707 & 8.0 & 7.5694 & TRN \\
\hline CHEMBL3946452 & 1640707 & 8.0 & 8.2218 & TRN \\
\hline CHEMBL 3936754 & 1640707 & 8.0 & 8.0951 & TRN \\
\hline CHEMBL 3922358 & 1640707 & 8.0 & 7.8949 & TRN \\
\hline CHEMBL3980126 & 1640707 & 8.0 & 7.6448 & TST \\
\hline CHEMBL 3894958 & 1640707 & 8.0 & 7.7959 & TRN \\
\hline CHEMBL3956904 & 1640707 & 7.0 & 7.0406 & TRN \\
\hline CHEMBL3941016 & 1640707 & 5.0 & 6.5633 & TRN \\
\hline CHEMBL3586498 & 1640707 & 8.0 & 6.6441 & TST \\
\hline
\end{tabular}




\begin{tabular}{|c|c|c|c|c|}
\hline & & & ient & $a \perp 1 a$ \\
\hline CHEMBL 3936227 & 1640707 & 7.0 & 6.6481 & TRN \\
\hline CHEMBL3921884 & 1640707 & 8.0 & 7.556 & TRN \\
\hline CHEMBL3586503 & 1640707 & 8.0 & 7.4674 & TST \\
\hline CHEMBL3986856 & 1640707 & 7.0 & 7.5175 & TRN \\
\hline CHEMBL 3974264 & 1640707 & 7.0 & 6.9927 & TRN \\
\hline CHEMBL3926214 & 1640707 & 7.0 & 6.608 & TRN \\
\hline CHEMBL 3942404 & 1640707 & 7.0 & 6.5736 & TRN \\
\hline CHEMBL3586504 & 1640707 & 8.0 & 7.9325 & TST \\
\hline CHEMBL 3941904 & 1640707 & 7.0 & 7.2286 & TRN \\
\hline CHEMBL3959174 & 1640707 & 7.0 & 6.6196 & TRN \\
\hline CHEMBL 3980247 & 1640707 & 8.0 & 7.5198 & TRN \\
\hline CHEMBL3984714 & 1640707 & 7.0 & 7.8743 & TST \\
\hline CHEMBL3975410 & 1640707 & 8.0 & 6.8149 & TRN \\
\hline CHEMBL 3919434 & 1640707 & 8.0 & 7.9358 & TRN \\
\hline CHEMBL3910160 & 1640707 & 7.0 & 6.3483 & TRN \\
\hline CHEMBL3962848 & 1640707 & 7.0 & 7.2783 & TST \\
\hline CHEMBL3924029 & 1640707 & 8.0 & 7.1355 & TRN \\
\hline CHEMBL3586486 & 1640707 & 8.0 & 7.0082 & TST \\
\hline CHEMBL3586493 & 1640707 & 8.0 & 6.4478 & TST \\
\hline CHEMBL3935941 & 1640707 & 5.0 & 6.3105 & TRN \\
\hline CHEMBL3969158 & 1640707 & 7.0 & 6.7412 & TRN \\
\hline CHEMBL3964604 & 1640707 & 7.0 & 6.9977 & TRN \\
\hline CHEMBL3927286 & 1640707 & 8.0 & 7.3426 & TRN \\
\hline CHEMBL3586507 & 1640707 & 8.0 & 6.7262 & TST \\
\hline CHEMBL3961746 & 1640707 & 8.0 & 7.5203 & TRN \\
\hline CHEMBL3970117 & 1640707 & 7.0 & 6.4242 & TRN \\
\hline CHEMBL3980091 & 1640707 & 8.0 & 7.3132 & TRN \\
\hline CHEMBL3946225 & 1640707 & 5.0 & 6.1421 & TST \\
\hline CHEMBL3586491 & 1640707 & 5.0 & 6.6794 & TST \\
\hline CHEMBL3931506 & 1640707 & 7.0 & 7.9632 & TRN \\
\hline CHEMBL3905205 & 1640707 & 7.0 & 7.0474 & TRN \\
\hline CHEMBL3953074 & 1640707 & 8.0 & 7.2739 & TRN \\
\hline CHEMBL3926943 & 1640707 & 8.0 & 7.2871 & TRN \\
\hline CHEMBL 3965787 & 1640707 & 7.0 & 7.1845 & TRN \\
\hline CHEMBL3972248 & 1640707 & 7.0 & 7.2147 & TST \\
\hline CHEMBL3954623 & 1640707 & 7.0 & 7.4997 & TST \\
\hline CHEMBL3921423 & 1640707 & 7.0 & 7.975 & TRN \\
\hline CHEMBL3955009 & 1640707 & 8.0 & 8.2877 & TRN \\
\hline CHEMBL 3963960 & 1640707 & 8.0 & 7.9157 & TST \\
\hline CHEMBL3971750 & 1640707 & 7.0 & 6.9708 & TRN \\
\hline CHEMBL3902196 & 1640707 & 7.0 & 6.5432 & TRN \\
\hline CHEMBL3900568 & 1640707 & 8.0 & 6.8563 & TST \\
\hline CHEMBL3932526 & 1640707 & 7.0 & 6.5913 & TST \\
\hline CHEMBL 3931740 & 1640707 & 8.0 & 7.1636 & TRN \\
\hline CHEMBL3981389 & 1640707 & 7.0 & 7.2736 & TRN \\
\hline CHEMBL 3940643 & 1640707 & 7.0 & 6.2341 & TST \\
\hline CHEMBL3955658 & 1640707 & 7.0 & 7.11 & TRN \\
\hline CHEMBL3903061 & 1640707 & 5.0 & 7.2372 & TST \\
\hline
\end{tabular}




\begin{tabular}{|c|c|c|c|c|}
\hline & & & & $a \perp 1 a$ \\
\hline CHEMBL 3970564 & 1640707 & 7.0 & 6.1128 & TST \\
\hline CHEMBL3922205 & 1640707 & 8.0 & 7.8195 & TRN \\
\hline CHEMBL3971390 & 1640707 & 8.0 & 7.669 & TRN \\
\hline CHEMBL 3906500 & 1640707 & 8.0 & 8.5433 & TRN \\
\hline CHEMBL3936244 & 1640707 & 7.0 & 7.3588 & TRN \\
\hline CHEMBL3967745 & 1640707 & 7.0 & 6.4689 & TST \\
\hline CHEMBL3969713 & 1640707 & 8.0 & 7.9141 & TRN \\
\hline CHEMBL3958640 & 1640707 & 7.0 & 7.3389 & TRN \\
\hline CHEMBL 3894494 & 1640707 & 8.0 & 7.3603 & TRN \\
\hline CHEMBL3934160 & 1640707 & 7.0 & 6.9446 & TRN \\
\hline CHEMBL3353208 & 1640707 & 8.0 & 8.1228 & TST \\
\hline CHEMBL3941465 & 1640707 & 8.0 & 7.6566 & TRN \\
\hline CHEMBL3971677 & 1640707 & 7.0 & 6.4383 & TST \\
\hline CHEMBL3938948 & 1640707 & 7.0 & 6.7177 & TRN \\
\hline CHEMBL3965902 & 1640707 & 7.0 & 7.3697 & TST \\
\hline CHEMBL3919757 & 1640707 & 5.0 & 6.8194 & TRN \\
\hline CHEMBL3894684 & 1640707 & 7.0 & 7.2068 & TRN \\
\hline CHEMBL3936302 & 1640707 & 8.0 & 7.7802 & TRN \\
\hline CHEMBL3932601 & 1640707 & 7.0 & 8.0906 & TRN \\
\hline CHEMBL3951115 & 1640707 & 5.0 & 6.8424 & TRN \\
\hline CHEMBL 3945694 & 1640707 & 8.0 & 8.4866 & TRN \\
\hline CHEMBL3955046 & 1640707 & 7.0 & 6.7414 & TST \\
\hline CHEMBL3924798 & 1640707 & 8.0 & 7.386 & TRN \\
\hline CHEMBL3914986 & 1640707 & 7.0 & 6.9409 & TRN \\
\hline CHEMBL3945877 & 1640707 & 8.0 & 7.7976 & TRN \\
\hline CHEMBL 3951041 & 1640707 & 8.0 & 7.0763 & TRN \\
\hline CHEMBL3920387 & 1640707 & 7.0 & 7.3522 & TST \\
\hline CHEMBL3966073 & 1640707 & 7.0 & 7.5174 & TRN \\
\hline CHEMBL 3952231 & 1640707 & 7.0 & 6.1828 & TRN \\
\hline CHEMBL3586485 & 1640707 & 8.0 & 7.4158 & TST \\
\hline CHEMBL3890992 & 1640707 & 7.0 & 6.8459 & TRN \\
\hline CHEMBL3966402 & 1640707 & 7.0 & 7.4081 & TRN \\
\hline CHEMBL3972219 & 1640707 & 7.0 & 7.1222 & TST \\
\hline CHEMBL 3985685 & 1640707 & 8.0 & 7.5322 & TRN \\
\hline CHEMBL3912863 & 1640707 & 8.0 & 8.0592 & TRN \\
\hline CHEMBL3915495 & 1640707 & 7.0 & 7.3756 & TRN \\
\hline CHEMBL3957868 & 1640707 & 8.0 & 7.6061 & TRN \\
\hline CHEMBL3980732 & 1640707 & 7.0 & 7.0975 & TRN \\
\hline CHEMBL 3908722 & 1640707 & 5.0 & 6.3173 & TRN \\
\hline CHEMBL3969090 & 1640707 & 8.0 & 7.4575 & TRN \\
\hline CHEMBL3586488 & 1640707 & 8.0 & 7.0032 & TST \\
\hline CHEMBL3901098 & 1640707 & 8.0 & 7.402 & TRN \\
\hline CHEMBL3900596 & 1640707 & 7.0 & 7.4906 & TST \\
\hline CHEMBL 3971842 & 1640707 & 7.0 & 7.5115 & TRN \\
\hline CHEMBL3975331 & 1640707 & 8.0 & 7.9291 & TST \\
\hline CHEMBL3353207 & 1640707 & 8.0 & 7.8652 & TST \\
\hline CHEMBL3942315 & 1640707 & 7.0 & 7.2927 & TRN \\
\hline CHEMBL3934792 & 1640707 & 7.0 & 7.2887 & TRN \\
\hline
\end{tabular}




\begin{tabular}{|c|c|c|c|c|c|}
\hline CHEMBL 3901586 & 1640707 & 5.0 & 6.4441 & TRN & \\
\hline CHEMBL 3905346 & 1640707 & 7.0 & 7.5656 & TRN & \\
\hline CHEMBL3903627 & 1640707 & 7.0 & 6.6861 & TST & \\
\hline CHEMBL 3908242 & 1640707 & 7.0 & 6.5484 & TRN & \\
\hline CHEMBL3927487 & 1640707 & 8.0 & 7.7384 & TRN & \\
\hline CHEMBL3944644 & 1640707 & 7.0 & 7.0453 & TRN & \\
\hline CHEMBL 3969785 & 1640707 & 8.0 & 7.9987 & TRN & \\
\hline CHEMBL3927995 & 1640707 & 8.0 & 8.0751 & TST & \\
\hline CHEMBL3922501 & 1640707 & 8.0 & 7.6097 & TRN & \\
\hline CHEMBL3891604 & 1640707 & 7.0 & 7.2822 & TST & \\
\hline CHEMBL3923644 & 1640707 & 7.0 & 7.08799 & 9999999999 & TST \\
\hline CHEMBL 3973751 & 1640707 & 7.0 & 7.09200 & 00000000005 & TRN \\
\hline CHEMBL3353209 & 1640707 & 8.0 & 7.9144 & TST & \\
\hline CHEMBL3984259 & 1640707 & 7.0 & 6.3104 & TRN & \\
\hline CHEMBL3980372 & 1640707 & 7.0 & 7.1042 & TRN & \\
\hline CHEMBL3586497 & 1640707 & 7.0 & 6.9735 & TST & \\
\hline CHEMBL3586487 & 1640707 & 7.0 & 7.3317 & TST & \\
\hline CHEMBL3914235 & 1640707 & 5.0 & 6.9451 & TRN & \\
\hline CHEMBL3969501 & 1640707 & 5.0 & 6.4699 & TST & \\
\hline CHEMBL3911353 & 1640707 & 7.0 & 7.2917 & TRN & \\
\hline CHEMBL3958308 & 1640707 & 8.0 & 7.4436 & TRN & \\
\hline CHEMBL 3917117 & 1640707 & 5.0 & 6.5728 & TRN & \\
\hline CHEMBL3586502 & 1640707 & 8.0 & 7.141 & TST & \\
\hline CHEMBL3586494 & 1640707 & 7.0 & 6.6881 & TST & \\
\hline CHEMBL3891709 & 1640707 & 5.0 & 6.8304 & TRN & \\
\hline CHEMBL3945695 & 1640707 & 7.0 & 7.4197 & TST & \\
\hline CHEMBL3586505 & 1640707 & 8.0 & 7.2109 & TST & \\
\hline CHEMBL 3984189 & 1640707 & 7.0 & 6.7161 & TRN & \\
\hline CHEMBL3920485 & 1640707 & 8.0 & 8.0024 & TRN & \\
\hline CHEMBL3936946 & 1640707 & 8.0 & 7.7883 & TRN & \\
\hline CHEMBL3959961 & 1640707 & 7.0 & 7.103 & TRN & \\
\hline CHEMBL 3947203 & 1640707 & 7.0 & 6.4924 & TST & \\
\hline CHEMBL3950439 & 1640707 & 7.0 & 8.6667 & TST & \\
\hline CHEMBL3935887 & 1640707 & 7.0 & 7.4551 & TRN & \\
\hline CHEMBL3917931 & 1640707 & 8.0 & 7.3352 & TST & \\
\hline CHEMBL3972812 & 1640707 & 7.0 & 6.8615 & TRN & \\
\hline CHEMBL3975355 & 1640707 & 8.0 & 6.7212 & TST & \\
\hline CHEMBL3932967 & 1640707 & 8.0 & 7.6315 & TRN & \\
\hline CHEMBL3955114 & 1640707 & 8.0 & 7.3053 & TRN & \\
\hline CHEMBL3933253 & 1640707 & 7.0 & 7.8285 & TRN & \\
\hline CHEMBL3899755 & 1640707 & 8.0 & 7.1589 & TRN & \\
\hline CHEMBL3903995 & 1640707 & 7.0 & 7.5845 & TST & \\
\hline CHEMBL3892251 & 1640707 & 7.0 & 7.5234 & TST & \\
\hline CHEMBL3973605 & 1640707 & 5.0 & 6.711 & TRN & \\
\hline CHEMBL 3916738 & 1640707 & 7.0 & 7.7616 & TRN & \\
\hline CHEMBL 3890086 & 1640707 & 8.0 & \multicolumn{2}{|c|}{7.9910000000000005} & TRN \\
\hline CHEMBL 3943689 & 1640707 & 8.0 & 8.157 & TRN & \\
\hline CHEMBL3922852 & 1640707 & 7.0 & 7.025 & TRN & \\
\hline
\end{tabular}




\begin{tabular}{|c|c|c|c|c|}
\hline & & & EIIC & al Tabl \\
\hline CHEMBL3950483 & 1640707 & 8.0 & 7.9752 & TRN \\
\hline CHEMBL3905240 & 1640707 & 8.0 & 7.1054 & TST \\
\hline CHEMBL3916129 & 1640707 & 7.0 & 6.7613 & TRN \\
\hline CHEMBL3926498 & 1640707 & 7.0 & 6.8229 & TST \\
\hline CHEMBL3952252 & 1640707 & 8.0 & 7.1994 & TST \\
\hline CHEMBL 3945782 & 1640707 & 7.0 & 7.5382 & TRN \\
\hline CHEMBL3967335 & 1640707 & 7.0 & 7.0033 & TST \\
\hline CHEMBL3960624 & 1640707 & 7.0 & 6.9005 & TST \\
\hline CHEMBL3948235 & 1640707 & 7.0 & 7.1829 & TRN \\
\hline CHEMBL3891363 & 1640707 & 8.0 & 6.871 & TRN \\
\hline CHEMBL3918584 & 1640707 & 7.0 & 7.8164 & TRN \\
\hline CHEMBL3890521 & 1640707 & 7.0 & 7.3568 & TRN \\
\hline CHEMBL3921310 & 1640707 & 8.0 & 8.2254 & TRN \\
\hline CHEMBL3944066 & 1640707 & 7.0 & 7.3817 & TRN \\
\hline CHEMBL3926860 & 1640707 & 5.0 & 6.7883 & TST \\
\hline CHEMBL 3895084 & 1640707 & 7.0 & 7.1495 & TRN \\
\hline CHEMBL3949384 & 1640707 & 8.0 & 7.7017 & TRN \\
\hline CHEMBL3928306 & 1640707 & 7.0 & 6.9142 & TRN \\
\hline CHEMBL3936469 & 1640707 & 8.0 & 7.3845 & TRN \\
\hline CHEMBL3914760 & 1640707 & 7.0 & 6.461 & TST \\
\hline CHEMBL3897287 & 1640707 & 7.0 & $7.0420 e$ & 0000000001 \\
\hline CHEMBL3922407 & 1640707 & 8.0 & 7.9869 & TRN \\
\hline CHEMBL3969956 & 1640707 & 7.0 & 7.3669 & TRN \\
\hline CHEMBL3914414 & 1640707 & 8.0 & 7.4601 & TRN \\
\hline CHEMBL3892227 & 1640707 & 7.0 & 7.1785 & TST \\
\hline CHEMBL3944185 & 1640707 & 8.0 & 7.289 & TRN \\
\hline CHEMBL3968849 & 1640707 & 6.0 & 7.0666 & TRN \\
\hline CHEMBL3976036 & 1640707 & 8.0 & 7.4449 & TST \\
\hline CHEMBL3946284 & 1640707 & 8.0 & 7.3284 & TST \\
\hline CHEMBL3913530 & 1640707 & 7.0 & 7.2027 & TST \\
\hline CHEMBL3904543 & 1640707 & 7.0 & 7.4794 & TRN \\
\hline CHEMBL3914020 & 1640707 & 7.0 & 6.5528 & TRN \\
\hline CHEMBL3960163 & 1640707 & 7.0 & 6.2406 & TST \\
\hline CHEMBL3957749 & 1640707 & 7.0 & 7.1167 & TST \\
\hline CHEMBL3968413 & 1640707 & 8.0 & 7.5008 & TRN \\
\hline CHEMBL3942073 & 1640707 & 7.0 & 6.7865 & TST \\
\hline CHEMBL1895345 & 752339 & 5.9666 & 5.1797 & TRN \\
\hline CHEMBL1354361 & 752339 & 5.5901 & 5.0103 & TRN \\
\hline CHEMBL1470242 & 752339 & 5.7144 & 5.0239 & TRN \\
\hline CHEMBL1734645 & 752339 & 5.3307 & 4.9991 & TRN \\
\hline CHEMBL1496814 & 752339 & 5.7696 & 4.9794 & TRN \\
\hline CHEMBL1608757 & 752339 & 4.5352 & 5.0509 & TST \\
\hline CHEMBL1392341 & 752339 & 5.4067 & 5.1649 & TRN \\
\hline CHEMBL1491238 & 752339 & 5.3125 & 5.1882 & TRN \\
\hline CHEMBL1986514 & 752339 & 5.7447 & 5.4715 & TRN \\
\hline CHEMBL26260 & 752339 & 6.1898 & 5.2449 & TRN \\
\hline CHEMBL3195168 & 752339 & 5.1811 & 5.1485 & TRN \\
\hline CHEMBL1365689 & 752339 & 5.8962 & 5.4175 & TRN \\
\hline
\end{tabular}

TRN 
Supplemental Table S2.txt

\begin{tabular}{|c|c|c|c|c|c|c|}
\hline CHEMBL1990258 & 752339 & 5.6216 & 5.5372 & TRN & & \\
\hline CHEMBL3190891 & 752339 & 5.4078 & 5.6101 & TRN & & \\
\hline CHEMBL1591222 & 752339 & 5.5867 & 5.2691 & TRN & & \\
\hline CHEMBL1379178 & 752339 & 5.3478 & 5.0386 & TRN & & \\
\hline CHEMBL1335944 & 752339 & 5.1972 & 4.8813 & TRN & & \\
\hline CHEMBL1493538 & 752339 & 5.4776 & 5.0578 & TRN & & \\
\hline CHEMBL1560534 & 752339 & 2.4559 & 4.7431 & TRN & & \\
\hline CHEMBL1417732 & 752339 & 5.5622 & 5.2005 & TRN & & \\
\hline CHEMBL1887233 & 752339 & 4.8389 & 5.4746 & TRN & & \\
\hline CHEMBL1987820 & 752339 & 5.5287 & 5.5144 & TRN & & \\
\hline CHEMBL1882125 & 752339 & 5.5622 & 5.3001 & TRN & & \\
\hline CHEMBL1899528 & 752339 & 4.8362 & 5.5381 & TRN & & \\
\hline CHEMBL1898104 & 752339 & \multicolumn{3}{|c|}{6.7620000000000005} & 5.5741 & TRN \\
\hline CHEMBL585266 & 752339 & 5.3487 & 5.2819 & TRN & & \\
\hline CHEMBL406845 & 752339 & 4.9122 & 5.5238 & TST & & \\
\hline CHEMBL1359215 & 752339 & 4.5518 & 5.2866 & TRN & & \\
\hline CHEMBL1372947 & 752339 & 5.118 & 4.5325 & TST & & \\
\hline CHEMBL1597913 & 752339 & 4.2905 & 4.6761 & TST & & \\
\hline CHEMBL1541260 & 752339 & 4.4848 & 5.0814 & TRN & & \\
\hline CHEMBL1706685 & 752339 & 5.4802 & 4.8382 & TST & & \\
\hline CHEMBL1387790 & 752339 & 5.308 & 5.193 & TRN & & \\
\hline CHEMBL1376120 & 752339 & 5.2807 & 5.3507 & TRN & & \\
\hline CHEMBL3195997 & 752339 & 5.1506 & 5.2076 & TRN & & \\
\hline CHEMBL1599915 & 752339 & 4.5642 & 5.1395 & TRN & & \\
\hline CHEMBL1312788 & 752339 & 5.0595 & 5.1631 & TRN & & \\
\hline CHEMBL1713327 & 752339 & 5.279 & 5.2237 & TRN & & \\
\hline CHEMBL1581212 & 752339 & 5.0039 & 4.9922 & TRN & & \\
\hline CHEMBL1530152 & 752339 & 4.4034 & 4.7939 & TRN & & \\
\hline CHEMBL1299470 & 752339 & 4.9278 & 5.1468 & TRN & & \\
\hline CHEMBL1343265 & 752339 & 5.9508 & 5.4699 & TRN & & \\
\hline CHEMBL1454278 & 752339 & 5.3788 & 5.1629 & TRN & & \\
\hline CHEMBL1528669 & 752339 & 5.1681 & 5.1489 & TRN & & \\
\hline CHEMBL1307933 & 752339 & 5.7167 & 5.2869 & TRN & & \\
\hline CHEMBL1459202 & 752339 & 5.8861 & 5.2041 & TRN & & \\
\hline CHEMBL3196861 & 752339 & 6.0511 & 5.3971 & TRN & & \\
\hline CHEMBL1354085 & 752339 & 4.7565 & 5.0012 & TST & & \\
\hline CHEMBL1503689 & 752339 & 6.1302 & 5.1306 & TRN & & \\
\hline CHEMBL1896407 & 752339 & 6.1355 & 5.8243 & TST & & \\
\hline CHEMBL1587842 & 752339 & 3.8701 & 5.0745 & TRN & & \\
\hline CHEMBL 1580272 & 752339 & 4.5148 & 5.2323 & TRN & & \\
\hline CHEMBL1451293 & 752339 & 5.8041 & 5.4407 & TRN & & \\
\hline CHEMBL1568892 & 752339 & 4.7908 & 5.4747 & TRN & & \\
\hline CHEMBL1736765 & 752339 & 3.5711 & 4.4452 & TRN & & \\
\hline CHEMBL1326457 & 752339 & 4.3284 & 5.0587 & TST & & \\
\hline CHEMBL 3197200 & 752339 & 6.0088 & 5.6155 & TRN & & \\
\hline CHEMBL 3145303 & 752339 & 5.6108 & 5.6035 & TRN & & \\
\hline CHEMBL1725468 & 752339 & 5.5287 & 5.8325 & TRN & & \\
\hline CHEMBL1494159 & 752339 & 5.6635 & 5.0032 & TRN & & \\
\hline
\end{tabular}

Page 22211 


\begin{tabular}{|c|c|c|c|c|c|c|}
\hline & & \multicolumn{5}{|c|}{ Supplemental Table S2.txt } \\
\hline CHEMBL1351758 & 752339 & 5.5834 & 5.1539 & TRN & & \\
\hline CHEMBL 2000750 & 752339 & 5.289 & 5.5469 & TRN & & \\
\hline CHEMBL1481616 & 752339 & 5.8297 & 5.4623 & TRN & & \\
\hline CHEMBL1428820 & 752339 & 5.8182 & 5.2003 & TRN & & \\
\hline CHEMBL1579491 & 752339 & 5.5086 & 5.0956 & TST & & \\
\hline CHEMBL1600763 & 752339 & \multicolumn{3}{|c|}{5.3420000000000005} & 4.774 & TRN \\
\hline CHEMBL1609391 & 752339 & 5.6003 & 4.7081 & TRN & & \\
\hline CHEMBL1342147 & 752339 & 5.8477 & 5.7731 & TRN & & \\
\hline CHEMBL1455993 & 752339 & 5.4145 & \multicolumn{3}{|c|}{5.281000000000001} & TRN \\
\hline CHEMBL1864766 & 752339 & 4.4841 & 5.0356 & TST & & \\
\hline CHEMBL1544409 & 752339 & 5.0334 & 4.9308 & TRN & & \\
\hline CHEMBL1473464 & 752339 & 5.5229 & 5.3896 & TRN & & \\
\hline CHEMBL1362860 & 752339 & 3.7613 & 4.7129 & TRN & & \\
\hline CHEMBL1300250 & 752339 & 5.0137 & 5.6064 & TRN & & \\
\hline CHEMBL455284 & 752339 & 6.3072 & 6.59 & TRN & & \\
\hline CHEMBL1597459 & 752339 & 5.5186 & 5.1875 & TRN & & \\
\hline CHEMBL3190911 & 752339 & 5.2125 & 5.0423 & TRN & & \\
\hline CHEMBL600778 & 752339 & 5.3726 & 5.3486 & TRN & & \\
\hline CHEMBL1486726 & 752339 & 5.6383 & 5.85 & TRN & & \\
\hline CHEMBL3191632 & 752339 & 5.8356 & 5.3621 & TRN & & \\
\hline CHEMBL1595820 & 752339 & 5.4597 & 5.2663 & TRN & & \\
\hline CHEMBL547285 & 752339 & 5.3063 & 5.1839 & TRN & & \\
\hline CHEMBL1577174 & 752339 & 5.8153 & 5.7029 & TRN & & \\
\hline CHEMBL1984721 & 752339 & 5.7721 & 5.5175 & TRN & & \\
\hline CHEMBL1979954 & 752339 & 4.9927 & 5.2137 & TRN & & \\
\hline CHEMBL534423 & 752339 & 7.2388 & 5.9654 & TRN & & \\
\hline CHEMBL3195241 & 752339 & 5.1898 & 5.2528 & TRN & & \\
\hline CHEMBL 2006168 & 752339 & 5.5702 & 5.0421 & TRN & & \\
\hline CHEMBL1902169 & 752339 & 4.6678 & 5.5463 & TRN & & \\
\hline CHEMBL1386622 & 752339 & 5.4989 & 5.4607 & TST & & \\
\hline CHEMBL1448282 & 752339 & 5.3458 & 5.1262 & TRN & & \\
\hline CHEMBL1474280 & 752339 & 5.4841 & 5.5425 & TRN & & \\
\hline CHEMBL1714115 & 752339 & 5.8861 & 4.717 & TRN & & \\
\hline CHEMBL1964614 & 752339 & 5.2434 & 5.1575 & TRN & & \\
\hline CHEMBL1312275 & 752339 & 4.8677 & 5.2086 & TRN & & \\
\hline CHEMBL1485358 & 752339 & 5.5528 & 5.4647 & TST & & \\
\hline CHEMBL1339219 & 752339 & 4.2792 & 4.6931 & TRN & & \\
\hline CHEMBL1317322 & 752339 & \multicolumn{3}{|c|}{5.821000000000001} & 5.2659 & TRN \\
\hline CHEMBL1497325 & 752339 & 4.2648 & 5.0387 & TRN & & \\
\hline CHEMBL1409963 & 752339 & 5.1439 & 5.2294 & TRN & & \\
\hline CHEMBL1464261 & 752339 & 5.1024 & 4.923 & TRN & & \\
\hline CHEMBL1464448 & 752339 & 5.5719 & 5.385 & TRN & & \\
\hline CHEMBL1556766 & 752339 & 2.4559 & 5.0703 & TST & & \\
\hline CHEMBL1583665 & 752339 & 5.3307 & 5.3385 & TRN & & \\
\hline CHEMBL1425919 & 752339 & 5.5214 & 5.0515 & TRN & & \\
\hline CHEMBL3196960 & 752339 & 5.7878 & 5.3804 & TRN & & \\
\hline CHEMBL1426340 & 752339 & 4.8539 & 5.4513 & TRN & & \\
\hline \multirow[t]{2}{*}{ CHEMBL591876 } & 752339 & 5.3449 & 5.26200 & 00000 & & TRN \\
\hline & & \multicolumn{5}{|c|}{ Page 22212} \\
\hline
\end{tabular}




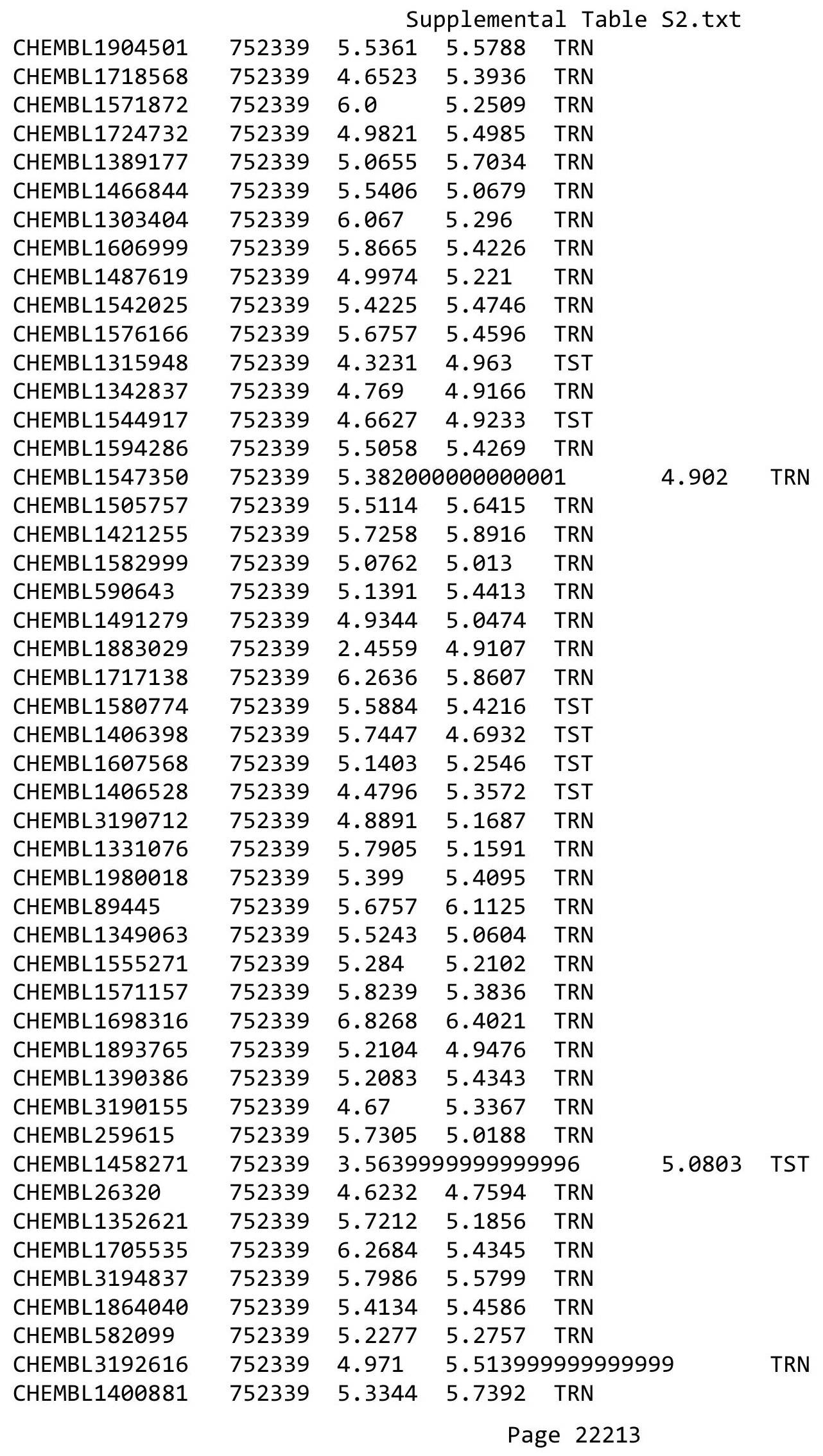


Supplemental Table S2.txt

\begin{tabular}{|c|c|c|c|c|c|c|}
\hline CHEMBL1507820 & 752339 & 5.6757 & \multicolumn{2}{|c|}{5.303999999999999} & TRN & \\
\hline CHEMBL1500966 & 752339 & 4.8788 & 4.9996 & TRN & & \\
\hline CHEMBL1605879 & 752339 & 5.2684 & 5.3211 & TRN & & \\
\hline CHEMBL1609219 & 752339 & 5.1343 & 5.0976 & TRN & & \\
\hline CHEMBL1542378 & 752339 & 5.7282 & 5.4722 & TRN & & \\
\hline CHEMBL1304363 & 752339 & 6.2882 & 5.8676 & TRN & & \\
\hline CHEMBL1345505 & 752339 & 5.3556 & 5.697 & TRN & & \\
\hline CHEMBL1559644 & 752339 & 5.7375 & 5.1967 & TRN & & \\
\hline CHEMBL1723915 & 752339 & 4.7416 & 5.2235 & TST & & \\
\hline CHEMBL1414273 & 752339 & 5.5817 & 5.3168 & TRN & & \\
\hline CHEMBL1479393 & 752339 & 4.6402 & 4.7982 & TRN & & \\
\hline CHEMBL3209179 & 752339 & 3.7913 & 5.3355 & TRN & & \\
\hline CHEMBL1377924 & 752339 & 5.0372 & 5.2556 & TRN & & \\
\hline CHEMBL1701797 & 752339 & 7.0521 & 5.8788 & TRN & & \\
\hline CHEMBL1550518 & 752339 & 5.0701 & 4.9384 & TRN & & \\
\hline CHEMBL1604217 & 752339 & 5.3958 & 4.8969 & TRN & & \\
\hline CHEMBL1588024 & 752339 & 5.6108 & 4.9428 & TRN & & \\
\hline CHEMBL1515267 & 752339 & 5.8761 & 5.5078 & TRN & & \\
\hline CHEMBL1332415 & 752339 & 5.1325 & 5.3832 & TRN & & \\
\hline CHEMBL3190805 & 752339 & 3.977 & 5.5471 & TRN & & \\
\hline CHEMBL1329129 & 752339 & 5.2161 & 5.5974 & TRN & & \\
\hline CHEMBL1388121 & 752339 & 6.1688 & 5.0953 & TRN & & \\
\hline CHEMBL1864760 & 752339 & 5.1445 & 4.9109 & TST & & \\
\hline CHEMBL512749 & 752339 & 5.8996 & 5.3053 & TRN & & \\
\hline CHEMBL1342237 & 752339 & 2.4559 & 4.9738 & TST & & \\
\hline CHEMBL1421605 & 752339 & 4.9477 & 4.8908 & TST & & \\
\hline CHEMBL591363 & 752339 & 5.3893 & 5.2658 & TRN & & \\
\hline CHEMBL1460032 & 752339 & $4.3610 e$ & 00000000 & 01 & 5.156000000000001 & TST \\
\hline CHEMBL1531394 & 752339 & 6.1035 & 5.0963 & TRN & & \\
\hline CHEMBL1417731 & 752339 & 5.9788 & 5.2873 & TST & & \\
\hline CHEMBL1343448 & 752339 & 6.0 & 5.4301 & TRN & & \\
\hline CHEMBL1487664 & 752339 & 3.7079 & 5.1681 & TST & & \\
\hline CHEMBL 3189712 & 752339 & 5.0381 & 5.3896 & TRN & & \\
\hline CHEMBL1440685 & 752339 & 6.2774 & 5.2096 & TRN & & \\
\hline CHEMBL1482362 & 752339 & 5.0685 & 4.9111 & TRN & & \\
\hline CHEMBL1478602 & 752339 & 5.3893 & 5.0691 & TRN & & \\
\hline CHEMBL1600506 & 752339 & 5.4976 & 4.9074 & TRN & & \\
\hline CHEMBL1366321 & 752339 & 5.6073 & 5.3548 & TRN & & \\
\hline CHEMBL1459140 & 752339 & 5.6055 & 5.5228 & TRN & & \\
\hline CHEMBL3191623 & 752339 & 5.2291 & 5.5205 & TRN & & \\
\hline CHEMBL1307349 & 752339 & 4.923 & 5.3372 & TST & & \\
\hline CHEMBL1404522 & 752339 & 5.3335 & 5.4015 & TRN & & \\
\hline CHEMBL1450780 & 752339 & 5.8665 & 5.7972 & TRN & & \\
\hline CHEMBL602218 & 752339 & 5.1232 & 5.1435 & TRN & & \\
\hline CHEMBL1525735 & 752339 & 4.8153 & 4.7572 & TRN & & \\
\hline CHEMBL1983939 & 752339 & 5.2062 & 5.046 & TRN & & \\
\hline CHEMBL1421358 & 752339 & 4.4458 & 5.0824 & TST & & \\
\hline CHEMBL1600459 & 752339 & 5.4828 & 5.2536 & TRN & & \\
\hline
\end{tabular}

Page 22214 
Supplemental Table S2.txt

\begin{tabular}{|c|c|c|c|c|c|c|}
\hline CHEMBL1489605 & 752339 & 5.3098 & 5.0978 & TRN & & \\
\hline CHEMBL1524937 & 752339 & 2.4559 & 4.8707 & TST & & \\
\hline CHEMBL607553 & 752339 & 5.5114 & 5.0838 & TRN & & \\
\hline CHEMBL1511363 & 752339 & 4.7222 & 4.8782 & TST & & \\
\hline CHEMBL1510020 & 752339 & 4.5882 & 5.1879 & TST & & \\
\hline CHEMBL1538328 & 752339 & 5.5867 & 5.047 & TST & & \\
\hline CHEMBL1425875 & 752339 & 5.3915 & 4.8622 & TRN & & \\
\hline CHEMBL1529190 & 752339 & 5.3585 & 5.268 & TRN & & \\
\hline CHEMBL1405344 & 752339 & 5.1593 & 5.0542 & TRN & & \\
\hline CHEMBL1360505 & 752339 & 4.7846 & 4.8689 & TRN & & \\
\hline CHEMBL1700106 & 752339 & 4.8539 & 6.0259 & TRN & & \\
\hline CHEMBL1556306 & 752339 & 5.3645 & 5.1267 & TST & & \\
\hline CHEMBL1441116 & 752339 & 3.6253 & 4.7754 & TRN & & \\
\hline CHEMBL1341497 & 752339 & 4.9115 & 5.2245 & TRN & & \\
\hline CHEMBL 3197432 & 752339 & 5.104 & 5.7813 & TRN & & \\
\hline CHEMBL1348501 & 752339 & 3.9309 & 5.0364 & TST & & \\
\hline CHEMBL1319713 & 752339 & 4.9772 & 5.1496 & TST & & \\
\hline CHEMBL 2358182 & 752339 & 4.9393 & 5.5516 & TRN & & \\
\hline CHEMBL42178 & 752339 & 4.9041 & 5.1844 & TRN & & \\
\hline CHEMBL1588513 & 752339 & 5.1593 & 5.6984 & TRN & & \\
\hline CHEMBL1543742 & 752339 & 5.6073 & 5.2691 & TRN & & \\
\hline CHEMBL1327926 & 752339 & 5.5768 & 5.3116 & TRN & & \\
\hline CHEMBL1898999 & 752339 & 5.7328 & 5.1297 & TRN & & \\
\hline CHEMBL1605795 & 752339 & 5.4737 & 5.3651 & TRN & & \\
\hline CHEMBL1376974 & 752339 & 6.4789 & 5.5842 & TST & & \\
\hline CHEMBL 3198588 & 752339 & 4.5955 & 5.1895 & TRN & & \\
\hline CHEMBL1412855 & 752339 & 5.7825 & 5.3178 & TRN & & \\
\hline CHEMBL1523683 & 752339 & 5.067 & 4.8523 & TRN & & \\
\hline CHEMBL1408629 & 752339 & 5.8633 & 5.2188 & TST & & \\
\hline CHEMBL492267 & 752339 & 4.5535 & 5.0753 & TRN & & \\
\hline CHEMBL3194964 & 752339 & 5.3143 & 5.1134 & TRN & & \\
\hline CHEMBL3198754 & 752339 & 4.8268 & 5.4461 & TRN & & \\
\hline CHEMBL1391630 & 752339 & 6.1046 & 4.8211 & TRN & & \\
\hline CHEMBL1875537 & 752339 & 7.2984 & 4.8756 & TST & & \\
\hline CHEMBL1468783 & 752339 & 5.3546 & 5.1374 & TRN & & \\
\hline CHEMBL592600 & 752339 & 5.284 & 5.2328 & TRN & & \\
\hline CHEMBL470420 & 752339 & \multicolumn{3}{|c|}{6.172000000000001} & 5.3115 & TRN \\
\hline CHEMBL1353520 & 752339 & 2.4559 & 4.8561 & TST & & \\
\hline CHEMBL1367721 & 752339 & 4.3132 & 5.0586 & TRN & & \\
\hline CHEMBL563577 & 752339 & 5.1007 & 5.7819 & TRN & & \\
\hline CHEMBL3189405 & 752339 & 5.3546 & 5.0784 & TRN & & \\
\hline CHEMBL1880417 & 752339 & \multicolumn{3}{|c|}{7.821000000000001} & 6.166 & TRN \\
\hline CHEMBL1468488 & 752339 & 6.0141 & 5.1338 & TST & & \\
\hline CHEMBL1415374 & 752339 & 5.7496 & 4.9971 & TRN & & \\
\hline CHEMBL1900376 & 752339 & 4.0755 & 5.2149 & TRN & & \\
\hline CHEMBL1408427 & 752339 & 5.2733 & 5.0097 & TRN & & \\
\hline CHEMBL1345724 & 752339 & 4.9682 & 5.4288 & TRN & & \\
\hline CHEMBL1603731 & 752339 & 3.9805 & 4.7379 & TRN & & \\
\hline
\end{tabular}

Page 22215 


\begin{tabular}{|c|c|c|c|c|c|c|}
\hline & & & & & & \\
\hline CHEMBL1452967 & 752339 & 5.4248 & 5.3291 & TRN & & \\
\hline CHEMBL1991779 & 752339 & 5.5638 & 5.5934 & TRN & & \\
\hline CHEMBL1333755 & 752339 & 5.063 & 4.92399 & 99999999 & 95 & TRN \\
\hline CHEMBL1731367 & 752339 & 5.1871 & 4.8397 & TST & & \\
\hline CHEMBL1608383 & 752339 & 6.0894 & 5.3991 & TRN & & \\
\hline CHEMBL1423387 & 752339 & 5.7825 & 5.1837 & TRN & & \\
\hline CHEMBL1364572 & 752339 & 5.4023 & 5.4144 & TRN & & \\
\hline CHEMBL1462882 & 752339 & 4.9772 & 5.5594 & TRN & & \\
\hline CHEMBL1372760 & 752339 & 5.3344 & 5.2445 & TRN & & \\
\hline CHEMBL1999458 & 752339 & 5.2907 & 5.2599 & TRN & & \\
\hline CHEMBL225903 & 752339 & 6.0013 & 5.2651 & TRN & & \\
\hline CHEMBL1987419 & 752339 & 5.4763 & 5.2791 & TRN & & \\
\hline CHEMBL1171204 & 752339 & 4.9512 & 4.9029 & TRN & & \\
\hline CHEMBL1705854 & 752339 & 5.6144 & 5.4491 & TRN & & \\
\hline CHEMBL1599290 & 752339 & 5.2692 & 5.3948 & TRN & & \\
\hline CHEMBL1603253 & 752339 & 5.3809 & 5.7013 & TRN & & \\
\hline CHEMBL3207418 & 752339 & 4.9389 & 5.2271 & TRN & & \\
\hline CHEMBL3199428 & 752339 & 5.2668 & 5.2935 & TRN & & \\
\hline CHEMBL1404301 & 752339 & 4.708 & 4.7427 & TRN & & \\
\hline CHEMBL1904071 & 752339 & 6.6757 & 5.671 & TRN & & \\
\hline CHEMBL1424065 & 752339 & 5.6819 & 5.7931 & TRN & & \\
\hline CHEMBL1557619 & 752339 & 5.5391 & 5.027 & TRN & & \\
\hline CHEMBL1509707 & 752339 & 5.6655 & 5.318 & TRN & & \\
\hline CHEMBL1536720 & 752339 & 2.4559 & 4.5636 & TRN & & \\
\hline CHEMBL1550547 & 752339 & 5.8069 & 5.1243 & TRN & & \\
\hline CHEMBL1472117 & 752339 & 4.5 & 5.06 & TRN & & \\
\hline CHEMBL1565344 & 752339 & 6.2411 & 4.8107 & TRN & & \\
\hline CHEMBL1547169 & 752339 & 6.4225 & 4.8546 & TRN & & \\
\hline CHEMBL1526148 & 752339 & 4.5733 & 5.0303 & TRN & & \\
\hline CHEMBL1878618 & 752339 & 4.9385 & 5.5241 & TST & & \\
\hline CHEMBL3197978 & 752339 & 5.75700 & 30000000 & $\partial 1$ & 5.5727 & TRN \\
\hline CHEMBL1530357 & 752339 & 5.4908 & 5.0297 & TRN & & \\
\hline CHEMBL3196046 & 752339 & 3.9709 & 5.1803 & TRN & & \\
\hline CHEMBL1573963 & 752339 & 5.6819 & 5.524 & TRN & & \\
\hline CHEMBL1585733 & 752339 & 6.295 & 5.4793 & TRN & & \\
\hline CHEMBL1478427 & 752339 & 4.6478 & 4.9846 & TST & & \\
\hline CHEMBL1522827 & 752339 & 5.6003 & 5.1712 & TRN & & \\
\hline CHEMBL1490043 & 752339 & 5.4413 & 5.4284 & TRN & & \\
\hline CHEMBL1363032 & 752339 & 5.5331 & 4.7714 & TRN & & \\
\hline CHEMBL1864112 & 752339 & 5.3458 & 5.1342 & TRN & & \\
\hline CHEMBL1603631 & 752339 & 3.8853 & 5.0595 & TRN & & \\
\hline CHEMBL580955 & 752339 & 5.2976 & 5.2167 & TRN & & \\
\hline CHEMBL1608635 & 752339 & 5.7825 & 5.5398 & TRN & & \\
\hline CHEMBL 224367 & 752339 & 5.6757 & 4.6634 & TRN & & \\
\hline CHEMBL1462938 & 752339 & 7.3391 & 6.3074 & TST & & \\
\hline CHEMBL1611300 & 752339 & 5.6402 & 5.4985 & TRN & & \\
\hline CHEMBL1341936 & 752339 & 4.8173 & 4.7499 & TRN & & \\
\hline CHEMBL1460705 & 752339 & 5.7055 & 5.4306 & TRN & & \\
\hline
\end{tabular}




\begin{tabular}{|c|c|c|c|c|c|}
\hline \multirow[b]{2}{*}{ CHEMBL380071 } & \multicolumn{5}{|c|}{ Supplemental Table S2.txt } \\
\hline & 752339 & 3.8414 & 5.3244 & TST & \\
\hline CHEMBL1575124 & 752339 & 5.983 & 5.8741 & TRN & \\
\hline CHEMBL1576130 & 752339 & 5.7399 & 5.3153 & TRN & \\
\hline CHEMBL1874585 & 752339 & 4.6842 & 4.9105 & TRN & \\
\hline CHEMBL1530816 & 752339 & 5.0926 & 5.0277 & TST & \\
\hline CHEMBL1876866 & 752339 & 3.6252 & 4.8919 & TST & \\
\hline CHEMBL1699228 & 752339 & 5.2426 & 5.1078 & TST & \\
\hline CHEMBL1322588 & 752339 & 4.4983 & 5.0493 & TRN & \\
\hline CHEMBL1332756 & 752339 & 5.3307 & 5.3526 & TRN & \\
\hline CHEMBL1497602 & 752339 & 6.0472 & 4.9389 & TRN & \\
\hline CHEMBL3192251 & 752339 & 5.5482 & 5.5766 & TRN & \\
\hline CHEMBL1545435 & 752339 & 3.9498 & 5.0632 & TRN & \\
\hline CHEMBL1309548 & 752339 & 4.845 & 5.0699 & TRN & \\
\hline CHEMBL1508578 & 752339 & 3.7129 & 4.8583 & TRN & \\
\hline CHEMBL1491194 & 752339 & 5.6234 & 5.8238 & TRN & \\
\hline CHEMBL1413671 & 752339 & 5.4377 & 5.5118 & TRN & \\
\hline CHEMBL1531895 & 752339 & 5.1752 & 5.2277 & TRN & \\
\hline CHEMBL1905020 & 752339 & 5.0137 & 5.8545 & TRN & \\
\hline CHEMBL1706042 & 752339 & 3.738 & 4.9665 & TST & \\
\hline CHEMBL3189519 & 752339 & 5.3478 & 5.4229 & TRN & \\
\hline CHEMBL1893344 & 752339 & 5.5467 & 5.2367 & TST & \\
\hline CHEMBL3213965 & 752339 & 6.0424 & 6.0147 & TST & \\
\hline CHEMBL1329989 & 752339 & 5.0035 & 4.8376 & TRN & \\
\hline CHEMBL1318556 & 752339 & 4.4225 & 4.8679 & TRN & \\
\hline CHEMBL1397022 & 752339 & 4.9435 & 5.3395 & TRN & \\
\hline CHEMBL3213419 & 752339 & 5.7878 & 5.9849 & TRN & \\
\hline CHEMBL1568409 & 752339 & 5.3536 & 5.0822 & TRN & \\
\hline CHEMBL3197431 & 752339 & 5.6162 & 5.8637 & TRN & \\
\hline CHEMBL1423060 & 752339 & 5.6055 & 5.3537 & TRN & \\
\hline CHEMBL1427463 & 752339 & 4.5974 & 5.1278 & TRN & \\
\hline CHEMBL1544114 & 752339 & 5.4437 & 5.6283 & TRN & \\
\hline CHEMBL1501694 & 752339 & 5.8386 & 5.6515 & TRN & \\
\hline CHEMBL199194 & 752339 & 6.0 & 5.3433 & TRN & \\
\hline CHEMBL1339433 & 752339 & 4.6698 & 4.9549 & TRN & \\
\hline CHEMBL1902131 & 752339 & 5.0348 & 4.9084 & TST & \\
\hline CHEMBL1300497 & 752339 & 5.5686 & 5.0593 & TRN & \\
\hline CHEMBL1611182 & 752339 & 5.4389 & 5.24700 & $\partial 000000001$ & TST \\
\hline CHEMBL1878035 & 752339 & 5.3125 & 5.2237 & TRN & \\
\hline CHEMBL1559383 & 752339 & 4.9212 & 5.0491 & TST & \\
\hline CHEMBL1497295 & 752339 & 4.9024 & 5.2101 & TST & \\
\hline CHEMBL1562280 & 752339 & 5.1965 & 5.7562 & TRN & \\
\hline CHEMBL1518682 & 752339 & 5.4001 & 5.2901 & TRN & \\
\hline CHEMBL1441042 & 752339 & 5.0716 & 5.7961 & TRN & \\
\hline CHEMBL1514530 & 752339 & 5.3382 & 5.2064 & TRN & \\
\hline CHEMBL1708343 & 752339 & 5.5622 & 5.6677 & TRN & \\
\hline CHEMBL1421559 & 752339 & 4.9333 & 4.9418 & TST & \\
\hline CHEMBL1573883 & 752339 & 5.7696 & 5.1306 & TRN & \\
\hline CHEMBL1410917 & 752339 & 4.6728 & 5.2477 & TST & \\
\hline
\end{tabular}

Page 22217 


\begin{tabular}{|c|c|c|c|c|c|c|}
\hline & & \multicolumn{5}{|c|}{ Supplemental Table S2.txt } \\
\hline CHEMBL1331875 & 752339 & 5.7696 & 5.1129 & TRN & & \\
\hline CHEMBL1607086 & 752339 & 6.1494 & 5.3404 & TRN & & \\
\hline CHEMBL1470421 & 752339 & 4.6615 & 5.6813 & TRN & & \\
\hline CHEMBL1587624 & 752339 & 4.8945 & 4.6192 & TRN & & \\
\hline CHEMBL 1365550 & 752339 & 5.2007 & 5.2935 & TRN & & \\
\hline CHEMBL1336684 & 752339 & 2.4559 & 5.4304 & TRN & & \\
\hline CHEMBL1481319 & 752339 & 5.6536 & 5.0511 & TRN & & \\
\hline CHEMBL1887755 & 752339 & \multicolumn{3}{|c|}{4.4510000000000005} & 5.2627 & TST \\
\hline CHEMBL1979727 & 752339 & 4.6682 & 5.0089 & TRN & & \\
\hline CHEMBL1406568 & 752339 & 5.5607 & 5.8587 & TRN & & \\
\hline CHEMBL1499202 & 752339 & 5.6091 & 5.2106 & TRN & & \\
\hline CHEMBL1308027 & 752339 & 5.6459 & 5.4136 & TRN & & \\
\hline CHEMBL1698608 & 752339 & 5.3526 & 5.6833 & TRN & & \\
\hline CHEMBL1440910 & 752339 & 5.5969 & 4.9169 & TRN & & \\
\hline CHEMBL1602730 & 752339 & 4.2743 & 4.5982 & TRN & & \\
\hline CHEMBL1365471 & 752339 & 5.6364 & 5.2963 & TRN & & \\
\hline CHEMBL3194516 & 752339 & 5.129 & 5.4654 & TRN & & \\
\hline CHEMBL3189416 & 752339 & 4.9543 & 5.2683 & TRN & & \\
\hline CHEMBL1880661 & 752339 & 4.8739 & 5.099 & TRN & & \\
\hline CHEMBL1567308 & 752339 & 6.0752 & 5.1032 & TRN & & \\
\hline CHEMBL1713017 & 752339 & 5.8013 & 5.2745 & TRN & & \\
\hline CHEMBL1330417 & 752339 & 5.51 & 5.6396 & TRN & & \\
\hline CHEMBL1323525 & 752339 & 4.3218 & 5.5788 & TRN & & \\
\hline CHEMBL1572496 & 752339 & 5.9957 & 4.7322 & TRN & & \\
\hline CHEMBL1328370 & 752339 & \multicolumn{3}{|c|}{5.752000000000001} & 5.3008 & TRN \\
\hline CHEMBL1883309 & 752339 & 5.7825 & 5.1768 & TST & & \\
\hline CHEMBL1484622 & 752339 & 5.9626 & 5.4435 & TRN & & \\
\hline CHEMBL1316462 & 752339 & 4.9884 & 5.0377 & TRN & & \\
\hline CHEMBL1535532 & 752339 & 4.9172 & 5.1022 & TST & & \\
\hline CHEMBL1323992 & 752339 & 5.3449 & 5.1584 & TRN & & \\
\hline CHEMBL1331851 & 752339 & 5.4685 & 5.2031 & TRN & & \\
\hline CHEMBL1316074 & 752339 & 5.5918 & 5.1356 & TRN & & \\
\hline CHEMBL3198332 & 752339 & 5.251 & 5.5752 & TRN & & \\
\hline CHEMBL1469251 & 752339 & 4.4751 & \multicolumn{3}{|c|}{4.8180000000000005} & TRN \\
\hline CHEMBL1567738 & 752339 & 5.8356 & 5.6954 & TRN & & \\
\hline CHEMBL1589625 & 752339 & 5.1543 & 5.1938 & TST & & \\
\hline CHEMBL1306800 & 752339 & 6.1561 & 4.6572 & TRN & & \\
\hline CHEMBL1891329 & 752339 & 5.6253 & 5.3663 & TRN & & \\
\hline CHEMBL1413983 & 752339 & 3.8406 & 4.8136 & TRN & & \\
\hline CHEMBL1309466 & 752339 & 5.6799 & 5.2608 & TRN & & \\
\hline CHEMBL1573366 & 752339 & 5.8601 & 5.4662 & TRN & & \\
\hline CHEMBL3195688 & 752339 & 5.2976 & 5.1267 & TRN & & \\
\hline CHEMBL3193559 & 752339 & 5.0742 & 5.3151 & TRN & & \\
\hline CHEMBL1412624 & 752339 & 3.4628 & 4.8838 & TRN & & \\
\hline CHEMBL1332689 & 752339 & 6.7773 & 4.9618 & TRN & & \\
\hline CHEMBL1595015 & 752339 & 5.2441 & 5.482 & TST & & \\
\hline CHEMBL1386750 & 752339 & 5.7496 & 5.3749 & TRN & & \\
\hline CHEMBL1464822 & 752339 & 2.4559 & 4.749 & TRN & & \\
\hline
\end{tabular}




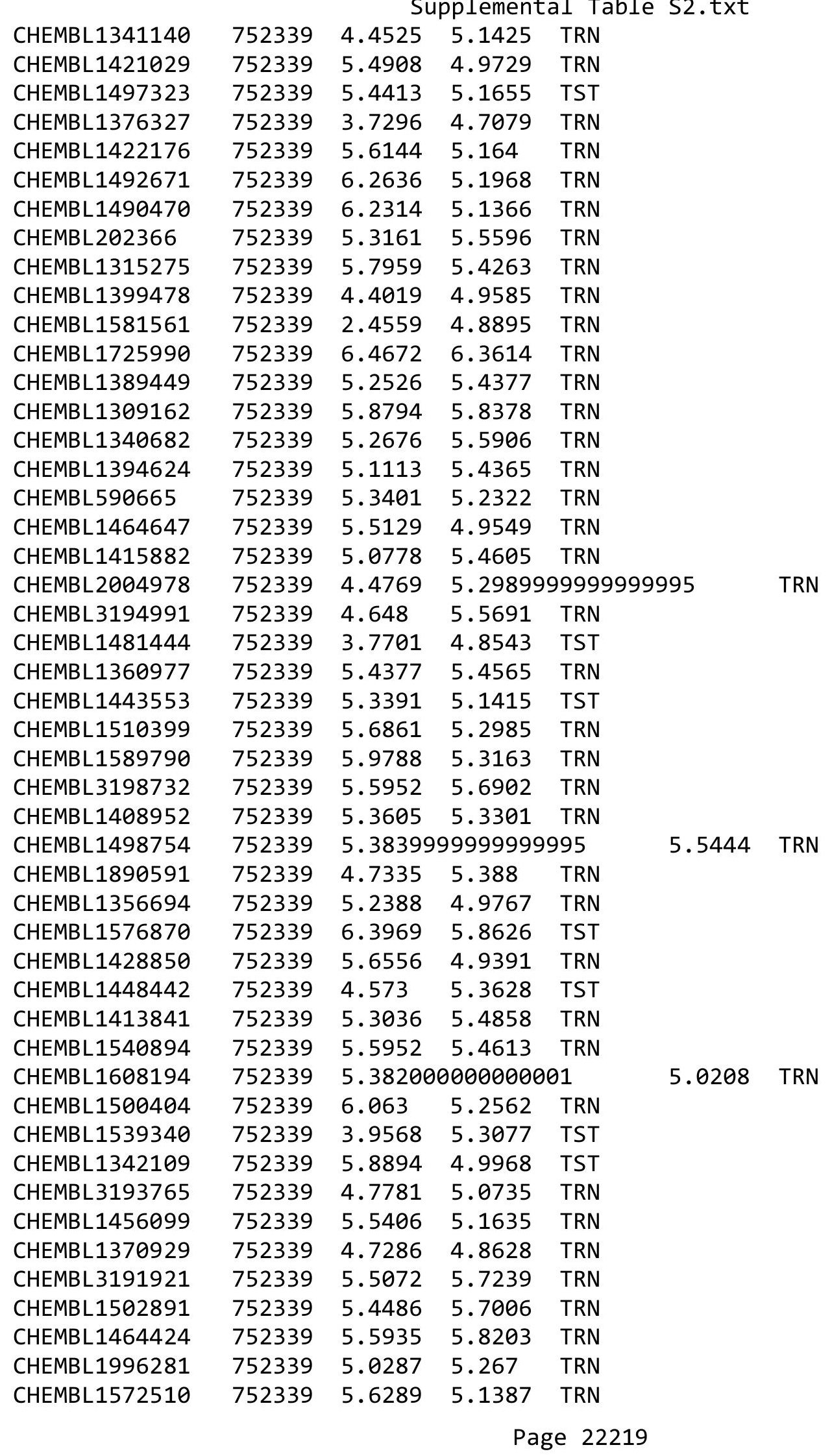




\begin{tabular}{|c|c|c|c|c|c|}
\hline & & \multicolumn{4}{|c|}{ Supplemental Table S2.txt } \\
\hline CHEMBL1466352 & 752339 & 3.7384 & 4.8374 & TRN & \\
\hline CHEMBL3193044 & 752339 & 2.4559 & 4.9303 & TRN & \\
\hline CHEMBL1427335 & 752339 & 6.2692 & 6.0511 & TRN & \\
\hline CHEMBL1378654 & 752339 & 4.6043 & 5.4072 & TRN & \\
\hline CHEMBL3195066 & 752339 & 5.7212 & 5.42 & TRN & \\
\hline CHEMBL1989260 & 752339 & 5.1319 & 5.5533 & TRN & \\
\hline CHEMBL3198800 & 752339 & 5.7471 & 5.2368 & TRN & \\
\hline CHEMBL1991388 & 752339 & 5.5391 & 4.8741 & TRN & \\
\hline CHEMBL3190636 & 752339 & 4.9512 & 5.5886 & TRN & \\
\hline CHEMBL1874572 & 752339 & 5.8996 & 5.0718 & TRN & \\
\hline CHEMBL1305469 & 752339 & 5.5452 & 4.9434 & TRN & \\
\hline CHEMBL1899158 & 752339 & 5.9136 & 5.28299 & 99999999995 & TRN \\
\hline CHEMBL1731017 & 752339 & 5.3107 & 5.4096 & TST & \\
\hline CHEMBL1532863 & 752339 & 4.6548 & 5.0015 & TRN & \\
\hline CHEMBL1302164 & 752339 & 5.5157 & 5.3401 & TRN & \\
\hline CHEMBL3198886 & 752339 & 5.4168 & 5.3407 & TRN & \\
\hline CHEMBL1338961 & 752339 & 5.4597 & 5.5316 & TRN & \\
\hline CHEMBL1527400 & 752339 & 5.7747 & 5.6951 & TRN & \\
\hline CHEMBL1585578 & 752339 & 4.9041 & 4.6817 & TRN & \\
\hline CHEMBL1893101 & 752339 & 5.5171 & 5.1438 & TRN & \\
\hline CHEMBL1454300 & 752339 & 5.5867 & 5.7202 & TRN & \\
\hline CHEMBL1597777 & 752339 & 5.3585 & 5.1657 & TRN & \\
\hline CHEMBL1902678 & 752339 & 2.4559 & 4.7034 & TST & \\
\hline CHEMBL1531184 & 752339 & 5.2161 & 5.0355 & TRN & \\
\hline CHEMBL1431189 & 752339 & 5.8729 & 5.11100 & 0000000001 & TRN \\
\hline CHEMBL 2354875 & 752339 & 5.1198 & 5.3197 & TRN & \\
\hline CHEMBL1500035 & 752339 & 5.3382 & 5.0847 & TRN & \\
\hline CHEMBL1568714 & 752339 & 3.6477 & 5.0869 & TRN & \\
\hline CHEMBL1510652 & 752339 & 5.2676 & 4.9861 & TRN & \\
\hline CHEMBL1410454 & 752339 & 6.1433 & 5.3257 & TRN & \\
\hline CHEMBL1341124 & 752339 & 4.8468 & 5.0468 & TST & \\
\hline CHEMBL1906369 & 752339 & 5.5436 & 5.4957 & TRN & \\
\hline CHEMBL1867591 & 752339 & 7.0022 & 6.4724 & TRN & \\
\hline CHEMBL1609946 & 752339 & 5.6003 & 4.9382 & TRN & \\
\hline CHEMBL1487959 & 752339 & 4.8965 & 5.1001 & TRN & \\
\hline CHEMBL3208365 & 752339 & 5.4101 & 5.4861 & TRN & \\
\hline CHEMBL265699 & 752339 & 5.5157 & 6.0943 & TRN & \\
\hline CHEMBL1504945 & 752339 & 5.7352 & 5.3497 & TRN & \\
\hline CHEMBL429335 & 752339 & 5.6326 & 5.6522 & TRN & \\
\hline CHEMBL1557820 & 752339 & 4.971 & 5.3125 & TRN & \\
\hline CHEMBL1566488 & 752339 & 5.1649 & 5.29700 & 0000000001 & TRN \\
\hline CHEMBL1343831 & 752339 & 5.8182 & 4.9829 & TRN & \\
\hline CHEMBL1504701 & 752339 & 6.6819 & 6.3952 & TRN & \\
\hline CHEMBL1501483 & 752339 & 6.0066 & 4.9372 & TRN & \\
\hline CHEMBL1980322 & 752339 & 5.3089 & 4.8116 & TRN & \\
\hline CHEMBL1498801 & 752339 & 4.5445 & 4.9285 & TRN & \\
\hline CHEMBL1700879 & 752339 & 5.0017 & 5.3719 & TST & \\
\hline CHEMBL1595473 & 752339 & 5.5031 & 5.4318 & TRN & \\
\hline
\end{tabular}


Supplemental Table S2.txt

\begin{tabular}{|c|c|c|c|c|c|}
\hline CHEMBL1346584 & 752339 & 5.0367 & 5.3272 & TRN & \\
\hline CHEMBL1978733 & 752339 & 5.4647 & 5.2687 & TRN & \\
\hline CHEMBL1313979 & 752339 & 5.4535 & 5.5487 & TRN & \\
\hline CHEMBL1441122 & 752339 & 5.6271 & 5.1671 & TRN & \\
\hline CHEMBL1346464 & 752339 & 6.2255 & 4.9991 & TRN & \\
\hline CHEMBL1442280 & 752339 & 5.699 & 5.3411 & TRN & \\
\hline CHEMBL1594807 & 752339 & 3.7734 & 5.0807 & TRN & \\
\hline CHEMBL1416442 & 752339 & 4.5829 & 5.1813 & TST & \\
\hline CHEMBL1451790 & 752339 & 3.6527 & 5.0092 & TRN & \\
\hline CHEMBL1441350 & 752339 & 5.5452 & 5.5496 & TRN & \\
\hline CHEMBL1586348 & 752339 & 4.8582 & 5.092 & TRN & \\
\hline CHEMBL1409708 & 752339 & 5.5114 & 5.3853 & TRN & \\
\hline CHEMBL1452426 & 752339 & 5.5918 & 5.0606 & TRN & \\
\hline CHEMBL1370296 & 752339 & 4.4552 & 5.0088 & TRN & \\
\hline CHEMBL1718825 & 752339 & 5.9172 & 5.4067 & TRN & \\
\hline CHEMBL3196134 & 752339 & 5.341 & 5.4366 & TRN & \\
\hline CHEMBL1460869 & 752339 & 5.6819 & 5.3768 & TRN & \\
\hline CHEMBL1730853 & 752339 & 5.3251 & 4.8123 & TST & \\
\hline CHEMBL3195761 & 752339 & 6.1146 & 5.6116 & TRN & \\
\hline CHEMBL1523369 & 752339 & 5.5031 & 5.5019 & TRN & \\
\hline CHEMBL1472016 & 752339 & 4.0084 & 5.0986 & TRN & \\
\hline CHEMBL1486329 & 752339 & 5.0947 & 5.1047 & TRN & \\
\hline CHEMBL1523635 & 752339 & 4.9559 & 5.186 & TRN & \\
\hline CHEMBL1307163 & 752339 & 5.0013 & 5.1507 & TST & \\
\hline CHEMBL1541017 & 752339 & 6.1561 & 5.2172 & TST & \\
\hline CHEMBL1323139 & 752339 & 5.1537 & 5.5447 & TRN & \\
\hline CHEMBL1537781 & 752339 & 4.8019 & 5.8515 & TRN & \\
\hline CHEMBL1373096 & 752339 & 5.3788 & 5.2914 & TRN & \\
\hline CHEMBL494326 & 752339 & 5.2984 & 4.909 & TRN & \\
\hline CHEMBL1411665 & 752339 & 5.6882 & 5.4504 & TRN & \\
\hline CHEMBL1720801 & 752339 & 5.9101 & 5.752006 & 2000000001 & TRN \\
\hline CHEMBL3199467 & 752339 & 5.3316 & 5.5702 & TRN & \\
\hline CHEMBL1342242 & 752339 & 3.9959 & 5.1498 & TRN & \\
\hline CHEMBL586628 & 752339 & 2.4559 & 4.8996 & TRN & \\
\hline CHEMBL1577926 & 752339 & 3.5488 & 4.8699 & TRN & \\
\hline CHEMBL1478962 & 752339 & 5.6421 & 5.0543 & TRN & \\
\hline CHEMBL600862 & 752339 & 5.2874 & 5.4146 & TRN & \\
\hline CHEMBL2359467 & 752339 & 5.3298 & 5.3493 & TRN & \\
\hline CHEMBL1865393 & 752339 & 5.2233 & 5.09 & TST & \\
\hline CHEMBL1422379 & 752339 & 3.7962 & 5.1719 & TST & \\
\hline CHEMBL1412445 & 752339 & 4.1089 & 4.7204 & TRN & \\
\hline CHEMBL1518085 & 752339 & 5.9066 & 5.4382 & TRN & \\
\hline CHEMBL1426107 & 752339 & 5.4012 & 5.2115 & TRN & \\
\hline CHEMBL1563149 & 752339 & 5.9706 & 5.3893 & TRN & \\
\hline CHEMBL1976392 & 752339 & 4.6214 & 5.0106 & TST & \\
\hline CHEMBL1488020 & 752339 & 5.6635 & 5.2563 & TRN & \\
\hline CHEMBL1986418 & 752339 & 5.7471 & 5.7326 & TRN & \\
\hline CHEMBL1409113 & 752339 & 5.0022 & 5.3283 & TST & \\
\hline
\end{tabular}


Supplemental Table S2.txt

\begin{tabular}{|c|c|c|c|c|c|}
\hline CHEMBL1981002 & 752339 & 5.5376 & 5.1848 & TRN & \\
\hline CHEMBL1706381 & 752339 & 5.1007 & 5.0261 & TRN & \\
\hline CHEMBL1384771 & 752339 & 5.4711 & 5.4436 & TRN & \\
\hline CHEMBL1577545 & 752339 & 4.3444 & 4.7843 & TRN & \\
\hline CHEMBL1580472 & 752339 & 4.9646 & \multicolumn{2}{|c|}{5.053999999999999} & TRN \\
\hline CHEMBL548615 & 752339 & 6.1959 & 5.7687 & TRN & \\
\hline CHEMBL1563317 & 752339 & 5.7144 & 5.4445 & TRN & \\
\hline CHEMBL1708568 & 752339 & 5.3686 & 5.106 & TRN & \\
\hline CHEMBL1412266 & 752339 & 5.1891 & 5.5644 & TRN & \\
\hline CHEMBL1506065 & 752339 & 5.3536 & \multicolumn{2}{|c|}{5.2989999999999995} & TRN \\
\hline CHEMBL1502883 & 752339 & 5.8356 & 5.1796 & TRN & \\
\hline CHEMBL1533086 & 752339 & 4.6819 & 5.6111 & TRN & \\
\hline CHEMBL1424057 & 752339 & 2.4559 & 4.8899 & TRN & \\
\hline CHEMBL1718849 & 752339 & 2.4559 & 4.8566 & TRN & \\
\hline CHEMBL1521187 & 752339 & 5.7696 & 5.5975 & TRN & \\
\hline CHEMBL1484158 & 752339 & 5.4473 & 5.4735 & TRN & \\
\hline CHEMBL3196324 & 752339 & 5.8827 & 6.3659 & TRN & \\
\hline CHEMBL 3192578 & 752339 & 4.971 & 5.5395 & TRN & \\
\hline CHEMBL3199168 & 752339 & 4.0145 & 5.0337 & TRN & \\
\hline CHEMBL1536459 & 752339 & 2.4559 & 4.6611 & TRN & \\
\hline CHEMBL1532595 & 752339 & 4.4777 & 5.4586 & TRN & \\
\hline CHEMBL1393813 & 752339 & 5.3063 & 5.442 & TRN & \\
\hline CHEMBL1558462 & 752339 & 5.1035 & 4.9336 & TRN & \\
\hline CHEMBL1875410 & 752339 & 4.8094 & 5.307 & TRN & \\
\hline CHEMBL1366310 & 752339 & 5.4306 & 5.2033 & TST & \\
\hline CHEMBL1554436 & 752339 & 3.8773 & 4.8561 & TST & \\
\hline CHEMBL1316631 & 752339 & 5.4145 & 5.3998 & TST & \\
\hline CHEMBL1593484 & 752339 & 6.1397 & \multicolumn{2}{|c|}{5.2379999999999995} & \\
\hline CHEMBL1363742 & 752339 & 3.8694 & 5.0593 & TST & \\
\hline CHEMBL1598696 & 752339 & 5.5686 & 5.4384 & TST & \\
\hline CHEMBL1869505 & 752339 & 5.3036 & 4.8272 & TST & \\
\hline CHEMBL1370744 & 752339 & 5.2097 & 5.0576 & TST & \\
\hline CHEMBL1310701 & 752339 & 6.1624 & 4.829 & TST & \\
\hline CHEMBL1882863 & 752339 & 3.7123 & 5.0268 & TST & \\
\hline CHEMBL1415692 & 752339 & 4.7737 & \multicolumn{2}{|c|}{5.031000000000001} & ST \\
\hline CHEMBL1527433 & 752339 & 5.4763 & 5.9386 & TST & \\
\hline CHEMBL1546730 & 752339 & 5.8539 & 4.9945 & TST & \\
\hline CHEMBL1414166 & 752339 & \multicolumn{3}{|c|}{5.617999999999999} & כו \\
\hline CHEMBL1383149 & 752339 & 6.1397 & 5.3372 & TST & \\
\hline CHEMBL 3210088 & 752339 & 5.8894 & 5.6707 & TST & \\
\hline CHEMBL1407646 & 752339 & 4.7781 & 5.3055 & TST & \\
\hline CHEMBL1596434 & 752339 & 4.0742 & 4.4817 & TST & \\
\hline CHEMBL1360295 & 752339 & 5.8356 & 5.4854 & TST & \\
\hline CHEMBL1602614 & 752339 & 5.7212 & 5.3227 & TST & \\
\hline CHEMBL1339283 & 752339 & 5.7282 & 5.4559 & TST & \\
\hline CHEMBL1889367 & 752339 & 4.8027 & 5.1805 & TST & \\
\hline CHEMBL1989897 & 752339 & 5.2832 & 5.2286 & TST & \\
\hline CHEMBL1583375 & 752339 & 5.3605 & 5.1199 & TST & \\
\hline
\end{tabular}




\begin{tabular}{|c|c|c|c|c|c|}
\hline \multirow{2}{*}{\multicolumn{2}{|c|}{ CHFMRI 3195299}} & \\
\hline & & 5.426 & 5.4301 & TST & \\
\hline CHEMBL1392776 & 752339 & 6.5243 & 5.4724 & TST & \\
\hline CHEMBL1347449 & 752339 & 4.1953 & 5.1641 & TST & \\
\hline CHEMBL1978830 & 752339 & 5.0904 & 5.9121 & TST & \\
\hline CHEMBL1469715 & 752339 & 4.8351 & 5.386 & TST & \\
\hline CHEMBL1402974 & 752339 & 4.4556 & 4.863 & TST & \\
\hline CHEMBL116919 & 752339 & 4.4804 & 4.8296 & TST & \\
\hline CHEMBL1323467 & 752339 & 4.8881 & 5.1756 & TST & \\
\hline CHEMBL1450526 & 752339 & 5.0292 & 5.6742 & TST & \\
\hline CHEMBL314090 & 752339 & 5.1701 & 5.38700 & 00000000005 & TST \\
\hline CHEMBL1891517 & 752339 & 5.5622 & 5.0029 & TST & \\
\hline CHEMBL3145296 & 752339 & 5.4295 & 5.1704 & TST & \\
\hline CHEMBL1410758 & 752339 & 5.1898 & 5.2665 & TST & \\
\hline CHEMBL1524751 & 752339 & 2.4559 & 5.0425 & TST & \\
\hline CHEMBL 3198912 & 752339 & 5.2518 & 5.6314 & TST & \\
\hline CHEMBL1532068 & 752339 & 5.34200 & 00000000 & 5.2601 & TST \\
\hline CHEMBL1721075 & 752339 & 4.5031 & 5.2252 & TST & \\
\hline CHEMBL1578584 & 752339 & 4.4944 & 4.9753 & TST & \\
\hline CHEMBL1415585 & 752339 & 5.3536 & 5.0538 & TST & \\
\hline CHEMBL1707626 & 752339 & 5.5017 & 5.1551 & TST & \\
\hline CHEMBL1410859 & 752339 & 4.7212 & 5.0644 & TST & \\
\hline CHEMBL1091556 & 752339 & 4.7224 & 5.0696 & TST & \\
\hline CHEMBL1600275 & 752339 & 5.6055 & 4.9963 & TST & \\
\hline CHEMBL1406208 & 752339 & 4.445 & 5.1972 & TST & \\
\hline CHEMBL1256751 & 752339 & 4.6139 & 4.7556 & TST & \\
\hline CHEMBL1725875 & 752339 & 6.0306 & 5.38700 & 00000000005 & TST \\
\hline CHEMBL1487901 & 752339 & 5.3904 & 5.1168 & TST & \\
\hline CHEMBL1866510 & 752339 & 5.8097 & 5.4164 & TST & \\
\hline CHEMBL1308451 & 752339 & 5.5346 & 5.0519 & TST & \\
\hline CHEMBL1431403 & 752339 & 2.4559 & 5.2355 & TST & \\
\hline CHEMBL 225951 & 752339 & 5.4191 & 5.5609 & TST & \\
\hline CHEMBL1323794 & 752339 & 3.6382 & 4.7929 & TST & \\
\hline CHEMBL1899001 & 752339 & 5.75200 & 00000000 & 5.4969 & TST \\
\hline CHEMBL1389748 & 752339 & 5.1701 & 5.8486 & TST & \\
\hline CHEMBL1596270 & 752339 & 5.5735 & 5.4249 & TST & \\
\hline CHEMBL1441685 & 752339 & 5.6737 & 5.7292 & TST & \\
\hline CHEMBL1331913 & 752339 & 6.1203 & 5.02800 & 00000000005 & 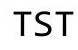 \\
\hline CHEMBL1493194 & 752339 & 5.0482 & 4.9718 & TST & \\
\hline CHEMBL1576722 & 752339 & 5.3595 & 4.7172 & TST & \\
\hline CHEMBL1328321 & 752339 & 4.4402 & 5.0021 & TST & \\
\hline CHEMBL1904727 & 752339 & 5.0 & 5.4302 & TST & \\
\hline CHEMBL1883210 & 752339 & 6.1918 & 5.5214 & TST & \\
\hline CHEMBL1713163 & 752339 & 4.9642 & 5.2359 & TST & \\
\hline CHEMBL1377754 & 752339 & 4.9622 & 5.2863 & TST & \\
\hline CHEMBL1374745 & 752339 & 5.433 & 5.8105 & TST & \\
\hline CHEMBL1730953 & 752339 & 4.3737 & 5.2194 & TST & \\
\hline CHEMBL1987461 & 752339 & 5.1506 & 5.6708 & TST & \\
\hline CHEMBL1309142 & 752339 & 5.8041 & 5.5537 & TST & \\
\hline
\end{tabular}

Page 22223 
Supplemental Table S2.txt

\begin{tabular}{|c|c|c|c|c|c|c|c|}
\hline CHEMBL1965654 & 752339 & 6.0762 & 6.1115 & TST & & & \\
\hline CHEMBL1400298 & 752339 & 5.1302 & 5.6856 & TST & & & \\
\hline CHEMBL1612383 & 752339 & 5.6126 & 4.9918 & TST & & & \\
\hline CHEMBL1568213 & 752339 & 5.6882 & 5.5951 & TST & & & \\
\hline CHEMBL1497562 & 752339 & 5.644 & 5.5491 & TST & & & \\
\hline CHEMBL3196193 & 752339 & 4.4662 & \multicolumn{3}{|c|}{5.497999999999999} & TST & \\
\hline CHEMBL1363046 & 752339 & 4.006 & 4.7697 & TST & & & \\
\hline CHEMBL180127 & 954955 & 3.9338 & 4.0518 & TRN & & & \\
\hline CHEMBL1643959 & 954955 & 3.7554 & 3.8259 & TRN & & & \\
\hline CHEMBL1256459 & 954955 & 7.8668 & 7.8325 & TRN & & & \\
\hline CHEMBL 259181 & 954955 & 4.2245 & 4.1578 & TRN & & & \\
\hline CHEMBL512504 & 954955 & 4.082 & 4.1097 & TRN & & & \\
\hline CHEMBL483849 & 954955 & 3.2004 & 2.0031 & TST & & & \\
\hline CHEMBL1357247 & 954955 & 3.4761 & 3.4927 & TRN & & & \\
\hline CHEMBL3392440 & 954955 & 3.6831 & 3.6805 & TRN & & & \\
\hline CHEMBL 210618 & 954955 & 3.3904 & 3.4062 & TRN & & & \\
\hline CHEMBL188678 & 954955 & \multicolumn{3}{|c|}{ 4. 781000000000001} & 4.6211 & TRN & \\
\hline CHEMBL1516890 & 954955 & 3.6181 & 3.4904 & TRN & & & \\
\hline CHEMBL1404918 & 954955 & 2.8436 & 2.85 & TRN & & & \\
\hline CHEMBL102714 & 954955 & 3.1957 & \multicolumn{3}{|c|}{3.4130000000000003} & TRN & \\
\hline CHEMBL65 & 954955 & 7.9751 & 8.0226 & TRN & & & \\
\hline CHEMBL 2144069 & 954955 & 5.2443 & 5.2368 & TRN & & & \\
\hline CHEMBL373751 & 954955 & 3.5921 & 3.6537 & TRN & & & \\
\hline CHEMBL573107 & 954955 & 4.926 & 4.9635 & TRN & & & \\
\hline CHEMBL399530 & 954955 & 4.7959 & 4.7653 & TRN & & & \\
\hline CHEMBL 2134202 & 954955 & 4.5891 & 4.5221 & TRN & & & \\
\hline CHEMBL449158 & 954955 & 6.2178 & 7.155 & TST & & & \\
\hline CHEMBL558642 & 954955 & 4.4243 & 4.3707 & TRN & & & \\
\hline CHEMBL483847 & 954955 & 3.9745 & 3.8464 & TRN & & & \\
\hline CHEMBL379300 & 954955 & 6.9293 & 6.9796 & TRN & & & \\
\hline CHEMBL9470 & 954955 & 5.8836 & 6.5815 & TST & & & \\
\hline CHEMBL472940 & 954955 & 4.9076 & 4.9638 & TRN & & & \\
\hline CHEMBL379975 & 954955 & 5.7736 & 5.7322 & TRN & & & \\
\hline CHEMBL514499 & 954955 & 7.4785 & 7.4777 & TRN & & & \\
\hline CHEMBL585951 & 954955 & 6.6447 & 6.645 & TRN & & & \\
\hline CHEMBL191334 & 954955 & 5.5108 & 5.5186 & TRN & & & \\
\hline CHEMBL 213100 & 954955 & 5.9779 & 5.9347 & TRN & & & \\
\hline CHEMBL3199475 & 954955 & 5.6679 & 5.6512 & TRN & & & \\
\hline CHEMBL189584 & 954955 & 4.0862 & 4.0267 & TRN & & & \\
\hline CHEMBL 221137 & 954955 & 5.4925 & 5.1873 & TST & & & \\
\hline CHEMBL 258844 & 954955 & 4.306 & 4.2828 & TRN & & & \\
\hline CHEMBL1590308 & 954955 & 2.7228 & 3.5745 & TST & & & \\
\hline CHEMBL192566 & 954955 & 9.6533 & 8.5231 & TST & & & \\
\hline CHEMBL577784 & 954955 & 5.6525 & 5.7073 & TRN & & & \\
\hline CHEMBL 222102 & 954955 & 3.79699 & 99999999 & 997 & 3.8289 & 99999999997 & TRN \\
\hline CHEMBL1970879 & 954955 & 6.0521 & 6.0468 & TRN & & & \\
\hline CHEMBL3186408 & 954955 & 5.0752 & 3.9356 & TST & & & \\
\hline CHEMBL 300389 & 954955 & 7.9801 & 7.9527 & TRN & & & \\
\hline
\end{tabular}

Page 22224 


\begin{tabular}{|c|c|c|c|c|c|c|}
\hline \multirow[b]{2}{*}{ CHEMBL412142 } & \multicolumn{6}{|c|}{ Supplemental Table S2.txt } \\
\hline & 954955 & 4.2679 & 4.2474 & TRN & & \\
\hline CHEMBL1190711 & 954955 & 5.8117 & 5.8796 & TRN & & \\
\hline CHEMBL 255342 & 954955 & 3.7751 & 3.662 & TRN & & \\
\hline CHEMBL1788116 & 954955 & 5.2327 & 5.2985 & TRN & & \\
\hline CHEMBL220241 & 954955 & 6.2461 & 6.1341 & TRN & & \\
\hline CHEMBL515416 & 954955 & 4.481 & 4.5255 & TRN & & \\
\hline CHEMBL509032 & 954955 & 6.1794 & 6.2589 & TRN & & \\
\hline CHEMBL1230020 & 954955 & 4.447 & 4.4544 & TRN & & \\
\hline CHEMBL393929 & 954955 & 3.4106 & 3.4158 & TRN & & \\
\hline CHEMBL 2363137 & 954955 & 5.3771 & 5.3315 & TRN & & \\
\hline CHEMBL3349342 & 954955 & 5.5523 & 5.5869 & TRN & & \\
\hline CHEMBL1909414 & 954955 & 3.3807 & 3.3828 & TRN & & \\
\hline CHEMBL1186585 & 954955 & 4.2648 & 4.3562 & TRN & & \\
\hline CHEMBL1242367 & 954955 & 5.1321 & 5.1 & TRN & & \\
\hline CHEMBL240954 & 954955 & 3.6687 & 3.6372 & TST & & \\
\hline CHEMBL392695 & 954955 & 6.2063 & 5.6013 & TST & & \\
\hline CHEMBL202721 & 954955 & 5.3747 & 5.4256 & TST & & \\
\hline CHEMBL92309 & 954955 & 4.2023 & 3.3998 & TST & & \\
\hline CHEMBL1673039 & 954955 & 5.5538 & 5.3906 & TST & & \\
\hline CHEMBL217354 & 954955 & 6.3603 & 6.5589 & TST & & \\
\hline CHEMBL135561 & 954955 & 5.3681 & 4.7159 & TST & & \\
\hline CHEMBL209148 & 954955 & 4.7301 & 5.3309 & TST & & \\
\hline CHEMBL 2137530 & 954955 & 5.7904 & 5.4177 & TST & & \\
\hline CHEMBL 2005886 & 954955 & 5.96399 & 99999999 & 995 & 2534 & TST \\
\hline CHEMBL 3679913 & 1527879 & 6.8153 & 7.6654 & TST & & \\
\hline CHEMBL 3684582 & 1527879 & 7.4685 & 7.645 & TST & & \\
\hline CHEMBL3684546 & 1527879 & 6.3675 & 7.4619 & TST & & \\
\hline CHEMBL3684581 & 1527879 & 8.3979 & 8.3841 & TRN & & \\
\hline CHEMBL3669855 & 1527879 & 6.4895 & 6.9956 & TST & & \\
\hline CHEMBL3674824 & 1527879 & 7.2676 & 6.9877 & TRN & & \\
\hline CHEMBL 3669758 & 1527879 & 7.0132 & 7.2358 & TRN & & \\
\hline CHEMBL3679930 & 1527879 & 7.4949 & 7.5667 & TRN & & \\
\hline CHEMBL3684634 & 1527879 & 7.7696 & 7.1028 & TRN & & \\
\hline CHEMBL 3674945 & 1527879 & 8.301 & 7.9012 & TST & & \\
\hline CHEMBL3669746 & 1527879 & 7.3188 & 7.3522 & TRN & & \\
\hline CHEMBL3674755 & 1527879 & 8.0969 & 8.1071 & TRN & & \\
\hline CHEMBL3679785 & 1527879 & 7.4815 & 7.1954 & TRN & & \\
\hline CHEMBL3679869 & 1527879 & 7.6576 & 7.1943 & TRN & & \\
\hline CHEMBL3679759 & 1527879 & 6.9788 & 7.1285 & TRN & & \\
\hline CHEMBL3674902 & 1527879 & 6.0241 & 6.2731 & TRN & & \\
\hline CHEMBL 3674958 & 1527879 & 8.2218 & 8.0458 & TRN & & \\
\hline CHEMBL3674915 & 1527879 & 7.5376 & 6.9894 & TRN & & \\
\hline CHEMBL3679898 & 1527879 & 7.9586 & 7.6522 & TRN & & \\
\hline CHEMBL 3669787 & 1527879 & 6.4609 & 6.6807 & TRN & & \\
\hline CHEMBL3674934 & 1527879 & 6.8153 & 6.9535 & TRN & & \\
\hline CHEMBL 3674827 & 1527879 & 6.7399 & 6.6085 & TRN & & \\
\hline CHEMBL3674811 & 1527879 & 6.8962 & 7.3892 & TRN & & \\
\hline CHEMBL 3639835 & 1527879 & 6.3872 & 5.8756 & TRN & & \\
\hline
\end{tabular}


Supplemental Table S2.txt

\begin{tabular}{|c|c|c|c|c|}
\hline CHEMBL 3669820 & 1527879 & 8.301 & 8.0473 & TRN \\
\hline CHEMBL 3669734 & 1527879 & 6.8633 & 6.6573 & TRN \\
\hline CHEMBL 3679772 & 1527879 & 6.9508 & 7.7322 & TST \\
\hline CHEMBL 3679827 & 1527879 & 7.1805 & 7.3942 & TRN \\
\hline CHEMBL 3669850 & 1527879 & 7.6576 & 7.5034 & TRN \\
\hline CHEMBL 3684548 & 1527879 & 6.3335 & 6.9338 & TRN \\
\hline CHEMBL 3679907 & 1527879 & 6.3063 & 6.8763 & TST \\
\hline CHEMBL 3679797 & 1527879 & 7.3098 & 7.155 & TRN \\
\hline CHEMBL 3674751 & 1527879 & 7.9208 & 7.7156 & TRN \\
\hline CHEMBL 3674795 & 1527879 & 6.3089 & 6.3091 & TRN \\
\hline CHEMBL 3674938 & 1527879 & 7.0862 & 6.9595 & TRN \\
\hline CHEMBL 3679889 & 1527879 & 7.8539 & 7.5446 & TRN \\
\hline CHEMBL 3679900 & 1527879 & 7.9586 & 8.1201 & TRN \\
\hline CHEMBL 3679812 & 1527879 & 8.301 & 8.3612 & TRN \\
\hline CHEMBL 3674962 & 1527879 & 6.9872 & 6.8767 & TST \\
\hline CHEMBL 3679733 & 1527879 & 6.5436 & 7.5421 & TST \\
\hline CHEMBL 3679849 & 1527879 & 7.5086 & 8.0245 & TRN \\
\hline CHEMBL 3669836 & 1527879 & 6.0 & 6.9098 & TRN \\
\hline CHEMBL 3669727 & 1527879 & 6.1925 & 6.187 & TST \\
\hline CHEMBL 3684629 & 1527879 & 7.0862 & 6.3304 & TST \\
\hline CHEMBL 3674909 & 1527879 & 7.3565 & 7.3798 & TRN \\
\hline CHEMBL 3679817 & 1527879 & 6.3526 & 6.7934 & TRN \\
\hline CHEMBL 3669735 & 1527879 & 6.3625 & 6.1787 & TRN \\
\hline CHEMBL 3669828 & 1527879 & 7.8539 & 7.7536 & TRN \\
\hline CHEMBL 3684603 & 1527879 & 6.1062 & 6.5188 & TRN \\
\hline CHEMBL 3684623 & 1527879 & 7.8539 & 7.8127 & TRN \\
\hline CHEMBL 3679842 & 1527879 & 6.7773 & 6.9104 & TRN \\
\hline CHEMBL 3679945 & 1527879 & 7.5686 & 7.5691 & TRN \\
\hline CHEMBL 3639685 & 1527879 & 7.9208 & 7.8554 & TST \\
\hline CHEMBL 3684571 & 1527879 & 6.3851 & 6.62 & TRN \\
\hline CHEMBL 3679801 & 1527879 & 7.2076 & 6.8473 & TRN \\
\hline CHEMBL 3679867 & 1527879 & 6.8013 & 6.9397 & TRN \\
\hline CHEMBL 3674817 & 1527879 & 8.0969 & 8.0793 & TRN \\
\hline CHEMBL 3669716 & 1527879 & 6.1549 & 6.3149 & TST \\
\hline CHEMBL 3684543 & 1527879 & 7.9208 & 8.221 & TRN \\
\hline CHEMBL 3674797 & 1527879 & 6.9318 & 6.5787 & TRN \\
\hline CHEMBL 3684552 & 1527879 & 6.6556 & 7.1753 & TRN \\
\hline CHEMBL 3669791 & 1527879 & 7.7959 & 7.6732 & TRN \\
\hline CHEMBL 3684556 & 1527879 & 7.0555 & 7.6269 & TRN \\
\hline CHEMBL 3684576 & 1527879 & 7.4437 & 7.8908 & TST \\
\hline CHEMBL 3674963 & 1527879 & 7.4437 & 6.8107 & TST \\
\hline CHEMBL 3684597 & 1527879 & 6.0472 & 7.5539 & TST \\
\hline CHEMBL 3679883 & 1527879 & 8.2218 & 7.9996 & TRN \\
\hline CHEMBL 3674876 & 1527879 & 7.3188 & 7.5277 & TRN \\
\hline CHEMBL 3679804 & 1527879 & 7.2366 & 7.1555 & TRN \\
\hline CHEMBL 3674885 & 1527879 & 6.7122 & 6.5693 & TRN \\
\hline CHEMBL 3679877 & 1527879 & 7.6383 & 7.3719 & TRN \\
\hline CHEMBL 3669753 & 1527879 & 6.71 & 7.5614 & TST \\
\hline
\end{tabular}


Supplemental Table S2.txt

\begin{tabular}{|c|c|c|c|c|c|}
\hline CHEMBL 3674760 & 1527879 & 6.9066 & 6.97 & TRN & \\
\hline CHEMBL 3674842 & 1527879 & 6.9626 & 6.6062 & TRN & \\
\hline CHEMBL 3684596 & 1527879 & 6.8069 & 7.37 & TST & \\
\hline CHEMBL3669726 & 1527879 & 6.1238 & 6.0414 & TRN & \\
\hline CHEMBL 3674894 & 1527879 & 6.9281 & 6.9123 & TRN & \\
\hline CHEMBL 3674816 & 1527879 & 6.5702 & 6.5286 & TRN & \\
\hline CHEMBL3669826 & 1527879 & 7.0655 & 6.8896 & TRN & \\
\hline CHEMBL 3679887 & 1527879 & 6.6364 & 6.9427 & TRN & \\
\hline CHEMBL 3674941 & 1527879 & 6.3098 & 6.2678 & TST & \\
\hline CHEMBL 3679751 & 1527879 & 6.6615 & 6.57 & TRN & \\
\hline CHEMBL 3684613 & 1527879 & 6.9508 & 6.7738 & TRN & \\
\hline CHEMBL 3679865 & 1527879 & 7.7696 & 7.3335 & TRN & \\
\hline CHEMBL 3679918 & 1527879 & 7.4949 & 7.6372 & TST & \\
\hline CHEMBL 3674780 & 1527879 & 7.6383 & 7.2286 & TRN & \\
\hline CHEMBL 3674892 & 1527879 & 6.8297 & 7.0585 & TRN & \\
\hline CHEMBL 3674911 & 1527879 & 7.1024 & 7.0154 & TRN & \\
\hline CHEMBL3679830 & 1527879 & 7.2218 & 7.3813 & TRN & \\
\hline CHEMBL 3669706 & 1527879 & 6.8729 & 7.5731 & TST & \\
\hline CHEMBL 3679919 & 1527879 & 6.8153 & 7.3131 & TRN & \\
\hline CHEMBL 3674752 & 1527879 & 7.1367 & 7.0338 & TRN & \\
\hline CHEMBL3669837 & 1527879 & 7.7212 & 7.1594 & TRN & \\
\hline CHEMBL 3674966 & 1527879 & 6.3439 & 6.95799 & 9999999999 & TST \\
\hline CHEMBL 3674773 & 1527879 & 8.0 & 7.8808 & TRN & \\
\hline CHEMBL 3674834 & 1527879 & 6.8861 & 6.8649 & TRN & \\
\hline CHEMBL 3684661 & 1527879 & 7.5086 & 7.8577 & TRN & \\
\hline CHEMBL3669829 & 1527879 & 7.3979 & 7.1794 & TRN & \\
\hline CHEMBL 3674953 & 1527879 & 7.4437 & 7.072 & TRN & \\
\hline CHEMBL 3679860 & 1527879 & 7.2676 & 7.40600 & 0000000001 & TRN \\
\hline CHEMBL 3679741 & 1527879 & 6.7423 & 6.6858 & TRN & \\
\hline CHEMBL3679873 & 1527879 & 8.3979 & 7.7377 & TRN & \\
\hline CHEMBL 3674848 & 1527879 & 7.1549 & 7.3776 & TRN & \\
\hline CHEMBL3669694 & 1527879 & 6.4949 & 6.6364 & TST & \\
\hline CHEMBL 3679886 & 1527879 & 8.2218 & 7.8913 & TRN & \\
\hline CHEMBL 3674822 & 1527879 & 7.6778 & 7.25899 & 99999999995 & TRN \\
\hline CHEMBL 3669702 & 1527879 & 7.8539 & 6.9591 & TST & \\
\hline CHEMBL3679888 & 1527879 & 8.0969 & 7.6662 & TRN & \\
\hline CHEMBL3679946 & 1527879 & 7.1192 & 7.1939 & TRN & \\
\hline CHEMBL3669770 & 1527879 & 6.466 & 6.9541 & TRN & \\
\hline CHEMBL 3684649 & 1527879 & 8.0969 & 8.1962 & TRN & \\
\hline CHEMBL 3674853 & 1527879 & 6.4547 & 6.6089 & TRN & \\
\hline CHEMBL 3674813 & 1527879 & 7.2676 & 7.055 & TRN & \\
\hline CHEMBL3684665 & 1527879 & 7.6021 & 7.3282 & TRN & \\
\hline CHEMBL3674916 & 1527879 & 7.7447 & 7.6533 & TRN & \\
\hline CHEMBL 3684574 & 1527879 & 6.4437 & 6.5659 & TST & \\
\hline CHEMBL 3674917 & 1527879 & $6.7520 e$ & 00000000 & 7.0317 & TRN \\
\hline CHEMBL 3684541 & 1527879 & 6.4101 & 6.5917 & TRN & \\
\hline CHEMBL 3684588 & 1527879 & 8.0 & 8.0576 & TRN & \\
\hline CHEMBL 3684654 & 1527879 & 7.4815 & 7.5423 & TRN & \\
\hline
\end{tabular}

Page 22227 


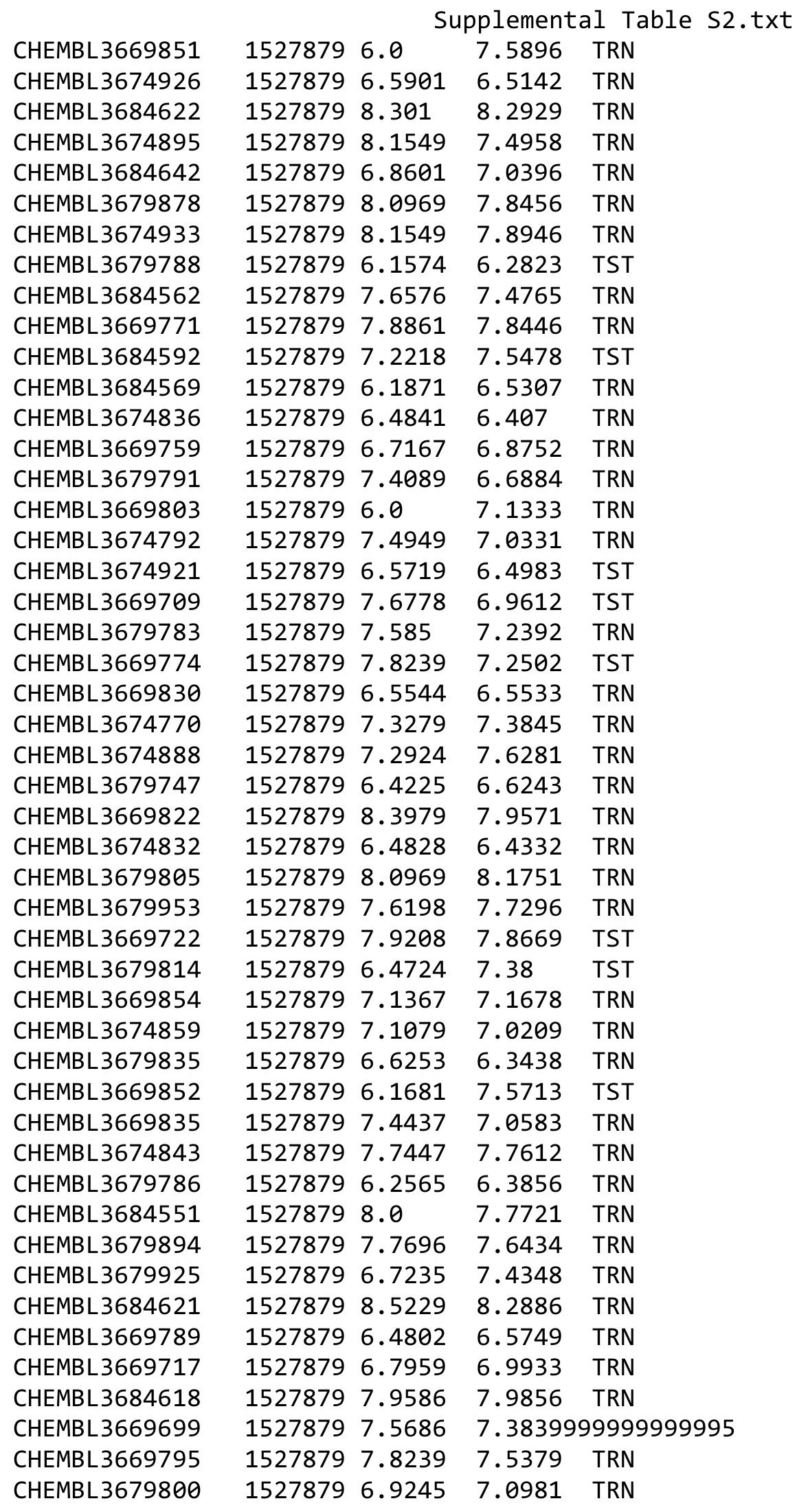


Supplemental Table S2.txt

\begin{tabular}{|c|c|c|c|c|c|}
\hline CHEMBL3669832 & 1527879 & 6.0026 & 6.7333 & TRN & \\
\hline CHEMBL3679818 & 1527879 & 8.0969 & 7.8889 & TRN & \\
\hline CHEMBL3669707 & 1527879 & 7.1024 & 6.6972 & TST & \\
\hline CHEMBL3669755 & 1527879 & 6.8729 & 6.5425 & TST & \\
\hline CHEMBL 3674803 & 1527879 & 6.3261 & 6.2263 & TRN & \\
\hline CHEMBL3679774 & 1527879 & 6.8761 & 6.9451 & TRN & \\
\hline CHEMBL3679914 & 1527879 & 6.2941 & 6.5278 & TRN & \\
\hline CHEMBL3679766 & 1527879 & 7.9208 & 7.9934 & TRN & \\
\hline CHEMBL3684555 & 1527879 & 8.3979 & 8.5064 & TRN & \\
\hline CHEMBL3669847 & 1527879 & 6.8041 & 7.7522 & TST & \\
\hline CHEMBL 3679794 & 1527879 & 6.5436 & 6.5335 & TRN & \\
\hline CHEMBL3674873 & 1527879 & 7.6021 & 7.5608 & TRN & \\
\hline CHEMBL3937845 & 1527879 & 6.4271 & 7.7463 & TST & \\
\hline CHEMBL3674845 & 1527879 & 7.0315 & 6.9491 & TRN & \\
\hline CHEMBL3669730 & 1527879 & 6.2248 & 6.3109 & TST & \\
\hline CHEMBL 3669713 & 1527879 & 7.1249 & 7.2124 & TST & \\
\hline CHEMBL3669793 & 1527879 & 7.7696 & 7.6641 & TRN & \\
\hline CHEMBL3674928 & 1527879 & 6.4425 & 6.397 & TRN & \\
\hline CHEMBL3679777 & 1527879 & 6.9318 & 7.2007 & TRN & \\
\hline CHEMBL3679951 & 1527879 & 7.8239 & 7.5146 & TRN & \\
\hline CHEMBL3684615 & 1527879 & 6.091 & 5.9503 & TRN & \\
\hline CHEMBL3684604 & 1527879 & 6.9747 & 6.5891 & TRN & \\
\hline CHEMBL3679839 & 1527879 & 6.3316 & 6.812 & TRN & \\
\hline CHEMBL3679929 & 1527879 & 7.6383 & 7.66799 & 9999999999 & TRN \\
\hline CHEMBL3669765 & 1527879 & 7.1135 & 7.0112 & TRN & \\
\hline CHEMBL3679902 & 1527879 & 8.301 & 8.2286 & TRN & \\
\hline CHEMBL3684659 & 1527879 & 6.9666 & 6.9903 & TRN & \\
\hline CHEMBL3669736 & 1527879 & 6.5157 & 6.4396 & TRN & \\
\hline CHEMBL3669737 & 1527879 & 6.2848 & 6.1589 & TRN & \\
\hline CHEMBL3674965 & 1527879 & 6.8962 & 7.1258 & TRN & \\
\hline CHEMBL3674959 & 1527879 & 6.3116 & 6.4651 & TRN & \\
\hline CHEMBL3679880 & 1527879 & 7.0458 & 6.7042 & TRN & \\
\hline CHEMBL 3674762 & 1527879 & 7.4559 & 6.8636 & TRN & \\
\hline CHEMBL3679757 & 1527879 & 6.8097 & 6.8666 & TRN & \\
\hline CHEMBL3674893 & 1527879 & 6.7167 & 6.9892 & TRN & \\
\hline CHEMBL3669750 & 1527879 & 7.0362 & 7.1357 & TRN & \\
\hline CHEMBL3674922 & 1527879 & 6.4921 & 6.5474 & TRN & \\
\hline CHEMBL 3684572 & 1527879 & 6.2807 & 6.4317 & TST & \\
\hline CHEMBL3674927 & 1527879 & 6.71899 & 79999999 & 6.7233 & TRN \\
\hline CHEMBL3684624 & 1527879 & 7.1612 & 7.0169 & TRN & \\
\hline CHEMBL3639834 & 1527879 & 6.8508 & 7.4731 & TRN & \\
\hline CHEMBL3679799 & 1527879 & 7.0809 & 7.1863 & TRN & \\
\hline CHEMBL3679941 & 1527879 & 6.4461 & 6.7141 & TRN & \\
\hline CHEMBL3679857 & 1527879 & 6.4225 & 6.5341 & TRN & \\
\hline CHEMBL3679840 & 1527879 & 6.4449 & 6.3708 & TRN & \\
\hline CHEMBL3674868 & 1527879 & 6.6778 & 5.91299 & 9999999999 & TST \\
\hline CHEMBL3669745 & 1527879 & 6.1871 & 6.7781 & TRN & \\
\hline CHEMBL3674748 & 1527879 & 8.301 & 7.9208 & TRN & \\
\hline
\end{tabular}


Supplemental Table S2.txt

\begin{tabular}{|c|c|c|c|c|}
\hline CHEMBL 3669700 & 1527879 & 7.0 & 7.6673 & TST \\
\hline CHEMBL 3684641 & 1527879 & 6.8182 & 7.1705 & TRN \\
\hline CHEMBL3684617 & 1527879 & 6.6234 & 6.3731 & TRN \\
\hline CHEMBL 3674898 & 1527879 & 7.4437 & 7.3584 & TRN \\
\hline CHEMBL 3679837 & 1527879 & 6.4134 & 6.5561 & TRN \\
\hline CHEMBL 3679809 & 1527879 & 7.1135 & 7.3339 & TST \\
\hline CHEMBL 3674759 & 1527879 & 7.6198 & 7.6027 & TRN \\
\hline CHEMBL3669767 & 1527879 & 6.5498 & 6.6342 & TRN \\
\hline CHEMBL 3679765 & 1527879 & 6.4001 & 6.0813 & TST \\
\hline CHEMBL3679911 & 1527879 & 6.9508 & 7.2158 & TST \\
\hline CHEMBL 3679885 & 1527879 & 7.3372 & 7.1991 & TRN \\
\hline CHEMBL 3674826 & 1527879 & 6.7144 & 6.4069 & TRN \\
\hline CHEMBL3669739 & 1527879 & 7.8861 & 7.6996 & TRN \\
\hline CHEMBL 3679854 & 1527879 & 6.983 & 6.8088 & TRN \\
\hline CHEMBL3669703 & 1527879 & 6.2255 & 6.2944 & TRN \\
\hline CHEMBL 3674850 & 1527879 & 6.5513 & 6.6334 & TRN \\
\hline CHEMBL 3679771 & 1527879 & 6.7747 & 7.4175 & TST \\
\hline CHEMBL 3679948 & 1527879 & 7.8861 & 7.8736 & TRN \\
\hline CHEMBL 3684580 & 1527879 & 6.9957 & 7.1448 & TRN \\
\hline CHEMBL 3674837 & 1527879 & 6.6536 & 6.3599 & TRN \\
\hline CHEMBL 3684550 & 1527879 & 8.0969 & 7.7928 & TRN \\
\hline CHEMBL 3679864 & 1527879 & 7.7212 & 7.5966 & TRN \\
\hline CHEMBL 3684607 & 1527879 & 6.3487 & 6.8662 & TST \\
\hline CHEMBL 3674896 & 1527879 & 8.1549 & 7.7067 & TRN \\
\hline CHEMBL 3684637 & 1527879 & 7.7212 & 7.4002 & TRN \\
\hline CHEMBL 3684656 & 1527879 & 7.4437 & 7.3045 & TRN \\
\hline CHEMBL 3669807 & 1527879 & 7.1308 & 7.1335 & TRN \\
\hline CHEMBL 3674802 & 1527879 & 6.1959 & 5.8886 & TRN \\
\hline CHEMBL 3684647 & 1527879 & 7.8861 & 7.8457 & TRN \\
\hline CHEMBL3674776 & 1527879 & 6.0 & 7.1512 & TRN \\
\hline CHEMBL 3679784 & 1527879 & 7.0605 & 7.1371 & TRN \\
\hline CHEMBL 3679905 & 1527879 & 6.2612 & 6.9615 & TST \\
\hline CHEMBL 3674882 & 1527879 & 7.7212 & 7.61100 & 0000000001 \\
\hline CHEMBL 3669853 & 1527879 & 7.9208 & 7.9256 & TST \\
\hline CHEMBL 3674860 & 1527879 & 6.2262 & 5.9933 & TRN \\
\hline CHEMBL 3669810 & 1527879 & 7.8861 & 7.5935 & TRN \\
\hline CHEMBL 3679872 & 1527879 & 8.0458 & 8.2393 & TRN \\
\hline CHEMBL 3674897 & 1527879 & 8.2218 & 7.9829 & TRN \\
\hline CHEMBL 3684554 & 1527879 & 6.6655 & 7.0483 & TRN \\
\hline CHEMBL3674939 & 1527879 & 7.3768 & 7.3502 & TRN \\
\hline CHEMBL 3674936 & 1527879 & 6.0 & 7.3615 & TRN \\
\hline CHEMBL 3684614 & 1527879 & 7.0605 & 6.9867 & TRN \\
\hline CHEMBL 3679943 & 1527879 & 7.3372 & 7.5171 & TRN \\
\hline CHEMBL 3669762 & 1527879 & 7.9208 & 7.8234 & TRN \\
\hline CHEMBL 3684671 & 1527879 & 7.8861 & 7.8499 & TRN \\
\hline CHEMBL 3679944 & 1527879 & 7.5086 & 7.2053 & TRN \\
\hline CHEMBL 3679746 & 1527879 & 7.3768 & 7.1297 & TRN \\
\hline CHEMBL 3679740 & 1527879 & 7.1487 & 7.2337 & TRN \\
\hline
\end{tabular}

Page 22230 
Supplemental Table S2.txt

\begin{tabular}{|c|c|c|c|c|}
\hline 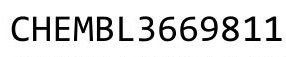 & & & 6.7963 & \\
\hline HEMBL3 & 527879 & 6.8153 & 7.0212 & \\
\hline & 27879 & 8.0 & 3829 & \\
\hline 855 & 27879 & 6.6635 & 4347 & \\
\hline IEMBL3674931 & 527879 & 1802 & 4661 & \\
\hline AEMBL3684591 & 527879 & 6.5214 & 6155 & \\
\hline HEMBL3679780 & 527879 & 6.8601 & 164 & \\
\hline IEMBL: & 79 & 457 & $\partial 21$ & \\
\hline EMBL 3679824 & 879 & 7.8861 & 7298 & \\
\hline AEMBL3684664 & 527879 & 6.4401 & 8378 & \\
\hline HEMBL3674805 & 379 & 6.5229 & 4164 & \\
\hline AEMBL3679843 & 79 & 6.8041 & 2865 & \\
\hline AEMBL & & 979 & & \\
\hline HEMBL & 79 & 239 & 2094 & \\
\hline AEMBL3674769 & 79 & 7.5686 & 8816 & \\
\hline AEMBL3679779 & 79 & L871 & 93 & \\
\hline AEMBL3 & 79 & 928 & 7514 & \\
\hline HEMBL & & 805 & 2442 & \\
\hline HEMBL & 79 & 851 & & \\
\hline HEMBL3674844 & 79 & 686 & 7208 & RN \\
\hline AEMBL3679829 & 79 & 7.1549 & 3763 & KIV \\
\hline HEMBL & 9 & 229 & 664 & RN \\
\hline HEMBL & & 441 & 852 & \\
\hline 875 & & 2076 & 9541 & RN \\
\hline AEMBL3679836 & & 7.3279 & 3996 & RN \\
\hline HEMBL3679745 & 79 & 8 & 35 & RN \\
\hline HEMBL3669724 & 9 & 366 & 961 & RN \\
\hline HEMBL 3 & & & 209 & KIN \\
\hline HEM & & & 375 & ST \\
\hline IEMBL 36 & & 8.0969 & 09 & RIN \\
\hline AEMBL3684609 & 79 & 6 & 083 & RN \\
\hline HEMBL3674783 & 79 & 29 & 851 & RN \\
\hline HEMBL3 & & 79 & 791 & RN \\
\hline 7 & & & 818 & RN \\
\hline HEMBL3674794 & 79 & & & RN \\
\hline AEMBL3679 & 79 & 825 & 388 & \\
\hline HEMBL3679882 & 79 & 447 & 843 & RIN \\
\hline & & & & 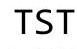 \\
\hline HEMBL3674819 & 99 & 7. & 1761 & $\mathrm{RN}$ \\
\hline HEMBL3669815 & 79 & 6.8633 & 786 & RN \\
\hline HEMBL $36697 €$ & & 539 & 247 & \\
\hline HEMBL3674820 & & 7.4685 & 7.4475 & RIN \\
\hline HEMBL 36 & & & & $\mathrm{RN}$ \\
\hline HEMBL3684672 & 79 & 225 & 8319 & RN \\
\hline AEMBL36697: & 879 & 59 & 1546 & ST \\
\hline & & & & \\
\hline CHEMBL 3 & 527879 & 7.2076 & 7.1413 & \\
\hline 367490 & $15<1$ & & & \\
\hline
\end{tabular}

Page 22231 
Supplemental Table S2.txt

\begin{tabular}{|c|c|c|c|c|c|c|}
\hline CHEMBL 3684590 & 1527879 & 6.5817 & 7.2964 & TST & & \\
\hline CHEMBL3669794 & 1527879 & 7.1367 & 7.6009 & TRN & & \\
\hline CHEMBL3679863 & 1527879 & 8.3979 & 8.2578 & TRN & & \\
\hline CHEMBL 3679768 & 1527879 & 7.1739 & 7.3315 & TRN & & \\
\hline CHEMBL3674907 & 1527879 & 6.9136 & 7.4092 & TRN & & \\
\hline CHEMBL3679920 & 1527879 & 7.9208 & 8.1925 & TRN & & \\
\hline CHEMBL3972791 & 1527879 & 6.1898 & 6.6369 & TST & & \\
\hline CHEMBL 3669744 & 1527879 & \multicolumn{3}{|c|}{6.821000000000001} & 6.9932 & TRN \\
\hline CHEMBL3679796 & 1527879 & 7.4815 & 7.2586 & TRN & & \\
\hline CHEMBL3674829 & 1527879 & 6.9172 & 6.9456 & TRN & & \\
\hline CHEMBL3674947 & 1527879 & 6.7645 & 6.8542 & TRN & & \\
\hline CHEMBL 3674846 & 1527879 & 7.1871 & 7.2696 & TRN & & \\
\hline CHEMBL 3674790 & 1527879 & 6.0 & 7.0596 & TRN & & \\
\hline CHEMBL3684643 & 1527879 & 6.8416 & 6.722 & TRN & & \\
\hline CHEMBL3679806 & 1527879 & 6.8477 & 6.7485 & TRN & & \\
\hline CHEMBL3684652 & 1527879 & 8.5229 & 7.9809 & TRN & & \\
\hline CHEMBL3679833 & 1527879 & 6.5528 & 6.319 & TRN & & \\
\hline CHEMBL 3684577 & 1527879 & 7.3872 & 7.3767 & TST & & \\
\hline CHEMBL3684545 & 1527879 & 6.4584 & 7.5132 & TST & & \\
\hline CHEMBL3669841 & 1527879 & 7.3665 & 7.0526 & TRN & & \\
\hline CHEMBL3674900 & 1527879 & 6.644 & 5.9503 & TST & & \\
\hline CHEMBL 3674874 & 1527879 & 7.6198 & \multicolumn{3}{|c|}{7.502000000000001} & TRN \\
\hline CHEMBL 3669740 & 1527879 & 7.3188 & 7.0231 & TRN & & \\
\hline CHEMBL3679841 & 1527879 & 7.0 & 6.4134 & TRN & & \\
\hline CHEMBL 3674840 & 1527879 & 6.9914 & 7.0553 & TRN & & \\
\hline CHEMBL3684558 & 1527879 & 7.2596 & 6.9165 & TRN & & \\
\hline CHEMBL3669723 & 1527879 & 6.3298 & 6.3091 & TRN & & \\
\hline CHEMBL3679901 & 1527879 & 8.1549 & 8.2807 & TRN & & \\
\hline CHEMBL3669769 & 1527879 & 7.1308 & 7.1481 & TRN & & \\
\hline CHEMBL 3674952 & 1527879 & 7.8861 & 8.0969 & TRN & & \\
\hline CHEMBL 3674763 & 1527879 & 6.3655 & 6.261 & TRN & & \\
\hline CHEMBL3669796 & 1527879 & \multicolumn{3}{|c|}{6.382000000000001} & 6.6755 & this \\
\hline CHEMBL 3674913 & 1527879 & 7.1487 & 6.992000 & 0000000001 & & TRN \\
\hline CHEMBL3679937 & 1527879 & 8.699 & 8.0315 & TRN & & \\
\hline CHEMBL 3684605 & 1527879 & 6.9101 & 7.3376 & TST & & \\
\hline CHEMBL3669833 & 1527879 & 7.2007 & 6.6669 & TRN & & \\
\hline CHEMBL3669808 & 1527879 & 7.0223 & 7.0563 & TRN & & \\
\hline CHEMBL 3684564 & 1527879 & 7.4815 & 7.2171 & TRN & & \\
\hline CHEMBL3669733 & 1527879 & 6.585 & 7.0292 & TRN & & \\
\hline CHEMBL 3679789 & 1527879 & 7.7447 & 7.3302 & TST & & \\
\hline CHEMBL3669748 & 1527879 & 6.2557 & 6.2279 & TRN & & \\
\hline CHEMBL3679813 & 1527879 & 6.7305 & 6.5387 & TRN & & \\
\hline CHEMBL3674793 & 1527879 & 6.4597 & 6.3357 & TST & & \\
\hline CHEMBL3669806 & 1527879 & 7.3872 & 6.7867 & TRN & & \\
\hline CHEMBL 3684573 & 1527879 & 6.1871 & 6.6748 & TST & & \\
\hline CHEMBL3674886 & 1527879 & 6.3497 & 6.5129 & TRN & & \\
\hline CHEMBL3674758 & 1527879 & 7.6383 & 7.2519 & TRN & & \\
\hline CHEMBL3679755 & 1527879 & 8.2218 & 7.8596 & TRN & & \\
\hline
\end{tabular}

Page 22232 
Supplemental Table S2.txt

\begin{tabular}{|c|c|c|c|c|}
\hline CHEMBL3679896 & 1527879 & 7.7959 & 7.9055 & TRN \\
\hline CHEMBL 3669800 & 1527879 & 6.7167 & 6.8766 & TRN \\
\hline CHEMBL 3679756 & 1527879 & 7.7696 & 7.9581 & TRN \\
\hline CHEMBL 3674891 & 1527879 & 6.6021 & 7.0081 & TRN \\
\hline CHEMBL 3674798 & 1527879 & 6.466 & 6.5288 & TRN \\
\hline CHEMBL 3679848 & 1527879 & 7.5528 & 7.7015 & TRN \\
\hline CHEMBL 3669766 & 1527879 & 6.4168 & 6.7499 & TRN \\
\hline CHEMBL 3684638 & 1527879 & 6.6882 & 6.754 & TRN \\
\hline CHEMBL 3674778 & 1527879 & 6.0 & 7.1957 & TRN \\
\hline CHEMBL 3679871 & 1527879 & 8.0969 & 8.2612 & TRN \\
\hline CHEMBL 3684673 & 1527879 & 6.6126 & 6.8486 & TRN \\
\hline CHEMBL 3674950 & 1527879 & 6.8928 & 6.8573 & TRN \\
\hline CHEMBL 3674923 & 1527879 & 6.7423 & 6.6303 & TRN \\
\hline CHEMBL3669721 & 1527879 & 6.0334 & 6.7013 & TST \\
\hline CHEMBL3639736 & 1527879 & 7.8239 & 7.4103 & TRN \\
\hline CHEMBL 3679935 & 1527879 & 8.699 & 8.4661 & TRN \\
\hline CHEMBL 3684601 & 1527879 & 6.4067 & 6.4902 & TST \\
\hline CHEMBL 3684560 & 1527879 & 7.3565 & 7.0077 & TRN \\
\hline CHEMBL 3684583 & 1527879 & 8.1549 & 8.2236 & TRN \\
\hline CHEMBL 3679947 & 1527879 & 8.5229 & 8.2914 & TRN \\
\hline CHEMBL3679899 & 1527879 & 7.2441 & 7.3511 & TRN \\
\hline CHEMBL 3679915 & 1527879 & 6.38299 & 99999999 & 6.8495 \\
\hline CHEMBL 3679940 & 1527879 & 6.6517 & 6.5417 & TRN \\
\hline CHEMBL 3679924 & 1527879 & 7.9586 & 8.1004 & TRN \\
\hline CHEMBL 3684547 & 1527879 & 6.8633 & 6.5445 & TRN \\
\hline CHEMBL 3679737 & 1527879 & 7.7212 & 7.8422 & TRN \\
\hline CHEMBL3679891 & 1527879 & 7.1549 & 7.3416 & TRN \\
\hline CHEMBL 3669712 & 1527879 & 7.3979 & 6.8872 & TRN \\
\hline CHEMBL3684663 & 1527879 & 7.6198 & 7.3883 & TRN \\
\hline CHEMBL 3684606 & 1527879 & 6.9469 & 6.7896 & TRN \\
\hline CHEMBL 3679834 & 1527879 & 6.5986 & 6.5332 & TRN \\
\hline CHEMBL 3674899 & 1527879 & 7.7212 & 7.7022 & TRN \\
\hline CHEMBL 3679928 & 1527879 & 7.7447 & 7.3157 & TRN \\
\hline CHEMBL3674785 & 1527879 & 7.7212 & 7.1959 & TRN \\
\hline CHEMBL 3674757 & 1527879 & 7.7447 & 7.6825 & TRN \\
\hline CHEMBL3679916 & 1527879 & 6.1314 & 6.4022 & TRN \\
\hline CHEMBL3679932 & 1527879 & 8.3979 & 7.9416 & TRN \\
\hline CHEMBL 3674929 & 1527879 & 6.2848 & 6.3748 & TRN \\
\hline CHEMBL3679931 & 1527879 & 8.0458 & 7.8189 & TRN \\
\hline CHEMBL 3684667 & 1527879 & 6.4067 & 6.6761 & TRN \\
\hline CHEMBL 3669731 & 1527879 & 6.7986 & 7.0775 & TRN \\
\hline CHEMBL 3674879 & 1527879 & 8.0458 & 8.0208 & TRN \\
\hline CHEMBL 3674823 & 1527879 & 7.699 & \multicolumn{2}{|c|}{7.5360000000000005} \\
\hline CHEMBL3669698 & 1527879 & 6.6073 & 6.9394 & TST \\
\hline CHEMBL 3684648 & 1527879 & 7.3665 & 7.6928 & TRN \\
\hline CHEMBL 3674919 & 1527879 & 6.5086 & 6.3491 & TST \\
\hline CHEMBL 3669838 & 1527879 & 7.8539 & 7.3551 & TRN \\
\hline CHEMBL 3684653 & 1527879 & 7.7447 & 8.0066 & TRN \\
\hline
\end{tabular}

Page 22233 
Supplemental Table S2.txt

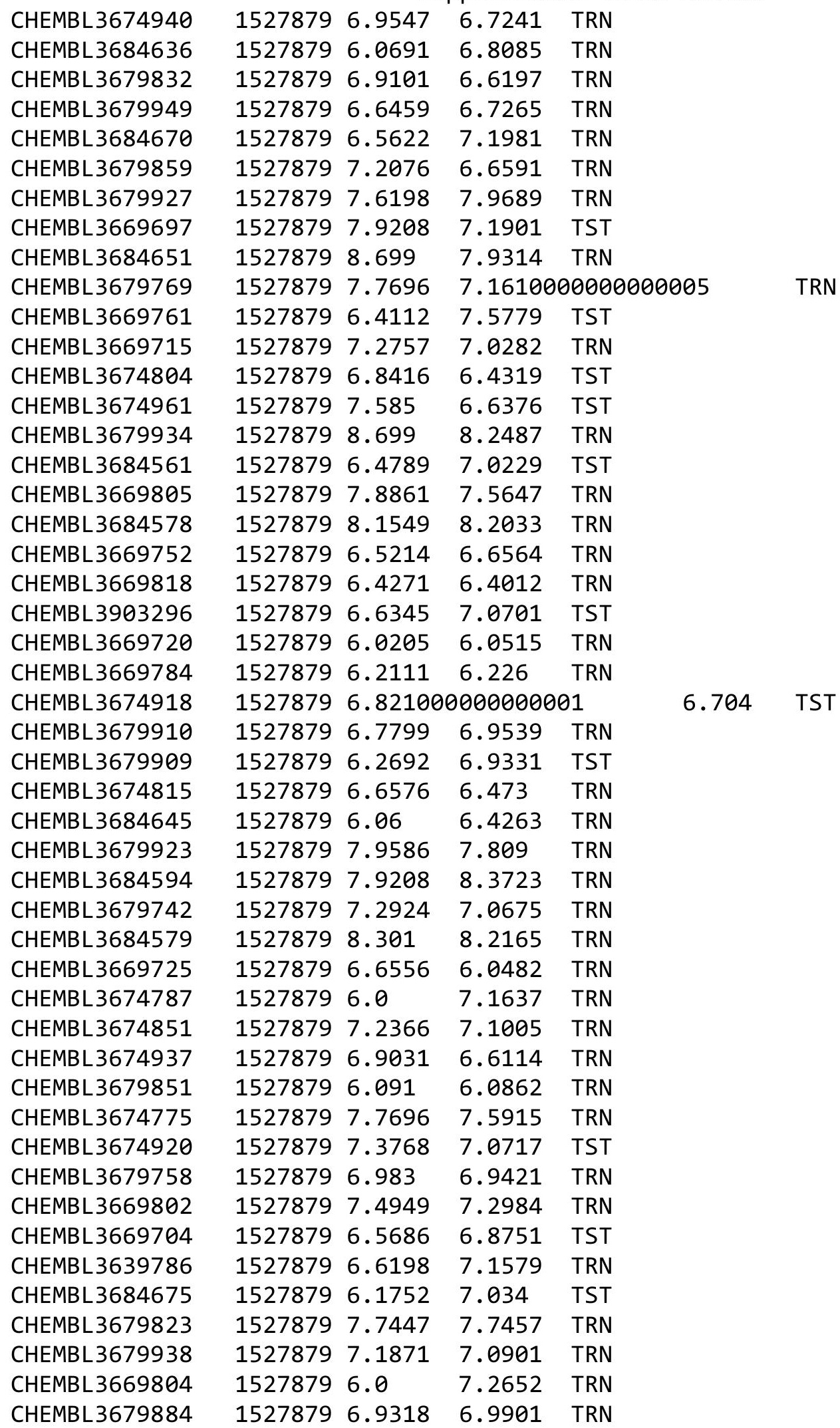

Page 22234 
Supplemental Table S2.txt

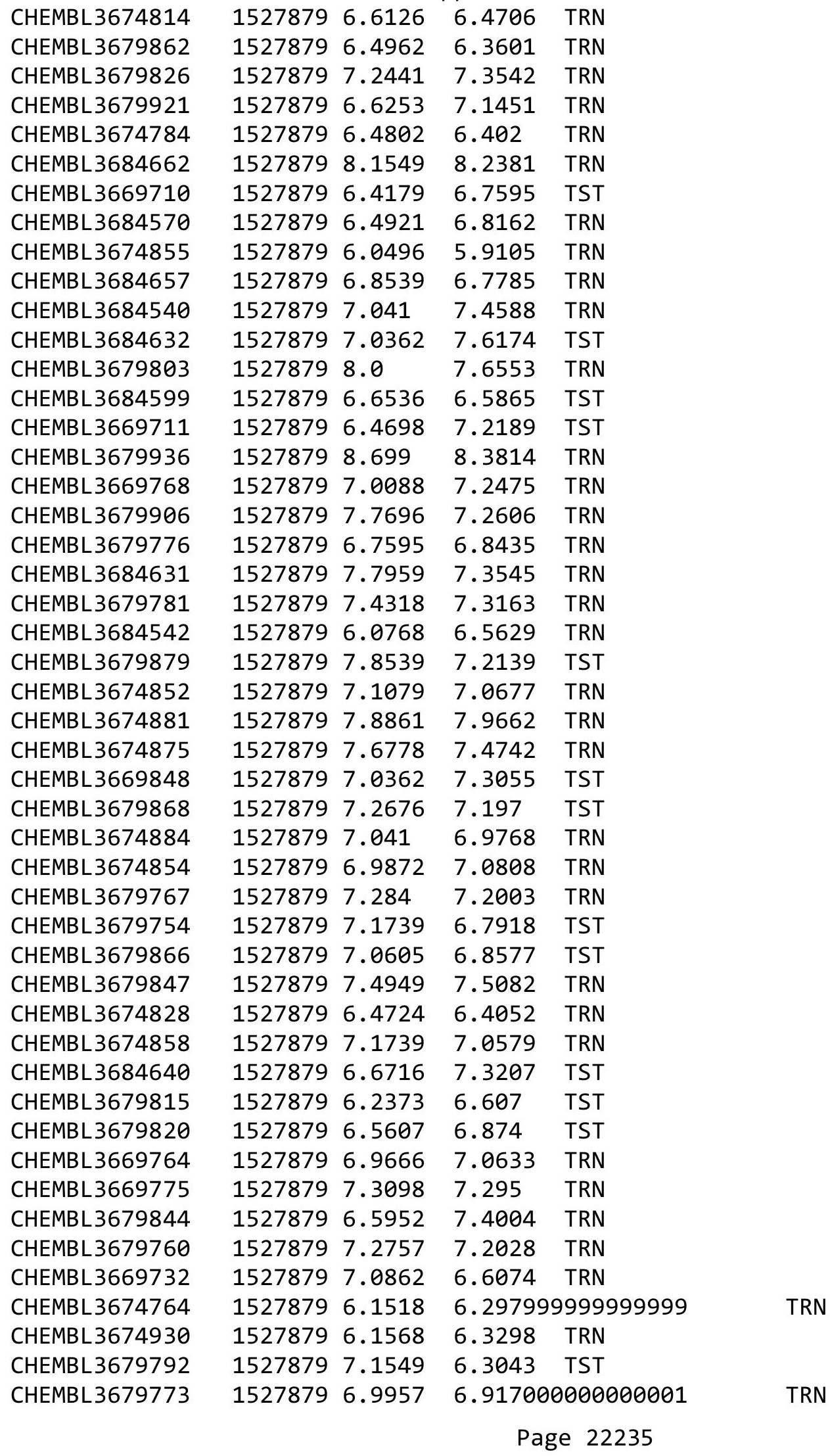


Supplemental Table S2.txt

\begin{tabular}{|c|c|c|c|c|}
\hline CHEMBL3669814 & 1527879 & 7.6198 & 7.4834 & TRN \\
\hline CHEMBL3669846 & 1527879 & 7.3279 & 7.1164 & TRN \\
\hline CHEMBL3684628 & 1527879 & 7.4685 & 7.2388 & TST \\
\hline CHEMBL3669776 & 1527879 & 6.8097 & 6.3622 & TRN \\
\hline CHEMBL3684619 & 1527879 & 7.8239 & 7.8837 & TST \\
\hline CHEMBL3679831 & 1527879 & 6.767 & 6.4828 & TRN \\
\hline CHEMBL3674861 & 1527879 & 6.0004 & 6.1976 & TRN \\
\hline CHEMBL3669708 & 1527879 & 6.8794 & 6.4796 & TRN \\
\hline CHEMBL3684669 & 1527879 & 7.5686 & 7.5963 & TST \\
\hline CHEMBL3679950 & 1527879 & 6.9431 & 6.87700 & 0000000001 \\
\hline CHEMBL3674960 & 1527879 & 6.1555 & 6.5023 & TRN \\
\hline CHEMBL3674925 & 1527879 & 7.4949 & 7.683 & TRN \\
\hline CHEMBL 3684585 & 1527879 & 8.3979 & 8.5673 & TST \\
\hline CHEMBL3679764 & 1527879 & 8.0969 & 7.9856 & TRN \\
\hline CHEMBL3679748 & 1527879 & 6.4776 & 6.1697 & TST \\
\hline CHEMBL3669742 & 1527879 & 7.6383 & 7.6006 & TRN \\
\hline CHEMBL3669743 & 1527879 & 7.7959 & 7.8016 & TRN \\
\hline CHEMBL3674849 & 1527879 & 6.1415 & 6.8282 & TST \\
\hline CHEMBL3674954 & 1527879 & 7.585 & 7.5742 & TRN \\
\hline CHEMBL3669798 & 1527879 & 6.6596 & 6.6125 & TRN \\
\hline CHEMBL3684633 & 1527879 & 6.8861 & 8.0072 & TST \\
\hline CHEMBL3679761 & 1527879 & 7.2291 & 7.5902 & TRN \\
\hline CHEMBL3679838 & 1527879 & 6.3675 & 6.4995 & TRN \\
\hline CHEMBL3669786 & 1527879 & 6.0315 & 6.5294 & TRN \\
\hline CHEMBL3669783 & 1527879 & 7.8239 & 7.2495 & TRN \\
\hline CHEMBL3679870 & 1527879 & 7.6778 & 7.7149 & TST \\
\hline CHEMBL3669801 & 1527879 & 7.4559 & 7.2462 & TRN \\
\hline CHEMBL3679736 & 1527879 & 6.0123 & 6.7914 & TRN \\
\hline CHEMBL3679903 & 1527879 & 7.4815 & 7.1923 & TST \\
\hline CHEMBL3674847 & 1527879 & 6.2381 & 7.3739 & TST \\
\hline CHEMBL3674872 & 1527879 & 7.699 & 7.4901 & TRN \\
\hline CHEMBL3674812 & 1527879 & 7.9208 & 8.0101 & TRN \\
\hline CHEMBL3669777 & 1527879 & 7.041 & 6.6417 & TRN \\
\hline CHEMBL3684559 & 1527879 & 6.8297 & 7.2972 & TST \\
\hline CHEMBL3674887 & 1527879 & 7.4559 & 7.5462 & TRN \\
\hline CHEMBL3674809 & 1527879 & 7.2924 & 7.4364 & TRN \\
\hline CHEMBL3674943 & 1527879 & 7.4559 & 7.42 & TRN \\
\hline CHEMBL3684660 & 1527879 & 7.9586 & 8.3259 & TST \\
\hline CHEMBL3669785 & 1527879 & 7.7959 & 7.5249 & TRN \\
\hline CHEMBL3684658 & 1527879 & 7.4089 & 7.285 & TST \\
\hline CHEMBL3674838 & 1527879 & 6.5622 & 6.558 & TRN \\
\hline CHEMBL3674818 & 1527879 & 6.9431 & 7.3145 & TRN \\
\hline CHEMBL3684611 & 1527879 & 7.7696 & 7.9377 & TST \\
\hline CHEMBL3639686 & 1527879 & 6.0 & 7.4927 & TRN \\
\hline CHEMBL3674830 & 1527879 & 7.2676 & 7.0258 & TRN \\
\hline CHEMBL3674754 & 1527879 & 7.9208 & 7.6872 & TRN \\
\hline CHEMBL3674768 & 1527879 & 6.4473 & 6.1957 & TRN \\
\hline CHEMBL3684650 & 1527879 & 7.699 & 7.3851 & TST \\
\hline
\end{tabular}


Supplemental Table S2.txt

\begin{tabular}{|c|c|c|c|c|c|}
\hline CHEMBL 3679775 & 1527879 & 6.6073 & 7.1022 & TRN & \\
\hline CHEMBL 3684587 & 1527879 & 8.5229 & 8.3628 & TST & \\
\hline CHEMBL 3679802 & 1527879 & 6.3045 & 6.8188 & TRN & \\
\hline CHEMBL3669799 & 1527879 & 6.6655 & 6.9445 & TRN & \\
\hline CHEMBL3674841 & 1527879 & 6.5086 & 6.6089 & TRN & \\
\hline CHEMBL3684544 & 1527879 & 7.9586 & 8.2207 & TST & \\
\hline CHEMBL 3674946 & 1527879 & 8.2218 & 8.0366 & TST & \\
\hline CHEMBL 3679933 & 1527879 & 6.9706 & 7.5639 & TST & \\
\hline CHEMBL3679787 & 1527879 & 6.4547 & \multicolumn{2}{|c|}{6.452999999999999} & TRN \\
\hline CHEMBL3674910 & 1527879 & 7.6576 & 7.6986 & TRN & \\
\hline CHEMBL3684566 & 1527879 & 6.0101 & 6.8791 & TST & \\
\hline CHEMBL3679782 & 1527879 & 7.4815 & 7.0867 & TRN & \\
\hline CHEMBL 3684620 & 1527879 & 6.3251 & 6.6931 & TST & \\
\hline CHEMBL3684595 & 1527879 & 7.9586 & 8.4188 & TST & \\
\hline CHEMBL3679816 & 1527879 & 7.4949 & 7.0737 & TRN & \\
\hline CHEMBL3684568 & 1527879 & 6.4237 & 6.4954 & TST & \\
\hline CHEMBL3679912 & 1527879 & 7.1249 & 6.7437 & TST & \\
\hline CHEMBL 3674944 & 1527879 & 7.8861 & 7.4827 & TRN & \\
\hline CHEMBL3679811 & 1527879 & 6.5952 & 6.7162 & TRN & \\
\hline CHEMBL3674771 & 1527879 & 7.8239 & 7.3475 & TRN & \\
\hline CHEMBL3674864 & 1527879 & 7.2596 & 7.2437 & TRN & \\
\hline CHEMBL 3674831 & 1527879 & 6.4949 & 6.4645 & TRN & \\
\hline CHEMBL 3674878 & 1527879 & 8.1549 & \multicolumn{2}{|c|}{7.9510000000000005} & TRN \\
\hline CHEMBL3674821 & 1527879 & 7.5086 & 7.0396 & TRN & \\
\hline CHEMBL 3684557 & 1527879 & 6.9355 & 7.0777 & TST & \\
\hline CHEMBL3684668 & 1527879 & 7.7212 & 7.5311 & TST & \\
\hline CHEMBL 3674782 & 1527879 & 7.6198 & 7.1995 & TRN & \\
\hline CHEMBL 3679822 & 1527879 & 7.3768 & 7.7388 & TST & \\
\hline CHEMBL3669781 & 1527879 & 6.4353 & 6.6346 & TRN & \\
\hline CHEMBL 3684593 & 1527879 & 6.3372 & 7.6075 & TST & \\
\hline CHEMBL 3674964 & 1527879 & 6.3696 & 6.6716 & TRN & \\
\hline CHEMBL 3684549 & 1527879 & 6.3655 & 6.959 & TST & \\
\hline CHEMBL 3669705 & 1527879 & 6.4685 & 7.0418 & TST & \\
\hline CHEMBL3674761 & 1527879 & 7.2518 & \multicolumn{2}{|c|}{6.992999999999999} & TRN \\
\hline CHEMBL 3679734 & 1527879 & 6.3307 & 7.2065 & TST & \\
\hline CHEMBL3669839 & 1527879 & 6.0 & 7.159 & TRN & \\
\hline CHEMBL3674867 & 1527879 & 6.9957 & 6.8743 & TRN & \\
\hline CHEMBL 3684644 & 1527879 & 8.2218 & 8.0011 & TST & \\
\hline CHEMBL3674912 & 1527879 & 7.0969 & 7.6455 & TRN & \\
\hline CHEMBL 3674880 & 1527879 & 7.0862 & 7.0277 & TRN & \\
\hline CHEMBL3669738 & 1527879 & 6.4535 & 6.0925 & TRN & \\
\hline CHEMBL3674877 & 1527879 & 7.3979 & 7.4292 & TRN & \\
\hline CHEMBL 3674883 & 1527879 & 7.7959 & 7.6708 & TRN & \\
\hline CHEMBL3684674 & 1527879 & 6.1778 & 6.5848 & TST & \\
\hline CHEMBL3679926 & 1527879 & 7.3565 & 7.763 & TST & \\
\hline CHEMBL3674956 & 1527879 & 7.4437 & 7.7073 & TST & \\
\hline CHEMBL3679770 & 1527879 & 6.6234 & 6.85 & TRN & \\
\hline CHEMBL3674781 & 1527879 & 7.4318 & 6.9569 & TRN & \\
\hline
\end{tabular}

Page 22237 
Supplemental Table S2.txt

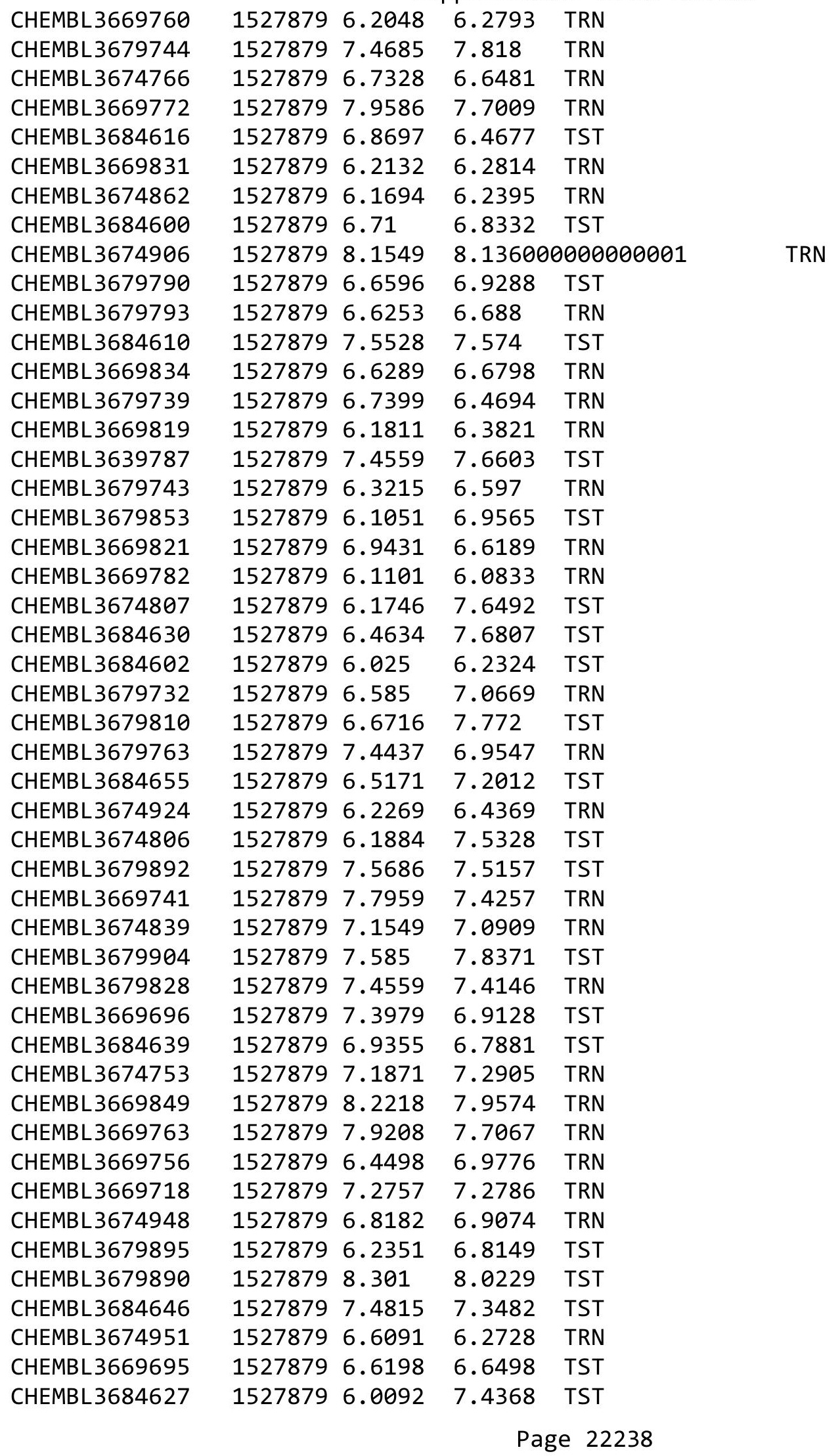


Supplemental Table S2.txt

\begin{tabular}{|c|c|c|c|c|}
\hline 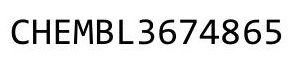 & 527879 & 7.4318 & & \\
\hline & 527879 & 7.5086 & 7.409 & \\
\hline AFMRI & 27879 & & 354 & \\
\hline IEMBL & 879 & & & \\
\hline AEMBL3669773 & 527879 & 6.9586 & 3228 & \\
\hline HEMBL 3684584 & 527879 & 586 & 5173 & \\
\hline 98 & 879 & & 2821 & \\
\hline HEMBL; & & & & \\
\hline HEMBL3674833 & 527879 & 6.5986 & & \\
\hline HEMBL3669780 & 527879 & 7. & 3841 & \\
\hline HEMBL3 & 79 & & & \\
\hline 86 & 79 & & & \\
\hline AEMBL: & & & & \\
\hline HEMBL3639737 & 879 & 6 . & & \\
\hline HEMBL366 & & & & \\
\hline HEMBL3 & $y$ & & & \\
\hline HEMBL & & & & \\
\hline HEMBL. & & & & \\
\hline HEMBI 3 & & & & \\
\hline AEMBL36 & & & 54 & 3 \\
\hline HEMBL & 79 & & & RN \\
\hline HEM & & & & 年 \\
\hline AEMBL & 79 & & & \\
\hline HEMPI & & & & IST \\
\hline AEMBL3 & & 6. & 08 & ISI \\
\hline HEMBL & & & 72 & RN \\
\hline 61 & & & & \\
\hline 79 & & & & \\
\hline HEMBL & & & & IST \\
\hline HEMBL368 & 99 & 8. & & ГST \\
\hline AEMBL & & & & RN \\
\hline 9 & & & & \\
\hline & & & & 「RN \\
\hline HEMBL3 & & & & IRN \\
\hline HEMBL 367 & 79 & & 922 & ГST \\
\hline 29 & & & & RN \\
\hline 1 & & & & RN \\
\hline HEMBL3 & & & & TST \\
\hline HEMBL3 & 9 & 7. & & ГRN \\
\hline 8 & & & & IST \\
\hline HEMBL3 & & & & 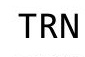 \\
\hline & & & 168 & RN \\
\hline HEMBL3 & 79 & 7.04 & 7.0386 & {$[R$} \\
\hline HEMBL3 & 79 & 8 . & & TS \\
\hline . & & & & \\
\hline HEMBL3 & & 6.9788 & 6.9075 & \\
\hline CHEMBL3 & 1527870 & 6.4711 & 6.4923 & \\
\hline CHEMBL3674772 & 1527879 & 7.5229 & 7.3349 & $1 \mathrm{~h}$ \\
\hline
\end{tabular}

Page 22239 
Supplemental Table S2.txt

\begin{tabular}{|c|c|c|c|c|}
\hline CHEMBL 3679762 & 1527879 & 7.2596 & 7.3728 & TRN \\
\hline CHEMBL 3674788 & 1527879 & 7.8539 & 7.6012 & TRN \\
\hline CHEMBL 3674835 & 1527879 & 7.1367 & 6.9435 & TRN \\
\hline CHEMBL 3674796 & 1527879 & 6.7645 & 6.5084 & TRN \\
\hline CHEMBL 3684575 & 1527879 & 7.4685 & 7.5341 & TST \\
\hline CHEMBL3679807 & 1527879 & 6.4034 & 7.4627 & TST \\
\hline CHEMBL 3679749 & 1527879 & 7.0506 & 7.4598 & TRN \\
\hline CHEMBL 3669754 & 1527879 & 6.4318 & 6.6458 & TRN \\
\hline CHEMBL 3684612 & 1527879 & 6.091 & 7.2025 & TST \\
\hline CHEMBL 3674756 & 1527879 & 7.5376 & 7.4094 & TRN \\
\hline CHEMBL3684625 & 1527879 & 7.6383 & 7.4857 & TST \\
\hline CHEMBL 3669827 & 1527879 & 7.6576 & 7.5914 & TRN \\
\hline CHEMBL 3940141 & 1527879 & 6.7144 & 7.7177 & TST \\
\hline CHEMBL 3669719 & 1527879 & 6.1549 & 6.7343 & TST \\
\hline CHEMBL 3674765 & 1527879 & 6.0 & 7.2265 & TRN \\
\hline CHEMBL3639738 & 1527879 & 7.7212 & 7.0498 & TRN \\
\hline CHEMBL3679897 & 1527879 & 6.065 & 6.8302 & TST \\
\hline CHEMBL 3679752 & 1527879 & 8.3979 & 7.9781 & TST \\
\hline CHEMBL3669747 & 1527879 & 6.1549 & 6.5812 & TRN \\
\hline CHEMBL 3669788 & 1527879 & 6.5017 & 6.3103 & TRN \\
\hline CHEMBL 3679846 & 1527879 & 7.5376 & 7.3282 & TRN \\
\hline CHEMBL 3679753 & 1527879 & 6.7773 & 6.9007 & TST \\
\hline CHEMBL 3684565 & 1527879 & 6.3809 & 7.2608 & TST \\
\hline CHEMBL3669728 & 1527879 & 6.5575 & 6.5124 & TRN \\
\hline CHEMBL 3679808 & 1527879 & 6.6635 & 7.0008 & TRN \\
\hline CHEMBL 3669778 & 1527879 & 6.3224 & 6.8137 & TRN \\
\hline CHEMBL3674799 & 1527879 & 6.4365 & 6.5808 & TRN \\
\hline CHEMBL 3679819 & 1527879 & 7.3979 & 7.5168 & TRN \\
\hline CHEMBL3669816 & 1527879 & 6.2426 & 6.4264 & TRN \\
\hline CHEMBL 3674932 & 1527879 & 6.399 & 6.2923 & TRN \\
\hline CHEMBL 3674856 & 1527879 & 6.4737 & 6.4918 & TRN \\
\hline CHEMBL 3684608 & 1527879 & 7.4815 & 7.0648 & TST \\
\hline CHEMBL 3674774 & 1527879 & 7.5376 & 7.6357 & TRN \\
\hline CHEMBL 3927648 & 1528149 & 6.0 & 6.282 & TRN \\
\hline CHEMBL3931096 & 1528149 & 8.3979 & 9.0859 & TST \\
\hline CHEMBL 3937290 & 1528149 & 9.4559 & 8.9359 & TRN \\
\hline CHEMBL3699493 & 1528149 & 6.0 & 6.4584 & TST \\
\hline CHEMBL 3905775 & 1528149 & 6.0 & 6.2416 & TRN \\
\hline CHEMBL 3986642 & 1528149 & 7.9208 & 8.0902 & TRN \\
\hline CHEMBL 3702968 & 1528149 & 7.6778 & 7.4543 & TRN \\
\hline CHEMBL 3647814 & 1528149 & 8.0458 & 8.8914 & TST \\
\hline CHEMBL 3926565 & 1528149 & 6.0 & 5.6096 & TRN \\
\hline CHEMBL3889706 & 1528149 & 8.699 & 8.7449 & TRN \\
\hline CHEMBL3979875 & 1528149 & 6.0 & 6.0889 & TRN \\
\hline CHEMBL3950153 & 1528149 & 8.2218 & 7.8298 & TRN \\
\hline CHEMBL3960937 & 1528149 & 6.0 & 6.8475 & TRN \\
\hline CHEMBL 3699489 & 1528149 & 7.9208 & 8.1959 & TRN \\
\hline CHEMBL3968168 & 1528149 & 6.0 & 6.0714 & TST \\
\hline
\end{tabular}




\begin{tabular}{|c|c|c|c|c|}
\hline \multicolumn{5}{|c|}{ Supplemental Table S2.txt } \\
\hline CHEMBL 3650680 & 1528149 & 9.0 & 8.5139 & TRN \\
\hline CHEMBL3949895 & 1528149 & 9.0 & 8.5028 & TRN \\
\hline CHEMBL3969843 & 1528149 & 6.0 & 6.1977 & TST \\
\hline CHEMBL 3913431 & 1528149 & 9.0458 & 9.7334 & TST \\
\hline CHEMBL3942197 & 1528149 & 6.0 & 6.3098 & TRN \\
\hline CHEMBL 3983874 & 1528149 & 6.0 & 6.1286 & TRN \\
\hline CHEMBL3985015 & 1528149 & 9.3468 & 9.7926 & TRN \\
\hline CHEMBL3986699 & 1528149 & 8.699 & 8.776 & TST \\
\hline CHEMBL3949390 & 1528149 & 6.0 & 6.23 & TST \\
\hline CHEMBL3927417 & 1528149 & 7.9208 & 8.2069 & TST \\
\hline CHEMBL3902006 & 1528149 & 9.5229 & 9.2015 & TST \\
\hline CHEMBL3906629 & 1528149 & 8.3979 & 7.9296 & TRN \\
\hline CHEMBL3971368 & 1528149 & 8.699 & 7.5255 & TRN \\
\hline CHEMBL3699522 & 1528149 & 6.0 & 5.9938 & TST \\
\hline CHEMBL 3927312 & 1528149 & 8.699 & 8.9689 & TST \\
\hline CHEMBL3702999 & 1528149 & 6.0 & 6.0035 & TRN \\
\hline CHEMBL3915548 & 1528149 & 8.699 & 8.5104 & TRN \\
\hline CHEMBL 3647828 & 1528149 & 6.0 & 6.7074 & TRN \\
\hline CHEMBL3912739 & 1528149 & 9.0 & 9.2472 & TRN \\
\hline CHEMBL3935071 & 1528149 & 10.0 & 9.5348 & TRN \\
\hline CHEMBL 3946964 & 1528149 & 8.699 & 8.3542 & TRN \\
\hline CHEMBL3930691 & 1528149 & 9.0 & 8.4572 & TRN \\
\hline CHEMBL 3703010 & 1528149 & 6.0 & 6.1628 & TRN \\
\hline CHEMBL 3947877 & 1528149 & 6.0 & 5.7234 & TRN \\
\hline CHEMBL3918625 & 1528149 & 6.0 & 6.6466 & TRN \\
\hline CHEMBL 3932785 & 1528149 & 8.5229 & 8.0089 & TST \\
\hline CHEMBL3936120 & 1528149 & 6.0 & 6.3043 & TRN \\
\hline CHEMBL3699460 & 1528149 & 6.0 & 5.9096 & TRN \\
\hline CHEMBL 3947274 & 1528149 & 9.6021 & 8.1179 & TRN \\
\hline CHEMBL3971955 & 1528149 & 6.0 & 6.1456 & TRN \\
\hline CHEMBL 3986434 & 1528149 & 8.3979 & 8.3514 & TRN \\
\hline CHEMBL3980321 & 1528149 & 8.699 & 8.6911 & TST \\
\hline CHEMBL3647901 & 1528149 & 6.0 & 6.1664 & TST \\
\hline CHEMBL3918791 & 1528149 & 6.0 & 5.9292 & TRN \\
\hline CHEMBL3699465 & 1528149 & 8.0458 & 7.9887 & TRN \\
\hline CHEMBL3898353 & 1528149 & 6.0 & 5.8646 & TRN \\
\hline CHEMBL3906377 & 1528149 & 8.2218 & 8.1942 & TRN \\
\hline CHEMBL3981024 & 1528149 & 6.0 & 6.2005 & TRN \\
\hline CHEMBL3969261 & 1528149 & 6.0 & 5.7261 & TRN \\
\hline CHEMBL3906754 & 1528149 & 8.3979 & 8.9432 & TST \\
\hline CHEMBL 3913841 & 1528149 & 8.3979 & 8.5116 & TRN \\
\hline CHEMBL 3944882 & 1528149 & 9.5229 & 10.1135 & TRN \\
\hline CHEMBL3913749 & 1528149 & 7.7447 & 7.7991 & TRN \\
\hline CHEMBL 3934454 & 1528149 & 9.0706 & 8.7902 & TST \\
\hline CHEMBL3920925 & 1528149 & 6.0 & 5.7984 & TRN \\
\hline CHEMBL 3647894 & 1528149 & 6.0 & 6.2917 & TST \\
\hline CHEMBL3891172 & 1528149 & 9.699 & 10.0413 & TST \\
\hline CHEMBL 3647896 & 1528149 & 6.0 & 6.2586 & TST \\
\hline
\end{tabular}




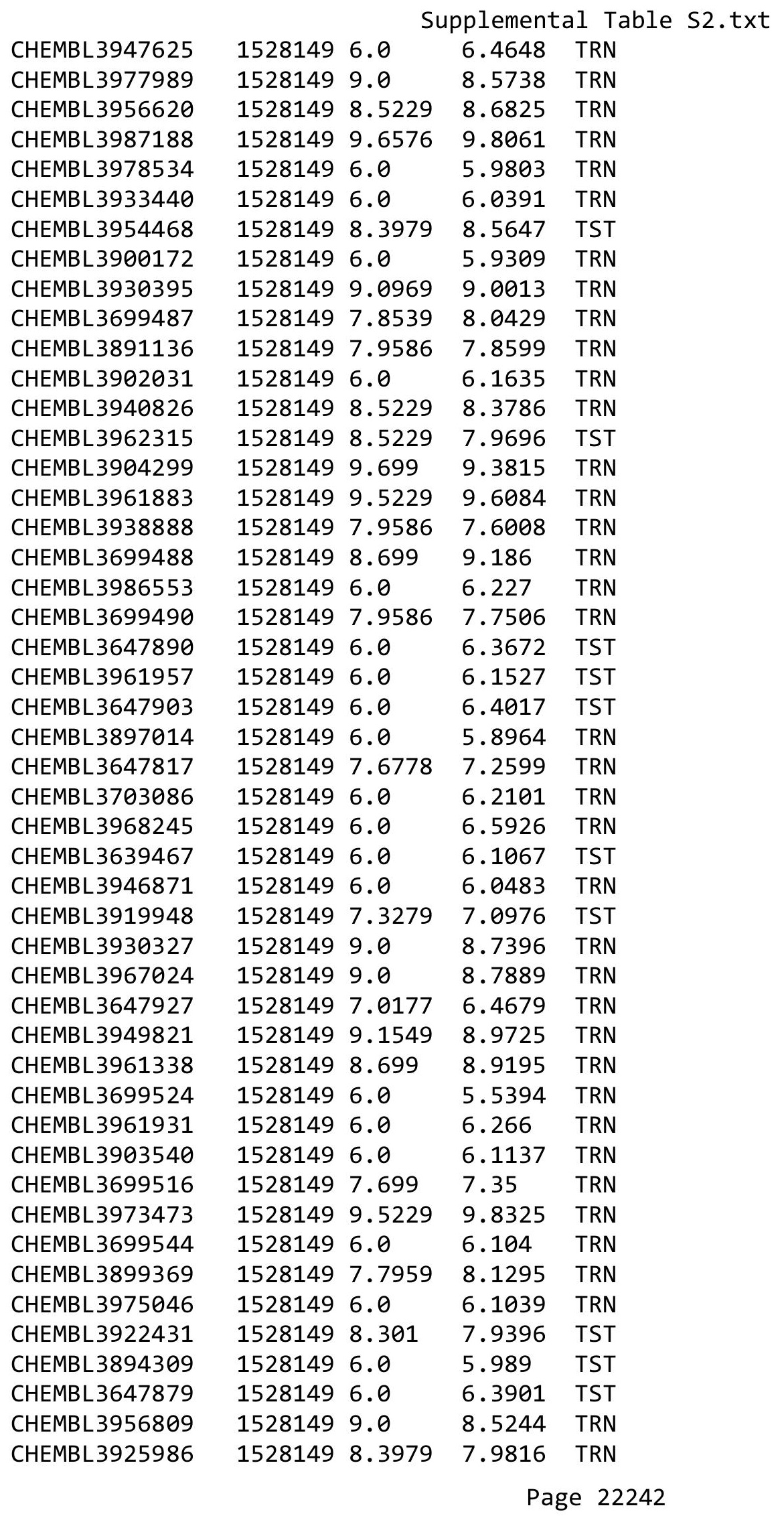


Supplemental Table S2.txt

\begin{tabular}{|c|c|c|c|c|}
\hline HEMBL3939342 & 528149 & & נים & ת \\
\hline HEMBL3699463 & 28149 & 8.5229 & 8.3852 & \\
\hline & 28149 & 6.0 & & \\
\hline 47822 & 28149 & 6.0 & 04 & \\
\hline IEMBL 3647763 & 528149 & 6.0 & 6755 & \\
\hline AEMBL3896610 & 528149 & 8.30 & 7272 & \\
\hline AEMBL3890435 & 528149 & 6.0 & 1835 & \\
\hline IEMBL 3944704 & 149 & & 677 & \\
\hline AEMBL3941713 & 528149 & 6.0 & .0679 & \\
\hline HEMBL3970898 & 528149 & 8.699 & 4807 & \\
\hline AEMBL3702889 & 528149 & 9.3979 & 6382 & \\
\hline IEMBL3958854 & 528149 & 8.04 & .9015 & \\
\hline _3979847 & 149 & & .1867 & RN \\
\hline AEMBL3699496 & 528149 & 6.8013 & & \\
\hline AEMBL3955512 & 528149 & 6.0 & 541 & \\
\hline AEMBL3955677 & 528149 & 9.04 & .0061 & \\
\hline AEMBL3980384 & 149 & 9.0 & 9.4731 & \\
\hline AEMBL3897086 & 149 & & 6.4669 & r \\
\hline L3928060 & 149 & 6.0 & 6.6059 & \\
\hline 3903615 & 149 & 6.0 & & \\
\hline AEMBL3955214 & 149 & 7.79 & 545 & SI \\
\hline L3889814 & 149 & 6.0 & 255 & $\mathrm{RN}$ \\
\hline L3702888 & 149 & 8.52 & 2909 & \\
\hline 920265 & 149 & 6.0 & $\partial 511$ & \\
\hline 251 & & 7 & 394 & \\
\hline L 3974285 & 149 & 6 & .5876 & SI \\
\hline 3911301 & 149 & 9 & 141 & RN \\
\hline 1766 & 49 & & 7596 & \\
\hline 714 & 149 & 6.0 & 3778 & \\
\hline MBL3647833 & 49 & 7 & & 3 \\
\hline AEMBL3947081 & 149 & 8.69 & 102 & Rl \\
\hline 3983950 & 149 & 6.0 & 429 & $m$ \\
\hline 875 & 49 & 6.0 & 907 & \\
\hline AEMBL3982012 & & 8.39 & 244 & RN \\
\hline AEMBL3935933 & 149 & 9.30 & 267 & $\mathrm{RI}$ \\
\hline MBL3703011 & 149 & 6 & 842 & $\mathrm{R}$ \\
\hline - 20 ו I & 49 & 6 & 11 & 10 \\
\hline & & 9.0 & 66 & RN \\
\hline HEMBL3890723 & 528149 & 8.69 & 578 & ГRN \\
\hline MBL 3893006 & 149 & & 106 & $\mathrm{R}$ \\
\hline IEMBL3949310 & 149 & 9.69 & 928 & $\mathrm{R}$ \\
\hline CHEMBL3924444 & & 9.0 & 9.6514 & . \\
\hline MBL3937800 & 149 & 6.0 & . 9957 & RN \\
\hline EML 3932800 & 528149 & 9.096 & 7371 & \\
\hline 3L3980592 & 149 & $y$ & & $\mathrm{R}$ \\
\hline EML 3953895 & & & 5822 & \\
\hline CHEMBL3703033 & 149 & 6.0 & 6.1351 & \\
\hline CHEMBL3981970 & 1528149 & 6.0 & 5.9746 & \\
\hline
\end{tabular}

Page 22243 
Supplemental Table S2.txt

\begin{tabular}{|c|c|c|c|c|c|}
\hline CHEMBL 3940602 & 1528149 & 9.0706 & 8.6558 & TRN & \\
\hline CHEMBL 3650677 & 1528149 & 6.0 & 6.4977 & TST & \\
\hline CHEMBL3647919 & 1528149 & 9.4559 & 9.5498 & TST & \\
\hline CHEMBL 3898629 & 1528149 & 8.3979 & 8.5221 & TST & \\
\hline CHEMBL 3702983 & 1528149 & 8.3979 & 8.3758 & TST & \\
\hline CHEMBL 3912434 & 1528149 & 8.699 & 8.5249 & TRN & \\
\hline CHEMBL3980212 & 1528149 & 9.7212 & 9.7426 & TRN & \\
\hline CHEMBL3891505 & 1528149 & 6.0 & 6.3272 & TRN & \\
\hline CHEMBL 3950304 & 1528149 & 9.0 & 8.9567 & TRN & \\
\hline CHEMBL3905139 & 1528149 & 6.0 & 5.7052 & TRN & \\
\hline CHEMBL3931852 & 1528149 & 9.3979 & 9.3894 & TRN & \\
\hline CHEMBL3965405 & 1528149 & 6.0 & 6.1967 & TRN & \\
\hline CHEMBL3915890 & 1528149 & 8.0 & 8.2921 & TRN & \\
\hline CHEMBL3699557 & 1528149 & 6.0 & 5.9548 & TRN & \\
\hline CHEMBL 3907546 & 1528149 & 6.0 & 6.4879 & TRN & \\
\hline CHEMBL3985892 & 1528149 & 6.0 & 6.3209 & TRN & \\
\hline CHEMBL3925967 & 1528149 & 8.2218 & 7.8591 & TRN & \\
\hline CHEMBL 3955280 & 1528149 & 6.0 & 6.2024 & TRN & \\
\hline CHEMBL 3944762 & 1528149 & 7.7212 & 7.3697 & TRN & \\
\hline CHEMBL3926832 & 1528149 & 8.2218 & 8.5317 & TST & \\
\hline CHEMBL 3944102 & 1528149 & 8.2218 & 8.8555 & TST & \\
\hline CHEMBL3926369 & 1528149 & 8.2218 & 7.8888 & TRN & \\
\hline CHEMBL3928280 & 1528149 & 6.0 & 6.1165 & TRN & \\
\hline CHEMBL 3951734 & 1528149 & 9.0 & 9.3799 & TRN & \\
\hline CHEMBL3962282 & 1528149 & 6.0 & 6.2264 & TRN & \\
\hline CHEMBL 3702887 & 1528149 & 9.4815 & 9.3485 & TRN & \\
\hline CHEMBL3650683 & 1528149 & 6.0 & 6.2344 & TRN & \\
\hline CHEMBL3702890 & 1528149 & 7.5229 & 7.0423 & TST & \\
\hline CHEMBL 3897877 & 1528149 & 9.3979 & 9.0983 & TST & \\
\hline CHEMBL3940540 & 1528149 & 9.0458 & 9.021 & TRN & \\
\hline CHEMBL3962416 & 1528149 & 6.0 & 5.96299 & 9999999999 & TRN \\
\hline CHEMBL 3913145 & 1528149 & 6.0 & 6.1976 & TRN & \\
\hline CHEMBL3699545 & 1528149 & 6.0 & 5.6655 & TRN & \\
\hline CHEMBL 3647931 & 1528149 & 6.0 & 6.527 & TRN & \\
\hline CHEMBL3699517 & 1528149 & 7.9586 & 7.7778 & TRN & \\
\hline CHEMBL 3963870 & 1528149 & 6.0 & 5.7597 & TRN & \\
\hline CHEMBL3942620 & 1528149 & 8.2218 & 8.1713 & TRN & \\
\hline CHEMBL 3647920 & 1528149 & 7.699 & 7.9914 & TST & \\
\hline CHEMBL 3914361 & 1528149 & 7.3979 & 6.6652 & TRN & \\
\hline CHEMBL3944520 & 1528149 & 9.5229 & 8.8809 & TRN & \\
\hline CHEMBL 3647885 & 1528149 & 6.0 & 6.1275 & TST & \\
\hline CHEMBL3955894 & 1528149 & 8.1549 & 8.2569 & TRN & \\
\hline CHEMBL3949813 & 1528149 & 6.0 & 6.1365 & TRN & \\
\hline CHEMBL 3954496 & 1528149 & 6.0 & 5.2718 & TRN & \\
\hline CHEMBL3894428 & 1528149 & 6.0 & 5.8674 & TRN & \\
\hline CHEMBL3911133 & 1528149 & 6.0 & 6.1018 & TRN & \\
\hline CHEMBL 3647922 & 1528149 & 6.0 & 5.7979 & TRN & \\
\hline CHEMBL 3926173 & 1528149 & 9.0 & 8.9587 & TRN & \\
\hline
\end{tabular}




$$
\text { Supplemental Table S2.txt }
$$

\begin{tabular}{|c|c|c|c|c|c|}
\hline CHEMBL3975871 & 1528149 & 8.5229 & 8.5481 & TRN & \\
\hline CHEMBL3939393 & 1528149 & 9.0 & 9.0778 & TRN & \\
\hline CHEMBL3647910 & 1528149 & 6.0 & 6.7557 & TST & \\
\hline CHEMBL3699491 & 1528149 & 7.2676 & 7.8384 & TRN & \\
\hline CHEMBL3986238 & 1528149 & 6.0 & 6.2126 & TRN & \\
\hline CHEMBL3890956 & 1528149 & 6.0 & 6.2419 & TRN & \\
\hline CHEMBL3926773 & 1528149 & 9.3979 & 10.4695 & TST & \\
\hline CHEMBL3965754 & 1528149 & 6.0 & 5.2094 & TST & \\
\hline CHEMBL3980805 & 1528149 & 6.0 & 6.41 & TRN & \\
\hline CHEMBL3966795 & 1528149 & 8.699 & 8.9237 & TRN & \\
\hline CHEMBL3911297 & 1528149 & 6.0 & 5.9113 & TRN & \\
\hline CHEMBL3895835 & 1528149 & 6.0 & 5.9768 & TRN & \\
\hline CHEMBL3905077 & 1528149 & 6.0 & 6.231 & TRN & \\
\hline CHEMBL3950555 & 1528149 & 7.9208 & 7.8598 & TRN & \\
\hline CHEMBL3933155 & 1528149 & 8.3979 & 8.2933 & TRN & \\
\hline CHEMBL3978412 & 1528149 & 9.301 & 9.15899 & 9999999999 & TRN \\
\hline CHEMBL3932299 & 1528149 & 6.0 & 6.597 & TRN & \\
\hline CHEMBL3905747 & 1528149 & 6.0 & 5.7305 & TRN & \\
\hline CHEMBL 3925680 & 1528149 & 6.0 & 5.5534 & TRN & \\
\hline CHEMBL3647897 & 1528149 & 6.0 & 6.5651 & TST & \\
\hline CHEMBL3703000 & 1528149 & 6.0 & 6.6947 & TRN & \\
\hline CHEMBL3968730 & 1528149 & 6.0 & 5.8302 & TRN & \\
\hline CHEMBL3951386 & 1528149 & 8.1549 & 8.1264 & TRN & \\
\hline CHEMBL3946519 & 1528149 & 9.0 & 8.7509 & TRN & \\
\hline CHEMBL3911534 & 1528149 & 8.301 & 7.9774 & TRN & \\
\hline CHEMBL3979432 & 1528149 & 6.0 & 5.8184 & TRN & \\
\hline CHEMBL3937969 & 1528149 & 6.0 & 6.1889 & TRN & \\
\hline CHEMBL3647895 & 1528149 & 8.1549 & 7.3647 & TST & \\
\hline CHEMBL3934905 & 1528149 & 6.0 & 5.9035 & TRN & \\
\hline CHEMBL3968521 & 1528149 & 9.0 & 8.8608 & TRN & \\
\hline CHEMBL3945564 & 1528149 & 6.0 & 6.1032 & TRN & \\
\hline CHEMBL3926117 & 1528149 & 9.301 & 10.1428 & TST & \\
\hline CHEMBL3946577 & 1528149 & 6.0 & 6.3998 & TRN & \\
\hline CHEMBL 3974198 & 1528149 & 9.2366 & 9.1849 & TRN & \\
\hline CHEMBL3904849 & 1528149 & 7.2218 & 7.2326 & TST & \\
\hline CHEMBL3699467 & 1528149 & 6.0 & 6.402 & TRN & \\
\hline CHEMBL3905087 & 1528149 & 6.0 & 6.1012 & TRN & \\
\hline CHEMBL3918665 & 1528149 & 8.699 & 8.5431 & TRN & \\
\hline CHEMBL3981519 & 1528149 & 8.3979 & 8.4642 & TRN & \\
\hline CHEMBL3919610 & 1528149 & 6.0 & \multicolumn{2}{|c|}{5.837000000000001} & TRN \\
\hline CHEMBL3933602 & 1528149 & 9.5229 & 9.6739 & TRN & \\
\hline CHEMBL3948095 & 1528149 & 9.4559 & 9.6586 & TRN & \\
\hline CHEMBL3702964 & 1528149 & 6.0 & 5.9247 & TRN & \\
\hline CHEMBL3911693 & 1528149 & 6.0 & 5.6634 & TRN & \\
\hline CHEMBL3927441 & 1528149 & 6.0 & \multicolumn{2}{|c|}{6.3870000000000005} & TRN \\
\hline CHEMBL3941329 & 1528149 & 6.0 & 6.3781 & TRN & \\
\hline CHEMBL3935016 & 1528149 & 9.301 & 8.9685 & TRN & \\
\hline CHEMBL3967801 & 1528149 & 8.699 & 8.4333 & TRN & \\
\hline
\end{tabular}




\begin{tabular}{|c|c|c|c|c|c|}
\hline \multirow[b]{2}{*}{ CHEMBL3647816 } & \multicolumn{5}{|c|}{ Supplemental Table s2.txt } \\
\hline & 1528149 & 9.0 & 8.207 & TRN & \\
\hline CHEMBL3639466 & 1528149 & 9.0706 & 8.9469 & TRN & \\
\hline CHEMBL 3904018 & 1528149 & 8.5229 & 9.1945 & TRN & \\
\hline CHEMBL 3946315 & 1528149 & 6.0 & 7.0006 & TRN & \\
\hline CHEMBL3961410 & 1528149 & 9.4559 & 9.642000 & 0000000001 & TST \\
\hline CHEMBL3973107 & 1528149 & 6.0 & 6.0152 & TRN & \\
\hline CHEMBL 3958728 & 1528149 & 8.3979 & 8.3008 & TRN & \\
\hline CHEMBL 3974844 & 1528149 & 9.0 & 8.9522 & TRN & \\
\hline CHEMBL3702928 & 1528149 & 8.0 & 9.7324 & TST & \\
\hline CHEMBL3702982 & 1528149 & 9.3979 & 9.3261 & TST & \\
\hline CHEMBL 3918680 & 1528149 & 6.4318 & 6.2552 & TRN & \\
\hline CHEMBL 3904552 & 1528149 & 8.1549 & 8.1054 & TRN & \\
\hline CHEMBL 3957578 & 1528149 & 9.2218 & 8.9628 & TRN & \\
\hline CHEMBL 3972903 & 1528149 & 6.0 & 6.6184 & TRN & \\
\hline CHEMBL3935674 & 1528149 & 9.0 & 9.0938 & TRN & \\
\hline CHEMBL3647933 & 1528149 & 8.5229 & 10.0221 & TST & \\
\hline CHEMBL3962506 & 1528149 & 9.6021 & 10.0229 & TRN & \\
\hline CHEMBL3906102 & 1528149 & 6.3737 & 4.7062 & TST & \\
\hline CHEMBL 3986153 & 1528149 & 6.0 & 6.2026 & TRN & \\
\hline CHEMBL3647907 & 1528149 & 6.0 & 6.4691 & TST & \\
\hline CHEMBL3699495 & 1528149 & 8.301 & 8.8103 & TST & \\
\hline CHEMBL3894930 & 1528149 & 6.0 & 5.8566 & TRN & \\
\hline CHEMBL3917754 & 1528149 & 6.0 & 6.8051 & TRN & \\
\hline CHEMBL 3647758 & 1528149 & 6.0 & 6.4284 & TRN & \\
\hline CHEMBL3896429 & 1528149 & 9.1871 & 9.8747 & TRN & \\
\hline CHEMBL3647932 & 1528149 & 9.4685 & 9.5116 & TRN & \\
\hline CHEMBL3911649 & 1528149 & 9.4949 & 9.2368 & TRN & \\
\hline CHEMBL3941828 & 1528149 & 9.2596 & 9.5493 & TST & \\
\hline CHEMBL 3927307 & 1528149 & 9.0 & 8.7333 & TRN & \\
\hline CHEMBL3909205 & 1528149 & 8.699 & 8.4769 & TST & \\
\hline CHEMBL 3943238 & 1528149 & 9.4559 & 9.8635 & TRN & \\
\hline CHEMBL 3647880 & 1528149 & 6.0 & 6.4171 & TST & \\
\hline CHEMBL 3949220 & 1528149 & 9.301 & 8.8817 & TRN & \\
\hline CHEMBL 3936080 & 1528149 & 9.301 & 9.469 & TRN & \\
\hline CHEMBL3939667 & 1528149 & 9.699 & $10.6540 e$ & 00000000002 & TRN \\
\hline CHEMBL3963187 & 1528149 & 8.699 & 8.3748 & TRN & \\
\hline CHEMBL3907111 & 1528149 & 6.0 & 6.4267 & TRN & \\
\hline CHEMBL3906920 & 1528149 & 8.699 & 9.1961 & TST & \\
\hline CHEMBL 3647882 & 1528149 & 6.0 & 6.0929 & TST & \\
\hline CHEMBL3647912 & 1528149 & 9.0969 & 9.2533 & TST & \\
\hline CHEMBL3953602 & 1528149 & 9.6021 & 9.7505 & TRN & \\
\hline CHEMBL3987003 & 1528149 & 8.5229 & 8.1256 & TRN & \\
\hline CHEMBL3981318 & 1528149 & 9.0 & 8.5795 & TRN & \\
\hline CHEMBL 3953459 & 1528149 & 6.0 & 5.8215 & TRN & \\
\hline CHEMBL3647819 & 1528149 & 8.2218 & 7.8849 & TRN & \\
\hline CHEMBL 3893424 & 1528149 & 9.0458 & 8.0092 & TRN & \\
\hline CHEMBL3978079 & 1528149 & 6.0 & 5.7583 & TRN & \\
\hline CHEMBL 3934845 & 1528149 & 8.699 & 8.5967 & TRN & \\
\hline
\end{tabular}




$$
\text { Supplemental Table S2.txt }
$$

\begin{tabular}{|c|c|c|c|c|}
\hline HEMBL 3920468 & 528149 & 8.699 & 8.2729 & TST \\
\hline HEMBL 3702936 & 528149 & 7.1739 & 7.4471 & \\
\hline HEMBL: & 28149 & 6.0 & 1828 & \\
\hline HEMBL3986157 & 28149 & 3979 & 1822 & \\
\hline HEMBL3942649 & 528149 & 7.7696 & .678 & \\
\hline HEMBL3897598 & 528149 & 8.699 & .0346 & \\
\hline 3226 & 528149 & 9.0 & 871 & \\
\hline HEMBL3904521 & 528149 & 6.0 & & $\mathrm{M}$ \\
\hline HEMBL3951452 & 528149 & 9.1249 & 9.0129 & \\
\hline HEMBL3986312 & 528149 & 6.0 & 6.3035 & \\
\hline HEMBL3699515 & 528149 & 7.0809 & 6.754 & \\
\hline AEMBL3 & 49 & 9. & 1065 & \\
\hline HEMBL3 & 49 & 6. & & \\
\hline HEMBL3647821 & 528149 & 7.7959 & 7.8 & \\
\hline HEMBL3699504 & 149 & 7.6383 & & \\
\hline HEMBL3E & 19 & 6. & 16 & RIN \\
\hline HEMBL3 & 19 & 9. & & ונס \\
\hline HEMBL3 & 49 & 229 & & \\
\hline HEMBL3 & 49 & 6.0 & & \\
\hline HEMBL3967854 & 49 & 9 & 97 & SI \\
\hline HEMBL3 & 49 & 9 & 15 & RN \\
\hline AEME & 19 & 6 & & RN \\
\hline HEMBL & 49 & 8.5229 & 45 & $\mathrm{RN}$ \\
\hline HEMBL3 & 49 & 6.0 & & TRN \\
\hline AEMBL3 & & 6 & 97 & IRN \\
\hline HEMBL3 & 19 & 6 & 87 & ST \\
\hline HEMBL & 49 & 6. & & $\mathrm{RN}$ \\
\hline HEMBL & & 8.22 & 45 & TST \\
\hline HEMBL3 & & 6. & & ГST \\
\hline HEMBL3703007 & & 6. & 9823 & TRN \\
\hline HEMBL. & & 9. & 45 & RN \\
\hline HFM & 19 & & & RN \\
\hline - & & & & TST \\
\hline HEMBL3889531 & 49 & & & 「RN \\
\hline HEMBL3699486 & 49 & 7.769 & 785 & ГRN \\
\hline$A F M P I 2$ & 19 & 6. & 78 & ГST \\
\hline 2 & 19 & 6. & 71 & ГRN \\
\hline HEMBL3 & & 9.259 & & TRN \\
\hline HEMBL3 & 49 & 6 & & TRN \\
\hline IEMBL & +9 & 6 & & RN \\
\hline HEMBL3 & & & 12 & \\
\hline HEMBL3 & 49 & 6.0 & 531 & ГST \\
\hline HEMBL3 & 49 & & 0246 & TRN \\
\hline HEMBL3 & 49 & & & $\Gamma R$ \\
\hline 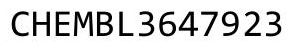 & & & & \\
\hline CHEMBL3647893 & 1528149 & 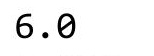 & 6.5222 & \\
\hline CHEMBL3903592 & 1528149 & $6.5 \varepsilon$ & 5.5698 & TRN \\
\hline CHEMBL3699494 & 1528149 & 8.1549 & 8.3821 & TRN \\
\hline
\end{tabular}

Page 22247 
Supplemental Table S2.txt

\begin{tabular}{|c|c|c|c|c|c|}
\hline CHEMBL3950053 & 1528149 & 8.699 & 8.0737 & TST & \\
\hline CHEMBL3647918 & 1528149 & 9.3468 & 9.8861 & TST & \\
\hline CHEMBL3892594 & 1528149 & 9.3468 & 9.2726 & TRN & \\
\hline CHEMBL3647820 & 1528149 & 8.2218 & 8.1325 & TRN & \\
\hline CHEMBL3904535 & 1528149 & 6.0 & 6.2358 & TST & \\
\hline CHEMBL3699472 & 1528149 & 6.0 & 6.2521 & TRN & \\
\hline CHEMBL3970949 & 1528149 & 9.0 & 9.4277 & TRN & \\
\hline CHEMBL 3892414 & 1528149 & 9.3468 & 8.9509 & TRN & \\
\hline CHEMBL3902508 & 1528149 & 8.2218 & 7.4836 & TST & \\
\hline CHEMBL3949116 & 1528149 & 9.2757 & 10.0042 & TRN & \\
\hline CHEMBL3940437 & 1528149 & 9.7959 & 9.5685 & TRN & \\
\hline CHEMBL3647928 & 1528149 & 8.699 & 7.8 & TST & \\
\hline CHEMBL3897122 & 1528149 & 9.1871 & 8.2577 & TST & \\
\hline CHEMBL 3899820 & 1528149 & 6.0 & 5.9814 & TRN & \\
\hline CHEMBL3927713 & 1528149 & 9.0 & 8.9974 & TRN & \\
\hline CHEMBL3890716 & 1528149 & 6.0 & 5.7796 & TRN & \\
\hline CHEMBL3949858 & 1528149 & 6.0 & 6.1678 & TRN & \\
\hline CHEMBL3965680 & 1528149 & 9.3468 & 8.6791 & TST & \\
\hline CHEMBL3699462 & 1528149 & 8.301 & 7.824 & TRN & \\
\hline CHEMBL3955379 & 1528149 & 9.0 & 9.4284 & TST & \\
\hline CHEMBL3942104 & 1642380 & 6.0 & 5.8733 & TRN & \\
\hline CHEMBL3913945 & 1642380 & 8.6946 & 8.6075 & TRN & \\
\hline CHEMBL3981104 & 1642380 & 8.9626 & 8.8649 & TRN & \\
\hline CHEMBL3975766 & 1642380 & 8.9172 & 9.2277 & TRN & \\
\hline CHEMBL3944062 & 1642380 & 10.3028 & 10.4118 & TRN & \\
\hline CHEMBL3924152 & 1642380 & 6.0 & 5.853 & TRN & \\
\hline CHEMBL3961287 & 1642380 & 7.5003 & 7.6047 & TST & \\
\hline CHEMBL3946970 & 1642380 & 10.3188 & 10.616 & TRN & \\
\hline CHEMBL3943705 & 1642380 & 10.7212 & 10.7683 & TRN & \\
\hline CHEMBL3906127 & 1642380 & 9.129 & 8.8167 & TRN & \\
\hline CHEMBL3893598 & 1642380 & 10.0315 & 9.935 & TRN & \\
\hline CHEMBL3900258 & 1642380 & 10.6383 & 10.2754 & TST & \\
\hline CHEMBL3976267 & 1642380 & 6.0 & 5.9485 & TRN & \\
\hline CHEMBL3909947 & 1642380 & 9.6799 & 9.5099 & TST & \\
\hline CHEMBL3927952 & 1642380 & 6.0 & 5.9706 & TRN & \\
\hline CHEMBL3934315 & 1642380 & 9.5768 & 9.7004 & TRN & \\
\hline CHEMBL3900834 & 1642380 & 8.8697 & 8.8647 & TRN & \\
\hline CHEMBL3906850 & 1642380 & 8.8013 & 8.7791 & TRN & \\
\hline CHEMBL3910536 & 1642380 & 10.7447 & 10.8539 & TRN & \\
\hline CHEMBL3902417 & 1642380 & 10.30099 & 999999999 & 998 & 9.9581 \\
\hline CHEMBL3900425 & 1642380 & 9.9031 & 10.2314 & TST & \\
\hline CHEMBL3965741 & 1642380 & 9.1858 & 9.7309 & TRN & \\
\hline CHEMBL3956717 & 1642380 & 9.1838 & 9.2888 & TRN & \\
\hline CHEMBL 3968140 & 1642380 & 9.0605 & 8.6349 & TRN & \\
\hline CHEMBL3930402 & 1642380 & 8.7905 & 8.7199 & TST & \\
\hline CHEMBL3943759 & 1642380 & 6.0 & 6.6124 & TRN & \\
\hline CHEMBL3918384 & 1642380 & 6.0 & 6.5141 & TST & \\
\hline CHEMBL3916902 & 1642380 & 9.0894 & 9.314 & TRN & \\
\hline
\end{tabular}


Supplemental Table S2.txt

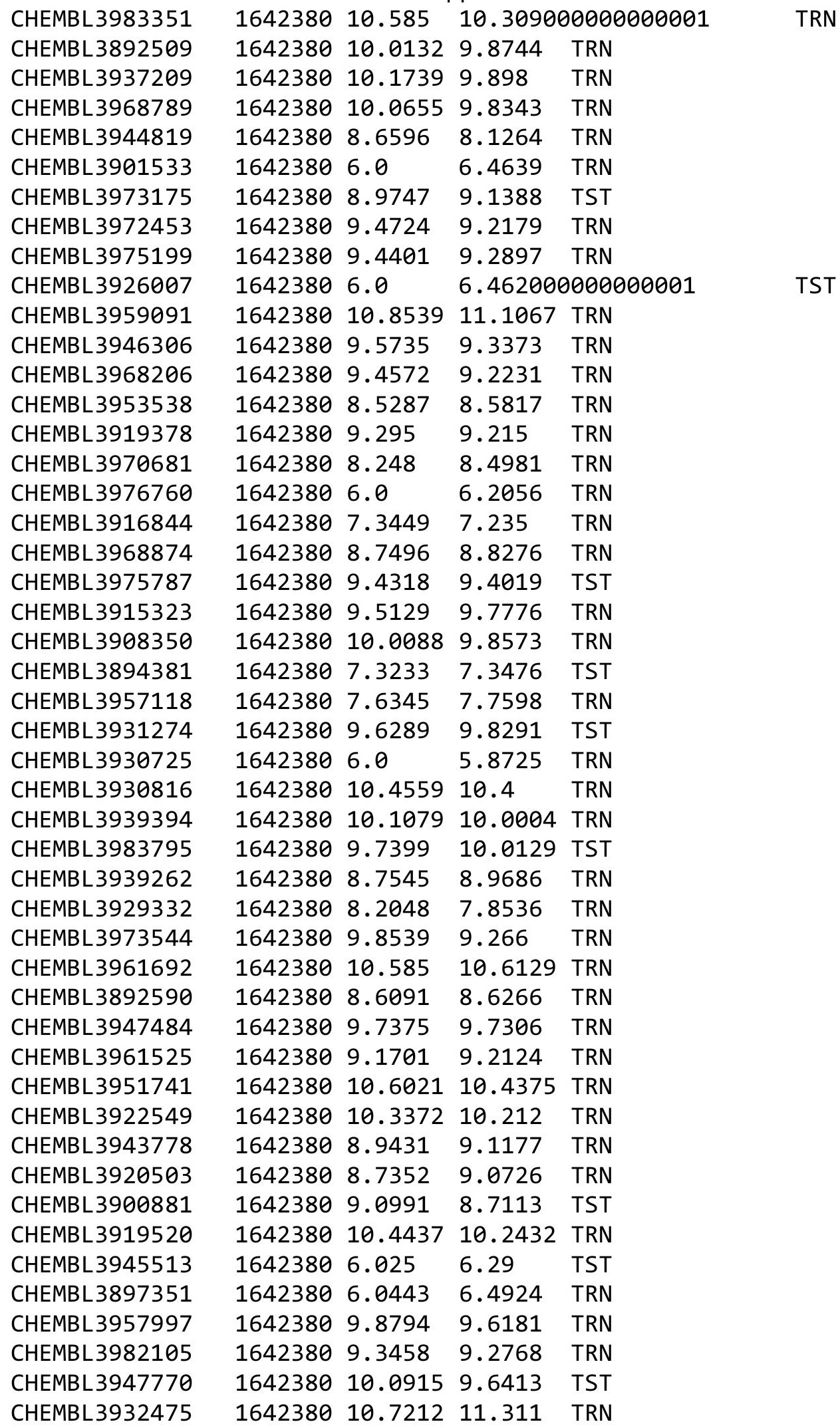

Page 22249 
Supplemental Table S2.txt

\begin{tabular}{|c|c|c|c|c|}
\hline & & & & \\
\hline & & & & \\
\hline & & & & \\
\hline 03 & 380 & & & \\
\hline 99 & 380 & & & \\
\hline AEMBL & 380 & 367 & 566 & \\
\hline 20 & 380 & & & \\
\hline 34 & 380 & & & \\
\hline IEMBL & 380 & 9. & & \\
\hline 935018 & 380 & 279 & 248 & \\
\hline 634 & 380 & & & \\
\hline 23 & 380 & & & \\
\hline 19 & & & & \\
\hline IEMBL & 380 & 10.8861 & 355 & \\
\hline MBL & 380 & 135 & & \\
\hline 56 & 30 & 38 & & \\
\hline 32 & 80 & & & \\
\hline 96 & 380 & & & \\
\hline 146 & 380 & & & \\
\hline 40 & & & & \\
\hline 54 & 30 & 71 & & \\
\hline & 80 & & & \\
\hline 12 & 380 & & & \\
\hline 49 & 380 & & & \\
\hline 82 & & & & \\
\hline 33 & 80 & & & TII \\
\hline & 30 & & & \\
\hline & 80 & 10 & 86 & \\
\hline & 380 & & & \\
\hline 23 & 30 & & & 15 \\
\hline & & & & 101 \\
\hline & 30 & 18 & & \\
\hline & 30 & & & \\
\hline & & & & RN \\
\hline & 80 & & & \\
\hline & & & & $\mathrm{R}$ \\
\hline & & & & RN \\
\hline & & & & TRN \\
\hline IEMBL 3917077 & 380 & 10.1675 & & 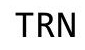 \\
\hline EML & 380 & & & 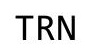 \\
\hline בנק & 80 & 10 & 752 & $\mathrm{R}$ \\
\hline 936808 & 80 & 9.51 & & $\mathrm{R}$ \\
\hline & & 10. & & $\mathrm{R}$ \\
\hline MBL & 380 & 10. & 879 & r \\
\hline מב וסבי & 20 & $8 . e$ & & \\
\hline & & 10. & & \\
\hline & 380 & & & \\
\hline CHEMBL394737 & 164238 & 9.0506 & 9.1951 & \\
\hline
\end{tabular}

Page 22250 
Supplemental Table S2.txt

\begin{tabular}{|c|c|c|c|c|c|c|}
\hline CHEMBL 3933868 & 1642380 & 9.8477 & \multicolumn{3}{|c|}{9.857000000000001} & TRN \\
\hline CHEMBL 3929264 & 1642380 & 9.1831 & 9.1363 & TRN & & \\
\hline CHEMBL3947309 & 1642380 & 10.0088 & 10.0724 & TRN & & \\
\hline CHEMBL 3951088 & 1642380 & 10.0315 & 10.2467 & TRN & & \\
\hline CHEMBL 3900423 & 1642380 & 9.4318 & 9.378 & TRN & & \\
\hline CHEMBL 3907848 & 1642380 & 9.3391 & 9.2333 & TRN & & \\
\hline CHEMBL 3960554 & 1642380 & 10.7011 & 10.7759 & TRN & & \\
\hline CHEMBL 3906421 & 1642380 & 6.0 & 6.2246 & TRN & & \\
\hline CHEMBL 3960858 & 1642380 & 8.1726 & 7.903 & TRN & & \\
\hline CHEMBL 3952845 & 1642380 & 6.0 & 5.9566 & TRN & & \\
\hline CHEMBL3926614 & 1642380 & 8.7352 & 8.9094 & TRN & & \\
\hline CHEMBL 3942446 & 1642380 & 10.0706 & 10.1539 & TRN & & \\
\hline CHEMBL3985113 & 1642380 & 6.5467 & 6.4685 & TRN & & \\
\hline CHEMBL3900796 & 1642380 & 8.6925 & 9.0174 & TST & & \\
\hline CHEMBL 3892885 & 1642380 & 10.2676 & 10.7782 & TRN & & \\
\hline CHEMBL3970953 & 1642380 & 10.30099 & 999999999 & 998 & 10.4512 & TRN \\
\hline CHEMBL3959083 & 1642380 & 8.3645 & 8.5861 & TST & & \\
\hline CHEMBL3952989 & 1642380 & 8.6716 & 8.8277 & TRN & & \\
\hline CHEMBL 3972017 & 1642380 & 8.466000 & 000000000 & $\partial 1$ & 8.5492 & TRN \\
\hline CHEMBL 3955604 & 1642380 & 9.8416 & 9.7722 & TST & & \\
\hline CHEMBL 3892308 & 1642380 & 8.5003 & 8.5274 & TST & & \\
\hline CHEMBL 3958785 & 1642380 & 9.7595 & 10.3877 & TRN & & \\
\hline CHEMBL3953164 & 1642380 & 10.9586 & 10.8167 & TRN & & \\
\hline CHEMBL 3952360 & 1642380 & 9.5735 & 9.4681 & TRN & & \\
\hline CHEMBL 3972050 & 1642380 & 9.757 & 9.7237 & TRN & & \\
\hline CHEMBL 3934383 & 1642380 & 10.4949 & 10.4768 & TRN & & \\
\hline CHEMBL3939101 & 1642380 & 9.9318 & 9.9861 & TRN & & \\
\hline CHEMBL3970183 & 1642380 & 7.4389 & 7.3908 & TRN & & \\
\hline CHEMBL3915913 & 1642380 & 10.0088 & 10.0369 & TST & & \\
\hline CHEMBL 3984839 & 1642380 & 7.5686 & 7.6892 & TRN & & \\
\hline CHEMBL 3944757 & 1642380 & 9.5867 & 9.8971 & TRN & & \\
\hline CHEMBL 3898989 & 1642380 & 10.69900 & 000000000 & 002 & 10.85 & TRN \\
\hline CHEMBL3951387 & 1642380 & 6.0 & 6.2703 & TRN & & \\
\hline CHEMBL3986159 & 1642380 & 9.0937 & 9.3427 & TRN & & \\
\hline CHEMBL3937096 & 1642380 & 6.0 & 6.4958 & TRN & & \\
\hline CHEMBL3906798 & 1642380 & 10.9586 & 10.5402 & TRN & & \\
\hline CHEMBL3908853 & 1642380 & 9.3925 & 9.5603 & TST & & \\
\hline CHEMBL3958435 & 1642380 & 9.5884 & 9.1558 & TST & & \\
\hline CHEMBL 3983224 & 1642380 & 9.9508 & 10.1337 & TST & & \\
\hline CHEMBL 3961360 & 1642380 & 9.9788 & 10.0173 & TST & & \\
\hline CHEMBL 3950820 & 1642380 & 6.0 & 5.7784 & TST & & \\
\hline CHEMBL 3956440 & 1642380 & 10.2596 & 9.9907 & TST & & \\
\hline CHEMBL3935096 & 1642380 & 10.4202 & 9.752 & TST & & \\
\hline CHEMBL 3907004 & 1642380 & 9.6459 & 9.3582 & TST & & \\
\hline CHEMBL3984183 & 1642380 & 10.1024 & 10.3382 & TST & & \\
\hline CHEMBL 3970981 & 1642380 & 9.9626 & 9.9511 & TST & & \\
\hline CHEMBL 3891851 & 1642380 & 10.3279 & 10.7278 & TST & & \\
\hline CHEMBL 3940227 & 1642380 & 9.7328 & 9.5587 & TST & & \\
\hline
\end{tabular}




\begin{tabular}{|c|c|c|c|c|c|}
\hline \multicolumn{6}{|c|}{ Supplemental Table S2.txt } \\
\hline CHEMBL 3974800 & 1642380 & 9.2487 & 9.3856 & TST & \\
\hline CHEMBL 3946464 & 1642380 & 10.6778 & 10.7231 & TST & \\
\hline CHEMBL 3963946 & 1642380 & 6.0 & 6.0615 & TST & \\
\hline CHEMBL 3931279 & 1642380 & 9.3497 & 9.5473 & TST & \\
\hline CHEMBL 3975198 & 1642380 & 6.0 & 6.2181 & TST & \\
\hline CHEMBL 3963170 & 1642380 & 10.1549 & 9.9253 & TST & \\
\hline CHEMBL 3958302 & 1642380 & 9.3429 & 8.7346 & TST & \\
\hline CHEMBL 3940744 & 1642380 & 10.7212 & 10.7787 & TST & \\
\hline CHEMBL207028 & 353243 & 5.9586 & 5.9584 & TRN & \\
\hline CHEMBL 207250 & 353243 & 5.6021 & 5.602 & TRN & \\
\hline CHEMBL 207173 & 353243 & 4.9872 & 4.9873 & TRN & \\
\hline CHEMBL383061 & 353243 & 3.4034 & 3.4033 & TRN & \\
\hline CHEMBL 382565 & 353243 & 5.7212 & 5.7214 & TRN & \\
\hline CHEMBL 383723 & 353243 & 5.7959 & 5.7959 & TRN & \\
\hline CHEMBL443571 & 353243 & 5.5376 & 5.537999 & 9999999999 & TRN \\
\hline CHEMBL 207205 & 353243 & 3.5607 & 3.5607 & TRN & \\
\hline CHEMBL 207987 & 353243 & 4.9586 & 4.9589 & TRN & \\
\hline CHEMBL207114 & 353243 & 4.8861 & 4.8861 & TRN & \\
\hline CHEMBL207663 & 353243 & 3.5229 & 3.5228 & TRN & \\
\hline CHEMBL 207204 & 353243 & 4.7011 & 4.7012 & TRN & \\
\hline CHEMBL444884 & 353243 & 5.1805 & 5.1803 & TRN & \\
\hline CHEMBL 207297 & 353243 & 4.4413 & 4.4414 & TRN & \\
\hline CHEMBL381518 & 353243 & 3.8097 & 4.8281 & TST & \\
\hline CHEMBL207609 & 353243 & 3.4881 & 4.0898 & TST & \\
\hline CHEMBL 207113 & 353243 & 5.2518 & 5.2518 & TRN & \\
\hline CHEMBL380073 & 353243 & 4.8665 & 4.8667 & TRN & \\
\hline CHEMBL 379327 & 353243 & 5.3279 & 5.3278 & TRN & \\
\hline CHEMBL 377928 & 353243 & 5.0969 & 5.096999 & 99999999995 & TRN \\
\hline CHEMBL 382765 & 353243 & 3.3098 & 3.3099 & TRN & \\
\hline CHEMBL311108 & 353243 & 6.0132 & 5.5532 & TST & \\
\hline CHEMBL382421 & 353243 & 3.301 & 3.301 & TRN & \\
\hline CHEMBL 206683 & 353243 & 4.5884 & 4.5884 & TRN & \\
\hline CHEMBL 208331 & 353243 & 4.4473 & 4.4473 & TRN & \\
\hline CHEMBL381932 & 353243 & 3.6289 & 3.6289 & TRN & \\
\hline CHEMBL 207404 & 353243 & 5.1805 & 5.1804 & TRN & \\
\hline CHEMBL206985 & 353243 & 4.9747 & 4.9746 & TRN & \\
\hline CHEMBL 206961 & 353243 & 4.8962 & 4.8962 & TRN & \\
\hline CHEMBL206896 & 353243 & 5.0862 & 5.1019 & TST & \\
\hline CHEMBL 383482 & 353243 & 5.2007 & 5.2006 & TRN & \\
\hline CHEMBL 377085 & 353243 & 5.6576 & 4.6528 & TST & \\
\hline CHEMBL 207002 & 353243 & 3.301 & 3.3011 & TRN & \\
\hline CHEMBL 206956 & 353243 & 5.0177 & 4.962 & TST & \\
\hline CHEMBL 207619 & 353243 & 5.2007 & 5.2006 & TRN & \\
\hline CHEMBL 207071 & 353243 & 5.585 & 5.5852 & TRN & \\
\hline CHEMBL540202 & 353243 & 4.821000 & 00000006 & 4.2152 & TST \\
\hline CHEMBL 382993 & 353243 & 4.8962 & 4.8962 & TRN & \\
\hline CHEMBL 206734 & 353243 & 3.4559 & 4.601 & TST & \\
\hline CHEMBL207409 & 353243 & 5.3872 & 4.5772 & TST & \\
\hline
\end{tabular}




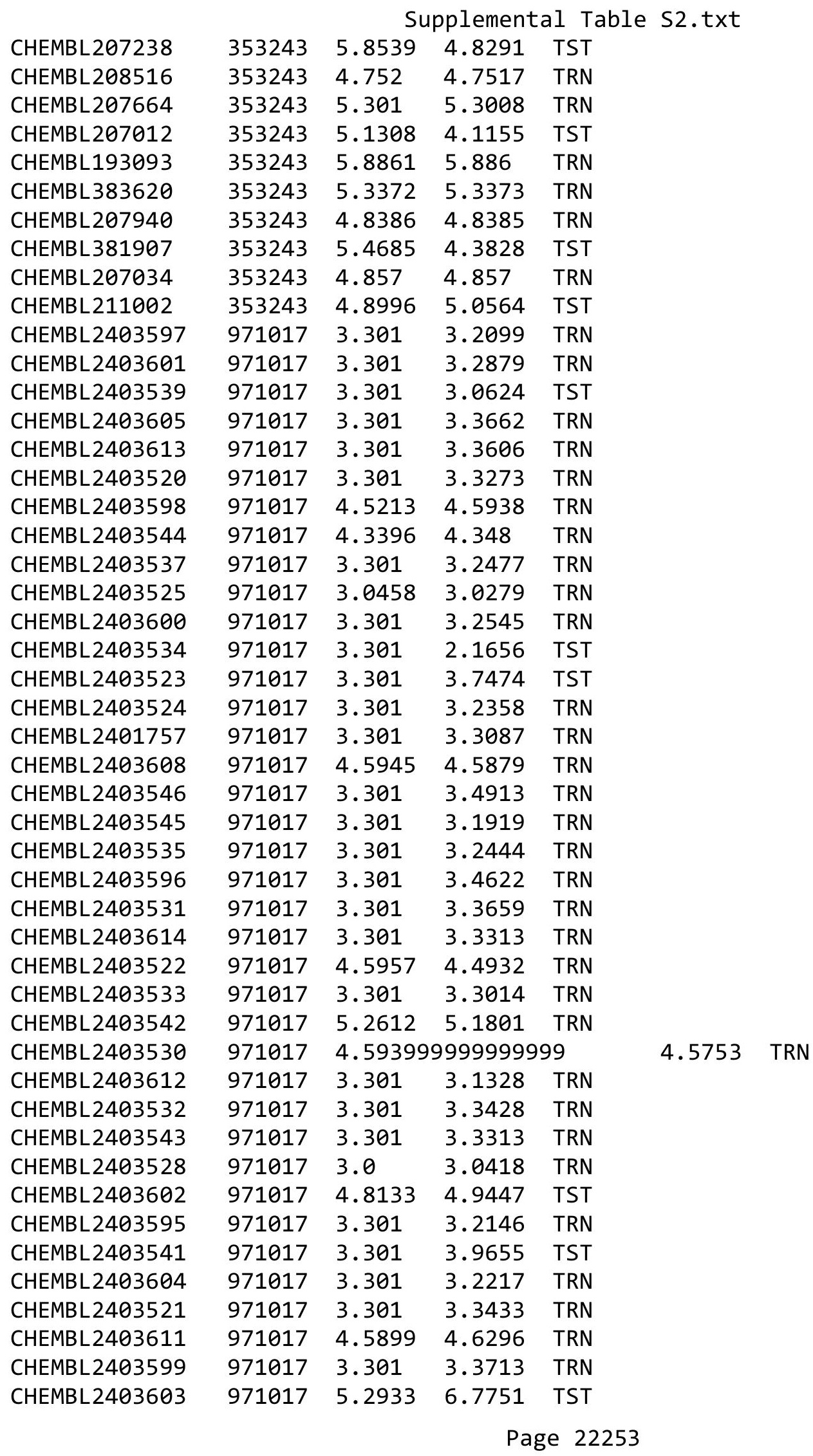




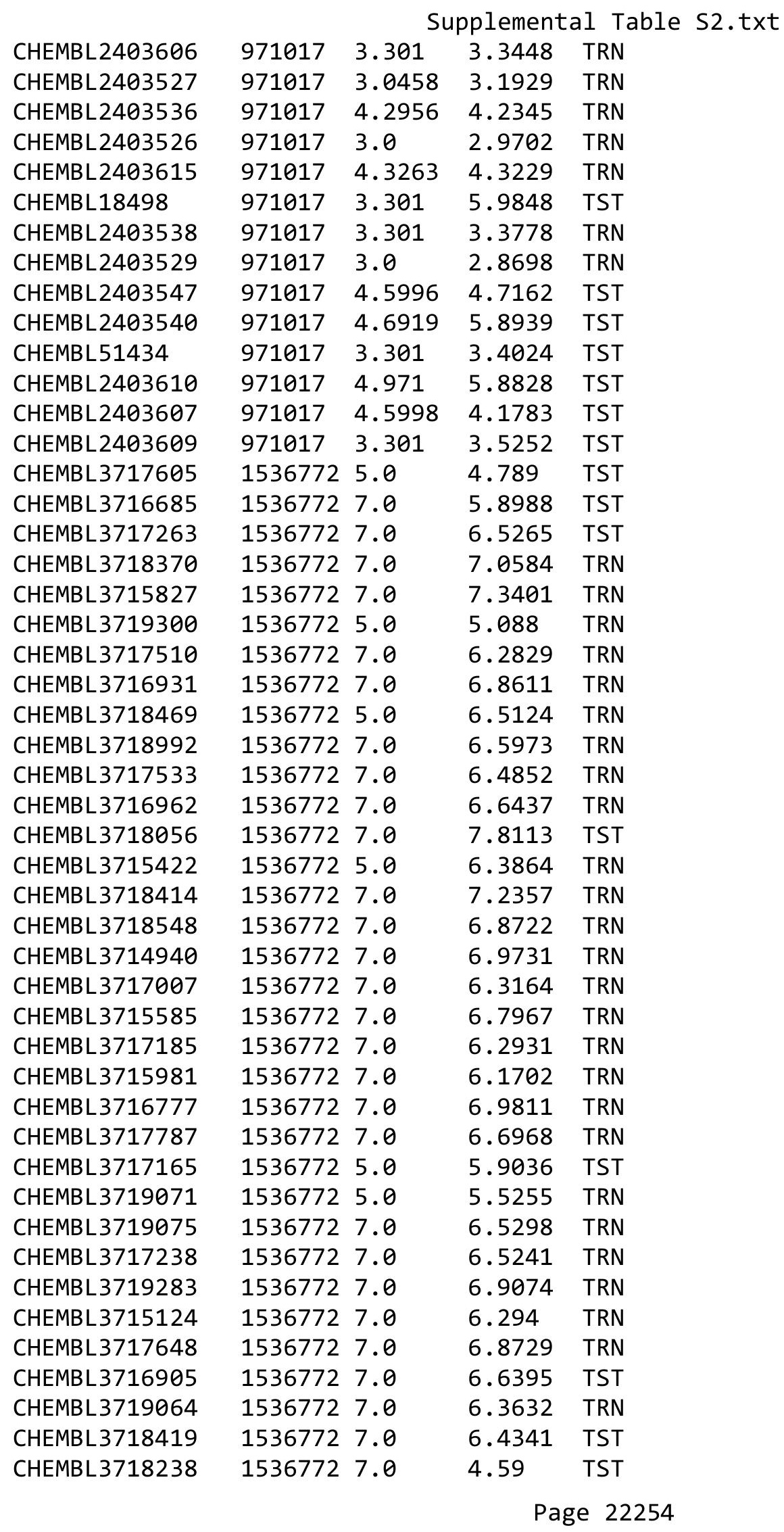




\begin{tabular}{|c|c|c|c|}
\hline & & ment & al Ta \\
\hline CHEMBL3718417 & 15367727.0 & 6.9924 & TRN \\
\hline CHEMBL 3717984 & 15367727.0 & 6.7735 & TRN \\
\hline CHEMBL3714947 & 15367727.0 & 7.2497 & TRN \\
\hline CHEMBL 3717558 & 15367725.0 & 5.9096 & TRN \\
\hline CHEMBL3716283 & 15367727.0 & 6.8239 & TRN \\
\hline CHEMBL3719306 & 15367727.0 & 6.8439 & TRN \\
\hline CHEMBL 3717351 & 15367727.0 & 7.0825 & TRN \\
\hline CHEMBL 3718972 & 15367725.0 & 6.896 & TST \\
\hline CHEMBL 3717697 & 15367727.0 & 6.3566 & TRN \\
\hline CHEMBL3717896 & 15367727.0 & 6.7999 & TRN \\
\hline CHEMBL3716331 & 15367727.0 & 7.0529 & TST \\
\hline CHEMBL3719279 & 15367727.0 & 6.9905 & TST \\
\hline CHEMBL 3717301 & 15367727.0 & 4.4233 & TST \\
\hline CHEMBL3715773 & 15367727.0 & 6.9284 & TRN \\
\hline CHEMBL3716743 & 15367727.0 & 6.3908 & TRN \\
\hline CHEMBL3715584 & 15367727.0 & 6.7421 & TRN \\
\hline CHEMBL3717083 & 15367727.0 & 6.7856 & TRN \\
\hline CHEMBL3717556 & 15367725.0 & 6.3881 & TST \\
\hline CHEMBL3718700 & 15367727.0 & 6.2643 & TRN \\
\hline CHEMBL3717495 & 15367727.0 & 6.8636 & TRN \\
\hline CHEMBL3717216 & 15367727.0 & 6.4758 & TST \\
\hline CHEMBL3716762 & 15367727.0 & 6.5923 & TRN \\
\hline CHEMBL 3717044 & 15367727.0 & 6.7036 & TRN \\
\hline CHEMBL 3717549 & 15367727.0 & 6.829 & TRN \\
\hline CHEMBL 3717057 & 15367727.0 & 6.5166 & TRN \\
\hline CHEMBL3717577 & 15367727.0 & 6.2743 & TRN \\
\hline CHEMBL3718911 & 15367727.0 & 6.5747 & TRN \\
\hline CHEMBL3718339 & 15367727.0 & 7.1575 & TRN \\
\hline CHEMBL3716181 & 15367727.0 & 7.4446 & TRN \\
\hline CHEMBL3717661 & 15367727.0 & 6.8077 & TRN \\
\hline CHEMBL 3715435 & 15367725.0 & 6.5091 & TRN \\
\hline CHEMBL3716490 & 15367725.0 & 6.2242 & TST \\
\hline CHEMBL3715343 & 15367727.0 & 6.2978 & TRN \\
\hline CHEMBL3714868 & 15367727.0 & 6.8944 & TRN \\
\hline CHEMBL3715892 & 15367725.0 & 5.7424 & TST \\
\hline CHEMBL3718270 & 15367727.0 & 6.8853 & TRN \\
\hline CHEMBL3716405 & 15367727.0 & 6.2461 & TRN \\
\hline CHEMBL3716513 & 15367727.0 & 6.8448 & TRN \\
\hline CHEMBL3715317 & 15367727.0 & 6.3762 & TRN \\
\hline CHEMBL 3718422 & 15367727.0 & 6.3398 & TRN \\
\hline CHEMBL3716565 & 15367727.0 & 6.7527 & TRN \\
\hline CHEMBL3716699 & 15367727.0 & 6.5379 & TRN \\
\hline CHEMBL3715712 & 15367727.0 & 6.3254 & TRN \\
\hline CHEMBL 3717522 & 15367725.0 & 6.4467 & TRN \\
\hline CHEMBL3719098 & 15367727.0 & 7.2181 & TRN \\
\hline CHEMBL3716151 & 15367727.0 & 6.4868 & TRN \\
\hline CHEMBL 3717474 & 15367727.0 & 6.5803 & TRN \\
\hline CHEMBL 3714974 & 15367727.0 & 6.8645 & TRN \\
\hline
\end{tabular}




\begin{tabular}{|c|c|c|c|c|}
\hline CHEMBL3717629 & 15367727.0 & \multicolumn{2}{|c|}{6.372999999999999} & \multirow[t]{2}{*}{ TRN } \\
\hline CHEMBL3714992 & 15367727.0 & 6.9457 & TRN & \\
\hline CHEMBL3715301 & 15367727.0 & 7.1918 & TRN & \\
\hline CHEMBL3718738 & 15367725.0 & 6.39 & TST & \\
\hline CHEMBL3715046 & 15367727.0 & 6.481 & TRN & \\
\hline CHEMBL3718191 & 15367725.0 & 6.3142 & TRN & \\
\hline CHEMBL 3717340 & 15367725.0 & 6.0839 & TRN & \\
\hline CHEMBL3718771 & 15367727.0 & 6.8325 & TRN & \\
\hline CHEMBL 3715444 & 15367727.0 & 7.2059 & TRN & \\
\hline CHEMBL3718322 & 15367727.0 & 7.3473 & TRN & \\
\hline CHEMBL 3716851 & 15367727.0 & 6.6867 & TRN & \\
\hline CHEMBL3716537 & 15367727.0 & 6.7089 & TRN & \\
\hline CHEMBL3716232 & 15367727.0 & 7.0655 & TST & \\
\hline CHEMBL3716042 & 15367727.0 & 7.5117 & TRN & \\
\hline CHEMBL3718094 & 15367725.0 & 6.3451 & TRN & \\
\hline CHEMBL 3714848 & 15367727.0 & \multicolumn{2}{|c|}{7.3660000000000005} & TRN \\
\hline CHEMBL3718816 & 15367727.0 & 6.7546 & TRN & \\
\hline CHEMBL3715437 & 15367727.0 & 6.9102 & TRN & \\
\hline CHEMBL3718571 & 15367725.0 & 5.7464 & TRN & \\
\hline CHEMBL3718850 & 15367727.0 & 6.4977 & TRN & \\
\hline CHEMBL 3719280 & 15367725.0 & 6.6945 & TRN & \\
\hline CHEMBL3715314 & 15367725.0 & 5.9919 & TST & \\
\hline CHEMBL3718969 & 15367727.0 & 6.3371 & TRN & \\
\hline CHEMBL3719199 & 15367727.0 & 6.3985 & TRN & \\
\hline CHEMBL3715272 & 15367727.0 & 6.8681 & TRN & \\
\hline CHEMBL3718876 & 15367725.0 & 5.0795 & TRN & \\
\hline CHEMBL3716706 & 15367727.0 & 6.5299 & TRN & \\
\hline CHEMBL3715636 & 15367727.0 & 6.7328 & TRN & \\
\hline CHEMBL3717878 & 15367727.0 & 6.9391 & TRN & \\
\hline CHEMBL3718874 & 15367725.0 & 6.4784 & TRN & \\
\hline CHEMBL 3716297 & 15367727.0 & 6.8276 & TRN & \\
\hline CHEMBL3719221 & 15367727.0 & 6.6566 & TRN & \\
\hline CHEMBL 3717223 & 15367727.0 & 7.1354 & TRN & \\
\hline CHEMBL3717222 & 15367727.0 & 7.1146 & TRN & \\
\hline CHEMBL3718556 & 15367725.0 & 6.4568 & TRN & \\
\hline CHEMBL 3717593 & 15367727.0 & 7.1425 & TST & \\
\hline CHEMBL3714925 & 15367727.0 & 7.3693 & TRN & \\
\hline CHEMBL3716188 & 15367727.0 & 6.6612 & TRN & \\
\hline CHEMBL3715580 & 15367727.0 & 6.6464 & TRN & \\
\hline CHEMBL3714829 & 15367727.0 & \multicolumn{2}{|c|}{6.497000000000001} & TRN \\
\hline CHEMBL3717177 & 15367727.0 & 7.796 & TST & \\
\hline CHEMBL3717476 & 15367725.0 & 5.1292 & TRN & \\
\hline CHEMBL 3717831 & 15367727.0 & 6.2555 & TST & \\
\hline CHEMBL3717142 & 15367725.0 & 6.1788 & TST & \\
\hline CHEMBL3718779 & 15367725.0 & 6.2351 & TRN & \\
\hline CHEMBL3715268 & 15367727.0 & 7.3093 & TRN & \\
\hline CHEMBL3717218 & 15367725.0 & 5.1811 & TST & \\
\hline CHEMBL3718694 & 15367727.0 & 6.5432 & TRN & \\
\hline & & & 22256 & \\
\hline
\end{tabular}




\begin{tabular}{|c|c|c|c|}
\hline & & ient & a 1 \\
\hline CHEMBL 3714794 & 15367727.0 & 6.8095 & TRN \\
\hline CHEMBL3719056 & 15367727.0 & 6.8233 & TRN \\
\hline CHEMBL3715487 & 15367727.0 & 7.1082 & TRN \\
\hline CHEMBL 3715287 & 15367727.0 & 6.9995 & TRN \\
\hline CHEMBL3719171 & 15367725.0 & 6.9383 & TST \\
\hline CHEMBL3715204 & 15367727.0 & 6.7713 & TRN \\
\hline CHEMBL3716295 & 15367727.0 & 7.1841 & TRN \\
\hline CHEMBL3715269 & 15367727.0 & 7.0075 & TRN \\
\hline CHEMBL 3717320 & 15367727.0 & 6.6913 & TRN \\
\hline CHEMBL3718988 & 15367725.0 & 6.0153 & TST \\
\hline CHEMBL3718112 & 15367727.0 & 7.0824 & TST \\
\hline CHEMBL3716880 & 15367727.0 & 7.2023 & TRN \\
\hline CHEMBL3715510 & 15367727.0 & 6.3713 & TRN \\
\hline CHEMBL3718943 & 15367725.0 & 6.2082 & TRN \\
\hline CHEMBL 3717793 & 15367727.0 & 7.2297 & TRN \\
\hline CHEMBL3718326 & 15367727.0 & 6.721 & TRN \\
\hline CHEMBL3718996 & 15367727.0 & 6.3012 & TRN \\
\hline CHEMBL 3714874 & 15367727.0 & 6.8526 & TRN \\
\hline CHEMBL3715881 & 15367727.0 & 7.3431 & TRN \\
\hline CHEMBL3719353 & 15367727.0 & 6.6608 & TRN \\
\hline CHEMBL3717859 & 15367727.0 & 7.0626 & TRN \\
\hline CHEMBL3716303 & 15367725.0 & 6.2757 & TRN \\
\hline CHEMBL3719122 & 15367727.0 & 6.7453 & TRN \\
\hline CHEMBL3718096 & 15367725.0 & 6.2235 & TRN \\
\hline CHEMBL3719182 & 15367727.0 & 6.2052 & TRN \\
\hline CHEMBL 3717408 & 15367725.0 & 6.3959 & TRN \\
\hline CHEMBL3716210 & 15367727.0 & 6.4632 & TRN \\
\hline CHEMBL 3716748 & 15367727.0 & 6.8335 & TRN \\
\hline CHEMBL3714975 & 15367725.0 & 6.6962 & TRN \\
\hline CHEMBL 3717826 & 15367725.0 & 6.3035 & TRN \\
\hline CHEMBL 3717930 & 15367727.0 & 6.9465 & TRN \\
\hline CHEMBL3715221 & 15367727.0 & 7.1038 & TRN \\
\hline CHEMBL3715134 & 15367725.0 & 5.8782 & TRN \\
\hline CHEMBL3716943 & 15367727.0 & 6.5678 & TST \\
\hline CHEMBL3718134 & 15367727.0 & 6.3585 & TRN \\
\hline CHEMBL3719028 & 15367727.0 & 7.0054 & TRN \\
\hline CHEMBL3716267 & 15367727.0 & 7.2979 & TRN \\
\hline CHEMBL3717501 & 15367727.0 & 7.0973 & TRN \\
\hline CHEMBL 3718089 & 15367727.0 & 7.0036 & TRN \\
\hline CHEMBL3718931 & 15367727.0 & 6.6607 & TRN \\
\hline CHEMBL3718628 & 15367727.0 & 6.5921 & TRN \\
\hline CHEMBL3719382 & 15367727.0 & 6.7039 & TRN \\
\hline CHEMBL3718690 & 15367727.0 & 7.0729 & TST \\
\hline CHEMBL 3715565 & 15367727.0 & 6.3554 & TST \\
\hline CHEMBL3715810 & 15367727.0 & 5.6356 & TST \\
\hline CHEMBL 3718525 & 15367727.0 & 6.985 & TST \\
\hline CHEMBL3716682 & 15367727.0 & 6.7777 & TST \\
\hline CHEMBL 3719297 & 15367725.0 & 6.3063 & TST \\
\hline
\end{tabular}




\begin{tabular}{|c|c|c|c|c|}
\hline \multicolumn{5}{|c|}{ Supplemental Table S2.txt } \\
\hline CHEMBL 3717232 & 1536772 & 7.0 & 7.4432 & TST \\
\hline CHEMBL3719367 & 1536772 & 7.0 & 7.0821 & TST \\
\hline CHEMBL3718967 & 1536772 & 7.0 & 7.1565 & TST \\
\hline CHEMBL 3717061 & 1536772 & 7.0 & 6.319 & TST \\
\hline CHEMBL3718207 & 1536772 & 7.0 & 7.0654 & TST \\
\hline CHEMBL3714920 & 1536772 & 7.0 & 6.4166 & TST \\
\hline CHEMBL 3717500 & 1536772 & 7.0 & 6.1131 & TST \\
\hline CHEMBL3716345 & 1536772 & 5.0 & 6.5703 & TST \\
\hline CHEMBL 3717380 & 1536772 & 7.0 & 7.2389 & TST \\
\hline CHEMBL3717576 & 1536772 & 7.0 & 6.8049 & TST \\
\hline CHEMBL 3715324 & 1536772 & 7.0 & 6.8271 & TST \\
\hline CHEMBL3718394 & 1536772 & 7.0 & 6.9003 & TST \\
\hline CHEMBL3715768 & 1536772 & 5.0 & 4.9987 & TST \\
\hline CHEMBL3716651 & 1536772 & 7.0 & 7.0174 & TST \\
\hline CHEMBL2355186 & 1301666 & 4.4339 & 4.4161 & TST \\
\hline CHEMBL2359406 & 1301666 & 5.0635 & 4.6222 & TST \\
\hline CHEMBL2360282 & 1301666 & 4.5047 & 3.9062 & TST \\
\hline CHEMBL2356820 & 1301666 & 6.0 & 5.0409 & TRN \\
\hline CHEMBL2357535 & 1301666 & 6.0 & 4.9037 & TST \\
\hline CHEMBL2136180 & 1301666 & 6.0 & 5.5397 & TRN \\
\hline CHEMBL 2362547 & 1301666 & 4.8292 & 3.6209 & TRN \\
\hline CHEMBL2356967 & 1301666 & 4.3853 & 3.9788 & TRN \\
\hline CHEMBL 2357224 & 1301666 & 3.1549 & 3.7263 & TRN \\
\hline CHEMBL2359667 & 1301666 & 4.3377 & 3.4363 & TRN \\
\hline CHEMBL2359895 & 1301666 & 4.9578 & 3.9996 & TRN \\
\hline CHEMBL 2357176 & 1301666 & 4.2346 & 5.3291 & TRN \\
\hline CHEMBL2360114 & 1301666 & 4.5857 & 3.9303 & TRN \\
\hline CHEMBL 2355313 & 1301666 & 4.2319 & 4.7112 & TRN \\
\hline CHEMBL 2355250 & 1301666 & 4.285 & 4.2164 & TST \\
\hline CHEMBL2360127 & 1301666 & 4.3593 & 3.9872 & TRN \\
\hline CHEMBL 2355724 & 1301666 & 6.0 & 4.9168 & TST \\
\hline CHEMBL2359997 & 1301666 & 4.8058 & 4.3131 & TRN \\
\hline CHEMBL2356002 & 1301666 & 6.0 & 4.9786 & TRN \\
\hline CHEMBL 2360358 & 1301666 & 4.497 & 4.1547 & TRN \\
\hline CHEMBL 3187781 & 1301666 & 3.1549 & 3.7005 & TRN \\
\hline CHEMBL2360167 & 1301666 & 4.4242 & 4.147 & TST \\
\hline CHEMBL3184193 & 1301666 & 3.1549 & 4.0201 & TST \\
\hline CHEMBL2354922 & 1301666 & 4.1986 & 4.6488 & TRN \\
\hline CHEMBL2354505 & 1301666 & 4.3937 & 3.6266 & TRN \\
\hline CHEMBL 2143863 & 1301666 & 6.0 & 4.5994 & TST \\
\hline CHEMBL 2361210 & 1301666 & 4.5464 & 3.6049 & TRN \\
\hline CHEMBL 2355480 & 1301666 & 4.467 & 4.024 & TST \\
\hline CHEMBL2354903 & 1301666 & 3.1549 & 3.9118 & TRN \\
\hline CHEMBL2360506 & 1301666 & 3.1549 & 4.4559 & TRN \\
\hline CHEMBL2360650 & 1301666 & 4.4978 & 3.3581 & TRN \\
\hline CHEMBL 2356076 & 1301666 & 4.3301 & 3.6729 & TRN \\
\hline CHEMBL3184551 & 1301666 & 3.1549 & 3.7909 & TRN \\
\hline CHEMBL2356186 & 1301666 & 4.7014 & 4.891 & TRN \\
\hline
\end{tabular}


Supplemental Table S2.txt

\begin{tabular}{|c|c|c|c|c|c|}
\hline CHEMBL2362260 & 1301666 & 3.1549 & 3.6205 & TRN & \\
\hline CHEMBL2356837 & 1301666 & 3.1549 & 3.9826 & TST & \\
\hline CHEMBL2360228 & 1301666 & 3.1549 & 3.9101 & TRN & \\
\hline CHEMBL2354737 & 1301666 & 3.1549 & 3.957 & TRN & \\
\hline CHEMBL 2360122 & 1301666 & 3.2218 & 4.1186 & TRN & \\
\hline CHEMBL 2361274 & 1301666 & 4.7817 & 4.3835 & TST & \\
\hline CHEMBL 2356893 & 1301666 & 4.5176 & 4.2658 & TRN & \\
\hline CHEMBL2359438 & 1301666 & 6.0 & 5.002 & TST & \\
\hline CHEMBL 2359250 & 1301666 & 6.0 & 5.3123 & TRN & \\
\hline CHEMBL2360439 & 1301666 & 4.6105 & 3.9858 & TST & \\
\hline CHEMBL 2358244 & 1301666 & 4.1555 & 4.385 & TRN & \\
\hline CHEMBL 3183001 & 1301666 & 4.2165 & 4.8424 & TRN & \\
\hline CHEMBL2355845 & 1301666 & 4.2009 & 4.0356 & TRN & \\
\hline CHEMBL 2357075 & 1301666 & 4.3654 & 4.1115 & TRN & \\
\hline CHEMBL 2357404 & 1301666 & 6.0 & 4.9284 & TRN & \\
\hline CHEMBL 2354913 & 1301666 & 4.351 & 3.5161 & TRN & \\
\hline CHEMBL2144222 & 1301666 & 3.1549 & 4.0429 & TST & \\
\hline CHEMBL3182095 & 1301666 & 3.1549 & \multicolumn{2}{|c|}{3.9560000000000004} & TRN \\
\hline CHEMBL 2356844 & 1301666 & 4.4807 & 4.1724 & TRN & \\
\hline CHEMBL2359429 & 1301666 & 3.1549 & 3.6559 & TRN & \\
\hline CHEMBL 2359934 & 1301666 & 4.7508 & 3.6802 & TRN & \\
\hline CHEMBL3188935 & 1301666 & 3.1549 & 4.3277 & TRN & \\
\hline CHEMBL2361605 & 1301666 & 4.4078 & 4.1765 & TRN & \\
\hline CHEMBL 3184535 & 1301666 & 3.1549 & 3.8588 & TST & \\
\hline CHEMBL2361659 & 1301666 & 6.0 & 4.6244 & TRN & \\
\hline CHEMBL 2358720 & 1301666 & 3.1549 & 4.4568 & TRN & \\
\hline CHEMBL 2357924 & 1301666 & 4.919 & 4.6179 & TRN & \\
\hline CHEMBL 2362712 & 1301666 & 3.1549 & 4.1275 & TRN & \\
\hline CHEMBL 2358051 & 1301666 & 4.2331 & 3.9277 & TRN & \\
\hline CHEMBL2354572 & 1301666 & 4.2083 & 4.1177 & TRN & \\
\hline CHEMBL 2361631 & 1301666 & 4.1844 & 4.3751 & TRN & \\
\hline CHEMBL 2355664 & 1301666 & 6.0 & 4.7866 & TRN & \\
\hline CHEMBL2361970 & 1301666 & 4.4089 & 4.2008 & TRN & \\
\hline CHEMBL 2358704 & 1301666 & 4.4062 & 3.9616 & TRN & \\
\hline CHEMBL2356019 & 1301666 & 4.5924 & 3.9339 & TRN & \\
\hline CHEMBL 2357556 & 1301666 & 3.1549 & 4.006 & TRN & \\
\hline CHEMBL 2360567 & 1301666 & 4.235 & 3.9974 & TST & \\
\hline CHEMBL 2360720 & 1301666 & 4.573 & 4.8093 & TRN & \\
\hline CHEMBL2359185 & 1301666 & 4.2818 & 4.957 & TST & \\
\hline CHEMBL2357552 & 1301666 & 3.1549 & 3.8381 & TRN & \\
\hline CHEMBL 2361127 & 1301666 & 4.3818 & 4.2619 & TRN & \\
\hline CHEMBL 2362598 & 1301666 & 3.1549 & 4.4981 & TRN & \\
\hline CHEMBL2355230 & 1301666 & 4.6251 & 3.9554 & TST & \\
\hline CHEMBL 2356209 & 1301666 & 4.6231 & 3.9879 & TRN & \\
\hline CHEMBL2356253 & 1301666 & 3.1549 & 3.8907 & TST & \\
\hline CHEMBL 2132750 & 1301666 & 4.2132 & 4.0497 & TRN & \\
\hline CHEMBL 2358729 & 1301666 & 4.8428 & 4.5039 & TST & \\
\hline CHEMBL2359882 & 1301666 & 4.4043 & 4.6552 & TRN & \\
\hline
\end{tabular}

Page 22259 
Supplemental Table S2.txt

\begin{tabular}{|c|c|c|c|c|c|}
\hline CHEMBL2362454 & 1301666 & 4.6108 & 4.1963 & TRN & \\
\hline CHEMBL 2359026 & 1301666 & 4.5926 & 4.183 & TRN & \\
\hline CHEMBL2360303 & 1301666 & 6.0 & 4.828 & TRN & \\
\hline CHEMBL 2358824 & 1301666 & 6.0 & 5.4238 & TRN & \\
\hline CHEMBL 2360811 & 1301666 & 4.9485 & 4.9793 & TST & \\
\hline CHEMBL 2357183 & 1301666 & 3.1549 & 3.6761 & TRN & \\
\hline CHEMBL2355923 & 1301666 & 3.1549 & 4.2445 & TRN & \\
\hline CHEMBL2355205 & 1301666 & 4.2648 & 4.4295 & TRN & \\
\hline CHEMBL 2357597 & 1301666 & 4.3476 & 4.7676 & TST & \\
\hline CHEMBL 2357390 & 1301666 & 3.1549 & 4.5941 & TRN & \\
\hline CHEMBL 2360842 & 1301666 & 4.6882 & 5.0166 & TRN & \\
\hline CHEMBL2359861 & 1301666 & 3.1549 & 3.6493 & TRN & \\
\hline CHEMBL2361968 & 1301666 & 3.1549 & 3.6027 & TRN & \\
\hline CHEMBL 2360787 & 1301666 & 6.0 & 4.5254 & TRN & \\
\hline CHEMBL2358020 & 1301666 & 3.1549 & 3.9372 & TRN & \\
\hline CHEMBL 2357369 & 1301666 & 4.3057 & 4.6046 & TRN & \\
\hline CHEMBL2358823 & 1301666 & 6.0 & 5.2109 & TRN & \\
\hline CHEMBL2359013 & 1301666 & 4.6726 & 4.207 & TRN & \\
\hline CHEMBL 2355634 & 1301666 & 4.4849 & 4.1231 & TRN & \\
\hline CHEMBL2354622 & 1301666 & 3.1549 & 4.0052 & TRN & \\
\hline CHEMBL2355817 & 1301666 & 4.6897 & 3.9898 & TRN & \\
\hline CHEMBL2360426 & 1301666 & 4.4077 & 4.3667 & TRN & \\
\hline CHEMBL 2361342 & 1301666 & 4.2212 & 5.1472 & TST & \\
\hline CHEMBL 3188783 & 1301666 & 4.1931 & 3.8464 & TRN & \\
\hline CHEMBL2354739 & 1301666 & 4.1991 & 4.7908 & TRN & \\
\hline CHEMBL2361591 & 1301666 & 6.0 & 4.6784 & TRN & \\
\hline CHEMBL2355359 & 1301666 & 4.5071 & 4.1782 & TRN & \\
\hline CHEMBL 2359385 & 1301666 & 3.1549 & 3.9611 & TST & \\
\hline CHEMBL2356813 & 1301666 & 3.1549 & 3.9958 & TRN & \\
\hline CHEMBL2359037 & 1301666 & 4.3848 & 4.1836 & TRN & \\
\hline CHEMBL2354712 & 1301666 & 6.0 & 4.5581 & TRN & \\
\hline CHEMBL 2362298 & 1301666 & 4.5891 & 4.1544 & TST & \\
\hline CHEMBL 2358870 & 1301666 & 3.1549 & 4.2953 & TRN & \\
\hline CHEMBL2359466 & 1301666 & 6.0 & 5.6603 & TRN & \\
\hline CHEMBL2358759 & 1301666 & 4.1847 & 4.4437 & TRN & \\
\hline CHEMBL2359974 & 1301666 & 3.1549 & 4.3102 & TRN & \\
\hline CHEMBL 2356688 & 1301666 & 4.2808 & 5.36299 & 99999999995 & TRN \\
\hline CHEMBL 2361222 & 1301666 & 6.0 & 4.9236 & TRN & \\
\hline CHEMBL2358200 & 1301666 & 4.3339 & 4.5702 & TRN & \\
\hline CHEMBL 2356442 & 1301666 & 4.4806 & 5.4291 & TRN & \\
\hline CHEMBL2359969 & 1301666 & 3.2218 & 3.9218 & TRN & \\
\hline CHEMBL2142762 & 1301666 & 4.3994 & 4.3843 & TRN & \\
\hline CHEMBL2355771 & 1301666 & 4.6304 & 4.3521 & TRN & \\
\hline CHEMBL 2354745 & 1301666 & 4.2865 & 3.9104 & TST & \\
\hline CHEMBL2362522 & 1301666 & 4.4066 & 4.1676 & TRN & \\
\hline CHEMBL2362001 & 1301666 & 4.6225 & 4.3399 & TST & \\
\hline CHEMBL2359007 & 1301666 & 3.1549 & 4.3555 & TST & \\
\hline CHEMBL 2356010 & 1301666 & 3.1549 & 5.0978 & TRN & \\
\hline
\end{tabular}


Supplemental Table S2.txt

\begin{tabular}{|c|c|c|c|c|c|}
\hline CHEMBL2361503 & 1301666 & 4.323 & 3.7228 & TST & \\
\hline CHEMBL2355402 & 1301666 & 3.1549 & 3.951 & TRN & \\
\hline CHEMBL1864597 & 1301666 & 4.1942 & 4.9245 & TST & \\
\hline CHEMBL 2362650 & 1301666 & 5.4685 & 4.6976 & TST & \\
\hline CHEMBL 2358924 & 1301666 & 4.9918 & 4.0045 & TRN & \\
\hline CHEMBL1891222 & 1301666 & 4.3806 & 3.8915 & TRN & \\
\hline CHEMBL 2357087 & 1301666 & 4.2747 & 4.5185 & TRN & \\
\hline CHEMBL2358709 & 1301666 & 3.1549 & 3.7772 & TRN & \\
\hline CHEMBL 2138317 & 1301666 & 4.306 & 3.9844 & TRN & \\
\hline CHEMBL2359040 & 1301666 & 4.3655 & 4.2056 & TST & \\
\hline CHEMBL2359728 & 1301666 & 4.6299 & 4.4949 & TRN & \\
\hline CHEMBL 2354467 & 1301666 & 4.6178 & 4.3658 & TST & \\
\hline CHEMBL2357235 & 1301666 & 3.1549 & 4.6047 & TRN & \\
\hline CHEMBL2360357 & 1301666 & 4.6755 & 4.2886 & TRN & \\
\hline CHEMBL2355506 & 1301666 & 3.1549 & 4.3783 & TRN & \\
\hline CHEMBL 2355103 & 1301666 & 4.4559 & 4.1614 & TRN & \\
\hline CHEMBL2357340 & 1301666 & 4.5381 & 4.4367 & TST & \\
\hline CHEMBL2355418 & 1301666 & 4.3108 & 3.8327 & TST & \\
\hline CHEMBL2360055 & 1301666 & 6.0 & 5.3291 & TRN & \\
\hline CHEMBL2358486 & 1301666 & 4.3807 & 4.0123 & TRN & \\
\hline CHEMBL2356879 & 1301666 & 4.5281 & 4.4371 & TRN & \\
\hline CHEMBL2360307 & 1301666 & 3.1549 & 4.2763 & TRN & \\
\hline CHEMBL 2354530 & 1301666 & 3.1549 & 4.1475 & TST & \\
\hline CHEMBL2356397 & 1301666 & 6.0 & 4.7913 & TRN & \\
\hline CHEMBL 2360750 & 1301666 & 3.1549 & 4.0135 & TRN & \\
\hline CHEMBL 2138714 & 1301666 & 5.3936 & 4.9203 & TST & \\
\hline CHEMBL2362415 & 1301666 & 4.3874 & 4.8546 & TRN & \\
\hline CHEMBL 2362783 & 1301666 & 4.2011 & 4.3081 & TRN & \\
\hline CHEMBL2357399 & 1301666 & 4.6413 & 4.3038 & TRN & \\
\hline CHEMBL2354539 & 1301666 & 4.7562 & 4.5239 & TST & \\
\hline CHEMBL2355076 & 1301666 & 4.5682 & 3.7003 & TRN & \\
\hline CHEMBL 2360483 & 1301666 & 4.4551 & 4.1593 & TST & \\
\hline CHEMBL 3185444 & 1301666 & 3.1549 & 4.0691 & TRN & \\
\hline CHEMBL2354318 & 1301666 & 4.2516 & 3.5789 & TRN & \\
\hline CHEMBL2354800 & 1301666 & 4.8794 & 3.7749 & TST & \\
\hline CHEMBL2362817 & 1301666 & 3.1549 & 4.0258 & TRN & \\
\hline CHEMBL2359727 & 1301666 & 4.4051 & 4.498 & TRN & \\
\hline CHEMBL 2360927 & 1301666 & 6.0 & 4.8387 & TRN & \\
\hline CHEMBL2357026 & 1301666 & 4.6538 & 4.6829 & TRN & \\
\hline CHEMBL2360635 & 1301666 & 4.2346 & 4.234 & TST & \\
\hline CHEMBL2359003 & 1301666 & 4.4735 & 4.4214 & TST & \\
\hline CHEMBL2359515 & 1301666 & 4.1638 & 4.3133 & TRN & \\
\hline CHEMBL2359869 & 1301666 & 6.0 & 5.3383 & TRN & \\
\hline CHEMBL2362669 & 1301666 & $4.6560 e$ & 00000000 & & 4.5339 \\
\hline CHEMBL2362639 & 1301666 & 4.2366 & 4.1833 & TST & \\
\hline CHEMBL2360345 & 1301666 & 4.2135 & 4.0384 & TST & \\
\hline CHEMBL2362273 & 1301666 & 6.0 & 5.2054 & TRN & \\
\hline CHEMBL2356655 & 1301666 & 4.3143 & 3.8022 & TRN & \\
\hline
\end{tabular}

Page 22261 
Supplemental Table S2.txt

\begin{tabular}{|c|c|c|c|c|}
\hline 㱠 & 01666 & 5.5654 & & \\
\hline & & 4.9767 & 4.8577 & \\
\hline & 01666 & & & \\
\hline IEMBL2136684 & 301666 & 4.3049 & & \\
\hline AEMBL 2359046 & 301666 & 4.2496 & & \\
\hline AEMBL2359372 & 566 & 4.4872 & & \\
\hline 29 & 56 & 4.3154 & & \\
\hline IEMB & 66 & & & \\
\hline AEMBL2359591 & 301666 & 4.2337 & & \\
\hline HEMBL1894888 & 666 & 3.1549 & & \\
\hline AEMBL & 6 & & & \\
\hline 39 & 56 & 4.1658 & & \\
\hline IEME & 56 & 6.0 & & \\
\hline AEMBL 2355430 & 1301666 & 6.0 & & \\
\hline 360775 & 666 & & & \\
\hline 8 & 6 & 5. & & \\
\hline 1 & 130 & 6 . & & \\
\hline HEME & 130 & & & \\
\hline 03 & 666 & & & \\
\hline 30 & 56 & & & \\
\hline 2 & $13 t$ & & & \\
\hline & 6 & & & \\
\hline 31 & 56 & 4. & & \\
\hline 85 & 566 & & & \\
\hline 74 & 56 & & & \\
\hline & 136 & & & \\
\hline & 0 & & & \\
\hline 2 & 56 & & & \\
\hline 1 & & & & \\
\hline 5 & $=6$ & & & \\
\hline & & & & \\
\hline & 6 & & & \\
\hline & & 4. & & \\
\hline & & & & \\
\hline 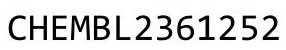 & 66 & & & \\
\hline & & & & \\
\hline & o & & & \\
\hline & & 4.6 & & \\
\hline 361755 & 1301666 & 6. & & $\mathrm{R}$ \\
\hline & 666 & & & \\
\hline & 130 & & & \\
\hline CHEMB & 130 & 6. & & \\
\hline CHEMB & 130 & 3.15 & & \\
\hline IEMBL & 1301666 & 4.1 & & \\
\hline 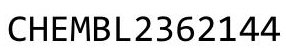 & 1301666 & & & \\
\hline $\mathrm{CH}$ & 130 & & & \\
\hline & 13016 & .3864 & 4.2439 & \\
\hline 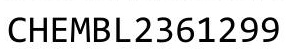 & 170 & 2 & 553 & \\
\hline
\end{tabular}

Page 22262 
Supplemental Table S2.txt

\begin{tabular}{|c|c|c|c|c|c|c|}
\hline CHEMBL 2355520 & 1301666 & 4.5971 & 4.2352 & TST & & \\
\hline CHEMBL3609266 & 1513931 & 10.1249 & 10.0574 & TRN & & \\
\hline CHEMBL3609076 & 1513931 & 9.097999 & 799999999 & 99 & 9.1311 & TST \\
\hline CHEMBL 3608997 & 1513931 & 10.1024 & 9.7961 & TST & & \\
\hline CHEMBL3609083 & 1513931 & 9.9136 & 9.9414 & TST & & \\
\hline CHEMBL3609070 & 1513931 & 9.8125 & 9.5324 & TRN & & \\
\hline CHEMBL 3609030 & 1513931 & 9.4949 & 9.2853 & TRN & & \\
\hline CHEMBL 3609241 & 1513931 & 7.4772 & 8.1295 & TRN & & \\
\hline CHEMBL 3609256 & 1513931 & 9.9872 & 9.7763 & TRN & & \\
\hline CHEMBL3609060 & 1513931 & 9.6556 & 9.9414 & TST & & \\
\hline CHEMBL3609269 & 1513931 & 8.8834 & 8.7161 & TRN & & \\
\hline CHEMBL 3609240 & 1513931 & 9.8125 & 9.5538 & TRN & & \\
\hline CHEMBL 3609074 & 1513931 & 9.7212 & 9.8108 & TST & & \\
\hline CHEMBL 3609272 & 1513931 & 9.8761 & 9.2853 & TRN & & \\
\hline CHEMBL3609062 & 1513931 & 9.8125 & 10.0396 & TRN & & \\
\hline CHEMBL3609262 & 1513931 & 9.7399 & 9.6114 & TST & & \\
\hline CHEMBL3609058 & 1513931 & 10.4202 & 9.5324 & TRN & & \\
\hline CHEMBL 3609042 & 1513931 & 10.0177 & 9.5324 & TRN & & \\
\hline CHEMBL 3609232 & 1513931 & 9.8697 & 9.5324 & TRN & & \\
\hline CHEMBL3609033 & 1513931 & 9.556000 & 00000000 & & 9.2853 & TRN \\
\hline CHEMBL3609025 & 1513931 & 7.4772 & 8.6024 & TST & & \\
\hline CHEMBL3609222 & 1513931 & 10.0706 & 9.5324 & TRN & & \\
\hline CHEMBL3609050 & 1513931 & 7.4772 & 9.5324 & TRN & & \\
\hline CHEMBL 3609080 & 1513931 & 9.0066 & 9.5324 & TRN & & \\
\hline CHEMBL 3609226 & 1513931 & 9.71 & 9.5324 & TRN & & \\
\hline CHEMBL3609024 & 1513931 & 7.4772 & 9.2853 & TRN & & \\
\hline CHEMBL 3609230 & 1513931 & 10.2076 & 9.5324 & TRN & & \\
\hline CHEMBL3609260 & 1513931 & 9.7932 & 9.0197 & TRN & & \\
\hline CHEMBL 3609228 & 1513931 & 9.341000 & 00000000 & & 9.5324 & TRN \\
\hline CHEMBL 3609246 & 1513931 & 9.0329 & 9.0197 & TRN & & \\
\hline CHEMBL 3609082 & 1513931 & 8.8486 & 9.5324 & TRN & & \\
\hline CHEMBL3608317 & 1513931 & 9.5186 & 8.6638 & TRN & & \\
\hline CHEMBL 3609257 & 1513931 & 9.684 & 9.0197 & TRN & & \\
\hline CHEMBL 3609247 & 1513931 & 9.6289 & 9.0197 & TRN & & \\
\hline CHEMBL 3609093 & 1513931 & 9.8794 & 9.5324 & TRN & & \\
\hline CHEMBL 3609048 & 1513931 & 9.982999 & 799999999 & & 9.5324 & TRN \\
\hline CHEMBL3609023 & 1513931 & 9.5918 & 9.6966 & TST & & \\
\hline CHEMBL3608999 & 1513931 & 9.7986 & 9.5324 & TRN & & \\
\hline CHEMBL 3609234 & 1513931 & 10.1549 & 9.5324 & TRN & & \\
\hline CHEMBL3609220 & 1513931 & 9.3655 & 9.5324 & TRN & & \\
\hline CHEMBL3608993 & 1513931 & 9.8069 & 10.1029 & TST & & \\
\hline CHEMBL3609026 & 1513931 & 7.4772 & 9.2853 & TRN & & \\
\hline CHEMBL3609034 & 1513931 & 9.6308 & 9.2853 & TRN & & \\
\hline CHEMBL3609051 & 1513931 & 9.5867 & 9.1311 & TST & & \\
\hline CHEMBL3608996 & 1513931 & 9.6968 & 9.1474 & TRN & & \\
\hline CHEMBL 3609253 & 1513931 & 9.0691 & 8.8205 & TST & & \\
\hline CHEMBL3608992 & 1513931 & 9.7799 & 10.0012 & TST & & \\
\hline CHEMBL3609046 & 1513931 & 10.0555 & 9.8108 & TST & & \\
\hline
\end{tabular}


Supplemental Table S2.txt

\begin{tabular}{|c|c|c|c|c|c|c|}
\hline CHEMBL 3609223 & 1513931 & 9.7077 & 9.8737 & TRN & & \\
\hline CHEMBL 3609078 & 1513931 & 10.0 & 9.7809 & TRN & & \\
\hline CHEMBL3609243 & 1513931 & 7.4772 & 8.5737 & TRN & & \\
\hline CHEMBL 3609037 & 1513931 & 10.1308 & 10.0764 & TRN & & \\
\hline CHEMBL 3609242 & 1513931 & 9.8153 & 9.2529 & TRN & & \\
\hline CHEMBL 3609043 & 1513931 & 10.1367 & 9.5324 & TRN & & \\
\hline CHEMBL3609255 & 1513931 & 7.4772 & 8.4188 & TRN & & \\
\hline CHEMBL3609231 & 1513931 & 9.9393 & 9.7809 & TRN & & \\
\hline CHEMBL3609039 & 1513931 & 7.4772 & 7.6763 & TRN & & \\
\hline CHEMBL3609049 & 1513931 & 10.0223 & 9.8108 & TST & & \\
\hline CHEMBL3609225 & 1513931 & 9.6198 & 9.8108 & TST & & \\
\hline CHEMBL3609029 & 1513931 & 9.6108 & 9.5209 & TRN & & \\
\hline CHEMBL 3609071 & 1513931 & 10.1367 & 9.8677 & TRN & & \\
\hline CHEMBL3609067 & 1513931 & 10.0809 & 9.7961 & TST & & \\
\hline CHEMBL 3609064 & 1513931 & 7.4772 & 7.6763 & TRN & & \\
\hline CHEMBL3609244 & 1513931 & 9.3261 & 9.0197 & TRN & & \\
\hline CHEMBL3609273 & 1513931 & 9.0074 & 9.2853 & TRN & & \\
\hline CHEMBL 3609221 & 1513931 & 9.8069 & 9.5324 & TRN & & \\
\hline CHEMBL3609265 & 1513931 & 10.0223 & 10.1816 & TRN & & \\
\hline CHEMBL 3609085 & 1513931 & 9.8539 & 9.857999 & 999999999 & & TRN \\
\hline CHEMBL3609271 & 1513931 & 9.8356 & 9.2853 & TRN & & \\
\hline CHEMBL3609088 & 1513931 & 10.2218 & 9.6911 & TST & & \\
\hline CHEMBL 3609270 & 1513931 & 10.0132 & 9.8247 & TST & & \\
\hline CHEMBL3608994 & 1513931 & 9.7471 & 10.2355 & TRN & & \\
\hline CHEMBL3609249 & 1513931 & 10.1367 & 9.7621 & TST & & \\
\hline CHEMBL 3609084 & 1513931 & 9.8153 & 9.8767 & TRN & & \\
\hline CHEMBL 3609268 & 1513931 & 9.767000 & 00000000 & & 9.8665 & TRN \\
\hline CHEMBL3609259 & 1513931 & 7.4772 & 9.0197 & TRN & & \\
\hline CHEMBL3609264 & 1513931 & 9.821 & 9.762 & TRN & & \\
\hline CHEMBL3609027 & 1513931 & 7.4772 & 7.6213 & TRN & & \\
\hline CHEMBL3609061 & 1513931 & 9.719 & 9.8767 & TRN & & \\
\hline CHEMBL 3609047 & 1513931 & 9.7799 & 9.8737 & TRN & & \\
\hline CHEMBL3609069 & 1513931 & 9.8761 & 9.5324 & TRN & & \\
\hline CHEMBL3609251 & 1513931 & 9.5528 & 9.7621 & TST & & \\
\hline CHEMBL3609041 & 1513931 & 9.3497 & 9.7961 & TST & & \\
\hline CHEMBL3608995 & 1513931 & 9.6459 & 9.5324 & TRN & & \\
\hline CHEMBL 3609038 & 1513931 & 9.9586 & 10.2355 & TRN & & \\
\hline CHEMBL3609068 & 1513931 & 9.7352 & 9.5324 & TRN & & \\
\hline CHEMBL3609075 & 1513931 & 9.7144 & 9.5324 & TRN & & \\
\hline CHEMBL3609035 & 1513931 & 10.2218 & 9.9988 & TST & & \\
\hline CHEMBL 3609263 & 1513931 & 10.1135 & 9.9361 & TRN & & \\
\hline CHEMBL3609079 & 1513931 & 9.9136 & 9.5324 & TRN & & \\
\hline CHEMBL3609089 & 1513931 & 10.3979 & 9.5804 & TST & & \\
\hline CHEMBL3609056 & 1513931 & 9.556000 & 00000000 & & 9.5324 & TRN \\
\hline CHEMBL 3609028 & 1513931 & 9.585 & 9.2853 & TRN & & \\
\hline CHEMBL 3609073 & 1513931 & 9.4535 & 9.8737 & TRN & & \\
\hline CHEMBL 3609235 & 1513931 & 9.762 & 9.5324 & TRN & & \\
\hline CHEMBL 3609224 & 1513931 & 9.7878 & 9.5324 & TRN & & \\
\hline
\end{tabular}

Page 22264 
Supplemental Table S2.txt

\begin{tabular}{|c|c|c|c|c|}
\hline 1 & & & & . \\
\hline & & & & \\
\hline 50 & & & & \\
\hline EMBL & & 772 & & \\
\hline AEMBL3608318 & 513931 & 9.6517 & 15 & \\
\hline HEMBL & 31 & 331 & 24 & \\
\hline 032 & & & & \\
\hline IEMBL & & & & \\
\hline HEMBL3609077 & 513931 & 10.1739 & 9.5324 & \\
\hline HEMBL3609275 & 513931 & 9.7055 & 9.5689 & \\
\hline HEMBL3609227 & & & 11 & \\
\hline 237 & & 49 & 14 & \\
\hline AEMBL & & & 324 & \\
\hline HEMBL3609090 & 513931 & 861 & & \\
\hline AEMBL3609252 & & & & \\
\hline HEMBL & 1 & & 302 & \\
\hline AEMBL & & & & \\
\hline AEMBL. & & & 853 & \\
\hline 09036 & & 739 & 3908 & \\
\hline AEMBL3609054 & & & 878 & TRN \\
\hline AEMBL & & & & RIN \\
\hline IEM & & & & \\
\hline AFMBI & & & 24 & \\
\hline 09040 & & & & \\
\hline AEMBL3 & & & 77 & IRIN \\
\hline HEMBL; & & & 08 & SI \\
\hline HFM & & & & RN \\
\hline 3 & & & 2355 & \\
\hline AEMBL & & & & |S| \\
\hline HEMBL3609277 & & 9. & 966 & ST \\
\hline IEMBL & & & 68 & ST \\
\hline 4 & & & & RN \\
\hline & & & & RN \\
\hline AEMBL3 & & & & ГRN \\
\hline HEMBL3609086 & 31 & 862 & 9 & RN \\
\hline 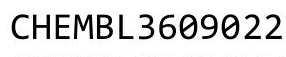 & & & 88 & P. \\
\hline 7 & & & & RN \\
\hline HEMBL3 & & & & RN \\
\hline HEMBL3 & & & & $\mathrm{RN}$ \\
\hline$T M$ & & & & RN \\
\hline HEMBL3 & & & 577 & ST \\
\hline & & 9. & 10.083 & RN \\
\hline HEMBL3609066 & & 9.2 & & RN \\
\hline HEMBL36089 & 1 & & & TS \\
\hline CHГMDI 26002 & & & & $\mathrm{~T}$ \\
\hline HEMBL3 & & 7.4772 & 53 & \\
\hline HEMBL1433456 & & 4.9 & 5.0684 & $\mathrm{~N}$ \\
\hline CHEMBL1530560 & 688407 & 5.7 & 5.8812 & $\boldsymbol{n}$ \\
\hline
\end{tabular}

Page 22265 


\begin{tabular}{|c|c|c|c|c|c|}
\hline \multicolumn{6}{|c|}{ Supplemental Table S2.txt } \\
\hline CHEMBL1605352 & 688407 & 6.8 & 6.2057 & TRN & \\
\hline CHEMBL1434092 & 688407 & 4.7 & 6.0709 & TRN & \\
\hline CHEMBL1554520 & 688407 & 4.9 & 5.0484 & TST & \\
\hline CHEMBL1554400 & 688407 & 5.2 & 5.933 & TRN & \\
\hline CHEMBL1613334 & 688407 & 6.2 & 5.2323 & TRN & \\
\hline CHEMBL1552546 & 688407 & 4.5 & 5.4101 & TRN & \\
\hline CHEMBL1595264 & 688407 & 5.1 & 5.2315 & TRN & \\
\hline CHEMBL1437317 & 688407 & 6.2 & 5.5991 & TRN & \\
\hline CHEMBL1554164 & 688407 & 5.5 & 6.1632 & TST & \\
\hline CHEMBL1433827 & 688407 & 4.9 & 4.7284 & TRN & \\
\hline CHEMBL1491122 & 688407 & 7.1002 & 6.2783 & TST & \\
\hline CHEMBL1397952 & 688407 & 5.6 & 5.5594 & TST & \\
\hline CHEMBL1340913 & 688407 & 6.7001 & 6.0401 & TRN & \\
\hline CHEMBL1444871 & 688407 & 8.1024 & 5.6806 & TRN & \\
\hline CHEMBL1414391 & 688407 & 5.0 & 5.2138 & TRN & \\
\hline CHEMBL1314994 & 688407 & 4.5 & 5.4223 & TRN & \\
\hline CHEMBL1608107 & 688407 & 4.5 & 5.6925 & TRN & \\
\hline CHEMBL1357814 & 688407 & 4.85 & 5.2397 & TRN & \\
\hline CHEMBL1482765 & 688407 & 4.9 & 5.3918 & TRN & \\
\hline CHEMBL1447506 & 688407 & 4.9 & 5.8531 & TST & \\
\hline CHEMBL1612372 & 688407 & 4.45 & 5.7524 & TRN & \\
\hline CHEMBL1316508 & 688407 & 6.5 & $6.4120 e$ & 0000000001 & TRN \\
\hline CHEMBL1396536 & 688407 & 4.9 & 4.7987 & TRN & \\
\hline CHEMBL1442632 & 688407 & 4.9 & 5.2929 & TRN & \\
\hline CHEMBL1394550 & 688407 & 4.7 & 4.5653 & TRN & \\
\hline CHEMBL1372601 & 688407 & 4.65 & 5.2339 & TRN & \\
\hline CHEMBL1553324 & 688407 & 4.9 & 5.1311 & TRN & \\
\hline CHEMBL1315748 & 688407 & 4.9 & 5.5443 & TRN & \\
\hline CHEMBL1325257 & 688407 & 4.8 & 5.3141 & TRN & \\
\hline CHEMBL3199853 & 688407 & 5.45 & 5.2501 & TST & \\
\hline CHEMBL1607833 & 688407 & 5.7 & 6.4507 & TST & \\
\hline CHEMBL1435665 & 688407 & 6.2 & 6.6048 & TRN & \\
\hline CHEMBL1474753 & 688407 & 4.95 & 4.6617 & TRN & \\
\hline CHEMBL1607672 & 688407 & 7.1002 & 5.0463 & TRN & \\
\hline CHEMBL1435271 & 688407 & 4.7 & 5.3102 & TRN & \\
\hline CHEMBL1552571 & 688407 & 7.6003 & 6.5877 & TRN & \\
\hline CHEMBL1599088 & 688407 & 4.7 & 5.2942 & TRN & \\
\hline CHEMBL1516121 & 688407 & 4.7 & 5.0622 & TRN & \\
\hline CHEMBL1395522 & 688407 & 7.0 & 5.4906 & TRN & \\
\hline CHEMBL1450799 & 688407 & 5.9 & 4.9739 & TRN & \\
\hline CHEMBL1574688 & 688407 & 5.1 & 5.7031 & TRN & \\
\hline CHEMBL1355130 & 688407 & 4.7 & 5.1605 & TST & \\
\hline CHEMBL1435100 & 688407 & 4.9 & 5.2404 & TRN & \\
\hline CHEMBL1357093 & 688407 & 7.2 & 5.5332 & TST & \\
\hline CHEMBL1490462 & 688407 & 5.4 & 6.1541 & TRN & \\
\hline CHEMBL1333957 & 688407 & 4.45 & 5.0429 & TRN & \\
\hline CHEMBL1402249 & 688407 & 4.6 & 5.0398 & TST & \\
\hline CHEMBL1358480 & 688407 & 6.4 & 5.9016 & TRN & \\
\hline
\end{tabular}




\begin{tabular}{|c|c|c|c|c|c|}
\hline \multicolumn{6}{|c|}{ Supplemental Table S2.txt } \\
\hline CHEMBL1515371 & 688407 & 5.65 & 5.2646 & TRN & \\
\hline CHEMBL1602484 & 688407 & 4.55 & 5.13200 & 0000000001 & TRN \\
\hline CHEMBL1493139 & 688407 & 4.8 & 5.3004 & TRN & \\
\hline CHEMBL1398935 & 688407 & 8.0 & 4.9984 & TST & \\
\hline CHEMBL1397981 & 688407 & 4.5 & 5.3667 & TST & \\
\hline CHEMBL1477877 & 688407 & 6.1 & 6.316 & TRN & \\
\hline CHEMBL1486098 & 688407 & 7.3002 & 5.3913 & TRN & \\
\hline CHEMBL1436131 & 688407 & 6.8 & 5.7356 & TRN & \\
\hline CHEMBL1476006 & 688407 & 4.5 & 5.4434 & TST & \\
\hline CHEMBL1608995 & 688407 & 4.8 & 5.6797 & TST & \\
\hline CHEMBL1356139 & 688407 & 4.9 & 4.6632 & TST & \\
\hline CHEMBL1367162 & 688407 & 6.9 & 6.0611 & TRN & \\
\hline CHEMBL1333767 & 688407 & 4.8 & 4.3479 & TRN & \\
\hline CHEMBL1411048 & 688407 & 8.0 & 5.6618 & TRN & \\
\hline CHEMBL1571657 & 688407 & 4.55 & 5.2277 & TRN & \\
\hline CHEMBL1515830 & 688407 & 5.2 & 4.678 & TRN & \\
\hline CHEMBL1612628 & 688407 & 5.45 & 5.4085 & TRN & \\
\hline CHEMBL1372589 & 688407 & 4.75 & 4.7207 & TRN & \\
\hline CHEMBL1396233 & 688407 & 4.7 & 5.0668 & TRN & \\
\hline CHEMBL1973647 & 688407 & 5.0 & 5.7912 & TST & \\
\hline CHEMBL1474675 & 688407 & 5.1 & 5.5732 & TRN & \\
\hline CHEMBL1435221 & 688407 & 6.6 & 6.1787 & TST & \\
\hline CHEMBL1417926 & 688407 & 4.6 & 4.792 & TRN & \\
\hline CHEMBL1590020 & 688407 & 5.3 & 5.5605 & TRN & \\
\hline CHEMBL1437680 & 688407 & 4.8 & 5.2504 & TRN & \\
\hline CHEMBL1560217 & 688407 & 4.8 & 4.4526 & TRN & \\
\hline CHEMBL1474682 & 688407 & 5.0 & 5.1374 & TST & \\
\hline CHEMBL1453389 & 688407 & 5.0 & 5.4782 & TRN & \\
\hline CHEMBL1604193 & 688407 & 4.45 & 5.2353 & TRN & \\
\hline CHEMBL1397048 & 688407 & 4.6 & 6.1622 & TRN & \\
\hline CHEMBL1551057 & 688407 & 7.8013 & 5.7719 & TRN & \\
\hline CHEMBL1555349 & 688407 & 4.65 & 5.4359 & TRN & \\
\hline CHEMBL3197793 & 688407 & 4.75 & 6.3884 & TST & \\
\hline CHEMBL1599062 & 688407 & 4.8 & 5.37700 & 0000000001 & TRN \\
\hline CHEMBL1435792 & 688407 & 6.1 & 4.6538 & TRN & \\
\hline CHEMBL1360117 & 688407 & 4.5 & 4.9767 & TST & \\
\hline CHEMBL1610241 & 688407 & 4.7 & 5.4205 & TRN & \\
\hline CHEMBL1314385 & 688407 & 7.5003 & 5.6464 & TST & \\
\hline CHEMBL598688 & 688407 & 4.5 & 5.9946 & TST & \\
\hline CHEMBL1512167 & 688407 & 6.2 & 5.6705 & TRN & \\
\hline CHEMBL1501793 & 688407 & 6.5501 & 6.1432 & TRN & \\
\hline CHEMBL1591231 & 688407 & 4.7 & 4.8675 & TRN & \\
\hline CHEMBL1354804 & 688407 & 4.9 & 4.6038 & TRN & \\
\hline CHEMBL1526956 & 688407 & 5.8 & 6.0541 & TRN & \\
\hline CHEMBL1594045 & 688407 & 8.301 & 5.7494 & TRN & \\
\hline CHEMBL1594926 & 688407 & 4.45 & 5.2423 & TST & \\
\hline CHEMBL1356554 & 688407 & 4.9 & 6.2155 & TRN & \\
\hline CHEMBL1553846 & 688407 & 5.8 & 5.8266 & TRN & \\
\hline
\end{tabular}




\begin{tabular}{|c|c|c|c|c|c|}
\hline \multirow[b]{2}{*}{ CHEMBL1339011 } & \multicolumn{5}{|c|}{ Supplemental Table S2.txt } \\
\hline & 688407 & 7.5003 & 6.178 & TRN & \\
\hline CHEMBL1566421 & 688407 & 6.1 & 5.1337 & TRN & \\
\hline CHEMBL1480389 & 688407 & 4.45 & 5.2891 & TRN & \\
\hline CHEMBL1476326 & 688407 & 8.301 & 4.9091 & TRN & \\
\hline CHEMBL1591142 & 688407 & 4.5 & 5.7489 & TRN & \\
\hline CHEMBL1355197 & 688407 & 4.8 & 4.7294 & TRN & \\
\hline CHEMBL 1408060 & 688407 & 4.45 & 5.4476 & TRN & \\
\hline CHEMBL1317182 & 688407 & 4.5 & 5.4452 & TRN & \\
\hline CHEMBL1453886 & 688407 & 4.9 & 6.0551 & TRN & \\
\hline CHEMBL1566436 & 688407 & 4.5 & 5.4211 & TRN & \\
\hline CHEMBL1442586 & 688407 & 4.5 & 4.8049 & TST & \\
\hline CHEMBL1570241 & 688407 & 5.2 & 5.5558 & TRN & \\
\hline CHEMBL1356816 & 688407 & 4.9 & 5.3312 & TRN & \\
\hline CHEMBL1437543 & 688407 & 8.0 & 6.1885 & TST & \\
\hline CHEMBL1366687 & 688407 & 5.5 & 5.3843 & TRN & \\
\hline CHEMBL1602408 & 688407 & 5.15 & 5.2492 & TST & \\
\hline CHEMBL1518990 & 688407 & 4.6 & 5.0655 & TRN & \\
\hline CHEMBL1600930 & 688407 & 4.9 & 4.9547 & TRN & \\
\hline CHEMBL1563545 & 688407 & 8.301 & 6.3833 & TRN & \\
\hline CHEMBL1395223 & 688407 & 4.5 & 5.0252 & TRN & \\
\hline CHEMBL1435966 & 688407 & 5.2 & 5.19 & TST & \\
\hline CHEMBL1580467 & 688407 & 4.9 & 5.2853 & TRN & \\
\hline CHEMBL1394475 & 688407 & 4.7 & 4.8415 & TRN & \\
\hline CHEMBL1554880 & 688407 & 4.65 & 5.3947 & TRN & \\
\hline CHEMBL1473013 & 688407 & 4.5 & 5.9402 & TRN & \\
\hline CHEMBL1553772 & 688407 & 5.5 & 5.164 & TST & \\
\hline CHEMBL1397329 & 688407 & 5.0 & 5.4707 & TST & \\
\hline CHEMBL1436407 & 688407 & 4.45 & 5.4204 & TRN & \\
\hline CHEMBL1361507 & 688407 & 4.8 & 4.7188 & TRN & \\
\hline CHEMBL1529567 & 688407 & 6.2 & 5.0352 & TRN & \\
\hline CHEMBL1593510 & 688407 & 5.5 & 5.8209 & TRN & \\
\hline CHEMBL1373256 & 688407 & 5.0 & 5.7163 & TRN & \\
\hline CHEMBL1513915 & 688407 & 8.301 & 6.0925 & TRN & \\
\hline CHEMBL1354391 & 688407 & 5.55 & 6.1162 & TRN & \\
\hline CHEMBL1331092 & 688407 & 5.9 & 6.1372 & TST & \\
\hline CHEMBL1600425 & 688407 & 4.5 & 5.3644 & TRN & \\
\hline CHEMBL1473043 & 688407 & 6.6 & 5.9265 & TRN & \\
\hline CHEMBL1558449 & 688407 & 4.65 & 5.3993 & TRN & \\
\hline CHEMBL599100 & 688407 & 8.3979 & 5.4046 & TST & \\
\hline CHEMBL1367037 & 688407 & 6.5 & 5.8123 & TST & \\
\hline CHEMBL1554048 & 688407 & 5.0 & 5.4672 & TRN & \\
\hline CHEMBL1394378 & 688407 & 4.9 & 5.0684 & TRN & \\
\hline CHEMBL1476501 & 688407 & 4.5 & 4.877 & TRN & \\
\hline CHEMBL1514496 & 688407 & 8.301 & 5.9776 & TRN & \\
\hline CHEMBL1398890 & 688407 & 5.35 & 5.2039 & TST & \\
\hline CHEMBL1512964 & 688407 & 4.5 & 5.65799 & 99999999995 & TRN \\
\hline CHEMBL1394342 & 688407 & 6.6 & 5.7523 & TRN & \\
\hline CHEMBL1527704 & 688407 & 4.95 & 5.11 & TST & \\
\hline
\end{tabular}




\begin{tabular}{|c|c|c|c|c|c|}
\hline \multirow[b]{2}{*}{ CHEMBL1551108 } & \multicolumn{5}{|c|}{ Supplemental Table S2.txt } \\
\hline & 688407 & 4.65 & 5.4379 & TRN & \\
\hline CHEMBL1592338 & 688407 & 4.45 & 5.1919 & TRN & \\
\hline CHEMBL1356294 & 688407 & 4.5 & 5.4212 & TRN & \\
\hline CHEMBL1601915 & 688407 & 4.5 & 5.2346 & TST & \\
\hline CHEMBL1377259 & 688407 & 6.8 & 5.6652 & TRN & \\
\hline CHEMBL1455774 & 688407 & 4.5 & 5.7554 & TRN & \\
\hline CHEMBL1567968 & 688407 & 4.75 & 4.5283 & TRN & \\
\hline CHEMBL1321245 & 688407 & 4.9 & \multicolumn{2}{|c|}{5.617999999999999} & TRN \\
\hline CHEMBL1528536 & 688407 & 5.3 & 4.6971 & TST & \\
\hline CHEMBL1314758 & 688407 & 4.5 & 5.3106 & TRN & \\
\hline CHEMBL365374 & 688407 & 4.5 & 5.1271 & TRN & \\
\hline CHEMBL1357166 & 688407 & 4.5 & 5.1648 & TRN & \\
\hline CHEMBL1557062 & 688407 & 5.4 & 5.8361 & TRN & \\
\hline CHEMBL1432745 & 688407 & 5.85 & 5.7745 & TRN & \\
\hline CHEMBL1409439 & 688407 & 4.5 & 5.5683 & TRN & \\
\hline CHEMBL1594555 & 688407 & 7.1002 & 5.4495 & TST & \\
\hline CHEMBL1354339 & 688407 & 5.2 & 6.0734 & TRN & \\
\hline CHEMBL1473491 & 688407 & 5.2 & 5.4695 & TST & \\
\hline CHEMBL1358465 & 688407 & 4.8 & 5.3775 & TST & \\
\hline CHEMBL1315803 & 688407 & 8.1024 & 5.1564 & TRN & \\
\hline CHEMBL1512341 & 688407 & 8.1024 & 5.9096 & TST & \\
\hline CHEMBL1394511 & 688407 & 4.5 & 4.8001 & TRN & \\
\hline CHEMBL1314978 & 688407 & 4.95 & 4.978 & TRN & \\
\hline CHEMBL1608518 & 688407 & 5.0 & 5.7096 & TRN & \\
\hline CHEMBL1611510 & 688407 & 7.8013 & \multicolumn{2}{|c|}{5.832999999999999} & TRN \\
\hline CHEMBL1555963 & 688407 & 5.7 & 5.4904 & TRN & \\
\hline CHEMBL1448584 & 688407 & 5.65 & 5.2373 & TST & \\
\hline CHEMBL1437107 & 688407 & 4.9 & 4.8255 & TST & \\
\hline CHEMBL1397179 & 688407 & 5.0 & 5.1333 & TRN & \\
\hline CHEMBL1375970 & 688407 & 4.7 & 4.6298 & TRN & \\
\hline CHEMBL1445895 & 688407 & 6.8 & 5.5222 & TRN & \\
\hline CHEMBL1594042 & 688407 & 5.0 & 4.8767 & TRN & \\
\hline CHEMBL1592891 & 688407 & 5.05 & 5.3227 & TRN & \\
\hline CHEMBL1402846 & 688407 & 4.8 & 5.4371 & TRN & \\
\hline CHEMBL1590606 & 688407 & 8.1487 & 6.8383 & TRN & \\
\hline CHEMBL1376817 & 688407 & 4.85 & 5.2037 & TRN & \\
\hline CHEMBL1365674 & 688407 & 7.3002 & 5.5379 & TRN & \\
\hline CHEMBL1419597 & 688407 & 5.1 & 5.7706 & TRN & \\
\hline CHEMBL1475844 & 688407 & 4.95 & 5.2133 & TRN & \\
\hline CHEMBL1513591 & 688407 & 4.5 & 5.7366 & TRN & \\
\hline CHEMBL1568157 & 688407 & 6.6 & 5.9419 & TRN & \\
\hline CHEMBL1436804 & 688407 & 4.5 & \multicolumn{2}{|c|}{5.3260000000000005} & TRN \\
\hline CHEMBL1355658 & 688407 & 4.9 & 5.2792 & TRN & \\
\hline CHEMBL1491632 & 688407 & 6.2 & 5.2832 & TRN & \\
\hline CHEMBL1435324 & 688407 & 5.5 & 4.7569 & TRN & \\
\hline CHEMBL1472652 & 688407 & 5.1 & 5.8247 & TRN & \\
\hline CHEMBL1472959 & 688407 & 4.7 & 5.57 & TRN & \\
\hline \multirow[t]{2}{*}{ CHEMBL1485379 } & 688407 & 5.1 & 5.7113 & TRN & \\
\hline & & \multicolumn{4}{|c|}{ Page 22269} \\
\hline
\end{tabular}




\begin{tabular}{|c|c|c|c|c|c|}
\hline \multicolumn{6}{|c|}{ Supplemental Table S2.txt } \\
\hline CHEMBL1417232 & 688407 & 4.5 & 5.1969 & TST & \\
\hline CHEMBL1317817 & 688407 & 4.9 & 5.1239 & TRN & \\
\hline CHEMBL1533443 & 688407 & 8.0 & 6.2272 & TST & \\
\hline CHEMBL1563271 & 688407 & 4.9 & 5.7771 & TRN & \\
\hline CHEMBL1435894 & 688407 & 4.85 & 5.2079 & TRN & \\
\hline CHEMBL1516105 & 688407 & 4.7 & 5.0335 & TRN & \\
\hline CHEMBL1375797 & 688407 & 4.8 & 5.0049 & TRN & \\
\hline CHEMBL1456554 & 688407 & 4.5 & 5.6155 & TST & \\
\hline CHEMBL1551288 & 688407 & 4.45 & 4.8074 & TRN & \\
\hline CHEMBL1397745 & 688407 & 5.85 & 5.0246 & TRN & \\
\hline CHEMBL1316255 & 688407 & 5.0 & 5.3674 & TST & \\
\hline CHEMBL1521428 & 688407 & 4.5 & 5.0572 & TRN & \\
\hline CHEMBL1514575 & 688407 & 4.9 & 5.456 & TRN & \\
\hline CHEMBL1516173 & 688407 & 5.0 & 5.5554 & TRN & \\
\hline CHEMBL601311 & 688407 & 4.95 & 5.1173 & TRN & \\
\hline CHEMBL1337982 & 688407 & 4.45 & 4.8403 & TRN & \\
\hline CHEMBL1406438 & 688407 & 4.9 & 4.8417 & TRN & \\
\hline CHEMBL1512931 & 688407 & 4.5 & 4.6074 & TRN & \\
\hline CHEMBL1403795 & 688407 & 5.4 & 5.4859 & TRN & \\
\hline CHEMBL1359375 & 688407 & 4.5 & 5.8461 & TRN & \\
\hline CHEMBL1316928 & 688407 & 4.5 & 4.2372 & TRN & \\
\hline CHEMBL1562701 & 688407 & 8.301 & 6.4225 & TST & \\
\hline CHEMBL1317561 & 688407 & 4.5 & 5.3996 & TRN & \\
\hline CHEMBL1325745 & 688407 & 6.6 & 5.5008 & TRN & \\
\hline CHEMBL1314968 & 688407 & 4.5 & 5.4432 & TRN & \\
\hline CHEMBL1571619 & 688407 & 7.8996 & 5.6963 & TST & \\
\hline CHEMBL1518945 & 688407 & 5.05 & 5.3771 & TRN & \\
\hline CHEMBL1593122 & 688407 & 4.95 & 4.9819 & TRN & \\
\hline CHEMBL1555084 & 688407 & 5.0 & 5.2377 & TRN & \\
\hline CHEMBL1476025 & 688407 & 4.9 & 4.762 & TRN & \\
\hline CHEMBL1551157 & 688407 & 6.9 & 5.8858 & TRN & \\
\hline CHEMBL1320089 & 688407 & 4.9 & 5.4459 & TRN & \\
\hline CHEMBL1551191 & 688407 & 4.45 & 5.3862 & TRN & \\
\hline CHEMBL1316026 & 688407 & 7.0 & 5.2594 & TRN & \\
\hline CHEMBL1395595 & 688407 & 4.5 & 4.9257 & TRN & \\
\hline CHEMBL1366627 & 688407 & 4.5 & 5.2623 & TST & \\
\hline CHEMBL1487273 & 688407 & 5.5 & 5.7504 & TRN & \\
\hline CHEMBL1474556 & 688407 & 4.45 & 4.6 & TST & \\
\hline CHEMBL1592143 & 688407 & 6.1 & 6.6347 & TRN & \\
\hline CHEMBL1551186 & 688407 & 5.6 & 6.25899 & 99999999995 & TRN \\
\hline CHEMBL1435533 & 688407 & 5.0 & 5.5005 & TRN & \\
\hline CHEMBL1448537 & 688407 & 8.301 & 6.1322 & TRN & \\
\hline CHEMBL1572485 & 688407 & 4.5 & 5.46 & TRN & \\
\hline CHEMBL1355018 & 688407 & 7.4001 & 5.5242 & TRN & \\
\hline CHEMBL1358047 & 688407 & 4.7 & 5.4324 & TRN & \\
\hline CHEMBL1410927 & 688407 & 8.0 & 5.7109 & TRN & \\
\hline CHEMBL1396506 & 688407 & 4.65 & 5.5297 & TRN & \\
\hline CHEMBL238873 & 688407 & 5.3 & 5.2333 & TRN & \\
\hline
\end{tabular}




\begin{tabular}{|c|c|c|c|c|}
\hline \multicolumn{5}{|c|}{ Supplemental Table S2.txt } \\
\hline CHEMBL1484911 & 688407 & 4.9 & 5.4641 & TRN \\
\hline CHEMBL1475180 & 688407 & 4.7 & 4.9212 & TRN \\
\hline CHEMBL1317444 & 688407 & 8.2007 & 5.6495 & TRN \\
\hline CHEMBL1316622 & 688407 & 5.0 & 5.4721 & TRN \\
\hline CHEMBL1552298 & 688407 & 5.3 & 5.6566 & TRN \\
\hline CHEMBL1515591 & 688407 & 4.7 & 5.4252 & TST \\
\hline CHEMBL1371139 & 688407 & 5.2 & 5.008 & TRN \\
\hline CHEMBL1404755 & 688407 & 7.3002 & 6.0397 & TRN \\
\hline CHEMBL1592953 & 688407 & 4.45 & 5.8634 & TST \\
\hline CHEMBL1556334 & 688407 & 8.1024 & 5.3172 & TST \\
\hline CHEMBL1396731 & 688407 & 5.1 & 5.0828 & TRN \\
\hline CHEMBL1418740 & 688407 & 4.8 & 5.5998 & TST \\
\hline CHEMBL1347274 & 688407 & 6.6499 & 5.6152 & TRN \\
\hline CHEMBL1417747 & 688407 & 4.95 & 5.8234 & TST \\
\hline CHEMBL1316987 & 688407 & 4.7 & 5.0021 & TRN \\
\hline CHEMBL1552023 & 688407 & 5.4 & 5.6942 & TST \\
\hline CHEMBL1476764 & 688407 & 4.6 & 4.9933 & TRN \\
\hline CHEMBL1514403 & 688407 & 6.9 & 5.9491 & TRN \\
\hline CHEMBL1519175 & 688407 & 4.7 & 5.1225 & TRN \\
\hline CHEMBL1319649 & 688407 & 5.8 & 6.2291 & TRN \\
\hline CHEMBL1474862 & 688407 & 7.3002 & 6.2692 & TRN \\
\hline CHEMBL1473678 & 688407 & 4.6 & 4.7511 & TRN \\
\hline CHEMBL1398442 & 688407 & 6.5 & 6.5334 & TRN \\
\hline CHEMBL1396414 & 688407 & 6.2 & 6.3672 & TRN \\
\hline CHEMBL1512459 & 688407 & 5.25 & 5.9555 & TRN \\
\hline CHEMBL596633 & 688407 & 4.8 & 5.2254 & TRN \\
\hline CHEMBL1547082 & 688407 & 6.8 & 5.3606 & TRN \\
\hline CHEMBL1589854 & 688407 & 4.7 & 5.1785 & TRN \\
\hline CHEMBL1474094 & 688407 & 4.95 & 5.3483 & TRN \\
\hline CHEMBL1515460 & 688407 & 6.3 & 5.7469 & TRN \\
\hline CHEMBL1473497 & 688407 & 5.3 & 4.9827 & TRN \\
\hline CHEMBL1448031 & 688407 & 5.05 & 5.1216 & TRN \\
\hline CHEMBL1420595 & 688407 & 4.95 & 5.3944 & TST \\
\hline CHEMBL1515992 & 688407 & 4.45 & 5.3757 & TRN \\
\hline CHEMBL1527797 & 688407 & 5.9 & 6.2549 & TRN \\
\hline CHEMBL1371880 & 688407 & 4.5 & 5.1166 & TRN \\
\hline CHEMBL1404519 & 688407 & 5.55 & 6.9353 & TST \\
\hline CHEMBL1555321 & 688407 & 6.7001 & 5.4117 & TRN \\
\hline CHEMBL1518438 & 688407 & 4.8 & 5.043 & TRN \\
\hline CHEMBL1524894 & 688407 & 5.1 & 5.3859 & TRN \\
\hline CHEMBL1532670 & 688407 & 6.9 & 6.0397 & TRN \\
\hline CHEMBL1382028 & 688407 & 4.95 & 5.5613 & TRN \\
\hline CHEMBL1435522 & 688407 & 4.7 & 5.6988 & TRN \\
\hline CHEMBL1520828 & 688407 & 4.5 & 5.7349 & TRN \\
\hline CHEMBL1452218 & 688407 & 6.8 & 5.3863 & TST \\
\hline CHEMBL1551237 & 688407 & 4.45 & 5.9464 & TRN \\
\hline CHEMBL1314925 & 688407 & 4.85 & 4.8017 & TRN \\
\hline CHEMBL1355337 & 688407 & 4.8 & 5.2848 & TST \\
\hline
\end{tabular}




\begin{tabular}{|c|c|c|c|c|}
\hline \multicolumn{5}{|c|}{ Supplemental Table S2.txt } \\
\hline CHEMBL1475160 & 688407 & 6.5 & 5.7354 & TST \\
\hline CHEMBL1514464 & 688407 & 6.4 & 5.365 & TST \\
\hline CHEMBL1595466 & 688407 & 4.6 & 5.8041 & TRN \\
\hline CHEMBL1592616 & 688407 & 4.8 & 5.2158 & TST \\
\hline CHEMBL1449484 & 688407 & 4.8 & 4.3082 & TRN \\
\hline CHEMBL1551853 & 688407 & 4.9 & 4.9663 & TRN \\
\hline CHEMBL1555204 & 688407 & 4.7 & 5.3439 & TST \\
\hline CHEMBL1412693 & 688407 & 5.2 & 5.063 & TRN \\
\hline CHEMBL1443536 & 688407 & 5.0 & 5.2638 & TRN \\
\hline CHEMBL1556254 & 688407 & 4.9 & 5.5139 & TST \\
\hline CHEMBL1564134 & 688407 & 4.85 & 5.1547 & TST \\
\hline CHEMBL1394691 & 688407 & 4.9 & 5.2024 & TRN \\
\hline CHEMBL1396497 & 688407 & 5.3 & 6.0417 & TRN \\
\hline CHEMBL1514145 & 688407 & 4.8 & 4.9514 & TRN \\
\hline CHEMBL1395961 & 688407 & 4.9 & 5.3605 & TRN \\
\hline CHEMBL1399432 & 688407 & 7.699 & 5.4496 & TRN \\
\hline CHEMBL1599306 & 688407 & 5.2 & 6.807 & TRN \\
\hline CHEMBL 1602945 & 688407 & 4.6 & 5.5712 & TRN \\
\hline CHEMBL1528105 & 688407 & 5.35 & 6.397 & TRN \\
\hline CHEMBL1564447 & 688407 & 7.0 & 5.5436 & TST \\
\hline CHEMBL1451527 & 688407 & 5.5 & 5.7443 & TRN \\
\hline CHEMBL1437217 & 688407 & 4.5 & 4.8927 & TRN \\
\hline CHEMBL 1317628 & 688407 & 7.9508 & 5.8474 & TRN \\
\hline CHEMBL1513757 & 688407 & 5.2 & 5.2229 & TRN \\
\hline CHEMBL 1572694 & 688407 & 4.9 & 6.2976 & TRN \\
\hline CHEMBL1435498 & 688407 & 8.301 & 6.1381 & TST \\
\hline CHEMBL1552879 & 688407 & 8.1024 & 5.9754 & TST \\
\hline CHEMBL1313953 & 688407 & 5.7 & 6.1846 & TRN \\
\hline CHEMBL 1446449 & 688407 & 7.9508 & 6.2061 & TRN \\
\hline CHEMBL1553868 & 688407 & 4.8 & 5.2948 & TRN \\
\hline CHEMBL1476988 & 688407 & 4.9 & 5.9237 & TST \\
\hline CHEMBL1355543 & 688407 & 4.6 & 4.8461 & TRN \\
\hline CHEMBL1397569 & 688407 & 4.5 & 5.1594 & TRN \\
\hline CHEMBL3193916 & 688407 & 4.75 & 6.1624 & TST \\
\hline CHEMBL1402619 & 688407 & 8.3979 & 6.9949 & TRN \\
\hline CHEMBL1600040 & 688407 & 4.45 & 5.5111 & TST \\
\hline CHEMBL1412114 & 688407 & 4.8 & 4.8983 & TST \\
\hline CHEMBL 1314646 & 688407 & 5.9 & 6.1184 & TRN \\
\hline CHEMBL1476783 & 688407 & 6.5 & 5.6797 & TST \\
\hline CHEMBL1316245 & 688407 & 4.65 & 5.6458 & TRN \\
\hline CHEMBL1325479 & 688407 & 4.7 & 4.5288 & TRN \\
\hline CHEMBL1488003 & 688407 & 4.5 & 5.6919 & TST \\
\hline CHEMBL1593890 & 688407 & 7.8996 & 5.6237 & TRN \\
\hline CHEMBL 1554832 & 688407 & 6.8 & 6.6974 & TRN \\
\hline CHEMBL 1445543 & 688407 & 5.1 & $5.7520 e$ & 0000000001 \\
\hline CHEMBL1359288 & 688407 & 4.5 & 5.8742 & TRN \\
\hline CHEMBL1356030 & 688407 & 4.55 & 5.0814 & TRN \\
\hline CHEMBL1514409 & 688407 & 5.0 & 5.8126 & TRN \\
\hline
\end{tabular}




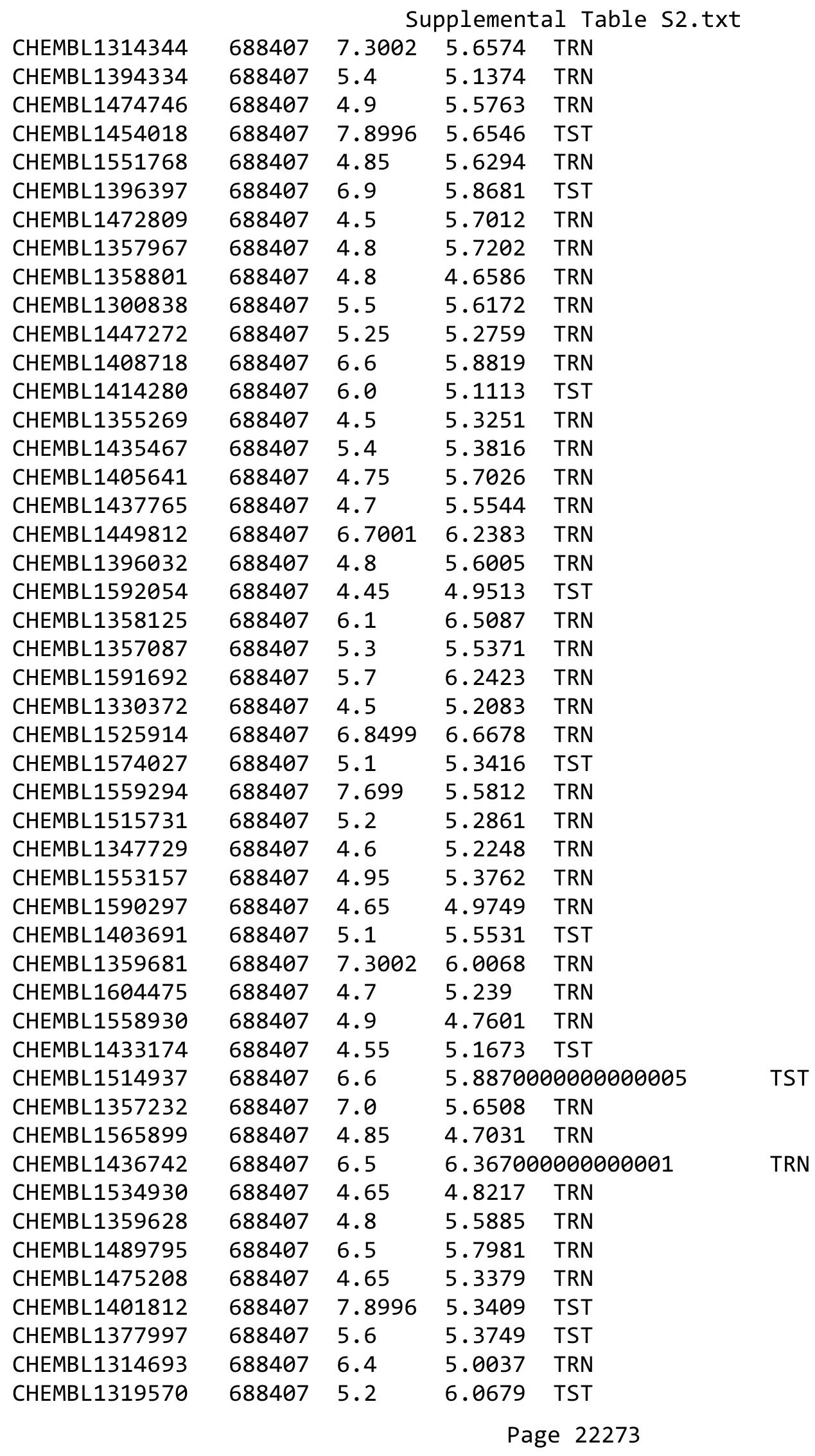




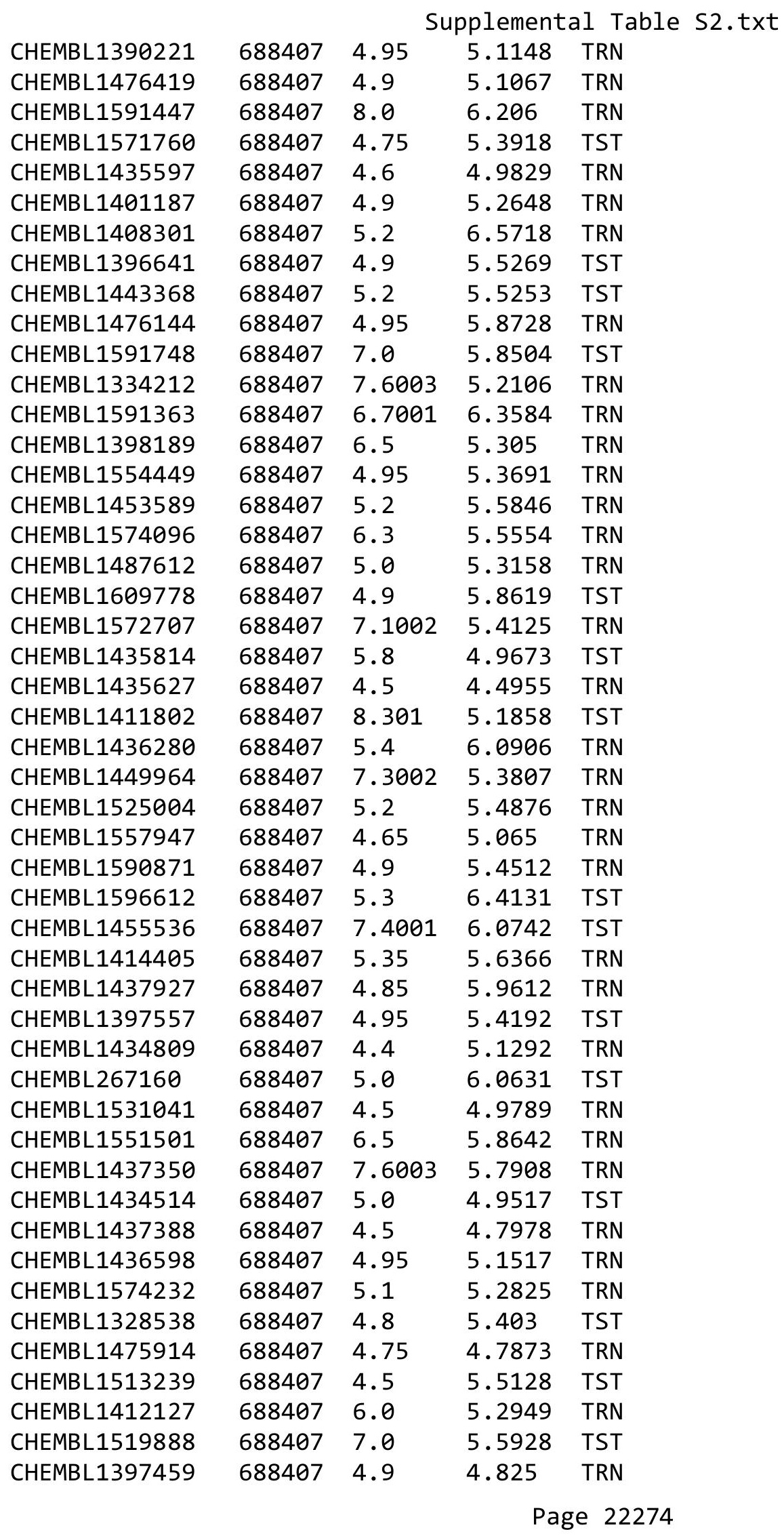




\begin{tabular}{|c|c|c|c|c|}
\hline \multicolumn{5}{|c|}{ Supplemental Table S2.txt } \\
\hline CHEMBL1435864 & 688407 & 8.0 & 6.0081 & TRN \\
\hline CHEMBL1434444 & 688407 & 4.8 & 5.6078 & TRN \\
\hline CHEMBL1361421 & 688407 & 5.0 & 5.6485 & TRN \\
\hline CHEMBL1469768 & 688407 & 7.5003 & 6.37299 & 9999999999 \\
\hline CHEMBL1590284 & 688407 & 4.8 & 5.6832 & TRN \\
\hline CHEMBL1435166 & 688407 & 6.4 & 6.2733 & TRN \\
\hline CHEMBL1355365 & 688407 & 5.25 & 6.153 & TST \\
\hline CHEMBL1433853 & 688407 & 7.3002 & 6.1648 & TRN \\
\hline CHEMBL1591901 & 688407 & 4.7 & 4.0141 & TST \\
\hline CHEMBL3213501 & 688407 & 5.05 & 5.7116 & TST \\
\hline CHEMBL1560639 & 688407 & 5.5 & 5.6372 & TST \\
\hline CHEMBL1600374 & 688407 & 6.35 & 6.364 & TRN \\
\hline CHEMBL1474836 & 688407 & 5.3 & 6.0514 & TRN \\
\hline CHEMBL1327072 & 688407 & 4.5 & 4.954 & TRN \\
\hline CHEMBL1475937 & 688407 & 5.0 & 4.6754 & TRN \\
\hline CHEMBL1482776 & 688407 & 7.4001 & 5.8653 & TRN \\
\hline CHEMBL1358530 & 688407 & 5.6 & 5.6673 & TRN \\
\hline CHEMBL1485198 & 688407 & 4.7 & 4.8917 & TRN \\
\hline CHEMBL1590695 & 688407 & 4.9 & 5.126 & TRN \\
\hline CHEMBL1592573 & 688407 & 8.301 & 5.5034 & TRN \\
\hline CHEMBL1521563 & 688407 & 4.45 & 5.0413 & TST \\
\hline CHEMBL1403048 & 688407 & 4.95 & 5.3099 & TST \\
\hline CHEMBL1372464 & 688407 & 5.0 & 5.6849 & TST \\
\hline CHEMBL1480958 & 688407 & 4.7 & 5.6802 & TST \\
\hline CHEMBL1551807 & 688407 & 6.0 & 5.9306 & TRN \\
\hline CHEMBL1437272 & 688407 & 4.45 & 6.0485 & TRN \\
\hline CHEMBL1554303 & 688407 & 4.5 & 5.1284 & TRN \\
\hline CHEMBL1372228 & 688407 & 4.95 & 5.6699 & TRN \\
\hline CHEMBL1592439 & 688407 & 6.3 & 5.695 & TRN \\
\hline CHEMBL1611842 & 688407 & 4.5 & 4.7294 & TRN \\
\hline CHEMBL1518527 & 688407 & 4.9 & 5.6296 & TRN \\
\hline CHEMBL1478812 & 688407 & 4.8 & 5.4661 & TRN \\
\hline CHEMBL1315721 & 688407 & 4.8 & 5.4227 & TRN \\
\hline CHEMBL1592935 & 688407 & 4.7 & 5.3567 & TRN \\
\hline CHEMBL1596465 & 688407 & 6.5 & 5.485 & TST \\
\hline CHEMBL1553084 & 688407 & 8.301 & 5.4865 & TRN \\
\hline CHEMBL1356502 & 688407 & 4.75 & 5.2123 & TRN \\
\hline CHEMBL1365093 & 688407 & 6.1 & 5.9683 & TRN \\
\hline CHEMBL1482541 & 688407 & 5.55 & 5.3409 & TRN \\
\hline CHEMBL1355110 & 688407 & 5.4 & 5.806 & TRN \\
\hline CHEMBL1474458 & 688407 & 4.6 & 5.0019 & TRN \\
\hline CHEMBL1404899 & 688407 & 4.5 & 5.3703 & TRN \\
\hline CHEMBL1474904 & 688407 & 4.7 & 5.4691 & TRN \\
\hline CHEMBL1316633 & 688407 & 7.5003 & 5.6317 & TRN \\
\hline CHEMBL1406046 & 688407 & 6.5 & 6.1381 & TRN \\
\hline CHEMBL1473320 & 688407 & 4.5 & 5.5243 & TST \\
\hline CHEMBL1612170 & 688407 & 4.85 & 5.9982 & TST \\
\hline CHEMBL1598888 & 688407 & 4.95 & 5.3742 & TRN \\
\hline
\end{tabular}




\begin{tabular}{|c|c|c|c|c|c|}
\hline & & \multicolumn{4}{|c|}{ Supplemental Table S2.txt } \\
\hline CHEMBL1609549 & 688407 & 8.0506 & 5.468 & TRN & \\
\hline CHEMBL1315327 & 688407 & 4.85 & 5.5282 & TRN & \\
\hline CHEMBL1553620 & 688407 & 8.4949 & 6.6092 & TRN & \\
\hline CHEMBL1595485 & 688407 & 6.1 & 5.8459 & TRN & \\
\hline CHEMBL1314438 & 688407 & 4.8 & 5.6027 & TRN & \\
\hline CHEMBL1446544 & 688407 & 8.301 & 5.3941 & TST & \\
\hline CHEMBL1590611 & 688407 & 4.7 & 6.0284 & TRN & \\
\hline CHEMBL1398464 & 688407 & 8.301 & 5.9557 & TRN & \\
\hline CHEMBL1593401 & 688407 & 5.2 & 5.4969 & TRN & \\
\hline CHEMBL1591497 & 688407 & 4.8 & 5.4882 & TST & \\
\hline CHEMBL1437739 & 688407 & 4.5 & 5.4341 & TRN & \\
\hline CHEMBL1316423 & 688407 & 4.75 & 5.9468 & TRN & \\
\hline CHEMBL1551401 & 688407 & 4.8 & 4.8298 & TRN & \\
\hline CHEMBL1457597 & 688407 & 5.05 & 5.7638 & TST & \\
\hline CHEMBL1407950 & 688407 & 4.65 & 5.7469 & TST & \\
\hline CHEMBL1516075 & 688407 & 8.2007 & 5.8864 & TST & \\
\hline CHEMBL1553127 & 688407 & 5.3 & 4.955 & TRN & \\
\hline CHEMBL1396182 & 688407 & 5.7 & 6.0311 & TST & \\
\hline CHEMBL1552826 & 688407 & 4.9 & 4.688 & TST & \\
\hline CHEMBL1317281 & 688407 & 5.0 & 5.5844 & TRN & \\
\hline CHEMBL1475773 & 688407 & 5.0 & 5.072 & TRN & \\
\hline CHEMBL1597711 & 688407 & 4.5 & 4.7508 & TRN & \\
\hline CHEMBL1449069 & 688407 & 4.5 & 4.1569 & TRN & \\
\hline CHEMBL1552328 & 688407 & 7.5498 & 6.53100 & 0000000001 & TRN \\
\hline CHEMBL1456248 & 688407 & 6.3 & 5.6703 & TRN & \\
\hline CHEMBL1327098 & 688407 & 4.9 & 5.4122 & TRN & \\
\hline CHEMBL1476431 & 688407 & 5.0 & 5.2701 & TRN & \\
\hline CHEMBL1513723 & 688407 & 5.95 & 5.2382 & TRN & \\
\hline CHEMBL1606986 & 688407 & 4.45 & 5.0152 & TRN & \\
\hline CHEMBL1365098 & 688407 & 4.45 & 5.4405 & TRN & \\
\hline CHEMBL1407340 & 688407 & 5.0 & 5.3937 & TRN & \\
\hline CHEMBL1515741 & 688407 & 4.5 & 5.1722 & TRN & \\
\hline CHEMBL1529796 & 688407 & 5.2 & 5.4757 & TRN & \\
\hline CHEMBL1086872 & 688407 & 4.6 & 5.6887 & TRN & \\
\hline CHEMBL1433881 & 688407 & 5.5 & 6.0351 & TRN & \\
\hline CHEMBL1516258 & 688407 & 4.7 & 5.517 & TRN & \\
\hline CHEMBL1515418 & 688407 & 4.5 & 4.5284 & TRN & \\
\hline CHEMBL1592650 & 688407 & 4.7 & 5.2455 & TRN & \\
\hline CHEMBL1592059 & 688407 & 4.9 & 6.796 & TRN & \\
\hline CHEMBL1394695 & 688407 & 4.7 & 4.7266 & TRN & \\
\hline CHEMBL1554068 & 688407 & 7.5003 & 5.9604 & TRN & \\
\hline CHEMBL1510389 & 688407 & 5.4 & 5.9552 & TRN & \\
\hline CHEMBL1334915 & 688407 & 4.9 & 5.1221 & TRN & \\
\hline CHEMBL1486154 & 688407 & 4.9 & 5.1775 & TRN & \\
\hline CHEMBL1559463 & 688407 & 6.5 & 6.0662 & TRN & \\
\hline CHEMBL1474698 & 688407 & 7.699 & 6.0629 & TRN & \\
\hline CHEMBL1451775 & 688407 & 5.2 & 5.7295 & TST & \\
\hline CHEMBL1443758 & 688407 & 7.5003 & 5.9006 & TRN & \\
\hline
\end{tabular}




\begin{tabular}{|c|c|c|c|c|c|}
\hline \multicolumn{6}{|c|}{ Supplemental Table S2.txt } \\
\hline CHEMBL1370271 & 688407 & 4.75 & 5.1443 & TRN & \\
\hline CHEMBL1554092 & 688407 & 5.0 & 5.58299 & 9999999999 & TST \\
\hline CHEMBL1513238 & 688407 & 4.45 & 4.75899 & 99999999995 & TST \\
\hline CHEMBL1572465 & 688407 & 4.8 & 6.019 & TRN & \\
\hline CHEMBL1394980 & 688407 & 5.0 & 5.0141 & TRN & \\
\hline CHEMBL1401530 & 688407 & 4.9 & 6.3846 & TST & \\
\hline CHEMBL1454906 & 688407 & 5.1 & 5.8394 & TRN & \\
\hline CHEMBL1457521 & 688407 & 6.1 & 5.9352 & TRN & \\
\hline CHEMBL1378681 & 688407 & 4.6 & 5.5467 & TRN & \\
\hline CHEMBL1440334 & 688407 & 4.75 & 4.8343 & TRN & \\
\hline CHEMBL235891 & 688407 & 4.8 & 4.8971 & TST & \\
\hline CHEMBL1442167 & 688407 & 4.5 & 5.2548 & TRN & \\
\hline CHEMBL1513611 & 688407 & 4.8 & 5.2894 & TRN & \\
\hline CHEMBL1568190 & 688407 & 5.05 & 4.5012 & TRN & \\
\hline CHEMBL1364753 & 688407 & 4.8 & 5.2427 & TRN & \\
\hline CHEMBL1358040 & 688407 & 4.5 & 5.9156 & TRN & \\
\hline CHEMBL1445636 & 688407 & 4.7 & 5.6148 & TRN & \\
\hline CHEMBL1522468 & 688407 & 4.5 & 4.9533 & TRN & \\
\hline CHEMBL3194563 & 688407 & 5.1 & 5.5121 & TST & \\
\hline CHEMBL1592910 & 688407 & 4.65 & 4.1913 & TRN & \\
\hline CHEMBL1501547 & 688407 & 4.9 & 5.7606 & TRN & \\
\hline CHEMBL1325362 & 688407 & 6.2 & 5.0744 & TRN & \\
\hline CHEMBL1598184 & 688407 & 5.35 & 5.0128 & TRN & \\
\hline CHEMBL1513457 & 688407 & 4.5 & 5.3441 & TST & \\
\hline CHEMBL1354770 & 688407 & 5.3 & 5.2038 & TRN & \\
\hline CHEMBL1512289 & 688407 & 4.95 & 5.2374 & TRN & \\
\hline CHEMBL1605134 & 688407 & 6.1 & 5.6626 & TRN & \\
\hline CHEMBL1553421 & 688407 & 5.0 & 5.4444 & TRN & \\
\hline CHEMBL1317024 & 688407 & 4.7 & 5.0958 & TRN & \\
\hline CHEMBL1552554 & 688407 & 7.5498 & 5.5239 & TST & \\
\hline CHEMBL1522393 & 688407 & 6.95 & 6.6362 & TRN & \\
\hline CHEMBL1514318 & 688407 & 4.5 & 6.414 & TST & \\
\hline CHEMBL1399128 & 688407 & 6.2 & 5.3389 & TRN & \\
\hline CHEMBL1564080 & 688407 & 4.5 & 5.7084 & TRN & \\
\hline CHEMBL1333356 & 688407 & 4.7 & 5.0954 & TRN & \\
\hline CHEMBL1524347 & 688407 & 5.6 & 5.8999 & TRN & \\
\hline CHEMBL1354402 & 688407 & 5.2 & 5.7175 & TRN & \\
\hline CHEMBL1608177 & 688407 & 4.5 & 5.3283 & TST & \\
\hline CHEMBL1483511 & 688407 & 7.7496 & 6.1852 & TRN & \\
\hline CHEMBL1591887 & 688407 & 4.9 & 5.6686 & TRN & \\
\hline CHEMBL1370019 & 688407 & 5.0 & 4.84399 & 9999999999 & TRN \\
\hline CHEMBL1590202 & 688407 & 4.95 & 5.1485 & TRN & \\
\hline CHEMBL1410778 & 688407 & 5.3 & 5.4034 & TRN & \\
\hline CHEMBL1409519 & 688407 & 5.1 & 5.4872 & TRN & \\
\hline CHEMBL1606482 & 688407 & 4.85 & 4.9475 & TRN & \\
\hline CHEMBL1370307 & 688407 & 7.2503 & 5.4011 & TST & \\
\hline CHEMBL1320917 & 688407 & 4.8 & 5.0215 & TST & \\
\hline CHEMBL1354321 & 688407 & 5.0 & 6.0065 & TST & \\
\hline
\end{tabular}




\begin{tabular}{|c|c|c|c|c|}
\hline & & & oplement & al $\mathrm{Ta}$ \\
\hline CHEMBL1595692 & 688407 & 6.9 & 6.1501 & TRN \\
\hline CHEMBL1593003 & 688407 & 4.45 & 5.2848 & TRN \\
\hline CHEMBL1492695 & 688407 & 8.0 & 6.351 & TRN \\
\hline CHEMBL1317341 & 688407 & 5.0 & 5.6266 & TRN \\
\hline CHEMBL1415771 & 688407 & 4.8 & 5.4072 & TST \\
\hline CHEMBL1522172 & 688407 & 4.65 & 5.0444 & TRN \\
\hline CHEMBL1481085 & 688407 & 4.45 & 4.1422 & TRN \\
\hline CHEMBL1590235 & 688407 & 4.5 & 6.1014 & TST \\
\hline CHEMBL1555410 & 688407 & 6.35 & 5.6314 & TRN \\
\hline CHEMBL1440705 & 688407 & 4.6 & 5.2979 & TRN \\
\hline CHEMBL1369018 & 688407 & 7.699 & 6.1627 & TRN \\
\hline CHEMBL1515062 & 688407 & 6.5 & 5.559 & TRN \\
\hline CHEMBL1518720 & 688407 & 4.6 & 4.7636 & TRN \\
\hline CHEMBL1592174 & 688407 & 6.0 & 5.8279 & TRN \\
\hline CHEMBL1590035 & 688407 & 4.7 & 5.3196 & TRN \\
\hline CHEMBL1551373 & 688407 & 4.7 & 5.3636 & TST \\
\hline CHEMBL1435877 & 688407 & 4.9 & 6.0183 & TRN \\
\hline CHEMBL1513292 & 688407 & 4.5 & 5.7675 & TRN \\
\hline CHEMBL1378138 & 688407 & 4.9 & 5.6607 & TST \\
\hline CHEMBL1593752 & 688407 & 5.6 & 5.317 & TRN \\
\hline CHEMBL1450862 & 688407 & 5.0 & 7.0399 & TRN \\
\hline CHEMBL1396586 & 688407 & 4.45 & 5.291 & TRN \\
\hline CHEMBL1376919 & 688407 & 5.3 & 5.8322 & TST \\
\hline CHEMBL1394540 & 688407 & 5.2 & 5.3013 & TRN \\
\hline CHEMBL1335347 & 688407 & 4.75 & 5.4182 & TRN \\
\hline CHEMBL1445523 & 688407 & 4.9 & 5.5987 & TST \\
\hline CHEMBL1396542 & 688407 & 4.9 & 4.9827 & TRN \\
\hline CHEMBL1363355 & 688407 & 7.0 & 6.1758 & TRN \\
\hline CHEMBL1448999 & 688407 & 5.0 & 5.2335 & TST \\
\hline CHEMBL1592421 & 688407 & 6.1 & 4.9725 & TRN \\
\hline CHEMBL1594048 & 688407 & 4.5 & 5.9665 & TRN \\
\hline CHEMBL600347 & 688407 & 4.5 & 4.9522 & TRN \\
\hline CHEMBL1405136 & 688407 & 4.9 & 5.0829 & TRN \\
\hline CHEMBL1440382 & 688407 & 4.6 & 5.4964 & TST \\
\hline CHEMBL1476540 & 688407 & 4.9 & 5.6173 & TRN \\
\hline CHEMBL1314616 & 688407 & 7.0 & 5.8331 & TST \\
\hline CHEMBL1316234 & 688407 & 4.45 & 5.9613 & TST \\
\hline CHEMBL1317848 & 688407 & 4.65 & 5.2378 & TST \\
\hline CHEMBL1475818 & 688407 & 4.8 & 5.6078 & TRN \\
\hline CHEMBL1354622 & 688407 & 4.7 & 5.5811 & TRN \\
\hline CHEMBL1599294 & 688407 & 4.7 & 5.2299 & TRN \\
\hline CHEMBL1324764 & 688407 & 8.0 & 5.6613 & TST \\
\hline CHEMBL1523592 & 688407 & 7.0 & 5.9866 & TRN \\
\hline CHEMBL1487634 & 688407 & 4.45 & 4.8928 & TRN \\
\hline CHEMBL1330174 & 688407 & 5.0 & 6.0575 & TRN \\
\hline CHEMBL1416275 & 688407 & 5.5 & 5.4424 & TRN \\
\hline CHEMBL1320387 & 688407 & 4.5 & 4.633 & TRN \\
\hline CHEMBL1515169 & 688407 & 4.9 & 5.5517 & TRN \\
\hline
\end{tabular}




\begin{tabular}{|c|c|c|c|c|c|}
\hline \\
\hline CHEMBL1459140 & 688407 & 4.7 & 6.0557 & TST & \\
\hline CHEMBL1436619 & 688407 & 4.8 & 5.3434 & TRN & \\
\hline CHEMBL1336580 & 688407 & 4.5 & 5.4994 & TRN & \\
\hline CHEMBL1559914 & 688407 & 5.5 & 5.6232 & TST & \\
\hline CHEMBL1591416 & 688407 & 7.1002 & 5.4733 & TRN & \\
\hline CHEMBL1310612 & 688407 & 5.55 & 5.3648 & TST & \\
\hline CHEMBL1526982 & 688407 & 4.5 & 5.6415 & TRN & \\
\hline CHEMBL1515740 & 688407 & 8.301 & 5.8162 & TRN & \\
\hline CHEMBL1410851 & 688407 & 4.45 & 5.9358 & TRN & \\
\hline CHEMBL1480224 & 688407 & 8.301 & 5.5026 & TRN & \\
\hline CHEMBL1320019 & 688407 & 4.5 & 4.7983 & TST & \\
\hline CHEMBL1318141 & 688407 & 5.6 & 5.9538 & TST & \\
\hline CHEMBL1342076 & 688407 & 4.9 & 5.4207 & TRN & \\
\hline CHEMBL1356368 & 688407 & 6.0 & 5.6526 & TRN & \\
\hline CHEMBL1395452 & 688407 & 4.9 & 4.8587 & TRN & \\
\hline CHEMBL1526702 & 688407 & 4.5 & 5.3469 & TRN & \\
\hline CHEMBL1515402 & 688407 & 4.8 & 5.0634 & TRN & \\
\hline CHEMBL1593942 & 688407 & 4.6 & 5.1564 & TRN & \\
\hline CHEMBL1315535 & 688407 & 4.7 & 5.1392 & TRN & \\
\hline CHEMBL1398633 & 688407 & 4.9 & 4.5361 & TRN & \\
\hline CHEMBL1562033 & 688407 & 4.9 & 4.9375 & TST & \\
\hline CHEMBL1593148 & 688407 & 5.4 & 4.9526 & TRN & \\
\hline CHEMBL1515006 & 688407 & 8.0506 & 5.4911 & TRN & \\
\hline CHEMBL1552986 & 688407 & 4.5 & 5.591 & TRN & \\
\hline CHEMBL1315799 & 688407 & 4.5 & 5.5839 & TST & \\
\hline CHEMBL1581445 & 688407 & 5.9 & 4.995 & TST & \\
\hline CHEMBL1315998 & 688407 & 5.0 & 4.9661 & TRN & \\
\hline CHEMBL1436696 & 688407 & 4.5 & 5.3764 & TRN & \\
\hline CHEMBL1591740 & 688407 & 4.8 & 4.9266 & TRN & \\
\hline CHEMBL1314480 & 688407 & 6.1 & 5.4185 & TST & \\
\hline CHEMBL1605897 & 688407 & 4.8 & 6.2508 & TST & \\
\hline CHEMBL1437143 & 688407 & 6.5 & 5.8715 & TRN & \\
\hline CHEMBL1478691 & 688407 & 4.5 & 5.4631 & TRN & \\
\hline CHEMBL3194101 & 688407 & 6.45 & 5.5823 & TST & \\
\hline CHEMBL1555234 & 688407 & 7.8996 & 6.6303 & TRN & \\
\hline CHEMBL1363563 & 688407 & 7.3002 & 4.8727 & TRN & \\
\hline CHEMBL1592256 & 688407 & 4.95 & 4.9854 & TRN & \\
\hline CHEMBL1318500 & 688407 & 8.301 & 5.766 & TRN & \\
\hline CHEMBL1394736 & 688407 & 6.9 & 5.6916 & TST & \\
\hline CHEMBL1405852 & 688407 & 7.3002 & 6.4192 & TRN & \\
\hline CHEMBL1611054 & 688407 & 6.4 & 6.1079 & TRN & \\
\hline CHEMBL1397646 & 688407 & 5.4 & 5.3216 & TRN & \\
\hline CHEMBL1437931 & 688407 & 4.9 & 6.0519 & TRN & \\
\hline CHEMBL1525000 & 688407 & 4.45 & 5.9259 & TRN & \\
\hline CHEMBL1582611 & 688407 & 8.301 & 5.6127 & TST & \\
\hline CHEMBL1553193 & 688407 & 4.45 & 5.53799 & 9999999999 & TRN \\
\hline CHEMBL1590410 & 688407 & 6.1 & 5.6969 & TST & \\
\hline CHEMBL1516980 & 688407 & 4.8 & 5.7138 & TST & \\
\hline
\end{tabular}




\begin{tabular}{|c|c|c|c|c|c|}
\hline \multicolumn{6}{|c|}{ Supplemental Table s2.txt } \\
\hline CHEMBL1437583 & 688407 & 4.9 & 5.7307 & TRN & \\
\hline CHEMBL1591558 & 688407 & 4.45 & 5.487 & TRN & \\
\hline CHEMBL1329816 & 688407 & 5.25 & 5.5938 & TRN & \\
\hline CHEMBL1565728 & 688407 & 4.5 & 5.8074 & TRN & \\
\hline CHEMBL1396189 & 688407 & 4.45 & 5.5003 & TRN & \\
\hline CHEMBL1484594 & 688407 & 6.9 & 6.2788 & TRN & \\
\hline CHEMBL1472904 & 688407 & 6.7001 & 5.8597 & TRN & \\
\hline CHEMBL1609353 & 688407 & 6.8 & 5.6197 & TRN & \\
\hline CHEMBL1594015 & 688407 & 4.9 & 5.1809 & TRN & \\
\hline CHEMBL1449209 & 688407 & 4.9 & 5.647 & TST & \\
\hline CHEMBL1557484 & 688407 & 4.6 & 4.4435 & TRN & \\
\hline CHEMBL1456630 & 688407 & 5.65 & \multicolumn{2}{|c|}{5.587000000000001} & TST \\
\hline CHEMBL1485820 & 688407 & 6.7001 & 5.3822 & TRN & \\
\hline CHEMBL1516339 & 688407 & 6.0 & 5.8346 & TRN & \\
\hline CHEMBL1401765 & 688407 & 8.2007 & 5.7055 & TRN & \\
\hline CHEMBL1377224 & 688407 & 6.4 & 5.2836 & TRN & \\
\hline CHEMBL1317065 & 688407 & 7.6498 & 5.8834 & TRN & \\
\hline CHEMBL1563797 & 688407 & 4.7 & 5.4371 & TST & \\
\hline CHEMBL1513443 & 688407 & 5.1 & 5.4176 & TST & \\
\hline CHEMBL1455023 & 688407 & 4.75 & 4.8669 & TRN & \\
\hline CHEMBL1568697 & 688407 & 5.1 & 6.3853 & TRN & \\
\hline CHEMBL1402759 & 688407 & 4.5 & 4.9869 & TRN & \\
\hline CHEMBL1566291 & 688407 & 4.8 & 6.5644 & TRN & \\
\hline CHEMBL1356735 & 688407 & 4.9 & 5.2229 & TST & \\
\hline CHEMBL1394500 & 688407 & 8.0506 & 5.9028 & TRN & \\
\hline CHEMBL1435405 & 688407 & 5.6 & 5.3931 & TRN & \\
\hline CHEMBL1397571 & 688407 & 4.9 & 4.9873 & TRN & \\
\hline CHEMBL1407828 & 688407 & 5.0 & 5.3917 & TRN & \\
\hline CHEMBL1602956 & 688407 & 5.0 & 4.8917 & TRN & \\
\hline CHEMBL1443191 & 688407 & 4.65 & 5.1529 & TRN & \\
\hline CHEMBL1526044 & 688407 & 5.45 & 5.356 & TRN & \\
\hline CHEMBL1591689 & 688407 & 4.5 & 5.8093 & TRN & \\
\hline CHEMBL1562445 & 688407 & 4.45 & 5.9263 & TRN & \\
\hline CHEMBL1330964 & 688407 & 8.1024 & 5.8228 & TRN & \\
\hline CHEMBL1435244 & 688407 & 5.0 & \multicolumn{2}{|c|}{5.837000000000001} & TRN \\
\hline CHEMBL1590434 & 688407 & 4.8 & 5.4776 & TRN & \\
\hline CHEMBL1436947 & 688407 & 4.95 & 5.6384 & TRN & \\
\hline CHEMBL1369164 & 688407 & 6.2 & 5.9413 & TRN & \\
\hline CHEMBL1596344 & 688407 & 4.5 & 5.0413 & TRN & \\
\hline CHEMBL1597905 & 688407 & 4.9 & 5.6574 & TST & \\
\hline CHEMBL1513327 & 688407 & 4.9 & 5.2336 & TRN & \\
\hline CHEMBL1437230 & 688407 & 5.05 & 4.316 & TRN & \\
\hline CHEMBL1315321 & 688407 & 8.4949 & 5.7944 & TST & \\
\hline CHEMBL1590820 & 688407 & 4.9 & 5.0222 & TRN & \\
\hline CHEMBL1512967 & 688407 & 4.5 & 5.4524 & TST & \\
\hline CHEMBL1315567 & 688407 & 4.5 & 4.9487 & TRN & \\
\hline CHEMBL1477142 & 688407 & 4.95 & 5.6593 & TRN & \\
\hline \multirow[t]{2}{*}{ CHEMBL1533169 } & 688407 & 4.9 & 5.42299 & 9999999999 & TRN \\
\hline & & & \multicolumn{2}{|c|}{$\begin{array}{r}\text { Page } 22280 \\
\text { Pa }\end{array}$} & \\
\hline
\end{tabular}




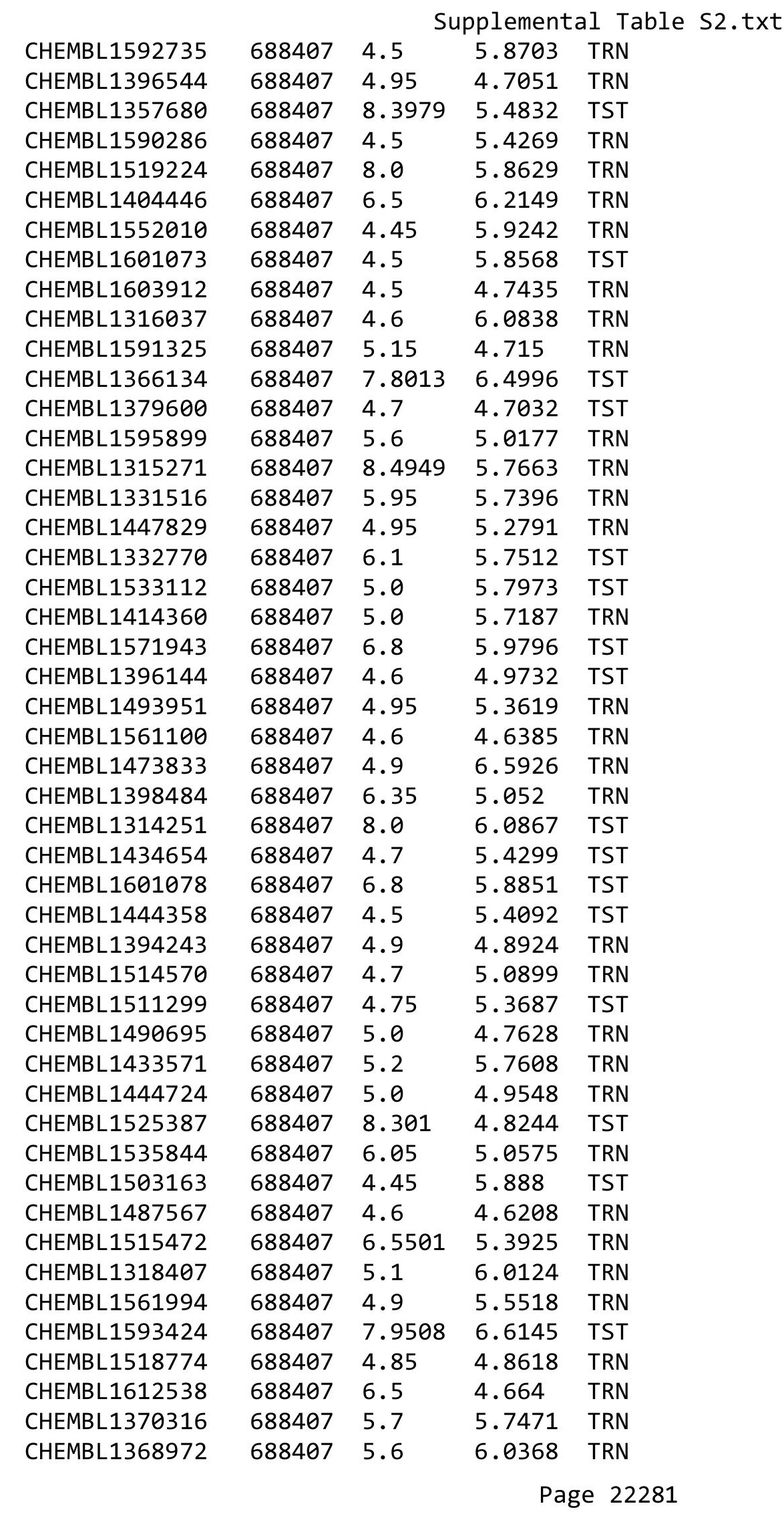




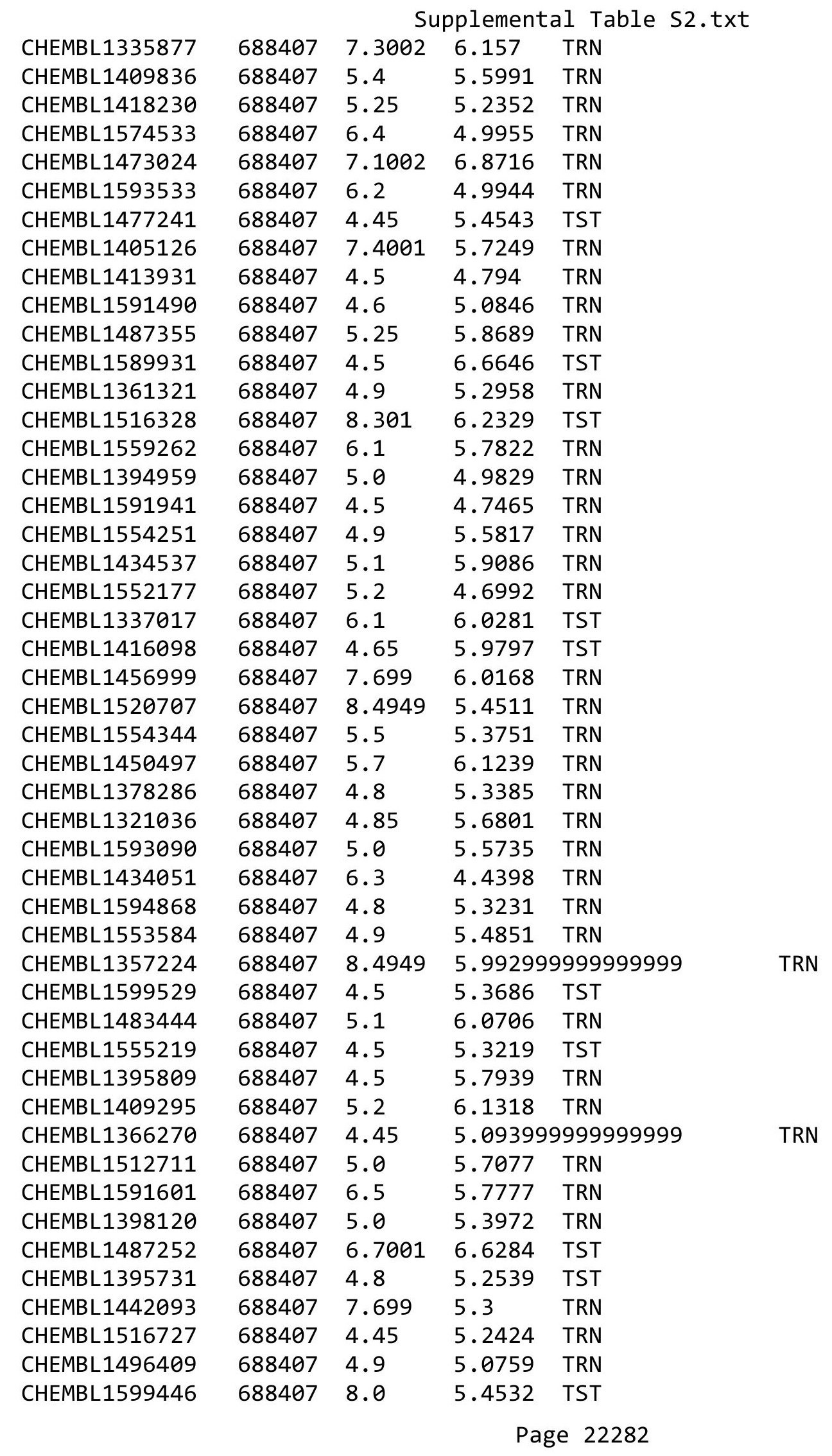




\begin{tabular}{|c|c|c|c|c|c|}
\hline \\
\hline CHEMBL1358198 & 688407 & 4.5 & 5.7099 & TRN & \\
\hline CHEMBL1476374 & 688407 & 5.6 & 5.5223 & TRN & \\
\hline CHEMBL1449781 & 688407 & 4.5 & 5.0981 & TRN & \\
\hline CHEMBL1521269 & 688407 & 5.05 & 5.8239 & TRN & \\
\hline CHEMBL1314417 & 688407 & 7.2 & 6.3752 & TRN & \\
\hline CHEMBL1442016 & 688407 & 7.3002 & 5.3667 & TRN & \\
\hline CHEMBL1397011 & 688407 & 4.5 & 5.3028 & TST & \\
\hline CHEMBL1553557 & 688407 & 5.3 & 5.9546 & TRN & \\
\hline CHEMBL1337846 & 688407 & 5.25 & 5.4895 & TRN & \\
\hline CHEMBL1405891 & 688407 & 6.4 & 5.8051 & TRN & \\
\hline CHEMBL1357622 & 688407 & 5.2 & 5.6709 & TRN & \\
\hline CHEMBL1553006 & 688407 & 8.0 & 6.3353 & TRN & \\
\hline CHEMBL1590529 & 688407 & 8.301 & 5.8958 & TRN & \\
\hline CHEMBL1590140 & 688407 & 5.4 & 5.74299 & 9999999999 & TRN \\
\hline CHEMBL1346891 & 688407 & 4.5 & 5.147 & TST & \\
\hline CHEMBL1328687 & 688407 & 4.9 & 4.8567 & TRN & \\
\hline CHEMBL1519048 & 688407 & 5.1 & 5.5615 & TRN & \\
\hline CHEMBL1590777 & 688407 & 4.6 & 4.9334 & TRN & \\
\hline CHEMBL1475835 & 688407 & 6.9 & 5.6056 & TRN & \\
\hline CHEMBL1593181 & 688407 & 4.9 & 4.8651 & TRN & \\
\hline CHEMBL1388197 & 688407 & 4.45 & 5.7267 & TST & \\
\hline CHEMBL1406256 & 688407 & 4.9 & 5.2755 & TRN & \\
\hline CHEMBL1613733 & 688407 & 5.0 & 5.6225 & TST & \\
\hline CHEMBL1516125 & 688407 & 4.45 & 4.9618 & TRN & \\
\hline CHEMBL1365876 & 688407 & 4.5 & 5.1093 & TRN & \\
\hline CHEMBL1334550 & 688407 & 4.95 & 4.9352 & TRN & \\
\hline CHEMBL1463491 & 688407 & 4.6 & 5.1588 & TRN & \\
\hline CHEMBL1474975 & 688407 & 7.8013 & 5.5102 & TRN & \\
\hline CHEMBL1564073 & 688407 & 7.6003 & 5.4841 & TRN & \\
\hline CHEMBL1377262 & 688407 & 7.2 & 5.5423 & TST & \\
\hline CHEMBL1599164 & 688407 & 4.7 & 6.2951 & TST & \\
\hline CHEMBL1512493 & 688407 & 8.301 & 6.7556 & TRN & \\
\hline CHEMBL1573866 & 688407 & 4.95 & 5.2366 & TST & \\
\hline CHEMBL1591137 & 688407 & 5.1 & 6.4304 & TRN & \\
\hline CHEMBL1440589 & 688407 & 5.5 & 5.4327 & TRN & \\
\hline CHEMBL1590712 & 688407 & 4.5 & 5.2486 & TRN & \\
\hline CHEMBL1514428 & 688407 & 4.7 & 5.0286 & TRN & \\
\hline CHEMBL1475470 & 688407 & 4.7 & 5.101 & TRN & \\
\hline CHEMBL1397008 & 688407 & 4.45 & 5.51200 & 00000000005 & TRN \\
\hline CHEMBL1354686 & 688407 & 5.9 & 5.5678 & TRN & \\
\hline CHEMBL1358726 & 688407 & 4.6 & 5.8127 & TRN & \\
\hline CHEMBL1491085 & 688407 & 4.45 & 6.3517 & TRN & \\
\hline CHEMBL1596666 & 688407 & 4.95 & 5.666 & TRN & \\
\hline CHEMBL1332323 & 688407 & 8.3979 & 7.0068 & TRN & \\
\hline CHEMBL1358639 & 688407 & 7.8013 & 5.4663 & TRN & \\
\hline CHEMBL1318453 & 688407 & 4.5 & 6.2111 & TRN & \\
\hline CHEMBL1380314 & 688407 & 5.0 & 4.8446 & TRN & \\
\hline CHEMBL1561897 & 688407 & 4.95 & 5.2875 & TRN & \\
\hline
\end{tabular}




\begin{tabular}{|c|c|c|c|c|c|}
\hline \multicolumn{6}{|c|}{ Supplemental Table S2.txt } \\
\hline CHEMBL1479632 & 688407 & 5.2 & 5.3 & TRN & \\
\hline CHEMBL1554244 & 688407 & 4.5 & 5.3405 & TRN & \\
\hline CHEMBL1362432 & 688407 & 5.2 & 5.0871 & TRN & \\
\hline CHEMBL1337084 & 688407 & 4.9 & 5.5417 & TST & \\
\hline CHEMBL1512071 & 688407 & 4.9 & 4.971 & TRN & \\
\hline CHEMBL1380514 & 688407 & 5.0 & 4.9104 & TRN & \\
\hline CHEMBL1447292 & 688407 & 6.8 & 5.4353 & TRN & \\
\hline CHEMBL1324637 & 688407 & 5.0 & 4.9554 & TRN & \\
\hline CHEMBL1398356 & 688407 & 4.7 & 5.8777 & TRN & \\
\hline CHEMBL1403609 & 688407 & 4.75 & 5.9556 & TST & \\
\hline CHEMBL1442508 & 688407 & 6.5 & 5.5811 & TST & \\
\hline CHEMBL1514871 & 688407 & 5.3 & 5.5028 & TRN & \\
\hline CHEMBL1394476 & 688407 & 5.6 & 4.9228 & TRN & \\
\hline CHEMBL1567156 & 688407 & 7.1002 & 5.5651 & TRN & \\
\hline CHEMBL1374776 & 688407 & 5.0 & 5.4057 & TRN & \\
\hline CHEMBL1567587 & 688407 & 4.85 & 5.0464 & TRN & \\
\hline CHEMBL1366360 & 688407 & 4.5 & 5.0573 & TRN & \\
\hline CHEMBL1516891 & 688407 & 7.9508 & 5.2411 & TRN & \\
\hline CHEMBL1434414 & 688407 & 4.8 & 5.3068 & TRN & \\
\hline CHEMBL1455671 & 688407 & 6.95 & 6.1195 & TRN & \\
\hline CHEMBL1367882 & 688407 & 4.9 & 5.7458 & TRN & \\
\hline CHEMBL1520395 & 688407 & 7.15 & 5.8525 & TRN & \\
\hline CHEMBL1611710 & 688407 & 4.5 & 5.0735 & TST & \\
\hline CHEMBL1518894 & 688407 & 4.9 & 5.3736 & TRN & \\
\hline CHEMBL1433440 & 688407 & 4.5 & 5.5465 & TRN & \\
\hline CHEMBL1512729 & 688407 & 5.9 & 5.7332 & TST & \\
\hline CHEMBL1356144 & 688407 & 4.6 & 5.0451 & TRN & \\
\hline CHEMBL1409420 & 688407 & 5.0 & 5.4805 & TRN & \\
\hline CHEMBL1592755 & 688407 & 4.5 & 4.5813 & TRN & \\
\hline CHEMBL1397306 & 688407 & 4.8 & 6.1349 & TRN & \\
\hline CHEMBL1396285 & 688407 & 4.9 & 5.5519 & TRN & \\
\hline CHEMBL1593462 & 688407 & 5.3 & 5.2543 & TRN & \\
\hline CHEMBL1591179 & 688407 & 5.7 & 5.3816 & TRN & \\
\hline CHEMBL1512187 & 688407 & 4.85 & 5.70299 & 9999999999 & TRN \\
\hline CHEMBL1434234 & 688407 & 4.9 & 4.6304 & TRN & \\
\hline CHEMBL1378320 & 688407 & 7.4498 & 4.9227 & TST & \\
\hline CHEMBL1474288 & 688407 & 4.65 & 5.3017 & TRN & \\
\hline CHEMBL1314479 & 688407 & 7.0 & 5.5563 & TRN & \\
\hline CHEMBL1496180 & 688407 & 6.3 & 5.6981 & TRN & \\
\hline CHEMBL1336975 & 688407 & 4.5 & 5.5221 & TST & \\
\hline CHEMBL1598480 & 688407 & 6.8 & 6.2668 & TRN & \\
\hline CHEMBL 1450040 & 688407 & 5.0 & 5.056 & TRN & \\
\hline CHEMBL1476639 & 688407 & 4.95 & 5.17299 & 9999999999 & TRN \\
\hline CHEMBL1338749 & 688407 & 4.8 & 5.6828 & TST & \\
\hline CHEMBL1318029 & 688407 & 4.9 & 5.0421 & TST & \\
\hline CHEMBL1428415 & 688407 & 4.5 & 4.7776 & TRN & \\
\hline CHEMBL1366549 & 688407 & 4.9 & 5.5809 & TRN & \\
\hline CHEMBL1413108 & 688407 & 6.1 & 5.8354 & TRN & \\
\hline
\end{tabular}




\begin{tabular}{|c|c|c|c|c|}
\hline \multicolumn{5}{|c|}{ Supplemental Table S2.txt } \\
\hline CHEMBL1365244 & 688407 & 4.8 & 5.8312 & TRN \\
\hline CHEMBL1610881 & 688407 & 4.45 & 5.2921 & TST \\
\hline CHEMBL1375240 & 688407 & 6.8 & 5.1456 & TST \\
\hline CHEMBL1553933 & 688407 & 5.0 & 4.9476 & TST \\
\hline CHEMBL1318273 & 688407 & 4.65 & 5.8099 & TRN \\
\hline CHEMBL1354599 & 688407 & 5.2 & 6.1367 & TRN \\
\hline CHEMBL1436423 & 688407 & 4.9 & 5.4708 & TRN \\
\hline CHEMBL1557659 & 688407 & 6.2 & 5.7663 & TRN \\
\hline CHEMBL1397414 & 688407 & 4.7 & 5.0028 & TRN \\
\hline CHEMBL1396283 & 688407 & 8.0 & 6.099 & TST \\
\hline CHEMBL1434732 & 688407 & 4.65 & 4.6472 & TRN \\
\hline CHEMBL1452842 & 688407 & 4.9 & 4.805 & TRN \\
\hline CHEMBL1314236 & 688407 & 5.6 & 5.4018 & TRN \\
\hline CHEMBL1318351 & 688407 & 5.7 & 5.6974 & TRN \\
\hline CHEMBL1563695 & 688407 & 5.1 & 5.3264 & TRN \\
\hline CHEMBL1455934 & 688407 & 4.9 & 4.9294 & TRN \\
\hline CHEMBL578890 & 688407 & 4.6 & 5.0481 & TRN \\
\hline CHEMBL1554698 & 688407 & 5.0 & 5.5485 & TST \\
\hline CHEMBL1445207 & 688407 & 6.7001 & 5.7829 & TRN \\
\hline CHEMBL1526054 & 688407 & 4.5 & 4.6701 & TRN \\
\hline CHEMBL1564695 & 688407 & 5.45 & 5.5888 & TST \\
\hline CHEMBL1553391 & 688407 & 8.301 & 5.2526 & TST \\
\hline CHEMBL1492259 & 688407 & 4.45 & 5.7305 & TRN \\
\hline CHEMBL1476809 & 688407 & 6.3 & 5.7918 & TRN \\
\hline CHEMBL1599764 & 688407 & 4.8 & 6.0564 & TRN \\
\hline CHEMBL1574222 & 688407 & 4.5 & 6.2864 & TRN \\
\hline CHEMBL1555205 & 688407 & 5.0 & 5.3805 & TRN \\
\hline CHEMBL1512499 & 688407 & 5.2 & 5.4874 & TRN \\
\hline CHEMBL602922 & 688407 & 4.9 & 5.2438 & TST \\
\hline CHEMBL1314926 & 688407 & 5.85 & 5.6709 & TRN \\
\hline CHEMBL1561980 & 688407 & 4.95 & 4.8791 & TRN \\
\hline CHEMBL1443440 & 688407 & 4.5 & 5.0062 & TST \\
\hline CHEMBL1335189 & 688407 & 6.1 & 5.3091 & TRN \\
\hline CHEMBL1518039 & 688407 & 5.9 & 5.2569 & TRN \\
\hline CHEMBL1589821 & 688407 & 5.0 & 5.3566 & TRN \\
\hline CHEMBL1356147 & 688407 & 5.2 & 4.9221 & TRN \\
\hline CHEMBL1590878 & 688407 & 7.0 & 6.3487 & TRN \\
\hline CHEMBL1314254 & 688407 & 5.2 & 6.2013 & TRN \\
\hline CHEMBL1434096 & 688407 & 4.85 & 5.4783 & TRN \\
\hline CHEMBL1592458 & 688407 & 4.8 & 4.8785 & TRN \\
\hline CHEMBL1611737 & 688407 & 6.0 & 6.5248 & TRN \\
\hline CHEMBL1573680 & 688407 & 7.9508 & 5.6978 & TRN \\
\hline CHEMBL1589640 & 688407 & 4.45 & 4.9684 & TRN \\
\hline CHEMBL1395975 & 688407 & 5.1 & 6.3852 & TRN \\
\hline CHEMBL1437948 & 688407 & 4.7 & 5.566 & TRN \\
\hline CHEMBL1472708 & 688407 & 4.9 & 5.136 & TRN \\
\hline CHEMBL1356603 & 688407 & 6.7001 & 6.1542 & TRN \\
\hline CHEMBL1591458 & 688407 & 4.45 & 4.9938 & TRN \\
\hline
\end{tabular}




\begin{tabular}{|c|c|c|c|c|}
\hline \multicolumn{5}{|c|}{ Supplemental Table S2.tx } \\
\hline CHEMBL1529164 & 688407 & 4.5 & 5.6742 & TRN \\
\hline CHEMBL1590786 & 688407 & 8.301 & 5.4907 & TRN \\
\hline CHEMBL1513624 & 688407 & 4.5 & 5.9105 & TST \\
\hline CHEMBL1593692 & 688407 & 5.45 & 6.5827 & TRN \\
\hline CHEMBL1315605 & 688407 & 4.9 & 5.1537 & TRN \\
\hline CHEMBL1436083 & 688407 & 6.4 & 5.9932 & TRN \\
\hline CHEMBL1593522 & 688407 & 4.8 & 5.2268 & TST \\
\hline CHEMBL1532908 & 688407 & 4.5 & 6.0372 & TRN \\
\hline CHEMBL1553086 & 688407 & 4.45 & 5.3582 & TST \\
\hline CHEMBL1314829 & 688407 & 7.5003 & 5.2965 & TST \\
\hline CHEMBL1418513 & 688407 & 5.5 & 5.5789 & TRN \\
\hline CHEMBL1590509 & 688407 & 4.45 & 5.5235 & TRN \\
\hline CHEMBL1434157 & 688407 & 4.9 & 5.1142 & TRN \\
\hline CHEMBL1590383 & 688407 & 5.0 & 4.5833 & TST \\
\hline CHEMBL1602456 & 688407 & 5.0 & 5.5827 & TRN \\
\hline CHEMBL1481040 & 688407 & 4.6 & 5.5883 & TRN \\
\hline CHEMBL1317709 & 688407 & 4.5 & 5.59 & TRN \\
\hline CHEMBL1315551 & 688407 & 4.45 & 4.7706 & TRN \\
\hline CHEMBL1512692 & 688407 & 5.0 & 5.4403 & TRN \\
\hline CHEMBL1591435 & 688407 & 4.7 & 5.8036 & TST \\
\hline CHEMBL1367834 & 688407 & 4.7 & 5.1409 & TRN \\
\hline CHEMBL1355524 & 688407 & 4.6 & 5.3516 & TRN \\
\hline CHEMBL1496429 & 688407 & 5.2 & 5.5364 & TRN \\
\hline CHEMBL1452256 & 688407 & 4.75 & 4.9666 & TRN \\
\hline CHEMBL1475634 & 688407 & 4.5 & 5.2075 & TRN \\
\hline CHEMBL1593669 & 688407 & 4.7 & 4.8742 & TRN \\
\hline CHEMBL1556277 & 688407 & 5.75 & 5.5375 & TST \\
\hline CHEMBL1358504 & 688407 & 6.8 & 6.5967 & TRN \\
\hline CHEMBL1398171 & 688407 & 4.9 & 5.0722 & TST \\
\hline CHEMBL1314431 & 688407 & 4.5 & 4.3478 & TRN \\
\hline CHEMBL1476790 & 688407 & 5.0 & 5.4103 & TRN \\
\hline CHEMBL1475435 & 688407 & 6.6 & 5.7211 & TST \\
\hline CHEMBL1372649 & 688407 & 4.9 & 5.0757 & TRN \\
\hline CHEMBL1494863 & 688407 & 5.4 & 4.9401 & TRN \\
\hline CHEMBL1397045 & 688407 & 5.3 & 5.2891 & TRN \\
\hline CHEMBL1315812 & 688407 & 4.9 & 5.092 & TRN \\
\hline CHEMBL1337373 & 688407 & 4.65 & 5.0013 & TRN \\
\hline CHEMBL1589870 & 688407 & 7.699 & 6.4232 & TRN \\
\hline CHEMBL1515037 & 688407 & 4.85 & 5.3176 & TRN \\
\hline CHEMBL1440037 & 688407 & 4.7 & 4.9898 & TRN \\
\hline CHEMBL1513884 & 688407 & 5.1 & 6.0648 & TRN \\
\hline CHEMBL1560278 & 688407 & 7.6003 & 4.7302 & TST \\
\hline CHEMBL1555159 & 688407 & 4.9 & 4.6054 & TRN \\
\hline CHEMBL1514537 & 688407 & 5.9 & 5.3336 & TST \\
\hline CHEMBL1563629 & 688407 & 4.6 & 5.1814 & TRN \\
\hline CHEMBL1372212 & 688407 & 4.8 & 5.9106 & TST \\
\hline CHEMBL1374980 & 688407 & 4.45 & 5.655 & TRN \\
\hline CHEMBL1552783 & 688407 & 4.7 & 5.2138 & TRN \\
\hline
\end{tabular}




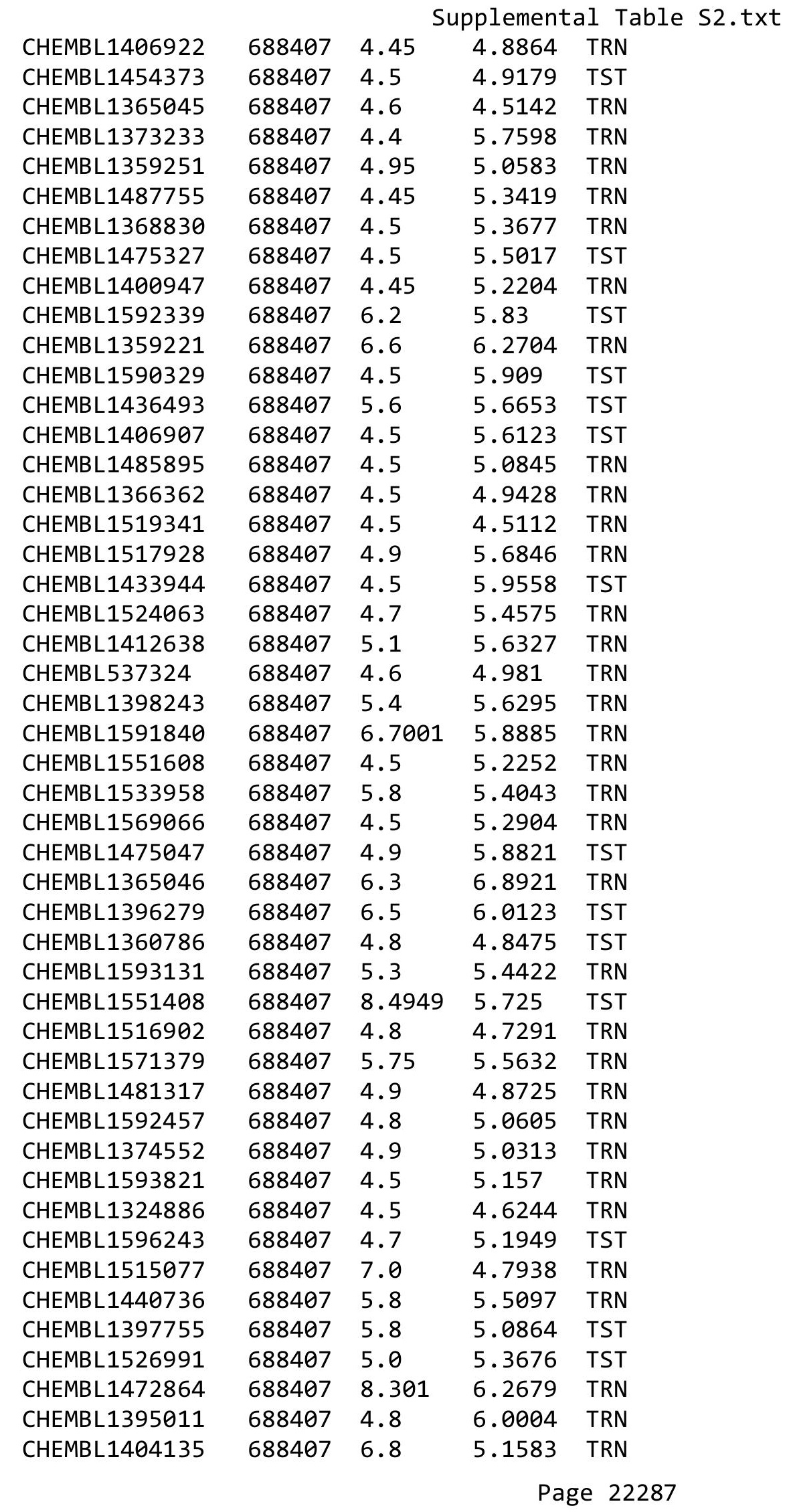




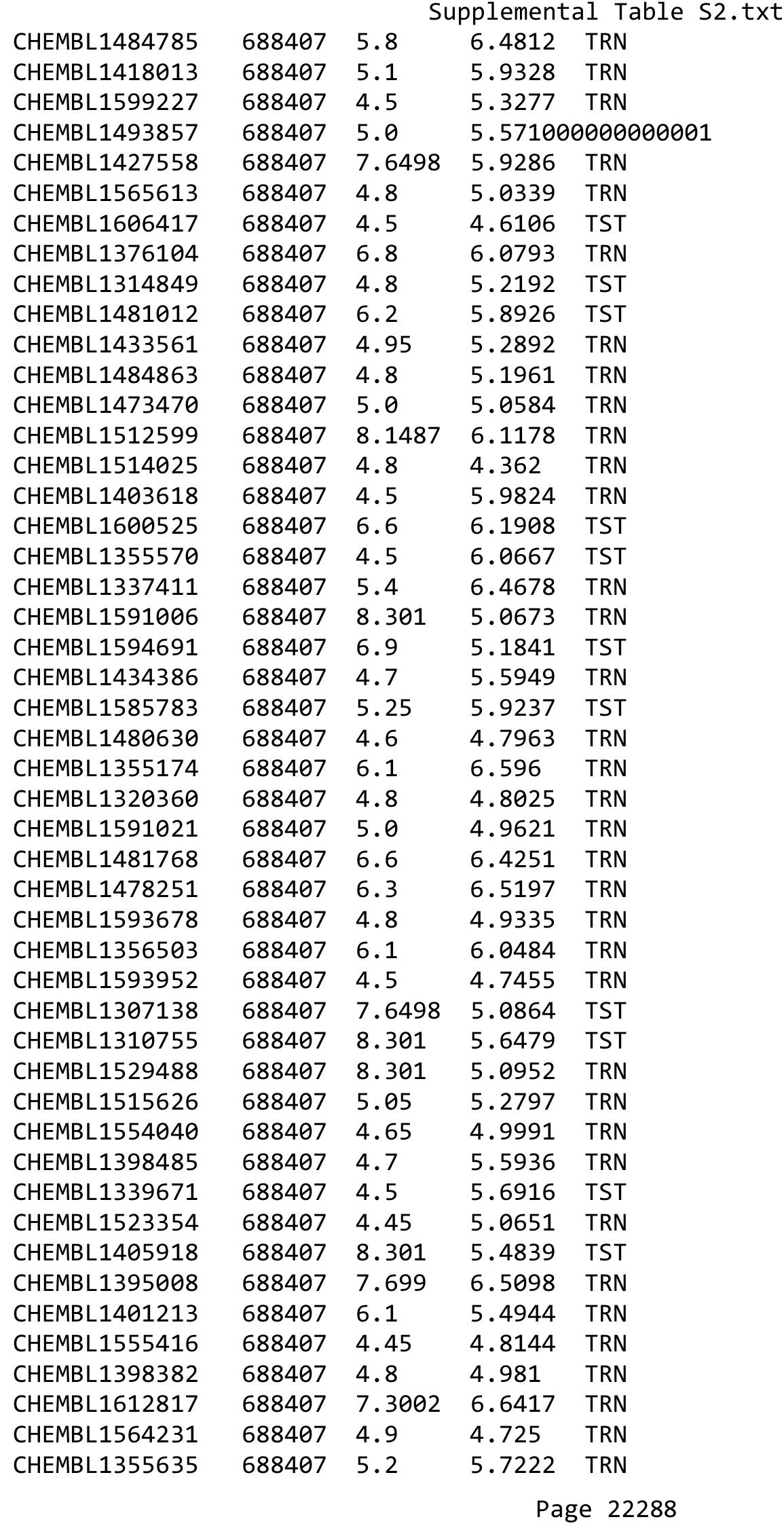




\begin{tabular}{|c|c|c|c|c|c|}
\hline & & \multicolumn{4}{|c|}{ Supplemental Table S2.txt } \\
\hline CHEMBL1540268 & 688407 & 7.9508 & 5.1951 & TRN & \\
\hline CHEMBL1508694 & 688407 & 5.05 & 5.2241 & TST & \\
\hline CHEMBL1440562 & 688407 & 4.5 & 5.2295 & TST & \\
\hline CHEMBL1395520 & 688407 & 4.8 & 5.3273 & TRN & \\
\hline CHEMBL1395146 & 688407 & 5.2 & 5.4299 & TRN & \\
\hline CHEMBL1536173 & 688407 & 8.4949 & 6.0367 & TRN & \\
\hline CHEMBL1602651 & 688407 & 6.5 & 5.3017 & TRN & \\
\hline CHEMBL1358344 & 688407 & 4.75 & 6.2545 & TRN & \\
\hline CHEMBL1596315 & 688407 & 6.5 & 5.7834 & TST & \\
\hline CHEMBL1593734 & 688407 & 4.5 & 5.10800 & 00000000005 & TRN \\
\hline CHEMBL1494257 & 688407 & 4.5 & 5.5305 & TST & \\
\hline CHEMBL1605712 & 688407 & 6.0 & 5.3513 & TRN & \\
\hline CHEMBL1362608 & 688407 & 4.9 & 5.4895 & TRN & \\
\hline CHEMBL1445080 & 688407 & 5.5 & 5.9055 & TRN & \\
\hline CHEMBL1476840 & 688407 & 4.7 & 5.4151 & TRN & \\
\hline CHEMBL1331640 & 688407 & 5.2 & 5.7091 & TRN & \\
\hline CHEMBL1436390 & 688407 & 8.0 & 6.8978 & TRN & \\
\hline CHEMBL1517722 & 688407 & 7.0 & 5.9719 & TRN & \\
\hline CHEMBL1515065 & 688407 & 5.4 & 6.3094 & TRN & \\
\hline CHEMBL1447536 & 688407 & 4.9 & 5.5617 & TRN & \\
\hline CHEMBL1473423 & 688407 & 5.0 & 5.6996 & TRN & \\
\hline CHEMBL1436741 & 688407 & 5.5 & 5.5567 & TRN & \\
\hline CHEMBL1407038 & 688407 & 4.95 & 5.0857 & TRN & \\
\hline CHEMBL1338190 & 688407 & 8.0506 & 5.0251 & TST & \\
\hline CHEMBL1398035 & 688407 & 4.5 & 5.1612 & TST & \\
\hline CHEMBL1592126 & 688407 & 4.85 & 6.0426 & TST & \\
\hline CHEMBL1594135 & 688407 & 4.5 & 4.542 & TRN & \\
\hline CHEMBL1553192 & 688407 & 4.5 & 4.1508 & TRN & \\
\hline CHEMBL1551670 & 688407 & 6.9 & 6.2545 & TRN & \\
\hline CHEMBL1611819 & 688407 & 4.45 & 5.1043 & TRN & \\
\hline CHEMBL1525817 & 688407 & 6.25 & 5.9122 & TRN & \\
\hline CHEMBL1435552 & 688407 & 7.2 & 6.4038 & TRN & \\
\hline CHEMBL1435403 & 688407 & 4.5 & 5.4212 & TRN & \\
\hline CHEMBL1516019 & 688407 & 6.2 & 5.6695 & TRN & \\
\hline CHEMBL1597191 & 688407 & 4.95 & 5.3872 & TRN & \\
\hline CHEMBL1480091 & 688407 & 4.6 & 5.3477 & TRN & \\
\hline CHEMBL1535800 & 688407 & 5.2 & 5.5738 & TST & \\
\hline CHEMBL1489968 & 688407 & 4.45 & 5.0535 & TRN & \\
\hline CHEMBL1591210 & 688407 & 4.7 & 6.4823 & TRN & \\
\hline CHEMBL1482766 & 688407 & 4.7 & 5.692 & TRN & \\
\hline CHEMBL1561128 & 688407 & 4.9 & 4.9264 & TRN & \\
\hline CHEMBL1551572 & 688407 & 7.8996 & 5.9646 & TST & \\
\hline CHEMBL1512981 & 688407 & 4.8 & 6.0355 & TST & \\
\hline CHEMBL1450122 & 688407 & 4.5 & 5.9801 & TRN & \\
\hline CHEMBL1361830 & 688407 & 4.65 & 5.7609 & TRN & \\
\hline CHEMBL1534014 & 688407 & 6.5501 & 5.9913 & TRN & \\
\hline CHEMBL1476033 & 688407 & 6.6 & 6.1158 & TRN & \\
\hline CHEMBL1518442 & 688407 & 4.95 & 5.2012 & TRN & \\
\hline
\end{tabular}




\begin{tabular}{|c|c|c|c|c|c|}
\hline \\
\hline CHEMBL1405907 & 688407 & 6.9 & 7.5403 & TRN & \\
\hline CHEMBL1594052 & 688407 & 4.6 & 5.4236 & TRN & \\
\hline CHEMBL1427801 & 688407 & 4.8 & 5.6028 & TST & \\
\hline CHEMBL1528247 & 688407 & 4.8 & 4.7282 & TRN & \\
\hline CHEMBL1394544 & 688407 & 7.5003 & 5.9478 & TRN & \\
\hline CHEMBL1435530 & 688407 & 7.3002 & 6.2198 & TRN & \\
\hline CHEMBL1478739 & 688407 & 8.301 & 4.9773 & TRN & \\
\hline CHEMBL1597683 & 688407 & 4.5 & 5.3004 & TRN & \\
\hline CHEMBL1407159 & 688407 & 8.0506 & 6.3171 & TST & \\
\hline CHEMBL1527300 & 688407 & 6.5 & 5.7712 & TRN & \\
\hline CHEMBL1511065 & 688407 & 5.0 & 5.3694 & TST & \\
\hline CHEMBL1566554 & 688407 & 4.45 & 5.5015 & TST & \\
\hline CHEMBL1407930 & 688407 & 5.0 & 5.2557 & TRN & \\
\hline CHEMBL1495347 & 688407 & 4.6 & 5.32299 & 99999999995 & TRN \\
\hline CHEMBL1440906 & 688407 & 5.4 & 5.8066 & TST & \\
\hline CHEMBL1401359 & 688407 & 5.2 & 5.3128 & TRN & \\
\hline CHEMBL1514885 & 688407 & 4.5 & 5.075 & TST & \\
\hline CHEMBL1354467 & 688407 & 8.4949 & 5.67299 & 9999999999 & TRN \\
\hline CHEMBL1396540 & 688407 & 4.7 & 5.0893 & TRN & \\
\hline CHEMBL1525585 & 688407 & 4.9 & 5.2703 & TRN & \\
\hline CHEMBL1593126 & 688407 & 4.5 & 4.6923 & TRN & \\
\hline CHEMBL1601966 & 688407 & 4.6 & 5.3343 & TRN & \\
\hline CHEMBL1395970 & 688407 & 5.7 & 5.3495 & TRN & \\
\hline CHEMBL1435819 & 688407 & 4.5 & 5.5121 & TST & \\
\hline CHEMBL1609203 & 688407 & 4.9 & 4.5989 & TRN & \\
\hline CHEMBL1482615 & 688407 & 7.1002 & 5.3352 & TRN & \\
\hline CHEMBL1433334 & 688407 & 8.4559 & 5.7751 & TRN & \\
\hline CHEMBL1434194 & 688407 & 4.8 & 5.4654 & TRN & \\
\hline CHEMBL227959 & 688407 & 4.8 & 5.2851 & TRN & \\
\hline CHEMBL1515987 & 688407 & 4.7 & 5.1368 & TRN & \\
\hline CHEMBL1554025 & 688407 & 4.5 & 5.7706 & TST & \\
\hline CHEMBL1518068 & 688407 & 4.5 & 5.1591 & TRN & \\
\hline CHEMBL1530393 & 688407 & 5.45 & 5.6785 & TRN & \\
\hline CHEMBL1591715 & 688407 & 8.4949 & 5.1497 & TRN & \\
\hline CHEMBL1377804 & 688407 & 7.0501 & 5.8222 & TST & \\
\hline CHEMBL1512156 & 688407 & 4.8 & 5.7362 & TST & \\
\hline CHEMBL1448208 & 688407 & 5.2 & 5.653 & TRN & \\
\hline CHEMBL1481398 & 688407 & 6.15 & 6.2377 & TRN & \\
\hline CHEMBL1404678 & 688407 & 5.3 & 5.8815 & TRN & \\
\hline CHEMBL1363214 & 688407 & 7.8013 & 5.926 & TRN & \\
\hline CHEMBL1523446 & 688407 & 4.5 & 5.6434 & TST & \\
\hline CHEMBL1341870 & 688407 & 4.5 & 4.9256 & TRN & \\
\hline CHEMBL1456954 & 688407 & 8.1024 & 5.6009 & TRN & \\
\hline CHEMBL1365935 & 688407 & 4.5 & 5.3097 & TRN & \\
\hline CHEMBL1545785 & 688407 & 4.95 & 5.1786 & TST & \\
\hline CHEMBL1513793 & 688407 & 4.9 & 5.2496 & TRN & \\
\hline CHEMBL1355454 & 688407 & 4.9 & 4.7904 & TST & \\
\hline CHEMBL1504032 & 688407 & 6.3 & 5.5969 & TST & \\
\hline
\end{tabular}




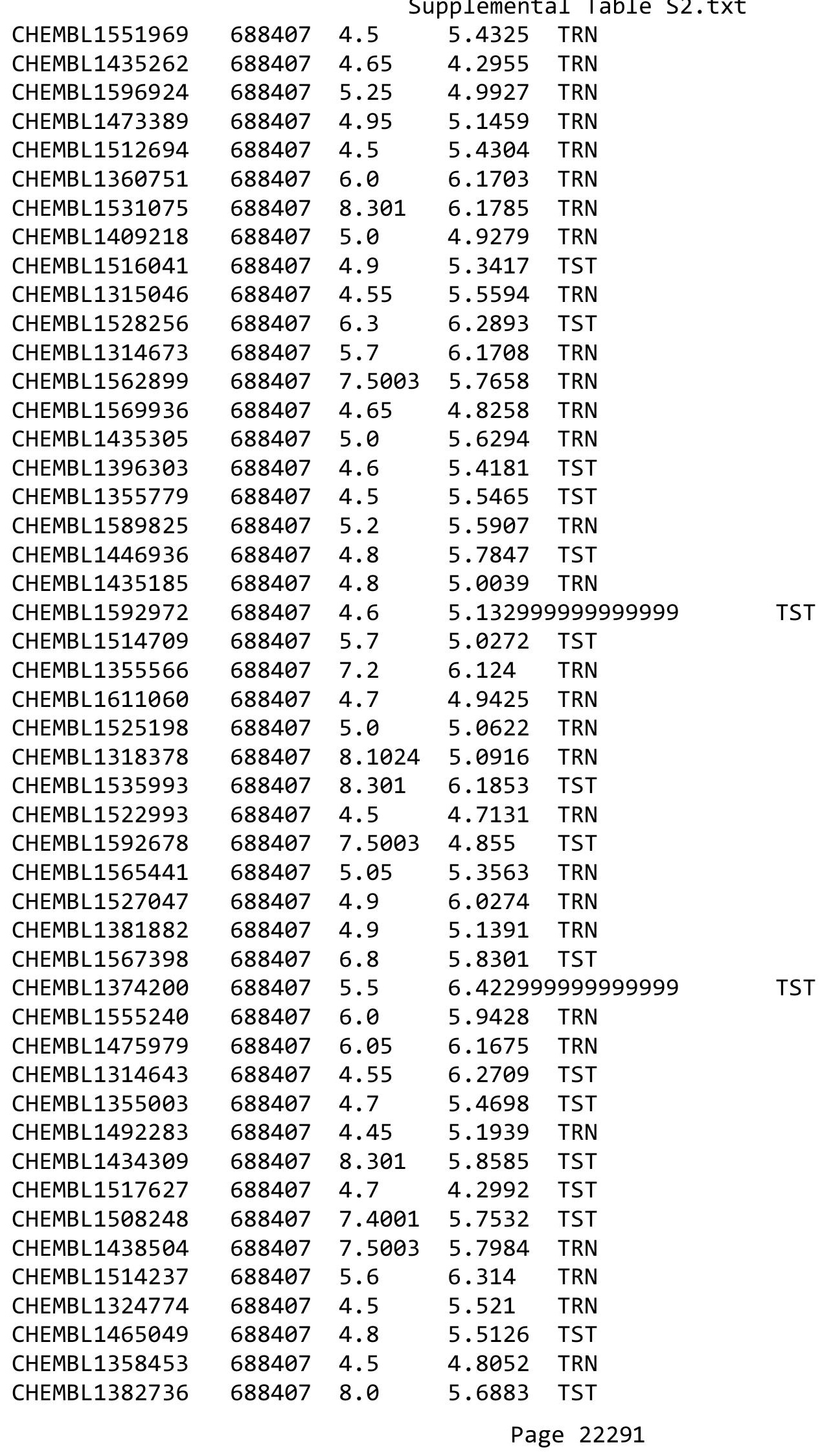




\begin{tabular}{|c|c|c|c|c|c|}
\hline & & \multicolumn{4}{|c|}{ Supplemental Table S2.txt } \\
\hline CHEMBL1354704 & 688407 & 7.699 & 5.3775 & TRN & \\
\hline CHEMBL1964614 & 688407 & 6.15 & 5.2024 & TST & \\
\hline CHEMBL1452591 & 688407 & 4.5 & 5.306 & TRN & \\
\hline CHEMBL1558421 & 688407 & 5.25 & 4.6402 & TRN & \\
\hline CHEMBL1592787 & 688407 & 4.6 & 5.3207 & TRN & \\
\hline CHEMBL1372240 & 688407 & 7.4001 & 5.6132 & TRN & \\
\hline CHEMBL1320214 & 688407 & 4.9 & 5.569 & TST & \\
\hline CHEMBL1315809 & 688407 & 8.1024 & 5.3492 & TST & \\
\hline CHEMBL1321669 & 688407 & 6.5 & 5.4841 & TRN & \\
\hline CHEMBL1416488 & 688407 & 4.5 & 5.4876 & TST & \\
\hline CHEMBL1357141 & 688407 & 8.1024 & 5.9895 & TRN & \\
\hline CHEMBL1396509 & 688407 & 6.9 & 5.1813 & TRN & \\
\hline CHEMBL1552980 & 688407 & 4.9 & 5.9469 & TRN & \\
\hline CHEMBL1567564 & 688407 & 8.1024 & 6.7735 & TRN & \\
\hline CHEMBL1516341 & 688407 & 8.3468 & 6.5225 & TRN & \\
\hline CHEMBL1396127 & 688407 & 4.95 & 5.6161 & TRN & \\
\hline CHEMBL1356421 & 688407 & 7.0 & 5.7666 & TRN & \\
\hline CHEMBL1532822 & 688407 & 7.699 & 5.6775 & TST & \\
\hline CHEMBL1446223 & 688407 & 7.8996 & 6.058 & TRN & \\
\hline CHEMBL1332609 & 688407 & 5.0 & 5.7766 & TRN & \\
\hline CHEMBL1514491 & 688407 & 4.8 & 5.2709 & TRN & \\
\hline CHEMBL1395771 & 688407 & 4.8 & 5.1447 & TRN & \\
\hline CHEMBL1355119 & 688407 & 5.3 & 4.7877 & TRN & \\
\hline CHEMBL1325610 & 688407 & 5.2 & 5.0996 & TRN & \\
\hline CHEMBL1591699 & 688407 & 4.7 & 5.0648 & TRN & \\
\hline CHEMBL1478747 & 688407 & 6.2 & 5.597 & TRN & \\
\hline CHEMBL1512706 & 688407 & 5.1 & 5.3976 & TST & \\
\hline CHEMBL1480128 & 688407 & 5.0 & 5.0997 & TRN & \\
\hline CHEMBL1552126 & 688407 & 4.5 & 6.1508 & TRN & \\
\hline CHEMBL1590074 & 688407 & 5.6 & 6.12700 & 2000000001 & TRN \\
\hline CHEMBL546137 & 688407 & 4.65 & 5.2553 & TRN & \\
\hline CHEMBL1494263 & 688407 & 4.95 & 5.016 & TRN & \\
\hline CHEMBL1415398 & 688407 & 4.9 & 5.7 & TST & \\
\hline CHEMBL1449347 & 688407 & 4.8 & 5.10800 & 00000000005 & TRN \\
\hline CHEMBL1515900 & 688407 & 4.8 & 5.3541 & TRN & \\
\hline CHEMBL1319460 & 688407 & 4.9 & 5.9289 & TST & \\
\hline CHEMBL1409268 & 688407 & 4.9 & 5.0224 & TRN & \\
\hline CHEMBL591618 & 688407 & 5.8 & 5.4853 & TST & \\
\hline CHEMBL1413999 & 688407 & 5.0 & 5.596 & TRN & \\
\hline CHEMBL1315095 & 688407 & 4.95 & 5.4363 & TRN & \\
\hline CHEMBL1592859 & 688407 & 6.5501 & 5.6777 & TRN & \\
\hline CHEMBL1314846 & 688407 & 5.5 & 5.1838 & TRN & \\
\hline CHEMBL1512749 & 688407 & 6.1 & 5.7116 & TRN & \\
\hline CHEMBL1480522 & 688407 & 4.9 & 5.0717 & TST & \\
\hline CHEMBL1592036 & 688407 & 7.699 & 5.2809 & TRN & \\
\hline CHEMBL1437553 & 688407 & 4.5 & 5.1594 & TRN & \\
\hline CHEMBL1398101 & 688407 & 6.5 & 5.7714 & TST & \\
\hline CHEMBL1451431 & 688407 & 6.3 & 5.5858 & TRN & \\
\hline & & & & רחרבר & \\
\hline
\end{tabular}




\begin{tabular}{|c|c|c|c|c|c|}
\hline \multicolumn{6}{|c|}{ Supplemental Table S2.txt } \\
\hline CHEMBL1608536 & 688407 & 4.9 & 5.5822 & TST & \\
\hline CHEMBL1400406 & 688407 & 5.6 & 5.7274 & TST & \\
\hline CHEMBL1397338 & 688407 & 5.0 & 4.8837 & TRN & \\
\hline CHEMBL1568279 & 688407 & 4.45 & 4.8055 & TRN & \\
\hline CHEMBL1594461 & 688407 & 5.0 & 5.24100 & 00000000005 & TRN \\
\hline CHEMBL1399168 & 688407 & 5.65 & 5.5577 & TRN & \\
\hline CHEMBL1471225 & 688407 & 4.95 & 5.5813 & TST & \\
\hline CHEMBL1354312 & 688407 & 4.9 & 5.4885 & TRN & \\
\hline CHEMBL1434160 & 688407 & 4.6 & 5.7544 & TRN & \\
\hline CHEMBL1325011 & 688407 & 5.25 & 6.4281 & TRN & \\
\hline CHEMBL1417342 & 688407 & 4.8 & 5.1745 & TST & \\
\hline CHEMBL1354925 & 688407 & 5.5 & 5.3935 & TRN & \\
\hline CHEMBL599088 & 688407 & 5.8 & 5.3368 & TRN & \\
\hline CHEMBL1417596 & 688407 & 4.8 & 6.1686 & TRN & \\
\hline CHEMBL1436104 & 688407 & 5.7 & 5.6604 & TRN & \\
\hline CHEMBL1451777 & 688407 & 5.6 & 6.3796 & TRN & \\
\hline CHEMBL1513145 & 688407 & 4.45 & 5.2802 & TRN & \\
\hline CHEMBL1435181 & 688407 & 5.75 & 5.4265 & TRN & \\
\hline CHEMBL1450226 & 688407 & 7.6003 & 5.864 & TRN & \\
\hline CHEMBL1586846 & 688407 & 4.95 & 5.58700 & 0000000001 & TRN \\
\hline CHEMBL1475143 & 688407 & 5.2 & 5.8422 & TST & \\
\hline CHEMBL3191027 & 688407 & 4.95 & 5.3039 & TST & \\
\hline CHEMBL1598938 & 688407 & 4.5 & 5.7173 & TRN & \\
\hline CHEMBL1403365 & 688407 & 4.45 & 5.7353 & TRN & \\
\hline CHEMBL1524011 & 688407 & 4.6 & 5.3531 & TST & \\
\hline CHEMBL1451846 & 688407 & 4.5 & 4.7363 & TST & \\
\hline CHEMBL1541441 & 688407 & 4.5 & 4.9276 & TST & \\
\hline CHEMBL1365525 & 688407 & 4.5 & 4.328 & TRN & \\
\hline CHEMBL1462300 & 688407 & 4.9 & 5.4577 & TST & \\
\hline CHEMBL1512319 & 688407 & 4.85 & 5.4395 & TRN & \\
\hline CHEMBL1437655 & 688407 & 6.4 & 6.2314 & TRN & \\
\hline CHEMBL1485149 & 688407 & 4.45 & 5.3362 & TRN & \\
\hline CHEMBL1491003 & 688407 & 6.5 & 5.6241 & TRN & \\
\hline CHEMBL1316415 & 688407 & 6.5 & 5.3081 & TRN & \\
\hline CHEMBL1435658 & 688407 & 4.8 & 5.1165 & TRN & \\
\hline CHEMBL1396502 & 688407 & 4.75 & 5.3828 & TRN & \\
\hline CHEMBL1513172 & 688407 & 8.1024 & 6.5598 & TRN & \\
\hline CHEMBL1318236 & 688407 & 7.8508 & 5.9476 & TST & \\
\hline CHEMBL1593268 & 688407 & 4.5 & 5.7347 & TRN & \\
\hline CHEMBL1327990 & 688407 & 5.2 & 4.9058 & TRN & \\
\hline CHEMBL1552496 & 688407 & 4.45 & 4.7963 & TRN & \\
\hline CHEMBL1394759 & 688407 & 4.85 & 5.2254 & TRN & \\
\hline CHEMBL1512279 & 688407 & 5.2 & 5.9527 & TRN & \\
\hline CHEMBL1365915 & 688407 & 4.95 & 6.4212 & TRN & \\
\hline CHEMBL1318620 & 688407 & 4.6 & 4.9797 & TST & \\
\hline CHEMBL1316269 & 688407 & 4.9 & 5.692 & TST & \\
\hline CHEMBL1604420 & 688407 & 6.7001 & 5.5927 & TRN & \\
\hline CHEMBL1591505 & 688407 & 4.9 & 4.9164 & TRN & \\
\hline
\end{tabular}




\begin{tabular}{|c|c|c|c|c|}
\hline \multicolumn{5}{|c|}{ Supplemental Table S2.txt } \\
\hline CHEMBL1452817 & 688407 & 5.5 & 4.9283 & TST \\
\hline CHEMBL1555692 & 688407 & 5.0 & 5.148 & TRN \\
\hline CHEMBL1518667 & 688407 & 5.3 & 6.2614 & TST \\
\hline CHEMBL1406802 & 688407 & 4.5 & 5.5633 & TRN \\
\hline CHEMBL1365820 & 688407 & 4.5 & 5.1826 & TRN \\
\hline CHEMBL1341192 & 688407 & 4.85 & 4.9865 & TST \\
\hline CHEMBL1304846 & 688407 & 5.4 & 5.7195 & TRN \\
\hline CHEMBL1516237 & 688407 & 5.9 & 5.3628 & TRN \\
\hline CHEMBL1490183 & 688407 & 4.8 & 5.2038 & TRN \\
\hline CHEMBL1443653 & 688407 & 6.2 & 5.5892 & TRN \\
\hline CHEMBL1551704 & 688407 & 4.9 & 5.1029 & TRN \\
\hline CHEMBL1472666 & 688407 & 4.7 & 5.1029 & TRN \\
\hline CHEMBL1524628 & 688407 & 6.1 & 5.6107 & TRN \\
\hline CHEMBL1541251 & 688407 & 7.4001 & 6.1943 & TRN \\
\hline CHEMBL1358455 & 688407 & 6.05 & 6.6639 & TRN \\
\hline CHEMBL1488172 & 688407 & 4.9 & 4.7226 & TST \\
\hline CHEMBL1473958 & 688407 & 5.0 & 5.3283 & TRN \\
\hline CHEMBL1325760 & 688407 & 4.45 & 6.3396 & TST \\
\hline CHEMBL1359956 & 688407 & 5.6 & 5.2563 & TRN \\
\hline CHEMBL1533216 & 688407 & 4.6 & 6.0129 & TRN \\
\hline CHEMBL1555248 & 688407 & 7.5003 & 5.9733 & TRN \\
\hline CHEMBL1495688 & 688407 & 5.1 & 5.3201 & TRN \\
\hline CHEMBL1438114 & 688407 & 7.0 & 5.7874 & TST \\
\hline CHEMBL1590419 & 688407 & 4.9 & 5.2879 & TRN \\
\hline CHEMBL1473004 & 688407 & 4.9 & 4.7855 & TRN \\
\hline CHEMBL1354761 & 688407 & 5.4 & 5.7771 & TRN \\
\hline CHEMBL1553608 & 688407 & 4.5 & 5.4957 & TRN \\
\hline CHEMBL1377179 & 688407 & 5.1 & 5.8731 & TST \\
\hline CHEMBL1397039 & 688407 & 6.6 & 5.1494 & TRN \\
\hline CHEMBL1596974 & 688407 & 4.45 & 5.5339 & TRN \\
\hline CHEMBL599943 & 688407 & 4.9 & 5.3207 & TRN \\
\hline CHEMBL1395589 & 688407 & 8.2007 & 6.4564 & TRN \\
\hline CHEMBL1436681 & 688407 & 5.0 & 5.0745 & TST \\
\hline CHEMBL582278 & 688407 & 4.45 & 5.13 & TRN \\
\hline CHEMBL1498470 & 688407 & 5.05 & 5.34 & TRN \\
\hline CHEMBL1565416 & 688407 & 5.05 & 5.7508 & TRN \\
\hline CHEMBL1513186 & 688407 & 7.1002 & 6.1523 & TRN \\
\hline CHEMBL1566449 & 688407 & 7.0 & 6.7064 & TRN \\
\hline CHEMBL1532990 & 688407 & 4.8 & 5.2583 & TRN \\
\hline CHEMBL1327845 & 688407 & 4.75 & 5.16 & TRN \\
\hline CHEMBL1399458 & 688407 & 6.7001 & 5.0545 & TRN \\
\hline CHEMBL1366307 & 688407 & 4.5 & 5.5244 & TRN \\
\hline CHEMBL1590893 & 688407 & 4.5 & 5.38299 & 9999999999 \\
\hline CHEMBL1367061 & 688407 & 6.9 & 5.7845 & TST \\
\hline CHEMBL1415678 & 688407 & 4.8 & 4.9117 & TRN \\
\hline CHEMBL1601150 & 688407 & 4.8 & 5.6339 & TRN \\
\hline CHEMBL1440521 & 688407 & 4.45 & 5.0824 & TRN \\
\hline CHEMBL1514111 & 688407 & 4.5 & 4.9988 & TRN \\
\hline
\end{tabular}




\begin{tabular}{|c|c|c|c|c|c|}
\hline \multicolumn{6}{|c|}{ Supplemental Table s2.txt } \\
\hline CHEMBL1435102 & 688407 & 4.7 & 5.4682 & TRN & \\
\hline CHEMBL1449070 & 688407 & 4.5 & 5.3606 & TRN & \\
\hline CHEMBL1522922 & 688407 & 4.85 & 5.744 & TRN & \\
\hline CHEMBL1478389 & 688407 & 5.05 & 5.8593 & TST & \\
\hline CHEMBL1553807 & 688407 & 5.05 & 5.4919 & TRN & \\
\hline CHEMBL1538094 & 688407 & 6.95 & 6.8586 & TRN & \\
\hline CHEMBL1355379 & 688407 & 4.8 & 5.4406 & TRN & \\
\hline CHEMBL1378493 & 688407 & 7.0 & 5.8611 & TST & \\
\hline CHEMBL1473365 & 688407 & 5.8 & 5.9643 & TRN & \\
\hline CHEMBL1569597 & 688407 & 6.0 & 5.4938 & TRN & \\
\hline CHEMBL1414878 & 688407 & 4.6 & 5.7582 & TST & \\
\hline CHEMBL1514857 & 688407 & 6.9 & 6.1842 & TRN & \\
\hline CHEMBL1373275 & 688407 & 4.5 & 5.4533 & TST & \\
\hline CHEMBL1367940 & 688407 & 4.7 & 5.3743 & TST & \\
\hline CHEMBL1516016 & 688407 & 4.5 & 5.7343 & TRN & \\
\hline CHEMBL1477769 & 688407 & 5.55 & 4.8089 & TRN & \\
\hline CHEMBL1370635 & 688407 & 7.6003 & 5.3235 & TST & \\
\hline CHEMBL1415463 & 688407 & 6.3 & 5.7435 & TRN & \\
\hline CHEMBL1514672 & 688407 & 4.85 & 5.1284 & TRN & \\
\hline CHEMBL1369970 & 688407 & 4.5 & 5.4376 & TRN & \\
\hline CHEMBL3193405 & 688407 & 4.85 & 5.6408 & TST & \\
\hline CHEMBL1375539 & 688407 & 5.5 & 4.8002 & TST & \\
\hline CHEMBL1557912 & 688407 & 4.8 & 5.0766 & TRN & \\
\hline CHEMBL1517088 & 688407 & 4.6 & 4.5548 & TRN & \\
\hline CHEMBL1512633 & 688407 & 4.5 & 4.8205 & TRN & \\
\hline CHEMBL1355650 & 688407 & 4.95 & 4.9836 & TRN & \\
\hline CHEMBL1324957 & 688407 & 4.5 & 5.0816 & TRN & \\
\hline CHEMBL1551589 & 688407 & 6.7001 & 5.4215 & TRN & \\
\hline CHEMBL1514297 & 688407 & 6.0 & 5.5535 & TRN & \\
\hline CHEMBL1332454 & 688407 & 4.5 & 4.5749 & TRN & \\
\hline CHEMBL1405679 & 688407 & 5.1 & 5.9396 & TST & \\
\hline CHEMBL1439913 & 688407 & 8.301 & 5.4698 & TRN & \\
\hline CHEMBL1444034 & 688407 & 4.9 & 5.0912 & TRN & \\
\hline CHEMBL1592283 & 688407 & 4.8 & 5.8467 & TST & \\
\hline CHEMBL1473202 & 688407 & 6.5 & 5.8689 & TST & \\
\hline CHEMBL1397116 & 688407 & 4.5 & 5.5235 & TST & \\
\hline CHEMBL1408951 & 688407 & 5.0 & 5.1815 & TRN & \\
\hline CHEMBL1486021 & 688407 & 4.6 & 5.8771 & TST & \\
\hline CHEMBL1478349 & 688407 & 6.8 & 5.8456 & TRN & \\
\hline CHEMBL1358725 & 688407 & 4.8 & 5.7931 & TRN & \\
\hline CHEMBL1552395 & 688407 & 4.7 & 4.5849 & TRN & \\
\hline CHEMBL1403366 & 688407 & 8.0 & 5.5489 & TRN & \\
\hline CHEMBL1482260 & 688407 & 6.8 & 4.8717 & TRN & \\
\hline CHEMBL1513844 & 688407 & 4.9 & 5.4413 & TST & \\
\hline CHEMBL1518055 & 688407 & 5.1 & 5.2941 & TRN & \\
\hline CHEMBL1331191 & 688407 & 4.45 & 5.3976 & TRN & \\
\hline CHEMBL1335326 & 688407 & 4.6 & 5.12706 & 0000000001 & TRN \\
\hline CHEMBL1396475 & 688407 & 4.9 & 5.6916 & TST & \\
\hline
\end{tabular}




\begin{tabular}{|c|c|c|c|c|c|}
\hline \\
\hline CHEMBL1481309 & 688407 & 4.9 & 5.4298 & TST & \\
\hline CHEMBL1319630 & 688407 & 6.6 & 5.7029 & TRN & \\
\hline CHEMBL1553948 & 688407 & 5.6 & 5.8302 & TRN & \\
\hline CHEMBL1398801 & 688407 & 4.9 & 5.8427 & TRN & \\
\hline CHEMBL1445563 & 688407 & 8.301 & 5.6587 & TRN & \\
\hline CHEMBL1555162 & 688407 & 6.1 & 5.3151 & TRN & \\
\hline CHEMBL1361374 & 688407 & 5.8 & 5.5572 & TST & \\
\hline CHEMBL1490596 & 688407 & 5.35 & 5.36100 & 0000000001 & TRN \\
\hline CHEMBL1534334 & 688407 & 5.3 & 4.987 & TRN & \\
\hline CHEMBL1378244 & 688407 & 5.15 & 6.2092 & TST & \\
\hline CHEMBL1488682 & 688407 & 4.65 & 5.575 & TRN & \\
\hline CHEMBL1554101 & 688407 & 4.9 & 5.8646 & TRN & \\
\hline CHEMBL1435278 & 688407 & 4.5 & 5.7597 & TRN & \\
\hline CHEMBL1554536 & 688407 & 5.5 & 5.4403 & TRN & \\
\hline CHEMBL1473551 & 688407 & 4.8 & 5.7131 & TRN & \\
\hline CHEMBL1397316 & 688407 & 6.45 & 5.42 & TRN & \\
\hline CHEMBL1565394 & 688407 & 4.9 & 5.4513 & TRN & \\
\hline CHEMBL1376268 & 688407 & 7.1002 & 5.159 & TRN & \\
\hline CHEMBL1403030 & 688407 & 5.3 & 5.9026 & TRN & \\
\hline CHEMBL1371318 & 688407 & 7.8013 & 5.9484 & TRN & \\
\hline CHEMBL1348758 & 688407 & 4.45 & 5.9995 & TST & \\
\hline CHEMBL1324551 & 688407 & 4.65 & 5.1622 & TRN & \\
\hline CHEMBL1316659 & 688407 & 7.0 & 6.4791 & TRN & \\
\hline CHEMBL1474085 & 688407 & 4.5 & 5.1848 & TRN & \\
\hline CHEMBL1520224 & 688407 & 4.5 & 5.3413 & TRN & \\
\hline CHEMBL1355696 & 688407 & 4.45 & 5.4662 & TRN & \\
\hline CHEMBL1593200 & 688407 & 7.4001 & 5.4305 & TST & \\
\hline CHEMBL1436502 & 688407 & 4.9 & 5.2678 & TRN & \\
\hline CHEMBL1509287 & 688407 & 4.9 & 5.1094 & TRN & \\
\hline CHEMBL1446288 & 688407 & 6.4 & 6.1806 & TST & \\
\hline CHEMBL1440783 & 688407 & 4.5 & 6.4367 & TRN & \\
\hline CHEMBL1514761 & 688407 & 5.7 & 5.7977 & TRN & \\
\hline CHEMBL1517043 & 688407 & 6.95 & 5.5117 & TRN & \\
\hline CHEMBL1473360 & 688407 & 5.7 & 5.8295 & TRN & \\
\hline CHEMBL1398957 & 688407 & 4.85 & 5.5382 & TST & \\
\hline CHEMBL1493048 & 688407 & 4.5 & 5.2079 & TRN & \\
\hline CHEMBL1427823 & 688407 & 4.95 & 4.9381 & TRN & \\
\hline CHEMBL1565001 & 688407 & 4.8 & 4.6379 & TRN & \\
\hline CHEMBL600334 & 688407 & 4.9 & 5.0432 & TST & \\
\hline CHEMBL1369635 & 688407 & 5.0 & 5.9944 & TST & \\
\hline CHEMBL1321672 & 688407 & 4.7 & 4.9381 & TRN & \\
\hline CHEMBL1359125 & 688407 & 5.0 & 5.404 & TRN & \\
\hline CHEMBL1318335 & 688407 & 6.1 & 6.101 & TRN & \\
\hline CHEMBL1516018 & 688407 & 6.3 & 5.3735 & TRN & \\
\hline CHEMBL1476242 & 688407 & 4.9 & 5.6716 & TRN & \\
\hline CHEMBL1317905 & 688407 & 4.5 & 5.6995 & TRN & \\
\hline CHEMBL1375367 & 688407 & 4.5 & 5.1911 & TRN & \\
\hline CHEMBL1589734 & 688407 & 4.5 & 5.1025 & TRN & \\
\hline
\end{tabular}




\begin{tabular}{|c|c|c|c|c|c|}
\hline \multicolumn{6}{|c|}{ Supplemental Table S2.txt } \\
\hline CHEMBL1362439 & 688407 & 5.35 & 6.1817 & TRN & \\
\hline CHEMBL1185172 & 688407 & 4.9 & 4.9499 & TRN & \\
\hline CHEMBL602927 & 688407 & 5.25 & 4.883 & TST & \\
\hline CHEMBL1453691 & 688407 & 5.0 & 5.0212 & TRN & \\
\hline CHEMBL 1358608 & 688407 & 6.6 & 5.8632 & TST & \\
\hline CHEMBL1316121 & 688407 & 5.0 & 5.3473 & TST & \\
\hline CHEMBL1551208 & 688407 & 4.9 & 5.9243 & TRN & \\
\hline CHEMBL1326593 & 688407 & 4.5 & 5.6287 & TRN & \\
\hline CHEMBL1595502 & 688407 & 4.9 & 5.3095 & TRN & \\
\hline CHEMBL1413815 & 688407 & 4.6 & 5.9875 & TRN & \\
\hline CHEMBL1314588 & 688407 & 4.8 & 5.4898 & TRN & \\
\hline CHEMBL1319015 & 688407 & 5.2 & 5.0187 & TRN & \\
\hline CHEMBL1488664 & 688407 & 5.2 & 6.019 & TRN & \\
\hline CHEMBL1555284 & 688407 & 4.5 & 5.654 & TRN & \\
\hline CHEMBL1520414 & 688407 & 4.95 & 5.02800 & 00000000005 & TRN \\
\hline CHEMBL1389366 & 688407 & 5.3 & 5.8424 & TRN & \\
\hline CHEMBL1374782 & 688407 & 7.1002 & 6.2105 & TRN & \\
\hline CHEMBL1496103 & 688407 & 4.8 & 4.7073 & TRN & \\
\hline CHEMBL1481131 & 688407 & 4.9 & 5.317 & TRN & \\
\hline CHEMBL1328648 & 688407 & 4.5 & 5.305 & TRN & \\
\hline CHEMBL1435643 & 688407 & 5.95 & 5.9285 & TST & \\
\hline CHEMBL1556372 & 688407 & 6.8 & 4.5068 & TRN & \\
\hline CHEMBL1525394 & 688407 & 4.5 & 5.3221 & TST & \\
\hline CHEMBL1600268 & 688407 & 4.5 & 5.6067 & TST & \\
\hline CHEMBL1576048 & 688407 & 5.6 & 5.1447 & TST & \\
\hline CHEMBL1612485 & 688407 & 8.3979 & 5.7763 & TRN & \\
\hline CHEMBL1551625 & 688407 & 7.0 & 6.2303 & TRN & \\
\hline CHEMBL1320283 & 688407 & 8.301 & 6.1499 & TRN & \\
\hline CHEMBL1336110 & 688407 & 4.5 & 5.4386 & TRN & \\
\hline CHEMBL1455745 & 688407 & 7.8996 & 6.5133 & TRN & \\
\hline CHEMBL1434332 & 688407 & 4.8 & 5.4255 & TRN & \\
\hline CHEMBL 1602480 & 688407 & 4.8 & 5.8711 & TST & \\
\hline CHEMBL1366212 & 688407 & 7.0 & 5.3876 & TRN & \\
\hline CHEMBL1574254 & 688407 & 6.9 & 6.4775 & TRN & \\
\hline CHEMBL1605909 & 688407 & 6.5 & 5.5568 & TST & \\
\hline CHEMBL1320271 & 688407 & 7.4001 & 5.6186 & TRN & \\
\hline CHEMBL1318017 & 688407 & 6.9 & 5.2091 & TRN & \\
\hline CHEMBL1551433 & 688407 & 5.0 & 5.1251 & TRN & \\
\hline CHEMBL1475660 & 688407 & 5.6 & 5.62 & TRN & \\
\hline CHEMBL1355281 & 688407 & 8.3468 & 6.2234 & TRN & \\
\hline CHEMBL1514320 & 688407 & 4.9 & 5.4602 & TST & \\
\hline CHEMBL 1317186 & 688407 & 7.0501 & 5.5436 & TRN & \\
\hline CHEMBL1450878 & 688407 & 4.8 & 5.2798 & TRN & \\
\hline CHEMBL1365293 & 688407 & 5.95 & 5.6536 & TRN & \\
\hline CHEMBL1337969 & 688407 & 4.85 & 5.2158 & TST & \\
\hline CHEMBL1317831 & 688407 & 4.7 & 5.1611 & TRN & \\
\hline CHEMBL1321836 & 688407 & 5.1 & 5.0849 & TRN & \\
\hline CHEMBL1589916 & 688407 & 4.8 & 5.6174 & TST & \\
\hline
\end{tabular}




\begin{tabular}{|c|c|c|c|c|c|}
\hline & & \multicolumn{4}{|c|}{ Supplemental Table S2.txt } \\
\hline CHEMBL1527185 & 688407 & 8.1024 & 6.1155 & TRN & \\
\hline CHEMBL1396045 & 688407 & 8.301 & 5.5561 & TST & \\
\hline CHEMBL1532008 & 688407 & 4.7 & 4.4985 & TRN & \\
\hline CHEMBL1434785 & 688407 & 4.95 & 5.4598 & TRN & \\
\hline CHEMBL1404118 & 688407 & 5.3 & 4.6572 & TST & \\
\hline CHEMBL1403903 & 688407 & 4.6 & 5.8183 & TRN & \\
\hline CHEMBL1355548 & 688407 & 4.9 & 6.0878 & TST & \\
\hline CHEMBL1396831 & 688407 & 4.9 & 5.1769 & TST & \\
\hline CHEMBL1355078 & 688407 & 5.5 & 6.1681 & TRN & \\
\hline CHEMBL1595800 & 688407 & 6.4 & 5.6492 & TRN & \\
\hline CHEMBL1608062 & 688407 & 5.1 & 6.3022 & TRN & \\
\hline CHEMBL1605693 & 688407 & 4.5 & 4.9508 & TRN & \\
\hline CHEMBL3192555 & 688407 & 5.45 & 4.9906 & TST & \\
\hline CHEMBL1359840 & 688407 & 8.3979 & 5.8435 & TRN & \\
\hline CHEMBL1590517 & 688407 & 4.5 & 4.7306 & TRN & \\
\hline CHEMBL1592789 & 688407 & 5.0 & 4.6732 & TRN & \\
\hline CHEMBL1334808 & 688407 & 4.8 & 5.0093 & TRN & \\
\hline CHEMBL1410233 & 688407 & 4.8 & 4.8934 & TRN & \\
\hline CHEMBL1435108 & 688407 & 6.2 & 6.1298 & TST & \\
\hline CHEMBL1316753 & 688407 & 4.8 & 4.8657 & TRN & \\
\hline CHEMBL1325365 & 688407 & 4.9 & 6.2321 & TST & \\
\hline CHEMBL1407292 & 688407 & 5.9 & 6.40600 & 0000000001 & TRN \\
\hline CHEMBL1315465 & 688407 & 4.8 & 6.0525 & TRN & \\
\hline CHEMBL1515852 & 688407 & 5.6 & 5.5503 & TST & \\
\hline CHEMBL1476653 & 688407 & 7.1002 & 5.5329 & TRN & \\
\hline CHEMBL1369691 & 688407 & 5.0 & 5.1534 & TST & \\
\hline CHEMBL1403938 & 688407 & 5.0 & 5.3392 & TRN & \\
\hline CHEMBL1354873 & 688407 & 8.3979 & 6.1644 & TRN & \\
\hline CHEMBL1444023 & 688407 & 5.65 & 5.897 & TRN & \\
\hline CHEMBL1356578 & 688407 & 5.25 & 5.5554 & TRN & \\
\hline CHEMBL1553148 & 688407 & 4.95 & 5.3285 & TRN & \\
\hline CHEMBL1574899 & 688407 & 4.45 & 5.7562 & TRN & \\
\hline CHEMBL1316250 & 688407 & 6.2 & 5.2579 & TST & \\
\hline CHEMBL1334755 & 688407 & 7.699 & 5.5538 & TST & \\
\hline CHEMBL1335003 & 688407 & 4.65 & 5.5821 & TST & \\
\hline CHEMBL1373929 & 688407 & 4.9 & 5.2593 & TRN & \\
\hline CHEMBL1334625 & 688407 & 6.5 & 5.8447 & TRN & \\
\hline CHEMBL1528120 & 688407 & 5.2 & 5.6015 & TRN & \\
\hline CHEMBL1442584 & 688407 & 5.4 & 5.6008 & TRN & \\
\hline CHEMBL1561819 & 688407 & 6.3 & 5.8656 & TRN & \\
\hline CHEMBL1395045 & 688407 & 5.45 & 5.4534 & TRN & \\
\hline CHEMBL1436461 & 688407 & 4.7 & 5.3076 & TRN & \\
\hline CHEMBL1437029 & 688407 & 4.5 & 5.1311 & TRN & \\
\hline CHEMBL1408548 & 688407 & 8.3979 & 5.95200 & 0000000001 & TRN \\
\hline CHEMBL1375116 & 688407 & 4.5 & 5.4212 & TRN & \\
\hline CHEMBL1610235 & 688407 & 8.4949 & 6.2085 & TRN & \\
\hline CHEMBL1466732 & 688407 & 5.45 & 5.5103 & TST & \\
\hline CHEMBL1414290 & 688407 & 6.7501 & 5.4467 & TRN & \\
\hline
\end{tabular}




\begin{tabular}{|c|c|c|c|c|c|}
\hline \multicolumn{6}{|c|}{ Supplemental Table S2.txt } \\
\hline CHEMBL1556551 & 688407 & 4.9 & 5.5187 & TRN & \\
\hline CHEMBL1315873 & 688407 & 5.1 & 5.3938 & TRN & \\
\hline CHEMBL1394193 & 688407 & 8.0 & 5.3326 & TRN & \\
\hline CHEMBL1596342 & 688407 & 4.9 & 4.7252 & TRN & \\
\hline CHEMBL1486349 & 688407 & 5.0 & 5.3973 & TRN & \\
\hline CHEMBL1380091 & 688407 & 4.9 & 4.3682 & TRN & \\
\hline CHEMBL1446184 & 688407 & 4.5 & 5.8487 & TRN & \\
\hline CHEMBL1327283 & 688407 & 4.9 & 5.0549 & TRN & \\
\hline CHEMBL1320008 & 688407 & 5.5 & 5.3247 & TRN & \\
\hline CHEMBL1314401 & 688407 & 4.45 & 5.5204 & TRN & \\
\hline CHEMBL1591882 & 688407 & 4.8 & 5.478 & TRN & \\
\hline CHEMBL1314036 & 688407 & 4.9 & 4.9777 & TRN & \\
\hline CHEMBL1515603 & 688407 & 4.9 & 5.4329 & TRN & \\
\hline CHEMBL1377117 & 688407 & 6.1 & 5.0828 & TRN & \\
\hline CHEMBL1413515 & 688407 & 7.8996 & 5.4687 & TRN & \\
\hline CHEMBL1365297 & 688407 & 5.1 & 6.0054 & TRN & \\
\hline CHEMBL1598324 & 688407 & 4.45 & 5.4692 & TRN & \\
\hline CHEMBL1446237 & 688407 & 5.6 & 5.9331 & TRN & \\
\hline CHEMBL1612783 & 688407 & 8.301 & 5.8147 & TRN & \\
\hline CHEMBL1571724 & 688407 & 4.6 & 5.8459 & TRN & \\
\hline CHEMBL1475922 & 688407 & 4.5 & 5.58700 & 2000000001 & TRN \\
\hline CHEMBL1566580 & 688407 & 4.5 & 5.6039 & TRN & \\
\hline CHEMBL1494073 & 688407 & 5.1 & 5.0014 & TRN & \\
\hline CHEMBL1418080 & 688407 & 5.0 & 5.6448 & TRN & \\
\hline CHEMBL1369454 & 688407 & 4.5 & 6.1038 & TRN & \\
\hline CHEMBL1415793 & 688407 & 4.9 & 5.3387 & TRN & \\
\hline CHEMBL1357513 & 688407 & 5.6 & 5.5669 & TRN & \\
\hline CHEMBL1320805 & 688407 & 6.5 & 5.2135 & TRN & \\
\hline CHEMBL1516206 & 688407 & 7.8996 & 6.1369 & TRN & \\
\hline CHEMBL1368451 & 688407 & 7.6003 & 5.8118 & TST & \\
\hline CHEMBL1438339 & 688407 & 4.9 & 5.4394 & TST & \\
\hline CHEMBL1358420 & 688407 & 5.6 & 4.8765 & TRN & \\
\hline CHEMBL1318348 & 688407 & 4.9 & 4.8167 & TRN & \\
\hline CHEMBL1357600 & 688407 & 6.9 & 5.6464 & TRN & \\
\hline CHEMBL1416809 & 688407 & 4.45 & 5.5799 & TRN & \\
\hline CHEMBL1524167 & 688407 & 4.7 & 5.24 & TST & \\
\hline CHEMBL1398405 & 688407 & 4.6 & 5.3855 & TRN & \\
\hline CHEMBL1222385 & 688407 & 4.95 & 5.2444 & TRN & \\
\hline CHEMBL1436810 & 688407 & 4.9 & 5.0512 & TRN & \\
\hline CHEMBL1335708 & 688407 & 7.8996 & 6.2228 & TRN & \\
\hline CHEMBL1355106 & 688407 & 4.9 & 5.4802 & TRN & \\
\hline CHEMBL1563821 & 688407 & 4.9 & 5.5749 & TST & \\
\hline CHEMBL1472787 & 688407 & 4.5 & 5.654 & TRN & \\
\hline CHEMBL1326958 & 688407 & 4.5 & 5.6878 & TRN & \\
\hline CHEMBL1996730 & 688407 & 5.55 & 5.7503 & TST & \\
\hline CHEMBL1613718 & 688407 & 4.5 & 4.8141 & TRN & \\
\hline CHEMBL1527993 & 688407 & 4.7 & 5.3948 & TST & \\
\hline CHEMBL1606894 & 688407 & 8.2007 & 5.4736 & TST & \\
\hline
\end{tabular}




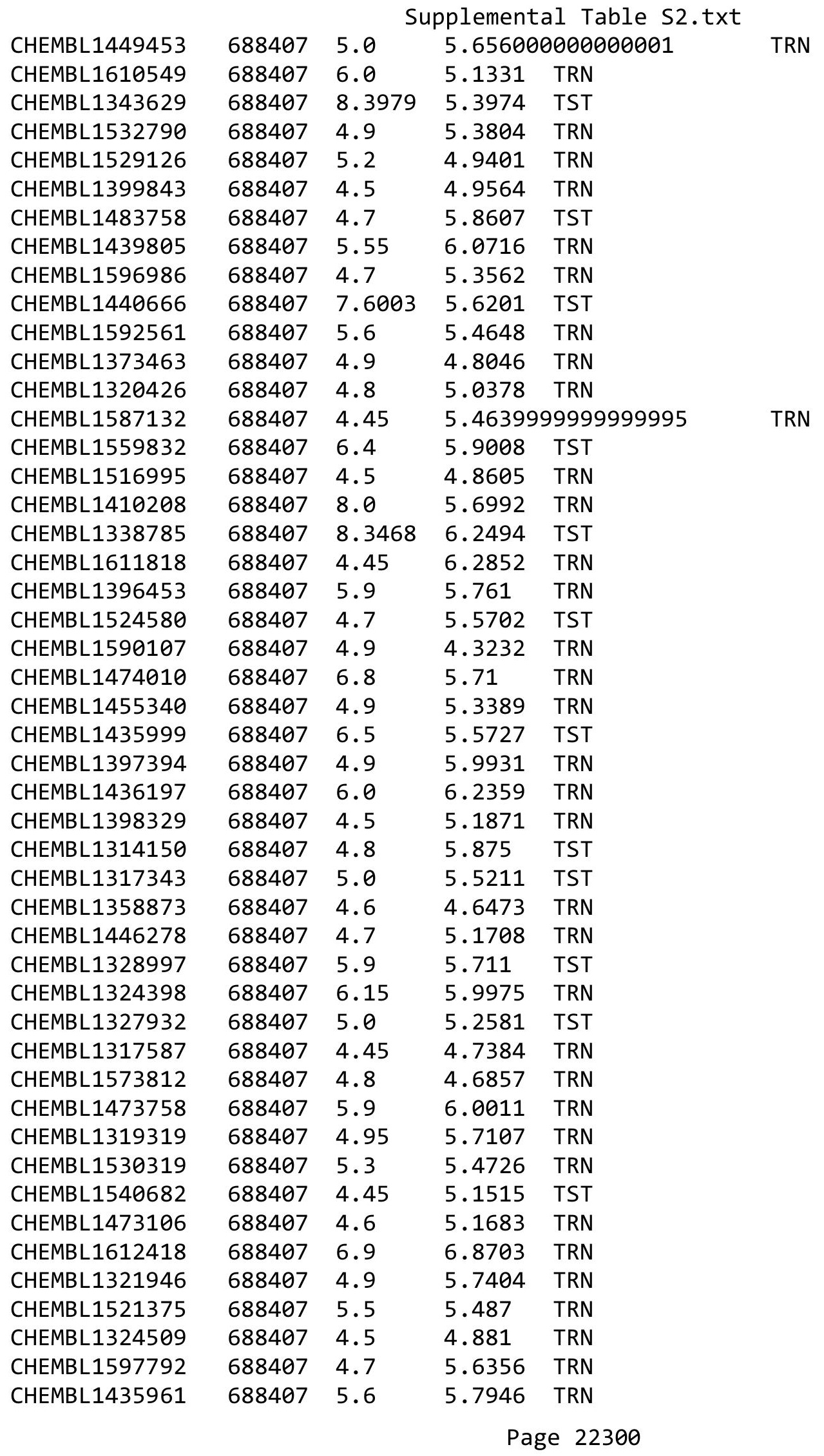




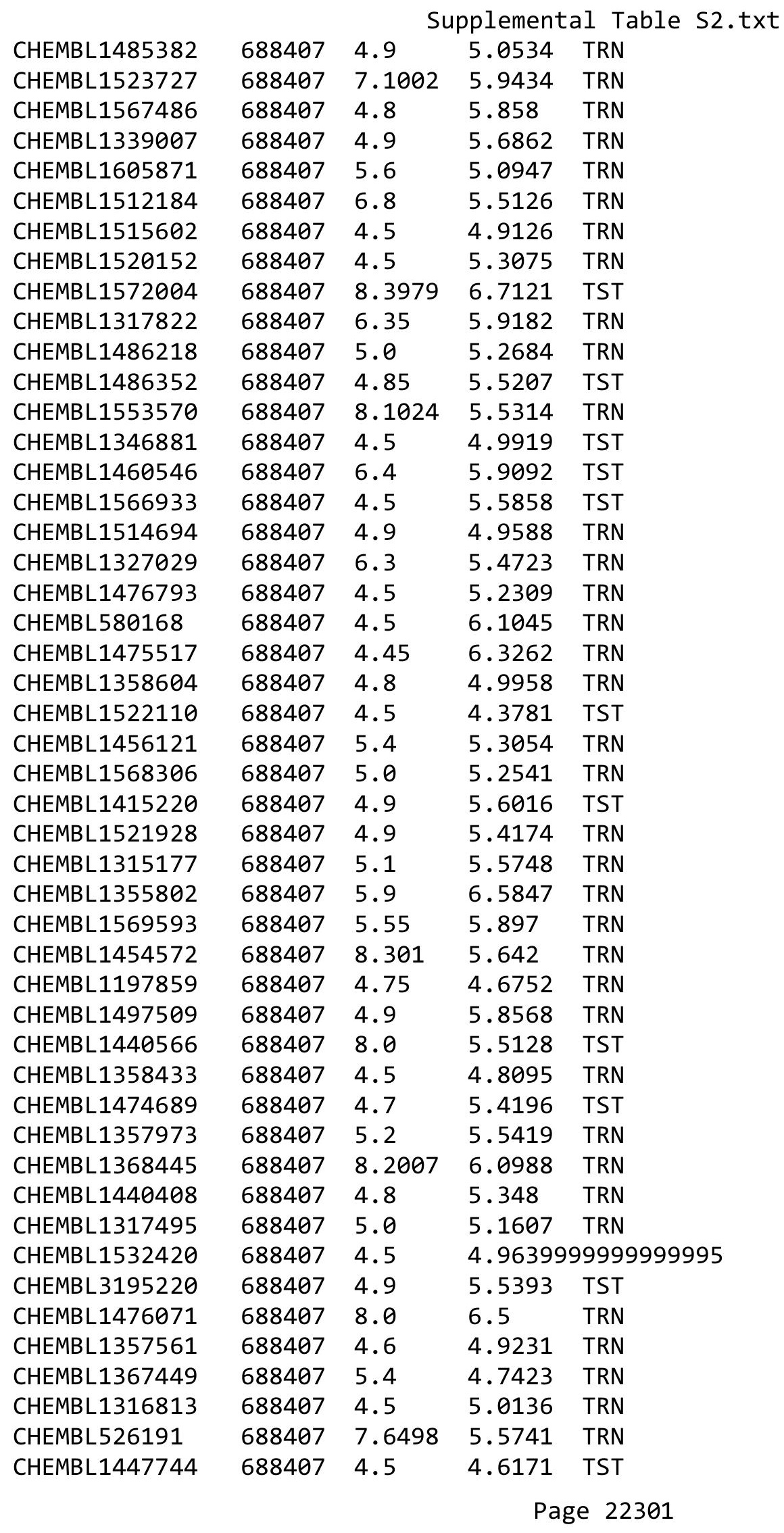




\begin{tabular}{|c|c|c|c|c|}
\hline \multicolumn{5}{|c|}{ Supplemental Table } \\
\hline CHEMBL1530798 & 688407 & 8.1024 & 6.3738 & TRN \\
\hline CHEMBL 1480450 & 688407 & 4.5 & 5.4071 & TRN \\
\hline CHEMBL1456514 & 688407 & 4.85 & 5.2073 & TRN \\
\hline CHEMBL1591226 & 688407 & 4.95 & 5.4073 & TST \\
\hline CHEMBL1522004 & 688407 & 8.301 & 5.9451 & TRN \\
\hline CHEMBL1324421 & 688407 & 6.1 & 5.5091 & TRN \\
\hline CHEMBL1416089 & 688407 & 4.5 & 4.3289 & TRN \\
\hline CHEMBL1521087 & 688407 & 4.7 & 4.8766 & TRN \\
\hline CHEMBL1605955 & 688407 & 4.95 & 5.3047 & TRN \\
\hline CHEMBL1524351 & 688407 & 5.0 & 5.9498 & TRN \\
\hline CHEMBL1562758 & 688407 & 4.45 & 5.3037 & TST \\
\hline CHEMBL1573471 & 688407 & 4.9 & 5.6012 & TRN \\
\hline CHEMBL1355190 & 688407 & 7.6003 & 5.4482 & TST \\
\hline CHEMBL1436351 & 688407 & 4.7 & 5.2891 & TRN \\
\hline CHEMBL1329382 & 688407 & 4.8 & 5.3437 & TRN \\
\hline CHEMBL1573951 & 688407 & 8.3468 & 6.0189 & TRN \\
\hline CHEMBL1321311 & 688407 & 8.301 & 6.3608 & TRN \\
\hline CHEMBL1416354 & 688407 & 4.9 & 5.8558 & TRN \\
\hline CHEMBL1590707 & 688407 & 8.301 & 5.6658 & TST \\
\hline CHEMBL1317796 & 688407 & 4.8 & 5.6119 & TRN \\
\hline CHEMBL1601638 & 688407 & 4.8 & 5.2454 & TRN \\
\hline CHEMBL1573209 & 688407 & 6.2 & 6.233 & TST \\
\hline CHEMBL1336747 & 688407 & 4.6 & 4.8874 & TRN \\
\hline CHEMBL1453086 & 688407 & 4.6 & 4.5622 & TRN \\
\hline CHEMBL1376910 & 688407 & 4.8 & 5.8255 & TRN \\
\hline CHEMBL1487271 & 688407 & 4.65 & 4.7286 & TST \\
\hline CHEMBL1472766 & 688407 & 8.301 & 5.2956 & TRN \\
\hline CHEMBL1513307 & 688407 & 4.5 & 5.3561 & TRN \\
\hline CHEMBL1584663 & 688407 & 5.0 & 5.4218 & TRN \\
\hline CHEMBL1457160 & 688407 & 5.3 & 6.2605 & TRN \\
\hline CHEMBL1593932 & 688407 & 4.9 & 5.1833 & TRN \\
\hline CHEMBL1449984 & 688407 & 5.7 & 5.5383 & TST \\
\hline CHEMBL1326185 & 688407 & 5.35 & 5.801 & TST \\
\hline CHEMBL1531112 & 688407 & 7.6003 & 5.8702 & TST \\
\hline CHEMBL1315385 & 688407 & 4.95 & 5.0639 & TRN \\
\hline CHEMBL1395033 & 688407 & 6.9 & 5.2406 & TRN \\
\hline CHEMBL1476367 & 688407 & 4.5 & 5.7128 & TRN \\
\hline CHEMBL1487599 & 688407 & 4.55 & 5.5246 & TST \\
\hline CHEMBL602740 & 688407 & 6.5 & 5.4949 & TRN \\
\hline CHEMBL1375408 & 688407 & 7.3002 & 5.9786 & TRN \\
\hline CHEMBL1475572 & 688407 & 4.8 & 5.5035 & TRN \\
\hline CHEMBL1474481 & 688407 & 6.1 & 5.7314 & TST \\
\hline CHEMBL1315273 & 688407 & 4.5 & 5.745 & TRN \\
\hline CHEMBL1489823 & 688407 & 4.5 & 5.1893 & TRN \\
\hline CHEMBL1597164 & 688407 & 5.6 & 4.6748 & TRN \\
\hline CHEMBL1575223 & 688407 & 5.3 & 5.3211 & TRN \\
\hline CHEMBL1561894 & 688407 & 4.5 & 5.8369 & TRN \\
\hline CHEMBL1409574 & 688407 & 4.5 & 5.4627 & TRN \\
\hline
\end{tabular}




\begin{tabular}{|c|c|c|c|c|}
\hline \multicolumn{5}{|c|}{ Supplemental Table s2.txt } \\
\hline CHEMBL1526437 & 688407 & 5.1 & 5.4793 & TRN \\
\hline CHEMBL1593627 & 688407 & 4.8 & 5.6566 & TST \\
\hline CHEMBL1395891 & 688407 & 8.699 & 5.5469 & TRN \\
\hline CHEMBL1492105 & 688407 & 4.9 & 5.1536 & TRN \\
\hline CHEMBL1489582 & 688407 & 4.95 & 5.2893 & TRN \\
\hline CHEMBL1436977 & 688407 & 4.6 & 5.101 & TRN \\
\hline CHEMBL1551481 & 688407 & 4.5 & 5.7564 & TRN \\
\hline CHEMBL1355079 & 688407 & 8.0 & 6.5438 & TRN \\
\hline CHEMBL1324354 & 688407 & 5.1 & 5.7162 & TRN \\
\hline CHEMBL1320212 & 688407 & 6.5 & 5.4258 & TRN \\
\hline CHEMBL1416873 & 688407 & 4.45 & 5.1136 & TST \\
\hline CHEMBL1437197 & 688407 & 4.5 & 5.5296 & TRN \\
\hline CHEMBL1358044 & 688407 & 4.9 & 5.7019 & TRN \\
\hline CHEMBL1080897 & 688407 & 4.85 & 6.6602 & TRN \\
\hline CHEMBL1435759 & 688407 & 4.5 & 5.3088 & TRN \\
\hline CHEMBL1611082 & 688407 & 8.0 & 6.0682 & TRN \\
\hline CHEMBL 2007403 & 688407 & 4.7 & 5.7542 & TRN \\
\hline CHEMBL1398457 & 688407 & 4.9 & 4.9095 & TRN \\
\hline CHEMBL1554626 & 688407 & 4.7 & 5.1677 & TRN \\
\hline CHEMBL1338460 & 688407 & 4.5 & 5.83700 & 0000000001 \\
\hline CHEMBL1516299 & 688407 & 5.0 & 5.3782 & TRN \\
\hline CHEMBL1373072 & 688407 & 4.5 & 5.9966 & TRN \\
\hline CHEMBL1394916 & 688407 & 5.1 & 5.2082 & TRN \\
\hline CHEMBL1373253 & 688407 & 5.9 & 5.428 & TRN \\
\hline CHEMBL601180 & 688407 & 4.7 & 5.124 & TST \\
\hline CHEMBL1473972 & 688407 & 5.2 & 5.0393 & TRN \\
\hline CHEMBL1513803 & 688407 & 7.3002 & 6.2122 & TRN \\
\hline CHEMBL1601522 & 688407 & 4.5 & 5.6079 & TRN \\
\hline CHEMBL1519556 & 688407 & 8.301 & 5.7184 & TST \\
\hline CHEMBL1356402 & 688407 & 6.7001 & 6.1553 & TRN \\
\hline CHEMBL1317789 & 688407 & 4.5 & 5.5368 & TRN \\
\hline CHEMBL1514262 & 688407 & 4.7 & 5.5501 & TST \\
\hline CHEMBL1434124 & 688407 & 4.45 & 5.3393 & TRN \\
\hline CHEMBL1597836 & 688407 & 4.5 & 4.8173 & TRN \\
\hline CHEMBL1591371 & 688407 & 7.699 & 4.7892 & TRN \\
\hline CHEMBL1459117 & 688407 & 4.7 & 5.4926 & TRN \\
\hline CHEMBL1593192 & 688407 & 4.85 & 5.6831 & TRN \\
\hline CHEMBL1477338 & 688407 & 4.5 & 5.3429 & TRN \\
\hline CHEMBL569088 & 688407 & 4.5 & 4.8552 & TRN \\
\hline CHEMBL1322696 & 688407 & 4.5 & 5.6956 & TRN \\
\hline CHEMBL1438725 & 688407 & 5.9 & 6.2527 & TRN \\
\hline CHEMBL1448065 & 688407 & 4.9 & 5.4274 & TRN \\
\hline CHEMBL1315925 & 688407 & 4.8 & 5.3585 & TST \\
\hline CHEMBL1362329 & 688407 & 4.5 & 4.974 & TRN \\
\hline CHEMBL1322889 & 688407 & 4.95 & 5.6525 & TRN \\
\hline CHEMBL1515674 & 688407 & 4.6 & 5.2115 & TRN \\
\hline CHEMBL1401025 & 688407 & 8.301 & 5.6514 & TRN \\
\hline CHEMBL1445407 & 688407 & 4.9 & 5.545 & TST \\
\hline
\end{tabular}

TRN 


\begin{tabular}{|c|c|c|c|c|}
\hline \multicolumn{5}{|c|}{ Supplemental Table S2.txt } \\
\hline CHEMBL1474565 & 688407 & 4.5 & 5.2308 & TRN \\
\hline CHEMBL1329594 & 688407 & 4.5 & 4.9415 & TRN \\
\hline CHEMBL1372938 & 688407 & 5.2 & 5.4381 & TST \\
\hline CHEMBL1521811 & 688407 & 8.301 & 5.4054 & TST \\
\hline CHEMBL1413864 & 688407 & 4.45 & 5.9215 & TRN \\
\hline CHEMBL1475334 & 688407 & 4.6 & 5.1729 & TST \\
\hline CHEMBL1324214 & 688407 & 5.5 & 5.5921 & TRN \\
\hline CHEMBL1592895 & 688407 & 8.1024 & 6.0172 & TRN \\
\hline CHEMBL1523033 & 688407 & 6.3 & 5.0487 & TRN \\
\hline CHEMBL1570780 & 688407 & 5.2 & 5.2446 & TST \\
\hline CHEMBL1548327 & 688407 & 4.6 & 5.2951 & TST \\
\hline CHEMBL1431033 & 688407 & 4.7 & 6.0271 & TST \\
\hline CHEMBL1513880 & 688407 & 4.85 & 5.1023 & TST \\
\hline CHEMBL1446739 & 688407 & 4.9 & 5.7264 & TRN \\
\hline CHEMBL1487369 & 688407 & 6.9 & 6.2636 & TST \\
\hline CHEMBL1443066 & 688407 & 6.8 & 5.3683 & TRN \\
\hline CHEMBL1590169 & 688407 & 5.55 & 5.5266 & TRN \\
\hline CHEMBL1359067 & 688407 & 4.8 & 5.9087 & TRN \\
\hline CHEMBL1573918 & 688407 & 8.4949 & 5.3657 & TST \\
\hline CHEMBL1578597 & 688407 & 4.85 & 5.6687 & TST \\
\hline CHEMBL1410350 & 688407 & 4.85 & 5.7234 & TST \\
\hline CHEMBL1514854 & 688407 & 6.0 & 5.5981 & TRN \\
\hline CHEMBL1391821 & 688407 & 4.5 & 5.7455 & TRN \\
\hline CHEMBL1405928 & 688407 & 4.95 & 5.3322 & TST \\
\hline CHEMBL1596242 & 688407 & 5.9 & 5.0299 & TST \\
\hline CHEMBL1331764 & 688407 & 5.2 & 5.7987 & TRN \\
\hline CHEMBL1602133 & 688407 & 4.5 & 5.8283 & TRN \\
\hline CHEMBL1515859 & 688407 & 6.8 & 6.0206 & TRN \\
\hline CHEMBL1591656 & 688407 & 6.2 & 6.855 & TRN \\
\hline CHEMBL1552906 & 688407 & 6.1 & 6.1566 & TRN \\
\hline CHEMBL1513462 & 688407 & 7.0501 & 5.6945 & TRN \\
\hline CHEMBL1371671 & 688407 & 4.65 & 5.0043 & TRN \\
\hline CHEMBL1417669 & 688407 & 4.5 & 5.5509 & TRN \\
\hline CHEMBL221219 & 688407 & 4.5 & 5.2667 & TRN \\
\hline CHEMBL1436071 & 688407 & 8.0 & 4.9542 & TRN \\
\hline CHEMBL1436542 & 688407 & 4.5 & 6.4271 & TST \\
\hline CHEMBL1355564 & 688407 & 7.5003 & 5.4239 & TST \\
\hline CHEMBL1384860 & 688407 & 6.7001 & 5.405 & TST \\
\hline CHEMBL1454749 & 688407 & 4.9 & 5.4592 & TRN \\
\hline CHEMBL1551999 & 688407 & 8.4949 & 6.1151 & TRN \\
\hline CHEMBL1452958 & 688407 & 4.6 & 5.7231 & TST \\
\hline CHEMBL1557392 & 688407 & 4.8 & 5.5603 & TRN \\
\hline CHEMBL1516181 & 688407 & 8.301 & 5.3379 & TST \\
\hline CHEMBL1575010 & 688407 & 8.301 & 5.2724 & TST \\
\hline CHEMBL1463272 & 688407 & 4.8 & 5.6197 & TST \\
\hline CHEMBL3213088 & 688407 & 4.8 & 5.5319 & TRN \\
\hline CHEMBL1354470 & 688407 & 4.5 & 6.4314 & TRN \\
\hline CHEMBL1522330 & 688407 & 5.0 & 5.3066 & TRN \\
\hline
\end{tabular}




\begin{tabular}{|c|c|c|c|c|c|}
\hline \multicolumn{6}{|c|}{ Supplemental Table S2.txt } \\
\hline CHEMBL1314966 & 688407 & 6.4 & 5.3296 & TRN & \\
\hline CHEMBL1613344 & 688407 & 6.0 & 5.187 & TRN & \\
\hline CHEMBL1560969 & 688407 & 6.2 & 5.9579 & TRN & \\
\hline CHEMBL1375735 & 688407 & 4.9 & 4.9554 & TST & \\
\hline CHEMBL1475581 & 688407 & 8.301 & 5.78606 & 00000000005 & TST \\
\hline CHEMBL1436631 & 688407 & 4.5 & 4.9417 & TRN & \\
\hline CHEMBL1373453 & 688407 & 7.699 & 5.4738 & TRN & \\
\hline CHEMBL1394110 & 688407 & 7.8996 & 6.3223 & TRN & \\
\hline CHEMBL1557875 & 688407 & 4.8 & 5.0461 & TRN & \\
\hline CHEMBL1433519 & 688407 & 8.301 & 5.9833 & TRN & \\
\hline CHEMBL1357058 & 688407 & 5.05 & 5.322 & TRN & \\
\hline CHEMBL1435396 & 688407 & 5.25 & 4.9651 & TRN & \\
\hline CHEMBL1569252 & 688407 & 6.3 & 6.5259 & TRN & \\
\hline CHEMBL1480808 & 688407 & 8.301 & 5.4859 & TRN & \\
\hline CHEMBL1591114 & 688407 & 4.6 & 4.2499 & TRN & \\
\hline CHEMBL1354772 & 688407 & 4.5 & 4.80699 & 99999999995 & TRN \\
\hline CHEMBL1554765 & 688407 & 7.3497 & 6.1589 & TRN & \\
\hline CHEMBL1590628 & 688407 & 5.0 & 5.1382 & TRN & \\
\hline CHEMBL1317445 & 688407 & 6.6 & 6.0156 & TRN & \\
\hline CHEMBL1476036 & 688407 & 4.45 & 5.0632 & TRN & \\
\hline CHEMBL1396229 & 688407 & 8.0 & 5.5437 & TST & \\
\hline CHEMBL1355692 & 688407 & 4.8 & 5.4569 & TRN & \\
\hline CHEMBL1516138 & 688407 & 5.2 & 5.3927 & TRN & \\
\hline CHEMBL1479295 & 688407 & 4.95 & 5.4609 & TRN & \\
\hline CHEMBL1553177 & 688407 & 4.45 & 6.3151 & TRN & \\
\hline CHEMBL1475369 & 688407 & 4.5 & 5.0201 & TRN & \\
\hline CHEMBL1598055 & 688407 & 5.0 & 5.055 & TRN & \\
\hline CHEMBL1357544 & 688407 & 5.9 & 4.6183 & TST & \\
\hline CHEMBL1512009 & 688407 & 8.301 & 6.0782 & TRN & \\
\hline CHEMBL1611952 & 688407 & 4.9 & 5.0741 & TRN & \\
\hline CHEMBL1434357 & 688407 & 5.6 & 6.4538 & TRN & \\
\hline CHEMBL1362924 & 688407 & 4.7 & 5.6542 & TRN & \\
\hline CHEMBL1512029 & 688407 & 5.3 & 6.4737 & TRN & \\
\hline CHEMBL1476249 & 688407 & 4.7 & 6.0151 & TRN & \\
\hline CHEMBL1561389 & 688407 & 4.65 & 5.0409 & TRN & \\
\hline CHEMBL1443022 & 688407 & 4.5 & 5.0938 & TRN & \\
\hline CHEMBL1314784 & 688407 & 5.4 & 5.7134 & TRN & \\
\hline CHEMBL1513810 & 688407 & 7.1002 & 5.904 & TRN & \\
\hline CHEMBL1378891 & 688407 & 7.8996 & 6.55 & TRN & \\
\hline CHEMBL1554624 & 688407 & 7.699 & 5.3071 & TRN & \\
\hline CHEMBL1326368 & 688407 & 5.5 & 5.3065 & TRN & \\
\hline CHEMBL1325470 & 688407 & 4.5 & 4.8975 & TRN & \\
\hline CHEMBL1396110 & 688407 & 4.9 & 6.041 & TRN & \\
\hline CHEMBL1396826 & 688407 & 4.8 & 4.5087 & TRN & \\
\hline CHEMBL1450023 & 688407 & 4.5 & 4.71399 & 99999999995 & TRN \\
\hline CHEMBL1456205 & 688407 & 6.9 & 6.0511 & TRN & \\
\hline CHEMBL1567381 & 688407 & 5.0 & 5.305 & TRN & \\
\hline CHEMBL1355287 & 688407 & 4.9 & 4.7259 & TRN & \\
\hline
\end{tabular}




\begin{tabular}{|c|c|c|c|c|}
\hline \multicolumn{5}{|c|}{ Supplemental Table S2.txt } \\
\hline CHEMBL1594193 & 688407 & 5.9 & 5.2965 & TRN \\
\hline CHEMBL1377723 & 688407 & 6.8 & 5.8759 & TRN \\
\hline CHEMBL1551502 & 688407 & 5.1 & 5.7117 & TRN \\
\hline CHEMBL1594352 & 688407 & 6.5 & 6.1199 & TRN \\
\hline CHEMBL1527400 & 688407 & 5.1 & 5.444 & TRN \\
\hline CHEMBL1433544 & 688407 & 4.5 & 5.2634 & TRN \\
\hline CHEMBL1477163 & 688407 & 5.1 & 5.7335 & TRN \\
\hline CHEMBL104728 & 688407 & 4.9 & 5.1266 & TST \\
\hline CHEMBL1514677 & 688407 & 5.65 & 5.9256 & TRN \\
\hline CHEMBL1492555 & 688407 & 8.301 & 6.3238 & TRN \\
\hline CHEMBL1415034 & 688407 & 7.3002 & 5.8566 & TRN \\
\hline CHEMBL1354564 & 688407 & 4.85 & 4.5351 & TRN \\
\hline CHEMBL1438554 & 688407 & 7.3002 & 5.3876 & TST \\
\hline CHEMBL1397805 & 688407 & 6.2 & 5.468 & TRN \\
\hline CHEMBL1606489 & 688407 & 7.0 & 5.9167 & TST \\
\hline CHEMBL1357549 & 688407 & 4.5 & 5.7533 & TRN \\
\hline CHEMBL1571408 & 688407 & 6.4 & 5.7345 & TRN \\
\hline CHEMBL1558366 & 688407 & 5.0 & 5.6022 & TRN \\
\hline CHEMBL1440577 & 688407 & 4.7 & 5.6445 & TRN \\
\hline CHEMBL1532930 & 688407 & 4.85 & 5.0089 & TRN \\
\hline CHEMBL1366385 & 688407 & 4.45 & 5.0188 & TRN \\
\hline CHEMBL1355162 & 688407 & 7.7496 & 5.8103 & TST \\
\hline CHEMBL1413940 & 688407 & 4.5 & 4.9029 & TRN \\
\hline CHEMBL1367010 & 688407 & 6.7501 & 5.4416 & TRN \\
\hline CHEMBL1377050 & 688407 & 4.5 & 5.1469 & TRN \\
\hline CHEMBL1591270 & 688407 & 8.301 & 5.2824 & TRN \\
\hline CHEMBL1500607 & 688407 & 5.55 & 6.3214 & TST \\
\hline CHEMBL1590019 & 688407 & 4.9 & 5.3314 & TRN \\
\hline CHEMBL1355113 & 688407 & 8.301 & 5.5771 & TRN \\
\hline CHEMBL1394126 & 688407 & 5.6 & 5.7101 & TST \\
\hline CHEMBL1514008 & 688407 & 4.7 & 4.9581 & TRN \\
\hline CHEMBL1474934 & 688407 & 4.9 & 6.0432 & TRN \\
\hline CHEMBL1493880 & 688407 & 4.9 & 6.0227 & TRN \\
\hline CHEMBL1453850 & 688407 & 4.9 & 5.7549 & TRN \\
\hline CHEMBL1407986 & 688407 & 4.7 & 4.8548 & TRN \\
\hline CHEMBL1475049 & 688407 & 5.65 & 5.8356 & TRN \\
\hline CHEMBL1328681 & 688407 & 8.0 & 6.6975 & TST \\
\hline CHEMBL1479647 & 688407 & 4.6 & 4.7919 & TRN \\
\hline CHEMBL1434180 & 688407 & 4.8 & 4.6845 & TRN \\
\hline CHEMBL1513809 & 688407 & 5.5 & 5.5181 & TST \\
\hline CHEMBL1367121 & 688407 & 5.1 & 5.3629 & TRN \\
\hline CHEMBL1401331 & 688407 & 4.8 & 5.6705 & TST \\
\hline CHEMBL1533816 & 688407 & 4.5 & 5.1443 & TRN \\
\hline CHEMBL1520905 & 688407 & 5.0 & 5.0224 & TRN \\
\hline CHEMBL1515966 & 688407 & 5.2 & 5.7906 & TRN \\
\hline CHEMBL1315389 & 688407 & 4.45 & 5.1533 & TRN \\
\hline CHEMBL1523285 & 688407 & 8.301 & 5.8109 & TST \\
\hline CHEMBL1551728 & 688407 & 7.699 & 5.687 & TST \\
\hline
\end{tabular}




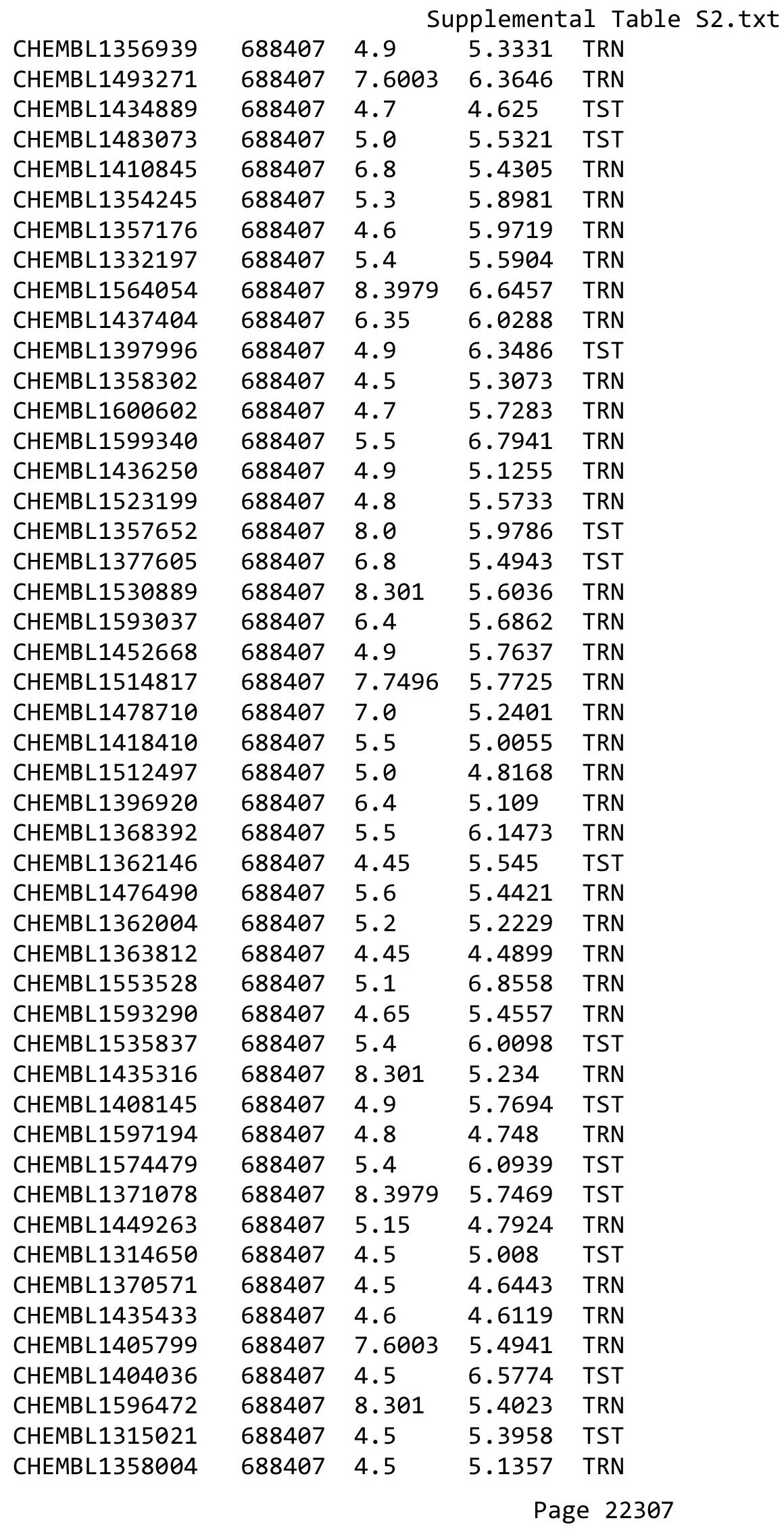




\begin{tabular}{|c|c|c|c|c|c|}
\hline \multicolumn{6}{|c|}{ Supplemental Table S2.txt } \\
\hline CHEMBL1552291 & 688407 & 5.0 & 5.0238 & TRN & \\
\hline CHEMBL1483671 & 688407 & 4.9 & 5.6451 & TRN & \\
\hline CHEMBL1446149 & 688407 & 7.8013 & 5.5859 & TST & \\
\hline CHEMBL1314289 & 688407 & 5.4 & 6.3235 & TRN & \\
\hline CHEMBL1436656 & 688407 & 5.15 & 5.4442 & TRN & \\
\hline CHEMBL1484093 & 688407 & 5.15 & 5.3026 & TST & \\
\hline CHEMBL1479225 & 688407 & 5.5 & 5.6484 & TST & \\
\hline CHEMBL1411211 & 688407 & 4.75 & 5.107 & TRN & \\
\hline CHEMBL1433832 & 688407 & 4.45 & 4.8753 & TRN & \\
\hline CHEMBL1324811 & 688407 & 5.3 & 5.8625 & TRN & \\
\hline CHEMBL1552451 & 688407 & 4.45 & 5.1323 & TRN & \\
\hline CHEMBL1497602 & 688407 & 6.2 & 6.3602 & TRN & \\
\hline CHEMBL1513285 & 688407 & 4.95 & 5.8764 & TRN & \\
\hline CHEMBL1409425 & 688407 & 6.4 & 6.0333 & TST & \\
\hline CHEMBL1534458 & 688407 & 5.2 & 4.3857 & TRN & \\
\hline CHEMBL1496024 & 688407 & 6.4 & 5.9708 & TRN & \\
\hline CHEMBL1314990 & 688407 & 4.5 & 6.0403 & TST & \\
\hline CHEMBL1533247 & 688407 & 5.5 & 5.6884 & TRN & \\
\hline CHEMBL1410605 & 688407 & 5.2 & 5.7099 & TST & \\
\hline CHEMBL1568047 & 688407 & 4.9 & 5.1312 & TRN & \\
\hline CHEMBL1443929 & 688407 & 4.9 & 5.9613 & TRN & \\
\hline CHEMBL1517293 & 688407 & 4.5 & 5.9313 & TRN & \\
\hline CHEMBL1516076 & 688407 & 4.6 & 4.4472 & TRN & \\
\hline CHEMBL1327439 & 688407 & 6.9 & 5.8174 & TST & \\
\hline CHEMBL1451916 & 688407 & 4.9 & 5.6168 & TST & \\
\hline CHEMBL1552385 & 688407 & 4.5 & 6.3371 & TST & \\
\hline CHEMBL1326206 & 688407 & 4.8 & 5.4747 & TRN & \\
\hline CHEMBL1553369 & 688407 & 4.6 & 4.9898 & TRN & \\
\hline CHEMBL1413911 & 688407 & 5.6 & 5.3629 & TST & \\
\hline CHEMBL1367304 & 688407 & 4.65 & 5.61799 & 9999999999 & TST \\
\hline CHEMBL1480144 & 688407 & 5.7 & 4.7335 & TRN & \\
\hline CHEMBL1412428 & 688407 & 7.699 & 5.7976 & TRN & \\
\hline CHEMBL1512179 & 688407 & 4.85 & 5.1141 & TRN & \\
\hline CHEMBL1409486 & 688407 & 4.6 & 4.8658 & TRN & \\
\hline CHEMBL1314202 & 688407 & 5.4 & 5.0494 & TRN & \\
\hline CHEMBL1316986 & 688407 & 8.301 & 6.1772 & TRN & \\
\hline CHEMBL1351149 & 688407 & 8.1487 & 5.9809 & TST & \\
\hline CHEMBL1370256 & 688407 & 4.8 & 5.6713 & TST & \\
\hline CHEMBL1513139 & 688407 & 4.45 & 5.1052 & TRN & \\
\hline CHEMBL1315962 & 688407 & 5.7 & 5.3165 & TRN & \\
\hline CHEMBL1319960 & 688407 & 4.6 & 5.2507 & TRN & \\
\hline CHEMBL1357448 & 688407 & 4.9 & 5.1758 & TRN & \\
\hline CHEMBL1409678 & 688407 & 6.1 & 5.9518 & TRN & \\
\hline CHEMBL1609966 & 688407 & 4.75 & 4.9944 & TRN & \\
\hline CHEMBL1522332 & 688407 & 4.75 & 4.4623 & TRN & \\
\hline CHEMBL1320556 & 688407 & 4.45 & 4.3014 & TRN & \\
\hline CHEMBL1551932 & 688407 & 5.1 & 4.7511 & TST & \\
\hline CHEMBL1365211 & 688407 & 4.5 & 5.5909 & TST & \\
\hline
\end{tabular}




\begin{tabular}{|c|c|c|c|c|}
\hline \multicolumn{5}{|c|}{ Supplemental Table s2.txt } \\
\hline CHEMBL1395440 & 688407 & 8.1024 & 5.9022 & TRN \\
\hline CHEMBL1593785 & 688407 & 5.0 & 5.5361 & TST \\
\hline CHEMBL603739 & 688407 & 5.2 & 5.6725 & TRN \\
\hline CHEMBL1412672 & 688407 & 4.8 & 4.5534 & TRN \\
\hline CHEMBL1474712 & 688407 & 4.5 & 5.275 & TRN \\
\hline CHEMBL1557256 & 688407 & 5.3 & 5.789 & TRN \\
\hline CHEMBL1523139 & 688407 & 4.5 & 5.0803 & TRN \\
\hline CHEMBL1482288 & 688407 & 5.0 & 5.7002 & TRN \\
\hline CHEMBL1404717 & 688407 & 4.5 & 5.2946 & TST \\
\hline CHEMBL1568359 & 688407 & 6.9 & 5.9672 & TRN \\
\hline CHEMBL1487113 & 688407 & 4.9 & 4.8227 & TRN \\
\hline CHEMBL1355215 & 688407 & 8.4949 & 5.9309 & TRN \\
\hline CHEMBL1592307 & 688407 & 6.5 & 6.1668 & TRN \\
\hline CHEMBL1561928 & 688407 & 4.75 & 5.3262 & TST \\
\hline CHEMBL1325291 & 688407 & 4.5 & 5.3941 & TRN \\
\hline CHEMBL1316964 & 688407 & 8.0 & 6.2658 & TRN \\
\hline CHEMBL1323874 & 688407 & 5.0 & 5.2448 & TRN \\
\hline CHEMBL1325349 & 688407 & 4.6 & 5.7686 & TRN \\
\hline CHEMBL1418245 & 688407 & 4.8 & 5.0644 & TRN \\
\hline CHEMBL1397162 & 688407 & 4.85 & 5.5264 & TRN \\
\hline CHEMBL1572881 & 688407 & 6.45 & 5.0574 & TST \\
\hline CHEMBL1518666 & 688407 & 5.0 & 5.356 & TRN \\
\hline CHEMBL1396578 & 688407 & 8.3979 & 6.8339 & TRN \\
\hline CHEMBL1397321 & 688407 & 8.301 & 5.0023 & TST \\
\hline CHEMBL1437195 & 688407 & 8.301 & 5.8539 & TRN \\
\hline CHEMBL1407856 & 688407 & 6.8 & 5.7801 & TRN \\
\hline CHEMBL1435132 & 688407 & 4.7 & 4.7032 & TRN \\
\hline CHEMBL1474418 & 688407 & 4.6 & 5.0504 & TRN \\
\hline CHEMBL1594524 & 688407 & 5.6 & 5.3389 & TRN \\
\hline CHEMBL1445472 & 688407 & 4.9 & 5.6791 & TRN \\
\hline CHEMBL1417954 & 688407 & 8.0 & 5.8942 & TRN \\
\hline CHEMBL1446925 & 688407 & 4.6 & 6.3025 & TRN \\
\hline CHEMBL1315305 & 688407 & 8.301 & 5.9578 & TRN \\
\hline CHEMBL1355695 & 688407 & 6.0 & 5.6923 & TRN \\
\hline CHEMBL1553106 & 688407 & 4.95 & 5.1993 & TRN \\
\hline CHEMBL1416747 & 688407 & 4.6 & 5.5951 & TRN \\
\hline CHEMBL1362251 & 688407 & 5.6 & 5.6217 & TST \\
\hline CHEMBL1317421 & 688407 & 4.5 & 4.805 & TRN \\
\hline CHEMBL1397829 & 688407 & 4.5 & 5.0771 & TRN \\
\hline CHEMBL1512794 & 688407 & 4.8 & 5.1869 & TST \\
\hline CHEMBL1354611 & 688407 & 7.0 & 5.1982 & TST \\
\hline CHEMBL1551944 & 688407 & 4.6 & 5.2193 & TRN \\
\hline CHEMBL1512325 & 688407 & 4.9 & 5.9998 & TST \\
\hline CHEMBL1483731 & 688407 & 4.75 & 5.1439 & TST \\
\hline CHEMBL1375479 & 688407 & 4.5 & 6.0253 & TRN \\
\hline CHEMBL1318247 & 688407 & 6.5 & 5.3543 & TST \\
\hline CHEMBL1516303 & 688407 & 5.1 & 5.0593 & TST \\
\hline CHEMBL1514180 & 688407 & 4.75 & 4.9682 & TST \\
\hline
\end{tabular}




\begin{tabular}{|c|c|c|c|c|}
\hline \multicolumn{5}{|c|}{ Supplemental Table S2.txt } \\
\hline CHEMBL1474678 & 688407 & 5.25 & 5.6754 & TRN \\
\hline CHEMBL1439122 & 688407 & 7.0 & 5.2958 & TRN \\
\hline CHEMBL1378268 & 688407 & 4.9 & 4.8084 & TRN \\
\hline CHEMBL1325252 & 688407 & 6.8499 & 5.2144 & TRN \\
\hline CHEMBL1591115 & 688407 & 4.65 & 5.3848 & TRN \\
\hline CHEMBL1444684 & 688407 & 4.45 & 5.7042 & TRN \\
\hline CHEMBL1555009 & 688407 & 4.6 & 4.7783 & TRN \\
\hline CHEMBL1417456 & 688407 & 7.4001 & 5.6369 & TRN \\
\hline CHEMBL1553117 & 688407 & 4.85 & 4.7959 & TRN \\
\hline CHEMBL1448383 & 688407 & 5.0 & 4.762 & TRN \\
\hline CHEMBL1515026 & 688407 & 5.8 & 6.234 & TRN \\
\hline CHEMBL3197489 & 688407 & 4.65 & 4.7786 & TST \\
\hline CHEMBL1336482 & 688407 & 4.7 & 5.4067 & TST \\
\hline CHEMBL1496115 & 688407 & 4.8 & 4.9846 & TRN \\
\hline CHEMBL1509175 & 688407 & 5.85 & 6.0524 & TST \\
\hline CHEMBL1438649 & 688407 & 4.65 & 5.6602 & TRN \\
\hline CHEMBL1475683 & 688407 & 8.0 & 5.303 & TRN \\
\hline CHEMBL1604461 & 688407 & 6.5501 & 5.688 & TST \\
\hline CHEMBL1329682 & 688407 & 4.5 & 5.5703 & TRN \\
\hline CHEMBL1449826 & 688407 & 4.9 & 4.9745 & TST \\
\hline CHEMBL1439296 & 688407 & 4.8 & 5.4899 & TRN \\
\hline CHEMBL1448432 & 688407 & 5.2 & 4.7484 & TRN \\
\hline CHEMBL1317121 & 688407 & 7.5003 & 5.83 & TST \\
\hline CHEMBL1590052 & 688407 & 7.8996 & 6.131 & TRN \\
\hline CHEMBL1315148 & 688407 & 4.5 & 5.3013 & TRN \\
\hline CHEMBL1514738 & 688407 & 4.5 & 6.2936 & TRN \\
\hline CHEMBL1553724 & 688407 & 6.0 & 5.5848 & TRN \\
\hline CHEMBL1592247 & 688407 & 4.9 & 4.9016 & TRN \\
\hline CHEMBL1516908 & 688407 & 4.95 & 5.7373 & TRN \\
\hline CHEMBL1312843 & 688407 & 5.0 & 5.44 & TST \\
\hline CHEMBL1436069 & 688407 & 5.4 & 5.5473 & TRN \\
\hline CHEMBL1443065 & 688407 & 4.8 & 5.5355 & TRN \\
\hline CHEMBL1515993 & 688407 & 5.0 & 5.6239 & TRN \\
\hline CHEMBL1472483 & 688407 & 5.5 & 5.3361 & TRN \\
\hline CHEMBL1522212 & 688407 & 8.0506 & 5.7038 & TRN \\
\hline CHEMBL1320391 & 688407 & 5.3 & 4.8441 & TST \\
\hline CHEMBL1314527 & 688407 & 4.9 & 4.5753 & TRN \\
\hline CHEMBL1436524 & 688407 & 7.1002 & 5.5642 & TST \\
\hline CHEMBL1523177 & 688407 & 6.2 & 5.8905 & TRN \\
\hline CHEMBL1354814 & 688407 & 4.5 & 5.6536 & TRN \\
\hline CHEMBL1552608 & 688407 & 4.45 & 5.2908 & TRN \\
\hline CHEMBL1396022 & 688407 & 4.9 & 5.6013 & TRN \\
\hline CHEMBL1609036 & 688407 & 4.9 & 5.829 & TRN \\
\hline CHEMBL1336480 & 688407 & 6.35 & 6.5261 & TST \\
\hline CHEMBL1434348 & 688407 & 4.45 & 4.8458 & TRN \\
\hline CHEMBL1474156 & 688407 & 5.9 & 5.7716 & TRN \\
\hline CHEMBL1579476 & 688407 & 5.6 & 5.3632 & TST \\
\hline CHEMBL1396138 & 688407 & 4.9 & 5.5301 & TRN \\
\hline
\end{tabular}




\begin{tabular}{|c|c|c|c|c|c|}
\hline \multicolumn{6}{|c|}{ Supplemental Table s2.txt } \\
\hline CHEMBL1594063 & 688407 & 4.7 & 5.2559 & TRN & \\
\hline CHEMBL1335587 & 688407 & 4.9 & 5.5046 & TRN & \\
\hline CHEMBL1438174 & 688407 & 8.0 & 6.4601 & TRN & \\
\hline CHEMBL1555399 & 688407 & 4.7 & 5.33799 & 9999999999 & TRN \\
\hline CHEMBL1394295 & 688407 & 7.3002 & 5.8226 & TRN & \\
\hline CHEMBL1436695 & 688407 & 5.2 & 5.7551 & TRN & \\
\hline CHEMBL1495019 & 688407 & 5.8 & 5.4722 & TRN & \\
\hline CHEMBL1602281 & 688407 & 5.25 & 5.0839 & TRN & \\
\hline CHEMBL1343527 & 688407 & 4.9 & 5.3664 & TRN & \\
\hline CHEMBL1314777 & 688407 & 5.1 & 5.4861 & TRN & \\
\hline CHEMBL1374408 & 688407 & 4.5 & 5.2383 & TST & \\
\hline CHEMBL1402580 & 688407 & 4.5 & 5.1021 & TRN & \\
\hline CHEMBL1475141 & 688407 & 6.6 & 5.3216 & TST & \\
\hline CHEMBL1574935 & 688407 & 5.0 & 5.2414 & TRN & \\
\hline CHEMBL1534823 & 688407 & 5.8 & 5.4165 & TRN & \\
\hline CHEMBL1557524 & 688407 & 4.5 & 6.1723 & TST & \\
\hline CHEMBL1488285 & 688407 & 4.45 & 4.9711 & TRN & \\
\hline CHEMBL1413081 & 688407 & 4.9 & 4.9959 & TRN & \\
\hline CHEMBL1329479 & 688407 & 5.55 & 5.6394 & TRN & \\
\hline CHEMBL1516445 & 688407 & 7.8013 & 5.7407 & TRN & \\
\hline CHEMBL1435240 & 688407 & 4.6 & 6.4438 & TRN & \\
\hline CHEMBL1513958 & 688407 & 4.6 & 5.6205 & TRN & \\
\hline CHEMBL1376045 & 688407 & 6.1 & 5.9698 & TRN & \\
\hline CHEMBL1589866 & 688407 & 7.4001 & 6.4997 & TST & \\
\hline CHEMBL1448749 & 688407 & 6.0 & 5.3991 & TRN & \\
\hline CHEMBL1365865 & 688407 & 4.5 & 5.8961 & TRN & \\
\hline CHEMBL1316641 & 688407 & 6.95 & 6.1403 & TRN & \\
\hline CHEMBL1557635 & 688407 & 6.4 & 5.6229 & TRN & \\
\hline CHEMBL1445277 & 688407 & 9.699 & 5.75799 & 9999999999 & TRN \\
\hline CHEMBL1378444 & 688407 & 4.9 & 5.5063 & TRN & \\
\hline CHEMBL1554645 & 688407 & 6.7501 & 6.5189 & TRN & \\
\hline CHEMBL1358690 & 688407 & 6.8 & 4.6032 & TRN & \\
\hline CHEMBL1434046 & 688407 & 4.7 & 5.2914 & TRN & \\
\hline CHEMBL1591800 & 688407 & 5.8 & 6.1106 & TRN & \\
\hline CHEMBL1442768 & 688407 & 5.3 & 6.2294 & TRN & \\
\hline CHEMBL1455646 & 688407 & 4.7 & 5.065 & TRN & \\
\hline CHEMBL1593924 & 688407 & 5.0 & 5.8498 & TST & \\
\hline CHEMBL1592723 & 688407 & 5.0 & 4.9521 & TRN & \\
\hline CHEMBL1436221 & 688407 & 5.0 & 5.1066 & TRN & \\
\hline CHEMBL1514653 & 688407 & 5.3 & 5.7285 & TRN & \\
\hline CHEMBL1579548 & 688407 & 5.55 & 4.7683 & TST & \\
\hline CHEMBL1553297 & 688407 & 5.35 & 5.4108 & TRN & \\
\hline CHEMBL1403856 & 688407 & 4.5 & 5.6325 & TST & \\
\hline CHEMBL1473850 & 688407 & 4.45 & 5.0192 & TRN & \\
\hline CHEMBL1535347 & 688407 & 5.5 & 5.6741 & TRN & \\
\hline CHEMBL1570250 & 688407 & 5.1 & 5.4187 & TST & \\
\hline CHEMBL1553402 & 688407 & 8.301 & 5.601 & TRN & \\
\hline CHEMBL1554356 & 688407 & 7.6498 & 5.904 & TRN & \\
\hline
\end{tabular}




\begin{tabular}{|c|c|c|c|c|c|}
\hline \multicolumn{6}{|c|}{ Supplemental Table S2.txt } \\
\hline CHEMBL1317729 & 688407 & 6.05 & 6.0396 & TRN & \\
\hline CHEMBL1317744 & 688407 & 4.95 & 5.1557 & TRN & \\
\hline CHEMBL1513509 & 688407 & 6.1 & 6.6065 & TRN & \\
\hline CHEMBL1328462 & 688407 & 4.5 & 5.1321 & TRN & \\
\hline CHEMBL1437455 & 688407 & 4.75 & 5.4957 & TRN & \\
\hline CHEMBL1567541 & 688407 & 7.8013 & 6.1181 & TRN & \\
\hline CHEMBL1555145 & 688407 & 6.7001 & 6.5199 & TRN & \\
\hline CHEMBL1363326 & 688407 & 4.6 & 4.84 & TRN & \\
\hline CHEMBL1562144 & 688407 & 4.5 & 4.7431 & TST & \\
\hline CHEMBL1512613 & 688407 & 7.699 & 6.6131 & TRN & \\
\hline CHEMBL1368023 & 688407 & 4.45 & 4.9628 & TRN & \\
\hline CHEMBL1472823 & 688407 & 4.45 & 5.0051 & TRN & \\
\hline CHEMBL1417812 & 688407 & 4.9 & 4.7395 & TRN & \\
\hline CHEMBL1370516 & 688407 & 4.8 & 5.3378 & TRN & \\
\hline CHEMBL1320658 & 688407 & 6.7001 & 5.7356 & TRN & \\
\hline CHEMBL1524718 & 688407 & 5.9 & 6.191 & TST & \\
\hline CHEMBL1439551 & 688407 & 6.05 & 5.3627 & TRN & \\
\hline CHEMBL1394335 & 688407 & 8.3979 & 5.7672 & TRN & \\
\hline CHEMBL1484934 & 688407 & 5.5 & 5.0929 & TST & \\
\hline CHEMBL1080861 & 688407 & 4.45 & 4.9825 & TRN & \\
\hline CHEMBL1516337 & 688407 & 5.3 & 5.3836 & TST & \\
\hline CHEMBL1351997 & 688407 & 5.35 & 5.2286 & TST & \\
\hline CHEMBL1366140 & 688407 & 4.8 & 5.01699 & 99999999995 & TRN \\
\hline CHEMBL1481949 & 688407 & 4.5 & 4.901 & TRN & \\
\hline CHEMBL1600964 & 688407 & 4.9 & 5.1823 & TST & \\
\hline CHEMBL1317083 & 688407 & 4.8 & 5.1704 & TRN & \\
\hline CHEMBL1479885 & 688407 & 5.25 & 5.9216 & TRN & \\
\hline CHEMBL1567510 & 688407 & 4.65 & 5.0293 & TRN & \\
\hline CHEMBL1590158 & 688407 & 5.05 & 5.7736 & TST & \\
\hline CHEMBL1451402 & 688407 & 5.3 & 5.5736 & TRN & \\
\hline CHEMBL1328843 & 688407 & 5.0 & 6.3472 & TRN & \\
\hline CHEMBL1401593 & 688407 & 4.8 & 5.6838 & TRN & \\
\hline CHEMBL1316862 & 688407 & 7.3002 & 5.6575 & TRN & \\
\hline CHEMBL1563710 & 688407 & 4.7 & 5.4608 & TST & \\
\hline CHEMBL1356510 & 688407 & 8.301 & 6.782 & TRN & \\
\hline CHEMBL1558942 & 688407 & 4.85 & 5.0864 & TRN & \\
\hline CHEMBL1515205 & 688407 & 6.7001 & 5.9578 & TRN & \\
\hline CHEMBL1381063 & 688407 & 5.1 & 5.3276 & TRN & \\
\hline CHEMBL1372942 & 688407 & 5.2 & 5.2601 & TRN & \\
\hline CHEMBL1596999 & 688407 & 7.699 & 6.7092 & TST & \\
\hline CHEMBL1402861 & 688407 & 6.9 & 5.9365 & TRN & \\
\hline CHEMBL1609632 & 688407 & 5.15 & 5.1379 & TRN & \\
\hline CHEMBL1555279 & 688407 & 6.45 & 5.8395 & TRN & \\
\hline CHEMBL1314454 & 688407 & 5.8 & 5.7744 & TRN & \\
\hline CHEMBL1488691 & 688407 & 5.6 & 5.8038 & TRN & \\
\hline CHEMBL1401514 & 688407 & 4.5 & 5.3153 & TRN & \\
\hline CHEMBL1595672 & 688407 & 8.301 & 5.7161 & TST & \\
\hline CHEMBL1398284 & 688407 & 4.6 & 4.9868 & TRN & \\
\hline
\end{tabular}




\begin{tabular}{|c|c|c|c|c|c|}
\hline \multicolumn{6}{|c|}{ Supplemental Table S2.txt } \\
\hline CHEMBL1590061 & 688407 & 6.1 & 5.513 & TST & \\
\hline CHEMBL1362912 & 688407 & 4.45 & 5.604 & TRN & \\
\hline CHEMBL1318060 & 688407 & 6.0 & 6.0933 & TRN & \\
\hline CHEMBL1452329 & 688407 & 6.5 & 5.5072 & TRN & \\
\hline CHEMBL1475093 & 688407 & 4.5 & 5.2447 & TRN & \\
\hline CHEMBL1592288 & 688407 & 6.45 & 6.0247 & TRN & \\
\hline CHEMBL1410928 & 688407 & 4.75 & 5.4347 & TRN & \\
\hline CHEMBL1607810 & 688407 & 4.6 & 5.5834 & TRN & \\
\hline CHEMBL1611513 & 688407 & 4.5 & 4.6669 & TRN & \\
\hline CHEMBL1316137 & 688407 & 7.6003 & 5.7788 & TST & \\
\hline CHEMBL1551155 & 688407 & 4.65 & 4.7553 & TRN & \\
\hline CHEMBL1612206 & 688407 & 6.9 & 5.8566 & TRN & \\
\hline CHEMBL1367262 & 688407 & 4.45 & 5.3616 & TST & \\
\hline CHEMBL1371474 & 688407 & 4.45 & 4.9159 & TRN & \\
\hline CHEMBL1553845 & 688407 & 4.5 & 6.3586 & TRN & \\
\hline CHEMBL1591162 & 688407 & 8.4949 & 5.8231 & TRN & \\
\hline CHEMBL1315651 & 688407 & 7.5003 & 5.3427 & TRN & \\
\hline CHEMBL1592389 & 688407 & 6.8 & 6.17899 & 9999999999 & TRN \\
\hline CHEMBL1404758 & 688407 & 4.8 & 5.524 & TRN & \\
\hline CHEMBL1475908 & 688407 & 4.9 & 5.2408 & TRN & \\
\hline CHEMBL1515457 & 688407 & 5.3 & 5.9186 & TST & \\
\hline CHEMBL1357947 & 688407 & 4.8 & 4.7056 & TRN & \\
\hline CHEMBL1595911 & 688407 & 4.9 & 5.1315 & TRN & \\
\hline CHEMBL1553509 & 688407 & 6.1 & 5.3527 & TRN & \\
\hline CHEMBL1341375 & 688407 & 5.3 & 5.7614 & TST & \\
\hline CHEMBL1473134 & 688407 & 5.25 & 6.766 & TRN & \\
\hline CHEMBL1590533 & 688407 & 5.2 & 5.0387 & TRN & \\
\hline CHEMBL1568781 & 688407 & 4.8 & 5.7582 & TRN & \\
\hline CHEMBL1354565 & 688407 & 6.6 & 4.9197 & TRN & \\
\hline CHEMBL1591622 & 688407 & 4.8 & 4.881 & TRN & \\
\hline CHEMBL1574936 & 688407 & 4.85 & 5.0643 & TRN & \\
\hline CHEMBL1558486 & 688407 & 4.55 & 5.8109 & TRN & \\
\hline CHEMBL1433718 & 688407 & 4.5 & 5.20299 & 9999999999 & TRN \\
\hline CHEMBL1435455 & 688407 & 5.0 & 5.5041 & TRN & \\
\hline CHEMBL1523002 & 688407 & 4.65 & 5.4707 & TRN & \\
\hline CHEMBL1512984 & 688407 & 7.8013 & 5.7862 & TST & \\
\hline CHEMBL1365296 & 688407 & 4.85 & 5.4913 & TRN & \\
\hline CHEMBL1327328 & 688407 & 4.8 & 5.2427 & TRN & \\
\hline CHEMBL1567427 & 688407 & 7.8013 & 6.4765 & TST & \\
\hline CHEMBL3189553 & 688407 & 7.5498 & 5.7649 & TST & \\
\hline CHEMBL1493329 & 688407 & 7.8508 & 6.0774 & TST & \\
\hline CHEMBL3195488 & 688407 & 5.35 & 5.5984 & TST & \\
\hline CHEMBL1338357 & 688407 & 8.0 & 5.4317 & TRN & \\
\hline CHEMBL1435205 & 688407 & 8.2007 & 5.5099 & TST & \\
\hline CHEMBL1535510 & 688407 & 4.8 & 5.2376 & TST & \\
\hline CHEMBL1574251 & 688407 & 5.7 & 5.6179 & TRN & \\
\hline CHEMBL1481970 & 688407 & 7.1002 & 5.6215 & TRN & \\
\hline CHEMBL1487596 & 688407 & 8.1024 & 6.3352 & TST & \\
\hline
\end{tabular}




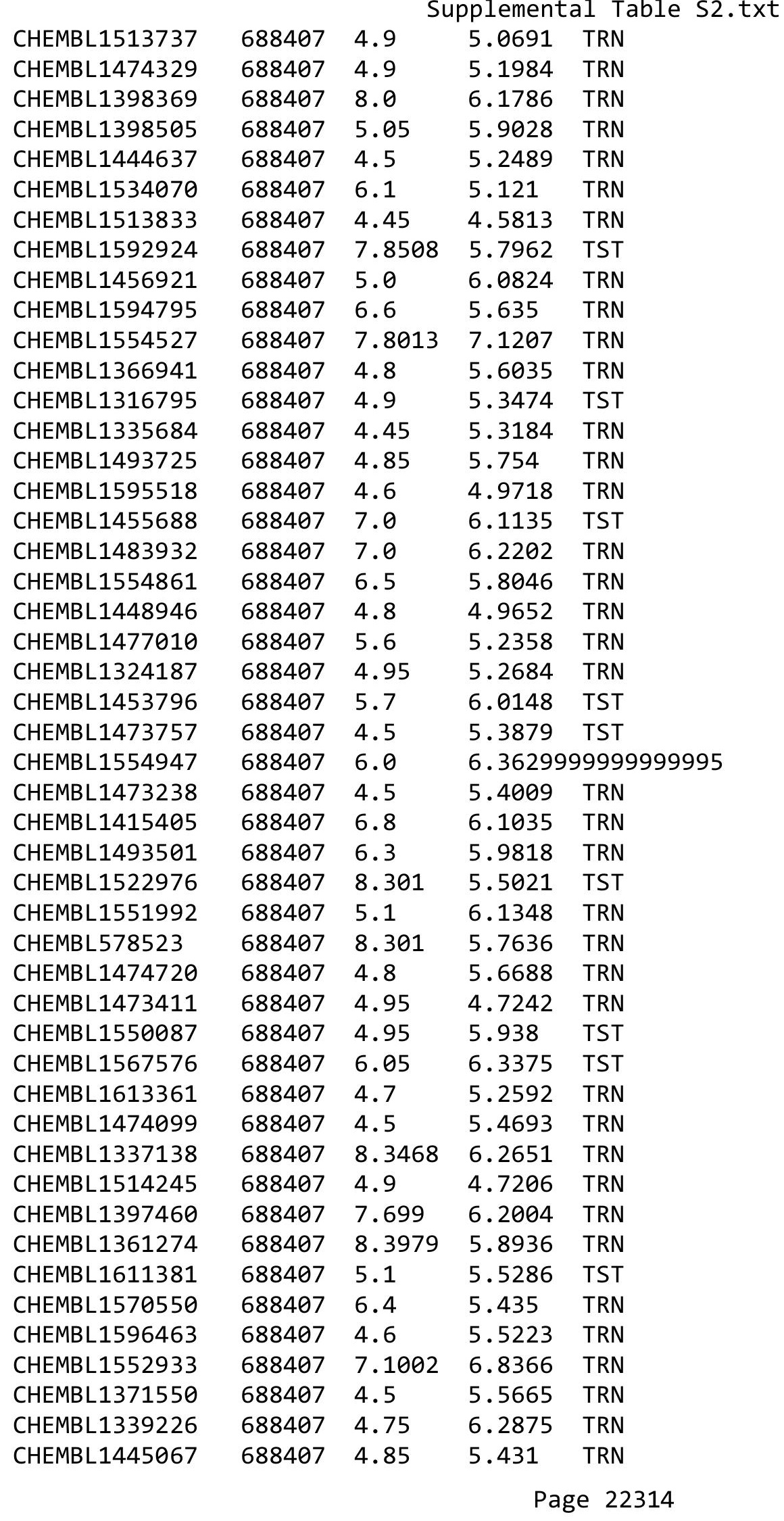




\begin{tabular}{|c|c|c|c|c|c|}
\hline \\
\hline CHEMBL1591942 & 688407 & 4.8 & 5.3525 & TST & \\
\hline CHEMBL1597750 & 688407 & 4.7 & 5.3213 & TRN & \\
\hline CHEMBL1552070 & 688407 & 6.8 & 5.8351 & TRN & \\
\hline CHEMBL1394578 & 688407 & 8.1024 & 5.8217 & TRN & \\
\hline CHEMBL1318694 & 688407 & 5.5 & 6.0365 & TRN & \\
\hline CHEMBL1478368 & 688407 & 4.45 & 5.5919 & TRN & \\
\hline CHEMBL1590971 & 688407 & 4.8 & 4.8372 & TRN & \\
\hline CHEMBL1476486 & 688407 & 6.1 & 5.9173 & TST & \\
\hline CHEMBL1404469 & 688407 & 5.7 & 4.8902 & TRN & \\
\hline CHEMBL1476629 & 688407 & 5.3 & 5.9821 & TRN & \\
\hline CHEMBL1315225 & 688407 & 4.8 & 5.7067 & TST & \\
\hline CHEMBL1511910 & 688407 & 4.9 & 5.6663 & TRN & \\
\hline CHEMBL1354910 & 688407 & 7.3002 & 5.6972 & TRN & \\
\hline CHEMBL1377437 & 688407 & 8.301 & 6.1102 & TST & \\
\hline CHEMBL1367357 & 688407 & 7.4001 & 6.3075 & TRN & \\
\hline CHEMBL1494907 & 688407 & 4.9 & 5.362 & TRN & \\
\hline CHEMBL1317694 & 688407 & 5.45 & $5.8020 e$ & 00000000005 & TST \\
\hline CHEMBL1593184 & 688407 & 5.1 & 5.6847 & TRN & \\
\hline CHEMBL1586641 & 688407 & 7.7496 & 5.0433 & TRN & \\
\hline CHEMBL1320320 & 688407 & 4.4 & 5.7218 & TST & \\
\hline CHEMBL1316846 & 688407 & 5.4 & 5.5852 & TST & \\
\hline CHEMBL1535880 & 688407 & 4.5 & 4.7896 & TRN & \\
\hline CHEMBL1368264 & 688407 & 4.5 & 6.0678 & TST & \\
\hline CHEMBL1358754 & 688407 & 4.5 & 5.1755 & TRN & \\
\hline CHEMBL1318442 & 688407 & 4.75 & 5.0918 & TRN & \\
\hline CHEMBL1317087 & 688407 & 6.2 & 5.7242 & TRN & \\
\hline CHEMBL1568361 & 688407 & 4.8 & 5.3523 & TRN & \\
\hline CHEMBL582715 & 688407 & 5.55 & 5.0782 & TRN & \\
\hline CHEMBL1593912 & 688407 & 4.7 & 5.7325 & TRN & \\
\hline CHEMBL1491058 & 688407 & 6.5 & 6.8108 & TRN & \\
\hline CHEMBL1493663 & 688407 & 4.9 & 5.0611 & TRN & \\
\hline CHEMBL1604007 & 688407 & 4.45 & 5.5925 & TST & \\
\hline CHEMBL1514209 & 688407 & 6.7501 & 5.891 & TRN & \\
\hline CHEMBL1365570 & 688407 & 5.2 & 4.7492 & TRN & \\
\hline CHEMBL1515917 & 688407 & 6.4 & 5.7806 & TRN & \\
\hline CHEMBL1442433 & 688407 & 8.301 & 5.5809 & TRN & \\
\hline CHEMBL1395587 & 688407 & 5.4 & 6.4133 & TRN & \\
\hline CHEMBL1472778 & 688407 & 4.9 & 6.0399 & TRN & \\
\hline CHEMBL1603459 & 688407 & 4.7 & 5.1334 & TRN & \\
\hline CHEMBL1397350 & 688407 & 5.3 & 5.9304 & TRN & \\
\hline CHEMBL1475635 & 688407 & 4.5 & 4.5316 & TRN & \\
\hline CHEMBL1607528 & 688407 & 8.301 & 5.1117 & TRN & \\
\hline CHEMBL1434727 & 688407 & 5.4 & 5.1711 & TRN & \\
\hline CHEMBL3208951 & 688407 & 5.4 & 5.9967 & TST & \\
\hline CHEMBL1409193 & 688407 & 8.3979 & 5.7942 & TRN & \\
\hline CHEMBL1441303 & 688407 & 7.0501 & 5.4393 & TST & \\
\hline CHEMBL1410278 & 688407 & 4.5 & 5.3456 & TRN & \\
\hline CHEMBL1595981 & 688407 & 4.5 & 5.5615 & TRN & \\
\hline & & & & 22315 & \\
\hline
\end{tabular}




\begin{tabular}{|c|c|c|c|c|c|}
\hline \multirow[b]{2}{*}{ CHEMBL1451091 } & \multicolumn{5}{|c|}{ Supplemental Table s2.txt } \\
\hline & 688407 & 4.95 & 5.8178 & TRN & \\
\hline CHEMBL1516504 & 688407 & 7.699 & 6.2675 & TRN & \\
\hline CHEMBL1416470 & 688407 & 4.5 & 5.0978 & TRN & \\
\hline CHEMBL1456501 & 688407 & 4.65 & 5.1903 & TST & \\
\hline CHEMBL1529502 & 688407 & 4.8 & 5.74700 & 0000000001 & TRN \\
\hline CHEMBL1564673 & 688407 & 4.9 & 5.749 & TRN & \\
\hline CHEMBL1355854 & 688407 & 4.5 & 4.4396 & TRN & \\
\hline CHEMBL1315706 & 688407 & 4.65 & 5.745 & TST & \\
\hline CHEMBL1412504 & 688407 & 5.4 & 5.4131 & TRN & \\
\hline CHEMBL1551440 & 688407 & 4.5 & 5.5826 & TRN & \\
\hline CHEMBL1395601 & 688407 & 6.95 & 5.9481 & TRN & \\
\hline CHEMBL587620 & 688407 & 4.9 & 5.069 & TRN & \\
\hline CHEMBL1354797 & 688407 & 6.2 & 6.0034 & TRN & \\
\hline CHEMBL1434090 & 688407 & 4.7 & 5.1999 & TRN & \\
\hline CHEMBL1390057 & 688407 & 8.4949 & 5.4346 & TST & \\
\hline CHEMBL1553366 & 688407 & 4.7 & 4.835 & TRN & \\
\hline CHEMBL1475994 & 688407 & 4.5 & 5.5544 & TRN & \\
\hline CHEMBL1609950 & 688407 & 4.5 & 6.6067 & TRN & \\
\hline CHEMBL1472916 & 688407 & 4.8 & 5.8502 & TRN & \\
\hline CHEMBL1417300 & 688407 & 4.95 & 5.2213 & TRN & \\
\hline CHEMBL1563410 & 688407 & 7.6003 & 6.8395 & TRN & \\
\hline CHEMBL1555741 & 688407 & 8.301 & 5.2662 & TRN & \\
\hline CHEMBL1357198 & 688407 & 6.9 & 5.6285 & TRN & \\
\hline CHEMBL1347923 & 688407 & 7.7496 & 5.8209 & TST & \\
\hline CHEMBL1436181 & 688407 & 4.75 & 4.7623 & TRN & \\
\hline CHEMBL1476103 & 688407 & 7.9508 & 6.0959 & TRN & \\
\hline CHEMBL1982304 & 688407 & 4.95 & 5.3398 & TST & \\
\hline CHEMBL1600414 & 688407 & 4.5 & 4.8202 & TST & \\
\hline CHEMBL1535513 & 688407 & 7.0 & 5.4418 & TST & \\
\hline CHEMBL1396413 & 688407 & 4.9 & 5.6608 & TRN & \\
\hline CHEMBL1358464 & 688407 & 6.35 & 5.9447 & TST & \\
\hline CHEMBL1373016 & 688407 & 5.3 & 5.4666 & TRN & \\
\hline CHEMBL1376571 & 688407 & 4.6 & 4.7067 & TRN & \\
\hline CHEMBL1395258 & 688407 & 5.5 & 6.3337 & TRN & \\
\hline CHEMBL1598734 & 688407 & 5.0 & 5.3529 & TRN & \\
\hline CHEMBL1508357 & 688407 & 5.15 & 5.9536 & TST & \\
\hline CHEMBL1473513 & 688407 & 5.4 & 5.3251 & TRN & \\
\hline CHEMBL1396034 & 688407 & 4.6 & 5.3002 & TRN & \\
\hline CHEMBL1551461 & 688407 & 6.5 & 5.9324 & TRN & \\
\hline CHEMBL1446354 & 688407 & 7.3002 & 5.6847 & TRN & \\
\hline CHEMBL1080147 & 688407 & 8.301 & 5.285 & TRN & \\
\hline CHEMBL1334378 & 688407 & 5.7 & 6.067 & TST & \\
\hline CHEMBL1594839 & 688407 & 8.1024 & 6.3795 & TRN & \\
\hline CHEMBL1371452 & 688407 & 5.5 & 5.1005 & TRN & \\
\hline CHEMBL1592942 & 688407 & 8.3468 & 4.9685 & TST & \\
\hline CHEMBL1569130 & 688407 & 4.8 & 5.0958 & TST & \\
\hline CHEMBL1556388 & 688407 & 8.301 & 5.5864 & TRN & \\
\hline CHEMBL1368581 & 688407 & 5.2 & 6.2107 & TRN & \\
\hline
\end{tabular}




\begin{tabular}{|c|c|c|c|c|c|}
\hline \\
\hline CHEMBL1401757 & 688407 & 4.5 & 5.4951 & TRN & \\
\hline CHEMBL1511624 & 688407 & 4.45 & 4.7489 & TRN & \\
\hline CHEMBL1438317 & 688407 & 4.8 & 6.0177 & TRN & \\
\hline CHEMBL1368959 & 688407 & 4.5 & 5.6333 & TRN & \\
\hline CHEMBL1976304 & 688407 & 4.45 & 5.9171 & TST & \\
\hline CHEMBL1360664 & 688407 & 5.9 & 5.6095 & TST & \\
\hline CHEMBL1481983 & 688407 & 7.0 & 5.9172 & TRN & \\
\hline CHEMBL1474258 & 688407 & 4.65 & 5.5295 & TST & \\
\hline CHEMBL1457513 & 688407 & 5.95 & 5.7108 & TST & \\
\hline CHEMBL1315684 & 688407 & 5.0 & 4.4022 & TRN & \\
\hline CHEMBL1354666 & 688407 & 5.9 & 5.3432 & TRN & \\
\hline CHEMBL1378663 & 688407 & 4.8 & 5.1457 & TRN & \\
\hline CHEMBL1356910 & 688407 & 4.5 & 5.1187 & TRN & \\
\hline CHEMBL1315622 & 688407 & 4.9 & 5.8262 & TRN & \\
\hline CHEMBL1322995 & 688407 & 4.8 & 4.6717 & TRN & \\
\hline CHEMBL1556802 & 688407 & 8.1024 & 5.3856 & TRN & \\
\hline CHEMBL1515382 & 688407 & 6.6499 & 5.3467 & TRN & \\
\hline CHEMBL1516413 & 688407 & 4.5 & 5.3728 & TRN & \\
\hline CHEMBL1405045 & 688407 & 6.8 & 5.9678 & TST & \\
\hline CHEMBL1490200 & 688407 & 4.45 & 5.2817 & TRN & \\
\hline CHEMBL1562509 & 688407 & 4.5 & 5.5901 & TRN & \\
\hline CHEMBL1574053 & 688407 & 4.9 & 5.4117 & TRN & \\
\hline CHEMBL1364854 & 688407 & 5.0 & 4.7739 & TRN & \\
\hline CHEMBL1611637 & 688407 & 4.5 & 5.6841 & TRN & \\
\hline CHEMBL1605999 & 688407 & 6.8499 & 6.3746 & TRN & \\
\hline CHEMBL1514485 & 688407 & 7.699 & 5.5632 & TRN & \\
\hline CHEMBL1586460 & 688407 & 4.95 & 5.144 & TRN & \\
\hline CHEMBL1355560 & 688407 & 5.0 & 5.45799 & 9999999999 & TRN \\
\hline CHEMBL1331692 & 688407 & 5.7 & 5.5892 & TST & \\
\hline CHEMBL1426980 & 688407 & 5.25 & 4.9823 & TST & \\
\hline CHEMBL1476207 & 688407 & 6.8 & 5.7789 & TRN & \\
\hline CHEMBL1474489 & 688407 & 5.0 & 4.6546 & TRN & \\
\hline CHEMBL1532354 & 688407 & 7.8996 & 5.7064 & TRN & \\
\hline CHEMBL1417864 & 688407 & 5.0 & 5.3198 & TRN & \\
\hline CHEMBL1591411 & 688407 & 6.9 & 5.9215 & TRN & \\
\hline CHEMBL1437598 & 688407 & 4.55 & 4.9577 & TRN & \\
\hline CHEMBL1475766 & 688407 & 4.5 & 5.2869 & TST & \\
\hline CHEMBL596836 & 688407 & 4.65 & 5.3604 & TST & \\
\hline CHEMBL1472917 & 688407 & 6.6499 & 5.7978 & TRN & \\
\hline CHEMBL1520868 & 688407 & 4.5 & 5.6785 & TRN & \\
\hline CHEMBL1443220 & 688407 & 8.301 & 6.4738 & TRN & \\
\hline CHEMBL1513722 & 688407 & 7.5003 & 6.249 & TRN & \\
\hline CHEMBL3192082 & 688407 & 4.8 & 5.7311 & TST & \\
\hline CHEMBL 261113 & 688407 & 5.2 & 5.5456 & TST & \\
\hline CHEMBL1404816 & 688407 & 5.5 & 5.0201 & TRN & \\
\hline CHEMBL1518363 & 688407 & 4.5 & 5.3324 & TRN & \\
\hline CHEMBL1590398 & 688407 & 4.8 & 5.4377 & TST & \\
\hline CHEMBL1415912 & 688407 & 5.5 & 6.2063 & TST & \\
\hline
\end{tabular}




\begin{tabular}{|c|c|c|c|c|c|}
\hline \\
\hline CHEMBL1559360 & 688407 & 5.5 & 5.409 & TRN & \\
\hline CHEMBL1475630 & 688407 & 5.0 & 5.5299 & TRN & \\
\hline CHEMBL1434946 & 688407 & 6.9 & 5.9346 & TRN & \\
\hline CHEMBL1448732 & 688407 & 4.85 & 5.1318 & TST & \\
\hline CHEMBL1447123 & 688407 & 5.4 & 5.1958 & TRN & \\
\hline CHEMBL1473738 & 688407 & 4.7 & 5.7752 & TST & \\
\hline CHEMBL1492068 & 688407 & 6.9 & 6.4038 & TRN & \\
\hline CHEMBL1544147 & 688407 & 4.95 & 5.8961 & TST & \\
\hline CHEMBL1437568 & 688407 & 6.2 & 5.7223 & TRN & \\
\hline CHEMBL1336512 & 688407 & 4.6 & 5.2864 & TRN & \\
\hline CHEMBL1444398 & 688407 & 4.5 & 5.4441 & TRN & \\
\hline CHEMBL1439041 & 688407 & 4.9 & 5.0606 & TRN & \\
\hline CHEMBL1483007 & 688407 & 4.6 & 5.3122 & TRN & \\
\hline CHEMBL1335303 & 688407 & 4.9 & 5.7678 & TRN & \\
\hline CHEMBL1355143 & 688407 & 4.9 & 5.79299 & 9999999999 & TRN \\
\hline CHEMBL1613206 & 688407 & 5.6 & 5.4524 & TST & \\
\hline CHEMBL1513516 & 688407 & 6.95 & 6.2791 & TRN & \\
\hline CHEMBL1360924 & 688407 & 8.4949 & 5.8819 & TST & \\
\hline CHEMBL1412891 & 688407 & 4.9 & 5.4081 & TRN & \\
\hline CHEMBL1455974 & 688407 & 8.4949 & 5.4078 & TRN & \\
\hline CHEMBL603130 & 688407 & 4.5 & 6.0091 & TST & \\
\hline CHEMBL1478264 & 688407 & 4.6 & 5.3579 & TRN & \\
\hline CHEMBL1442050 & 688407 & 4.7 & 4.8998 & TRN & \\
\hline CHEMBL1440763 & 688407 & 5.0 & 5.351 & TRN & \\
\hline CHEMBL1335051 & 688407 & 5.1 & 5.5906 & TRN & \\
\hline CHEMBL1512760 & 688407 & 4.5 & 5.1947 & TRN & \\
\hline CHEMBL1562374 & 688407 & 5.7 & 5.7437 & TRN & \\
\hline CHEMBL1370071 & 688407 & 5.9 & 5.2625 & TRN & \\
\hline CHEMBL1452896 & 688407 & 4.85 & 5.5553 & TRN & \\
\hline CHEMBL1567904 & 688407 & 5.0 & 5.01399 & 9999999999 & TRN \\
\hline CHEMBL1514377 & 688407 & 4.6 & 4.9406 & TRN & \\
\hline CHEMBL1355558 & 688407 & 4.5 & 5.3763 & TST & \\
\hline CHEMBL1524950 & 688407 & 4.95 & 5.2026 & TRN & \\
\hline CHEMBL1314894 & 688407 & 4.45 & 4.6179 & TRN & \\
\hline CHEMBL1368684 & 688407 & 5.9 & 4.9993 & TRN & \\
\hline CHEMBL1395004 & 688407 & 4.9 & 5.2814 & TRN & \\
\hline CHEMBL1554580 & 688407 & 5.0 & 4.728 & TST & \\
\hline CHEMBL1605762 & 688407 & 4.8 & 4.9909 & TRN & \\
\hline CHEMBL1354381 & 688407 & 5.0 & 5.8307 & TST & \\
\hline CHEMBL1356788 & 688407 & 4.6 & 4.9703 & TRN & \\
\hline CHEMBL1552919 & 688407 & 5.35 & 5.8234 & TST & \\
\hline CHEMBL1472799 & 688407 & 5.7 & 5.5137 & TRN & \\
\hline CHEMBL1554794 & 688407 & 5.0 & 4.9715 & TRN & \\
\hline CHEMBL1553251 & 688407 & 4.6 & 5.1168 & TRN & \\
\hline CHEMBL1534845 & 688407 & 4.5 & 4.9473 & TRN & \\
\hline CHEMBL1397930 & 688407 & 4.6 & 5.1947 & TRN & \\
\hline CHEMBL1552006 & 688407 & 8.301 & 5.5772 & TRN & \\
\hline CHEMBL1367972 & 688407 & 6.8 & 5.7013 & TST & \\
\hline
\end{tabular}




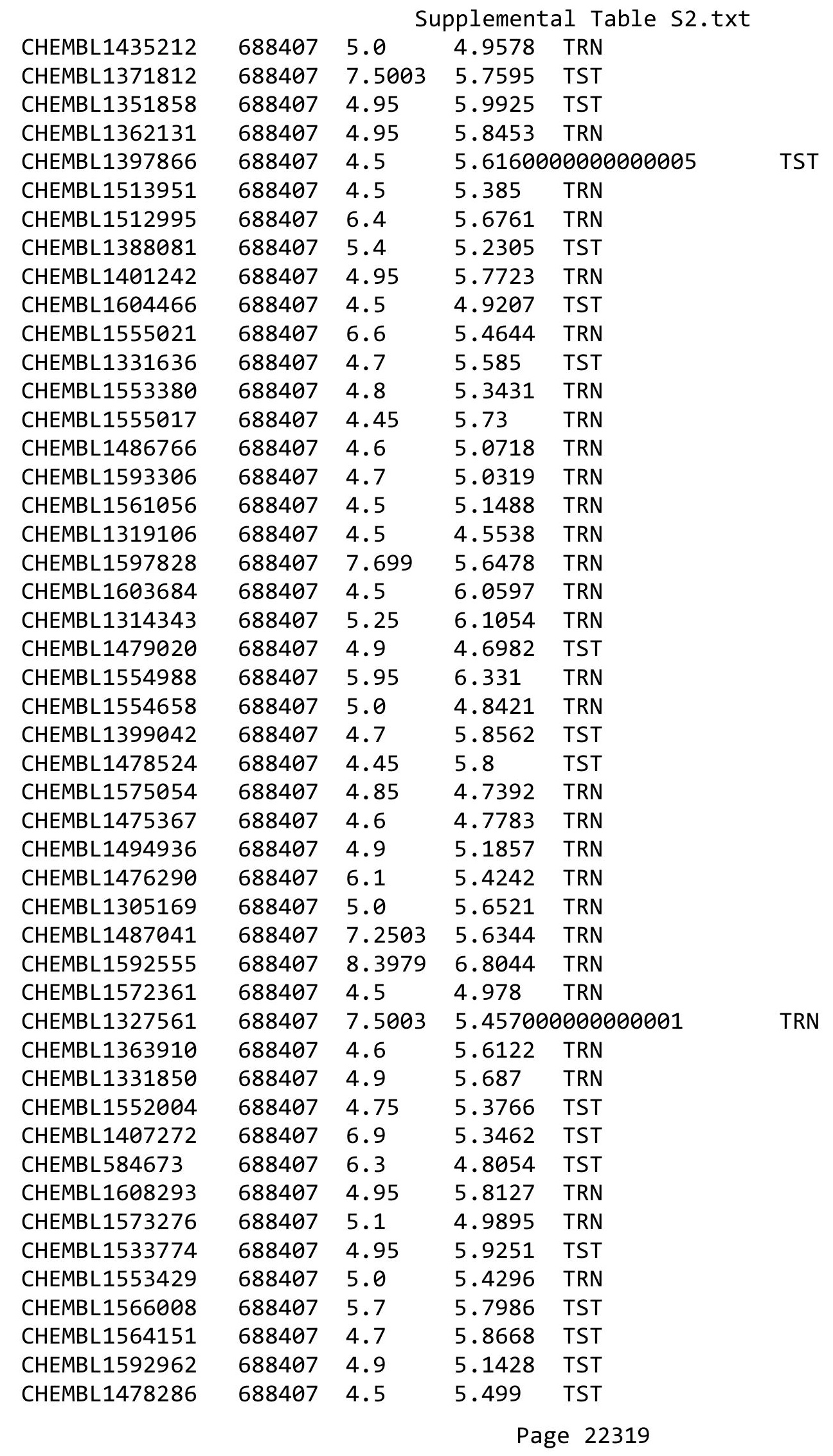




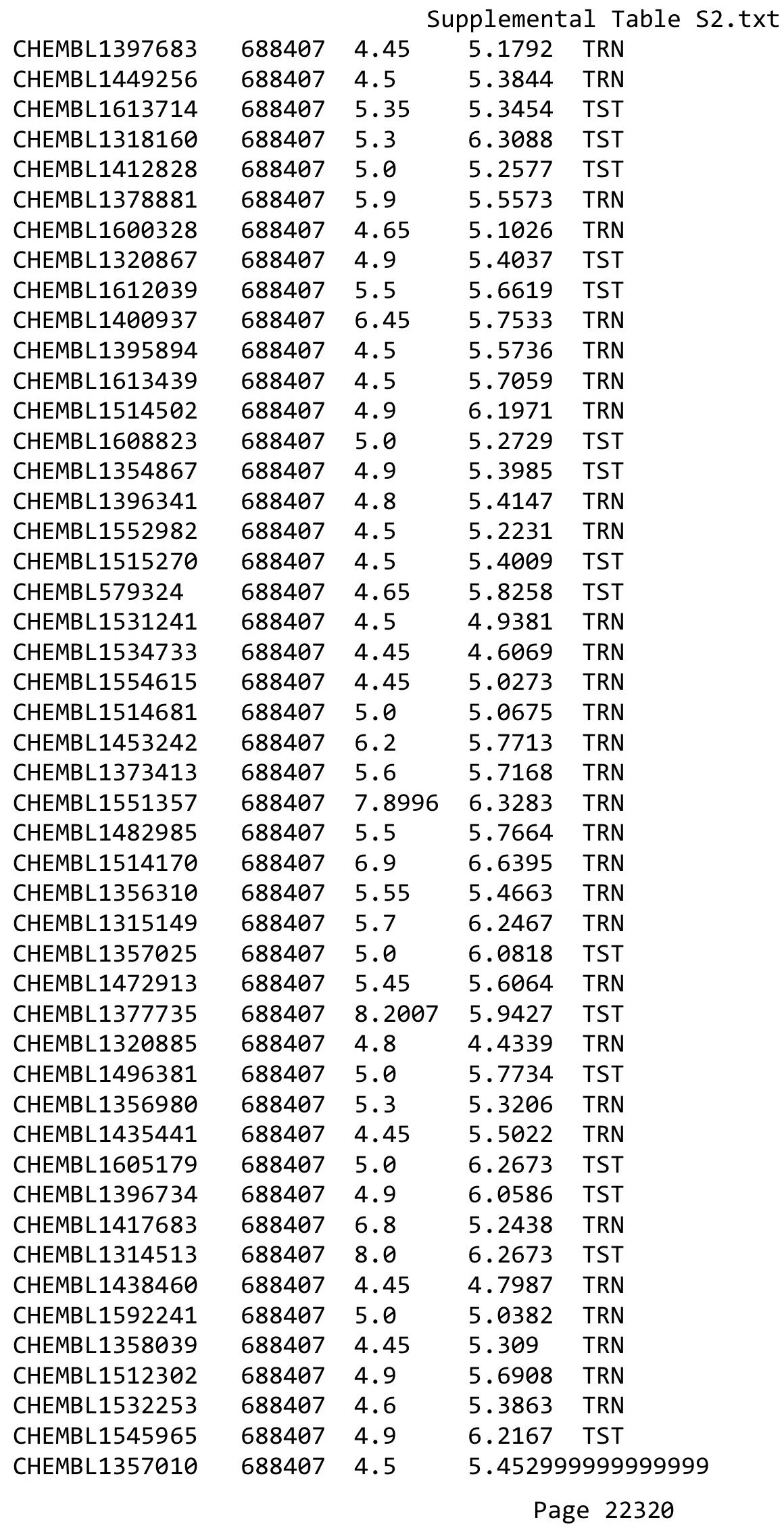

TRN 


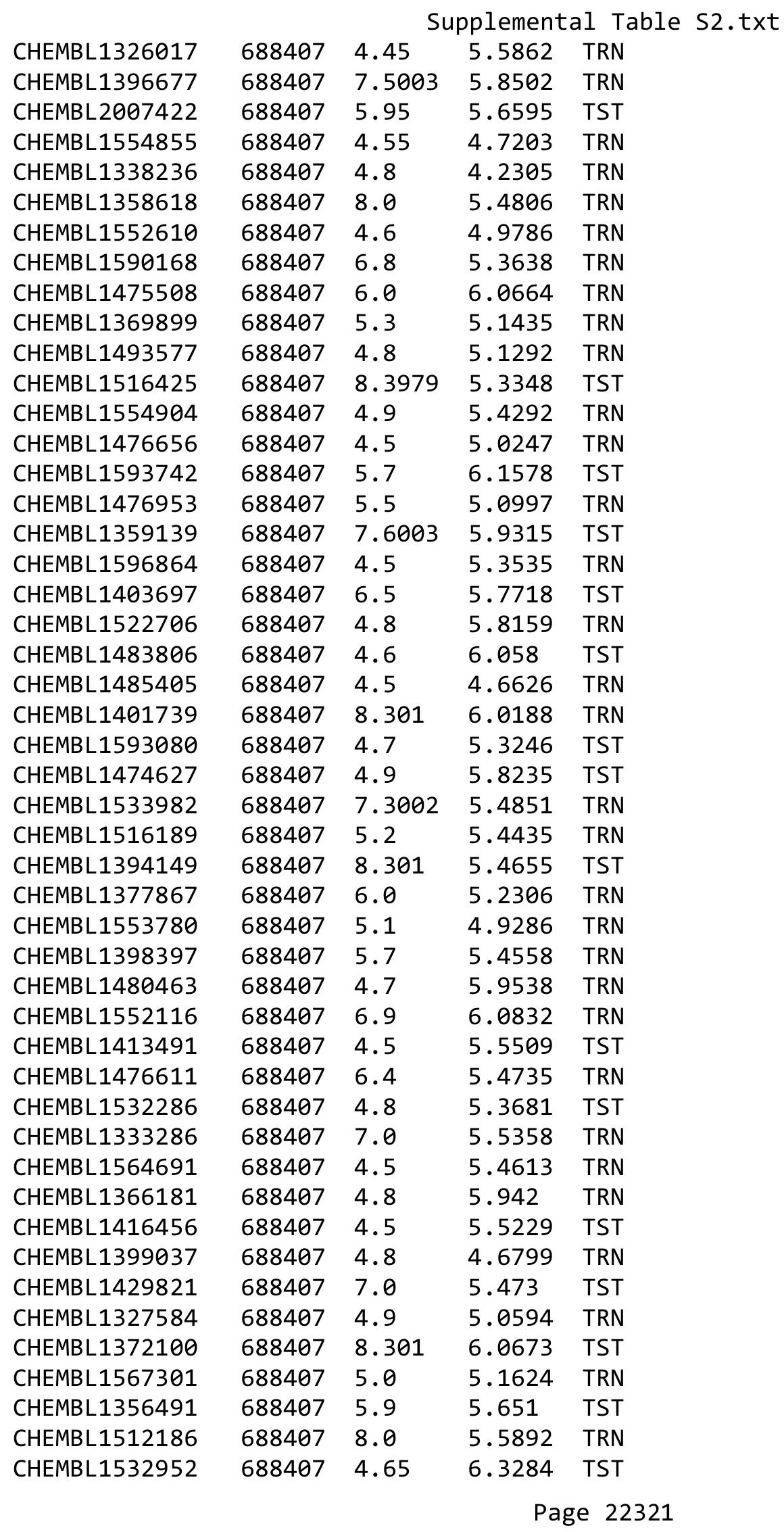




\begin{tabular}{|c|c|c|c|c|}
\hline \multicolumn{5}{|c|}{ Supplemental Table S2.txt } \\
\hline CHEMBL1575036 & 688407 & 4.85 & 5.1796 & TRN \\
\hline CHEMBL1362915 & 688407 & 4.9 & 4.8406 & TRN \\
\hline CHEMBL1318869 & 688407 & 4.6 & 5.4533 & TST \\
\hline CHEMBL1495296 & 688407 & 6.5 & 4.6696 & TRN \\
\hline CHEMBL1355474 & 688407 & 4.45 & 5.008 & TST \\
\hline CHEMBL1437245 & 688407 & 4.5 & 4.6366 & TRN \\
\hline CHEMBL1513221 & 688407 & 4.45 & 5.2519 & TRN \\
\hline CHEMBL1516492 & 688407 & 5.65 & 5.3976 & TRN \\
\hline CHEMBL1316707 & 688407 & 4.7 & 4.7693 & TRN \\
\hline CHEMBL1595736 & 688407 & 5.3 & 5.5972 & TRN \\
\hline CHEMBL1356180 & 688407 & 4.85 & 5.1441 & TRN \\
\hline CHEMBL1435211 & 688407 & 7.699 & 5.8957 & TRN \\
\hline CHEMBL1444885 & 688407 & 5.1 & 5.1476 & TST \\
\hline CHEMBL1569086 & 688407 & 4.5 & 5.6027 & TST \\
\hline CHEMBL1554534 & 688407 & 6.4 & 5.4783 & TRN \\
\hline CHEMBL1558740 & 688407 & 8.301 & 5.4047 & TRN \\
\hline CHEMBL1357587 & 688407 & 4.5 & 5.2178 & TRN \\
\hline CHEMBL1524221 & 688407 & 5.5 & 5.3539 & TRN \\
\hline CHEMBL1365615 & 688407 & 5.1 & 5.9714 & TST \\
\hline CHEMBL1552996 & 688407 & 6.4 & 6.5637 & TRN \\
\hline CHEMBL1560357 & 688407 & 4.45 & 5.2361 & TRN \\
\hline CHEMBL1448008 & 688407 & 4.65 & 5.6957 & TST \\
\hline CHEMBL1350671 & 688407 & 6.45 & 5.7267 & TST \\
\hline CHEMBL1609294 & 688407 & 4.8 & 5.8164 & TRN \\
\hline CHEMBL1314707 & 688407 & 4.5 & 5.4812 & TRN \\
\hline CHEMBL1473571 & 688407 & 6.8499 & 5.9926 & TST \\
\hline CHEMBL1355268 & 688407 & 4.9 & 5.7865 & TRN \\
\hline CHEMBL1608970 & 688407 & 4.5 & $5.7520 e$ & 0000000001 \\
\hline CHEMBL1556012 & 688407 & 5.8 & 5.9967 & TST \\
\hline CHEMBL1394301 & 688407 & 7.4001 & 6.4948 & TRN \\
\hline CHEMBL1473244 & 688407 & 5.7 & 5.3951 & TST \\
\hline CHEMBL1455411 & 688407 & 5.4 & 4.4893 & TRN \\
\hline CHEMBL1473103 & 688407 & 8.0 & 5.8299 & TRN \\
\hline CHEMBL1515160 & 688407 & 4.7 & 4.5857 & TRN \\
\hline CHEMBL1367341 & 688407 & 4.95 & 4.4484 & TRN \\
\hline CHEMBL1455630 & 688407 & 4.9 & 5.1057 & TRN \\
\hline CHEMBL1362919 & 688407 & 5.0 & 5.4211 & TRN \\
\hline CHEMBL1362424 & 688407 & 6.9 & 6.7769 & TRN \\
\hline CHEMBL1456565 & 688407 & 5.5 & 5.3559 & TRN \\
\hline CHEMBL1475170 & 688407 & 7.3002 & 5.2081 & TRN \\
\hline CHEMBL1436597 & 688407 & 6.6 & 6.4157 & TRN \\
\hline CHEMBL1364898 & 688407 & 4.7 & 5.4111 & TRN \\
\hline CHEMBL1473561 & 688407 & 8.0506 & 5.2671 & TRN \\
\hline CHEMBL1551221 & 688407 & 4.5 & 5.4158 & TRN \\
\hline CHEMBL1590044 & 688407 & 6.4 & 6.0239 & TRN \\
\hline CHEMBL1436424 & 688407 & 4.5 & 5.3389 & TRN \\
\hline CHEMBL1372940 & 688407 & 6.8 & 5.7233 & TRN \\
\hline CHEMBL1316175 & 688407 & 4.8 & 5.5647 & TRN \\
\hline
\end{tabular}




\begin{tabular}{|c|c|c|c|c|c|}
\hline \multicolumn{6}{|c|}{ Supplemental Table S2.txt } \\
\hline CHEMBL1520123 & 688407 & 8.0 & 5.5781 & TRN & \\
\hline CHEMBL1516098 & 688407 & 4.7 & 5.308 & TRN & \\
\hline CHEMBL1593840 & 688407 & 7.8013 & 6.4831 & TRN & \\
\hline CHEMBL1591706 & 688407 & 5.1 & 5.6357 & TRN & \\
\hline CHEMBL1450240 & 688407 & 4.5 & 5.45200 & 0000000001 & TRN \\
\hline CHEMBL1561120 & 688407 & 7.1002 & 6.1081 & TRN & \\
\hline CHEMBL1474810 & 688407 & 4.9 & 5.1289 & TRN & \\
\hline CHEMBL1374953 & 688407 & 4.9 & 5.1362 & TRN & \\
\hline CHEMBL1434742 & 688407 & 6.5 & 6.1183 & TST & \\
\hline CHEMBL1593679 & 688407 & 8.0 & 5.1519 & TRN & \\
\hline CHEMBL1522810 & 688407 & 4.5 & 5.1225 & TRN & \\
\hline CHEMBL1358554 & 688407 & 4.9 & 5.3905 & TRN & \\
\hline CHEMBL1513122 & 688407 & 4.65 & 5.33799 & 9999999999 & TRN \\
\hline CHEMBL1593529 & 688407 & 4.6 & 5.7094 & TRN & \\
\hline CHEMBL1358440 & 688407 & 8.301 & 6.1148 & TRN & \\
\hline CHEMBL1474383 & 688407 & 5.0 & 4.7503 & TST & \\
\hline CHEMBL1533049 & 688407 & 7.6003 & 5.5461 & TRN & \\
\hline CHEMBL1475511 & 688407 & 7.8013 & 6.2314 & TRN & \\
\hline CHEMBL1437252 & 688407 & 5.4 & 5.69600 & 0000000001 & TRN \\
\hline CHEMBL1604447 & 688407 & 4.65 & 4.7097 & TRN & \\
\hline CHEMBL1329694 & 688407 & 8.301 & 5.8601 & TRN & \\
\hline CHEMBL1405534 & 688407 & 6.45 & 6.2525 & TRN & \\
\hline CHEMBL1484541 & 688407 & 4.5 & 6.0082 & TRN & \\
\hline CHEMBL1360109 & 688407 & 4.85 & 4.9997 & TRN & \\
\hline CHEMBL1358314 & 688407 & 4.9 & 5.7474 & TRN & \\
\hline CHEMBL1554432 & 688407 & 6.0 & 6.0464 & TRN & \\
\hline CHEMBL1334161 & 688407 & 5.8 & 5.2537 & TRN & \\
\hline CHEMBL1398684 & 688407 & 4.5 & 5.4861 & TRN & \\
\hline CHEMBL1523634 & 688407 & 4.5 & 6.0489 & TRN & \\
\hline CHEMBL1474298 & 688407 & 5.3 & 5.1177 & TRN & \\
\hline CHEMBL1519969 & 688407 & 6.1 & 7.0753 & TRN & \\
\hline CHEMBL1477012 & 688407 & 7.0 & 6.1309 & TRN & \\
\hline CHEMBL1554727 & 688407 & 5.0 & 5.8784 & TRN & \\
\hline CHEMBL1396692 & 688407 & 7.5003 & 5.7594 & TST & \\
\hline CHEMBL1317655 & 688407 & 5.3 & 5.4203 & TRN & \\
\hline CHEMBL1555344 & 688407 & 4.9 & 5.3686 & TRN & \\
\hline CHEMBL1473749 & 688407 & 5.8 & 5.1702 & TRN & \\
\hline CHEMBL1514379 & 688407 & 4.9 & 5.1211 & TRN & \\
\hline CHEMBL1435001 & 688407 & 5.2 & 5.5361 & TRN & \\
\hline CHEMBL1551080 & 688407 & 4.9 & 4.8703 & TST & \\
\hline CHEMBL1434596 & 688407 & 4.8 & 5.4655 & TRN & \\
\hline CHEMBL1438782 & 688407 & 5.2 & 5.1688 & TRN & \\
\hline CHEMBL1486179 & 688407 & 4.8 & 6.1661 & TRN & \\
\hline CHEMBL1550971 & 688407 & 8.301 & 6.8559 & TRN & \\
\hline CHEMBL1314733 & 688407 & 8.301 & 6.7489 & TST & \\
\hline CHEMBL1553827 & 688407 & 6.5 & 7.5154 & TRN & \\
\hline CHEMBL1354545 & 688407 & 4.5 & 5.3909 & TRN & \\
\hline CHEMBL1495640 & 688407 & 6.8 & 5.4516 & TRN & \\
\hline
\end{tabular}




\begin{tabular}{|c|c|c|c|c|c|}
\hline \multicolumn{6}{|c|}{ oplemental labıe s2 } \\
\hline CHEMBL1520944 & 688407 & 5.2 & 5.6812 & TST & \\
\hline CHEMBL1398217 & 688407 & 4.65 & 5.5248 & TRN & \\
\hline CHEMBL1553504 & 688407 & 8.3979 & 4.8737 & TRN & \\
\hline CHEMBL1540377 & 688407 & 4.45 & 6.3535 & TST & \\
\hline CHEMBL1371865 & 688407 & 5.5 & 5.267 & TST & \\
\hline CHEMBL1591078 & 688407 & 4.8 & 5.5961 & TST & \\
\hline CHEMBL1474898 & 688407 & 4.5 & 5.3422 & TRN & \\
\hline CHEMBL1433697 & 688407 & 5.9 & 5.7023 & TRN & \\
\hline CHEMBL1494122 & 688407 & 6.8 & 6.3924 & TRN & \\
\hline CHEMBL1531991 & 688407 & 4.9 & 5.2758 & TRN & \\
\hline CHEMBL592123 & 688407 & 6.5 & 4.9814 & TST & \\
\hline CHEMBL1591545 & 688407 & 4.6 & 4.6993 & TRN & \\
\hline CHEMBL1605182 & 688407 & 4.8 & 4.7833 & TRN & \\
\hline CHEMBL1436055 & 688407 & 5.6 & 5.9285 & TRN & \\
\hline CHEMBL1495585 & 688407 & 5.3 & 5.4143 & TRN & \\
\hline CHEMBL1514596 & 688407 & 4.85 & 5.3547 & TST & \\
\hline CHEMBL1600515 & 688407 & 5.0 & 5.3304 & TRN & \\
\hline CHEMBL1397186 & 688407 & 4.9 & 4.6567 & TRN & \\
\hline CHEMBL1610097 & 688407 & 4.9 & 4.7446 & TRN & \\
\hline CHEMBL1594006 & 688407 & 4.5 & 4.974 & TRN & \\
\hline CHEMBL1592806 & 688407 & 4.6 & 5.1073 & TRN & \\
\hline CHEMBL1366485 & 688407 & 4.9 & 5.3615 & TRN & \\
\hline CHEMBL1315367 & 688407 & 6.15 & 5.8342 & TST & \\
\hline CHEMBL1333724 & 688407 & 4.45 & 5.8093 & TST & \\
\hline CHEMBL597874 & 688407 & 5.1 & 5.4112 & TRN & \\
\hline CHEMBL1473567 & 688407 & 8.301 & 5.1615 & TST & \\
\hline CHEMBL1592618 & 688407 & 6.2 & 6.0759 & TRN & \\
\hline CHEMBL1437652 & 688407 & 5.6 & 5.9592 & TRN & \\
\hline CHEMBL1503989 & 688407 & 8.2518 & 6.1618 & TST & \\
\hline CHEMBL1516021 & 688407 & 5.2 & 5.9752 & TST & \\
\hline CHEMBL1324818 & 688407 & 5.45 & 5.4989 & TRN & \\
\hline CHEMBL1474488 & 688407 & 5.5 & 6.46299 & 9999999999 & TRN \\
\hline CHEMBL1355803 & 688407 & 4.8 & 5.7262 & TST & \\
\hline CHEMBL1569319 & 688407 & 6.9 & 6.0218 & TRN & \\
\hline CHEMBL1590608 & 688407 & 6.05 & 6.4306 & TRN & \\
\hline CHEMBL1610698 & 688407 & 5.95 & 5.46399 & 99999999995 & TRN \\
\hline CHEMBL1594088 & 688407 & 4.45 & 5.0916 & TRN & \\
\hline CHEMBL3207690 & 688407 & 6.8499 & 6.436 & TST & \\
\hline CHEMBL1493192 & 688407 & 6.0 & 5.7925 & TRN & \\
\hline CHEMBL1397439 & 688407 & 4.8 & 5.4123 & TRN & \\
\hline CHEMBL1356290 & 688407 & 4.8 & 5.6023 & TST & \\
\hline CHEMBL1324329 & 688407 & 4.9 & 4.4699 & TST & \\
\hline CHEMBL1480801 & 688407 & 4.45 & 5.5566 & TRN & \\
\hline CHEMBL1403072 & 688407 & 4.5 & 5.5829 & TST & \\
\hline CHEMBL1335581 & 688407 & 5.0 & 5.3712 & TST & \\
\hline CHEMBL1447096 & 688407 & 8.4559 & 5.34399 & 9999999999 & TST \\
\hline CHEMBL1381270 & 688407 & 4.9 & 5.2521 & TRN & \\
\hline CHEMBL1344800 & 688407 & 4.65 & 4.9427 & TST & \\
\hline
\end{tabular}




\begin{tabular}{|c|c|c|c|c|c|}
\hline \multicolumn{6}{|c|}{ Supplemental Table S2.txt } \\
\hline CHEMBL1436058 & 688407 & 6.1 & 6.0567 & TRN & \\
\hline CHEMBL1372473 & 688407 & 4.5 & 4.7954 & TRN & \\
\hline CHEMBL1512441 & 688407 & 6.2 & 5.3608 & TRN & \\
\hline CHEMBL1512970 & 688407 & 4.5 & 5.5549 & TRN & \\
\hline CHEMBL1552582 & 688407 & 4.55 & 5.24799 & 9999999999 & TST \\
\hline CHEMBL1317152 & 688407 & 6.2 & 5.78100 & 0000000001 & TRN \\
\hline CHEMBL1400340 & 688407 & 8.1024 & 5.9856 & TST & \\
\hline CHEMBL1441164 & 688407 & 4.0 & 5.9811 & TST & \\
\hline CHEMBL1370762 & 688407 & 7.5003 & 5.6724 & TRN & \\
\hline CHEMBL1590285 & 688407 & 4.9 & 4.9956 & TST & \\
\hline CHEMBL1445297 & 688407 & 6.2 & 5.4188 & TRN & \\
\hline CHEMBL1558691 & 688407 & 5.3 & 5.5543 & TRN & \\
\hline CHEMBL1358212 & 688407 & 4.45 & 4.4803 & TRN & \\
\hline CHEMBL1397689 & 688407 & 6.5 & 6.1216 & TRN & \\
\hline CHEMBL1434185 & 688407 & 4.8 & 4.6757 & TRN & \\
\hline CHEMBL1521354 & 688407 & 4.5 & 5.2746 & TST & \\
\hline CHEMBL1414292 & 688407 & 4.7 & 6.3467 & TRN & \\
\hline CHEMBL1592734 & 688407 & 7.5003 & 6.0757 & TRN & \\
\hline CHEMBL1453741 & 688407 & 5.0 & 5.6091 & TRN & \\
\hline CHEMBL1553696 & 688407 & 5.3 & 5.186 & TRN & \\
\hline CHEMBL1515357 & 688407 & 4.95 & 5.3747 & TRN & \\
\hline CHEMBL1512687 & 688407 & 4.9 & 4.5241 & TRN & \\
\hline CHEMBL1360640 & 688407 & 6.2 & 5.8905 & TRN & \\
\hline CHEMBL1318955 & 688407 & 5.95 & 5.6361 & TST & \\
\hline CHEMBL1702181 & 688407 & 4.7 & 5.6807 & TRN & \\
\hline CHEMBL1396485 & 688407 & 5.3 & 5.4089 & TRN & \\
\hline CHEMBL1438973 & 688407 & 5.2 & 5.5623 & TST & \\
\hline CHEMBL1474385 & 688407 & 8.1024 & 6.0402 & TRN & \\
\hline CHEMBL1434024 & 688407 & 8.2007 & 5.9628 & TST & \\
\hline CHEMBL1552491 & 688407 & 7.0 & 6.1813 & TST & \\
\hline CHEMBL1473394 & 688407 & 5.6 & 4.5182 & TRN & \\
\hline CHEMBL1574506 & 688407 & 4.9 & 5.4902 & TRN & \\
\hline CHEMBL1554868 & 688407 & 4.9 & 6.2388 & TRN & \\
\hline CHEMBL1514193 & 688407 & 5.0 & 5.4909 & TRN & \\
\hline CHEMBL1592108 & 688407 & 7.6003 & 5.3904 & TST & \\
\hline CHEMBL1474641 & 688407 & 5.0 & 5.7915 & TRN & \\
\hline CHEMBL1524774 & 688407 & 4.45 & 5.1644 & TRN & \\
\hline CHEMBL1553892 & 688407 & 6.8 & 5.1308 & TRN & \\
\hline CHEMBL239009 & 688407 & 4.8 & 5.2475 & TRN & \\
\hline CHEMBL1436178 & 688407 & 4.9 & 4.6545 & TST & \\
\hline CHEMBL1518744 & 688407 & 6.3 & 5.3967 & TRN & \\
\hline CHEMBL1572333 & 688407 & 5.1 & 4.798 & TRN & \\
\hline CHEMBL1418048 & 688407 & 4.95 & 6.2539 & TRN & \\
\hline CHEMBL1387290 & 688407 & 4.8 & 4.8567 & TRN & \\
\hline CHEMBL1437666 & 688407 & 4.75 & 5.3209 & TST & \\
\hline CHEMBL1534295 & 688407 & 4.5 & 5.0882 & TST & \\
\hline CHEMBL1316935 & 688407 & 7.699 & 5.8103 & TRN & \\
\hline CHEMBL1521540 & 688407 & 5.0 & 5.6656 & TRN & \\
\hline
\end{tabular}




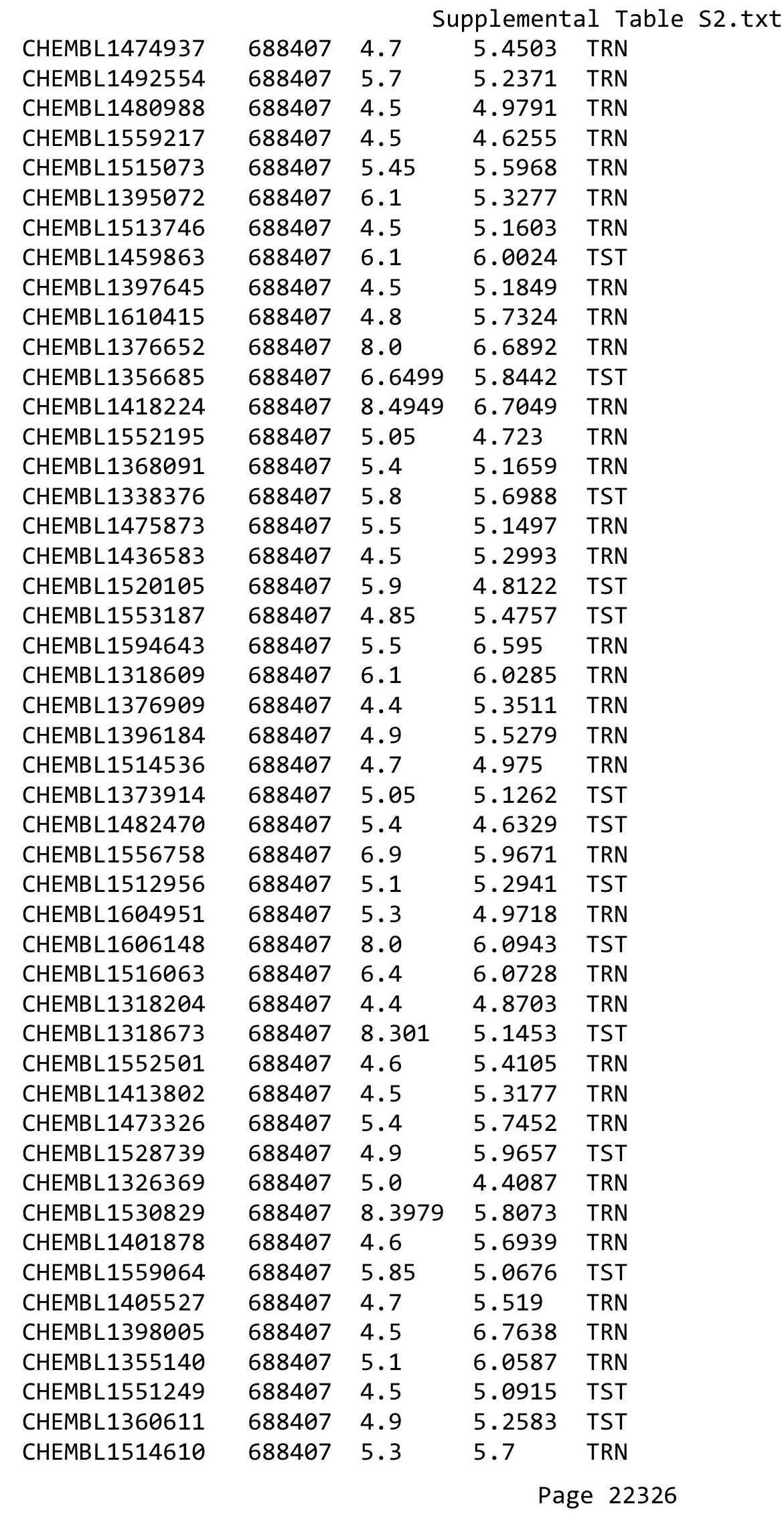




\begin{tabular}{|c|c|c|c|c|c|}
\hline \multicolumn{6}{|c|}{ Supplemental Table S2.txt } \\
\hline CHEMBL1566891 & 688407 & 5.1 & 5.2615 & TRN & \\
\hline CHEMBL1398024 & 688407 & 4.7 & 5.4885 & TRN & \\
\hline CHEMBL1401857 & 688407 & 5.0 & 5.7708 & TRN & \\
\hline CHEMBL1517789 & 688407 & 4.5 & 5.3615 & TRN & \\
\hline CHEMBL1362361 & 688407 & 7.4001 & 5.7276 & TST & \\
\hline CHEMBL1362179 & 688407 & 6.1 & 5.7784 & TRN & \\
\hline CHEMBL1395781 & 688407 & 4.75 & 4.9637 & TST & \\
\hline CHEMBL1612308 & 688407 & 7.8996 & 4.8061 & TRN & \\
\hline CHEMBL1400405 & 688407 & 4.5 & 5.3993 & TRN & \\
\hline CHEMBL1437358 & 688407 & 4.7 & 4.9838 & TRN & \\
\hline CHEMBL1449808 & 688407 & 6.2 & 5.6194 & TST & \\
\hline CHEMBL1435793 & 688407 & 8.301 & 5.6614 & TRN & \\
\hline CHEMBL1592002 & 688407 & 4.7 & 6.4557 & TRN & \\
\hline CHEMBL1593187 & 688407 & 4.5 & 5.8097 & TRN & \\
\hline CHEMBL1354701 & 688407 & 4.5 & 4.2538 & TRN & \\
\hline CHEMBL1316206 & 688407 & 4.7 & 5.4686 & TRN & \\
\hline CHEMBL1519399 & 688407 & 6.9 & 5.9568 & TRN & \\
\hline CHEMBL1318501 & 688407 & 6.5 & 5.8069 & TRN & \\
\hline CHEMBL1489948 & 688407 & 5.0 & 4.8336 & TRN & \\
\hline CHEMBL1567300 & 688407 & 4.5 & 5.4887 & TST & \\
\hline CHEMBL1517058 & 688407 & 4.5 & 5.9119 & TRN & \\
\hline CHEMBL1513918 & 688407 & 5.55 & 5.1621 & TRN & \\
\hline CHEMBL1451416 & 688407 & 4.9 & 5.0245 & TRN & \\
\hline CHEMBL1435593 & 688407 & 5.0 & 4.9178 & TRN & \\
\hline CHEMBL1484871 & 688407 & 7.699 & 6.318 & TRN & \\
\hline CHEMBL1398141 & 688407 & 5.1 & 5.7559 & TRN & \\
\hline CHEMBL1573580 & 688407 & 6.6499 & 5.6814 & TRN & \\
\hline CHEMBL1593186 & 688407 & 6.9 & 5.4037 & TRN & \\
\hline CHEMBL1317355 & 688407 & 7.0 & 5.5916 & TST & \\
\hline CHEMBL1366712 & 688407 & 5.4 & 5.0016 & TRN & \\
\hline CHEMBL1356026 & 688407 & 6.6499 & 6.2631 & TRN & \\
\hline CHEMBL1599618 & 688407 & 6.8499 & 5.5706 & TRN & \\
\hline CHEMBL1467405 & 688407 & 5.4 & 5.7916 & TST & \\
\hline CHEMBL1524459 & 688407 & 6.7001 & 6.3788 & TRN & \\
\hline CHEMBL1518762 & 688407 & 7.4001 & 6.1161 & TRN & \\
\hline CHEMBL1372857 & 688407 & 5.0 & 5.6573 & TRN & \\
\hline CHEMBL1503238 & 688407 & 4.75 & 5.7581 & TST & \\
\hline CHEMBL1316191 & 688407 & 4.45 & $4.8180 e$ & 00000000005 & TRN \\
\hline CHEMBL1553213 & 688407 & 7.3002 & 5.6271 & TRN & \\
\hline CHEMBL1329410 & 688407 & 4.8 & 5.4281 & TRN & \\
\hline CHEMBL1437693 & 688407 & 7.4001 & 5.9922 & TRN & \\
\hline CHEMBL1337231 & 688407 & 4.45 & 4.2153 & TST & \\
\hline CHEMBL1320584 & 688407 & 4.5 & 5.1695 & TRN & \\
\hline CHEMBL1356569 & 688407 & 5.8 & 6.5103 & TRN & \\
\hline CHEMBL1317354 & 688407 & 4.45 & 5.6714 & TRN & \\
\hline CHEMBL1484151 & 688407 & 7.1002 & 6.0918 & TRN & \\
\hline CHEMBL1564650 & 688407 & 8.2007 & 5.6822 & TST & \\
\hline CHEMBL1399401 & 688407 & 4.5 & 4.5692 & TRN & \\
\hline
\end{tabular}




\begin{tabular}{|c|c|c|c|c|c|}
\hline \multicolumn{6}{|c|}{ Supplemental Table S2.txt } \\
\hline CHEMBL1355824 & 688407 & 5.65 & 6.1763 & TRN & \\
\hline CHEMBL1356739 & 688407 & 5.5 & 5.5283 & TRN & \\
\hline CHEMBL1601841 & 688407 & 7.5003 & 5.8502 & TRN & \\
\hline CHEMBL1593833 & 688407 & 6.8 & 5.6578 & TST & \\
\hline CHEMBL1373167 & 688407 & 4.5 & 5.528 & TRN & \\
\hline CHEMBL1404203 & 688407 & 5.5 & 5.7653 & TRN & \\
\hline CHEMBL1514806 & 688407 & 4.9 & 5.4139 & TRN & \\
\hline CHEMBL1371039 & 688407 & 4.45 & 6.3496 & TST & \\
\hline CHEMBL 1398376 & 688407 & 4.45 & 5.0998 & TRN & \\
\hline CHEMBL1514096 & 688407 & 5.0 & 5.20700 & 0000000001 & TRN \\
\hline CHEMBL1515147 & 688407 & 4.45 & 4.6577 & TRN & \\
\hline CHEMBL1568396 & 688407 & 4.45 & 5.0323 & TST & \\
\hline CHEMBL1523517 & 688407 & 5.25 & 6.1165 & TRN & \\
\hline CHEMBL1475007 & 688407 & 4.5 & 5.3169 & TRN & \\
\hline CHEMBL1368872 & 688407 & 4.8 & 5.1662 & TRN & \\
\hline CHEMBL1354889 & 688407 & 5.0 & 5.6046 & TRN & \\
\hline CHEMBL1610709 & 688407 & 5.25 & 5.0703 & TRN & \\
\hline CHEMBL1475002 & 688407 & 5.0 & 5.3238 & TRN & \\
\hline CHEMBL1531920 & 688407 & 4.6 & 4.5229 & TRN & \\
\hline CHEMBL1484892 & 688407 & 7.4001 & 5.0712 & TRN & \\
\hline CHEMBL1555040 & 688407 & 4.9 & 4.8038 & TRN & \\
\hline CHEMBL1554457 & 688407 & 6.0 & 4.9924 & TRN & \\
\hline CHEMBL1593301 & 688407 & 6.8 & 6.2617 & TRN & \\
\hline CHEMBL1596781 & 688407 & 4.95 & 5.3547 & TST & \\
\hline CHEMBL1529491 & 688407 & 6.2 & 5.5473 & TRN & \\
\hline CHEMBL1571909 & 688407 & 5.35 & 5.3811 & TRN & \\
\hline CHEMBL1331075 & 688407 & 5.2 & 5.7564 & TRN & \\
\hline CHEMBL1512966 & 688407 & 4.6 & 5.3786 & TRN & \\
\hline CHEMBL1538761 & 688407 & 7.3002 & 5.2922 & TST & \\
\hline CHEMBL1476819 & 688407 & 4.95 & 4.3712 & TRN & \\
\hline CHEMBL1437380 & 688407 & 6.7001 & 5.5514 & TST & \\
\hline CHEMBL1401745 & 688407 & 5.7 & 6.1757 & TRN & \\
\hline CHEMBL1589891 & 688407 & 6.7001 & 6.2436 & TRN & \\
\hline CHEMBL 1487825 & 688407 & 4.5 & 5.6097 & TRN & \\
\hline CHEMBL1411203 & 688407 & 4.45 & 5.1454 & TRN & \\
\hline CHEMBL1363400 & 688407 & 7.9508 & 6.0619 & TRN & \\
\hline CHEMBL1319888 & 688407 & 4.8 & 5.4321 & TRN & \\
\hline CHEMBL1322076 & 688407 & 5.7 & 6.7623 & TRN & \\
\hline CHEMBL1409817 & 688407 & 4.95 & 4.8864 & TST & \\
\hline CHEMBL1398164 & 688407 & 7.8013 & 5.8634 & TRN & \\
\hline CHEMBL1613262 & 688407 & 5.2 & 5.9649 & TRN & \\
\hline CHEMBL1451751 & 688407 & 6.5 & 5.7075 & TRN & \\
\hline CHEMBL1357251 & 688407 & 6.6 & 5.7562 & TST & \\
\hline CHEMBL1394415 & 688407 & 4.9 & 5.7731 & TRN & \\
\hline CHEMBL1415806 & 688407 & 4.9 & 5.0943 & TST & \\
\hline CHEMBL1453936 & 688407 & 4.7 & 5.3275 & TRN & \\
\hline CHEMBL1514311 & 688407 & 5.1 & 5.1387 & TST & \\
\hline CHEMBL1437759 & 688407 & 4.7 & 5.2306 & TRN & \\
\hline
\end{tabular}




\begin{tabular}{|c|c|c|c|c|c|}
\hline \multicolumn{6}{|c|}{ Supplemental Table s2.txt } \\
\hline CHEMBL1476964 & 688407 & 4.6 & 5.1951 & TRN & \\
\hline CHEMBL1354352 & 688407 & 4.75 & 5.1673 & TRN & \\
\hline CHEMBL1336579 & 688407 & 7.699 & 6.6443 & TRN & \\
\hline CHEMBL1325619 & 688407 & 4.45 & 4.58 & TRN & \\
\hline CHEMBL1496084 & 688407 & 4.5 & 5.3353 & TRN & \\
\hline CHEMBL1559231 & 688407 & 7.699 & 5.4631 & TST & \\
\hline CHEMBL1439975 & 688407 & 5.1 & 4.8604 & TRN & \\
\hline CHEMBL1475652 & 688407 & 4.5 & 4.9829 & TRN & \\
\hline CHEMBL1591135 & 688407 & 4.8 & 5.3351 & TRN & \\
\hline CHEMBL1481524 & 688407 & 6.1 & 5.8094 & TRN & \\
\hline CHEMBL1376666 & 688407 & 5.0 & 5.5389 & TRN & \\
\hline CHEMBL1492923 & 688407 & 5.2 & 6.2001 & TRN & \\
\hline CHEMBL1334631 & 688407 & 4.45 & 4.6108 & TRN & \\
\hline CHEMBL1563292 & 688407 & 5.7 & $6.1170 e$ & 0000000001 & TRN \\
\hline CHEMBL1368943 & 688407 & 6.5 & $5.4110 e$ & 00000000005 & TRN \\
\hline CHEMBL1566071 & 688407 & 4.6 & 5.3137 & TRN & \\
\hline CHEMBL1371001 & 688407 & 6.15 & 6.0781 & TRN & \\
\hline CHEMBL1328206 & 688407 & 8.3979 & 5.9771 & TRN & \\
\hline CHEMBL1592711 & 688407 & 4.9 & 6.1737 & TRN & \\
\hline CHEMBL1557656 & 688407 & 6.0 & 6.0232 & TRN & \\
\hline CHEMBL1356530 & 688407 & 6.3 & 6.1734 & TRN & \\
\hline CHEMBL1416801 & 688407 & 4.9 & 5.0879 & TRN & \\
\hline CHEMBL1557722 & 688407 & 8.3468 & $5.8770 e$ & $\partial 000000001$ & TRN \\
\hline CHEMBL1454894 & 688407 & 6.2 & 5.7559 & TRN & \\
\hline CHEMBL1357455 & 688407 & 5.2 & 5.7074 & TRN & \\
\hline CHEMBL1492066 & 688407 & 4.5 & 5.239 & TRN & \\
\hline CHEMBL1396790 & 688407 & 5.4 & 5.8712 & TRN & \\
\hline CHEMBL1359337 & 688407 & 4.9 & 5.7796 & TRN & \\
\hline CHEMBL1486110 & 688407 & 4.5 & 6.1695 & TRN & \\
\hline CHEMBL1535512 & 688407 & 4.8 & 5.1573 & TRN & \\
\hline CHEMBL 377583 & 688407 & 5.5 & 5.5329 & TRN & \\
\hline CHEMBL1437269 & 688407 & 4.6 & 5.6901 & TRN & \\
\hline CHEMBL1593465 & 688407 & 4.9 & 5.8616 & TRN & \\
\hline CHEMBL1569758 & 688407 & 4.5 & 5.7714 & TST & \\
\hline CHEMBL1374674 & 688407 & 4.8 & 5.1375 & TRN & \\
\hline CHEMBL1512219 & 688407 & 5.3 & 5.3295 & TRN & \\
\hline CHEMBL1523500 & 688407 & 5.9 & 5.9661 & TST & \\
\hline CHEMBL1551587 & 688407 & 6.8499 & 6.6118 & TRN & \\
\hline CHEMBL1608562 & 688407 & 6.3 & 5.4509 & TST & \\
\hline CHEMBL1437055 & 688407 & 8.4559 & 5.8826 & TRN & \\
\hline CHEMBL1526748 & 688407 & 6.5 & 5.1653 & TRN & \\
\hline CHEMBL1551417 & 688407 & 5.2 & 5.9658 & TRN & \\
\hline CHEMBL1395917 & 688407 & 4.85 & 5.5018 & TST & \\
\hline CHEMBL1358391 & 688407 & 4.6 & 5.7107 & TST & \\
\hline CHEMBL1554430 & 688407 & 4.5 & 5.2627 & TRN & \\
\hline CHEMBL1608576 & 688407 & 4.45 & 4.8176 & TRN & \\
\hline CHEMBL1367616 & 688407 & 4.85 & 4.8097 & TRN & \\
\hline CHEMBL1513728 & 688407 & 5.0 & 5.3014 & TRN & \\
\hline
\end{tabular}




\begin{tabular}{|c|c|c|c|c|}
\hline \multicolumn{5}{|c|}{ Supplemental Table S2.tx } \\
\hline CHEMBL1591261 & 688407 & 4.9 & 5.4581 & TST \\
\hline CHEMBL1597368 & 688407 & 4.8 & 5.3996 & TRN \\
\hline CHEMBL2004809 & 688407 & 5.5 & 5.506 & TST \\
\hline CHEMBL1394188 & 688407 & 7.6003 & 5.6396 & TRN \\
\hline CHEMBL1394190 & 688407 & 6.5501 & 4.9582 & TRN \\
\hline CHEMBL1514327 & 688407 & 8.0 & 5.7527 & TRN \\
\hline CHEMBL1378106 & 688407 & 4.5 & 5.4591 & TRN \\
\hline CHEMBL1517271 & 688407 & 5.9 & 6.3556 & TRN \\
\hline CHEMBL1514781 & 688407 & 7.0 & 5.3649 & TRN \\
\hline CHEMBL1364231 & 688407 & 6.4 & 5.7987 & TRN \\
\hline CHEMBL1357113 & 688407 & 4.5 & \multicolumn{2}{|c|}{4.7589999999999995} \\
\hline CHEMBL1354848 & 688407 & 5.0 & 5.8511 & TRN \\
\hline CHEMBL1489821 & 688407 & 4.7 & 5.5305 & TRN \\
\hline CHEMBL1439014 & 688407 & 4.5 & 5.426 & TRN \\
\hline CHEMBL1480047 & 688407 & 4.45 & 5.1683 & TRN \\
\hline CHEMBL1467234 & 688407 & 8.0 & 6.1365 & TST \\
\hline CHEMBL1463425 & 688407 & 6.5 & 5.7785 & TRN \\
\hline CHEMBL1316201 & 688407 & 4.45 & 5.2088 & TRN \\
\hline CHEMBL1473514 & 688407 & 4.5 & 5.8194 & TRN \\
\hline CHEMBL1398402 & 688407 & 5.0 & 5.562 & TRN \\
\hline CHEMBL1589873 & 688407 & 5.5 & 5.6364 & TST \\
\hline CHEMBL1474075 & 688407 & 8.301 & 6.4148 & TST \\
\hline CHEMBL1571829 & 688407 & 7.4001 & 5.1107 & TST \\
\hline CHEMBL1329997 & 688407 & 4.65 & 5.0051 & TST \\
\hline CHEMBL1434183 & 688407 & 6.4 & 5.4765 & TRN \\
\hline CHEMBL1357386 & 688407 & 5.6 & 5.6623 & TRN \\
\hline CHEMBL1402683 & 688407 & 4.8 & 5.8402 & TRN \\
\hline CHEMBL1434613 & 688407 & 4.6 & 5.8109 & TRN \\
\hline CHEMBL1354342 & 688407 & 6.8 & 5.7764 & TRN \\
\hline CHEMBL1444469 & 688407 & 6.0 & 5.6664 & TST \\
\hline CHEMBL1321687 & 688407 & 8.0 & 6.046 & TST \\
\hline CHEMBL1551223 & 688407 & 7.8996 & 5.6419 & TRN \\
\hline CHEMBL1417440 & 688407 & 7.0501 & 4.9933 & TRN \\
\hline CHEMBL1403320 & 688407 & 4.5 & 4.9668 & TRN \\
\hline CHEMBL1593295 & 688407 & 5.2 & 5.4364 & TRN \\
\hline CHEMBL1566238 & 688407 & 7.5003 & 5.7177 & TRN \\
\hline CHEMBL1513494 & 688407 & 4.5 & 5.9712 & TRN \\
\hline CHEMBL1476795 & 688407 & 4.9 & 5.785 & TRN \\
\hline CHEMBL1399918 & 688407 & 8.3468 & 5.605 & TRN \\
\hline CHEMBL1513638 & 688407 & 4.6 & 5.2027 & TRN \\
\hline CHEMBL1371323 & 688407 & 4.9 & 4.782 & TRN \\
\hline CHEMBL1397848 & 688407 & 4.5 & 5.2099 & TRN \\
\hline CHEMBL1437022 & 688407 & 4.6 & 5.1869 & TRN \\
\hline CHEMBL1521694 & 688407 & 5.4 & 5.7695 & TST \\
\hline CHEMBL1405423 & 688407 & 4.45 & 5.7637 & TRN \\
\hline CHEMBL1595219 & 688407 & 4.45 & 5.7187 & TRN \\
\hline CHEMBL1397129 & 688407 & 5.2 & 6.2795 & TRN \\
\hline CHEMBL1554715 & 688407 & 4.7 & 5.6654 & TRN \\
\hline
\end{tabular}




\begin{tabular}{|c|c|c|c|c|}
\hline \multicolumn{5}{|c|}{ Supplemental Table S2.txt } \\
\hline CHEMBL1485630 & 688407 & 5.6 & 5.9008 & TRN \\
\hline CHEMBL1356298 & 688407 & 4.9 & 5.7435 & TST \\
\hline CHEMBL1395020 & 688407 & 4.9 & 5.4018 & TRN \\
\hline CHEMBL1476284 & 688407 & 4.7 & 5.5279 & TST \\
\hline CHEMBL1610691 & 688407 & 5.65 & 5.9566 & TRN \\
\hline CHEMBL1486491 & 688407 & 4.45 & 5.0535 & TRN \\
\hline CHEMBL1481594 & 688407 & 4.5 & 5.7603 & TRN \\
\hline CHEMBL1394148 & 688407 & 4.5 & 5.3408 & TRN \\
\hline CHEMBL1394740 & 688407 & 4.5 & 5.1563 & TRN \\
\hline CHEMBL1435468 & 688407 & 4.5 & 5.4495 & TRN \\
\hline CHEMBL1327560 & 688407 & 6.4 & 5.0674 & TST \\
\hline CHEMBL1366996 & 688407 & 5.2 & 5.8592 & TRN \\
\hline CHEMBL1397968 & 688407 & 6.6 & 5.4533 & TRN \\
\hline CHEMBL1317846 & 688407 & 6.4 & 5.7563 & TRN \\
\hline CHEMBL1495210 & 688407 & 8.3979 & 5.9657 & TST \\
\hline CHEMBL1531232 & 688407 & 6.8 & 6.7078 & TRN \\
\hline CHEMBL1490021 & 688407 & 5.0 & 5.1825 & TRN \\
\hline CHEMBL1555000 & 688407 & 5.35 & 5.2544 & TRN \\
\hline CHEMBL1357901 & 688407 & 4.5 & 5.1534 & TRN \\
\hline CHEMBL1539187 & 688407 & 5.4 & 5.5604 & TST \\
\hline CHEMBL1315474 & 688407 & 5.8 & 5.9935 & TST \\
\hline CHEMBL1398184 & 688407 & 4.5 & 5.4571 & TRN \\
\hline CHEMBL1558889 & 688407 & 4.9 & 5.4173 & TST \\
\hline CHEMBL1556955 & 688407 & 4.65 & 5.0222 & TST \\
\hline CHEMBL1396571 & 688407 & 8.0506 & 6.2921 & TST \\
\hline CHEMBL1316299 & 688407 & 4.5 & 5.6215 & TRN \\
\hline CHEMBL1454098 & 688407 & 5.5 & 5.7345 & TRN \\
\hline CHEMBL1554692 & 688407 & 5.7 & 5.5068 & TRN \\
\hline CHEMBL1555319 & 688407 & 4.5 & 5.5843 & TST \\
\hline CHEMBL1400250 & 688407 & 4.8 & 4.9339 & TRN \\
\hline CHEMBL1334073 & 688407 & 4.95 & 5.4829 & TST \\
\hline CHEMBL1516300 & 688407 & 8.301 & 5.2766 & TST \\
\hline CHEMBL1613692 & 688407 & 5.25 & 5.9258 & TRN \\
\hline CHEMBL1395184 & 688407 & 4.7 & 6.4127 & TRN \\
\hline CHEMBL1433908 & 688407 & 4.5 & 6.4011 & TST \\
\hline CHEMBL1360853 & 688407 & 4.9 & 5.2951 & TRN \\
\hline CHEMBL1451800 & 688407 & 5.3 & 5.2211 & TST \\
\hline CHEMBL1437682 & 688407 & 6.9 & 5.6881 & TRN \\
\hline CHEMBL1358461 & 688407 & 4.75 & 5.0426 & TRN \\
\hline CHEMBL1475786 & 688407 & 5.0 & 5.8455 & TRN \\
\hline CHEMBL1364321 & 688407 & 4.65 & 4.9819 & TRN \\
\hline CHEMBL1473984 & 688407 & 4.7 & 4.7617 & TRN \\
\hline CHEMBL1530902 & 688407 & 4.9 & 5.4897 & TRN \\
\hline CHEMBL1592258 & 688407 & 4.5 & 5.9162 & TST \\
\hline CHEMBL1358478 & 688407 & 4.8 & 5.6653 & TST \\
\hline CHEMBL1592716 & 688407 & 5.4 & 4.8616 & TST \\
\hline CHEMBL1535245 & 688407 & 5.0 & 5.8002 & TST \\
\hline CHEMBL 2095128 & 688407 & 4.95 & 5.3696 & TST \\
\hline
\end{tabular}




\begin{tabular}{|c|c|c|c|c|c|}
\hline \multicolumn{6}{|c|}{ Supplemental Table S2.txt } \\
\hline CHEMBL1434902 & 688407 & 5.2 & 5.397 & TST & \\
\hline CHEMBL1339158 & 688407 & 7.6498 & 5.5351 & TST & \\
\hline CHEMBL1592847 & 688407 & 4.9 & 5.2297 & TRN & \\
\hline CHEMBL1390925 & 688407 & 6.95 & 5.9432 & TST & \\
\hline CHEMBL1337977 & 688407 & 7.1002 & 5.6896 & TRN & \\
\hline CHEMBL1394859 & 688407 & 5.5 & 6.0654 & TRN & \\
\hline CHEMBL1356019 & 688407 & 4.5 & 4.9384 & TRN & \\
\hline CHEMBL1592109 & 688407 & 4.9 & 4.9531 & TRN & \\
\hline CHEMBL1531143 & 688407 & 6.1 & 5.0448 & TST & \\
\hline CHEMBL3210494 & 688407 & 4.45 & 5.6738 & TST & \\
\hline CHEMBL1473265 & 688407 & 6.35 & 6.2392 & TRN & \\
\hline CHEMBL1554144 & 688407 & 4.7 & 5.7029 & TST & \\
\hline CHEMBL1491887 & 688407 & 4.45 & 5.12299 & 9999999999 & TST \\
\hline CHEMBL1553510 & 688407 & 4.9 & 4.9854 & TRN & \\
\hline CHEMBL1314238 & 688407 & 8.3979 & 5.7868 & TRN & \\
\hline CHEMBL1360653 & 688407 & 4.45 & 4.7926 & TRN & \\
\hline CHEMBL1401010 & 688407 & 5.0 & 5.3439 & TRN & \\
\hline CHEMBL1365549 & 688407 & 4.7 & 5.8555 & TRN & \\
\hline CHEMBL1570489 & 688407 & 5.6 & 5.3644 & TST & \\
\hline CHEMBL1542791 & 688407 & 4.95 & 5.4993 & TRN & \\
\hline CHEMBL1443256 & 688407 & 7.3002 & 6.0463 & TST & \\
\hline CHEMBL1521105 & 688407 & 8.301 & 6.1336 & TRN & \\
\hline CHEMBL1437373 & 688407 & 4.8 & 6.0412 & TRN & \\
\hline CHEMBL1317067 & 688407 & 5.5 & 5.8543 & TRN & \\
\hline CHEMBL1412833 & 688407 & 7.8013 & 5.8743 & TRN & \\
\hline CHEMBL1394836 & 688407 & 4.5 & 5.8511 & TST & \\
\hline CHEMBL1473582 & 688407 & 4.5 & 4.846 & TRN & \\
\hline CHEMBL1354792 & 688407 & 5.4 & 5.4333 & TRN & \\
\hline CHEMBL1590279 & 688407 & 4.75 & 4.678 & TRN & \\
\hline CHEMBL1592515 & 688407 & 5.2 & 5.2711 & TST & \\
\hline CHEMBL601757 & 688407 & 5.5 & 6.597 & TST & \\
\hline CHEMBL1477918 & 688407 & 4.95 & 5.3372 & TRN & \\
\hline CHEMBL1534805 & 688407 & 8.1024 & 5.5088 & TRN & \\
\hline CHEMBL1569635 & 688407 & 4.5 & 5.4796 & TST & \\
\hline CHEMBL1513326 & 688407 & 4.9 & 4.7426 & TRN & \\
\hline CHEMBL1517686 & 688407 & 5.0 & 5.5495 & TST & \\
\hline CHEMBL1438727 & 688407 & 4.8 & 5.4022 & TRN & \\
\hline CHEMBL1358452 & 688407 & 5.9 & 6.4425 & TST & \\
\hline CHEMBL1474704 & 688407 & 4.5 & 4.8287 & TRN & \\
\hline CHEMBL1572558 & 688407 & 5.5 & 5.5283 & TST & \\
\hline CHEMBL1336410 & 688407 & 4.95 & 5.0382 & TRN & \\
\hline CHEMBL 1474547 & 688407 & 7.0501 & 5.3277 & TRN & \\
\hline CHEMBL1593195 & 688407 & 7.5003 & 5.5224 & TRN & \\
\hline CHEMBL1605421 & 688407 & 5.3 & 5.74 & TRN & \\
\hline CHEMBL1319322 & 688407 & 5.5 & 5.836 & TRN & \\
\hline CHEMBL1396899 & 688407 & 4.6 & 5.4096 & TRN & \\
\hline CHEMBL1408108 & 688407 & 4.5 & 5.1442 & TST & \\
\hline CHEMBL1533759 & 688407 & 8.301 & 6.2666 & TRN & \\
\hline
\end{tabular}




\begin{tabular}{|c|c|c|c|c|c|}
\hline \multirow[b]{2}{*}{ CHEMBL1553727 } & \\
\hline & 688407 & 4.7 & 5.4574 & TST & \\
\hline CHEMBL1484473 & 688407 & 5.6 & \multicolumn{2}{|c|}{5.247000000000001} & \multirow{2}{*}{ TRN } \\
\hline CHEMBL1437216 & 688407 & 4.8 & 4.928 & TRN & \\
\hline CHEMBL1522461 & 688407 & 5.0 & 6.2396 & TRN & \\
\hline CHEMBL1590040 & 688407 & 4.5 & 5.6116 & TRN & \\
\hline CHEMBL1329632 & 688407 & 4.9 & 5.4881 & TRN & \\
\hline CHEMBL1317673 & 688407 & 4.45 & 5.0087 & TRN & \\
\hline CHEMBL1414176 & 688407 & 7.5003 & 5.0468 & TRN & \\
\hline CHEMBL1438250 & 688407 & 4.9 & 4.6175 & TRN & \\
\hline CHEMBL1596972 & 688407 & 7.1002 & 6.3923 & TST & \\
\hline CHEMBL1315953 & 688407 & 4.5 & 5.2679 & TRN & \\
\hline CHEMBL1609811 & 688407 & 4.95 & 5.1911 & TRN & \\
\hline CHEMBL1402948 & 688407 & 6.1 & 6.1004 & TRN & \\
\hline CHEMBL1600154 & 688407 & 5.45 & 5.5895 & TRN & \\
\hline CHEMBL1434798 & 688407 & 5.4 & 4.8731 & TST & \\
\hline CHEMBL1372068 & 688407 & 7.0 & 5.9168 & TST & \\
\hline CHEMBL1559076 & 688407 & 8.0506 & 5.9248 & TST & \\
\hline CHEMBL1395095 & 688407 & 4.8 & 5.8589 & TST & \\
\hline CHEMBL1532668 & 688407 & 7.4498 & 5.3645 & TST & \\
\hline CHEMBL1492968 & 688407 & 4.5 & 5.2049 & TST & \\
\hline CHEMBL1435883 & 688407 & 4.5 & 5.0082 & TST & \\
\hline CHEMBL1325309 & 688407 & 4.8 & 5.3493 & TRN & \\
\hline CHEMBL1472609 & 688407 & 4.5 & 4.7087 & TRN & \\
\hline CHEMBL1473362 & 688407 & 4.9 & 4.808 & TRN & \\
\hline CHEMBL1512097 & 688407 & 4.65 & 5.1804 & TRN & \\
\hline CHEMBL1317527 & 688407 & 7.8013 & 5.6975 & TRN & \\
\hline CHEMBL1429637 & 688407 & 4.85 & 5.3479 & TST & \\
\hline CHEMBL1602563 & 688407 & 4.5 & 5.72 & TRN & \\
\hline CHEMBL1350341 & 688407 & 4.45 & 5.4714 & TRN & \\
\hline CHEMBL1570928 & 688407 & 4.9 & 5.9261 & TRN & \\
\hline CHEMBL1589937 & 688407 & 4.5 & 4.8582 & TRN & \\
\hline CHEMBL1516247 & 688407 & 5.2 & 5.3778 & TRN & \\
\hline CHEMBL1358052 & 688407 & 4.55 & 4.9481 & TRN & \\
\hline CHEMBL1333859 & 688407 & 5.0 & 5.4333 & TRN & \\
\hline CHEMBL1325515 & 688407 & 4.95 & 5.1114 & TRN & \\
\hline CHEMBL1434223 & 688407 & 5.0 & 5.138 & TRN & \\
\hline CHEMBL1485286 & 688407 & 5.4 & 5.4725 & TRN & \\
\hline CHEMBL1606236 & 688407 & 5.8 & 6.8197 & TST & \\
\hline CHEMBL1449409 & 688407 & 4.5 & 5.3414 & TRN & \\
\hline CHEMBL1527847 & 688407 & 5.1 & 5.7132 & TRN & \\
\hline CHEMBL1485506 & 688407 & 6.8 & 5.334 & TRN & \\
\hline CHEMBL1437726 & 688407 & 5.1 & 5.3406 & TRN & \\
\hline CHEMBL1451288 & 688407 & 5.85 & 5.9712 & TST & \\
\hline CHEMBL1524300 & 688407 & 4.5 & 5.5303 & TRN & \\
\hline CHEMBL1561594 & 688407 & 5.0 & 4.8625 & TST & \\
\hline CHEMBL1428003 & 688407 & 4.5 & 4.6930 & 00000000005 & TRN \\
\hline CHEMBL1592158 & 688407 & 4.75 & 5.48 & TRN & \\
\hline CHEMBL1323129 & 688407 & 4.8 & 5.2722 & TRN & \\
\hline & & & & 22333 & \\
\hline
\end{tabular}




\begin{tabular}{|c|c|c|c|c|}
\hline \multicolumn{5}{|c|}{ Supplemental Table S2.txt } \\
\hline CHEMBL1357330 & 688407 & 5.25 & 5.3676 & TST \\
\hline CHEMBL1515003 & 688407 & 4.7 & 5.2715 & TRN \\
\hline CHEMBL1434511 & 688407 & 6.8 & 5.7281 & TRN \\
\hline CHEMBL1365534 & 688407 & 4.7 & 5.78 & TRN \\
\hline CHEMBL1358301 & 688407 & 6.4 & 5.1193 & TST \\
\hline CHEMBL1440998 & 688407 & 4.5 & 6.3773 & TST \\
\hline CHEMBL1397648 & 688407 & 4.65 & 4.4742 & TRN \\
\hline CHEMBL1593009 & 688407 & 5.6 & 5.395 & TRN \\
\hline CHEMBL1433548 & 688407 & 4.45 & 5.9145 & TRN \\
\hline CHEMBL1436214 & 688407 & 6.5 & 5.5286 & TRN \\
\hline CHEMBL1513268 & 688407 & 4.5 & 5.1172 & TRN \\
\hline CHEMBL1557813 & 688407 & 5.2 & 5.1746 & TRN \\
\hline CHEMBL1512992 & 688407 & 4.9 & 4.9385 & TRN \\
\hline CHEMBL1474413 & 688407 & 4.4 & 5.7088 & TRN \\
\hline CHEMBL1585613 & 688407 & 8.4949 & 5.8781 & TRN \\
\hline CHEMBL1572762 & 688407 & 7.1002 & 6.0068 & TRN \\
\hline CHEMBL1483170 & 688407 & 5.3 & 5.4644 & TRN \\
\hline CHEMBL592611 & 688407 & 6.1 & 5.1706 & TST \\
\hline CHEMBL578284 & 688407 & 4.45 & 5.4998 & TRN \\
\hline CHEMBL1514448 & 688407 & 6.2 & 5.5861 & TST \\
\hline CHEMBL1591944 & 688407 & 7.6003 & 5.655 & TST \\
\hline CHEMBL1601695 & 688407 & 4.6 & 4.919 & TRN \\
\hline CHEMBL1611872 & 688407 & 4.5 & 5.0847 & TST \\
\hline CHEMBL1399693 & 688407 & 4.9 & 5.4963 & TRN \\
\hline CHEMBL1453920 & 688407 & 7.6003 & 6.1808 & TRN \\
\hline CHEMBL1316807 & 688407 & 6.3 & 5.3485 & TST \\
\hline CHEMBL1377782 & 688407 & 4.7 & 5.1823 & TRN \\
\hline CHEMBL1543742 & 688407 & 4.65 & 5.5829 & TST \\
\hline CHEMBL1590010 & 688407 & 4.9 & 4.8143 & TST \\
\hline CHEMBL1397030 & 688407 & 4.45 & 5.3756 & TRN \\
\hline CHEMBL1514449 & 688407 & 4.8 & 4.9782 & TRN \\
\hline CHEMBL3213953 & 688407 & 6.45 & 5.6298 & TST \\
\hline CHEMBL1593600 & 688407 & 5.0 & 5.7068 & TRN \\
\hline CHEMBL1436395 & 688407 & 7.6003 & 4.8432 & TRN \\
\hline CHEMBL1567860 & 688407 & 4.9 & 5.1309 & TRN \\
\hline CHEMBL1532430 & 688407 & 4.5 & 5.0179 & TRN \\
\hline CHEMBL1515196 & 688407 & 4.5 & 5.4686 & TST \\
\hline CHEMBL1551236 & 688407 & 6.4 & 6.1967 & TRN \\
\hline CHEMBL1403379 & 688407 & 4.5 & 5.5231 & TRN \\
\hline CHEMBL1354552 & 688407 & 5.5 & 5.2666 & TST \\
\hline CHEMBL1597573 & 688407 & 4.65 & 5.4755 & TST \\
\hline CHEMBL1323613 & 688407 & 4.6 & 5.0472 & TST \\
\hline CHEMBL1435728 & 688407 & 6.9 & 6.4086 & TRN \\
\hline CHEMBL1532192 & 688407 & 4.5 & 5.2364 & TST \\
\hline CHEMBL1316766 & 688407 & 6.4 & 5.7965 & TRN \\
\hline CHEMBL1472696 & 688407 & 4.6 & 4.7559 & TRN \\
\hline CHEMBL1593007 & 688407 & 4.65 & 4.5065 & TRN \\
\hline CHEMBL1362744 & 688407 & 4.45 & 5.0056 & TRN \\
\hline
\end{tabular}




\begin{tabular}{|c|c|c|c|c|c|}
\hline \multicolumn{6}{|c|}{ Supplemental Table S2.txt } \\
\hline CHEMBL1559346 & 688407 & 4.8 & 5.143 & TRN & \\
\hline CHEMBL1434310 & 688407 & 5.0 & 5.3993 & TRN & \\
\hline CHEMBL1317436 & 688407 & 4.6 & 4.8259 & TRN & \\
\hline CHEMBL1457178 & 688407 & 4.5 & 6.3817 & TRN & \\
\hline CHEMBL1452469 & 688407 & 5.4 & 4.7046 & TRN & \\
\hline CHEMBL1591685 & 688407 & 7.6003 & 5.0847 & TRN & \\
\hline CHEMBL1563121 & 688407 & 4.65 & 5.0586 & TRN & \\
\hline CHEMBL1362825 & 688407 & 4.5 & 4.8798 & TRN & \\
\hline CHEMBL1374318 & 688407 & 6.9 & 5.329 & TRN & \\
\hline CHEMBL1476113 & 688407 & 5.9 & 5.49 & TRN & \\
\hline CHEMBL1453606 & 688407 & 5.5 & 6.1437 & TRN & \\
\hline CHEMBL1354522 & 688407 & 5.05 & 5.4872 & TRN & \\
\hline CHEMBL1480704 & 688407 & 5.2 & 5.5217 & TRN & \\
\hline CHEMBL1358237 & 688407 & 8.301 & 5.3411 & TRN & \\
\hline CHEMBL1515416 & 688407 & 8.0 & 6.5275 & TRN & \\
\hline CHEMBL1451673 & 688407 & 5.0 & 5.1155 & TRN & \\
\hline CHEMBL1399347 & 688407 & 8.0 & 6.2084 & TRN & \\
\hline CHEMBL1476813 & 688407 & 4.9 & 5.5118 & TRN & \\
\hline CHEMBL1396964 & 688407 & 4.45 & 5.4095 & TRN & \\
\hline CHEMBL1396817 & 688407 & 4.5 & 4.8266 & TRN & \\
\hline CHEMBL1383967 & 688407 & 5.2 & 5.879 & TRN & \\
\hline CHEMBL1551354 & 688407 & 4.9 & 5.7985 & TRN & \\
\hline CHEMBL1338773 & 688407 & 5.3 & 6.2737 & TRN & \\
\hline CHEMBL1478870 & 688407 & 4.5 & 5.2452 & TRN & \\
\hline CHEMBL1403798 & 688407 & 5.9 & 5.8779 & TST & \\
\hline CHEMBL1482664 & 688407 & 4.8 & 5.7921 & TST & \\
\hline CHEMBL1548093 & 688407 & 5.0 & 5.2051 & TST & \\
\hline CHEMBL1377384 & 688407 & 5.6 & 5.5085 & TST & \\
\hline CHEMBL1395582 & 688407 & 5.0 & 5.516 & TRN & \\
\hline CHEMBL1325991 & 688407 & 5.2 & 5.6734 & TRN & \\
\hline CHEMBL1355390 & 688407 & 5.3 & 4.5593 & TRN & \\
\hline CHEMBL1574735 & 688407 & 4.5 & 5.325 & TRN & \\
\hline CHEMBL1513622 & 688407 & 4.5 & 6.1086 & TRN & \\
\hline CHEMBL1612049 & 688407 & 5.0 & 6.2196 & TRN & \\
\hline CHEMBL1396039 & 688407 & 8.1024 & 6.17700 & 00000000005 & TRN \\
\hline CHEMBL1456299 & 688407 & 6.3 & 5.0071 & TRN & \\
\hline CHEMBL1441350 & 688407 & 4.7 & 5.5644 & TST & \\
\hline CHEMBL1394591 & 688407 & 7.0 & 6.9917 & TST & \\
\hline CHEMBL1600101 & 688407 & 4.5 & 6.2794 & TST & \\
\hline CHEMBL1602662 & 688407 & 4.95 & 5.2893 & TRN & \\
\hline CHEMBL1481451 & 688407 & 5.0 & 5.7808 & TRN & \\
\hline CHEMBL1358114 & 688407 & 6.6499 & 5.9693 & TRN & \\
\hline CHEMBL1396547 & 688407 & 4.8 & 5.1664 & TST & \\
\hline CHEMBL1437162 & 688407 & 4.9 & 5.541 & TRN & \\
\hline CHEMBL1559944 & 688407 & 5.6 & 5.8314 & TRN & \\
\hline CHEMBL1355985 & 688407 & 4.5 & 5.6478 & TRN & \\
\hline CHEMBL1404458 & 688407 & 5.2 & 5.5266 & TRN & \\
\hline CHEMBL1556836 & 688407 & 5.1 & 4.8187 & TRN & \\
\hline
\end{tabular}




\begin{tabular}{|c|c|c|c|c|c|}
\hline \multicolumn{6}{|c|}{ Supplemental Table S2.txt } \\
\hline CHEMBL1456175 & 688407 & 4.65 & 5.4433 & TST & \\
\hline CHEMBL1590084 & 688407 & 4.9 & 5.6124 & TRN & \\
\hline CHEMBL1472780 & 688407 & 8.2007 & 5.5413 & TST & \\
\hline CHEMBL1356322 & 688407 & 4.45 & 5.5612 & TRN & \\
\hline CHEMBL1530646 & 688407 & 4.45 & 4.6496 & TRN & \\
\hline CHEMBL1317032 & 688407 & 4.9 & 5.3211 & TRN & \\
\hline CHEMBL1382022 & 688407 & 5.0 & 4.8516 & TRN & \\
\hline CHEMBL1597953 & 688407 & 4.6 & 5.2147 & TRN & \\
\hline CHEMBL1437602 & 688407 & 4.75 & 5.4404 & TRN & \\
\hline CHEMBL1436163 & 688407 & 4.5 & 6.6562 & TRN & \\
\hline CHEMBL1592150 & 688407 & 5.1 & 5.4341 & TST & \\
\hline CHEMBL1476800 & 688407 & 8.1024 & 6.1027 & TRN & \\
\hline CHEMBL1434035 & 688407 & 4.8 & 5.6312 & TRN & \\
\hline CHEMBL1334054 & 688407 & 5.0 & 5.6006 & TRN & \\
\hline CHEMBL1484528 & 688407 & 5.0 & 5.2319 & TRN & \\
\hline CHEMBL1481529 & 688407 & 8.301 & 6.1357 & TST & \\
\hline CHEMBL1389590 & 688407 & 4.45 & 5.2926 & TRN & \\
\hline CHEMBL1357210 & 688407 & 5.0 & 6.1818 & TRN & \\
\hline CHEMBL1591608 & 688407 & 8.301 & 6.1083 & TRN & \\
\hline CHEMBL1434764 & 688407 & 4.5 & 5.0367 & TRN & \\
\hline CHEMBL1593189 & 688407 & 7.0 & 6.3919 & TRN & \\
\hline CHEMBL1373521 & 688407 & 4.9 & 5.3056 & TRN & \\
\hline CHEMBL1591818 & 688407 & 4.9 & 5.5235 & TRN & \\
\hline CHEMBL1474284 & 688407 & 5.0 & 5.8962 & TRN & \\
\hline CHEMBL1441480 & 688407 & 4.6 & 5.5507 & TRN & \\
\hline CHEMBL1316744 & 688407 & 5.9 & 5.7185 & TRN & \\
\hline CHEMBL1569404 & 688407 & 4.5 & 5.7079 & TST & \\
\hline CHEMBL1527469 & 688407 & 6.3 & 5.16299 & 9999999999 & TRN \\
\hline CHEMBL1437196 & 688407 & 4.5 & 5.5617 & TRN & \\
\hline CHEMBL1329631 & 688407 & 4.8 & 5.0861 & TRN & \\
\hline CHEMBL1487251 & 688407 & 5.5 & 4.7398 & TRN & \\
\hline CHEMBL1496337 & 688407 & 5.0 & 5.239 & TRN & \\
\hline CHEMBL1397109 & 688407 & 8.301 & 5.319 & TRN & \\
\hline CHEMBL1551774 & 688407 & 4.8 & 5.3765 & TST & \\
\hline CHEMBL1528904 & 688407 & 4.65 & 4.8303 & TRN & \\
\hline CHEMBL1472867 & 688407 & 5.2 & 6.7657 & TRN & \\
\hline CHEMBL1433556 & 688407 & 5.0 & 4.9307 & TRN & \\
\hline CHEMBL1321321 & 688407 & 5.9 & 6.08200 & 0000000001 & TRN \\
\hline CHEMBL602234 & 688407 & 4.7 & 4.1991 & TRN & \\
\hline CHEMBL1314609 & 688407 & 4.5 & 5.2799 & TST & \\
\hline CHEMBL1394769 & 688407 & 4.5 & 5.6259 & TST & \\
\hline CHEMBL1443488 & 688407 & 5.5 & 5.2089 & TRN & \\
\hline CHEMBL1510815 & 688407 & 5.0 & 5.8194 & TST & \\
\hline CHEMBL1513883 & 688407 & 4.5 & 5.121 & TST & \\
\hline CHEMBL1535415 & 688407 & 4.95 & 5.4765 & TRN & \\
\hline CHEMBL1607091 & 688407 & 5.7 & 5.4214 & TRN & \\
\hline CHEMBL1552666 & 688407 & 4.7 & 5.8511 & TRN & \\
\hline CHEMBL1324142 & 688407 & 4.65 & 5.6523 & TST & \\
\hline
\end{tabular}




\begin{tabular}{|c|c|c|c|c|c|}
\hline \multicolumn{6}{|c|}{ Supplemental Table S2.txt } \\
\hline CHEMBL1594116 & 688407 & 4.5 & 4.8868 & TRN & \\
\hline CHEMBL1587350 & 688407 & 7.8508 & 6.0184 & TST & \\
\hline CHEMBL1591989 & 688407 & 6.1 & 5.7778 & TRN & \\
\hline CHEMBL1399719 & 688407 & 4.5 & 5.2924 & TST & \\
\hline CHEMBL1434854 & 688407 & 4.9 & 5.8651 & TST & \\
\hline CHEMBL1436796 & 688407 & 7.3002 & 6.7469 & TRN & \\
\hline CHEMBL1439533 & 688407 & 4.5 & $5.2620 e$ & 00000000005 & TRN \\
\hline CHEMBL1398002 & 688407 & 6.0 & 5.7647 & TRN & \\
\hline CHEMBL1433666 & 688407 & 5.0 & 4.7744 & TRN & \\
\hline CHEMBL1593639 & 688407 & 5.4 & 5.5765 & TRN & \\
\hline CHEMBL1436344 & 688407 & 5.0 & 5.6255 & TRN & \\
\hline CHEMBL1605974 & 688407 & 4.85 & 4.6475 & TRN & \\
\hline CHEMBL1593250 & 688407 & 5.5 & 6.1507 & TRN & \\
\hline CHEMBL1491350 & 688407 & 6.2 & 5.3868 & TRN & \\
\hline CHEMBL1516314 & 688407 & 4.45 & 5.4894 & TRN & \\
\hline CHEMBL1435681 & 688407 & 6.7001 & 5.4407 & TRN & \\
\hline CHEMBL1528191 & 688407 & 7.1002 & 5.7543 & TST & \\
\hline CHEMBL1434466 & 688407 & 4.55 & 5.744 & TRN & \\
\hline CHEMBL1328077 & 688407 & 4.9 & 4.8885 & TRN & \\
\hline CHEMBL1513594 & 688407 & 5.2 & 5.7647 & TRN & \\
\hline CHEMBL1410714 & 688407 & 5.75 & 5.9261 & TRN & \\
\hline CHEMBL1402276 & 688407 & 4.9 & 6.1694 & TRN & \\
\hline CHEMBL1435075 & 688407 & 8.301 & 5.6586 & TST & \\
\hline CHEMBL1406781 & 688407 & 4.5 & 4.7824 & TST & \\
\hline CHEMBL1356480 & 688407 & 5.3 & 5.5196 & TRN & \\
\hline CHEMBL1515121 & 688407 & 5.4 & 6.0496 & TRN & \\
\hline CHEMBL1516188 & 688407 & 5.1 & 5.3016 & TRN & \\
\hline CHEMBL1593130 & 688407 & 6.7001 & 5.4461 & TST & \\
\hline CHEMBL1317851 & 688407 & 4.85 & 5.4983 & TRN & \\
\hline CHEMBL1551739 & 688407 & 7.5003 & 5.6152 & TRN & \\
\hline CHEMBL1353679 & 688407 & 8.4559 & 5.4836 & TRN & \\
\hline CHEMBL1551568 & 688407 & 8.1024 & 5.6319 & TRN & \\
\hline CHEMBL1443889 & 688407 & 4.95 & 5.0994 & TRN & \\
\hline CHEMBL1516250 & 688407 & 4.7 & 5.2575 & TST & \\
\hline CHEMBL1534030 & 688407 & 5.5 & 4.9876 & TRN & \\
\hline CHEMBL1565549 & 688407 & 6.7001 & 6.4899 & TRN & \\
\hline CHEMBL1080918 & 688407 & 4.65 & 5.4734 & TRN & \\
\hline CHEMBL1362294 & 688407 & 5.7 & 4.8354 & TRN & \\
\hline CHEMBL1337984 & 688407 & 5.9 & 6.4121 & TST & \\
\hline CHEMBL1374530 & 688407 & 7.4001 & 5.375 & TRN & \\
\hline CHEMBL1553518 & 688407 & 7.2503 & 5.3153 & TRN & \\
\hline CHEMBL1476100 & 688407 & 4.5 & 5.1852 & TST & \\
\hline CHEMBL1554523 & 688407 & 7.1002 & 6.4729 & TST & \\
\hline CHEMBL1601677 & 688407 & 4.7 & 5.6058 & TRN & \\
\hline CHEMBL1521128 & 688407 & 4.8 & 4.9787 & TRN & \\
\hline CHEMBL1593433 & 688407 & 4.9 & 5.5572 & TRN & \\
\hline CHEMBL1502502 & 688407 & 4.45 & 6.107 & TST & \\
\hline CHEMBL1315746 & 688407 & 7.3497 & 5.225 & TRN & \\
\hline
\end{tabular}




\begin{tabular}{|c|c|c|c|c|c|}
\hline \multicolumn{6}{|c|}{ Supplemental Table S2.txt } \\
\hline CHEMBL1508519 & 688407 & 5.35 & 5.1304 & TST & \\
\hline CHEMBL1358148 & 688407 & 7.2503 & 6.231 & TRN & \\
\hline CHEMBL1354327 & 688407 & 4.45 & 4.7643 & TRN & \\
\hline CHEMBL1434318 & 688407 & 7.4001 & 5.4053 & TST & \\
\hline CHEMBL1401550 & 688407 & 5.9 & 5.4534 & TRN & \\
\hline CHEMBL1410697 & 688407 & 5.05 & 5.5276 & TST & \\
\hline CHEMBL1592889 & 688407 & 4.5 & 5.1182 & TRN & \\
\hline CHEMBL1318033 & 688407 & 4.65 & 4.4066 & TST & \\
\hline CHEMBL1337699 & 688407 & 4.45 & 5.9167 & TRN & \\
\hline CHEMBL1480185 & 688407 & 4.45 & 5.6199 & TRN & \\
\hline CHEMBL1611268 & 688407 & 6.3 & 6.2968 & TRN & \\
\hline CHEMBL1568115 & 688407 & 4.5 & 5.7242 & TST & \\
\hline CHEMBL1316027 & 688407 & 4.6 & 5.7099 & TRN & \\
\hline CHEMBL1590798 & 688407 & 5.0 & 4.8759 & TRN & \\
\hline CHEMBL1533566 & 688407 & 4.9 & 5.4071 & TRN & \\
\hline CHEMBL1433423 & 688407 & 5.45 & 6.1395 & TRN & \\
\hline CHEMBL1593320 & 688407 & 5.9 & 5.3237 & TST & \\
\hline CHEMBL1318311 & 688407 & 4.8 & 5.0029 & TRN & \\
\hline CHEMBL1537679 & 688407 & 5.9 & 5.7613 & TST & \\
\hline CHEMBL1569355 & 688407 & 4.9 & 5.8815 & TRN & \\
\hline CHEMBL1356580 & 688407 & 5.0 & 5.0592 & TRN & \\
\hline CHEMBL1572735 & 688407 & 5.8 & 5.3508 & TRN & \\
\hline CHEMBL1514798 & 688407 & 4.95 & 5.3461 & TST & \\
\hline CHEMBL1357278 & 688407 & 4.5 & 5.1439 & TRN & \\
\hline CHEMBL2369223 & 688407 & 4.95 & 5.6125 & TST & \\
\hline CHEMBL1565552 & 688407 & 7.0 & 5.8186 & TRN & \\
\hline CHEMBL1512272 & 688407 & 8.301 & 6.1977 & TRN & \\
\hline CHEMBL1417981 & 688407 & 4.7 & 4.7504 & TST & \\
\hline CHEMBL1514055 & 688407 & 4.5 & 5.7931 & TST & \\
\hline CHEMBL1499966 & 688407 & 4.8 & 5.20100 & 00000000005 & TST \\
\hline CHEMBL1551700 & 688407 & 4.9 & 5.5134 & TRN & \\
\hline CHEMBL1330233 & 688407 & 5.4 & 5.36299 & 99999999995 & TRN \\
\hline CHEMBL1397115 & 688407 & 5.0 & 5.0798 & TRN & \\
\hline CHEMBL1527850 & 688407 & 8.1024 & 5.2065 & TRN & \\
\hline CHEMBL1561693 & 688407 & 4.5 & 4.7736 & TRN & \\
\hline CHEMBL1445701 & 688407 & 7.4001 & 6.0581 & TST & \\
\hline CHEMBL1358721 & 688407 & 4.6 & 5.5614 & TRN & \\
\hline CHEMBL1436013 & 688407 & 4.5 & 5.4613 & TRN & \\
\hline CHEMBL1335173 & 688407 & 4.85 & 5.5621 & TRN & \\
\hline CHEMBL1357996 & 688407 & 4.95 & 4.9913 & TRN & \\
\hline CHEMBL1476644 & 688407 & 6.8 & 6.8795 & TRN & \\
\hline CHEMBL1373263 & 688407 & 4.45 & 4.7661 & TRN & \\
\hline CHEMBL1358217 & 688407 & 5.9 & 6.4109 & TRN & \\
\hline CHEMBL1442560 & 688407 & 4.45 & 5.5028 & TST & \\
\hline CHEMBL1523965 & 688407 & 4.6 & 4.8516 & TRN & \\
\hline CHEMBL1369808 & 688407 & 4.6 & 5.9878 & TRN & \\
\hline CHEMBL1314249 & 688407 & 6.3 & 5.2574 & TRN & \\
\hline CHEMBL1518636 & 688407 & 4.45 & 5.062 & TRN & \\
\hline
\end{tabular}




\begin{tabular}{|c|c|c|c|c|}
\hline & & & oplement & al $\mathrm{Ta}$ \\
\hline CHEMBL1567040 & 688407 & 5.2 & 5.8167 & TRN \\
\hline CHEMBL1367801 & 688407 & 4.45 & 4.9895 & TRN \\
\hline CHEMBL1417436 & 688407 & 5.1 & 5.9647 & TRN \\
\hline CHEMBL1496228 & 688407 & 5.9 & 5.3104 & TRN \\
\hline CHEMBL1435362 & 688407 & 4.45 & 5.6526 & TST \\
\hline CHEMBL1595721 & 688407 & 7.1002 & 5.4595 & TRN \\
\hline CHEMBL1495339 & 688407 & 4.6 & 5.3908 & TRN \\
\hline CHEMBL1521327 & 688407 & 4.7 & 5.5839 & TRN \\
\hline CHEMBL1355427 & 688407 & 4.5 & 6.7053 & TRN \\
\hline CHEMBL1473819 & 688407 & 4.7 & 5.5702 & TRN \\
\hline CHEMBL1514154 & 688407 & 5.4 & 5.5876 & TRN \\
\hline CHEMBL1350345 & 688407 & 5.55 & 5.9996 & TRN \\
\hline CHEMBL1560549 & 688407 & 4.5 & 5.3455 & TST \\
\hline CHEMBL1437001 & 688407 & 4.5 & 4.8948 & TRN \\
\hline CHEMBL1319437 & 688407 & 4.5 & 4.2921 & TST \\
\hline CHEMBL1515799 & 688407 & 4.65 & 5.8797 & TST \\
\hline CHEMBL1435561 & 688407 & 6.6 & 5.3905 & TST \\
\hline CHEMBL1357299 & 688407 & 8.0 & 5.6364 & TRN \\
\hline CHEMBL1399507 & 688407 & 4.7 & 5.1553 & TST \\
\hline CHEMBL1899419 & 688407 & 5.3 & 5.5341 & TRN \\
\hline CHEMBL1527959 & 688407 & 6.4 & 4.9891 & TRN \\
\hline CHEMBL1565629 & 688407 & 5.6 & 6.1694 & TRN \\
\hline CHEMBL1591611 & 688407 & 7.3002 & 5.5074 & TST \\
\hline CHEMBL1325308 & 688407 & 5.4 & 6.0404 & TRN \\
\hline CHEMBL1359129 & 688407 & 4.45 & 5.7158 & TST \\
\hline CHEMBL1552887 & 688407 & 4.8 & 5.0701 & TST \\
\hline CHEMBL1567239 & 688407 & 7.0 & 6.3156 & TRN \\
\hline CHEMBL1450474 & 688407 & 6.1 & 5.9314 & TRN \\
\hline CHEMBL1356222 & 688407 & 4.5 & 5.3917 & TST \\
\hline CHEMBL1331895 & 688407 & 5.4 & 5.9755 & TRN \\
\hline CHEMBL1355556 & 688407 & 5.35 & 5.8177 & TRN \\
\hline CHEMBL1516203 & 688407 & 4.7 & 5.7674 & TRN \\
\hline CHEMBL1437662 & 688407 & 4.5 & 5.5292 & TRN \\
\hline CHEMBL1375336 & 688407 & 4.5 & 5.2216 & TRN \\
\hline CHEMBL1377145 & 688407 & 5.2 & 4.8278 & TRN \\
\hline CHEMBL1396487 & 688407 & 6.1 & 5.5654 & TRN \\
\hline CHEMBL1405548 & 688407 & 6.0 & 5.4566 & TRN \\
\hline CHEMBL1598968 & 688407 & 4.75 & 5.2927 & TST \\
\hline CHEMBL1334056 & 688407 & 7.3002 & 5.6711 & TRN \\
\hline CHEMBL1400330 & 688407 & 6.2 & 5.7662 & TRN \\
\hline CHEMBL1359244 & 688407 & 4.45 & 5.433 & TRN \\
\hline CHEMBL1572201 & 688407 & 4.7 & 5.3731 & TRN \\
\hline CHEMBL1550909 & 688407 & 5.6 & 5.7403 & TST \\
\hline CHEMBL1324609 & 688407 & 8.301 & 6.1407 & TST \\
\hline CHEMBL1593616 & 688407 & 7.4001 & 5.5052 & TRN \\
\hline CHEMBL374236 & 688407 & 4.45 & 5.6221 & TRN \\
\hline CHEMBL1515197 & 688407 & 4.95 & 4.5266 & TRN \\
\hline CHEMBL1606350 & 688407 & 5.8 & 5.8917 & TRN \\
\hline
\end{tabular}




\begin{tabular}{|c|c|c|c|c|c|}
\hline \multicolumn{6}{|c|}{ Supplemental Table S2.txt } \\
\hline CHEMBL1444261 & 688407 & 5.4 & 5.4129 & TRN & \\
\hline CHEMBL1554176 & 688407 & 4.45 & 5.6633 & TRN & \\
\hline CHEMBL1527591 & 688407 & 5.55 & 6.1509 & TRN & \\
\hline CHEMBL1399937 & 688407 & 4.6 & 5.1905 & TRN & \\
\hline CHEMBL1317891 & 688407 & 8.301 & 5.9177 & TRN & \\
\hline CHEMBL1609724 & 688407 & 4.7 & 4.7085 & TRN & \\
\hline CHEMBL1401524 & 688407 & 4.95 & 4.97199 & 99999999995 & TRN \\
\hline CHEMBL1554253 & 688407 & 4.9 & 4.5897 & TRN & \\
\hline CHEMBL1397300 & 688407 & 4.8 & 5.9385 & TRN & \\
\hline CHEMBL1326138 & 688407 & 5.8 & 5.4942 & TRN & \\
\hline CHEMBL1479512 & 688407 & 6.5 & 6.0635 & TRN & \\
\hline CHEMBL1541530 & 688407 & 4.5 & 5.2566 & TRN & \\
\hline CHEMBL1356411 & 688407 & 4.5 & 5.3881 & TRN & \\
\hline CHEMBL 1451500 & 688407 & 5.3 & 5.94 & TRN & \\
\hline CHEMBL1328421 & 688407 & 6.4 & 5.7438 & TRN & \\
\hline CHEMBL1398429 & 688407 & 5.2 & 5.4256 & TRN & \\
\hline CHEMBL1314437 & 688407 & 4.8 & 5.4511 & TRN & \\
\hline CHEMBL1437694 & 688407 & 5.85 & 5.3686 & TST & \\
\hline CHEMBL1361510 & 688407 & 4.5 & 5.4351 & TST & \\
\hline CHEMBL1437468 & 688407 & 7.3497 & 6.61 & TRN & \\
\hline CHEMBL1356308 & 688407 & 6.3 & 5.0339 & TST & \\
\hline CHEMBL1514663 & 688407 & 4.8 & 6.2112 & TRN & \\
\hline CHEMBL1574866 & 688407 & 4.9 & 5.2111 & TRN & \\
\hline CHEMBL1518942 & 688407 & 5.65 & 5.5577 & TRN & \\
\hline CHEMBL1399211 & 688407 & 4.5 & 5.6938 & TST & \\
\hline CHEMBL1437014 & 688407 & 5.2 & 5.6656 & TRN & \\
\hline CHEMBL1357951 & 688407 & 4.9 & 5.6604 & TST & \\
\hline CHEMBL1355939 & 688407 & 7.699 & 6.3236 & TRN & \\
\hline CHEMBL1472806 & 688407 & 4.8 & 5.8126 & TRN & \\
\hline CHEMBL1454626 & 688407 & 5.1 & 4.7435 & TST & \\
\hline CHEMBL1473235 & 688407 & 5.0 & 5.4001 & TRN & \\
\hline CHEMBL1601644 & 688407 & 5.1 & 5.4613 & TRN & \\
\hline CHEMBL1405974 & 688407 & 6.5 & 6.2542 & TST & \\
\hline CHEMBL1492980 & 688407 & 4.75 & 4.9661 & TRN & \\
\hline CHEMBL1317149 & 688407 & 5.25 & 5.851 & TRN & \\
\hline CHEMBL1343078 & 688407 & 5.8 & 6.2232 & TST & \\
\hline CHEMBL1374010 & 688407 & 4.45 & 5.5964 & TRN & \\
\hline CHEMBL1597728 & 688407 & 5.0 & 5.7516 & TRN & \\
\hline CHEMBL1559088 & 688407 & 4.8 & 4.7792 & TRN & \\
\hline CHEMBL1445158 & 688407 & 5.4 & 6.106 & TRN & \\
\hline CHEMBL1473033 & 688407 & 4.95 & 6.3032 & TRN & \\
\hline CHEMBL1304044 & 688407 & 5.5 & 5.8592 & TST & \\
\hline CHEMBL1373600 & 688407 & 5.0 & 5.5481 & TRN & \\
\hline CHEMBL1335533 & 688407 & 5.1 & 6.2255 & TST & \\
\hline CHEMBL1492848 & 688407 & 4.45 & 5.0367 & TRN & \\
\hline CHEMBL1367624 & 688407 & 6.2 & 5.8042 & TRN & \\
\hline CHEMBL1418010 & 688407 & 6.4 & 4.8967 & TRN & \\
\hline CHEMBL1478012 & 688407 & 4.45 & 4.9366 & TRN & \\
\hline
\end{tabular}




\begin{tabular}{|c|c|c|c|c|}
\hline \multicolumn{5}{|c|}{ Supplemental Table S2.txt } \\
\hline CHEMBL1485936 & 688407 & 4.5 & 6.3668 & TRN \\
\hline CHEMBL1591653 & 688407 & 4.5 & 4.7075 & TRN \\
\hline CHEMBL1570623 & 688407 & 5.1 & 5.8294 & TRN \\
\hline CHEMBL1564022 & 688407 & 5.1 & 6.0102 & TRN \\
\hline CHEMBL1553722 & 688407 & 7.3002 & 5.1807 & TST \\
\hline CHEMBL1367939 & 688407 & 4.9 & 5.7332 & TST \\
\hline CHEMBL1372777 & 688407 & 4.5 & 4.9608 & TRN \\
\hline CHEMBL1513349 & 688407 & 4.9 & 6.4185 & TRN \\
\hline CHEMBL1327703 & 688407 & 4.8 & 5.3255 & TRN \\
\hline CHEMBL1443657 & 688407 & 7.5498 & 5.0989 & TRN \\
\hline CHEMBL1343754 & 688407 & 8.301 & 6.2322 & TST \\
\hline CHEMBL1436840 & 688407 & 4.9 & 5.1255 & TRN \\
\hline CHEMBL1355275 & 688407 & 7.2 & 5.5972 & TRN \\
\hline CHEMBL1476970 & 688407 & 4.5 & 4.8727 & TRN \\
\hline CHEMBL1483703 & 688407 & 5.5 & 6.0192 & TRN \\
\hline CHEMBL1512579 & 688407 & 6.0 & 5.1972 & TRN \\
\hline CHEMBL1333721 & 688407 & 6.8 & 5.7195 & TRN \\
\hline CHEMBL1475232 & 688407 & 8.1024 & 5.7592 & TRN \\
\hline CHEMBL1436207 & 688407 & 6.8 & 5.6058 & TRN \\
\hline CHEMBL1570234 & 688407 & 5.2 & 5.6978 & TRN \\
\hline CHEMBL1477629 & 688407 & 4.6 & 5.2698 & TRN \\
\hline CHEMBL1409336 & 688407 & 4.6 & 4.5545 & TRN \\
\hline CHEMBL1478843 & 688407 & 4.9 & 6.6834 & TST \\
\hline CHEMBL1338213 & 688407 & 8.3979 & 6.6627 & TRN \\
\hline CHEMBL1365493 & 688407 & 5.2 & 6.4501 & TST \\
\hline CHEMBL1335962 & 688407 & 6.8 & 5.6481 & TRN \\
\hline CHEMBL1416902 & 688407 & 5.35 & 4.9712 & TRN \\
\hline CHEMBL1401279 & 688407 & 7.2 & 5.3986 & TST \\
\hline CHEMBL1528359 & 688407 & 8.4949 & 5.3973 & TST \\
\hline CHEMBL1454795 & 688407 & 4.5 & 5.6972 & TRN \\
\hline CHEMBL1395966 & 688407 & 4.8 & 5.5021 & TST \\
\hline CHEMBL1515955 & 688407 & 4.5 & 4.8846 & TRN \\
\hline CHEMBL1324998 & 688407 & 4.5 & 4.6897 & TRN \\
\hline CHEMBL1473364 & 688407 & 4.9 & 5.8951 & TRN \\
\hline CHEMBL1494270 & 688407 & 4.5 & 4.8172 & TRN \\
\hline CHEMBL1318113 & 688407 & 7.0 & 5.5638 & TRN \\
\hline CHEMBL1445232 & 688407 & 4.8 & 5.3216 & TRN \\
\hline CHEMBL1534672 & 688407 & 4.6 & 5.62 & TRN \\
\hline CHEMBL1366731 & 688407 & 4.9 & 5.7328 & TST \\
\hline CHEMBL1439362 & 688407 & 4.45 & 5.4329 & TRN \\
\hline CHEMBL1373546 & 688407 & 4.95 & 5.7391 & TRN \\
\hline CHEMBL1402351 & 688407 & 4.85 & 4.1929 & TRN \\
\hline CHEMBL1436251 & 688407 & 5.1 & 5.0959 & TRN \\
\hline CHEMBL1512130 & 688407 & 4.5 & 5.5812 & TST \\
\hline CHEMBL1555531 & 688407 & 4.95 & 5.6042 & TRN \\
\hline CHEMBL1420252 & 688407 & 4.75 & 5.0936 & TST \\
\hline CHEMBL1372429 & 688407 & 4.9 & 5.6694 & TRN \\
\hline CHEMBL1475318 & 688407 & 6.3 & 6.256 & TRN \\
\hline
\end{tabular}




\begin{tabular}{|c|c|c|c|c|c|}
\hline & & & & & \\
\hline CHEMBL1344115 & 688407 & 4.5 & 5.2478 & TST & \\
\hline CHEMBL1492648 & 688407 & 4.8 & 4.7444 & TRN & \\
\hline CHEMBL1395525 & 688407 & 8.2007 & 5.5703 & TST & \\
\hline CHEMBL3199594 & 688407 & 4.45 & 5.7376 & TST & \\
\hline CHEMBL1398504 & 688407 & 4.7 & 5.38899 & 9999999999 & TST \\
\hline CHEMBL1597099 & 688407 & 4.8 & 5.4446 & TRN & \\
\hline CHEMBL1437677 & 688407 & 4.5 & 4.9708 & TRN & \\
\hline CHEMBL1591641 & 688407 & 5.3 & 5.2566 & TRN & \\
\hline CHEMBL1475651 & 688407 & 8.301 & 5.5842 & TRN & \\
\hline CHEMBL1361793 & 688407 & 4.95 & 4.3616 & TRN & \\
\hline CHEMBL1525243 & 688407 & 4.6 & 5.1334 & TRN & \\
\hline CHEMBL1482420 & 688407 & 4.9 & 4.7016 & TRN & \\
\hline CHEMBL1570512 & 688407 & 4.65 & 4.5308 & TRN & \\
\hline CHEMBL1516318 & 688407 & 4.7 & 5.1395 & TST & \\
\hline CHEMBL1601796 & 688407 & 5.6 & 5.6633 & TST & \\
\hline CHEMBL1361815 & 688407 & 4.95 & 4.7879 & TRN & \\
\hline CHEMBL1317691 & 688407 & 8.0 & 5.6906 & TRN & \\
\hline CHEMBL1397514 & 688407 & 5.45 & 5.3033 & TRN & \\
\hline CHEMBL1445081 & 688407 & 4.5 & 5.2471 & TRN & \\
\hline CHEMBL1358577 & 688407 & 4.45 & 5.1426 & TST & \\
\hline CHEMBL1335492 & 688407 & 4.5 & 5.2818 & TST & \\
\hline CHEMBL1413568 & 688407 & 4.8 & 5.5264 & TRN & \\
\hline CHEMBL1530435 & 688407 & 6.3 & 5.1993 & TRN & \\
\hline CHEMBL1590577 & 688407 & 8.0 & 4.8284 & TST & \\
\hline CHEMBL1435125 & 688407 & 6.2 & 4.9957 & TRN & \\
\hline CHEMBL1339742 & 688407 & 4.8 & 5.5085 & TST & \\
\hline CHEMBL1551484 & 688407 & 6.1 & 5.4104 & TRN & \\
\hline CHEMBL1515552 & 688407 & 4.5 & 5.365 & TRN & \\
\hline CHEMBL1414911 & 688407 & 7.3002 & 5.2409 & TRN & \\
\hline CHEMBL1434541 & 688407 & 4.5 & 4.9903 & TRN & \\
\hline CHEMBL1492456 & 688407 & 4.45 & 5.6992 & TST & \\
\hline CHEMBL1533540 & 688407 & 4.5 & 5.1638 & TRN & \\
\hline CHEMBL1322112 & 688407 & 5.1 & 4.9437 & TRN & \\
\hline CHEMBL1415664 & 688407 & 5.1 & 5.4586 & TRN & \\
\hline CHEMBL1336947 & 688407 & 4.9 & 4.8131 & TRN & \\
\hline CHEMBL1397468 & 688407 & 5.9 & 5.6584 & TST & \\
\hline CHEMBL1591237 & 688407 & 5.6 & 5.6283 & TRN & \\
\hline CHEMBL1433555 & 688407 & 4.65 & 4.7449 & TRN & \\
\hline CHEMBL1360522 & 688407 & 4.7 & 5.1554 & TRN & \\
\hline CHEMBL1409529 & 688407 & 4.7 & 6.0146 & TRN & \\
\hline CHEMBL1413730 & 688407 & 6.5 & 6.0236 & TST & \\
\hline CHEMBL1608241 & 688407 & 4.45 & 4.8076 & TRN & \\
\hline CHEMBL1591462 & 688407 & 4.9 & 5.0821 & TRN & \\
\hline CHEMBL1355134 & 688407 & 4.5 & 5.716 & TST & \\
\hline CHEMBL1357797 & 688407 & 4.8 & 5.1892 & TRN & \\
\hline CHEMBL1316307 & 688407 & 4.7 & 4.938 & TRN & \\
\hline CHEMBL1601546 & 688407 & 4.7 & 4.6367 & TRN & \\
\hline CHEMBL1553818 & 688407 & 6.4 & 5.45700 & 2000000001 & TRN \\
\hline & & & & 22342 & \\
\hline
\end{tabular}




\begin{tabular}{|c|c|c|c|c|c|}
\hline \multicolumn{6}{|c|}{ Supplemental Table S2.txt } \\
\hline CHEMBL1317756 & 688407 & 6.8 & 5.4611 & TRN & \\
\hline CHEMBL1521751 & 688407 & 5.4 & 6.1204 & TRN & \\
\hline CHEMBL1315123 & 688407 & 7.699 & 5.4733 & TST & \\
\hline CHEMBL1593766 & 688407 & 5.3 & 4.4535 & TST & \\
\hline CHEMBL1396894 & 688407 & 4.95 & 4.902 & TRN & \\
\hline CHEMBL1529030 & 688407 & 4.7 & 5.0532 & TRN & \\
\hline CHEMBL1513637 & 688407 & 5.8 & 6.2528 & TRN & \\
\hline CHEMBL1315044 & 688407 & 4.7 & 5.0283 & TRN & \\
\hline CHEMBL1527663 & 688407 & 4.7 & 5.3419 & TRN & \\
\hline CHEMBL1476020 & 688407 & 4.6 & 4.8921 & TRN & \\
\hline CHEMBL1518698 & 688407 & 4.7 & 4.6017 & TRN & \\
\hline CHEMBL1394411 & 688407 & 5.4 & 5.3132 & TST & \\
\hline CHEMBL1555053 & 688407 & 5.0 & 5.1822 & TRN & \\
\hline CHEMBL1397347 & 688407 & 4.5 & 4.9289 & TRN & \\
\hline CHEMBL1576917 & 688407 & 4.5 & 5.9116 & TST & \\
\hline CHEMBL1354329 & 688407 & 5.45 & 6.0159 & TST & \\
\hline CHEMBL1443592 & 688407 & 5.5 & 5.7323 & TRN & \\
\hline CHEMBL1476761 & 688407 & 4.85 & 5.8538 & TST & \\
\hline CHEMBL1512686 & 688407 & 4.75 & 5.2735 & TRN & \\
\hline CHEMBL1437548 & 688407 & 7.0 & 5.0958 & TRN & \\
\hline CHEMBL1590072 & 688407 & 5.0 & 4.6641 & TRN & \\
\hline CHEMBL1515192 & 688407 & 7.6498 & 5.37700 & 0000000001 & TRN \\
\hline CHEMBL1408374 & 688407 & 4.75 & 6.0669 & TST & \\
\hline CHEMBL1440569 & 688407 & 4.9 & 5.8616 & TST & \\
\hline CHEMBL1517005 & 688407 & 4.8 & 5.6209 & TRN & \\
\hline CHEMBL1394692 & 688407 & 7.3002 & 5.1997 & TRN & \\
\hline CHEMBL1354811 & 688407 & 4.6 & 5.5339 & TRN & \\
\hline CHEMBL1551348 & 688407 & 4.5 & 4.7529 & TST & \\
\hline CHEMBL1376497 & 688407 & 5.1 & 4.7929 & TRN & \\
\hline CHEMBL1590029 & 688407 & 5.0 & 4.727 & TRN & \\
\hline CHEMBL1437000 & 688407 & 4.45 & 5.2555 & TST & \\
\hline CHEMBL1481599 & 688407 & 6.2 & 6.5273 & TRN & \\
\hline CHEMBL1593372 & 688407 & 5.3 & 5.7519 & TRN & \\
\hline CHEMBL1452502 & 688407 & 4.9 & 5.7668 & TRN & \\
\hline CHEMBL1317482 & 688407 & 5.25 & 5.6316 & TRN & \\
\hline CHEMBL1408247 & 688407 & 6.1 & 5.3509 & TST & \\
\hline CHEMBL1362428 & 688407 & 5.7 & 5.403 & TRN & \\
\hline CHEMBL1398695 & 688407 & 4.5 & 4.4868 & TRN & \\
\hline CHEMBL1377414 & 688407 & 4.5 & 4.5021 & TRN & \\
\hline CHEMBL1409276 & 688407 & 4.5 & 5.6159 & TST & \\
\hline CHEMBL1378843 & 688407 & 4.8 & 5.0872 & TRN & \\
\hline CHEMBL1478663 & 688407 & 4.6 & 5.1972 & TRN & \\
\hline CHEMBL548681 & 688407 & 5.5 & 5.0896 & TRN & \\
\hline CHEMBL1593939 & 688407 & 4.5 & 4.7807 & TRN & \\
\hline CHEMBL1553869 & 688407 & 4.9 & 5.2057 & TRN & \\
\hline CHEMBL1435249 & 688407 & 7.8508 & 6.5489 & TRN & \\
\hline CHEMBL1357964 & 688407 & 4.6 & 5.6133 & TRN & \\
\hline CHEMBL1319095 & 688407 & 4.9 & 5.9738 & TRN & \\
\hline
\end{tabular}




\begin{tabular}{|c|c|c|c|c|c|}
\hline \\
\hline CHEMBL1591364 & 688407 & 5.0 & 5.5953 & TRN & \\
\hline CHEMBL1519406 & 688407 & 5.0 & 5.5775 & TST & \\
\hline CHEMBL1406675 & 688407 & 4.85 & 5.586 & TST & \\
\hline CHEMBL1569287 & 688407 & 4.75 & 5.2956 & TRN & \\
\hline CHEMBL1476725 & 688407 & 4.8 & 4.91100 & 00000000005 & TRN \\
\hline CHEMBL1325144 & 688407 & 5.25 & 5.7494 & TRN & \\
\hline CHEMBL1441621 & 688407 & 8.2007 & 5.0071 & TRN & \\
\hline CHEMBL1364285 & 688407 & 5.2 & 5.8805 & TRN & \\
\hline CHEMBL1421493 & 688407 & 4.7 & 5.3025 & TRN & \\
\hline CHEMBL1435526 & 688407 & 4.95 & 5.45100 & 00000000005 & TRN \\
\hline CHEMBL1435545 & 688407 & 6.5 & 5.2508 & TRN & \\
\hline CHEMBL1475535 & 688407 & 5.6 & 5.7732 & TRN & \\
\hline CHEMBL1501198 & 688407 & 4.9 & 5.4393 & TRN & \\
\hline CHEMBL1491191 & 688407 & 4.85 & 5.0216 & TRN & \\
\hline CHEMBL1600279 & 688407 & 4.6 & 5.2399 & TRN & \\
\hline CHEMBL3195192 & 688407 & 7.699 & 5.7149 & TST & \\
\hline CHEMBL1597562 & 688407 & 4.5 & 4.8988 & TRN & \\
\hline CHEMBL1332685 & 688407 & 4.9 & 5.3871 & TRN & \\
\hline CHEMBL1513373 & 688407 & 5.2 & 5.2883 & TRN & \\
\hline CHEMBL1411299 & 688407 & 7.2 & 5.5381 & TRN & \\
\hline CHEMBL1607889 & 688407 & 7.3002 & 6.0681 & TRN & \\
\hline CHEMBL1511994 & 688407 & 8.3979 & 5.9313 & TST & \\
\hline CHEMBL 2001857 & 688407 & 7.5003 & 5.3227 & TST & \\
\hline CHEMBL1433692 & 688407 & 4.9 & 5.1289 & TRN & \\
\hline CHEMBL1436245 & 688407 & 4.9 & 4.6195 & TRN & \\
\hline CHEMBL1590774 & 688407 & 7.3002 & 5.7682 & TRN & \\
\hline CHEMBL1439740 & 688407 & 5.1 & 5.9569 & TST & \\
\hline CHEMBL1473764 & 688407 & 4.8 & 6.1414 & TST & \\
\hline CHEMBL1434674 & 688407 & 8.301 & 6.1386 & TRN & \\
\hline CHEMBL1436867 & 688407 & 4.9 & 5.5234 & TRN & \\
\hline CHEMBL1367795 & 688407 & 5.8 & 5.6976 & TRN & \\
\hline CHEMBL1553478 & 688407 & 7.699 & 6.3239 & TRN & \\
\hline CHEMBL1473077 & 688407 & 5.85 & 6.6464 & TRN & \\
\hline CHEMBL1375893 & 688407 & 5.1 & 6.4157 & TST & \\
\hline CHEMBL1594817 & 688407 & 4.5 & 5.5339 & TRN & \\
\hline CHEMBL1608432 & 688407 & 7.6003 & 5.525 & TRN & \\
\hline CHEMBL1407161 & 688407 & 4.85 & 4.9166 & TRN & \\
\hline CHEMBL1552911 & 688407 & 6.0 & 5.3122 & TRN & \\
\hline CHEMBL1356246 & 688407 & 4.6 & 5.3651 & TRN & \\
\hline CHEMBL1472608 & 688407 & 7.0 & 5.7121 & TRN & \\
\hline CHEMBL579550 & 688407 & 5.6 & 4.8524 & TST & \\
\hline CHEMBL1454806 & 688407 & 6.1 & 5.8024 & TRN & \\
\hline CHEMBL1554801 & 688407 & 4.45 & 5.295 & TST & \\
\hline CHEMBL1423555 & 688407 & 5.25 & 5.5836 & TST & \\
\hline CHEMBL1413171 & 688407 & 4.65 & 5.7884 & TRN & \\
\hline CHEMBL1564109 & 688407 & 4.9 & 5.0047 & TRN & \\
\hline CHEMBL1593916 & 688407 & 4.65 & 4.9074 & TRN & \\
\hline CHEMBL1401409 & 688407 & 4.95 & 5.4121 & TRN & \\
\hline
\end{tabular}




\begin{tabular}{|c|c|c|c|c|}
\hline & & & pplement & al $\mathrm{T}$ \\
\hline CHEMBL1515356 & 688407 & 4.5 & 5.0493 & TRN \\
\hline CHEMBL1566498 & 688407 & 5.8 & 6.3091 & TRN \\
\hline CHEMBL1355661 & 688407 & 5.1 & 5.0348 & TRN \\
\hline CHEMBL1435354 & 688407 & 8.301 & 5.4717 & TRN \\
\hline CHEMBL1315331 & 688407 & 5.8 & 5.7042 & TST \\
\hline CHEMBL1476900 & 688407 & 5.7 & 5.3858 & TRN \\
\hline CHEMBL1590790 & 688407 & 5.2 & 5.8249 & TRN \\
\hline CHEMBL1590717 & 688407 & 4.8 & 4.6637 & TRN \\
\hline CHEMBL1395837 & 688407 & 4.55 & 4.7328 & TRN \\
\hline CHEMBL1434142 & 688407 & 7.3002 & 6.1435 & TRN \\
\hline CHEMBL1403637 & 688407 & 5.3 & 6.4431 & TST \\
\hline CHEMBL1377304 & 688407 & 5.0 & 6.0702 & TRN \\
\hline CHEMBL1440544 & 688407 & 4.5 & 5.3959 & TST \\
\hline CHEMBL1355283 & 688407 & 8.301 & 5.9659 & TRN \\
\hline CHEMBL1569155 & 688407 & 7.5498 & 5.487 & TST \\
\hline CHEMBL1361775 & 688407 & 5.1 & 5.5338 & TRN \\
\hline CHEMBL1516494 & 688407 & 8.0 & 5.6327 & TST \\
\hline CHEMBL1525495 & 688407 & 4.65 & 5.7498 & TST \\
\hline CHEMBL1590470 & 688407 & 6.7001 & 5.3634 & TST \\
\hline CHEMBL1459604 & 688407 & 6.5501 & 6.2974 & TST \\
\hline CHEMBL1513791 & 688407 & 4.45 & 5.3395 & TRN \\
\hline CHEMBL1557082 & 688407 & 4.7 & 5.7807 & TRN \\
\hline CHEMBL1375762 & 688407 & 4.5 & 5.8356 & TST \\
\hline CHEMBL1516315 & 688407 & 6.1 & 5.3921 & TRN \\
\hline CHEMBL1563526 & 688407 & 4.5 & 6.2313 & TRN \\
\hline CHEMBL1508591 & 688407 & 4.8 & 5.8678 & TST \\
\hline CHEMBL1335301 & 688407 & 5.55 & 6.0503 & TST \\
\hline CHEMBL1473563 & 688407 & 7.8996 & 5.3256 & TST \\
\hline CHEMBL602150 & 688407 & 5.75 & 5.1665 & TRN \\
\hline CHEMBL1598736 & 688407 & 5.4 & 5.9033 & TRN \\
\hline CHEMBL1513260 & 688407 & 5.0 & 5.1725 & TST \\
\hline CHEMBL1355333 & 688407 & 7.6003 & 5.8761 & TRN \\
\hline CHEMBL1457225 & 688407 & 5.8 & 4.7851 & TRN \\
\hline CHEMBL1535698 & 688407 & 5.7 & 6.0471 & TST \\
\hline CHEMBL1502098 & 688407 & 4.8 & 4.769 & TRN \\
\hline CHEMBL1479545 & 688407 & 4.7 & 5.1005 & TST \\
\hline CHEMBL1316661 & 688407 & 4.9 & 5.3624 & TRN \\
\hline CHEMBL1396810 & 688407 & 4.9 & 4.9021 & TRN \\
\hline CHEMBL1357582 & 688407 & 4.95 & 5.5138 & TRN \\
\hline CHEMBL1472951 & 688407 & 6.5 & 6.3872 & TRN \\
\hline CHEMBL1518956 & 688407 & 5.9 & 5.4195 & TST \\
\hline CHEMBL602718 & 688407 & 5.05 & 5.2314 & TST \\
\hline CHEMBL1393523 & 688407 & 6.0 & 5.185 & TST \\
\hline CHEMBL1442780 & 688407 & 5.4 & 5.4604 & TST \\
\hline CHEMBL1473756 & 688407 & 4.7 & 5.5716 & TST \\
\hline CHEMBL1422097 & 688407 & 4.8 & 5.4224 & TST \\
\hline CHEMBL1374006 & 688407 & 5.1 & 5.7476 & TRN \\
\hline CHEMBL1314234 & 688407 & 4.9 & 6.157 & TRN \\
\hline
\end{tabular}




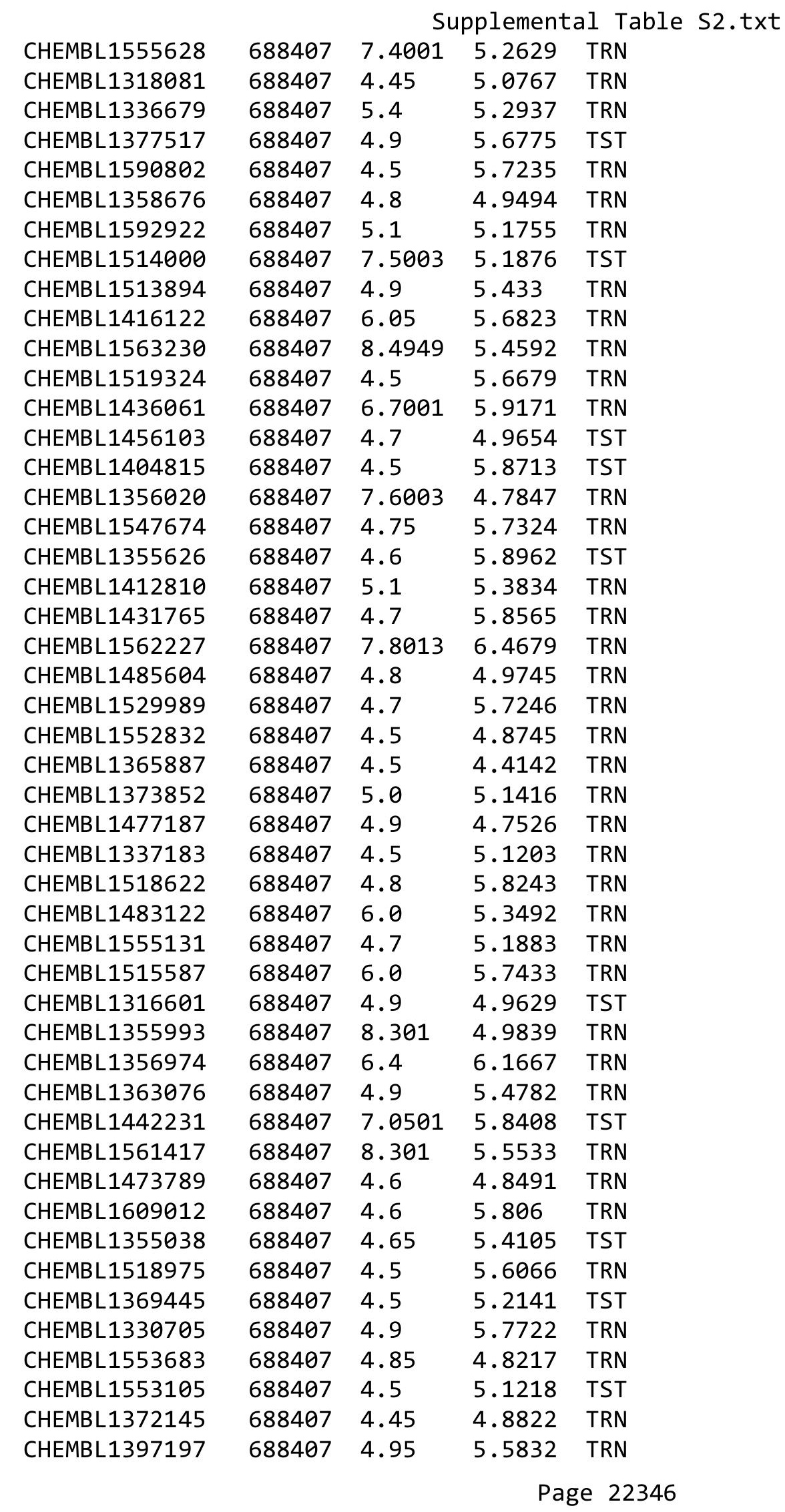




\begin{tabular}{|c|c|c|c|c|}
\hline \multicolumn{5}{|c|}{ Supplemental Table S2.txt } \\
\hline CHEMBL1481911 & 688407 & 4.5 & 5.3147 & TRN \\
\hline CHEMBL1446140 & 688407 & 4.5 & 4.7704 & TRN \\
\hline CHEMBL1455215 & 688407 & 7.699 & 5.7433 & TRN \\
\hline CHEMBL1437970 & 688407 & 4.5 & 5.7751 & TRN \\
\hline CHEMBL1483161 & 688407 & 4.45 & 5.1877 & TST \\
\hline CHEMBL1568535 & 688407 & 6.4 & 5.522 & TST \\
\hline CHEMBL1407036 & 688407 & 4.9 & 5.484 & TRN \\
\hline CHEMBL1513589 & 688407 & 4.5 & 5.4785 & TRN \\
\hline CHEMBL1595737 & 688407 & 4.5 & 5.2655 & TRN \\
\hline CHEMBL1414686 & 688407 & 5.1 & 6.0277 & TST \\
\hline CHEMBL1590957 & 688407 & 5.55 & 5.2869 & TRN \\
\hline CHEMBL1514074 & 688407 & 4.9 & 5.1144 & TRN \\
\hline CHEMBL1557282 & 688407 & 4.5 & 5.8072 & TRN \\
\hline CHEMBL1434058 & 688407 & 4.7 & 5.5428 & TST \\
\hline CHEMBL1531385 & 688407 & 4.7 & 5.3428 & TRN \\
\hline CHEMBL1572069 & 688407 & 4.45 & 5.9859 & TRN \\
\hline CHEMBL1553014 & 688407 & 4.85 & 5.1998 & TRN \\
\hline CHEMBL1409103 & 688407 & 4.75 & 5.1723 & TRN \\
\hline CHEMBL1512892 & 688407 & 4.45 & 6.1406 & TRN \\
\hline CHEMBL1531810 & 688407 & 4.95 & 5.5626 & TRN \\
\hline CHEMBL1445117 & 688407 & 6.1 & 5.7964 & TST \\
\hline CHEMBL1435463 & 688407 & 4.6 & 6.0177 & TRN \\
\hline CHEMBL1565641 & 688407 & 4.5 & 5.2715 & TRN \\
\hline CHEMBL1590708 & 688407 & 5.5 & 5.0776 & TRN \\
\hline CHEMBL1525652 & 688407 & 4.5 & 5.7889 & TRN \\
\hline CHEMBL1337979 & 688407 & 5.0 & 5.4186 & TRN \\
\hline CHEMBL1368503 & 688407 & 4.7 & 4.9444 & TRN \\
\hline CHEMBL1413259 & 688407 & 8.301 & 5.7961 & TST \\
\hline CHEMBL1343751 & 688407 & 7.3002 & 6.1336 & TRN \\
\hline CHEMBL1364908 & 688407 & 5.8 & 5.4463 & TST \\
\hline CHEMBL1399241 & 688407 & 4.5 & 4.4129 & TRN \\
\hline CHEMBL1336441 & 688407 & 4.45 & 5.6885 & TRN \\
\hline CHEMBL1331325 & 688407 & 8.2007 & 5.7444 & TRN \\
\hline CHEMBL1510976 & 688407 & 8.3979 & 5.0422 & TST \\
\hline CHEMBL1513147 & 688407 & 4.7 & 5.1113 & TRN \\
\hline CHEMBL1364332 & 688407 & 4.8 & 5.9872 & TST \\
\hline CHEMBL1357390 & 688407 & 6.9 & 5.5806 & TRN \\
\hline CHEMBL1552786 & 688407 & 7.8996 & 5.4172 & TST \\
\hline CHEMBL1355230 & 688407 & 5.25 & 4.9397 & TST \\
\hline CHEMBL1355598 & 688407 & 6.5 & 5.9406 & TRN \\
\hline CHEMBL1320864 & 688407 & 4.45 & 5.7363 & TRN \\
\hline CHEMBL1572839 & 688407 & 8.0 & 5.5996 & TRN \\
\hline CHEMBL1324580 & 688407 & 8.2007 & 5.4755 & TRN \\
\hline CHEMBL1433479 & 688407 & 6.8 & 5.0191 & TRN \\
\hline CHEMBL1512891 & 688407 & 7.3002 & 6.4854 & TRN \\
\hline CHEMBL1320967 & 688407 & 8.301 & 5.7225 & TST \\
\hline CHEMBL1398274 & 688407 & 4.5 & 4.7478 & TRN \\
\hline CHEMBL1476692 & 688407 & 4.9 & 5.5297 & TRN \\
\hline
\end{tabular}




\begin{tabular}{|c|c|c|c|c|c|}
\hline \multicolumn{6}{|c|}{ Supplemental Table S2.txt } \\
\hline CHEMBL1396455 & 688407 & 4.65 & 4.2442 & TRN & \\
\hline CHEMBL1357934 & 688407 & 4.85 & 4.9032 & TRN & \\
\hline CHEMBL1512362 & 688407 & 5.9 & 5.4283 & TST & \\
\hline CHEMBL1486765 & 688407 & 5.2 & 4.54 & TRN & \\
\hline CHEMBL1512661 & 688407 & 5.3 & 5.2542 & TRN & \\
\hline CHEMBL1492539 & 688407 & 4.95 & 5.3924 & TST & \\
\hline CHEMBL1613393 & 688407 & 7.3002 & 6.317 & TRN & \\
\hline CHEMBL1414663 & 688407 & 7.5003 & 5.2732 & TRN & \\
\hline CHEMBL1367547 & 688407 & 5.3 & 5.5077 & TRN & \\
\hline CHEMBL1396245 & 688407 & 6.3 & 6.353 & TST & \\
\hline CHEMBL1332767 & 688407 & 5.9 & 5.5725 & TST & \\
\hline CHEMBL1413522 & 688407 & 8.301 & 5.8654 & TRN & \\
\hline CHEMBL1399654 & 688407 & 4.7 & 5.9219 & TRN & \\
\hline CHEMBL1591394 & 688407 & 4.7 & 6.056 & TRN & \\
\hline CHEMBL1482888 & 688407 & 5.2 & 5.4117 & TRN & \\
\hline CHEMBL1598429 & 688407 & 4.9 & 5.9643 & TST & \\
\hline CHEMBL1514685 & 688407 & 4.6 & 4.8559 & TRN & \\
\hline CHEMBL1591304 & 688407 & 4.9 & 6.1349 & TRN & \\
\hline CHEMBL1592892 & 688407 & 4.85 & 5.8027 & TST & \\
\hline CHEMBL1355653 & 688407 & 5.4 & 6.1404 & TRN & \\
\hline CHEMBL1358397 & 688407 & 5.2 & 5.8688 & TRN & \\
\hline CHEMBL1611949 & 688407 & 5.8 & 5.654 & TST & \\
\hline CHEMBL1555651 & 688407 & 8.1024 & 6.3655 & TST & \\
\hline CHEMBL1356212 & 688407 & 8.0 & 6.0139 & TST & \\
\hline CHEMBL1436942 & 688407 & 4.8 & 4.7896 & TRN & \\
\hline CHEMBL1354878 & 688407 & 8.1024 & 6.4824 & TRN & \\
\hline CHEMBL1428134 & 688407 & 4.85 & 4.8501 & TRN & \\
\hline CHEMBL1318239 & 688407 & 5.1 & 5.7954 & TRN & \\
\hline CHEMBL1433411 & 688407 & 4.5 & 5.2749 & TST & \\
\hline CHEMBL1357688 & 688407 & 5.9 & 5.4626 & TRN & \\
\hline CHEMBL1450031 & 688407 & 4.95 & 5.6681 & TST & \\
\hline CHEMBL1530602 & 688407 & 4.5 & 5.2445 & TRN & \\
\hline CHEMBL1526041 & 688407 & 4.5 & 4.9956 & TRN & \\
\hline CHEMBL1495373 & 688407 & 6.1 & 5.9665 & TRN & \\
\hline CHEMBL1476330 & 688407 & 4.45 & 5.29899 & 99999999995 & TRN \\
\hline CHEMBL1573442 & 688407 & 5.2 & 4.7058 & TRN & \\
\hline CHEMBL1565121 & 688407 & 4.55 & 6.1811 & TST & \\
\hline CHEMBL1358262 & 688407 & 4.5 & 5.0212 & TRN & \\
\hline CHEMBL1457047 & 688407 & 4.6 & 5.0253 & TRN & \\
\hline CHEMBL1479330 & 688407 & 7.3002 & 5.9192 & TRN & \\
\hline CHEMBL1430680 & 688407 & 7.2503 & 5.2326 & TST & \\
\hline CHEMBL1601738 & 688407 & 5.0 & 5.2375 & TST & \\
\hline CHEMBL1565018 & 688407 & 7.6003 & 5.9306 & TST & \\
\hline CHEMBL1396482 & 688407 & 5.6 & 5.371 & TRN & \\
\hline CHEMBL1418337 & 688407 & 5.4 & 5.5833 & TRN & \\
\hline CHEMBL1513751 & 688407 & 4.8 & 5.2519 & TST & \\
\hline CHEMBL1398497 & 688407 & 4.95 & 5.0417 & TRN & \\
\hline CHEMBL1318027 & 688407 & 4.7 & 4.9671 & TRN & \\
\hline
\end{tabular}




\begin{tabular}{|c|c|c|c|c|}
\hline \multicolumn{5}{|c|}{ Supplemental Table S2.txt } \\
\hline CHEMBL1446914 & 688407 & 4.85 & 5.0218 & TRN \\
\hline CHEMBL1613253 & 688407 & 4.9 & 5.0401 & TRN \\
\hline CHEMBL1405249 & 688407 & 4.5 & 5.439 & TST \\
\hline CHEMBL1567796 & 688407 & 5.2 & 5.9835 & TRN \\
\hline CHEMBL1357253 & 688407 & 8.0 & 5.7173 & TRN \\
\hline CHEMBL1483358 & 688407 & 4.5 & 6.1019 & TRN \\
\hline CHEMBL1315281 & 688407 & 4.7 & 5.0813 & TST \\
\hline CHEMBL1356155 & 688407 & 4.9 & 4.7661 & TRN \\
\hline CHEMBL1571426 & 688407 & 5.0 & 5.737 & TRN \\
\hline CHEMBL1403565 & 688407 & 4.6 & 5.3835 & TRN \\
\hline CHEMBL1594062 & 688407 & 6.2 & 5.4539 & TRN \\
\hline CHEMBL1445382 & 688407 & 4.45 & 5.6928 & TST \\
\hline CHEMBL1338686 & 688407 & 6.3 & 6.1813 & TST \\
\hline CHEMBL1465114 & 688407 & 4.8 & 4.9065 & TRN \\
\hline CHEMBL1309497 & 688407 & 5.0 & 4.7602 & TST \\
\hline CHEMBL1396518 & 688407 & 6.9 & 6.4461 & TRN \\
\hline CHEMBL1317728 & 688407 & 4.5 & 4.8946 & TRN \\
\hline CHEMBL1551835 & 688407 & 4.9 & 5.0873 & TRN \\
\hline CHEMBL1513881 & 688407 & 6.2 & 5.6394 & TRN \\
\hline CHEMBL1447312 & 688407 & 7.8013 & 6.1207 & TRN \\
\hline CHEMBL1377598 & 688407 & 4.45 & 5.0537 & TRN \\
\hline CHEMBL1558202 & 688407 & 6.1 & 5.5905 & TST \\
\hline CHEMBL1532839 & 688407 & 4.8 & 5.2532 & TRN \\
\hline CHEMBL1397036 & 688407 & 6.15 & 6.0297 & TRN \\
\hline CHEMBL1451448 & 688407 & 5.45 & 6.0696 & TST \\
\hline CHEMBL1436415 & 688407 & 4.9 & 4.6993 & TRN \\
\hline CHEMBL1317677 & 688407 & 4.5 & 5.381 & TST \\
\hline CHEMBL1395660 & 688407 & 4.75 & 5.1496 & TRN \\
\hline CHEMBL589912 & 688407 & 5.25 & 5.1308 & TST \\
\hline CHEMBL1407377 & 688407 & 5.0 & 5.5087 & TRN \\
\hline CHEMBL1395080 & 688407 & 4.85 & 4.9131 & TRN \\
\hline CHEMBL1361154 & 688407 & 4.9 & 6.0463 & TRN \\
\hline CHEMBL1590573 & 688407 & 4.95 & 5.49 & TST \\
\hline CHEMBL1403985 & 688407 & 4.5 & 5.3803 & TRN \\
\hline CHEMBL1355251 & 688407 & 4.6 & 4.7426 & TRN \\
\hline CHEMBL1402890 & 688407 & 7.6003 & 5.5701 & TRN \\
\hline CHEMBL1395734 & 688407 & 4.7 & 5.7 & TRN \\
\hline CHEMBL1407367 & 688407 & 6.0 & 5.5671 & TST \\
\hline CHEMBL1474432 & 688407 & 5.4 & 5.51399 & 9999999999 \\
\hline CHEMBL1566743 & 688407 & 5.35 & 6.2603 & TST \\
\hline CHEMBL1478201 & 688407 & 5.45 & 5.5792 & TRN \\
\hline CHEMBL1377122 & 688407 & 5.8 & 5.2152 & TRN \\
\hline CHEMBL1552220 & 688407 & 6.5501 & 4.947 & TRN \\
\hline CHEMBL1357353 & 688407 & 7.5003 & 5.6347 & TRN \\
\hline CHEMBL1316576 & 688407 & 4.5 & 4.7098 & TRN \\
\hline CHEMBL1315738 & 688407 & 5.2 & 5.9115 & TRN \\
\hline CHEMBL1315732 & 688407 & 4.8 & 4.7768 & TST \\
\hline CHEMBL1406079 & 688407 & 4.9 & 6.6747 & TST \\
\hline
\end{tabular}




\begin{tabular}{|c|c|c|c|c|c|}
\hline \multicolumn{6}{|c|}{ Supplemental Table s2.txt } \\
\hline CHEMBL1474650 & 688407 & 5.0 & 5.8703 & TRN & \\
\hline CHEMBL1448124 & 688407 & 4.5 & 5.3069 & TRN & \\
\hline CHEMBL1567428 & 688407 & 5.65 & 6.38399 & 99999999995 & TRN \\
\hline CHEMBL1404188 & 688407 & 4.5 & 5.3742 & TRN & \\
\hline CHEMBL1395945 & 688407 & 8.2007 & 5.9716 & TRN & \\
\hline CHEMBL1410833 & 688407 & 7.9508 & 5.50700 & 0000000001 & TST \\
\hline CHEMBL1591644 & 688407 & 4.45 & 5.17 & TRN & \\
\hline CHEMBL1436654 & 688407 & 4.9 & 5.7512 & TRN & \\
\hline CHEMBL1534660 & 688407 & 4.8 & 4.8849 & TST & \\
\hline CHEMBL1329430 & 688407 & 4.6 & 5.0893 & TST & \\
\hline CHEMBL1480266 & 688407 & 4.45 & 5.5776 & TRN & \\
\hline CHEMBL1436762 & 688407 & 7.2 & 5.7736 & TRN & \\
\hline CHEMBL1400215 & 688407 & 7.4001 & 5.9946 & TRN & \\
\hline CHEMBL1442927 & 688407 & 5.35 & 6.1086 & TST & \\
\hline CHEMBL1551355 & 688407 & 8.301 & 5.3155 & TRN & \\
\hline CHEMBL1358149 & 688407 & 6.6 & 6.886 & TRN & \\
\hline CHEMBL1512331 & 688407 & 4.6 & 5.6357 & TRN & \\
\hline CHEMBL1398099 & 688407 & 4.75 & 4.92 & TRN & \\
\hline CHEMBL1372890 & 688407 & 5.1 & 5.86 & TRN & \\
\hline CHEMBL1317687 & 688407 & 4.8 & 6.1175 & TRN & \\
\hline CHEMBL1596367 & 688407 & 5.8 & 5.7492 & TRN & \\
\hline CHEMBL1356931 & 688407 & 4.9 & 4.8574 & TRN & \\
\hline CHEMBL1358088 & 688407 & 8.301 & 6.2002 & TST & \\
\hline CHEMBL1327128 & 688407 & 4.7 & 4.7371 & TRN & \\
\hline CHEMBL1371651 & 688407 & 6.8 & 5.3133 & TRN & \\
\hline CHEMBL1554584 & 688407 & 5.5 & 5.4771 & TRN & \\
\hline CHEMBL1591151 & 688407 & 5.0 & 5.5542 & TRN & \\
\hline CHEMBL1567089 & 688407 & 6.1 & 5.63399 & 99999999995 & TRN \\
\hline CHEMBL1494328 & 688407 & 4.6 & 5.0791 & TRN & \\
\hline CHEMBL1366426 & 688407 & 4.6 & 5.6419 & TRN & \\
\hline CHEMBL1356546 & 688407 & 4.9 & 5.0677 & TRN & \\
\hline CHEMBL1433723 & 688407 & 7.6003 & 5.5989 & TST & \\
\hline CHEMBL1457325 & 688407 & 4.45 & 6.0151 & TRN & \\
\hline CHEMBL1410046 & 688407 & 7.4001 & 5.968 & TRN & \\
\hline CHEMBL1515991 & 688407 & 5.8 & 5.6511 & TRN & \\
\hline CHEMBL1533191 & 688407 & 7.5003 & 5.8822 & TST & \\
\hline CHEMBL1439781 & 688407 & 4.6 & 4.7925 & TRN & \\
\hline CHEMBL1551338 & 688407 & 4.95 & 4.6099 & TST & \\
\hline CHEMBL1399062 & 688407 & 5.25 & 5.5264 & TRN & \\
\hline CHEMBL1364359 & 688407 & 7.6003 & 5.5486 & TRN & \\
\hline CHEMBL1444350 & 688407 & 4.95 & 4.9397 & TRN & \\
\hline CHEMBL1435213 & 688407 & 6.5 & 5.8736 & TRN & \\
\hline CHEMBL1315978 & 688407 & 5.4 & 5.3057 & TRN & \\
\hline CHEMBL1473014 & 688407 & 4.5 & 4.8656 & TRN & \\
\hline CHEMBL1332494 & 688407 & 5.1 & 5.1205 & TRN & \\
\hline CHEMBL1494714 & 688407 & 7.8996 & 5.9472 & TRN & \\
\hline CHEMBL1515136 & 688407 & 7.0 & 5.2802 & TRN & \\
\hline CHEMBL1315164 & 688407 & 7.5003 & 6.0642 & TRN & \\
\hline
\end{tabular}




\begin{tabular}{|c|c|c|c|c|c|}
\hline & & \multicolumn{4}{|c|}{ Supplemental Table S2.txt } \\
\hline CHEMBL1311362 & 688407 & 7.3497 & 6.0647 & TST & \\
\hline CHEMBL1610894 & 688407 & 4.9 & 5.4903 & TRN & \\
\hline CHEMBL1608018 & 688407 & 4.5 & 4.8184 & TRN & \\
\hline CHEMBL1484125 & 688407 & 6.5 & 5.4526 & TRN & \\
\hline CHEMBL1607834 & 688407 & 5.4 & 5.5128 & TRN & \\
\hline CHEMBL1329090 & 688407 & 5.0 & 5.1104 & TRN & \\
\hline CHEMBL1317423 & 688407 & 4.5 & 5.3187 & TST & \\
\hline CHEMBL1455386 & 688407 & 4.75 & 5.4219 & TRN & \\
\hline CHEMBL1404117 & 688407 & 8.301 & 5.8884 & TRN & \\
\hline CHEMBL1530387 & 688407 & 4.9 & 6.0403 & TST & \\
\hline CHEMBL1559740 & 688407 & 4.65 & 5.301 & TRN & \\
\hline CHEMBL1440950 & 688407 & 7.2503 & \multicolumn{2}{|c|}{6.117999999999999} & TRN \\
\hline CHEMBL1314893 & 688407 & 7.6003 & 5.7052 & TRN & \\
\hline CHEMBL1475522 & 688407 & 4.95 & 5.218 & TST & \\
\hline CHEMBL1515958 & 688407 & 5.0 & 5.5174 & TST & \\
\hline CHEMBL1592873 & 688407 & 5.8 & 6.2197 & TRN & \\
\hline CHEMBL1602807 & 688407 & 4.6 & 4.8357 & TST & \\
\hline CHEMBL1303448 & 688407 & 5.25 & 5.3121 & TST & \\
\hline CHEMBL3193652 & 688407 & 5.65 & 5.3502 & TST & \\
\hline CHEMBL1396304 & 688407 & 4.45 & 5.8292 & TST & \\
\hline CHEMBL394143 & 688407 & 4.5 & 6.2723 & TRN & \\
\hline CHEMBL1358117 & 688407 & 7.8013 & 5.6851 & TRN & \\
\hline CHEMBL 1410780 & 688407 & 8.4949 & 6.7867 & TRN & \\
\hline CHEMBL1360989 & 688407 & 4.9 & 4.726 & TRN & \\
\hline CHEMBL1552144 & 688407 & 4.5 & 5.8929 & TRN & \\
\hline CHEMBL1478347 & 688407 & 5.5 & 5.4793 & TRN & \\
\hline CHEMBL1474165 & 688407 & 4.5 & 5.3043 & TRN & \\
\hline CHEMBL1326757 & 688407 & 6.5 & 5.7172 & TST & \\
\hline CHEMBL1454110 & 688407 & 4.7 & 6.1358 & TRN & \\
\hline CHEMBL1435258 & 688407 & 7.699 & 5.8824 & TRN & \\
\hline CHEMBL1563691 & 688407 & 5.55 & 5.4493 & TST & \\
\hline CHEMBL1593965 & 688407 & 5.55 & 5.6788 & TRN & \\
\hline CHEMBL1334435 & 688407 & 5.4 & 5.5134 & TST & \\
\hline CHEMBL1478586 & 688407 & 7.4001 & 5.5179 & TRN & \\
\hline CHEMBL1513560 & 688407 & 4.8 & 5.9253 & TRN & \\
\hline CHEMBL1441225 & 688407 & 5.5 & 5.14 & TST & \\
\hline CHEMBL1554800 & 688407 & 4.6 & 5.3466 & TRN & \\
\hline CHEMBL1565356 & 688407 & 4.5 & 5.1171 & TRN & \\
\hline CHEMBL1315730 & 688407 & 6.1 & 5.2898 & TRN & \\
\hline CHEMBL1407870 & 688407 & 6.1 & 6.3464 & TRN & \\
\hline CHEMBL1514240 & 688407 & 8.1024 & 6.3116 & TRN & \\
\hline CHEMBL1435070 & 688407 & 4.5 & 5.1625 & TRN & \\
\hline CHEMBL1590310 & 688407 & 4.9 & 5.426 & TRN & \\
\hline CHEMBL1360225 & 688407 & 4.9 & 5.3013 & TRN & \\
\hline CHEMBL1592845 & 688407 & 4.5 & 5.2781 & TRN & \\
\hline CHEMBL1376258 & 688407 & 4.95 & 5.3825 & TRN & \\
\hline CHEMBL1611610 & 688407 & 8.4949 & \multicolumn{2}{|c|}{6.167000000000001} & TRN \\
\hline CHEMBL1553000 & 688407 & 6.8 & 5.5817 & TRN & \\
\hline
\end{tabular}




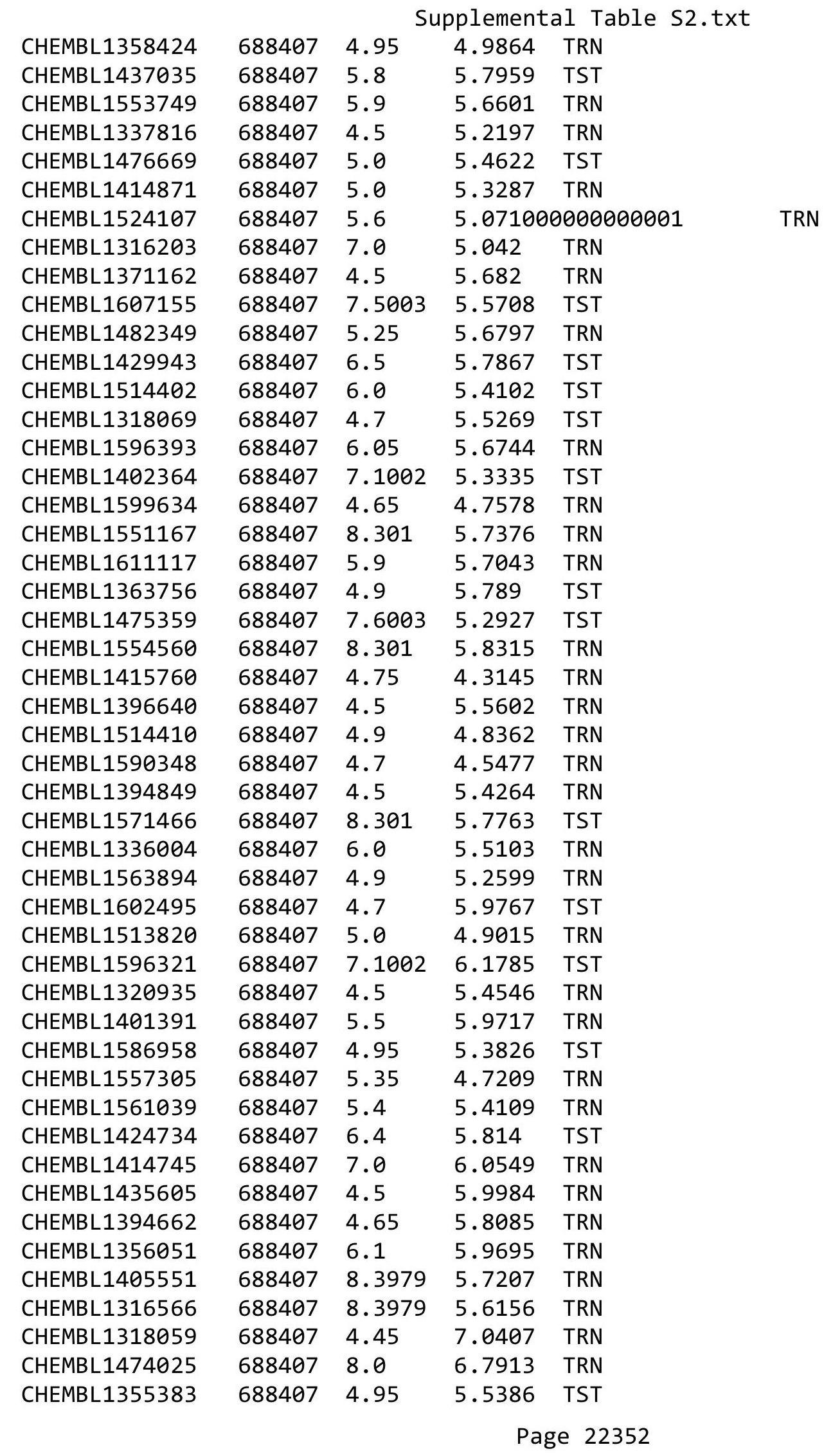




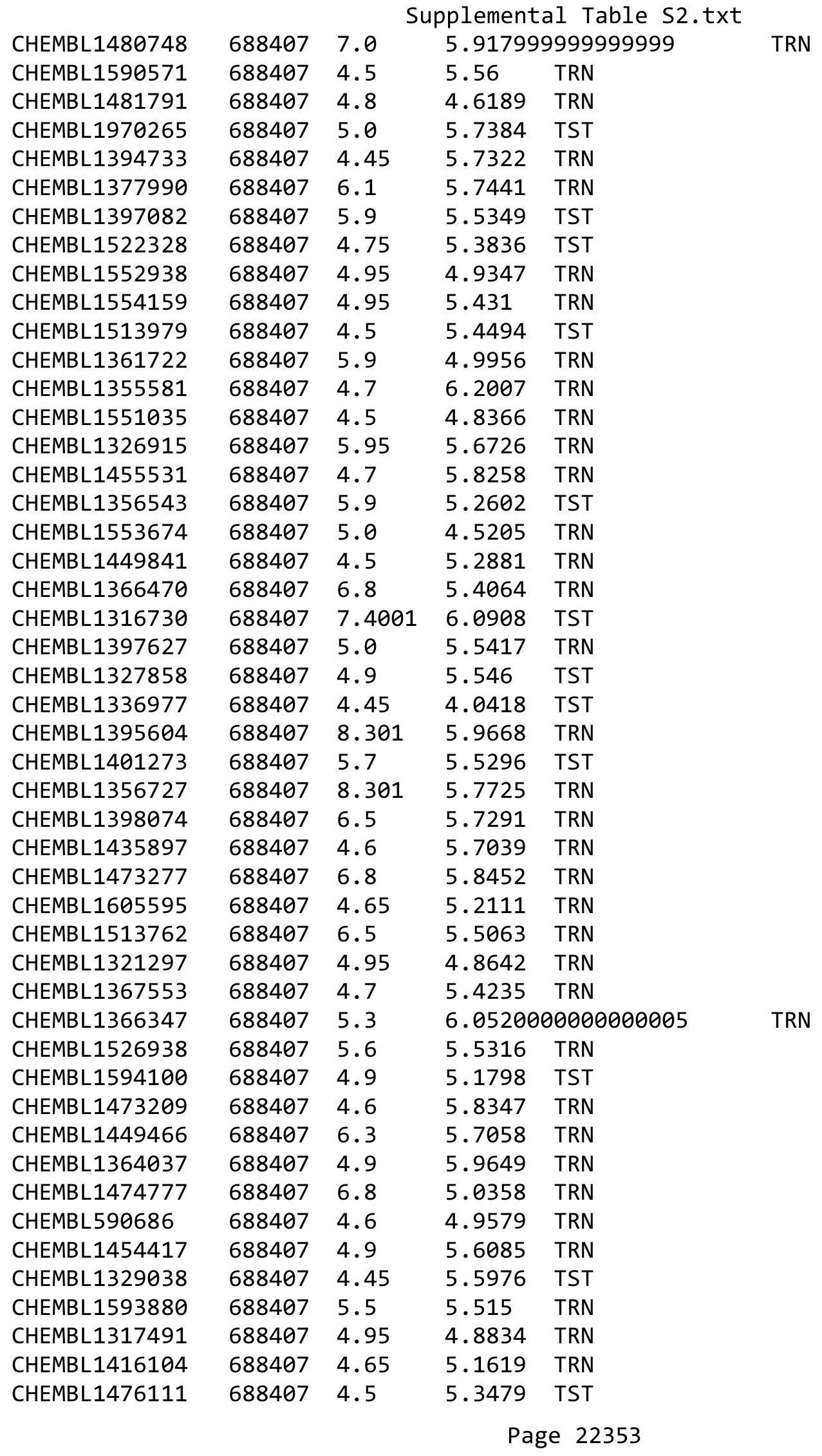




\begin{tabular}{|c|c|c|c|c|c|}
\hline \multicolumn{6}{|c|}{ Supplemental Table S2.txt } \\
\hline CHEMBL1363958 & 688407 & 5.6 & 6.0849 & TRN & \\
\hline CHEMBL1517347 & 688407 & 4.9 & 5.7151 & TRN & \\
\hline CHEMBL1475195 & 688407 & 4.9 & 4.6778 & TRN & \\
\hline CHEMBL1505084 & 688407 & 7.8996 & 5.6642 & TRN & \\
\hline CHEMBL1369399 & 688407 & 7.9508 & 6.2343 & TST & \\
\hline CHEMBL1314550 & 688407 & 4.9 & 5.3505 & TRN & \\
\hline CHEMBL1356761 & 688407 & 4.5 & 4.4751 & TRN & \\
\hline CHEMBL1531937 & 688407 & 8.301 & 5.5614 & TST & \\
\hline CHEMBL1474126 & 688407 & 5.3 & 5.7959 & TRN & \\
\hline CHEMBL1433741 & 688407 & 4.8 & 4.7895 & TST & \\
\hline CHEMBL1395912 & 688407 & 4.5 & 5.0394 & TRN & \\
\hline CHEMBL1434630 & 688407 & 6.2 & 5.1945 & TRN & \\
\hline CHEMBL1314140 & 688407 & 4.65 & 6.5468 & TST & \\
\hline CHEMBL1331065 & 688407 & 4.65 & 5.1436 & TRN & \\
\hline CHEMBL1606755 & 688407 & 4.5 & 5.1361 & TRN & \\
\hline CHEMBL1450286 & 688407 & 5.0 & 5.7547 & TRN & \\
\hline CHEMBL1569459 & 688407 & 4.6 & 5.6627 & TRN & \\
\hline CHEMBL1355470 & 688407 & 4.5 & 5.4919 & TRN & \\
\hline CHEMBL1611607 & 688407 & 4.7 & 4.9655 & TRN & \\
\hline CHEMBL1400621 & 688407 & 5.9 & 5.8722 & TST & \\
\hline CHEMBL1439819 & 688407 & 4.5 & 5.8269 & TST & \\
\hline CHEMBL1376405 & 688407 & 4.9 & 5.0725 & TST & \\
\hline CHEMBL1598171 & 688407 & 5.5 & 5.0262 & TRN & \\
\hline CHEMBL1338170 & 688407 & 6.4 & 5.6655 & TRN & \\
\hline CHEMBL1433729 & 688407 & 5.1 & 5.8428 & TST & \\
\hline CHEMBL1591133 & 688407 & 5.85 & 4.9831 & TST & \\
\hline CHEMBL1354248 & 688407 & 6.8 & 5.2154 & TRN & \\
\hline CHEMBL1316132 & 688407 & 6.2 & 5.7563 & TRN & \\
\hline CHEMBL1407248 & 688407 & 6.6 & 5.4409 & TRN & \\
\hline CHEMBL1330184 & 688407 & 4.45 & 4.8231 & TRN & \\
\hline CHEMBL1562811 & 688407 & 4.5 & 5.5592 & TRN & \\
\hline CHEMBL1604870 & 688407 & 8.3468 & 6.1895 & TRN & \\
\hline CHEMBL1594061 & 688407 & 4.6 & 5.12 & TRN & \\
\hline CHEMBL1359389 & 688407 & 5.05 & 5.5539 & TRN & \\
\hline CHEMBL1434043 & 688407 & 4.5 & 5.26399 & 9999999999 & TRN \\
\hline CHEMBL1512968 & 688407 & 6.3 & 6.1095 & TRN & \\
\hline CHEMBL1552695 & 688407 & 5.9 & 5.8118 & TRN & \\
\hline CHEMBL1515107 & 688407 & 5.2 & 5.6071 & TRN & \\
\hline CHEMBL1475777 & 688407 & 4.45 & 5.0057 & TRN & \\
\hline CHEMBL1357628 & 688407 & 4.9 & 4.7998 & TRN & \\
\hline CHEMBL1556025 & 688407 & 4.5 & 5.5626 & TST & \\
\hline CHEMBL1561858 & 688407 & 5.1 & 5.6267 & TRN & \\
\hline CHEMBL1593214 & 688407 & 5.7 & 5.9067 & TRN & \\
\hline CHEMBL1476086 & 688407 & 5.8 & 5.3484 & TST & \\
\hline CHEMBL1403687 & 688407 & 4.45 & 5.7792 & TST & \\
\hline CHEMBL1333686 & 688407 & 5.7 & 5.8865 & TRN & \\
\hline CHEMBL1526095 & 688407 & 5.05 & 5.4158 & TRN & \\
\hline CHEMBL1323217 & 688407 & 4.5 & 5.4259 & TST & \\
\hline
\end{tabular}




\begin{tabular}{|c|c|c|c|c|}
\hline \multicolumn{5}{|c|}{ Supplemental Table S2.txt } \\
\hline CHEMBL1356891 & 688407 & 4.8 & 5.1422 & TRN \\
\hline CHEMBL1556790 & 688407 & 4.5 & 6.006 & TRN \\
\hline CHEMBL1370999 & 688407 & 4.7 & 5.7011 & TST \\
\hline CHEMBL1481670 & 688407 & 4.45 & 5.8932 & TRN \\
\hline CHEMBL1514498 & 688407 & 5.2 & 5.1542 & TRN \\
\hline CHEMBL1403950 & 688407 & 4.85 & 5.0014 & TRN \\
\hline CHEMBL1407482 & 688407 & 8.3979 & 5.6661 & TST \\
\hline CHEMBL1352758 & 688407 & 4.9 & 6.2019 & TST \\
\hline CHEMBL1356126 & 688407 & 5.1 & 5.2719 & TRN \\
\hline CHEMBL1445290 & 688407 & 5.9 & 4.7984 & TRN \\
\hline CHEMBL1396128 & 688407 & 8.0 & 5.7311 & TRN \\
\hline CHEMBL1356885 & 688407 & 4.9 & 6.4339 & TRN \\
\hline CHEMBL528807 & 688407 & 4.65 & 4.979 & TRN \\
\hline CHEMBL1597144 & 688407 & 4.45 & 5.6046 & TST \\
\hline CHEMBL1436466 & 688407 & 4.5 & 5.5616 & TST \\
\hline CHEMBL1495711 & 688407 & 4.5 & 5.5109 & TRN \\
\hline CHEMBL1598768 & 688407 & 7.0 & 5.603 & TRN \\
\hline CHEMBL1394547 & 688407 & 8.301 & 5.1054 & TRN \\
\hline CHEMBL1528709 & 688407 & 4.9 & 5.5963 & TRN \\
\hline CHEMBL1554305 & 688407 & 5.5 & 5.0841 & TRN \\
\hline CHEMBL1408717 & 688407 & 5.0 & 5.0267 & TRN \\
\hline CHEMBL1513597 & 688407 & 6.3 & 5.6677 & TRN \\
\hline CHEMBL1330082 & 688407 & 4.7 & 5.78 & TRN \\
\hline CHEMBL1363477 & 688407 & 6.8 & 5.6053 & TRN \\
\hline CHEMBL1368212 & 688407 & 5.25 & 5.2346 & TST \\
\hline CHEMBL1472946 & 688407 & 6.4 & 6.255 & TRN \\
\hline CHEMBL1397343 & 688407 & 7.699 & 6.5347 & TRN \\
\hline CHEMBL1400483 & 688407 & 7.9508 & 5.7097 & TRN \\
\hline CHEMBL1366921 & 688407 & 5.2 & 6.2451 & TRN \\
\hline CHEMBL1593058 & 688407 & 6.5 & 5.7995 & TST \\
\hline CHEMBL1435037 & 688407 & 4.45 & 4.5156 & TRN \\
\hline CHEMBL1515232 & 688407 & 6.2 & 5.7023 & TRN \\
\hline CHEMBL1520027 & 688407 & 5.0 & 6.1784 & TRN \\
\hline CHEMBL1602958 & 688407 & 5.5 & 5.1357 & TRN \\
\hline CHEMBL1473088 & 688407 & 4.9 & 5.1972 & TST \\
\hline CHEMBL1354932 & 688407 & 4.6 & 5.6358 & TST \\
\hline CHEMBL1434606 & 688407 & 4.9 & 4.7865 & TRN \\
\hline CHEMBL1337071 & 688407 & 4.5 & 5.6681 & TRN \\
\hline CHEMBL1590915 & 688407 & 4.5 & 5.0793 & TRN \\
\hline CHEMBL1314275 & 688407 & 7.3002 & 6.0978 & TRN \\
\hline CHEMBL1434871 & 688407 & 4.5 & 5.2462 & TST \\
\hline CHEMBL1355338 & 688407 & 6.5501 & 6.2818 & TRN \\
\hline CHEMBL1553266 & 688407 & 5.5 & 5.6565 & TST \\
\hline CHEMBL1446906 & 688407 & 4.7 & 5.5868 & TST \\
\hline CHEMBL1607268 & 688407 & 5.8 & 6.0446 & TRN \\
\hline CHEMBL1378262 & 688407 & 4.65 & 4.7179 & TRN \\
\hline CHEMBL1377082 & 688407 & 6.7001 & 5.4241 & TST \\
\hline CHEMBL1332249 & 688407 & 4.5 & 5.7404 & TST \\
\hline
\end{tabular}




\begin{tabular}{|c|c|c|c|c|}
\hline \multicolumn{5}{|c|}{ Supplemental Tab } \\
\hline CHEMBL1590852 & 688407 & 5.0 & 4.9959 & TRN \\
\hline CHEMBL1604350 & 688407 & 4.6 & 4.7215 & TRN \\
\hline CHEMBL1535576 & 688407 & 5.2 & 5.5286 & TRN \\
\hline CHEMBL1551282 & 688407 & 4.8 & 5.4655 & TRN \\
\hline CHEMBL1334849 & 688407 & 5.4 & 5.3967 & TST \\
\hline CHEMBL1513396 & 688407 & 4.8 & 5.3932 & TRN \\
\hline CHEMBL1551953 & 688407 & 4.9 & 5.5716 & TST \\
\hline CHEMBL1319178 & 688407 & 5.4 & 5.0524 & TRN \\
\hline CHEMBL1398327 & 688407 & 6.2 & 5.1947 & TST \\
\hline CHEMBL1417703 & 688407 & 6.1 & 5.9887 & TST \\
\hline CHEMBL1591214 & 688407 & 8.301 & 6.4558 & TST \\
\hline CHEMBL1433867 & 688407 & 4.8 & 6.0586 & TRN \\
\hline CHEMBL1413504 & 688407 & 4.9 & 5.3351 & TST \\
\hline CHEMBL1337286 & 688407 & 5.0 & 5.7406 & TRN \\
\hline CHEMBL1401131 & 688407 & 4.45 & 5.4316 & TRN \\
\hline CHEMBL1495344 & 688407 & 5.5 & 6.1928 & TRN \\
\hline CHEMBL1552620 & 688407 & 8.3979 & 5.8603 & TRN \\
\hline CHEMBL1446073 & 688407 & 4.7 & 4.4313 & TRN \\
\hline CHEMBL1516225 & 688407 & 5.7 & 5.5375 & TST \\
\hline CHEMBL1415527 & 688407 & 5.4 & 5.4857 & TRN \\
\hline CHEMBL1442329 & 688407 & 8.301 & 5.7891 & TST \\
\hline CHEMBL1319321 & 688407 & 8.0 & 5.6865 & TRN \\
\hline CHEMBL1447547 & 688407 & 5.15 & 5.4587 & TRN \\
\hline CHEMBL1437203 & 688407 & 7.699 & 6.1509 & TRN \\
\hline CHEMBL1402645 & 688407 & 7.5003 & 5.7774 & TRN \\
\hline CHEMBL1487711 & 688407 & 6.8 & 5.5159 & TRN \\
\hline CHEMBL1395963 & 688407 & 5.8 & 5.0991 & TRN \\
\hline CHEMBL1568330 & 688407 & 6.95 & 5.4716 & TRN \\
\hline CHEMBL1489776 & 688407 & 6.1 & 6.2853 & TRN \\
\hline CHEMBL1530975 & 688407 & 4.7 & 5.1079 & TRN \\
\hline CHEMBL1526132 & 688407 & 4.85 & 5.8233 & TST \\
\hline CHEMBL1520523 & 688407 & 4.9 & 5.5454 & TRN \\
\hline CHEMBL1314412 & 688407 & 4.5 & 5.5036 & TST \\
\hline CHEMBL1530419 & 688407 & 5.35 & 5.8705 & TRN \\
\hline CHEMBL1559471 & 688407 & 7.3002 & 5.4759 & TRN \\
\hline CHEMBL1398107 & 688407 & 7.8996 & 5.8035 & TST \\
\hline CHEMBL1359022 & 688407 & 6.15 & 6.2421 & TRN \\
\hline CHEMBL1474823 & 688407 & 7.4001 & 6.0931 & TRN \\
\hline CHEMBL1405493 & 688407 & 5.2 & 4.8827 & TRN \\
\hline CHEMBL1363934 & 688407 & 6.5 & 5.7975 & TST \\
\hline CHEMBL1551583 & 688407 & 4.95 & 5.0148 & TRN \\
\hline CHEMBL1474330 & 688407 & 5.1 & 4.8614 & TRN \\
\hline CHEMBL1519263 & 688407 & 7.3002 & 5.2604 & TRN \\
\hline CHEMBL1374629 & 688407 & 4.85 & 5.1911 & TRN \\
\hline CHEMBL1496493 & 688407 & 5.6 & 5.4053 & TST \\
\hline CHEMBL1475070 & 688407 & 4.8 & 5.8666 & TRN \\
\hline CHEMBL1439236 & 688407 & 6.4 & 4.9767 & TRN \\
\hline CHEMBL1354465 & 688407 & 6.05 & 6.1204 & TST \\
\hline
\end{tabular}




\begin{tabular}{|c|c|c|c|c|}
\hline \multicolumn{5}{|c|}{ Supplemental Table S2.txt } \\
\hline CHEMBL1527303 & 688407 & 4.5 & 4.9273 & TST \\
\hline CHEMBL1372928 & 688407 & 5.4 & 5.9475 & TRN \\
\hline CHEMBL1373857 & 688407 & 4.5 & 5.3038 & TRN \\
\hline CHEMBL1504546 & 688407 & 4.45 & 6.1829 & TST \\
\hline CHEMBL1321606 & 688407 & 4.8 & 4.9538 & TRN \\
\hline CHEMBL1552999 & 688407 & 4.45 & 5.525 & TST \\
\hline CHEMBL1437328 & 688407 & 4.85 & 5.2522 & TST \\
\hline CHEMBL1573196 & 688407 & 4.85 & 5.6041 & TRN \\
\hline CHEMBL1548306 & 688407 & 5.0 & 5.7149 & TST \\
\hline CHEMBL1437551 & 688407 & 4.45 & 5.695 & TRN \\
\hline CHEMBL1317583 & 688407 & 6.4 & 5.568 & TST \\
\hline CHEMBL1513609 & 688407 & 5.55 & 5.3456 & TRN \\
\hline CHEMBL1364592 & 688407 & 4.8 & 4.1353 & TRN \\
\hline CHEMBL1474766 & 688407 & 4.5 & 4.8717 & TRN \\
\hline CHEMBL1337527 & 688407 & 5.95 & 5.7097 & TST \\
\hline CHEMBL1356673 & 688407 & 7.0 & 4.8764 & TST \\
\hline CHEMBL1611154 & 688407 & 8.301 & 6.6519 & TRN \\
\hline CHEMBL1368745 & 688407 & 7.4498 & 5.4509 & TRN \\
\hline CHEMBL1398144 & 688407 & 4.7 & 5.3853 & TRN \\
\hline CHEMBL1397730 & 688407 & 4.55 & 5.8837 & TRN \\
\hline CHEMBL1473619 & 688407 & 4.5 & 5.3952 & TRN \\
\hline CHEMBL1474849 & 688407 & 8.301 & 6.4692 & TRN \\
\hline CHEMBL1317601 & 688407 & 4.7 & 3.9166 & TRN \\
\hline CHEMBL1394609 & 688407 & 5.4 & 5.6769 & TRN \\
\hline CHEMBL1355184 & 688407 & 4.5 & 5.443 & TRN \\
\hline CHEMBL1325198 & 688407 & 4.8 & 4.3475 & TRN \\
\hline CHEMBL1354369 & 688407 & 6.1 & 5.5313 & TRN \\
\hline CHEMBL1396195 & 688407 & 4.8 & 5.7504 & TRN \\
\hline CHEMBL1355814 & 688407 & 4.8 & 5.4961 & TRN \\
\hline CHEMBL1397822 & 688407 & 4.8 & 5.2106 & TRN \\
\hline CHEMBL1435777 & 688407 & 4.65 & 6.1875 & TRN \\
\hline CHEMBL1552486 & 688407 & 7.4001 & 5.3043 & TST \\
\hline CHEMBL1589834 & 688407 & 5.5 & 5.369 & TRN \\
\hline CHEMBL1332306 & 688407 & 5.2 & 6.0082 & TRN \\
\hline CHEMBL1442272 & 688407 & 8.3979 & 6.0395 & TST \\
\hline CHEMBL1571460 & 688407 & 4.7 & 4.7339 & TRN \\
\hline CHEMBL1435531 & 688407 & 5.55 & 6.0106 & TST \\
\hline CHEMBL1553967 & 688407 & 8.301 & 5.3394 & TST \\
\hline CHEMBL1473040 & 688407 & 4.75 & 5.8433 & TRN \\
\hline CHEMBL1317531 & 688407 & 4.5 & 5.5213 & TRN \\
\hline CHEMBL1554261 & 688407 & 6.2 & 5.494 & TRN \\
\hline CHEMBL1559936 & 688407 & 8.3979 & 6.0647 & TST \\
\hline CHEMBL1571714 & 688407 & 8.2007 & 6.3472 & TST \\
\hline CHEMBL1552904 & 688407 & 4.9 & 5.3123 & TRN \\
\hline CHEMBL1610775 & 688407 & 5.2 & 5.3308 & TRN \\
\hline CHEMBL1571958 & 688407 & 7.1002 & 5.7418 & TRN \\
\hline CHEMBL1534210 & 688407 & 4.45 & 4.9807 & TRN \\
\hline CHEMBL1354290 & 688407 & 5.0 & 5.0316 & TRN \\
\hline
\end{tabular}




\begin{tabular}{|c|c|c|c|c|}
\hline \multicolumn{5}{|c|}{ Supplemental Table S2.txt } \\
\hline CHEMBL1513739 & 688407 & 4.45 & 5.3408 & TRN \\
\hline CHEMBL1336651 & 688407 & 5.0 & 5.2521 & TRN \\
\hline CHEMBL1395542 & 688407 & 4.6 & 4.609 & TRN \\
\hline CHEMBL1590416 & 688407 & 4.7 & 5.0169 & TRN \\
\hline CHEMBL1554396 & 688407 & 6.8499 & 5.6645 & TRN \\
\hline CHEMBL1357853 & 688407 & 4.65 & 5.211 & TRN \\
\hline CHEMBL1518592 & 688407 & 5.1 & 5.3674 & TRN \\
\hline CHEMBL1359362 & 688407 & 4.65 & 5.7749 & TRN \\
\hline CHEMBL1452714 & 688407 & 5.5 & 6.2048 & TST \\
\hline CHEMBL1567967 & 688407 & 4.9 & 4.9538 & TRN \\
\hline CHEMBL1330348 & 688407 & 4.5 & 5.7176 & TRN \\
\hline CHEMBL1434202 & 688407 & 5.95 & 5.6296 & TRN \\
\hline CHEMBL1514132 & 688407 & 4.5 & 5.3792 & TST \\
\hline CHEMBL1337578 & 688407 & 5.6 & 6.3054 & TRN \\
\hline CHEMBL1356820 & 688407 & 4.8 & 5.1035 & TRN \\
\hline CHEMBL1514160 & 688407 & 4.5 & 5.1819 & TRN \\
\hline CHEMBL1498955 & 688407 & 4.5 & 5.3133 & TST \\
\hline CHEMBL1475152 & 688407 & 7.5003 & 6.2327 & TRN \\
\hline CHEMBL1363619 & 688407 & 7.1002 & 6.4577 & TRN \\
\hline CHEMBL1451190 & 688407 & 7.5003 & 6.635 & TST \\
\hline CHEMBL1594046 & 688407 & 8.1024 & 5.3653 & TRN \\
\hline CHEMBL1308350 & 688407 & 4.45 & 5.9479 & TST \\
\hline CHEMBL1593270 & 688407 & 6.6 & 5.9357 & TRN \\
\hline CHEMBL1551766 & 688407 & 5.4 & 5.7975 & TRN \\
\hline CHEMBL1555426 & 688407 & 4.85 & 5.6998 & TST \\
\hline CHEMBL1399510 & 688407 & 5.5 & 5.925 & TRN \\
\hline CHEMBL1435427 & 688407 & 5.2 & 5.6766 & TRN \\
\hline CHEMBL1482917 & 688407 & 5.9 & 5.8794 & TRN \\
\hline CHEMBL1593293 & 688407 & 5.1 & 5.3116 & TRN \\
\hline CHEMBL1593426 & 688407 & 6.3 & 5.8237 & TRN \\
\hline CHEMBL1361524 & 688407 & 4.6 & 5.8321 & TST \\
\hline CHEMBL1357595 & 688407 & 4.9 & 4.8383 & TRN \\
\hline CHEMBL1473449 & 688407 & 4.9 & 5.254 & TRN \\
\hline CHEMBL1365802 & 688407 & 4.45 & 5.5381 & TRN \\
\hline CHEMBL1354568 & 688407 & 5.4 & 5.8577 & TST \\
\hline CHEMBL1555152 & 688407 & 7.4001 & 5.4926 & TST \\
\hline CHEMBL1396297 & 688407 & 4.5 & 5.4901 & TRN \\
\hline CHEMBL1476992 & 688407 & 4.7 & 5.2217 & TRN \\
\hline CHEMBL1434800 & 688407 & 4.5 & 5.0705 & TRN \\
\hline CHEMBL1398454 & 688407 & 4.95 & 4.9903 & TRN \\
\hline CHEMBL1356845 & 688407 & 6.0 & 4.795 & TRN \\
\hline CHEMBL1551923 & 688407 & 4.5 & 5.6356 & TST \\
\hline CHEMBL1592591 & 688407 & 4.95 & 5.2634 & TST \\
\hline CHEMBL1513851 & 688407 & 5.0 & 5.9433 & TRN \\
\hline CHEMBL1591810 & 688407 & 4.45 & 5.1853 & TRN \\
\hline CHEMBL1362507 & 688407 & 4.9 & 5.3151 & TST \\
\hline CHEMBL1357856 & 688407 & 4.65 & 5.4138 & TRN \\
\hline CHEMBL1404601 & 688407 & 4.9 & 5.119 & TRN \\
\hline
\end{tabular}




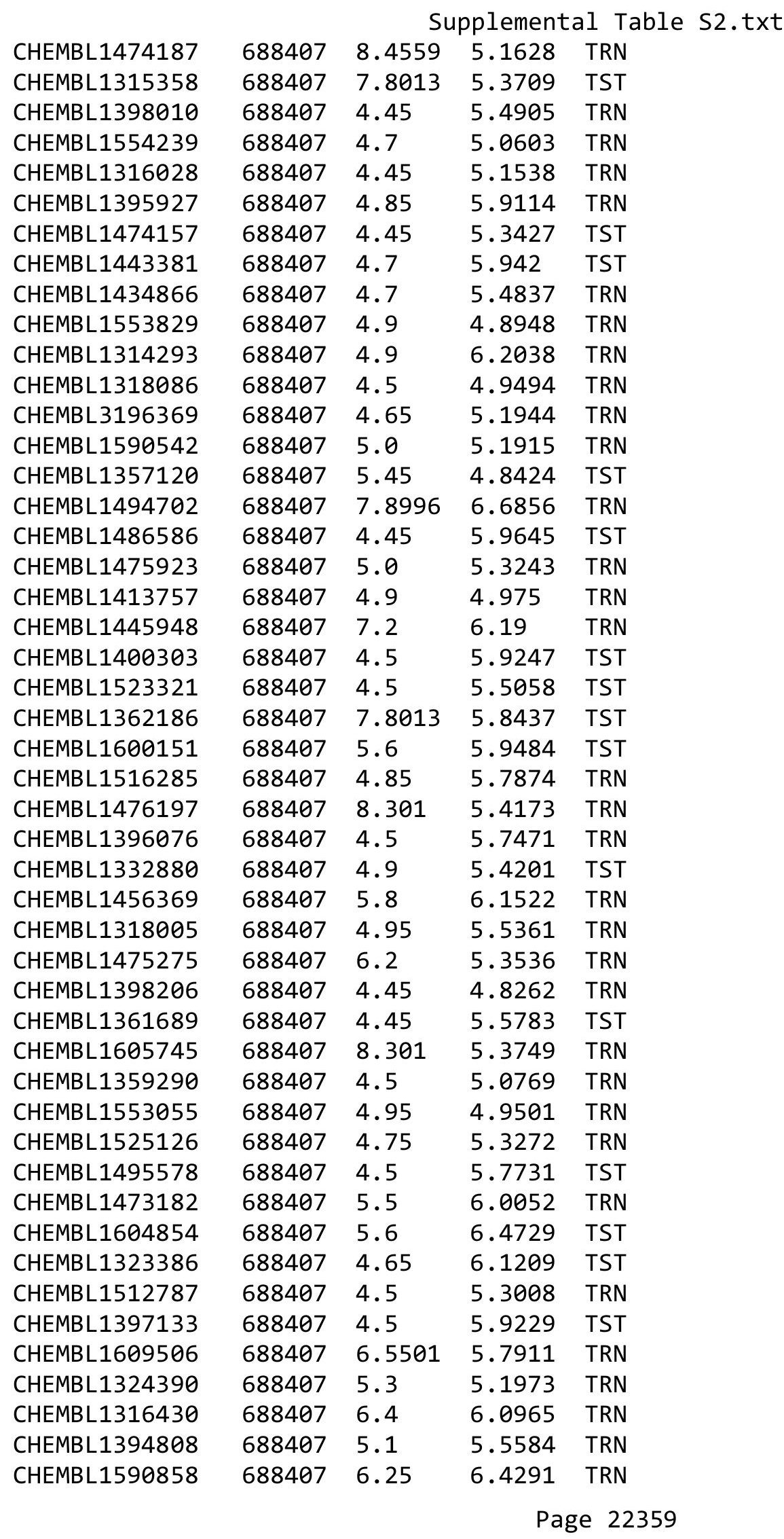




\begin{tabular}{|c|c|c|c|c|c|}
\hline \multicolumn{6}{|c|}{ Supplemental Table s2.txt } \\
\hline CHEMBL1358102 & 688407 & 4.9 & 5.0751 & TRN & \\
\hline CHEMBL1374121 & 688407 & 6.2 & 5.8503 & TRN & \\
\hline CHEMBL1447374 & 688407 & 7.3002 & 5.7204 & TRN & \\
\hline CHEMBL1564031 & 688407 & 5.0 & 4.7419 & TRN & \\
\hline CHEMBL1357128 & 688407 & 4.7 & 4.4172 & TRN & \\
\hline CHEMBL1435311 & 688407 & 4.5 & 5.3174 & TRN & \\
\hline CHEMBL1397757 & 688407 & 5.9 & 5.9892 & TRN & \\
\hline CHEMBL1518248 & 688407 & 8.1487 & 5.3731 & TST & \\
\hline CHEMBL1513469 & 688407 & 4.9 & 6.0206 & TRN & \\
\hline CHEMBL1364829 & 688407 & 5.5 & 5.2646 & TRN & \\
\hline CHEMBL1453436 & 688407 & 4.75 & 6.0261 & TST & \\
\hline CHEMBL1515325 & 688407 & 5.0 & 5.318 & TRN & \\
\hline CHEMBL1322741 & 688407 & 5.05 & 5.2915 & TRN & \\
\hline CHEMBL1398092 & 688407 & 5.45 & 5.5986 & TST & \\
\hline CHEMBL1407780 & 688407 & 4.5 & 5.4153 & TRN & \\
\hline CHEMBL1328176 & 688407 & 4.9 & 5.8903 & TST & \\
\hline CHEMBL1534331 & 688407 & 4.9 & 5.1972 & TRN & \\
\hline CHEMBL1450676 & 688407 & 5.55 & 5.5827 & TRN & \\
\hline CHEMBL1591068 & 688407 & 4.5 & 5.4608 & TRN & \\
\hline CHEMBL1554174 & 688407 & 4.5 & 4.7581 & TRN & \\
\hline CHEMBL1475061 & 688407 & 7.1002 & 5.2031 & TRN & \\
\hline CHEMBL1367196 & 688407 & 4.5 & 5.6209 & TRN & \\
\hline CHEMBL1518339 & 688407 & 5.9 & 5.88399 & 99999999995 & TRN \\
\hline CHEMBL1495721 & 688407 & 4.45 & 5.2784 & TRN & \\
\hline CHEMBL1437571 & 688407 & 6.0 & 4.9297 & TST & \\
\hline CHEMBL1405597 & 688407 & 4.9 & 4.9818 & TRN & \\
\hline CHEMBL1327162 & 688407 & 6.7001 & 5.3259 & TRN & \\
\hline CHEMBL1512452 & 688407 & 5.8 & 5.6193 & TRN & \\
\hline CHEMBL1535153 & 688407 & 4.45 & 4.4418 & TRN & \\
\hline CHEMBL1592088 & 688407 & 5.3 & 5.6493 & TRN & \\
\hline CHEMBL1611178 & 688407 & 7.699 & 5.4418 & TRN & \\
\hline CHEMBL1478855 & 688407 & 6.5 & 6.1084 & TRN & \\
\hline CHEMBL1314529 & 688407 & 5.0 & 5.2289 & TRN & \\
\hline CHEMBL1480392 & 688407 & 4.8 & 5.6729 & TRN & \\
\hline CHEMBL1406177 & 688407 & 4.5 & 4.6149 & TRN & \\
\hline CHEMBL1570960 & 688407 & 7.4498 & 5.6658 & TRN & \\
\hline CHEMBL1318628 & 688407 & 4.9 & 5.2134 & TST & \\
\hline CHEMBL1590865 & 688407 & 6.35 & 6.593 & TRN & \\
\hline CHEMBL1612493 & 688407 & 4.9 & 5.4552 & TST & \\
\hline CHEMBL1490523 & 688407 & 5.6 & 4.5957 & TRN & \\
\hline CHEMBL1490987 & 688407 & 5.0 & 4.5607 & TRN & \\
\hline CHEMBL1354865 & 688407 & 8.301 & 6.0245 & TST & \\
\hline CHEMBL1606585 & 688407 & 4.6 & 5.276 & TRN & \\
\hline CHEMBL1595047 & 688407 & 5.9 & 5.1837 & TRN & \\
\hline CHEMBL1492408 & 688407 & 4.5 & 5.487 & TRN & \\
\hline CHEMBL1417074 & 688407 & 6.1 & 4.636 & TRN & \\
\hline CHEMBL1552341 & 688407 & 4.45 & 4.7433 & TST & \\
\hline CHEMBL1373842 & 688407 & 5.0 & 6.21700 & 00000000005 & TRN \\
\hline & & & & 22360 & \\
\hline
\end{tabular}




\begin{tabular}{|c|c|c|c|c|}
\hline \multicolumn{5}{|c|}{ Supplemental Table s2.txt } \\
\hline CHEMBL1434637 & 688407 & 4.7 & 5.3298 & TRN \\
\hline CHEMBL1441836 & 688407 & 7.6003 & 5.3373 & TRN \\
\hline CHEMBL1395288 & 688407 & 4.5 & 6.0471 & TST \\
\hline CHEMBL1356317 & 688407 & 4.5 & 5.3955 & TRN \\
\hline CHEMBL1565909 & 688407 & 5.1 & 5.506 & TRN \\
\hline CHEMBL1375055 & 688407 & 5.4 & 5.4806 & TRN \\
\hline CHEMBL1357389 & 688407 & 4.9 & 5.5875 & TRN \\
\hline CHEMBL1559383 & 688407 & 4.95 & 5.829 & TST \\
\hline CHEMBL1354356 & 688407 & 5.05 & 5.556 & TRN \\
\hline CHEMBL1592928 & 688407 & 4.8 & 4.8432 & TRN \\
\hline CHEMBL1332878 & 688407 & 5.6 & 5.3681 & TRN \\
\hline CHEMBL1474155 & 688407 & 5.0 & 5.4926 & TRN \\
\hline CHEMBL1336460 & 688407 & 4.3 & 5.8713 & TST \\
\hline CHEMBL1444359 & 688407 & 5.1 & 5.4376 & TRN \\
\hline CHEMBL1485582 & 688407 & 5.1 & 5.2701 & TRN \\
\hline CHEMBL1329145 & 688407 & 5.0 & 4.8064 & TRN \\
\hline CHEMBL1395669 & 688407 & 4.8 & 4.7801 & TRN \\
\hline CHEMBL1483776 & 688407 & 4.9 & 5.6946 & TRN \\
\hline CHEMBL1590288 & 688407 & 5.2 & 5.4105 & TRN \\
\hline CHEMBL1354621 & 688407 & 5.6 & 5.5066 & TRN \\
\hline CHEMBL1592308 & 688407 & 4.8 & 4.9328 & TRN \\
\hline CHEMBL1551511 & 688407 & 8.0 & 6.4446 & TRN \\
\hline CHEMBL1402727 & 688407 & 5.0 & 5.7107 & TST \\
\hline CHEMBL1553021 & 688407 & 6.35 & 5.8483 & TRN \\
\hline CHEMBL1406593 & 688407 & 4.9 & 5.7609 & TST \\
\hline CHEMBL1348863 & 688407 & 5.25 & 6.0298 & TRN \\
\hline CHEMBL1481656 & 688407 & 4.8 & 4.9231 & TRN \\
\hline CHEMBL1590260 & 688407 & 8.2007 & 5.5603 & TRN \\
\hline CHEMBL1593449 & 688407 & 4.75 & 5.2739 & TRN \\
\hline CHEMBL1170681 & 688407 & 7.6003 & 5.6539 & TRN \\
\hline CHEMBL1592153 & 688407 & 6.5 & 5.1169 & TRN \\
\hline CHEMBL1599897 & 688407 & 4.7 & 5.1635 & TRN \\
\hline CHEMBL1316727 & 688407 & 4.8 & 5.5563 & TRN \\
\hline CHEMBL1436909 & 688407 & 7.6003 & 5.0481 & TRN \\
\hline CHEMBL1573553 & 688407 & 5.4 & 5.8983 & TRN \\
\hline CHEMBL1485663 & 688407 & 6.6499 & 5.9538 & TRN \\
\hline CHEMBL1591347 & 688407 & 8.0 & 5.9362 & TRN \\
\hline CHEMBL1330618 & 688407 & 4.45 & 5.3126 & TRN \\
\hline CHEMBL1552711 & 688407 & 6.5 & 6.814 & TRN \\
\hline CHEMBL1315403 & 688407 & 4.7 & 5.9432 & TST \\
\hline CHEMBL1474273 & 688407 & 7.699 & 6.9706 & TST \\
\hline CHEMBL1433869 & 688407 & 4.95 & 4.9517 & TST \\
\hline CHEMBL1474861 & 688407 & 7.699 & 5.6941 & TRN \\
\hline CHEMBL1509623 & 688407 & 4.75 & 6.157 & TST \\
\hline CHEMBL1554267 & 688407 & 4.75 & 5.3975 & TRN \\
\hline CHEMBL1472948 & 688407 & 4.9 & 6.0111 & TRN \\
\hline CHEMBL1591335 & 688407 & 4.5 & 5.8629 & TRN \\
\hline CHEMBL1404034 & 688407 & 4.75 & 4.5836 & TRN \\
\hline
\end{tabular}




\begin{tabular}{|c|c|c|c|c|c|}
\hline \multirow[b]{2}{*}{ CHEMBL1515694 } & \multirow[b]{2}{*}{688407} & \multicolumn{4}{|c|}{ Supplemental Table s2.txt } \\
\hline & & 7.8996 & 5.7094 & TRN & \\
\hline CHEMBL1514599 & 688407 & 5.6 & 5.5673 & TRN & \\
\hline CHEMBL1444513 & 688407 & 4.5 & 4.1678 & TRN & \\
\hline CHEMBL1476285 & 688407 & 4.6 & 5.182 & TRN & \\
\hline CHEMBL1407313 & 688407 & 5.9 & 5.1953 & TST & \\
\hline CHEMBL1574129 & 688407 & 6.8 & 5.6363 & TST & \\
\hline CHEMBL1442646 & 688407 & 5.1 & 5.5418 & TRN & \\
\hline CHEMBL1538973 & 688407 & 4.8 & 5.2888 & TRN & \\
\hline CHEMBL1464502 & 688407 & 7.0 & 5.6663 & TRN & \\
\hline CHEMBL1476786 & 688407 & 7.2 & 5.64 & TST & \\
\hline CHEMBL1559605 & 688407 & 4.9 & 5.6732 & TST & \\
\hline CHEMBL1564923 & 688407 & 5.55 & 5.9201 & TRN & \\
\hline CHEMBL1552079 & 688407 & 4.9 & 5.136 & TRN & \\
\hline CHEMBL1353069 & 688407 & 4.95 & 5.0844 & TRN & \\
\hline CHEMBL1590384 & 688407 & 8.0 & 5.5001 & TRN & \\
\hline CHEMBL1483588 & 688407 & 4.9 & 5.1306 & TRN & \\
\hline CHEMBL1317052 & 688407 & 4.9 & 5.8455 & TRN & \\
\hline CHEMBL1404653 & 688407 & 5.2 & 5.6091 & TST & \\
\hline CHEMBL1607223 & 688407 & 4.8 & 5.733 & TRN & \\
\hline CHEMBL1396554 & 688407 & 4.5 & 6.2202 & TRN & \\
\hline CHEMBL1551529 & 688407 & 8.2007 & 6.9031 & TRN & \\
\hline CHEMBL1475348 & 688407 & 4.5 & 5.4546 & TRN & \\
\hline CHEMBL1486073 & 688407 & 4.7 & 4.9783 & TST & \\
\hline CHEMBL1486036 & 688407 & 4.5 & 5.5489 & TRN & \\
\hline CHEMBL1455403 & 688407 & 4.45 & 5.1258 & TST & \\
\hline CHEMBL1314347 & 688407 & 6.8 & 4.783 & TST & \\
\hline CHEMBL1514306 & 688407 & 6.6499 & 6.0107 & TRN & \\
\hline CHEMBL1512533 & 688407 & 4.8 & 5.091 & TRN & \\
\hline CHEMBL1499436 & 688407 & 4.5 & 5.0685 & TST & \\
\hline CHEMBL1328167 & 688407 & 6.0 & 6.1963 & TRN & \\
\hline CHEMBL1515952 & 688407 & 5.55 & 6.12200 & 0000000001 & TST \\
\hline CHEMBL1356817 & 688407 & 4.5 & 5.0662 & TRN & \\
\hline CHEMBL1357616 & 688407 & 6.7001 & 5.4143 & TRN & \\
\hline CHEMBL1595446 & 688407 & 4.95 & 4.6828 & TST & \\
\hline CHEMBL1316998 & 688407 & 4.7 & 5.8961 & TST & \\
\hline CHEMBL1437901 & 688407 & 5.8 & 6.04299 & 9999999999 & TST \\
\hline CHEMBL1509595 & 688407 & 4.9 & 5.2237 & TRN & \\
\hline CHEMBL1403150 & 688407 & 4.5 & 4.5802 & TRN & \\
\hline CHEMBL1590435 & 688407 & 8.301 & 5.9687 & TRN & \\
\hline CHEMBL1592700 & 688407 & 6.6 & 6.445 & TRN & \\
\hline CHEMBL1453397 & 688407 & 7.2 & 5.5116 & TRN & \\
\hline CHEMBL1608696 & 688407 & 4.5 & 5.5131 & TRN & \\
\hline CHEMBL1354826 & 688407 & 7.0 & 6.1148 & TRN & \\
\hline CHEMBL1397676 & 688407 & 4.5 & 5.3201 & TST & \\
\hline CHEMBL1519128 & 688407 & 7.3002 & 5.9766 & TST & \\
\hline CHEMBL1351714 & 688407 & 6.6 & 5.6965 & TRN & \\
\hline CHEMBL1536103 & 688407 & 4.9 & 5.4701 & TRN & \\
\hline CHEMBL1561222 & 688407 & 4.7 & 4.7508 & TRN & \\
\hline & & & & 22362 & \\
\hline
\end{tabular}




\begin{tabular}{|c|c|c|c|c|}
\hline \multicolumn{5}{|c|}{ Supplemental Table S2.txt } \\
\hline CHEMBL1474512 & 688407 & 7.0 & 6.3174 & TRN \\
\hline CHEMBL1360702 & 688407 & 6.1 & 6.2931 & TRN \\
\hline CHEMBL1554182 & 688407 & 6.95 & 5.5493 & TRN \\
\hline CHEMBL1367678 & 688407 & 5.4 & 5.7025 & TRN \\
\hline CHEMBL1363299 & 688407 & 8.0 & 6.0179 & TRN \\
\hline CHEMBL1534994 & 688407 & 4.5 & 4.6077 & TRN \\
\hline CHEMBL1565994 & 688407 & 8.4559 & 6.3726 & TST \\
\hline CHEMBL1588135 & 688407 & 5.2 & 5.2271 & TST \\
\hline CHEMBL1532569 & 688407 & 4.8 & 5.309 & TRN \\
\hline CHEMBL1487581 & 688407 & 8.0 & 6.8592 & TRN \\
\hline CHEMBL1568287 & 688407 & 4.5 & 5.1467 & TRN \\
\hline CHEMBL1552344 & 688407 & 4.9 & 5.2937 & TRN \\
\hline CHEMBL1437193 & 688407 & 6.1 & 5.8856 & TST \\
\hline CHEMBL1319405 & 688407 & 5.0 & 4.9116 & TST \\
\hline CHEMBL1513105 & 688407 & 5.5 & 6.1557 & TST \\
\hline CHEMBL1592441 & 688407 & 4.45 & 5.2082 & TRN \\
\hline CHEMBL1515130 & 688407 & 5.2 & 5.3402 & TRN \\
\hline CHEMBL1358264 & 688407 & 4.7 & 5.2562 & TRN \\
\hline CHEMBL1444762 & 688407 & 7.1002 & 5.3471 & TRN \\
\hline CHEMBL1317046 & 688407 & 4.5 & 5.0336 & TRN \\
\hline CHEMBL1351906 & 688407 & 4.8 & 5.7159 & TST \\
\hline CHEMBL1552375 & 688407 & 4.7 & 5.6604 & TRN \\
\hline CHEMBL1474926 & 688407 & 4.6 & 5.5321 & TST \\
\hline CHEMBL1532789 & 688407 & 7.0 & 5.7729 & TRN \\
\hline CHEMBL1374156 & 688407 & 5.4 & 5.5782 & TRN \\
\hline CHEMBL1472796 & 688407 & 4.6 & 6.2564 & TRN \\
\hline CHEMBL1316850 & 688407 & 4.8 & 4.7337 & TRN \\
\hline CHEMBL1326223 & 688407 & 5.1 & 5.4365 & TST \\
\hline CHEMBL1454996 & 688407 & 4.8 & 4.7424 & TRN \\
\hline CHEMBL1608426 & 688407 & 4.9 & 5.4679 & TRN \\
\hline CHEMBL1315579 & 688407 & 5.0 & 5.5193 & TST \\
\hline CHEMBL1322622 & 688407 & 6.35 & 5.2249 & TST \\
\hline CHEMBL1319879 & 688407 & 6.1 & 5.8621 & TRN \\
\hline CHEMBL1434823 & 688407 & 7.5003 & 5.5889 & TRN \\
\hline CHEMBL1434258 & 688407 & 4.85 & 5.0929 & TRN \\
\hline CHEMBL1522608 & 688407 & 4.6 & 5.1872 & TRN \\
\hline CHEMBL1394320 & 688407 & 4.95 & 5.9453 & TRN \\
\hline CHEMBL1513782 & 688407 & 7.5003 & 6.8751 & TRN \\
\hline CHEMBL1594447 & 688407 & 4.5 & 4.8844 & TRN \\
\hline CHEMBL1493785 & 688407 & 7.1002 & 5.6606 & TRN \\
\hline CHEMBL1331852 & 688407 & 7.699 & 5.7784 & TST \\
\hline CHEMBL1610732 & 688407 & 4.95 & 5.7221 & TRN \\
\hline CHEMBL1434901 & 688407 & 6.8 & 5.3723 & TRN \\
\hline CHEMBL1591373 & 688407 & 8.301 & 4.913 & TRN \\
\hline CHEMBL1477213 & 688407 & 4.6 & 4.8181 & TRN \\
\hline CHEMBL1436767 & 688407 & 6.8 & 5.3495 & TRN \\
\hline CHEMBL1488710 & 688407 & 5.3 & 5.9628 & TRN \\
\hline CHEMBL1586081 & 688407 & 7.8508 & 5.8437 & TRN \\
\hline
\end{tabular}

Page 22363 


\begin{tabular}{|c|c|c|c|c|c|}
\hline \multicolumn{6}{|c|}{ plemental } \\
\hline CHEMBL2000815 & 688407 & 6.1 & 6.647 & TST & \\
\hline CHEMBL1484143 & 688407 & 5.5 & 5.3335 & TST & \\
\hline CHEMBL1494950 & 688407 & 5.1 & 5.7684 & TRN & \\
\hline CHEMBL1437005 & 688407 & 6.25 & 5.6465 & TRN & \\
\hline CHEMBL1314555 & 688407 & 4.6 & 5.3556 & TRN & \\
\hline CHEMBL1358617 & 688407 & 4.45 & 5.1624 & TRN & \\
\hline CHEMBL1414344 & 688407 & 5.0 & 5.6842 & TRN & \\
\hline CHEMBL1588589 & 688407 & 7.699 & 5.7925 & TST & \\
\hline CHEMBL1377888 & 688407 & 4.7 & 5.6172 & TST & \\
\hline CHEMBL1314958 & 688407 & 6.9 & 6.545 & TRN & \\
\hline CHEMBL1589939 & 688407 & 4.45 & 5.7448 & TST & \\
\hline CHEMBL1395194 & 688407 & 4.5 & 5.6275 & TRN & \\
\hline CHEMBL1370442 & 688407 & 4.7 & 5.6736 & TRN & \\
\hline CHEMBL1592201 & 688407 & 5.5 & 6.3747 & TST & \\
\hline CHEMBL1439110 & 688407 & 5.35 & 5.3559 & TRN & \\
\hline CHEMBL1565928 & 688407 & 4.8 & 5.5772 & TRN & \\
\hline CHEMBL1344000 & 688407 & 4.75 & 4.5985 & TST & \\
\hline CHEMBL601140 & 688407 & 5.0 & 5.6659 & TST & \\
\hline CHEMBL1398009 & 688407 & 5.3 & 6.6162 & TRN & \\
\hline CHEMBL1565955 & 688407 & 4.9 & 5.1412 & TST & \\
\hline CHEMBL1553486 & 688407 & 6.7001 & 5.5101 & TRN & \\
\hline CHEMBL1485271 & 688407 & 7.8996 & 5.3834 & TRN & \\
\hline CHEMBL1357538 & 688407 & 4.8 & 4.7359 & TRN & \\
\hline CHEMBL1434782 & 688407 & 5.4 & 6.7708 & TRN & \\
\hline CHEMBL1594589 & 688407 & 4.8 & 5.2252 & TRN & \\
\hline CHEMBL1514315 & 688407 & 7.1002 & 5.3298 & TRN & \\
\hline CHEMBL1445623 & 688407 & 6.8 & 6.2698 & TRN & \\
\hline CHEMBL1397783 & 688407 & 6.8 & 6.1288 & TRN & \\
\hline CHEMBL1604405 & 688407 & 4.9 & 4.7997 & TRN & \\
\hline CHEMBL1478339 & 688407 & 5.2 & 5.3538 & TRN & \\
\hline CHEMBL1362406 & 688407 & 4.9 & 4.9166 & TRN & \\
\hline CHEMBL1519019 & 688407 & 4.9 & 5.3075 & TRN & \\
\hline CHEMBL1398475 & 688407 & 4.95 & 5.0926 & TRN & \\
\hline CHEMBL1524880 & 688407 & 8.4949 & 5.4173 & TST & \\
\hline CHEMBL1591057 & 688407 & 5.2 & 5.23600 & 0000000001 & TRN \\
\hline CHEMBL1325491 & 688407 & 5.3 & 4.5113 & TST & \\
\hline CHEMBL1434536 & 688407 & 4.45 & 4.603 & TRN & \\
\hline CHEMBL1359760 & 688407 & 4.5 & 5.3388 & TST & \\
\hline CHEMBL1473744 & 688407 & 4.45 & 4.6478 & TST & \\
\hline CHEMBL1370542 & 688407 & 4.5 & 5.1747 & TRN & \\
\hline CHEMBL1600428 & 688407 & 7.2 & 6.4739 & TRN & \\
\hline CHEMBL1366676 & 688407 & 5.0 & 5.0597 & TRN & \\
\hline CHEMBL1554426 & 688407 & 4.8 & 4.6472 & TRN & \\
\hline CHEMBL1595100 & 688407 & 4.6 & 5.482 & TRN & \\
\hline CHEMBL1400590 & 688407 & 4.5 & 5.0212 & TRN & \\
\hline CHEMBL1336600 & 688407 & 8.301 & 6.5266 & TRN & \\
\hline CHEMBL1434001 & 688407 & 4.5 & 4.8085 & TST & \\
\hline CHEMBL1554709 & 688407 & 4.9 & 4.6237 & TRN & \\
\hline
\end{tabular}




\begin{tabular}{|c|c|c|c|c|}
\hline \multicolumn{5}{|c|}{ Supplemental Table S2.txt } \\
\hline CHEMBL1593141 & 688407 & 4.9 & 5.3772 & TRN \\
\hline CHEMBL579749 & 688407 & 4.65 & 5.357 & TRN \\
\hline CHEMBL1574951 & 688407 & 4.9 & 5.3704 & TRN \\
\hline CHEMBL1478117 & 688407 & 4.6 & 5.0377 & TRN \\
\hline CHEMBL1363692 & 688407 & 4.8 & 5.6084 & TRN \\
\hline CHEMBL1374788 & 688407 & 5.0 & 5.8783 & TRN \\
\hline CHEMBL1553911 & 688407 & 6.1 & 5.8435 & TST \\
\hline CHEMBL1574352 & 688407 & 4.9 & 5.4035 & TRN \\
\hline CHEMBL1534548 & 688407 & 6.2 & 5.9274 & TRN \\
\hline CHEMBL1557604 & 688407 & 5.0 & 6.0164 & TRN \\
\hline CHEMBL1378293 & 688407 & 4.45 & 5.4941 & TRN \\
\hline CHEMBL1532062 & 688407 & 4.5 & 5.7831 & TST \\
\hline CHEMBL1396005 & 688407 & 4.45 & 5.4464 & TRN \\
\hline CHEMBL1592971 & 688407 & 8.301 & 5.8535 & TST \\
\hline CHEMBL1436677 & 688407 & 5.0 & 5.6811 & TRN \\
\hline CHEMBL1591945 & 688407 & 8.4949 & 5.5462 & TST \\
\hline CHEMBL1491857 & 688407 & 6.6499 & 5.8176 & TRN \\
\hline CHEMBL1590322 & 688407 & 5.0 & 6.0713 & TRN \\
\hline CHEMBL1574245 & 688407 & 7.0 & 5.4081 & TRN \\
\hline CHEMBL1594872 & 688407 & 4.8 & 5.41700 & 0000000001 \\
\hline CHEMBL1397137 & 688407 & 6.4 & 6.2989 & TRN \\
\hline CHEMBL1396785 & 688407 & 4.7 & 5.6591 & TRN \\
\hline CHEMBL1440282 & 688407 & 5.4 & 5.0804 & TRN \\
\hline CHEMBL1352291 & 688407 & 7.699 & 6.1692 & TRN \\
\hline CHEMBL1573281 & 688407 & 5.9 & 6.5329 & TST \\
\hline CHEMBL1339151 & 688407 & 6.7001 & 5.2388 & TST \\
\hline CHEMBL1599945 & 688407 & 4.75 & 5.0502 & TRN \\
\hline CHEMBL1404648 & 688407 & 8.301 & 6.1199 & TST \\
\hline CHEMBL1368498 & 688407 & 8.3979 & 6.034 & TRN \\
\hline CHEMBL1334001 & 688407 & 4.5 & 4.9458 & TRN \\
\hline CHEMBL1453100 & 688407 & 5.1 & 5.4472 & TRN \\
\hline CHEMBL1515063 & 688407 & 5.4 & 5.165 & TRN \\
\hline CHEMBL1316733 & 688407 & 5.9 & 6.1451 & TRN \\
\hline CHEMBL1315616 & 688407 & 4.5 & 6.1318 & TRN \\
\hline CHEMBL1357752 & 688407 & 5.9 & 5.4954 & TST \\
\hline CHEMBL1316544 & 688407 & 5.1 & 6.143 & TRN \\
\hline CHEMBL1594684 & 688407 & 5.0 & 5.7181 & TRN \\
\hline CHEMBL1437418 & 688407 & 4.5 & 5.6418 & TST \\
\hline CHEMBL1473401 & 688407 & 4.8 & 5.5887 & TST \\
\hline CHEMBL1553936 & 688407 & 8.0 & 5.4184 & TRN \\
\hline CHEMBL1416102 & 688407 & 6.6 & 5.1412 & TRN \\
\hline CHEMBL1316937 & 688407 & 6.1 & 5.7222 & TRN \\
\hline CHEMBL1589849 & 688407 & 5.8 & 5.8129 & TRN \\
\hline CHEMBL1411429 & 688407 & 5.3 & 5.3601 & TRN \\
\hline CHEMBL1483842 & 688407 & 5.5 & 5.5428 & TST \\
\hline CHEMBL528712 & 688407 & 4.9 & 4.9458 & TST \\
\hline CHEMBL1494905 & 688407 & 5.4 & 5.5662 & TRN \\
\hline CHEMBL601367 & 688407 & 4.6 & 4.9811 & TST \\
\hline
\end{tabular}




\begin{tabular}{|c|c|c|c|c|}
\hline \multicolumn{5}{|c|}{ Supplemental Table s2.txt } \\
\hline CHEMBL1377126 & 688407 & 5.1 & 5.3974 & TRN \\
\hline CHEMBL1552684 & 688407 & 4.9 & 5.5266 & TRN \\
\hline CHEMBL582473 & 688407 & 4.75 & 5.0688 & TRN \\
\hline CHEMBL1356130 & 688407 & 8.2007 & 5.825 & TST \\
\hline CHEMBL1553108 & 688407 & 4.5 & 5.0119 & TRN \\
\hline CHEMBL1317719 & 688407 & 4.9 & 5.33 & TST \\
\hline CHEMBL1395481 & 688407 & 6.0 & 5.2334 & TRN \\
\hline CHEMBL1554234 & 688407 & 6.6 & 6.9415 & TRN \\
\hline CHEMBL1514908 & 688407 & 5.3 & 6.3809 & TRN \\
\hline CHEMBL1606319 & 688407 & 4.7 & 5.3521 & TRN \\
\hline CHEMBL1531410 & 688407 & 4.5 & 5.4597 & TRN \\
\hline CHEMBL1560395 & 688407 & 4.5 & 5.2659 & TRN \\
\hline CHEMBL1398021 & 688407 & 4.45 & 5.6132 & TST \\
\hline CHEMBL1439235 & 688407 & 7.6003 & 5.6185 & TRN \\
\hline CHEMBL1495306 & 688407 & 4.9 & 5.8198 & TRN \\
\hline CHEMBL1360191 & 688407 & 4.5 & 5.3731 & TRN \\
\hline CHEMBL1372686 & 688407 & 4.9 & 5.5689 & TRN \\
\hline CHEMBL1590162 & 688407 & 5.0 & 5.3673 & TRN \\
\hline CHEMBL1474624 & 688407 & 4.7 & 5.4733 & TRN \\
\hline CHEMBL1434576 & 688407 & 5.8 & 4.6708 & TRN \\
\hline CHEMBL1553284 & 688407 & 4.95 & 5.9391 & TRN \\
\hline CHEMBL1590457 & 688407 & 4.5 & 5.36100 & 0000000001 \\
\hline CHEMBL1328598 & 688407 & 6.3 & 5.6966 & TRN \\
\hline CHEMBL1552768 & 688407 & 7.1002 & 6.4721 & TRN \\
\hline CHEMBL1319380 & 688407 & 4.95 & 6.7334 & TRN \\
\hline CHEMBL1396037 & 688407 & 5.7 & 5.7829 & TRN \\
\hline CHEMBL1448159 & 688407 & 7.15 & 5.2962 & TST \\
\hline CHEMBL1592596 & 688407 & 5.05 & 5.7653 & TRN \\
\hline CHEMBL1473162 & 688407 & 4.7 & 5.3243 & TST \\
\hline CHEMBL1340792 & 688407 & 4.45 & 4.5906 & TST \\
\hline CHEMBL1336778 & 688407 & 6.4 & 5.3925 & TRN \\
\hline CHEMBL1434163 & 688407 & 7.2 & 6.1083 & TRN \\
\hline CHEMBL1439717 & 688407 & 5.0 & 5.6328 & TST \\
\hline CHEMBL1513911 & 688407 & 5.6 & 5.5507 & TST \\
\hline CHEMBL1475095 & 688407 & 4.8 & 4.7738 & TRN \\
\hline CHEMBL1397624 & 688407 & 6.0 & 5.9341 & TRN \\
\hline CHEMBL1435458 & 688407 & 4.6 & 4.8431 & TRN \\
\hline CHEMBL1436764 & 688407 & 7.0 & 5.6758 & TST \\
\hline CHEMBL1429512 & 688407 & 4.5 & 5.3105 & TST \\
\hline CHEMBL1378033 & 688407 & 4.55 & 5.4937 & TRN \\
\hline CHEMBL1512137 & 688407 & 4.65 & 4.9902 & TRN \\
\hline CHEMBL1396767 & 688407 & 4.7 & 4.8065 & TRN \\
\hline CHEMBL1435501 & 688407 & 5.7 & 5.6781 & TRN \\
\hline CHEMBL1473496 & 688407 & 7.2 & 6.0964 & TST \\
\hline CHEMBL1525404 & 688407 & 4.85 & 5.1721 & TRN \\
\hline CHEMBL1320735 & 688407 & 7.2 & 5.0284 & TRN \\
\hline CHEMBL1607640 & 688407 & 5.0 & 5.8593 & TRN \\
\hline CHEMBL1333682 & 688407 & 8.2007 & 6.0325 & TRN \\
\hline
\end{tabular}




\begin{tabular}{|c|c|c|c|c|}
\hline \multicolumn{5}{|c|}{ Supplemental Table S2.txt } \\
\hline CHEMBL1334273 & 688407 & 6.0 & 5.4775 & TST \\
\hline CHEMBL1473368 & 688407 & 4.95 & 5.1337 & TRN \\
\hline CHEMBL1512414 & 688407 & 5.0 & 4.9885 & TST \\
\hline CHEMBL1516624 & 688407 & 4.9 & 4.9217 & TRN \\
\hline CHEMBL1315394 & 688407 & 4.6 & 5.1881 & TRN \\
\hline CHEMBL1317327 & 688407 & 4.85 & 5.4217 & TST \\
\hline CHEMBL1413812 & 688407 & 5.25 & 5.7464 & TRN \\
\hline CHEMBL1433447 & 688407 & 8.3979 & 6.6073 & TRN \\
\hline CHEMBL1436193 & 688407 & 5.0 & 5.8409 & TRN \\
\hline CHEMBL1605355 & 688407 & 6.0 & 5.776 & TST \\
\hline CHEMBL1357013 & 688407 & 4.9 & 5.7916 & TRN \\
\hline CHEMBL1395035 & 688407 & 6.35 & 5.7284 & TRN \\
\hline CHEMBL1378006 & 688407 & 5.3 & 5.9041 & TRN \\
\hline CHEMBL1472909 & 688407 & 7.0 & 5.7195 & TRN \\
\hline CHEMBL1315927 & 688407 & 5.0 & 5.624 & TST \\
\hline CHEMBL1513828 & 688407 & 7.2 & 5.2507 & TRN \\
\hline CHEMBL1435612 & 688407 & 4.4 & 5.6298 & TRN \\
\hline CHEMBL1534644 & 688407 & 6.8 & 6.1176 & TRN \\
\hline CHEMBL1417441 & 688407 & 8.0 & 6.1538 & TST \\
\hline CHEMBL1450914 & 688407 & 4.75 & 4.8739 & TST \\
\hline CHEMBL1476724 & 688407 & 4.5 & 5.3956 & TRN \\
\hline CHEMBL1531582 & 688407 & 4.9 & 4.4155 & TST \\
\hline CHEMBL1345749 & 688407 & 6.0 & 5.9323 & TST \\
\hline CHEMBL1332750 & 688407 & 8.301 & 6.2248 & TST \\
\hline CHEMBL1356582 & 688407 & 4.5 & 5.1835 & TRN \\
\hline CHEMBL1609032 & 688407 & 6.9 & 5.7624 & TRN \\
\hline CHEMBL1354244 & 688407 & 4.45 & 5.0799 & TRN \\
\hline CHEMBL1534119 & 688407 & 7.1002 & 5.7226 & TRN \\
\hline CHEMBL1555170 & 688407 & 4.45 & 5.1473 & TRN \\
\hline CHEMBL1474039 & 688407 & 7.1002 & 5.2968 & TRN \\
\hline CHEMBL1473321 & 688407 & 4.5 & 5.0777 & TRN \\
\hline CHEMBL1396459 & 688407 & 4.55 & 4.9576 & TRN \\
\hline CHEMBL1319419 & 688407 & 4.9 & 4.8404 & TRN \\
\hline CHEMBL1356854 & 688407 & 5.5 & 5.1767 & TRN \\
\hline CHEMBL1452743 & 688407 & 4.45 & 4.9489 & TRN \\
\hline CHEMBL1595399 & 688407 & 8.301 & 5.5566 & TRN \\
\hline CHEMBL1568967 & 688407 & 8.301 & 6.2436 & TRN \\
\hline CHEMBL1314724 & 688407 & 5.1 & 5.7065 & TST \\
\hline CHEMBL1315128 & 688407 & 4.7 & 5.2041 & TRN \\
\hline CHEMBL1436190 & 688407 & 5.8 & 4.6367 & TRN \\
\hline CHEMBL1357554 & 688407 & 4.5 & 6.0626 & TRN \\
\hline CHEMBL1436786 & 688407 & 4.7 & 4.9911 & TST \\
\hline CHEMBL1596973 & 688407 & 5.9 & 6.3769 & TRN \\
\hline CHEMBL1330759 & 688407 & 4.45 & 5.5477 & TST \\
\hline CHEMBL1609627 & 688407 & 4.5 & 4.9093 & TRN \\
\hline CHEMBL1523000 & 688407 & 5.1 & 5.1893 & TST \\
\hline CHEMBL1406333 & 688407 & 7.5003 & 5.2572 & TRN \\
\hline CHEMBL1356773 & 688407 & 4.5 & 4.2499 & TST \\
\hline
\end{tabular}




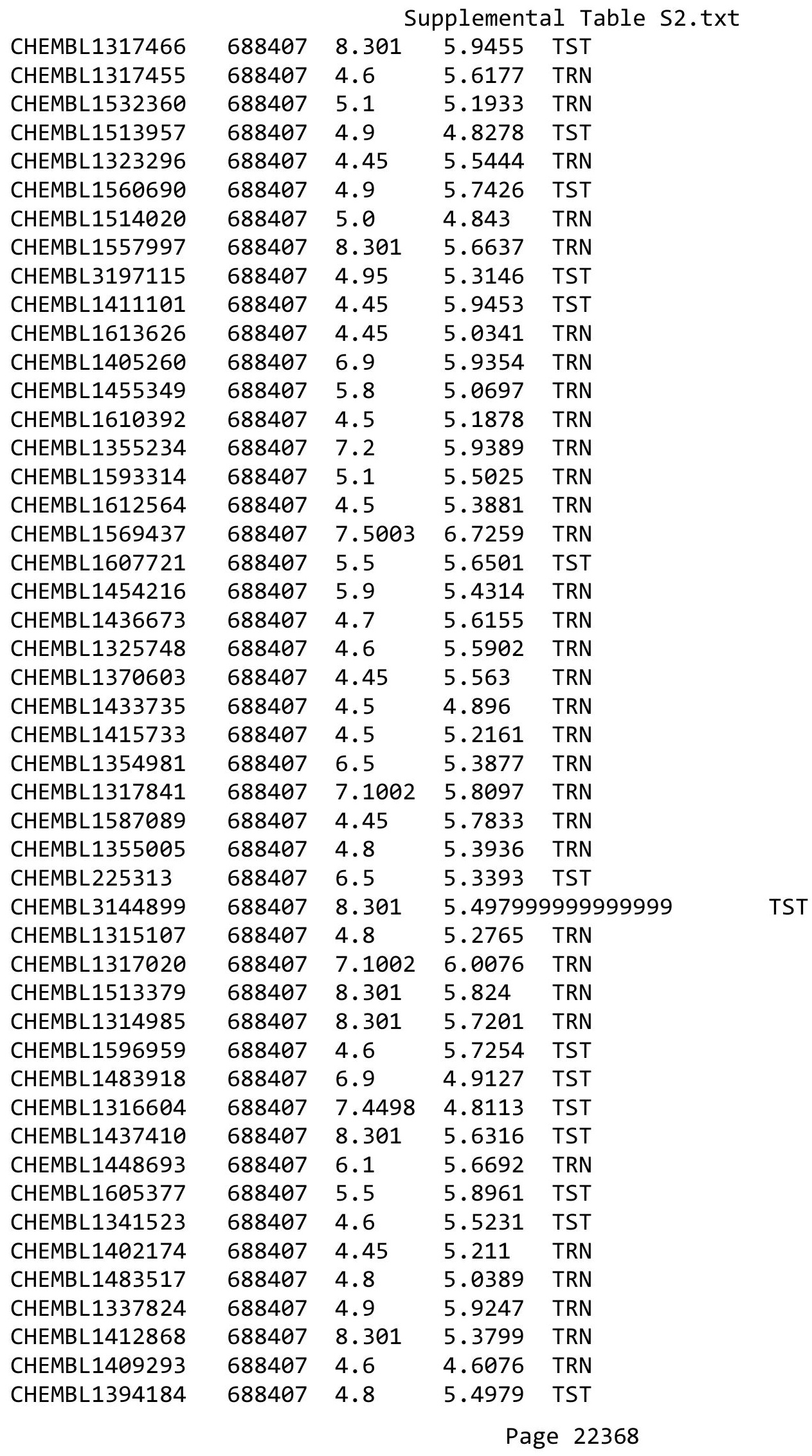




\begin{tabular}{|c|c|c|c|c|c|}
\hline \\
\hline CHEMBL1551965 & 688407 & 8.301 & 6.5437 & TRN & \\
\hline CHEMBL1531154 & 688407 & 7.0 & 5.9815 & TRN & \\
\hline CHEMBL1477803 & 688407 & 4.65 & 4.6394 & TRN & \\
\hline CHEMBL1404430 & 688407 & 4.7 & 4.9717 & TRN & \\
\hline CHEMBL1515569 & 688407 & 6.4 & 5.322 & TRN & \\
\hline CHEMBL1605948 & 688407 & 4.5 & 5.3982 & TRN & \\
\hline CHEMBL1533784 & 688407 & 4.9 & 5.9431 & TRN & \\
\hline CHEMBL1491829 & 688407 & 5.9 & 6.0278 & TRN & \\
\hline CHEMBL1554028 & 688407 & 6.2 & 4.955 & TRN & \\
\hline CHEMBL1316536 & 688407 & 4.9 & 5.0828 & TRN & \\
\hline CHEMBL1551681 & 688407 & 4.95 & 5.07600 & 00000000005 & TST \\
\hline CHEMBL1564738 & 688407 & 7.699 & 5.7615 & TST & \\
\hline CHEMBL1395958 & 688407 & 5.15 & 5.5995 & TRN & \\
\hline CHEMBL 1457410 & 688407 & 4.5 & 5.0994 & TRN & \\
\hline CHEMBL1477025 & 688407 & 4.8 & 4.4164 & TRN & \\
\hline CHEMBL1396322 & 688407 & 4.9 & 5.4472 & TRN & \\
\hline CHEMBL1314161 & 688407 & 4.7 & 4.8787 & TRN & \\
\hline CHEMBL1512119 & 688407 & 5.3 & 4.9825 & TRN & \\
\hline CHEMBL1583839 & 688407 & 5.0 & 6.3761 & TST & \\
\hline CHEMBL1558353 & 688407 & 4.7 & 6.1883 & TRN & \\
\hline CHEMBL1397811 & 688407 & 7.3002 & 5.8684 & TST & \\
\hline CHEMBL1396227 & 688407 & 8.301 & 6.1727 & TRN & \\
\hline CHEMBL1512926 & 688407 & 4.9 & 5.4309 & TST & \\
\hline CHEMBL1606781 & 688407 & 5.2 & 6.2493 & TRN & \\
\hline CHEMBL1552089 & 688407 & 4.45 & 4.7941 & TRN & \\
\hline CHEMBL1362161 & 688407 & 4.8 & 5.8053 & TRN & \\
\hline CHEMBL1231450 & 688407 & 8.0506 & 5.1325 & TST & \\
\hline CHEMBL1400055 & 688407 & 4.5 & 4.9221 & TRN & \\
\hline CHEMBL1524437 & 688407 & 8.301 & 5.9163 & TRN & \\
\hline CHEMBL1528936 & 688407 & 4.45 & 5.5441 & TRN & \\
\hline CHEMBL1356766 & 688407 & 5.0 & 5.2238 & TST & \\
\hline CHEMBL1315989 & 688407 & 6.4 & 5.5826 & TRN & \\
\hline CHEMBL1531822 & 688407 & 8.3468 & 5.8951 & TRN & \\
\hline CHEMBL1481567 & 688407 & 4.9 & 5.4338 & TRN & \\
\hline CHEMBL1322781 & 688407 & 6.3 & 5.5684 & TRN & \\
\hline CHEMBL1512483 & 688407 & 4.9 & 4.704 & TRN & \\
\hline CHEMBL1597357 & 688407 & 4.5 & 5.2653 & TRN & \\
\hline CHEMBL1318153 & 688407 & 6.1 & 5.976 & TST & \\
\hline CHEMBL1476836 & 688407 & 8.0 & 5.8403 & TRN & \\
\hline CHEMBL1556082 & 688407 & 6.3 & 5.1787 & TRN & \\
\hline CHEMBL1358104 & 688407 & 4.6 & 4.8171 & TRN & \\
\hline CHEMBL1966367 & 688407 & 5.55 & 6.1499 & TST & \\
\hline CHEMBL1316161 & 688407 & 4.85 & 5.4944 & TST & \\
\hline CHEMBL1357460 & 688407 & 5.2 & 5.9057 & TRN & \\
\hline CHEMBL1473169 & 688407 & 6.6499 & 6.9282 & TRN & \\
\hline CHEMBL1416079 & 688407 & 5.4 & 6.4092 & TRN & \\
\hline CHEMBL592118 & 688407 & 4.45 & 5.5625 & TRN & \\
\hline CHEMBL1473089 & 688407 & 4.6 & 4.6702 & TRN & \\
\hline
\end{tabular}




\begin{tabular}{|c|c|c|c|c|c|}
\hline \multicolumn{6}{|c|}{ Supplemental Table S2.txt } \\
\hline CHEMBL1435511 & 688407 & 4.5 & 6.0105 & TST & \\
\hline CHEMBL1316030 & 688407 & 6.4 & 5.2287 & TRN & \\
\hline CHEMBL1367014 & 688407 & 8.4559 & 6.4727 & TRN & \\
\hline CHEMBL1591401 & 688407 & 4.45 & 5.5863 & TRN & \\
\hline CHEMBL1387134 & 688407 & 7.1002 & 6.2549 & TRN & \\
\hline CHEMBL1474133 & 688407 & 7.0 & 5.7962 & TRN & \\
\hline CHEMBL1417353 & 688407 & 4.9 & 5.4333 & TRN & \\
\hline CHEMBL1441357 & 688407 & 4.9 & 5.876 & TRN & \\
\hline CHEMBL1491304 & 688407 & 4.6 & 5.6886 & TRN & \\
\hline CHEMBL1380512 & 688407 & 5.1 & 5.6245 & TST & \\
\hline CHEMBL1479303 & 688407 & 7.699 & 5.4931 & TST & \\
\hline CHEMBL1375955 & 688407 & 4.9 & 4.4682 & TRN & \\
\hline CHEMBL1320337 & 688407 & 5.1 & 5.518 & TRN & \\
\hline CHEMBL1609805 & 688407 & 4.6 & 4.8542 & TRN & \\
\hline CHEMBL1318642 & 688407 & 6.0 & 5.4861 & TRN & \\
\hline CHEMBL1401545 & 688407 & 8.3979 & 5.4713 & TRN & \\
\hline CHEMBL1477337 & 688407 & 4.8 & 5.6279 & TST & \\
\hline CHEMBL1554951 & 688407 & 5.1 & 6.0302 & TRN & \\
\hline CHEMBL1397550 & 688407 & 5.35 & 5.9651 & TRN & \\
\hline CHEMBL1559532 & 688407 & 4.65 & 5.0825 & TST & \\
\hline CHEMBL1474009 & 688407 & 8.0 & 6.0426 & TRN & \\
\hline CHEMBL1357852 & 688407 & 4.45 & 5.2818 & TRN & \\
\hline CHEMBL1590157 & 688407 & 8.301 & 5.4961 & TRN & \\
\hline CHEMBL1476215 & 688407 & 5.1 & 5.3434 & TRN & \\
\hline CHEMBL1552579 & 688407 & 4.7 & 5.3521 & TRN & \\
\hline CHEMBL1593915 & 688407 & 4.45 & 5.5822 & TST & \\
\hline CHEMBL1415243 & 688407 & 5.0 & 5.1466 & TRN & \\
\hline CHEMBL1436966 & 688407 & 4.9 & 4.8318 & TRN & \\
\hline CHEMBL1394570 & 688407 & 4.5 & 5.2094 & TRN & \\
\hline CHEMBL1593588 & 688407 & 4.45 & 5.7913 & TRN & \\
\hline CHEMBL1442283 & 688407 & 7.2 & 6.3208 & TRN & \\
\hline CHEMBL1593951 & 688407 & 4.45 & 4.7732 & TST & \\
\hline CHEMBL1325661 & 688407 & 4.45 & 5.5858 & TST & \\
\hline CHEMBL1557378 & 688407 & 5.0 & 5.4436 & TRN & \\
\hline CHEMBL1595176 & 688407 & 4.95 & 5.5032 & TRN & \\
\hline CHEMBL1396193 & 688407 & 4.9 & 5.24700 & 0000000001 & TRN \\
\hline CHEMBL1490465 & 688407 & 4.5 & 5.3441 & TRN & \\
\hline CHEMBL1515834 & 688407 & 4.5 & 6.0177 & TRN & \\
\hline CHEMBL1408299 & 688407 & 7.1002 & 6.2806 & TRN & \\
\hline CHEMBL1398221 & 688407 & 4.95 & 5.5578 & TRN & \\
\hline CHEMBL1317062 & 688407 & 4.5 & 5.7394 & TRN & \\
\hline CHEMBL1562849 & 688407 & 4.65 & 5.1889 & TST & \\
\hline CHEMBL1374746 & 688407 & 5.1 & 5.23 & TST & \\
\hline CHEMBL1512789 & 688407 & 4.8 & 5.215 & TRN & \\
\hline CHEMBL1612172 & 688407 & 4.7 & 4.8895 & TRN & \\
\hline CHEMBL1476319 & 688407 & 4.75 & 5.50700 & 0000000001 & TRN \\
\hline CHEMBL1475715 & 688407 & 4.5 & 5.2119 & TRN & \\
\hline CHEMBL1436874 & 688407 & 4.7 & 5.0131 & TRN & \\
\hline
\end{tabular}




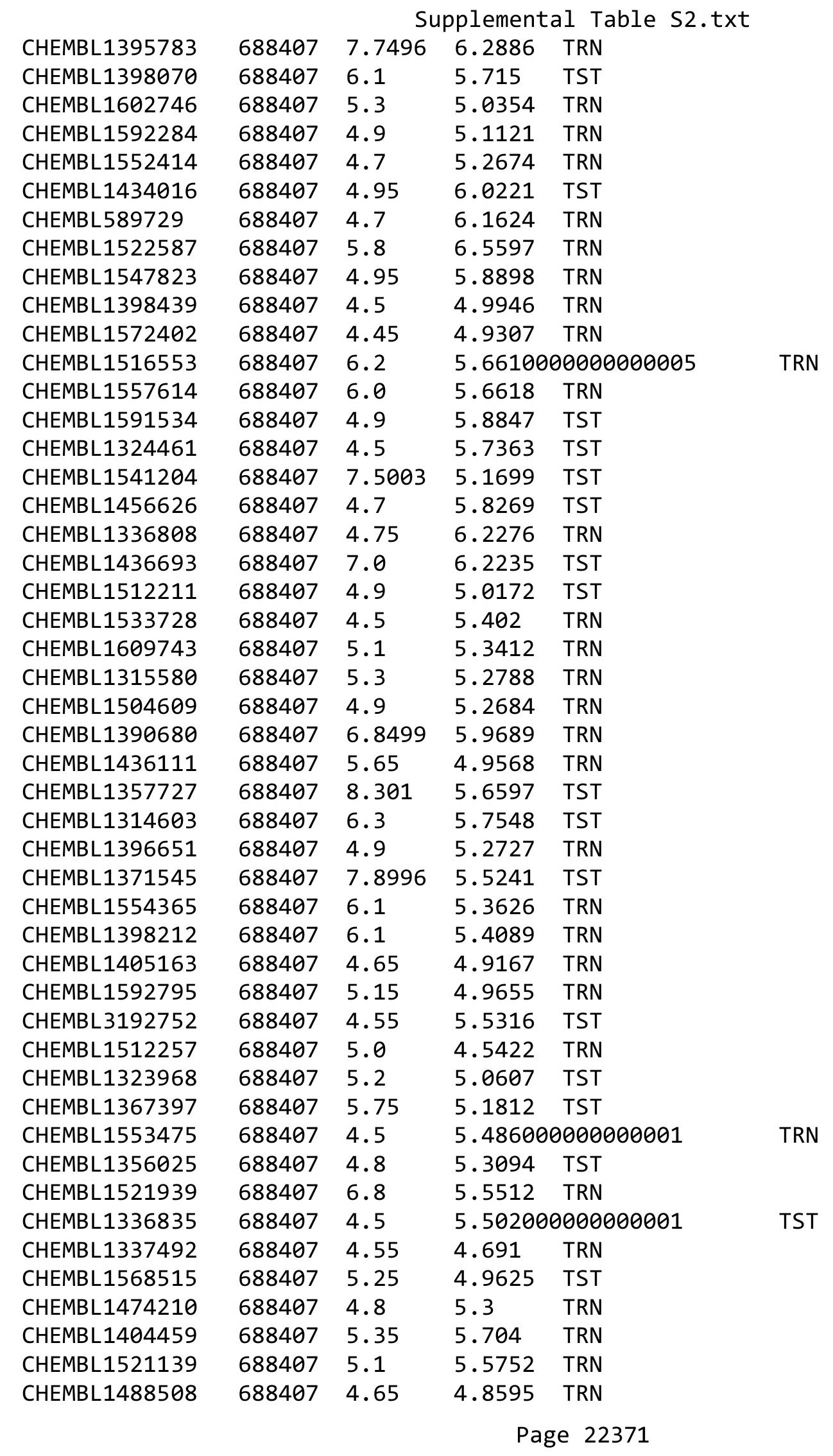




\begin{tabular}{|c|c|c|c|c|c|}
\hline \multicolumn{6}{|c|}{ Supplemental Table S2.txt } \\
\hline CHEMBL1486028 & 688407 & 5.65 & 5.7437 & TRN & \\
\hline CHEMBL1333413 & 688407 & 5.3 & 5.5797 & TST & \\
\hline CHEMBL1552002 & 688407 & 6.35 & 5.5894 & TRN & \\
\hline CHEMBL1495982 & 688407 & 4.5 & 5.2749 & TRN & \\
\hline CHEMBL1341112 & 688407 & 5.0 & 5.6168 & TST & \\
\hline CHEMBL1602114 & 688407 & 4.7 & 4.8562 & TRN & \\
\hline CHEMBL1411124 & 688407 & 5.1 & 5.7177 & TST & \\
\hline CHEMBL1591914 & 688407 & 5.85 & 5.8993 & TST & \\
\hline CHEMBL1415630 & 688407 & 4.5 & 5.4863 & TST & \\
\hline CHEMBL1554259 & 688407 & 7.699 & 6.4972 & TRN & \\
\hline CHEMBL1364512 & 688407 & 4.5 & 5.2809 & TRN & \\
\hline CHEMBL1442839 & 688407 & 4.6 & 5.9073 & TRN & \\
\hline CHEMBL1509303 & 688407 & 4.8 & 5.5819 & TST & \\
\hline CHEMBL1356313 & 688407 & 8.1024 & 6.0308 & TRN & \\
\hline CHEMBL1490766 & 688407 & 4.7 & 5.9067 & TST & \\
\hline CHEMBL1355643 & 688407 & 5.0 & 5.3416 & TRN & \\
\hline CHEMBL1359457 & 688407 & 4.8 & 5.4174 & TRN & \\
\hline CHEMBL1327724 & 688407 & 7.2 & 5.3381 & TRN & \\
\hline CHEMBL1590839 & 688407 & 4.8 & 4.3376 & TRN & \\
\hline CHEMBL1330480 & 688407 & 4.9 & 5.2221 & TRN & \\
\hline CHEMBL1364251 & 688407 & 4.8 & 5.2493 & TRN & \\
\hline CHEMBL1593065 & 688407 & 6.0 & 5.2602 & TST & \\
\hline CHEMBL1593262 & 688407 & 4.5 & 5.1887 & TST & \\
\hline CHEMBL1514829 & 688407 & 4.5 & 5.5477 & TST & \\
\hline CHEMBL1554699 & 688407 & 8.0 & 6.3576 & TRN & \\
\hline CHEMBL1551190 & 688407 & 8.1024 & 5.4203 & TRN & \\
\hline CHEMBL1373999 & 688407 & 6.7001 & 6.0509 & TRN & \\
\hline CHEMBL1480826 & 688407 & 5.2 & 4.9503 & TRN & \\
\hline CHEMBL1320173 & 688407 & 4.5 & 4.7308 & TRN & \\
\hline CHEMBL1554058 & 688407 & 5.2 & 4.8986 & TRN & \\
\hline CHEMBL1518591 & 688407 & 4.6 & 5.4694 & TRN & \\
\hline CHEMBL1329988 & 688407 & 8.0 & 6.0549 & TRN & \\
\hline CHEMBL1450007 & 688407 & 4.9 & 5.6005 & TST & \\
\hline CHEMBL1610959 & 688407 & 4.7 & 4.7649 & TRN & \\
\hline CHEMBL1480333 & 688407 & 5.3 & 6.2008 & TRN & \\
\hline CHEMBL1574638 & 688407 & 4.5 & 5.1065 & TST & \\
\hline CHEMBL1489449 & 688407 & 4.5 & 5.44799 & 99999999995 & TRN \\
\hline CHEMBL1438828 & 688407 & 4.85 & 5.3738 & TST & \\
\hline CHEMBL1356016 & 688407 & 5.4 & 5.4326 & TST & \\
\hline CHEMBL1321914 & 688407 & 5.0 & 4.617 & TRN & \\
\hline CHEMBL1570243 & 688407 & 4.6 & 4.959 & TRN & \\
\hline CHEMBL1600795 & 688407 & 4.8 & 4.7143 & TRN & \\
\hline CHEMBL1315329 & 688407 & 8.0 & 5.7054 & TST & \\
\hline CHEMBL1365927 & 688407 & 4.9 & 5.4347 & TRN & \\
\hline CHEMBL1513815 & 688407 & 4.6 & 5.5149 & TST & \\
\hline CHEMBL1436429 & 688407 & 4.8 & 4.7186 & TRN & \\
\hline CHEMBL1592221 & 688407 & 4.9 & 5.2389 & TRN & \\
\hline CHEMBL1360626 & 688407 & 7.4001 & 5.9784 & TRN & \\
\hline
\end{tabular}




\begin{tabular}{|c|c|c|c|c|}
\hline \multicolumn{5}{|c|}{ Supplemental Table s2.txt } \\
\hline CHEMBL1534235 & 688407 & 5.4 & 5.5843 & TRN \\
\hline CHEMBL1456586 & 688407 & 7.0 & 5.3303 & TRN \\
\hline CHEMBL1402332 & 688407 & 4.9 & 4.8392 & TRN \\
\hline CHEMBL1591856 & 688407 & 4.9 & 5.3412 & TRN \\
\hline CHEMBL1553046 & 688407 & 4.9 & 4.9352 & TRN \\
\hline CHEMBL1317919 & 688407 & 4.5 & 4.828 & TRN \\
\hline CHEMBL1590217 & 688407 & 4.7 & 5.1166 & TST \\
\hline CHEMBL1338443 & 688407 & 5.4 & 4.9456 & TRN \\
\hline CHEMBL1317047 & 688407 & 5.5 & 6.1018 & TST \\
\hline CHEMBL1472817 & 688407 & 5.9 & 6.3994 & TRN \\
\hline CHEMBL1373251 & 688407 & 5.7 & 5.4346 & TST \\
\hline CHEMBL1359984 & 688407 & 4.6 & 5.5385 & TST \\
\hline CHEMBL1571188 & 688407 & 8.1024 & 7.3479 & TRN \\
\hline CHEMBL1512431 & 688407 & 4.65 & 4.9359 & TRN \\
\hline CHEMBL1489584 & 688407 & 8.4949 & 5.8905 & TRN \\
\hline CHEMBL1554338 & 688407 & 4.55 & 4.6397 & TRN \\
\hline CHEMBL1529419 & 688407 & 5.0 & 5.4313 & TRN \\
\hline CHEMBL1408656 & 688407 & 4.5 & 5.0336 & TRN \\
\hline CHEMBL1485355 & 688407 & 6.4 & 5.5259 & TRN \\
\hline CHEMBL1404845 & 688407 & 7.699 & 5.8243 & TRN \\
\hline CHEMBL1308128 & 688407 & 4.9 & 5.1234 & TST \\
\hline CHEMBL1494069 & 688407 & 4.5 & 5.1238 & TRN \\
\hline CHEMBL1357125 & 688407 & 4.9 & 6.0829 & TST \\
\hline CHEMBL1448594 & 688407 & 7.5003 & 5.6413 & TST \\
\hline CHEMBL1376648 & 688407 & 8.301 & 6.1854 & TRN \\
\hline CHEMBL1356407 & 688407 & 5.0 & 5.1088 & TRN \\
\hline CHEMBL1338385 & 688407 & 4.45 & 4.7355 & TRN \\
\hline CHEMBL1554039 & 688407 & 4.8 & 5.0296 & TRN \\
\hline CHEMBL1414835 & 688407 & 6.1 & 5.6379 & TRN \\
\hline CHEMBL1317971 & 688407 & 7.0 & 6.2147 & TST \\
\hline CHEMBL1555685 & 688407 & 5.4 & 5.8868 & TRN \\
\hline CHEMBL1413449 & 688407 & 7.3002 & 5.8433 & TRN \\
\hline CHEMBL1514150 & 688407 & 5.5 & 6.4477 & TRN \\
\hline CHEMBL1460577 & 688407 & 4.8 & 5.351 & TST \\
\hline CHEMBL1406722 & 688407 & 8.1024 & 5.8754 & TRN \\
\hline CHEMBL1448453 & 688407 & 5.0 & 5.8276 & TST \\
\hline CHEMBL1330852 & 688407 & 5.25 & 5.204 & TST \\
\hline CHEMBL1531521 & 688407 & 5.0 & 5.065 & TRN \\
\hline CHEMBL1574649 & 688407 & 6.6 & 4.984 & TRN \\
\hline CHEMBL1359834 & 688407 & 8.301 & 6.034 & TRN \\
\hline CHEMBL1513647 & 688407 & 6.9 & 6.0083 & TRN \\
\hline CHEMBL1521402 & 688407 & 7.0 & 5.5535 & TRN \\
\hline CHEMBL1360684 & 688407 & 4.5 & 5.5634 & TST \\
\hline CHEMBL1554923 & 688407 & 4.85 & 5.9827 & TRN \\
\hline CHEMBL1600774 & 688407 & 6.1 & 5.4403 & TRN \\
\hline CHEMBL1316098 & 688407 & 5.4 & 5.3867 & TRN \\
\hline CHEMBL1555689 & 688407 & 4.9 & 4.8236 & TRN \\
\hline CHEMBL1412549 & 688407 & 4.7 & 4.5894 & TRN \\
\hline
\end{tabular}




\begin{tabular}{|c|c|c|c|c|c|}
\hline \multicolumn{6}{|c|}{ Supplemental Table s2.txt } \\
\hline CHEMBL1590729 & 688407 & 4.8 & 5.6626 & TRN & \\
\hline CHEMBL1551199 & 688407 & 5.2 & 5.8366 & TRN & \\
\hline CHEMBL1602339 & 688407 & 7.1002 & 6.1305 & TRN & \\
\hline CHEMBL1446849 & 688407 & 4.9 & 5.1175 & TRN & \\
\hline CHEMBL1362541 & 688407 & 6.3 & 5.9526 & TRN & \\
\hline CHEMBL1568897 & 688407 & 4.9 & 4.9999 & TRN & \\
\hline CHEMBL1533599 & 688407 & 4.9 & 5.7197 & TRN & \\
\hline CHEMBL1574439 & 688407 & 8.301 & 5.7223 & TRN & \\
\hline CHEMBL1525773 & 688407 & 4.5 & 5.9246 & TST & \\
\hline CHEMBL1336396 & 688407 & 4.8 & 5.7604 & TRN & \\
\hline CHEMBL1534443 & 688407 & 4.9 & 5.6205 & TST & \\
\hline CHEMBL1593142 & 688407 & 5.7 & 5.8702 & TRN & \\
\hline CHEMBL1437497 & 688407 & 8.301 & 6.0731 & TRN & \\
\hline CHEMBL1440798 & 688407 & 4.8 & 5.2019 & TRN & \\
\hline CHEMBL1553699 & 688407 & 4.7 & 5.7528 & TRN & \\
\hline CHEMBL1493651 & 688407 & 4.5 & 5.7347 & TST & \\
\hline CHEMBL1512048 & 688407 & 7.3002 & 5.6589 & TRN & \\
\hline CHEMBL1453042 & 688407 & 4.95 & 4.5295 & TST & \\
\hline CHEMBL1594050 & 688407 & 8.301 & 5.9097 & TRN & \\
\hline CHEMBL1478130 & 688407 & 5.0 & 5.7365 & TRN & \\
\hline CHEMBL1593138 & 688407 & 4.55 & 5.1244 & TRN & \\
\hline CHEMBL1373515 & 688407 & 5.2 & 5.7348 & TRN & \\
\hline CHEMBL1554605 & 688407 & 6.1 & 5.3245 & TST & \\
\hline CHEMBL1512043 & 688407 & 4.8 & 4.7373 & TRN & \\
\hline CHEMBL1445596 & 688407 & 5.7 & 5.1577 & TRN & \\
\hline CHEMBL1482365 & 688407 & 5.3 & 5.2517 & TST & \\
\hline CHEMBL1520733 & 688407 & 4.8 & 5.1557 & TRN & \\
\hline CHEMBL1558853 & 688407 & 4.8 & 5.4765 & TRN & \\
\hline CHEMBL1563336 & 688407 & 5.5 & 5.8065 & TST & \\
\hline CHEMBL1316434 & 688407 & 4.9 & 5.1232 & TRN & \\
\hline CHEMBL1402086 & 688407 & 4.5 & 4.3967 & TRN & \\
\hline CHEMBL1535821 & 688407 & 5.7 & 5.4034 & TST & \\
\hline CHEMBL1403851 & 688407 & 4.5 & 5.6841 & TRN & \\
\hline CHEMBL1561016 & 688407 & 5.0 & 5.6448 & TST & \\
\hline CHEMBL1609599 & 688407 & 4.45 & 4.9226 & TRN & \\
\hline CHEMBL1489788 & 688407 & 8.4949 & 5.4502 & TRN & \\
\hline CHEMBL1302250 & 688407 & 5.35 & 5.2917 & TST & \\
\hline CHEMBL1357441 & 688407 & 4.5 & 5.3171 & TRN & \\
\hline CHEMBL1590953 & 688407 & 6.3 & 5.62799 & 9999999999 & TRN \\
\hline CHEMBL1080510 & 688407 & 5.6 & 5.4243 & TRN & \\
\hline CHEMBL1518986 & 688407 & 7.3002 & 5.8617 & TRN & \\
\hline CHEMBL1358681 & 688407 & 4.5 & 4.8709 & TRN & \\
\hline CHEMBL1453341 & 688407 & 4.9 & 5.4683 & TRN & \\
\hline CHEMBL1516147 & 688407 & 4.7 & 5.5178 & TRN & \\
\hline CHEMBL1415430 & 688407 & 5.4 & 4.912 & TRN & \\
\hline CHEMBL1368862 & 688407 & 4.6 & 5.7069 & TST & \\
\hline CHEMBL1473009 & 688407 & 4.45 & 5.117 & TRN & \\
\hline CHEMBL1434440 & 688407 & 6.9 & 5.7539 & TRN & \\
\hline
\end{tabular}




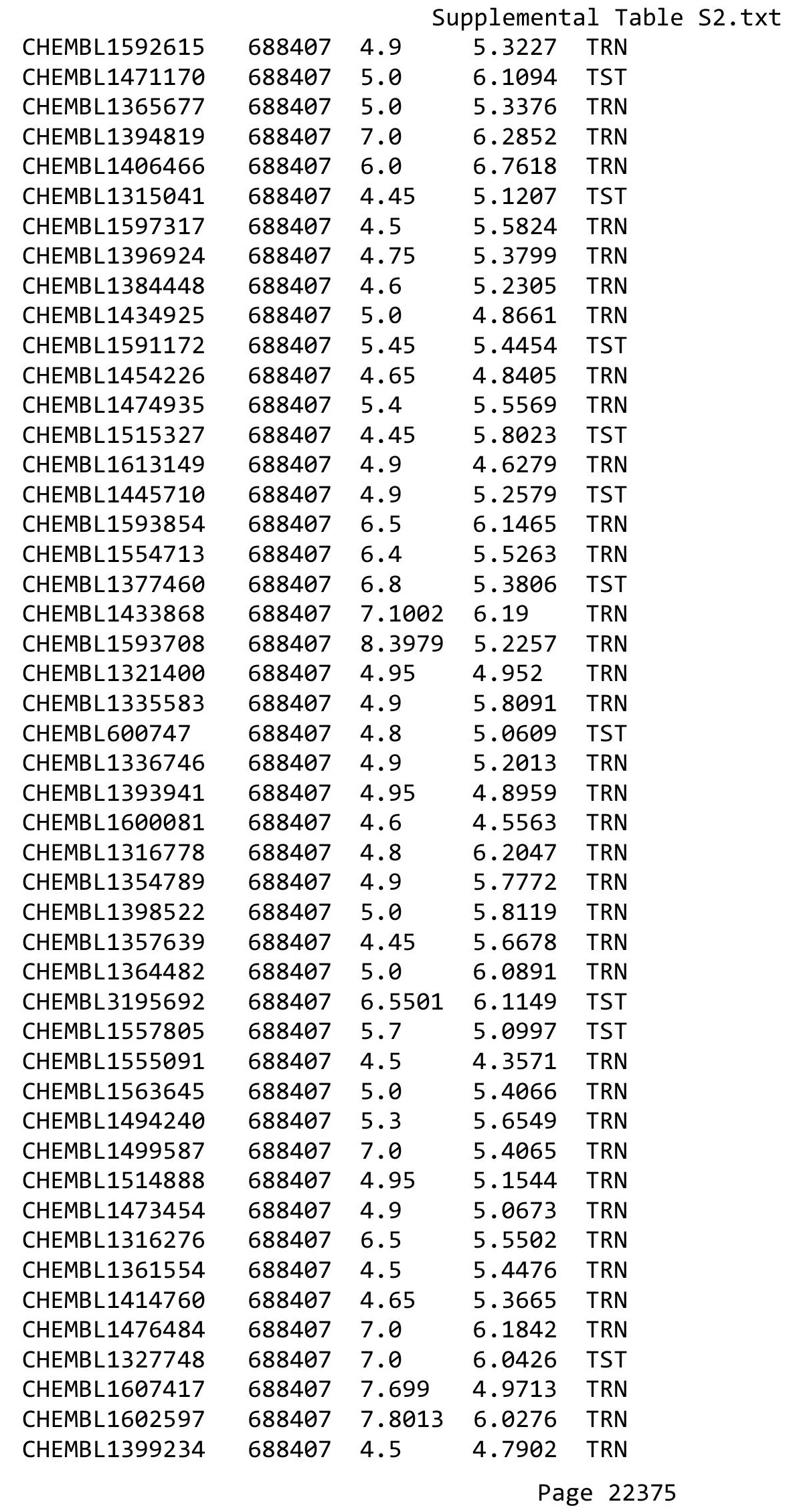




\begin{tabular}{|c|c|c|c|c|c|}
\hline \multicolumn{6}{|c|}{ Supplemental Table S2.txt } \\
\hline CHEMBL1547533 & 688407 & 4.95 & 6.125 & TST & \\
\hline CHEMBL1514097 & 688407 & 5.5 & 5.4916 & TRN & \\
\hline CHEMBL1472643 & 688407 & 5.2 & 5.82600 & 00000000005 & TRN \\
\hline CHEMBL1397330 & 688407 & 4.9 & 5.477 & TST & \\
\hline CHEMBL1451531 & 688407 & 7.8013 & 4.3304 & TST & \\
\hline CHEMBL1570136 & 688407 & 7.1002 & 5.6007 & TST & \\
\hline CHEMBL1572399 & 688407 & 4.95 & 5.2927 & TRN & \\
\hline CHEMBL1590089 & 688407 & 7.5003 & 5.6096 & TRN & \\
\hline CHEMBL1543951 & 688407 & 4.6 & 5.5038 & TST & \\
\hline CHEMBL1335105 & 688407 & 6.7001 & 5.92299 & 9999999999 & TRN \\
\hline CHEMBL1525752 & 688407 & 4.65 & 5.6268 & TRN & \\
\hline CHEMBL1477540 & 688407 & 4.9 & 5.2834 & TRN & \\
\hline CHEMBL1395953 & 688407 & 4.6 & 5.7135 & TRN & \\
\hline CHEMBL1457674 & 688407 & 7.8508 & 5.5823 & TRN & \\
\hline CHEMBL1436623 & 688407 & 4.45 & 5.3577 & TRN & \\
\hline CHEMBL1552241 & 688407 & 4.9 & 5.6054 & TRN & \\
\hline CHEMBL1481981 & 688407 & 5.6 & 5.9191 & TRN & \\
\hline CHEMBL1590461 & 688407 & 4.7 & 6.1554 & TRN & \\
\hline CHEMBL1396288 & 688407 & 6.8 & 5.9459 & TRN & \\
\hline CHEMBL1323214 & 688407 & 4.5 & 4.6563 & TRN & \\
\hline CHEMBL1475763 & 688407 & 4.7 & 5.2866 & TRN & \\
\hline CHEMBL1318286 & 688407 & 4.45 & 5.4643 & TRN & \\
\hline CHEMBL1367413 & 688407 & 6.8 & 5.6929 & TRN & \\
\hline CHEMBL1554140 & 688407 & 5.0 & 5.1865 & TST & \\
\hline CHEMBL1524492 & 688407 & 5.2 & 5.6899 & TST & \\
\hline CHEMBL1473137 & 688407 & 5.8 & 4.9688 & TST & \\
\hline CHEMBL1595237 & 688407 & 4.7 & 4.8654 & TST & \\
\hline CHEMBL1354609 & 688407 & 4.5 & 5.5729 & TST & \\
\hline CHEMBL1518449 & 688407 & 6.1 & 5.5181 & TRN & \\
\hline CHEMBL1436903 & 688407 & 5.6 & 5.5832 & TRN & \\
\hline CHEMBL1549435 & 688407 & 6.05 & 5.6936 & TST & \\
\hline CHEMBL 1357818 & 688407 & 6.0 & 5.3901 & TRN & \\
\hline CHEMBL1480268 & 688407 & 4.9 & 6.0946 & TST & \\
\hline CHEMBL1315886 & 688407 & 5.2 & 5.0765 & TRN & \\
\hline CHEMBL1602418 & 688407 & 5.6 & 5.6952 & TRN & \\
\hline CHEMBL1554119 & 688407 & 4.85 & 5.4761 & TRN & \\
\hline CHEMBL1506175 & 688407 & 4.9 & 5.5785 & TRN & \\
\hline CHEMBL1357178 & 688407 & 4.65 & 5.3282 & TST & \\
\hline CHEMBL1535323 & 688407 & 8.1024 & 5.6121 & TRN & \\
\hline CHEMBL1525590 & 688407 & 6.0 & 5.32 & TST & \\
\hline CHEMBL1435634 & 688407 & 4.5 & 5.3364 & TRN & \\
\hline CHEMBL 1602210 & 688407 & 8.301 & 6.3242 & TRN & \\
\hline CHEMBL1515797 & 688407 & 5.4 & 5.6197 & TRN & \\
\hline CHEMBL1530872 & 688407 & 4.9 & 5.8886 & TST & \\
\hline CHEMBL1446937 & 688407 & 8.1024 & 5.4388 & TST & \\
\hline CHEMBL1327028 & 688407 & 4.45 & 4.7775 & TRN & \\
\hline CHEMBL1311489 & 688407 & 4.8 & 5.409 & TST & \\
\hline CHEMBL1488818 & 688407 & 4.7 & 5.6059 & TST & \\
\hline
\end{tabular}




\begin{tabular}{|c|c|c|c|c|c|}
\hline \multicolumn{6}{|c|}{ Supplemental Table S2.txt } \\
\hline CHEMBL1513692 & 688407 & 6.0 & 5.5466 & TRN & \\
\hline CHEMBL1337230 & 688407 & 4.45 & 5.8549 & TST & \\
\hline CHEMBL1475771 & 688407 & 5.6 & 5.7523 & TST & \\
\hline CHEMBL1596582 & 688407 & 4.8 & \multicolumn{2}{|c|}{5.912000000000001} & TRN \\
\hline CHEMBL1473242 & 688407 & 4.65 & 5.5038 & TRN & \\
\hline CHEMBL1397959 & 688407 & 4.5 & 5.7373 & TST & \\
\hline CHEMBL1555024 & 688407 & 7.8996 & 5.524 & TRN & \\
\hline CHEMBL1606231 & 688407 & 6.7001 & 5.4998 & TRN & \\
\hline CHEMBL 3198156 & 688407 & 4.65 & 6.2253 & TST & \\
\hline CHEMBL1378373 & 688407 & 4.9 & 5.3152 & TRN & \\
\hline CHEMBL1408331 & 688407 & 7.5003 & 5.8714 & TRN & \\
\hline CHEMBL1472792 & 688407 & 4.45 & 5.0217 & TRN & \\
\hline CHEMBL1314762 & 688407 & 5.4 & 4.8151 & TRN & \\
\hline CHEMBL1531231 & 688407 & 4.9 & 5.4795 & TRN & \\
\hline CHEMBL1592013 & 688407 & 4.6 & 5.4068 & TRN & \\
\hline CHEMBL1412874 & 688407 & 4.85 & 5.1395 & TRN & \\
\hline CHEMBL1403000 & 688407 & 4.65 & 4.8122 & TRN & \\
\hline CHEMBL1368089 & 688407 & 4.5 & 4.6296 & TRN & \\
\hline CHEMBL1493200 & 688407 & 5.8 & 5.6733 & TRN & \\
\hline CHEMBL1512446 & 688407 & 6.8499 & 6.0453 & TRN & \\
\hline CHEMBL1553227 & 688407 & 4.9 & 4.6763 & TRN & \\
\hline CHEMBL1374262 & 688407 & 8.1024 & 6.1907 & TRN & \\
\hline CHEMBL1514969 & 688407 & 4.5 & 5.8046 & TRN & \\
\hline CHEMBL1320593 & 688407 & 5.2 & 5.4524 & TRN & \\
\hline CHEMBL1315118 & 688407 & 4.95 & 5.4423 & TRN & \\
\hline CHEMBL1513087 & 688407 & 7.2 & 5.9487 & TRN & \\
\hline CHEMBL1488604 & 688407 & 4.9 & 5.4751 & TRN & \\
\hline CHEMBL1593698 & 688407 & 5.1 & 5.6899 & TRN & \\
\hline CHEMBL1317352 & 688407 & 4.5 & 4.5694 & TRN & \\
\hline CHEMBL1555114 & 688407 & 5.55 & 6.3525 & TRN & \\
\hline CHEMBL1447690 & 688407 & 4.45 & 4.7523 & TRN & \\
\hline CHEMBL1520657 & 688407 & 6.6 & 5.9077 & TRN & \\
\hline CHEMBL1308118 & 688407 & 4.85 & 5.6682 & TST & \\
\hline CHEMBL1442361 & 688407 & 4.95 & 5.6947 & TRN & \\
\hline CHEMBL1475164 & 688407 & 4.9 & 5.5165 & TRN & \\
\hline CHEMBL1318131 & 688407 & 4.45 & 5.8671 & TST & \\
\hline CHEMBL1433476 & 688407 & 6.8 & 6.4168 & TRN & \\
\hline CHEMBL1436876 & 688407 & 8.1024 & 5.4955 & TST & \\
\hline CHEMBL1331896 & 688407 & 7.6003 & 5.5656 & TRN & \\
\hline CHEMBL1423890 & 688407 & 4.45 & 5.6529 & TRN & \\
\hline CHEMBL1378150 & 688407 & 7.1002 & 5.684 & TRN & \\
\hline CHEMBL1442940 & 688407 & 6.1 & 5.6657 & TST & \\
\hline CHEMBL1435751 & 688407 & 4.9 & 5.2304 & TRN & \\
\hline CHEMBL1344695 & 688407 & 5.15 & 5.765 & TST & \\
\hline CHEMBL1515210 & 688407 & 7.3002 & 5.5271 & TST & \\
\hline CHEMBL1367884 & 688407 & 6.8499 & 5.5874 & TRN & \\
\hline CHEMBL1314543 & 688407 & 6.9 & 5.1945 & TRN & \\
\hline CHEMBL1492074 & 688407 & 4.5 & 5.2244 & TRN & \\
\hline & & & & 22377 & \\
\hline
\end{tabular}




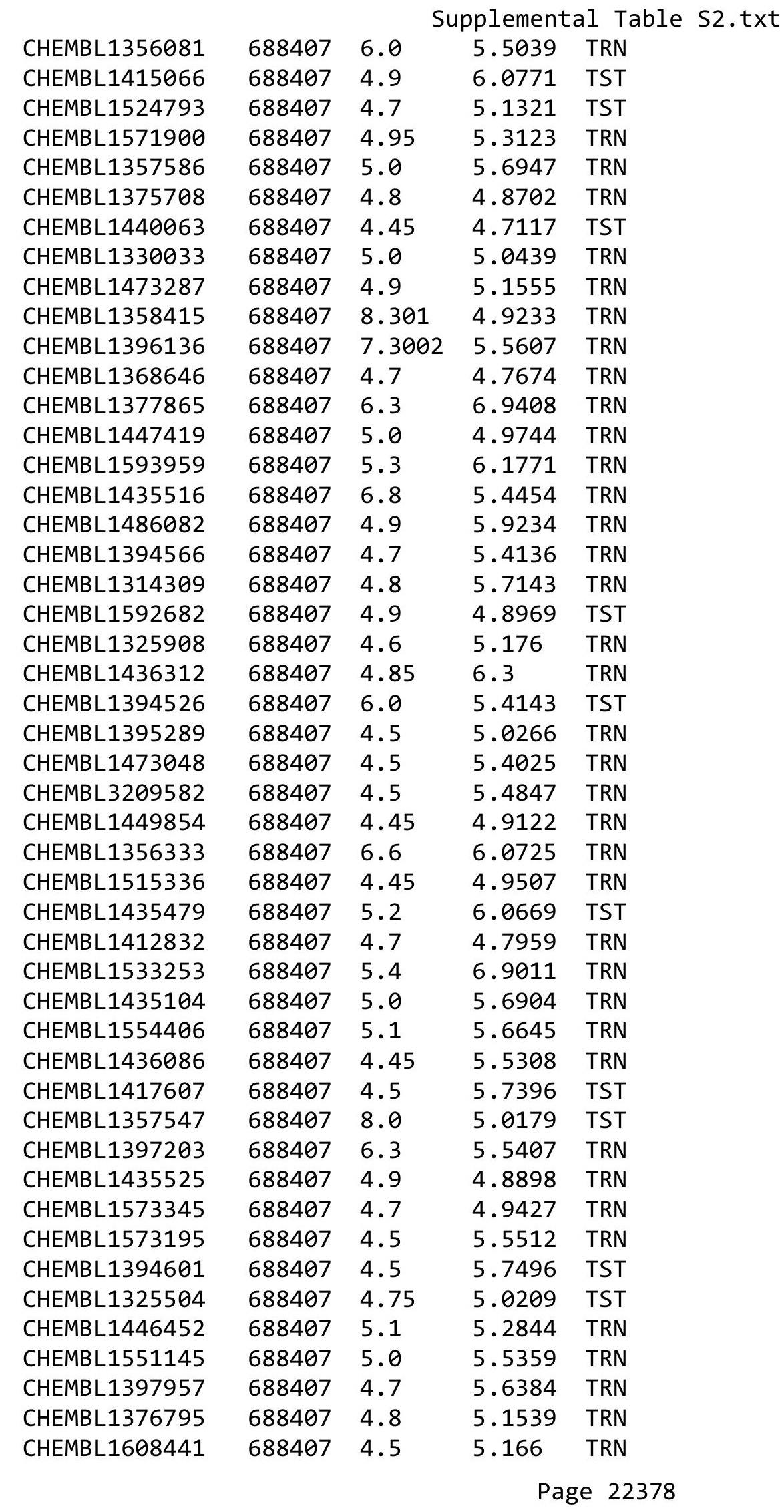




\begin{tabular}{|c|c|c|c|c|c|}
\hline & & & & & \\
\hline CHEMBL1514144 & 688407 & 4.7 & 5.3068 & TRN & \\
\hline CHEMBL1307919 & 688407 & 6.0 & 6.1722 & TST & \\
\hline CHEMBL1516257 & 688407 & 4.5 & 5.9652 & TRN & \\
\hline CHEMBL1571028 & 688407 & 8.301 & 5.9927 & TRN & \\
\hline CHEMBL1405451 & 688407 & 4.45 & 4.7042 & TRN & \\
\hline CHEMBL1330603 & 688407 & 5.9 & 5.3998 & TST & \\
\hline CHEMBL1492311 & 688407 & 7.5003 & 5.8536 & TST & \\
\hline CHEMBL1454661 & 688407 & 8.301 & 6.345 & TRN & \\
\hline CHEMBL1310261 & 688407 & 4.65 & 5.0322 & TRN & \\
\hline CHEMBL1513968 & 688407 & 5.0 & 5.2862 & TRN & \\
\hline CHEMBL1329768 & 688407 & 5.2 & 6.1007 & TRN & \\
\hline CHEMBL1592392 & 688407 & 5.4 & 6.1175 & TST & \\
\hline CHEMBL1403829 & 688407 & 4.6 & 4.7056 & TRN & \\
\hline CHEMBL1515448 & 688407 & 4.5 & 5.8019 & TRN & \\
\hline CHEMBL1515785 & 688407 & 7.2 & 5.1251 & TRN & \\
\hline CHEMBL1401815 & 688407 & 4.8 & 5.5664 & TRN & \\
\hline CHEMBL1324670 & 688407 & 4.9 & 5.0804 & TRN & \\
\hline CHEMBL1557770 & 688407 & 5.0 & 5.1254 & TRN & \\
\hline CHEMBL1479784 & 688407 & 5.4 & 6.125 & TST & \\
\hline CHEMBL1494361 & 688407 & 4.75 & 5.2798 & TRN & \\
\hline CHEMBL1498407 & 688407 & 4.95 & 5.8081 & TRN & \\
\hline CHEMBL1401486 & 688407 & 4.6 & 5.07100 & 0000000001 & TRN \\
\hline CHEMBL1568005 & 688407 & 6.2 & 5.7154 & TRN & \\
\hline CHEMBL1360143 & 688407 & 5.1 & 5.3287 & TRN & \\
\hline CHEMBL1457017 & 688407 & 8.0 & 5.8588 & TRN & \\
\hline CHEMBL1395023 & 688407 & 4.7 & 5.3064 & TRN & \\
\hline CHEMBL1515135 & 688407 & 4.45 & 4.8442 & TRN & \\
\hline CHEMBL545900 & 688407 & 4.9 & 5.9759 & TRN & \\
\hline CHEMBL1433909 & 688407 & 4.9 & 5.5354 & TRN & \\
\hline CHEMBL1314681 & 688407 & 8.0 & 6.1618 & TRN & \\
\hline CHEMBL1474395 & 688407 & 6.9 & 5.7461 & TRN & \\
\hline CHEMBL1457234 & 688407 & 7.5003 & 6.0921 & TST & \\
\hline CHEMBL1437722 & 688407 & 4.8 & 4.8194 & TRN & \\
\hline CHEMBL1397223 & 688407 & 4.5 & 5.6746 & TRN & \\
\hline CHEMBL1414582 & 688407 & 4.6 & 5.3871 & TRN & \\
\hline CHEMBL1551876 & 688407 & 8.1024 & 7.0228 & TRN & \\
\hline CHEMBL1553017 & 688407 & 8.1024 & 6.2395 & TST & \\
\hline CHEMBL1326401 & 688407 & 5.4 & 5.0501 & TST & \\
\hline CHEMBL1592292 & 688407 & 5.65 & 4.9266 & TRN & \\
\hline CHEMBL1513868 & 688407 & 8.301 & 5.5271 & TST & \\
\hline CHEMBL1457496 & 688407 & 4.9 & 5.66299 & 9999999999 & TRN \\
\hline CHEMBL1514856 & 688407 & 4.5 & 5.2663 & TRN & \\
\hline CHEMBL1593283 & 688407 & 4.45 & 5.2801 & TRN & \\
\hline CHEMBL1565377 & 688407 & 6.0 & 5.9424 & TST & \\
\hline CHEMBL1473771 & 688407 & 7.0501 & 6.308 & TRN & \\
\hline CHEMBL1474767 & 688407 & 7.8996 & 5.7157 & TRN & \\
\hline CHEMBL1336940 & 688407 & 7.8013 & 6.5596 & TRN & \\
\hline CHEMBL1481351 & 688407 & 4.65 & 5.1637 & TST & \\
\hline
\end{tabular}




\begin{tabular}{|c|c|c|c|c|c|}
\hline \multirow[b]{2}{*}{ CHEMBL1590482 } & \\
\hline & 688407 & 4.8 & 5.0382 & TRN & \\
\hline CHEMBL1366741 & 688407 & 4.7 & 4.8893 & TRN & \\
\hline CHEMBL1373404 & 688407 & 4.95 & 5.2805 & TRN & \\
\hline CHEMBL1487793 & 688407 & 6.1 & 5.0267 & TRN & \\
\hline CHEMBL1355586 & 688407 & 4.8 & 5.06800 & 00000000005 & TRN \\
\hline CHEMBL1498272 & 688407 & 4.45 & 5.9362 & TRN & \\
\hline CHEMBL1373837 & 688407 & 6.0 & 5.4755 & TRN & \\
\hline CHEMBL1356050 & 688407 & 5.35 & 5.8394 & TRN & \\
\hline CHEMBL1512720 & 688407 & 4.45 & 5.3977 & TRN & \\
\hline CHEMBL1334195 & 688407 & 4.6 & 5.6572 & TRN & \\
\hline CHEMBL1357002 & 688407 & 4.9 & 5.5251 & TRN & \\
\hline CHEMBL1437254 & 688407 & 8.4949 & 5.5732 & TRN & \\
\hline CHEMBL1395177 & 688407 & 4.95 & 4.5346 & TRN & \\
\hline CHEMBL1398218 & 688407 & 6.3 & 5.3514 & TST & \\
\hline CHEMBL1338273 & 688407 & 4.45 & 5.7123 & TRN & \\
\hline CHEMBL1314620 & 688407 & 5.4 & 5.7103 & TRN & \\
\hline CHEMBL1569128 & 688407 & 6.3 & 5.8446 & TRN & \\
\hline CHEMBL1602222 & 688407 & 6.5 & 5.3264 & TST & \\
\hline CHEMBL1994902 & 688407 & 4.95 & 5.7934 & TST & \\
\hline CHEMBL1396132 & 688407 & 4.45 & 4.9342 & TRN & \\
\hline CHEMBL1323279 & 688407 & 6.1 & 4.9664 & TRN & \\
\hline CHEMBL1555957 & 688407 & 5.8 & 5.6392 & TST & \\
\hline CHEMBL1531398 & 688407 & 4.5 & 5.5474 & TST & \\
\hline CHEMBL1516160 & 688407 & 4.65 & 4.9859 & TST & \\
\hline CHEMBL1506864 & 688407 & 5.6 & 5.436 & TRN & \\
\hline CHEMBL1478830 & 688407 & 6.1 & 4.9157 & TST & \\
\hline CHEMBL1394209 & 688407 & 4.45 & 4.1601 & TRN & \\
\hline CHEMBL1517257 & 688407 & 4.5 & 5.9457 & TST & \\
\hline CHEMBL1495584 & 688407 & 5.4 & 5.9495 & TRN & \\
\hline CHEMBL1339239 & 688407 & 4.75 & 5.5358 & TRN & \\
\hline CHEMBL1377144 & 688407 & 5.9 & 5.7114 & TST & \\
\hline CHEMBL1314243 & 688407 & 4.7 & 6.20100 & 00000000005 & TRN \\
\hline CHEMBL1439277 & 688407 & 4.5 & 5.5208 & TRN & \\
\hline CHEMBL1475643 & 688407 & 4.9 & 5.5694 & TRN & \\
\hline CHEMBL1318900 & 688407 & 4.8 & 4.8624 & TRN & \\
\hline CHEMBL1476295 & 688407 & 4.45 & 5.4522 & TRN & \\
\hline CHEMBL1366792 & 688407 & 5.0 & 4.9431 & TRN & \\
\hline CHEMBL1598598 & 688407 & 5.3 & 4.9349 & TRN & \\
\hline CHEMBL1394280 & 688407 & 5.2 & 5.0745 & TST & \\
\hline CHEMBL1399789 & 688407 & 6.6 & 5.4207 & TRN & \\
\hline CHEMBL1493446 & 688407 & 4.5 & 5.0622 & TRN & \\
\hline CHEMBL1593875 & 688407 & 4.8 & 5.7124 & TRN & \\
\hline CHEMBL1402189 & 688407 & 4.5 & 5.3385 & TRN & \\
\hline CHEMBL1551780 & 688407 & 4.9 & 5.6959 & TRN & \\
\hline CHEMBL1446347 & 688407 & 4.5 & 6.0349 & TST & \\
\hline CHEMBL1435069 & 688407 & 4.9 & 5.5509 & TRN & \\
\hline CHEMBL1515104 & 688407 & 4.7 & 5.1415 & TRN & \\
\hline CHEMBL1595162 & 688407 & 5.9 & 4.9208 & TST & \\
\hline & & & & 223 & \\
\hline
\end{tabular}




\begin{tabular}{|c|c|c|c|c|c|}
\hline \multicolumn{6}{|c|}{ Supplemental Table S2.txt } \\
\hline CHEMBL1378284 & 688407 & 6.1 & 6.4805 & TRN & \\
\hline CHEMBL1395782 & 688407 & 7.0 & 5.9487 & TRN & \\
\hline CHEMBL1572395 & 688407 & 4.45 & 5.0044 & TRN & \\
\hline CHEMBL1479626 & 688407 & 4.8 & 5.4872 & TST & \\
\hline CHEMBL1314199 & 688407 & 6.05 & 5.2909 & TRN & \\
\hline CHEMBL1325689 & 688407 & 4.8 & 5.1509 & TRN & \\
\hline CHEMBL1396133 & 688407 & 5.1 & 4.9644 & TRN & \\
\hline CHEMBL1446790 & 688407 & 4.5 & 5.8916 & TRN & \\
\hline CHEMBL1474427 & 688407 & 4.95 & 5.1188 & TRN & \\
\hline CHEMBL1398263 & 688407 & 4.6 & 5.9275 & TRN & \\
\hline CHEMBL1476607 & 688407 & 5.55 & 4.8207 & TRN & \\
\hline CHEMBL1394866 & 688407 & 4.7 & 5.3826 & TST & \\
\hline CHEMBL1513406 & 688407 & 5.6 & 5.727 & TRN & \\
\hline CHEMBL1444193 & 688407 & 5.4 & 5.6518 & TST & \\
\hline CHEMBL1337548 & 688407 & 4.8 & 5.4558 & TST & \\
\hline CHEMBL1396929 & 688407 & 4.9 & $5.7020 e$ & 0000000001 & TRN \\
\hline CHEMBL1448613 & 688407 & 4.9 & 6.0002 & TRN & \\
\hline CHEMBL1303281 & 688407 & 4.9 & 5.5458 & TST & \\
\hline CHEMBL1590236 & 688407 & 4.75 & 5.0002 & TST & \\
\hline CHEMBL1395188 & 688407 & 4.7 & 5.5827 & TRN & \\
\hline CHEMBL1513428 & 688407 & 4.5 & 4.715 & TRN & \\
\hline CHEMBL1357245 & 688407 & 4.5 & 4.9482 & TRN & \\
\hline CHEMBL1437484 & 688407 & 5.3 & 4.8872 & TRN & \\
\hline CHEMBL1530631 & 688407 & 4.65 & 5.1994 & TST & \\
\hline CHEMBL1395301 & 688407 & 6.05 & 5.7299 & TRN & \\
\hline CHEMBL1553763 & 688407 & 4.9 & 6.1511 & TRN & \\
\hline CHEMBL1573832 & 688407 & 4.9 & 4.977 & TRN & \\
\hline CHEMBL1556135 & 688407 & 7.3002 & 5.5988 & TRN & \\
\hline CHEMBL1442465 & 688407 & 4.9 & 5.0142 & TRN & \\
\hline CHEMBL1589965 & 688407 & 4.5 & 5.4308 & TRN & \\
\hline CHEMBL1605576 & 688407 & 4.7 & 6.1349 & TRN & \\
\hline CHEMBL1396152 & 688407 & 4.6 & 5.7593 & TRN & \\
\hline CHEMBL1315699 & 688407 & 4.5 & 5.6209 & TRN & \\
\hline CHEMBL1572372 & 688407 & 5.0 & 5.1002 & TST & \\
\hline CHEMBL1475211 & 688407 & 5.2 & 5.8201 & TST & \\
\hline CHEMBL1435842 & 688407 & 5.6 & 5.121 & TRN & \\
\hline CHEMBL1599338 & 688407 & 4.5 & 4.703 & TRN & \\
\hline CHEMBL1994803 & 688407 & 5.55 & 5.3987 & TST & \\
\hline CHEMBL1514362 & 688407 & 4.6 & 4.8302 & TRN & \\
\hline CHEMBL1342169 & 688407 & 4.5 & 4.4497 & TRN & \\
\hline CHEMBL1318440 & 688407 & 8.0 & 5.295 & TRN & \\
\hline CHEMBL1591398 & 688407 & 4.8 & 5.4519 & TRN & \\
\hline CHEMBL1411382 & 688407 & 4.5 & 5.7356 & TRN & \\
\hline CHEMBL1582814 & 688407 & 7.5498 & 5.9304 & TST & \\
\hline CHEMBL1517437 & 688407 & 5.7 & 5.09 & TRN & \\
\hline CHEMBL1356670 & 688407 & 4.95 & 5.2325 & TST & \\
\hline CHEMBL1402181 & 688407 & 5.0 & 5.314 & TRN & \\
\hline CHEMBL1355297 & 688407 & 5.0 & 4.7836 & TST & \\
\hline
\end{tabular}




\begin{tabular}{|c|c|c|c|c|c|}
\hline \multicolumn{6}{|c|}{ plemental } \\
\hline CHEMBL524407 & 688407 & 4.5 & 4.8794 & TRN & \\
\hline CHEMBL1535524 & 688407 & 4.5 & 5.9951 & TST & \\
\hline CHEMBL1535507 & 688407 & 6.0 & 6.013 & TRN & \\
\hline CHEMBL1520717 & 688407 & 8.0 & 6.2868 & TRN & \\
\hline CHEMBL1554153 & 688407 & 4.7 & 5.3261 & TRN & \\
\hline CHEMBL1478719 & 688407 & 7.8013 & 5.7679 & TRN & \\
\hline CHEMBL1334925 & 688407 & 4.9 & 6.3194 & TST & \\
\hline CHEMBL1472741 & 688407 & 8.3979 & 5.4324 & TRN & \\
\hline CHEMBL1358283 & 688407 & 6.1 & 6.0807 & TST & \\
\hline CHEMBL1363240 & 688407 & 5.7 & 5.624 & TRN & \\
\hline CHEMBL1404455 & 688407 & 4.85 & 5.0646 & TRN & \\
\hline CHEMBL1532647 & 688407 & 5.4 & 5.4149 & TRN & \\
\hline CHEMBL1529427 & 688407 & 5.0 & 4.6938 & TRN & \\
\hline CHEMBL1398282 & 688407 & 5.0 & 5.4501 & TRN & \\
\hline CHEMBL1434307 & 688407 & 4.75 & 5.1763 & TST & \\
\hline CHEMBL1534448 & 688407 & 8.0 & 5.3536 & TRN & \\
\hline CHEMBL1338800 & 688407 & 4.7 & 4.8936 & TRN & \\
\hline CHEMBL1475712 & 688407 & 4.9 & 5.4607 & TRN & \\
\hline CHEMBL1555110 & 688407 & 8.0 & 6.36299 & 99999999995 & TST \\
\hline CHEMBL1552713 & 688407 & 4.5 & 5.38 & TRN & \\
\hline CHEMBL1528373 & 688407 & 4.75 & 5.7719 & TRN & \\
\hline CHEMBL1366341 & 688407 & 4.45 & 5.7669 & TRN & \\
\hline CHEMBL1478905 & 688407 & 5.0 & 5.1831 & TRN & \\
\hline CHEMBL1482864 & 688407 & 4.45 & 6.1667 & TRN & \\
\hline CHEMBL1518138 & 688407 & 4.5 & 5.6908 & TRN & \\
\hline CHEMBL1494324 & 688407 & 4.9 & 5.9784 & TRN & \\
\hline CHEMBL1317485 & 688407 & 4.8 & 5.6115 & TST & \\
\hline CHEMBL1314218 & 688407 & 7.2 & 5.4157 & TRN & \\
\hline CHEMBL1476045 & 688407 & 4.9 & 5.1143 & TRN & \\
\hline CHEMBL1532020 & 688407 & 5.0 & 5.2591 & TRN & \\
\hline CHEMBL1594652 & 688407 & 4.9 & 5.4811 & TRN & \\
\hline CHEMBL1402522 & 688407 & 4.9 & 5.2534 & TRN & \\
\hline CHEMBL1356146 & 688407 & 4.7 & 4.2084 & TRN & \\
\hline CHEMBL1566838 & 688407 & 4.95 & 5.5585 & TST & \\
\hline CHEMBL1330988 & 688407 & 4.7 & 4.5585 & TST & \\
\hline CHEMBL1355857 & 688407 & 4.5 & 5.6073 & TRN & \\
\hline CHEMBL1476510 & 688407 & 5.6 & 5.5119 & TRN & \\
\hline CHEMBL1435124 & 688407 & 8.4949 & 5.3348 & TRN & \\
\hline CHEMBL1550095 & 688407 & 6.3 & 5.7725 & TRN & \\
\hline CHEMBL1473862 & 688407 & 4.75 & 5.4143 & TRN & \\
\hline CHEMBL1560154 & 688407 & 5.0 & 5.4185 & TRN & \\
\hline CHEMBL1476756 & 688407 & 5.0 & 5.3191 & TRN & \\
\hline CHEMBL1433891 & 688407 & 4.95 & 5.0383 & TRN & \\
\hline CHEMBL1455903 & 688407 & 8.301 & 6.1911 & TRN & \\
\hline CHEMBL1472775 & 688407 & 4.5 & 5.9381 & TRN & \\
\hline CHEMBL1440272 & 688407 & 6.5 & 6.2454 & TRN & \\
\hline CHEMBL1482873 & 688407 & 4.5 & 5.401 & TST & \\
\hline CHEMBL1474403 & 688407 & 4.5 & 5.9791 & TRN & \\
\hline
\end{tabular}




\begin{tabular}{|c|c|c|c|c|c|}
\hline \multicolumn{6}{|c|}{ splemental Table Sz } \\
\hline CHEMBL1597447 & 688407 & 4.5 & 5.6554 & TRN & \\
\hline CHEMBL1320515 & 688407 & 4.6 & 5.9486 & TRN & \\
\hline CHEMBL1612725 & 688407 & 6.0 & 5.9956 & TRN & \\
\hline CHEMBL1601419 & 688407 & 8.3979 & 4.9433 & TRN & \\
\hline CHEMBL1536911 & 688407 & 5.25 & 6.3221 & TST & \\
\hline CHEMBL1570913 & 688407 & 4.7 & 5.0396 & TRN & \\
\hline CHEMBL1433988 & 688407 & 4.5 & 5.3889 & TRN & \\
\hline CHEMBL1570954 & 688407 & 4.45 & 4.7014 & TRN & \\
\hline CHEMBL1443469 & 688407 & 7.2 & 5.6049 & TRN & \\
\hline CHEMBL1532428 & 688407 & 4.8 & 4.7635 & TST & \\
\hline CHEMBL1551648 & 688407 & 4.6 & 5.2425 & TRN & \\
\hline CHEMBL1544633 & 688407 & 5.0 & 5.6241 & TST & \\
\hline CHEMBL1436267 & 688407 & 6.9 & 5.9604 & TRN & \\
\hline CHEMBL1332398 & 688407 & 4.8 & 4.8467 & TRN & \\
\hline CHEMBL1598545 & 688407 & 4.45 & 5.0175 & TST & \\
\hline CHEMBL1448768 & 688407 & 6.6 & 5.4867 & TRN & \\
\hline CHEMBL1360267 & 688407 & 6.6 & 6.0567 & TRN & \\
\hline CHEMBL1536077 & 688407 & 6.9 & 5.6524 & TRN & \\
\hline CHEMBL1532578 & 688407 & 4.5 & 5.4557 & TRN & \\
\hline CHEMBL1335417 & 688407 & 5.1 & 6.4279 & TRN & \\
\hline CHEMBL1533814 & 688407 & 4.5 & 5.5847 & TRN & \\
\hline CHEMBL1401130 & 688407 & 7.4001 & 5.8656 & TRN & \\
\hline CHEMBL1440457 & 688407 & 4.5 & 4.8297 & TRN & \\
\hline CHEMBL1436234 & 688407 & 4.85 & 5.2977 & TRN & \\
\hline CHEMBL1527186 & 688407 & 4.9 & 5.3536 & TST & \\
\hline CHEMBL1314403 & 688407 & 4.6 & 5.9634 & TST & \\
\hline CHEMBL1446075 & 688407 & 5.9 & 6.4959 & TRN & \\
\hline CHEMBL1528652 & 688407 & 4.45 & 5.5092 & TRN & \\
\hline CHEMBL1573489 & 688407 & 4.8 & 5.9396 & TRN & \\
\hline CHEMBL1476044 & 688407 & 7.8996 & 5.9806 & TRN & \\
\hline CHEMBL1472844 & 688407 & 7.699 & 5.428 & TRN & \\
\hline CHEMBL1375937 & 688407 & 5.0 & 5.5995 & TRN & \\
\hline CHEMBL1555133 & 688407 & 5.4 & 5.8671 & TRN & \\
\hline CHEMBL1562200 & 688407 & 4.5 & 5.5453 & TST & \\
\hline CHEMBL1314209 & 688407 & 4.85 & 5.2988 & TRN & \\
\hline CHEMBL1495690 & 688407 & 4.5 & 5.5541 & TRN & \\
\hline CHEMBL1354494 & 688407 & 4.7 & 5.1521 & TST & \\
\hline CHEMBL1465805 & 688407 & 4.9 & 5.7113 & TRN & \\
\hline CHEMBL1512651 & 688407 & 4.45 & 5.33899 & 99999999995 & TRN \\
\hline CHEMBL1440733 & 688407 & 4.5 & 5.1678 & TRN & \\
\hline CHEMBL1366679 & 688407 & 4.8 & 5.0857 & TRN & \\
\hline CHEMBL1380706 & 688407 & 4.45 & 5.1191 & TST & \\
\hline CHEMBL1527661 & 688407 & 4.6 & 5.8024 & TRN & \\
\hline CHEMBL1512354 & 688407 & 6.8 & 6.5734 & TRN & \\
\hline CHEMBL1478463 & 688407 & 4.45 & 4.9514 & TRN & \\
\hline CHEMBL1566380 & 688407 & 4.5 & 5.6378 & TST & \\
\hline CHEMBL1356837 & 688407 & 7.8996 & 5.6388 & TRN & \\
\hline CHEMBL1405361 & 688407 & 8.4949 & 6.1616 & TRN & \\
\hline
\end{tabular}




\begin{tabular}{|c|c|c|c|c|c|}
\hline \multicolumn{6}{|c|}{ Supplemental Table S2.txt } \\
\hline CHEMBL1473803 & 688407 & 4.45 & 5.2479 & TRN & \\
\hline CHEMBL1593151 & 688407 & 4.95 & 5.75299 & 9999999999 & TRN \\
\hline CHEMBL1552498 & 688407 & 4.8 & 5.3657 & TST & \\
\hline CHEMBL1317653 & 688407 & 4.45 & 6.2217 & TRN & \\
\hline CHEMBL1610849 & 688407 & 4.7 & 5.6621 & TRN & \\
\hline CHEMBL1371963 & 688407 & 8.0 & 5.7935 & TRN & \\
\hline CHEMBL1591131 & 688407 & 4.6 & 5.2161 & TRN & \\
\hline CHEMBL1398793 & 688407 & 5.1 & 5.1069 & TST & \\
\hline CHEMBL1604357 & 688407 & 5.2 & 5.3364 & TRN & \\
\hline CHEMBL1354484 & 688407 & 4.6 & 4.289 & TRN & \\
\hline CHEMBL1398444 & 688407 & 8.0 & 5.972 & TRN & \\
\hline CHEMBL1551850 & 688407 & 5.7 & 6.1393 & TRN & \\
\hline CHEMBL1331738 & 688407 & 4.9 & 5.2675 & TRN & \\
\hline CHEMBL1356265 & 688407 & 7.4001 & 6.0389 & TST & \\
\hline CHEMBL1494903 & 688407 & 5.5 & 5.9441 & TRN & \\
\hline CHEMBL1360216 & 688407 & 5.6 & 5.7851 & TRN & \\
\hline CHEMBL1570940 & 688407 & 7.699 & 5.8009 & TRN & \\
\hline CHEMBL1434392 & 688407 & 4.5 & 5.0789 & TRN & \\
\hline CHEMBL1452386 & 688407 & 6.4 & 6.1709 & TRN & \\
\hline CHEMBL1371440 & 688407 & 8.4949 & 5.9697 & TRN & \\
\hline CHEMBL1513875 & 688407 & 4.9 & 5.5897 & TRN & \\
\hline CHEMBL1313521 & 688407 & 4.6 & 4.5693 & TST & \\
\hline CHEMBL1439033 & 688407 & 4.5 & 6.07600 & 00000000005 & TRN \\
\hline CHEMBL1396447 & 688407 & 4.5 & 5.8884 & TRN & \\
\hline CHEMBL1474986 & 688407 & 4.9 & 5.4201 & TRN & \\
\hline CHEMBL1591023 & 688407 & 6.5 & 5.6192 & TST & \\
\hline CHEMBL1981612 & 688407 & 4.45 & 5.3701 & TST & \\
\hline CHEMBL1452108 & 688407 & 5.0 & 4.9738 & TST & \\
\hline CHEMBL1370728 & 688407 & 7.5003 & 5.5872 & TRN & \\
\hline CHEMBL1455790 & 688407 & 4.7 & 4.791 & TRN & \\
\hline CHEMBL1561182 & 688407 & 4.95 & 5.862 & TST & \\
\hline CHEMBL1434786 & 688407 & 4.9 & 4.8381 & TRN & \\
\hline CHEMBL1440118 & 688407 & 5.3 & 5.4988 & TRN & \\
\hline CHEMBL1368969 & 688407 & 4.9 & 5.6178 & TRN & \\
\hline CHEMBL1476179 & 688407 & 4.9 & 5.6277 & TST & \\
\hline CHEMBL1412877 & 688407 & 6.5 & 6.4181 & TRN & \\
\hline CHEMBL1554189 & 688407 & 8.2007 & 6.1084 & TRN & \\
\hline CHEMBL1514747 & 688407 & 4.9 & 5.58200 & $\partial 000000001$ & TST \\
\hline CHEMBL1397018 & 688407 & 4.7 & 5.5265 & TST & \\
\hline CHEMBL1394421 & 688407 & 4.5 & 4.9736 & TRN & \\
\hline CHEMBL1414645 & 688407 & 4.9 & 4.7811 & TRN & \\
\hline CHEMBL1435306 & 688407 & 4.5 & 5.78600 & 20000000005 & TRN \\
\hline CHEMBL1476328 & 688407 & 5.4 & 6.4152 & TRN & \\
\hline CHEMBL1551719 & 688407 & 4.7 & 4.8737 & TRN & \\
\hline CHEMBL1354317 & 688407 & 5.1 & 5.2611 & TST & \\
\hline CHEMBL1519534 & 688407 & 5.4 & 5.6869 & TST & \\
\hline CHEMBL1515667 & 688407 & 5.0 & 5.3122 & TRN & \\
\hline CHEMBL1594065 & 688407 & 5.2 & 5.5952 & TST & \\
\hline
\end{tabular}




\begin{tabular}{|c|c|c|c|c|}
\hline \multicolumn{5}{|c|}{ Supplemental Table S2.txt } \\
\hline CHEMBL1462474 & 688407 & 4.85 & 4.8854 & TST \\
\hline CHEMBL1362031 & 688407 & 4.65 & 5.0577 & TRN \\
\hline CHEMBL1533336 & 688407 & 4.45 & 5.5648 & TST \\
\hline CHEMBL1611761 & 688407 & 6.2 & 5.2244 & TST \\
\hline CHEMBL1606251 & 688407 & 7.699 & 5.6663 & TST \\
\hline CHEMBL1532138 & 688407 & 7.5003 & 5.7102 & TRN \\
\hline CHEMBL1397658 & 688407 & 5.0 & 5.2205 & TRN \\
\hline CHEMBL1562717 & 688407 & 5.0 & 5.3159 & TRN \\
\hline CHEMBL1591605 & 688407 & 4.5 & 5.5895 & TST \\
\hline CHEMBL1566463 & 688407 & 4.7 & 5.1461 & TRN \\
\hline CHEMBL1592039 & 688407 & 7.8996 & 5.2856 & TST \\
\hline CHEMBL1551055 & 688407 & 5.2 & 5.7275 & TRN \\
\hline CHEMBL1436622 & 688407 & 6.3 & 5.0511 & TRN \\
\hline CHEMBL1314864 & 688407 & 4.5 & 5.3394 & TRN \\
\hline CHEMBL1373577 & 688407 & 5.45 & 4.8848 & TST \\
\hline CHEMBL1515988 & 688407 & 4.5 & 4.7561 & TRN \\
\hline CHEMBL1436931 & 688407 & 4.45 & 5.8935 & TRN \\
\hline CHEMBL1594699 & 688407 & 4.9 & 4.5833 & TST \\
\hline CHEMBL1515466 & 688407 & 8.301 & 5.0532 & TRN \\
\hline CHEMBL1373012 & 688407 & 5.0 & 4.5353 & TRN \\
\hline CHEMBL1601096 & 688407 & 6.0 & 5.8218 & TST \\
\hline CHEMBL1592230 & 688407 & 6.4 & 5.9268 & TRN \\
\hline CHEMBL1447409 & 688407 & 8.4949 & 5.1595 & TST \\
\hline CHEMBL1319016 & 688407 & 4.5 & 5.581 & TRN \\
\hline CHEMBL1417496 & 688407 & 4.9 & 5.4668 & TST \\
\hline CHEMBL1598285 & 688407 & 4.9 & 4.8349 & TRN \\
\hline CHEMBL1331594 & 688407 & 4.85 & 5.558 & TRN \\
\hline CHEMBL1450101 & 688407 & 4.7 & 6.3721 & TRN \\
\hline CHEMBL1486824 & 688407 & 4.8 & 5.5577 & TST \\
\hline CHEMBL1591362 & 688407 & 5.2 & 5.7315 & TRN \\
\hline CHEMBL1317399 & 688407 & 4.5 & 5.4593 & TRN \\
\hline CHEMBL1598809 & 688407 & 4.5 & 4.9918 & TRN \\
\hline CHEMBL1524192 & 688407 & 5.0 & 5.2232 & TRN \\
\hline CHEMBL1478817 & 688407 & 5.05 & 5.5429 & TRN \\
\hline CHEMBL3212832 & 688407 & 5.95 & 6.0902 & TST \\
\hline CHEMBL1475217 & 688407 & 6.3 & 5.9805 & TRN \\
\hline CHEMBL1551844 & 688407 & 5.5 & 5.4193 & TRN \\
\hline CHEMBL1612025 & 688407 & 4.5 & 5.1778 & TRN \\
\hline CHEMBL1315924 & 688407 & 6.6499 & 6.081 & TRN \\
\hline CHEMBL1483381 & 688407 & 5.5 & 5.2109 & TRN \\
\hline CHEMBL1359340 & 688407 & 8.3979 & 6.0567 & TRN \\
\hline CHEMBL1170891 & 688407 & 4.5 & 5.4141 & TRN \\
\hline CHEMBL1479371 & 688407 & 5.9 & 5.5839 & TST \\
\hline CHEMBL1433933 & 688407 & 4.7 & 5.471 & TRN \\
\hline CHEMBL1381634 & 688407 & 5.0 & 6.4142 & TST \\
\hline CHEMBL1402201 & 688407 & 5.25 & 5.8391 & TRN \\
\hline CHEMBL1599253 & 688407 & 4.9 & 5.5027 & TRN \\
\hline CHEMBL1612427 & 688407 & 6.1 & 5.6456 & TST \\
\hline
\end{tabular}




\begin{tabular}{|c|c|c|c|c|c|}
\hline \multirow{2}{*}{\multicolumn{2}{|c|}{ CHEMBL1552511 }} & \\
\hline & & 4.6 & 5.0466 & TRN & \\
\hline CHEMBL1475838 & 688407 & 4.6 & 5.6972 & TRN & \\
\hline CHEMBL602206 & 688407 & 4.5 & 4.8063 & TST & \\
\hline CHEMBL1441427 & 688407 & 5.0 & 5.0833 & TRN & \\
\hline CHEMBL1517340 & 688407 & 5.5 & 5.5582 & TRN & \\
\hline CHEMBL1395043 & 688407 & 4.5 & 5.5801 & TRN & \\
\hline CHEMBL1484559 & 688407 & 4.8 & 5.7181 & TRN & \\
\hline CHEMBL1441000 & 688407 & 6.25 & 6.1905 & TRN & \\
\hline CHEMBL1396242 & 688407 & 4.5 & \multicolumn{2}{|c|}{5.7589999999999995} & TRN \\
\hline CHEMBL1554440 & 688407 & 7.1002 & 4.7638 & TRN & \\
\hline CHEMBL1566196 & 688407 & 7.0 & 5.7692 & TRN & \\
\hline CHEMBL1589999 & 688407 & 8.0 & \multicolumn{2}{|c|}{ 5.327999999999999 } & TRN \\
\hline CHEMBL1553541 & 688407 & 6.2 & 6.0919 & TST & \\
\hline CHEMBL1402244 & 688407 & 4.45 & 5.4957 & TST & \\
\hline CHEMBL1532765 & 688407 & 5.1 & 5.3651 & TRN & \\
\hline CHEMBL1375273 & 688407 & 4.5 & 5.1061 & TRN & \\
\hline CHEMBL1481470 & 688407 & 5.0 & 5.4515 & TRN & \\
\hline CHEMBL1437502 & 688407 & 6.1 & 5.7429 & TST & \\
\hline CHEMBL1338421 & 688407 & 4.7 & 5.4259 & TRN & \\
\hline CHEMBL1315214 & 688407 & 4.45 & 5.5079 & TRN & \\
\hline CHEMBL1597594 & 688407 & 5.0 & 6.0907 & TST & \\
\hline CHEMBL1484915 & 688407 & 4.45 & 4.8526 & TRN & \\
\hline CHEMBL1449163 & 688407 & 4.85 & 6.0162 & TRN & \\
\hline CHEMBL1396856 & 688407 & 4.9 & 6.0819 & TRN & \\
\hline CHEMBL1406561 & 688407 & 8.301 & \multicolumn{2}{|c|}{6.4639999999999995} & TRN \\
\hline CHEMBL1396849 & 688407 & 4.6 & 5.0668 & TRN & \\
\hline CHEMBL1565140 & 688407 & 7.699 & 6.766 & TRN & \\
\hline CHEMBL1396263 & 688407 & 5.1 & 5.0357 & TRN & \\
\hline CHEMBL1434368 & 688407 & 4.5 & 5.8285 & TRN & \\
\hline CHEMBL1321958 & 688407 & 4.8 & 5.3003 & TST & \\
\hline CHEMBL1326861 & 688407 & 4.85 & 5.2849 & TST & \\
\hline CHEMBL1553321 & 688407 & 4.8 & 4.8233 & TRN & \\
\hline CHEMBL1484815 & 688407 & 7.4001 & 5.7298 & TRN & \\
\hline CHEMBL1353955 & 688407 & 6.4 & 5.9963 & TST & \\
\hline CHEMBL1332337 & 688407 & 5.7 & 4.9706 & TRN & \\
\hline CHEMBL1592431 & 688407 & 6.9 & 5.4187 & TRN & \\
\hline CHEMBL1551394 & 688407 & 5.0 & 5.7642 & TRN & \\
\hline CHEMBL1397496 & 688407 & 4.6 & 4.921 & TRN & \\
\hline CHEMBL1367274 & 688407 & 4.45 & 5.442 & TST & \\
\hline CHEMBL1398215 & 688407 & 5.7 & 6.0899 & TST & \\
\hline CHEMBL3189265 & 688407 & 5.15 & 5.7286 & TST & \\
\hline CHEMBL1532493 & 688407 & 4.5 & 4.9469 & TRN & \\
\hline CHEMBL1337987 & 688407 & 4.5 & 5.11100 & 0000000001 & TRN \\
\hline CHEMBL1435408 & 688407 & 4.45 & 5.1958 & TRN & \\
\hline CHEMBL1489395 & 688407 & 4.75 & 4.8107 & TRN & \\
\hline CHEMBL1403125 & 688407 & 5.0 & 5.3405 & TST & \\
\hline CHEMBL1322763 & 688407 & 8.1024 & 5.4704 & TST & \\
\hline \multirow[t]{2}{*}{ CHEMBL1315059 } & 688407 & 5.55 & \multicolumn{2}{|c|}{5.5760000000000005} & TRN \\
\hline & & & \multicolumn{2}{|c|}{ Page 22386} & \\
\hline
\end{tabular}




\begin{tabular}{|c|c|c|c|c|c|}
\hline & & \multicolumn{4}{|c|}{ Supplemental Table S2.txt } \\
\hline CHEMBL1357599 & 688407 & 5.9 & 6.13299 & 9999999999 & TRN \\
\hline CHEMBL1611065 & 688407 & 7.6498 & 4.6167 & TST & \\
\hline CHEMBL1316301 & 688407 & 5.3 & 5.244 & TRN & \\
\hline CHEMBL1358556 & 688407 & 4.5 & 5.0548 & TRN & \\
\hline CHEMBL1314857 & 688407 & 4.7 & 5.2945 & TRN & \\
\hline CHEMBL1514926 & 688407 & 6.1 & 5.5656 & TRN & \\
\hline CHEMBL1393900 & 688407 & 5.5 & 5.4888 & TST & \\
\hline CHEMBL1326784 & 688407 & 7.6003 & 6.0579 & TRN & \\
\hline CHEMBL1433535 & 688407 & 4.5 & 5.0345 & TRN & \\
\hline CHEMBL1397191 & 688407 & 4.65 & 4.8831 & TRN & \\
\hline CHEMBL1450510 & 688407 & 4.5 & 5.2579 & TRN & \\
\hline CHEMBL1593772 & 688407 & 5.4 & 5.7605 & TRN & \\
\hline CHEMBL1337284 & 688407 & 6.5 & 5.9328 & TRN & \\
\hline CHEMBL1443795 & 688407 & 8.0 & 5.7799 & TST & \\
\hline CHEMBL1445316 & 688407 & 4.5 & 4.7845 & TRN & \\
\hline CHEMBL1410178 & 688407 & 4.9 & 4.6294 & TRN & \\
\hline CHEMBL1575034 & 688407 & 4.9 & 4.8296 & TRN & \\
\hline CHEMBL1552083 & 688407 & 5.75 & 5.5402 & TRN & \\
\hline CHEMBL1593118 & 688407 & 5.05 & 5.5128 & TRN & \\
\hline CHEMBL1442775 & 688407 & 7.5003 & 5.9281 & TRN & \\
\hline CHEMBL1334897 & 688407 & 4.7 & 5.7193 & TRN & \\
\hline CHEMBL1439787 & 688407 & 8.301 & 5.3819 & TST & \\
\hline CHEMBL1472712 & 688407 & 6.4 & 5.806 & TRN & \\
\hline CHEMBL1590327 & 688407 & 4.9 & 5.4768 & TST & \\
\hline CHEMBL1525065 & 688407 & 4.5 & 5.4287 & TRN & \\
\hline CHEMBL1493104 & 688407 & 7.0501 & 5.3538 & TST & \\
\hline CHEMBL1396396 & 688407 & 4.5 & 5.3594 & TRN & \\
\hline CHEMBL1367589 & 688407 & 4.7 & 6.5407 & TRN & \\
\hline CHEMBL 1317472 & 688407 & 5.0 & 5.2058 & TRN & \\
\hline CHEMBL1356125 & 688407 & 4.9 & 5.2462 & TRN & \\
\hline CHEMBL1492860 & 688407 & 4.65 & 5.8403 & TRN & \\
\hline CHEMBL1408674 & 688407 & 5.4 & 5.8673 & TRN & \\
\hline CHEMBL1551349 & 688407 & 4.95 & 5.1485 & TRN & \\
\hline CHEMBL1553030 & 688407 & 5.1 & 6.0979 & TST & \\
\hline CHEMBL1513877 & 688407 & 8.4949 & 5.5332 & TRN & \\
\hline CHEMBL1337243 & 688407 & 5.35 & 5.0904 & TRN & \\
\hline CHEMBL1369161 & 688407 & 6.2 & 6.9519 & TRN & \\
\hline CHEMBL1357800 & 688407 & 5.0 & 5.3835 & TRN & \\
\hline CHEMBL1331613 & 688407 & 4.45 & 5.11600 & 00000000005 & TRI \\
\hline CHEMBL1612612 & 688407 & 7.1002 & 5.4651 & TRN & \\
\hline CHEMBL1324999 & 688407 & 5.05 & 5.4877 & TRN & \\
\hline CHEMBL1451194 & 688407 & 6.2 & 5.6545 & TRN & \\
\hline CHEMBL1481190 & 688407 & 4.7 & 5.0039 & TRN & \\
\hline CHEMBL3209291 & 688407 & 5.5 & 5.3128 & TRN & \\
\hline CHEMBL1357904 & 688407 & 5.1 & 4.8247 & TST & \\
\hline CHEMBL1358641 & 688407 & 4.45 & 7.1171 & TRN & \\
\hline CHEMBL1592670 & 688407 & 5.2 & 4.9138 & TRN & \\
\hline CHEMBL1318401 & 688407 & 8.0 & 5.9376 & TRN & \\
\hline
\end{tabular}




\begin{tabular}{|c|c|c|c|c|}
\hline \multicolumn{5}{|c|}{ Supplemental Table S2.txt } \\
\hline CHEMBL1396952 & 688407 & 4.9 & 5.9169 & TRN \\
\hline CHEMBL1610184 & 688407 & 4.5 & 5.3337 & TST \\
\hline CHEMBL1371222 & 688407 & 4.9 & 5.5203 & TST \\
\hline CHEMBL1409849 & 688407 & 4.5 & 4.8177 & TRN \\
\hline CHEMBL1555447 & 688407 & 5.8 & 5.7101 & TRN \\
\hline CHEMBL1413274 & 688407 & 4.9 & 5.3065 & TRN \\
\hline CHEMBL1494432 & 688407 & 5.0 & 4.5533 & TRN \\
\hline CHEMBL1590160 & 688407 & 5.5 & 5.3434 & TRN \\
\hline CHEMBL1553537 & 688407 & 5.45 & 5.3383 & TRN \\
\hline CHEMBL1397921 & 688407 & 5.0 & 5.1779 & TST \\
\hline CHEMBL1478539 & 688407 & 4.5 & 5.4387 & TRN \\
\hline CHEMBL1356715 & 688407 & 6.8 & 5.0317 & TRN \\
\hline CHEMBL1330326 & 688407 & 4.5 & 4.6289 & TRN \\
\hline CHEMBL1374110 & 688407 & 4.7 & 5.0217 & TRN \\
\hline CHEMBL1534354 & 688407 & 6.15 & 5.8524 & TST \\
\hline CHEMBL1433850 & 688407 & 4.5 & 4.9244 & TRN \\
\hline CHEMBL1604498 & 688407 & 8.3979 & 6.2581 & TRN \\
\hline CHEMBL1398248 & 688407 & 4.5 & 5.6161 & TST \\
\hline CHEMBL1314850 & 688407 & 6.6 & 5.3502 & TRN \\
\hline CHEMBL1564291 & 688407 & 4.9 & 5.1644 & TRN \\
\hline CHEMBL1397621 & 688407 & 5.5 & 5.7808 & TRN \\
\hline CHEMBL1445391 & 688407 & 8.301 & 6.3163 & TRN \\
\hline CHEMBL1437440 & 688407 & 4.5 & 6.09 & TRN \\
\hline CHEMBL1589986 & 688407 & 4.7 & 5.2975 & TRN \\
\hline CHEMBL1516550 & 688407 & 5.8 & 5.9585 & TRN \\
\hline CHEMBL1535096 & 688407 & 5.2 & 5.9034 & TRN \\
\hline CHEMBL1457612 & 688407 & 4.45 & 4.8677 & TRN \\
\hline CHEMBL1526774 & 688407 & 4.65 & 5.016 & TST \\
\hline CHEMBL1475720 & 688407 & 4.9 & 5.8157 & TRN \\
\hline CHEMBL1595519 & 688407 & 4.8 & 5.4418 & TRN \\
\hline CHEMBL1512819 & 688407 & 7.8013 & 5.5568 & TST \\
\hline CHEMBL1418216 & 688407 & 4.9 & 4.7348 & TRN \\
\hline CHEMBL1316443 & 688407 & 4.8 & 5.575 & TST \\
\hline CHEMBL1446715 & 688407 & 5.7 & 6.1442 & TRN \\
\hline CHEMBL1475403 & 688407 & 5.0 & 6.7385 & TRN \\
\hline CHEMBL1442027 & 688407 & 5.1 & 5.2462 & TRN \\
\hline CHEMBL1317877 & 688407 & 4.7 & 5.4147 & TRN \\
\hline CHEMBL1515126 & 688407 & 6.2 & 6.1439 & TRN \\
\hline CHEMBL1610384 & 688407 & 4.5 & 5.9872 & TRN \\
\hline CHEMBL1402959 & 688407 & 5.3 & 5.4047 & TRN \\
\hline CHEMBL1434777 & 688407 & 5.0 & 5.4475 & TRN \\
\hline CHEMBL1551243 & 688407 & 4.6 & 4.9781 & TRN \\
\hline CHEMBL1315421 & 688407 & 4.7 & 5.2232 & TRN \\
\hline CHEMBL1395078 & 688407 & 4.5 & 5.7858 & TST \\
\hline CHEMBL1607745 & 688407 & 4.6 & 6.0189 & TST \\
\hline CHEMBL1397890 & 688407 & 5.1 & 4.9894 & TRN \\
\hline CHEMBL1600438 & 688407 & 4.5 & 4.9922 & TRN \\
\hline CHEMBL1571094 & 688407 & 4.8 & 5.3663 & TRN \\
\hline
\end{tabular}




\begin{tabular}{|c|c|c|c|c|c|}
\hline \multirow[b]{2}{*}{ CHEMBL1473918 } & \multirow[b]{2}{*}{688407} & \multicolumn{4}{|c|}{ Supplemental Table S2.txt } \\
\hline & & 7.8013 & 5.629 & TRN & \\
\hline CHEMBL1521740 & 688407 & 5.8 & 5.8557 & TRN & \\
\hline CHEMBL1356784 & 688407 & 4.6 & 5.6881 & TST & \\
\hline CHEMBL1355923 & 688407 & 6.8 & 4.9713 & TRN & \\
\hline CHEMBL1441573 & 688407 & 4.6 & 5.0496 & TST & \\
\hline CHEMBL1524096 & 688407 & 5.0 & 5.8579 & TRN & \\
\hline CHEMBL1485139 & 688407 & 5.1 & 4.7864 & TRN & \\
\hline CHEMBL1473541 & 688407 & 4.8 & 5.1326 & TRN & \\
\hline CHEMBL1533813 & 688407 & 4.5 & 5.6951 & TST & \\
\hline CHEMBL1417686 & 688407 & 4.5 & 5.1345 & TRN & \\
\hline CHEMBL1443596 & 688407 & 4.9 & 5.5038 & TRN & \\
\hline CHEMBL1555564 & 688407 & 8.3468 & 6.4777 & TRN & \\
\hline CHEMBL1520284 & 688407 & 4.9 & 5.5762 & TRN & \\
\hline CHEMBL1558915 & 688407 & 5.25 & 6.3578 & TRN & \\
\hline CHEMBL1397832 & 688407 & 5.25 & 5.4842 & TRN & \\
\hline CHEMBL 1474198 & 688407 & 4.9 & 5.041 & TST & \\
\hline CHEMBL1598269 & 688407 & 5.6 & 6.3078 & TRN & \\
\hline CHEMBL1592805 & 688407 & 4.5 & 5.8267 & TRN & \\
\hline CHEMBL1572128 & 688407 & 4.5 & 5.3695 & TRN & \\
\hline CHEMBL1364846 & 688407 & 7.6003 & 5.5436 & TST & \\
\hline CHEMBL1434937 & 688407 & 5.0 & 5.1659 & TRN & \\
\hline CHEMBL1451551 & 688407 & 5.1 & 5.5072 & TRN & \\
\hline CHEMBL1463307 & 688407 & 6.2 & 5.8134 & TST & \\
\hline CHEMBL1490901 & 688407 & 5.7 & 5.8158 & TST & \\
\hline CHEMBL1591521 & 688407 & 4.7 & 6.0819 & TRN & \\
\hline CHEMBL1397165 & 688407 & 8.3979 & 6.5007 & TRN & \\
\hline CHEMBL1435875 & 688407 & 5.5 & 5.0368 & TRN & \\
\hline CHEMBL1592642 & 688407 & 4.8 & 5.6358 & TRN & \\
\hline CHEMBL1476038 & 688407 & 4.45 & 4.9308 & TRN & \\
\hline CHEMBL1558600 & 688407 & 4.5 & 5.2287 & TRN & \\
\hline CHEMBL1433819 & 688407 & 4.65 & 4.54899 & 99999999995 & TRN \\
\hline CHEMBL1326916 & 688407 & 4.8 & 5.0564 & TRN & \\
\hline CHEMBL1564573 & 688407 & 4.8 & 5.6831 & TRN & \\
\hline CHEMBL1433624 & 688407 & 5.0 & 5.3588 & TRN & \\
\hline CHEMBL1517259 & 688407 & 4.8 & 5.0569 & TRN & \\
\hline CHEMBL1397695 & 688407 & 4.7 & 5.1585 & TRN & \\
\hline CHEMBL1610810 & 688407 & 4.65 & 5.1132 & TRN & \\
\hline CHEMBL1434191 & 688407 & 5.25 & 6.2692 & TRN & \\
\hline CHEMBL1547176 & 688407 & 4.6 & 5.9386 & TRN & \\
\hline CHEMBL1597186 & 688407 & 4.7 & 5.3634 & TRN & \\
\hline CHEMBL1608466 & 688407 & 8.301 & 6.5024 & TRN & \\
\hline CHEMBL1494395 & 688407 & 5.0 & 4.9568 & TRN & \\
\hline CHEMBL1417736 & 688407 & 4.5 & 4.7501 & TRN & \\
\hline CHEMBL1567202 & 688407 & 4.65 & 4.5096 & TRN & \\
\hline CHEMBL1554221 & 688407 & 4.9 & 5.0645 & TRN & \\
\hline CHEMBL1570085 & 688407 & 5.4 & 5.58799 & 9999999999 & TRN \\
\hline CHEMBL1357001 & 688407 & 5.1 & 6.1246 & TRN & \\
\hline CHEMBL1453940 & 688407 & 5.2 & 5.6238 & TRN & \\
\hline & & & & 22389 & \\
\hline
\end{tabular}




\begin{tabular}{|c|c|c|c|c|c|}
\hline \multicolumn{6}{|c|}{ Supplemental Table S2.txt } \\
\hline CHEMBL1434344 & 688407 & 4.85 & 5.2983 & TRN & \\
\hline CHEMBL1317703 & 688407 & 5.5 & 5.8609 & TRN & \\
\hline CHEMBL1323093 & 688407 & 5.5 & 5.1483 & TRN & \\
\hline CHEMBL1405481 & 688407 & 5.4 & 5.6352 & TRN & \\
\hline CHEMBL1512059 & 688407 & 4.9 & 4.6658 & TRN & \\
\hline CHEMBL1355037 & 688407 & 4.5 & 5.9024 & TRN & \\
\hline CHEMBL1607281 & 688407 & 4.8 & 4.9537 & TST & \\
\hline CHEMBL1396284 & 688407 & 5.8 & 6.0653 & TST & \\
\hline CHEMBL1316440 & 688407 & 4.85 & 5.6862 & TST & \\
\hline CHEMBL1444575 & 688407 & 4.6 & 4.7553 & TRN & \\
\hline CHEMBL1412090 & 688407 & 6.6 & 6.3668 & TRN & \\
\hline CHEMBL1358179 & 688407 & 4.5 & 4.4339 & TRN & \\
\hline CHEMBL1317643 & 688407 & 4.95 & 5.2904 & TRN & \\
\hline CHEMBL1590804 & 688407 & 4.9 & 5.037 & TRN & \\
\hline CHEMBL1452460 & 688407 & 8.301 & 5.4622 & TST & \\
\hline CHEMBL1553965 & 688407 & 5.4 & 5.6924 & TRN & \\
\hline CHEMBL1532169 & 688407 & 7.699 & 5.6603 & TRN & \\
\hline CHEMBL1440146 & 688407 & 5.7 & 4.9656 & TST & \\
\hline CHEMBL1316249 & 688407 & 5.0 & 4.82600 & 00000000005 & TRN \\
\hline CHEMBL1534550 & 688407 & 7.0 & 6.6415 & TRN & \\
\hline CHEMBL1608534 & 688407 & 5.4 & 5.9041 & TRN & \\
\hline CHEMBL1354868 & 688407 & 4.7 & 5.4733 & TST & \\
\hline CHEMBL1516043 & 688407 & 5.0 & 5.4741 & TRN & \\
\hline CHEMBL1554992 & 688407 & 8.4949 & 5.5468 & TRN & \\
\hline CHEMBL1436130 & 688407 & 8.301 & 5.5733 & TRN & \\
\hline CHEMBL1574276 & 688407 & 4.8 & 5.5717 & TST & \\
\hline CHEMBL1322265 & 688407 & 8.2518 & 6.3188 & TRN & \\
\hline CHEMBL1434517 & 688407 & 4.5 & 5.6822 & TRN & \\
\hline CHEMBL1395810 & 688407 & 7.699 & 6.9527 & TRN & \\
\hline CHEMBL1591634 & 688407 & 4.8 & 5.63700 & 00000000005 & TRN \\
\hline CHEMBL1592684 & 688407 & 5.2 & 5.9834 & TRN & \\
\hline CHEMBL1363294 & 688407 & 6.2 & 5.2181 & TRN & \\
\hline CHEMBL1369934 & 688407 & 8.0 & 6.9694 & TRN & \\
\hline CHEMBL1396879 & 688407 & 4.9 & 5.0284 & TRN & \\
\hline CHEMBL1416034 & 688407 & 5.1 & 5.6449 & TRN & \\
\hline CHEMBL1396566 & 688407 & 5.2 & 5.0152 & TRN & \\
\hline CHEMBL1334191 & 688407 & 4.5 & 5.1134 & TRN & \\
\hline CHEMBL1321983 & 688407 & 5.0 & 5.8342 & TST & \\
\hline CHEMBL1497004 & 688407 & 5.4 & 4.7138 & TST & \\
\hline CHEMBL1475552 & 688407 & 5.0 & 5.6296 & TRN & \\
\hline CHEMBL1488414 & 688407 & 4.5 & 6.0708 & TRN & \\
\hline CHEMBL1318593 & 688407 & 4.85 & 5.1612 & TRN & \\
\hline CHEMBL1321824 & 688407 & 4.9 & 5.4028 & TRN & \\
\hline CHEMBL1402344 & 688407 & 6.5 & 6.3437 & TRN & \\
\hline CHEMBL1453925 & 688407 & 4.5 & 5.4918 & TRN & \\
\hline CHEMBL1419880 & 688407 & 4.95 & 5.371 & TRN & \\
\hline CHEMBL1395156 & 688407 & 4.9 & 5.7649 & TRN & \\
\hline CHEMBL1396027 & 688407 & 4.8 & 5.4265 & TST & \\
\hline
\end{tabular}




\begin{tabular}{|c|c|c|c|c|c|}
\hline \multicolumn{6}{|c|}{ Supplemental Table S2.txt } \\
\hline CHEMBL1437262 & 688407 & 4.95 & 5.0624 & TST & \\
\hline CHEMBL1596396 & 688407 & 4.5 & 5.3085 & TST & \\
\hline CHEMBL1611263 & 688407 & 5.7 & 6.1633 & TRN & \\
\hline CHEMBL1438244 & 688407 & 7.6003 & 5.0271 & TRN & \\
\hline CHEMBL1516538 & 688407 & 7.0 & 5.4312 & TRN & \\
\hline CHEMBL1551846 & 688407 & 4.95 & 5.5179 & TRN & \\
\hline CHEMBL1474106 & 688407 & 4.6 & 4.808 & TRN & \\
\hline CHEMBL1494944 & 688407 & 4.95 & 5.4834 & TRN & \\
\hline CHEMBL1414664 & 688407 & 4.8 & 6.2893 & TST & \\
\hline CHEMBL1485205 & 688407 & 4.8 & 5.9014 & TRN & \\
\hline CHEMBL1395906 & 688407 & 4.45 & 5.6787 & TRN & \\
\hline CHEMBL1519114 & 688407 & 4.5 & 5.2133 & TST & \\
\hline CHEMBL1438707 & 688407 & 6.95 & 5.8459 & TST & \\
\hline CHEMBL1557832 & 688407 & 4.6 & 5.045 & TRN & \\
\hline CHEMBL1366277 & 688407 & 4.45 & 5.0962 & TRN & \\
\hline CHEMBL1443699 & 688407 & 4.7 & 5.029 & TRN & \\
\hline CHEMBL1316015 & 688407 & 4.5 & 5.0525 & TRN & \\
\hline CHEMBL1364494 & 688407 & 5.0 & 5.0675 & TRN & \\
\hline CHEMBL1409447 & 688407 & 4.8 & 5.3031 & TST & \\
\hline CHEMBL1439621 & 688407 & 5.0 & 6.2008 & TST & \\
\hline CHEMBL1487625 & 688407 & 4.7 & 5.7275 & TRN & \\
\hline CHEMBL1355421 & 688407 & 5.1 & 5.6346 & TST & \\
\hline CHEMBL1361402 & 688407 & 8.3468 & 5.6344 & TRN & \\
\hline CHEMBL1357459 & 688407 & 4.5 & 5.3271 & TRN & \\
\hline CHEMBL1396357 & 688407 & 4.5 & 5.1714 & TRN & \\
\hline CHEMBL1593032 & 688407 & 7.4001 & 5.8248 & TST & \\
\hline CHEMBL1598906 & 688407 & 6.35 & 6.3696 & TRN & \\
\hline CHEMBL1600638 & 688407 & 4.5 & 5.6456 & TRN & \\
\hline CHEMBL1604590 & 688407 & 4.75 & 5.75200 & 0000000001 & TRN \\
\hline CHEMBL1610750 & 688407 & 5.2 & 5.4017 & TST & \\
\hline CHEMBL1434380 & 688407 & 4.45 & 5.447 & TRN & \\
\hline CHEMBL1435387 & 688407 & 5.05 & 5.5599 & TRN & \\
\hline CHEMBL1554981 & 688407 & 4.9 & 5.6449 & TRN & \\
\hline CHEMBL1426270 & 688407 & 5.9 & 5.9057 & TST & \\
\hline CHEMBL1374468 & 688407 & 6.3 & 6.4893 & TRN & \\
\hline CHEMBL1569103 & 688407 & 4.7 & 5.4498 & TRN & \\
\hline CHEMBL1568028 & 688407 & 4.85 & 5.5989 & TRN & \\
\hline CHEMBL1475346 & 688407 & 4.45 & 5.7356 & TRN & \\
\hline CHEMBL1566712 & 688407 & 5.5 & 5.3126 & TRN & \\
\hline CHEMBL1398864 & 688407 & 5.1 & 5.6912 & TRN & \\
\hline CHEMBL1317902 & 688407 & 4.75 & 5.1253 & TRN & \\
\hline CHEMBL1606261 & 688407 & 8.301 & 5.3472 & TRN & \\
\hline CHEMBL3198449 & 688407 & 5.5 & 6.1094 & TST & \\
\hline CHEMBL1552324 & 688407 & 5.1 & 5.8149 & TRN & \\
\hline CHEMBL1474446 & 688407 & 7.1002 & 6.7552 & TST & \\
\hline CHEMBL1372416 & 688407 & 5.05 & 5.5638 & TRN & \\
\hline CHEMBL 1487548 & 688407 & 4.7 & 5.5817 & TST & \\
\hline CHEMBL1402541 & 688407 & 5.0 & 5.5576 & TRN & \\
\hline
\end{tabular}




\begin{tabular}{|c|c|c|c|c|}
\hline & & & pplement & al $\mathrm{Ta}$ \\
\hline CHEMBL1448777 & 688407 & 4.8 & 5.3465 & TRN \\
\hline CHEMBL1446494 & 688407 & 4.85 & 5.8886 & TST \\
\hline CHEMBL1455968 & 688407 & 8.0 & 6.0972 & TST \\
\hline CHEMBL1551539 & 688407 & 4.5 & 4.8329 & TRN \\
\hline CHEMBL1609342 & 688407 & 4.45 & 5.2778 & TRN \\
\hline CHEMBL1512098 & 688407 & 4.6 & 5.1892 & TRN \\
\hline CHEMBL1602955 & 688407 & 4.95 & 5.9925 & TRN \\
\hline CHEMBL1395065 & 688407 & 4.9 & 5.364 & TRN \\
\hline CHEMBL1553370 & 688407 & 4.7 & 5.3015 & TRN \\
\hline CHEMBL1590671 & 688407 & 4.65 & 5.0612 & TRN \\
\hline CHEMBL1354651 & 688407 & 6.1 & 6.3665 & TRN \\
\hline CHEMBL1402755 & 688407 & 4.8 & 5.3516 & TST \\
\hline CHEMBL1397922 & 688407 & 5.0 & 5.4385 & TRN \\
\hline CHEMBL1322172 & 688407 & 6.1 & 5.3685 & TRN \\
\hline CHEMBL1456607 & 688407 & 4.5 & 5.2712 & TRN \\
\hline CHEMBL1378198 & 688407 & 4.8 & 4.7706 & TRN \\
\hline CHEMBL1534423 & 688407 & 6.8 & 6.3562 & TRN \\
\hline CHEMBL1444446 & 688407 & 4.8 & 6.0245 & TRN \\
\hline CHEMBL1552307 & 688407 & 4.5 & 4.9851 & TRN \\
\hline CHEMBL1474691 & 688407 & 4.5 & 4.6908 & TRN \\
\hline CHEMBL1535554 & 688407 & 5.5 & 5.8633 & TRN \\
\hline CHEMBL1397743 & 688407 & 6.0 & 5.1983 & TST \\
\hline CHEMBL1529690 & 688407 & 6.5 & 5.5048 & TRN \\
\hline CHEMBL1355647 & 688407 & 5.1 & 5.7736 & TRN \\
\hline CHEMBL3194991 & 688407 & 4.95 & 5.1702 & TST \\
\hline CHEMBL1317720 & 688407 & 4.45 & 5.7307 & TST \\
\hline CHEMBL1554428 & 688407 & 4.8 & 5.1198 & TRN \\
\hline CHEMBL1356919 & 688407 & 4.5 & 5.1541 & TRN \\
\hline CHEMBL1404668 & 688407 & 6.4 & 6.5998 & TRN \\
\hline CHEMBL1514802 & 688407 & 4.5 & 5.0896 & TRN \\
\hline CHEMBL1515379 & 688407 & 4.6 & 4.6002 & TRN \\
\hline CHEMBL1337962 & 688407 & 6.8 & 6.7609 & TRN \\
\hline CHEMBL1516599 & 688407 & 5.0 & 5.7877 & TRN \\
\hline CHEMBL1552965 & 688407 & 6.0 & 5.9342 & TST \\
\hline CHEMBL1400137 & 688407 & 6.3 & 5.7132 & TRN \\
\hline CHEMBL1518923 & 688407 & 7.6003 & 5.6233 & TRN \\
\hline CHEMBL1402255 & 688407 & 4.45 & 5.35 & TST \\
\hline CHEMBL1561634 & 688407 & 8.0 & 6.5535 & TRN \\
\hline CHEMBL1503002 & 688407 & 4.9 & 5.69 & TRN \\
\hline CHEMBL1320977 & 688407 & 4.9 & 5.2412 & TRN \\
\hline CHEMBL1435186 & 688407 & 4.55 & 5.4955 & TRN \\
\hline CHEMBL1611214 & 688407 & 4.7 & 5.3315 & TRN \\
\hline CHEMBL1333387 & 688407 & 5.15 & 5.2504 & TRN \\
\hline CHEMBL1494331 & 688407 & 6.0 & 5.7013 & TRN \\
\hline CHEMBL1572541 & 688407 & 6.9 & 5.7045 & TST \\
\hline CHEMBL1610016 & 688407 & 7.0 & 6.1242 & TRN \\
\hline CHEMBL1441555 & 688407 & 4.9 & 5.8322 & TRN \\
\hline CHEMBL1600111 & 688407 & 7.3002 & 6.4947 & TRN \\
\hline
\end{tabular}




\begin{tabular}{|c|c|c|c|c|}
\hline \multicolumn{5}{|c|}{ Supplemental Table S2.txt } \\
\hline CHEMBL1592377 & 688407 & 5.9 & 6.4509 & TRN \\
\hline CHEMBL1402941 & 688407 & 5.0 & 4.8435 & TRN \\
\hline CHEMBL1397479 & 688407 & 5.0 & 5.0436 & TRN \\
\hline CHEMBL1452922 & 688407 & 4.6 & 5.0136 & TRN \\
\hline CHEMBL1435174 & 688407 & 6.8 & 6.0665 & TRN \\
\hline CHEMBL1316693 & 688407 & 8.301 & 6.0798 & TST \\
\hline CHEMBL1405080 & 688407 & 7.699 & 5.8977 & TRN \\
\hline CHEMBL1358317 & 688407 & 4.65 & 5.1854 & TRN \\
\hline CHEMBL1593674 & 688407 & 4.9 & 5.0385 & TST \\
\hline CHEMBL1366528 & 688407 & 7.2 & 5.9365 & TRN \\
\hline CHEMBL1516298 & 688407 & 4.45 & 5.0876 & TRN \\
\hline CHEMBL1485418 & 688407 & 4.9 & 5.0381 & TST \\
\hline CHEMBL1599457 & 688407 & 4.9 & 4.9273 & TRN \\
\hline CHEMBL1601511 & 688407 & 7.0501 & 5.4222 & TST \\
\hline CHEMBL1357409 & 688407 & 4.5 & 5.2554 & TST \\
\hline CHEMBL1369344 & 688407 & 7.3497 & 5.1119 & TRN \\
\hline CHEMBL1514367 & 688407 & 6.1 & 5.4813 & TRN \\
\hline CHEMBL1526782 & 688407 & 4.7 & 5.563 & TST \\
\hline CHEMBL1395118 & 688407 & 5.35 & 6.2315 & TRN \\
\hline CHEMBL1412866 & 688407 & 5.25 & 5.4246 & TRN \\
\hline CHEMBL3192873 & 688407 & 5.05 & 6.5417 & TST \\
\hline CHEMBL1554748 & 688407 & 6.5501 & 5.8647 & TST \\
\hline CHEMBL1441198 & 688407 & 4.45 & 5.1576 & TRN \\
\hline CHEMBL1552311 & 688407 & 5.2 & 5.0266 & TRN \\
\hline CHEMBL1599968 & 688407 & 4.7 & 4.4242 & TRN \\
\hline CHEMBL1315850 & 688407 & 5.0 & 5.8543 & TRN \\
\hline CHEMBL1608035 & 688407 & 4.5 & 5.6156 & TRN \\
\hline CHEMBL1323825 & 688407 & 4.6 & 5.1848 & TRN \\
\hline CHEMBL1475025 & 688407 & 5.6 & 5.9131 & TRN \\
\hline CHEMBL1309799 & 688407 & 4.7 & 5.1794 & TST \\
\hline CHEMBL1397944 & 688407 & 4.45 & 6.1572 & TRN \\
\hline CHEMBL1437582 & 688407 & 6.4 & 6.1706 & TRN \\
\hline CHEMBL1353194 & 688407 & 5.5 & 4.8173 & TRN \\
\hline CHEMBL1360774 & 688407 & 5.8 & 6.1062 & TRN \\
\hline CHEMBL1607804 & 688407 & 4.85 & 5.1424 & TRN \\
\hline CHEMBL1355559 & 688407 & 5.4 & 6.4411 & TRN \\
\hline CHEMBL1535105 & 688407 & 4.5 & 5.4268 & TRN \\
\hline CHEMBL1479983 & 688407 & 6.8 & 5.7486 & TST \\
\hline CHEMBL1512202 & 688407 & 8.301 & 5.5402 & TRN \\
\hline CHEMBL3190958 & 688407 & 4.8 & 5.5585 & TRN \\
\hline CHEMBL1530140 & 688407 & 4.45 & 5.1096 & TRN \\
\hline CHEMBL1476773 & 688407 & 4.5 & 4.4743 & TRN \\
\hline CHEMBL1436113 & 688407 & 7.0 & 5.4536 & TRN \\
\hline CHEMBL1433623 & 688407 & 4.9 & 5.0852 & TRN \\
\hline CHEMBL1530843 & 688407 & 5.5 & 5.4032 & TST \\
\hline CHEMBL1409970 & 688407 & 8.0 & 5.4859 & TRN \\
\hline CHEMBL1394326 & 688407 & 5.3 & 5.4315 & TRN \\
\hline CHEMBL1600781 & 688407 & 4.9 & 5.3888 & TRN \\
\hline
\end{tabular}




\begin{tabular}{|c|c|c|c|c|}
\hline \multicolumn{5}{|c|}{ Supplemental Table S2.txt } \\
\hline CHEMBL1372014 & 688407 & 4.9 & 5.6612 & TRN \\
\hline CHEMBL1554146 & 688407 & 4.6 & 4.6236 & TRN \\
\hline CHEMBL1356119 & 688407 & 4.7 & 5.6852 & TRN \\
\hline CHEMBL1610770 & 688407 & 5.0 & 5.53100 & 0000000001 \\
\hline CHEMBL1480437 & 688407 & 5.0 & 5.0778 & TRN \\
\hline CHEMBL1314951 & 688407 & 4.65 & 4.898 & TRN \\
\hline CHEMBL1535498 & 688407 & 4.8 & 5.0719 & TRN \\
\hline CHEMBL1476476 & 688407 & 4.8 & 5.055 & TRN \\
\hline CHEMBL1446795 & 688407 & 5.2 & 5.3472 & TRN \\
\hline CHEMBL1590938 & 688407 & 4.5 & 5.4781 & TST \\
\hline CHEMBL1600827 & 688407 & 4.5 & 5.2208 & TRN \\
\hline CHEMBL1554756 & 688407 & 4.7 & 4.9926 & TRN \\
\hline CHEMBL1593904 & 688407 & 7.699 & 6.0154 & TRN \\
\hline CHEMBL1365239 & 688407 & 4.95 & 5.6708 & TRN \\
\hline CHEMBL1330699 & 688407 & 5.2 & 5.5411 & TRN \\
\hline CHEMBL1473574 & 688407 & 5.4 & 5.5673 & TRN \\
\hline CHEMBL1613289 & 688407 & 7.5003 & 5.4571 & TRN \\
\hline CHEMBL1395638 & 688407 & 6.0 & 5.5636 & TST \\
\hline CHEMBL1334871 & 688407 & 4.9 & 5.4351 & TRN \\
\hline CHEMBL1339164 & 688407 & 4.5 & 5.4628 & TRN \\
\hline CHEMBL1403091 & 688407 & 6.4 & 4.5438 & TRN \\
\hline CHEMBL1441297 & 688407 & 4.45 & 6.3768 & TRN \\
\hline CHEMBL1328940 & 688407 & 4.45 & 5.1305 & TRN \\
\hline CHEMBL1376718 & 688407 & 4.5 & 5.0391 & TRN \\
\hline CHEMBL1561989 & 688407 & 4.5 & 4.7302 & TRN \\
\hline CHEMBL1401730 & 688407 & 6.5 & 6.0205 & TRN \\
\hline CHEMBL1552437 & 688407 & 6.7001 & 5.8276 & TRN \\
\hline CHEMBL1562244 & 688407 & 5.0 & 5.2633 & TRN \\
\hline CHEMBL1357202 & 688407 & 8.2007 & 6.1211 & TRN \\
\hline CHEMBL1590997 & 688407 & 8.1024 & 5.4025 & TST \\
\hline CHEMBL1314812 & 688407 & 4.9 & 5.2712 & TRN \\
\hline CHEMBL1436731 & 688407 & 6.05 & 5.3116 & TST \\
\hline CHEMBL1589967 & 688407 & 5.9 & 6.1045 & TRN \\
\hline CHEMBL1197976 & 688407 & 4.7 & 4.4784 & TRN \\
\hline CHEMBL1611321 & 688407 & 4.55 & 5.6666 & TRN \\
\hline CHEMBL1496870 & 688407 & 7.699 & 5.4339 & TST \\
\hline CHEMBL1315596 & 688407 & 5.9 & 6.282 & TRN \\
\hline CHEMBL1591727 & 688407 & 4.45 & 4.9531 & TRN \\
\hline CHEMBL1434896 & 688407 & 4.5 & 5.8825 & TST \\
\hline CHEMBL1317784 & 688407 & 5.0 & 5.3899 & TST \\
\hline CHEMBL1357810 & 688407 & 4.45 & 5.1194 & TRN \\
\hline CHEMBL1437923 & 688407 & 4.85 & 4.6908 & TST \\
\hline CHEMBL1551112 & 688407 & 4.5 & 6.0801 & TRN \\
\hline CHEMBL1439977 & 688407 & 4.75 & 5.0152 & TRN \\
\hline CHEMBL1356479 & 688407 & 4.95 & 5.9818 & TRN \\
\hline CHEMBL1552691 & 688407 & 8.301 & 6.5467 & TRN \\
\hline CHEMBL1481939 & 688407 & 4.5 & 5.5187 & TRN \\
\hline CHEMBL1494565 & 688407 & 8.0 & 5.2471 & TST \\
\hline
\end{tabular}




\begin{tabular}{|c|c|c|c|c|c|}
\hline \multicolumn{6}{|c|}{ Supplemental Table S2.txt } \\
\hline CHEMBL1357326 & 688407 & 5.1 & 5.8529 & TRN & \\
\hline CHEMBL1523310 & 688407 & 4.45 & 6.3775 & TRN & \\
\hline CHEMBL1358256 & 688407 & 4.6 & 5.1566 & TRN & \\
\hline CHEMBL1356157 & 688407 & 8.4949 & 5.9744 & TRN & \\
\hline CHEMBL1476125 & 688407 & 4.6 & 6.1494 & TRN & \\
\hline CHEMBL1525640 & 688407 & 5.0 & 5.062 & TRN & \\
\hline CHEMBL1603055 & 688407 & 6.5 & 5.2871 & TRN & \\
\hline CHEMBL1326289 & 688407 & 5.9 & 5.8527 & TST & \\
\hline CHEMBL1394612 & 688407 & 4.9 & 4.7568 & TST & \\
\hline CHEMBL1472748 & 688407 & 5.1 & 5.7541 & TRN & \\
\hline CHEMBL1443693 & 688407 & 5.0 & 5.4921 & TRN & \\
\hline CHEMBL1445201 & 688407 & 7.8013 & 6.0631 & TRN & \\
\hline CHEMBL1327626 & 688407 & 8.0 & 5.9566 & TRN & \\
\hline CHEMBL1556980 & 688407 & 5.8 & 5.9938 & TRN & \\
\hline CHEMBL3692583 & 1528525 & 7.2676 & 6.1416 & TRN & \\
\hline CHEMBL3692614 & 1528525 & 7.5229 & 6.3221 & TRN & \\
\hline CHEMBL 3918370 & 1528525 & 8.7447 & 8.8796 & TST & \\
\hline CHEMBL3944406 & 1528525 & 9.1249 & 9.1243 & TRN & \\
\hline CHEMBL 3688147 & 1528525 & 6.2366 & 5.9224 & TST & \\
\hline CHEMBL3692594 & 1528525 & 6.1871 & 6.3198 & TRN & \\
\hline CHEMBL3688146 & 1528525 & 6.0177 & 6.0646 & TRN & \\
\hline CHEMBL 3692602 & 1528525 & 6.4815 & 6.2586 & TRN & \\
\hline CHEMBL3897135 & 1528525 & 7.8861 & 7.1251 & TST & \\
\hline CHEMBL 3692657 & 1528525 & 6.0 & 7.7414 & TRN & \\
\hline CHEMBL3692591 & 1528525 & 5.5528 & 5.8828 & TRN & \\
\hline CHEMBL3692642 & 1528525 & 7.0315 & 7.3037 & TRN & \\
\hline CHEMBL 3692598 & 1528525 & 6.2218 & 6.2454 & TRN & \\
\hline CHEMBL3688141 & 1528525 & 6.2757 & 6.0448 & TRN & \\
\hline CHEMBL 3692576 & 1528525 & 6.3372 & 6.6772 & TST & \\
\hline CHEMBL3692688 & 1528525 & 7.9208 & 8.0679 & TRN & \\
\hline CHEMBL3692677 & 1528525 & 6.7447 & 6.6928 & TRN & \\
\hline CHEMBL 3692584 & 1528525 & 6.8539 & 6.496 & TRN & \\
\hline CHEMBL3688159 & 1528525 & 6.1367 & 6.2324 & TRN & \\
\hline CHEMBL 3688140 & 1528525 & 6.4437 & $6.1160 e$ & 00000000005 & TRN \\
\hline CHEMBL3639914 & 1528525 & 5.9208 & 6.0236 & TRN & \\
\hline CHEMBL3692590 & 1528525 & 5.699 & 5.9323 & TRN & \\
\hline CHEMBL3692609 & 1528525 & 7.2757 & 6.5275 & TRN & \\
\hline CHEMBL3692575 & 1528525 & 6.5229 & 6.3259 & TRN & \\
\hline CHEMBL3692627 & 1528525 & 6.0 & 6.7887 & TRN & \\
\hline CHEMBL3692589 & 1528525 & 6.0 & 7.0798 & TRN & \\
\hline CHEMBL3952684 & 1528525 & 9.0706 & 8.2599 & TRN & \\
\hline CHEMBL3692643 & 1528525 & 7.0132 & 6.6422 & TRN & \\
\hline CHEMBL3692648 & 1528525 & 6.2007 & 6.4719 & TST & \\
\hline CHEMBL3692628 & 1528525 & 6.284 & 6.5233 & TRN & \\
\hline CHEMBL3940445 & 1528525 & 8.0757 & 7.0521 & TST & \\
\hline CHEMBL3692610 & 1528525 & 6.7212 & 6.2633 & TRN & \\
\hline CHEMBL3688152 & 1528525 & 6.0 & 6.0748 & TRN & \\
\hline CHEMBL3692632 & 1528525 & 6.4437 & 6.7382 & TST & \\
\hline
\end{tabular}


Supplemental Table S2.txt

\begin{tabular}{|c|c|c|c|c|}
\hline CHEMBL3692620 & 1528525 & 6.0 & 6.7157 & TRN \\
\hline CHEMBL3692574 & 1528525 & 6.4685 & 6.3698 & TRN \\
\hline CHEMBL3692587 & 1528525 & 7.0458 & 6.6025 & TRN \\
\hline CHEMBL3977713 & 1528525 & 5.4949 & 6.4921 & TST \\
\hline CHEMBL3692597 & 1528525 & 6.1024 & 6.0979 & TRN \\
\hline CHEMBL3958525 & 1528525 & 9.0132 & 8.9386 & TRN \\
\hline CHEMBL 3692644 & 1528525 & 6.699 & 6.5602 & TRN \\
\hline CHEMBL3692612 & 1528525 & 6.8239 & 6.1908 & TRN \\
\hline CHEMBL3692588 & 1528525 & 5.4949 & 6.3958 & TRN \\
\hline CHEMBL3692645 & 1528525 & 6.5376 & 6.3475 & TRN \\
\hline CHEMBL3692646 & 1528525 & 6.0862 & 6.7141 & TST \\
\hline CHEMBL3692601 & 1528525 & 6.6198 & 6.4496 & TRN \\
\hline CHEMBL 3692578 & 1528525 & 5.3768 & 5.8038 & TRN \\
\hline CHEMBL3692599 & 1528525 & 6.1079 & 6.0974 & TRN \\
\hline CHEMBL 3943688 & 1528525 & 8.9586 & 9.1642 & TRN \\
\hline CHEMBL 3910908 & 1528525 & 7.9586 & 6.523 & TST \\
\hline CHEMBL3692569 & 1528525 & 5.3565 & 5.8182 & TRN \\
\hline CHEMBL3692581 & 1528525 & 5.3768 & 6.0315 & TRN \\
\hline CHEMBL3692656 & 1528525 & 7.0706 & 7.1985 & TRN \\
\hline CHEMBL 3688151 & 1528525 & 6.3665 & 6.2019 & TRN \\
\hline CHEMBL 3692650 & 1528525 & 6.7959 & 6.43 & TST \\
\hline CHEMBL 3692651 & 1528525 & 6.0 & 6.8225 & TRN \\
\hline CHEMBL 3890376 & 1528525 & 8.0 & 7.1371 & TST \\
\hline CHEMBL 3688148 & 1528525 & 6.0706 & 5.8889 & TRN \\
\hline CHEMBL3692635 & 1528525 & 5.5302 & 6.4605 & TST \\
\hline CHEMBL 3945309 & 1528525 & 7.3188 & 6.7782 & TRN \\
\hline CHEMBL3692566 & 1528525 & 5.9208 & 6.0855 & TRN \\
\hline CHEMBL3951915 & 1528525 & 6.5086 & 6.8498 & TST \\
\hline CHEMBL3692653 & 1528525 & 7.4437 & 6.3517 & TST \\
\hline CHEMBL3688154 & 1528525 & 6.0044 & 6.3527 & TRN \\
\hline CHEMBL 3692607 & 1528525 & 6.0362 & 6.3674 & TRN \\
\hline CHEMBL 3688164 & 1528525 & 6.2147 & 6.2154 & TRN \\
\hline CHEMBL 3692638 & 1528525 & 6.0757 & 6.3268 & TRN \\
\hline CHEMBL 3688143 & 1528525 & 6.2076 & 6.1349 & TRN \\
\hline CHEMBL3941794 & 1528525 & 8.3468 & 7.1544 & TRN \\
\hline CHEMBL3692631 & 1528525 & 6.3665 & 6.1999 & TST \\
\hline CHEMBL3932719 & 1528525 & 8.7959 & 8.7486 & TST \\
\hline CHEMBL3692595 & 1528525 & 5.8539 & 6.12799 & 9999999999 \\
\hline CHEMBL3692596 & 1528525 & 5.6021 & 6.1448 & TRN \\
\hline CHEMBL3688153 & 1528525 & 6.0458 & 6.3074 & TRN \\
\hline CHEMBL 3930432 & 1528525 & 8.4437 & 7.3493 & TRN \\
\hline CHEMBL3688165 & 1528525 & 5.9208 & 6.1953 & TRN \\
\hline CHEMBL3692573 & 1528525 & 5.5686 & 5.83299 & 9999999999 \\
\hline CHEMBL3692592 & 1528525 & 6.2596 & 6.2315 & TRN \\
\hline CHEMBL3692654 & 1528525 & 6.6778 & 6.3868 & TST \\
\hline CHEMBL 3692647 & 1528525 & 6.5229 & 6.7674 & TST \\
\hline CHEMBL 3692625 & 1528525 & 6.301 & 6.425 & TRN \\
\hline CHEMBL 3692624 & 1528525 & 6.3565 & 6.2559 & TRN \\
\hline
\end{tabular}

Page 22396 
Supplemental Table S2.txt

\begin{tabular}{|c|c|c|c|c|}
\hline 2603 & 528525 & 6.7959 & & \\
\hline & 528525 & 61210 & & \\
\hline & 28525 & 6.0 & & \\
\hline 668 & 528525 & .0088 & & \\
\hline AEMBL & 528525 & 8861 & 3972 & \\
\hline AEMBL3688161 & 528525 & 5.8239 & 7458 & \\
\hline 591 & 528525 & 437 & & \\
\hline EMB & 528525 & & & \\
\hline AEMBL36 & 528525 & 6.8539 & & \\
\hline AEMBL3692582 & 528525 & 6.1079 & & \\
\hline AEMBL 3934360 & 528525 & 8.1427 & & \\
\hline IEMBL & 528525 & 202 & & \\
\hline EMBL & 528525 & & & \\
\hline AEMBL & 528525 & 6.1135 & & \\
\hline IEMBL: & 528525 & 024 & & \\
\hline EMBL: & 528525 & 2007 & 24 & \\
\hline EMBL & 528 & 586 & & \\
\hline IEMBL & 25 & 969 & & \\
\hline IEMBL & 528525 & 132 & & \\
\hline IEMBL & 25 & 697 & & \\
\hline IEMBL & $5<8$ & & & \\
\hline EMB & 528 & 76 & & \\
\hline 27 & 528 & & & \\
\hline 529 & & & & \\
\hline IEMBL3 & & & & KN \\
\hline IEMBL & 528 & 99 & & \\
\hline 30 & 2 & 8 & & \\
\hline 60 & 5285 & 05 & & $\operatorname{liv}$ \\
\hline IEMBL & 5201 & 979 & & \\
\hline IEMBL39e & 2 & & & ST \\
\hline IEMBL & 285 & & & RI \\
\hline 4 & 285 & & & $\mathrm{R} \Lambda$ \\
\hline & 25 & 86 & 54 & \\
\hline IEMBL: & 528525 & 69 & & RN \\
\hline AEMBL3935456 & 528525 & 229 & & $S$ \\
\hline IEMBL & 285 & 06 & & $\mathrm{RN}$ \\
\hline 5 & & & & \\
\hline & & & & RN \\
\hline IEMBL3692630 & 528525 & 177 & & \\
\hline EMBL & 528525 & 969 & & \\
\hline AEMBL: & 5285 & 089 & & \\
\hline 23 & & & & RI \\
\hline HEMBL & 528525 & 5.7212 & & $\mathrm{RA}$ \\
\hline IEMBL3692600 & 28525 & 6.2924 & & $\mathrm{R}$ \\
\hline 93 & 5285 & & & $\mathrm{R}$ \\
\hline HEMBL; & " & 938 & & \\
\hline CHEMBL 3692605 & 528525 & & 6.3268 & \\
\hline CHEMBL3692585 & 152852 & 6.0044 & 6.2361 & K \\
\hline
\end{tabular}

Page 22397 


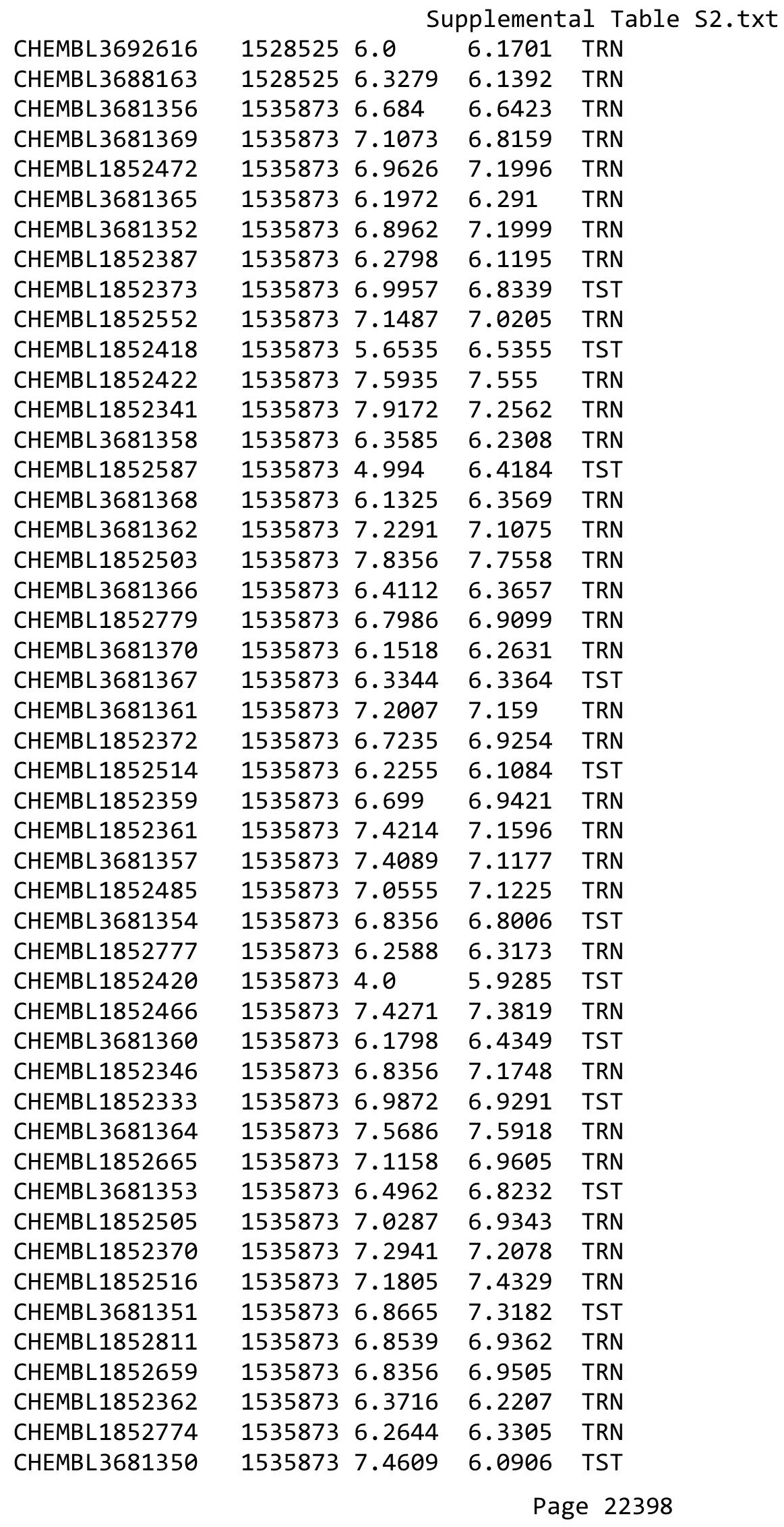


Supplemental Table S2.txt

\begin{tabular}{|c|c|c|c|c|}
\hline CHEMBL1852358 & 1535873 & 6.2725 & 6.3461 & TRN \\
\hline CHEMBL1852517 & 1535873 & 6.6904 & 6.751 & TRN \\
\hline CHEMBL3681359 & 1535873 & 6.266 & 6.1498 & TRN \\
\hline CHEMBL1852345 & 1535873 & 6.8861 & 6.7634 & TRN \\
\hline CHEMBL1852666 & 1535873 & 7.0255 & 7.155 & TRN \\
\hline CHEMBL3681371 & 1535873 & 6.4935 & 6.7485 & TST \\
\hline CHEMBL 3681355 & 1535873 & 6.0888 & 6.1096 & TST \\
\hline CHEMBL1852339 & 1535873 & 7.2076 & 7.2469 & TRN \\
\hline CHEMBL 3681363 & 1535873 & 7.3372 & 7.3516 & TRN \\
\hline CHEMBL1852617 & 1535873 & 6.5376 & 6.7519 & TRN \\
\hline CHEMBL 3694714 & 1528489 & 8.4318 & 8.2049 & TRN \\
\hline CHEMBL 3694660 & 1528489 & 8.0155 & 8.2499 & TRN \\
\hline CHEMBL 3690504 & 1528489 & 8.5406 & 8.2896 & TST \\
\hline CHEMBL 3690428 & 1528489 & 8.1113 & 8.3466 & TRN \\
\hline CHEMBL 3690493 & 1528489 & 8.4498 & 8.2052 & TRN \\
\hline CHEMBL 3690460 & 1528489 & 8.8861 & 8.3976 & TRN \\
\hline CHEMBL 3690574 & 1528489 & 8.9208 & 8.8995 & TST \\
\hline CHEMBL 3690447 & 1528489 & 7.1029 & 7.5454 & TRN \\
\hline CHEMBL 3690384 & 1528489 & 7.6073 & 7.9032 & TRN \\
\hline CHEMBL3690477 & 1528489 & 6.5302 & 7.1823 & TRN \\
\hline CHEMBL3690473 & 1528489 & 8.1972 & 7.8869 & TRN \\
\hline CHEMBL 3690492 & 1528489 & 9.3152 & 9.2728 & TRN \\
\hline CHEMBL 3694656 & 1528489 & 9.0 & 8.9454 & TRN \\
\hline CHEMBL 3926486 & 1528489 & 8.8386 & 8.6907 & TST \\
\hline CHEMBL 3690453 & 1528489 & 7.9066 & 8.1248 & TRN \\
\hline CHEMBL 3694682 & 1528489 & 8.0706 & 8.03399 & э9999999999 \\
\hline CHEMBL 3690554 & 1528489 & 9.0044 & 8.779 & TRN \\
\hline CHEMBL 3690513 & 1528489 & 8.6055 & 8.2845 & TST \\
\hline CHEMBL 3694712 & 1528489 & 7.9586 & 7.7539 & TRN \\
\hline CHEMBL3694723 & 1528489 & 8.025 & 7.5423 & TRN \\
\hline CHEMBL3690556 & 1528489 & 8.1135 & 8.1065 & TST \\
\hline CHEMBL 3690557 & 1528489 & 8.9586 & 8.8269 & TRN \\
\hline CHEMBL 3694647 & 1528489 & 8.2924 & 7.9732 & TRN \\
\hline CHEMBL 3690515 & 1528489 & 7.5317 & 7.7364 & TRN \\
\hline CHEMBL 3690502 & 1528489 & 7.0376 & 7.803 & TRN \\
\hline CHEMBL3639935 & 1528489 & 9.2676 & 9.0054 & TRN \\
\hline CHEMBL 3690379 & 1528489 & 7.9586 & 8.0643 & TRN \\
\hline CHEMBL 3690452 & 1528489 & 8.0809 & 8.1961 & TRN \\
\hline CHEMBL 3690553 & 1528489 & 7.6198 & 7.8014 & TRN \\
\hline CHEMBL 3690490 & 1528489 & 8.7799 & 8.8796 & TRN \\
\hline CHEMBL 3690559 & 1528489 & 7.9586 & 8.1028 & TRN \\
\hline CHEMBL 3690590 & 1528489 & 9.0809 & 8.7108 & TRN \\
\hline CHEMBL3690393 & 1528489 & 7.6615 & 8.1686 & TST \\
\hline CHEMBL 3690395 & 1528489 & 8.0334 & 8.2533 & TRN \\
\hline CHEMBL 3690391 & 1528489 & 7.7721 & 7.8284 & TRN \\
\hline CHEMBL 3690451 & 1528489 & 8.104 & 8.378 & TRN \\
\hline CHEMBL3690536 & 1528489 & 8.0223 & 8.2075 & TRN \\
\hline CHEMBL 3690394 & 1528489 & 7.7773 & 7.7573 & TST \\
\hline
\end{tabular}

Page 22399 
Supplemental Table S2.txt

\begin{tabular}{|c|c|c|c|c|c|}
\hline CHEMBL 3690594 & 1528489 & 8.3665 & 8.8578 & TRN & \\
\hline CHEMBL 3690512 & 1528489 & 7.2984 & 7.8351 & TRN & \\
\hline CHEMBL 3690457 & 1528489 & 8.3233 & 8.4723 & TRN & \\
\hline CHEMBL 3690570 & 1528489 & 7.8861 & 7.9208 & TRN & \\
\hline CHEMBL 3690499 & 1528489 & 7.767 & 7.8746 & TRN & \\
\hline CHEMBL 3690535 & 1528489 & 8.3768 & 8.2337 & TRN & \\
\hline CHEMBL 3690442 & 1528489 & 8.426 & 8.5016 & TRN & \\
\hline CHEMBL 3690482 & 1528489 & 7.8861 & 7.853 & TRN & \\
\hline CHEMBL3690591 & 1528489 & 6.3872 & 7.2602 & TRN & \\
\hline CHEMBL3694649 & 1528489 & 7.9208 & 7.584 & TRN & \\
\hline CHEMBL 3690406 & 1528489 & 7.5686 & 7.9066 & TRN & \\
\hline CHEMBL 3686066 & 1528489 & 9.2596 & 9.0583 & TRN & \\
\hline CHEMBL 3690411 & 1528489 & 9.266 & 8.9909 & TST & \\
\hline CHEMBL3694713 & 1528489 & 8.2518 & 7.8319 & TRN & \\
\hline CHEMBL 3690486 & 1528489 & 9.1029 & 8.9008 & TRN & \\
\hline CHEMBL3690396 & 1528489 & 7.0969 & 7.2809 & TRN & \\
\hline CHEMBL 3690507 & 1528489 & 8.6421 & 8.4996 & TST & \\
\hline CHEMBL 3690466 & 1528489 & 8.4318 & 8.3553 & TRN & \\
\hline CHEMBL 3690544 & 1528489 & 7.7932 & 7.8303 & TRN & \\
\hline CHEMBL3690377 & 1528489 & 8.9586 & 9.1576 & TRN & \\
\hline CHEMBL 3690484 & 1528489 & 9.1524 & 8.9323 & TRN & \\
\hline CHEMBL 3694688 & 1528489 & 6.5686 & 7.5054 & TRN & \\
\hline CHEMBL 3694646 & 1528489 & 6.0 & 8.9366 & TRN & \\
\hline CHEMBL 3690376 & 1528489 & 7.983 & 8.0257 & TRN & \\
\hline CHEMBL 3690489 & 1528489 & 8.6383 & 8.764 & TRN & \\
\hline CHEMBL 3690465 & 1528489 & 8.317 & 7.9094 & TRN & \\
\hline CHEMBL 3690398 & 1528489 & 8.5157 & 8.4727 & TRN & \\
\hline CHEMBL 3694692 & 1528489 & 8.2596 & 7.8117 & TRN & \\
\hline CHEMBL 3690441 & 1528489 & 8.5544 & 8.4353 & TRN & \\
\hline CHEMBL 3690423 & 1528489 & 7.8386 & 7.8986 & TRN & \\
\hline CHEMBL 3694650 & 1528489 & 8.7825 & 8.7371 & TRN & \\
\hline CHEMBL 3986468 & 1528489 & 8.5528 & 8.7221 & TST & \\
\hline CHEMBL 3694706 & 1528489 & 8.3768 & 7.9741 & TRN & \\
\hline CHEMBL3690481 & 1528489 & 7.0329 & 7.4532 & TST & \\
\hline CHEMBL 3690470 & 1528489 & 8.5719 & 8.6575 & TRN & \\
\hline CHEMBL 3690528 & 1528489 & 7.6383 & 7.8688 & TRN & \\
\hline CHEMBL 3690413 & 1528489 & 8.6478 & 8.5855 & TRN & \\
\hline CHEMBL 3690576 & 1528489 & 8.4685 & 8.1491 & TRN & \\
\hline CHEMBL3925109 & 1528489 & 9.1308 & 8.8754 & TST & \\
\hline CHEMBL3690399 & 1528489 & 7.426 & 7.6605 & TRN & \\
\hline CHEMBL 3690588 & 1528489 & 7.3188 & 7.935 & TRN & \\
\hline CHEMBL 3694662 & 1528489 & 7.9208 & 7.9181 & TRN & \\
\hline CHEMBL3694702 & 1528489 & 8.28399 & 99999999 & 99 & 7.8948 \\
\hline CHEMBL 3690495 & 1528489 & 8.3768 & 8.3348 & TRN & \\
\hline CHEMBL 3694657 & 1528489 & 7.5406 & 7.9144 & TRN & \\
\hline CHEMBL 3694711 & 1528489 & 7.7212 & 7.5882 & TRN & \\
\hline CHEMBL 3694708 & 1528489 & 9.1918 & 8.9573 & TRN & \\
\hline CHEMBL3686064 & 1528489 & 8.9393 & 8.5847 & TST & \\
\hline
\end{tabular}

Page 22400 
Supplemental Table S2.txt

\begin{tabular}{|c|c|c|c|c|c|}
\hline CHEMBL3690569 & 1528489 & 8.5229 & 8.1368 & TRN & \\
\hline CHEMBL3690498 & 1528489 & 7.7471 & 7.8613 & TRN & \\
\hline CHEMBL3690586 & 1528489 & 7.8861 & 8.1255 & TRN & \\
\hline CHEMBL 3690555 & 1528489 & 8.8861 & 8.5853 & TRN & \\
\hline CHEMBL3690520 & 1528489 & 8.1568 & 7.7883 & TRN & \\
\hline CHEMBL 3694686 & 1528489 & 7.4089 & 7.7454 & TRN & \\
\hline CHEMBL3957271 & 1528489 & 9.2351 & 9.1429 & TST & \\
\hline CHEMBL 3694707 & 1528489 & 8.3768 & 8.4589 & TST & \\
\hline CHEMBL 3690592 & 1528489 & 7.7799 & 7.7774 & TRN & \\
\hline CHEMBL3694651 & 1528489 & 8.5528 & 8.2587 & TRN & \\
\hline CHEMBL 3690487 & 1528489 & 7.1824 & 7.6684 & TRN & \\
\hline CHEMBL3694670 & 1528489 & 8.4202 & 8.145 & TRN & \\
\hline CHEMBL3690540 & 1528489 & 7.9586 & 8.0475 & TST & \\
\hline CHEMBL 3690472 & 1528489 & 7.7328 & 7.8732 & TRN & \\
\hline CHEMBL3690579 & 1528489 & 7.3565 & 7.7607 & TRN & \\
\hline CHEMBL 3690444 & 1528489 & 9.3497 & 9.0568 & TRN & \\
\hline CHEMBL3694699 & 1528489 & 8.0862 & 7.891 & TRN & \\
\hline CHEMBL 3690422 & 1528489 & 7.6289 & 7.7051 & TRN & \\
\hline CHEMBL3690563 & 1528489 & 7.7696 & 8.0645 & TRN & \\
\hline CHEMBL3694720 & 1528489 & 8.2676 & 7.9805 & TRN & \\
\hline CHEMBL3690525 & 1528489 & 8.4056 & 7.8738 & TRN & \\
\hline CHEMBL3690439 & 1528489 & 9.1367 & 9.1064 & TRN & \\
\hline CHEMBL 3690545 & 1528489 & 8.1871 & 8.0049 & TRN & \\
\hline CHEMBL3925050 & 1528489 & 9.2125 & 9.1004 & TST & \\
\hline CHEMBL3690496 & 1528489 & 8.1046 & 7.9524 & TRN & \\
\hline CHEMBL3690531 & 1528489 & 7.0362 & 6.5403 & TRN & \\
\hline CHEMBL 3690581 & 1528489 & 7.1249 & 8.3889 & TRN & \\
\hline CHEMBL 3690425 & 1528489 & 8.4318 & 8.7619 & TRN & \\
\hline CHEMBL 3690403 & 1528489 & 8.8861 & 8.6502 & TST & \\
\hline CHEMBL 3690488 & 1528489 & 8.5719 & 8.7007 & TRN & \\
\hline CHEMBL 3690518 & 1528489 & 7.4572 & \multicolumn{2}{|c|}{7.6770000000000005} & TRN \\
\hline CHEMBL 3690440 & 1528489 & 7.0 & 7.4219 & TST & \\
\hline CHEMBL 3690449 & 1528489 & 8.202 & 8.1578 & TRN & \\
\hline CHEMBL 3690459 & 1528489 & 8.757 & 8.6678 & TRN & \\
\hline CHEMBL 3690511 & 1528489 & 6.6778 & 7.3131 & TST & \\
\hline CHEMBL3690427 & 1528489 & 8.3054 & 8.1962 & TRN & \\
\hline CHEMBL3690572 & 1528489 & 7.9586 & 8.644 & TRN & \\
\hline CHEMBL 3694718 & 1528489 & 7.3188 & 7.8718 & TRN & \\
\hline CHEMBL 3690424 & 1528489 & 8.3851 & 8.3937 & TRN & \\
\hline CHEMBL 3690550 & 1528489 & 7.7447 & 7.7568 & TRN & \\
\hline CHEMBL 3931244 & 1528489 & 8.3979 & 8.3882 & TST & \\
\hline CHEMBL3686063 & 1528489 & 9.2441 & 9.1315 & TST & \\
\hline CHEMBL3690430 & 1528489 & 9.2449 & 9.1075 & TRN & \\
\hline CHEMBL3690407 & 1528489 & 7.9872 & 7.9733 & TST & \\
\hline CHEMBL3953693 & 1528489 & 8.9031 & 8.6539 & TST & \\
\hline CHEMBL 3690501 & 1528489 & 9.2518 & 8.9792 & TRN & \\
\hline CHEMBL 3686065 & 1528489 & 9.2636 & 9.0773 & TST & \\
\hline CHEMBL 3694663 & 1528489 & 8.041 & 7.7107 & TRN & \\
\hline
\end{tabular}

Page 22401 
Supplemental Table S2.txt

\begin{tabular}{|c|c|c|c|c|}
\hline . & & & & \\
\hline & 528489 & 7.8539 & & \\
\hline & & & & \\
\hline AEMBL & & & & $\mathrm{MI}$ \\
\hline AEMBL3694685 & 528489 & & & \\
\hline HEMBL3694669 & 528489 & 8.585 & .9521 & \\
\hline & 89 & & 519 & \\
\hline |FMRI & & & & \\
\hline AEMBL3690390 & 528489 & & 1203 & \\
\hline HEMBL369 & 528489 & 02 & 19 & \\
\hline AEMBL369 & 528489 & & 64 & \\
\hline IEMBL & 39 & & 083 & \\
\hline IEMBL: & & & & \\
\hline HEMBL36 & 528489 & & 7.7677 & \\
\hline HEMBL 368 & 528489 & & 75 & \\
\hline AEMBL 369 & 39 & 7. & 55 & \\
\hline AEMBL3 & 39 & & & \\
\hline HEMBL3 & & & & \\
\hline AEMBL36 & 528489 & & 8.5659 & \\
\hline IEMBL36 & 39 & & & IST \\
\hline HEMBL= & 39 & & 501 & I NIV \\
\hline HEMBL: & 9 & & 7.7173 & RN \\
\hline HEMBL; & & & 339 & \\
\hline AFMRI 360 & & & & \\
\hline HEMBL 369 & & & & I RIV \\
\hline HEMBL & 9 & & 302 & RN \\
\hline HEMBL & 9 & & & Niv \\
\hline HFMBI : & 39 & & 7055 & \\
\hline HEMBL369 & & & & 「RN \\
\hline HEMBL369 & & & & $\Gamma \mathrm{RN}$ \\
\hline HEMBL 369 & 39 & & 5821 & RIV \\
\hline HEMBL & 9 & & 66 & ST \\
\hline 8 & 39 & & 06 & RN \\
\hline HEMBL369 & & & & is \\
\hline HEMBL 369 & 528489 & & 8.0296 & TRN \\
\hline HEMBL 369 & 89 & & 2953 & ST \\
\hline HᄃMP = & 9 & & 94 & $\Gamma \mathrm{RN}$ \\
\hline & & & 8.5492 & RN \\
\hline HEMBL369 & 528489 & & .9234 & TRN \\
\hline AEMBL3 & -2 & & 8.0869 & TRN \\
\hline HEMBL3 & 5284 & & .2208 & \\
\hline HEMBL369 & 39 & & 7.6598 & ГST \\
\hline HEMBL369 & 528489 & & 8.8047 & ГST \\
\hline AEMBL 369 & 528489 & 8. & 8.1987 & TR \\
\hline 1 & & & 7.8185 & $\mathrm{~N}$ \\
\hline HEMBL369 & & & 7.5682 & \\
\hline CHEMBL 369 & 5284 & 8.0362 & 7.846 & \\
\hline CHEMBL3690378 & 1528489 & 8.3507 & 8.137 & ГRN \\
\hline
\end{tabular}

Page 22402 
Supplemental Table S2.txt

\begin{tabular}{|c|c|c|c|c|}
\hline CHEMBL3690560 & 1528489 & 8.4559 & 8.3088 & TRN \\
\hline CHEMBL3967812 & 1528489 & 7.4672 & 8.236 & TST \\
\hline CHEMBL3690500 & 1528489 & 8.6198 & 8.6117 & TST \\
\hline CHEMBL3694654 & 1528489 & 8.699 & 8.167 & TRN \\
\hline CHEMBL3694683 & 1528489 & 7.7959 & 7.5921 & TRN \\
\hline CHEMBL3694691 & 1528489 & 7.7696 & 8.0699 & TRN \\
\hline CHEMBL3690409 & 1528489 & 9.2197 & 9.2219 & TST \\
\hline CHEMBL 3694684 & 1528489 & 8.28399 & 999999999 & 8.2025 \\
\hline CHEMBL3690414 & 1528489 & 8.7595 & 8.8593 & TRN \\
\hline CHEMBL3690538 & 1528489 & 6.0 & 7.6738 & TST \\
\hline CHEMBL3690508 & 1528489 & 8.3372 & 8.3518 & TST \\
\hline CHEMBL3690494 & 1528489 & 7.2218 & 7.8819 & TRN \\
\hline CHEMBL3694681 & 1528489 & 9.0044 & 8.763 & TRN \\
\hline CHEMBL3958378 & 1528489 & 9.1938 & 9.0151 & TST \\
\hline CHEMBL3690475 & 1528489 & 9.2147 & 9.1789 & TRN \\
\hline CHEMBL3690583 & 1528489 & 9.0555 & 7.9802 & TRN \\
\hline CHEMBL3690400 & 1528489 & 9.0862 & 9.1854 & TRN \\
\hline CHEMBL3694695 & 1528489 & 7.2596 & 7.7139 & TRN \\
\hline CHEMBL3690392 & 1528489 & 7.8861 & 8.1995 & TST \\
\hline CHEMBL3694721 & 1528489 & 8.0915 & 8.0177 & TRN \\
\hline CHEMBL3690373 & 1528489 & 8.9586 & 8.9029 & TST \\
\hline CHEMBL3690478 & 1528489 & 6.6478 & 7.6366 & TST \\
\hline CHEMBL 3690587 & 1528489 & 7.6383 & 7.923999 & \\
\hline CHEMBL3690461 & 1528489 & 8.5935 & 8.5005 & TRN \\
\hline CHEMBL3690503 & 1528489 & 8.4622 & 8.3196 & TRN \\
\hline CHEMBL3690485 & 1528489 & 8.9208 & 8.8949 & TST \\
\hline CHEMBL3690524 & 1528489 & 8.426 & 8.5423 & TRN \\
\hline CHEMBL3690532 & 1528489 & 7.585 & 7.4314 & TRN \\
\hline CHEMBL 3690529 & 1528489 & 7.3565 & 7.0196 & TRN \\
\hline CHEMBL3690582 & 1528489 & 8.6021 & 8.1249 & TRN \\
\hline CHEMBL3690419 & 1528489 & 8.3372 & 8.0707 & TRN \\
\hline CHEMBL3690445 & 1528489 & 9.1457 & 9.1457 & TRN \\
\hline CHEMBL3690522 & 1528489 & 7.2233 & 7.603 & TRN \\
\hline CHEMBL3690542 & 1528489 & 6.284 & 6.1186 & TRN \\
\hline CHEMBL3694724 & 1528489 & 7.4522 & 7.6775 & TST \\
\hline CHEMBL3694666 & 1528489 & 7.585 & 7.6936 & TRN \\
\hline CHEMBL3690416 & 1528489 & 9.1707 & 9.1533 & TST \\
\hline CHEMBL3690567 & 1528489 & 9.0 & 8.7695 & TRN \\
\hline CHEMBL3690446 & 1528489 & 8.8125 & 8.6098 & TRN \\
\hline CHEMBL3690497 & 1528489 & 7.4622 & 7.7792 & TST \\
\hline CHEMBL3690387 & 1528489 & 9.1524 & 9.0754 & TRN \\
\hline CHEMBL3690505 & 1528489 & 7.3565 & 7.8002 & TRN \\
\hline CHEMBL3690381 & 1528489 & 7.6162 & 7.7035 & TRN \\
\hline CHEMBL3694709 & 1528489 & 8.7447 & 8.6221 & TRN \\
\hline CHEMBL3690421 & 1528489 & 7.8239 & 7.8704 & TRN \\
\hline CHEMBL3690575 & 1528489 & 8.5528 & 8.5065 & TRN \\
\hline CHEMBL3694679 & 1528489 & 8.3372 & 7.8088 & TRN \\
\hline CHEMBL3690479 & 1528489 & 5.9393 & 7.436 & TST \\
\hline
\end{tabular}


Supplemental Table S2.txt

\begin{tabular}{|c|c|c|c|c|c|c|}
\hline CHEMBL3694687 & 1528489 & 7.1079 & 7.6361 & TRN & & \\
\hline CHEMBL3690476 & 1528489 & 7.8697 & 7.825 & TRN & & \\
\hline CHEMBL3690462 & 1528489 & 8.3778 & 8.2847 & TRN & & \\
\hline CHEMBL3690412 & 1528489 & 7.6576 & 6.1748 & TRN & & \\
\hline CHEMBL 3690404 & 1528489 & 9.2132 & 9.2248 & TST & & \\
\hline CHEMBL3690469 & 1528489 & \multicolumn{3}{|c|}{8.857000000000001} & 8.7063 & TRN \\
\hline CHEMBL3690401 & 1528489 & 9.0931 & 9.1258 & TST & & \\
\hline CHEMBL3694696 & 1528489 & 8.8861 & 7.9074 & TRN & & \\
\hline CHEMBL3690458 & 1528489 & 9.2757 & 9.154 & TRN & & \\
\hline CHEMBL3686062 & 1528489 & 8.9208 & 8.6183 & TRN & & \\
\hline CHEMBL3690516 & 1528489 & 7.7212 & 7.6218 & TRN & & \\
\hline CHEMBL3690549 & 1528489 & 8.0325 & 8.1286 & TRN & & \\
\hline CHEMBL3694645 & 1528489 & 9.0177 & 8.7651 & TST & & \\
\hline CHEMBL 3690568 & 1528489 & 8.6778 & 8.464 & TST & & \\
\hline CHEMBL 3690450 & 1528489 & 7.8861 & 8.1942 & TRN & & \\
\hline CHEMBL3690382 & 1528489 & 8.4023 & 8.5176 & TRN & & \\
\hline CHEMBL3690547 & 1528489 & 7.6198 & 7.9489 & TRN & & \\
\hline CHEMBL3690519 & 1528489 & 8.2396 & 7.9715 & TRN & & \\
\hline CHEMBL3694677 & 1528489 & 6.8239 & 7.1572 & TRN & & \\
\hline CHEMBL 3690474 & 1528489 & 9.0506 & 8.735 & TRN & & \\
\hline CHEMBL3690561 & 1528489 & 7.8861 & 7.7999 & TST & & \\
\hline CHEMBL3694689 & 1528489 & 7.6778 & 7.7544 & TRN & & \\
\hline CHEMBL3694658 & 1528489 & 5.3872 & 6.2828 & TRN & & \\
\hline CHEMBL3920309 & 1528489 & 9.2147 & 9.1135 & TST & & \\
\hline CHEMBL3690577 & 1528489 & 7.7696 & 8.2914 & TRN & & \\
\hline CHEMBL 3690464 & 1528489 & 8.5528 & 8.3658 & TRN & & \\
\hline CHEMBL3690383 & 1528489 & 7.8761 & 8.1072 & TRN & & \\
\hline CHEMBL3690443 & 1528489 & 9.0506 & 9.0246 & TRN & & \\
\hline CHEMBL3694701 & 1528489 & 7.4685 & 7.1719 & TRN & & \\
\hline CHEMBL3694693 & 1528489 & 6.9586 & 7.5453 & TRN & & \\
\hline CHEMBL3694716 & 1528489 & 8.0862 & 7.6344 & TRN & & \\
\hline CHEMBL3690585 & 1528489 & 7.9586 & 8.2002 & TRN & & \\
\hline CHEMBL3686060 & 1528489 & 9.0809 & 8.6537 & TST & & \\
\hline CHEMBL 3690534 & 1528489 & 7.2557 & 7.6091 & TRN & & \\
\hline CHEMBL3690389 & 1528489 & 8.0969 & 8.2184 & TST & & \\
\hline CHEMBL3694659 & 1528489 & 8.0625 & 7.901 & TRN & & \\
\hline CHEMBL3690589 & 1528489 & 8.2147 & 8.5701 & TRN & & \\
\hline CHEMBL3694698 & 1528489 & 8.6576 & 8.1721 & TRN & & \\
\hline CHEMBL3694676 & 1528489 & 6.699 & 7.0837 & TST & & \\
\hline CHEMBL3690526 & 1528489 & 7.8761 & 7.848 & TRN & & \\
\hline CHEMBL 3694648 & 1528489 & 7.4437 & 6.9001 & TRN & & \\
\hline CHEMBL3690386 & 1528489 & 8.2013 & 8.4132 & TRN & & \\
\hline CHEMBL3690410 & 1528489 & 7.4157 & 7.5658 & TRN & & \\
\hline CHEMBL3690593 & 1528489 & 8.1308 & 8.02700 & 0000000001 & & TRN \\
\hline CHEMBL3690510 & 1528489 & 7.3665 & 8.1252 & TST & & \\
\hline CHEMBL 3694690 & 1528489 & 7.0315 & 7.5678 & TST & & \\
\hline CHEMBL3694675 & 1528489 & 5.0 & 6.50299 & 9999999999 & & I \\
\hline CHEMBL3690491 & 1528489 & 9.1487 & 9.0491 & TST & & \\
\hline
\end{tabular}


Supplemental Table S2.txt

\begin{tabular}{|c|c|c|c|c|c|c|}
\hline CHEMBL3690438 & 1528489 & 9.2716 & 9.2742 & TST & & \\
\hline CHEMBL3690415 & 1528489 & 8.6108 & 8.7332 & TST & & \\
\hline CHEMBL 3690483 & 1528489 & 7.0645 & 7.8254 & TST & & \\
\hline CHEMBL 3694694 & 1528489 & 8.3565 & 7.9487 & TST & & \\
\hline CHEMBL3690385 & 1528489 & 8.1331 & 8.2527 & TST & & \\
\hline CHEMBL 3690448 & 1528489 & 8.3107 & 8.418 & TST & & \\
\hline CHEMBL 3690521 & 1528489 & 7.82100 & 000000000 & & 7.7285 & TST \\
\hline CHEMBL 3690417 & 1528489 & 8.9031 & 8.963 & TST & & \\
\hline CHEMBL1076195 & 619939 & 5.8652 & 6.015 & TRN & & \\
\hline CHEMBL1088028 & 619939 & 6.3335 & 6.7068 & TRN & & \\
\hline CHEMBL1087513 & 619939 & 4.0 & 3.7602 & TRN & & \\
\hline CHEMBL1076480 & 619939 & 6.5287 & 6.0015 & TRN & & \\
\hline CHEMBL1075628 & 619939 & 7.2007 & 7.0524 & TST & & \\
\hline CHEMBL1076196 & 619939 & 5.67899 & 999999999 & 99 & 6.039 & TRN \\
\hline CHEMBL1076471 & 619939 & 6.4976 & 6.2573 & TRN & & \\
\hline CHEMBL1087638 & 619939 & 6.2291 & 5.9151 & TRN & & \\
\hline CHEMBL1076468 & 619939 & 5.763 & 5.9351 & TRN & & \\
\hline CHEMBL1076472 & 619939 & 6.0264 & 6.2165 & TRN & & \\
\hline CHEMBL1079422 & 619939 & 6.2396 & 6.1203 & TRN & & \\
\hline CHEMBL1076474 & 619939 & 5.7665 & 5.8046 & TRN & & \\
\hline CHEMBL1076194 & 619939 & 5.8248 & 6.1098 & TRN & & \\
\hline CHEMBL1080299 & 619939 & 6.5528 & 6.5176 & TRN & & \\
\hline CHEMBL1076203 & 619939 & 6.8761 & 6.8871 & TRN & & \\
\hline CHEMBL1076202 & 619939 & 6.6108 & 6.421 & TRN & & \\
\hline CHEMBL1079424 & 619939 & 6.8697 & 6.0033 & TRN & & \\
\hline CHEMBL1079945 & 619939 & 7.4437 & 7.1823 & TRN & & \\
\hline CHEMBL1076433 & 619939 & 7.5229 & 7.4112 & TST & & \\
\hline CHEMBL1076432 & 619939 & 7.1805 & 7.5257 & TRN & & \\
\hline CHEMBL1079946 & 619939 & 5.1962 & 5.4533 & TRN & & \\
\hline CHEMBL1087524 & 619939 & 7.2596 & 7.3658 & TRN & & \\
\hline CHEMBL1081436 & 619939 & 4.9756 & 5.3453 & TRN & & \\
\hline CHEMBL1087127 & 619939 & 7.7696 & 7.5677 & TRN & & \\
\hline CHEMBL1076473 & 619939 & 6.2154 & 5.7696 & TRN & & \\
\hline CHEMBL1076478 & 619939 & 6.2351 & 6.5809 & TRN & & \\
\hline CHEMBL1076199 & 619939 & 6.6144 & 6.8016 & TRN & & \\
\hline CHEMBL1076469 & 619939 & 5.8649 & 6.0979 & TRN & & \\
\hline CHEMBL1076437 & 619939 & 8.301 & 7.9702 & TRN & & \\
\hline CHEMBL1080294 & 619939 & 5.0872 & 4.9867 & TRN & & \\
\hline CHEMBL1088153 & 619939 & 6.3458 & 6.5846 & TST & & \\
\hline CHEMBL1076477 & 619939 & 6.2182 & 6.3128 & TRN & & \\
\hline CHEMBL1076197 & 619939 & 5.9535 & 6.0831 & TRN & & \\
\hline CHEMBL1086860 & 619939 & 7.3188 & 6.8918 & TST & & \\
\hline CHEMBL1076475 & 619939 & 6.2604 & 6.1034 & TRN & & \\
\hline CHEMBL1076465 & 619939 & 5.8321 & 5.995 & TRN & & \\
\hline CHEMBL1076201 & 619939 & 6.9318 & 6.9725 & TRN & & \\
\hline CHEMBL1076193 & 619939 & 7.699 & 7.6782 & TRN & & \\
\hline CHEMBL1088429 & 619939 & 5.0424 & 4.9843 & TRN & & \\
\hline CHEMBL1076200 & 619939 & 6.7328 & 6.722 & TRN & & \\
\hline
\end{tabular}




\begin{tabular}{|c|c|c|c|c|c|}
\hline \multicolumn{6}{|c|}{ Supplemental Table s2.txt } \\
\hline CHEMBL1080930 & 619939 & 4.0 & 4.3307 & TRN & \\
\hline CHEMBL1076466 & 619939 & 6.2226 & 5.9233 & TRN & \\
\hline CHEMBL1081090 & 619939 & 6.2874 & 6.5117 & TRN & \\
\hline CHEMBL1087128 & 619939 & 7.284 & 7.2959 & TRN & \\
\hline CHEMBL1076198 & 619939 & 6.6038 & 6.5165 & TST & \\
\hline CHEMBL1087649 & 619939 & 6.585 & 6.3379 & TST & \\
\hline CHEMBL1076533 & 619939 & 5.0547 & 5.8388 & TST & \\
\hline CHEMBL1087636 & 619939 & 5.7575 & 6.0615 & TST & \\
\hline CHEMBL1076476 & 619939 & 4.0 & 4.1627 & TST & \\
\hline CHEMBL1088027 & 619939 & 7.0362 & 6.9457 & TST & \\
\hline CHEMBL1076470 & 619939 & 6.0531 & 6.5729 & TST & \\
\hline CHEMBL1076436 & 619939 & 7.3665 & 7.8863 & TST & \\
\hline CHEMBL1086731 & 619939 & 8.3979 & 7.8067 & TST & \\
\hline CHEMBL1087002 & 619939 & 5.9935 & 6.6171 & TST & \\
\hline CHEMBL3919840 & 1638428 & 5.1656 & 5.0701 & TRN & \\
\hline CHEMBL 3944404 & 1638428 & 6.5376 & 5.8376 & TRN & \\
\hline CHEMBL 3970847 & 1638428 & 6.4089 & 6.2754 & TRN & \\
\hline CHEMBL3927717 & 1638428 & 6.6778 & 6.4071 & TRN & \\
\hline CHEMBL 3971964 & 1638428 & 5.9666 & 6.0351 & TRN & \\
\hline CHEMBL3969514 & 1638428 & 6.8861 & 6.856 & TRN & \\
\hline CHEMBL3906782 & 1638428 & 6.6198 & 6.6708 & TRN & \\
\hline CHEMBL 3980096 & 1638428 & 7.0 & 6.8242 & TRN & \\
\hline CHEMBL3949179 & 1638428 & 6.699 & 5.4441 & TST & \\
\hline CHEMBL 3975606 & 1638428 & 5.5867 & 5.7641 & TRN & \\
\hline CHEMBL3950682 & 1638428 & 7.301 & 6.9242 & TRN & \\
\hline CHEMBL3940637 & 1638428 & 5.2076 & 5.4077 & TRN & \\
\hline CHEMBL3921679 & 1638428 & 5.2798 & 5.3377 & TRN & \\
\hline CHEMBL3965457 & 1638428 & 6.7696 & 6.8096 & TRN & \\
\hline CHEMBL 3942986 & 1638428 & 6.284 & 5.9925 & TRN & \\
\hline CHEMBL3929908 & 1638428 & 6.4815 & 6.255 & TRN & \\
\hline CHEMBL3909282 & 1638428 & 6.1487 & 6.0351 & TRN & \\
\hline CHEMBL 3974454 & 1638428 & 5.6055 & 5.9665 & TST & \\
\hline CHEMBL3958381 & 1638428 & 6.3872 & 6.4526 & TRN & \\
\hline CHEMBL3918514 & 1638428 & 5.9508 & 6.0351 & TRN & \\
\hline CHEMBL 3982744 & 1638428 & 5.1858 & 5.8073 & TRN & \\
\hline CHEMBL 3949081 & 1638428 & 6.1938 & 6.2821 & TRN & \\
\hline CHEMBL3903381 & 1638428 & 6.4437 & 6.0351 & TRN & \\
\hline CHEMBL3965347 & 1638428 & 5.3851 & 5.9914 & TRN & \\
\hline CHEMBL3952104 & 1638428 & 6.5086 & 6.5073 & TRN & \\
\hline CHEMBL3917162 & 1638428 & 5.3625 & 5.9665 & TST & \\
\hline CHEMBL3899025 & 1638428 & 6.1308 & 5.9884 & TRN & \\
\hline CHEMBL3915051 & 1638428 & 6.5528 & 5.9032 & TST & \\
\hline CHEMBL3937934 & 1638428 & 6.6021 & 6.4514 & TRN & \\
\hline CHEMBL3952366 & 1638428 & 6.6198 & 6.36799 & 9999999999 & TRN \\
\hline CHEMBL 3920502 & 1638428 & 6.7447 & 6.7676 & TRN & \\
\hline CHEMBL3980208 & 1638428 & 6.3279 & 6.4133 & TRN & \\
\hline CHEMBL3937994 & 1638428 & 6.3279 & 6.1794 & TST & \\
\hline CHEMBL3930209 & 1638428 & 5.8297 & 6.0351 & TRN & \\
\hline
\end{tabular}


Supplemental Table S2.txt

\begin{tabular}{|c|c|c|c|c|}
\hline CHEMBL3907845 & 1638428 & 6.4685 & 6.0258 & TST \\
\hline CHEMBL3960826 & 1638428 & 6.6021 & 5.9665 & TST \\
\hline CHEMBL3932312 & 1638428 & 6.5086 & 5.8376 & TRN \\
\hline CHEMBL3976722 & 1638428 & 6.7959 & 6.5099 & TST \\
\hline CHEMBL3950581 & 1638428 & 6.2757 & 6.2821 & TRN \\
\hline CHEMBL3958999 & 1638428 & 6.0915 & 5.6838 & TST \\
\hline CHEMBL3966877 & 1638428 & 5.6757 & 6.0351 & TRN \\
\hline CHEMBL 3966760 & 1638428 & 6.4437 & 6.0676 & TRN \\
\hline CHEMBL3915524 & 1638428 & 6.5686 & 6.16700 & 0000000001 \\
\hline CHEMBL3971577 & 1638428 & 5.1537 & 5.1799 & TRN \\
\hline CHEMBL 3896345 & 1638428 & 5.3706 & 5.1862 & TRN \\
\hline CHEMBL3940948 & 1638428 & 6.1135 & 6.2821 & TRN \\
\hline CHEMBL3899092 & 1638428 & 6.5376 & 5.4077 & TRN \\
\hline CHEMBL3908160 & 1638428 & 5.4486 & 5.8376 & TRN \\
\hline CHEMBL3965493 & 1638428 & 6.2757 & 5.2446 & TST \\
\hline CHEMBL3909190 & 1638428 & 5.8794 & 5.6476 & TRN \\
\hline CHEMBL3969991 & 1638428 & 5.9666 & 6.0351 & TRN \\
\hline CHEMBL3981290 & 1638428 & 6.0132 & 5.934 & TRN \\
\hline CHEMBL3929419 & 1638428 & 7.3979 & 6.7377 & TST \\
\hline CHEMBL3912278 & 1638428 & 6.1427 & 6.1149 & TRN \\
\hline CHEMBL3939160 & 1638428 & 6.1192 & 6.2863 & TRN \\
\hline CHEMBL3937166 & 1638428 & 6.3565 & 5.8376 & TRN \\
\hline CHEMBL3986750 & 1638428 & 5.6421 & 5.8376 & TRN \\
\hline CHEMBL3945156 & 1638428 & 5.9136 & 6.0351 & TRN \\
\hline CHEMBL 3896444 & 1638428 & 5.567 & 5.9884 & TRN \\
\hline CHEMBL3910631 & 1638428 & 6.3565 & 6.3074 & TST \\
\hline CHEMBL 3929337 & 1638428 & 6.4949 & 6.2821 & TRN \\
\hline CHEMBL3910006 & 1638428 & 5.8125 & 5.9884 & TRN \\
\hline CHEMBL3936598 & 1638428 & 5.5528 & 5.8376 & TRN \\
\hline CHEMBL3899635 & 1638428 & 7.5229 & 5.5441 & TST \\
\hline CHEMBL3935011 & 1638428 & 5.7986 & 5.8376 & TRN \\
\hline CHEMBL 3920162 & 1638428 & 6.1367 & 6.0351 & TRN \\
\hline CHEMBL3953245 & 1638428 & 6.2757 & 6.2821 & TRN \\
\hline CHEMBL3958151 & 1638428 & 6.4318 & 5.8376 & TRN \\
\hline CHEMBL 3908454 & 1638428 & 6.5229 & 6.6039 & TRN \\
\hline CHEMBL3913399 & 1638428 & 6.4318 & 6.5631 & TST \\
\hline CHEMBL 3902697 & 1638428 & 6.5528 & 6.4417 & TST \\
\hline CHEMBL3976800 & 1638428 & 6.7212 & 6.6224 & TRN \\
\hline CHEMBL3924693 & 1638428 & 6.2518 & 5.8376 & TRN \\
\hline CHEMBL 3940008 & 1638428 & 6.1135 & 6.2821 & TRN \\
\hline CHEMBL3926198 & 1638428 & 6.4089 & 6.5073 & TRN \\
\hline CHEMBL3916916 & 1638428 & 6.7447 & 6.6425 & TRN \\
\hline CHEMBL3937894 & 1638428 & 4.3476 & 4.5699 & TRN \\
\hline CHEMBL3907128 & 1638428 & 6.6021 & 6.1279 & TRN \\
\hline CHEMBL3923344 & 1638428 & 6.3872 & 6.2692 & TRN \\
\hline CHEMBL3902164 & 1638428 & 6.4202 & 6.2821 & TRN \\
\hline CHEMBL3931437 & 1638428 & 6.3768 & 5.8376 & TRN \\
\hline CHEMBL3958577 & 1638428 & 6.1024 & 6.0351 & TRN \\
\hline
\end{tabular}


Supplemental Table S2.txt

\begin{tabular}{|c|c|c|c|c|}
\hline TL & & & & \\
\hline & & 5.7235 & 5.065 & \\
\hline 13 & & & & \\
\hline AEMBL & & & & \\
\hline AEMBL3967876 & 538428 & 35 & 1805 & \\
\hline HEMBL3901896 & 638428 & 6.6021 & 8376 & \\
\hline 913 & 28 & 6.8861 & $\partial 856$ & \\
\hline IFMPI & & & & \\
\hline AEMBL3894172 & 638428 & 599 & 2915 & \\
\hline HEMBL3891294 & 638428 & 383 & 2821 & \\
\hline HEMBL3904040 & 638428 & 59 & 5284 & \\
\hline IEMBL38 & 28 & 76 & 933 & \\
\hline IEMBL3 & & & & \\
\hline AEMBL397 & 638428 & 778 & 5982 & \\
\hline AEMBL39 & 28 & 93 & 06 & \\
\hline AEMBL39 & 28 & 7 & 1786 & \\
\hline AEMBL39 & 28 & & 376 & \\
\hline HEMBL38 & & & & \\
\hline AEMBL3980062 & 638428 & 5.52 & & \\
\hline AEMBL3S & & & & \\
\hline HEIMBLSל & 28 & & 86 & \\
\hline AEMBL: & 8 & & & \\
\hline AEMBL & & & & \\
\hline 56 & & & & \\
\hline AEMBL3S & & & & \\
\hline HEMBL3 & 8 & 6 & 37 & SI \\
\hline HEMBL & & & 76 & RN \\
\hline$H F M B I=$ & 28 & & 332 & \\
\hline AEMBL3 & & & & IS \\
\hline HEMBL 393 & & & 676 & $\Gamma \mathrm{RN}$ \\
\hline HEMBL3 & 28 & & 364 & RIN \\
\hline HEMBL & & 8 & 79 & niv \\
\hline 59 & 28 & 7 & 63 & ST \\
\hline HEMBL 393 & & & 601 & IRN \\
\hline HEMBL3919004 & 638428 & 6 . & 539 & TRN \\
\hline HEMBL3 & & & 821 & RN \\
\hline HCMP - & & & 58 & ונס \\
\hline HEMBL3 & & & 722 & RN \\
\hline HEMBL3978085 & 638428 & & 5066 & $\Gamma \mathrm{RN}$ \\
\hline IEMBL39 & 538428 & 6 . & 2821 & TRN \\
\hline HEMBL3S & 638 & 6 & 425 & \\
\hline HEMBL 39 & & & 821 & RIV \\
\hline HEMBL39 & 1638428 & & 5601 & TRN \\
\hline AEMBL3933091 & 638428 & 6.4949 & 106 & ST \\
\hline $\mathrm{MRI}=$ & 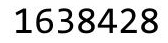 & & 351 & RN \\
\hline HEMBL3S & גרי & 212 & 7012 & \\
\hline CHEMBL 389 & 638428 & .699 & .6206 & \\
\hline CHEMBL3907531 & 1638428 & 6.0706 & 6.1047 & ГST \\
\hline
\end{tabular}

Page 22408 
Supplemental Table S2.txt

\begin{tabular}{|c|c|c|c|c|}
\hline - & & 6.6576 & & \\
\hline & 638428 & 6.6576 & 6039 & \\
\hline & & & & \\
\hline HEMBL393 & & 3089 & & Ne \\
\hline AEMBL3894045 & 538428 & 3098 & & \\
\hline HEMBL3966852 & 638428 & 6.1249 & 0676 & \\
\hline & 28 & 468 & 3376 & \\
\hline IFMBI 392 & & & & \\
\hline HEMBL 391 & 638428 & 949 & 6224 & \\
\hline HEMBL3980958 & 638428 & 5.0862 & 3218 & \\
\hline HEMBL3902569 & 638428 & 5.7375 & 8376 & \\
\hline IEMBL396 & 28 & 302 & 3376 & \\
\hline AEMBL39 & & & & \\
\hline HEMBL 393 & 638428 & 3861 & 9661 & \\
\hline HEMBL393 & 28 & & 3376 & \\
\hline AEMBL396 & 28 & 595 & 84 & \\
\hline HEMBL39 & 99 & 96 & & \\
\hline HEMBL39 & & & & \\
\hline HEMBL392 & $\partial 9$ & 208 & 3612 & \\
\hline HEMBL390 & $\partial 9$ & & & \\
\hline AEMBL & 99 & 8 & 52 & RIN \\
\hline AEMBL3S & 19 & & 23 & 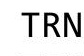 \\
\hline HEMBL3S & & & 51 & \\
\hline HFMRI 389 & $\partial 9$ & 8 & 058 & \\
\hline HEMBL 389 & & & & IST \\
\hline HEMBL39 & 64 & & 679 & RN \\
\hline HEMBL & & & & RN \\
\hline$H F M B I=$ & & $\partial 6$ & & \\
\hline HEMBL39 & & 8 & 964 & IRIV \\
\hline HEMBL395 & & 7. & & IRIV \\
\hline HEMBL 389 & 64 & 8 & 446 & RN \\
\hline HEMBL & 9 & & 557 & RN \\
\hline HEMBL & & 58 & & $\Gamma R N$ \\
\hline HEMBL39390€ & & 5 & 831 & IRN \\
\hline HEMBL3927081 & 6404 & & 779 & TRN \\
\hline HEMBL39 & 39 & & 898 & RN \\
\hline HFMRI 3 & 9 & & 73 & $\Gamma \mathrm{RN}$ \\
\hline HEMBL 395 & & 6 . & 058 & RN \\
\hline HEMBL3961212 & 640 & 6.9208 & 2704 & TST \\
\hline AEMBL396 & & & 3026 & TRN \\
\hline HEMBL 398 & 9 & 586 & 378 & \\
\hline HEMBL397 & 9 & & & TRN \\
\hline HEMBL3922 & 1640409 & 7.8861 & 9073 & $\Gamma \mathrm{RN}$ \\
\hline AEMBL 3902 & 640409 & 6.2366 & 9668 & TRN \\
\hline MBL3 & & & 446 & $\mathrm{~N}$ \\
\hline HEMBL392 & 64 & 815 & 7716 & \\
\hline CHEMBL3918496 & 1640 & 6.8239 & .8312 & \\
\hline CHEMBL3981035 & 1640409 & 8.0 & 8.1863 & \\
\hline
\end{tabular}

Page 22409 
Supplemental Table S2.txt

\begin{tabular}{|c|c|c|c|c|}
\hline-1 & & & & \\
\hline HEMBL3926221 & 640409 & 7.7447 & 7669 & \\
\hline & & 8.301 & & \\
\hline 803 & 109 & 8.0 & 19 & \\
\hline AEMBL3924733 & 640409 & 8.0969 & 9471 & \\
\hline HEMBL3920829 & 640409 & 8.5229 & 5428 & \\
\hline HEMBL3951932 & 640409 & 7.7959 & 6909 & \\
\hline IEMBL3S & 09 & 3468 & 5198 & \\
\hline IEMBL 3944300 & 09 & 3539 & 0341 & \\
\hline HEMBL3949819 & 640409 & 8.3979 & 2194 & \\
\hline HEMBL3959706 & 09 & 7.5086 & 3612 & \\
\hline AEMBL39 & 640409 & 80 & 8338 & \\
\hline AEMBL3 & & 979 & & \\
\hline HEMBL & & 586 & 9316 & \\
\hline AEMBL3981192 & 09 & 441 & 7436 & \\
\hline AEMBL394 & $\partial 9$ & 458 & 79 & \\
\hline AEMBL3 & $\partial 9$ & 208 & 3504 & \\
\hline HEMBL & & 458 & 369 & \\
\hline 069 & & 539 & 964 & RN \\
\hline HEMBL3985471 & 09 & 212 & & 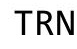 \\
\hline AEMBL3908581 & 39 & 8.3979 & 8.4965 & KIV \\
\hline HEMBL3S & 39 & 938 & 926 & SI \\
\hline HEMBL & & 383 & 19 & $\mathrm{RN}$ \\
\hline 824 & & 5086 & 095 & KIV \\
\hline AEMBL38 & $\partial 9$ & 1024 & 17 & $\mathrm{RN}$ \\
\hline HEMBL3934738 & 99 & 8. & 724 & 「RN \\
\hline HEMBL39 & 29 & 7.6021 & 36 & RN \\
\hline HEMBL3 & & 92 & 373 & ST \\
\hline 370 & & 7 & 194 & RN \\
\hline 726 & 39 & 29 & & RIN \\
\hline AEMBL3959161 & 99 & 86 & 578 & RN \\
\hline HEMBL3948141 & 29 & 739 & 557 & 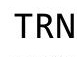 \\
\hline HEMBL3 & & & & RN \\
\hline 731 & & & 303 & RN \\
\hline AEMBL3923931 & 39 & 7. & 599 & RN \\
\hline EMBL39 & 09 & 96 & 517 & \\
\hline HEMBL 39 & 39 & 959 & 349 & וכ \\
\hline & & & & ST \\
\hline HEMBL3970685 & $\partial 9$ & & 503 & $\mathrm{RN}$ \\
\hline HEMBL3975774 & 09 & 49 & 724 & R \\
\hline AEMBL3934535 & 39 & 367 & 311 & \\
\hline HEMBL3949131 & & & 5114 & I \\
\hline HEMBL3 & & & 2113 & $\mathrm{RN}$ \\
\hline HEMBL3953811 & 09 & 229 & .7342 & TST \\
\hline AEMBL3916883 & 09 & 18 & 2482 & ST \\
\hline & & & 309 & \\
\hline 987 & & .5229 & 8.2194 & ST \\
\hline 396244 & 64040 & & 338 & \\
\hline
\end{tabular}

Page 22410 
Supplemental Table S2.txt

\begin{tabular}{|c|c|c|c|c|c|}
\hline CHEMBL3958866 & 1640409 & 7.6021 & 7.682 & TST & \\
\hline CHEMBL3958376 & 1640409 & 7.5376 & 7.5422 & TST & \\
\hline CHEMBL3945208 & 1640409 & 5.0 & 6.7407 & TST & \\
\hline CHEMBL3985396 & 1640409 & 7.3979 & 7.3466 & TST & \\
\hline CHEMBL3925204 & 1640409 & 5.9208 & 7.8576 & TST & \\
\hline CHEMBL3897359 & 1640409 & 6.6778 & 6.8877 & TST & \\
\hline CHEMBL3916647 & 1640409 & 8.1549 & 7.669 & TST & \\
\hline CHEMBL3954637 & 1640409 & 8.1549 & 8.4965 & TST & \\
\hline CHEMBL3983806 & 1640409 & 6.0044 & 7.9238 & TST & \\
\hline CHEMBL 2037246 & 820998 & 3.1135 & 3.1579 & TRN & \\
\hline CHEMBL 2037247 & 820998 & 3.0 & 3.0896 & TRN & \\
\hline CHEMBL 2037240 & 820998 & 3.7212 & 3.5837 & TRN & \\
\hline CHEMBL 2037245 & 820998 & 4.0706 & 3.6652 & TRN & \\
\hline CHEMBL 2037248 & 820998 & 3.0088 & 3.0063 & TRN & \\
\hline CHEMBL 2037242 & 820998 & 3.0 & 3.1971 & TRN & \\
\hline CHEMBL 2037252 & 820998 & 3.0 & 3.0728 & TRN & \\
\hline CHEMBL 2037243 & 820998 & 3.4815 & 3.36800 & 00000000003 & TRN \\
\hline CHEMBL 2037179 & 820998 & 3.8861 & 3.9627 & TRN & \\
\hline CHEMBL2035004 & 820998 & 3.0 & 3.1398 & TRN & \\
\hline CHEMBL 2037266 & 820998 & 4.5686 & 2.5675 & TST & \\
\hline CHEMBL 2037160 & 820998 & 3.0 & 3.342 & TRN & \\
\hline CHEMBL2037162 & 820998 & 3.0 & 3.2896 & TRN & \\
\hline CHEMBL1093220 & 820998 & 3.0 & 3.0615 & TRN & \\
\hline CHEMBL 2037170 & 820998 & 3.0 & 2.96199 & э99999999997 & TRN \\
\hline CHEMBL 2037267 & 820998 & 4.7959 & 2.7486 & TST & \\
\hline CHEMBL 2037265 & 820998 & 5.2218 & 2.6888 & TST & \\
\hline CHEMBL 2037244 & 820998 & 4.8729 & 3.948 & TRN & \\
\hline CHEMBL418899 & 820998 & 5.7212 & 3.64 & TST & \\
\hline CHEMBL 2037260 & 820998 & 3.7696 & 3.8211 & TRN & \\
\hline CHEMBL 2037258 & 820998 & 3.0 & 3.2349 & TRN & \\
\hline CHEMBL 2037255 & 820998 & 3.0 & 2.8788 & TRN & \\
\hline CHEMBL 2037171 & 820998 & 3.0 & 3.0401 & TRN & \\
\hline CHEMBL 2037159 & 820998 & 3.0 & 2.98 & TRN & \\
\hline CHEMBL 2037250 & 820998 & 3.0 & 2.9933 & TRN & \\
\hline CHEMBL 2037173 & 820998 & 3.0 & 3.1876 & TRN & \\
\hline CHEMBL 2037261 & 820998 & 3.0 & 3.1519 & TRN & \\
\hline CHEMBL 2037257 & 820998 & 5.0458 & 3.3378 & TST & \\
\hline CHEMBL 2037163 & 820998 & 3.0 & 2.9918 & TRN & \\
\hline CHEMBL 2037172 & 820998 & 3.0 & 2.8676 & TRN & \\
\hline CHEMBL1092985 & 820998 & 3.301 & 3.406 & TRN & \\
\hline CHEMBL 2037176 & 820998 & 3.4948 & 3.3433 & TRN & \\
\hline CHEMBL 2037254 & 820998 & 3.0 & 2.9108 & TST & \\
\hline CHEMBL 2037161 & 820998 & 3.3979 & 3.648 & TRN & \\
\hline CHEMBL 2037169 & 820998 & 3.0 & 3.3233 & TRN & \\
\hline CHEMBL 2037165 & 820998 & 3.0 & 2.9534 & TRN & \\
\hline CHEMBL 2037263 & 820998 & 3.0 & 3.1222 & TRN & \\
\hline CHEMBL 2037241 & 820998 & 4.8794 & 3.2804 & TST & \\
\hline CHEMBL 2037177 & 820998 & 3.0 & 3.3146 & TRN & \\
\hline
\end{tabular}




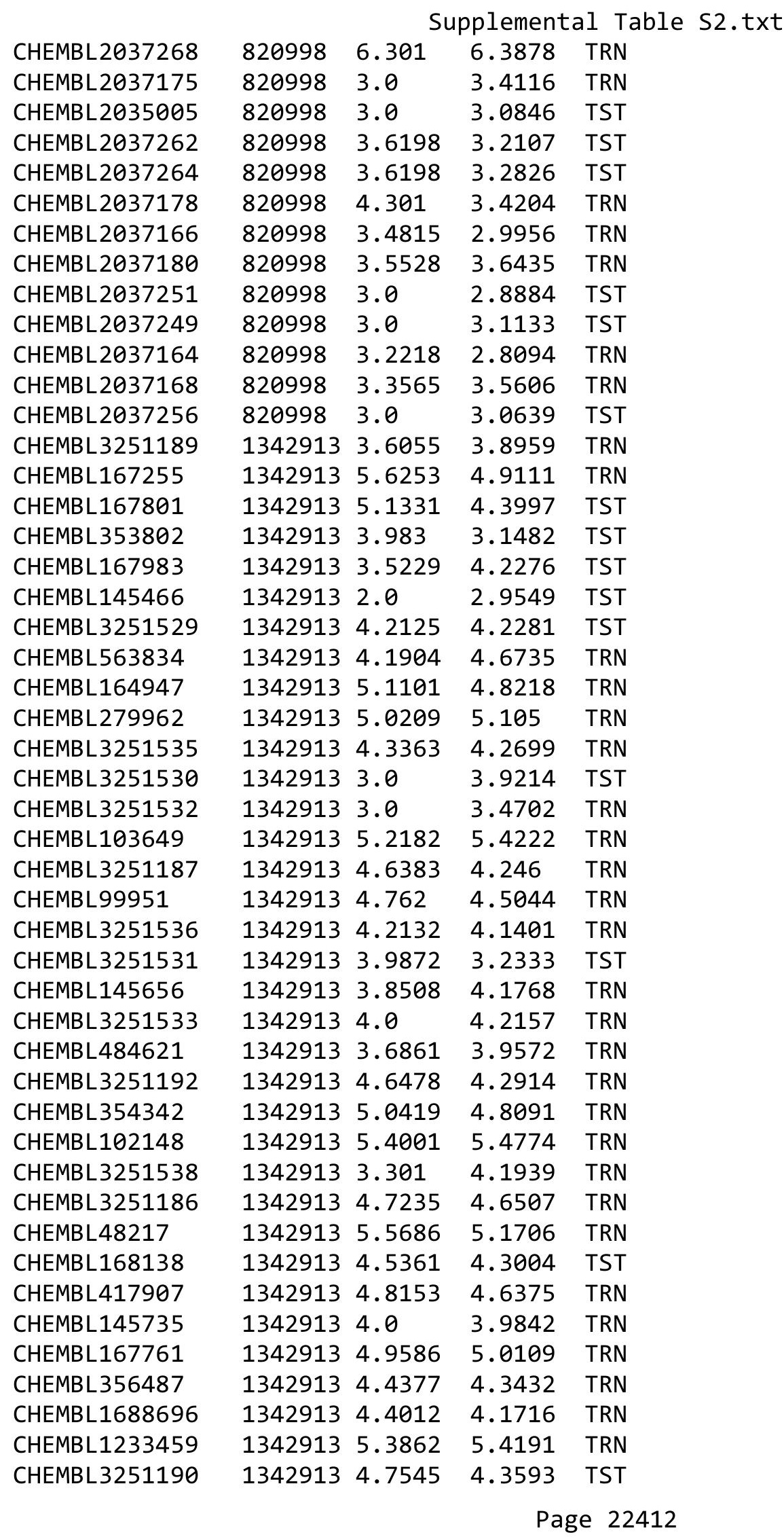


Supplemental Table S2.txt

\begin{tabular}{|c|c|c|c|}
\hline CHEMBL165312 & 1342913 & 4.9115 & 5.2875 \\
\hline CHEMBL 3244501 & 1342913 & 4.3979 & 4.5233 \\
\hline CHEMBL101261 & 1342913 & 4.9469 & 5.388 \\
\hline CHEMBL168077 & 1342913 & 4.4202 & 4.6458 \\
\hline CHEMBL297403 & L342913 & 4.5031 & 4.5359 \\
\hline CHEMBL3251194 & 1342913 & 4.9101 & 4.6435 \\
\hline CHEMBL164489 & 1342913 & 5.3325 & 4.73 \\
\hline CHEMBL352553 & 1342913 & 5.0615 & 4.7868 \\
\hline CHEMBL 3251193 & 1342913 & 3.5229 & 3.4472 \\
\hline CHEMBL52393 & 1342913 & 4.7423 & 4.5359 \\
\hline CHEMBL3251185 & 1342913 & 4.5901 & 4.5343 \\
\hline CHEMBL166236 & 1342913 & 4.1445 & 4.6631 \\
\hline CHEMBL101672 & 1342913 & 5.2874 & 5.4222 \\
\hline CHEMBL 3251188 & 1342913 & 4.3161 & 4.8658 \\
\hline CHEMBL 3251534 & 1342913 & 5.3307 & 5.4909 \\
\hline CHEMBL167762 & 1342913 & 5.295 & 5.0452 \\
\hline CHEMBL167845 & 1342913 & 4.9747 & 4.9731 \\
\hline CHEMBL 3251528 & 1342913 & 4.4486 & 4.2266 \\
\hline CHEMBL388768 & 1342913 & 5.0501 & 4.1889 \\
\hline CHEMBL500330 & 1342913 & 4.2503 & 4.6535 \\
\hline CHEMBL352718 & 1342913 & 4.2765 & 4.3476 \\
\hline CHEMBL352923 & 1342913 & 6.1367 & 4.822 \\
\hline CHEMBL 3251537 & 1342913 & 4.4056 & 4.1551 \\
\hline CHEMBL297809 & 1342913 & 4.8697 & 4.5359 \\
\hline CHEMBL275938 & 688618 & 4.8 & 4.8714 \\
\hline CHEMBL605003 & 688618 & 5.8 & 5.5764 \\
\hline CHEMBL 1 & 688618 & 5.4 & 5.2472 \\
\hline CHEMBL269733 & 688618 & 4.5 & 4.6097 \\
\hline CHEMBL1480516 & 688618 & 4.6 & 4.3294 \\
\hline CHEMBL328710 & 688618 & 4.6 & 5.1303 \\
\hline CHEMBL1257003 & 688 & 5 . & 5.0943 \\
\hline CHEMBL & $68 \varepsilon$ & 4.9 & 5.0723 \\
\hline CHEMBL56393 & 688 & 4.8 & 5.1344 \\
\hline CHEMBL293749 & 688618 & 5.0 & 4.8701 \\
\hline CHEMBL1256186 & 688618 & 5.3 & 4.7921 \\
\hline CHEMBL78150 & 688618 & 5.4 & 5.1194 \\
\hline CHEMBL $\angle$ & $68 \varepsilon$ & 4.6 & 5.3281 \\
\hline CHEMBL51085 & 688618 & 4.9 & 4.6183 \\
\hline CHEMBL1256814 & 688618 & 4.5 & 4.3224 \\
\hline CHEMBL1356280 & 688618 & 4.6 & 4.525 \\
\hline CHEMBL51697 & 688618 & 4.4 & 4.6546 \\
\hline CHEMBL397209 & 688618 & 5.2 & 4.5338 \\
\hline CHEMBL 72365 & 688618 & 5.1 & 4.9832 \\
\hline CHEMBL546257 & 688618 & 4.6 & 4.7464 \\
\hline CHEMBL1329033 & 688618 & 4.9 & 4.6698 \\
\hline CHEMBL1597692 & 688618 & 4.7 & 4.5865 \\
\hline CHEMBL1725279 & 688618 & 4.6 & 4.9939 \\
\hline CHEMBL310798 & 688618 & 5.6 & 5.3408 \\
\hline
\end{tabular}

Page 22413 
Supplemental Table S2.txt

\begin{tabular}{|c|c|c|c|c|}
\hline CHEMBL1515691 & 688618 & 7.699 & 7.4502 & TRN \\
\hline CHEMBL1257041 & 688618 & 4.6 & 4.2759 & TRN \\
\hline CHEMBL1318512 & 688618 & 5.4 & 5.9496 & TST \\
\hline CHEMBL542493 & 688618 & 4.4 & 4.317 & TRN \\
\hline CHEMBL225230 & 688618 & 4.6 & 4.4125 & TRN \\
\hline CHEMBL1284 & 688618 & 4.6 & 4.5492 & TRN \\
\hline CHEMBL188 & 688618 & 5.2 & 5.2032 & TRN \\
\hline CHEMBL28 & 688618 & 4.6 & 4.4577 & TRN \\
\hline CHEMBL1255653 & 688618 & 4.4 & 4.8426 & TST \\
\hline CHEMBL47940 & 688618 & 5.0 & 5.1315 & TRN \\
\hline CHEMBL1256623 & 688618 & 4.8 & 4.9256 & TRN \\
\hline CHEMBL109037 & 688618 & 4.8 & 4.7558 & TRN \\
\hline CHEMBL 338790 & 688618 & 6.1 & 5.7717 & TRN \\
\hline CHEMBL1972346 & 688618 & 4.5 & 4.6313 & TRN \\
\hline CHEMBL1257080 & 688618 & 5.3 & 5.0501 & TST \\
\hline CHEMBL 2374259 & 688618 & 4.6 & 4.8347 & TRN \\
\hline CHEMBL1593930 & 688618 & 4.6 & 4.6628 & TRN \\
\hline CHEMBL30432 & 688618 & 5.4 & 5.2722 & TRN \\
\hline CHEMBL1200938 & 688618 & 4.5 & 4.6258 & TRN \\
\hline CHEMBL56731 & 688618 & 5.0 & 5.1979 & TRN \\
\hline CHEMBL1376723 & 688618 & 4.9 & 5.3435 & TST \\
\hline CHEMBL164 & 688618 & 5.0 & 5.2279 & TST \\
\hline CHEMBL102714 & 688618 & 5.5 & 5.3012 & TST \\
\hline CHEMBL77030 & 688618 & 4.9 & 5.1581 & TST \\
\hline CHEMBL288096 & 688618 & 4.5 & 4.4498 & TST \\
\hline CHEMBL105739 & 688618 & 5.6 & 5.1168 & TST \\
\hline CHEMBL80155 & 688618 & 4.9 & 5.2941 & TST \\
\hline CHEMBL268868 & 688618 & 4.6 & 4.617 & TST \\
\hline CHEMBL299390 & 725152 & 2.83 & 3.2599 & TRN \\
\hline CHEMBL53321 & 725152 & 2.7 & 3.3566 & TRN \\
\hline CHEMBL300907 & 725152 & 2.46 & 3.2095 & TRN \\
\hline CHEMBL1673435 & 725152 & 3.96 & 5.2005 & TST \\
\hline CHEMBL440464 & 725152 & 3.61 & 5.9073 & TRN \\
\hline CHEMBL1333019 & 725152 & 4.76 & 5.78 & TRN \\
\hline CHEMBL300927 & 725152 & 4.13 & 6.3141 & TRN \\
\hline CHEMBL52348 & 725152 & 1.59 & 3.208 & TRN \\
\hline CHEMBL53871 & 725152 & 4.8 & 3.3774 & TRN \\
\hline CHEMBL1673437 & 725152 & 4.89 & 6.2929 & TST \\
\hline CHEMBL1673438 & 725152 & 4.25 & 4.9564 & TST \\
\hline CHEMBL1125 & 725152 & 4.9 & 5.6839 & TRN \\
\hline CHEMBL 845 & 725152 & 4.5 & 5.0486 & TRN \\
\hline CHEMBL1673440 & 725152 & 5.5 & 6.151 & TRN \\
\hline CHEMBL52794 & 725152 & 2.34 & 3.2581 & TRN \\
\hline CHEMBL422330 & 725152 & 5.09 & 4.1177 & TRN \\
\hline CHEMBL1421212 & 725152 & 5.84 & 5.6692 & TST \\
\hline CHEMBL55835 & 725152 & 6.24 & 6.2717 & TRN \\
\hline CHEMBL53661 & 725152 & 6.86 & 6.3542 & TRN \\
\hline CHEMBL415944 & 725152 & 6.88 & 6.2144 & TRN \\
\hline
\end{tabular}




\begin{tabular}{|c|c|c|c|c|c|}
\hline \multicolumn{6}{|c|}{ Supplemental Table S2.txt } \\
\hline CHEMBL52832 & 725152 & 6.34 & 6.2917 & TRN & \\
\hline CHEMBL273235 & 725152 & 6.69 & 4.3947 & TRN & \\
\hline CHEMBL1673442 & 725152 & 6.97 & 6.2741 & TRN & \\
\hline CHEMBL1673443 & 725152 & 6.3 & 5.4905 & TRN & \\
\hline CHEMBL 7463 & 725152 & 6.0 & 5.9855 & TRN & \\
\hline CHEMBL443476 & 725152 & 7.06 & 6.5138 & TRN & \\
\hline CHEMBL52999 & 725152 & 7.44 & 6.1858 & TRN & \\
\hline CHEMBL556312 & 725152 & 7.63 & 6.9734 & TRN & \\
\hline CHEMBL1671884 & 725152 & 7.1 & 6.4836 & TRN & \\
\hline CHEMBL1671885 & 725152 & 7.0 & 5.0833 & TRN & \\
\hline CHEMBL298978 & 725152 & 8.21 & 6.6783 & TRN & \\
\hline CHEMBL12780 & 725152 & 8.16 & 6.9017 & TRN & \\
\hline CHEMBL124754 & 725152 & 4.92 & 5.8096 & TRN & \\
\hline CHEMBL1328576 & 725152 & 4.14 & 5.8284 & TST & \\
\hline CHEMBL1512198 & 725152 & 4.44 & 6.0737 & TST & \\
\hline CHEMBL498572 & 725152 & 4.92 & 5.70700 & 0000000001 & TRN \\
\hline CHEMBL53089 & 725152 & 5.0 & 3.3789 & TRN & \\
\hline CHEMBL299590 & 725152 & 5.0 & 3.9622 & TRN & \\
\hline CHEMBL 301992 & 725152 & 5.0 & 3.4115 & TRN & \\
\hline CHEMBL1671889 & 725152 & 5.22 & 5.9646 & TST & \\
\hline CHEMBL1671890 & 725152 & 5.18 & 6.3366 & TRN & \\
\hline CHEMBL42557 & 725152 & 5.31 & 6.1414 & TRN & \\
\hline CHEMBL1671892 & 725152 & 6.3 & 5.7558 & TRN & \\
\hline CHEMBL1671893 & 725152 & 6.6 & 6.9316 & TRN & \\
\hline CHEMBL94664 & 725152 & 6.7 & 6.8178 & TRN & \\
\hline CHEMBL1671894 & 725152 & 7.75 & 6.1499 & TRN & \\
\hline CHEMBL536480 & 725152 & 7.92 & 6.7774 & TRN & \\
\hline CHEMBL12186 & 725152 & 8.0 & 5.3678 & TRN & \\
\hline CHEMBL1671895 & 725152 & 2.4 & 5.5646 & TRN & \\
\hline CHEMBL1671896 & 725152 & 3.27 & 4.104 & TRN & \\
\hline CHEMBL300117 & 725152 & 5.56 & 5.0141 & TRN & \\
\hline CHEMBL1671897 & 725152 & 5.0 & 5.6168 & TRN & \\
\hline CHEMBL1380684 & 725152 & 5.62 & 5.5406 & TRN & \\
\hline CHEMBL441472 & 725152 & 6.0 & 5.6583 & TRN & \\
\hline CHEMBL1671898 & 725152 & 5.59 & 5.4605 & TRN & \\
\hline CHEMBL1671899 & 725152 & 3.66 & 5.5005 & TRN & \\
\hline CHEMBL1671900 & 725152 & 4.3 & 4.689 & TRN & \\
\hline CHEMBL 297453 & 725152 & 5.22 & 5.1084 & TRN & \\
\hline CHEMBL1232472 & 725152 & 3.38 & 4.9555 & TRN & \\
\hline CHEMBL290242 & 725152 & 3.5 & 5.8627 & TST & \\
\hline CHEMBL1671901 & 725152 & 5.0 & 5.5806 & TRN & \\
\hline CHEMBL1671902 & 725152 & 4.3 & 5.143 & TST & \\
\hline CHEMBL1326015 & 725152 & 3.99 & 6.0603 & TST & \\
\hline CHEMBL182977 & 725152 & 8.66 & 4.8365 & TST & \\
\hline CHEMBL1494 & 725152 & 5.64 & 4.6628 & TRN & \\
\hline CHEMBL53866 & 725152 & 2.66 & 3.3622 & TRN & \\
\hline CHEMBL1671904 & 725152 & 4.48 & 5.8128 & TST & \\
\hline CHEMBL1671905 & 725152 & 4.0 & 5.8555 & TRN & \\
\hline
\end{tabular}




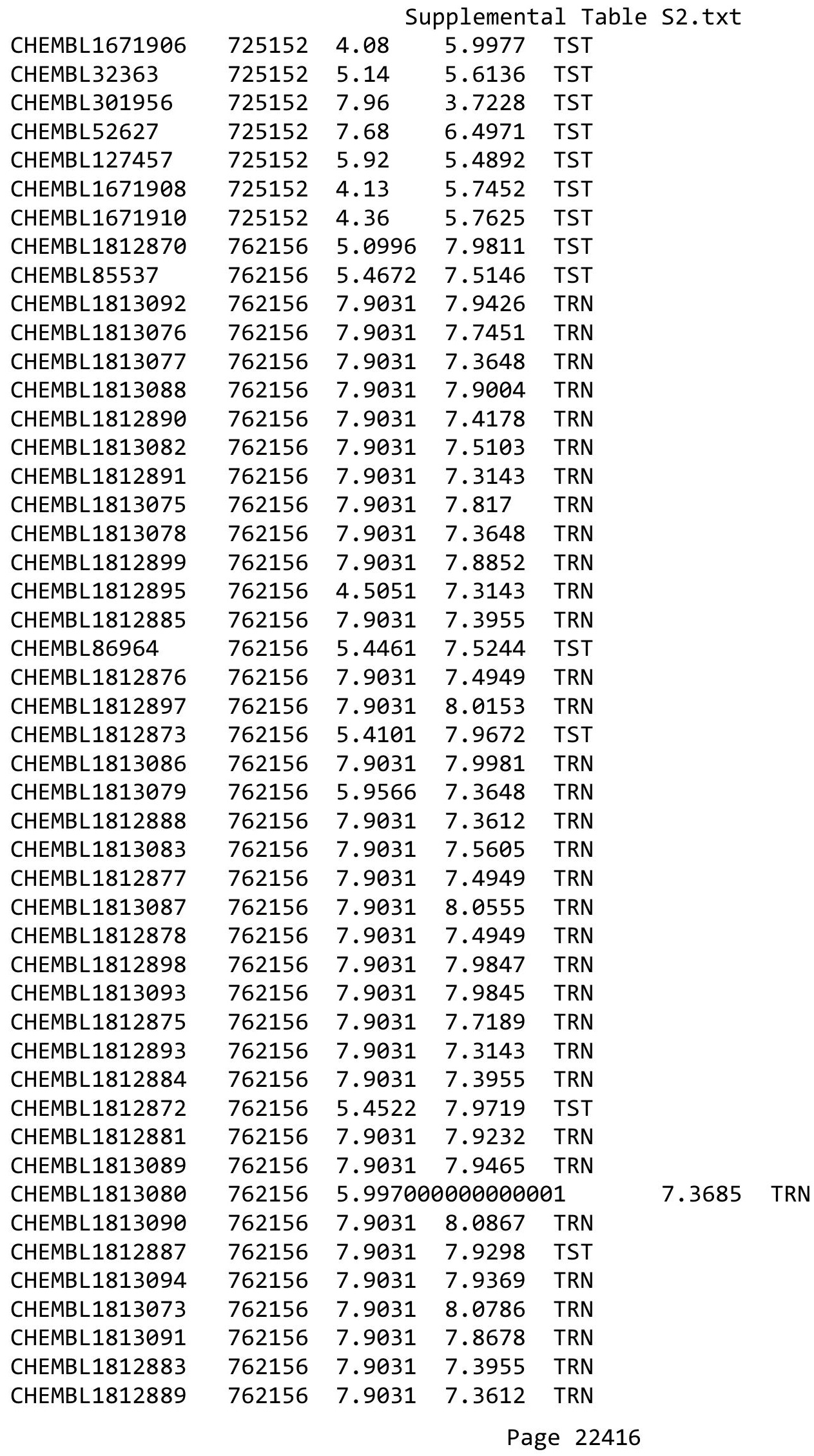


Supplemental Table S2.txt

\begin{tabular}{|c|c|c|c|c|}
\hline CHEMBL1813084 & 762156 & 7.9031 & 7.5605 & TRN \\
\hline CHEMBL1812896 & 762156 & 7.9031 & 7.4733 & TRN \\
\hline CHEMBL1812886 & 762156 & 5.4403 & 7.3955 & TRN \\
\hline CHEMBL1813081 & 762156 & 5.8351 & 7.5103 & TST \\
\hline CHEMBL1813085 & 762156 & 7.9031 & 7.8573 & TST \\
\hline CHEMBL1812892 & 762156 & 7.9031 & 7.3143 & TST \\
\hline CHEMBL1811930 & 762156 & 5.6737 & 7.562 & TST \\
\hline CHEMBL1812894 & 762156 & 5.4083 & 7.3143 & TST \\
\hline CHEMBL1812882 & 762156 & 7.9031 & 7.6259 & TST \\
\hline CHEMBL1812871 & 762156 & 6.0088 & 7.5504 & TST \\
\hline CHEMBL2144069 & 954518 & 3.2129 & 3.7458 & TRN \\
\hline CHEMBL102714 & 954518 & 3.3098 & 4.083 & TRN \\
\hline CHEMBL577784 & 954518 & 4.0669 & 4.1648 & TRN \\
\hline CHEMBL 3392440 & 954518 & 3.3391 & 3.1695 & TRN \\
\hline CHEMBL135561 & 954518 & 3.9881 & 3.9352 & TRN \\
\hline CHEMBL1516890 & 954518 & 4.0326 & 3.845 & TRN \\
\hline CHEMBL 209148 & 954518 & 3.3341 & 3.1643 & TRN \\
\hline CHEMBL 3199475 & 954518 & 4.4037 & 4.2237 & TRN \\
\hline CHEMBL509032 & 954518 & 3.4095 & 3.1231 & TRN \\
\hline CHEMBL1788116 & 954518 & 3.9378 & 3.9423 & TRN \\
\hline CHEMBL558642 & 954518 & 2.4223 & 3.1398 & TRN \\
\hline CHEMBL393929 & 954518 & 3.6798 & 3.9651 & TRN \\
\hline CHEMBL512504 & 954518 & 5.4452 & 5.7569 & TRN \\
\hline CHEMBL379300 & 954518 & 4.2594 & 4.6817 & TRN \\
\hline CHEMBL483849 & 954518 & 2.5586 & 2.327 & TRN \\
\hline CHEMBL379975 & 954518 & 5.2702 & 5.4244 & TRN \\
\hline CHEMBL1230020 & 954518 & 3.5881 & 3.6936 & TRN \\
\hline CHEMBL222102 & 954518 & 3.2583 & 3.9573 & TRN \\
\hline CHEMBL220241 & 954518 & 3.9633 & 3.5543 & TRN \\
\hline CHEMBL258844 & 954518 & 3.2919 & 3.6952 & TRN \\
\hline CHEMBL573107 & 954518 & 3.63 & 4.2944 & TRN \\
\hline CHEMBL210618 & 954518 & 3.1092 & 3.2701 & TRN \\
\hline CHEMBL92309 & 954518 & 1.797 & \multicolumn{2}{|c|}{3.0180000000000002} \\
\hline CHEMBL514499 & 954518 & 4.8964 & 5.5669 & TRN \\
\hline CHEMBL1590308 & 954518 & 2.5084 & 3.1396 & TST \\
\hline CHEMBL180127 & 954518 & 3.9015 & 3.7794 & TRN \\
\hline CHEMBL189584 & 954518 & 4.1048 & 3.9599 & TRN \\
\hline CHEMBL1242367 & 954518 & 2.8302 & 3.1536 & TRN \\
\hline CHEMBL483847 & 954518 & 3.4591 & 3.4598 & TRN \\
\hline CHEMBL188678 & 954518 & 4.7678 & 4.6153 & TRN \\
\hline CHEMBL 3186408 & 954518 & 3.2647 & 3.7286 & TST \\
\hline CHEMBL1190711 & 954518 & 4.1811 & 4.2905 & TRN \\
\hline CHEMBL9470 & 954518 & 6.2708 & 5.4658 & TST \\
\hline CHEMBL392695 & 954518 & 5.1565 & 4.901 & TRN \\
\hline CHEMBL1404918 & 954518 & 3.4804 & 3.1248 & TRN \\
\hline CHEMBL 3349342 & 954518 & 3.4162 & 3.8638 & TRN \\
\hline CHEMBL1970879 & 954518 & 3.2144 & 2.592 & TRN \\
\hline CHEMBL65 & 954518 & 8.7632 & 8.2214 & TRN \\
\hline
\end{tabular}

Page 22417 


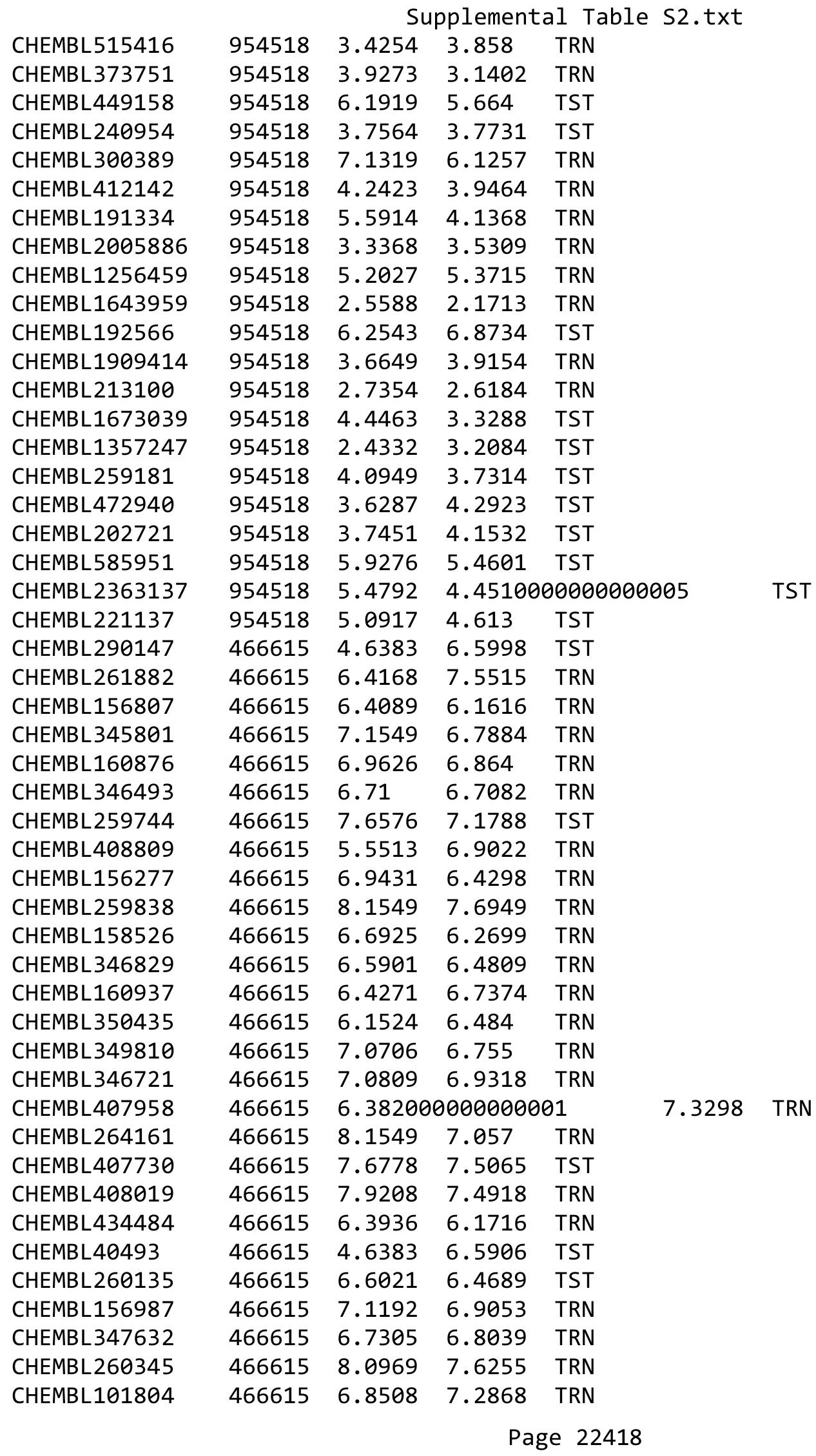




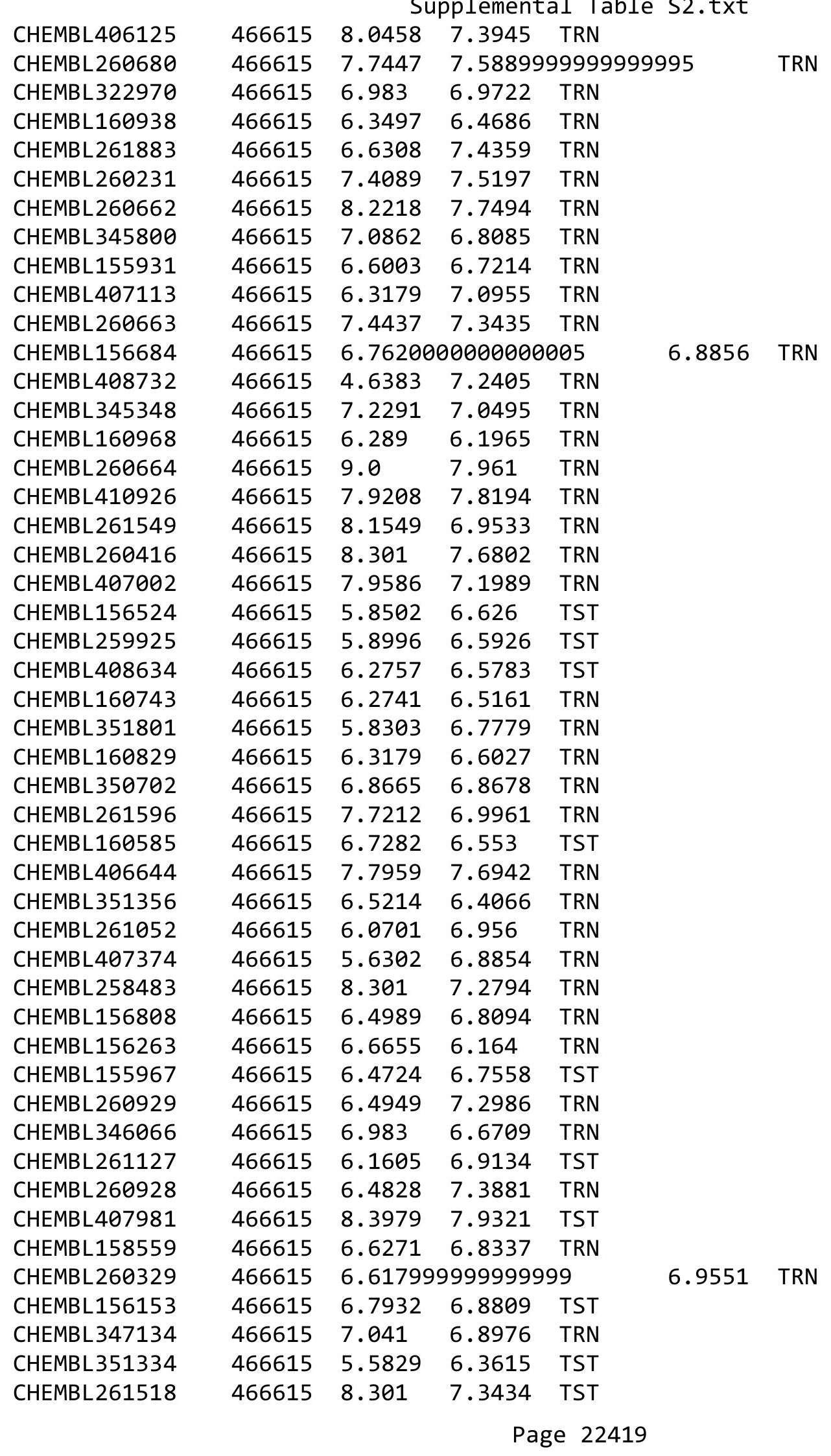


Supplemental Table S2.txt

\begin{tabular}{|c|c|c|c|c|}
\hline CHEMBL346996 & 466615 & 6.8182 & 6.6065 & TRN \\
\hline CHEMBL349540 & 466615 & 6.9586 & 6.2551 & TRN \\
\hline CHEMBL346107 & 466615 & 6.3372 & 6.8055 & TST \\
\hline CHEMBL428968 & 466615 & 4.6383 & 6.4483 & TST \\
\hline CHEMBL347647 & 466615 & 6.6655 & 6.3546 & TRN \\
\hline CHEMBL352222 & 466615 & 7.699 & 7.0632 & TRN \\
\hline CHEMBL156801 & 466615 & 5.8545 & 6.7299 & TST \\
\hline CHEMBL 260344 & 466615 & 6.3716 & 7.181 & TRN \\
\hline CHEMBL156506 & 466615 & 6.71 & 6.5458 & TRN \\
\hline CHEMBL260243 & 466615 & 7.4559 & 7.3682 & TRN \\
\hline CHEMBL347857 & 466615 & 6.8268 & 6.7471 & TRN \\
\hline CHEMBL287731 & 466615 & 5.4471 & 6.63899 & 9999999999 \\
\hline CHEMBL 261690 & 466615 & 7.0044 & 7.6644 & TRN \\
\hline CHEMBL155680 & 466615 & 6.9101 & 6.9976 & TRN \\
\hline CHEMBL406701 & 466615 & 7.3665 & 6.9635 & TST \\
\hline CHEMBL348505 & 466615 & 6.5361 & 6.6534 & TRN \\
\hline CHEMBL 288448 & 466615 & 6.5361 & 6.8536 & TST \\
\hline CHEMBL 264162 & 466615 & 6.4486 & 7.3086 & TST \\
\hline CHEMBL258701 & 466615 & 7.2518 & 6.9405 & TST \\
\hline CHEMBL408979 & 466615 & 5.7978 & 7.0939 & TRN \\
\hline CHEMBL263907 & 466615 & 7.699 & 7.1534 & TST \\
\hline CHEMBL261659 & 466615 & 7.3768 & 7.4806 & TRN \\
\hline CHEMBL347580 & 466615 & 6.1586 & 6.5881 & TST \\
\hline CHEMBL 261440 & 466615 & 6.0 & 7.3466 & TRN \\
\hline CHEMBL157141 & 466615 & 6.8182 & 6.8542 & TRN \\
\hline CHEMBL261129 & 466615 & 9.0 & 8.0453 & TRN \\
\hline CHEMBL317657 & 466615 & 7.8539 & 7.6729 & TRN \\
\hline CHEMBL347681 & 466615 & 7.1487 & 7.153 & TRN \\
\hline CHEMBL407980 & 466615 & 8.1549 & 7.5457 & TRN \\
\hline CHEMBL407373 & 466615 & 7.7447 & 6.9584 & TST \\
\hline CHEMBL405145 & 466615 & 8.0969 & 7.6823 & TRN \\
\hline CHEMBL435045 & 466615 & 5.6411 & 6.4624 & TST \\
\hline CHEMBL158835 & 466615 & 6.4067 & 6.642 & TRN \\
\hline CHEMBL 259270 & 466615 & 7.1249 & 7.3872 & TRN \\
\hline CHEMBL407003 & 466615 & 7.5686 & 7.0539 & TST \\
\hline CHEMBL406062 & 466615 & 6.7721 & 7.1544 & TST \\
\hline CHEMBL157258 & 466615 & 7.0315 & 6.8548 & TRN \\
\hline CHEMBL408564 & 466615 & 8.1549 & 7.5033 & TRN \\
\hline CHEMBL160598 & 466615 & 6.6144 & 6.3743 & TRN \\
\hline CHEMBL409738 & 466615 & 8.1549 & 7.3341 & TST \\
\hline CHEMBL160333 & 466615 & 7.0269 & 6.9015 & TRN \\
\hline CHEMBL261661 & 466615 & 5.5691 & 6.8824 & TST \\
\hline CHEMBL345212 & 466615 & 7.1308 & 6.8252 & TRN \\
\hline CHEMBL160373 & 466615 & 6.3261 & 6.5258 & TRN \\
\hline CHEMBL158208 & 466615 & 6.8069 & 6.5376 & TRN \\
\hline CHEMBL406620 & 466615 & 6.9031 & 7.2329 & TRN \\
\hline CHEMBL427909 & 466615 & 7.6198 & 7.6612 & TRN \\
\hline CHEMBL40835 & 466615 & 4.6383 & 6.6163 & TST \\
\hline
\end{tabular}




\begin{tabular}{|c|c|c|c|c|c|c|}
\hline & & \multicolumn{5}{|c|}{ Supplemental Table S2.txt } \\
\hline CHEMBL345364 & 466615 & 6.8729 & 6.9458 & TRN & & \\
\hline CHEMBL156563 & 466615 & 6.7932 & 6.4157 & TRN & & \\
\hline CHEMBL160231 & 466615 & 6.5867 & 6.5317 & TRN & & \\
\hline CHEMBL261881 & 466615 & 7.0605 & 7.2721 & TRN & & \\
\hline CHEMBL259271 & 466615 & 8.301 & 7.3334 & TST & & \\
\hline CHEMBL347419 & 466615 & 6.3904 & 6.6479 & TRN & & \\
\hline CHEMBL158719 & 466615 & 6.8827 & 6.7807 & TST & & \\
\hline CHEMBL261264 & 466615 & 6.3536 & 7.1553 & TST & & \\
\hline CHEMBL261439 & 466615 & 6.3665 & 6.544 & TST & & \\
\hline CHEMBL160586 & 466615 & 7.5528 & 6.9758 & TRN & & \\
\hline CHEMBL260417 & 466615 & 9.0969 & 7.901 & TRN & & \\
\hline CHEMBL260163 & 466615 & 7.8239 & 7.6129 & TRN & & \\
\hline CHEMBL157089 & 466615 & 6.857 & 6.8182 & TRN & & \\
\hline CHEMBL157348 & 466615 & 6.8477 & 6.745 & TRN & & \\
\hline CHEMBL158885 & 466615 & 7.284 & 6.9924 & TRN & & \\
\hline CHEMBL160251 & 466615 & 6.8447 & 6.7335 & TRN & & \\
\hline CHEMBL422714 & 466615 & 7.2366 & 6.9165 & TRN & & \\
\hline CHEMBL351342 & 466615 & 6.2765 & 6.4217 & TRN & & \\
\hline CHEMBL156218 & 466615 & 6.6696 & 6.7626 & TRN & & \\
\hline CHEMBL346371 & 466615 & 6.8508 & 6.4754 & TRN & & \\
\hline CHEMBL261441 & 466615 & 7.9586 & 7.4257 & TST & & \\
\hline CHEMBL318522 & 466615 & 6.6676 & 7.2698 & TRN & & \\
\hline CHEMBL159149 & 466615 & 7.1024 & 7.0029 & TRN & & \\
\hline CHEMBL156379 & 466615 & 7.585 & 7.0588 & TRN & & \\
\hline CHEMBL261660 & 466615 & 6.08200 & 30000000 & $\partial 1$ & 7.184 & TRN \\
\hline CHEMBL346551 & 466615 & 6.2291 & 6.0904 & TRN & & \\
\hline CHEMBL405021 & 466615 & 6.3028 & 7.1079 & TRN & & \\
\hline CHEMBL261366 & 466615 & 7.0044 & 7.187 & TST & & \\
\hline CHEMBL3976817 & 1627813 & 4.4437 & 5.3239 & TST & & \\
\hline CHEMBL3962835 & 1627813 & 2.5302 & 3.6778 & TRN & & \\
\hline CHEMBL3984389 & 1627813 & 3.8327 & 4.3739 & TRN & & \\
\hline CHEMBL3923582 & 1627813 & 4.3675 & 4.2699 & TRN & & \\
\hline CHEMBL 3946075 & 1627813 & 3.6778 & 3.5496 & TRN & & \\
\hline CHEMBL3968293 & 1627813 & 4.1871 & 4.2959 & TST & & \\
\hline CHEMBL3938439 & 1627813 & 6.6556 & 6.2747 & TRN & & \\
\hline CHEMBL3986658 & 1627813 & 7.065 & 6.2887 & TRN & & \\
\hline CHEMBL3902876 & 1627813 & 5.9586 & 3.8342 & TST & & \\
\hline CHEMBL 3901783 & 1627813 & 2.8542 & 3.2871 & TST & & \\
\hline CHEMBL3945415 & 1627813 & 4.4622 & 3.2308 & TST & & \\
\hline CHEMBL3985576 & 1627813 & 5.3288 & 5.4526 & TRN & & \\
\hline CHEMBL 3895588 & 1627813 & 4.5072 & 4.7149 & TRN & & \\
\hline CHEMBL3971168 & 1627813 & 2.8268 & 4.1034 & TST & & \\
\hline CHEMBL3948106 & 1627813 & 5.7645 & 5.9552 & TRN & & \\
\hline CHEMBL3929888 & 1627813 & 6.4498 & 6.4021 & TRN & & \\
\hline CHEMBL3983525 & 1627813 & 7.4134 & 7.2997 & TRN & & \\
\hline CHEMBL 3985047 & 1627813 & 4.2132 & 4.4802 & TRN & & \\
\hline CHEMBL3906853 & 1627813 & 4.9208 & 5.8318 & TRN & & \\
\hline CHEMBL3953360 & 1627813 & 6.7696 & 6.5029 & TRN & & \\
\hline
\end{tabular}

Page 22421 
Supplemental Table S2.txt

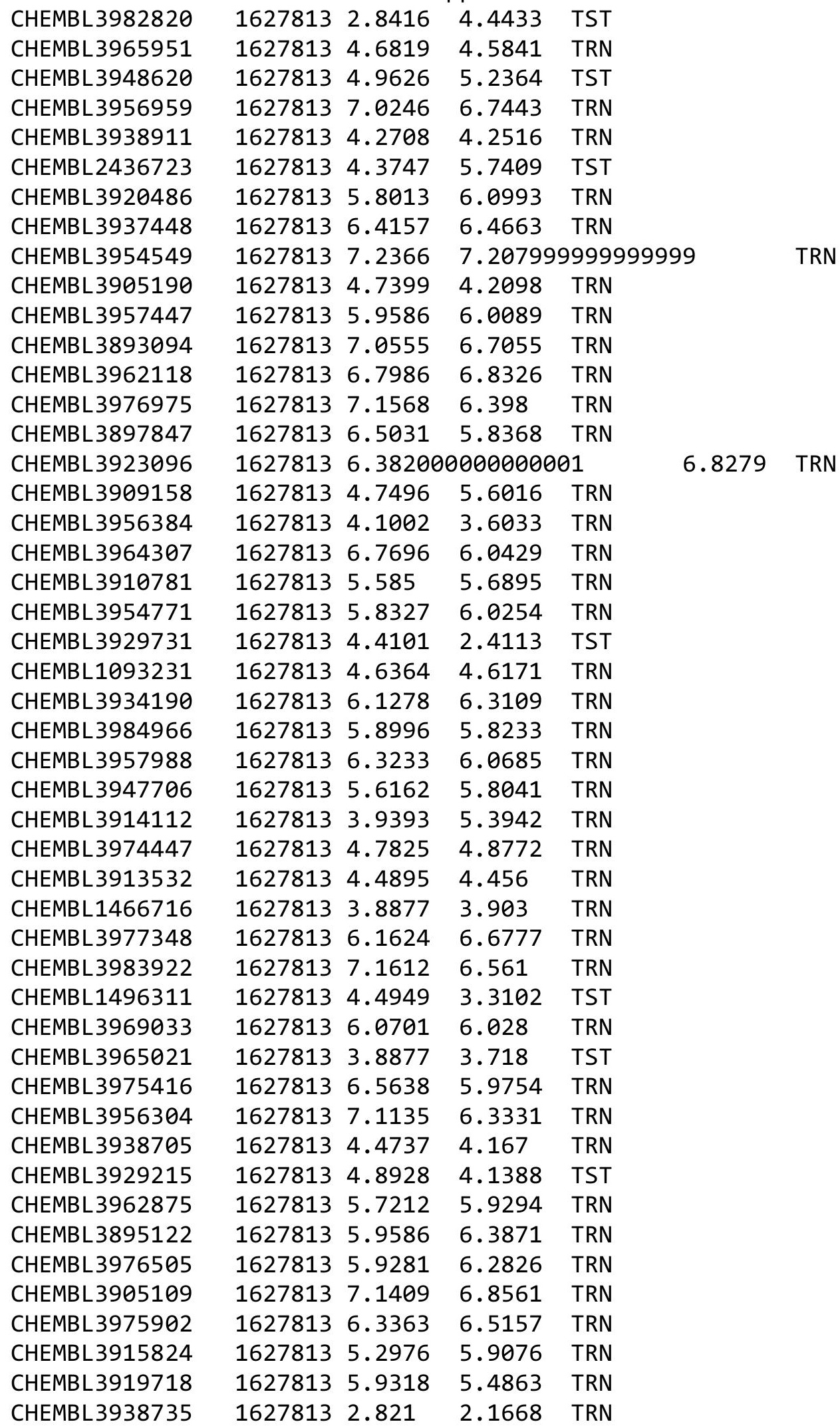

Page 22422 
Supplemental Table S2.txt

\begin{tabular}{|c|c|c|c|c|c|}
\hline CHEMBL1383982 & 1627813 & 4.6778 & \multicolumn{2}{|c|}{4.64199999999999995} & TRN \\
\hline CHEMBL3947214 & 1627813 & 6.0958 & 6.0417 & TRN & \\
\hline CHEMBL3904528 & 1627813 & 4.2565 & 4.7588 & TRN & \\
\hline CHEMBL3913633 & 1627813 & 5.279 & 4.449 & TRN & \\
\hline CHEMBL3983404 & 1627813 & 5.8894 & 6.4343 & TRN & \\
\hline CHEMBL3966927 & 1627813 & 4.6383 & 4.6627 & TRN & \\
\hline CHEMBL3914558 & 1627813 & 3.7011 & 4.2067 & TRN & \\
\hline CHEMBL3932045 & 1627813 & 6.1669 & 6.5105 & TRN & \\
\hline CHEMBL3937177 & 1627813 & 6.2993 & 5.8479 & TRN & \\
\hline CHEMBL3968466 & 1627813 & 5.0264 & 5.2042 & TRN & \\
\hline CHEMBL3924826 & 1627813 & 5.5544 & 5.1577 & TRN & \\
\hline CHEMBL3894566 & 1627813 & 3.8928 & 3.7654 & TRN & \\
\hline CHEMBL3893929 & 1627813 & 3.0655 & 2.2942 & TST & \\
\hline CHEMBL3948302 & 1627813 & 6.2262 & 6.2907 & TST & \\
\hline CHEMBL3904048 & 1627813 & 6.0799 & 6.5442 & TST & \\
\hline CHEMBL3896780 & 1627813 & 6.0953 & 6.0679 & TST & \\
\hline CHEMBL3893884 & 1627813 & 3.3947 & 3.4556 & TST & \\
\hline CHEMBL3910234 & 1627813 & 3.7305 & 4.0916 & TST & \\
\hline CHEMBL1302108 & 1627813 & 2.8969 & 4.6659 & TST & \\
\hline CHEMBL3977477 & 1627813 & 5.5607 & 5.705 & TST & \\
\hline CHEMBL3967988 & 1627813 & 5.6308 & 6.1257 & TST & \\
\hline CHEMBL1904746 & 1627813 & 4.6676 & 5.5423 & TST & \\
\hline CHEMBL11369 & 65465 & 9.301 & 8.5627 & TRN & \\
\hline CHEMBL10697 & 65465 & 8.9208 & 7.9095 & TRN & \\
\hline CHEMBL11176 & 65465 & 8.0706 & 7.7067 & TRN & \\
\hline CHEMBL11345 & 65465 & 6.699 & 7.2652 & TRN & \\
\hline CHEMBL11162 & 65465 & 6.7212 & 7.5267 & TRN & \\
\hline CHEMBL10834 & 65465 & 7.8861 & 7.5613 & TST & \\
\hline CHEMBL417978 & 65465 & 7.7212 & 5.8093 & TRN & \\
\hline CHEMBL276601 & 65465 & 4.7959 & 7.6691 & TST & \\
\hline CHEMBL10926 & 65465 & 6.8239 & 7.79799 & 9999999999 & TRN \\
\hline CHEMBL10622 & 65465 & 6.3979 & 6.3322 & TRN & \\
\hline CHEMBL10911 & 65465 & 6.7696 & 5.9877 & TRN & \\
\hline CHEMBL417067 & 65465 & 9.9208 & 8.4872 & TRN & \\
\hline CHEMBL10636 & 65465 & 8.4089 & 7.8334 & TRN & \\
\hline CHEMBL267094 & 65465 & 6.3665 & 5.7129 & TRN & \\
\hline CHEMBL10819 & 65465 & 5.8861 & 7.7865 & TRN & \\
\hline CHEMBL10744 & 65465 & 8.0969 & 7.815 & TRN & \\
\hline CHEMBL273723 & 65465 & 8.6778 & 8.6355 & TRN & \\
\hline CHEMBL273948 & 65465 & 7.8861 & 8.145 & TST & \\
\hline CHEMBL10644 & 65465 & 7.5229 & 8.6098 & TST & \\
\hline CHEMBL10940 & 65465 & 6.0969 & 7.6792 & TRN & \\
\hline CHEMBL10589 & 65465 & 7.6021 & 7.4668 & TRN & \\
\hline CHEMBL 276018 & 65465 & 7.1549 & 7.6168 & TRN & \\
\hline CHEMBL275701 & 65465 & 8.7447 & 8.5173 & TRN & \\
\hline CHEMBL274359 & 65465 & 8.7696 & 8.0688 & TRN & \\
\hline CHEMBL10951 & 65465 & 6.2441 & 7.5279 & TRN & \\
\hline CHEMBL11131 & 65465 & 6.2218 & 5.7013 & TRN & \\
\hline
\end{tabular}

Page 22423 


\begin{tabular}{|c|c|c|c|c|c|}
\hline \multicolumn{6}{|c|}{ Supplemental Table S2.txt } \\
\hline CHEMBL269453 & 65465 & 7.8539 & 7.6845 & TRN & \\
\hline CHEMBL10781 & 65465 & 9.301 & 8.8658 & TRN & \\
\hline CHEMBL276639 & 65465 & 7.7959 & 7.9354 & TRN & \\
\hline CHEMBL274857 & 65465 & 6.301 & 7.0257 & TRN & \\
\hline CHEMBL275991 & 65465 & 6.3979 & 5.7864 & TRN & \\
\hline CHEMBL273613 & 65465 & 5.3098 & 5.9076 & TRN & \\
\hline CHEMBL10794 & 65465 & 8.1739 & 7.8243 & TRN & \\
\hline CHEMBL276173 & 65465 & 6.5229 & 7.1584 & TST & \\
\hline CHEMBL10860 & 65465 & 8.0 & 7.8508 & TST & \\
\hline CHEMBL8981 & 65465 & 9.5229 & 8.7112 & TRN & \\
\hline CHEMBL274175 & 65465 & 7.9208 & 8.7127 & TRN & \\
\hline CHEMBL275559 & 65465 & 8.0862 & 7.6638 & TRN & \\
\hline CHEMBL268480 & 65465 & 8.8539 & 8.599 & TRN & \\
\hline CHEMBL10607 & 65465 & 8.5229 & 7.9145 & TRN & \\
\hline CHEMBL10588 & 65465 & 7.9208 & 7.4697 & TRN & \\
\hline CHEMBL10915 & 65465 & 7.301 & 7.2702 & TRN & \\
\hline CHEMBL273951 & 65465 & 6.4949 & 7.9383 & TRN & \\
\hline CHEMBL269409 & 65465 & 7.7447 & 7.7865 & TRN & \\
\hline CHEMBL10996 & 65465 & 6.7696 & 7.6041 & TST & \\
\hline CHEMBL276252 & 65465 & 7.9586 & 8.5879 & TRN & \\
\hline CHEMBL11064 & 65465 & 5.9393 & 6.4002 & TRN & \\
\hline CHEMBL11106 & 65465 & 7.8539 & 8.508 & TRN & \\
\hline CHEMBL11174 & 65465 & 3.6021 & 5.53700 & 0000000001 & TRN \\
\hline CHEMBL10808 & 65465 & 6.5229 & 7.5004 & TST & \\
\hline CHEMBL11115 & 65465 & 8.7447 & 7.8652 & TRN & \\
\hline CHEMBL11082 & 65465 & 6.2218 & 8.6468 & TST & \\
\hline CHEMBL10846 & 65465 & 7.9586 & 7.4172 & TRN & \\
\hline CHEMBL274805 & 65465 & 6.2007 & 5.9861 & TRN & \\
\hline CHEMBL11341 & 65465 & 6.0223 & 6.25700 & 0000000001 & TRN \\
\hline CHEMBL267096 & 65465 & 6.6198 & 7.6064 & TST & \\
\hline CHEMBL10661 & 65465 & 8.3979 & 7.8191 & TRN & \\
\hline CHEMBL10843 & 65465 & 8.0 & 8.1087 & TST & \\
\hline CHEMBL11152 & 65465 & 6.1549 & 7.1893 & TST & \\
\hline CHEMBL10897 & 65465 & 5.6576 & 6.921 & TST & \\
\hline CHEMBL10733 & 65465 & 6.9586 & 7.6532 & TRN & \\
\hline CHEMBL417428 & 65465 & 7.9586 & 7.7697 & TRN & \\
\hline CHEMBL268754 & 65465 & 7.3372 & 7.0822 & TST & \\
\hline CHEMBL10374 & 65465 & 7.2924 & 7.8224 & TRN & \\
\hline CHEMBL10635 & 65465 & 8.1249 & 7.9643 & TRN & \\
\hline CHEMBL10854 & 65465 & 9.0458 & 8.725 & TRN & \\
\hline CHEMBL10901 & 65465 & 7.1549 & 7.6929 & TST & \\
\hline CHEMBL10648 & 65465 & 6.1549 & 7.37 & TST & \\
\hline CHEMBL10919 & 65465 & 7.4559 & 8.145 & TST & \\
\hline CHEMBL274383 & 65465 & 8.1308 & 7.2076 & TRN & \\
\hline CHEMBL10910 & 65465 & 7.3979 & 7.7847 & TRN & \\
\hline CHEMBL10948 & 65465 & 7.5528 & 7.8981 & TRN & \\
\hline CHEMBL274307 & 65465 & 7.0458 & 6.9951 & TST & \\
\hline CHEMBL10924 & 65465 & 8.6198 & 8.5075 & TRN & \\
\hline
\end{tabular}

Page 22424 


\begin{tabular}{|c|c|c|c|c|c|}
\hline \multicolumn{6}{|c|}{ Supplemental Table S2.txt } \\
\hline CHEMBL 269461 & 65465 & 6.3188 & 7.1719 & TST & \\
\hline CHEMBL10676 & 65465 & 7.3665 & 7.6917 & TRN & \\
\hline CHEMBL344545 & 105962 & 7.3768 & 7.4515 & TRN & \\
\hline CHEMBL147005 & 105962 & 6.2441 & 6.1603 & TRN & \\
\hline CHEMBL149431 & 105962 & 6.8539 & 6.4654 & TST & \\
\hline CHEMBL 356079 & 105962 & 6.5229 & 6.2625 & TRN & \\
\hline CHEMBL145999 & 105962 & 6.6576 & 6.6582 & TRN & \\
\hline CHEMBL146951 & 105962 & 6.1249 & 6.1802 & TST & \\
\hline CHEMBL357904 & 105962 & 5.5086 & 5.5307 & TRN & \\
\hline CHEMBL358812 & 105962 & 6.699 & 6.7469 & TRN & \\
\hline CHEMBL144430 & 105962 & 6.2518 & 6.2382 & TRN & \\
\hline CHEMBL147738 & 105962 & 6.3565 & 6.2884 & TRN & \\
\hline CHEMBL148120 & 105962 & 6.585 & 6.5594 & TST & \\
\hline CHEMBL 342570 & 105962 & 6.5686 & 6.2051 & TST & \\
\hline CHEMBL145641 & 105962 & 6.6383 & 6.5783 & TRN & \\
\hline CHEMBL147004 & 105962 & 6.3098 & 6.3383 & TRN & \\
\hline CHEMBL343860 & 105962 & 6.2366 & 6.295 & TRN & \\
\hline CHEMBL147107 & 105962 & 6.5086 & 6.4952 & TRN & \\
\hline CHEMBL146725 & 105962 & 5.0 & 6.57100 & 0000000001 & TST \\
\hline CHEMBL144313 & 105962 & 7.699 & 7.6709 & TRN & \\
\hline CHEMBL148178 & 105962 & 6.3468 & 6.3242 & TRN & \\
\hline CHEMBL147561 & 105962 & 6.8539 & 6.8667 & TRN & \\
\hline CHEMBL147261 & 105962 & 5.7447 & 5.6094 & TRN & \\
\hline CHEMBL422848 & 105962 & 7.7212 & 7.7691 & TRN & \\
\hline CHEMBL 344714 & 105962 & 6.585 & 6.5641 & TRN & \\
\hline CHEMBL147910 & 105962 & 6.4559 & 6.3224 & TRN & \\
\hline CHEMBL343414 & 105962 & 6.2218 & 6.306 & TRN & \\
\hline CHEMBL145175 & 105962 & 6.5528 & 6.7065 & TRN & \\
\hline CHEMBL357871 & 105962 & 6.4202 & 6.4696 & TRN & \\
\hline CHEMBL423572 & 105962 & 6.1549 & 6.1716 & TRN & \\
\hline CHEMBL424311 & 105962 & 6.8239 & 6.8015 & TRN & \\
\hline CHEMBL148081 & 105962 & 6.4559 & 6.5398 & TRN & \\
\hline CHEMBL145930 & 105962 & 6.585 & 6.66700 & $\partial 000000001$ & TRN \\
\hline CHEMBL 342102 & 105962 & 6.0362 & 6.1178 & TRN & \\
\hline CHEMBL343653 & 105962 & 7.7696 & 7.7805 & TRN & \\
\hline CHEMBL147629 & 105962 & 7.4815 & 6.8835 & TST & \\
\hline CHEMBL421766 & 105962 & 7.7212 & 7.685 & TRN & \\
\hline CHEMBL358061 & 105962 & 6.6778 & 6.54200 & 0000000001 & TRN \\
\hline CHEMBL344999 & 105962 & 6.0362 & 5.8814 & TRN & \\
\hline CHEMBL434505 & 105962 & 6.3188 & 6.1299 & TRN & \\
\hline CHEMBL146256 & 105962 & 5.699 & 5.6919 & TRN & \\
\hline CHEMBL342548 & 105962 & 7.7212 & 6.785 & TST & \\
\hline CHEMBL149983 & 105962 & 5.9208 & 5.9824 & TRN & \\
\hline CHEMBL147804 & 105962 & 7.0605 & 6.9281 & TST & \\
\hline CHEMBL 356520 & 105962 & 5.9208 & 6.3913 & TST & \\
\hline CHEMBL 358064 & 105962 & 5.8861 & 6.0928 & TST & \\
\hline CHEMBL343911 & 105962 & 6.6198 & 6.2528 & TST & \\
\hline CHEMBL147494 & 105962 & 5.6021 & 5.6612 & TRN & \\
\hline
\end{tabular}




\begin{tabular}{|c|c|c|c|c|c|}
\hline & & & optim & & \\
\hline CHEMBL344778 & 105962 & 5.699 & 5.769 & TRN & \\
\hline CHEMBL144176 & 105962 & 5.0 & 5.1981 & TRN & \\
\hline CHEMBL147903 & 105962 & 6.5229 & 6.49799 & 9999999999 & TRN \\
\hline CHEMBL423015 & 105962 & 6.1079 & 6.1802 & TRN & \\
\hline CHEMBL147844 & 105962 & 6.6021 & 7.0181 & TST & \\
\hline CHEMBL148136 & 105962 & 7.1308 & 5.9759 & TST & \\
\hline CHEMBL343220 & 105962 & 6.5686 & 6.3725 & TST & \\
\hline CHEMBL343855 & 105962 & 7.6778 & 7.6525 & TRN & \\
\hline CHEMBL148212 & 105962 & 6.301 & 6.4582 & TST & \\
\hline CHEMBL148213 & 105962 & 7.0 & 7.0668 & TRN & \\
\hline CHEMBL356504 & 105962 & 5.5376 & 5.5895 & TRN & \\
\hline CHEMBL3659205 & 1528623 & 6.9706 & 6.6663 & TRN & \\
\hline CHEMBL3663493 & 1528623 & 6.2573 & 5.3854 & TST & \\
\hline CHEMBL3663388 & 1528623 & 5.5376 & 4.3334 & TST & \\
\hline CHEMBL3663454 & 1528623 & 5.0 & 5.55200 & 00000000005 & TRN \\
\hline CHEMBL3659237 & 1528623 & 6.7595 & 6.454 & TRN & \\
\hline CHEMBL3663464 & 1528623 & 5.8386 & 5.7895 & TRN & \\
\hline CHEMBL 3663445 & 1528623 & 6.5229 & 6.0665 & TST & \\
\hline CHEMBL3659185 & 1528623 & 7.3768 & 7.3008 & TRN & \\
\hline CHEMBL3663530 & 1528623 & 5.9905 & 6.8563 & TST & \\
\hline CHEMBL 3663566 & 1528623 & 6.3799 & 6.4682 & TRN & \\
\hline CHEMBL 3663547 & 1528623 & 5.9586 & 5.7042 & TRN & \\
\hline CHEMBL3663519 & 1528623 & 5.4815 & 5.4743 & TRN & \\
\hline CHEMBL3663533 & 1528623 & 5.2518 & 5.6705 & TRN & \\
\hline CHEMBL3663395 & 1528623 & 6.1612 & 6.5464 & TRN & \\
\hline CHEMBL 3663494 & 1528623 & 6.2581 & 5.433 & TRN & \\
\hline CHEMBL3663409 & 1528623 & 5.4437 & 5.5359 & TRN & \\
\hline CHEMBL 3663414 & 1528623 & 7.0044 & 6.5869 & TRN & \\
\hline CHEMBL3659189 & 1528623 & 6.4389 & 6.5328 & TRN & \\
\hline CHEMBL3659191 & 1528623 & 7.301 & 6.7479 & TRN & \\
\hline CHEMBL 3659230 & 1528623 & 6.7258 & 6.6196 & TRN & \\
\hline CHEMBL3663560 & 1528623 & 5.6021 & 5.4113 & TRN & \\
\hline CHEMBL3659208 & 1528623 & 7.5686 & 7.1637 & TRN & \\
\hline CHEMBL3659201 & 1528623 & 6.9101 & 7.0169 & TRN & \\
\hline CHEMBL3663462 & 1528623 & 6.1046 & 5.919 & TRN & \\
\hline CHEMBL3663425 & 1528623 & 6.4685 & 6.7198 & TRN & \\
\hline CHEMBL3663538 & 1528623 & 6.4237 & 6.2588 & TRN & \\
\hline CHEMBL3663509 & 1528623 & 5.0458 & 5.1781 & TRN & \\
\hline CHEMBL3659235 & 1528623 & 6.5884 & 6.5365 & TRN & \\
\hline CHEMBL3659196 & 1528623 & 6.4202 & 5.7975 & TST & \\
\hline CHEMBL3659243 & 1528623 & 6.6576 & 6.8916 & TRN & \\
\hline CHEMBL3663561 & 1528623 & 5.1308 & 4.8996 & TRN & \\
\hline CHEMBL3659221 & 1528623 & 4.0 & 5.0595 & TRN & \\
\hline CHEMBL3663390 & 1528623 & 6.0 & 5.8179 & TRN & \\
\hline CHEMBL3659240 & 1528623 & 5.6198 & 5.4459 & TST & \\
\hline CHEMBL 3663387 & 1528623 & 4.0 & 4.8314 & TST & \\
\hline CHEMBL3659184 & 1528623 & 6.9208 & 6.8728 & TRN & \\
\hline CHEMBL3663407 & 1528623 & 5.7447 & 5.50899 & 99999999995 & TRN \\
\hline & & & & 22426 & \\
\hline
\end{tabular}


Supplemental Table S2.txt

\begin{tabular}{|c|c|c|c|c|}
\hline . & & & 5.6877 & \\
\hline & 528623 & 5.7496 & 4.9363 & \\
\hline & 623 & & & \\
\hline AEMBL & 8623 & 0297 & & \\
\hline AEMBL & 528623 & 4.0 & & \\
\hline HEMBL3659206 & 528623 & 6.0 & 2874 & \\
\hline 216 & 523 & 5.3279 & & \\
\hline |FMRI & 623 & & & \\
\hline 59239 & 528623 & 4318 & & \\
\hline HEMBL3663420 & 528623 & 6.5017 & & \\
\hline HEMBL3663484 & 528623 & 5.9208 & & \\
\hline IEMBL & 8623 & 308 & & \\
\hline IEMBL: & & & & \\
\hline HEMBL3 & 528623 & 7.0362 & & \\
\hline AEMBL3 & 528623 & 12 & & \\
\hline AEMBL3663506 & 528623 & 3098 & 87 & \\
\hline AEMBL & 23 & 861 & & \\
\hline HEMBL & & & & \\
\hline AEMBL3 & 528623 & 615 & & \\
\hline IEMBL3 & 23 & & & \\
\hline HEMBL & 3 & 33 & & Niv \\
\hline IEMBL & 3 & & & RN \\
\hline AEMBL & & & & \\
\hline 53497 & 23 & 98 & & \\
\hline AEMBL 366354 & & & & TST \\
\hline HEMBL; & 23 & & & IST \\
\hline AEMBL & -3 & & & ST \\
\hline HFMBI : & 23 & 86 & & RN \\
\hline HEMBL3 & & & & RIV \\
\hline HEMBL36592 & 23 & 6 . & & IK \\
\hline HEMBL3 & 623 & 78 & & RN \\
\hline HEMBL & 3 & 89 & & RN \\
\hline HEMBL & 23 & 77 & & 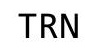 \\
\hline HEMBL3663383 & & & & is \\
\hline HEMBL3663475 & 528623 & & 51 & TRN \\
\hline HEMBL3 & 23 & & 36 & RN \\
\hline HCMP - & & & & ST \\
\hline HEMBL; & & & & IRN \\
\hline HEMBL3659209 & 528623 & & 49 & TST \\
\hline IEMBL3 & 528623 & 35 & & IRN \\
\hline HEMBL3659 & 528623 & 4 & 68 & DN \\
\hline HEMBL3 & & & & TRN \\
\hline HEMBL3659193 & 528623 & 6 & 6.7695 & RN \\
\hline AEMBL3663514 & 528623 & 86 & 584 & TR \\
\hline $\mathrm{MPI}=$ & $2-1+3$ & & & RN \\
\hline HEMBL36635 & & (1) & 5.8297 & \\
\hline CHEMBL3663392 & 528623 & & 3.6703 & \\
\hline CHEMBL3663496 & 1528623 & 6.3526 & 6.0236 & ГST \\
\hline
\end{tabular}

Page 22427 
Supplemental Table S2.txt

\begin{tabular}{|c|c|c|c|c|c|}
\hline CHEMBL 3663430 & 1528623 & 6.6364 & 7.0488 & TRN & \\
\hline CHEMBL 3659203 & 1528623 & 6.3307 & 6.4547 & TRN & \\
\hline CHEMBL 3663521 & 1528623 & 4.0 & 3.7558 & TRN & \\
\hline CHEMBL 3663468 & 1528623 & 5.1367 & 5.1178 & TRN & \\
\hline CHEMBL 3659232 & 1528623 & 7.0915 & 6.9136 & TRN & \\
\hline CHEMBL 3663495 & 1528623 & 5.9586 & 5.0684 & TST & \\
\hline CHEMBL 3659222 & 1528623 & 5.6576 & 5.2525 & TRN & \\
\hline CHEMBL 3659241 & 1528623 & 5.1024 & 5.1916 & TST & \\
\hline CHEMBL 3663437 & 1528623 & 6.0223 & 5.8358 & TST & \\
\hline CHEMBL3663539 & 1528623 & 6.5768 & 6.1572 & TRN & \\
\hline CHEMBL 3663411 & 1528623 & 6.8125 & 6.779 & TRN & \\
\hline CHEMBL3663389 & 1528623 & 4.0 & 3.7897 & TST & \\
\hline CHEMBL 3663556 & 1528623 & 6.1296 & 6.3447 & TRN & \\
\hline CHEMBL3659207 & 1528623 & 6.4168 & 6.6571 & TRN & \\
\hline CHEMBL 3663492 & 1528623 & 6.1524 & 6.013 & TST & \\
\hline CHEMBL 3659194 & 1528623 & 6.7959 & 6.7653 & TRN & \\
\hline CHEMBL 3663429 & 1528623 & 6.8794 & 6.816 & TRN & \\
\hline CHEMBL 3663550 & 1528623 & 6.9172 & 6.8833 & TRN & \\
\hline CHEMBL 3663577 & 1528623 & 6.9431 & 7.0502 & TRN & \\
\hline CHEMBL 3663416 & 1528623 & 6.0 & 5.7414 & TRN & \\
\hline CHEMBL 3663537 & 1528623 & 5.0177 & 5.346 & TRN & \\
\hline CHEMBL 3663478 & 1528623 & 5.3872 & 5.5244 & TRN & \\
\hline CHEMBL 3663526 & 1528623 & 6.6216 & 6.9243 & TRN & \\
\hline CHEMBL 3663571 & 1528623 & 6.2534 & 6.3808 & TRN & \\
\hline CHEMBL 3663474 & 1528623 & 5.3979 & 5.4158 & TRN & \\
\hline CHEMBL 3663546 & 1528623 & 5.3768 & 5.0798 & TRN & \\
\hline CHEMBL3659195 & 1528623 & 6.4045 & 6.3769 & TRN & \\
\hline CHEMBL 3663568 & 1528623 & 4.0 & 5.6384 & TST & \\
\hline CHEMBL 3663573 & 1528623 & 4.0 & 4.0063 & TRN & \\
\hline CHEMBL 3663490 & 1528623 & 5.8239 & 6.249 & TRN & \\
\hline CHEMBL 3663554 & 1528623 & 6.8386 & \multicolumn{2}{|c|}{5.332000000000001} & TST \\
\hline CHEMBL 3663498 & 1528623 & 6.6576 & 6.5742 & TRN & \\
\hline CHEMBL 3659204 & 1528623 & 6.1593 & 6.6816 & TRN & \\
\hline CHEMBL3663520 & 1528623 & 4.0 & 4.3229 & TRN & \\
\hline CHEMBL 3663400 & 1528623 & 6.0778 & 5.7365 & TRN & \\
\hline CHEMBL 3659233 & 1528623 & 5.2076 & 4.9177 & TRN & \\
\hline CHEMBL 3663434 & 1528623 & 5.1427 & 4.9378 & TRN & \\
\hline CHEMBL 3663513 & 1528623 & 5.7696 & 5.8674 & TRN & \\
\hline CHEMBL3663472 & 1528623 & 6.0 & 5.9929 & TRN & \\
\hline CHEMBL 3663536 & 1528623 & 5.9101 & 5.9986 & TRN & \\
\hline CHEMBL 3663417 & 1528623 & 5.3188 & 5.5123 & TRN & \\
\hline CHEMBL 3663422 & 1528623 & 5.6576 & 6.0091 & TRN & \\
\hline CHEMBL 3663404 & 1528623 & 6.0757 & 5.8259 & TRN & \\
\hline CHEMBL 3663570 & 1528623 & \multicolumn{3}{|c|}{6.7620000000000005} & TRN \\
\hline CHEMBL 3659198 & 1528623 & 7.2218 & 6.2487 & TST & \\
\hline CHEMBL 3659188 & 1528623 & 6.0 & 6.4361 & TRN & \\
\hline CHEMBL 3663535 & 1528623 & 5.2757 & 5.1849 & TST & \\
\hline CHEMBL 3663419 & 1528623 & 6.9666 & 7.0432 & TRN & \\
\hline
\end{tabular}

Page 22428 
Supplemental Table S2.txt

\begin{tabular}{|c|c|c|c|c|}
\hline 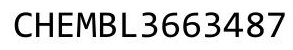 & & & & \\
\hline AEMBL3639580 & 28623 & 6.983 & 9038 & \\
\hline IEMBL3663442 & 528623 & 6.6021 & 3883 & \\
\hline AEMBL3663555 & 28623 & 383 & 6915 & \\
\hline & 8623 & 4.0 & 031 & \\
\hline IEMBL 3663463 & 528623 & 4.0 & 508 & \\
\hline AEMBL3663567 & 528623 & 5.7696 & 8306 & \\
\hline AEMBL3659213 & 528623 & 7.2291 & 1361 & \\
\hline AEMBL3663426 & 528623 & 6.0 & & \\
\hline 444 & 528623 & 383 & 139 & \\
\hline IEMBL 3 & 528623 & & & \\
\hline AEMBL3639624 & 528623 & 6.1152 & 5049 & \\
\hline AEMBL 366 & 528623 & 6.0223 & 7919 & $\mathrm{RI}$ \\
\hline IEMBL 366 & 528623 & 5 . & 767 & \\
\hline EMBL & 528623 & & 233 & \\
\hline IEMBL: & 528623 & & & \\
\hline AEMBL3659227 & 528623 & 098 & 277 & RN \\
\hline AEMBL36 & 528623 & 409 & 338 & \\
\hline IEMBL 36 & 528623 & 5 . & & \\
\hline AEMBL. & 528623 & 7. & 87 & \\
\hline HEMBL; & 528623 & 4. & 385 & \\
\hline AEMBL3663447 & 528623 & & 847 & RN \\
\hline IEMBL 3663512 & & & 59 & \\
\hline IEMBL36 & 8623 & & 146 & \\
\hline 2 & 3 & & 08 & ST \\
\hline ICMPI. & 528623 & & 13 & NIV \\
\hline 3663476 & 528623 & 49 & 493 & RN \\
\hline IEMBL 3663443 & & & & RN \\
\hline IEMBL3663455 & 528623 & & 066 & RN \\
\hline 24 & 5286 & 56 & & 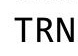 \\
\hline 97 & 23 & 86 & & RN \\
\hline AEMBL3659223 & & & & RN \\
\hline AEMBL3659182 & 528623 & & 48 & RI \\
\hline AEMBL3663549 & 528623 & 258 & 588 & RI \\
\hline 29 & 3 & 6. & 35 & RIV \\
\hline 4 & 23 & 8. & 57 & ST \\
\hline AEMBL3663459 & 528623 & 4.0 & 769 & TS \\
\hline AEMBL3663473 & 528623 & & & $\Gamma \mathrm{R}$ \\
\hline IEIMDLJO & 528623 & & & ST \\
\hline & 500 & 7. & 789 & m \\
\hline & 23 & & 95 & RN \\
\hline AEMBL3659211 & 528623 & 6.5969 & 4606 & $\lceil\mathrm{RN}$ \\
\hline AEMBL3663398 & 528623 & 5 . & & TS \\
\hline 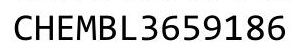 & & & & \\
\hline & & & & \\
\hline CHEMBL3663469 & 1528623 & 5.5976 & 189 & RN \\
\hline AEMBL3663516 & 1528623 & 4.0 & 4.1608 & $\mathrm{TR}$ \\
\hline HFMRI 3653195 & 1528623 & 5.5376 & 5.3542 & \\
\hline
\end{tabular}

Page 22429 
Supplemental Table S2.txt

\begin{tabular}{|c|c|c|c|c|}
\hline 1 & & & & \\
\hline & 528623 & 6.2396 & & \\
\hline EN & 28623 & 4.0 & & \\
\hline IEMBL & 3623 & 6 & & \\
\hline AEMBL3663559 & 528623 & 4.0 & 9959 & \\
\hline HEMBL3663481 & 528623 & 6.2076 & 2 & \\
\hline 396 & 28623 & 202 & & \\
\hline AEMBL: & 8623 & 5.9208 & & \\
\hline HEMBL3659199 & 528623 & 6.8268 & & \\
\hline HEMBL3663480 & 528623 & 5.9208 & & \\
\hline HEMBL3663523 & 528623 & 6.3098 & & \\
\hline AEMBL & 28623 & 6.0 & 336 & ST \\
\hline AEMBL: & & & & \\
\hline HEMBL3659226 & 528623 & 5.6198 & 5001 & \\
\hline AEMBL3659180 & 528623 & 6.0 & & \\
\hline AEMBL3 & 3 & 6. & & \\
\hline AEMBL & 23 & & & 年 \\
\hline HEMBL. & 23 & 6 . & & \\
\hline 63460 & 528623 & 6.27 & & \\
\hline HEMBL3663386 & & 706 & 36 & 151 \\
\hline HEMBL & 23 & 7. & 63 & ГRN \\
\hline IEM & & & & ונס \\
\hline FMBI & 23 & 86 & & BN \\
\hline 63452 & 23 & & & | \\
\hline AEMBL3 & & 5 . & 97 & I RN \\
\hline HEMBL & S & 9 & & RN \\
\hline HEM & 3 & & & KIV \\
\hline 544 & 23 & 48 & & \\
\hline HEMBL & & & & 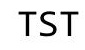 \\
\hline AEMBL3659183 & 528623 & 7.1487 & 91 & TRN \\
\hline EMB I & 623 & 5 & & RN \\
\hline 6 & & 5 & & ST \\
\hline IFMD & & & 97 & TST \\
\hline HEMBL3 & 23 & & & 「RN \\
\hline HEMBL3663564 & 28623 & 5 . & 301 & ГST \\
\hline 15 & 3 & 15 & & ГST \\
\hline 8 & 23 & 2 & & TRN \\
\hline HEMBL 3639623 & & & & TST \\
\hline HEMBL36634 & $\delta<c$ & 239 & & $\Gamma \mathrm{R}$ \\
\hline U & 23 & 91 & & RN \\
\hline HEMBL3 & & 5 . & & TRN \\
\hline & 23 & & & IST \\
\hline HEMBL3663508 & 5286 & 5.50 & & TST \\
\hline HEMBL36635 & 52 & 458 & & TS \\
\hline CHEMBL3663545 & & & & II \\
\hline HEMBL3 & & .5901 & 9591 & \\
\hline HEMBL3663458 & 5200 & .4437 & .1775 & RN \\
\hline HEMBL 3663441 & 1528623 & 6.3716 & 5.8487 & - \\
\hline
\end{tabular}

Page 22430 
Supplemental Table S2.txt

\begin{tabular}{|c|c|c|c|c|c|}
\hline CHEMBL 3663457 & 1528623 & 6.5229 & 6.7512 & TRN & \\
\hline CHEMBL3663531 & 1528623 & 5.9469 & \multicolumn{2}{|c|}{5.242999999999999} & TST \\
\hline CHEMBL3659228 & 1528623 & 4.0 & 4.5462 & TRN & \\
\hline CHEMBL 3663432 & 1528623 & 5.0 & 4.8128 & TRN & \\
\hline CHEMBL3663482 & 1528623 & 5.8239 & 5.7973 & TST & \\
\hline CHEMBL3663439 & 1528623 & 5.4089 & 5.4574 & TRN & \\
\hline CHEMBL 3659187 & 1528623 & 7.3565 & 7.4463 & TRN & \\
\hline CHEMBL 3663451 & 1528623 & 5.4949 & 5.0833 & TRN & \\
\hline CHEMBL 3663402 & 1528623 & 5.4318 & 5.4688 & TRN & \\
\hline CHEMBL3659192 & 1528623 & 5.8239 & 6.2015 & TRN & \\
\hline CHEMBL3663510 & 1528623 & 6.3233 & 6.0625 & TST & \\
\hline CHEMBL3659218 & 1528623 & 5.3566 & 5.7581 & TST & \\
\hline CHEMBL3663433 & 1528623 & 6.0 & 5.6891 & TRN & \\
\hline CHEMBL3663524 & 1528623 & 5.6778 & 5.5716 & TST & \\
\hline CHEMBL3663428 & 1528623 & 6.4498 & 6.4035 & TRN & \\
\hline CHEMBL3663552 & 1528623 & 5.4318 & 4.8124 & TST & \\
\hline CHEMBL3663485 & 1528623 & 5.0555 & 5.5241 & TST & \\
\hline CHEMBL 3663440 & 1528623 & 5.9208 & 5.4872 & TRN & \\
\hline CHEMBL3659238 & 1528623 & 6.2048 & 6.4324 & TRN & \\
\hline CHEMBL3663557 & 1528623 & 6.4841 & 6.5813 & TST & \\
\hline CHEMBL3659200 & 1528623 & 6.9136 & 6.6052 & TRN & \\
\hline CHEMBL3663384 & 1528623 & 6.062 & 4.94 & TST & \\
\hline CHEMBL1376633 & 1527823 & 5.4896 & 6.9152 & TST & \\
\hline CHEMBL3642612 & 1527823 & 5.1739 & 5.1721 & TRN & \\
\hline CHEMBL 3645164 & 1527823 & 6.7878 & 6.7783 & TRN & \\
\hline CHEMBL1601822 & 1527823 & 6.5784 & 5.0534 & TST & \\
\hline CHEMBL3936271 & 1527823 & 7.2147 & 6.2496 & TST & \\
\hline CHEMBL3645171 & 1527823 & 7.5686 & 7.5667 & TRN & \\
\hline CHEMBL3642633 & 1527823 & 5.8239 & 5.8284 & TRN & \\
\hline CHEMBL1233882 & 1527823 & 6.6576 & 6.6583 & TRN & \\
\hline CHEMBL 3645174 & 1527823 & 7.2676 & 7.2683 & TRN & \\
\hline CHEMBL3642599 & 1527823 & 5.1135 & 5.112 & TRN & \\
\hline CHEMBL 3642616 & 1527823 & 5.0969 & 5.0982 & TRN & \\
\hline CHEMBL3645177 & 1527823 & 6.7595 & 6.7615 & TRN & \\
\hline CHEMBL3919635 & 1527823 & 5.0915 & 5.0927 & TRN & \\
\hline CHEMBL3955419 & 1527823 & 5.3468 & 5.3467 & TRN & \\
\hline CHEMBL3642613 & 1527823 & 6.0883 & 6.0885 & TRN & \\
\hline CHEMBL 3937030 & 1527823 & 6.8861 & 4.3712 & TST & \\
\hline CHEMBL3642609 & 1527823 & 5.1024 & 5.1014 & TRN & \\
\hline CHEMBL 3642605 & 1527823 & 5.2924 & 5.2925 & TRN & \\
\hline CHEMBL3645170 & 1527823 & 6.7959 & 6.7952 & TRN & \\
\hline CHEMBL3645169 & 1527823 & 6.2967 & 6.2965 & TRN & \\
\hline CHEMBL3645166 & 1527823 & 7.3098 & 7.3174 & TRN & \\
\hline CHEMBL3642617 & 1527823 & 5.5528 & 5.5548 & TRN & \\
\hline CHEMBL 3642623 & 1527823 & 6.8539 & 6.8499 & TRN & \\
\hline CHEMBL1570219 & 1527823 & 5.704 & 6.1483 & TST & \\
\hline CHEMBL1241481 & 1527823 & 6.6402 & 6.6401 & TRN & \\
\hline CHEMBL3642610 & 1527823 & 5.2518 & 5.2537 & TRN & \\
\hline
\end{tabular}

Page 22431 
Supplemental Table S2.txt

\begin{tabular}{|c|c|c|c|c|c|c|c|}
\hline CHEMBL 3642622 & 1527823 & 5.3979 & 5.3954 & TRN & & & \\
\hline CHEMBL 3645168 & 1527823 & 7.4318 & 7.4324 & TRN & & & \\
\hline CHEMBL 3645163 & 1527823 & 6.7825 & 6.7849 & TRN & & & \\
\hline CHEMBL 3642632 & 1527823 & 6.04 & 6.0388 & TRN & & & \\
\hline CHEMBL 3645176 & 1527823 & \multicolumn{3}{|c|}{5.638999999999999} & \multicolumn{2}{|c|}{5.638999999999999} & TRN \\
\hline CHEMBL 3642635 & 1527823 & 5.3386 & 5.3364 & TRN & & & \\
\hline CHEMBL 3642620 & 1527823 & 5.2441 & 5.2417 & TRN & & & \\
\hline CHEMBL 3951035 & 1527823 & 5.83 & 5.8289 & TRN & & & \\
\hline CHEMBL 3642614 & 1527823 & 6.3468 & 6.3482 & TRN & & & \\
\hline CHEMBL3950821 & 1527823 & 5.2291 & 5.231 & TRN & & & \\
\hline CHEMBL 3642600 & 1527823 & 7.4045 & 7.3962 & TRN & & & \\
\hline CHEMBL 3907072 & 1527823 & 5.6021 & 5.6022 & TRN & & & \\
\hline CHEMBL 3642619 & 1527823 & 6.1427 & 6.1401 & TRN & & & \\
\hline CHEMBL 3645162 & 1527823 & 5.0 & 5.0001 & TRN & & & \\
\hline CHEMBL3642618 & 1527823 & 5.5913 & 5.5934 & TRN & & & \\
\hline CHEMBL 3645175 & 1527823 & 6.0794 & 6.0795 & TRN & & & \\
\hline CHEMBL1241578 & 1527823 & 6.75700 & 000000000 & & 6.7566 & TRN & \\
\hline CHEMBL 3949846 & 1527823 & 5.301 & 5.2991 & TRN & & & \\
\hline CHEMBL 3642607 & 1527823 & 6.8268 & 6.8369 & TRN & & & \\
\hline CHEMBL1526260 & 1527823 & 5.8239 & 6.8964 & TST & & & \\
\hline CHEMBL 3645172 & 1527823 & 7.4949 & 7.4948 & TRN & & & \\
\hline CHEMBL 3642602 & 1527823 & 5.1549 & 5.1559 & TRN & & & \\
\hline CHEMBL1312649 & 1527823 & 5.8901 & 7.042999 & 999999999 & & TST & \\
\hline CHEMBL1589705 & 1527823 & 6.7825 & 6.7826 & TRN & & & \\
\hline CHEMBL 3642634 & 1527823 & 5.0707 & 5.0709 & TRN & & & \\
\hline CHEMBL 3645167 & 1527823 & 6.6536 & 6.6549 & TRN & & & \\
\hline CHEMBL1610040 & 1527823 & 6.0315 & 6.1504 & TST & & & \\
\hline CHEMBL 3645165 & 1527823 & 6.6144 & 6.2695 & TST & & & \\
\hline CHEMBL584726 & 1527823 & 5.6424 & 6.6405 & TST & & & \\
\hline CHEMBL 3642601 & 1527823 & 5.5376 & 5.8258 & TST & & & \\
\hline CHEMBL 3642636 & 1527823 & 5.4387 & 5.7544 & TST & & & \\
\hline CHEMBL 3642611 & 1527823 & 6.8069 & 6.3628 & TST & & & \\
\hline CHEMBL 3642604 & 1527823 & 6.556 & 6.882000 & 000000000 & & TST & \\
\hline CHEMBL 3645173 & 1527823 & 6.3615 & 6.9024 & TST & & & \\
\hline CHEMBL1469921 & 736953 & 4.7258 & 4.9463 & TRN & & & \\
\hline CHEMBL1387581 & 736953 & 5.1135 & 4.8746 & TRN & & & \\
\hline CHEMBL 3189343 & 736953 & 3.0 & 4.184 & TRN & & & \\
\hline CHEMBL1469576 & 736953 & 3.0 & 4.1714 & TST & & & \\
\hline CHEMBL1331373 & 736953 & 3.0 & 3.3141 & TRN & & & \\
\hline CHEMBL1463851 & 736953 & 5.0074 & 4.9644 & TRN & & & \\
\hline CHEMBL1527436 & 736953 & 4.8962 & 5.1037 & TRN & & & \\
\hline CHEMBL1719094 & 736953 & 5.1959 & 4.9104 & TRN & & & \\
\hline CHEMBL1255778 & 736953 & 5.26200 & 000000000 & 305 & 4.84 & TST & \\
\hline CHEMBL1510541 & 736953 & 4.9872 & 4.5737 & TRN & & & \\
\hline CHEMBL1387562 & 736953 & 3.0 & 4.2629 & TRN & & & \\
\hline CHEMBL1587750 & 736953 & 3.0 & 3.5715 & TRN & & & \\
\hline CHEMBL1352305 & 736953 & 4.82100 & 000000000 & & 4.4739 & TRN & \\
\hline CHEMBL1556273 & 736953 & 4.1824 & 4.9098 & TRN & & & \\
\hline
\end{tabular}




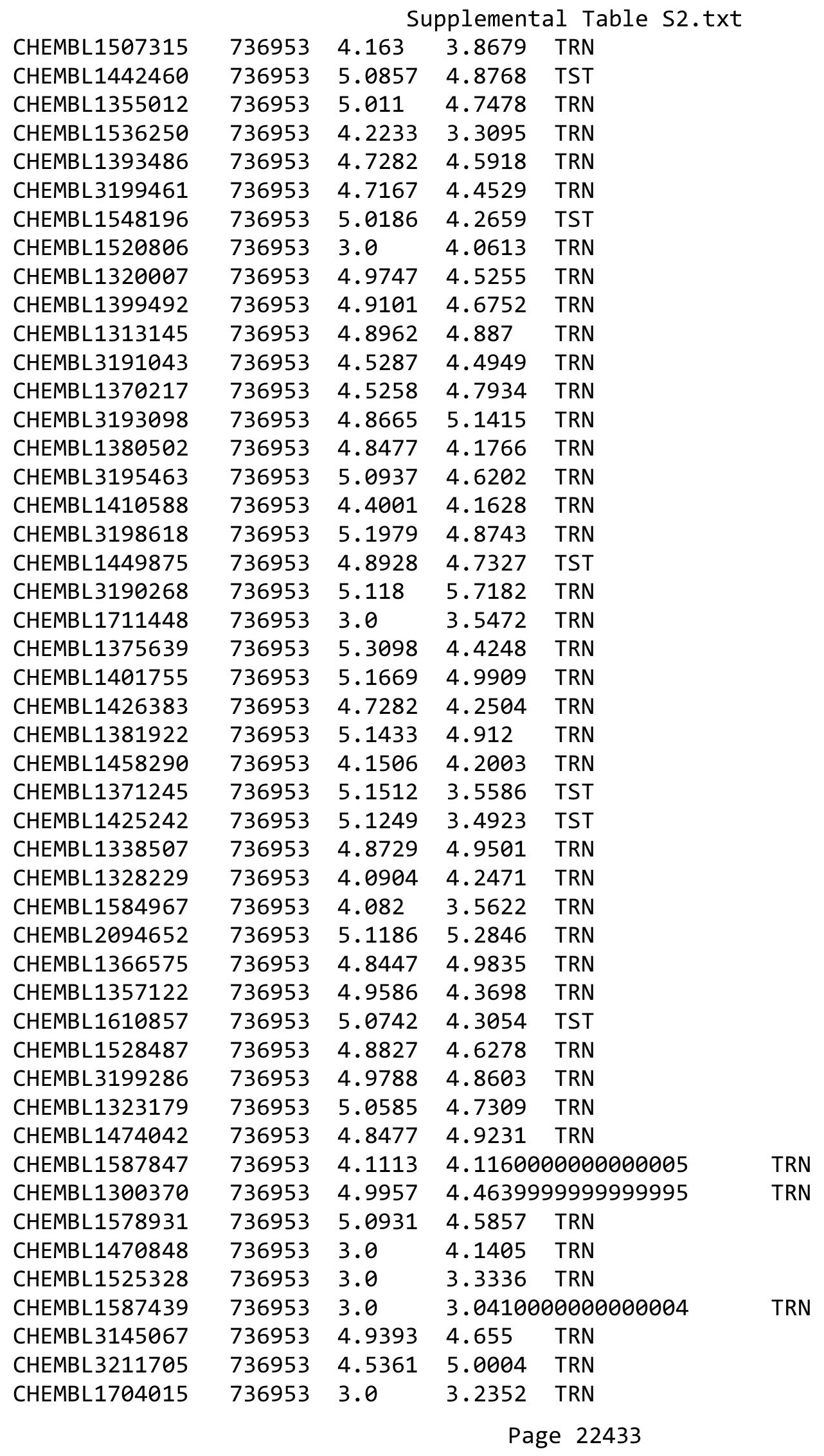




\begin{tabular}{|c|c|c|c|c|c|}
\hline \multirow[b]{2}{*}{ CHEMBL1370019 } & \multicolumn{5}{|c|}{ Supplemental Table S2.txt } \\
\hline & 736953 & 4.6364 & 3.4251 & TRN & \\
\hline CHEMBL1376939 & 736953 & 3.0 & 4.3152 & TST & \\
\hline CHEMBL1340782 & 736953 & 4.9872 & 5.0006 & TRN & \\
\hline CHEMBL3199528 & 736953 & 4.6676 & 4.5572 & TRN & \\
\hline CHEMBL3199041 & 736953 & 5.2434 & 5.2586 & TRN & \\
\hline CHEMBL1393616 & 736953 & 4.5528 & 4.6136 & TRN & \\
\hline CHEMBL3189698 & 736953 & 4.8827 & 4.9423 & TRN & \\
\hline CHEMBL1503528 & 736953 & 5.1445 & 4.7212 & TRN & \\
\hline CHEMBL1981063 & 736953 & 4.3904 & 4.2087 & TST & \\
\hline CHEMBL1544375 & 736953 & 5.059 & 4.6876 & TRN & \\
\hline CHEMBL1406734 & 736953 & 4.8827 & 4.8377 & TRN & \\
\hline CHEMBL1319190 & 736953 & 4.8508 & 4.4559 & TRN & \\
\hline CHEMBL1398243 & 736953 & 4.2125 & 3.5846 & TRN & \\
\hline CHEMBL195258 & 736953 & 5.0867 & 4.8602 & TRN & \\
\hline CHEMBL1699830 & 736953 & 4.1506 & 4.3798 & TRN & \\
\hline CHEMBL1721433 & 736953 & 4.9281 & 4.1994 & TRN & \\
\hline CHEMBL1721503 & 736953 & 4.1308 & 3.9095 & TRN & \\
\hline CHEMBL1585596 & 736953 & 4.9431 & 4.4265 & TRN & \\
\hline CHEMBL3199267 & 736953 & 5.1791 & 4.8325 & TRN & \\
\hline CHEMBL1510785 & 736953 & 4.2226 & 4.1415 & TRN & \\
\hline CHEMBL1306695 & 736953 & 3.0 & 4.4777 & TRN & \\
\hline CHEMBL1732408 & 736953 & 4.9208 & 4.6119 & TRN & \\
\hline CHEMBL1701850 & 736953 & 4.1549 & 3.7091 & TRN & \\
\hline CHEMBL1326265 & 736953 & 4.9706 & 4.7079 & TRN & \\
\hline CHEMBL1461502 & 736953 & 4.1135 & 4.5365 & TRN & \\
\hline CHEMBL3207619 & 736953 & 4.9172 & 5.2637 & TRN & \\
\hline CHEMBL3209555 & 736953 & 3.0 & 3.7636 & TRN & \\
\hline CHEMBL1431219 & 736953 & 3.0 & 3.5669 & TRN & \\
\hline CHEMBL1405239 & 736953 & 4.8996 & 5.0117 & TRN & \\
\hline CHEMBL1348355 & 736953 & 5.0381 & 5.0972 & TRN & \\
\hline CHEMBL1559033 & 736953 & 3.0 & 3.4075 & TRN & \\
\hline CHEMBL3196753 & 736953 & 5.0788 & 5.232 & TRN & \\
\hline CHEMBL1476029 & 736953 & 5.0645 & 4.6961 & TST & \\
\hline CHEMBL3198018 & 736953 & 3.0 & 4.4739 & TRN & \\
\hline CHEMBL1341833 & 736953 & 4.6021 & 4.2089 & TRN & \\
\hline CHEMBL578061 & 736953 & 3.0 & 4.3232 & TST & \\
\hline CHEMBL1443436 & 736953 & 4.9172 & 4.8291 & TRN & \\
\hline CHEMBL1386267 & 736953 & 4.8013 & 4.352 & TRN & \\
\hline CHEMBL1701354 & 736953 & 5.3036 & 4.1374 & TRN & \\
\hline CHEMBL3197995 & 736953 & 3.0 & 4.3447 & TST & \\
\hline CHEMBL1730620 & 736953 & 4.9393 & 4.4301 & TRN & \\
\hline CHEMBL1969992 & 736953 & 5.1215 & 5.2102 & TRN & \\
\hline CHEMBL1458979 & 736953 & 3.0 & 3.6874 & TRN & \\
\hline CHEMBL1373061 & 736953 & 3.0 & 4.07600 & 00000000005 & TRN \\
\hline CHEMBL1505198 & 736953 & 4.9469 & 4.1551 & TRN & \\
\hline CHEMBL1604431 & 736953 & 3.0 & 3.6722 & TRN & \\
\hline CHEMBL3199008 & 736953 & 5.1851 & 4.6145 & TRN & \\
\hline CHEMBL1702573 & 736953 & 4.8297 & 4.7965 & TRN & \\
\hline
\end{tabular}

Page 22434 


\begin{tabular}{|c|c|c|c|c|c|}
\hline \multirow[b]{2}{*}{ CHEMBL1728960 } & \multicolumn{5}{|c|}{ Supplemental Table S2.txt } \\
\hline & 736953 & 5.0516 & 4.2479 & TST & \\
\hline CHEMBL1987472 & 736953 & 5.1746 & 5.3351 & TRN & \\
\hline CHEMBL89445 & 736953 & 4.7747 & 4.7148 & TST & \\
\hline CHEMBL1333209 & 736953 & 3.0 & 3.8816 & TRN & \\
\hline CHEMBL3213353 & 736953 & 5.0809 & 5.7723 & TRN & \\
\hline CHEMBL1444891 & 736953 & 4.4622 & 4.28100 & 3000000001 & TRN \\
\hline CHEMBL1323450 & 736953 & 5.0168 & 5.0632 & TRN & \\
\hline CHEMBL1405443 & 736953 & 3.0 & 3.5222 & TRN & \\
\hline CHEMBL1572583 & 736953 & 4.8861 & 4.8069 & TRN & \\
\hline CHEMBL1506262 & 736953 & 5.1007 & 5.1114 & TRN & \\
\hline CHEMBL1707286 & 736953 & 4.7932 & 4.7363 & TST & \\
\hline CHEMBL1590634 & 736953 & 4.9957 & 4.5486 & TST & \\
\hline CHEMBL1718303 & 736953 & 5.007 & 4.2407 & TST & \\
\hline CHEMBL1721630 & 736953 & 3.0 & 3.7661 & TST & \\
\hline CHEMBL1477428 & 736953 & 3.0 & 4.6043 & TST & \\
\hline CHEMBL3191453 & 736953 & 5.1267 & 5.0878 & TST & \\
\hline CHEMBL1583835 & 736953 & 4.9393 & 4.3519 & TST & \\
\hline CHEMBL 3207816 & 736953 & 5.109 & 5.3638 & TST & \\
\hline CHEMBL1731731 & 736953 & 3.0 & 4.6045 & TST & \\
\hline CHEMBL1974613 & 736953 & 5.2197 & 5.1227 & TST & \\
\hline CHEMBL1715135 & 736953 & 3.0 & 4.2202 & TST & \\
\hline CHEMBL1381655 & 736953 & 5.1931 & 4.7683 & TST & \\
\hline CHEMBL1357672 & 736953 & 4.9957 & 3.9851 & TST & \\
\hline CHEMBL1499914 & 736953 & 5.0555 & 5.1293 & TST & \\
\hline CHEMBL1459664 & 736953 & 4.0655 & 3.9924 & TST & \\
\hline CHEMBL1406348 & 736953 & 4.9172 & 4.6313 & TST & \\
\hline CHEMBL1323839 & 736953 & 3.0 & 3.5884 & TST & \\
\hline CHEMBL1537821 & 736953 & 3.0 & 4.1021 & TST & \\
\hline CHEMBL1411435 & 736953 & 5.0835 & 5.008 & TST & \\
\hline CHEMBL1594374 & 736953 & 5.0357 & 4.0452 & TST & \\
\hline CHEMBL1530684 & 688265 & 4.4 & 4.3564 & TRN & \\
\hline CHEMBL1565705 & 688265 & 4.3 & 4.3337 & TRN & \\
\hline CHEMBL1489064 & 688265 & 4.4 & 4.2744 & TRN & \\
\hline CHEMBL224282 & 688265 & 4.3 & 4.2384 & TRN & \\
\hline CHEMBL1499545 & 688265 & 5.3 & 5.2623 & TRN & \\
\hline CHEMBL1309179 & 688265 & 4.9 & 4.7673 & TRN & \\
\hline CHEMBL1562104 & 688265 & 5.3 & 5.392 & TRN & \\
\hline CHEMBL140 & 688265 & 4.4 & 4.385 & TRN & \\
\hline CHEMBL1450123 & 688265 & 4.3 & 4.3538 & TST & \\
\hline CHEMBL1492104 & 688265 & 4.9 & 4.7596 & TST & \\
\hline CHEMBL538146 & 688265 & 4.1 & 4.7144 & TRN & \\
\hline CHEMBL36296 & 688265 & 4.2 & 4.2676 & TRN & \\
\hline CHEMBL105712 & 688265 & 5.0 & 5.0123 & TRN & \\
\hline CHEMBL110739 & 688265 & 4.3 & 4.815 & TST & \\
\hline CHEMBL1370662 & 688265 & 4.4 & 4.3923 & TRN & \\
\hline CHEMBL1569493 & 688265 & 5.9 & 5.9121 & TRN & \\
\hline CHEMBL1409985 & 688265 & 5.5 & 5.2109 & TRN & \\
\hline CHEMBL1602699 & 688265 & 5.4 & 5.2137 & TRN & \\
\hline
\end{tabular}




\begin{tabular}{|c|c|c|c|c|c|}
\hline \multicolumn{6}{|c|}{ Supplemental Table S2.txt } \\
\hline CHEMBL1449018 & 688265 & 4.7 & 4.5883 & TRN & \\
\hline CHEMBL1408847 & 688265 & 5.1 & 5.2958 & TRN & \\
\hline CHEMBL1492884 & 688265 & 4.4 & 4.3448 & TRN & \\
\hline CHEMBL1526721 & 688265 & 5.1 & 5.0453 & TST & \\
\hline CHEMBL1456906 & 688265 & 4.3 & 4.601 & TST & \\
\hline CHEMBL1518369 & 688265 & 4.3 & 4.3761 & TRN & \\
\hline CHEMBL1462419 & 688265 & 4.4 & 4.4574 & TRN & \\
\hline CHEMBL1569226 & 688265 & 5.5 & 5.2124 & TRN & \\
\hline CHEMBL1526319 & 688265 & 4.3 & 4.3293 & TRN & \\
\hline CHEMBL1519327 & 688265 & 6.4 & 6.3189 & TRN & \\
\hline CHEMBL509531 & 688265 & 4.6 & 4.8264 & TST & \\
\hline CHEMBL1524617 & 688265 & 5.1 & 5.1377 & TRN & \\
\hline CHEMBL1485974 & 688265 & 4.5 & 4.3683 & TRN & \\
\hline CHEMBL1421613 & 688265 & 4.1 & 4.4081 & TST & \\
\hline CHEMBL1549844 & 688265 & 5.1 & 4.6045 & TST & \\
\hline CHEMBL1448387 & 688265 & 4.5 & 4.6053 & TRN & \\
\hline CHEMBL162598 & 688265 & 4.4 & 4.3539 & TST & \\
\hline CHEMBL1485360 & 688265 & 4.9 & 4.6046 & TRN & \\
\hline CHEMBL1338613 & 688265 & 4.5 & 4.3208 & TST & \\
\hline CHEMBL1609459 & 688265 & 5.1 & 5.1064 & TRN & \\
\hline CHEMBL1330518 & 688265 & 4.3 & 4.3065 & TRN & \\
\hline CHEMBL289277 & 688265 & 4.6 & 4.4026 & TRN & \\
\hline CHEMBL1418603 & 688265 & 4.4 & 4.2225 & TRN & \\
\hline CHEMBL1331245 & 688265 & 4.3 & 4.2833 & TRN & \\
\hline CHEMBL1447588 & 688265 & 5.1 & 4.9809 & TST & \\
\hline CHEMBL3391990 & 688265 & 4.4 & 4.4138 & TST & \\
\hline CHEMBL1407826 & 688265 & 4.9 & 4.7233 & TST & \\
\hline CHEMBL1510786 & 688265 & 4.5 & 4.4506 & TST & \\
\hline CHEMBL1558796 & 688265 & 4.5 & 4.5512 & TRN & \\
\hline CHEMBL454173 & 688265 & 4.3 & 4.7548 & TRN & \\
\hline CHEMBL1496957 & 688265 & 4.8 & 4.6689 & TRN & \\
\hline CHEMBL1451833 & 688265 & 4.5 & 4.4678 & TRN & \\
\hline CHEMBL1492729 & 688265 & 4.8 & 4.6689 & TRN & \\
\hline CHEMBL1600998 & 688265 & 5.4 & 5.42 & TRN & \\
\hline CHEMBL462576 & 688265 & 4.3 & 4.4918 & TST & \\
\hline CHEMBL44072 & 688265 & 4.4 & 4.3693 & TST & \\
\hline CHEMBL1452158 & 688265 & 4.3 & 4.2646 & TRN & \\
\hline CHEMBL935 & 688265 & 4.4 & 4.3461 & TRN & \\
\hline CHEMBL28 & 688265 & 4.3 & 4.4215 & TRN & \\
\hline CHEMBL280998 & 688265 & 4.8 & 4.4576 & TRN & \\
\hline CHEMBL1304981 & 688265 & 4.4 & 4.2501 & TST & \\
\hline CHEMBL1303139 & 688265 & 5.3 & 5.15799 & 99999999995 & TRN \\
\hline CHEMBL1142 & 688265 & 4.4 & 4.359 & TRN & \\
\hline CHEMBL334255 & 688265 & 4.9 & 4.9778 & TRN & \\
\hline CHEMBL1414154 & 688265 & 4.4 & 4.1507 & TRN & \\
\hline CHEMBL167423 & 688265 & 4.2 & 4.2611 & TRN & \\
\hline CHEMBL1612246 & 688265 & 4.4 & 4.5435 & TRN & \\
\hline CHEMBL1450607 & 688265 & 4.6 & 4.6286 & TST & \\
\hline
\end{tabular}




\begin{tabular}{|c|c|c|c|c|c|}
\hline \multicolumn{6}{|c|}{ Supplemental Table S2.txt } \\
\hline CHEMBL1535689 & 688265 & 4.4 & 4.3691 & TRN & \\
\hline CHEMBL192627 & 688265 & 4.4 & 4.623 & TST & \\
\hline CHEMBL1545634 & 688265 & 6.7001 & 6.5571 & TRN & \\
\hline CHEMBL8739 & 688265 & 4.3 & 4.2257 & TRN & \\
\hline CHEMBL1585396 & 688265 & 4.5 & 4.3883 & TST & \\
\hline CHEMBL8320 & 688265 & 4.5 & 4.4089 & TST & \\
\hline CHEMBL1517425 & 688265 & 4.3 & 4.1457 & TRN & \\
\hline CHEMBL1308088 & 688265 & 4.9 & 4.8403 & TRN & \\
\hline CHEMBL1236200 & 688265 & 4.1 & 4.3359 & TRN & \\
\hline CHEMBL85811 & 688265 & 4.3 & 4.1861 & TRN & \\
\hline CHEMBL195953 & 688265 & 4.0 & 4.2753 & TST & \\
\hline CHEMBL443949 & 688265 & 4.1 & 4.3998 & TRN & \\
\hline CHEMBL1580759 & 688265 & 4.7 & 4.4496 & TST & \\
\hline CHEMBL402063 & 688265 & 6.0 & 5.2716 & TST & \\
\hline CHEMBL144530 & 688265 & 4.5 & 4.2375 & TRN & \\
\hline CHEMBL1566504 & 688265 & 4.3 & 4.3658 & TST & \\
\hline CHEMBL175193 & 688265 & 4.1 & 4.2149 & TRN & \\
\hline CHEMBL230156 & 688265 & 4.3 & 4.2568 & TRN & \\
\hline CHEMBL1527567 & 688265 & 4.5 & 4.2162 & TRN & \\
\hline CHEMBL440287 & 688265 & 4.5 & 4.507 & TRN & \\
\hline CHEMBL1364985 & 688265 & 4.3 & 4.5784 & TRN & \\
\hline CHEMBL1576086 & 688265 & 4.4 & 4.4082 & TRN & \\
\hline CHEMBL1331832 & 688265 & 4.4 & 4.6674 & TRN & \\
\hline CHEMBL242080 & 688265 & 4.3 & 4.5198 & TRN & \\
\hline CHEMBL1344952 & 688265 & 4.3 & 4.2966 & TRN & \\
\hline CHEMBL1393325 & 688265 & 4.3 & 4.4183 & TRN & \\
\hline CHEMBL220845 & 688265 & 4.1 & 4.2271 & TRN & \\
\hline CHEMBL1366408 & 688265 & 4.4 & 4.6292 & TRN & \\
\hline CHEMBL1471289 & 688265 & 4.3 & 4.3775 & TRN & \\
\hline CHEMBL1430204 & 688265 & 4.4 & 4.416 & TRN & \\
\hline CHEMBL1559341 & 688265 & 4.4 & 4.3992 & TRN & \\
\hline CHEMBL1319452 & 688265 & 4.3 & 4.47199 & 99999999995 & TRN \\
\hline CHEMBL486193 & 688265 & 4.3 & 4.6838 & TST & \\
\hline CHEMBL1200471 & 688265 & 6.6 & 6.6926 & TRN & \\
\hline CHEMBL1522486 & 688265 & 4.6 & 4.641 & TRN & \\
\hline CHEMBL260972 & 477677 & 4.0 & 4.9607 & TRN & \\
\hline CHEMBL258961 & 477677 & 4.0 & 5.4031 & TRN & \\
\hline CHEMBL408221 & 477677 & 7.284 & 5.4114 & TST & \\
\hline CHEMBL264964 & 477677 & 7.3768 & 7.24 & TRN & \\
\hline CHEMBL 260265 & 477677 & 5.6383 & 4.331 & TRN & \\
\hline CHEMBL261357 & 477677 & 4.9586 & 4.7239 & TRN & \\
\hline CHEMBL262359 & 477677 & 4.8861 & 4.6101 & TRN & \\
\hline CHEMBL258962 & 477677 & 5.7212 & 4.5802 & TRN & \\
\hline CHEMBL258587 & 477677 & 3.4948 & 5.0373 & TRN & \\
\hline CHEMBL261504 & 477677 & 5.8861 & 5.3823 & TRN & \\
\hline CHEMBL259800 & 477677 & 4.0 & 5.3823 & TRN & \\
\hline CHEMBL261275 & 477677 & 6.3279 & 5.3248 & TRN & \\
\hline CHEMBL258796 & 477677 & 4.0 & 4.6542 & TRN & \\
\hline
\end{tabular}




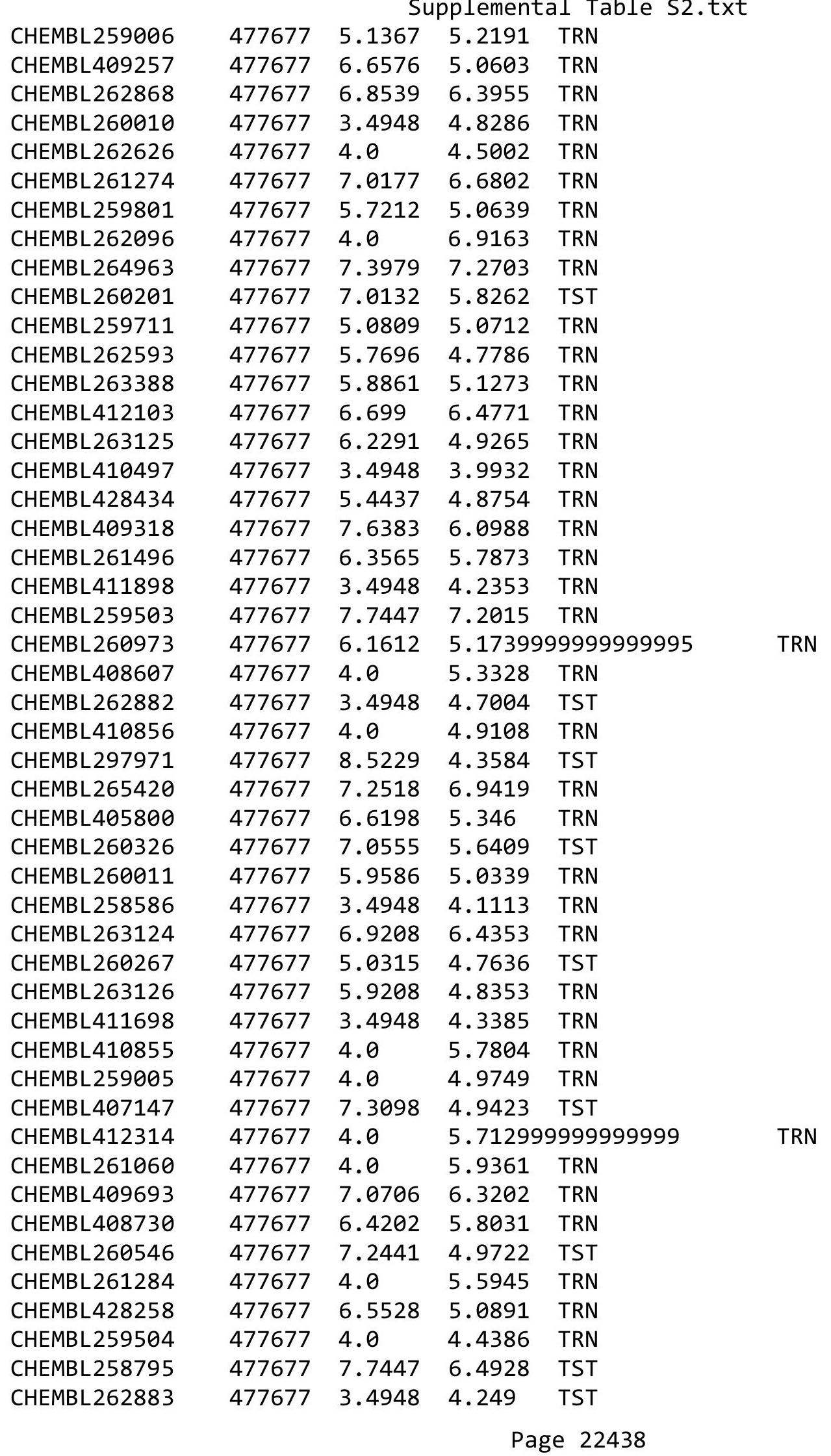




\begin{tabular}{|c|c|c|c|c|}
\hline \multicolumn{5}{|c|}{ Supplemental Table S2.txt } \\
\hline CHEMBL259598 & 477677 & 4.0 & 4.9277 & TRN \\
\hline CHEMBL260266 & 477677 & 4.0 & 4.3621 & TRN \\
\hline CHEMBL259502 & 477677 & 7.9586 & 7.0228 & TST \\
\hline CHEMBL 263387 & 477677 & 3.4948 & 5.271 & TST \\
\hline CHEMBL 261062 & 477677 & 7.5086 & 6.9469 & TRN \\
\hline CHEMBL410916 & 477677 & 6.6198 & 5.1375 & TRN \\
\hline CHEMBL259446 & 477677 & 3.4948 & 4.5423 & TRN \\
\hline CHEMBL410073 & 477677 & 6.699 & 5.234 & TRN \\
\hline CHEMBL 258549 & 477677 & 4.0 & 4.9238 & TRN \\
\hline CHEMBL261502 & 477677 & 8.0 & 7.2169 & TST \\
\hline CHEMBL 261356 & 477677 & 5.4815 & 4.6983 & TRN \\
\hline CHEMBL261503 & 477677 & 4.0 & 5.4784 & TRN \\
\hline CHEMBL262854 & 477677 & 3.4948 & 4.5268 & TST \\
\hline CHEMBL 262853 & 477677 & 5.4559 & 4.857 & TRN \\
\hline CHEMBL411258 & 477677 & 3.4948 & 4.2865 & TST \\
\hline CHEMBL 260591 & 477677 & 3.4948 & 4.4035 & TST \\
\hline CHEMBL406347 & 477677 & 5.9586 & 4.9921 & TRN \\
\hline CHEMBL 258793 & 477677 & 7.0706 & 6.6548 & TST \\
\hline CHEMBL 261273 & 477677 & 6.9208 & 4.5274 & TST \\
\hline CHEMBL428785 & 477677 & 6.0458 & 5.1915 & TRN \\
\hline CHEMBL 260324 & 477677 & 7.0362 & 4.9217 & TST \\
\hline CHEMBL 260012 & 477677 & 3.4948 & 4.5778 & TST \\
\hline CHEMBL 259710 & 477677 & 7.8239 & 6.9385 & TST \\
\hline CHEMBL 3234816 & 1336828 & 5.3516 & 5.3948 & TST \\
\hline CHEMBL 3234811 & 1336828 & 5.2565 & 4.779 & TRN \\
\hline CHEMBL 3234789 & 1336828 & 5.3054 & 4.4185 & TST \\
\hline CHEMBL 3234831 & 1336828 & 6.1249 & 6.2084 & TRN \\
\hline CHEMBL 3234802 & 1336828 & 5.6716 & 5.5773 & TRN \\
\hline CHEMBL 3234803 & 1336828 & 4.0 & 4.0939 & TRN \\
\hline CHEMBL 3234818 & 1336828 & 4.0 & 4.2767 & TRN \\
\hline CHEMBL 3234805 & 1336828 & 5.8601 & 5.7974 & TRN \\
\hline CHEMBL 3234827 & 1336828 & 6.284 & 6.4991 & TRN \\
\hline CHEMBL 3234796 & 1336828 & 5.4908 & 5.3143 & TRN \\
\hline CHEMBL 3234833 & 1336828 & 6.3372 & 6.1772 & TRN \\
\hline CHEMBL 3234839 & 1336828 & 5.8153 & 5.8757 & TRN \\
\hline CHEMBL 3234809 & 1336828 & 5.4609 & 5.4361 & TRN \\
\hline CHEMBL 3234834 & 1336828 & 6.2007 & 6.0759 & TRN \\
\hline CHEMBL 3234799 & 1336828 & 5.51 & 5.5673 & TRN \\
\hline CHEMBL 3234820 & 1336828 & 4.0 & 3.9088 & TRN \\
\hline CHEMBL 3234812 & 1336828 & 4.0 & 4.2648 & TRN \\
\hline CHEMBL 3234840 & 1336828 & 6.0655 & 6.2106 & TRN \\
\hline CHEMBL 3234835 & 1336828 & 6.1739 & 5.989 & TRN \\
\hline CHEMBL 3234838 & 1336828 & 6.2076 & 5.1004 & TST \\
\hline CHEMBL 3234844 & 1336828 & 6.2441 & 5.5314 & TST \\
\hline CHEMBL 3234790 & 1336828 & 5.118 & 4.1442 & TST \\
\hline CHEMBL 3234832 & 1336828 & 6.1079 & 6.0204 & TRN \\
\hline CHEMBL 3234815 & 1336828 & 6.0757 & 5.9429 & TRN \\
\hline CHEMBL3234843 & 1336828 & 5.8097 & 5.9745 & TRN \\
\hline
\end{tabular}

Page 22439 
Supplemental Table S2.txt

\begin{tabular}{|c|c|c|c|c|c|}
\hline CHEMBL 3234817 & 1336828 & 5.0531 & 5.075 & TRN & \\
\hline CHEMBL 2041121 & 1336828 & 5.82100 & 000000006 & 4.574 & TST \\
\hline CHEMBL3234836 & 1336828 & 6.0132 & 5.9322 & TRN & \\
\hline CHEMBL3234797 & 1336828 & 5.7496 & 5.9047 & TRN & \\
\hline CHEMBL3234823 & 1336828 & 4.0 & 4.0068 & TRN & \\
\hline CHEMBL3234806 & 1336828 & 4.0 & 3.8877 & TRN & \\
\hline CHEMBL3234794 & 1336828 & 4.0 & 4.0114 & TRN & \\
\hline CHEMBL3234819 & 1336828 & 4.0 & 3.737 & TRN & \\
\hline CHEMBL3234826 & 1336828 & 4.0 & 4.0109 & TRN & \\
\hline CHEMBL3234810 & 1336828 & 5.5607 & 5.3358 & TRN & \\
\hline CHEMBL 3234788 & 1336828 & 5.9747 & 4.7915 & TST & \\
\hline CHEMBL3234829 & 1336828 & 6.4318 & 6.4489 & TRN & \\
\hline CHEMBL3234792 & 1336828 & 5.6517 & 5.5322 & TRN & \\
\hline CHEMBL3234813 & 1336828 & 4.0 & \multicolumn{2}{|c|}{ 4.29899999999999995 } & TRN \\
\hline CHEMBL3234828 & 1336828 & 6.6576 & 6.6737 & TRN & \\
\hline CHEMBL 3234842 & 1336828 & 5.7282 & 5.6746 & TRN & \\
\hline CHEMBL3234821 & 1336828 & 4.0 & 3.9948 & TRN & \\
\hline CHEMBL3234825 & 1336828 & 4.0 & 3.7901 & TRN & \\
\hline CHEMBL 3234822 & 1336828 & 4.0 & 4.2633 & TRN & \\
\hline CHEMBL3234801 & 1336828 & 5.7122 & \multicolumn{2}{|c|}{5.792999999999999} & TRN \\
\hline CHEMBL3234798 & 1336828 & 5.5607 & 5.4508 & TRN & \\
\hline CHEMBL3234791 & 1336828 & 5.3279 & 5.3753 & TRN & \\
\hline CHEMBL 3234800 & 1336828 & 4.0 & 3.9589 & TRN & \\
\hline CHEMBL 3234804 & 1336828 & 4.0 & 4.3316 & TRN & \\
\hline CHEMBL3234841 & 1336828 & 6.1249 & 6.2873 & TRN & \\
\hline CHEMBL3234795 & 1336828 & 5.5513 & 5.6034 & TRN & \\
\hline CHEMBL3234793 & 1336828 & 5.5214 & 5.4372 & TST & \\
\hline CHEMBL3234807 & 1336828 & 4.0 & 5.5375 & TST & \\
\hline CHEMBL 3234837 & 1336828 & 6.1612 & \multicolumn{2}{|c|}{5.412000000000001} & TST \\
\hline CHEMBL3234787 & 1336828 & 5.0768 & 4.3251 & TST & \\
\hline CHEMBL3234814 & 1336828 & 4.0 & 4.5352 & TST & \\
\hline CHEMBL3234824 & 1336828 & 4.0 & 3.7344 & TST & \\
\hline CHEMBL 3234808 & 1336828 & 5.6615 & \multicolumn{2}{|c|}{6.446000000000001} & TST \\
\hline CHEMBL3234830 & 1336828 & 6.0362 & 6.303 & TST & \\
\hline CHEMBL10223 & 40166 & 3.2041 & 3.7538 & TRN & \\
\hline CHEMBL10117 & 40166 & 4.3279 & 4.2426 & TRN & \\
\hline CHEMBL274816 & 40166 & 5.699 & 5.6253 & TRN & \\
\hline CHEMBL10340 & 40166 & 3.2041 & 4.1846 & TRN & \\
\hline CHEMBL10252 & 40166 & 6.0458 & 4.9628 & TRN & \\
\hline CHEMBL9945 & 40166 & 3.2041 & 3.3742 & TRN & \\
\hline CHEMBL10770 & 40166 & 6.699 & 4.46399 & 99999999995 & TRN \\
\hline CHEMBL274319 & 40166 & 6.0969 & 6.289 & TRN & \\
\hline CHEMBL10156 & 40166 & 3.2041 & 3.5733 & TST & \\
\hline CHEMBL10248 & 40166 & 6.0969 & 4.4862 & TRN & \\
\hline CHEMBL10312 & 40166 & 6.3979 & 5.1532 & TRN & \\
\hline CHEMBL10337 & 40166 & 3.2041 & 3.6939 & TRN & \\
\hline CHEMBL10065 & 40166 & 6.0969 & 5.0247 & TRN & \\
\hline CHEMBL10254 & 40166 & 5.3979 & 4.1058 & TRN & \\
\hline
\end{tabular}




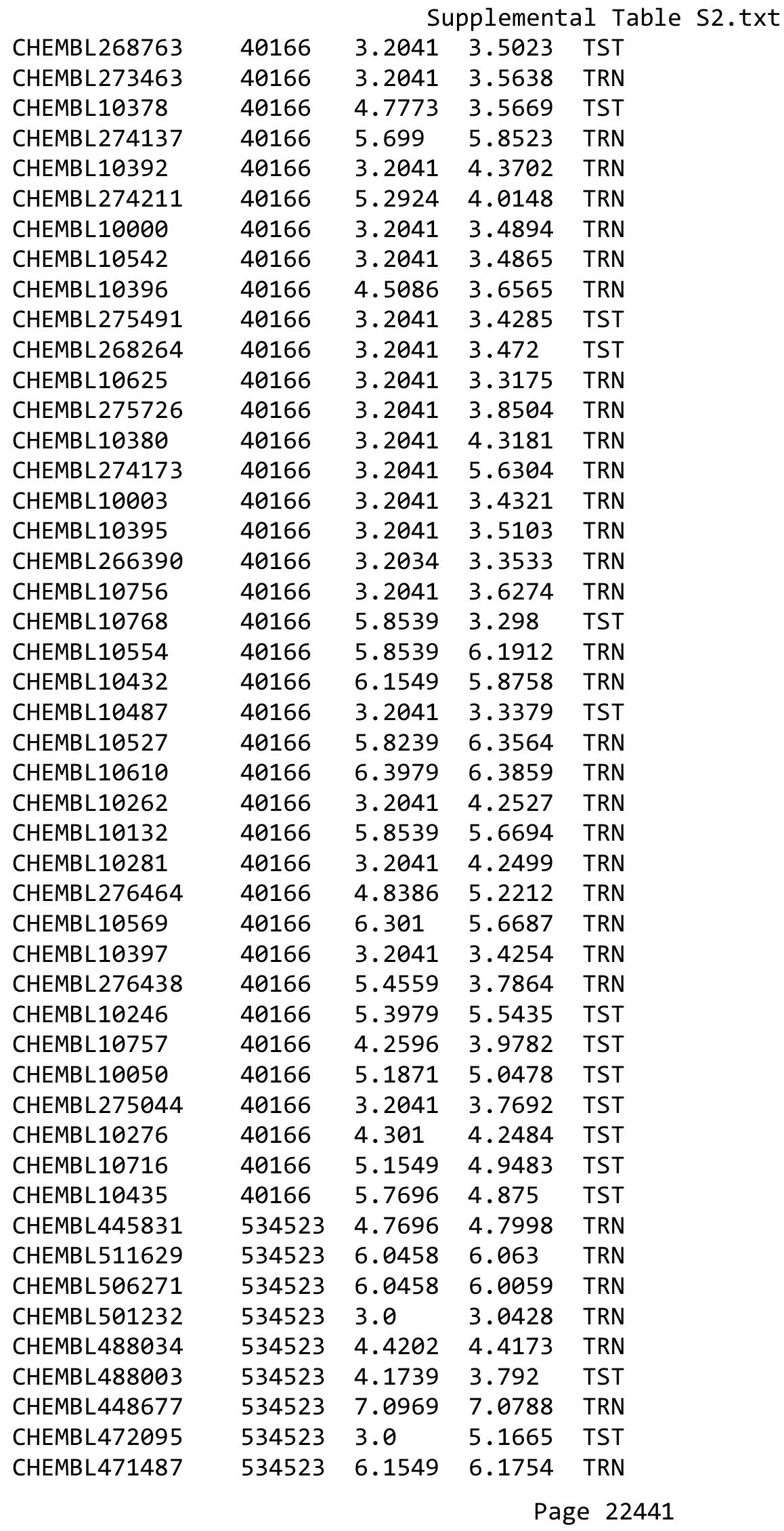




\begin{tabular}{|c|c|c|c|c|}
\hline & & & & \\
\hline CHEMBL506818 & 534523 & 4.284 & 4.4498 & $\mathrm{~T}$ \\
\hline CHEMBL488214 & 534523 & 5.8861 & 5.8829 & $\mathrm{TR}$ \\
\hline CHEMBL445728 & 34523 & 3.4202 & 3.8465 & \\
\hline CHEMBL487846 & 34523 & 3.0 & 3.0134 & \\
\hline CHEMBL469454 & 534523 & 6.301 & 6.2797 & \\
\hline CHEMBL499395 & 534523 & 6.3979 & 6.4277 & \\
\hline CHEMBL469868 & 534523 & 5.585 & 5.5873 & \\
\hline CHEMBL469870 & 534523 & 4.0862 & 4.0944 & \\
\hline CHEMBL488220 & 534523 & 5.1024 & 5.0761 & \\
\hline CHEMBL470069 & 534523 & 3.0 & 2.9914 & \\
\hline CHEMBL454206 & 534523 & 5.0458 & 5.0288 & \\
\hline CHEMBL488809 & 534523 & 3.0 & 3.0651 & \\
\hline CHEMBL487671 & 534523 & 5.8239 & 5.8449 & \\
\hline CHEMBL448845 & 534 & 5.2218 & 5.2322 & \\
\hline CHEMBL4 & 53 & 5.5376 & 5.5919 & \\
\hline CHEMBL471690 & 534523 & 3.1427 & 3.0179 & \\
\hline CHEMBL442602 & 534523 & 6.0 & 5.9664 & \\
\hline CHEMBL488009 & 534 & 6.5229 & 6.4703 & \\
\hline CHEMBL 51 & 534 & 5.0 & 4.965 & \\
\hline CHEMBL47 & 53 & 4.9586 & 4.9852 & \\
\hline CHEMBL521405 & 534 & 5.4318 & 5.4641 & \\
\hline CHEMBL470067 & 534 & 7.1549 & 7.1373 & \\
\hline CHEMBL487679 & 534 & 6.699 & 6.6766 & \\
\hline CHEMBL4 & 53 & 3.0 & 5.0705 & \\
\hline CHEMBL4 & 53 & 6.301 & 6.3415 & \\
\hline CHEMBL504628 & 534 & 4.7212 & 4.7468 & \\
\hline CHEMBL487811 & 534 & 6.5229 & 6.5588 & \\
\hline CHEMBL487858 & 534 & 5.1549 & 459 & \\
\hline CHEMBL4 & 53 & 4.9208 & 203 & \\
\hline CHEMBL487859 & 53 & 5.2366 & 5.2524 & \\
\hline CHEMBL452357 & 534 & 5.2757 & 5.2468 & \\
\hline CHEMBL470044 & 534 & 6.5229 & 6.5034 & $\mathrm{TH}$ \\
\hline CHEMBL511483 & 534 & 5.7959 & 5.8726 & \\
\hline CHEMBL4 & 53 & 5.0706 & 5.0255 & \\
\hline CHEMBL471896 & 53 & 5.1549 & 5.1578 & \\
\hline CHEMBL487677 & 534523 & 4.8861 & 4.9513 & \\
\hline CHEMBL487678 & 534523 & 5.8539 & 5.8824 & \\
\hline CHEMBL47 & 53 & 5.699 & 5.5773 & \\
\hline CHEMBL47 & 534 & 5.9208 & 5.9591 & \\
\hline CHEMBL527207 & 534523 & 4.7696 & 4.7569 & \\
\hline CHEMBL487857 & 534523 & 6.301 & 6.3233 & \\
\hline CHEMBL488008 & 534523 & 5.699 & 5.675 & \\
\hline CHEMBL46 & 534 & 5.3979 & 5.3471 & \\
\hline CHEMBL470068 & 534523 & 7.0 & 6.7637 & \\
\hline CHEMBL488215 & 534523 & 4.1739 & 4.6245 & TS \\
\hline CHEMBL454430 & 534523 & 5.0 & 6.7708 & \\
\hline CHEMBL488219 & 534523 & 6.699 & 6.8775 & \\
\hline CHEMBL513714 & 534523 & 4.2441 & 5.9378 & \\
\hline
\end{tabular}

Page 22442 


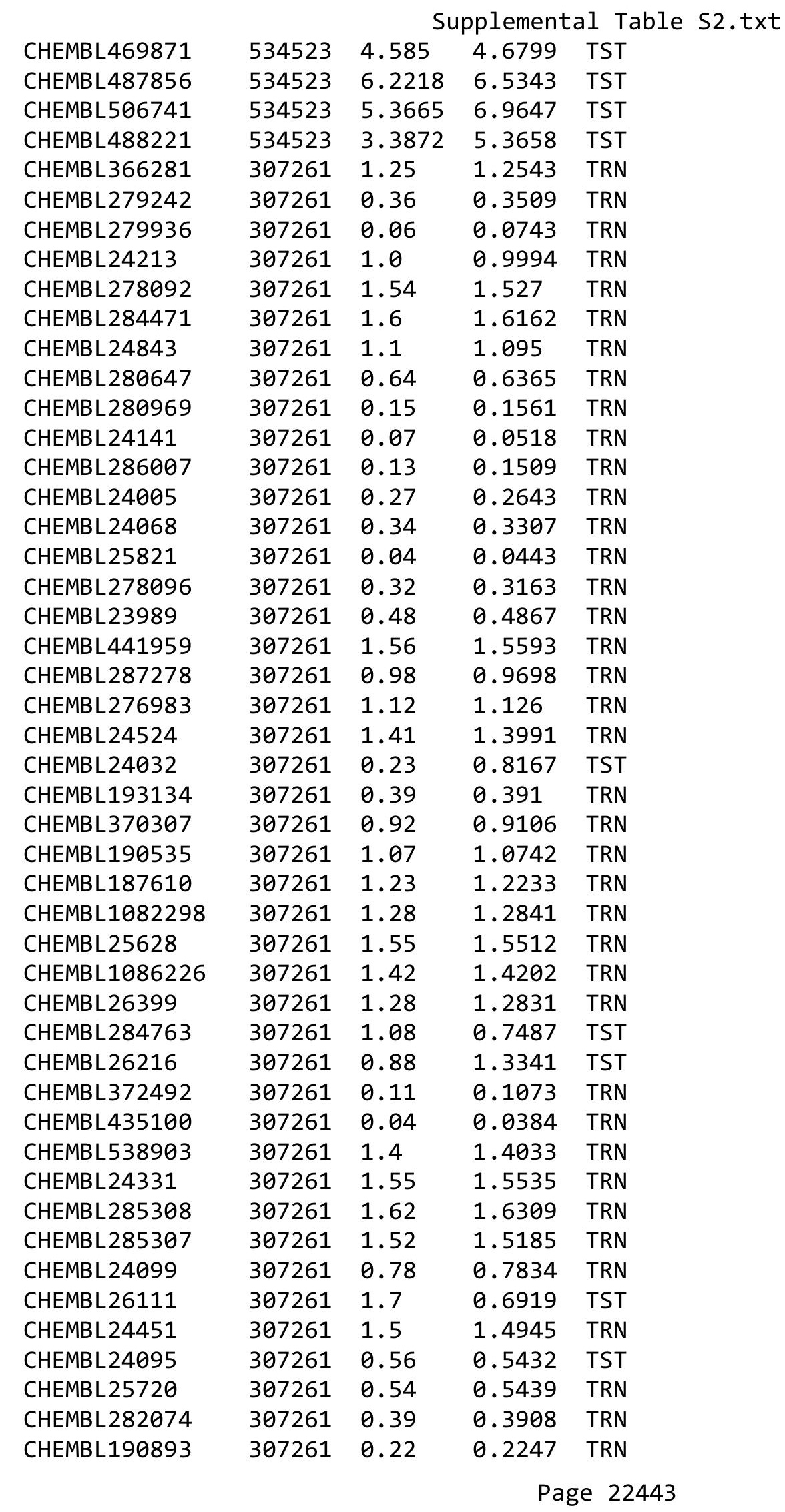




\begin{tabular}{|c|c|c|c|c|}
\hline \multicolumn{5}{|c|}{ Supplemental Table } \\
\hline CHEMBL191477 & 307261 & 0.23 & 0.2312 & TRN \\
\hline CHEMBL187946 & 307261 & 0.36 & 0.8189 & TST \\
\hline CHEMBL190476 & 307261 & 0.67 & 0.5988 & TST \\
\hline CHEMBL280667 & 307261 & 0.56 & 0.5456 & TRN \\
\hline CHEMBL282480 & 307261 & 0.32 & 0.3278 & TRN \\
\hline CHEMBL370026 & 307261 & 0.08 & 1.3876 & TST \\
\hline CHEMBL280138 & 307261 & 2.4 & 0.4402 & TST \\
\hline CHEMBL277402 & 307261 & 1.9 & 0.8703 & TST \\
\hline CHEMBL280863 & 307261 & 2.0 & 0.7848 & TST \\
\hline CHEMBL276985 & 307261 & 1.2 & 0.6905 & TST \\
\hline CHEMBL25079 & 307261 & 2.5 & 0.2707 & TST \\
\hline CHEMBL24204 & 307261 & 0.72 & 0.9445 & TST \\
\hline CHEMBL 30078 & 63217 & 5.301 & 5.2133 & TRN \\
\hline CHEMBL30075 & 63217 & 6.1805 & 5.3108 & TRN \\
\hline CHEMBL 30032 & 63217 & 7.5229 & 5.8384 & TRN \\
\hline CHEMBL267458 & 63217 & 7.8239 & 6.4266 & TRN \\
\hline CHEMBL285122 & 63217 & 6.5376 & 5.4297 & TRN \\
\hline CHEMBL 27063 & 63217 & 6.8239 & 5.5864 & TRN \\
\hline CHEMBL30245 & 63217 & 4.7986 & 6.2895 & TRN \\
\hline CHEMBL26527 & 63217 & 5.4685 & 5.5441 & TRN \\
\hline CHEMBL286521 & 63217 & 5.8861 & 5.4526 & TRN \\
\hline CHEMBL283300 & 63217 & 5.3098 & 5.3474 & TRN \\
\hline CHEMBL440653 & 63217 & 6.2291 & 5.8743 & TRN \\
\hline CHEMBL26470 & 63217 & 5.1871 & 4.7038 & TRN \\
\hline CHEMBL281942 & 63217 & 5.2441 & 5.894 & TRN \\
\hline CHEMBL 27344 & 63217 & 5.9318 & 5.6188 & TRN \\
\hline CHEMBL285814 & 63217 & 4.6198 & 5.8271 & TRN \\
\hline CHEMBL 26786 & 63217 & 5.5157 & 5.8846 & TRN \\
\hline CHEMBL27148 & 63217 & 3.4948 & 5.0207 & TST \\
\hline CHEMBL28692 & 63217 & 5.1871 & 5.8231 & TRN \\
\hline CHEMBL 27178 & 63217 & 5.7545 & 5.8596 & TRN \\
\hline CHEMBL27420 & 63217 & 4.762 & 5.1498 & TRN \\
\hline CHEMBL 29705 & 63217 & 4.5017 & 5.7024 & TRN \\
\hline CHEMBL27248 & 63217 & 4.2757 & 4.9121 & TST \\
\hline CHEMBL281427 & 63217 & 5.0 & 5.2482 & TRN \\
\hline CHEMBL431300 & 63217 & 5.5391 & 5.898 & TRN \\
\hline CHEMBL287451 & 63217 & 5.2518 & 6.1552 & TRN \\
\hline CHEMBL416026 & 63217 & 7.699 & 6.3373 & TRN \\
\hline CHEMBL26978 & 63217 & 7.2218 & 6.1981 & TRN \\
\hline CHEMBL27262 & 63217 & 4.3372 & 5.4865 & TRN \\
\hline CHEMBL282401 & 63217 & 5.8539 & 5.4905 & TRN \\
\hline CHEMBL282557 & 63217 & 4.9208 & 5.0266 & TRN \\
\hline CHEMBL417651 & 63217 & 5.2676 & 5.306 & TRN \\
\hline CHEMBL29954 & 63217 & 5.1079 & 5.8729 & TRN \\
\hline CHEMBL282961 & 63217 & 5.0362 & 5.1877 & TRN \\
\hline CHEMBL26252 & 63217 & 6.0555 & 6.1851 & TRN \\
\hline CHEMBL283652 & 63217 & 6.8861 & 6.3803 & TRN \\
\hline CHEMBL286682 & 63217 & 4.5686 & 4.9913 & TRN \\
\hline
\end{tabular}




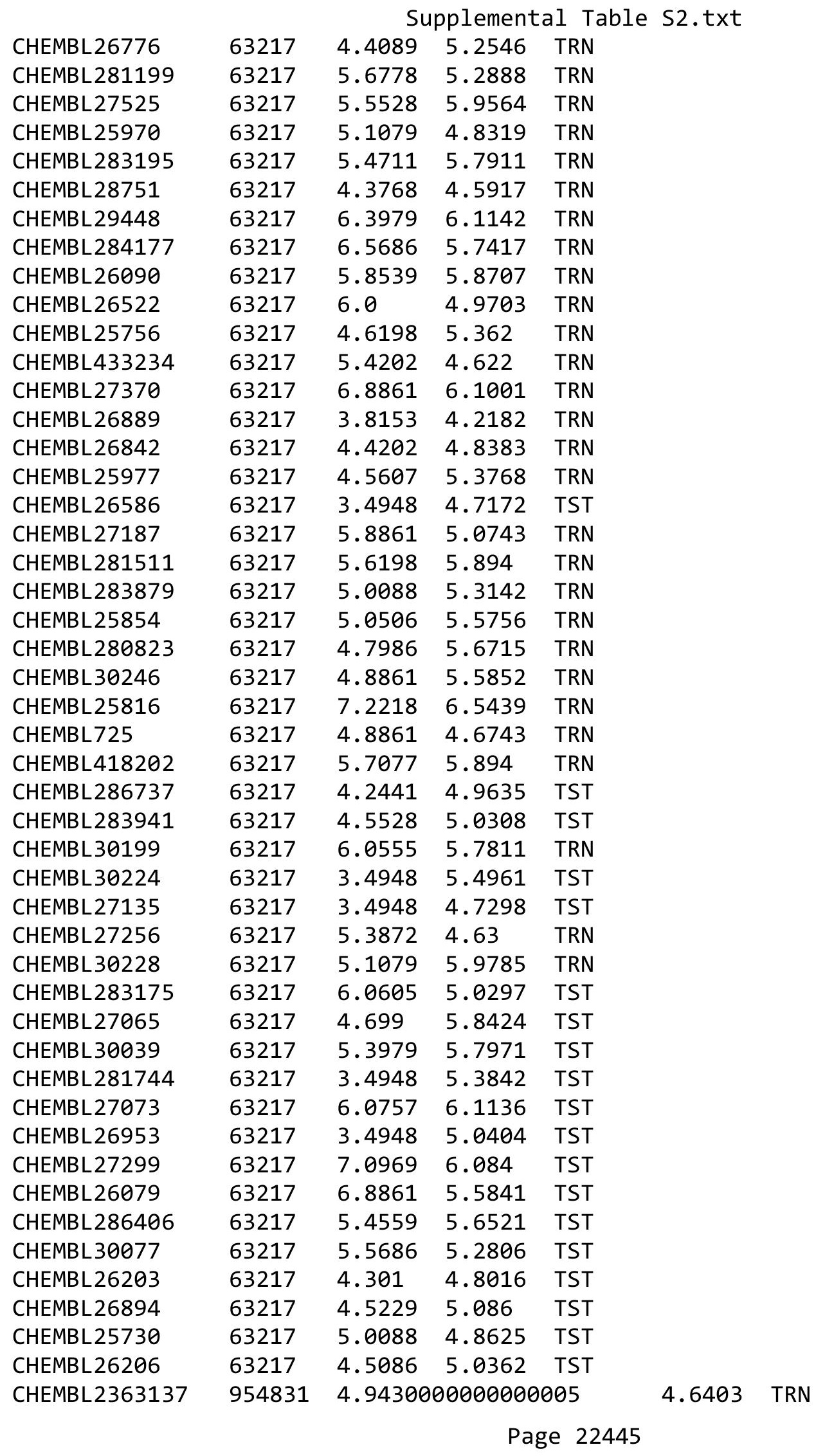


Supplemental Table S2.txt

\begin{tabular}{|c|c|c|c|c|}
\hline CHEMBL393929 & 954831 & 4.6777 & 4.5639 & TRN \\
\hline CHEMBL509032 & 954831 & 5.5501 & 5.2931 & TRN \\
\hline CHEMBL 2137530 & 954831 & 5.4524 & 5.0121 & TRN \\
\hline CHEMBL 399530 & 954831 & 3.6471 & 4.9619 & TRN \\
\hline CHEMBL1970879 & 954831 & 3.6431 & 3.4749 & TRN \\
\hline CHEMBL1190711 & 954831 & 5.6241 & 5.3503 & TRN \\
\hline CHEMBL189584 & 954831 & 4.4047 & 4.8145 & TRN \\
\hline CHEMBL392695 & 954831 & 5.7856 & 5.3051 & TRN \\
\hline CHEMBL210618 & 954831 & 4.2144 & 3.6866 & TRN \\
\hline CHEMBL 217354 & 954831 & 6.8875 & 6.3703 & TRN \\
\hline CHEMBL 3392440 & 954831 & 5.4751 & 4.3185 & TRN \\
\hline CHEMBL 2144069 & 954831 & 3.827 & 4.0205 & TRN \\
\hline CHEMBL1404918 & 954831 & 4.15 & 3.392 & TRN \\
\hline CHEMBL180127 & 954831 & 4.4866 & 4.4246 & TRN \\
\hline CHEMBL514499 & 954831 & 7.6021 & 7.0654 & TRN \\
\hline CHEMBL3349342 & 954831 & 3.5704 & 4.083 & TRN \\
\hline CHEMBL 255342 & 954831 & 3.5356 & 4.0284 & TRN \\
\hline CHEMBL1643959 & 954831 & 3.1215 & 3.4378 & TRN \\
\hline CHEMBL 258844 & 954831 & 5.0105 & 4.6903 & TRN \\
\hline CHEMBL379975 & 954831 & 5.6733 & 5.8364 & TRN \\
\hline CHEMBL188678 & 954831 & 4.525 & 4.9447 & TRN \\
\hline CHEMBL1230020 & 954831 & 3.9525 & 4.0303 & TRN \\
\hline CHEMBL577784 & 954831 & 5.7558 & 5.7675 & TRN \\
\hline CHEMBL 222102 & 954831 & 4.1799 & 4.2592 & TRN \\
\hline CHEMBL 202721 & 954831 & 5.7524 & 5.5075 & TRN \\
\hline CHEMBL1673039 & 954831 & 3.8227 & 4.3521 & TRN \\
\hline CHEMBL412142 & 954831 & 3.5056 & 3.6391 & TRN \\
\hline CHEMBL 373751 & 954831 & 3.5405 & 3.8236 & TRN \\
\hline CHEMBL3199475 & 954831 & 4.5669 & 4.8232 & TRN \\
\hline CHEMBL1186585 & 954831 & 5.0405 & 5.1919 & TRN \\
\hline CHEMBL102714 & 954831 & 3.6233 & 3.6899 & TRN \\
\hline CHEMBL 2005886 & 954831 & 5.7918 & 4.9441 & TRN \\
\hline CHEMBL65 & 954831 & 10.0189 & 9.721 & TRN \\
\hline CHEMBL191334 & 954831 & 3.3538 & 4.0789 & TRN \\
\hline CHEMBL 213100 & 954831 & 3.366 & 2.8013 & TRN \\
\hline CHEMBL1256459 & 954831 & 7.5091 & 7.1872 & TRN \\
\hline CHEMBL558642 & 954831 & 4.4801 & 4.2801 & TRN \\
\hline CHEMBL483847 & 954831 & 3.6533 & 4.0422 & TRN \\
\hline CHEMBL1516890 & 954831 & 4.9688 & 4.4301 & TRN \\
\hline CHEMBL209148 & 954831 & 5.1287 & 4.4063 & TRN \\
\hline CHEMBL 240954 & 954831 & 3.2032 & 4.2297 & TST \\
\hline CHEMBL1590308 & 954831 & 3.3441 & 3.4299 & TST \\
\hline CHEMBL221137 & 954831 & 5.1073 & 4.9333 & TST \\
\hline CHEMBL135561 & 954831 & 3.9717 & 4.374 & TRN \\
\hline CHEMBL3186408 & 954831 & 4.9933 & 3.9057 & TST \\
\hline CHEMBL512504 & 954831 & 4.0602 & 5.3994 & TRN \\
\hline CHEMBL573107 & 954831 & 5.3009 & 5.517 & TRN \\
\hline \multirow[t]{2}{*}{ CHEMBL 220241} & 954831 & 5.2564 & 4.8180 & 20000000005 \\
\hline & & \multicolumn{3}{|c|}{ Page 22446} \\
\hline
\end{tabular}




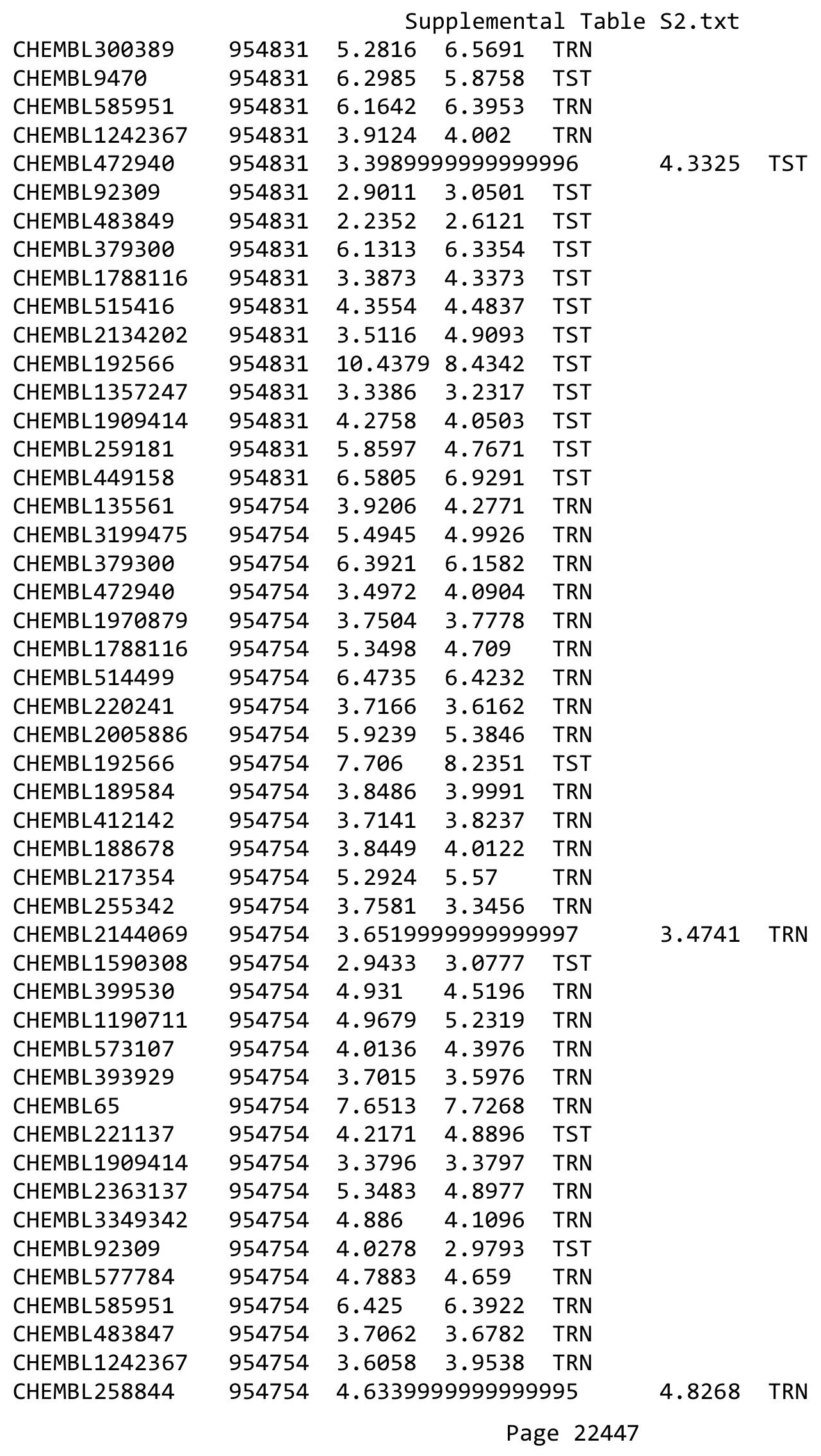




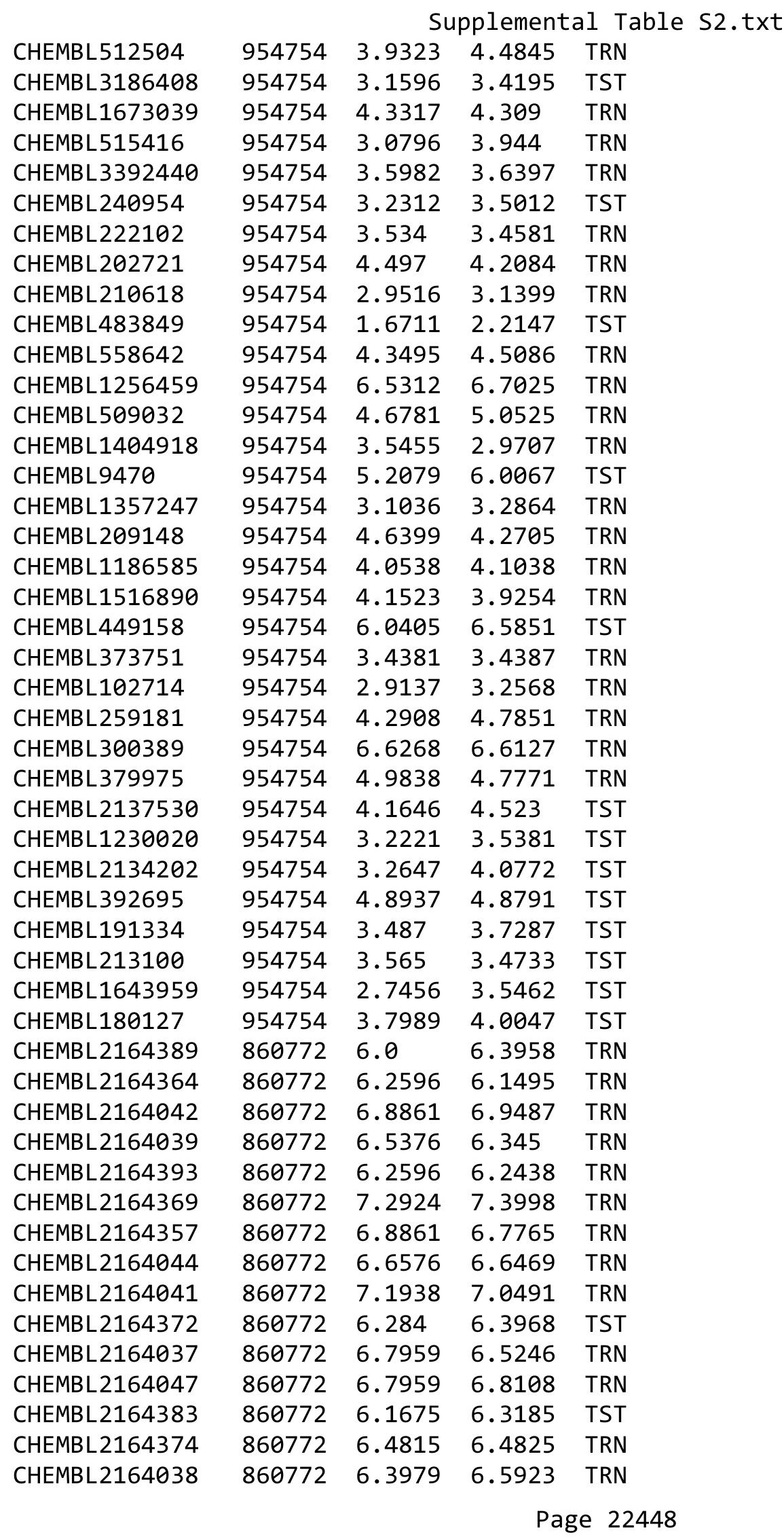




\begin{tabular}{|c|c|c|c|c|c|c|}
\hline \multirow{3}{*}{ CHEMBL 2164395} & \multirow[b]{2}{*}{860772} & \multicolumn{5}{|c|}{ Supplemental Table S2.txt } \\
\hline & & 6.4685 & \multicolumn{2}{|c|}{6.242000000000001} & & \multirow{2}{*}{ TRN } \\
\hline & 860772 & 6.8239 & 7.1238 & TST & & \\
\hline CHEMBL2164368 & 860772 & 7.0605 & 7.1063 & TRN & & \\
\hline CHEMBL2164394 & 860772 & 5.7212 & 5.7511 & TRN & & \\
\hline CHEMBL 2164362 & 860772 & 5.7959 & 5.8209 & TRN & & \\
\hline CHEMBL 2164385 & 860772 & 6.4559 & 6.5919 & TRN & & \\
\hline CHEMBL 2164045 & 860772 & 6.8539 & 6.8627 & TRN & & \\
\hline CHEMBL2164390 & 860772 & 7.3098 & 7.2453 & TRN & & \\
\hline CHEMBL 2164040 & 860772 & 5.5086 & 5.7249 & TRN & & \\
\hline CHEMBL 2164387 & 860772 & 6.7696 & 6.7137 & TRN & & \\
\hline CHEMBL 2164382 & 860772 & 6.7212 & 6.7745 & TRN & & \\
\hline CHEMBL 2164365 & 860772 & 6.4202 & 6.4 & TRN & & \\
\hline CHEMBL 2164370 & 860772 & 6.1487 & 6.276 & TRN & & \\
\hline CHEMBL2164363 & 860772 & 7.3468 & 7.1746 & TRN & & \\
\hline CHEMBL 2164375 & 860772 & 6.9586 & 6.8568 & TRN & & \\
\hline CHEMBL 2164046 & 860772 & 6.5086 & 6.4962 & TRN & & \\
\hline CHEMBL2164392 & 860772 & 6.4437 & 6.4297 & TRN & & \\
\hline CHEMBL 2164386 & 860772 & 3.9586 & 3.9884 & TRN & & \\
\hline CHEMBL2164376 & 860772 & 6.7212 & 6.7426 & TRN & & \\
\hline CHEMBL 2164378 & 860772 & 6.3768 & 6.4141 & TRN & & \\
\hline CHEMBL 2164361 & 860772 & 7.0132 & 6.9689 & TRN & & \\
\hline CHEMBL 2164388 & 860772 & 5.7959 & 5.5818 & TRN & & \\
\hline CHEMBL 2164043 & 860772 & 6.8539 & 6.9173 & TRN & & \\
\hline CHEMBL2164396 & 860772 & 6.3468 & 6.3913 & TRN & & \\
\hline CHEMBL 2164384 & 860772 & 6.4559 & 6.5245 & TRN & & \\
\hline CHEMBL2164379 & 860772 & 6.1249 & 6.066 & TRN & & \\
\hline CHEMBL 2164380 & 860772 & 6.3665 & 6.2474 & TST & & \\
\hline CHEMBL 2164358 & 860772 & 7.0862 & 7.2423 & TRN & & \\
\hline CHEMBL 2164371 & 860772 & 6.0 & 6.2505 & TST & & \\
\hline CHEMBL 2164397 & 860772 & 6.4949 & 6.3412 & TST & & \\
\hline CHEMBL 2164377 & 860772 & 6.2757 & 6.9836 & TST & & \\
\hline CHEMBL2164391 & 860772 & 6.585 & 6.5664 & TST & & \\
\hline CHEMBL 2164381 & 860772 & 6.0506 & 6.00200 & 0000000001 & & TST \\
\hline CHEMBL 2164356 & 860772 & 7.1367 & 6.69799 & 99999999995 & & TST \\
\hline CHEMBL2164359 & 860772 & 6.3665 & 7.13200 & 0000000001 & & TST \\
\hline CHEMBL2164366 & 860772 & 6.6383 & 6.4582 & TST & & \\
\hline CHEMBL 2163357 & 860772 & 6.2441 & 6.5627 & TST & & \\
\hline CHEMBL3945835 & 1637074 & 9.8539 & 9.9412 & TRN & & \\
\hline CHEMBL3984069 & 1637074 & 9.5229 & 9.5751 & TRN & & \\
\hline CHEMBL 3966138 & 1637074 & 9.699 & 9.5016 & TRN & & \\
\hline CHEMBL 3914134 & 1637074 & 11.0458 & 12.0336 & TST & & \\
\hline CHEMBL3948465 & 1637074 & 14.3009 & 79999999 & 998 & .4 .5172 & TRN \\
\hline CHEMBL3903349 & 1637074 & 9.0 & 9.6219 & TRN & & \\
\hline CHEMBL3968193 & 1637074 & 8.3979 & 8.6445 & TRN & & \\
\hline CHEMBL3909513 & 1637074 & 6.4191 & 6.4889 & TRN & & \\
\hline CHEMBL 3969701 & 1637074 & 6.9586 & 6.9123 & TRN & & \\
\hline CHEMBL3976968 & 1637074 & 14.3009 & 99999999 & 998 & 4.0796 & TRN \\
\hline CHEMBL3959086 & 1637074 & 7.3768 & 6.3273 & TST & & \\
\hline
\end{tabular}


Supplemental Table S2.txt

\begin{tabular}{|c|c|c|c|c|c|c|}
\hline CHEMBL 3931580 & 1637074 & 7.5686 & 7.9247 & TRN & & \\
\hline CHEMBL 3904357 & 1637074 & 14.3009 & 999999999 & 998 & 13.877 & TRN \\
\hline CHEMBL3933309 & 1637074 & 7.8539 & \multicolumn{3}{|c|}{7.627999999999999} & TRN \\
\hline CHEMBL3975338 & 1637074 & 7.9208 & 8.1728 & TRN & & \\
\hline CHEMBL 3943042 & 1637074 & 7.3979 & 7.5883 & TRN & & \\
\hline CHEMBL3977174 & 1637074 & 6.7773 & 6.8508 & TRN & & \\
\hline CHEMBL3907615 & 1637074 & 10.0 & 9.9292 & TRN & & \\
\hline CHEMBL3986182 & 1637074 & 8.5229 & 8.6498 & TRN & & \\
\hline CHEMBL 3973378 & 1637074 & 9.6198 & 9.7071 & TRN & & \\
\hline CHEMBL 3922081 & 1637074 & 9.0 & 9.0501 & TRN & & \\
\hline CHEMBL 3951495 & 1637074 & 9.0 & 9.0911 & TRN & & \\
\hline CHEMBL 3946325 & 1637074 & 9.699 & 9.568 & TRN & & \\
\hline CHEMBL 3892002 & 1637074 & 7.0706 & 6.3066 & TRN & & \\
\hline CHEMBL 3987024 & 1637074 & 6.9508 & \multicolumn{3}{|c|}{7.2410000000000005} & TRN \\
\hline CHEMBL 3956877 & 1637074 & 9.699 & 9.5502 & TRN & & \\
\hline CHEMBL3903926 & 1637074 & 9.0 & 9.0806 & TRN & & \\
\hline CHEMBL3963565 & 1637074 & 7.2518 & 7.2638 & TRN & & \\
\hline CHEMBL 3941750 & 1637074 & 6.5751 & 6.917999 & 999999999 & & TRN \\
\hline CHEMBL 3906794 & 1637074 & 9.2218 & 13.9516 & TST & & \\
\hline CHEMBL 3938188 & 1637074 & 6.8794 & 7.029 & TRN & & \\
\hline CHEMBL3911932 & 1637074 & \multicolumn{3}{|c|}{14.300999999999998} & 14.3596 & TRN \\
\hline CHEMBL 3967271 & 1637074 & 10.0 & 9.8947 & TRN & & \\
\hline CHEMBL3959115 & 1637074 & 6.5114 & 8.221 & TST & & \\
\hline CHEMBL 3968483 & 1637074 & 7.3979 & 7.4161 & TRN & & \\
\hline CHEMBL3981640 & 1637074 & 8.0969 & 7.6315 & TRN & & \\
\hline CHEMBL3922889 & 1637074 & 8.2218 & 8.0537 & TRN & & \\
\hline CHEMBL3919353 & 1637074 & \multicolumn{3}{|c|}{14.300999999999998} & 14.08 & TRN \\
\hline CHEMBL 3947747 & 1637074 & 8.2218 & 8.1117 & TRN & & \\
\hline CHEMBL3957692 & 1637074 & 8.5229 & 8.2966 & TRN & & \\
\hline CHEMBL 3977448 & 1637074 & 8.699 & 11.5543 & TST & & \\
\hline CHEMBL3918379 & 1637074 & \multicolumn{3}{|c|}{14.300999999999998} & 14.4376 & TRN \\
\hline CHEMBL 3963181 & 1637074 & 10.0458 & 9.8379 & TRN & & \\
\hline CHEMBL 3962687 & 1637074 & 10.0 & 10.0586 & TRN & & \\
\hline CHEMBL 3924295 & 1637074 & 9.699 & 12.6845 & TST & & \\
\hline CHEMBL 3902862 & 1637074 & 8.699 & 7.9062 & TST & & \\
\hline CHEMBL3957054 & 1637074 & 7.5528 & 7.6364 & TRN & & \\
\hline CHEMBL 3981985 & 1637074 & 9.5229 & 9.3798 & TRN & & \\
\hline CHEMBL 3931971 & 1637074 & \multicolumn{3}{|c|}{14.300999999999998} & 14.4205 & TRN \\
\hline CHEMBL 3961813 & 1637074 & 8.5229 & 11.0991 & TST & & \\
\hline CHEMBL 3907113 & 1637074 & 14.3009 & 999999999 & 998 & 13.1458 & TRN \\
\hline CHEMBL3910565 & 1637074 & 7.5086 & 8.8887 & TRN & & \\
\hline CHEMBL 3982158 & 1637074 & 6.9469 & 6.8047 & TRN & & \\
\hline CHEMBL 3979222 & 1637074 & 8.699 & 8.8964 & TRN & & \\
\hline CHEMBL 3974482 & 1637074 & 9.5229 & 9.2379 & TRN & & \\
\hline CHEMBL 3938293 & 1637074 & 7.0088 & 7.0559 & TST & & \\
\hline CHEMBL3984666 & 1637074 & 8.699 & 8.7291 & TRN & & \\
\hline CHEMBL3928832 & 1637074 & 6.7447 & 6.2741 & TRN & & \\
\hline CHEMBL 3969282 & 1637074 & 7.4318 & 7.2187 & TRN & & \\
\hline
\end{tabular}

Page 22450 
Supplemental Table S2.txt

\begin{tabular}{|c|c|c|c|c|c|c|}
\hline CHEMBL3920177 & 1637074 & 7.5528 & 7.3159 & TRN & & \\
\hline CHEMBL3924426 & 1637074 & 7.4815 & 7.9277 & TRN & & \\
\hline CHEMBL3974146 & 1637074 & 9.3979 & 9.4857 & TRN & & \\
\hline CHEMBL3934690 & 1637074 & 14.30099 & 999999999 & 998 & 14.0638 & TRN \\
\hline CHEMBL3918500 & 1637074 & 9.0 & 9.1179 & TRN & & \\
\hline CHEMBL3953372 & 1637074 & 9.5229 & 12.9636 & TST & & \\
\hline CHEMBL3954194 & 1637074 & 6.2557 & 8.7589 & TST & & \\
\hline CHEMBL3928885 & 1637074 & 11.0 & 11.1391 & TRN & & \\
\hline CHEMBL 3986797 & 1637074 & 7.3098 & 7.631 & TRN & & \\
\hline CHEMBL3908489 & 1637074 & 8.5229 & 8.7166 & TRN & & \\
\hline CHEMBL3921571 & 1637074 & 9.8041 & 9.5437 & TRN & & \\
\hline CHEMBL3921680 & 1637074 & 7.5528 & 7.3584 & TRN & & \\
\hline CHEMBL3960385 & 1637074 & 7.699 & 8.0805 & TRN & & \\
\hline CHEMBL3915642 & 1637074 & 12.69900 & 000000000 & 002 & 12.7133 & TRN \\
\hline CHEMBL3911161 & 1637074 & 9.0 & 8.6822 & TRN & & \\
\hline CHEMBL3923845 & 1637074 & 7.0655 & 6.8802 & TRN & & \\
\hline CHEMBL3948990 & 1637074 & 10.0969 & 10.2331 & TRN & & \\
\hline CHEMBL3900100 & 1637074 & 8.699 & 7.3586 & TST & & \\
\hline CHEMBL3902032 & 1637074 & 6.2336 & 6.3972 & TST & & \\
\hline CHEMBL3891215 & 1637074 & 9.7905 & 9.2973 & TRN & & \\
\hline CHEMBL3932657 & 1637074 & 13.1549 & 14.2698 & TRN & & \\
\hline CHEMBL3966691 & 1637074 & 6.8794 & 7.2279 & TRN & & \\
\hline CHEMBL3971618 & 1637074 & 14.30099 & 999999999 & 998 & 14.2085 & TRN \\
\hline CHEMBL3930153 & 1637074 & 9.3979 & 9.3559 & TRN & & \\
\hline CHEMBL3975815 & 1637074 & 9.5229 & 9.2665 & TRN & & \\
\hline CHEMBL3919148 & 1637074 & 7.3768 & 7.1701 & TRN & & \\
\hline CHEMBL3900884 & 1637074 & 9.699 & 9.584 & TRN & & \\
\hline CHEMBL3971221 & 1637074 & 7.4815 & 5.9754 & TST & & \\
\hline CHEMBL3967892 & 1637074 & 6.1911 & 7.1847 & TST & & \\
\hline CHEMBL3938191 & 1637074 & 8.0 & 9.0163 & TST & & \\
\hline CHEMBL3959492 & 1637074 & 8.2218 & 10.8371 & TST & & \\
\hline CHEMBL3928246 & 1637074 & 7.3468 & 6.8662 & TST & & \\
\hline CHEMBL 3954444 & 1637074 & 7.1249 & 7.8577 & TST & & \\
\hline CHEMBL3904860 & 1637074 & 9.0 & 10.2221 & TST & & \\
\hline CHEMBL3974885 & 1637074 & 6.8601 & 6.7607 & TST & & \\
\hline CHEMBL3898194 & 1637074 & 9.5229 & 9.796 & TST & & \\
\hline CHEMBL3935358 & 1637074 & 10.0969 & 9.4268 & TST & & \\
\hline CHEMBL3921608 & 1637074 & 7.3372 & 11.8682 & TST & & \\
\hline CHEMBL3961846 & 1637074 & 6.5969 & 9.5624 & TST & & \\
\hline CHEMBL 79908 & 1330619 & 3.5229 & 3.756999 & 999999999 & 97 & TRN \\
\hline CHEMBL3220714 & 1330619 & 6.0 & 5.5208 & TST & & \\
\hline CHEMBL3220442 & 1330619 & 7.1549 & 5.2491 & TST & & \\
\hline CHEMBL3220711 & 1330619 & 5.8239 & 5.2351 & TST & & \\
\hline CHEMBL3220185 & 1330619 & 5.1249 & 5.4881 & TST & & \\
\hline CHEMBL3220712 & 1330619 & 6.0 & 5.3103 & TST & & \\
\hline CHEMBL81790 & 1330619 & 5.5229 & 4.2912 & TRN & & \\
\hline CHEMBL3220443 & 1330619 & 7.3665 & 5.4321 & TST & & \\
\hline CHEMBL81717 & 1330619 & 6.301 & 5.1752 & TRN & & \\
\hline
\end{tabular}


Supplemental Table S2.txt

\begin{tabular}{|c|c|c|c|c|}
\hline CHEMBL83932 & 1330619 & 3.699 & 3.6799 & TRN \\
\hline CHEMBL3220446 & 1330619 & 9.0 & 4.9905 & TRN \\
\hline CHEMBL51955 & 1330619 & 4.2218 & 3.7388 & TRN \\
\hline CHEMBL 309192 & 1330619 & 6.0 & 5.0985 & TRN \\
\hline CHEMBL459837 & 1330619 & 5.8861 & 5.9035 & TRN \\
\hline CHEMBL79524 & 1330619 & 3.699 & 4.8267 & TRN \\
\hline CHEMBL3220439 & 1330619 & 3.8861 & \multicolumn{2}{|c|}{5.667000000000001} \\
\hline CHEMBL418913 & 1330619 & 3.6778 & 3.6664 & TRN \\
\hline CHEMBL 3220179 & 1330619 & 5.7959 & 5.5917 & TRN \\
\hline CHEMBL312637 & 1330619 & 4.0 & 3.9747 & TRN \\
\hline CHEMBL 3220187 & 1330619 & 4.0177 & 5.6174 & TST \\
\hline CHEMBL81953 & 1330619 & 3.5686 & 3.6664 & TRN \\
\hline CHEMBL3220182 & 1330619 & 4.7212 & 5.8152 & TRN \\
\hline CHEMBL311274 & 1330619 & 3.2218 & 3.6664 & TRN \\
\hline CHEMBL81637 & 1330619 & 3.7447 & 3.6664 & TRN \\
\hline CHEMBL81159 & 1330619 & 2.2007 & 3.4944 & TRN \\
\hline CHEMBL 3220177 & 1330619 & 4.6021 & 4.7691 & TRN \\
\hline CHEMBL3220176 & 1330619 & 4.6576 & 5.0671 & TRN \\
\hline CHEMBL 3220183 & 1330619 & 4.3372 & 5.8104 & TRN \\
\hline CHEMBL312047 & 1330619 & 2.4318 & 3.4255 & TRN \\
\hline CHEMBL298659 & 1330619 & 3.2757 & 3.5651 & TRN \\
\hline CHEMBL82771 & 1330619 & 3.8239 & 3.6664 & TRN \\
\hline CHEMBL 3220180 & 1330619 & 5.3979 & 5.4241 & TRN \\
\hline CHEMBL430814 & 1330619 & 4.7959 & 4.9664 & TRN \\
\hline CHEMBL3220188 & 1330619 & 6.5528 & 5.7054 & TST \\
\hline CHEMBL 3220184 & 1330619 & 4.8861 & 5.7903 & TRN \\
\hline CHEMBL311288 & 1330619 & 6.0 & 4.9676 & TRN \\
\hline CHEMBL311205 & 1330619 & 5.699 & 4.2273 & TRN \\
\hline CHEMBL 3220710 & 1330619 & 8.5229 & 5.2525 & TST \\
\hline CHEMBL54758 & 1330619 & 3.7447 & 3.6888 & TRN \\
\hline CHEMBL81083 & 1330619 & 4.0458 & 3.7069 & TRN \\
\hline CHEMBL310004 & 1330619 & 6.0 & 5.0481 & TRN \\
\hline CHEMBL 3220178 & 1330619 & 4.4949 & 4.8653 & TRN \\
\hline CHEMBL 3220440 & 1330619 & 6.0 & 5.5823 & TST \\
\hline CHEMBL3220186 & 1330619 & 4.7959 & 5.6183 & TST \\
\hline CHEMBL460452 & 1330619 & 3.2076 & 4.6874 & TRN \\
\hline CHEMBL511178 & 1330619 & 5.699 & 5.9207 & TRN \\
\hline CHEMBL 309419 & 1330619 & 2.699 & 3.7066 & TRN \\
\hline CHEMBL459838 & 1330619 & 5.8861 & 5.666 & TRN \\
\hline CHEMBL3220447 & 1330619 & 5.6383 & 5.0911 & TST \\
\hline CHEMBL 3220181 & 1330619 & 4.6778 & 5.7844 & TRN \\
\hline CHEMBL460871 & 1330619 & 5.6778 & 5.9139 & TRN \\
\hline CHEMBL315261 & 1330619 & 6.0 & 5.1528 & TRN \\
\hline CHEMBL569338 & 787660 & 3.0 & 4.2715 & TRN \\
\hline CHEMBL1917663 & 787660 & 5.1146 & 4.252 & TRN \\
\hline CHEMBL1917832 & 787660 & 4.7055 & 4.0598 & TST \\
\hline CHEMBL1917655 & 787660 & 4.6048 & 4.671 & TRN \\
\hline CHEMBL1917829 & 787660 & 3.0 & 3.3901 & TST \\
\hline
\end{tabular}




\begin{tabular}{|c|c|c|c|c|}
\hline & & & oplement & al $\mathrm{T}$ \\
\hline CHEMBL576070 & 787660 & 4.8931 & 4.3755 & TRN \\
\hline CHEMBL1917664 & 787660 & 3.0 & 3.2118 & TRN \\
\hline CHEMBL570511 & 787660 & 4.0598 & 3.6462 & TRN \\
\hline CHEMBL1917835 & 787660 & 4.5913 & 4.4825 & TST \\
\hline CHEMBL572236 & 787660 & 3.0 & 3.2845 & TRN \\
\hline CHEMBL569115 & 787660 & 5.3788 & 5.1433 & TRN \\
\hline CHEMBL1917838 & 787660 & 3.0 & 3.665 & TST \\
\hline CHEMBL571146 & 787660 & 5.0655 & 4.6101 & TRN \\
\hline CHEMBL1917671 & 787660 & 4.6902 & 3.5925 & TRN \\
\hline CHEMBL1917670 & 787660 & 3.0 & 3.5613 & TRN \\
\hline CHEMBL1917837 & 787660 & 3.0 & 3.4749 & TST \\
\hline CHEMBL570510 & 787660 & 4.2264 & 4.1583 & TRN \\
\hline CHEMBL569558 & 787660 & 3.0 & 3.763 & TRN \\
\hline CHEMBL1917828 & 787660 & 4.8242 & 4.5871 & TRN \\
\hline CHEMBL572024 & 787660 & 5.6925 & 5.6509 & TRN \\
\hline CHEMBL1917657 & 787660 & 5.3449 & 5.3222 & TRN \\
\hline CHEMBL1917666 & 787660 & 4.738 & 4.5366 & TRN \\
\hline CHEMBL570466 & 787660 & 4.5763 & 4.3934 & TRN \\
\hline CHEMBL1917656 & 787660 & 4.7804 & 4.9086 & TRN \\
\hline CHEMBL583335 & 787660 & 4.7978 & 4.5499 & TRN \\
\hline CHEMBL1917669 & 787660 & 3.0 & 3.0636 & TRN \\
\hline CHEMBL584953 & 787660 & 4.9344 & 4.3009 & TRN \\
\hline CHEMBL1917665 & 787660 & 3.0 & 3.2161 & TRN \\
\hline CHEMBL570059 & 787660 & 5.6478 & 4.952 & TRN \\
\hline CHEMBL571359 & 787660 & 5.1226 & 3.763 & TRN \\
\hline CHEMBL569557 & 787660 & 3.0 & 3.6907 & TRN \\
\hline CHEMBL1914493 & 787660 & 4.8128 & 4.4357 & TST \\
\hline CHEMBL1917831 & 787660 & 3.0 & 3.2267 & TST \\
\hline CHEMBL1917660 & 787660 & 4.9851 & 4.052 & TRN \\
\hline CHEMBL1917839 & 787660 & 3.0 & 3.725 & TST \\
\hline CHEMBL1917661 & 787660 & 4.5605 & 4.0218 & TRN \\
\hline CHEMBL578814 & 787660 & 5.5986 & 5.6422 & TRN \\
\hline CHEMBL1917667 & 787660 & 3.0 & 3.3803 & TRN \\
\hline CHEMBL1917654 & 787660 & 3.0 & 5.2119 & TRN \\
\hline CHEMBL570465 & 787660 & 3.0 & 3.1103 & TRN \\
\hline CHEMBL1917830 & 787660 & 3.0 & 3.4128 & TST \\
\hline CHEMBL1917668 & 787660 & 3.0 & 3.1104 & TRN \\
\hline CHEMBL1917834 & 787660 & 3.0 & 3.2421 & TST \\
\hline CHEMBL1917827 & 787660 & 3.0 & 3.0368 & TRN \\
\hline CHEMBL1917658 & 787660 & 3.0 & 3.5285 & TRN \\
\hline CHEMBL1917836 & 787660 & 3.0 & 3.6066 & TST \\
\hline CHEMBL1917833 & 787660 & 4.7215 & 4.1437 & TST \\
\hline CHEMBL1917662 & 787660 & 3.0 & 3.1843 & TST \\
\hline CHEMBL1917659 & 787660 & 4.744 & 5.1311 & TRN \\
\hline CHEMBL572026 & 787660 & 3.0 & 3.6789 & TRN \\
\hline CHEMBL3966915 & 1528273 & 8.1284 & 8.3921 & TST \\
\hline CHEMBL3914682 & 1528273 & 8.6925 & 8.6761 & TRN \\
\hline CHEMBL3985666 & 1528273 & 9.4365 & 8.7086 & TRN \\
\hline
\end{tabular}

Page 22453 
Supplemental Table S2.txt

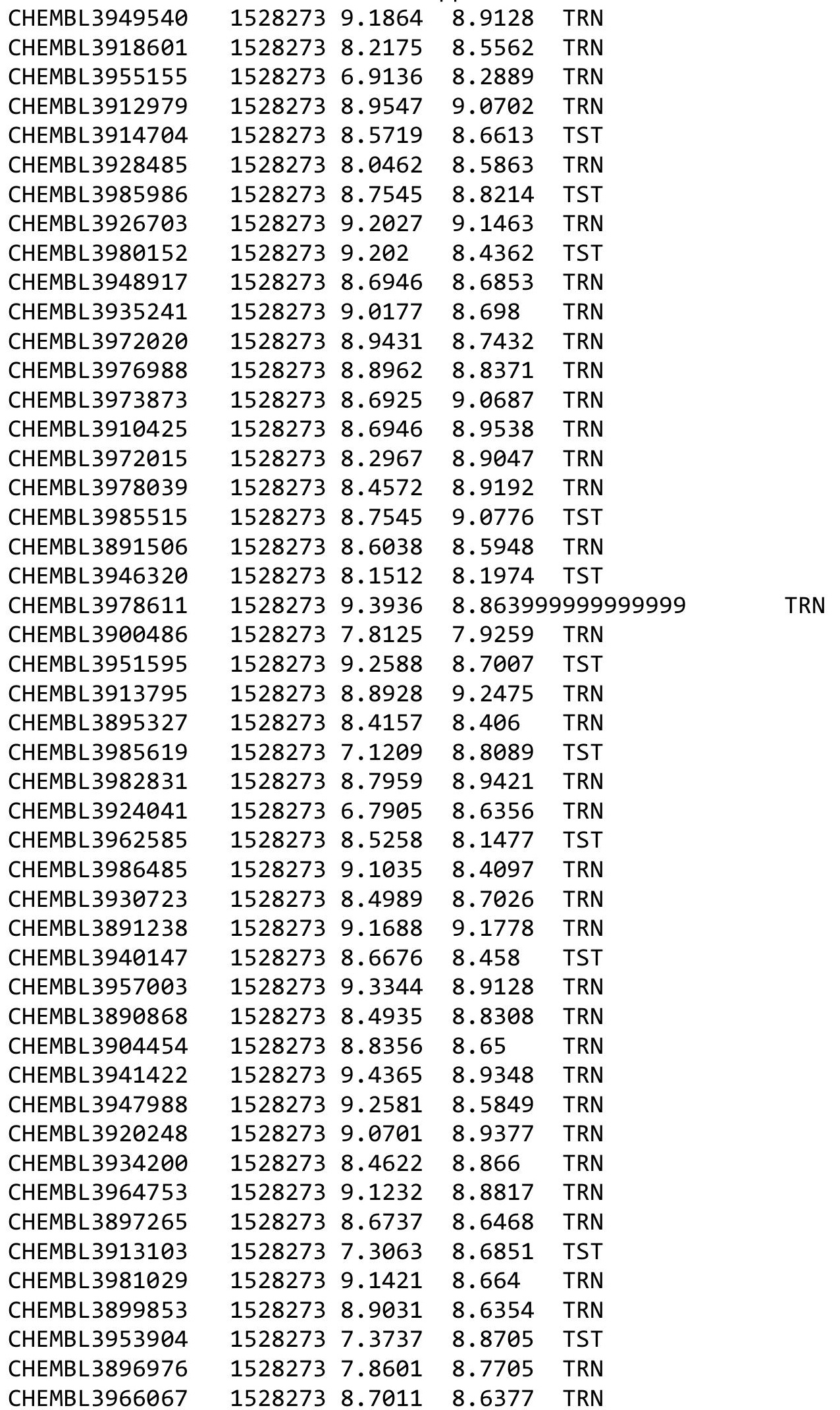

Page 22454 
Supplemental Table S2.txt

\begin{tabular}{|c|c|c|c|c|c|}
\hline CHEMBL3890765 & 1528273 & 8.7328 & 8.6983 & TST & \\
\hline CHEMBL3920190 & 1528273 & 9.0448 & 8.5029 & TRN & \\
\hline CHEMBL3962748 & 1528273 & 8.8041 & 8.7862 & TRN & \\
\hline CHEMBL3914534 & 1528273 & 9.0348 & 8.8534 & TRN & \\
\hline CHEMBL3975248 & 1528273 & 8.6364 & 9.1422 & TST & \\
\hline CHEMBL3920694 & 1528273 & 8.7545 & 8.6704 & TRN & \\
\hline CHEMBL3922472 & 1528273 & 8.0164 & 8.4891 & TRN & \\
\hline CHEMBL3900879 & 1528273 & 8.7423 & 8.4653 & TRN & \\
\hline CHEMBL3944253 & 1528273 & 8.4921 & 8.7922 & TRN & \\
\hline CHEMBL3936142 & 1528273 & 8.8962 & 8.8908 & TRN & \\
\hline CHEMBL3942824 & 1528273 & 8.5498 & 8.6432 & TRN & \\
\hline CHEMBL3893587 & 1528273 & 8.6216 & 8.6045 & TST & \\
\hline CHEMBL3925736 & 1528273 & 8.118 & 8.4962 & TST & \\
\hline CHEMBL3937391 & 1528273 & 7.4547 & 8.6717 & TRN & \\
\hline CHEMBL3986424 & 1528273 & 9.0535 & 8.8683 & TRN & \\
\hline CHEMBL3917348 & 1528273 & 8.8928 & 8.9732 & TRN & \\
\hline CHEMBL3908013 & 1528273 & 8.3585 & 8.7278 & TRN & \\
\hline CHEMBL 3911924 & 1528273 & 9.1669 & 8.9002 & TRN & \\
\hline CHEMBL3936852 & 1528273 & 8.7399 & 8.7796 & TRN & \\
\hline CHEMBL3908499 & 1528273 & 8.7852 & 8.4257 & TRN & \\
\hline CHEMBL3897262 & 1528273 & 8.7447 & 8.9069 & TRN & \\
\hline CHEMBL3957483 & 1528273 & 8.9957 & 8.9313 & TRN & \\
\hline CHEMBL3925359 & 1528273 & 9.1643 & 8.8393 & TRN & \\
\hline CHEMBL 3972440 & 1528273 & 8.8729 & 8.9029 & TRN & \\
\hline CHEMBL3972146 & 1528273 & 9.1319 & 9.0417 & TRN & \\
\hline CHEMBL3951029 & 1528273 & 6.2411 & 8.9869 & TST & \\
\hline CHEMBL3928526 & 1528273 & 8.5935 & 8.263 & TRN & \\
\hline CHEMBL3895052 & 1528273 & 7.1051 & 8.0538 & TRN & \\
\hline CHEMBL3897026 & 1528273 & 7.4101 & 8.0794 & TRN & \\
\hline CHEMBL3950464 & 1528273 & 9.1062 & 8.4355 & TST & \\
\hline CHEMBL3925246 & 1528273 & 9.2104 & 8.8639 & TRN & \\
\hline CHEMBL3978805 & 1528273 & 9.1798 & 9.129 & TRN & \\
\hline CHEMBL3898668 & 1528273 & 9.1343 & 8.5772 & TRN & \\
\hline CHEMBL3924618 & 1528273 & 8.5884 & 8.4131 & TRN & \\
\hline CHEMBL3926816 & 1528273 & 7.7423 & 9.2131 & TST & \\
\hline CHEMBL3962731 & 1528273 & 8.3747 & 8.6227 & TRN & \\
\hline CHEMBL3963308 & 1528273 & 9.0794 & 8.852 & TRN & \\
\hline CHEMBL3964519 & 1528273 & 8.9136 & 8.8277 & TRN & \\
\hline CHEMBL 3948494 & 1528273 & 8.9626 & 8.9221 & TST & \\
\hline CHEMBL3933656 & 1528273 & 8.4486 & 8.6517 & TRN & \\
\hline CHEMBL3966741 & 1528273 & 8.9355 & 8.68799 & 9999999999 & TRN \\
\hline CHEMBL3911877 & 1528273 & 8.2757 & 8.3003 & TRN & \\
\hline CHEMBL3933924 & 1528273 & 8.7399 & 8.592 & TRN & \\
\hline CHEMBL3897639 & 1528273 & 8.4353 & 8.2389 & TRN & \\
\hline CHEMBL3906321 & 1528273 & 9.0595 & 8.7462 & TRN & \\
\hline CHEMBL3938011 & 1528273 & 8.7077 & 8.5447 & TRN & \\
\hline CHEMBL3905912 & 1528273 & 7.9788 & 8.8165 & TRN & \\
\hline CHEMBL3939659 & 1528273 & 8.5817 & 8.26 & TST & \\
\hline
\end{tabular}


Supplemental Table S2.txt

\begin{tabular}{|c|c|c|c|c|c|}
\hline CHEMBL 3957804 & 1528273 & 8.7399 & 8.7629 & TRN & \\
\hline CHEMBL 3922322 & 1528273 & 9.1439 & 8.9247 & TRN & \\
\hline CHEMBL 3962288 & 1528273 & 8.699 & 8.6657 & TRN & \\
\hline CHEMBL 3911808 & 1528273 & 7.5361 & 8.3408 & TST & \\
\hline CHEMBL3973164 & 1528273 & 9.0783 & 8.7985 & TRN & \\
\hline CHEMBL 3916232 & 1528273 & 8.3526 & 8.8036 & TST & \\
\hline CHEMBL 3977003 & 1528273 & 8.7258 & 8.7696 & TRN & \\
\hline CHEMBL 3934024 & 1528273 & 8.9666 & 9.216000 & 0000000001 & TRN \\
\hline CHEMBL 3932029 & 1528273 & 8.9393 & 8.857000 & 0000000001 & TRN \\
\hline CHEMBL 3978480 & 1528273 & 8.0168 & 9.0218 & TRN & \\
\hline CHEMBL 3924191 & 1528273 & 8.9872 & 9.0879 & TST & \\
\hline CHEMBL 3901017 & 1528273 & 8.0458 & 9.1002 & TST & \\
\hline CHEMBL 3947275 & 1528273 & 8.9666 & 8.6389 & TRN & \\
\hline CHEMBL 3908196 & 1528273 & 8.7932 & 8.7052 & TRN & \\
\hline CHEMBL3975294 & 1528273 & 8.7496 & 8.5629 & TRN & \\
\hline CHEMBL 3913193 & 1528273 & 8.0237 & 8.3446 & TRN & \\
\hline CHEMBL3903122 & 1528273 & 8.2381 & 8.2169 & TRN & \\
\hline CHEMBL 3900960 & 1528273 & 8.9914 & 8.8091 & TRN & \\
\hline CHEMBL 3901054 & 1528273 & 7.2503 & 9.0012 & TST & \\
\hline CHEMBL3933445 & 1528273 & 9.041 & 8.6196 & TRN & \\
\hline CHEMBL 3986261 & 1528273 & 8.7825 & 8.7396 & TRN & \\
\hline CHEMBL 3970224 & 1528273 & 8.2132 & 8.3558 & TRN & \\
\hline CHEMBL 3929019 & 1528273 & 9.3429 & 8.5534 & TST & \\
\hline CHEMBL 3930392 & 1528273 & 8.8182 & 8.8371 & TRN & \\
\hline CHEMBL 3945871 & 1528273 & 8.3799 & 8.3841 & TST & \\
\hline CHEMBL 3934520 & 1528273 & 8.6162 & 8.6983 & TRN & \\
\hline CHEMBL 3932736 & 1528273 & 8.6635 & 8.2926 & TST & \\
\hline CHEMBL 3964016 & 1528273 & 8.7645 & 8.6515 & TST & \\
\hline CHEMBL 3963393 & 1528273 & 8.426 & 8.6342 & TST & \\
\hline CHEMBL 3895344 & 1528273 & 8.9547 & 8.7907 & TRN & \\
\hline CHEMBL 3939744 & 1528273 & 9.0106 & 9.1729 & TST & \\
\hline CHEMBL 3969710 & 1528273 & 8.8153 & 8.6657 & TRN & \\
\hline CHEMBL 3893601 & 1528273 & 8.9626 & 8.9277 & TRN & \\
\hline CHEMBL 3917669 & 1528273 & 8.3809 & 8.6401 & TRN & \\
\hline CHEMBL 3928952 & 1528273 & 8.0419 & 8.4552 & TST & \\
\hline CHEMBL 3964064 & 1528273 & 8.2676 & 8.8911 & TRN & \\
\hline CHEMBL 3901329 & 1528273 & 8.9393 & 8.6763 & TRN & \\
\hline CHEMBL 3973087 & 1528273 & 8.757 & 9.0928 & TRN & \\
\hline CHEMBL 3930661 & 1528273 & 6.5607 & 8.8105 & TST & \\
\hline CHEMBL 3973637 & 1528273 & 9.0655 & 8.7583 & TRN & \\
\hline CHEMBL 3966687 & 1528273 & 8.4283 & 8.1742 & TST & \\
\hline CHEMBL 3952173 & 1528273 & 9.0097 & 8.7205 & TRN & \\
\hline CHEMBL3703881 & 1528273 & 8.8697 & 8.7501 & TRN & \\
\hline CHEMBL 3982248 & 1528273 & 8.9355 & 8.956 & TRN & \\
\hline CHEMBL 3937224 & 1528273 & 9.2588 & 9.0615 & TRN & \\
\hline CHEMBL 3986604 & 1528273 & 9.06299 & 99999999 & 8.4226 & TST \\
\hline CHEMBL3915769 & 1528273 & 8.8013 & 8.948 & TST & \\
\hline CHEMBL 3961373 & 1528273 & 8.6655 & 8.2976 & TST & \\
\hline
\end{tabular}


Supplemental Table S2.txt

\begin{tabular}{|c|c|c|c|c|c|c|}
\hline CHEMBL 3900385 & 1528273 & 9.0926 & 8.7678 & TRN & & \\
\hline CHEMBL 3945073 & 1528273 & 8.3316 & 8.5037 & TRN & & \\
\hline CHEMBL 3912144 & 1528273 & 8.5243 & 8.458 & TST & & \\
\hline CHEMBL 3897355 & 1528273 & 8.8928 & 8.8685 & TRN & & \\
\hline CHEMBL 3941827 & 1528273 & 8.9318 & 8.926 & TRN & & \\
\hline CHEMBL 3927853 & 1528273 & 9.1379 & 8.7725 & TRN & & \\
\hline CHEMBL 3946216 & 1528273 & 9.0531 & 9.0404 & TRN & & \\
\hline CHEMBL 3922128 & 1528273 & 9.0 & 8.6093 & TRN & & \\
\hline CHEMBL 3949487 & 1528273 & 8.8996 & 8.5288 & TRN & & \\
\hline CHEMBL3927999 & 1528273 & 8.28399 & 99999999 & 99 & 8.4294 & TRN \\
\hline CHEMBL 3908751 & 1528273 & 8.7825 & 8.7982 & TRN & & \\
\hline CHEMBL 3931857 & 1528273 & 8.9469 & 8.8357 & TRN & & \\
\hline CHEMBL 3941537 & 1528273 & 9.0501 & 8.6634 & TRN & & \\
\hline CHEMBL 3915262 & 1528273 & 8.064 & 8.9193 & TST & & \\
\hline CHEMBL3924919 & 1528273 & 8.7282 & 8.6555 & TRN & & \\
\hline CHEMBL 3912315 & 1528273 & 8.5498 & 8.8885 & TRN & & \\
\hline CHEMBL3918489 & 1528273 & 9.06200 & $\partial 0000000$ & 1 & 8.6383 & $\mathrm{TR}$ \\
\hline CHEMBL 3932916 & 1528273 & 8.757 & 8.1336 & TST & & \\
\hline CHEMBL 3889639 & 1528273 & 8.9872 & 8.4025 & TRN & & \\
\hline CHEMBL3927911 & 1528273 & 7.0491 & 8.451 & TST & & \\
\hline CHEMBL 3931780 & 1528273 & 8.7878 & 8.7753 & TRN & & \\
\hline CHEMBL 3893646 & 1528273 & 8.9136 & 8.4549 & TRN & & \\
\hline CHEMBL 3896279 & 1528273 & 8.2518 & 8.7951 & TRN & & \\
\hline CHEMBL 3944329 & 1528273 & 8.8097 & 8.8834 & TRN & & \\
\hline CHEMBL 3946467 & 1528273 & 6.7852 & 8.861 & TRN & & \\
\hline CHEMBL 3971256 & 1528273 & 9.3233 & 9.0123 & TRN & & \\
\hline CHEMBL 3978879 & 1528273 & 8.9101 & 8.3987 & TST & & \\
\hline CHEMBL 3922749 & 1528273 & 9.2976 & 8.3096 & TST & & \\
\hline CHEMBL 3912401 & 1528273 & 8.7055 & 8.6405 & TRN & & \\
\hline CHEMBL 3918944 & 1528273 & 7.7328 & 8.2611 & TST & & \\
\hline CHEMBL 3955606 & 1528273 & 9.2411 & 8.6913 & TRN & & \\
\hline CHEMBL 3958617 & 1528273 & 8.7645 & 8.689 & TRN & & \\
\hline CHEMBL3977952 & 1528273 & 9.0731 & 8.8966 & TRN & & \\
\hline CHEMBL 3911388 & 1528273 & 9.5114 & 8.6072 & TST & & \\
\hline CHEMBL 3971622 & 1528273 & 8.7399 & 8.4262 & TST & & \\
\hline CHEMBL3928437 & 1528273 & 8.9666 & 8.8477 & TRN & & \\
\hline CHEMBL 3936938 & 1528273 & 9.2013 & 8.4372 & TST & & \\
\hline CHEMBL 3894439 & 1528273 & 8.4168 & \multicolumn{3}{|c|}{8.738999999999999} & $\mathrm{TR}$ \\
\hline CHEMBL 3934625 & 1528273 & 8.475 & 8.3187 & TST & & \\
\hline CHEMBL 3962173 & 1528273 & 9.1002 & 8.7364 & TRN & & \\
\hline CHEMBL 3913459 & 1528273 & 8.8928 & 8.5948 & TRN & & \\
\hline CHEMBL 3943897 & 1528273 & 9.1457 & 8.8534 & TRN & & \\
\hline CHEMBL 3913037 & 1528273 & 9.1512 & 9.0162 & TRN & & \\
\hline CHEMBL 3968501 & 1528273 & 8.6799 & 8.6971 & TRN & & \\
\hline CHEMBL 3931191 & 1528273 & 9.1296 & 8.9598 & TRN & & \\
\hline CHEMBL 3902672 & 1528273 & 8.8633 & 8.7629 & TRN & & \\
\hline CHEMBL 3982872 & 1528273 & 7.0301 & 8.2234 & TST & & \\
\hline CHEMBL3960303 & 1528273 & 8.8601 & 8.7319 & TRN & & \\
\hline
\end{tabular}

Page 22457 


\begin{tabular}{|c|c|c|c|c|}
\hline \multicolumn{5}{|c|}{ Supplemental Tabl } \\
\hline CHEMBL3912813 & 1528273 & 8.8416 & 8.6823 & TRN \\
\hline CHEMBL3909458 & 1528273 & 8.2549 & 8.4978 & TRN \\
\hline CHEMBL3894077 & 1528273 & 9.055 & 8.9228 & TRN \\
\hline CHEMBL328710 & 737825 & 5.0 & 4.8952 & TST \\
\hline CHEMBL1288014 & 737825 & 5.4 & 5.3691 & TRN \\
\hline CHEMBL1607752 & 737825 & 4.8 & 5.1381 & TRN \\
\hline CHEMBL1977709 & 737825 & 5.45 & 5.2149 & TRN \\
\hline CHEMBL1361596 & 737825 & 5.7 & 6.0012 & TST \\
\hline CHEMBL1396358 & 737825 & 5.3 & 5.0149 & TRN \\
\hline CHEMBL 286077 & 737825 & 6.8 & 5.9972 & TST \\
\hline CHEMBL1313121 & 737825 & 5.7 & 5.1566 & TRN \\
\hline CHEMBL1300309 & 737825 & 5.05 & 5.1383 & TRN \\
\hline CHEMBL1357491 & 737825 & 4.6 & 4.4873 & TRN \\
\hline CHEMBL1593068 & 737825 & 5.1 & 4.9769 & TRN \\
\hline CHEMBL1591896 & 737825 & 6.2 & 6.1763 & TRN \\
\hline CHEMBL1554717 & 737825 & 5.6 & 5.3518 & TRN \\
\hline CHEMBL1543205 & 737825 & 4.85 & 5.2632 & TRN \\
\hline CHEMBL274844 & 737825 & 4.6 & 4.657 & TST \\
\hline CHEMBL1523570 & 737825 & 4.6 & 5.0391 & TRN \\
\hline CHEMBL1514071 & 737825 & 5.0 & 4.8157 & TRN \\
\hline CHEMBL1388488 & 737825 & 4.6 & 5.0116 & TRN \\
\hline CHEMBL1324402 & 737825 & 5.15 & 5.2222 & TRN \\
\hline CHEMBL3192957 & 737825 & 4.8 & 5.1356 & TST \\
\hline CHEMBL1311026 & 737825 & 4.7 & 5.063 & TST \\
\hline CHEMBL1588603 & 737825 & 5.15 & 5.3536 & TRN \\
\hline CHEMBL1561474 & 737825 & 5.9 & 5.4932 & TST \\
\hline CHEMBL1551557 & 737825 & 4.8 & 4.5912 & TRN \\
\hline CHEMBL1518689 & 737825 & 5.6 & 5.6212 & TRN \\
\hline CHEMBL1394499 & 737825 & 4.8 & 4.7788 & TRN \\
\hline CHEMBL1396698 & 737825 & 4.6 & 4.5728 & TRN \\
\hline CHEMBL3212319 & 737825 & 6.05 & 5.2055 & TRN \\
\hline CHEMBL1488997 & 737825 & 5.15 & 5.3913 & TRN \\
\hline CHEMBL1606574 & 737825 & 6.0 & 5.7667 & TRN \\
\hline CHEMBL1476670 & 737825 & 4.9 & 4.9674 & TRN \\
\hline CHEMBL1361797 & 737825 & 5.0 & 5.0078 & TRN \\
\hline CHEMBL1580216 & 737825 & 4.75 & 5.0255 & TRN \\
\hline CHEMBL1591543 & 737825 & 5.4 & 5.2407 & TRN \\
\hline CHEMBL1469460 & 737825 & 5.85 & 5.0953 & TRN \\
\hline CHEMBL1430016 & 737825 & 4.95 & 5.2956 & TRN \\
\hline CHEMBL1364168 & 737825 & 4.8 & 4.8204 & TRN \\
\hline CHEMBL1736563 & 737825 & 5.85 & 5.3772 & TRN \\
\hline CHEMBL1354455 & 737825 & 4.5 & 4.453 & TRN \\
\hline CHEMBL1446731 & 737825 & 5.4 & 5.5241 & TRN \\
\hline CHEMBL1317214 & 737825 & 5.5 & 5.4745 & TRN \\
\hline CHEMBL1330448 & 737825 & 4.9 & 5.1448 & TRN \\
\hline CHEMBL1338095 & 737825 & 5.4 & 5.2497 & TRN \\
\hline CHEMBL1507015 & 737825 & 4.9 & 5.2155 & TRN \\
\hline CHEMBL1396407 & 737825 & 5.9 & 5.9257 & TRN \\
\hline
\end{tabular}




\begin{tabular}{|c|c|c|c|c|c|}
\hline & & & & & \\
\hline CHEMBL1475358 & 737825 & 5.6 & 5.6055 & TRN & \\
\hline CHEMBL 299613 & 737825 & 6.0 & 5.5529 & TST & \\
\hline CHEMBL1400243 & 737825 & 4.85 & 5.0498 & TST & \\
\hline CHEMBL1463968 & 737825 & 5.9 & 5.16299 & 9999999999 & TRN \\
\hline CHEMBL 1357157 & 737825 & 4.7 & 4.7907 & TRN & \\
\hline CHEMBL1409261 & 737825 & 5.0 & 5.0655 & TRN & \\
\hline CHEMBL1742322 & 737825 & 4.8 & 5.154 & TRN & \\
\hline CHEMBL1398540 & 737825 & 4.8 & 4.7482 & TRN & \\
\hline CHEMBL1436042 & 737825 & 4.7 & 4.5659 & TRN & \\
\hline CHEMBL1568026 & 737825 & 4.9 & 5.0968 & TST & \\
\hline CHEMBL1362464 & 737825 & 4.45 & 5.0663 & TRN & \\
\hline CHEMBL1432306 & 737825 & 5.1 & 5.1781 & TRN & \\
\hline CHEMBL1465534 & 737825 & 5.05 & 4.9967 & TST & \\
\hline CHEMBL1741728 & 737825 & 4.8 & $5.1670 €$ & 0000000001 & TRN \\
\hline CHEMBL1396261 & 737825 & 6.4 & 6.5515 & TRN & \\
\hline CHEMBL1421060 & 737825 & 5.4 & 5.2539 & TRN & \\
\hline CHEMBL1561667 & 737825 & 5.5 & 5.0885 & TRN & \\
\hline CHEMBL1487111 & 737825 & 5.8 & 5.6716 & TRN & \\
\hline CHEMBL1335401 & 737825 & 5.4 & 5.1367 & TST & \\
\hline CHEMBL1324697 & 737825 & 4.9 & 4.711 & TST & \\
\hline CHEMBL1301326 & 737825 & 5.4 & $5.2010 €$ & 00000000005 & TRN \\
\hline CHEMBL1321552 & 737825 & 7.3 & 6.6002 & TST & \\
\hline CHEMBL1544155 & 737825 & 5.0 & 5.1929 & TRN & \\
\hline CHEMBL3195524 & 737825 & 4.8 & 4.9599 & TST & \\
\hline CHEMBL1231330 & 737825 & 7.5 & 6.4881 & TST & \\
\hline CHEMBL1499077 & 737825 & 6.3 & 6.1988 & TRN & \\
\hline CHEMBL1592584 & 737825 & 5.4 & 5.2323 & TRN & \\
\hline CHEMBL490718 & 737825 & 6.2 & 6.2935 & TRN & \\
\hline CHEMBL1385305 & 737825 & 4.9 & 5.3192 & TRN & \\
\hline CHEMBL1347829 & 737825 & 5.35 & 5.0768 & TRN & \\
\hline CHEMBL1741518 & 737825 & 4.6 & 5.1129 & TRN & \\
\hline CHEMBL1434783 & 737825 & 4.6 & 4.5321 & TRN & \\
\hline CHEMBL1549419 & 737825 & 4.65 & 5.0928 & TRN & \\
\hline CHEMBL1320750 & 737825 & 5.15 & 5.1771 & TRN & \\
\hline CHEMBL1570792 & 737825 & 5.9 & 5.2399 & TRN & \\
\hline CHEMBL1727976 & 737825 & 4.85 & 5.3203 & TRN & \\
\hline CHEMBL1520727 & 737825 & 6.0 & 5.9798 & TRN & \\
\hline CHEMBL1375382 & 737825 & 5.2 & 5.0751 & TRN & \\
\hline CHEMBL1477982 & 737825 & 5.3 & 5.3252 & TRN & \\
\hline CHEMBL1492136 & 737825 & 5.35 & 5.3664 & TRN & \\
\hline CHEMBL75913 & 737825 & 4.5 & 5.0054 & TST & \\
\hline CHEMBL1513300 & 737825 & 4.7 & 4.8103 & TRN & \\
\hline CHEMBL1240673 & 737825 & 4.65 & 4.8141 & TRN & \\
\hline CHEMBL1562791 & 737825 & 5.3 & 5.24 & TRN & \\
\hline CHEMBL1329094 & 737825 & 5.15 & 5.1082 & TRN & \\
\hline CHEMBL1518686 & 737825 & 5.8 & 5.7555 & TRN & \\
\hline CHEMBL 1408176 & 737825 & 5.4 & 5.2467 & TRN & \\
\hline CHEMBL1714794 & 737825 & 4.8 & 5.0882 & TST & \\
\hline & & & & 22459 & \\
\hline
\end{tabular}




\begin{tabular}{|c|c|c|c|c|}
\hline & & & pplemen & al $\mathrm{T}$ \\
\hline CHEMBL1381200 & 737825 & 4.5 & 5.1627 & TRN \\
\hline CHEMBL1433726 & 737825 & 5.0 & 4.9749 & TST \\
\hline CHEMBL1449339 & 737825 & 5.4 & 5.1947 & TRN \\
\hline CHEMBL1358263 & 737825 & 6.6 & 6.654 & TRN \\
\hline CHEMBL1536007 & 737825 & 4.9 & 4.9265 & TRN \\
\hline CHEMBL1591460 & 737825 & 5.1 & 5.0177 & TRN \\
\hline CHEMBL1562085 & 737825 & 4.9 & 4.7142 & TRN \\
\hline CHEMBL1711658 & 737825 & 4.8 & 5.197 & TST \\
\hline CHEMBL1452742 & 737825 & 4.85 & 5.1263 & TRN \\
\hline CHEMBL1470996 & 737825 & 5.35 & 5.0845 & TRN \\
\hline CHEMBL1587716 & 737825 & 6.0 & 5.4235 & TRN \\
\hline CHEMBL1566105 & 737825 & 5.3 & 5.1462 & TST \\
\hline CHEMBL1456334 & 737825 & 5.35 & 5.0963 & TST \\
\hline CHEMBL1451317 & 737825 & 4.85 & 5.1529 & TRN \\
\hline CHEMBL1529694 & 737825 & 5.45 & 5.4667 & TRN \\
\hline CHEMBL1492429 & 737825 & 4.8 & 5.2297 & TRN \\
\hline CHEMBL1590242 & 737825 & 4.7 & 4.6304 & TRN \\
\hline CHEMBL428814 & 737825 & 5.6 & 5.5765 & TRN \\
\hline CHEMBL1391744 & 737825 & 5.25 & 4.8213 & TST \\
\hline CHEMBL1436160 & 737825 & 4.8 & 4.5916 & TRN \\
\hline CHEMBL1547700 & 737825 & 4.8 & 5.1968 & TRN \\
\hline CHEMBL1449916 & 737825 & 4.65 & 5.102 & TRN \\
\hline CHEMBL1564746 & 737825 & 5.65 & 5.239 & TST \\
\hline CHEMBL1453872 & 737825 & 6.0 & 5.8108 & TRN \\
\hline CHEMBL1423034 & 737825 & 6.1 & 5.2086 & TRN \\
\hline CHEMBL1351344 & 737825 & 5.05 & 5.2277 & TRN \\
\hline CHEMBL1548012 & 737825 & 5.95 & 5.0232 & TRN \\
\hline CHEMBL1567236 & 737825 & 7.0 & 6.6022 & TRN \\
\hline CHEMBL1406274 & 737825 & 4.8 & 5.459 & TRN \\
\hline CHEMBL1551090 & 737825 & 4.8 & 4.6461 & TRN \\
\hline CHEMBL3191636 & 737825 & 4.75 & 5.2782 & TST \\
\hline CHEMBL1316557 & 737825 & 5.4 & 5.1659 & TRN \\
\hline CHEMBL1475788 & 737825 & 4.9 & 4.7338 & TRN \\
\hline CHEMBL1370553 & 737825 & 4.6 & 4.4862 & TRN \\
\hline CHEMBL1402894 & 737825 & 5.4 & 5.3307 & TRN \\
\hline CHEMBL1361505 & 737825 & 5.35 & 5.2911 & TST \\
\hline CHEMBL1479420 & 737825 & 4.85 & 5.034 & TRN \\
\hline CHEMBL1436865 & 737825 & 4.9 & 4.6419 & TRN \\
\hline CHEMBL1741955 & 737825 & 4.85 & 5.1452 & TRN \\
\hline CHEMBL1436179 & 737825 & 4.8 & 4.7301 & TRN \\
\hline CHEMBL1578130 & 737825 & 5.5 & 5.1137 & TRN \\
\hline CHEMBL13647 & 737825 & 6.0 & 5.5909 & TRN \\
\hline CHEMBL1361133 & 737825 & 5.4 & 5.3705 & TST \\
\hline CHEMBL1316456 & 737825 & 5.4 & 5.3008 & TST \\
\hline CHEMBL1502885 & 737825 & 4.55 & 4.9602 & TRN \\
\hline CHEMBL1446716 & 737825 & 6.2 & 6.4781 & TRN \\
\hline CHEMBL 283130 & 737825 & 4.8 & 4.7803 & TST \\
\hline CHEMBL1321738 & 737825 & 4.55 & 5.2239 & TRN \\
\hline
\end{tabular}




\begin{tabular}{|c|c|c|c|c|c|}
\hline \multicolumn{6}{|c|}{ Supplemental Table S2.txt } \\
\hline CHEMBL1564379 & 737825 & 4.45 & 5.1504 & TRN & \\
\hline CHEMBL1517718 & 737825 & 4.8 & 4.7439 & TRN & \\
\hline CHEMBL1434975 & 737825 & 5.4 & 5.3035 & TST & \\
\hline CHEMBL 3195855 & 737825 & 5.6 & 5.1559 & TRN & \\
\hline CHEMBL1432632 & 737825 & 4.85 & 5.12799 & 9999999999 & TRN \\
\hline CHEMBL1487687 & 737825 & 5.7 & 5.5659 & TST & \\
\hline CHEMBL1317950 & 737825 & 7.0 & 6.9069 & TRN & \\
\hline CHEMBL1490181 & 737825 & 6.15 & 5.3897 & TRN & \\
\hline CHEMBL1511648 & 737825 & 5.05 & 5.2403 & TRN & \\
\hline CHEMBL1491966 & 737825 & 5.6 & 5.5975 & TRN & \\
\hline CHEMBL1513684 & 737825 & 4.4 & 4.519 & TRN & \\
\hline CHEMBL1460036 & 737825 & 6.1 & 5.0658 & TRN & \\
\hline CHEMBL1355718 & 737825 & 4.8 & 4.72 & TRN & \\
\hline CHEMBL1584092 & 737825 & 5.0 & 5.0559 & TRN & \\
\hline CHEMBL1595998 & 737825 & 5.5 & 5.1223 & TRN & \\
\hline CHEMBL1565578 & 737825 & 4.8 & 4.75 & TRN & \\
\hline CHEMBL1353921 & 737825 & 5.8 & 5.0357 & TRN & \\
\hline CHEMBL1531754 & 737825 & 5.6 & 5.8671 & TRN & \\
\hline CHEMBL1478552 & 737825 & 4.4 & 4.6802 & TRN & \\
\hline CHEMBL1590259 & 737825 & 4.9 & 4.7874 & TRN & \\
\hline CHEMBL1400233 & 737825 & 5.4 & 5.2392 & TRN & \\
\hline CHEMBL 250711 & 737825 & 5.5 & 5.2297 & TRN & \\
\hline CHEMBL1451315 & 737825 & 4.8 & 4.7553 & TRN & \\
\hline CHEMBL1441222 & 737825 & 5.6 & 5.4794 & TRN & \\
\hline CHEMBL1483214 & 737825 & 4.65 & 5.1399 & TRN & \\
\hline CHEMBL1589925 & 737825 & 4.8 & 4.7233 & TRN & \\
\hline CHEMBL1742160 & 737825 & 5.4 & 5.17700 & 00000000005 & TST \\
\hline CHEMBL1465401 & 737825 & 4.6 & 5.1682 & TRN & \\
\hline CHEMBL1403145 & 737825 & 4.85 & 5.3758 & TRN & \\
\hline CHEMBL1572029 & 737825 & 5.7 & 5.2403 & TRN & \\
\hline CHEMBL1361742 & 737825 & 4.85 & 5.104 & TRN & \\
\hline CHEMBL1404788 & 737825 & 5.0 & 5.0428 & TRN & \\
\hline CHEMBL1302643 & 737825 & 4.7 & 5.2564 & TRN & \\
\hline CHEMBL1475951 & 737825 & 5.9 & 6.1323 & TRN & \\
\hline CHEMBL1573949 & 737825 & 4.8 & 5.0319 & TRN & \\
\hline CHEMBL1486902 & 737825 & 5.4 & 5.4554 & TRN & \\
\hline CHEMBL1407287 & 737825 & 4.85 & 5.2551 & TRN & \\
\hline CHEMBL1557167 & 737825 & 4.9 & 4.8267 & TST & \\
\hline CHEMBL1330587 & 737825 & 5.6 & 5.3674 & TRN & \\
\hline CHEMBL1714329 & 737825 & 5.05 & 5.5429 & TRN & \\
\hline CHEMBL1484181 & 737825 & 4.65 & 5.2636 & TRN & \\
\hline CHEMBL1595371 & 737825 & 5.5 & 5.1011 & TRN & \\
\hline CHEMBL1388530 & 737825 & 5.2 & 4.9894 & TST & \\
\hline CHEMBL1447158 & 737825 & 5.05 & 5.0409 & TRN & \\
\hline CHEMBL1447946 & 737825 & 5.4 & 5.1157 & TRN & \\
\hline CHEMBL1596987 & 737825 & 6.0 & 5.9928 & TRN & \\
\hline CHEMBL1352931 & 737825 & 4.85 & 5.2938 & TRN & \\
\hline CHEMBL1496811 & 737825 & 4.6 & 5.1698 & TRN & \\
\hline
\end{tabular}




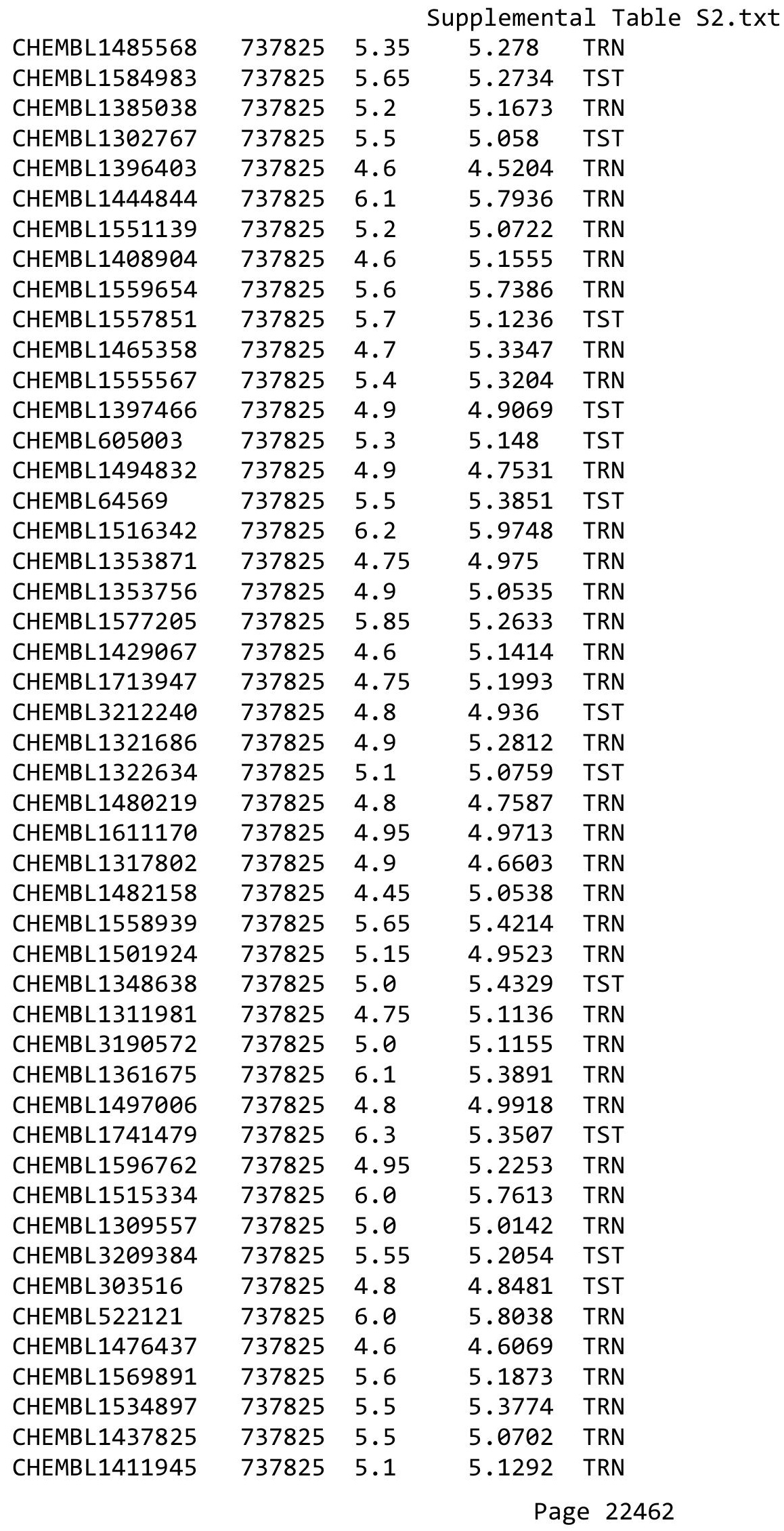




\begin{tabular}{|c|c|c|c|c|c|}
\hline \\
\hline CHEMBL1605586 & 737825 & 4.7 & 5.2265 & TRN & \\
\hline CHEMBL1337419 & 737825 & 6.6 & 5.985 & TST & \\
\hline CHEMBL1512895 & 737825 & 4.8 & 4.6067 & TRN & \\
\hline CHEMBL1544773 & 737825 & 5.2 & 4.9012 & TST & \\
\hline CHEMBL1256750 & 737825 & 4.6 & 4.7711 & TRN & \\
\hline CHEMBL448741 & 737825 & 4.5 & 4.46399 & 99999999995 & TST \\
\hline CHEMBL1317148 & 737825 & 5.0 & 5.0391 & TST & \\
\hline CHEMBL1558519 & 737825 & 4.4 & 5.4371 & TRN & \\
\hline CHEMBL1414668 & 737825 & 4.85 & 5.1029 & TRN & \\
\hline CHEMBL1338571 & 737825 & 5.85 & 5.1393 & TRN & \\
\hline CHEMBL1520907 & 737825 & 5.4 & 5.2141 & TST & \\
\hline CHEMBL1559560 & 737825 & 5.4 & 5.398 & TRN & \\
\hline CHEMBL1742180 & 737825 & 5.1 & 5.3205 & TST & \\
\hline CHEMBL1434747 & 737825 & 5.6 & 5.2618 & TRN & \\
\hline CHEMBL1452910 & 737825 & 5.3 & 5.0256 & TRN & \\
\hline CHEMBL1551445 & 737825 & 4.7 & 4.5148 & TRN & \\
\hline CHEMBL1741418 & 737825 & 4.85 & 5.02 & TRN & \\
\hline CHEMBL1331048 & 737825 & 4.85 & 5.0748 & TST & \\
\hline CHEMBL1343632 & 737825 & 4.55 & 4.9832 & TRN & \\
\hline CHEMBL1435544 & 737825 & 4.8 & 4.5708 & TRN & \\
\hline CHEMBL1552814 & 737825 & 4.6 & 4.4191 & TRN & \\
\hline CHEMBL1480087 & 737825 & 4.95 & 5.018 & TRN & \\
\hline CHEMBL1580282 & 737825 & 4.4 & 5.1393 & TRN & \\
\hline CHEMBL1569985 & 737825 & 5.5 & 5.3287 & TRN & \\
\hline CHEMBL1462816 & 737825 & 5.85 & 5.2102 & TRN & \\
\hline CHEMBL1307309 & 737825 & 4.85 & 5.1185 & TRN & \\
\hline CHEMBL1355387 & 737825 & 5.4 & 5.237 & TRN & \\
\hline CHEMBL1317913 & 737825 & 5.2 & 4.9838 & TRN & \\
\hline CHEMBL1577187 & 737825 & 4.8 & 5.0903 & TRN & \\
\hline CHEMBL 1358380 & 737825 & 5.5 & 5.3183 & TRN & \\
\hline CHEMBL1469862 & 737825 & 5.45 & 5.3307 & TRN & \\
\hline CHEMBL1396822 & 737825 & 5.5 & 5.3424 & TST & \\
\hline CHEMBL371811 & 737825 & 4.5 & 4.5443 & TRN & \\
\hline CHEMBL1366106 & 737825 & 5.1 & 4.7809 & TRN & \\
\hline CHEMBL1551036 & 737825 & 4.4 & 4.4186 & TRN & \\
\hline CHEMBL1497592 & 737825 & 4.6 & 5.1889 & TRN & \\
\hline CHEMBL1553173 & 737825 & 5.6 & 5.5074 & TRN & \\
\hline CHEMBL1393189 & 737825 & 5.6 & 5.4478 & TRN & \\
\hline CHEMBL1705167 & 737825 & 5.4 & 5.1114 & TRN & \\
\hline CHEMBL1403307 & 737825 & 5.7 & 5.2103 & TRN & \\
\hline CHEMBL1484422 & 737825 & 5.5 & 5.4239 & TRN & \\
\hline CHEMBL1464044 & 737825 & 5.25 & 5.0682 & TRN & \\
\hline CHEMBL1356721 & 737825 & 5.4 & 5.2024 & TRN & \\
\hline CHEMBL18701 & 737825 & 4.8 & 4.8591 & TRN & \\
\hline CHEMBL1501406 & 737825 & 4.85 & 5.1259 & TRN & \\
\hline CHEMBL398673 & 737825 & 4.5 & 4.6726 & TRN & \\
\hline CHEMBL1408422 & 737825 & 6.0 & 6.001 & TRN & \\
\hline CHEMBL1318067 & 737825 & 4.8 & 4.5998 & TRN & \\
\hline
\end{tabular}




\begin{tabular}{|c|c|c|c|c|c|}
\hline \multicolumn{6}{|c|}{ Supplemental Table S2.txt } \\
\hline CHEMBL1415957 & 737825 & 5.5 & 5.3108 & TRN & \\
\hline CHEMBL576997 & 737825 & 4.9 & 5.7741 & TST & \\
\hline CHEMBL1580932 & 737825 & 5.55 & 5.4132 & TRN & \\
\hline CHEMBL1488179 & 737825 & 4.9 & 4.8955 & TRN & \\
\hline CHEMBL1337096 & 737825 & 5.2 & 4.9754 & TRN & \\
\hline CHEMBL1336166 & 737825 & 4.9 & 4.9792 & TRN & \\
\hline CHEMBL1414673 & 737825 & 5.4 & 5.3967 & TRN & \\
\hline CHEMBL1437007 & 737825 & 4.8 & 4.6733 & TRN & \\
\hline CHEMBL1606259 & 737825 & 5.05 & 5.3085 & TRN & \\
\hline CHEMBL1366112 & 737825 & 4.8 & 5.0473 & TRN & \\
\hline CHEMBL1742036 & 737825 & 5.15 & 5.0898 & TRN & \\
\hline CHEMBL1313693 & 737825 & 4.85 & 5.0333 & TST & \\
\hline CHEMBL1549242 & 737825 & 7.25 & 5.0058 & TRN & \\
\hline CHEMBL1575193 & 737825 & 5.35 & 5.0803 & TRN & \\
\hline CHEMBL1562639 & 737825 & 5.45 & 5.0897 & TRN & \\
\hline CHEMBL1481185 & 737825 & 5.3 & 5.098 & TRN & \\
\hline CHEMBL1591860 & 737825 & 5.8 & 5.5178 & TRN & \\
\hline CHEMBL1523995 & 737825 & 4.9 & 5.0634 & TST & \\
\hline CHEMBL1386540 & 737825 & 4.8 & 5.1126 & TRN & \\
\hline CHEMBL1375753 & 737825 & 5.5 & 5.2906 & TRN & \\
\hline CHEMBL1604879 & 737825 & 4.85 & 4.9434 & TRN & \\
\hline CHEMBL1477833 & 737825 & 6.0 & 5.8529 & TRN & \\
\hline CHEMBL1306620 & 737825 & 4.8 & 4.8843 & TRN & \\
\hline CHEMBL1313827 & 737825 & 5.6 & 5.2755 & TST & \\
\hline CHEMBL1354678 & 737825 & 4.6 & 4.5023 & TRN & \\
\hline CHEMBL1410175 & 737825 & 5.4 & 5.2585 & TRN & \\
\hline CHEMBL1543356 & 737825 & 4.9 & 5.0508 & TRN & \\
\hline CHEMBL1369140 & 737825 & 5.5 & 5.2353 & TST & \\
\hline CHEMBL1487693 & 737825 & 5.55 & 5.3239 & TRN & \\
\hline CHEMBL1423337 & 737825 & 4.55 & 5.2251 & TRN & \\
\hline CHEMBL1568413 & 737825 & 4.9 & 5.1938 & TRN & \\
\hline CHEMBL1357184 & 737825 & 5.5 & 5.4235 & TRN & \\
\hline CHEMBL1355963 & 737825 & 4.8 & 4.9359 & TST & \\
\hline CHEMBL1429565 & 737825 & 6.1 & 5.1616 & TRN & \\
\hline CHEMBL1519856 & 737825 & 4.65 & 5.0067 & TRN & \\
\hline CHEMBL1333637 & 737825 & 4.8 & 5.4741 & TST & \\
\hline CHEMBL1316353 & 737825 & 4.8 & 4.6999 & TRN & \\
\hline CHEMBL1586621 & 737825 & 4.75 & 5.2853 & TRN & \\
\hline CHEMBL1345724 & 737825 & 4.8 & 5.03100 & 0000000001 & TRN \\
\hline CHEMBL1474244 & 737825 & 4.7 & 4.6352 & TRN & \\
\hline CHEMBL1409720 & 737825 & 5.2 & 5.1437 & TRN & \\
\hline CHEMBL1742223 & 737825 & 4.8 & 5.0448 & TRN & \\
\hline CHEMBL1479767 & 737825 & 5.0 & 4.9666 & TRN & \\
\hline CHEMBL467085 & 737825 & 4.5 & 4.6336 & TRN & \\
\hline CHEMBL1565236 & 737825 & 4.7 & 5.2181 & TRN & \\
\hline CHEMBL1741716 & 737825 & 6.45 & 5.3698 & TRN & \\
\hline CHEMBL1318045 & 737825 & 4.7 & 4.671 & TRN & \\
\hline CHEMBL1365848 & 737825 & 6.2 & 5.2253 & TRN & \\
\hline
\end{tabular}




\begin{tabular}{|c|c|c|c|c|}
\hline & & & pplemen & al $\mathrm{T}$ \\
\hline CHEMBL1312749 & 737825 & 5.4 & 5.2895 & TRN \\
\hline CHEMBL 225230 & 737825 & 4.9 & 4.8724 & TRN \\
\hline CHEMBL1433724 & 737825 & 6.2 & 6.1904 & TRN \\
\hline CHEMBL1574956 & 737825 & 5.3 & 5.1822 & TRN \\
\hline CHEMBL1563190 & 737825 & 4.9 & 5.2395 & TRN \\
\hline CHEMBL1452389 & 737825 & 5.7 & 5.4885 & TRN \\
\hline CHEMBL286721 & 737825 & 6.5 & 5.9155 & TRN \\
\hline CHEMBL1465342 & 737825 & 6.35 & 5.1772 & TRN \\
\hline CHEMBL1416272 & 737825 & 4.9 & 5.1393 & TRN \\
\hline CHEMBL1551009 & 737825 & 5.1 & 4.9267 & TRN \\
\hline CHEMBL15192 & 737825 & 4.8 & 4.7633 & TST \\
\hline CHEMBL1314477 & 737825 & 6.9 & 6.0122 & TRN \\
\hline CHEMBL1331120 & 737825 & 5.4 & 5.1967 & TRN \\
\hline CHEMBL1322311 & 737825 & 6.05 & 5.3583 & TRN \\
\hline CHEMBL1559472 & 737825 & 5.45 & 5.1538 & TRN \\
\hline CHEMBL1371698 & 737825 & 6.0 & 5.9434 & TRN \\
\hline CHEMBL3213479 & 737825 & 4.9 & 5.216 & TRN \\
\hline CHEMBL1537799 & 737825 & 4.8 & 5.0785 & TRN \\
\hline CHEMBL1569277 & 737825 & 6.3 & 5.5349 & TRN \\
\hline CHEMBL85139 & 737825 & 5.4 & 5.1256 & TRN \\
\hline CHEMBL1536220 & 737825 & 4.9 & 5.086 & TRN \\
\hline CHEMBL1406513 & 737825 & 4.9 & 4.9729 & TST \\
\hline CHEMBL1481984 & 737825 & 4.9 & 4.8344 & TST \\
\hline CHEMBL1473191 & 737825 & 5.4 & 5.2333 & TST \\
\hline CHEMBL1403448 & 737825 & 4.85 & 5.1334 & TRN \\
\hline CHEMBL1377410 & 737825 & 5.0 & 5.2434 & TRN \\
\hline CHEMBL1549240 & 737825 & 4.85 & 5.175 & TRN \\
\hline CHEMBL1404858 & 737825 & 4.55 & 5.0845 & TRN \\
\hline CHEMBL1705750 & 737825 & 4.8 & 5.0404 & TRN \\
\hline CHEMBL1418097 & 737825 & 5.3 & 5.1561 & TRN \\
\hline CHEMBL1487944 & 737825 & 5.7 & 5.5431 & TST \\
\hline CHEMBL1338276 & 737825 & 6.1 & 5.1066 & TST \\
\hline CHEMBL1507864 & 737825 & 5.45 & 5.0979 & TST \\
\hline CHEMBL1585534 & 737825 & 5.65 & 5.3514 & TRN \\
\hline CHEMBL542493 & 737825 & 4.5 & 4.6276 & TRN \\
\hline CHEMBL1393667 & 737825 & 4.8 & 5.0946 & TST \\
\hline CHEMBL1329761 & 737825 & 4.9 & 5.1919 & TRN \\
\hline CHEMBL1316779 & 737825 & 5.7 & 5.5057 & TRN \\
\hline CHEMBL1611496 & 737825 & 5.3 & 5.3616 & TRN \\
\hline CHEMBL1503270 & 737825 & 4.65 & 5.1076 & TRN \\
\hline CHEMBL1701448 & 737825 & 4.9 & 4.9654 & TRN \\
\hline CHEMBL1605233 & 737825 & 4.8 & 4.6806 & TRN \\
\hline CHEMBL1417604 & 737825 & 5.95 & 5.0469 & TST \\
\hline CHEMBL1364980 & 737825 & 5.5 & 5.3409 & TRN \\
\hline CHEMBL1530558 & 737825 & 4.7 & 5.121 & TRN \\
\hline CHEMBL 258893 & 737825 & 4.5 & 4.6341 & TST \\
\hline CHEMBL1256709 & 737825 & 4.7 & 4.7312 & TRN \\
\hline CHEMBL1574278 & 737825 & 6.5 & 6.0667 & TRN \\
\hline
\end{tabular}




\begin{tabular}{|c|c|c|c|c|}
\hline \multicolumn{5}{|c|}{ Supplemental Table s2.txt } \\
\hline CHEMBL1438434 & 737825 & 5.2 & 5.2363 & TST \\
\hline CHEMBL1741429 & 737825 & 4.65 & 5.2457 & TRN \\
\hline CHEMBL1172911 & 737825 & 5.4 & 5.2739 & TRN \\
\hline CHEMBL1392359 & 737825 & 5.2 & 5.3156 & TRN \\
\hline CHEMBL1573418 & 737825 & 4.85 & 5.1918 & TRN \\
\hline CHEMBL1593774 & 737825 & 5.2 & 5.0281 & TRN \\
\hline CHEMBL1592202 & 737825 & 4.9 & 4.7155 & TRN \\
\hline CHEMBL1596756 & 737825 & 5.7 & 5.485 & TRN \\
\hline CHEMBL1438677 & 737825 & 4.9 & 4.9129 & TRN \\
\hline CHEMBL1476298 & 737825 & 5.6 & 5.5072 & TRN \\
\hline CHEMBL 3213682 & 737825 & 4.85 & 5.0687 & TRN \\
\hline CHEMBL13790 & 737825 & 4.1 & 5.7248 & TRN \\
\hline CHEMBL1408334 & 737825 & 6.0 & 6.0467 & TRN \\
\hline CHEMBL1386418 & 737825 & 4.85 & 5.1125 & TRN \\
\hline CHEMBL1333445 & 737825 & 5.6 & 5.6027 & TRN \\
\hline CHEMBL1531038 & 737825 & 5.2 & 5.187 & TRN \\
\hline CHEMBL1349872 & 737825 & 4.7 & 5.1074 & TRN \\
\hline CHEMBL1345517 & 737825 & 4.75 & 4.9287 & TRN \\
\hline CHEMBL1412557 & 737825 & 4.75 & 4.9668 & TRN \\
\hline CHEMBL1591209 & 737825 & 4.9 & 4.8853 & TRN \\
\hline CHEMBL1473868 & 737825 & 5.4 & 5.3074 & TRN \\
\hline CHEMBL1328943 & 737825 & 5.3 & 5.3295 & TRN \\
\hline CHEMBL1382823 & 737825 & 5.1 & 5.0312 & TST \\
\hline CHEMBL1353181 & 737825 & 5.45 & 5.2484 & TRN \\
\hline CHEMBL1424521 & 737825 & 5.65 & 5.1975 & TRN \\
\hline CHEMBL1504999 & 737825 & 4.9 & 5.2489 & TST \\
\hline CHEMBL1527466 & 737825 & 6.0 & 5.9957 & TRN \\
\hline CHEMBL1461511 & 737825 & 5.5 & 5.4542 & TRN \\
\hline CHEMBL1519372 & 737825 & 5.5 & 5.1194 & TRN \\
\hline CHEMBL129795 & 737825 & 5.5 & 5.7483 & TRN \\
\hline CHEMBL1513511 & 737825 & 6.3 & 6.0588 & TRN \\
\hline CHEMBL1472922 & 737825 & 6.5 & 6.4757 & TRN \\
\hline CHEMBL3214392 & 737825 & 4.75 & 5.2171 & TRN \\
\hline CHEMBL1481399 & 737825 & 4.9 & 4.7679 & TRN \\
\hline CHEMBL1418721 & 737825 & 5.4 & 5.0046 & TRN \\
\hline CHEMBL1864040 & 737825 & 5.15 & 5.2629 & TRN \\
\hline CHEMBL1361876 & 737825 & 4.9 & 5.0645 & TRN \\
\hline CHEMBL1741337 & 737825 & 5.05 & 5.1889 & TRN \\
\hline CHEMBL1323183 & 737825 & 5.65 & 5.3313 & TRN \\
\hline CHEMBL1473429 & 737825 & 4.9 & 4.8982 & TST \\
\hline CHEMBL1473934 & 737825 & 4.5 & 4.422 & TRN \\
\hline CHEMBL1492339 & 737825 & 5.0 & 5.0346 & TRN \\
\hline CHEMBL1533962 & 737825 & 5.95 & 5.1018 & TRN \\
\hline CHEMBL1571005 & 737825 & 4.95 & 5.0867 & TRN \\
\hline CHEMBL1256844 & 737825 & 6.0 & 5.5782 & TST \\
\hline CHEMBL1742381 & 737825 & 5.15 & 5.0454 & TRN \\
\hline CHEMBL 3210000 & 737825 & 5.35 & 5.1955 & TRN \\
\hline CHEMBL1474261 & 737825 & 4.5 & 4.5416 & TRN \\
\hline
\end{tabular}




\begin{tabular}{|c|c|c|c|c|c|}
\hline \multirow{2}{*}{\multicolumn{2}{|c|}{ CHEMBL3190499 }} & \\
\hline & & 4.8 & 5.0396 & TST & \\
\hline CHEMBL1402435 & 737825 & 4.8 & 4.8167 & TST & \\
\hline CHEMBL399705 & 737825 & 4.9 & 4.9181 & TST & \\
\hline CHEMBL 2141452 & 737825 & 5.5 & 5.1432 & TRN & \\
\hline CHEMBL1496246 & 737825 & 5.4 & 5.4288 & TRN & \\
\hline CHEMBL1742323 & 737825 & 6.05 & 5.4585 & TRN & \\
\hline CHEMBL 234978 & 737825 & 4.9 & 5.2354 & TRN & \\
\hline CHEMBL1724190 & 737825 & 4.8 & 5.0544 & TRN & \\
\hline CHEMBL1546034 & 737825 & 5.05 & 5.3868 & TST & \\
\hline CHEMBL1325119 & 737825 & 5.0 & 5.0177 & TST & \\
\hline CHEMBL1473990 & 737825 & 6.0 & 5.6477 & TRN & \\
\hline CHEMBL1599607 & 737825 & 5.4 & 5.1688 & TRN & \\
\hline CHEMBL1607830 & 737825 & 5.5 & 5.3919 & TST & \\
\hline CHEMBL1388707 & 737825 & 4.8 & 4.8086 & TRN & \\
\hline CHEMBL1477725 & 737825 & 5.05 & 5.2127 & TRN & \\
\hline CHEMBL1301792 & 737825 & 4.65 & 5.0964 & TST & \\
\hline CHEMBL1594350 & 737825 & 5.2 & 5.1647 & TRN & \\
\hline CHEMBL1443967 & 737825 & 4.85 & 5.1241 & TRN & \\
\hline CHEMBL1549097 & 737825 & 6.0 & 5.2887 & TRN & \\
\hline CHEMBL 267458 & 737825 & 4.7 & 4.8181 & TRN & \\
\hline CHEMBL1306134 & 737825 & 4.85 & 5.0736 & TRN & \\
\hline CHEMBL1424426 & 737825 & 4.8 & 5.1664 & TRN & \\
\hline CHEMBL1299899 & 737825 & 6.7 & 5.4375 & TRN & \\
\hline CHEMBL1590354 & 737825 & 5.7 & 5.7735 & TRN & \\
\hline CHEMBL1307447 & 737825 & 5.1 & 5.2281 & TST & \\
\hline CHEMBL1592215 & 737825 & 5.0 & 4.8162 & TRN & \\
\hline CHEMBL1318447 & 737825 & 4.6 & 4.5531 & TRN & \\
\hline CHEMBL1549118 & 737825 & 5.15 & 5.2331 & TRN & \\
\hline CHEMBL1448350 & 737825 & 4.85 & 5.1626 & TST & \\
\hline CHEMBL1476055 & 737825 & 5.2 & 5.0206 & TRN & \\
\hline CHEMBL1525058 & 737825 & 4.9 & 5.1599 & TRN & \\
\hline CHEMBL1474195 & 737825 & 5.0 & 4.8391 & TRN & \\
\hline CHEMBL1368892 & 737825 & 5.4 & 5.2666 & TRN & \\
\hline CHEMBL1500867 & 737825 & 4.9 & 5.0241 & TST & \\
\hline CHEMBL1173475 & 737825 & 6.0 & 5.7561 & TRN & \\
\hline CHEMBL1607888 & 737825 & 4.8 & 5.2394 & TRN & \\
\hline CHEMBL1610375 & 737825 & 5.4 & 5.2056 & TRN & \\
\hline CHEMBL1998893 & 737825 & 5.4 & 5.2372 & TRN & \\
\hline CHEMBL1391888 & 737825 & 5.5 & 5.3079 & TST & \\
\hline CHEMBL1564734 & 737825 & 4.9 & 5.1482 & TRN & \\
\hline CHEMBL3194219 & 737825 & 4.9 & 5.235 & TRN & \\
\hline CHEMBL168461 & 737825 & 6.7 & 6.17899 & 9999999999 & TST \\
\hline CHEMBL1447719 & 737825 & 6.2 & 5.3367 & TRN & \\
\hline CHEMBL1394661 & 737825 & 5.5 & 5.3752 & TRN & \\
\hline CHEMBL1323342 & 737825 & 5.1 & 5.1306 & TRN & \\
\hline CHEMBL1322414 & 737825 & 5.6 & 5.5211 & TST & \\
\hline CHEMBL1403769 & 737825 & 4.5 & 4.4444 & TRN & \\
\hline CHEMBL1577940 & 737825 & 4.6 & $5.1110 e$ & 2000000001 & TRN \\
\hline & & & & 22467 & \\
\hline
\end{tabular}




\begin{tabular}{|c|c|c|c|c|}
\hline \multicolumn{5}{|c|}{ Supplemental Table S2.txt } \\
\hline CHEMBL1580127 & 737825 & 4.55 & 5.1575 & TRN \\
\hline CHEMBL1374288 & 737825 & 5.45 & 5.1663 & TRN \\
\hline CHEMBL1474402 & 737825 & 5.3 & 5.2497 & TRN \\
\hline CHEMBL1604925 & 737825 & 5.0 & 5.6977 & TST \\
\hline CHEMBL1509124 & 737825 & 4.6 & 4.9584 & TRN \\
\hline CHEMBL1328533 & 737825 & 6.1 & 6.0042 & TRN \\
\hline CHEMBL1530505 & 737825 & 4.7 & 4.7335 & TRN \\
\hline CHEMBL1326533 & 737825 & 4.85 & 5.0199 & TRN \\
\hline CHEMBL1312105 & 737825 & 5.05 & 5.087 & TRN \\
\hline CHEMBL1382385 & 737825 & 5.3 & 5.0941 & TRN \\
\hline CHEMBL1382389 & 737825 & 5.35 & 5.0681 & TRN \\
\hline CHEMBL1383143 & 737825 & 5.4 & 5.2368 & TRN \\
\hline CHEMBL1407380 & 737825 & 4.9 & 5.2511 & TRN \\
\hline CHEMBL1528262 & 737825 & 5.15 & 5.3206 & TRN \\
\hline CHEMBL1495099 & 737825 & 4.95 & 5.2875 & TRN \\
\hline CHEMBL47814 & 737825 & 5.0 & 4.8946 & TRN \\
\hline CHEMBL1551295 & 737825 & 4.4 & 4.3752 & TRN \\
\hline CHEMBL1496569 & 737825 & 4.5 & 4.423 & TRN \\
\hline CHEMBL1504240 & 737825 & 5.4 & 5.1432 & TRN \\
\hline CHEMBL1329507 & 737825 & 4.55 & 5.2905 & TRN \\
\hline CHEMBL1371655 & 737825 & 4.85 & 5.0855 & TRN \\
\hline CHEMBL1393461 & 737825 & 4.6 & 5.1097 & TRN \\
\hline CHEMBL1256876 & 737825 & 6.0 & 5.5768 & TST \\
\hline CHEMBL1520153 & 737825 & 5.7 & 5.1228 & TRN \\
\hline CHEMBL1555713 & 737825 & 5.7 & 5.7494 & TRN \\
\hline CHEMBL1562792 & 737825 & 4.75 & 4.8827 & TRN \\
\hline CHEMBL1412815 & 737825 & 5.65 & 5.039 & TRN \\
\hline CHEMBL1335471 & 737825 & 5.1 & 4.852 & TST \\
\hline CHEMBL1418917 & 737825 & 4.6 & 5.1087 & TST \\
\hline CHEMBL1308821 & 737825 & 5.0 & 5.2562 & TRN \\
\hline CHEMBL428768 & 737825 & 6.0 & 5.7099 & TRN \\
\hline CHEMBL1572239 & 737825 & 5.2 & 5.2514 & TRN \\
\hline CHEMBL1544565 & 737825 & 4.85 & 5.2418 & TRN \\
\hline CHEMBL1519649 & 737825 & 6.3 & 6.0687 & TRN \\
\hline CHEMBL1324891 & 737825 & 4.8 & 5.1283 & TRN \\
\hline CHEMBL3189154 & 737825 & 5.1 & 5.1746 & TRN \\
\hline CHEMBL1327059 & 737825 & 4.6 & 4.5226 & TRN \\
\hline CHEMBL1372330 & 737825 & 6.0 & 6.0202 & TRN \\
\hline CHEMBL1323465 & 737825 & 5.05 & 5.1842 & TRN \\
\hline CHEMBL490742 & 737825 & 5.9 & 6.0344 & TRN \\
\hline CHEMBL1729717 & 737825 & 4.5 & 5.0343 & TRN \\
\hline CHEMBL1358276 & 737825 & 5.9 & 5.795 & TRN \\
\hline CHEMBL1564545 & 737825 & 4.8 & 4.7232 & TRN \\
\hline CHEMBL1418947 & 737825 & 4.6 & 5.1585 & TRN \\
\hline CHEMBL1430657 & 737825 & 5.0 & 5.199 & TRN \\
\hline CHEMBL1554411 & 737825 & 5.5 & 5.4323 & TRN \\
\hline CHEMBL1554588 & 737825 & 4.9 & 4.8665 & TRN \\
\hline CHEMBL1442538 & 737825 & 4.5 & 4.4869 & TRN \\
\hline
\end{tabular}




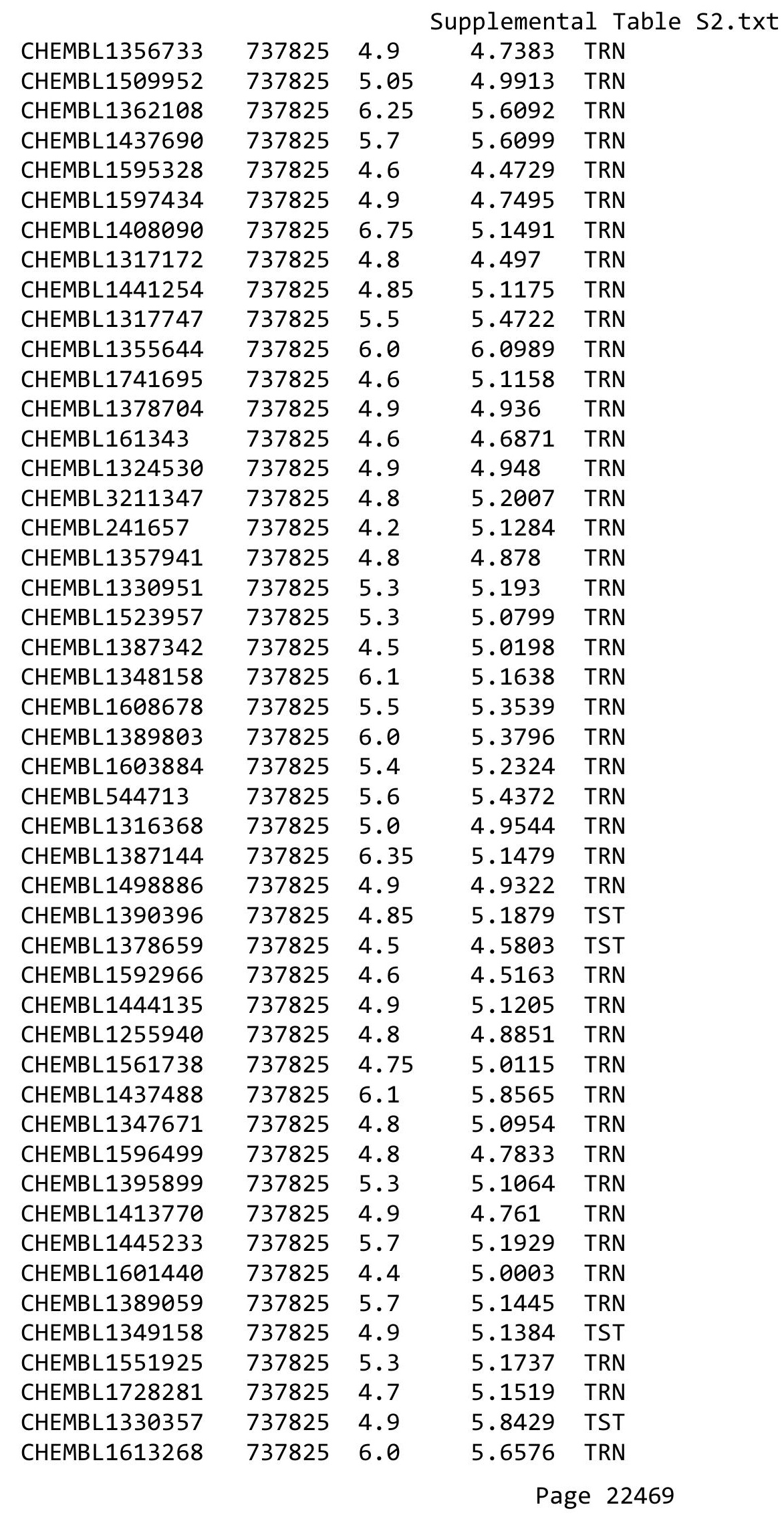




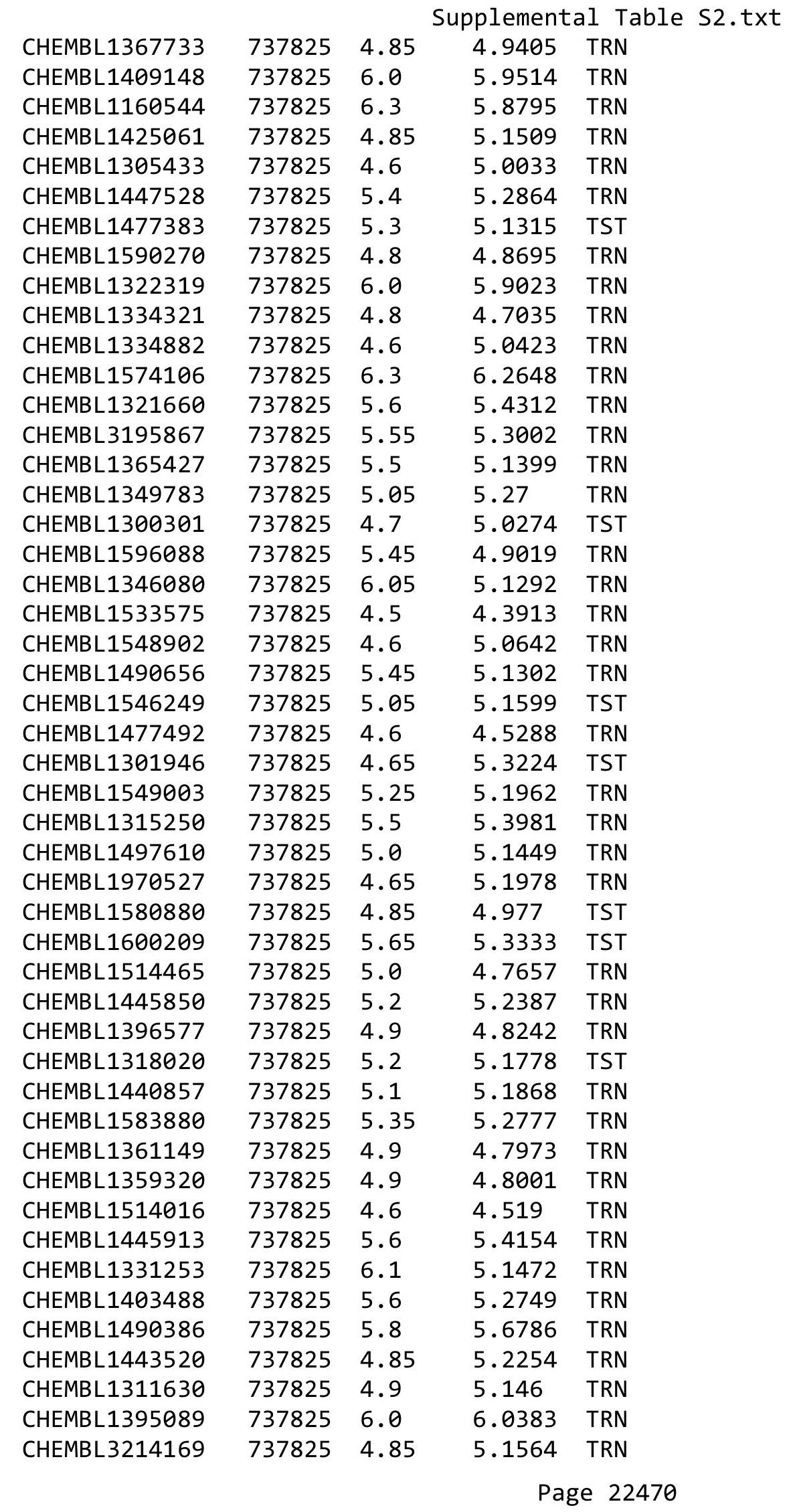




\begin{tabular}{|c|c|c|c|c|c|}
\hline \multicolumn{6}{|c|}{ pplemental } \\
\hline CHEMBL1358628 & 737825 & 6.0 & 5.7234 & TRN & \\
\hline CHEMBL1356068 & 737825 & 4.9 & 5.6113 & TST & \\
\hline CHEMBL1593511 & 737825 & 5.5 & 5.2422 & TRN & \\
\hline CHEMBL1484738 & 737825 & 4.8 & 4.7678 & TST & \\
\hline CHEMBL1498995 & 737825 & 4.55 & 5.0022 & TST & \\
\hline CHEMBL1529478 & 737825 & 5.4 & 5.2408 & TRN & \\
\hline CHEMBL1393270 & 737825 & 5.45 & 5.0387 & TRN & \\
\hline CHEMBL1514976 & 737825 & 4.9 & 4.7449 & TRN & \\
\hline CHEMBL1385123 & 737825 & 5.5 & 5.0303 & TRN & \\
\hline CHEMBL3213210 & 737825 & 5.5 & 5.4173 & TRN & \\
\hline CHEMBL491940 & 737825 & 5.8 & 5.5658 & TRN & \\
\hline CHEMBL1332990 & 737825 & 6.4 & 5.2018 & TRN & \\
\hline CHEMBL1365512 & 737825 & 5.5 & 5.4533 & TRN & \\
\hline CHEMBL131171 & 737825 & 5.5 & 5.2933 & TST & \\
\hline CHEMBL1370751 & 737825 & 4.4 & 5.1416 & TRN & \\
\hline CHEMBL1495397 & 737825 & 5.55 & 5.316 & TRN & \\
\hline CHEMBL1381972 & 737825 & 5.85 & 5.3492 & TRN & \\
\hline CHEMBL1316760 & 737825 & 5.3 & 5.1499 & TRN & \\
\hline CHEMBL1605605 & 737825 & 4.8 & 5.8039 & 9999999999 & TST \\
\hline CHEMBL1559248 & 737825 & 5.0 & 5.1032 & TRN & \\
\hline CHEMBL1514626 & 737825 & 4.8 & 4.8027 & TRN & \\
\hline CHEMBL1350860 & 737825 & 4.6 & 4.91 & TRN & \\
\hline CHEMBL1488305 & 737825 & 5.2 & 5.0961 & TRN & \\
\hline CHEMBL1312422 & 737825 & 4.8 & 5.0837 & TRN & \\
\hline CHEMBL1609585 & 737825 & 4.9 & 5.2121 & TRN & \\
\hline CHEMBL1424763 & 737825 & 4.9 & 5.1631 & TRN & \\
\hline CHEMBL1741390 & 737825 & 4.75 & 5.0891 & TRN & \\
\hline CHEMBL3212657 & 737825 & 5.3 & 5.2171 & TRN & \\
\hline CHEMBL1466277 & 737825 & 4.85 & 5.0015 & TST & \\
\hline CHEMBL1551834 & 737825 & 4.9 & 4.8736 & TRN & \\
\hline CHEMBL276727 & 737825 & 7.2 & 6.32606 & 00000000005 & TST \\
\hline CHEMBL1707407 & 737825 & 5.8 & 5.6664 & TRN & \\
\hline CHEMBL1398537 & 737825 & 6.0 & 5.5737 & TRN & \\
\hline CHEMBL1611048 & 737825 & 6.15 & 5.3252 & TRN & \\
\hline CHEMBL1512199 & 737825 & 4.5 & 4.5614 & TST & \\
\hline CHEMBL1438358 & 737825 & 4.8 & 5.1771 & TRN & \\
\hline CHEMBL1536942 & 737825 & 4.4 & 5.2601 & TRN & \\
\hline CHEMBL1556928 & 737825 & 4.75 & $4.9460 €$ & 0000000001 & TRN \\
\hline CHEMBL1304215 & 737825 & 4.85 & 5.1755 & TRN & \\
\hline CHEMBL1379187 & 737825 & 4.4 & 5.0594 & TRN & \\
\hline CHEMBL1582125 & 737825 & 6.05 & 5.2419 & TRN & \\
\hline CHEMBL1325709 & 737825 & 6.05 & 5.2504 & TRN & \\
\hline CHEMBL1317932 & 737825 & 5.8 & 5.6134 & TRN & \\
\hline CHEMBL 1350113 & 737825 & 4.9 & 5.0781 & TST & \\
\hline CHEMBL1588818 & 737825 & 5.3 & 5.2091 & TRN & \\
\hline CHEMBL1555392 & 737825 & 4.6 & 4.534 & TRN & \\
\hline CHEMBL3208933 & 737825 & 5.5 & 5.058 & TST & \\
\hline CHEMBL1513063 & 737825 & 4.8 & 4.705 & TRN & \\
\hline
\end{tabular}




\begin{tabular}{|c|c|c|c|c|c|}
\hline \multicolumn{6}{|c|}{ Supplemental Table S2.txt } \\
\hline CHEMBL1311695 & 737825 & 4.65 & 5.0662 & TRN & \\
\hline CHEMBL1518067 & 737825 & 4.8 & 4.7492 & TRN & \\
\hline CHEMBL1443979 & 737825 & 4.6 & 5.0468 & TRN & \\
\hline CHEMBL1323927 & 737825 & 4.5 & 4.4932 & TRN & \\
\hline CHEMBL1331690 & 737825 & 5.0 & 5.154 & TRN & \\
\hline CHEMBL9843 & 737825 & 5.1 & 5.0214 & TRN & \\
\hline CHEMBL1433776 & 737825 & 4.9 & 4.8702 & TRN & \\
\hline CHEMBL1601477 & 737825 & 5.1 & 4.882 & TRN & \\
\hline CHEMBL1558843 & 737825 & 6.0 & 5.9328 & TRN & \\
\hline CHEMBL1256760 & 737825 & 6.0 & 5.7261 & TST & \\
\hline CHEMBL1390028 & 737825 & 5.9 & 5.2388 & TRN & \\
\hline CHEMBL1400902 & 737825 & 4.9 & 4.9336 & TRN & \\
\hline CHEMBL1511972 & 737825 & 4.4 & 4.3087 & TRN & \\
\hline CHEMBL1325530 & 737825 & 5.35 & 5.5369 & TRN & \\
\hline CHEMBL1324493 & 737825 & 4.8 & 4.7776 & TRN & \\
\hline CHEMBL1454544 & 737825 & 5.6 & 5.5732 & TRN & \\
\hline CHEMBL1447809 & 737825 & 4.55 & 5.109 & TRN & \\
\hline CHEMBL1462299 & 737825 & 4.4 & 5.164 & TRN & \\
\hline CHEMBL1302790 & 737825 & 6.75 & 5.2332 & TRN & \\
\hline CHEMBL1394135 & 737825 & 4.9 & 4.9219 & TRN & \\
\hline CHEMBL1401214 & 737825 & 5.5 & 5.5657 & TRN & \\
\hline CHEMBL1475191 & 737825 & 4.8 & 4.7973 & TRN & \\
\hline CHEMBL1597288 & 737825 & 5.2 & 4.9648 & TRN & \\
\hline CHEMBL1741340 & 737825 & 4.8 & 5.1504 & TST & \\
\hline CHEMBL1332143 & 737825 & 4.85 & 5.0398 & TST & \\
\hline CHEMBL1592556 & 737825 & 5.6 & 5.5104 & TRN & \\
\hline CHEMBL1412756 & 737825 & 5.35 & 5.0027 & TRN & \\
\hline CHEMBL1495854 & 737825 & 5.3 & 5.0439 & TRN & \\
\hline CHEMBL1515526 & 737825 & 5.4 & 5.2086 & TRN & \\
\hline CHEMBL1741971 & 737825 & 4.95 & 5.16700 & 0000000001 & TRN \\
\hline CHEMBL1343012 & 737825 & 5.1 & 5.1 & TRN & \\
\hline CHEMBL1447970 & 737825 & 5.8 & 5.3327 & TRN & \\
\hline CHEMBL1553262 & 737825 & 4.5 & 4.5487 & TRN & \\
\hline CHEMBL3208462 & 737825 & 4.65 & 5.147 & TST & \\
\hline CHEMBL1505091 & 737825 & 4.95 & 5.2621 & TST & \\
\hline CHEMBL1720466 & 737825 & 4.9 & 5.0634 & TRN & \\
\hline CHEMBL1576417 & 737825 & 4.8 & 5.0715 & TST & \\
\hline CHEMBL1352042 & 737825 & 6.1 & 5.2151 & TRN & \\
\hline CHEMBL1449517 & 737825 & 5.4 & 5.2321 & TRN & \\
\hline CHEMBL490743 & 737825 & 5.7 & 5.78299 & 99999999995 & TRN \\
\hline CHEMBL601110 & 737825 & 5.4 & 4.9816 & TRN & \\
\hline CHEMBL1393830 & 737825 & 4.6 & 5.1884 & TST & \\
\hline CHEMBL1593096 & 737825 & 5.4 & 5.2531 & TRN & \\
\hline CHEMBL1434156 & 737825 & 4.8 & 4.6756 & TRN & \\
\hline CHEMBL1306550 & 737825 & 4.9 & 5.3687 & TRN & \\
\hline CHEMBL1405744 & 737825 & 4.9 & 4.8261 & TRN & \\
\hline CHEMBL1320518 & 737825 & 5.4 & 5.3517 & TST & \\
\hline CHEMBL1389823 & 737825 & 5.4 & 4.9744 & TST & \\
\hline
\end{tabular}




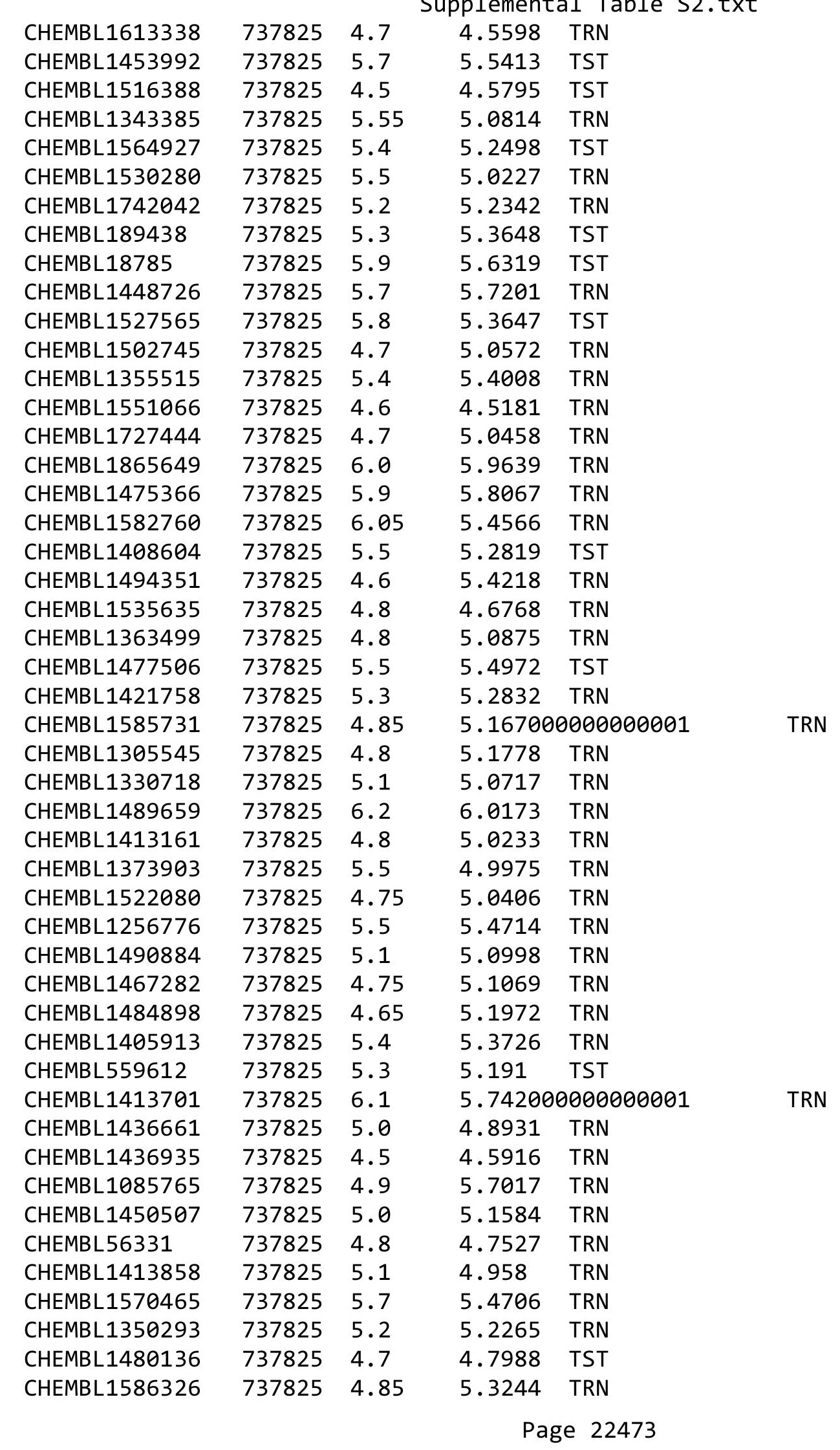




\begin{tabular}{|c|c|c|c|c|}
\hline \multicolumn{5}{|c|}{ Supplemental Table s2.txt } \\
\hline CHEMBL1718203 & 737825 & 5.4 & 5.3267 & TRN \\
\hline CHEMBL83954 & 737825 & 4.6 & 4.5673 & TRN \\
\hline CHEMBL1355135 & 737825 & 5.3 & 5.1112 & TRN \\
\hline CHEMBL1480008 & 737825 & 5.7 & 5.2934 & TRN \\
\hline CHEMBL1597343 & 737825 & 5.0 & 5.1993 & TRN \\
\hline CHEMBL1372952 & 737825 & 4.85 & 5.1752 & TRN \\
\hline CHEMBL1516005 & 737825 & 5.3 & 5.1526 & TRN \\
\hline CHEMBL1337755 & 737825 & 6.0 & 5.7427 & TRN \\
\hline CHEMBL1487421 & 737825 & 5.5 & 5.1427 & TRN \\
\hline CHEMBL1474326 & 737825 & 5.1 & 4.8467 & TRN \\
\hline CHEMBL1546667 & 737825 & 4.6 & 5.2215 & TST \\
\hline CHEMBL1355002 & 737825 & 4.9 & 4.7402 & TRN \\
\hline CHEMBL1607419 & 737825 & 4.95 & 5.1851 & TRN \\
\hline CHEMBL1742283 & 737825 & 6.15 & 5.1134 & TRN \\
\hline CHEMBL1741744 & 737825 & 4.85 & 5.2324 & TRN \\
\hline CHEMBL1447904 & 737825 & 4.7 & 5.1226 & TRN \\
\hline CHEMBL1502500 & 737825 & 5.2 & 5.2629 & TRN \\
\hline CHEMBL1379079 & 737825 & 4.55 & 4.9968 & TST \\
\hline CHEMBL1600243 & 737825 & 5.45 & 5.1957 & TRN \\
\hline CHEMBL1366296 & 737825 & 7.6 & 6.6726 & TRN \\
\hline CHEMBL1572530 & 737825 & 4.8 & 5.1514 & TST \\
\hline CHEMBL1412128 & 737825 & 5.35 & 5.0714 & TRN \\
\hline CHEMBL1481348 & 737825 & 5.6 & 5.2122 & TRN \\
\hline CHEMBL1350835 & 737825 & 4.65 & 5.2464 & TRN \\
\hline CHEMBL1318635 & 737825 & 5.4 & 5.2568 & TRN \\
\hline CHEMBL1515221 & 737825 & 4.9 & 4.9201 & TRN \\
\hline CHEMBL1702814 & 737825 & 4.8 & 5.2002 & TRN \\
\hline CHEMBL 25230 & 737825 & 4.9 & 5.0893 & TST \\
\hline CHEMBL1369125 & 737825 & 5.6 & 5.2756 & TRN \\
\hline CHEMBL1537880 & 737825 & 5.3 & 4.9043 & TST \\
\hline CHEMBL1447663 & 737825 & 5.6 & 5.4165 & TRN \\
\hline CHEMBL1487159 & 737825 & 5.85 & 5.0278 & TST \\
\hline CHEMBL1322137 & 737825 & 6.1 & 5.7929 & TRN \\
\hline CHEMBL1373014 & 737825 & 4.65 & 5.2658 & TST \\
\hline CHEMBL1401938 & 737825 & 5.8 & 5.3131 & TRN \\
\hline CHEMBL1437138 & 737825 & 6.0 & 5.9122 & TRN \\
\hline CHEMBL492610 & 737825 & 5.6 & 5.3489 & TRN \\
\hline CHEMBL492130 & 737825 & 4.8 & 4.8144 & TRN \\
\hline CHEMBL1415115 & 737825 & 4.55 & 5.1689 & TRN \\
\hline CHEMBL1392924 & 737825 & 4.85 & 5.0471 & TRN \\
\hline CHEMBL1741458 & 737825 & 5.75 & 5.2970 & 0000000001 \\
\hline CHEMBL1404254 & 737825 & 5.45 & 5.1355 & TRN \\
\hline CHEMBL1464417 & 737825 & 5.7 & 5.5142 & TRN \\
\hline CHEMBL1366979 & 737825 & 4.75 & 5.0918 & TRN \\
\hline CHEMBL1525226 & 737825 & 5.6 & 5.4761 & TRN \\
\hline CHEMBL1337934 & 737825 & 5.5 & 5.4851 & TRN \\
\hline CHEMBL1366390 & 737825 & 4.6 & 5.1641 & TRN \\
\hline CHEMBL1607968 & 737825 & 4.8 & 5.0101 & TRN \\
\hline
\end{tabular}




\begin{tabular}{|c|c|c|c|c|c|}
\hline \multicolumn{6}{|c|}{ Supplemental Table S2.txt } \\
\hline CHEMBL1436507 & 737825 & 5.5 & 5.4129 & TRN & \\
\hline CHEMBL1475075 & 737825 & 5.8 & 5.6451 & TRN & \\
\hline CHEMBL1490528 & 737825 & 4.8 & 4.6384 & TRN & \\
\hline CHEMBL190259 & 737825 & 5.0 & 5.5887 & TST & \\
\hline CHEMBL1419628 & 737825 & 5.1 & 5.1121 & TRN & \\
\hline CHEMBL474415 & 737825 & 5.1 & 5.1263 & TRN & \\
\hline CHEMBL1394533 & 737825 & 5.1 & 4.8396 & TRN & \\
\hline CHEMBL1571146 & 737825 & 5.15 & 5.1404 & TRN & \\
\hline CHEMBL1538866 & 737825 & 4.65 & 4.8535 & TRN & \\
\hline CHEMBL1607868 & 737825 & 5.9 & 6.0242 & TRN & \\
\hline CHEMBL1354355 & 737825 & 4.8 & 4.8607 & TRN & \\
\hline CHEMBL1514779 & 737825 & 4.8 & 4.5789 & TRN & \\
\hline CHEMBL518430 & 737825 & 4.8 & 5.1961 & TRN & \\
\hline CHEMBL1440157 & 737825 & 6.7 & 6.7302 & TRN & \\
\hline CHEMBL369142 & 737825 & 4.8 & 4.9654 & TST & \\
\hline CHEMBL1442091 & 737825 & 4.85 & 5.2177 & TRN & \\
\hline CHEMBL1363569 & 737825 & 4.85 & 5.1201 & TRN & \\
\hline CHEMBL1492669 & 737825 & 5.4 & 5.2161 & TST & \\
\hline CHEMBL1306717 & 737825 & 5.4 & 5.401 & TRN & \\
\hline CHEMBL1496350 & 737825 & 6.0 & 5.6538 & TRN & \\
\hline CHEMBL1580610 & 737825 & 4.8 & 5.1091 & TST & \\
\hline CHEMBL1343329 & 737825 & 5.35 & 5.1753 & TST & \\
\hline CHEMBL1405758 & 737825 & 4.5 & 5.23799 & 99999999995 & TST \\
\hline CHEMBL1736877 & 737825 & 8.25 & 5.0203 & TST & \\
\hline CHEMBL467706 & 737825 & 6.0 & 5.6181 & TST & \\
\hline CHEMBL 8867 & 737825 & 4.8 & 6.1148 & TST & \\
\hline CHEMBL1322608 & 737825 & 4.9 & 5.5764 & TST & \\
\hline CHEMBL1419997 & 737825 & 5.3 & 5.416 & TRN & \\
\hline CHEMBL1352779 & 737825 & 5.3 & 5.1562 & TRN & \\
\hline CHEMBL1481465 & 737825 & 5.4 & 5.4321 & TRN & \\
\hline CHEMBL1544757 & 737825 & 4.9 & 5.2146 & TRN & \\
\hline CHEMBL1475617 & 737825 & 4.7 & 4.5533 & TRN & \\
\hline CHEMBL1536509 & 737825 & 5.25 & 5.3989 & TRN & \\
\hline CHEMBL1461573 & 737825 & 4.6 & 5.1105 & TST & \\
\hline CHEMBL1540034 & 737825 & 5.2 & 5.2126 & TRN & \\
\hline CHEMBL 3197677 & 737825 & 5.1 & 5.5148 & TRN & \\
\hline CHEMBL1450162 & 737825 & 5.2 & 5.0022 & TRN & \\
\hline CHEMBL1515001 & 737825 & 4.8 & 4.7964 & TST & \\
\hline CHEMBL1612976 & 737825 & 4.9 & 5.1938 & TRN & \\
\hline CHEMBL1551981 & 737825 & 5.1 & 5.0565 & TRN & \\
\hline CHEMBL1557929 & 737825 & 5.5 & 5.0782 & TRN & \\
\hline CHEMBL1520971 & 737825 & 5.1 & 5.2918 & TST & \\
\hline CHEMBL155265 & 737825 & 4.6 & 4.5888 & TST & \\
\hline CHEMBL1435210 & 737825 & 5.5 & 5.4949 & TRN & \\
\hline CHEMBL1595377 & 737825 & 5.0 & 4.8763 & TRN & \\
\hline CHEMBL1434111 & 737825 & 4.8 & 4.6748 & TRN & \\
\hline CHEMBL1434973 & 737825 & 4.8 & 4.6454 & TRN & \\
\hline CHEMBL1591374 & 737825 & 5.7 & 5.5086 & TRN & \\
\hline
\end{tabular}




\begin{tabular}{|c|c|c|c|c|c|}
\hline \multicolumn{6}{|c|}{ Supplemental Table S2.txt } \\
\hline CHEMBL1572683 & 737825 & 4.9 & 4.7358 & TRN & \\
\hline CHEMBL1565546 & 737825 & 4.85 & 4.973 & TRN & \\
\hline CHEMBL1742100 & 737825 & 5.2 & 5.2342 & TRN & \\
\hline CHEMBL 3192856 & 737825 & 4.7 & 5.1951 & TRN & \\
\hline CHEMBL572203 & 737825 & 4.7 & 4.6616 & TRN & \\
\hline CHEMBL533542 & 737825 & 5.4 & 5.535 & TRN & \\
\hline CHEMBL1516500 & 737825 & 4.8 & $5.0280 e$ & 00000000005 & TRN \\
\hline CHEMBL1608233 & 737825 & 5.35 & 5.4932 & TRN & \\
\hline CHEMBL1413831 & 737825 & 5.3 & 5.2085 & TRN & \\
\hline CHEMBL188641 & 737825 & 5.4 & 5.2659 & TST & \\
\hline CHEMBL536480 & 737825 & 5.2 & 5.0658 & TRN & \\
\hline CHEMBL1374524 & 737825 & 5.4 & 5.2445 & TRN & \\
\hline CHEMBL1312826 & 737825 & 5.8 & 5.5308 & TRN & \\
\hline CHEMBL1339380 & 737825 & 5.3 & 5.0861 & TRN & \\
\hline CHEMBL602314 & 737825 & 4.85 & 5.1073 & TRN & \\
\hline CHEMBL1354172 & 737825 & 6.1 & 5.6794 & TST & \\
\hline CHEMBL1533465 & 737825 & 4.8 & 4.773 & TRN & \\
\hline CHEMBL3197330 & 737825 & 5.45 & 5.2784 & TST & \\
\hline CHEMBL1395054 & 737825 & 5.0 & 4.9199 & TRN & \\
\hline CHEMBL1484447 & 737825 & 4.8 & 4.6875 & TRN & \\
\hline CHEMBL1563507 & 737825 & 5.6 & 5.5427 & TRN & \\
\hline CHEMBL1591958 & 737825 & 4.4 & 4.6093 & TRN & \\
\hline CHEMBL1489435 & 737825 & 5.4 & 5.2465 & TRN & \\
\hline CHEMBL1706520 & 737825 & 4.7 & 5.1828 & TRN & \\
\hline CHEMBL1338917 & 737825 & 5.15 & 5.1875 & TRN & \\
\hline CHEMBL1436195 & 737825 & 5.1 & 4.9951 & TRN & \\
\hline CHEMBL1358142 & 737825 & 4.6 & 4.4937 & TRN & \\
\hline CHEMBL1374696 & 737825 & 4.8 & 4.7855 & TRN & \\
\hline CHEMBL1591731 & 737825 & 5.6 & 5.5699 & TST & \\
\hline CHEMBL1553352 & 737825 & 4.9 & 4.8093 & TRN & \\
\hline CHEMBL1366061 & 737825 & 5.0 & 5.0844 & TRN & \\
\hline CHEMBL1447964 & 737825 & 4.85 & 4.9084 & TRN & \\
\hline CHEMBL1574219 & 737825 & 4.6 & 4.9915 & TST & \\
\hline CHEMBL98572 & 737825 & 4.9 & 4.9276 & TRN & \\
\hline CHEMBL 259140 & 737825 & 5.3 & 5.4678 & TRN & \\
\hline CHEMBL509150 & 737825 & 6.7 & 6.5996 & TRN & \\
\hline CHEMBL1512624 & 737825 & 5.3 & 5.2447 & TRN & \\
\hline CHEMBL1256873 & 737825 & 4.9 & 4.8438 & TRN & \\
\hline CHEMBL1371017 & 737825 & 5.35 & 4.9597 & TRN & \\
\hline CHEMBL1610955 & 737825 & 5.4 & 5.2096 & TRN & \\
\hline CHEMBL1299525 & 737825 & 6.45 & 5.6893 & TRN & \\
\hline CHEMBL565856 & 737825 & 5.7 & 5.7436 & TRN & \\
\hline CHEMBL1300567 & 737825 & 5.95 & 5.1336 & TST & \\
\hline CHEMBL1354941 & 737825 & 5.0 & 4.851 & TRN & \\
\hline CHEMBL1560487 & 737825 & 5.8 & 5.4762 & TRN & \\
\hline CHEMBL1578807 & 737825 & 5.1 & 5.1779 & TRN & \\
\hline CHEMBL1316348 & 737825 & 4.8 & 4.7 & TRN & \\
\hline CHEMBL1499289 & 737825 & 5.2 & 5.1673 & TRN & \\
\hline
\end{tabular}




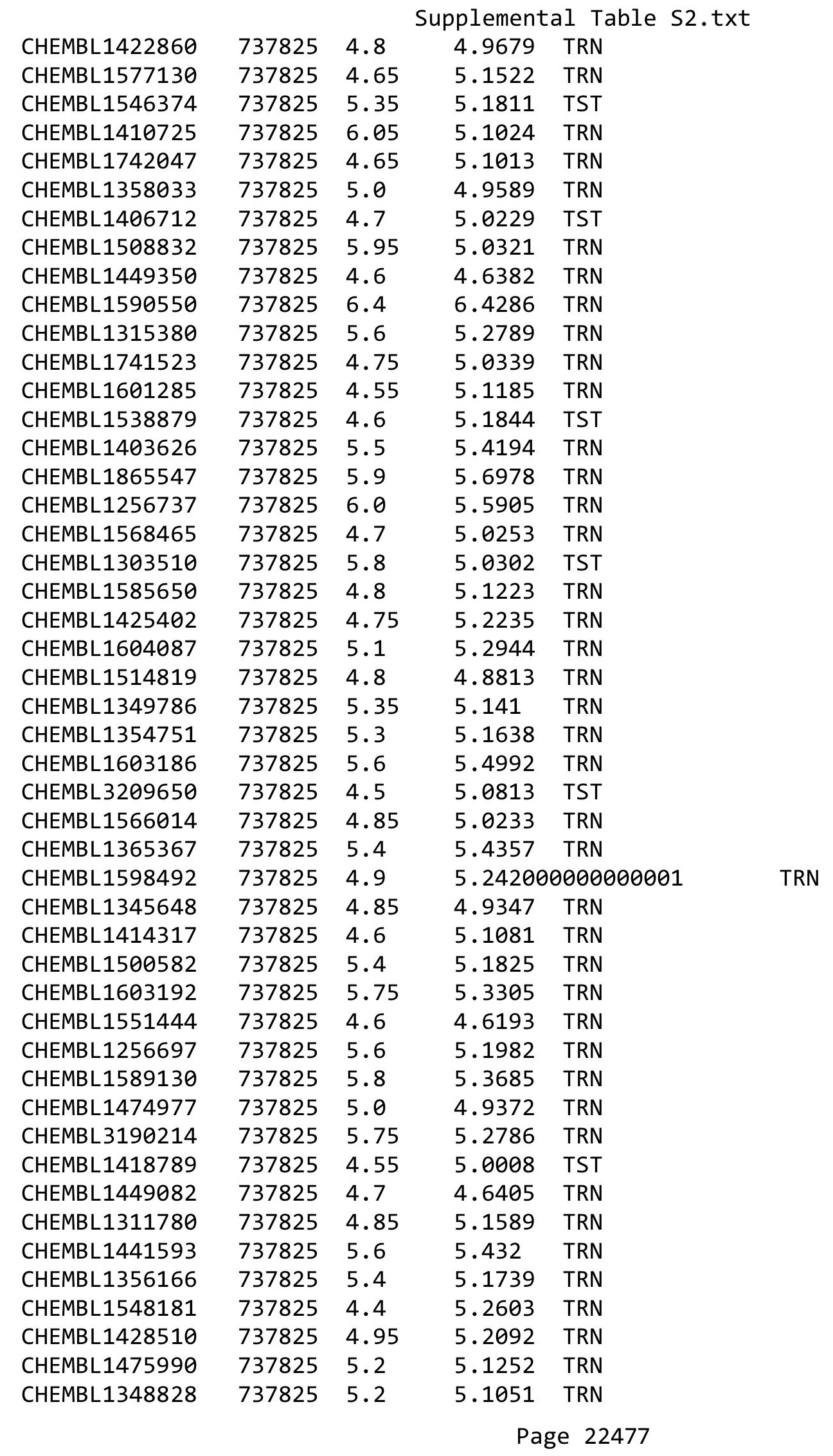




\begin{tabular}{|c|c|c|c|c|c|}
\hline & & & & & \\
\hline CHEMBL1394118 & 737825 & 4.9 & 4.7119 & TRN & \\
\hline CHEMBL1413340 & 737825 & 5.7 & 5.4827 & TRN & \\
\hline CHEMBL1492293 & 737825 & 4.6 & 5.0843 & TRN & \\
\hline CHEMBL1381203 & 737825 & 6.25 & 5.0325 & TRN & \\
\hline CHEMBL1531688 & 737825 & 4.5 & 5.1943 & TRN & \\
\hline CHEMBL1392755 & 737825 & 4.95 & 4.9549 & TRN & \\
\hline CHEMBL1356196 & 737825 & 5.3 & 5.1533 & TRN & \\
\hline CHEMBL65 & 737825 & 5.2 & 5.0334 & TRN & \\
\hline CHEMBL1605085 & 737825 & 5.7 & 5.4134 & TRN & \\
\hline CHEMBL239439 & 737825 & 5.8 & 5.4981 & TST & \\
\hline CHEMBL1336469 & 737825 & 5.0 & 4.9316 & TRN & \\
\hline CHEMBL1491137 & 737825 & 4.9 & $5.0310 e$ & 0000000001 & TRN \\
\hline CHEMBL1729654 & 737825 & 5.0 & 5.2174 & TRN & \\
\hline CHEMBL1435293 & 737825 & 5.5 & 5.7797 & TRN & \\
\hline CHEMBL172064 & 737825 & 4.9 & 5.6718 & TST & \\
\hline CHEMBL1567472 & 737825 & 5.3 & 5.1299 & TRN & \\
\hline CHEMBL1525487 & 737825 & 5.4 & 5.1386 & TRN & \\
\hline CHEMBL1469742 & 737825 & 5.2 & 4.9565 & TRN & \\
\hline CHEMBL1563724 & 737825 & 5.35 & 5.0433 & TRN & \\
\hline CHEMBL1611678 & 737825 & 5.4 & 5.3358 & TRN & \\
\hline CHEMBL1456464 & 737825 & 4.7 & 5.0782 & TRN & \\
\hline CHEMBL326967 & 737825 & 4.6 & 4.6808 & TST & \\
\hline CHEMBL1439338 & 737825 & 5.45 & 5.1616 & TRN & \\
\hline CHEMBL1317232 & 737825 & 4.8 & 4.7723 & TRN & \\
\hline CHEMBL1529795 & 737825 & 4.6 & 5.0032 & TRN & \\
\hline CHEMBL1551732 & 737825 & 5.4 & 5.4698 & TRN & \\
\hline CHEMBL1474625 & 737825 & 6.0 & 5.6485 & TRN & \\
\hline CHEMBL1473754 & 737825 & 4.7 & 4.6447 & TRN & \\
\hline CHEMBL1322527 & 737825 & 4.8 & 5.1016 & TST & \\
\hline CHEMBL1529490 & 737825 & 5.3 & $5.7520 e$ & 0000000001 & TRN \\
\hline CHEMBL407874 & 737825 & 5.1 & 5.0463 & TRN & \\
\hline CHEMBL1526043 & 737825 & 4.4 & 4.3962 & TRN & \\
\hline CHEMBL1256625 & 737825 & 4.6 & 4.6377 & TST & \\
\hline CHEMBL1396949 & 737825 & 4.9 & 4.84 & TRN & \\
\hline CHEMBL1331037 & 737825 & 5.7 & 5.7603 & TRN & \\
\hline CHEMBL1358208 & 737825 & 5.6 & 5.4345 & TRN & \\
\hline CHEMBL1312233 & 737825 & 5.55 & 5.1596 & TST & \\
\hline CHEMBL1544332 & 737825 & 4.4 & 4.9994 & TRN & \\
\hline CHEMBL1302425 & 737825 & 4.75 & 4.9334 & TST & \\
\hline CHEMBL1598318 & 737825 & 4.7 & 4.995 & TRN & \\
\hline CHEMBL1515355 & 737825 & 6.2 & 6.1646 & TRN & \\
\hline CHEMBL1398425 & 737825 & 4.8 & 4.8091 & TRN & \\
\hline CHEMBL1477727 & 737825 & 5.5 & 5.3286 & TRN & \\
\hline CHEMBL1491888 & 737825 & 6.05 & 5.0766 & TST & \\
\hline CHEMBL1356299 & 737825 & 5.7 & 5.6414 & TRN & \\
\hline CHEMBL1371756 & 737825 & 5.0 & 5.051 & TRN & \\
\hline CHEMBL1538593 & 737825 & 5.7 & 5.2936 & TRN & \\
\hline CHEMBL3207650 & 737825 & 5.2 & 5.1355 & TST & \\
\hline & & & & 22478 & \\
\hline
\end{tabular}




\begin{tabular}{|c|c|c|c|c|c|}
\hline \\
\hline CHEMBL67535 & 737825 & 5.7 & 5.3291 & TRN & \\
\hline CHEMBL1406078 & 737825 & 4.9 & 4.626 & TRN & \\
\hline CHEMBL3196379 & 737825 & 4.85 & 5.2711 & TRN & \\
\hline CHEMBL1368962 & 737825 & 5.1 & 5.33200 & 0000000001 & TRN \\
\hline CHEMBL1317982 & 737825 & 4.4 & 4.4175 & TRN & \\
\hline CHEMBL1572157 & 737825 & 5.5 & 5.4214 & TRN & \\
\hline CHEMBL1705149 & 737825 & 4.6 & 5.1651 & TRN & \\
\hline CHEMBL1465250 & 737825 & 5.3 & 5.2311 & TRN & \\
\hline CHEMBL1490740 & 737825 & 5.0 & 5.2175 & TRN & \\
\hline CHEMBL1308408 & 737825 & 4.85 & 5.0991 & TRN & \\
\hline CHEMBL1531174 & 737825 & 5.1 & 5.0785 & TRN & \\
\hline CHEMBL1485152 & 737825 & 5.4 & 5.4062 & TRN & \\
\hline CHEMBL1321758 & 737825 & 5.75 & 5.336 & TRN & \\
\hline CHEMBL1335233 & 737825 & 5.8 & 5.1252 & TRN & \\
\hline CHEMBL1714369 & 737825 & 5.4 & 5.1016 & TST & \\
\hline CHEMBL1533572 & 737825 & 5.0 & 4.80399 & 9999999999 & TRN \\
\hline CHEMBL1568086 & 737825 & 5.3 & 5.2554 & TRN & \\
\hline CHEMBL1435809 & 737825 & 4.6 & 4.6178 & TRN & \\
\hline CHEMBL1438323 & 737825 & 6.0 & 5.9368 & TRN & \\
\hline CHEMBL1386397 & 737825 & 5.3 & 5.15 & TRN & \\
\hline CHEMBL1554976 & 737825 & 6.2 & 5.8823 & TRN & \\
\hline CHEMBL1309064 & 737825 & 5.1 & 5.2489 & TRN & \\
\hline CHEMBL1398707 & 737825 & 4.8 & 5.4389 & TRN & \\
\hline CHEMBL 254348 & 737825 & 5.5 & 5.5571 & TRN & \\
\hline CHEMBL1445647 & 737825 & 4.8 & 5.0901 & TRN & \\
\hline CHEMBL1518419 & 737825 & 4.9 & 5.166 & TRN & \\
\hline CHEMBL1426283 & 737825 & 5.45 & 5.0564 & TRN & \\
\hline CHEMBL1414662 & 737825 & 4.45 & 5.1135 & TRN & \\
\hline CHEMBL1397427 & 737825 & 4.8 & 4.6998 & TRN & \\
\hline CHEMBL1512317 & 737825 & 4.7 & 4.5611 & TRN & \\
\hline CHEMBL1333449 & 737825 & 5.45 & 5.0503 & TRN & \\
\hline CHEMBL1606193 & 737825 & 4.85 & 5.0975 & TRN & \\
\hline CHEMBL1256797 & 737825 & 6.0 & 5.6437 & TRN & \\
\hline CHEMBL1394964 & 737825 & 4.7 & 4.5953 & TRN & \\
\hline CHEMBL1606201 & 737825 & 4.6 & 5.1219 & TRN & \\
\hline CHEMBL1458869 & 737825 & 5.05 & 5.3048 & TRN & \\
\hline CHEMBL1450553 & 737825 & 6.0 & 5.7921 & TRN & \\
\hline CHEMBL1395277 & 737825 & 5.6 & 5.45799 & 9999999999 & TRN \\
\hline CHEMBL1479088 & 737825 & 5.6 & 5.68 & TRN & \\
\hline CHEMBL1610514 & 737825 & 5.0 & 5.1086 & TRN & \\
\hline CHEMBL 3212722 & 737825 & 5.4 & 5.4418 & TRN & \\
\hline CHEMBL1511553 & 737825 & 6.2 & 5.3194 & TRN & \\
\hline CHEMBL1492178 & 737825 & 4.4 & 5.1528 & TRN & \\
\hline CHEMBL1513824 & 737825 & 6.0 & 5.7035 & TRN & \\
\hline CHEMBL1405595 & 737825 & 5.2 & 5.1811 & TRN & \\
\hline CHEMBL1416727 & 737825 & 4.8 & 5.0548 & TRN & \\
\hline CHEMBL 77287 & 737825 & 4.4 & 4.5567 & TRN & \\
\hline CHEMBL1517644 & 737825 & 5.4 & 5.3939 & TST & \\
\hline
\end{tabular}




\begin{tabular}{|c|c|c|c|c|}
\hline \multicolumn{5}{|c|}{ Supplemental Table S2.txt } \\
\hline CHEMBL1316056 & 737825 & 5.5 & 5.3199 & TRN \\
\hline CHEMBL1486796 & 737825 & 4.55 & 4.9062 & TRN \\
\hline CHEMBL1321655 & 737825 & 5.9 & 5.8291 & TRN \\
\hline CHEMBL1433805 & 737825 & 4.8 & 4.726 & TRN \\
\hline CHEMBL1428357 & 737825 & 5.05 & 5.0991 & TRN \\
\hline CHEMBL235453 & 737825 & 5.2 & 5.343 & TRN \\
\hline CHEMBL1410933 & 737825 & 5.1 & 5.1357 & TRN \\
\hline CHEMBL1588453 & 737825 & 4.5 & 5.0025 & TST \\
\hline CHEMBL1302930 & 737825 & 5.15 & 5.2297 & TRN \\
\hline CHEMBL 288174 & 737825 & 5.5 & 5.3394 & TST \\
\hline CHEMBL1395737 & 737825 & 4.6 & 4.7499 & TRN \\
\hline CHEMBL1445840 & 737825 & 5.35 & 5.0556 & TRN \\
\hline CHEMBL1526170 & 737825 & 5.4 & 5.4104 & TRN \\
\hline CHEMBL1408386 & 737825 & 5.7 & 5.1808 & TRN \\
\hline CHEMBL1466047 & 737825 & 4.75 & 5.1545 & TRN \\
\hline CHEMBL1577408 & 737825 & 4.85 & 5.0359 & TRN \\
\hline CHEMBL1579324 & 737825 & 4.6 & 5.0596 & TRN \\
\hline CHEMBL1533932 & 737825 & 5.1 & 5.209 & TRN \\
\hline CHEMBL1331444 & 737825 & 6.0 & 5.7014 & TRN \\
\hline CHEMBL1533144 & 737825 & 4.75 & 5.2589 & TRN \\
\hline CHEMBL1419692 & 737825 & 5.55 & 5.3189 & TST \\
\hline CHEMBL1188431 & 737825 & 5.2 & 5.1965 & TRN \\
\hline CHEMBL1548325 & 737825 & 5.4 & 5.1452 & TRN \\
\hline CHEMBL3213318 & 737825 & 4.85 & 5.0045 & TRN \\
\hline CHEMBL1354713 & 737825 & 5.2 & 4.9699 & TRN \\
\hline CHEMBL1606003 & 737825 & 4.65 & 5.1415 & TRN \\
\hline CHEMBL3191489 & 737825 & 4.6 & 5.3873 & TRN \\
\hline CHEMBL 88402 & 737825 & 5.1 & 5.0605 & TST \\
\hline CHEMBL1392464 & 737825 & 5.3 & 5.166 & TRN \\
\hline CHEMBL1316616 & 737825 & 5.6 & 5.6244 & TRN \\
\hline CHEMBL1473448 & 737825 & 4.8 & 4.7457 & TRN \\
\hline CHEMBL1567447 & 737825 & 5.2 & 5.3143 & TRN \\
\hline CHEMBL1597692 & 737825 & 5.7 & 5.6274 & TST \\
\hline CHEMBL1470016 & 737825 & 4.85 & 5.1304 & TRN \\
\hline CHEMBL1454920 & 737825 & 5.0 & 4.8354 & TRN \\
\hline CHEMBL1472899 & 737825 & 4.6 & 4.4821 & TRN \\
\hline CHEMBL3214295 & 737825 & 5.95 & 5.1934 & TRN \\
\hline CHEMBL1529656 & 737825 & 4.85 & 5.08 & TRN \\
\hline CHEMBL1741681 & 737825 & 5.3 & 5.1714 & TRN \\
\hline CHEMBL 27403 & 737825 & 4.6 & 4.5776 & TRN \\
\hline CHEMBL1519261 & 737825 & 5.6 & 5.5544 & TRN \\
\hline CHEMBL1742155 & 737825 & 4.8 & 5.4205 & TRN \\
\hline CHEMBL1741657 & 737825 & 4.8 & 5.1459 & TRN \\
\hline CHEMBL1316317 & 737825 & 4.8 & 4.7078 & TRN \\
\hline CHEMBL1411164 & 737825 & 5.7 & 5.7214 & TRN \\
\hline CHEMBL1343750 & 737825 & 5.75 & 5.1076 & TRN \\
\hline CHEMBL1458713 & 737825 & 6.8 & 6.25299 & 9999999999 \\
\hline CHEMBL1554459 & 737825 & 5.4 & 5.3535 & TRN \\
\hline
\end{tabular}




\begin{tabular}{|c|c|c|c|c|}
\hline \multicolumn{5}{|c|}{ Supplemental Table S2.txt } \\
\hline CHEMBL1536459 & 737825 & 5.0 & 5.2371 & TRN \\
\hline CHEMBL1448473 & 737825 & 4.85 & 5.2745 & TRN \\
\hline CHEMBL1512190 & 737825 & 5.3 & 5.0668 & TRN \\
\hline CHEMBL1477964 & 737825 & 4.8 & 4.6232 & TRN \\
\hline CHEMBL 1722610 & 737825 & 4.65 & 5.0675 & TRN \\
\hline CHEMBL1355307 & 737825 & 5.4 & 5.1065 & TRN \\
\hline CHEMBL1600973 & 737825 & 4.8 & 4.617 & TRN \\
\hline CHEMBL1304607 & 737825 & 5.0 & 5.0751 & TRN \\
\hline CHEMBL1554745 & 737825 & 5.6 & 5.63 & TRN \\
\hline CHEMBL1394854 & 737825 & 6.3 & 6.2436 & TRN \\
\hline CHEMBL1416184 & 737825 & 4.6 & 5.2879 & TRN \\
\hline CHEMBL1445572 & 737825 & 4.7 & 4.6479 & TRN \\
\hline CHEMBL3210161 & 737825 & 5.4 & 5.4144 & TRN \\
\hline CHEMBL 3197172 & 737825 & 5.5 & 5.2046 & TRN \\
\hline CHEMBL3145189 & 737825 & 5.25 & 5.1175 & TRN \\
\hline CHEMBL1498420 & 737825 & 5.1 & 4.9592 & TRN \\
\hline CHEMBL1545534 & 737825 & 5.15 & 5.1016 & TST \\
\hline CHEMBL1310142 & 737825 & 4.85 & 5.1402 & TRN \\
\hline CHEMBL35888 & 737825 & 4.55 & 5.2074 & TRN \\
\hline CHEMBL1349372 & 737825 & 4.85 & 4.9983 & TRN \\
\hline CHEMBL3196296 & 737825 & 4.6 & 5.318 & TST \\
\hline CHEMBL1519798 & 737825 & 5.3 & 5.0347 & TRN \\
\hline CHEMBL1560912 & 737825 & 4.85 & 4.9262 & TST \\
\hline CHEMBL1310796 & 737825 & 4.95 & 5.1784 & TRN \\
\hline CHEMBL1730467 & 737825 & 4.6 & 5.02 & TRN \\
\hline CHEMBL1588072 & 737825 & 4.95 & 5.0695 & TST \\
\hline CHEMBL3193586 & 737825 & 5.4 & 5.25 & TRN \\
\hline CHEMBL1437906 & 737825 & 4.9 & 4.8362 & TRN \\
\hline CHEMBL1318799 & 737825 & 5.5 & 5.6682 & TRN \\
\hline CHEMBL1741558 & 737825 & 5.0 & 5.2857 & TST \\
\hline CHEMBL1353404 & 737825 & 4.4 & 5.311 & TRN \\
\hline CHEMBL1256814 & 737825 & 5.0 & 4.8183 & TRN \\
\hline CHEMBL1256940 & 737825 & 5.7 & 5.6503 & TRN \\
\hline CHEMBL1331105 & 737825 & 5.4 & 5.3213 & TRN \\
\hline CHEMBL1605814 & 737825 & 4.55 & 5.2115 & TRN \\
\hline CHEMBL1396142 & 737825 & 4.8 & 4.6506 & TRN \\
\hline CHEMBL1510194 & 737825 & 4.9 & 5.0505 & TRN \\
\hline CHEMBL1478762 & 737825 & 5.1 & 5.0487 & TRN \\
\hline CHEMBL1424325 & 737825 & 6.1 & 5.2041 & TST \\
\hline CHEMBL1535905 & 737825 & 5.7 & 5.2907 & TRN \\
\hline CHEMBL1609896 & 737825 & 5.5 & 5.2306 & TRN \\
\hline CHEMBL1525813 & 737825 & 5.5 & 5.4261 & TST \\
\hline CHEMBL1530194 & 737825 & 4.95 & 5.2461 & TRN \\
\hline CHEMBL1565139 & 737825 & 5.4 & 5.1999 & TRN \\
\hline CHEMBL1512434 & 737825 & 6.0 & 5.9303 & TRN \\
\hline CHEMBL1593440 & 737825 & 5.2 & 5.0166 & TRN \\
\hline CHEMBL1314446 & 737825 & 5.1 & 4.8265 & TRN \\
\hline CHEMBL3194183 & 737825 & 4.6 & 5.1444 & TRN \\
\hline
\end{tabular}




\begin{tabular}{|c|c|c|c|c|}
\hline & & & pplemen & al $\mathrm{T}$ \\
\hline CHEMBL1436237 & 737825 & 5.4 & 5.3657 & TRN \\
\hline CHEMBL1359611 & 737825 & 4.4 & 5.1345 & TRN \\
\hline CHEMBL1329846 & 737825 & 5.4 & 5.2126 & TRN \\
\hline CHEMBL1558574 & 737825 & 4.95 & 5.0431 & TRN \\
\hline CHEMBL1320765 & 737825 & 4.9 & 4.829 & TRN \\
\hline CHEMBL1553635 & 737825 & 5.3 & 5.1916 & TST \\
\hline CHEMBL1360725 & 737825 & 6.0 & 5.7379 & TST \\
\hline CHEMBL1335865 & 737825 & 5.6 & 5.2488 & TRN \\
\hline CHEMBL72631 & 737825 & 5.3 & 5.2137 & TRN \\
\hline CHEMBL1355408 & 737825 & 6.2 & 6.1448 & TRN \\
\hline CHEMBL1515614 & 737825 & 4.8 & 4.8577 & TRN \\
\hline CHEMBL1368286 & 737825 & 5.4 & 5.2607 & TRN \\
\hline CHEMBL1383931 & 737825 & 4.6 & 5.1209 & TRN \\
\hline CHEMBL1422796 & 737825 & 5.45 & 5.0794 & TRN \\
\hline CHEMBL1435908 & 737825 & 6.0 & 5.9646 & TRN \\
\hline CHEMBL1514455 & 737825 & 5.5 & 5.1406 & TRN \\
\hline CHEMBL1354693 & 737825 & 4.7 & 4.6215 & TRN \\
\hline CHEMBL1355982 & 737825 & 5.3 & 5.1963 & TRN \\
\hline CHEMBL1333382 & 737825 & 4.95 & 5.2517 & TRN \\
\hline CHEMBL1436979 & 737825 & 4.9 & 4.7159 & TRN \\
\hline CHEMBL1364808 & 737825 & 4.7 & 4.7596 & TST \\
\hline CHEMBL1533882 & 737825 & 4.6 & 5.1467 & TRN \\
\hline CHEMBL1511998 & 737825 & 6.0 & 5.8815 & TST \\
\hline CHEMBL1443480 & 737825 & 4.6 & 4.6549 & TRN \\
\hline CHEMBL490756 & 737825 & 5.9 & 5.7765 & TRN \\
\hline CHEMBL1550463 & 737825 & 4.9 & 4.9197 & TRN \\
\hline CHEMBL1320206 & 737825 & 4.9 & 4.7826 & TRN \\
\hline CHEMBL1435481 & 737825 & 4.7 & 4.573 & TRN \\
\hline CHEMBL1741506 & 737825 & 4.85 & 5.1662 & TRN \\
\hline CHEMBL1981770 & 737825 & 4.55 & 5.1413 & TRN \\
\hline CHEMBL1601300 & 737825 & 5.55 & 5.2419 & TST \\
\hline CHEMBL1397454 & 737825 & 4.8 & 4.5799 & TRN \\
\hline CHEMBL1335668 & 737825 & 5.5 & 5.3521 & TRN \\
\hline CHEMBL1504144 & 737825 & 4.55 & 5.0982 & TRN \\
\hline CHEMBL16671 & 737825 & 4.6 & 5.7321 & TRN \\
\hline CHEMBL1450521 & 737825 & 6.6 & 6.7428 & TRN \\
\hline CHEMBL1479036 & 737825 & 5.4 & 5.2631 & TRN \\
\hline CHEMBL1580037 & 737825 & 4.5 & 5.2217 & TRN \\
\hline CHEMBL1361226 & 737825 & 6.0 & 6.0398 & TRN \\
\hline CHEMBL1442425 & 737825 & 4.6 & 4.5352 & TRN \\
\hline CHEMBL1526455 & 737825 & 4.6 & 5.0103 & TRN \\
\hline CHEMBL1599844 & 737825 & 5.3 & 5.1635 & TRN \\
\hline CHEMBL1703180 & 737825 & 4.8 & 5.141 & TRN \\
\hline CHEMBL1395219 & 737825 & 4.8 & 4.6023 & TRN \\
\hline CHEMBL1534573 & 737825 & 4.6 & 4.4758 & TRN \\
\hline CHEMBL1465834 & 737825 & 4.6 & 5.1154 & TRN \\
\hline CHEMBL1355710 & 737825 & 5.0 & 4.8321 & TRN \\
\hline CHEMBL1304990 & 737825 & 4.9 & 4.9739 & TST \\
\hline
\end{tabular}




\begin{tabular}{|c|c|c|c|c|}
\hline \multicolumn{5}{|c|}{ pplemental $\mathrm{T}$} \\
\hline CHEMBL1422270 & 737825 & 4.5 & 5.0534 & TST \\
\hline CHEMBL1395862 & 737825 & 5.4 & 5.2445 & TRN \\
\hline CHEMBL1489778 & 737825 & 4.8 & 5.0931 & TRN \\
\hline CHEMBL1527622 & 737825 & 5.8 & 5.5883 & TRN \\
\hline CHEMBL1605334 & 737825 & 4.95 & 5.0498 & TRN \\
\hline CHEMBL1563219 & 737825 & 4.85 & 5.2041 & TRN \\
\hline CHEMBL 70880 & 737825 & 6.2 & 5.8941 & TRN \\
\hline CHEMBL1255934 & 737825 & 5.9 & 5.4632 & TST \\
\hline CHEMBL1470578 & 737825 & 5.25 & 5.0729 & TRN \\
\hline CHEMBL1335102 & 737825 & 4.85 & 5.1885 & TRN \\
\hline CHEMBL1512594 & 737825 & 5.1 & 5.0196 & TRN \\
\hline CHEMBL1368572 & 737825 & 5.6 & 5.4892 & TRN \\
\hline CHEMBL1965376 & 737825 & 5.0 & 5.1797 & TRN \\
\hline CHEMBL1372635 & 737825 & 6.0 & 6.0375 & TRN \\
\hline CHEMBL1409815 & 737825 & 5.7 & 5.0989 & TRN \\
\hline CHEMBL1487790 & 737825 & 5.1 & 5.0312 & TRN \\
\hline CHEMBL202752 & 737825 & 5.8 & 5.5251 & TRN \\
\hline CHEMBL1539897 & 737825 & 5.4 & 5.2796 & TST \\
\hline CHEMBL1591893 & 737825 & 4.9 & 5.0327 & TRN \\
\hline CHEMBL1348987 & 737825 & 5.8 & 5.1657 & TST \\
\hline CHEMBL1593438 & 737825 & 4.7 & 4.5582 & TRN \\
\hline CHEMBL1545995 & 737825 & 4.75 & 5.1692 & TRN \\
\hline CHEMBL1359108 & 737825 & 6.6 & 6.1751 & TRN \\
\hline CHEMBL1576980 & 737825 & 5.1 & 5.0522 & TRN \\
\hline CHEMBL1363077 & 737825 & 5.1 & 5.4074 & TRN \\
\hline CHEMBL1317749 & 737825 & 5.4 & 5.3243 & TST \\
\hline CHEMBL1476430 & 737825 & 5.3 & 5.2952 & TRN \\
\hline CHEMBL1464066 & 737825 & 4.8 & 5.4331 & TRN \\
\hline CHEMBL1502952 & 737825 & 5.6 & 5.4783 & TRN \\
\hline CHEMBL1341789 & 737825 & 4.95 & 5.2151 & TRN \\
\hline CHEMBL1527579 & 737825 & 5.4 & 5.4267 & TRN \\
\hline CHEMBL1535457 & 737825 & 4.7 & 5.1865 & TRN \\
\hline CHEMBL1741878 & 737825 & 5.2 & 5.2982 & TRN \\
\hline CHEMBL1568277 & 737825 & 5.15 & 5.0038 & TRN \\
\hline CHEMBL1314844 & 737825 & 5.4 & 5.3734 & TRN \\
\hline CHEMBL429023 & 737825 & 4.6 & 5.4704 & TST \\
\hline CHEMBL1552353 & 737825 & 4.5 & 4.4398 & TRN \\
\hline CHEMBL1595291 & 737825 & 5.1 & 4.8998 & TRN \\
\hline CHEMBL344127 & 737825 & 4.8 & 4.9281 & TRN \\
\hline CHEMBL1742309 & 737825 & 4.9 & 5.1427 & TRN \\
\hline CHEMBL1434789 & 737825 & 4.4 & 4.4742 & TRN \\
\hline CHEMBL1542385 & 737825 & 4.65 & 5.0865 & TRN \\
\hline CHEMBL1333287 & 737825 & 4.9 & 4.6436 & TRN \\
\hline CHEMBL1430379 & 737825 & 6.0 & 5.3328 & TRN \\
\hline CHEMBL1391282 & 737825 & 4.4 & 5.2134 & TRN \\
\hline CHEMBL1329939 & 737825 & 5.5 & 5.5527 & TRN \\
\hline CHEMBL1474281 & 737825 & 4.8 & 4.6197 & TRN \\
\hline CHEMBL1601662 & 737825 & 4.8 & 4.8071 & TRN \\
\hline
\end{tabular}




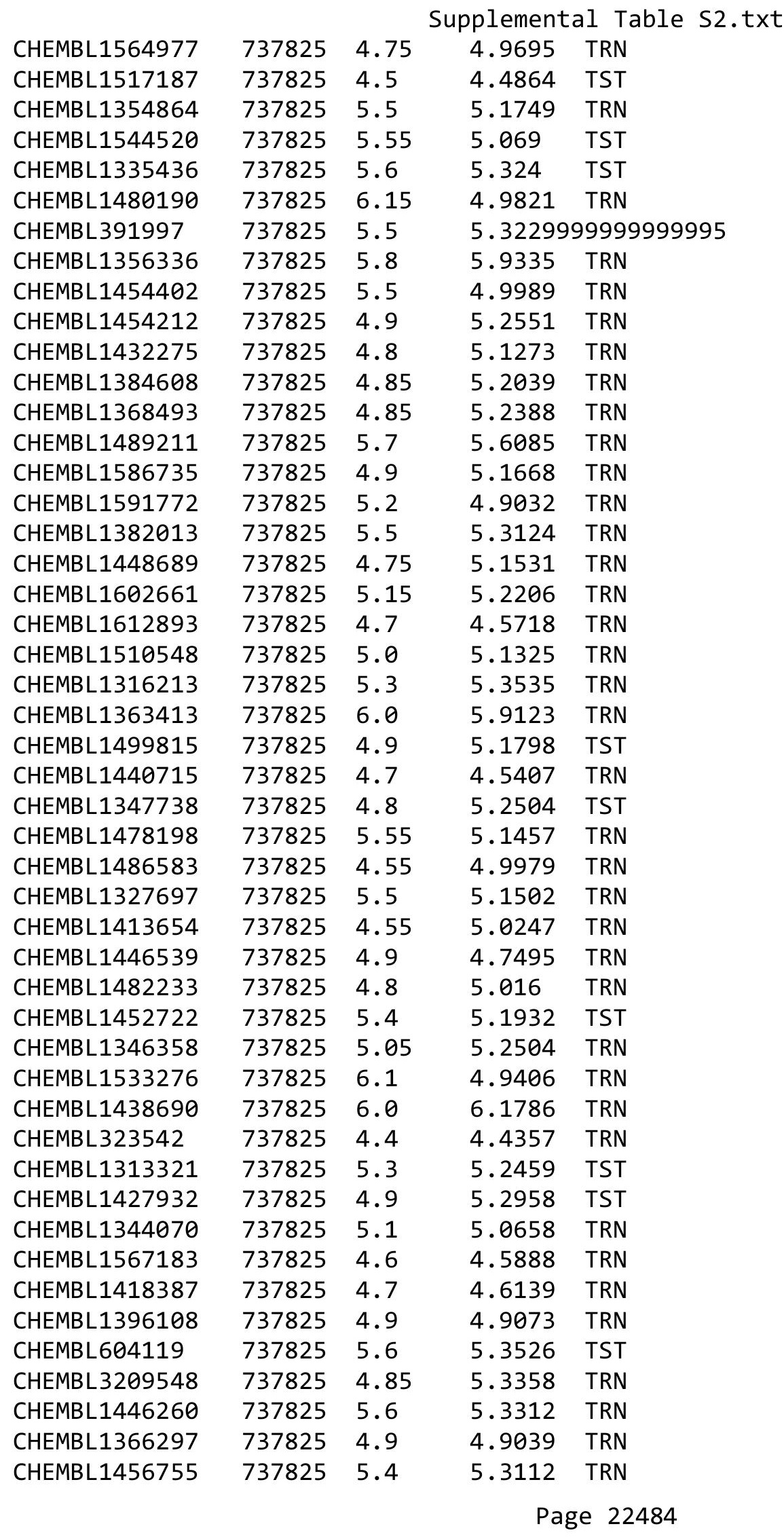




\begin{tabular}{|c|c|c|c|c|c|}
\hline \multicolumn{6}{|c|}{ Supplemental Table S2.txt } \\
\hline CHEMBL1507021 & 737825 & 4.65 & 5.1457 & TRN & \\
\hline CHEMBL1355242 & 737825 & 4.9 & 4.9798 & TRN & \\
\hline CHEMBL1517073 & 737825 & 5.4 & 5.3384 & TRN & \\
\hline CHEMBL1452192 & 737825 & 4.95 & 5.1573 & TST & \\
\hline CHEMBL1470386 & 737825 & 5.45 & 5.1909 & TRN & \\
\hline CHEMBL1256693 & 737825 & 5.1 & 5.0068 & TRN & \\
\hline CHEMBL1415013 & 737825 & 4.8 & 5.1149 & TST & \\
\hline CHEMBL1404907 & 737825 & 5.3 & 5.0794 & TRN & \\
\hline CHEMBL1741471 & 737825 & 4.85 & 5.1111 & TRN & \\
\hline CHEMBL1604492 & 737825 & 4.85 & 5.2462 & TRN & \\
\hline CHEMBL566899 & 737825 & 6.0 & 6.1029 & TRN & \\
\hline CHEMBL1468406 & 737825 & 4.8 & 5.0983 & TRN & \\
\hline CHEMBL1507563 & 737825 & 4.9 & 5.1321 & TRN & \\
\hline CHEMBL1574385 & 737825 & 4.4 & 5.1099 & TRN & \\
\hline CHEMBL1458309 & 737825 & 4.85 & 5.3026 & TST & \\
\hline CHEMBL1496125 & 737825 & 5.5 & 5.42299 & 7999999999 & TRN \\
\hline CHEMBL1406530 & 737825 & 4.8 & 5.1392 & TRN & \\
\hline CHEMBL1448288 & 737825 & 5.6 & 5.5236 & TRN & \\
\hline CHEMBL1551021 & 737825 & 5.3 & 5.2177 & TRN & \\
\hline CHEMBL1447149 & 737825 & 5.3 & 5.0943 & TRN & \\
\hline CHEMBL1367149 & 737825 & 5.25 & 5.1282 & TRN & \\
\hline CHEMBL1723390 & 737825 & 4.85 & 5.1933 & TRN & \\
\hline CHEMBL502044 & 737825 & 4.5 & 4.5103 & TST & \\
\hline CHEMBL3212717 & 737825 & 4.8 & 5.3736 & TRN & \\
\hline CHEMBL1337787 & 737825 & 5.5 & 5.2162 & TRN & \\
\hline CHEMBL1331054 & 737825 & 5.1 & 5.1522 & TST & \\
\hline CHEMBL1465187 & 737825 & 5.65 & 5.1104 & TRN & \\
\hline CHEMBL1445399 & 737825 & 4.8 & 4.7562 & TST & \\
\hline CHEMBL1370100 & 737825 & 6.45 & 5.3767 & TRN & \\
\hline CHEMBL1581737 & 737825 & 5.45 & 5.1737 & TRN & \\
\hline CHEMBL1554888 & 737825 & 5.6 & 5.5373 & TRN & \\
\hline CHEMBL1303855 & 737825 & 5.05 & 5.1485 & TRN & \\
\hline CHEMBL1612586 & 737825 & 4.75 & 5.2435 & TRN & \\
\hline CHEMBL1399944 & 737825 & 4.6 & 5.1578 & TRN & \\
\hline CHEMBL1471648 & 737825 & 4.85 & 5.1558 & TST & \\
\hline CHEMBL3192271 & 737825 & 5.65 & 5.0964 & TST & \\
\hline CHEMBL1369966 & 737825 & 5.8 & 5.8207 & TRN & \\
\hline CHEMBL1599025 & 737825 & 4.85 & 5.1056 & TRN & \\
\hline CHEMBL1361050 & 737825 & 4.55 & 5.1629 & TRN & \\
\hline CHEMBL1365616 & 737825 & 4.9 & 4.8681 & TRN & \\
\hline CHEMBL3212040 & 737825 & 5.5 & 5.0808 & TRN & \\
\hline CHEMBL1613081 & 737825 & 5.45 & 5.0197 & TRN & \\
\hline CHEMBL1489353 & 737825 & 5.0 & 4.93 & TRN & \\
\hline CHEMBL1236602 & 737825 & 6.6 & 5.9925 & TRN & \\
\hline CHEMBL1582671 & 737825 & 4.8 & 5.3561 & TRN & \\
\hline CHEMBL1363467 & 737825 & 4.8 & 4.6048 & TRN & \\
\hline CHEMBL1351822 & 737825 & 4.55 & 4.9648 & TRN & \\
\hline CHEMBL1523959 & 737825 & 4.6 & 4.5221 & TRN & \\
\hline
\end{tabular}




\begin{tabular}{|c|c|c|c|c|c|}
\hline \multicolumn{6}{|c|}{ Supplemental Table s2.txt } \\
\hline CHEMBL1453758 & 737825 & 4.75 & 5.0135 & TRN & \\
\hline CHEMBL1587623 & 737825 & 5.1 & 5.1826 & TRN & \\
\hline CHEMBL126077 & 737825 & 5.1 & 4.8756 & TST & \\
\hline CHEMBL1335686 & 737825 & 4.6 & 4.993 & TRN & \\
\hline CHEMBL1514505 & 737825 & 4.8 & 4.6485 & TRN & \\
\hline CHEMBL1612968 & 737825 & 5.15 & \multicolumn{2}{|c|}{5.252000000000001} & TRN \\
\hline CHEMBL1361813 & 737825 & 6.3 & 5.1225 & TRN & \\
\hline CHEMBL1354137 & 737825 & 4.6 & 5.0389 & TST & \\
\hline CHEMBL1607106 & 737825 & 5.5 & 5.4271 & TRN & \\
\hline CHEMBL1369322 & 737825 & 4.9 & 5.1442 & TRN & \\
\hline CHEMBL1335329 & 737825 & 5.4 & 5.2688 & TRN & \\
\hline CHEMBL1423586 & 737825 & 4.8 & 5.2179 & TRN & \\
\hline CHEMBL1357444 & 737825 & 5.7 & 5.6193 & TRN & \\
\hline CHEMBL1466200 & 737825 & 5.45 & 5.0525 & TRN & \\
\hline CHEMBL26915 & 737825 & 4.4 & 4.4999 & TST & \\
\hline CHEMBL1381498 & 737825 & 5.05 & 5.0932 & TST & \\
\hline CHEMBL1554170 & 737825 & 5.6 & 5.6218 & TRN & \\
\hline CHEMBL1515874 & 737825 & 4.9 & 4.9208 & TRN & \\
\hline CHEMBL491555 & 737825 & 6.3 & 6.4509 & TRN & \\
\hline CHEMBL1580156 & 737825 & 4.65 & 5.1588 & TRN & \\
\hline CHEMBL1401539 & 737825 & 4.8 & 5.0831 & TRN & \\
\hline CHEMBL1498694 & 737825 & 5.7 & \multicolumn{2}{|c|}{5.2989999999999995} & TST \\
\hline CHEMBL1558076 & 737825 & 5.35 & 5.088 & TST & \\
\hline CHEMBL1474989 & 737825 & 5.2 & 5.0026 & TRN & \\
\hline CHEMBL1601955 & 737825 & 4.45 & 5.0733 & TRN & \\
\hline CHEMBL1551049 & 737825 & 5.3 & 4.9871 & TRN & \\
\hline CHEMBL1448803 & 737825 & 5.2 & 5.0403 & TRN & \\
\hline CHEMBL1514639 & 737825 & 5.6 & 5.3976 & TST & \\
\hline CHEMBL1498627 & 737825 & 5.0 & 5.2091 & TRN & \\
\hline CHEMBL1311520 & 737825 & 4.8 & 5.1425 & TRN & \\
\hline CHEMBL1457414 & 737825 & 4.8 & 5.2624 & TRN & \\
\hline CHEMBL1573058 & 737825 & 4.8 & 4.5862 & TRN & \\
\hline CHEMBL1315609 & 737825 & 5.4 & 5.3974 & TRN & \\
\hline CHEMBL1307390 & 737825 & 5.45 & 5.1299 & TRN & \\
\hline CHEMBL1570894 & 737825 & 5.4 & 5.2516 & TRN & \\
\hline CHEMBL1544357 & 737825 & 4.65 & 4.984 & TST & \\
\hline CHEMBL1572173 & 737825 & 4.8 & 4.6996 & TRN & \\
\hline CHEMBL1489879 & 737825 & 4.75 & 5.0733 & TST & \\
\hline CHEMBL1498258 & 737825 & 5.0 & 5.2212 & TRN & \\
\hline CHEMBL47529 & 737825 & 4.8 & 4.8372 & TRN & \\
\hline CHEMBL3209598 & 737825 & 4.6 & 5.0847 & TST & \\
\hline CHEMBL1390261 & 737825 & 6.4 & 5.6981 & TRN & \\
\hline CHEMBL1527436 & 737825 & 4.55 & 5.0964 & TRN & \\
\hline CHEMBL1510935 & 737825 & 4.4 & 4.9997 & TRN & \\
\hline CHEMBL1403937 & 737825 & 5.35 & 5.1844 & TRN & \\
\hline CHEMBL492127 & 737825 & 6.5 & 6.6391 & TRN & \\
\hline CHEMBL1542230 & 737825 & 4.6 & 5.2379 & TRN & \\
\hline \multirow[t]{2}{*}{ CHEMBL1443323 } & 737825 & 4.9 & \multicolumn{2}{|c|}{4.7410000000000005} & TRN \\
\hline & & & & 22486 & \\
\hline
\end{tabular}




\begin{tabular}{|c|c|c|c|c|c|}
\hline \\
\hline CHEMBL1302636 & 737825 & 6.0 & 5.3475 & TRN & \\
\hline CHEMBL1349366 & 737825 & 5.0 & 5.0551 & TRN & \\
\hline CHEMBL1459858 & 737825 & 4.8 & 5.1137 & TRN & \\
\hline CHEMBL1540401 & 737825 & 5.0 & 5.15 & TST & \\
\hline CHEMBL1357089 & 737825 & 5.3 & 5.0578 & TRN & \\
\hline CHEMBL1551274 & 737825 & 5.4 & 5.2725 & TRN & \\
\hline CHEMBL1419702 & 737825 & 5.6 & 5.2571 & TRN & \\
\hline CHEMBL1340482 & 737825 & 4.8 & 5.1044 & TRN & \\
\hline CHEMBL1562277 & 737825 & 6.3 & 5.329 & TRN & \\
\hline CHEMBL1991234 & 737825 & 4.9 & 5.0877 & TST & \\
\hline CHEMBL3214362 & 737825 & 4.8 & 5.1752 & TRN & \\
\hline CHEMBL1404882 & 737825 & 5.6 & 5.5717 & TRN & \\
\hline CHEMBL1387625 & 737825 & 5.05 & 5.2292 & TRN & \\
\hline CHEMBL1440067 & 737825 & 5.7 & 5.2243 & TRN & \\
\hline CHEMBL1526199 & 737825 & 5.5 & 5.2111 & TRN & \\
\hline CHEMBL1573964 & 737825 & 4.8 & 4.7352 & TRN & \\
\hline CHEMBL389390 & 737825 & 4.6 & 5.7027 & TRN & \\
\hline CHEMBL1523579 & 737825 & 4.8 & 4.5669 & TRN & \\
\hline CHEMBL1392213 & 737825 & 4.45 & 5.1014 & TST & \\
\hline CHEMBL1413404 & 737825 & 4.85 & 5.1039 & TRN & \\
\hline CHEMBL1591459 & 737825 & 5.4 & 5.3738 & TRN & \\
\hline CHEMBL3214412 & 737825 & 4.9 & 5.1661 & TRN & \\
\hline CHEMBL1315991 & 737825 & 4.8 & 4.6708 & TRN & \\
\hline CHEMBL1503387 & 737825 & 5.2 & 5.2087 & TRN & \\
\hline CHEMBL1441359 & 737825 & 6.3 & 5.1486 & TRN & \\
\hline CHEMBL3189655 & 737825 & 5.15 & 5.2159 & TST & \\
\hline CHEMBL1463617 & 737825 & 4.9 & 5.2396 & TRN & \\
\hline CHEMBL 1371710 & 737825 & 5.2 & 5.1577 & TRN & \\
\hline CHEMBL1736254 & 737825 & 5.5 & 5.4025 & TST & \\
\hline CHEMBL1438058 & 737825 & 4.55 & 5.0333 & TRN & \\
\hline CHEMBL1305215 & 737825 & 5.4 & 5.1217 & TRN & \\
\hline CHEMBL1256364 & 737825 & 4.8 & 4.7454 & TRN & \\
\hline CHEMBL1433752 & 737825 & 5.4 & 5.4883 & TRN & \\
\hline CHEMBL1414493 & 737825 & 5.7 & 5.544 & TRN & \\
\hline CHEMBL1570413 & 737825 & 4.8 & 4.5397 & TRN & \\
\hline CHEMBL1435638 & 737825 & 5.7 & 5.6694 & TRN & \\
\hline CHEMBL1334512 & 737825 & 4.4 & 5.1666 & TST & \\
\hline CHEMBL1413605 & 737825 & 4.45 & 4.9402 & TRN & \\
\hline CHEMBL1405203 & 737825 & 4.75 & 4.9023 & TRN & \\
\hline CHEMBL1353128 & 737825 & 4.6 & 5.1668 & TRN & \\
\hline CHEMBL1316808 & 737825 & 4.9 & 4.747 & TRN & \\
\hline CHEMBL1495077 & 737825 & 4.9 & 4.7389 & TRN & \\
\hline CHEMBL1741988 & 737825 & 5.3 & 5.0743 & TRN & \\
\hline CHEMBL1438766 & 737825 & 4.9 & 5.3971 & TRN & \\
\hline CHEMBL1369376 & 737825 & 5.0 & 5.142 & TRN & \\
\hline CHEMBL1601589 & 737825 & 4.75 & 5.08899 & 99999999995 & TRN \\
\hline CHEMBL1463367 & 737825 & 5.5 & 5.2419 & TRN & \\
\hline CHEMBL 2003798 & 737825 & 5.4 & 5.1533 & TRN & \\
\hline
\end{tabular}




\begin{tabular}{|c|c|c|c|c|}
\hline \multicolumn{5}{|c|}{ Supplemental Table } \\
\hline CHEMBL1330299 & 737825 & 6.45 & 5.648 & TRN \\
\hline CHEMBL1361449 & 737825 & 5.3 & 5.3093 & TRN \\
\hline CHEMBL1374913 & 737825 & 4.8 & 4.8154 & TRN \\
\hline CHEMBL1528351 & 737825 & 4.95 & 5.1933 & TRN \\
\hline CHEMBL1352225 & 737825 & 5.9 & 5.3162 & TRN \\
\hline CHEMBL1411123 & 737825 & 4.75 & 4.9572 & TRN \\
\hline CHEMBL1358614 & 737825 & 6.0 & 6.0852 & TRN \\
\hline CHEMBL1710203 & 737825 & 4.85 & 5.3565 & TRN \\
\hline CHEMBL1410008 & 737825 & 5.5 & 5.1175 & TRN \\
\hline CHEMBL326958 & 737825 & 4.6 & 4.6007 & TRN \\
\hline CHEMBL1396225 & 737825 & 4.9 & 4.6623 & TRN \\
\hline CHEMBL1467618 & 737825 & 5.7 & 5.2243 & TRN \\
\hline CHEMBL1424743 & 737825 & 5.2 & 5.0394 & TRN \\
\hline CHEMBL1319720 & 737825 & 5.5 & 5.3503 & TST \\
\hline CHEMBL1319789 & 737825 & 5.0 & 5.3156 & TRN \\
\hline CHEMBL1390555 & 737825 & 5.05 & 5.2236 & TRN \\
\hline CHEMBL1358756 & 737825 & 4.8 & 4.579 & TRN \\
\hline CHEMBL1342399 & 737825 & 4.6 & 5.1433 & TRN \\
\hline CHEMBL1515724 & 737825 & 5.1 & 4.8865 & TRN \\
\hline CHEMBL1406485 & 737825 & 4.7 & 4.6582 & TRN \\
\hline CHEMBL1256719 & 737825 & 5.0 & 4.8877 & TST \\
\hline CHEMBL1489512 & 737825 & 4.95 & 5.2596 & TRN \\
\hline CHEMBL1581408 & 737825 & 4.8 & 5.0879 & TRN \\
\hline CHEMBL1531070 & 737825 & 5.0 & 5.0311 & TRN \\
\hline CHEMBL1611388 & 737825 & 5.55 & 5.0929 & TRN \\
\hline CHEMBL1358588 & 737825 & 5.3 & 5.0864 & TRN \\
\hline CHEMBL1580116 & 737825 & 4.85 & 5.1599 & TRN \\
\hline CHEMBL1514359 & 737825 & 4.8 & 4.7639 & TRN \\
\hline CHEMBL1570350 & 737825 & 4.6 & 4.6068 & TRN \\
\hline CHEMBL1532443 & 737825 & 5.55 & 5.2813 & TRN \\
\hline CHEMBL1419890 & 737825 & 5.2 & 5.0868 & TRN \\
\hline CHEMBL1487748 & 737825 & 6.0 & 6.0087 & TRN \\
\hline CHEMBL1306491 & 737825 & 4.8 & 5.1422 & TRN \\
\hline CHEMBL1518362 & 737825 & 4.95 & 5.1284 & TRN \\
\hline CHEMBL1476511 & 737825 & 5.1 & 4.8565 & TRN \\
\hline CHEMBL1363345 & 737825 & 5.15 & 5.2527 & TRN \\
\hline CHEMBL 1476712 & 737825 & 5.5 & 5.1696 & TRN \\
\hline CHEMBL1322537 & 737825 & 4.85 & 5.1589 & TRN \\
\hline CHEMBL1598062 & 737825 & 5.9 & 5.816 & TRN \\
\hline CHEMBL1359613 & 737825 & 4.8 & 4.8615 & TRN \\
\hline CHEMBL1436992 & 737825 & 4.8 & 4.6629 & TST \\
\hline CHEMBL1366635 & 737825 & 5.15 & 5.0005 & TRN \\
\hline CHEMBL1492056 & 737825 & 5.45 & 5.0615 & TRN \\
\hline CHEMBL1464912 & 737825 & 5.7 & 5.2723 & TRN \\
\hline CHEMBL1982203 & 737825 & 4.4 & 5.3146 & TRN \\
\hline CHEMBL1590857 & 737825 & 5.2 & 5.0195 & TRN \\
\hline CHEMBL1355970 & 737825 & 4.6 & 4.4276 & TRN \\
\hline CHEMBL1717189 & 737825 & 4.6 & 5.1488 & TRN \\
\hline
\end{tabular}




\begin{tabular}{|c|c|c|c|c|c|}
\hline \\
\hline CHEMBL1478660 & 737825 & 4.85 & 5.1487 & TRN & \\
\hline CHEMBL1524363 & 737825 & 5.3 & 5.104 & TST & \\
\hline CHEMBL1308401 & 737825 & 4.85 & 5.103 & TST & \\
\hline CHEMBL1545653 & 737825 & 4.9 & 5.2123 & TRN & \\
\hline CHEMBL1425640 & 737825 & 4.9 & 5.2384 & TRN & \\
\hline CHEMBL1566936 & 737825 & 4.8 & 4.6765 & TRN & \\
\hline CHEMBL1406703 & 737825 & 4.65 & 5.1123 & TST & \\
\hline CHEMBL1328118 & 737825 & 5.25 & 5.12299 & 9999999999 & TRN \\
\hline CHEMBL1386361 & 737825 & 4.95 & 5.3833 & TRN & \\
\hline CHEMBL1519567 & 737825 & 5.15 & 5.0996 & TRN & \\
\hline CHEMBL1335037 & 737825 & 6.5 & 5.4236 & TRN & \\
\hline CHEMBL1465935 & 737825 & 4.4 & 5.1285 & TRN & \\
\hline CHEMBL1396561 & 737825 & 5.8 & 5.6498 & TRN & \\
\hline CHEMBL1359919 & 737825 & 5.4 & 5.3044 & TRN & \\
\hline CHEMBL1411081 & 737825 & 6.0 & 5.82299 & 99999999995 & TRN \\
\hline CHEMBL1522796 & 737825 & 5.4 & 5.1653 & TST & \\
\hline CHEMBL1509992 & 737825 & 4.55 & 4.94600 & 0000000001 & TRN \\
\hline CHEMBL1507494 & 737825 & 4.95 & 5.0104 & TST & \\
\hline CHEMBL1569975 & 737825 & 4.4 & 5.0507 & TRN & \\
\hline CHEMBL94734 & 737825 & 4.9 & 4.8699 & TRN & \\
\hline CHEMBL1342661 & 737825 & 5.0 & 5.124 & TRN & \\
\hline CHEMBL1356094 & 737825 & 4.5 & 4.61600 & 00000000005 & TRN \\
\hline CHEMBL1329104 & 737825 & 4.8 & 4.948 & TRN & \\
\hline CHEMBL1363873 & 737825 & 5.0 & 4.7136 & TRN & \\
\hline CHEMBL1370622 & 737825 & 5.7 & 5.6277 & TRN & \\
\hline CHEMBL1232207 & 737825 & 4.9 & 4.8739 & TST & \\
\hline CHEMBL1529665 & 737825 & 5.5 & 5.2593 & TST & \\
\hline CHEMBL1413668 & 737825 & 4.6 & 5.0389 & TST & \\
\hline CHEMBL1518718 & 737825 & 4.4 & 4.5014 & TRN & \\
\hline CHEMBL1419019 & 737825 & 5.0 & 5.2235 & TRN & \\
\hline CHEMBL1322864 & 737825 & 5.5 & 5.2058 & TRN & \\
\hline CHEMBL1493877 & 737825 & 4.85 & 5.2422 & TST & \\
\hline CHEMBL3192809 & 737825 & 4.65 & 5.2147 & TRN & \\
\hline CHEMBL1316828 & 737825 & 4.5 & 4.7003 & TST & \\
\hline CHEMBL1429698 & 737825 & 6.2 & 5.2018 & TRN & \\
\hline CHEMBL1566015 & 737825 & 5.35 & 5.474 & TRN & \\
\hline CHEMBL1742326 & 737825 & 5.85 & 5.0547 & TRN & \\
\hline CHEMBL1382247 & 737825 & 4.85 & 5.1904 & TRN & \\
\hline CHEMBL1725515 & 737825 & 4.8 & 5.2111 & TRN & \\
\hline CHEMBL1485991 & 737825 & 5.45 & 5.2069 & TRN & \\
\hline CHEMBL1370136 & 737825 & 5.4 & 5.4595 & TRN & \\
\hline CHEMBL1742219 & 737825 & 4.75 & 5.1497 & TRN & \\
\hline CHEMBL1515287 & 737825 & 5.3 & 5.0788 & TRN & \\
\hline CHEMBL1534630 & 737825 & 5.0 & 4.8104 & TST & \\
\hline CHEMBL1299778 & 737825 & 4.8 & 5.2951 & TRN & \\
\hline CHEMBL1485069 & 737825 & 5.3 & 5.2858 & TRN & \\
\hline CHEMBL1556431 & 737825 & 4.8 & 4.6099 & TRN & \\
\hline CHEMBL1325149 & 737825 & 5.45 & 5.4977 & TRN & \\
\hline
\end{tabular}




\begin{tabular}{|c|c|c|c|c|c|}
\hline \multicolumn{6}{|c|}{ Supplemental Table S2.txt } \\
\hline CHEMBL1513800 & 737825 & 4.6 & 4.5689 & TRN & \\
\hline CHEMBL1525169 & 737825 & 4.9 & 5.1188 & TRN & \\
\hline CHEMBL1330468 & 737825 & 4.8 & 5.1414 & TRN & \\
\hline CHEMBL1424761 & 737825 & 5.5 & 5.2269 & TRN & \\
\hline CHEMBL1727631 & 737825 & 5.0 & 4.9842 & TRN & \\
\hline CHEMBL296586 & 737825 & 4.9 & 4.8961 & TST & \\
\hline CHEMBL1362669 & 737825 & 5.25 & 5.1851 & TRN & \\
\hline CHEMBL1397913 & 737825 & 5.1 & 5.2185 & TRN & \\
\hline CHEMBL3189779 & 737825 & 4.9 & 5.1742 & TRN & \\
\hline CHEMBL1446314 & 737825 & 4.85 & 5.1339 & TST & \\
\hline CHEMBL1415500 & 737825 & 5.55 & 5.0595 & TRN & \\
\hline CHEMBL1483332 & 737825 & 6.0 & 4.9731 & TRN & \\
\hline CHEMBL1332463 & 737825 & 6.0 & 6.0214 & TRN & \\
\hline CHEMBL1587412 & 737825 & 5.35 & 5.0494 & TST & \\
\hline CHEMBL34730 & 737825 & 4.8 & 4.7908 & TRN & \\
\hline CHEMBL1605678 & 737825 & 4.9 & 5.059 & TRN & \\
\hline CHEMBL1358449 & 737825 & 7.5 & 6.9043 & TST & \\
\hline CHEMBL546597 & 737825 & 5.5 & 4.9819 & TRN & \\
\hline CHEMBL1476348 & 737825 & 4.6 & 4.4608 & TRN & \\
\hline CHEMBL1454533 & 737825 & 5.25 & 5.13899 & 9999999999 & TRN \\
\hline CHEMBL1496004 & 737825 & 6.7 & 5.2787 & TRN & \\
\hline CHEMBL3194874 & 737825 & 5.65 & 5.2529 & TRN & \\
\hline CHEMBL1602710 & 737825 & 5.1 & 5.126 & TRN & \\
\hline CHEMBL1413371 & 737825 & 5.0 & 5.0756 & TRN & \\
\hline CHEMBL1736619 & 737825 & 4.65 & 5.2531 & TRN & \\
\hline CHEMBL1391592 & 737825 & 4.9 & 5.1323 & TRN & \\
\hline CHEMBL1476288 & 737825 & 4.5 & 4.4174 & TRN & \\
\hline CHEMBL1419479 & 737825 & 4.85 & 5.0732 & TST & \\
\hline CHEMBL1456341 & 737825 & 4.95 & 5.2756 & TRN & \\
\hline CHEMBL1719114 & 737825 & 4.6 & 5.2335 & TRN & \\
\hline CHEMBL1611192 & 737825 & 4.8 & 4.7471 & TST & \\
\hline CHEMBL1478772 & 737825 & 4.7 & 4.6282 & TRN & \\
\hline CHEMBL1552277 & 737825 & 5.6 & 5.5309 & TRN & \\
\hline CHEMBL1506666 & 737825 & 4.85 & 5.0937 & TRN & \\
\hline CHEMBL1446112 & 737825 & 6.1 & 5.7937 & TRN & \\
\hline CHEMBL1356628 & 737825 & 4.6 & 4.6266 & TRN & \\
\hline CHEMBL1490809 & 737825 & 4.6 & 4.9284 & TRN & \\
\hline CHEMBL127421 & 737825 & 4.8 & 4.7629 & TRN & \\
\hline CHEMBL 3195142 & 737825 & 5.65 & 5.1263 & TRN & \\
\hline CHEMBL1741759 & 737825 & 4.8 & 5.114 & TST & \\
\hline CHEMBL1395252 & 737825 & 4.8 & 4.662 & TRN & \\
\hline CHEMBL1509804 & 737825 & 5.75 & 4.7224 & TRN & \\
\hline CHEMBL523283 & 737825 & 6.4 & 6.5914 & TRN & \\
\hline CHEMBL1373326 & 737825 & 4.9 & 4.7888 & TRN & \\
\hline CHEMBL1376258 & 737825 & 4.75 & 4.9051 & TRN & \\
\hline CHEMBL1414913 & 737825 & 4.6 & 5.2379 & TRN & \\
\hline CHEMBL90882 & 737825 & 4.5 & 4.5773 & TST & \\
\hline CHEMBL164747 & 737825 & 4.8 & 4.8219 & TST & \\
\hline
\end{tabular}




\begin{tabular}{|c|c|c|c|c|c|}
\hline \multicolumn{6}{|c|}{ Supplemental Table S2.txt } \\
\hline CHEMBL1535796 & 737825 & 5.2 & 4.8878 & TRN & \\
\hline CHEMBL492121 & 737825 & 4.9 & 4.8471 & TRN & \\
\hline CHEMBL1382870 & 737825 & 5.45 & 5.1712 & TRN & \\
\hline CHEMBL1531620 & 737825 & 4.6 & 5.0237 & TST & \\
\hline CHEMBL1474578 & 737825 & 4.9 & 4.6671 & TRN & \\
\hline CHEMBL1413296 & 737825 & 4.85 & 5.2046 & TRN & \\
\hline CHEMBL1436976 & 737825 & 4.8 & 4.6826 & TRN & \\
\hline CHEMBL498770 & 737825 & 6.1 & 5.9568 & TST & \\
\hline CHEMBL1498141 & 737825 & 5.05 & 5.0688 & TRN & \\
\hline CHEMBL491547 & 737825 & 5.7 & 5.6403 & TRN & \\
\hline CHEMBL1447894 & 737825 & 5.4 & $5.4170 e$ & 0000000001 & TRN \\
\hline CHEMBL1533232 & 737825 & 5.9 & 5.9485 & TRN & \\
\hline CHEMBL1515034 & 737825 & 5.7 & 5.8845 & TRN & \\
\hline CHEMBL1368937 & 737825 & 5.3 & 5.31 & TRN & \\
\hline CHEMBL1256770 & 737825 & 5.5 & 5.4319 & TRN & \\
\hline CHEMBL1317761 & 737825 & 4.8 & 4.6174 & TRN & \\
\hline CHEMBL1356256 & 737825 & 4.9 & 4.8324 & TRN & \\
\hline CHEMBL1443393 & 737825 & 4.8 & 4.6499 & TRN & \\
\hline CHEMBL1585324 & 737825 & 6.05 & 5.3946 & TRN & \\
\hline CHEMBL1987514 & 737825 & 6.05 & 5.4454 & TRN & \\
\hline CHEMBL1324889 & 737825 & 5.9 & 6.0053 & TRN & \\
\hline CHEMBL1428605 & 737825 & 4.6 & 5.1966 & TRN & \\
\hline CHEMBL1396721 & 737825 & 5.5 & 5.3035 & TST & \\
\hline CHEMBL1570079 & 737825 & 4.55 & 5.1321 & TRN & \\
\hline CHEMBL1487126 & 737825 & 5.3 & 5.2962 & TRN & \\
\hline CHEMBL3212919 & 737825 & 5.2 & 5.1819 & TRN & \\
\hline CHEMBL1422980 & 737825 & 5.5 & 5.221 & TRN & \\
\hline CHEMBL1467643 & 737825 & 6.0 & 5.1375 & TRN & \\
\hline CHEMBL1366479 & 737825 & 4.9 & 4.9755 & TRN & \\
\hline CHEMBL1472837 & 737825 & 5.2 & 5.1209 & TRN & \\
\hline CHEMBL1558864 & 737825 & 4.7 & 5.0001 & TRN & \\
\hline CHEMBL1891843 & 737825 & 4.65 & 5.0391 & TST & \\
\hline CHEMBL1398622 & 737825 & 6.05 & 5.3843 & TRN & \\
\hline CHEMBL3213530 & 737825 & 5.15 & 5.2945 & TRN & \\
\hline CHEMBL1573532 & 737825 & 5.5 & 5.5166 & TRN & \\
\hline CHEMBL1595524 & 737825 & 4.4 & 4.6406 & TRN & \\
\hline CHEMBL1393680 & 737825 & 6.0 & 5.1681 & TRN & \\
\hline CHEMBL1494717 & 737825 & 5.45 & 5.0935 & TRN & \\
\hline CHEMBL1318580 & 737825 & 4.8 & 4.6689 & TRN & \\
\hline CHEMBL1410859 & 737825 & 5.1 & 5.027 & TRN & \\
\hline CHEMBL1476043 & 737825 & 5.1 & 5.0612 & TRN & \\
\hline CHEMBL1562420 & 737825 & 4.4 & 4.4336 & TRN & \\
\hline CHEMBL1566442 & 737825 & 5.3 & 5.0418 & TRN & \\
\hline CHEMBL1348872 & 737825 & 5.55 & 5.2436 & TRN & \\
\hline CHEMBL1590818 & 737825 & 4.5 & 4.4917 & TRN & \\
\hline CHEMBL1339377 & 737825 & 4.85 & 5.1497 & TRN & \\
\hline CHEMBL1321887 & 737825 & 5.4 & 5.2347 & TRN & \\
\hline CHEMBL1484689 & 737825 & 5.4 & 5.4161 & TRN & \\
\hline
\end{tabular}




\begin{tabular}{|c|c|c|c|c|c|}
\hline \multicolumn{6}{|c|}{ Supplemental Table S2.txt } \\
\hline CHEMBL1341642 & 737825 & 4.75 & 5.1285 & TRN & \\
\hline CHEMBL1522460 & 737825 & 4.8 & 4.7553 & TRN & \\
\hline CHEMBL1471318 & 737825 & 5.75 & 5.1418 & TST & \\
\hline CHEMBL560832 & 737825 & 6.3 & 5.2893 & TRN & \\
\hline CHEMBL1474211 & 737825 & 4.7 & 4.5819 & TRN & \\
\hline CHEMBL1483207 & 737825 & 4.85 & 5.1287 & TRN & \\
\hline CHEMBL1408343 & 737825 & 5.4 & 5.3669 & TRN & \\
\hline CHEMBL 3195528 & 737825 & 4.75 & 5.3158 & TRN & \\
\hline CHEMBL1602002 & 737825 & 5.45 & 5.2312 & TRN & \\
\hline CHEMBL1325971 & 737825 & 4.6 & 4.974 & TRN & \\
\hline CHEMBL1489541 & 737825 & 6.0 & 5.8529 & TRN & \\
\hline CHEMBL1482575 & 737825 & 6.1 & 5.9142 & TRN & \\
\hline CHEMBL1377727 & 737825 & 6.2 & 5.9879 & TRN & \\
\hline CHEMBL1741331 & 737825 & 5.65 & 5.2738 & TRN & \\
\hline CHEMBL 1256740 & 737825 & 6.0 & 5.7621 & TST & \\
\hline CHEMBL1391995 & 737825 & 6.05 & 5.0683 & TRN & \\
\hline CHEMBL1590484 & 737825 & 4.6 & 4.7139 & TRN & \\
\hline CHEMBL68534 & 737825 & 5.1 & 4.9551 & TRN & \\
\hline CHEMBL1584911 & 737825 & 4.95 & 5.1518 & TRN & \\
\hline CHEMBL1312104 & 737825 & 4.6 & 5.0735 & TRN & \\
\hline CHEMBL1376289 & 737825 & 4.65 & 4.9851 & TRN & \\
\hline CHEMBL1162521 & 737825 & 5.4 & 5.2175 & TRN & \\
\hline CHEMBL1515280 & 737825 & 4.8 & 4.6363 & TRN & \\
\hline CHEMBL1553741 & 737825 & 4.9 & 4.8927 & TRN & \\
\hline CHEMBL1357930 & 737825 & 5.0 & 5.595 & TST & \\
\hline CHEMBL1326341 & 737825 & 5.0 & 4.7895 & TRN & \\
\hline CHEMBL1482566 & 737825 & 6.05 & 5.9513 & TRN & \\
\hline CHEMBL1392455 & 737825 & 5.0 & 5.5235 & TST & \\
\hline CHEMBL1340579 & 737825 & 4.55 & 5.0804 & TRN & \\
\hline CHEMBL1509383 & 737825 & 5.1 & 5.12799 & 9999999999 & TRN \\
\hline CHEMBL3209943 & 737825 & 5.4 & 5.3604 & TRN & \\
\hline CHEMBL1555862 & 737825 & 5.35 & 5.0443 & TRN & \\
\hline CHEMBL1318509 & 737825 & 4.9 & 4.8742 & TRN & \\
\hline CHEMBL1444413 & 737825 & 5.4 & 5.3335 & TRN & \\
\hline CHEMBL1446341 & 737825 & 5.55 & 5.2129 & TRN & \\
\hline CHEMBL1534591 & 737825 & 5.3 & 5.0082 & TRN & \\
\hline CHEMBL1554308 & 737825 & 5.5 & 5.1485 & TRN & \\
\hline CHEMBL1357872 & 737825 & 4.6 & 4.5104 & TRN & \\
\hline CHEMBL1475541 & 737825 & 5.0 & 5.1258 & TRN & \\
\hline CHEMBL1558029 & 737825 & 4.9 & 5.1401 & TRN & \\
\hline CHEMBL1415656 & 737825 & 4.8 & 4.5369 & TRN & \\
\hline CHEMBL1516015 & 737825 & 4.6 & 4.6714 & TST & \\
\hline CHEMBL1568250 & 737825 & 5.0 & 5.0434 & TRN & \\
\hline CHEMBL1610056 & 737825 & 5.0 & 5.3215 & TST & \\
\hline CHEMBL1362504 & 737825 & 7.45 & 5.1841 & TRN & \\
\hline CHEMBL1471612 & 737825 & 5.85 & 5.0512 & TST & \\
\hline CHEMBL1394714 & 737825 & 4.5 & 4.4403 & TRN & \\
\hline CHEMBL1347066 & 737825 & 4.85 & 5.2352 & TRN & \\
\hline
\end{tabular}




\begin{tabular}{|c|c|c|c|c|c|}
\hline \multicolumn{6}{|c|}{ Supplemental Table S2.txt } \\
\hline CHEMBL 3198264 & 737825 & 5.15 & 5.1565 & TST & \\
\hline CHEMBL1734683 & 737825 & 4.5 & 4.8735 & TST & \\
\hline CHEMBL1414232 & 737825 & 6.0 & 5.9621 & TRN & \\
\hline CHEMBL1578011 & 737825 & 5.0 & 5.265 & TRN & \\
\hline CHEMBL1340458 & 737825 & 5.35 & 5.0408 & TRN & \\
\hline CHEMBL1511012 & 737825 & 4.8 & 4.8886 & TRN & \\
\hline CHEMBL1320172 & 737825 & 5.35 & 5.1499 & TRN & \\
\hline CHEMBL1512722 & 737825 & 5.1 & 4.9054 & TRN & \\
\hline CHEMBL1478351 & 737825 & 5.65 & 5.2284 & TRN & \\
\hline CHEMBL1331489 & 737825 & 6.4 & 5.7693 & TRN & \\
\hline CHEMBL1742369 & 737825 & 5.05 & 5.1316 & TRN & \\
\hline CHEMBL1413137 & 737825 & 6.9 & 5.0147 & TST & \\
\hline CHEMBL 88272 & 737825 & 4.8 & 4.8894 & TST & \\
\hline CHEMBL1590886 & 737825 & 5.0 & 4.7788 & TRN & \\
\hline CHEMBL1547277 & 737825 & 4.8 & 5.2391 & TRN & \\
\hline CHEMBL1327351 & 737825 & 4.65 & 5.2352 & TRN & \\
\hline CHEMBL1336347 & 737825 & 4.7 & 5.0317 & TRN & \\
\hline CHEMBL1613444 & 737825 & 4.85 & 5.0101 & TST & \\
\hline CHEMBL1506245 & 737825 & 5.1 & 5.23 & TRN & \\
\hline CHEMBL1442440 & 737825 & 6.3 & 6.0966 & TRN & \\
\hline CHEMBL1443628 & 737825 & 5.5 & 5.4814 & TRN & \\
\hline CHEMBL1411045 & 737825 & 5.5 & 5.4762 & TST & \\
\hline CHEMBL1501701 & 737825 & 5.35 & 5.2969 & TRN & \\
\hline CHEMBL1530445 & 737825 & 5.5 & 5.3686 & TRN & \\
\hline CHEMBL1466628 & 737825 & 5.0 & 5.05699 & 99999999995 & TRN \\
\hline CHEMBL1325093 & 737825 & 4.6 & 5.25899 & 99999999995 & TST \\
\hline CHEMBL1300958 & 737825 & 4.9 & 5.0348 & TRN & \\
\hline CHEMBL1403583 & 737825 & 4.65 & 5.1604 & TRN & \\
\hline CHEMBL1314288 & 737825 & 5.6 & 5.669 & TRN & \\
\hline CHEMBL1380424 & 737825 & 4.85 & 5.1098 & TRN & \\
\hline CHEMBL1361909 & 737825 & 5.2 & 5.084 & TRN & \\
\hline CHEMBL1596513 & 737825 & 5.15 & 5.0615 & TST & \\
\hline CHEMBL1437011 & 737825 & 5.1 & 4.976 & TRN & \\
\hline CHEMBL1491776 & 737825 & 5.4 & $5.3820 e$ & 0000000001 & TRN \\
\hline CHEMBL1607115 & 737825 & 5.2 & 5.1572 & TRN & \\
\hline CHEMBL1523822 & 737825 & 5.4 & 5.4338 & TST & \\
\hline CHEMBL1407677 & 737825 & 5.1 & 5.2227 & TRN & \\
\hline CHEMBL1606547 & 737825 & 5.35 & 5.0761 & TST & \\
\hline CHEMBL3213894 & 737825 & 6.0 & 6.01 & TRN & \\
\hline CHEMBL1381224 & 737825 & 5.2 & 5.2822 & TRN & \\
\hline CHEMBL1316656 & 737825 & 5.4 & 5.3781 & TRN & \\
\hline CHEMBL1505574 & 737825 & 4.9 & 5.2127 & TRN & \\
\hline CHEMBL1304386 & 737825 & 5.15 & 5.0689 & TRN & \\
\hline CHEMBL1515858 & 737825 & 4.9 & 4.6487 & TRN & \\
\hline CHEMBL169233 & 737825 & 4.9 & 4.8314 & TST & \\
\hline CHEMBL1372037 & 737825 & 6.1 & 6.2406 & TRN & \\
\hline CHEMBL1463576 & 737825 & 4.85 & 5.1459 & TRN & \\
\hline CHEMBL1402822 & 737825 & 5.35 & 5.0573 & TRN & \\
\hline
\end{tabular}




\begin{tabular}{|c|c|c|c|c|}
\hline \multicolumn{5}{|c|}{ Supplemental Table S2.txt } \\
\hline CHEMBL3211511 & 737825 & 4.65 & 5.2509 & TRN \\
\hline CHEMBL1443491 & 737825 & 6.1 & 5.7406 & TRN \\
\hline CHEMBL1502591 & 737825 & 4.9 & 5.2486 & TRN \\
\hline CHEMBL1519490 & 737825 & 6.0 & 5.8271 & TRN \\
\hline CHEMBL1208858 & 737825 & 4.8 & 5.0634 & TRN \\
\hline CHEMBL1475428 & 737825 & 5.2 & 4.9026 & TRN \\
\hline CHEMBL1335889 & 737825 & 4.6 & 4.6828 & TRN \\
\hline CHEMBL1484214 & 737825 & 4.85 & 5.3077 & TRN \\
\hline CHEMBL1512027 & 737825 & 4.5 & 4.4228 & TRN \\
\hline CHEMBL1333658 & 737825 & 4.6 & 5.1698 & TST \\
\hline CHEMBL1301725 & 737825 & 5.5 & 5.1495 & TRN \\
\hline CHEMBL1333531 & 737825 & 4.6 & 4.5262 & TRN \\
\hline CHEMBL1722408 & 737825 & 4.6 & 5.0847 & TRN \\
\hline CHEMBL1361808 & 737825 & 4.4 & 5.0843 & TRN \\
\hline CHEMBL1567569 & 737825 & 4.6 & 4.6278 & TRN \\
\hline CHEMBL1552181 & 737825 & 5.0 & 4.8351 & TRN \\
\hline CHEMBL1439839 & 737825 & 5.9 & 5.8627 & TRN \\
\hline CHEMBL180162 & 737825 & 4.9 & 5.0112 & TRN \\
\hline CHEMBL1606258 & 737825 & 7.7501 & 4.9953 & TRN \\
\hline CHEMBL1503135 & 737825 & 4.55 & 4.9925 & TRN \\
\hline CHEMBL1517817 & 737825 & 4.8 & 5.2095 & TRN \\
\hline CHEMBL1332726 & 737825 & 4.8 & 4.7433 & TRN \\
\hline CHEMBL1337108 & 737825 & 5.3 & 4.9894 & TRN \\
\hline CHEMBL1566670 & 737825 & 4.6 & 4.5095 & TRN \\
\hline CHEMBL1502348 & 737825 & 4.65 & 5.2485 & TRN \\
\hline CHEMBL3194069 & 737825 & 4.85 & 5.2781 & TRN \\
\hline CHEMBL3193950 & 737825 & 5.95 & 5.0674 & TRN \\
\hline CHEMBL512908 & 737825 & 6.3 & 5.8253 & TST \\
\hline CHEMBL 3207394 & 737825 & 5.4 & 5.3484 & TRN \\
\hline CHEMBL1390695 & 737825 & 4.55 & 5.2418 & TRN \\
\hline CHEMBL1496056 & 737825 & 4.4 & 5.3104 & TRN \\
\hline CHEMBL 1444270 & 737825 & 5.8 & 5.8071 & TRN \\
\hline CHEMBL1463191 & 737825 & 4.5 & 5.2118 & TRN \\
\hline CHEMBL1741625 & 737825 & 5.05 & 5.2078 & TST \\
\hline CHEMBL1476082 & 737825 & 4.8 & 4.7381 & TRN \\
\hline CHEMBL1437436 & 737825 & 5.4 & 5.3227 & TST \\
\hline CHEMBL 1473438 & 737825 & 4.5 & 4.4633 & TRN \\
\hline CHEMBL1563513 & 737825 & 4.8 & 5.2217 & TRN \\
\hline CHEMBL1542526 & 737825 & 5.2 & 5.0793 & TRN \\
\hline CHEMBL1335890 & 737825 & 6.0 & 6.0545 & TRN \\
\hline CHEMBL1587080 & 737825 & 4.5 & 4.9908 & TST \\
\hline CHEMBL1256775 & 737825 & 4.4 & 4.5325 & TRN \\
\hline CHEMBL1312830 & 737825 & 5.35 & 5.1514 & TRN \\
\hline CHEMBL1355835 & 737825 & 6.3 & 5.9973 & TRN \\
\hline CHEMBL3195854 & 737825 & 4.9 & 5.1011 & TRN \\
\hline CHEMBL1570134 & 737825 & 5.0 & 4.9595 & TRN \\
\hline CHEMBL 1317300 & 737825 & 4.8 & 5.7608 & TST \\
\hline CHEMBL1481378 & 737825 & 5.4 & 5.5112 & TRN \\
\hline
\end{tabular}




\begin{tabular}{|c|c|c|c|c|c|}
\hline \\
\hline CHEMBL1372363 & 737825 & 4.8 & 4.743 & TRN & \\
\hline CHEMBL1358197 & 737825 & 5.9 & 5.892 & TRN & \\
\hline CHEMBL1496560 & 737825 & 4.9 & 4.8008 & TRN & \\
\hline CHEMBL1355701 & 737825 & 5.3 & 5.1104 & TRN & \\
\hline CHEMBL1530789 & 737825 & 5.4 & 5.073 & TRN & \\
\hline CHEMBL1529384 & 737825 & 5.4 & 5.352 & TRN & \\
\hline CHEMBL1583174 & 737825 & 4.55 & 5.0272 & TST & \\
\hline CHEMBL1600620 & 737825 & 5.3 & 5.0334 & TRN & \\
\hline CHEMBL1331634 & 737825 & 6.0 & 6.0022 & TRN & \\
\hline CHEMBL1476051 & 737825 & 6.2 & 6.1366 & TRN & \\
\hline CHEMBL1554453 & 737825 & 5.1 & 5.0308 & TRN & \\
\hline CHEMBL1330692 & 737825 & 5.4 & 5.4542 & TRN & \\
\hline CHEMBL1315109 & 737825 & 5.1 & 5.0172 & TRN & \\
\hline CHEMBL1548480 & 737825 & 4.95 & 5.4621 & TRN & \\
\hline CHEMBL1527851 & 737825 & 5.15 & 5.1887 & TRN & \\
\hline CHEMBL1524331 & 737825 & 5.8 & 5.5657 & TRN & \\
\hline CHEMBL1524295 & 737825 & 4.65 & 5.1295 & TRN & \\
\hline CHEMBL1606337 & 737825 & 5.2 & 5.0682 & TST & \\
\hline CHEMBL1698387 & 737825 & 4.5 & 5.1954 & TRN & \\
\hline CHEMBL1471206 & 737825 & 4.95 & 5.1855 & TRN & \\
\hline CHEMBL1361656 & 737825 & 5.8 & 5.9309 & TRN & \\
\hline CHEMBL1402827 & 737825 & 4.6 & 4.917 & TRN & \\
\hline CHEMBL1358525 & 737825 & 4.5 & 4.59399 & 9999999999 & TRN \\
\hline CHEMBL1466677 & 737825 & 4.8 & 5.6026 & TRN & \\
\hline CHEMBL1378132 & 737825 & 4.6 & 4.6275 & TRN & \\
\hline CHEMBL1394887 & 737825 & 5.9 & 5.3577 & TRN & \\
\hline CHEMBL1522909 & 737825 & 4.8 & 5.1357 & TST & \\
\hline CHEMBL1314906 & 737825 & 4.9 & 4.7622 & TRN & \\
\hline CHEMBL1554018 & 737825 & 6.0 & 5.9822 & TRN & \\
\hline CHEMBL1573480 & 737825 & 4.9 & 4.7945 & TRN & \\
\hline CHEMBL1256654 & 737825 & 6.0 & 5.7142 & TRN & \\
\hline CHEMBL1332937 & 737825 & 5.7 & 5.6542 & TRN & \\
\hline CHEMBL1561206 & 737825 & 5.05 & 5.254 & TRN & \\
\hline CHEMBL1337092 & 737825 & 4.7 & 4.5958 & TRN & \\
\hline CHEMBL1590261 & 737825 & 4.8 & 4.7524 & TRN & \\
\hline CHEMBL3212534 & 737825 & 5.1 & 5.1348 & TRN & \\
\hline CHEMBL1368786 & 737825 & 5.05 & 5.1831 & TRN & \\
\hline CHEMBL3198125 & 737825 & 4.55 & 5.1906 & TRN & \\
\hline CHEMBL1488095 & 737825 & 5.9 & 5.215 & TRN & \\
\hline CHEMBL1416476 & 737825 & 5.6 & 5.49100 & 00000000005 & TRN \\
\hline CHEMBL1531466 & 737825 & 5.3 & 5.0812 & TRN & \\
\hline CHEMBL1435028 & 737825 & 4.9 & 4.7853 & TRN & \\
\hline CHEMBL1437054 & 737825 & 5.8 & 5.5669 & TST & \\
\hline CHEMBL1596221 & 737825 & 5.15 & 5.2422 & TRN & \\
\hline CHEMBL1571514 & 737825 & 5.0 & 5.0626 & TST & \\
\hline CHEMBL1430849 & 737825 & 4.75 & 5.0759 & TRN & \\
\hline CHEMBL1600131 & 737825 & 5.1 & 4.9953 & TRN & \\
\hline CHEMBL1544517 & 737825 & 6.0 & 5.2255 & TRN & \\
\hline
\end{tabular}




\begin{tabular}{|c|c|c|c|c|}
\hline & & & pplement & \\
\hline CHEMBL1390189 & 737825 & 4.5 & 5.085 & TRN \\
\hline CHEMBL1541166 & 737825 & 5.35 & 5.2223 & TRN \\
\hline CHEMBL1532067 & 737825 & 5.35 & 5.0356 & TRN \\
\hline CHEMBL1489708 & 737825 & 4.9 & 4.8644 & TRN \\
\hline CHEMBL1405043 & 737825 & 5.4 & 5.2863 & TRN \\
\hline CHEMBL1511209 & 737825 & 4.8 & 5.1411 & TRN \\
\hline CHEMBL1728559 & 737825 & 4.8 & 5.2697 & TRN \\
\hline CHEMBL1361725 & 737825 & 5.5 & 5.1938 & TRN \\
\hline CHEMBL 845 & 737825 & 5.3 & 5.2168 & TRN \\
\hline CHEMBL1596952 & 737825 & 5.3 & 5.0242 & TRN \\
\hline CHEMBL1607197 & 737825 & 4.85 & 5.2707 & TRN \\
\hline CHEMBL1511286 & 737825 & 5.9 & 5.1826 & TRN \\
\hline CHEMBL1561132 & 737825 & 5.4 & 5.2409 & TST \\
\hline CHEMBL1465070 & 737825 & 6.9 & 5.3815 & TRN \\
\hline CHEMBL1741851 & 737825 & 5.5 & 4.9996 & TRN \\
\hline CHEMBL1600269 & 737825 & 4.9 & 4.7303 & TRN \\
\hline CHEMBL1494444 & 737825 & 4.9 & 5.4718 & TST \\
\hline CHEMBL1579444 & 737825 & 5.05 & 5.3735 & TRN \\
\hline CHEMBL1359378 & 737825 & 5.4 & 5.5162 & TRN \\
\hline CHEMBL1557498 & 737825 & 5.6 & 5.2436 & TRN \\
\hline CHEMBL1534237 & 737825 & 4.9 & 4.8598 & TRN \\
\hline CHEMBL1521391 & 737825 & 6.0 & 5.8893 & TRN \\
\hline CHEMBL1344451 & 737825 & 4.85 & 5.1184 & TRN \\
\hline CHEMBL1506066 & 737825 & 4.8 & 5.1857 & TRN \\
\hline CHEMBL1450809 & 737825 & 5.45 & 5.2038 & TRN \\
\hline CHEMBL1450617 & 737825 & 4.8 & 5.2557 & TRN \\
\hline CHEMBL1322570 & 737825 & 4.45 & 5.1496 & TRN \\
\hline CHEMBL1388651 & 737825 & 5.45 & 5.1635 & TRN \\
\hline CHEMBL1554465 & 737825 & 5.4 & 5.1877 & TRN \\
\hline CHEMBL1609726 & 737825 & 4.8 & 5.06 & TRN \\
\hline CHEMBL1416629 & 737825 & 4.8 & 5.2075 & TRN \\
\hline CHEMBL1456346 & 737825 & 4.9 & 5.1626 & TST \\
\hline CHEMBL1388541 & 737825 & 5.1 & 5.0866 & TRN \\
\hline CHEMBL1968402 & 737825 & 5.05 & 5.1743 & TRN \\
\hline CHEMBL1352043 & 737825 & 5.45 & 5.4538 & TRN \\
\hline CHEMBL1397192 & 737825 & 4.8 & 4.8053 & TRN \\
\hline CHEMBL 1307320 & 737825 & 4.9 & 5.0938 & TRN \\
\hline CHEMBL1603582 & 737825 & 5.3 & 5.66 & TST \\
\hline CHEMBL 388342 & 737825 & 4.8 & 5.572 & TRN \\
\hline CHEMBL1741781 & 737825 & 4.8 & 5.2338 & TRN \\
\hline CHEMBL1439893 & 737825 & 5.3 & 5.2414 & TRN \\
\hline CHEMBL1323854 & 737825 & 5.65 & 5.1657 & TRN \\
\hline CHEMBL56393 & 737825 & 4.8 & 4.7229 & TRN \\
\hline CHEMBL1313409 & 737825 & 5.35 & 4.9836 & TST \\
\hline CHEMBL3208062 & 737825 & 4.55 & 5.1454 & TRN \\
\hline CHEMBL1571975 & 737825 & 5.8 & 5.7028 & TST \\
\hline CHEMBL1392763 & 737825 & 4.9 & 5.0626 & TST \\
\hline CHEMBL1480885 & 737825 & 5.4 & 5.3299 & TRN \\
\hline
\end{tabular}




\begin{tabular}{|c|c|c|c|c|}
\hline \multicolumn{5}{|c|}{ Supplemental Table S2.txt } \\
\hline CHEMBL1510151 & 737825 & 5.4 & 5.1323 & TRN \\
\hline CHEMBL1407646 & 737825 & 4.65 & 5.1379 & TRN \\
\hline CHEMBL1495395 & 737825 & 5.5 & 5.3272 & TRN \\
\hline CHEMBL1514740 & 737825 & 5.7 & \multicolumn{2}{|c|}{5.787000000000001} \\
\hline CHEMBL1314434 & 737825 & 4.8 & 4.6691 & TRN \\
\hline CHEMBL8747 & 737825 & 4.9 & 4.921 & TST \\
\hline CHEMBL1224512 & 737825 & 5.5 & 5.2075 & TRN \\
\hline CHEMBL1565125 & 737825 & 5.4 & 5.2412 & TRN \\
\hline CHEMBL1387585 & 737825 & 4.85 & 5.0952 & TST \\
\hline CHEMBL1594421 & 737825 & 5.0 & 4.8531 & TRN \\
\hline CHEMBL1346217 & 737825 & 4.8 & 5.0162 & TRN \\
\hline CHEMBL1376097 & 737825 & 4.95 & 5.1582 & TRN \\
\hline CHEMBL1607586 & 737825 & 4.95 & 5.2127 & TRN \\
\hline CHEMBL1490544 & 737825 & 4.8 & 5.0697 & TRN \\
\hline CHEMBL1595910 & 737825 & 5.5 & 5.2014 & TRN \\
\hline CHEMBL1439401 & 737825 & 5.7 & 5.6824 & TRN \\
\hline CHEMBL1495634 & 737825 & 5.5 & 5.4217 & TRN \\
\hline CHEMBL1742217 & 737825 & 4.85 & 5.2045 & TRN \\
\hline CHEMBL1366629 & 737825 & 5.3 & 4.9963 & TRN \\
\hline CHEMBL1426479 & 737825 & 6.0 & 5.3002 & TRN \\
\hline CHEMBL1599014 & 737825 & 6.1 & 5.8763 & TRN \\
\hline CHEMBL1724774 & 737825 & 4.95 & 4.8598 & TRN \\
\hline CHEMBL1493099 & 737825 & 4.9 & 5.2065 & TST \\
\hline CHEMBL338115 & 737825 & 5.3 & 5.2418 & TRN \\
\hline CHEMBL1327566 & 737825 & 4.85 & 4.9972 & TRN \\
\hline CHEMBL1506225 & 737825 & 4.7 & 4.8426 & TST \\
\hline CHEMBL1597869 & 737825 & 4.55 & 5.1667 & TRN \\
\hline CHEMBL1413489 & 737825 & 6.0 & 5.767 & TRN \\
\hline CHEMBL1536766 & 737825 & 5.2 & 5.0583 & TRN \\
\hline CHEMBL1362657 & 737825 & 5.4 & 5.2744 & TRN \\
\hline CHEMBL1316979 & 737825 & 5.9 & 5.8818 & TRN \\
\hline CHEMBL1606094 & 737825 & 6.0 & 5.8123 & TST \\
\hline CHEMBL1557355 & 737825 & 5.05 & 5.301 & TST \\
\hline CHEMBL1485818 & 737825 & 5.05 & 5.1546 & TRN \\
\hline CHEMBL1529853 & 737825 & 4.65 & 5.142 & TRN \\
\hline CHEMBL1518620 & 737825 & 6.7 & 4.9463 & TST \\
\hline CHEMBL1394757 & 737825 & 6.0 & 5.6205 & TST \\
\hline CHEMBL1594242 & 737825 & 4.95 & 5.2323 & TRN \\
\hline CHEMBL3212090 & 737825 & 4.65 & 5.2218 & TRN \\
\hline CHEMBL1435947 & 737825 & 4.7 & 4.6269 & TRN \\
\hline CHEMBL3211761 & 737825 & 5.8 & 5.1388 & TST \\
\hline CHEMBL1330957 & 737825 & 5.4 & 5.2423 & TRN \\
\hline CHEMBL1326272 & 737825 & 4.5 & 5.0741 & TRN \\
\hline CHEMBL1473834 & 737825 & 5.2 & 5.1186 & TRN \\
\hline CHEMBL3195443 & 737825 & 5.9 & 5.24 & TRN \\
\hline CHEMBL1335579 & 737825 & 4.85 & 5.231 & TRN \\
\hline CHEMBL1570763 & 737825 & 5.9 & 5.1288 & TRN \\
\hline \multirow[t]{2}{*}{ CHEMBL8618 } & 737825 & 6.0 & 5.5215 & TRN \\
\hline & & & \multicolumn{2}{|c|}{ Page 22497} \\
\hline
\end{tabular}

TRN 


\begin{tabular}{|c|c|c|c|c|c|}
\hline \multicolumn{6}{|c|}{ Supplemental Table S2.txt } \\
\hline CHEMBL1366453 & 737825 & 5.7 & 5.1529 & TST & \\
\hline CHEMBL1554817 & 737825 & 5.5 & 5.4709 & TRN & \\
\hline CHEMBL289233 & 737825 & 4.8 & 4.8001 & TRN & \\
\hline CHEMBL1474633 & 737825 & 5.7 & 5.6525 & TRN & \\
\hline CHEMBL1444310 & 737825 & 4.85 & 5.1153 & TRN & \\
\hline CHEMBL1600871 & 737825 & 4.85 & 5.1625 & TRN & \\
\hline CHEMBL1522087 & 737825 & 5.35 & 5.0365 & TST & \\
\hline CHEMBL491976 & 737825 & 6.4 & 6.5486 & TRN & \\
\hline CHEMBL1515315 & 737825 & 5.3 & 5.2619 & TRN & \\
\hline CHEMBL1421692 & 737825 & 5.15 & 5.1305 & TRN & \\
\hline CHEMBL1478769 & 737825 & 4.85 & 5.3093 & TRN & \\
\hline CHEMBL1335406 & 737825 & 4.8 & 4.7638 & TST & \\
\hline CHEMBL1314989 & 737825 & 4.4 & 4.5101 & TST & \\
\hline CHEMBL1396298 & 737825 & 4.7 & 4.7413 & TST & \\
\hline CHEMBL1519326 & 737825 & 4.8 & 4.6436 & TRN & \\
\hline CHEMBL1741952 & 737825 & 4.75 & 4.9454 & TRN & \\
\hline CHEMBL1448896 & 737825 & 5.3 & 5.1463 & TRN & \\
\hline CHEMBL1358796 & 737825 & 5.7 & 5.6888 & TRN & \\
\hline CHEMBL1594648 & 737825 & 5.2 & 5.1177 & TRN & \\
\hline CHEMBL489943 & 737825 & 6.5 & 6.6953 & TRN & \\
\hline CHEMBL1543084 & 737825 & 4.6 & 5.1966 & TRN & \\
\hline CHEMBL1333080 & 737825 & 6.0 & 5.2564 & TRN & \\
\hline CHEMBL1356777 & 737825 & 4.5 & 4.7385 & TST & \\
\hline CHEMBL1332357 & 737825 & 6.6 & 4.8179 & TRN & \\
\hline CHEMBL1742258 & 737825 & 5.35 & 5.1529 & TRN & \\
\hline CHEMBL1316219 & 737825 & 5.3 & 5.2178 & TST & \\
\hline CHEMBL1330385 & 737825 & 5.6 & 5.5518 & TRN & \\
\hline CHEMBL1435447 & 737825 & 4.9 & 4.8976 & TRN & \\
\hline CHEMBL1537500 & 737825 & 5.05 & 5.2664 & TRN & \\
\hline CHEMBL1340207 & 737825 & 5.35 & 5.1727 & TRN & \\
\hline CHEMBL1586390 & 737825 & 4.8 & 5.1235 & TST & \\
\hline CHEMBL1314587 & 737825 & 5.3 & 5.2896 & TRN & \\
\hline CHEMBL1470051 & 737825 & 4.85 & $5.3260 e$ & 00000000005 & TRN \\
\hline CHEMBL1980826 & 737825 & 5.5 & 5.32799 & 9999999999 & TRN \\
\hline CHEMBL1609583 & 737825 & 4.9 & 4.7018 & TRN & \\
\hline CHEMBL1359473 & 737825 & 5.15 & 5.2502 & TRN & \\
\hline CHEMBL1550240 & 737825 & 4.6 & 4.9888 & TST & \\
\hline CHEMBL1365983 & 737825 & 5.5 & 5.0112 & TRN & \\
\hline CHEMBL1358731 & 737825 & 5.4 & 5.0787 & TRN & \\
\hline CHEMBL1326935 & 737825 & 4.55 & 5.2789 & TRN & \\
\hline CHEMBL1400491 & 737825 & 5.6 & 5.3302 & TRN & \\
\hline CHEMBL1529571 & 737825 & 5.65 & 5.4141 & TRN & \\
\hline CHEMBL1480880 & 737825 & 5.4 & 5.4389 & TST & \\
\hline CHEMBL1558771 & 737825 & 4.8 & 5.2522 & TRN & \\
\hline CHEMBL 2374027 & 737825 & 6.0 & 5.73799 & 99999999995 & TST \\
\hline CHEMBL1527363 & 737825 & 4.8 & 4.9335 & TRN & \\
\hline CHEMBL1320190 & 737825 & 5.0 & 4.7844 & TRN & \\
\hline CHEMBL1367020 & 737825 & 4.7 & 4.6028 & TRN & \\
\hline
\end{tabular}




\begin{tabular}{|c|c|c|c|c|}
\hline & & & & \\
\hline CHEMBL3192772 & 737825 & 4.6 & 5.0895 & TRN \\
\hline CHEMBL1734883 & 737825 & 4.85 & 5.1373 & TRN \\
\hline CHEMBL1402562 & 737825 & 7.0 & 5.2518 & TRN \\
\hline CHEMBL1382427 & 737825 & 6.4 & 5.2976 & TRN \\
\hline CHEMBL1410872 & 737825 & 4.9 & 5.4555 & TRN \\
\hline CHEMBL1574886 & 737825 & 4.9 & 5.1026 & TRN \\
\hline CHEMBL1481847 & 737825 & 5.0 & 4.9346 & TRN \\
\hline CHEMBL1314185 & 737825 & 4.4 & 4.3686 & TRN \\
\hline CHEMBL1554194 & 737825 & 5.4 & 5.3661 & TRN \\
\hline CHEMBL3190889 & 737825 & 5.9 & 5.3023 & TRN \\
\hline CHEMBL1611026 & 737825 & 5.35 & 5.2251 & TRN \\
\hline CHEMBL1570788 & 737825 & 4.9 & 4.915 & TST \\
\hline CHEMBL521970 & 737825 & 5.7 & 5.4934 & TRN \\
\hline CHEMBL1741849 & 737825 & 5.35 & 5.2326 & TRN \\
\hline CHEMBL1592327 & 737825 & 5.5 & 5.2863 & TRN \\
\hline CHEMBL1545903 & 737825 & 5.0 & 5.0274 & TRN \\
\hline CHEMBL1576215 & 737825 & 4.8 & 5.2036 & TRN \\
\hline CHEMBL1502536 & 737825 & 5.15 & 5.1791 & TST \\
\hline CHEMBL1528906 & 737825 & 6.4 & 5.3418 & TRN \\
\hline CHEMBL1455018 & 737825 & 4.7 & 4.6253 & TRN \\
\hline CHEMBL1540150 & 737825 & 4.65 & 5.1361 & TRN \\
\hline CHEMBL1517335 & 737825 & 4.85 & 5.073 & TRN \\
\hline CHEMBL1592557 & 737825 & 5.7 & 5.4139 & TRN \\
\hline CHEMBL1561515 & 737825 & 5.1 & 5.083 & TST \\
\hline CHEMBL1356439 & 737825 & 5.2 & 5.1712 & TRN \\
\hline CHEMBL1363594 & 737825 & 4.8 & 4.65300 & 20000000005 \\
\hline CHEMBL1519291 & 737825 & 4.85 & 5.3374 & TRN \\
\hline CHEMBL3210486 & 737825 & 4.75 & 5.1819 & TRN \\
\hline CHEMBL1353136 & 737825 & 5.2 & 5.1526 & TST \\
\hline CHEMBL1408013 & 737825 & 6.0 & 6.0277 & TRN \\
\hline CHEMBL1531699 & 737825 & 5.6 & 5.5694 & TRN \\
\hline CHEMBL1551777 & 737825 & 6.5 & 6.31 & TRN \\
\hline CHEMBL1422932 & 737825 & 4.85 & 5.0549 & TRN \\
\hline CHEMBL1305631 & 737825 & 4.6 & 5.1921 & TRN \\
\hline CHEMBL1568019 & 737825 & 5.5 & 5.4802 & TRN \\
\hline CHEMBL1436024 & 737825 & 4.6 & 4.5876 & TRN \\
\hline CHEMBL1530189 & 737825 & 4.6 & 5.152 & TST \\
\hline CHEMBL38832 & 737825 & 5.9 & 5.5255 & TST \\
\hline CHEMBL1733458 & 737825 & 4.75 & 5.0297 & TRN \\
\hline CHEMBL1568786 & 737825 & 6.85 & 5.1348 & TRN \\
\hline CHEMBL1518285 & 737825 & 4.85 & 5.3237 & TST \\
\hline CHEMBL3207422 & 737825 & 5.0 & 5.1004 & TRN \\
\hline CHEMBL1547349 & 737825 & 4.65 & 5.1442 & TST \\
\hline CHEMBL1318708 & 737825 & 5.0 & 4.8361 & TST \\
\hline CHEMBL1398713 & 737825 & 5.2 & 5.0784 & TST \\
\hline CHEMBL1353889 & 737825 & 5.15 & 5.1055 & TRN \\
\hline CHEMBL1741528 & 737825 & 5.25 & 5.1856 & TRN \\
\hline CHEMBL1446649 & 737825 & 5.3 & 5.1794 & TRN \\
\hline
\end{tabular}




\begin{tabular}{|c|c|c|c|c|}
\hline \multicolumn{5}{|c|}{ Supplemental Table S2.txt } \\
\hline CHEMBL1445578 & 737825 & 5.3 & 5.2083 & TRN \\
\hline CHEMBL1461461 & 737825 & 5.85 & 5.2358 & TRN \\
\hline CHEMBL1571716 & 737825 & 4.9 & 5.0835 & TRN \\
\hline CHEMBL1566017 & 737825 & 5.1 & 5.0701 & TRN \\
\hline CHEMBL1319741 & 737825 & 4.4 & 4.5276 & TST \\
\hline CHEMBL1392865 & 737825 & 5.65 & 5.4105 & TRN \\
\hline CHEMBL1370467 & 737825 & 6.0 & 5.9597 & TRN \\
\hline CHEMBL 3196573 & 737825 & 4.85 & 5.1518 & TRN \\
\hline CHEMBL1352745 & 737825 & 5.0 & 4.9369 & TRN \\
\hline CHEMBL1470219 & 737825 & 4.85 & 5.1447 & TRN \\
\hline CHEMBL1723812 & 737825 & 4.5 & 5.3545 & TRN \\
\hline CHEMBL1376212 & 737825 & 5.5 & 5.4489 & TRN \\
\hline CHEMBL1392169 & 737825 & 5.35 & 5.4042 & TRN \\
\hline CHEMBL1428979 & 737825 & 4.85 & 5.3678 & TRN \\
\hline CHEMBL1568071 & 737825 & 5.8 & 5.6957 & TRN \\
\hline CHEMBL1453591 & 737825 & 5.2 & 5.2814 & TRN \\
\hline CHEMBL1432016 & 737825 & 4.85 & 5.3013 & TST \\
\hline CHEMBL1569352 & 737825 & 5.15 & 5.2689 & TRN \\
\hline CHEMBL1484398 & 737825 & 6.75 & 5.4013 & TRN \\
\hline CHEMBL1591847 & 737825 & 4.8 & 4.7433 & TRN \\
\hline CHEMBL1580710 & 737825 & 4.55 & 5.1392 & TRN \\
\hline CHEMBL336467 & 737825 & 4.9 & 4.7747 & TST \\
\hline CHEMBL1472753 & 737825 & 4.6 & 4.5784 & TRN \\
\hline CHEMBL 3189672 & 737825 & 4.8 & 5.0798 & TRN \\
\hline CHEMBL 3214150 & 737825 & 4.55 & 5.1952 & TRN \\
\hline CHEMBL1742336 & 737825 & 5.15 & 5.1866 & TRN \\
\hline CHEMBL1508951 & 737825 & 5.4 & 5.2311 & TRN \\
\hline CHEMBL1594020 & 737825 & 4.8 & 4.7566 & TRN \\
\hline CHEMBL 30432 & 737825 & 5.3 & 5.1446 & TST \\
\hline CHEMBL1161461 & 737825 & 4.7 & 5.0104 & TST \\
\hline CHEMBL1371217 & 737825 & 5.4 & 5.2807 & TRN \\
\hline CHEMBL1594134 & 737825 & 5.6 & 5.5905 & TRN \\
\hline CHEMBL1593486 & 737825 & 5.3 & 5.2299 & TRN \\
\hline CHEMBL1457494 & 737825 & 5.0 & 4.9269 & TRN \\
\hline CHEMBL1318114 & 737825 & 5.5 & 5.5321 & TRN \\
\hline CHEMBL1365994 & 737825 & 5.9 & 5.8378 & TRN \\
\hline CHEMBL3191729 & 737825 & 4.9 & 5.0029 & TRN \\
\hline CHEMBL1404031 & 737825 & 5.45 & 5.2239 & TRN \\
\hline CHEMBL 3189190 & 737825 & 5.4 & 5.3875 & TRN \\
\hline CHEMBL1337740 & 737825 & -0.0 & 5.3974 & TRN \\
\hline CHEMBL1352082 & 737825 & 4.4 & 5.4917 & TRN \\
\hline CHEMBL1476939 & 737825 & 5.4 & 5.3517 & TST \\
\hline CHEMBL1470136 & 737825 & 5.5 & 5.209 & TRN \\
\hline CHEMBL1540475 & 737825 & 6.05 & 5.3236 & TRN \\
\hline CHEMBL1547788 & 737825 & 4.8 & 5.6463 & TRN \\
\hline CHEMBL1513241 & 737825 & 4.7 & 4.5635 & TRN \\
\hline CHEMBL3192281 & 737825 & 6.05 & 5.4535 & TRN \\
\hline CHEMBL1607623 & 737825 & 5.5 & 5.5279 & TRN \\
\hline
\end{tabular}




\begin{tabular}{|c|c|c|c|c|c|}
\hline & & \multicolumn{4}{|c|}{ Supplemental Table S2.txt } \\
\hline CHEMBL1596387 & 737825 & 6.15 & 5.0838 & TRN & \\
\hline CHEMBL 8145 & 737825 & 4.8 & 5.4785 & TRN & \\
\hline CHEMBL313737 & 737825 & 5.3 & 5.1557 & TST & \\
\hline CHEMBL1525602 & 737825 & 5.1 & 5.0268 & TRN & \\
\hline CHEMBL1538161 & 737825 & 5.0 & 5.3411 & TRN & \\
\hline CHEMBL153648 & 737825 & 5.6 & 5.4969 & TST & \\
\hline CHEMBL1547922 & 737825 & 4.6 & 4.9382 & TRN & \\
\hline CHEMBL1412900 & 737825 & 6.1 & 5.9168 & TRN & \\
\hline CHEMBL3199536 & 737825 & 5.7 & 5.4621 & TRN & \\
\hline CHEMBL1421523 & 737825 & 4.4 & 5.2567 & TST & \\
\hline CHEMBL1424815 & 737825 & 5.3 & 5.1782 & TST & \\
\hline CHEMBL1373464 & 737825 & 6.0 & 5.8766 & TRN & \\
\hline CHEMBL1441981 & 737825 & 6.0 & 5.9351 & TRN & \\
\hline CHEMBL1359705 & 737825 & 4.85 & 5.0619 & TRN & \\
\hline CHEMBL1532878 & 737825 & 5.55 & 5.2772 & TRN & \\
\hline CHEMBL1561151 & 737825 & 6.0 & 5.1347 & TRN & \\
\hline CHEMBL1451875 & 737825 & 5.45 & 5.0584 & TRN & \\
\hline CHEMBL1555396 & 737825 & 5.8 & 5.3003 & TRN & \\
\hline CHEMBL1424121 & 737825 & 4.95 & 5.1925 & TRN & \\
\hline CHEMBL1469597 & 737825 & 5.7 & 5.3978 & TRN & \\
\hline CHEMBL1360026 & 737825 & 4.85 & 5.2548 & TRN & \\
\hline CHEMBL1451562 & 737825 & 5.4 & 5.3822 & TRN & \\
\hline CHEMBL1310810 & 737825 & 4.85 & 5.2002 & TRN & \\
\hline CHEMBL1551064 & 737825 & 5.3 & 5.2378 & TRN & \\
\hline CHEMBL1369822 & 737825 & 6.0 & 5.87700 & 0000000001 & TRN \\
\hline CHEMBL1440290 & 737825 & 4.95 & 5.087 & TRN & \\
\hline CHEMBL1375723 & 737825 & 5.5 & 5.4556 & TRN & \\
\hline CHEMBL1446286 & 737825 & 4.45 & 5.131 & TRN & \\
\hline CHEMBL1383867 & 737825 & 4.8 & 5.1334 & TRN & \\
\hline CHEMBL1338245 & 737825 & 4.5 & 5.0907 & TRN & \\
\hline CHEMBL1597203 & 737825 & 4.85 & 5.2585 & TRN & \\
\hline CHEMBL1424808 & 737825 & 5.95 & 5.1235 & TRN & \\
\hline CHEMBL1270410 & 737825 & 5.1 & 5.2597 & TRN & \\
\hline CHEMBL3209398 & 737825 & 5.05 & 5.166 & TRN & \\
\hline CHEMBL1492541 & 737825 & 5.35 & 5.1297 & TST & \\
\hline CHEMBL1389204 & 737825 & 5.0 & 5.1187 & TRN & \\
\hline CHEMBL3211592 & 737825 & 4.65 & 5.2412 & TST & \\
\hline CHEMBL1577148 & 737825 & 4.85 & 5.1176 & TRN & \\
\hline CHEMBL1473317 & 737825 & 5.4 & 5.126 & TRN & \\
\hline CHEMBL1473117 & 737825 & 4.7 & 4.727 & TRN & \\
\hline CHEMBL1698558 & 737825 & 4.75 & 5.0995 & TRN & \\
\hline CHEMBL1387681 & 737825 & 4.8 & 4.9977 & TRN & \\
\hline CHEMBL1340592 & 737825 & 4.85 & 5.0579 & TRN & \\
\hline CHEMBL1480779 & 737825 & 5.9 & 5.5168 & TRN & \\
\hline CHEMBL1568113 & 737825 & 5.15 & 5.3609 & TST & \\
\hline CHEMBL1353758 & 737825 & 4.9 & 5.2167 & TST & \\
\hline CHEMBL3198104 & 737825 & 4.7 & 4.9241 & TRN & \\
\hline CHEMBL1452881 & 737825 & 6.0 & 5.73799 & 99999999995 & TST \\
\hline & & & & 22501 & \\
\hline
\end{tabular}




\begin{tabular}{|c|c|c|c|c|c|}
\hline \multirow{2}{*}{ CHEMBL1373259 } & \multirow{2}{*}{737825} & \\
\hline & & 5.6 & 5.3084 & TRN & \\
\hline CHEMBL1435053 & 737825 & 5.0 & 4.9948 & TST & \\
\hline CHEMBL1581163 & 737825 & 4.7 & 5.0647 & TRN & \\
\hline CHEMBL1357429 & 737825 & 6.1 & 5.9828 & TRN & \\
\hline CHEMBL1530091 & 737825 & 4.8 & 4.6938 & TRN & \\
\hline CHEMBL1325833 & 737825 & 5.7 & 5.489 & TRN & \\
\hline CHEMBL1390454 & 737825 & 5.05 & 5.2322 & TRN & \\
\hline CHEMBL1256835 & 737825 & 6.0 & 5.7207 & TRN & \\
\hline CHEMBL1481014 & 737825 & 5.5 & 5.178 & TST & \\
\hline CHEMBL1603852 & 737825 & 6.4 & 6.3322 & TRN & \\
\hline CHEMBL1559163 & 737825 & 5.4 & 5.3251 & TRN & \\
\hline CHEMBL1742376 & 737825 & 4.9 & 5.1356 & TRN & \\
\hline CHEMBL1326406 & 737825 & 4.6 & 5.1903 & TRN & \\
\hline CHEMBL1517418 & 737825 & 4.4 & 5.1635 & TRN & \\
\hline CHEMBL 1355720 & 737825 & 5.8 & 5.4528 & TRN & \\
\hline CHEMBL1455942 & 737825 & 5.5 & 5.26 & TRN & \\
\hline CHEMBL1592371 & 737825 & 5.1 & 5.0161 & TRN & \\
\hline CHEMBL1480012 & 737825 & 4.8 & 5.1986 & TRN & \\
\hline CHEMBL340807 & 737825 & 5.6 & 5.6224 & TRN & \\
\hline CHEMBL1509009 & 737825 & 4.7 & 5.3073 & TRN & \\
\hline CHEMBL1542467 & 737825 & 4.95 & 5.0636 & TRN & \\
\hline CHEMBL1516054 & 737825 & 5.9 & 5.8416 & TRN & \\
\hline CHEMBL1534872 & 737825 & 5.6 & 5.2661 & TST & \\
\hline CHEMBL1332265 & 737825 & 5.05 & 5.1124 & TST & \\
\hline CHEMBL1463002 & 737825 & 5.3 & 5.2633 & TRN & \\
\hline CHEMBL1522673 & 737825 & 7.4 & 5.776 & TRN & \\
\hline CHEMBL489935 & 737825 & 6.5 & 6.5301 & TRN & \\
\hline CHEMBL1334193 & 737825 & 4.5 & 5.2931 & TRN & \\
\hline CHEMBL1533607 & 737825 & 5.3 & 5.2792 & TRN & \\
\hline CHEMBL1451526 & 737825 & 5.5 & 5.3138 & TRN & \\
\hline CHEMBL1417552 & 737825 & 4.9 & 4.988 & TRN & \\
\hline CHEMBL 1474410 & 737825 & 5.1 & 4.9901 & TRN & \\
\hline CHEMBL1522877 & 737825 & 5.05 & 5.2094 & TST & \\
\hline CHEMBL1337408 & 737825 & 4.75 & 5.2761 & TRN & \\
\hline CHEMBL1323905 & 737825 & 5.0 & $4.9910 e$ & 00000000005 & TRN \\
\hline CHEMBL1410009 & 737825 & 4.85 & 5.3003 & TRN & \\
\hline CHEMBL1490634 & 737825 & 5.15 & 5.2479 & 9999999999 & TRN \\
\hline CHEMBL1544319 & 737825 & 5.9 & 5.1841 & TRN & \\
\hline CHEMBL1547486 & 737825 & 4.6 & 5.2892 & TRN & \\
\hline CHEMBL1397914 & 737825 & 4.6 & 4.5395 & TRN & \\
\hline CHEMBL1555238 & 737825 & 4.7 & 4.663 & TRN & \\
\hline CHEMBL1716016 & 737825 & 5.65 & 5.13706 & 00000000005 & TRN \\
\hline CHEMBL1315457 & 737825 & 5.0 & 4.8362 & TST & \\
\hline CHEMBL1536844 & 737825 & 5.7 & 5.3112 & TST & \\
\hline CHEMBL1607605 & 737825 & 4.85 & 5.2039 & TRN & \\
\hline CHEMBL1372210 & 737825 & 5.6 & 5.2507 & TRN & \\
\hline CHEMBL1742195 & 737825 & 5.65 & 5.1293 & TRN & \\
\hline CHEMBL1455073 & 737825 & 5.4 & 5.1768 & TST & \\
\hline
\end{tabular}




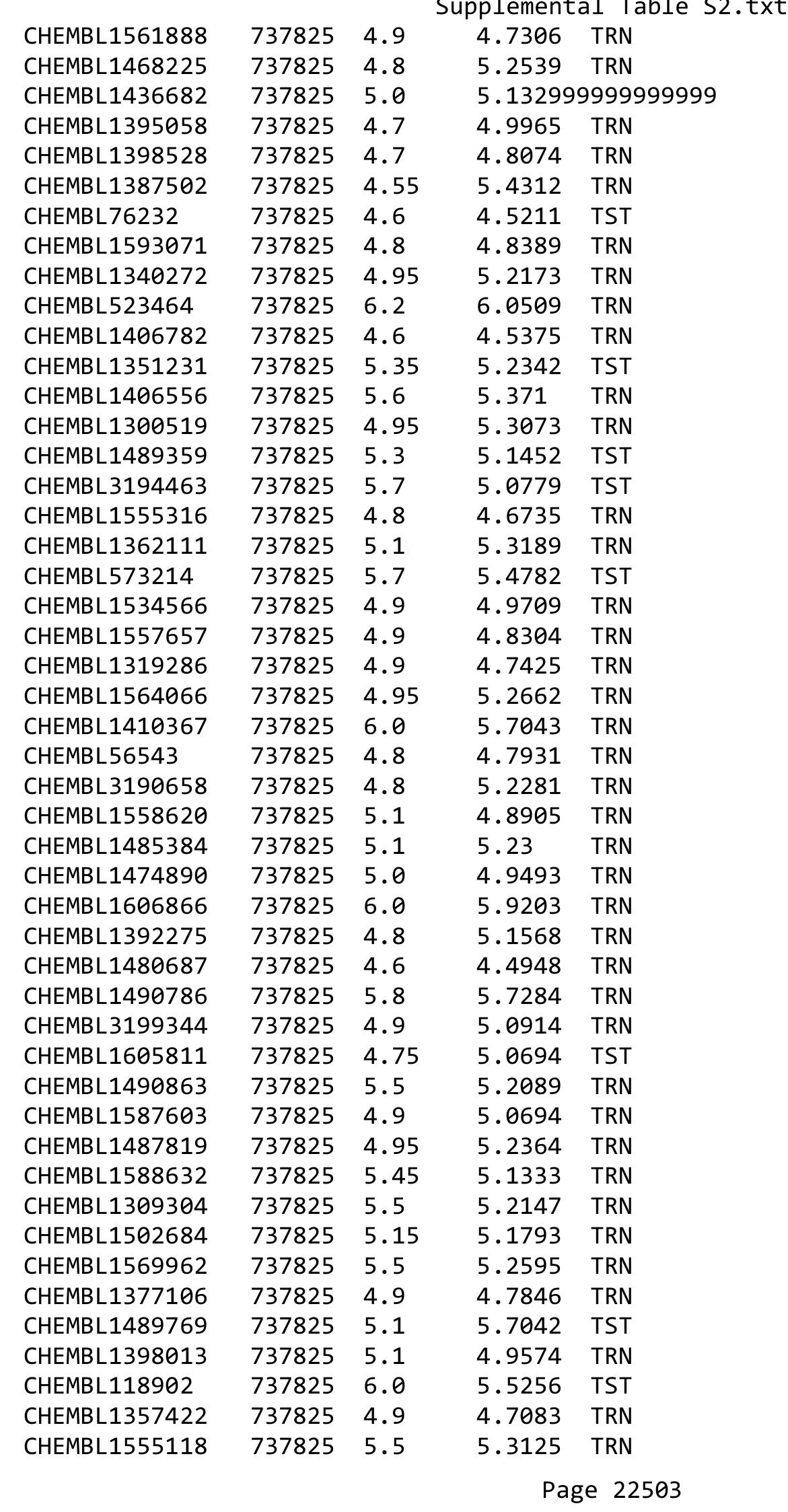

TRN 


\begin{tabular}{|c|c|c|c|c|c|}
\hline \\
\hline CHEMBL1568732 & 737825 & 5.3 & 5.2708 & TRN & \\
\hline CHEMBL1467110 & 737825 & 4.9 & 5.1256 & TST & \\
\hline CHEMBL1609209 & 737825 & 4.7 & 4.6248 & TRN & \\
\hline CHEMBL1403333 & 737825 & 5.3 & 5.064 & TRN & \\
\hline CHEMBL1355537 & 737825 & 4.9 & 4.8079 & TST & \\
\hline CHEMBL313833 & 737825 & 5.1 & 5.023 & TST & \\
\hline CHEMBL1324529 & 737825 & 4.6 & 4.5124 & TRN & \\
\hline CHEMBL1516851 & 737825 & 5.65 & 5.2874 & TRN & \\
\hline CHEMBL3207405 & 737825 & 4.7 & 5.0924 & TST & \\
\hline CHEMBL1562229 & 737825 & 5.7 & 5.1308 & TRN & \\
\hline CHEMBL1473620 & 737825 & 4.6 & 4.5199 & TRN & \\
\hline CHEMBL1741610 & 737825 & 4.55 & 5.2236 & TST & \\
\hline CHEMBL1394983 & 737825 & 4.8 & 4.6782 & TRN & \\
\hline CHEMBL1421262 & 737825 & 4.95 & 5.0936 & TRN & \\
\hline CHEMBL1318622 & 737825 & 5.6 & 5.5099 & TRN & \\
\hline CHEMBL1436816 & 737825 & 5.4 & 5.3657 & TRN & \\
\hline CHEMBL77456 & 737825 & 4.7 & 4.6249 & TRN & \\
\hline CHEMBL1582419 & 737825 & 5.0 & 5.1249 & TRN & \\
\hline CHEMBL1355111 & 737825 & 4.8 & 4.7439 & TRN & \\
\hline CHEMBL1305322 & 737825 & 5.15 & 5.2488 & TRN & \\
\hline CHEMBL1473123 & 737825 & 5.2 & 4.9651 & TRN & \\
\hline CHEMBL1562987 & 737825 & 5.3 & 5.2679 & TRN & \\
\hline CHEMBL1590106 & 737825 & 4.7 & 4.8596 & TRN & \\
\hline CHEMBL1362852 & 737825 & 6.0 & $5.9570 e$ & 0000000001 & TRN \\
\hline CHEMBL1389184 & 737825 & 5.7 & 5.2532 & TRN & \\
\hline CHEMBL1322091 & 737825 & 4.8 & 5.1968 & TRN & \\
\hline CHEMBL1473760 & 737825 & 5.2 & 5.1659 & TRN & \\
\hline CHEMBL1354372 & 737825 & 4.9 & 4.849 & TRN & \\
\hline CHEMBL1333282 & 737825 & 5.85 & 5.23 & TRN & \\
\hline CHEMBL 1703300 & 737825 & 4.6 & 4.9833 & TRN & \\
\hline CHEMBL1413967 & 737825 & 5.4 & 5.3204 & TRN & \\
\hline CHEMBL3208819 & 737825 & 4.9 & 5.20799 & 9999999999 & TRN \\
\hline CHEMBL1570633 & 737825 & 5.4 & 5.4266 & TRN & \\
\hline CHEMBL1324982 & 737825 & 5.95 & 5.2289 & TRN & \\
\hline CHEMBL1539107 & 737825 & 4.85 & 5.2753 & TRN & \\
\hline CHEMBL1554664 & 737825 & 5.5 & 5.3632 & TRN & \\
\hline CHEMBL1437164 & 737825 & 4.8 & 4.6028 & TRN & \\
\hline CHEMBL1513669 & 737825 & 5.4 & $5.2360 e$ & $\partial 000000001$ & TRN \\
\hline CHEMBL1553034 & 737825 & 5.7 & 4.8491 & TRN & \\
\hline CHEMBL1318565 & 737825 & 5.5 & 5.3935 & TRN & \\
\hline CHEMBL1577699 & 737825 & 4.55 & 5.2205 & TRN & \\
\hline CHEMBL1612675 & 737825 & 4.9 & 4.9327 & TRN & \\
\hline CHEMBL1475257 & 737825 & 4.4 & 4.3626 & TRN & \\
\hline CHEMBL1611902 & 737825 & 5.95 & 5.33 & TST & \\
\hline CHEMBL1544545 & 737825 & 4.9 & 5.1903 & TRN & \\
\hline CHEMBL1576560 & 737825 & 5.95 & 4.9775 & TRN & \\
\hline CHEMBL1710661 & 737825 & 5.5 & 5.2047 & TRN & \\
\hline CHEMBL1469402 & 737825 & 5.65 & 4.9491 & TRN & \\
\hline & & & & 22504 & \\
\hline
\end{tabular}




\begin{tabular}{|c|c|c|c|c|c|}
\hline \\
\hline CHEMBL17468 & 737825 & 4.8 & 4.8264 & TST & \\
\hline CHEMBL1532858 & 737825 & 4.85 & 5.1146 & TRN & \\
\hline CHEMBL1552098 & 737825 & 4.5 & 4.4465 & TRN & \\
\hline CHEMBL1488127 & 737825 & 5.95 & 5.1167 & TRN & \\
\hline CHEMBL1581905 & 737825 & 6.0 & 5.3066 & TRN & \\
\hline CHEMBL1450096 & 737825 & 6.25 & 5.6028 & TRN & \\
\hline CHEMBL1460094 & 737825 & 5.25 & 5.2328 & TST & \\
\hline CHEMBL1396661 & 737825 & 5.6 & 5.3552 & TST & \\
\hline CHEMBL1491098 & 737825 & 4.9 & 4.9964 & TST & \\
\hline CHEMBL1397177 & 737825 & 5.5 & 5.3754 & TRN & \\
\hline CHEMBL1348414 & 737825 & 5.15 & 5.3564 & TST & \\
\hline CHEMBL1699708 & 737825 & 4.95 & 5.2049 & TRN & \\
\hline CHEMBL1526543 & 737825 & 6.0 & 5.7258 & TST & \\
\hline CHEMBL1472248 & 737825 & 5.1 & 5.2659 & TRN & \\
\hline CHEMBL1433762 & 737825 & 4.9 & 4.8998 & TRN & \\
\hline CHEMBL541847 & 737825 & 5.7 & 5.6631 & TRN & \\
\hline CHEMBL1491258 & 737825 & 4.8 & 4.7446 & TRN & \\
\hline CHEMBL1323759 & 737825 & 4.8 & 4.675 & TRN & \\
\hline CHEMBL1479144 & 737825 & 5.85 & 5.1255 & TST & \\
\hline CHEMBL3195990 & 737825 & 4.5 & 5.1345 & TRN & \\
\hline CHEMBL1336865 & 737825 & 4.9 & 5.0309 & TRN & \\
\hline CHEMBL1485223 & 737825 & 5.1 & 5.1287 & TRN & \\
\hline CHEMBL63102 & 737825 & 4.4 & 4.5235 & TST & \\
\hline CHEMBL1476159 & 737825 & 5.5 & 5.4257 & TRN & \\
\hline CHEMBL 3210395 & 737825 & 5.95 & 5.319 & TRN & \\
\hline CHEMBL1386373 & 737825 & 4.85 & 5.1862 & TRN & \\
\hline CHEMBL1331410 & 737825 & 5.7 & 5.6175 & TRN & \\
\hline CHEMBL1567251 & 737825 & 4.6 & 4.5695 & TRN & \\
\hline CHEMBL1527775 & 737825 & 4.85 & 5.1973 & TRN & \\
\hline CHEMBL1567295 & 737825 & 6.8 & 6.7471 & TRN & \\
\hline CHEMBL60518 & 737825 & 4.4 & 4.4722 & TST & \\
\hline CHEMBL 1420930 & 737825 & 6.0 & 4.976 & TRN & \\
\hline CHEMBL1436169 & 737825 & 6.2 & 6.1411 & TRN & \\
\hline CHEMBL1602112 & 737825 & 5.9 & 5.778 & TRN & \\
\hline CHEMBL1513431 & 737825 & 5.3 & $5.3770 e$ & 0000000001 & TRN \\
\hline CHEMBL491910 & 737825 & 7.1 & 7.0305 & TRN & \\
\hline CHEMBL1320242 & 737825 & 5.3 & 4.8833 & TRN & \\
\hline CHEMBL1567805 & 737825 & 4.8 & 5.0496 & TRN & \\
\hline CHEMBL 3197425 & 737825 & 4.85 & 5.1047 & TRN & \\
\hline CHEMBL1741636 & 737825 & 4.85 & 4.8837 & TRN & \\
\hline CHEMBL1341328 & 737825 & 4.85 & 5.1529 & TRN & \\
\hline CHEMBL489737 & 737825 & 6.7 & 6.6847 & TRN & \\
\hline CHEMBL1353190 & 737825 & 5.45 & 5.2406 & TRN & \\
\hline CHEMBL1333414 & 737825 & 4.85 & 5.1565 & TRN & \\
\hline CHEMBL1256914 & 737825 & 5.0 & 4.9126 & TST & \\
\hline CHEMBL1540956 & 737825 & 5.9 & 5.3782 & TRN & \\
\hline CHEMBL1607206 & 737825 & 4.6 & 5.2815 & TRN & \\
\hline CHEMBL1437732 & 737825 & 5.4 & 5.3508 & TRN & \\
\hline
\end{tabular}




\begin{tabular}{|c|c|c|c|c|c|}
\hline \multicolumn{6}{|c|}{ Supplemental Table S2.txt } \\
\hline CHEMBL1377215 & 737825 & 5.55 & 5.1394 & TRN & \\
\hline CHEMBL1405101 & 737825 & 4.9 & 5.2604 & TST & \\
\hline CHEMBL1445984 & 737825 & 4.8 & 4.6465 & TRN & \\
\hline CHEMBL1461021 & 737825 & 5.7 & 4.9595 & TRN & \\
\hline CHEMBL1464877 & 737825 & 7.5501 & 5.176 & TRN & \\
\hline CHEMBL3213163 & 737825 & 5.5 & \multicolumn{2}{|c|}{5.4270000000000005} & TRN \\
\hline CHEMBL1455570 & 737825 & 4.9 & 4.8293 & TRN & \\
\hline CHEMBL1350898 & 737825 & 5.45 & 4.9849 & TRN & \\
\hline CHEMBL1587776 & 737825 & 4.7 & 5.0067 & TRN & \\
\hline CHEMBL1441011 & 737825 & 4.75 & 5.2124 & TRN & \\
\hline CHEMBL1512833 & 737825 & 4.8 & 4.7004 & TRN & \\
\hline CHEMBL1606038 & 737825 & 5.5 & 5.4502 & TRN & \\
\hline CHEMBL1453240 & 737825 & 4.8 & 4.8628 & TRN & \\
\hline CHEMBL1590556 & 737825 & 4.8 & 4.7864 & TRN & \\
\hline CHEMBL1494481 & 737825 & 5.2 & 4.8759 & TRN & \\
\hline CHEMBL1533099 & 737825 & 4.85 & 4.9928 & TRN & \\
\hline CHEMBL1568870 & 737825 & 5.0 & 4.9521 & TRN & \\
\hline CHEMBL1531163 & 737825 & 5.4 & 5.2228 & TST & \\
\hline CHEMBL475198 & 737825 & 5.4 & 5.345 & TRN & \\
\hline CHEMBL1405001 & 737825 & 5.0 & 4.8441 & TRN & \\
\hline CHEMBL1391420 & 737825 & 4.85 & 5.1401 & TRN & \\
\hline CHEMBL1482759 & 737825 & 5.1 & 4.8367 & TRN & \\
\hline CHEMBL1418522 & 737825 & 4.85 & 5.1601 & TST & \\
\hline CHEMBL1513247 & 737825 & 4.9 & \multicolumn{2}{|c|}{5.0489999999999995} & TRN \\
\hline CHEMBL492132 & 737825 & 6.4 & 6.4381 & TRN & \\
\hline CHEMBL1553751 & 737825 & 5.1 & 5.3062 & TRN & \\
\hline CHEMBL1331363 & 737825 & 7.2 & 6.9385 & TRN & \\
\hline CHEMBL1368942 & 737825 & 5.7 & 5.6209 & TRN & \\
\hline CHEMBL1970734 & 737825 & 5.15 & 5.353 & TRN & \\
\hline CHEMBL3190530 & 737825 & 5.3 & 5.2787 & TST & \\
\hline CHEMBL1454711 & 737825 & 4.8 & 5.2102 & TST & \\
\hline CHEMBL1544694 & 737825 & 4.9 & 5.1672 & TST & \\
\hline CHEMBL1393776 & 737825 & 4.4 & 5.0143 & TRN & \\
\hline CHEMBL1386546 & 737825 & 5.55 & \multicolumn{2}{|c|}{5.263999999999999} & TST \\
\hline CHEMBL1378443 & 737825 & 5.6 & 5.3166 & TRN & \\
\hline CHEMBL59532 & 737825 & 4.9 & 4.8982 & TST & \\
\hline CHEMBL1579521 & 737825 & 5.1 & 5.2461 & TRN & \\
\hline CHEMBL1520216 & 737825 & 5.5 & 5.4867 & TRN & \\
\hline CHEMBL1611806 & 737825 & 5.3 & 5.0536 & TRN & \\
\hline CHEMBL1525473 & 737825 & 5.5 & 5.1592 & TST & \\
\hline CHEMBL1555122 & 737825 & 4.8 & 4.7245 & TRN & \\
\hline CHEMBL1557279 & 737825 & 4.5 & 5.0197 & TST & \\
\hline CHEMBL1332471 & 737825 & 5.6 & 5.5814 & TRN & \\
\hline CHEMBL1340191 & 737825 & 5.55 & 5.2684 & TRN & \\
\hline CHEMBL491977 & 737825 & 6.4 & 6.3897 & TRN & \\
\hline CHEMBL1399760 & 737825 & 4.8 & 4.669 & TRN & \\
\hline CHEMBL1552854 & 737825 & 5.7 & 5.603 & TRN & \\
\hline CHEMBL1328527 & 737825 & 4.75 & 5.1435 & TRN & \\
\hline
\end{tabular}




\begin{tabular}{|c|c|c|c|c|c|}
\hline \multicolumn{6}{|c|}{ Supplemental Table S2.txt } \\
\hline CHEMBL1305452 & 737825 & 5.15 & 5.0496 & TRN & \\
\hline CHEMBL1395137 & 737825 & 4.9 & 4.6941 & TRN & \\
\hline CHEMBL1593545 & 737825 & 4.7 & 4.6339 & TRN & \\
\hline CHEMBL1442011 & 737825 & 5.7 & 5.4172 & TRN & \\
\hline CHEMBL1396211 & 737825 & 4.9 & 4.8209 & TRN & \\
\hline CHEMBL 3213929 & 737825 & 4.9 & 5.1574 & TST & \\
\hline CHEMBL1536670 & 737825 & 5.15 & 5.1718 & TRN & \\
\hline CHEMBL1334357 & 737825 & 5.5 & 5.3117 & TST & \\
\hline CHEMBL1317066 & 737825 & 4.9 & 4.8311 & TRN & \\
\hline CHEMBL1602394 & 737825 & 5.5 & 5.4456 & TRN & \\
\hline CHEMBL1373126 & 737825 & 5.4 & 5.3088 & TST & \\
\hline CHEMBL1357850 & 737825 & 6.0 & 5.9823 & TRN & \\
\hline CHEMBL1320272 & 737825 & 5.3 & 5.0814 & TRN & \\
\hline CHEMBL1418916 & 737825 & 6.7 & 5.444 & TRN & \\
\hline CHEMBL1590321 & 737825 & 4.7 & 4.5903 & TRN & \\
\hline CHEMBL1609497 & 737825 & 4.6 & 5.0566 & TST & \\
\hline CHEMBL1493411 & 737825 & 4.9 & 5.2479 & TST & \\
\hline CHEMBL1605255 & 737825 & 5.0 & 4.891 & TRN & \\
\hline CHEMBL1567121 & 737825 & 4.85 & 5.0282 & TRN & \\
\hline CHEMBL 1451238 & 737825 & 4.6 & 5.0309 & TST & \\
\hline CHEMBL1442986 & 737825 & 5.3 & 5.1414 & TRN & \\
\hline CHEMBL1397782 & 737825 & 5.7 & 5.3376 & TRN & \\
\hline CHEMBL1490285 & 737825 & 5.1 & 5.2154 & TRN & \\
\hline CHEMBL1448849 & 737825 & 4.7 & 5.2405 & TRN & \\
\hline CHEMBL497939 & 737825 & 4.5 & 5.6861 & TRN & \\
\hline CHEMBL1433725 & 737825 & 4.6 & 4.3844 & TRN & \\
\hline CHEMBL1369863 & 737825 & 5.0 & 4.8091 & TRN & \\
\hline CHEMBL1409809 & 737825 & 5.4 & 5.1132 & TRN & \\
\hline CHEMBL1483550 & 737825 & 4.85 & 5.0099 & TRN & \\
\hline CHEMBL1741579 & 737825 & 4.6 & 5.0175 & TRN & \\
\hline CHEMBL1568370 & 737825 & 5.45 & 5.24200 & 0000000001 & TRN \\
\hline CHEMBL1394765 & 737825 & 5.0 & 4.882 & TRN & \\
\hline CHEMBL1466542 & 737825 & 4.9 & 5.4163 & TRN & \\
\hline CHEMBL1479218 & 737825 & 6.3 & 5.4437 & TRN & \\
\hline CHEMBL1492374 & 737825 & 4.85 & 5.1913 & TRN & \\
\hline CHEMBL1474664 & 737825 & 4.8 & 4.9679 & TRN & \\
\hline CHEMBL1374050 & 737825 & 4.95 & 5.1777 & TRN & \\
\hline CHEMBL1320662 & 737825 & 4.9 & 4.7903 & TRN & \\
\hline CHEMBL1504734 & 737825 & 6.15 & 5.0063 & TST & \\
\hline CHEMBL1600239 & 737825 & 5.95 & 5.4222 & TRN & \\
\hline CHEMBL1481588 & 737825 & 5.5 & 5.2265 & TRN & \\
\hline CHEMBL1463991 & 737825 & 4.65 & 4.9926 & TRN & \\
\hline CHEMBL1708288 & 737825 & 4.8 & 5.1179 & TRN & \\
\hline CHEMBL1355262 & 737825 & 5.0 & 4.908 & TRN & \\
\hline CHEMBL1519172 & 737825 & 4.65 & 5.3422 & TRN & \\
\hline CHEMBL1472900 & 737825 & 4.6 & 4.4994 & TRN & \\
\hline CHEMBL 1422586 & 737825 & 4.85 & 5.124 & TRN & \\
\hline CHEMBL1320947 & 737825 & 6.2 & 5.8632 & TRN & \\
\hline
\end{tabular}




\begin{tabular}{|c|c|c|c|c|c|}
\hline \\
\hline CHEMBL1460996 & 737825 & 4.9 & 5.1444 & TRN & \\
\hline CHEMBL1455565 & 737825 & 5.2 & 5.0851 & TRN & \\
\hline CHEMBL3197073 & 737825 & 5.1 & 5.067 & TST & \\
\hline CHEMBL1524904 & 737825 & 4.9 & 5.3885 & TRN & \\
\hline CHEMBL1521133 & 737825 & 5.5 & 5.2523 & TRN & \\
\hline CHEMBL1612582 & 737825 & 5.1 & 4.9669 & TRN & \\
\hline CHEMBL1356764 & 737825 & 5.3 & 5.2641 & TRN & \\
\hline CHEMBL1534714 & 737825 & 4.9 & 5.2693 & TRN & \\
\hline CHEMBL1597474 & 737825 & 5.4 & 5.1819 & TRN & \\
\hline CHEMBL338314 & 737825 & 4.6 & 4.6832 & TST & \\
\hline CHEMBL1511512 & 737825 & 6.05 & 5.3461 & TRN & \\
\hline CHEMBL1591336 & 737825 & 4.8 & 4.633 & TRN & \\
\hline CHEMBL1484079 & 737825 & 5.05 & 5.0653 & TRN & \\
\hline CHEMBL1546161 & 737825 & 5.45 & 5.0906 & TST & \\
\hline CHEMBL153036 & 737825 & 6.0 & 5.83200 & 3000000001 & TRN \\
\hline CHEMBL1400192 & 737825 & 4.7 & 5.0066 & TRN & \\
\hline CHEMBL1589923 & 737825 & 4.7 & 4.7092 & TRN & \\
\hline CHEMBL1596938 & 737825 & 4.85 & 5.1419 & TRN & \\
\hline CHEMBL1537973 & 737825 & 4.95 & 4.9952 & TRN & \\
\hline CHEMBL1301031 & 737825 & 5.4 & 5.052 & TST & \\
\hline CHEMBL1437650 & 737825 & 4.6 & 4.502 & TRN & \\
\hline CHEMBL1507167 & 737825 & 4.8 & 5.1816 & TST & \\
\hline CHEMBL1591592 & 737825 & 5.4 & 5.3916 & TRN & \\
\hline CHEMBL1334657 & 737825 & 4.6 & 4.5035 & TRN & \\
\hline CHEMBL3208805 & 737825 & 5.35 & 5.1139 & TRN & \\
\hline CHEMBL3145119 & 737825 & 4.85 & 5.1567 & TST & \\
\hline CHEMBL1512702 & 737825 & 5.1 & 5.0466 & TRN & \\
\hline CHEMBL1359661 & 737825 & 5.55 & 5.2755 & TRN & \\
\hline CHEMBL3195516 & 737825 & 4.4 & 5.1262 & TRN & \\
\hline CHEMBL1611348 & 737825 & 4.9 & 4.7928 & TRN & \\
\hline CHEMBL1485000 & 737825 & 5.4 & 5.2404 & TST & \\
\hline CHEMBL1510330 & 737825 & 5.4 & 5.0222 & TRN & \\
\hline CHEMBL1366433 & 737825 & 5.1 & 4.9245 & TRN & \\
\hline CHEMBL186526 & 737825 & 5.6 & 5.3986 & TRN & \\
\hline CHEMBL577455 & 737825 & 4.8 & 4.7785 & TST & \\
\hline CHEMBL1447959 & 737825 & 5.1 & 4.9945 & TRN & \\
\hline CHEMBL1574576 & 737825 & 5.5 & 5.315 & TRN & \\
\hline CHEMBL1358395 & 737825 & 5.4 & 5.3175 & TST & \\
\hline CHEMBL1544377 & 737825 & 4.95 & 5.0564 & TRN & \\
\hline CHEMBL1500518 & 737825 & 4.45 & 5.022 & TRN & \\
\hline CHEMBL1426357 & 737825 & 5.45 & 5.3431 & TRN & \\
\hline CHEMBL1356135 & 737825 & 4.9 & 4.8558 & TRN & \\
\hline CHEMBL1557807 & 737825 & 4.55 & 5.0669 & TST & \\
\hline CHEMBL1471546 & 737825 & 4.8 & 5.0937 & TST & \\
\hline CHEMBL1388771 & 737825 & 5.1 & 5.2986 & TRN & \\
\hline CHEMBL1514110 & 737825 & 5.1 & 4.9168 & TRN & \\
\hline CHEMBL1374863 & 737825 & 5.5 & 5.3727 & TRN & \\
\hline CHEMBL1425093 & 737825 & 6.15 & 5.2505 & TRN & \\
\hline
\end{tabular}




\begin{tabular}{|c|c|c|c|c|}
\hline & & & pplemen & al $\mathrm{T}$ \\
\hline CHEMBL1332719 & 737825 & 5.4 & 5.2115 & TST \\
\hline CHEMBL1437990 & 737825 & 5.6 & 5.4708 & TRN \\
\hline CHEMBL1741780 & 737825 & 4.8 & 5.1585 & TRN \\
\hline CHEMBL1515366 & 737825 & 5.3 & 4.9859 & TRN \\
\hline CHEMBL1413343 & 737825 & 4.8 & 4.6583 & TRN \\
\hline CHEMBL1575476 & 737825 & 4.75 & 5.1565 & TST \\
\hline CHEMBL1253351 & 737825 & 5.7 & 5.5312 & TRN \\
\hline CHEMBL1742135 & 737825 & 4.45 & 5.1493 & TST \\
\hline CHEMBL1511621 & 737825 & 5.8 & 5.1549 & TRN \\
\hline CHEMBL1720911 & 737825 & 4.5 & 5.2618 & TRN \\
\hline CHEMBL1592560 & 737825 & 4.4 & 4.3483 & TRN \\
\hline CHEMBL1548763 & 737825 & 5.15 & 5.4134 & TRN \\
\hline CHEMBL1508456 & 737825 & 4.6 & 5.0361 & TRN \\
\hline CHEMBL1390427 & 737825 & 4.85 & 5.1922 & TRN \\
\hline CHEMBL1519978 & 737825 & 5.4 & 5.3094 & TRN \\
\hline CHEMBL1303450 & 737825 & 5.15 & 5.1215 & TRN \\
\hline CHEMBL1396809 & 737825 & 5.6 & 5.3805 & TRN \\
\hline CHEMBL1600552 & 737825 & 5.65 & 5.2446 & TRN \\
\hline CHEMBL1316831 & 737825 & 4.8 & 4.7495 & TST \\
\hline CHEMBL1518618 & 737825 & 4.8 & 4.7058 & TRN \\
\hline CHEMBL1533413 & 737825 & 5.4 & 5.2889 & TST \\
\hline CHEMBL1561402 & 737825 & 4.9 & 4.7728 & TRN \\
\hline CHEMBL3214056 & 737825 & 5.85 & 5.471 & TRN \\
\hline CHEMBL1560276 & 737825 & 4.75 & 5.0481 & TST \\
\hline CHEMBL1604421 & 737825 & 6.5 & 6.3866 & TRN \\
\hline CHEMBL1309305 & 737825 & 4.85 & 5.098 & TRN \\
\hline CHEMBL1533853 & 737825 & 6.1 & 6.153 & TRN \\
\hline CHEMBL1417540 & 737825 & 4.6 & 5.4079 & TRN \\
\hline CHEMBL1592213 & 737825 & 4.8 & 4.7409 & TRN \\
\hline CHEMBL1331118 & 737825 & 5.3 & 5.2183 & TRN \\
\hline CHEMBL1475255 & 737825 & 6.2 & 6.2064 & TRN \\
\hline CHEMBL1493039 & 737825 & 5.5 & 5.3003 & TRN \\
\hline CHEMBL1318278 & 737825 & 4.6 & 4.5045 & TRN \\
\hline CHEMBL1329312 & 737825 & 5.65 & 5.6145 & TST \\
\hline CHEMBL1741697 & 737825 & 4.85 & 5.0882 & TRN \\
\hline CHEMBL1560095 & 737825 & 4.5 & 4.6238 & TRN \\
\hline CHEMBL1335220 & 737825 & 5.2 & 5.0954 & TRN \\
\hline CHEMBL1394855 & 737825 & 5.4 & 5.3943 & TRN \\
\hline CHEMBL1544965 & 737825 & 4.85 & 5.2331 & TRN \\
\hline CHEMBL1314674 & 737825 & 4.8 & 4.7116 & TRN \\
\hline CHEMBL1729658 & 737825 & 4.75 & 5.0821 & TRN \\
\hline CHEMBL1496349 & 737825 & 6.15 & 5.0487 & TST \\
\hline CHEMBL3199347 & 737825 & 4.8 & 5.0543 & TRN \\
\hline CHEMBL1370169 & 737825 & 6.1 & 5.7627 & TRN \\
\hline CHEMBL1517886 & 737825 & 4.55 & 5.0246 & TRN \\
\hline CHEMBL1451979 & 737825 & 4.85 & 5.0218 & TRN \\
\hline CHEMBL1382909 & 737825 & 5.45 & 5.1142 & TRN \\
\hline CHEMBL1531213 & 737825 & 5.65 & 5.1165 & TRN \\
\hline
\end{tabular}




\begin{tabular}{|c|c|c|c|c|}
\hline \multicolumn{5}{|c|}{ Supplemental Table S2.txt } \\
\hline CHEMBL1438371 & 737825 & 5.1 & 4.9923 & TRN \\
\hline CHEMBL1527611 & 737825 & 4.85 & 5.1508 & TRN \\
\hline CHEMBL3210945 & 737825 & 4.8 & 5.3149 & TRN \\
\hline CHEMBL1491104 & 737825 & 5.1 & 4.9161 & TRN \\
\hline CHEMBL1529948 & 737825 & 4.9 & 5.1906 & TRN \\
\hline CHEMBL1331112 & 737825 & 5.3 & 5.1495 & TST \\
\hline CHEMBL287045 & 737825 & 4.5 & 4.5458 & TRN \\
\hline CHEMBL1503625 & 737825 & 5.35 & 5.2386 & TRN \\
\hline CHEMBL1515945 & 737825 & 7.3 & 6.5085 & TRN \\
\hline CHEMBL1558934 & 737825 & 4.6 & 5.1819 & TRN \\
\hline CHEMBL1301444 & 737825 & 4.75 & 5.0301 & TRN \\
\hline CHEMBL1613725 & 737825 & 4.9 & 4.7516 & TRN \\
\hline CHEMBL1439262 & 737825 & 4.6 & 4.8145 & TRN \\
\hline CHEMBL1563722 & 737825 & 4.7 & 5.1063 & TRN \\
\hline CHEMBL899 & 737825 & 4.95 & 5.2504 & TST \\
\hline CHEMBL1309130 & 737825 & 4.75 & 5.0909 & TRN \\
\hline CHEMBL1500383 & 737825 & 4.6 & 5.1366 & TRN \\
\hline CHEMBL1523670 & 737825 & 5.4 & 5.2332 & TRN \\
\hline CHEMBL1569972 & 737825 & 5.7 & 5.6811 & TRN \\
\hline CHEMBL1478808 & 737825 & 4.55 & 5.1127 & TRN \\
\hline CHEMBL1427738 & 737825 & 4.95 & 5.1682 & TRN \\
\hline CHEMBL1461321 & 737825 & 5.6 & 5.3636 & TRN \\
\hline CHEMBL1338432 & 737825 & 5.5 & 5.2058 & TRN \\
\hline CHEMBL1492580 & 737825 & 4.7 & 5.1572 & TRN \\
\hline CHEMBL510009 & 737825 & 5.6 & 5.4087 & TRN \\
\hline CHEMBL1544918 & 737825 & 5.05 & 5.2228 & TRN \\
\hline CHEMBL1519456 & 737825 & 5.3 & 5.1697 & TRN \\
\hline CHEMBL3189794 & 737825 & 4.5 & 4.9012 & TRN \\
\hline CHEMBL1501140 & 737825 & 6.05 & 5.5774 & TST \\
\hline CHEMBL3213666 & 737825 & 4.85 & 5.1423 & TRN \\
\hline CHEMBL1441088 & 737825 & 5.1 & 5.6881 & TRN \\
\hline CHEMBL1561209 & 737825 & 4.8 & 5.0316 & TRN \\
\hline CHEMBL1318120 & 737825 & 5.5 & 5.4412 & TRN \\
\hline CHEMBL1538117 & 737825 & 4.8 & 5.098 & TRN \\
\hline CHEMBL3209999 & 737825 & 5.4 & 5.3251 & TRN \\
\hline CHEMBL 362863 & 737825 & 6.5 & 6.1203 & TST \\
\hline CHEMBL 1256646 & 737825 & 4.8 & 4.9019 & TST \\
\hline CHEMBL3197177 & 737825 & 4.8 & 5.1649 & TRN \\
\hline CHEMBL1522579 & 737825 & 5.5 & 5.1593 & TRN \\
\hline CHEMBL1505285 & 737825 & 4.6 & 5.1476 & TRN \\
\hline CHEMBL1306942 & 737825 & 4.85 & 5.0841 & TRN \\
\hline CHEMBL342375 & 737825 & 6.3 & 6.0029 & TST \\
\hline CHEMBL1357016 & 737825 & 4.7 & 4.6992 & TRN \\
\hline CHEMBL1565360 & 737825 & 4.7 & 4.6022 & TRN \\
\hline CHEMBL1413566 & 737825 & 6.6 & 6.5775 & TRN \\
\hline CHEMBL1400535 & 737825 & 4.65 & 5.3254 & TRN \\
\hline CHEMBL1256751 & 737825 & 5.0 & 4.9432 & TRN \\
\hline CHEMBL1398800 & 737825 & 4.9 & 4.7921 & TRN \\
\hline
\end{tabular}




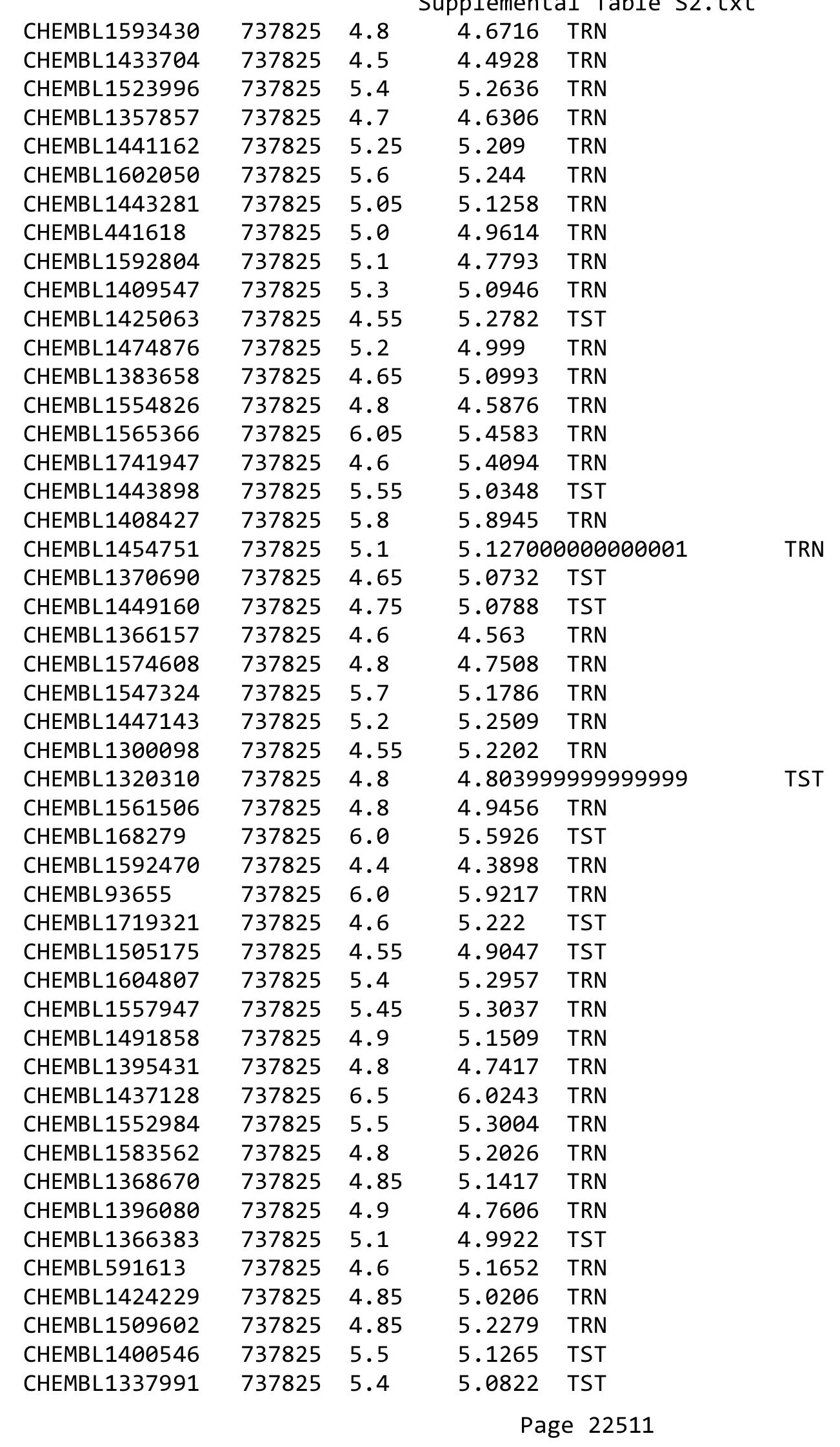




\begin{tabular}{|c|c|c|c|c|c|}
\hline & & & & & \\
\hline CHEMBL1312033 & 737825 & 4.6 & 5.118 & TRN & \\
\hline CHEMBL1597580 & 737825 & 5.9 & 5.1453 & TRN & \\
\hline CHEMBL1544930 & 737825 & 4.8 & 5.1099 & TRN & \\
\hline CHEMBL1358297 & 737825 & 5.0 & 4.9858 & TST & \\
\hline CHEMBL1489446 & 737825 & 4.7 & 4.5365 & TRN & \\
\hline CHEMBL1449821 & 737825 & 4.9 & 4.7839 & TRN & \\
\hline CHEMBL1715733 & 737825 & 5.05 & 4.9842 & TRN & \\
\hline CHEMBL1568588 & 737825 & 4.55 & 5.0872 & TRN & \\
\hline CHEMBL1572789 & 737825 & 4.9 & 5.13899 & 9999999999 & TRN \\
\hline CHEMBL1378758 & 737825 & 5.5 & 5.3481 & TRN & \\
\hline CHEMBL1522222 & 737825 & 4.7 & 5.3268 & TRN & \\
\hline CHEMBL1469083 & 737825 & 5.35 & 5.1705 & TST & \\
\hline CHEMBL1325732 & 737825 & 6.2 & 5.8737 & TST & \\
\hline CHEMBL1492558 & 737825 & 4.5 & 4.4122 & TRN & \\
\hline CHEMBL1437013 & 737825 & 5.0 & 5.0466 & TRN & \\
\hline CHEMBL1462156 & 737825 & 6.05 & 5.0176 & TRN & \\
\hline CHEMBL1496345 & 737825 & 4.8 & 4.76 & TRN & \\
\hline CHEMBL1383268 & 737825 & 4.55 & 5.125 & TST & \\
\hline CHEMBL3190590 & 737825 & 4.8 & 5.3399 & TST & \\
\hline CHEMBL3190830 & 737825 & 5.1 & 5.2141 & TST & \\
\hline CHEMBL1556828 & 737825 & 5.4 & 5.3722 & TRN & \\
\hline CHEMBL1593219 & 737825 & 5.0 & 4.798 & TRN & \\
\hline CHEMBL 1433173 & 737825 & 4.8 & 5.3001 & TRN & \\
\hline CHEMBL1326322 & 737825 & 4.9 & 4.7918 & TRN & \\
\hline CHEMBL1378322 & 737825 & 4.6 & 5.1853 & TRN & \\
\hline CHEMBL1356870 & 737825 & 6.0 & 5.6147 & TRN & \\
\hline CHEMBL1501395 & 737825 & 4.95 & 5.1181 & TST & \\
\hline CHEMBL 1742050 & 737825 & 5.05 & 5.1838 & TRN & \\
\hline CHEMBL1355351 & 737825 & 4.9 & 4.8092 & TRN & \\
\hline CHEMBL1999906 & 737825 & 6.1 & 5.481 & TST & \\
\hline CHEMBL1472152 & 737825 & 4.85 & 5.1505 & TST & \\
\hline CHEMBL1362562 & 737825 & 5.3 & 5.3112 & TRN & \\
\hline CHEMBL1741734 & 737825 & 5.55 & 5.5011 & TRN & \\
\hline CHEMBL1451149 & 737825 & 5.1 & 5.1564 & TRN & \\
\hline CHEMBL1466109 & 737825 & 5.2 & 5.1069 & TRN & \\
\hline CHEMBL1410491 & 737825 & 5.6 & 5.3982 & TRN & \\
\hline CHEMBL1311035 & 737825 & 4.85 & 5.0653 & TRN & \\
\hline CHEMBL450493 & 737825 & 6.5 & 6.4973 & TRN & \\
\hline CHEMBL1483978 & 737825 & 5.1 & 5.0746 & TRN & \\
\hline CHEMBL1365271 & 737825 & 5.0 & 4.9094 & TRN & \\
\hline CHEMBL1497777 & 737825 & 4.6 & 5.1096 & TRN & \\
\hline CHEMBL1512444 & 737825 & 4.6 & 4.5039 & TRN & \\
\hline CHEMBL1575007 & 737825 & 5.35 & 5.3689 & TRN & \\
\hline CHEMBL1577418 & 737825 & 4.6 & 5.1568 & TRN & \\
\hline CHEMBL1369374 & 737825 & 5.5 & 5.2497 & TST & \\
\hline CHEMBL1450805 & 737825 & 5.1 & 4.7898 & TRN & \\
\hline CHEMBL1418864 & 737825 & 5.15 & 5.6281 & TRN & \\
\hline CHEMBL1483608 & 737825 & 4.7 & $4.9910 e$ & 20000000005 & TST \\
\hline & & & & 22512 & \\
\hline
\end{tabular}




\begin{tabular}{|c|c|c|c|c|c|}
\hline \multicolumn{6}{|c|}{ Supplemental Table S2.txt } \\
\hline CHEMBL1382292 & 737825 & 4.65 & 5.1611 & TRN & \\
\hline CHEMBL1495580 & 737825 & 5.15 & 5.2724 & TST & \\
\hline CHEMBL106437 & 737825 & 4.9 & 4.9177 & TRN & \\
\hline CHEMBL1557696 & 737825 & 4.9 & 4.7443 & TRN & \\
\hline CHEMBL1454049 & 737825 & 5.9 & 5.9137 & TRN & \\
\hline CHEMBL1609142 & 737825 & 5.5 & 5.3737 & TRN & \\
\hline CHEMBL1519225 & 737825 & 5.4 & 5.1973 & TRN & \\
\hline CHEMBL1548310 & 737825 & 4.85 & 5.0868 & TRN & \\
\hline CHEMBL275097 & 737825 & 5.1 & 5.1078 & TRN & \\
\hline CHEMBL1475381 & 737825 & 5.0 & 4.831 & TRN & \\
\hline CHEMBL1551503 & 737825 & 4.9 & 4.8417 & TRN & \\
\hline CHEMBL1528491 & 737825 & 5.5 & 5.4251 & TRN & \\
\hline CHEMBL1454709 & 737825 & 4.65 & 5.2632 & TRN & \\
\hline CHEMBL1371944 & 737825 & 5.5 & 5.61299 & 99999999995 & TRN \\
\hline CHEMBL1322901 & 737825 & 4.6 & 5.0613 & TST & \\
\hline CHEMBL1414122 & 737825 & 4.8 & 5.2488 & TRN & \\
\hline CHEMBL1346997 & 737825 & 4.8 & 5.1902 & TRN & \\
\hline CHEMBL1535937 & 737825 & 4.8 & 5.1698 & TRN & \\
\hline CHEMBL1741802 & 737825 & 4.8 & 5.4725 & TRN & \\
\hline CHEMBL1316897 & 737825 & 5.0 & 4.8188 & TRN & \\
\hline CHEMBL3197511 & 737825 & 5.4 & 5.3421 & TRN & \\
\hline CHEMBL1535372 & 737825 & 5.3 & 5.0798 & TRN & \\
\hline CHEMBL1489204 & 737825 & 6.25 & 5.8182 & TRN & \\
\hline CHEMBL568379 & 737825 & 5.0 & 4.9733 & TRN & \\
\hline CHEMBL1718206 & 737825 & 4.9 & 5.1253 & TST & \\
\hline CHEMBL491742 & 737825 & 6.9 & 6.824 & TRN & \\
\hline CHEMBL1256865 & 737825 & 6.0 & 5.7547 & TRN & \\
\hline CHEMBL3192460 & 737825 & 4.85 & 5.2369 & TST & \\
\hline CHEMBL1486231 & 737825 & 5.3 & 5.2741 & TRN & \\
\hline CHEMBL1428519 & 737825 & 5.05 & 5.0342 & TST & \\
\hline CHEMBL1454855 & 737825 & 5.8 & 5.7297 & TRN & \\
\hline CHEMBL1362324 & 737825 & 4.9 & 5.3191 & TRN & \\
\hline CHEMBL1626013 & 737825 & 4.75 & 5.2338 & TST & \\
\hline CHEMBL1421737 & 737825 & 5.05 & 5.0796 & TRN & \\
\hline CHEMBL1333076 & 737825 & 4.8 & 5.0672 & TRN & \\
\hline CHEMBL72365 & 737825 & 5.3 & 5.0934 & TST & \\
\hline CHEMBL1343568 & 737825 & 4.4 & 4.998 & TRN & \\
\hline CHEMBL1892270 & 737825 & 4.6 & 5.1928 & TRN & \\
\hline CHEMBL1584775 & 737825 & 4.8 & 5.2142 & TRN & \\
\hline CHEMBL1587070 & 737825 & 4.7 & 5.095 & TRN & \\
\hline CHEMBL1366219 & 737825 & 5.5 & 5.0765 & TRN & \\
\hline CHEMBL1491193 & 737825 & 5.15 & 5.0351 & TRN & \\
\hline CHEMBL1741465 & 737825 & 4.85 & 5.0108 & TRN & \\
\hline CHEMBL1719399 & 737825 & 5.3 & 5.0771 & TRN & \\
\hline CHEMBL 6634 & 737825 & 7.4 & 6.7967 & TST & \\
\hline CHEMBL3208230 & 737825 & 4.8 & 5.2363 & TRN & \\
\hline CHEMBL1337078 & 737825 & 4.9 & 5.1381 & TRN & \\
\hline CHEMBL1406406 & 737825 & 4.8 & 5.0267 & TST & \\
\hline
\end{tabular}




\begin{tabular}{|c|c|c|c|c|c|}
\hline \multicolumn{6}{|c|}{ Supplemental Table S2.txt } \\
\hline CHEMBL1486399 & 737825 & 4.7 & 4.6414 & TRN & \\
\hline CHEMBL258465 & 737825 & 5.5 & 5.2505 & TST & \\
\hline CHEMBL1427884 & 737825 & 5.0 & 5.4512 & TST & \\
\hline CHEMBL1529879 & 737825 & 5.4 & 5.3775 & TRN & \\
\hline CHEMBL1358758 & 737825 & 5.2 & 5.3312 & TRN & \\
\hline CHEMBL1554723 & 737825 & 5.4 & 5.2417 & TRN & \\
\hline CHEMBL522600 & 737825 & 6.7 & 6.7887 & TRN & \\
\hline CHEMBL1394169 & 737825 & 4.8 & 4.707 & TRN & \\
\hline CHEMBL1604396 & 737825 & 5.15 & 5.266 & TRN & \\
\hline CHEMBL1553700 & 737825 & 6.0 & 5.7071 & TRN & \\
\hline CHEMBL1572383 & 737825 & 4.85 & 5.1922 & TRN & \\
\hline CHEMBL1368895 & 737825 & 4.8 & 4.6538 & TST & \\
\hline CHEMBL1390616 & 737825 & 4.8 & 4.9564 & TRN & \\
\hline CHEMBL1515698 & 737825 & 5.5 & 5.3775 & TRN & \\
\hline CHEMBL1455816 & 737825 & 4.9 & 5.1183 & TST & \\
\hline CHEMBL1591619 & 737825 & 5.0 & 4.8955 & TRN & \\
\hline CHEMBL1476266 & 737825 & 5.5 & 5.4648 & TRN & \\
\hline CHEMBL1463032 & 737825 & 4.5 & 5.1279 & TRN & \\
\hline CHEMBL1522370 & 737825 & 4.6 & 4.5034 & TRN & \\
\hline CHEMBL1255583 & 737825 & 4.4 & 4.6063 & TRN & \\
\hline CHEMBL1350756 & 737825 & 4.7 & 5.2071 & TRN & \\
\hline CHEMBL1317451 & 737825 & 4.8 & 4.5905 & TRN & \\
\hline CHEMBL1511350 & 737825 & 4.75 & 5.0495 & TST & \\
\hline CHEMBL1335052 & 737825 & 5.05 & 5.0955 & TRN & \\
\hline CHEMBL1329806 & 737825 & 5.15 & 5.1796 & TRN & \\
\hline CHEMBL1458916 & 737825 & 4.8 & 5.0614 & TRN & \\
\hline CHEMBL1535118 & 737825 & 5.6 & 5.21200 & 0000000001 & TRN \\
\hline CHEMBL1530613 & 737825 & 6.1 & 6.0227 & TST & \\
\hline CHEMBL1605496 & 737825 & 5.1 & 4.8335 & TRN & \\
\hline CHEMBL1434022 & 737825 & 4.8 & 4.6421 & TRN & \\
\hline CHEMBL1596235 & 737825 & 5.2 & 4.921 & TRN & \\
\hline CHEMBL1526486 & 737825 & 5.0 & 4.8263 & TST & \\
\hline CHEMBL1552194 & 737825 & 5.1 & 4.9847 & TRN & \\
\hline CHEMBL1558444 & 737825 & 5.35 & 5.4863 & TRN & \\
\hline CHEMBL1473752 & 737825 & 4.7 & 4.4965 & TRN & \\
\hline CHEMBL1537865 & 737825 & 4.8 & 5.0324 & TRN & \\
\hline CHEMBL1578679 & 737825 & 4.55 & 5.0897 & TRN & \\
\hline CHEMBL1533335 & 737825 & 5.5 & 5.3809 & TRN & \\
\hline CHEMBL1453980 & 737825 & 4.8 & 4.6353 & TRN & \\
\hline CHEMBL1323124 & 737825 & 4.8 & 4.7038 & TRN & \\
\hline CHEMBL1530695 & 737825 & 4.55 & 5.0806 & TRN & \\
\hline CHEMBL1346850 & 737825 & 4.85 & 5.0085 & TRN & \\
\hline CHEMBL1442105 & 737825 & 4.9 & 5.0262 & TRN & \\
\hline CHEMBL1361513 & 737825 & 4.9 & 4.8308 & TRN & \\
\hline CHEMBL1335465 & 737825 & 4.8 & 4.6552 & TRN & \\
\hline CHEMBL1316745 & 737825 & 4.5 & 4.4314 & TRN & \\
\hline CHEMBL1604095 & 737825 & 4.8 & 4.7202 & TRN & \\
\hline CHEMBL1513643 & 737825 & 5.4 & 5.2575 & TST & \\
\hline
\end{tabular}




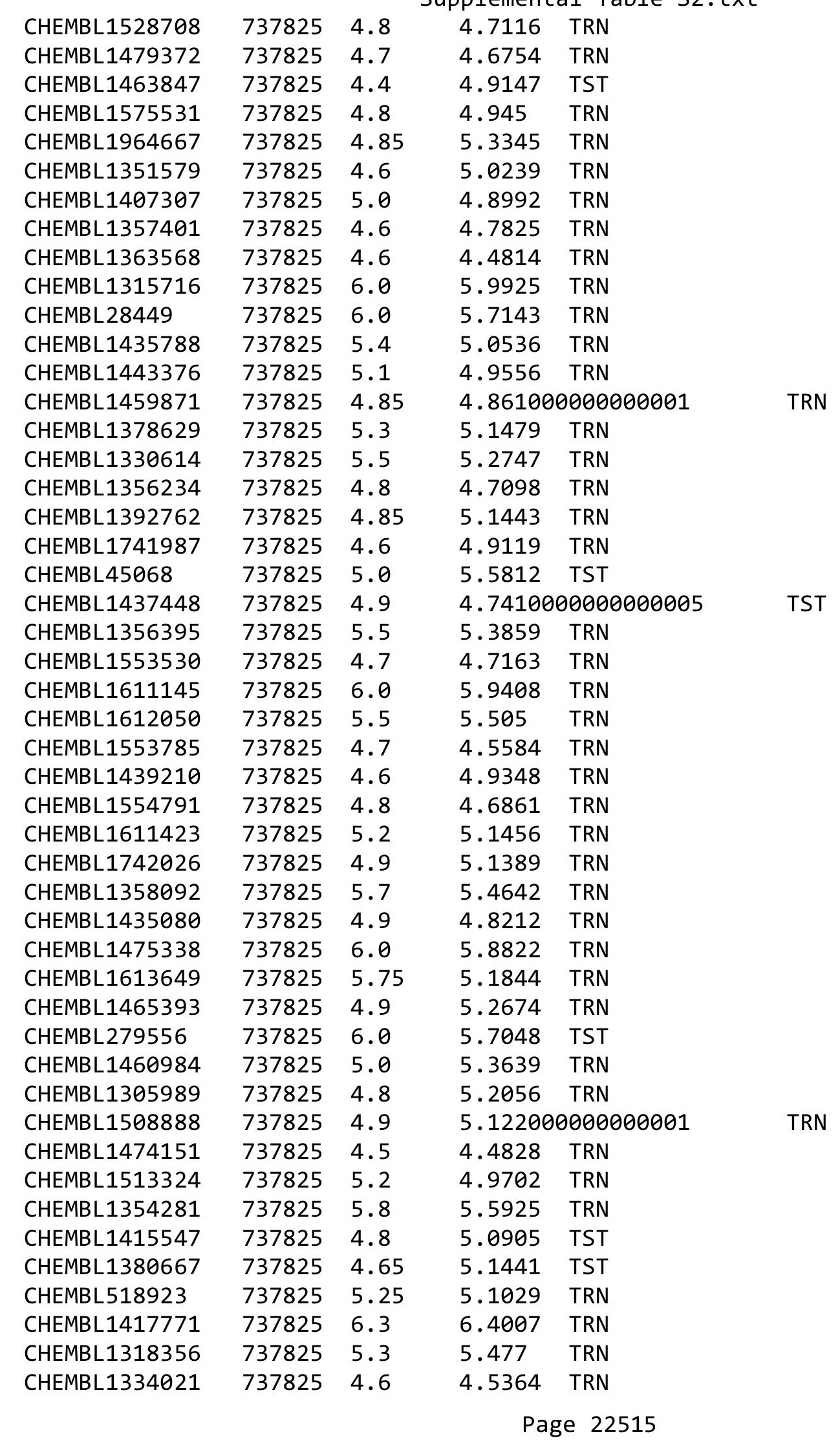




\begin{tabular}{|c|c|c|c|c|}
\hline & & & ipplemen & al $\mathrm{T}$ \\
\hline CHEMBL1391390 & 737825 & 4.75 & 5.1386 & TRN \\
\hline CHEMBL1543808 & 737825 & 4.85 & 4.9925 & TRN \\
\hline CHEMBL1374226 & 737825 & 4.75 & 5.0369 & TRN \\
\hline CHEMBL 86676 & 737825 & 6.0 & 5.5902 & TST \\
\hline CHEMBL52387 & 737825 & 4.9 & 4.879 & TRN \\
\hline CHEMBL1353342 & 737825 & 5.4 & 5.2256 & TRN \\
\hline CHEMBL1414633 & 737825 & 5.3 & 5.2206 & TRN \\
\hline CHEMBL1369642 & 737825 & 4.85 & 5.0375 & TRN \\
\hline CHEMBL1481510 & 737825 & 4.9 & 4.7344 & TRN \\
\hline CHEMBL1364182 & 737825 & 5.4 & 5.4238 & TRN \\
\hline CHEMBL1492727 & 737825 & 4.6 & 4.508 & TRN \\
\hline CHEMBL1379839 & 737825 & 4.8 & 4.9426 & TST \\
\hline CHEMBL1590974 & 737825 & 5.4 & 5.1451 & TRN \\
\hline CHEMBL1588356 & 737825 & 4.55 & 5.1949 & TRN \\
\hline CHEMBL1531727 & 737825 & 5.4 & 5.2749 & TST \\
\hline CHEMBL1566101 & 737825 & 5.5 & 5.0765 & TRN \\
\hline CHEMBL83899 & 737825 & 4.8 & 4.8783 & TRN \\
\hline CHEMBL1325411 & 737825 & 5.4 & 5.1325 & TRN \\
\hline CHEMBL1601121 & 737825 & 5.6 & 5.4348 & TRN \\
\hline CHEMBL1554743 & 737825 & 4.8 & 4.6545 & TRN \\
\hline CHEMBL1434882 & 737825 & 6.0 & 5.9621 & TRN \\
\hline CHEMBL1325554 & 737825 & 5.85 & 5.2538 & TRN \\
\hline CHEMBL1404451 & 737825 & 5.9 & 5.8968 & TRN \\
\hline CHEMBL1389326 & 737825 & 5.15 & 5.3008 & TRN \\
\hline CHEMBL1721668 & 737825 & 4.65 & 5.0999 & TRN \\
\hline CHEMBL3194142 & 737825 & 4.95 & 5.1495 & TRN \\
\hline CHEMBL1591758 & 737825 & 4.9 & 4.7604 & TRN \\
\hline CHEMBL1554348 & 737825 & 4.9 & 4.8411 & TRN \\
\hline CHEMBL1741881 & 737825 & 5.3 & 5.2134 & TRN \\
\hline CHEMBL1488918 & 737825 & 6.1 & 5.9899 & TRN \\
\hline CHEMBL1372282 & 737825 & 5.4 & 5.3184 & TST \\
\hline CHEMBL45244 & 737825 & 4.5 & 4.6059 & TRN \\
\hline CHEMBL1408484 & 737825 & 6.15 & 5.499 & TRN \\
\hline CHEMBL1371014 & 737825 & 4.65 & 4.83 & TST \\
\hline CHEMBL1600038 & 737825 & 4.85 & 5.2093 & TRN \\
\hline CHEMBL1551643 & 737825 & 4.8 & 4.9293 & TST \\
\hline CHEMBL1450525 & 737825 & 5.5 & 5.3046 & TST \\
\hline CHEMBL1393658 & 737825 & 5.3 & 4.8931 & TRN \\
\hline CHEMBL1340386 & 737825 & 5.5 & 5.2328 & TRN \\
\hline CHEMBL1402799 & 737825 & 4.8 & 4.7811 & TRN \\
\hline CHEMBL1396236 & 737825 & 5.3 & 5.1565 & TST \\
\hline CHEMBL1313647 & 737825 & 4.85 & 5.1308 & TRN \\
\hline CHEMBL1466869 & 737825 & 5.2 & 5.2229 & TRN \\
\hline CHEMBL1357759 & 737825 & 4.8 & 4.7381 & TRN \\
\hline CHEMBL1523948 & 737825 & 4.7 & 5.0753 & TRN \\
\hline CHEMBL1310531 & 737825 & 5.3 & 5.357 & TRN \\
\hline CHEMBL1326159 & 737825 & 4.85 & 5.0182 & TRN \\
\hline CHEMBL1364717 & 737825 & 5.1 & 4.8923 & TRN \\
\hline
\end{tabular}




\begin{tabular}{|c|c|c|c|c|c|}
\hline & & & & & \\
\hline CHEMBL1417789 & 737825 & 5.4 & 5.3405 & TRN & \\
\hline CHEMBL1598896 & 737825 & 5.5 & 5.1104 & TRN & \\
\hline CHEMBL1588323 & 737825 & 4.8 & 5.1815 & TRN & \\
\hline CHEMBL1512708 & 737825 & 5.8 & 5.9941 & TRN & \\
\hline CHEMBL1376224 & 737825 & 4.9 & $5.1160 e$ & 00000000005 & TRN \\
\hline CHEMBL1395974 & 737825 & 4.5 & 4.4115 & TRN & \\
\hline CHEMBL1410496 & 737825 & 4.85 & 5.0395 & TRN & \\
\hline CHEMBL1603539 & 737825 & 5.15 & 5.1626 & TST & \\
\hline CHEMBL1569718 & 737825 & 4.7 & 4.5649 & TRN & \\
\hline CHEMBL1527923 & 737825 & 5.7 & 5.4313 & TRN & \\
\hline CHEMBL1376952 & 737825 & 5.5 & 5.4729 & TRN & \\
\hline CHEMBL1319049 & 737825 & 6.0 & 5.9718 & TRN & \\
\hline CHEMBL1455353 & 737825 & 4.85 & 5.1582 & TRN & \\
\hline CHEMBL1342892 & 737825 & 5.5 & 5.3016 & TRN & \\
\hline CHEMBL1368773 & 737825 & 5.8 & 5.7556 & TRN & \\
\hline CHEMBL1437648 & 737825 & 5.2 & 5.1332 & TST & \\
\hline CHEMBL1593269 & 737825 & 5.3 & 5.1553 & TRN & \\
\hline CHEMBL1483625 & 737825 & 4.9 & 4.8022 & TRN & \\
\hline CHEMBL1370314 & 737825 & 5.5 & 5.1066 & TRN & \\
\hline CHEMBL1593337 & 737825 & 5.1 & 4.8511 & TRN & \\
\hline CHEMBL1256836 & 737825 & 5.4 & 5.8118 & TST & \\
\hline CHEMBL244743 & 737825 & 4.9 & 4.6648 & TST & \\
\hline CHEMBL1568178 & 737825 & 5.9 & 5.8385 & TRN & \\
\hline CHEMBL1398810 & 737825 & 4.8 & 4.7254 & TRN & \\
\hline CHEMBL1565060 & 737825 & 5.3 & 5.1173 & TRN & \\
\hline CHEMBL1398639 & 737825 & 5.1 & 5.1366 & TRN & \\
\hline CHEMBL1512782 & 737825 & 4.8 & 4.7348 & TRN & \\
\hline CHEMBL1518901 & 737825 & 4.75 & 5.1414 & TRN & \\
\hline CHEMBL1391059 & 737825 & 5.65 & 5.2912 & TST & \\
\hline CHEMBL1467227 & 737825 & 4.65 & 5.16299 & 9999999999 & TRN \\
\hline CHEMBL1466055 & 737825 & 4.7 & 5.1807 & TRN & \\
\hline CHEMBL1442300 & 737825 & 5.95 & 5.1121 & TRN & \\
\hline CHEMBL1552864 & 737825 & 4.9 & 4.9063 & TRN & \\
\hline CHEMBL1437314 & 737825 & 5.4 & 5.381 & TRN & \\
\hline CHEMBL1392042 & 737825 & 5.65 & 5.3141 & TRN & \\
\hline CHEMBL1973500 & 737825 & 4.55 & 5.1612 & TST & \\
\hline CHEMBL 1477222 & 737825 & 4.8 & 5.1236 & TRN & \\
\hline CHEMBL1440534 & 737825 & 5.4 & 5.3159 & TRN & \\
\hline CHEMBL1370255 & 737825 & 5.35 & 5.251 & TRN & \\
\hline CHEMBL602418 & 737825 & 5.6 & 5.4475 & TRN & \\
\hline CHEMBL1595576 & 737825 & 5.4 & 5.2965 & TRN & \\
\hline CHEMBL1526526 & 737825 & 4.7 & 5.1346 & TRN & \\
\hline CHEMBL1563047 & 737825 & 4.4 & 4.4912 & TRN & \\
\hline CHEMBL1360337 & 737825 & 4.65 & 5.2279 & TRN & \\
\hline CHEMBL1392640 & 737825 & 5.55 & 5.1662 & TRN & \\
\hline CHEMBL590670 & 737825 & 5.35 & 5.0693 & TRN & \\
\hline CHEMBL1451788 & 737825 & 5.5 & 5.5576 & TRN & \\
\hline CHEMBL1480796 & 737825 & 4.85 & 5.101 & TRN & \\
\hline & & & & 22517 & \\
\hline
\end{tabular}




\begin{tabular}{|c|c|c|c|c|c|}
\hline \\
\hline CHEMBL491939 & 737825 & 5.8 & 5.7428 & TRN & \\
\hline CHEMBL1496744 & 737825 & 5.0 & 4.8577 & TRN & \\
\hline CHEMBL1511085 & 737825 & 5.0 & 4.9846 & TRN & \\
\hline CHEMBL1578418 & 737825 & 4.45 & 5.0795 & TRN & \\
\hline CHEMBL1451411 & 737825 & 6.1 & 5.7927 & TRN & \\
\hline CHEMBL1398216 & 737825 & 5.5 & 5.4394 & TRN & \\
\hline CHEMBL1352188 & 737825 & 4.8 & 5.2157 & TST & \\
\hline CHEMBL1529009 & 737825 & 6.0 & 5.6433 & TRN & \\
\hline CHEMBL1476791 & 737825 & 5.1 & 5.01399 & 9999999999 & TRN \\
\hline CHEMBL12129 & 737825 & 6.2 & 5.96299 & 9999999999 & TRN \\
\hline CHEMBL1510930 & 737825 & 4.85 & 5.2114 & TST & \\
\hline CHEMBL64119 & 737825 & 4.8 & 4.7961 & TRN & \\
\hline CHEMBL1590341 & 737825 & 4.6 & 4.7039 & TRN & \\
\hline CHEMBL1437075 & 737825 & 5.0 & 4.9283 & TRN & \\
\hline CHEMBL1449224 & 737825 & 4.5 & 4.3625 & TRN & \\
\hline CHEMBL1386594 & 737825 & 5.3 & 5.0725 & TRN & \\
\hline CHEMBL1452932 & 737825 & 4.8 & 5.2541 & TRN & \\
\hline CHEMBL3195193 & 737825 & 4.95 & 5.0551 & TRN & \\
\hline CHEMBL1555037 & 737825 & 5.6 & 5.0944 & TRN & \\
\hline CHEMBL1557383 & 737825 & 4.9 & 5.6221 & TST & \\
\hline CHEMBL1307577 & 737825 & 5.9 & 5.1924 & TRN & \\
\hline CHEMBL1437088 & 737825 & 4.9 & 4.785 & TRN & \\
\hline CHEMBL1590909 & 737825 & 5.5 & 5.5266 & TRN & \\
\hline CHEMBL1556027 & 737825 & 5.8 & 5.1521 & TRN & \\
\hline CHEMBL1472036 & 737825 & 5.05 & 5.34 & TRN & \\
\hline CHEMBL 319244 & 737825 & 4.8 & 5.5938 & TRN & \\
\hline CHEMBL1600490 & 737825 & 5.5 & 5.0626 & TST & \\
\hline CHEMBL1433930 & 737825 & 5.8 & 5.5213 & TST & \\
\hline CHEMBL1318544 & 737825 & 5.6 & 5.6375 & TRN & \\
\hline CHEMBL1406460 & 737825 & 4.95 & 5.1774 & TST & \\
\hline CHEMBL1350038 & 737825 & 4.85 & 5.3306 & TRN & \\
\hline CHEMBL1329402 & 737825 & 4.8 & 5.1835 & TRN & \\
\hline CHEMBL1512250 & 737825 & 4.7 & 4.5321 & TRN & \\
\hline CHEMBL1436361 & 737825 & 5.8 & 5.7386 & TRN & \\
\hline CHEMBL1539794 & 737825 & 5.95 & 5.0191 & TRN & \\
\hline CHEMBL1512413 & 737825 & 5.1 & 4.919 & TRN & \\
\hline CHEMBL1422344 & 737825 & 5.0 & 5.04899 & 99999999995 & TRN \\
\hline CHEMBL1339054 & 737825 & 4.9 & 5.1093 & TRN & \\
\hline CHEMBL9352 & 737825 & 5.3 & 5.5238 & TRN & \\
\hline CHEMBL1256851 & 737825 & 6.4 & 5.9303 & TST & \\
\hline CHEMBL1741700 & 737825 & 4.6 & 5.0684 & TST & \\
\hline CHEMBL1420088 & 737825 & 4.65 & 5.0363 & TRN & \\
\hline CHEMBL1517696 & 737825 & 4.95 & 5.2633 & TRN & \\
\hline CHEMBL1329499 & 737825 & 5.5 & 5.2488 & TRN & \\
\hline CHEMBL 1490500 & 737825 & 5.6 & 4.9942 & TST & \\
\hline CHEMBL1445473 & 737825 & 4.9 & 4.6477 & TRN & \\
\hline CHEMBL1729994 & 737825 & 5.5 & 5.187 & TRN & \\
\hline CHEMBL1527911 & 737825 & 5.1 & 5.1743 & TRN & \\
\hline
\end{tabular}




\begin{tabular}{|c|c|c|c|c|c|}
\hline \\
\hline CHEMBL1709072 & 737825 & 4.6 & 5.1678 & TRN & \\
\hline CHEMBL1442770 & 737825 & 4.7 & 4.663 & TST & \\
\hline CHEMBL1354648 & 737825 & 5.4 & 5.3752 & TRN & \\
\hline CHEMBL1411519 & 737825 & 5.0 & 4.88 & TRN & \\
\hline CHEMBL1335862 & 737825 & 5.9 & 5.6353 & TST & \\
\hline CHEMBL1449000 & 737825 & 4.85 & 5.191 & TST & \\
\hline CHEMBL1514221 & 737825 & 5.4 & 5.4431 & TRN & \\
\hline CHEMBL1377781 & 737825 & 5.0 & 4.7531 & TRN & \\
\hline CHEMBL3196667 & 737825 & 5.15 & 5.2617 & TRN & \\
\hline CHEMBL1351886 & 737825 & 5.6 & 5.2232 & TST & \\
\hline CHEMBL1606369 & 737825 & 5.0 & 4.9082 & TRN & \\
\hline CHEMBL1710092 & 737825 & 4.75 & 5.1459 & TRN & \\
\hline CHEMBL1741439 & 737825 & 4.9 & 5.1452 & TRN & \\
\hline CHEMBL1516262 & 737825 & 4.8 & 4.68199 & 99999999995 & TRN \\
\hline CHEMBL1409109 & 737825 & 5.0 & 4.8735 & TST & \\
\hline CHEMBL1337479 & 737825 & 4.9 & 4.6847 & TRN & \\
\hline CHEMBL1299810 & 737825 & 4.6 & 5.0772 & TRN & \\
\hline CHEMBL1449669 & 737825 & 5.0 & 4.9747 & TRN & \\
\hline CHEMBL1338083 & 737825 & 5.4 & 5.3502 & TRN & \\
\hline CHEMBL1322078 & 737825 & 4.6 & 5.1002 & TRN & \\
\hline CHEMBL3194967 & 737825 & 4.65 & 5.1903 & TRN & \\
\hline CHEMBL1454793 & 737825 & 5.2 & 5.1389 & TRN & \\
\hline CHEMBL1509370 & 737825 & 5.2 & 5.2812 & TRN & \\
\hline CHEMBL1472898 & 737825 & 5.4 & 5.2216 & TRN & \\
\hline CHEMBL1536139 & 737825 & 4.85 & 5.0709 & TRN & \\
\hline CHEMBL1383848 & 737825 & 5.7 & 5.3195 & TRN & \\
\hline CHEMBL1354547 & 737825 & 5.7 & 5.6409 & TRN & \\
\hline CHEMBL1256749 & 737825 & 6.0 & 5.5847 & TST & \\
\hline CHEMBL1389765 & 737825 & 4.8 & 5.0851 & TRN & \\
\hline CHEMBL1742259 & 737825 & 4.75 & 5.1138 & TRN & \\
\hline CHEMBL1592963 & 737825 & 5.4 & 5.3461 & TRN & \\
\hline CHEMBL1422181 & 737825 & 5.35 & 5.1219 & TRN & \\
\hline CHEMBL1256283 & 737825 & 5.5 & 5.2895 & TST & \\
\hline CHEMBL1485081 & 737825 & 4.6 & 5.0343 & TST & \\
\hline CHEMBL1489549 & 737825 & 4.55 & 4.9647 & TRN & \\
\hline CHEMBL1314222 & 737825 & 5.5 & 5.3406 & TRN & \\
\hline CHEMBL1380096 & 737825 & 5.0 & 5.0555 & TRN & \\
\hline CHEMBL1498788 & 737825 & 5.0 & 5.1512 & TRN & \\
\hline CHEMBL1559387 & 737825 & 4.65 & 5.1819 & TRN & \\
\hline CHEMBL1716896 & 737825 & 4.6 & 5.2455 & TRN & \\
\hline CHEMBL1327247 & 737825 & 6.1 & 5.6354 & TRN & \\
\hline CHEMBL1409262 & 737825 & 4.85 & 5.0632 & TRN & \\
\hline CHEMBL1742096 & 737825 & 4.7 & 5.1333 & TRN & \\
\hline CHEMBL1587133 & 737825 & 4.6 & 5.0235 & TRN & \\
\hline CHEMBL1317302 & 737825 & 5.1 & 4.8709 & TRN & \\
\hline CHEMBL1452561 & 737825 & 5.6 & 5.305 & TST & \\
\hline CHEMBL321820 & 737825 & 4.9 & 4.9825 & TST & \\
\hline CHEMBL1477140 & 737825 & 6.1 & 5.8669 & TRN & \\
\hline & & & & 22519 & \\
\hline
\end{tabular}




\begin{tabular}{|c|c|c|c|c|}
\hline & & & ipplement & al $\mathrm{T}$ \\
\hline CHEMBL1700937 & 737825 & 4.85 & 5.1368 & TRN \\
\hline CHEMBL1351404 & 737825 & 4.5 & 5.2469 & TST \\
\hline CHEMBL 3213672 & 737825 & 5.3 & 5.2225 & TST \\
\hline CHEMBL1324334 & 737825 & 5.1 & 5.0525 & TRN \\
\hline CHEMBL1437012 & 737825 & 5.5 & 5.2475 & TST \\
\hline CHEMBL1328340 & 737825 & 5.3 & 5.324 & TRN \\
\hline CHEMBL1554098 & 737825 & 5.1 & 5.6456 & TST \\
\hline CHEMBL1311840 & 737825 & 5.15 & 5.1754 & TRN \\
\hline CHEMBL1339670 & 737825 & 5.1 & 5.1644 & TRN \\
\hline CHEMBL1558184 & 737825 & 4.6 & 4.4675 & TRN \\
\hline CHEMBL1328880 & 737825 & 5.3 & 5.2836 & TRN \\
\hline CHEMBL44 & 737825 & 4.9 & 5.5755 & TRN \\
\hline CHEMBL1505390 & 737825 & 5.0 & 5.0198 & TST \\
\hline CHEMBL1608337 & 737825 & 5.4 & 5.3511 & TRN \\
\hline CHEMBL1316265 & 737825 & 5.0 & 4.9131 & TRN \\
\hline CHEMBL1532175 & 737825 & 4.8 & 5.1355 & TST \\
\hline CHEMBL1485948 & 737825 & 4.85 & 5.1178 & TRN \\
\hline CHEMBL1548380 & 737825 & 5.45 & 5.13 & TRN \\
\hline CHEMBL1480192 & 737825 & 6.3 & 5.3647 & TST \\
\hline CHEMBL1456076 & 737825 & 5.2 & 4.9947 & TRN \\
\hline CHEMBL270299 & 737825 & 4.6 & 4.5524 & TRN \\
\hline CHEMBL1462374 & 737825 & 5.0 & 5.2067 & TRN \\
\hline CHEMBL1518558 & 737825 & 5.6 & 5.1675 & TRN \\
\hline CHEMBL1422579 & 737825 & 4.5 & 5.1606 & TST \\
\hline CHEMBL1390980 & 737825 & 4.85 & 5.2401 & TST \\
\hline CHEMBL1452221 & 737825 & 5.6 & 5.6058 & TRN \\
\hline CHEMBL1406851 & 737825 & 6.4 & 6.4298 & TRN \\
\hline CHEMBL1496528 & 737825 & 4.85 & 5.0581 & TRN \\
\hline CHEMBL1703266 & 737825 & 5.95 & 5.1647 & TRN \\
\hline CHEMBL1314211 & 737825 & 5.6 & 5.6296 & TRN \\
\hline CHEMBL 269362 & 737825 & 6.0 & 5.7179 & TST \\
\hline CHEMBL1455200 & 737825 & 5.7 & 5.6142 & TRN \\
\hline CHEMBL1353886 & 737825 & 5.9 & 5.2464 & TRN \\
\hline CHEMBL1410627 & 737825 & 5.4 & 5.1956 & TRN \\
\hline CHEMBL1399844 & 737825 & 5.1 & 5.2956 & TRN \\
\hline CHEMBL1319346 & 737825 & 4.85 & 4.9206 & TRN \\
\hline CHEMBL1610945 & 737825 & 5.4 & 5.2809 & TST \\
\hline CHEMBL1492095 & 737825 & 5.1 & 5.1346 & TRN \\
\hline CHEMBL1605356 & 737825 & 5.6 & 5.5954 & TRN \\
\hline CHEMBL1361855 & 737825 & 5.5 & 5.3304 & TST \\
\hline CHEMBL112816 & 737825 & 4.7 & 4.8668 & TST \\
\hline CHEMBL1559062 & 737825 & 4.7 & 5.1858 & TRN \\
\hline CHEMBL1590132 & 737825 & 4.9 & 4.8249 & TRN \\
\hline CHEMBL1416429 & 737825 & 5.5 & 5.2426 & TRN \\
\hline CHEMBL1458985 & 737825 & 4.8 & 5.1058 & TRN \\
\hline CHEMBL77030 & 737825 & 6.0 & 5.5829 & TRN \\
\hline CHEMBL1602084 & 737825 & 4.85 & 5.2031 & TRN \\
\hline CHEMBL1741658 & 737825 & 5.0 & 5.1163 & TRN \\
\hline
\end{tabular}




\begin{tabular}{|c|c|c|c|c|}
\hline \multicolumn{5}{|c|}{ Supplemental Table S2.txt } \\
\hline CHEMBL1427238 & 737825 & 4.65 & 5.3371 & TRN \\
\hline CHEMBL1471635 & 737825 & 5.5 & 5.2008 & TRN \\
\hline CHEMBL1600985 & 737825 & 4.85 & 5.1331 & TST \\
\hline CHEMBL1324151 & 737825 & 4.9 & 4.7297 & TRN \\
\hline CHEMBL363506 & 737825 & 5.0 & 5.5787 & TST \\
\hline CHEMBL1396693 & 737825 & 5.8 & 5.58700 & 0000000001 \\
\hline CHEMBL1561366 & 737825 & 6.6 & 6.6436 & TRN \\
\hline CHEMBL1327915 & 737825 & 4.8 & 4.6497 & TRN \\
\hline CHEMBL1343368 & 737825 & 5.5 & 5.0752 & TRN \\
\hline CHEMBL1550370 & 737825 & 4.6 & 5.0471 & TRN \\
\hline CHEMBL1403505 & 737825 & 5.8 & 5.9187 & TRN \\
\hline CHEMBL1565160 & 737825 & 5.4 & 5.2908 & TRN \\
\hline CHEMBL1307908 & 737825 & 5.55 & 5.1856 & TRN \\
\hline CHEMBL1451733 & 737825 & 5.4 & 5.2277 & TST \\
\hline CHEMBL1384330 & 737825 & 5.95 & 5.1909 & TRN \\
\hline CHEMBL1320525 & 737825 & 5.0 & 4.9681 & TRN \\
\hline CHEMBL1410055 & 737825 & 4.55 & 5.1184 & TRN \\
\hline CHEMBL1607997 & 737825 & 4.85 & 5.0786 & TST \\
\hline CHEMBL1476170 & 737825 & 6.0 & 5.8704 & TST \\
\hline CHEMBL1588349 & 737825 & 5.1 & 5.1386 & TRN \\
\hline CHEMBL1454841 & 737825 & 4.7 & 4.8093 & TST \\
\hline CHEMBL1353775 & 737825 & 4.65 & 5.1575 & TRN \\
\hline CHEMBL1321695 & 737825 & 4.8 & 4.9902 & TRN \\
\hline CHEMBL1316337 & 737825 & 5.3 & 5.1121 & TRN \\
\hline CHEMBL 3210380 & 737825 & 4.75 & 5.1904 & TRN \\
\hline CHEMBL1453450 & 737825 & 4.6 & 5.0327 & TRN \\
\hline CHEMBL1553136 & 737825 & 5.1 & 4.9464 & TRN \\
\hline CHEMBL1500226 & 737825 & 4.75 & 5.0326 & TST \\
\hline CHEMBL3213624 & 737825 & 6.05 & 5.3071 & TRN \\
\hline CHEMBL1361214 & 737825 & 4.85 & 5.0929 & TRN \\
\hline CHEMBL472656 & 737825 & 5.5 & 5.3691 & TST \\
\hline CHEMBL1443086 & 737825 & 4.85 & 5.0576 & TRN \\
\hline CHEMBL1519980 & 737825 & 5.15 & 4.8819 & TRN \\
\hline CHEMBL1405696 & 737825 & 6.75 & 5.3217 & TRN \\
\hline CHEMBL1451087 & 737825 & 5.9 & 5.6344 & TRN \\
\hline CHEMBL1436817 & 737825 & 4.9 & 4.794 & TRN \\
\hline CHEMBL1741555 & 737825 & 4.55 & 5.2014 & TRN \\
\hline CHEMBL1450026 & 737825 & 4.7 & 4.5958 & TRN \\
\hline CHEMBL3192865 & 737825 & 5.8 & 5.3062 & TRN \\
\hline CHEMBL1518589 & 737825 & 4.8 & 5.0116 & TRN \\
\hline CHEMBL1583279 & 737825 & 4.6 & 5.119 & TRN \\
\hline CHEMBL1459503 & 737825 & 4.65 & 4.9639 & TRN \\
\hline CHEMBL1509960 & 737825 & 5.6 & 5.1897 & TRN \\
\hline CHEMBL1383190 & 737825 & 6.1 & 5.1916 & TRN \\
\hline CHEMBL1380684 & 737825 & 5.9 & 5.5488 & TRN \\
\hline CHEMBL1444936 & 737825 & 5.65 & 5.3368 & TRN \\
\hline CHEMBL1339696 & 737825 & 5.35 & 5.1007 & TRN \\
\hline CHEMBL1450864 & 737825 & 4.65 & 5.0576 & TRN \\
\hline
\end{tabular}

TRN 


\begin{tabular}{|c|c|c|c|c|c|}
\hline \\
\hline CHEMBL1345940 & 737825 & 4.75 & 5.1584 & TRN & \\
\hline CHEMBL1734782 & 737825 & 4.6 & 5.0124 & TRN & \\
\hline CHEMBL1357195 & 737825 & 4.9 & 5.7833 & TST & \\
\hline CHEMBL1573063 & 737825 & 5.9 & 5.9411 & TRN & \\
\hline CHEMBL3212828 & 737825 & 5.9 & 5.1286 & TRN & \\
\hline CHEMBL1541487 & 737825 & 6.1 & 5.1125 & TRN & \\
\hline CHEMBL1450373 & 737825 & 5.3 & 5.1723 & TRN & \\
\hline CHEMBL1390792 & 737825 & 5.05 & 5.193 & TRN & \\
\hline CHEMBL1548111 & 737825 & 4.95 & 5.0492 & TRN & \\
\hline CHEMBL1549333 & 737825 & 5.3 & 5.21 & TRN & \\
\hline CHEMBL1255832 & 737825 & 4.9 & 4.8663 & TRN & \\
\hline CHEMBL1460922 & 737825 & 4.85 & 5.343 & TST & \\
\hline CHEMBL1452408 & 737825 & 4.8 & 4.6754 & TRN & \\
\hline CHEMBL3193871 & 737825 & 5.5 & 5.3688 & TRN & \\
\hline CHEMBL1356262 & 737825 & 5.0 & 4.9125 & TRN & \\
\hline CHEMBL1255655 & 737825 & 4.9 & 4.8053 & TST & \\
\hline CHEMBL1304993 & 737825 & 4.9 & 5.0292 & TRN & \\
\hline CHEMBL1600780 & 737825 & 6.0 & 5.6355 & TRN & \\
\hline CHEMBL1537750 & 737825 & 5.55 & 5.234 & TRN & \\
\hline CHEMBL1353420 & 737825 & 4.85 & 5.1167 & TRN & \\
\hline CHEMBL1380994 & 737825 & 5.35 & 5.3032 & TRN & \\
\hline CHEMBL1443713 & 737825 & 4.6 & 4.5734 & TRN & \\
\hline CHEMBL1358161 & 737825 & 4.8 & 4.8893 & TRN & \\
\hline CHEMBL1716417 & 737825 & 5.4 & 5.1773 & TRN & \\
\hline CHEMBL1604519 & 737825 & 5.65 & 5.3373 & TRN & \\
\hline CHEMBL1535980 & 737825 & 4.65 & 5.0906 & TRN & \\
\hline CHEMBL1360821 & 737825 & 5.15 & 5.1171 & TRN & \\
\hline CHEMBL1365979 & 737825 & 4.9 & 4.651 & TRN & \\
\hline CHEMBL1742209 & 737825 & 5.3 & 5.5141 & TRN & \\
\hline CHEMBL1610944 & 737825 & 6.0 & 5.9763 & TRN & \\
\hline CHEMBL1581594 & 737825 & 6.15 & 5.399 & TRN & \\
\hline CHEMBL1590919 & 737825 & 4.5 & 4.4345 & TRN & \\
\hline CHEMBL362223 & 737825 & 4.6 & 4.6732 & TRN & \\
\hline CHEMBL1318066 & 737825 & 5.4 & 5.1697 & TST & \\
\hline CHEMBL1545958 & 737825 & 5.7 & 5.4472 & TRN & \\
\hline CHEMBL1256573 & 737825 & 6.0 & 5.6695 & TST & \\
\hline CHEMBL1434199 & 737825 & 6.0 & 5.938 & TRN & \\
\hline CHEMBL1302204 & 737825 & 4.8 & 4.9791 & TRN & \\
\hline CHEMBL1483257 & 737825 & 4.8 & 5.2324 & TRN & \\
\hline CHEMBL1357180 & 737825 & 5.2 & 4.9059 & TRN & \\
\hline CHEMBL1394923 & 737825 & 4.8 & 4.7679 & TRN & \\
\hline CHEMBL1555014 & 737825 & 5.0 & 4.8145 & TRN & \\
\hline CHEMBL1532517 & 737825 & 4.7 & 4.6064 & TRN & \\
\hline CHEMBL1435254 & 737825 & 5.8 & $5.6620 \ell$ & 0000000001 & TRN \\
\hline CHEMBL1516170 & 737825 & 6.7 & 6.5729 & 99999999995 & TRN \\
\hline CHEMBL1360952 & 737825 & 6.05 & 5.2211 & TST & \\
\hline CHEMBL3199738 & 737825 & 5.95 & 5.4251 & TRN & \\
\hline CHEMBL1337128 & 737825 & 6.0 & 5.8835 & TRN & \\
\hline
\end{tabular}




\begin{tabular}{|c|c|c|c|c|}
\hline \multirow[b]{2}{*}{ CHEMBL1404884 } & & & ipplement & $a+1$ \\
\hline & 737825 & 5.1 & 4.9541 & TRN \\
\hline CHEMBL1342006 & 737825 & 5.6 & 5.1838 & TRN \\
\hline CHEMBL1454368 & 737825 & 4.4 & 5.083 & TRN \\
\hline CHEMBL1592186 & 737825 & 5.0 & 4.8513 & TRN \\
\hline CHEMBL1315833 & 737825 & 5.3 & 5.1627 & TRN \\
\hline CHEMBL1506343 & 737825 & 4.7 & 5.0455 & TRN \\
\hline CHEMBL1565927 & 737825 & 4.8 & 4.9166 & TRN \\
\hline CHEMBL1566244 & 737825 & 5.15 & 5.082 & TRN \\
\hline CHEMBL1415310 & 737825 & 4.95 & 5.2682 & TRN \\
\hline CHEMBL1421764 & 737825 & 6.15 & 5.0678 & TRN \\
\hline CHEMBL1483801 & 737825 & 5.4 & 5.37 & TRN \\
\hline CHEMBL1495875 & 737825 & 4.9 & 4.8599 & TRN \\
\hline CHEMBL1502107 & 737825 & 5.4 & 5.1629 & TRN \\
\hline CHEMBL42485 & 737825 & 4.7 & 4.7556 & TST \\
\hline CHEMBL1356132 & 737825 & 5.3 & 5.0644 & TRN \\
\hline CHEMBL1306881 & 737825 & 5.4 & 5.1411 & TST \\
\hline CHEMBL1376005 & 737825 & 5.3 & 5.1771 & TST \\
\hline CHEMBL286615 & 737825 & 5.1 & 5.1047 & TRN \\
\hline CHEMBL1485287 & 737825 & 4.85 & 5.0529 & TRN \\
\hline CHEMBL 21260 & 737825 & 6.0 & 5.7912 & TRN \\
\hline CHEMBL 1539830 & 737825 & 5.4 & 5.2723 & TST \\
\hline CHEMBL1378306 & 737825 & 4.8 & 5.2584 & TRN \\
\hline CHEMBL1494609 & 737825 & 4.8 & 4.6689 & TRN \\
\hline CHEMBL1464371 & 737825 & 4.6 & 5.2398 & TRN \\
\hline CHEMBL1491340 & 737825 & 6.0 & 5.6516 & TST \\
\hline CHEMBL 1464580 & 737825 & 5.1 & 5.2549 & TRN \\
\hline CHEMBL1609123 & 737825 & 4.75 & 5.0263 & TRN \\
\hline CHEMBL1557170 & 737825 & 5.4 & 5.362 & TRN \\
\hline CHEMBL1598680 & 737825 & 6.0 & 5.8499 & TRN \\
\hline CHEMBL 269521 & 737825 & 4.8 & 4.8357 & TST \\
\hline CHEMBL1468272 & 737825 & 5.4 & 5.2059 & TRN \\
\hline CHEMBL1449255 & 737825 & 5.0 & 5.1476 & TRN \\
\hline CHEMBL1473099 & 737825 & 6.2 & 6.3584 & TRN \\
\hline CHEMBL1386497 & 737825 & 5.7 & 5.1988 & TRN \\
\hline CHEMBL1539972 & 737825 & 4.95 & 5.0983 & TRN \\
\hline CHEMBL1408286 & 737825 & 4.6 & 4.6675 & TRN \\
\hline CHEMBL1514719 & 737825 & 4.6 & 4.6123 & TRN \\
\hline CHEMBL1442996 & 737825 & 4.9 & 4.8666 & TRN \\
\hline CHEMBL1593867 & 737825 & 5.0 & 5.6392 & TRN \\
\hline CHEMBL1394258 & 737825 & 4.9 & 4.8254 & TRN \\
\hline CHEMBL1525767 & 737825 & 4.4 & 4.3613 & TRN \\
\hline CHEMBL1528441 & 737825 & 5.7 & 5.144 & TRN \\
\hline CHEMBL3210202 & 737825 & 4.75 & 5.0751 & TRN \\
\hline CHEMBL1500132 & 737825 & 4.75 & 5.3131 & TRN \\
\hline CHEMBL1363697 & 737825 & 5.4 & 5.5551 & TRN \\
\hline CHEMBL1568970 & 737825 & 4.8 & 4.7004 & TRN \\
\hline CHEMBL402468 & 737825 & 4.7 & 4.6237 & TRN \\
\hline \multirow[t]{2}{*}{ CHEMBL522311 } & 737825 & 7.0 & 6.9706 & TRN \\
\hline & & & \multicolumn{2}{|c|}{ Page 2252} \\
\hline
\end{tabular}




\begin{tabular}{|c|c|c|c|c|}
\hline \multicolumn{5}{|c|}{ Supplemental Table S2.txt } \\
\hline CHEMBL1555896 & 737825 & 5.95 & 5.1511 & TRN \\
\hline CHEMBL1474708 & 737825 & 5.4 & 5.3607 & TRN \\
\hline CHEMBL1306308 & 737825 & 5.15 & 5.1498 & TST \\
\hline CHEMBL1591677 & 737825 & 5.5 & 5.2839 & TRN \\
\hline CHEMBL1599378 & 737825 & 4.9 & 5.0077 & TRN \\
\hline CHEMBL1551633 & 737825 & 4.6 & 4.5227 & TRN \\
\hline CHEMBL1521453 & 737825 & 6.0 & 5.7007 & TST \\
\hline CHEMBL1496514 & 737825 & 6.0 & 5.6871 & TST \\
\hline CHEMBL1571531 & 737825 & 4.9 & 5.0388 & TRN \\
\hline CHEMBL1255662 & 737825 & 5.7 & 5.7325 & TRN \\
\hline CHEMBL3209702 & 737825 & 6.0 & 5.9132 & TRN \\
\hline CHEMBL 3351080 & 737825 & 5.5 & 5.3449 & TRN \\
\hline CHEMBL1552551 & 737825 & 5.6 & 5.4831 & TRN \\
\hline CHEMBL1489182 & 737825 & 5.9 & 5.9249 & TRN \\
\hline CHEMBL1485581 & 737825 & 4.65 & 5.0351 & TRN \\
\hline CHEMBL1440650 & 737825 & 5.2 & 4.9738 & TRN \\
\hline CHEMBL1442506 & 737825 & 4.8 & 5.103 & TRN \\
\hline CHEMBL1722621 & 737825 & 5.35 & 5.1329 & TRN \\
\hline CHEMBL1513280 & 737825 & 4.6 & 4.4341 & TRN \\
\hline CHEMBL1593001 & 737825 & 4.9 & 4.8203 & TRN \\
\hline CHEMBL574181 & 737825 & 5.5 & 5.2957 & TRN \\
\hline CHEMBL1256359 & 737825 & 5.1 & 4.9786 & TRN \\
\hline CHEMBL1516254 & 737825 & 4.8 & 4.6056 & TRN \\
\hline CHEMBL1408856 & 737825 & 5.3 & 5.1488 & TRN \\
\hline CHEMBL1398580 & 737825 & 5.2 & 5.3765 & TRN \\
\hline CHEMBL1461462 & 737825 & 5.3 & 4.9817 & TRN \\
\hline CHEMBL1610400 & 737825 & 4.9 & 4.671 & TRN \\
\hline CHEMBL475375 & 737825 & 5.4 & 5.4295 & TRN \\
\hline CHEMBL 3208377 & 737825 & 4.75 & 4.8728 & TRN \\
\hline CHEMBL1501953 & 737825 & 5.1 & 5.1539 & TST \\
\hline CHEMBL1322026 & 737825 & 5.4 & 5.3566 & TST \\
\hline CHEMBL3212051 & 737825 & 4.9 & 5.1769 & TST \\
\hline CHEMBL1529543 & 737825 & 5.4 & 5.249 & TRN \\
\hline CHEMBL1329418 & 737825 & 5.95 & 5.2803 & TRN \\
\hline CHEMBL1529730 & 737825 & 5.0 & 5.1838 & TRN \\
\hline CHEMBL1452057 & 737825 & 4.9 & 4.8371 & TRN \\
\hline CHEMBL 1437846 & 737825 & 5.4 & 5.3226 & TST \\
\hline CHEMBL1436715 & 737825 & 5.9 & 5.6276 & TRN \\
\hline CHEMBL1356003 & 737825 & 4.5 & 4.44 & TRN \\
\hline CHEMBL1594058 & 737825 & 6.7 & 6.1379 & TRN \\
\hline CHEMBL1407160 & 737825 & 4.8 & 5.0869 & TRN \\
\hline CHEMBL1315530 & 737825 & 4.7 & 4.5648 & TRN \\
\hline CHEMBL1507419 & 737825 & 5.0 & 5.0141 & TST \\
\hline CHEMBL1515449 & 737825 & 6.2 & 6.2732 & TRN \\
\hline CHEMBL1374456 & 737825 & 5.3 & 5.2723 & TRN \\
\hline CHEMBL3213185 & 737825 & 4.8 & 4.9804 & TRN \\
\hline CHEMBL1389327 & 737825 & 4.45 & 5.1351 & TRN \\
\hline CHEMBL1269022 & 737825 & 5.6 & 5.4629 & TST \\
\hline
\end{tabular}




\begin{tabular}{|c|c|c|c|c|c|}
\hline \multicolumn{6}{|c|}{ Supplemental Table S2.txt } \\
\hline CHEMBL3210612 & 737825 & 5.45 & 5.0788 & TRN & \\
\hline CHEMBL1455670 & 737825 & 5.4 & 5.3327 & TRN & \\
\hline CHEMBL1565842 & 737825 & 4.8 & 4.7421 & TRN & \\
\hline CHEMBL1316075 & 737825 & 5.7 & 5.459 & TRN & \\
\hline CHEMBL1330087 & 737825 & 6.0 & 6.0185 & TRN & \\
\hline CHEMBL1550414 & 737825 & 4.8 & 4.9893 & TRN & \\
\hline CHEMBL1415521 & 737825 & 6.0 & 6.0209 & TRN & \\
\hline CHEMBL236789 & 737825 & 6.0 & 5.70700 & 3000000001 & TRN \\
\hline CHEMBL1328979 & 737825 & 5.3 & 5.434 & TRN & \\
\hline CHEMBL1450860 & 737825 & 5.9 & 5.5997 & TRN & \\
\hline CHEMBL1541564 & 737825 & 4.85 & 5.1367 & TRN & \\
\hline CHEMBL1741622 & 737825 & 4.85 & 5.0026 & TRN & \\
\hline CHEMBL1501081 & 737825 & 5.15 & 5.0798 & TRN & \\
\hline CHEMBL1558526 & 737825 & 5.0 & 4.9225 & TRN & \\
\hline CHEMBL1497504 & 737825 & 6.55 & 5.6694 & TRN & \\
\hline CHEMBL1307784 & 737825 & 4.85 & 5.2172 & TRN & \\
\hline CHEMBL1594030 & 737825 & 4.6 & 4.4952 & TRN & \\
\hline CHEMBL1531277 & 737825 & 5.15 & 4.9593 & TST & \\
\hline CHEMBL1452750 & 737825 & 5.3 & 5.1721 & TRN & \\
\hline CHEMBL1315207 & 737825 & 4.6 & 4.702 & TST & \\
\hline CHEMBL1373723 & 737825 & 5.9 & 5.7912 & TRN & \\
\hline CHEMBL10 & 737825 & 6.0 & 6.0266 & TRN & \\
\hline CHEMBL216504 & 737825 & 5.8 & 5.657 & TRN & \\
\hline CHEMBL1361837 & 737825 & 4.95 & 5.4854 & TRN & \\
\hline CHEMBL1325879 & 737825 & 4.9 & 4.7924 & TRN & \\
\hline CHEMBL1358215 & 737825 & 5.1 & 4.8838 & TRN & \\
\hline CHEMBL1511687 & 737825 & 5.45 & 5.2121 & TRN & \\
\hline CHEMBL3208715 & 737825 & 4.9 & 5.0771 & TRN & \\
\hline CHEMBL1561363 & 737825 & 5.2 & 5.0067 & TRN & \\
\hline CHEMBL1513659 & 737825 & 4.6 & 4.5078 & TRN & \\
\hline CHEMBL1300933 & 737825 & 5.0 & 4.9614 & TRN & \\
\hline CHEMBL1571290 & 737825 & 6.3 & 5.5074 & TRN & \\
\hline CHEMBL545523 & 737825 & 6.0 & 5.8746 & TRN & \\
\hline CHEMBL68997 & 737825 & 5.4 & 5.3896 & TRN & \\
\hline CHEMBL1508113 & 737825 & 5.1 & 5.0595 & TRN & \\
\hline CHEMBL1079460 & 737825 & 5.3 & 5.2229 & TST & \\
\hline CHEMBL1394089 & 737825 & 4.9 & 5.7619 & TST & \\
\hline CHEMBL1532921 & 737825 & 5.5 & 5.3261 & TRN & \\
\hline CHEMBL1416795 & 737825 & 5.5 & 5.2529 & TRN & \\
\hline CHEMBL1545514 & 737825 & 4.9 & 5.2374 & TRN & \\
\hline CHEMBL1364611 & 737825 & 5.9 & 5.6856 & TRN & \\
\hline CHEMBL1555368 & 737825 & 5.5 & 5.5265 & TRN & \\
\hline CHEMBL1408236 & 737825 & 5.45 & 5.2415 & TRN & \\
\hline CHEMBL 3210878 & 737825 & 4.85 & 5.37700 & 2000000001 & TRN \\
\hline CHEMBL1449111 & 737825 & 5.45 & 5.1835 & TRN & \\
\hline CHEMBL1397175 & 737825 & 6.0 & 5.9463 & TRN & \\
\hline CHEMBL1364880 & 737825 & 4.8 & 5.1044 & TRN & \\
\hline CHEMBL1593592 & 737825 & 5.8 & 5.6211 & TRN & \\
\hline
\end{tabular}




\begin{tabular}{|c|c|c|c|c|c|}
\hline & & & & & \\
\hline CHEMBL1384353 & 737825 & 5.3 & 5.0594 & TRN & \\
\hline CHEMBL1553990 & 737825 & 4.8 & 4.8038 & TRN & \\
\hline CHEMBL1585305 & 737825 & 5.2 & 5.1953 & TRN & \\
\hline CHEMBL1446815 & 737825 & 4.9 & 4.7775 & TRN & \\
\hline CHEMBL1461188 & 737825 & 4.95 & 5.3068 & TRN & \\
\hline CHEMBL1414375 & 737825 & 4.5 & 4.9879 & TRN & \\
\hline CHEMBL1566407 & 737825 & 5.45 & 5.3168 & TRN & \\
\hline CHEMBL1256839 & 737825 & 6.0 & 5.6519 & TRN & \\
\hline CHEMBL1310248 & 737825 & 5.2 & 5.2106 & TRN & \\
\hline CHEMBL1484614 & 737825 & 4.6 & 4.6332 & TRN & \\
\hline CHEMBL1309312 & 737825 & 5.55 & 5.0239 & TRN & \\
\hline CHEMBL3145019 & 737825 & 4.8 & 5.0723 & TST & \\
\hline CHEMBL1341070 & 737825 & 4.7 & 5.1057 & TRN & \\
\hline CHEMBL1462862 & 737825 & 4.9 & 5.2292 & TST & \\
\hline CHEMBL1456942 & 737825 & 4.85 & 4.9392 & TRN & \\
\hline CHEMBL1492299 & 737825 & 4.5 & 5.3707 & TRN & \\
\hline CHEMBL1454270 & 737825 & 4.8 & 4.7621 & TRN & \\
\hline CHEMBL148296 & 737825 & 4.6 & 4.6224 & TRN & \\
\hline CHEMBL1556023 & 737825 & 6.4 & 5.9024 & TST & \\
\hline CHEMBL1593443 & 737825 & 5.2 & 5.2035 & TRN & \\
\hline CHEMBL1379383 & 737825 & 5.8 & 5.2968 & TRN & \\
\hline CHEMBL1574966 & 737825 & 6.0 & 5.8067 & TRN & \\
\hline CHEMBL1476526 & 737825 & 4.8 & 4.7542 & TRN & \\
\hline CHEMBL1356391 & 737825 & 5.5 & 5.4209 & TRN & \\
\hline CHEMBL1410759 & 737825 & 5.5 & 5.2555 & TST & \\
\hline CHEMBL1414780 & 737825 & 4.8 & 4.6659 & TRN & \\
\hline CHEMBL1372371 & 737825 & 5.0 & 4.8465 & TRN & \\
\hline CHEMBL1368855 & 737825 & 5.1 & 5.0851 & TRN & \\
\hline CHEMBL1417646 & 737825 & 6.7 & 6.4993 & TRN & \\
\hline CHEMBL1526032 & 737825 & 4.8 & 4.6841 & TRN & \\
\hline CHEMBL1330394 & 737825 & 6.0 & 5.83299 & 9999999999 & TRN \\
\hline CHEMBL1381238 & 737825 & 5.65 & 5.33299 & 9999999999 & TST \\
\hline CHEMBL1383753 & 737825 & 5.65 & 5.1471 & TRN & \\
\hline CHEMBL1742363 & 737825 & 4.6 & 5.1551 & TRN & \\
\hline CHEMBL3194051 & 737825 & 4.95 & 5.1599 & TST & \\
\hline CHEMBL1444973 & 737825 & 4.9 & 4.9431 & TRN & \\
\hline CHEMBL1395915 & 737825 & 5.5 & 5.2716 & TRN & \\
\hline CHEMBL1490333 & 737825 & 6.95 & 5.1161 & TRN & \\
\hline CHEMBL1502413 & 737825 & 4.85 & 5.2383 & TRN & \\
\hline CHEMBL1566217 & 737825 & 4.8 & 5.0067 & TRN & \\
\hline CHEMBL1499214 & 737825 & 4.4 & 5.2281 & TRN & \\
\hline CHEMBL1453970 & 737825 & 5.45 & 4.9451 & TRN & \\
\hline CHEMBL1388234 & 737825 & 5.15 & 5.1782 & TRN & \\
\hline CHEMBL1452708 & 737825 & 5.65 & 5.1337 & TRN & \\
\hline CHEMBL1553404 & 737825 & 5.1 & 4.8489 & TRN & \\
\hline CHEMBL1496576 & 737825 & 6.2 & 6.1003 & TRN & \\
\hline CHEMBL1413524 & 737825 & 4.8 & 5.035 & TRN & \\
\hline CHEMBL1485494 & 737825 & 6.25 & 5.4304 & TRN & \\
\hline & & & & 22526 & \\
\hline
\end{tabular}




\begin{tabular}{|c|c|c|c|c|}
\hline \multicolumn{5}{|c|}{ Supplemental Table s2.txt } \\
\hline CHEMBL1395112 & 737825 & 4.6 & 4.8691 & TRN \\
\hline CHEMBL1467717 & 737825 & 4.85 & 5.2048 & TRN \\
\hline CHEMBL1317358 & 737825 & 4.6 & 4.5297 & TRN \\
\hline CHEMBL 3145283 & 737825 & 4.85 & 5.1842 & TST \\
\hline CHEMBL1317712 & 737825 & 4.6 & 4.5218 & TRN \\
\hline CHEMBL1351531 & 737825 & 5.0 & 5.1395 & TRN \\
\hline CHEMBL1513633 & 737825 & 6.3 & 6.2342 & TRN \\
\hline CHEMBL3197624 & 737825 & 4.65 & 5.1633 & TRN \\
\hline CHEMBL1440329 & 737825 & 4.85 & 4.9652 & TRN \\
\hline CHEMBL540294 & 737825 & 6.0 & 5.6744 & TST \\
\hline CHEMBL1461491 & 737825 & 7.3 & 6.5269 & TST \\
\hline CHEMBL1374614 & 737825 & 4.8 & 5.314 & TRN \\
\hline CHEMBL1318454 & 737825 & 4.9 & 4.6879 & TRN \\
\hline CHEMBL1596743 & 737825 & 5.2 & 5.0227 & TRN \\
\hline CHEMBL3192255 & 737825 & 4.85 & 5.1907 & TRN \\
\hline CHEMBL1370526 & 737825 & 5.3 & 5.1315 & TST \\
\hline CHEMBL1409986 & 737825 & 5.4 & 5.2394 & TRN \\
\hline CHEMBL1374605 & 737825 & 5.1 & 5.2307 & TRN \\
\hline CHEMBL1445026 & 737825 & 5.6 & 5.4042 & TRN \\
\hline CHEMBL3193279 & 737825 & 5.65 & 5.3952 & TRN \\
\hline CHEMBL1513439 & 737825 & 4.9 & 4.7584 & TRN \\
\hline CHEMBL1429915 & 737825 & 5.0 & 5.3312 & TRN \\
\hline CHEMBL1410012 & 737825 & 4.8 & 4.6026 & TRN \\
\hline CHEMBL1360744 & 737825 & 4.8 & 5.1542 & TRN \\
\hline CHEMBL1484231 & 737825 & 5.15 & 5.1062 & TRN \\
\hline CHEMBL410063 & 737825 & 4.8 & 4.783 & TST \\
\hline CHEMBL1316491 & 737825 & 4.8 & 4.6416 & TRN \\
\hline CHEMBL1474125 & 737825 & 4.4 & 4.2934 & TRN \\
\hline CHEMBL1482035 & 737825 & 4.65 & 5.0618 & TRN \\
\hline CHEMBL1547564 & 737825 & 4.8 & 5.1293 & TRN \\
\hline CHEMBL1552478 & 737825 & 4.5 & 4.5818 & TRN \\
\hline CHEMBL1567305 & 737825 & 4.6 & 5.3209 & TRN \\
\hline CHEMBL1332964 & 737825 & 5.6 & 5.644 & TRN \\
\hline CHEMBL1442243 & 737825 & 5.0 & 4.9448 & TRN \\
\hline CHEMBL3193269 & 737825 & 5.5 & 5.0354 & TST \\
\hline CHEMBL1345410 & 737825 & 4.9 & 5.191 & TRN \\
\hline CHEMBL1518559 & 737825 & 5.0 & 5.1936 & TRN \\
\hline CHEMBL471728 & 737825 & 5.5 & 5.4062 & TST \\
\hline CHEMBL1610387 & 737825 & 4.9 & 4.7923 & TRN \\
\hline CHEMBL1376070 & 737825 & 5.5 & 5.3109 & TRN \\
\hline CHEMBL1722649 & 737825 & 4.95 & 5.1502 & TRN \\
\hline CHEMBL1598771 & 737825 & 6.0 & 5.21200 & 0000000001 \\
\hline CHEMBL1256695 & 737825 & 6.0 & 5.7832 & TRN \\
\hline CHEMBL1360650 & 737825 & 5.6 & 5.7211 & TRN \\
\hline CHEMBL1507611 & 737825 & 6.5 & 5.2823 & TRN \\
\hline CHEMBL1509341 & 737825 & 4.8 & 5.2802 & TRN \\
\hline CHEMBL1522136 & 737825 & 4.85 & 5.0656 & TRN \\
\hline CHEMBL1525674 & 737825 & 6.45 & 5.1415 & TRN \\
\hline
\end{tabular}




\begin{tabular}{|c|c|c|c|c|}
\hline \multicolumn{5}{|c|}{ Supplemental Table S2.txt } \\
\hline CHEMBL1451815 & 737825 & 5.55 & 5.3386 & TRN \\
\hline CHEMBL1539331 & 737825 & 4.6 & 5.151 & TRN \\
\hline CHEMBL1538333 & 737825 & 5.35 & 5.1881 & TRN \\
\hline CHEMBL1551200 & 737825 & 5.4 & 5.2514 & TRN \\
\hline CHEMBL1389308 & 737825 & 5.4 & 5.1523 & TRN \\
\hline CHEMBL1476604 & 737825 & 4.8 & 4.6156 & TRN \\
\hline CHEMBL1514765 & 737825 & 5.5 & 5.3951 & TST \\
\hline CHEMBL1471858 & 737825 & 5.4 & 5.5216 & TRN \\
\hline CHEMBL1518570 & 737825 & 5.95 & 4.9294 & TST \\
\hline CHEMBL1358462 & 737825 & 4.8 & 4.7046 & TST \\
\hline CHEMBL1497812 & 737825 & 4.85 & 5.1094 & TRN \\
\hline CHEMBL1486304 & 737825 & 5.4 & 5.171 & TRN \\
\hline CHEMBL1319243 & 737825 & 4.95 & 5.0284 & TRN \\
\hline CHEMBL1490139 & 737825 & 5.0 & 4.8818 & TRN \\
\hline CHEMBL1412842 & 737825 & 6.0 & 5.9206 & TRN \\
\hline CHEMBL1400398 & 737825 & 6.05 & 5.1731 & TRN \\
\hline CHEMBL1406491 & 737825 & 4.5 & 4.8541 & TST \\
\hline CHEMBL1344002 & 737825 & 4.75 & 5.2124 & TST \\
\hline CHEMBL527271 & 737825 & 4.6 & 5.1664 & TRN \\
\hline CHEMBL1525292 & 737825 & 4.85 & 5.2171 & TST \\
\hline CHEMBL1605632 & 737825 & 6.0 & 5.8304 & TRN \\
\hline CHEMBL1409852 & 737825 & 4.9 & 4.8125 & TRN \\
\hline CHEMBL1318307 & 737825 & 4.8 & 4.8136 & TST \\
\hline CHEMBL1324022 & 737825 & 4.8 & 4.7731 & TST \\
\hline CHEMBL1436521 & 737825 & 5.1 & 4.9922 & TRN \\
\hline CHEMBL1445255 & 737825 & 5.2 & 5.3399 & TRN \\
\hline CHEMBL1408703 & 737825 & 4.8 & 4.7063 & TRN \\
\hline CHEMBL1435509 & 737825 & 5.4 & 5.2517 & TRN \\
\hline CHEMBL1535431 & 737825 & 4.9 & 4.6858 & TRN \\
\hline CHEMBL1742255 & 737825 & 5.5 & 5.0854 & TRN \\
\hline CHEMBL1515401 & 737825 & 4.9 & 4.8696 & TRN \\
\hline CHEMBL1490330 & 737825 & 4.6 & 4.9496 & TRN \\
\hline CHEMBL1396615 & 737825 & 4.8 & 4.7688 & TRN \\
\hline CHEMBL1378246 & 737825 & 4.75 & 5.0164 & TST \\
\hline CHEMBL1433013 & 737825 & 4.9 & 5.2068 & TRN \\
\hline CHEMBL3208065 & 737825 & 5.3 & 5.4106 & TRN \\
\hline CHEMBL1459606 & 737825 & 5.5 & 5.1832 & TRN \\
\hline CHEMBL1494296 & 737825 & 5.35 & 5.4144 & TRN \\
\hline CHEMBL53898 & 737825 & 5.6 & 5.3733 & TRN \\
\hline CHEMBL1512780 & 737825 & 5.0 & 4.9276 & TRN \\
\hline CHEMBL1511207 & 737825 & 4.55 & 5.1249 & TRN \\
\hline CHEMBL1482677 & 737825 & 4.85 & 5.2116 & TRN \\
\hline CHEMBL1451667 & 737825 & 4.75 & 4.9638 & TST \\
\hline CHEMBL1557015 & 737825 & 5.8 & 5.25899 & 99999999995 \\
\hline CHEMBL1552066 & 737825 & 5.4 & 5.2721 & TRN \\
\hline CHEMBL1429612 & 737825 & 5.15 & 5.1096 & TRN \\
\hline CHEMBL1485865 & 737825 & 4.7 & 5.1198 & TST \\
\hline CHEMBL429711 & 737825 & 4.4 & 4.4358 & TRN \\
\hline
\end{tabular}

TRN 


\begin{tabular}{|c|c|c|c|c|c|}
\hline \multicolumn{6}{|c|}{ Supplemental Table S2.txt } \\
\hline CHEMBL1323355 & 737825 & 5.1 & 5.1169 & TST & \\
\hline CHEMBL1358654 & 737825 & 5.6 & 5.2613 & TRN & \\
\hline CHEMBL1471369 & 737825 & 6.15 & 5.2743 & TRN & \\
\hline CHEMBL3196775 & 737825 & 5.6 & 5.2413 & TRN & \\
\hline CHEMBL490913 & 737825 & 6.8 & 6.7067 & TRN & \\
\hline CHEMBL1374334 & 737825 & 6.2 & 5.9642 & TST & \\
\hline CHEMBL1391286 & 737825 & 5.05 & 5.2734 & TRN & \\
\hline CHEMBL1429370 & 737825 & 5.3 & 5.1126 & TRN & \\
\hline CHEMBL1592812 & 737825 & 5.1 & 4.935 & TRN & \\
\hline CHEMBL1557752 & 737825 & 4.8 & 5.0838 & TRN & \\
\hline CHEMBL3194024 & 737825 & 4.9 & 5.2882 & TST & \\
\hline CHEMBL1605713 & 737825 & 5.15 & 4.8801 & TRN & \\
\hline CHEMBL1537220 & 737825 & 5.0 & 4.9564 & TRN & \\
\hline CHEMBL1435702 & 737825 & 5.0 & 4.9422 & TRN & \\
\hline CHEMBL1317853 & 737825 & 5.1 & 4.9268 & TRN & \\
\hline CHEMBL1708647 & 737825 & 5.15 & 5.1119 & TRN & \\
\hline CHEMBL1547741 & 737825 & 4.55 & 5.166 & TRN & \\
\hline CHEMBL1484861 & 737825 & 5.6 & 5.5855 & TRN & \\
\hline CHEMBL1591674 & 737825 & 4.6 & 4.5793 & TRN & \\
\hline CHEMBL1537183 & 737825 & 4.9 & 5.1561 & TRN & \\
\hline CHEMBL1304918 & 737825 & 5.8 & 5.5886 & TRN & \\
\hline CHEMBL1471064 & 737825 & 4.85 & 4.9709 & TRN & \\
\hline CHEMBL1457730 & 737825 & 5.4 & 5.4927 & TRN & \\
\hline CHEMBL1361758 & 737825 & 5.0 & 4.9128 & TRN & \\
\hline CHEMBL1451364 & 737825 & 4.7 & 4.6142 & TRN & \\
\hline CHEMBL1317378 & 737825 & 4.8 & 4.555 & TRN & \\
\hline CHEMBL1480840 & 737825 & 4.85 & 5.1565 & TRN & \\
\hline CHEMBL1525963 & 737825 & 5.1 & 5.2174 & TRN & \\
\hline CHEMBL1500945 & 737825 & 4.45 & 5.1542 & TRN & \\
\hline CHEMBL1366776 & 737825 & 4.7 & 4.9591 & TRN & \\
\hline CHEMBL1316294 & 737825 & 5.5 & 5.3678 & TRN & \\
\hline CHEMBL1516068 & 737825 & 4.9 & 5.6372 & TRN & \\
\hline CHEMBL80155 & 737825 & 5.0 & 4.841 & TRN & \\
\hline CHEMBL1522134 & 737825 & 4.6 & 5.2361 & TRN & \\
\hline CHEMBL1530523 & 737825 & 5.25 & 5.3092 & TRN & \\
\hline CHEMBL1516468 & 737825 & 6.0 & $5.9270 e$ & 20000000005 & TRN \\
\hline CHEMBL1358384 & 737825 & 8.9 & 7.6729 & TST & \\
\hline CHEMBL1359843 & 737825 & 4.9 & 4.766 & TRN & \\
\hline CHEMBL1516503 & 737825 & 4.55 & 5.1096 & TRN & \\
\hline CHEMBL1329562 & 737825 & 5.75 & 5.1278 & TRN & \\
\hline CHEMBL1469535 & 737825 & 4.65 & 4.9902 & TRN & \\
\hline CHEMBL1387238 & 737825 & 5.4 & 5.0637 & TRN & \\
\hline CHEMBL1320000 & 737825 & 4.7 & 5.0358 & TST & \\
\hline CHEMBL1557234 & 737825 & 5.1 & 4.9651 & TRN & \\
\hline CHEMBL1563008 & 737825 & 5.0 & 5.1227 & TRN & \\
\hline CHEMBL1359877 & 737825 & 5.5 & 5.1653 & TRN & \\
\hline CHEMBL1724577 & 737825 & 4.8 & 5.0394 & TST & \\
\hline CHEMBL1340104 & 737825 & 4.8 & 5.1311 & TST & \\
\hline
\end{tabular}




\begin{tabular}{|c|c|c|c|c|}
\hline & & & pplement & al \\
\hline CHEMBL1519603 & 737825 & 6.7 & 5.2907 & TRN \\
\hline CHEMBL1514931 & 737825 & 4.5 & 4.6425 & TST \\
\hline CHEMBL1570285 & 737825 & 5.6 & 5.4675 & TRN \\
\hline CHEMBL1257014 & 737825 & 4.6 & 4.6182 & TRN \\
\hline CHEMBL1405922 & 737825 & 5.0 & 5.6898 & TRN \\
\hline CHEMBL1547410 & 737825 & 4.85 & 5.0812 & TRN \\
\hline CHEMBL1417837 & 737825 & 5.4 & 5.2672 & TRN \\
\hline CHEMBL 2369261 & 737825 & 4.95 & 5.0797 & TST \\
\hline CHEMBL1451031 & 737825 & 4.6 & 5.1761 & TRN \\
\hline CHEMBL1478570 & 737825 & 4.85 & 5.0579 & TRN \\
\hline CHEMBL1452905 & 737825 & 4.55 & 5.1716 & TRN \\
\hline CHEMBL1410676 & 737825 & 6.9 & 6.8697 & TRN \\
\hline CHEMBL1481963 & 737825 & 4.75 & 5.1882 & TST \\
\hline CHEMBL3189455 & 737825 & 4.8 & 5.2261 & TST \\
\hline CHEMBL1521520 & 737825 & 5.1 & 5.2776 & TRN \\
\hline CHEMBL588859 & 737825 & 4.85 & 5.0432 & TRN \\
\hline CHEMBL1470566 & 737825 & 5.15 & 5.2781 & TRN \\
\hline CHEMBL1724748 & 737825 & 5.5 & 5.1678 & TRN \\
\hline CHEMBL1327772 & 737825 & 5.3 & 5.018 & TRN \\
\hline CHEMBL1541013 & 737825 & 4.4 & 5.142 & TRN \\
\hline CHEMBL1584758 & 737825 & 4.55 & 5.1205 & TRN \\
\hline CHEMBL1362918 & 737825 & 5.3 & 5.2113 & TST \\
\hline CHEMBL1734974 & 737825 & 4.55 & 5.147 & TRN \\
\hline CHEMBL1453749 & 737825 & 5.1 & 5.2031 & TRN \\
\hline CHEMBL1256660 & 737825 & 4.7 & 4.8037 & TRN \\
\hline CHEMBL1544132 & 737825 & 4.65 & 5.4481 & TRN \\
\hline CHEMBL1582278 & 737825 & 5.5 & 5.5767 & TRN \\
\hline CHEMBL1462483 & 737825 & 4.85 & 5.2063 & TRN \\
\hline CHEMBL1595929 & 737825 & 4.6 & 5.0323 & TST \\
\hline CHEMBL1367387 & 737825 & 5.05 & 5.1501 & TRN \\
\hline CHEMBL1356113 & 737825 & 5.5 & 5.4553 & TRN \\
\hline CHEMBL1742228 & 737825 & 4.65 & 5.1967 & TRN \\
\hline CHEMBL1318789 & 737825 & 4.5 & 4.5684 & TST \\
\hline CHEMBL1406307 & 737825 & 5.5 & 5.3366 & TRN \\
\hline CHEMBL1332929 & 737825 & 6.2 & 6.2635 & TRN \\
\hline CHEMBL1542112 & 737825 & 5.35 & 5.3068 & TRN \\
\hline CHEMBL1529578 & 737825 & 5.95 & 5.1346 & TRN \\
\hline CHEMBL1420145 & 737825 & 5.3 & 5.2832 & TST \\
\hline CHEMBL 2062333 & 737825 & 4.6 & 4.6128 & TRN \\
\hline CHEMBL1360739 & 737825 & 4.9 & 5.0548 & TRN \\
\hline CHEMBL1548959 & 737825 & 5.05 & 5.0699 & TRN \\
\hline CHEMBL3198972 & 737825 & 4.65 & 4.9657 & TRN \\
\hline CHEMBL1332984 & 737825 & 5.35 & 5.1757 & TRN \\
\hline CHEMBL1094842 & 737825 & 4.85 & 5.3032 & TRN \\
\hline CHEMBL1351153 & 737825 & 4.6 & 5.2505 & TRN \\
\hline CHEMBL1425688 & 737825 & 4.95 & 5.3086 & TRN \\
\hline CHEMBL1469385 & 737825 & 4.65 & 5.004 & TST \\
\hline CHEMBL1514416 & 737825 & 5.1 & 5.1114 & TRN \\
\hline
\end{tabular}




\begin{tabular}{|c|c|c|c|c|c|}
\hline \multicolumn{6}{|c|}{ Supplemental Table S2.txt } \\
\hline CHEMBL1531899 & 737825 & 5.0 & 4.6773 & TRN & \\
\hline CHEMBL1450537 & 737825 & 6.05 & 5.1586 & TST & \\
\hline CHEMBL1527221 & 737825 & 5.7 & 5.7713 & TRN & \\
\hline CHEMBL1427186 & 737825 & 5.35 & \multicolumn{2}{|c|}{5.127999999999999} & TRN \\
\hline CHEMBL1450934 & 737825 & 5.95 & 5.2574 & TRN & \\
\hline CHEMBL1414438 & 737825 & 5.35 & 5.1459 & TRN & \\
\hline CHEMBL1255837 & 737825 & 6.0 & 5.9461 & TST & \\
\hline CHEMBL1381730 & 737825 & 6.5 & 5.3258 & TRN & \\
\hline CHEMBL1382384 & 737825 & 4.9 & 5.251 & TRN & \\
\hline CHEMBL1399249 & 737825 & 5.9 & 5.6999 & TST & \\
\hline CHEMBL1333338 & 737825 & 5.1 & 5.2142 & TST & \\
\hline CHEMBL1478520 & 737825 & 4.9 & 5.1039 & TRN & \\
\hline CHEMBL1408908 & 737825 & 5.55 & \multicolumn{2}{|c|}{5.0889999999999995} & TST \\
\hline CHEMBL1315083 & 737825 & 5.7 & 5.5901 & TRN & \\
\hline CHEMBL1554654 & 737825 & 5.5 & 5.4302 & TRN & \\
\hline CHEMBL1201074 & 737825 & 5.0 & 4.9249 & TRN & \\
\hline CHEMBL1488845 & 737825 & 5.0 & 4.7629 & TST & \\
\hline CHEMBL1552270 & 737825 & 5.6 & 5.4162 & TRN & \\
\hline CHEMBL1490268 & 737825 & 4.9 & 4.88 & TRN & \\
\hline CHEMBL1400385 & 737825 & 5.1 & 5.1587 & TRN & \\
\hline CHEMBL1395605 & 737825 & 4.8 & \multicolumn{2}{|c|}{4.6419999999999995} & TRN \\
\hline CHEMBL1971875 & 737825 & 4.8 & 5.2289 & TRN & \\
\hline CHEMBL1592465 & 737825 & 4.8 & 4.6202 & TRN & \\
\hline CHEMBL1474479 & 737825 & 4.4 & 4.5241 & TRN & \\
\hline CHEMBL1362416 & 737825 & 5.8 & 5.4131 & TRN & \\
\hline CHEMBL1359620 & 737825 & 5.05 & 4.9852 & TRN & \\
\hline CHEMBL1355935 & 737825 & 4.8 & 4.7955 & TRN & \\
\hline CHEMBL1436743 & 737825 & 5.4 & 5.4787 & TRN & \\
\hline CHEMBL1459485 & 737825 & 4.55 & 4.9008 & TRN & \\
\hline CHEMBL1590601 & 737825 & 5.5 & 5.4801 & TRN & \\
\hline CHEMBL1576205 & 737825 & 4.95 & 5.0931 & TRN & \\
\hline CHEMBL1452436 & 737825 & 5.7 & 5.4174 & TST & \\
\hline CHEMBL1317748 & 737825 & 5.0 & 4.8195 & TRN & \\
\hline CHEMBL1597107 & 737825 & 5.1 & 4.9764 & TRN & \\
\hline CHEMBL1442542 & 737825 & 6.5 & 5.2854 & TST & \\
\hline CHEMBL1597569 & 737825 & 4.55 & 5.0529 & TRN & \\
\hline CHEMBL1436925 & 737825 & 5.8 & 5.6709 & TRN & \\
\hline CHEMBL1324032 & 737825 & 5.3 & 5.2041 & TST & \\
\hline CHEMBL1446139 & 737825 & 5.2 & 5.285 & TRN & \\
\hline CHEMBL1400744 & 737825 & 4.95 & 4.9954 & TRN & \\
\hline CHEMBL1486821 & 737825 & 6.0 & 5.9625 & TRN & \\
\hline CHEMBL1342562 & 737825 & 5.5 & 5.2704 & TRN & \\
\hline CHEMBL1571807 & 737825 & 4.9 & 5.3585 & TRN & \\
\hline CHEMBL1354596 & 737825 & 4.6 & 4.5785 & TRN & \\
\hline CHEMBL78150 & 737825 & 5.5 & 5.2619 & TRN & \\
\hline CHEMBL1523363 & 737825 & 5.6 & 5.1389 & TRN & \\
\hline CHEMBL1374335 & 737825 & 5.5 & 5.3624 & TRN & \\
\hline \multirow[t]{2}{*}{ CHEMBL1337781 } & 737825 & 5.4 & 5.1898 & TST & \\
\hline & & \multicolumn{4}{|c|}{ Page 22531} \\
\hline
\end{tabular}




\begin{tabular}{|c|c|c|c|c|c|}
\hline & & & & & \\
\hline CHEMBL1538647 & 737825 & 5.1 & 5.0049 & TRN & \\
\hline CHEMBL1558135 & 737825 & 4.8 & 4.7747 & TRN & \\
\hline CHEMBL1559126 & 737825 & 5.8 & 5.8485 & TRN & \\
\hline CHEMBL1425931 & 737825 & 5.2 & 5.0944 & TRN & \\
\hline CHEMBL1572834 & 737825 & 6.1 & 6.1696 & TRN & \\
\hline CHEMBL1363933 & 737825 & 4.6 & 4.9665 & TST & \\
\hline CHEMBL1972346 & 737825 & 4.7 & 4.86 & TRN & \\
\hline CHEMBL1507026 & 737825 & 5.35 & 5.1614 & TRN & \\
\hline CHEMBL1395029 & 737825 & 4.8 & 4.6733 & TRN & \\
\hline CHEMBL1512222 & 737825 & 4.7 & 4.5309 & TRN & \\
\hline CHEMBL1473793 & 737825 & 4.6 & 4.5086 & TRN & \\
\hline CHEMBL1327793 & 737825 & 5.4 & 5.2475 & TST & \\
\hline CHEMBL1598994 & 737825 & 4.7 & 4.717 & TRN & \\
\hline CHEMBL1593796 & 737825 & 5.4 & 5.3722 & TRN & \\
\hline CHEMBL441282 & 737825 & 5.6 & 5.3229 & 99999999995 & TST \\
\hline CHEMBL1982520 & 737825 & 5.7 & 5.3393 & TST & \\
\hline CHEMBL1356941 & 737825 & 5.9 & 5.6459 & TRN & \\
\hline CHEMBL1461873 & 737825 & 5.2 & 5.1816 & TRN & \\
\hline CHEMBL1337713 & 737825 & 5.2 & 5.1058 & TRN & \\
\hline CHEMBL3189813 & 737825 & 5.65 & 5.1602 & TRN & \\
\hline CHEMBL1713677 & 737825 & 4.65 & 5.2394 & TRN & \\
\hline CHEMBL1330751 & 737825 & 6.05 & 5.5401 & TRN & \\
\hline CHEMBL1447909 & 737825 & 5.7 & 5.8391 & TRN & \\
\hline CHEMBL1337829 & 737825 & 5.0 & 4.788 & TRN & \\
\hline CHEMBL1409605 & 737825 & 4.65 & 5.1134 & TRN & \\
\hline CHEMBL1564094 & 737825 & 4.95 & 5.282 & TRN & \\
\hline CHEMBL1551749 & 737825 & 4.5 & 4.4095 & TRN & \\
\hline CHEMBL1483693 & 737825 & 6.0 & 5.9239 & TRN & \\
\hline CHEMBL1486647 & 737825 & 4.55 & 5.1822 & TRN & \\
\hline CHEMBL1481741 & 737825 & 4.5 & 4.5415 & TRN & \\
\hline CHEMBL1481168 & 737825 & 4.6 & 5.2751 & TRN & \\
\hline CHEMBL1471561 & 737825 & 5.35 & 5.0831 & TRN & \\
\hline CHEMBL1524401 & 737825 & 4.65 & 5.1342 & TRN & \\
\hline CHEMBL1409669 & 737825 & 4.6 & 5.0529 & TRN & \\
\hline CHEMBL1578181 & 737825 & 4.75 & 5.263 & TRN & \\
\hline CHEMBL1378237 & 737825 & 5.9 & 5.8259 & TRN & \\
\hline CHEMBL1379481 & 737825 & 5.3 & 5.0536 & TRN & \\
\hline CHEMBL1369796 & 737825 & 4.6 & 4.5796 & TRN & \\
\hline CHEMBL1433596 & 737825 & 4.8 & 4.8866 & TRN & \\
\hline CHEMBL1723921 & 737825 & 4.8 & 5.1519 & TRN & \\
\hline CHEMBL1529777 & 737825 & 4.4 & 5.3154 & TRN & \\
\hline CHEMBL1494196 & 737825 & 4.5 & 4.622 & TRN & \\
\hline CHEMBL1590048 & 737825 & 5.0 & 5.0938 & TRN & \\
\hline CHEMBL1572734 & 737825 & 4.95 & 5.2554 & TRN & \\
\hline CHEMBL1360327 & 737825 & 4.4 & 5.2625 & TST & \\
\hline CHEMBL1516521 & 737825 & 4.9 & 5.2429 & TRN & \\
\hline CHEMBL1551567 & 737825 & 5.2 & 5.2385 & TRN & \\
\hline CHEMBL1612774 & 737825 & 5.05 & 5.0706 & TRN & \\
\hline & & & & 22532 & \\
\hline
\end{tabular}




\begin{tabular}{|c|c|c|c|c|c|}
\hline \multirow{3}{*}{$\begin{array}{l}\text { CHEMBL1478734 } \\
\text { CHEMBL1562589 }\end{array}$} & \multirow{3}{*}{$\begin{array}{l}737825 \\
737825\end{array}$} & \multicolumn{4}{|c|}{ Supplemental Table S2.txt } \\
\hline & & 4.9 & \multicolumn{2}{|c|}{5.172999999999999} & TRN \\
\hline & & 5.8 & 5.5351 & TRN & \\
\hline CHEMBL1318937 & 737825 & 4.8 & 5.1343 & TRN & \\
\hline CHEMBL1462692 & 737825 & 4.85 & 5.1403 & TST & \\
\hline CHEMBL1531342 & 737825 & 5.5 & 5.3967 & TST & \\
\hline CHEMBL1333454 & 737825 & 5.2 & 5.0649 & TRN & \\
\hline CHEMBL3199540 & 737825 & 4.8 & 5.0559 & TRN & \\
\hline CHEMBL3195954 & 737825 & 5.0 & 5.0816 & TRN & \\
\hline CHEMBL606675 & 737825 & 4.5 & 4.8367 & TST & \\
\hline CHEMBL1318228 & 737825 & 6.6 & 6.1045 & TRN & \\
\hline CHEMBL261011 & 737825 & 5.0 & 4.897 & TRN & \\
\hline CHEMBL1406495 & 737825 & 4.85 & 5.1725 & TRN & \\
\hline CHEMBL1504465 & 737825 & 5.0 & 5.4378 & TRN & \\
\hline CHEMBL159096 & 737825 & 4.7 & 4.8215 & TST & \\
\hline CHEMBL1496986 & 737825 & 5.4 & 5.3009 & TRN & \\
\hline CHEMBL1611261 & 737825 & 4.8 & 4.7031 & TRN & \\
\hline CHEMBL1611463 & 737825 & 5.35 & 5.3134 & TRN & \\
\hline CHEMBL1493002 & 737825 & 5.2 & 4.905 & TRN & \\
\hline CHEMBL1304606 & 737825 & 4.8 & 5.0709 & TRN & \\
\hline CHEMBL1570480 & 737825 & 5.2 & 5.1101 & TST & \\
\hline CHEMBL1457317 & 737825 & 5.1 & 5.013 & TRN & \\
\hline CHEMBL1459145 & 737825 & 5.15 & 5.1328 & TRN & \\
\hline CHEMBL1316461 & 737825 & 5.9 & 5.567 & TRN & \\
\hline CHEMBL1357231 & 737825 & 5.4 & 5.3012 & TRN & \\
\hline CHEMBL1343857 & 737825 & 4.95 & 5.2047 & TRN & \\
\hline CHEMBL1315373 & 737825 & 5.4 & 5.3116 & TRN & \\
\hline CHEMBL1590598 & 737825 & 5.2 & 5.0209 & TRN & \\
\hline CHEMBL1553161 & 737825 & 5.4 & 5.4047 & TRN & \\
\hline CHEMBL1323732 & 737825 & 4.75 & 5.3237 & TST & \\
\hline CHEMBL1458255 & 737825 & 5.0 & 5.1267 & TRN & \\
\hline CHEMBL1741433 & 737825 & 4.65 & 5.1123 & TRN & \\
\hline CHEMBL1366737 & 737825 & 4.8 & 4.5996 & TRN & \\
\hline CHEMBL3213468 & 737825 & 5.95 & 5.3453 & TRN & \\
\hline CHEMBL1435899 & 737825 & 4.8 & 4.6112 & TRN & \\
\hline CHEMBL1537099 & 737825 & 4.95 & 5.2789 & TST & \\
\hline CHEMBL1430486 & 737825 & 5.45 & 5.1775 & TRN & \\
\hline CHEMBL1422722 & 737825 & 4.75 & 5.1888 & TRN & \\
\hline CHEMBL1556106 & 737825 & 5.0 & 5.0369 & TRN & \\
\hline CHEMBL1310477 & 737825 & 5.4 & 5.2158 & TRN & \\
\hline CHEMBL1482582 & 737825 & 4.8 & 4.7387 & TRN & \\
\hline CHEMBL1388158 & 737825 & 5.0 & 5.02 & TST & \\
\hline CHEMBL581929 & 737825 & 4.85 & 5.1633 & TRN & \\
\hline CHEMBL1593765 & 737825 & 4.5 & 4.5871 & TRN & \\
\hline CHEMBL1414073 & 737825 & 5.9 & 5.5864 & TRN & \\
\hline CHEMBL1450903 & 737825 & 5.7 & 5.6428 & TRN & \\
\hline CHEMBL1397517 & 737825 & 5.1 & 4.9438 & TRN & \\
\hline CHEMBL1532949 & 737825 & 5.4 & 5.3012 & TRN & \\
\hline CHEMBL1340566 & 737825 & 4.6 & 5.1148 & TRN & \\
\hline
\end{tabular}




\begin{tabular}{|c|c|c|c|c|c|}
\hline \\
\hline CHEMBL1376755 & 737825 & 6.2 & 5.1372 & TRN & \\
\hline CHEMBL1349535 & 737825 & 5.75 & 5.136 & TRN & \\
\hline CHEMBL1366361 & 737825 & 5.3 & 5.3013 & TRN & \\
\hline CHEMBL1441823 & 737825 & 5.9 & 5.3505 & TRN & \\
\hline CHEMBL3212645 & 737825 & 5.5 & 5.4671 & TRN & \\
\hline CHEMBL1379007 & 737825 & 4.9 & 5.1027 & TRN & \\
\hline CHEMBL1333742 & 737825 & 5.45 & 5.2286 & TRN & \\
\hline CHEMBL1557790 & 737825 & 4.95 & 5.2503 & TRN & \\
\hline CHEMBL3208184 & 737825 & 5.45 & 5.1925 & TRN & \\
\hline CHEMBL1325511 & 737825 & 5.4 & 5.2001 & TST & \\
\hline CHEMBL1352616 & 737825 & 5.0 & 5.1704 & TRN & \\
\hline CHEMBL1357167 & 737825 & 5.0 & 4.9562 & TRN & \\
\hline CHEMBL1531837 & 737825 & 6.6 & 6.3863 & TRN & \\
\hline CHEMBL1417583 & 737825 & 5.35 & 5.1368 & TST & \\
\hline CHEMBL1449417 & 737825 & 4.9 & 4.7894 & TRN & \\
\hline CHEMBL1410452 & 737825 & 4.8 & 5.135 & TRN & \\
\hline CHEMBL21396 & 737825 & 5.1 & 5.6596 & TST & \\
\hline CHEMBL1306278 & 737825 & 5.0 & 5.2358 & TRN & \\
\hline CHEMBL1333056 & 737825 & 6.0 & 5.7404 & TST & \\
\hline CHEMBL1590992 & 737825 & 5.3 & 4.949 & TRN & \\
\hline CHEMBL540848 & 737825 & 6.0 & 5.6397 & TRN & \\
\hline CHEMBL76904 & 737825 & 4.5 & 4.4966 & TRN & \\
\hline CHEMBL1333783 & 737825 & 6.1 & 5.947 & TRN & \\
\hline CHEMBL1504668 & 737825 & 4.4 & 5.115 & TRN & \\
\hline CHEMBL1438061 & 737825 & 4.5 & 5.1515 & TRN & \\
\hline CHEMBL1365785 & 737825 & 4.65 & 5.1456 & TRN & \\
\hline CHEMBL1433559 & 737825 & 5.1 & 5.0629 & TRN & \\
\hline CHEMBL1483344 & 737825 & 5.1 & $5.1110 e$ & 0000000001 & TRN \\
\hline CHEMBL1398786 & 737825 & 4.8 & 5.1362 & TRN & \\
\hline CHEMBL1592876 & 737825 & 5.4 & 5.3842 & TRN & \\
\hline CHEMBL1312774 & 737825 & 5.65 & 5.1957 & TST & \\
\hline CHEMBL1741932 & 737825 & 4.85 & 5.1153 & TRN & \\
\hline CHEMBL3191343 & 737825 & 4.65 & 5.0442 & TRN & \\
\hline CHEMBL36148 & 737825 & 6.0 & 5.7765 & TRN & \\
\hline CHEMBL1378731 & 737825 & 5.3 & 5.2303 & TST & \\
\hline CHEMBL1332630 & 737825 & 5.65 & 5.1797 & TRN & \\
\hline CHEMBL1322959 & 737825 & 6.0 & 5.7778 & TST & \\
\hline CHEMBL1398137 & 737825 & 5.1 & 4.9338 & TRN & \\
\hline CHEMBL1326360 & 737825 & 5.8 & 5.8242 & TRN & \\
\hline CHEMBL1969457 & 737825 & 5.55 & 5.2444 & TRN & \\
\hline CHEMBL1591903 & 737825 & 5.4 & 5.3658 & TRN & \\
\hline CHEMBL1570869 & 737825 & 4.85 & 5.3198 & TRN & \\
\hline CHEMBL1349241 & 737825 & 4.8 & 5.026 & TRN & \\
\hline CHEMBL1561910 & 737825 & 4.75 & 5.0197 & TRN & \\
\hline CHEMBL1301059 & 737825 & 5.15 & 5.1057 & TST & \\
\hline CHEMBL1342069 & 737825 & 5.35 & 5.2611 & TST & \\
\hline CHEMBL1461936 & 737825 & 4.5 & 5.1864 & TRN & \\
\hline CHEMBL490577 & 737825 & 5.5 & 5.3377 & TRN & \\
\hline
\end{tabular}




\begin{tabular}{|c|c|c|c|c|}
\hline \multicolumn{5}{|c|}{ Supplemental Table S2.txt } \\
\hline CHEMBL1490307 & 737825 & 4.4 & 4.5568 & TRN \\
\hline CHEMBL1353281 & 737825 & 4.55 & 5.2002 & TRN \\
\hline CHEMBL1370043 & 737825 & 4.7 & 4.6656 & TRN \\
\hline CHEMBL1596765 & 737825 & 5.0 & 5.1069 & TST \\
\hline CHEMBL1517765 & 737825 & 5.4 & 5.51 & TRN \\
\hline CHEMBL1588312 & 737825 & 4.75 & 5.2487 & TRN \\
\hline CHEMBL1408486 & 737825 & 5.5 & 5.1024 & TRN \\
\hline CHEMBL 3212320 & 737825 & 5.3 & 5.1065 & TRN \\
\hline CHEMBL1437408 & 737825 & 5.4 & 5.2363 & TRN \\
\hline CHEMBL1373998 & 737825 & 5.2 & 5.1316 & TRN \\
\hline CHEMBL1380975 & 737825 & 4.55 & 5.1764 & TRN \\
\hline CHEMBL1341687 & 737825 & 5.45 & 4.9533 & TST \\
\hline CHEMBL1327836 & 737825 & 4.95 & 5.2092 & TRN \\
\hline CHEMBL1552588 & 737825 & 5.0 & 4.8509 & TRN \\
\hline CHEMBL1555480 & 737825 & 4.8 & 4.688 & TRN \\
\hline CHEMBL3214406 & 737825 & 5.6 & 5.3647 & TST \\
\hline CHEMBL1595856 & 737825 & 5.4 & 5.391 & TRN \\
\hline CHEMBL1489178 & 737825 & 5.45 & 4.971 & TRN \\
\hline CHEMBL1404954 & 737825 & 4.5 & 4.4544 & TRN \\
\hline CHEMBL1435912 & 737825 & 4.9 & 4.9447 & TRN \\
\hline CHEMBL1731530 & 737825 & 4.65 & 5.2655 & TRN \\
\hline CHEMBL1741548 & 737825 & 5.4 & 5.1032 & TRN \\
\hline CHEMBL495068 & 737825 & 5.5 & 5.4001 & TRN \\
\hline CHEMBL 3145061 & 737825 & 4.85 & 5.144 & TRN \\
\hline CHEMBL1463060 & 737825 & 5.2 & 5.1862 & TRN \\
\hline CHEMBL1374710 & 737825 & 4.9 & 4.8112 & TRN \\
\hline CHEMBL1382075 & 737825 & 4.4 & 5.117 & TRN \\
\hline CHEMBL1371311 & 737825 & 5.4 & 5.2581 & TST \\
\hline CHEMBL1558511 & 737825 & 5.0 & 4.9285 & TRN \\
\hline CHEMBL117 & 737825 & 5.5 & 5.8049 & TRN \\
\hline CHEMBL1338985 & 737825 & 5.1 & 5.0154 & TRN \\
\hline CHEMBL140220 & 737825 & 5.1 & 5.0411 & TRN \\
\hline CHEMBL1480350 & 737825 & 4.8 & 4.7331 & TRN \\
\hline CHEMBL1256392 & 737825 & 4.6 & 4.7281 & TRN \\
\hline CHEMBL1481746 & 737825 & 6.05 & 4.9838 & TST \\
\hline CHEMBL1490998 & 737825 & 5.1 & 4.9901 & TRN \\
\hline CHEMBL1602633 & 737825 & 5.7 & 5.5798 & TRN \\
\hline CHEMBL1306798 & 737825 & 6.05 & 5.2613 & TRN \\
\hline CHEMBL1370053 & 737825 & 5.4 & 5.1144 & TRN \\
\hline CHEMBL1315292 & 737825 & 5.9 & 6.0443 & TRN \\
\hline CHEMBL1484196 & 737825 & 5.9 & 5.8166 & TRN \\
\hline CHEMBL1504000 & 737825 & 5.6 & 5.2604 & TRN \\
\hline CHEMBL1591537 & 737825 & 5.2 & 5.3412 & TRN \\
\hline CHEMBL1504272 & 737825 & 4.45 & 5.1432 & TRN \\
\hline CHEMBL1473430 & 737825 & 5.9 & 5.6144 & TRN \\
\hline CHEMBL1414477 & 737825 & 5.4 & 5.4166 & TRN \\
\hline CHEMBL1543533 & 737825 & 5.45 & 5.2091 & TRN \\
\hline CHEMBL3212160 & 737825 & 5.4 & 5.3638 & TRN \\
\hline
\end{tabular}




\begin{tabular}{|c|c|c|c|c|c|}
\hline \multicolumn{6}{|c|}{ Supplemental Table S2.txt } \\
\hline CHEMBL1321459 & 737825 & 5.4 & 5.4205 & TRN & \\
\hline CHEMBL1355432 & 737825 & 4.5 & 4.4999 & TRN & \\
\hline CHEMBL1364859 & 737825 & 4.9 & 4.8657 & TRN & \\
\hline CHEMBL1552519 & 737825 & 4.8 & 4.8531 & TRN & \\
\hline CHEMBL1714603 & 737825 & 5.65 & 5.113 & TRN & \\
\hline CHEMBL1532000 & 737825 & 5.3 & 5.28700 & 0000000001 & TRN \\
\hline CHEMBL1563066 & 737825 & 5.4 & 5.20200 & 0000000001 & TRN \\
\hline CHEMBL1393997 & 737825 & 5.9 & 5.2382 & TRN & \\
\hline CHEMBL1356463 & 737825 & 5.4 & 5.4416 & TRN & \\
\hline CHEMBL1348021 & 737825 & 4.85 & 5.1724 & TRN & \\
\hline CHEMBL1341270 & 737825 & 4.8 & 5.072 & TRN & \\
\hline CHEMBL1370805 & 737825 & 5.2 & 5.1675 & TRN & \\
\hline CHEMBL1394112 & 737825 & 4.8 & 4.5953 & TRN & \\
\hline CHEMBL1353336 & 737825 & 5.2 & 5.1114 & TRN & \\
\hline CHEMBL1608975 & 737825 & 5.4 & 5.2573 & TRN & \\
\hline CHEMBL1353611 & 737825 & 4.9 & 5.1432 & TRN & \\
\hline CHEMBL1610129 & 737825 & 4.8 & 4.8687 & TST & \\
\hline CHEMBL1355227 & 737825 & 4.9 & 4.7064 & TRN & \\
\hline CHEMBL1569655 & 737825 & 5.3 & 5.1873 & TRN & \\
\hline CHEMBL3213016 & 737825 & 4.85 & 4.9988 & TRN & \\
\hline CHEMBL1496571 & 737825 & 5.7 & 5.2462 & TRN & \\
\hline CHEMBL1447245 & 737825 & 4.85 & 5.2044 & TRN & \\
\hline CHEMBL1364298 & 737825 & 6.45 & 5.4543 & TRN & \\
\hline CHEMBL1539333 & 737825 & 6.1 & 5.2421 & TST & \\
\hline CHEMBL1323166 & 737825 & 4.6 & 4.9916 & TRN & \\
\hline CHEMBL1494695 & 737825 & 5.5 & 5.2091 & TRN & \\
\hline CHEMBL1455802 & 737825 & 5.7 & 5.0422 & TRN & \\
\hline CHEMBL1457785 & 737825 & 5.95 & 5.2371 & TST & \\
\hline CHEMBL3197465 & 737825 & 5.65 & 5.3024 & TRN & \\
\hline CHEMBL3192752 & 737825 & 4.9 & 5.267 & TRN & \\
\hline CHEMBL1355090 & 737825 & 4.6 & 4.654 & TRN & \\
\hline CHEMBL3196654 & 737825 & 4.95 & 5.2037 & TRN & \\
\hline CHEMBL1523520 & 737825 & 5.5 & 5.1419 & TST & \\
\hline CHEMBL1410311 & 737825 & 4.55 & 4.7682 & TRN & \\
\hline CHEMBL1475689 & 737825 & 4.4 & 4.331 & TRN & \\
\hline CHEMBL1741492 & 737825 & 5.85 & 5.3797 & TRN & \\
\hline CHEMBL1593134 & 737825 & 4.9 & 4.7578 & TRN & \\
\hline CHEMBL1576499 & 737825 & 5.65 & 5.2895 & TRN & \\
\hline CHEMBL1493476 & 737825 & 4.5 & 4.3975 & TRN & \\
\hline CHEMBL1395567 & 737825 & 5.7 & 5.5245 & TRN & \\
\hline CHEMBL1420885 & 737825 & 5.1 & 5.0638 & TST & \\
\hline CHEMBL335231 & 737825 & 5.5 & 5.274 & TST & \\
\hline CHEMBL1452049 & 737825 & 5.8 & 5.6031 & TRN & \\
\hline CHEMBL1440842 & 737825 & 6.6 & 6.3277 & TST & \\
\hline CHEMBL1456312 & 737825 & 5.1 & 5.0251 & TRN & \\
\hline CHEMBL1365537 & 737825 & 5.4 & 5.3972 & TRN & \\
\hline CHEMBL1588064 & 737825 & 5.4 & 5.1939 & TRN & \\
\hline CHEMBL1411578 & 737825 & 4.8 & 4.6464 & TST & \\
\hline
\end{tabular}




\begin{tabular}{|c|c|c|c|c|c|}
\hline \\
\hline CHEMBL1306540 & 737825 & 4.9 & 5.2313 & TRN & \\
\hline CHEMBL1398066 & 737825 & 4.9 & 4.8801 & TRN & \\
\hline CHEMBL1480632 & 737825 & 4.8 & 5.1016 & TRN & \\
\hline CHEMBL3194920 & 737825 & 4.9 & 5.3812 & TRN & \\
\hline CHEMBL1572599 & 737825 & 5.35 & 5.1525 & TRN & \\
\hline CHEMBL1551841 & 737825 & 5.5 & 5.3074 & TRN & \\
\hline CHEMBL434063 & 737825 & 5.0 & 5.2992 & TST & \\
\hline CHEMBL1336932 & 737825 & 5.0 & 4.7889 & TRN & \\
\hline CHEMBL1400006 & 737825 & 5.15 & 5.2678 & TRN & \\
\hline CHEMBL1402495 & 737825 & 5.4 & 5.3409 & TRN & \\
\hline CHEMBL1378691 & 737825 & 5.1 & 4.8528 & TRN & \\
\hline CHEMBL1503340 & 737825 & 5.35 & 5.2082 & TST & \\
\hline CHEMBL1516211 & 737825 & 5.0 & 5.0636 & TRN & \\
\hline CHEMBL1534202 & 737825 & 4.9 & 4.9464 & TRN & \\
\hline CHEMBL1413443 & 737825 & 4.85 & 5.3041 & TRN & \\
\hline CHEMBL1475945 & 737825 & 5.4 & 5.3952 & TRN & \\
\hline CHEMBL1473996 & 737825 & 6.0 & 5.9676 & TRN & \\
\hline CHEMBL1438566 & 737825 & 6.0 & 5.71399 & 99999999995 & TRN \\
\hline CHEMBL1476230 & 737825 & 4.6 & 4.6035 & TRN & \\
\hline CHEMBL1587518 & 737825 & 4.9 & 5.1189 & TST & \\
\hline CHEMBL1335690 & 737825 & 5.35 & 5.1612 & TRN & \\
\hline CHEMBL3192627 & 737825 & 4.85 & 5.3213 & TRN & \\
\hline CHEMBL1585833 & 737825 & 4.85 & 5.175 & TST & \\
\hline CHEMBL1473753 & 737825 & 5.3 & 5.2119 & TRN & \\
\hline CHEMBL1741630 & 737825 & 5.1 & 5.1584 & TRN & \\
\hline CHEMBL1995904 & 737825 & 5.4 & 5.1152 & TRN & \\
\hline CHEMBL1350935 & 737825 & 4.85 & 5.2257 & TRN & \\
\hline CHEMBL1493284 & 737825 & 4.6 & 4.5108 & TRN & \\
\hline CHEMBL1559333 & 737825 & 4.6 & 5.0511 & TRN & \\
\hline CHEMBL1327850 & 737825 & 4.7 & 5.2332 & TRN & \\
\hline CHEMBL1578522 & 737825 & 4.75 & 5.3241 & TRN & \\
\hline CHEMBL1445094 & 737825 & 5.0 & 5.048 & TRN & \\
\hline CHEMBL1473965 & 737825 & 6.7 & 5.9749 & TRN & \\
\hline CHEMBL3210860 & 737825 & 5.05 & 5.2014 & TRN & \\
\hline CHEMBL1358810 & 737825 & 5.5 & 5.3237 & TRN & \\
\hline CHEMBL1548199 & 737825 & 4.6 & 5.3071 & TRN & \\
\hline CHEMBL1370610 & 737825 & 4.9 & 5.7246 & TST & \\
\hline CHEMBL1302114 & 737825 & 4.45 & 5.0683 & TRN & \\
\hline CHEMBL1256923 & 737825 & 5.2 & 5.0649 & TST & \\
\hline CHEMBL1458664 & 737825 & 5.0 & 5.0856 & TRN & \\
\hline CHEMBL1383447 & 737825 & 4.85 & 5.0297 & TRN & \\
\hline CHEMBL1414592 & 737825 & 4.7 & 4.5759 & TRN & \\
\hline CHEMBL3194935 & 737825 & 4.9 & 5.2344 & TRN & \\
\hline CHEMBL1433052 & 737825 & 5.15 & 5.0353 & TST & \\
\hline CHEMBL3193129 & 737825 & 6.3 & 5.2453 & TRN & \\
\hline CHEMBL1565724 & 737825 & 5.0 & 5.2338 & TRN & \\
\hline CHEMBL1538789 & 737825 & 5.45 & 5.2735 & TRN & \\
\hline CHEMBL1566120 & 737825 & 4.7 & 5.1036 & TRN & \\
\hline & & & & 22537 & \\
\hline
\end{tabular}




\begin{tabular}{|c|c|c|c|c|}
\hline \multicolumn{5}{|c|}{ Supplemental Table S2.txt } \\
\hline CHEMBL 247378 & 737825 & 4.4 & 4.5813 & TST \\
\hline CHEMBL1551477 & 737825 & 5.1 & 4.9557 & TRN \\
\hline CHEMBL1570971 & 737825 & 5.4 & 5.1701 & TRN \\
\hline CHEMBL1378653 & 737825 & 4.5 & 5.1325 & TRN \\
\hline CHEMBL1322757 & 737825 & 5.2 & 5.107 & TRN \\
\hline CHEMBL1560435 & 737825 & 4.85 & 5.2528 & TRN \\
\hline CHEMBL 3208441 & 737825 & 4.45 & 5.19 & TRN \\
\hline CHEMBL1545790 & 737825 & 4.85 & 5.2546 & TRN \\
\hline CHEMBL1558480 & 737825 & 5.6 & 5.3215 & TRN \\
\hline CHEMBL1515899 & 737825 & 6.0 & 5.9389 & TRN \\
\hline CHEMBL1380304 & 737825 & 4.6 & 5.14 & TRN \\
\hline CHEMBL1317884 & 737825 & 5.0 & 4.8024 & TRN \\
\hline CHEMBL1542604 & 737825 & 4.85 & 5.0468 & TST \\
\hline CHEMBL1583076 & 737825 & 5.15 & 5.0855 & TST \\
\hline CHEMBL1393431 & 737825 & 5.45 & 5.2222 & TRN \\
\hline CHEMBL1328109 & 737825 & 5.5 & 5.3033 & TST \\
\hline CHEMBL1604670 & 737825 & 5.45 & 5.0913 & TRN \\
\hline CHEMBL1364466 & 737825 & 4.8 & 5.1788 & TRN \\
\hline CHEMBL1513876 & 737825 & 5.2 & 4.8833 & TRN \\
\hline CHEMBL1525465 & 737825 & 5.85 & 5.1464 & TRN \\
\hline CHEMBL338790 & 737825 & 5.5 & 5.2223 & TST \\
\hline CHEMBL1324640 & 737825 & 4.85 & 5.0103 & TST \\
\hline CHEMBL1441649 & 737825 & 4.7 & 4.739 & TRN \\
\hline CHEMBL1412997 & 737825 & 5.55 & 5.1768 & TRN \\
\hline CHEMBL2373666 & 737825 & 4.6 & 4.6538 & TST \\
\hline CHEMBL1439882 & 737825 & 6.1 & 5.7695 & TRN \\
\hline CHEMBL1424384 & 737825 & 5.55 & 5.2814 & TRN \\
\hline CHEMBL1079374 & 737825 & 4.85 & 5.0242 & TRN \\
\hline CHEMBL1440108 & 737825 & 5.2 & 5.2122 & TRN \\
\hline CHEMBL1363883 & 737825 & 6.0 & 5.7353 & TST \\
\hline CHEMBL1587843 & 737825 & 4.55 & 5.1334 & TRN \\
\hline CHEMBL1433021 & 737825 & 6.0 & 5.4487 & TRN \\
\hline CHEMBL227298 & 737825 & 5.3 & 5.1832 & TST \\
\hline CHEMBL1321338 & 737825 & 4.8 & 4.7434 & TRN \\
\hline CHEMBL1556045 & 737825 & 6.7 & 6.405 & TRN \\
\hline CHEMBL1270168 & 737825 & 5.4 & 5.2327 & TRN \\
\hline CHEMBL1437804 & 737825 & 4.8 & 4.8635 & TST \\
\hline CHEMBL1589942 & 737825 & 5.9 & 5.6734 & TST \\
\hline CHEMBL490706 & 737825 & 5.7 & 5.5876 & TRN \\
\hline CHEMBL1523055 & 737825 & 4.6 & 5.0951 & TRN \\
\hline CHEMBL1380396 & 737825 & 6.35 & 5.7338 & TRN \\
\hline CHEMBL1412697 & 737825 & 4.95 & 5.1332 & TRN \\
\hline CHEMBL1432368 & 737825 & 6.05 & 5.273 & TRN \\
\hline CHEMBL1604742 & 737825 & 5.55 & 5.4529 & TRN \\
\hline CHEMBL1495773 & 737825 & 4.6 & 4.5303 & TRN \\
\hline CHEMBL1553797 & 737825 & 4.7 & 4.6096 & TRN \\
\hline CHEMBL1515804 & 737825 & 5.3 & 5.1731 & TRN \\
\hline CHEMBL1482542 & 737825 & 5.4 & 5.2287 & TRN \\
\hline
\end{tabular}




\begin{tabular}{|c|c|c|c|c|}
\hline & & & pplement & $\mathrm{a} \perp \mathrm{Ta}$ \\
\hline CHEMBL1474471 & 737825 & 4.8 & 4.6999 & TRN \\
\hline CHEMBL1496370 & 737825 & 5.95 & 5.3065 & TST \\
\hline CHEMBL1591190 & 737825 & 4.8 & 4.7646 & TRN \\
\hline CHEMBL1573507 & 737825 & 4.4 & 5.1803 & TST \\
\hline CHEMBL601616 & 737825 & 4.6 & 5.1366 & TRN \\
\hline CHEMBL1714881 & 737825 & 4.7 & 4.8956 & TRN \\
\hline CHEMBL1411360 & 737825 & 6.0 & 5.6671 & TST \\
\hline CHEMBL1436644 & 737825 & 4.8 & 4.7 & TRN \\
\hline CHEMBL1534376 & 737825 & 5.1 & 5.2523 & TRN \\
\hline CHEMBL1483855 & 737825 & 5.5 & 5.5525 & TRN \\
\hline CHEMBL1465191 & 737825 & 4.8 & 5.2458 & TRN \\
\hline CHEMBL 259073 & 737825 & 5.0 & 4.8706 & TRN \\
\hline CHEMBL1605000 & 737825 & 5.2 & 5.1445 & TRN \\
\hline CHEMBL1350415 & 737825 & 5.95 & 5.1506 & TRN \\
\hline CHEMBL1566900 & 737825 & 4.8 & 5.0898 & TRN \\
\hline CHEMBL1729853 & 737825 & 5.7 & 5.2043 & TRN \\
\hline CHEMBL1489589 & 737825 & 4.6 & 4.5336 & TRN \\
\hline CHEMBL1358252 & 737825 & 4.8 & 4.7042 & TRN \\
\hline CHEMBL1494227 & 737825 & 5.5 & 5.4198 & TRN \\
\hline CHEMBL1255653 & 737825 & 6.5 & 6.0631 & TST \\
\hline CHEMBL1502553 & 737825 & 4.55 & 5.0784 & TRN \\
\hline CHEMBL1546319 & 737825 & 5.2 & 5.1727 & TST \\
\hline CHEMBL1981379 & 737825 & 4.85 & 5.1163 & TST \\
\hline CHEMBL1554088 & 737825 & 4.9 & 4.8351 & TRN \\
\hline CHEMBL1566571 & 737825 & 5.0 & 4.7637 & TRN \\
\hline CHEMBL3198835 & 737825 & 5.85 & 5.334 & TRN \\
\hline CHEMBL1594473 & 737825 & 4.85 & 4.9393 & TRN \\
\hline CHEMBL1404071 & 737825 & 4.85 & 5.3015 & TRN \\
\hline CHEMBL1452413 & 737825 & 5.1 & 4.9532 & TRN \\
\hline CHEMBL1396792 & 737825 & 5.5 & 5.3333 & TRN \\
\hline CHEMBL1516232 & 737825 & 7.5 & 6.1736 & TRN \\
\hline CHEMBL1590738 & 737825 & 5.1 & 4.9395 & TRN \\
\hline CHEMBL95431 & 737825 & 5.5 & 5.2748 & TST \\
\hline CHEMBL1741334 & 737825 & 4.85 & 5.0976 & TRN \\
\hline CHEMBL1410635 & 737825 & 5.5 & 5.5131 & TRN \\
\hline CHEMBL1593645 & 737825 & 5.4 & 5.4179 & TRN \\
\hline CHEMBL1488990 & 737825 & 5.4 & 5.2548 & TRN \\
\hline CHEMBL1520919 & 737825 & 5.1 & 5.1783 & TST \\
\hline CHEMBL1591876 & 737825 & 4.8 & 4.8248 & TRN \\
\hline CHEMBL1449528 & 737825 & 5.8 & 5.6478 & TRN \\
\hline CHEMBL1441843 & 737825 & 4.7 & 4.524 & TRN \\
\hline CHEMBL1566012 & 737825 & 5.8 & 5.5222 & TST \\
\hline CHEMBL1303217 & 737825 & 4.75 & 5.0453 & TRN \\
\hline CHEMBL1597209 & 737825 & 4.6 & 4.5392 & TRN \\
\hline CHEMBL1965223 & 737825 & 5.3 & 5.2732 & TRN \\
\hline CHEMBL1508636 & 737825 & 4.6 & 5.0948 & TRN \\
\hline CHEMBL1435086 & 737825 & 4.8 & 4.6899 & TRN \\
\hline CHEMBL1339319 & 737825 & 5.45 & 5.1385 & TRN \\
\hline
\end{tabular}




\begin{tabular}{|c|c|c|c|c|c|}
\hline & & & & & \\
\hline CHEMBL1369871 & 737825 & 4.8 & 4.7124 & TRN & \\
\hline CHEMBL1393435 & 737825 & 4.9 & 5.2003 & TST & \\
\hline CHEMBL1601416 & 737825 & 4.5 & 4.3785 & TRN & \\
\hline CHEMBL1520238 & 737825 & 5.1 & 5.2404 & TRN & \\
\hline CHEMBL1729447 & 737825 & 4.95 & 5.20299 & 9999999999 & TRN \\
\hline CHEMBL1574231 & 737825 & 5.3 & 5.3635 & TRN & \\
\hline CHEMBL1401085 & 737825 & 4.95 & 5.2023 & TRN & \\
\hline CHEMBL1552623 & 737825 & 6.3 & 6.3849 & TRN & \\
\hline CHEMBL1524497 & 737825 & 4.85 & 5.0024 & TRN & \\
\hline CHEMBL1450936 & 737825 & 5.1 & 4.9221 & TRN & \\
\hline CHEMBL1439334 & 737825 & 6.0 & 5.9193 & TRN & \\
\hline CHEMBL1351426 & 737825 & 4.9 & 5.1854 & TST & \\
\hline CHEMBL1347660 & 737825 & 4.6 & 5.1983 & TRN & \\
\hline CHEMBL1457332 & 737825 & 5.6 & 5.5404 & TRN & \\
\hline CHEMBL1256984 & 737825 & 5.6 & 5.5289 & TST & \\
\hline CHEMBL1400667 & 737825 & 5.1 & 4.9689 & TST & \\
\hline CHEMBL1409802 & 737825 & 4.85 & 5.1223 & TST & \\
\hline CHEMBL1613049 & 737825 & 5.5 & 5.17899 & 9999999999 & TRN \\
\hline CHEMBL1406800 & 737825 & 4.55 & 5.1207 & TRN & \\
\hline CHEMBL1321846 & 737825 & 5.5 & 5.5719 & TRN & \\
\hline CHEMBL1503191 & 737825 & 4.8 & 4.9951 & TRN & \\
\hline CHEMBL1475924 & 737825 & 7.1 & 6.5988 & TRN & \\
\hline CHEMBL1599132 & 737825 & 4.95 & 5.1793 & TRN & \\
\hline CHEMBL1329895 & 737825 & 5.65 & 5.2825 & TST & \\
\hline CHEMBL1315079 & 737825 & 4.6 & 4.4857 & TRN & \\
\hline CHEMBL1532380 & 737825 & 5.45 & 4.9745 & TRN & \\
\hline CHEMBL3199340 & 737825 & 4.85 & 5.1729 & TRN & \\
\hline CHEMBL1429594 & 737825 & 5.65 & 5.4191 & TRN & \\
\hline CHEMBL1408815 & 737825 & 5.4 & 5.115 & TRN & \\
\hline CHEMBL3211338 & 737825 & 6.0 & 5.9765 & TRN & \\
\hline CHEMBL1523108 & 737825 & 5.1 & 5.0322 & TRN & \\
\hline CHEMBL85194 & 737825 & 5.0 & 5.1032 & TRN & \\
\hline CHEMBL1578122 & 737825 & 4.8 & 5.1535 & TRN & \\
\hline CHEMBL1373773 & 737825 & 6.5 & 6.1353 & TRN & \\
\hline CHEMBL3197636 & 737825 & 4.5 & 5.1204 & TRN & \\
\hline CHEMBL1527443 & 737825 & 5.7 & 5.681 & TRN & \\
\hline CHEMBL1399438 & 737825 & 5.0 & 4.8696 & TST & \\
\hline CHEMBL1606968 & 737825 & 5.5 & 5.0911 & TRN & \\
\hline CHEMBL1362159 & 737825 & 4.85 & 5.0306 & TRN & \\
\hline CHEMBL166161 & 737825 & 4.5 & 4.6772 & TST & \\
\hline CHEMBL1387271 & 737825 & 6.0 & 5.2186 & TRN & \\
\hline CHEMBL1518415 & 737825 & 6.5 & 6.3749 & TRN & \\
\hline CHEMBL1418178 & 737825 & 5.3 & 5.1183 & TRN & \\
\hline CHEMBL1541553 & 737825 & 4.9 & 5.2461 & TRN & \\
\hline CHEMBL1741782 & 737825 & 4.6 & 5.0812 & TRN & \\
\hline CHEMBL1451899 & 737825 & 4.95 & 5.1116 & TRN & \\
\hline CHEMBL1480371 & 737825 & 5.0 & 5.0845 & TRN & \\
\hline CHEMBL1314388 & 737825 & 6.0 & 5.9769 & TRN & \\
\hline & & & & 22540 & \\
\hline
\end{tabular}




\begin{tabular}{|c|c|c|c|c|}
\hline \multicolumn{5}{|c|}{ Supplemental Table S2.txt } \\
\hline CHEMBL1330459 & 737825 & 5.3 & 5.6281 & TRN \\
\hline CHEMBL3198365 & 737825 & 4.85 & 5.3314 & TRN \\
\hline CHEMBL1301415 & 737825 & 4.6 & 5.1761 & TRN \\
\hline CHEMBL1576725 & 737825 & 5.85 & 5.7039 & TRN \\
\hline CHEMBL1323167 & 737825 & 5.5 & 5.3216 & TST \\
\hline CHEMBL491748 & 737825 & 5.1 & 5.1274 & TRN \\
\hline CHEMBL1491455 & 737825 & 5.4 & 5.2267 & TST \\
\hline CHEMBL1538611 & 737825 & 4.85 & 5.0639 & TRN \\
\hline CHEMBL1475131 & 737825 & 6.4 & 6.4302 & TRN \\
\hline CHEMBL1501724 & 737825 & 4.85 & 5.006 & TRN \\
\hline CHEMBL1345018 & 737825 & 4.65 & 5.1325 & TRN \\
\hline CHEMBL1339404 & 737825 & 4.75 & 5.1306 & TRN \\
\hline CHEMBL1330057 & 737825 & 5.5 & 5.3421 & TRN \\
\hline CHEMBL1365175 & 737825 & 5.15 & 5.1247 & TRN \\
\hline CHEMBL1463140 & 737825 & 4.7 & 5.0329 & TRN \\
\hline CHEMBL3214526 & 737825 & 5.75 & 5.1645 & TRN \\
\hline CHEMBL1397079 & 737825 & 4.6 & 4.5216 & TRN \\
\hline CHEMBL1558777 & 737825 & 4.8 & 4.7372 & TRN \\
\hline CHEMBL1567373 & 737825 & 4.4 & 5.199 & TRN \\
\hline CHEMBL1592517 & 737825 & 4.8 & 4.6067 & TRN \\
\hline CHEMBL1563497 & 737825 & 5.6 & 5.5427 & TRN \\
\hline CHEMBL 3197274 & 737825 & 4.6 & 5.0274 & TRN \\
\hline CHEMBL1533616 & 737825 & 5.45 & 5.1837 & TRN \\
\hline CHEMBL1412450 & 737825 & 5.5 & 5.1992 & TRN \\
\hline CHEMBL1492687 & 737825 & 4.8 & 5.1126 & TRN \\
\hline CHEMBL1385943 & 737825 & 5.3 & 5.0588 & TRN \\
\hline CHEMBL1609324 & 737825 & 4.9 & 4.7437 & TRN \\
\hline CHEMBL3211795 & 737825 & 4.75 & 5.2124 & TRN \\
\hline CHEMBL75773 & 737825 & 4.9 & 4.9785 & TRN \\
\hline CHEMBL1552753 & 737825 & 5.4 & 5.4386 & TRN \\
\hline CHEMBL1474209 & 737825 & 5.4 & 5.4403 & TRN \\
\hline CHEMBL1597812 & 737825 & 6.0 & 5.6865 & TST \\
\hline CHEMBL1550134 & 737825 & 5.15 & 5.0717 & TRN \\
\hline CHEMBL1525376 & 737825 & 4.8 & 4.8752 & TST \\
\hline CHEMBL1493402 & 737825 & 5.45 & 5.2619 & TRN \\
\hline CHEMBL1458493 & 737825 & 4.4 & 5.3383 & TRN \\
\hline CHEMBL1512562 & 737825 & 5.3 & 5.0464 & TRN \\
\hline CHEMBL1441737 & 737825 & 5.1 & 4.9784 & TRN \\
\hline CHEMBL1490869 & 737825 & 5.4 & 5.3592 & TRN \\
\hline CHEMBL1363867 & 737825 & 4.85 & 5.1497 & TRN \\
\hline CHEMBL1579981 & 737825 & 5.45 & 5.2728 & TRN \\
\hline CHEMBL1318553 & 737825 & 6.0 & 5.7618 & TST \\
\hline CHEMBL1512312 & 737825 & 4.8 & 4.7214 & TRN \\
\hline CHEMBL1330483 & 737825 & 5.5 & 5.2149 & TRN \\
\hline CHEMBL1429162 & 737825 & 5.05 & 5.2237 & TRN \\
\hline CHEMBL3190415 & 737825 & 5.65 & 5.3425 & TRN \\
\hline CHEMBL1333519 & 737825 & 4.4 & 5.3118 & TRN \\
\hline CHEMBL1535604 & 737825 & 4.9 & 5.1315 & TRN \\
\hline
\end{tabular}




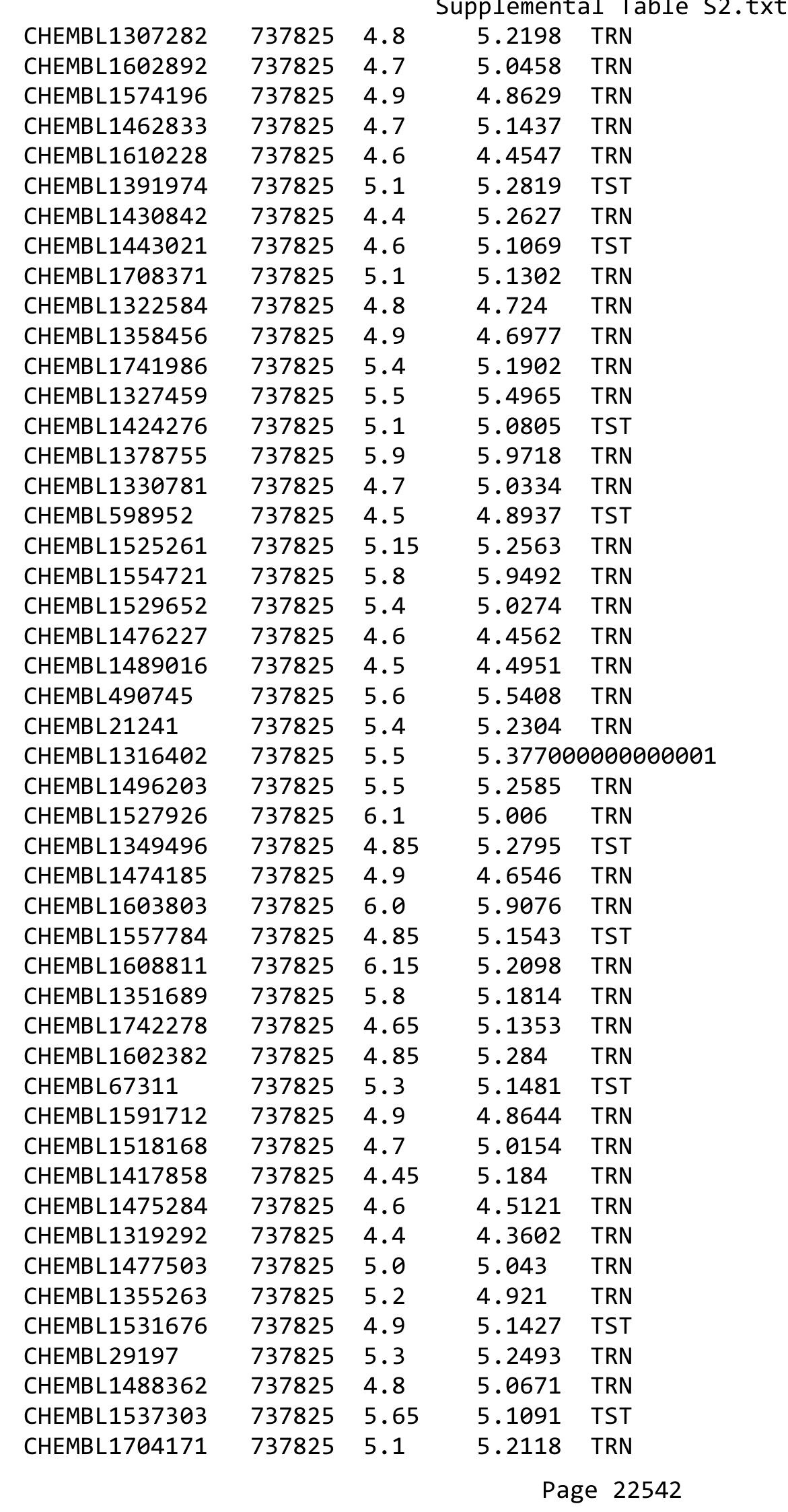

TRN 


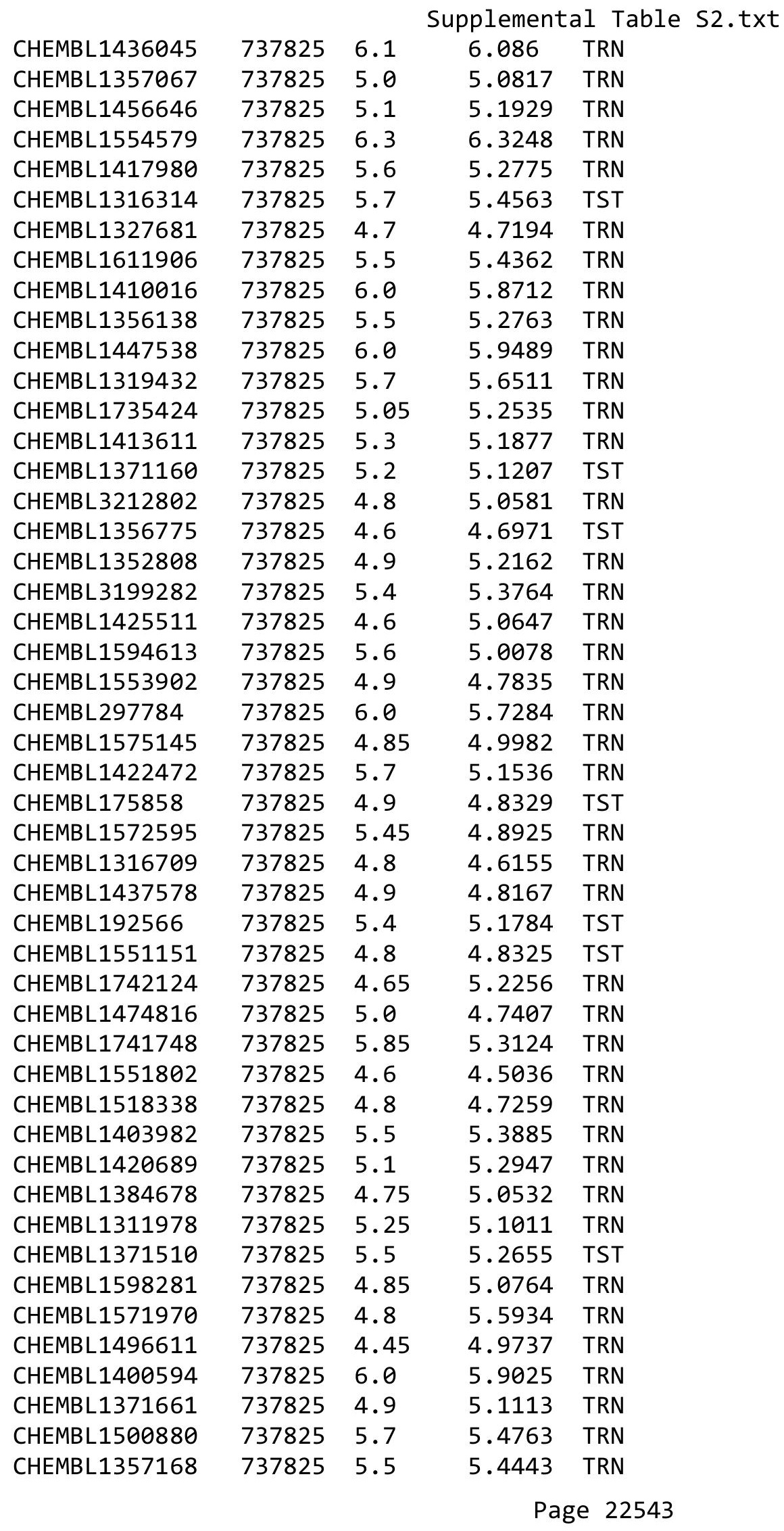




\begin{tabular}{|c|c|c|c|c|c|}
\hline & & \multicolumn{4}{|c|}{ Supplemental Table S2.txt } \\
\hline CHEMBL1524001 & 737825 & 5.1 & 4.7826 & TRN & \\
\hline CHEMBL1450125 & 737825 & 4.6 & 5.3258 & TRN & \\
\hline CHEMBL1453108 & 737825 & 4.7 & 5.1969 & TRN & \\
\hline CHEMBL1520285 & 737825 & 5.9 & 5.5485 & TRN & \\
\hline CHEMBL1409682 & 737825 & 6.1 & 5.7969 & TST & \\
\hline CHEMBL1361731 & 737825 & 4.9 & 4.7566 & TRN & \\
\hline CHEMBL1456034 & 737825 & 4.65 & 4.9777 & TST & \\
\hline CHEMBL1457635 & 737825 & 4.5 & 5.1215 & TRN & \\
\hline CHEMBL1439455 & 737825 & 5.4 & 5.2276 & TRN & \\
\hline CHEMBL310310 & 737825 & 6.0 & 5.6573 & TRN & \\
\hline CHEMBL60718 & 737825 & 5.5 & 5.3523 & TRN & \\
\hline CHEMBL1355089 & 737825 & 5.5 & 5.2993 & TRN & \\
\hline CHEMBL1371898 & 737825 & 4.85 & 5.1189 & TRN & \\
\hline CHEMBL1551133 & 737825 & 5.4 & 5.3854 & TRN & \\
\hline CHEMBL1329026 & 737825 & 5.5 & 5.3741 & TST & \\
\hline CHEMBL1599492 & 737825 & 4.75 & 5.05 & TRN & \\
\hline CHEMBL1361455 & 737825 & 5.85 & 5.2437 & TRN & \\
\hline CHEMBL1357294 & 737825 & 4.8 & 4.7855 & TRN & \\
\hline CHEMBL1585050 & 737825 & 6.0 & 5.0655 & TRN & \\
\hline CHEMBL1355896 & 737825 & 6.5 & 6.3695 & TRN & \\
\hline CHEMBL1479817 & 737825 & 5.1 & 4.9738 & TRN & \\
\hline CHEMBL1567159 & 737825 & 4.65 & 5.2314 & TRN & \\
\hline CHEMBL1559342 & 737825 & 4.85 & 5.2045 & TST & \\
\hline CHEMBL39947 & 737825 & 4.9 & 5.7415 & TST & \\
\hline CHEMBL1411146 & 737825 & 5.1 & 5.0095 & TRN & \\
\hline CHEMBL1527317 & 737825 & 5.9 & 5.6194 & TST & \\
\hline CHEMBL1256911 & 737825 & 4.9 & 4.8731 & TRN & \\
\hline CHEMBL1481347 & 737825 & 4.5 & 4.8666 & TST & \\
\hline CHEMBL1404945 & 737825 & 5.15 & 5.0597 & TST & \\
\hline CHEMBL1476049 & 737825 & 4.6 & 4.5745 & TRN & \\
\hline CHEMBL1411457 & 737825 & 5.9 & 5.0773 & TRN & \\
\hline CHEMBL1412390 & 737825 & 5.5 & 5.5322 & TRN & \\
\hline CHEMBL1399862 & 737825 & 4.8 & 5.0864 & TRN & \\
\hline CHEMBL1460438 & 737825 & 5.05 & 5.0982 & TRN & \\
\hline CHEMBL1371547 & 737825 & -0.0 & 5.3029 & TRN & \\
\hline CHEMBL1556272 & 737825 & 4.85 & 5.2457 & TRN & \\
\hline CHEMBL1416235 & 737825 & 6.2 & 5.1696 & TRN & \\
\hline CHEMBL125569 & 737825 & 4.6 & 4.7033 & TST & \\
\hline CHEMBL1398543 & 737825 & 6.0 & 5.6274 & TRN & \\
\hline CHEMBL523167 & 737825 & 4.8 & 4.8453 & TST & \\
\hline CHEMBL1520743 & 737825 & 5.15 & 5.2647 & TRN & \\
\hline CHEMBL491909 & 737825 & 7.1 & 7.0606 & TRN & \\
\hline CHEMBL1422112 & 737825 & 5.0 & 5.1457 & TRN & \\
\hline CHEMBL1299692 & 737825 & 5.45 & 5.13899 & 9999999999 & TRN \\
\hline CHEMBL1332591 & 737825 & 5.8 & 5.7237 & TRN & \\
\hline CHEMBL1589352 & 737825 & 5.4 & 5.029 & TRN & \\
\hline CHEMBL48449 & 737825 & 6.0 & 5.5121 & TST & \\
\hline CHEMBL1355010 & 737825 & 4.7 & 4.5467 & TRN & \\
\hline
\end{tabular}




\begin{tabular}{|c|c|c|c|c|c|}
\hline \multirow[b]{2}{*}{ CHEMBL1497925 } & \multicolumn{5}{|c|}{ )lemental Table S2 } \\
\hline & 737825 & 4.85 & 5.3063 & TRN & \\
\hline CHEMBL1574160 & 737825 & 5.3 & 4.9561 & TRN & \\
\hline CHEMBL1712760 & 737825 & 4.9 & $5.0760 e$ & 00000000005 & TRN \\
\hline CHEMBL1578454 & 737825 & 4.9 & 5.1245 & TRN & \\
\hline CHEMBL 275084 & 737825 & 5.4 & 5.5737 & TST & \\
\hline CHEMBL1594704 & 737825 & 5.1 & 5.1099 & TRN & \\
\hline CHEMBL1480806 & 737825 & 5.7 & 5.8763 & TRN & \\
\hline CHEMBL1450115 & 737825 & 4.65 & 4.9026 & TRN & \\
\hline CHEMBL1407527 & 737825 & 5.4 & 5.2868 & TRN & \\
\hline CHEMBL1593707 & 737825 & 5.1 & 4.8453 & TRN & \\
\hline CHEMBL1503047 & 737825 & 4.85 & 5.3032 & TRN & \\
\hline CHEMBL35482 & 737825 & 5.1 & 4.926 & TST & \\
\hline CHEMBL1362249 & 737825 & 5.05 & 5.1583 & TST & \\
\hline CHEMBL1592117 & 737825 & 5.1 & 4.8857 & TRN & \\
\hline CHEMBL1523894 & 737825 & 4.8 & 4.4711 & TST & \\
\hline CHEMBL1606673 & 737825 & 4.65 & 5.0423 & TRN & \\
\hline CHEMBL1311969 & 737825 & 5.3 & 5.1589 & TRN & \\
\hline CHEMBL1506391 & 737825 & 6.65 & 5.0031 & TST & \\
\hline CHEMBL1321719 & 737825 & 4.6 & 5.0318 & TRN & \\
\hline CHEMBL1443019 & 737825 & 5.1 & 5.3123 & TRN & \\
\hline CHEMBL 3207490 & 737825 & 5.15 & 5.2405 & TRN & \\
\hline CHEMBL1726069 & 737825 & 4.8 & 5.053 & TST & \\
\hline CHEMBL1457224 & 737825 & 4.9 & 5.0597 & TST & \\
\hline CHEMBL1551578 & 737825 & 5.6 & 5.2051 & TRN & \\
\hline CHEMBL1493851 & 737825 & 5.5 & 5.4467 & TRN & \\
\hline CHEMBL1314516 & 737825 & 4.8 & 4.9782 & TRN & \\
\hline CHEMBL1574531 & 737825 & 5.5 & 5.0638 & TRN & \\
\hline CHEMBL1404501 & 737825 & 4.8 & 4.6446 & TRN & \\
\hline CHEMBL1375985 & 737825 & 5.15 & 5.2623 & TRN & \\
\hline CHEMBL1452716 & 737825 & 5.1 & 5.7499 & TST & \\
\hline CHEMBL1548344 & 737825 & 5.05 & 5.2095 & TRN & \\
\hline CHEMBL1454463 & 737825 & 4.55 & 5.2659 & TRN & \\
\hline CHEMBL1565437 & 737825 & 5.4 & 5.0893 & TRN & \\
\hline CHEMBL1472322 & 737825 & 4.8 & 5.2554 & TRN & \\
\hline CHEMBL1569474 & 737825 & 4.6 & 5.1409 & TRN & \\
\hline CHEMBL1517241 & 737825 & 4.8 & 4.7888 & TRN & \\
\hline CHEMBL1599118 & 737825 & 5.0 & 4.914 & TRN & \\
\hline CHEMBL 1355712 & 737825 & 5.8 & 5.7986 & TRN & \\
\hline CHEMBL1543168 & 737825 & 4.6 & 5.2465 & TRN & \\
\hline CHEMBL1422591 & 737825 & 4.7 & 5.0261 & TRN & \\
\hline CHEMBL69710 & 737825 & 4.5 & 4.3879 & TST & \\
\hline CHEMBL1553491 & 737825 & 4.9 & 4.8208 & TRN & \\
\hline CHEMBL1530832 & 737825 & 5.6 & 5.6233 & TRN & \\
\hline CHEMBL1366754 & 737825 & 4.9 & 4.8199 & TRN & \\
\hline CHEMBL1337524 & 737825 & 4.75 & 5.2028 & TRN & \\
\hline CHEMBL1741463 & 737825 & 6.7 & 5.5782 & TRN & \\
\hline CHEMBL1357956 & 737825 & 4.8 & 4.7311 & TRN & \\
\hline \multirow[t]{2}{*}{ CHEMBL1317986 } & 737825 & 5.3 & 5.24799 & 9999999999 & TST \\
\hline & & \multicolumn{4}{|c|}{ Page 22545} \\
\hline
\end{tabular}




\begin{tabular}{|c|c|c|c|c|c|}
\hline \\
\hline CHEMBL157351 & 737825 & 4.9 & 4.9228 & TST & \\
\hline CHEMBL1572988 & 737825 & 5.7 & 5.6771 & TRN & \\
\hline CHEMBL1466831 & 737825 & 5.15 & 5.1494 & TRN & \\
\hline CHEMBL1497183 & 737825 & 4.8 & 5.2294 & TRN & \\
\hline CHEMBL1498873 & 737825 & 5.0 & 5.1185 & TRN & \\
\hline CHEMBL1545573 & 737825 & 4.6 & 5.1749 & TST & \\
\hline CHEMBL1611820 & 737825 & 4.8 & 4.6229 & TRN & \\
\hline CHEMBL1514517 & 737825 & 5.0 & 4.8312 & TRN & \\
\hline CHEMBL1575273 & 737825 & 4.9 & 5.3629 & TRN & \\
\hline CHEMBL1555637 & 737825 & 4.95 & 5.079 & TRN & \\
\hline CHEMBL1596477 & 737825 & 5.1 & 5.1807 & TRN & \\
\hline CHEMBL1507984 & 737825 & 5.45 & 5.1039 & TST & \\
\hline CHEMBL1440255 & 737825 & 4.4 & 5.1678 & TRN & \\
\hline CHEMBL1357289 & 737825 & 5.0 & 4.8097 & TRN & \\
\hline CHEMBL1448799 & 737825 & 4.85 & 4.9944 & TRN & \\
\hline CHEMBL1416473 & 737825 & 4.8 & 5.1375 & TST & \\
\hline CHEMBL1475657 & 737825 & 5.0 & 4.8785 & TRN & \\
\hline CHEMBL1444545 & 737825 & 4.95 & 5.1139 & TRN & \\
\hline CHEMBL1416351 & 737825 & 6.3 & 5.7074 & TRN & \\
\hline CHEMBL1577515 & 737825 & 4.65 & 5.23799 & 99999999995 & TRN \\
\hline CHEMBL1488115 & 737825 & 4.85 & 5.0015 & TRN & \\
\hline CHEMBL1364804 & 737825 & 4.9 & 5.2302 & TRN & \\
\hline CHEMBL1594612 & 737825 & 6.5 & 6.4774 & TRN & \\
\hline CHEMBL1717404 & 737825 & 4.55 & 4.9825 & TRN & \\
\hline CHEMBL1591487 & 737825 & 4.5 & 4.3801 & TRN & \\
\hline CHEMBL491953 & 737825 & 4.9 & 4.9294 & TRN & \\
\hline CHEMBL257359 & 737825 & 4.5 & 5.1506 & TST & \\
\hline CHEMBL1318285 & 737825 & 5.5 & 5.3182 & TRN & \\
\hline CHEMBL3191520 & 737825 & 4.9 & 5.2286 & TRN & \\
\hline CHEMBL1556436 & 737825 & 6.1 & 5.4243 & TRN & \\
\hline CHEMBL1551584 & 737825 & 6.0 & 5.9455 & TRN & \\
\hline CHEMBL1414269 & 737825 & 4.8 & 4.6367 & TRN & \\
\hline CHEMBL1572589 & 737825 & 5.35 & 5.0387 & TRN & \\
\hline CHEMBL1449268 & 737825 & 4.9 & 5.0731 & TRN & \\
\hline CHEMBL1741919 & 737825 & 5.65 & 5.2884 & TRN & \\
\hline CHEMBL1364963 & 737825 & 5.45 & 5.273 & TRN & \\
\hline CHEMBL1399489 & 737825 & 4.9 & 4.7934 & TRN & \\
\hline CHEMBL1741363 & 737825 & -0.0 & 5.6614 & TRN & \\
\hline CHEMBL1490904 & 737825 & 6.0 & 5.7147 & TRN & \\
\hline CHEMBL1507284 & 737825 & 4.8 & 5.1847 & TRN & \\
\hline CHEMBL1443332 & 737825 & 5.2 & 5.1286 & TRN & \\
\hline CHEMBL1602849 & 737825 & 6.9 & 5.4007 & TRN & \\
\hline CHEMBL3212934 & 737825 & 4.85 & 5.2215 & TST & \\
\hline CHEMBL1569502 & 737825 & 4.9 & 5.1921 & TRN & \\
\hline CHEMBL1741811 & 737825 & 4.8 & 5.1995 & TRN & \\
\hline CHEMBL1491674 & 737825 & 6.2 & 5.3179 & TRN & \\
\hline CHEMBL1400043 & 737825 & 4.8 & 4.7697 & TRN & \\
\hline CHEMBL1575261 & 737825 & 5.9 & 5.3218 & TRN & \\
\hline
\end{tabular}




\begin{tabular}{|c|c|c|c|c|}
\hline \multicolumn{5}{|c|}{ Supplemental Table S2.txt } \\
\hline CHEMBL1356652 & 737825 & 6.2 & 6.2278 & TRN \\
\hline CHEMBL1362616 & 737825 & 4.9 & 5.0874 & TRN \\
\hline CHEMBL1305594 & 737825 & 4.8 & 5.1531 & TRN \\
\hline CHEMBL1394348 & 737825 & 6.0 & 5.7116 & TRN \\
\hline CHEMBL1370377 & 737825 & 4.85 & 5.0859 & TRN \\
\hline CHEMBL1552643 & 737825 & 5.0 & 4.8609 & TRN \\
\hline CHEMBL1404529 & 737825 & 4.85 & 5.1232 & TRN \\
\hline CHEMBL 3196565 & 737825 & 5.15 & 5.2955 & TRN \\
\hline CHEMBL1528993 & 737825 & 4.85 & 5.0793 & TRN \\
\hline CHEMBL1344097 & 737825 & 4.85 & 5.1203 & TST \\
\hline CHEMBL1706828 & 737825 & 5.45 & 5.0868 & TRN \\
\hline CHEMBL1313862 & 737825 & 4.85 & 5.142 & TRN \\
\hline CHEMBL1529538 & 737825 & 4.9 & 4.7288 & TRN \\
\hline CHEMBL1594372 & 737825 & 6.7 & 6.7421 & TRN \\
\hline CHEMBL1353351 & 737825 & 7.4 & 5.4315 & TRN \\
\hline CHEMBL1469165 & 737825 & 4.8 & 5.2093 & TST \\
\hline CHEMBL1379706 & 737825 & 4.9 & 4.9399 & TRN \\
\hline CHEMBL1446743 & 737825 & 5.1 & 5.0222 & TST \\
\hline CHEMBL1705804 & 737825 & 5.05 & 5.1173 & TST \\
\hline CHEMBL1491168 & 737825 & 5.0 & 5.523 & TRN \\
\hline CHEMBL1474483 & 737825 & 5.3 & 5.0376 & TRN \\
\hline CHEMBL1533923 & 737825 & 5.3 & 5.3031 & TRN \\
\hline CHEMBL1436355 & 737825 & 5.3 & 5.2171 & TRN \\
\hline CHEMBL 273094 & 737825 & 5.6 & 5.4802 & TST \\
\hline CHEMBL1256186 & 737825 & 5.5 & 5.2954 & TST \\
\hline CHEMBL1568723 & 737825 & 5.4 & 5.506 & TRN \\
\hline CHEMBL3211920 & 737825 & 6.0 & 5.0453 & TST \\
\hline CHEMBL1363622 & 737825 & 4.5 & 4.4688 & TRN \\
\hline CHEMBL1521784 & 737825 & 4.95 & 5.3419 & TRN \\
\hline CHEMBL1507850 & 737825 & 4.65 & 5.2095 & TRN \\
\hline CHEMBL1455043 & 737825 & 4.6 & 4.9751 & TRN \\
\hline CHEMBL611494 & 737825 & 6.0 & 5.7156 & TST \\
\hline CHEMBL1568946 & 737825 & 5.2 & 5.1855 & TRN \\
\hline CHEMBL1358738 & 737825 & 5.5 & 5.3548 & TRN \\
\hline CHEMBL1365504 & 737825 & 4.9 & 5.5405 & TRN \\
\hline CHEMBL1512878 & 737825 & 5.8 & 5.9082 & TRN \\
\hline CHEMBL1405546 & 737825 & 5.5 & 5.2682 & TRN \\
\hline CHEMBL1330929 & 737825 & 5.0 & 5.2698 & TRN \\
\hline CHEMBL516616 & 737825 & 5.4 & 5.1881 & TST \\
\hline CHEMBL1483672 & 737825 & 6.0 & 5.8438 & TRN \\
\hline CHEMBL 37312 & 737825 & 5.4 & 5.3277 & TRN \\
\hline CHEMBL1349620 & 737825 & 5.4 & 5.0756 & TST \\
\hline CHEMBL1405464 & 737825 & 5.3 & 5.1682 & TRN \\
\hline CHEMBL1316408 & 737825 & 5.5 & 5.5146 & TRN \\
\hline CHEMBL1404940 & 737825 & 5.1 & 5.1222 & TRN \\
\hline CHEMBL1514027 & 737825 & 4.5 & 4.5123 & TRN \\
\hline CHEMBL1374204 & 737825 & 5.1 & 5.5467 & TRN \\
\hline CHEMBL1593859 & 737825 & 4.6 & 4.5059 & TRN \\
\hline
\end{tabular}




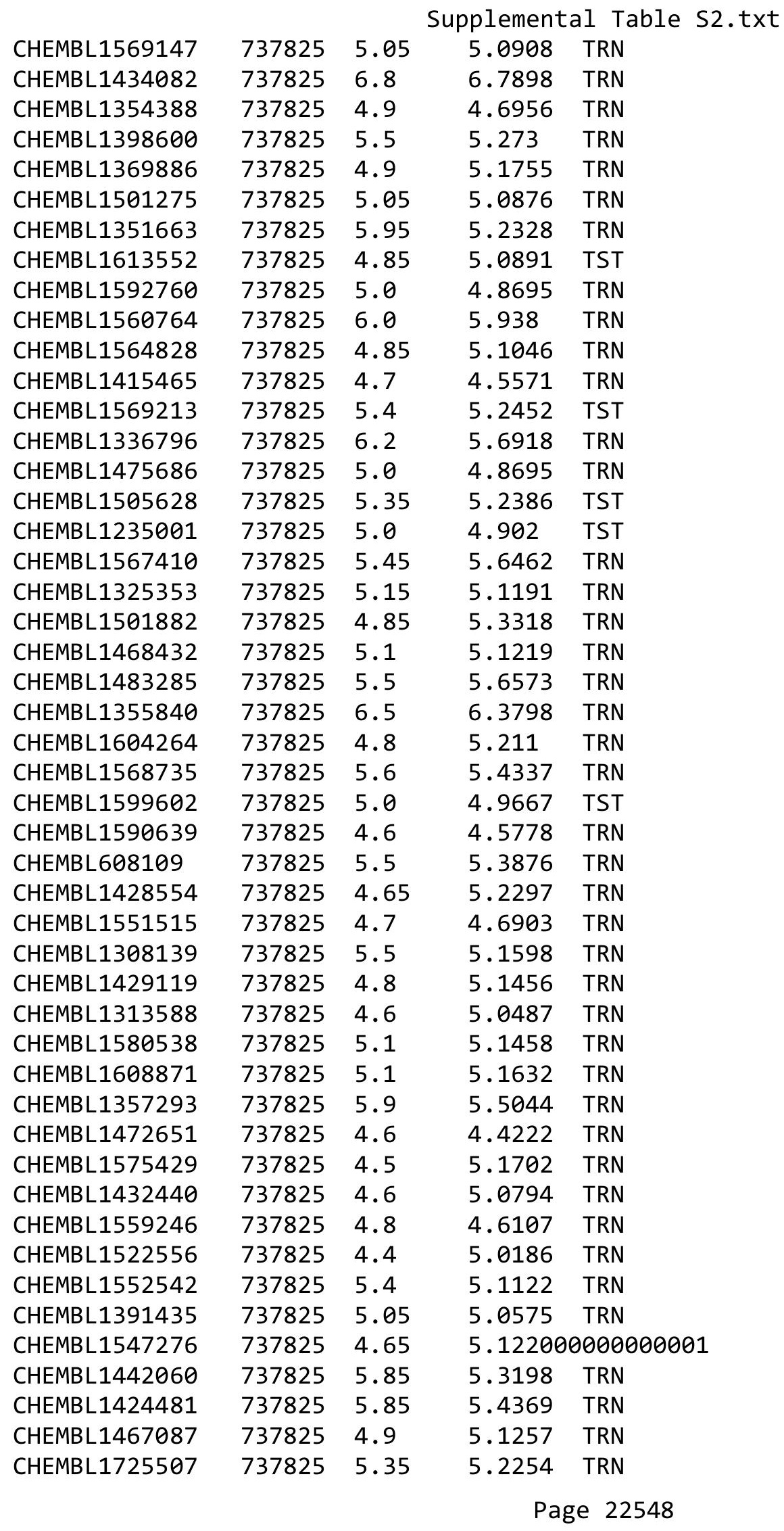

TRN 


\begin{tabular}{|c|c|c|c|c|c|}
\hline \\
\hline CHEMBL1459170 & 737825 & 4.8 & 5.0005 & TRN & \\
\hline CHEMBL1742231 & 737825 & 5.7 & 5.2982 & TRN & \\
\hline CHEMBL3195510 & 737825 & 7.4 & 5.0834 & TRN & \\
\hline CHEMBL51697 & 737825 & 6.0 & 5.6454 & TST & \\
\hline CHEMBL1412847 & 737825 & 5.5 & 5.3192 & TRN & \\
\hline CHEMBL1364255 & 737825 & 4.85 & 4.9714 & TRN & \\
\hline CHEMBL123 & 737825 & 6.8 & 5.6114 & TRN & \\
\hline CHEMBL1317620 & 737825 & 4.7 & 4.5633 & TRN & \\
\hline CHEMBL1423810 & 737825 & 4.6 & 4.7175 & TST & \\
\hline CHEMBL1355463 & 737825 & 5.8 & 5.4264 & TRN & \\
\hline CHEMBL1515918 & 737825 & 4.5 & 4.4005 & TRN & \\
\hline CHEMBL1741487 & 737825 & 4.65 & 5.5061 & TRN & \\
\hline CHEMBL1368395 & 737825 & 5.3 & 5.1449 & TRN & \\
\hline CHEMBL1580099 & 737825 & 4.9 & 5.048 & TRN & \\
\hline CHEMBL1437226 & 737825 & 5.9 & 5.8955 & TRN & \\
\hline CHEMBL1321454 & 737825 & 4.65 & 5.2442 & TRN & \\
\hline CHEMBL1558146 & 737825 & 4.7 & 4.7522 & TRN & \\
\hline CHEMBL1326688 & 737825 & 4.6 & 5.069 & TRN & \\
\hline CHEMBL1484944 & 737825 & 4.9 & 4.75899 & 99999999995 & TRN \\
\hline CHEMBL1375469 & 737825 & 6.0 & 5.9691 & TRN & \\
\hline CHEMBL1404703 & 737825 & 4.9 & 4.7801 & TRN & \\
\hline CHEMBL 260374 & 737825 & 6.0 & 5.6688 & TST & \\
\hline CHEMBL1534710 & 737825 & 4.9 & 4.7192 & TRN & \\
\hline CHEMBL1726083 & 737825 & 5.45 & 5.2995 & TRN & \\
\hline CHEMBL1606723 & 737825 & 5.05 & 5.0183 & TRN & \\
\hline CHEMBL1519576 & 737825 & 5.1 & 5.0308 & TST & \\
\hline CHEMBL1576353 & 737825 & 5.0 & 5.199 & TST & \\
\hline CHEMBL1477557 & 737825 & 4.8 & 4.6578 & TRN & \\
\hline CHEMBL1489663 & 737825 & 5.4 & 5.3008 & TRN & \\
\hline CHEMBL1315743 & 737825 & 6.0 & 5.6814 & TST & \\
\hline CHEMBL1582432 & 737825 & 5.1 & 5.0539 & TRN & \\
\hline CHEMBL1595166 & 737825 & 6.5 & 6.0722 & TRN & \\
\hline CHEMBL1473442 & 737825 & 5.4 & 5.3419 & TRN & \\
\hline CHEMBL1561927 & 737825 & 6.0 & 5.1825 & TRN & \\
\hline CHEMBL1309259 & 737825 & 6.25 & 5.2831 & TRN & \\
\hline CHEMBL1400637 & 737825 & 5.1 & 4.7336 & TRN & \\
\hline CHEMBL1520177 & 737825 & 5.4 & 5.1261 & TRN & \\
\hline CHEMBL1448870 & 737825 & 5.85 & 5.2646 & TRN & \\
\hline CHEMBL1500199 & 737825 & 4.9 & 5.2355 & TRN & \\
\hline CHEMBL1404209 & 737825 & 5.4 & 5.1673 & TRN & \\
\hline CHEMBL1349227 & 737825 & 5.15 & 5.2772 & TRN & \\
\hline CHEMBL1401793 & 737825 & 5.4 & 5.2181 & TST & \\
\hline CHEMBL1408475 & 737825 & 4.8 & 4.9592 & TRN & \\
\hline CHEMBL1509024 & 737825 & 4.85 & 5.1881 & TRN & \\
\hline CHEMBL1435120 & 737825 & 5.0 & 4.8935 & TRN & \\
\hline CHEMBL1366732 & 737825 & 5.8 & 6.0231 & TRN & \\
\hline CHEMBL1461359 & 737825 & 6.3 & 5.0728 & TRN & \\
\hline CHEMBL 301707 & 737825 & 4.8 & 4.7468 & TRN & \\
\hline
\end{tabular}




\begin{tabular}{|c|c|c|c|c|c|}
\hline \multirow[b]{2}{*}{ CHEMBL323356 } & \multicolumn{5}{|c|}{ plemental } \\
\hline & 737825 & 4.9 & 4.9228 & TRN & \\
\hline CHEMBL1328562 & 737825 & 5.1 & \multicolumn{2}{|c|}{5.196000000000001} & TRN \\
\hline CHEMBL1451548 & 737825 & 4.7 & 5.0684 & TRN & \\
\hline CHEMBL1449218 & 737825 & 5.7 & 5.4492 & TRN & \\
\hline CHEMBL 2373622 & 737825 & 4.8 & 4.7344 & TST & \\
\hline CHEMBL1368965 & 737825 & 5.8 & 5.7683 & TRN & \\
\hline CHEMBL3145111 & 737825 & 4.85 & 5.0229 & TRN & \\
\hline CHEMBL1502803 & 737825 & 4.8 & 5.0584 & TRN & \\
\hline CHEMBL1610961 & 737825 & 4.8 & 5.0606 & TRN & \\
\hline CHEMBL1552922 & 737825 & 4.6 & 4.5313 & TRN & \\
\hline CHEMBL1442106 & 737825 & 4.8 & 4.65 & TRN & \\
\hline CHEMBL1505006 & 737825 & 5.45 & 5.2196 & TRN & \\
\hline CHEMBL2369181 & 737825 & 4.85 & 5.2799 & TRN & \\
\hline CHEMBL1437176 & 737825 & 5.2 & 4.9808 & TRN & \\
\hline CHEMBL1473925 & 737825 & 4.8 & 4.7465 & TRN & \\
\hline CHEMBL1475902 & 737825 & 4.9 & 4.8329 & TRN & \\
\hline CHEMBL1589070 & 737825 & 4.5 & 4.9077 & TRN & \\
\hline CHEMBL1554183 & 737825 & 4.8 & \multicolumn{2}{|c|}{ 4.76699999999999995 } & TST \\
\hline CHEMBL1396829 & 737825 & 5.5 & 5.4514 & TRN & \\
\hline CHEMBL1594405 & 737825 & 6.2 & 6.4749 & TRN & \\
\hline CHEMBL1391091 & 737825 & 5.35 & 5.1401 & TRN & \\
\hline CHEMBL1595826 & 737825 & 6.0 & 5.1067 & TRN & \\
\hline CHEMBL1435477 & 737825 & 6.0 & 5.5875 & TST & \\
\hline CHEMBL1540834 & 737825 & 5.9 & 5.0667 & TST & \\
\hline CHEMBL1590213 & 737825 & 5.4 & 5.0694 & TRN & \\
\hline CHEMBL585045 & 737825 & 6.1 & 5.2109 & TRN & \\
\hline CHEMBL1526751 & 737825 & 4.9 & 5.2446 & TST & \\
\hline CHEMBL44297 & 737825 & 4.8 & 4.6841 & TST & \\
\hline CHEMBL1591205 & 737825 & 5.5 & 5.3203 & TST & \\
\hline CHEMBL1475151 & 737825 & 5.5 & \multicolumn{2}{|c|}{5.412000000000001} & TRN \\
\hline CHEMBL1358666 & 737825 & 5.4 & 5.4388 & TRN & \\
\hline CHEMBL1403311 & 737825 & 5.1 & 5.1743 & TST & \\
\hline CHEMBL1551979 & 737825 & 4.8 & 4.7441 & TRN & \\
\hline CHEMBL1742034 & 737825 & 4.85 & 5.2554 & TRN & \\
\hline CHEMBL1356744 & 737825 & 6.5 & 6.2559 & TRN & \\
\hline CHEMBL1535101 & 737825 & 4.65 & 5.1032 & TRN & \\
\hline CHEMBL1578982 & 737825 & 4.6 & 5.2473 & TRN & \\
\hline CHEMBL3196390 & 737825 & 4.6 & 5.1528 & TRN & \\
\hline CHEMBL1448161 & 737825 & 4.95 & 5.0697 & TST & \\
\hline CHEMBL1417135 & 737825 & 4.8 & 4.7226 & TRN & \\
\hline CHEMBL576349 & 737825 & 5.6 & 5.2484 & TST & \\
\hline CHEMBL1544379 & 737825 & 5.0 & 5.2267 & TST & \\
\hline CHEMBL1432354 & 737825 & 5.4 & 5.2865 & TRN & \\
\hline CHEMBL1567600 & 737825 & 4.9 & 4.68 & TRN & \\
\hline CHEMBL1331004 & 737825 & 5.9 & 5.6332 & TRN & \\
\hline CHEMBL405912 & 737825 & 6.0 & 5.9874 & TRN & \\
\hline CHEMBL1590982 & 737825 & 5.5 & 5.2547 & TRN & \\
\hline \multirow[t]{2}{*}{ CHEMBL1305037 } & 737825 & 5.4 & 5.2529 & TRN & \\
\hline & & \multicolumn{4}{|c|}{ Page 22550} \\
\hline
\end{tabular}




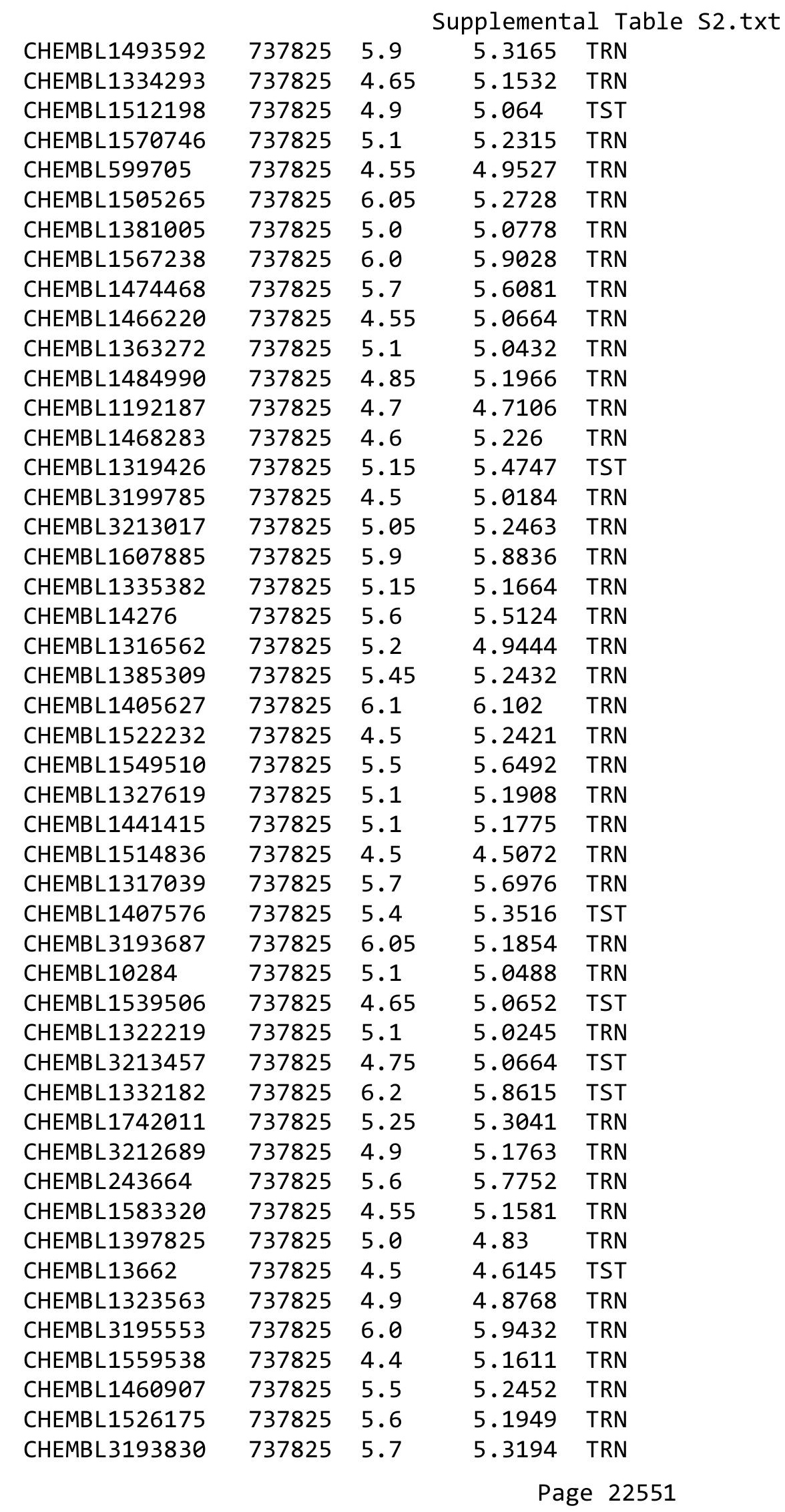




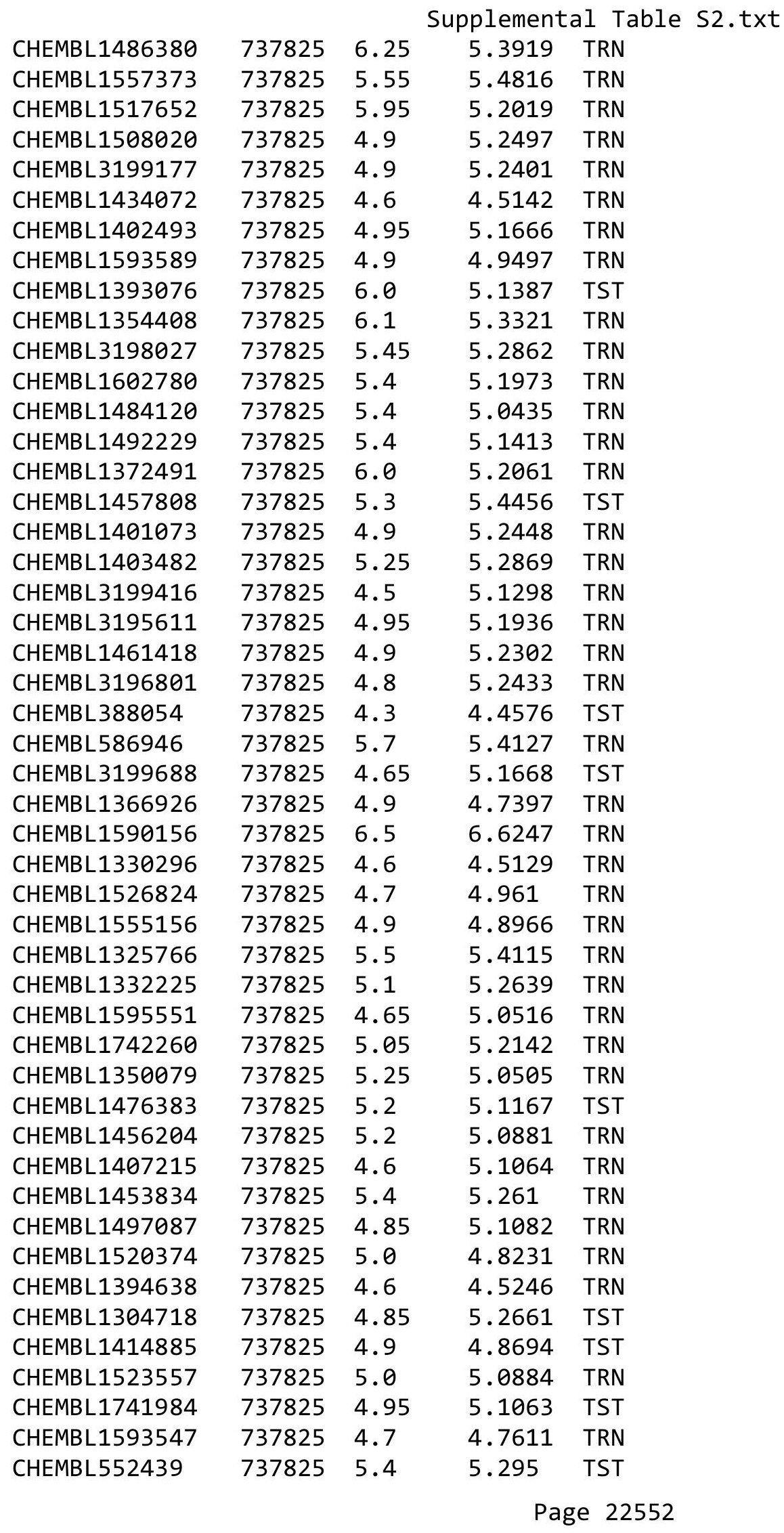




\begin{tabular}{|c|c|c|c|c|c|}
\hline \multicolumn{6}{|c|}{ Supplemental Table S2.txt } \\
\hline CHEMBL1509171 & 737825 & 5.35 & 5.1432 & TRN & \\
\hline CHEMBL1343639 & 737825 & 5.2 & 5.2498 & TRN & \\
\hline CHEMBL1419252 & 737825 & 4.6 & 5.1271 & TST & \\
\hline CHEMBL1706489 & 737825 & 4.85 & 5.0485 & TRN & \\
\hline CHEMBL1515033 & 737825 & 5.1 & 4.9864 & TRN & \\
\hline CHEMBL1355201 & 737825 & 5.2 & 5.1203 & TRN & \\
\hline CHEMBL1546114 & 737825 & 5.45 & 5.0535 & TST & \\
\hline CHEMBL1334292 & 737825 & 5.05 & 5.1514 & TRN & \\
\hline CHEMBL1404955 & 737825 & 6.75 & 5.1447 & TRN & \\
\hline CHEMBL1567530 & 737825 & 5.7 & 5.2348 & TRN & \\
\hline CHEMBL 2373284 & 737825 & 5.5 & 5.2925 & TST & \\
\hline CHEMBL1702153 & 737825 & 4.8 & 5.0843 & TST & \\
\hline CHEMBL 2002517 & 737825 & 5.95 & 5.4329 & TRN & \\
\hline CHEMBL574985 & 737825 & 4.4 & 4.5889 & TST & \\
\hline CHEMBL1741436 & 737825 & 5.4 & 5.3709 & TRN & \\
\hline CHEMBL1501813 & 737825 & 4.85 & 5.1662 & TRN & \\
\hline CHEMBL1361585 & 737825 & 5.1 & 5.1 & TST & \\
\hline CHEMBL1588389 & 737825 & 5.5 & 5.2605 & TRN & \\
\hline CHEMBL1356657 & 737825 & 5.3 & 5.0946 & TRN & \\
\hline CHEMBL1741639 & 737825 & 4.85 & 5.1298 & TRN & \\
\hline CHEMBL3191841 & 737825 & 5.6 & 5.3147 & TST & \\
\hline CHEMBL1515131 & 737825 & 5.5 & 5.3228 & TRN & \\
\hline CHEMBL1389041 & 737825 & 5.5 & 5.0462 & TRN & \\
\hline CHEMBL1519953 & 737825 & 4.6 & 5.1358 & TRN & \\
\hline CHEMBL1256667 & 737825 & 5.5 & 5.3112 & TST & \\
\hline CHEMBL1741783 & 737825 & 4.85 & 5.1969 & TRN & \\
\hline CHEMBL268609 & 737825 & 6.0 & 5.8296 & TRN & \\
\hline CHEMBL1399879 & 737825 & 4.45 & 5.2165 & TRN & \\
\hline CHEMBL1407012 & 737825 & 4.9 & 4.9568 & TRN & \\
\hline CHEMBL1561023 & 737825 & 5.2 & 5.0085 & TRN & \\
\hline CHEMBL1318495 & 737825 & 5.9 & 6.0075 & TRN & \\
\hline CHEMBL1327466 & 737825 & 5.6 & 5.6381 & TRN & \\
\hline CHEMBL19980 & 737825 & 4.5 & 4.6627 & TST & \\
\hline CHEMBL1320051 & 737825 & 5.15 & 5.1875 & TST & \\
\hline CHEMBL1416213 & 737825 & 5.2 & 5.2752 & TST & \\
\hline CHEMBL1535180 & 737825 & 5.05 & 5.3345 & TRN & \\
\hline CHEMBL1402049 & 737825 & 5.5 & 5.3628 & TRN & \\
\hline CHEMBL1320730 & 737825 & 4.8 & 4.7431 & TRN & \\
\hline CHEMBL1556561 & 737825 & 4.55 & 5.01399 & 7999999999 & TRN \\
\hline CHEMBL1730020 & 737825 & 5.0 & 4.777 & TRN & \\
\hline CHEMBL1374028 & 737825 & 5.4 & 5.1784 & TST & \\
\hline CHEMBL1464341 & 737825 & 4.6 & 4.9914 & TRN & \\
\hline CHEMBL1417999 & 737825 & 4.5 & 4.9528 & TST & \\
\hline CHEMBL1366766 & 737825 & 5.3 & 5.3087 & TRN & \\
\hline CHEMBL1704202 & 737825 & 5.05 & 5.3307 & TRN & \\
\hline CHEMBL1450275 & 737825 & 4.8 & 5.188 & TRN & \\
\hline CHEMBL1546060 & 737825 & 4.9 & 4.9527 & TRN & \\
\hline CHEMBL3192742 & 737825 & 5.2 & 5.2499 & TRN & \\
\hline
\end{tabular}




\begin{tabular}{|c|c|c|c|c|c|}
\hline \\
\hline CHEMBL1508610 & 737825 & 5.7 & 5.0694 & TRN & \\
\hline CHEMBL1358586 & 737825 & 4.8 & 4.6962 & TRN & \\
\hline CHEMBL1613160 & 737825 & 5.3 & 5.1994 & TST & \\
\hline CHEMBL1398335 & 737825 & 5.5 & 5.3224 & TST & \\
\hline CHEMBL1436536 & 737825 & 4.6 & 4.6687 & TRN & \\
\hline CHEMBL1493037 & 737825 & 4.5 & 4.5389 & TST & \\
\hline CHEMBL1509858 & 737825 & 4.55 & 5.0372 & TRN & \\
\hline CHEMBL1334122 & 737825 & 5.55 & 5.1865 & TRN & \\
\hline CHEMBL 36121 & 737825 & 4.7 & 4.7814 & TST & \\
\hline CHEMBL1405461 & 737825 & 6.0 & 5.9378 & TRN & \\
\hline CHEMBL1512454 & 737825 & 5.9 & 5.5283 & TRN & \\
\hline CHEMBL1347205 & 737825 & 4.95 & 5.2765 & TRN & \\
\hline CHEMBL39317 & 737825 & 4.8 & 4.8594 & TRN & \\
\hline CHEMBL1594329 & 737825 & 5.7 & 5.7244 & TRN & \\
\hline CHEMBL1367917 & 737825 & 5.8 & 5.3374 & TRN & \\
\hline CHEMBL1435216 & 737825 & 4.9 & 4.8107 & TRN & \\
\hline CHEMBL1478761 & 737825 & 5.3 & 5.0144 & TRN & \\
\hline CHEMBL1339544 & 737825 & 4.9 & 5.1446 & TRN & \\
\hline CHEMBL1556456 & 737825 & 5.1 & 5.0008 & TRN & \\
\hline CHEMBL1304396 & 737825 & 4.75 & 5.17 & TST & \\
\hline CHEMBL1501400 & 737825 & 4.6 & 5.0811 & TRN & \\
\hline CHEMBL1593128 & 737825 & 5.6 & 5.42299 & 9999999999 & TRN \\
\hline CHEMBL1573306 & 737825 & 4.65 & 5.3094 & TRN & \\
\hline CHEMBL1576777 & 737825 & 6.1 & 5.3177 & TRN & \\
\hline CHEMBL1741989 & 737825 & 4.85 & 5.1151 & TRN & \\
\hline CHEMBL1530672 & 737825 & 5.3 & 5.0813 & TRN & \\
\hline CHEMBL1323524 & 737825 & 4.9 & 4.6027 & TRN & \\
\hline CHEMBL1405892 & 737825 & 5.35 & 5.2134 & TST & \\
\hline CHEMBL1357553 & 737825 & 4.8 & 4.6867 & TRN & \\
\hline CHEMBL1496315 & 737825 & 6.4 & 6.0728 & TRN & \\
\hline CHEMBL490744 & 737825 & 5.6 & 5.7713 & TRN & \\
\hline CHEMBL1710426 & 737825 & 4.65 & 5.1053 & TRN & \\
\hline CHEMBL1366393 & 737825 & 4.9 & 4.9372 & TRN & \\
\hline CHEMBL1371604 & 737825 & 5.6 & 5.5528 & TRN & \\
\hline CHEMBL1568575 & 737825 & 4.7 & 4.6869 & TRN & \\
\hline CHEMBL1723467 & 737825 & 4.7 & 5.2568 & TRN & \\
\hline CHEMBL1379480 & 737825 & 5.45 & 5.0181 & TST & \\
\hline CHEMBL1742347 & 737825 & 4.6 & 5.1961 & TRN & \\
\hline CHEMBL397209 & 737825 & 4.4 & 4.5195 & TST & \\
\hline CHEMBL 250892 & 737825 & 5.0 & 4.9275 & TRN & \\
\hline CHEMBL 227725 & 737825 & 5.7 & 5.4738 & TST & \\
\hline CHEMBL1551962 & 737825 & 5.6 & 5.4129 & TRN & \\
\hline CHEMBL1729979 & 737825 & 4.7 & 5.1167 & TRN & \\
\hline CHEMBL1605148 & 737825 & 5.1 & 5.26 & TRN & \\
\hline CHEMBL1588028 & 737825 & 4.85 & 5.0472 & TRN & \\
\hline CHEMBL1470330 & 737825 & 5.35 & 5.1842 & TRN & \\
\hline CHEMBL1395997 & 737825 & 6.6 & 6.2168 & TRN & \\
\hline CHEMBL1545486 & 737825 & 4.8 & 5.1363 & TST & \\
\hline
\end{tabular}




\begin{tabular}{|c|c|c|c|c|c|}
\hline \multicolumn{6}{|c|}{ Supplemental Table S2.txt } \\
\hline CHEMBL1547186 & 737825 & 4.85 & 5.3277 & TST & \\
\hline CHEMBL294590 & 737825 & 7.4 & 6.6038 & TRN & \\
\hline CHEMBL1334652 & 737825 & 5.1 & 5.0098 & TRN & \\
\hline CHEMBL3212049 & 737825 & 4.7 & 5.2725 & TRN & \\
\hline CHEMBL113142 & 737825 & 4.8 & 4.7794 & TRN & \\
\hline CHEMBL1317494 & 737825 & 5.7 & 5.6197 & TRN & \\
\hline CHEMBL1561188 & 737825 & 5.4 & 5.2708 & TRN & \\
\hline CHEMBL1553114 & 737825 & 5.3 & 5.1312 & TRN & \\
\hline CHEMBL 2373602 & 737825 & 6.0 & 5.7523 & TST & \\
\hline CHEMBL1538975 & 737825 & 5.35 & 5.1674 & TRN & \\
\hline CHEMBL1717653 & 737825 & 5.0 & 5.2134 & TRN & \\
\hline CHEMBL1355788 & 737825 & 4.8 & 4.7332 & TRN & \\
\hline CHEMBL 3209931 & 737825 & 5.0 & 5.2441 & TRN & \\
\hline CHEMBL1474475 & 737825 & 5.3 & 5.0682 & TRN & \\
\hline CHEMBL1256647 & 737825 & 5.4 & 5.1671 & TST & \\
\hline CHEMBL1541286 & 737825 & 4.85 & 5.3918 & TRN & \\
\hline CHEMBL3198645 & 737825 & 5.45 & 5.0361 & TRN & \\
\hline CHEMBL1416812 & 737825 & 5.5 & 5.3742 & TRN & \\
\hline CHEMBL1419672 & 737825 & 5.95 & 5.2555 & TRN & \\
\hline CHEMBL1612230 & 737825 & 5.4 & 5.1614 & TST & \\
\hline CHEMBL1354913 & 737825 & 5.2 & 5.231 & TST & \\
\hline CHEMBL1601898 & 737825 & 5.4 & 5.1256 & TRN & \\
\hline CHEMBL1346226 & 737825 & 4.85 & 5.21 & TRN & \\
\hline CHEMBL3197506 & 737825 & 4.65 & 5.0236 & TRN & \\
\hline CHEMBL107251 & 737825 & 5.0 & 4.8962 & TST & \\
\hline CHEMBL1416685 & 737825 & 4.55 & 5.0755 & TRN & \\
\hline CHEMBL1396463 & 737825 & 4.5 & 4.6133 & TST & \\
\hline CHEMBL1452850 & 737825 & 5.4 & 5.3914 & TRN & \\
\hline CHEMBL1483152 & 737825 & 4.9 & 4.9902 & TRN & \\
\hline CHEMBL1496761 & 737825 & 6.05 & 5.3006 & TRN & \\
\hline CHEMBL3195224 & 737825 & 4.85 & 5.2496 & TRN & \\
\hline CHEMBL1595709 & 737825 & 5.9 & 5.8168 & TST & \\
\hline CHEMBL3198312 & 737825 & 5.4 & 5.15 & TRN & \\
\hline CHEMBL1393246 & 737825 & 5.2 & 5.1286 & TRN & \\
\hline CHEMBL1391756 & 737825 & 4.9 & 5.24700 & 0000000001 & TRN \\
\hline CHEMBL1511199 & 737825 & 5.2 & 5.1473 & TRN & \\
\hline CHEMBL1440487 & 737825 & 5.6 & 5.3503 & TRN & \\
\hline CHEMBL1395753 & 737825 & 5.4 & 5.3023 & TRN & \\
\hline CHEMBL 3213793 & 737825 & 5.5 & 5.1673 & TRN & \\
\hline CHEMBL1513870 & 737825 & 5.3 & 5.3558 & TRN & \\
\hline CHEMBL1592452 & 737825 & 4.8 & 4.755 & TRN & \\
\hline CHEMBL1381739 & 737825 & 5.65 & 5.5032 & TRN & \\
\hline CHEMBL1594487 & 737825 & 5.4 & 5.3671 & TRN & \\
\hline CHEMBL1301140 & 737825 & 4.65 & 5.2205 & TRN & \\
\hline CHEMBL1478279 & 737825 & 4.9 & 4.6973 & TRN & \\
\hline CHEMBL188 & 737825 & 5.9 & 5.6625 & TRN & \\
\hline CHEMBL 322970 & 737825 & 4.7 & 4.899 & TST & \\
\hline CHEMBL1603393 & 737825 & 4.8 & 4.8404 & TRN & \\
\hline
\end{tabular}




\begin{tabular}{|c|c|c|c|c|c|}
\hline \\
\hline CHEMBL1469557 & 737825 & 4.7 & 5.2201 & TRN & \\
\hline CHEMBL1559877 & 737825 & 4.9 & 5.1036 & TRN & \\
\hline CHEMBL1364826 & 737825 & 4.6 & 5.3231 & TRN & \\
\hline CHEMBL1553808 & 737825 & 5.8 & 5.3392 & TRN & \\
\hline CHEMBL1524520 & 737825 & 6.2 & 6.0831 & TRN & \\
\hline CHEMBL1301598 & 737825 & 4.4 & 5.2108 & TRN & \\
\hline CHEMBL1417581 & 737825 & 5.1 & 5.0783 & TRN & \\
\hline CHEMBL3192578 & 737825 & 5.15 & 5.0992 & TST & \\
\hline CHEMBL1413962 & 737825 & 6.1 & 5.9429 & TRN & \\
\hline CHEMBL1484261 & 737825 & 6.3 & 6.3962 & TRN & \\
\hline CHEMBL1452675 & 737825 & 5.1 & 5.1039 & TRN & \\
\hline CHEMBL1599905 & 737825 & 4.4 & 5.0674 & TST & \\
\hline CHEMBL3195449 & 737825 & 5.35 & 5.3133 & TRN & \\
\hline CHEMBL1993145 & 737825 & 5.7 & $4.9860 e$ & 0000000001 & TRN \\
\hline CHEMBL3193293 & 737825 & 5.0 & 5.0281 & TST & \\
\hline CHEMBL1407743 & 737825 & 4.55 & 4.9992 & TST & \\
\hline CHEMBL1438689 & 737825 & 5.4 & 5.3357 & TRN & \\
\hline CHEMBL399121 & 737825 & 5.0 & 5.5048 & TRN & \\
\hline CHEMBL1328319 & 737825 & 5.1 & 5.1327 & TRN & \\
\hline CHEMBL1378642 & 737825 & 4.8 & 5.0436 & TST & \\
\hline CHEMBL1303031 & 737825 & 6.0 & 5.3122 & TRN & \\
\hline CHEMBL1466642 & 737825 & 4.9 & 5.1507 & TRN & \\
\hline CHEMBL1361905 & 737825 & 4.9 & 4.779 & TRN & \\
\hline CHEMBL1606199 & 737825 & 5.6 & 5.7348 & TRN & \\
\hline CHEMBL1393740 & 737825 & 4.7 & 5.232 & TRN & \\
\hline CHEMBL1313661 & 737825 & 4.65 & 5.0364 & TRN & \\
\hline CHEMBL3195205 & 737825 & 4.95 & 5.1532 & TST & \\
\hline CHEMBL1357551 & 737825 & 4.7 & 4.6808 & TRN & \\
\hline CHEMBL1484253 & 737825 & 4.5 & 4.4508 & TRN & \\
\hline CHEMBL1517885 & 737825 & 4.8 & 4.5849 & TRN & \\
\hline CHEMBL1516276 & 737825 & 4.5 & 4.4173 & TRN & \\
\hline CHEMBL1356794 & 737825 & 5.2 & 5.0395 & TRN & \\
\hline CHEMBL1332569 & 737825 & 4.85 & 5.0497 & TRN & \\
\hline CHEMBL1512023 & 737825 & 4.8 & 4.6812 & TRN & \\
\hline CHEMBL1551919 & 737825 & 5.0 & 4.813 & TRN & \\
\hline CHEMBL1741546 & 737825 & 5.1 & 5.2616 & TRN & \\
\hline CHEMBL521971 & 737825 & 6.6 & 6.6046 & TRN & \\
\hline CHEMBL1311432 & 737825 & 4.9 & 5.2383 & TRN & \\
\hline CHEMBL1591908 & 737825 & 5.1 & 4.9795 & TRN & \\
\hline CHEMBL1413637 & 737825 & 5.0 & 4.8757 & TRN & \\
\hline CHEMBL1256735 & 737825 & 4.8 & 4.8669 & TRN & \\
\hline CHEMBL1741496 & 737825 & 5.2 & 5.2283 & TRN & \\
\hline CHEMBL3192875 & 737825 & 5.3 & 5.2561 & TRN & \\
\hline CHEMBL1523892 & 737825 & 5.6 & 5.2508 & TRN & \\
\hline CHEMBL38576 & 737825 & 5.2 & 5.1737 & TRN & \\
\hline CHEMBL1465552 & 737825 & 4.6 & 5.051 & TRN & \\
\hline CHEMBL1383526 & 737825 & 5.3 & 5.1967 & TRN & \\
\hline CHEMBL1548020 & 737825 & 4.95 & 5.0771 & TRN & \\
\hline & & & & 25 & \\
\hline
\end{tabular}




\begin{tabular}{|c|c|c|c|c|}
\hline \multicolumn{5}{|c|}{ Supplemental Table S2.txt } \\
\hline CHEMBL580421 & 737825 & 4.5 & 4.4868 & TST \\
\hline CHEMBL1503678 & 737825 & 5.15 & 5.075 & TRN \\
\hline CHEMBL1533197 & 737825 & 5.1 & 4.9553 & TRN \\
\hline CHEMBL1414083 & 737825 & 5.1 & 5.1573 & TRN \\
\hline CHEMBL274438 & 737825 & 5.9 & 5.6987 & TRN \\
\hline CHEMBL1489528 & 737825 & 5.9 & 5.9268 & TRN \\
\hline CHEMBL1553322 & 737825 & 4.8 & 4.6287 & TRN \\
\hline CHEMBL1358402 & 737825 & 6.0 & 5.7359 & TST \\
\hline CHEMBL1725279 & 737825 & 5.4 & 5.1737 & TST \\
\hline CHEMBL1475083 & 737825 & 5.6 & 5.5298 & TRN \\
\hline CHEMBL1742187 & 737825 & 5.45 & 5.2072 & TST \\
\hline CHEMBL1447487 & 737825 & 5.3 & 5.3002 & TRN \\
\hline CHEMBL1335332 & 737825 & 4.8 & 4.7337 & TRN \\
\hline CHEMBL1554725 & 737825 & 5.5 & 5.3119 & TRN \\
\hline CHEMBL1408735 & 737825 & 5.8 & 5.7534 & TRN \\
\hline CHEMBL1518970 & 737825 & 4.9 & 5.0404 & TRN \\
\hline CHEMBL1342336 & 737825 & 4.85 & 5.0786 & TRN \\
\hline CHEMBL1523175 & 737825 & 5.6 & 5.0832 & TRN \\
\hline CHEMBL1498833 & 737825 & 4.55 & 4.8655 & TRN \\
\hline CHEMBL1573862 & 737825 & 4.9 & 4.7976 & TRN \\
\hline CHEMBL1402241 & 737825 & 5.4 & 5.3549 & TRN \\
\hline CHEMBL1561383 & 737825 & 4.9 & 4.712 & TRN \\
\hline CHEMBL1483182 & 737825 & 4.75 & 5.0661 & TRN \\
\hline CHEMBL1572915 & 737825 & 5.4 & 5.2062 & TRN \\
\hline CHEMBL1499721 & 737825 & 4.6 & 5.1613 & TRN \\
\hline CHEMBL1433002 & 737825 & 4.9 & 5.1768 & TRN \\
\hline CHEMBL1512817 & 737825 & 4.9 & 4.9019 & TRN \\
\hline CHEMBL1446922 & 737825 & 5.0 & 4.9228 & TRN \\
\hline CHEMBL1561156 & 737825 & 5.6 & 5.3426 & TRN \\
\hline CHEMBL1376143 & 737825 & 4.8 & 4.6897 & TRN \\
\hline CHEMBL1552172 & 737825 & 5.5 & 5.4858 & TRN \\
\hline CHEMBL1375321 & 737825 & 4.5 & 5.0945 & TRN \\
\hline CHEMBL1451071 & 737825 & 5.4 & 5.3976 & TRN \\
\hline CHEMBL1472955 & 737825 & 5.4 & 5.4596 & TRN \\
\hline CHEMBL1741907 & 737825 & 4.9 & 5.2674 & TRN \\
\hline CHEMBL1356485 & 737825 & 5.1 & 4.9795 & TRN \\
\hline CHEMBL 1447746 & 737825 & 5.5 & 5.3286 & TST \\
\hline CHEMBL1487692 & 737825 & 4.75 & 5.1336 & TRN \\
\hline CHEMBL1417125 & 737825 & 6.0 & 5.042 & TST \\
\hline CHEMBL1336812 & 737825 & 4.9 & 4.9072 & TST \\
\hline CHEMBL1333968 & 737825 & 4.9 & 4.7328 & TRN \\
\hline CHEMBL3196953 & 737825 & 6.3 & 5.3147 & TRN \\
\hline CHEMBL1302696 & 737825 & 5.2 & 5.3043 & TRN \\
\hline CHEMBL448966 & 737825 & 6.6 & 6.6503 & TRN \\
\hline CHEMBL1437962 & 737825 & 5.4 & 5.2297 & TST \\
\hline CHEMBL1435227 & 737825 & 4.6 & 4.4157 & TRN \\
\hline CHEMBL1524591 & 737825 & 4.85 & 5.0629 & TRN \\
\hline CHEMBL1545061 & 737825 & 5.75 & 5.2725 & TRN \\
\hline
\end{tabular}




\begin{tabular}{|c|c|c|c|c|}
\hline & & & pplement & \\
\hline CHEMBL1435404 & 737825 & 7.6 & 6.6069 & TRN \\
\hline CHEMBL164 & 737825 & 6.0 & 5.7251 & TRN \\
\hline CHEMBL1741498 & 737825 & 5.45 & 5.5025 & TRN \\
\hline CHEMBL490749 & 737825 & 6.7 & 6.7778 & TRN \\
\hline CHEMBL1331782 & 737825 & 4.85 & 5.2262 & TRN \\
\hline CHEMBL1571457 & 737825 & 4.6 & 5.0621 & TRN \\
\hline CHEMBL1438722 & 737825 & 4.95 & 5.1308 & TRN \\
\hline CHEMBL1457723 & 737825 & 4.55 & 5.0788 & TRN \\
\hline CHEMBL1357968 & 737825 & 4.8 & 4.6665 & TRN \\
\hline CHEMBL1316647 & 737825 & 4.7 & 4.5684 & TRN \\
\hline CHEMBL 3213021 & 737825 & 5.0 & 5.3432 & TRN \\
\hline CHEMBL1401960 & 737825 & 4.75 & 5.0101 & TRN \\
\hline CHEMBL1321421 & 737825 & 4.7 & 4.7173 & TST \\
\hline CHEMBL 3212912 & 737825 & 4.9 & 5.1602 & TST \\
\hline CHEMBL1397634 & 737825 & 5.5 & 5.449 & TRN \\
\hline CHEMBL1458145 & 737825 & 5.05 & 5.1416 & TRN \\
\hline CHEMBL1434833 & 737825 & 5.0 & 4.9528 & TRN \\
\hline CHEMBL1558201 & 737825 & 4.8 & 5.3192 & TST \\
\hline CHEMBL1549980 & 737825 & 5.5 & 5.2362 & TRN \\
\hline CHEMBL1560551 & 737825 & 5.8 & 5.476 & TRN \\
\hline CHEMBL1576649 & 737825 & 5.4 & 5.1708 & TRN \\
\hline CHEMBL1596258 & 737825 & 4.65 & 5.1872 & TRN \\
\hline CHEMBL1352096 & 737825 & 5.4 & 5.2439 & TRN \\
\hline CHEMBL1972348 & 737825 & 5.15 & 5.0327 & TRN \\
\hline CHEMBL1585900 & 737825 & 5.05 & 5.1186 & TRN \\
\hline CHEMBL3209087 & 737825 & 4.85 & 5.0418 & TRN \\
\hline CHEMBL1318316 & 737825 & 5.4 & 5.2669 & TST \\
\hline CHEMBL1302342 & 737825 & 5.0 & 5.0675 & TRN \\
\hline CHEMBL1257002 & 737825 & 6.0 & 5.8056 & TRN \\
\hline CHEMBL 23731 & 737825 & 6.0 & 5.7899 & TRN \\
\hline CHEMBL1355879 & 737825 & 4.9 & 4.9918 & TST \\
\hline CHEMBL1520388 & 737825 & 5.3 & 5.1352 & TRN \\
\hline CHEMBL3208450 & 737825 & 5.65 & 5.2949 & TRN \\
\hline CHEMBL1553001 & 737825 & 4.8 & 4.5871 & TRN \\
\hline CHEMBL1522815 & 737825 & 5.1 & 5.1814 & TRN \\
\hline CHEMBL1416531 & 737825 & 4.8 & 5.0861 & TRN \\
\hline CHEMBL1597843 & 737825 & 4.95 & 5.1664 & TST \\
\hline CHEMBL1322702 & 737825 & 5.4 & 5.2835 & TRN \\
\hline CHEMBL1436075 & 737825 & 5.2 & 5.101 & TRN \\
\hline CHEMBL1523594 & 737825 & 5.2 & 4.9525 & TRN \\
\hline CHEMBL1482806 & 737825 & 4.6 & 5.0359 & TST \\
\hline CHEMBL1374931 & 737825 & 4.9 & 5.2472 & TRN \\
\hline CHEMBL1468251 & 737825 & 5.35 & 5.4917 & TRN \\
\hline CHEMBL1349875 & 737825 & 4.9 & 5.4047 & TRN \\
\hline CHEMBL1317741 & 737825 & 4.8 & 4.6815 & TRN \\
\hline CHEMBL1559127 & 737825 & 5.1 & 5.0814 & TRN \\
\hline CHEMBL 1565333 & 737825 & 5.5 & 5.2997 & TST \\
\hline CHEMBL1524866 & 737825 & 4.9 & 5.1755 & TST \\
\hline
\end{tabular}




\begin{tabular}{|c|c|c|c|c|c|}
\hline & & & & & \\
\hline CHEMBL1394731 & 737825 & 5.1 & 4.9663 & TRN & \\
\hline CHEMBL490717 & 737825 & 6.2 & 6.2844 & TRN & \\
\hline CHEMBL1411543 & 737825 & 7.6 & 6.7427 & TRN & \\
\hline CHEMBL1560555 & 737825 & 4.7 & 5.3617 & TRN & \\
\hline CHEMBL1590266 & 737825 & 5.1 & 4.9606 & TRN & \\
\hline CHEMBL1423250 & 737825 & 4.9 & 5.17700 & 00000000005 & TRN \\
\hline CHEMBL375629 & 737825 & 5.0 & 5.0644 & TST & \\
\hline CHEMBL1318927 & 737825 & 5.4 & 5.1855 & TRN & \\
\hline CHEMBL479014 & 737825 & 4.9 & 4.8402 & TST & \\
\hline CHEMBL1416252 & 737825 & 4.8 & 5.5571 & TRN & \\
\hline CHEMBL1576446 & 737825 & 5.2 & 5.1619 & TRN & \\
\hline CHEMBL1357574 & 737825 & 6.5 & 6.0117 & TRN & \\
\hline CHEMBL1565215 & 737825 & 5.65 & 5.3527 & TRN & \\
\hline CHEMBL1453102 & 737825 & 5.7 & 5.2731 & TRN & \\
\hline CHEMBL1411881 & 737825 & 4.7 & 5.0448 & TRN & \\
\hline CHEMBL1564740 & 737825 & 4.65 & 5.2143 & TRN & \\
\hline CHEMBL1544016 & 737825 & 4.85 & 5.1844 & TRN & \\
\hline CHEMBL1486217 & 737825 & 5.8 & 5.2649 & TRN & \\
\hline CHEMBL1487013 & 737825 & 5.2 & 5.1547 & TRN & \\
\hline CHEMBL119841 & 737825 & 5.8 & 5.7925 & TRN & \\
\hline CHEMBL58353 & 737825 & 4.4 & 4.5541 & TST & \\
\hline CHEMBL1316528 & 737825 & 5.5 & 5.3258 & TRN & \\
\hline CHEMBL1323029 & 737825 & 4.75 & 4.9656 & TRN & \\
\hline CHEMBL1590262 & 737825 & 4.8 & 4.5993 & TRN & \\
\hline CHEMBL1373610 & 737825 & 5.7 & 5.45799 & 9999999999 & TRN \\
\hline CHEMBL1410865 & 737825 & 6.0 & 6.0019 & TRN & \\
\hline CHEMBL1539637 & 737825 & 4.6 & 5.1109 & TST & \\
\hline CHEMBL1466675 & 737825 & 4.75 & 5.4328 & TRN & \\
\hline CHEMBL1741430 & 737825 & 4.9 & 5.0728 & TRN & \\
\hline CHEMBL1476139 & 737825 & 4.9 & 4.6772 & TRN & \\
\hline CHEMBL1565258 & 737825 & 4.9 & 5.1844 & TRN & \\
\hline CHEMBL1255936 & 737825 & 6.7 & 6.0607 & TRN & \\
\hline CHEMBL1318400 & 737825 & 6.0 & 6.0039 & TRN & \\
\hline CHEMBL1346685 & 737825 & 4.8 & 5.0109 & TRN & \\
\hline CHEMBL1256020 & 737825 & 5.0 & 4.8984 & TRN & \\
\hline CHEMBL1514149 & 737825 & 4.9 & 4.8225 & TRN & \\
\hline CHEMBL1388353 & 737825 & 5.05 & 4.9187 & TRN & \\
\hline CHEMBL1347942 & 737825 & 4.8 & 4.9972 & TRN & \\
\hline CHEMBL1315184 & 737825 & 5.1 & 5.149 & TRN & \\
\hline CHEMBL1582268 & 737825 & 6.05 & 5.2031 & TRN & \\
\hline CHEMBL150 & 737825 & 5.1 & 5.8346 & TRN & \\
\hline CHEMBL1483498 & 737825 & 5.6 & 5.1073 & TRN & \\
\hline CHEMBL1570996 & 737825 & 5.6 & 5.4074 & TRN & \\
\hline CHEMBL3193076 & 737825 & 4.9 & 5.1189 & TRN & \\
\hline CHEMBL1501668 & 737825 & 5.45 & 5.0808 & TRN & \\
\hline CHEMBL1414719 & 737825 & 5.95 & 5.3086 & TRN & \\
\hline CHEMBL1417375 & 737825 & 6.3 & 6.0412 & TRN & \\
\hline CHEMBL1323270 & 737825 & 4.95 & 5.0963 & TRN & \\
\hline
\end{tabular}




\begin{tabular}{|c|c|c|c|c|c|}
\hline & & & & & \\
\hline CHEMBL1992293 & 737825 & 5.1 & 4.9662 & TST & \\
\hline CHEMBL1742029 & 737825 & 4.5 & 5.2074 & TRN & \\
\hline CHEMBL1498803 & 737825 & 4.9 & 4.9526 & TRN & \\
\hline CHEMBL 3214600 & 737825 & 5.9 & 5.4784 & TRN & \\
\hline CHEMBL1494529 & 737825 & 4.8 & 4.7379 & TRN & \\
\hline CHEMBL1434149 & 737825 & 5.1 & 4.995 & TRN & \\
\hline CHEMBL 303579 & 737825 & 5.9 & $5.5760 e$ & 00000000005 & TRN \\
\hline CHEMBL1457544 & 737825 & 5.0 & 4.8303 & TRN & \\
\hline CHEMBL1444331 & 737825 & 5.1 & 5.0506 & TRN & \\
\hline CHEMBL1485060 & 737825 & 5.0 & 5.0523 & TRN & \\
\hline CHEMBL1403562 & 737825 & 5.0 & $4.8260 e$ & 00000000005 & TRN \\
\hline CHEMBL1301542 & 737825 & 5.6 & 5.1863 & TRN & \\
\hline CHEMBL 3194842 & 737825 & 4.55 & 5.2069 & TRN & \\
\hline CHEMBL1368474 & 737825 & 4.8 & 4.7581 & TRN & \\
\hline CHEMBL1379319 & 737825 & 4.55 & 5.0528 & TRN & \\
\hline CHEMBL1497138 & 737825 & 5.65 & 5.1597 & TRN & \\
\hline CHEMBL1495867 & 737825 & 5.9 & 5.0329 & TRN & \\
\hline CHEMBL1414358 & 737825 & 5.3 & 5.4712 & TRN & \\
\hline CHEMBL1432279 & 737825 & 5.8 & 5.1535 & TRN & \\
\hline CHEMBL1606727 & 737825 & 5.6 & 5.6906 & TRN & \\
\hline CHEMBL1356808 & 737825 & 5.8 & 5.8911 & TRN & \\
\hline CHEMBL1516477 & 737825 & 6.0 & 5.7322 & TST & \\
\hline CHEMBL1523982 & 737825 & 5.8 & 5.23 & TRN & \\
\hline CHEMBL 7917 & 737825 & 5.5 & 5.2986 & TRN & \\
\hline CHEMBL3213815 & 737825 & 4.85 & 4.9686 & TRN & \\
\hline CHEMBL1333616 & 737825 & 4.8 & 5.0895 & TRN & \\
\hline CHEMBL1533516 & 737825 & 4.5 & 4.4962 & TRN & \\
\hline CHEMBL1480516 & 737825 & 6.0 & 5.7621 & TST & \\
\hline CHEMBL1470796 & 737825 & 5.8 & 5.1485 & TRN & \\
\hline CHEMBL1741342 & 737825 & 4.6 & 5.1375 & TRN & \\
\hline CHEMBL1531607 & 737825 & 4.8 & 5.2716 & TRN & \\
\hline CHEMBL1557599 & 737825 & 5.2 & 5.0634 & TRN & \\
\hline CHEMBL1518546 & 737825 & 4.4 & 5.1346 & TRN & \\
\hline CHEMBL66 & 737825 & 5.0 & 5.5125 & TRN & \\
\hline CHEMBL1373004 & 737825 & 5.6 & 5.5632 & TRN & \\
\hline CHEMBL 1482510 & 737825 & 4.8 & 5.1379 & TRN & \\
\hline CHEMBL1401933 & 737825 & 4.8 & 5.1574 & TRN & \\
\hline CHEMBL1612234 & 737825 & 5.45 & 5.2035 & TRN & \\
\hline CHEMBL1317626 & 737825 & 4.8 & 4.6038 & TRN & \\
\hline CHEMBL1367958 & 737825 & 4.7 & 5.0952 & TST & \\
\hline CHEMBL1323164 & 737825 & 6.0 & 5.9386 & TRN & \\
\hline CHEMBL1320225 & 737825 & 5.8 & 5.2245 & TRN & \\
\hline CHEMBL1538146 & 737825 & 4.75 & 5.1914 & TRN & \\
\hline CHEMBL1526515 & 737825 & 5.4 & 5.0506 & TRN & \\
\hline CHEMBL1608125 & 737825 & 5.6 & 5.4171 & TRN & \\
\hline CHEMBL1519330 & 737825 & 4.4 & 5.2006 & TRN & \\
\hline CHEMBL3197594 & 737825 & 4.65 & 5.2016 & TRN & \\
\hline CHEMBL1516331 & 737825 & 4.9 & 4.6786 & TRN & \\
\hline & & & & 22560 & \\
\hline
\end{tabular}




\begin{tabular}{|c|c|c|c|c|c|}
\hline \multicolumn{6}{|c|}{ Supplemental Table S2.txt } \\
\hline CHEMBL1346170 & 737825 & 7.45 & 5.1208 & TRN & \\
\hline CHEMBL1580242 & 737825 & 4.95 & 5.3815 & TRN & \\
\hline CHEMBL1549020 & 737825 & 4.5 & 5.0254 & TRN & \\
\hline CHEMBL1572006 & 737825 & 4.8 & 5.2027 & TRN & \\
\hline CHEMBL1324194 & 737825 & 5.35 & 5.2425 & TRN & \\
\hline CHEMBL1446523 & 737825 & 6.0 & 5.6622 & TRN & \\
\hline CHEMBL1591874 & 737825 & 4.9 & 4.5036 & TRN & \\
\hline CHEMBL1419356 & 737825 & 6.35 & 5.2642 & TRN & \\
\hline CHEMBL1465121 & 737825 & 4.95 & 5.1065 & TRN & \\
\hline CHEMBL1403294 & 737825 & 5.1 & 5.0069 & TRN & \\
\hline CHEMBL1455106 & 737825 & 4.95 & 5.2039 & TRN & \\
\hline CHEMBL1308019 & 737825 & 4.85 & 4.9372 & TRN & \\
\hline CHEMBL1305256 & 737825 & 5.05 & 5.0925 & TRN & \\
\hline CHEMBL3210053 & 737825 & 5.45 & 5.3508 & TRN & \\
\hline CHEMBL1400275 & 737825 & 5.2 & 5.2425 & TRN & \\
\hline CHEMBL1436054 & 737825 & 4.9 & 4.8801 & TRN & \\
\hline CHEMBL1525112 & 737825 & 4.6 & 4.463 & TRN & \\
\hline CHEMBL1741829 & 737825 & 4.8 & 5.1635 & TRN & \\
\hline CHEMBL1415180 & 737825 & 6.1 & 5.8323 & TRN & \\
\hline CHEMBL1611856 & 737825 & 5.3 & 5.1328 & TRN & \\
\hline CHEMBL1375431 & 737825 & 4.8 & 4.7377 & TRN & \\
\hline CHEMBL1428732 & 737825 & 5.75 & 5.1312 & TRN & \\
\hline CHEMBL1567292 & 737825 & 4.9 & 4.6776 & TRN & \\
\hline CHEMBL1572371 & 737825 & 5.0 & 5.3496 & TST & \\
\hline CHEMBL1571929 & 737825 & 4.9 & 5.8083 & TST & \\
\hline CHEMBL 2002680 & 737825 & 5.1 & 5.1639 & TRN & \\
\hline CHEMBL3198484 & 737825 & 5.45 & 5.3818 & TRN & \\
\hline CHEMBL416657 & 737825 & 4.7 & 4.6863 & TRN & \\
\hline CHEMBL1405325 & 737825 & 5.2 & 5.0911 & TRN & \\
\hline CHEMBL1374218 & 737825 & 5.4 & 5.2671 & TRN & \\
\hline CHEMBL1596170 & 737825 & 4.9 & 4.7629 & TRN & \\
\hline CHEMBL582444 & 737825 & 5.0 & 5.038 & TST & \\
\hline CHEMBL1566556 & 737825 & 4.8 & 4.7618 & TRN & \\
\hline CHEMBL1444972 & 737825 & 4.9 & 5.1435 & TRN & \\
\hline CHEMBL1300494 & 737825 & 4.8 & 5.26399 & 9999999999 & TRN \\
\hline CHEMBL1555483 & 737825 & 4.95 & 5.1071 & TRN & \\
\hline CHEMBL1514953 & 737825 & 5.4 & 5.2958 & TRN & \\
\hline CHEMBL1606796 & 737825 & 5.2 & 4.9407 & TRN & \\
\hline CHEMBL1404317 & 737825 & 5.5 & 5.3668 & TRN & \\
\hline CHEMBL1496243 & 737825 & 4.7 & 4.5368 & TRN & \\
\hline CHEMBL1476722 & 737825 & 4.9 & 5.2732 & TRN & \\
\hline CHEMBL1423713 & 737825 & 4.6 & 5.2122 & TRN & \\
\hline CHEMBL1418420 & 737825 & 5.4 & 5.29700 & 0000000001 & TRN \\
\hline CHEMBL1605341 & 737825 & 5.4 & 5.1033 & TRN & \\
\hline CHEMBL1337725 & 737825 & 6.1 & 5.3966 & TRN & \\
\hline CHEMBL1489424 & 737825 & 6.5 & 5.9356 & TRN & \\
\hline CHEMBL3350578 & 737825 & 5.5 & 5.3139 & TST & \\
\hline CHEMBL1482804 & 737825 & 5.0 & 5.3632 & TRN & \\
\hline
\end{tabular}




\begin{tabular}{|c|c|c|c|c|c|}
\hline \multicolumn{6}{|c|}{ Supplemental Table S2.txt } \\
\hline CHEMBL1472523 & 737825 & 5.5 & 5.3903 & TRN & \\
\hline CHEMBL1350243 & 737825 & 5.9 & 5.3176 & TRN & \\
\hline CHEMBL1511729 & 737825 & 5.35 & 5.1952 & TST & \\
\hline CHEMBL3194323 & 737825 & 5.1 & 5.3759 & TRN & \\
\hline CHEMBL1417448 & 737825 & 4.9 & 4.742 & TRN & \\
\hline CHEMBL1554236 & 737825 & 4.7 & 4.5227 & TRN & \\
\hline CHEMBL1483307 & 737825 & 4.75 & 5.2365 & TRN & \\
\hline CHEMBL1342850 & 737825 & 4.8 & $5.0710 e$ & 0000000001 & TRN \\
\hline CHEMBL1377767 & 737825 & 4.85 & 5.2799 & TRN & \\
\hline CHEMBL1411094 & 737825 & 5.6 & 5.5966 & TRN & \\
\hline CHEMBL1582666 & 737825 & 5.5 & 5.2474 & TRN & \\
\hline CHEMBL1741545 & 737825 & 4.55 & 5.2704 & TRN & \\
\hline CHEMBL1318349 & 737825 & 4.9 & 4.8545 & TRN & \\
\hline CHEMBL1435886 & 737825 & 4.9 & 4.7506 & TRN & \\
\hline CHEMBL1742054 & 737825 & 4.6 & 5.1298 & TRN & \\
\hline CHEMBL1337292 & 737825 & 5.05 & 5.0705 & TRN & \\
\hline CHEMBL1985350 & 737825 & 4.8 & 5.1826 & TRN & \\
\hline CHEMBL1397636 & 737825 & 5.5 & 5.4458 & TRN & \\
\hline CHEMBL1441891 & 737825 & 5.1 & 4.9048 & TRN & \\
\hline CHEMBL1541936 & 737825 & 5.5 & 5.3346 & TRN & \\
\hline CHEMBL1407783 & 737825 & 5.5 & 5.4564 & TRN & \\
\hline CHEMBL1331525 & 737825 & 6.4 & 6.46 & TRN & \\
\hline CHEMBL1358018 & 737825 & 5.5 & 5.1162 & TRN & \\
\hline CHEMBL1483088 & 737825 & 4.7 & 5.0872 & TRN & \\
\hline CHEMBL1577007 & 737825 & 4.7 & $5.3370 e$ & 0000000001 & TRN \\
\hline CHEMBL1602123 & 737825 & 4.5 & 4.3599 & TRN & \\
\hline CHEMBL1424424 & 737825 & 5.55 & 5.0998 & TRN & \\
\hline CHEMBL1312757 & 737825 & 4.75 & 5.1391 & TRN & \\
\hline CHEMBL1733088 & 737825 & 5.3 & 5.4626 & TRN & \\
\hline CHEMBL1601104 & 737825 & 4.95 & 5.1276 & TST & \\
\hline CHEMBL1429809 & 737825 & 4.75 & 5.2842 & TRN & \\
\hline CHEMBL1572635 & 737825 & 4.85 & 5.1204 & TRN & \\
\hline CHEMBL 279218 & 737825 & 4.9 & 4.8576 & TST & \\
\hline CHEMBL1336532 & 737825 & 5.7 & 5.2156 & TST & \\
\hline CHEMBL420539 & 737825 & 6.0 & 5.6722 & TRN & \\
\hline CHEMBL1490477 & 737825 & 5.5 & 5.2762 & TRN & \\
\hline CHEMBL1366573 & 737825 & 5.0 & 5.1588 & TRN & \\
\hline CHEMBL1380635 & 737825 & 4.8 & 5.1841 & TRN & \\
\hline CHEMBL1464079 & 737825 & 4.6 & 5.4205 & TRN & \\
\hline CHEMBL1409830 & 737825 & 5.7 & 5.8083 & TRN & \\
\hline CHEMBL1571734 & 737825 & 5.35 & 5.093 & TRN & \\
\hline CHEMBL1456872 & 737825 & 6.4 & 6.3124 & TRN & \\
\hline CHEMBL1590397 & 737825 & 5.5 & 5.5385 & TRN & \\
\hline CHEMBL3194627 & 737825 & 5.5 & 5.436 & TRN & \\
\hline CHEMBL1430383 & 737825 & 4.7 & 4.992 & TRN & \\
\hline CHEMBL1609404 & 737825 & 4.75 & 5.007 & TRN & \\
\hline CHEMBL1312265 & 737825 & 5.4 & 5.1336 & TRN & \\
\hline CHEMBL1376736 & 737825 & 4.8 & 4.6599 & TRN & \\
\hline
\end{tabular}




\begin{tabular}{|c|c|c|c|c|c|}
\hline & & & & & \\
\hline CHEMBL1613702 & 737825 & 5.6 & 5.2664 & TRN & \\
\hline CHEMBL1399058 & 737825 & 5.1 & 5.2358 & TRN & \\
\hline CHEMBL 2028085 & 737825 & 6.0 & 5.6484 & TRN & \\
\hline CHEMBL1369939 & 737825 & 4.9 & 5.0977 & TST & \\
\hline CHEMBL1437263 & 737825 & 5.4 & 5.2332 & TRN & \\
\hline CHEMBL1409613 & 737825 & 6.5 & 6.058 & TRN & \\
\hline CHEMBL1378764 & 737825 & 6.0 & 5.8355 & TRN & \\
\hline CHEMBL1519709 & 737825 & 4.7 & 5.026 & TRN & \\
\hline CHEMBL1517172 & 737825 & 4.8 & 4.8423 & TRN & \\
\hline CHEMBL1434460 & 737825 & 5.5 & 5.4156 & TRN & \\
\hline CHEMBL1433039 & 737825 & 5.95 & 5.4112 & TST & \\
\hline CHEMBL1337320 & 737825 & 5.1 & 5.2266 & TRN & \\
\hline CHEMBL1729999 & 737825 & 5.2 & 5.2129 & TRN & \\
\hline CHEMBL1434411 & 737825 & 4.8 & 4.6085 & TRN & \\
\hline CHEMBL103469 & 737825 & 4.8 & 4.8476 & TRN & \\
\hline CHEMBL 1456714 & 737825 & 5.1 & 4.8879 & TRN & \\
\hline CHEMBL1447244 & 737825 & 5.45 & 5.1796 & TRN & \\
\hline CHEMBL1741855 & 737825 & 4.9 & 5.2748 & TRN & \\
\hline CHEMBL1513392 & 737825 & 5.3 & $5.1560 e$ & 0000000001 & TRN \\
\hline CHEMBL1475562 & 737825 & 4.9 & 4.7736 & TRN & \\
\hline CHEMBL1714574 & 737825 & 5.8 & 5.8368 & TST & \\
\hline CHEMBL1562088 & 737825 & 5.3 & 5.1831 & TST & \\
\hline CHEMBL1527251 & 737825 & 4.9 & 5.1788 & TRN & \\
\hline CHEMBL1524211 & 737825 & 4.9 & 4.8069 & TRN & \\
\hline CHEMBL1403831 & 737825 & 4.95 & 4.9763 & TRN & \\
\hline CHEMBL1602926 & 737825 & 5.6 & 5.5457 & TRN & \\
\hline CHEMBL1572935 & 737825 & 4.85 & 5.2227 & TRN & \\
\hline CHEMBL1302442 & 737825 & 4.9 & 5.1318 & TRN & \\
\hline CHEMBL1545552 & 737825 & 4.85 & 5.2755 & TRN & \\
\hline CHEMBL1512850 & 737825 & 4.6 & 4.505 & TRN & \\
\hline CHEMBL1340051 & 737825 & 4.6 & 5.2757 & TRN & \\
\hline CHEMBL1512701 & 737825 & 5.6 & 5.5196 & TRN & \\
\hline CHEMBL1368113 & 737825 & 4.8 & 4.6769 & TRN & \\
\hline CHEMBL1359691 & 737825 & 5.3 & 5.2088 & TRN & \\
\hline CHEMBL1531056 & 737825 & 4.6 & 4.6318 & TRN & \\
\hline CHEMBL1481127 & 737825 & 5.0 & 4.825 & TRN & \\
\hline CHEMBL1565564 & 737825 & 4.5 & 4.4845 & TRN & \\
\hline CHEMBL1400132 & 737825 & 4.55 & 5.0108 & TRN & \\
\hline CHEMBL1338430 & 737825 & 4.95 & 4.9059 & TST & \\
\hline CHEMBL1400995 & 737825 & 4.5 & 4.9787 & TST & \\
\hline CHEMBL1547764 & 737825 & 4.8 & 5.2982 & TRN & \\
\hline CHEMBL1724565 & 737825 & 4.8 & 5.1377 & TRN & \\
\hline CHEMBL1516187 & 737825 & 5.5 & 5.3747 & TRN & \\
\hline CHEMBL1479131 & 737825 & 5.15 & 5.1068 & TRN & \\
\hline CHEMBL1578210 & 737825 & 4.7 & 5.2745 & TRN & \\
\hline CHEMBL1511408 & 737825 & 5.4 & 5.2406 & TRN & \\
\hline CHEMBL1316033 & 737825 & 5.0 & 4.7918 & TRN & \\
\hline CHEMBL1610892 & 737825 & 5.0 & 4.8347 & TRN & \\
\hline & & & & 22563 & \\
\hline
\end{tabular}




\begin{tabular}{|c|c|c|c|c|}
\hline \multicolumn{5}{|c|}{ Supplemental Table S2.txt } \\
\hline CHEMBL1462161 & 737825 & 5.0 & 5.2632 & TRN \\
\hline CHEMBL 3189483 & 737825 & 6.0 & 5.8597 & TRN \\
\hline CHEMBL1456354 & 737825 & 5.05 & 5.2207 & TRN \\
\hline CHEMBL 3208021 & 737825 & 5.4 & 5.3838 & TRN \\
\hline CHEMBL352396 & 737825 & 4.8 & 4.867 & TST \\
\hline CHEMBL1433486 & 737825 & 5.0 & 4.7854 & TRN \\
\hline CHEMBL1399207 & 737825 & 5.1 & 5.2626 & TRN \\
\hline CHEMBL1303348 & 737825 & 5.4 & 5.1595 & TST \\
\hline CHEMBL1575087 & 737825 & 5.35 & 5.0846 & TRN \\
\hline CHEMBL 1256325 & 737825 & 4.5 & 4.6001 & TRN \\
\hline CHEMBL1449103 & 737825 & 5.55 & 5.3958 & TRN \\
\hline CHEMBL1396203 & 737825 & 5.5 & 5.2848 & TRN \\
\hline CHEMBL1324162 & 737825 & 4.55 & 5.1729 & TRN \\
\hline CHEMBL1474317 & 737825 & 5.7 & 5.6836 & TRN \\
\hline CHEMBL1519453 & 737825 & 5.6 & 5.6004 & TST \\
\hline CHEMBL3391702 & 737825 & 6.4 & 5.9173 & TST \\
\hline CHEMBL34241 & 737825 & 4.9 & 5.0673 & TST \\
\hline CHEMBL1433883 & 737825 & 4.9 & 4.8075 & TRN \\
\hline CHEMBL1371202 & 737825 & 5.85 & 5.1605 & TRN \\
\hline CHEMBL1610350 & 737825 & 5.5 & 5.2901 & TRN \\
\hline CHEMBL1372132 & 737825 & 4.6 & 5.027 & TRN \\
\hline CHEMBL1474875 & 737825 & 4.8 & 4.6748 & TRN \\
\hline CHEMBL1588011 & 737825 & 5.2 & 5.2842 & TRN \\
\hline CHEMBL1571679 & 737825 & 5.6 & 5.3362 & TRN \\
\hline CHEMBL1742131 & 737825 & 4.85 & 5.0849 & TST \\
\hline CHEMBL1314273 & 737825 & 5.5 & 5.4239 & TRN \\
\hline CHEMBL1378800 & 737825 & 5.4 & 5.3267 & TST \\
\hline CHEMBL1592227 & 737825 & 5.7 & 5.7975 & TRN \\
\hline CHEMBL1378440 & 737825 & 5.6 & 5.3862 & TRN \\
\hline CHEMBL1547568 & 737825 & 4.95 & 5.1155 & TRN \\
\hline CHEMBL1400835 & 737825 & 4.9 & 5.175 & TRN \\
\hline CHEMBL3195422 & 737825 & 5.0 & 5.1634 & TRN \\
\hline CHEMBL230056 & 737825 & 4.9 & 4.9258 & TST \\
\hline CHEMBL546257 & 737825 & 6.0 & 5.7617 & TST \\
\hline CHEMBL1431290 & 737825 & 4.8 & 4.9835 & TRN \\
\hline CHEMBL1592500 & 737825 & 5.4 & 5.8213 & TRN \\
\hline CHEMBL489534 & 737825 & 6.3 & 6.4338 & TRN \\
\hline CHEMBL1355146 & 737825 & 5.1 & 4.8635 & TRN \\
\hline CHEMBL1741388 & 737825 & 5.35 & 5.2089 & TRN \\
\hline CHEMBL3212941 & 737825 & 5.3 & 5.2302 & TRN \\
\hline CHEMBL1447317 & 737825 & 5.3 & 5.1978 & TST \\
\hline CHEMBL1310543 & 737825 & 5.15 & 5.254 & TRN \\
\hline CHEMBL1455754 & 737825 & 4.6 & 5.115 & TRN \\
\hline CHEMBL1492177 & 737825 & 4.85 & 5.0802 & TRN \\
\hline CHEMBL1395417 & 737825 & 5.0 & 4.8254 & TRN \\
\hline CHEMBL1591971 & 737825 & 6.4 & 6.4904 & TRN \\
\hline CHEMBL1339949 & 737825 & 4.55 & 5.0594 & TRN \\
\hline CHEMBL1468521 & 737825 & 5.45 & 5.3976 & TRN \\
\hline
\end{tabular}




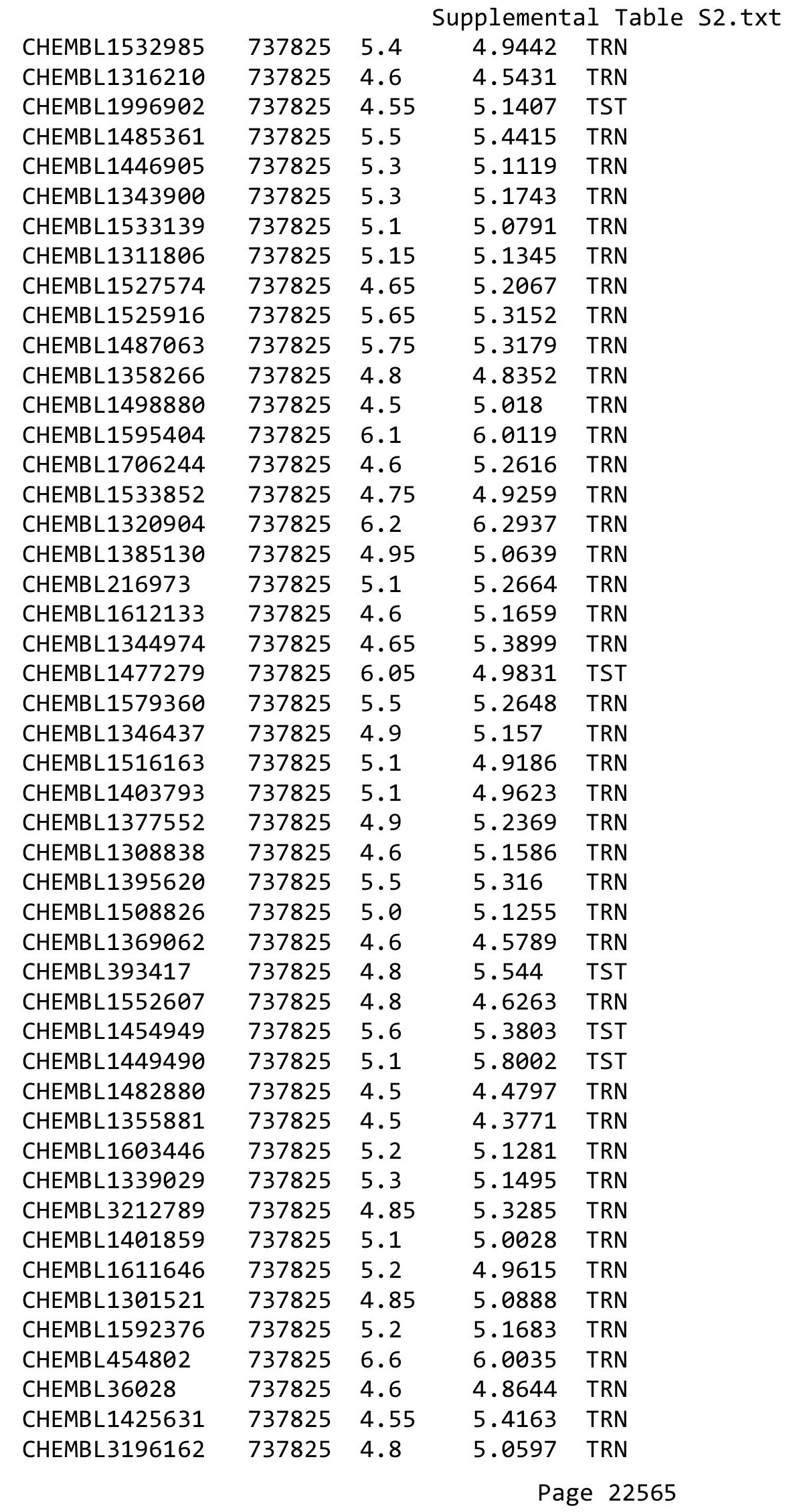




\begin{tabular}{|c|c|c|c|c|c|}
\hline \multicolumn{6}{|c|}{ Supplemental Table S2.txt } \\
\hline CHEMBL1516103 & 737825 & 5.4 & 5.0776 & TRN & \\
\hline CHEMBL3190163 & 737825 & 4.55 & 5.1807 & TRN & \\
\hline CHEMBL1405676 & 737825 & 4.95 & 4.9728 & TRN & \\
\hline CHEMBL1476831 & 737825 & 4.8 & 4.6783 & TRN & \\
\hline CHEMBL3209977 & 737825 & 5.9 & 5.0753 & TST & \\
\hline CHEMBL1409756 & 737825 & 5.5 & 5.3726 & TRN & \\
\hline CHEMBL1523038 & 737825 & 5.7 & 5.2654 & TRN & \\
\hline CHEMBL1546843 & 737825 & 5.1 & 5.187 & TRN & \\
\hline CHEMBL1582074 & 737825 & 5.35 & 5.1423 & TRN & \\
\hline CHEMBL1475120 & 737825 & 5.0 & 4.9182 & TRN & \\
\hline CHEMBL1532386 & 737825 & 5.85 & 5.2767 & TRN & \\
\hline CHEMBL1395344 & 737825 & 6.7 & 6.5213 & TRN & \\
\hline CHEMBL1405538 & 737825 & 5.8 & 5.7695 & TRN & \\
\hline CHEMBL1369008 & 737825 & 6.0 & 5.8052 & TRN & \\
\hline CHEMBL1495604 & 737825 & 4.55 & 5.2759 & TRN & \\
\hline CHEMBL3197789 & 737825 & 5.85 & 5.2389 & TRN & \\
\hline CHEMBL1327355 & 737825 & 4.5 & 4.5792 & TRN & \\
\hline CHEMBL1603418 & 737825 & 4.8 & 4.7614 & TRN & \\
\hline CHEMBL1328391 & 737825 & 6.3 & 5.2253 & TRN & \\
\hline CHEMBL1487070 & 737825 & 5.6 & $5.5920 e$ & 00000000005 & TRN \\
\hline CHEMBL1388133 & 737825 & 5.55 & 5.2907 & TRN & \\
\hline CHEMBL1476084 & 737825 & 5.4 & 5.461 & TRN & \\
\hline CHEMBL1356842 & 737825 & 6.3 & 6.0246 & TRN & \\
\hline CHEMBL1256663 & 737825 & 4.8 & 4.7716 & TRN & \\
\hline CHEMBL1330954 & 737825 & 4.55 & 4.9883 & TRN & \\
\hline CHEMBL1326359 & 737825 & 5.15 & 4.9624 & TRN & \\
\hline CHEMBL1322233 & 737825 & 4.7 & 4.6742 & TRN & \\
\hline CHEMBL1598049 & 737825 & 4.95 & 5.1374 & TRN & \\
\hline CHEMBL1439483 & 737825 & 5.7 & 5.4834 & TRN & \\
\hline CHEMBL 3190254 & 737825 & 5.05 & 4.9638 & TRN & \\
\hline CHEMBL1605426 & 737825 & 4.7 & 4.5899 & TST & \\
\hline CHEMBL1338077 & 737825 & 4.7 & 5.2249 & TRN & \\
\hline CHEMBL1441650 & 737825 & 4.9 & 5.1204 & TRN & \\
\hline CHEMBL1517999 & 737825 & 4.8 & 4.6328 & TRN & \\
\hline CHEMBL1413058 & 737825 & 4.85 & 5.226 & TRN & \\
\hline CHEMBL1318042 & 737825 & 5.4 & 5.4873 & TRN & \\
\hline CHEMBL1331881 & 737825 & 4.8 & 4.9982 & TRN & \\
\hline CHEMBL3213467 & 737825 & 4.9 & 5.1132 & TRN & \\
\hline CHEMBL1603113 & 737825 & 5.6 & 5.495 & TRN & \\
\hline CHEMBL1587467 & 737825 & 5.6 & 5.4542 & TRN & \\
\hline CHEMBL1560567 & 737825 & 5.5 & 5.5214 & TRN & \\
\hline CHEMBL1410926 & 737825 & 5.2 & 5.0826 & TRN & \\
\hline CHEMBL1707011 & 737825 & 4.9 & 5.239 & TRN & \\
\hline CHEMBL1329823 & 737825 & 4.9 & 4.9525 & TRN & \\
\hline CHEMBL1549843 & 737825 & 5.85 & 5.1572 & TST & \\
\hline CHEMBL1430904 & 737825 & 4.6 & 5.1258 & TRN & \\
\hline CHEMBL1309731 & 737825 & 4.8 & 5.1651 & TRN & \\
\hline CHEMBL1315318 & 737825 & 5.4 & 5.3461 & TRN & \\
\hline
\end{tabular}




\begin{tabular}{|c|c|c|c|c|c|}
\hline \multicolumn{6}{|c|}{ Supplemental Table S2.txt } \\
\hline CHEMBL3198385 & 737825 & 4.65 & 5.1678 & TRN & \\
\hline CHEMBL1446323 & 737825 & 4.7 & 4.6482 & TRN & \\
\hline CHEMBL1583365 & 737825 & 4.7 & 4.9634 & TRN & \\
\hline CHEMBL3198037 & 737825 & 5.55 & 5.2451 & TRN & \\
\hline CHEMBL3207894 & 737825 & 6.0 & 5.9164 & TRN & \\
\hline CHEMBL1357222 & 737825 & 4.9 & 4.9428 & TRN & \\
\hline CHEMBL1481747 & 737825 & 4.8 & 4.7807 & TRN & \\
\hline CHEMBL1507561 & 737825 & 4.6 & 5.2028 & TRN & \\
\hline CHEMBL1389433 & 737825 & 4.65 & 5.0426 & TST & \\
\hline CHEMBL1357724 & 737825 & 5.3 & 5.3018 & TRN & \\
\hline CHEMBL1421887 & 737825 & 4.85 & 5.1899 & TRN & \\
\hline CHEMBL1726157 & 737825 & 5.15 & 5.1704 & TRN & \\
\hline CHEMBL1311461 & 737825 & 4.85 & 5.1839 & TRN & \\
\hline CHEMBL1474313 & 737825 & 5.5 & 5.4112 & TRN & \\
\hline CHEMBL1360980 & 737825 & 4.8 & 4.9615 & TST & \\
\hline CHEMBL1593861 & 737825 & 4.8 & 4.7416 & TRN & \\
\hline CHEMBL3213001 & 737825 & 4.4 & 5.3703 & TRN & \\
\hline CHEMBL1591533 & 737825 & 4.4 & 4.3392 & TRN & \\
\hline CHEMBL1487894 & 737825 & 4.4 & 5.1153 & TRN & \\
\hline CHEMBL1444394 & 737825 & 6.25 & 5.9099 & TRN & \\
\hline CHEMBL1372850 & 737825 & 5.5 & 5.3738 & TRN & \\
\hline CHEMBL1442537 & 737825 & 4.85 & 5.2316 & TRN & \\
\hline CHEMBL1471962 & 737825 & 5.45 & 5.192 & TRN & \\
\hline CHEMBL1435077 & 737825 & 5.9 & 5.8878 & TRN & \\
\hline CHEMBL1319718 & 737825 & 4.65 & 5.0275 & TRN & \\
\hline CHEMBL1383532 & 737825 & 4.85 & 4.9051 & TST & \\
\hline CHEMBL1467606 & 737825 & 4.9 & 5.0862 & TRN & \\
\hline CHEMBL1448668 & 737825 & 5.7 & 5.5360 & 00000000005 & TRN \\
\hline CHEMBL1475036 & 737825 & 6.0 & 5.8753 & TRN & \\
\hline CHEMBL1586264 & 737825 & 4.7 & 5.1101 & TRN & \\
\hline CHEMBL1317400 & 737825 & 4.9 & 4.7388 & TRN & \\
\hline CHEMBL1515361 & 737825 & 4.8 & 4.7899 & TRN & \\
\hline CHEMBL1454249 & 737825 & 6.1 & 5.1032 & TRN & \\
\hline CHEMBL1606292 & 737825 & 5.9 & 5.8507 & TRN & \\
\hline CHEMBL1742098 & 737825 & 5.2 & 5.1584 & TST & \\
\hline CHEMBL1580660 & 737825 & 5.1 & 5.3131 & TST & \\
\hline CHEMBL3212699 & 737825 & 5.15 & 5.1864 & TRN & \\
\hline CHEMBL1705686 & 737825 & 4.75 & 5.1994 & TRN & \\
\hline CHEMBL1529151 & 737825 & 4.8 & 4.6552 & TRN & \\
\hline CHEMBL1552396 & 737825 & 5.4 & 5.3851 & TRN & \\
\hline CHEMBL1396374 & 737825 & 6.4 & 6.2456 & TRN & \\
\hline CHEMBL3197893 & 737825 & 4.85 & 5.3156 & TRN & \\
\hline CHEMBL1547685 & 737825 & 5.0 & 5.0989 & TRN & \\
\hline CHEMBL197027 & 737825 & 6.9 & 6.2217 & TST & \\
\hline CHEMBL3189564 & 737825 & 5.0 & 5.2769 & TRN & \\
\hline CHEMBL1559912 & 737825 & 5.4 & 5.1746 & TRN & \\
\hline CHEMBL1589879 & 737825 & 5.2 & 5.2641 & TRN & \\
\hline CHEMBL1475509 & 737825 & 5.4 & 5.3389 & 99999999995 & TRN \\
\hline
\end{tabular}




\begin{tabular}{|c|c|c|c|c|c|}
\hline \multirow{3}{*}{$\begin{array}{l}\text { CHEMBL1493054 } \\
\text { CHEMBL1555314 }\end{array}$} & \multirow{3}{*}{$\begin{array}{l}737825 \\
737825\end{array}$} & \multicolumn{4}{|c|}{ Supplemental Table S2.txt } \\
\hline & & 5.1 & 5.2429 & 9999999999 & TRN \\
\hline & & 5.6 & 5.5499 & TRN & \\
\hline CHEMBL1488466 & 737825 & 6.0 & 5.3494 & TRN & \\
\hline CHEMBL3194362 & 737825 & 4.9 & 5.1645 & TRN & \\
\hline CHEMBL478501 & 737825 & 4.45 & 5.1473 & TRN & \\
\hline CHEMBL1521039 & 737825 & 5.2 & 5.0744 & TRN & \\
\hline CHEMBL1354734 & 737825 & 4.9 & 4.9533 & TST & \\
\hline CHEMBL1433886 & 737825 & 5.4 & 5.3821 & TRN & \\
\hline CHEMBL1451950 & 737825 & 4.55 & 5.2845 & TRN & \\
\hline CHEMBL375126 & 737825 & 5.1 & 5.0234 & TRN & \\
\hline CHEMBL3208639 & 737825 & 4.6 & 5.1831 & TST & \\
\hline CHEMBL1313465 & 737825 & 5.55 & 5.0933 & TRN & \\
\hline CHEMBL1604172 & 737825 & 4.9 & 5.0098 & TST & \\
\hline CHEMBL1403134 & 737825 & 5.0 & 5.0396 & TRN & \\
\hline CHEMBL1360601 & 737825 & 4.9 & 5.0727 & TRN & \\
\hline CHEMBL1313549 & 737825 & 5.85 & 5.0367 & TRN & \\
\hline CHEMBL1456420 & 737825 & 5.4 & 5.2499 & TRN & \\
\hline CHEMBL1497639 & 737825 & 5.5 & 5.3068 & TRN & \\
\hline CHEMBL1487502 & 737825 & 5.1 & 5.1266 & TRN & \\
\hline CHEMBL 2373584 & 737825 & 5.5 & 5.4293 & TRN & \\
\hline CHEMBL1476981 & 737825 & 4.8 & 4.6381 & TRN & \\
\hline CHEMBL1372404 & 737825 & 6.15 & 5.4621 & TRN & \\
\hline CHEMBL299052 & 737825 & 5.5 & 5.4692 & TRN & \\
\hline CHEMBL1419308 & 737825 & 4.85 & 5.261 & TRN & \\
\hline CHEMBL 2000196 & 737825 & 4.5 & 5.1817 & TRN & \\
\hline CHEMBL1461239 & 737825 & 5.55 & 5.2286 & TRN & \\
\hline CHEMBL1515295 & 737825 & 4.9 & 4.8213 & TRN & \\
\hline CHEMBL1611508 & 737825 & 5.55 & 5.1889 & TRN & \\
\hline CHEMBL1303741 & 737825 & 6.2 & 5.0695 & TRN & \\
\hline CHEMBL1453311 & 737825 & 5.15 & 5.183 & TRN & \\
\hline CHEMBL1552293 & 737825 & 4.7 & 4.5815 & TRN & \\
\hline CHEMBL1493707 & 737825 & 5.5 & 5.4653 & TRN & \\
\hline CHEMBL1725964 & 737825 & 5.65 & 5.3433 & TST & \\
\hline CHEMBL3193309 & 737825 & 5.95 & 5.3166 & TRN & \\
\hline CHEMBL1506056 & 737825 & 4.95 & 5.2106 & TRN & \\
\hline CHEMBL1337617 & 737825 & 4.8 & 5.1489 & TRN & \\
\hline CHEMBL 1314625 & 737825 & 5.6 & 5.6534 & TRN & \\
\hline CHEMBL1468324 & 737825 & 4.85 & 5.2821 & TRN & \\
\hline CHEMBL1317537 & 737825 & 5.1 & 4.8203 & TRN & \\
\hline CHEMBL1420898 & 737825 & 4.85 & 5.2926 & TRN & \\
\hline CHEMBL1318056 & 737825 & 5.5 & 5.5481 & TRN & \\
\hline CHEMBL1379160 & 737825 & 5.1 & 5.1073 & TRN & \\
\hline CHEMBL1460531 & 737825 & 4.75 & 5.0463 & TST & \\
\hline CHEMBL3211204 & 737825 & 4.4 & 5.2006 & TRN & \\
\hline CHEMBL1370189 & 737825 & 5.7 & 5.3783 & TRN & \\
\hline CHEMBL1531294 & 737825 & 6.0 & 5.9025 & TRN & \\
\hline CHEMBL1601305 & 737825 & 5.1 & 4.8791 & TRN & \\
\hline CHEMBL399491 & 737825 & 4.5 & 4.4787 & TST & \\
\hline
\end{tabular}




\begin{tabular}{|c|c|c|c|c|}
\hline & & & upplement & al Table S \\
\hline CHEMBL1567229 & 737825 & 4.85 & 4.9757 & TRN \\
\hline CHEMBL513116 & 737825 & 6.0 & 5.6996 & TRN \\
\hline CHEMBL1476521 & 737825 & 5.2 & 5.0746 & TRN \\
\hline CHEMBL1318104 & 737825 & 4.8 & 4.8001 & TRN \\
\hline CHEMBL1402633 & 737825 & 6.2 & 5.6793 & TRN \\
\hline CHEMBL1396326 & 737825 & 5.0 & 4.8945 & TRN \\
\hline CHEMBL1515706 & 737825 & 5.5 & 5.3833 & TRN \\
\hline CHEMBL1356060 & 737825 & 6.1 & 6.1973 & TRN \\
\hline CHEMBL1370726 & 737825 & 5.5 & 5.314 & TST \\
\hline CHEMBL1558371 & 737825 & 4.7 & 5.1737 & TRN \\
\hline CHEMBL1433668 & 737825 & 4.8 & 4.7009 & TRN \\
\hline CHEMBL1523126 & 737825 & 5.1 & 5.2588 & TRN \\
\hline CHEMBL1398586 & 737825 & 5.4 & 5.3651 & TRN \\
\hline CHEMBL1351829 & 737825 & 5.45 & 5.2134 & TRN \\
\hline CHEMBL1405151 & 737825 & 5.35 & 5.0491 & TRN \\
\hline CHEMBL1414849 & 737825 & 4.55 & 5.1211 & TRN \\
\hline CHEMBL1598543 & 737825 & 4.9 & 5.1257 & TRN \\
\hline CHEMBL1327881 & 737825 & 5.0 & 4.8939 & TRN \\
\hline CHEMBL1445772 & 737825 & 5.3 & 5.2443 & TRN \\
\hline CHEMBL3211454 & 737825 & 4.4 & 5.5427 & TRN \\
\hline CHEMBL1318958 & 737825 & 5.25 & 5.2536 & TRN \\
\hline CHEMBL 2374058 & 737825 & 4.6 & 4.7115 & TST \\
\hline CHEMBL1396975 & 737825 & 5.1 & 4.8641 & TRN \\
\hline CHEMBL1357085 & 737825 & 5.5 & 5.4299 & TRN \\
\hline CHEMBL1557255 & 737825 & 4.8 & 4.885 & TRN \\
\hline CHEMBL1335455 & 737825 & 5.5 & 5.2534 & TST \\
\hline CHEMBL1601630 & 737825 & 4.9 & 4.7443 & TRN \\
\hline CHEMBL1475860 & 737825 & 5.7 & 5.483 & TRN \\
\hline CHEMBL1552747 & 737825 & 5.1 & 4.9159 & TRN \\
\hline CHEMBL1401126 & 737825 & 5.0 & 5.1992 & TRN \\
\hline CHEMBL1605237 & 737825 & 5.0 & 5.3248 & TRN \\
\hline CHEMBL1433687 & 737825 & 5.1 & 4.9998 & TRN \\
\hline CHEMBL1435313 & 737825 & 5.4 & 5.29299 & 9999999999 \\
\hline CHEMBL1709586 & 737825 & 5.45 & 5.1427 & TST \\
\hline CHEMBL1551479 & 737825 & 6.1 & 5.682 & TRN \\
\hline CHEMBL1565645 & 737825 & 4.8 & 5.0109 & TRN \\
\hline CHEMBL1327708 & 737825 & 4.6 & 4.4855 & TRN \\
\hline CHEMBL1530955 & 737825 & 4.9 & 5.0973 & TRN \\
\hline CHEMBL1438748 & 737825 & 4.6 & 4.6938 & TRN \\
\hline CHEMBL1560839 & 737825 & 4.85 & 5.1968 & TRN \\
\hline CHEMBL1439172 & 737825 & 4.4 & 4.5071 & TST \\
\hline CHEMBL1592580 & 737825 & 5.1 & 4.9706 & TRN \\
\hline CHEMBL1302141 & 737825 & 5.45 & 5.2455 & TRN \\
\hline CHEMBL1409626 & 737825 & 4.85 & 5.2298 & TRN \\
\hline CHEMBL1537227 & 737825 & 5.55 & 5.209 & TRN \\
\hline CHEMBL1421334 & 737825 & 5.65 & 5.4201 & TST \\
\hline CHEMBL1531779 & 737825 & 4.55 & 5.0231 & TST \\
\hline CHEMBL1532107 & 737825 & 4.6 & 5.075 & TST \\
\hline
\end{tabular}




\begin{tabular}{|c|c|c|c|c|c|}
\hline & & & & & \\
\hline CHEMBL287327 & 737825 & 4.6 & 4.6644 & TST & \\
\hline CHEMBL1556610 & 737825 & 4.4 & 4.9706 & TRN & \\
\hline CHEMBL1592464 & 737825 & 6.4 & 6.5936 & TRN & \\
\hline CHEMBL1555369 & 737825 & 5.4 & $5.3660 e$ & 20000000005 & TRN \\
\hline CHEMBL 3084891 & 737825 & 4.9 & 4.9379 & TRN & \\
\hline CHEMBL1347463 & 737825 & 5.45 & 5.2004 & TRN & \\
\hline CHEMBL1463049 & 737825 & 5.95 & 5.1438 & TRN & \\
\hline CHEMBL1376830 & 737825 & 4.95 & 5.2799 & TRN & \\
\hline CHEMBL1513740 & 737825 & 4.8 & 4.7835 & TRN & \\
\hline CHEMBL1303518 & 737825 & 5.65 & 5.0623 & TST & \\
\hline CHEMBL1256291 & 737825 & 4.7 & 4.7113 & TST & \\
\hline CHEMBL1365701 & 737825 & 6.0 & 5.7221 & TRN & \\
\hline CHEMBL1451307 & 737825 & 6.0 & 5.112 & TRN & \\
\hline CHEMBL1315508 & 737825 & 4.8 & 4.7054 & TRN & \\
\hline CHEMBL1594078 & 737825 & 4.9 & 4.8487 & TRN & \\
\hline CHEMBL 22870 & 737825 & 4.8 & 5.0743 & TRN & \\
\hline CHEMBL1466281 & 737825 & 4.8 & 5.223 & TRN & \\
\hline CHEMBL1482653 & 737825 & 5.15 & 5.0914 & TRN & \\
\hline CHEMBL1320042 & 737825 & 5.15 & 5.125 & TST & \\
\hline CHEMBL1460429 & 737825 & 6.0 & 5.2169 & TRN & \\
\hline CHEMBL1459899 & 737825 & 5.95 & 5.0718 & TRN & \\
\hline CHEMBL1980031 & 737825 & 5.45 & 5.0921 & TRN & \\
\hline CHEMBL1382729 & 737825 & 5.7 & 5.1511 & TRN & \\
\hline CHEMBL1712617 & 737825 & 5.65 & 5.2775 & TRN & \\
\hline CHEMBL3189369 & 737825 & 5.1 & 5.3718 & TRN & \\
\hline CHEMBL1491853 & 737825 & 5.5 & 5.4201 & TRN & \\
\hline CHEMBL1604505 & 737825 & 4.4 & 5.0857 & TRN & \\
\hline CHEMBL1363513 & 737825 & 6.0 & 5.6404 & TRN & \\
\hline CHEMBL1400113 & 737825 & 4.85 & 5.3254 & TRN & \\
\hline CHEMBL3189225 & 737825 & 5.15 & 5.0832 & TRN & \\
\hline CHEMBL1361182 & 737825 & 5.05 & 5.0972 & TRN & \\
\hline CHEMBL1400976 & 737825 & 6.0 & 5.9303 & TRN & \\
\hline CHEMBL420060 & 737825 & 4.7 & 4.7181 & TRN & \\
\hline CHEMBL1435373 & 737825 & 6.6 & 6.3723 & TRN & \\
\hline CHEMBL1316055 & 737825 & 5.0 & 5.0166 & TRN & \\
\hline CHEMBL1582783 & 737825 & 5.45 & 5.1312 & TST & \\
\hline CHEMBL478 & 737825 & 7.4 & 6.4683 & TRN & \\
\hline CHEMBL1475487 & 737825 & 6.0 & 5.7729 & TRN & \\
\hline CHEMBL1308538 & 737825 & 5.85 & 5.5327 & TRN & \\
\hline CHEMBL1597695 & 737825 & 4.6 & 5.0766 & TST & \\
\hline CHEMBL491978 & 737825 & 6.3 & 6.2034 & TRN & \\
\hline CHEMBL 3194740 & 737825 & 4.65 & $5.1620 e$ & 0000000001 & TRN \\
\hline CHEMBL1494452 & 737825 & 4.9 & 5.0063 & TRN & \\
\hline CHEMBL1584523 & 737825 & 4.75 & 5.0261 & TRN & \\
\hline CHEMBL1565961 & 737825 & 5.2 & $5.1160 e$ & 00000000005 & TRN \\
\hline CHEMBL1313506 & 737825 & 4.8 & 5.0966 & TRN & \\
\hline CHEMBL1482342 & 737825 & 5.5 & 5.2046 & TRN & \\
\hline CHEMBL1521414 & 737825 & 4.95 & 5.2178 & TRN & \\
\hline & & & & 22570 & \\
\hline
\end{tabular}




\begin{tabular}{|c|c|c|c|c|c|}
\hline \multicolumn{6}{|c|}{ Supplemental Table S2.txt } \\
\hline CHEMBL1374585 & 737825 & 4.4 & 4.4556 & TRN & \\
\hline CHEMBL1467940 & 737825 & 5.35 & 5.2825 & TST & \\
\hline CHEMBL1579818 & 737825 & 4.85 & 5.1502 & TRN & \\
\hline CHEMBL1409313 & 737825 & 5.15 & 5.3368 & TRN & \\
\hline CHEMBL1326132 & 737825 & 4.6 & 5.3062 & TRN & \\
\hline CHEMBL1407257 & 737825 & 5.1 & 5.0192 & TRN & \\
\hline CHEMBL1433898 & 737825 & 5.0 & 4.8488 & TRN & \\
\hline CHEMBL1501526 & 737825 & 5.05 & 5.4494 & TRN & \\
\hline CHEMBL1512693 & 737825 & 4.8 & 4.7362 & TRN & \\
\hline CHEMBL1335726 & 737825 & 5.2 & 5.1858 & TRN & \\
\hline CHEMBL1361114 & 737825 & 4.75 & 5.1896 & TST & \\
\hline CHEMBL1522755 & 737825 & 5.25 & 5.1541 & TRN & \\
\hline CHEMBL1561718 & 737825 & 4.95 & 5.0023 & TST & \\
\hline CHEMBL1361406 & 737825 & 4.9 & 4.7957 & TRN & \\
\hline CHEMBL39 & 737825 & 4.6 & 5.53799 & 9999999999 & TRN \\
\hline CHEMBL3196561 & 737825 & 4.8 & 5.1953 & TRN & \\
\hline CHEMBL1455203 & 737825 & 5.4 & 5.3444 & TRN & \\
\hline CHEMBL1526648 & 737825 & 5.0 & 5.0155 & TRN & \\
\hline CHEMBL1314799 & 737825 & 5.6 & 5.3657 & TRN & \\
\hline CHEMBL1523040 & 737825 & 5.15 & 5.2479 & TRN & \\
\hline CHEMBL1507893 & 737825 & 5.5 & 5.1244 & TRN & \\
\hline CHEMBL1568854 & 737825 & 5.0 & 5.0093 & TRN & \\
\hline CHEMBL1304054 & 737825 & 5.55 & 5.4221 & TRN & \\
\hline CHEMBL1400427 & 737825 & 4.8 & 5.2668 & TRN & \\
\hline CHEMBL1358122 & 737825 & 4.9 & 4.7915 & TRN & \\
\hline CHEMBL1378353 & 737825 & 5.0 & 5.0664 & TRN & \\
\hline CHEMBL1306727 & 737825 & 5.1 & 5.2423 & TRN & \\
\hline CHEMBL1476274 & 737825 & 5.3 & 5.1564 & TST & \\
\hline CHEMBL1708264 & 737825 & 4.85 & 5.0664 & TRN & \\
\hline CHEMBL1374527 & 737825 & 4.6 & 5.2064 & TRN & \\
\hline CHEMBL1723585 & 737825 & 4.55 & 5.2341 & TRN & \\
\hline CHEMBL1440742 & 737825 & 5.2 & 5.04 & TRN & \\
\hline CHEMBL1329630 & 737825 & 5.6 & 5.2185 & TRN & \\
\hline CHEMBL1366699 & 737825 & 4.5 & 4.4886 & TRN & \\
\hline CHEMBL1571692 & 737825 & 6.0 & 5.6174 & TST & \\
\hline CHEMBL1369515 & 737825 & 4.7 & 4.6493 & TRN & \\
\hline CHEMBL1362547 & 737825 & 4.5 & 4.9888 & TRN & \\
\hline CHEMBL1521830 & 737825 & 6.0 & 5.2371 & TRN & \\
\hline CHEMBL1332504 & 737825 & 6.4 & 6.0133 & TRN & \\
\hline CHEMBL1457014 & 737825 & 4.45 & 5.0471 & TST & \\
\hline CHEMBL1326815 & 737825 & 5.5 & 5.4309 & TRN & \\
\hline CHEMBL1397443 & 737825 & 5.5 & 5.3601 & TST & \\
\hline CHEMBL1411389 & 737825 & 5.2 & 5.1774 & TRN & \\
\hline CHEMBL1256746 & 737825 & 4.9 & 4.9068 & TRN & \\
\hline CHEMBL 3207362 & 737825 & 4.6 & 5.0403 & TST & \\
\hline CHEMBL3207903 & 737825 & 5.5 & 5.5057 & TRN & \\
\hline CHEMBL1466684 & 737825 & 4.8 & 5.0544 & TRN & \\
\hline CHEMBL1420257 & 737825 & 5.15 & 5.0521 & TRN & \\
\hline
\end{tabular}




\begin{tabular}{|c|c|c|c|c|c|}
\hline \multicolumn{6}{|c|}{ Supplemental Table S2.txt } \\
\hline CHEMBL1486506 & 737825 & 6.0 & 5.3582 & TST & \\
\hline CHEMBL1600394 & 737825 & 4.7 & 4.593 & TRN & \\
\hline CHEMBL1593743 & 737825 & 4.9 & 4.9097 & TST & \\
\hline CHEMBL1417349 & 737825 & 5.5 & 5.5376 & TRN & \\
\hline CHEMBL1450716 & 737825 & 5.0 & 4.9951 & TRN & \\
\hline CHEMBL1314647 & 737825 & 5.2 & 4.9754 & TRN & \\
\hline CHEMBL1441667 & 737825 & 4.85 & 5.1401 & TRN & \\
\hline CHEMBL1323391 & 737825 & 5.2 & 5.1798 & TST & \\
\hline CHEMBL1317458 & 737825 & 4.6 & 5.0176 & TST & \\
\hline CHEMBL440084 & 737825 & 5.0 & 5.061 & TRN & \\
\hline CHEMBL1601111 & 737825 & 5.8 & 5.1227 & TST & \\
\hline CHEMBL1741417 & 737825 & 4.6 & 5.0785 & TRN & \\
\hline CHEMBL1314225 & 737825 & 4.8 & 4.6832 & TRN & \\
\hline CHEMBL1376048 & 737825 & 5.05 & 5.3102 & TRN & \\
\hline CHEMBL1467157 & 737825 & 6.2 & 5.3568 & TRN & \\
\hline CHEMBL1374043 & 737825 & 4.85 & 5.0156 & TRN & \\
\hline CHEMBL1727680 & 737825 & 5.4 & 5.4358 & TRN & \\
\hline CHEMBL1725604 & 737825 & 4.45 & 5.1843 & TRN & \\
\hline CHEMBL1433464 & 737825 & 5.2 & 5.1563 & TRN & \\
\hline CHEMBL1450602 & 737825 & 5.7 & 5.3609 & TRN & \\
\hline CHEMBL1474114 & 737825 & 6.1 & 6.2209 & TRN & \\
\hline CHEMBL1384675 & 737825 & 6.0 & 5.2049 & TRN & \\
\hline CHEMBL1400342 & 737825 & 4.8 & 4.68199 & 99999999995 & TRN \\
\hline CHEMBL1308683 & 737825 & 5.4 & 5.087 & TST & \\
\hline CHEMBL1377507 & 737825 & 6.0 & 5.4732 & TST & \\
\hline CHEMBL1302300 & 737825 & 4.8 & 4.9602 & TST & \\
\hline CHEMBL1384157 & 737825 & 5.6 & 5.1512 & TST & \\
\hline CHEMBL1389235 & 737825 & 5.6 & 5.1153 & TRN & \\
\hline CHEMBL1320922 & 737825 & 5.3 & 5.3947 & TST & \\
\hline CHEMBL1515691 & 737825 & 4.8 & 4.8068 & TST & \\
\hline CHEMBL1377321 & 737825 & 4.65 & 5.1286 & TRN & \\
\hline CHEMBL1414185 & 737825 & 6.5 & 6.1169 & TST & \\
\hline CHEMBL1609472 & 737825 & 4.7 & 5.0757 & TST & \\
\hline CHEMBL1534755 & 737825 & 4.4 & 5.0863 & TRN & \\
\hline CHEMBL1594359 & 737825 & 6.0 & 5.6564 & TRN & \\
\hline CHEMBL1316731 & 737825 & 5.1 & 4.7878 & TRN & \\
\hline CHEMBL1451097 & 737825 & 4.9 & 4.6982 & TST & \\
\hline CHEMBL1407035 & 737825 & 5.1 & 5.006 & TRN & \\
\hline CHEMBL1526369 & 737825 & 5.4 & 5.0158 & TRN & \\
\hline CHEMBL1484337 & 737825 & 5.8 & 5.7218 & TRN & \\
\hline CHEMBL1383348 & 737825 & 4.85 & 5.2 & TRN & \\
\hline CHEMBL1428282 & 737825 & 4.5 & 5.0053 & TRN & \\
\hline CHEMBL1474854 & 737825 & 4.8 & 4.5839 & TRN & \\
\hline CHEMBL3193223 & 737825 & 4.55 & 5.1942 & TRN & \\
\hline CHEMBL1418280 & 737825 & 6.7 & 5.0797 & TRN & \\
\hline CHEMBL1256191 & 737825 & 4.8 & 4.7553 & TST & \\
\hline CHEMBL1306015 & 737825 & 5.55 & 5.265 & TRN & \\
\hline CHEMBL1542248 & 737825 & 5.8 & 5.2042 & TRN & \\
\hline
\end{tabular}




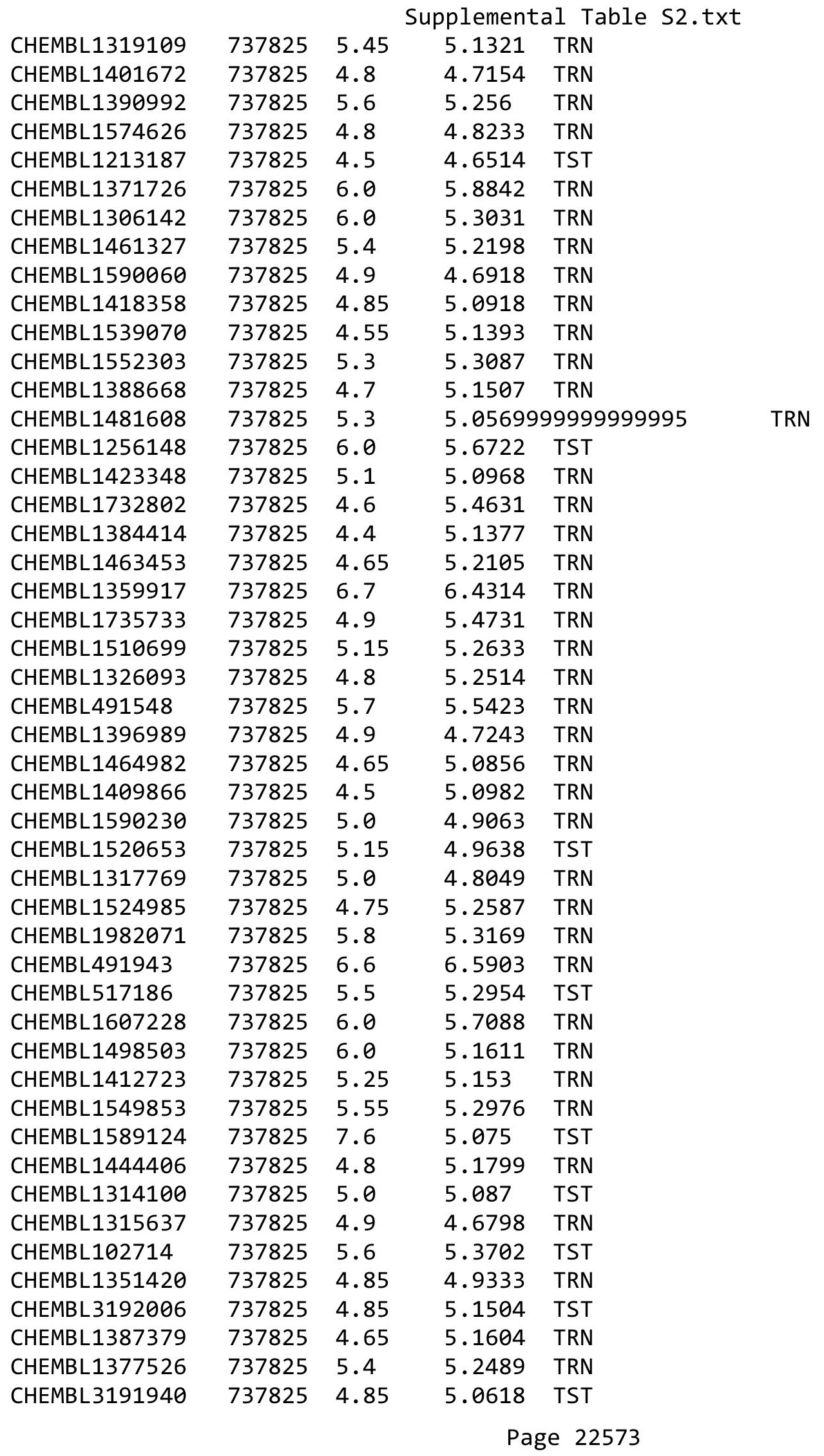




\begin{tabular}{|c|c|c|c|c|}
\hline \multicolumn{5}{|c|}{ Supplemental Table S2.txt } \\
\hline CHEMBL3211853 & 737825 & 4.8 & 5.1129 & TRN \\
\hline CHEMBL1435409 & 737825 & 6.3 & 6.2837 & TRN \\
\hline CHEMBL1395278 & 737825 & 5.5 & 5.4101 & TRN \\
\hline CHEMBL1315690 & 737825 & 4.7 & 4.5276 & TRN \\
\hline CHEMBL1334847 & 737825 & 5.0 & 4.6535 & TRN \\
\hline CHEMBL73310 & 737825 & 4.9 & 4.7667 & TRN \\
\hline CHEMBL1370045 & 737825 & 4.85 & 5.3979 & TRN \\
\hline CHEMBL1572747 & 737825 & 6.3 & 6.3549 & TRN \\
\hline CHEMBL1468264 & 737825 & 5.0 & 5.147 & TST \\
\hline CHEMBL9225 & 737825 & 5.3 & 5.0993 & TRN \\
\hline CHEMBL1305916 & 737825 & 6.15 & 5.0341 & TST \\
\hline CHEMBL1552635 & 737825 & 5.9 & 5.8684 & TRN \\
\hline CHEMBL1561570 & 737825 & 4.95 & 5.1234 & TRN \\
\hline CHEMBL1375098 & 737825 & 5.45 & 4.9089 & TRN \\
\hline CHEMBL1356630 & 737825 & 6.1 & 6.1546 & TRN \\
\hline CHEMBL1488574 & 737825 & 5.7 & 5.7683 & TRN \\
\hline CHEMBL1487648 & 737825 & 6.2 & 5.2324 & TRN \\
\hline CHEMBL1442250 & 737825 & 4.9 & 4.8351 & TRN \\
\hline CHEMBL1256869 & 737825 & 4.5 & 4.6256 & TST \\
\hline CHEMBL1575899 & 737825 & 4.85 & 5.3578 & TRN \\
\hline CHEMBL287689 & 737825 & 5.5 & 5.2996 & TST \\
\hline CHEMBL1318340 & 737825 & 4.9 & 4.8196 & TRN \\
\hline CHEMBL1599163 & 737825 & 4.6 & 4.5233 & TRN \\
\hline CHEMBL1366030 & 737825 & 5.05 & 5.1371 & TRN \\
\hline CHEMBL1528565 & 737825 & 5.7 & 5.261 & TST \\
\hline CHEMBL1560798 & 737825 & 5.1 & 4.9827 & TRN \\
\hline CHEMBL1302086 & 737825 & 4.9 & 5.1189 & TST \\
\hline CHEMBL1477076 & 737825 & 5.25 & 5.5345 & TRN \\
\hline CHEMBL1532426 & 737825 & 4.8 & 4.6453 & TRN \\
\hline CHEMBL1390245 & 737825 & 4.75 & 5.1827 & TST \\
\hline CHEMBL1349109 & 737825 & 5.85 & 5.1438 & TRN \\
\hline CHEMBL1437159 & 737825 & 4.5 & 4.3571 & TRN \\
\hline CHEMBL1589282 & 737825 & 5.55 & 5.1936 & TST \\
\hline CHEMBL1592506 & 737825 & 4.8 & 4.6709 & TRN \\
\hline CHEMBL476513 & 737825 & 5.1 & 5.2082 & TRN \\
\hline CHEMBL1456743 & 737825 & 6.4 & 5.3696 & TRN \\
\hline CHEMBL1323956 & 737825 & 4.6 & 4.4774 & TRN \\
\hline CHEMBL1605152 & 737825 & 5.5 & 5.4741 & TRN \\
\hline CHEMBL1325735 & 737825 & 5.6 & 5.5568 & TRN \\
\hline CHEMBL1317314 & 737825 & 5.1 & 5.0172 & TRN \\
\hline CHEMBL1611022 & 737825 & 4.7 & 5.0504 & TST \\
\hline CHEMBL1448291 & 737825 & 6.0 & 5.164 & TRN \\
\hline CHEMBL1377908 & 737825 & 4.9 & 4.7857 & TRN \\
\hline CHEMBL1416703 & 737825 & 4.9 & 5.2127 & TRN \\
\hline CHEMBL1315417 & 737825 & 4.9 & 4.8163 & TST \\
\hline CHEMBL1527279 & 737825 & 5.4 & 5.072 & TRN \\
\hline CHEMBL1600561 & 737825 & 4.8 & 4.6293 & TRN \\
\hline CHEMBL1357674 & 737825 & 4.5 & 4.5404 & TST \\
\hline
\end{tabular}




\begin{tabular}{|c|c|c|c|c|c|}
\hline \multicolumn{6}{|c|}{ Supplemental Table S2.txt } \\
\hline CHEMBL1406644 & 737825 & 5.15 & 5.2422 & TRN & \\
\hline CHEMBL87385 & 737825 & 4.9 & 4.9808 & TRN & \\
\hline CHEMBL1302090 & 737825 & 4.75 & 4.9691 & TST & \\
\hline CHEMBL1394520 & 737825 & 4.4 & 4.3293 & TRN & \\
\hline CHEMBL 3212989 & 737825 & 4.8 & 5.2083 & TRN & \\
\hline CHEMBL1543760 & 737825 & 5.65 & 5.5654 & TRN & \\
\hline CHEMBL1499774 & 737825 & 5.1 & 5.1254 & TRN & \\
\hline CHEMBL1515717 & 737825 & 5.4 & 5.3056 & TRN & \\
\hline CHEMBL1529954 & 737825 & 4.85 & 5.0153 & TRN & \\
\hline CHEMBL1493861 & 737825 & 5.5 & 5.3033 & TRN & \\
\hline CHEMBL1311260 & 737825 & 4.55 & 5.1555 & TRN & \\
\hline CHEMBL1490646 & 737825 & 4.65 & 5.1197 & TRN & \\
\hline CHEMBL1363331 & 737825 & 5.3 & 5.1904 & TRN & \\
\hline CHEMBL1551308 & 737825 & 4.8 & 4.7198 & TRN & \\
\hline CHEMBL1502052 & 737825 & 5.85 & 5.5624 & TRN & \\
\hline CHEMBL1449589 & 737825 & 4.8 & 5.092 & TRN & \\
\hline CHEMBL1553740 & 737825 & 5.3 & 5.1341 & TRN & \\
\hline CHEMBL18132 & 737825 & 5.8 & 5.4748 & TST & \\
\hline CHEMBL1475789 & 737825 & 6.2 & 6.2541 & TRN & \\
\hline CHEMBL1565914 & 737825 & 5.4 & 5.2382 & TST & \\
\hline CHEMBL1975888 & 737825 & 4.85 & 5.3025 & TRN & \\
\hline CHEMBL1338163 & 737825 & 5.4 & 5.2806 & TRN & \\
\hline CHEMBL1361552 & 737825 & 5.0 & 4.842 & TRN & \\
\hline CHEMBL1405759 & 737825 & 4.9 & 4.9345 & TST & \\
\hline CHEMBL3192331 & 737825 & 4.8 & 5.2264 & TRN & \\
\hline CHEMBL76589 & 737825 & 4.4 & 4.53600 & 00000000005 & TRN \\
\hline CHEMBL 269550 & 737825 & 4.8 & 4.7703 & TRN & \\
\hline CHEMBL1359469 & 737825 & 5.55 & 5.1748 & TRN & \\
\hline CHEMBL1569337 & 737825 & 6.05 & 5.2061 & TRN & \\
\hline CHEMBL1538337 & 737825 & 4.6 & 5.0947 & TRN & \\
\hline CHEMBL1606892 & 737825 & 4.9 & 4.8549 & TRN & \\
\hline CHEMBL1551284 & 737825 & 5.0 & 4.9964 & TRN & \\
\hline CHEMBL1381863 & 737825 & 4.7 & 5.2251 & TRN & \\
\hline CHEMBL1374962 & 737825 & 6.15 & 5.5705 & TRN & \\
\hline CHEMBL1395297 & 737825 & 5.5 & 5.1384 & TRN & \\
\hline CHEMBL1590968 & 737825 & 4.8 & 4.7404 & TRN & \\
\hline CHEMBL1544880 & 737825 & 4.8 & 5.1416 & TRN & \\
\hline CHEMBL1419233 & 737825 & 4.75 & 4.9636 & TST & \\
\hline CHEMBL1723995 & 737825 & 4.85 & 5.2863 & TRN & \\
\hline CHEMBL1435916 & 737825 & 5.3 & 5.3496 & TRN & \\
\hline CHEMBL1357498 & 737825 & 4.8 & 4.6767 & TRN & \\
\hline CHEMBL1742292 & 737825 & 4.85 & 5.1875 & TRN & \\
\hline CHEMBL1500528 & 737825 & 5.5 & 5.2109 & TST & \\
\hline CHEMBL1327171 & 737825 & 5.65 & 5.1518 & TRN & \\
\hline CHEMBL1404792 & 737825 & 5.05 & 5.0817 & TST & \\
\hline CHEMBL1320469 & 737825 & 5.4 & 5.398 & TRN & \\
\hline CHEMBL1547055 & 737825 & 6.2 & 5.1605 & TRN & \\
\hline CHEMBL1330422 & 737825 & 5.5 & 5.3332 & TRN & \\
\hline
\end{tabular}




\begin{tabular}{|c|c|c|c|c|}
\hline \multicolumn{5}{|c|}{ Supplemental Table S2.txt } \\
\hline CHEMBL491952 & 737825 & 5.0 & 4.9495 & TRN \\
\hline CHEMBL1595253 & 737825 & 4.85 & 5.1734 & TRN \\
\hline CHEMBL1351838 & 737825 & 5.1 & 5.0354 & TST \\
\hline CHEMBL1300005 & 737825 & 4.75 & 5.1006 & TST \\
\hline CHEMBL1475079 & 737825 & 4.9 & 4.7427 & TRN \\
\hline CHEMBL1386058 & 737825 & 4.9 & 5.4206 & TRN \\
\hline CHEMBL1741773 & 737825 & 4.95 & 5.0346 & TST \\
\hline CHEMBL1331734 & 737825 & 5.1 & 4.9819 & TST \\
\hline CHEMBL1343107 & 737825 & 5.3 & 5.2708 & TRN \\
\hline CHEMBL1318293 & 737825 & 4.8 & 4.7123 & TRN \\
\hline CHEMBL1256290 & 737825 & 4.5 & 4.5521 & TST \\
\hline CHEMBL1433093 & 737825 & 4.8 & 5.0291 & TST \\
\hline CHEMBL1474695 & 737825 & 5.2 & 5.0894 & TRN \\
\hline CHEMBL1469798 & 737825 & 5.0 & 5.0724 & TST \\
\hline CHEMBL177809 & 737825 & 5.5 & 5.2677 & TRN \\
\hline CHEMBL1543685 & 737825 & 4.6 & 4.9141 & TST \\
\hline CHEMBL1346628 & 737825 & 5.05 & 5.1253 & TRN \\
\hline CHEMBL1741605 & 737825 & 5.65 & 5.2308 & TRN \\
\hline CHEMBL1356497 & 737825 & 5.0 & 4.853 & TRN \\
\hline CHEMBL1394353 & 737825 & 6.0 & 6.1697 & TRN \\
\hline CHEMBL1400788 & 737825 & 5.4 & 5.318 & TST \\
\hline CHEMBL1551122 & 737825 & 5.7 & 5.6684 & TRN \\
\hline CHEMBL1394223 & 737825 & 4.8 & 4.6791 & TRN \\
\hline CHEMBL1564756 & 737825 & 4.85 & 4.9764 & TRN \\
\hline CHEMBL1526635 & 737825 & 4.9 & 5.1691 & TRN \\
\hline CHEMBL1710312 & 737825 & 4.65 & 5.2693 & TRN \\
\hline CHEMBL1592803 & 737825 & 6.1 & 5.971 & TRN \\
\hline CHEMBL 2373286 & 737825 & 6.0 & 5.6737 & TST \\
\hline CHEMBL80941 & 737825 & 4.9 & 4.7235 & TRN \\
\hline CHEMBL1539526 & 737825 & 6.3 & 5.0348 & TST \\
\hline CHEMBL1302560 & 737825 & 4.75 & 5.0901 & TST \\
\hline CHEMBL1496965 & 737825 & 5.15 & 5.1987 & TRN \\
\hline CHEMBL1423999 & 737825 & 4.6 & 5.0169 & TRN \\
\hline CHEMBL1523188 & 737825 & 4.55 & 5.0187 & TST \\
\hline CHEMBL1514272 & 737825 & 4.8 & 4.538 & TRN \\
\hline CHEMBL1338884 & 737825 & 4.85 & 5.0805 & TRN \\
\hline CHEMBL1597277 & 737825 & 4.4 & 4.3573 & TRN \\
\hline CHEMBL1741617 & 737825 & 4.55 & 4.9932 & TRN \\
\hline CHEMBL 20963 & 737825 & 4.8 & 4.8801 & TRN \\
\hline CHEMBL1346774 & 737825 & 4.85 & 5.2446 & TRN \\
\hline CHEMBL1609624 & 737825 & 4.9 & 4.7533 & TRN \\
\hline CHEMBL 1405510 & 737825 & 4.95 & 5.1854 & TRN \\
\hline CHEMBL275006 & 737825 & 6.0 & 5.7331 & TST \\
\hline CHEMBL1508867 & 737825 & 4.85 & 5.0213 & TRN \\
\hline CHEMBL1318262 & 737825 & 4.7 & 4.5781 & TRN \\
\hline CHEMBL3189630 & 737825 & 5.35 & 5.1758 & TST \\
\hline CHEMBL1485231 & 737825 & 4.85 & 5.1113 & TST \\
\hline CHEMBL1476504 & 737825 & 5.3 & 5.1131 & TRN \\
\hline
\end{tabular}




\begin{tabular}{|c|c|c|c|c|c|}
\hline \multicolumn{6}{|c|}{ Supplemental Table S2.txt } \\
\hline CHEMBL93403 & 737825 & 4.8 & 4.7975 & TRN & \\
\hline CHEMBL1450689 & 737825 & 4.9 & 5.1594 & TRN & \\
\hline CHEMBL1527332 & 737825 & 5.6 & 5.3938 & TRN & \\
\hline CHEMBL1428339 & 737825 & 5.4 & 5.3024 & TRN & \\
\hline CHEMBL1502201 & 737825 & 5.0 & 5.0808 & TST & \\
\hline CHEMBL3195211 & 737825 & 4.7 & 5.3185 & TRN & \\
\hline CHEMBL1256666 & 737825 & 5.0 & 4.9416 & TRN & \\
\hline CHEMBL3210786 & 737825 & 4.85 & 5.3201 & TST & \\
\hline CHEMBL1331627 & 737825 & 5.4 & 5.1544 & TST & \\
\hline CHEMBL1361022 & 737825 & 5.35 & 5.0885 & TRN & \\
\hline CHEMBL1308249 & 737825 & 5.35 & 5.3295 & TRN & \\
\hline CHEMBL539947 & 737825 & 5.4 & 5.3841 & TRN & \\
\hline CHEMBL1413367 & 737825 & 5.45 & 5.3527 & TRN & \\
\hline CHEMBL1385365 & 737825 & 4.55 & 4.9759 & TRN & \\
\hline CHEMBL1609754 & 737825 & 5.05 & 5.1712 & TRN & \\
\hline CHEMBL1322136 & 737825 & 5.15 & 5.0839 & TRN & \\
\hline CHEMBL3197815 & 737825 & 5.4 & 5.1986 & TRN & \\
\hline CHEMBL1387796 & 737825 & 5.05 & 5.2436 & TST & \\
\hline CHEMBL1531376 & 737825 & 4.95 & 5.227 & TRN & \\
\hline CHEMBL1487503 & 737825 & 5.4 & 5.3165 & TST & \\
\hline CHEMBL1318310 & 737825 & 5.4 & 5.3456 & TRN & \\
\hline CHEMBL1349528 & 737825 & 4.55 & 4.9178 & TRN & \\
\hline CHEMBL1409320 & 737825 & 5.7 & 5.6656 & TRN & \\
\hline CHEMBL104264 & 737825 & 5.8 & 5.62799 & 7999999999 & TRN \\
\hline CHEMBL1591140 & 737825 & 4.5 & 4.4975 & TRN & \\
\hline CHEMBL14690 & 737825 & 5.8 & 5.61100 & 0000000001 & TRN \\
\hline CHEMBL1441066 & 737825 & 5.5 & 5.0552 & TST & \\
\hline CHEMBL1307004 & 737825 & 5.15 & 5.0678 & TRN & \\
\hline CHEMBL1595703 & 737825 & 4.8 & 5.0859 & TRN & \\
\hline CHEMBL1344685 & 737825 & 5.1 & 5.0181 & TRN & \\
\hline CHEMBL1480944 & 737825 & 5.7 & 5.0952 & TRN & \\
\hline CHEMBL48278 & 737825 & 4.6 & 4.6069 & TRN & \\
\hline CHEMBL1512919 & 737825 & 5.6 & 5.6102 & TRN & \\
\hline CHEMBL1432729 & 737825 & 4.55 & 5.0883 & TRN & \\
\hline CHEMBL1551231 & 737825 & 4.6 & 4.4987 & TRN & \\
\hline CHEMBL1580108 & 737825 & 4.9 & 5.4088 & TRN & \\
\hline CHEMBL305881 & 737825 & 6.0 & 5.6289 & TRN & \\
\hline CHEMBL 3209256 & 737825 & 4.95 & 5.1546 & TRN & \\
\hline CHEMBL1200717 & 737825 & 4.8 & 4.8448 & TST & \\
\hline CHEMBL1459217 & 737825 & 5.85 & 4.9679 & TRN & \\
\hline CHEMBL1512307 & 737825 & 5.4 & 5.3826 & TRN & \\
\hline CHEMBL1563032 & 737825 & 4.8 & 4.8466 & TRN & \\
\hline CHEMBL86931 & 737825 & 4.5 & 4.6488 & TST & \\
\hline CHEMBL1482437 & 737825 & 4.75 & 5.0686 & TRN & \\
\hline CHEMBL1470632 & 737825 & 4.85 & 5.1144 & TRN & \\
\hline CHEMBL1435032 & 737825 & 5.9 & 5.7964 & TRN & \\
\hline CHEMBL 265177 & 737825 & 5.4 & 5.2404 & TST & \\
\hline CHEMBL1422219 & 737825 & 5.7 & 5.2634 & TRN & \\
\hline
\end{tabular}




\begin{tabular}{|c|c|c|c|c|}
\hline \multicolumn{5}{|c|}{ Supplemental Table S2.txt } \\
\hline CHEMBL1359930 & 737825 & 5.5 & 5.37 & TRN \\
\hline CHEMBL1348385 & 737825 & 4.75 & 4.9952 & TRN \\
\hline CHEMBL1706086 & 737825 & 4.8 & 5.1918 & TRN \\
\hline CHEMBL1374763 & 737825 & 5.5 & 5.1135 & TRN \\
\hline CHEMBL1569400 & 737825 & 4.7 & 4.623 & TRN \\
\hline CHEMBL1512740 & 737825 & 5.8 & 5.7592 & TRN \\
\hline CHEMBL1392232 & 737825 & 4.85 & 5.1337 & TRN \\
\hline CHEMBL1394899 & 737825 & 5.4 & 5.3646 & TRN \\
\hline CHEMBL1537075 & 737825 & 5.8 & 5.0238 & TST \\
\hline CHEMBL1567365 & 737825 & 5.5 & 5.395 & TRN \\
\hline CHEMBL1449371 & 737825 & 5.8 & 5.3998 & TRN \\
\hline CHEMBL1565536 & 737825 & 4.8 & 5.144 & TRN \\
\hline CHEMBL1425498 & 737825 & 4.85 & 5.2389 & TRN \\
\hline CHEMBL1590813 & 737825 & 4.8 & 4.7219 & TRN \\
\hline CHEMBL1382099 & 737825 & 4.9 & 4.8934 & TST \\
\hline CHEMBL1593827 & 737825 & 5.7 & 5.5564 & TRN \\
\hline CHEMBL1399273 & 737825 & 4.6 & 5.1915 & TST \\
\hline CHEMBL1461862 & 737825 & 4.8 & 5.1163 & TRN \\
\hline CHEMBL356688 & 737825 & 5.0 & 4.9616 & TRN \\
\hline CHEMBL3214238 & 737825 & 6.35 & 5.1919 & TRN \\
\hline CHEMBL1467857 & 737825 & 5.8 & 5.3622 & TRN \\
\hline CHEMBL1741927 & 737825 & 5.1 & 5.1308 & TST \\
\hline CHEMBL1466951 & 737825 & 5.0 & 5.2459 & TRN \\
\hline CHEMBL1545055 & 737825 & 6.3 & 5.3023 & TRN \\
\hline CHEMBL1496623 & 737825 & 5.15 & 5.1726 & TRN \\
\hline CHEMBL1428217 & 737825 & 6.15 & 5.6292 & TRN \\
\hline CHEMBL1366020 & 737825 & 5.7 & 5.4975 & TRN \\
\hline CHEMBL77387 & 737825 & 5.8 & 5.3141 & TRN \\
\hline CHEMBL1316796 & 737825 & 4.9 & 4.73 & TRN \\
\hline CHEMBL1341335 & 737825 & 4.8 & 5.1967 & TRN \\
\hline CHEMBL1552051 & 737825 & 4.6 & 4.4775 & TRN \\
\hline CHEMBL153 & 737825 & 4.9 & 4.7854 & TST \\
\hline CHEMBL1301765 & 737825 & 5.05 & 5.0326 & TRN \\
\hline CHEMBL1303049 & 737825 & 4.55 & 5.0642 & TRN \\
\hline CHEMBL1590975 & 737825 & 5.0 & 4.8402 & TRN \\
\hline CHEMBL1547069 & 737825 & 4.9 & 5.0782 & TRN \\
\hline CHEMBL1367995 & 737825 & 4.4 & 4.3522 & TRN \\
\hline CHEMBL1524453 & 737825 & 6.0 & 5.8921 & TRN \\
\hline CHEMBL1352396 & 737825 & 5.0 & 5.2793 & TRN \\
\hline CHEMBL3207937 & 737825 & 5.3 & 5.2172 & TST \\
\hline CHEMBL1363376 & 737825 & 5.0 & 5.1079 & TRN \\
\hline CHEMBL1453244 & 737825 & 5.3 & 5.2218 & TRN \\
\hline CHEMBL1486554 & 737825 & 5.3 & 5.0748 & TRN \\
\hline CHEMBL1391737 & 737825 & 5.4 & 5.2245 & TRN \\
\hline CHEMBL1741578 & 737825 & 5.05 & 5.23 & TRN \\
\hline CHEMBL1471701 & 737825 & 4.85 & 5.0882 & TRN \\
\hline CHEMBL1583793 & 737825 & 4.8 & 5.1538 & TRN \\
\hline CHEMBL1402381 & 737825 & 5.0 & 4.9618 & TRN \\
\hline
\end{tabular}




\begin{tabular}{|c|c|c|c|c|c|}
\hline \\
\hline CHEMBL409902 & 737825 & 5.0 & 4.9026 & TRN & \\
\hline CHEMBL1456217 & 737825 & 4.6 & 5.2379 & TRN & \\
\hline CHEMBL1311526 & 737825 & 4.85 & 4.9643 & TRN & \\
\hline CHEMBL1472926 & 737825 & 5.7 & 5.4717 & TRN & \\
\hline CHEMBL1604398 & 737825 & 5.4 & 5.2197 & TRN & \\
\hline CHEMBL1357676 & 737825 & 5.1 & 5.0361 & TRN & \\
\hline CHEMBL1475737 & 737825 & 5.2 & 5.1565 & TRN & \\
\hline CHEMBL1558834 & 737825 & 4.6 & 4.5856 & TRN & \\
\hline CHEMBL363332 & 737825 & 5.8 & 5.74100 & 00000000005 & TST \\
\hline CHEMBL1529232 & 737825 & 6.1 & 5.3354 & TRN & \\
\hline CHEMBL1335352 & 737825 & 4.8 & 5.2293 & TRN & \\
\hline CHEMBL3211748 & 737825 & 4.6 & 5.1089 & TRN & \\
\hline CHEMBL1478221 & 737825 & 4.8 & 4.7012 & TRN & \\
\hline CHEMBL1569529 & 737825 & 4.9 & 4.8614 & TRN & \\
\hline CHEMBL1701090 & 737825 & 5.15 & 5.1451 & TRN & \\
\hline CHEMBL1513578 & 737825 & 5.4 & 5.0722 & TRN & \\
\hline CHEMBL1355831 & 737825 & 5.0 & 4.7546 & TRN & \\
\hline CHEMBL1434369 & 737825 & 5.5 & 5.2448 & TRN & \\
\hline CHEMBL1418130 & 737825 & 4.8 & 4.99100 & 00000000005 & TRN \\
\hline CHEMBL1566184 & 737825 & 5.05 & 5.2093 & TRN & \\
\hline CHEMBL1491709 & 737825 & 5.5 & 5.3738 & TRN & \\
\hline CHEMBL1377706 & 737825 & 4.6 & 4.6007 & TRN & \\
\hline CHEMBL1359713 & 737825 & 6.7 & 6.7566 & TRN & \\
\hline CHEMBL1483851 & 737825 & 5.2 & 5.1239 & TRN & \\
\hline CHEMBL1363587 & 737825 & 6.35 & 5.2767 & TRN & \\
\hline CHEMBL1479340 & 737825 & 5.0 & 5.2881 & TST & \\
\hline CHEMBL1526761 & 737825 & 4.5 & 5.1548 & TRN & \\
\hline CHEMBL307639 & 737825 & 5.9 & 5.6112 & TST & \\
\hline CHEMBL1602568 & 737825 & 5.0 & 4.7978 & TRN & \\
\hline CHEMBL1502235 & 737825 & 4.9 & 5.4278 & TRN & \\
\hline CHEMBL1467631 & 737825 & 5.15 & 5.0863 & TRN & \\
\hline CHEMBL1475241 & 737825 & 4.7 & 4.5385 & TRN & \\
\hline CHEMBL1336793 & 737825 & 5.0 & 4.8428 & TRN & \\
\hline CHEMBL1576264 & 737825 & 5.25 & 5.1579 & TST & \\
\hline CHEMBL1097940 & 737825 & 4.9 & 4.9833 & TST & \\
\hline CHEMBL1351222 & 737825 & 5.0 & 5.1427 & TRN & \\
\hline CHEMBL1380300 & 737825 & 5.4 & 5.2346 & TRN & \\
\hline CHEMBL1566928 & 737825 & 5.1 & 4.8546 & TST & \\
\hline CHEMBL18879 & 737825 & 4.6 & 4.7485 & TST & \\
\hline CHEMBL1484866 & 737825 & 7.1 & 6.0185 & TRN & \\
\hline CHEMBL1402957 & 737825 & 5.4 & 5.9684 & TST & \\
\hline CHEMBL1412209 & 737825 & 4.8 & 5.4248 & TRN & \\
\hline CHEMBL1350707 & 737825 & 5.5 & 5.5683 & TRN & \\
\hline CHEMBL1579754 & 737825 & 5.45 & 5.0877 & TST & \\
\hline CHEMBL1354231 & 737825 & 4.9 & 5.0849 & TST & \\
\hline CHEMBL1608425 & 737825 & 4.95 & 5.3132 & TRN & \\
\hline CHEMBL1363110 & 737825 & 4.7 & 5.1601 & TRN & \\
\hline CHEMBL1488197 & 737825 & 6.0 & 5.9612 & TRN & \\
\hline
\end{tabular}




\begin{tabular}{|c|c|c|c|c|c|}
\hline \\
\hline CHEMBL1443360 & 737825 & 5.0 & 4.8573 & TRN & \\
\hline CHEMBL124267 & 737825 & 5.3 & 5.0853 & TRN & \\
\hline CHEMBL1447682 & 737825 & 4.75 & 5.0777 & TRN & \\
\hline CHEMBL1316158 & 737825 & 4.7 & 4.5553 & TRN & \\
\hline CHEMBL1358009 & 737825 & 5.3 & 5.2062 & TRN & \\
\hline CHEMBL1548924 & 737825 & 4.95 & 5.1539 & TST & \\
\hline CHEMBL1573555 & 737825 & 5.2 & 4.9745 & TRN & \\
\hline CHEMBL1386134 & 737825 & 4.4 & 5.0483 & TST & \\
\hline CHEMBL1483133 & 737825 & 4.6 & 4.4688 & TRN & \\
\hline CHEMBL101168 & 737825 & 5.2 & 5.0535 & TST & \\
\hline CHEMBL458765 & 737825 & 5.5 & 5.2942 & TRN & \\
\hline CHEMBL1446324 & 737825 & 4.8 & 4.8104 & TRN & \\
\hline CHEMBL1550537 & 737825 & 4.65 & 5.1189 & TST & \\
\hline CHEMBL1432402 & 737825 & 5.2 & 5.1451 & TST & \\
\hline CHEMBL1534554 & 737825 & 5.5 & 5.1824 & TRN & \\
\hline CHEMBL1374718 & 737825 & 5.35 & 5.1973 & TRN & \\
\hline CHEMBL1434085 & 737825 & 4.9 & 4.8168 & TRN & \\
\hline CHEMBL1493475 & 737825 & 4.9 & 5.16700 & 2000000001 & TST \\
\hline CHEMBL3197350 & 737825 & 4.9 & 5.0989 & TST & \\
\hline CHEMBL1718423 & 737825 & 5.1 & 5.1437 & TRN & \\
\hline CHEMBL1566428 & 737825 & 5.0 & 5.0206 & TRN & \\
\hline CHEMBL1527499 & 737825 & 5.7 & 5.2577 & TRN & \\
\hline CHEMBL1469723 & 737825 & 4.8 & 5.0643 & TRN & \\
\hline CHEMBL1602940 & 737825 & 4.95 & 5.0201 & TRN & \\
\hline CHEMBL1513478 & 737825 & 4.7 & 4.6384 & TRN & \\
\hline CHEMBL1340380 & 737825 & 4.6 & 5.1306 & TST & \\
\hline CHEMBL1602083 & 737825 & 4.8 & 5.0455 & TRN & \\
\hline CHEMBL3213218 & 737825 & 4.7 & 4.9817 & TST & \\
\hline CHEMBL1318461 & 737825 & 5.3 & 5.2179 & TRN & \\
\hline CHEMBL3209319 & 737825 & 5.3 & 5.3114 & TRN & \\
\hline CHEMBL1514923 & 737825 & 6.6 & 6.0467 & TRN & \\
\hline CHEMBL1399528 & 737825 & 4.9 & 4.785 & TRN & \\
\hline CHEMBL1257075 & 737825 & 6.0 & 5.5879 & TRN & \\
\hline CHEMBL1436037 & 737825 & 5.4 & 5.3792 & TRN & \\
\hline CHEMBL1546037 & 737825 & 4.55 & 5.0614 & TRN & \\
\hline CHEMBL1473480 & 737825 & 5.3 & 5.0927 & TRN & \\
\hline CHEMBL1368860 & 737825 & 6.0 & 5.8736 & TRN & \\
\hline CHEMBL1316464 & 737825 & 5.4 & 5.206 & TRN & \\
\hline CHEMBL1587524 & 737825 & 5.3 & 5.1474 & TRN & \\
\hline CHEMBL1967062 & 737825 & 5.2 & 5.3835 & TRN & \\
\hline CHEMBL1547372 & 737825 & 4.85 & 5.0436 & TRN & \\
\hline CHEMBL1317009 & 737825 & 5.0 & 4.8412 & TRN & \\
\hline CHEMBL1374355 & 737825 & 4.9 & 4.8133 & TRN & \\
\hline CHEMBL1585219 & 737825 & 5.85 & 5.2343 & TRN & \\
\hline CHEMBL1566647 & 737825 & 5.05 & 5.32299 & 99999999995 & TRN \\
\hline CHEMBL1391936 & 737825 & 4.6 & 5.3088 & TRN & \\
\hline CHEMBL1388293 & 737825 & 4.55 & 5.1706 & TRN & \\
\hline CHEMBL1446335 & 737825 & 4.8 & 4.8213 & TRN & \\
\hline
\end{tabular}




\begin{tabular}{|c|c|c|c|c|}
\hline \multicolumn{5}{|c|}{ Supplemental Table S2.txt } \\
\hline CHEMBL1515961 & 737825 & 5.5 & 5.3826 & TST \\
\hline CHEMBL1371238 & 737825 & 4.85 & 5.1269 & TST \\
\hline CHEMBL1358234 & 737825 & 5.8 & 5.8441 & TRN \\
\hline CHEMBL500996 & 737825 & 5.0 & 4.871 & TRN \\
\hline CHEMBL1605363 & 737825 & 6.0 & 5.1735 & TRN \\
\hline CHEMBL1529440 & 737825 & 4.65 & 5.2807 & TRN \\
\hline CHEMBL1543213 & 737825 & 5.1 & 5.105 & TRN \\
\hline CHEMBL1320019 & 737825 & 5.6 & 5.4123 & TRN \\
\hline CHEMBL1515540 & 737825 & 5.1 & 4.8099 & TRN \\
\hline CHEMBL1529076 & 737825 & 4.95 & 5.0814 & TRN \\
\hline CHEMBL1436049 & 737825 & 5.2 & 5.1484 & TRN \\
\hline CHEMBL3195972 & 737825 & 4.8 & 5.1124 & TRN \\
\hline CHEMBL1352421 & 737825 & 5.1 & 5.1863 & TRN \\
\hline CHEMBL1538230 & 737825 & 5.65 & 5.0918 & TST \\
\hline CHEMBL1399136 & 737825 & 5.1 & 4.999 & TRN \\
\hline CHEMBL1450993 & 737825 & 4.7 & 4.6104 & TRN \\
\hline CHEMBL1603700 & 737825 & 4.7 & 5.0383 & TRN \\
\hline CHEMBL1311531 & 737825 & 5.9 & 5.2297 & TRN \\
\hline CHEMBL1314371 & 737825 & 5.4 & 5.2752 & TRN \\
\hline CHEMBL1321476 & 737825 & 4.8 & 5.1568 & TRN \\
\hline CHEMBL3199291 & 737825 & 5.45 & 5.2533 & TST \\
\hline CHEMBL1705301 & 737825 & 5.1 & 5.4466 & TRN \\
\hline CHEMBL1558245 & 737825 & 5.4 & 5.3779 & TRN \\
\hline CHEMBL1472761 & 737825 & 5.7 & 5.197 & TRN \\
\hline CHEMBL1597037 & 737825 & 5.5 & 5.3385 & TRN \\
\hline CHEMBL1401324 & 737825 & 5.5 & 5.3498 & TRN \\
\hline CHEMBL1501014 & 737825 & 5.05 & 5.0539 & TRN \\
\hline CHEMBL1541179 & 737825 & 5.25 & 5.0887 & TRN \\
\hline CHEMBL1556705 & 737825 & 5.5 & 5.2457 & TRN \\
\hline CHEMBL1553428 & 737825 & 5.0 & 5.0011 & TRN \\
\hline CHEMBL1314935 & 737825 & 5.6 & 5.3919 & TST \\
\hline CHEMBL12014 & 737825 & 5.4 & 5.1222 & TRN \\
\hline CHEMBL1741512 & 737825 & 4.85 & 5.3955 & TRN \\
\hline CHEMBL 1491778 & 737825 & 4.6 & 5.1028 & TRN \\
\hline CHEMBL1378878 & 737825 & 4.85 & 5.2883 & TRN \\
\hline CHEMBL1609103 & 737825 & 6.6 & 5.0381 & TRN \\
\hline CHEMBL1255749 & 737825 & 4.6 & 4.6032 & TST \\
\hline CHEMBL1594011 & 737825 & 6.0 & 5.7373 & TRN \\
\hline CHEMBL1463543 & 737825 & 5.0 & 5.3093 & TRN \\
\hline CHEMBL1340893 & 737825 & 4.8 & 4.9913 & TRN \\
\hline CHEMBL1595862 & 737825 & 4.55 & 5.131 & TST \\
\hline CHEMBL1360125 & 737825 & 5.1 & 4.9157 & TRN \\
\hline CHEMBL1370244 & 737825 & 5.0 & 5.3875 & TRN \\
\hline CHEMBL1468814 & 737825 & 4.7 & 5.0271 & TRN \\
\hline CHEMBL1315636 & 737825 & 5.4 & 5.3854 & TRN \\
\hline CHEMBL1372199 & 737825 & 5.4 & 5.0181 & TRN \\
\hline CHEMBL1436811 & 737825 & 4.8 & 4.603 & TRN \\
\hline CHEMBL1322549 & 737825 & 5.6 & 5.4458 & TST \\
\hline
\end{tabular}




\begin{tabular}{|c|c|c|c|c|}
\hline \multicolumn{5}{|c|}{ Supplemental Table S2.txt } \\
\hline CHEMBL3209986 & 737825 & 5.15 & 5.0573 & TRN \\
\hline CHEMBL1741698 & 737825 & 4.85 & 5.1459 & TRN \\
\hline CHEMBL1703799 & 737825 & 5.0 & 5.5854 & TRN \\
\hline CHEMBL1618718 & 737825 & 4.7 & 4.7713 & TST \\
\hline CHEMBL1317344 & 737825 & 5.0 & 5.0131 & TRN \\
\hline CHEMBL1378030 & 737825 & 4.55 & 5.0745 & TRN \\
\hline CHEMBL1573171 & 737825 & 6.9 & 5.8014 & TRN \\
\hline CHEMBL3210057 & 737825 & 5.05 & 5.1273 & TST \\
\hline CHEMBL1993788 & 737825 & 4.65 & 5.1486 & TRN \\
\hline CHEMBL1385652 & 737825 & 5.8 & 5.2015 & TRN \\
\hline CHEMBL1316401 & 737825 & 5.4 & 5.3657 & TRN \\
\hline CHEMBL1532016 & 737825 & 6.0 & 5.9628 & TRN \\
\hline CHEMBL1373587 & 737825 & 5.4 & 5.2235 & TST \\
\hline CHEMBL1553941 & 737825 & 4.8 & 4.7789 & TRN \\
\hline CHEMBL1741768 & 737825 & 5.4 & 5.1823 & TRN \\
\hline CHEMBL1592212 & 737825 & 4.5 & 4.5203 & TRN \\
\hline CHEMBL1437778 & 737825 & 4.8 & 4.7304 & TRN \\
\hline CHEMBL1357982 & 737825 & 5.7 & 5.724 & TRN \\
\hline CHEMBL3209385 & 737825 & 4.55 & 5.2166 & TRN \\
\hline CHEMBL1364047 & 737825 & 4.65 & 5.3079 & TRN \\
\hline CHEMBL1425523 & 737825 & 4.95 & 5.0347 & TRN \\
\hline CHEMBL410873 & 737825 & 4.8 & 4.8667 & TRN \\
\hline CHEMBL1514129 & 737825 & 4.9 & 4.8435 & TRN \\
\hline CHEMBL1382819 & 737825 & 4.8 & 5.083 & TST \\
\hline CHEMBL1313747 & 737825 & 7.3 & 5.0693 & TRN \\
\hline CHEMBL1579123 & 737825 & 4.95 & 5.1029 & TRN \\
\hline CHEMBL1569843 & 737825 & 5.55 & 5.3973 & TRN \\
\hline CHEMBL1437905 & 737825 & 4.85 & 5.3761 & TRN \\
\hline CHEMBL1304249 & 737825 & 5.4 & 5.169 & TRN \\
\hline CHEMBL1547490 & 737825 & 5.35 & 5.1552 & TRN \\
\hline CHEMBL1561349 & 737825 & 4.9 & 5.1468 & TRN \\
\hline CHEMBL1498835 & 737825 & 4.7 & 5.0536 & TRN \\
\hline CHEMBL1395226 & 737825 & 5.1 & 4.8628 & TRN \\
\hline CHEMBL1484006 & 737825 & 6.0 & 6.0195 & TRN \\
\hline CHEMBL1519391 & 737825 & 4.9 & 5.1634 & TRN \\
\hline CHEMBL1581512 & 737825 & 5.0 & 5.1162 & TRN \\
\hline CHEMBL1322942 & 737825 & 4.85 & 4.9954 & TRN \\
\hline CHEMBL1345307 & 737825 & 4.85 & 5.0123 & TRN \\
\hline CHEMBL1480742 & 737825 & 5.5 & 5.46 & TRN \\
\hline CHEMBL1472456 & 737825 & 4.55 & 5.0561 & TRN \\
\hline CHEMBL1334477 & 737825 & 5.0 & 4.9406 & TRN \\
\hline CHEMBL1346159 & 737825 & 4.9 & 5.3261 & TST \\
\hline CHEMBL119264 & 737825 & 5.9 & 5.7387 & TRN \\
\hline CHEMBL1385182 & 737825 & 5.8 & 5.3952 & TRN \\
\hline CHEMBL1323499 & 737825 & 4.55 & 4.9897 & TST \\
\hline CHEMBL1303868 & 737825 & 5.65 & 5.1038 & TST \\
\hline CHEMBL 1354190 & 737825 & 5.5 & 5.4225 & TST \\
\hline CHEMBL1450241 & 737825 & 5.45 & 5.3072 & TRN \\
\hline
\end{tabular}




\begin{tabular}{|c|c|c|c|c|}
\hline & & & upplement & al $\mathrm{T}$ \\
\hline CHEMBL1331980 & 737825 & 6.0 & 5.7123 & TST \\
\hline CHEMBL1465386 & 737825 & 4.6 & 5.3222 & TRN \\
\hline CHEMBL1555677 & 737825 & 4.65 & 5.1912 & TRN \\
\hline CHEMBL1734210 & 737825 & 4.5 & 5.1445 & TRN \\
\hline CHEMBL1456911 & 737825 & 4.75 & 5.143 & TRN \\
\hline CHEMBL1369940 & 737825 & 5.0 & 4.9669 & TRN \\
\hline CHEMBL1603627 & 737825 & 4.7 & 4.6335 & TRN \\
\hline CHEMBL1399301 & 737825 & 4.6 & 4.5549 & TRN \\
\hline CHEMBL1424441 & 737825 & 5.0 & 5.3421 & TRN \\
\hline CHEMBL1389304 & 737825 & 4.85 & 5.1424 & TRN \\
\hline CHEMBL37081 & 737825 & 4.7 & 4.8077 & TRN \\
\hline CHEMBL1603542 & 737825 & 5.2 & 5.1227 & TRN \\
\hline CHEMBL1724898 & 737825 & 4.8 & 5.1741 & TRN \\
\hline CHEMBL1581457 & 737825 & 5.0 & 5.0391 & TST \\
\hline CHEMBL1574390 & 737825 & 4.5 & 4.4922 & TRN \\
\hline CHEMBL1331913 & 737825 & 6.0 & 5.7864 & TRN \\
\hline CHEMBL1513121 & 737825 & 5.1 & 4.9342 & TRN \\
\hline CHEMBL1554637 & 737825 & 4.6 & 4.5701 & TRN \\
\hline CHEMBL1441920 & 737825 & 6.0 & 5.6775 & TST \\
\hline CHEMBL1360714 & 737825 & 4.75 & 5.1238 & TRN \\
\hline CHEMBL1552752 & 737825 & 5.6 & 5.5488 & TRN \\
\hline CHEMBL 3192068 & 737825 & 5.3 & 5.2296 & TRN \\
\hline CHEMBL1554609 & 737825 & 5.5 & 5.4529 & TRN \\
\hline CHEMBL1562477 & 737825 & 4.5 & 4.3589 & TRN \\
\hline CHEMBL1434334 & 737825 & 5.3 & 5.6891 & TST \\
\hline CHEMBL1407910 & 737825 & 5.75 & 5.7182 & TST \\
\hline CHEMBL1301918 & 737825 & 4.8 & 5.0378 & TRN \\
\hline CHEMBL1735134 & 737825 & 6.0 & 5.6715 & TRN \\
\hline CHEMBL291536 & 737825 & 5.0 & 4.7826 & TST \\
\hline CHEMBL1396862 & 737825 & 5.4 & 5.3772 & TRN \\
\hline CHEMBL1525558 & 737825 & 5.45 & 5.2312 & TRN \\
\hline CHEMBL1363474 & 737825 & 4.85 & 5.2697 & TRN \\
\hline CHEMBL1741914 & 737825 & 5.65 & 5.2983 & TRN \\
\hline CHEMBL1322376 & 737825 & 5.45 & 5.1276 & TRN \\
\hline CHEMBL1552985 & 737825 & 6.0 & 6.1673 & TRN \\
\hline CHEMBL1357199 & 737825 & 4.7 & 4.6294 & TRN \\
\hline CHEMBL1521440 & 737825 & 5.4 & 5.5702 & TRN \\
\hline CHEMBL1503178 & 737825 & 5.05 & 5.1912 & TRN \\
\hline CHEMBL1473420 & 737825 & 5.6 & 5.3691 & TRN \\
\hline CHEMBL1435558 & 737825 & 5.2 & 5.0691 & TRN \\
\hline CHEMBL1594044 & 737825 & 5.9 & 5.4794 & TRN \\
\hline CHEMBL1342700 & 737825 & 4.9 & 4.9765 & TRN \\
\hline CHEMBL1443340 & 737825 & 4.9 & 5.3615 & TRN \\
\hline CHEMBL1492346 & 737825 & 6.0 & 5.7594 & TRN \\
\hline CHEMBL1409758 & 737825 & 5.1 & 5.0267 & TRN \\
\hline CHEMBL1368340 & 737825 & 4.4 & 4.3751 & TST \\
\hline CHEMBL1475698 & 737825 & 5.3 & 5.6276 & TST \\
\hline CHEMBL1429076 & 737825 & 5.15 & 5.0915 & TRN \\
\hline
\end{tabular}




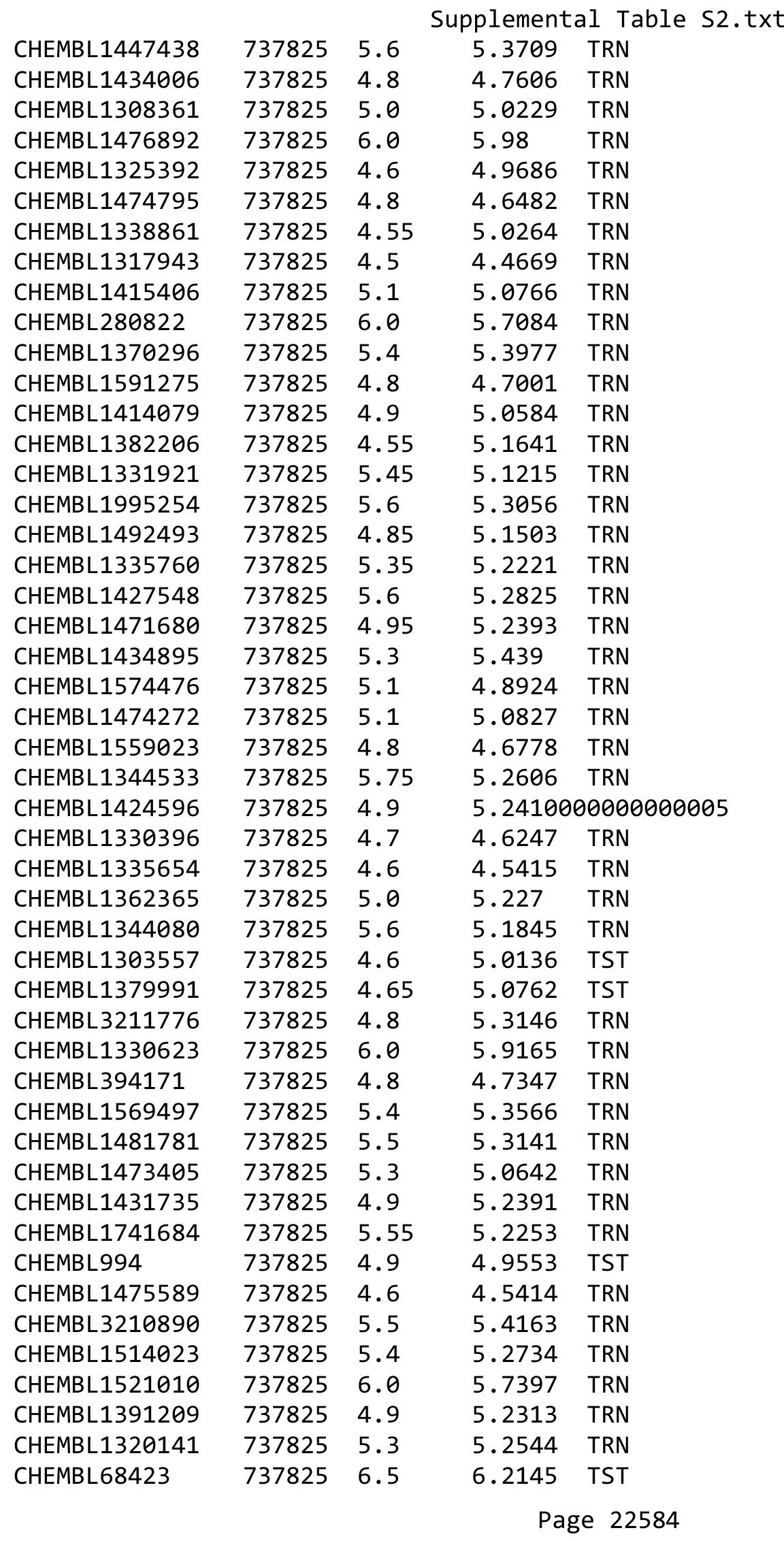




\begin{tabular}{|c|c|c|c|c|c|}
\hline \multicolumn{6}{|c|}{ Supplemental Table S2.txt } \\
\hline CHEMBL1568012 & 737825 & 6.4 & 5.3557 & TRN & \\
\hline CHEMBL1337409 & 737825 & 5.1 & 5.3702 & TRN & \\
\hline CHEMBL1448158 & 737825 & 4.85 & 5.5917 & TRN & \\
\hline CHEMBL1595521 & 737825 & 5.3 & 5.1762 & TRN & \\
\hline CHEMBL1732963 & 737825 & 4.6 & 5.20100 & 00000000005 & TRN \\
\hline CHEMBL1388224 & 737825 & 4.95 & 5.4233 & TRN & \\
\hline CHEMBL1435654 & 737825 & 5.3 & 5.1763 & TRN & \\
\hline CHEMBL1396146 & 737825 & 4.8 & 4.7334 & TRN & \\
\hline CHEMBL1722019 & 737825 & 5.65 & 5.2149 & TRN & \\
\hline CHEMBL1369318 & 737825 & 5.8 & 5.8135 & TRN & \\
\hline CHEMBL1402656 & 737825 & 5.0 & 4.7489 & TRN & \\
\hline CHEMBL1565164 & 737825 & 4.6 & 5.1152 & TST & \\
\hline CHEMBL1317885 & 737825 & 4.8 & 4.7694 & TRN & \\
\hline CHEMBL1516817 & 737825 & 5.1 & 5.1806 & TRN & \\
\hline CHEMBL1610082 & 737825 & 4.9 & 4.7619 & TRN & \\
\hline CHEMBL1448728 & 737825 & 4.9 & 4.7315 & TRN & \\
\hline CHEMBL1973705 & 737825 & 5.15 & 5.1595 & TST & \\
\hline CHEMBL584854 & 737825 & 6.1 & 5.5059 & TRN & \\
\hline CHEMBL1571483 & 737825 & 5.0 & 5.2011 & TRN & \\
\hline CHEMBL1316463 & 737825 & 4.9 & 4.7665 & TRN & \\
\hline CHEMBL1407848 & 737825 & 6.1 & 5.3727 & TRN & \\
\hline CHEMBL1741481 & 737825 & 5.3 & 5.5378 & TRN & \\
\hline CHEMBL1538954 & 737825 & 4.5 & 4.9274 & TRN & \\
\hline CHEMBL1369631 & 737825 & 5.1 & 5.2361 & TRN & \\
\hline CHEMBL1494408 & 737825 & 5.5 & 5.5858 & TRN & \\
\hline CHEMBL1488504 & 737825 & 5.1 & 5.0985 & TRN & \\
\hline CHEMBL1704069 & 737825 & 5.0 & 5.2522 & TRN & \\
\hline CHEMBL1603406 & 737825 & 4.6 & 4.5794 & TRN & \\
\hline CHEMBL1555537 & 737825 & 5.3 & 5.1747 & TST & \\
\hline CHEMBL1472356 & 737825 & 4.6 & 5.1222 & TRN & \\
\hline CHEMBL1562786 & 737825 & 5.3 & 5.2249 & TRN & \\
\hline CHEMBL1301997 & 737825 & 4.8 & 5.2105 & TRN & \\
\hline CHEMBL1471761 & 737825 & 4.65 & 5.0812 & TRN & \\
\hline CHEMBL1396664 & 737825 & 4.4 & 4.5878 & TRN & \\
\hline CHEMBL1404315 & 737825 & 5.4 & 5.3237 & TRN & \\
\hline CHEMBL1559009 & 737825 & 5.5 & 5.3431 & TRN & \\
\hline CHEMBL1441052 & 737825 & 4.5 & 4.4408 & TRN & \\
\hline CHEMBL1729271 & 737825 & 4.55 & 5.0605 & TRN & \\
\hline CHEMBL1531108 & 737825 & 4.7 & 4.6929 & TRN & \\
\hline CHEMBL1370770 & 737825 & 6.0 & 5.5928 & TRN & \\
\hline CHEMBL1505689 & 737825 & 5.65 & 5.3537 & TRN & \\
\hline CHEMBL1353478 & 737825 & 5.1 & 5.1264 & TST & \\
\hline CHEMBL1518947 & 737825 & 4.8 & 4.6639 & TRN & \\
\hline CHEMBL1398031 & 737825 & 4.6 & 4.5445 & TST & \\
\hline CHEMBL1727071 & 737825 & 5.55 & 5.1047 & TRN & \\
\hline CHEMBL1582197 & 737825 & 5.65 & 5.3313 & TST & \\
\hline CHEMBL1597612 & 737825 & 4.9 & 4.9964 & TST & \\
\hline CHEMBL1570716 & 737825 & 6.0 & 5.8771 & TRN & \\
\hline
\end{tabular}




\begin{tabular}{|c|c|c|c|c|c|}
\hline \\
\hline CHEMBL1603595 & 737825 & 4.8 & 4.6702 & TRN & \\
\hline CHEMBL1433897 & 737825 & 4.7 & 4.8056 & TRN & \\
\hline CHEMBL1307437 & 737825 & 5.65 & 5.2022 & TRN & \\
\hline CHEMBL1358708 & 737825 & 4.9 & 5.0073 & TST & \\
\hline CHEMBL1434266 & 737825 & 4.6 & 4.4663 & TRN & \\
\hline CHEMBL1371458 & 737825 & 5.1 & 4.7972 & TRN & \\
\hline CHEMBL286722 & 737825 & 5.2 & 5.0975 & TRN & \\
\hline CHEMBL1319626 & 737825 & 5.4 & 5.2899 & TRN & \\
\hline CHEMBL1557811 & 737825 & 5.0 & 5.2283 & TRN & \\
\hline CHEMBL1314286 & 737825 & 6.0 & 5.7317 & TST & \\
\hline CHEMBL1707095 & 737825 & 4.55 & 5.1236 & TRN & \\
\hline CHEMBL1301722 & 737825 & 4.65 & 5.1576 & TST & \\
\hline CHEMBL1474927 & 737825 & 5.7 & 5.5974 & TRN & \\
\hline CHEMBL1566202 & 737825 & 4.85 & 5.1352 & TRN & \\
\hline CHEMBL1561692 & 737825 & 5.25 & 5.215 & TRN & \\
\hline CHEMBL1433785 & 737825 & 4.5 & 4.5088 & TRN & \\
\hline CHEMBL1563819 & 737825 & 4.4 & 5.1898 & TST & \\
\hline CHEMBL1427101 & 737825 & 5.65 & 5.2192 & TRN & \\
\hline CHEMBL1413165 & 737825 & 6.4 & 6.2204 & TRN & \\
\hline CHEMBL1458424 & 737825 & 4.6 & 4.9853 & TRN & \\
\hline CHEMBL1562921 & 737825 & 4.5 & 5.0533 & TRN & \\
\hline CHEMBL1600408 & 737825 & 5.5 & 5.6205 & TRN & \\
\hline CHEMBL1525886 & 737825 & 5.4 & 5.2907 & TRN & \\
\hline CHEMBL1591635 & 737825 & 4.8 & 4.71 & TRN & \\
\hline CHEMBL1484127 & 737825 & 4.9 & 4.7352 & TRN & \\
\hline CHEMBL1460432 & 737825 & 4.85 & 5.2570 & 0000000001 & TRN \\
\hline CHEMBL1601908 & 737825 & 4.9 & 5.1237 & TRN & \\
\hline CHEMBL1339209 & 737825 & 5.5 & 5.4931 & TRN & \\
\hline CHEMBL1510728 & 737825 & 4.8 & 5.4042 & TRN & \\
\hline CHEMBL1395402 & 737825 & 5.1 & 4.945 & TRN & \\
\hline CHEMBL1566780 & 737825 & 6.1 & 6.1795 & TRN & \\
\hline CHEMBL1435907 & 737825 & 5.6 & 5.3353 & TRN & \\
\hline CHEMBL1333236 & 737825 & 4.6 & 5.0838 & TRN & \\
\hline CHEMBL1398762 & 737825 & 5.0 & 5.0478 & TRN & \\
\hline CHEMBL1407769 & 737825 & 4.9 & 4.9689 & TRN & \\
\hline CHEMBL1552540 & 737825 & 5.0 & 5.0266 & TRN & \\
\hline CHEMBL3213904 & 737825 & 5.95 & 5.5295 & TST & \\
\hline CHEMBL3209355 & 737825 & 4.8 & 5.0644 & TRN & \\
\hline CHEMBL1453438 & 737825 & 4.8 & 5.1014 & TRN & \\
\hline CHEMBL1432807 & 737825 & 4.85 & 5.0866 & TST & \\
\hline CHEMBL1304696 & 737825 & 5.05 & 5.2318 & TRN & \\
\hline CHEMBL1455767 & 737825 & 4.4 & 4.3176 & TRN & \\
\hline CHEMBL1392360 & 737825 & 5.4 & 5.277 & TRN & \\
\hline CHEMBL1741821 & 737825 & 4.8 & 5.0532 & TRN & \\
\hline CHEMBL1314486 & 737825 & 6.1 & 6.1292 & TRN & \\
\hline CHEMBL1367222 & 737825 & 5.5 & 5.5021 & TRN & \\
\hline CHEMBL1317177 & 737825 & 4.5 & 4.4475 & TRN & \\
\hline CHEMBL1563147 & 737825 & 4.6 & 4.4765 & TRN & \\
\hline & & & & 22586 & \\
\hline
\end{tabular}




\begin{tabular}{|c|c|c|c|c|c|}
\hline \multicolumn{6}{|c|}{ Supplemental Table S2.txt } \\
\hline CHEMBL1439144 & 737825 & 5.65 & 5.2718 & TST & \\
\hline CHEMBL1591009 & 737825 & 4.9 & 5.6524 & TST & \\
\hline CHEMBL1591673 & 737825 & 4.5 & 4.4489 & TRN & \\
\hline CHEMBL1555028 & 737825 & 4.7 & 4.6109 & TRN & \\
\hline CHEMBL11458 & 737825 & 5.3 & 5.3444 & TST & \\
\hline CHEMBL1457902 & 737825 & 6.2 & 5.1257 & TRN & \\
\hline CHEMBL1479506 & 737825 & 5.1 & 4.98600 & 0000000001 & TRN \\
\hline CHEMBL1723524 & 737825 & 5.15 & 5.2661 & TRN & \\
\hline CHEMBL1530213 & 737825 & 5.2 & 5.2714 & TRN & \\
\hline CHEMBL1494697 & 737825 & 4.9 & 4.9153 & TRN & \\
\hline CHEMBL 3210244 & 737825 & 5.4 & 5.3807 & TRN & \\
\hline CHEMBL58033 & 737825 & 6.0 & 5.7006 & TRN & \\
\hline CHEMBL1418542 & 737825 & 5.6 & 5.3954 & TST & \\
\hline CHEMBL 3192647 & 737825 & 4.85 & 5.254 & TRN & \\
\hline CHEMBL1531299 & 737825 & 4.9 & 4.8945 & TRN & \\
\hline CHEMBL3190392 & 737825 & 5.55 & 5.1505 & TRN & \\
\hline CHEMBL1445893 & 737825 & 4.9 & 4.8007 & TRN & \\
\hline CHEMBL1256816 & 737825 & 4.8 & 4.7685 & TST & \\
\hline CHEMBL1472011 & 737825 & 4.85 & 5.1664 & TRN & \\
\hline CHEMBL1566751 & 737825 & 4.95 & 4.9672 & TST & \\
\hline CHEMBL165 & 737825 & 6.0 & 5.6034 & TRN & \\
\hline CHEMBL1332094 & 737825 & 5.2 & 5.0621 & TST & \\
\hline CHEMBL1482482 & 737825 & 6.0 & 5.2129 & TRN & \\
\hline CHEMBL1315141 & 737825 & 4.6 & 4.5246 & TRN & \\
\hline CHEMBL1592964 & 737825 & 5.2 & 5.1386 & TRN & \\
\hline CHEMBL3199657 & 737825 & 5.9 & 5.3064 & TST & \\
\hline CHEMBL198159 & 737825 & 4.9 & 4.8697 & TRN & \\
\hline CHEMBL1610924 & 737825 & 4.9 & 5.1514 & TRN & \\
\hline CHEMBL1724116 & 737825 & 4.45 & 5.0033 & TRN & \\
\hline CHEMBL1526697 & 737825 & 5.5 & 5.41200 & 0000000001 & TRN \\
\hline CHEMBL1388203 & 737825 & 5.15 & 5.1226 & TST & \\
\hline CHEMBL1410599 & 737825 & 4.8 & 5.1446 & TRN & \\
\hline CHEMBL1528648 & 737825 & 4.8 & 5.0621 & TRN & \\
\hline CHEMBL1395241 & 737825 & 6.0 & 6.0116 & TRN & \\
\hline CHEMBL1399750 & 737825 & 4.85 & 5.1049 & TRN & \\
\hline CHEMBL1711282 & 737825 & 4.85 & 5.3421 & TRN & \\
\hline CHEMBL1505844 & 737825 & 5.6 & 5.3057 & TRN & \\
\hline CHEMBL1571395 & 737825 & 4.9 & 5.1055 & TST & \\
\hline CHEMBL1546136 & 737825 & 4.8 & 5.1921 & TRN & \\
\hline CHEMBL1444269 & 737825 & 4.6 & 5.216 & TRN & \\
\hline CHEMBL3214365 & 737825 & 5.45 & 5.2672 & TRN & \\
\hline CHEMBL1611715 & 737825 & 5.0 & 5.0658 & TRN & \\
\hline CHEMBL1544991 & 737825 & 4.6 & 5.1294 & TRN & \\
\hline CHEMBL1362872 & 737825 & 5.0 & 5.0502 & TRN & \\
\hline CHEMBL1603371 & 737825 & 5.0 & 5.0828 & TRN & \\
\hline CHEMBL1590789 & 737825 & 5.0 & 4.7745 & TRN & \\
\hline CHEMBL1324418 & 737825 & 4.7 & 4.5768 & TRN & \\
\hline CHEMBL1521744 & 737825 & 4.8 & 5.1223 & TRN & \\
\hline
\end{tabular}




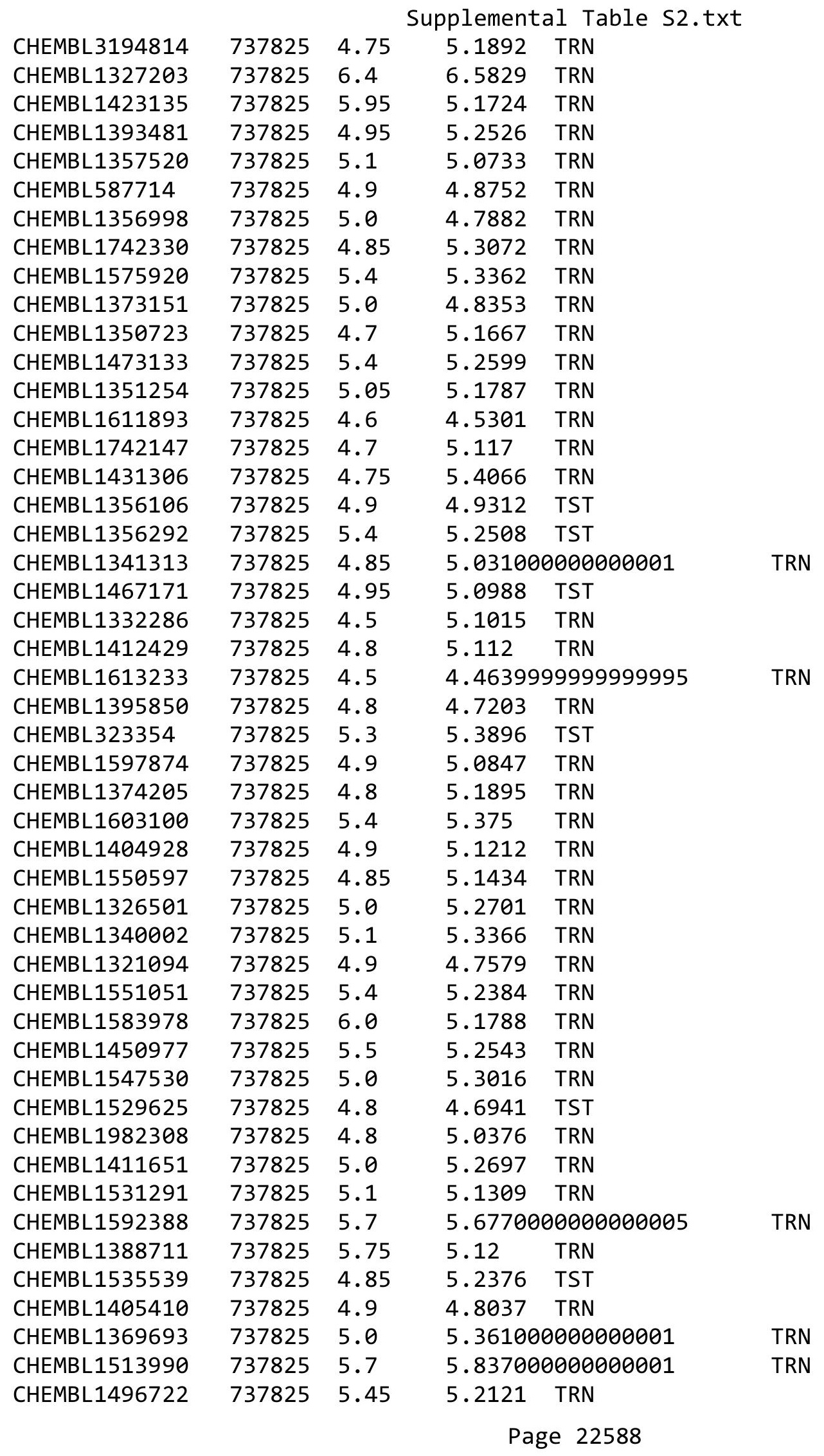




\begin{tabular}{|c|c|c|c|c|c|}
\hline \multirow{3}{*}{$\begin{array}{l}\text { CHEMBL } 1544254 \\
\text { CHEMBL1375285 }\end{array}$} & \multirow{3}{*}{$\begin{array}{l}737825 \\
737825\end{array}$} & \multicolumn{4}{|c|}{ Supplemental Table S2.txt } \\
\hline & & 4.85 & 5.1629 & 9999999999 & TRN \\
\hline & & 6.0 & 5.9423 & TRN & \\
\hline CHEMBL1409097 & 737825 & 5.9 & 5.5704 & TST & \\
\hline CHEMBL1492898 & 737825 & 4.85 & 5.1833 & TST & \\
\hline CHEMBL1400520 & 737825 & 4.6 & 5.0887 & TRN & \\
\hline CHEMBL1488294 & 737825 & 4.65 & 5.0471 & TRN & \\
\hline CHEMBL1505071 & 737825 & 4.6 & 5.013 & TST & \\
\hline CHEMBL1721237 & 737825 & 5.0 & 5.2207 & TRN & \\
\hline CHEMBL1741527 & 737825 & 4.65 & 5.1395 & TRN & \\
\hline CHEMBL1256910 & 737825 & 4.9 & 5.5873 & TST & \\
\hline CHEMBL332898 & 737825 & 5.1 & 5.0763 & TRN & \\
\hline CHEMBL1424097 & 737825 & 6.0 & 5.0738 & TST & \\
\hline CHEMBL1475395 & 737825 & 5.2 & 5.2528 & TRN & \\
\hline CHEMBL1584461 & 737825 & 5.5 & 5.1844 & TRN & \\
\hline CHEMBL1299856 & 737825 & 4.4 & 5.206 & TRN & \\
\hline CHEMBL1354563 & 737825 & 5.5 & 5.3489 & TRN & \\
\hline CHEMBL1342714 & 737825 & 4.8 & 5.2287 & TRN & \\
\hline CHEMBL1395523 & 737825 & 6.0 & 5.9427 & TRN & \\
\hline CHEMBL1358272 & 737825 & 5.0 & 4.9473 & TRN & \\
\hline CHEMBL1335826 & 737825 & 4.8 & 4.8277 & TRN & \\
\hline CHEMBL1612363 & 737825 & 5.0 & 4.7985 & TRN & \\
\hline CHEMBL1422113 & 737825 & 4.8 & 5.1042 & TRN & \\
\hline CHEMBL1368866 & 737825 & 4.8 & 5.0935 & TRN & \\
\hline CHEMBL1405262 & 737825 & 4.85 & 5.0642 & TST & \\
\hline CHEMBL1741760 & 737825 & 4.7 & 5.2879 & TST & \\
\hline CHEMBL1593019 & 737825 & 4.9 & 4.7139 & TRN & \\
\hline CHEMBL1358939 & 737825 & 4.75 & 5.022 & TRN & \\
\hline CHEMBL428496 & 737825 & 5.1 & 5.0669 & TST & \\
\hline CHEMBL1363275 & 737825 & 5.3 & 5.1631 & TRN & \\
\hline CHEMBL1334327 & 737825 & 5.4 & 5.2829 & TRN & \\
\hline CHEMBL1365609 & 737825 & 4.8 & 4.751 & TRN & \\
\hline CHEMBL1365902 & 737825 & 5.55 & 5.314 & TRN & \\
\hline CHEMBL1741975 & 737825 & 4.8 & 5.101 & TRN & \\
\hline CHEMBL1553185 & 737825 & 6.1 & 5.9771 & TRN & \\
\hline CHEMBL1440619 & 737825 & 5.0 & 4.9962 & TRN & \\
\hline CHEMBL1533658 & 737825 & 5.0 & 5.1889 & TRN & \\
\hline CHEMBL1446854 & 737825 & 4.6 & 5.0672 & TRN & \\
\hline CHEMBL1552095 & 737825 & 6.0 & 5.9277 & TST & \\
\hline CHEMBL587259 & 737825 & 5.05 & 5.0792 & TRN & \\
\hline CHEMBL1329033 & 737825 & 5.5 & 5.308 & TRN & \\
\hline CHEMBL1460723 & 737825 & 4.4 & 5.1948 & TST & \\
\hline CHEMBL1353037 & 737825 & 4.8 & 5.0516 & TRN & \\
\hline CHEMBL1443124 & 737825 & 4.9 & 4.9987 & TRN & \\
\hline CHEMBL1362892 & 737825 & 4.8 & 4.6856 & TRN & \\
\hline CHEMBL1461496 & 737825 & 5.1 & 5.033 & TRN & \\
\hline CHEMBL3190602 & 737825 & 4.6 & 5.0432 & TRN & \\
\hline CHEMBL1352766 & 737825 & 5.2 & 5.3762 & TRN & \\
\hline CHEMBL1339627 & 737825 & 4.8 & 5.0616 & TRN & \\
\hline
\end{tabular}




\begin{tabular}{|c|c|c|c|c|c|}
\hline \multicolumn{6}{|c|}{ Supplemental Table S2.txt } \\
\hline CHEMBL1536326 & 737825 & 5.15 & 5.3532 & TRN & \\
\hline CHEMBL1590458 & 737825 & 4.9 & 4.9567 & TRN & \\
\hline CHEMBL1533661 & 737825 & 5.0 & 5.1623 & TRN & \\
\hline CHEMBL 3211021 & 737825 & 4.95 & 5.2732 & TRN & \\
\hline CHEMBL1561791 & 737825 & 4.9 & 5.1036 & TRN & \\
\hline CHEMBL1606729 & 737825 & 5.35 & 5.1427 & TRN & \\
\hline CHEMBL1524598 & 737825 & 4.95 & 5.1953 & TRN & \\
\hline CHEMBL1444164 & 737825 & 4.8 & $5.1110 e$ & 0000000001 & TRN \\
\hline CHEMBL1458143 & 737825 & 5.1 & 5.2139 & TRN & \\
\hline CHEMBL1468982 & 737825 & 5.55 & 5.2082 & TST & \\
\hline CHEMBL1358178 & 737825 & 5.6 & 5.4043 & TRN & \\
\hline CHEMBL1551254 & 737825 & 5.5 & 5.3258 & TST & \\
\hline CHEMBL1531672 & 737825 & 6.1 & 5.2027 & TRN & \\
\hline CHEMBL1325775 & 737825 & 5.5 & 5.4035 & TRN & \\
\hline CHEMBL1713512 & 737825 & 5.2 & 5.1191 & TRN & \\
\hline CHEMBL1435301 & 737825 & 4.7 & 4.5775 & TRN & \\
\hline CHEMBL1578653 & 737825 & 4.6 & 5.0404 & TST & \\
\hline CHEMBL1507792 & 737825 & 4.75 & 5.0631 & TRN & \\
\hline CHEMBL1370480 & 737825 & 4.5 & 4.5805 & TRN & \\
\hline CHEMBL1421520 & 737825 & 4.4 & 5.2914 & TRN & \\
\hline CHEMBL1458583 & 737825 & 4.55 & 5.1786 & TRN & \\
\hline CHEMBL1580790 & 737825 & 5.5 & 5.1372 & TRN & \\
\hline CHEMBL1395429 & 737825 & 4.9 & 4.8065 & TRN & \\
\hline CHEMBL1450153 & 737825 & 4.6 & 4.9531 & TRN & \\
\hline CHEMBL1534919 & 737825 & 5.65 & 5.1877 & TRN & \\
\hline CHEMBL1581598 & 737825 & 4.9 & 5.1836 & TRN & \\
\hline CHEMBL1534248 & 737825 & 5.4 & 5.6647 & TRN & \\
\hline CHEMBL334378 & 737825 & 5.0 & 5.0646 & TST & \\
\hline CHEMBL 365739 & 737825 & 5.5 & 5.2723 & TST & \\
\hline CHEMBL1440943 & 737825 & 6.3 & 6.3333 & TRN & \\
\hline CHEMBL3199708 & 737825 & 5.4 & 5.3921 & TRN & \\
\hline CHEMBL1537501 & 737825 & 5.4 & 5.0307 & TRN & \\
\hline CHEMBL1518270 & 737825 & 5.35 & 4.9343 & TST & \\
\hline CHEMBL1742156 & 737825 & 4.9 & 5.1502 & TRN & \\
\hline CHEMBL1453354 & 737825 & 6.0 & 5.0062 & TRN & \\
\hline CHEMBL1397752 & 737825 & 5.5 & 5.362 & TRN & \\
\hline CHEMBL3213731 & 737825 & 4.9 & 5.112 & TRN & \\
\hline CHEMBL1482847 & 737825 & 4.9 & 4.7257 & TRN & \\
\hline CHEMBL3190580 & 737825 & 4.8 & 5.2698 & TST & \\
\hline CHEMBL1331579 & 737825 & 5.5 & 5.3635 & TRN & \\
\hline CHEMBL1309131 & 737825 & 6.35 & 5.2433 & TRN & \\
\hline CHEMBL1552165 & 737825 & 5.0 & 5.0592 & TRN & \\
\hline CHEMBL23327 & 737825 & 4.9 & 5.0526 & TRN & \\
\hline CHEMBL 273807 & 737825 & 6.0 & 5.6561 & TST & \\
\hline CHEMBL1594008 & 737825 & 5.5 & 5.3505 & TRN & \\
\hline CHEMBL1471931 & 737825 & 5.65 & 5.1666 & TRN & \\
\hline CHEMBL 1437442 & 737825 & 5.4 & 5.2964 & TRN & \\
\hline CHEMBL1410547 & 737825 & 4.8 & 5.0989 & TRN & \\
\hline
\end{tabular}




\begin{tabular}{|c|c|c|c|c|}
\hline \multicolumn{5}{|c|}{ Supplemental Table S2.txt } \\
\hline CHEMBL1480273 & 737825 & 4.55 & 5.0783 & TRN \\
\hline CHEMBL1319717 & 737825 & 6.1 & 5.5079 & 9999999999 \\
\hline CHEMBL1308218 & 737825 & 4.9 & 5.1068 & TRN \\
\hline CHEMBL1463577 & 737825 & 4.75 & 5.4239 & TRN \\
\hline CHEMBL1435917 & 737825 & 4.9 & 4.7166 & TRN \\
\hline CHEMBL1314422 & 737825 & 4.9 & 4.7258 & TRN \\
\hline CHEMBL1437119 & 737825 & 4.7 & 4.5265 & TRN \\
\hline CHEMBL1582527 & 737825 & 4.85 & 5.0938 & TRN \\
\hline CHEMBL1410841 & 737825 & 5.3 & 5.3469 & TST \\
\hline CHEMBL664 & 737825 & 4.7 & 4.9235 & TRN \\
\hline CHEMBL1492205 & 737825 & 5.5 & 5.5369 & TRN \\
\hline CHEMBL1724477 & 737825 & 4.75 & 5.0502 & TRN \\
\hline CHEMBL265699 & 737825 & 5.4 & 5.312 & TRN \\
\hline CHEMBL1329119 & 737825 & 4.85 & 5.1573 & TRN \\
\hline CHEMBL1568643 & 737825 & 4.8 & 5.2428 & TST \\
\hline CHEMBL1408303 & 737825 & 6.3 & 5.4439 & TRN \\
\hline CHEMBL1483700 & 737825 & 5.5 & 5.3752 & TRN \\
\hline CHEMBL1490195 & 737825 & 5.0 & 5.0244 & TRN \\
\hline CHEMBL1420005 & 737825 & 4.6 & 5.1841 & TRN \\
\hline CHEMBL1524305 & 737825 & 4.9 & 4.8218 & TRN \\
\hline CHEMBL596674 & 737825 & 6.0 & 5.6856 & TRN \\
\hline CHEMBL1574831 & 737825 & 5.4 & 5.2278 & TRN \\
\hline CHEMBL1396010 & 737825 & 4.7 & 4.5958 & TRN \\
\hline CHEMBL1605510 & 737825 & 5.0 & 4.7642 & TRN \\
\hline CHEMBL1436272 & 737825 & 4.8 & 4.8912 & TRN \\
\hline CHEMBL1515802 & 737825 & 5.3 & 5.2053 & TRN \\
\hline CHEMBL1333030 & 737825 & 5.55 & 5.2762 & TRN \\
\hline CHEMBL1589893 & 737825 & 5.1 & 4.8506 & TRN \\
\hline CHEMBL1381586 & 737825 & 5.3 & 5.1466 & TRN \\
\hline CHEMBL1388180 & 737825 & 5.5 & 5.2656 & TST \\
\hline CHEMBL1337830 & 737825 & 4.75 & 5.0201 & TST \\
\hline CHEMBL1318448 & 737825 & 5.2 & 5.1052 & TRN \\
\hline CHEMBL1612407 & 737825 & 4.65 & 5.0954 & TRN \\
\hline CHEMBL1552953 & 737825 & 5.4 & 5.388 & TRN \\
\hline CHEMBL1433551 & 737825 & 5.5 & 5.3873 & TRN \\
\hline CHEMBL1525571 & 737825 & 5.35 & 5.22 & TRN \\
\hline CHEMBL1513347 & 737825 & 4.9 & 4.7808 & TRN \\
\hline CHEMBL1301471 & 737825 & 4.65 & 4.9946 & TRN \\
\hline CHEMBL1463609 & 737825 & 6.1 & 5.5098 & TRN \\
\hline CHEMBL1348996 & 737825 & 4.7 & 5.1199 & TRN \\
\hline CHEMBL1454224 & 737825 & 4.9 & 4.7946 & TRN \\
\hline CHEMBL1445889 & 737825 & 5.7 & 5.1614 & TRN \\
\hline CHEMBL1257078 & 737825 & 4.9 & 5.621 & TST \\
\hline CHEMBL1523936 & 737825 & 4.65 & 5.1274 & TRN \\
\hline CHEMBL1600612 & 737825 & 4.4 & 4.3955 & TRN \\
\hline CHEMBL1566987 & 737825 & 6.8 & 6.3133 & TRN \\
\hline CHEMBL1353322 & 737825 & 4.9 & 5.1532 & TRN \\
\hline CHEMBL1709275 & 737825 & 5.6 & 5.2163 & TRN \\
\hline
\end{tabular}

TRN 


\begin{tabular}{|c|c|c|c|c|c|}
\hline \multicolumn{6}{|c|}{ Supplemental Table S2.txt } \\
\hline CHEMBL1316496 & 737825 & 7.5 & 6.6606 & TRN & \\
\hline CHEMBL1408140 & 737825 & 4.8 & 5.1699 & TRN & \\
\hline CHEMBL1336803 & 737825 & 4.6 & 4.5751 & TRN & \\
\hline CHEMBL1389097 & 737825 & 5.45 & 5.1102 & TRN & \\
\hline CHEMBL1336557 & 737825 & 4.9 & 5.2783 & TRN & \\
\hline CHEMBL1579814 & 737825 & 4.75 & 5.1219 & TRN & \\
\hline CHEMBL1594947 & 737825 & 5.6 & 5.5871 & TST & \\
\hline CHEMBL1415728 & 737825 & 4.9 & 4.8215 & TRN & \\
\hline CHEMBL1515774 & 737825 & 5.4 & 5.2011 & TRN & \\
\hline CHEMBL1499485 & 737825 & 4.4 & 5.1573 & TST & \\
\hline CHEMBL1500967 & 737825 & 5.7 & 5.0195 & TRN & \\
\hline CHEMBL1306083 & 737825 & 4.6 & 5.2771 & TST & \\
\hline CHEMBL1314367 & 737825 & 6.3 & 6.4362 & TRN & \\
\hline CHEMBL1314386 & 737825 & 4.9 & 4.753 & TRN & \\
\hline CHEMBL1488727 & 737825 & 4.65 & 5.1317 & TRN & \\
\hline CHEMBL1331137 & 737825 & 4.9 & 5.1189 & TRN & \\
\hline CHEMBL1384399 & 737825 & 4.85 & 4.9819 & TRN & \\
\hline CHEMBL1507862 & 737825 & 4.8 & 5.1263 & TST & \\
\hline CHEMBL1322756 & 737825 & 4.8 & 4.7563 & TRN & \\
\hline CHEMBL1331064 & 737825 & 4.8 & 4.9908 & TRN & \\
\hline CHEMBL2006154 & 737825 & 6.65 & 5.2767 & TRN & \\
\hline CHEMBL1563936 & 737825 & 4.85 & 5.1559 & TRN & \\
\hline CHEMBL1338480 & 737825 & 4.8 & 5.1744 & TRN & \\
\hline CHEMBL1380712 & 737825 & 4.6 & 5.1806 & TST & \\
\hline CHEMBL1451471 & 737825 & 4.6 & 5.3597 & TRN & \\
\hline CHEMBL3195378 & 737825 & 4.8 & 5.1808 & TST & \\
\hline CHEMBL1394031 & 737825 & 5.2 & 5.245 & TRN & \\
\hline CHEMBL1557212 & 737825 & 4.85 & 4.9964 & TST & \\
\hline CHEMBL1517085 & 737825 & 5.15 & 5.224 & TRN & \\
\hline CHEMBL1496590 & 737825 & 4.8 & 4.7156 & TRN & \\
\hline CHEMBL1452250 & 737825 & 5.9 & 5.9186 & TRN & \\
\hline CHEMBL1448819 & 737825 & 5.5 & 5.5571 & TRN & \\
\hline CHEMBL1576355 & 737825 & 5.05 & 5.2873 & TST & \\
\hline CHEMBL1388665 & 737825 & 4.85 & 5.3303 & TRN & \\
\hline CHEMBL 375270 & 737825 & 4.6 & 4.6035 & TRN & \\
\hline CHEMBL1464956 & 737825 & 4.9 & 5.1316 & TRN & \\
\hline CHEMBL1318518 & 737825 & 4.9 & 4.7125 & TRN & \\
\hline CHEMBL1256686 & 737825 & 5.3 & 5.1715 & TST & \\
\hline CHEMBL1527029 & 737825 & 4.6 & 4.5569 & TRN & \\
\hline CHEMBL1452079 & 737825 & 4.6 & 5.09399 & 9999999999 & TRN \\
\hline CHEMBL1417025 & 737825 & 4.7 & 4.7092 & TRN & \\
\hline CHEMBL1551913 & 737825 & 5.4 & 5.2004 & TRN & \\
\hline CHEMBL1323656 & 737825 & 5.4 & 5.32799 & 9999999999 & TRN \\
\hline CHEMBL1490045 & 737825 & 4.55 & 5.2184 & TST & \\
\hline CHEMBL1389176 & 737825 & 5.35 & 5.1649 & TRN & \\
\hline CHEMBL1741361 & 737825 & 6.0 & 5.9707 & TRN & \\
\hline CHEMBL 3210104 & 737825 & 4.85 & 5.2312 & TRN & \\
\hline CHEMBL1568061 & 737825 & 4.8 & 5.2597 & TRN & \\
\hline
\end{tabular}




\begin{tabular}{|c|c|c|c|c|}
\hline & & & upplemen & al $\mathrm{T}$ \\
\hline CHEMBL1476407 & 737825 & 4.8 & 4.7213 & TRN \\
\hline CHEMBL1494332 & 737825 & 4.95 & 5.1312 & TRN \\
\hline CHEMBL1732228 & 737825 & 5.9 & 5.3981 & TRN \\
\hline CHEMBL1364243 & 737825 & 6.0 & 6.0006 & TRN \\
\hline CHEMBL1416414 & 737825 & 4.6 & 5.1557 & TRN \\
\hline CHEMBL1428398 & 737825 & 4.55 & 5.2222 & TRN \\
\hline CHEMBL3189450 & 737825 & 4.7 & 5.073 & TRN \\
\hline CHEMBL1720268 & 737825 & 4.95 & 5.4302 & TRN \\
\hline CHEMBL1483874 & 737825 & 5.1 & 5.2569 & TRN \\
\hline CHEMBL1347250 & 737825 & 4.9 & 5.1434 & TRN \\
\hline CHEMBL1516530 & 737825 & 4.8 & 4.7202 & TRN \\
\hline CHEMBL475376 & 737825 & 5.2 & 5.1 & TRN \\
\hline CHEMBL1451747 & 737825 & 4.75 & 5.164 & TRN \\
\hline CHEMBL1424582 & 737825 & 6.25 & 5.3726 & TRN \\
\hline CHEMBL1485397 & 737825 & 5.45 & 5.2102 & TRN \\
\hline CHEMBL1488771 & 737825 & 5.4 & 5.3049 & TST \\
\hline CHEMBL1522582 & 737825 & 5.65 & 5.2079 & TRN \\
\hline CHEMBL1396539 & 737825 & 5.1 & 5.1323 & TRN \\
\hline CHEMBL1372773 & 737825 & 5.4 & 5.1471 & TRN \\
\hline CHEMBL1256974 & 737825 & 4.9 & 4.9995 & TRN \\
\hline CHEMBL1597410 & 737825 & 6.0 & 5.9686 & TRN \\
\hline CHEMBL1380069 & 737825 & 4.65 & 5.2501 & TRN \\
\hline CHEMBL1442173 & 737825 & 5.8 & 5.862 & TRN \\
\hline CHEMBL1376629 & 737825 & 5.5 & 5.1261 & TRN \\
\hline CHEMBL 384903 & 737825 & 4.8 & 4.8223 & TST \\
\hline CHEMBL63154 & 737825 & 5.6 & 5.3291 & TRN \\
\hline CHEMBL1510347 & 737825 & 4.8 & 5.1277 & TST \\
\hline CHEMBL1434848 & 737825 & 5.5 & 5.5388 & TRN \\
\hline CHEMBL1330158 & 737825 & 5.45 & 5.1766 & TRN \\
\hline CHEMBL1601970 & 737825 & 4.8 & 5.1247 & TRN \\
\hline CHEMBL1493910 & 737825 & 4.65 & 5.0374 & TRN \\
\hline CHEMBL1559650 & 737825 & 5.0 & 5.0614 & TRN \\
\hline CHEMBL1450653 & 737825 & 4.9 & 5.0669 & TRN \\
\hline CHEMBL1741515 & 737825 & 4.85 & 5.1142 & TRN \\
\hline CHEMBL1431665 & 737825 & 4.85 & 4.9921 & TRN \\
\hline CHEMBL1366068 & 737825 & 4.5 & 4.4802 & TRN \\
\hline CHEMBL1356004 & 737825 & 4.9 & 4.6645 & TRN \\
\hline CHEMBL1456688 & 737825 & 4.6 & 4.5955 & TRN \\
\hline CHEMBL1366323 & 737825 & 4.9 & 5.0689 & TRN \\
\hline CHEMBL1310284 & 737825 & 5.0 & 5.1302 & TRN \\
\hline CHEMBL1395792 & 737825 & 5.2 & 5.2697 & TRN \\
\hline CHEMBL1256913 & 737825 & 5.0 & 4.8516 & TST \\
\hline CHEMBL1524183 & 737825 & 5.05 & 4.9912 & TRN \\
\hline CHEMBL1330580 & 737825 & 5.5 & 5.1508 & TRN \\
\hline CHEMBL1331031 & 737825 & 5.5 & 5.4274 & TRN \\
\hline CHEMBL1459535 & 737825 & 4.6 & 5.199 & TRN \\
\hline CHEMBL1467355 & 737825 & 4.9 & 5.2599 & TST \\
\hline CHEMBL1562937 & 737825 & 4.4 & 4.8673 & TRN \\
\hline
\end{tabular}




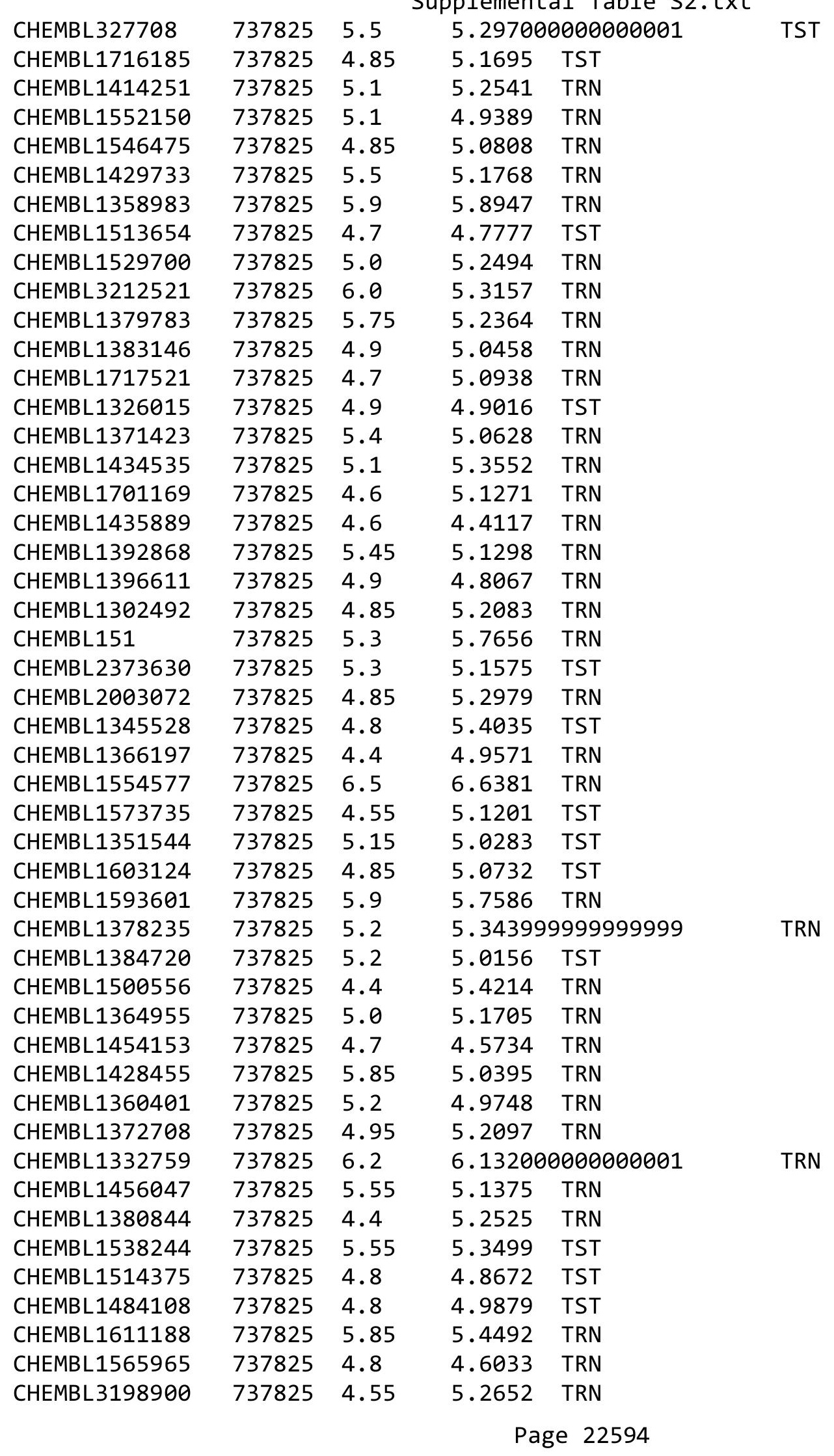




\begin{tabular}{|c|c|c|c|c|c|}
\hline \\
\hline CHEMBL1601482 & 737825 & 4.85 & 5.0679 & TRN & \\
\hline CHEMBL1741845 & 737825 & 4.85 & 5.1225 & TST & \\
\hline CHEMBL1444856 & 737825 & 4.7 & 4.5159 & TRN & \\
\hline CHEMBL1510139 & 737825 & 4.6 & 4.984 & TRN & \\
\hline CHEMBL1612814 & 737825 & 5.35 & 5.0635 & TST & \\
\hline CHEMBL1515194 & 737825 & 4.8 & 4.59399 & 9999999999 & TRN \\
\hline CHEMBL3209784 & 737825 & 4.7 & 5.1573 & TST & \\
\hline CHEMBL1396377 & 737825 & 4.6 & 4.6218 & TRN & \\
\hline CHEMBL1337387 & 737825 & 5.3 & 5.289 & TRN & \\
\hline CHEMBL1366446 & 737825 & 5.3 & 5.1906 & TST & \\
\hline CHEMBL1355139 & 737825 & 6.3 & 6.4045 & TRN & \\
\hline CHEMBL1508885 & 737825 & 4.65 & 4.9738 & TRN & \\
\hline CHEMBL3196906 & 737825 & 4.4 & 5.2999 & TRN & \\
\hline CHEMBL1533537 & 737825 & 4.8 & 4.6571 & TRN & \\
\hline CHEMBL1348181 & 737825 & 5.5 & 5.1706 & TRN & \\
\hline CHEMBL1447089 & 737825 & 5.1 & 5.1814 & TST & \\
\hline CHEMBL1395337 & 737825 & 5.4 & 5.6352 & TRN & \\
\hline CHEMBL1551518 & 737825 & 4.9 & 4.8575 & TRN & \\
\hline CHEMBL1374849 & 737825 & 5.8 & 5.6921 & TRN & \\
\hline CHEMBL1554935 & 737825 & 5.5 & 5.3656 & TRN & \\
\hline CHEMBL67378 & 737825 & 6.0 & 5.7473 & TST & \\
\hline CHEMBL1486915 & 737825 & 5.4 & 5.4067 & TRN & \\
\hline CHEMBL1594086 & 737825 & 5.0 & 4.7693 & TRN & \\
\hline CHEMBL1598705 & 737825 & 4.4 & 5.1993 & TRN & \\
\hline CHEMBL1494802 & 737825 & 5.2 & 5.0991 & TRN & \\
\hline CHEMBL 263972 & 737825 & 5.6 & 5.3315 & TRN & \\
\hline CHEMBL1459301 & 737825 & 4.9 & 5.1401 & TRN & \\
\hline CHEMBL3211009 & 737825 & 5.55 & 5.3019 & TRN & \\
\hline CHEMBL1315845 & 737825 & 4.7 & 4.5164 & TRN & \\
\hline CHEMBL1390207 & 737825 & 4.6 & 5.1027 & TRN & \\
\hline CHEMBL1306988 & 737825 & 5.45 & 5.1528 & TRN & \\
\hline CHEMBL1728383 & 737825 & 4.85 & 5.4306 & TRN & \\
\hline CHEMBL1506622 & 737825 & 4.6 & 5.187 & TRN & \\
\hline CHEMBL1513928 & 737825 & 5.0 & 5.2392 & TRN & \\
\hline CHEMBL1552329 & 737825 & 4.9 & 4.8044 & TRN & \\
\hline CHEMBL1514748 & 737825 & 5.6 & 5.3323 & TRN & \\
\hline CHEMBL1702111 & 737825 & 4.75 & 5.4836 & TRN & \\
\hline CHEMBL1301015 & 737825 & 4.5 & 4.9066 & TRN & \\
\hline CHEMBL1569058 & 737825 & 6.5 & 5.099 & TRN & \\
\hline CHEMBL1319038 & 737825 & 6.05 & 5.5642 & TST & \\
\hline CHEMBL1354398 & 737825 & 4.5 & 4.699 & TST & \\
\hline CHEMBL1741688 & 737825 & -0.0 & 4.9126 & TST & \\
\hline CHEMBL1741335 & 737825 & 5.25 & 5.1674 & TRN & \\
\hline CHEMBL1722356 & 737825 & 4.65 & 5.2598 & TRN & \\
\hline CHEMBL1302645 & 737825 & 5.45 & 5.1941 & TST & \\
\hline CHEMBL1590173 & 737825 & 5.5 & 5.4213 & TRN & \\
\hline CHEMBL1403902 & 737825 & 5.35 & 5.1906 & TRN & \\
\hline CHEMBL1433798 & 737825 & 5.1 & 4.9748 & TRN & \\
\hline
\end{tabular}




\begin{tabular}{|c|c|c|c|c|}
\hline \multicolumn{5}{|c|}{ Supplemental Table S2.txt } \\
\hline CHEMBL1742253 & 737825 & 5.15 & 5.2359 & TRN \\
\hline CHEMBL1518560 & 737825 & 5.0 & 5.0979 & TRN \\
\hline CHEMBL1256360 & 737825 & 5.0 & 4.9428 & TRN \\
\hline CHEMBL1554763 & 737825 & 4.5 & 4.5004 & TRN \\
\hline CHEMBL400875 & 737825 & 5.3 & 5.313 & TRN \\
\hline CHEMBL1318480 & 737825 & 4.9 & 4.7156 & TRN \\
\hline CHEMBL1327945 & 737825 & 6.3 & 6.3473 & TRN \\
\hline CHEMBL1432327 & 737825 & 4.4 & 5.2288 & TRN \\
\hline CHEMBL1453217 & 737825 & 6.0 & 5.5056 & TRN \\
\hline CHEMBL 30024 & 737825 & 4.8 & 4.7402 & TST \\
\hline CHEMBL1455438 & 737825 & 4.6 & 4.4654 & TRN \\
\hline CHEMBL1256924 & 737825 & 5.4 & 5.17 & TRN \\
\hline CHEMBL1353317 & 737825 & 5.85 & 5.0833 & TRN \\
\hline CHEMBL56731 & 737825 & 4.8 & 4.7078 & TRN \\
\hline CHEMBL1541518 & 737825 & 5.05 & 5.1134 & TRN \\
\hline CHEMBL92708 & 737825 & 4.8 & 4.8009 & TRN \\
\hline CHEMBL1490799 & 737825 & 5.5 & 5.1528 & TST \\
\hline CHEMBL1435384 & 737825 & 5.6 & 5.4027 & TRN \\
\hline CHEMBL1439148 & 737825 & 5.15 & 5.2789 & TRN \\
\hline CHEMBL1365235 & 737825 & 4.55 & 5.164 & TRN \\
\hline CHEMBL1496311 & 737825 & 6.0 & 5.4071 & TRN \\
\hline CHEMBL1482155 & 737825 & 4.9 & 4.7774 & TRN \\
\hline CHEMBL1408874 & 737825 & 4.6 & 5.0463 & TRN \\
\hline CHEMBL1437776 & 737825 & 4.9 & 4.8184 & TRN \\
\hline CHEMBL3191740 & 737825 & 5.8 & 5.1144 & TST \\
\hline CHEMBL1448223 & 737825 & 4.9 & 5.1019 & TST \\
\hline CHEMBL1397671 & 737825 & 5.1 & 5.0223 & TRN \\
\hline CHEMBL1475685 & 737825 & 5.0 & 4.7747 & TRN \\
\hline CHEMBL1306897 & 737825 & 4.85 & 5.2069 & TRN \\
\hline CHEMBL1340538 & 737825 & 6.4 & 5.2951 & TRN \\
\hline CHEMBL1583260 & 737825 & 5.55 & 5.1044 & TST \\
\hline CHEMBL3193407 & 737825 & 4.7 & 5.2067 & TST \\
\hline CHEMBL1356690 & 737825 & 4.6 & 4.4607 & TRN \\
\hline CHEMBL1319120 & 737825 & 5.6 & 5.803 & TRN \\
\hline CHEMBL1515565 & 737825 & 4.6 & 4.493 & TRN \\
\hline CHEMBL1604232 & 737825 & 5.5 & 5.1778 & TRN \\
\hline CHEMBL 244948 & 737825 & 4.9 & 4.7521 & TST \\
\hline CHEMBL1386793 & 737825 & 4.9 & 5.0088 & TRN \\
\hline CHEMBL1730483 & 737825 & 4.9 & 5.2047 & TRN \\
\hline CHEMBL1385596 & 737825 & 5.6 & 5.0815 & TRN \\
\hline CHEMBL1485598 & 737825 & 6.3 & 5.4215 & TRN \\
\hline CHEMBL1425687 & 737825 & 4.6 & 5.0673 & TRN \\
\hline CHEMBL1361427 & 737825 & 4.95 & 5.4717 & TRN \\
\hline CHEMBL1304072 & 737825 & 4.85 & 5.2079 & TRN \\
\hline CHEMBL1536842 & 737825 & 4.4 & 4.9156 & TRN \\
\hline CHEMBL1361461 & 737825 & 4.4 & 5.0626 & TRN \\
\hline CHEMBL1501836 & 737825 & 6.25 & 5.1138 & TST \\
\hline CHEMBL1612252 & 737825 & 4.9 & 4.921 & TRN \\
\hline
\end{tabular}




\begin{tabular}{|c|c|c|c|c|c|}
\hline & & \multicolumn{4}{|c|}{ Supplemental Table S2.txt } \\
\hline CHEMBL1717360 & 737825 & 6.35 & 5.4064 & TRN & \\
\hline CHEMBL1505375 & 737825 & 4.6 & 5.0742 & TRN & \\
\hline CHEMBL1473809 & 737825 & 4.9 & 4.7531 & TRN & \\
\hline CHEMBL471226 & 737825 & 5.4 & 5.38299 & 9999999999 & TST \\
\hline CHEMBL429095 & 737825 & 4.6 & 4.7554 & TST & \\
\hline CHEMBL1569485 & 737825 & 5.6 & 5.6661 & TRN & \\
\hline CHEMBL1551534 & 737825 & 4.8 & 4.6772 & TRN & \\
\hline CHEMBL1395049 & 737825 & 5.4 & 5.2691 & TRN & \\
\hline CHEMBL1515246 & 737825 & 5.7 & 5.4036 & TRN & \\
\hline CHEMBL1309630 & 737825 & 4.85 & 5.0011 & TST & \\
\hline CHEMBL15927 & 737825 & 4.3 & 4.3151 & TRN & \\
\hline CHEMBL3193117 & 737825 & 4.85 & 5.23 & TRN & \\
\hline CHEMBL 2001481 & 737825 & 4.85 & 5.0529 & TRN & \\
\hline CHEMBL1596872 & 737825 & 4.8 & 4.6608 & TRN & \\
\hline CHEMBL1459527 & 737825 & 5.75 & 5.1673 & TRN & \\
\hline CHEMBL1387287 & 737825 & 4.9 & 5.1408 & TRN & \\
\hline CHEMBL1404295 & 737825 & 5.05 & 5.2809 & TRN & \\
\hline CHEMBL1482426 & 737825 & 5.2 & 5.1896 & TRN & \\
\hline CHEMBL1395935 & 737825 & 5.4 & 5.494 & TRN & \\
\hline CHEMBL1600653 & 737825 & 4.95 & 4.9496 & TST & \\
\hline CHEMBL1589856 & 737825 & 5.8 & 5.3222 & TRN & \\
\hline CHEMBL1389078 & 737825 & 4.5 & 5.2695 & TRN & \\
\hline CHEMBL1462914 & 737825 & 5.55 & 5.3437 & TRN & \\
\hline CHEMBL1386709 & 737825 & 4.8 & 5.0307 & TRN & \\
\hline CHEMBL1610003 & 737825 & 4.6 & 4.433 & TRN & \\
\hline CHEMBL1528376 & 737825 & 5.5 & 4.9967 & TST & \\
\hline CHEMBL1413982 & 737825 & 5.1 & 5.1624 & TRN & \\
\hline CHEMBL1463376 & 737825 & 5.3 & 5.2568 & TRN & \\
\hline CHEMBL1741332 & 737825 & 4.65 & 5.1967 & TRN & \\
\hline CHEMBL1356844 & 737825 & 4.6 & 4.6249 & TRN & \\
\hline CHEMBL1412520 & 737825 & 5.15 & 5.2535 & TRN & \\
\hline CHEMBL1448542 & 737825 & 4.8 & 4.817 & TRN & \\
\hline CHEMBL1505211 & 737825 & 4.8 & 5.1533 & TRN & \\
\hline CHEMBL1741345 & 737825 & 5.35 & 5.0746 & TRN & \\
\hline CHEMBL1562047 & 737825 & 5.6 & 5.1464 & TRN & \\
\hline CHEMBL1306752 & 737825 & 6.05 & 5.1917 & TRN & \\
\hline CHEMBL1555164 & 737825 & 5.4 & 5.4483 & TRN & \\
\hline CHEMBL1565342 & 737825 & 6.0 & 5.9832 & TRN & \\
\hline CHEMBL1358090 & 737825 & 5.3 & 5.1128 & TRN & \\
\hline CHEMBL1313043 & 737825 & 5.05 & 5.24200 & 0000000001 & TRN \\
\hline CHEMBL1389640 & 737825 & 5.15 & 5.1626 & TRN & \\
\hline CHEMBL1360767 & 737825 & 5.4 & 5.2577 & TRN & \\
\hline CHEMBL1553070 & 737825 & 6.4 & 6.4226 & TRN & \\
\hline CHEMBL1522566 & 737825 & 5.2 & 5.2781 & TRN & \\
\hline CHEMBL40004 & 737825 & 4.7 & 5.7007 & TRN & \\
\hline CHEMBL1398608 & 737825 & 5.4 & 5.3203 & TRN & \\
\hline CHEMBL3196157 & 737825 & 4.85 & 5.1328 & TRN & \\
\hline CHEMBL1495091 & 737825 & 5.5 & 5.1541 & TRN & \\
\hline
\end{tabular}




\begin{tabular}{|c|c|c|c|c|c|}
\hline \multicolumn{6}{|c|}{ Supplemental Table S2.txt } \\
\hline CHEMBL1441353 & 737825 & 5.55 & 5.0357 & TRN & \\
\hline CHEMBL3193992 & 737825 & 5.15 & 5.0528 & TRN & \\
\hline CHEMBL1475004 & 737825 & 4.8 & 4.6811 & TRN & \\
\hline CHEMBL1308621 & 737825 & 4.9 & 5.1191 & TST & \\
\hline CHEMBL1568080 & 737825 & 5.5 & 5.3635 & TRN & \\
\hline CHEMBL1524242 & 737825 & 4.8 & 5.0378 & TRN & \\
\hline CHEMBL1415777 & 737825 & 4.8 & 5.6574 & TST & \\
\hline CHEMBL1606345 & 737825 & 5.0 & 5.1026 & TRN & \\
\hline CHEMBL1455462 & 737825 & 5.5 & $5.2920 e$ & $\partial 000000001$ & TRN \\
\hline CHEMBL1554693 & 737825 & 6.2 & 5.9628 & TRN & \\
\hline CHEMBL1473331 & 737825 & 4.8 & 4.6546 & TRN & \\
\hline CHEMBL1572457 & 737825 & 5.05 & 5.2098 & TRN & \\
\hline CHEMBL1381896 & 737825 & 4.6 & 5.1259 & TRN & \\
\hline CHEMBL1356771 & 737825 & 5.0 & 4.8616 & TRN & \\
\hline CHEMBL1466170 & 737825 & 4.9 & 5.1011 & TRN & \\
\hline CHEMBL1319195 & 737825 & 4.85 & 5.0423 & TRN & \\
\hline CHEMBL1442087 & 737825 & 6.0 & 5.7206 & TRN & \\
\hline CHEMBL1728158 & 737825 & 4.75 & 5.2753 & TRN & \\
\hline CHEMBL1964464 & 737825 & 4.85 & 5.1491 & TRN & \\
\hline CHEMBL1519373 & 737825 & 4.95 & 5.2057 & TRN & \\
\hline CHEMBL1478640 & 737825 & 5.05 & 4.9514 & TRN & \\
\hline CHEMBL1474318 & 737825 & 5.1 & 4.9554 & TRN & \\
\hline CHEMBL1408323 & 737825 & 4.95 & 4.8049 & TRN & \\
\hline CHEMBL1525073 & 737825 & 4.8 & 5.1684 & TRN & \\
\hline CHEMBL1317135 & 737825 & 6.4 & 6.0031 & TST & \\
\hline CHEMBL136906 & 737825 & 5.5 & 5.2715 & TRN & \\
\hline CHEMBL3192169 & 737825 & 4.6 & 5.1415 & TST & \\
\hline CHEMBL1544662 & 737825 & 4.7 & 5.1932 & TRN & \\
\hline CHEMBL1353502 & 737825 & 5.15 & 5.18 & TRN & \\
\hline CHEMBL1724517 & 737825 & 4.65 & 5.0867 & TRN & \\
\hline CHEMBL1323385 & 737825 & 5.1 & 5.0045 & TRN & \\
\hline CHEMBL1486160 & 737825 & 5.05 & 5.23799 & 99999999995 & TST \\
\hline CHEMBL1395009 & 737825 & 5.3 & 5.233 & TRN & \\
\hline CHEMBL1573743 & 737825 & 5.4 & 4.9507 & TRN & \\
\hline CHEMBL1364372 & 737825 & 5.5 & 5.4146 & TRN & \\
\hline CHEMBL489934 & 737825 & 6.5 & 6.4757 & TRN & \\
\hline CHEMBL1553694 & 737825 & 5.8 & 5.8447 & TRN & \\
\hline CHEMBL1490198 & 737825 & 4.5 & 5.0025 & TRN & \\
\hline CHEMBL1609078 & 737825 & 5.5 & 4.8601 & TRN & \\
\hline CHEMBL1395107 & 737825 & 4.4 & 4.3567 & TRN & \\
\hline CHEMBL329872 & 737825 & 4.85 & 4.9456 & TRN & \\
\hline CHEMBL 2374062 & 737825 & 6.0 & 5.7272 & TST & \\
\hline CHEMBL1608942 & 737825 & 5.15 & 5.4377 & TRN & \\
\hline CHEMBL1384971 & 737825 & 6.05 & 5.0005 & TRN & \\
\hline CHEMBL1408822 & 737825 & 5.3 & 5.3292 & TRN & \\
\hline CHEMBL1334817 & 737825 & 4.5 & 4.6516 & TST & \\
\hline CHEMBL1544250 & 737825 & 4.75 & 5.2458 & TRN & \\
\hline CHEMBL3193339 & 737825 & 5.65 & 5.4211 & TRN & \\
\hline
\end{tabular}




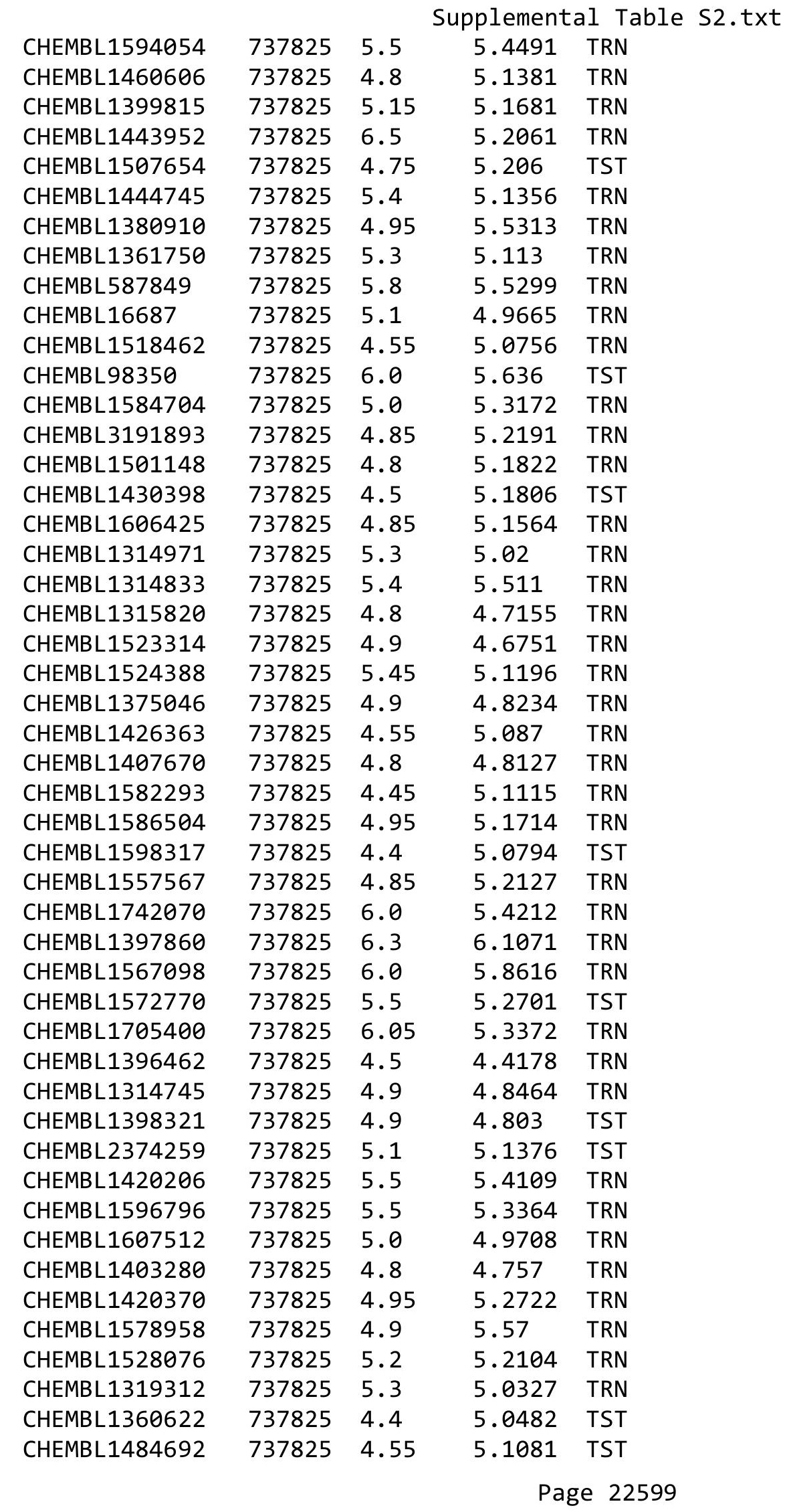




\begin{tabular}{|c|c|c|c|c|c|}
\hline \multicolumn{6}{|c|}{ Supplemental Table S2.txt } \\
\hline CHEMBL3192246 & 737825 & 4.9 & 5.0527 & TRN & \\
\hline CHEMBL1345104 & 737825 & 5.0 & 5.2298 & TRN & \\
\hline CHEMBL1490012 & 737825 & 4.95 & 5.1926 & TRN & \\
\hline CHEMBL1302827 & 737825 & 5.4 & 5.2246 & TST & \\
\hline CHEMBL1394640 & 737825 & 6.0 & 6.0064 & TRN & \\
\hline CHEMBL1501536 & 737825 & 5.15 & 5.2873 & TRN & \\
\hline CHEMBL1493566 & 737825 & 5.35 & 5.1834 & TRN & \\
\hline CHEMBL1373204 & 737825 & 5.4 & 5.4195 & TRN & \\
\hline CHEMBL1288013 & 737825 & 5.6 & 5.442 & TRN & \\
\hline CHEMBL1721191 & 737825 & 5.05 & 5.46399 & 99999999995 & TRN \\
\hline CHEMBL1741958 & 737825 & 4.65 & 5.5333 & TRN & \\
\hline CHEMBL1524650 & 737825 & 5.0 & 4.8402 & TRN & \\
\hline CHEMBL1488477 & 737825 & 4.7 & 4.621 & TRN & \\
\hline CHEMBL1490857 & 737825 & 4.65 & 5.2377 & TRN & \\
\hline CHEMBL1742168 & 737825 & 5.45 & 5.0957 & TRN & \\
\hline CHEMBL1495004 & 737825 & 5.4 & 5.2751 & TRN & \\
\hline CHEMBL1498179 & 737825 & 4.8 & 5.325 & TRN & \\
\hline CHEMBL1328833 & 737825 & 6.1 & 5.5078 & TRN & \\
\hline CHEMBL1542520 & 737825 & 5.6 & 5.1421 & TRN & \\
\hline CHEMBL1494592 & 737825 & 4.8 & 4.6587 & TRN & \\
\hline CHEMBL171064 & 737825 & 4.5 & 4.6576 & TRN & \\
\hline CHEMBL1495886 & 737825 & 5.35 & 5.1444 & TST & \\
\hline CHEMBL1536604 & 737825 & 5.4 & 5.1292 & TRN & \\
\hline CHEMBL1421016 & 737825 & 4.8 & 4.7924 & TRN & \\
\hline CHEMBL3198657 & 737825 & 6.0 & 5.9371 & TRN & \\
\hline CHEMBL1582012 & 737825 & 4.85 & 5.086 & TRN & \\
\hline CHEMBL1305666 & 737825 & 4.4 & 5.1308 & TRN & \\
\hline CHEMBL1570515 & 737825 & 4.6 & 4.9952 & TRN & \\
\hline CHEMBL1725130 & 737825 & 4.85 & 5.0803 & TRN & \\
\hline CHEMBL1358359 & 737825 & 5.4 & $5.2010 e$ & 00000000005 & TST \\
\hline CHEMBL1514440 & 737825 & 6.0 & 5.8173 & TRN & \\
\hline CHEMBL1461732 & 737825 & 4.65 & 5.153 & TRN & \\
\hline CHEMBL1585542 & 737825 & 5.55 & 5.153 & TRN & \\
\hline CHEMBL1507467 & 737825 & 4.9 & 5.3757 & TRN & \\
\hline CHEMBL1532939 & 737825 & 4.9 & 5.091 & TST & \\
\hline CHEMBL1474294 & 737825 & 6.2 & 5.7464 & TST & \\
\hline CHEMBL1388783 & 737825 & 5.5 & 5.0865 & TRN & \\
\hline CHEMBL1592220 & 737825 & 5.3 & 5.008 & TRN & \\
\hline CHEMBL1355634 & 737825 & 4.8 & 4.747 & TRN & \\
\hline CHEMBL1483427 & 737825 & 4.7 & 4.5362 & TRN & \\
\hline CHEMBL1602211 & 737825 & 4.9 & 5.144 & TST & \\
\hline CHEMBL1361839 & 737825 & 4.8 & 4.6909 & TRN & \\
\hline CHEMBL1464487 & 737825 & 4.85 & 5.4599 & TST & \\
\hline CHEMBL1352020 & 737825 & 4.85 & 5.1721 & TRN & \\
\hline CHEMBL1396384 & 737825 & 5.3 & 5.4158 & TRN & \\
\hline CHEMBL565654 & 737825 & 5.1 & 5.1102 & TRN & \\
\hline CHEMBL1741745 & 737825 & 5.5 & 5.4744 & TRN & \\
\hline CHEMBL1593663 & 737825 & 5.2 & 4.9956 & TRN & \\
\hline
\end{tabular}




\begin{tabular}{|c|c|c|c|c|c|}
\hline \\
\hline CHEMBL1603577 & 737825 & 4.8 & 5.1363 & TRN & \\
\hline CHEMBL1512385 & 737825 & 5.4 & 5.2817 & TRN & \\
\hline CHEMBL1545141 & 737825 & 5.05 & 5.1674 & TST & \\
\hline CHEMBL1369212 & 737825 & 6.0 & 6.025 & TRN & \\
\hline CHEMBL1448655 & 737825 & 5.6 & 5.2034 & TRN & \\
\hline CHEMBL1480575 & 737825 & 4.55 & 5.1 & TRN & \\
\hline CHEMBL1392170 & 737825 & 4.8 & 5.2393 & TRN & \\
\hline CHEMBL1741541 & 737825 & 4.85 & 5.0676 & TST & \\
\hline CHEMBL1741467 & 737825 & 5.1 & 5.2758 & TRN & \\
\hline CHEMBL276140 & 737825 & 5.4 & 5.4743 & TRN & \\
\hline CHEMBL1380806 & 737825 & 5.3 & 5.1239 & TRN & \\
\hline CHEMBL1307366 & 737825 & 4.7 & 5.2587 & TRN & \\
\hline CHEMBL1507058 & 737825 & 5.35 & $5.2120 e$ & 0000000001 & TRN \\
\hline CHEMBL7162 & 737825 & 4.7 & 4.7698 & TST & \\
\hline CHEMBL3214128 & 737825 & 4.65 & 5.0926 & TRN & \\
\hline CHEMBL1562333 & 737825 & 5.1 & 5.1734 & TRN & \\
\hline CHEMBL1424256 & 737825 & 5.1 & 5.2174 & TRN & \\
\hline CHEMBL1591238 & 737825 & 5.9 & 5.9356 & TRN & \\
\hline CHEMBL1328726 & 737825 & 6.6 & 5.2441 & TRN & \\
\hline CHEMBL1395882 & 737825 & 4.5 & 4.5381 & TRN & \\
\hline CHEMBL1590077 & 737825 & 6.0 & 5.9995 & TRN & \\
\hline CHEMBL1442987 & 737825 & 6.0 & 6.0325 & TRN & \\
\hline CHEMBL1396936 & 737825 & 5.7 & 5.7409 & TRN & \\
\hline CHEMBL1362300 & 737825 & 5.05 & 5.4104 & TRN & \\
\hline CHEMBL1347400 & 737825 & 5.0 & 5.0277 & TRN & \\
\hline CHEMBL311158 & 737825 & 4.9 & 5.7258 & TRN & \\
\hline CHEMBL1362068 & 737825 & 5.5 & 5.3324 & TRN & \\
\hline CHEMBL1327394 & 737825 & 4.7 & 4.5291 & TRN & \\
\hline CHEMBL1476280 & 737825 & 5.4 & 5.6079 & TRN & \\
\hline CHEMBL1383656 & 737825 & 5.4 & 5.0657 & TRN & \\
\hline CHEMBL1362305 & 737825 & 4.95 & 5.4175 & TRN & \\
\hline CHEMBL1362729 & 737825 & 5.4 & 5.4078 & TRN & \\
\hline CHEMBL1528911 & 737825 & 5.7 & 5.2368 & TRN & \\
\hline CHEMBL1416438 & 737825 & 6.15 & 5.6089 & TRN & \\
\hline CHEMBL1711322 & 737825 & 4.65 & 4.96 & TRN & \\
\hline CHEMBL1506736 & 737825 & 5.15 & 5.2567 & TRN & \\
\hline CHEMBL1408520 & 737825 & 4.9 & 4.9084 & TRN & \\
\hline CHEMBL1493183 & 737825 & 4.85 & 5.2536 & TRN & \\
\hline CHEMBL1451346 & 737825 & 4.85 & 4.915 & TRN & \\
\hline CHEMBL1485450 & 737825 & 4.85 & 5.0802 & TRN & \\
\hline CHEMBL1590123 & 737825 & 5.5 & 5.3934 & TRN & \\
\hline CHEMBL164269 & 737825 & 5.5 & 5.3023 & TRN & \\
\hline CHEMBL1537215 & 737825 & 5.1 & 5.1256 & TRN & \\
\hline CHEMBL1508431 & 737825 & 5.05 & 5.3405 & TRN & \\
\hline CHEMBL1493838 & 737825 & 5.0 & 5.2655 & TRN & \\
\hline CHEMBL 2004183 & 737825 & 5.05 & 5.2222 & TST & \\
\hline CHEMBL1436917 & 737825 & 5.2 & 4.9678 & TRN & \\
\hline CHEMBL1555348 & 737825 & 4.8 & 4.7862 & TRN & \\
\hline & & & & 22601 & \\
\hline
\end{tabular}




\begin{tabular}{|c|c|c|c|c|c|}
\hline & & \multicolumn{4}{|c|}{ Supplemental Table s2.txt } \\
\hline CHEMBL 3212631 & 737825 & 4.65 & 5.0428 & TRN & \\
\hline CHEMBL1456686 & 737825 & 5.05 & 5.2389 & TRN & \\
\hline CHEMBL1456015 & 737825 & 4.8 & 4.6753 & TRN & \\
\hline CHEMBL1352133 & 737825 & 5.7 & 5.1736 & TRN & \\
\hline CHEMBL1299867 & 737825 & 5.05 & 5.3035 & TRN & \\
\hline CHEMBL1602117 & 737825 & 4.6 & 5.0788 & TRN & \\
\hline CHEMBL1560706 & 737825 & 5.15 & 5.1854 & TRN & \\
\hline CHEMBL1458544 & 737825 & 5.0 & 5.1939 & TRN & \\
\hline CHEMBL1546073 & 737825 & 4.85 & 5.1943 & TRN & \\
\hline CHEMBL1525456 & 737825 & 5.3 & 5.194 & TRN & \\
\hline CHEMBL1349613 & 737825 & 4.85 & 4.9419 & TRN & \\
\hline CHEMBL1530805 & 737825 & 4.85 & 5.0633 & TRN & \\
\hline CHEMBL1447248 & 737825 & 4.75 & 5.3056 & TRN & \\
\hline CHEMBL1593853 & 737825 & 5.7 & 5.5403 & TRN & \\
\hline CHEMBL1394181 & 737825 & 5.0 & 4.8127 & TRN & \\
\hline CHEMBL1477299 & 737825 & 4.95 & 5.1755 & TRN & \\
\hline CHEMBL1489263 & 737825 & 4.85 & 5.0954 & TRN & \\
\hline CHEMBL1571264 & 737825 & 5.0 & 4.8826 & TRN & \\
\hline CHEMBL1699675 & 737825 & 4.85 & 4.9964 & TRN & \\
\hline CHEMBL1376290 & 737825 & 4.9 & 4.7996 & TRN & \\
\hline CHEMBL1546326 & 737825 & 4.8 & 5.1425 & TRN & \\
\hline CHEMBL1588849 & 737825 & 4.8 & 5.0227 & TRN & \\
\hline CHEMBL1382502 & 737825 & 4.9 & 5.164 & TRN & \\
\hline CHEMBL3191557 & 737825 & 6.0 & 5.5241 & TRN & \\
\hline CHEMBL1405129 & 737825 & 5.15 & 5.2226 & TRN & \\
\hline CHEMBL1347208 & 737825 & 6.4 & 5.001 & TST & \\
\hline CHEMBL1516905 & 737825 & 5.45 & 5.19 & TRN & \\
\hline CHEMBL1364366 & 737825 & 5.1 & 5.1354 & TRN & \\
\hline CHEMBL1411049 & 737825 & 5.6 & 5.5987 & TRN & \\
\hline CHEMBL1498144 & 737825 & 4.75 & 5.0218 & TRN & \\
\hline CHEMBL1358664 & 737825 & 5.4 & 5.3847 & TRN & \\
\hline CHEMBL1309281 & 737825 & 4.95 & 5.1392 & TRN & \\
\hline CHEMBL1315521 & 737825 & 5.3 & 5.0384 & TRN & \\
\hline CHEMBL1366616 & 737825 & 5.4 & 5.1599 & TRN & \\
\hline CHEMBL1742157 & 737825 & 4.7 & 5.0252 & TRN & \\
\hline CHEMBL1469707 & 737825 & 4.65 & 5.1035 & TST & \\
\hline CHEMBL1359391 & 737825 & 4.6 & 4.5331 & TRN & \\
\hline CHEMBL1386207 & 737825 & 4.85 & 5.211 & TRN & \\
\hline CHEMBL1443681 & 737825 & 4.9 & 4.997 & TRN & \\
\hline CHEMBL1552727 & 737825 & 4.7 & 4.465 & TRN & \\
\hline CHEMBL1391169 & 737825 & 4.85 & 5.1449 & TRN & \\
\hline CHEMBL1418190 & 737825 & 5.8 & 5.3784 & TRN & \\
\hline CHEMBL1595282 & 737825 & 4.8 & 4.9286 & TRN & \\
\hline CHEMBL1530586 & 737825 & 5.1 & 4.9935 & TRN & \\
\hline CHEMBL1403101 & 737825 & 5.3 & 5.1781 & TRN & \\
\hline CHEMBL1331572 & 737825 & 6.95 & 5.54299 & 9999999999 & TRN \\
\hline CHEMBL3208454 & 737825 & 4.8 & 5.2306 & TRN & \\
\hline CHEMBL1562730 & 737825 & 6.35 & 5.29299 & 9999999999 & TRN \\
\hline & & & & 22602 & \\
\hline
\end{tabular}




\begin{tabular}{|c|c|c|c|c|c|}
\hline & & & & & \\
\hline CHEMBL1490024 & 737825 & 4.9 & 4.7781 & TRN & \\
\hline CHEMBL278332 & 737825 & 4.7 & 4.6557 & TST & \\
\hline CHEMBL1569592 & 737825 & 6.6 & 6.38299 & 9999999999 & TRN \\
\hline CHEMBL1534816 & 737825 & 4.45 & 5.3173 & TRN & \\
\hline CHEMBL1336521 & 737825 & 6.05 & 5.1436 & TST & \\
\hline CHEMBL1515209 & 737825 & 5.4 & 5.26399 & & TST \\
\hline CHEMBL1315779 & 737825 & 6.0 & 5.6293 & TRN & \\
\hline CHEMBL1344743 & 737825 & 5.45 & 5.1909 & TRN & \\
\hline CHEMBL1504920 & 737825 & 5.8 & 5.1653 & TRN & \\
\hline CHEMBL1443425 & 737825 & 4.6 & 4.4516 & TRN & \\
\hline CHEMBL3192769 & 737825 & 4.85 & 5.0826 & TRN & \\
\hline CHEMBL1448974 & 737825 & 5.4 & 5.0161 & TRN & \\
\hline CHEMBL1613194 & 737825 & 5.3 & 5.2277 & TST & \\
\hline CHEMBL1315504 & 737825 & 6.1 & 5.9454 & TRN & \\
\hline CHEMBL1347641 & 737825 & 4.9 & 5.1954 & TST & \\
\hline CHEMBL1317373 & 737825 & 5.9 & 5.83799 & 9999999999 & TRN \\
\hline CHEMBL1572275 & 737825 & 4.7 & 5.0682 & TRN & \\
\hline CHEMBL1365082 & 737825 & 5.3 & 5.2599 & TST & \\
\hline CHEMBL1406391 & 737825 & 5.15 & 5.1968 & TRN & \\
\hline CHEMBL1601536 & 737825 & 4.9 & 4.9498 & TRN & \\
\hline CHEMBL1397902 & 737825 & 5.4 & 5.3877 & TRN & \\
\hline CHEMBL1717461 & 737825 & 4.85 & 5.2678 & TST & \\
\hline CHEMBL1741663 & 737825 & 4.9 & 5.2466 & TRN & \\
\hline CHEMBL1439518 & 737825 & 4.7 & 5.2459 & TRN & \\
\hline CHEMBL1324882 & 737825 & 6.0 & 5.9748 & TRN & \\
\hline CHEMBL1577686 & 737825 & 5.4 & 4.9655 & TRN & \\
\hline CHEMBL1474435 & 737825 & 5.5 & 5.3925 & TRN & \\
\hline CHEMBL1319632 & 737825 & 5.9 & 5.2637 & TRN & \\
\hline CHEMBL1467331 & 737825 & 4.85 & 5.0475 & TRN & \\
\hline CHEMBL1443741 & 737825 & 4.6 & 4.5335 & TRN & \\
\hline CHEMBL3190647 & 737825 & 4.85 & 5.1066 & TRN & \\
\hline CHEMBL1553422 & 737825 & 5.5 & 5.3248 & TRN & \\
\hline CHEMBL1443252 & 737825 & 5.65 & 5.101 & TRN & \\
\hline CHEMBL1408259 & 737825 & 6.0 & 5.8993 & TRN & \\
\hline CHEMBL1425091 & 737825 & 4.7 & 5.0139 & TRN & \\
\hline CHEMBL1559279 & 737825 & 4.8 & 4.6231 & TRN & \\
\hline CHEMBL1585273 & 737825 & 4.4 & 5.1864 & TST & \\
\hline CHEMBL1973886 & 737825 & 4.85 & 5.2607 & TRN & \\
\hline CHEMBL1554569 & 737825 & 4.8 & 4.8394 & TRN & \\
\hline CHEMBL115225 & 737825 & 8.5 & 7.3636 & TST & \\
\hline CHEMBL 310798 & 737825 & 5.0 & 4.8088 & TRN & \\
\hline CHEMBL1436125 & 737825 & 6.1 & 5.9487 & TRN & \\
\hline CHEMBL1600524 & 737825 & 4.85 & 5.0815 & TRN & \\
\hline CHEMBL1359716 & 737825 & 5.35 & 5.2035 & TRN & \\
\hline CHEMBL3392050 & 737825 & 4.4 & 4.5113 & TST & \\
\hline CHEMBL1367935 & 737825 & 5.4 & 5.233 & TRN & \\
\hline CHEMBL1546010 & 737825 & 4.65 & 5.1358 & TST & \\
\hline CHEMBL1341999 & 737825 & 6.4 & 5.2427 & TRN & \\
\hline & & & & 22603 & \\
\hline
\end{tabular}




\begin{tabular}{|c|c|c|c|c|c|}
\hline \multicolumn{6}{|c|}{ Supplemental Table S2.txt } \\
\hline CHEMBL1309874 & 737825 & 4.85 & 5.1752 & TRN & \\
\hline CHEMBL1343951 & 737825 & 4.65 & 5.2781 & TRN & \\
\hline CHEMBL1315268 & 737825 & 4.9 & 4.7357 & TRN & \\
\hline CHEMBL1479912 & 737825 & 5.5 & 5.3766 & TRN & \\
\hline CHEMBL1409258 & 737825 & 6.0 & 5.3681 & TRN & \\
\hline CHEMBL1473755 & 737825 & 5.6 & 5.5107 & TRN & \\
\hline CHEMBL1514390 & 737825 & 4.8 & 4.7642 & TRN & \\
\hline CHEMBL1997370 & 737825 & 4.75 & 5.1521 & TRN & \\
\hline CHEMBL 3208355 & 737825 & 5.45 & 5.1688 & TRN & \\
\hline CHEMBL1328576 & 737825 & 4.9 & 5.565 & TST & \\
\hline CHEMBL1588523 & 737825 & 4.4 & 5.2953 & TRN & \\
\hline CHEMBL1470840 & 737825 & 6.1 & 5.2314 & TRN & \\
\hline CHEMBL259389 & 737825 & 6.9 & 6.3366 & TST & \\
\hline CHEMBL1469167 & 737825 & 4.85 & 5.0475 & TRN & \\
\hline CHEMBL1435604 & 737825 & 4.8 & 4.7487 & TRN & \\
\hline CHEMBL1591381 & 737825 & 4.8 & 4.5864 & TRN & \\
\hline CHEMBL1432433 & 737825 & 4.85 & 5.3227 & TRN & \\
\hline CHEMBL1571027 & 737825 & 5.4 & 5.3958 & TRN & \\
\hline CHEMBL1338714 & 737825 & 5.15 & 5.17200 & 0000000001 & TRN \\
\hline CHEMBL1400050 & 737825 & 6.0 & 5.9157 & TRN & \\
\hline CHEMBL1540313 & 737825 & 6.25 & 5.5745 & TST & \\
\hline CHEMBL1742117 & 737825 & 4.85 & 5.2927 & TRN & \\
\hline CHEMBL1587168 & 737825 & 4.95 & 5.1202 & TRN & \\
\hline CHEMBL1499919 & 737825 & 4.85 & 5.185 & TRN & \\
\hline CHEMBL1450334 & 737825 & 4.8 & 4.8099 & TST & \\
\hline CHEMBL1473260 & 737825 & 4.7 & 4.7407 & TRN & \\
\hline CHEMBL1562832 & 737825 & 5.8 & 5.4113 & TRN & \\
\hline CHEMBL1422120 & 737825 & 4.85 & 5.1282 & TRN & \\
\hline CHEMBL67212 & 737825 & 5.8 & 5.5064 & TRN & \\
\hline CHEMBL1338060 & 737825 & 5.15 & 5.301 & TST & \\
\hline CHEMBL1355855 & 737825 & 5.5 & 5.3472 & TST & \\
\hline CHEMBL1380212 & 737825 & 5.9 & 5.8884 & TRN & \\
\hline CHEMBL1435296 & 737825 & 4.8 & 4.7201 & TRN & \\
\hline CHEMBL1362959 & 737825 & 5.15 & 5.4368 & TST & \\
\hline CHEMBL1528626 & 737825 & 5.75 & 5.4042 & TRN & \\
\hline CHEMBL1505597 & 737825 & 4.75 & 5.0234 & TRN & \\
\hline CHEMBL1565409 & 737825 & 5.35 & 5.2257 & TRN & \\
\hline CHEMBL1591965 & 737825 & 5.2 & 4.9919 & TRN & \\
\hline CHEMBL 3195732 & 737825 & 5.05 & 5.1852 & TST & \\
\hline CHEMBL1454305 & 737825 & 4.75 & 5.3182 & TRN & \\
\hline CHEMBL1533024 & 737825 & 4.85 & 5.2782 & TRN & \\
\hline CHEMBL1599391 & 737825 & 5.65 & 5.2704 & TRN & \\
\hline CHEMBL1610778 & 737825 & 5.5 & 5.8045 & TST & \\
\hline CHEMBL1352270 & 737825 & 5.0 & 5.2226 & TRN & \\
\hline CHEMBL1452052 & 737825 & 6.0 & 5.9333 & TRN & \\
\hline CHEMBL1509145 & 737825 & 5.65 & 5.4685 & TRN & \\
\hline CHEMBL1601015 & 737825 & 5.35 & 5.0036 & TRN & \\
\hline CHEMBL1454734 & 737825 & 5.1 & 5.2385 & TST & \\
\hline
\end{tabular}




\begin{tabular}{|c|c|c|c|c|}
\hline & & & pplemen & al $\mathrm{T}$ \\
\hline CHEMBL1447383 & 737825 & 5.0 & 5.7497 & TST \\
\hline CHEMBL1408954 & 737825 & 5.6 & 5.4542 & TRN \\
\hline CHEMBL1447745 & 737825 & 4.5 & 4.9839 & TRN \\
\hline CHEMBL1333773 & 737825 & 6.1 & 5.3615 & TRN \\
\hline CHEMBL1470690 & 737825 & 5.05 & 5.2115 & TRN \\
\hline CHEMBL1432973 & 737825 & 5.2 & 5.1968 & TRN \\
\hline CHEMBL1565525 & 737825 & 6.2 & 6.2409 & TRN \\
\hline CHEMBL293749 & 737825 & 5.4 & 5.2559 & TRN \\
\hline CHEMBL1516080 & 737825 & 5.0 & 5.0431 & TST \\
\hline CHEMBL1522433 & 737825 & 5.8 & 5.2679 & TST \\
\hline CHEMBL1314545 & 737825 & 6.0 & 5.8303 & TST \\
\hline CHEMBL1313226 & 737825 & 5.7 & 5.3133 & TRN \\
\hline CHEMBL1485338 & 737825 & 4.95 & 5.1415 & TRN \\
\hline CHEMBL1571883 & 737825 & 6.2 & 5.1683 & TRN \\
\hline CHEMBL1438674 & 737825 & 5.4 & 5.3588 & TRN \\
\hline CHEMBL1578021 & 737825 & 5.55 & 5.2171 & TRN \\
\hline CHEMBL1309540 & 737825 & 4.95 & 5.2938 & TRN \\
\hline CHEMBL1610132 & 737825 & 5.8 & 5.3597 & TRN \\
\hline CHEMBL1516787 & 737825 & 5.9 & 5.8936 & TRN \\
\hline CHEMBL1299997 & 737825 & 4.85 & 4.8733 & TST \\
\hline CHEMBL66105 & 737825 & 6.0 & 5.6253 & TST \\
\hline CHEMBL1552677 & 737825 & 4.5 & 4.6182 & TRN \\
\hline CHEMBL1591508 & 737825 & 4.8 & 4.8156 & TST \\
\hline CHEMBL 3191244 & 737825 & 4.6 & 5.18 & TRN \\
\hline CHEMBL1453216 & 737825 & 5.3 & 5.2076 & TRN \\
\hline CHEMBL 3210166 & 737825 & 5.5 & 5.0925 & TRN \\
\hline CHEMBL1742296 & 737825 & 5.75 & 5.2593 & TRN \\
\hline CHEMBL281622 & 737825 & 4.8 & 4.8389 & TST \\
\hline CHEMBL1611225 & 737825 & 5.3 & 5.2625 & TRN \\
\hline CHEMBL1361984 & 737825 & 4.9 & 5.1589 & TRN \\
\hline CHEMBL1460553 & 737825 & 4.95 & 5.2867 & TRN \\
\hline CHEMBL333985 & 737825 & 4.9 & 4.8414 & TST \\
\hline CHEMBL1357018 & 737825 & 6.0 & 6.0733 & TRN \\
\hline CHEMBL1560697 & 737825 & 5.05 & 5.1648 & TST \\
\hline CHEMBL1598717 & 737825 & 5.6 & 5.6184 & TRN \\
\hline CHEMBL1435381 & 737825 & 4.6 & 4.4864 & TST \\
\hline CHEMBL1356834 & 737825 & 5.0 & 4.8673 & TRN \\
\hline CHEMBL1496972 & 737825 & 5.65 & 5.1978 & TRN \\
\hline CHEMBL1352069 & 737825 & 4.8 & 4.9785 & TST \\
\hline CHEMBL1367845 & 737825 & 5.65 & 5.2989 & TRN \\
\hline CHEMBL 3196138 & 737825 & 4.95 & 5.1382 & TST \\
\hline CHEMBL 39878 & 737825 & 5.3 & 5.0985 & TRN \\
\hline CHEMBL1435698 & 737825 & 4.8 & 4.6544 & TRN \\
\hline CHEMBL1599388 & 737825 & 4.7 & 5.0935 & TST \\
\hline CHEMBL1529308 & 737825 & 5.6 & 5.362 & TST \\
\hline CHEMBL1348252 & 737825 & 4.95 & 5.0709 & TRN \\
\hline CHEMBL1443975 & 737825 & 4.7 & 5.2007 & TRN \\
\hline CHEMBL 3214276 & 737825 & 5.1 & 5.0898 & TRN \\
\hline
\end{tabular}




\begin{tabular}{|c|c|c|c|c|c|}
\hline \\
\hline CHEMBL1338623 & 737825 & 5.5 & 5.4495 & TRN & \\
\hline CHEMBL1316893 & 737825 & 5.1 & 4.8986 & TRN & \\
\hline CHEMBL1609519 & 737825 & 4.85 & 5.1319 & TST & \\
\hline CHEMBL1488679 & 737825 & 5.8 & 5.687 & TST & \\
\hline CHEMBL1414666 & 737825 & 4.85 & 4.9398 & TRN & \\
\hline CHEMBL1506638 & 737825 & 6.0 & 5.1668 & TRN & \\
\hline CHEMBL1563331 & 737825 & 5.35 & 5.1635 & TRN & \\
\hline CHEMBL3209838 & 737825 & 5.5 & 5.4667 & TRN & \\
\hline CHEMBL1591956 & 737825 & 5.6 & 5.5903 & TRN & \\
\hline CHEMBL1612920 & 737825 & 4.75 & 5.1053 & TRN & \\
\hline CHEMBL1304201 & 737825 & 5.55 & 5.2246 & TRN & \\
\hline CHEMBL1520928 & 737825 & 4.7 & 5.1873 & TRN & \\
\hline CHEMBL1341772 & 737825 & 5.45 & 5.1657 & TRN & \\
\hline CHEMBL1371329 & 737825 & 5.05 & 5.2631 & TRN & \\
\hline CHEMBL1325335 & 737825 & 4.6 & 4.4097 & TRN & \\
\hline CHEMBL1545452 & 737825 & 5.0 & 5.1316 & TRN & \\
\hline CHEMBL1403270 & 737825 & 4.6 & 5.1913 & TST & \\
\hline CHEMBL1356372 & 737825 & 4.7 & 4.5858 & TRN & \\
\hline CHEMBL1589809 & 737825 & 4.85 & 5.0223 & TRN & \\
\hline CHEMBL1461827 & 737825 & 4.85 & 5.1165 & TRN & \\
\hline CHEMBL1741623 & 737825 & 5.55 & 5.2317 & TRN & \\
\hline CHEMBL1438164 & 737825 & 4.8 & 4.8284 & TRN & \\
\hline CHEMBL1493496 & 737825 & 5.8 & 5.8255 & TRN & \\
\hline CHEMBL1412937 & 737825 & 5.2 & 5.0922 & TRN & \\
\hline CHEMBL1308013 & 737825 & 6.05 & 5.2699 & TST & \\
\hline CHEMBL1587519 & 737825 & 5.25 & 5.24799 & 9999999999 & TRN \\
\hline CHEMBL1490820 & 737825 & 4.85 & 5.4764 & TRN & \\
\hline CHEMBL1604846 & 737825 & 4.9 & 5.0845 & TRN & \\
\hline CHEMBL1553179 & 737825 & 5.3 & 5.0053 & TRN & \\
\hline CHEMBL1451128 & 737825 & 5.85 & 5.2281 & TRN & \\
\hline CHEMBL1533148 & 737825 & 4.95 & 5.1745 & TST & \\
\hline CHEMBL1340328 & 737825 & 4.95 & 5.105 & TRN & \\
\hline CHEMBL3210605 & 737825 & 5.15 & 5.3349 & TRN & \\
\hline CHEMBL1374544 & 737825 & 5.6 & 5.5431 & TRN & \\
\hline CHEMBL1465487 & 737825 & 4.4 & 5.1968 & TRN & \\
\hline CHEMBL1435713 & 737825 & 4.8 & 4.7084 & TRN & \\
\hline CHEMBL1325701 & 737825 & 5.3 & 5.0996 & TRN & \\
\hline CHEMBL1310938 & 737825 & 6.25 & 5.3961 & TRN & \\
\hline CHEMBL1527840 & 737825 & 4.9 & 5.2016 & TRN & \\
\hline CHEMBL1311749 & 737825 & 5.55 & 5.2609 & TST & \\
\hline CHEMBL1451119 & 737825 & 5.2 & 5.0977 & TRN & \\
\hline CHEMBL1456454 & 737825 & 5.4 & 5.4803 & TRN & \\
\hline CHEMBL1546137 & 737825 & 5.05 & 5.0965 & TRN & \\
\hline CHEMBL1454660 & 737825 & 6.05 & 4.9925 & TRN & \\
\hline CHEMBL1526411 & 737825 & 5.5 & 5.3541 & TRN & \\
\hline CHEMBL1598394 & 737825 & 4.9 & 4.9091 & TRN & \\
\hline CHEMBL1442458 & 737825 & 4.6 & 4.5746 & TRN & \\
\hline CHEMBL1314247 & 737825 & 5.7 & 5.6389 & TRN & \\
\hline & & & & 266 & \\
\hline
\end{tabular}




\begin{tabular}{|c|c|c|c|c|c|}
\hline \\
\hline CHEMBL1328490 & 737825 & 5.5 & 5.4522 & TRN & \\
\hline CHEMBL1326152 & 737825 & 4.8 & 4.4977 & TRN & \\
\hline CHEMBL1399481 & 737825 & 5.9 & 5.9462 & TRN & \\
\hline CHEMBL1415331 & 737825 & 5.8 & 5.3612 & TRN & \\
\hline CHEMBL1318222 & 737825 & 4.5 & 4.7762 & TRN & \\
\hline CHEMBL1592571 & 737825 & 5.1 & 4.9648 & TRN & \\
\hline CHEMBL1547955 & 737825 & 4.9 & 5.2076 & TRN & \\
\hline CHEMBL1331952 & 737825 & 4.85 & 5.2994 & TRN & \\
\hline CHEMBL1301162 & 737825 & 4.8 & 5.0915 & TST & \\
\hline CHEMBL1718033 & 737825 & 4.75 & 5.0669 & TRN & \\
\hline CHEMBL1331288 & 737825 & 5.6 & 5.4827 & TRN & \\
\hline CHEMBL1369013 & 737825 & 5.1 & 4.8198 & TRN & \\
\hline CHEMBL1437095 & 737825 & 6.2 & 6.1913 & TRN & \\
\hline CHEMBL1611691 & 737825 & 4.8 & 5.0965 & TRN & \\
\hline CHEMBL1318041 & 737825 & 4.9 & 4.7422 & TRN & \\
\hline CHEMBL1441039 & 737825 & 5.1 & 5.1773 & TRN & \\
\hline CHEMBL267014 & 737825 & 4.9 & 4.7743 & TST & \\
\hline CHEMBL1336060 & 737825 & 4.8 & 4.7366 & TRN & \\
\hline CHEMBL1557564 & 737825 & 7.1 & 6.7031 & TRN & \\
\hline CHEMBL1519293 & 737825 & 5.25 & 5.0957 & TRN & \\
\hline CHEMBL3212471 & 737825 & 4.5 & 4.9429 & TST & \\
\hline CHEMBL1395162 & 737825 & 4.6 & $4.5310 e$ & 0000000001 & TRN \\
\hline CHEMBL1385489 & 737825 & 5.0 & 5.0049 & TST & \\
\hline CHEMBL1741327 & 737825 & 5.0 & 5.0998 & TRN & \\
\hline CHEMBL1456417 & 737825 & 5.1 & 5.0489 & TRN & \\
\hline CHEMBL1735768 & 737825 & 4.6 & 5.1655 & TRN & \\
\hline CHEMBL1523486 & 737825 & 4.55 & 5.2005 & TRN & \\
\hline CHEMBL3189354 & 737825 & 5.0 & 5.2033 & TST & \\
\hline CHEMBL1270169 & 737825 & 5.7 & 5.4193 & TST & \\
\hline CHEMBL1496054 & 737825 & 5.5 & 5.2978 & TRN & \\
\hline CHEMBL1436540 & 737825 & 4.8 & 4.6701 & TRN & \\
\hline CHEMBL1306964 & 737825 & 4.9 & 5.2616 & TRN & \\
\hline CHEMBL432608 & 737825 & 6.1 & 5.7307 & TRN & \\
\hline CHEMBL1597366 & 737825 & 4.9 & 4.8557 & TRN & \\
\hline CHEMBL1602490 & 737825 & 4.85 & $5.1620 e$ & 2000000001 & TRN \\
\hline CHEMBL1987087 & 737825 & 4.85 & 5.2325 & TST & \\
\hline CHEMBL1407064 & 737825 & 4.75 & 5.0985 & TRN & \\
\hline CHEMBL1333019 & 737825 & 6.0 & 5.7328 & TST & \\
\hline CHEMBL1332636 & 737825 & 5.4 & 5.3849 & TRN & \\
\hline CHEMBL1345478 & 737825 & 4.8 & 5.2649 & TRN & \\
\hline CHEMBL1431605 & 737825 & 4.55 & 5.0557 & TRN & \\
\hline CHEMBL1308726 & 737825 & 5.45 & 5.2746 & TRN & \\
\hline CHEMBL1973729 & 737825 & 5.2 & 5.1473 & TRN & \\
\hline CHEMBL1530168 & 737825 & 4.9 & 4.6804 & TRN & \\
\hline CHEMBL3207808 & 737825 & 4.9 & 5.0271 & TRN & \\
\hline CHEMBL1255867 & 737825 & 4.8 & 5.5895 & TRN & \\
\hline CHEMBL1366260 & 737825 & 4.8 & 5.1791 & TRN & \\
\hline CHEMBL1348133 & 737825 & 4.9 & 5.2047 & TRN & \\
\hline
\end{tabular}




\begin{tabular}{|c|c|c|c|c|c|}
\hline & & \multicolumn{4}{|c|}{ Supplemental Table S2.txt } \\
\hline CHEMBL1413631 & 737825 & 4.95 & 5.1528 & TRN & \\
\hline CHEMBL1372102 & 737825 & 4.85 & 5.1633 & TST & \\
\hline CHEMBL1498495 & 737825 & 4.65 & 5.24299 & 7999999999 & TRN \\
\hline CHEMBL452153 & 737825 & 5.55 & 5.5868 & TRN & \\
\hline CHEMBL1741411 & 737825 & 4.65 & 5.1549 & TRN & \\
\hline CHEMBL1425971 & 737825 & 5.0 & 5.184 & TRN & \\
\hline CHEMBL1357130 & 737825 & 5.0 & 5.6098 & TST & \\
\hline CHEMBL1507172 & 737825 & 4.75 & 5.2651 & TRN & \\
\hline CHEMBL1570435 & 737825 & 5.85 & 5.4673 & TRN & \\
\hline CHEMBL87285 & 737825 & 4.8 & 5.6562 & TST & \\
\hline CHEMBL1497099 & 737825 & 5.85 & 5.2634 & TRN & \\
\hline CHEMBL1515253 & 737825 & 4.8 & 4.6125 & TRN & \\
\hline CHEMBL1340722 & 737825 & 4.7 & 5.2632 & TRN & \\
\hline CHEMBL1510192 & 737825 & 6.75 & 5.2041 & TRN & \\
\hline CHEMBL1436441 & 737825 & 5.5 & 5.485 & TRN & \\
\hline CHEMBL1404660 & 737825 & 5.9 & 5.7574 & TRN & \\
\hline CHEMBL1514640 & 737825 & 4.6 & 4.4554 & TRN & \\
\hline CHEMBL1412639 & 737825 & 4.6 & 5.4647 & TRN & \\
\hline CHEMBL1420061 & 737825 & 5.35 & 5.1475 & TRN & \\
\hline CHEMBL1516476 & 737825 & 6.0 & 5.7354 & TRN & \\
\hline CHEMBL1439665 & 737825 & 4.8 & 4.7196 & TRN & \\
\hline CHEMBL15060 & 737825 & 4.9 & 4.8387 & TRN & \\
\hline CHEMBL1438661 & 737825 & 4.4 & 5.1602 & TRN & \\
\hline CHEMBL1591107 & 737825 & 5.2 & 5.118 & TRN & \\
\hline CHEMBL1425077 & 737825 & 4.9 & 5.5828 & TRN & \\
\hline CHEMBL1741640 & 737825 & 5.7 & 5.4038 & TRN & \\
\hline CHEMBL1385847 & 737825 & 5.85 & 5.1233 & TRN & \\
\hline CHEMBL1475484 & 737825 & 5.3 & 5.03100 & 0000000001 & TRN \\
\hline CHEMBL1520292 & 737825 & 5.9 & 6.0245 & TRN & \\
\hline CHEMBL1487735 & 737825 & 4.8 & 4.6993 & TRN & \\
\hline CHEMBL1350809 & 737825 & 4.75 & 5.1658 & TRN & \\
\hline CHEMBL1454735 & 737825 & 7.45 & 5.2545 & TRN & \\
\hline CHEMBL1449457 & 737825 & 5.3 & 5.2924 & TRN & \\
\hline CHEMBL1528428 & 737825 & 4.85 & 5.0953 & TST & \\
\hline CHEMBL1346500 & 737825 & 5.1 & 5.1772 & TST & \\
\hline CHEMBL1450573 & 737825 & 6.4 & 6.0211 & TRN & \\
\hline CHEMBL1399313 & 737825 & 5.5 & 5.2039 & TRN & \\
\hline CHEMBL68230 & 737825 & 4.65 & 5.0629 & TRN & \\
\hline CHEMBL1335595 & 737825 & 6.3 & 5.7115 & TRN & \\
\hline CHEMBL1331122 & 737825 & 5.4 & 5.25299 & 9999999999 & TST \\
\hline CHEMBL1555991 & 737825 & 4.8 & 4.6697 & TRN & \\
\hline CHEMBL1571756 & 737825 & 5.5 & 5.3416 & TRN & \\
\hline CHEMBL 2110371 & 737825 & 5.1 & 5.0522 & TRN & \\
\hline CHEMBL1544437 & 737825 & 4.9 & 5.2346 & TRN & \\
\hline CHEMBL1460680 & 737825 & 5.95 & 4.9076 & TST & \\
\hline CHEMBL1506831 & 737825 & 4.8 & 5.0473 & TRN & \\
\hline CHEMBL1256687 & 737825 & 6.1 & 5.8718 & TST & \\
\hline CHEMBL1442392 & 737825 & 5.45 & 5.0912 & TRN & \\
\hline
\end{tabular}




\begin{tabular}{|c|c|c|c|c|c|}
\hline \multicolumn{6}{|c|}{ Supplemental Table S2.txt } \\
\hline CHEMBL1530314 & 737825 & 5.5 & 5.3951 & TST & \\
\hline CHEMBL3208773 & 737825 & 5.9 & 5.4701 & TST & \\
\hline CHEMBL1444489 & 737825 & 4.5 & 4.5655 & TRN & \\
\hline CHEMBL1567353 & 737825 & 4.7 & 4.6458 & TRN & \\
\hline CHEMBL1357338 & 737825 & 4.9 & 4.6991 & TRN & \\
\hline CHEMBL1322352 & 737825 & 4.9 & 5.17 & TRN & \\
\hline CHEMBL1504596 & 737825 & 5.55 & 5.1841 & TST & \\
\hline CHEMBL1317056 & 737825 & 5.9 & 5.7707 & TRN & \\
\hline CHEMBL1579887 & 737825 & 5.3 & 5.1586 & TRN & \\
\hline CHEMBL1518301 & 737825 & 5.9 & 5.8047 & TRN & \\
\hline CHEMBL1351656 & 737825 & 4.55 & 5.003 & TRN & \\
\hline CHEMBL19439 & 737825 & 6.0 & 5.7091 & TRN & \\
\hline CHEMBL1409938 & 737825 & 4.8 & 4.9691 & TRN & \\
\hline CHEMBL1420945 & 737825 & 5.3 & 5.27 & TRN & \\
\hline CHEMBL1588802 & 737825 & 5.1 & 5.1599 & TRN & \\
\hline CHEMBL1475627 & 737825 & 4.8 & 4.9176 & TRN & \\
\hline CHEMBL1521490 & 737825 & 6.1 & 6.0 & TRN & \\
\hline CHEMBL1436222 & 737825 & 4.9 & 4.6968 & TRN & \\
\hline CHEMBL1446244 & 737825 & 4.85 & 5.2237 & TRN & \\
\hline CHEMBL1408878 & 737825 & 5.1 & 4.9943 & TRN & \\
\hline CHEMBL1337895 & 737825 & 6.3 & 5.4357 & TRN & \\
\hline CHEMBL1513134 & 737825 & 4.7 & 4.5538 & TRN & \\
\hline CHEMBL1363142 & 737825 & 5.6 & 5.6163 & TRN & \\
\hline CHEMBL1304570 & 737825 & 5.65 & 5.2659 & TRN & \\
\hline CHEMBL1314808 & 737825 & 5.0 & 5.3309 & TRN & \\
\hline CHEMBL1317163 & 737825 & 4.8 & 4.7655 & TRN & \\
\hline CHEMBL1421286 & 737825 & 5.4 & 5.2465 & TRN & \\
\hline CHEMBL1575591 & 737825 & 4.8 & 5.2549 & TRN & \\
\hline CHEMBL1588074 & 737825 & 5.6 & 5.0404 & TST & \\
\hline CHEMBL1501021 & 737825 & 4.85 & 5.1452 & TST & \\
\hline CHEMBL1485319 & 737825 & 5.0 & 5.1709 & TRN & \\
\hline CHEMBL1515324 & 737825 & 5.4 & 5.1701 & TRN & \\
\hline CHEMBL1451037 & 737825 & 4.8 & 5.0786 & TST & \\
\hline CHEMBL1492604 & 737825 & 4.85 & 5.1433 & TST & \\
\hline CHEMBL1341152 & 737825 & 5.65 & 5.2764 & TRN & \\
\hline CHEMBL1487191 & 737825 & 5.4 & 5.3052 & TRN & \\
\hline CHEMBL1461795 & 737825 & 5.0 & 5.2397 & TRN & \\
\hline CHEMBL 3210074 & 737825 & 4.65 & 5.0948 & TRN & \\
\hline CHEMBL1544968 & 737825 & 4.9 & 5.1385 & TRN & \\
\hline CHEMBL 72410 & 737825 & 4.6 & 4.675 & TRN & \\
\hline CHEMBL1467429 & 737825 & 4.85 & 5.0007 & TRN & \\
\hline CHEMBL1305982 & 737825 & 5.15 & 5.3173 & TRN & \\
\hline CHEMBL1310193 & 737825 & 5.5 & 5.2408 & TRN & \\
\hline CHEMBL1232474 & 737825 & 6.5 & 6.6504 & TRN & \\
\hline CHEMBL1329046 & 737825 & 5.5 & 5.2813 & TRN & \\
\hline CHEMBL1444983 & 737825 & 5.2 & 5.12299 & 9999999999 & TRN \\
\hline CHEMBL1532720 & 737825 & 4.9 & 4.81800 & 00000000005 & TRN \\
\hline CHEMBL1742111 & 737825 & 4.8 & 5.1863 & TST & \\
\hline
\end{tabular}




\begin{tabular}{|c|c|c|c|c|}
\hline & & & pplement & al $\mathrm{T}$ \\
\hline CHEMBL1427178 & 737825 & 4.85 & 5.08 & TRN \\
\hline CHEMBL1509210 & 737825 & 4.8 & 5.2036 & TRN \\
\hline CHEMBL1735112 & 737825 & 5.5 & 5.175 & TST \\
\hline CHEMBL1319554 & 737825 & 4.6 & 4.9779 & TRN \\
\hline CHEMBL1307715 & 737825 & 5.15 & 5.2998 & TRN \\
\hline CHEMBL472994 & 737825 & 6.5 & 6.2201 & TST \\
\hline CHEMBL1741628 & 737825 & 5.0 & 5.0257 & TRN \\
\hline CHEMBL1389497 & 737825 & 4.5 & 5.1376 & TRN \\
\hline CHEMBL1307848 & 737825 & 5.55 & 5.1978 & TRN \\
\hline CHEMBL1549831 & 737825 & 5.2 & 5.2698 & TRN \\
\hline CHEMBL1514075 & 737825 & 4.8 & 4.7229 & TRN \\
\hline CHEMBL1314416 & 737825 & 4.8 & 4.7282 & TRN \\
\hline CHEMBL1558087 & 737825 & 4.9 & 5.0374 & TRN \\
\hline CHEMBL1549000 & 737825 & 4.8 & 5.22 & TRN \\
\hline CHEMBL1434801 & 737825 & 4.9 & 4.9033 & TRN \\
\hline CHEMBL1554982 & 737825 & 5.5 & 5.5563 & TRN \\
\hline CHEMBL117405 & 737825 & 5.1 & 5.0224 & TST \\
\hline CHEMBL1594075 & 737825 & 5.3 & 5.1792 & TRN \\
\hline CHEMBL1343101 & 737825 & 5.55 & 5.3048 & TST \\
\hline CHEMBL516075 & 737825 & 5.3 & 5.1988 & TRN \\
\hline CHEMBL1571138 & 737825 & 5.6 & 5.4837 & TRN \\
\hline CHEMBL1521352 & 737825 & 6.0 & 5.1017 & TRN \\
\hline CHEMBL1437713 & 737825 & 4.9 & 4.9637 & TRN \\
\hline CHEMBL1303074 & 737825 & 5.3 & 5.1722 & TST \\
\hline CHEMBL3189237 & 737825 & 4.8 & 5.2286 & TST \\
\hline CHEMBL1448411 & 737825 & 4.85 & 5.2503 & TRN \\
\hline CHEMBL1534082 & 737825 & 5.3 & 5.2317 & TRN \\
\hline CHEMBL1326308 & 737825 & 4.9 & 5.112 & TRN \\
\hline CHEMBL1600813 & 737825 & 5.2 & 5.3502 & TRN \\
\hline CHEMBL1607455 & 737825 & 5.6 & 5.3893 & TRN \\
\hline CHEMBL1515417 & 737825 & 5.2 & 5.0846 & TRN \\
\hline CHEMBL1448839 & 737825 & 4.9 & 4.7097 & TRN \\
\hline CHEMBL1741977 & 737825 & 4.9 & 4.9746 & TRN \\
\hline CHEMBL274778 & 737825 & 5.8 & 5.0714 & TST \\
\hline CHEMBL1474568 & 737825 & 6.2 & 5.6439 & TRN \\
\hline CHEMBL1368664 & 737825 & 5.1 & 5.0182 & TRN \\
\hline CHEMBL1345906 & 737825 & 4.6 & 5.1019 & TST \\
\hline CHEMBL1600753 & 737825 & 5.6 & 5.1002 & TRN \\
\hline CHEMBL1354626 & 737825 & 5.5 & 5.4403 & TRN \\
\hline CHEMBL1511986 & 737825 & 5.7 & 5.4288 & TRN \\
\hline CHEMBL1479727 & 737825 & 5.1 & 4.973 & TRN \\
\hline CHEMBL1562612 & 737825 & 5.3 & 5.2531 & TRN \\
\hline CHEMBL495069 & 737825 & 5.5 & 5.3649 & TRN \\
\hline CHEMBL1590645 & 737825 & 5.2 & 5.1268 & TRN \\
\hline CHEMBL1332346 & 737825 & 5.9 & 5.8867 & TRN \\
\hline CHEMBL1524128 & 737825 & 4.95 & 5.0946 & TST \\
\hline CHEMBL1478806 & 737825 & 4.9 & 4.9306 & TRN \\
\hline CHEMBL1529705 & 737825 & 5.35 & 5.2811 & TST \\
\hline
\end{tabular}




\begin{tabular}{|c|c|c|c|c|c|}
\hline \\
\hline CHEMBL1414754 & 737825 & 4.4 & 4.9725 & TRN & \\
\hline CHEMBL1447313 & 737825 & 4.6 & 4.9698 & TRN & \\
\hline CHEMBL1567160 & 737825 & 5.7 & 5.5215 & TST & \\
\hline CHEMBL471225 & 737825 & 5.1 & 5.0424 & TST & \\
\hline CHEMBL1257003 & 737825 & 4.9 & 4.8583 & TRN & \\
\hline CHEMBL1435647 & 737825 & 4.6 & 4.5085 & TST & \\
\hline CHEMBL1355256 & 737825 & 5.2 & 5.0207 & TRN & \\
\hline CHEMBL1308386 & 737825 & 5.0 & 5.6595 & TRN & \\
\hline CHEMBL1529330 & 737825 & 6.4 & 5.975 & TRN & \\
\hline CHEMBL1512540 & 737825 & 5.0 & 5.0087 & TRN & \\
\hline CHEMBL1403809 & 737825 & 5.05 & 5.16100 & 00000000005 & TRN \\
\hline CHEMBL1443307 & 737825 & 4.85 & 5.013 & TRN & \\
\hline CHEMBL1476129 & 737825 & 5.6 & 5.374 & TRN & \\
\hline CHEMBL415737 & 737825 & -0.0 & 5.3965 & TRN & \\
\hline CHEMBL1504724 & 737825 & 5.65 & 5.3174 & TST & \\
\hline CHEMBL1327204 & 737825 & 4.8 & 4.6542 & TRN & \\
\hline CHEMBL1607133 & 737825 & 5.9 & 5.8655 & TRN & \\
\hline CHEMBL3189663 & 737825 & 5.1 & 5.0799 & TRN & \\
\hline CHEMBL1703229 & 737825 & 5.1 & 4.9703 & TRN & \\
\hline CHEMBL1406457 & 737825 & 5.15 & 5.1266 & TRN & \\
\hline CHEMBL1543793 & 737825 & 6.0 & 5.3505 & TRN & \\
\hline CHEMBL1449458 & 737825 & 4.6 & 4.5721 & TRN & \\
\hline CHEMBL1603471 & 737825 & 5.7 & 5.2858 & TRN & \\
\hline CHEMBL1496101 & 737825 & 5.9 & 5.1743 & TRN & \\
\hline CHEMBL1543038 & 737825 & 4.8 & 5.2307 & TRN & \\
\hline CHEMBL1457550 & 737825 & 6.0 & 5.8934 & TRN & \\
\hline CHEMBL3208403 & 737825 & 4.75 & 5.2144 & TRN & \\
\hline CHEMBL1358019 & 737825 & 4.7 & 4.8608 & TRN & \\
\hline CHEMBL1330317 & 737825 & 4.8 & 4.7582 & TRN & \\
\hline CHEMBL1601163 & 737825 & 6.4 & 6.5602 & TRN & \\
\hline CHEMBL1409996 & 737825 & 5.7 & 5.6453 & TRN & \\
\hline CHEMBL1715395 & 737825 & 4.7 & 5.1102 & TRN & \\
\hline CHEMBL1375286 & 737825 & 5.3 & 5.26 & TRN & \\
\hline CHEMBL1336787 & 737825 & 5.1 & 5.0212 & TRN & \\
\hline CHEMBL1568009 & 737825 & 4.85 & 5.2414 & TRN & \\
\hline CHEMBL1404656 & 737825 & 5.35 & 5.0718 & TRN & \\
\hline CHEMBL1357247 & 737825 & 4.8 & 4.7866 & TST & \\
\hline CHEMBL38288 & 737825 & 6.1 & 5.6908 & TRN & \\
\hline CHEMBL1256998 & 737825 & 5.5 & 5.3083 & TRN & \\
\hline CHEMBL1343091 & 737825 & 4.45 & 5.1061 & TRN & \\
\hline CHEMBL1372099 & 737825 & 4.5 & 5.0923 & TRN & \\
\hline CHEMBL1741670 & 737825 & 5.9 & 5.1184 & TRN & \\
\hline CHEMBL1353749 & 737825 & 5.05 & 5.239 & TRN & \\
\hline CHEMBL3192219 & 737825 & 5.25 & 5.1733 & TRN & \\
\hline CHEMBL118109 & 737825 & 5.4 & 5.3271 & TRN & \\
\hline CHEMBL1366680 & 737825 & 5.3 & 5.1145 & TST & \\
\hline CHEMBL63426 & 737825 & 5.2 & 5.0696 & TST & \\
\hline CHEMBL1525024 & 737825 & 5.4 & 5.2515 & TRN & \\
\hline
\end{tabular}




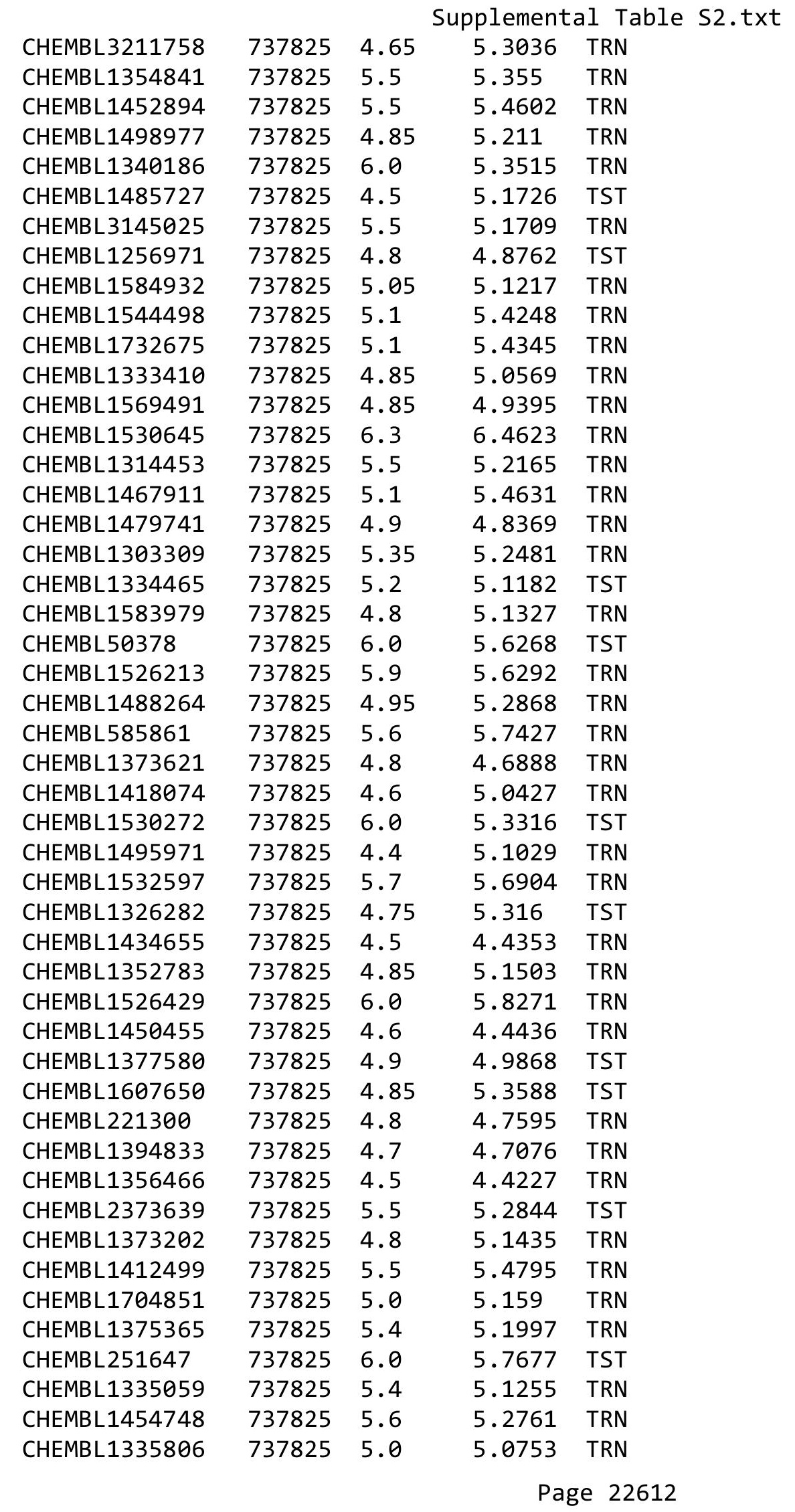




\begin{tabular}{|c|c|c|c|c|c|}
\hline \multicolumn{6}{|c|}{ Supplemental Table S2.txt } \\
\hline CHEMBL1542591 & 737825 & 4.85 & 5.0524 & TST & \\
\hline CHEMBL1416055 & 737825 & 5.2 & 5.3214 & TRN & \\
\hline CHEMBL3191906 & 737825 & 4.75 & 5.0619 & TRN & \\
\hline CHEMBL1402552 & 737825 & 5.25 & 5.6596 & TRN & \\
\hline CHEMBL1479994 & 737825 & 6.4 & 5.0552 & TRN & \\
\hline CHEMBL1606591 & 737825 & 4.9 & 4.7918 & TRN & \\
\hline CHEMBL1724554 & 737825 & 4.8 & 5.1386 & TST & \\
\hline CHEMBL1568233 & 737825 & 5.5 & 5.3833 & TST & \\
\hline CHEMBL1713992 & 737825 & 4.5 & 4.545 & TST & \\
\hline CHEMBL1540708 & 737825 & 5.45 & 5.06 & TRN & \\
\hline CHEMBL1395098 & 737825 & 4.5 & 4.5159 & TRN & \\
\hline CHEMBL 3208514 & 737825 & 5.4 & 5.1658 & TRN & \\
\hline CHEMBL1459860 & 737825 & 5.1 & 5.1987 & TRN & \\
\hline CHEMBL1490214 & 737825 & 4.8 & 5.1538 & TST & \\
\hline CHEMBL1558951 & 737825 & 4.95 & 5.2193 & TRN & \\
\hline CHEMBL1367220 & 737825 & 5.6 & 5.5312 & TRN & \\
\hline CHEMBL1349604 & 737825 & 4.85 & 5.021 & TRN & \\
\hline CHEMBL1328324 & 737825 & 4.9 & 5.6181 & TST & \\
\hline CHEMBL1441237 & 737825 & 5.1 & 4.8278 & TRN & \\
\hline CHEMBL1379350 & 737825 & 4.9 & 4.9122 & TST & \\
\hline CHEMBL1492815 & 737825 & 4.85 & 5.36100 & 0000000001 & TRN \\
\hline CHEMBL1421390 & 737825 & 5.95 & 5.3378 & TRN & \\
\hline CHEMBL1596455 & 737825 & 4.6 & 5.1875 & TRN & \\
\hline CHEMBL1412519 & 737825 & 5.4 & 5.2848 & TRN & \\
\hline CHEMBL1593997 & 737825 & 5.7 & 5.6826 & TRN & \\
\hline CHEMBL1320841 & 737825 & 4.95 & 5.0604 & TRN & \\
\hline CHEMBL1719582 & 737825 & 5.45 & 5.267 & TRN & \\
\hline CHEMBL1490573 & 737825 & 4.65 & 5.2386 & TRN & \\
\hline CHEMBL1513812 & 737825 & 4.8 & 4.8052 & TRN & \\
\hline CHEMBL1571526 & 737825 & 4.8 & 5.266 & TRN & \\
\hline CHEMBL1364135 & 737825 & 5.5 & 5.2127 & TRN & \\
\hline CHEMBL1564665 & 737825 & 5.7 & 5.2259 & TRN & \\
\hline CHEMBL1360799 & 737825 & 5.4 & 5.2221 & TRN & \\
\hline CHEMBL481537 & 737825 & 4.7 & 4.7485 & TST & \\
\hline CHEMBL1419811 & 737825 & 4.8 & 5.1325 & TST & \\
\hline CHEMBL1323684 & 737825 & 6.0 & 5.9124 & TRN & \\
\hline CHEMBL1499610 & 737825 & 5.0 & 5.0925 & TST & \\
\hline CHEMBL1472233 & 737825 & 5.15 & 5.0998 & TRN & \\
\hline CHEMBL1355909 & 737825 & 4.6 & 4.4821 & TRN & \\
\hline CHEMBL1366591 & 737825 & 5.4 & 5.3168 & TRN & \\
\hline CHEMBL1511690 & 737825 & 4.6 & 5.0949 & TST & \\
\hline CHEMBL10009 & 737825 & 5.6 & 5.5212 & TRN & \\
\hline CHEMBL1518719 & 737825 & 4.8 & 5.10800 & 00000000005 & TST \\
\hline CHEMBL1324494 & 737825 & 5.5 & 5.2864 & TRN & \\
\hline CHEMBL1419723 & 737825 & 5.95 & 4.9884 & TRN & \\
\hline CHEMBL1472129 & 737825 & 5.6 & 5.3257 & TRN & \\
\hline CHEMBL1520025 & 737825 & 5.1 & 5.6998 & TST & \\
\hline CHEMBL3193388 & 737825 & 6.5 & 5.0511 & TRN & \\
\hline
\end{tabular}




\begin{tabular}{|c|c|c|c|c|}
\hline \multicolumn{5}{|c|}{ Supplemental Table S2.tx } \\
\hline CHEMBL1345025 & 737825 & 4.8 & 5.1671 & TRN \\
\hline CHEMBL1533645 & 737825 & 4.9 & 5.2253 & TRN \\
\hline CHEMBL404613 & 737825 & 5.4 & 5.3156 & TST \\
\hline CHEMBL1501500 & 737825 & 5.35 & 5.229 & TRN \\
\hline CHEMBL1590855 & 737825 & 5.2 & 5.0547 & TRN \\
\hline CHEMBL1396109 & 737825 & 5.3 & 5.0613 & TRN \\
\hline CHEMBL1410999 & 737825 & 4.85 & 4.9813 & TRN \\
\hline CHEMBL1344860 & 737825 & 4.85 & 5.0234 & TST \\
\hline CHEMBL1313335 & 737825 & 4.45 & 5.2289 & TST \\
\hline CHEMBL1448379 & 737825 & 4.55 & 4.8375 & TST \\
\hline CHEMBL1415080 & 737825 & 4.7 & 4.6055 & TRN \\
\hline CHEMBL1554070 & 737825 & 5.5 & 5.4595 & TRN \\
\hline CHEMBL1450942 & 737825 & 5.0 & 5.1887 & TRN \\
\hline CHEMBL1591121 & 737825 & 4.8 & 4.7649 & TRN \\
\hline CHEMBL1368904 & 737825 & 5.1 & 5.2567 & TRN \\
\hline CHEMBL187216 & 737825 & 5.5 & 5.2922 & TST \\
\hline CHEMBL3207333 & 737825 & 4.45 & 5.1088 & TRN \\
\hline CHEMBL1398683 & 737825 & 4.8 & 4.7872 & TST \\
\hline CHEMBL1476206 & 737825 & 5.8 & 5.7862 & TST \\
\hline CHEMBL1364517 & 737825 & 6.05 & 5.1366 & TST \\
\hline CHEMBL1379951 & 737825 & 5.0 & 5.2351 & TST \\
\hline CHEMBL1699751 & 737825 & 4.85 & 5.088 & TST \\
\hline CHEMBL1370855 & 737825 & 5.45 & 5.3626 & TST \\
\hline CHEMBL1433950 & 737825 & 4.8 & 4.6282 & TST \\
\hline CHEMBL1550866 & 737825 & 4.85 & 5.0559 & TST \\
\hline CHEMBL1357530 & 737825 & 4.7 & 4.6428 & TST \\
\hline CHEMBL1592982 & 737825 & 5.7 & 5.7216 & TST \\
\hline CHEMBL1521167 & 737825 & 5.4 & 5.6728 & TST \\
\hline CHEMBL1612486 & 737825 & 5.8 & 5.3291 & TST \\
\hline CHEMBL1317498 & 737825 & 4.8 & 4.6009 & TST \\
\hline CHEMBL489738 & 737825 & 6.7 & 6.695 & TST \\
\hline CHEMBL1536243 & 737825 & 4.65 & 5.1939 & TST \\
\hline CHEMBL1343749 & 737825 & 5.85 & $5.1270 €$ & 2000000001 \\
\hline CHEMBL282489 & 737825 & 4.8 & 4.7359 & TST \\
\hline CHEMBL1554851 & 737825 & 5.2 & 5.05 & TST \\
\hline CHEMBL3194695 & 737825 & 4.8 & 5.1199 & TST \\
\hline CHEMBL 1487092 & 737825 & 4.9 & 5.3054 & TST \\
\hline CHEMBL1511940 & 737825 & 5.35 & 5.3231 & TST \\
\hline CHEMBL1552071 & 737825 & 5.2 & 5.0134 & TST \\
\hline CHEMBL1476293 & 737825 & 5.0 & 4.7854 & TST \\
\hline CHEMBL1404408 & 737825 & 4.9 & 4.718 & TST \\
\hline CHEMBL1349047 & 737825 & 4.4 & 5.113 & TST \\
\hline CHEMBL1383786 & 737825 & 4.85 & 5.1073 & TST \\
\hline CHEMBL45281 & 737825 & 4.8 & 4.8847 & TST \\
\hline CHEMBL1468692 & 737825 & 4.85 & 5.0275 & TST \\
\hline CHEMBL1610687 & 737825 & 4.65 & 5.4672 & TST \\
\hline CHEMBL3211211 & 737825 & 5.5 & 5.5359 & TST \\
\hline CHEMBL345124 & 737825 & 4.8 & 4.8321 & TST \\
\hline
\end{tabular}




\begin{tabular}{|c|c|c|c|c|}
\hline & & & & $a \perp \mid a b \perp \epsilon$ \\
\hline CHEMBL1374260 & 737825 & 4.65 & 5.0165 & TST \\
\hline CHEMBL1308884 & 737825 & 4.9 & 5.1718 & TST \\
\hline CHEMBL1323438 & 737825 & 4.9 & 4.8721 & TST \\
\hline CHEMBL1578220 & 737825 & 4.7 & 5.1971 & TST \\
\hline CHEMBL1591992 & 737825 & 4.8 & 4.7064 & TST \\
\hline CHEMBL1355665 & 737825 & 5.9 & 5.4432 & TST \\
\hline CHEMBL1551639 & 737825 & 5.0 & 5.018 & TST \\
\hline CHEMBL1355292 & 737825 & 4.5 & 4.4001 & TST \\
\hline CHEMBL1354600 & 737825 & 4.6 & 4.508 & TST \\
\hline CHEMBL1401243 & 737825 & 5.0 & 4.9719 & TST \\
\hline CHEMBL1493944 & 737825 & 4.6 & \multicolumn{2}{|c|}{5.156000000000001} \\
\hline CHEMBL1570196 & 737825 & 5.6 & 5.3902 & TST \\
\hline CHEMBL1331148 & 737825 & 5.6 & 5.6996 & TST \\
\hline CHEMBL1310701 & 737825 & 4.8 & 5.0015 & TST \\
\hline CHEMBL1438688 & 737825 & 5.5 & 5.4497 & TST \\
\hline CHEMBL1371140 & 737825 & 5.0 & 4.8487 & TST \\
\hline CHEMBL1425173 & 737825 & 5.4 & 5.1407 & TST \\
\hline CHEMBL1593923 & 737825 & 5.2 & 4.8478 & TST \\
\hline CHEMBL1573944 & 737825 & 5.35 & 5.083 & TST \\
\hline CHEMBL1325634 & 737825 & 4.65 & 5.1061 & TST \\
\hline CHEMBL1372997 & 737825 & 5.5 & 5.3375 & TST \\
\hline CHEMBL433461 & 737825 & 6.1 & 5.6503 & TST \\
\hline CHEMBL1440663 & 737825 & 4.8 & 5.0593 & TST \\
\hline CHEMBL11348 & 737825 & 5.4 & 5.2742 & TST \\
\hline CHEMBL1306989 & 737825 & 5.5 & 5.2186 & TST \\
\hline CHEMBL1741421 & 737825 & 5.15 & 5.1168 & TST \\
\hline CHEMBL1523773 & 737825 & 5.35 & 5.0196 & TST \\
\hline CHEMBL1552294 & 737825 & 4.8 & 4.7397 & TST \\
\hline CHEMBL280074 & 737825 & 4.8 & 4.7721 & TST \\
\hline CHEMBL1343075 & 737825 & 4.85 & 5.056 & TST \\
\hline CHEMBL1489085 & 737825 & 5.4 & 5.3945 & TST \\
\hline CHEMBL1319672 & 737825 & 5.3 & 5.2113 & TST \\
\hline CHEMBL3197180 & 737825 & 4.8 & 5.1756 & TST \\
\hline CHEMBL520107 & 737825 & 5.5 & 5.2881 & TST \\
\hline CHEMBL448602 & 737825 & 5.5 & 5.4529 & TST \\
\hline CHEMBL1590616 & 737825 & 4.6 & 4.5573 & TST \\
\hline CHEMBL1519647 & 737825 & 4.8 & 4.9882 & TST \\
\hline CHEMBL1407667 & 737825 & 4.55 & 5.3577 & TST \\
\hline CHEMBL34704 & 737825 & 6.0 & 5.5925 & TST \\
\hline CHEMBL1335644 & 737825 & 5.15 & 5.1144 & TST \\
\hline CHEMBL75035 & 737825 & 4.5 & 4.5847 & TST \\
\hline CHEMBL1437273 & 737825 & 5.2 & 4.9012 & TST \\
\hline CHEMBL3192412 & 737825 & 4.85 & 5.1133 & TST \\
\hline CHEMBL1516856 & 737825 & 4.95 & 5.4196 & TST \\
\hline CHEMBL1725270 & 737825 & 4.7 & 5.2175 & TST \\
\hline CHEMBL1549864 & 737825 & 6.05 & \multicolumn{2}{|c|}{5.202000000000001} \\
\hline CHEMBL1592651 & 737825 & 5.0 & 4.9299 & TST \\
\hline CHEMBL1414683 & 737825 & 4.6 & 5.2 & TST \\
\hline
\end{tabular}




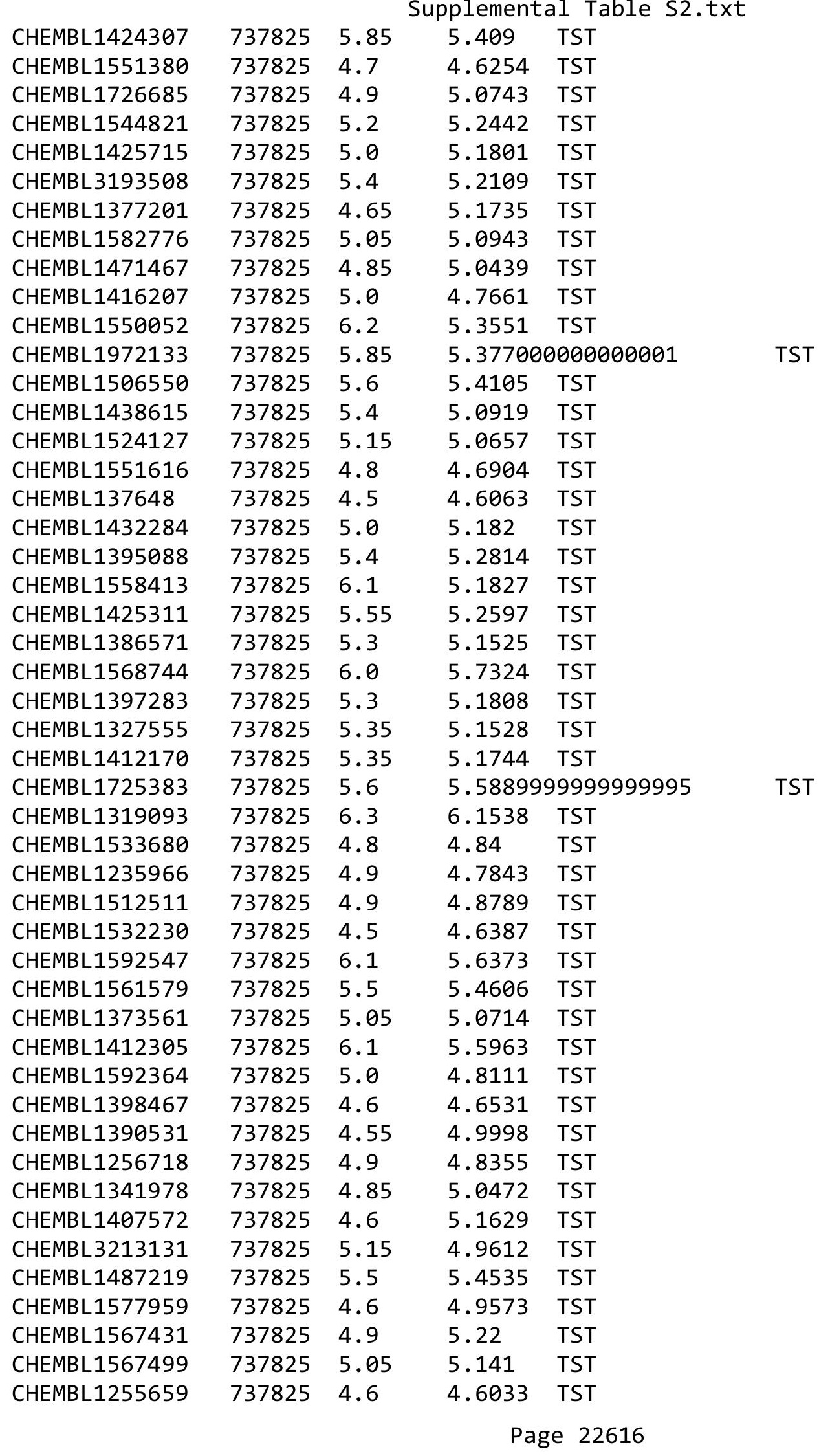




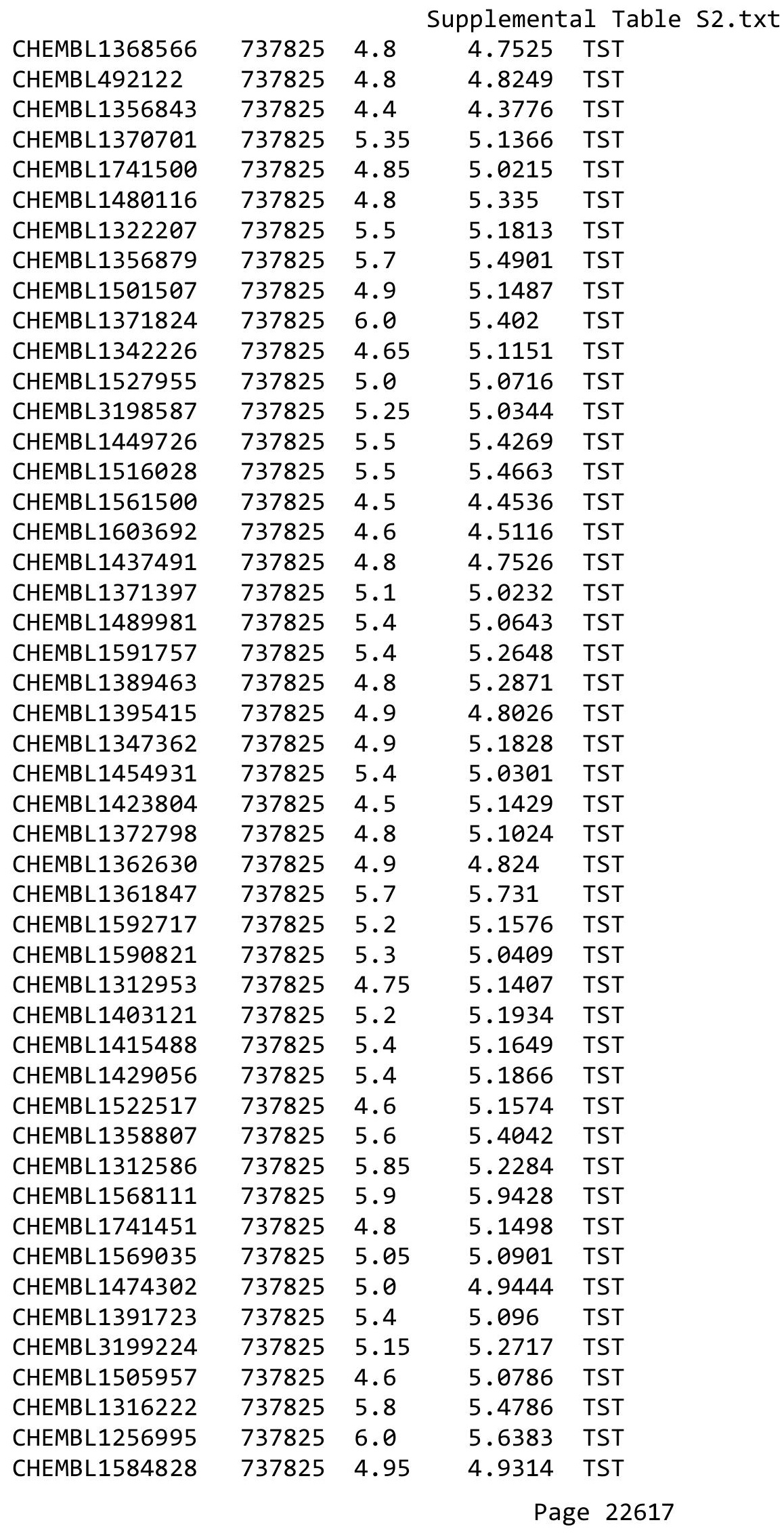




\begin{tabular}{|c|c|c|c|c|}
\hline \multicolumn{5}{|c|}{ Supplemental Table S2.txt } \\
\hline CHEMBL3199351 & 737825 & 6.1 & 5.3148 & TST \\
\hline CHEMBL 3195730 & 737825 & 5.3 & 5.3153 & TST \\
\hline CHEMBL1317998 & 737825 & 5.3 & 5.1547 & TST \\
\hline CHEMBL1342307 & 737825 & 5.1 & 5.1414 & TST \\
\hline CHEMBL1497805 & 737825 & 6.95 & 5.2387 & TST \\
\hline CHEMBL1742000 & 737825 & 7.25 & 4.9207 & TST \\
\hline CHEMBL1331657 & 737825 & 4.6 & 4.808 & TST \\
\hline CHEMBL1535022 & 737825 & 4.95 & 5.1984 & TST \\
\hline CHEMBL1320565 & 737825 & 5.1 & 4.8718 & TST \\
\hline CHEMBL1406879 & 737825 & 4.8 & 4.6765 & TST \\
\hline CHEMBL1589133 & 737825 & 5.3 & 4.9617 & TST \\
\hline CHEMBL3192674 & 737825 & 5.3 & 5.3613 & TST \\
\hline CHEMBL1536254 & 737825 & 4.85 & 5.1473 & TST \\
\hline CHEMBL8260 & 737825 & 4.5 & 4.6119 & TST \\
\hline CHEMBL1742044 & 737825 & 5.0 & 5.1935 & TST \\
\hline CHEMBL1314465 & 737825 & 4.8 & 4.6817 & TST \\
\hline CHEMBL3193159 & 737825 & 4.8 & 5.2845 & TST \\
\hline CHEMBL1324352 & 737825 & 4.6 & 5.0781 & TST \\
\hline CHEMBL1590081 & 737825 & 6.1 & 6.1342 & TST \\
\hline CHEMBL1500686 & 737825 & 5.05 & 5.2341 & TST \\
\hline CHEMBL24510 & 737825 & 4.6 & 4.6257 & TST \\
\hline CHEMBL1383394 & 737825 & 4.8 & 5.1136 & TST \\
\hline CHEMBL1491744 & 737825 & 5.4 & 5.51 & TST \\
\hline CHEMBL1526262 & 737825 & 4.5 & 5.1566 & TST \\
\hline CHEMBL1318064 & 737825 & 4.8 & 4.9879 & TST \\
\hline CHEMBL1396595 & 737825 & 6.0 & 6.1306 & TST \\
\hline CHEMBL1443163 & 737825 & 5.6 & 5.3855 & TST \\
\hline CHEMBL1453364 & 737825 & 5.1 & 5.1441 & TST \\
\hline CHEMBL1435450 & 737825 & 5.6 & 5.5446 & TST \\
\hline CHEMBL1411148 & 737825 & 4.55 & 5.1109 & TST \\
\hline CHEMBL1591380 & 737825 & 5.0 & 4.8879 & TST \\
\hline CHEMBL1357558 & 737825 & 4.6 & 4.7236 & TST \\
\hline CHEMBL 3196704 & 737825 & 4.65 & 5.1775 & TST \\
\hline CHEMBL1430749 & 737825 & 5.35 & 5.2596 & TST \\
\hline CHEMBL1491874 & 737825 & 6.25 & 5.5774 & TST \\
\hline CHEMBL1602812 & 737825 & 5.9 & 5.8707 & TST \\
\hline CHEMBL1434643 & 737825 & 5.1 & 5.0311 & TST \\
\hline CHEMBL491578 & 737825 & 6.9 & 6.8787 & TST \\
\hline CHEMBL1436488 & 737825 & 5.1 & 4.6878 & TST \\
\hline CHEMBL1516701 & 737825 & 4.7 & 4.6772 & TST \\
\hline CHEMBL1430137 & 737825 & 4.5 & 4.9471 & TST \\
\hline CHEMBL1374784 & 737825 & 5.4 & 5.3698 & TST \\
\hline CHEMBL1400921 & 737825 & 6.55 & 5.5233 & TST \\
\hline CHEMBL1562643 & 737825 & 4.85 & 5.1216 & TST \\
\hline CHEMBL 3194238 & 737825 & 5.25 & 5.1203 & TST \\
\hline CHEMBL1406437 & 737825 & 6.1 & 5.1358 & TST \\
\hline CHEMBL1575911 & 737825 & 4.4 & 5.0332 & TST \\
\hline CHEMBL1548101 & 737825 & 5.9 & 5.1505 & TST \\
\hline
\end{tabular}




\begin{tabular}{|c|c|c|c|c|c|}
\hline \multirow[b]{2}{*}{ CHEMBL491960 } & \multirow[b]{2}{*}{737825} & \\
\hline & & 6.2 & 5.7953 & TST & \\
\hline CHEMBL1528124 & 737825 & 4.4 & 5.1562 & TST & \\
\hline CHEMBL1316749 & 737825 & 5.5 & 5.4327 & TST & \\
\hline CHEMBL1338329 & 737825 & 6.0 & 5.7689 & TST & \\
\hline CHEMBL507122 & 737825 & 4.7 & 4.7286 & TST & \\
\hline CHEMBL1437667 & 737825 & 5.8 & 5.5726 & TST & \\
\hline CHEMBL1428990 & 737825 & 4.8 & 5.169 & TST & \\
\hline CHEMBL1578674 & 737825 & 4.55 & 4.9036 & TST & \\
\hline CHEMBL1417636 & 737825 & 5.9 & 5.9705 & TST & \\
\hline CHEMBL25236 & 737825 & 5.1 & 4.9848 & TST & \\
\hline CHEMBL536950 & 737825 & 4.5 & 4.5449 & TST & \\
\hline CHEMBL567332 & 737825 & 6.1 & 5.8185 & TST & \\
\hline CHEMBL1428264 & 737825 & 5.95 & 5.4017 & TST & \\
\hline CHEMBL1305576 & 737825 & 5.0 & 5.2996 & TST & \\
\hline CHEMBL1450395 & 737825 & 5.6 & 5.3314 & TST & \\
\hline CHEMBL1306876 & 737825 & 4.8 & 5.1915 & TST & \\
\hline CHEMBL1597015 & 737825 & 4.75 & 5.0624 & TST & \\
\hline CHEMBL1348883 & 737825 & 4.6 & \multicolumn{2}{|c|}{5.242000000000001} & TST \\
\hline CHEMBL1354319 & 737825 & 5.4 & 5.2798 & TST & \\
\hline CHEMBL1578496 & 737825 & 5.85 & 5.2365 & TST & \\
\hline CHEMBL1473338 & 737825 & 4.6 & 4.5229 & TST & \\
\hline CHEMBL1586480 & 737825 & 5.1 & 5.1419 & TST & \\
\hline CHEMBL1458289 & 737825 & 4.9 & 5.1373 & TST & \\
\hline CHEMBL1330323 & 737825 & 5.6 & \multicolumn{2}{|c|}{5.5760000000000005} & TST \\
\hline CHEMBL24909 & 737825 & 6.2 & \multicolumn{2}{|c|}{5.832000000000001} & TST \\
\hline CHEMBL1741329 & 737825 & 5.1 & 5.06 & TST & \\
\hline CHEMBL1303722 & 737825 & 5.65 & 5.0794 & TST & \\
\hline CHEMBL1713586 & 737825 & 4.75 & 5.2066 & TST & \\
\hline CHEMBL1380031 & 737825 & 4.95 & 5.227 & TST & \\
\hline CHEMBL1435033 & 737825 & 5.5 & 5.4912 & TST & \\
\hline CHEMBL1358659 & 737825 & 4.5 & 4.6064 & TST & \\
\hline CHEMBL1520681 & 737825 & 5.3 & 5.0238 & TST & \\
\hline CHEMBL1419738 & 737825 & 4.45 & 4.9679 & TST & \\
\hline CHEMBL1500365 & 737825 & 4.9 & 5.3045 & TST & \\
\hline CHEMBL1391234 & 737825 & 5.45 & 5.2725 & TST & \\
\hline CHEMBL1367485 & 737825 & 4.4 & 4.4962 & TST & \\
\hline CHEMBL1434146 & 737825 & 5.4 & 5.4531 & TST & \\
\hline CHEMBL1447392 & 737825 & 5.7 & 5.7233 & TST & \\
\hline CHEMBL33103 & 737825 & 5.1 & 5.6404 & TST & \\
\hline CHEMBL1434739 & 737825 & 4.9 & 4.8181 & TST & \\
\hline CHEMBL1600340 & 737825 & 4.6 & 4.4881 & TST & \\
\hline CHEMBL3207571 & 737825 & 5.3 & 5.2702 & TST & \\
\hline CHEMBL3210478 & 737825 & 4.85 & 4.891 & TST & \\
\hline CHEMBL1421734 & 737825 & 4.85 & 5.187 & TST & \\
\hline CHEMBL1530692 & 737825 & 4.45 & 5.0893 & TST & \\
\hline CHEMBL1374796 & 737825 & 6.15 & 5.5147 & TST & \\
\hline CHEMBL1340514 & 737825 & 4.75 & 5.2856 & TST & \\
\hline \multirow[t]{2}{*}{ CHEMBL1454052 } & 737825 & 4.9 & 4.9259 & TST & \\
\hline & & \multicolumn{4}{|c|}{ Page 22619} \\
\hline
\end{tabular}




\begin{tabular}{|c|c|c|c|c|c|}
\hline \multicolumn{6}{|c|}{ Supplemental Table S2.txt } \\
\hline CHEMBL1611218 & 737825 & 5.0 & 4.8773 & TST & \\
\hline CHEMBL1594883 & 737825 & 5.35 & $5.3260 e$ & 00000000005 & TST \\
\hline CHEMBL1391308 & 737825 & 4.85 & 5.1263 & TST & \\
\hline CHEMBL1312952 & 737825 & 5.6 & 5.272 & TST & \\
\hline CHEMBL1445737 & 737825 & 5.2 & 5.1688 & TST & \\
\hline CHEMBL1514717 & 737825 & 4.6 & 4.5935 & TST & \\
\hline CHEMBL1446270 & 737825 & 6.55 & 5.2371 & TST & \\
\hline CHEMBL1698533 & 737825 & 5.15 & 5.0982 & TST & \\
\hline CHEMBL1576031 & 737825 & 4.6 & 5.2085 & TST & \\
\hline CHEMBL 1255778 & 737825 & 4.8 & 4.7729 & TST & \\
\hline CHEMBL1428167 & 737825 & 5.4 & 5.2872 & TST & \\
\hline CHEMBL1320903 & 737825 & 5.4 & 5.3234 & TST & \\
\hline CHEMBL1369948 & 737825 & 6.1 & 5.5028 & TST & \\
\hline CHEMBL1330449 & 737825 & 4.65 & 5.0226 & TST & \\
\hline CHEMBL1566621 & 737825 & 4.8 & 4.6067 & TST & \\
\hline CHEMBL3191804 & 737825 & 4.85 & 4.9957 & TST & \\
\hline CHEMBL1440032 & 737825 & 5.4 & 4.9938 & TST & \\
\hline CHEMBL1488236 & 737825 & 5.0 & 4.813 & TST & \\
\hline CHEMBL1300755 & 737825 & 4.85 & 5.034 & TST & \\
\hline CHEMBL1484896 & 737825 & 4.8 & 4.6725 & TST & \\
\hline CHEMBL1543570 & 737825 & 4.5 & 5.2403 & TST & \\
\hline CHEMBL3190824 & 737825 & 5.65 & 5.2892 & TST & \\
\hline CHEMBL1424953 & 737825 & 4.95 & 5.1271 & TST & \\
\hline CHEMBL1466551 & 737825 & 5.2 & 5.2358 & TST & \\
\hline CHEMBL1607620 & 737825 & 5.6 & 5.1054 & TST & \\
\hline CHEMBL1603906 & 737825 & 4.9 & 5.005 & TST & \\
\hline CHEMBL1409369 & 737825 & 5.5 & 5.3155 & TST & \\
\hline CHEMBL1567944 & 737825 & 6.5 & 5.7042 & TST & \\
\hline CHEMBL1373994 & 737825 & 5.15 & 5.1637 & TST & \\
\hline CHEMBL1527209 & 737825 & 6.0 & 5.8644 & TST & \\
\hline CHEMBL1431724 & 737825 & 4.9 & 5.087 & TST & \\
\hline CHEMBL1411201 & 737825 & 5.7 & 5.6281 & TST & \\
\hline CHEMBL1526852 & 737825 & 4.4 & 4.4357 & TST & \\
\hline CHEMBL1741375 & 737825 & 5.5 & 5.1024 & TST & \\
\hline CHEMBL1367708 & 737825 & 4.45 & 5.1424 & TST & \\
\hline CHEMBL1358631 & 737825 & 5.6 & 5.643 & TST & \\
\hline CHEMBL1435079 & 737825 & 5.0 & 4.9478 & TST & \\
\hline CHEMBL1321535 & 737825 & 5.0 & 5.0736 & TST & \\
\hline CHEMBL1720126 & 737825 & 6.55 & 5.1416 & TST & \\
\hline CHEMBL1359094 & 737825 & 4.95 & 5.1561 & TST & \\
\hline CHEMBL1492215 & 737825 & 5.5 & 5.2896 & TST & \\
\hline CHEMBL1437985 & 737825 & 4.85 & 5.1655 & TST & \\
\hline CHEMBL1509329 & 737825 & 5.1 & 5.1559 & TST & \\
\hline CHEMBL1411496 & 737825 & 5.3 & 5.0495 & TST & \\
\hline CHEMBL1561457 & 737825 & 4.85 & 5.0215 & TST & \\
\hline CHEMBL1415790 & 737825 & 4.9 & 4.7283 & TST & \\
\hline CHEMBL1395165 & 737825 & 5.7 & 5.645 & TST & \\
\hline CHEMBL1368186 & 737825 & 5.45 & 5.2392 & TST & \\
\hline
\end{tabular}




\begin{tabular}{|c|c|c|c|c|}
\hline & & & pplement & al Tá \\
\hline CHEMBL258767 & 737825 & 6.0 & 5.6885 & TST \\
\hline CHEMBL1590663 & 737825 & 4.9 & 4.6319 & TST \\
\hline CHEMBL1997220 & 737825 & 5.05 & 5.0931 & TST \\
\hline CHEMBL1509337 & 737825 & 5.7 & 5.1098 & TST \\
\hline CHEMBL1396559 & 737825 & 5.1 & 4.9566 & TST \\
\hline CHEMBL 3186408 & 737825 & 6.0 & 5.7178 & TST \\
\hline CHEMBL105739 & 737825 & 5.1 & 4.9902 & TST \\
\hline CHEMBL1392564 & 737825 & 4.6 & 5.1674 & TST \\
\hline CHEMBL1397257 & 737825 & 4.8 & 4.6396 & TST \\
\hline CHEMBL1328688 & 737825 & 4.8 & 5.2085 & TST \\
\hline CHEMBL1607837 & 737825 & 5.65 & 5.2682 & TST \\
\hline CHEMBL1405909 & 737825 & 4.6 & 4.6516 & TST \\
\hline CHEMBL1447520 & 737825 & 5.0 & 4.9356 & TST \\
\hline CHEMBL1612620 & 737825 & 5.2 & 4.9015 & TST \\
\hline CHEMBL1320471 & 737825 & 4.95 & 5.1352 & TST \\
\hline CHEMBL1340383 & 737825 & 4.85 & 5.1538 & TST \\
\hline CHEMBL1426147 & 737825 & 4.8 & 5.1157 & TST \\
\hline CHEMBL1347492 & 737825 & 5.85 & 5.4904 & TST \\
\hline CHEMBL1528606 & 737825 & 6.0 & 5.8328 & TST \\
\hline CHEMBL1577673 & 737825 & 5.45 & 5.1003 & TST \\
\hline CHEMBL1397225 & 737825 & 6.0 & 5.9074 & TST \\
\hline CHEMBL3197283 & 737825 & 5.4 & 5.3415 & TST \\
\hline CHEMBL1306585 & 737825 & 5.75 & 5.1424 & TST \\
\hline CHEMBL1329110 & 737825 & 5.0 & 4.9753 & TST \\
\hline CHEMBL1528170 & 737825 & 4.9 & 4.7175 & TST \\
\hline CHEMBL1403617 & 737825 & 4.95 & 5.3307 & TST \\
\hline CHEMBL1555519 & 737825 & 5.0 & 5.2071 & TST \\
\hline CHEMBL1554937 & 737825 & 4.8 & 4.5998 & TST \\
\hline CHEMBL1702472 & 737825 & 4.5 & 5.1494 & TST \\
\hline CHEMBL1503434 & 737825 & 4.6 & 5.1558 & TST \\
\hline CHEMBL1352774 & 737825 & 5.35 & 5.1637 & TST \\
\hline CHEMBL3208361 & 737825 & 5.65 & 5.2808 & TST \\
\hline CHEMBL95606 & 737825 & 4.5 & 4.6078 & TST \\
\hline CHEMBL1710363 & 737825 & 4.95 & 5.0618 & TST \\
\hline CHEMBL1364473 & 737825 & 4.9 & 4.9207 & TST \\
\hline CHEMBL1408138 & 737825 & 6.2 & 5.9496 & TST \\
\hline CHEMBL1520940 & 737825 & 7.9 & 6.9876 & TST \\
\hline CHEMBL1481724 & 737825 & 4.6 & 5.2167 & TST \\
\hline CHEMBL1517121 & 737825 & 5.65 & 5.1495 & TST \\
\hline CHEMBL1449724 & 737825 & 4.65 & 5.0079 & TST \\
\hline CHEMBL1609528 & 737825 & 5.1 & 4.9893 & TST \\
\hline CHEMBL1577056 & 737825 & 4.85 & 5.1192 & TST \\
\hline CHEMBL1430702 & 737825 & 6.3 & 5.4118 & TST \\
\hline CHEMBL1493117 & 737825 & 5.4 & 5.2335 & TST \\
\hline CHEMBL1707729 & 737825 & 5.05 & 5.2103 & TST \\
\hline CHEMBL1387125 & 737825 & 6.2 & 4.9434 & TST \\
\hline CHEMBL1512676 & 737825 & 4.9 & 4.8077 & TST \\
\hline CHEMBL 3196226 & 737825 & 4.5 & 5.0347 & TST \\
\hline
\end{tabular}




\begin{tabular}{|c|c|c|c|c|c|}
\hline & & & & & \\
\hline CHEMBL1474681 & 737825 & 6.3 & 6.4008 & TST & \\
\hline CHEMBL1553768 & 737825 & 6.0 & 5.7334 & TST & \\
\hline CHEMBL1355216 & 737825 & 5.4 & 5.2329 & TST & \\
\hline CHEMBL1458036 & 737825 & 4.6 & 4.9679 & TST & \\
\hline CHEMBL1314011 & 737825 & 4.8 & 5.1438 & TST & \\
\hline CHEMBL1493835 & 737825 & 5.0 & 4.9005 & TST & \\
\hline CHEMBL1742307 & 737825 & 5.3 & 5.2059 & TST & \\
\hline CHEMBL1413306 & 737825 & 4.95 & 4.9479 & TST & \\
\hline CHEMBL1373767 & 737825 & 4.5 & 5.1766 & TST & \\
\hline CHEMBL1599203 & 737825 & 4.6 & 5.0573 & TST & \\
\hline CHEMBL1518057 & 737825 & 4.85 & 5.0542 & TST & \\
\hline CHEMBL1332361 & 737825 & 4.5 & 4.6322 & TST & \\
\hline CHEMBL1374108 & 737825 & 5.1 & 5.0323 & TST & \\
\hline CHEMBL1555610 & 737825 & 4.6 & 4.5068 & TST & \\
\hline CHEMBL1473472 & 737825 & 5.4 & 5.3504 & TST & \\
\hline CHEMBL1610995 & 737825 & 5.5 & 5.2041 & TST & \\
\hline CHEMBL1479112 & 737825 & 5.5 & 5.3892 & TST & \\
\hline CHEMBL1357221 & 737825 & 4.8 & 4.7576 & TST & \\
\hline CHEMBL1597865 & 737825 & 5.15 & 5.1305 & TST & \\
\hline CHEMBL1983266 & 737825 & 5.3 & 5.0819 & TST & \\
\hline CHEMBL1485605 & 737825 & 5.7 & 5.3313 & TST & \\
\hline CHEMBL3208837 & 737825 & 4.75 & 4.9306 & TST & \\
\hline CHEMBL1467364 & 737825 & 4.6 & 5.0785 & TST & \\
\hline CHEMBL1328307 & 737825 & 5.35 & 5.0217 & TST & \\
\hline CHEMBL3193048 & 737825 & 4.45 & 5.0922 & TST & \\
\hline CHEMBL1456931 & 737825 & 5.5 & 5.1856 & TST & \\
\hline CHEMBL1406944 & 737825 & 4.95 & 5.1669 & TST & \\
\hline CHEMBL1518484 & 737825 & 4.75 & 5.2656 & TST & \\
\hline CHEMBL1453817 & 737825 & 4.95 & 4.895 & TST & \\
\hline CHEMBL29097 & 737825 & 4.8 & 4.6996 & TST & \\
\hline CHEMBL476135 & 737825 & 6.0 & 5.7581 & TST & \\
\hline CHEMBL1447160 & 737825 & 5.5 & 5.2647 & TST & \\
\hline CHEMBL1439936 & 737825 & 4.85 & 5.13899 & 9999999999 & TST \\
\hline CHEMBL1319393 & 737825 & 4.45 & 5.1421 & TST & \\
\hline CHEMBL1411743 & 737825 & 5.6 & 5.5737 & TST & \\
\hline CHEMBL1591548 & 737825 & 5.1 & 4.9846 & TST & \\
\hline CHEMBL1350410 & 737825 & 4.85 & 5.2347 & TST & \\
\hline CHEMBL1446009 & 737825 & 4.9 & 4.8848 & TST & \\
\hline CHEMBL1402965 & 737825 & 5.35 & 5.125 & TST & \\
\hline CHEMBL1451057 & 737825 & 6.0 & 5.7955 & TST & \\
\hline CHEMBL1437056 & 737825 & 4.7 & 4.5592 & TST & \\
\hline CHEMBL1329102 & 737825 & 6.2 & 6.0391 & TST & \\
\hline CHEMBL1383897 & 737825 & 5.95 & 5.3594 & TST & \\
\hline CHEMBL1543676 & 737825 & 4.8 & 5.1576 & TST & \\
\hline CHEMBL1302009 & 737825 & 5.65 & 5.1087 & TST & \\
\hline CHEMBL1465985 & 737825 & 5.5 & 5.435 & TST & \\
\hline CHEMBL1356041 & 737825 & 5.6 & 5.5912 & TST & \\
\hline CHEMBL1367548 & 737825 & 5.0 & 5.24100 & 00000000005 & TST \\
\hline & & & & 22622 & \\
\hline
\end{tabular}




\begin{tabular}{|c|c|c|c|c|}
\hline & & & pplement & al $\mathrm{Ta}$ \\
\hline CHEMBL1368887 & 737825 & 6.0 & 5.9248 & TST \\
\hline CHEMBL1515508 & 737825 & 4.5 & 4.3832 & TST \\
\hline CHEMBL 278041 & 737825 & 6.3 & 5.9578 & TST \\
\hline CHEMBL1490442 & 737825 & 4.7 & 4.9713 & TST \\
\hline CHEMBL1357781 & 737825 & 5.4 & 5.4865 & TST \\
\hline CHEMBL1460362 & 737825 & 4.8 & 5.2639 & TST \\
\hline CHEMBL1467491 & 737825 & 4.9 & 5.1289 & TST \\
\hline CHEMBL1362034 & 737825 & 4.85 & 5.1831 & TST \\
\hline CHEMBL1457390 & 737825 & 4.6 & 4.5617 & TST \\
\hline CHEMBL1741708 & 737825 & 4.5 & 5.0782 & TST \\
\hline CHEMBL1532941 & 737825 & 5.4 & 5.0907 & TST \\
\hline CHEMBL1420830 & 737825 & 5.4 & 5.2116 & TST \\
\hline CHEMBL1570733 & 737825 & 4.8 & 5.2535 & TST \\
\hline CHEMBL1384477 & 737825 & 5.7 & 5.0315 & TST \\
\hline CHEMBL1591544 & 737825 & 4.5 & 4.3863 & TST \\
\hline CHEMBL1355156 & 737825 & 5.5 & 5.4572 & TST \\
\hline CHEMBL3194986 & 737825 & 4.85 & 5.3796 & TST \\
\hline CHEMBL1358503 & 737825 & 5.5 & 5.5949 & TST \\
\hline CHEMBL1340013 & 737825 & 4.95 & 5.3816 & TST \\
\hline CHEMBL1382242 & 737825 & 5.0 & 5.1515 & TST \\
\hline CHEMBL1597572 & 737825 & 5.6 & 5.3663 & TST \\
\hline CHEMBL1405921 & 737825 & 5.0 & 5.3369 & TST \\
\hline CHEMBL1326616 & 737825 & 4.85 & 5.3165 & TST \\
\hline CHEMBL1334179 & 737825 & 5.4 & 5.0667 & TST \\
\hline CHEMBL491771 & 737825 & 5.8 & 5.7116 & TST \\
\hline CHEMBL1330272 & 737825 & 6.1 & 6.0165 & TST \\
\hline CHEMBL1449987 & 737825 & 5.0 & 4.9909 & TST \\
\hline CHEMBL1513966 & 737825 & 5.4 & 5.3529 & TST \\
\hline CHEMBL1477786 & 737825 & 4.9 & 5.1657 & TST \\
\hline CHEMBL158507 & 737825 & 5.6 & 5.3582 & TST \\
\hline CHEMBL1377111 & 737825 & 6.0 & 5.8411 & TST \\
\hline CHEMBL1472880 & 737825 & 5.5 & 5.2598 & TST \\
\hline CHEMBL1329927 & 737825 & 4.9 & 5.5821 & TST \\
\hline CHEMBL1451363 & 737825 & 4.6 & 5.2525 & TST \\
\hline CHEMBL1533643 & 737825 & 5.05 & 5.3564 & TST \\
\hline CHEMBL1422116 & 737825 & 4.85 & 5.0476 & TST \\
\hline CHEMBL1741905 & 737825 & 5.1 & 5.2842 & TST \\
\hline CHEMBL1462462 & 737825 & 4.85 & 4.9669 & TST \\
\hline CHEMBL1486831 & 737825 & 4.85 & 4.9809 & TST \\
\hline CHEMBL1422001 & 737825 & 4.85 & 5.3059 & TST \\
\hline CHEMBL1334959 & 737825 & 5.2 & 5.3028 & TST \\
\hline CHEMBL1361757 & 737825 & 4.8 & 5.1817 & TST \\
\hline CHEMBL1394113 & 737825 & 5.1 & 5.0295 & TST \\
\hline CHEMBL1560502 & 737825 & 5.9 & 5.7773 & TST \\
\hline CHEMBL1603445 & 737825 & 4.5 & 5.0574 & TST \\
\hline CHEMBL1593466 & 737825 & 5.4 & 5.3172 & TST \\
\hline CHEMBL1366762 & 737825 & 5.3 & 5.3286 & TST \\
\hline CHEMBL1447768 & 737825 & 6.15 & 5.1415 & TST \\
\hline
\end{tabular}




\begin{tabular}{|c|c|c|c|c|}
\hline \multicolumn{5}{|c|}{ Supplemental Table S2.txt } \\
\hline CHEMBL1377868 & 737825 & 5.9 & 5.1054 & TST \\
\hline CHEMBL3211113 & 737825 & 5.4 & 5.4067 & TST \\
\hline CHEMBL1519435 & 737825 & 5.7 & 5.6451 & TST \\
\hline CHEMBL1565302 & 737825 & 5.8 & 5.6212 & TST \\
\hline CHEMBL1378901 & 737825 & 4.6 & 4.4863 & TST \\
\hline CHEMBL1499237 & 737825 & 5.7 & 5.0434 & TST \\
\hline CHEMBL430893 & 737825 & 6.0 & 5.6767 & TST \\
\hline CHEMBL1575205 & 737825 & 4.4 & 5.1933 & TST \\
\hline CHEMBL1409782 & 737825 & 5.85 & 5.0994 & TST \\
\hline CHEMBL1428733 & 737825 & 4.65 & 5.263 & TST \\
\hline CHEMBL1486289 & 737825 & 6.0 & 5.8823 & TST \\
\hline CHEMBL 362051 & 737825 & 4.8 & 4.8609 & TST \\
\hline CHEMBL1357770 & 737825 & 5.2 & 5.1532 & TST \\
\hline CHEMBL1548428 & 737825 & 4.6 & 5.1715 & TST \\
\hline CHEMBL1440921 & 737825 & 4.9 & 5.1995 & TST \\
\hline CHEMBL492611 & 737825 & 5.6 & 5.4752 & TST \\
\hline CHEMBL1570658 & 737825 & 6.85 & 5.5149 & TST \\
\hline CHEMBL1527132 & 737825 & 5.7 & 5.6492 & TST \\
\hline CHEMBL3198273 & 737825 & 5.4 & 5.4615 & TST \\
\hline CHEMBL1409689 & 737825 & 6.3 & 6.2854 & TST \\
\hline CHEMBL1601019 & 737825 & 4.9 & 4.9316 & TST \\
\hline CHEMBL1441287 & 737825 & 4.8 & 4.7714 & TST \\
\hline CHEMBL1301014 & 737825 & 4.5 & 5.0626 & TST \\
\hline CHEMBL1590962 & 737825 & 4.4 & 4.336 & TST \\
\hline CHEMBL10347 & 737825 & 6.0 & 5.6289 & TST \\
\hline CHEMBL1382296 & 737825 & 5.5 & 5.1985 & TST \\
\hline CHEMBL1320641 & 737825 & 5.25 & 5.1598 & TST \\
\hline CHEMBL1316956 & 737825 & 6.9 & 6.9125 & TST \\
\hline CHEMBL1473055 & 737825 & 4.9 & 4.7749 & TST \\
\hline CHEMBL395446 & 737825 & 4.65 & 4.8997 & TST \\
\hline CHEMBL1474056 & 737825 & 5.6 & 5.3175 & TST \\
\hline CHEMBL1336727 & 737825 & 4.9 & 4.9259 & TST \\
\hline CHEMBL1308520 & 737825 & 5.1 & 5.0162 & TST \\
\hline CHEMBL1481361 & 737825 & 5.8 & 5.6256 & TST \\
\hline CHEMBL1422230 & 737825 & 5.75 & 5.3595 & TST \\
\hline CHEMBL1586684 & 737825 & 5.2 & 5.5065 & TST \\
\hline CHEMBL1573692 & 737825 & 5.35 & 5.0728 & TST \\
\hline CHEMBL1411396 & 737825 & 5.1 & 5.2067 & TST \\
\hline CHEMBL1395338 & 737825 & 7.1 & 6.2916 & TST \\
\hline CHEMBL1741816 & 737825 & 4.9 & 5.131 & TST \\
\hline CHEMBL181633 & 737825 & 5.3 & 5.1255 & TST \\
\hline CHEMBL1417861 & 737825 & 5.7 & 6.0272 & TST \\
\hline CHEMBL1524323 & 737825 & 4.75 & 4.9176 & TST \\
\hline CHEMBL1317924 & 737825 & 5.0 & 4.8563 & TST \\
\hline CHEMBL1532555 & 737825 & 4.9 & 4.7227 & TST \\
\hline CHEMBL1374713 & 737825 & 5.4 & 5.4799 & TST \\
\hline CHEMBL1475695 & 737825 & 5.1 & 4.9097 & TST \\
\hline CHEMBL3208849 & 737825 & 5.05 & 5.1103 & TST \\
\hline
\end{tabular}




\begin{tabular}{|c|c|c|c|c|c|}
\hline \multirow{2}{*}{ CHEMBL1353174 } & \multirow{2}{*}{737825} & \\
\hline & & 4.8 & 5.2057 & \multicolumn{2}{|l|}{$\begin{array}{l}\text { TST } \\
\text { TST }\end{array}$} \\
\hline CHEMBL1603926 & 737825 & 4.6 & 4.869 & TST & \\
\hline CHEMBL1491545 & 737825 & 5.3 & 5.4498 & \multicolumn{2}{|l|}{ TST } \\
\hline CHEMBL1726451 & 737825 & 4.8 & 5.1865 & \multicolumn{2}{|l|}{ TST } \\
\hline CHEMBL1378037 & 737825 & 4.9 & 5.206 & \multicolumn{2}{|l|}{ TST } \\
\hline CHEMBL1475010 & 737825 & 5.2 & 4.9146 & \multicolumn{2}{|l|}{ TST } \\
\hline CHEMBL1433232 & 737825 & 5.15 & 5.1948 & \multicolumn{2}{|l|}{ TST } \\
\hline CHEMBL1459455 & 737825 & 6.0 & 5.2504 & \multicolumn{2}{|l|}{ TST } \\
\hline CHEMBL34450 & 737825 & 5.6 & 5.479 & \multicolumn{2}{|l|}{ TST } \\
\hline CHEMBL1393149 & 737825 & 4.95 & 5.2214 & \multicolumn{2}{|l|}{ TST } \\
\hline CHEMBL1322216 & 737825 & 5.0 & 4.8496 & \multicolumn{2}{|l|}{ TST } \\
\hline CHEMBL1486638 & 737825 & 5.7 & 5.5278 & \multicolumn{2}{|l|}{ TST } \\
\hline CHEMBL1397559 & 737825 & 5.4 & 5.3192 & \multicolumn{2}{|l|}{ TST } \\
\hline CHEMBL1495763 & 737825 & 5.8 & 5.2363 & \multicolumn{2}{|l|}{ TST } \\
\hline CHEMBL447507 & 737825 & 6.4 & 6.5327 & \multicolumn{2}{|l|}{ TST } \\
\hline CHEMBL77971 & 737825 & 6.4 & 5.966 & \multicolumn{2}{|l|}{ TST } \\
\hline CHEMBL1402960 & 737825 & 4.85 & 5.2293 & \multicolumn{2}{|l|}{ TST } \\
\hline CHEMBL1609440 & 737825 & 4.7 & 4.5143 & \multicolumn{2}{|l|}{ TST } \\
\hline CHEMBL1466103 & 737825 & 4.9 & 5.3952 & TST & \\
\hline CHEMBL1554960 & 737825 & 4.8 & 4.6747 & TST & \\
\hline CHEMBL1570950 & 737825 & 4.6 & 5.1877 & TST & \\
\hline CHEMBL1366995 & 737825 & 6.05 & 5.206 & TST & \\
\hline CHEMBL1741922 & 737825 & 5.05 & 5.2164 & TST & \\
\hline CHEMBL1495665 & 737825 & 5.2 & 5.0465 & TST & \\
\hline CHEMBL1502064 & 737825 & 5.7 & 5.2963 & TST & \\
\hline CHEMBL1556022 & 737825 & 4.4 & 5.0436 & TST & \\
\hline CHEMBL1472765 & 737825 & 5.3 & 5.1443 & TST & \\
\hline CHEMBL1374947 & 737825 & 5.45 & 5.1911 & TST & \\
\hline CHEMBL1369444 & 737825 & 4.5 & 5.1034 & TST & \\
\hline CHEMBL1593754 & 737825 & 5.3 & 5.6539 & TST & \\
\hline CHEMBL1592211 & 737825 & 6.1 & 6.2125 & TST & \\
\hline CHEMBL1436532 & 737825 & 5.5 & 5.40799 & 99999999995 & TST \\
\hline CHEMBL1556619 & 737825 & 5.1 & 5.08899 & 99999999995 & TST \\
\hline CHEMBL 28 & 737825 & 6.0 & 5.8787 & TST & \\
\hline CHEMBL1304478 & 737825 & 4.8 & 5.222 & TST & \\
\hline CHEMBL1393064 & 737825 & 4.65 & 5.2275 & TST & \\
\hline CHEMBL1585809 & 737825 & 4.8 & 5.1623 & TST & \\
\hline CHEMBL1351101 & 737825 & 5.0 & 5.0501 & TST & \\
\hline CHEMBL1481810 & 737825 & 5.1 & 5.0701 & TST & \\
\hline CHEMBL1359181 & 737825 & 4.4 & 4.5442 & TST & \\
\hline CHEMBL1305298 & 737825 & 4.6 & 5.1912 & TST & \\
\hline CHEMBL1517935 & 737825 & 5.5 & 5.3893 & TST & \\
\hline CHEMBL1596241 & 737825 & 4.9 & 4.8714 & TST & \\
\hline CHEMBL1564813 & 737825 & 5.6 & 5.5041 & TST & \\
\hline CHEMBL 280065 & 737825 & 4.5 & 4.4588 & TST & \\
\hline CHEMBL1720109 & 737825 & 5.65 & 5.2281 & TST & \\
\hline CHEMBL1324667 & 737825 & 5.7 & 5.8579 & TST & \\
\hline CHEMBL1517051 & 737825 & 4.6 & 4.5819 & TST & \\
\hline & & & & 22625 & \\
\hline
\end{tabular}




\begin{tabular}{|c|c|c|c|c|c|}
\hline \multirow[b]{2}{*}{ CHEMBL1712981 } & \multicolumn{5}{|c|}{ Supplemental Table S2.txt } \\
\hline & 737825 & 5.5 & 5.2253 & TST & \\
\hline CHEMBL1300546 & 737825 & 4.75 & 5.24799 & 9999999999 & TST \\
\hline CHEMBL3207783 & 737825 & 5.4 & 5.4058 & TST & \\
\hline CHEMBL1423338 & 737825 & 5.2 & 4.9363 & TST & \\
\hline CHEMBL1392952 & 737825 & 4.4 & 5.0942 & TST & \\
\hline CHEMBL583849 & 737825 & 5.0 & 5.0296 & TST & \\
\hline CHEMBL1554842 & 737825 & 5.3 & 5.2996 & TST & \\
\hline CHEMBL1371490 & 737825 & 4.8 & 5.114 & TST & \\
\hline CHEMBL1533768 & 737825 & 5.35 & 5.1302 & TST & \\
\hline CHEMBL1407217 & 737825 & 4.6 & 4.4912 & TST & \\
\hline CHEMBL1438199 & 737825 & 4.4 & 5.1172 & TST & \\
\hline CHEMBL1454730 & 737825 & 5.7 & 5.5466 & TST & \\
\hline CHEMBL1427330 & 737825 & 4.6 & 5.1699 & TST & \\
\hline CHEMBL1506687 & 737825 & 5.65 & 5.1272 & TST & \\
\hline CHEMBL1312936 & 737825 & 5.7 & 5.2701 & TST & \\
\hline CHEMBL1348869 & 737825 & 5.45 & 5.0747 & TST & \\
\hline CHEMBL1552949 & 737825 & 5.4 & 5.3833 & TST & \\
\hline CHEMBL1371221 & 737825 & 5.4 & 5.2426 & TST & \\
\hline CHEMBL1385673 & 737825 & 5.55 & 5.1243 & TST & \\
\hline CHEMBL1554622 & 737825 & 5.5 & 5.2855 & TST & \\
\hline CHEMBL1699304 & 737825 & 4.8 & 5.103 & TST & \\
\hline CHEMBL1401813 & 737825 & 5.0 & 5.1496 & TST & \\
\hline CHEMBL1435276 & 737825 & 5.0 & 4.939 & TST & \\
\hline CHEMBL1505565 & 737825 & 4.75 & 5.0436 & TST & \\
\hline CHEMBL1307306 & 737825 & 5.5 & 5.3202 & TST & \\
\hline CHEMBL1491574 & 737825 & 5.6 & 5.4612 & TST & \\
\hline CHEMBL1330763 & 737825 & 5.5 & 5.4015 & TST & \\
\hline CHEMBL1489140 & 737825 & 4.7 & 4.6189 & TST & \\
\hline CHEMBL1491271 & 737825 & 4.6 & 5.1026 & TST & \\
\hline CHEMBL1326964 & 737825 & 4.95 & 5.1826 & TST & \\
\hline CHEMBL1491288 & 737825 & 5.5 & 5.2605 & TST & \\
\hline CHEMBL1356085 & 737825 & 5.6 & 5.3762 & TST & \\
\hline CHEMBL1567725 & 737825 & 5.4 & 5.3368 & TST & \\
\hline CHEMBL1358560 & 737825 & 5.4 & 5.4132 & TST & \\
\hline CHEMBL1409461 & 737825 & 4.5 & 4.7026 & TST & \\
\hline CHEMBL1741490 & 737825 & 5.2 & 5.2671 & TST & \\
\hline CHEMBL1535931 & 737825 & 4.8 & 4.6723 & TST & \\
\hline CHEMBL1530982 & 737825 & 5.9 & 5.8575 & TST & \\
\hline CHEMBL1595145 & 737825 & 4.85 & 4.9473 & TST & \\
\hline CHEMBL1432821 & 737825 & 5.1 & 5.0996 & TST & \\
\hline CHEMBL1358007 & 737825 & 5.5 & 5.3387 & TST & \\
\hline CHEMBL3195544 & 737825 & 4.6 & 5.0368 & TST & \\
\hline CHEMBL1601527 & 737825 & 5.45 & 5.2051 & TST & \\
\hline CHEMBL1553804 & 737825 & 4.8 & 4.6887 & TST & \\
\hline CHEMBL90769 & 737825 & 4.7 & 4.677 & TST & \\
\hline CHEMBL1520442 & 737825 & 5.5 & 5.4523 & TST & \\
\hline CHEMBL1309858 & 737825 & 4.85 & 4.9813 & TST & \\
\hline CHEMBL1330730 & 737825 & 5.35 & 5.1985 & TST & \\
\hline
\end{tabular}




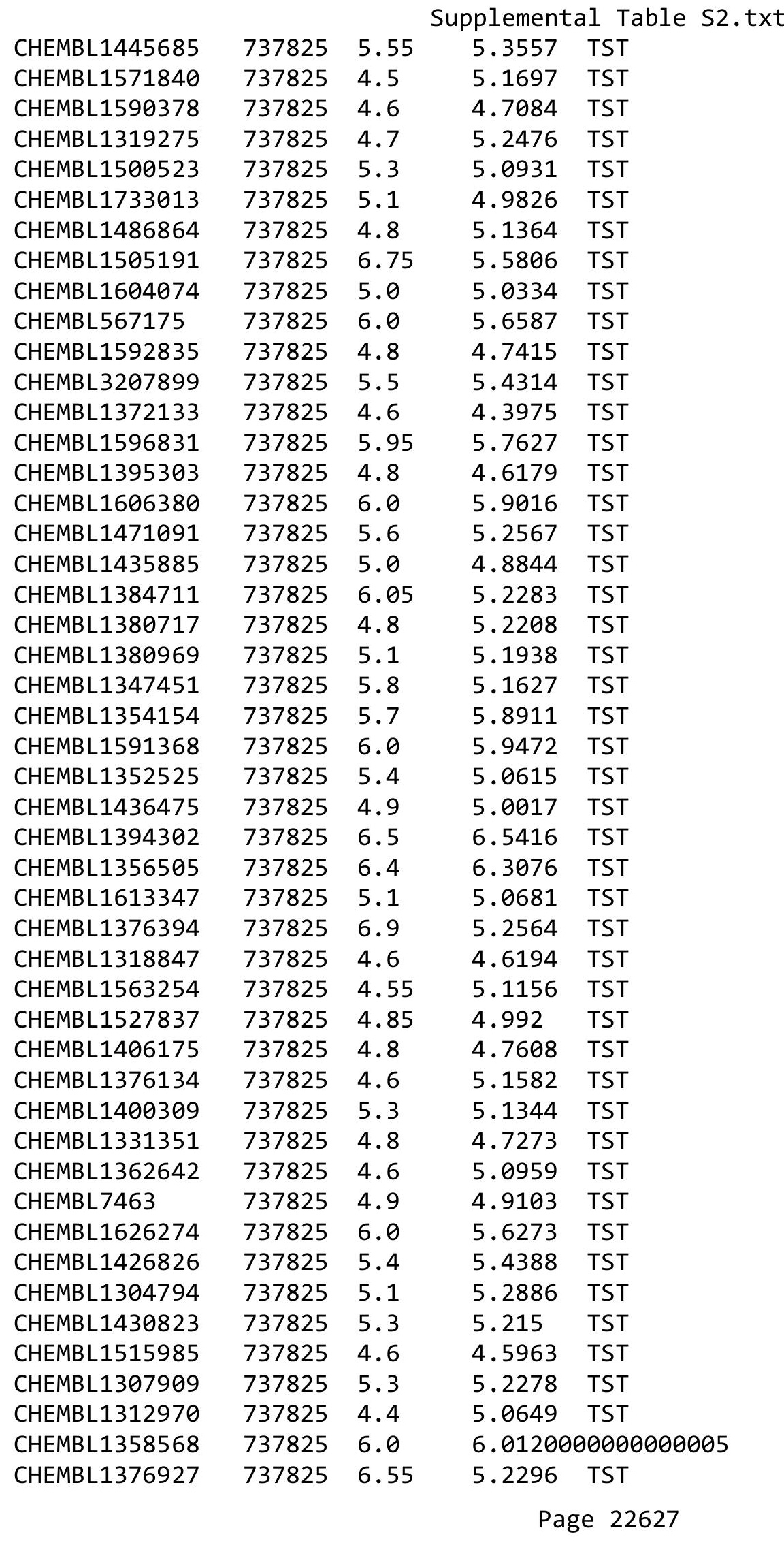




\begin{tabular}{|c|c|c|c|c|c|}
\hline CHEMBL3211898 & 737825 & 4.8 & \multicolumn{2}{|c|}{5.0760000000000005} & TST \\
\hline CHEMBL1303328 & 737825 & 4.55 & 5.1018 & TST & \\
\hline CHEMBL1612691 & 737825 & 4.9 & 5.1119 & TST & \\
\hline CHEMBL1518035 & 737825 & 4.8 & 4.6952 & TST & \\
\hline CHEMBL1399008 & 737825 & 4.8 & 4.9919 & TST & \\
\hline CHEMBL3210042 & 737825 & 5.05 & 5.3218 & TST & \\
\hline CHEMBL 3213748 & 737825 & 5.4 & 5.3765 & TST & \\
\hline CHEMBL1403023 & 737825 & 4.8 & 5.1722 & TST & \\
\hline CHEMBL1308948 & 737825 & 5.6 & 5.5286 & TST & \\
\hline CHEMBL1569585 & 737825 & 5.1 & 5.096 & TST & \\
\hline CHEMBL1599585 & 737825 & 5.1 & 5.0824 & TST & \\
\hline CHEMBL1354262 & 737825 & 4.9 & 4.7495 & TST & \\
\hline CHEMBL1395869 & 737825 & 5.5 & 5.4199 & TST & \\
\hline CHEMBL1587109 & 737825 & 4.55 & 4.9883 & TST & \\
\hline CHEMBL1573739 & 737825 & 5.55 & 5.1452 & TST & \\
\hline CHEMBL1411424 & 737825 & 5.3 & 4.9261 & TST & \\
\hline CHEMBL1579705 & 737825 & 5.45 & 5.2632 & TST & \\
\hline CHEMBL1523323 & 737825 & 4.55 & \multicolumn{2}{|c|}{5.337000000000001} & TST \\
\hline CHEMBL1486930 & 737825 & 4.9 & 4.9113 & TST & \\
\hline CHEMBL1385649 & 737825 & 5.0 & 5.1401 & TST & \\
\hline CHEMBL1316108 & 737825 & 4.6 & 4.4845 & TST & \\
\hline CHEMBL1479470 & 737825 & 4.8 & \multicolumn{2}{|c|}{4.7139999999999995} & TST \\
\hline CHEMBL1514398 & 737825 & 5.4 & 5.5301 & TST & \\
\hline CHEMBL1484032 & 737825 & 5.8 & 5.4751 & TST & \\
\hline CHEMBL1482184 & 737825 & 5.4 & 5.6245 & TST & \\
\hline CHEMBL1512744 & 737825 & 5.4 & 5.2397 & TST & \\
\hline CHEMBL1452398 & 737825 & 5.45 & 5.053 & TST & \\
\hline CHEMBL1440509 & 737825 & 5.0 & 4.9639 & TST & \\
\hline CHEMBL1443362 & 737825 & 5.45 & 5.0227 & TST & \\
\hline CHEMBL1473149 & 737825 & 4.7 & 4.515 & TST & \\
\hline CHEMBL3193784 & 737825 & 4.85 & 5.0794 & TST & \\
\hline CHEMBL1698063 & 737825 & 4.65 & 5.1427 & TST & \\
\hline CHEMBL1360944 & 737825 & 4.6 & 4.7044 & TST & \\
\hline CHEMBL1552720 & 737825 & 5.3 & 5.0313 & TST & \\
\hline CHEMBL1472029 & 737825 & 4.85 & 5.3987 & TST & \\
\hline CHEMBL1475620 & 737825 & 5.8 & 5.5941 & TST & \\
\hline CHEMBL1442612 & 737825 & 5.35 & 5.4965 & TST & \\
\hline CHEMBL1523143 & 737825 & 5.1 & 5.1362 & TST & \\
\hline CHEMBL1565852 & 737825 & 4.45 & 5.2191 & TST & \\
\hline CHEMBL1494612 & 737825 & 7.3 & 5.0556 & TST & \\
\hline CHEMBL1488931 & 737825 & 4.9 & 5.1087 & TST & \\
\hline CHEMBL1476632 & 737825 & 6.5 & 6.2879 & TST & \\
\hline CHEMBL1391721 & 737825 & 4.7 & 5.0671 & TST & \\
\hline CHEMBL1411438 & 737825 & 5.5 & 5.4781 & TST & \\
\hline CHEMBL1408836 & 737825 & 5.4 & 5.2234 & TST & \\
\hline CHEMBL1321439 & 737825 & 4.8 & 4.7256 & TST & \\
\hline CHEMBL 278755 & 737825 & 4.8 & 4.7712 & TST & \\
\hline \multirow[t]{2}{*}{ CHEMBL1532023 } & 737825 & 5.4 & 5.3678 & TST & \\
\hline & & \multicolumn{4}{|c|}{ Page 22628} \\
\hline
\end{tabular}




\begin{tabular}{|c|c|c|c|c|c|}
\hline \multicolumn{6}{|c|}{ oplemental la } \\
\hline CHEMBL1407289 & 737825 & 4.9 & 5.2424 & TST & \\
\hline CHEMBL1517040 & 737825 & 5.9 & 5.3929 & TST & \\
\hline CHEMBL1567101 & 737825 & 5.6 & 5.1822 & TST & \\
\hline CHEMBL1742257 & 737825 & 4.7 & 5.1985 & TST & \\
\hline CHEMBL1362517 & 737825 & 4.9 & 4.8284 & TST & \\
\hline CHEMBL1352445 & 737825 & 5.35 & 5.1201 & TST & \\
\hline CHEMBL1414213 & 737825 & 5.15 & 5.2662 & TST & \\
\hline CHEMBL1457798 & 737825 & 5.05 & 5.0557 & TST & \\
\hline CHEMBL1395634 & 737825 & 6.0 & 5.7098 & TST & \\
\hline CHEMBL1256173 & 737825 & 4.5 & 4.5669 & TST & \\
\hline CHEMBL1715711 & 737825 & 4.9 & 5.1253 & TST & \\
\hline CHEMBL1336443 & 737825 & 6.0 & 5.9571 & TST & \\
\hline CHEMBL1439945 & 737825 & 4.8 & 4.7718 & TST & \\
\hline CHEMBL1590980 & 737825 & 6.6 & 6.5238 & TST & \\
\hline CHEMBL1315236 & 737825 & 4.5 & 4.4035 & TST & \\
\hline CHEMBL1334821 & 737825 & 5.7 & 5.24799 & 9999999999 & TST \\
\hline CHEMBL1476741 & 737825 & 5.0 & 4.9025 & TST & \\
\hline CHEMBL3198953 & 737825 & 5.9 & 5.28 & TST & \\
\hline CHEMBL1393480 & 737825 & 4.9 & 5.0726 & TST & \\
\hline CHEMBL1593371 & 737825 & 4.8 & 4.8062 & TST & \\
\hline CHEMBL1706994 & 737825 & 4.6 & 5.1102 & TST & \\
\hline CHEMBL1583603 & 737825 & 4.85 & 5.4025 & TST & \\
\hline CHEMBL1429416 & 737825 & 4.7 & 5.3291 & TST & \\
\hline CHEMBL1376723 & 737825 & 4.6 & 4.6183 & TST & \\
\hline CHEMBL3198234 & 737825 & 4.85 & 5.0033 & TST & \\
\hline CHEMBL1539061 & 737825 & 4.65 & 4.9849 & TST & \\
\hline CHEMBL1325662 & 737825 & 4.5 & 5.1074 & TST & \\
\hline CHEMBL1580159 & 737825 & 5.55 & 5.29799 & 9999999999 & TST \\
\hline CHEMBL1328166 & 737825 & 5.15 & 5.2029 & TST & \\
\hline CHEMBL1513030 & 737825 & 5.1 & 4.9299 & TST & \\
\hline CHEMBL1373907 & 737825 & 4.6 & 4.6244 & TST & \\
\hline CHEMBL1522524 & 737825 & 5.05 & 5.4269 & TST & \\
\hline CHEMBL1375759 & 737825 & 5.45 & 5.1517 & TST & \\
\hline CHEMBL1376253 & 737825 & 5.1 & 4.9367 & TST & \\
\hline CHEMBL 277525 & 737825 & 6.2 & 6.1979 & TST & \\
\hline CHEMBL1552707 & 737825 & 6.2 & 6.0234 & TST & \\
\hline CHEMBL1465072 & 737825 & 5.95 & 5.1804 & TST & \\
\hline CHEMBL1472732 & 737825 & 4.8 & 4.6126 & TST & \\
\hline CHEMBL1589098 & 737825 & 4.8 & 5.0771 & TST & \\
\hline CHEMBL1444914 & 737825 & 6.5 & 6.5364 & TST & \\
\hline CHEMBL1333156 & 737825 & 5.5 & 5.4482 & TST & \\
\hline CHEMBL1421029 & 737825 & 4.85 & 4.9748 & TST & \\
\hline CHEMBL1496596 & 737825 & 4.8 & 4.6674 & TST & \\
\hline CHEMBL1306504 & 737825 & 4.85 & 5.3037 & TST & \\
\hline CHEMBL1440867 & 737825 & 6.05 & 5.3279 & TST & \\
\hline CHEMBL1350043 & 737825 & 5.05 & 5.0991 & TST & \\
\hline CHEMBL1600586 & 737825 & 5.3 & 5.2194 & TST & \\
\hline CHEMBL1538039 & 737825 & 4.85 & 5.1599 & TST & \\
\hline
\end{tabular}




\begin{tabular}{|c|c|c|c|c|c|}
\hline \multicolumn{6}{|c|}{ Supplemental Table S2.txt } \\
\hline CHEMBL1322719 & 737825 & 5.8 & 5.6472 & TST & \\
\hline CHEMBL1358012 & 737825 & 5.6 & 5.3355 & TST & \\
\hline CHEMBL1527006 & 737825 & 4.7 & 5.1571 & TST & \\
\hline CHEMBL1485850 & 737825 & 4.8 & 4.7016 & TST & \\
\hline CHEMBL1404598 & 737825 & 6.2 & 6.3213 & TST & \\
\hline CHEMBL1522767 & 737825 & 4.85 & 5.2597 & TST & \\
\hline CHEMBL3198283 & 737825 & 4.6 & 5.0052 & TST & \\
\hline CHEMBL1393271 & 737825 & 5.15 & 5.0004 & TST & \\
\hline CHEMBL1495011 & 737825 & 4.85 & 4.9967 & TST & \\
\hline CHEMBL1341809 & 737825 & 5.0 & 5.2593 & TST & \\
\hline CHEMBL1310409 & 737825 & 4.55 & 5.197 & TST & \\
\hline CHEMBL1612602 & 737825 & 4.85 & 5.1915 & TST & \\
\hline CHEMBL1324528 & 737825 & 5.6 & 5.2683 & TST & \\
\hline CHEMBL2094549 & 737825 & 5.95 & 5.1519 & TST & \\
\hline CHEMBL1502534 & 737825 & 4.85 & 5.1232 & TST & \\
\hline CHEMBL1366562 & 737825 & 4.7 & 5.3954 & TST & \\
\hline CHEMBL1350570 & 737825 & 5.45 & 5.1134 & TST & \\
\hline CHEMBL1525931 & 737825 & 5.15 & 5.2265 & TST & \\
\hline CHEMBL1330251 & 737825 & 5.7 & 5.5334 & TST & \\
\hline CHEMBL1393716 & 737825 & 5.55 & 5.3285 & TST & \\
\hline CHEMBL1566684 & 737825 & 5.2 & 5.1649 & TST & \\
\hline CHEMBL1565311 & 737825 & 6.0 & 6.0704 & TST & \\
\hline CHEMBL1428877 & 737825 & 5.15 & 5.0937 & TST & \\
\hline CHEMBL111545 & 737825 & 5.0 & 4.8949 & TST & \\
\hline CHEMBL1369824 & 737825 & 5.4 & 5.0983 & TST & \\
\hline CHEMBL1332033 & 737825 & 4.6 & 4.6046 & TST & \\
\hline CHEMBL1318261 & 737825 & 5.0 & 4.9107 & TST & \\
\hline CHEMBL1450619 & 737825 & 5.5 & 5.5032 & TST & \\
\hline CHEMBL1724475 & 737825 & 4.6 & 5.1349 & TST & \\
\hline CHEMBL1725648 & 737825 & 5.15 & 5.107 & TST & \\
\hline CHEMBL1445522 & 737825 & 4.8 & 4.6977 & TST & \\
\hline CHEMBL1453542 & 737825 & 4.7 & 4.5858 & TST & \\
\hline CHEMBL1422254 & 737825 & 5.95 & 5.2293 & TST & \\
\hline CHEMBL1547886 & 737825 & 6.35 & 5.26200 & 00000000005 & TST \\
\hline CHEMBL1564477 & 737825 & 4.8 & 4.6597 & TST & \\
\hline CHEMBL1315091 & 737825 & 4.8 & 4.7683 & TST & \\
\hline CHEMBL1320453 & 737825 & 4.8 & 4.971 & TST & \\
\hline CHEMBL1417140 & 737825 & 5.7 & 5.3435 & TST & \\
\hline CHEMBL1317461 & 737825 & 6.3 & 6.2365 & TST & \\
\hline CHEMBL1527442 & 737825 & 4.6 & 4.6403 & TST & \\
\hline CHEMBL88147 & 737825 & 5.5 & 5.2864 & TST & \\
\hline CHEMBL1452961 & 737825 & 5.0 & 5.1235 & TST & \\
\hline CHEMBL1355547 & 737825 & 5.3 & 5.2995 & TST & \\
\hline CHEMBL275809 & 737825 & 5.1 & 4.9655 & TST & \\
\hline CHEMBL1334106 & 737825 & 6.0 & 5.9472 & TST & \\
\hline CHEMBL1409446 & 737825 & 6.1 & 5.2079 & TST & \\
\hline CHEMBL1565610 & 737825 & 6.6 & 5.3442 & TST & \\
\hline CHEMBL1518164 & 737825 & 4.9 & 4.8965 & TST & \\
\hline
\end{tabular}




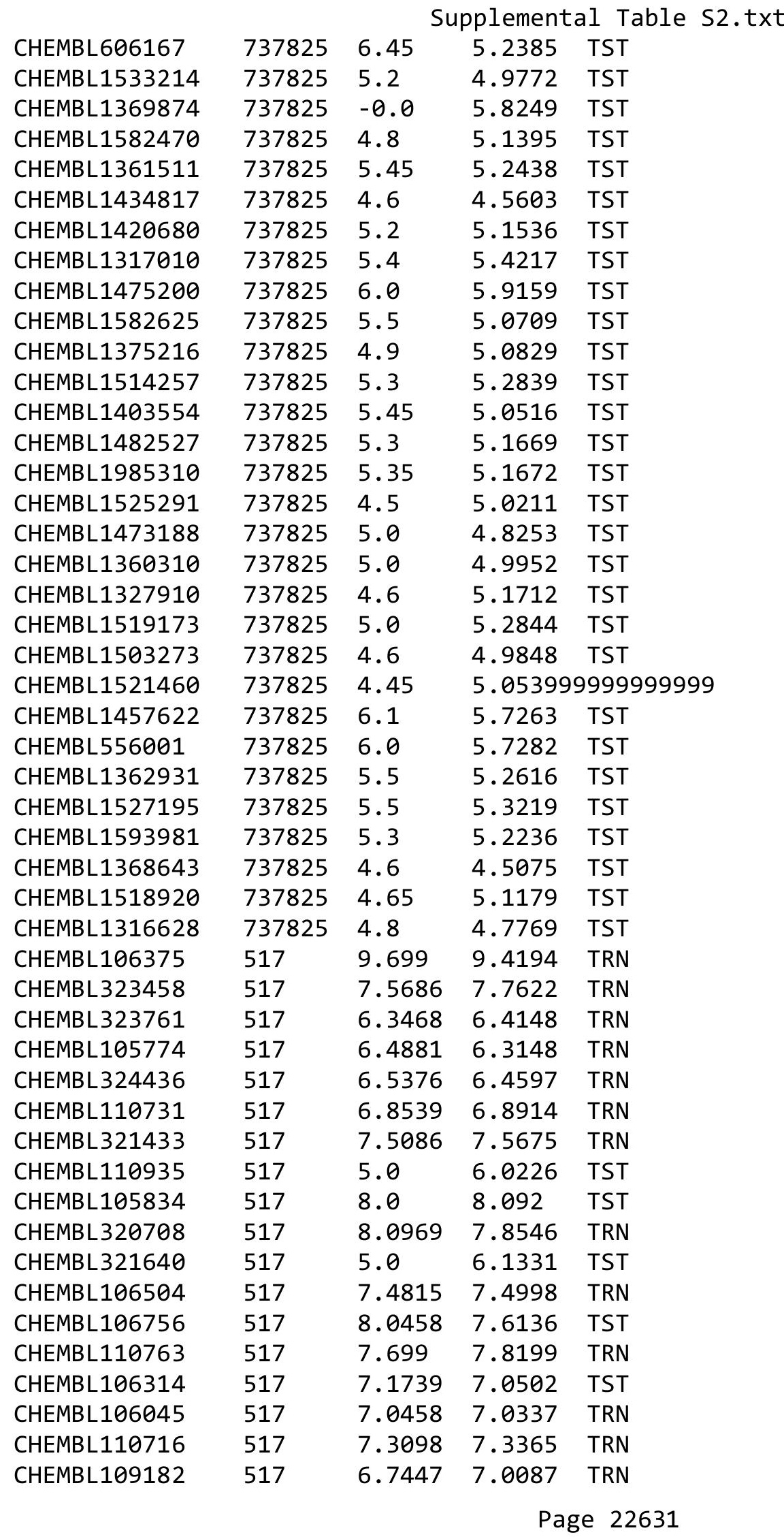




\begin{tabular}{|c|c|c|c|c|c|}
\hline \multicolumn{6}{|c|}{ Supplemental Table S2.txt } \\
\hline CHEMBL107365 & 517 & 7.9208 & 8.4425 & TST & \\
\hline CHEMBL106784 & 517 & 8.3979 & 8.3718 & TRN & \\
\hline CHEMBL110166 & 517 & 7.2924 & 7.3114 & TRN & \\
\hline CHEMBL321483 & 517 & 7.3188 & 7.3549 & TRN & \\
\hline CHEMBL320327 & 517 & 5.0 & 5.0314 & TRN & \\
\hline CHEMBL106581 & 517 & 7.7447 & 7.9297 & TRN & \\
\hline CHEMBL423140 & 517 & 6.2218 & 5.4305 & TST & \\
\hline CHEMBL323173 & 517 & 6.75200 & 000000006 & 7.6444 & TST \\
\hline CHEMBL316549 & 517 & 6.8697 & 5.923999 & 99999999995 & TST \\
\hline CHEMBL322536 & 517 & 5.0 & 4.8858 & TRN & \\
\hline CHEMBL106503 & 517 & 6.699 & 6.5949 & TRN & \\
\hline CHEMBL106987 & 517 & 7.1367 & 7.1241 & TRN & \\
\hline CHEMBL317643 & 517 & 6.7696 & 6.7838 & TRN & \\
\hline CHEMBL110343 & 517 & 8.699 & 8.763 & TRN & \\
\hline CHEMBL323419 & 517 & 7.0088 & 7.1879 & TRN & \\
\hline CHEMBL325369 & 517 & 6.9208 & 6.8248 & TRN & \\
\hline CHEMBL108207 & 517 & 7.2147 & 7.1727 & TRN & \\
\hline CHEMBL321903 & 517 & 7.6576 & 7.7622 & TRN & \\
\hline CHEMBL108568 & 517 & 7.2518 & 7.2448 & TRN & \\
\hline CHEMBL110597 & 517 & 6.7212 & 6.9253 & TST & \\
\hline CHEMBL110596 & 517 & 6.0969 & 6.0216 & TRN & \\
\hline CHEMBL108325 & 517 & 7.6198 & 7.3992 & TRN & \\
\hline CHEMBL107197 & 517 & 8.5229 & 7.0888 & TST & \\
\hline CHEMBL322794 & 517 & 8.0 & 8.0236 & TRN & \\
\hline CHEMBL419197 & 517 & 7.8861 & 7.9355 & TRN & \\
\hline CHEMBL317407 & 517 & 8.3979 & 8.3748 & TRN & \\
\hline CHEMBL106927 & 517 & 5.0 & 5.0915 & TRN & \\
\hline CHEMBL107712 & 517 & 6.8239 & 6.752000 & 0000000001 & 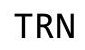 \\
\hline CHEMBL320700 & 517 & 6.3979 & 6.4224 & TRN & \\
\hline CHEMBL106200 & 517 & 6.7212 & 6.2439 & TST & \\
\hline CHEMBL317242 & 517 & 6.5229 & 6.7056 & TST & \\
\hline CHEMBL110717 & 517 & 6.8239 & 6.8702 & TRN & \\
\hline CHEMBL110388 & 517 & 5.0 & 5.1635 & TRN & \\
\hline CHEMBL106729 & 517 & 6.6676 & 6.8968 & TRN & \\
\hline CHEMBL106319 & 517 & 6.6091 & 6.5216 & TRN & \\
\hline CHEMBL110322 & 517 & 7.0458 & 7.1256 & TRN & \\
\hline CHEMBL324434 & 517 & 5.0 & 5.1494 & TRN & \\
\hline CHEMBL109116 & 517 & 7.1249 & 6.8968 & TRN & \\
\hline CHEMBL322780 & 517 & 6.1838 & 6.218 & TRN & \\
\hline CHEMBL106420 & 517 & 6.0 & 7.1452 & TST & \\
\hline CHEMBL320525 & 517 & 7.5528 & 7.1466 & TRN & \\
\hline CHEMBL320249 & 517 & 8.301 & 8.3435 & TRN & \\
\hline CHEMBL107352 & 517 & 5.0 & 4.9433 & TRN & \\
\hline CHEMBL107235 & 517 & 5.0 & 6.5727 & TST & \\
\hline CHEMBL108326 & 517 & 5.8962 & 5.9849 & TST & \\
\hline CHEMBL322051 & 517 & 5.0 & 7.2009 & TST & \\
\hline CHEMBL110428 & 517 & 6.4202 & 6.4666 & TRN & \\
\hline CHEMBL108519 & 517 & 7.3979 & 7.3107 & TRN & \\
\hline
\end{tabular}




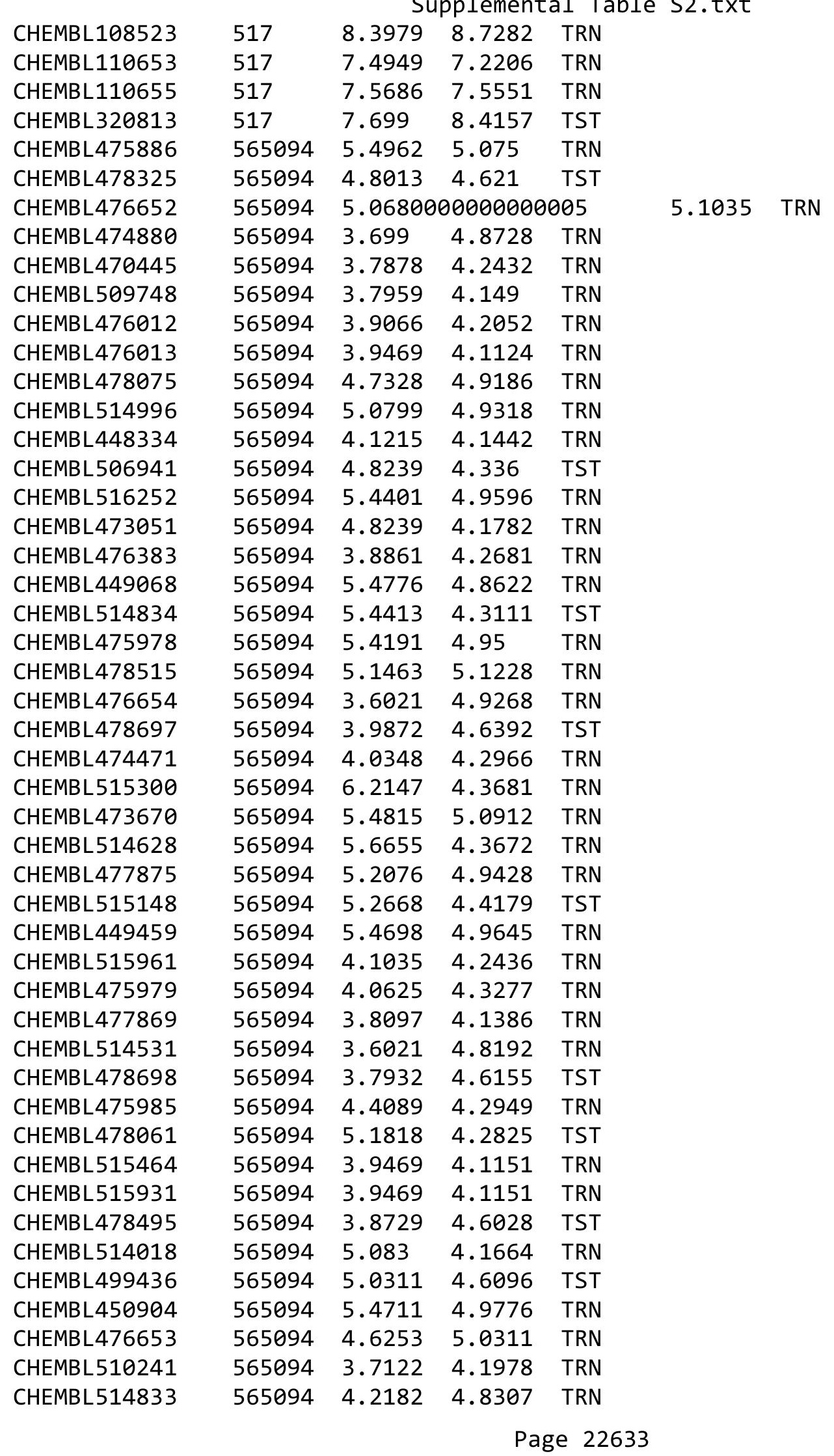




\begin{tabular}{|c|c|c|c|c|c|}
\hline & & & oplement & al Table S & \\
\hline CHEMBL507262 & 565094 & 3.7905 & 4.9071 & TRN & \\
\hline CHEMBL476390 & 565094 & 5.5436 & 4.21399 & 99999999995 & TST \\
\hline CHEMBL478128 & 565094 & 5.6308 & 4.9186 & TRN & \\
\hline CHEMBL474071 & 565094 & 5.9281 & 4.9681 & TRN & \\
\hline CHEMBL449379 & 565094 & 4.1238 & 4.8742 & TRN & \\
\hline CHEMBL476234 & 565094 & 5.5143 & 5.1087 & TRN & \\
\hline CHEMBL476061 & 565094 & 4.6556 & 5.0352 & TRN & \\
\hline CHEMBL478494 & 565094 & 3.7852 & 4.7556 & TST & \\
\hline CHEMBL478060 & 565094 & 4.2418 & 4.3101 & TST & \\
\hline CHEMBL476027 & 565094 & 5.0809 & 5.0943 & TRN & \\
\hline CHEMBL514079 & 565094 & 3.9318 & 4.6395 & TST & \\
\hline CHEMBL476068 & 565094 & 5.4609 & 4.8159 & TST & \\
\hline CHEMBL336232 & 165094 & 6.301 & 6.5037 & TRN & \\
\hline CHEMBL140546 & 165094 & 5.5229 & 5.2614 & TRN & \\
\hline CHEMBL140411 & 165094 & 3.0 & 2.6597 & TST & \\
\hline CHEMBL140488 & 165094 & 4.7212 & 4.0813 & TRN & \\
\hline CHEMBL139433 & 165094 & 6.0 & 6.2234 & TRN & \\
\hline CHEMBL138668 & 165094 & 5.6021 & 4.5152 & TST & \\
\hline CHEMBL140489 & 165094 & 3.0 & 4.5081 & TRN & \\
\hline CHEMBL345036 & 165094 & 6.0 & 4.9437 & TRN & \\
\hline CHEMBL139225 & 165094 & 5.6021 & 5.5111 & TRN & \\
\hline CHEMBL138553 & 165094 & 3.0 & 2.7856 & TRN & \\
\hline CHEMBL138555 & 165094 & 6.2218 & 6.0097 & TRN & \\
\hline CHEMBL344219 & 165094 & 4.5086 & 4.2061 & TRN & \\
\hline CHEMBL138420 & 165094 & 5.4437 & 5.5237 & TRN & \\
\hline CHEMBL140657 & 165094 & 6.0 & 5.3378 & TST & \\
\hline CHEMBL342169 & 165094 & 5.2218 & 4.3199 & TST & \\
\hline CHEMBL142091 & 165094 & 6.5229 & 6.0402 & TRN & \\
\hline CHEMBL141859 & 165094 & 3.5229 & 4.5112 & TST & \\
\hline CHEMBL138563 & 165094 & 5.0 & 5.1501 & TRN & \\
\hline CHEMBL138307 & 165094 & 6.0 & 5.7281 & TRN & \\
\hline CHEMBL138444 & 165094 & 5.699 & 5.3732 & TRN & \\
\hline CHEMBL341550 & 165094 & 5.5229 & 2.2609 & TST & \\
\hline CHEMBL140883 & 165094 & 4.5086 & 3.4293 & TST & \\
\hline CHEMBL141978 & 165094 & 4.8239 & 4.0562 & TST & \\
\hline CHEMBL423360 & 165094 & 3.71 & 3.8345 & TRN & \\
\hline CHEMBL142035 & 165094 & 5.6576 & 5.0605 & TRN & \\
\hline CHEMBL141735 & 165094 & 6.2218 & 6.278 & TRN & \\
\hline CHEMBL344250 & 165094 & 5.9586 & 6.2263 & TRN & \\
\hline CHEMBL139628 & 165094 & 6.1549 & 6.2429 & TRN & \\
\hline CHEMBL138021 & 165094 & 6.0 & 4.4882 & TST & \\
\hline CHEMBL140658 & 165094 & 5.3979 & 5.1846 & TRN & \\
\hline CHEMBL434456 & 165094 & 6.301 & 6.518 & TRN & \\
\hline CHEMBL141957 & 165094 & 4.301 & 4.8068 & TRN & \\
\hline CHEMBL142140 & 165094 & 6.3979 & 6.5878 & TRN & \\
\hline CHEMBL140688 & 165094 & 5.5229 & 5.7109 & TRN & \\
\hline CHEMBL138559 & 165094 & 6.0 & 5.0124 & TRN & \\
\hline CHEMBL138148 & 165094 & 4.6778 & 4.9472 & TRN & \\
\hline
\end{tabular}




\begin{tabular}{|c|c|c|c|c|c|}
\hline & & & & & \\
\hline CHEMBL141264 & 165094 & 5.9586 & 6.0902 & TRN & \\
\hline CHEMBL139138 & 165094 & 5.9586 & 5.9726 & TRN & \\
\hline CHEMBL335350 & 165094 & 4.4949 & 3.9611 & TST & \\
\hline CHEMBL140714 & 165094 & 6.0 & 6.4264 & TRN & \\
\hline CHEMBL336258 & 165094 & 4.6021 & 4.9093 & TRN & \\
\hline CHEMBL342856 & 165094 & 5.5229 & 5.7585 & TRN & \\
\hline CHEMBL343307 & 165094 & 5.699 & 5.5028 & TRN & \\
\hline CHEMBL141427 & 165094 & 3.0 & 2.7649 & TST & \\
\hline CHEMBL139018 & 165094 & 5.0458 & 5.0756 & TRN & \\
\hline CHEMBL139197 & 165094 & 3.0 & 3.6751 & TRN & \\
\hline CHEMBL138196 & 165094 & 6.0 & 5.9912 & TRN & \\
\hline CHEMBL137943 & 165094 & 6.301 & 6.4691 & TRN & \\
\hline CHEMBL140923 & 165094 & 6.5229 & 6.6658 & TRN & \\
\hline CHEMBL139408 & 165094 & 5.5229 & 6.1735 & TRN & \\
\hline CHEMBL138250 & 165094 & 3.0 & 3.3281 & TRN & \\
\hline CHEMBL138554 & 165094 & 5.5229 & 5.0701 & TRN & \\
\hline CHEMBL140951 & 165094 & 3.0 & 2.5348 & TRN & \\
\hline CHEMBL140836 & 165094 & 5.6383 & 5.5653 & TRN & \\
\hline CHEMBL344406 & 165094 & 5.699 & 5.3797 & TRN & \\
\hline CHEMBL343109 & 165094 & 3.0 & 3.3091 & TRN & \\
\hline CHEMBL138702 & 165094 & 5.699 & 5.8017 & TRN & \\
\hline CHEMBL140772 & 165094 & 6.301 & 5.5834 & TRN & \\
\hline CHEMBL140889 & 165094 & 5.3768 & 2.6248 & TST & \\
\hline CHEMBL138701 & 165094 & 6.0 & 5.2643 & TRN & \\
\hline CHEMBL139148 & 165094 & 4.2147 & 4.6415 & TRN & \\
\hline CHEMBL140604 & 165094 & 5.4318 & 4.6896 & TST & \\
\hline CHEMBL414616 & 165094 & 3.6383 & 3.6223 & TRN & \\
\hline CHEMBL141807 & 165094 & 4.7212 & 4.5497 & TRN & \\
\hline CHEMBL141355 & 165094 & 6.0969 & 5.3559 & TRN & \\
\hline CHEMBL138606 & 165094 & 5.2218 & 4.4442 & TST & \\
\hline CHEMBL138748 & 165094 & 4.9208 & 3.3257 & TST & \\
\hline CHEMBL344025 & 165094 & 3.0 & 4.46399 & 99999999995 & TRN \\
\hline CHEMBL139135 & 165094 & 6.301 & 6.2156 & TRN & \\
\hline CHEMBL342046 & 165094 & 3.0 & 3.2741 & TRN & \\
\hline CHEMBL138248 & 165094 & 4.0915 & 3.9727 & TRN & \\
\hline CHEMBL138507 & 165094 & 3.0 & 4.1304 & TST & \\
\hline CHEMBL138290 & 165094 & 4.585 & 5.4093 & TST & \\
\hline CHEMBL334908 & 165094 & 3.9208 & 4.0107 & TST & \\
\hline CHEMBL344655 & 165094 & 6.0 & 6.1577 & TST & \\
\hline CHEMBL1509707 & 688692 & 4.4 & 4.7834 & TRN & \\
\hline CHEMBL1363633 & 688692 & 5.0 & 5.1947 & TRN & \\
\hline CHEMBL1576392 & 688692 & 6.05 & 5.6384 & TRN & \\
\hline CHEMBL1512538 & 688692 & 4.85 & 5.1424 & TST & \\
\hline CHEMBL1333944 & 688692 & 5.4 & 5.5572 & TRN & \\
\hline CHEMBL1435662 & 688692 & 4.45 & 5.088 & TRN & \\
\hline CHEMBL1605269 & 688692 & 5.15 & 4.8475 & TST & \\
\hline CHEMBL1313356 & 688692 & 4.95 & 4.8534 & TRN & \\
\hline CHEMBL461622 & 688692 & 5.15 & 5.2342 & TRN & \\
\hline
\end{tabular}




\begin{tabular}{|c|c|c|c|c|c|}
\hline \multicolumn{6}{|c|}{ Supplemental Table S2.txt } \\
\hline CHEMBL1592419 & 688692 & 5.3 & 5.2872 & TRN & \\
\hline CHEMBL1489990 & 688692 & 4.15 & 4.3601 & TRN & \\
\hline CHEMBL1360508 & 688692 & 4.45 & 5.0288 & TRN & \\
\hline CHEMBL1338115 & 688692 & 4.45 & 4.5255 & TRN & \\
\hline CHEMBL1523317 & 688692 & 4.4 & 4.5693 & TRN & \\
\hline CHEMBL1555483 & 688692 & 6.15 & 6.0976 & TRN & \\
\hline CHEMBL1523420 & 688692 & 4.75 & 4.6216 & TRN & \\
\hline CHEMBL1487571 & 688692 & 5.85 & 5.1436 & TRN & \\
\hline CHEMBL1324177 & 688692 & 4.9 & 4.7954 & TRN & \\
\hline CHEMBL1372464 & 688692 & 4.4 & 4.6234 & TRN & \\
\hline CHEMBL1575084 & 688692 & 4.3 & 4.6355 & TST & \\
\hline CHEMBL1437387 & 688692 & 5.9 & 5.6133 & TRN & \\
\hline CHEMBL1437644 & 688692 & 5.4 & 5.0463 & TRN & \\
\hline CHEMBL1593876 & 688692 & 4.9 & 4.8729 & TST & \\
\hline CHEMBL1360979 & 688692 & 5.2 & 5.2761 & TRN & \\
\hline CHEMBL1607032 & 688692 & 4.3 & 4.1742 & TRN & \\
\hline CHEMBL1478967 & 688692 & 4.9 & 4.8382 & TRN & \\
\hline CHEMBL1374242 & 688692 & 5.1 & 5.1416 & TRN & \\
\hline CHEMBL1392875 & 688692 & 4.25 & 5.0224 & TRN & \\
\hline CHEMBL1395110 & 688692 & 4.75 & 4.7648 & TST & \\
\hline CHEMBL1607263 & 688692 & 5.05 & 5.1317 & TRN & \\
\hline CHEMBL3191602 & 688692 & 5.05 & 4.8394 & TST & \\
\hline CHEMBL1572845 & 688692 & 4.55 & 4.1842 & TRN & \\
\hline CHEMBL1468886 & 688692 & 4.6 & 4.2627 & TRN & \\
\hline CHEMBL1315022 & 688692 & 5.35 & 5.5252 & TRN & \\
\hline CHEMBL1525233 & 688692 & 4.2 & 4.623 & TRN & \\
\hline CHEMBL1562251 & 688692 & 5.05 & 5.2685 & TRN & \\
\hline CHEMBL1414089 & 688692 & 5.2 & 5.2073 & TRN & \\
\hline CHEMBL1417290 & 688692 & 4.85 & 5.0219 & TST & \\
\hline CHEMBL1331665 & 688692 & 5.2 & 5.3027 & TRN & \\
\hline CHEMBL1405919 & 688692 & 5.95 & 5.0966 & TRN & \\
\hline CHEMBL1406350 & 688692 & 4.75 & 5.0593 & TRN & \\
\hline CHEMBL1513778 & 688692 & 6.05 & 5.7994 & TRN & \\
\hline CHEMBL1384803 & 688692 & 4.8 & 4.5847 & TRN & \\
\hline CHEMBL1397200 & 688692 & 4.3 & 4.7913 & TST & \\
\hline CHEMBL1598092 & 688692 & 5.15 & 4.4404 & TST & \\
\hline CHEMBL1448371 & 688692 & 5.45 & 5.3498 & TRN & \\
\hline CHEMBL1455993 & 688692 & 4.3 & 4.3904 & TRN & \\
\hline CHEMBL1346932 & 688692 & 4.45 & 4.5964 & TRN & \\
\hline CHEMBL1370182 & 688692 & 4.45 & 4.3974 & TRN & \\
\hline CHEMBL1338049 & 688692 & 5.15 & 4.4842 & TRN & \\
\hline CHEMBL1584975 & 688692 & 4.35 & 4.3341 & TRN & \\
\hline CHEMBL1339042 & 688692 & 4.3 & 4.3492 & TRN & \\
\hline CHEMBL1329974 & 688692 & 5.55 & 5.4516 & TRN & \\
\hline CHEMBL1363585 & 688692 & 4.2 & 4.2563 & TRN & \\
\hline CHEMBL1339433 & 688692 & 5.55 & 5.0175 & TRN & \\
\hline CHEMBL1395042 & 688692 & 4.25 & 4.42399 & 99999999995 & TRN \\
\hline CHEMBL1593746 & 688692 & 5.15 & 5.3349 & TRN & \\
\hline
\end{tabular}




\begin{tabular}{|c|c|c|c|c|c|}
\hline \multirow{3}{*}{$\begin{array}{l}\text { CHEMBL } 1487660 \\
\text { CHEMBL } 1367795\end{array}$} & \multirow{3}{*}{$\begin{array}{l}688692 \\
688692\end{array}$} & \multicolumn{4}{|c|}{ Supplemental Table s2.txt } \\
\hline & & 5.1 & \multicolumn{2}{|c|}{5.452999999999999} & \multirow{2}{*}{ TRN } \\
\hline & & 4.6 & 4.6321 & TRN & \\
\hline CHEMBL1320902 & 688692 & 5.05 & 4.8864 & TST & \\
\hline CHEMBL3192031 & 688692 & 5.8 & 5.499 & TST & \\
\hline CHEMBL1509389 & 688692 & 4.9 & 4.6071 & TST & \\
\hline CHEMBL1416512 & 688692 & 5.5 & 5.3199 & TRN & \\
\hline CHEMBL3197999 & 688692 & 4.3 & 4.6467 & TST & \\
\hline CHEMBL1469728 & 688692 & 4.3 & 4.2577 & TST & \\
\hline CHEMBL1540929 & 688692 & 5.15 & 5.2474 & TST & \\
\hline CHEMBL1098087 & 688692 & 5.45 & 5.6349 & TST & \\
\hline CHEMBL525953 & 688692 & 5.9 & 5.4108 & TST & \\
\hline CHEMBL1589350 & 688692 & 4.15 & 4.8071 & TST & \\
\hline CHEMBL96212 & 77063 & 2.4948 & 4.5942 & TST & \\
\hline CHEMBL95006 & 77063 & 4.5528 & 3.5307 & TST & \\
\hline CHEMBL 327828 & 77063 & 5.301 & 5.6176 & TRN & \\
\hline CHEMBL95019 & 77063 & 4.7447 & 3.6905 & TST & \\
\hline CHEMBL96930 & 77063 & 6.0506 & 5.9917 & TRN & \\
\hline CHEMBL98733 & 77063 & 3.0 & 2.94 & TRN & \\
\hline CHEMBL320457 & 77063 & 4.7959 & 3.8614 & TRN & \\
\hline CHEMBL96177 & 77063 & 4.3768 & 4.6058 & TRN & \\
\hline CHEMBL318125 & 77063 & 5.4949 & 5.6518 & TRN & \\
\hline CHEMBL264531 & 77063 & 3.8013 & 3.7525 & TRN & \\
\hline CHEMBL97329 & 77063 & 3.6021 & 3.6646 & TRN & \\
\hline CHEMBL97274 & 77063 & 4.7959 & 4.9353 & TRN & \\
\hline CHEMBL96933 & 77063 & 2.4948 & 2.73100 & 00000000003 & TRN \\
\hline CHEMBL93875 & 77063 & 5.4437 & 5.98 & TRN & \\
\hline CHEMBL96380 & 77063 & 2.4948 & 2.8399 & TRN & \\
\hline CHEMBL323529 & 77063 & 4.3279 & 4.199 & TRN & \\
\hline CHEMBL97820 & 77063 & 4.9586 & 4.6488 & TRN & \\
\hline CHEMBL96211 & 77063 & 3.3565 & 4.8916 & TST & \\
\hline CHEMBL94740 & 77063 & 5.5229 & 5.0656 & TRN & \\
\hline CHEMBL 327603 & 77063 & 2.4948 & 2.9712 & TRN & \\
\hline CHEMBL320456 & 77063 & 5.3979 & 4.9295 & TRN & \\
\hline CHEMBL 262762 & 77063 & 5.3979 & 5.49100 & 00000000005 & TRN \\
\hline CHEMBL328796 & 77063 & 4.7696 & 4.0745 & TRN & \\
\hline CHEMBL 94688 & 77063 & 4.7959 & 5.1831 & TST & \\
\hline CHEMBL264800 & 77063 & 4.3468 & 4.6985 & TRN & \\
\hline CHEMBL329736 & 77063 & 4.2518 & 4.4227 & TRN & \\
\hline CHEMBL319826 & 77063 & 4.6576 & 4.4633 & TRN & \\
\hline CHEMBL328433 & 77063 & 5.4949 & 5.5226 & TRN & \\
\hline CHEMBL94875 & 77063 & 4.301 & 4.257 & TRN & \\
\hline CHEMBL405139 & 77063 & 3.0 & 4.6054 & TST & \\
\hline CHEMBL97647 & 77063 & 4.6576 & 4.3962 & TRN & \\
\hline CHEMBL94981 & 77063 & 3.699 & 3.8751 & TRN & \\
\hline CHEMBL94757 & 77063 & 2.4948 & 5.0929 & TST & \\
\hline CHEMBL 328211 & 77063 & 2.4948 & 2.3509 & TRN & \\
\hline CHEMBL275760 & 77063 & 4.2518 & 4.0916 & TRN & \\
\hline CHEMBL97514 & 77063 & 4.0 & 3.7652 & TRN & \\
\hline & & & & 22637 & \\
\hline
\end{tabular}




\begin{tabular}{|c|c|c|c|c|c|}
\hline \multicolumn{6}{|c|}{ Supplemental Table S2.txt } \\
\hline CHEMBL330437 & 77063 & 5.8539 & 5.6729 & TRN & \\
\hline CHEMBL317763 & 77063 & 5.2518 & 4.9292 & TRN & \\
\hline CHEMBL19648 & 77063 & 6.2676 & 6.2302 & TRN & \\
\hline CHEMBL264749 & 77063 & 2.4948 & 3.3045 & TRN & \\
\hline CHEMBL318039 & 77063 & 5.7959 & 6.2097 & TRN & \\
\hline CHEMBL97278 & 77063 & 6.2518 & 5.8975 & TRN & \\
\hline CHEMBL263231 & 77063 & 3.8996 & 4.3083 & TRN & \\
\hline CHEMBL96445 & 77063 & 3.0 & 3.8868 & TRN & \\
\hline CHEMBL96682 & 77063 & 2.4948 & 2.4597 & TRN & \\
\hline CHEMBL319844 & 77063 & 4.4949 & 4.7484 & TRN & \\
\hline CHEMBL50384 & 77063 & 3.0 & 4.335 & TST & \\
\hline CHEMBL94049 & 77063 & 5.6198 & 5.6601 & TRN & \\
\hline CHEMBL330155 & 77063 & 2.4948 & 2.2152 & TRN & \\
\hline CHEMBL328482 & 77063 & 5.7696 & 5.4229 & TRN & \\
\hline CHEMBL94576 & 77063 & 4.7447 & 4.5036 & TRN & \\
\hline CHEMBL96388 & 77063 & 6.1487 & 4.0739 & TST & \\
\hline CHEMBL96446 & 77063 & 6.301 & 6.3586 & TRN & \\
\hline CHEMBL91239 & 77063 & 2.4948 & 2.3048 & TRN & \\
\hline CHEMBL 262510 & 77063 & 3.0 & 3.0158 & TST & \\
\hline CHEMBL94503 & 77063 & 3.0 & 4.6217 & TST & \\
\hline CHEMBL319205 & 77063 & 2.4948 & 5.5109 & TST & \\
\hline CHEMBL 94660 & 77063 & 5.284 & 5.2435 & TST & \\
\hline CHEMBL96553 & 77063 & 5.7447 & 4.2181 & TST & \\
\hline CHEMBL95000 & 77063 & 5.699 & 5.0697 & TST & \\
\hline CHEMBL95181 & 77063 & 2.4948 & 5.4196 & TST & \\
\hline CHEMBL367382 & 63688 & 6.0799 & 6.1129 & TRN & \\
\hline CHEMBL 368829 & 63688 & 7.0 & 6.9426 & TRN & \\
\hline CHEMBL366885 & 63688 & 6.1831 & 6.3353 & TRN & \\
\hline CHEMBL176999 & 63688 & 6.4365 & 6.6017 & TRN & \\
\hline CHEMBL172184 & 63688 & 5.71 & 5.2634 & TRN & \\
\hline CHEMBL368929 & 63688 & 6.1273 & 6.6535 & TRN & \\
\hline CHEMBL175005 & 63688 & 5.5272 & 5.5582 & TRN & \\
\hline CHEMBL368996 & 63688 & 7.8861 & 7.3743 & TRN & \\
\hline CHEMBL176664 & 63688 & 5.9872 & 5.6129 & TRN & \\
\hline CHEMBL173358 & 63688 & 7.3565 & 7.3213 & TRN & \\
\hline CHEMBL173465 & 63688 & 6.0443 & 5.7929 & TRN & \\
\hline CHEMBL174326 & 63688 & 5.3391 & 5.145 & TRN & \\
\hline CHEMBL177143 & 63688 & 6.0846 & 6.3498 & TRN & \\
\hline CHEMBL170342 & 63688 & 6.7375 & 6.6483 & TST & \\
\hline CHEMBL94786 & 63688 & 7.3768 & 7.2684 & TRN & \\
\hline CHEMBL264035 & 63688 & 7.5528 & 7.7243 & TST & \\
\hline CHEMBL 275897 & 63688 & 6.6271 & 6.9211 & TRN & \\
\hline CHEMBL367339 & 63688 & 5.6809 & 5.62299 & э999999999 & TRN \\
\hline CHEMBL 368989 & 63688 & 6.684 & 6.5563 & TST & \\
\hline CHEMBL368386 & 63688 & 6.9101 & 6.8896 & TRN & \\
\hline CHEMBL176963 & 63688 & 5.0 & 5.3848 & TRN & \\
\hline CHEMBL139734 & 63688 & 6.7011 & 6.6307 & TRN & \\
\hline CHEMBL369362 & 63688 & 6.2132 & 6.0078 & TST & \\
\hline
\end{tabular}




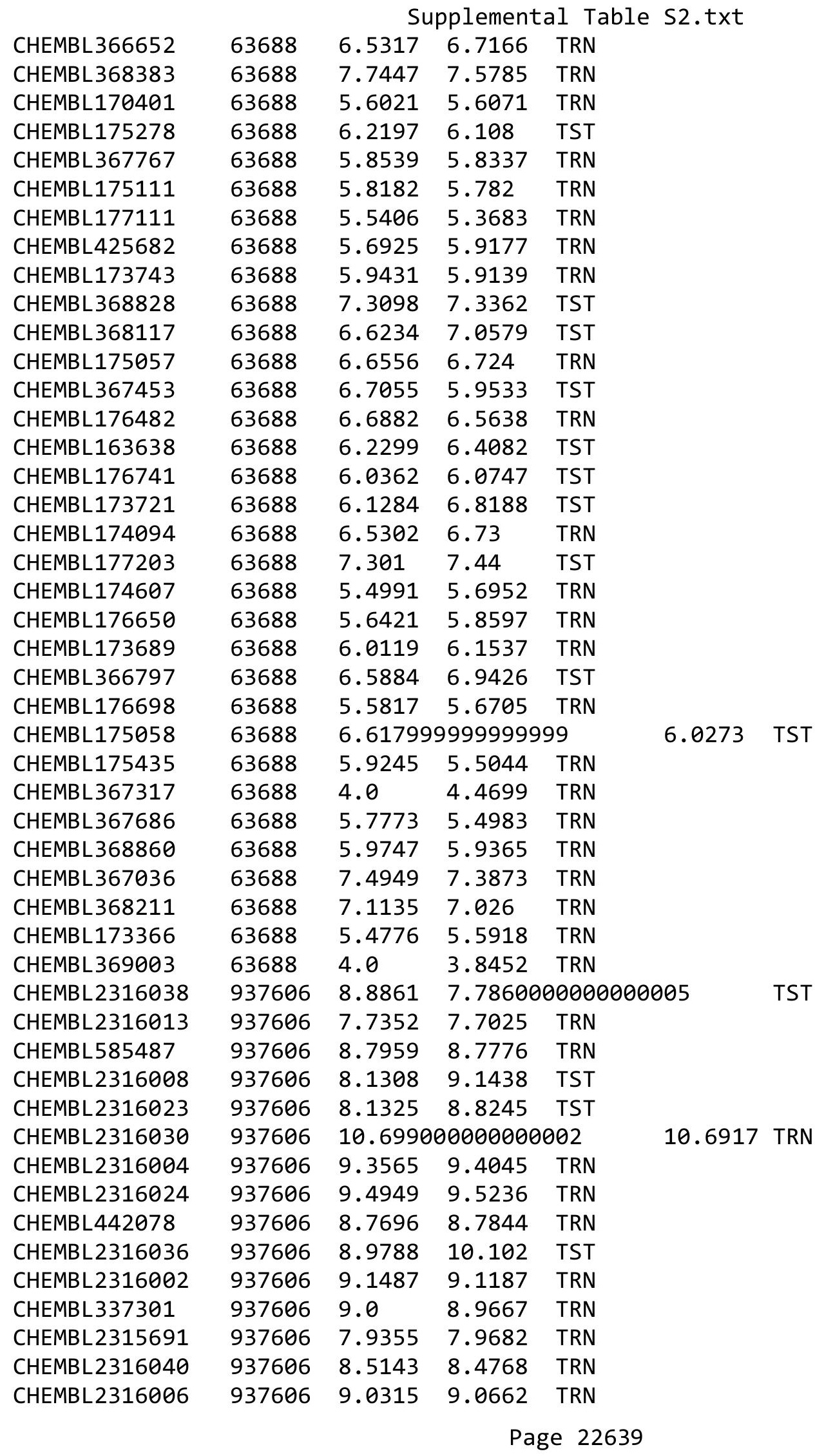




\begin{tabular}{|c|c|c|c|c|c|c|}
\hline & & \multicolumn{5}{|c|}{ Supplemental Table s2.txt } \\
\hline CHEMBL2316011 & 937606 & 9.0555 & 9.0603 & TRN & & \\
\hline CHEMBL 2316034 & 937606 & 10.0 & 10.0806 & TRN & & \\
\hline CHEMBL2316033 & 937606 & 10.3979 & 10.3894 & TRN & & \\
\hline CHEMBL2315686 & 937606 & 9.2291 & 9.2322 & TRN & & \\
\hline CHEMBL2315689 & 937606 & 7.6271 & 7.6509 & TRN & & \\
\hline CHEMBL2316009 & 937606 & 9.4949 & 9.4763 & TRN & & \\
\hline CHEMBL 2316026 & 937606 & 9.5686 & 9.5538 & TRN & & \\
\hline CHEMBL2316027 & 937606 & 9.3665 & 9.3462 & TRN & & \\
\hline CHEMBL2315693 & 937606 & 9.6778 & 9.6706 & TRN & & \\
\hline CHEMBL585498 & 937606 & 6.2366 & 6.2379 & TRN & & \\
\hline CHEMBL2316031 & 937606 & 9.7447 & 9.7373 & TRN & & \\
\hline CHEMBL2316028 & 937606 & 8.4685 & 8.4968 & TRN & & \\
\hline CHEMBL 2316020 & 937606 & \multicolumn{3}{|c|}{9.283999999999999} & 9.2943 & TRN \\
\hline CHEMBL2315690 & 937606 & 7.9747 & 7.9613 & TRN & & \\
\hline CHEMBL2316037 & 937606 & 7.3344 & 7.3818 & TRN & & \\
\hline CHEMBL 2316003 & 937606 & 9.7212 & 9.68 & TRN & & \\
\hline CHEMBL2316022 & 937606 & 9.2007 & 9.2052 & TRN & & \\
\hline CHEMBL571578 & 937606 & 9.0969 & 8.7033 & TST & & \\
\hline CHEMBL567570 & 937606 & 8.3098 & 8.3181 & TRN & & \\
\hline CHEMBL2316025 & 937606 & 9.1675 & 9.1888 & TRN & & \\
\hline CHEMBL 2316012 & 937606 & 9.0506 & 9.0493 & TRN & & \\
\hline CHEMBL2316014 & 937606 & 7.9101 & 7.9018 & TRN & & \\
\hline CHEMBL2315684 & 937606 & 9.5086 & 9.6108 & TRN & & \\
\hline CHEMBL2316019 & 937606 & 9.699 & 9.7353 & TRN & & \\
\hline CHEMBL2315687 & 937606 & 7.9666 & 7.9521 & TRN & & \\
\hline CHEMBL 2315694 & 937606 & 9.4685 & 9.4514 & TRN & & \\
\hline CHEMBL2316001 & 937606 & 9.5086 & 9.4525 & TRN & & \\
\hline CHEMBL 2316041 & 937606 & 8.4711 & 8.4588 & TRN & & \\
\hline CHEMBL 2316010 & 937606 & 9.1938 & 9.1735 & TRN & & \\
\hline CHEMBL2316021 & 937606 & 8.6055 & 8.6034 & TRN & & \\
\hline CHEMBL 2311584 & 937606 & 9.4089 & 9.4261 & TRN & & \\
\hline CHEMBL2316032 & 937606 & 10.0 & 9.98299 & 9999999999 & & TRN \\
\hline CHEMBL2316039 & 937606 & 8.9136 & 8.9102 & TRN & & \\
\hline CHEMBL2316016 & 937606 & 9.5376 & 9.4636 & TST & & \\
\hline CHEMBL2315685 & 937606 & 8.2725 & 8.2481 & TRN & & \\
\hline CHEMBL2316018 & 937606 & 10.0458 & 9.2131 & TST & & \\
\hline CHEMBL2315688 & 937606 & 9.6778 & 9.5972 & TRN & & \\
\hline CHEMBL2316015 & 937606 & 10.6990 & 00000000 & 002 & 9.6127 & TST \\
\hline CHEMBL2316017 & 937606 & 9.6778 & 9.4259 & TST & & \\
\hline CHEMBL2316029 & 937606 & 7.21399 & 99999999 & 995 & 9.0626 & TST \\
\hline CHEMBL 2316005 & 937606 & 9.3372 & 9.0554 & TST & & \\
\hline CHEMBL2315683 & 937606 & 8.7986 & 9.3304 & TST & & \\
\hline CHEMBL2315692 & 937606 & 9.6198 & 10.0349 & TST & & \\
\hline CHEMBL2316007 & 937606 & 8.76700 & 000000006 & & 8.7993 & TST \\
\hline CHEMBL583867 & 937606 & 7.6576 & 6.7862 & TST & & \\
\hline CHEMBL 2316035 & 937606 & 9.7447 & 10.165 & TST & & \\
\hline CHEMBL389689 & 440669 & 5.5686 & 5.4809 & TRN & & \\
\hline CHEMBL242871 & 440669 & 3.0 & 3.4309 & TRN & & \\
\hline
\end{tabular}




\begin{tabular}{|c|c|c|c|c|}
\hline \multicolumn{5}{|c|}{ Supplemental Table S2.txt } \\
\hline CHEMBL389445 & 440669 & 3.0 & 3.2545 & TRN \\
\hline CHEMBL 396776 & 440669 & 3.0 & 3.2146 & TRN \\
\hline CHEMBL 228877 & 440669 & 3.0 & 3.1728 & TRN \\
\hline CHEMBL 228765 & 440669 & 3.0 & 3.0425 & TRN \\
\hline CHEMBL 228922 & 440669 & 3.0 & 3.0965 & TRN \\
\hline CHEMBL268532 & 440669 & 3.0 & 2.8476 & TRN \\
\hline CHEMBL 229080 & 440669 & 4.3936 & 4.2195 & TRN \\
\hline CHEMBL 228873 & 440669 & 5.3372 & 5.0031 & TRN \\
\hline CHEMBL 388072 & 440669 & 3.0 & 2.5955 & TRN \\
\hline CHEMBL426909 & 440669 & 4.0872 & 3.6216 & TRN \\
\hline CHEMBL228533 & 440669 & 3.0 & 3.0998 & TRN \\
\hline CHEMBL 389471 & 440669 & 5.1739 & 5.6809 & TST \\
\hline CHEMBL438679 & 440669 & 3.0 & 3.0615 & TRN \\
\hline CHEMBL 387903 & 440669 & 4.9914 & 4.9337 & TRN \\
\hline CHEMBL 427465 & 440669 & 3.0 & 2.8275 & TRN \\
\hline CHEMBL228930 & 440669 & 4.7878 & 4.2404 & TRN \\
\hline CHEMBL 228982 & 440669 & 3.0 & 3.6334 & TRN \\
\hline CHEMBL 228532 & 440669 & 5.3768 & 5.4593 & TRN \\
\hline CHEMBL 228868 & 440669 & 3.0 & 2.9852 & TRN \\
\hline CHEMBL442226 & 440669 & 3.0 & 2.9043 & TST \\
\hline CHEMBL 228640 & 440669 & 3.0 & 3.29600 & 00000000003 \\
\hline CHEMBL 228609 & 440669 & 3.0 & 3.1557 & TST \\
\hline CHEMBL 228906 & 440669 & 3.0 & 2.8094 & TST \\
\hline CHEMBL 228425 & 440669 & 3.0 & 2.8357 & TRN \\
\hline CHEMBL 228446 & 440669 & 4.248 & 3.7291 & TRN \\
\hline CHEMBL 229026 & 440669 & 4.5638 & 4.7228 & TRN \\
\hline CHEMBL 228974 & 440669 & 3.0 & 2.9808 & TRN \\
\hline CHEMBL 243751 & 440669 & 5.6778 & 5.3626 & TRN \\
\hline CHEMBL 229027 & 440669 & 3.0 & 3.0126 & TRN \\
\hline CHEMBL 228531 & 440669 & 3.0 & 3.0262 & TST \\
\hline CHEMBL229028 & 440669 & 3.0 & 2.9261 & TRN \\
\hline CHEMBL 228476 & 440669 & 3.0 & 2.9918 & TST \\
\hline CHEMBL 228975 & 440669 & 3.0 & 3.4891 & TST \\
\hline CHEMBL 228905 & 440669 & 3.0 & 2.7988 & TRN \\
\hline CHEMBL 228589 & 440669 & 3.0 & 2.9941 & TRN \\
\hline CHEMBL228931 & 440669 & 4.8327 & 3.3148 & TRN \\
\hline CHEMBL 228590 & 440669 & 3.0 & 3.3628 & TRN \\
\hline CHEMBL 229079 & 440669 & 5.6198 & 5.5637 & TRN \\
\hline CHEMBL 268533 & 440669 & 3.0 & 3.2605 & TRN \\
\hline CHEMBL 390523 & 440669 & 5.3872 & 5.7402 & TRN \\
\hline CHEMBL448429 & 440669 & 3.0 & 2.9648 & TST \\
\hline CHEMBL 228698 & 440669 & 5.1427 & 4.8176 & TST \\
\hline CHEMBL 243533 & 440669 & 3.0 & 3.6316 & TRN \\
\hline CHEMBL 390744 & 440669 & 3.0 & 3.0055 & TST \\
\hline CHEMBL 228448 & 440669 & 3.0 & 3.3069 & TRN \\
\hline CHEMBL 397225 & 440669 & 3.0 & 3.0475 & TRN \\
\hline CHEMBL 228879 & 440669 & 4.6421 & 4.5451 & TRN \\
\hline CHEMBL 387902 & 440669 & 4.5607 & 2.8392 & TST \\
\hline
\end{tabular}




\begin{tabular}{|c|c|c|c|c|c|}
\hline \multirow[b]{2}{*}{ CHEMBL228819 } & \multicolumn{5}{|c|}{ Supplemental Table S2.txt } \\
\hline & 440669 & 3.0 & 3.1963 & TRN & \\
\hline CHEMBL228714 & 440669 & 3.0 & 2.9096 & TRN & \\
\hline CHEMBL228820 & 440669 & 4.2832 & 3.4354 & TRN & \\
\hline CHEMBL228556 & 440669 & 3.0 & 2.9404 & TST & \\
\hline CHEMBL242659 & 440669 & 3.0 & 3.7273 & TRN & \\
\hline CHEMBL397019 & 440669 & 3.0 & 3.6673 & TRN & \\
\hline CHEMBL228923 & 440669 & 3.0 & 3.0932 & TRN & \\
\hline CHEMBL228871 & 440669 & 3.0 & 2.8283 & TRN & \\
\hline CHEMBL 228475 & 440669 & 3.0 & 2.7497 & TST & \\
\hline CHEMBL228921 & 440669 & 3.0 & 3.3658 & TRN & \\
\hline CHEMBL228973 & 440669 & 3.0 & 2.9596 & TRN & \\
\hline CHEMBL 228662 & 440669 & 3.0 & 3.2582 & TRN & \\
\hline CHEMBL390522 & 440669 & 3.0 & 2.8936 & TST & \\
\hline CHEMBL228869 & 440669 & 3.0 & 2.8622 & TST & \\
\hline CHEMBL228557 & 440669 & 3.0 & 3.2775 & TST & \\
\hline CHEMBL3959158 & 1642539 & 8.699 & 8.8919 & TRN & \\
\hline CHEMBL3893731 & 1642539 & 8.6021 & 9.4416 & TRN & \\
\hline CHEMBL3933835 & 1642539 & 9.0969 & 8.8798 & TRN & \\
\hline CHEMBL 3982877 & 1642539 & 8.2676 & 8.0989 & TRN & \\
\hline CHEMBL3899562 & 1642539 & 8.8861 & 8.5909 & TRN & \\
\hline CHEMBL3952882 & 1642539 & 6.0 & 8.7672 & TRN & \\
\hline CHEMBL3939027 & 1642539 & 9.699 & 9.2873 & TRN & \\
\hline CHEMBL3923163 & 1642539 & 9.3979 & 8.80600 & $\partial 000000001$ & TRN \\
\hline CHEMBL3900216 & 1642539 & 8.3979 & 8.613 & TRN & \\
\hline CHEMBL3986616 & 1642539 & 8.2007 & 8.3704 & TRN & \\
\hline CHEMBL3913546 & 1642539 & 7.3872 & 7.4777 & TRN & \\
\hline CHEMBL3927972 & 1642539 & 8.4437 & 8.0512 & TRN & \\
\hline CHEMBL3984487 & 1642539 & 8.0969 & 8.3082 & TRN & \\
\hline CHEMBL 3974768 & 1642539 & 9.1549 & 9.0565 & TRN & \\
\hline CHEMBL3924423 & 1642539 & 8.3188 & 8.1301 & TRN & \\
\hline CHEMBL3982144 & 1642539 & 8.4815 & 8.4307 & TRN & \\
\hline CHEMBL3977481 & 1642539 & 8.585 & 8.73200 & 0000000001 & TRN \\
\hline CHEMBL3981164 & 1642539 & 8.1549 & 7.8754 & TRN & \\
\hline CHEMBL3921992 & 1642539 & 7.5157 & 7.61299 & 99999999995 & TRN \\
\hline CHEMBL3953610 & 1642539 & 9.2218 & 9.1177 & TRN & \\
\hline CHEMBL3895315 & 1642539 & 8.7959 & 8.3309 & TRN & \\
\hline CHEMBL3897438 & 1642539 & 7.9706 & 7.8325 & TRN & \\
\hline CHEMBL3895913 & 1642539 & 8.1367 & 8.2159 & TST & \\
\hline CHEMBL 3915828 & 1642539 & 8.1871 & 8.1552 & TST & \\
\hline CHEMBL3896785 & 1642539 & 8.28399 & 99999999 & 8.3685 & TRN \\
\hline CHEMBL3895318 & 1642539 & 9.301 & 9.0567 & TRN & \\
\hline CHEMBL3910319 & 1642539 & 8.7696 & 9.5365 & TRN & \\
\hline CHEMBL3972492 & 1642539 & 8.585 & 8.2732 & TRN & \\
\hline CHEMBL 3905231 & 1642539 & 8.8539 & 8.824 & TRN & \\
\hline CHEMBL3969708 & 1642539 & 8.2518 & 8.245 & TRN & \\
\hline CHEMBL3926825 & 1642539 & 9.3979 & 9.0875 & TRN & \\
\hline CHEMBL3948521 & 1642539 & 9.3979 & 8.721 & TST & \\
\hline CHEMBL3963299 & 1642539 & 8.0506 & 8.4374 & TRN & \\
\hline
\end{tabular}


Supplemental Table S2.txt

\begin{tabular}{|c|c|c|c|c|}
\hline CHEMBL3950183 & 1642539 & 9.2218 & 8.6121 & TST \\
\hline CHEMBL3907683 & 1642539 & 8.5086 & 7.8165 & TST \\
\hline CHEMBL3899986 & 1642539 & 7.5171 & 7.4619 & TRN \\
\hline CHEMBL3943891 & 1642539 & 8.3188 & 8.4424 & TRN \\
\hline CHEMBL3962177 & 1642539 & 10.0 & 9.5957 & TRN \\
\hline CHEMBL3986343 & 1642539 & 8.4318 & 8.3975 & TRN \\
\hline CHEMBL3946336 & 1642539 & 8.585 & 8.6081 & TRN \\
\hline CHEMBL3932365 & 1642539 & 8.2596 & 8.3825 & TRN \\
\hline CHEMBL3922012 & 1642539 & 8.8539 & 8.9803 & TST \\
\hline CHEMBL3919335 & 1642539 & 8.2218 & 7.9436 & TST \\
\hline CHEMBL3955665 & 1642539 & 8.4815 & 8.4184 & TRN \\
\hline CHEMBL3958671 & 1642539 & 8.2676 & 8.5612 & TRN \\
\hline CHEMBL3924829 & 1642539 & 8.3872 & 8.4958 & TST \\
\hline CHEMBL 3925884 & 1642539 & 8.3468 & 8.4552 & TRN \\
\hline CHEMBL 3893406 & 1642539 & 9.0 & 8.7648 & TRN \\
\hline CHEMBL3909481 & 1642539 & 8.6021 & 8.602 & TRN \\
\hline CHEMBL3987095 & 1642539 & 7.5513 & 7.5645 & TRN \\
\hline CHEMBL3895186 & 1642539 & 8.699 & 8.7414 & TRN \\
\hline CHEMBL3963771 & 1642539 & 8.1079 & 8.2034 & TRN \\
\hline CHEMBL3933511 & 1642539 & 8.6778 & 8.9463 & TRN \\
\hline CHEMBL3925264 & 1642539 & 6.06 & 6.7279 & TST \\
\hline CHEMBL3910210 & 1642539 & 7.4609 & 7.3392 & TRN \\
\hline CHEMBL3909456 & 1642539 & 9.1367 & 8.6449 & TRN \\
\hline CHEMBL3986585 & 1642539 & 9.5229 & 9.517006 & 0000000001 \\
\hline CHEMBL3931942 & 1642539 & 9.3979 & 9.2296 & TRN \\
\hline CHEMBL3921458 & 1642539 & 7.9872 & 7.8499 & TST \\
\hline CHEMBL3946925 & 1642539 & 7.8477 & 7.92200 & 0000000001 \\
\hline CHEMBL3976870 & 1642539 & 8.0706 & 8.0247 & TRN \\
\hline CHEMBL3941685 & 1642539 & 8.2366 & 8.4056 & TRN \\
\hline CHEMBL 3910402 & 1642539 & 8.3872 & 8.4716 & TRN \\
\hline CHEMBL3916526 & 1642539 & 9.0458 & 8.9361 & TST \\
\hline CHEMBL 3937324 & 1642539 & 7.7959 & 7.831 & TRN \\
\hline CHEMBL3941604 & 1642539 & 8.585 & 8.6955 & TRN \\
\hline CHEMBL3985580 & 1642539 & 7.9281 & 8.0958 & TRN \\
\hline CHEMBL3889600 & 1642539 & 6.0 & 7.6047 & TRN \\
\hline CHEMBL3939255 & 1642539 & 8.1487 & 8.0685 & TRN \\
\hline CHEMBL3891165 & 1642539 & 8.1135 & 8.0066 & TRN \\
\hline CHEMBL3900211 & 1642539 & 8.6021 & 8.624 & TRN \\
\hline CHEMBL3907925 & 1642539 & 9.0969 & 8.9585 & TRN \\
\hline CHEMBL3987018 & 1642539 & 7.0132 & 7.6877 & TST \\
\hline CHEMBL3905181 & 1642539 & 8.3872 & 8.7455 & TRN \\
\hline CHEMBL3981952 & 1642539 & 9.5229 & 9.4803 & TRN \\
\hline CHEMBL3913183 & 1642539 & 8.1612 & 8.279 & TRN \\
\hline CHEMBL3975556 & 1642539 & 8.3372 & 8.1642 & TRN \\
\hline CHEMBL3977152 & 1642539 & 7.8356 & 7.7517 & TST \\
\hline CHEMBL3981818 & 1642539 & 8.2518 & 7.9921 & TST \\
\hline CHEMBL 3898566 & 1642539 & 6.3615 & 7.3839 & TRN \\
\hline CHEMBL3929204 & 1642539 & 8.3665 & 8.4374 & TRN \\
\hline
\end{tabular}


Supplemental Table S2.txt

\begin{tabular}{|c|c|c|}
\hline 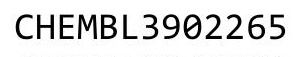 & 39 & \\
\hline CHEMBL3906580 & 642539 & \\
\hline HEMBL3932627 & 642539 & \\
\hline HEMBL3907589 & 1642539 & \\
\hline HEMBL3923060 & 1642539 & \\
\hline HEMBL3962919 & 1642539 & \\
\hline HEMBL3902286 & 1642539 & \\
\hline HEMBL3969521 & 1642539 & \\
\hline AEMBL3900391 & 1642539 & \\
\hline HEMBL3925387 & 539 & \\
\hline HEMBL3935382 & 1642539 & \\
\hline HEMBL3915816 & 1642539 & \\
\hline HEMBL3963973 & 539 & 9 \\
\hline HEMBL 3909877 & 539 & \\
\hline CHEMBL 3983364 & 539 & \\
\hline CHEMBL 3930261 & 539 & \\
\hline CHEMBL3936977 & 539 & \\
\hline CHEMBL3964687 & 539 & 8 \\
\hline CHEMBL3951515 & 539 & \\
\hline LHEMBL3907142 & 539 & \\
\hline CHEMBL3914746 & 539 & \\
\hline CHEMBL3967723 & 539 & \\
\hline CHEMBL3941721 & 16 & \\
\hline CHEMBL3913000 & 539 & \\
\hline CHEMBL3965423 & 539 & \\
\hline CHEMBL3903876 & 539 & 8. \\
\hline CHEMBL3916656 & 164 & 9.3 \\
\hline CHEMBL 3936537 & 16 & \\
\hline CHEMBL3980426 & 16 & \\
\hline CHEMBL3889723 & 539 & \\
\hline CHEMBL 3974872 & 539 & \\
\hline CHEMBL3934241 & 539 & 9. \\
\hline CHEMBL3960227 & 39 & \\
\hline CHEMBL3970214 & 16 & \\
\hline CHEMBL 3922374 & 539 & \\
\hline CHEMBL3912884 & 1642539 & 9.0 \\
\hline CHEMBL 3899096 & 1642539 & 8.3 \\
\hline CHEMBL3938867 & 16 & 9.3 \\
\hline CHEMBL 3949364 & 16 & 9.0 \\
\hline CHEMBL 3947948 & 1642539 & \\
\hline CHEMBL3926405 & 1642539 & 9.6 \\
\hline CHEMBL3930043 & 164 & \\
\hline CHEMBL3972305 & 1642539 & \\
\hline CHEMBL3915283 & 1642539 & 9.36 \\
\hline CHEMBL3939825 & 1642539 & $8.76-r-1$ \\
\hline CHEMBL3932369 & 1642539 & 9.0 \\
\hline CHEMBL3960818 & 1642539 & \\
\hline CHEMBL392351] & & \\
\hline
\end{tabular}

8

9.5662 TRN

9.2329 TRN

8.5214 TST

8.154 TRN

8.8447 TST

8.3064 TRN

8.5706 TST

8.203 TRN

9.6809 TRN

8.7906 TST

8.9039 TST

9.3159 TRN

8.8403 TRN

8.7712 TRN

7.8754 TRN

8.3519 TST

7.8495 TRN

8.3563 TST

8.3725 TRN

8.502 TRN

8.3306 TRN

8.1856 TRN

8.2763 TRN

7.9777 TST

7.2125 TST

8.8882 TST

8.9203 TRN

8.1742 TRN

8.3024 TRN

8.2329 TRN

8.4661 TRN

8.836 TRN

8.3122 TRN

8.3563 TRN

8.6999 TRN

9.8418 TRN

8.8622 TST

9.0962 TRN

8.487 TRN

8.6835 TRN

9.3235 TRN

8.3496 TRN

8.3961 TRN

8.9418 TRN

8.6414 TRN

8.6569 TST

8.2639 TRN

7.867999999999999 TRN

Page 22644 
Supplemental Table S2.txt

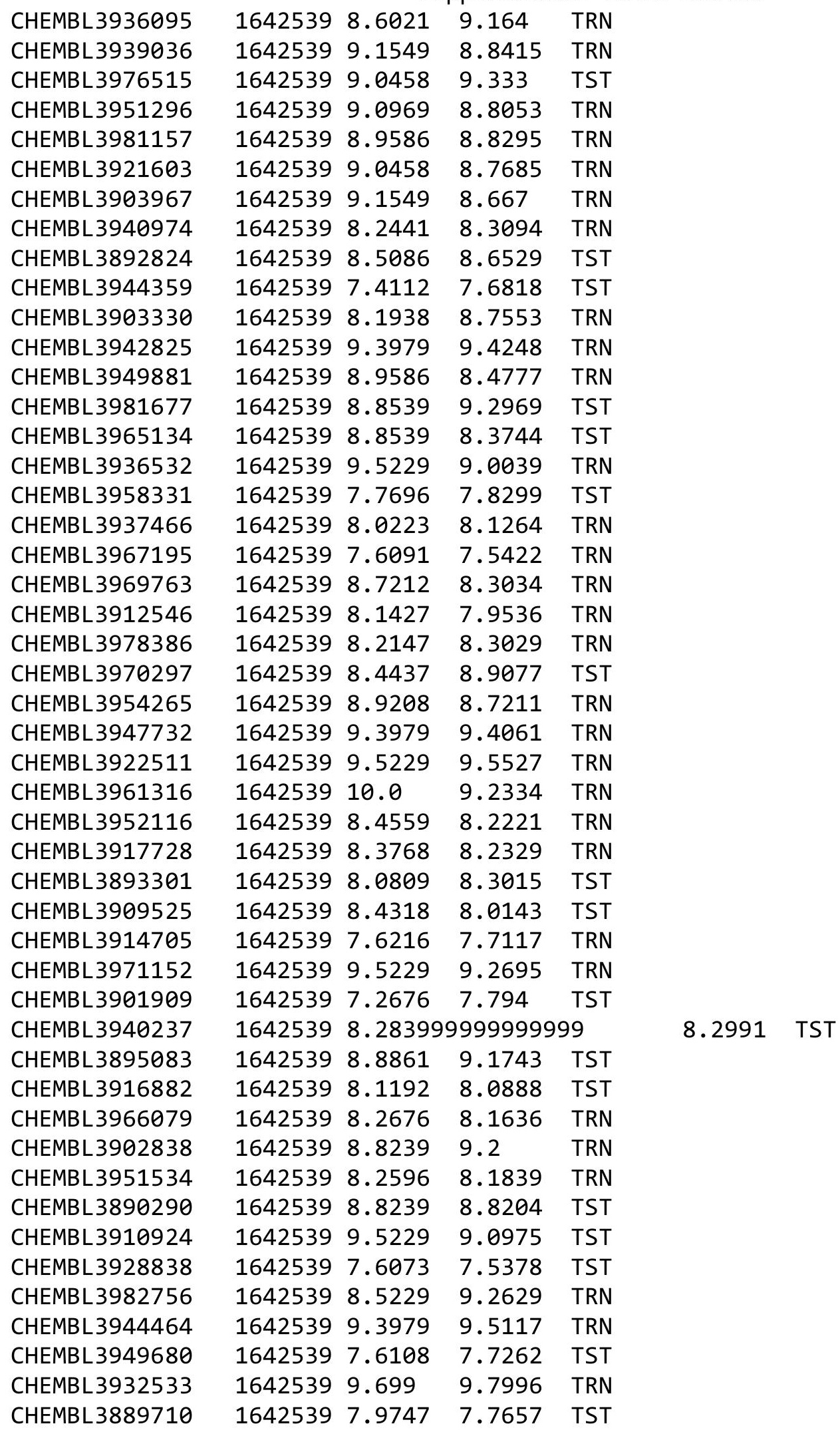

Page 22645 
Supplemental Table S2.txt

\begin{tabular}{|c|c|c|c|c|}
\hline CHEMBL 3893281 & 1642539 & 9.301 & 8.9774 & TRN \\
\hline CHEMBL 3889846 & 1642539 & 9.0458 & 8.7611 & TST \\
\hline CHEMBL3896955 & 1642539 & 8.7696 & 8.7065 & TRN \\
\hline CHEMBL3943491 & 1642539 & 9.5229 & 9.3031 & TRN \\
\hline CHEMBL 3978116 & 1642539 & 9.5229 & 9.8088 & TRN \\
\hline CHEMBL 3981324 & 1642539 & 8.5528 & 8.3189 & TST \\
\hline CHEMBL3957543 & 1642539 & 8.8539 & 9.2044 & TRN \\
\hline CHEMBL3904017 & 1642539 & 8.3768 & 8.1856 & TST \\
\hline CHEMBL 3894100 & 1642539 & 7.7959 & 7.7397 & TST \\
\hline CHEMBL 3902451 & 1642539 & 8.2441 & 8.3557 & TRN \\
\hline CHEMBL 3893155 & 1642539 & 8.4815 & 7.8756 & TST \\
\hline CHEMBL3959875 & 1642539 & 8.1308 & 8.3818 & TRN \\
\hline CHEMBL3919122 & 1642539 & 8.3565 & 8.1182 & TRN \\
\hline CHEMBL3935757 & 1642539 & 8.7212 & 8.4672 & TRN \\
\hline CHEMBL 3953061 & 1642539 & 8.5528 & 8.4829 & TRN \\
\hline CHEMBL3975103 & 1642539 & 8.4202 & 8.6112 & TRN \\
\hline CHEMBL3909742 & 1642539 & 8.8539 & 8.531 & TRN \\
\hline CHEMBL3940555 & 1642539 & 8.7696 & 9.1264 & TRN \\
\hline CHEMBL 3938335 & 1642539 & 7.8416 & 8.2456 & TRN \\
\hline CHEMBL1812515 & 761927 & 4.3979 & 4.409 & TRN \\
\hline CHEMBL1812539 & 761927 & 6.0 & 6.0226 & TRN \\
\hline CHEMBL1812519 & 761927 & 2.699 & 2.7087 & TRN \\
\hline CHEMBL1812526 & 761927 & 4.301 & 4.3097 & TRN \\
\hline CHEMBL168956 & 761927 & 5.301 & 5.3089 & TRN \\
\hline CHEMBL1812653 & 761927 & 2.699 & 3.8209 & TST \\
\hline CHEMBL46724 & 761927 & 3.0969 & 2.4738 & TST \\
\hline CHEMBL1812514 & 761927 & 2.699 & 2.6935 & TRN \\
\hline CHEMBL1812507 & 761927 & 3.3979 & 3.4018 & TRN \\
\hline CHEMBL1812659 & 761927 & 3.0969 & 1.6538 & TST \\
\hline CHEMBL1812513 & 761927 & 4.3979 & 4.3943 & TRN \\
\hline CHEMBL1812545 & 761927 & 5.699 & 5.7001 & TRN \\
\hline CHEMBL1812529 & 761927 & 2.699 & 2.7065 & TRN \\
\hline CHEMBL441669 & 761927 & 6.0 & 5.9689 & TRN \\
\hline CHEMBL1812521 & 761927 & 2.699 & 2.7444 & TRN \\
\hline CHEMBL1812497 & 761927 & 2.699 & 2.7159 & TRN \\
\hline CHEMBL1812658 & 761927 & 3.0969 & 3.5806 & TST \\
\hline CHEMBL435072 & 761927 & 5.5229 & 5.5501 & TRN \\
\hline CHEMBL1812527 & 761927 & 2.699 & 2.6824 & TRN \\
\hline CHEMBL1812547 & 761927 & 5.5229 & 5.5206 & TRN \\
\hline CHEMBL1812504 & 761927 & 2.699 & 2.7134 & TRN \\
\hline CHEMBL1812500 & 761927 & 2.699 & 1.8701 & TST \\
\hline CHEMBL1812522 & 761927 & 2.699 & 2.6737 & TRN \\
\hline CHEMBL1812530 & 761927 & 2.699 & 2.7143 & TRN \\
\hline CHEMBL1812508 & 761927 & 2.699 & 2.7182 & TRN \\
\hline CHEMBL1812550 & 761927 & 3.0969 & \multicolumn{2}{|c|}{3.1060000000000003} \\
\hline CHEMBL1812498 & 761927 & 4.7447 & 4.7474 & TRN \\
\hline CHEMBL1812512 & 761927 & 4.699 & 4.7133 & TRN \\
\hline CHEMBL1812551 & 761927 & 3.0969 & 3.0757 & TRN \\
\hline
\end{tabular}

Page 22646 


\begin{tabular}{|c|c|c|c|c|c|}
\hline \multirow[b]{2}{*}{ CHEMBL1812549 } & \multicolumn{5}{|c|}{ Supplemental Table S2.txt } \\
\hline & 761927 & 3.0969 & 3.117 & TRN & \\
\hline CHEMBL1812534 & 761927 & 2.699 & 2.699 & TRN & \\
\hline CHEMBL1812518 & 761927 & 2.699 & 2.68399 & 99999999997 & TRN \\
\hline CHEMBL1812501 & 761927 & 2.699 & 4.2091 & TST & \\
\hline CHEMBL1812535 & 761927 & 5.0 & 4.9853 & TRN & \\
\hline CHEMBL1812506 & 761927 & 5.0 & 4.9792 & TRN & \\
\hline CHEMBL171548 & 761927 & 4.699 & 4.7094 & TRN & \\
\hline CHEMBL1812495 & 761927 & 2.699 & 0.9374 & TST & \\
\hline CHEMBL1812499 & 761927 & 2.699 & 2.7082 & TRN & \\
\hline CHEMBL1812544 & 761927 & 5.0 & 5.011 & TRN & \\
\hline CHEMBL445966 & 761927 & 4.7447 & 4.7473 & TRN & \\
\hline CHEMBL1812525 & 761927 & 2.699 & 2.72899 & 99999999996 & TRN \\
\hline CHEMBL1812502 & 761927 & 2.699 & -0.2155 & TST & \\
\hline CHEMBL1812528 & 761927 & 3.699 & 3.7034 & TRN & \\
\hline CHEMBL1812533 & 761927 & 4.3979 & 4.3932 & TRN & \\
\hline CHEMBL1812524 & 761927 & 2.699 & 2.6846 & TRN & \\
\hline CHEMBL166509 & 761927 & 4.699 & 4.673 & TRN & \\
\hline CHEMBL1812543 & 761927 & 5.5229 & 5.5121 & TRN & \\
\hline CHEMBL1812546 & 761927 & 5.699 & 5.6956 & TRN & \\
\hline CHEMBL1812520 & 761927 & 4.699 & 4.6761 & TRN & \\
\hline CHEMBL1812656 & 761927 & 3.0969 & 3.5242 & TST & \\
\hline CHEMBL1812553 & 761927 & 4.0969 & 4.1591 & TST & \\
\hline CHEMBL1812536 & 761927 & 2.699 & 2.7292 & TRN & \\
\hline CHEMBL355606 & 761927 & 6.0 & 5.9956 & TRN & \\
\hline CHEMBL1812655 & 761927 & 3.0969 & 2.59 & TST & \\
\hline CHEMBL1812503 & 761927 & 2.699 & 2.6728 & TRN & \\
\hline CHEMBL1812548 & 761927 & 4.0969 & 4.0859 & TRN & \\
\hline CHEMBL1812516 & 761927 & 2.699 & 2.6851 & TRN & \\
\hline CHEMBL1812554 & 761927 & 5.2218 & 4.6749 & TST & \\
\hline CHEMBL1812552 & 761927 & 3.0969 & 3.1007 & TRN & \\
\hline CHEMBL1812532 & 761927 & 3.0969 & 3.0876 & TRN & \\
\hline CHEMBL1812537 & 761927 & 2.699 & 2.6576 & TRN & \\
\hline CHEMBL1812540 & 761927 & 5.5229 & 5.5373 & TRN & \\
\hline CHEMBL1812531 & 761927 & 5.5229 & 5.5278 & TRN & \\
\hline CHEMBL1812505 & 761927 & 2.699 & 2.7008 & TRN & \\
\hline CHEMBL1812510 & 761927 & 2.699 & 2.6949 & TRN & \\
\hline CHEMBL1812654 & 761927 & 3.0969 & 2.3745 & TST & \\
\hline CHEMBL1812517 & 761927 & 2.699 & 2.6911 & TRN & \\
\hline CHEMBL1812511 & 761927 & 2.699 & 2.6747 & TRN & \\
\hline CHEMBL1812509 & 761927 & 2.699 & 2.7696 & TST & \\
\hline CHEMBL176991 & 761927 & 4.3565 & 2.9023 & TST & \\
\hline CHEMBL1812496 & 761927 & 2.699 & 2.1962 & TST & \\
\hline CHEMBL1812523 & 761927 & 2.699 & 4.3377 & TST & \\
\hline CHEMBL1812538 & 761927 & 5.0 & 5.1962 & TST & \\
\hline CHEMBL1812657 & 761927 & 3.0969 & 3.2411 & TST & \\
\hline CHEMBL1964290 & 809183 & 6.1 & 6.3837 & TRN & \\
\hline CHEMBL2003768 & 809183 & 4.2 & 4.0749 & TRN & \\
\hline CHEMBL213505 & 809183 & 4.2 & 4.3071 & TRN & \\
\hline
\end{tabular}




\begin{tabular}{|c|c|c|c|c|}
\hline & & & pplement & al $\mathrm{Ta}$ \\
\hline CHEMBL1982880 & 809183 & 6.0 & 4.9943 & TRN \\
\hline CHEMBL1987034 & 809183 & 8.4 & 7.1402 & TRN \\
\hline CHEMBL1993941 & 809183 & 4.2 & 3.9067 & TRN \\
\hline CHEMBL377383 & 809183 & 4.2 & 3.9209 & TRN \\
\hline CHEMBL578061 & 809183 & 4.8 & 5.4929 & TRN \\
\hline CHEMBL 2005886 & 809183 & 4.2 & 4.5611 & TRN \\
\hline CHEMBL481491 & 809183 & 4.2 & 3.1948 & TST \\
\hline CHEMBL1682345 & 809183 & 6.0 & 6.0318 & TRN \\
\hline CHEMBL1973142 & 809183 & 5.4 & 4.6342 & TST \\
\hline CHEMBL1973145 & 809183 & 4.2 & 4.4698 & TRN \\
\hline CHEMBL1982924 & 809183 & 5.5 & 5.3653 & TRN \\
\hline CHEMBL2005936 & 809183 & 6.1 & 5.5338 & TRN \\
\hline CHEMBL1807515 & 809183 & 5.6 & 6.3697 & TRN \\
\hline CHEMBL1971141 & 809183 & 4.2 & 4.666 & TRN \\
\hline CHEMBL1995813 & 809183 & 4.2 & 5.6798 & TRN \\
\hline CHEMBL1979718 & 809183 & 4.2 & 4.8369 & TRN \\
\hline CHEMBL206236 & 809183 & 4.2 & 4.4731 & TRN \\
\hline CHEMBL523823 & 809183 & 6.0 & 5.6292 & TST \\
\hline CHEMBL1562756 & 809183 & 5.6 & 5.072 & TST \\
\hline CHEMBL 244378 & 809183 & 8.0 & 7.7991 & TRN \\
\hline CHEMBL 2001957 & 809183 & 4.2 & 4.2166 & TRN \\
\hline CHEMBL1969372 & 809183 & 4.2 & 4.3441 & TRN \\
\hline CHEMBL1990583 & 809183 & 4.2 & 4.4222 & TRN \\
\hline CHEMBL1986943 & 809183 & 6.8 & 6.685 & TRN \\
\hline CHEMBL 2006263 & 809183 & 6.0 & 5.3316 & TST \\
\hline CHEMBL1993584 & 809183 & 4.2 & 4.7895 & TRN \\
\hline CHEMBL1986263 & 809183 & 5.5 & 5.8395 & TRN \\
\hline CHEMBL 2000114 & 809183 & 4.2 & 3.8191 & TRN \\
\hline CHEMBL 210618 & 809183 & 4.2 & 4.6049 & TRN \\
\hline CHEMBL1998975 & 809183 & 5.0 & 4.6877 & TRN \\
\hline CHEMBL1975647 & 809183 & 5.4 & 5.7508 & TRN \\
\hline CHEMBL1968380 & 809183 & 4.2 & 4.6429 & TRN \\
\hline CHEMBL1964644 & 809183 & 4.2 & 4.2117 & TRN \\
\hline CHEMBL1981782 & 809183 & 5.5 & 4.3953 & TRN \\
\hline CHEMBL1977681 & 809183 & 6.0 & 4.9358 & TRN \\
\hline CHEMBL1970142 & 809183 & 4.2 & 3.9737 & TRN \\
\hline CHEMBL1990912 & 809183 & 4.2 & 4.6493 & TRN \\
\hline CHEMBL1988163 & 809183 & 7.4 & 6.6505 & TRN \\
\hline CHEMBL1995592 & 809183 & 4.2 & 5.0093 & TST \\
\hline CHEMBL2006493 & 809183 & 4.2 & 4.4102 & TST \\
\hline CHEMBL1982541 & 809183 & 4.2 & 4.0857 & TRN \\
\hline CHEMBL1996923 & 809183 & 4.2 & 4.4172 & TST \\
\hline CHEMBL1983449 & 809183 & 4.2 & 4.0253 & TRN \\
\hline CHEMBL1992323 & 809183 & 5.8 & 5.109 & TST \\
\hline CHEMBL1969735 & 809183 & 4.2 & 4.1185 & TRN \\
\hline CHEMBL 2003524 & 809183 & 4.2 & 4.9514 & TST \\
\hline CHEMBL 2002649 & 809183 & 4.2 & 4.9321 & TRN \\
\hline CHEMBL437747 & 809183 & 4.2 & 4.7702 & TRN \\
\hline
\end{tabular}




\begin{tabular}{|c|c|c|c|c|}
\hline \multicolumn{5}{|c|}{ lemental Table s } \\
\hline CHEMBL1995172 & 809183 & 4.2 & 4.1631 & TST \\
\hline CHEMBL507936 & 809183 & 6.1 & 4.7283 & TRN \\
\hline CHEMBL104264 & 809183 & 4.2 & 5.2904 & TST \\
\hline CHEMBL1994321 & 809183 & 4.2 & 4.3941 & TRN \\
\hline CHEMBL1997129 & 809183 & 6.4 & \multicolumn{2}{|c|}{6.922999999999999} \\
\hline CHEMBL1984788 & 809183 & 4.2 & 4.2903 & TRN \\
\hline CHEMBL451964 & 809183 & 4.2 & 4.1465 & TRN \\
\hline CHEMBL1964307 & 809183 & 5.9 & 4.4321 & TRN \\
\hline CHEMBL 2000508 & 809183 & 4.2 & 4.4283 & TRN \\
\hline CHEMBL1971694 & 809183 & 4.2 & 4.0952 & TST \\
\hline CHEMBL 2001547 & 809183 & 4.2 & 4.0943 & TRN \\
\hline CHEMBL210928 & 809183 & 4.2 & 4.1306 & TRN \\
\hline CHEMBL1994361 & 809183 & 4.2 & 4.0417 & TRN \\
\hline CHEMBL1986603 & 809183 & 4.2 & 3.9897 & TST \\
\hline CHEMBL1972840 & 809183 & 4.2 & 4.8132 & TRN \\
\hline CHEMBL 1977148 & 809183 & 4.2 & 3.8406 & TRN \\
\hline CHEMBL 2003286 & 809183 & 8.4 & 7.8284 & TRN \\
\hline CHEMBL1992306 & 809183 & 4.2 & 4.0839 & TRN \\
\hline CHEMBL 2002165 & 809183 & 4.2 & 4.1354 & TRN \\
\hline CHEMBL 2001668 & 809183 & 4.2 & 4.9786 & TST \\
\hline CHEMBL1979318 & 809183 & 4.2 & 4.1637 & TRN \\
\hline CHEMBL206382 & 809183 & 4.2 & 4.3541 & TRN \\
\hline CHEMBL1998585 & 809183 & 4.2 & 4.2938 & TRN \\
\hline CHEMBL127898 & 809183 & 4.2 & 4.4824 & TST \\
\hline CHEMBL519697 & 809183 & 4.2 & 4.7812 & TST \\
\hline CHEMBL 2004934 & 809183 & 4.2 & 4.0014 & TRN \\
\hline CHEMBL1975128 & 809183 & 6.6 & 6.2592 & TRN \\
\hline CHEMBL1996048 & 809183 & 4.2 & 4.1366 & TST \\
\hline CHEMBL1970369 & 809183 & 4.2 & 4.1916 & TRN \\
\hline CHEMBL461876 & 809183 & 6.2 & 5.5917 & TRN \\
\hline CHEMBL 2001485 & 809183 & 4.2 & 3.8578 & TRN \\
\hline CHEMBL504950 & 809183 & 4.2 & 4.8168 & TRN \\
\hline CHEMBL1966425 & 809183 & 4.2 & 4.1884 & TRN \\
\hline CHEMBL1984363 & 809183 & 4.2 & 3.9346 & TRN \\
\hline CHEMBL1978099 & 809183 & 5.6 & 5.4174 & TRN \\
\hline CHEMBL1977041 & 809183 & 4.2 & 4.7794 & TRN \\
\hline CHEMBL1968070 & 809183 & 5.7 & 4.9124 & TRN \\
\hline CHEMBL1988608 & 809183 & 5.5 & 5.1201 & TRN \\
\hline CHEMBL184847 & 809183 & 4.2 & 4.2204 & TRN \\
\hline CHEMBL1984367 & 809183 & 4.2 & 3.9589 & TRN \\
\hline CHEMBL178737 & 809183 & 4.2 & 5.2478 & TST \\
\hline CHEMBL226898 & 809183 & 6.1 & 4.8478 & TRN \\
\hline CHEMBL1982563 & 809183 & 4.2 & 4.3813 & TRN \\
\hline CHEMBL539474 & 809183 & 7.1 & 5.1017 & TST \\
\hline CHEMBL575824 & 809183 & 4.3 & 4.4785 & TRN \\
\hline CHEMBL1988387 & 809183 & 4.2 & 4.211 & TRN \\
\hline CHEMBL1997759 & 809183 & 4.2 & 4.4959 & TRN \\
\hline CHEMBL1989708 & 809183 & 4.2 & 4.2458 & TRN \\
\hline
\end{tabular}




\begin{tabular}{|c|c|c|c|c|}
\hline & & & pplement & al $\mathrm{Ta}$ \\
\hline CHEMBL1990288 & 809183 & 4.2 & 4.1876 & TRN \\
\hline CHEMBL1974803 & 809183 & 5.4 & 5.6363 & TST \\
\hline CHEMBL1970074 & 809183 & 4.2 & 4.1112 & TRN \\
\hline CHEMBL 2002635 & 809183 & 4.9 & 5.1149 & TST \\
\hline CHEMBL1825138 & 809183 & 4.2 & 4.2433 & TST \\
\hline CHEMBL1986970 & 809183 & 4.2 & 4.227 & TRN \\
\hline CHEMBL 2005112 & 809183 & 6.4 & 6.1526 & TST \\
\hline CHEMBL1958401 & 809183 & 5.4 & 5.9366 & TRN \\
\hline CHEMBL1984044 & 809183 & 4.2 & 4.4143 & TRN \\
\hline CHEMBL2003456 & 809183 & 4.2 & 4.7573 & TRN \\
\hline CHEMBL1966816 & 809183 & 7.1 & 5.7983 & TRN \\
\hline CHEMBL1972584 & 809183 & 4.2 & 3.7467 & TRN \\
\hline CHEMBL2002992 & 809183 & 4.2 & 3.6839 & TRN \\
\hline CHEMBL560813 & 809183 & 6.9 & 6.0536 & TRN \\
\hline CHEMBL1968791 & 809183 & 4.2 & 4.1583 & TRN \\
\hline CHEMBL326282 & 809183 & 4.2 & 4.6918 & TST \\
\hline CHEMBL2002682 & 809183 & 4.2 & 4.1151 & TST \\
\hline CHEMBL1992732 & 809183 & 4.2 & 4.6971 & TST \\
\hline CHEMBL1971186 & 809183 & 4.2 & 4.4596 & TRN \\
\hline CHEMBL2003482 & 809183 & 4.2 & 3.9738 & TRN \\
\hline CHEMBL1973211 & 809183 & 4.2 & 4.4431 & TRN \\
\hline CHEMBL1984700 & 809183 & 4.2 & 4.2674 & TRN \\
\hline CHEMBL 2007151 & 809183 & 4.2 & 4.4142 & TRN \\
\hline CHEMBL1972125 & 809183 & 4.2 & 4.3494 & TRN \\
\hline CHEMBL1461728 & 809183 & 5.4 & 5.4956 & TRN \\
\hline CHEMBL1976134 & 809183 & 5.8 & 5.2834 & TRN \\
\hline CHEMBL1965131 & 809183 & 5.6 & 5.0322 & TST \\
\hline CHEMBL1995448 & 809183 & 4.2 & 4.8598 & TRN \\
\hline CHEMBL1972158 & 809183 & 6.3 & 6.1359 & TRN \\
\hline CHEMBL1974457 & 809183 & 5.7 & 5.4868 & TRN \\
\hline CHEMBL 2006580 & 809183 & 5.4 & 5.4509 & TRN \\
\hline CHEMBL 2006581 & 809183 & 4.2 & 3.9339 & TRN \\
\hline CHEMBL 2006481 & 809183 & 4.2 & 4.3677 & TRN \\
\hline CHEMBL1979855 & 809183 & 4.2 & 4.8735 & TRN \\
\hline CHEMBL1970340 & 809183 & 4.2 & 4.6778 & TRN \\
\hline CHEMBL 2005186 & 809183 & 7.0 & 5.3285 & TRN \\
\hline CHEMBL1995927 & 809183 & 4.2 & 4.2472 & TST \\
\hline CHEMBL1975534 & 809183 & 4.2 & 4.1282 & TRN \\
\hline CHEMBL1993424 & 809183 & 5.3 & 5.6508 & TRN \\
\hline CHEMBL1966703 & 809183 & 4.2 & 4.2233 & TST \\
\hline CHEMBL1969561 & 809183 & 4.2 & 4.2833 & TRN \\
\hline CHEMBL1975121 & 809183 & 4.2 & 4.0192 & TRN \\
\hline CHEMBL1997023 & 809183 & 6.3 & 4.8777 & TST \\
\hline CHEMBL1964687 & 809183 & 4.2 & 3.9644 & TRN \\
\hline CHEMBL1971943 & 809183 & 4.2 & 4.4792 & TRN \\
\hline CHEMBL1999918 & 809183 & 4.2 & 4.9713 & TRN \\
\hline CHEMBL1974254 & 809183 & 4.2 & 3.8872 & TRN \\
\hline CHEMBL1988537 & 809183 & 5.6 & 4.977 & TST \\
\hline
\end{tabular}




\begin{tabular}{|c|c|c|c|c|c|}
\hline & & & & & \\
\hline CHEMBL1969049 & 809183 & 4.2 & 4.0352 & TRN & \\
\hline CHEMBL 2005828 & 809183 & 4.2 & 4.2298 & TRN & \\
\hline CHEMBL 2002240 & 809183 & 4.2 & 4.7082 & TRN & \\
\hline CHEMBL1991143 & 809183 & 4.2 & 3.8314 & TST & \\
\hline CHEMBL1998611 & 809183 & 5.9 & 4.9947 & TST & \\
\hline CHEMBL485556 & 809183 & 4.2 & 4.5793 & TST & \\
\hline CHEMBL1975900 & 809183 & 4.2 & 4.3674 & TRN & \\
\hline CHEMBL1972221 & 809183 & 4.2 & 4.6528 & TRN & \\
\hline CHEMBL 2006778 & 809183 & 5.5 & 4.6814 & TRN & \\
\hline CHEMBL378627 & 809183 & 4.2 & 4.436 & TRN & \\
\hline CHEMBL1996979 & 809183 & 5.9 & 5.0172 & TRN & \\
\hline CHEMBL1997025 & 809183 & 4.2 & 4.6853 & TRN & \\
\hline CHEMBL1968406 & 809183 & 4.2 & 3.7294 & TRN & \\
\hline CHEMBL1982476 & 809183 & 4.2 & 4.246 & TRN & \\
\hline CHEMBL1984274 & 809183 & 4.2 & 4.9669 & TST & \\
\hline CHEMBL1998545 & 809183 & 4.2 & 4.1015 & TRN & \\
\hline CHEMBL1986869 & 809183 & 4.2 & 3.8046 & TRN & \\
\hline CHEMBL 2006010 & 809183 & 4.2 & 4.9572 & TRN & \\
\hline CHEMBL1682558 & 809183 & 4.2 & 4.6335 & TRN & \\
\hline CHEMBL1990496 & 809183 & 4.2 & 3.8933 & TRN & \\
\hline CHEMBL1997623 & 809183 & 6.0 & 4.3126 & TRN & \\
\hline CHEMBL 2002479 & 809183 & 4.2 & 4.3583 & TRN & \\
\hline CHEMBL1993166 & 809183 & 4.2 & 3.8039 & TRN & \\
\hline CHEMBL1967094 & 809183 & 4.2 & 3.9406 & TRN & \\
\hline CHEMBL1966035 & 809183 & 4.2 & 4.5728 & TRN & \\
\hline CHEMBL 2003341 & 809183 & 4.2 & 3.7949 & TRN & \\
\hline CHEMBL1992644 & 809183 & 3.8 & 4.2487 & TRN & \\
\hline CHEMBL1992645 & 809183 & 4.2 & 5.6554 & TST & \\
\hline CHEMBL1982992 & 809183 & 6.0 & 5.813 & TRN & \\
\hline CHEMBL1999590 & 809183 & 4.2 & 4.6122 & TST & \\
\hline CHEMBL1981079 & 809183 & 6.4 & 6.2884 & TRN & \\
\hline CHEMBL1972276 & 809183 & 4.2 & 4.261 & TRN & \\
\hline CHEMBL1980489 & 809183 & 4.2 & 3.7769 & TRN & \\
\hline CHEMBL 2000832 & 809183 & 4.2 & 5.4212 & TRN & \\
\hline CHEMBL1967116 & 809183 & 4.2 & 4.829 & TRN & \\
\hline CHEMBL1977814 & 809183 & 4.2 & 3.8961 & TST & \\
\hline CHEMBL513846 & 809183 & 6.4 & 5.8822 & TRN & \\
\hline CHEMBL1970709 & 809183 & 4.2 & $4.1560 e$ & 0000000001 & TRN \\
\hline CHEMBL1965660 & 809183 & 6.7 & 6.6138 & TRN & \\
\hline CHEMBL1998112 & 809183 & 4.2 & 4.2396 & TRN & \\
\hline CHEMBL1969126 & 809183 & 4.2 & 4.2984 & TRN & \\
\hline CHEMBL1980896 & 809183 & 4.2 & 4.1556 & TRN & \\
\hline CHEMBL1975208 & 809183 & 4.2 & 4.272 & TST & \\
\hline CHEMBL1970104 & 809183 & 5.9 & 5.5236 & TRN & \\
\hline CHEMBL1991429 & 809183 & 4.2 & 4.4043 & TRN & \\
\hline CHEMBL1964777 & 809183 & 5.4 & 5.2837 & TRN & \\
\hline CHEMBL1971149 & 809183 & 4.2 & 4.1784 & TRN & \\
\hline CHEMBL1999714 & 809183 & 4.2 & 4.05399 & 9999999999 & TRN \\
\hline & & & & 22651 & \\
\hline
\end{tabular}




\begin{tabular}{|c|c|c|c|c|c|}
\hline \\
\hline CHEMBL1987533 & 809183 & 4.2 & 4.0858 & TRN & \\
\hline CHEMBL1994040 & 809183 & 4.2 & 4.3095 & TRN & \\
\hline CHEMBL388978 & 809183 & 5.8 & 6.2895 & TST & \\
\hline CHEMBL579246 & 809183 & 4.2 & 4.0856 & TRN & \\
\hline CHEMBL398951 & 809183 & 4.2 & 4.1267 & TST & \\
\hline CHEMBL1982506 & 809183 & 4.2 & 5.0765 & TST & \\
\hline CHEMBL2004716 & 809183 & 4.2 & 4.5095 & TRN & \\
\hline CHEMBL1968127 & 809183 & 4.2 & 4.0312 & TRN & \\
\hline CHEMBL1975233 & 809183 & 4.2 & 4.3215 & TRN & \\
\hline CHEMBL1985406 & 809183 & 4.2 & 4.5203 & TRN & \\
\hline CHEMBL 207400 & 809183 & 4.2 & 4.4289 & TST & \\
\hline CHEMBL 2000894 & 809183 & 4.2 & 4.5431 & TST & \\
\hline CHEMBL 2002553 & 809183 & 6.1 & 4.4918 & TST & \\
\hline CHEMBL1982135 & 809183 & 4.2 & 3.9299 & TRN & \\
\hline CHEMBL1976090 & 809183 & 6.1 & 5.2732 & TRN & \\
\hline CHEMBL1993243 & 809183 & 4.2 & 4.3823 & TRN & \\
\hline CHEMBL1992922 & 809183 & 4.2 & 4.2455 & TRN & \\
\hline CHEMBL 2004771 & 809183 & 4.2 & 4.3331 & TRN & \\
\hline CHEMBL399021 & 809183 & 4.2 & 4.0996 & TRN & \\
\hline CHEMBL1997597 & 809183 & 4.2 & 4.3686 & TRN & \\
\hline CHEMBL1969537 & 809183 & 7.1 & 5.1735 & TST & \\
\hline CHEMBL1976093 & 809183 & 4.2 & 4.0662 & TRN & \\
\hline CHEMBL 210032 & 809183 & 4.2 & 4.7063 & TRN & \\
\hline CHEMBL1996543 & 809183 & 4.2 & 4.1683 & TRN & \\
\hline CHEMBL1975256 & 809183 & 4.2 & 4.5482 & TST & \\
\hline CHEMBL508928 & 809183 & 4.2 & 4.8346 & TRN & \\
\hline CHEMBL1991356 & 809183 & 4.2 & 5.102 & TST & \\
\hline CHEMBL1983309 & 809183 & 4.2 & 4.2623 & TRN & \\
\hline CHEMBL 2004892 & 809183 & 5.2 & 4.8243 & TRN & \\
\hline CHEMBL1999126 & 809183 & 6.3 & 5.8889 & TST & \\
\hline CHEMBL1997503 & 809183 & 4.2 & 4.4933 & TST & \\
\hline CHEMBL116070 & 809183 & 4.2 & 5.3039 & TRN & \\
\hline CHEMBL1990821 & 809183 & 4.2 & 4.502 & TST & \\
\hline CHEMBL1970314 & 809183 & 4.2 & 4.6224 & TRN & \\
\hline CHEMBL 2004871 & 809183 & 4.2 & 4.0492 & TRN & \\
\hline CHEMBL 2004872 & 809183 & 4.2 & 4.1197 & TRN & \\
\hline CHEMBL1727312 & 809183 & 4.2 & 3.6618 & TRN & \\
\hline CHEMBL1969879 & 809183 & 4.2 & 3.6797 & TRN & \\
\hline CHEMBL1971463 & 809183 & 5.4 & 5.3294 & TST & \\
\hline CHEMBL1981720 & 809183 & 5.7 & 5.4664 & TRN & \\
\hline CHEMBL419932 & 809183 & 4.2 & 4.7412 & TRN & \\
\hline CHEMBL262433 & 809183 & 4.2 & 3.9186 & TRN & \\
\hline CHEMBL 306380 & 809183 & 4.2 & 4.2656 & TRN & \\
\hline CHEMBL1966722 & 809183 & 5.8 & 5.1025 & TST & \\
\hline CHEMBL1975500 & 809183 & 5.9 & 5.5976 & TRN & \\
\hline CHEMBL1976328 & 809183 & 4.2 & 4.0638 & TRN & \\
\hline CHEMBL394619 & 809183 & 4.2 & 4.4755 & TRN & \\
\hline CHEMBL1964399 & 809183 & 6.5 & 6.23600 & 0000000001 & TRN \\
\hline & & & & 22652 & \\
\hline
\end{tabular}




\begin{tabular}{|c|c|c|c|c|c|}
\hline & & & & & \\
\hline CHEMBL1996831 & 809183 & 6.3 & 5.1814 & TST & \\
\hline CHEMBL411903 & 809183 & 4.2 & 4.0559 & TRN & \\
\hline CHEMBL1965988 & 809183 & 4.2 & 4.4463 & TRN & \\
\hline CHEMBL418203 & 809183 & 4.2 & 5.1813 & TST & \\
\hline CHEMBL1989646 & 809183 & 5.8 & 5.9321 & TRN & \\
\hline CHEMBL1682357 & 809183 & 4.2 & 4.9305 & TRN & \\
\hline CHEMBL225519 & 809183 & 5.5 & 6.1958 & TRN & \\
\hline CHEMBL 209534 & 809183 & 4.2 & 4.495 & TRN & \\
\hline CHEMBL1978200 & 809183 & 4.2 & 4.3065 & TRN & \\
\hline CHEMBL1970522 & 809183 & 7.5 & 8.1918 & TRN & \\
\hline CHEMBL402846 & 809183 & 4.2 & 4.0846 & TRN & \\
\hline CHEMBL1990415 & 809183 & 5.4 & 5.0216 & TRN & \\
\hline CHEMBL1966087 & 809183 & 4.2 & 4.7108 & TRN & \\
\hline CHEMBL1964692 & 809183 & 4.2 & 4.2523 & TRN & \\
\hline CHEMBL1996931 & 809183 & 4.2 & 3.6179 & TRN & \\
\hline CHEMBL1964413 & 809183 & 4.2 & 4.7 & TRN & \\
\hline CHEMBL1973483 & 809183 & 4.2 & 5.0625 & TRN & \\
\hline CHEMBL1984432 & 809183 & 4.2 & 5.2047 & TRN & \\
\hline CHEMBL1970735 & 809183 & 4.2 & 4.1967 & TRN & \\
\hline CHEMBL 219722 & 809183 & 4.2 & 4.8033 & TRN & \\
\hline CHEMBL1997340 & 809183 & 4.2 & 4.316 & TRN & \\
\hline CHEMBL 2004365 & 809183 & 5.9 & 4.3185 & TST & \\
\hline CHEMBL1522508 & 809183 & 4.2 & 4.6171 & TRN & \\
\hline CHEMBL1989474 & 809183 & 4.2 & 4.1317 & TRN & \\
\hline CHEMBL1090360 & 809183 & 4.2 & 4.4028 & TRN & \\
\hline CHEMBL 210887 & 809183 & 4.2 & 5.4566 & TST & \\
\hline CHEMBL458997 & 809183 & 7.0 & 6.5846 & TRN & \\
\hline CHEMBL1971021 & 809183 & 4.2 & 4.2053 & TRN & \\
\hline CHEMBL 227271 & 809183 & 5.3 & $5.1320 e$ & 0000000001 & TRN \\
\hline CHEMBL583144 & 809183 & 6.9 & 5.7015 & TST & \\
\hline CHEMBL1974310 & 809183 & 5.3 & 4.8533 & TRN & \\
\hline CHEMBL1982660 & 809183 & 4.5 & 5.5688 & TRN & \\
\hline CHEMBL1994693 & 809183 & 4.2 & 4.0979 & TRN & \\
\hline CHEMBL1982957 & 809183 & 6.3 & 5.8551 & TRN & \\
\hline CHEMBL1725279 & 809183 & 6.3 & 6.3545 & TST & \\
\hline CHEMBL1975138 & 809183 & 4.2 & 5.0267 & TST & \\
\hline CHEMBL424872 & 809183 & 4.2 & 4.526 & TRN & \\
\hline CHEMBL 2006836 & 809183 & 6.5 & 5.8292 & TST & \\
\hline CHEMBL1971947 & 809183 & 4.2 & 4.7387 & TRN & \\
\hline CHEMBL412142 & 809183 & 4.2 & 4.5055 & TST & \\
\hline CHEMBL1980704 & 809183 & 6.0 & 4.0934 & TST & \\
\hline CHEMBL 2003271 & 809183 & 5.7 & 4.8326 & TST & \\
\hline CHEMBL1966808 & 809183 & 7.0 & 5.5042 & TST & \\
\hline CHEMBL 2004447 & 809183 & 4.2 & 4.2809 & TRN & \\
\hline CHEMBL1983111 & 809183 & 5.8 & 5.9836 & TST & \\
\hline CHEMBL1973860 & 809183 & 4.2 & 4.5261 & TRN & \\
\hline CHEMBL 260135 & 809183 & 4.2 & 4.4715 & TRN & \\
\hline CHEMBL 220241 & 809183 & 4.2 & 5.0534 & TST & \\
\hline & & & & 22653 & \\
\hline
\end{tabular}




\begin{tabular}{|c|c|c|c|c|c|}
\hline \\
\hline CHEMBL 2004544 & 809183 & 6.2 & 5.0032 & TST & \\
\hline CHEMBL1982610 & 809183 & 5.8 & 5.0426 & TST & \\
\hline CHEMBL1989569 & 809183 & 5.5 & 4.6977 & TRN & \\
\hline CHEMBL1999496 & 809183 & 4.2 & 4.3131 & TRN & \\
\hline CHEMBL 2006933 & 809183 & 6.3 & 6.1503 & TST & \\
\hline CHEMBL1988300 & 809183 & 4.2 & 5.0604 & TRN & \\
\hline CHEMBL1991078 & 809183 & 7.8 & 7.6269 & TRN & \\
\hline CHEMBL1987359 & 809183 & 5.7 & 3.8917 & TST & \\
\hline CHEMBL 2000685 & 809183 & 4.2 & 5.0277 & TRN & \\
\hline CHEMBL1985311 & 809183 & 5.6 & 4.5386 & TRN & \\
\hline CHEMBL1989265 & 809183 & 4.2 & 4.6513 & TST & \\
\hline CHEMBL1969502 & 809183 & 6.0 & 5.0597 & TRN & \\
\hline CHEMBL1965910 & 809183 & 4.2 & 4.3732 & TRN & \\
\hline CHEMBL1682553 & 809183 & 6.8 & 6.3694 & TRN & \\
\hline CHEMBL1971430 & 809183 & 4.2 & 4.2056 & TRN & \\
\hline CHEMBL1997764 & 809183 & 5.7 & 4.9897 & TRN & \\
\hline CHEMBL1983963 & 809183 & 4.2 & 4.671 & TRN & \\
\hline CHEMBL 2000271 & 809183 & 4.2 & 5.0325 & TRN & \\
\hline CHEMBL1985092 & 809183 & 4.2 & 5.08899 & 99999999995 & TST \\
\hline CHEMBL 2004692 & 809183 & 4.2 & 4.337 & TST & \\
\hline CHEMBL1981410 & 809183 & 4.2 & 4.0662 & TRN & \\
\hline CHEMBL1996234 & 809183 & 4.2 & 3.8777 & TRN & \\
\hline CHEMBL1991434 & 809183 & 6.8 & 5.6752 & TST & \\
\hline CHEMBL1967544 & 809183 & 4.2 & 4.375 & TRN & \\
\hline CHEMBL223367 & 809183 & 4.2 & 4.0722 & TST & \\
\hline CHEMBL340384 & 809183 & 4.2 & 5.5678 & TST & \\
\hline CHEMBL1996587 & 809183 & 4.2 & 3.9752 & TRN & \\
\hline CHEMBL1964804 & 809183 & 4.2 & 4.6553 & TRN & \\
\hline CHEMBL443962 & 809183 & 5.5 & 5.1396 & TST & \\
\hline CHEMBL1996282 & 809183 & 5.5 & 4.9792 & TRN & \\
\hline CHEMBL2000354 & 809183 & 7.7 & 8.234 & TRN & \\
\hline CHEMBL1965507 & 809183 & 4.2 & 4.198 & TRN & \\
\hline CHEMBL1981107 & 809183 & 4.8 & 4.4156 & TST & \\
\hline CHEMBL 274064 & 809183 & 6.1 & 4.8684 & TRN & \\
\hline CHEMBL1967564 & 809183 & 4.2 & 4.2139 & TRN & \\
\hline CHEMBL592030 & 809183 & 7.0 & 5.3818 & TST & \\
\hline CHEMBL 2000071 & 809183 & 4.2 & 4.1889 & TRN & \\
\hline CHEMBL1979176 & 809183 & 4.2 & 4.7984 & TRN & \\
\hline CHEMBL1970317 & 809183 & 4.2 & 4.5495 & TRN & \\
\hline CHEMBL 2000408 & 809183 & 4.2 & 4.4421 & TRN & \\
\hline CHEMBL248757 & 809183 & 4.2 & 4.6814 & TST & \\
\hline CHEMBL1978014 & 809183 & 4.2 & 4.7489 & TRN & \\
\hline CHEMBL1994538 & 809183 & 7.4 & 5.3806 & TRN & \\
\hline CHEMBL1983195 & 809183 & 5.8 & 4.7187 & TST & \\
\hline CHEMBL1975490 & 809183 & 4.2 & 4.075 & TRN & \\
\hline CHEMBL1964444 & 809183 & 6.6 & 5.5022 & TRN & \\
\hline CHEMBL 2006567 & 809183 & 5.7 & 4.8309 & TRN & \\
\hline CHEMBL1986139 & 809183 & 5.7 & 4.9181 & TRN & \\
\hline & & & & 2265 & \\
\hline
\end{tabular}




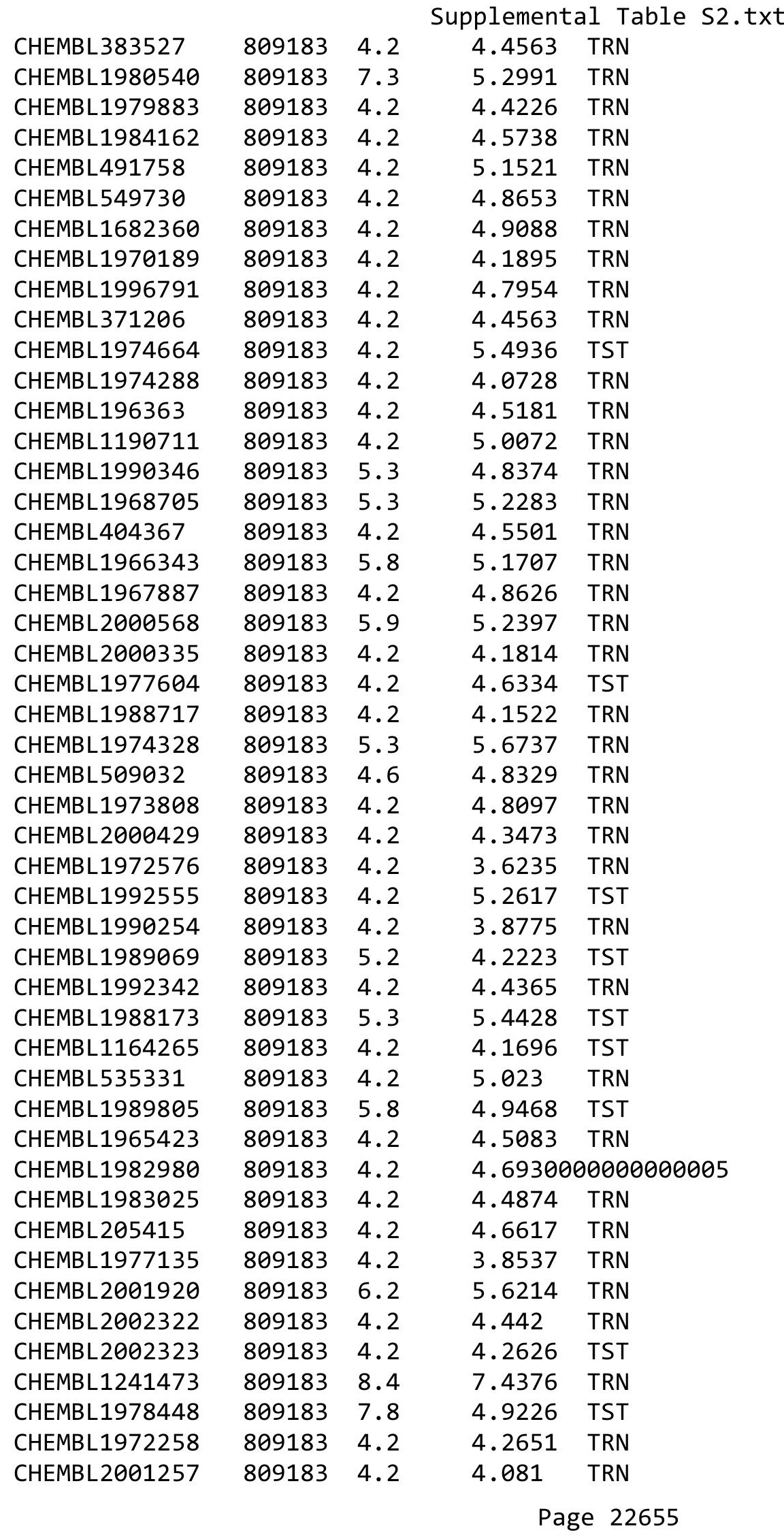




\begin{tabular}{|c|c|c|c|c|c|}
\hline \\
\hline CHEMBL 2005548 & 809183 & 4.2 & 3.9327 & TRN & \\
\hline CHEMBL1992536 & 809183 & 4.2 & 4.5769 & TRN & \\
\hline CHEMBL1987793 & 809183 & 4.2 & 4.5635 & TST & \\
\hline CHEMBL1992740 & 809183 & 4.2 & 4.2229 & TRN & \\
\hline CHEMBL 2002373 & 809183 & 4.2 & 4.3588 & TRN & \\
\hline CHEMBL439340 & 809183 & 4.2 & 4.003 & TRN & \\
\hline CHEMBL 2006188 & 809183 & 4.2 & 3.4365 & TRN & \\
\hline CHEMBL1967531 & 809183 & 4.2 & 4.4691 & TRN & \\
\hline CHEMBL1970913 & 809183 & 4.2 & 4.4146 & TRN & \\
\hline CHEMBL1973893 & 809183 & 4.2 & 4.6156 & TRN & \\
\hline CHEMBL1995736 & 809183 & 4.2 & 4.4175 & TRN & \\
\hline CHEMBL1997534 & 809183 & 4.2 & 3.8175 & TRN & \\
\hline CHEMBL1996500 & 809183 & 4.2 & 4.0794 & TRN & \\
\hline CHEMBL1985095 & 809183 & 4.2 & 5.2735 & TST & \\
\hline CHEMBL1998551 & 809183 & 4.2 & 4.1285 & TRN & \\
\hline CHEMBL1977374 & 809183 & 4.2 & 4.1214 & TRN & \\
\hline CHEMBL1991180 & 809183 & 5.8 & 5.2094 & TST & \\
\hline CHEMBL1682540 & 809183 & 6.2 & 5.9916 & TRN & \\
\hline CHEMBL1978656 & 809183 & 4.2 & 5.1948 & TRN & \\
\hline CHEMBL1976420 & 809183 & 4.2 & 4.83899 & 99999999995 & TST \\
\hline CHEMBL1994864 & 809183 & 4.2 & 3.9921 & TRN & \\
\hline CHEMBL413779 & 809183 & 4.2 & 4.5392 & TST & \\
\hline CHEMBL2002446 & 809183 & 4.2 & 4.0506 & TST & \\
\hline CHEMBL497151 & 809183 & 7.0 & 6.3338 & TRN & \\
\hline CHEMBL1973961 & 809183 & 4.2 & 4.2728 & TRN & \\
\hline CHEMBL246970 & 809183 & 4.2 & 4.7194 & TRN & \\
\hline CHEMBL340921 & 809183 & 4.2 & 4.9288 & TST & \\
\hline CHEMBL373598 & 809183 & 4.2 & 4.4692 & TST & \\
\hline CHEMBL1999718 & 809183 & 4.2 & 4.8832 & TRN & \\
\hline CHEMBL1276446 & 809183 & 6.3 & 6.5467 & TST & \\
\hline CHEMBL1977346 & 809183 & 4.2 & 4.5922 & TRN & \\
\hline CHEMBL1971649 & 809183 & 4.2 & 4.2554 & TRN & \\
\hline CHEMBL2003657 & 809183 & 4.2 & 4.6508 & TRN & \\
\hline CHEMBL1998435 & 809183 & 4.2 & 4.003 & TRN & \\
\hline CHEMBL2006439 & 809183 & 6.4 & 6.2938 & TRN & \\
\hline CHEMBL2006156 & 809183 & 5.4 & 4.6413 & TST & \\
\hline CHEMBL1969190 & 809183 & 4.2 & 3.7847 & TRN & \\
\hline CHEMBL1973937 & 809183 & 4.2 & 4.3178 & TRN & \\
\hline CHEMBL1991674 & 809183 & 7.0 & 6.37200 & 0000000001 & TRN \\
\hline CHEMBL1982711 & 809183 & 5.8 & 5.2671 & TRN & \\
\hline CHEMBL1984842 & 809183 & 4.2 & 4.2351 & TRN & \\
\hline CHEMBL1969102 & 809183 & 4.2 & 4.7911 & TRN & \\
\hline CHEMBL1682346 & 809183 & 5.8 & 6.4418 & TRN & \\
\hline CHEMBL 2007044 & 809183 & 4.2 & 3.9538 & TST & \\
\hline CHEMBL2001998 & 809183 & 4.2 & 4.1906 & TST & \\
\hline CHEMBL223460 & 809183 & 4.2 & 4.4652 & TST & \\
\hline CHEMBL1998829 & 809183 & 4.2 & 4.5423 & TRN & \\
\hline CHEMBL50894 & 809183 & 6.4 & 5.7579 & TRN & \\
\hline & & & & 265 & \\
\hline
\end{tabular}




\begin{tabular}{|c|c|c|c|c|c|}
\hline \multirow[b]{2}{*}{ CHEMBL1988838 } & \multirow[b]{2}{*}{809183} & \\
\hline & & 6.2 & 6.1319 & TRN & \\
\hline CHEMBL1981725 & 809183 & 4.2 & 4.8709 & TRN & \\
\hline CHEMBL375284 & 809183 & 4.2 & 4.6418 & TRN & \\
\hline CHEMBL1982866 & 809183 & 4.2 & 3.7016 & TRN & \\
\hline CHEMBL2005792 & 809183 & 4.2 & 4.3384 & TRN & \\
\hline CHEMBL1968926 & 809183 & 4.2 & 4.2426 & TRN & \\
\hline CHEMBL1984206 & 809183 & 5.5 & 4.3229 & TRN & \\
\hline CHEMBL462120 & 809183 & 4.2 & \multicolumn{2}{|c|}{ 4.968999999999999 } & TST \\
\hline CHEMBL1991577 & 809183 & 4.2 & 4.355 & TRN & \\
\hline CHEMBL1965570 & 809183 & 4.2 & 4.3465 & TRN & \\
\hline CHEMBL2007592 & 809183 & 5.7 & 5.1601 & TST & \\
\hline CHEMBL210963 & 809183 & 4.2 & 4.6885 & TRN & \\
\hline CHEMBL1082440 & 809183 & 4.2 & 4.691 & TST & \\
\hline CHEMBL1614705 & 809183 & 4.2 & 3.9262 & TRN & \\
\hline CHEMBL1972362 & 809183 & 5.5 & 5.003 & TRN & \\
\hline CHEMBL1984633 & 809183 & 4.2 & 3.7653 & TRN & \\
\hline CHEMBL2007372 & 809183 & 4.2 & 4.0239 & TRN & \\
\hline CHEMBL1965845 & 809183 & 4.2 & 4.6617 & TRN & \\
\hline CHEMBL1982167 & 809183 & 4.2 & 4.8789 & TRN & \\
\hline CHEMBL2006715 & 809183 & 4.2 & 4.6559 & TRN & \\
\hline CHEMBL1986597 & 809183 & 5.8 & 5.7551 & TRN & \\
\hline CHEMBL1971017 & 809183 & 5.4 & 5.1087 & TRN & \\
\hline CHEMBL1990482 & 809183 & 4.2 & 5.0225 & TRN & \\
\hline CHEMBL1990904 & 809183 & 4.2 & 4.3379 & TRN & \\
\hline CHEMBL2005475 & 809183 & 4.2 & 4.402 & TRN & \\
\hline CHEMBL2000104 & 809183 & 5.4 & 4.7565 & TRN & \\
\hline CHEMBL1997349 & 809183 & 5.9 & 5.7253 & TST & \\
\hline CHEMBL183844 & 809183 & 4.2 & 4.3865 & TRN & \\
\hline CHEMBL220057 & 809183 & 4.4 & 4.9061 & TRN & \\
\hline CHEMBL1682545 & 809183 & 5.3 & 5.4174 & TRN & \\
\hline CHEMBL383541 & 809183 & 4.2 & 4.7674 & TRN & \\
\hline CHEMBL2001224 & 809183 & 4.2 & 3.9968 & TRN & \\
\hline CHEMBL10 & 809183 & 4.2 & 4.6289 & TRN & \\
\hline CHEMBL1976732 & 809183 & 4.2 & 4.0701 & TRN & \\
\hline CHEMBL1969506 & 809183 & 4.2 & 4.3841 & TRN & \\
\hline CHEMBL1964937 & 809183 & 4.2 & 4.4164 & TRN & \\
\hline CHEMBL1980163 & 809183 & 4.2 & 4.4041 & TRN & \\
\hline CHEMBL590109 & 809183 & 4.2 & 5.4159 & TST & \\
\hline CHEMBL1970879 & 809183 & 4.2 & 4.0372 & TRN & \\
\hline CHEMBL1989856 & 809183 & 7.2 & 5.7102 & TST & \\
\hline CHEMBL 2005899 & 809183 & 4.2 & 4.8859 & TRN & \\
\hline CHEMBL1682552 & 809183 & 6.5 & 6.2071 & TRN & \\
\hline CHEMBL259850 & 809183 & 4.2 & 4.09399 & 9999999999 & TRN \\
\hline CHEMBL1972568 & 809183 & 4.2 & 4.643 & TRN & \\
\hline CHEMBL1996155 & 809183 & 4.2 & 4.124 & TRN & \\
\hline CHEMBL229799 & 809183 & 5.4 & 5.1887 & TRN & \\
\hline CHEMBL1682359 & 809183 & 4.2 & 4.6256 & TRN & \\
\hline CHEMBL105739 & 809183 & 4.2 & 4.5281 & TRN & \\
\hline & & & & 22657 & \\
\hline
\end{tabular}




\begin{tabular}{|c|c|c|c|c|}
\hline & & & pplement & al $\mathrm{Ta}$ \\
\hline CHEMBL 379300 & 809183 & 4.2 & 4.8332 & TRN \\
\hline CHEMBL 203673 & 809183 & 4.2 & 4.3182 & TRN \\
\hline CHEMBL1969523 & 809183 & 6.5 & 6.4947 & TRN \\
\hline CHEMBL 207995 & 809183 & 4.2 & 4.8052 & TRN \\
\hline CHEMBL1988995 & 809183 & 4.2 & 3.9998 & TRN \\
\hline CHEMBL2001923 & 809183 & 4.2 & 4.2316 & TRN \\
\hline CHEMBL1986781 & 809183 & 4.2 & 4.4643 & TRN \\
\hline CHEMBL526133 & 809183 & 7.6 & 6.5074 & TRN \\
\hline CHEMBL1979057 & 809183 & 4.2 & 4.881 & TRN \\
\hline CHEMBL1981045 & 809183 & 4.2 & 4.2849 & TRN \\
\hline CHEMBL387971 & 809183 & 4.2 & 4.0114 & TST \\
\hline CHEMBL1975418 & 809183 & 5.8 & 5.3402 & TRN \\
\hline CHEMBL1992796 & 809183 & 4.2 & 4.787 & TST \\
\hline CHEMBL1999428 & 809183 & 4.2 & 4.1102 & TRN \\
\hline CHEMBL223257 & 809183 & 4.2 & 4.4109 & TST \\
\hline CHEMBL1967560 & 809183 & 4.2 & 4.3282 & TRN \\
\hline CHEMBL1516890 & 809183 & 5.9 & 5.6738 & TRN \\
\hline CHEMBL 211378 & 809183 & 5.6 & 4.6948 & TRN \\
\hline CHEMBL1982465 & 809183 & 4.2 & 4.5188 & TRN \\
\hline CHEMBL 2001751 & 809183 & 4.2 & 5.1121 & TRN \\
\hline CHEMBL 2003420 & 809183 & 4.2 & 3.7023 & TRN \\
\hline CHEMBL1984586 & 809183 & 4.2 & 4.0766 & TRN \\
\hline CHEMBL1999774 & 809183 & 5.2 & 4.0162 & TST \\
\hline CHEMBL1972659 & 809183 & 4.2 & 4.5517 & TST \\
\hline CHEMBL1973395 & 809183 & 4.2 & 4.4925 & TRN \\
\hline CHEMBL 272453 & 809183 & 4.2 & 4.0167 & TRN \\
\hline CHEMBL1970217 & 809183 & 4.2 & 4.1498 & TRN \\
\hline CHEMBL1971801 & 809183 & 4.2 & 4.5088 & TRN \\
\hline CHEMBL1968850 & 809183 & 4.2 & 4.5266 & TRN \\
\hline CHEMBL 2005528 & 809183 & 4.2 & 5.4167 & TST \\
\hline CHEMBL185569 & 809183 & 5.8 & 4.5561 & TRN \\
\hline CHEMBL1969843 & 809183 & 5.5 & 5.5203 & TRN \\
\hline CHEMBL 2007002 & 809183 & 5.8 & 5.6091 & TRN \\
\hline CHEMBL1987007 & 809183 & 4.2 & 4.1613 & TRN \\
\hline CHEMBL1969588 & 809183 & 5.8 & 6.3188 & TRN \\
\hline CHEMBL1984711 & 809183 & 5.4 & 5.4945 & TRN \\
\hline CHEMBL1990212 & 809183 & 5.3 & 4.9057 & TRN \\
\hline CHEMBL484390 & 809183 & 4.2 & 4.2921 & TST \\
\hline CHEMBL1979252 & 809183 & 4.2 & 4.1496 & TRN \\
\hline CHEMBL1682341 & 809183 & 4.2 & 5.0027 & TRN \\
\hline CHEMBL 2004290 & 809183 & 4.2 & 3.8572 & TRN \\
\hline CHEMBL1986499 & 809183 & 6.4 & 5.8328 & TRN \\
\hline CHEMBL1972937 & 809183 & 7.2 & 6.3501 & TRN \\
\hline CHEMBL1972250 & 809183 & 4.2 & 4.6869 & TST \\
\hline CHEMBL 2000393 & 809183 & 4.2 & 5.0338 & TST \\
\hline CHEMBL 2004311 & 809183 & 4.2 & 4.3767 & TRN \\
\hline CHEMBL1992634 & 809183 & 6.1 & 5.1233 & TRN \\
\hline CHEMBL1242373 & 809183 & 4.2 & 4.2278 & TRN \\
\hline
\end{tabular}




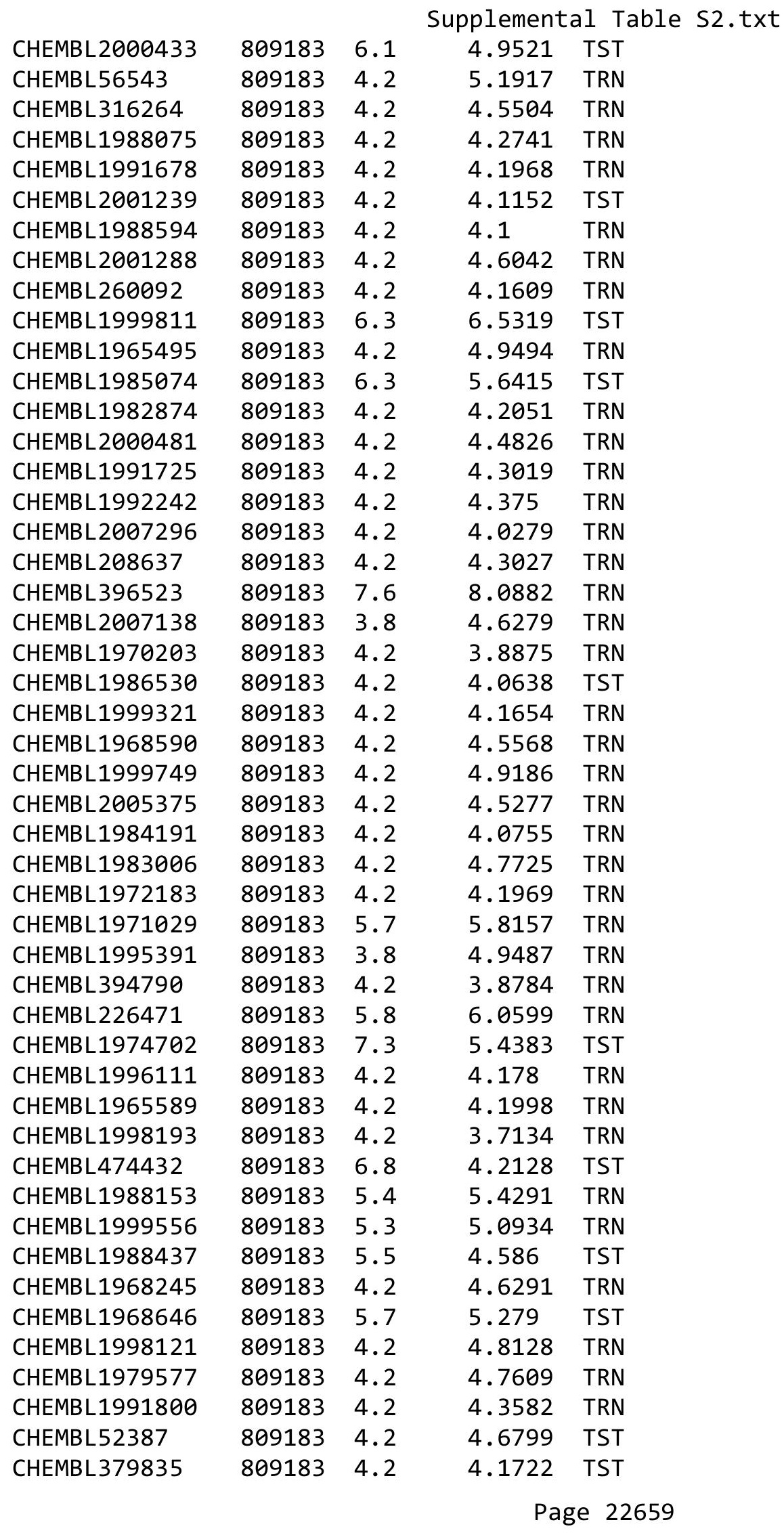




\begin{tabular}{|c|c|c|c|c|c|}
\hline \\
\hline CHEMBL1979357 & 809183 & 4.2 & 4.3437 & TRN & \\
\hline CHEMBL1980802 & 809183 & 4.2 & 4.4661 & TST & \\
\hline CHEMBL1979554 & 809183 & 4.2 & 4.3607 & TRN & \\
\hline CHEMBL1996817 & 809183 & 5.4 & 4.708 & TRN & \\
\hline CHEMBL3197315 & 809183 & 4.2 & 4.4168 & TST & \\
\hline CHEMBL 2004355 & 809183 & 4.2 & 4.6263 & TRN & \\
\hline CHEMBL468280 & 809183 & 4.3 & 4.6081 & TST & \\
\hline CHEMBL1990884 & 809183 & 4.2 & 4.2332 & TRN & \\
\hline CHEMBL3109278 & 809183 & 4.3 & 4.4876 & TRN & \\
\hline CHEMBL 256835 & 809183 & 4.2 & 4.3621 & TRN & \\
\hline CHEMBL1980142 & 809183 & 4.2 & 5.0351 & TRN & \\
\hline CHEMBL41783 & 809183 & 4.2 & 4.206 & TRN & \\
\hline CHEMBL 2004438 & 809183 & 4.2 & 4.1625 & TRN & \\
\hline CHEMBL 2006276 & 809183 & 4.2 & 4.6064 & TRN & \\
\hline CHEMBL 271381 & 809183 & 4.2 & 4.2966 & TRN & \\
\hline CHEMBL 2006785 & 809183 & 6.0 & 4.83899 & 99999999995 & TST \\
\hline CHEMBL1982466 & 809183 & 4.2 & 4.1587 & TRN & \\
\hline CHEMBL1995740 & 809183 & 4.2 & 5.2766 & TRN & \\
\hline CHEMBL1996390 & 809183 & 5.9 & 5.3334 & TRN & \\
\hline CHEMBL 234085 & 809183 & 4.2 & 4.0584 & TRN & \\
\hline CHEMBL1995832 & 809183 & 4.2 & 4.4329 & TRN & \\
\hline CHEMBL1998414 & 809183 & 4.2 & 3.6602 & TRN & \\
\hline CHEMBL1969042 & 809183 & 4.2 & 5.0494 & TST & \\
\hline CHEMBL1999931 & 809183 & 8.5 & 7.9073 & TRN & \\
\hline CHEMBL1991640 & 809183 & 4.2 & 4.3295 & TST & \\
\hline CHEMBL1375418 & 809183 & 4.2 & 4.0096 & TRN & \\
\hline CHEMBL 302449 & 809183 & 4.2 & 5.6283 & TST & \\
\hline CHEMBL 2007064 & 809183 & 5.4 & 4.6238 & TRN & \\
\hline CHEMBL1981047 & 809183 & 4.2 & 4.343 & TRN & \\
\hline CHEMBL 229968 & 809183 & 4.2 & 4.9917 & TRN & \\
\hline CHEMBL1976240 & 809183 & 4.2 & 3.9225 & TRN & \\
\hline CHEMBL1979093 & 809183 & 4.2 & 3.6431 & TRN & \\
\hline CHEMBL1968151 & 809183 & 6.9 & 5.4168 & TST & \\
\hline CHEMBL1381197 & 809183 & 4.2 & 3.8222 & TRN & \\
\hline CHEMBL1987009 & 809183 & 4.2 & 4.699 & TRN & \\
\hline CHEMBL379218 & 809183 & 6.5 & 5.0198 & TRN & \\
\hline CHEMBL 2003817 & 809183 & 4.2 & 5.1215 & TRN & \\
\hline CHEMBL336961 & 809183 & 5.6 & 6.1651 & TRN & \\
\hline CHEMBL1994830 & 809183 & 5.6 & 5.694 & TRN & \\
\hline CHEMBL1987054 & 809183 & 4.2 & 4.5883 & TRN & \\
\hline CHEMBL1970083 & 809183 & 4.2 & 4.3194 & TRN & \\
\hline CHEMBL 226403 & 809183 & 6.2 & 6.5381 & TRN & \\
\hline CHEMBL 2005631 & 809183 & 4.2 & 4.3787 & TRN & \\
\hline CHEMBL1994938 & 809183 & 4.2 & 4.3176 & TRN & \\
\hline CHEMBL1977223 & 809183 & 6.5 & 6.5926 & TRN & \\
\hline CHEMBL1236126 & 809183 & 4.2 & 4.9641 & TST & \\
\hline CHEMBL1966279 & 809183 & 4.2 & 4.3005 & TRN & \\
\hline CHEMBL1997846 & 809183 & 6.6 & 5.95 & TRN & \\
\hline
\end{tabular}




\begin{tabular}{|c|c|c|c|c|c|}
\hline \multicolumn{6}{|c|}{ Supplemental Table S2.txt } \\
\hline CHEMBL 2004419 & 809183 & 4.2 & 4.0865 & TRN & \\
\hline CHEMBL1991728 & 809183 & 4.2 & 4.1767 & TRN & \\
\hline CHEMBL1975787 & 809183 & 4.3 & 4.9131 & TRN & \\
\hline CHEMBL 2002407 & 809183 & 8.3 & 6.9151 & TRN & \\
\hline CHEMBL1972489 & 809183 & 4.2 & 4.5103 & TRN & \\
\hline CHEMBL1994074 & 809183 & 5.3 & 5.3227 & TRN & \\
\hline CHEMBL1992937 & 809183 & 5.3 & 5.7989 & TST & \\
\hline CHEMBL1985566 & 809183 & 4.2 & 4.4179 & TRN & \\
\hline CHEMBL1972119 & 809183 & 7.3 & 5.3469 & TRN & \\
\hline CHEMBL1986328 & 809183 & 5.8 & 4.9084 & TST & \\
\hline CHEMBL95692 & 809183 & 4.2 & 4.3986 & TRN & \\
\hline CHEMBL1090356 & 809183 & 4.2 & 4.20100 & 00000000005 & TRN \\
\hline CHEMBL1976455 & 809183 & 6.8 & 5.5125 & TRN & \\
\hline CHEMBL1983923 & 809183 & 4.2 & 5.4343 & TST & \\
\hline CHEMBL1983534 & 809183 & 4.2 & 4.351 & TRN & \\
\hline CHEMBL1982361 & 809183 & 4.2 & 4.0613 & TRN & \\
\hline CHEMBL1999112 & 809183 & 4.2 & 4.4087 & TST & \\
\hline CHEMBL1982122 & 809183 & 4.2 & 4.3034 & TRN & \\
\hline CHEMBL 2000801 & 809183 & 4.2 & 3.875 & TRN & \\
\hline CHEMBL1682546 & 809183 & 4.2 & 4.6022 & TRN & \\
\hline CHEMBL1991395 & 809183 & 4.2 & 4.2872 & TRN & \\
\hline CHEMBL1971245 & 809183 & 4.2 & 4.3658 & TRN & \\
\hline CHEMBL1987648 & 809183 & 4.2 & 4.1699 & TRN & \\
\hline CHEMBL1996780 & 809183 & 4.2 & 4.4755 & TST & \\
\hline CHEMBL1972142 & 809183 & 4.2 & 4.5762 & TRN & \\
\hline CHEMBL1966514 & 809183 & 4.2 & 4.5043 & TRN & \\
\hline CHEMBL 2003638 & 809183 & 8.2 & 7.8087 & TRN & \\
\hline CHEMBL296586 & 809183 & 6.4 & 5.9553 & TRN & \\
\hline CHEMBL1996066 & 809183 & 7.2 & 5.4594 & TST & \\
\hline CHEMBL516429 & 809183 & 6.4 & 5.0494 & TRN & \\
\hline CHEMBL1993722 & 809183 & 5.8 & 5.4797 & TRN & \\
\hline CHEMBL1970806 & 809183 & 4.2 & 5.0381 & TST & \\
\hline CHEMBL1375640 & 809183 & 4.2 & 5.3481 & TST & \\
\hline CHEMBL1979970 & 809183 & 5.3 & 4.0667 & TRN & \\
\hline CHEMBL 249282 & 809183 & 4.2 & 4.1774 & TST & \\
\hline CHEMBL1969264 & 809183 & 8.2 & 6.229 & TRN & \\
\hline CHEMBL1973711 & 809183 & 6.6 & 5.454 & TST & \\
\hline CHEMBL 2006237 & 809183 & 4.2 & 4.6081 & TRN & \\
\hline CHEMBL1967720 & 809183 & 4.2 & 4.6547 & TRN & \\
\hline CHEMBL1572266 & 809183 & 4.2 & 4.6443 & TST & \\
\hline CHEMBL1991138 & 809183 & 4.2 & 4.0524 & TRN & \\
\hline CHEMBL1969755 & 809183 & 4.2 & 3.5749 & TRN & \\
\hline CHEMBL1979516 & 809183 & 4.2 & 3.8234 & TRN & \\
\hline CHEMBL1605605 & 809183 & 4.2 & 3.2224 & TRN & \\
\hline CHEMBL1972820 & 809183 & 4.2 & 4.9503 & TST & \\
\hline CHEMBL1996208 & 809183 & 4.2 & 4.8945 & TST & \\
\hline CHEMBL1989029 & 809183 & 5.4 & 5.2024 & TRN & \\
\hline CHEMBL392642 & 809183 & 5.3 & 4.6073 & TRN & \\
\hline
\end{tabular}




\begin{tabular}{|c|c|c|c|c|c|}
\hline & & \\
\hline CHEMBL1965631 & 809183 & 5.5 & 6.3439 & TRN & \\
\hline CHEMBL1980144 & 809183 & 4.2 & 3.7127 & TRN & \\
\hline CHEMBL1991188 & 809183 & 4.2 & 3.9243 & TRN & \\
\hline CHEMBL1972849 & 809183 & 4.2 & 3.8004 & TRN & \\
\hline CHEMBL377408 & 809183 & 4.2 & 4.459 & TST & \\
\hline CHEMBL215152 & 809183 & 4.2 & 4.1802 & TST & \\
\hline CHEMBL231209 & 809183 & 4.2 & 4.2366 & TST & \\
\hline CHEMBL1976220 & 809183 & 4.2 & 4.3852 & TST & \\
\hline CHEMBL259922 & 809183 & 4.2 & 4.7851 & TST & \\
\hline CHEMBL1997617 & 809183 & 4.2 & 3.9446 & TST & \\
\hline CHEMBL1982383 & 809183 & 4.2 & 3.9579 & TST & \\
\hline CHEMBL1969301 & 809183 & 4.2 & 4.8309 & TST & \\
\hline CHEMBL17370 & 809183 & 4.2 & 4.5929 & TST & \\
\hline CHEMBL1966068 & 809183 & 5.8 & 5.2834 & TST & \\
\hline CHEMBL1987910 & 809183 & 4.2 & 3.7828 & TST & \\
\hline CHEMBL1983932 & 809183 & 4.2 & 5.6245 & TST & \\
\hline CHEMBL1966069 & 809183 & 4.2 & 4.9287 & TST & \\
\hline CHEMBL1997822 & 809183 & 4.2 & 5.1976 & TST & \\
\hline CHEMBL1991285 & 809183 & 4.2 & 4.1368 & TST & \\
\hline CHEMBL 243088 & 809183 & 7.1 & 8.2112 & TST & \\
\hline CHEMBL1984038 & 809183 & 4.2 & 4.4226 & TST & \\
\hline CHEMBL1993661 & 809183 & 6.9 & 6.348 & TST & \\
\hline CHEMBL1974416 & 809183 & 4.2 & 4.553 & TST & \\
\hline CHEMBL 2004615 & 809183 & 4.2 & 4.7413 & TST & \\
\hline CHEMBL1984039 & 809183 & 4.2 & 4.4985 & TST & \\
\hline CHEMBL1997872 & 809183 & 4.2 & 5.1306 & TST & \\
\hline CHEMBL1459628 & 688555 & 3.1003 & 3.0519 & TRN & \\
\hline CHEMBL1583115 & 688555 & 3.1003 & 3.1361 & TRN & \\
\hline CHEMBL1526221 & 688555 & 3.1003 & 3.0562 & TRN & \\
\hline CHEMBL1507954 & 688555 & 4.4358 & 4.1209 & TRN & \\
\hline CHEMBL1528698 & 688555 & 3.1003 & 3.2111 & TRN & \\
\hline CHEMBL1509978 & 688555 & 3.1003 & 3.1768 & TRN & \\
\hline CHEMBL1428286 & 688555 & 4.4121 & 4.537 & TRN & \\
\hline CHEMBL1389115 & 688555 & 3.1003 & 3.065 & TRN & \\
\hline CHEMBL1478894 & 688555 & 3.1003 & 3.0689 & TST & \\
\hline CHEMBL1447164 & 688555 & 4.8671 & 4.5214 & TRN & \\
\hline CHEMBL1419387 & 688555 & 3.1003 & 3.8746 & TRN & \\
\hline CHEMBL1381203 & 688555 & 3.1003 & 3.0347 & TRN & \\
\hline CHEMBL1608327 & 688555 & 3.1003 & 2.9804 & TST & \\
\hline CHEMBL1336097 & 688555 & 3.1003 & 3.17199 & 99999999997 & TRN \\
\hline CHEMBL1470470 & 688555 & 4.1011 & 3.73100 & 00000000003 & TRN \\
\hline CHEMBL1613102 & 688555 & 3.1003 & 3.0405 & TRN & \\
\hline CHEMBL3189578 & 688555 & 3.1003 & 3.0399 & TRN & \\
\hline CHEMBL1999900 & 688555 & 3.1003 & 3.0549 & TRN & \\
\hline CHEMBL1538696 & 688555 & 3.1003 & 3.1478 & TRN & \\
\hline CHEMBL1605172 & 688555 & 3.1003 & 3.0646 & TRN & \\
\hline CHEMBL1335142 & 688555 & 3.1003 & 3.6779 & TRN & \\
\hline CHEMBL1526833 & 688555 & 3.1003 & 3.1275 & TRN & \\
\hline
\end{tabular}

Page 22662 
Supplemental Table S2.txt

\begin{tabular}{|c|c|c|c|c|c|}
\hline CHEMBL1603658 & 688555 & 3.1003 & 3.4208 & TRN & \\
\hline CHEMBL1371533 & 688555 & 3.1003 & 3.0838 & TRN & \\
\hline CHEMBL1563782 & 688555 & 3.1003 & 3.1317 & TRN & \\
\hline CHEMBL1604376 & 688555 & 4.5191 & 4.5274 & TRN & \\
\hline CHEMBL1480319 & 688555 & 3.1003 & 3.0229 & TRN & \\
\hline CHEMBL1439946 & 688555 & 3.1003 & 3.0671 & TRN & \\
\hline CHEMBL1478329 & 688555 & 3.1003 & 3.1918 & TRN & \\
\hline CHEMBL1489593 & 688555 & 4.3052 & 4.1437 & TRN & \\
\hline CHEMBL1968355 & 688555 & 3.1003 & 3.1035 & TST & \\
\hline CHEMBL1542114 & 688555 & 3.1003 & 3.0126 & TRN & \\
\hline CHEMBL1336006 & 688555 & 3.1003 & 3.0732 & TRN & \\
\hline CHEMBL1470283 & 688555 & 3.1003 & 3.0286 & TST & \\
\hline CHEMBL1478908 & 688555 & 3.1003 & 3.0807 & TRN & \\
\hline CHEMBL1505538 & 688555 & 3.1003 & 3.1443 & TST & \\
\hline CHEMBL1588102 & 688555 & 4.9344 & 4.502 & TRN & \\
\hline CHEMBL1414445 & 688555 & 4.8871 & 4.9292 & TRN & \\
\hline CHEMBL1454659 & 688555 & 3.1003 & 3.2166 & TRN & \\
\hline CHEMBL1346107 & 688555 & 3.1003 & 3.4649 & TRN & \\
\hline CHEMBL1506760 & 688555 & 3.1003 & 3.0211 & TRN & \\
\hline CHEMBL1301961 & 688555 & 3.1003 & 3.0527 & TRN & \\
\hline CHEMBL1412254 & 688555 & 3.1003 & 3.2191 & TRN & \\
\hline CHEMBL566064 & 688555 & 4.75899 & 99999999 & 4.3832 & \\
\hline CHEMBL1557929 & 688555 & 3.1003 & 3.093 & TRN & \\
\hline CHEMBL581929 & 688555 & 3.1003 & 3.076 & TRN & \\
\hline CHEMBL1584541 & 688555 & 3.1003 & 3.21 & TRN & \\
\hline CHEMBL1382919 & 688555 & 3.1003 & 3.0509 & TRN & \\
\hline CHEMBL1528515 & 688555 & 3.1003 & 3.9466 & TRN & \\
\hline CHEMBL1380816 & 688555 & 3.1003 & 4.6904 & TRN & \\
\hline CHEMBL1351240 & 688555 & 3.1003 & 2.9816 & TRN & \\
\hline CHEMBL3194630 & 688555 & 3.1003 & 3.1602 & TRN & \\
\hline CHEMBL1451889 & 688555 & 4.0721 & 3.5465 & TRN & \\
\hline CHEMBL1328108 & 688555 & 3.1003 & 2.9858 & TRN & \\
\hline CHEMBL1439119 & 688555 & 3.1003 & 3.0939 & TRN & \\
\hline CHEMBL1484719 & 688555 & 3.1003 & 3.0769 & TRN & \\
\hline CHEMBL1458535 & 688555 & 3.1003 & 3.0501 & TRN & \\
\hline CHEMBL1329604 & 688555 & 4.9492 & 4.5175 & TRN & \\
\hline CHEMBL1427125 & 688555 & 3.1003 & 3.1219 & TST & \\
\hline CHEMBL1471920 & 688555 & 4.4074 & 4.0881 & TRN & \\
\hline CHEMBL 3208420 & 688555 & 4.8453 & 4.7425 & TRN & \\
\hline CHEMBL1595850 & 688555 & 3.1003 & 3.06100 & 00000000004 & TRN \\
\hline CHEMBL1557326 & 688555 & 4.5258 & 4.2227 & TRN & \\
\hline CHEMBL1583062 & 688555 & 3.1003 & 3.0331 & TRN & \\
\hline CHEMBL1300045 & 688555 & 3.1003 & 3.188999 & 99999999996 & 1 \\
\hline CHEMBL1427319 & 688555 & 3.1003 & 3.3242 & TRN & \\
\hline CHEMBL1337316 & 688555 & 3.1003 & 3.2417 & TRN & \\
\hline CHEMBL1353338 & 688555 & 3.1003 & 3.2804 & TRN & \\
\hline CHEMBL1447108 & 688555 & 3.1003 & 3.6306 & TRN & \\
\hline CHEMBL1456983 & 688555 & 3.1003 & 3.0798 & TRN & \\
\hline
\end{tabular}

Page 22663 


\begin{tabular}{|c|c|c|c|c|}
\hline & & & oplement & al Ta \\
\hline CHEMBL1344196 & 688555 & 3.1003 & 3.114 & TRN \\
\hline CHEMBL1300592 & 688555 & 3.1003 & 3.1778 & TRN \\
\hline CHEMBL1306899 & 688555 & 3.1003 & 3.0238 & TRN \\
\hline CHEMBL1977734 & 688555 & 3.1003 & 3.0641 & TRN \\
\hline CHEMBL1581201 & 688555 & 3.1003 & 3.2546 & TRN \\
\hline CHEMBL1986690 & 688555 & 3.1003 & 3.523 & TRN \\
\hline CHEMBL1468869 & 688555 & 4.7385 & 4.9515 & TRN \\
\hline CHEMBL1341820 & 688555 & 3.1003 & 3.0209 & TRN \\
\hline CHEMBL3214432 & 688555 & 4.6916 & 4.6905 & TRN \\
\hline CHEMBL1528003 & 688555 & 3.1003 & 3.3576 & TRN \\
\hline CHEMBL1398618 & 688555 & 4.5408 & 4.2808 & TRN \\
\hline CHEMBL1484427 & 688555 & 3.1003 & 3.0431 & TRN \\
\hline CHEMBL1463869 & 688555 & 3.1003 & 3.6962 & TRN \\
\hline CHEMBL1542477 & 688555 & 4.1159 & 4.101 & TRN \\
\hline CHEMBL1560867 & 688555 & 3.1003 & 3.1232 & TRN \\
\hline CHEMBL1522046 & 688555 & 3.1003 & 3.0915 & TRN \\
\hline CHEMBL1352863 & 688555 & 3.1003 & 3.0607 & TRN \\
\hline CHEMBL1399673 & 688555 & 3.1003 & 3.0477 & TRN \\
\hline CHEMBL1320870 & 688555 & 3.1003 & 3.0172 & TRN \\
\hline CHEMBL1597754 & 688555 & 3.1003 & 3.5687 & TRN \\
\hline CHEMBL1368233 & 688555 & 3.1003 & 3.0962 & TRN \\
\hline CHEMBL3197880 & 688555 & 3.1003 & 3.0027 & TRN \\
\hline CHEMBL1506506 & 688555 & 4.669 & 4.6403 & TRN \\
\hline CHEMBL1578636 & 688555 & 3.1003 & 3.1972 & TRN \\
\hline CHEMBL1612392 & 688555 & 4.431 & 4.4891 & TRN \\
\hline CHEMBL1505656 & 688555 & 3.1003 & 3.0099 & TRN \\
\hline CHEMBL3194048 & 688555 & 3.1003 & 3.1462 & TRN \\
\hline CHEMBL533954 & 688555 & 3.1003 & 3.1897 & TRN \\
\hline CHEMBL3209573 & 688555 & 4.7752 & 4.5509 & TRN \\
\hline CHEMBL1301738 & 688555 & 3.1003 & 3.0361 & TRN \\
\hline CHEMBL1488539 & 688555 & 3.1003 & 4.1464 & TRN \\
\hline CHEMBL1505844 & 688555 & 3.1003 & 3.9755 & TRN \\
\hline CHEMBL1608778 & 688555 & 3.1003 & 3.1005 & TST \\
\hline CHEMBL1532532 & 688555 & 4.5209 & 4.3065 & TRN \\
\hline CHEMBL1342967 & 688555 & 3.1003 & 3.0998 & TRN \\
\hline CHEMBL1377287 & 688555 & 3.1003 & 3.0717 & TRN \\
\hline CHEMBL1313434 & 688555 & 3.1003 & 3.8003 & TST \\
\hline CHEMBL1367765 & 688555 & 3.1003 & 4.8783 & TRN \\
\hline CHEMBL1564775 & 688555 & 3.1003 & 3.1958 & TRN \\
\hline CHEMBL1352697 & 688555 & 3.1003 & 3.08 & TST \\
\hline CHEMBL1386483 & 688555 & 3.1003 & 3.0915 & TST \\
\hline CHEMBL1339881 & 688555 & 3.1003 & 3.042 & TRN \\
\hline CHEMBL1390323 & 688555 & 3.1003 & 3.1247 & TRN \\
\hline CHEMBL1462713 & 688555 & 5.1394 & 5.0123 & TRN \\
\hline CHEMBL1449312 & 688555 & 3.1003 & 3.1063 & TST \\
\hline CHEMBL1400006 & 688555 & 4.5586 & 4.502 & TRN \\
\hline CHEMBL3195359 & 688555 & 3.1003 & 3.0185 & TST \\
\hline CHEMBL1561316 & 688555 & 4.6623 & 4.3672 & TRN \\
\hline
\end{tabular}


Supplemental Table S2.txt

\begin{tabular}{|c|c|c|c|c|}
\hline CHEMBL1312906 & 688555 & 3.1003 & 3.0259 & TRN \\
\hline CHEMBL1415986 & 688555 & 3.1003 & 3.156 & TRN \\
\hline CHEMBL1343936 & 688555 & 4.2939 & 4.0835 & TRN \\
\hline CHEMBL1373371 & 688555 & 3.1003 & 3.0395 & TST \\
\hline CHEMBL1411662 & 688555 & 3.1003 & 3.1219 & TST \\
\hline CHEMBL1579477 & 688555 & 3.1003 & 3.1935 & TRN \\
\hline CHEMBL1320358 & 688555 & 3.1003 & 3.0686 & TRN \\
\hline CHEMBL1386273 & 688555 & 4.5284 & 4.3227 & TRN \\
\hline CHEMBL601578 & 688555 & 3.1003 & 3.0624 & TRN \\
\hline CHEMBL1544695 & 688555 & 3.1003 & 3.1093 & TRN \\
\hline CHEMBL1558616 & 688555 & 3.1003 & 3.1232 & TRN \\
\hline CHEMBL1585187 & 688555 & 3.1003 & 3.1151 & TRN \\
\hline CHEMBL1524916 & 688555 & 3.1003 & 3.096 & TST \\
\hline CHEMBL1433290 & 688555 & 4.6396 & 4.3383 & TRN \\
\hline CHEMBL1606721 & 688555 & 3.1003 & 3.0631 & TRN \\
\hline CHEMBL1601494 & 688555 & 3.1003 & 3.1979 & TRN \\
\hline CHEMBL3210083 & 688555 & 3.1003 & 3.0319 & TRN \\
\hline CHEMBL1606245 & 688555 & 3.1003 & 3.0007 & TRN \\
\hline CHEMBL1448381 & 688555 & 4.1092 & 3.8549 & TRN \\
\hline CHEMBL1597380 & 688555 & 3.1003 & 3.1164 & TRN \\
\hline CHEMBL1508357 & 688555 & 3.1003 & 3.1454 & TST \\
\hline CHEMBL2369261 & 688555 & 3.1003 & 3.0544 & TRN \\
\hline CHEMBL1325903 & 688555 & 3.1003 & 3.0421 & TRN \\
\hline CHEMBL1579143 & 688555 & 3.1003 & 3.0164 & TST \\
\hline CHEMBL3208768 & 688555 & 3.1003 & 3.1345 & TRN \\
\hline CHEMBL1352206 & 688555 & 3.1003 & 3.1033 & TRN \\
\hline CHEMBL1418035 & 688555 & 4.1739 & 4.1202 & TRN \\
\hline CHEMBL1351131 & 688555 & 5.1822 & 4.5462 & TRN \\
\hline CHEMBL1521594 & 688555 & 4.1561 & 4.2019 & TRN \\
\hline CHEMBL1540811 & 688555 & 5.1003 & 4.08899 & 99999999995 \\
\hline CHEMBL1565229 & 688555 & 3.1003 & 3.16300 & 00000000003 \\
\hline CHEMBL1602811 & 688555 & 4.738 & 4.4725 & TRN \\
\hline CHEMBL 3210223 & 688555 & 3.1003 & 3.1304 & TRN \\
\hline CHEMBL1324769 & 688555 & 3.1003 & 3.0811 & TRN \\
\hline CHEMBL1519736 & 688555 & 3.1003 & 3.0501 & TRN \\
\hline CHEMBL1341675 & 688555 & 3.1003 & 2.9755 & TRN \\
\hline CHEMBL1457789 & 688555 & 3.1003 & 3.0191 & TST \\
\hline CHEMBL1547693 & 688555 & 4.0932 & 4.0493 & TRN \\
\hline CHEMBL1600402 & 688555 & 3.1003 & 3.8601 & TRN \\
\hline CHEMBL1423417 & 688555 & 4.2469 & 4.2668 & TRN \\
\hline CHEMBL1439888 & 688555 & 4.474 & 4.2303 & TRN \\
\hline CHEMBL3190678 & 688555 & 3.1003 & 3.0639 & TST \\
\hline CHEMBL1389672 & 688555 & 3.1003 & 2.9908 & TRN \\
\hline CHEMBL1607599 & 688555 & 4.5859 & 4.3441 & TST \\
\hline CHEMBL1405306 & 688555 & 4.6474 & 4.4816 & TRN \\
\hline CHEMBL1488126 & 688555 & 3.1003 & 3.0228 & TRN \\
\hline CHEMBL1390367 & 688555 & 3.1003 & 3.0052 & TRN \\
\hline CHEMBL1453481 & 688555 & 3.1003 & 3.0314 & TRN \\
\hline
\end{tabular}


Supplemental Table S2.txt

\begin{tabular}{|c|c|c|c|c|c|}
\hline CHEMBL1444824 & 688555 & 3.1003 & 3.2549 & TRN & \\
\hline CHEMBL1468866 & 688555 & 4.1722 & 3.1625 & TRN & \\
\hline CHEMBL1608186 & 688555 & 3.1003 & 3.3048 & TRN & \\
\hline CHEMBL1563940 & 688555 & 3.1003 & 3.2109 & TRN & \\
\hline CHEMBL1492278 & 688555 & 3.1003 & 3.1171 & TRN & \\
\hline CHEMBL1472502 & 688555 & 3.1003 & \multicolumn{2}{|c|}{3.1210000000000004} & TRN \\
\hline CHEMBL1425135 & 688555 & 4.9458 & 4.6052 & TRN & \\
\hline CHEMBL1420624 & 688555 & 3.1003 & 3.0759 & TST & \\
\hline CHEMBL1407650 & 688555 & 4.0741 & 3.1382 & TST & \\
\hline CHEMBL1600071 & 688555 & 3.1003 & 3.0215 & TST & \\
\hline CHEMBL69086 & 688555 & 3.1003 & 3.0622 & TST & \\
\hline CHEMBL1567518 & 688555 & 4.7865 & 4.6101 & TRN & \\
\hline CHEMBL1575265 & 688555 & 3.1003 & 2.9915 & TRN & \\
\hline CHEMBL1507076 & 688555 & 4.6819 & 4.7067 & TRN & \\
\hline CHEMBL1522598 & 688555 & 3.1003 & 3.0201 & TRN & \\
\hline CHEMBL1306142 & 688555 & 3.1003 & 3.1728 & TRN & \\
\hline CHEMBL1432295 & 688555 & 3.1003 & 3.0495 & TST & \\
\hline CHEMBL1333282 & 688555 & 3.1003 & 3.0461 & TRN & \\
\hline CHEMBL1490883 & 688555 & 3.1003 & \multicolumn{2}{|c|}{3.0869999999999997} & TRN \\
\hline CHEMBL1427163 & 688555 & 3.1003 & 3.0496 & TRN & \\
\hline CHEMBL1430645 & 688555 & 3.1003 & 3.0793 & TST & \\
\hline CHEMBL1372549 & 688555 & 3.1003 & 3.1315 & TRN & \\
\hline CHEMBL3191374 & 688555 & 3.1003 & 3.116 & TST & \\
\hline CHEMBL1582123 & 688555 & 5.1003 & 4.0712 & TRN & \\
\hline CHEMBL1539280 & 688555 & 5.0932 & 5.1843 & TRN & \\
\hline CHEMBL1518205 & 688555 & 3.1003 & \multicolumn{2}{|c|}{3.0589999999999997} & TRN \\
\hline CHEMBL1461351 & 688555 & 4.6749 & 4.4054 & TRN & \\
\hline CHEMBL1404571 & 688555 & 3.1003 & 3.0684 & TRN & \\
\hline CHEMBL1300026 & 688555 & 3.1003 & 3.0553 & TRN & \\
\hline CHEMBL3209698 & 688555 & 4.6666 & 4.4371 & TRN & \\
\hline CHEMBL1374288 & 688555 & 3.1003 & \multicolumn{2}{|c|}{3.1189999999999998} & TRN \\
\hline CHEMBL1507486 & 688555 & 3.1003 & 3.0591 & TST & \\
\hline CHEMBL 2000686 & 688555 & 3.1003 & \multicolumn{2}{|c|}{3.0580000000000003} & TRN \\
\hline CHEMBL1338594 & 688555 & 3.1003 & 3.0642 & TRN & \\
\hline CHEMBL 2365639 & 688555 & 3.1003 & 3.0093 & TRN & \\
\hline CHEMBL1579471 & 688555 & 3.1003 & 3.185 & TRN & \\
\hline CHEMBL1425489 & 688555 & 3.1003 & 3.122 & TST & \\
\hline CHEMBL 2143919 & 688555 & 4.9446 & \multicolumn{2}{|c|}{4.861000000000001} & TRN \\
\hline CHEMBL1428087 & 688555 & 3.1003 & 3.3131 & TRN & \\
\hline CHEMBL1351640 & 688555 & 3.1003 & 3.1526 & TRN & \\
\hline CHEMBL1458189 & 688555 & 3.1003 & 3.0003 & TRN & \\
\hline CHEMBL1411341 & 688555 & 3.1003 & 2.9901 & TST & \\
\hline CHEMBL1511120 & 688555 & 4.4717 & 4.2444 & TRN & \\
\hline CHEMBL1519242 & 688555 & 3.1003 & 3.2126 & TRN & \\
\hline CHEMBL1531952 & 688555 & 3.1003 & 3.091 & TRN & \\
\hline CHEMBL1373843 & 688555 & 4.4488 & 4.0959 & TRN & \\
\hline CHEMBL1558820 & 688555 & 4.4769 & 4.4009 & TRN & \\
\hline CHEMBL1529358 & 688555 & 3.1003 & 3.1564 & TRN & \\
\hline
\end{tabular}


Supplemental Table S2.txt

\begin{tabular}{|c|c|c|c|c|}
\hline 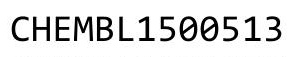 & & & & \\
\hline HEMBL1332678 & 88555 & 1003 & 3.0573 & \\
\hline & & & & \\
\hline EMRI 318 , & 8555 & 003 & 38 & \\
\hline IEMBL1311094 & 38555 & 1003 & 1416 & \\
\hline AEMBL1528496 & 88555 & 2714 & 3163 & \\
\hline HEMBL1312030 & 5 & .5936 & .4073 & \\
\hline 22 & & 472 & 7106 & \\
\hline EMBL1379482 & 88555 & 003 & .1895 & \\
\hline AEMBL1543543 & 88555 & 1003 & .9439 & \\
\hline HEMBL1387238 & 885 & 234 & 2682 & \\
\hline AEMBL1520457 & 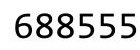 & 003 & .0952 & \\
\hline AEMBL1: & & 12 & 52 & \\
\hline AEMBL132S & 5 & 003 & .1125 & \\
\hline AEMBL3195801 & 5 & 039 & .6023 & \\
\hline AEMBL1328380 & & 003 & 0746 & \\
\hline AEMBL1546304 & 5 & 003 & 0796 & \\
\hline HEMBL1C & & 203 & 94 & \\
\hline HEMBL1 $1 \angle$ & 5 & 747 & 32 & \\
\hline AEMBL1387439 & & 1003 & & RN \\
\hline AEMBL1495975 & כ & 03 & .6468 & RIN \\
\hline AEMBL 14 & & 03 & 1274 & 1 \\
\hline HEMBL 15 & & 003 & .1285 & RN \\
\hline 94 & & 003 & 3.013 & RN \\
\hline IEMBL1321442 & & 003 & 3 & RIV \\
\hline IEMBL1599069 & 5 & 33 & .0 & KIV \\
\hline HEMBL1362807 & & 003 & .0929 & RN \\
\hline HEMBL 153 & & 86 & .3055 & \\
\hline 85 & & 03 & & RN \\
\hline L1424 & & & .005 & RIV \\
\hline AEMBL3145293 & & 003 & .1393 & ST \\
\hline HEMBL1516879 & & 003 & 2.9985 & $\mathrm{RN}$ \\
\hline AFMBI 159 & & $\partial 3$ & . 9919 & RN \\
\hline & & & & RN \\
\hline IEMBL13041 & & 03 & .1201 & ST \\
\hline IEMBL13061 & & 278 & .3121 & $\mathrm{RN}$ \\
\hline HEMBL15434 & 5 & 003 & .1878 & I NIV \\
\hline & & & & RN \\
\hline HEMBL1393451 & & 003 & .0811 & RN \\
\hline AEMBL1471858 & 5 & 003 & .2788 & $\Gamma \mathrm{RN}$ \\
\hline HEMBL3190105 & נעבסטק & 003 & 3.1009 & \\
\hline HEMBL1312133 & & & & \\
\hline 年 & & & 4.5677 & $\mathrm{RN}$ \\
\hline HEMBL1300937 & 5 & 1003 & 3.0088 & RN \\
\hline IEMBL14577€ & 8555 & 003 & 3.1165 & $n$ \\
\hline & & & & \\
\hline HEMBL1406 & & & 3.7985 & \\
\hline HEMBL137226 & & 3.1003 & 3.1177 & \\
\hline
\end{tabular}

Page 22667 
Supplemental Table S2.txt

\begin{tabular}{|c|c|c|c|c|c|c|}
\hline CHEMBL1414438 & 688555 & 3.1003 & 3.1612 & TRN & & \\
\hline CHEMBL1372206 & 688555 & 3.1003 & 3.0584 & TRN & & \\
\hline CHEMBL1532527 & 688555 & 4.2961 & 4.498 & TRN & & \\
\hline CHEMBL1334835 & 688555 & 3.1003 & 3.0683 & TRN & & \\
\hline CHEMBL1504012 & 688555 & 4.4311 & 4.5733 & TRN & & \\
\hline CHEMBL3189337 & 688555 & 3.1003 & 3.2121 & TRN & & \\
\hline CHEMBL1359239 & 688555 & 3.1003 & 3.3536 & TRN & & \\
\hline CHEMBL1332063 & 688555 & 3.1003 & 3.1132 & TRN & & \\
\hline CHEMBL1526244 & 688555 & 3.1003 & 2.9765 & TRN & & \\
\hline CHEMBL3189201 & 688555 & 4.817 & 4.8895 & TRN & & \\
\hline CHEMBL1439502 & 688555 & 3.1003 & 3.0726 & TRN & & \\
\hline CHEMBL1565236 & 688555 & 4.4787 & 4.1968 & TRN & & \\
\hline CHEMBL1521835 & 688555 & 3.1003 & 3.1295 & TRN & & \\
\hline CHEMBL1562550 & 688555 & 4.2349 & 4.0804 & TRN & & \\
\hline CHEMBL1525574 & 688555 & 4.9147 & 4.985 & TRN & & \\
\hline CHEMBL1445372 & 688555 & 4.4407 & 4.2536 & TST & & \\
\hline CHEMBL1478573 & 688555 & 4.3157 & 4.1888 & TRN & & \\
\hline CHEMBL1488374 & 688555 & 3.1003 & 4.1167 & TRN & & \\
\hline CHEMBL1478352 & 688555 & 3.1003 & 3.1004 & TST & & \\
\hline CHEMBL1575435 & 688555 & 4.7014 & 4.2432 & TRN & & \\
\hline CHEMBL1495320 & 688555 & 4.5399 & 4.4278 & TRN & & \\
\hline CHEMBL1370690 & 688555 & 3.1003 & 3.0244 & TST & & \\
\hline CHEMBL1306015 & 688555 & 3.1003 & 3.3501 & TRN & & \\
\hline CHEMBL1450472 & 688555 & 3.1003 & 3.1013 & TRN & & \\
\hline CHEMBL1352382 & 688555 & 3.1003 & 3.0727 & TRN & & \\
\hline CHEMBL235260 & 688555 & 3.1003 & 3.2134 & TRN & & \\
\hline CHEMBL1373790 & 688555 & 4.1635 & 3.9707 & TRN & & \\
\hline CHEMBL1519059 & 688555 & 3.1003 & 3.0904 & TRN & & \\
\hline CHEMBL1578181 & 688555 & 4.7282 & 4.7041 & TRN & & \\
\hline CHEMBL1440467 & 688555 & 3.1003 & 3.2293 & TRN & & \\
\hline CHEMBL1320697 & 688555 & 3.1003 & 3.1071 & TRN & & \\
\hline CHEMBL1407515 & 688555 & 3.1003 & 3.7435 & TRN & & \\
\hline CHEMBL1479296 & 688555 & 4.2838 & 4.105 & TRN & & \\
\hline CHEMBL3192152 & 688555 & 3.1003 & 3.1895 & TRN & & \\
\hline CHEMBL1310089 & 688555 & 3.1003 & 3.0892 & TRN & & \\
\hline CHEMBL1595702 & 688555 & 4.63899 & 799999999 & 99 & 4.3449 & TRN \\
\hline CHEMBL1602928 & 688555 & 3.1003 & 3.0186 & TRN & & \\
\hline CHEMBL 3207839 & 688555 & 3.1003 & 3.4374 & TST & & \\
\hline CHEMBL1470921 & 688555 & 3.1003 & 3.2293 & TST & & \\
\hline CHEMBL1366259 & 688555 & 4.3226 & 4.3273 & TST & & \\
\hline CHEMBL1324080 & 688555 & 3.1003 & 3.2044 & TST & & \\
\hline CHEMBL1405757 & 688555 & 3.1003 & 3.0482 & TST & & \\
\hline CHEMBL1334936 & 688555 & 3.1003 & 3.0483 & TST & & \\
\hline CHEMBL1370692 & 688555 & 3.1003 & 3.0356 & TST & & \\
\hline CHEMBL1426120 & 688555 & 3.1003 & 3.022 & TST & & \\
\hline CHEMBL1505466 & 688555 & 4.2811 & 4.1111 & TST & & \\
\hline CHEMBL1321430 & 688555 & 4.7726 & 4.4292 & TST & & \\
\hline CHEMBL1305056 & 688555 & 3.1003 & 3.0089 & TST & & \\
\hline
\end{tabular}

Page 22668 
Supplemental Table S2.txt

\begin{tabular}{|c|c|c|c|c|}
\hline CHEMBL1598467 & 688555 & 3.1003 & 3.0567 & TST \\
\hline CHEMBL1968356 & 688555 & 3.1003 & 3.2263 & TST \\
\hline CHEMBL1300069 & 688555 & 4.4911 & 4.3406 & TST \\
\hline CHEMBL 3197588 & 688555 & 3.1003 & 3.1492 & TST \\
\hline CHEMBL1563536 & 688555 & 3.1003 & 3.1467 & TST \\
\hline CHEMBL1609070 & 688555 & 3.1003 & 3.076 & TST \\
\hline CHEMBL1449791 & 688555 & 3.1003 & 3.0137 & TST \\
\hline CHEMBL1492681 & 688555 & 3.1003 & 3.1053 & TST \\
\hline CHEMBL1601884 & 688555 & 3.1003 & 3.02399 & 99999999996 \\
\hline CHEMBL1362098 & 688555 & 3.1003 & 3.096 & TST \\
\hline CHEMBL1421554 & 688555 & 3.1003 & 3.3425 & TST \\
\hline CHEMBL1449055 & 688555 & 3.1003 & 3.0979 & TST \\
\hline CHEMBL 3193904 & 688555 & 3.1003 & 3.0166 & TST \\
\hline CHEMBL3209557 & 688555 & 3.1003 & 3.1166 & TST \\
\hline CHEMBL1521729 & 688555 & 3.1003 & 3.2489 & TST \\
\hline CHEMBL1472426 & 688555 & 4.6055 & 4.6511 & TST \\
\hline CHEMBL1385846 & 688555 & 3.1003 & 3.1193 & TST \\
\hline CHEMBL 3196561 & 688555 & 3.1003 & 3.0918 & TST \\
\hline CHEMBL1308745 & 688555 & 3.1003 & 3.1059 & TST \\
\hline CHEMBL1430993 & 688555 & 3.1003 & 3.0235 & TST \\
\hline CHEMBL546475 & 688555 & 3.1003 & 3.0563 & TST \\
\hline CHEMBL1540443 & 688555 & 3.1003 & 4.1798 & TST \\
\hline CHEMBL1365995 & 688555 & 3.1003 & 3.057 & TST \\
\hline CHEMBL1565213 & 688555 & 3.1003 & 3.1909 & TST \\
\hline CHEMBL1324127 & 688555 & 3.1003 & 3.0576 & TST \\
\hline CHEMBL1333009 & 688555 & 3.1003 & 3.1004 & TST \\
\hline CHEMBL1574032 & 688555 & 3.1003 & 3.0969 & TST \\
\hline CHEMBL1339272 & 688555 & 3.1003 & 2.9771 & TST \\
\hline CHEMBL1583907 & 688555 & 3.1003 & 3.6859 & TST \\
\hline CHEMBL1492457 & 688555 & 4.4455 & 4.0398 & TST \\
\hline CHEMBL1579409 & 688555 & 3.1003 & 3.1624 & TST \\
\hline CHEMBL1472393 & 688555 & 4.9626 & 4.5046 & TST \\
\hline CHEMBL1426581 & 688555 & 4.6535 & 4.8445 & TST \\
\hline CHEMBL1457449 & 688555 & 3.1003 & 3.3024 & TST \\
\hline CHEMBL1465049 & 688555 & 3.1003 & 2.9871 & TST \\
\hline CHEMBL1299851 & 688555 & 3.1003 & 3.0459 & TST \\
\hline CHEMBL1348905 & 688555 & 3.1003 & 3.0046 & TST \\
\hline CHEMBL1432578 & 688555 & 3.1003 & 3.2728 & TST \\
\hline CHEMBL163923 & 75743 & 7.1739 & 7.1312 & TRN \\
\hline CHEMBL163873 & 75743 & 6.2899 & 6.0385 & TST \\
\hline CHEMBL349655 & 75743 & 7.1135 & 6.6573 & TST \\
\hline CHEMBL163681 & 75743 & 7.6778 & 7.7925 & TRN \\
\hline CHEMBL163867 & 75743 & 6.9872 & 6.8944 & TRN \\
\hline CHEMBL162850 & 75743 & 4.301 & 5.8284 & TRN \\
\hline CHEMBL159861 & 75743 & 7.1612 & 7.1627 & TRN \\
\hline CHEMBL162451 & 75743 & 7.3098 & 7.0333 & TRN \\
\hline CHEMBL162517 & 75743 & 6.9706 & 7.0854 & TRN \\
\hline CHEMBL163534 & 75743 & 5.4187 & 4.5806 & TRN \\
\hline
\end{tabular}




\begin{tabular}{|c|c|c|c|c|c|}
\hline \multirow[b]{2}{*}{ CHEMBL164742 } & \multicolumn{5}{|c|}{ enco } \\
\hline & 75743 & 6.8327 & 6.7535 & TRN & \\
\hline CHEMBL159920 & 75743 & 7.041 & 6.7991 & TRN & \\
\hline CHEMBL165982 & 75743 & 7.3188 & \multicolumn{2}{|c|}{6.962999999999999} & TRN \\
\hline CHEMBL413524 & 75743 & 7.1079 & 6.843 & TRN & \\
\hline CHEMBL163031 & 75743 & 6.8097 & 6.638 & TRN & \\
\hline CHEMBL162318 & 75743 & 7.5376 & 7.157 & TRN & \\
\hline CHEMBL163345 & 75743 & 6.4841 & 6.5776 & TRN & \\
\hline CHEMBL162310 & 75743 & 6.0 & 6.1306 & TST & \\
\hline CHEMBL163353 & 75743 & 6.224 & 6.4109 & TRN & \\
\hline CHEMBL422019 & 75743 & 6.9208 & 6.4966 & TST & \\
\hline CHEMBL162233 & 75743 & 6.0585 & 6.3314 & TRN & \\
\hline CHEMBL423463 & 75743 & 5.3022 & 4.5331 & TRN & \\
\hline CHEMBL163457 & 75743 & 4.301 & 6.3186 & TST & \\
\hline CHEMBL162372 & 75743 & 6.1925 & 6.2521 & TST & \\
\hline CHEMBL350655 & 75743 & 7.6021 & 7.3735 & TRN & \\
\hline CHEMBL350794 & 75743 & 6.9281 & 6.8803 & TST & \\
\hline CHEMBL163513 & 75743 & 4.301 & 6.0084 & TST & \\
\hline CHEMBL350316 & 75743 & 7.6459 & 7.2516 & TST & \\
\hline CHEMBL350370 & 75743 & 5.9983 & 5.9447 & TST & \\
\hline CHEMBL163139 & 75743 & 4.301 & 4.038 & TRN & \\
\hline CHEMBL163399 & 75743 & 6.7328 & 6.9511 & TRN & \\
\hline CHEMBL162169 & 75743 & 7.6198 & 7.2766 & TRN & \\
\hline CHEMBL351632 & 75743 & 7.041 & \multicolumn{2}{|c|}{6.747000000000001} & TRN \\
\hline CHEMBL350542 & 75743 & 7.0 & 7.289 & TRN & \\
\hline CHEMBL348746 & 75743 & 4.301 & 5.1447 & TRN & \\
\hline CHEMBL162440 & 75743 & 5.9996 & 6.1936 & TRN & \\
\hline CHEMBL354691 & 75743 & 4.301 & 4.2979 & TRN & \\
\hline CHEMBL349468 & 75743 & 6.6308 & 6.6511 & TRN & \\
\hline CHEMBL350709 & 75743 & 7.2366 & 7.2604 & TRN & \\
\hline CHEMBL351646 & 75743 & 6.8447 & 6.8004 & TRN & \\
\hline CHEMBL424343 & 75743 & 4.301 & 6.2032 & TST & \\
\hline CHEMBL350096 & 75743 & 6.7144 & 6.6774 & TRN & \\
\hline CHEMBL162320 & 75743 & 7.6021 & 7.7137 & TRN & \\
\hline CHEMBL162448 & 75743 & 6.8996 & 6.6584 & TST & \\
\hline CHEMBL349901 & 75743 & 7.0269 & 6.5799 & TRN & \\
\hline CHEMBL350797 & 75743 & 6.9914 & 7.0424 & TRN & \\
\hline CHEMBL162309 & 75743 & 6.0947 & 6.17 & TRN & \\
\hline CHEMBL353784 & 75743 & 6.8601 & 6.8772 & TRN & \\
\hline CHEMBL163617 & 75743 & 6.6271 & 6.3911 & TST & \\
\hline CHEMBL163594 & 75743 & 6.7399 & 6.9051 & TRN & \\
\hline CHEMBL162830 & 75743 & 6.7144 & 6.4859 & TRN & \\
\hline CHEMBL162112 & 75743 & 6.8861 & 6.6751 & TRN & \\
\hline CHEMBL164618 & 75743 & 6.0545 & 5.6826 & TRN & \\
\hline CHEMBL350094 & 75743 & 5.4414 & 6.024 & TRN & \\
\hline CHEMBL424182 & 75743 & 7.0088 & \multicolumn{2}{|c|}{6.6739999999999995} & TRN \\
\hline CHEMBL162231 & 75743 & 7.5528 & 7.1093 & TST & \\
\hline CHEMBL349751 & 75743 & 4.301 & 4.9948 & TRN & \\
\hline \multirow[t]{2}{*}{ CHEMBL163393 } & 75743 & 6.7747 & 6.999 & TRN & \\
\hline & & \multicolumn{4}{|c|}{ Page 22670} \\
\hline
\end{tabular}




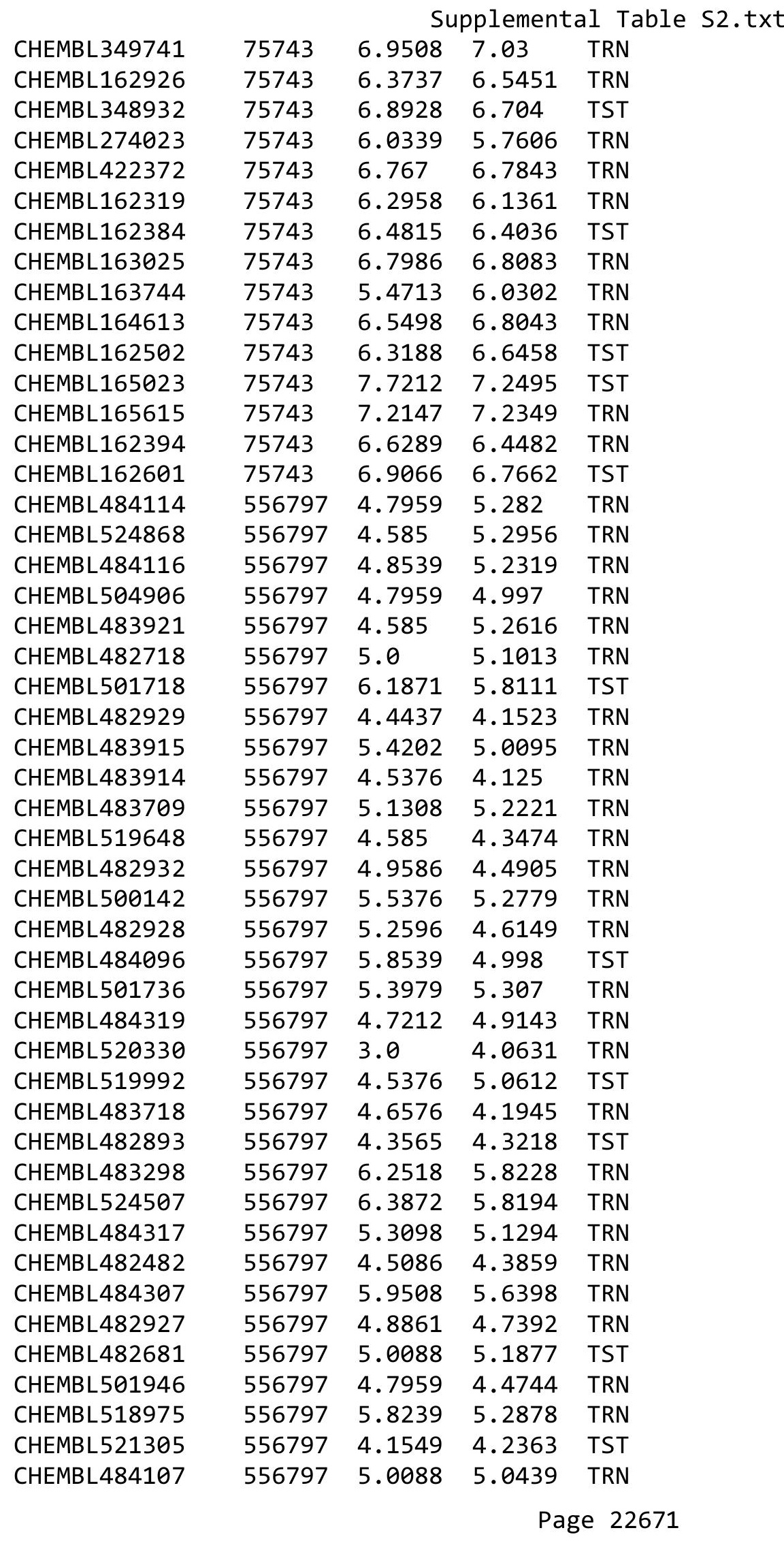




\begin{tabular}{|c|c|c|c|c|c|}
\hline & & \multicolumn{4}{|c|}{ Supplemental Table S2.txt } \\
\hline CHEMBL484301 & 556797 & 4.7447 & 4.9658 & TST & \\
\hline CHEMBL483717 & 556797 & 4.7447 & 5.0148 & TST & \\
\hline CHEMBL482926 & 556797 & 4.3468 & 4.8787 & TRN & \\
\hline CHEMBL482680 & 556797 & 4.3468 & 4.4423 & TRN & \\
\hline CHEMBL484320 & 556797 & 5.9208 & 5.2224 & TRN & \\
\hline CHEMBL443770 & 556797 & 6.5086 & 5.7859 & TST & \\
\hline CHEMBL484917 & 556797 & 3.0 & 4.9012 & TRN & \\
\hline CHEMBL501719 & 556797 & 5.6021 & 5.8893 & TST & \\
\hline CHEMBL520162 & 556797 & 4.9208 & 4.7764 & TRN & \\
\hline CHEMBL483297 & 556797 & 4.0362 & 4.2113 & TST & \\
\hline CHEMBL483916 & 556797 & 4.1192 & 4.2848 & TST & \\
\hline CHEMBL500416 & 556797 & 4.8539 & 5.3716 & TST & \\
\hline CHEMBL482689 & 556797 & 5.0 & 5.2582 & TRN & \\
\hline CHEMBL200114 & 556797 & 5.4559 & 5.3466 & TRN & \\
\hline CHEMBL520623 & 556797 & 4.2518 & 4.2408 & TRN & \\
\hline CHEMBL484106 & 556797 & 5.9355 & 5.6766 & TRN & \\
\hline CHEMBL521480 & 556797 & 5.5229 & 5.3755 & TRN & \\
\hline CHEMBL525079 & 556797 & 4.6576 & 5.047 & TRN & \\
\hline CHEMBL500151 & 556797 & 4.7447 & 5.41700 & 0000000001 & TRN \\
\hline CHEMBL520632 & 556797 & 4.0655 & 4.1582 & TST & \\
\hline CHEMBL482931 & 556797 & 4.7212 & 4.5621 & TRN & \\
\hline CHEMBL520625 & 556797 & 4.4685 & 4.4459 & TRN & \\
\hline CHEMBL484115 & 556797 & 5.3279 & 4.9884 & TRN & \\
\hline CHEMBL102430 & 27924 & 5.0458 & 5.3622 & TRN & \\
\hline CHEMBL321330 & 27924 & 5.1249 & 4.5629 & TRN & \\
\hline CHEMBL17127 & 27924 & 8.4881 & 7.6078 & TST & \\
\hline CHEMBL328214 & 27924 & 5.1871 & 3.8839 & TST & \\
\hline CHEMBL97037 & 27924 & 5.699 & 4.6851 & TRN & \\
\hline CHEMBL102974 & 27924 & 4.0 & 3.8471 & TRN & \\
\hline CHEMBL102429 & 27924 & 5.8861 & 5.6858 & TRN & \\
\hline CHEMBL104999 & 27924 & 6.9586 & 6.7261 & TRN & \\
\hline CHEMBL328334 & 27924 & 4.0 & 4.1885 & TRN & \\
\hline CHEMBL97665 & 27924 & 4.0 & 4.5524 & TRN & \\
\hline CHEMBL 95384 & 27924 & 7.3979 & 6.9793 & TRN & \\
\hline CHEMBL183 & 27924 & 6.8416 & 7.1635 & TST & \\
\hline CHEMBL103588 & 27924 & 4.0 & 4.751 & TRN & \\
\hline CHEMBL97344 & 27924 & 4.0 & 4.1655 & TRN & \\
\hline CHEMBL100121 & 27924 & 4.0 & 4.1692 & TRN & \\
\hline CHEMBL 329293 & 27924 & 6.6383 & 6.2207 & TRN & \\
\hline CHEMBL105000 & 27924 & 6.6778 & 5.3906 & TRN & \\
\hline CHEMBL323288 & 27924 & 5.4202 & 4.3161 & TST & \\
\hline CHEMBL102017 & 27924 & 4.0 & 4.0143 & TRN & \\
\hline CHEMBL415697 & 27924 & 4.0 & 3.9975 & TST & \\
\hline CHEMBL 97904 & 27924 & 4.0 & 4.205 & TRN & \\
\hline CHEMBL97337 & 27924 & 6.6778 & 6.1365 & TRN & \\
\hline CHEMBL97896 & 27924 & 5.3188 & 4.9195 & TRN & \\
\hline CHEMBL102753 & 27924 & 5.8539 & 4.5053 & TST & \\
\hline CHEMBL103278 & 27924 & 4.0 & 4.042 & TRN & \\
\hline
\end{tabular}




\begin{tabular}{|c|c|c|c|c|c|}
\hline & & \multicolumn{4}{|c|}{ Supplemental Table s2.txt } \\
\hline CHEMBL97757 & 27924 & 5.5686 & 6.519 & TRN & \\
\hline CHEMBL103559 & 27924 & 6.0132 & 5.809 & TRN & \\
\hline CHEMBL321769 & 27924 & 5.4685 & 6.3267 & TRN & \\
\hline CHEMBL418797 & 27924 & 5.7696 & 5.9651 & TRN & \\
\hline CHEMBL103553 & 27924 & 5.7447 & 3.8036 & TST & \\
\hline CHEMBL94538 & 27924 & 5.3872 & 5.2982 & TRN & \\
\hline CHEMBL313864 & 27924 & 6.3565 & 6.6338 & TRN & \\
\hline CHEMBL317411 & 27924 & 4.0 & 3.9385 & TRN & \\
\hline CHEMBL329294 & 27924 & 6.3098 & 5.75899 & 99999999995 & TRN \\
\hline CHEMBL97778 & 27924 & 4.0 & 4.1173 & TRN & \\
\hline CHEMBL97624 & 27924 & 6.3098 & 6.3537 & TRN & \\
\hline CHEMBL316630 & 27924 & 6.1938 & 6.4112 & TRN & \\
\hline CHEMBL96576 & 27924 & 4.0 & 4.3968 & TRN & \\
\hline CHEMBL319580 & 27924 & 4.0 & 4.0178 & TRN & \\
\hline CHEMBL97760 & 27924 & 6.3468 & 6.6238 & TRN & \\
\hline CHEMBL104998 & 27924 & 5.7959 & 6.08899 & 99999999995 & TRN \\
\hline CHEMBL 98227 & 27924 & 4.0 & 3.467 & TST & \\
\hline CHEMBL102178 & 27924 & 4.0 & 4.2666 & TRN & \\
\hline CHEMBL102491 & 27924 & 4.0 & 3.80800 & 00000000003 & TRN \\
\hline CHEMBL97687 & 27924 & 7.0 & 7.0062 & TRN & \\
\hline CHEMBL96617 & 27924 & 4.0 & 4.1922 & TRN & \\
\hline CHEMBL 103150 & 27924 & 6.0 & 5.8089 & TRN & \\
\hline CHEMBL441815 & 27924 & 4.0 & 4.1025 & TST & \\
\hline CHEMBL 323303 & 27924 & 5.8861 & 6.5197 & TST & \\
\hline CHEMBL97549 & 27924 & 6.2596 & 6.5889 & TST & \\
\hline CHEMBL103796 & 27924 & 4.0 & 4.3455 & TST & \\
\hline CHEMBL102126 & 27924 & 4.0 & 4.0941 & TST & \\
\hline CHEMBL97895 & 27924 & 5.8239 & 4.4946 & TST & \\
\hline CHEMBL3354085 & 1439182 & 6.0269 & 6.3866 & TST & \\
\hline CHEMBL3354098 & 1439182 & 6.5686 & 6.4976 & TRN & \\
\hline CHEMBL3354109 & 1439182 & 5.5186 & 5.2859 & TST & \\
\hline CHEMBL3354116 & 1439182 & 5.9914 & 5.9701 & TRN & \\
\hline CHEMBL3354099 & 1439182 & 5.3809 & 5.3607 & TRN & \\
\hline CHEMBL3354106 & 1439182 & 5.6289 & 5.5989 & TRN & \\
\hline CHEMBL3354102 & 1439182 & 5.3325 & 5.3843 & TRN & \\
\hline CHEMBL3354113 & 1439182 & 5.5935 & 5.5014 & TRN & \\
\hline CHEMBL3354080 & 1439182 & 5.6925 & 5.7165 & TST & \\
\hline CHEMBL3354115 & 1439182 & 5.7932 & 5.7972 & TRN & \\
\hline CHEMBL3354082 & 1439182 & 5.6326 & 5.4349 & TST & \\
\hline CHEMBL3354090 & 1439182 & 5.7799 & 5.8121 & TRN & \\
\hline CHEMBL3354123 & 1439182 & 5.0888 & 5.1398 & TRN & \\
\hline CHEMBL3354083 & 1439182 & 5.7399 & 5.3622 & TST & \\
\hline CHEMBL 278315 & 1439182 & 7.301 & 5.5565 & TST & \\
\hline CHEMBL3354089 & 1439182 & 5.3098 & 5.2297 & TRN & \\
\hline CHEMBL3354092 & 1439182 & 5.76200 & 00000000 & 5.6837 & TRN \\
\hline CHEMBL3354114 & 1439182 & 5.4023 & 5.4269 & TRN & \\
\hline CHEMBL3354110 & 1439182 & 5.289 & 5.3893 & TRN & \\
\hline CHEMBL3354104 & 1439182 & 5.5302 & 5.5254 & TRN & \\
\hline
\end{tabular}


Supplemental Table S2.txt

\begin{tabular}{|c|c|c|c|c|c|}
\hline CHEMBL3354097 & 1439182 & 6.0132 & 6.005 & TRN & \\
\hline CHEMBL3354124 & 1439182 & 6.5229 & 6.5528 & TRN & \\
\hline CHEMBL3354105 & 1439182 & 5.3615 & 5.3452 & TRN & \\
\hline CHEMBL3354119 & 1439182 & 5.4789 & 5.4256 & TRN & \\
\hline CHEMBL 3354101 & 1439182 & 5.4698 & 5.4631 & TRN & \\
\hline CHEMBL 3352834 & 1439182 & 5.5031 & 5.5187 & TRN & \\
\hline CHEMBL3354095 & 1439182 & 5.5058 & 5.5003 & TRN & \\
\hline CHEMBL3354646 & 1439182 & 6.7212 & 6.6819 & TRN & \\
\hline CHEMBL 3354086 & 1439182 & 5.3883 & 5.7679 & TRN & \\
\hline CHEMBL3354121 & 1439182 & 5.8327 & 5.8432 & TRN & \\
\hline CHEMBL 3354108 & 1439182 & 5.9136 & 5.8913 & TRN & \\
\hline CHEMBL3354100 & 1439182 & 5.3872 & 5.4206 & TRN & \\
\hline CHEMBL 3354093 & 1439182 & 6.301 & 5.9645 & TRN & \\
\hline CHEMBL3354103 & 1439182 & 5.4023 & 5.4729 & TRN & \\
\hline CHEMBL 3354120 & 1439182 & 5.3429 & 5.3042 & TRN & \\
\hline CHEMBL 3354647 & 1439182 & 4.0 & 3.9996 & TRN & \\
\hline CHEMBL3354648 & 1439182 & 4.0 & 3.9645 & TRN & \\
\hline CHEMBL 3354084 & 1439182 & 5.7747 & 5.8005 & TST & \\
\hline CHEMBL 3354645 & 1439182 & 5.7305 & 5.7408 & TRN & \\
\hline CHEMBL 3354107 & 1439182 & 6.0362 & 5.9437 & TST & \\
\hline CHEMBL3354111 & 1439182 & 5.2815 & 5.2152 & TRN & \\
\hline CHEMBL3354649 & 1439182 & 5.6757 & 5.6742 & TRN & \\
\hline CHEMBL3354122 & 1439182 & 5.2197 & 5.2015 & TRN & \\
\hline CHEMBL 3354081 & 1439182 & 5.5467 & 5.5784 & TST & \\
\hline CHEMBL 3354117 & 1439182 & 5.9066 & 5.9754 & TRN & \\
\hline CHEMBL 3354094 & 1439182 & 6.0506 & 5.5083 & TST & \\
\hline CHEMBL3354096 & 1439182 & 5.21899 & 999999999 & 99 & 5.4207 \\
\hline CHEMBL3354079 & 1439182 & 5.9508 & 5.4636 & TST & \\
\hline CHEMBL 3354118 & 1439182 & 5.4056 & 5.4155 & TRN & \\
\hline CHEMBL3354112 & 1439182 & 5.1605 & 5.1976 & TRN & \\
\hline CHEMBL 3354088 & 1439182 & 5.0731 & 5.3149 & TST & \\
\hline CHEMBL3354087 & 1439182 & 5.4622 & 5.3157 & TST & \\
\hline CHEMBL3354091 & 1439182 & 6.2596 & 6.3171 & TRN & \\
\hline CHEMBL 3354125 & 1439182 & 5.7696 & 5.829 & TRN & \\
\hline CHEMBL 307152 & 75622 & 5.9788 & 6.2517 & TRN & \\
\hline CHEMBL306047 & 75622 & 5.7878 & 5.6336 & TRN & \\
\hline CHEMBL308594 & 75622 & 5.9469 & 5.9861 & TRN & \\
\hline CHEMBL76499 & 75622 & 4.0 & 5.0054 & TRN & \\
\hline CHEMBL 74883 & 75622 & 5.7212 & 5.8971 & TRN & \\
\hline CHEMBL 73781 & 75622 & 5.8097 & 6.2696 & TRN & \\
\hline CHEMBL306527 & 75622 & 4.0 & 4.364 & TRN & \\
\hline CHEMBL 73767 & 75622 & 5.4145 & 5.08 & TRN & \\
\hline CHEMBL 73413 & 75622 & 5.52 & 5.6364 & TRN & \\
\hline CHEMBL306611 & 75622 & 5.7447 & 5.4011 & TRN & \\
\hline CHEMBL 73772 & 75622 & 5.5498 & 5.6478 & TRN & \\
\hline CHEMBL 308541 & 75622 & 6.2366 & 5.349 & TRN & \\
\hline CHEMBL306367 & 75622 & 5.3279 & 4.8467 & TRN & \\
\hline CHEMBL 76326 & 75622 & 6.7696 & 6.5092 & TRN & \\
\hline
\end{tabular}

Page 22674 


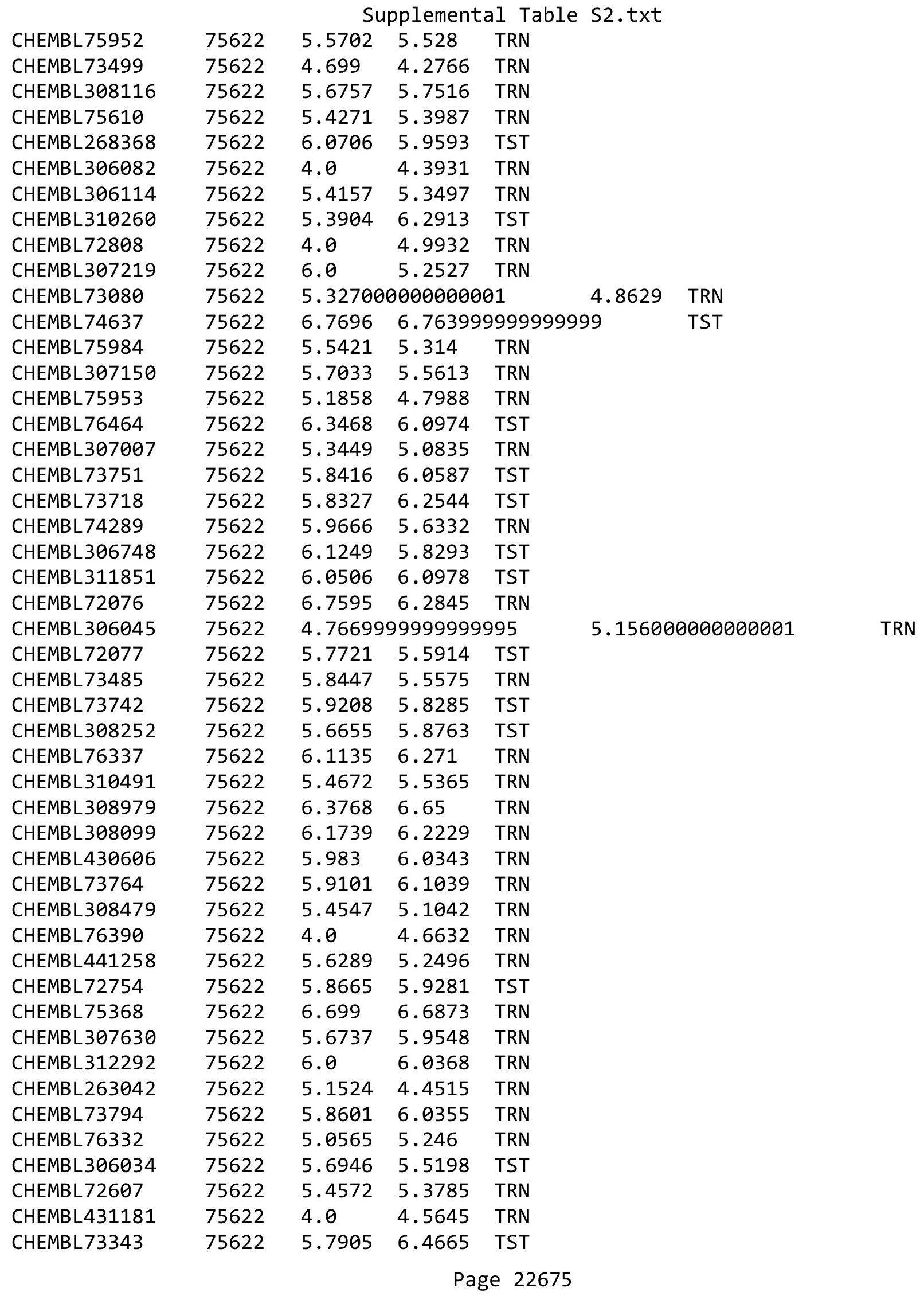




\begin{tabular}{|c|c|c|c|c|c|c|}
\hline & & \multicolumn{5}{|c|}{ Supplemental Table S2.txt } \\
\hline CHEMBL72069 & 75622 & 5.9469 & 6.0271 & TRN & & \\
\hline CHEMBL72661 & 75622 & 5.6216 & 5.4398 & TST & & \\
\hline CHEMBL73832 & 75622 & 4.0 & 4.4899 & TRN & & \\
\hline CHEMBL 306501 & 75622 & 5.7077 & 5.9179 & TST & & \\
\hline CHEMBL308994 & 75622 & 4.0 & 4.1702 & TRN & & \\
\hline CHEMBL 309343 & 75622 & 4.0 & 4.039 & TRN & & \\
\hline CHEMBL306856 & 75622 & 5.8996 & 6.1874 & TST & & \\
\hline CHEMBL308542 & 75622 & 4.0 & 5.0294 & TST & & \\
\hline CHEMBL1505994 & 736855 & 3.8916 & 4.0929 & TRN & & \\
\hline CHEMBL1610049 & 736855 & \multicolumn{3}{|c|}{5.247000000000001} & .218 & TRN \\
\hline CHEMBL1610901 & 736855 & 4.3749 & 4.4379 & TRN & & \\
\hline CHEMBL1331439 & 736855 & 4.4449 & 4.1861 & TRN & & \\
\hline CHEMBL1358066 & 736855 & 2.71 & 2.5735 & TRN & & \\
\hline CHEMBL1455906 & 736855 & 2.71 & 4.3373 & TST & & \\
\hline CHEMBL1503911 & 736855 & 4.4895 & 4.5223 & TRN & & \\
\hline CHEMBL1578032 & 736855 & 2.71 & 2.6794 & TRN & & \\
\hline CHEMBL1383420 & 736855 & 4.1425 & 4.3734 & TRN & & \\
\hline CHEMBL3198239 & 736855 & 4.6098 & 4.6468 & TRN & & \\
\hline CHEMBL1309548 & 736855 & 4.4851 & 4.412 & TRN & & \\
\hline CHEMBL1581490 & 736855 & 4.3919 & 4.3009 & TRN & & \\
\hline CHEMBL1440300 & 736855 & 5.7421 & 5.7626 & TRN & & \\
\hline CHEMBL1562059 & 736855 & 3.9716 & 4.369 & TRN & & \\
\hline CHEMBL1411322 & 736855 & 2.71 & 2.7535 & TRN & & \\
\hline CHEMBL1605795 & 736855 & 4.1893 & 3.9865 & TRN & & \\
\hline CHEMBL1561774 & 736855 & 4.207 & 4.2836 & TRN & & \\
\hline CHEMBL267099 & 736855 & 4.9793 & 4.9917 & TRN & & \\
\hline CHEMBL1344368 & 736855 & 4.3428 & 4.4229 & TRN & & \\
\hline CHEMBL1349063 & 736855 & 5.6815 & 5.8593 & TRN & & \\
\hline CHEMBL1507404 & 736855 & 4.5218 & 4.1815 & TST & & \\
\hline CHEMBL1613578 & 736855 & 5.2417 & 5.3215 & TRN & & \\
\hline CHEMBL1400375 & 736855 & 5.2544 & 5.3113 & TRN & & \\
\hline CHEMBL580955 & 736855 & 4.2568 & 4.0052 & TRN & & \\
\hline CHEMBL1322078 & 736855 & 2.71 & 2.9923 & TRN & & \\
\hline CHEMBL1501680 & 736855 & 5.3212 & 5.106 & TRN & & \\
\hline CHEMBL1469091 & 736855 & 3.8932 & 3.912 & TRN & & \\
\hline CHEMBL1497165 & 736855 & 2.71 & 2.8619 & TRN & & \\
\hline CHEMBL1438636 & 736855 & 5.2505 & 5.3478 & TRN & & \\
\hline CHEMBL1345979 & 736855 & 4.9049 & 4.0861 & TST & & \\
\hline CHEMBL1350133 & 736855 & 4.1103 & 4.1195 & TRN & & \\
\hline CHEMBL1459140 & 736855 & 6.0173 & 6.1368 & TRN & & \\
\hline CHEMBL1389555 & 736855 & 3.9374 & 3.8689 & TRN & & \\
\hline CHEMBL1967184 & 736855 & 4.3248 & 4.3759 & TRN & & \\
\hline CHEMBL1310617 & 736855 & 4.7278 & 4.0326 & TST & & \\
\hline CHEMBL1448374 & 736855 & 4.2047 & 3.8254 & TRN & & \\
\hline CHEMBL2002162 & 736855 & 4.813 & 4.7532 & TST & & \\
\hline CHEMBL1453299 & 736855 & 4.1928 & 4.0311 & TRN & & \\
\hline CHEMBL3194571 & 736855 & 5.6192 & 4.8665 & TST & & \\
\hline CHEMBL1612398 & 736855 & 4.7924 & 4.86100 & 2000000001 & & TRN \\
\hline & & & & 22676 & & \\
\hline
\end{tabular}




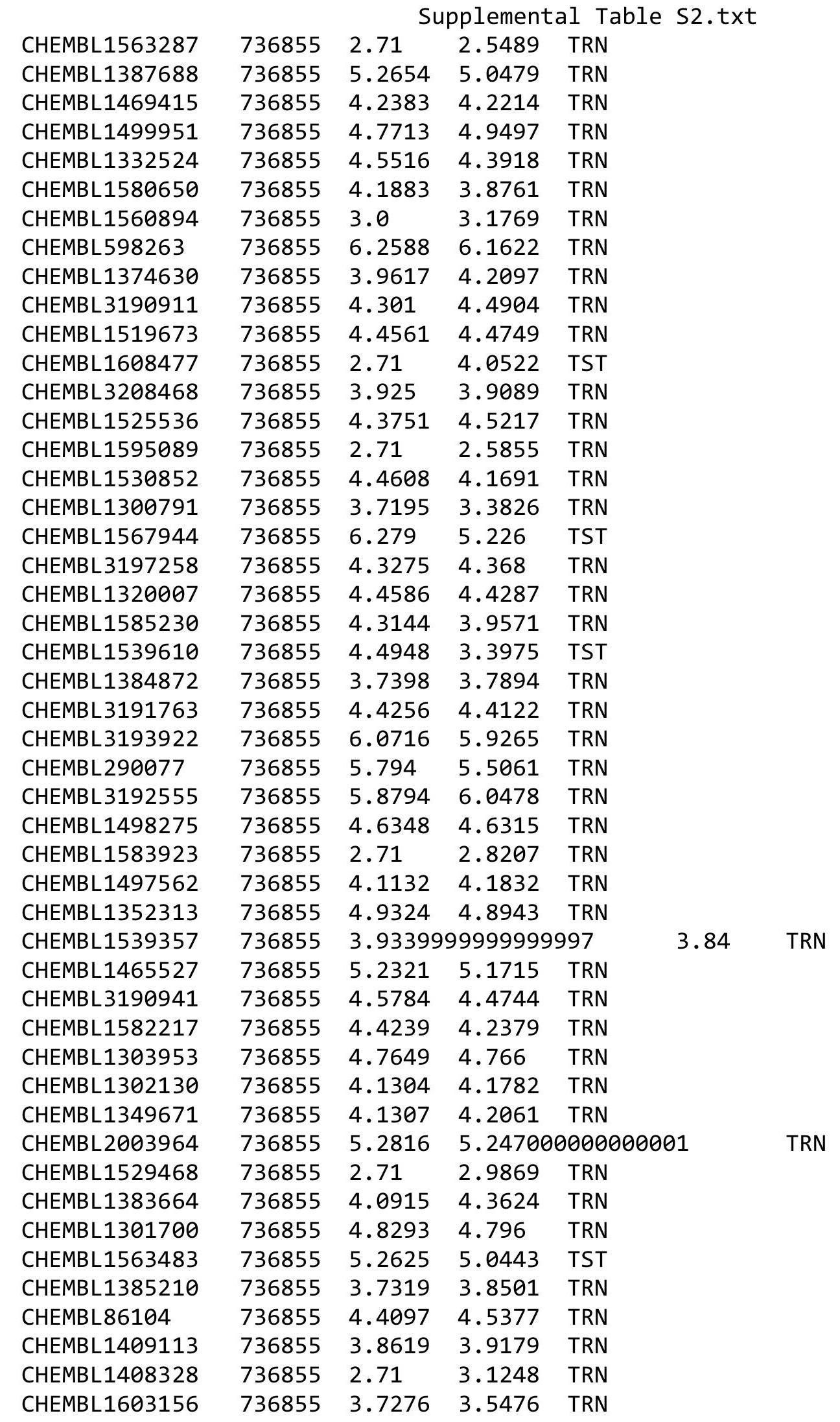

Page 22677 
Supplemental Table S2.txt

\begin{tabular}{|c|c|c|c|c|}
\hline CHEMBL1573883 & 736855 & 4.1212 & 4.2733 & TRN \\
\hline CHEMBL1358722 & 736855 & 6.4737 & 4.8252 & TST \\
\hline CHEMBL1987894 & 736855 & 5.7587 & 5.7097 & TRN \\
\hline CHEMBL1339909 & 736855 & 5.2486 & 4.4919 & TST \\
\hline CHEMBL1364999 & 736855 & 5.2434 & 5.4133 & TST \\
\hline CHEMBL 3208883 & 736855 & 3.8422 & 4.1306 & TST \\
\hline CHEMBL1450564 & 736855 & 4.6268 & 4.6497 & TST \\
\hline CHEMBL1345974 & 736855 & 4.9055 & 3.8765 & TST \\
\hline CHEMBL1534472 & 736855 & 3.9836 & 3.7395 & TST \\
\hline CHEMBL1461738 & 736855 & 4.5325 & 4.20100 & 00000000005 \\
\hline CHEMBL1319020 & 736855 & 4.2783 & 4.0417 & TST \\
\hline CHEMBL1443453 & 736855 & 4.3631 & 3.4825 & TST \\
\hline CHEMBL1477985 & 736855 & 2.71 & 3.4153 & TST \\
\hline CHEMBL1606097 & 736855 & 4.6427 & 4.7872 & TST \\
\hline CHEMBL1384253 & 736855 & 5.8551 & 5.0045 & TST \\
\hline CHEMBL1462352 & 736855 & 2.71 & 4.0252 & TST \\
\hline CHEMBL1501755 & 736855 & 5.2853 & 4.1082 & TST \\
\hline CHEMBL1565115 & 736855 & 3.7342 & 3.5309 & TST \\
\hline CHEMBL1506808 & 736855 & 4.2711 & 3.7104 & TST \\
\hline CHEMBL 2431624 & 984872 & 9.301 & 8.7625 & TRN \\
\hline CHEMBL2431642 & 984872 & 6.1013 & 8.9922 & TST \\
\hline CHEMBL 2431545 & 984872 & 9.301 & 9.5815 & TRN \\
\hline CHEMBL 2431531 & 984872 & 9.301 & 9.1306 & TRN \\
\hline CHEMBL 2431537 & 984872 & 9.301 & 9.1838 & TRN \\
\hline CHEMBL 2431621 & 984872 & 9.301 & 9.1065 & TRN \\
\hline CHEMBL 2431626 & 984872 & 9.301 & 9.1827 & TRN \\
\hline CHEMBL 2431540 & 984872 & 9.301 & 9.4208 & TRN \\
\hline CHEMBL 2431634 & 984872 & 9.301 & 8.8672 & TRN \\
\hline CHEMBL 2431548 & 984872 & 9.301 & 9.2123 & TRN \\
\hline CHEMBL 2429885 & 984872 & 9.301 & 9.5104 & TRN \\
\hline CHEMBL2431546 & 984872 & 9.301 & 9.3117 & TRN \\
\hline CHEMBL 2431532 & 984872 & 9.301 & 9.2014 & TRN \\
\hline CHEMBL 2431623 & 984872 & 9.301 & 8.7996 & TRN \\
\hline CHEMBL 2431543 & 984872 & 9.301 & 9.3502 & TRN \\
\hline CHEMBL 2431549 & 984872 & 9.301 & 9.3188 & TRN \\
\hline CHEMBL2431633 & 984872 & 7.5229 & 7.3026 & TRN \\
\hline CHEMBL 2431647 & 984872 & 7.8539 & 8.5811 & TRN \\
\hline CHEMBL 2431635 & 984872 & 9.301 & 9.1004 & TRN \\
\hline CHEMBL 2431528 & 984872 & 5.1612 & 8.7376 & TST \\
\hline CHEMBL 2431630 & 984872 & 7.0223 & 8.5215 & TRN \\
\hline CHEMBL2431632 & 984872 & 7.2218 & 6.9189 & TRN \\
\hline CHEMBL 2431622 & 984872 & 9.301 & 8.9312 & TRN \\
\hline CHEMBL 2431641 & 984872 & 6.6576 & 8.2903 & TST \\
\hline CHEMBL 2431539 & 984872 & 9.301 & 9.2359 & TRN \\
\hline CHEMBL 2431637 & 984872 & 7.301 & 7.1871 & TRN \\
\hline CHEMBL2431648 & 984872 & 9.301 & 8.7995 & TRN \\
\hline CHEMBL 2431544 & 984872 & 7.301 & 8.7644 & TRN \\
\hline CHEMBL2431541 & 984872 & 9.301 & 9.4507 & TRN \\
\hline
\end{tabular}




\begin{tabular}{|c|c|c|c|c|c|}
\hline \multirow[b]{2}{*}{ CHEMBL2431644 } & \multicolumn{5}{|c|}{ Supplemental Table S2.txt } \\
\hline & 984872 & 9.301 & 9.0658 & TRN & \\
\hline CHEMBL 2431627 & 984872 & 9.301 & 8.8367 & TRN & \\
\hline CHEMBL2431631 & 984872 & 9.301 & 9.0211 & TRN & \\
\hline CHEMBL 2431650 & 984872 & 9.301 & 8.8573 & TRN & \\
\hline CHEMBL 2431529 & 984872 & 5.0362 & 8.6489 & TST & \\
\hline CHEMBL 2431535 & 984872 & 9.301 & 9.34100 & 0000000001 & TRN \\
\hline CHEMBL 2431646 & 984872 & 7.9208 & 8.4315 & TRN & \\
\hline CHEMBL2431542 & 984872 & 9.301 & 9.3673 & TRN & \\
\hline CHEMBL 2431649 & 984872 & 9.301 & 9.2094 & TRN & \\
\hline CHEMBL 2429886 & 984872 & 9.301 & 8.8541 & TST & \\
\hline CHEMBL 2431536 & 984872 & 9.301 & 9.3739 & TRN & \\
\hline CHEMBL 2431639 & 984872 & 7.041 & 9.1293 & TST & \\
\hline CHEMBL2431643 & 984872 & 9.301 & 9.1125 & TRN & \\
\hline CHEMBL 2431636 & 984872 & 9.301 & 8.8735 & TRN & \\
\hline CHEMBL 2431538 & 984872 & 9.301 & 8.6818 & TRN & \\
\hline CHEMBL 2431534 & 984872 & 9.301 & 9.6328 & TRN & \\
\hline CHEMBL 2431638 & 984872 & 9.301 & 9.0539 & TST & \\
\hline CHEMBL2431629 & 984872 & 7.0969 & 8.3357 & TRN & \\
\hline CHEMBL 2431640 & 984872 & 9.301 & 9.1753 & TST & \\
\hline CHEMBL474704 & 984872 & 8.3768 & 8.98200 & 0000000001 & TST \\
\hline CHEMBL 2431628 & 984872 & 7.4202 & 8.6538 & TST & \\
\hline CHEMBL 2431547 & 984872 & 9.301 & 9.4019 & TST & \\
\hline CHEMBL 2431645 & 984872 & 9.301 & 9.1663 & TST & \\
\hline CHEMBL 2431533 & 984872 & 9.301 & 9.2943 & TST & \\
\hline CHEMBL2431625 & 984872 & 9.301 & 8.7769 & TST & \\
\hline CHEMBL188365 & 311595 & 5.0 & 5.0178 & TRN & \\
\hline CHEMBL188877 & 311595 & 7.0 & 6.9296 & TRN & \\
\hline CHEMBL185487 & 311595 & 6.699 & 6.6665 & TRN & \\
\hline CHEMBL363066 & 311595 & 6.3979 & 6.4554 & TRN & \\
\hline CHEMBL 364403 & 311595 & 6.699 & 6.7233 & TRN & \\
\hline CHEMBL366692 & 311595 & 7.2218 & 6.1807 & TST & \\
\hline CHEMBL361250 & 311595 & 5.0 & 4.9885 & TRN & \\
\hline CHEMBL186128 & 311595 & 5.0 & 5.0368 & TRN & \\
\hline CHEMBL189458 & 311595 & 7.1549 & 7.1237 & TRN & \\
\hline CHEMBL363952 & 311595 & 7.2218 & 7.1483 & TRN & \\
\hline CHEMBL362435 & 311595 & 6.0 & 6.0574 & TRN & \\
\hline CHEMBL188995 & 311595 & 7.5229 & 7.468 & TRN & \\
\hline CHEMBL184175 & 311595 & 4.0 & 4.1655 & TRN & \\
\hline CHEMBL181683 & 311595 & 5.8013 & 4.7768 & TST & \\
\hline CHEMBL188223 & 311595 & 6.8239 & 6.9775 & TRN & \\
\hline CHEMBL182846 & 311595 & 6.2007 & 6.1845 & TRN & \\
\hline CHEMBL186723 & 311595 & 5.2 & 5.1513 & TRN & \\
\hline CHEMBL181747 & 311595 & 6.5086 & 6.5287 & TRN & \\
\hline CHEMBL361839 & 311595 & 6.301 & 3.7809 & TST & \\
\hline CHEMBL359749 & 311595 & 5.9031 & 5.8258 & TRN & \\
\hline CHEMBL182725 & 311595 & 6.4089 & 6.4334 & TRN & \\
\hline CHEMBL184880 & 311595 & 4.2007 & 4.1506 & TRN & \\
\hline CHEMBL187305 & 311595 & 7.0969 & 7.1083 & TRN & \\
\hline
\end{tabular}




\begin{tabular}{|c|c|c|c|c|c|}
\hline \\
\hline CHEMBL186129 & 311595 & 4.0 & 3.9479 & TRN & \\
\hline CHEMBL183249 & 311595 & 6.8239 & 6.796 & TRN & \\
\hline CHEMBL426242 & 311595 & 5.0 & 4.9463 & TRN & \\
\hline CHEMBL184934 & 311595 & 2.4 & 2.416 & TRN & \\
\hline CHEMBL187832 & 311595 & 5.0 & 4.9289 & TRN & \\
\hline CHEMBL188580 & 311595 & 7.3979 & 7.5218 & TRN & \\
\hline CHEMBL188745 & 311595 & 6.0 & 5.8582 & TRN & \\
\hline CHEMBL181497 & 311595 & 5.4123 & 6.0066 & TST & \\
\hline CHEMBL188489 & 311595 & 6.699 & 5.9374 & TST & \\
\hline CHEMBL434518 & 311595 & 6.9208 & 7.0673 & TST & \\
\hline CHEMBL 361069 & 311595 & 7.2218 & 6.3502 & TST & \\
\hline CHEMBL185715 & 311595 & 8.0 & 8.06 & TRN & \\
\hline CHEMBL182299 & 311595 & 6.2007 & 5.21700 & 00000000005 & TST \\
\hline CHEMBL186390 & 311595 & 6.301 & 6.9025 & TST & \\
\hline CHEMBL188547 & 311595 & 6.6021 & 7.2341 & TST & \\
\hline CHEMBL189760 & 311595 & 6.9208 & 6.9974 & TST & \\
\hline CHEMBL185865 & 311595 & 8.2218 & 8.0866 & TRN & \\
\hline CHEMBL188595 & 311595 & 5.6003 & 5.6761 & TRN & \\
\hline CHEMBL338047 & 311595 & 7.0 & 7.3551 & TST & \\
\hline CHEMBL187786 & 311595 & 7.699 & 7.6631 & TRN & \\
\hline CHEMBL188878 & 311595 & 6.4949 & 6.5324 & TRN & \\
\hline CHEMBL184294 & 311595 & 6.7959 & 6.8563 & TRN & \\
\hline CHEMBL361479 & 311595 & 6.7959 & 6.817 & TRN & \\
\hline CHEMBL182580 & 311595 & 6.9208 & 6.76399 & 9999999999 & TST \\
\hline CHEMBL189030 & 311595 & 6.8861 & 6.848 & TRN & \\
\hline CHEMBL 366120 & 311595 & 6.301 & 6.4 & TRN & \\
\hline CHEMBL188941 & 311595 & 7.5229 & 5.7214 & TST & \\
\hline CHEMBL187513 & 311595 & 5.0 & 4.9881 & TRN & \\
\hline CHEMBL185622 & 311595 & 6.0 & 5.99299 & 9999999999 & TRN \\
\hline CHEMBL184026 & 311595 & 5.0 & 4.9783 & TRN & \\
\hline CHEMBL1504701 & 737148 & 3.0969 & 4.8326 & TRN & \\
\hline CHEMBL1564935 & 737148 & 4.7258 & 4.7895 & TRN & \\
\hline CHEMBL154358 & 737148 & 3.0969 & 4.362 & TRN & \\
\hline CHEMBL1540099 & 737148 & 6.3872 & 5.6643 & TRN & \\
\hline CHEMBL 2004141 & 737148 & 5.8386 & 6.325 & TRN & \\
\hline CHEMBL1314757 & 737148 & 5.8268 & 4.7947 & TRN & \\
\hline CHEMBL 2360527 & 737148 & 3.0969 & 4.8228 & TRN & \\
\hline CHEMBL1460612 & 737148 & 4.1649 & 5.2229 & TST & \\
\hline CHEMBL1575557 & 737148 & 5.3354 & 5.0803 & TST & \\
\hline CHEMBL1970422 & 737148 & 6.4685 & 5.8864 & TST & \\
\hline CHEMBL1427457 & 737148 & 6.4685 & 5.4772 & TRN & \\
\hline CHEMBL1481347 & 737148 & 5.8894 & 5.6588 & TRN & \\
\hline CHEMBL1444020 & 737148 & 3.0969 & 4.8246 & TRN & \\
\hline CHEMBL1608412 & 737148 & 3.0969 & 4.9415 & TRN & \\
\hline CHEMBL1506503 & 737148 & 7.7959 & 5.7606 & TRN & \\
\hline CHEMBL1998940 & 737148 & 4.8601 & 5.6709 & TST & \\
\hline CHEMBL1370513 & 737148 & 5.7932 & 3.827 & TRN & \\
\hline CHEMBL1483201 & 737148 & 5.8097 & 5.3003 & TRN & \\
\hline
\end{tabular}




\begin{tabular}{|c|c|c|c|c|c|c|}
\hline & & & & & & \\
\hline CHEMBL1489779 & 737148 & 6.2441 & 5.6246 & TRN & & \\
\hline CHEMBL1459746 & 737148 & 4.4089 & 4.8468 & TRN & & \\
\hline CHEMBL1971142 & 737148 & 5.7645 & 5.8739 & TRN & & \\
\hline CHEMBL1316247 & 737148 & 4.6402 & 5.1039 & TRN & & \\
\hline CHEMBL1300558 & 737148 & 7.7959 & 5.88700 & 0000000000 & & TRN \\
\hline CHEMBL3199286 & 737148 & 6.6576 & 5.2378 & TRN & & \\
\hline CHEMBL1364681 & 737148 & 4.8327 & 5.2586 & TRN & & \\
\hline CHEMBL1309542 & 737148 & 5.2118 & 5.28100 & 0000000001 & & TRN \\
\hline CHEMBL1415844 & 737148 & 6.0 & 5.6684 & TRN & & \\
\hline CHEMBL1371264 & 737148 & 6.3872 & 5.3406 & TRN & & \\
\hline CHEMBL1509896 & 737148 & 6.5086 & 4.6334 & TRN & & \\
\hline CHEMBL579318 & 737148 & 5.8297 & 5.8482 & TRN & & \\
\hline CHEMBL1425889 & 737148 & 5.0283 & 5.2643 & TRN & & \\
\hline CHEMBL1595169 & 737148 & 5.3809 & 5.2157 & TRN & & \\
\hline CHEMBL277148 & 737148 & 4.8097 & 4.8447 & TRN & & \\
\hline CHEMBL1360484 & 737148 & 5.6421 & 4.8895 & TRN & & \\
\hline CHEMBL1304383 & 737148 & 6.0555 & 5.3283 & TRN & & \\
\hline CHEMBL455284 & 737148 & 3.0969 & 5.1912 & TRN & & \\
\hline CHEMBL1536342 & 737148 & 5.0283 & 5.50899 & 9999999999 & 95 & TRN \\
\hline CHEMBL1606115 & 737148 & 5.1463 & 5.2418 & TRN & & \\
\hline CHEMBL2359072 & 737148 & 4.6757 & 5.0372 & TRN & & \\
\hline CHEMBL1462064 & 737148 & 5.0706 & 5.4497 & TRN & & \\
\hline CHEMBL1971727 & 737148 & 4.8894 & 5.2395 & TRN & & \\
\hline CHEMBL586602 & 737148 & 6.1675 & 5.7863 & TRN & & \\
\hline CHEMBL1505088 & 737148 & 4.8665 & 4.6479 & TRN & & \\
\hline CHEMBL1480238 & 737148 & 6.2924 & 5.3959 & TRN & & \\
\hline CHEMBL15968 & 737148 & 4.71899 & 99999999 & & 4.8323 & TRN \\
\hline CHEMBL1723154 & 737148 & 4.6716 & 4.6757 & TRN & & \\
\hline CHEMBL1435226 & 737148 & 4.8827 & 5.216 & TRN & & \\
\hline CHEMBL1525381 & 737148 & 3.0969 & 4.6553 & TRN & & \\
\hline CHEMBL1564737 & 737148 & 5.9586 & 4.7058 & TRN & & \\
\hline CHEMBL1256655 & 737148 & 3.0969 & 4.7924 & TRN & & \\
\hline CHEMBL1507347 & 737148 & 3.0969 & 4.6121 & TRN & & \\
\hline CHEMBL1519450 & 737148 & 3.0969 & 3.3871 & TRN & & \\
\hline CHEMBL1380996 & 737148 & 5.7496 & 5.5111 & TRN & & \\
\hline CHEMBL1966865 & 737148 & 5.71899 & 99999999 & 99 & 4.6924 & TRN \\
\hline CHEMBL1592124 & 737148 & 5.7696 & 4.9761 & TRN & & \\
\hline CHEMBL1514534 & 737148 & 5.1255 & 4.4282 & TRN & & \\
\hline CHEMBL1995045 & 737148 & 6.4815 & 5.2522 & TST & & \\
\hline CHEMBL1422513 & 737148 & 3.0969 & 4.1476 & TRN & & \\
\hline CHEMBL1300273 & 737148 & 4.76699 & 79999999 & 995 & 4.4159 & TRN \\
\hline CHEMBL1400459 & 737148 & 4.9914 & 4.6326 & TRN & & \\
\hline CHEMBL1393195 & 737148 & 3.0969 & 4.6922 & TRN & & \\
\hline CHEMBL576349 & 737148 & 5.2034 & 5.1097 & TRN & & \\
\hline CHEMBL3189714 & 737148 & 6.3872 & 5.85 & TRN & & \\
\hline CHEMBL1381439 & 737148 & 5.3382 & 4.9421 & TST & & \\
\hline CHEMBL1368418 & 737148 & 5.3726 & 4.6614 & TRN & & \\
\hline CHEMBL1469379 & 737148 & 5.7055 & 4.7713 & TRN & & \\
\hline
\end{tabular}




\begin{tabular}{|c|c|c|c|c|c|}
\hline \multirow[b]{2}{*}{ CHEMBL1995692 } & \multicolumn{5}{|c|}{ Supplemental Table s2.txt } \\
\hline & 737148 & 4.4168 & 4.9258 & TRN & \\
\hline CHEMBL1723033 & 737148 & 6.1308 & 4.8867 & TRN & \\
\hline CHEMBL1538246 & 737148 & 5.8447 & 5.58799 & 9999999999 & TST \\
\hline CHEMBL1450116 & 737148 & 5.4921 & 5.0246 & TRN & \\
\hline CHEMBL1352801 & 737148 & 5.0315 & 5.4661 & TRN & \\
\hline CHEMBL1714459 & 737148 & 3.0969 & 4.9452 & TRN & \\
\hline CHEMBL1331290 & 737148 & 3.0969 & 4.5086 & TRN & \\
\hline CHEMBL1440300 & 737148 & 5.0057 & 4.7804 & TRN & \\
\hline CHEMBL600100 & 737148 & 5.5686 & 5.4884 & TRN & \\
\hline CHEMBL1382884 & 737148 & 4.6799 & 5.02800 & 00000000005 & TRN \\
\hline CHEMBL1491637 & 737148 & 5.8894 & 5.02800 & 00000000005 & TRN \\
\hline CHEMBL1569543 & 737148 & 3.0969 & 5.0657 & TRN & \\
\hline CHEMBL1490339 & 737148 & 5.1838 & 5.0958 & TRN & \\
\hline CHEMBL1537124 & 737148 & 5.2541 & 4.1268 & TRN & \\
\hline CHEMBL1303161 & 737148 & 5.3107 & 5.2016 & TRN & \\
\hline CHEMBL3197767 & 737148 & 3.0969 & 4.8458 & TRN & \\
\hline CHEMBL1318350 & 737148 & 4.2007 & 5.5227 & TST & \\
\hline CHEMBL1524014 & 737148 & 7.7959 & 4.881 & TST & \\
\hline CHEMBL1531851 & 737148 & 3.0969 & 4.312 & TRN & \\
\hline CHEMBL1392527 & 737148 & 5.8356 & 4.8828 & TST & \\
\hline CHEMBL1380507 & 737148 & 5.5229 & 5.6239 & TRN & \\
\hline CHEMBL1482542 & 737148 & 6.0706 & 5.3869 & TRN & \\
\hline CHEMBL1390968 & 737148 & 4.8327 & 4.6312 & TRN & \\
\hline CHEMBL1457201 & 737148 & 5.0778 & 5.7189 & TRN & \\
\hline CHEMBL1352521 & 737148 & 5.3382 & 6.0152 & TRN & \\
\hline CHEMBL1491534 & 737148 & 4.5751 & 4.7146 & TRN & \\
\hline CHEMBL1597772 & 737148 & 3.0969 & 4.6337 & TRN & \\
\hline CHEMBL1322738 & 737148 & 3.0969 & 4.1672 & TRN & \\
\hline CHEMBL1990582 & 737148 & 5.5143 & 4.7924 & TRN & \\
\hline CHEMBL1410008 & 737148 & 6.1675 & 4.9048 & TRN & \\
\hline CHEMBL1364793 & 737148 & 3.0969 & 3.9731 & TRN & \\
\hline CHEMBL1998531 & 737148 & 5.71 & 5.0631 & TRN & \\
\hline CHEMBL1460440 & 737148 & 4.5918 & 4.5505 & TRN & \\
\hline CHEMBL1363437 & 737148 & 6.3768 & 5.8459 & TRN & \\
\hline CHEMBL1347071 & 737148 & 6.2596 & 5.3879 & TRN & \\
\hline CHEMBL1537481 & 737148 & 5.082 & 5.5002 & TRN & \\
\hline CHEMBL1612042 & 737148 & 4.466 & 4.5033 & TRN & \\
\hline CHEMBL1609770 & 737148 & 5.3605 & 4.6923 & TRN & \\
\hline CHEMBL1720152 & 737148 & 5.4045 & 5.4632 & TST & \\
\hline CHEMBL600862 & 737148 & 3.0969 & 3.8431 & TRN & \\
\hline CHEMBL1565338 & 737148 & 5.0675 & 4.3248 & TRN & \\
\hline CHEMBL1563899 & 737148 & 5.4855 & 5.7062 & TRN & \\
\hline CHEMBL1504204 & 737148 & 5.7399 & 5.7304 & TRN & \\
\hline CHEMBL1986418 & 737148 & 6.284 & 5.2746 & TRN & \\
\hline CHEMBL1330459 & 737148 & 5.5784 & 5.19799 & 99999999995 & TST \\
\hline CHEMBL1432186 & 737148 & 5.1675 & 4.295 & TRN & \\
\hline CHEMBL1309091 & 737148 & 5.4425 & 5.3387 & TRN & \\
\hline CHEMBL1299946 & 737148 & 3.0969 & 4.5381 & TRN & \\
\hline & & & & 2268 & \\
\hline
\end{tabular}




\begin{tabular}{|c|c|c|c|c|c|c|}
\hline & & \multicolumn{5}{|c|}{ Supplemental Table s2.txt } \\
\hline CHEMBL1319414 & 737148 & 4.308 & 5.0653 & TRN & & \\
\hline CHEMBL1336485 & 737148 & 5.6216 & 5.32600 & 0000000000 & 05 & TRN \\
\hline CHEMBL1580219 & 737148 & 5.2161 & 5.3991 & TRN & & \\
\hline CHEMBL1570647 & 737148 & 4.585 & 5.194 & TRN & & \\
\hline CHEMBL1521172 & 737148 & 5.6402 & 4.8961 & TRN & & \\
\hline CHEMBL1468435 & 737148 & 5.4202 & 5.3331 & TRN & & \\
\hline CHEMBL1448642 & 737148 & 5.4034 & 5.1261 & TRN & & \\
\hline CHEMBL1369033 & 737148 & 5.5214 & 5.2174 & TRN & & \\
\hline CHEMBL1509493 & 737148 & 6.1024 & 4.7421 & TRN & & \\
\hline CHEMBL1535161 & 737148 & 3.0969 & 4.64 & TRN & & \\
\hline CHEMBL1448945 & 737148 & 4.9706 & 4.6512 & TRN & & \\
\hline CHEMBL1568294 & 737148 & 4.8356 & 4.6557 & TRN & & \\
\hline CHEMBL1418818 & 737148 & 5.684 & 5.4234 & TRN & & \\
\hline CHEMBL 261113 & 737148 & 5.1013 & 5.4169 & TRN & & \\
\hline CHEMBL1410731 & 737148 & 4.3747 & 4.9807 & TRN & & \\
\hline CHEMBL1447442 & 737148 & $5.8210 \ell$ & 30000000 & & 5.0444 & TRN \\
\hline CHEMBL1487720 & 737148 & 5.0419 & 4.5348 & TRN & & \\
\hline CHEMBL1483112 & 737148 & 5.0255 & 5.2897 & TRN & & \\
\hline CHEMBL1606309 & 737148 & 5.5607 & 4.9653 & TRN & & \\
\hline CHEMBL1588217 & 737148 & 6.3979 & 4.8727 & TRN & & \\
\hline CHEMBL1301125 & 737148 & 4.6968 & 5.32799 & 9999999999 & & TST \\
\hline CHEMBL1482052 & 737148 & 5.3372 & 5.5373 & TRN & & \\
\hline CHEMBL1346112 & 737148 & 4.7033 & 5.5954 & TRN & & \\
\hline CHEMBL 2005364 & 737148 & 5.0491 & 5.374 & TRN & & \\
\hline CHEMBL1602808 & 737148 & 5.2233 & 5.1487 & TRN & & \\
\hline CHEMBL3190965 & 737148 & 5.5317 & 5.4462 & TRN & & \\
\hline CHEMBL1484623 & 737148 & 5.2218 & 4.4801 & TRN & & \\
\hline CHEMBL2002169 & 737148 & 5.0742 & 5.2497 & TRN & & \\
\hline CHEMBL1456060 & 737148 & 3.0969 & 4.8299 & TST & & \\
\hline CHEMBL1398260 & 737148 & 6.2366 & 4.9914 & TST & & \\
\hline CHEMBL1327693 & 737148 & 4.7011 & 4.6323 & TRN & & \\
\hline CHEMBL1499792 & 737148 & 4.684 & 5.4191 & TRN & & \\
\hline CHEMBL 274070 & 737148 & 5.2204 & 6.4261 & TST & & \\
\hline CHEMBL1514530 & 737148 & 3.0969 & 3.6609 & TRN & & \\
\hline CHEMBL1544465 & 737148 & 6.2007 & 5.8517 & TRN & & \\
\hline CHEMBL3193419 & 737148 & 4.9508 & 4.5064 & TRN & & \\
\hline CHEMBL1374718 & 737148 & 4.6038 & 5.5412 & TRN & & \\
\hline CHEMBL2094567 & 737148 & 3.0969 & 4.5361 & TRN & & \\
\hline CHEMBL1579258 & 737148 & 4.7471 & 5.9394 & TST & & \\
\hline CHEMBL1372889 & 737148 & 5.9586 & 6.5688 & TRN & & \\
\hline CHEMBL1536981 & 737148 & 6.2291 & 5.95700 & 0000000001 & & TRN \\
\hline CHEMBL1457561 & 737148 & 4.9666 & 4.3283 & TRN & & \\
\hline CHEMBL1432638 & 737148 & 4.9626 & 5.1677 & TRN & & \\
\hline CHEMBL1481122 & 737148 & 6.1308 & 4.7998 & TST & & \\
\hline CHEMBL1303623 & 737148 & 5.9431 & 5.5301 & TRN & & \\
\hline CHEMBL602722 & 737148 & 5.5143 & 5.2644 & TRN & & \\
\hline CHEMBL1335177 & 737148 & 4.9547 & 4.7787 & TRN & & \\
\hline CHEMBL1482145 & 737148 & 5.2581 & 5.0619 & TRN & & \\
\hline
\end{tabular}


Supplemental Table S2.txt

\begin{tabular}{|c|c|c|c|c|c|}
\hline CHEMBL1602385 & 737148 & 7.7959 & 5.6493 & TRN & \\
\hline CHEMBL1577720 & 737148 & 5.3458 & 5.5142 & TST & \\
\hline CHEMBL1452130 & 737148 & 5.6615 & 5.3415 & TRN & \\
\hline CHEMBL1573994 & 737148 & 5.8447 & 6.1273 & TST & \\
\hline CHEMBL578487 & 737148 & 5.7905 & 5.6987 & TRN & \\
\hline CHEMBL1573050 & 737148 & 4.9281 & 4.357 & TRN & \\
\hline CHEMBL1576851 & 737148 & 4.7055 & 4.671 & TRN & \\
\hline CHEMBL1333930 & 737148 & 4.9066 & 6.1377 & TRN & \\
\hline CHEMBL1585715 & 737148 & 5.4225 & 5.0752 & TRN & \\
\hline CHEMBL1341270 & 737148 & 5.7905 & 5.8195 & TST & \\
\hline CHEMBL1324319 & 737148 & 3.0969 & 4.36 & TRN & \\
\hline CHEMBL1392776 & 737148 & 7.7959 & 6.154 & TRN & \\
\hline CHEMBL1535490 & 737148 & 5.2708 & 5.7836 & TST & \\
\hline CHEMBL1407572 & 737148 & 5.5186 & 5.3734 & TST & \\
\hline CHEMBL1602083 & 737148 & 4.8928 & 5.1043 & TRN & \\
\hline CHEMBL494255 & 737148 & 5.2336 & 5.3446 & TST & \\
\hline CHEMBL3199744 & 737148 & 5.0057 & 4.563 & TST & \\
\hline CHEMBL486504 & 737148 & 3.0969 & 4.6265 & TRN & \\
\hline CHEMBL1422378 & 737148 & 5.5376 & 5.337999 & 9999999999 & \\
\hline CHEMBL3195749 & 737148 & 5.983 & 5.4751 & TRN & \\
\hline CHEMBL1578527 & 737148 & 3.0969 & 5.1364 & TRN & \\
\hline CHEMBL1383397 & 737148 & 5.4672 & 5.1204 & TST & \\
\hline CHEMBL 299613 & 737148 & 4.6383 & 4.1953 & TST & \\
\hline CHEMBL1335110 & 737148 & 6.1427 & 5.3727 & TRN & \\
\hline CHEMBL1493942 & 737148 & 5.059 & 5.8876 & TRN & \\
\hline CHEMBL1966890 & 737148 & 5.6073 & 5.3451 & TRN & \\
\hline CHEMBL1391377 & 737148 & 4.8827 & 4.7832 & TRN & \\
\hline CHEMBL 2359467 & 737148 & 6.6021 & 5.638999 & 9999999999 & \\
\hline CHEMBL1306816 & 737148 & 5.301 & 5.105 & TST & \\
\hline CHEMBL1593286 & 737148 & 6.1079 & 5.553 & TRN & \\
\hline CHEMBL1555271 & 737148 & 3.0969 & 3.7063 & TRN & \\
\hline CHEMBL1325943 & 737148 & 6.0269 & 5.6589 & TRN & \\
\hline CHEMBL1492399 & 737148 & 5.8861 & 6.0191 & TRN & \\
\hline CHEMBL1331733 & 737148 & 5.1844 & 5.1946 & TRN & \\
\hline CHEMBL1454000 & 737148 & 5.9666 & 5.845 & TRN & \\
\hline CHEMBL1464206 & 737148 & \multicolumn{3}{|c|}{4.9830000000000005} & TRN \\
\hline CHEMBL1524791 & 737148 & 3.0969 & 4.314 & TRN & \\
\hline CHEMBL592600 & 737148 & 4.3904 & 3.4656 & TRN & \\
\hline CHEMBL1444542 & 737148 & 5.2062 & 5.5238 & TST & \\
\hline CHEMBL1387181 & 737148 & 6.1367 & 5.3865 & TST & \\
\hline CHEMBL3197908 & 737148 & 4.6498 & 5.3629 & TRN & \\
\hline CHEMBL577635 & 737148 & 5.7055 & 5.0987 & TST & \\
\hline CHEMBL1492096 & 737148 & 5.61799 & 99999999 & 5.8793 & KI \\
\hline CHEMBL1704858 & 737148 & 4.9957 & 4.7396 & TRN & \\
\hline CHEMBL1577966 & 737148 & 4.9031 & 5.1418 & TST & \\
\hline CHEMBL1567899 & 737148 & 3.0969 & 4.2364 & TRN & \\
\hline CHEMBL1400298 & 737148 & 3.0969 & 4.6749 & TRN & \\
\hline CHEMBL1448627 & 737148 & 3.0969 & 5.5779 & TST & \\
\hline
\end{tabular}


Supplemental Table S2.txt

\begin{tabular}{|c|c|c|c|c|}
\hline CHEMBL1469102 & 737148 & 5.3936 & 4.9682 & TST \\
\hline CHEMBL1420462 & 737148 & 4.1938 & 4.3448 & TST \\
\hline CHEMBL590665 & 737148 & 3.0969 & 3.6814 & TRN \\
\hline CHEMBL1326180 & 737148 & 4.7545 & 5.0476 & TRN \\
\hline CHEMBL1486690 & 737148 & 3.0969 & 5.5986 & TST \\
\hline CHEMBL1342029 & 737148 & 5.2565 & 5.1521 & TST \\
\hline CHEMBL1324011 & 737148 & 4.6778 & 4.4888 & TRN \\
\hline CHEMBL1335846 & 737148 & 5.9586 & 5.70799 & 9999999999 \\
\hline CHEMBL1547232 & 737148 & 6.0269 & 5.5781 & TST \\
\hline CHEMBL1542868 & 737148 & 4.8601 & 5.3885 & TRN \\
\hline CHEMBL1465527 & 737148 & 5.1669 & 5.475 & TST \\
\hline CHEMBL1732859 & 737148 & 4.9547 & 5.205 & TRN \\
\hline CHEMBL1407659 & 737148 & 5.4895 & 5.7323 & TRN \\
\hline CHEMBL1411388 & 737148 & 5.3224 & 4.9932 & TRN \\
\hline CHEMBL1430060 & 737148 & 4.5884 & 4.755 & TRN \\
\hline CHEMBL1491324 & 737148 & 5.2984 & 5.3262 & TRN \\
\hline CHEMBL222409 & 737148 & 5.8386 & 5.5074 & TRN \\
\hline CHEMBL1410350 & 737148 & 4.9281 & 4.9054 & TRN \\
\hline CHEMBL1976638 & 737148 & 4.9431 & 4.5403 & TST \\
\hline CHEMBL1385053 & 737148 & 5.2104 & 4.5471 & TRN \\
\hline CHEMBL1467599 & 737148 & 3.0969 & 5.0061 & TST \\
\hline CHEMBL297323 & 737148 & 4.8097 & 5.0388 & TRN \\
\hline CHEMBL1397089 & 737148 & 3.0969 & 5.0407 & TRN \\
\hline CHEMBL1450086 & 737148 & 4.3307 & 5.0433 & TRN \\
\hline CHEMBL585071 & 737148 & 5.2441 & 5.1509 & TST \\
\hline CHEMBL1497989 & 737148 & 3.0969 & 4.0691 & TRN \\
\hline CHEMBL1372082 & 737148 & 5.5157 & 5.6368 & TRN \\
\hline CHEMBL3196472 & 737148 & 5.4437 & 5.4255 & TRN \\
\hline CHEMBL1401272 & 737148 & 3.0969 & 5.148 & TRN \\
\hline CHEMBL373137 & 737148 & 5.4486 & 5.4109 & TRN \\
\hline CHEMBL1387338 & 737148 & 4.172 & 4.9591 & TRN \\
\hline CHEMBL1367034 & 737148 & 6.2518 & 4.8915 & TRN \\
\hline CHEMBL1605536 & 737148 & 5.7645 & 4.7366 & TRN \\
\hline CHEMBL 3198633 & 737148 & 7.7959 & 5.6311 & TST \\
\hline CHEMBL131037 & 737148 & 5.4023 & 5.055 & TRN \\
\hline CHEMBL3199403 & 737148 & 3.0969 & 4.5401 & TRN \\
\hline CHEMBL1602086 & 737148 & 5.7212 & 6.3364 & TRN \\
\hline CHEMBL1583768 & 737148 & 4.7305 & 5.364 & TRN \\
\hline CHEMBL1569988 & 737148 & 6.5086 & 6.3461 & TRN \\
\hline CHEMBL193872 & 737148 & 6.1079 & 5.7266 & TST \\
\hline CHEMBL1344838 & 737148 & 5.699 & 4.9197 & TRN \\
\hline CHEMBL1420393 & 737148 & 4.2899 & 4.7587 & TRN \\
\hline CHEMBL1438667 & 737148 & 5.4672 & 5.2725 & TRN \\
\hline CHEMBL1491621 & 737148 & 4.8477 & 5.0258 & TST \\
\hline CHEMBL1547706 & 737148 & 4.8356 & 4.7278 & TRN \\
\hline CHEMBL1486874 & 737148 & 5.0516 & 5.8115 & TRN \\
\hline CHEMBL428064 & 737148 & 6.5528 & 5.1443 & TRN \\
\hline \multirow[t]{2}{*}{ CHEMBL1584985 } & 737148 & 6.0132 & 5.19799 & 99999999995 \\
\hline & & \multicolumn{3}{|c|}{ Page 22685} \\
\hline
\end{tabular}


Supplemental Table S2.txt

\begin{tabular}{|c|c|c|c|c|c|}
\hline CHEMBL1432368 & 737148 & 4.5482 & 5.0373 & TRN & \\
\hline CHEMBL1481849 & 737148 & 4.8928 & 5.5618 & TST & \\
\hline CHEMBL1727333 & 737148 & 5.9393 & 4.7809 & TRN & \\
\hline CHEMBL1463659 & 737148 & 5.2457 & 5.7321 & TRN & \\
\hline CHEMBL1568923 & 737148 & 5.9788 & 4.7857 & TRN & \\
\hline CHEMBL1429850 & 737148 & 5.4841 & 5.1323 & TST & \\
\hline CHEMBL1497939 & 737148 & 5.4168 & 5.9936 & TRN & \\
\hline CHEMBL1409398 & 737148 & 5.1135 & 5.2346 & TRN & \\
\hline CHEMBL 2003909 & 737148 & 5.9547 & 5.1845 & TRN & \\
\hline CHEMBL1484195 & 737148 & 4.9208 & 4.5855 & TRN & \\
\hline CHEMBL1321427 & 737148 & 5.2147 & 5.0374 & TRN & \\
\hline CHEMBL1531073 & 737148 & 4.6819 & 5.4138 & TRN & \\
\hline CHEMBL1576251 & 737148 & 6.0809 & 5.4267 & TRN & \\
\hline CHEMBL518292 & 737148 & 4.5072 & 5.3061 & TST & \\
\hline CHEMBL1486253 & 737148 & 4.5031 & 5.2748 & TST & \\
\hline CHEMBL1563483 & 737148 & 4.6946 & 5.1907 & TST & \\
\hline CHEMBL600060 & 737148 & 5.4056 & 5.36799 & 9999999999 & TRN \\
\hline CHEMBL532160 & 737148 & 3.0969 & 5.1123 & TRN & \\
\hline CHEMBL1461400 & 737148 & 4.2636 & 5.0771 & TRN & \\
\hline CHEMBL1455137 & 737148 & 5.224 & 5.044 & TRN & \\
\hline CHEMBL1608078 & 737148 & 4.6968 & 5.2069 & TRN & \\
\hline CHEMBL1562664 & 737148 & 6.2147 & 5.4305 & TRN & \\
\hline CHEMBL1439227 & 737148 & 4.9245 & 4.4819 & TRN & \\
\hline CHEMBL1445297 & 737148 & 6.0757 & 5.7059 & TRN & \\
\hline CHEMBL1387172 & 737148 & 5.8601 & 4.3969 & TRN & \\
\hline CHEMBL1426762 & 737148 & 4.2907 & 4.6218 & TST & \\
\hline CHEMBL1456851 & 737148 & 5.7122 & 5.3902 & TRN & \\
\hline CHEMBL1609686 & 737148 & 4.6968 & 4.9218 & TRN & \\
\hline CHEMBL1566488 & 737148 & 4.1759 & 4.7627 & TRN & \\
\hline CHEMBL1392611 & 737148 & 5.7496 & 5.84 & TRN & \\
\hline CHEMBL1600855 & 737148 & 4.3904 & 5.1806 & TRN & \\
\hline CHEMBL1350673 & 737148 & 4.9872 & 4.5178 & TRN & \\
\hline CHEMBL1371989 & 737148 & 3.0969 & 4.6751 & TRN & \\
\hline CHEMBL1367311 & 737148 & 3.0969 & 4.0844 & TRN & \\
\hline CHEMBL1411912 & 737148 & 5.8894 & 5.3045 & TRN & \\
\hline CHEMBL 89445 & 737148 & 3.0969 & 5.2593 & TRN & \\
\hline CHEMBL1466542 & 737148 & 4.4237 & 4.073 & TRN & \\
\hline CHEMBL1486214 & 737148 & 4.567 & 4.3209 & TRN & \\
\hline CHEMBL3196754 & 737148 & 5.3372 & 5.942 & TRN & \\
\hline CHEMBL1376759 & 737148 & 5.5421 & 5.1686 & TRN & \\
\hline CHEMBL1392570 & 737148 & 5.5346 & 4.7756 & TRN & \\
\hline CHEMBL1465706 & 737148 & 6.1367 & 5.2149 & TRN & \\
\hline CHEMBL414890 & 737148 & 4.6882 & 4.9584 & TST & \\
\hline CHEMBL1444065 & 737148 & 4.7696 & 4.9694 & TRN & \\
\hline CHEMBL 261114 & 737148 & 6.1079 & 5.6496 & TRN & \\
\hline CHEMBL1362055 & 737148 & 3.0969 & 4.6626 & TRN & \\
\hline CHEMBL1518625 & 737148 & 5.857 & 5.6522 & TRN & \\
\hline CHEMBL1533321 & 737148 & 5.6073 & 5.4106 & TST & \\
\hline
\end{tabular}




\begin{tabular}{|c|c|c|c|c|c|c|}
\hline & & \multicolumn{5}{|c|}{ Supplemental Table S2.txt } \\
\hline CHEMBL1587868 & 737148 & 5.1158 & 5.3517 & TRN & & \\
\hline CHEMBL1476734 & 737148 & 5.5986 & 4.7326 & TRN & & \\
\hline CHEMBL3145303 & 737148 & 6.699 & 6.3071 & TRN & & \\
\hline CHEMBL1546843 & 737148 & 4.6737 & 5.0511 & TRN & & \\
\hline CHEMBL1368007 & 737148 & 4.5406 & 4.4824 & TRN & & \\
\hline CHEMBL1424468 & 737148 & 5.3585 & 5.6402 & TRN & & \\
\hline CHEMBL1310753 & 737148 & 6.5229 & 5.1628 & TRN & & \\
\hline CHEMBL1532328 & 737148 & \multicolumn{3}{|c|}{5.327000000000001} & 5.4868 & TRN \\
\hline CHEMBL1577016 & 737148 & 4.5361 & 4.6118 & TST & & \\
\hline CHEMBL1537680 & 737148 & 5.6021 & 4.8662 & TRN & & \\
\hline CHEMBL1479301 & 737148 & 3.0969 & 5.8166 & TST & & \\
\hline CHEMBL1525220 & 737148 & 5.6345 & 5.3058 & TRN & & \\
\hline CHEMBL1362402 & 737148 & 4.5186 & 5.0552 & TRN & & \\
\hline CHEMBL1540682 & 737148 & 4.8041 & 5.1195 & TST & & \\
\hline CHEMBL1467533 & 737148 & 5.4012 & 4.8294 & TRN & & \\
\hline CHEMBL1571885 & 737148 & 5.5031 & 4.9324 & TRN & & \\
\hline CHEMBL1362490 & 737148 & 5.7932 & 5.3792 & TST & & \\
\hline CHEMBL1497681 & 737148 & 5.3116 & 4.9772 & TST & & \\
\hline CHEMBL1437139 & 737148 & 6.4685 & 5.3123 & TST & & \\
\hline CHEMBL1528469 & 737148 & 4.4425 & 4.7909 & TST & & \\
\hline CHEMBL1452795 & 737148 & 6.284 & 6.0295 & TRN & & \\
\hline CHEMBL1598986 & 737148 & 6.0 & 5.2977 & TRN & & \\
\hline CHEMBL590927 & 737148 & 3.0969 & 3.423 & TRN & & \\
\hline CHEMBL1529115 & 737148 & 5.0585 & 5.6521 & TRN & & \\
\hline CHEMBL1391387 & 737148 & 5.8327 & 5.7621 & TRN & & \\
\hline CHEMBL374107 & 737148 & 3.0969 & 4.9202 & TST & & \\
\hline CHEMBL1343705 & 737148 & 3.0969 & 4.6913 & TRN & & \\
\hline CHEMBL1491981 & 737148 & 4.752 & 4.8681 & TRN & & \\
\hline CHEMBL 1382438 & 737148 & 5.4034 & 5.0471 & TRN & & \\
\hline CHEMBL1403322 & 737148 & 5.7144 & 4.9353 & TRN & & \\
\hline CHEMBL1468181 & 737148 & 6.6383 & 6.1412 & TRN & & \\
\hline CHEMBL1545191 & 737148 & 5.4365 & 5.0978 & TRN & & \\
\hline CHEMBL1979536 & 737148 & 5.3233 & 5.5343 & TRN & & \\
\hline CHEMBL1402010 & 737148 & 5.6326 & 5.8045 & TRN & & \\
\hline CHEMBL1590016 & 737148 & 4.9318 & 4.9354 & TRN & & \\
\hline CHEMBL1533161 & 737148 & 5.0004 & 4.9533 & TRN & & \\
\hline CHEMBL1610821 & 737148 & \multicolumn{3}{|c|}{5.757000000000001} & 5.5522 & TRN \\
\hline CHEMBL1331541 & 737148 & 5.6126 & 4.7471 & TRN & & \\
\hline CHEMBL1590553 & 737148 & 4.2807 & 4.4963 & TRN & & \\
\hline CHEMBL1441701 & 737148 & 6.6576 & 4.8982 & TST & & \\
\hline CHEMBL1445650 & 737148 & 5.7825 & 4.5085 & TRN & & \\
\hline CHEMBL1529161 & 737148 & 3.0969 & 4.8822 & TRN & & \\
\hline CHEMBL3194964 & 737148 & 6.5086 & 5.2312 & TRN & & \\
\hline CHEMBL1542713 & 737148 & 6.585 & 5.2635 & TRN & & \\
\hline CHEMBL3196124 & 737148 & 6.6383 & 4.8377 & TRN & & \\
\hline CHEMBL1558156 & 737148 & 4.9957 & 5.2809 & TRN & & \\
\hline CHEMBL1309059 & 737148 & 4.7595 & 5.4355 & TRN & & \\
\hline CHEMBL1564136 & 737148 & 6.2612 & 5.2431 & TST & & \\
\hline
\end{tabular}


Supplemental Table S2.txt

\begin{tabular}{|c|c|c|c|c|}
\hline 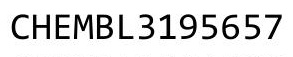 & 148 & & - & \\
\hline HEMBL1544486 & 37148 & 6635 & 5.1978 & \\
\hline HEMBL1339270 & 37148 & & 3529 & \\
\hline 8547 & 7148 & & & \\
\hline AEMBL1493731 & 7148 & & 3688 & \\
\hline HEMBL3199673 & 37148 & 872 & 5592 & \\
\hline HEMBL1716112 & 37148 & .7959 & 0355 & \\
\hline HEMBL150 & 37148 & & 1873 & \\
\hline HEMBL146 & 37148 & & 9633 & \\
\hline IEMBL13 & 37148 & & & \\
\hline HEMBL1488760 & 37148 & 21 & 6213 & \\
\hline HEMBL1591205 & 37148 & 59 & 5.01 & \\
\hline HEMBL146 & 37148 & & 739 & \\
\hline HEMBL19 & 48 & & & \\
\hline HEMBL15 & 48 & & 588 & \\
\hline HEMBL133 & 37148 & 96 & 5.461 & \\
\hline HEMBL1526767 & & & & \\
\hline HEMBL 14 & 48 & & 3.8471 & \\
\hline L14 & 18 & & 7185 & \\
\hline HEMBL16 & 18 & & 901 & \\
\hline HEMBL 145 & 37148 & $\partial 8$ & $\partial 23$ & \\
\hline HEMBL134 & & & & \\
\hline HEMBL14 & 48 & 21 & 636 & \\
\hline L15 & & & 512 & \\
\hline 34 & 18 & & 588 & $R N$ \\
\hline AEMBL152 & & & 9772 & 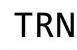 \\
\hline HEMBL17e & & & & RN \\
\hline HEMBL15 & 48 & & 99 & \\
\hline HEN & +8 & & & KIV \\
\hline AFMRI $1 /$ & 48 & & 664 & ST \\
\hline HEMBL171 & & & 5942 & RN \\
\hline HEMBL156 & & & 87 & \\
\hline AEMBL1] & & & 79 & ST \\
\hline 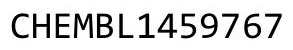 & 8 & & 861 & RN \\
\hline 33 & 18 & & 268 & ST \\
\hline HEMBL137 & 37148 & & 231 & RN \\
\hline HEMBL 578 & 37148 & & 393 & ST \\
\hline 7 & & & 593 & RN \\
\hline ג1 & 8 & & 34 & RIN \\
\hline HEMBL134 & & & 3741 & RN \\
\hline AEMBL 1468 & 37148 & 82 & 8953 & RN \\
\hline AEMBL19 & 48 & & 778 & RN \\
\hline ת & & & & \\
\hline CHEMBL155 & & & 4.3327 & RN \\
\hline HEMBL1332916 & 737148 & & & RN \\
\hline IEMBL14 & 37148 & & 0008 & RN \\
\hline & & & & \\
\hline HEMBL15 & 737148 & 5.3768 & & \\
\hline
\end{tabular}

Page 22688 
Supplemental Table S2.txt

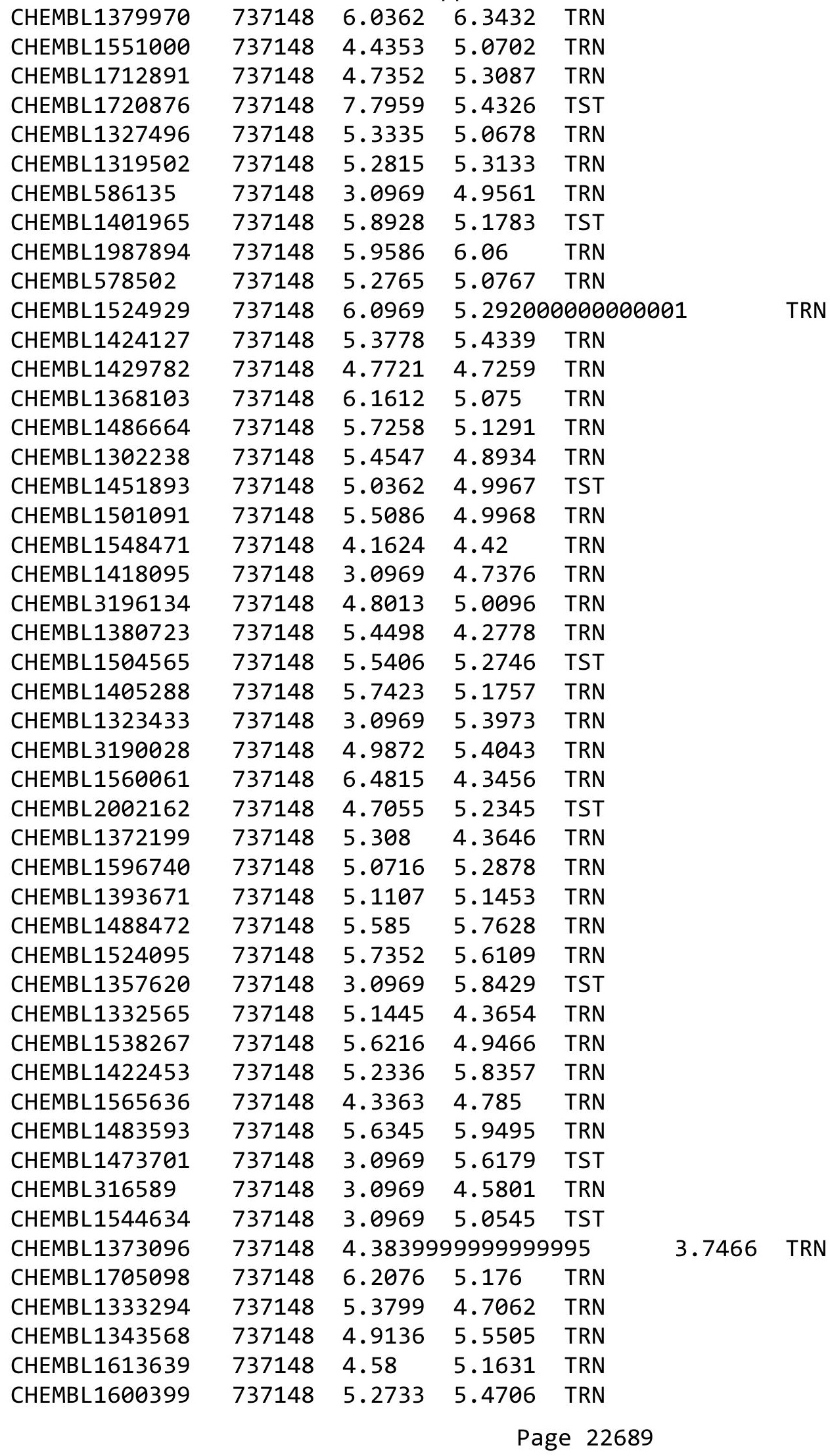


Supplemental Table S2.txt

\begin{tabular}{|c|c|c|c|c|c|c|}
\hline CHEMBL1451921 & 737148 & 4.1192 & 5.0819 & TRN & & \\
\hline CHEMBL1300908 & 737148 & 4.3915 & 4.6306 & TRN & & \\
\hline CHEMBL1459187 & 737148 & 5.0996 & 4.5516 & TRN & & \\
\hline CHEMBL1346432 & 737148 & 5.1979 & 4.987 & TRN & & \\
\hline CHEMBL1369930 & 737148 & 6.3468 & 5.3191 & TRN & & \\
\hline CHEMBL1363043 & 737148 & 5.3161 & 4.7087 & TRN & & \\
\hline CHEMBL1408150 & 737148 & 4.8761 & 5.144 & TRN & & \\
\hline CHEMBL1595790 & 737148 & 7.7959 & 5.8059 & TST & & \\
\hline CHEMBL1701791 & 737148 & 5.2197 & 4.5248 & TRN & & \\
\hline CHEMBL1993194 & 737148 & 3.0969 & 4.4733 & TRN & & \\
\hline CHEMBL1417726 & 737148 & \multicolumn{3}{|c|}{5.172000000000001} & 4.3913 & TRN \\
\hline CHEMBL1339678 & 737148 & 5.4908 & 5.3062 & TRN & & \\
\hline CHEMBL1734695 & 737148 & 5.5031 & 5.0921 & TRN & & \\
\hline CHEMBL1412747 & 737148 & 4.8327 & 5.0118 & TST & & \\
\hline CHEMBL1322272 & 737148 & \multicolumn{3}{|c|}{ 4.718999999999999 } & 5.0948 & TRN \\
\hline CHEMBL1592774 & 737148 & 5.3915 & 5.2215 & TRN & & \\
\hline CHEMBL1494120 & 737148 & 5.1163 & 5.5884 & TRN & & \\
\hline CHEMBL 261115 & 737148 & 5.0146 & 5.6917 & TRN & & \\
\hline CHEMBL1566108 & 737148 & 4.8477 & 4.5292 & TRN & & \\
\hline CHEMBL1515116 & 737148 & 5.0182 & 4.9072 & TRN & & \\
\hline CHEMBL1354093 & 737148 & 5.0969 & 5.6198 & TRN & & \\
\hline CHEMBL1582099 & 737148 & 5.4776 & 5.0439 & TST & & \\
\hline CHEMBL1465720 & 737148 & 5.6536 & 5.7261 & TRN & & \\
\hline CHEMBL3189873 & 737148 & 4.3625 & 5.2984 & TRN & & \\
\hline CHEMBL1412002 & 737148 & 3.0969 & 3.6901 & TRN & & \\
\hline CHEMBL1517461 & 737148 & 3.0969 & 4.5183 & TRN & & \\
\hline CHEMBL1600688 & 737148 & 3.0969 & 5.2725 & TRN & & \\
\hline CHEMBL1457403 & 737148 & 5.5654 & 5.7388 & TRN & & \\
\hline CHEMBL1357385 & 737148 & 5.6108 & 5.2626 & TRN & & \\
\hline CHEMBL1535665 & 737148 & 4.9706 & 4.6646 & TRN & & \\
\hline CHEMBL1520424 & 737148 & 5.0438 & 5.3978 & TRN & & \\
\hline CHEMBL1511029 & 737148 & 5.2351 & 5.101 & TRN & & \\
\hline CHEMBL1410857 & 737148 & 4.3862 & 5.2428 & TST & & \\
\hline CHEMBL1396209 & 737148 & 5.9245 & 6.1228 & TRN & & \\
\hline CHEMBL1479240 & 737148 & 5.1858 & 4.8792 & TRN & & \\
\hline CHEMBL279539 & 737148 & 5.5817 & 4.8282 & TRN & & \\
\hline CHEMBL 3195389 & 737148 & 7.7959 & 6.8986 & TRN & & \\
\hline CHEMBL1476264 & 737148 & 3.0969 & 4.3487 & TST & & \\
\hline CHEMBL1561596 & 737148 & 5.3002 & 5.1518 & TRN & & \\
\hline CHEMBL1332139 & 737148 & 5.5467 & 5.266 & TRN & & \\
\hline CHEMBL1200512 & 737148 & 3.0969 & 5.4312 & TST & & \\
\hline CHEMBL1339245 & 737148 & 5.6676 & 5.3979 & TRN & & \\
\hline CHEMBL1528118 & 737148 & 4.9245 & 4.8064 & TRN & & \\
\hline CHEMBL1565526 & 737148 & 5.8125 & 4.6861 & TRN & & \\
\hline CHEMBL1515023 & 737148 & 5.556 & 5.1666 & TRN & & \\
\hline CHEMBL1310995 & 737148 & 4.6478 & 5.2967 & TRN & & \\
\hline CHEMBL1420037 & 737148 & 5.9031 & 5.5465 & TST & & \\
\hline CHEMBL 3209306 & 737148 & 3.0969 & 5.371 & TRN & & \\
\hline
\end{tabular}




\begin{tabular}{|c|c|c|c|c|c|c|}
\hline & & \multicolumn{5}{|c|}{ Supplemental Table S2.txt } \\
\hline CHEMBL1507250 & 737148 & 7.7959 & 6.0437 & TRN & & \\
\hline CHEMBL551783 & 737148 & 5.51 & 5.5928 & TRN & & \\
\hline CHEMBL1455279 & 737148 & 5.1101 & 4.699 & TRN & & \\
\hline CHEMBL265686 & 737148 & 5.4949 & 5.7847 & TRN & & \\
\hline CHEMBL1548492 & 737148 & 3.0969 & 3.6815 & TRN & & \\
\hline CHEMBL1569585 & 737148 & 4.9586 & 5.3163 & TRN & & \\
\hline CHEMBL1310479 & 737148 & 5.58 & 5.4702 & TRN & & \\
\hline CHEMBL1595952 & 737148 & 5.5884 & 4.7233 & TRN & & \\
\hline CHEMBL578512 & 737148 & 5.9547 & 5.6604 & TRN & & \\
\hline CHEMBL1711969 & 737148 & 4.3307 & 5.4223 & TST & & \\
\hline CHEMBL1500188 & 737148 & 6.0605 & 5.7234 & TRN & & \\
\hline CHEMBL1341442 & 737148 & 4.5243 & 4.9169 & TRN & & \\
\hline CHEMBL1419096 & 737148 & 5.4237 & 5.2817 & TRN & & \\
\hline CHEMBL1309487 & 737148 & 4.6882 & 5.4543 & TRN & & \\
\hline CHEMBL1481543 & 737148 & 6.2757 & 6.0284 & TRN & & \\
\hline CHEMBL 3198970 & 737148 & 7.7959 & 5.3691 & TRN & & \\
\hline CHEMBL1333314 & 737148 & 4.9208 & 4.4381 & TRN & & \\
\hline CHEMBL1989858 & 737148 & 5.2118 & 4.93 & TST & & \\
\hline CHEMBL1370884 & 737148 & 5.2541 & 5.9775 & TRN & & \\
\hline CHEMBL1708144 & 737148 & 4.1746 & 5.1177 & TRN & & \\
\hline CHEMBL1736070 & 737148 & 3.0969 & 4.6663 & TRN & & \\
\hline CHEMBL1572746 & 737148 & 4.8182 & 5.5355 & TRN & & \\
\hline CHEMBL1416089 & 737148 & 4.6946 & 4.9851 & TRN & & \\
\hline CHEMBL1491238 & 737148 & 4.76699 & و9999999 & 995 & 5.1781 & TRN \\
\hline CHEMBL1460007 & 737148 & 4.9208 & 5.0254 & TRN & & \\
\hline CHEMBL1700777 & 737148 & 5.1158 & 5.2992 & TRN & & \\
\hline CHEMBL1586489 & 737148 & 5.317 & 5.3379 & TRN & & \\
\hline CHEMBL1521217 & 737148 & 7.7959 & 5.6275 & TRN & & \\
\hline CHEMBL1735990 & 737148 & 4.7852 & 4.675 & TRN & & \\
\hline CHEMBL601757 & 737148 & 5.7258 & 5.7554 & TRN & & \\
\hline CHEMBL1377693 & 737148 & 5.8182 & 5.0867 & TRN & & \\
\hline CHEMBL603129 & 737148 & 3.0969 & 5.124 & TRN & & \\
\hline CHEMBL1983939 & 737148 & 6.2596 & 4.9504 & TRN & & \\
\hline CHEMBL1326803 & 737148 & 6.4685 & 5.6567 & TRN & & \\
\hline CHEMBL1714537 & 737148 & 5.4295 & 5.18 & TST & & \\
\hline CHEMBL1300193 & 737148 & 3.0969 & 4.4839 & TRN & & \\
\hline CHEMBL547285 & 737148 & 6.3665 & 3.8208 & TRN & & \\
\hline CHEMBL1497999 & 737148 & 5.5229 & 5.37799 & 9999999999 & & TRN \\
\hline CHEMBL1328466 & 737148 & 5.5702 & 5.3518 & TRN & & \\
\hline CHEMBL1409606 & 737148 & 5.567 & 5.2278 & TST & & \\
\hline CHEMBL3191151 & 737148 & 4.5528 & 5.4993 & TRN & & \\
\hline CHEMBL1453108 & 737148 & 4.7399 & 5.1765 & TRN & & \\
\hline CHEMBL1427279 & 737148 & 6.0809 & 5.4837 & TRN & & \\
\hline CHEMBL1464071 & 737148 & 4.8097 & 4.8881 & TRN & & \\
\hline CHEMBL1729978 & 737148 & 4.6778 & 4.8775 & TRN & & \\
\hline CHEMBL1353271 & 737148 & 4.9031 & 4.4466 & TRN & & \\
\hline CHEMBL1437715 & 737148 & 5.0004 & 4.6546 & TRN & & \\
\hline CHEMBL1332878 & 737148 & 5.5421 & 5.2327 & TRN & & \\
\hline
\end{tabular}

Page 22691 
Supplemental Table S2.txt

\begin{tabular}{|c|c|c|c|c|c|c|}
\hline CHEMBL1994193 & 737148 & 6.1079 & 4.7902 & TRN & & \\
\hline CHEMBL1359789 & 737148 & 3.0969 & 4.6208 & TRN & & \\
\hline CHEMBL1989603 & 737148 & 3.0969 & 5.1672 & TRN & & \\
\hline CHEMBL562566 & 737148 & 5.4342 & 6.0094 & TRN & & \\
\hline CHEMBL1571901 & 737148 & 4.6364 & 4.738 & TRN & & \\
\hline CHEMBL1399125 & 737148 & 3.0969 & 5.2347 & TRN & & \\
\hline CHEMBL1526339 & 737148 & 5.2774 & 4.4528 & TRN & & \\
\hline CHEMBL2135351 & 737148 & 6.6576 & 6.2377 & TRN & & \\
\hline CHEMBL1382128 & 737148 & 5.0526 & 5.1319 & TRN & & \\
\hline CHEMBL1461730 & 737148 & 6.5686 & 5.7428 & TRN & & \\
\hline CHEMBL577662 & 737148 & 6.0044 & 5.6522 & TRN & & \\
\hline CHEMBL1422161 & 737148 & 4.2857 & 4.7391 & TRN & & \\
\hline CHEMBL580955 & 737148 & 6.1805 & 3.5846 & TRN & & \\
\hline CHEMBL 3194944 & 737148 & 7.7959 & 5.8121 & TRN & & \\
\hline CHEMBL1515368 & 737148 & 4.8996 & 4.4133 & TRN & & \\
\hline CHEMBL303579 & 737148 & 4.7986 & 5.4554 & TRN & & \\
\hline CHEMBL1713509 & 737148 & 4.9788 & 4.5684 & TRN & & \\
\hline CHEMBL1562712 & 737148 & 4.9788 & 5.3623 & TRN & & \\
\hline CHEMBL147514 & 737148 & 4.6003 & 4.9736 & TRN & & \\
\hline CHEMBL1448054 & 737148 & 5.7167 & 5.0832 & TRN & & \\
\hline CHEMBL1309521 & 737148 & 6.3279 & 5.3391 & TRN & & \\
\hline CHEMBL1495527 & 737148 & 4.8633 & 4.7042 & TRN & & \\
\hline CHEMBL1331836 & 737148 & 5.6478 & 5.3209 & TRN & & \\
\hline CHEMBL1442155 & 737148 & 5.2132 & 5.6624 & TST & & \\
\hline CHEMBL1348108 & 737148 & 4.6576 & 5.1561 & TRN & & \\
\hline CHEMBL1610510 & 737148 & 5.2865 & 5.186 & TST & & \\
\hline CHEMBL1300302 & 737148 & \multicolumn{3}{|c|}{5.3839999999999995} & 5.7474 & TRN \\
\hline CHEMBL1594114 & 737148 & 4.8268 & 5.1296 & TRN & & \\
\hline CHEMBL3191453 & 737148 & 3.0969 & 5.1339 & TRN & & \\
\hline CHEMBL1574879 & 737148 & 5.06 & 5.4942 & TRN & & \\
\hline CHEMBL1470568 & 737148 & 5.5834 & 5.7026 & TRN & & \\
\hline CHEMBL1317996 & 737148 & 3.0969 & 5.0223 & TRN & & \\
\hline CHEMBL 2000440 & 737148 & 5.1158 & 5.505 & TRN & & \\
\hline CHEMBL1418432 & 737148 & 5.6635 & 4.9148 & TRN & & \\
\hline CHEMBL1391582 & 737148 & 5.2541 & 5.4809 & TST & & \\
\hline CHEMBL1475884 & 737148 & 3.0969 & 5.6049 & TST & & \\
\hline CHEMBL585502 & 737148 & 6.1427 & 5.3453 & TRN & & \\
\hline CHEMBL1393480 & 737148 & \multicolumn{3}{|c|}{5.617999999999999} & 5.5177 & TRN \\
\hline CHEMBL578944 & 737148 & 5.3969 & 5.6013 & TRN & & \\
\hline CHEMBL1307769 & 737148 & 5.7282 & 6.0158 & TRN & & \\
\hline CHEMBL1511424 & 737148 & 5.1337 & 5.2821 & TRN & & \\
\hline CHEMBL1397445 & 737148 & 5.1605 & 5.0692 & TRN & & \\
\hline CHEMBL1343823 & 737148 & 5.8297 & 5.6001 & TRN & & \\
\hline CHEMBL1305054 & 737148 & 5.9914 & 5.1633 & TRN & & \\
\hline CHEMBL1547979 & 737148 & 5.3625 & 5.3582 & TST & & \\
\hline CHEMBL1570491 & 737148 & 4.8665 & 4.7609 & TRN & & \\
\hline CHEMBL1542955 & 737148 & 5.5952 & 5.1986 & TRN & & \\
\hline CHEMBL1396619 & 737148 & 5.4225 & 5.1229 & TRN & & \\
\hline
\end{tabular}

Page 22692 


\begin{tabular}{|c|c|c|c|c|c|c|}
\hline \multirow{3}{*}{$\begin{array}{l}\text { CHEMBL1519651 } \\
\text { CHEMBL1505209 }\end{array}$} & \multirow{3}{*}{$\begin{array}{l}737148 \\
737148\end{array}$} & \multicolumn{5}{|c|}{ Supplemental Table S2.txt } \\
\hline & & \multicolumn{4}{|c|}{$45 \quad 5.332999999999999$} & TRN \\
\hline & & \multicolumn{3}{|c|}{5.7620000000000005} & 5.0118 & TST \\
\hline CHEMBL1499414 & 737148 & 4.8601 & 4.8294 & TRN & & \\
\hline CHEMBL1459140 & 737148 & 4.8125 & 4.8049 & TRN & & \\
\hline CHEMBL1703925 & 737148 & 4.7167 & 4.4431 & TRN & & \\
\hline CHEMBL 78150 & 737148 & 4.8827 & 4.7694 & TST & & \\
\hline CHEMBL467987 & 737148 & 4.3468 & 4.3511 & TST & & \\
\hline CHEMBL 2007135 & 737148 & 4.2874 & 5.249 & TRN & & \\
\hline CHEMBL3196351 & 737148 & 6.4949 & 4.4517 & TRN & & \\
\hline CHEMBL1387610 & 737148 & 5.8539 & 5.857 & TRN & & \\
\hline CHEMBL1558285 & 737148 & 5.6968 & 5.6758 & TRN & & \\
\hline CHEMBL1519279 & 737148 & 4.9031 & 4.4091 & TRN & & \\
\hline CHEMBL1339830 & 737148 & 4.5017 & 4.5044 & TRN & & \\
\hline CHEMBL1538784 & 737148 & 5.5143 & 4.4078 & TST & & \\
\hline CHEMBL1170485 & 737148 & 4.6536 & 5.7455 & TST & & \\
\hline CHEMBL1543337 & 737148 & 6.0555 & 6.1511 & TST & & \\
\hline CHEMBL1515626 & 737148 & 5.3439 & 5.8031 & TST & & \\
\hline CHEMBL1332955 & 737148 & 4.426 & 5.0484 & TST & & \\
\hline CHEMBL1304363 & 737148 & 5.3526 & 4.7262 & TST & & \\
\hline CHEMBL1426542 & 737148 & 5.6402 & 4.9031 & TST & & \\
\hline CHEMBL1338667 & 737148 & 3.0969 & 4.8118 & TST & & \\
\hline CHEMBL1306460 & 737148 & 5.0737 & 4.8809 & TST & & \\
\hline CHEMBL1553738 & 737148 & 4.5331 & 4.3296 & TST & & \\
\hline CHEMBL408702 & 737148 & 5.6517 & 5.6868 & TST & & \\
\hline CHEMBL1346039 & 737148 & 5.1046 & 5.2187 & TST & & \\
\hline CHEMBL1348332 & 737148 & 4.9586 & 5.3365 & TST & & \\
\hline CHEMBL1978733 & 737148 & 4.5901 & 5.0836 & TST & & \\
\hline CHEMBL1331593 & 737148 & 5.6308 & 5.1643 & TST & & \\
\hline CHEMBL1497812 & 737148 & 4.8729 & 4.8052 & TST & & \\
\hline CHEMBL1596798 & 737148 & 5.7696 & 5.74 & TST & & \\
\hline CHEMBL1332347 & 737148 & 4.4535 & 4.9157 & TST & & \\
\hline CHEMBL1361989 & 737148 & 3.0969 & 4.7362 & TST & & \\
\hline CHEMBL1484459 & 737148 & 3.0969 & 4.0 & TST & & \\
\hline CHEMBL1365398 & 737148 & 5.2 & 5.5062 & TST & & \\
\hline CHEMBL1556278 & 737148 & 4.1415 & 4.498 & TST & & \\
\hline CHEMBL1599776 & 737148 & 5.3625 & 4.6653 & TST & & \\
\hline CHEMBL1451284 & 737148 & 5.3288 & 5.1513 & TST & & \\
\hline CHEMBL1550278 & 737148 & 5.4841 & 5.3376 & TST & & \\
\hline CHEMBL1393625 & 737148 & 5.6126 & 5.6498 & TST & & \\
\hline CHEMBL1454029 & 737148 & 6.1739 & 5.396 & TST & & \\
\hline CHEMBL1411639 & 737148 & 3.0969 & 4.7788 & TST & & \\
\hline CHEMBL1513046 & 737148 & 4.8894 & 5.1838 & TST & & \\
\hline CHEMBL1383415 & 737148 & 5.5528 & 4.2408 & TST & & \\
\hline CHEMBL1312935 & 737148 & 5.4134 & 5.0351 & TST & & \\
\hline CHEMBL1344225 & 737148 & 5.2596 & 5.7702 & TST & & \\
\hline CHEMBL1445707 & 737148 & 3.0969 & 5.0079 & TST & & \\
\hline CHEMBL601180 & 737148 & 3.0969 & 4.9289 & TST & & \\
\hline CHEMBL1533166 & 737148 & 4.9957 & 5.972 & TST & & \\
\hline
\end{tabular}


Supplemental Table S2.txt

\begin{tabular}{|c|c|c|c|c|}
\hline $\mathrm{HEN}$ & 8 & 6.1249 & & $x^{2}+2$ \\
\hline -1 & 37148 & 4.3904 & 4.3716 & \\
\hline ICN & 48 & 655 & & \\
\hline AEMBL1 & 7148 & & & \\
\hline HEMBL1412127 & 37148 & & 7741 & \\
\hline HEMBL1612997 & 37148 & .0969 & 7607 & \\
\hline HEMBL 580918 & 7148 & 447 & 363 & \\
\hline IEMBL146922 & & & & \\
\hline HEMBL1530673 & 37148 & 269 & & \\
\hline HEMBL579322 & 37148 & 012 & & \\
\hline HEMBL1537452 & 37148 & 214 & 64 & \\
\hline AEMBL13 & 148 & 126 & & \\
\hline IEMBL 14 & & & & \\
\hline HEMBL1359872 & 37148 & 959 & & \\
\hline AEMBL 48 & 148 & 05 & & \\
\hline AEMBL153 & 48 & 969 & 39 & \\
\hline HEMBL13 & 48 & & & \\
\hline HEMBL 25 & & 871 & & \\
\hline HEMBL155 & 148 & 449 & 84 & \\
\hline AEMBL153 & & & & \\
\hline HEMBLIt & 48 & $\partial 8$ & & \\
\hline AEMBL13 & & 57 & & \\
\hline HEMBL17 & 48 & 24 & & \\
\hline 379 & & 101 & & \\
\hline JEMBL14 & & & & \\
\hline HEMBL1: & 48 & & & \\
\hline HEMBL1 & & & & \\
\hline HFMBI 3 & 48 & & & \\
\hline HEMBL1 & & & & \\
\hline HEMBL14 & & & & 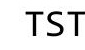 \\
\hline HEMBL1 & & 52 & 38 & ST \\
\hline AFMBI 3 & & 91 & & 位 \\
\hline HEMBL & & & & \\
\hline HEMBL 214 & & & & \\
\hline HEMBL514499 & 4697 & 638 & 325 & RN \\
\hline HEMBL12 & & 836 & & \\
\hline HFMRI 2 & & 86 & & NIV \\
\hline HEMBL47 & & & & RN \\
\hline HEMBL 577784 & 4697 & 852 & 4.8523 & RN \\
\hline IEMBL2 & & 514 & 86 & RN \\
\hline HEMBL1C & 97 & & 993 & \\
\hline CHEMBL1357247 & & & & RIV \\
\hline HEMBL373751 & & 3.7989 & & RN \\
\hline HEMBL 20272 & 697 & 367 & 14 & RN \\
\hline $\mathrm{MB} \mid 1$ & & & & \\
\hline HEMBL57 & & 812 & & \\
\hline CHEMBL 25918 & 54697 & .353 & .5234 & \\
\hline HEMBL124236 & 954697 & 5.2971 & 5.2899 & ГRN \\
\hline
\end{tabular}

Page 22694 


\begin{tabular}{|c|c|c|c|c|c|c|}
\hline & & \multicolumn{5}{|c|}{ Supplemental Table S2.txt } \\
\hline CHEMBL483847 & 954697 & 4.644 & 4.6227 & TRN & & \\
\hline CHEMBL1190711 & 954697 & 6.2747 & 6.3373 & TRN & & \\
\hline CHEMBL558642 & 954697 & 5.7009 & 5.7468 & TRN & & \\
\hline CHEMBL512504 & 954697 & 4.0431 & 3.9532 & TRN & & \\
\hline CHEMBL65 & 954697 & 6.5763 & 6.6537 & TRN & & \\
\hline CHEMBL 209148 & 954697 & 5.6162 & 5.6005 & TRN & & \\
\hline CHEMBL3349342 & 954697 & 4.1449 & 4.0164 & TRN & & \\
\hline CHEMBL393929 & 954697 & 4.6275 & 4.5452 & TRN & & \\
\hline CHEMBL 9470 & 954697 & 5.6302 & 5.1901 & TST & & \\
\hline CHEMBL220241 & 954697 & 4.4893 & 4.5301 & TRN & & \\
\hline CHEMBL379975 & 954697 & \multicolumn{3}{|c|}{5.678999999999999} & 5.7414 & TRN \\
\hline CHEMBL3186408 & 954697 & 4.4944 & \multicolumn{3}{|c|}{3.8539999999999996} & TST \\
\hline CHEMBL189584 & 954697 & 5.1722 & 5.1953 & TRN & & \\
\hline CHEMBL515416 & 954697 & 5.1713 & 5.0887 & TRN & & \\
\hline CHEMBL1590308 & 954697 & 3.2626 & 3.9293 & TST & & \\
\hline CHEMBL192566 & 954697 & 7.9751 & 8.2866 & TST & & \\
\hline CHEMBL 222102 & 954697 & 3.9888 & 3.8889 & TRN & & \\
\hline CHEMBL1516890 & 954697 & 4.0184 & 4.1817 & TRN & & \\
\hline CHEMBL509032 & 954697 & 6.2729 & 6.1903 & TRN & & \\
\hline CHEMBL180127 & 954697 & 4.9456 & 4.8715 & TRN & & \\
\hline CHEMBL 300389 & 954697 & 7.3138 & 7.261 & TRN & & \\
\hline CHEMBL412142 & 954697 & 4.0488 & 4.2739 & TRN & & \\
\hline CHEMBL392695 & 954697 & 5.1634 & 5.1052 & TRN & & \\
\hline CHEMBL1643959 & 954697 & 5.6282 & 5.6052 & TRN & & \\
\hline CHEMBL 2005886 & 954697 & 6.7543 & 6.9206 & TRN & & \\
\hline CHEMBL1909414 & 954697 & 4.4144 & 4.2188 & TRN & & \\
\hline CHEMBL1788116 & 954697 & 5.8524 & 5.7076 & TRN & & \\
\hline CHEMBL 221137 & 954697 & 4.8424 & 4.7012 & TST & & \\
\hline CHEMBL2363137 & 954697 & \multicolumn{3}{|c|}{5.531000000000001} & 5.3715 & TRN \\
\hline CHEMBL483849 & 954697 & 2.5488 & 2.3246 & TRN & & \\
\hline CHEMBL188678 & 954697 & 4.4062 & 4.2545 & TRN & & \\
\hline CHEMBL1404918 & 954697 & \multicolumn{3}{|c|}{2.8810000000000002} & 2.9303 & TRN \\
\hline CHEMBL 379300 & 954697 & 6.7126 & 6.9157 & TST & & \\
\hline CHEMBL135561 & 954697 & 4.4821 & 5.0199 & TST & & \\
\hline CHEMBL 3392440 & 954697 & 4.2517 & 3.9922 & TST & & \\
\hline CHEMBL240954 & 954697 & 4.1171 & 4.1275 & TST & & \\
\hline CHEMBL1970879 & 954697 & 6.3935 & 5.9545 & TST & & \\
\hline CHEMBL585951 & 954697 & 5.9171 & 5.7879 & TST & & \\
\hline CHEMBL449158 & 954697 & 6.7969 & 6.5641 & TST & & \\
\hline CHEMBL92309 & 954697 & 3.7392 & 3.284 & TST & & \\
\hline CHEMBL1673039 & 954697 & 5.2598 & 5.5073 & TST & & \\
\hline CHEMBL191334 & 954697 & 4.2478 & 4.7162 & TST & & \\
\hline CHEMBL1327628 & 688547 & 2.9352 & 2.9101 & TRN & & \\
\hline CHEMBL 3213880 & 688547 & 2.9347 & 2.9543 & TRN & & \\
\hline CHEMBL1567449 & 688547 & 2.9351 & 2.9525 & TRN & & \\
\hline CHEMBL1311023 & 688547 & 2.9348 & 2.9336 & TRN & & \\
\hline CHEMBL1383935 & 688547 & 2.9347 & 3.8406 & TST & & \\
\hline CHEMBL1491587 & 688547 & 2.9351 & 2.9383 & TRN & & \\
\hline
\end{tabular}

Page 22695 


\begin{tabular}{|c|c|c|c|c|c|}
\hline \multirow[b]{2}{*}{ CHEMBL1975888 } & \multicolumn{5}{|c|}{ Supplemental Table S2.txt } \\
\hline & 688547 & 2.935 & 2.8914 & TRN & \\
\hline CHEMBL1600251 & 688547 & 2.9353 & 2.9278 & TRN & \\
\hline CHEMBL3198275 & 688547 & 4.0332 & 4.0201 & TRN & \\
\hline CHEMBL1319897 & 688547 & 2.9354 & 2.924 & TRN & \\
\hline CHEMBL1346834 & 688547 & 2.9354 & 2.93899 & 99999999996 & TRN \\
\hline CHEMBL1605416 & 688547 & 2.9351 & 2.9261 & TRN & \\
\hline CHEMBL1213905 & 688547 & 2.9354 & 2.9484 & TRN & \\
\hline CHEMBL1509099 & 688547 & 2.935 & 2.9227 & TRN & \\
\hline CHEMBL1964748 & 688547 & 4.1876 & 4.1863 & TRN & \\
\hline CHEMBL1414242 & 688547 & 2.9351 & 2.9538 & TRN & \\
\hline CHEMBL1425667 & 688547 & 2.935 & 3.3616 & TST & \\
\hline CHEMBL532504 & 688547 & 2.9351 & 2.9352 & TRN & \\
\hline CHEMBL1991679 & 688547 & 4.7886 & 4.7841 & TRN & \\
\hline CHEMBL232148 & 688547 & 2.9347 & 3.1778 & TST & \\
\hline CHEMBL1579318 & 688547 & 2.9346 & 2.9018 & TRN & \\
\hline CHEMBL1432238 & 688547 & 2.935 & 2.9425 & TRN & \\
\hline CHEMBL1518278 & 688547 & 2.9348 & 2.9243 & TRN & \\
\hline CHEMBL1506957 & 688547 & 4.4146 & 4.4084 & TRN & \\
\hline CHEMBL1373822 & 688547 & 2.9351 & 2.9343 & TRN & \\
\hline CHEMBL1527352 & 688547 & 4.1541 & 4.1397 & TRN & \\
\hline CHEMBL1459296 & 688547 & 2.935 & 2.9277 & TRN & \\
\hline CHEMBL1318995 & 688547 & 2.9349 & 2.9264 & TRN & \\
\hline CHEMBL1430347 & 688547 & 2.9349 & 3.2615 & TST & \\
\hline CHEMBL1486581 & 688547 & 2.935 & 2.9429 & TRN & \\
\hline CHEMBL1337776 & 688547 & 2.9346 & 2.9368 & TRN & \\
\hline CHEMBL3214386 & 688547 & 2.9348 & 2.9266 & TRN & \\
\hline CHEMBL 2004756 & 688547 & 4.1173 & 4.1055 & TRN & \\
\hline CHEMBL 3193884 & 688547 & 2.935 & 2.9338 & TRN & \\
\hline CHEMBL1488455 & 688547 & 4.2191 & 4.2213 & TRN & \\
\hline CHEMBL585222 & 688547 & 4.1717 & 4.1597 & TRN & \\
\hline CHEMBL1509929 & 688547 & 2.9357 & 2.9152 & TRN & \\
\hline CHEMBL 2006030 & 688547 & 4.1053 & 3.9502 & TST & \\
\hline CHEMBL1386446 & 688547 & 2.9349 & 2.9469 & TRN & \\
\hline CHEMBL1448943 & 688547 & 2.935 & 2.9406 & TRN & \\
\hline CHEMBL1413196 & 688547 & 2.9349 & 2.9438 & TRN & \\
\hline CHEMBL1510252 & 688547 & 2.935 & 2.9428 & TRN & \\
\hline CHEMBL1506607 & 688547 & 2.9348 & 2.9478 & TRN & \\
\hline CHEMBL1535518 & 688547 & 2.9351 & 2.9164 & TRN & \\
\hline CHEMBL1557667 & 688547 & 4.1795 & 4.1823 & TRN & \\
\hline CHEMBL3192859 & 688547 & 2.9358 & 2.9476 & TRN & \\
\hline CHEMBL1383970 & 688547 & 2.9353 & 2.94100 & 00000000003 & TRN \\
\hline CHEMBL400585 & 688547 & 2.9354 & 2.9365 & TRN & \\
\hline CHEMBL3190223 & 688547 & 2.935 & 2.9561 & TRN & \\
\hline CHEMBL1600434 & 688547 & 2.9348 & 2.9262 & TRN & \\
\hline CHEMBL1300615 & 688547 & 3.943 & 3.9567 & TRN & \\
\hline CHEMBL 3213524 & 688547 & 2.9348 & 2.9358 & TRN & \\
\hline CHEMBL1554350 & 688547 & 2.9347 & 2.9325 & TRN & \\
\hline CHEMBL1340000 & 688547 & 2.935 & 2.9288 & TRN & \\
\hline
\end{tabular}




\begin{tabular}{|c|c|c|c|c|}
\hline & & & oplement & al Ta \\
\hline CHEMBL1501549 & 688547 & 2.935 & 2.9242 & TRN \\
\hline CHEMBL1596262 & 688547 & 4.3182 & 4.3098 & TRN \\
\hline CHEMBL582980 & 688547 & 2.9347 & 2.9693 & TRN \\
\hline CHEMBL1462325 & 688547 & 2.9351 & 2.8856 & TRN \\
\hline CHEMBL1336615 & 688547 & 2.9351 & 2.8869 & TRN \\
\hline CHEMBL3197908 & 688547 & 2.9347 & 2.9171 & TRN \\
\hline CHEMBL1544647 & 688547 & 2.935 & 2.9332 & TRN \\
\hline CHEMBL1324157 & 688547 & 2.9352 & 2.9508 & TRN \\
\hline CHEMBL 295786 & 688547 & 4.3675 & 3.4504 & TST \\
\hline CHEMBL244683 & 688547 & 2.9355 & 2.9096 & TRN \\
\hline CHEMBL1400961 & 688547 & 2.9351 & 2.9392 & TRN \\
\hline CHEMBL 3190804 & 688547 & 2.9349 & 2.9202 & TRN \\
\hline CHEMBL1601528 & 688547 & 2.9347 & 2.9548 & TRN \\
\hline CHEMBL3192787 & 688547 & 2.9349 & 2.9321 & TRN \\
\hline CHEMBL 3195346 & 688547 & 2.935 & 2.9769 & TRN \\
\hline CHEMBL1489187 & 688547 & 2.9353 & 2.9506 & TRN \\
\hline CHEMBL1979558 & 688547 & 2.9354 & 3.0613 & TST \\
\hline CHEMBL1613234 & 688547 & 2.9349 & 2.9509 & TRN \\
\hline CHEMBL1577852 & 688547 & 2.935 & 2.9385 & TRN \\
\hline CHEMBL1375468 & 688547 & 2.9349 & 2.9231 & TRN \\
\hline CHEMBL1402878 & 688547 & 4.1651 & 4.1863 & TRN \\
\hline CHEMBL1545746 & 688547 & 2.9347 & 2.943 & TRN \\
\hline CHEMBL1578889 & 688547 & 2.9353 & 2.9393 & TRN \\
\hline CHEMBL3189738 & 688547 & 2.9353 & 2.9168 & TRN \\
\hline CHEMBL1303116 & 688547 & 2.9349 & 2.9235 & TRN \\
\hline CHEMBL1344938 & 688547 & 2.9347 & 2.9282 & TRN \\
\hline CHEMBL1561576 & 688547 & 3.9571 & 3.9774 & TRN \\
\hline CHEMBL1303938 & 688547 & 2.9351 & 2.9504 & TRN \\
\hline CHEMBL1398824 & 688547 & 4.1757 & 3.2232 & TST \\
\hline CHEMBL1307677 & 688547 & 2.9353 & 2.9986 & TST \\
\hline CHEMBL3194048 & 688547 & 2.9348 & 2.9833 & TRN \\
\hline CHEMBL1533640 & 688547 & 2.9352 & 2.9516 & TRN \\
\hline CHEMBL1542516 & 688547 & 2.9357 & 2.935 & TRN \\
\hline CHEMBL1404230 & 688547 & 2.9355 & 2.9377 & TRN \\
\hline CHEMBL1481360 & 688547 & 4.052 & 4.0328 & TRN \\
\hline CHEMBL1584969 & 688547 & 2.9345 & 2.9391 & TRN \\
\hline CHEMBL1331513 & 688547 & 4.1002 & 4.1113 & TRN \\
\hline CHEMBL1537068 & 688547 & 2.9348 & 2.9385 & TRN \\
\hline CHEMBL1382475 & 688547 & 2.935 & 2.9277 & TRN \\
\hline CHEMBL1372374 & 688547 & 2.9352 & 2.9454 & TRN \\
\hline CHEMBL1487460 & 688547 & 2.9356 & 3.3557 & TST \\
\hline CHEMBL1483899 & 688547 & 4.0211 & 4.0236 & TRN \\
\hline CHEMBL1407509 & 688547 & 4.158 & 4.1546 & TRN \\
\hline CHEMBL1576542 & 688547 & 4.0811 & 3.1453 & TST \\
\hline CHEMBL3190491 & 688547 & 2.9346 & 2.9239 & TST \\
\hline CHEMBL597452 & 688547 & 2.935 & 2.9344 & TRN \\
\hline CHEMBL1569192 & 688547 & 2.9351 & 2.9184 & TRN \\
\hline CHEMBL1545718 & 688547 & 4.0026 & 4.0005 & TRN \\
\hline
\end{tabular}


Supplemental Table S2.txt

\begin{tabular}{|c|c|c|c|c|c|}
\hline CHEMBL1445852 & 688547 & 2.9349 & 2.9475 & TRN & \\
\hline CHEMBL1430231 & 688547 & 4.0108 & 4.0043 & TRN & \\
\hline CHEMBL1529540 & 688547 & 4.0938 & 4.1087 & TRN & \\
\hline CHEMBL1520832 & 688547 & 2.9346 & 2.972 & TRN & \\
\hline CHEMBL490592 & 688547 & 4.1328 & 3.343 & TST & \\
\hline CHEMBL1369293 & 688547 & 2.9351 & 2.8996 & TST & \\
\hline CHEMBL1427162 & 688547 & 4.4053 & 3.5032 & TST & \\
\hline CHEMBL1551329 & 688547 & 2.9353 & 2.9451 & TST & \\
\hline CHEMBL1481388 & 688547 & 2.9351 & 3.0556 & TST & \\
\hline CHEMBL1392445 & 688547 & 2.935 & 3.0006 & TST & \\
\hline CHEMBL3195512 & 688547 & 2.9351 & 3.0085 & TST & \\
\hline CHEMBL1485041 & 688547 & 2.935 & 2.572 & TST & \\
\hline CHEMBL 26138 & 688547 & 2.9358 & 3.6987 & TST & \\
\hline CHEMBL1421125 & 688547 & 2.9353 & 2.8786 & TST & \\
\hline CHEMBL1516375 & 688547 & 2.9347 & 3.0089 & TST & \\
\hline CHEMBL1484640 & 688547 & 2.9351 & 3.0783 & TST & \\
\hline CHEMBL1393674 & 688547 & 2.9351 & 3.0329 & TST & \\
\hline CHEMBL1427854 & 688547 & 2.9345 & 2.9479 & TST & \\
\hline CHEMBL1577703 & 688547 & 3.9986 & 3.5434 & TST & \\
\hline CHEMBL448245 & 688547 & 4.1266 & 3.3042 & TST & \\
\hline CHEMBL1369106 & 688547 & 4.7507 & 3.18899 & 99999999996 & TST \\
\hline CHEMBL1351173 & 688547 & 2.935 & 3.02 & TST & \\
\hline CHEMBL3210930 & 688547 & 2.9351 & 2.8384 & TST & \\
\hline CHEMBL1476893 & 688547 & 2.9348 & 3.1152 & TST & \\
\hline CHEMBL70492 & 205492 & 7.3372 & 7.542006 & 0000000001 & TRN \\
\hline CHEMBL 70965 & 205492 & 7.2441 & 7.7358 & TRN & \\
\hline CHEMBL 74182 & 205492 & 7.4815 & 7.3528 & TRN & \\
\hline CHEMBL72678 & 205492 & 7.5086 & 7.4732 & TST & \\
\hline CHEMBL308228 & 205492 & 6.9208 & 7.1995 & TRN & \\
\hline CHEMBL 308032 & 205492 & 4.3372 & 5.3893 & TST & \\
\hline CHEMBL72788 & 205492 & 7.699 & 7.5406 & TRN & \\
\hline CHEMBL 307090 & 205492 & 7.9208 & 7.6023 & TRN & \\
\hline CHEMBL 303918 & 205492 & 4.4089 & 6.3779 & TST & \\
\hline CHEMBL72337 & 205492 & 7.1024 & 6.6881 & TRN & \\
\hline CHEMBL 71468 & 205492 & 5.4437 & 6.2316 & TST & \\
\hline CHEMBL306871 & 205492 & 7.3768 & 7.6324 & TRN & \\
\hline CHEMBL70398 & 205492 & 7.8861 & 7.2966 & TST & \\
\hline CHEMBL 302368 & 205492 & 7.9586 & 7.3881 & TRN & \\
\hline CHEMBL 71071 & 205492 & 7.4089 & 7.3562 & TRN & \\
\hline CHEMBL 306470 & 205492 & 7.3768 & 7.2709 & TRN & \\
\hline CHEMBL303155 & 205492 & 7.2366 & 7.4847 & TRN & \\
\hline CHEMBL305222 & 205492 & 6.9208 & 7.3888 & TRN & \\
\hline CHEMBL69506 & 205492 & 6.8861 & 7.4 & TRN & \\
\hline CHEMBL308429 & 205492 & 7.0 & 6.5723 & TST & \\
\hline CHEMBL71630 & 205492 & 6.8239 & 6.6788 & TRN & \\
\hline CHEMBL 71713 & 205492 & 6.9355 & 7.1537 & TRN & \\
\hline CHEMBL 70570 & 205492 & 6.8861 & 7.3372 & TST & \\
\hline CHEMBL422948 & 205492 & 7.5229 & 7.3538 & TRN & \\
\hline
\end{tabular}


Supplemental Table S2.txt

\begin{tabular}{|c|c|c|c|c|}
\hline CHEMBL306524 & 205492 & 7.9586 & 7.6756 & TRN \\
\hline CHEMBL68049 & 205492 & 5.5229 & 5.8979 & TRN \\
\hline CHEMBL 71482 & 205492 & 8.0809 & 7.7604 & TRN \\
\hline CHEMBL 306912 & 205492 & 7.8539 & 7.599 & TRN \\
\hline CHEMBL306224 & 205492 & 8.2757 & 7.5084 & TRN \\
\hline CHEMBL68149 & 205492 & 7.2518 & 6.7092 & TRN \\
\hline CHEMBL 308012 & 205492 & 6.3872 & 7.0077 & TRN \\
\hline CHEMBL 70430 & 205492 & 7.9208 & 7.3889 & TRN \\
\hline CHEMBL 71618 & 205492 & 7.2924 & 7.1478 & TRN \\
\hline CHEMBL69072 & 205492 & 7.3665 & 6.4389 & TRN \\
\hline CHEMBL 72743 & 205492 & 7.585 & 7.2005 & TRN \\
\hline CHEMBL 70354 & 205492 & 6.0757 & 6.6325 & TRN \\
\hline CHEMBL 70571 & 205492 & 7.699 & 7.3641 & TST \\
\hline CHEMBL 306189 & 205492 & 7.9101 & 7.7604 & TRN \\
\hline CHEMBL 70049 & 205492 & 6.5528 & 6.5686 & TRN \\
\hline CHEMBL 70426 & 205492 & 6.6383 & 6.7068 & TRN \\
\hline CHEMBL 74175 & 205492 & 7.0706 & 7.3072 & TRN \\
\hline CHEMBL 70315 & 205492 & 7.1805 & 7.2732 & TRN \\
\hline CHEMBL 308397 & 205492 & 5.7212 & 6.7885 & TRN \\
\hline CHEMBL 71014 & 205492 & 6.1549 & 6.5808 & TRN \\
\hline CHEMBL310249 & 205492 & 7.4089 & 7.7181 & TRN \\
\hline CHEMBL 308598 & 205492 & 6.699 & 6.3987 & TRN \\
\hline CHEMBL 71995 & 205492 & 7.5086 & 7.6674 & TRN \\
\hline CHEMBL 302311 & 205492 & 7.3372 & 7.2771 & TRN \\
\hline CHEMBL69024 & 205492 & 7.2924 & 7.3172 & TRN \\
\hline CHEMBL302954 & 205492 & 6.7959 & 6.5249 & TRN \\
\hline CHEMBL430612 & 205492 & 6.3188 & 6.5011 & TST \\
\hline CHEMBL68890 & 205492 & 7.3872 & 7.7577 & TRN \\
\hline CHEMBL 305780 & 205492 & 6.8539 & 6.9567 & TST \\
\hline CHEMBL 70639 & 205492 & 6.0809 & 6.5917 & TST \\
\hline CHEMBL 70406 & 205492 & 6.6021 & 6.5726 & TST \\
\hline CHEMBL 71800 & 205492 & 6.8861 & 6.8466 & TST \\
\hline CHEMBL420932 & 205492 & 7.4318 & 7.6181 & TST \\
\hline CHEMBL 70417 & 205492 & 7.5376 & 7.8495 & TST \\
\hline CHEMBL448154 & 70619 & 6.9586 & 6.9918 & TRN \\
\hline CHEMBL299347 & 70619 & 3.301 & 4.4211 & TST \\
\hline CHEMBL113070 & 70619 & 6.9586 & 6.9618 & TRN \\
\hline CHEMBL301612 & 70619 & 6.3372 & 6.3728 & TRN \\
\hline CHEMBL111913 & 70619 & 5.2366 & 5.246 & TRN \\
\hline CHEMBL 324926 & 70619 & 6.3665 & 6.3621 & TRN \\
\hline CHEMBL113863 & 70619 & 6.2366 & 6.2546 & TRN \\
\hline CHEMBL113521 & 70619 & 7.1805 & 7.1748 & TRN \\
\hline CHEMBL109631 & 70619 & 6.9586 & 6.9618 & TRN \\
\hline CHEMBL110034 & 70619 & 5.5017 & 5.4922 & TRN \\
\hline CHEMBL 320705 & 70619 & 5.4949 & \multicolumn{2}{|c|}{5.497000000000001} \\
\hline CHEMBL 325589 & 70619 & 6.8239 & 6.8184 & TRN \\
\hline CHEMBL50470 & 70619 & 4.857 & 4.8726 & TRN \\
\hline CHEMBL332269 & 70619 & 5.3487 & 5.3396 & TRN \\
\hline
\end{tabular}

Page 22699 


\begin{tabular}{|c|c|c|c|c|}
\hline & & & oplement & al $\mathrm{Ta}$ \\
\hline CHEMBL51283 & 70619 & 7.5528 & 7.5622 & TRN \\
\hline CHEMBL321193 & 70619 & 6.7447 & 6.7363 & TRN \\
\hline CHEMBL109725 & 70619 & 3.301 & 4.4785 & TST \\
\hline CHEMBL112706 & 70619 & 7.3098 & 7.2971 & TRN \\
\hline CHEMBL113023 & 70619 & 6.3468 & 6.3498 & TRN \\
\hline CHEMBL109547 & 70619 & 5.8239 & 5.8311 & TRN \\
\hline CHEMBL109296 & 70619 & 6.0177 & 6.0184 & TRN \\
\hline CHEMBL111197 & 70619 & 6.4318 & 6.4314 & TRN \\
\hline CHEMBL109525 & 70619 & 4.4737 & 4.4622 & TRN \\
\hline CHEMBL324543 & 70619 & 7.3979 & 7.3931 & TRN \\
\hline CHEMBL50647 & 70619 & 7.2147 & 7.2122 & TRN \\
\hline CHEMBL326041 & 70619 & 5.4935 & 5.4794 & TRN \\
\hline CHEMBL49596 & 70619 & 5.8861 & 5.3827 & TST \\
\hline CHEMBL327127 & 70619 & 7.0969 & 7.0822 & TRN \\
\hline CHEMBL104244 & 70619 & 6.4949 & 6.5371 & TRN \\
\hline CHEMBL106232 & 70619 & 6.6198 & 6.5747 & TRN \\
\hline CHEMBL331366 & 70619 & 7.2596 & 7.2651 & TRN \\
\hline CHEMBL48172 & 70619 & 5.8508 & 5.8464 & TRN \\
\hline CHEMBL419022 & 70619 & 5.585 & 5.5852 & TRN \\
\hline CHEMBL323775 & 70619 & 7.4089 & 7.4069 & TRN \\
\hline CHEMBL110905 & 70619 & 7.4815 & 7.4688 & TRN \\
\hline CHEMBL297523 & 70619 & 7.4949 & 6.8351 & TST \\
\hline CHEMBL104779 & 70619 & 6.7212 & 6.6951 & TRN \\
\hline CHEMBL109759 & 70619 & 6.1549 & 6.1555 & TRN \\
\hline CHEMBL111339 & 70619 & 6.041 & 6.0523 & TRN \\
\hline CHEMBL113356 & 70619 & 4.8539 & 4.8488 & TRN \\
\hline CHEMBL112080 & 70619 & 7.4685 & 7.4787 & TRN \\
\hline CHEMBL113128 & 70619 & 5.1675 & 5.5752 & TST \\
\hline CHEMBL322298 & 70619 & 6.6778 & 6.6487 & TRN \\
\hline CHEMBL104153 & 70619 & 6.3872 & 6.3915 & TRN \\
\hline CHEMBL323405 & 70619 & 6.8239 & 6.8368 & TRN \\
\hline CHEMBL107472 & 70619 & 5.6021 & 5.8082 & TST \\
\hline CHEMBL111434 & 70619 & 5.6198 & 6.4779 & TST \\
\hline CHEMBL320339 & 70619 & 7.3372 & 7.4511 & TST \\
\hline CHEMBL111365 & 70619 & 6.2676 & 6.401 & TST \\
\hline CHEMBL323699 & 70619 & 5.1851 & 5.3224 & TST \\
\hline CHEMBL299194 & 70619 & 6.4202 & 6.4188 & TST \\
\hline CHEMBL51573 & 70619 & 3.301 & 4.3072 & TST \\
\hline CHEMBL111618 & 70619 & 5.7799 & 5.6739 & TST \\
\hline CHEMBL111247 & 70619 & 5.5229 & 6.2712 & TST \\
\hline CHEMBL1086226 & 161563 & 7.4202 & 7.1931 & TRN \\
\hline CHEMBL 276983 & 161563 & 7.1249 & 6.7751 & TRN \\
\hline CHEMBL24141 & 161563 & 5.9245 & 6.0282 & TRN \\
\hline CHEMBL 24566 & 161563 & 7.4949 & 7.3198 & TRN \\
\hline CHEMBL366281 & 161563 & 7.2518 & 7.1291 & TRN \\
\hline CHEMBL25008 & 161563 & 6.3279 & 6.4699 & TST \\
\hline CHEMBL285125 & 161563 & 6.0458 & 6.0027 & TST \\
\hline CHEMBL416743 & 161563 & 5.9586 & 5.8297 & TRN \\
\hline
\end{tabular}




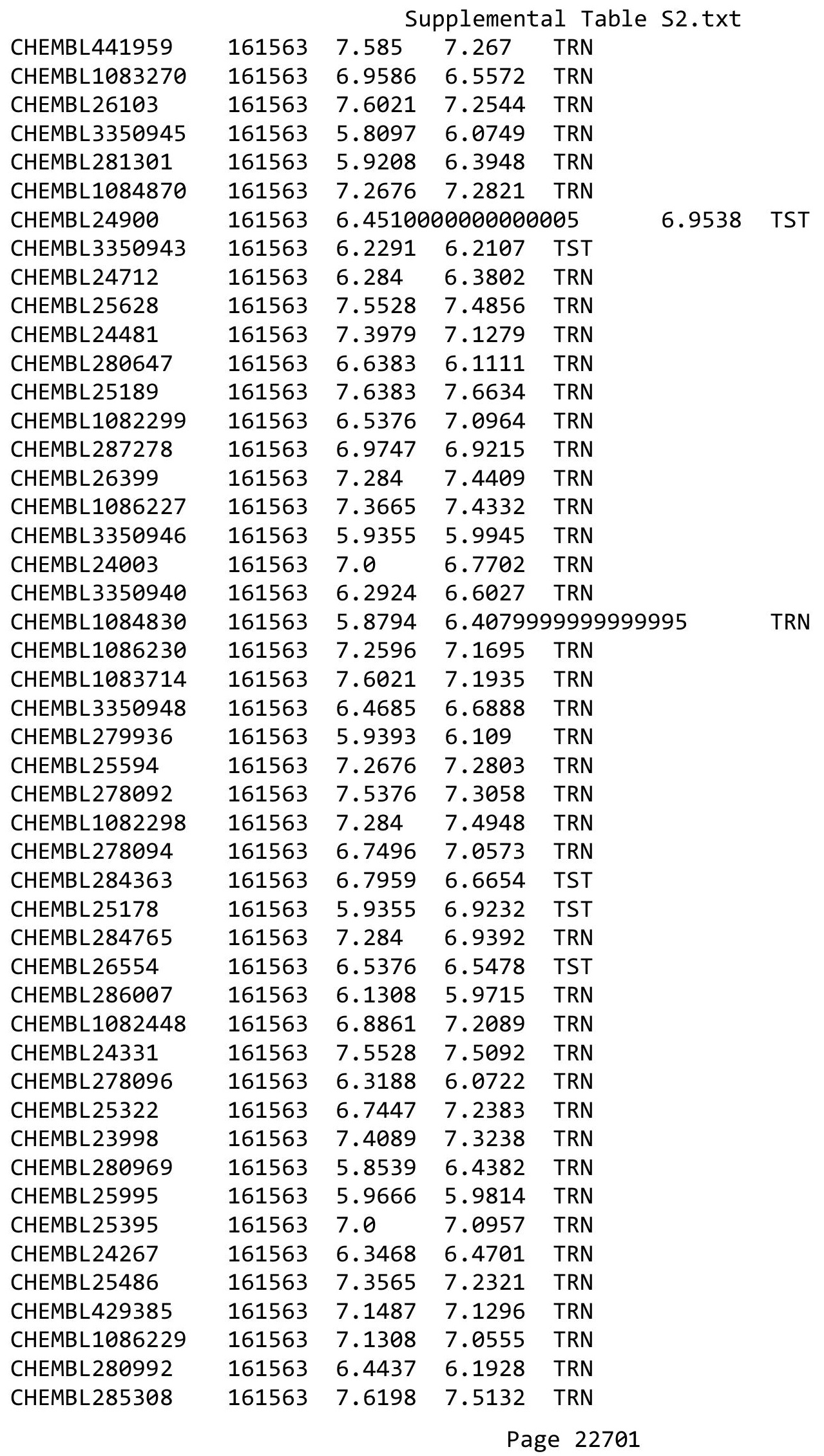




\begin{tabular}{|c|c|c|c|c|c|}
\hline \multirow[b]{2}{*}{ CHEMBL3350947 } & \multicolumn{5}{|c|}{ Supplemental Table S2.txt } \\
\hline & 161563 & 6.8861 & 6.8965 & TRN & \\
\hline CHEMBL24096 & 161563 & 5.8539 & 6.0816 & TRN & \\
\hline CHEMBL 281687 & 161563 & 5.7959 & 6.7141 & TST & \\
\hline CHEMBL1085961 & 161563 & 6.6576 & 6.5455 & TRN & \\
\hline CHEMBL23989 & 161563 & 6.4815 & 6.0042 & TRN & \\
\hline CHEMBL 279242 & 161563 & 6.3565 & 6.62200 & 0000000001 & TRN \\
\hline CHEMBL 282113 & 161563 & 6.0969 & 5.9274 & TST & \\
\hline CHEMBL190535 & 161563 & 7.0706 & 7.2405 & TRN & \\
\hline CHEMBL 26216 & 161563 & 6.8861 & 7.0054 & TST & \\
\hline CHEMBL 25821 & 161563 & 5.9586 & 5.9664 & TRN & \\
\hline CHEMBL282708 & 161563 & 6.4949 & 6.4607 & TRN & \\
\hline CHEMBL24201 & 161563 & 5.8861 & 5.8749 & TRN & \\
\hline CHEMBL1084871 & 161563 & 7.0223 & 6.6502 & TRN & \\
\hline CHEMBL3350944 & 161563 & 6.3872 & 6.756 & TRN & \\
\hline CHEMBL 24843 & 161563 & 7.0969 & 7.0548 & TRN & \\
\hline CHEMBL3350938 & 161563 & 7.1135 & 7.0885 & TRN & \\
\hline CHEMBL1086499 & 161563 & 6.7696 & 6.6838 & TRN & \\
\hline CHEMBL282855 & 161563 & 5.8861 & 6.2218 & TST & \\
\hline CHEMBL 24557 & 161563 & 6.2924 & 5.9978 & TRN & \\
\hline CHEMBL1082297 & 161563 & 7.2757 & 7.4878 & TRN & \\
\hline CHEMBL1083272 & 161563 & 7.1135 & 6.8968 & TRN & \\
\hline CHEMBL193134 & 161563 & 6.3979 & 6.6212 & TRN & \\
\hline CHEMBL282306 & 161563 & 6.0362 & 6.0665 & TST & \\
\hline CHEMBL24524 & 161563 & 7.4685 & 7.4704 & TRN & \\
\hline CHEMBL 285307 & 161563 & 7.5229 & 7.471 & TRN & \\
\hline CHEMBL24005 & 161563 & 6.2676 & 6.2068 & TRN & \\
\hline CHEMBL 24607 & 161563 & 7.3279 & 7.4273 & TRN & \\
\hline CHEMBL 24032 & 161563 & 6.2366 & 6.153 & TRN & \\
\hline CHEMBL 24068 & 161563 & 5.6596 & 6.0868 & TRN & \\
\hline CHEMBL 280388 & 161563 & 6.1871 & 6.1623 & TST & \\
\hline CHEMBL3350942 & 161563 & 6.4559 & 6.5402 & TST & \\
\hline CHEMBL 25243 & 161563 & 6.4318 & 6.5449 & TRN & \\
\hline CHEMBL284763 & 161563 & 7.0862 & 6.4602 & TST & \\
\hline CHEMBL 283635 & 161563 & 6.4437 & 6.6948 & TRN & \\
\hline CHEMBL 24501 & 161563 & 6.1308 & 5.7656 & TST & \\
\hline CHEMBL538903 & 161563 & 7.5376 & 7.4223 & TRN & \\
\hline CHEMBL187610 & 161563 & 7.2366 & 7.1523 & TRN & \\
\hline CHEMBL1083271 & 161563 & 6.9208 & 6.7943 & TRN & \\
\hline CHEMBL1085070 & 161563 & 6.9586 & 6.6406 & TRN & \\
\hline CHEMBL370307 & 161563 & 6.9208 & 7.0548 & TRN & \\
\hline CHEMBL26100 & 161563 & 6.1549 & 5.8974 & TRN & \\
\hline CHEMBL 282372 & 161563 & 6.7696 & 6.671 & TRN & \\
\hline CHEMBL 25881 & 161563 & 5.8861 & 6.4494 & TST & \\
\hline CHEMBL 24606 & 161563 & 5.9706 & 6.5151 & TRN & \\
\hline CHEMBL1083269 & 161563 & 6.1675 & 6.3298 & TST & \\
\hline CHEMBL 25368 & 161563 & 7.5528 & 7.2884 & TST & \\
\hline CHEMBL 24680 & 161563 & 6.4202 & 6.0226 & TST & \\
\hline CHEMBL 284664 & 161563 & 6.1549 & 6.0177 & TST & \\
\hline
\end{tabular}




\begin{tabular}{|c|c|c|c|c|c|}
\hline \multicolumn{6}{|c|}{ Supplemental Table S2.txt } \\
\hline CHEMBL24213 & 161563 & 7.0 & 6.7995 & TST & \\
\hline CHEMBL3350941 & 161563 & 6.0132 & 6.3757 & TST & \\
\hline CHEMBL3350939 & 161563 & 6.9208 & 6.8508 & TST & \\
\hline CHEMBL 25584 & 161563 & 6.7696 & 6.6807 & TST & \\
\hline CHEMBL280198 & 161563 & 6.8539 & 6.444 & TST & \\
\hline CHEMBL284471 & 161563 & 7.6021 & 7.0748 & TST & \\
\hline CHEMBL1086228 & 161563 & 6.6383 & 7.0735 & TST & \\
\hline CHEMBL2441526 & 990348 & 5.0706 & 5.357 & TST & \\
\hline CHEMBL2441516 & 990348 & 5.585 & 5.796 & TRN & \\
\hline CHEMBL 2441734 & 990348 & 5.6576 & 5.5742 & TRN & \\
\hline CHEMBL 2441513 & 990348 & 6.2218 & 6.5491 & TRN & \\
\hline CHEMBL 2441733 & 990348 & 5.7696 & 5.7932 & TRN & \\
\hline CHEMBL2441739 & 990348 & 5.1249 & 4.7661 & TST & \\
\hline CHEMBL 2441522 & 990348 & 5.0 & 5.0576 & TRN & \\
\hline CHEMBL 2441517 & 990348 & 5.5528 & 5.5711 & TRN & \\
\hline CHEMBL 2441514 & 990348 & 6.1249 & 6.3279 & TRN & \\
\hline CHEMBL 2441541 & 990348 & 6.3372 & 6.1419 & TRN & \\
\hline CHEMBL 2441725 & 990348 & 6.4202 & 6.2441 & TRN & \\
\hline CHEMBL2441534 & 990348 & 5.6778 & 5.7986 & TRN & \\
\hline CHEMBL1312639 & 990348 & 5.1739 & 4.8208 & TRN & \\
\hline CHEMBL 2441722 & 990348 & 3.699 & 3.4131 & TRN & \\
\hline CHEMBL 2441525 & 990348 & 3.699 & 3.7817 & TRN & \\
\hline CHEMBL 2441535 & 990348 & 5.4949 & 5.5693 & TRN & \\
\hline CHEMBL2441723 & 990348 & 4.699 & 5.0145 & TRN & \\
\hline CHEMBL 2441532 & 990348 & 6.5376 & 6.731 & TRN & \\
\hline CHEMBL 2441720 & 990348 & 3.699 & 4.84399 & 9999999999 & TST \\
\hline CHEMBL 2441730 & 990348 & 5.9208 & 5.8433 & TRN & \\
\hline CHEMBL 2441712 & 990348 & 6.041 & 6.2417 & TRN & \\
\hline CHEMBL 2441536 & 990348 & 5.4815 & 5.4232 & TRN & \\
\hline CHEMBL 2441537 & 990348 & 5.4202 & 5.3109 & TRN & \\
\hline CHEMBL 2441511 & 990348 & 6.3565 & 6.3859 & TRN & \\
\hline CHEMBL 2441506 & 990348 & 6.4437 & 6.6562 & TRN & \\
\hline CHEMBL 2441508 & 990348 & 6.4202 & 6.306 & TRN & \\
\hline CHEMBL 2441528 & 990348 & 6.9586 & 6.7916 & TRN & \\
\hline CHEMBL 2441721 & 990348 & 3.699 & 4.7248 & TST & \\
\hline CHEMBL 2441544 & 990348 & 6.1739 & 6.0067 & TRN & \\
\hline CHEMBL 2441729 & 990348 & 6.0915 & 6.0117 & TRN & \\
\hline CHEMBL 2441716 & 990348 & 5.6021 & 5.7848 & TRN & \\
\hline CHEMBL2441713 & 990348 & 6.0 & 5.971 & TRN & \\
\hline CHEMBL2441521 & 990348 & 5.0 & 5.0178 & TRN & \\
\hline CHEMBL 2441502 & 990348 & 6.5376 & 6.5453 & TRN & \\
\hline CHEMBL 2441732 & 990348 & 5.7959 & 5.6341 & TRN & \\
\hline CHEMBL 2441718 & 990348 & 3.699 & 3.9857 & TRN & \\
\hline CHEMBL 2441505 & 990348 & 6.4685 & 6.5827 & TRN & \\
\hline CHEMBL 2441503 & 990348 & 6.5229 & 6.5946 & TRN & \\
\hline CHEMBL 2441504 & 990348 & 6.4815 & 6.3206 & TRN & \\
\hline CHEMBL 2441735 & 990348 & 5.6383 & 5.4952 & TST & \\
\hline CHEMBL 2441717 & 990348 & 4.7447 & 4.805 & TRN & \\
\hline
\end{tabular}


Supplemental Table S2.txt

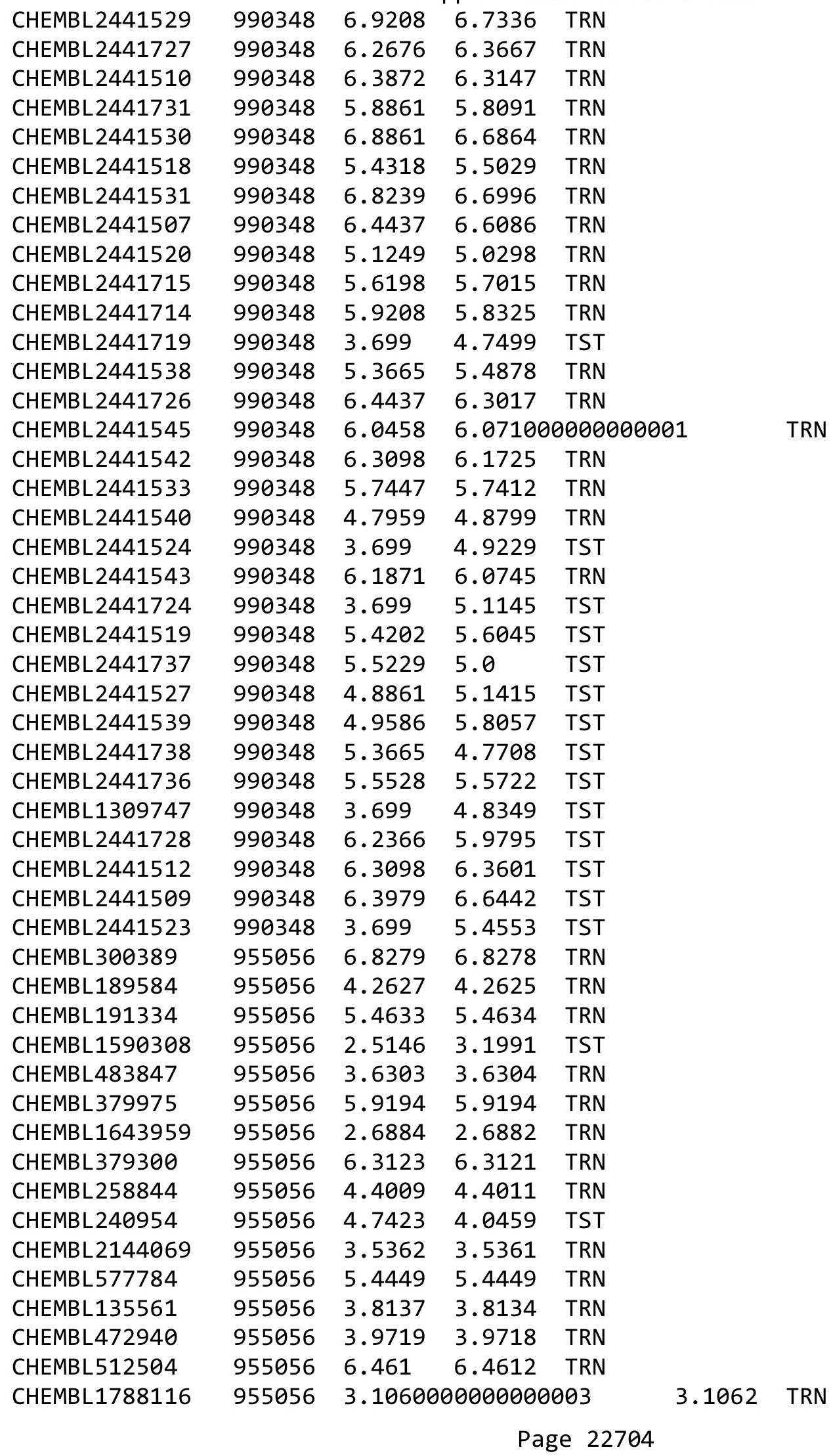




\begin{tabular}{|c|c|c|c|c|c|}
\hline \multirow[b]{2}{*}{ CHEMBL209148 } & \\
\hline & 955056 & 4.1826 & 4.1827 & TRN & \\
\hline CHEMBL210618 & 955056 & 4.4435 & 4.4433 & TRN & \\
\hline CHEMBL1404918 & 955056 & 2.9613 & 2.9611 & TRN & \\
\hline CHEMBL509032 & 955056 & 5.114 & 5.1141 & TRN & \\
\hline CHEMBL483849 & 955056 & 1.1895 & 1.1896 & TRN & \\
\hline CHEMBL 2005886 & 955056 & 4.5966 & 4.5964 & TRN & \\
\hline CHEMBL1516890 & 955056 & 4.0288 & 4.0288 & TRN & \\
\hline CHEMBL221137 & 955056 & 4.4096 & 4.3108 & TST & \\
\hline CHEMBL180127 & 955056 & 2.5402 & 2.5403 & TRN & \\
\hline CHEMBL3349342 & 955056 & 4.072 & 4.0721 & TRN & \\
\hline CHEMBL558642 & 955056 & 2.6413 & 2.6415 & TRN & \\
\hline CHEMBL1909414 & 955056 & 4.1342 & 4.1341 & TRN & \\
\hline CHEMBL585951 & 955056 & 6.0486 & 6.0485 & TRN & \\
\hline CHEMBL65 & 955056 & 8.2939 & 8.2939 & TRN & \\
\hline CHEMBL1673039 & 955056 & 4.966 & 4.9661 & TRN & \\
\hline CHEMBL393929 & 955056 & 5.3589 & 5.3592 & TRN & \\
\hline CHEMBL222102 & 955056 & 4.2014 & \multicolumn{2}{|c|}{4.2010000000000005} & TRN \\
\hline CHEMBL3199475 & 955056 & 4.2617 & 4.2616 & TRN & \\
\hline CHEMBL515416 & 955056 & 3.5435 & 3.5436 & TRN & \\
\hline CHEMBL3186408 & 955056 & 3.415 & 3.6583 & TST & \\
\hline CHEMBL 213100 & 955056 & 3.7858 & 3.7857 & TRN & \\
\hline CHEMBL 373751 & 955056 & 3.1509 & \multicolumn{2}{|c|}{3.1510000000000002} & TRN \\
\hline CHEMBL514499 & 955056 & 5.4057 & 5.4058 & TRN & \\
\hline CHEMBL1970879 & 955056 & 3.6736 & 3.6738 & TRN & \\
\hline CHEMBL412142 & 955056 & 3.4046 & 3.4046 & TRN & \\
\hline CHEMBL 220241 & 955056 & 3.7444 & 3.7443 & TRN & \\
\hline CHEMBL 202721 & 955056 & 4.9692 & 4.9693 & TRN & \\
\hline CHEMBL449158 & 955056 & 6.2698 & 6.2745 & TST & \\
\hline CHEMBL1190711 & 955056 & 4.8617 & 4.8617 & TRN & \\
\hline CHEMBL573107 & 955056 & \multicolumn{2}{|c|}{5.611000000000001} & 5.6111 & TRN \\
\hline CHEMBL9470 & 955056 & 6.4586 & 5.5972 & TST & \\
\hline CHEMBL192566 & 955056 & 7.1597 & 7.2929 & TST & \\
\hline CHEMBL1357247 & 955056 & 3.7202 & 3.7203 & TRN & \\
\hline CHEMBL1242367 & 955056 & 4.1747 & 4.1748 & TRN & \\
\hline CHEMBL259181 & 955056 & 4.203 & 4.2027 & TRN & \\
\hline CHEMBL1230020 & 955056 & 4.4704 & 3.9166 & TST & \\
\hline CHEMBL1256459 & 955056 & 6.5243 & 5.8606 & TST & \\
\hline CHEMBL92309 & 955056 & 3.8318 & 2.9028 & TST & \\
\hline CHEMBL102714 & 955056 & 4.2243 & 4.3692 & TST & \\
\hline CHEMBL188678 & 955056 & 4.6046 & 5.0725 & TST & \\
\hline CHEMBL2363137 & 955056 & 4.5683 & 4.6341 & TST & \\
\hline CHEMBL3392440 & 955056 & 3.4201 & 3.4247 & TST & \\
\hline CHEMBL392695 & 955056 & 4.283 & 3.8138 & TST & \\
\hline CHEMBL8776 & 64008 & 5.2993 & 4.9875 & TST & \\
\hline CHEMBL 267483 & 64008 & 4.9547 & 5.1578 & TRN & \\
\hline CHEMBL9168 & 64008 & 4.5638 & 5.0253 & TRN & \\
\hline CHEMBL8677 & 64008 & 5.4685 & 5.2964 & TRN & \\
\hline \multirow[t]{2}{*}{ CHEMBL8925 } & 64008 & 5.8327 & 5.4191 & TRN & \\
\hline & & \multicolumn{4}{|c|}{ Page 22705} \\
\hline
\end{tabular}




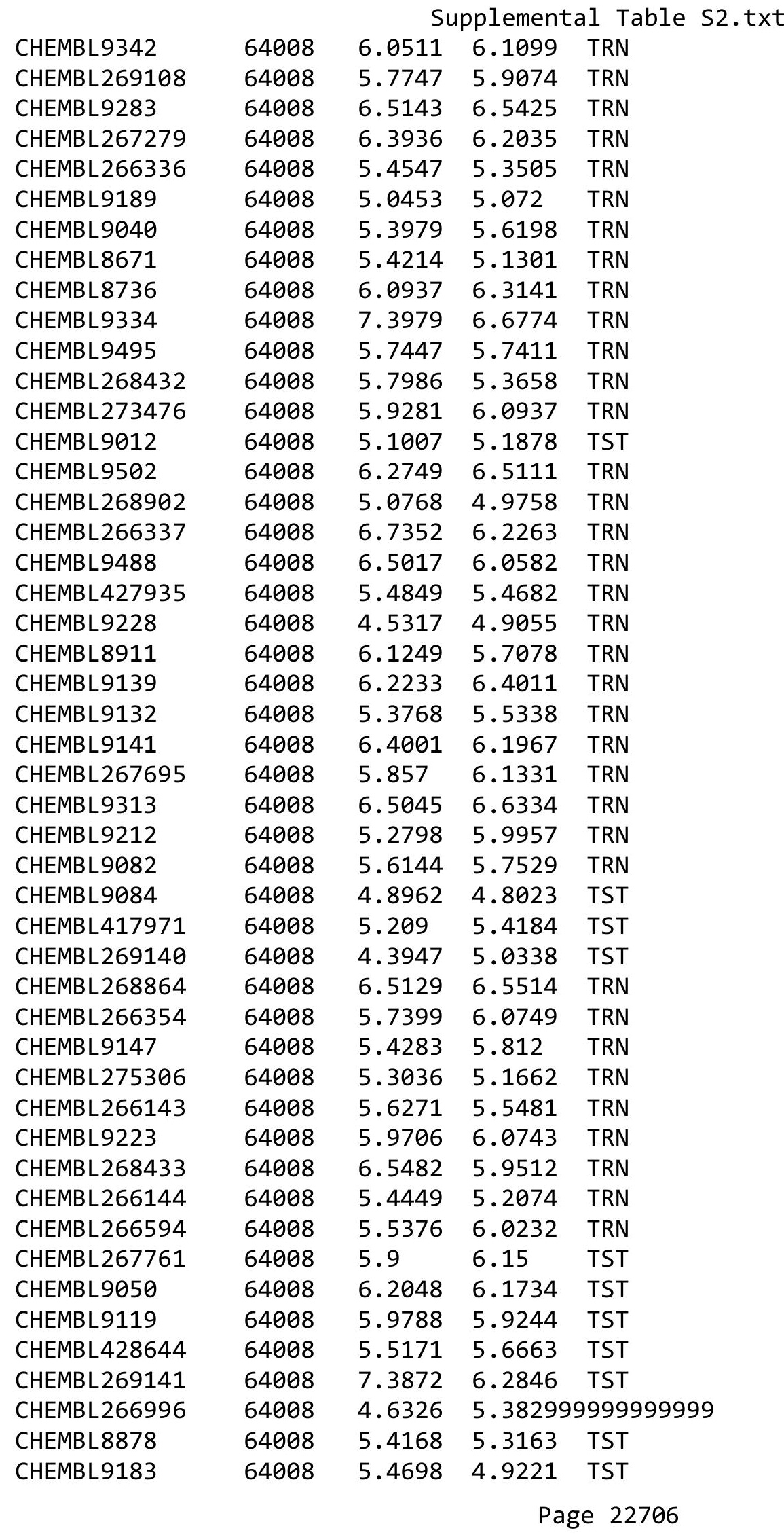




\begin{tabular}{|c|c|c|c|c|c|}
\hline & & \multicolumn{4}{|c|}{ Supplemental Table S2.txt } \\
\hline CHEMBL417972 & 64008 & 6.0788 & 5.3693 & TST & \\
\hline CHEMBL17224 & 88003 & 6.301 & 6.6356 & TRN & \\
\hline CHEMBL279767 & 88003 & 5.6383 & 6.2594 & TRN & \\
\hline CHEMBL17220 & 88003 & 6.1675 & 5.94799 & 99999999995 & TRN \\
\hline CHEMBL17158 & 88003 & 6.2218 & 6.6167 & TRN & \\
\hline CHEMBL280265 & 88003 & 6.3665 & 6.3737 & TRN & \\
\hline CHEMBL17722 & 88003 & 6.4318 & 6.5519 & TRN & \\
\hline CHEMBL17339 & 88003 & 5.1675 & 6.6671 & TST & \\
\hline CHEMBL16911 & 88003 & 6.1487 & 5.8215 & TRN & \\
\hline CHEMBL276063 & 88003 & 6.3979 & 6.7638 & TRN & \\
\hline CHEMBL6252 & 88003 & 6.301 & 6.506 & TRN & \\
\hline CHEMBL278262 & 88003 & 4.301 & 5.171 & TRN & \\
\hline CHEMBL16838 & 88003 & 6.0862 & 6.169 & TRN & \\
\hline CHEMBL280239 & 88003 & 6.0 & 6.5915 & TRN & \\
\hline CHEMBL278724 & 88003 & 4.301 & 6.0569 & TST & \\
\hline CHEMBL278491 & 88003 & 5.3645 & 5.5178 & TRN & \\
\hline CHEMBL17736 & 88003 & 7.301 & 6.9498 & TRN & \\
\hline CHEMBL417087 & 88003 & 7.0969 & 6.8853 & TRN & \\
\hline CHEMBL279568 & 88003 & 5.5229 & 6.1761 & TRN & \\
\hline CHEMBL17293 & 88003 & 6.699 & 6.7428 & TRN & \\
\hline CHEMBL17389 & 88003 & 7.0969 & 5.9028 & TRN & \\
\hline CHEMBL17210 & 88003 & 7.301 & 6.7246 & TRN & \\
\hline CHEMBL17792 & 88003 & 6.1308 & 6.0761 & TRN & \\
\hline CHEMBL278041 & 88003 & 7.301 & 6.8743 & TRN & \\
\hline CHEMBL17641 & 88003 & 6.0315 & 6.2976 & TRN & \\
\hline CHEMBL17148 & 88003 & 6.3768 & 6.7792 & TST & \\
\hline CHEMBL 275365 & 88003 & 6.1871 & 6.4381 & TST & \\
\hline CHEMBL276114 & 88003 & 6.1871 & 5.5663 & TRN & \\
\hline CHEMBL17204 & 88003 & 6.1938 & 5.8492 & TRN & \\
\hline CHEMBL17334 & 88003 & 6.9208 & 6.7945 & TRN & \\
\hline CHEMBL17135 & 88003 & 5.9431 & 5.6309 & TRN & \\
\hline CHEMBL17370 & 88003 & 6.2366 & 6.7713 & TRN & \\
\hline CHEMBL17445 & 88003 & 7.301 & 6.9084 & TRN & \\
\hline CHEMBL17396 & 88003 & 7.0 & 6.8943 & TRN & \\
\hline CHEMBL416169 & 88003 & 6.5229 & 6.2295 & TRN & \\
\hline CHEMBL280317 & 88003 & 6.699 & 6.6486 & TRN & \\
\hline CHEMBL17688 & 88003 & 6.2596 & 6.7949 & TST & \\
\hline CHEMBL277587 & 88003 & 6.1487 & 6.1479 & TRN & \\
\hline CHEMBL 276548 & 88003 & 4.301 & 5.3774 & TRN & \\
\hline CHEMBL17331 & 88003 & 7.301 & 6.6728 & TRN & \\
\hline CHEMBL10 & 88003 & 7.0969 & 6.7672 & TRN & \\
\hline CHEMBL17023 & 88003 & 6.1135 & 5.6238 & TRN & \\
\hline CHEMBL276529 & 88003 & 6.1549 & 6.1495 & TRN & \\
\hline CHEMBL17238 & 88003 & 6.2291 & 5.6676 & TRN & \\
\hline CHEMBL17325 & 88003 & 6.4559 & 6.8393 & TRN & \\
\hline CHEMBL17493 & 88003 & 6.5686 & 6.4675 & TRN & \\
\hline CHEMBL 280457 & 88003 & 6.0655 & 6.685 & TRN & \\
\hline CHEMBL17273 & 88003 & 6.2076 & 6.1676 & TRN & \\
\hline
\end{tabular}




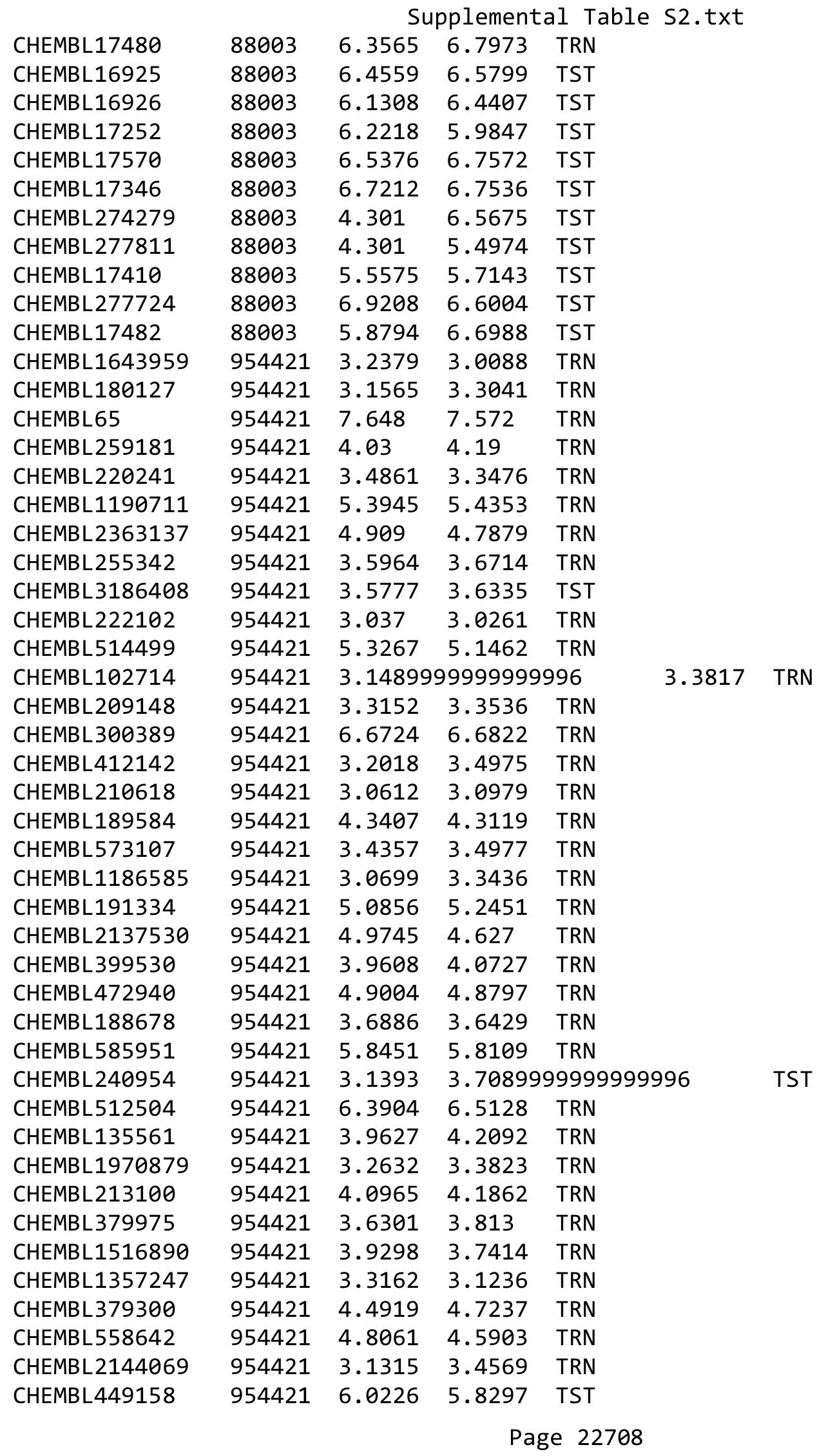


Supplemental Table S2.txt

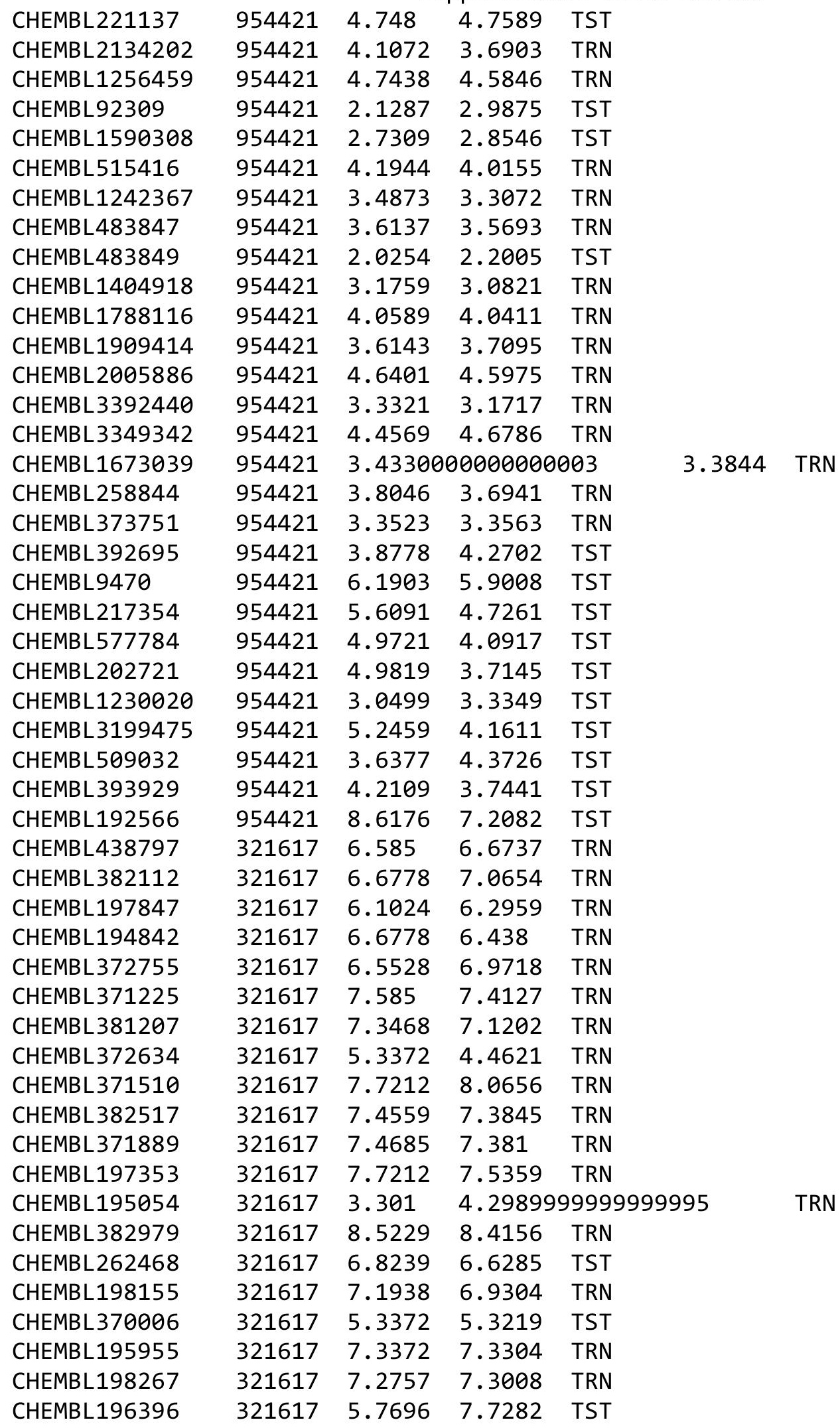

Page 22709 


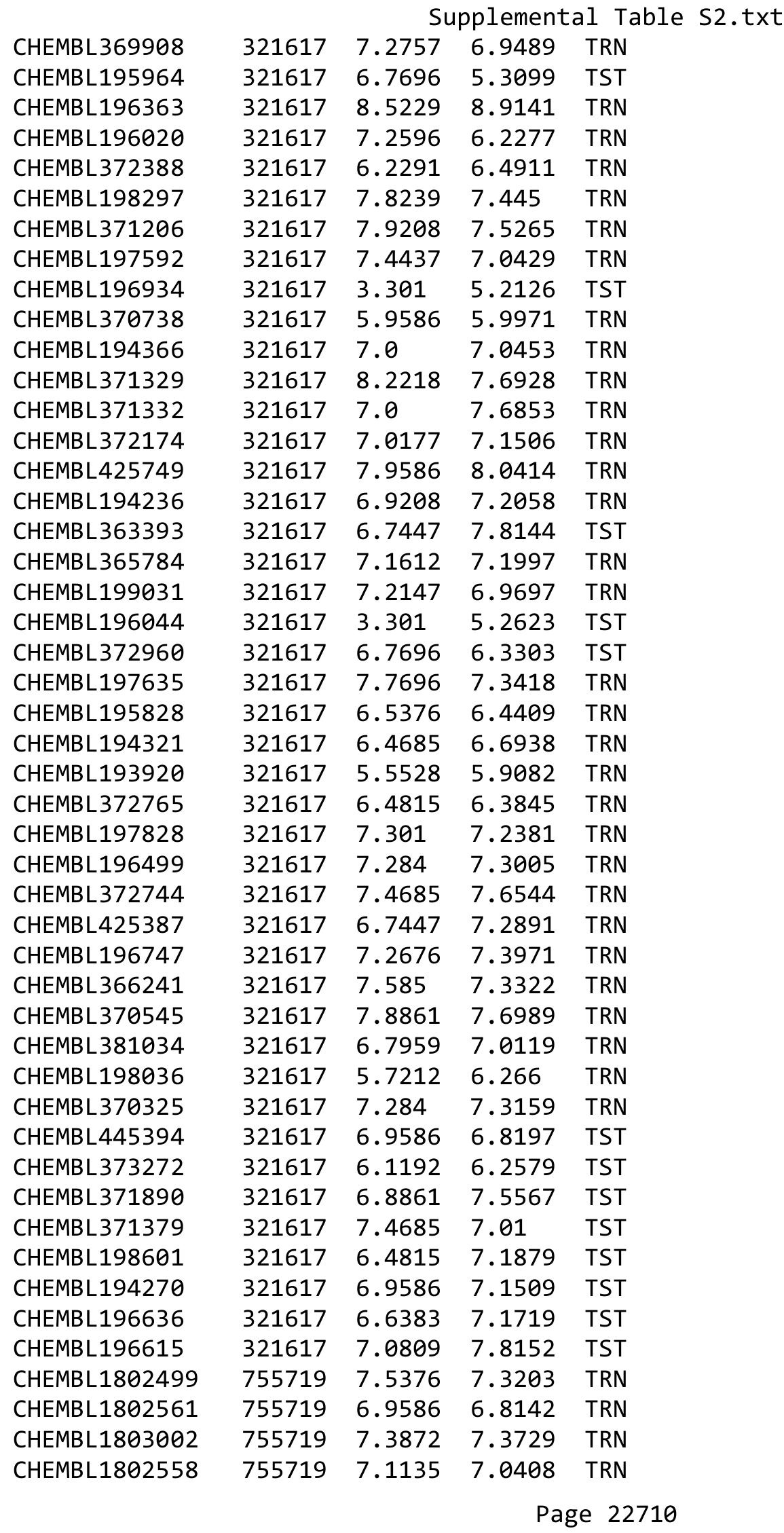




\begin{tabular}{|c|c|c|c|c|c|}
\hline & & & & & \\
\hline CHEMBL1802564 & 755719 & 7.0605 & 6.8738 & TRN & \\
\hline CHEMBL1802578 & 755719 & 6.3665 & 6.3971 & TRN & \\
\hline CHEMBL1802579 & 755719 & 5.0 & 5.1096 & TRN & \\
\hline CHEMBL1802567 & 755719 & 5.0 & 5.4051 & TRN & \\
\hline CHEMBL1802506 & 755719 & 7.4949 & 7.5983 & TRN & \\
\hline CHEMBL1803063 & 755719 & 5.0 & 5.12200 & 0000000001 & TRN \\
\hline CHEMBL1802584 & 755719 & 7.3979 & 7.4782 & TRN & \\
\hline CHEMBL1802505 & 755719 & 6.0 & 6.5578 & TRN & \\
\hline CHEMBL1802495 & 755719 & 6.1427 & 5.0775 & TRN & \\
\hline CHEMBL1802513 & 755719 & 7.4437 & 7.4852 & TRN & \\
\hline CHEMBL1802507 & 755719 & 7.4685 & 7.4856 & TRN & \\
\hline CHEMBL1803059 & 755719 & 5.0 & 5.193 & TRN & \\
\hline CHEMBL1802997 & 755719 & 7.2924 & 7.4033 & TRN & \\
\hline CHEMBL1802512 & 755719 & 7.1249 & 7.1221 & TRN & \\
\hline CHEMBL1803057 & 755719 & 5.0 & 5.1336 & TRN & \\
\hline CHEMBL1802514 & 755719 & 7.1367 & 7.2413 & TRN & \\
\hline CHEMBL1802500 & 755719 & 7.7447 & 7.79200 & 0000000001 & TRN \\
\hline CHEMBL67 & 755719 & 7.2147 & 8.1063 & TST & \\
\hline CHEMBL1802998 & 755719 & 8.0 & 7.9856 & TRN & \\
\hline CHEMBL1802576 & 755719 & 6.9208 & 6.777 & TRN & \\
\hline CHEMBL1802562 & 755719 & 6.2676 & 6.2476 & TRN & \\
\hline CHEMBL1802571 & 755719 & 6.3188 & 6.0122 & TST & \\
\hline CHEMBL1802557 & 755719 & 6.8239 & 6.8571 & TRN & \\
\hline CHEMBL1802510 & 755719 & 8.3979 & 8.405 & TRN & \\
\hline CHEMBL1802515 & 755719 & 6.1739 & 6.2594 & TRN & \\
\hline CHEMBL1802509 & 755719 & 8.0969 & 8.1371 & TRN & \\
\hline CHEMBL1800100 & 755719 & 6.8539 & 6.8614 & TRN & \\
\hline CHEMBL1802582 & 755719 & 7.1192 & 7.13899 & 9999999999 & TRN \\
\hline CHEMBL1802992 & 755719 & 7.1805 & 7.3103 & TRN & \\
\hline CHEMBL1802993 & 755719 & 7.2924 & 7.325 & TRN & \\
\hline CHEMBL1802559 & 755719 & 6.1079 & 6.0615 & TST & \\
\hline CHEMBL1803058 & 755719 & 6.4685 & 6.7211 & TRN & \\
\hline CHEMBL1802508 & 755719 & 7.1739 & 7.2883 & TRN & \\
\hline CHEMBL1802498 & 755719 & 7.4685 & 7.3428 & TRN & \\
\hline CHEMBL1803060 & 755719 & 5.0 & 5.2354 & TRN & \\
\hline CHEMBL1802572 & 755719 & 5.0 & 4.7131 & TRN & \\
\hline CHEMBL1802502 & 755719 & 7.3768 & 6.9529 & TRN & \\
\hline CHEMBL1802996 & 755719 & 7.5086 & 7.5327 & TRN & \\
\hline CHEMBL1802577 & 755719 & 6.8861 & 6.8818 & TRN & \\
\hline CHEMBL1802994 & 755719 & 7.2596 & 7.3878 & TRN & \\
\hline CHEMBL1802575 & 755719 & 7.1192 & 7.15 & TRN & \\
\hline CHEMBL441724 & 755719 & 6.8239 & 6.4646 & TST & \\
\hline CHEMBL1803003 & 755719 & 7.5376 & 7.50899 & 99999999995 & TRN \\
\hline CHEMBL1803061 & 755719 & 5.0 & 5.2277 & TRN & \\
\hline CHEMBL1802503 & 755719 & 7.9586 & 7.7342 & TRN & \\
\hline CHEMBL1802569 & 755719 & 6.7447 & 6.7175 & TST & \\
\hline CHEMBL1802565 & 755719 & 6.9208 & 6.6723 & TRN & \\
\hline CHEMBL1802581 & 755719 & 7.2147 & 7.1566 & TRN & \\
\hline
\end{tabular}




\begin{tabular}{|c|c|c|c|c|c|}
\hline \multicolumn{6}{|c|}{ Supplemental Table S2.txt } \\
\hline CHEMBL1803066 & 755719 & 5.0 & 4.9674 & TRN & \\
\hline CHEMBL1802583 & 755719 & 6.7447 & 6.9871 & TRN & \\
\hline CHEMBL1802496 & 755719 & 5.0 & 5.0901 & TRN & \\
\hline CHEMBL1802566 & 755719 & 6.8239 & 6.7255 & TRN & \\
\hline CHEMBL1803000 & 755719 & 7.5229 & 7.4185 & TRN & \\
\hline CHEMBL1802995 & 755719 & 6.7212 & 6.8034 & TST & \\
\hline CHEMBL1802497 & 755719 & 5.0 & 5.0218 & TRN & \\
\hline CHEMBL1802501 & 755719 & 7.8239 & 7.8296 & TRN & \\
\hline CHEMBL1802570 & 755719 & 7.1549 & 7.1065 & TST & \\
\hline CHEMBL1803001 & 755719 & 6.9586 & 6.80399 & 9999999999 & TRN \\
\hline CHEMBL1802563 & 755719 & 5.0 & 4.9888 & TST & \\
\hline CHEMBL1802504 & 755719 & 7.0 & 6.8864 & TRN & \\
\hline CHEMBL1802494 & 755719 & 6.3098 & 6.6816 & TST & \\
\hline CHEMBL1802573 & 755719 & 5.0 & 4.8064 & TST & \\
\hline CHEMBL1802560 & 755719 & 7.3565 & 7.2886 & TST & \\
\hline CHEMBL1803065 & 755719 & 5.0 & 5.1352 & TST & \\
\hline CHEMBL1802574 & 755719 & 7.4815 & 7.4347 & TST & \\
\hline CHEMBL1803064 & 755719 & 5.0 & 4.9816 & TST & \\
\hline CHEMBL1802568 & 755719 & 5.0 & 5.3577 & TST & \\
\hline CHEMBL1802580 & 755719 & 5.0 & 5.037 & TST & \\
\hline CHEMBL1802999 & 755719 & 7.3768 & 7.3397 & TST & \\
\hline CHEMBL1803062 & 755719 & 5.0 & 5.2101 & TST & \\
\hline CHEMBL1802511 & 755719 & 8.0 & 8.0562 & TST & \\
\hline CHEMBL1915645 & 788035 & 8.301 & 8.5892 & TRN & \\
\hline CHEMBL1915435 & 788035 & 7.0362 & 7.0678 & TRN & \\
\hline CHEMBL1915439 & 788035 & 7.8239 & 7.5759 & TST & \\
\hline CHEMBL1915425 & 788035 & 6.8013 & 6.7528 & TRN & \\
\hline CHEMBL1915636 & 788035 & 9.0 & 9.026 & TRN & \\
\hline CHEMBL1915432 & 788035 & 6.7595 & 7.7323 & TST & \\
\hline CHEMBL1915423 & 788035 & 4.6021 & 4.6086 & TRN & \\
\hline CHEMBL1915649 & 788035 & 8.0 & 7.9951 & TRN & \\
\hline CHEMBL1915448 & 788035 & 8.1549 & 8.0896 & TRN & \\
\hline CHEMBL1915446 & 788035 & 7.3565 & 7.4027 & TRN & \\
\hline CHEMBL1915427 & 788035 & 6.9318 & 7.0062 & TST & \\
\hline CHEMBL1915424 & 788035 & 7.1308 & 7.0788 & TRN & \\
\hline CHEMBL1915444 & 788035 & 7.5086 & 7.4349 & TRN & \\
\hline CHEMBL1915638 & 788035 & 8.2218 & 8.2305 & TRN & \\
\hline CHEMBL1915650 & 788035 & 8.3979 & 8.2566 & TRN & \\
\hline CHEMBL1915637 & 788035 & 7.9208 & 8.0139 & TRN & \\
\hline CHEMBL1915639 & 788035 & 8.0 & 7.9853 & TRN & \\
\hline CHEMBL1915441 & 788035 & 7.7959 & 7.8584 & TRN & \\
\hline CHEMBL1915643 & 788035 & 8.0969 & 8.0513 & TRN & \\
\hline CHEMBL1915426 & 788035 & 7.7447 & 7.8681 & TRN & \\
\hline CHEMBL1649765 & 788035 & 7.0269 & 7.1193 & TRN & \\
\hline CHEMBL1915419 & 788035 & 4.6021 & 5.7926 & TST & \\
\hline CHEMBL1915642 & 788035 & 7.699 & 7.7676 & TRN & \\
\hline CHEMBL1915449 & 788035 & 7.9208 & 7.9949 & TRN & \\
\hline CHEMBL1649586 & 788035 & 6.5317 & 6.4226 & TST & \\
\hline
\end{tabular}




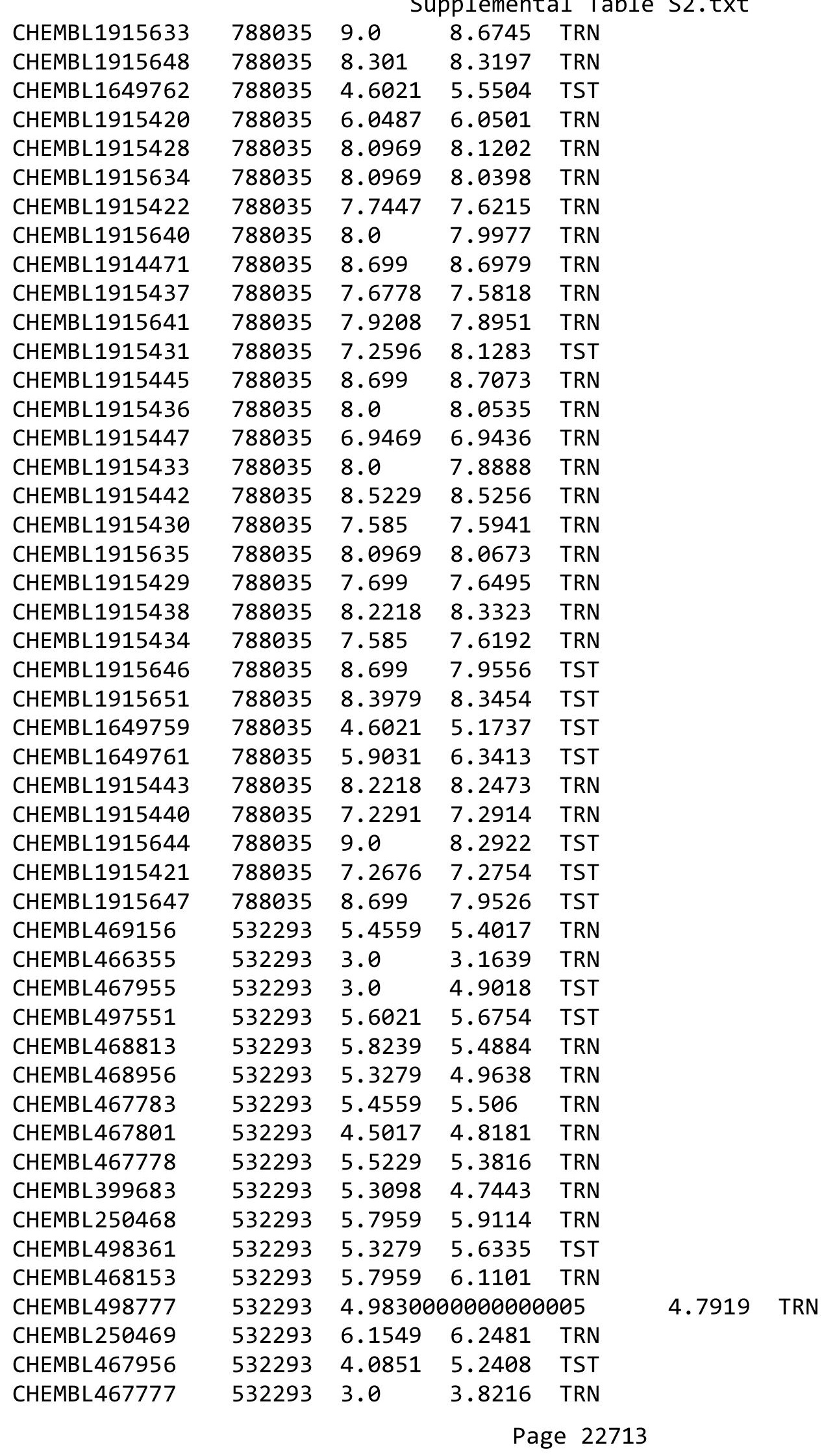




\begin{tabular}{|c|c|c|c|c|c|}
\hline \multicolumn{6}{|c|}{ Supplemental Table S2.txt } \\
\hline CHEMBL468148 & 532293 & 5.8239 & 5.4855 & TRN & \\
\hline CHEMBL452104 & 532293 & 3.0 & 3.9362 & TST & \\
\hline CHEMBL513179 & 532293 & 5.1487 & 5.0979 & TRN & \\
\hline CHEMBL506055 & 532293 & 5.6778 & 5.3488 & TRN & \\
\hline CHEMBL513337 & 532293 & 5.3872 & 5.6161 & TRN & \\
\hline CHEMBL444762 & 532293 & 5.4685 & 5.5381 & TRN & \\
\hline CHEMBL467785 & 532293 & 5.4815 & 5.4477 & TRN & \\
\hline CHEMBL467784 & 532293 & 5.7959 & 5.8657 & TRN & \\
\hline CHEMBL468814 & 532293 & 5.0757 & 5.1649 & TRN & \\
\hline CHEMBL468147 & 532293 & 6.301 & 6.3906 & TRN & \\
\hline CHEMBL 250467 & 532293 & 5.3098 & 5.4124 & TRN & \\
\hline CHEMBL513825 & 532293 & 5.4685 & 5.50899 & 99999999995 & TRN \\
\hline CHEMBL513844 & 532293 & 5.7212 & 5.37700 & 0000000001 & TST \\
\hline CHEMBL468152 & 532293 & 6.0458 & 5.8127 & TRN & \\
\hline CHEMBL468770 & 532293 & 4.1656 & 4.1768 & TRN & \\
\hline CHEMBL468957 & 532293 & 6.1549 & 5.5309 & TST & \\
\hline CHEMBL430020 & 532293 & 5.6576 & 5.8077 & TRN & \\
\hline CHEMBL498776 & 532293 & 5.2366 & 5.4774 & TRN & \\
\hline CHEMBL468996 & 532293 & 5.5376 & 5.7395 & TST & \\
\hline CHEMBL 249829 & 532293 & 5.4437 & 5.5641 & TRN & \\
\hline CHEMBL467764 & 532293 & 3.0 & 4.9668 & TST & \\
\hline CHEMBL401138 & 532293 & 6.0 & 5.7987 & TRN & \\
\hline CHEMBL525561 & 532293 & 5.5086 & 5.4991 & TRN & \\
\hline CHEMBL512115 & 532293 & 4.8996 & 4.7596 & TST & \\
\hline CHEMBL498997 & 532293 & 5.699 & 6.0338 & TST & \\
\hline CHEMBL451176 & 532293 & 4.6757 & 4.9551 & TRN & \\
\hline CHEMBL467950 & 532293 & 6.0458 & 6.1627 & TRN & \\
\hline CHEMBL 250654 & 532293 & 5.4559 & 5.853 & TRN & \\
\hline CHEMBL468023 & 532293 & 5.7959 & 5.5792 & TRN & \\
\hline CHEMBL399844 & 532293 & 4.6308 & 4.1995 & TRN & \\
\hline CHEMBL467800 & 532293 & 5.699 & 5.2915 & TRN & \\
\hline CHEMBL495682 & 532293 & 5.3279 & 5.9023 & TST & \\
\hline CHEMBL249828 & 532293 & 5.4202 & 5.5377 & TRN & \\
\hline CHEMBL468771 & 532293 & 4.4157 & 4.3201 & TRN & \\
\hline CHEMBL447195 & 532293 & 5.2218 & 4.9023 & TST & \\
\hline CHEMBL 3675574 & 1535845 & 7.0132 & 6.231 & TRN & \\
\hline CHEMBL 3675597 & 1535845 & 6.2823 & 5.399 & TRN & \\
\hline CHEMBL 3675583 & 1535845 & 5.0 & 5.1565 & TRN & \\
\hline CHEMBL 3670710 & 1535845 & 6.2596 & 5.9758 & TST & \\
\hline CHEMBL 3675556 & 1535845 & 4.0 & 5.1829 & TRN & \\
\hline CHEMBL3670703 & 1535845 & 7.5229 & 7.4138 & TRN & \\
\hline CHEMBL1232489 & 1535845 & 5.0 & 6.1252 & TRN & \\
\hline CHEMBL3675566 & 1535845 & 7.6383 & 6.6279 & TRN & \\
\hline CHEMBL 3675571 & 1535845 & 7.0915 & 6.2268 & TRN & \\
\hline CHEMBL 3675582 & 1535845 & 6.0964 & 5.1292 & TRN & \\
\hline CHEMBL 3675547 & 1535845 & 5.0 & 6.231 & TRN & \\
\hline CHEMBL 3675549 & 1535845 & 5.0 & 6.3973 & TRN & \\
\hline CHEMBL 3675579 & 1535845 & 6.4353 & 7.175 & TRN & \\
\hline
\end{tabular}


Supplemental Table S2.txt

\begin{tabular}{|c|c|c|c|c|c|}
\hline CHEMBL 3675604 & 1535845 & 5.0 & 5.3155 & TST & \\
\hline CHEMBL3675603 & 1535845 & 6.8794 & 6.5073 & TST & \\
\hline CHEMBL3675602 & 1535845 & 5.0 & 5.4191 & TRN & \\
\hline CHEMBL 3675590 & 1535845 & 5.0 & 4.662 & TST & \\
\hline CHEMBL 3675548 & 1535845 & 5.0 & 6.351 & TRN & \\
\hline CHEMBL3675594 & 1535845 & 7.4815 & 6.605 & TRN & \\
\hline CHEMBL3675543 & 1535845 & 6.8729 & 7.1746 & TRN & \\
\hline CHEMBL 3670707 & 1535845 & 6.3605 & 6.2383 & TRN & \\
\hline CHEMBL 3675577 & 1535845 & 6.3696 & 7.1739 & TRN & \\
\hline CHEMBL3675544 & 1535845 & 6.1618 & 5.9885 & TRN & \\
\hline CHEMBL3675589 & 1535845 & 5.0 & 5.0513 & TRN & \\
\hline CHEMBL3670708 & 1535845 & 7.0969 & 7.1795 & TRN & \\
\hline CHEMBL3670705 & 1535845 & 6.6308 & 7.0235 & TRN & \\
\hline CHEMBL 3675573 & 1535845 & 7.9914 & 6.5557 & TST & \\
\hline CHEMBL3675601 & 1535845 & 6.2495 & 5.5976 & TRN & \\
\hline CHEMBL3670704 & 1535845 & 7.6198 & 7.2925 & TRN & \\
\hline CHEMBL 3675560 & 1535845 & 5.0 & 5.5996 & TRN & \\
\hline CHEMBL 3675562 & 1535845 & 4.301 & 5.184 & TRN & \\
\hline CHEMBL 3675607 & 1535845 & 6.2197 & 5.9187 & TRN & \\
\hline CHEMBL 3670719 & 1535845 & 5.0 & 5.8743 & TST & \\
\hline CHEMBL3670706 & 1535845 & 7.3098 & 7.0235 & TRN & \\
\hline CHEMBL3639744 & 1535845 & 5.0 & 6.6279 & TRN & \\
\hline CHEMBL 3670718 & 1535845 & 6.2857 & 5.3894 & TST & \\
\hline CHEMBL3675588 & 1535845 & 5.0 & 5.1319 & TRN & \\
\hline CHEMBL3675591 & 1535845 & 6.4365 & 5.5939 & TST & \\
\hline CHEMBL 3675565 & 1535845 & 7.2596 & 6.231 & TRN & \\
\hline CHEMBL 3675569 & 1535845 & 7.4437 & 6.2122 & TRN & \\
\hline CHEMBL3675551 & 1535845 & 5.0 & 6.6175 & TRN & \\
\hline CHEMBL3670699 & 1535845 & 7.041 & 6.8449 & TRN & \\
\hline CHEMBL 3675575 & 1535845 & 7.8697 & 7.4642 & TRN & \\
\hline CHEMBL 3670698 & 1535845 & 7.284 & 7.044 & TST & \\
\hline CHEMBL 3675587 & 1535845 & 5.0 & 5.0113 & TRN & \\
\hline CHEMBL 3670714 & 1535845 & 6.9318 & 5.7478 & TRN & \\
\hline CHEMBL3670715 & 1535845 & 6.2233 & 6.2826 & TRN & \\
\hline CHEMBL 3675546 & 1535845 & 6.5867 & 6.2222 & TRN & \\
\hline CHEMBL3675586 & 1535845 & 5.0 & 5.1795 & TRN & \\
\hline CHEMBL3675559 & 1535845 & 4.301 & 5.1756 & TRN & \\
\hline CHEMBL 3670721 & 1535845 & 5.0 & 5.7726 & TRN & \\
\hline CHEMBL3670712 & 1535845 & 6.0458 & 6.2003 & TST & \\
\hline CHEMBL 3675545 & 1535845 & 6.0535 & 6.04299 & 9999999999 & TRN \\
\hline CHEMBL3670696 & 1535845 & 7.4559 & 6.938 & TST & \\
\hline CHEMBL3675585 & 1535845 & 6.2336 & 5.2767 & TRN & \\
\hline CHEMBL3675557 & 1535845 & 6.3605 & 6.1332 & TRN & \\
\hline CHEMBL3670700 & 1535845 & 5.0 & 6.1207 & TST & \\
\hline CHEMBL 3675580 & 1535845 & 6.3536 & 6.8712 & TRN & \\
\hline CHEMBL3670709 & 1535845 & 4.301 & 6.2006 & TST & \\
\hline CHEMBL3670701 & 1535845 & 7.2218 & 7.5514 & TST & \\
\hline CHEMBL3675541 & 1535845 & 6.6198 & 5.6249 & TRN & \\
\hline
\end{tabular}

Page 22715 
Supplemental Table S2.txt

\begin{tabular}{|c|c|c|c|c|c|c|}
\hline CHEMBL 3670716 & 1535845 & 5.0 & 5.4556 & TST & & \\
\hline CHEMBL 3675600 & 1535845 & 6.1972 & 5.4518 & TRN & & \\
\hline CHEMBL3639695 & 1535845 & 7.7447 & 7.1876 & TST & & \\
\hline CHEMBL 3670720 & 1535845 & 6.6737 & 6.5733 & TRN & & \\
\hline CHEMBL 3675550 & 1535845 & 5.0 & 6.2122 & TRN & & \\
\hline CHEMBL 3675568 & 1535845 & 7.7852 & 6.3973 & TRN & & \\
\hline CHEMBL 3675570 & 1535845 & 7.7799 & 6.6175 & TRN & & \\
\hline CHEMBL3670695 & 1535845 & 7.5229 & 7.0108 & TST & & \\
\hline CHEMBL3670691 & 1535845 & 7.3372 & 7.0144 & TST & & \\
\hline CHEMBL3675599 & 1535845 & 6.0301 & 5.6338 & TRN & & \\
\hline CHEMBL 3675572 & 1535845 & 7.7696 & 6.254 & TST & & \\
\hline CHEMBL 3675584 & 1535845 & 5.0 & 5.1112 & TRN & & \\
\hline CHEMBL3670697 & 1535845 & 6.71899 & 79999999 & 99 & 6.8064 & TST \\
\hline CHEMBL3675555 & 1535845 & 5.0 & 5.5722 & TRN & & \\
\hline CHEMBL 3675552 & 1535845 & 5.0 & 6.2268 & TRN & & \\
\hline CHEMBL 3670702 & 1535845 & 7.4437 & 7.1951 & TST & & \\
\hline CHEMBL3675553 & 1535845 & 5.0 & 6.254 & TST & & \\
\hline CHEMBL 3675564 & 1535845 & 7.699 & 6.9339 & TRN & & \\
\hline CHEMBL 3675592 & 1535845 & 6.2487 & 5.9061 & TRN & & \\
\hline CHEMBL 3675558 & 1535845 & 4.301 & 5.1786 & TRN & & \\
\hline CHEMBL 3675593 & 1535845 & 6.699 & 6.9029 & TRN & & \\
\hline CHEMBL 3675595 & 1535845 & 5.0 & 5.6382 & TRN & & \\
\hline CHEMBL 3675605 & 1535845 & 6.7033 & 6.4284 & TRN & & \\
\hline CHEMBL 3675581 & 1535845 & 6.4935 & 5.3989 & TRN & & \\
\hline CHEMBL 3675596 & 1535845 & 5.0 & 5.399 & TRN & & \\
\hline CHEMBL 3675578 & 1535845 & 6.4237 & 6.1875 & TRN & & \\
\hline CHEMBL 3675576 & 1535845 & 6.6345 & 6.9676 & TRN & & \\
\hline CHEMBL 3670717 & 1535845 & 6.1931 & 5.8056 & TRN & & \\
\hline CHEMBL3670711 & 1535845 & 5.0 & 5.9629 & TST & & \\
\hline CHEMBL 3675561 & 1535845 & 4.301 & 5.1346 & TRN & & \\
\hline CHEMBL 3675567 & 1535845 & 7.4815 & 6.351 & TRN & & \\
\hline CHEMBL 3675554 & 1535845 & 5.0 & 6.5557 & TST & & \\
\hline CHEMBL 3670713 & 1535845 & 6.51 & 5.813 & TRN & & \\
\hline CHEMBL 3675598 & 1535845 & 6.2526 & 5.9187 & TRN & & \\
\hline CHEMBL 3675542 & 1535845 & 6.2741 & 6.3664 & TRN & & \\
\hline CHEMBL2181933 & 1528056 & 8.1487 & 8.1535 & TRN & & \\
\hline CHEMBL3643694 & 1528056 & 6.0706 & 6.968 & TST & & \\
\hline CHEMBL 3643674 & 1528056 & 7.9586 & 7.9675 & TRN & & \\
\hline CHEMBL3643696 & 1528056 & 6.9586 & 7.6317 & TST & & \\
\hline CHEMBL 3643670 & 1528056 & 6.3188 & 6.3216 & TRN & & \\
\hline CHEMBL 3643698 & 1528056 & 6.8539 & 7.0873 & TST & & \\
\hline CHEMBL3643650 & 1528056 & 5.9586 & 5.9569 & TRN & & \\
\hline CHEMBL3643672 & 1528056 & 4.0 & 3.9984 & TRN & & \\
\hline CHEMBL3643669 & 1528056 & 7.0655 & 7.0756 & TRN & & \\
\hline CHEMBL 3643646 & 1528056 & 6.8861 & 6.888 & TRN & & \\
\hline CHEMBL 3643680 & 1528056 & 7.2676 & 7.2665 & TRN & & \\
\hline CHEMBL3643671 & 1528056 & 5.1487 & 5.1484 & TRN & & \\
\hline CHEMBL3643662 & 1528056 & 7.6021 & 7.598 & TRN & & \\
\hline
\end{tabular}

Page 22716 
Supplemental Table S2.txt

\begin{tabular}{|c|c|c|c|c|}
\hline . & & 212 & 6.7189 & \\
\hline HEMBL3643652 & & 6.1024 & 6.1036 & \\
\hline 57 & 28956 & & & \\
\hline HEMBL & 28056 & $\partial 269$ & 0299 & \\
\hline AEMBL3 & 528056 & 147 & 2167 & \\
\hline HEMBL3643699 & 528056 & 6.5686 & 2392 & \\
\hline HEMBL & 28056 & 202 & 4214 & \\
\hline 84 & 20056 & 7.6021 & & \\
\hline AEMBL36 & 528056 & 7.0 & 0076 & \\
\hline HEMBL 364 & 528056 & 6.1739 & 1772 & \\
\hline AEMBL364 & 528056 & 6.7959 & 7939 & \\
\hline IEMBL3 & 28056 & 959 & 949 & \\
\hline AEMBL & & & & RN \\
\hline HEMBL36 & 528056 & 5.1675 & .1673 & \\
\hline AEMBL36 & 528056 & 67 & 19 & \\
\hline AEMBL36 & $8<8656$ & 92 & 65 & \\
\hline AEMBL3 & 0 & & 955 & \\
\hline HEMBL3 & & & 44 & \\
\hline AEMBL 3 & 528056 & & 3775 & \\
\hline IEMBL36 & & & & \\
\hline AEMBL & 56 & 15 & 349 & KIV \\
\hline AEMBL: & 6 & 79 & 089 & (1) \\
\hline HEMBL; & 6 & 61 & 3852 & \\
\hline 566 & & & & \\
\hline AEMBL36 & & & & I RIV \\
\hline HEMBL & 8056 & 99 & 223 & RN \\
\hline AEMBL & 0 & 29 & 98 & Niv \\
\hline AFMRI : & 56 & & 702 & \\
\hline AEMBL3 & & & 518 & IS \\
\hline HEMBL36 & 56 & & & IK \\
\hline HEMBL3 & 8056 & 861 & 656 & SI \\
\hline HEMBL & 0 & 9 & 984 & ST \\
\hline AEMBL & 56 & 4 . & 232 & IST \\
\hline HEMBL36 & & 7.3279 & 132 & ISI \\
\hline HEMBL 364 & 528056 & 5.7447 & 7432 & TRN \\
\hline HEMBL3 & 8056 & 7 & 033 & TRN \\
\hline HFMRI & & 7 & 3859 & $\Gamma \mathrm{RN}$ \\
\hline HEMBL; & & 7. & 109 & ГST \\
\hline HEMBL36 & 528056 & 5.7696 & 7698 & TRN \\
\hline AEMBL3 & 528056 & & 1917 & TST \\
\hline HEMBL36 & 8056 & 18 & 277 & TRN \\
\hline CHEMBL 36 & & & 2711 & ГST \\
\hline HEMBL36 & 528056 & 6.5528 & 6721 & TST \\
\hline HEMBL 36 & 528056 & 7.6576 & 5494 & $\Gamma R$ \\
\hline MBL1 & & & 394 & 1 \\
\hline HEMBL13 & & & 5718 & \\
\hline HEMBL 56 & 88448 & 7.0 & .0723 & RN \\
\hline CHEMBL568166 & 688448 & 5.05 & 4.9513 & $\Gamma \mathrm{RN}$ \\
\hline
\end{tabular}

Page 22717 


\begin{tabular}{|c|c|c|c|c|}
\hline \multicolumn{5}{|c|}{ pplement } \\
\hline CHEMBL1314875 & 688448 & 5.1 & 5.1277 & TRN \\
\hline CHEMBL1408593 & 688448 & 4.6 & 4.55399 & 9999999999 \\
\hline CHEMBL566283 & 688448 & 6.15 & 6.1486 & TRN \\
\hline CHEMBL566495 & 688448 & 5.75 & 5.8037 & TRN \\
\hline CHEMBL565654 & 688448 & 5.95 & 5.9356 & TRN \\
\hline CHEMBL1473959 & 688448 & 5.0 & 5.0257 & TRN \\
\hline CHEMBL1557298 & 688448 & 5.65 & 5.6395 & TRN \\
\hline CHEMBL568169 & 688448 & 6.05 & 6.0087 & TRN \\
\hline CHEMBL566899 & 688448 & 5.35 & 5.5635 & TRN \\
\hline CHEMBL568636 & 688448 & 6.25 & 6.1992 & TRN \\
\hline CHEMBL1405981 & 688448 & 5.15 & 5.0684 & TRN \\
\hline CHEMBL1410859 & 688448 & 6.6 & 6.5208 & TST \\
\hline CHEMBL1435151 & 688448 & 4.95 & 5.0069 & TRN \\
\hline CHEMBL1592581 & 688448 & 5.05 & 5.0776 & TRN \\
\hline CHEMBL1494159 & 688448 & 6.05 & 5.8863 & TRN \\
\hline CHEMBL566501 & 688448 & 5.9 & 5.921 & TRN \\
\hline CHEMBL1399528 & 688448 & 6.35 & 5.8603 & TST \\
\hline CHEMBL1418485 & 688448 & 4.9 & 4.9582 & TRN \\
\hline CHEMBL1326793 & 688448 & 4.45 & 4.5946 & TRN \\
\hline CHEMBL1529880 & 688448 & 6.6 & 6.144 & TST \\
\hline CHEMBL566061 & 688448 & 6.8 & 7.0129 & TRN \\
\hline CHEMBL1408602 & 688448 & 5.0 & 5.1108 & TRN \\
\hline CHEMBL568614 & 688448 & 6.15 & 6.1359 & TRN \\
\hline CHEMBL1408427 & 688448 & 6.0 & 6.05 & TRN \\
\hline CHEMBL1316791 & 688448 & 5.2 & 5.129 & TRN \\
\hline CHEMBL1408995 & 688448 & 4.95 & 5.0396 & TRN \\
\hline CHEMBL1473748 & 688448 & 5.15 & 4.9276 & TRN \\
\hline CHEMBL1516785 & 688448 & 5.1 & 4.8862 & TRN \\
\hline CHEMBL1374544 & 688448 & 7.3002 & 6.8804 & TST \\
\hline CHEMBL1444364 & 688448 & 4.75 & 4.8874 & TRN \\
\hline CHEMBL1394132 & 688448 & 4.55 & 4.6039 & TST \\
\hline CHEMBL566701 & 688448 & 7.0501 & 6.9777 & TRN \\
\hline CHEMBL1446506 & 688448 & 5.65 & 5.6269 & TRN \\
\hline CHEMBL1330317 & 688448 & 4.8 & 4.9435 & TST \\
\hline CHEMBL566062 & 688448 & 4.55 & 4.744 & TST \\
\hline CHEMBL1370296 & 688448 & 6.5501 & 6.32 & TRN \\
\hline CHEMBL1609579 & 688448 & 5.15 & 5.1205 & TRN \\
\hline CHEMBL566687 & 688448 & 6.8 & 6.6458 & TRN \\
\hline CHEMBL1332463 & 688448 & 5.3 & 5.178 & TRN \\
\hline CHEMBL1397881 & 688448 & 4.4 & 4.5617 & TRN \\
\hline CHEMBL1434389 & 688448 & 5.45 & 5.6855 & TRN \\
\hline CHEMBL1332033 & 688448 & 6.5 & 6.3313 & TST \\
\hline CHEMBL567331 & 688448 & 7.3497 & 7.3958 & TRN \\
\hline CHEMBL1610597 & 688448 & 6.25 & 6.2785 & TRN \\
\hline CHEMBL1516009 & 688448 & 5.8 & 5.3511 & TST \\
\hline CHEMBL1480806 & 688448 & 4.9 & 4.902 & TRN \\
\hline CHEMBL1372954 & 688448 & 4.95 & 5.0293 & TRN \\
\hline CHEMBL1315609 & 688448 & 5.4 & 5.2249 & TST \\
\hline
\end{tabular}




\begin{tabular}{|c|c|c|c|c|c|}
\hline \multicolumn{6}{|c|}{ Supplemental Table S2.txt } \\
\hline CHEMBL1526962 & 688448 & 5.05 & 5.0766 & TRN & \\
\hline CHEMBL1355644 & 688448 & 4.9 & 4.9681 & TRN & \\
\hline CHEMBL1475370 & 688448 & 4.55 & 4.9169 & TST & \\
\hline CHEMBL1355974 & 688448 & 5.5 & 5.2837 & TST & \\
\hline CHEMBL1433941 & 688448 & 4.8 & 5.0212 & TST & \\
\hline CHEMBL566722 & 688448 & 7.0501 & 7.0347 & TRN & \\
\hline CHEMBL1489767 & 688448 & 5.35 & 5.1572 & TRN & \\
\hline CHEMBL1592698 & 688448 & 4.85 & 4.6842 & TRN & \\
\hline CHEMBL594454 & 605405 & 8.2218 & 8.0288 & TST & \\
\hline CHEMBL595843 & 605405 & 7.0555 & 7.0689 & TRN & \\
\hline CHEMBL609304 & 605405 & 6.8928 & 6.9296 & TRN & \\
\hline CHEMBL593749 & 605405 & 5.7632 & 5.7882 & TRN & \\
\hline CHEMBL594136 & 605405 & 8.6021 & 8.7644 & TST & \\
\hline CHEMBL611964 & 605405 & 6.5969 & 6.6627 & TRN & \\
\hline CHEMBL611954 & 605405 & 7.7696 & 7.8219 & TRN & \\
\hline CHEMBL595146 & 605405 & 7.0132 & 7.0194 & TRN & \\
\hline CHEMBL596088 & 605405 & 7.4437 & 7.5416 & TRN & \\
\hline CHEMBL608093 & 605405 & 6.5935 & 6.5738 & TRN & \\
\hline CHEMBL596308 & 605405 & 8.699 & 8.8155 & TST & \\
\hline CHEMBL596307 & 605405 & 7.9208 & 7.1639 & TST & \\
\hline CHEMBL593975 & 605405 & 8.0458 & 8.0935 & TRN & \\
\hline CHEMBL611337 & 605405 & 7.5528 & 7.5609 & TRN & \\
\hline CHEMBL594677 & 605405 & 7.0362 & 7.0097 & TRN & \\
\hline CHEMBL607550 & 605405 & 7.2441 & 7.3115 & TRN & \\
\hline CHEMBL594197 & 605405 & 6.8097 & 7.1822 & TST & \\
\hline CHEMBL610456 & 605405 & 5.4828 & 5.4842 & TRN & \\
\hline CHEMBL607542 & 605405 & 7.2007 & 7.2161 & TRN & \\
\hline CHEMBL609578 & 605405 & 8.6021 & 8.5851 & TRN & \\
\hline CHEMBL595131 & 605405 & 7.5528 & 7.4934 & TRN & \\
\hline CHEMBL594000 & 605405 & 8.1249 & 8.1351 & TRN & \\
\hline CHEMBL596291 & 605405 & 6.8153 & 6.7513 & TRN & \\
\hline CHEMBL595863 & 605405 & 6.8097 & 6.8846 & TRN & \\
\hline CHEMBL593973 & 605405 & 7.8539 & 7.9136 & TRN & \\
\hline CHEMBL596075 & 605405 & 7.5376 & 7.5534 & TRN & \\
\hline CHEMBL549885 & 605405 & 8.3665 & 8.3636 & TRN & \\
\hline CHEMBL594363 & 605405 & 9.0 & 8.6129 & TST & \\
\hline CHEMBL595174 & 605405 & 7.3279 & 7.21700 & 00000000005 & TRN \\
\hline CHEMBL595147 & 605405 & 5.9519 & 5.9328 & TRN & \\
\hline CHEMBL595844 & 605405 & 6.3768 & 7.096 & TST & \\
\hline CHEMBL609603 & 605405 & 8.3098 & 7.7032 & TST & \\
\hline CHEMBL611955 & 605405 & 6.7375 & 7.2866 & TST & \\
\hline CHEMBL594906 & 605405 & 7.6198 & 7.6058 & TRN & \\
\hline CHEMBL594226 & 605405 & 7.7959 & 7.7224 & TRN & \\
\hline CHEMBL594907 & 605405 & 7.6383 & 7.6948 & TRN & \\
\hline CHEMBL608102 & 605405 & 8.5229 & 8.5195 & TRN & \\
\hline CHEMBL593058 & 605405 & 7.5086 & 7.5314 & TRN & \\
\hline CHEMBL594676 & 605405 & 8.5528 & 8.5055 & TRN & \\
\hline CHEMBL596074 & 605405 & 6.9101 & 6.8847 & TRN & \\
\hline
\end{tabular}

Page 22719 


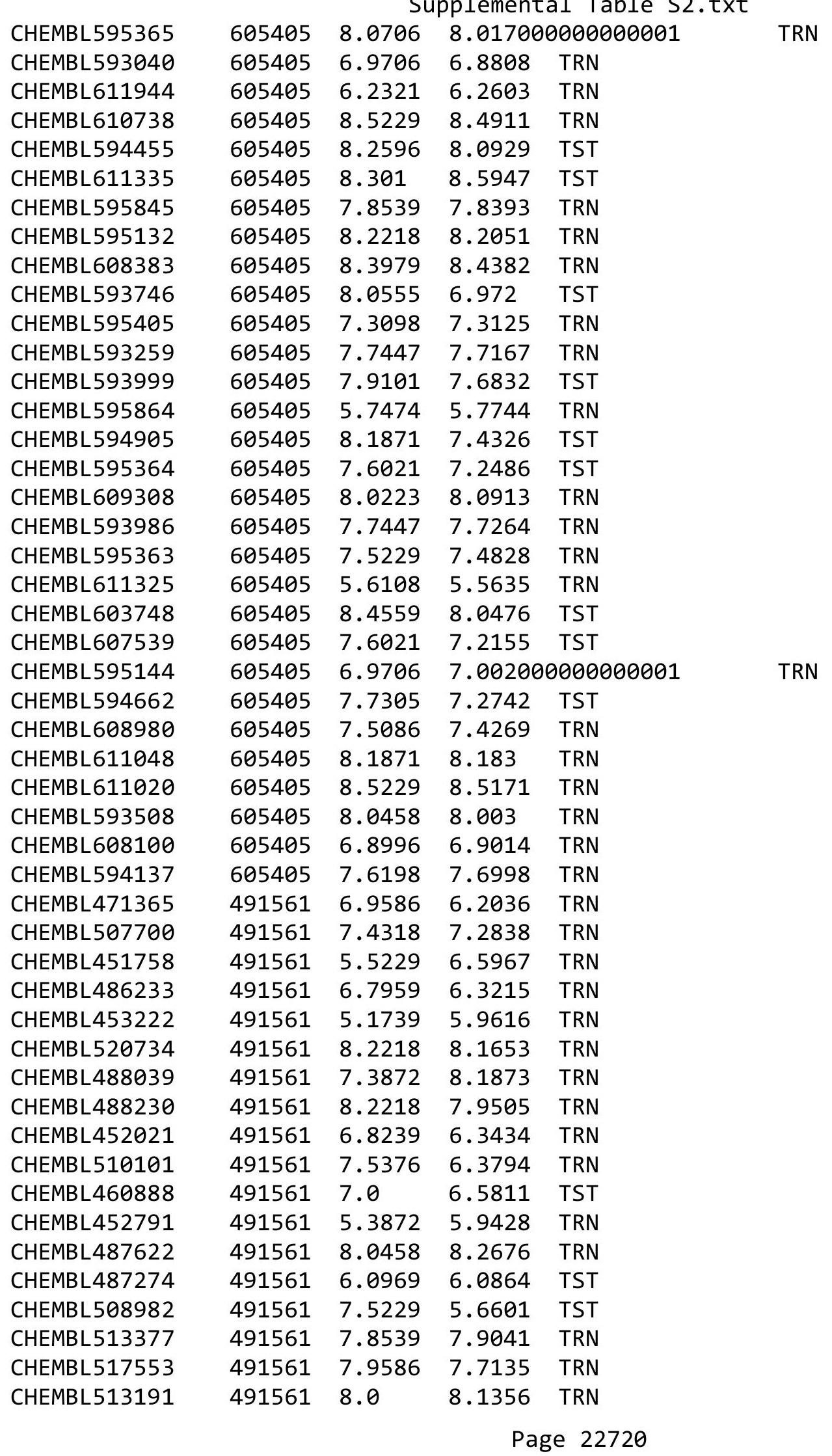


Supplemental Table S2.txt

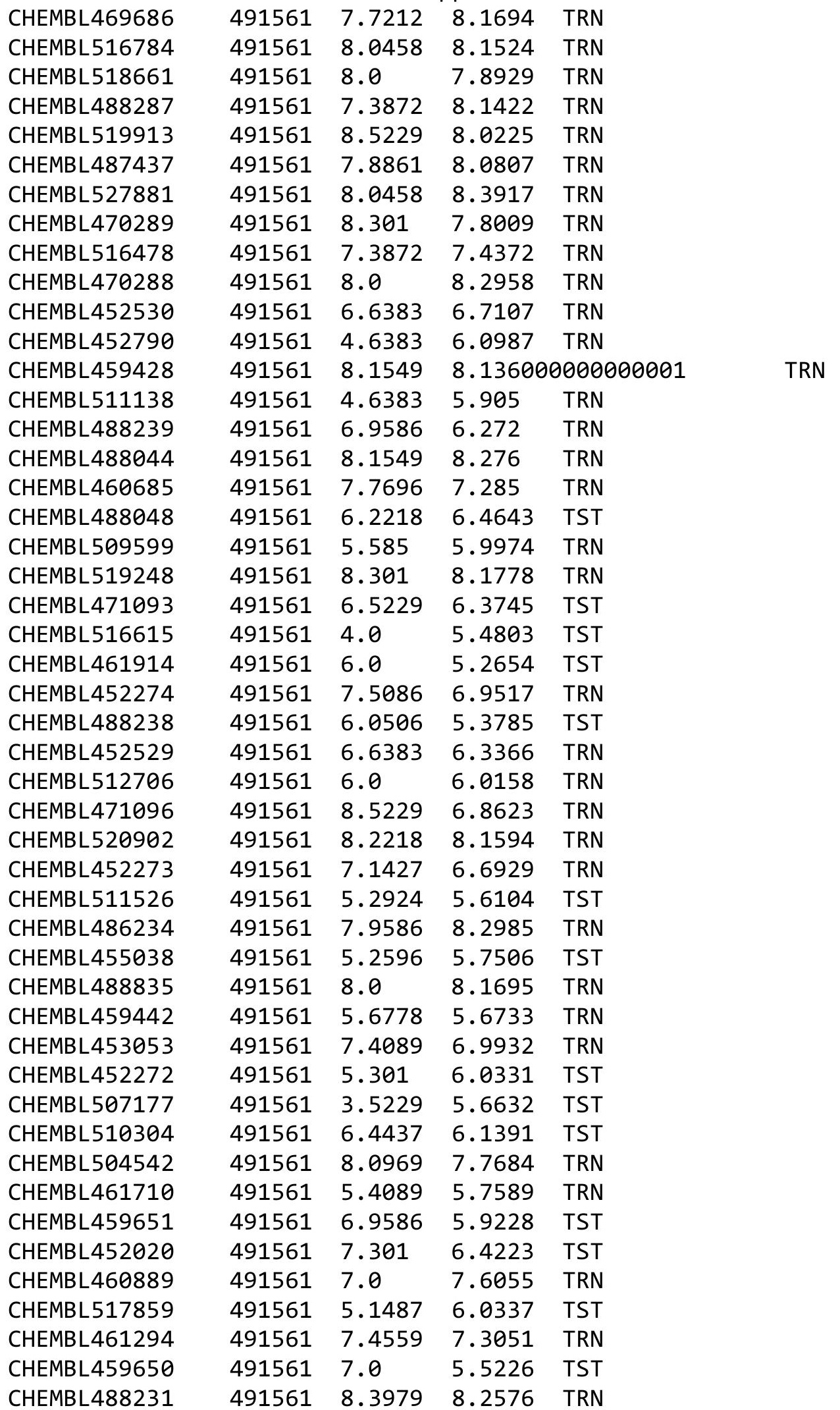

Page 22721 
Supplemental Table S2.txt

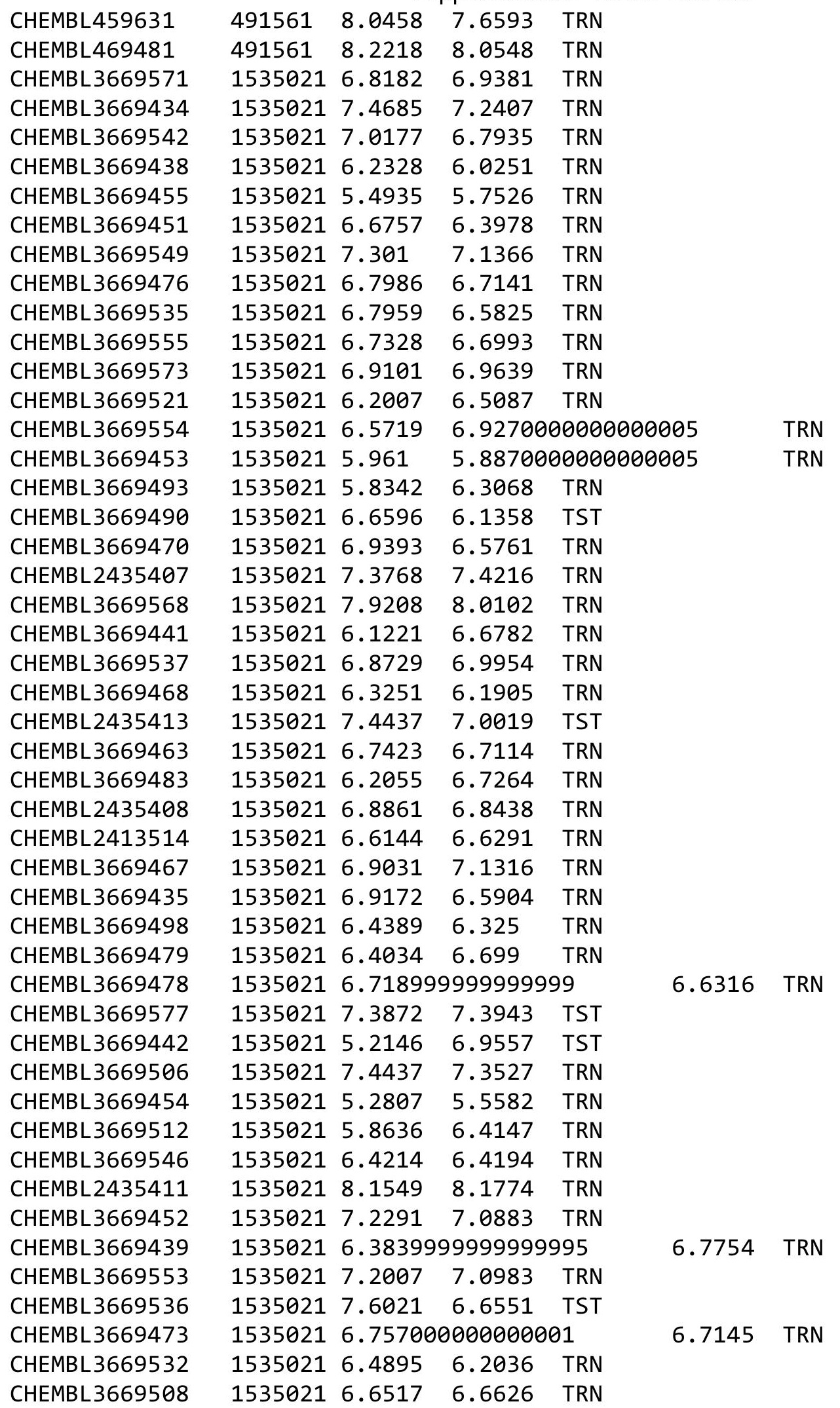


Supplemental Table S2.txt

\begin{tabular}{|c|c|c|c|c|c|}
\hline CHEMBL 3669481 & 1535021 & 6.0443 & 6.1133 & TRN & \\
\hline CHEMBL 3669457 & 1535021 & 6.7721 & 6.5871 & TRN & \\
\hline CHEMBL 3669560 & 1535021 & 6.857 & 7.1234 & TST & \\
\hline CHEMBL 3669519 & 1535021 & 6.2526 & 6.1722 & TST & \\
\hline CHEMBL 3669440 & 1535021 & 6.3575 & 5.9117 & TRN & \\
\hline CHEMBL 2435409 & 1535021 & 7.9208 & 7.7216 & TRN & \\
\hline CHEMBL 3669445 & 1535021 & 6.5406 & 6.397 & TRN & \\
\hline CHEMBL 3669444 & 1535021 & 6.6757 & 6.3526 & TRN & \\
\hline CHEMBL 3669471 & 1535021 & 4.0 & 6.3264 & TST & \\
\hline CHEMBL 3669443 & 1535021 & 7.2076 & 7.0116 & TRN & \\
\hline CHEMBL 3669564 & 1535021 & 6.9547 & 7.268 & TST & \\
\hline CHEMBL 3669557 & 1535021 & 7.0757 & 6.8414 & TST & \\
\hline CHEMBL 2435414 & 1535021 & 6.5229 & 6.3725 & TST & \\
\hline CHEMBL 3669437 & 1535021 & 5.0057 & 5.9452 & TST & \\
\hline CHEMBL 3669469 & 1535021 & 6.8327 & 7.2452 & TST & \\
\hline CHEMBL 3669497 & 1535021 & 6.2048 & 6.2934 & TST & \\
\hline CHEMBL 3669578 & 1535021 & 7.4685 & 7.0064 & TST & \\
\hline CHEMBL 2435412 & 1535021 & 6.7077 & 7.7037 & TST & \\
\hline CHEMBL 3669436 & 1535021 & 7.0088 & 6.877006 & 0000000001 & TST \\
\hline CHEMBL 3968842 & 1640190 & 8.5003 & 8.7604 & TRN & \\
\hline CHEMBL550453 & 1640190 & 8.1244 & 8.3097 & TRN & \\
\hline CHEMBL 3958789 & 1640190 & 8.5003 & 8.506 & TRN & \\
\hline CHEMBL196551 & 1640190 & 8.0794 & 7.978 & TRN & \\
\hline CHEMBL 3305961 & 1640190 & 7.6696 & 7.8402 & TRN & \\
\hline CHEMBL 3974641 & 1640190 & 7.5287 & 7.3996 & TST & \\
\hline CHEMBL197624 & 1640190 & 7.4711 & 7.4479 & TRN & \\
\hline CHEMBL 3972799 & 1640190 & 9.1325 & 8.9665 & TRN & \\
\hline CHEMBL 383361 & 1640190 & 9.0357 & 9.0377 & TRN & \\
\hline CHEMBL196492 & 1640190 & 8.308 & 8.0198 & TRN & \\
\hline CHEMBL 3957468 & 1640190 & 7.7645 & 7.8013 & TRN & \\
\hline CHEMBL198654 & 1640190 & 8.2248 & 8.3899 & TRN & \\
\hline CHEMBL 3955803 & 1640190 & 8.7282 & 8.8123 & TRN & \\
\hline CHEMBL196162 & 1640190 & 8.4559 & 7.638 & TRN & \\
\hline CHEMBL 3912108 & 1640190 & 8.8013 & 8.5252 & TRN & \\
\hline CHEMBL 3928201 & 1640190 & 7.6478 & 7.2622 & TST & \\
\hline CHEMBL 3972969 & 1640190 & 8.0565 & 8.346 & TRN & \\
\hline CHEMBL 3907419 & 1640190 & 8.4306 & 8.5863 & TRN & \\
\hline CHEMBL371106 & 1640190 & 7.4535 & 7.6774 & TRN & \\
\hline CHEMBL 370614 & 1640190 & 8.9431 & 8.7529 & TRN & \\
\hline CHEMBL 3979386 & 1640190 & 8.9586 & 9.0068 & TRN & \\
\hline CHEMBL196589 & 1640190 & 7.0526 & 7.1947 & TRN & \\
\hline CHEMBL 364284 & 1640190 & 9.6108 & 9.7095 & TRN & \\
\hline CHEMBL197377 & 1640190 & 9.1319 & 9.0497 & TRN & \\
\hline CHEMBL 93087 & 1640190 & 7.1057 & 7.2182 & TST & \\
\hline CHEMBL 3956658 & 1640190 & 8.0114 & 8.2697 & TRN & \\
\hline CHEMBL 3966335 & 1640190 & 5.9747 & 5.892 & TST & \\
\hline CHEMBL190142 & 1640190 & 8.7986 & 8.5948 & TRN & \\
\hline CHEMBL370176 & 1640190 & 6.76200 & 30000000 & 6.885 & TRN \\
\hline
\end{tabular}


Supplemental Table S2.txt

\begin{tabular}{|c|c|c|c|c|c|}
\hline CHEMBL3961484 & 1640190 & 9.0092 & 8.8476 & TRN & \\
\hline CHEMBL3904655 & 1640190 & 8.5421 & 8.6246 & TRN & \\
\hline CHEMBL194889 & 1640190 & 6.289 & 6.4493 & TRN & \\
\hline CHEMBL196539 & 1640190 & 9.064 & 9.1401 & TRN & \\
\hline CHEMBL3986101 & 1640190 & 8.9706 & 8.9488 & TRN & \\
\hline CHEMBL197547 & 1640190 & 7.3382 & 7.1649 & TRN & \\
\hline CHEMBL3304291 & 1640190 & 8.2503 & 8.4257 & TRN & \\
\hline CHEMBL557915 & 1640190 & 8.684 & 8.7502 & TRN & \\
\hline CHEMBL194810 & 1640190 & 7.7471 & 7.9085 & TRN & \\
\hline CHEMBL1235423 & 1640190 & 7.5591 & 7.2858 & TST & \\
\hline CHEMBL198421 & 1640190 & 6.567 & 6.7057 & TRN & \\
\hline CHEMBL120413 & 1640190 & 7.2716 & 7.0991 & TST & \\
\hline CHEMBL381866 & 1640190 & 8.3449 & 8.2699 & TRN & \\
\hline CHEMBL436293 & 1640190 & 7.058 & 6.8238 & TRN & \\
\hline CHEMBL3959350 & 1640190 & 7.466 & 7.3531 & TRN & \\
\hline CHEMBL196669 & 1640190 & 5.1993 & 5.2691 & TRN & \\
\hline CHEMBL48813 & 1640190 & 8.719 & 8.8871 & TST & \\
\hline CHEMBL3960154 & 1640190 & 9.1319 & 9.1186 & TST & \\
\hline CHEMBL372956 & 1640190 & 8.6737 & 8.4221 & TRN & \\
\hline CHEMBL372568 & 1640190 & 6.3188 & 6.3682 & TST & \\
\hline CHEMBL564248 & 1640190 & 8.8097 & 8.9121 & TST & \\
\hline CHEMBL3910588 & 1640190 & 9.1113 & 9.0323 & TST & \\
\hline CHEMBL194186 & 1640190 & 9.1158 & 9.1903 & TST & \\
\hline CHEMBL316053 & 1640190 & 7.4271 & 7.2983 & TST & \\
\hline CHEMBL3942651 & 1640190 & 5.3686 & 5.5687 & TST & \\
\hline CHEMBL2204817 & 886679 & 7.3768 & 7.1578 & TRN & \\
\hline CHEMBL2204840 & 886679 & 4.6383 & 5.3749 & TRN & \\
\hline CHEMBL 2204805 & 886679 & 6.3872 & 6.8616 & TRN & \\
\hline CHEMBL2204816 & 886679 & 6.4559 & 6.8419 & TRN & \\
\hline CHEMBL2204819 & 886679 & 5.3468 & 5.0271 & TRN & \\
\hline CHEMBL 2204844 & 886679 & 4.3768 & 5.2299 & TST & \\
\hline CHEMBL312218 & 886679 & 4.7212 & 4.6713 & TRN & \\
\hline CHEMBL 2204835 & 886679 & 5.7696 & 4.5922 & TRN & \\
\hline CHEMBL 2204828 & 886679 & 4.7447 & 4.8037 & TRN & \\
\hline CHEMBL2204811 & 886679 & 4.8861 & 5.0293 & TRN & \\
\hline CHEMBL 2204834 & 886679 & 5.0915 & 5.0683 & TRN & \\
\hline CHEMBL2204818 & 886679 & 5.5229 & 4.7667 & TRN & \\
\hline CHEMBL515083 & 886679 & 3.4622 & 4.1882 & TRN & \\
\hline CHEMBL2204822 & 886679 & 5.0 & 4.96399 & 99999999995 & TRN \\
\hline CHEMBL2204083 & 886679 & 6.4202 & 6.8344 & TRN & \\
\hline CHEMBL 2204832 & 886679 & 5.7696 & 4.5398 & TRN & \\
\hline CHEMBL 2204820 & 886679 & 6.0458 & 5.3994 & TRN & \\
\hline CHEMBL2204807 & 886679 & 6.5376 & 5.3168 & TRN & \\
\hline CHEMBL 2204813 & 886679 & 4.8539 & 4.771 & TRN & \\
\hline CHEMBL 2204800 & 886679 & 6.0 & 5.5203 & TRN & \\
\hline CHEMBL 2204846 & 886679 & 5.5528 & 4.8812 & TST & \\
\hline CHEMBL2204815 & 886679 & 7.0315 & 7.1347 & TRN & \\
\hline CHEMBL2204087 & 886679 & 8.0 & 7.0916 & TRN & \\
\hline
\end{tabular}




\begin{tabular}{|c|c|c|c|c|c|}
\hline \multicolumn{6}{|c|}{ Supplemental Table S2.txt } \\
\hline CHEMBL 2204842 & 886679 & 2.8239 & 5.0601 & TST & \\
\hline CHEMBL 2204089 & 886679 & 7.2218 & 6.9099 & TRN & \\
\hline CHEMBL 2204799 & 886679 & 5.6576 & 5.3372 & TRN & \\
\hline CHEMBL 2204823 & 886679 & 5.3098 & 5.3275 & TRN & \\
\hline CHEMBL 2204829 & 886679 & 4.1739 & 4.8405 & TRN & \\
\hline CHEMBL 2204827 & 886679 & 4.1367 & 4.1856 & TRN & \\
\hline CHEMBL 2204810 & 886679 & 5.3279 & 4.7525 & TRN & \\
\hline CHEMBL 2204843 & 886679 & 4.0706 & 5.0761 & TST & \\
\hline CHEMBL 82783 & 886679 & 4.5376 & 4.4298 & TRN & \\
\hline CHEMBL 2204814 & 886679 & 5.0269 & 4.7333 & TRN & \\
\hline CHEMBL 2204086 & 886679 & 6.5229 & 6.99799 & 9999999999 & TRN \\
\hline CHEMBL 2204802 & 886679 & 7.0969 & 5.8062 & TRN & \\
\hline CHEMBL 2204847 & 886679 & 4.1612 & 4.378 & TRN & \\
\hline CHEMBL 2204845 & 886679 & 5.0 & 4.42899 & 9999999999 & TST \\
\hline CHEMBL 2204821 & 886679 & 4.5528 & 4.8181 & TRN & \\
\hline CHEMBL 2204090 & 886679 & 3.7799 & 4.5265 & TST & \\
\hline CHEMBL 2204836 & 886679 & 6.0 & 5.2874 & TRN & \\
\hline CHEMBL 82868 & 886679 & 4.7959 & 4.5607 & TRN & \\
\hline CHEMBL 2204826 & 886679 & 3.7773 & 4.159 & TRN & \\
\hline CHEMBL 2204803 & 886679 & 6.3979 & 5.8921 & TRN & \\
\hline CHEMBL 2204084 & 886679 & 6.1079 & 6.8338 & TRN & \\
\hline CHEMBL 2204831 & 886679 & 4.0915 & 4.836 & TRN & \\
\hline CHEMBL 2204825 & 886679 & 4.4685 & 4.6249 & TRN & \\
\hline CHEMBL 2204804 & 886679 & 5.1487 & 5.7158 & TRN & \\
\hline CHEMBL 2204812 & 886679 & 3.0 & 4.8722 & TRN & \\
\hline CHEMBL 2204841 & 886679 & 4.3979 & 5.1752 & TST & \\
\hline CHEMBL82331 & 886679 & 4.7447 & 4.9341 & TRN & \\
\hline CHEMBL84594 & 886679 & 3.9508 & 4.1 & TRN & \\
\hline CHEMBL 2203295 & 886679 & 4.3768 & 5.2359 & TRN & \\
\hline CHEMBL 2204809 & 886679 & 4.7696 & 5.4852 & TRN & \\
\hline CHEMBL 2204830 & 886679 & 3.9914 & 4.4001 & TRN & \\
\hline CHEMBL 2204837 & 886679 & 5.6383 & 5.356 & TST & \\
\hline CHEMBL 2204092 & 886679 & 4.2596 & 4.9476 & TST & \\
\hline CHEMBL 2204833 & 886679 & 6.0 & 4.8567 & TST & \\
\hline CHEMBL 2204091 & 886679 & 5.1739 & 5.3267 & TST & \\
\hline CHEMBL 2204808 & 886679 & 5.041 & 5.5195 & TST & \\
\hline CHEMBL 2204839 & 886679 & 4.9586 & 5.3727 & TST & \\
\hline CHEMBL 2204088 & 886679 & 7.5229 & 7.0848 & TST & \\
\hline CHEMBL 2204806 & 886679 & 6.3279 & 6.2042 & TST & \\
\hline CHEMBL 2204085 & 886679 & 7.1367 & 7.1011 & TST & \\
\hline CHEMBL3905956 & 1641722 & 8.0 & 6.9696 & TRN & \\
\hline CHEMBL3983112 & 1641722 & 7.0 & 6.8951 & TRN & \\
\hline CHEMBL3947655 & 1641722 & 7.0 & 7.24 & TRN & \\
\hline CHEMBL3907363 & 1641722 & 7.0 & 7.1465 & TRN & \\
\hline CHEMBL3958865 & 1641722 & 6.0 & 6.3206 & TRN & \\
\hline CHEMBL3903566 & 1641722 & 8.0 & 7.0683 & TRN & \\
\hline CHEMBL3938478 & 1641722 & 6.0 & 6.6939 & TRN & \\
\hline CHEMBL3956306 & 1641722 & 8.0 & 7.6582 & TRN & \\
\hline
\end{tabular}




\begin{tabular}{|c|c|c|c|}
\hline & & ent & al \\
\hline CHEMBL3893565 & 16417227.0 & 7.2608 & TST \\
\hline CHEMBL3971392 & 16417227.0 & 7.1543 & TST \\
\hline CHEMBL3948446 & 16417226.0 & 5.9585 & TRN \\
\hline CHEMBL3916563 & 16417228.0 & 8.2675 & TRN \\
\hline CHEMBL3922209 & 16417229.0 & 7.7401 & TRN \\
\hline CHEMBL 3958886 & 16417228.0 & 6.9002 & TRN \\
\hline CHEMBL3909265 & 16417227.0 & 6.9605 & TRN \\
\hline CHEMBL3909729 & 16417228.0 & 8.1814 & TRN \\
\hline CHEMBL3925293 & 16417227.0 & 7.0884 & TRN \\
\hline CHEMBL3910544 & 16417228.0 & 7.1682 & TST \\
\hline CHEMBL 3893068 & 16417227.0 & 7.3206 & TST \\
\hline CHEMBL3960846 & 16417228.0 & 8.2625 & TRN \\
\hline CHEMBL3976082 & 16417226.0 & 6.3905 & TST \\
\hline CHEMBL3969217 & 16417228.0 & 8.0965 & TRN \\
\hline CHEMBL3979085 & 16417227.0 & 8.0995 & TRN \\
\hline CHEMBL3914935 & 16417228.0 & 7.7049 & TRN \\
\hline CHEMBL3951865 & 16417228.0 & 8.0172 & TST \\
\hline CHEMBL3906215 & 16417226.0 & 5.9435 & TRN \\
\hline CHEMBL3903497 & 16417226.0 & 5.7611 & TRN \\
\hline CHEMBL3918539 & 16417228.0 & 8.6542 & TRN \\
\hline CHEMBL 3927412 & 16417227.0 & 7.1648 & TRN \\
\hline CHEMBL3958855 & 16417227.0 & 7.2207 & TRN \\
\hline CHEMBL3982064 & 16417227.0 & 7.2971 & TST \\
\hline CHEMBL3890472 & 16417227.0 & 6.6395 & TRN \\
\hline CHEMBL 3965580 & 16417226.0 & 6.6343 & TRN \\
\hline CHEMBL 3982783 & 16417227.0 & 7.9195 & TRN \\
\hline CHEMBL3942965 & 16417228.0 & 7.0065 & TRN \\
\hline CHEMBL3917685 & 16417227.0 & 7.3554 & TRN \\
\hline CHEMBL 3917092 & 16417227.0 & 7.4878 & TRN \\
\hline CHEMBL 3897252 & 16417226.0 & 6.2095 & TRN \\
\hline CHEMBL 3955551 & 16417228.0 & 8.2924 & TRN \\
\hline CHEMBL3903925 & 16417227.0 & 6.5746 & TRN \\
\hline CHEMBL 3925128 & 16417227.0 & 6.8755 & TRN \\
\hline CHEMBL3961608 & 16417228.0 & 7.6327 & TRN \\
\hline CHEMBL3913673 & 16417228.0 & 8.1002 & TRN \\
\hline CHEMBL3966808 & 16417228.0 & 7.7164 & TRN \\
\hline CHEMBL3953471 & 16417228.0 & 8.4659 & TRN \\
\hline CHEMBL 3922044 & 16417228.0 & 7.4137 & TRN \\
\hline CHEMBL 3922824 & 16417228.0 & 8.1225 & TRN \\
\hline CHEMBL3966827 & 16417228.0 & 8.3125 & TRN \\
\hline CHEMBL 3964883 & 16417227.0 & 6.7646 & TST \\
\hline CHEMBL3945762 & 16417227.0 & 7.0533 & TRN \\
\hline CHEMBL3973756 & 16417227.0 & 6.9922 & TRN \\
\hline CHEMBL 3918007 & 16417228.0 & 7.3404 & TST \\
\hline CHEMBL3897077 & 16417228.0 & 7.2643 & TST \\
\hline CHEMBL 3892675 & 16417228.0 & 7.7318 & TRN \\
\hline CHEMBL3913402 & 16417228.0 & 8.3399 & TRN \\
\hline CHEMBL 3912396 & 16417227.0 & 6.8197 & TRN \\
\hline
\end{tabular}




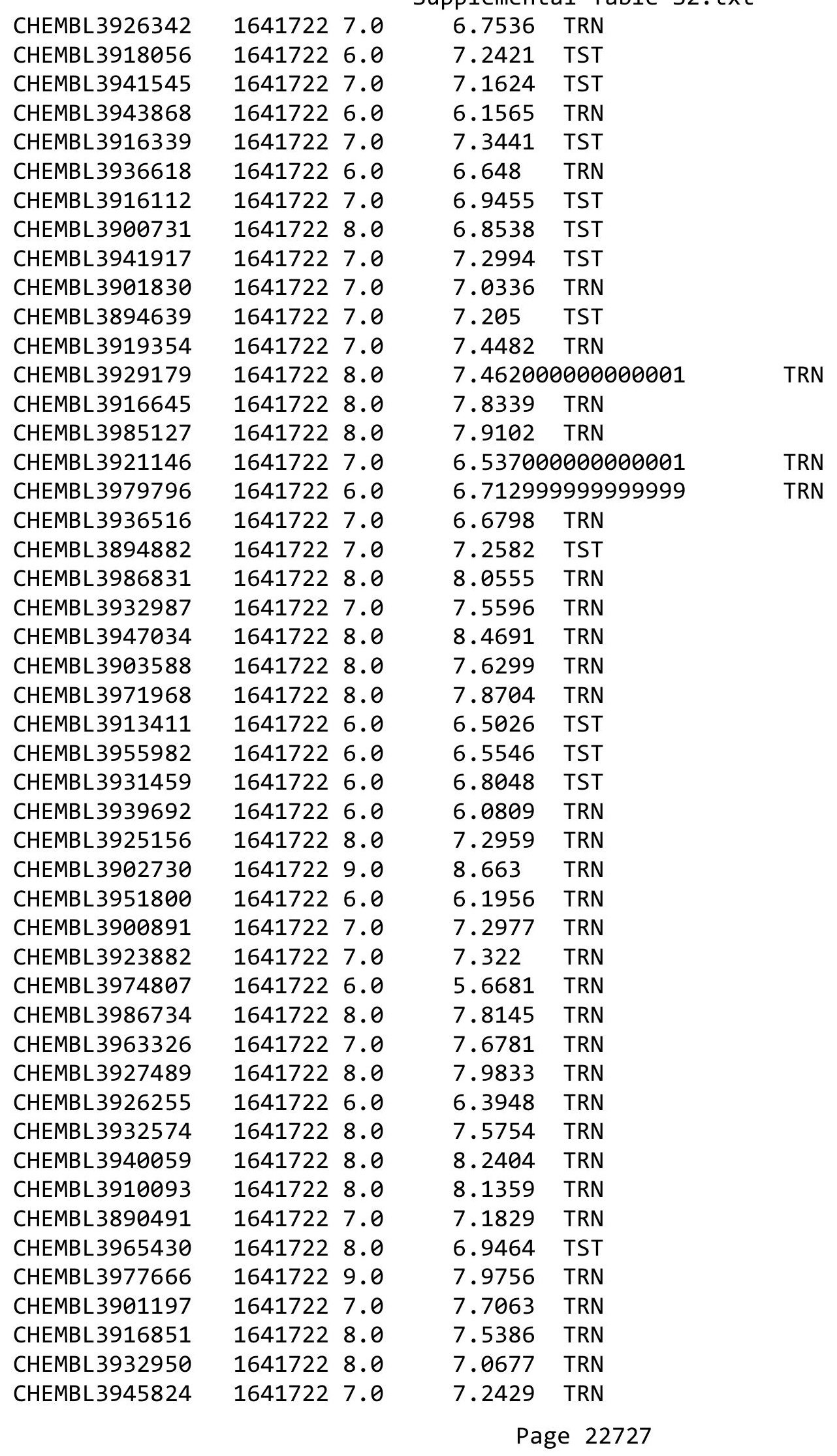




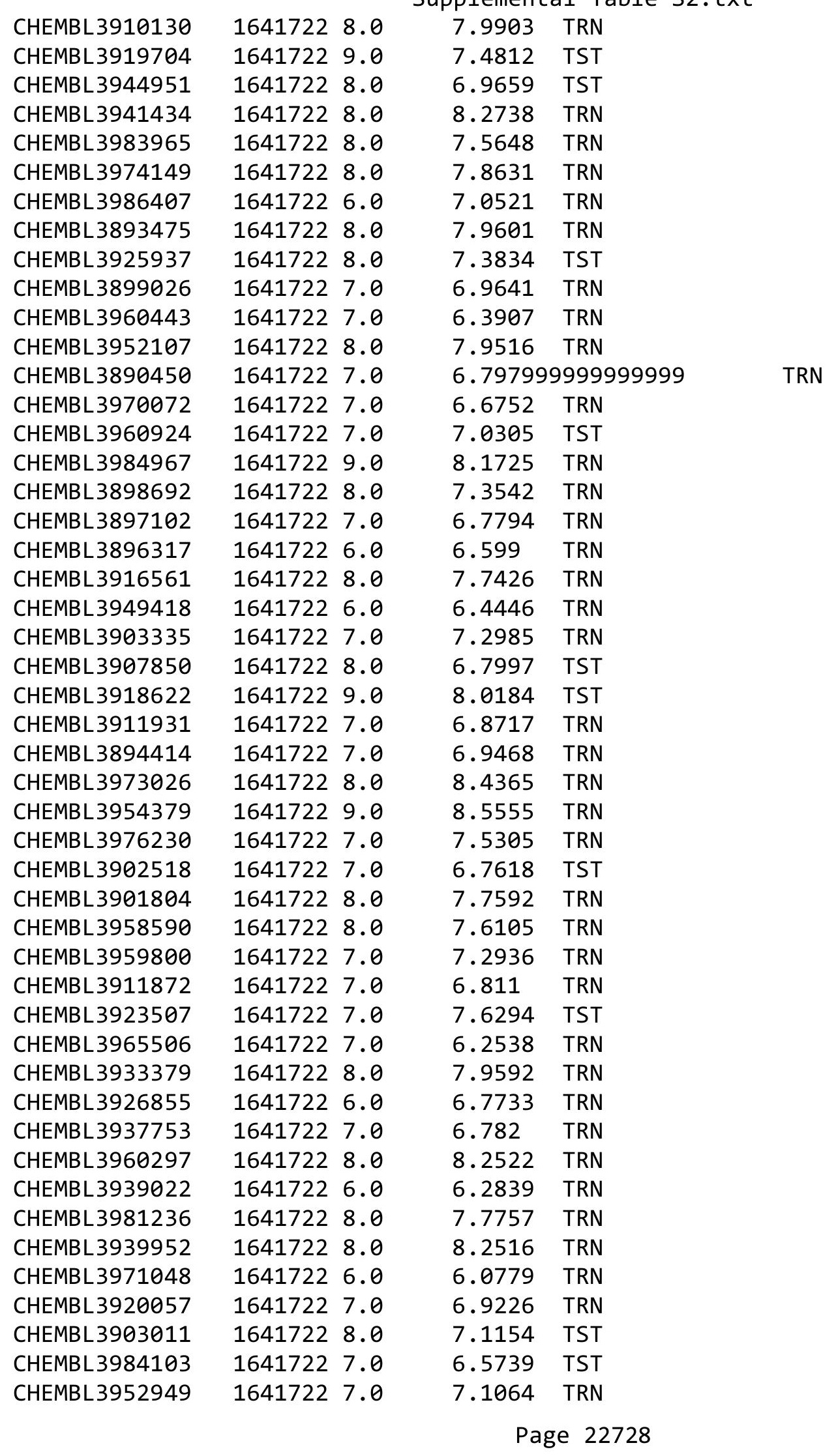




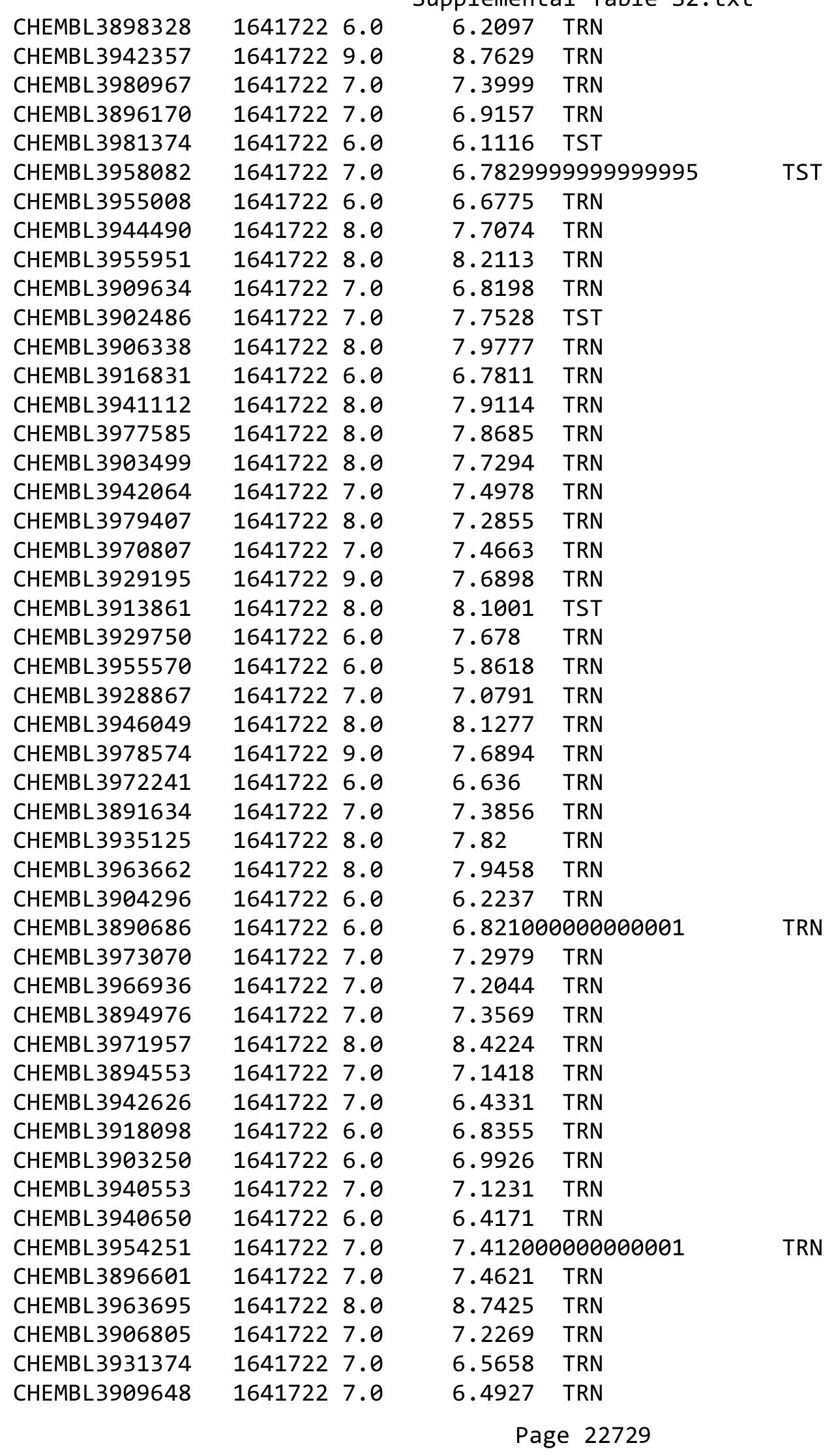




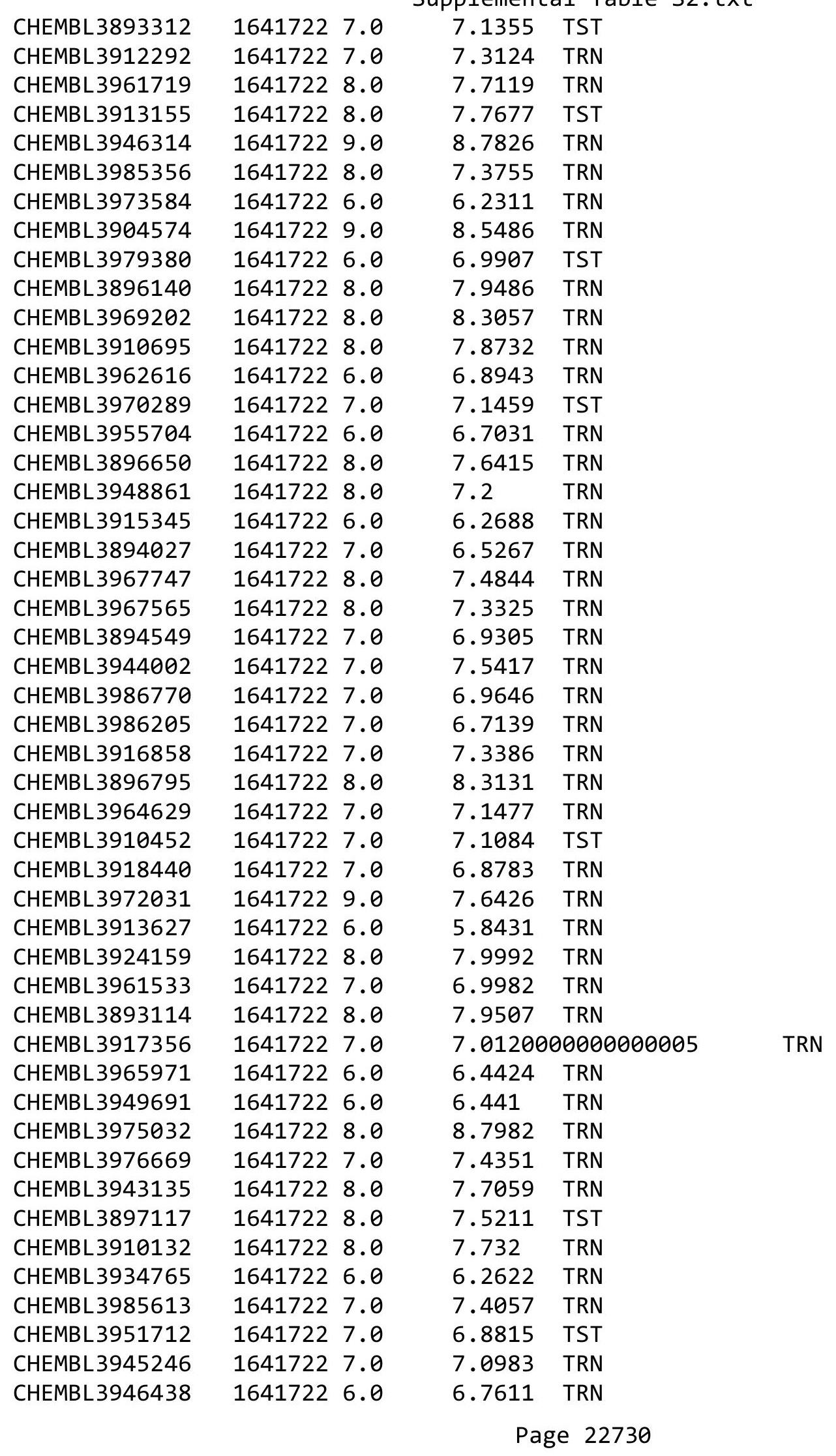




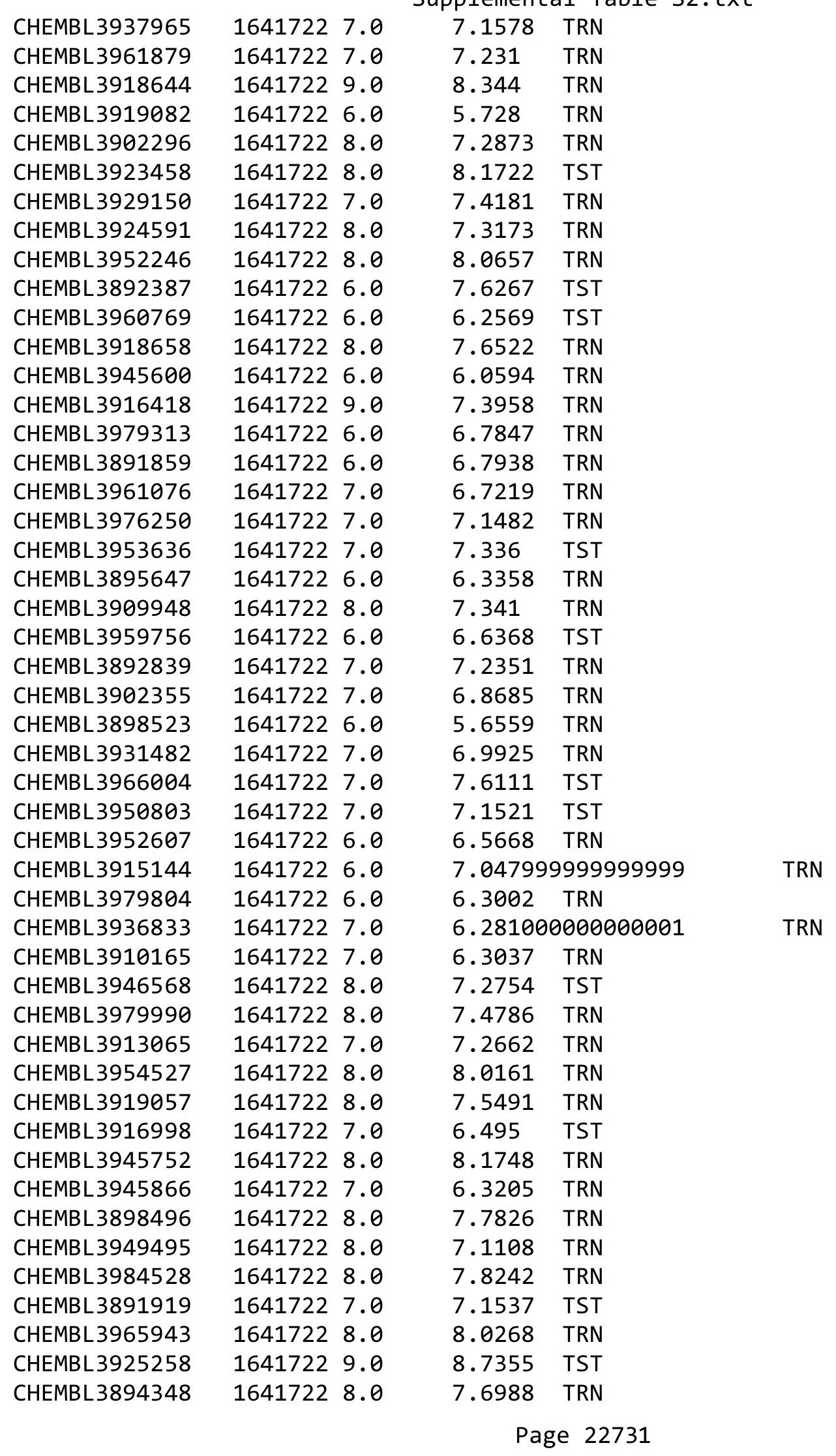




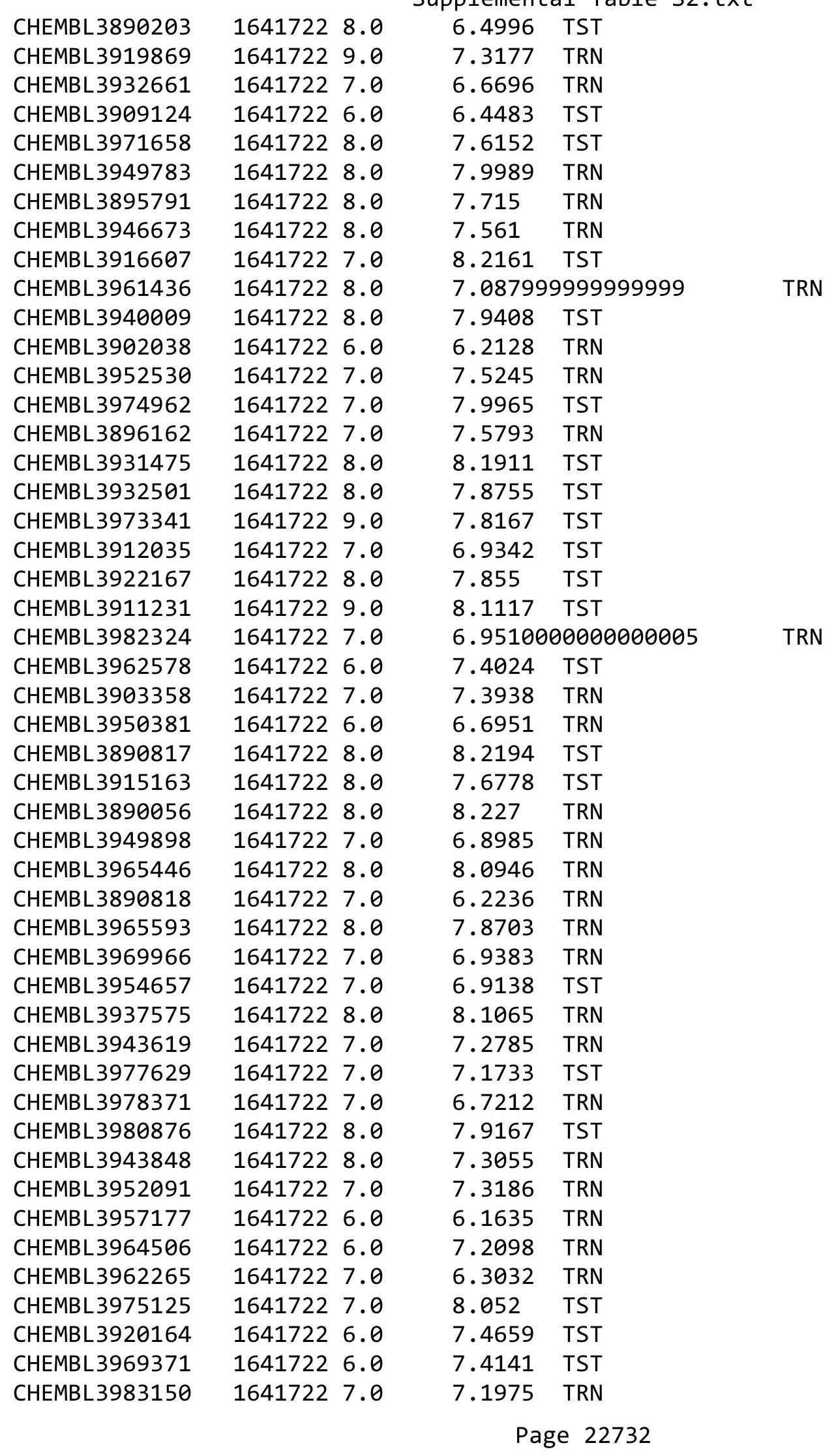




\begin{tabular}{|c|c|c|c|c|c|}
\hline \multirow{3}{*}{ CHEMBL 3896464} & \multirow{2}{*}{1641722} & \\
\hline & & 8.0 & 7.482 & TRN & \\
\hline & 1641722 & 8.0 & 8.663 & TST & \\
\hline CHEMBL3914431 & 1641722 & 8.0 & 8.0832 & TRN & \\
\hline CHEMBL3918565 & 1641722 & 8.0 & 7.6067 & TST & \\
\hline CHEMBL3892124 & 1641722 & 6.0 & 7.6705 & TST & \\
\hline CHEMBL3958801 & 1641722 & 6.0 & 6.6747 & TST & \\
\hline CHEMBL3973100 & 1641722 & 9.0 & 7.7105 & TST & \\
\hline CHEMBL3946765 & 1641722 & 7.0 & 7.0301 & TST & \\
\hline CHEMBL3977517 & 1641722 & 8.0 & 7.6278 & TRN & \\
\hline CHEMBL3962495 & 1641722 & 7.0 & 6.39 & TST & \\
\hline CHEMBL3984576 & 1641722 & 9.0 & 8.7597 & TRN & \\
\hline CHEMBL3907989 & 1641722 & 8.0 & 7.5081 & TST & \\
\hline CHEMBL3960164 & 1641722 & 8.0 & 7.3528 & TST & \\
\hline CHEMBL3946406 & 1641722 & 7.0 & 7.1459 & TST & \\
\hline CHEMBL3930430 & 1641722 & 6.0 & 6.0141 & TRN & \\
\hline CHEMBL3908240 & 1641722 & 8.0 & 7.4682 & TRN & \\
\hline CHEMBL3908113 & 1641722 & 8.0 & 7.4831 & TRN & \\
\hline CHEMBL 3924834 & 1641722 & 6.0 & 6.9416 & TRN & \\
\hline CHEMBL3940790 & 1641722 & 6.0 & 6.2767 & TRN & \\
\hline CHEMBL3967128 & 1641722 & 9.0 & 8.1442 & TST & \\
\hline CHEMBL3976647 & 1641722 & 7.0 & 6.4857 & TRN & \\
\hline CHEMBL3947037 & 1641722 & 8.0 & \multicolumn{2}{|c|}{7.9879999999999995} & TST \\
\hline CHEMBL3937736 & 1641722 & 6.0 & 6.4276 & TRN & \\
\hline CHEMBL3907645 & 1641722 & 7.0 & 7.9747 & TST & \\
\hline CHEMBL 3895522 & 1641722 & 8.0 & 8.3623 & TRN & \\
\hline CHEMBL 3902918 & 1641722 & 7.0 & 6.9084 & TRN & \\
\hline CHEMBL3889945 & 1641722 & 7.0 & \multicolumn{2}{|c|}{7.446000000000001} & TRN \\
\hline CHEMBL3892753 & 1641722 & 8.0 & 7.6143 & TRN & \\
\hline CHEMBL3910309 & 1641722 & 7.0 & 6.7019 & TRN & \\
\hline CHEMBL3929356 & 1641722 & 7.0 & 7.6054 & TRN & \\
\hline CHEMBL 3946253 & 1641722 & 7.0 & 7.3746 & TRN & \\
\hline CHEMBL3918162 & 1641722 & 7.0 & 7.3327 & TST & \\
\hline CHEMBL3940183 & 1641722 & 6.0 & 6.3721 & TRN & \\
\hline CHEMBL3935253 & 1641722 & 7.0 & \multicolumn{2}{|c|}{6.8020000000000005} & TRN \\
\hline CHEMBL3899653 & 1641722 & 8.0 & 7.5978 & TST & \\
\hline CHEMBL 3895026 & 1641722 & 8.0 & 8.1507 & TST & \\
\hline CHEMBL3896315 & 1641722 & 7.0 & 6.7665 & TST & \\
\hline CHEMBL 3978484 & 1641722 & 8.0 & 7.7543 & TRN & \\
\hline CHEMBL3961264 & 1641722 & 7.0 & 7.4952 & TRN & \\
\hline CHEMBL3916969 & 1641722 & 7.0 & 7.1576 & TST & \\
\hline CHEMBL3954758 & 1641722 & 8.0 & 8.0741 & TRN & \\
\hline CHEMBL3950941 & 1641722 & 8.0 & 8.1556 & TST & \\
\hline CHEMBL3936401 & 1641722 & 6.0 & 6.689 & TRN & \\
\hline CHEMBL3975305 & 1641722 & 6.0 & 6.2942 & TRN & \\
\hline CHEMBL3916519 & 1641722 & 7.0 & 7.4755 & TRN & \\
\hline CHEMBL 3930862 & 1641722 & 8.0 & 8.1981 & TST & \\
\hline CHEMBL3941617 & 1641722 & 7.0 & 6.87799 & 9999999999 & TRN \\
\hline \multirow[t]{2}{*}{ CHEMBL3950061 } & 1641722 & 8.0 & 7.1541 & TRN & \\
\hline & & & \multicolumn{2}{|c|}{ Page 22733} & \\
\hline
\end{tabular}




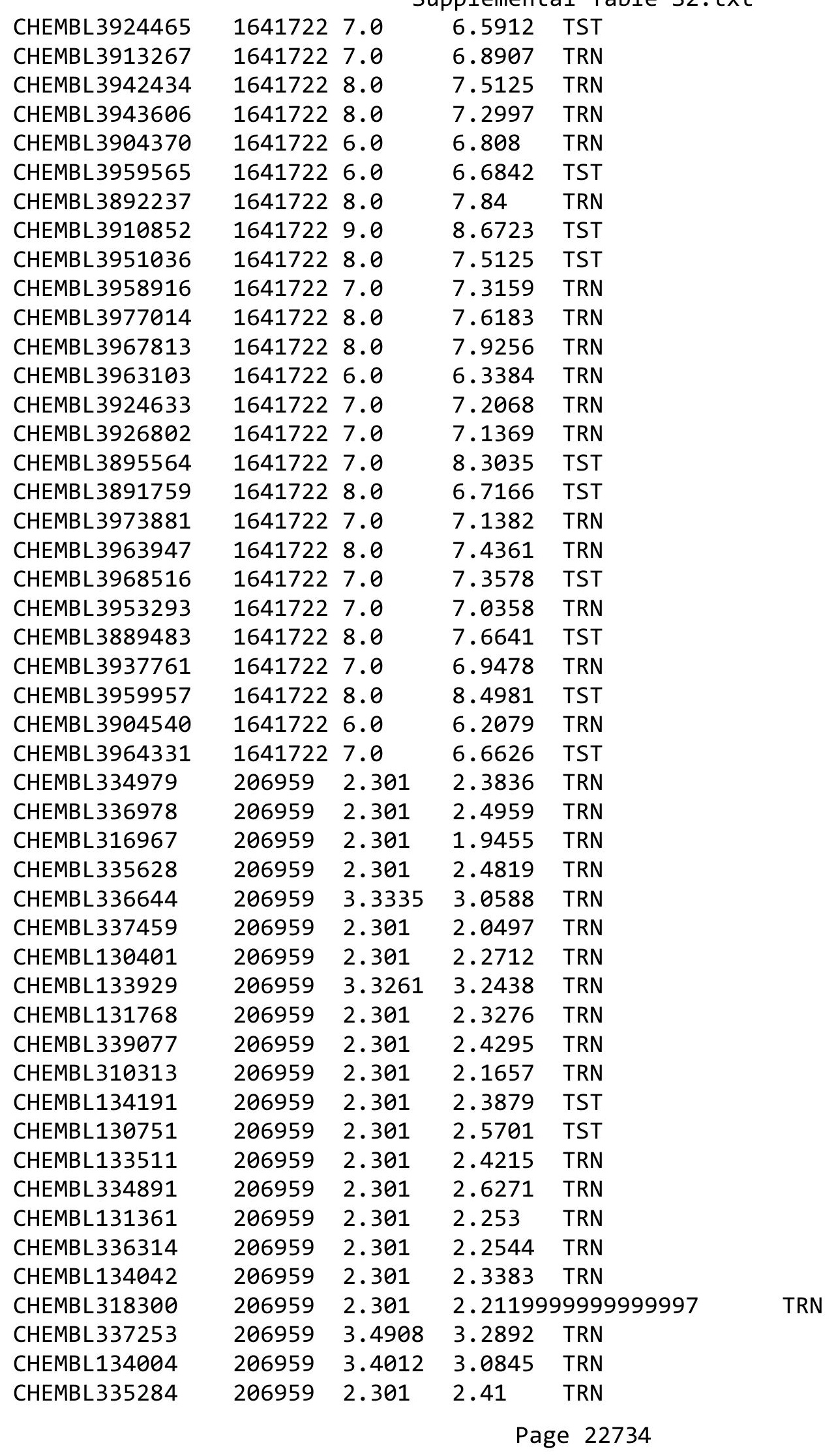




\begin{tabular}{|c|c|c|c|c|}
\hline & & & oplement & al $\mathrm{Ta}$ \\
\hline CHEMBL133185 & 206959 & 2.301 & 2.332 & TRN \\
\hline CHEMBL336957 & 206959 & 3.4101 & 3.0264 & TST \\
\hline CHEMBL336864 & 206959 & 3.52 & 3.0774 & TRN \\
\hline CHEMBL411163 & 206959 & 6.3188 & 3.0446 & TST \\
\hline CHEMBL132963 & 206959 & 2.301 & 2.4307 & TRN \\
\hline CHEMBL133644 & 206959 & 2.301 & 2.8235 & TRN \\
\hline CHEMBL103838 & 206959 & 2.301 & 2.6455 & TRN \\
\hline CHEMBL311937 & 206959 & 3.767 & 2.2457 & TST \\
\hline CHEMBL336949 & 206959 & 3.6021 & 2.8296 & TRN \\
\hline CHEMBL76963 & 206959 & 2.301 & 2.4673 & TRN \\
\hline CHEMBL132007 & 206959 & 2.301 & 2.1525 & TRN \\
\hline CHEMBL131944 & 206959 & 2.301 & 2.5513 & TRN \\
\hline CHEMBL130931 & 206959 & 2.301 & 3.2725 & TRN \\
\hline CHEMBL424449 & 206959 & 2.301 & 2.2272 & TRN \\
\hline CHEMBL134030 & 206959 & 2.301 & 2.1575 & TRN \\
\hline CHEMBL337737 & 206959 & 3.4976 & 3.1304 & TRN \\
\hline CHEMBL132006 & 206959 & 3.3449 & 2.9779 & TRN \\
\hline CHEMBL132014 & 206959 & 2.301 & 2.8146 & TST \\
\hline CHEMBL334539 & 206959 & 2.301 & 2.7089 & TRN \\
\hline CHEMBL129842 & 206959 & 2.301 & 2.1727 & TRN \\
\hline CHEMBL131229 & 206959 & 3.3635 & 3.0637 & TRN \\
\hline CHEMBL336958 & 206959 & 2.301 & 2.5851 & TRN \\
\hline CHEMBL337451 & 206959 & 2.301 & 2.5485 & TRN \\
\hline CHEMBL130106 & 206959 & 2.301 & 2.3141 & TRN \\
\hline CHEMBL341314 & 206959 & 2.301 & 2.3516 & TST \\
\hline CHEMBL77067 & 206959 & 2.301 & 2.8566 & TST \\
\hline CHEMBL430059 & 206959 & 3.3768 & 2.2201 & TST \\
\hline CHEMBL423330 & 206959 & 2.301 & 2.0663 & TST \\
\hline CHEMBL130871 & 206959 & 2.301 & 2.5686 & TST \\
\hline CHEMBL134243 & 206959 & 2.301 & 2.3814 & TST \\
\hline CHEMBL407143 & 206959 & 3.5406 & 2.8728 & TST \\
\hline CHEMBL340977 & 206959 & 2.301 & 2.9009 & TST \\
\hline CHEMBL298296 & 158729 & 3.0 & 3.0247 & TST \\
\hline CHEMBL45197 & 158729 & 5.6778 & 4.8027 & TRN \\
\hline CHEMBL43331 & 158729 & 4.041 & 3.5221 & TRN \\
\hline CHEMBL289169 & 158729 & 3.0 & 2.9152 & TRN \\
\hline CHEMBL46761 & 158729 & 3.0 & 3.0212 & TRN \\
\hline CHEMBL46637 & 158729 & 3.0 & 2.6522 & TST \\
\hline CHEMBL295654 & 158729 & 3.0 & 2.9021 & TST \\
\hline CHEMBL42996 & 158729 & 5.301 & 5.2954 & TRN \\
\hline CHEMBL43089 & 158729 & 3.0 & 3.4615 & TRN \\
\hline CHEMBL42595 & 158729 & 3.0 & 3.4732 & TRN \\
\hline CHEMBL47147 & 158729 & 5.5622 & 5.4432 & TRN \\
\hline CHEMBL296515 & 158729 & 3.0 & 4.2458 & TRN \\
\hline CHEMBL42223 & 158729 & 3.0 & 3.5137 & TRN \\
\hline CHEMBL46636 & 158729 & 3.0 & 2.852 & TRN \\
\hline CHEMBL289561 & 158729 & 5.0655 & 4.9277 & TRN \\
\hline CHEMBL290945 & 158729 & 5.1057 & 4.1788 & TRN \\
\hline
\end{tabular}




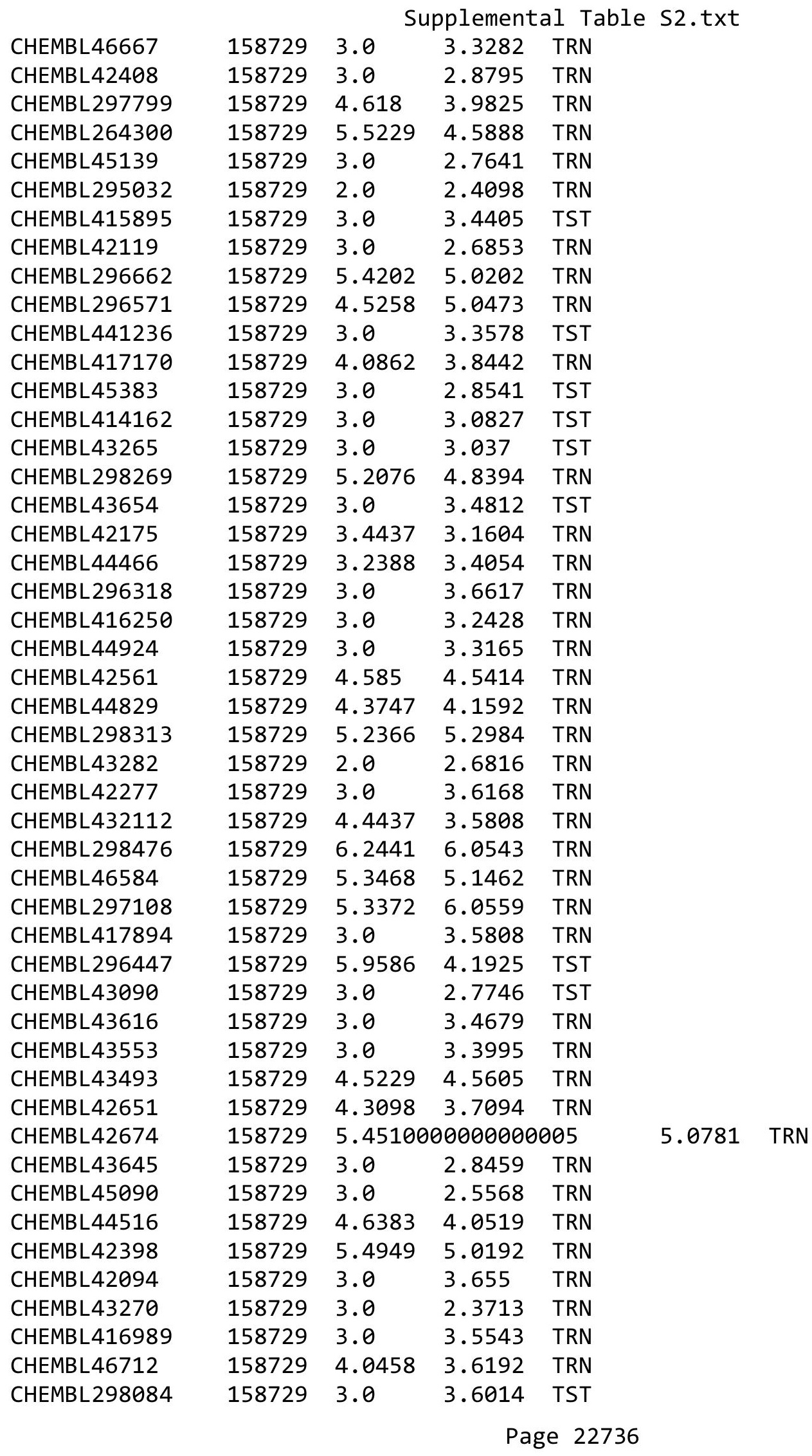




\begin{tabular}{|c|c|c|c|c|c|c|}
\hline \multicolumn{7}{|c|}{ Supplemental Table S2.txt } \\
\hline CHEMBL43217 & 158729 & 3.0 & 2.8098 & TST & & \\
\hline CHEMBL42940 & 158729 & 3.0 & 3.1918 & TRN & & \\
\hline CHEMBL45192 & 158729 & 5.7959 & 5.7617 & TRN & & \\
\hline CHEMBL43640 & 158729 & 4.1739 & 2.5628 & TRN & & \\
\hline CHEMBL44468 & 158729 & 3.0 & 3.2336 & TRN & & \\
\hline CHEMBL44926 & 158729 & 4.6517 & 4.465 & TRN & & \\
\hline CHEMBL42074 & 158729 & 3.0 & 3.1477 & TRN & & \\
\hline CHEMBL43149 & 158729 & 3.5287 & 3.8888 & TRN & & \\
\hline CHEMBL42549 & 158729 & 3.0 & 2.8458 & TRN & & \\
\hline CHEMBL42225 & 158729 & 3.1409 & 3.6467 & TRN & & \\
\hline CHEMBL43103 & 158729 & 4.2716 & 4.2316 & TRN & & \\
\hline CHEMBL295707 & 158729 & 3.0 & 3.0544 & TRN & & \\
\hline CHEMBL43672 & 158729 & 4.1694 & 4.2318 & TRN & & \\
\hline CHEMBL46576 & 158729 & 3.0 & 2.9675 & TST & & \\
\hline CHEMBL289484 & 158729 & 3.0 & 2.9636 & TST & & \\
\hline CHEMBL294969 & 158729 & 3.0 & 3.0487 & TST & & \\
\hline CHEMBL42884 & 158729 & 3.0 & 2.4573 & TRN & & \\
\hline CHEMBL274798 & 158729 & 3.0 & 2.2612 & TST & & \\
\hline CHEMBL42174 & 158729 & 3.0 & 3.8594 & TRN & & \\
\hline CHEMBL296984 & 158729 & 4.7144 & 5.3005 & TRN & & \\
\hline CHEMBL42709 & 158729 & 3.0 & 3.8251 & TRN & & \\
\hline CHEMBL46623 & 158729 & 5.7212 & 5.3304 & TRN & & \\
\hline CHEMBL296673 & 158729 & 4.9208 & 4.5914 & TRN & & \\
\hline CHEMBL42180 & 158729 & 3.0 & 3.8769 & TRN & & \\
\hline CHEMBL44977 & 158729 & 4.76699 & 99999999 & 995 & 3.9631 & TST \\
\hline CHEMBL43933 & 158729 & 3.0 & 3.2154 & TST & & \\
\hline CHEMBL291129 & 158729 & 3.0 & 2.8312 & TST & & \\
\hline CHEMBL294967 & 158729 & 5.0862 & 4.85 & TST & & \\
\hline CHEMBL295752 & 158729 & 3.0 & 2.2082 & TST & & \\
\hline CHEMBL43317 & 158729 & 4.4559 & 4.0217 & TST & & \\
\hline CHEMBL296078 & 158729 & 5.8069 & 4.1072 & TST & & \\
\hline CHEMBL 187000 & 306463 & 6.2684 & 6.2711 & TRN & & \\
\hline CHEMBL360189 & 306463 & 6.6778 & 6.6604 & TRN & & \\
\hline CHEMBL189822 & 306463 & 6.3233 & 6.4106 & TRN & & \\
\hline CHEMBL362356 & 306463 & 6.3335 & 6.3 & TRN & & \\
\hline CHEMBL189073 & 306463 & 5.7627 & 5.8119 & TRN & & \\
\hline CHEMBL185918 & 306463 & 6.9318 & 7.3114 & TRN & & \\
\hline CHEMBL187219 & 306463 & 7.6198 & 7.5637 & TRN & & \\
\hline CHEMBL187313 & 306463 & 5.4202 & 5.8011 & TRN & & \\
\hline CHEMBL362793 & 306463 & 5.7416 & 5.7963 & TRN & & \\
\hline CHEMBL189706 & 306463 & 5.1064 & 5.1886 & TST & & \\
\hline CHEMBL187473 & 306463 & 5.3906 & 5.6912 & TRN & & \\
\hline CHEMBL361272 & 306463 & 6.7077 & 6.4475 & TRN & & \\
\hline CHEMBL 435090 & 306463 & 7.301 & 7.2746 & TRN & & \\
\hline CHEMBL185783 & 306463 & 5.8861 & 4.7726 & TST & & \\
\hline CHEMBL189025 & 306463 & 5.61799 & 99999999 & 99 & 5.6115 & TRN \\
\hline CHEMBL361871 & 306463 & 5.9846 & 5.6174 & TST & & \\
\hline CHEMBL184003 & 306463 & 6.3028 & 6.3103 & TRN & & \\
\hline
\end{tabular}

Page 22737 


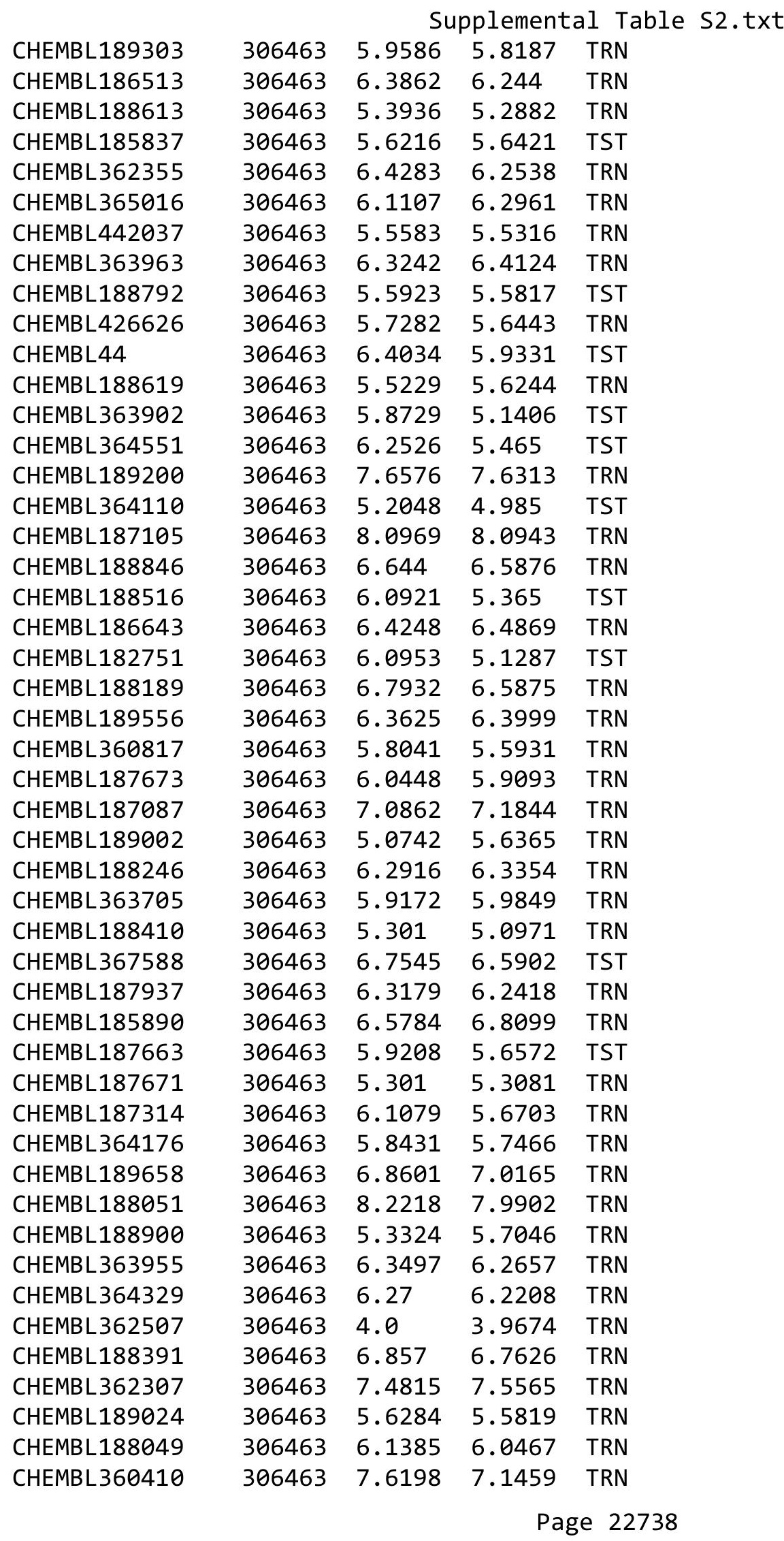




\begin{tabular}{|c|c|c|c|c|c|}
\hline \multirow[b]{2}{*}{ CHEMBL189039 } & \multicolumn{5}{|c|}{ Supplemental Table S2.txt } \\
\hline & 306463 & 5.5265 & 5.5386 & TRN & \multirow[b]{2}{*}{ TRN } \\
\hline CHEMBL188458 & 306463 & 6.4437 & \multicolumn{2}{|c|}{6.502999999999999} & \\
\hline CHEMBL188527 & 306463 & 5.7258 & 5.5325 & TRN & \\
\hline CHEMBL189077 & 306463 & 7.4559 & 7.3693 & TRN & \\
\hline CHEMBL361063 & 306463 & 5.9523 & 6.1739 & TRN & \\
\hline CHEMBL189356 & 306463 & 7.0088 & 6.9972 & TRN & \\
\hline CHEMBL189287 & 306463 & 6.7212 & 6.6455 & TST & \\
\hline CHEMBL186073 & 306463 & 5.2916 & 5.1532 & TST & \\
\hline CHEMBL183368 & 306463 & 6.7878 & 7.3821 & TST & \\
\hline CHEMBL186598 & 306463 & 7.8861 & 7.7542 & TRN & \\
\hline CHEMBL188299 & 306463 & 6.3344 & 6.3549 & TRN & \\
\hline CHEMBL361078 & 306463 & 7.5229 & 7.5913 & TRN & \\
\hline CHEMBL188882 & 306463 & 6.0888 & 6.4691 & TRN & \\
\hline CHEMBL360651 & 306463 & 6.5638 & 6.8342 & TRN & \\
\hline CHEMBL186597 & 306463 & 7.1871 & 7.1719 & TRN & \\
\hline CHEMBL361266 & 306463 & 4.301 & 4.9744 & TST & \\
\hline CHEMBL365045 & 306463 & 5.7033 & 5.1722 & TST & \\
\hline CHEMBL188951 & 306463 & 4.301 & 4.3777 & TRN & \\
\hline CHEMBL187915 & 306463 & 7.3279 & 7.4596 & TRN & \\
\hline CHEMBL189080 & 306463 & 6.7375 & 6.7072 & TRN & \\
\hline CHEMBL187393 & 306463 & 7.3098 & 7.303 & TRN & \\
\hline CHEMBL362349 & 306463 & 5.2774 & 5.4673 & TST & \\
\hline CHEMBL363017 & 306463 & 5.7212 & 5.5907 & TST & \\
\hline CHEMBL187392 & 306463 & 5.9112 & 5.9554 & TST & \\
\hline CHEMBL 364345 & 306463 & 5.9957 & 5.1458 & TST & \\
\hline CHEMBL187978 & 306463 & 5.9872 & 5.53 & TST & \\
\hline CHEMBL188230 & 306463 & 5.5787 & 5.5498 & TRN & \\
\hline CHEMBL187311 & 306463 & 7.3565 & 7.2295 & TRN & \\
\hline CHEMBL188957 & 306463 & 6.4089 & 6.4665 & TRN & \\
\hline CHEMBL187207 & 306463 & 6.585 & 6.5271 & TRN & \\
\hline CHEMBL188517 & 306463 & 6.6038 & 6.6484 & TRN & \\
\hline CHEMBL365293 & 306463 & 5.2147 & 5.3346 & TRN & \\
\hline CHEMBL187069 & 306463 & 6.0867 & 5.7023 & TRN & \\
\hline CHEMBL365903 & 306463 & 5.0168 & 5.24299 & 9999999999 & TST \\
\hline CHEMBL 364333 & 306463 & 4.301 & 3.5832 & TST & \\
\hline CHEMBL365625 & 306463 & 6.1445 & 6.0076 & TRN & \\
\hline CHEMBL361762 & 306463 & 5.5738 & 5.4399 & TST & \\
\hline CHEMBL188528 & 306463 & 6.8097 & 6.8398 & TRN & \\
\hline CHEMBL186945 & 306463 & 6.3655 & 6.3603 & TRN & \\
\hline CHEMBL183367 & 306463 & 6.8153 & 7.1087 & TST & \\
\hline CHEMBL144206 & 212923 & 5.8239 & 5.8232 & TRN & \\
\hline CHEMBL356259 & 212923 & 5.8861 & 5.8872 & TRN & \\
\hline CHEMBL147149 & 212923 & 5.1805 & 5.1811 & TRN & \\
\hline CHEMBL147051 & 212923 & 5.2076 & 5.2072 & TRN & \\
\hline CHEMBL144780 & 212923 & 6.1549 & 6.1546 & TRN & \\
\hline CHEMBL144293 & 212923 & 5.9586 & 5.9591 & TRN & \\
\hline CHEMBL432079 & 212923 & 5.6383 & 6.0876 & TST & \\
\hline CHEMBL357414 & 212923 & 5.9208 & 5.9208 & TRN & \\
\hline & & & & 22739 & \\
\hline
\end{tabular}


Supplemental Table S2.txt

\begin{tabular}{|c|c|c|c|c|}
\hline HEMBL 144169 & 12923 & 3.699 & 3.6992 & TRI \\
\hline CHEMBL357203 & 12923 & 5.3665 & 5.3669 & \\
\hline HEMBL344759 & 12923 & .3565 & 3567 & \\
\hline HEMBL144525 & 12923 & 5.5229 & 0073 & \\
\hline HEMBL 29976 & 12923 & 5.0555 & .1554 & \\
\hline HEMBL439983 & 12923 & 4.4685 & .4694 & \\
\hline HEMBL144021 & 12923 & .2147 & 5.2149 & \\
\hline HEMBL147091 & 12923 & 5.6383 & 5.638 & \\
\hline HEMBL145069 & 212923 & 5.5086 & 5.5089 & RN \\
\hline HEMBL144001 & 12923 & 5.1739 & 5.1727 & \\
\hline HEMBL358129 & 12923 & 5.3565 & 5.3566 & \\
\hline HEMBL 355900 & 12923 & .5528 & 5.5527 & \\
\hline HEMBL $35^{\circ}$ & 2923 & 778 & 5.678 & \\
\hline HEMBL342069 & 212923 & 5.4815 & 5.4813 & \\
\hline HEMBL148048 & 12923 & 5.3098 & 5.3104 & RN \\
\hline HEMBL357446 & 12923 & 3372 & 5.3377 & \\
\hline HEMBL14 & 12923 & 192 & 5.1187 & NIV \\
\hline HEMBL14 & 12923 & 969 & 5.0967 & \\
\hline HEMBL 344060 & 212923 & 5.5229 & 5.5226 & N \\
\hline CHEMBL144843 & 2923 & 915 & 5.0903 & TRN \\
\hline HEMBL34 & 2923 & 229 & 5.5229 & $\mathrm{RN}$ \\
\hline HEMBL42 & 2923 & 528 & 5.5525 & $\mathrm{RN}$ \\
\hline HEMBL43 & 2923 & 4.9586 & 4.9583 & $\Gamma R N$ \\
\hline HEMBL144363 & 12923 & 6.1135 & 6.1134 & RN \\
\hline HEMBL43 & & 4.9469 & 4.9463 & TRN \\
\hline HEMBL 34 & 12923 & 367 & 5.1379 & RN \\
\hline HEMBL 35 & 12923 & 441 & 5.244 & RN \\
\hline CHEMBL14 & 12923 & 5.7959 & 5.7965 & RN \\
\hline CHEMBL148395 & 12923 & 192 & 5.1184 & TRN \\
\hline CHEMBL 357195 & 12923 & 5.301 & 5.301 & TRN \\
\hline CHEMBL14 & 2923 & 3565 & 5.3566 & $\Gamma \mathrm{RN}$ \\
\hline CHEMBL14 & 2923 & 89 & 5.6287 & TRN \\
\hline CHEMBL 34 & 923 & 468 & 5.3469 & TRN \\
\hline CHEMBL147383 & 12923 & 5 . & 5.4437 & TRN \\
\hline HEMBL148331 & 12923 & 5.1871 & 5.8681 & TST \\
\hline HEMBL114427 & 12923 & .2757 & 6.3101 & TST \\
\hline CHEMBL14 & 2923 & 862 & 5.0868 & $\mathrm{RN}$ \\
\hline CHEMBL144736 & 2923 & 5.3098 & 5.0137 & TST \\
\hline CHEMBL145836 & 12923 & 5.2518 & 5.4493 & TST \\
\hline CHEMBL14 & 12923 & 5.4559 & 5.1307 & TST \\
\hline CHEMBL14 & 12923 & .4202 & 6.1465 & TST \\
\hline CHEMBL144283 & 212923 & 5.9208 & 5.6999 & TST \\
\hline CHEMBL144229 & 12923 & 5.6198 & 5.6603 & TST \\
\hline CHEMBL144611 & 12923 & 5.8416 & 5.4853 & TST \\
\hline CHEMBL14 & 12923 & 5.2147 & 5.1479 & TST \\
\hline CHEMBL16520 & 212923 & 3.301 & 5.015 & וד \\
\hline CHEMBL481229 & 515702 & 5.5229 & 4.8077 & RN \\
\hline CHEMBL472314 & 515702 & 3.0 & 3.3228 & TRN \\
\hline
\end{tabular}

Page 22740 


\begin{tabular}{|c|c|c|c|c|c|}
\hline & & & \multirow{2}{*}{\multicolumn{2}{|c|}{3.1439999999999997}} & \\
\hline CHEMBL480257 & 515702 & 3.0 & & & TST \\
\hline CHEMBL455805 & 515702 & 3.0 & \multicolumn{2}{|c|}{4.5680000000000005} & TRN \\
\hline CHEMBL479456 & 515702 & 4.9208 & 4.5688 & TRN & \\
\hline CHEMBL481628 & 515702 & 4.7959 & 4.4479 & TRN & \\
\hline CHEMBL480438 & 515702 & 4.6021 & 4.4183 & TRN & \\
\hline CHEMBL479857 & 515702 & 4.3872 & 4.6563 & TRN & \\
\hline CHEMBL479467 & 515702 & 4.9208 & 4.6953 & TRN & \\
\hline CHEMBL481225 & 515702 & 4.2218 & 4.4975 & TST & \\
\hline CHEMBL481226 & 515702 & 4.8539 & 5.796 & TRN & \\
\hline CHEMBL481007 & 515702 & 4.5686 & 3.2903 & TST & \\
\hline CHEMBL452131 & 515702 & 5.5229 & 4.7805 & TRN & \\
\hline CHEMBL482401 & 515702 & 4.5229 & 4.8182 & TRN & \\
\hline CHEMBL480833 & 515702 & 4.8239 & 4.6428 & TRN & \\
\hline CHEMBL518954 & 515702 & 4.4815 & 4.6412 & TRN & \\
\hline CHEMBL481426 & 515702 & 3.0 & 3.4695 & TRN & \\
\hline CHEMBL482403 & 515702 & 5.0458 & 4.5896 & TRN & \\
\hline CHEMBL471965 & 515702 & 4.2218 & 3.2589 & TRN & \\
\hline CHEMBL480061 & 515702 & 3.0 & 2.5725 & TRN & \\
\hline CHEMBL480421 & 515702 & 3.0 & 3.2886 & TST & \\
\hline CHEMBL480439 & 515702 & 5.699 & 4.9378 & TRN & \\
\hline CHEMBL480643 & 515702 & 3.0 & 2.9864 & TST & \\
\hline CHEMBL521083 & 515702 & 3.0 & 2.9307 & TRN & \\
\hline CHEMBL471964 & 515702 & 3.0 & 4.3235 & TST & \\
\hline CHEMBL481607 & 515702 & 3.0 & 3.5669 & TRN & \\
\hline CHEMBL479659 & 515702 & 4.7696 & 4.7362 & TRN & \\
\hline CHEMBL479855 & 515702 & 4.0655 & 4.2051 & TRN & \\
\hline CHEMBL519605 & 515702 & 5.699 & 5.114 & TRN & \\
\hline CHEMBL 479442 & 515702 & 3.0 & 3.0726 & TRN & \\
\hline CHEMBL517545 & 515702 & 5.1549 & 3.0981 & TST & \\
\hline CHEMBL481217 & 515702 & 5.2218 & 4.8973 & TRN & \\
\hline CHEMBL479448 & 515702 & 3.0 & 3.2826 & TRN & \\
\hline CHEMBL452161 & 515702 & 4.0555 & 3.12899 & 99999999996 & TRN \\
\hline CHEMBL516920 & 515702 & 3.0 & 5.4385 & TRN & \\
\hline CHEMBL481417 & 515702 & 5.3979 & 4.8953 & TRN & \\
\hline CHEMBL482392 & 515702 & 4.1549 & 3.17199 & 99999999997 & TST \\
\hline CHEMBL482402 & 515702 & 4.8539 & 4.8088 & TRN & \\
\hline CHEMBL480060 & 515702 & 3.0 & 3.03899 & 99999999997 & TST \\
\hline CHEMBL516909 & 515702 & 5.2218 & 4.8186 & TRN & \\
\hline CHEMBL520113 & 515702 & 3.0 & 3.5151 & TRN & \\
\hline CHEMBL479859 & 515702 & 4.3665 & 4.2051 & TRN & \\
\hline CHEMBL481821 & 515702 & 4.8539 & 4.8163 & TRN & \\
\hline CHEMBL471963 & 515702 & 3.0 & 3.29100 & 00000000004 & TRN \\
\hline CHEMBL479443 & 515702 & 5.5229 & 4.9083 & TRN & \\
\hline CHEMBL480632 & 515702 & 5.5229 & 4.7773 & TRN & \\
\hline CHEMBL516443 & 515702 & 5.301 & 5.3593 & TST & \\
\hline CHEMBL481224 & 515702 & 3.0 & 3.9501 & TRN & \\
\hline CHEMBL479455 & 515702 & 4.1549 & 4.56800 & 00000000005 & TRN \\
\hline CHEMBL480055 & 515702 & 4.8539 & 4.7564 & TST & \\
\hline & & & & 227 & \\
\hline
\end{tabular}




\begin{tabular}{|c|c|c|c|c|c|}
\hline & & \multicolumn{4}{|c|}{ Supplemental Table s2.txt } \\
\hline CHEMBL521430 & 515702 & 4.8239 & 5.5195 & TST & \\
\hline CHEMBL481822 & 515702 & 4.8539 & 4.697 & TRN & \\
\hline CHEMBL481416 & 515702 & 3.0 & 3.3858 & TRN & \\
\hline CHEMBL520255 & 515702 & 5.0969 & 4.8641 & TRN & \\
\hline CHEMBL481430 & 515702 & 3.0 & 2.8761 & TST & \\
\hline CHEMBL479651 & 515702 & 5.5229 & 4.6738 & TRN & \\
\hline CHEMBL520101 & 515702 & 3.0 & 3.2825 & TRN & \\
\hline CHEMBL502727 & 515702 & 3.0 & 3.4099 & TRN & \\
\hline CHEMBL481427 & 515702 & 3.0 & 3.2691 & TRN & \\
\hline CHEMBL481429 & 515702 & 3.0 & 2.6543 & TST & \\
\hline CHEMBL479854 & 515702 & 5.301 & 4.9779 & TST & \\
\hline CHEMBL481428 & 515702 & 4.7959 & 4.5867 & TST & \\
\hline CHEMBL1713770 & 737018 & 3.8069 & 4.5202 & TRN & \\
\hline CHEMBL1701998 & 737018 & 4.6162 & 3.7509 & TRN & \\
\hline CHEMBL1709480 & 737018 & 3.4948 & 3.7681 & TST & \\
\hline CHEMBL1706882 & 737018 & 3.4948 & 3.70600 & 00000000004 & TRN \\
\hline CHEMBL1726562 & 737018 & 4.5719 & 4.1145 & TST & \\
\hline CHEMBL1730076 & 737018 & 4.8794 & 4.5863 & TRN & \\
\hline CHEMBL1449870 & 737018 & 3.4948 & 3.4901 & TRN & \\
\hline CHEMBL1382214 & 737018 & 3.4948 & 3.4748 & TRN & \\
\hline CHEMBL1710129 & 737018 & 3.4948 & 3.7546 & TRN & \\
\hline CHEMBL1708243 & 737018 & 4.6234 & 4.1492 & TST & \\
\hline CHEMBL1707517 & 737018 & 3.7447 & 4.4182 & TRN & \\
\hline CHEMBL1703285 & 737018 & 3.8182 & 3.6991 & TRN & \\
\hline CHEMBL1386647 & 737018 & 3.4948 & 3.7691 & TRN & \\
\hline CHEMBL1586567 & 737018 & 3.4948 & 3.425 & TRN & \\
\hline CHEMBL1729109 & 737018 & 3.4948 & 4.4096 & TRN & \\
\hline CHEMBL1720072 & 737018 & 3.4948 & 3.4308 & TRN & \\
\hline CHEMBL1402210 & 737018 & 3.4948 & 3.5077 & TRN & \\
\hline CHEMBL1420151 & 737018 & 3.4948 & 3.7744 & TRN & \\
\hline CHEMBL1368569 & 737018 & 3.9666 & 3.6313 & TRN & \\
\hline CHEMBL1484306 & 737018 & 3.4948 & 3.6801 & TRN & \\
\hline CHEMBL1718220 & 737018 & 5.4123 & 4.4133 & TRN & \\
\hline CHEMBL1702412 & 737018 & 3.4948 & 3.693 & TRN & \\
\hline CHEMBL1443900 & 737018 & 3.4948 & 3.9976 & TST & \\
\hline CHEMBL1705660 & 737018 & 3.4948 & 3.4637 & TRN & \\
\hline CHEMBL1305795 & 737018 & 3.4948 & 3.62100 & 00000000004 & TRN \\
\hline CHEMBL1721058 & 737018 & 3.4948 & 3.4395 & TRN & \\
\hline CHEMBL1465869 & 737018 & 3.4948 & 3.4903 & TRN & \\
\hline CHEMBL1730381 & 737018 & 3.4948 & 3.4597 & TRN & \\
\hline CHEMBL1336209 & 737018 & 3.4948 & 3.5872 & TRN & \\
\hline CHEMBL1719526 & 737018 & 3.4948 & 3.8734 & TST & \\
\hline CHEMBL1430124 & 737018 & 3.4948 & 3.515 & TRN & \\
\hline CHEMBL1586706 & 737018 & 3.4948 & 3.5055 & TRN & \\
\hline CHEMBL1542448 & 737018 & $4.9830 e$ & 00000000 & 4.4689 & TRN \\
\hline CHEMBL1705807 & 737018 & 3.4948 & 3.6943 & TRN & \\
\hline CHEMBL1698745 & 737018 & 3.4948 & 3.5761 & TRN & \\
\hline CHEMBL1734939 & 737018 & 4.5361 & 4.1096 & TST & \\
\hline
\end{tabular}




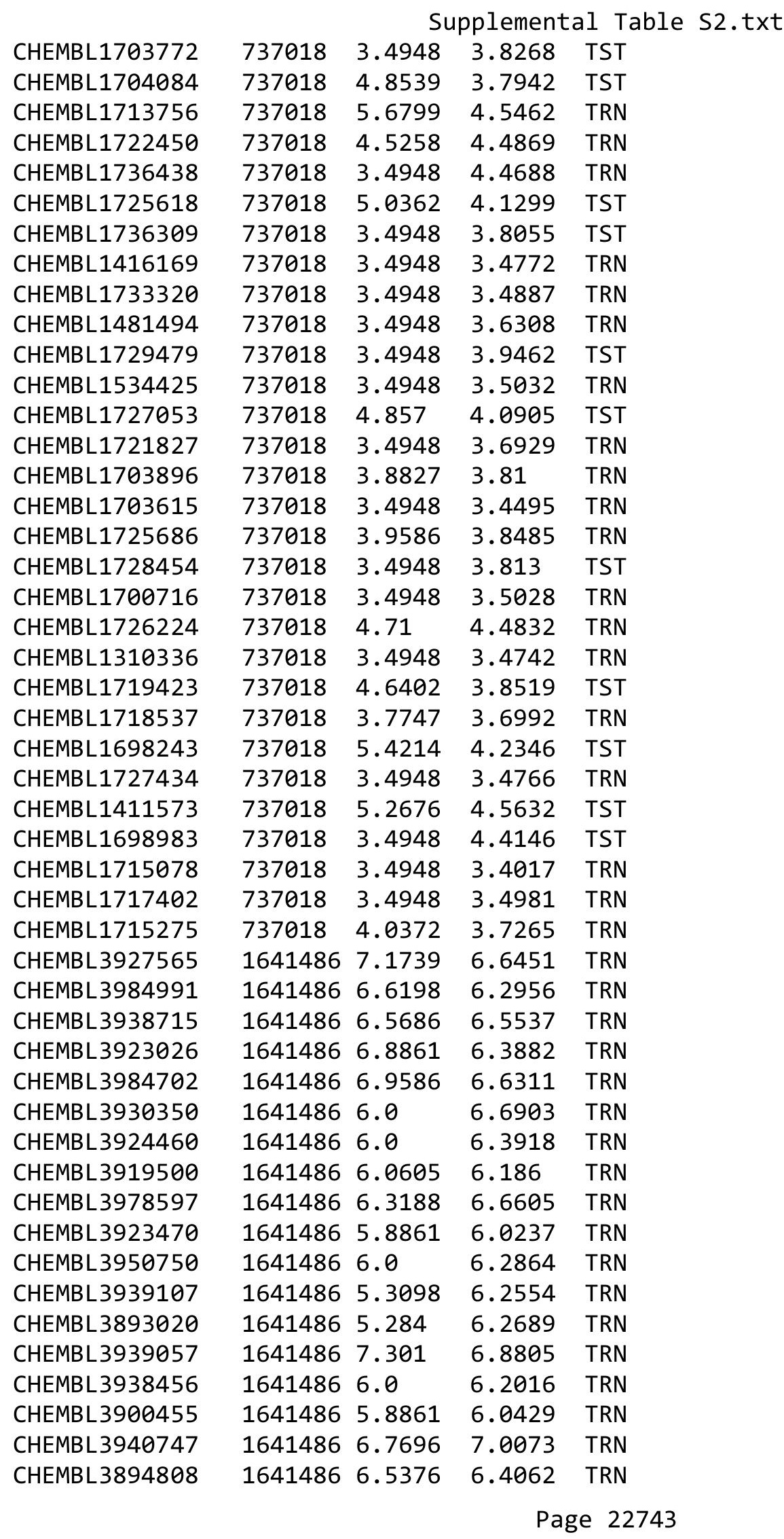


Supplemental Table S2.txt

\begin{tabular}{|c|c|c|c|c|c|}
\hline CHEMBL 3967700 & 1641486 & 7.8239 & 7.3814 & TRN & \\
\hline CHEMBL3921995 & 1641486 & 6.0 & 6.1881 & TST & \\
\hline CHEMBL3929824 & 1641486 & 6.2676 & 6.3731 & TRN & \\
\hline CHEMBL3980984 & 1641486 & 6.0862 & 6.3919 & TRN & \\
\hline CHEMBL3935317 & 1641486 & 7.3098 & 6.9127 & TRN & \\
\hline CHEMBL3915199 & 1641486 & 6.5376 & 6.0358 & TRN & \\
\hline CHEMBL3946472 & 1641486 & 6.0 & 6.7902 & TRN & \\
\hline CHEMBL3956015 & 1641486 & 6.1249 & 6.1962 & TRN & \\
\hline CHEMBL3908610 & 1641486 & 6.2757 & 6.1497 & TRN & \\
\hline CHEMBL3931116 & 1641486 & 6.3279 & 6.4588 & TRN & \\
\hline CHEMBL3942341 & 1641486 & 6.0 & 6.0972 & TRN & \\
\hline CHEMBL3980786 & 1641486 & 7.3188 & 6.8149 & TRN & \\
\hline CHEMBL3914460 & 1641486 & 6.4949 & 6.342006 & 00000000005 & TRN \\
\hline CHEMBL3926284 & 1641486 & 6.0 & 6.2967 & TRN & \\
\hline CHEMBL3918686 & 1641486 & 6.4559 & 6.505 & TRN & \\
\hline CHEMBL3926571 & 1641486 & 7.0 & 6.5267 & TRN & \\
\hline CHEMBL3970677 & 1641486 & 7.4318 & 6.7361 & TST & \\
\hline CHEMBL3958428 & 1641486 & 6.6778 & 6.8905 & TRN & \\
\hline CHEMBL3971370 & 1641486 & 6.8239 & 7.1913 & TRN & \\
\hline CHEMBL3938036 & 1641486 & 6.0 & 6.2936 & TRN & \\
\hline CHEMBL3952644 & 1641486 & 7.8861 & 6.3893 & TRN & \\
\hline CHEMBL3963231 & 1641486 & 6.585 & 6.8245 & TRN & \\
\hline CHEMBL3928808 & 1641486 & 5.6576 & 6.5308 & TRN & \\
\hline CHEMBL3978915 & 1641486 & 6.4559 & 6.5351 & TRN & \\
\hline CHEMBL3967442 & 1641486 & 6.7447 & 6.1581 & TRN & \\
\hline CHEMBL3934888 & 1641486 & 6.8861 & 6.3223 & TST & \\
\hline CHEMBL3939982 & 1641486 & 5.699 & 6.0033 & TST & \\
\hline CHEMBL3917686 & 1641486 & 6.5528 & 6.9308 & TRN & \\
\hline CHEMBL3945666 & 1641486 & 6.0 & 6.3829 & TRN & \\
\hline CHEMBL3975511 & 1641486 & 6.4318 & 5.949 & TRN & \\
\hline CHEMBL3937451 & 1641486 & 5.7447 & 6.1518 & TRN & \\
\hline CHEMBL3962797 & 1641486 & 7.0458 & 7.206 & TRN & \\
\hline CHEMBL3956457 & 1641486 & 6.0 & 6.2654 & TST & \\
\hline CHEMBL3964723 & 1641486 & 7.5229 & 6.853 & TRN & \\
\hline CHEMBL3896332 & 1641486 & 6.0269 & 6.6872 & TST & \\
\hline CHEMBL3931745 & 1641486 & 6.0 & 6.308 & TRN & \\
\hline CHEMBL3942026 & 1641486 & 6.8239 & 7.2622 & TST & \\
\hline CHEMBL3966685 & 1641486 & 6.699 & 6.4839 & TST & \\
\hline CHEMBL3910250 & 1641486 & 7.1871 & $6.49200 t$ & 0000000001 & TRN \\
\hline CHEMBL3939739 & 1641486 & 6.0 & 6.3462 & TRN & \\
\hline CHEMBL3920963 & 1641486 & 5.9208 & 6.1434 & TRN & \\
\hline CHEMBL3973754 & 1641486 & 5.718999 & 99999999 & 6.5172 & TST \\
\hline CHEMBL3980978 & 1641486 & 7.1871 & 6.7031 & TRN & \\
\hline CHEMBL3976141 & 1641486 & 5.9208 & 6.3298 & TRN & \\
\hline CHEMBL3963706 & 1641486 & 6.6021 & 6.3853 & TRN & \\
\hline CHEMBL3905999 & 1641486 & 5.3279 & 6.0997 & TRN & \\
\hline CHEMBL3923071 & 1641486 & 6.8861 & 6.6819 & TRN & \\
\hline CHEMBL3932941 & 1641486 & 7.3565 & 6.8258 & TRN & \\
\hline
\end{tabular}


Supplemental Table S2.txt

\begin{tabular}{|c|c|c|c|c|}
\hline CHEMBL3896581 & 1641486 & 6.1079 & 5.9351 & TRN \\
\hline CHEMBL3909518 & 1641486 & 6.699 & 6.5268 & TST \\
\hline CHEMBL3947216 & 1641486 & 6.4202 & 6.4374 & TRN \\
\hline CHEMBL3903209 & 1641486 & 6.4949 & 6.0498 & TST \\
\hline CHEMBL3902082 & 1641486 & 6.8539 & 6.7922 & TRN \\
\hline CHEMBL 3971482 & 1641486 & 5.6021 & 6.2859 & TRN \\
\hline CHEMBL3982851 & 1641486 & 5.699 & 6.0484 & TRN \\
\hline CHEMBL3901831 & 1641486 & 6.9031 & 6.5979 & TRN \\
\hline CHEMBL3945716 & 1641486 & 7.0044 & 6.5709 & TRN \\
\hline CHEMBL3902854 & 1641486 & 6.6021 & 6.2118 & TRN \\
\hline CHEMBL 3907297 & 1641486 & 7.3098 & 6.4003 & TRN \\
\hline CHEMBL3955158 & 1641486 & 6.6383 & 6.8435 & TRN \\
\hline CHEMBL3931470 & 1641486 & 7.2366 & 6.9389 & TRN \\
\hline CHEMBL3969413 & 1641486 & 6.5528 & 6.6056 & TRN \\
\hline CHEMBL 3964638 & 1641486 & 5.4949 & 6.0215 & TRN \\
\hline CHEMBL 3924417 & 1641486 & 6.0 & 6.2411 & TRN \\
\hline CHEMBL 3942000 & 1641486 & 6.0862 & 6.0356 & TRN \\
\hline CHEMBL3924196 & 1641486 & 6.8861 & 6.4521 & TRN \\
\hline CHEMBL 3914325 & 1641486 & 6.3872 & 6.0255 & TRN \\
\hline CHEMBL3916351 & 1641486 & 7.0969 & 7.1787 & TRN \\
\hline CHEMBL 3895014 & 1641486 & 6.0458 & 6.3577 & TRN \\
\hline CHEMBL3915911 & 1641486 & 7.3979 & 6.8615 & TRN \\
\hline CHEMBL3957776 & 1641486 & 6.2218 & 6.3284 & TST \\
\hline CHEMBL 3917200 & 1641486 & 6.3279 & 6.8932 & TST \\
\hline CHEMBL 3982034 & 1641486 & 7.1367 & 6.99299 & э999999999 \\
\hline CHEMBL 3918481 & 1641486 & 6.699 & 6.1396 & TRN \\
\hline CHEMBL3895095 & 1641486 & 6.2596 & 6.5675 & TRN \\
\hline CHEMBL 3947525 & 1641486 & 6.0 & 6.1345 & TRN \\
\hline CHEMBL3983894 & 1641486 & 6.7959 & 6.5264 & TST \\
\hline CHEMBL3954312 & 1641486 & 6.5086 & 6.6689 & TRN \\
\hline CHEMBL3930537 & 1641486 & 6.301 & 6.2913 & TRN \\
\hline CHEMBL3986332 & 1641486 & 6.4202 & 6.1555 & TRN \\
\hline CHEMBL 3982025 & 1641486 & 7.0605 & 7.1458 & TRN \\
\hline CHEMBL 3956378 & 1641486 & 6.6383 & 6.53299 & 99999999995 \\
\hline CHEMBL3986481 & 1641486 & 5.585 & 6.1071 & TRN \\
\hline CHEMBL3891957 & 1641486 & 5.7447 & 6.138 & TRN \\
\hline CHEMBL3895872 & 1641486 & 6.7212 & 7.0001 & TST \\
\hline CHEMBL3915307 & 1641486 & 6.1739 & 7.3872 & TST \\
\hline CHEMBL 3893576 & 1641486 & 5.4318 & 6.2082 & TRN \\
\hline CHEMBL3904959 & 1641486 & 5.7696 & 6.442 & TRN \\
\hline CHEMBL 3895208 & 1641486 & 6.1487 & 6.5583 & TRN \\
\hline CHEMBL3909697 & 1641486 & 6.6198 & 6.3768 & TRN \\
\hline CHEMBL3954225 & 1641486 & 6.0 & 6.7476 & TRN \\
\hline CHEMBL3903199 & 1641486 & 6.0 & 6.197 & TRN \\
\hline CHEMBL 3950801 & 1641486 & 6.1612 & 6.4361 & TRN \\
\hline CHEMBL 3891834 & 1641486 & 6.4685 & 6.4529 & TRN \\
\hline CHEMBL3985368 & 1641486 & 6.1739 & 6.5178 & TST \\
\hline CHEMBL 3954380 & 1641486 & 5.3468 & 6.0891 & TRN \\
\hline
\end{tabular}

Page 22745 
Supplemental Table S2.txt

\begin{tabular}{|c|c|c|c|c|}
\hline CHEMBL3970409 & 1641486 & 7.2676 & 6.7356 & TRN \\
\hline CHEMBL3901885 & 1641486 & 6.8539 & 6.2453 & TRN \\
\hline CHEMBL3935607 & 1641486 & 6.7447 & 6.1947 & TRN \\
\hline CHEMBL 3977606 & 1641486 & 6.0 & 6.2409 & TRN \\
\hline CHEMBL3953759 & 1641486 & 5.4949 & 6.4591 & TST \\
\hline CHEMBL3955365 & 1641486 & 6.4685 & 6.3511 & TRN \\
\hline CHEMBL3940703 & 1641486 & 6.7212 & 6.7355 & TRN \\
\hline CHEMBL3906181 & 1641486 & 6.4949 & 6.9524 & TRN \\
\hline CHEMBL3917795 & 1641486 & 6.0 & 6.6394 & TRN \\
\hline CHEMBL 3932322 & 1641486 & 6.1871 & 6.0885 & TRN \\
\hline CHEMBL3949144 & 1641486 & 5.9586 & 5.8656 & TRN \\
\hline CHEMBL3949141 & 1641486 & 7.3098 & 7.1644 & TRN \\
\hline CHEMBL3898113 & 1641486 & 5.8861 & 5.7843 & TRN \\
\hline CHEMBL 3896320 & 1641486 & 7.0969 & 7.0602 & TRN \\
\hline CHEMBL3916516 & 1641486 & 6.0809 & 6.5255 & TRN \\
\hline CHEMBL 3896268 & 1641486 & 6.699 & 6.4717 & TRN \\
\hline CHEMBL3923515 & 1641486 & 6.0555 & 6.67299 & 9999999999 \\
\hline CHEMBL3923019 & 1641486 & 7.3979 & 7.2153 & TRN \\
\hline CHEMBL 3927543 & 1641486 & 6.0044 & 6.3669 & TST \\
\hline CHEMBL3898615 & 1641486 & 6.0 & 6.341 & TST \\
\hline CHEMBL 3982747 & 1641486 & 6.5376 & 7.0698 & TRN \\
\hline CHEMBL3935443 & 1641486 & 6.6383 & 6.2717 & TRN \\
\hline CHEMBL3943223 & 1641486 & 5.2676 & 5.8527 & TRN \\
\hline CHEMBL3910567 & 1641486 & 6.6778 & 6.0477 & TRN \\
\hline CHEMBL3967459 & 1641486 & 5.8861 & 6.3605 & TRN \\
\hline CHEMBL3955229 & 1641486 & 6.4685 & 6.2403 & TRN \\
\hline CHEMBL3927094 & 1641486 & 5.8861 & 6.1624 & TRN \\
\hline CHEMBL3897183 & 1641486 & 7.1308 & 6.2249 & TRN \\
\hline CHEMBL3969234 & 1641486 & 6.6021 & 6.3591 & TRN \\
\hline CHEMBL3950718 & 1641486 & 6.3279 & 6.42200 & 3000000001 \\
\hline CHEMBL3973351 & 1641486 & 5.6576 & 6.2363 & TRN \\
\hline CHEMBL3984436 & 1641486 & 6.9586 & 6.3 & TRN \\
\hline CHEMBL3969187 & 1641486 & 6.2596 & 6.3325 & TRN \\
\hline CHEMBL3970665 & 1641486 & 6.5086 & 6.2477 & TRN \\
\hline CHEMBL3914894 & 1641486 & 6.0 & 6.3789 & TST \\
\hline CHEMBL3924111 & 1641486 & 6.0706 & 6.1537 & TRN \\
\hline CHEMBL3921006 & 1641486 & 6.5086 & 6.3675 & TRN \\
\hline CHEMBL3947683 & 1641486 & 6.0 & 6.3013 & TST \\
\hline CHEMBL3917658 & 1641486 & 5.9586 & 5.8529 & TRN \\
\hline CHEMBL3928903 & 1641486 & 6.7447 & 6.3968 & TRN \\
\hline CHEMBL 3944752 & 1641486 & 6.3665 & 5.9846 & TST \\
\hline CHEMBL3957765 & 1641486 & 5.6198 & 5.48799 & 99999999995 \\
\hline CHEMBL3977956 & 1641486 & 6.0132 & 6.6466 & TRN \\
\hline CHEMBL3912008 & 1641486 & 6.5376 & 6.635 & TST \\
\hline CHEMBL3985061 & 1641486 & 6.7447 & 6.7276 & TRN \\
\hline CHEMBL3916181 & 1641486 & 6.2076 & 6.3702 & TST \\
\hline CHEMBL3933436 & 1641486 & 6.8239 & 6.7462 & TRN \\
\hline CHEMBL3987029 & 1641486 & 6.6576 & 6.6549 & TRN \\
\hline
\end{tabular}

Page 22746 
Supplemental Table S2.txt

\begin{tabular}{|c|c|c|c|c|c|}
\hline CHEMBL3958238 & 1641486 & 6.2596 & 5.8832 & TRN & \\
\hline CHEMBL3944675 & 1641486 & 5.6576 & 6.4194 & TRN & \\
\hline CHEMBL3911248 & 1641486 & 6.0 & 6.1542 & TRN & \\
\hline CHEMBL3958618 & 1641486 & 7.0 & 6.8907 & TST & \\
\hline CHEMBL3959945 & 1641486 & 6.2218 & 6.2025 & TST & \\
\hline CHEMBL3970716 & 1641486 & 6.1805 & 5.9774 & TRN & \\
\hline CHEMBL3938846 & 1641486 & 6.1871 & 6.5191 & TST & \\
\hline CHEMBL3896772 & 1641486 & 6.7212 & 6.7713 & TST & \\
\hline CHEMBL3946531 & 1641486 & 6.5528 & 6.6188 & TRN & \\
\hline CHEMBL3904181 & 1641486 & 6.3979 & 6.3726 & TRN & \\
\hline CHEMBL3922619 & 1641486 & 6.2757 & 6.2364 & TRN & \\
\hline CHEMBL3935526 & 1641486 & 6.1079 & 5.8266 & TRN & \\
\hline CHEMBL3968666 & 1641486 & 7.0 & 6.4886 & TRN & \\
\hline CHEMBL3953806 & 1641486 & 6.4815 & 5.9681 & TRN & \\
\hline CHEMBL3891601 & 1641486 & 7.1192 & 6.5643 & TRN & \\
\hline CHEMBL3941070 & 1641486 & 6.5086 & 6.6097 & TRN & \\
\hline CHEMBL3904671 & 1641486 & 6.5686 & 6.7371 & TST & \\
\hline CHEMBL3944518 & 1641486 & 6.3098 & 6.426 & TRN & \\
\hline CHEMBL3894932 & 1641486 & 5.3279 & 5.9719 & TRN & \\
\hline CHEMBL3941459 & 1641486 & 7.0223 & 7.276 & TRN & \\
\hline CHEMBL3911022 & 1641486 & 6.5528 & 6.4237 & TRN & \\
\hline CHEMBL3907265 & 1641486 & 7.4437 & \multicolumn{2}{|c|}{6.4510000000000005} & TRN \\
\hline CHEMBL3962390 & 1641486 & 5.8239 & 6.1437 & TRN & \\
\hline CHEMBL3978932 & 1641486 & 7.0132 & 6.9802 & TRN & \\
\hline CHEMBL 3983823 & 1641486 & 6.7959 & 6.2762 & TRN & \\
\hline CHEMBL 3892295 & 1641486 & 6.2676 & 6.5175 & TST & \\
\hline CHEMBL3917290 & 1641486 & 6.7212 & 6.5694 & TRN & \\
\hline CHEMBL3945477 & 1641486 & 6.9208 & 6.5121 & TRN & \\
\hline CHEMBL3921092 & 1641486 & 5.8827 & 5.9025 & TRN & \\
\hline CHEMBL3903744 & 1641486 & 6.0 & 6.2217 & TRN & \\
\hline CHEMBL3903898 & 1641486 & 6.4437 & 6.1957 & TRN & \\
\hline CHEMBL3922170 & 1641486 & 6.7696 & 6.9778 & TRN & \\
\hline CHEMBL3917394 & 1641486 & 6.0269 & 5.8969 & TST & \\
\hline CHEMBL3930635 & 1641486 & 6.3279 & 6.3573 & TST & \\
\hline CHEMBL3976564 & 1641486 & 6.4559 & 6.1729 & TRN & \\
\hline CHEMBL3957250 & 1641486 & 6.2518 & 6.1067 & TRN & \\
\hline CHEMBL3972656 & 1641486 & 6.0 & 6.2394 & TRN & \\
\hline CHEMBL3892721 & 1641486 & 5.8539 & 6.1267 & TRN & \\
\hline CHEMBL3932671 & 1641486 & 7.4815 & 7.3076 & TRN & \\
\hline CHEMBL 3894004 & 1641486 & 6.1871 & 6.2256 & TRN & \\
\hline CHEMBL3918516 & 1641486 & 6.5686 & 7.1594 & TRN & \\
\hline CHEMBL3891701 & 1641486 & 6.2596 & 6.4217 & TRN & \\
\hline CHEMBL3950211 & 1641486 & 6.7696 & 6.7798 & TRN & \\
\hline CHEMBL3982118 & 1641486 & 6.3468 & 6.31 & TRN & \\
\hline CHEMBL 3892807 & 1641486 & 6.1308 & 6.3478 & TRN & \\
\hline CHEMBL3904818 & 1641486 & 5.2924 & 5.9859 & TRN & \\
\hline CHEMBL 3907873 & 1641486 & 6.7212 & 7.0766 & TRN & \\
\hline CHEMBL3934391 & 1641486 & 5.6198 & 6.1958 & TRN & \\
\hline
\end{tabular}

Page 22747 
Supplemental Table S2.txt

\begin{tabular}{|c|c|c|c|c|}
\hline CHEMBL3943433 & 1641486 & 6.8539 & 6.5639 & TRN \\
\hline CHEMBL3893963 & 1641486 & 7.0458 & 7.0103 & TST \\
\hline CHEMBL3909753 & 1641486 & 6.3565 & 6.2154 & TRN \\
\hline CHEMBL3921491 & 1641486 & 6.0362 & 6.0424 & TRN \\
\hline CHEMBL3941921 & 1641486 & 5.7212 & 6.0412 & TRN \\
\hline CHEMBL3941186 & 1641486 & 6.3372 & 6.1918 & TRN \\
\hline CHEMBL3956964 & 1641486 & 6.6021 & 6.526 & TRN \\
\hline CHEMBL3954834 & 1641486 & 5.5436 & 5.9799 & TRN \\
\hline CHEMBL3974017 & 1641486 & 6.6576 & 7.2605 & TST \\
\hline CHEMBL3963599 & 1641486 & 6.3279 & 6.03799 & 9999999999 \\
\hline CHEMBL3970629 & 1641486 & 6.3565 & 6.5233 & TRN \\
\hline CHEMBL3925619 & 1641486 & 6.6198 & 6.4663 & TRN \\
\hline CHEMBL3979044 & 1641486 & 5.3665 & 5.931 & TRN \\
\hline CHEMBL3982063 & 1641486 & 5.8539 & 6.0061 & TRN \\
\hline CHEMBL3959190 & 1641486 & 7.3372 & 6.7446 & TST \\
\hline CHEMBL3937289 & 1641486 & 6.1739 & 6.0032 & TRN \\
\hline CHEMBL3928406 & 1641486 & 6.3468 & 6.0197 & TRN \\
\hline CHEMBL3944449 & 1641486 & 6.6778 & 6.9195 & TRN \\
\hline CHEMBL3929783 & 1641486 & 7.2076 & 6.8218 & TST \\
\hline CHEMBL3985663 & 1641486 & 6.0 & 6.0789 & TRN \\
\hline CHEMBL3951438 & 1641486 & 6.8239 & 6.2113 & TRN \\
\hline CHEMBL3957603 & 1641486 & 6.0 & 6.3016 & TRN \\
\hline CHEMBL3931980 & 1641486 & 6.5686 & 6.5549 & TST \\
\hline CHEMBL3981304 & 1641486 & 6.9586 & 6.9011 & TRN \\
\hline CHEMBL 3954364 & 1641486 & 6.4949 & 6.5255 & TRN \\
\hline CHEMBL3952946 & 1641486 & 6.5086 & 6.8009 & TRN \\
\hline CHEMBL3912222 & 1641486 & 6.6198 & 6.5935 & TRN \\
\hline CHEMBL3925223 & 1641486 & 5.7696 & 6.0313 & TRN \\
\hline CHEMBL3921592 & 1641486 & 6.7447 & 6.2159 & TRN \\
\hline CHEMBL3914050 & 1641486 & 6.0757 & 6.4653 & TRN \\
\hline CHEMBL3977835 & 1641486 & 6.3098 & 6.2326 & TRN \\
\hline CHEMBL3956591 & 1641486 & 5.7212 & 6.5398 & TRN \\
\hline CHEMBL3926424 & 1641486 & 6.7959 & 6.6384 & TST \\
\hline CHEMBL 3974151 & 1641486 & 6.9586 & 6.2601 & TRN \\
\hline CHEMBL3893027 & 1641486 & 7.6778 & 6.7307 & TRN \\
\hline CHEMBL3939116 & 1641486 & 6.0 & 6.6489 & TRN \\
\hline CHEMBL3975607 & 1641486 & 6.4202 & 6.4026 & TRN \\
\hline CHEMBL3907236 & 1641486 & 6.1024 & 6.4238 & TRN \\
\hline CHEMBL3913562 & 1641486 & 6.2218 & 6.2471 & TRN \\
\hline CHEMBL3969368 & 1641486 & 6.6021 & 6.9616 & TRN \\
\hline CHEMBL3958545 & 1641486 & 6.6198 & 6.3449 & TRN \\
\hline CHEMBL3934259 & 1641486 & 6.0 & 6.3412 & TST \\
\hline CHEMBL3907130 & 1641486 & 6.0362 & 5.6744 & TRN \\
\hline CHEMBL3899335 & 1641486 & 5.4437 & 6.4645 & TST \\
\hline CHEMBL3967930 & 1641486 & 6.0458 & 6.1942 & TRN \\
\hline CHEMBL3940749 & 1641486 & 7.2147 & 6.7265 & TRN \\
\hline CHEMBL3917495 & 1641486 & 6.1612 & 6.4221 & TRN \\
\hline \multirow[t]{2}{*}{ CHEMBL3949991 } & 1641486 & 6.0 & 5.99299 & 9999999999 \\
\hline & & & \multicolumn{2}{|c|}{ Page 22748} \\
\hline
\end{tabular}


Supplemental Table S2.txt

\begin{tabular}{|c|c|c|c|c|}
\hline CHEMBL3952149 & 1641486 & 6.8539 & 6.4837 & TRN \\
\hline CHEMBL 3922942 & 1641486 & 6.699 & 6.0491 & TRN \\
\hline CHEMBL3905599 & 1641486 & 6.6778 & 6.334 & TRN \\
\hline CHEMBL3912136 & 1641486 & 6.5086 & 6.1096 & TRN \\
\hline CHEMBL3946451 & 1641486 & 6.0 & 6.1182 & TRN \\
\hline CHEMBL3913355 & 1641486 & 6.9208 & 6.5237 & TST \\
\hline CHEMBL3982469 & 1641486 & 6.2076 & 6.4568 & TST \\
\hline CHEMBL3937930 & 1641486 & 6.0862 & 6.1542 & TRN \\
\hline CHEMBL 3913821 & 1641486 & 6.4685 & 6.9839 & TST \\
\hline CHEMBL3959667 & 1641486 & 6.1367 & 6.1327 & TRN \\
\hline CHEMBL3913042 & 1641486 & 6.3468 & 6.0478 & TRN \\
\hline CHEMBL3984054 & 1641486 & 6.7212 & 6.3702 & TRN \\
\hline CHEMBL3977809 & 1641486 & 6.8539 & 6.4255 & TRN \\
\hline CHEMBL 3983800 & 1641486 & 6.8239 & 6.7323 & TRN \\
\hline CHEMBL3928349 & 1641486 & 5.6778 & 5.7371 & TRN \\
\hline CHEMBL3910632 & 1641486 & 6.2291 & 6.4717 & TRN \\
\hline CHEMBL3928433 & 1641486 & 6.9208 & 6.5475 & TRN \\
\hline CHEMBL3960279 & 1641486 & 6.6778 & 6.3805 & TST \\
\hline CHEMBL3963892 & 1641486 & 6.2218 & 6.2673 & TRN \\
\hline CHEMBL3954176 & 1641486 & 6.6778 & 6.4725 & TST \\
\hline CHEMBL3961619 & 1641486 & 7.0362 & 7.2676 & TST \\
\hline CHEMBL3964866 & 1641486 & 7.0315 & 6.8574 & TRN \\
\hline CHEMBL3908731 & 1641486 & 7.1249 & 6.6183 & TST \\
\hline CHEMBL3912795 & 1641486 & 6.8239 & 6.0227 & TRN \\
\hline CHEMBL3899505 & 1641486 & 7.5686 & 7.1687 & TRN \\
\hline CHEMBL3922579 & 1641486 & 6.0 & 6.0284 & TRN \\
\hline CHEMBL3974867 & 1641486 & 5.9586 & 6.1988 & TRN \\
\hline CHEMBL 3898567 & 1641486 & 5.7696 & 6.6628 & TRN \\
\hline CHEMBL3906620 & 1641486 & 6.3098 & 5.9973 & TRN \\
\hline CHEMBL 3987087 & 1641486 & 6.3768 & 6.0951 & TRN \\
\hline CHEMBL3901651 & 1641486 & 5.7212 & 5.7794 & TRN \\
\hline CHEMBL 3984283 & 1641486 & 6.3188 & 6.3087 & TRN \\
\hline CHEMBL 3916254 & 1641486 & 7.8861 & 7.1134 & TRN \\
\hline CHEMBL3895391 & 1641486 & 5.5528 & 6.1039 & TRN \\
\hline CHEMBL3958530 & 1641486 & 6.8539 & 6.5466 & TST \\
\hline CHEMBL3972797 & 1641486 & 6.2518 & 6.1947 & TRN \\
\hline CHEMBL3985980 & 1641486 & 5.301 & 5.9831 & TRN \\
\hline CHEMBL3900633 & 1641486 & 6.0 & 6.3409 & TST \\
\hline CHEMBL3987153 & 1641486 & 6.0 & 6.7216 & TST \\
\hline CHEMBL 3948789 & 1641486 & 6.5686 & 6.4357 & TRN \\
\hline CHEMBL3907140 & 1641486 & 6.0 & 6.274 & TRN \\
\hline CHEMBL3982184 & 1641486 & 7.3188 & 6.6601 & TRN \\
\hline CHEMBL3903699 & 1641486 & 6.6576 & 6.9353 & TST \\
\hline CHEMBL3967149 & 1641486 & 6.4815 & $6.5120 €$ & 00000000005 \\
\hline CHEMBL3920132 & 1641486 & 6.8861 & 6.7894 & TST \\
\hline CHEMBL3895982 & 1641486 & 5.6021 & 6.1551 & TST \\
\hline CHEMBL3960634 & 1641486 & 6.0 & 6.3928 & TST \\
\hline CHEMBL3916207 & 1641486 & 7.301 & 6.5765 & TST \\
\hline
\end{tabular}


Supplemental Table S2.txt

\begin{tabular}{|c|c|c|c|c|}
\hline CHEMBL3951254 & 1641486 & 5.9586 & 6.4124 & TST \\
\hline CHEMBL3931240 & 1641486 & 5.8239 & 6.1684 & TST \\
\hline CHEMBL3909147 & 1641486 & 7.0315 & 7.0028 & TST \\
\hline CHEMBL3915314 & 1641486 & 7.1675 & 6.6148 & TST \\
\hline CHEMBL3972942 & 1641486 & 6.7447 & 6.4999 & TST \\
\hline CHEMBL3939690 & 1641486 & 6.0 & 6.6314 & TST \\
\hline CHEMBL3923180 & 1641486 & 6.7696 & 6.7797 & TST \\
\hline CHEMBL3961794 & 1641486 & 6.7696 & 6.3806 & TST \\
\hline CHEMBL3899413 & 1641486 & 6.5229 & 7.0829 & TST \\
\hline CHEMBL3890790 & 1641486 & 6.4949 & 6.9036 & TST \\
\hline CHEMBL 3917148 & 1641486 & 5.7212 & 6.0937 & TST \\
\hline CHEMBL3982446 & 1641486 & 7.1938 & 6.8319 & TST \\
\hline CHEMBL3913430 & 1641486 & 6.4202 & 6.1897 & TST \\
\hline CHEMBL3941131 & 1641486 & 6.9208 & 6.8434 & TST \\
\hline CHEMBL 3917080 & 1641486 & 7.0 & 6.2615 & TST \\
\hline CHEMBL 3914497 & 1641486 & 6.7959 & 7.0213 & TST \\
\hline CHEMBL3943020 & 1641486 & 6.5086 & 6.4428 & TST \\
\hline CHEMBL 3958744 & 1641486 & 6.284 & 6.6433 & TST \\
\hline CHEMBL3953966 & 1641486 & 5.5086 & 6.6425 & TST \\
\hline CHEMBL 3962720 & 1641486 & 6.0362 & 6.3201 & TST \\
\hline CHEMBL 3948965 & 1641486 & 5.5686 & 5.9302 & TST \\
\hline CHEMBL 3959381 & 1641486 & 6.3468 & 6.58299 & 999999999 \\
\hline CHEMBL3957423 & 1641486 & 5.7212 & 6.3327 & TST \\
\hline CHEMBL3906873 & 1641486 & 6.9208 & 6.3744 & TST \\
\hline CHEMBL 3983788 & 1641486 & 6.3768 & 6.0085 & TST \\
\hline CHEMBL 3951078 & 1641486 & 6.8861 & 6.1312 & TST \\
\hline CHEMBL3907647 & 1641486 & 6.041 & 6.3655 & TST \\
\hline CHEMBL372140 & 325793 & 3.9586 & 5.1323 & TST \\
\hline CHEMBL200166 & 325793 & 5.9586 & 5.959 & TRN \\
\hline CHEMBL372139 & 325793 & 4.0044 & 5.1479 & TST \\
\hline CHEMBL200494 & 325793 & 6.1739 & 6.0508 & TRN \\
\hline CHEMBL200545 & 325793 & 2.8239 & 5.1015 & TST \\
\hline CHEMBL200776 & 325793 & 2.8239 & 5.039 & TST \\
\hline CHEMBL200167 & 325793 & 5.5086 & 5.2249 & TRN \\
\hline CHEMBL200775 & 325793 & 2.8239 & 5.1479 & TST \\
\hline CHEMBL200151 & 325793 & 4.1938 & 5.1684 & TST \\
\hline CHEMBL199483 & 325793 & 2.8239 & 5.1116 & TST \\
\hline CHEMBL199470 & 325793 & 5.7696 & 6.0501 & TRN \\
\hline CHEMBL200426 & 325793 & 6.2757 & 6.1225 & TRN \\
\hline CHEMBL200289 & 325793 & 5.0809 & 5.2783 & TRN \\
\hline CHEMBL199214 & 325793 & 6.2676 & 6.13299 & 999999999 \\
\hline CHEMBL200506 & 325793 & 5.8239 & 5.9492 & TRN \\
\hline CHEMBL200287 & 325793 & 6.1192 & 6.0359 & TRN \\
\hline CHEMBL198859 & 325793 & 5.284 & 5.3875 & TRN \\
\hline CHEMBL371059 & 325793 & 2.8239 & 5.1304 & TST \\
\hline CHEMBL 372410 & 325793 & 6.1938 & 6.1582 & TRN \\
\hline CHEMBL371133 & 325793 & 6.3768 & 5.9205 & TRN \\
\hline CHEMBL370165 & 325793 & 6.4202 & 5.7998 & TRN \\
\hline
\end{tabular}

Page 22750 


\begin{tabular}{|c|c|c|c|c|c|}
\hline \multicolumn{6}{|c|}{ Supplemental Table S2.txt } \\
\hline CHEMBL200203 & 325793 & 5.0 & 5.211 & TRN & \\
\hline CHEMBL382971 & 325793 & 4.1549 & 5.1237 & TST & \\
\hline CHEMBL197440 & 325793 & 4.2518 & 5.5448 & TRN & \\
\hline CHEMBL199488 & 325793 & 5.5086 & 5.3116 & TRN & \\
\hline CHEMBL200744 & 325793 & 6.1308 & 6.1644 & TST & \\
\hline CHEMBL370786 & 325793 & 5.6383 & 5.1703 & TRN & \\
\hline CHEMBL200301 & 325793 & 5.0655 & 5.25799 & 9999999999 & TRN \\
\hline CHEMBL200619 & 325793 & 5.8861 & 5.5194 & TRN & \\
\hline CHEMBL200529 & 325793 & 4.2007 & 5.1156 & TST & \\
\hline CHEMBL414669 & 325793 & 6.0506 & 6.0123 & TRN & \\
\hline CHEMBL200672 & 325793 & 6.2924 & 5.6927 & TRN & \\
\hline CHEMBL372977 & 325793 & 2.8239 & 5.2604 & TST & \\
\hline CHEMBL200531 & 325793 & 2.8239 & 5.2459 & TST & \\
\hline CHEMBL199487 & 325793 & 4.8861 & 5.3811 & TRN & \\
\hline CHEMBL426819 & 325793 & 6.0 & 6.0343 & TRN & \\
\hline CHEMBL199163 & 325793 & 4.1192 & 5.7046 & TRN & \\
\hline CHEMBL435913 & 325793 & 6.0605 & 6.0813 & TRN & \\
\hline CHEMBL440035 & 325793 & 5.5686 & 5.4331 & TRN & \\
\hline CHEMBL200599 & 325793 & 5.9586 & 5.3319 & TRN & \\
\hline CHEMBL199358 & 325793 & 5.5086 & 5.8534 & TRN & \\
\hline CHEMBL200602 & 325793 & 5.8861 & 6.08200 & 0000000001 & TRN \\
\hline CHEMBL371771 & 325793 & 5.0315 & 5.5861 & TST & \\
\hline CHEMBL381190 & 325793 & 6.4685 & 6.045 & TRN & \\
\hline CHEMBL383186 & 325793 & 6.1675 & 5.7303 & TRN & \\
\hline CHEMBL381026 & 325793 & 5.4202 & 5.7984 & TRN & \\
\hline CHEMBL200482 & 325793 & 5.1024 & 5.0168 & TRN & \\
\hline CHEMBL200708 & 325793 & 6.041 & 5.93 & TRN & \\
\hline CHEMBL198798 & 325793 & 6.1612 & 6.0661 & TRN & \\
\hline CHEMBL200596 & 325793 & 5.8539 & 6.0876 & TRN & \\
\hline CHEMBL200507 & 325793 & 5.5229 & 5.9847 & TRN & \\
\hline CHEMBL200455 & 325793 & 5.8539 & 6.0424 & TRN & \\
\hline CHEMBL200788 & 325793 & 6.5528 & 5.9007 & TRN & \\
\hline CHEMBL200954 & 325793 & 5.5229 & 5.2793 & TST & \\
\hline CHEMBL199014 & 325793 & 5.7447 & 5.7008 & TRN & \\
\hline CHEMBL 200543 & 325793 & 6.0757 & 6.0516 & TRN & \\
\hline CHEMBL198802 & 325793 & 6.2291 & 6.0817 & TRN & \\
\hline CHEMBL1964290 & 809188 & 5.3 & 4.5772 & TRN & \\
\hline CHEMBL213505 & 809188 & 6.1 & 5.6893 & TRN & \\
\hline CHEMBL202721 & 809188 & 4.4 & 4.5346 & TRN & \\
\hline CHEMBL1987034 & 809188 & 7.0 & 7.532 & TRN & \\
\hline CHEMBL1993941 & 809188 & 7.3 & 7.7016 & TRN & \\
\hline CHEMBL377383 & 809188 & 4.3 & 4.1722 & TRN & \\
\hline CHEMBL578061 & 809188 & 5.7 & 5.638 & TRN & \\
\hline CHEMBL 2005886 & 809188 & 7.0 & 6.5878 & TRN & \\
\hline CHEMBL481491 & 809188 & 4.3 & 4.6827 & TST & \\
\hline CHEMBL1682345 & 809188 & 5.4 & 4.621 & TRN & \\
\hline CHEMBL1973142 & 809188 & 5.5 & 4.9481 & TRN & \\
\hline CHEMBL388311 & 809188 & 6.9 & 6.5451 & TRN & \\
\hline
\end{tabular}




\begin{tabular}{|c|c|c|c|c|}
\hline \multicolumn{5}{|c|}{ Supplemental T } \\
\hline CHEMBL1973145 & 809188 & 6.2 & 5.3318 & TRN \\
\hline CHEMBL1982924 & 809188 & 5.4 & 4.6287 & TRN \\
\hline CHEMBL 2005936 & 809188 & 4.3 & 4.6101 & TRN \\
\hline CHEMBL1807515 & 809188 & 5.4 & 5.0259 & TRN \\
\hline CHEMBL1964948 & 809188 & 4.4 & 4.3394 & TRN \\
\hline CHEMBL1971141 & 809188 & 4.3 & 4.8442 & TRN \\
\hline CHEMBL1995813 & 809188 & 4.3 & 5.063 & TRN \\
\hline CHEMBL1979718 & 809188 & 4.3 & 4.6683 & TRN \\
\hline CHEMBL206236 & 809188 & 4.3 & 4.3193 & TRN \\
\hline CHEMBL1989834 & 809188 & 3.7 & 3.8255 & TRN \\
\hline CHEMBL523823 & 809188 & 4.3 & 4.4607 & TST \\
\hline CHEMBL1562756 & 809188 & 4.3 & 4.4692 & TST \\
\hline CHEMBL1987430 & 809188 & 4.4 & 4.2455 & TRN \\
\hline CHEMBL 244378 & 809188 & 6.3 & 6.4986 & TRN \\
\hline CHEMBL 2001957 & 809188 & 5.4 & 4.7331 & TRN \\
\hline CHEMBL1969372 & 809188 & 4.3 & 4.7207 & TRN \\
\hline CHEMBL1993413 & 809188 & 4.4 & 4.4725 & TRN \\
\hline CHEMBL1990583 & 809188 & 4.3 & 4.7983 & TRN \\
\hline CHEMBL1986943 & 809188 & 5.7 & 5.6505 & TRN \\
\hline CHEMBL 289959 & 809188 & 3.3 & 3.4169 & TRN \\
\hline CHEMBL 2006263 & 809188 & 4.3 & 4.3817 & TST \\
\hline CHEMBL1993584 & 809188 & 4.3 & 4.2751 & TRN \\
\hline CHEMBL1986263 & 809188 & 5.9 & 6.0128 & TRN \\
\hline CHEMBL 2000114 & 809188 & 5.8 & 4.812 & TRN \\
\hline CHEMBL 210618 & 809188 & 4.3 & 4.1709 & TRN \\
\hline CHEMBL1986265 & 809188 & 4.4 & 4.0812 & TRN \\
\hline CHEMBL1975647 & 809188 & 4.3 & 4.8309 & TRN \\
\hline CHEMBL1968380 & 809188 & 4.3 & 4.2296 & TRN \\
\hline CHEMBL1964644 & 809188 & 4.3 & 4.2351 & TRN \\
\hline CHEMBL1991734 & 809188 & 6.0 & 5.4629 & TST \\
\hline CHEMBL1981782 & 809188 & 4.3 & 4.3986 & TRN \\
\hline CHEMBL1977681 & 809188 & 5.4 & 4.8313 & TRN \\
\hline CHEMBL1970142 & 809188 & 7.7 & 7.4767 & TRN \\
\hline CHEMBL1990912 & 809188 & 4.3 & 4.5087 & TRN \\
\hline CHEMBL1991782 & 809188 & 3.1 & 3.1873 & TRN \\
\hline CHEMBL 2002105 & 809188 & 4.3 & 4.3807 & TRN \\
\hline CHEMBL1983348 & 809188 & 5.9 & 5.3244 & TRN \\
\hline CHEMBL1988163 & 809188 & 6.9 & 6.6778 & TRN \\
\hline CHEMBL1995592 & 809188 & 6.0 & 5.5144 & TST \\
\hline CHEMBL 1974480 & 809188 & 6.0 & 4.675 & TRN \\
\hline CHEMBL 2000934 & 809188 & 4.4 & 4.2371 & TRN \\
\hline CHEMBL1980671 & 809188 & 4.6 & 4.8525 & TRN \\
\hline CHEMBL 2006493 & 809188 & 4.3 & 4.3057 & TST \\
\hline CHEMBL1986177 & 809188 & 4.4 & 4.6236 & TRN \\
\hline CHEMBL1996923 & 809188 & 4.3 & 4.1613 & TST \\
\hline CHEMBL1983449 & 809188 & 4.3 & 4.1733 & TRN \\
\hline CHEMBL1992323 & 809188 & 4.3 & 4.3116 & TRN \\
\hline CHEMBL1969735 & 809188 & 4.3 & 4.4805 & TRN \\
\hline
\end{tabular}




\begin{tabular}{|c|c|c|c|c|}
\hline \multirow{3}{*}{$\begin{array}{l}\text { CHEMBL2003524 } \\
\text { CHEMBL } 2002649\end{array}$} & \multirow{2}{*}{809188} & \multicolumn{3}{|c|}{ pplemental } \\
\hline & & 4.3 & 4.4823 & TST \\
\hline & 809188 & 5.9 & 5.6623 & TRN \\
\hline CHEMBL1989423 & 809188 & 3.3 & 3.8206 & TRN \\
\hline CHEMBL1985367 & 809188 & 4.4 & 4.6832 & TST \\
\hline CHEMBL1996510 & 809188 & 4.6 & 4.7325 & TST \\
\hline CHEMBL437747 & 809188 & 4.3 & 4.5888 & TRN \\
\hline CHEMBL1995172 & 809188 & 4.3 & 4.0171 & TST \\
\hline CHEMBL 2001584 & 809188 & 4.4 & 4.2383 & TRN \\
\hline CHEMBL507936 & 809188 & 4.3 & 4.9439 & TRN \\
\hline CHEMBL1971227 & 809188 & 5.4 & 4.8178 & TST \\
\hline CHEMBL104264 & 809188 & 4.3 & 4.9443 & TST \\
\hline CHEMBL1967998 & 809188 & 7.1 & 6.7862 & TRN \\
\hline CHEMBL1994321 & 809188 & 7.5 & 7.1137 & TRN \\
\hline CHEMBL1978562 & 809188 & 5.9 & 4.9879 & TST \\
\hline CHEMBL1997129 & 809188 & 5.7 & 5.3596 & TRN \\
\hline CHEMBL1984788 & 809188 & 4.3 & 4.4354 & TRN \\
\hline CHEMBL451964 & 809188 & 4.3 & 4.1594 & TRN \\
\hline CHEMBL1974875 & 809188 & 4.1 & 4.3006 & TST \\
\hline CHEMBL1964307 & 809188 & 4.3 & 5.7049 & TRN \\
\hline CHEMBL1989471 & 809188 & 4.4 & 5.4851 & TST \\
\hline CHEMBL 2000508 & 809188 & 5.3 & 4.3699 & TRN \\
\hline CHEMBL1971694 & 809188 & 4.3 & 4.235 & TST \\
\hline CHEMBL 2001547 & 809188 & 4.3 & 4.3012 & TRN \\
\hline CHEMBL 210928 & 809188 & 4.3 & 4.2231 & TRN \\
\hline CHEMBL1978195 & 809188 & 4.4 & 5.1401 & TRN \\
\hline CHEMBL1994361 & 809188 & 4.3 & 4.3133 & TRN \\
\hline CHEMBL1986603 & 809188 & 4.3 & 4.5072 & TST \\
\hline CHEMBL1972840 & 809188 & 4.3 & 4.724 & TRN \\
\hline CHEMBL1977148 & 809188 & 7.7 & 6.5959 & TRN \\
\hline CHEMBL1966842 & 809188 & 4.4 & 5.0548 & TRN \\
\hline CHEMBL 2003286 & 809188 & 4.3 & 4.1223 & TRN \\
\hline CHEMBL 2002165 & 809188 & 7.5 & 7.7363 & TRN \\
\hline CHEMBL1979318 & 809188 & 4.3 & 4.7074 & TRN \\
\hline CHEMBL206382 & 809188 & 4.3 & 4.2207 & TRN \\
\hline CHEMBL1998585 & 809188 & 7.7 & 7.0622 & TRN \\
\hline CHEMBL127898 & 809188 & 4.3 & 4.3454 & TST \\
\hline CHEMBL519697 & 809188 & 4.3 & 4.4465 & TRN \\
\hline CHEMBL 2004934 & 809188 & 4.3 & 4.34 & TRN \\
\hline CHEMBL1977619 & 809188 & 3.3 & 3.9233 & TST \\
\hline CHEMBL1996345 & 809188 & 4.4 & 4.8147 & TST \\
\hline CHEMBL1975128 & 809188 & 5.7 & 5.3941 & TRN \\
\hline CHEMBL 2004025 & 809188 & 6.2 & 5.0548 & TRN \\
\hline CHEMBL1996048 & 809188 & 4.4 & 4.3747 & TST \\
\hline CHEMBL1970369 & 809188 & 4.3 & 4.3027 & TRN \\
\hline CHEMBL461876 & 809188 & 4.4 & 4.0361 & TST \\
\hline CHEMBL1965033 & 809188 & 4.4 & 4.4308 & TRN \\
\hline CHEMBL 2001485 & 809188 & 6.8 & 6.9493 & TRN \\
\hline \multirow[t]{2}{*}{ CHEMBL1971519 } & 809188 & 4.2 & 4.4473 & TRN \\
\hline & & & \multicolumn{2}{|c|}{ Page 227} \\
\hline
\end{tabular}




\begin{tabular}{|c|c|c|c|c|c|}
\hline & & & & & \\
\hline CHEMBL504950 & 809188 & 4.3 & 5.0267 & TRN & \\
\hline CHEMBL1997335 & 809188 & 4.4 & 5.0382 & TRN & \\
\hline CHEMBL1966425 & 809188 & 4.3 & 4.3374 & TRN & \\
\hline CHEMBL1984363 & 809188 & 5.3 & 5.5803 & TRN & \\
\hline CHEMBL1978099 & 809188 & 6.6 & 6.4983 & TRN & \\
\hline CHEMBL1977041 & 809188 & 7.3 & 6.6394 & TRN & \\
\hline CHEMBL1968070 & 809188 & 5.5 & 4.7955 & TRN & \\
\hline CHEMBL1988608 & 809188 & 4.3 & 4.3024 & TRN & \\
\hline CHEMBL184847 & 809188 & 4.3 & 4.3178 & TRN & \\
\hline CHEMBL1971132 & 809188 & 4.4 & 4.0112 & TRN & \\
\hline CHEMBL1984367 & 809188 & 4.3 & 4.8365 & TRN & \\
\hline CHEMBL178737 & 809188 & 4.3 & 4.4263 & TST & \\
\hline CHEMBL226898 & 809188 & 4.3 & 4.8318 & TRN & \\
\hline CHEMBL1982563 & 809188 & 4.3 & 4.4481 & TRN & \\
\hline CHEMBL1991377 & 809188 & 4.4 & 4.4776 & TRN & \\
\hline CHEMBL539474 & 809188 & 4.3 & 4.7784 & TST & \\
\hline CHEMBL575824 & 809188 & 4.3 & 4.3129 & TRN & \\
\hline CHEMBL1988387 & 809188 & 7.5 & 7.8098 & TRN & \\
\hline CHEMBL1973868 & 809188 & 4.4 & 4.3152 & TRN & \\
\hline CHEMBL1972462 & 809188 & 4.4 & 4.1808 & TRN & \\
\hline CHEMBL1997759 & 809188 & 4.3 & 4.3935 & TRN & \\
\hline CHEMBL1990288 & 809188 & 4.3 & 4.5236 & TRN & \\
\hline CHEMBL1974803 & 809188 & 4.3 & 4.5913 & TRN & \\
\hline CHEMBL1970074 & 809188 & 4.3 & 5.5256 & TRN & \\
\hline CHEMBL1984500 & 809188 & 3.2 & 3.9999 & TRN & \\
\hline CHEMBL1986970 & 809188 & 4.3 & 4.3657 & TRN & \\
\hline CHEMBL2005112 & 809188 & 4.3 & 4.2638 & TST & \\
\hline CHEMBL1958401 & 809188 & 4.3 & 4.192 & TRN & \\
\hline CHEMBL 2003456 & 809188 & 4.3 & 4.5803 & TRN & \\
\hline CHEMBL1966816 & 809188 & 4.3 & 4.6135 & TRN & \\
\hline CHEMBL1972584 & 809188 & 5.9 & 5.897 & TRN & \\
\hline CHEMBL 2002992 & 809188 & 4.4 & 4.4052 & TRN & \\
\hline CHEMBL560813 & 809188 & 4.3 & 4.4646 & TRN & \\
\hline CHEMBL1982700 & 809188 & 4.4 & 4.2182 & TST & \\
\hline CHEMBL1968791 & 809188 & 5.9 & 5.4434 & TRN & \\
\hline CHEMBL326282 & 809188 & 4.3 & 4.4054 & TST & \\
\hline CHEMBL 2002682 & 809188 & 4.3 & 4.621 & TST & \\
\hline CHEMBL1977634 & 809188 & 4.4 & 4.4678 & TRN & \\
\hline CHEMBL1992732 & 809188 & 4.3 & 4.2419 & TST & \\
\hline CHEMBL1971186 & 809188 & 4.3 & 4.4396 & TRN & \\
\hline CHEMBL 2003482 & 809188 & 4.3 & 4.2303 & TRN & \\
\hline CHEMBL1976872 & 809188 & 3.3 & 3.8041 & TST & \\
\hline CHEMBL 2004887 & 809188 & 4.1 & 4.5511 & TRN & \\
\hline CHEMBL1969156 & 809188 & 4.6 & 4.1399 & TRN & \\
\hline CHEMBL1973211 & 809188 & 7.2 & 7.07299 & 99999999995 & TRN \\
\hline CHEMBL1984700 & 809188 & 5.4 & 4.5054 & TRN & \\
\hline CHEMBL2007151 & 809188 & 6.2 & 5.6046 & TRN & \\
\hline CHEMBL1998953 & 809188 & 4.4 & 5.0023 & TRN & \\
\hline & & & & 22754 & \\
\hline
\end{tabular}




\begin{tabular}{|c|c|c|c|c|}
\hline \\
\hline CHEMBL1971606 & 809188 & 4.4 & 4.1861 & TRN \\
\hline CHEMBL1972125 & 809188 & 4.3 & 4.2114 & TRN \\
\hline CHEMBL1461728 & 809188 & 4.3 & 4.3149 & TRN \\
\hline CHEMBL1999120 & 809188 & 4.2 & 4.2436 & TST \\
\hline CHEMBL1976134 & 809188 & 5.9 & 5.4078 & TRN \\
\hline CHEMBL1965131 & 809188 & 5.5 & 4.9234 & TRN \\
\hline CHEMBL1972158 & 809188 & 4.3 & 4.7285 & TRN \\
\hline CHEMBL1981215 & 809188 & 4.4 & 4.6392 & TRN \\
\hline CHEMBL1974457 & 809188 & 4.3 & 4.5729 & TRN \\
\hline CHEMBL 2006580 & 809188 & 4.3 & 4.3009 & TRN \\
\hline CHEMBL1999414 & 809188 & 7.8 & 7.7616 & TRN \\
\hline CHEMBL1967336 & 809188 & 4.4 & 4.4534 & TRN \\
\hline CHEMBL 2001228 & 809188 & 4.4 & 5.0097 & TRN \\
\hline CHEMBL 2006581 & 809188 & 4.3 & 4.2759 & TRN \\
\hline CHEMBL1979855 & 809188 & 4.3 & 4.2715 & TRN \\
\hline CHEMBL1970340 & 809188 & 4.8 & 4.3468 & TRN \\
\hline CHEMBL1967992 & 809188 & 4.4 & 4.1977 & TRN \\
\hline CHEMBL 2005186 & 809188 & 4.3 & 4.3184 & TRN \\
\hline CHEMBL1981671 & 809188 & 4.4 & 4.4001 & TRN \\
\hline CHEMBL 2006450 & 809188 & 4.4 & 4.4308 & TRN \\
\hline CHEMBL1975534 & 809188 & 4.3 & 4.6664 & TRN \\
\hline CHEMBL1993424 & 809188 & 7.1 & 6.6003 & TRN \\
\hline CHEMBL1966703 & 809188 & 4.3 & 4.402 & TST \\
\hline CHEMBL 2001987 & 809188 & 4.4 & $4.4110 e$ & 00000000005 \\
\hline CHEMBL1969561 & 809188 & 4.3 & 4.475 & TRN \\
\hline CHEMBL1994555 & 809188 & 4.4 & 5.3651 & TST \\
\hline CHEMBL1983640 & 809188 & 6.2 & 5.7121 & TRN \\
\hline CHEMBL1997023 & 809188 & 4.3 & 4.0357 & TST \\
\hline CHEMBL1964687 & 809188 & 4.3 & 5.3436 & TRN \\
\hline CHEMBL1971943 & 809188 & 4.5 & 4.7588 & TRN \\
\hline CHEMBL1999918 & 809188 & 6.5 & 5.5796 & TRN \\
\hline CHEMBL1974254 & 809188 & 7.5 & 7.2603 & TRN \\
\hline CHEMBL1997924 & 809188 & 8.3 & 7.2908 & TRN \\
\hline CHEMBL1988537 & 809188 & 4.3 & 4.6261 & TST \\
\hline CHEMBL1969049 & 809188 & 4.3 & 4.2641 & TRN \\
\hline CHEMBL 2005828 & 809188 & 4.3 & 5.1362 & TRN \\
\hline CHEMBL1978267 & 809188 & 4.4 & 4.5047 & TRN \\
\hline CHEMBL1998611 & 809188 & 4.3 & 5.3266 & TRN \\
\hline CHEMBL485556 & 809188 & 5.7 & 5.0449 & TRN \\
\hline CHEMBL1975900 & 809188 & 4.3 & 4.0706 & TRN \\
\hline CHEMBL 255822 & 809188 & 4.3 & 4.0661 & TRN \\
\hline CHEMBL1972221 & 809188 & 4.3 & 4.4328 & TRN \\
\hline CHEMBL 2006778 & 809188 & 8.8 & 8.7043 & TRN \\
\hline CHEMBL378627 & 809188 & 4.3 & 4.1624 & TRN \\
\hline CHEMBL1996979 & 809188 & 5.4 & 5.3596 & TRN \\
\hline CHEMBL1997025 & 809188 & 4.3 & 4.3728 & TRN \\
\hline CHEMBL1968406 & 809188 & 6.0 & 5.4958 & TRN \\
\hline CHEMBL1975921 & 809188 & 4.3 & 4.3166 & TRN \\
\hline
\end{tabular}

TRN 


\begin{tabular}{|c|c|c|c|c|}
\hline & & & 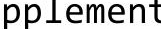 & al Ta \\
\hline CHEMBL1982476 & 809188 & 8.2 & 8.4509 & TRN \\
\hline CHEMBL1998545 & 809188 & 4.3 & 4.228 & TRN \\
\hline CHEMBL1986869 & 809188 & 4.3 & 4.4056 & TRN \\
\hline CHEMBL 2004033 & 809188 & 5.4 & 4.6323 & TST \\
\hline CHEMBL1975923 & 809188 & 6.0 & 4.841 & TST \\
\hline CHEMBL 2005449 & 809188 & 6.1 & 5.7117 & TRN \\
\hline CHEMBL1987998 & 809188 & 4.4 & 4.3644 & TRN \\
\hline CHEMBL 2006010 & 809188 & 4.3 & 4.5401 & TRN \\
\hline CHEMBL1682558 & 809188 & 4.3 & 4.2313 & TRN \\
\hline CHEMBL1971534 & 809188 & 4.2 & 4.48 & TRN \\
\hline CHEMBL1990496 & 809188 & 4.4 & 4.2106 & TRN \\
\hline CHEMBL 242865 & 809188 & 4.4 & 6.0645 & TRN \\
\hline CHEMBL1997623 & 809188 & 4.3 & 5.3301 & TRN \\
\hline CHEMBL 2002479 & 809188 & 4.3 & 4.3447 & TRN \\
\hline CHEMBL1983884 & 809188 & 3.1 & 4.3515 & TST \\
\hline CHEMBL1993166 & 809188 & 4.3 & 4.6397 & TRN \\
\hline CHEMBL1967094 & 809188 & 6.2 & 4.8657 & TRN \\
\hline CHEMBL1966035 & 809188 & 4.3 & 4.3118 & TRN \\
\hline CHEMBL1965437 & 809188 & 5.5 & 5.8738 & TRN \\
\hline CHEMBL 2003341 & 809188 & 4.3 & 4.2561 & TRN \\
\hline CHEMBL1992644 & 809188 & 5.0 & 4.3356 & TRN \\
\hline CHEMBL1992645 & 809188 & 4.3 & 4.5118 & TST \\
\hline CHEMBL1982992 & 809188 & 4.3 & 4.502 & TRN \\
\hline CHEMBL1998110 & 809188 & 4.4 & 4.0968 & TRN \\
\hline CHEMBL1999590 & 809188 & 4.3 & 4.933 & TST \\
\hline CHEMBL1981079 & 809188 & 4.3 & 4.6028 & TRN \\
\hline CHEMBL1978166 & 809188 & 6.8 & 6.7411 & TRN \\
\hline CHEMBL1972276 & 809188 & 4.3 & 4.2363 & TRN \\
\hline CHEMBL1980489 & 809188 & 4.3 & 4.1095 & TRN \\
\hline CHEMBL 2000832 & 809188 & 4.3 & 4.9021 & TRN \\
\hline CHEMBL1967116 & 809188 & 8.1 & 8.3337 & TRN \\
\hline CHEMBL1990590 & 809188 & 4.4 & 4.1533 & TRN \\
\hline CHEMBL1977814 & 809188 & 4.4 & 4.3189 & TST \\
\hline CHEMBL513846 & 809188 & 4.3 & 4.6597 & TRN \\
\hline CHEMBL1970709 & 809188 & 4.3 & 4.3253 & TRN \\
\hline CHEMBL1974617 & 809188 & 4.7 & 4.476 & TRN \\
\hline CHEMBL1965660 & 809188 & 4.4 & 4.8439 & TRN \\
\hline CHEMBL1992125 & 809188 & 5.4 & 5.2983 & TRN \\
\hline CHEMBL1998112 & 809188 & 4.3 & 4.8217 & TRN \\
\hline CHEMBL1969126 & 809188 & 5.7 & 4.3019 & TRN \\
\hline CHEMBL1980896 & 809188 & 6.0 & 5.3213 & TRN \\
\hline CHEMBL1975208 & 809188 & 4.3 & 4.3546 & TST \\
\hline CHEMBL1970104 & 809188 & 6.3 & 6.3404 & TRN \\
\hline CHEMBL1991429 & 809188 & 5.9 & 5.9846 & TRN \\
\hline CHEMBL1964777 & 809188 & 4.3 & 4.7679 & TRN \\
\hline CHEMBL1971149 & 809188 & 4.3 & 4.2676 & TRN \\
\hline CHEMBL1999714 & 809188 & 4.3 & 4.2773 & TRN \\
\hline CHEMBL1987533 & 809188 & 4.3 & 4.2347 & TRN \\
\hline
\end{tabular}




\begin{tabular}{|c|c|c|c|c|}
\hline & & & oplement & al Table S \\
\hline CHEMBL1994040 & 809188 & 4.3 & 4.4882 & TRN \\
\hline CHEMBL388978 & 809188 & 7.4 & 7.4211 & TST \\
\hline CHEMBL579246 & 809188 & 4.3 & 4.3536 & TRN \\
\hline CHEMBL398951 & 809188 & 4.4 & 4.51399 & 9999999999 \\
\hline CHEMBL1982506 & 809188 & 4.3 & 4.5716 & TST \\
\hline CHEMBL 2004716 & 809188 & 7.5 & 8.1808 & TRN \\
\hline CHEMBL1968127 & 809188 & 4.3 & 4.3892 & TRN \\
\hline CHEMBL1975233 & 809188 & 4.3 & 4.4404 & TRN \\
\hline CHEMBL1985406 & 809188 & 4.3 & 4.3607 & TRN \\
\hline CHEMBL2007603 & 809188 & 4.4 & 4.2721 & TRN \\
\hline CHEMBL207400 & 809188 & 4.3 & 4.2223 & TST \\
\hline CHEMBL 2000894 & 809188 & 4.3 & 4.4502 & TST \\
\hline CHEMBL1421720 & 809188 & 6.2 & 4.8198 & TRN \\
\hline CHEMBL1968130 & 809188 & 4.4 & 4.434 & TRN \\
\hline CHEMBL1982135 & 809188 & 5.5 & 4.6796 & TRN \\
\hline CHEMBL1976090 & 809188 & 4.3 & 4.8652 & TRN \\
\hline CHEMBL1993243 & 809188 & 7.3 & 7.7832 & TRN \\
\hline CHEMBL 2004771 & 809188 & 4.3 & 4.4425 & TRN \\
\hline CHEMBL1992922 & 809188 & 5.8 & 5.4699 & TRN \\
\hline CHEMBL399021 & 809188 & 5.4 & 5.2239 & TRN \\
\hline CHEMBL1997597 & 809188 & 4.3 & 4.4639 & TRN \\
\hline CHEMBL1969537 & 809188 & 5.6 & 4.9579 & TST \\
\hline CHEMBL576113 & 809188 & 4.4 & 4.5947 & TRN \\
\hline CHEMBL1976093 & 809188 & 4.3 & 4.4583 & TRN \\
\hline CHEMBL1996543 & 809188 & 4.3 & 4.3383 & TRN \\
\hline CHEMBL1975256 & 809188 & 4.3 & 4.3703 & TST \\
\hline CHEMBL508928 & 809188 & 5.8 & 6.5214 & TRN \\
\hline CHEMBL1991356 & 809188 & 4.3 & 4.556 & TST \\
\hline CHEMBL2004892 & 809188 & 4.3 & 4.3965 & TRN \\
\hline CHEMBL1949855 & 809188 & 5.0 & 4.207 & TRN \\
\hline CHEMBL1997503 & 809188 & 4.3 & 4.6642 & TST \\
\hline CHEMBL116070 & 809188 & 4.3 & 4.425 & TRN \\
\hline CHEMBL1990821 & 809188 & 4.3 & 4.6245 & TST \\
\hline CHEMBL1970314 & 809188 & 4.3 & 4.0945 & TRN \\
\hline CHEMBL 2004871 & 809188 & 4.3 & 4.1985 & TRN \\
\hline CHEMBL2004872 & 809188 & 4.3 & 4.2914 & TRN \\
\hline CHEMBL1727312 & 809188 & 3.6 & 3.7888 & TRN \\
\hline CHEMBL1990223 & 809188 & 4.4 & 4.0612 & TRN \\
\hline CHEMBL1969879 & 809188 & 4.3 & 4.5275 & TRN \\
\hline CHEMBL1964382 & 809188 & 4.4 & 4.459 & TST \\
\hline CHEMBL101311 & 809188 & 5.4 & 5.3135 & TRN \\
\hline CHEMBL1981720 & 809188 & 4.3 & 4.6838 & TRN \\
\hline CHEMBL419932 & 809188 & 4.3 & 4.4384 & TRN \\
\hline CHEMBL262433 & 809188 & 7.4 & 5.9622 & TRN \\
\hline CHEMBL306380 & 809188 & 6.5 & 6.1807 & TRN \\
\hline CHEMBL1986588 & 809188 & 3.3 & 4.2743 & TRN \\
\hline CHEMBL1966722 & 809188 & 4.3 & 4.3188 & TST \\
\hline CHEMBL1988581 & 809188 & 7.2 & 5.6646 & TST \\
\hline
\end{tabular}




\begin{tabular}{|c|c|c|c|c|c|}
\hline & & & & & \\
\hline CHEMBL2005699 & 809188 & 4.4 & 4.1978 & TRN & \\
\hline CHEMBL1975500 & 809188 & 4.3 & 5.0566 & TRN & \\
\hline CHEMBL1976328 & 809188 & 5.8 & 5.3788 & TRN & \\
\hline CHEMBL394619 & 809188 & 6.8 & 5.904 & TRN & \\
\hline CHEMBL2006564 & 809188 & 6.3 & 6.1009 & TRN & \\
\hline CHEMBL1964399 & 809188 & 5.7 & 6.0129 & TRN & \\
\hline CHEMBL1996831 & 809188 & 4.3 & 4.1915 & TST & \\
\hline CHEMBL411903 & 809188 & 5.4 & 5.8971 & TRN & \\
\hline CHEMBL1991008 & 809188 & 4.1 & 4.34 & TRN & \\
\hline CHEMBL1978167 & 809188 & 4.4 & 5.0589 & TST & \\
\hline CHEMBL1965988 & 809188 & 7.6 & 7.0867 & TRN & \\
\hline CHEMBL418203 & 809188 & 4.4 & 4.2694 & TST & \\
\hline CHEMBL1989646 & 809188 & 4.3 & 4.6737 & TRN & \\
\hline CHEMBL1682357 & 809188 & 5.6 & 4.7717 & TRN & \\
\hline CHEMBL225519 & 809188 & 4.4 & 4.3465 & TRN & \\
\hline CHEMBL209534 & 809188 & 4.3 & 4.2543 & TRN & \\
\hline CHEMBL1978200 & 809188 & 4.3 & 4.3573 & TRN & \\
\hline CHEMBL1994159 & 809188 & 4.2 & 4.3316 & TRN & \\
\hline CHEMBL1970522 & 809188 & 4.3 & 4.1254 & TRN & \\
\hline CHEMBL402846 & 809188 & 5.5 & 5.7318 & TRN & \\
\hline CHEMBL1990415 & 809188 & 4.3 & 4.4409 & TRN & \\
\hline CHEMBL1966087 & 809188 & 4.3 & 4.2626 & TRN & \\
\hline CHEMBL1964692 & 809188 & 6.6 & 6.2716 & TRN & \\
\hline CHEMBL1996931 & 809188 & 4.3 & 4.2749 & TRN & \\
\hline CHEMBL1964413 & 809188 & 4.3 & 4.4564 & TRN & \\
\hline CHEMBL1973483 & 809188 & 4.3 & 4.6682 & TRN & \\
\hline CHEMBL1998470 & 809188 & 4.4 & 4.6455 & TRN & \\
\hline CHEMBL1984432 & 809188 & 4.3 & 4.4718 & TRN & \\
\hline CHEMBL1970735 & 809188 & 4.3 & 4.13899 & 9999999999 & TRN \\
\hline CHEMBL219722 & 809188 & 5.7 & 5.9936 & TRN & \\
\hline CHEMBL1975903 & 809188 & 5.6 & 5.44 & TRN & \\
\hline CHEMBL1997340 & 809188 & 4.3 & $4.2810 e$ & 2000000001 & TRN \\
\hline CHEMBL 2004365 & 809188 & 4.3 & 4.1474 & TST & \\
\hline CHEMBL1522508 & 809188 & 4.3 & 3.8787 & TRN & \\
\hline CHEMBL1989474 & 809188 & 4.3 & 4.2621 & TRN & \\
\hline CHEMBL1090360 & 809188 & 6.4 & 5.7554 & TRN & \\
\hline CHEMBL1988805 & 809188 & 4.4 & 4.7688 & TST & \\
\hline CHEMBL458997 & 809188 & 6.2 & 5.6333 & TRN & \\
\hline CHEMBL1971021 & 809188 & 4.3 & 4.5705 & TRN & \\
\hline CHEMBL227271 & 809188 & 4.3 & 4.7283 & TRN & \\
\hline CHEMBL583144 & 809188 & 4.3 & 4.6225 & TRN & \\
\hline CHEMBL1974310 & 809188 & 5.3 & 5.1498 & TRN & \\
\hline CHEMBL1969942 & 809188 & 4.4 & 4.0739 & TRN & \\
\hline CHEMBL1978567 & 809188 & 4.4 & 4.0968 & TRN & \\
\hline CHEMBL1982660 & 809188 & 5.4 & 5.2413 & TRN & \\
\hline CHEMBL1994693 & 809188 & 5.3 & 5.2406 & TRN & \\
\hline CHEMBL1982957 & 809188 & 6.0 & 6.2731 & TRN & \\
\hline CHEMBL1725279 & 809188 & 6.6 & 5.8207 & TST & \\
\hline & & & & 22758 & \\
\hline
\end{tabular}




\begin{tabular}{|c|c|c|c|c|c|}
\hline \\
\hline CHEMBL 2002346 & 809188 & 6.1 & 5.2989 & TRN & \\
\hline CHEMBL1975138 & 809188 & 4.3 & 4.1939 & TST & \\
\hline CHEMBL424872 & 809188 & 4.4 & 4.0738 & TRN & \\
\hline CHEMBL2006836 & 809188 & 4.3 & 4.3193 & TST & \\
\hline CHEMBL1971947 & 809188 & 7.6 & 6.3425 & TRN & \\
\hline CHEMBL412142 & 809188 & 4.3 & 4.6569 & TST & \\
\hline CHEMBL1980704 & 809188 & 4.3 & 4.2535 & TST & \\
\hline CHEMBL2003271 & 809188 & 5.4 & 4.7819 & TRN & \\
\hline CHEMBL1972365 & 809188 & 5.0 & 4.4155 & TRN & \\
\hline CHEMBL1966808 & 809188 & 4.3 & 4.1958 & TRN & \\
\hline CHEMBL 2004447 & 809188 & 4.3 & 4.3664 & TRN & \\
\hline CHEMBL1983111 & 809188 & 7.7 & 7.3784 & TRN & \\
\hline CHEMBL1973860 & 809188 & 4.3 & 4.301 & TRN & \\
\hline CHEMBL260135 & 809188 & 4.3 & 4.59699 & 99999999995 & TRN \\
\hline CHEMBL220241 & 809188 & 4.3 & 4.5577 & TRN & \\
\hline CHEMBL 2004544 & 809188 & 4.3 & 4.3604 & TST & \\
\hline CHEMBL1988141 & 809188 & 6.8 & 4.9179 & TST & \\
\hline CHEMBL1982610 & 809188 & 5.5 & 4.3554 & TST & \\
\hline CHEMBL1977134 & 809188 & 4.4 & 5.7952 & TRN & \\
\hline CHEMBL1999496 & 809188 & 4.3 & 4.473 & TRN & \\
\hline CHEMBL1970873 & 809188 & 3.6 & 4.1235 & TRN & \\
\hline CHEMBL2006933 & 809188 & 6.1 & 4.9817 & TST & \\
\hline CHEMBL1985206 & 809188 & 4.4 & 4.2495 & TST & \\
\hline CHEMBL1988300 & 809188 & 6.4 & 6.88899 & 9999999999 & TRN \\
\hline CHEMBL1991078 & 809188 & 6.3 & 6.3758 & TRN & \\
\hline CHEMBL1987359 & 809188 & 4.3 & 4.453 & TST & \\
\hline CHEMBL1977749 & 809188 & 4.4 & 4.4332 & TST & \\
\hline CHEMBL1975212 & 809188 & 4.7 & 4.9772 & TRN & \\
\hline CHEMBL 2000685 & 809188 & 4.3 & 5.1272 & TRN & \\
\hline CHEMBL2001613 & 809188 & 4.5 & 4.34 & TRN & \\
\hline CHEMBL1997275 & 809188 & 4.4 & 4.5918 & TRN & \\
\hline CHEMBL1993904 & 809188 & 5.7 & 4.8897 & TRN & \\
\hline CHEMBL1980376 & 809188 & 4.1 & 4.3489 & TRN & \\
\hline CHEMBL1967513 & 809188 & 4.4 & 4.30399 & 9999999999 & TRN \\
\hline CHEMBL 2000724 & 809188 & 4.4 & 4.3117 & TRN & \\
\hline CHEMBL1985311 & 809188 & 5.6 & 5.92899 & 9999999999 & TRN \\
\hline CHEMBL1989265 & 809188 & 4.3 & 4.3487 & TST & \\
\hline CHEMBL1982413 & 809188 & 5.8 & 4.5618 & TST & \\
\hline CHEMBL1969502 & 809188 & 7.0 & 6.6338 & TRN & \\
\hline CHEMBL1965910 & 809188 & 5.7 & 5.3844 & TRN & \\
\hline CHEMBL1682553 & 809188 & 4.3 & 4.436 & TRN & \\
\hline CHEMBL1971430 & 809188 & 4.3 & 4.34 & TRN & \\
\hline CHEMBL1983963 & 809188 & 6.5 & 5.9588 & TRN & \\
\hline CHEMBL1997764 & 809188 & 4.3 & 4.5573 & TRN & \\
\hline CHEMBL 2000271 & 809188 & 5.3 & 5.1736 & TRN & \\
\hline CHEMBL562488 & 809188 & 3.3 & 3.9817 & TRN & \\
\hline CHEMBL1981792 & 809188 & 5.5 & 4.3433 & TRN & \\
\hline CHEMBL1987535 & 809188 & 4.4 & 4.6428 & TRN & \\
\hline & & & & 2275 & \\
\hline
\end{tabular}




\begin{tabular}{|c|c|c|c|c|c|}
\hline \multirow[b]{2}{*}{ CHEMBL1985092 } & \multirow[b]{2}{*}{809188} & \\
\hline & & 4.3 & 4.6832 & TRN & \\
\hline CHEMBL 2004692 & 809188 & 4.3 & 4.2921 & TST & \\
\hline CHEMBL1981410 & 809188 & 4.3 & 5.2794 & TRN & \\
\hline CHEMBL2002586 & 809188 & 4.4 & 5.0536 & TRN & \\
\hline CHEMBL1987815 & 809188 & 4.2 & 4.0808 & TST & \\
\hline CHEMBL1996234 & 809188 & 5.3 & 5.0186 & TRN & \\
\hline CHEMBL383264 & 809188 & 4.4 & 4.6506 & TRN & \\
\hline CHEMBL2007421 & 809188 & 7.6 & 5.8835 & TST & \\
\hline CHEMBL1991434 & 809188 & 4.3 & 4.3257 & TST & \\
\hline CHEMBL1967544 & 809188 & 4.3 & 4.4829 & TRN & \\
\hline CHEMBL1973138 & 809188 & 4.4 & 4.1989 & TRN & \\
\hline CHEMBL223367 & 809188 & 4.3 & 4.4388 & TST & \\
\hline CHEMBL1992673 & 809188 & 4.2 & 4.2028 & TRN & \\
\hline CHEMBL340384 & 809188 & 5.4 & 4.8858 & TST & \\
\hline CHEMBL1969151 & 809188 & 4.4 & 4.8726 & TRN & \\
\hline CHEMBL1996587 & 809188 & 4.3 & 4.3756 & TRN & \\
\hline CHEMBL1993335 & 809188 & 6.3 & 5.4381 & TST & \\
\hline CHEMBL1988692 & 809188 & 5.6 & 5.1377 & TRN & \\
\hline CHEMBL 2007574 & 809188 & 4.4 & 4.6972 & TRN & \\
\hline CHEMBL1964804 & 809188 & 4.3 & 4.3257 & TRN & \\
\hline CHEMBL443962 & 809188 & 5.4 & 4.9044 & TST & \\
\hline CHEMBL 2000354 & 809188 & 4.3 & 4.2953 & TRN & \\
\hline CHEMBL1965507 & 809188 & 4.4 & 4.5924 & TRN & \\
\hline CHEMBL274064 & 809188 & 4.3 & 4.6813 & TRN & \\
\hline CHEMBL1998680 & 809188 & 4.4 & 4.2372 & TRN & \\
\hline CHEMBL1967564 & 809188 & 4.3 & 4.29899 & 99999999995 & TRN \\
\hline CHEMBL592030 & 809188 & 4.4 & 4.421 & TST & \\
\hline CHEMBL 2000071 & 809188 & 5.6 & 5.34399 & 9999999999 & TRN \\
\hline CHEMBL1979176 & 809188 & 4.3 & 4.8577 & TRN & \\
\hline CHEMBL1970317 & 809188 & 5.8 & 7.8627 & TRN & \\
\hline CHEMBL2000408 & 809188 & 4.3 & 4.5657 & TRN & \\
\hline CHEMBL 248757 & 809188 & 4.3 & 4.2651 & TST & \\
\hline CHEMBL1978014 & 809188 & 4.3 & 4.3707 & TRN & \\
\hline CHEMBL2002736 & 809188 & 4.4 & 4.4814 & TRN & \\
\hline CHEMBL1997007 & 809188 & 4.4 & 4.6692 & TRN & \\
\hline CHEMBL1994538 & 809188 & 4.3 & 4.6418 & TRN & \\
\hline CHEMBL1983195 & 809188 & 4.3 & 4.1106 & TST & \\
\hline CHEMBL1975490 & 809188 & 4.3 & 4.4097 & TRN & \\
\hline CHEMBL1964444 & 809188 & 4.4 & 4.4231 & TRN & \\
\hline CHEMBL 2002690 & 809188 & 4.4 & 4.7622 & TRN & \\
\hline CHEMBL2006567 & 809188 & 4.3 & 4.2029 & TRN & \\
\hline CHEMBL1986139 & 809188 & 4.3 & 4.1834 & TRN & \\
\hline CHEMBL383527 & 809188 & 4.3 & 4.7048 & TRN & \\
\hline CHEMBL1980540 & 809188 & 4.3 & 4.4227 & TRN & \\
\hline CHEMBL278041 & 809188 & 4.4 & 4.2927 & TRN & \\
\hline CHEMBL1979883 & 809188 & 7.0 & 7.0667 & TRN & \\
\hline CHEMBL1984162 & 809188 & 8.1 & 7.4809 & TRN & \\
\hline CHEMBL1997051 & 809188 & 4.4 & 5.0943 & TRN & \\
\hline & & & & 22760 & \\
\hline
\end{tabular}




\begin{tabular}{|c|c|c|c|c|c|}
\hline \\
\hline CHEMBL491758 & 809188 & 5.9 & 6.4428 & TRN & \\
\hline CHEMBL1986590 & 809188 & 4.4 & 4.6574 & TRN & \\
\hline CHEMBL549730 & 809188 & 4.3 & 4.2304 & TRN & \\
\hline CHEMBL1682360 & 809188 & 4.3 & 4.7099 & TRN & \\
\hline CHEMBL1970189 & 809188 & 4.3 & 4.5245 & TRN & \\
\hline CHEMBL1870106 & 809188 & 4.4 & 4.4205 & TRN & \\
\hline CHEMBL1996791 & 809188 & 4.3 & 4.9182 & TRN & \\
\hline CHEMBL371206 & 809188 & 7.6 & 6.5447 & TRN & \\
\hline CHEMBL1974664 & 809188 & 5.5 & 5.0391 & TST & \\
\hline CHEMBL1998477 & 809188 & 5.7 & 4.7259 & TRN & \\
\hline CHEMBL406845 & 809188 & 4.4 & 5.5465 & TRN & \\
\hline CHEMBL482538 & 809188 & 4.6 & 4.5282 & TRN & \\
\hline CHEMBL1974288 & 809188 & 4.3 & 4.3254 & TRN & \\
\hline CHEMBL1984296 & 809188 & 5.8 & 5.0952 & TST & \\
\hline CHEMBL196363 & 809188 & 7.4 & 6.7338 & TRN & \\
\hline CHEMBL1996837 & 809188 & 3.3 & 4.0835 & TRN & \\
\hline CHEMBL1190711 & 809188 & 4.3 & 4.34399 & 9999999999 & TRN \\
\hline CHEMBL1990346 & 809188 & 5.5 & 4.689 & TRN & \\
\hline CHEMBL1968705 & 809188 & 4.4 & 4.1973 & TRN & \\
\hline CHEMBL1991410 & 809188 & 4.4 & 4.5603 & TRN & \\
\hline CHEMBL1964441 & 809188 & 6.7 & 6.6881 & TRN & \\
\hline CHEMBL546797 & 809188 & 5.6 & 4.8065 & TRN & \\
\hline CHEMBL404367 & 809188 & 5.7 & 5.8552 & TRN & \\
\hline CHEMBL1966343 & 809188 & 4.3 & 4.6632 & TRN & \\
\hline CHEMBL1978271 & 809188 & 4.4 & 4.2263 & TRN & \\
\hline CHEMBL1967887 & 809188 & 4.3 & 4.5039 & TRN & \\
\hline CHEMBL 2007266 & 809188 & 4.4 & 4.9102 & TRN & \\
\hline CHEMBL 2000568 & 809188 & 4.4 & 4.4964 & TRN & \\
\hline CHEMBL1994308 & 809188 & 4.4 & 4.4458 & TRN & \\
\hline CHEMBL 2000335 & 809188 & 7.8 & 6.7691 & TRN & \\
\hline CHEMBL1980161 & 809188 & 3.3 & 4.2985 & TRN & \\
\hline CHEMBL 2007097 & 809188 & 4.3 & 4.2631 & TRN & \\
\hline CHEMBL1988717 & 809188 & 6.4 & 6.6933 & TRN & \\
\hline CHEMBL1974328 & 809188 & 5.5 & 5.0913 & TRN & \\
\hline CHEMBL509032 & 809188 & 7.6 & 7.0535 & TRN & \\
\hline CHEMBL143703 & 809188 & 3.3 & 4.5079 & TRN & \\
\hline CHEMBL1973808 & 809188 & 4.3 & 4.178 & TRN & \\
\hline CHEMBL 2000429 & 809188 & 5.7 & 4.3771 & TRN & \\
\hline CHEMBL1972576 & 809188 & 4.3 & 4.6733 & TRN & \\
\hline CHEMBL1992555 & 809188 & 4.3 & 4.5941 & TRN & \\
\hline CHEMBL1989069 & 809188 & 5.0 & 4.5402 & TRN & \\
\hline CHEMBL1992342 & 809188 & 4.3 & 4.5708 & TRN & \\
\hline CHEMBL 2002202 & 809188 & 4.2 & 4.084 & TRN & \\
\hline CHEMBL1988173 & 809188 & 4.3 & 4.4788 & TST & \\
\hline CHEMBL1973013 & 809188 & 5.6 & 5.1677 & TST & \\
\hline CHEMBL1164265 & 809188 & 6.1 & 5.2777 & TST & \\
\hline CHEMBL535331 & 809188 & 4.3 & 4.5331 & TRN & \\
\hline CHEMBL1989805 & 809188 & 4.3 & 4.466 & TST & \\
\hline & & & & 22761 & \\
\hline
\end{tabular}




\begin{tabular}{|c|c|c|c|c|}
\hline & & & pplement & al $\mathrm{Ta}$ \\
\hline CHEMBL1982980 & 809188 & 4.3 & 4.6188 & TST \\
\hline CHEMBL1965423 & 809188 & 5.4 & 4.6778 & TRN \\
\hline CHEMBL1983025 & 809188 & 6.7 & 6.8344 & TRN \\
\hline CHEMBL1975927 & 809188 & 6.0 & 5.8988 & TRN \\
\hline CHEMBL205415 & 809188 & 4.4 & 4.3911 & TRN \\
\hline CHEMBL1977135 & 809188 & 4.3 & 4.301 & TRN \\
\hline CHEMBL 2001920 & 809188 & 4.3 & 4.4743 & TRN \\
\hline CHEMBL2002322 & 809188 & 4.3 & 4.6238 & TRN \\
\hline CHEMBL1977138 & 809188 & 6.9 & 5.4262 & TST \\
\hline CHEMBL2002323 & 809188 & 4.3 & 4.4433 & TRN \\
\hline CHEMBL1241473 & 809188 & 7.5 & 7.0516 & TRN \\
\hline CHEMBL1978448 & 809188 & 4.4 & 4.1386 & TST \\
\hline CHEMBL1972258 & 809188 & 4.3 & 4.2441 & TRN \\
\hline CHEMBL1969483 & 809188 & 5.5 & 5.103 & TRN \\
\hline CHEMBL1980329 & 809188 & 5.9 & 5.7589 & TRN \\
\hline CHEMBL 2004515 & 809188 & 4.8 & 5.0408 & TRN \\
\hline CHEMBL2001257 & 809188 & 6.2 & 6.7422 & TRN \\
\hline CHEMBL1992042 & 809188 & 6.1 & 4.8225 & TST \\
\hline CHEMBL 2005548 & 809188 & 4.3 & 4.2448 & TRN \\
\hline CHEMBL1987793 & 809188 & 4.3 & 4.746 & TST \\
\hline CHEMBL1992536 & 809188 & 4.3 & 4.1769 & TRN \\
\hline CHEMBL 21156 & 809188 & 4.4 & 4.4575 & TST \\
\hline CHEMBL1992740 & 809188 & 4.3 & 4.3658 & TRN \\
\hline CHEMBL1994724 & 809188 & 4.4 & 4.3228 & TRN \\
\hline CHEMBL1989267 & 809188 & 5.5 & 7.0753 & TRN \\
\hline CHEMBL 2002373 & 809188 & 4.3 & 4.3066 & TRN \\
\hline CHEMBL439340 & 809188 & 4.3 & 4.3263 & TRN \\
\hline CHEMBL1974574 & 809188 & 4.4 & 4.5744 & TST \\
\hline CHEMBL 2006188 & 809188 & 4.3 & 4.3335 & TRN \\
\hline CHEMBL1970290 & 809188 & 5.4 & 4.9397 & TRN \\
\hline CHEMBL1967531 & 809188 & 6.4 & 5.9414 & TRN \\
\hline CHEMBL1970913 & 809188 & 4.3 & 4.3808 & TRN \\
\hline CHEMBL1973893 & 809188 & 4.3 & 4.5188 & TRN \\
\hline CHEMBL1995736 & 809188 & 4.3 & 4.255 & TRN \\
\hline CHEMBL1997534 & 809188 & 4.3 & 4.6564 & TRN \\
\hline CHEMBL1993877 & 809188 & 5.5 & 5.3654 & TRN \\
\hline CHEMBL1985095 & 809188 & 4.3 & 4.9394 & TST \\
\hline CHEMBL1996500 & 809188 & 4.4 & 4.1291 & TRN \\
\hline CHEMBL1977374 & 809188 & 4.3 & 4.3883 & TRN \\
\hline CHEMBL1991180 & 809188 & 4.3 & 4.9955 & TST \\
\hline CHEMBL1682540 & 809188 & 4.3 & 4.3574 & TRN \\
\hline CHEMBL1976420 & 809188 & 5.6 & 5.5971 & TST \\
\hline CHEMBL1998253 & 809188 & 4.4 & 4.3291 & TST \\
\hline CHEMBL413779 & 809188 & 4.3 & 4.6671 & TST \\
\hline CHEMBL1994864 & 809188 & 4.3 & 4.152 & TRN \\
\hline CHEMBL1981744 & 809188 & 4.4 & 4.4986 & TRN \\
\hline CHEMBL 2002446 & 809188 & 5.9 & 5.7266 & TST \\
\hline CHEMBL497151 & 809188 & 5.4 & 4.4002 & TRN \\
\hline
\end{tabular}




\begin{tabular}{|c|c|c|c|c|}
\hline & & & upplement & al $\mathrm{Ta}$ \\
\hline CHEMBL 2000029 & 809188 & 4.4 & 4.4934 & TRN \\
\hline CHEMBL1973961 & 809188 & 4.4 & 4.2701 & TRN \\
\hline CHEMBL246970 & 809188 & 4.3 & 4.6065 & TRN \\
\hline CHEMBL340921 & 809188 & 4.3 & 4.461 & TST \\
\hline CHEMBL1994977 & 809188 & 4.4 & 4.2193 & TRN \\
\hline CHEMBL373598 & 809188 & 4.3 & 4.4488 & TST \\
\hline CHEMBL 2001149 & 809188 & 4.4 & 4.6475 & TRN \\
\hline CHEMBL1999718 & 809188 & 4.3 & 4.5078 & TRN \\
\hline CHEMBL 2000078 & 809188 & 4.4 & 5.1971 & TRN \\
\hline CHEMBL1276446 & 809188 & 7.6 & 6.7924 & TST \\
\hline CHEMBL 2005478 & 809188 & 6.1 & 5.1203 & TST \\
\hline CHEMBL1996646 & 809188 & 5.8 & 5.647 & TRN \\
\hline CHEMBL1979773 & 809188 & 4.4 & 4.2784 & TRN \\
\hline CHEMBL1977346 & 809188 & 5.8 & 5.2568 & TRN \\
\hline CHEMBL 2003657 & 809188 & 5.7 & 4.9225 & TRN \\
\hline CHEMBL1971649 & 809188 & 4.3 & 4.7165 & TRN \\
\hline CHEMBL 2005482 & 809188 & 6.4 & 5.9604 & TRN \\
\hline CHEMBL1996702 & 809188 & 4.4 & 5.0947 & TRN \\
\hline CHEMBL1997909 & 809188 & 4.4 & 5.2285 & TRN \\
\hline CHEMBL 2007124 & 809188 & 4.4 & 4.5048 & TRN \\
\hline CHEMBL 2006439 & 809188 & 4.4 & 5.0985 & TRN \\
\hline CHEMBL 2006156 & 809188 & 4.3 & 4.2214 & TST \\
\hline CHEMBL1985681 & 809188 & 5.5 & 4.6763 & TST \\
\hline CHEMBL1969190 & 809188 & 5.8 & 5.8766 & TRN \\
\hline CHEMBL1973937 & 809188 & 5.8 & 5.8102 & TRN \\
\hline CHEMBL1991674 & 809188 & 4.7 & 5.0413 & TRN \\
\hline CHEMBL1982711 & 809188 & 4.4 & 4.8303 & TRN \\
\hline CHEMBL262623 & 809188 & 4.2 & 4.6037 & TRN \\
\hline CHEMBL1984842 & 809188 & 4.4 & 4.5118 & TRN \\
\hline CHEMBL1969102 & 809188 & 7.9 & 8.0732 & TRN \\
\hline CHEMBL 2004118 & 809188 & 4.4 & 4.934 & TRN \\
\hline CHEMBL1682346 & 809188 & 5.5 & 4.9551 & TRN \\
\hline CHEMBL 2007044 & 809188 & 4.3 & 4.2531 & TST \\
\hline CHEMBL2001998 & 809188 & 5.5 & 4.6641 & TST \\
\hline CHEMBL1994241 & 809188 & 4.3 & 4.465 & TRN \\
\hline CHEMBL 223460 & 809188 & 4.3 & 4.4353 & TST \\
\hline CHEMBL1998829 & 809188 & 4.3 & 4.7119 & TRN \\
\hline CHEMBL50894 & 809188 & 5.4 & 4.9279 & TRN \\
\hline CHEMBL1995211 & 809188 & 4.4 & 4.8968 & TRN \\
\hline CHEMBL1988838 & 809188 & 6.7 & 6.9985 & TRN \\
\hline CHEMBL1981725 & 809188 & 7.6 & 6.3802 & TRN \\
\hline CHEMBL1982753 & 809188 & 4.4 & 4.5252 & TRN \\
\hline CHEMBL 375284 & 809188 & 4.3 & 5.2815 & TRN \\
\hline CHEMBL 2006299 & 809188 & 4.4 & 4.0469 & TRN \\
\hline CHEMBL1972346 & 809188 & 6.2 & 4.7992 & TST \\
\hline CHEMBL1965169 & 809188 & 4.4 & 4.6306 & TST \\
\hline CHEMBL1991818 & 809188 & 4.4 & 4.6705 & TST \\
\hline CHEMBL1081312 & 809188 & 7.0 & 6.3365 & TRN \\
\hline
\end{tabular}




\begin{tabular}{|c|c|c|c|c|c|}
\hline & & & & & \\
\hline CHEMBL1965170 & 809188 & 6.3 & 6.64 & TRN & \\
\hline CHEMBL1982866 & 809188 & 4.3 & 4.2768 & TRN & \\
\hline CHEMBL2005792 & 809188 & 4.4 & 4.4628 & TRN & \\
\hline CHEMBL1968926 & 809188 & 4.3 & 4.3256 & TRN & \\
\hline CHEMBL1984206 & 809188 & 4.3 & 4.2189 & TRN & \\
\hline CHEMBL462120 & 809188 & 4.3 & 4.5602 & TRN & \\
\hline CHEMBL1991577 & 809188 & 4.3 & 4.0957 & TRN & \\
\hline CHEMBL1991867 & 809188 & 3.2 & 4.6542 & TST & \\
\hline CHEMBL1986503 & 809188 & 4.4 & 4.303 & TST & \\
\hline CHEMBL2007592 & 809188 & 4.3 & 4.2449 & TRN & \\
\hline CHEMBL1965570 & 809188 & 6.7 & 6.6877 & TRN & \\
\hline CHEMBL1972355 & 809188 & 6.3 & 5.3899 & TST & \\
\hline CHEMBL1997892 & 809188 & 4.4 & 4.7403 & TRN & \\
\hline CHEMBL2001641 & 809188 & 4.4 & 4.2577 & TRN & \\
\hline CHEMBL1997193 & 809188 & 6.0 & 4.621 & TST & \\
\hline CHEMBL210963 & 809188 & 4.3 & 4.1279 & TRN & \\
\hline CHEMBL1964902 & 809188 & 4.4 & 4.2077 & TRN & \\
\hline CHEMBL1082440 & 809188 & 6.1 & 4.7718 & TST & \\
\hline CHEMBL1614705 & 809188 & 4.3 & 4.3427 & TRN & \\
\hline CHEMBL1972362 & 809188 & 4.3 & 5.1059 & TRN & \\
\hline CHEMBL1984633 & 809188 & 4.3 & 4.3982 & TRN & \\
\hline CHEMBL1965845 & 809188 & 5.5 & 4.9596 & TRN & \\
\hline CHEMBL 2007372 & 809188 & 4.3 & 4.3899 & TRN & \\
\hline CHEMBL1983715 & 809188 & 6.6 & 6.5402 & TRN & \\
\hline CHEMBL1982167 & 809188 & 4.3 & 4.3872 & TRN & \\
\hline CHEMBL1971017 & 809188 & 6.0 & 5.42 & TRN & \\
\hline CHEMBL2006715 & 809188 & 5.3 & 5.9801 & TRN & \\
\hline CHEMBL1986597 & 809188 & 4.3 & 4.4421 & TRN & \\
\hline CHEMBL1990482 & 809188 & 4.3 & 4.1028 & TRN & \\
\hline CHEMBL1990904 & 809188 & 5.5 & 4.6715 & TRN & \\
\hline CHEMBL2000104 & 809188 & 4.3 & 5.0071 & TRN & \\
\hline CHEMBL2005475 & 809188 & 5.5 & 4.6954 & TRN & \\
\hline CHEMBL1997349 & 809188 & 4.3 & 4.2733 & TST & \\
\hline CHEMBL183844 & 809188 & 4.3 & 5.2282 & TRN & \\
\hline CHEMBL220057 & 809188 & 6.1 & 6.2241 & TRN & \\
\hline CHEMBL1682545 & 809188 & 4.3 & 4.7605 & TRN & \\
\hline CHEMBL383541 & 809188 & 4.3 & 4.3821 & TRN & \\
\hline CHEMBL 2001224 & 809188 & 4.3 & 4.211 & TRN & \\
\hline CHEMBL10 & 809188 & 4.4 & 4.1964 & TRN & \\
\hline CHEMBL1976732 & 809188 & 4.3 & $4.4030 e$ & 00000000005 & TRN \\
\hline CHEMBL1969506 & 809188 & 4.3 & 4.4587 & TRN & \\
\hline CHEMBL1980763 & 809188 & 4.4 & 5.1467 & TRN & \\
\hline CHEMBL1964937 & 809188 & 5.3 & 4.7012 & TRN & \\
\hline CHEMBL1980163 & 809188 & 4.3 & 3.8792 & TRN & \\
\hline CHEMBL590109 & 809188 & 4.3 & 4.5949 & TST & \\
\hline CHEMBL1977931 & 809188 & 4.2 & 4.1885 & TRN & \\
\hline CHEMBL1970879 & 809188 & 4.3 & 5.9108 & TRN & \\
\hline CHEMBL1989856 & 809188 & 4.3 & 4.4942 & TST & \\
\hline & & & & 22764 & \\
\hline
\end{tabular}




\begin{tabular}{|c|c|c|c|c|c|}
\hline \\
\hline CHEMBL2005899 & 809188 & 4.3 & 4.3306 & TRN & \\
\hline CHEMBL1972568 & 809188 & 4.3 & 4.2615 & TRN & \\
\hline CHEMBL1682552 & 809188 & 4.3 & 4.3154 & TRN & \\
\hline CHEMBL 259850 & 809188 & 4.3 & 4.1284 & TRN & \\
\hline CHEMBL2007479 & 809188 & 4.4 & 4.3125 & TRN & \\
\hline CHEMBL1996155 & 809188 & 4.3 & 4.3525 & TRN & \\
\hline CHEMBL1986851 & 809188 & 7.6 & 7.62 & TRN & \\
\hline CHEMBL229799 & 809188 & 5.3 & 5.0004 & TRN & \\
\hline CHEMBL1971223 & 809188 & 4.4 & 4.1852 & TRN & \\
\hline CHEMBL105739 & 809188 & 5.9 & 5.7468 & TRN & \\
\hline CHEMBL1682359 & 809188 & 4.3 & 4.4591 & TRN & \\
\hline CHEMBL1972220 & 809188 & 7.7 & 7.3404 & TRN & \\
\hline CHEMBL 379300 & 809188 & 5.5 & 4.8085 & TRN & \\
\hline CHEMBL 203673 & 809188 & 4.3 & 4.3141 & TRN & \\
\hline CHEMBL 2003785 & 809188 & 4.6 & 4.3511 & TST & \\
\hline CHEMBL1973720 & 809188 & 5.4 & 4.9421 & TRN & \\
\hline CHEMBL1969523 & 809188 & 5.6 & 5.9825 & TRN & \\
\hline CHEMBL1988995 & 809188 & 4.3 & 4.4168 & TRN & \\
\hline CHEMBL207995 & 809188 & 4.3 & 4.3713 & TRN & \\
\hline CHEMBL2001923 & 809188 & 4.4 & 4.2139 & TRN & \\
\hline CHEMBL1986781 & 809188 & 4.3 & 4.5186 & TRN & \\
\hline CHEMBL1983070 & 809188 & 4.4 & 4.4401 & TRN & \\
\hline CHEMBL526133 & 809188 & 5.4 & 4.3561 & TRN & \\
\hline CHEMBL 2003514 & 809188 & 4.4 & 4.1039 & TRN & \\
\hline CHEMBL1989043 & 809188 & 4.4 & 4.7726 & TRN & \\
\hline CHEMBL1967538 & 809188 & 3.3 & 4.3379 & TRN & \\
\hline CHEMBL1979057 & 809188 & 4.3 & 4.0615 & TRN & \\
\hline CHEMBL1981045 & 809188 & 4.3 & 4.4479 & TRN & \\
\hline CHEMBL 387971 & 809188 & 5.7 & 5.4369 & TST & \\
\hline CHEMBL1975418 & 809188 & 5.4 & 4.83899 & 99999999995 & TRN \\
\hline CHEMBL1992796 & 809188 & 4.3 & 4.5474 & TRN & \\
\hline CHEMBL1164180 & 809188 & 5.9 & 5.4038 & TST & \\
\hline CHEMBL223257 & 809188 & 4.3 & 4.4027 & TST & \\
\hline CHEMBL1999428 & 809188 & 4.3 & 4.7187 & TRN & \\
\hline CHEMBL 1967560 & 809188 & 4.3 & 4.2882 & TRN & \\
\hline CHEMBL1997611 & 809188 & 4.4 & 4.8667 & TST & \\
\hline CHEMBL1516890 & 809188 & 5.3 & 5.2493 & TRN & \\
\hline CHEMBL211378 & 809188 & 5.3 & 5.3222 & TRN & \\
\hline CHEMBL1982465 & 809188 & 7.2 & 7.1608 & TRN & \\
\hline CHEMBL2001751 & 809188 & 6.1 & 5.3031 & TRN & \\
\hline CHEMBL 2003420 & 809188 & 4.3 & 4.4997 & TRN & \\
\hline CHEMBL1984586 & 809188 & 5.6 & 5.0151 & TRN & \\
\hline CHEMBL1999774 & 809188 & 4.3 & 4.3116 & TST & \\
\hline CHEMBL1972659 & 809188 & 4.3 & 4.3687 & TST & \\
\hline CHEMBL 2002723 & 809188 & 5.9 & 4.8852 & TST & \\
\hline CHEMBL1973395 & 809188 & 5.8 & 5.6272 & TRN & \\
\hline CHEMBL 272453 & 809188 & 6.1 & 5.7749 & TRN & \\
\hline CHEMBL1987143 & 809188 & 5.0 & 4.431 & TRN & \\
\hline
\end{tabular}




\begin{tabular}{|c|c|c|c|c|}
\hline \multicolumn{5}{|c|}{ pplemental Table } \\
\hline CHEMBL1970217 & 809188 & 4.3 & 4.3085 & TRN \\
\hline CHEMBL1971801 & 809188 & 4.3 & 4.2734 & TRN \\
\hline CHEMBL1968850 & 809188 & 4.3 & 4.6726 & TRN \\
\hline CHEMBL 2005528 & 809188 & 4.3 & 4.4747 & TST \\
\hline CHEMBL1984686 & 809188 & 4.4 & 4.4108 & TRN \\
\hline CHEMBL185569 & 809188 & 4.3 & 5.2537 & TRN \\
\hline CHEMBL1969843 & 809188 & 4.3 & 4.2711 & TRN \\
\hline CHEMBL 2007002 & 809188 & 4.3 & 4.7897 & TRN \\
\hline CHEMBL1987007 & 809188 & 4.3 & 4.5845 & TRN \\
\hline CHEMBL1973793 & 809188 & 4.4 & 4.26 & TST \\
\hline CHEMBL1969588 & 809188 & 6.5 & 5.7072 & TRN \\
\hline CHEMBL1984711 & 809188 & 5.3 & 5.6363 & TRN \\
\hline CHEMBL1992073 & 809188 & 5.9 & 5.0911 & TRN \\
\hline CHEMBL484390 & 809188 & 4.3 & 4.4019 & TRN \\
\hline CHEMBL1979252 & 809188 & 4.3 & 4.2261 & TRN \\
\hline CHEMBL1986143 & 809188 & 4.4 & 4.1573 & TRN \\
\hline CHEMBL1972934 & 809188 & 4.5 & 4.4163 & TRN \\
\hline CHEMBL 2007559 & 809188 & 4.4 & 4.8024 & TRN \\
\hline CHEMBL1992581 & 809188 & 6.1 & 5.165 & TRN \\
\hline CHEMBL1682341 & 809188 & 4.3 & 4.5302 & TRN \\
\hline CHEMBL 2004290 & 809188 & 6.8 & 6.7441 & TRN \\
\hline CHEMBL1986499 & 809188 & 4.3 & 4.7433 & TRN \\
\hline CHEMBL1972937 & 809188 & 4.3 & 4.1452 & TRN \\
\hline CHEMBL1972250 & 809188 & 4.3 & 4.4275 & TST \\
\hline CHEMBL 2000393 & 809188 & 6.5 & 5.6679 & 9999999999 \\
\hline CHEMBL1983573 & 809188 & 5.1 & 4.155 & TRN \\
\hline CHEMBL 2004311 & 809188 & 5.5 & 4.9547 & TRN \\
\hline CHEMBL1992634 & 809188 & 5.3 & 5.4249 & TRN \\
\hline CHEMBL1242373 & 809188 & 5.6 & 5.5082 & TRN \\
\hline CHEMBL1984847 & 809188 & 4.4 & 4.5685 & TRN \\
\hline CHEMBL1984402 & 809188 & 4.2 & 4.2676 & TST \\
\hline CHEMBL316264 & 809188 & 4.3 & 4.2536 & TRN \\
\hline CHEMBL1988075 & 809188 & 6.2 & 6.75 & TRN \\
\hline CHEMBL1996576 & 809188 & 4.4 & 4.3073 & TST \\
\hline CHEMBL1988076 & 809188 & 4.4 & 5.1838 & TRN \\
\hline CHEMBL1991678 & 809188 & 4.4 & 4.1912 & TRN \\
\hline CHEMBL 2001239 & 809188 & 4.3 & 4.7104 & TST \\
\hline CHEMBL1988594 & 809188 & 4.3 & 4.4745 & TRN \\
\hline CHEMBL 2001288 & 809188 & 4.3 & 4.6543 & TRN \\
\hline CHEMBL 260092 & 809188 & 5.5 & 6.0905 & TRN \\
\hline CHEMBL1999811 & 809188 & 5.3 & 4.9187 & TRN \\
\hline CHEMBL1965495 & 809188 & 6.1 & 5.5827 & TRN \\
\hline CHEMBL235157 & 809188 & 4.4 & 4.4545 & TST \\
\hline CHEMBL1985074 & 809188 & 4.3 & 4.3734 & TST \\
\hline CHEMBL 2000481 & 809188 & 4.3 & 4.5139 & TRN \\
\hline CHEMBL1982874 & 809188 & 5.4 & 4.8127 & TRN \\
\hline CHEMBL1991725 & 809188 & 4.3 & 4.5836 & TRN \\
\hline CHEMBL1992242 & 809188 & 4.3 & 4.9734 & TRN \\
\hline
\end{tabular}




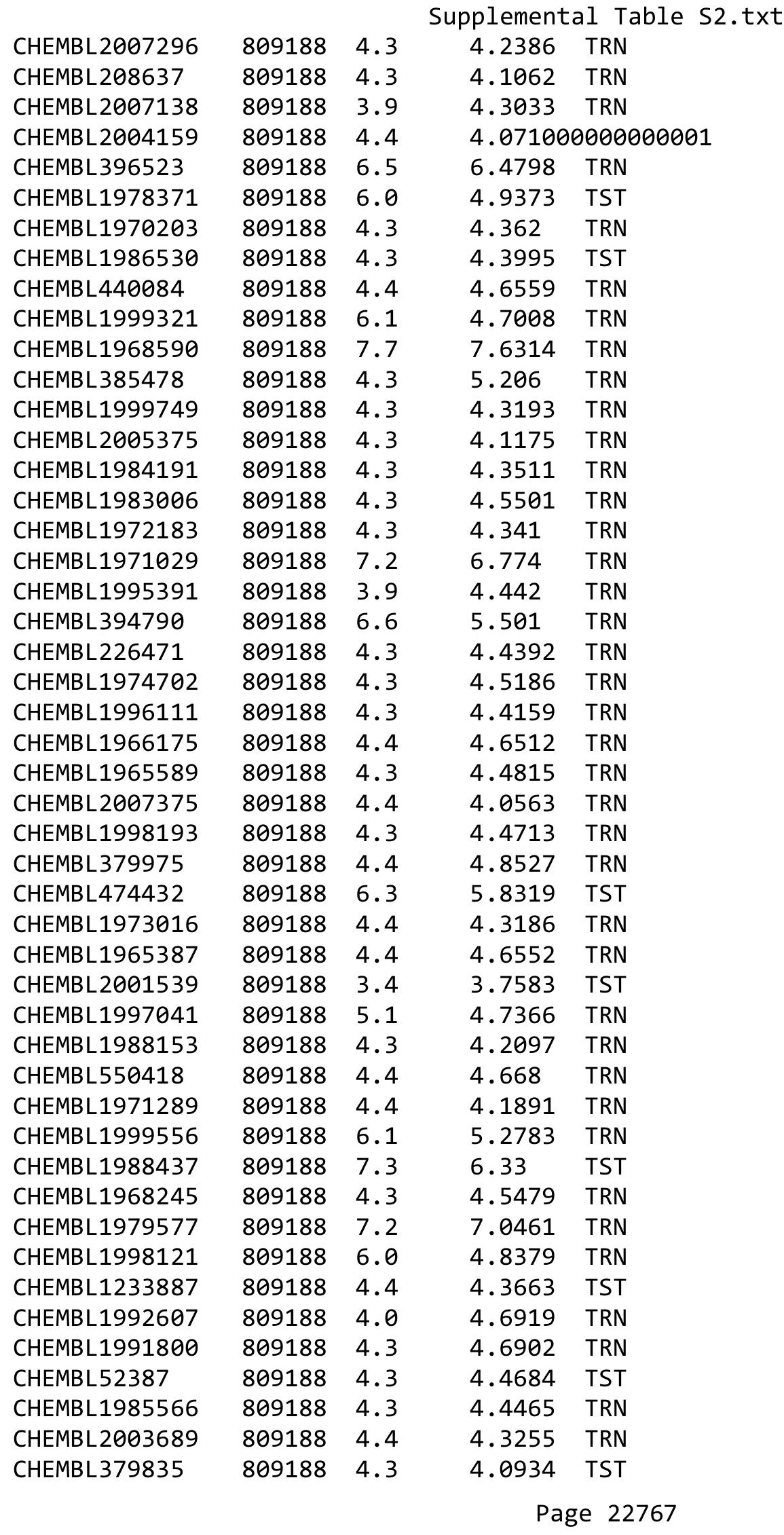

TRN 


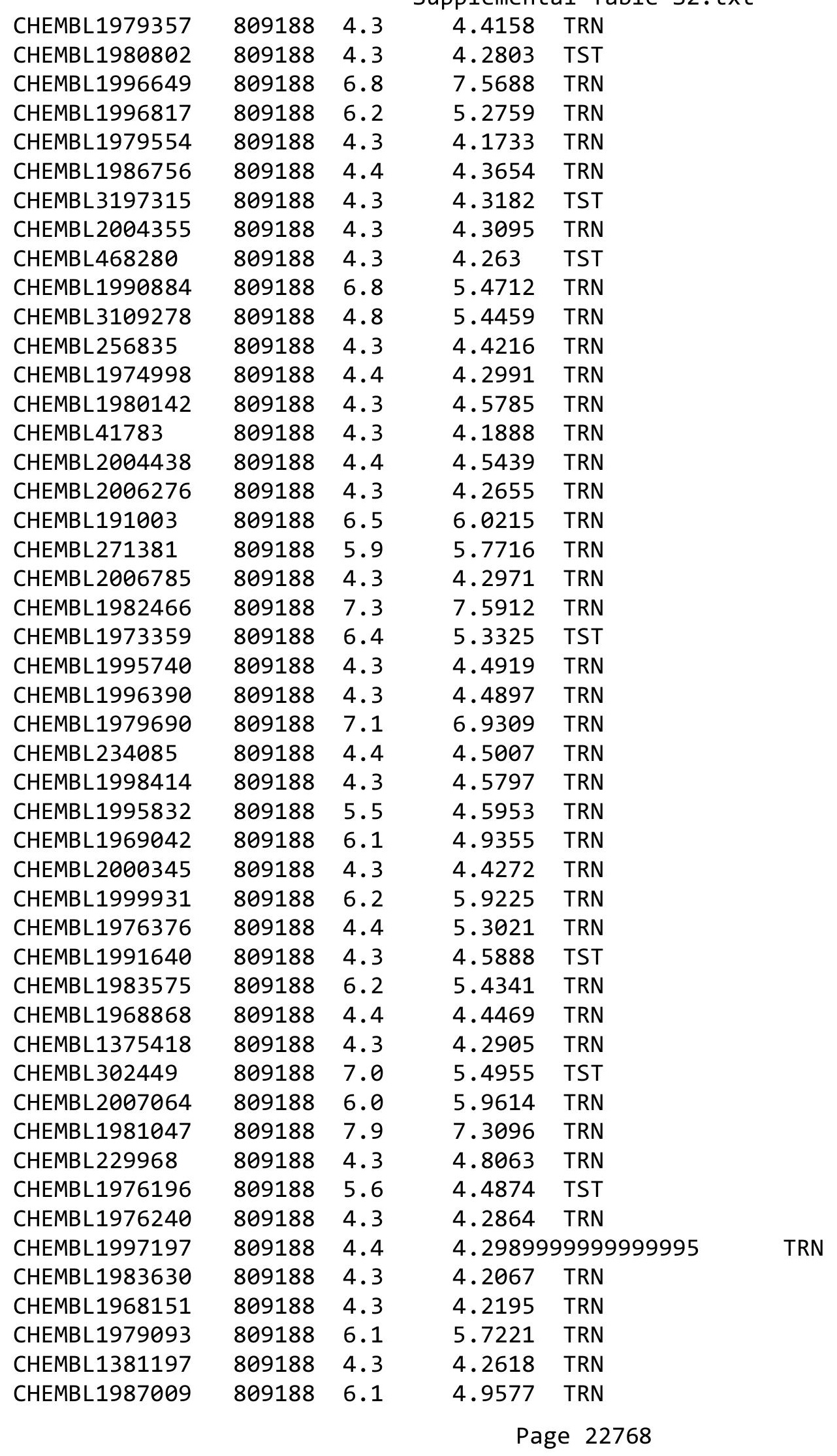




\begin{tabular}{|c|c|c|c|c|}
\hline & & & pl & \\
\hline CHEMBL379218 & 809188 & 4.3 & 4.8911 & TRN \\
\hline CHEMBL 2003817 & 809188 & 5.5 & 4.7169 & TRN \\
\hline CHEMBL336961 & 809188 & 4.3 & 4.8458 & TRN \\
\hline CHEMBL1994830 & 809188 & 4.3 & 4.2774 & TRN \\
\hline CHEMBL1987054 & 809188 & 8.0 & 7.4779 & TRN \\
\hline CHEMBL1970083 & 809188 & 7.7 & 7.6903 & TRN \\
\hline CHEMBL226403 & 809188 & 4.3 & 4.2727 & TRN \\
\hline CHEMBL 2005631 & 809188 & 8.5 & 8.2477 & TRN \\
\hline CHEMBL1994938 & 809188 & 7.2 & 7.5885 & TRN \\
\hline CHEMBL1977223 & 809188 & 4.3 & 4.7326 & TRN \\
\hline CHEMBL1995765 & 809188 & 4.5 & 4.5384 & TST \\
\hline CHEMBL1966279 & 809188 & 4.3 & 4.3216 & TRN \\
\hline CHEMBL1236126 & 809188 & 4.3 & 4.245 & TRN \\
\hline CHEMBL1997846 & 809188 & 4.4 & 4.6248 & TRN \\
\hline CHEMBL1984760 & 809188 & 4.4 & 4.7375 & TRN \\
\hline CHEMBL 2004419 & 809188 & 4.3 & 4.3555 & TRN \\
\hline CHEMBL1991728 & 809188 & 4.3 & 4.7705 & TRN \\
\hline CHEMBL360847 & 809188 & 4.4 & 4.6115 & TST \\
\hline CHEMBL 2007073 & 809188 & 4.4 & 4.1667 & TRN \\
\hline CHEMBL1995811 & 809188 & 4.4 & 4.9211 & TRN \\
\hline CHEMBL1975787 & 809188 & 6.0 & 5.4071 & TRN \\
\hline CHEMBL 2002407 & 809188 & 4.3 & 4.7458 & TRN \\
\hline CHEMBL1972489 & 809188 & 4.3 & 4.1726 & TRN \\
\hline CHEMBL1994074 & 809188 & 4.3 & 4.5254 & TRN \\
\hline CHEMBL1992937 & 809188 & 4.4 & 4.83 & TST \\
\hline CHEMBL451401 & 809188 & 4.8 & 3.7546 & TRN \\
\hline CHEMBL1972119 & 809188 & 4.3 & 4.3983 & TRN \\
\hline CHEMBL1986328 & 809188 & 4.3 & 4.1027 & TST \\
\hline CHEMBL95692 & 809188 & 4.3 & 4.3776 & TRN \\
\hline CHEMBL1090356 & 809188 & 5.8 & 5.7682 & TRN \\
\hline CHEMBL1976455 & 809188 & 4.4 & 4.6508 & TRN \\
\hline CHEMBL261849 & 809188 & 4.4 & 4.5187 & TST \\
\hline CHEMBL1983923 & 809188 & 7.2 & 6.6483 & TRN \\
\hline CHEMBL1983534 & 809188 & 4.3 & 4.3182 & TRN \\
\hline CHEMBL1982361 & 809188 & 4.3 & 4.1392 & TRN \\
\hline CHEMBL1999112 & 809188 & 6.1 & 4.8272 & TST \\
\hline CHEMBL1982122 & 809188 & 4.3 & 4.3393 & TRN \\
\hline CHEMBL 2000801 & 809188 & 5.4 & 4.7924 & TRN \\
\hline CHEMBL1682546 & 809188 & 4.3 & 4.4864 & TST \\
\hline CHEMBL1991395 & 809188 & 4.3 & 4.578 & TST \\
\hline CHEMBL1971245 & 809188 & 6.4 & 5.4117 & TST \\
\hline CHEMBL1987648 & 809188 & 4.3 & 4.5025 & TST \\
\hline CHEMBL1996780 & 809188 & 4.3 & 4.2987 & TST \\
\hline CHEMBL1972142 & 809188 & 4.3 & 4.9516 & TST \\
\hline CHEMBL1966514 & 809188 & 7.1 & 6.972 & TST \\
\hline CHEMBL 2003638 & 809188 & 5.8 & 5.8231 & TST \\
\hline CHEMBL296586 & 809188 & 4.3 & 5.3228 & TST \\
\hline CHEMBL1996066 & 809188 & 7.1 & 6.0551 & TST \\
\hline
\end{tabular}




\begin{tabular}{|c|c|c|c|c|}
\hline & & & Supplement & \\
\hline CHEMBL1983393 & 809188 & 4.4 & 3.9862 & TST \\
\hline CHEMBL516429 & 809188 & 5.6 & 5.0538 & TST \\
\hline CHEMBL1970806 & 809188 & 4.3 & 4.2732 & TST \\
\hline CHEMBL1993722 & 809188 & 4.3 & 5.4236 & TST \\
\hline CHEMBL2006674 & 809188 & 4.4 & 4.3344 & TST \\
\hline CHEMBL1984236 & 809188 & 4.4 & 4.1376 & TST \\
\hline CHEMBL1992371 & 809188 & 5.5 & 4.6098 & TST \\
\hline CHEMBL1375640 & 809188 & 4.3 & 4.5779 & TST \\
\hline CHEMBL1979970 & 809188 & 4.3 & 4.4359 & TST \\
\hline CHEMBL2002599 & 809188 & 4.4 & 4.6031 & TST \\
\hline CHEMBL 249282 & 809188 & 4.3 & 4.3291 & TST \\
\hline CHEMBL1967252 & 809188 & 4.3 & 4.3318 & TST \\
\hline CHEMBL 2004637 & 809188 & 4.4 & 4.7078 & TST \\
\hline CHEMBL1993374 & 809188 & 4.4 & 4.6689 & TST \\
\hline CHEMBL1969264 & 809188 & 4.3 & 4.4961 & TST \\
\hline CHEMBL1994318 & 809188 & 4.4 & 4.3448 & TST \\
\hline CHEMBL1973711 & 809188 & 4.3 & 4.4613 & TST \\
\hline CHEMBL 2006237 & 809188 & 4.3 & 4.4826 & TST \\
\hline CHEMBL1999506 & 809188 & 4.4 & 4.2754 & TST \\
\hline CHEMBL1967720 & 809188 & 7.4 & 7.7931 & TST \\
\hline CHEMBL1572266 & 809188 & 4.3 & 4.5692 & TST \\
\hline CHEMBL1991138 & 809188 & 5.4 & 4.7348 & TST \\
\hline CHEMBL1969755 & 809188 & 4.3 & 4.3086 & TST \\
\hline CHEMBL1979516 & 809188 & 7.9 & 7.6876 & TST \\
\hline CHEMBL1972820 & 809188 & 4.3 & 4.3046 & TST \\
\hline CHEMBL1605605 & 809188 & 4.4 & 4.0327 & TST \\
\hline CHEMBL1996208 & 809188 & 4.4 & 4.9982 & TST \\
\hline CHEMBL1989029 & 809188 & 5.6 & 4.6744 & TST \\
\hline CHEMBL392642 & 809188 & 4.3 & 4.4996 & TST \\
\hline CHEMBL514499 & 809188 & 5.4 & 5.1258 & TST \\
\hline CHEMBL1970352 & 809188 & 5.6 & 4.69 & TST \\
\hline CHEMBL1965631 & 809188 & 4.3 & 4.4872 & TST \\
\hline CHEMBL1980144 & 809188 & 4.3 & 4.2923 & TST \\
\hline CHEMBL1991188 & 809188 & 4.3 & 4.4341 & TST \\
\hline CHEMBL1980167 & 809188 & 6.0 & 4.965 & TST \\
\hline CHEMBL1972849 & 809188 & 4.3 & 4.308 & TST \\
\hline CHEMBL 377408 & 809188 & 4.4 & 4.1803 & TST \\
\hline CHEMBL 215152 & 809188 & 4.4 & 4.6434 & TST \\
\hline CHEMBL231209 & 809188 & 6.2 & 5.4523 & TST \\
\hline CHEMBL1976220 & 809188 & 7.0 & 5.5892 & TST \\
\hline CHEMBL 2006765 & 809188 & 5.6 & 5.1943 & TST \\
\hline CHEMBL 259922 & 809188 & 4.3 & 4.4248 & TST \\
\hline CHEMBL1997617 & 809188 & 8.0 & 6.9335 & TST \\
\hline CHEMBL1969301 & 809188 & 4.3 & 4.3273 & TST \\
\hline CHEMBL1982383 & 809188 & 4.3 & 4.4998 & TST \\
\hline CHEMBL17370 & 809188 & 4.3 & 4.3748 & TST \\
\hline CHEMBL1980246 & 809188 & 4.4 & 4.6473 & TST \\
\hline CHEMBL1987910 & 809188 & 5.9 & 4.8346 & TST \\
\hline
\end{tabular}




\begin{tabular}{|c|c|c|c|c|}
\hline & & & lemer & \\
\hline CHEMBL1983932 & 809188 & 4.3 & 4.8292 & TST \\
\hline CHEMBL1983980 & 809188 & 5.9 & 5.28 & TST \\
\hline CHEMBL1999484 & 809188 & 7.0 & 6.4614 & TST \\
\hline CHEMBL1966069 & 809188 & 4.3 & 4.4813 & TST \\
\hline CHEMBL1986899 & 809188 & 4.4 & 4.3001 & TST \\
\hline CHEMBL1991285 & 809188 & 4.3 & 4.4987 & TST \\
\hline CHEMBL1997822 & 809188 & 7.7 & 7.6799 & TST \\
\hline CHEMBL243088 & 809188 & 6.4 & 6.4474 & TST \\
\hline CHEMBL1984038 & 809188 & 4.4 & 4.2087 & TST \\
\hline CHEMBL1974416 & 809188 & 4.3 & 5.0345 & TST \\
\hline CHEMBL1993661 & 809188 & 7.9 & 8.0166 & TST \\
\hline CHEMBL 2004615 & 809188 & 4.3 & 4.3893 & TST \\
\hline CHEMBL1997872 & 809188 & 5.4 & 4.709 & TST \\
\hline CHEMBL111934 & 65802 & 9.1192 & 9.401 & TRN \\
\hline CHEMBL324304 & 65802 & 6.0 & 6.8207 & TRN \\
\hline CHEMBL 326380 & 65802 & 13.0 & 13.1214 & TRN \\
\hline CHEMBL177373 & 65802 & 7.6576 & 9.6344 & TST \\
\hline CHEMBL353317 & 65802 & 13.0 & 13.4184 & TRN \\
\hline CHEMBL326160 & 65802 & 7.8182 & 7.9463 & TRN \\
\hline CHEMBL114863 & 65802 & 11.7696 & 10.4648 & TRN \\
\hline CHEMBL114700 & 65802 & 10.2924 & 10.5739 & TRN \\
\hline CHEMBL442031 & 65802 & 8.2076 & 7.5227 & TRN \\
\hline CHEMBL114105 & 65802 & 8.0555 & 7.4771 & TRN \\
\hline CHEMBL334263 & 65802 & 8.5528 & 8.4798 & TRN \\
\hline CHEMBL324246 & 65802 & 8.9208 & 7.2904 & TRN \\
\hline CHEMBL113927 & 65802 & 7.4045 & 7.1482 & TRN \\
\hline CHEMBL115333 & 65802 & 10.5528 & 10.0509 & TRN \\
\hline CHEMBL116698 & 65802 & 6.0 & 6.9936 & TRN \\
\hline CHEMBL177924 & 65802 & 9.7959 & 8.2379 & TRN \\
\hline CHEMBL114933 & 65802 & 9.0655 & 9.35 & TRN \\
\hline CHEMBL114964 & 65802 & 10.2291 & 10.7401 & TRN \\
\hline CHEMBL324943 & 65802 & 7.6108 & 7.7987 & TRN \\
\hline CHEMBL116281 & 65802 & 9.5376 & 10.3535 & TRN \\
\hline CHEMBL420501 & 65802 & 8.0044 & 8.3665 & TRN \\
\hline CHEMBL112134 & 65802 & 9.0 & 8.5678 & TRN \\
\hline CHEMBL321226 & 65802 & 6.7696 & 7.0822 & TRN \\
\hline CHEMBL112144 & 65802 & 11.4089 & 11.6225 & TRN \\
\hline CHEMBL116002 & 65802 & 8.4685 & 9.2892 & TST \\
\hline CHEMBL112141 & 65802 & 9.7959 & 9.2504 & TRN \\
\hline CHEMBL441277 & 65802 & 9.0506 & 9.5615 & TRN \\
\hline CHEMBL325049 & 65802 & 13.0 & 11.6599 & TRN \\
\hline CHEMBL114985 & 65802 & 7.0362 & 6.7763 & TRN \\
\hline CHEMBL420132 & 65802 & 13.0 & 12.2146 & TRN \\
\hline CHEMBL112502 & 65802 & 8.5376 & 9.4452 & TRN \\
\hline CHEMBL115724 & 65802 & 10.7447 & 10.6689 & TST \\
\hline CHEMBL114380 & 65802 & 10.8239 & 9.6728 & TRN \\
\hline CHEMBL430515 & 65802 & 7.0292 & 8.8709 & TRN \\
\hline CHEMBL114704 & 65802 & 7.3429 & 8.7034 & TST \\
\hline
\end{tabular}




\begin{tabular}{|c|c|c|c|c|c|}
\hline \multirow[b]{2}{*}{ CHEMBL115230 } & \multicolumn{5}{|c|}{ Supplemental Table S2.txt } \\
\hline & 65802 & 8.9208 & 10.2008 & TRN & \\
\hline CHEMBL113888 & 65802 & 7.289 & 7.3566 & TST & \\
\hline CHEMBL362276 & 65802 & 6.0 & 6.6434 & TST & \\
\hline CHEMBL175616 & 65802 & 8.1249 & 6.3972 & TST & \\
\hline CHEMBL324204 & 65802 & 13.0 & 12.3209 & TRN & \\
\hline CHEMBL111876 & 65802 & 7.1871 & 7.374 & TST & \\
\hline CHEMBL321242 & 65802 & 9.9586 & 9.6707 & TRN & \\
\hline CHEMBL177173 & 65802 & 10.4437 & 11.6458 & TRN & \\
\hline CHEMBL116220 & 65802 & 9.0 & 8.7894 & TRN & \\
\hline CHEMBL114683 & 65802 & 8.5086 & 9.4506 & TST & \\
\hline CHEMBL116046 & 65802 & 13.0 & 11.409 & TRN & \\
\hline CHEMBL325511 & 65802 & 11.9586 & 11.7681 & TRN & \\
\hline CHEMBL175523 & 65802 & 11.0706 & 11.0974 & TRN & \\
\hline CHEMBL115133 & 65802 & 6.0 & 6.9636 & TST & \\
\hline CHEMBL175931 & 65802 & 8.7212 & 9.8159 & TRN & \\
\hline CHEMBL332922 & 65802 & 10.8861 & 11.1532 & TRN & \\
\hline CHEMBL116108 & 65802 & 13.0 & 12.9346 & TRN & \\
\hline CHEMBL 323243 & 65802 & 13.0 & 12.7315 & TRN & \\
\hline CHEMBL 331580 & 65802 & 7.9208 & 8.0587 & TST & \\
\hline CHEMBL112531 & 65802 & 13.0 & 12.6195 & TRN & \\
\hline CHEMBL114660 & 65802 & 9.4318 & 10.3673 & TST & \\
\hline CHEMBL115017 & 65802 & 8.8539 & 10.2639 & TRN & \\
\hline CHEMBL115951 & 65802 & 6.7959 & 5.7448 & TST & \\
\hline CHEMBL113757 & 65802 & 11.7696 & 12.5148 & TRN & \\
\hline CHEMBL326105 & 65802 & 7.5884 & 7.8218 & TST & \\
\hline CHEMBL175647 & 65802 & 6.0 & 6.9873 & TST & \\
\hline CHEMBL112162 & 65802 & 9.1938 & 8.9501 & TRN & \\
\hline CHEMBL114201 & 65802 & 8.7212 & 7.7109 & TST & \\
\hline CHEMBL3928908 & 1642021 & 6.0 & 5.7199 & TST & \\
\hline CHEMBL 3979795 & 1642021 & 6.9208 & 7.0349 & TRN & \\
\hline CHEMBL 3928744 & 1642021 & 6.3665 & 6.0668 & TST & \\
\hline CHEMBL 3955574 & 1642021 & 7.2676 & 7.3375 & TRN & \\
\hline CHEMBL 3984999 & 1642021 & 6.3872 & 6.3678 & TRN & \\
\hline CHEMBL3950503 & 1642021 & 5.5528 & 5.6024 & TRN & \\
\hline CHEMBL 3940905 & 1642021 & 5.6021 & $5.61700 t$ & 0000000001 & TRN \\
\hline CHEMBL3975910 & 1642021 & 5.9208 & 5.6645 & TST & \\
\hline CHEMBL3920169 & 1642021 & 6.9586 & 7.0169 & TRN & \\
\hline CHEMBL 3948288 & 1642021 & 6.0 & 6.1508 & TRN & \\
\hline CHEMBL 3965767 & 1642021 & 6.0 & 6.1698 & TRN & \\
\hline CHEMBL 3948612 & 1642021 & 5.2147 & 5.1177 & TRN & \\
\hline CHEMBL3972660 & 1642021 & 7.1549 & 7.2301 & TRN & \\
\hline CHEMBL 3960734 & 1642021 & 5.6383 & 6.3497 & TST & \\
\hline CHEMBL 3895277 & 1642021 & 6.0 & 6.1935 & TRN & \\
\hline CHEMBL 3904347 & 1642021 & 6.9208 & 6.7958 & TRN & \\
\hline CHEMBL 3963857 & 1642021 & 6.7447 & 6.7508 & TRN & \\
\hline CHEMBL 3937762 & 1642021 & 6.2924 & 6.2748 & TRN & \\
\hline CHEMBL 3958505 & 1642021 & 6.9208 & 6.4242 & TST & \\
\hline CHEMBL 3930354 & 1642021 & 6.2441 & 6.2397 & TRN & \\
\hline
\end{tabular}

Page 22772 
Supplemental Table S2.txt

\begin{tabular}{|c|c|c|c|c|c|}
\hline CHEMBL3934033 & 1642021 & 7.1024 & 6.6236 & TST & \\
\hline CHEMBL3900949 & 1642021 & 7.0862 & 6.8675 & TST & \\
\hline CHEMBL3926303 & 1642021 & 7.0706 & 7.098 & TRN & \\
\hline CHEMBL3921301 & 1642021 & 6.6576 & 6.1206 & TST & \\
\hline CHEMBL3962688 & 1642021 & 5.4949 & 5.4793 & TRN & \\
\hline CHEMBL3939051 & 1642021 & 7.4318 & 7.4609 & TRN & \\
\hline CHEMBL 3908134 & 1642021 & 6.0 & 6.0346 & TRN & \\
\hline CHEMBL 3906828 & 1642021 & 6.1739 & 5.4229 & TST & \\
\hline CHEMBL 3977804 & 1642021 & 6.3565 & 6.276 & TRN & \\
\hline CHEMBL3931719 & 1642021 & 6.0 & 6.0274 & TRN & \\
\hline CHEMBL3901559 & 1642021 & 6.3565 & 6.4861 & TRN & \\
\hline CHEMBL3976809 & 1642021 & 7.0 & 7.0716 & TRN & \\
\hline CHEMBL3981214 & 1642021 & 6.0 & 5.9596 & TRN & \\
\hline CHEMBL3959766 & 1642021 & 6.2676 & 6.1185 & TST & \\
\hline CHEMBL3985963 & 1642021 & 6.9586 & 6.4101 & TST & \\
\hline CHEMBL3965341 & 1642021 & 6.4949 & 6.4385 & TST & \\
\hline CHEMBL3964013 & 1642021 & 5.6021 & 5.7187 & TST & \\
\hline CHEMBL3960704 & 1642021 & 7.284 & 7.2701 & TRN & \\
\hline CHEMBL3948739 & 1642021 & 6.5686 & 6.6861 & TRN & \\
\hline CHEMBL3899594 & 1642021 & 6.699 & 6.642 & TRN & \\
\hline CHEMBL3984202 & 1642021 & 7.0969 & 7.0165 & TRN & \\
\hline CHEMBL3947556 & 1642021 & 6.0 & 6.0671 & TRN & \\
\hline CHEMBL3979196 & 1642021 & 7.6021 & 7.4921 & TRN & \\
\hline CHEMBL3903943 & 1642021 & 7.5686 & 7.4265 & TRN & \\
\hline CHEMBL3943949 & 1642021 & 6.8239 & 6.7782 & TRN & \\
\hline CHEMBL3955162 & 1642021 & 6.0 & 5.8353 & TRN & \\
\hline CHEMBL 3898472 & 1642021 & 7.1192 & 7.0412 & TRN & \\
\hline CHEMBL3942998 & 1642021 & 6.8239 & 6.0563 & TST & \\
\hline CHEMBL3902075 & 1642021 & 6.8539 & 6.7 & TRN & \\
\hline CHEMBL 3933922 & 1642021 & 6.0 & 6.1596 & TRN & \\
\hline CHEMBL3941065 & 1642021 & 6.0 & 5.9539 & TRN & \\
\hline CHEMBL 3952038 & 1642021 & 7.0088 & 6.9901 & TRN & \\
\hline CHEMBL3923986 & 1642021 & 5.4318 & 5.4682 & TRN & \\
\hline CHEMBL3903530 & 1642021 & 7.1135 & 6.9901 & TRN & \\
\hline CHEMBL3918920 & 1642021 & 7.0757 & \multicolumn{2}{|c|}{7.162000000000001} & TRN \\
\hline CHEMBL3913437 & 1642021 & 6.0 & 5.989 & TRN & \\
\hline CHEMBL3905005 & 1642021 & 6.0 & 5.7815 & TRN & \\
\hline CHEMBL 3925627 & 1642021 & 6.8539 & 6.9031 & TRN & \\
\hline CHEMBL3961817 & 1642021 & 6.0 & 6.2946 & TRN & \\
\hline CHEMBL3896599 & 1642021 & 6.9586 & 7.0144 & TRN & \\
\hline CHEMBL3924629 & 1642021 & 7.0706 & 6.9603 & TRN & \\
\hline CHEMBL3916616 & 1642021 & 7.2924 & 7.2251 & TRN & \\
\hline CHEMBL3978169 & 1642021 & 7.3098 & 7.4461 & TRN & \\
\hline CHEMBL3911095 & 1642021 & 6.0 & 5.8873 & TRN & \\
\hline CHEMBL3950010 & 1642021 & 5.6383 & 6.0297 & TST & \\
\hline CHEMBL3957312 & 1642021 & 6.0 & 5.9496 & TRN & \\
\hline CHEMBL3932341 & 1642021 & 6.8861 & 6.8273 & TRN & \\
\hline CHEMBL3967404 & 1642021 & 6.0706 & 6.33299 & 9999999999 & TRN \\
\hline
\end{tabular}

Page 22773 
Supplemental Table S2.txt

\begin{tabular}{|c|c|c|c|c|}
\hline CHEMBL3986374 & 1642021 & 7.2757 & 7.2188 & TRN \\
\hline CHEMBL3970036 & 1642021 & 5.4089 & 5.9621 & TST \\
\hline CHEMBL3891645 & 1642021 & 5.7959 & 6.4991 & TST \\
\hline CHEMBL3929288 & 1642021 & 6.0 & 6.1153 & TRN \\
\hline CHEMBL3926520 & 1642021 & 6.9208 & 6.9979 & TRN \\
\hline CHEMBL3970624 & 1642021 & 6.7447 & 6.7491 & TRN \\
\hline CHEMBL3950357 & 1642021 & 6.4202 & 6.3595 & TRN \\
\hline CHEMBL3961297 & 1642021 & 6.4202 & 6.3988 & TRN \\
\hline CHEMBL3903298 & 1642021 & 7.0 & 6.7276 & TRN \\
\hline CHEMBL3787210 & 1642021 & 6.0 & 5.8309 & TST \\
\hline CHEMBL3897104 & 1642021 & 7.2366 & 7.2304 & TRN \\
\hline CHEMBL3939853 & 1642021 & 7.1079 & 7.0475 & TRN \\
\hline CHEMBL3964316 & 1642021 & 7.0757 & 7.0759 & TRN \\
\hline CHEMBL3895413 & 1642021 & 6.0 & 6.1971 & TRN \\
\hline CHEMBL3952921 & 1642021 & 6.0 & 5.9373 & TRN \\
\hline CHEMBL3987051 & 1642021 & 6.0 & 6.0623 & TRN \\
\hline CHEMBL3902414 & 1642021 & 6.585 & 6.5213 & TRN \\
\hline CHEMBL3909850 & 1642021 & 5.8861 & 5.8699 & TRN \\
\hline CHEMBL3911202 & 1642021 & 6.3979 & 6.1758 & TRN \\
\hline CHEMBL3915337 & 1642021 & 7.4437 & 7.44799 & 99999999995 \\
\hline CHEMBL3933546 & 1642021 & 7.0269 & 7.0597 & TST \\
\hline CHEMBL3901095 & 1642021 & 6.9208 & 6.9526 & TRN \\
\hline CHEMBL3963603 & 1642021 & 6.2007 & 6.2174 & TRN \\
\hline CHEMBL3919918 & 1642021 & 6.9208 & 6.8906 & TST \\
\hline CHEMBL3957448 & 1642021 & 6.3468 & 6.1617 & TST \\
\hline CHEMBL3942255 & 1642021 & 7.2007 & 7.0507 & TST \\
\hline CHEMBL3985788 & 1642021 & 6.2518 & 6.3806 & TST \\
\hline CHEMBL3938299 & 1642021 & 6.0 & 5.9137 & TRN \\
\hline CHEMBL3191078 & 688500 & 4.9 & 5.8829 & TRN \\
\hline CHEMBL1465144 & 688500 & 5.05 & 5.65 & TRN \\
\hline CHEMBL1596010 & 688500 & 4.1 & 5.9309 & TRN \\
\hline CHEMBL1610056 & 688500 & 7.699 & 5.711 & TRN \\
\hline CHEMBL1990342 & 688500 & 6.05 & 5.6962 & TRN \\
\hline CHEMBL1457022 & 688500 & 4.8 & 4.6169 & TRN \\
\hline CHEMBL1566927 & 688500 & 5.0 & 5.5832 & TRN \\
\hline CHEMBL1470333 & 688500 & 5.2 & 5.61799 & 9999999999 \\
\hline CHEMBL1543904 & 688500 & 7.4001 & 6.3154 & TRN \\
\hline CHEMBL1483809 & 688500 & 5.35 & 4.9646 & TRN \\
\hline CHEMBL1321739 & 688500 & 4.65 & 4.4392 & TST \\
\hline CHEMBL1516834 & 688500 & 4.75 & 5.4117 & TRN \\
\hline CHEMBL1446211 & 688500 & 4.6 & 5.3487 & TRN \\
\hline CHEMBL1504611 & 688500 & 7.5003 & 5.8814 & TST \\
\hline CHEMBL1397706 & 688500 & 4.6 & 5.8238 & TST \\
\hline CHEMBL1525860 & 688500 & 7.4498 & 5.9317 & TRN \\
\hline CHEMBL3144999 & 688500 & 5.4 & 5.3939 & TRN \\
\hline CHEMBL1306199 & 688500 & 6.7501 & 5.9598 & TRN \\
\hline CHEMBL1572845 & 688500 & 4.95 & 5.6211 & TRN \\
\hline CHEMBL1590938 & 688500 & 4.4 & 5.1586 & TRN \\
\hline
\end{tabular}




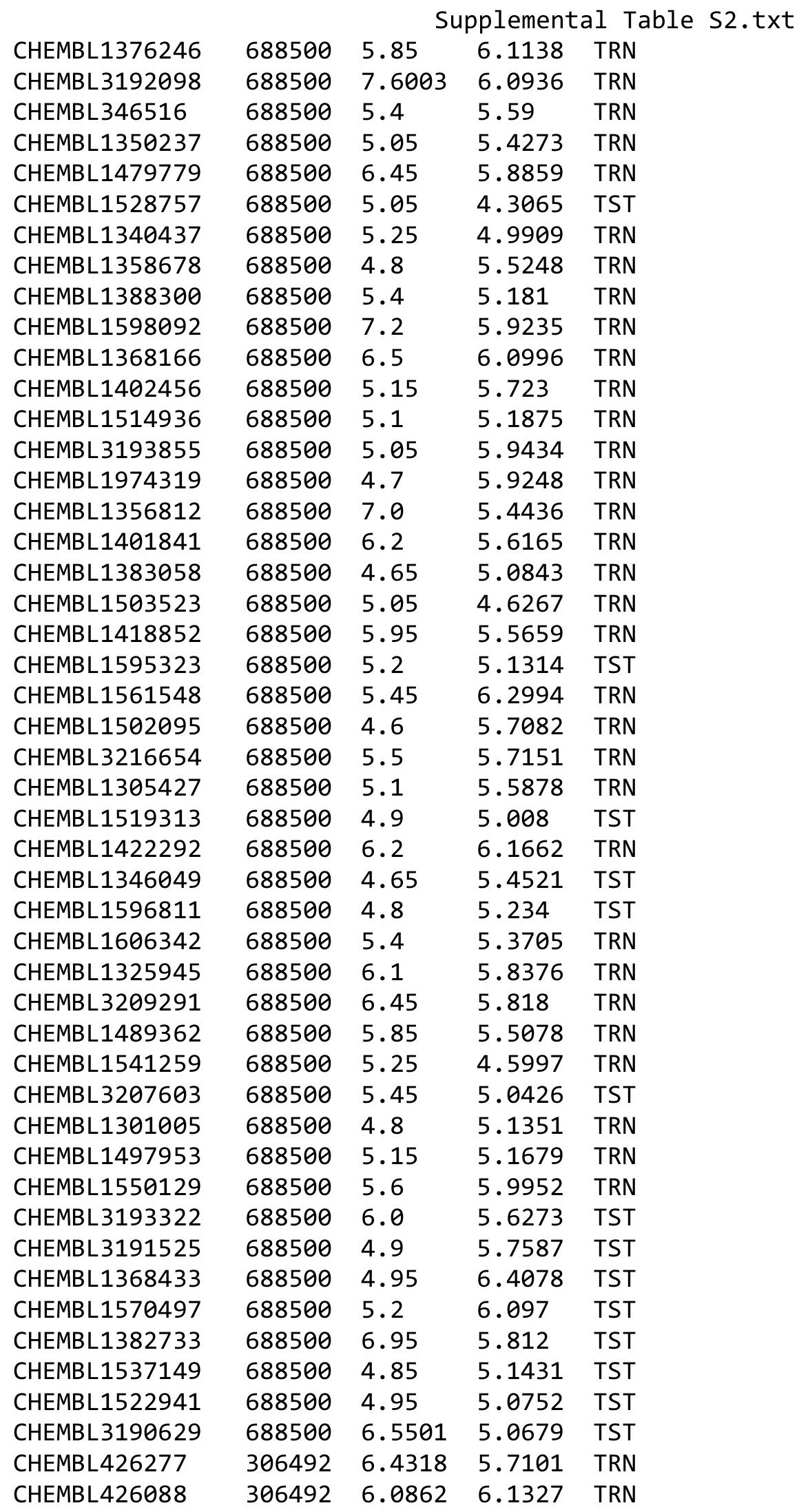

Page 22775 


\begin{tabular}{|c|c|c|c|c|c|}
\hline \multicolumn{6}{|c|}{ Supplemental Table S2.txt } \\
\hline CHEMBL193049 & 306492 & 5.1739 & 6.0877 & TST & \\
\hline CHEMBL192137 & 306492 & 5.3188 & 5.4067 & TRN & \\
\hline CHEMBL192674 & 306492 & 5.1487 & 5.3904 & TRN & \\
\hline CHEMBL192821 & 306492 & 6.6383 & 7.1628 & TRN & \\
\hline CHEMBL364684 & 306492 & 6.0 & 5.6204 & TRN & \\
\hline CHEMBL195211 & 306492 & 5.699 & 5.63299 & 9999999999 & TRN \\
\hline CHEMBL372277 & 306492 & 3.0 & 4.9549 & TRN & \\
\hline CHEMBL371345 & 306492 & 7.2218 & 6.1495 & TRN & \\
\hline CHEMBL192896 & 306492 & 7.0969 & 6.6904 & TRN & \\
\hline CHEMBL191832 & 306492 & 6.0 & 6.1517 & TRN & \\
\hline CHEMBL192222 & 306492 & 5.6576 & 6.1906 & TRN & \\
\hline CHEMBL193333 & 306492 & 3.0 & 4.4483 & TRN & \\
\hline CHEMBL193835 & 306492 & 6.0706 & 5.8389 & TRN & \\
\hline CHEMBL192269 & 306492 & 5.5528 & 5.7603 & TST & \\
\hline CHEMBL188442 & 306492 & 7.0 & 6.5218 & TRN & \\
\hline CHEMBL192831 & 306492 & 6.6021 & 6.7492 & TRN & \\
\hline CHEMBL195149 & 306492 & 6.0969 & 6.2894 & TRN & \\
\hline CHEMBL366197 & 306492 & 7.5229 & 7.1965 & TRN & \\
\hline CHEMBL193596 & 306492 & 4.9208 & 4.1115 & TRN & \\
\hline CHEMBL191820 & 306492 & 7.1549 & 6.2679 & TST & \\
\hline CHEMBL189927 & 306492 & 6.7447 & 7.4109 & TRN & \\
\hline CHEMBL372685 & 306492 & 5.2007 & 5.0393 & TRN & \\
\hline CHEMBL427171 & 306492 & 6.0269 & 6.2642 & TRN & \\
\hline CHEMBL190800 & 306492 & 6.9586 & 6.8458 & TRN & \\
\hline CHEMBL365977 & 306492 & 6.1024 & 5.9111 & TRN & \\
\hline CHEMBL191749 & 306492 & 5.2218 & 5.5912 & TST & \\
\hline CHEMBL195832 & 306492 & 6.3979 & 5.6203 & TRN & \\
\hline CHEMBL371601 & 306492 & 4.8861 & 5.5317 & TST & \\
\hline CHEMBL365135 & 306492 & 7.301 & 6.7104 & TRN & \\
\hline CHEMBL371821 & 306492 & 6.6383 & 6.9696 & TRN & \\
\hline CHEMBL192358 & 306492 & 7.0 & 6.1806 & TST & \\
\hline CHEMBL194554 & 306492 & 6.301 & 6.2133 & TRN & \\
\hline CHEMBL192215 & 306492 & 6.0 & 5.8951 & TRN & \\
\hline CHEMBL195549 & 306492 & 6.301 & 6.3512 & TRN & \\
\hline CHEMBL191977 & 306492 & 6.699 & 6.0012 & TST & \\
\hline CHEMBL363426 & 306492 & 5.5086 & 5.5233 & TST & \\
\hline CHEMBL192112 & 306492 & 4.8539 & 5.3069 & TST & \\
\hline CHEMBL192804 & 306492 & 7.0458 & 6.8328 & TRN & \\
\hline CHEMBL194448 & 306492 & 6.0809 & 5.8264 & TST & \\
\hline CHEMBL195227 & 306492 & 5.6576 & 5.7669 & TST & \\
\hline CHEMBL192842 & 306492 & 5.1549 & 5.2175 & TST & \\
\hline CHEMBL191661 & 306492 & 5.5686 & 5.8197 & TRN & \\
\hline CHEMBL194227 & 306492 & 5.585 & 6.2061 & TRN & \\
\hline CHEMBL195802 & 306492 & 6.2218 & 6.3217 & TRN & \\
\hline CHEMBL365105 & 306492 & 6.9208 & 6.7624 & TRN & \\
\hline CHEMBL192409 & 306492 & 4.8239 & 5.9888 & TST & \\
\hline CHEMBL365748 & 306492 & 5.7212 & 4.4523 & TRN & \\
\hline CHEMBL195300 & 306492 & 4.8239 & 5.3972 & TRN & \\
\hline
\end{tabular}




\begin{tabular}{|c|c|c|c|c|c|}
\hline \multirow[b]{2}{*}{ CHEMBL378719 } & \multicolumn{5}{|c|}{ Supplemental Table Sa } \\
\hline & 383093 & 6.301 & 6.4570 & 0000000001 & TRN \\
\hline CHEMBL213847 & 383093 & 4.301 & 4.7881 & TRN & \\
\hline CHEMBL213651 & 383093 & 6.6576 & 6.9599 & TRN & \\
\hline CHEMBL209675 & 383093 & 4.301 & 4.4094 & TRN & \\
\hline CHEMBL213563 & 383093 & 6.3768 & 6.3356 & TRN & \\
\hline CHEMBL211382 & 383093 & 4.301 & 4.6379 & TRN & \\
\hline CHEMBL375609 & 383093 & 7.4202 & 7.1382 & TRN & \\
\hline CHEMBL378296 & 383093 & 4.301 & 4.2456 & TRN & \\
\hline CHEMBL210154 & 383093 & 4.301 & 4.5465 & TRN & \\
\hline CHEMBL219860 & 383093 & 4.301 & 6.3789 & TST & \\
\hline CHEMBL378493 & 383093 & 4.301 & 4.2434 & TST & \\
\hline CHEMBL211359 & 383093 & 7.2076 & 6.9856 & TRN & \\
\hline CHEMBL208778 & 383093 & 4.301 & 4.33 & TRN & \\
\hline CHEMBL211316 & 383093 & 4.301 & 4.0301 & TRN & \\
\hline CHEMBL 380328 & 383093 & 6.3872 & 6.8218 & TRN & \\
\hline CHEMBL213167 & 383093 & 7.3565 & 7.5409 & TRN & \\
\hline CHEMBL209793 & 383093 & 5.1549 & 4.9464 & TRN & \\
\hline CHEMBL213797 & 383093 & 4.699 & 6.0534 & TST & \\
\hline CHEMBL214348 & 383093 & 4.301 & 4.3092 & TRN & \\
\hline CHEMBL 212214 & 383093 & 6.301 & 5.8742 & TRN & \\
\hline CHEMBL377592 & 383093 & 6.4559 & 6.2385 & TRN & \\
\hline CHEMBL212110 & 383093 & 6.3665 & 6.41 & TRN & \\
\hline CHEMBL377547 & 383093 & 4.301 & 4.1815 & TRN & \\
\hline CHEMBL211546 & 383093 & 4.301 & 4.3464 & TRN & \\
\hline CHEMBL 209428 & 383093 & 4.699 & 5.9245 & TST & \\
\hline CHEMBL209845 & 383093 & 6.2076 & 6.3639 & TRN & \\
\hline CHEMBL211481 & 383093 & 4.301 & 4.4305 & TRN & \\
\hline CHEMBL209489 & 383093 & 5.857 & 5.7484 & TRN & \\
\hline CHEMBL377783 & 383093 & 7.1675 & 6.8611 & TRN & \\
\hline CHEMBL377591 & 383093 & 5.9101 & 5.4987 & TRN & \\
\hline CHEMBL386373 & 383093 & 4.301 & 4.6385 & TST & \\
\hline CHEMBL211796 & 383093 & 4.301 & 4.3846 & TRN & \\
\hline CHEMBL378688 & 383093 & 6.1739 & 5.7572 & TRN & \\
\hline CHEMBL378351 & 383093 & 4.301 & 4.3202 & TRN & \\
\hline CHEMBL 214349 & 383093 & 4.301 & 4.3627 & TRN & \\
\hline CHEMBL209520 & 383093 & 5.8386 & 5.8023 & TRN & \\
\hline CHEMBL213168 & 383093 & 7.0655 & 7.0195 & TRN & \\
\hline CHEMBL213992 & 383093 & 7.3768 & 7.3754 & TRN & \\
\hline CHEMBL 378014 & 383093 & 6.301 & 6.3567 & TRN & \\
\hline CHEMBL 269552 & 383093 & 4.301 & 6.3062 & TST & \\
\hline CHEMBL427239 & 383093 & 4.301 & 6.4676 & TST & \\
\hline CHEMBL210072 & 383093 & 4.699 & 5.5961 & TST & \\
\hline CHEMBL214067 & 383093 & 4.301 & 4.4266 & TRN & \\
\hline CHEMBL380295 & 383093 & 4.301 & 4.0383 & TRN & \\
\hline CHEMBL 211488 & 383093 & 4.301 & 4.1674 & TRN & \\
\hline CHEMBL211201 & 383093 & 7.1367 & 7.1515 & TRN & \\
\hline CHEMBL378278 & 383093 & 4.699 & 6.3269 & TST & \\
\hline CHEMBL215185 & 383093 & 4.301 & 4.3946 & TRN & \\
\hline
\end{tabular}




\begin{tabular}{|c|c|c|c|c|c|c|}
\hline & & \multicolumn{5}{|c|}{ Supplemental Table s2.txt } \\
\hline CHEMBL212474 & 383093 & 6.0969 & 5.8625 & TRN & & \\
\hline CHEMBL209502 & 383093 & 6.1612 & 6.5685 & TRN & & \\
\hline CHEMBL213562 & 383093 & 5.8416 & 6.0257 & TRN & & \\
\hline CHEMBL385439 & 383093 & 4.301 & 5.0409 & TST & & \\
\hline CHEMBL385820 & 383093 & 6.6021 & 6.4196 & TRN & & \\
\hline CHEMBL378938 & 383093 & 4.301 & 4.3831 & TRN & & \\
\hline CHEMBL378833 & 383093 & 6.1024 & 6.2919 & TRN & & \\
\hline CHEMBL386042 & 383093 & 4.301 & 3.8751 & TST & & \\
\hline CHEMBL212305 & 383093 & 6.1871 & 5.63899 & 9999999999 & & TST \\
\hline CHEMBL212061 & 383093 & 4.301 & 4.1435 & TST & & \\
\hline CHEMBL375410 & 383093 & 5.8416 & 6.778 & TST & & \\
\hline CHEMBL209868 & 383093 & 6.2924 & 6.6123 & TST & & \\
\hline CHEMBL425065 & 383093 & 6.3872 & 5.8268 & TST & & \\
\hline CHEMBL454487 & 739780 & \multicolumn{3}{|c|}{0.8859999999999999} & 0.9829 & TRN \\
\hline CHEMBL464597 & 739780 & 2.456 & 2.5384 & TRN & & \\
\hline CHEMBL464333 & 739780 & 1.0 & 0.9124 & TRN & & \\
\hline CHEMBL464798 & 739780 & 1.824 & 2.1298 & TRN & & \\
\hline CHEMBL464799 & 739780 & \multicolumn{3}{|c|}{1.5230000000000001} & 1.2255 & TRN \\
\hline CHEMBL456107 & 739780 & 1.155 & 1.7094 & TRN & & \\
\hline CHEMBL444747 & 739780 & 2.222 & 1.2283 & TRN & & \\
\hline CHEMBL460610 & 739780 & 0.77 & 1.1603 & TRN & & \\
\hline CHEMBL460608 & 739780 & 2.398 & 2.2845 & TRN & & \\
\hline CHEMBL503807 & 739780 & 2.187 & 1.7798 & TRN & & \\
\hline CHEMBL460609 & 739780 & 2.301 & 0.9564 & TRN & & \\
\hline CHEMBL460599 & 739780 & 3.036 & 2.0675 & TRN & & \\
\hline CHEMBL507759 & 739780 & 1.0 & 0.8432 & TRN & & \\
\hline CHEMBL459336 & 739780 & 1.357 & 1.5579 & TRN & & \\
\hline CHEMBL459543 & 739780 & 0.342 & 0.753 & TRN & & \\
\hline CHEMBL459544 & 739780 & 1.0 & 1.746 & TRN & & \\
\hline CHEMBL461244 & 739780 & 0.0 & 1.2416 & TRN & & \\
\hline CHEMBL447043 & 739780 & 1.0 & 1.357 & TST & & \\
\hline CHEMBL461245 & 739780 & 2.0 & 2.2967 & TRN & & \\
\hline CHEMBL449889 & 739780 & 2.0 & 1.2783 & TST & & \\
\hline CHEMBL459962 & 739780 & 2.222 & 2.0978 & TRN & & \\
\hline CHEMBL45511 & 739780 & 0.322 & 1.5715 & TST & & \\
\hline CHEMBL462054 & 739780 & 1.222 & 1.4342 & TRN & & \\
\hline CHEMBL462096 & 739780 & 0.857 & 1.156 & TRN & & \\
\hline CHEMBL446960 & 739780 & 0.204 & 1.5684 & TST & & \\
\hline CHEMBL462097 & 739780 & 3.0 & 2.0514 & TRN & & \\
\hline CHEMBL460828 & 739780 & 2.155 & 1.7734 & TRN & & \\
\hline CHEMBL450824 & 739780 & 1.137 & 1.5954 & TRN & & \\
\hline CHEMBL460829 & 739780 & 1.051 & 1.3166 & TRN & & \\
\hline CHEMBL455981 & 739780 & 1.0 & 1.1276 & TST & & \\
\hline CHEMBL376643 & 739780 & \multicolumn{3}{|c|}{0.39799999999999996} & 0.4084 & TRN \\
\hline CHEMBL174040 & 739780 & 0.602 & 0.6644 & TRN & & \\
\hline CHEMBL352538 & 739780 & 0.222 & 0.9301 & TRN & & \\
\hline CHEMBL426546 & 739780 & 0.377 & 0.6373 & TRN & & \\
\hline CHEMBL221333 & 739780 & 2.155 & 1.5134 & TRN & & \\
\hline
\end{tabular}




\begin{tabular}{|c|c|c|c|c|c|c|}
\hline \multirow[b]{2}{*}{ CHEMBL221171 } & & \\
\hline & 739780 & 0.155 & 0.4206 & TRN & & \\
\hline CHEMBL375415 & 739780 & \multicolumn{3}{|c|}{1.3980000000000001} & 1.3097 & TRN \\
\hline CHEMBL220677 & 739780 & 1.26 & 0.2282 & TRN & & \\
\hline CHEMBL220678 & 739780 & 1.046 & 0.9878 & TRN & & \\
\hline CHEMBL223618 & 739780 & 0.456 & 0.9759 & TST & & \\
\hline CHEMBL 374335 & 739780 & 0.544 & 0.8839 & TRN & & \\
\hline CHEMBL 375788 & 739780 & \multicolumn{3}{|c|}{0.8240000000000001} & 0.2424 & TST \\
\hline CHEMBL222368 & 739780 & 1.699 & 0.9842 & TST & & \\
\hline CHEMBL 374119 & 739780 & 1.301 & 1.4992 & TRN & & \\
\hline CHEMBL222672 & 739780 & 1.301 & 1.0613 & TRN & & \\
\hline CHEMBL222673 & 739780 & 1.0 & 0.7527 & TRN & & \\
\hline CHEMBL 220265 & 739780 & 1.699 & 1.3674 & TST & & \\
\hline CHEMBL266769 & 739780 & 0.638 & 1.0194 & TRN & & \\
\hline CHEMBL353159 & 739780 & 1.125 & 1.5534 & TRN & & \\
\hline CHEMBL 375574 & 739780 & 0.081 & 0.8009 & TRN & & \\
\hline CHEMBL220116 & 739780 & \multicolumn{3}{|c|}{2.2680000000000002} & 1.7907 & TRN \\
\hline CHEMBL 223433 & 739780 & \multicolumn{3}{|c|}{0.35700000000000004} & 1.0853 & \\
\hline CHEMBL170635 & 739780 & 0.585 & 0.2052 & TRN & & \\
\hline CHEMBL171588 & 739780 & 0.268 & 0.2316 & TRN & & \\
\hline CHEMBL 366390 & 739780 & \multicolumn{3}{|c|}{0.14300000000000002} & 0.3607 & \\
\hline CHEMBL173596 & 739780 & \multicolumn{3}{|c|}{0.39799999999999996} & -0.0284 & \\
\hline CHEMBL354639 & 739780 & 0.444 & 0.0102 & TST & & \\
\hline CHEMBL172812 & 739780 & 0.469 & 0.547 & TRN & & \\
\hline CHEMBL174289 & 739780 & \multicolumn{3}{|c|}{0.6990000000000001} & 0.1049 & \\
\hline CHEMBL173436 & 739780 & \multicolumn{3}{|c|}{0.009000000000000001} & 0.2511 & \\
\hline CHEMBL171239 & 739780 & \multicolumn{3}{|c|}{0.39799999999999996} & 0.6172 & \\
\hline CHEMBL354285 & 739780 & \multicolumn{3}{|c|}{0.22899999999999998} & 0.1059 & \\
\hline CHEMBL354971 & 739780 & 0.745 & 0.3794 & TST & & \\
\hline CHEMBL170087 & 739780 & 0.301 & 0.9798 & TST & & \\
\hline CHEMBL1649842 & 714824 & 4.3915 & 4.2908 & TRN & & \\
\hline CHEMBL1649801 & 714824 & 4.9469 & 4.6628 & TRN & & \\
\hline CHEMBL1649777 & 714824 & 4.3391 & 3.4542 & TST & & \\
\hline CHEMBL1649808 & 714824 & 4.6517 & 4.831 & TRN & & \\
\hline CHEMBL1649864 & 714824 & 5.301 & 5.1126 & TST & & \\
\hline CHEMBL1410311 & 714824 & 4.0214 & 4.2224 & TST & & \\
\hline CHEMBL1649826 & 714824 & 4.2541 & 4.9143 & TRN & & \\
\hline CHEMBL1649814 & 714824 & 4.3809 & 4.2529 & TRN & & \\
\hline CHEMBL1649871 & 714824 & 4.2848 & 4.3697 & TRN & & \\
\hline CHEMBL1649883 & 714824 & 4.71 & 4.7424 & TRN & & \\
\hline CHEMBL1649791 & 714824 & 5.6778 & 4.436 & TRN & & \\
\hline CHEMBL1649839 & 714824 & 5.9208 & 5.956 & TRN & & \\
\hline CHEMBL1649861 & 714824 & 5.1805 & 3.7575 & TRN & & \\
\hline CHEMBL1649869 & 714824 & 4.2381 & 4.151 & TRN & & \\
\hline CHEMBL1649882 & 714824 & 5.0605 & 5.4774 & TRN & & \\
\hline CHEMBL1649796 & 714824 & 4.8239 & 4.9325 & TRN & & \\
\hline CHEMBL1649806 & 714824 & 5.3979 & 4.831 & TRN & & \\
\hline CHEMBL1649846 & 714824 & 4.4559 & 4.4745 & TRN & & \\
\hline CHEMBL1649884 & 714824 & 4.8962 & 4.8981 & TRN & & \\
\hline
\end{tabular}

Page 22779 


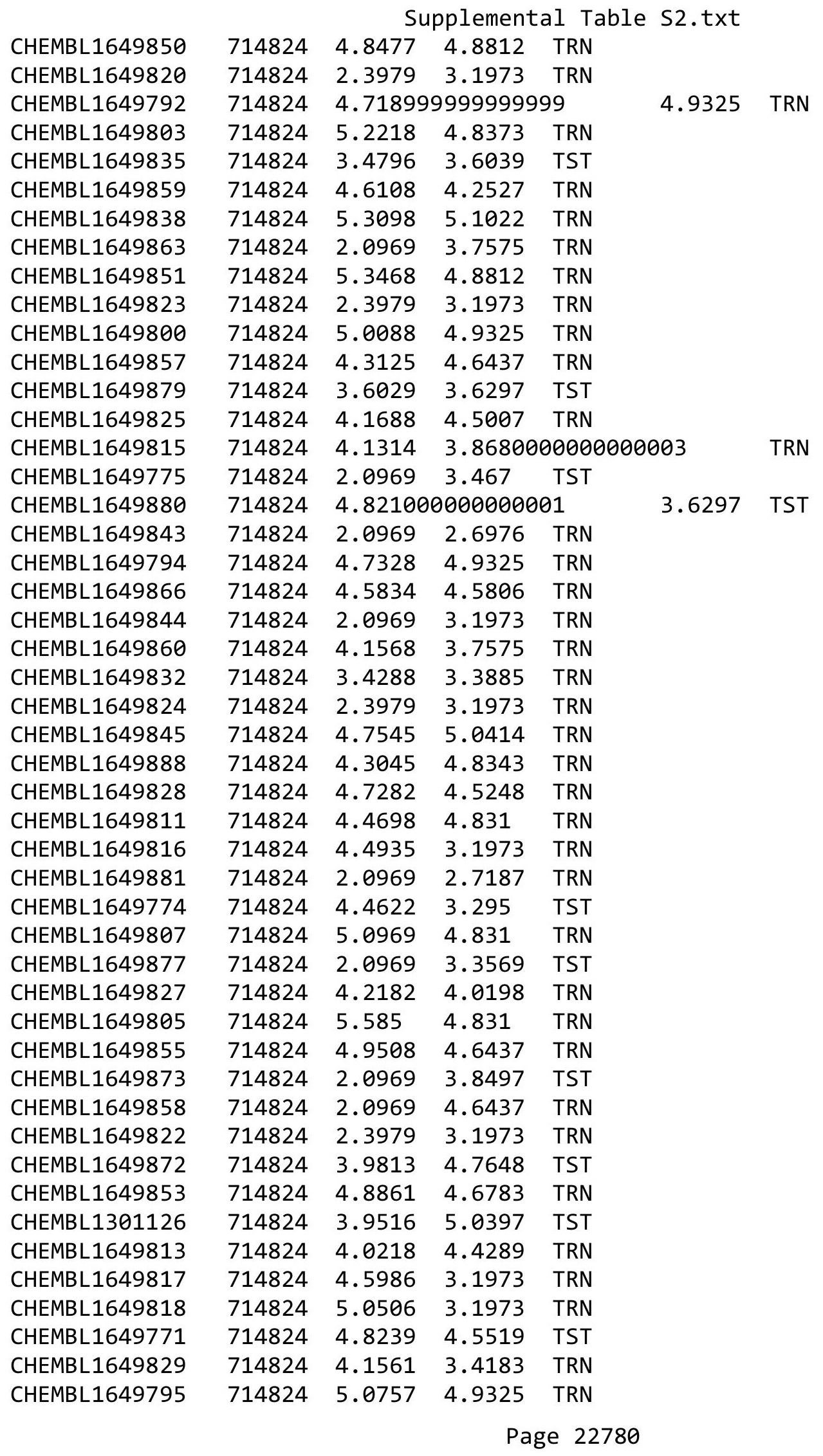


Supplemental Table S2.txt

\begin{tabular}{|c|c|c|c|c|c|}
\hline CHEMBL1649773 & 714824 & 5.4949 & 4.0001 & TST & \\
\hline CHEMBL1649831 & 714824 & 2.0969 & 2.6199 & TRN & \\
\hline CHEMBL1649868 & 714824 & 4.8297 & 5.1506 & TRN & \\
\hline CHEMBL1649862 & 714824 & 5.4949 & 3.7575 & TRN & \\
\hline CHEMBL1649809 & 714824 & 4.3565 & 4.831 & TRN & \\
\hline CHEMBL1649821 & 714824 & 2.3979 & 3.1973 & TRN & \\
\hline CHEMBL1649830 & 714824 & 3.9003 & 3.1888 & TRN & \\
\hline CHEMBL1649810 & 714824 & 4.3036 & 4.831 & TRN & \\
\hline CHEMBL1649870 & 714824 & 3.7978 & 3.9864 & TRN & \\
\hline CHEMBL1649793 & 714824 & 5.1675 & 4.9325 & TRN & \\
\hline CHEMBL1649848 & 714824 & 4.8996 & 4.2163 & TRN & \\
\hline CHEMBL1649804 & 714824 & 5.2676 & 4.831 & TRN & \\
\hline CHEMBL1649834 & 714824 & 3.6192 & 3.7572 & TRN & \\
\hline CHEMBL1649776 & 714824 & 3.7298 & 4.9884 & TST & \\
\hline CHEMBL1649587 & 714824 & 3.4521 & 3.9316 & TRN & \\
\hline CHEMBL1649798 & 714824 & 4.8928 & 4.9325 & TRN & \\
\hline CHEMBL1649878 & 714824 & 4.7282 & 3.1491 & TST & \\
\hline CHEMBL1649772 & 714824 & 5.4559 & 4.5592 & TST & \\
\hline CHEMBL1649812 & 714824 & 4.71899 & 99999999 & 9 & 4.831 \\
\hline CHEMBL1649833 & 714824 & 4.4989 & 4.5537 & TST & \\
\hline CHEMBL1649856 & 714824 & 5.3979 & 4.6437 & TRN & \\
\hline CHEMBL1649847 & 714824 & 4.7011 & 4.7455 & TRN & \\
\hline CHEMBL1649887 & 714824 & 6.0 & 3.5203 & TST & \\
\hline CHEMBL1649790 & 714824 & 5.6778 & 4.8191 & TRN & \\
\hline CHEMBL1649836 & 714824 & 5.3098 & 4.8862 & TRN & \\
\hline CHEMBL1649865 & 714824 & 2.0969 & 2.9695 & TST & \\
\hline CHEMBL1649757 & 714824 & 4.1391 & 4.0088 & TST & \\
\hline CHEMBL1649799 & 714824 & 4.5638 & 4.9325 & TRN & \\
\hline CHEMBL1649788 & 714824 & 4.684 & 4.68 & TRN & \\
\hline CHEMBL1649819 & 714824 & 2.3979 & 3.1973 & TRN & \\
\hline CHEMBL1649849 & 714824 & 5.3372 & 4.8812 & TRN & \\
\hline CHEMBL1649789 & 714824 & 5.3468 & 4.294 & TRN & \\
\hline CHEMBL1649876 & 714824 & 2.0969 & 2.0293 & TST & \\
\hline CHEMBL1649840 & 714824 & 5.5528 & 4.8757 & TRN & \\
\hline CHEMBL1649802 & 714824 & 4.7773 & 4.8153 & TRN & \\
\hline CHEMBL1649854 & 714824 & 5.2218 & 5.0551 & TRN & \\
\hline CHEMBL1649874 & 714824 & 2.0969 & 1.8139 & TST & \\
\hline CHEMBL1649875 & 714824 & 2.0969 & 2.7586 & TST & \\
\hline CHEMBL1649867 & 714824 & 4.4949 & 4.3465 & TRN & \\
\hline CHEMBL1649889 & 714824 & 5.0315 & 4.6798 & TST & \\
\hline CHEMBL1649886 & 714824 & 5.1675 & 4.8026 & TST & \\
\hline CHEMBL1649885 & 714824 & 5.1549 & 4.7635 & TST & \\
\hline CHEMBL1649778 & 714824 & 5.0655 & 5.2601 & TST & \\
\hline CHEMBL1649797 & 714824 & 4.7878 & 4.9325 & TRN & \\
\hline CHEMBL1649852 & 714824 & 2.0969 & 4.8812 & TRN & \\
\hline CHEMBL375937 & 429363 & 3.0 & 6.4959 & TST & \\
\hline CHEMBL 223559 & 429363 & 5.3768 & 5.4073 & TRN & \\
\hline CHEMBL 221893 & 429363 & 3.0 & 5.5763 & TST & \\
\hline
\end{tabular}




\begin{tabular}{|c|c|c|c|c|c|}
\hline & & \multicolumn{4}{|c|}{ Supplemental Table S2.txt } \\
\hline CHEMBL105521 & 429363 & 6.4559 & 6.4285 & TRN & \\
\hline CHEMBL 222765 & 429363 & 5.6021 & 5.8339 & TRN & \\
\hline CHEMBL431228 & 429363 & 6.0757 & 5.86799 & 9999999999 & TST \\
\hline CHEMBL 321784 & 429363 & 6.5528 & 6.4755 & TRN & \\
\hline CHEMBL102396 & 429363 & 5.9586 & 6.0432 & TRN & \\
\hline CHEMBL 222545 & 429363 & 6.0969 & 6.1017 & TRN & \\
\hline CHEMBL 222820 & 429363 & 6.1675 & 6.1454 & TRN & \\
\hline CHEMBL427096 & 429363 & 3.0 & 5.4424 & TST & \\
\hline CHEMBL 373940 & 429363 & 4.0 & 4.24100 & 00000000005 & TST \\
\hline CHEMBL225273 & 429363 & 5.4437 & 5.3608 & TRN & \\
\hline CHEMBL221409 & 429363 & 5.7447 & 5.7884 & TRN & \\
\hline CHEMBL223031 & 429363 & 4.0 & 4.9987 & TST & \\
\hline CHEMBL222745 & 429363 & 6.3979 & 6.5115 & TRN & \\
\hline CHEMBL376878 & 429363 & 3.0 & 5.2721 & TST & \\
\hline CHEMBL223775 & 429363 & 6.0 & 6.0954 & TRN & \\
\hline CHEMBL105678 & 429363 & 6.7959 & 6.8077 & TRN & \\
\hline CHEMBL102529 & 429363 & 6.3188 & 6.1992 & TRN & \\
\hline CHEMBL 224142 & 429363 & 5.4949 & 5.5742 & TRN & \\
\hline CHEMBL 105612 & 429363 & 6.7447 & 6.7554 & TRN & \\
\hline CHEMBL319909 & 429363 & 6.1612 & 6.2086 & TRN & \\
\hline CHEMBL 223320 & 429363 & 3.0 & 5.9109 & TST & \\
\hline CHEMBL 224092 & 429363 & 6.4089 & 6.3543 & TRN & \\
\hline CHEMBL 222815 & 429363 & 6.0 & 6.1426 & TRN & \\
\hline CHEMBL 221403 & 429363 & 5.6778 & 5.7922 & TRN & \\
\hline CHEMBL224827 & 429363 & 5.9747 & 5.9889 & TRN & \\
\hline CHEMBL222821 & 429363 & 6.3279 & 6.2871 & TRN & \\
\hline CHEMBL106543 & 429363 & 6.2676 & 6.2196 & TRN & \\
\hline CHEMBL105256 & 429363 & 6.5086 & 6.4433 & TRN & \\
\hline CHEMBL223437 & 429363 & 5.6021 & 5.5359 & TRN & \\
\hline CHEMBL221412 & 429363 & 6.0 & 5.8026 & TRN & \\
\hline CHEMBL224782 & 429363 & 4.9586 & 4.9518 & TRN & \\
\hline CHEMBL223980 & 429363 & 5.8861 & 5.79799 & 9999999999 & TRN \\
\hline CHEMBL222179 & 429363 & 5.7447 & 5.735 & TRN & \\
\hline CHEMBL375346 & 429363 & 5.1079 & 5.0951 & TRN & \\
\hline CHEMBL415057 & 429363 & 3.5229 & 4.6818 & TST & \\
\hline CHEMBL225609 & 429363 & 5.8861 & 5.869 & TRN & \\
\hline CHEMBL102581 & 429363 & 6.7959 & 6.6508 & TRN & \\
\hline CHEMBL221459 & 429363 & 5.0555 & 5.1604 & TRN & \\
\hline CHEMBL225796 & 429363 & 6.041 & 5.9898 & TRN & \\
\hline CHEMBL373699 & 429363 & 5.4949 & 5.5075 & TRN & \\
\hline CHEMBL223667 & 429363 & 5.9586 & 5.9783 & TRN & \\
\hline CHEMBL374133 & 429363 & 5.9586 & 6.0596 & TRN & \\
\hline CHEMBL375210 & 429363 & 5.7212 & 5.6083 & TRN & \\
\hline CHEMBL225150 & 429363 & 5.0915 & 5.347 & TST & \\
\hline CHEMBL222102 & 429363 & 5.7447 & 5.517 & TRN & \\
\hline CHEMBL222766 & 429363 & 5.4437 & 5.4787 & TRN & \\
\hline CHEMBL373526 & 429363 & 4.7212 & 4.6817 & TRN & \\
\hline CHEMBL223251 & 429363 & 3.0 & 3.0651 & TRN & \\
\hline
\end{tabular}




\begin{tabular}{|c|c|c|c|c|c|}
\hline \multicolumn{6}{|c|}{ 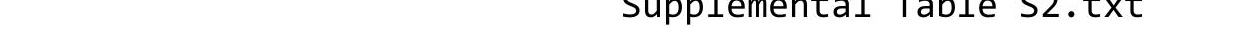 } \\
\hline CHEMBL221350 & 429363 & 3.0 & 3.0177 & TRN & \\
\hline CHEMBL319261 & 429363 & 6.6576 & 6.7688 & TRN & \\
\hline CHEMBL223436 & 429363 & 5.3279 & 5.2615 & TRN & \\
\hline CHEMBL367537 & 429363 & 5.9031 & 5.3624 & TST & \\
\hline CHEMBL225517 & 429363 & 3.0 & 3.028 & TRN & \\
\hline CHEMBL323145 & 429363 & 6.1549 & 6.2238 & TRN & \\
\hline CHEMBL316769 & 429363 & 6.1675 & 5.9301 & TRN & \\
\hline CHEMBL222181 & 429363 & 4.8239 & 4.8412 & TRN & \\
\hline CHEMBL374290 & 429363 & 6.301 & 6.3101 & TRN & \\
\hline CHEMBL384668 & 429363 & 3.0 & 4.3972 & TST & \\
\hline CHEMBL222294 & 429363 & 3.5229 & 2.99600 & 00000000004 & TST \\
\hline CHEMBL389267 & 429363 & 5.8861 & 5.7122 & TRN & \\
\hline CHEMBL222544 & 429363 & 6.2218 & 6.2895 & TRN & \\
\hline CHEMBL223382 & 429363 & 5.0132 & 5.0514 & TRN & \\
\hline CHEMBL373979 & 429363 & 5.9208 & 5.9608 & TRN & \\
\hline CHEMBL276746 & 429363 & 6.1871 & 6.1141 & TRN & \\
\hline CHEMBL223610 & 429363 & 5.2007 & 5.1745 & TRN & \\
\hline CHEMBL426894 & 429363 & 6.0969 & 6.1875 & TRN & \\
\hline CHEMBL222977 & 429363 & 3.0 & 3.14399 & 99999999997 & TRN \\
\hline CHEMBL221565 & 429363 & 5.3768 & 5.4191 & TRN & \\
\hline CHEMBL222264 & 429363 & 5.1367 & 3.5705 & TST & \\
\hline CHEMBL222524 & 429363 & 3.0 & 6.0916 & TST & \\
\hline CHEMBL374930 & 429363 & 5.4437 & 5.5505 & TRN & \\
\hline CHEMBL323136 & 429363 & 6.2757 & 6.3047 & TRN & \\
\hline CHEMBL222525 & 429363 & 5.3768 & 5.4051 & TRN & \\
\hline CHEMBL104644 & 429363 & 6.0362 & 6.0038 & TRN & \\
\hline CHEMBL222324 & 429363 & 3.0 & 2.8979 & TRN & \\
\hline CHEMBL222180 & 429363 & 5.1427 & 5.025 & TRN & \\
\hline CHEMBL104682 & 429363 & 6.585 & 6.7848 & TRN & \\
\hline CHEMBL223041 & 429363 & 6.0458 & 5.9853 & TRN & \\
\hline CHEMBL223034 & 429363 & 5.5086 & 5.4914 & TST & \\
\hline CHEMBL105613 & 429363 & 5.8861 & 6.2465 & TST & \\
\hline CHEMBL223526 & 429363 & 3.0 & 3.2572 & TST & \\
\hline CHEMBL222929 & 429363 & 5.2291 & 4.9029 & TST & \\
\hline CHEMBL225608 & 429363 & 5.6383 & 5.9766 & TST & \\
\hline CHEMBL223381 & 429363 & 5.7959 & 5.6238 & TST & \\
\hline CHEMBL221410 & 429363 & 6.2757 & 6.2799 & TST & \\
\hline CHEMBL316232 & 104740 & 5.301 & 5.3009 & TRN & \\
\hline CHEMBL83091 & 104740 & 5.9469 & 6.7611 & TST & \\
\hline CHEMBL315043 & 104740 & 6.0 & 6.0004 & TRN & \\
\hline CHEMBL 84408 & 104740 & 6.1549 & 6.1552 & TRN & \\
\hline CHEMBL 82783 & 104740 & 6.983 & 6.9832 & TRN & \\
\hline CHEMBL84255 & 104740 & 6.5157 & 6.5154 & TRN & \\
\hline CHEMBL 82558 & 104740 & 5.4855 & 5.4854 & TRN & \\
\hline CHEMBL312152 & 104740 & 7.0 & 7.0011 & TRN & \\
\hline CHEMBL314059 & 104740 & 6.82100 & 30000000 & 6.8217 & TRN \\
\hline CHEMBL84235 & 104740 & 7.1549 & 7.1552 & TRN & \\
\hline CHEMBL314918 & 104740 & 7.2147 & 7.1759 & TST & \\
\hline
\end{tabular}


Supplemental Table S2.txt

\begin{tabular}{|c|c|c|c|c|}
\hline CHEMBL85108 & 104740 & 6.6271 & 6.7049 & ST \\
\hline CHEMBL310520 & 104740 & 5.4855 & 5.4859 & \\
\hline HEMBL82855 & 104740 & 0706 & 7.0709 & \\
\hline HEMBL84153 & 04740 & .5086 & .5088 & \\
\hline HEMBL 310422 & 04740 & 5.7545 & 5.7548 & \\
\hline HEMBL 315905 & 04740 & .4737 & .4731 & \\
\hline HEMBL432572 & 104740 & .1612 & .1623 & \\
\hline HEMBL85869 & 104740 & 6.8729 & 6.8725 & \\
\hline HEMBL432760 & 104740 & 7.301 & 7.2998 & \\
\hline HEMBL313836 & 104740 & 7.3372 & 7.3446 & \\
\hline HEMBL 86189 & 04740 & 7.0269 & 7.0267 & \\
\hline HEMBL 315949 & 40 & 6.7167 & 6.7173 & RN \\
\hline HEMBL86113 & 104 & 7.2147 & 7.216 & \\
\hline HEMBL419491 & 104740 & 7.3768 & 7.3764 & \\
\hline HEMBL 82827 & 104740 & 6.983 & 6.9833 & RIV \\
\hline HEMBL 312218 & 40 & 269 & 269 & Tiv \\
\hline HEMBL 8 & 10 & 99 & 393 & RN \\
\hline HEMBL314596 & 10 & 469 & 9398 & $\mathrm{RN}$ \\
\hline HEMBL 82212 & 40 & 528 & 5546 & \\
\hline HEMBL 82047 & 40 & 7.2007 & 7.1991 & RIN \\
\hline HEMBL 331342 & 10 & 383 & 293 & RN \\
\hline HEMBL3 & 0 & 58 & 57 & $\mathrm{RN}$ \\
\hline HEMBL311932 & 10 & 761 & 3767 & 「RN \\
\hline HEMBL310559 & 40 & 565 & 571 & 「RN \\
\hline HEMBL 85427 & 40 & 5.6021 & 3746 & TST \\
\hline HEMBL313406 & 10 & 549 & 2902 & ST \\
\hline SHEMBL2 & 0 & 6 & 225 & ST \\
\hline HEMBL310347 & 10 & 716 & 5.2713 & TRN \\
\hline HEMBL420784 & 0 & & 14 & TST \\
\hline HEMBL 85620 & 104 & 7.4089 & 6.4043 & TST \\
\hline HEMBL 8 & 10 & 366 & 384 & TRN \\
\hline CHEMBL & 0 & 31 & & 「RN \\
\hline CHEMBL 82232 & 10 & & & TRN \\
\hline HEMBL312952 & 104 & 7.3188 & 06 & TST \\
\hline HEMBL 82868 & 104 & 7.1549 & 594 & TRN \\
\hline HEMBL314369 & 10 & 706 & 707 & TRN \\
\hline CHEMBL8 & 0 & 71 & & ST \\
\hline CHEMBL432385 & 104 & 7.0915 & 9314 & TST \\
\hline LHEMBL 83508 & 104 & 5.3565 & 738 & TST \\
\hline HEMBL 82869 & 10 & 5.9469 & 461 & TRN \\
\hline CHEMBL 84814 & 104 & 7.4202 & 7.2431 & IS \\
\hline CHEMBL 85319 & 104 & 7.3565 & 7.6016 & TST \\
\hline CHEMBL 82203 & 104740 & 6.0255 & 6.0249 & TRN \\
\hline CHEMBL 82331 & 104 & 7.1805 & 7.181 & TRN \\
\hline CHEMBL 297373 & 283 & 4 & 2.8935 & TST \\
\hline CHEMBL44885 & 28336 & 5.9208 & 5.9112 & \\
\hline CHEMBL295362 & 28336 & 3.301 & 3.2992 & $\Gamma \mathrm{RN}$ \\
\hline CHEMBL417531 & 28336 & 7.3372 & 7.3706 & 「RN \\
\hline
\end{tabular}

Page 22784 


\begin{tabular}{|c|c|c|c|c|}
\hline & & & oplement & al $\mathrm{T}$ \\
\hline CHEMBL46854 & 28336 & 4.301 & 4.2962 & TRN \\
\hline CHEMBL47256 & 28336 & 5.0088 & 5.0315 & TRN \\
\hline CHEMBL45429 & 28336 & 6.284 & 6.2949 & TRN \\
\hline CHEMBL46744 & 28336 & 6.1612 & 4.4676 & TST \\
\hline CHEMBL47640 & 28336 & 7.3188 & 7.1523 & TRN \\
\hline CHEMBL46417 & 28336 & 6.4949 & 6.5698 & TRN \\
\hline CHEMBL298465 & 28336 & 6.2147 & 6.2977 & TRN \\
\hline CHEMBL47099 & 28336 & 4.301 & 4.2954 & TRN \\
\hline CHEMBL46985 & 28336 & 6.0458 & 5.9773 & TRN \\
\hline CHEMBL46706 & 28336 & 4.0 & 3.7475 & TST \\
\hline CHEMBL42354 & 28336 & 6.7959 & 6.6833 & TRN \\
\hline CHEMBL288988 & 28336 & 4.0 & 3.9701 & TRN \\
\hline CHEMBL44423 & 28336 & 5.2676 & 5.2785 & TRN \\
\hline CHEMBL42343 & 28336 & 7.0 & 7.3525 & TRN \\
\hline CHEMBL297135 & 28336 & 7.1549 & 6.5414 & TRN \\
\hline CHEMBL40519 & 28336 & 7.3565 & 7.3612 & TRN \\
\hline CHEMBL46373 & 28336 & 4.0 & 5.0521 & TST \\
\hline CHEMBL415924 & 28336 & 5.5086 & 5.5067 & TRN \\
\hline CHEMBL46978 & 28336 & 4.0 & 3.6407 & TST \\
\hline CHEMBL42897 & 28336 & 7.284 & 7.2851 & TRN \\
\hline CHEMBL44652 & 28336 & 7.4318 & 7.4104 & TRN \\
\hline CHEMBL45438 & 28336 & 3.0 & 3.0081 & TRN \\
\hline CHEMBL44331 & 28336 & 6.0655 & 6.0158 & TRN \\
\hline CHEMBL46480 & 28336 & 7.301 & 7.3029 & TRN \\
\hline CHEMBL46689 & 28336 & 7.3665 & 7.3778 & TRN \\
\hline CHEMBL41330 & 28336 & 7.284 & 7.2845 & TRN \\
\hline CHEMBL46460 & 28336 & 5.2676 & 5.2714 & TRN \\
\hline CHEMBL46741 & 28336 & 4.301 & 4.3259 & TRN \\
\hline CHEMBL47206 & 28336 & 6.0088 & 6.0035 & TRN \\
\hline CHEMBL47218 & 28336 & 7.6778 & 7.3525 & TRN \\
\hline CHEMBL44609 & 28336 & 4.0 & 5.1237 & TST \\
\hline CHEMBL296287 & 28336 & 5.2441 & 5.2398 & TRN \\
\hline CHEMBL47233 & 28336 & 4.0 & 4.0241 & TRN \\
\hline CHEMBL295580 & 28336 & 5.5376 & 5.5406 & TRN \\
\hline CHEMBL42603 & 28336 & 7.7447 & 7.4129 & TRN \\
\hline CHEMBL44760 & 28336 & 7.1367 & 7.2263 & TRN \\
\hline CHEMBL46827 & 28336 & 4.301 & 4.3076 & TRN \\
\hline CHEMBL42902 & 28336 & 5.6091 & 5.5973 & TRN \\
\hline CHEMBL416626 & 28336 & 6.0458 & 6.0448 & TRN \\
\hline CHEMBL46709 & 28336 & 4.301 & 4.3049 & TRN \\
\hline CHEMBL46481 & 28336 & 7.3279 & 7.2263 & TRN \\
\hline CHEMBL45093 & 28336 & 7.0044 & 7.1523 & TRN \\
\hline CHEMBL46376 & 28336 & 6.3979 & 6.3792 & TRN \\
\hline CHEMBL46690 & 28336 & 6.7447 & 6.8106 & TRN \\
\hline CHEMBL47105 & 28336 & 7.0605 & 7.4129 & TRN \\
\hline CHEMBL44847 & 28336 & 4.301 & 4.3 & TRN \\
\hline CHEMBL45333 & 28336 & 5.0269 & 4.9884 & TRN \\
\hline CHEMBL44480 & 28336 & 6.9586 & 6.9229 & TRN \\
\hline
\end{tabular}

Page 22785 


\begin{tabular}{|c|c|c|c|c|c|}
\hline \multicolumn{6}{|c|}{ Supplemental Table S2.txt } \\
\hline CHEMBL46966 & 28336 & 5.3468 & 5.3353 & TRN & \\
\hline CHEMBL444831 & 28336 & 6.2007 & 6.2066 & TRN & \\
\hline CHEMBL47522 & 28336 & 5.9586 & 6.5414 & TRN & \\
\hline CHEMBL44334 & 28336 & 6.6021 & 6.6001 & TRN & \\
\hline CHEMBL43316 & 28336 & 5.1487 & 5.1975 & TRN & \\
\hline CHEMBL47221 & 28336 & 6.4685 & 6.4679 & TRN & \\
\hline CHEMBL 295248 & 28336 & 7.3468 & 7.3466 & TRN & \\
\hline CHEMBL42673 & 28336 & 7.2518 & 7.1523 & TST & \\
\hline CHEMBL46510 & 28336 & 7.3665 & 7.26200 & 00000000005 & TST \\
\hline CHEMBL295847 & 28336 & 4.6021 & 6.8501 & TST & \\
\hline CHEMBL43257 & 28336 & 7.3372 & 7.2263 & TST & \\
\hline CHEMBL 297460 & 28336 & 5.3279 & 6.6193 & TST & \\
\hline CHEMBL297985 & 28336 & 7.5528 & 7.4462 & TST & \\
\hline CHEMBL45379 & 28336 & 6.301 & 6.0408 & TST & \\
\hline CHEMBL45036 & 28336 & 5.1675 & 5.4521 & TST & \\
\hline CHEMBL46586 & 28336 & 6.6778 & 7.005 & TST & \\
\hline CHEMBL46426 & 28336 & 4.0 & 4.8644 & TST & \\
\hline CHEMBL42602 & 28336 & 6.699 & 6.8837 & TST & \\
\hline CHEMBL 297184 & 28336 & 5.4815 & 5.7136 & TST & \\
\hline CHEMBL3971620 & 1640747 & 8.0177 & 8.0132 & TRN & \\
\hline CHEMBL3701036 & 1640747 & 6.0117 & 6.015 & TRN & \\
\hline CHEMBL3701042 & 1640747 & 8.3372 & 8.3324 & TRN & \\
\hline CHEMBL3769849 & 1640747 & 7.3788 & 7.3806 & TRN & \\
\hline CHEMBL3916086 & 1640747 & 8.0269 & 8.0229 & TRN & \\
\hline CHEMBL3963830 & 1640747 & 8.2366 & 8.2395 & TRN & \\
\hline CHEMBL 3770184 & 1640747 & 8.6576 & 8.6537 & TRN & \\
\hline CHEMBL3937573 & 1640747 & 8.2441 & 8.2537 & TRN & \\
\hline CHEMBL3910693 & 1640747 & 8.6576 & 8.6615 & TRN & \\
\hline CHEMBL3971862 & 1640747 & 8.5528 & 8.5581 & TRN & \\
\hline CHEMBL3933289 & 1640747 & 8.3468 & 8.3522 & TRN & \\
\hline CHEMBL3909934 & 1640747 & 8.0655 & 8.0709 & TRN & \\
\hline CHEMBL3956266 & 1640747 & 8.7959 & 8.7791 & TRN & \\
\hline CHEMBL3938638 & 1640747 & 8.7959 & 8.7953 & TRN & \\
\hline CHEMBL 3945718 & 1640747 & 7.8356 & 7.8408 & TRN & \\
\hline CHEMBL3893981 & 1640747 & 8.1367 & 8.1255 & TRN & \\
\hline CHEMBL 3939074 & 1640747 & 8.3768 & 8.3633 & TRN & \\
\hline CHEMBL 3942268 & 1640747 & 8.3979 & 8.4321 & TRN & \\
\hline CHEMBL3918857 & 1640747 & 7.5003 & 7.1965 & TST & \\
\hline CHEMBL 3895049 & 1640747 & 7.7167 & 7.7196 & TRN & \\
\hline CHEMBL3701034 & 1640747 & 8.5086 & 8.5033 & TRN & \\
\hline CHEMBL3701037 & 1640747 & 8.4559 & 8.4548 & TRN & \\
\hline CHEMBL3946376 & 1640747 & 7.8962 & 7.5108 & TST & \\
\hline CHEMBL3941351 & 1640747 & 7.9136 & 7.92399 & 99999999995 & $\mathrm{TR}$ \\
\hline CHEMBL3940475 & 1640747 & 8.5376 & 8.5516 & TRN & \\
\hline CHEMBL3908410 & 1640747 & 8.8239 & 8.8117 & TRN & \\
\hline CHEMBL3961483 & 1640747 & 6.0 & 5.9995 & TRN & \\
\hline CHEMBL3701035 & 1640747 & 8.2007 & 8.2007 & TRN & \\
\hline CHEMBL3946689 & 1640747 & 6.6716 & 6.8047 & TST & \\
\hline
\end{tabular}


Supplemental Table S2.txt

\begin{tabular}{|c|c|c|c|c|}
\hline $\mathrm{HEI}$ & 540747 & 8.5686 & 9558 & (1) \\
\hline & 640747 & 7.9208 & 7.9234 & \\
\hline 38 & & & 746 & \\
\hline AEMBL3 & 40747 & 7212 & 7369 & \\
\hline AEMBL3 & 640747 & & 3723 & \\
\hline HEMBL3911120 & 640747 & 8.4685 & .4712 & \\
\hline HEMBL & 747 & 86 & 636 & \\
\hline AEMBL: & & & & \\
\hline HEMBL3942740 & 640747 & 6.0 & .9902 & \\
\hline HEMBL3701033 & 640747 & 28 & & \\
\hline HEMBL3 & 640747 & & 62 & \\
\hline AEMBL3 & 47 & & & \\
\hline HEMBL $\angle$ & & & & \\
\hline HEMBL3 & 747 & & & \\
\hline AEMBL3 & 640747 & & & \\
\hline AEMBL3 & 64 & 72 & 42 & \\
\hline HEMBL3 & 17 & & & \\
\hline HEMBL3 & & & & \\
\hline HEMBL3 & 47 & & 8162 & \\
\hline AEMBL3 & 47 & & & \\
\hline HEMBL & +1 & & 33 & \\
\hline HEMBL & 8 & & & \\
\hline HEMBL & & 9. & & \\
\hline HEMBL & & & & \\
\hline AEMBL3 & & & & \\
\hline HEMBL; & 8 & & 47 & \\
\hline HEMBL; & 88 & 9 & & \\
\hline HFMBI : & & & 19 & RN \\
\hline HEMBL3 & & & & $\mathrm{RN}$ \\
\hline HEMBL3 & & & & KN \\
\hline HEMBL3 & 62 & 9 & & RN \\
\hline HEMBL: & & & & RIV \\
\hline 48 & & 8 & & RN \\
\hline HEMBL3 & & & & RN \\
\hline HEMBL3934474 & 98 & 6 . & 7.0424 & TRN \\
\hline HEMBL3 & 88 & 9 & 41 & $\mathrm{RN}$ \\
\hline HEMRI & & 7 & 77 & RN \\
\hline HEMBL & & 9. & 384 & RN \\
\hline HEMBL3S & 98 & 6 & 25 & TRN \\
\hline AEMBL & & & & ST \\
\hline HEMBL3 & 64 & 6 & 34 & \\
\hline CHEMBL3 & & 9 . & & RN \\
\hline HEMBL3 & & 7.25 & 6.7099 & RN \\
\hline HEMBL39 & 698 & 7.6021 & 6993 & ГRN \\
\hline $\mathrm{MPI}=$ & & 9 & & \\
\hline HEMBL3 & 64 & & & \\
\hline EHEMBL3 & 1640698 & 9.0 & 8.5532 & \\
\hline THEMBL3931564 & 1640698 & 6.306 & 6.4133 & ГRN \\
\hline
\end{tabular}

Page 22787 
Supplemental Table S2.txt

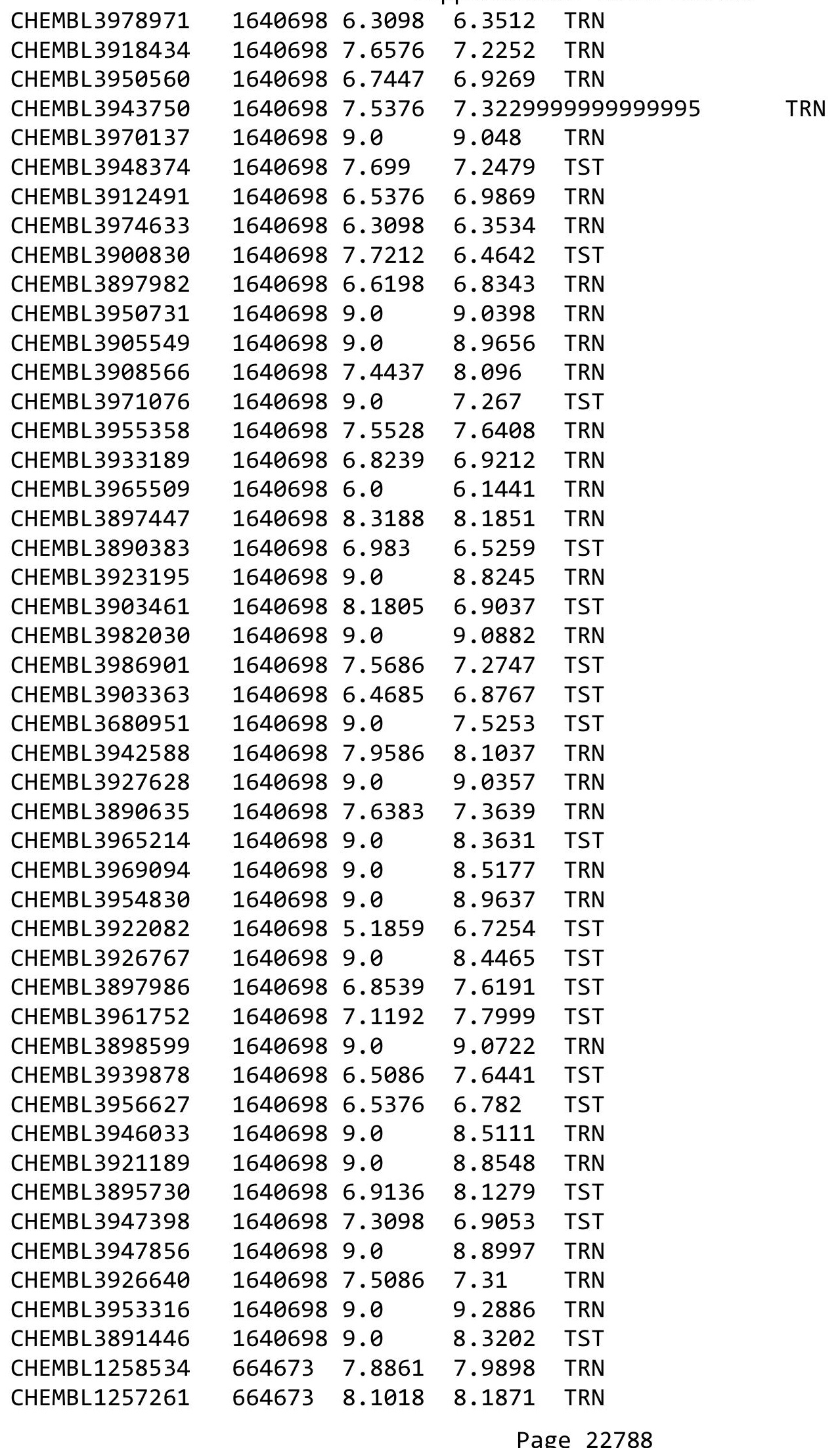

Page 22788 
Supplemental Table S2.txt

\begin{tabular}{|c|c|c|c|c|}
\hline - & 54673 & 302 & & \\
\hline & & .6861 & 8.6588 & \\
\hline & & & & \\
\hline IEMBL12 & & 73 & & \\
\hline AEMBL1258762 & 54673 & & 041 & \\
\hline HEMBL1258650 & 54673 & 5719 & 9355 & \\
\hline 16 & & & .33 & \\
\hline IFMBI 12 & & & & \\
\hline AEMBL1258763 & & 145 & 7688 & \\
\hline AEMBL1258428 & 73 & 935 & 8939 & \\
\hline AEMBL125 & 3 & 969 & 29 & \\
\hline IEMBL12 & & 69 & 01 & \\
\hline IEMBL12 & & & & \\
\hline HEMBL 125 & & 556 & 8.7486 & \\
\hline HEMBL125 & 73 & 35 & & \\
\hline AEMBL1 & 73 & 55 & 16 & \\
\hline IEMBL12 & & & & \\
\hline HEMBL12 & & & & \\
\hline HEMBL125 & & 668 & 8.479 & \\
\hline AEMBL125 & & 14 & & \\
\hline AEMBLI2 & 3 & 22 & 93 & Niv \\
\hline AEMBL12 & & & & RN \\
\hline AEMBL12 & & & & \\
\hline AEMBL125 & & & & \\
\hline JEMBL12 & & & & \\
\hline HEMBL12 & 3 & & 37 & | \\
\hline HEMBL12 & & & 975 & (1) \\
\hline AFMBI 12 & & & 48 & \\
\hline AEMBL125 & & & & 15 15 \\
\hline HEMBL125 & & & & IRN \\
\hline HEMBL12 & & & 04 & SI \\
\hline HEMBL1 & & 6 & 25 & RN \\
\hline$\triangle 5 M P$ & & 34 & & \\
\hline AEMBL1258426 & & & & is \\
\hline HEMBL1258648 & 73 & & 2605 & Th \\
\hline HEMBL125 & & & 255 & $\mid$ \\
\hline HEMDI1 & & & 91 & $\Gamma \mathrm{RN}$ \\
\hline HEMBL12 & & & & 「RN \\
\hline HEMBL1257856 & 73 & 547 & 3609 & TST \\
\hline AEMBL125 & & 824 & 3242 & TRN \\
\hline HEMBL 125 & 73 & 08 & 847 & \\
\hline HEMBL125 & & 622 & 3.7789 & TRN \\
\hline HEMBL125 & & 996 & & ST \\
\hline AEMBL1258879 & 73 & 7375 & 3135 & TR \\
\hline 1 & & & 2196 & TST \\
\hline HEMBL 125 & & & & \\
\hline CHEMBL1257262 & & 8.5003 & 8.1515 & \\
\hline HEMBL1258086 & 664673 & 7.284 & 7.1519 & ГRN \\
\hline
\end{tabular}

Page 22789 


\begin{tabular}{|c|c|c|c|c|c|c|}
\hline & & \multicolumn{5}{|c|}{ Supplemental Table S2.txt } \\
\hline CHEMBL1257147 & 664673 & 8.9469 & 8.7523 & TRN & & \\
\hline CHEMBL1257614 & 664673 & 8.475 & 8.2665 & TST & & \\
\hline CHEMBL1257615 & 664673 & 7.7932 & 8.2789 & TRN & & \\
\hline CHEMBL1257859 & 664673 & 7.4342 & 7.3565 & TRN & & \\
\hline CHEMBL1257382 & 664673 & 7.9957 & 8.2464 & TST & & \\
\hline CHEMBL1258084 & 664673 & 8.9666 & 8.8444 & TRN & & \\
\hline CHEMBL1258760 & 664673 & 7.9431 & 8.3605 & TRN & & \\
\hline CHEMBL1258313 & 664673 & 8.6778 & 8.742 & TRN & & \\
\hline CHEMBL1258647 & 664673 & 8.3054 & 8.3048 & TRN & & \\
\hline CHEMBL1257613 & 664673 & 8.3134 & 8.1685 & TST & & \\
\hline CHEMBL1257736 & 664673 & 7.9031 & 7.9806 & TRN & & \\
\hline CHEMBL3806002 & 1577526 & 5.3188 & 5.5157 & TRN & & \\
\hline CHEMBL 3804834 & 1577526 & 7.7212 & 7.0998 & TRN & & \\
\hline CHEMBL3805381 & 1577526 & 6.2426 & 6.21 & TRN & & \\
\hline CHEMBL3804891 & 1577526 & 7.4802 & 6.7346 & TST & & \\
\hline CHEMBL3806073 & 1577526 & 6.8601 & 6.7762 & TRN & & \\
\hline CHEMBL3805997 & 1577526 & 5.38200 & 00000000 & 01 & 5.602 & TRN \\
\hline CHEMBL3805464 & 1577526 & 7.1463 & 7.2655 & TRN & & \\
\hline CHEMBL 3805538 & 1577526 & 6.9508 & 7.1755 & TRN & & \\
\hline CHEMBL3804901 & 1577526 & 6.7077 & 6.7738 & TRN & & \\
\hline CHEMBL3805630 & 1577526 & 7.3497 & 7.1886 & TRN & & \\
\hline CHEMBL 3805835 & 1577526 & 7.644 & 7.8044 & TRN & & \\
\hline CHEMBL3806211 & 1577526 & 6.3468 & 5.9873 & TST & & \\
\hline CHEMBL 3805001 & 1577526 & 7.8697 & 7.7398 & TRN & & \\
\hline CHEMBL 3805574 & 1577526 & 6.6655 & 6.8696 & TRN & & \\
\hline CHEMBL3805709 & 1577526 & 6.2628 & 6.2497 & TST & & \\
\hline CHEMBL 3805448 & 1577526 & 6.4365 & 6.88399 & 99999 & 995 & TRN \\
\hline CHEMBL3805492 & 1577526 & 7.3372 & 7.8277 & TRN & & \\
\hline CHEMBL 3805478 & 1577526 & 6.9706 & 6.7634 & TST & & \\
\hline CHEMBL3806001 & 1577526 & 6.2366 & 6.2385 & TRN & & \\
\hline CHEMBL 3805740 & 1577526 & 7.45100 & 00000000 & 005 & 7.6141 & TRN \\
\hline CHEMBL3805568 & 1577526 & 5.5884 & 6.5472 & TRN & & \\
\hline CHEMBL3805306 & 1577526 & 6.8761 & 6.8198 & TRN & & \\
\hline CHEMBL3806274 & 1577526 & 6.2967 & 5.9598 & TST & & \\
\hline CHEMBL 3804850 & 1577526 & 7.4342 & 7.5031 & TRN & & \\
\hline CHEMBL3806221 & 1577526 & 5.8633 & 5.5872 & TRN & & \\
\hline CHEMBL3805694 & 1577526 & 7.3298 & 7.6322 & TRN & & \\
\hline CHEMBL3805929 & 1577526 & 7.8041 & 7.9083 & TRN & & \\
\hline CHEMBL3805650 & 1577526 & 7.1226 & 6.9596 & TRN & & \\
\hline CHEMBL3805331 & 1577526 & 5.71 & 5.9521 & TRN & & \\
\hline CHEMBL3806238 & 1577526 & $6.8210 €$ & 30000000 & 01 & 6.7546 & TRN \\
\hline CHEMBL3804932 & 1577526 & 6.301 & 5.9753 & TRN & & \\
\hline CHEMBL3805724 & 1577526 & 6.2848 & 6.7409 & TRN & & \\
\hline CHEMBL3806225 & 1577526 & 6.6289 & 6.6726 & TRN & & \\
\hline CHEMBL3805790 & 1577526 & 6.3595 & 7.0107 & TST & & \\
\hline CHEMBL 3805107 & 1577526 & 6.983 & 6.9008 & TRN & & \\
\hline CHEMBL 3805687 & 1577526 & 6.3325 & 6.5909 & TRN & & \\
\hline CHEMBL3805639 & 1577526 & 7.5391 & 7.478 & TRN & & \\
\hline
\end{tabular}


Supplemental Table S2.txt

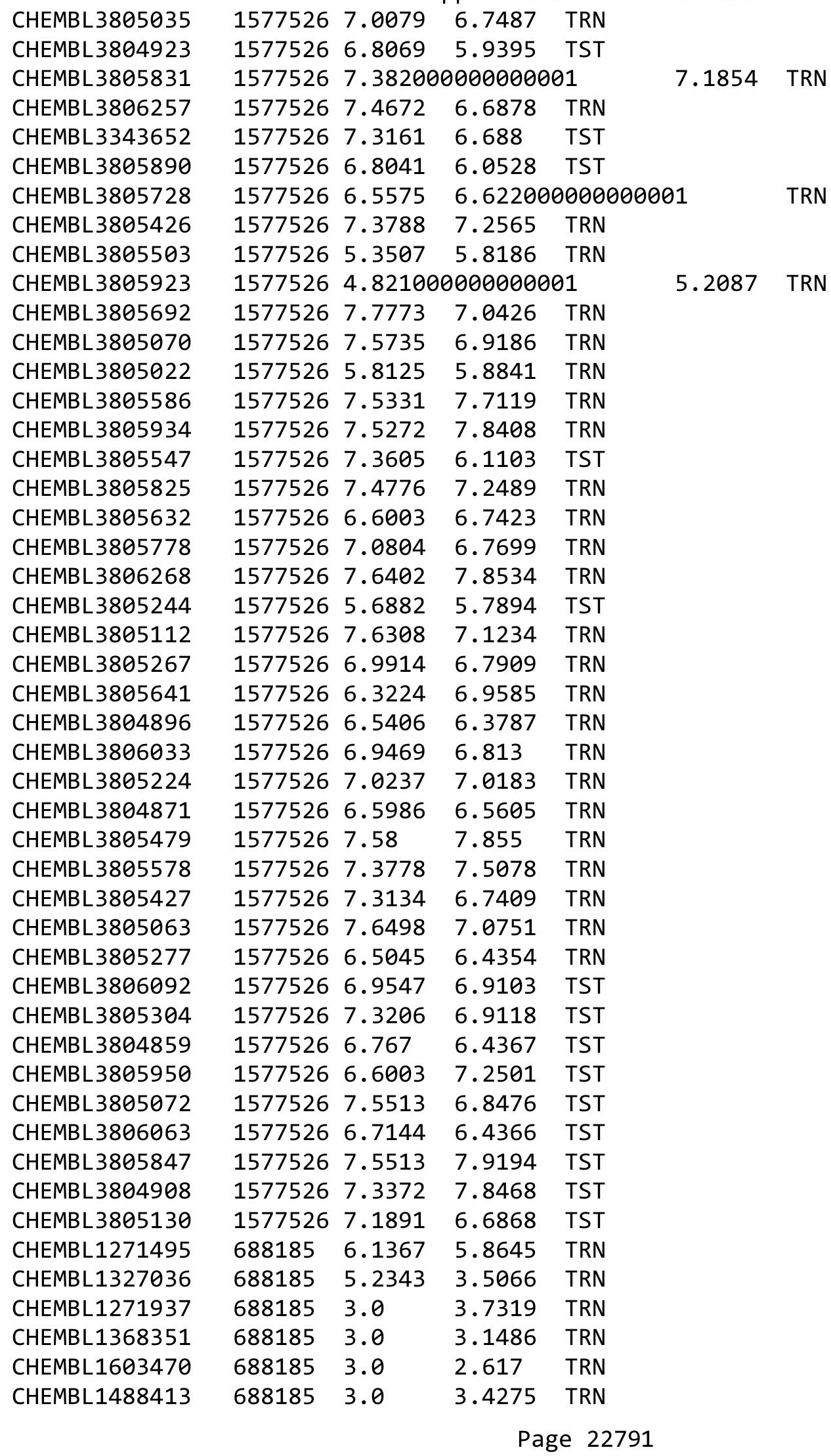




\begin{tabular}{|c|c|c|c|c|c|c|c|}
\hline \multicolumn{8}{|c|}{ Supplemental Table S2.txt } \\
\hline CHEMBL1375917 & 688185 & 4.1838 & 3.571 & TRN & & & \\
\hline CHEMBL1439481 & 688185 & 3.0 & 2.8429 & TRN & & & \\
\hline CHEMBL1503307 & 688185 & 3.0 & 2.8725 & TRN & & & \\
\hline CHEMBL1487799 & 688185 & 3.0 & 2.9542 & TRN & & & \\
\hline CHEMBL1364744 & 688185 & 5.3382 & 5.0802 & TRN & & & \\
\hline CHEMBL1272155 & 688185 & 5.38399 & 79999999 & 995 & 4.63399 & 99999999995 & TRN \\
\hline CHEMBL1271882 & 688185 & 4.9666 & 5.0355 & TRN & & & \\
\hline CHEMBL1335191 & 688185 & 3.0 & 3.2339 & TRN & & & \\
\hline CHEMBL1271824 & 688185 & 4.9547 & 4.9609 & TRN & & & \\
\hline CHEMBL1453492 & 688185 & 3.0 & 2.864 & TRN & & & \\
\hline CHEMBL1272313 & 688185 & 5.7852 & 5.3001 & TRN & & & \\
\hline CHEMBL1369154 & 688185 & 3.0 & 3.4681 & TST & & & \\
\hline CHEMBL1272100 & 688185 & 6.2291 & 6.2236 & TRN & & & \\
\hline CHEMBL1566663 & 688185 & 3.0 & 2.6686 & TRN & & & \\
\hline CHEMBL1490956 & 688185 & 3.0 & 3.2132 & TRN & & & \\
\hline CHEMBL1374336 & 688185 & 4.6968 & 3.9799 & TRN & & & \\
\hline CHEMBL1566104 & 688185 & 3.0 & 2.8959 & TRN & & & \\
\hline CHEMBL1314651 & 688185 & 3.0 & 3.1979 & TRN & & & \\
\hline CHEMBL1272210 & 688185 & 5.3161 & 5.5548 & TRN & & & \\
\hline CHEMBL1595347 & 688185 & 3.0 & 2.9716 & TRN & & & \\
\hline CHEMBL1516834 & 688185 & 3.0 & 2.9719 & TRN & & & \\
\hline CHEMBL1385840 & 688185 & 3.0 & 3.2003 & TST & & & \\
\hline CHEMBL1604250 & 688185 & 3.0 & 3.1702 & TRN & & & \\
\hline CHEMBL1312063 & 688185 & 3.0 & 3.1729 & TRN & & & \\
\hline CHEMBL1612321 & 688185 & 3.0 & 3.1536 & TST & & & \\
\hline CHEMBL1269036 & 688185 & 3.0 & 3.3808 & TRN & & & \\
\hline CHEMBL1272263 & 688185 & 5.1681 & 5.8171 & TRN & & & \\
\hline CHEMBL1346587 & 688185 & 6.0 & 5.0319 & TRN & & & \\
\hline CHEMBL1403496 & 688185 & 3.0 & 3.1521 & TRN & & & \\
\hline CHEMBL1568497 & 688185 & 3.0 & 2.89899 & 999999999 & 996 & TRN & \\
\hline CHEMBL1272264 & 688185 & 3.0 & 3.2776 & TRN & & & \\
\hline CHEMBL1406829 & 688185 & 3.0 & 3.4268 & TST & & & \\
\hline CHEMBL1414442 & 688185 & 5.8182 & 5.5667 & TRN & & & \\
\hline CHEMBL1354593 & 688185 & 3.0 & 3.6499 & TRN & & & \\
\hline CHEMBL1368471 & 688185 & 5.0814 & 5.0837 & TRN & & & \\
\hline CHEMBL1534131 & 688185 & 3.0 & 3.3981 & TST & & & \\
\hline CHEMBL1271823 & 688185 & 5.5918 & 5.7603 & TRN & & & \\
\hline CHEMBL1271766 & 688185 & 5.8665 & 5.6605 & TRN & & & \\
\hline CHEMBL3392041 & 688185 & 3.0 & 2.9261 & TST & & & \\
\hline CHEMBL1328468 & 688185 & 5.8761 & 6.183 & TRN & & & \\
\hline CHEMBL1528528 & 688185 & 5.0857 & 5.0941 & TRN & & & \\
\hline CHEMBL1360686 & 688185 & 5.4389 & 5.7836 & TRN & & & \\
\hline CHEMBL1370457 & 688185 & 3.0 & 2.8176 & TRN & & & \\
\hline CHEMBL1533807 & 688185 & 4.82100 & 30000000 & & 5.1159 & TRN & \\
\hline CHEMBL1438721 & 688185 & 3.0 & 3.2175 & TST & & & \\
\hline CHEMBL1359585 & 688185 & 3.0 & 5.4357 & TRN & & & \\
\hline CHEMBL1530429 & 688185 & 3.0 & 3.1368 & TRN & & & \\
\hline CHEMBL1334552 & 688185 & 5.2343 & 4.015 & TRN & & & \\
\hline
\end{tabular}




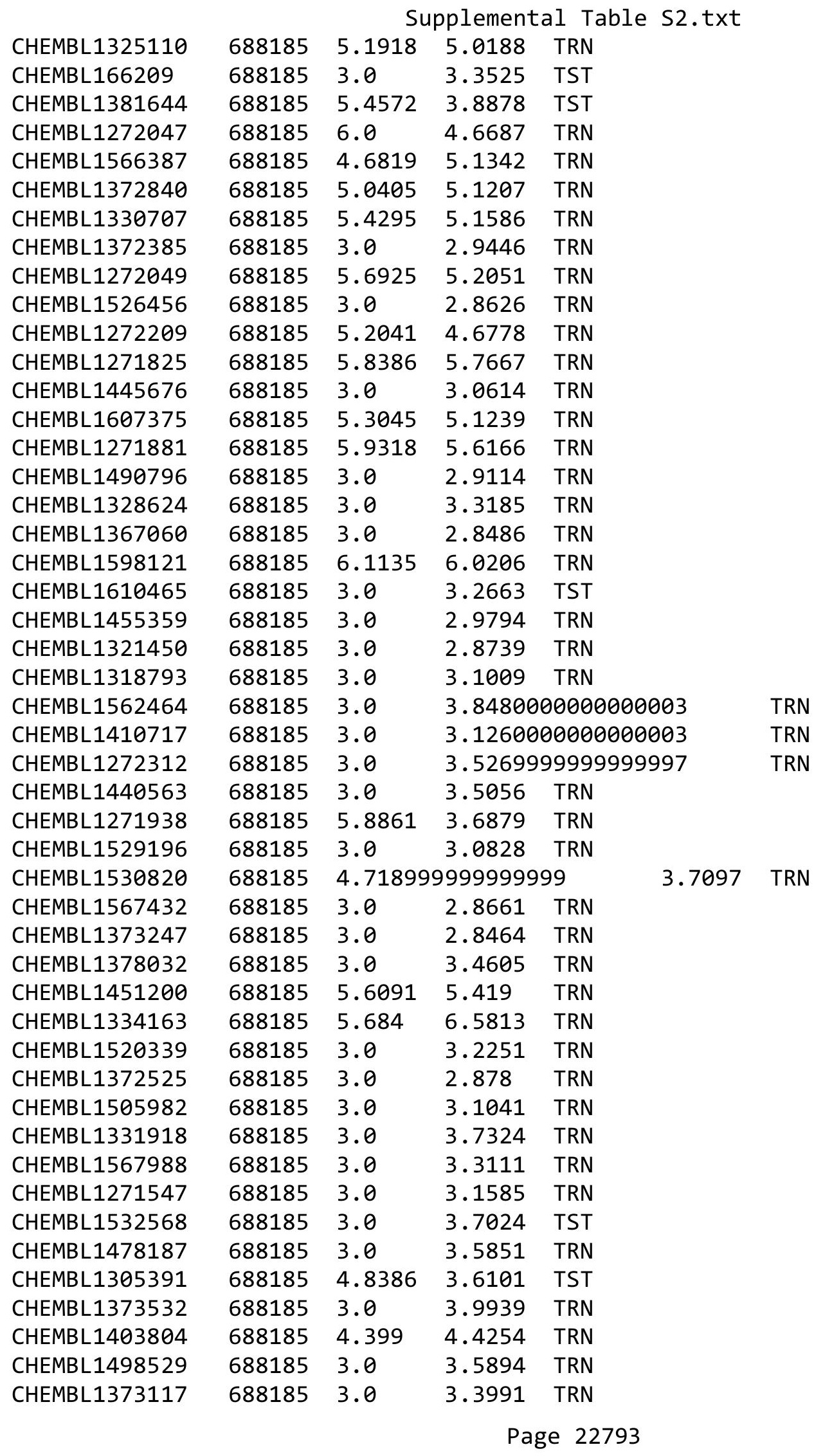




\begin{tabular}{|c|c|c|c|c|}
\hline & & & oplement & al $\mathrm{T}$ \\
\hline CHEMBL1448273 & 688185 & 4.4486 & 5.0701 & TRN \\
\hline CHEMBL1272154 & 688185 & 6.3768 & 6.2762 & TRN \\
\hline CHEMBL1366249 & 688185 & 4.4711 & 4.1506 & TRN \\
\hline CHEMBL1572273 & 688185 & 3.0 & 3.6851 & TRN \\
\hline CHEMBL1399711 & 688185 & 6.0 & 4.6091 & TRN \\
\hline CHEMBL1325138 & 688185 & 3.0 & 3.0497 & TRN \\
\hline CHEMBL1524205 & 688185 & 3.0 & 3.2401 & TRN \\
\hline CHEMBL1610524 & 688185 & 4.7852 & 5.2913 & TRN \\
\hline CHEMBL1371985 & 688185 & 4.0155 & 4.0758 & TRN \\
\hline CHEMBL1399595 & 688185 & 3.0 & 3.4915 & TST \\
\hline CHEMBL1321179 & 688185 & 5.1959 & 5.1648 & TRN \\
\hline CHEMBL1531467 & 688185 & 5.2865 & 5.7912 & TRN \\
\hline CHEMBL1415029 & 688185 & 4.9393 & 4.7583 & TRN \\
\hline CHEMBL1271994 & 688185 & 6.0132 & 5.7115 & TRN \\
\hline CHEMBL1329808 & 688185 & 5.4547 & 5.4928 & TRN \\
\hline CHEMBL1531647 & 688185 & 6.301 & 6.5762 & TRN \\
\hline CHEMBL1550296 & 688185 & 3.0 & 3.2632 & TRN \\
\hline CHEMBL1271992 & 688185 & 4.1325 & 3.6237 & TRN \\
\hline CHEMBL1438551 & 688185 & 3.0 & 2.9546 & TRN \\
\hline CHEMBL1487918 & 688185 & 3.0 & 4.2363 & TST \\
\hline CHEMBL1517654 & 688185 & 5.0443 & 4.7938 & TRN \\
\hline CHEMBL1329955 & 688185 & 5.0894 & 4.9265 & TRN \\
\hline CHEMBL1271993 & 688185 & 5.8894 & 5.811 & TRN \\
\hline CHEMBL1450886 & 688185 & 5.6498 & 5.0259 & TRN \\
\hline CHEMBL1310494 & 688185 & 3.0 & 3.4829 & TST \\
\hline CHEMBL1397246 & 688185 & 3.0 & 3.2144 & TRN \\
\hline CHEMBL1351212 & 688185 & 5.5751 & 3.6504 & TST \\
\hline CHEMBL1402456 & 688185 & 3.0 & 3.2892 & TRN \\
\hline CHEMBL1370758 & 688185 & 5.6402 & 5.8718 & TRN \\
\hline CHEMBL1323507 & 688185 & 6.0809 & 5.9426 & TRN \\
\hline CHEMBL1481612 & 688185 & 3.0 & 3.2235 & TRN \\
\hline CHEMBL1353989 & 688185 & 3.0 & 3.8574 & TRN \\
\hline CHEMBL1272099 & 688185 & 5.4841 & 5.3477 & TRN \\
\hline CHEMBL1269202 & 688185 & 6.2676 & 6.2485 & TRN \\
\hline CHEMBL1449204 & 688185 & 6.0 & 4.9428 & TRN \\
\hline CHEMBL1507695 & 688185 & 3.0 & 2.7468 & TST \\
\hline CHEMBL1526405 & 688185 & 3.0 & 3.2183 & TST \\
\hline CHEMBL1271883 & 688185 & 5.4045 & 5.1421 & TRN \\
\hline CHEMBL1451903 & 688185 & 3.0 & 2.9947 & TRN \\
\hline CHEMBL1365898 & 688185 & 3.0 & 3.8915 & TST \\
\hline CHEMBL1371036 & 688185 & 3.0 & 3.0657 & TRN \\
\hline CHEMBL1325071 & 688185 & 3.0 & 3.4198 & TRN \\
\hline CHEMBL1394462 & 688185 & 3.0 & 3.1498 & TST \\
\hline CHEMBL1370355 & 688185 & 4.5229 & 4.2687 & TST \\
\hline CHEMBL1604856 & 688185 & 3.0 & 2.5836 & TST \\
\hline CHEMBL1484952 & 688185 & 5.8356 & 6.0994 & TST \\
\hline CHEMBL1519581 & 688185 & 6.1308 & 6.0022 & TST \\
\hline CHEMBL1331084 & 688185 & 6.0 & 4.8167 & TST \\
\hline
\end{tabular}




\begin{tabular}{|c|c|c|c|c|}
\hline & & & pplement & al $\mathrm{T}$ \\
\hline CHEMBL1271765 & 688185 & 5.7799 & 6.1879 & TST \\
\hline CHEMBL1379677 & 688185 & 3.0 & 3.7995 & TST \\
\hline CHEMBL1271764 & 688185 & 6.0 & 6.2477 & TST \\
\hline CHEMBL1567695 & 688185 & 5.5952 & 5.7203 & TST \\
\hline CHEMBL1374667 & 688185 & 4.9666 & 4.5477 & TST \\
\hline CHEMBL1449293 & 688185 & 3.0 & 3.2762 & TST \\
\hline CHEMBL1606869 & 688185 & 3.0 & 2.9777 & TST \\
\hline CHEMBL1337701 & 688185 & 4.3279 & 4.0199 & TST \\
\hline CHEMBL1393593 & 688185 & 3.0 & 5.0269 & TST \\
\hline CHEMBL1271494 & 688185 & 5.6696 & 5.4205 & TST \\
\hline CHEMBL1606857 & 688185 & 4.6882 & 4.8113 & TST \\
\hline CHEMBL1501864 & 688185 & 3.0 & 3.5407 & TST \\
\hline CHEMBL1515929 & 688185 & 3.0 & 3.4676 & TST \\
\hline CHEMBL1610258 & 688185 & 3.0 & 3.9379 & TST \\
\hline CHEMBL1487009 & 688185 & 4.7144 & 3.2665 & TST \\
\hline CHEMBL1368004 & 688185 & 3.0 & 3.1207 & TST \\
\hline CHEMBL1374367 & 688185 & 3.0 & 3.2335 & TST \\
\hline CHEMBL2334398 & 948452 & 6.7305 & 6.9726 & TRN \\
\hline CHEMBL 2334022 & 948452 & 8.3098 & 8.1341 & TRN \\
\hline CHEMBL 2334373 & 948452 & 7.6778 & 7.4955 & TRN \\
\hline CHEMBL 2334035 & 948452 & 8.3098 & 7.4616 & TRN \\
\hline CHEMBL 2334048 & 948452 & 9.0458 & 8.9766 & TRN \\
\hline CHEMBL 2334047 & 948452 & 7.0088 & 6.9521 & TRN \\
\hline CHEMBL 2334033 & 948452 & 6.9281 & 6.5254 & TRN \\
\hline CHEMBL 2334043 & 948452 & 8.7959 & 7.98 & TRN \\
\hline CHEMBL 2334375 & 948452 & 7.6198 & 7.6297 & TRN \\
\hline CHEMBL 2334010 & 948452 & 6.3526 & 6.2884 & TST \\
\hline CHEMBL 2334372 & 948452 & 9.8239 & 8.3445 & TRN \\
\hline CHEMBL 2334026 & 948452 & 7.4318 & 7.1938 & TRN \\
\hline CHEMBL 2334024 & 948452 & 7.6383 & 7.55 & TRN \\
\hline CHEMBL 2334009 & 948452 & 6.4572 & 6.846 & TRN \\
\hline CHEMBL 2334014 & 948452 & 5.301 & 5.1424 & TRN \\
\hline CHEMBL 2334012 & 948452 & 5.301 & 5.6311 & TRN \\
\hline CHEMBL 2334029 & 948452 & 6.4776 & 6.8935 & TRN \\
\hline CHEMBL 2334386 & 948452 & 5.301 & 5.4174 & TRN \\
\hline CHEMBL 2334383 & 948452 & 5.301 & 6.8596 & TST \\
\hline CHEMBL 2334041 & 948452 & 8.4089 & 9.0382 & TRN \\
\hline CHEMBL 2334046 & 948452 & 7.0088 & 7.6838 & TRN \\
\hline CHEMBL 2334367 & 948452 & 7.6778 & 6.8718 & TST \\
\hline CHEMBL 2334399 & 948452 & 5.301 & 7.1156 & TRN \\
\hline CHEMBL 2334388 & 948452 & 5.301 & 5.0192 & TRN \\
\hline CHEMBL 2334007 & 948452 & 6.5229 & 6.8126 & TRN \\
\hline CHEMBL 2334045 & 948452 & 9.2218 & 9.2587 & TRN \\
\hline CHEMBL 2334054 & 948452 & 7.6778 & 7.8207 & TRN \\
\hline CHEMBL 2334032 & 948452 & 6.4473 & 5.8143 & TRN \\
\hline CHEMBL 2334038 & 948452 & 7.7696 & 8.6358 & TRN \\
\hline CHEMBL 2334031 & 948452 & 7.1871 & 7.4083 & TRN \\
\hline CHEMBL 2334368 & 948452 & 7.7212 & 7.6569 & TRN \\
\hline
\end{tabular}

Page 22795 


\begin{tabular}{|c|c|c|c|c|c|}
\hline & & \multicolumn{4}{|c|}{ Supplemental Table S2.txt } \\
\hline CHEMBL2334005 & 948452 & 6.8356 & 7.2893 & TRN & \\
\hline CHEMBL2334018 & 948452 & 5.301 & 5.9477 & TST & \\
\hline CHEMBL2334382 & 948452 & 7.9208 & 7.3619 & TRN & \\
\hline CHEMBL2334376 & 948452 & 9.1079 & 7.8816 & TRN & \\
\hline CHEMBL2334028 & 948452 & 6.9914 & 7.0132 & TRN & \\
\hline CHEMBL2334039 & 948452 & 9.1079 & 8.5372 & TRN & \\
\hline CHEMBL2334389 & 948452 & 7.6198 & 7.6208 & TRN & \\
\hline CHEMBL 2334390 & 948452 & 7.1079 & 6.9978 & TRN & \\
\hline CHEMBL2334017 & 948452 & 5.301 & 5.5811 & TRN & \\
\hline CHEMBL2334378 & 948452 & 6.9355 & 7.1272 & TRN & \\
\hline CHEMBL2334380 & 948452 & 7.3188 & 7.6171 & TRN & \\
\hline CHEMBL2334042 & 948452 & 5.301 & 4.9461 & TRN & \\
\hline CHEMBL 2334015 & 948452 & 5.301 & 5.3593 & TRN & \\
\hline CHEMBL2334023 & 948452 & 7.1079 & 7.4463 & TRN & \\
\hline CHEMBL2334052 & 948452 & 8.0605 & 8.0225 & TRN & \\
\hline CHEMBL2334006 & 948452 & 6.7905 & 7.3176 & TST & \\
\hline CHEMBL2334403 & 948452 & 7.2596 & 7.6952 & TRN & \\
\hline CHEMBL 2334027 & 948452 & 7.3565 & 7.3223 & TRN & \\
\hline CHEMBL 2334040 & 948452 & 7.6576 & 8.3054 & TRN & \\
\hline CHEMBL2334036 & 948452 & 8.0809 & 8.5683 & TRN & \\
\hline CHEMBL 2334051 & 948452 & 7.9208 & 7.6292 & TRN & \\
\hline CHEMBL2334396 & 948452 & 5.301 & 6.1076 & TRN & \\
\hline CHEMBL 2334370 & 948452 & 7.0506 & 7.6942 & TRN & \\
\hline CHEMBL 2334374 & 948452 & 8.0177 & 7.6864 & TRN & \\
\hline CHEMBL2334379 & 948452 & 7.3468 & 7.3659 & TRN & \\
\hline CHEMBL 2334387 & 948452 & 7.0915 & 6.3825 & TRN & \\
\hline CHEMBL2334050 & 948452 & 8.4202 & 8.3032 & TRN & \\
\hline CHEMBL 2334400 & 948452 & 8.1192 & 7.50799 & 9999999999 & TRN \\
\hline CHEMBL2334366 & 948452 & 7.699 & 6.9085 & TST & \\
\hline CHEMBL 2334008 & 948452 & 6.4572 & 6.5316 & TRN & \\
\hline CHEMBL2334034 & 948452 & 6.5834 & 6.769 & TRN & \\
\hline CHEMBL2334011 & 948452 & 5.301 & 5.7013 & TST & \\
\hline CHEMBL 2334384 & 948452 & 5.301 & 7.0313 & TST & \\
\hline CHEMBL2334021 & 948452 & 5.301 & 5.1506 & TRN & \\
\hline CHEMBL2334019 & 948452 & 5.301 & 6.0242 & TST & \\
\hline CHEMBL2334030 & 948452 & 6.9208 & 7.2295 & TRN & \\
\hline CHEMBL 2334377 & 948452 & 7.8861 & 7.7137 & TRN & \\
\hline CHEMBL2334057 & 948452 & 8.0088 & 7.9511 & TST & \\
\hline CHEMBL2334013 & 948452 & 5.301 & 7.1725 & TST & \\
\hline CHEMBL 2334020 & 948452 & 5.301 & 5.6004 & TST & \\
\hline CHEMBL2334044 & 948452 & 5.301 & 5.4556 & TRN & \\
\hline CHEMBL 2334055 & 948452 & 8.3565 & 7.7661 & TRN & \\
\hline CHEMBL2334037 & 948452 & 8.0269 & 8.3588 & TRN & \\
\hline CHEMBL2334049 & 948452 & 8.3098 & 8.1996 & TRN & \\
\hline CHEMBL 2334025 & 948452 & 6.8013 & 7.5978 & TST & \\
\hline CHEMBL2331582 & 948452 & 8.3979 & 7.9511 & TRN & \\
\hline CHEMBL2334053 & 948452 & 6.7212 & 7.3235 & TST & \\
\hline CHEMBL2334393 & 948452 & 8.1487 & 7.4502 & TST & \\
\hline
\end{tabular}




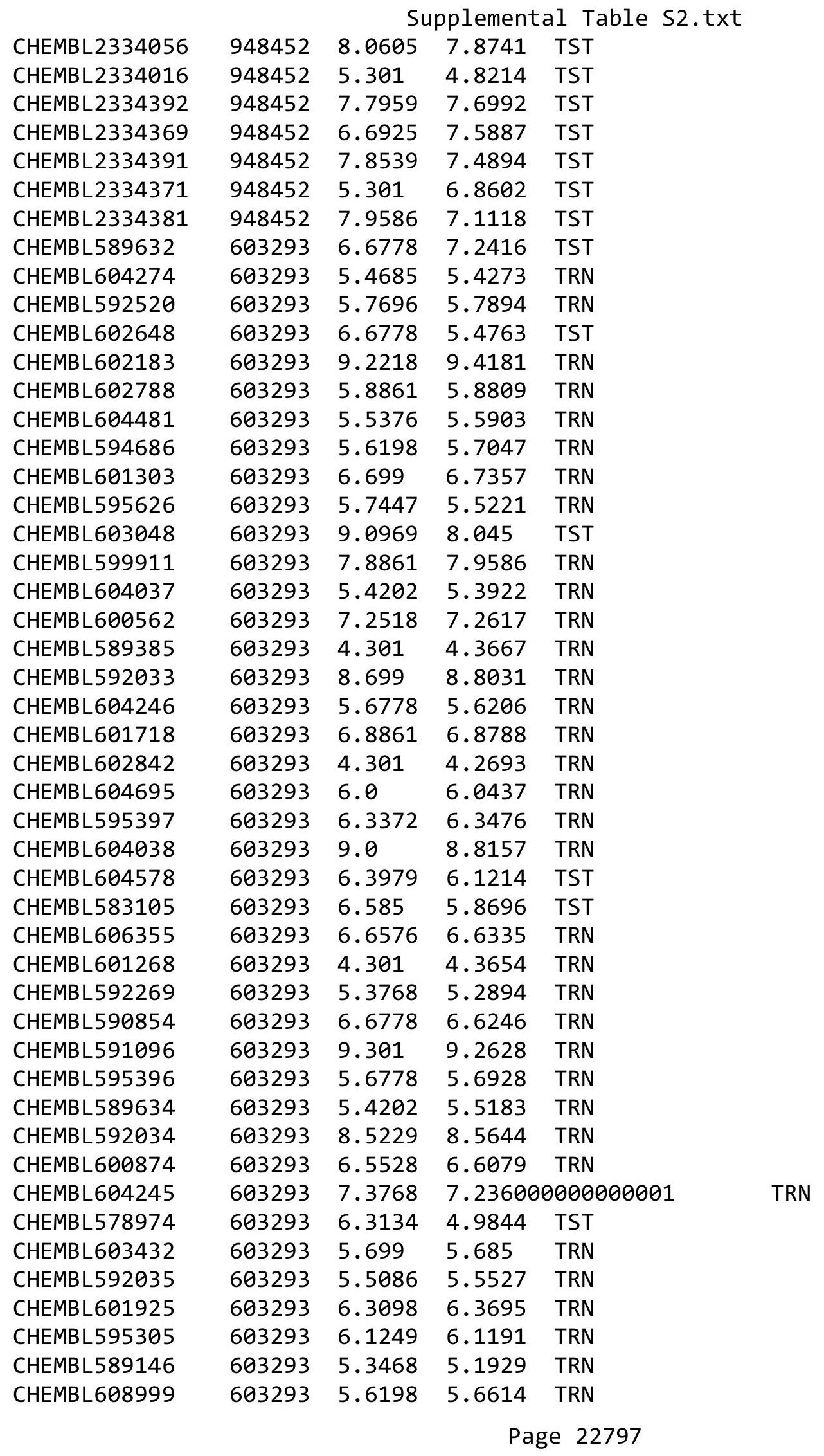




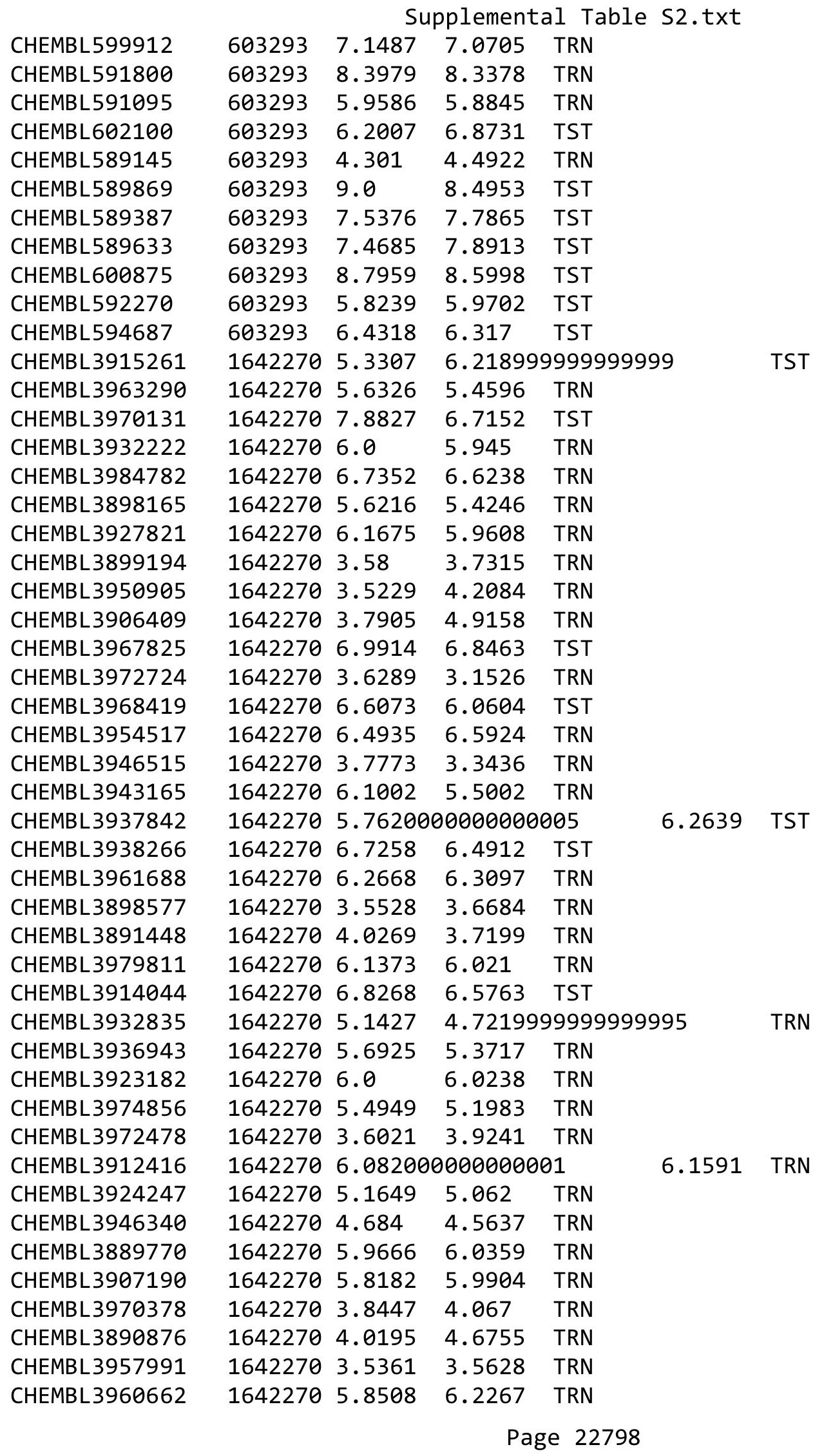




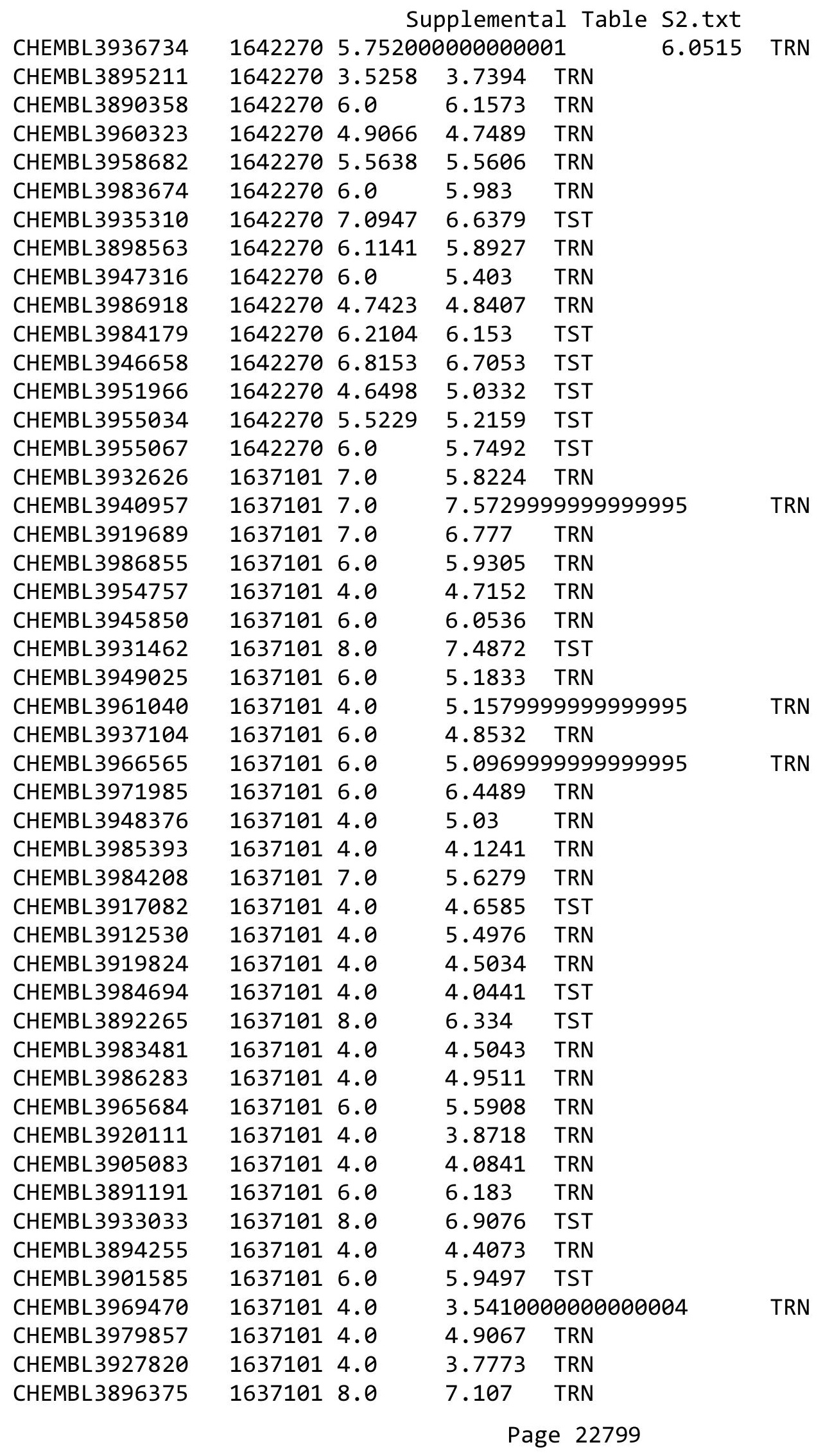




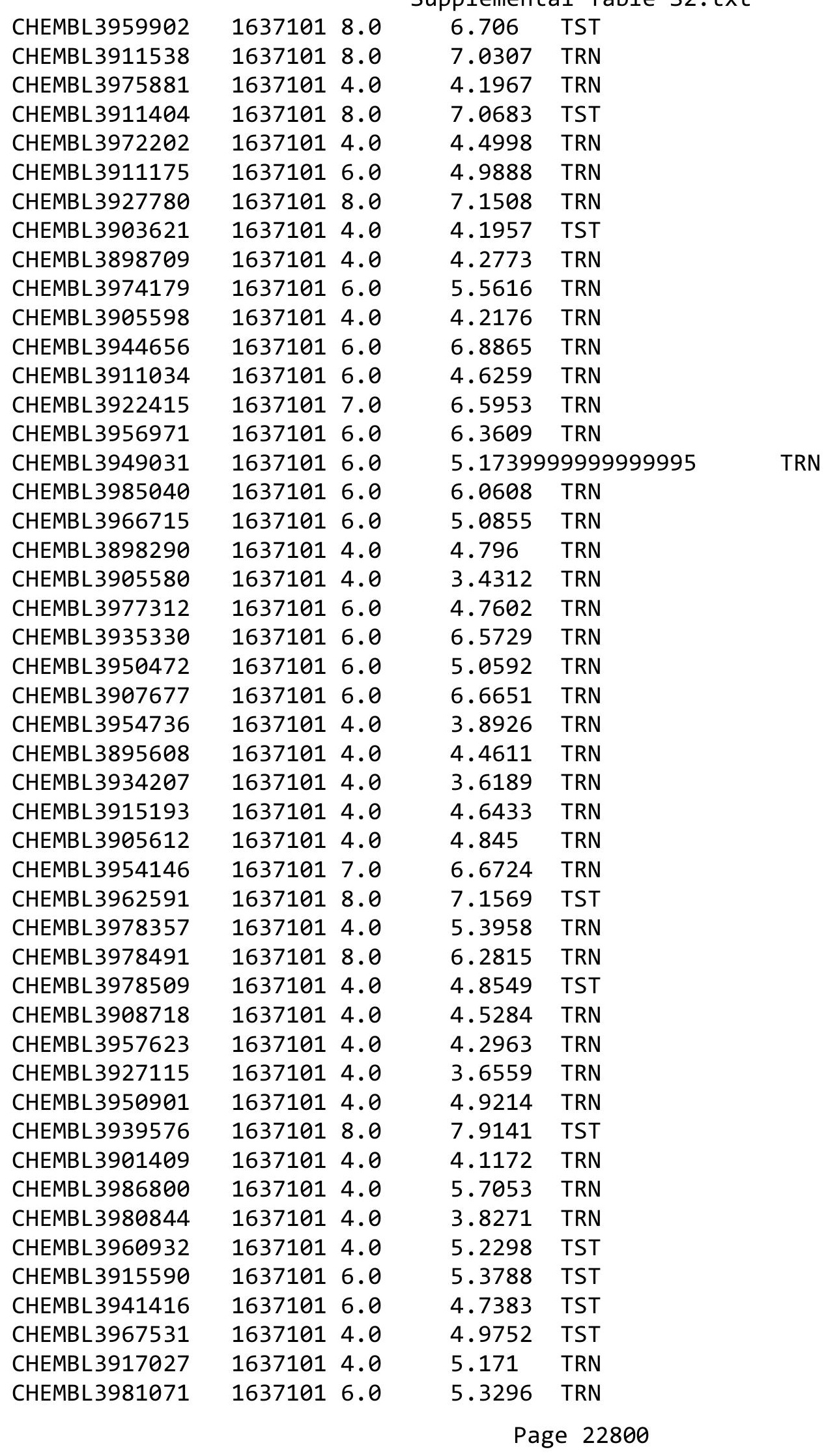




\begin{tabular}{|c|c|c|c|c|}
\hline \\
\hline CHEMBL3951888 & 16371016.0 & 4.8805 & TRN & \\
\hline CHEMBL3923285 & 16371018.0 & 7.8796 & TST & \\
\hline CHEMBL3910833 & 16371017.0 & 5.7757 & TRN & \\
\hline CHEMBL3955730 & 16371016.0 & 5.4719 & TRN & \\
\hline CHEMBL3966914 & 16371014.0 & 4.2974 & TRN & \\
\hline CHEMBL3920973 & 16371016.0 & 6.9612 & TRN & \\
\hline CHEMBL 3982444 & 16371014.0 & 3.6209 & TRN & \\
\hline CHEMBL3969965 & 16371018.0 & 7.4867 & TST & \\
\hline CHEMBL3891079 & 16371016.0 & 6.3403 & TRN & \\
\hline CHEMBL3903458 & 16371014.0 & 3.6772 & TRN & \\
\hline CHEMBL3947509 & 16371016.0 & 5.0025 & TRN & \\
\hline CHEMBL3959833 & 16371016.0 & 5.1607 & TRN & \\
\hline CHEMBL3936676 & 16371017.0 & 6.9531 & TRN & \\
\hline CHEMBL3934197 & 16371017.0 & 6.4935 & TST & \\
\hline CHEMBL3955031 & 16371018.0 & 7.7924 & TST & \\
\hline CHEMBL3958438 & 16371014.0 & 4.4038 & TRN & \\
\hline CHEMBL3926573 & 16371016.0 & 5.3295 & TRN & \\
\hline CHEMBL3962439 & 16371014.0 & 4.0487 & TRN & \\
\hline CHEMBL3944887 & 16371017.0 & 6.8244 & TRN & \\
\hline CHEMBL3955440 & 16371017.0 & 6.9285 & TRN & \\
\hline CHEMBL3925129 & 16371018.0 & 6.4265 & TST & \\
\hline CHEMBL3932968 & 16371014.0 & 4.4186 & TRN & \\
\hline CHEMBL3917917 & 16371016.0 & 6.3073 & TRN & \\
\hline CHEMBL3954505 & 16371014.0 & 4.405 & TRN & \\
\hline CHEMBL3918763 & 16371014.0 & 4.4136 & TRN & \\
\hline CHEMBL3907964 & 16371016.0 & 5.9711 & TRN & \\
\hline CHEMBL3971922 & 16371016.0 & 5.4245 & TRN & \\
\hline CHEMBL3969492 & 16371016.0 & 5.856 & TRN & \\
\hline CHEMBL3898101 & 16371017.0 & 6.6453 & TRN & \\
\hline CHEMBL 3949014 & 16371016.0 & 5.2828 & TRN & \\
\hline CHEMBL3971177 & 16371016.0 & 6.2491 & TRN & \\
\hline CHEMBL3893129 & 16371014.0 & 3.97399 & 99999999998 & TRN \\
\hline CHEMBL3938839 & 16371017.0 & 5.5075 & TST & \\
\hline CHEMBL3958075 & 16371018.0 & 7.5221 & TRN & \\
\hline CHEMBL 3981434 & 16371016.0 & 5.7332 & TRN & \\
\hline CHEMBL3962612 & 16371014.0 & 4.7716 & TRN & \\
\hline CHEMBL 3939554 & 16371017.0 & 6.3898 & TRN & \\
\hline CHEMBL3957382 & 16371014.0 & 4.288 & TRN & \\
\hline CHEMBL3915138 & 16371016.0 & 5.8653 & TST & \\
\hline CHEMBL 3976027 & 16371017.0 & 6.474 & TRN & \\
\hline CHEMBL3929045 & 16371016.0 & 4.9115 & TST & \\
\hline CHEMBL 3895375 & 16371014.0 & 4.1128 & TRN & \\
\hline CHEMBL3944680 & 16371017.0 & 6.9187 & TRN & \\
\hline CHEMBL3971853 & 16371014.0 & 5.0664 & TRN & \\
\hline CHEMBL3920543 & 16371016.0 & 5.3794 & TRN & \\
\hline CHEMBL 3944018 & 16371016.0 & 6.2716 & TRN & \\
\hline CHEMBL 3920754 & 16371014.0 & 4.4509 & TRN & \\
\hline CHEMBL3928309 & 16371014.0 & 3.76 & TRN & \\
\hline
\end{tabular}




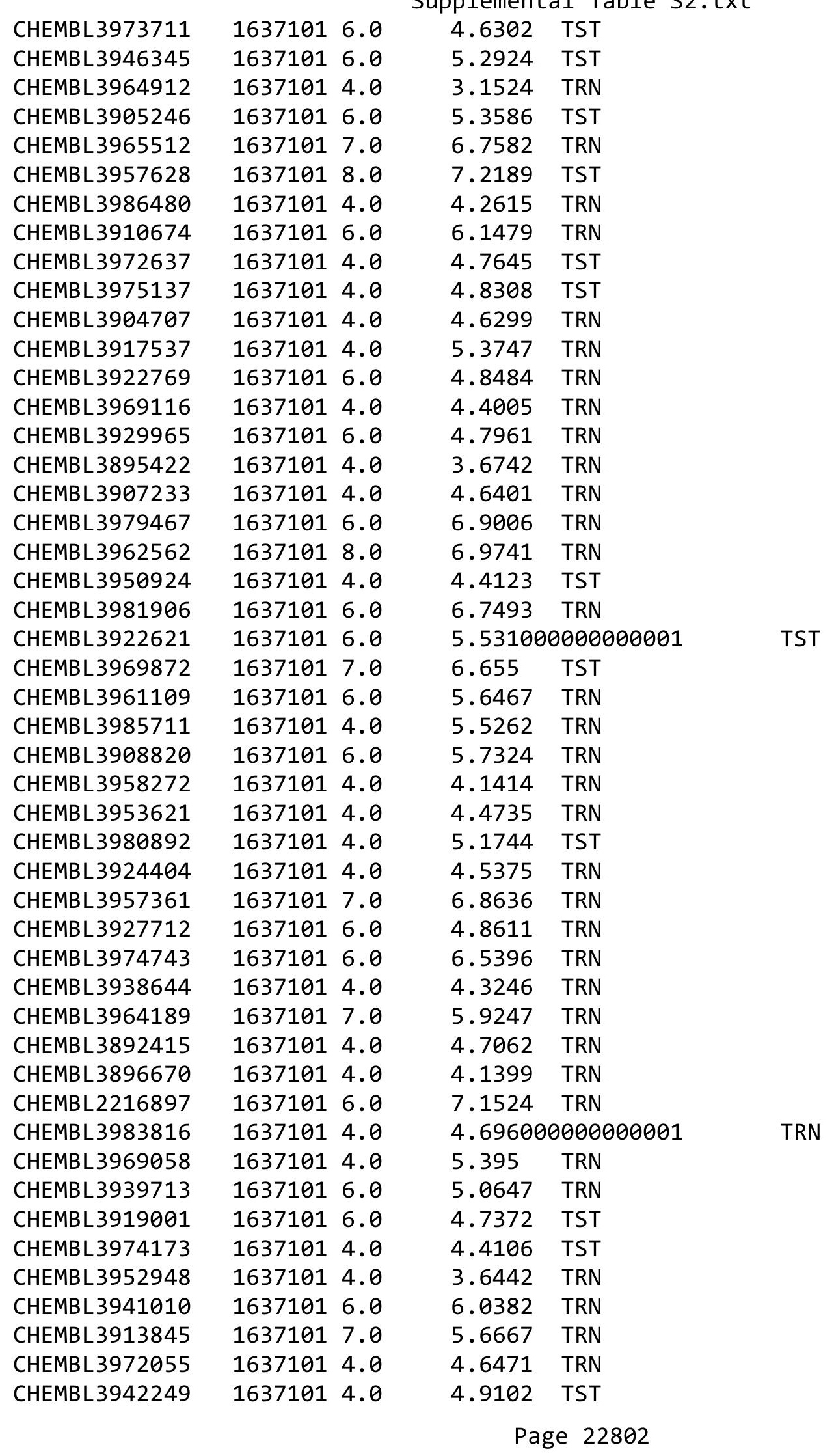




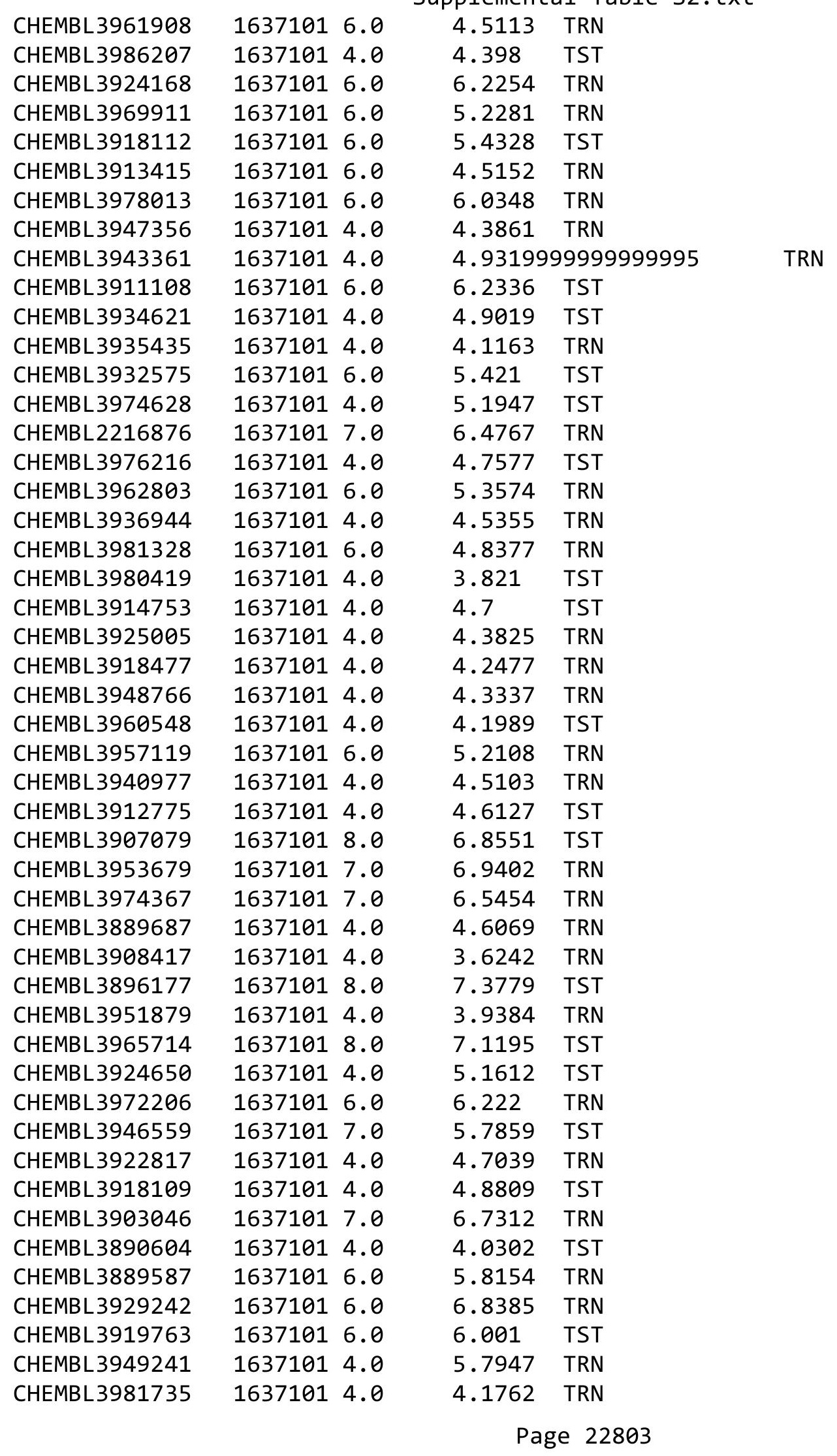




\begin{tabular}{|c|c|c|c|c|c|c|}
\hline \multicolumn{7}{|c|}{ Supplemental Table S2.txt } \\
\hline CHEMBL3915312 & 1637101 & 8.0 & 6.5189 & TST & & \\
\hline CHEMBL3902945 & 1637101 & 6.0 & 6.0567 & TRN & & \\
\hline CHEMBL3942692 & 1637101 & 6.0 & 6.694 & TRN & & \\
\hline CHEMBL 2030005 & 820194 & 6.1707 & 6.3625 & TRN & & \\
\hline CHEMBL 2030010 & 820194 & 6.9318 & 7.3638 & TRN & & \\
\hline CHEMBL 2030043 & 820194 & 6.3536 & 7.0527 & TST & & \\
\hline CHEMBL 2030024 & 820194 & 7.4685 & 7.6667 & TRN & & \\
\hline CHEMBL 2030008 & 820194 & 6.2518 & 6.045 & TRN & & \\
\hline CHEMBL 2030013 & 820194 & 7.4559 & 7.1698 & TRN & & \\
\hline CHEMBL 2030029 & 820194 & 6.6383 & 6.9487 & TRN & & \\
\hline CHEMBL 2030041 & 820194 & 7.4089 & 7.4386 & TRN & & \\
\hline CHEMBL 2030035 & 820194 & 7.1612 & 7.3504 & TRN & & \\
\hline CHEMBL 2030056 & 820194 & 7.5686 & 7.3311 & TST & & \\
\hline CHEMBL 2030285 & 820194 & 6.1433 & 6.6938 & TST & & \\
\hline CHEMBL 2030050 & 820194 & 6.0985 & 7.1877 & TST & & \\
\hline CHEMBL 2030286 & 820194 & 6.4498 & 6.8111 & TST & & \\
\hline CHEMBL 2030061 & 820194 & 6.58 & 7.2118 & TST & & \\
\hline CHEMBL 2029826 & 820194 & 5.0 & 4.6844 & TRN & & \\
\hline CHEMBL 2030037 & 820194 & 6.2958 & 6.074 & TRN & & \\
\hline CHEMBL 2030038 & 820194 & 7.3188 & 7.4337 & TRN & & \\
\hline CHEMBL 2030007 & 820194 & 6.2899 & 6.2359 & TRN & & \\
\hline CHEMBL 2030036 & 820194 & 7.6198 & 7.3875 & TRN & & \\
\hline CHEMBL 2030015 & 820194 & 6.6737 & 6.8602 & TRN & & \\
\hline CHEMBL 2030021 & 820194 & 8.0969 & 7.3549 & TRN & & \\
\hline CHEMBL 2030004 & 820194 & 6.2373 & 5.5663 & TST & & \\
\hline CHEMBL 2030009 & 820194 & 6.9706 & 7.0779 & TRN & & \\
\hline CHEMBL 2030063 & 820194 & 5.0 & 6.6677 & TST & & \\
\hline CHEMBL 2029825 & 820194 & 5.0 & 6.3227 & TRN & & \\
\hline CHEMBL 2030031 & 820194 & 6.857 & 6.6051 & TRN & & \\
\hline CHEMBL 2030046 & 820194 & 5.0 & 6.6074 & TST & & \\
\hline CHEMBL 2030052 & 820194 & 7.585 & 7.3705 & TRN & & \\
\hline CHEMBL 2030040 & 820194 & 7.5528 & 7.2194 & TST & & \\
\hline CHEMBL 2030027 & 820194 & 7.585 & 7.0389 & TRN & & \\
\hline CHEMBL 2030060 & 820194 & 6.75700 & 00000000 & & .2962 & TRN \\
\hline CHEMBL 2030059 & 820194 & 6.8268 & 7.274 & TRN & & \\
\hline CHEMBL 2030011 & 820194 & 7.585 & 7.7127 & TRN & & \\
\hline CHEMBL1373079 & 820194 & 5.0 & 6.1883 & TST & & \\
\hline CHEMBL 2030047 & 820194 & 7.7212 & 7.2982 & TRN & & \\
\hline CHEMBL 2030039 & 820194 & 7.7959 & 7.4856 & TST & & \\
\hline CHEMBL 2030051 & 820194 & 7.4023 & 7.352 & TRN & & \\
\hline CHEMBL 2029824 & 820194 & 6.1238 & 5.5216 & TRN & & \\
\hline CHEMBL 2030019 & 820194 & 6.1778 & 6.17700 & 00000000005 & & TRN \\
\hline CHEMBL 2030018 & 820194 & 7.4202 & 7.3603 & TRN & & \\
\hline CHEMBL 2029355 & 820194 & 7.041 & 7.0916 & TRN & & \\
\hline CHEMBL 2030055 & 820194 & 7.5686 & 7.2615 & TST & & \\
\hline CHEMBL 2030001 & 820194 & 5.0 & 5.4262 & TRN & & \\
\hline CHEMBL 2030044 & 820194 & 6.5654 & 6.6665 & TST & & \\
\hline CHEMBL 2030058 & 820194 & 7.6576 & 7.5587 & TRN & & \\
\hline
\end{tabular}

Page 22804 
Supplemental Table S2.txt

\begin{tabular}{|c|c|c|c|c|}
\hline HEMBL2030054 & 20194 & 6.699 & 6.7887 & TR \\
\hline CHEMBL2030030 & 20194 & 6.3325 & 6.2536 & \\
\hline AFMBL 2030034 & 0194 & & & \\
\hline IEMBL2030057 & 0194 & 2218 & 1343 & $C T$ \\
\hline AEMBL2030023 & 20194 & 3.0757 & 3822 & \\
\hline HEMBL2030022 & 20194 & 6.4191 & 4676 & \\
\hline HEMBL2030003 & 20194 & 5.0 & 9402 & \\
\hline AEMBL 2030028 & 20194 & .1367 & .9952 & PN \\
\hline HEMBL 2030062 & 20194 & 7.4559 & 7.2807 & \\
\hline HEMBL2030045 & 20194 & 5.0 & 6.9223 & \\
\hline HEMBL2030014 & 320194 & 6.1844 & 4931 & \\
\hline HEMBL 2030020 & 20194 & 6.3325 & .8572 & DN \\
\hline AEMBL2030012 & 94 & 7.0809 & 398 & RN \\
\hline HEMBL2030026 & 20194 & 7.5229 & 7.6332 & RN \\
\hline AEMBL2030016 & 20194 & 7.4437 & 3663 & RN \\
\hline AEMBL2030025 & 320194 & 6.9788 & 16 & \\
\hline HEMBL2030053 & 20194 & 7.2007 & 6.9527 & RN \\
\hline HEMBL2030033 & 20194 & 6.3893 & 6.1237 & $\mathrm{RN}$ \\
\hline HEMBL2030049 & 20194 & 8.0 & 7.6207 & RN \\
\hline AEMBL2030032 & 94 & 6.0867 & 864 & TRN \\
\hline HEMBL 2030048 & 20194 & 7.4437 & 7.6271 & RIV \\
\hline HEMBL2030006 & 94 & 5 . & 452 & $S$ \\
\hline HEMBL2030002 & 94 & 5.0 & 5.1969 & $\mathrm{RN}$ \\
\hline AEMBL2030017 & & 7.1549 & 051 & DN \\
\hline IEMBL 2030042 & 94 & 6.3665 & 719 & ISI \\
\hline AEMBL56073 & 8 & 2.1612 & 332 & RN \\
\hline HEMBL55371 & 3228 & 3.1255 & 3.0472 & $\mathrm{RN}$ \\
\hline$\triangle 5 M P \mid 20$ & & 1.9052 & 567 & ST \\
\hline 954 & & 3.0696 & 607 & ST \\
\hline HEMBL 299443 & & 4.0009 & 568 & TRN \\
\hline AEMBL55608 & 8 & 3.6737 & 2.8726 & RN \\
\hline AEMBL433833 & 3228 & 3.6757 & 4.0306 & $\mathrm{RN}$ \\
\hline 735 & & 2. & 699 & $\mathrm{RN}$ \\
\hline & & 1.9961 & 759 & ST \\
\hline HEMBL56028 & 8 & 3.556 & 3.6353 & TRN \\
\hline AEMBL55837 & 8 & 2.1373 & 078 & RN \\
\hline AEMBL55359 & 3228 & 2.1273 & 111 & $\Gamma \mathrm{RN}$ \\
\hline & & 58 & 976 & RN \\
\hline MBL294192 & & 3.8416 & 4.2752 & TRN \\
\hline HEMBL55353 & & 1.9767 & & TST \\
\hline HEMBL56254 & & 2. & 226 & RN \\
\hline CHEMBL293522 & & 2.0947 & 1.8706 & TRN \\
\hline CHEMBL55264 & & 3.9626 & 3.3078 & TRN \\
\hline CHEMBL54344 & & 3.0921 & 3.5667 & TST \\
\hline CHEMBL52137 & 8 & 1.9626 & 3.1455 & ГST \\
\hline MBL54004 & & 2.1107 & 078 & RN \\
\hline CHEMBL417932 & & 3.6615 & 4.0376 & $\Gamma \mathrm{RN}$ \\
\hline CHEMBL55518 & 3228 & 3.5031 & 2.4367 & \\
\hline
\end{tabular}

Page 22805 


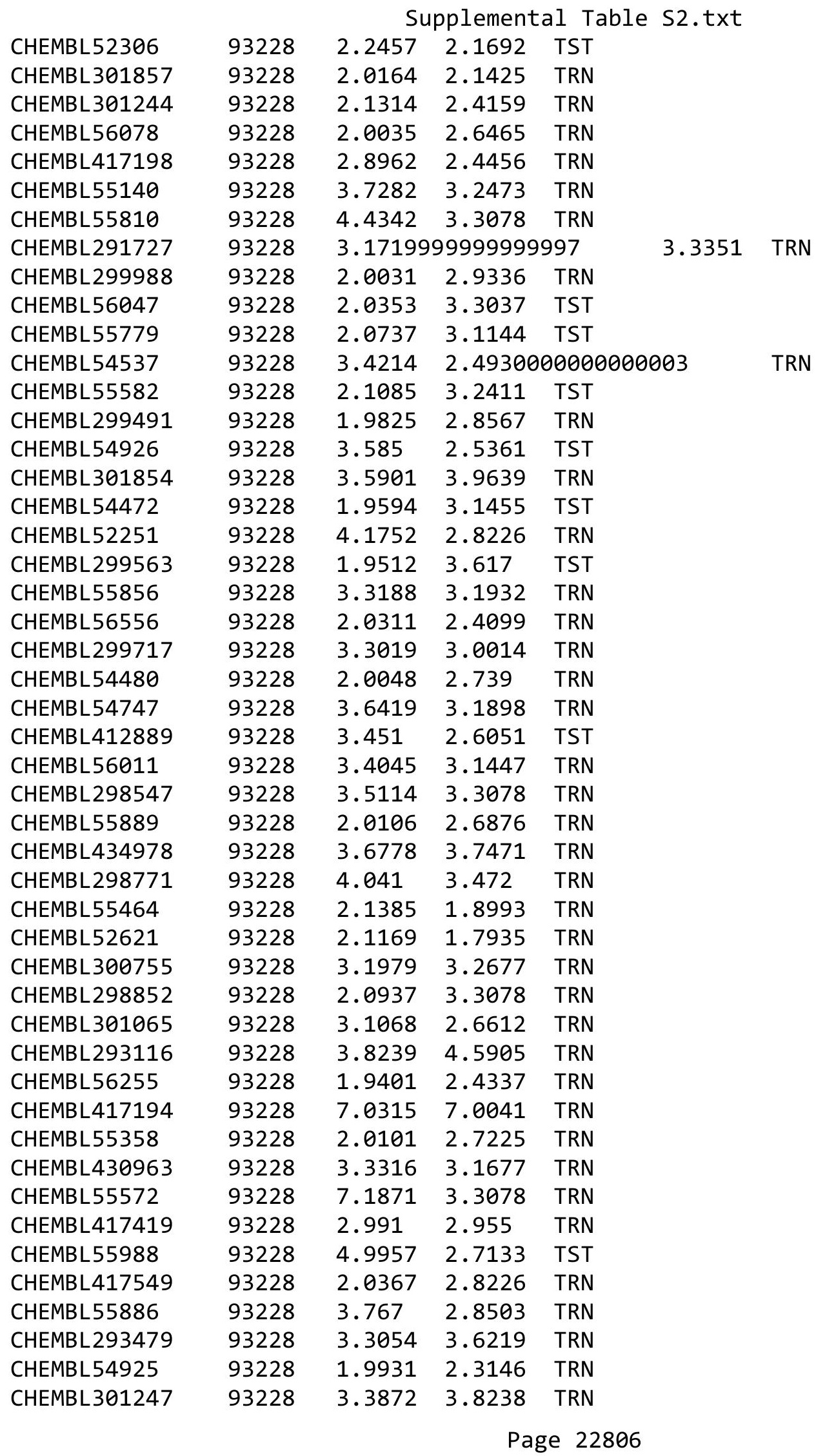




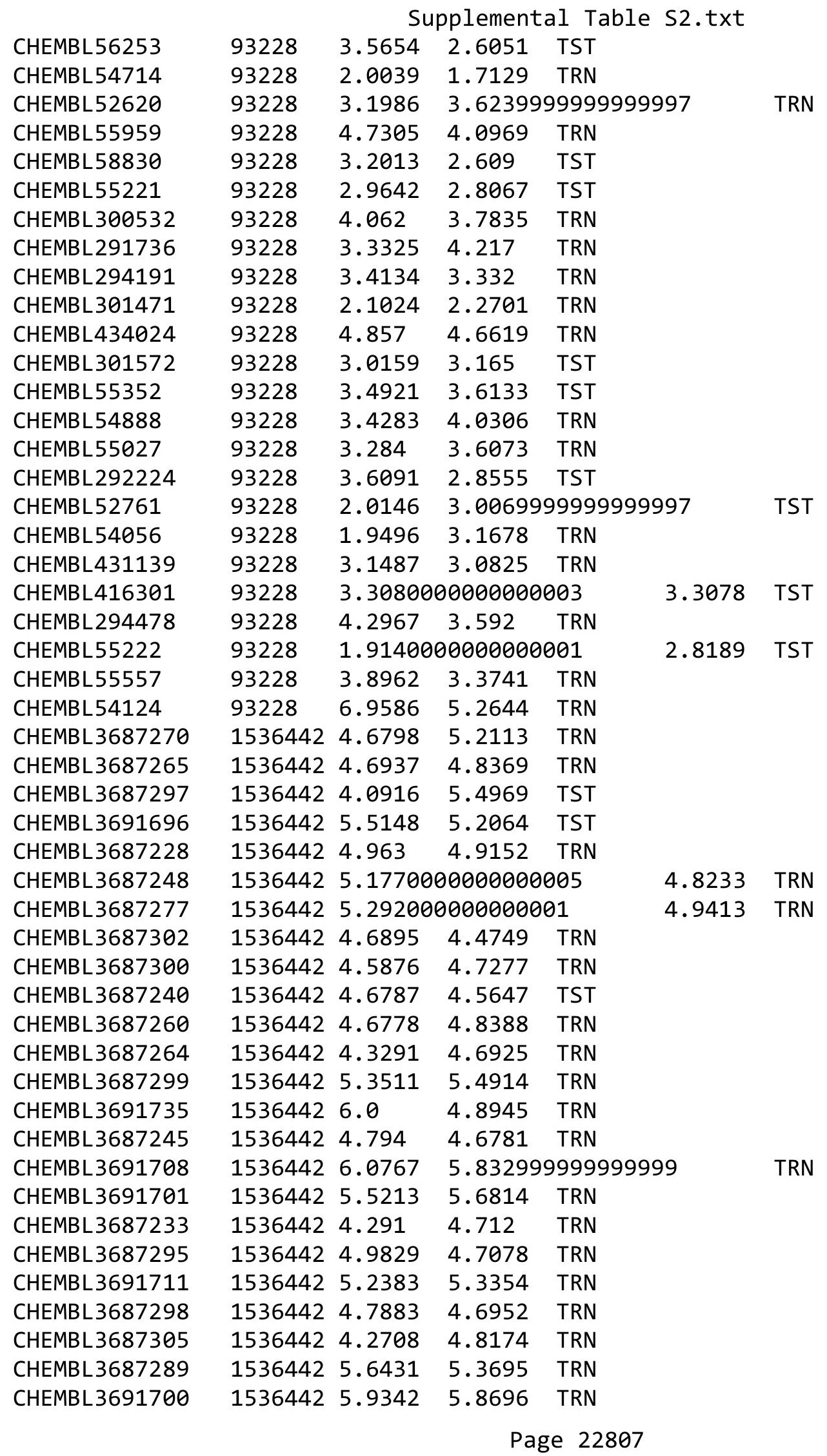


Supplemental Table S2.txt

\begin{tabular}{|c|c|c|c|c|}
\hline CHEMBL 3691714 & 1536442 & 5.3544 & 5.4108 & TRN \\
\hline CHEMBL 3687244 & 1536442 & 4.7878 & 4.8234 & TRN \\
\hline CHEMBL 3687252 & 1536442 & 4.9245 & 4.836 & TRN \\
\hline CHEMBL 3687316 & 1536442 & 5.0336 & 4.9972 & TST \\
\hline CHEMBL 3687275 & 1536442 & 5.2496 & 5.2512 & TRN \\
\hline CHEMBL 3687309 & 1536442 & 4.8403 & 5.1326 & TRN \\
\hline CHEMBL 3687283 & 1536442 & 4.6935 & 4.8203 & TRN \\
\hline CHEMBL 3687259 & 1536442 & 5.0739 & 4.8035 & TRN \\
\hline CHEMBL 3687261 & 1536442 & 4.8489 & 5.2329 & TRN \\
\hline CHEMBL 3687294 & 1536442 & 4.2127 & 4.9808 & TST \\
\hline CHEMBL 3687230 & 1536442 & 5.0072 & 4.9621 & TST \\
\hline CHEMBL3691698 & 1536442 & 6.7151 & 6.9777 & TRN \\
\hline CHEMBL 3691704 & 1536442 & 5.6858 & 5.2434 & TRN \\
\hline CHEMBL 3691697 & 1536442 & 6.1872 & 6.5718 & TRN \\
\hline CHEMBL 3687253 & 1536442 & 4.9579 & 4.9955 & TRN \\
\hline CHEMBL 3687236 & 1536442 & 5.1826 & 4.8725 & TRN \\
\hline CHEMBL3691692 & 1536442 & 4.8896 & 5.2692 & TST \\
\hline CHEMBL3687258 & 1536442 & 4.7844 & 5.2261 & TRN \\
\hline CHEMBL 3691718 & 1536442 & 4.7687 & 5.5141 & TRN \\
\hline CHEMBL3687308 & 1536442 & 4.6262 & 4.6378 & TRN \\
\hline CHEMBL 3691702 & 1536442 & 6.3005 & 6.3618 & TRN \\
\hline CHEMBL3687291 & 1536442 & 4.9445 & 4.4799 & TRN \\
\hline CHEMBL3691721 & 1536442 & 6.3449 & 6.08 & TRN \\
\hline CHEMBL 3687282 & 1536442 & 4.5657 & 4.7016 & TRN \\
\hline CHEMBL3691695 & 1536442 & 5.8168 & 5.1844 & TST \\
\hline CHEMBL 3687271 & 1536442 & 5.0437 & 4.9731 & TRN \\
\hline CHEMBL 3687268 & 1536442 & 5.3126 & 4.9729 & TRN \\
\hline CHEMBL3687246 & 1536442 & 4.6274 & 4.8013 & TRN \\
\hline CHEMBL 3687235 & 1536442 & 4.9041 & 4.7734 & TRN \\
\hline CHEMBL 3687290 & 1536442 & 6.2326 & 5.4781 & TRN \\
\hline CHEMBL 3691720 & 1536442 & 5.9199 & 5.4499 & TST \\
\hline CHEMBL3691693 & 1536442 & 4.4523 & 4.6847 & TRN \\
\hline CHEMBL 3691715 & 1536442 & 5.8252 & 5.3767 & TRN \\
\hline CHEMBL 3687286 & 1536442 & 4.3195 & 4.4779 & TRN \\
\hline CHEMBL 3687303 & 1536442 & 5.6745 & 5.048 & TRN \\
\hline CHEMBL 3691705 & 1536442 & 5.72 & 5.3688 & TRN \\
\hline CHEMBL 3687284 & 1536442 & 4.9007 & 4.8835 & TRN \\
\hline CHEMBL 3687281 & 1536442 & 4.3285 & 4.7527 & TRN \\
\hline CHEMBL 3687304 & 1536442 & 4.6847 & 4.6552 & TRN \\
\hline CHEMBL 3687257 & 1536442 & 4.8701 & 4.9183 & TRN \\
\hline CHEMBL 3687310 & 1536442 & 4.9744 & 5.4001 & TRN \\
\hline CHEMBL 3639860 & 1536442 & 4.8454 & 4.7792 & TRN \\
\hline CHEMBL 3687237 & 1536442 & 4.49 & 4.80399 & 9999999999 \\
\hline CHEMBL3691709 & 1536442 & 6.2038 & 5.6965 & TRN \\
\hline CHEMBL 3687311 & 1536442 & 4.8 & 4.8553 & TRN \\
\hline CHEMBL 3691694 & 1536442 & 4.4874 & 5.0424 & TRN \\
\hline CHEMBL 3687263 & 1536442 & 4.7687 & 4.9804 & TRN \\
\hline CHEMBL 3687243 & 1536442 & 4.7238 & 4.6909 & TRN \\
\hline
\end{tabular}

Page 22808 
Supplemental Table S2.txt

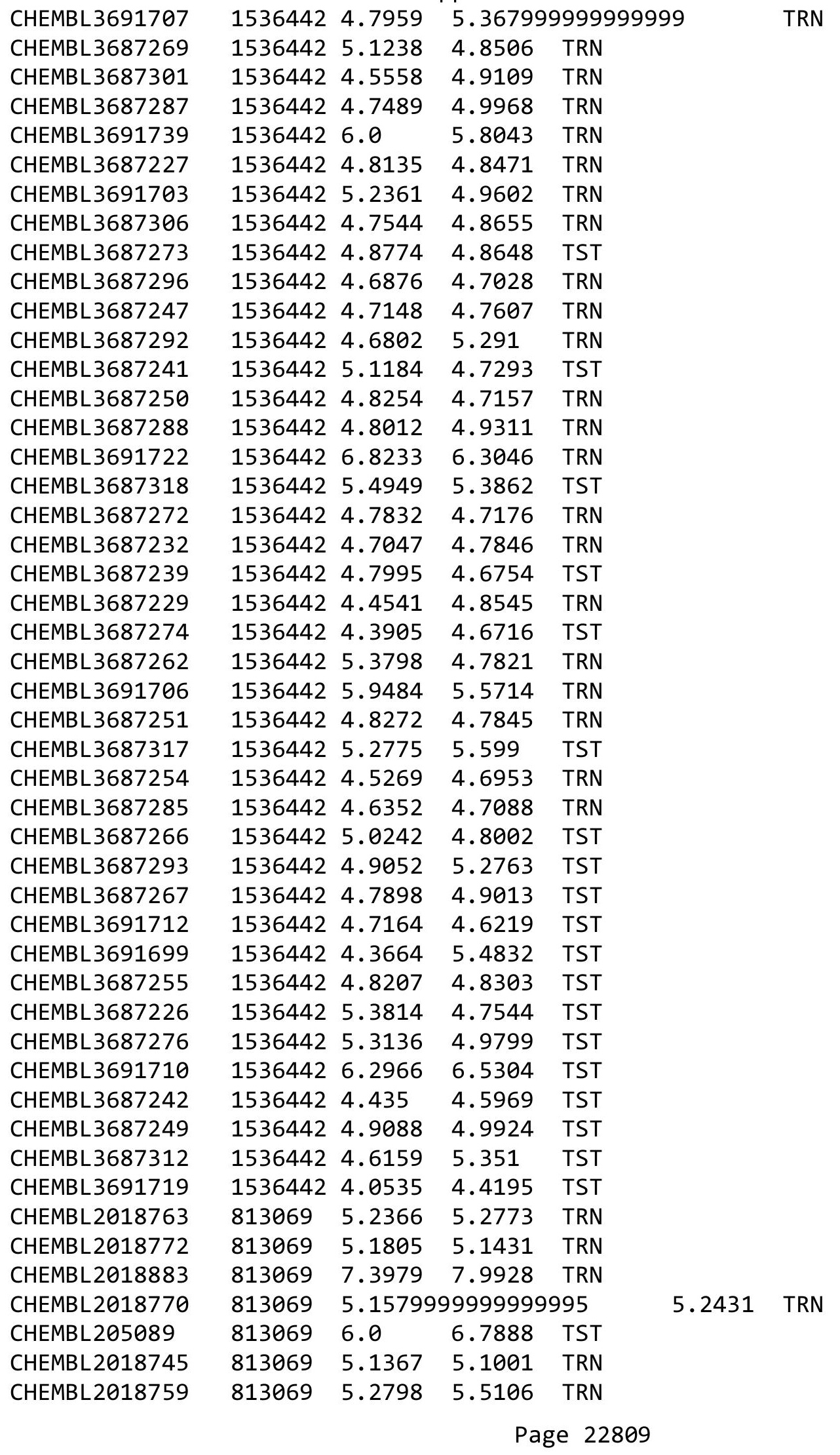


Supplemental Table S2.txt

\begin{tabular}{|c|c|c|c|c|}
\hline AEMBL301018 & & 5.2757 & & \\
\hline HEMBL2018767 & 13069 & 5.1904 & & \\
\hline FMRI 1761939 & 069 & 3979 & & \\
\hline IEMBL2018884 & 069 & 3979 & & \\
\hline HEMBL2018760 & 3069 & 2557 & 566 & \\
\hline AEMBL2018749 & 13069 & .1675 & & \\
\hline IEMBL 201 & 3069 & .3979 & & \\
\hline IEMBL176 & 3069 & & & \\
\hline IEMBL 2018754 & 3069 & 3098 & $\partial 96$ & \\
\hline HEMBL1761938 & 3069 & 458 & 75 & \\
\hline HEMBL17€ & 069 & & & \\
\hline IEMBL20 & 069 & 1278 & & \\
\hline IEMBL 201 & 269 & .1397 & & \\
\hline AEMBL1277162 & 3069 & 2218 & 878 & \\
\hline HEMBL 201 & 069 & & & \\
\hline AEMBL 201 & 69 & .0269 & & \\
\hline IEMBL] & & .2218 & & \\
\hline IEMBL 20 & 269 & .3325 & & \\
\hline IEMBL127 & 069 & 218 & & \\
\hline AEMBL 201 & $\partial 69$ & & & \\
\hline AEMBL & 59 & 55 & & \\
\hline EMB & & & & \\
\hline IEMBL 201 & 69 & .301 & & \\
\hline IEMBL201 & $\partial 69$ & 706 & & \\
\hline IEMBL 201 & & & & \\
\hline IEMBL] & 59 & 8 & & \\
\hline IEMBL & & 18 & & \\
\hline EMB & & .284 & & \\
\hline IEMBL: & & & & \\
\hline IEMBL201 & & 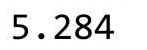 & & RN \\
\hline EMBL & & & & w \\
\hline 1 & & 7 & & \\
\hline & & & & - \\
\hline IEMBL17 & & & & $S$ \\
\hline IEMBL176 & 59 & 4 & & $\mathrm{RI}$ \\
\hline & & & & . \\
\hline 1 & & 8 & & $\Gamma \mathrm{R}$ \\
\hline HEMBL 201 & & & & RN \\
\hline IEMBL201 & & & & is \\
\hline EMBL & 59 & 99 & & \\
\hline HEMBL & & & & \\
\hline HEMBL & & 5.1308 & 38 & $\Gamma R$ \\
\hline HEMBL176 & & .2518 & & RI \\
\hline AEMBL 201 & 69 & 18 & & s \\
\hline 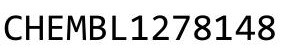 & & & & \\
\hline CHEMBL 2018753 & & & & \\
\hline CHEMBL 2018755 & & 6.0706 & 842 & \\
\hline CHEMBL 2018756 & 813069 & 6.1871 & 5.8148 & \\
\hline
\end{tabular}

Page 22810 


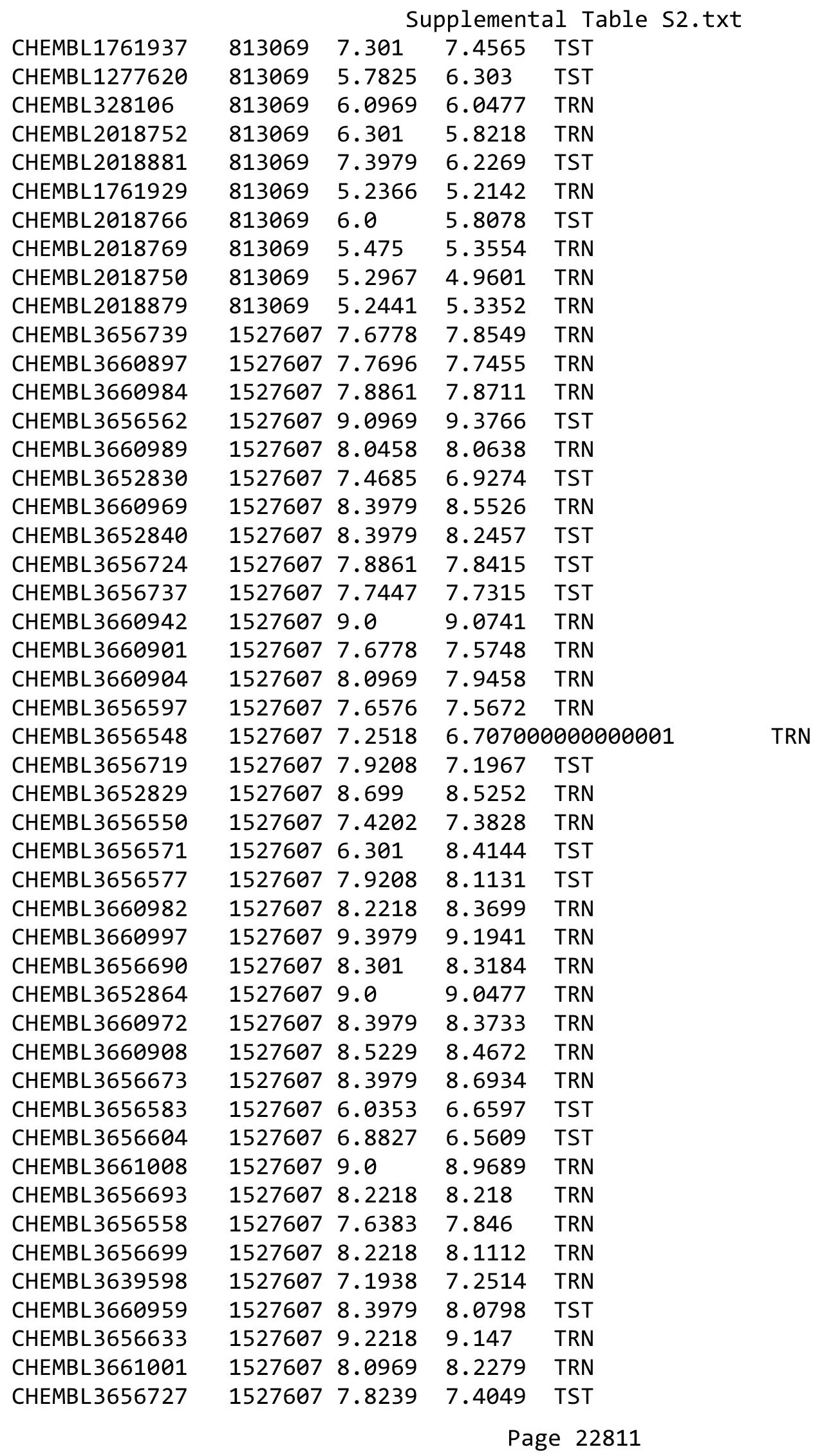


Supplemental Table S2.txt

\begin{tabular}{|c|c|c|c|c|}
\hline CHEMBL 3660961 & 1527607 & 6.9318 & 6.8598 & TRN \\
\hline CHEMBL3661022 & 1527607 & 6.7447 & 7.3713 & TST \\
\hline CHEMBL 3656716 & 1527607 & 8.0 & 8.0667 & TRN \\
\hline CHEMBL3656712 & 1527607 & 8.0 & 8.0914 & TRN \\
\hline CHEMBL 3656641 & 1527607 & 9.3979 & 7.8989 & TST \\
\hline CHEMBL3656732 & 1527607 & 7.7696 & 7.5691 & TRN \\
\hline CHEMBL 3656647 & 1527607 & 9.2218 & 9.1586 & TRN \\
\hline CHEMBL 3656653 & 1527607 & 8.699 & \multicolumn{2}{|c|}{8.613999999999999} \\
\hline CHEMBL3656613 & 1527607 & 7.8861 & 7.9365 & TRN \\
\hline CHEMBL3656698 & 1527607 & 8.2218 & 8.104 & TRN \\
\hline CHEMBL 3656538 & 1527607 & 8.301 & 8.1842 & TRN \\
\hline CHEMBL3660934 & 1527607 & 9.0 & 9.0668 & TRN \\
\hline CHEMBL 3656715 & 1527607 & 8.0 & 8.0501 & TRN \\
\hline CHEMBL 3656551 & 1527607 & 6.3595 & 6.4934 & TRN \\
\hline CHEMBL 3656607 & 1527607 & 8.3979 & 8.5014 & TRN \\
\hline CHEMBL 3660960 & 1527607 & 8.2218 & 7.9928 & TRN \\
\hline CHEMBL 3660895 & 1527607 & 7.2147 & 7.1471 & TRN \\
\hline CHEMBL 3656728 & 1527607 & 7.8239 & 8.192 & TRN \\
\hline CHEMBL 3656676 & 1527607 & 8.3979 & 8.332 & TRN \\
\hline CHEMBL 3660941 & 1527607 & 9.0 & 8.8756 & TRN \\
\hline CHEMBL3652839 & 1527607 & 8.5229 & 8.6714 & TST \\
\hline CHEMBL3656627 & 1527607 & 6.8297 & 6.9398 & TRN \\
\hline CHEMBL 3656588 & 1527607 & 5.5829 & 6.477 & TST \\
\hline CHEMBL 3656598 & 1527607 & 5.9462 & 6.2162 & TRN \\
\hline CHEMBL 3660924 & 1527607 & 8.699 & 8.7119 & TRN \\
\hline CHEMBL3656639 & 1527607 & 9.3979 & 8.8662 & TST \\
\hline CHEMBL3660973 & 1527607 & 7.9208 & 7.9705 & TRN \\
\hline CHEMBL 3652825 & 1527607 & 8.699 & 8.6787 & TRN \\
\hline CHEMBL3656696 & 1527607 & 8.2218 & 7.0159 & TST \\
\hline CHEMBL 3661000 & 1527607 & 8.301 & 8.6407 & TRN \\
\hline CHEMBL3656691 & 1527607 & 8.2218 & 8.1275 & TRN \\
\hline CHEMBL 3656584 & 1527607 & 5.7124 & 5.6593 & TRN \\
\hline CHEMBL3656645 & 1527607 & 9.2218 & 9.2648 & TST \\
\hline CHEMBL3661019 & 1527607 & 8.1549 & 8.4016 & TST \\
\hline CHEMBL 3660888 & 1527607 & 7.1367 & 7.0317 & TRN \\
\hline CHEMBL3656672 & 1527607 & 8.5229 & 8.2945 & TRN \\
\hline CHEMBL3652859 & 1527607 & 6.6459 & 6.6389 & TRN \\
\hline CHEMBL3656649 & 1527607 & 9.0 & 8.8928 & TST \\
\hline CHEMBL 3652866 & 1527607 & 7.5229 & 7.635 & TRN \\
\hline CHEMBL 3656702 & 1527607 & 8.2218 & 8.4279 & TRN \\
\hline CHEMBL3660970 & 1527607 & 8.0 & 8.0945 & TRN \\
\hline CHEMBL 3656720 & 1527607 & 7.9208 & 7.7556 & TRN \\
\hline CHEMBL3652856 & 1527607 & 7.041 & 7.0289 & TRN \\
\hline CHEMBL 3656654 & 1527607 & 8.699 & 9.11 & TST \\
\hline CHEMBL 3656622 & 1527607 & 7.7959 & 8.2399 & TRN \\
\hline CHEMBL3660939 & 1527607 & 9.0 & 9.0555 & TRN \\
\hline CHEMBL 3656751 & 1527607 & 7.2441 & 7.0219 & TST \\
\hline CHEMBL3656752 & 1527607 & 7.2366 & 7.2056 & TST \\
\hline
\end{tabular}

TST 
Supplemental Table S2.txt

\begin{tabular}{|c|c|c|c|c|c|}
\hline CHEMBL3661011 & 1527607 & 9.0 & 8.8506 & TST & \\
\hline CHEMBL3660971 & 1527607 & 8.301 & 8.3197 & TRN & \\
\hline CHEMBL3656642 & 1527607 & 9.301 & 9.3357 & TST & \\
\hline CHEMBL3656651 & 1527607 & 9.0 & 7.8568 & TST & \\
\hline CHEMBL3652846 & 1527607 & 6.0 & 7.3599 & TRN & \\
\hline CHEMBL3660894 & 1527607 & 7.0269 & 7.3658 & TST & \\
\hline CHEMBL3661009 & 1527607 & 9.301 & 9.3062 & TRN & \\
\hline CHEMBL3656689 & 1527607 & 8.301 & 8.3545 & TRN & \\
\hline CHEMBL3661015 & 1527607 & 8.699 & 8.7329 & TRN & \\
\hline CHEMBL3660946 & 1527607 & 8.2218 & 8.2067 & TRN & \\
\hline CHEMBL3661007 & 1527607 & 9.0 & 9.1087 & TRN & \\
\hline CHEMBL3656704 & 1527607 & 8.0969 & 8.2602 & TRN & \\
\hline CHEMBL3660914 & 1527607 & 9.0 & 8.8964 & TRN & \\
\hline CHEMBL 3656741 & 1527607 & 7.6383 & 7.6127 & TRN & \\
\hline CHEMBL3660907 & 1527607 & 8.5229 & 8.2834 & TRN & \\
\hline CHEMBL3656749 & 1527607 & 7.3188 & 7.2987 & TRN & \\
\hline CHEMBL3656552 & 1527607 & 7.8239 & 7.9619 & TRN & \\
\hline CHEMBL3660936 & 1527607 & 9.0 & 9.0464 & TRN & \\
\hline CHEMBL 3656634 & 1527607 & 6.0 & 8.4954 & TST & \\
\hline CHEMBL3656717 & 1527607 & 8.0 & 7.9144 & TRN & \\
\hline CHEMBL3656578 & 1527607 & 9.0605 & 9.0483 & TRN & \\
\hline CHEMBL3652843 & 1527607 & 6.7077 & 7.5278 & TST & \\
\hline CHEMBL3652865 & 1527607 & 8.699 & 8.7839 & TRN & \\
\hline CHEMBL 3656721 & 1527607 & 7.9208 & 7.7207 & TRN & \\
\hline CHEMBL3660931 & 1527607 & 8.5229 & 8.6053 & TRN & \\
\hline CHEMBL3660920 & 1527607 & 8.699 & 8.8337 & TRN & \\
\hline CHEMBL3660951 & 1527607 & 7.4437 & 7.5032 & TST & \\
\hline CHEMBL 3656680 & 1527607 & 8.301 & 8.2211 & TST & \\
\hline CHEMBL 3656581 & 1527607 & \multicolumn{2}{|c|}{6.327000000000001} & 6.6959 & TST \\
\hline CHEMBL3661020 & 1527607 & 8.0969 & 8.3855 & TST & \\
\hline CHEMBL3656643 & 1527607 & 9.301 & 8.1942 & TST & \\
\hline CHEMBL3656638 & 1527607 & 9.5229 & 8.7403 & TST & \\
\hline CHEMBL3660919 & 1527607 & 9.0 & 9.0095 & TRN & \\
\hline CHEMBL 3656707 & 1527607 & 8.0969 & 7.8318 & TRN & \\
\hline CHEMBL3656631 & 1527607 & 6.9788 & 5.1277 & TST & \\
\hline CHEMBL3660929 & 1527607 & 8.5229 & 8.5771 & TRN & \\
\hline CHEMBL3656554 & 1527607 & 7.9586 & 7.9756 & TRN & \\
\hline CHEMBL3656594 & 1527607 & 7.0177 & 7.2984 & TST & \\
\hline CHEMBL 3660899 & 1527607 & 7.3565 & 7.5795 & TRN & \\
\hline CHEMBL3660930 & 1527607 & 8.5229 & 8.5359 & TRN & \\
\hline CHEMBL3656753 & 1527607 & 7.2291 & 7.6501 & TRN & \\
\hline CHEMBL3652814 & 1527607 & 7.8861 & 7.3313 & TST & \\
\hline CHEMBL3661018 & 1527607 & 8.301 & 8.6929 & TST & \\
\hline CHEMBL3660917 & 1527607 & 8.699 & 8.7584 & TRN & \\
\hline CHEMBL3656626 & 1527607 & 7.6021 & 7.777 & TRN & \\
\hline CHEMBL3652818 & 1527607 & 7.301 & 8.4446 & TST & \\
\hline CHEMBL3660943 & 1527607 & 8.699 & 8.466000 & 0000000001 & TRN \\
\hline CHEMBL3661017 & 1527607 & 7.8861 & 8.1716 & TST & \\
\hline
\end{tabular}


Supplemental Table S2.txt

\begin{tabular}{|c|c|c|c|c|c|}
\hline CHEMBL 3661021 & 1527607 & 8.1549 & 8.1796 & TST & \\
\hline CHEMBL 3656664 & 1527607 & 8.5229 & 8.1903 & TST & \\
\hline CHEMBL 3656687 & 1527607 & 8.301 & 8.032 & TST & \\
\hline CHEMBL3660906 & 1527607 & 7.9586 & 7.8328 & TRN & \\
\hline CHEMBL3656632 & 1527607 & 9.2218 & 8.9742 & TRN & \\
\hline CHEMBL3652826 & 1527607 & 9.7447 & 9.3859 & TRN & \\
\hline CHEMBL3652867 & 1527607 & 6.6596 & 6.8136 & TRN & \\
\hline CHEMBL 3656618 & 1527607 & 7.8861 & 7.6888 & TRN & \\
\hline CHEMBL3660892 & 1527607 & 6.5498 & 6.5114 & TRN & \\
\hline CHEMBL3656619 & 1527607 & 9.0 & 8.6633 & TRN & \\
\hline CHEMBL3656688 & 1527607 & 8.301 & 8.2009 & TRN & \\
\hline CHEMBL3660893 & 1527607 & 6.6126 & 6.0851 & TRN & \\
\hline CHEMBL3660927 & 1527607 & 8.699 & 8.5427 & TRN & \\
\hline CHEMBL3656544 & 1527607 & 9.0362 & 8.9405 & TRN & \\
\hline CHEMBL3661012 & 1527607 & 9.0 & 8.2813 & TST & \\
\hline CHEMBL3652833 & 1527607 & 6.6459 & 6.9156 & TRN & \\
\hline CHEMBL3656560 & 1527607 & 8.699 & 8.4214 & TRN & \\
\hline CHEMBL 3656709 & 1527607 & 8.0969 & 7.8397 & TST & \\
\hline CHEMBL3656738 & 1527607 & 7.7212 & 7.7692 & TRN & \\
\hline CHEMBL3652821 & 1527607 & 7.9208 & 7.8584 & TRN & \\
\hline CHEMBL3660945 & 1527607 & 6.7375 & 6.6636 & TRN & \\
\hline CHEMBL3656705 & 1527607 & 8.0969 & 8.3165 & TRN & \\
\hline CHEMBL 3656541 & 1527607 & 6.6596 & 6.6461 & TRN & \\
\hline CHEMBL3660996 & 1527607 & 9.5229 & 9.6062 & TRN & \\
\hline CHEMBL 3660891 & 1527607 & 7.5376 & 7.5953 & TRN & \\
\hline CHEMBL 3652860 & 1527607 & 6.684 & 6.5907 & TRN & \\
\hline CHEMBL 3652817 & 1527607 & 7.8239 & 7.8365 & TRN & \\
\hline CHEMBL 3656557 & 1527607 & 8.699 & 8.7052 & TRN & \\
\hline CHEMBL 3652854 & 1527607 & 7.6576 & 7.8011 & TRN & \\
\hline CHEMBL3660910 & 1527607 & 8.301 & 8.3438 & TRN & \\
\hline CHEMBL3652816 & 1527607 & 8.5229 & 8.8202 & TRN & \\
\hline CHEMBL3656682 & 1527607 & 8.301 & 8.5291 & TRN & \\
\hline CHEMBL 3656677 & 1527607 & 8.3979 & 8.5675 & TRN & \\
\hline CHEMBL3639597 & 1527607 & 6.301 & 6.5622 & TRN & \\
\hline CHEMBL 3656656 & 1527607 & 8.699 & 8.6423 & TRN & \\
\hline CHEMBL 3656718 & 1527607 & 7.9208 & 7.7524 & TRN & \\
\hline CHEMBL3660998 & 1527607 & 9.0 & 9.2351 & TRN & \\
\hline CHEMBL 3656549 & 1527607 & 7.6778 & 7.7907 & TRN & \\
\hline CHEMBL3652851 & 1527607 & 6.3233 & 6.7253 & TST & \\
\hline CHEMBL 3660980 & 1527607 & 9.0605 & 9.1938 & TRN & \\
\hline CHEMBL 3656587 & 1527607 & 5.58299 & 99999999 & 99 & 7.3256 \\
\hline CHEMBL3660921 & 1527607 & 8.699 & 9.1531 & TRN & \\
\hline CHEMBL3660954 & 1527607 & 9.2441 & 8.818 & TRN & \\
\hline CHEMBL3656708 & 1527607 & 8.0969 & 8.1858 & TRN & \\
\hline CHEMBL 3656582 & 1527607 & 6.1051 & 5.5499 & TST & \\
\hline CHEMBL3656543 & 1527607 & 8.1549 & 8.0959 & TRN & \\
\hline CHEMBL3656701 & 1527607 & 8.2218 & 8.1931 & TRN & \\
\hline CHEMBL 3652819 & 1527607 & 7.2076 & 7.1032 & TRN & \\
\hline
\end{tabular}

Page 22814 
Supplemental Table S2.txt

\begin{tabular}{|c|c|c|c|c|c|}
\hline CHEMBL 3656729 & 1527607 & 7.8239 & 7.7569 & TRN & \\
\hline CHEMBL3656606 & 1527607 & 9.301 & 9.2402 & TRN & \\
\hline CHEMBL 3656612 & 1527607 & 9.0 & 8.8279 & TRN & \\
\hline CHEMBL 3656559 & 1527607 & 9.0 & 8.7796 & TRN & \\
\hline CHEMBL3656742 & 1527607 & 7.6383 & 7.5293 & TRN & \\
\hline CHEMBL3660912 & 1527607 & 8.0458 & 8.0752 & TRN & \\
\hline CHEMBL3656556 & 1527607 & 6.1549 & 6.3746 & TRN & \\
\hline CHEMBL 3656660 & 1527607 & 8.699 & 8.5853 & TRN & \\
\hline CHEMBL 3656574 & 1527607 & 6.0 & 7.8515 & TST & \\
\hline CHEMBL3661014 & 1527607 & 7.8539 & 7.6765 & TRN & \\
\hline CHEMBL3656608 & 1527607 & 9.5229 & 9.4751 & TRN & \\
\hline CHEMBL3656564 & 1527607 & 7.8861 & 7.9907 & TRN & \\
\hline CHEMBL3656655 & 1527607 & 8.699 & 8.4006 & TST & \\
\hline CHEMBL 3660889 & 1527607 & 7.6778 & 7.6714 & TRN & \\
\hline CHEMBL3656667 & 1527607 & 6.0 & 7.0256 & TRN & \\
\hline CHEMBL3660963 & 1527607 & 8.699 & 8.635 & TRN & \\
\hline CHEMBL3656744 & 1527607 & 7.6383 & 7.4542 & TST & \\
\hline CHEMBL3656595 & 1527607 & 7.9586 & 8.0465 & TRN & \\
\hline CHEMBL3661010 & 1527607 & 9.0 & 9.324 & TRN & \\
\hline CHEMBL3652853 & 1527607 & 7.041 & 7.2114 & TRN & \\
\hline CHEMBL3660928 & 1527607 & 8.3979 & 8.2972 & TRN & \\
\hline CHEMBL3660987 & 1527607 & 8.0 & 8.2575 & TRN & \\
\hline CHEMBL 3660952 & 1527607 & 8.301 & 8.7889 & TRN & \\
\hline CHEMBL3652831 & 1527607 & 6.3635 & 6.4527 & TST & \\
\hline CHEMBL 3639555 & 1527607 & 9.5229 & 9.0909 & TST & \\
\hline CHEMBL3660948 & 1527607 & 7.9586 & 8.0382 & TRN & \\
\hline CHEMBL 3656674 & 1527607 & 8.3979 & 8.2205 & TRN & \\
\hline CHEMBL3656539 & 1527607 & 7.9586 & 8.0201 & TRN & \\
\hline CHEMBL3660898 & 1527607 & 7.7696 & 7.9189 & TRN & \\
\hline CHEMBL 3656683 & 1527607 & 8.301 & 8.2701 & TRN & \\
\hline CHEMBL 3639554 & 1527607 & 6.6819 & 6.4712 & TRN & \\
\hline CHEMBL3656697 & 1527607 & 8.2218 & 7.2098 & TST & \\
\hline CHEMBL 3660905 & 1527607 & 8.3979 & \multicolumn{2}{|c|}{8.261000000000001} & TRN \\
\hline CHEMBL3656730 & 1527607 & 7.7959 & 7.7632 & TRN & \\
\hline CHEMBL 3656568 & 1527607 & 7.7696 & 7.6315 & TRN & \\
\hline CHEMBL3660983 & 1527607 & 8.2218 & 8.0499 & TRN & \\
\hline CHEMBL3660935 & 1527607 & 8.699 & 8.5377 & TRN & \\
\hline CHEMBL 3656735 & 1527607 & 7.7447 & 7.8851 & TRN & \\
\hline CHEMBL3652836 & 1527607 & 6.5784 & 6.6656 & TRN & \\
\hline CHEMBL3656659 & 1527607 & 8.699 & 8.7294 & TST & \\
\hline CHEMBL3656710 & 1527607 & 8.0458 & 8.1372 & TRN & \\
\hline CHEMBL3660890 & 1527607 & 6.6091 & 6.2773 & TRN & \\
\hline CHEMBL3652822 & 1527607 & 8.699 & 8.496 & TST & \\
\hline CHEMBL3660903 & 1527607 & 6.0 & 5.9297 & TRN & \\
\hline CHEMBL 3652824 & 1527607 & 7.3188 & 7.3479 & TST & \\
\hline CHEMBL3660922 & 1527607 & 9.0 & 9.0013 & TRN & \\
\hline CHEMBL3656665 & 1527607 & 8.5229 & 8.4041 & TRN & \\
\hline CHEMBL3656726 & 1527607 & 7.8539 & 7.5849 & TRN & \\
\hline
\end{tabular}

Page 22815 
Supplemental Table S2.txt

\begin{tabular}{|c|c|c|c|c|}
\hline CHEMBL 3656745 & 1527607 & 7.6021 & 7.5372 & TRN \\
\hline CHEMBL3656610 & 1527607 & 7.8239 & 7.8824 & TRN \\
\hline CHEMBL3656537 & 1527607 & 6.6364 & 6.903 & TRN \\
\hline CHEMBL 3660964 & 1527607 & 8.2218 & 8.3812 & TRN \\
\hline CHEMBL3660966 & 1527607 & 8.699 & 8.45 & TRN \\
\hline CHEMBL3656605 & 1527607 & 7.2007 & 7.3857 & TRN \\
\hline CHEMBL3656599 & 1527607 & 6.0 & 5.6801 & TRN \\
\hline CHEMBL 3660965 & 1527607 & 7.8239 & 7.8592 & TRN \\
\hline CHEMBL 3656706 & 1527607 & 8.0969 & 8.198 & TRN \\
\hline CHEMBL3656586 & 1527607 & 5.6282 & 6.7703 & TST \\
\hline CHEMBL3656644 & 1527607 & 9.2218 & 8.5836 & TST \\
\hline CHEMBL3656620 & 1527607 & 7.1487 & 7.3597 & TRN \\
\hline CHEMBL3660926 & 1527607 & 9.0 & 9.1374 & TRN \\
\hline CHEMBL 3661005 & 1527607 & 9.5086 & 9.186 & TRN \\
\hline CHEMBL3656553 & 1527607 & 7.2218 & 7.0137 & TRN \\
\hline CHEMBL3656725 & 1527607 & 7.8539 & 8.0028 & TRN \\
\hline CHEMBL3660962 & 1527607 & 8.5229 & 8.5263 & TRN \\
\hline CHEMBL3656657 & 1527607 & 8.699 & 8.8329 & TRN \\
\hline CHEMBL3660981 & 1527607 & 8.1549 & 8.1407 & TRN \\
\hline CHEMBL3660902 & 1527607 & 8.1549 & 8.2777 & TRN \\
\hline CHEMBL3656542 & 1527607 & 9.0 & 8.8749 & TRN \\
\hline CHEMBL3656746 & 1527607 & 7.5528 & 6.7643 & TST \\
\hline CHEMBL 3656646 & 1527607 & 9.2218 & 8.9527 & TST \\
\hline CHEMBL3639556 & 1527607 & 7.7212 & 7.8489 & TRN \\
\hline CHEMBL 3656640 & 1527607 & 9.3979 & 9.3427 & TRN \\
\hline CHEMBL3656694 & 1527607 & 8.2218 & 8.2879 & TRN \\
\hline CHEMBL3660953 & 1527607 & 8.699 & 8.5216 & TRN \\
\hline CHEMBL 3660925 & 1527607 & 9.0 & 9.0922 & TRN \\
\hline CHEMBL3656585 & 1527607 & 5.6914 & 6.5711 & TST \\
\hline CHEMBL 3656580 & 1527607 & 6.8539 & 7.4426 & TST \\
\hline CHEMBL 3656575 & 1527607 & 8.2218 & 8.01799 & 9999999999 \\
\hline CHEMBL3660986 & 1527607 & 8.0 & 8.109 & TRN \\
\hline CHEMBL3660999 & 1527607 & 8.301 & 8.2505 & TRN \\
\hline CHEMBL3656678 & 1527607 & 8.3979 & 7.8755 & TST \\
\hline CHEMBL 3661023 & 1527607 & 6.9626 & 7.5283 & TST \\
\hline CHEMBL3656611 & 1527607 & 6.5575 & 7.6021 & TST \\
\hline CHEMBL3656731 & 1527607 & 7.7959 & 7.4746 & TRN \\
\hline CHEMBL3652832 & 1527607 & 6.4001 & 6.3656 & TRN \\
\hline CHEMBL3656695 & 1527607 & 8.2218 & 7.7749 & TST \\
\hline CHEMBL3661006 & 1527607 & 9.585 & 9.414 & TRN \\
\hline CHEMBL3656573 & 1527607 & 7.7696 & 8.7973 & TST \\
\hline CHEMBL3652845 & 1527607 & 8.0458 & 8.0577 & TRN \\
\hline CHEMBL3656614 & 1527607 & 9.0 & 8.882 & TRN \\
\hline CHEMBL3656692 & 1527607 & 8.2218 & 7.9633 & TRN \\
\hline CHEMBL 3656625 & 1527607 & 7.3768 & 7.1794 & TRN \\
\hline CHEMBL3660900 & 1527607 & 7.8861 & 7.8208 & TRN \\
\hline CHEMBL3652863 & 1527607 & 7.4318 & 7.6586 & TRN \\
\hline CHEMBL3656630 & 1527607 & 7.1487 & 7.5863 & TRN \\
\hline
\end{tabular}

Page 22816 
Supplemental Table S2.txt

\begin{tabular}{|c|c|c|c|c|}
\hline CHEMBL3656569 & 1527607 & 6.7721 & 6.4967 & TST \\
\hline CHEMBL3652862 & 1527607 & 9.0 & 9.0475 & TRN \\
\hline CHEMBL3656591 & 1527607 & 7.5686 & \multicolumn{2}{|c|}{7.571000000000001} \\
\hline CHEMBL3656684 & 1527607 & 8.301 & 8.4802 & TRN \\
\hline CHEMBL3656628 & 1527607 & 8.0969 & 8.2394 & TRN \\
\hline CHEMBL3656662 & 1527607 & 8.5229 & 8.708 & TRN \\
\hline CHEMBL3656636 & 1527607 & 8.5229 & 8.4164 & TRN \\
\hline CHEMBL3661002 & 1527607 & 9.2007 & 9.2443 & TRN \\
\hline CHEMBL3656601 & 1527607 & 6.5784 & 5.8245 & TST \\
\hline CHEMBL3660985 & 1527607 & 7.9586 & \multirow{2}{*}{\multicolumn{2}{|c|}{$\begin{array}{l}8.056000000000001 \\
7.1979999999999995\end{array}$}} \\
\hline CHEMBL3652835 & 1527607 & 6.3883 & & \\
\hline CHEMBL3660918 & 1527607 & 8.699 & 8.9065 & TRN \\
\hline CHEMBL3656754 & 1527607 & 7.1549 & 7.2724 & TRN \\
\hline CHEMBL3652838 & 1527607 & 7.2007 & 8.366 & TST \\
\hline CHEMBL3656621 & 1527607 & 8.699 & 8.3624 & TRN \\
\hline CHEMBL3660978 & 1527607 & 8.699 & 8.6313 & TRN \\
\hline CHEMBL3656740 & 1527607 & 7.6576 & 7.6628 & TRN \\
\hline CHEMBL3660993 & 1527607 & 6.7144 & 7.0135 & TRN \\
\hline CHEMBL3656565 & 1527607 & 7.8861 & 7.8524 & TRN \\
\hline CHEMBL3656561 & 1527607 & 6.9747 & 7.1697 & TRN \\
\hline CHEMBL3652823 & 1527607 & 8.301 & 8.5246 & TRN \\
\hline CHEMBL3656629 & 1527607 & 7.8861 & 8.0165 & TRN \\
\hline CHEMBL3656670 & 1527607 & 8.5229 & 7.9104 & TST \\
\hline CHEMBL3660933 & 1527607 & 8.699 & 8.8381 & TRN \\
\hline CHEMBL3652828 & 1527607 & 8.301 & 8.531 & TST \\
\hline CHEMBL3660968 & 1527607 & 8.5229 & 8.4742 & TRN \\
\hline CHEMBL3656686 & 1527607 & 8.301 & 8.6047 & TRN \\
\hline CHEMBL3656743 & 1527607 & 7.6383 & 7.5446 & TRN \\
\hline CHEMBL3656609 & 1527607 & 9.3979 & 9.2063 & TRN \\
\hline CHEMBL3656547 & 1527607 & 7.699 & 7.8091 & TRN \\
\hline CHEMBL3660949 & 1527607 & 8.1549 & 8.2049 & TRN \\
\hline CHEMBL3656536 & 1527607 & 8.0458 & 7.9781 & TRN \\
\hline CHEMBL3656624 & 1527607 & 8.3979 & 8.0884 & TRN \\
\hline CHEMBL3660938 & 1527607 & 8.699 & 8.9194 & TRN \\
\hline CHEMBL3656593 & 1527607 & 8.1549 & 8.2086 & TST \\
\hline CHEMBL3661003 & 1527607 & 8.699 & 8.6313 & TST \\
\hline CHEMBL3656615 & 1527607 & 7.4089 & 7.3997 & TRN \\
\hline CHEMBL3660956 & 1527607 & 7.1192 & 7.28600 & 00000000005 \\
\hline CHEMBL3656602 & 1527607 & 7.6383 & 7.4841 & TRN \\
\hline CHEMBL3656616 & 1527607 & 8.699 & 8.4768 & TRN \\
\hline CHEMBL3660955 & 1527607 & 8.301 & 8.5661 & TRN \\
\hline CHEMBL3656600 & 1527607 & 7.3372 & 7.5262 & TRN \\
\hline CHEMBL3660975 & 1527607 & 8.3979 & 8.5637 & TRN \\
\hline CHEMBL3656750 & 1527607 & 7.2924 & 7.4391 & TRN \\
\hline CHEMBL3661004 & 1527607 & 9.3665 & 9.0555 & TRN \\
\hline CHEMBL3656590 & 1527607 & 6.8697 & 6.7836 & TRN \\
\hline CHEMBL 3656567 & 1527607 & 7.9586 & 8.0146 & TRN \\
\hline CHEMBL3660932 & 1527607 & 9.0 & 9.054 & TRN \\
\hline
\end{tabular}


Supplemental Table S2.txt

\begin{tabular}{|c|c|c|c|c|c|}
\hline CHEMBL3656592 & 1527607 & 7.1135 & 7.4043 & TST & \\
\hline CHEMBL3656563 & 1527607 & 9.7212 & 9.6465 & TRN & \\
\hline CHEMBL3660913 & 1527607 & 9.1249 & 9.0226 & TRN & \\
\hline CHEMBL 3656540 & 1527607 & 6.7721 & 6.6572 & TRN & \\
\hline CHEMBL 3652848 & 1527607 & 8.699 & 8.8116 & TRN & \\
\hline CHEMBL3656748 & 1527607 & 7.4437 & 7.5987 & TST & \\
\hline CHEMBL3656747 & 1527607 & 7.5086 & 7.551 & TRN & \\
\hline CHEMBL 3660988 & 1527607 & 8.1549 & 8.2199 & TRN & \\
\hline CHEMBL 3660887 & 1527607 & 7.0506 & 7.0553 & TRN & \\
\hline CHEMBL 3656545 & 1527607 & 8.699 & 8.4437 & TRN & \\
\hline CHEMBL 3652844 & 1527607 & 7.9586 & 7.8092 & TRN & \\
\hline CHEMBL3656637 & 1527607 & 9.699 & 8.8253 & TRN & \\
\hline CHEMBL 3652827 & 1527607 & 6.7471 & 6.8537 & TRN & \\
\hline CHEMBL 3656713 & 1527607 & 8.0 & 8.3116 & TRN & \\
\hline CHEMBL 3660957 & 1527607 & 7.6576 & 7.6649 & TST & \\
\hline CHEMBL3656675 & 1527607 & 8.3979 & 8.2885 & TRN & \\
\hline CHEMBL3656555 & 1527607 & 7.699 & 7.6481 & TRN & \\
\hline CHEMBL3660947 & 1527607 & 8.0969 & 8.1677 & TRN & \\
\hline CHEMBL3661016 & 1527607 & 7.9208 & 8.3826 & TST & \\
\hline CHEMBL 3656714 & 1527607 & 8.0 & 7.6066 & TST & \\
\hline CHEMBL3660967 & 1527607 & 8.2218 & 8.3585 & TRN & \\
\hline CHEMBL3660992 & 1527607 & 7.4685 & 7.4304 & TRN & \\
\hline CHEMBL3660958 & 1527607 & 7.6778 & 7.525 & TST & \\
\hline CHEMBL3652815 & 1527607 & 8.3979 & 8.6346 & TRN & \\
\hline CHEMBL3656681 & 1527607 & 8.301 & 8.1276 & TRN & \\
\hline CHEMBL3656663 & 1527607 & 8.5229 & 8.5507 & TRN & \\
\hline CHEMBL3656679 & 1527607 & 8.301 & 8.3141 & TRN & \\
\hline CHEMBL3656579 & 1527607 & 7.5376 & 7.8405 & TRN & \\
\hline CHEMBL3656711 & 1527607 & 8.0458 & 8.0735 & TRN & \\
\hline CHEMBL3656733 & 1527607 & 7.7696 & 7.8537 & TRN & \\
\hline CHEMBL3656572 & 1527607 & 6.0 & 7.9873 & TST & \\
\hline CHEMBL3660909 & 1527607 & 8.301 & 8.10700 & 0000000001 & TRN \\
\hline CHEMBL3656700 & 1527607 & 8.2218 & 8.1245 & TRN & \\
\hline CHEMBL 3656722 & 1527607 & 7.8861 & 7.9159 & TRN & \\
\hline CHEMBL3656566 & 1527607 & 7.301 & 7.2214 & TST & \\
\hline CHEMBL3660916 & 1527607 & 9.5686 & 8.9182 & TRN & \\
\hline CHEMBL3652861 & 1527607 & 6.8097 & 6.6218 & TRN & \\
\hline CHEMBL3656596 & 1527607 & 7.2676 & 7.2446 & TRN & \\
\hline CHEMBL3652858 & 1527607 & 7.4437 & 7.3408 & TRN & \\
\hline CHEMBL3660915 & 1527607 & 9.2676 & 9.1331 & TRN & \\
\hline CHEMBL3652834 & 1527607 & 6.6162 & 6.0559 & TST & \\
\hline CHEMBL3656589 & 1527607 & 5.5264 & 7.0901 & TST & \\
\hline CHEMBL3656661 & 1527607 & 8.5229 & 8.9637 & TST & \\
\hline CHEMBL3652849 & 1527607 & 9.0 & 9.1022 & TRN & \\
\hline CHEMBL3656623 & 1527607 & 9.0 & 9.1217 & TRN & \\
\hline CHEMBL 3656755 & 1527607 & 7.1549 & 7.5195 & TST & \\
\hline CHEMBL 3656648 & 1527607 & 9.1549 & 8.6309 & TST & \\
\hline CHEMBL3656668 & 1527607 & 8.5229 & 7.7662 & TRN & \\
\hline
\end{tabular}

Page 22818 
Supplemental Table S2.txt

\begin{tabular}{|c|c|c|c|c|}
\hline CHEMBL 3660944 & 1527607 & 7.585 & 7.8041 & TRN \\
\hline CHEMBL3652811 & 1527607 & 7.1367 & 7.1903 & TRN \\
\hline CHEMBL3660950 & 1527607 & 8.0969 & 8.0843 & TRN \\
\hline CHEMBL 3652837 & 1527607 & 6.5243 & 6.5436 & TRN \\
\hline CHEMBL3652812 & 1527607 & 7.6021 & 7.8014 & TRN \\
\hline CHEMBL3660974 & 1527607 & 8.5229 & 8.4524 & TRN \\
\hline CHEMBL3656703 & 1527607 & 8.1549 & 8.0531 & TRN \\
\hline CHEMBL 3656666 & 1527607 & 8.5229 & 8.5107 & TRN \\
\hline CHEMBL 3652855 & 1527607 & 6.9208 & \multicolumn{2}{|c|}{7.632000000000001} \\
\hline CHEMBL3660995 & 1527607 & 7.2676 & 7.4522 & TRN \\
\hline CHEMBL3660976 & 1527607 & 8.0969 & 8.2182 & TRN \\
\hline CHEMBL3660923 & 1527607 & 9.0 & 8.9732 & TRN \\
\hline CHEMBL 3656576 & 1527607 & 9.7212 & 9.4907 & TRN \\
\hline CHEMBL3660977 & 1527607 & 9.0 & 9.0511 & TRN \\
\hline CHEMBL3660940 & 1527607 & 8.5229 & 8.6059 & TRN \\
\hline CHEMBL3660994 & 1527607 & 7.6778 & 7.2745 & TRN \\
\hline CHEMBL3652813 & 1527607 & 7.8539 & 7.6441 & TST \\
\hline CHEMBL 3656723 & 1527607 & 7.8861 & 7.6109 & TRN \\
\hline CHEMBL3656635 & 1527607 & 9.699 & 8.8069 & TST \\
\hline CHEMBL3661013 & 1527607 & 9.0 & 9.0197 & TST \\
\hline CHEMBL3656570 & 1527607 & 7.9586 & 8.1467 & TST \\
\hline CHEMBL3656546 & 1527607 & 7.3665 & 7.3325 & TRN \\
\hline CHEMBL3656603 & 1527607 & 6.9666 & 7.2013 & TRN \\
\hline CHEMBL3660937 & 1527607 & 9.0 & 8.8788 & TRN \\
\hline CHEMBL 3652820 & 1527607 & 8.699 & 8.4537 & TRN \\
\hline CHEMBL3652857 & 1527607 & 7.9586 & 7.8587 & TRN \\
\hline CHEMBL3656736 & 1527607 & 7.7447 & 8.1632 & TST \\
\hline CHEMBL3656685 & 1527607 & 8.301 & 8.176 & TST \\
\hline CHEMBL3660896 & 1527607 & 8.0 & 7.7469 & TRN \\
\hline CHEMBL 3656617 & 1527607 & 8.699 & 8.6862 & TRN \\
\hline CHEMBL 3652852 & 1527607 & 7.9586 & 7.5313 & TRN \\
\hline CHEMBL3652841 & 1527607 & 9.0 & 8.7934 & TST \\
\hline CHEMBL3656652 & 1527607 & 9.0 & 8.9029 & TRN \\
\hline CHEMBL3660991 & 1527607 & 6.4123 & 6.2422 & TRN \\
\hline CHEMBL 3656650 & 1527607 & 9.0 & 9.208 & TRN \\
\hline CHEMBL3660979 & 1527607 & 8.5229 & 8.5629 & TRN \\
\hline CHEMBL3660911 & 1527607 & 8.301 & 7.9887 & TRN \\
\hline CHEMBL380221 & 373920 & 6.2218 & 6.2458 & TRN \\
\hline CHEMBL212209 & 373920 & 6.585 & 6.5844 & TRN \\
\hline CHEMBL378643 & 373920 & 5.4685 & 5.4645 & TRN \\
\hline CHEMBL378657 & 373920 & 5.7696 & 5.7629 & TRN \\
\hline CHEMBL209841 & 373920 & 5.0506 & 5.044 & TRN \\
\hline CHEMBL379194 & 373920 & 5.4437 & 5.5017 & TRN \\
\hline CHEMBL212271 & 373920 & 5.1612 & 5.1347 & TRN \\
\hline CHEMBL379068 & 373920 & 5.7447 & 5.7526 & TRN \\
\hline CHEMBL211794 & 373920 & 4.6021 & 5.4735 & TST \\
\hline CHEMBL209794 & 373920 & 5.6383 & 5.6356 & TRN \\
\hline CHEMBL379586 & 373920 & 5.9586 & 5.9537 & TRN \\
\hline
\end{tabular}




\begin{tabular}{|c|c|c|c|c|}
\hline \multicolumn{5}{|c|}{ Supplemental Table S2.txt } \\
\hline CHEMBL211939 & 373920 & 5.6383 & 5.6133 & TRN \\
\hline CHEMBL211549 & 373920 & 4.2518 & 4.2596 & TRN \\
\hline CHEMBL212538 & 373920 & 6.0605 & 6.068 & TRN \\
\hline CHEMBL379960 & 373920 & 5.9586 & 5.9623 & TRN \\
\hline CHEMBL212577 & 373920 & 4.9586 & 4.9585 & TRN \\
\hline CHEMBL379357 & 373920 & 5.8861 & 5.8907 & TRN \\
\hline CHEMBL210815 & 373920 & 5.6778 & 5.7168 & TRN \\
\hline CHEMBL212310 & 373920 & 5.6383 & 5.6247 & TRN \\
\hline CHEMBL210386 & 373920 & 5.8239 & 5.8305 & TRN \\
\hline CHEMBL212031 & 373920 & 6.2076 & 6.2011 & TRN \\
\hline CHEMBL211209 & 373920 & 5.0862 & 5.0803 & TRN \\
\hline CHEMBL426501 & 373920 & 4.7212 & 4.7227 & TRN \\
\hline CHEMBL379958 & 373920 & 5.3979 & 5.4076 & TRN \\
\hline CHEMBL3706847 & 373920 & 4.585 & 4.5777 & TRN \\
\hline CHEMBL3706845 & 373920 & 5.1135 & 5.1235 & TRN \\
\hline CHEMBL3706846 & 373920 & 5.4437 & 5.4423 & TRN \\
\hline CHEMBL211367 & 373920 & 4.9208 & 5.8678 & TST \\
\hline CHEMBL212014 & 373920 & 5.0969 & 5.0881 & TRN \\
\hline CHEMBL209586 & 373920 & 5.1805 & 5.1625 & TRN \\
\hline CHEMBL 377627 & 373920 & 6.4949 & 6.4942 & TRN \\
\hline CHEMBL 380220 & 373920 & 5.4437 & 5.4401 & TST \\
\hline CHEMBL107955 & 373920 & 6.3872 & 5.9964 & TST \\
\hline CHEMBL3706844 & 373920 & 4.5086 & 4.5117 & TRN \\
\hline CHEMBL209910 & 373920 & 6.0915 & 6.0609 & TST \\
\hline CHEMBL212616 & 373920 & 6.1938 & 5.808 & TST \\
\hline CHEMBL211086 & 373920 & 4.9788 & 4.9897 & TRN \\
\hline CHEMBL379957 & 373920 & 4.7447 & 5.8337 & TST \\
\hline CHEMBL377763 & 373920 & 5.9208 & 6.0502 & TST \\
\hline CHEMBL209963 & 373920 & 5.9208 & 5.6807 & TST \\
\hline CHEMBL211659 & 373920 & 5.6778 & 5.6753 & TRN \\
\hline CHEMBL208586 & 373920 & 5.6021 & 5.4572 & TST \\
\hline CHEMBL210771 & 373920 & 5.8861 & 5.8876 & TRN \\
\hline CHEMBL211401 & 373920 & 6.0862 & 6.0691 & TRN \\
\hline CHEMBL379186 & 373920 & 5.9208 & 5.6063 & TST \\
\hline CHEMBL 210244 & 373920 & 6.0862 & 6.2088 & TST \\
\hline CHEMBL378192 & 373920 & 5.9208 & 5.9089 & TRN \\
\hline CHEMBL378830 & 373920 & 5.7212 & 5.7342 & TRN \\
\hline CHEMBL438959 & 373920 & 5.3372 & 5.8351 & TST \\
\hline CHEMBL379075 & 373920 & 5.2147 & 5.2076 & TRN \\
\hline CHEMBL210189 & 373920 & 5.6576 & 5.6669 & TRN \\
\hline CHEMBL209334 & 373920 & 4.3665 & 4.3755 & TRN \\
\hline CHEMBL 211754 & 373920 & 5.7959 & 5.7943 & TST \\
\hline CHEMBL437307 & 373920 & 5.8239 & 5.7745 & TRN \\
\hline CHEMBL196782 & 474247 & 4.32 & 7.9189 & TST \\
\hline CHEMBL402897 & 474247 & 6.74 & 6.7077 & TRN \\
\hline CHEMBL255589 & 474247 & 7.3 & 7.5153 & TST \\
\hline CHEMBL 271740 & 474247 & 6.42 & 7.314 & TST \\
\hline CHEMBL257010 & 474247 & 7.85 & 7.2534 & TST \\
\hline
\end{tabular}




\begin{tabular}{|c|c|c|c|c|c|}
\hline \multicolumn{6}{|c|}{ Supplemental Table S2.txt } \\
\hline CHEMBL404311 & 474247 & 5.8 & 7.4152 & TST & \\
\hline CHEMBL257012 & 474247 & 5.96 & 7.1006 & TST & \\
\hline CHEMBL257247 & 474247 & 5.97 & 7.3521 & TST & \\
\hline CHEMBL403848 & 474247 & 5.1 & 7.2873 & TST & \\
\hline CHEMBL246678 & 474247 & 7.96 & 8.0024 & TRN & \\
\hline CHEMBL246677 & 474247 & 6.96 & 6.9753 & TRN & \\
\hline CHEMBL246676 & 474247 & 8.05 & 7.8705 & TRN & \\
\hline CHEMBL397074 & 474247 & 7.92 & 7.9595 & TRN & \\
\hline CHEMBL246057 & 474247 & 7.8 & 7.8719 & TRN & \\
\hline CHEMBL394884 & 474247 & 8.22 & 8.137 & TRN & \\
\hline CHEMBL245851 & 474247 & 8.22 & 7.9016 & TRN & \\
\hline CHEMBL555375 & 474247 & 7.66 & 7.4896 & TRN & \\
\hline CHEMBL245647 & 474247 & 7.82 & 7.7746 & TRN & \\
\hline CHEMBL246047 & 474247 & 8.1 & 8.1378 & TRN & \\
\hline CHEMBL429655 & 474247 & 8.3 & 8.0486 & TRN & \\
\hline CHEMBL247286 & 474247 & 7.41 & 7.6142 & TRN & \\
\hline CHEMBL256800 & 474247 & 7.54 & 7.5924 & TRN & \\
\hline CHEMBL404703 & 474247 & 7.33 & 7.3636 & TRN & \\
\hline CHEMBL403215 & 474247 & 7.85 & 7.8428 & TRN & \\
\hline CHEMBL407945 & 474247 & 8.3 & 8.3554 & TRN & \\
\hline CHEMBL270998 & 474247 & 6.73 & 6.6532 & TRN & \\
\hline CHEMBL269973 & 474247 & 7.36 & 7.3561 & TRN & \\
\hline CHEMBL404399 & 474247 & 7.55 & 7.7638 & TRN & \\
\hline CHEMBL257011 & 474247 & 8.22 & 8.2003 & TRN & \\
\hline CHEMBL404185 & 474247 & 8.0 & 7.9044 & TRN & \\
\hline CHEMBL429501 & 474247 & 7.46 & 7.5573 & TRN & \\
\hline CHEMBL403849 & 474247 & 7.05 & 7.1296 & TRN & \\
\hline CHEMBL272996 & 474247 & 7.39 & 7.4555 & TRN & \\
\hline CHEMBL402545 & 474247 & 7.35 & 7.3617 & TRN & \\
\hline CHEMBL270423 & 474247 & 7.41 & 7.5804 & TRN & \\
\hline CHEMBL 255144 & 474247 & 6.98 & 6.98799 & 99999999995 & TRN \\
\hline CHEMBL270185 & 474247 & 7.96 & 7.7644 & TRN & \\
\hline CHEMBL3085038 & 474247 & 7.82 & 7.9205 & TRN & \\
\hline CHEMBL376272 & 474247 & 7.6 & 7.806 & TRN & \\
\hline CHEMBL219606 & 474247 & 7.89 & 7.8812 & TRN & \\
\hline CHEMBL374409 & 474247 & 7.36 & 6.8806 & TST & \\
\hline CHEMBL216783 & 474247 & 7.01 & 6.9141 & TST & \\
\hline CHEMBL218247 & 474247 & 7.64 & 7.3422 & TST & \\
\hline CHEMBL370362 & 474247 & 8.72 & 8.6544 & TRN & \\
\hline CHEMBL198849 & 474247 & 8.38 & 8.3539 & TRN & \\
\hline CHEMBL197220 & 474247 & 8.31 & 8.4149 & TRN & \\
\hline CHEMBL426835 & 474247 & 8.39 & 8.4926 & TRN & \\
\hline CHEMBL371262 & 474247 & 7.7 & 7.5012 & TRN & \\
\hline CHEMBL403283 & 474247 & 8.33 & 8.333 & TRN & \\
\hline CHEMBL257059 & 474247 & 8.28 & 8.3626 & TRN & \\
\hline CHEMBL373257 & 474247 & 8.7 & 8.6265 & TRN & \\
\hline CHEMBL372945 & 474247 & 8.14 & 8.1668 & TRN & \\
\hline CHEMBL198690 & 474247 & 8.01 & 7.9579 & TRN & \\
\hline
\end{tabular}




\begin{tabular}{|c|c|c|c|c|c|c|}
\hline \multicolumn{7}{|c|}{ Supplemental Table S2.txt } \\
\hline CHEMBL402558 & 474247 & 7.66 & 7.6919 & TRN & & \\
\hline CHEMBL271211 & 474247 & 8.03 & 8.0511 & TRN & & \\
\hline CHEMBL373034 & 474247 & 8.07 & 8.0794 & TRN & & \\
\hline CHEMBL372851 & 474247 & 8.59 & 8.5916 & TRN & & \\
\hline CHEMBL197489 & 474247 & 8.4 & 8.4358 & TRN & & \\
\hline CHEMBL383352 & 474247 & 8.7 & 8.6793 & TRN & & \\
\hline CHEMBL402046 & 474247 & 8.3 & 8.036 & TST & & \\
\hline CHEMBL404186 & 474247 & 7.14 & 8.0156 & TST & & \\
\hline CHEMBL401923 & 474247 & 7.96 & 7.8979 & TST & & \\
\hline CHEMBL256173 & 474247 & 7.28 & 8.0325 & TST & & \\
\hline CHEMBL383820 & 474247 & 5.05 & 8.0289 & TST & & \\
\hline CHEMBL425022 & 474247 & 4.64 & 8.1588 & TST & & \\
\hline CHEMBL 3934738 & 1640410 & 8.5229 & 7.8393 & TRN & & \\
\hline CHEMBL3902089 & 1640410 & 7.1938 & 7.6129 & TRN & & \\
\hline CHEMBL 3892892 & 1640410 & 8.3979 & 8.729 & TRN & & \\
\hline CHEMBL3948141 & 1640410 & 6.0726 & 6.0983 & TRN & & \\
\hline CHEMBL3919579 & 1640410 & 7.3098 & 7.7455 & TRN & & \\
\hline CHEMBL 3948834 & 1640410 & 7.3098 & 6.8805 & TRN & & \\
\hline CHEMBL 3916883 & 1640410 & 7.9586 & 7.7195 & TRN & & \\
\hline CHEMBL3917284 & 1640410 & 7.2757 & 7.1355 & TRN & & \\
\hline CHEMBL3962445 & 1640410 & 6.9469 & 7.1355 & TRN & & \\
\hline CHEMBL3920829 & 1640410 & 8.3979 & 8.1674 & TRN & & \\
\hline CHEMBL3973022 & 1640410 & 6.9586 & 6.6852 & TRN & & \\
\hline CHEMBL 3916647 & 1640410 & 7.3565 & 7.119 & TRN & & \\
\hline CHEMBL3911373 & 1640410 & 7.2366 & 7.7094 & TST & & \\
\hline CHEMBL3896263 & 1640410 & 7.3372 & 7.9302 & TRN & & \\
\hline CHEMBL3904285 & 1640410 & 6.684 & 6.7617 & TST & & \\
\hline CHEMBL3971353 & 1640410 & 6.7721 & 6.7568 & TRN & & \\
\hline CHEMBL3959161 & 1640410 & 6.5528 & 6.6677 & TRN & & \\
\hline CHEMBL 3922740 & 1640410 & 6.7696 & 6.8805 & TRN & & \\
\hline CHEMBL 3956794 & 1640410 & 6.6289 & 6.5092 & TRN & & \\
\hline CHEMBL3949819 & 1640410 & 7.9586 & 8.0133 & TRN & & \\
\hline CHEMBL3927296 & 1640410 & 6.4425 & 6.9148 & TRN & & \\
\hline CHEMBL 3977453 & 1640410 & 6.5768 & 6.5713 & TRN & & \\
\hline CHEMBL3908581 & 1640410 & 8.699 & 8.1598 & TRN & & \\
\hline CHEMBL3961212 & 1640410 & 6.1244 & 7.0592 & TST & & \\
\hline CHEMBL 3961414 & 1640410 & 6.48600 & 00000000 & $\partial 1$ & 6.8703 & TST \\
\hline CHEMBL 3946370 & 1640410 & 6.5157 & 6.4346 & TRN & & \\
\hline CHEMBL3931692 & 1640410 & 7.5686 & 7.5519 & TRN & & \\
\hline CHEMBL3970685 & 1640410 & 8.699 & 7.6156 & TST & & \\
\hline CHEMBL3924733 & 1640410 & 7.4437 & 7.0231 & TRN & & \\
\hline CHEMBL3906824 & 1640410 & 6.4045 & 6.28700 & 0000000001 & & TRN \\
\hline CHEMBL3927081 & 1640410 & 7.3665 & 7.2289 & TRN & & \\
\hline CHEMBL 3973750 & 1640410 & 7.6778 & 7.4064 & TRN & & \\
\hline CHEMBL 3917268 & 1640410 & 6.6073 & 6.5341 & TST & & \\
\hline CHEMBL3982727 & 1640410 & 7.0655 & 6.9367 & TRN & & \\
\hline CHEMBL 3975774 & 1640410 & 8.5229 & 7.8393 & TST & & \\
\hline CHEMBL 3945192 & 1640410 & 7.041 & 7.2289 & TRN & & \\
\hline
\end{tabular}


Supplemental Table S2.txt

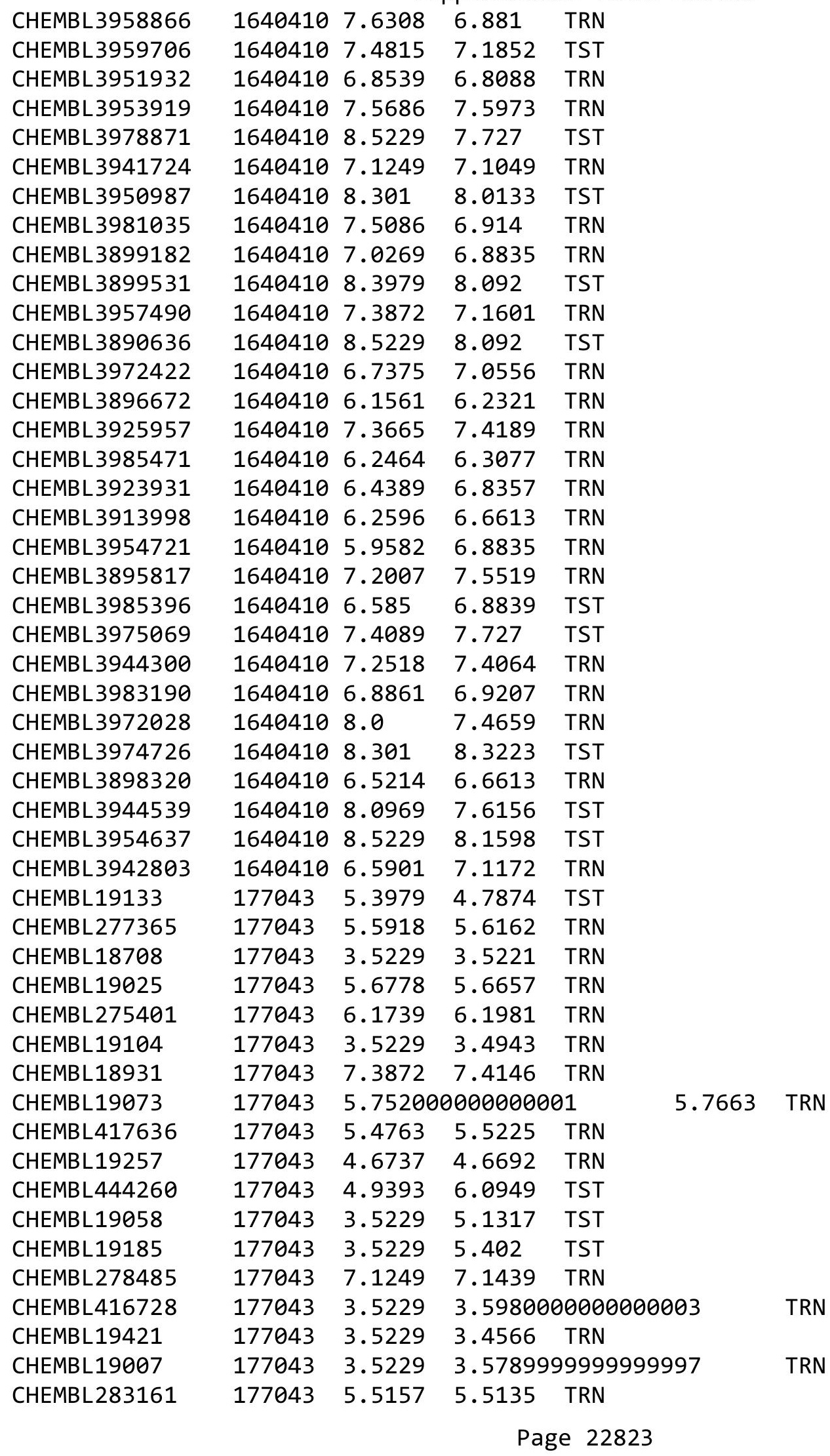




\begin{tabular}{|c|c|c|c|c|}
\hline \multirow[b]{2}{*}{ CHEMBL19122 } & \multicolumn{4}{|c|}{ Supplemental Table S2.txt } \\
\hline & 177043 & 3.5229 & 3.4662 & TRN \\
\hline CHEMBL19196 & 177043 & 4.8447 & 4.8692 & TRN \\
\hline CHEMBL18996 & 177043 & 3.5229 & 3.4745 & TRN \\
\hline CHEMBL276328 & 177043 & 6.5376 & 6.5213 & TRN \\
\hline CHEMBL19112 & 177043 & 3.5229 & 3.5538 & TRN \\
\hline CHEMBL 273362 & 177043 & 5.9666 & 6.0207 & TRN \\
\hline CHEMBL 279150 & 177043 & 6.2518 & 6.0222 & TRN \\
\hline CHEMBL18482 & 177043 & 5.0915 & 5.1695 & TRN \\
\hline CHEMBL18999 & 177043 & 3.5229 & 6.098 & TST \\
\hline CHEMBL19492 & 177043 & 4.6364 & 4.638 & TRN \\
\hline CHEMBL70996 & 177043 & 6.0315 & 3.318 & TST \\
\hline CHEMBL19169 & 177043 & 6.7212 & 5.9026 & TST \\
\hline CHEMBL1907922 & 177043 & 6.0 & 5.8523 & TRN \\
\hline CHEMBL 2062142 & 177043 & 7.0458 & 5.5436 & TST \\
\hline CHEMBL18951 & 177043 & 6.2007 & 6.2192 & TRN \\
\hline CHEMBL19245 & 177043 & 4.7545 & 5.3982 & TST \\
\hline CHEMBL18859 & 177043 & 6.4685 & 6.4463 & TRN \\
\hline CHEMBL 278694 & 177043 & 5.8996 & 5.9248 & TRN \\
\hline CHEMBL18971 & 177043 & 5.3372 & 5.3712 & TRN \\
\hline CHEMBL19200 & 177043 & 3.5229 & 3.5769 & TRN \\
\hline CHEMBL18731 & 177043 & 3.5229 & 5.7163 & TST \\
\hline CHEMBL18900 & 177043 & 5.2676 & 5.2046 & TRN \\
\hline CHEMBL18639 & 177043 & 5.7212 & 5.7282 & TRN \\
\hline CHEMBL18831 & 177043 & 3.5229 & 3.5491 & TRN \\
\hline CHEMBL282699 & 177043 & 3.5229 & 3.4957 & TRN \\
\hline CHEMBL18963 & 177043 & 3.5229 & 3.5584 & TRN \\
\hline CHEMBL19012 & 177043 & 3.5229 & 3.5499 & TRN \\
\hline CHEMBL 283724 & 177043 & 3.5229 & 3.5335 & TRN \\
\hline CHEMBL18829 & 177043 & 3.5229 & 3.4955 & TRN \\
\hline CHEMBL19192 & 177043 & 5.7352 & 5.6685 & TRN \\
\hline CHEMBL18680 & 177043 & 3.5229 & 3.5463 & TRN \\
\hline CHEMBL19253 & 177043 & 5.2182 & 5.1767 & TRN \\
\hline CHEMBL19403 & 177043 & 3.5229 & 4.8206 & TST \\
\hline CHEMBL19110 & 177043 & 6.1308 & 6.1675 & TRN \\
\hline CHEMBL 275166 & 177043 & 5.3206 & 5.2611 & TRN \\
\hline CHEMBL19198 & 177043 & 3.5229 & 3.4448 & TRN \\
\hline CHEMBL19303 & 177043 & 3.5229 & 3.5389 & TRN \\
\hline CHEMBL278535 & 177043 & 3.5229 & 3.5326 & TRN \\
\hline CHEMBL19420 & 177043 & 5.3665 & 5.3495 & TRN \\
\hline CHEMBL19088 & 177043 & 5.5528 & 5.769 & TRN \\
\hline CHEMBL18830 & 177043 & 3.5229 & 5.3518 & TST \\
\hline CHEMBL18934 & 177043 & 5.6198 & 4.8179 & TST \\
\hline CHEMBL278299 & 177043 & 4.9303 & 6.41799 & 9999999999 \\
\hline CHEMBL19089 & 177043 & 4.8633 & 5.5128 & TST \\
\hline CHEMBL279392 & 177043 & 7.5229 & 2.1015 & TST \\
\hline CHEMBL100716 & 143354 & 4.4685 & 4.4287 & TRN \\
\hline CHEMBL 328830 & 143354 & 4.6198 & 4.7775 & TRN \\
\hline CHEMBL101107 & 143354 & 4.3372 & 4.4897 & TRN \\
\hline
\end{tabular}




\begin{tabular}{|c|c|c|c|c|c|}
\hline \multicolumn{6}{|c|}{ Supplemental Table S2.txt } \\
\hline CHEMBL100766 & 143354 & 4.5528 & 4.2697 & TRN & \\
\hline CHEMBL101216 & 143354 & 3.7645 & 4.0117 & TRN & \\
\hline CHEMBL98655 & 143354 & 3.1871 & 4.247 & TST & \\
\hline CHEMBL 98437 & 143354 & 4.8861 & 4.9386 & TRN & \\
\hline CHEMBL98103 & 143354 & 4.6778 & 4.6893 & TRN & \\
\hline CHEMBL101495 & 143354 & 4.0458 & 3.8293 & TRN & \\
\hline CHEMBL100285 & 143354 & 4.3565 & 4.2604 & TRN & \\
\hline CHEMBL419723 & 143354 & 4.2218 & 4.1408 & TRN & \\
\hline CHEMBL101738 & 143354 & 4.4089 & 4.4372 & TRN & \\
\hline CHEMBL101879 & 143354 & 4.8861 & 4.9737 & TRN & \\
\hline CHEMBL430490 & 143354 & 4.5229 & 4.447 & TRN & \\
\hline CHEMBL101062 & 143354 & 5.699 & 5.6501 & TRN & \\
\hline CHEMBL 99648 & 143354 & 4.6021 & 4.6517 & TRN & \\
\hline CHEMBL101620 & 143354 & 3.7447 & 3.9921 & TRN & \\
\hline CHEMBL98001 & 143354 & 4.4949 & 4.4999 & TRN & \\
\hline CHEMBL99612 & 143354 & 4.5376 & 4.4803 & TRN & \\
\hline CHEMBL420453 & 143354 & 4.699 & 4.6898 & TRN & \\
\hline CHEMBL100930 & 143354 & 4.4685 & 4.2904 & TRN & \\
\hline CHEMBL 98632 & 143354 & 4.4202 & 4.1609 & TRN & \\
\hline CHEMBL101565 & 143354 & 5.1367 & 4.8987 & TRN & \\
\hline CHEMBL101513 & 143354 & 4.1249 & 4.0027 & TRN & \\
\hline CHEMBL99163 & 143354 & 4.3188 & 4.38 & TRN & \\
\hline CHEMBL101267 & 143354 & 4.2007 & 4.3283 & TRN & \\
\hline CHEMBL316947 & 143354 & 4.585 & 4.57600 & 00000000005 & TRN \\
\hline CHEMBL101037 & 143354 & 4.3768 & 4.313 & TRN & \\
\hline CHEMBL101450 & 143354 & 4.5229 & 4.3549 & TRN & \\
\hline CHEMBL451487 & 143354 & 4.2218 & 4.1801 & TRN & \\
\hline CHEMBL100658 & 143354 & 4.3979 & 4.4533 & TRN & \\
\hline CHEMBL102100 & 143354 & 5.0969 & 5.0777 & TRN & \\
\hline CHEMBL99500 & 143354 & 4.5229 & 4.8412 & TST & \\
\hline CHEMBL318427 & 143354 & 5.0458 & 5.0386 & TRN & \\
\hline CHEMBL 317940 & 143354 & 3.8386 & 3.7657 & TRN & \\
\hline CHEMBL101104 & 143354 & 4.3768 & 4.5391 & TRN & \\
\hline CHEMBL101885 & 143354 & 4.3979 & 4.3166 & TST & \\
\hline CHEMBL319369 & 143354 & 3.8539 & 4.1202 & TRN & \\
\hline CHEMBL100659 & 143354 & 5.3979 & 5.4723 & TRN & \\
\hline CHEMBL98630 & 143354 & 4.5229 & 4.3038 & TRN & \\
\hline CHEMBL101541 & 143354 & 3.7447 & 4.0389 & TST & \\
\hline CHEMBL101494 & 143354 & 4.0915 & 4.4429 & TRN & \\
\hline CHEMBL318704 & 143354 & 4.0555 & 4.1583 & TRN & \\
\hline CHEMBL316837 & 143354 & 4.3565 & 4.3291 & TRN & \\
\hline CHEMBL101399 & 143354 & 5.5229 & 5.4457 & TRN & \\
\hline CHEMBL319722 & 143354 & 5.0969 & 5.0546 & TRN & \\
\hline CHEMBL 98577 & 143354 & 4.0862 & 4.3732 & TRN & \\
\hline CHEMBL98051 & 143354 & 3.8861 & 3.9844 & TRN & \\
\hline CHEMBL321741 & 143354 & 4.7959 & 4.6408 & TST & \\
\hline CHEMBL100113 & 143354 & 4.301 & 4.2885 & TRN & \\
\hline CHEMBL101598 & 143354 & 4.0269 & 4.3189 & TST & \\
\hline
\end{tabular}




\begin{tabular}{|c|c|c|c|c|c|}
\hline & & & & & \\
\hline CHEMBL98259 & 143354 & 5.0969 & 5.0488 & TRN & \\
\hline CHEMBL102099 & 143354 & 4.9586 & 4.9581 & TRN & \\
\hline CHEMBL101405 & 143354 & 4.5229 & 4.4113 & TRN & \\
\hline CHEMBL102198 & 143354 & 3.7212 & 4.1581 & TST & \\
\hline CHEMBL317367 & 143354 & 3.9031 & 4.1559 & TST & \\
\hline CHEMBL328636 & 143354 & 3.5229 & 4.1731 & TST & \\
\hline CHEMBL98741 & 143354 & 5.2218 & 4.7917 & TST & \\
\hline CHEMBL98547 & 143354 & 5.301 & 5.29799 & 9999999999 & TST \\
\hline CHEMBL99497 & 143354 & 3.7167 & 4.5047 & TST & \\
\hline CHEMBL327287 & 143354 & 5.2218 & 4.9879 & TST & \\
\hline CHEMBL101527 & 143354 & 4.3768 & 4.5315 & TST & \\
\hline CHEMBL98102 & 143354 & 5.0969 & 4.367 & TST & \\
\hline CHEMBL100932 & 143354 & 4.1308 & 4.3711 & TST & \\
\hline CHEMBL100785 & 143354 & 4.3979 & 4.4733 & TST & \\
\hline CHEMBL2314671 & 936908 & 3.0 & 3.7511 & TRN & \\
\hline CHEMBL 2314668 & 936908 & 4.2076 & 4.0026 & TST & \\
\hline CHEMBL2314669 & 936908 & 3.0 & 3.6978 & TRN & \\
\hline CHEMBL1199826 & 936908 & 4.7305 & 4.0877 & TRN & \\
\hline CHEMBL2314885 & 936908 & 3.0 & 4.2818 & TRN & \\
\hline CHEMBL2314884 & 936908 & 3.0 & 3.9537 & TRN & \\
\hline CHEMBL2314902 & 936908 & 6.0915 & 5.6626 & TST & \\
\hline CHEMBL2314909 & 936908 & 4.8697 & 4.0802 & TRN & \\
\hline CHEMBL 2314900 & 936908 & 5.8861 & 5.5111 & TRN & \\
\hline CHEMBL1165622 & 936908 & 4.8996 & 5.4115 & TRN & \\
\hline CHEMBL2314904 & 936908 & 4.3605 & 4.0797 & TRN & \\
\hline CHEMBL2314898 & 936908 & 5.3665 & 5.6221 & TRN & \\
\hline CHEMBL1593867 & 936908 & 4.2676 & 3.7967 & TST & \\
\hline CHEMBL2314895 & 936908 & 5.5686 & 5.5513 & TRN & \\
\hline CHEMBL1199532 & 936908 & 4.5622 & 3.9025 & TRN & \\
\hline CHEMBL1164796 & 936908 & 5.3979 & 5.3633 & TRN & \\
\hline CHEMBL2314888 & 936908 & 4.4647 & 4.3458 & TRN & \\
\hline CHEMBL2314906 & 936908 & 4.6596 & 4.1312 & TRN & \\
\hline CHEMBL1164886 & 936908 & 5.301 & 5.4815 & TRN & \\
\hline CHEMBL2314666 & 936908 & 4.5918 & 4.0916 & TRN & \\
\hline CHEMBL1199533 & 936908 & 3.0 & 3.985 & TRN & \\
\hline CHEMBL1200104 & 936908 & 4.6615 & 3.9923 & TRN & \\
\hline CHEMBL2314886 & 936908 & 4.4584 & 4.0756 & TRN & \\
\hline CHEMBL 2314670 & 936908 & 3.0 & 4.0524 & TRN & \\
\hline CHEMBL2314892 & 936908 & 5.4949 & 5.582006 & 0000000001 & TRN \\
\hline CHEMBL 2314667 & 936908 & 4.6676 & 4.0897 & TRN & \\
\hline CHEMBL1165565 & 936908 & 5.699 & 5.3318 & TRN & \\
\hline CHEMBL2314672 & 936908 & 3.0 & 4.1036 & TRN & \\
\hline CHEMBL2314901 & 936908 & 5.6021 & 5.359 & TST & \\
\hline CHEMBL 2314896 & 936908 & 6.0655 & 5.3209 & TST & \\
\hline CHEMBL2314907 & 936908 & 3.0 & 3.7424 & TRN & \\
\hline CHEMBL 2314891 & 936908 & 5.5376 & 5.3508 & TST & \\
\hline CHEMBL1178003 & 936908 & 4.3716 & 4.041 & TRN & \\
\hline CHEMBL2314903 & 936908 & 5.699 & 5.3463 & TST & \\
\hline
\end{tabular}




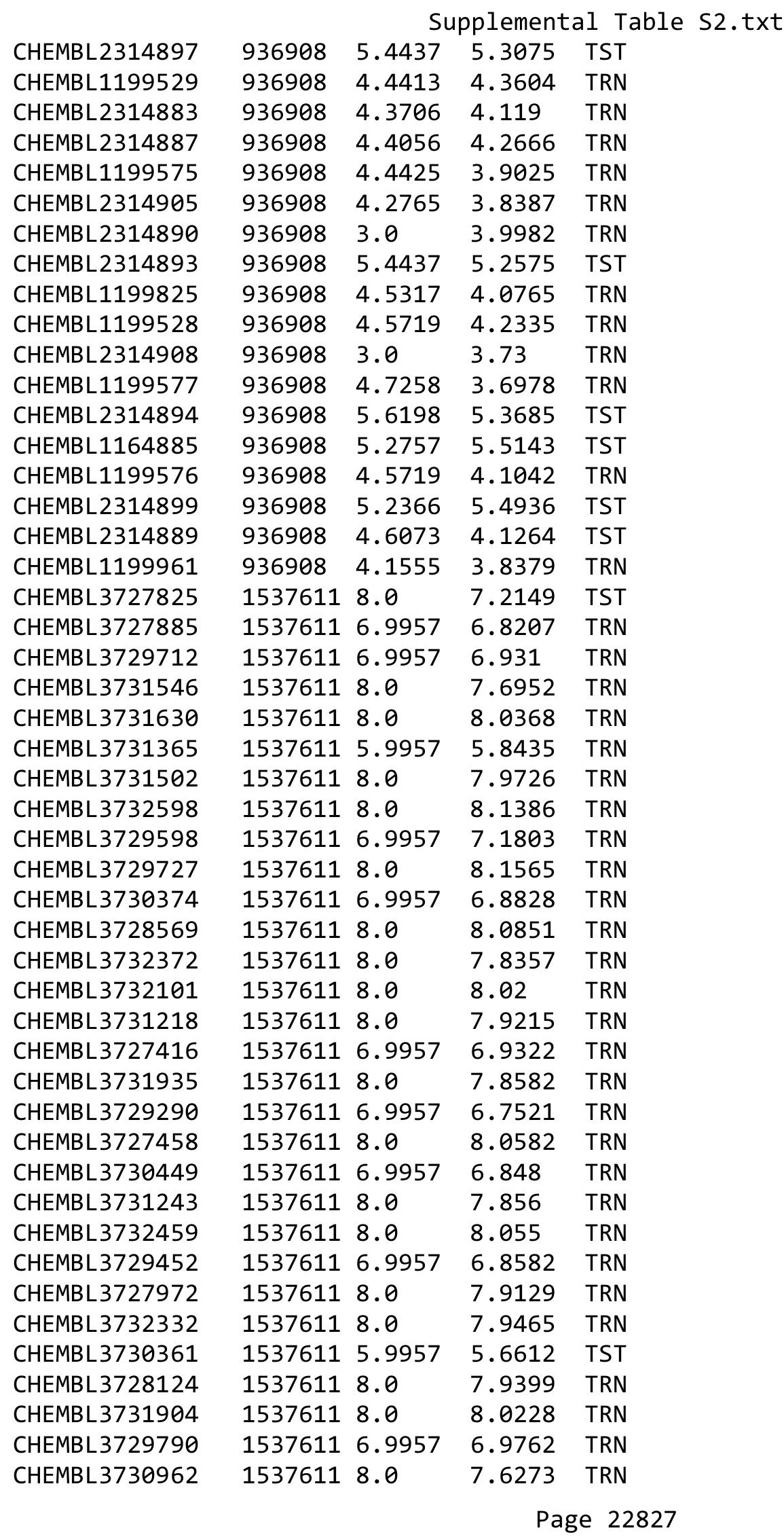


Supplemental Table S2.txt

\begin{tabular}{|c|c|c|c|c|c|}
\hline CHEMBL3729496 & 1537611 & 8.0 & 8.1853 & TRN & \\
\hline CHEMBL3732176 & 1537611 & 8.0 & 8.0565 & TRN & \\
\hline CHEMBL3731909 & 1537611 & 8.0 & 8.1075 & TRN & \\
\hline CHEMBL 3729744 & 1537611 & 8.0 & 7.7358 & TRN & \\
\hline CHEMBL3731412 & 1537611 & 3.9996 & 4.1271 & TRN & \\
\hline CHEMBL3731856 & 1537611 & 8.0 & 8.0054 & TRN & \\
\hline CHEMBL3728269 & 1537611 & 8.0 & 8.0149 & TRN & \\
\hline CHEMBL3729924 & 1537611 & 3.9996 & 4.3833 & TRN & \\
\hline CHEMBL 3729454 & 1537611 & 8.0 & 8.0247 & TRN & \\
\hline CHEMBL3732710 & 1537611 & 8.0 & 8.1393 & TRN & \\
\hline CHEMBL3733226 & 1537611 & 8.0 & 8.1325 & TRN & \\
\hline CHEMBL 3728823 & 1537611 & 8.0 & 8.1864 & TRN & \\
\hline CHEMBL3732873 & 1537611 & 5.9957 & 6.1638 & TST & \\
\hline CHEMBL 3728568 & 1537611 & 6.9957 & 7.0117 & TRN & \\
\hline CHEMBL3727939 & 1537611 & 6.9957 & 6.1883 & TRN & \\
\hline CHEMBL3732466 & 1537611 & 5.9957 & 7.6747 & TRN & \\
\hline CHEMBL3730421 & 1537611 & 6.9957 & 6.6619 & TST & \\
\hline CHEMBL 3732133 & 1537611 & 8.0 & 8.1072 & TRN & \\
\hline CHEMBL 3732746 & 1537611 & 8.0 & 7.9443 & TRN & \\
\hline CHEMBL3731126 & 1537611 & 6.9957 & 6.8378 & TRN & \\
\hline CHEMBL3730795 & 1537611 & 8.0 & 7.972 & TRN & \\
\hline CHEMBL3730127 & 1537611 & 6.9957 & 6.8533 & TRN & \\
\hline CHEMBL3731819 & 1537611 & 6.9957 & 7.2315 & TRN & \\
\hline CHEMBL 3728233 & 1537611 & 8.0 & 8.0767 & TRN & \\
\hline CHEMBL 3729745 & 1537611 & 6.9957 & 7.5543 & TRN & \\
\hline CHEMBL3732816 & 1537611 & 3.9996 & 4.5451 & TST & \\
\hline CHEMBL 3729403 & 1537611 & 8.0 & 7.7423 & TRN & \\
\hline CHEMBL 3728355 & 1537611 & 8.0 & 8.0919 & TRN & \\
\hline CHEMBL 3731425 & 1537611 & 6.9957 & 6.843 & TRN & \\
\hline CHEMBL 3730232 & 1537611 & 8.0 & 7.7415 & TRN & \\
\hline CHEMBL 3731821 & 1537611 & 8.0 & 7.749 & TRN & \\
\hline CHEMBL 3729200 & 1537611 & 6.9957 & 7.3155 & TRN & \\
\hline CHEMBL3729439 & 1537611 & 8.0 & 7.9416 & TST & \\
\hline CHEMBL3729395 & 1537611 & 8.0 & 7.1829 & TRN & \\
\hline CHEMBL 3728076 & 1537611 & 6.9957 & 7.0066 & TRN & \\
\hline CHEMBL 3732451 & 1537611 & 6.9957 & 7.305 & TRN & \\
\hline CHEMBL3732435 & 1537611 & 8.0 & 8.1372 & TRN & \\
\hline CHEMBL 3727855 & 1537611 & 8.0 & \multicolumn{2}{|c|}{7.837999999999999} & TRN \\
\hline CHEMBL3730439 & 1537611 & 5.9957 & 5.4523 & TRN & \\
\hline CHEMBL3728358 & 1537611 & 5.9957 & 6.3567 & TST & \\
\hline CHEMBL3731920 & 1537611 & 6.9957 & 7.1562 & TRN & \\
\hline CHEMBL3730038 & 1537611 & 6.9957 & 7.6712 & TRN & \\
\hline CHEMBL3727804 & 1537611 & 8.0 & 7.9628 & TRN & \\
\hline CHEMBL 3730101 & 1537611 & 8.0 & 7.9812 & TRN & \\
\hline CHEMBL 3730284 & 1537611 & 8.0 & 8.1447 & TRN & \\
\hline CHEMBL 3727743 & 1537611 & 8.0 & \multicolumn{2}{|c|}{6.8420000000000005} & TRN \\
\hline CHEMBL3729357 & 1537611 & 5.9957 & 6.1405 & TRN & \\
\hline CHEMBL3731301 & 1537611 & 6.9957 & 7.0959 & TRN & \\
\hline
\end{tabular}

Page 22828 
Supplemental Table S2.txt

\begin{tabular}{|c|c|c|c|c|c|}
\hline CHEMBL 3727787 & 1537611 & 6.9957 & 6.9955 & TRN & \\
\hline CHEMBL3733146 & 1537611 & 6.9957 & 6.3027 & TRN & \\
\hline CHEMBL3728609 & 1537611 & 8.0 & 7.9923 & TRN & \\
\hline CHEMBL3730039 & 1537611 & 8.0 & 8.0674 & TRN & \\
\hline CHEMBL3727915 & 1537611 & 8.0 & 8.0309 & TRN & \\
\hline CHEMBL3729685 & 1537611 & 8.0 & 8.0907 & TRN & \\
\hline CHEMBL3729049 & 1537611 & 8.0 & 7.9403 & TRN & \\
\hline CHEMBL3730083 & 1537611 & 8.0 & 8.0276 & TRN & \\
\hline CHEMBL3731897 & 1537611 & 8.0 & 7.966 & TRN & \\
\hline CHEMBL3730320 & 1537611 & 6.9957 & 7.9925 & TST & \\
\hline CHEMBL3733174 & 1537611 & 8.0 & 7.9746 & TRN & \\
\hline CHEMBL3728828 & 1537611 & 8.0 & 7.9562 & TRN & \\
\hline CHEMBL3729450 & 1537611 & 8.0 & 8.2044 & TST & \\
\hline CHEMBL3727585 & 1537611 & 6.9957 & 6.7046 & TRN & \\
\hline CHEMBL3731834 & 1537611 & 8.0 & 7.9429 & TRN & \\
\hline CHEMBL3728537 & 1537611 & 6.9957 & 6.2593 & TST & \\
\hline CHEMBL3728388 & 1537611 & 8.0 & 8.076 & TRN & \\
\hline CHEMBL3731923 & 1537611 & 8.0 & 8.0626 & TRN & \\
\hline CHEMBL3727945 & 1537611 & 8.0 & 7.9444 & TRN & \\
\hline CHEMBL3730486 & 1537611 & 3.9996 & 3.998 & TST & \\
\hline CHEMBL3728730 & 1537611 & 8.0 & 8.1518 & TST & \\
\hline CHEMBL3727658 & 1537611 & 8.0 & 8.1232 & TRN & \\
\hline CHEMBL3728183 & 1537611 & 8.0 & 7.1575 & TRN & \\
\hline CHEMBL3729860 & 1537611 & 8.0 & 7.818 & TRN & \\
\hline CHEMBL3729684 & 1537611 & 8.0 & 8.1918 & TST & \\
\hline CHEMBL3729037 & 1537611 & 8.0 & 8.0284 & TRN & \\
\hline CHEMBL3727977 & 1537611 & 8.0 & \multicolumn{2}{|c|}{7.917000000000001} & TRN \\
\hline CHEMBL 3727540 & 1537611 & 3.9996 & 5.9051 & TRN & \\
\hline CHEMBL 3731188 & 1537611 & 8.0 & 8.215 & TRN & \\
\hline CHEMBL3731762 & 1537611 & 6.9957 & 7.2603 & TST & \\
\hline CHEMBL3730769 & 1537611 & 8.0 & 7.64 & TRN & \\
\hline CHEMBL 3730648 & 1537611 & 6.9957 & 6.8706 & TRN & \\
\hline CHEMBL3729041 & 1537611 & 8.0 & 8.1366 & TRN & \\
\hline CHEMBL 3728465 & 1537611 & 8.0 & 8.1819 & TRN & \\
\hline CHEMBL3732921 & 1537611 & 5.9957 & 5.7235 & TRN & \\
\hline CHEMBL3732790 & 1537611 & 6.9957 & 6.8973 & TRN & \\
\hline CHEMBL3730617 & 1537611 & 6.9957 & 6.8327 & TRN & \\
\hline CHEMBL3728929 & 1537611 & 6.9957 & 7.3625 & TRN & \\
\hline CHEMBL3730171 & 1537611 & 8.0 & 8.06 & TRN & \\
\hline CHEMBL3727452 & 1537611 & 8.0 & 8.0457 & TRN & \\
\hline CHEMBL3732129 & 1537611 & 6.9957 & 6.7317 & TRN & \\
\hline CHEMBL3730448 & 1537611 & 5.9957 & 5.1811 & TRN & \\
\hline CHEMBL3728608 & 1537611 & 8.0 & 7.9418 & TRN & \\
\hline CHEMBL3732065 & 1537611 & 8.0 & 7.9444 & TRN & \\
\hline CHEMBL3730830 & 1537611 & 6.9957 & 7.0329 & TRN & \\
\hline CHEMBL3728399 & 1537611 & 6.9957 & 7.468 & TST & \\
\hline CHEMBL3731496 & 1537611 & 8.0 & 7.398 & TST & \\
\hline CHEMBL3731350 & 1537611 & 3.9996 & 5.8654 & TRN & \\
\hline
\end{tabular}


Supplemental Table S2.txt

\begin{tabular}{|c|c|c|c|c|}
\hline CHEMBL 3729298 & 1537611 & 6.9957 & 6.7658 & TST \\
\hline CHEMBL3727986 & 1537611 & 5.9957 & 6.397 & TST \\
\hline CHEMBL3729310 & 1537611 & 6.9957 & 6.8131 & TRN \\
\hline CHEMBL 3733027 & 1537611 & 8.0 & 7.9177 & TRN \\
\hline CHEMBL3727803 & 1537611 & 8.0 & 8.1774 & TRN \\
\hline CHEMBL3728469 & 1537611 & 8.0 & 8.1111 & TRN \\
\hline CHEMBL3729954 & 1537611 & 6.9957 & 6.8792 & TRN \\
\hline CHEMBL 3732561 & 1537611 & 8.0 & 8.0839 & TRN \\
\hline CHEMBL 3728572 & 1537611 & 6.9957 & 7.0764 & TRN \\
\hline CHEMBL3728225 & 1537611 & 6.9957 & 7.8091 & TST \\
\hline CHEMBL3732776 & 1537611 & 8.0 & 7.9813 & TRN \\
\hline CHEMBL3729994 & 1537611 & 8.0 & 7.9247 & TRN \\
\hline CHEMBL3732573 & 1537611 & 8.0 & 8.109 & TRN \\
\hline CHEMBL3729895 & 1537611 & 5.9957 & 4.9775 & TRN \\
\hline CHEMBL3731540 & 1537611 & 8.0 & 7.7818 & TRN \\
\hline CHEMBL3729477 & 1537611 & 3.9996 & 4.0592 & TRN \\
\hline CHEMBL3733159 & 1537611 & 5.9957 & 5.319 & TST \\
\hline CHEMBL3730556 & 1537611 & 3.9996 & 3.9498 & TRN \\
\hline CHEMBL3730243 & 1537611 & 6.9957 & 6.7024 & TRN \\
\hline CHEMBL3728648 & 1537611 & 8.0 & 7.9509 & TRN \\
\hline CHEMBL3733188 & 1537611 & 8.0 & 8.1253 & TST \\
\hline CHEMBL3731941 & 1537611 & 6.9957 & 6.5197 & TRN \\
\hline CHEMBL 3729180 & 1537611 & 6.9957 & 6.6372 & TST \\
\hline CHEMBL3728461 & 1537611 & 6.9957 & 6.8048 & TRN \\
\hline CHEMBL3731974 & 1537611 & 8.0 & 7.9618 & TRN \\
\hline CHEMBL3733139 & 1537611 & 6.9957 & 7.0353 & TST \\
\hline CHEMBL3732269 & 1537611 & 8.0 & 8.0831 & TRN \\
\hline CHEMBL 3730137 & 1537611 & 6.9957 & 6.9909 & TRN \\
\hline CHEMBL3730290 & 1537611 & 8.0 & 8.0192 & TRN \\
\hline CHEMBL3730256 & 1537611 & 5.9957 & 5.4882 & TST \\
\hline CHEMBL 3728841 & 1537611 & 8.0 & 7.8847 & TRN \\
\hline CHEMBL3728151 & 1537611 & 8.0 & 8.0186 & TRN \\
\hline CHEMBL3730979 & 1537611 & 5.9957 & 5.82299 & \\
\hline CHEMBL3732321 & 1537611 & 5.9957 & 6.1981 & TRN \\
\hline CHEMBL3731187 & 1537611 & 8.0 & 7.7984 & TRN \\
\hline CHEMBL3729723 & 1537611 & 8.0 & 7.9384 & TRN \\
\hline CHEMBL3730613 & 1537611 & 8.0 & 7.8933 & TRN \\
\hline CHEMBL 3732174 & 1537611 & 8.0 & 7.0349 & TRN \\
\hline CHEMBL3732713 & 1537611 & 6.9957 & 7.2109 & TRN \\
\hline CHEMBL3733161 & 1537611 & 8.0 & 7.9634 & TRN \\
\hline CHEMBL3730546 & 1537611 & 8.0 & 7.846 & TRN \\
\hline CHEMBL3727633 & 1537611 & 8.0 & 7.8363 & TRN \\
\hline CHEMBL3728835 & 1537611 & 6.9957 & 7.1136 & TRN \\
\hline CHEMBL3728131 & 1537611 & 8.0 & 7.9873 & TRN \\
\hline CHEMBL3731420 & 1537611 & 8.0 & 8.0337 & TRN \\
\hline CHEMBL3730713 & 1537611 & 3.9996 & 5.8668 & TRN \\
\hline CHEMBL3728504 & 1537611 & 6.9957 & 7.7768 & TRN \\
\hline CHEMBL3733100 & 1537611 & 6.9957 & 7.1091 & TST \\
\hline
\end{tabular}

Page 22830 


\begin{tabular}{|c|c|c|c|c|c|}
\hline \multicolumn{6}{|c|}{ Supplemental Table S2.txt } \\
\hline CHEMBL 3732980 & 1537611 & 8.0 & 8.2134 & TRN & \\
\hline CHEMBL 3732200 & 1537611 & 3.9996 & 4.4815 & TRN & \\
\hline CHEMBL3732582 & 1537611 & 5.9957 & 5.6064 & TRN & \\
\hline CHEMBL 3728532 & 1537611 & 8.0 & 8.2197 & TRN & \\
\hline CHEMBL3731747 & 1537611 & 8.0 & 8.0181 & TRN & \\
\hline CHEMBL 3730708 & 1537611 & 8.0 & 7.9815 & TRN & \\
\hline CHEMBL 3730200 & 1537611 & 6.9957 & 7.0035 & TRN & \\
\hline CHEMBL3729784 & 1537611 & 5.9957 & 5.9353 & TST & \\
\hline CHEMBL 3730288 & 1537611 & 8.0 & 8.2763 & TST & \\
\hline CHEMBL3729570 & 1537611 & 8.0 & 8.1536 & TRN & \\
\hline CHEMBL 3731238 & 1537611 & 6.9957 & 6.8474 & TRN & \\
\hline CHEMBL 3731627 & 1537611 & 6.9957 & 6.85 & TRN & \\
\hline CHEMBL3731601 & 1537611 & 6.9957 & 7.1274 & TRN & \\
\hline CHEMBL3727837 & 1537611 & 8.0 & 8.0298 & TRN & \\
\hline CHEMBL3732452 & 1537611 & 6.9957 & 7.0567 & TRN & \\
\hline CHEMBL3732299 & 1537611 & 8.0 & 8.1034 & TRN & \\
\hline CHEMBL3731650 & 1537611 & 6.9957 & 5.8447 & TRN & \\
\hline CHEMBL3731482 & 1537611 & 8.0 & 7.9849 & TRN & \\
\hline CHEMBL3727819 & 1537611 & 6.9957 & 6.3196 & TST & \\
\hline CHEMBL3729064 & 1537611 & 8.0 & 7.7802 & TRN & \\
\hline CHEMBL3732399 & 1537611 & 8.0 & 7.7516 & TRN & \\
\hline CHEMBL 3729782 & 1537611 & 5.9957 & 5.8786 & TRN & \\
\hline CHEMBL 3728780 & 1537611 & 8.0 & 7.8177 & TRN & \\
\hline CHEMBL3731645 & 1537611 & 8.0 & 7.9847 & TRN & \\
\hline CHEMBL 3728514 & 1537611 & 8.0 & 7.7364 & TRN & \\
\hline CHEMBL 3733328 & 1537611 & 6.9957 & 6.9968 & TRN & \\
\hline CHEMBL 3732587 & 1537611 & 8.0 & 7.66100 & 00000000005 & TRN \\
\hline CHEMBL3729797 & 1537611 & 6.9957 & 7.9865 & TST & \\
\hline CHEMBL3732662 & 1537611 & 8.0 & 7.9424 & TRN & \\
\hline CHEMBL 3729025 & 1537611 & 8.0 & 7.9751 & TRN & \\
\hline CHEMBL 3727727 & 1537611 & 3.9996 & 5.8691 & TRN & \\
\hline CHEMBL3731643 & 1537611 & 8.0 & 7.9968 & TRN & \\
\hline CHEMBL 3729848 & 1537611 & 8.0 & 8.0933 & TRN & \\
\hline CHEMBL3729906 & 1537611 & 8.0 & 7.8346 & TRN & \\
\hline CHEMBL3730709 & 1537611 & 8.0 & 7.4347 & TST & \\
\hline CHEMBL3731329 & 1537611 & 5.9957 & 5.95200 & $\partial 000000001$ & TST \\
\hline CHEMBL3729808 & 1537611 & 8.0 & 8.0127 & TRN & \\
\hline CHEMBL 3732251 & 1537611 & 8.0 & 7.9626 & TRN & \\
\hline CHEMBL3728064 & 1537611 & 6.9957 & 7.0418 & TRN & \\
\hline CHEMBL3730459 & 1537611 & 5.9957 & 5.7132 & TST & \\
\hline CHEMBL3732233 & 1537611 & 5.9957 & 5.9627 & TRN & \\
\hline CHEMBL3731500 & 1537611 & 5.9957 & 5.6362 & TST & \\
\hline CHEMBL3732664 & 1537611 & 5.9957 & 5.2728 & TST & \\
\hline CHEMBL3733113 & 1537611 & 8.0 & 7.82100 & 0000000001 & TRN \\
\hline CHEMBL3729011 & 1537611 & 8.0 & 7.9968 & TRN & \\
\hline CHEMBL3732143 & 1537611 & 8.0 & 8.1923 & TRN & \\
\hline CHEMBL3729081 & 1537611 & 8.0 & 7.8451 & TRN & \\
\hline CHEMBL3731556 & 1537611 & 6.9957 & 6.6841 & TRN & \\
\hline
\end{tabular}


Supplemental Table S2.txt

\begin{tabular}{|c|c|c|c|c|c|}
\hline CHEMBL3732905 & 1537611 & 6.9957 & 7.1971 & TRN & \\
\hline CHEMBL3733115 & 1537611 & 8.0 & 8.0597 & TRN & \\
\hline CHEMBL3733360 & 1537611 & 8.0 & 8.0567 & TRN & \\
\hline CHEMBL 3732830 & 1537611 & 8.0 & \multicolumn{2}{|c|}{7.5520000000000005} & TRN \\
\hline CHEMBL3729836 & 1537611 & 8.0 & 7.9461 & TRN & \\
\hline CHEMBL 3730872 & 1537611 & 6.9957 & 6.9625 & TRN & \\
\hline CHEMBL3730602 & 1537611 & 6.9957 & 6.3898 & TST & \\
\hline CHEMBL 3732340 & 1537611 & 8.0 & 8.0339 & TRN & \\
\hline CHEMBL 3732867 & 1537611 & 8.0 & 8.0169 & TRN & \\
\hline CHEMBL3727693 & 1537611 & 8.0 & 6.9602 & TRN & \\
\hline CHEMBL 3732480 & 1537611 & 5.9957 & 6.2752 & TRN & \\
\hline CHEMBL3729188 & 1537611 & 6.9957 & 6.8097 & TRN & \\
\hline CHEMBL3731224 & 1537611 & 8.0 & 8.0975 & TRN & \\
\hline CHEMBL3729679 & 1537611 & 6.9957 & 7.1838 & TRN & \\
\hline CHEMBL3732526 & 1537611 & 8.0 & 8.0213 & TRN & \\
\hline CHEMBL3732969 & 1537611 & 8.0 & 7.8009 & TRN & \\
\hline CHEMBL3732749 & 1537611 & 8.0 & 8.0988 & TST & \\
\hline CHEMBL3731144 & 1537611 & 8.0 & 7.8319 & TRN & \\
\hline CHEMBL3728118 & 1537611 & 6.9957 & 7.4136 & TRN & \\
\hline CHEMBL3729074 & 1537611 & 6.9957 & 6.6383 & TST & \\
\hline CHEMBL3729689 & 1537611 & 8.0 & 8.0325 & TRN & \\
\hline CHEMBL3728052 & 1537611 & 8.0 & 8.0934 & TRN & \\
\hline CHEMBL3730879 & 1537611 & 5.9957 & 5.557 & TST & \\
\hline CHEMBL 3730000 & 1537611 & 8.0 & 7.0793 & TRN & \\
\hline CHEMBL 3732458 & 1537611 & 6.9957 & 7.1621 & TRN & \\
\hline CHEMBL3731444 & 1537611 & 6.9957 & 7.1141 & TRN & \\
\hline CHEMBL 3733291 & 1537611 & 8.0 & 7.9616 & TRN & \\
\hline CHEMBL3732520 & 1537611 & 6.9957 & 7.1577 & TRN & \\
\hline CHEMBL 3729317 & 1537611 & 5.9957 & 6.3838 & TST & \\
\hline CHEMBL 3729444 & 1537611 & 6.9957 & 6.9147 & TRN & \\
\hline CHEMBL3731801 & 1537611 & 6.9957 & 7.8894 & TRN & \\
\hline CHEMBL3732691 & 1537611 & 3.9996 & 3.9866 & TST & \\
\hline CHEMBL3728339 & 1537611 & 8.0 & 8.0986 & TRN & \\
\hline CHEMBL 3731824 & 1537611 & 6.9957 & 7.0446 & TRN & \\
\hline CHEMBL3731863 & 1537611 & 8.0 & 8.1508 & TRN & \\
\hline CHEMBL3732693 & 1537611 & 8.0 & 8.0022 & TRN & \\
\hline CHEMBL3729915 & 1537611 & 3.9996 & 4.13 & TST & \\
\hline CHEMBL3731497 & 1537611 & 6.9957 & 7.8377 & TRN & \\
\hline CHEMBL 3727867 & 1537611 & 8.0 & 7.97 & TRN & \\
\hline CHEMBL3730249 & 1537611 & 8.0 & 8.0848 & TRN & \\
\hline CHEMBL3733140 & 1537611 & 8.0 & 7.9266 & TRN & \\
\hline CHEMBL 3727870 & 1537611 & 8.0 & 7.8121 & TRN & \\
\hline CHEMBL3729336 & 1537611 & 8.0 & 7.7587 & TRN & \\
\hline CHEMBL 3728243 & 1537611 & 8.0 & 7.8548 & TRN & \\
\hline CHEMBL3729893 & 1537611 & 8.0 & 8.149 & TRN & \\
\hline CHEMBL3729795 & 1537611 & 5.9957 & 5.9852 & TST & \\
\hline CHEMBL3731625 & 1537611 & 5.9957 & 6.4247 & TRN & \\
\hline CHEMBL 3730068 & 1537611 & 6.9957 & 7.2048 & TRN & \\
\hline
\end{tabular}

Page 22832 


\begin{tabular}{|c|c|c|c|c|c|}
\hline \multicolumn{6}{|c|}{ Supplemental Table S2.txt } \\
\hline CHEMBL3730388 & 1537611 & 8.0 & 7.9736 & TRN & \\
\hline CHEMBL3731459 & 1537611 & 5.9957 & 5.95799 & 9999999999 & TRN \\
\hline CHEMBL3728057 & 1537611 & 6.9957 & 7.2817 & TRN & \\
\hline CHEMBL3731675 & 1537611 & 8.0 & 8.09100 & 0000000001 & TRN \\
\hline CHEMBL3727799 & 1537611 & 5.9957 & 5.8747 & TRN & \\
\hline CHEMBL 3729506 & 1537611 & 8.0 & 7.8134 & TRN & \\
\hline CHEMBL 3732412 & 1537611 & 8.0 & 8.0877 & TRN & \\
\hline CHEMBL 3727380 & 1537611 & 8.0 & 7.8464 & TRN & \\
\hline CHEMBL 3733227 & 1537611 & 8.0 & 7.6057 & TRN & \\
\hline CHEMBL3730733 & 1537611 & 5.9957 & 6.2357 & TRN & \\
\hline CHEMBL3728331 & 1537611 & 8.0 & 7.3287 & TST & \\
\hline CHEMBL3732933 & 1537611 & 3.9996 & 5.4482 & TST & \\
\hline CHEMBL3728102 & 1537611 & 6.9957 & 7.1106 & TST & \\
\hline CHEMBL3732950 & 1537611 & 3.9996 & 3.7999 & TST & \\
\hline CHEMBL3733007 & 1537611 & 8.0 & 7.8264 & TRN & \\
\hline CHEMBL3730678 & 1537611 & 8.0 & 7.6413 & TRN & \\
\hline CHEMBL3728691 & 1537611 & 8.0 & 8.0841 & TRN & \\
\hline CHEMBL3730300 & 1537611 & 3.9996 & 5.6468 & TRN & \\
\hline CHEMBL3731479 & 1537611 & 6.9957 & 6.3925 & TRN & \\
\hline CHEMBL3730681 & 1537611 & 6.9957 & 7.0446 & TRN & \\
\hline CHEMBL3727953 & 1537611 & 5.9957 & 5.6479 & TRN & \\
\hline CHEMBL 3727429 & 1537611 & 8.0 & 7.8545 & TRN & \\
\hline CHEMBL3728122 & 1537611 & 8.0 & 8.2192 & TRN & \\
\hline CHEMBL3732558 & 1537611 & 8.0 & 8.1315 & TRN & \\
\hline CHEMBL 3728230 & 1537611 & 6.9957 & 6.7142 & TST & \\
\hline CHEMBL3732495 & 1537611 & 8.0 & 7.8738 & TST & \\
\hline CHEMBL 3728624 & 1537611 & 6.9957 & 7.1247 & TST & \\
\hline CHEMBL3731982 & 1537611 & 3.9996 & 4.301 & TST & \\
\hline CHEMBL3729704 & 1537611 & 8.0 & 7.8542 & TST & \\
\hline CHEMBL3731361 & 1537611 & 6.9957 & 6.9292 & TST & \\
\hline CHEMBL3732405 & 1537611 & 8.0 & 8.0258 & TST & \\
\hline CHEMBL 3730753 & 1537611 & 5.9957 & 5.3409 & TST & \\
\hline CHEMBL 3729057 & 1537611 & 8.0 & 8.2227 & TST & \\
\hline CHEMBL3731336 & 1537611 & 5.9957 & 5.8991 & TST & \\
\hline CHEMBL3731565 & 1537611 & 8.0 & 7.6946 & TST & \\
\hline CHEMBL3730677 & 1537611 & 8.0 & 7.7568 & TST & \\
\hline CHEMBL3728941 & 1537611 & 6.9957 & 7.0694 & TST & \\
\hline CHEMBL3732331 & 1537611 & 5.9957 & 5.8425 & TST & \\
\hline CHEMBL3729451 & 1537611 & 6.9957 & 6.7126 & TST & \\
\hline CHEMBL 3727441 & 1537611 & 6.9957 & 6.9571 & TST & \\
\hline CHEMBL3729821 & 1537611 & 8.0 & 8.0969 & TST & \\
\hline CHEMBL3729620 & 1537611 & 6.9957 & 6.9784 & TST & \\
\hline CHEMBL3728928 & 1537611 & 8.0 & 8.0426 & TST & \\
\hline CHEMBL3727583 & 1537611 & 6.9957 & 7.0439 & TST & \\
\hline CHEMBL3728909 & 1537611 & 6.9957 & 7.6704 & TST & \\
\hline CHEMBL3732377 & 1537611 & 8.0 & 8.0257 & TST & \\
\hline CHEMBL3732647 & 1537611 & 8.0 & 7.9493 & TST & \\
\hline CHEMBL3730831 & 1537611 & 3.9996 & 3.1103 & TST & \\
\hline
\end{tabular}


Supplemental Table S2.txt

\begin{tabular}{|c|c|c|c|c|}
\hline CHEMBL 3732996 & 1537611 & 6.9957 & 6.4701 & TST \\
\hline CHEMBL 3728498 & 1537611 & 8.0 & 8.1137 & TST \\
\hline CHEMBL 3733045 & 1537611 & 8.0 & 8.1446 & TST \\
\hline CHEMBL 3732015 & 1537611 & 8.0 & 8.1333 & TST \\
\hline CHEMBL 3732704 & 1537611 & 6.9957 & 6.944 & TST \\
\hline CHEMBL 3733231 & 1537611 & 6.9957 & 7.2459 & TST \\
\hline CHEMBL 3729108 & 1537611 & 8.0 & 7.0717 & TST \\
\hline CHEMBL 3732945 & 1537611 & 8.0 & 7.9615 & TST \\
\hline CHEMBL 3728733 & 1537611 & 3.9996 & 3.0943 & TST \\
\hline CHEMBL 3727751 & 1537611 & 8.0 & 8.067 & TST \\
\hline CHEMBL 3728251 & 1537611 & 6.9957 & 8.0752 & TST \\
\hline CHEMBL 3733051 & 1537611 & 8.0 & 7.9438 & TST \\
\hline CHEMBL1970314 & 809165 & 5.7 & 4.683 & TRN \\
\hline CHEMBL 2004871 & 809165 & 4.4 & 4.2886 & TRN \\
\hline CHEMBL 2004872 & 809165 & 4.4 & 4.6449 & TRN \\
\hline CHEMBL1727312 & 809165 & 4.4 & 4.221 & TRN \\
\hline CHEMBL1969879 & 809165 & 4.4 & 5.2067 & TST \\
\hline CHEMBL1981720 & 809165 & 6.6 & 5.9983 & TRN \\
\hline CHEMBL419932 & 809165 & 4.4 & 5.7328 & TRN \\
\hline CHEMBL 262433 & 809165 & 4.4 & 4.5166 & TRN \\
\hline CHEMBL 306380 & 809165 & 4.4 & 4.9224 & TRN \\
\hline CHEMBL1966722 & 809165 & 4.4 & 5.5097 & TST \\
\hline CHEMBL1983595 & 809165 & 6.8 & 6.9188 & TRN \\
\hline CHEMBL 1975500 & 809165 & 7.5 & 6.312 & TRN \\
\hline CHEMBL394619 & 809165 & 4.4 & 4.3225 & TRN \\
\hline CHEMBL1996831 & 809165 & 4.4 & 4.8331 & TST \\
\hline CHEMBL411903 & 809165 & 5.7 & 5.6231 & TRN \\
\hline CHEMBL1980253 & 809165 & 6.7 & 7.0165 & TRN \\
\hline CHEMBL418203 & 809165 & 4.4 & 5.2497 & TST \\
\hline CHEMBL1989646 & 809165 & 6.5 & 7.0892 & TRN \\
\hline CHEMBL 225519 & 809165 & 7.2 & 6.8875 & TRN \\
\hline CHEMBL 1978200 & 809165 & 4.4 & 4.4926 & TRN \\
\hline CHEMBL1970522 & 809165 & 6.3 & 6.6226 & TRN \\
\hline CHEMBL1990415 & 809165 & 4.4 & 5.3119 & TRN \\
\hline CHEMBL1966087 & 809165 & 4.4 & 5.2614 & TRN \\
\hline CHEMBL1964692 & 809165 & 4.4 & 4.8782 & TRN \\
\hline CHEMBL1996931 & 809165 & 4.4 & 4.4532 & TRN \\
\hline CHEMBL1973483 & 809165 & 4.4 & 4.5516 & TRN \\
\hline CHEMBL1998470 & 809165 & 6.5 & 6.5437 & TRN \\
\hline CHEMBL1996980 & 809165 & 7.5 & 7.4821 & TRN \\
\hline CHEMBL1970735 & 809165 & 4.4 & 4.6007 & TST \\
\hline CHEMBL 1997340 & 809165 & 6.3 & 4.8533 & TRN \\
\hline CHEMBL1994669 & 809165 & 8.2 & \multicolumn{2}{|c|}{7.486000000000001} \\
\hline CHEMBL 2004365 & 809165 & 4.4 & 5.024 & TST \\
\hline CHEMBL1522508 & 809165 & 4.4 & 4.0496 & TRN \\
\hline CHEMBL1989474 & 809165 & 4.4 & 4.4611 & TRN \\
\hline CHEMBL1090360 & 809165 & 4.4 & 4.3628 & TRN \\
\hline CHEMBL210887 & 809165 & 4.4 & 4.5611 & TST \\
\hline
\end{tabular}




\begin{tabular}{|c|c|c|c|c|c|}
\hline & & & & & \\
\hline CHEMBL458997 & 809165 & 5.4 & 6.3007 & TRN & \\
\hline CHEMBL1971021 & 809165 & 4.4 & 4.0118 & TRN & \\
\hline CHEMBL 227271 & 809165 & 6.2 & 6.125 & TRN & \\
\hline CHEMBL583144 & 809165 & 6.3 & 6.3028 & TRN & \\
\hline CHEMBL1974310 & 809165 & 5.6 & 5.9541 & TST & \\
\hline CHEMBL1982660 & 809165 & 6.3 & 5.1823 & TRN & \\
\hline CHEMBL1994693 & 809165 & 4.4 & 5.1106 & TRN & \\
\hline CHEMBL1982957 & 809165 & 6.4 & 6.2108 & TRN & \\
\hline CHEMBL1725279 & 809165 & 7.4 & 6.4315 & TST & \\
\hline CHEMBL1975138 & 809165 & 4.4 & 5.7318 & TST & \\
\hline CHEMBL 2006836 & 809165 & 4.4 & 5.17700 & 00000000005 & TST \\
\hline CHEMBL1980704 & 809165 & 4.4 & 5.2948 & TST & \\
\hline CHEMBL 2003271 & 809165 & 6.3 & 5.7506 & TRN & \\
\hline CHEMBL1966808 & 809165 & 4.4 & 5.7537 & TST & \\
\hline CHEMBL 2004447 & 809165 & 4.4 & 4.3789 & TST & \\
\hline CHEMBL1992231 & 809165 & 6.9 & 5.67700 & 00000000005 & TRN \\
\hline CHEMBL1983111 & 809165 & 8.5 & 6.8726 & TST & \\
\hline CHEMBL1973860 & 809165 & 7.0 & 5.5346 & TRN & \\
\hline CHEMBL260135 & 809165 & 4.4 & 5.3858 & TRN & \\
\hline CHEMBL 220241 & 809165 & 6.8 & 5.843 & TRN & \\
\hline CHEMBL 2004544 & 809165 & 4.4 & 5.2529 & TST & \\
\hline CHEMBL1982610 & 809165 & 4.4 & 5.5553 & TST & \\
\hline CHEMBL1989569 & 809165 & 5.5 & 5.4158 & TRN & \\
\hline CHEMBL1999496 & 809165 & 4.4 & 4.6818 & TRN & \\
\hline CHEMBL1988300 & 809165 & 4.4 & 5.1392 & TRN & \\
\hline CHEMBL1991078 & 809165 & 7.3 & 7.4066 & TRN & \\
\hline CHEMBL1987359 & 809165 & 4.4 & 4.225 & TST & \\
\hline CHEMBL1994438 & 809165 & 7.2 & 6.6799 & TRN & \\
\hline CHEMBL1989265 & 809165 & 4.4 & 4.8194 & TST & \\
\hline CHEMBL1965660 & 809165 & 7.6 & 6.8818 & TRN & \\
\hline CHEMBL1969502 & 809165 & 6.9 & 6.4294 & TRN & \\
\hline CHEMBL1682553 & 809165 & 6.8 & 6.8536 & TRN & \\
\hline CHEMBL1971430 & 809165 & 4.4 & 4.8881 & TRN & \\
\hline CHEMBL1983963 & 809165 & 4.4 & 4.7853 & TRN & \\
\hline CHEMBL1997764 & 809165 & 4.4 & 4.9949 & TRN & \\
\hline CHEMBL1985092 & 809165 & 7.2 & 5.3882 & TST & \\
\hline CHEMBL 2004692 & 809165 & 4.4 & 4.5235 & TST & \\
\hline CHEMBL1981410 & 809165 & 5.7 & 5.0035 & TRN & \\
\hline CHEMBL1996234 & 809165 & 4.4 & 4.4485 & TRN & \\
\hline CHEMBL1991434 & 809165 & 4.4 & 5.0556 & TRN & \\
\hline CHEMBL1967544 & 809165 & 5.7 & 5.7758 & TRN & \\
\hline CHEMBL340384 & 809165 & 4.4 & 5.7766 & TST & \\
\hline CHEMBL1969151 & 809165 & 6.9 & 7.278 & TRN & \\
\hline CHEMBL1996587 & 809165 & 4.4 & 4.9352 & TRN & \\
\hline CHEMBL1964804 & 809165 & 6.7 & 5.9721 & TRN & \\
\hline CHEMBL 2000354 & 809165 & 6.2 & 6.5302 & TRN & \\
\hline CHEMBL1965507 & 809165 & 4.4 & 4.6255 & TRN & \\
\hline CHEMBL1967564 & 809165 & 5.4 & 5.0053 & TRN & \\
\hline & & & & 22835 & \\
\hline
\end{tabular}




\begin{tabular}{|c|c|c|c|c|}
\hline \multicolumn{5}{|c|}{ Supplemental Table S2.txt } \\
\hline CHEMBL592030 & 809165 & 7.4 & 6.8306 & TST \\
\hline CHEMBL 2000071 & 809165 & 6.2 & 5.3017 & TRN \\
\hline CHEMBL1979176 & 809165 & 6.8 & 4.6534 & TRN \\
\hline CHEMBL1970317 & 809165 & 4.5 & 4.8269 & TRN \\
\hline CHEMBL2002613 & 809165 & 7.5 & 7.08799 & 9999999999 \\
\hline CHEMBL 2000408 & 809165 & 4.4 & 4.5496 & TRN \\
\hline CHEMBL1978014 & 809165 & 4.4 & 5.0445 & TRN \\
\hline CHEMBL1994538 & 809165 & 6.0 & 5.0604 & TRN \\
\hline CHEMBL1983195 & 809165 & 4.4 & 4.7569 & TST \\
\hline CHEMBL1975490 & 809165 & 5.6 & 5.5848 & TRN \\
\hline CHEMBL1964444 & 809165 & 4.4 & 4.9365 & TRN \\
\hline CHEMBL1986139 & 809165 & 4.4 & 4.4782 & TRN \\
\hline CHEMBL1980540 & 809165 & 4.4 & 4.4635 & TRN \\
\hline CHEMBL1979883 & 809165 & 4.4 & 4.2999 & TRN \\
\hline CHEMBL1984162 & 809165 & 4.4 & 5.6813 & TRN \\
\hline CHEMBL1998432 & 809165 & 7.5 & 7.4358 & TRN \\
\hline CHEMBL491758 & 809165 & 5.9 & 5.2766 & TRN \\
\hline CHEMBL549730 & 809165 & 7.0 & 5.6502 & TRN \\
\hline CHEMBL1970189 & 809165 & 4.4 & 4.8109 & TST \\
\hline CHEMBL1996791 & 809165 & 4.4 & 5.4177 & TRN \\
\hline CHEMBL371206 & 809165 & 4.4 & 4.2658 & TRN \\
\hline CHEMBL1974664 & 809165 & 4.4 & 5.0308 & TRN \\
\hline CHEMBL1970104 & 809165 & 7.1 & 6.5174 & TRN \\
\hline CHEMBL1974288 & 809165 & 4.4 & 4.5449 & TRN \\
\hline CHEMBL196363 & 809165 & 4.4 & 4.4729 & TRN \\
\hline CHEMBL1190711 & 809165 & 4.4 & 5.4715 & TRN \\
\hline CHEMBL1968705 & 809165 & 5.8 & 5.0785 & TRN \\
\hline CHEMBL1991410 & 809165 & 6.4 & 5.2606 & TRN \\
\hline CHEMBL404367 & 809165 & 4.4 & 4.495 & TRN \\
\hline CHEMBL1966343 & 809165 & 7.9 & 7.1418 & TRN \\
\hline CHEMBL1967887 & 809165 & 5.5 & 6.5258 & TRN \\
\hline CHEMBL 2000568 & 809165 & 6.2 & 5.1953 & TRN \\
\hline CHEMBL 2000335 & 809165 & 4.4 & 4.1225 & TRN \\
\hline CHEMBL1988717 & 809165 & 4.4 & 4.7645 & TRN \\
\hline CHEMBL1974328 & 809165 & 6.1 & 5.8676 & TRN \\
\hline CHEMBL1985507 & 809165 & 5.6 & 4.5427 & TST \\
\hline CHEMBL509032 & 809165 & 5.5 & 6.4479 & TRN \\
\hline CHEMBL 243298 & 809165 & 7.5 & 7.2039 & TRN \\
\hline CHEMBL1973808 & 809165 & 6.8 & 5.4922 & TRN \\
\hline CHEMBL 2000429 & 809165 & 4.4 & 4.1322 & TRN \\
\hline CHEMBL1972576 & 809165 & 4.4 & 4.6077 & TRN \\
\hline CHEMBL1992555 & 809165 & 4.4 & 4.6849 & TST \\
\hline CHEMBL1992342 & 809165 & 7.1 & 7.2119 & TRN \\
\hline CHEMBL1988173 & 809165 & 4.4 & 5.8414 & TST \\
\hline CHEMBL535331 & 809165 & 4.4 & 4.9544 & TRN \\
\hline CHEMBL1966204 & 809165 & 7.9 & 7.1515 & TRN \\
\hline CHEMBL1989805 & 809165 & 4.4 & 5.4331 & TST \\
\hline CHEMBL1965423 & 809165 & 4.4 & 4.773 & TRN \\
\hline
\end{tabular}

TRN 


\begin{tabular}{|c|c|c|c|c|}
\hline & & & pplement & al $\mathrm{Ta}$ \\
\hline CHEMBL1982980 & 809165 & 4.4 & 4.7924 & TST \\
\hline CHEMBL205415 & 809165 & 7.7 & 5.7931 & TRN \\
\hline CHEMBL1977135 & 809165 & 4.4 & 4.6896 & TRN \\
\hline CHEMBL 2001920 & 809165 & 6.2 & 6.1564 & TRN \\
\hline CHEMBL1978448 & 809165 & 4.4 & 4.2546 & TST \\
\hline CHEMBL1972258 & 809165 & 6.0 & 5.267 & TRN \\
\hline CHEMBL 2001257 & 809165 & 4.4 & 3.9205 & TRN \\
\hline CHEMBL1992536 & 809165 & 4.4 & 5.1847 & TRN \\
\hline CHEMBL1987793 & 809165 & 5.4 & 4.2321 & TST \\
\hline CHEMBL439340 & 809165 & 4.4 & 4.8443 & TRN \\
\hline CHEMBL2002373 & 809165 & 4.4 & 4.5136 & TRN \\
\hline CHEMBL 2006188 & 809165 & 4.4 & 4.8877 & TRN \\
\hline CHEMBL1967531 & 809165 & 4.4 & 4.3634 & TRN \\
\hline CHEMBL1973893 & 809165 & 6.3 & 6.716 & TRN \\
\hline CHEMBL1970913 & 809165 & 4.4 & 4.9508 & TRN \\
\hline CHEMBL1995736 & 809165 & 6.4 & 5.4794 & TRN \\
\hline CHEMBL1997534 & 809165 & 4.4 & 6.0575 & TRN \\
\hline CHEMBL1996500 & 809165 & 4.4 & 4.3125 & TRN \\
\hline CHEMBL1985095 & 809165 & 6.6 & 6.4593 & TST \\
\hline CHEMBL1977374 & 809165 & 4.4 & 4.7631 & TRN \\
\hline CHEMBL1989708 & 809165 & 4.4 & 4.7525 & TRN \\
\hline CHEMBL1682540 & 809165 & 6.0 & 6.7397 & TRN \\
\hline CHEMBL1976420 & 809165 & 5.9 & 4.3092 & TST \\
\hline CHEMBL1994864 & 809165 & 4.4 & 5.4914 & TRN \\
\hline CHEMBL497151 & 809165 & 7.0 & 5.7176 & TST \\
\hline CHEMBL1973961 & 809165 & 4.5 & 4.9469 & TRN \\
\hline CHEMBL 246970 & 809165 & 4.4 & 5.1854 & TST \\
\hline CHEMBL340921 & 809165 & 4.4 & 5.0137 & TST \\
\hline CHEMBL1999718 & 809165 & 5.6 & 4.5327 & TRN \\
\hline CHEMBL1987073 & 809165 & 7.1 & 6.9279 & TRN \\
\hline CHEMBL1276446 & 809165 & 8.4 & 7.1326 & TST \\
\hline CHEMBL1995712 & 809165 & 6.1 & 6.5579 & TRN \\
\hline CHEMBL1977346 & 809165 & 5.7 & 5.1891 & TRN \\
\hline CHEMBL1971649 & 809165 & 4.4 & 4.6161 & TRN \\
\hline CHEMBL 2006439 & 809165 & 6.0 & 6.5996 & TRN \\
\hline CHEMBL 2006156 & 809165 & 4.4 & 4.7248 & TST \\
\hline CHEMBL1969190 & 809165 & 4.4 & 4.2798 & TRN \\
\hline CHEMBL1973937 & 809165 & 4.4 & 4.5369 & TRN \\
\hline CHEMBL1991674 & 809165 & 6.2 & 6.9408 & TRN \\
\hline CHEMBL1982711 & 809165 & 7.1 & 6.6418 & TRN \\
\hline CHEMBL1998829 & 809165 & 4.4 & 5.2286 & TRN \\
\hline CHEMBL1988838 & 809165 & 5.9 & 6.4515 & TRN \\
\hline CHEMBL1981725 & 809165 & 4.4 & 5.235 & TRN \\
\hline CHEMBL1980562 & 809165 & 6.4 & 6.9464 & TRN \\
\hline CHEMBL1982866 & 809165 & 4.4 & 4.5103 & TRN \\
\hline CHEMBL1968926 & 809165 & 4.4 & 4.9054 & TRN \\
\hline CHEMBL462120 & 809165 & 5.6 & 4.9047 & TST \\
\hline CHEMBL1979933 & 809165 & 6.9 & 6.3502 & TRN \\
\hline
\end{tabular}




\begin{tabular}{|c|c|c|c|c|}
\hline & & & Lenterl & \\
\hline CHEMBL1965570 & 809165 & 4.4 & 4.877 & TRN \\
\hline CHEMBL 2007592 & 809165 & 4.4 & 5.1578 & TST \\
\hline CHEMBL1976936 & 809165 & 7.2 & 6.8444 & TRN \\
\hline CHEMBL 210963 & 809165 & 4.4 & 3.9224 & TST \\
\hline CHEMBL1614705 & 809165 & 4.4 & 4.4345 & TRN \\
\hline CHEMBL1984633 & 809165 & 5.5 & 4.6166 & TRN \\
\hline CHEMBL1972988 & 809165 & 6.4 & 6.7032 & TRN \\
\hline CHEMBL 2007372 & 809165 & 4.4 & 4.2676 & TRN \\
\hline CHEMBL1965845 & 809165 & 5.9 & 6.7124 & TRN \\
\hline CHEMBL 2006715 & 809165 & 4.4 & 4.2407 & TRN \\
\hline CHEMBL1986597 & 809165 & 4.4 & 5.2234 & TRN \\
\hline CHEMBL1990482 & 809165 & 6.9 & 5.4855 & TRN \\
\hline CHEMBL1990904 & 809165 & 4.4 & 4.6434 & TRN \\
\hline CHEMBL1987448 & 809165 & 7.6 & 7.4758 & TRN \\
\hline CHEMBL1975121 & 809165 & 4.4 & 4.467 & TRN \\
\hline CHEMBL 2005475 & 809165 & 7.9 & 6.434 & TRN \\
\hline CHEMBL402846 & 809165 & 4.4 & 4.4702 & TRN \\
\hline CHEMBL183844 & 809165 & 4.4 & 4.3241 & TRN \\
\hline CHEMBL1997349 & 809165 & 4.4 & 5.4617 & TST \\
\hline CHEMBL220057 & 809165 & 4.4 & 5.0062 & TRN \\
\hline CHEMBL1682545 & 809165 & 6.6 & 5.6594 & TRN \\
\hline CHEMBL383541 & 809165 & 6.4 & 6.1329 & TRN \\
\hline CHEMBL 2001224 & 809165 & 4.4 & 5.403 & TRN \\
\hline CHEMBL10 & 809165 & 4.4 & 4.4155 & TRN \\
\hline CHEMBL1976732 & 809165 & 4.4 & 4.5085 & TRN \\
\hline CHEMBL 2005216 & 809165 & 6.5 & 6.6383 & TRN \\
\hline CHEMBL1964937 & 809165 & 6.0 & 6.3687 & TRN \\
\hline CHEMBL1969506 & 809165 & 4.4 & 5.1036 & TRN \\
\hline CHEMBL1980163 & 809165 & 4.4 & 4.3816 & TRN \\
\hline CHEMBL 2005899 & 809165 & 6.8 & 5.4856 & TRN \\
\hline CHEMBL1682552 & 809165 & 6.1 & 6.7068 & TRN \\
\hline CHEMBL1972568 & 809165 & 5.5 & 5.186 & TRN \\
\hline CHEMBL1986851 & 809165 & 4.5 & 4.7261 & TRN \\
\hline CHEMBL229799 & 809165 & 6.3 & 6.5515 & TRN \\
\hline CHEMBL105739 & 809165 & 6.9 & 5.4871 & TRN \\
\hline CHEMBL 379300 & 809165 & 6.9 & 6.8323 & TRN \\
\hline CHEMBL1973720 & 809165 & 7.5 & 7.4752 & TRN \\
\hline CHEMBL1988995 & 809165 & 4.4 & 4.6351 & TRN \\
\hline CHEMBL1986781 & 809165 & 4.4 & 4.3914 & TRN \\
\hline CHEMBL526133 & 809165 & 6.4 & 6.8804 & TRN \\
\hline CHEMBL387971 & 809165 & 5.6 & 4.4741 & TST \\
\hline CHEMBL1979057 & 809165 & 4.4 & 5.0354 & TRN \\
\hline CHEMBL1164180 & 809165 & 5.8 & 5.3541 & TST \\
\hline CHEMBL1999428 & 809165 & 4.4 & 4.5912 & TRN \\
\hline CHEMBL1967560 & 809165 & 4.4 & 4.5225 & TRN \\
\hline CHEMBL 211378 & 809165 & 4.4 & 4.8588 & TRN \\
\hline CHEMBL1516890 & 809165 & 6.9 & 5.5758 & TRN \\
\hline CHEMBL2001751 & 809165 & 7.8 & 7.5334 & TRN \\
\hline
\end{tabular}




\begin{tabular}{|c|c|c|c|c|}
\hline & & & upplemen & al $\mathrm{T}$ \\
\hline CHEMBL2003420 & 809165 & 4.4 & 4.7098 & TRN \\
\hline CHEMBL1984586 & 809165 & 4.4 & 4.479 & TRN \\
\hline CHEMBL1972659 & 809165 & 4.4 & 4.9974 & TST \\
\hline CHEMBL 272453 & 809165 & 4.4 & 4.3009 & TRN \\
\hline CHEMBL1970217 & 809165 & 4.4 & 4.8447 & TRN \\
\hline CHEMBL2005528 & 809165 & 6.8 & 6.1094 & TST \\
\hline CHEMBL185569 & 809165 & 4.4 & 4.4382 & TRN \\
\hline CHEMBL1969843 & 809165 & 6.3 & 6.0283 & TRN \\
\hline CHEMBL2007002 & 809165 & 4.4 & 5.7043 & TRN \\
\hline CHEMBL1990288 & 809165 & 4.4 & 4.5535 & TRN \\
\hline CHEMBL1987007 & 809165 & 6.5 & 5.2346 & TRN \\
\hline CHEMBL1969588 & 809165 & 6.8 & 7.9154 & TRN \\
\hline CHEMBL484390 & 809165 & 4.4 & 4.4958 & TST \\
\hline CHEMBL1979252 & 809165 & 6.3 & 5.9341 & TRN \\
\hline CHEMBL 2004290 & 809165 & 4.4 & 4.1901 & TRN \\
\hline CHEMBL1986499 & 809165 & 6.5 & 6.3529 & TRN \\
\hline CHEMBL1972937 & 809165 & 4.4 & 5.7421 & TRN \\
\hline CHEMBL 2000393 & 809165 & 6.4 & 5.7313 & TST \\
\hline CHEMBL 2004311 & 809165 & 4.4 & 4.3482 & TRN \\
\hline CHEMBL1992634 & 809165 & 6.4 & 6.0269 & TRN \\
\hline CHEMBL1242373 & 809165 & 4.4 & 5.0991 & TRN \\
\hline CHEMBL1988075 & 809165 & 4.4 & 4.773 & TRN \\
\hline CHEMBL316264 & 809165 & 4.4 & 4.4666 & TRN \\
\hline CHEMBL1991678 & 809165 & 4.4 & 4.3884 & TRN \\
\hline CHEMBL2001239 & 809165 & 6.3 & 5.5702 & TST \\
\hline CHEMBL1988594 & 809165 & 4.4 & 4.5363 & TRN \\
\hline CHEMBL 2001288 & 809165 & 4.4 & 5.5587 & TRN \\
\hline CHEMBL1992363 & 809165 & 8.1 & 6.9348 & TRN \\
\hline CHEMBL1999811 & 809165 & 5.9 & 6.4419 & TST \\
\hline CHEMBL1985074 & 809165 & 5.6 & 5.4508 & TST \\
\hline CHEMBL1982874 & 809165 & 4.4 & 5.0087 & TRN \\
\hline CHEMBL 2000481 & 809165 & 5.4 & 4.8606 & TRN \\
\hline CHEMBL1991725 & 809165 & 6.2 & 5.8177 & TRN \\
\hline CHEMBL1982271 & 809165 & 6.9 & 6.9076 & TRN \\
\hline CHEMBL2007296 & 809165 & 4.4 & 4.731 & TRN \\
\hline CHEMBL396523 & 809165 & 7.4 & 7.9196 & TRN \\
\hline CHEMBL208637 & 809165 & 5.6 & 4.6903 & TST \\
\hline CHEMBL1970203 & 809165 & 4.4 & 4.367 & TRN \\
\hline CHEMBL1986530 & 809165 & 4.4 & 5.1157 & TST \\
\hline CHEMBL1999321 & 809165 & 4.4 & 4.6511 & TRN \\
\hline CHEMBL1968590 & 809165 & 4.4 & 4.9679 & TRN \\
\hline CHEMBL 2005375 & 809165 & 4.4 & 4.5521 & TRN \\
\hline CHEMBL1984191 & 809165 & 4.4 & 4.7434 & TRN \\
\hline CHEMBL1972183 & 809165 & 4.4 & 5.2595 & TST \\
\hline CHEMBL394790 & 809165 & 4.4 & 4.5096 & TRN \\
\hline CHEMBL1996111 & 809165 & 4.4 & 5.4047 & TRN \\
\hline CHEMBL1974702 & 809165 & 4.4 & 6.1613 & TRN \\
\hline CHEMBL1965589 & 809165 & 4.4 & 4.5813 & TRN \\
\hline
\end{tabular}




\begin{tabular}{|c|c|c|c|c|}
\hline \multirow[b]{2}{*}{ CHEMBL1998193 } & \multicolumn{4}{|c|}{ suppiemental } \\
\hline & 809165 & 4.4 & 4.421 & TRN \\
\hline CHEMBL379975 & 809165 & 8.1 & 5.8069 & TST \\
\hline CHEMBL1988153 & 809165 & 5.4 & 4.8844 & TST \\
\hline CHEMBL1986666 & 809165 & 7.7 & 6.881 & TRN \\
\hline CHEMBL1972584 & 809165 & 4.4 & 4.2853 & TRN \\
\hline CHEMBL1998121 & 809165 & 6.5 & 7.1254 & TRN \\
\hline CHEMBL52387 & 809165 & 4.4 & 5.8189 & TST \\
\hline CHEMBL379835 & 809165 & 4.4 & 4.6517 & TST \\
\hline CHEMBL1996649 & 809165 & 4.5 & 4.3424 & TRN \\
\hline CHEMBL1979357 & 809165 & 6.4 & 5.1935 & TRN \\
\hline CHEMBL1996817 & 809165 & 6.2 & 5.308 & TRN \\
\hline CHEMBL3197315 & 809165 & 4.4 & 4.5295 & TST \\
\hline CHEMBL468280 & 809165 & 4.4 & 4.9733 & TST \\
\hline CHEMBL1990884 & 809165 & 4.4 & 4.638 & TRN \\
\hline CHEMBL3109278 & 809165 & 6.1 & 5.7309 & TRN \\
\hline CHEMBL 256835 & 809165 & 4.4 & 4.4725 & TRN \\
\hline CHEMBL1980142 & 809165 & 4.4 & 4.1417 & TRN \\
\hline CHEMBL41783 & 809165 & 4.4 & 5.225 & TRN \\
\hline CHEMBL 2006276 & 809165 & 5.8 & 5.6853 & TRN \\
\hline CHEMBL 271381 & 809165 & 4.4 & 4.6569 & TRN \\
\hline CHEMBL 2006785 & 809165 & 4.4 & 5.0361 & TRN \\
\hline CHEMBL1982466 & 809165 & 4.4 & 4.2243 & TRN \\
\hline CHEMBL1995740 & 809165 & 7.6 & 5.6847 & TRN \\
\hline CHEMBL1990162 & 809165 & 7.8 & 7.1721 & TRN \\
\hline CHEMBL1992220 & 809165 & 7.1 & 7.0447 & TRN \\
\hline CHEMBL1986943 & 809165 & 7.4 & 7.396 & TRN \\
\hline CHEMBL 234085 & 809165 & 4.4 & 5.4067 & TST \\
\hline CHEMBL1995832 & 809165 & 4.4 & 4.4151 & TRN \\
\hline CHEMBL1998414 & 809165 & 4.4 & 5.3025 & TRN \\
\hline CHEMBL1969042 & 809165 & 6.9 & 5.5934 & TST \\
\hline CHEMBL1999931 & 809165 & 8.0 & 7.7384 & TRN \\
\hline CHEMBL1375418 & 809165 & 4.4 & 4.7352 & TRN \\
\hline CHEMBL 2007064 & 809165 & 7.3 & 6.3035 & TRN \\
\hline CHEMBL229968 & 809165 & 6.4 & 6.3981 & TRN \\
\hline CHEMBL1976240 & 809165 & 4.4 & 5.1528 & TRN \\
\hline CHEMBL1987948 & 809165 & 6.6 & 6.8736 & TRN \\
\hline CHEMBL1979093 & 809165 & 4.4 & 4.1114 & TRN \\
\hline CHEMBL1968151 & 809165 & 4.4 & 5.6397 & TST \\
\hline CHEMBL1987009 & 809165 & 7.2 & 6.4036 & TRN \\
\hline CHEMBL 379218 & 809165 & 5.5 & 6.7162 & TRN \\
\hline CHEMBL 2003817 & 809165 & 6.7 & 5.5383 & TRN \\
\hline CHEMBL1994830 & 809165 & 5.9 & 5.5387 & TST \\
\hline CHEMBL226403 & 809165 & 7.2 & 6.5556 & TRN \\
\hline CHEMBL1994938 & 809165 & 4.4 & 4.9782 & TRN \\
\hline CHEMBL1966279 & 809165 & 4.4 & 4.7596 & TRN \\
\hline CHEMBL1997846 & 809165 & 4.6 & 5.8467 & TRN \\
\hline CHEMBL 2004419 & 809165 & 4.4 & 4.8198 & TRN \\
\hline CHEMBL1995811 & 809165 & 6.7 & 6.6949 & TRN \\
\hline
\end{tabular}




\begin{tabular}{|c|c|c|c|c|c|}
\hline \multirow[b]{2}{*}{ CHEMBL1972489 } & \multicolumn{5}{|c|}{ olement } \\
\hline & 809165 & 4.4 & 5.1922 & TRN & \\
\hline CHEMBL1994074 & 809165 & 5.9 & 5.2792 & TRN & \\
\hline CHEMBL1968930 & 809165 & 7.2 & 7.41706 & 0000000001 & TRN \\
\hline CHEMBL1972119 & 809165 & 4.4 & 4.4761 & TRN & \\
\hline CHEMBL1090356 & 809165 & 4.4 & 4.6132 & TRN & \\
\hline CHEMBL95692 & 809165 & 4.4 & 4.2491 & TRN & \\
\hline CHEMBL1986328 & 809165 & 4.4 & 4.753 & TST & \\
\hline CHEMBL1976455 & 809165 & 6.1 & 5.6965 & TRN & \\
\hline CHEMBL1983923 & 809165 & 6.6 & 6.2265 & TST & \\
\hline CHEMBL1983534 & 809165 & 4.4 & 5.4996 & TRN & \\
\hline CHEMBL1982361 & 809165 & 6.8 & 6.0086 & TRN & \\
\hline CHEMBL1982122 & 809165 & 4.4 & 5.1375 & TRN & \\
\hline CHEMBL 2000801 & 809165 & 4.4 & 4.3531 & TRN & \\
\hline CHEMBL1999112 & 809165 & 4.4 & 4.8693 & TST & \\
\hline CHEMBL1682546 & 809165 & 5.9 & 5.3272 & TRN & \\
\hline CHEMBL1991395 & 809165 & 4.4 & 4.6884 & TRN & \\
\hline CHEMBL1971245 & 809165 & 4.4 & 4.9959 & TRN & \\
\hline CHEMBL1972142 & 809165 & 7.8 & 5.1009 & TRN & \\
\hline CHEMBL 2003638 & 809165 & 7.1 & 7.314 & TRN & \\
\hline CHEMBL1996066 & 809165 & 5.6 & 5.9005 & TST & \\
\hline CHEMBL1970806 & 809165 & 4.4 & 5.1868 & TST & \\
\hline CHEMBL1375640 & 809165 & 6.5 & 5.4698 & TST & \\
\hline CHEMBL 2006237 & 809165 & 5.8 & 5.7237 & TRN & \\
\hline CHEMBL1967720 & 809165 & 5.7 & 4.5422 & TRN & \\
\hline CHEMBL 2005509 & 809165 & 7.3 & 7.1188 & TRN & \\
\hline CHEMBL1572266 & 809165 & 4.4 & 4.4104 & TST & \\
\hline CHEMBL1991138 & 809165 & 4.4 & 4.4534 & TRN & \\
\hline CHEMBL1969755 & 809165 & 4.4 & 4.3064 & TRN & \\
\hline CHEMBL1979516 & 809165 & 4.4 & 4.5267 & TRN & \\
\hline CHEMBL1972820 & 809165 & 4.4 & 5.0326 & TST & \\
\hline CHEMBL1996208 & 809165 & 4.4 & 5.1813 & TST & \\
\hline CHEMBL1989029 & 809165 & 4.4 & 4.9894 & TRN & \\
\hline CHEMBL392642 & 809165 & 4.4 & 5.3395 & TST & \\
\hline CHEMBL1980144 & 809165 & 4.4 & 4.5647 & TRN & \\
\hline CHEMBL1991188 & 809165 & 4.4 & 4.6603 & TRN & \\
\hline CHEMBL1972849 & 809165 & 4.4 & 4.5205 & TRN & \\
\hline CHEMBL1986855 & 809165 & 6.8 & 6.6166 & TRN & \\
\hline CHEMBL231209 & 809165 & 4.4 & 4.4835 & TRN & \\
\hline CHEMBL1976220 & 809165 & 4.4 & 4.3589 & TRN & \\
\hline CHEMBL259922 & 809165 & 4.4 & 4.3266 & TST & \\
\hline CHEMBL1997617 & 809165 & 4.4 & 4.0795 & TRN & \\
\hline CHEMBL1982383 & 809165 & 4.4 & 4.4673 & TRN & \\
\hline CHEMBL1969301 & 809165 & 4.4 & 4.246 & TST & \\
\hline CHEMBL 17370 & 809165 & 4.4 & $4.4060 e$ & 0000000001 & TRN \\
\hline CHEMBL1987910 & 809165 & 4.4 & 4.069 & TRN & \\
\hline CHEMBL1983932 & 809165 & 7.4 & 5.5013 & TRN & \\
\hline CHEMBL1991285 & 809165 & 4.4 & 5.4144 & TRN & \\
\hline CHEMBL243088 & 809165 & 7.4 & 7.2538 & TRN & \\
\hline & & & & 22841 & \\
\hline
\end{tabular}




\begin{tabular}{|c|c|c|c|c|c|}
\hline \multirow[b]{2}{*}{ CHEMBL1984038 } & \multirow[b]{2}{*}{809165} & \\
\hline & & 4.4 & 4.6237 & TRN & \\
\hline CHEMBL1993661 & 809165 & 7.0 & 5.8012 & TRN & \\
\hline CHEMBL1974416 & 809165 & 5.6 & 5.1042 & TRN & \\
\hline CHEMBL 2004615 & 809165 & 5.8 & 5.0452 & TST & \\
\hline CHEMBL1997872 & 809165 & 4.4 & 5.3526 & TRN & \\
\hline CHEMBL1964290 & 809165 & 6.7 & 5.9198 & TRN & \\
\hline CHEMBL 213505 & 809165 & 4.4 & 4.6713 & TRN & \\
\hline CHEMBL1987034 & 809165 & 6.7 & 6.9972 & TRN & \\
\hline CHEMBL1993941 & 809165 & 4.4 & 4.5144 & TRN & \\
\hline CHEMBL1980435 & 809165 & 7.4 & 7.2866 & TRN & \\
\hline CHEMBL377383 & 809165 & 4.4 & 4.3655 & TST & \\
\hline CHEMBL 2005886 & 809165 & 6.5 & 5.9911 & TRN & \\
\hline CHEMBL481491 & 809165 & 4.4 & 4.8873 & TST & \\
\hline CHEMBL1973142 & 809165 & 6.9 & 6.0635 & TRN & \\
\hline CHEMBL1973145 & 809165 & 4.4 & 4.2237 & TRN & \\
\hline CHEMBL1982924 & 809165 & 4.4 & 5.0593 & TRN & \\
\hline CHEMBL 2005936 & 809165 & 6.4 & 6.1259 & TRN & \\
\hline CHEMBL1807515 & 809165 & 7.5 & 7.3281 & TRN & \\
\hline CHEMBL1971141 & 809165 & 4.4 & $4.4860 €$ & 0000000001 & TRN \\
\hline CHEMBL1995813 & 809165 & 6.1 & 6.7797 & TRN & \\
\hline CHEMBL206236 & 809165 & 5.7 & 5.5462 & TRN & \\
\hline CHEMBL244378 & 809165 & 7.6 & 7.9251 & TRN & \\
\hline CHEMBL 2001957 & 809165 & 4.4 & 4.2467 & TRN & \\
\hline CHEMBL1969372 & 809165 & 4.4 & 4.878 & TRN & \\
\hline CHEMBL1993413 & 809165 & 5.8 & 5.3943 & TRN & \\
\hline CHEMBL 2006263 & 809165 & 4.4 & 4.9385 & TST & \\
\hline CHEMBL1993584 & 809165 & 6.1 & 5.5298 & TRN & \\
\hline CHEMBL1986263 & 809165 & 7.7 & 6.6928 & TRN & \\
\hline CHEMBL 2000114 & 809165 & 4.4 & 5.1244 & TRN & \\
\hline CHEMBL1971172 & 809165 & 7.4 & 7.3547 & TRN & \\
\hline CHEMBL1975647 & 809165 & 5.9 & $5.4120 e$ & 3000000001 & TRN \\
\hline CHEMBL1968380 & 809165 & 4.4 & 5.084 & TRN & \\
\hline CHEMBL1964644 & 809165 & 4.4 & 4.5667 & TRN & \\
\hline CHEMBL1981782 & 809165 & 6.7 & 5.468 & TRN & \\
\hline CHEMBL1977681 & 809165 & 6.7 & 5.8457 & TRN & \\
\hline CHEMBL1970142 & 809165 & 4.4 & 4.1 & TRN & \\
\hline CHEMBL1990912 & 809165 & 5.6 & 5.522 & TRN & \\
\hline CHEMBL1988163 & 809165 & 7.5 & 7.0989 & TRN & \\
\hline CHEMBL 2006493 & 809165 & 4.4 & 4.7384 & TST & \\
\hline CHEMBL1996923 & 809165 & 4.4 & 5.0997 & TST & \\
\hline CHEMBL1983449 & 809165 & 4.4 & 4.9533 & TRN & \\
\hline CHEMBL1992323 & 809165 & 4.4 & 5.3572 & TRN & \\
\hline CHEMBL1969735 & 809165 & 4.4 & 4.526 & TRN & \\
\hline CHEMBL 2002649 & 809165 & 7.1 & 6.2109 & TRN & \\
\hline CHEMBL1983589 & 809165 & 6.5 & 6.6934 & TRN & \\
\hline CHEMBL2005718 & 809165 & 7.8 & 7.2565 & TRN & \\
\hline CHEMBL1995172 & 809165 & 5.4 & 4.3018 & TST & \\
\hline CHEMBL1984788 & 809165 & 4.4 & 5.1291 & TRN & \\
\hline & & & & 22842 & \\
\hline
\end{tabular}




\begin{tabular}{|c|c|c|c|c|}
\hline \multicolumn{5}{|c|}{ Supplemental Table S2.txt } \\
\hline CHEMBL 2000508 & 809165 & 4.4 & 4.5048 & TRN \\
\hline CHEMBL1971694 & 809165 & 6.0 & 5.6221 & TST \\
\hline CHEMBL2001547 & 809165 & 4.4 & 4.1185 & TRN \\
\hline CHEMBL 210928 & 809165 & 4.4 & 4.27800 & 00000000005 \\
\hline CHEMBL1986603 & 809165 & 4.4 & 5.0964 & TST \\
\hline CHEMBL1977148 & 809165 & 4.4 & 4.0598 & TRN \\
\hline CHEMBL 2003286 & 809165 & 6.0 & 6.5832 & TRN \\
\hline CHEMBL1992306 & 809165 & 4.4 & 4.6888 & TRN \\
\hline CHEMBL 2002165 & 809165 & 5.7 & 4.8823 & TRN \\
\hline CHEMBL1979318 & 809165 & 4.4 & 4.6845 & TST \\
\hline CHEMBL 206382 & 809165 & 5.8 & 5.4841 & TRN \\
\hline CHEMBL1998585 & 809165 & 4.4 & 5.0379 & TRN \\
\hline CHEMBL127898 & 809165 & 4.4 & 4.5579 & TST \\
\hline CHEMBL519697 & 809165 & 5.8 & 4.7868 & TST \\
\hline CHEMBL 2004934 & 809165 & 4.4 & 4.3473 & TRN \\
\hline CHEMBL1987261 & 809165 & 7.8 & 7.2854 & TRN \\
\hline CHEMBL1975128 & 809165 & 7.2 & 7.6064 & TRN \\
\hline CHEMBL1970369 & 809165 & 6.5 & 5.0789 & TRN \\
\hline CHEMBL 2001485 & 809165 & 4.4 & 4.0068 & TRN \\
\hline CHEMBL1966425 & 809165 & 5.4 & 5.5634 & TRN \\
\hline CHEMBL1984363 & 809165 & 4.4 & 5.039 & TRN \\
\hline CHEMBL1978099 & 809165 & 6.0 & 6.2691 & TRN \\
\hline CHEMBL1988608 & 809165 & 6.7 & 6.8672 & TRN \\
\hline CHEMBL184847 & 809165 & 4.4 & 4.4634 & TRN \\
\hline CHEMBL1984367 & 809165 & 5.7 & 5.0389 & TRN \\
\hline CHEMBL1985723 & 809165 & 7.9 & 7.4005 & TRN \\
\hline CHEMBL178737 & 809165 & 4.4 & 5.46 & TST \\
\hline CHEMBL 226898 & 809165 & 6.3 & 6.665 & TRN \\
\hline CHEMBL1982563 & 809165 & 4.4 & 4.4037 & TRN \\
\hline CHEMBL539474 & 809165 & 4.4 & 4.378 & TST \\
\hline CHEMBL575824 & 809165 & 5.6 & 6.3825 & TRN \\
\hline CHEMBL1988387 & 809165 & 4.4 & 4.2013 & TRN \\
\hline CHEMBL1977128 & 809165 & 6.9 & 7.0691 & TRN \\
\hline CHEMBL1974803 & 809165 & 5.5 & 4.84 & TST \\
\hline CHEMBL1965702 & 809165 & 6.6 & 6.9224 & TRN \\
\hline CHEMBL1986970 & 809165 & 4.4 & 5.353 & TRN \\
\hline CHEMBL 2005112 & 809165 & 4.4 & 5.3741 & TST \\
\hline CHEMBL1958401 & 809165 & 4.4 & 5.2054 & TRN \\
\hline CHEMBL1984044 & 809165 & 5.6 & 5.6068 & TRN \\
\hline CHEMBL 2003456 & 809165 & 5.4 & 5.375 & TRN \\
\hline CHEMBL1966816 & 809165 & 4.4 & 5.2331 & TRN \\
\hline CHEMBL 2002992 & 809165 & 5.4 & 5.3174 & TST \\
\hline CHEMBL560813 & 809165 & 6.4 & 5.5188 & TRN \\
\hline CHEMBL1968791 & 809165 & 6.1 & 4.1775 & TRN \\
\hline CHEMBL 2002682 & 809165 & 4.4 & 4.8106 & TST \\
\hline CHEMBL1971186 & 809165 & 4.4 & 4.5171 & TRN \\
\hline CHEMBL 2003482 & 809165 & 4.4 & 4.5896 & TRN \\
\hline CHEMBL 2006456 & 809165 & 6.5 & 6.9556 & TRN \\
\hline
\end{tabular}




\begin{tabular}{|c|c|c|c|c|}
\hline & & & Supplement & al $\mathrm{T}$ \\
\hline CHEMBL1973211 & 809165 & 4.4 & 4.2628 & TRN \\
\hline CHEMBL1984700 & 809165 & 4.4 & 4.1276 & TRN \\
\hline CHEMBL1972125 & 809165 & 4.4 & 5.2378 & TRN \\
\hline CHEMBL1461728 & 809165 & 4.4 & 5.0029 & TRN \\
\hline CHEMBL1976134 & 809165 & 7.5 & 6.2124 & TRN \\
\hline CHEMBL1965131 & 809165 & 6.6 & 5.8741 & TRN \\
\hline CHEMBL1972158 & 809165 & 6.4 & 6.6772 & TRN \\
\hline CHEMBL 2006580 & 809165 & 4.4 & 4.6394 & TRN \\
\hline CHEMBL1999414 & 809165 & 4.5 & 4.4902 & TRN \\
\hline CHEMBL 2006481 & 809165 & 6.3 & 5.1436 & TRN \\
\hline CHEMBL1979855 & 809165 & 4.4 & 3.889 & TRN \\
\hline CHEMBL1970340 & 809165 & 4.4 & 4.3105 & TRN \\
\hline CHEMBL 2005186 & 809165 & 5.5 & 5.0143 & TRN \\
\hline CHEMBL 2006450 & 809165 & 4.5 & 5.716 & TRN \\
\hline CHEMBL1975534 & 809165 & 4.4 & 5.0666 & TRN \\
\hline CHEMBL1993424 & 809165 & 6.5 & 6.5304 & TRN \\
\hline CHEMBL1966703 & 809165 & 4.4 & 4.5908 & TST \\
\hline CHEMBL1969561 & 809165 & 5.5 & 5.4994 & TRN \\
\hline CHEMBL1972795 & 809165 & 6.0 & 5.9555 & TRN \\
\hline CHEMBL1997023 & 809165 & 6.4 & 5.7241 & TST \\
\hline CHEMBL1964687 & 809165 & 5.7 & 4.6627 & TRN \\
\hline CHEMBL1971943 & 809165 & 4.4 & 5.3305 & TRN \\
\hline CHEMBL1974254 & 809165 & 4.4 & 4.5798 & TRN \\
\hline CHEMBL1988537 & 809165 & 6.2 & 5.8079 & TST \\
\hline CHEMBL1969049 & 809165 & 4.4 & 4.5787 & TRN \\
\hline CHEMBL 2005828 & 809165 & 4.4 & 4.4783 & TRN \\
\hline CHEMBL1980178 & 809165 & 6.2 & 6.9006 & TRN \\
\hline CHEMBL1998611 & 809165 & 6.0 & 6.5678 & TRN \\
\hline CHEMBL1975900 & 809165 & 6.1 & 6.0628 & TRN \\
\hline CHEMBL 255822 & 809165 & 6.6 & 6.6758 & TRN \\
\hline CHEMBL1972221 & 809165 & 6.1 & 6.5469 & TRN \\
\hline CHEMBL378627 & 809165 & 4.4 & 4.2265 & TST \\
\hline CHEMBL1996979 & 809165 & 5.9 & 5.0918 & TRN \\
\hline CHEMBL1968406 & 809165 & 4.4 & 4.8875 & TRN \\
\hline CHEMBL1984274 & 809165 & 5.4 & 4.7506 & TST \\
\hline CHEMBL1998545 & 809165 & 4.4 & 4.3636 & TRN \\
\hline CHEMBL1986869 & 809165 & 4.4 & 4.5411 & TRN \\
\hline CHEMBL 2006010 & 809165 & 4.4 & 4.2807 & TRN \\
\hline CHEMBL1682558 & 809165 & 4.4 & 4.8706 & TRN \\
\hline CHEMBL1990496 & 809165 & 4.4 & 4.9941 & TRN \\
\hline CHEMBL 2002479 & 809165 & 5.7 & 6.0746 & TRN \\
\hline CHEMBL1967094 & 809165 & 6.7 & 5.6355 & TRN \\
\hline CHEMBL1966035 & 809165 & 5.6 & 5.1571 & TRN \\
\hline CHEMBL 2003341 & 809165 & 4.4 & 4.8506 & TRN \\
\hline CHEMBL1982992 & 809165 & 4.4 & 4.7224 & TRN \\
\hline CHEMBL1999590 & 809165 & 4.4 & 4.387 & TST \\
\hline CHEMBL1981079 & 809165 & 6.8 & 6.4946 & TRN \\
\hline CHEMBL1972276 & 809165 & 4.4 & 5.3052 & TRN \\
\hline
\end{tabular}




\begin{tabular}{|c|c|c|c|c|c|}
\hline \multicolumn{6}{|c|}{ Supplemental Table S2.txt } \\
\hline CHEMBL1980489 & 809165 & 4.4 & 5.7352 & TRN & \\
\hline CHEMBL 2000832 & 809165 & 7.5 & 6.1938 & TRN & \\
\hline CHEMBL513846 & 809165 & 5.6 & 5.4869 & TRN & \\
\hline CHEMBL1970709 & 809165 & 4.4 & 4.9797 & TST & \\
\hline CHEMBL1998112 & 809165 & 5.9 & 4.9496 & TST & \\
\hline CHEMBL1972290 & 809165 & 8.1 & 7.0363 & TST & \\
\hline CHEMBL1969126 & 809165 & 4.4 & 4.5631 & TST & \\
\hline CHEMBL1980896 & 809165 & 4.4 & 4.4986 & TST & \\
\hline CHEMBL1975208 & 809165 & 4.4 & 4.5402 & TST & \\
\hline CHEMBL1991429 & 809165 & 4.4 & 4.3807 & TST & \\
\hline CHEMBL1964777 & 809165 & 5.4 & 5.4361 & TST & \\
\hline CHEMBL1971149 & 809165 & 4.4 & 4.2031 & TST & \\
\hline CHEMBL1999714 & 809165 & 4.4 & 4.2749 & TST & \\
\hline CHEMBL1987533 & 809165 & 6.7 & 5.2506 & TST & \\
\hline CHEMBL1994040 & 809165 & 4.4 & 4.2242 & TST & \\
\hline CHEMBL 388978 & 809165 & 8.6 & 9.0334 & TST & \\
\hline CHEMBL1984548 & 809165 & 8.5 & 7.329 & TST & \\
\hline CHEMBL579246 & 809165 & 5.8 & 6.2763 & TST & \\
\hline CHEMBL1982506 & 809165 & 5.5 & 5.4082 & TST & \\
\hline CHEMBL 2004716 & 809165 & 4.4 & 4.8342 & TST & \\
\hline CHEMBL1968127 & 809165 & 4.4 & 4.452 & TST & \\
\hline CHEMBL1975233 & 809165 & 4.4 & 5.2004 & TST & \\
\hline CHEMBL1985406 & 809165 & 4.4 & 5.9144 & TST & \\
\hline CHEMBL207400 & 809165 & 4.4 & 4.7032 & TST & \\
\hline CHEMBL 2000894 & 809165 & 4.4 & 4.8742 & TST & \\
\hline CHEMBL1982135 & 809165 & 4.4 & 4.8741 & TST & \\
\hline CHEMBL1976090 & 809165 & 7.4 & 6.3444 & TST & \\
\hline CHEMBL1993243 & 809165 & 4.4 & 5.0479 & TST & \\
\hline CHEMBL2004771 & 809165 & 4.4 & 4.855 & TST & \\
\hline CHEMBL1997597 & 809165 & 5.7 & 7.0204 & TST & \\
\hline CHEMBL1969537 & 809165 & 4.4 & 5.8924 & TST & \\
\hline CHEMBL1976093 & 809165 & 4.4 & 4.663 & TST & \\
\hline CHEMBL1975256 & 809165 & 4.4 & 4.7122 & TST & \\
\hline CHEMBL508928 & 809165 & 6.0 & 4.5766 & TST & \\
\hline CHEMBL1991356 & 809165 & 6.2 & 4.9932 & TST & \\
\hline CHEMBL1983309 & 809165 & 5.4 & $4.7780 e$ & 00000000005 & TST \\
\hline CHEMBL 2004892 & 809165 & 4.4 & 7.1292 & TST & \\
\hline CHEMBL1997503 & 809165 & 4.4 & 4.7744 & TST & \\
\hline CHEMBL1972339 & 809165 & 7.1 & 6.2201 & TST & \\
\hline CHEMBL116070 & 809165 & 5.9 & 5.6118 & TST & \\
\hline CHEMBL1990821 & 809165 & 4.4 & 4.6759 & TST & \\
\hline CHEMBL3601676 & 1508820 & 4.5918 & 4.4521 & TRN & \\
\hline CHEMBL3601817 & 1508820 & 5.2676 & 5.7234 & TRN & \\
\hline CHEMBL 3601662 & 1508820 & 2.699 & 2.347 & TST & \\
\hline CHEMBL3601671 & 1508820 & 4.3915 & 4.5377 & TRN & \\
\hline CHEMBL3600617 & 1508820 & 5.2924 & 5.4631 & TRN & \\
\hline CHEMBL3601673 & 1508820 & 4.6326 & 4.401 & TRN & \\
\hline CHEMBL3600621 & 1508820 & 5.4202 & 5.5386 & TRN & \\
\hline
\end{tabular}


Supplemental Table S2.txt

\begin{tabular}{|c|c|c|c|c|}
\hline CHEMBL3601665 & 1508820 & 4.2233 & 4.5523 & TST \\
\hline CHEMBL3600923 & 1508820 & 4.699 & 4.4128 & TRN \\
\hline CHEMBL3601677 & 1508820 & 5.2366 & 5.1029 & TRN \\
\hline CHEMBL3601824 & 1508820 & 5.0269 & 5.4446 & TRN \\
\hline CHEMBL3600388 & 1508820 & 9.5229 & 7.6053 & TRN \\
\hline CHEMBL3601828 & 1508820 & 5.2757 & 4.8423 & TRN \\
\hline CHEMBL3601666 & 1508820 & 5.2757 & 4.438 & TST \\
\hline CHEMBL3601822 & 1508820 & 5.6383 & 5.2846 & TRN \\
\hline CHEMBL 3600612 & 1508820 & 5.9208 & 6.6694 & TRN \\
\hline CHEMBL3601829 & 1508820 & 5.6383 & 5.5249 & TRN \\
\hline CHEMBL3601678 & 1508820 & 5.8539 & 6.7262 & TRN \\
\hline CHEMBL3601522 & 1508820 & 4.6271 & 3.8369 & TST \\
\hline CHEMBL3600930 & 1508820 & 9.5229 & 9.4594 & TRN \\
\hline CHEMBL3601813 & 1508820 & 4.4306 & 3.7283 & TRN \\
\hline CHEMBL3600622 & 1508820 & 2.699 & 3.1128 & TRN \\
\hline CHEMBL3601674 & 1508820 & 4.1475 & 4.14 & TRN \\
\hline CHEMBL3601675 & 1508820 & 5.1739 & 4.2269 & TRN \\
\hline CHEMBL 3600625 & 1508820 & 5.5686 & 5.1642 & TRN \\
\hline CHEMBL 3601825 & 1508820 & 5.2366 & 5.006 & TRN \\
\hline CHEMBL3600932 & 1508820 & 4.3372 & 2.7766 & TST \\
\hline CHEMBL3601806 & 1508820 & 4.4191 & 4.2392 & TRN \\
\hline CHEMBL3600619 & 1508820 & 5.2518 & 4.9858 & TRN \\
\hline CHEMBL3601821 & 1508820 & 2.699 & 3.3701 & TRN \\
\hline CHEMBL3601823 & 1508820 & 4.3686 & 4.3439 & TRN \\
\hline CHEMBL3600926 & 1508820 & 2.699 & 2.1534 & TST \\
\hline CHEMBL3601679 & 1508820 & 4.8601 & 5.8018 & TRN \\
\hline CHEMBL3601660 & 1508820 & 4.8125 & 5.3217 & TST \\
\hline CHEMBL473368 & 1508820 & 5.5086 & 5.1518 & TRN \\
\hline CHEMBL 3600608 & 1508820 & 4.2725 & 3.7531 & TRN \\
\hline CHEMBL3601812 & 1508820 & 2.699 & 2.5577 & TRN \\
\hline CHEMBL3600610 & 1508820 & 9.5229 & 8.4574 & TRN \\
\hline CHEMBL 3601524 & 1508820 & 4.0227 & 4.2405 & TST \\
\hline CHEMBL3601809 & 1508820 & 5.0605 & 5.1339 & TRN \\
\hline CHEMBL3601803 & 1508820 & 5.1739 & 4.6017 & TRN \\
\hline CHEMBL3601815 & 1508820 & 4.6003 & 5.1279 & TRN \\
\hline CHEMBL3601658 & 1508820 & 4.1163 & 3.5488 & TST \\
\hline CHEMBL3600615 & 1508820 & 5.1549 & 5.9491 & TRN \\
\hline CHEMBL3601807 & 1508820 & 5.6778 & 5.4151 & TRN \\
\hline CHEMBL3600609 & 1508820 & 4.7282 & 5.6199 & TRN \\
\hline CHEMBL3601670 & 1508820 & 5.6556 & 6.2882 & TRN \\
\hline CHEMBL3600616 & 1508820 & 9.5229 & 9.2733 & TRN \\
\hline CHEMBL3601520 & 1508820 & 2.699 & 2.2182 & TST \\
\hline CHEMBL3600613 & 1508820 & 6.301 & 6.4456 & TRN \\
\hline CHEMBL 3600623 & 1508820 & 4.5361 & 4.5875 & TRN \\
\hline CHEMBL3601669 & 1508820 & 7.3979 & 8.1633 & TRN \\
\hline CHEMBL3601521 & 1508820 & 3.7156 & 2.71100 & 00000000003 \\
\hline CHEMBL3600620 & 1508820 & 4.3526 & 4.5507 & TRN \\
\hline CHEMBL3601680 & 1508820 & 2.699 & 2.6683 & TRN \\
\hline
\end{tabular}


Supplemental Table S2.txt

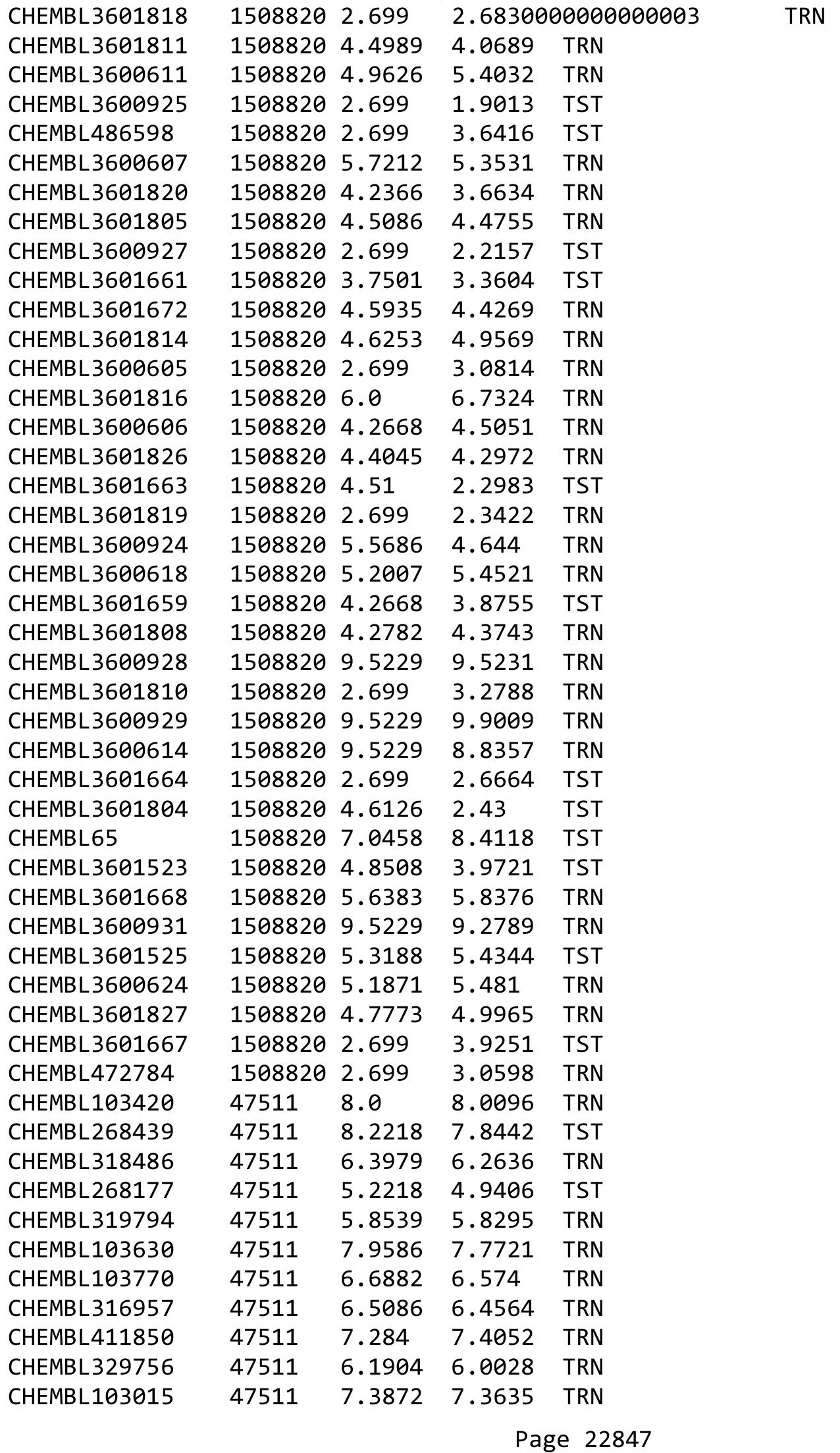




\begin{tabular}{|c|c|c|c|c|c|}
\hline & & \multicolumn{4}{|c|}{ Supplemental Table s2.txt } \\
\hline CHEMBL319182 & 47511 & 6.4559 & 6.4824 & TRN & \\
\hline CHEMBL431421 & 47511 & 7.8861 & 7.9347 & TRN & \\
\hline CHEMBL102904 & 47511 & 6.1549 & 6.1602 & TRN & \\
\hline CHEMBL439957 & 47511 & 6.5229 & 6.6964 & TRN & \\
\hline CHEMBL100860 & 47511 & 7.8539 & 7.9496 & TRN & \\
\hline CHEMBL100733 & 47511 & 7.3872 & 7.3569 & TRN & \\
\hline CHEMBL102793 & 47511 & 4.6364 & 4.68199 & 99999999995 & TRN \\
\hline CHEMBL99958 & 47511 & 4.6198 & 4.4889 & TRN & \\
\hline CHEMBL319030 & 47511 & 6.5229 & 6.4989 & TRN & \\
\hline CHEMBL102401 & 47511 & 6.5229 & 6.55399 & 9999999999 & TRN \\
\hline CHEMBL316576 & 47511 & 4.7959 & 4.7517 & TRN & \\
\hline CHEMBL6852 & 47511 & 4.6021 & 4.0708 & TST & \\
\hline CHEMBL316875 & 47511 & 4.4685 & 4.5786 & TRN & \\
\hline CHEMBL269122 & 47511 & 7.3768 & 7.1674 & TST & \\
\hline CHEMBL103945 & 47511 & 7.3372 & 7.2772 & TRN & \\
\hline CHEMBL100906 & 47511 & 8.0458 & 8.0508 & TRN & \\
\hline CHEMBL6724 & 47511 & 5.1871 & 4.8327 & TST & \\
\hline CHEMBL 320840 & 47511 & 4.5528 & 4.5288 & TRN & \\
\hline CHEMBL102722 & 47511 & 7.9208 & 7.9571 & TRN & \\
\hline CHEMBL102656 & 47511 & 6.1675 & 6.21399 & 99999999995 & TRN \\
\hline CHEMBL103825 & 47511 & 7.4559 & 7.3916 & TRN & \\
\hline CHEMBL321795 & 47511 & 6.4559 & 6.4297 & TRN & \\
\hline CHEMBL269628 & 47511 & 5.2147 & 5.1592 & TST & \\
\hline CHEMBL 99855 & 47511 & 7.4815 & 7.3563 & TRN & \\
\hline CHEMBL103802 & 47511 & 5.7696 & 5.8045 & TRN & \\
\hline CHEMBL319297 & 47511 & 6.5229 & 6.5852 & TRN & \\
\hline CHEMBL6705 & 47511 & 4.3429 & 3.8619 & TST & \\
\hline CHEMBL317015 & 47511 & 5.8386 & 5.8334 & TRN & \\
\hline CHEMBL100760 & 47511 & 6.1249 & 6.1117 & TRN & \\
\hline CHEMBL430667 & 47511 & 5.7447 & 5.6143 & TRN & \\
\hline CHEMBL323550 & 47511 & 6.1107 & 6.1204 & TRN & \\
\hline CHEMBL6919 & 47511 & 4.6198 & 4.4689 & TST & \\
\hline CHEMBL99638 & 47511 & 5.7696 & 5.6809 & TRN & \\
\hline CHEMBL100873 & 47511 & 4.5157 & 4.5885 & TRN & \\
\hline CHEMBL6784 & 47511 & 4.7447 & 4.615 & TST & \\
\hline CHEMBL318839 & 47511 & 6.5229 & 6.5517 & TRN & \\
\hline CHEMBL317256 & 47511 & 7.8861 & 7.7911 & TRN & \\
\hline CHEMBL420105 & 47511 & 7.8861 & 7.684 & TRN & \\
\hline CHEMBL101196 & 47511 & 5.8697 & 5.8961 & TRN & \\
\hline CHEMBL319486 & 47511 & 7.3872 & 7.303 & TRN & \\
\hline CHEMBL328410 & 47511 & 6.1427 & 6.1512 & TRN & \\
\hline CHEMBL13646 & 47511 & 6.34200 & 00000000 & 6.19 & TST \\
\hline CHEMBL327964 & 47511 & 6.4949 & 6.7027 & TRN & \\
\hline CHEMBL102316 & 47511 & 6.1249 & 6.1357 & TRN & \\
\hline CHEMBL102870 & 47511 & 6.2007 & 6.1037 & TRN & \\
\hline CHEMBL419536 & 47511 & 6.2076 & 6.1497 & TRN & \\
\hline CHEMBL103325 & 47511 & 4.8239 & 4.9422 & TRN & \\
\hline CHEMBL319487 & 47511 & 8.0 & 8.0463 & TRN & \\
\hline
\end{tabular}




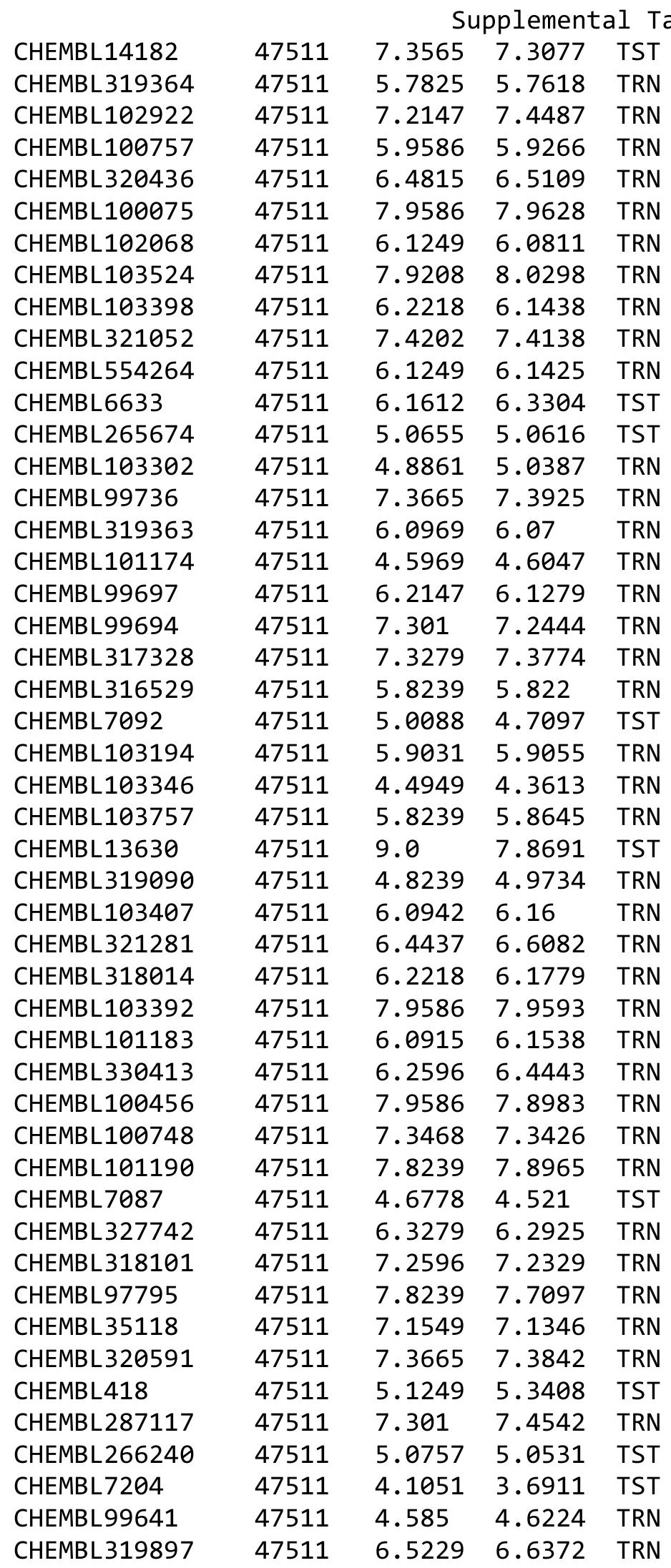

Page 22849 


\begin{tabular}{|c|c|c|c|c|c|c|}
\hline & & \multicolumn{5}{|c|}{ Supplemental Table S2.txt } \\
\hline CHEMBL317249 & 47511 & 6.4559 & 6.4444 & TRN & & \\
\hline CHEMBL100580 & 47511 & 4.4559 & 4.3494 & TRN & & \\
\hline CHEMBL101330 & 47511 & 7.8239 & 7.6871 & TRN & & \\
\hline CHEMBL321586 & 47511 & 4.6615 & 4.6818 & TRN & & \\
\hline CHEMBL318969 & 47511 & 6.2218 & 6.3009 & TRN & & \\
\hline CHEMBL101002 & 47511 & \multicolumn{3}{|c|}{5.752000000000001} & 5.7392 & TRN \\
\hline CHEMBL318953 & 47511 & 6.699 & 6.6451 & TRN & & \\
\hline CHEMBL6753 & 47511 & 5.0315 & 5.2837 & TST & & \\
\hline CHEMBL103415 & 47511 & 6.5086 & 6.4708 & TRN & & \\
\hline CHEMBL318047 & 47511 & 4.7077 & 4.7677 & TST & & \\
\hline CHEMBL420096 & 47511 & 6.2147 & 6.1914 & TST & & \\
\hline CHEMBL103615 & 47511 & 7.9586 & 7.6697 & TST & & \\
\hline CHEMBL103413 & 47511 & 6.4202 & 6.319 & TST & & \\
\hline CHEMBL103182 & 47511 & 4.5607 & 4.5741 & TST & & \\
\hline CHEMBL103361 & 47511 & 6.2111 & 6.0607 & TST & & \\
\hline CHEMBL421200 & 47511 & 8.0 & 7.7384 & TST & & \\
\hline CHEMBL102705 & 47511 & 7.8239 & 7.6939 & TST & & \\
\hline CHEMBL6685 & 47511 & 7.2596 & 7.0792 & TST & & \\
\hline CHEMBL98673 & 47511 & 7.2757 & 7.3622 & TST & & \\
\hline CHEMBL6853 & 47511 & 5.0809 & 4.6909 & TST & & \\
\hline CHEMBL103478 & 47511 & 7.9208 & 7.8826 & TST & & \\
\hline CHEMBL 3941468 & 1636712 & 5.2291 & 5.5476 & TRN & & \\
\hline CHEMBL3945022 & 1636712 & 5.9586 & 6.0231 & TRN & & \\
\hline CHEMBL3935576 & 1636712 & 6.5229 & 5.8498 & TRN & & \\
\hline CHEMBL3978331 & 1636712 & 5.699 & 6.4352 & TRN & & \\
\hline CHEMBL3970831 & 1636712 & 3.8239 & 4.0514 & TRN & & \\
\hline CHEMBL 3981507 & 1636712 & 5.5086 & 5.605 & TRN & & \\
\hline CHEMBL3891960 & 1636712 & 5.5086 & 5.4263 & TRN & & \\
\hline CHEMBL 3903263 & 1636712 & 5.3565 & 4.9741 & TRN & & \\
\hline CHEMBL 3943390 & 1636712 & 5.4949 & 5.5071 & TRN & & \\
\hline CHEMBL3899569 & 1636712 & 5.3279 & 5.50299 & 9999999999 & & TRN \\
\hline CHEMBL 218562 & 1636712 & 5.2676 & 5.1333 & TRN & & \\
\hline CHEMBL3912275 & 1636712 & 5.4815 & 4.6828 & TST & & \\
\hline CHEMBL3904117 & 1636712 & 5.5376 & 5.5793 & TRN & & \\
\hline CHEMBL3942321 & 1636712 & 4.9431 & 4.6978 & TRN & & \\
\hline CHEMBL2261529 & 1636712 & 5.8539 & 6.0017 & TRN & & \\
\hline CHEMBL 2261006 & 1636712 & 3.8239 & 4.2896 & TRN & & \\
\hline CHEMBL2261005 & 1636712 & 6.1871 & 5.5385 & TRN & & \\
\hline CHEMBL3933348 & 1636712 & 5.2924 & 5.3529 & TRN & & \\
\hline CHEMBL3959993 & 1636712 & 5.301 & 4.6389 & TRN & & \\
\hline CHEMBL3965510 & 1636712 & 5.4318 & 5.5646 & TST & & \\
\hline CHEMBL3971926 & 1636712 & 5.1612 & 5.4405 & TST & & \\
\hline CHEMBL2261007 & 1636712 & 6.0458 & 5.7514 & TRN & & \\
\hline CHEMBL3220144 & 1636712 & 6.0969 & 5.6088 & TRN & & \\
\hline CHEMBL165 & 1636712 & 5.2676 & 4.2446 & TST & & \\
\hline CHEMBL242396 & 1636712 & 5.3372 & 5.4229 & TRN & & \\
\hline CHEMBL 2261527 & 1636712 & 5.3768 & 5.2585 & TRN & & \\
\hline CHEMBL48802 & 1636712 & 5.9208 & 5.6152 & TST & & \\
\hline
\end{tabular}


Supplemental Table S2.txt

\begin{tabular}{|c|c|c|c|c|c|c|c|}
\hline CHEMBL3960809 & 1636712 & 5.7959 & 5.4642 & TRN & & & \\
\hline CHEMBL 3952774 & 1636712 & 5.4202 & 4.9316 & TRN & & & \\
\hline CHEMBL 3924415 & 1636712 & 3.8239 & 4.1525 & TRN & & & \\
\hline CHEMBL 2261528 & 1636712 & 5.4437 & 5.3928 & TRN & & & \\
\hline CHEMBL 3907816 & 1636712 & 5.0177 & 5.5918 & TRN & & & \\
\hline CHEMBL 3952108 & 1636712 & 3.8239 & 5.381 & TRN & & & \\
\hline CHEMBL1896623 & 1636712 & 5.5229 & 4.9271 & TST & & & \\
\hline CHEMBL215767 & 1636712 & 5.0506 & 5.1681 & TRN & & & \\
\hline CHEMBL1173003 & 1636712 & 5.585 & 4.9742 & TRN & & & \\
\hline CHEMBL3915421 & 1636712 & 5.585 & 4.9582 & TRN & & & \\
\hline CHEMBL3973512 & 1636712 & 6.0969 & 6.1257 & TRN & & & \\
\hline CHEMBL414893 & 1636712 & 3.8239 & 3.8909 & TRN & & & \\
\hline CHEMBL 3970725 & 1636712 & 5.5376 & 5.7056 & TRN & & & \\
\hline CHEMBL 3940266 & 1636712 & 3.8239 & 4.9604 & TRN & & & \\
\hline CHEMBL2261530 & 1636712 & 4.9066 & 5.3901 & TRN & & & \\
\hline CHEMBL 3972608 & 1636712 & 5.6576 & 5.5484 & TRN & & & \\
\hline CHEMBL 3960954 & 1636712 & 6.1549 & 5.55 & TRN & & & \\
\hline CHEMBL 2387062 & 1636712 & 5.3565 & 5.5903 & TRN & & & \\
\hline CHEMBL 3899680 & 1636712 & 5.3665 & 5.4738 & TRN & & & \\
\hline CHEMBL 3936138 & 1636712 & 5.7212 & 5.6144 & TRN & & & \\
\hline CHEMBL3918400 & 1636712 & 5.5686 & 5.4473 & TRN & & & \\
\hline CHEMBL3962219 & 1636712 & 6.3468 & 5.8931 & TRN & & & \\
\hline CHEMBL3959000 & 1636712 & 5.4318 & 3.9352 & TST & & & \\
\hline CHEMBL3926781 & 1636712 & 5.8239 & 5.6999 & TST & & & \\
\hline CHEMBL452888 & 1636712 & 5.0223 & 5.2213 & TST & & & \\
\hline CHEMBL 3891875 & 1636712 & 6.0 & 5.5219 & TST & & & \\
\hline CHEMBL215717 & 1636712 & 5.5086 & 5.2313 & TST & & & \\
\hline CHEMBL3961457 & 1636712 & 5.6383 & 5.2686 & TST & & & \\
\hline CHEMBL 3892462 & 1636712 & 5.2218 & 4.9906 & TST & & & \\
\hline CHEMBL 3932493 & 1636712 & 5.8539 & 5.5538 & TST & & & \\
\hline CHEMBL 2261016 & 1636712 & 5.8861 & 6.1908 & TST & & & \\
\hline CHEMBL 212911 & 822293 & 8.155 & 8.4621 & TRN & & & \\
\hline CHEMBL 213315 & 822293 & 8.301 & 8.0281 & TRN & & & \\
\hline CHEMBL214921 & 822293 & 8.301 & 8.0674 & TRN & & & \\
\hline CHEMBL 213314 & 822293 & $8.2220 e$ & 00000000 & & 7.12299 & 9999999999 & TRN \\
\hline CHEMBL 2037003 & 822293 & 8.301 & 7.9591 & TRN & & & \\
\hline CHEMBL 2036997 & 822293 & 8.09700 & 00000000 & & 8.4631 & TRN & \\
\hline CHEMBL237519 & 822293 & $8.2220 e$ & 00000000 & & 7.9576 & TRN & \\
\hline CHEMBL237307 & 822293 & 8.523 & 8.1392 & TRN & & & \\
\hline CHEMBL 215245 & 822293 & 8.398 & 8.1615 & TRN & & & \\
\hline CHEMBL 2037004 & 822293 & $8.2220 e$ & 00000000 & & 8.2766 & TRN & \\
\hline CHEMBL 344282 & 822293 & 6.131 & 6.2502 & TRN & & & \\
\hline CHEMBL149438 & 822293 & 6.056 & 5.2863 & TRN & & & \\
\hline CHEMBL 237520 & 822293 & 8.523 & 7.8791 & TRN & & & \\
\hline CHEMBL 237305 & 822293 & 7.268 & 8.0674 & TRN & & & \\
\hline CHEMBL149676 & 822293 & 5.921 & 5.72 & TRN & & & \\
\hline CHEMBL148639 & 822293 & 5.77 & 5.879 & TRN & & & \\
\hline \multirow[t]{2}{*}{ CHEMBL215701 } & 822293 & 8.398 & 8.0529 & 79999 & & TRN & \\
\hline & \multicolumn{6}{|c|}{ Page 22851} & \\
\hline
\end{tabular}




\begin{tabular}{|c|c|c|c|c|c|c|}
\hline & & \multicolumn{5}{|c|}{ Supplemental Table s2.txt } \\
\hline CHEMBL 377660 & 822293 & 8.398 & 8.221 & TRN & & \\
\hline CHEMBL213361 & 822293 & 8.301 & 8.3935 & TRN & & \\
\hline CHEMBL214026 & 822293 & 8.398 & 8.1023 & TRN & & \\
\hline CHEMBL237306 & 822293 & 7.921 & 7.8295 & TRN & & \\
\hline CHEMBL237277 & 822293 & 8.523 & 8.1126 & TST & & \\
\hline CHEMBL 236877 & 822293 & 8.523 & 8.1813 & TRN & & \\
\hline CHEMBL 237485 & 822293 & 8.398 & 8.0403 & TST & & \\
\hline CHEMBL392058 & 822293 & \multicolumn{3}{|c|}{8.222000000000001} & 7.8229 & TR \\
\hline CHEMBL236875 & 822293 & 8.398 & 8.2547 & TRN & & \\
\hline CHEMBL236664 & 822293 & 8.523 & 8.0999 & TRN & & \\
\hline CHEMBL232396 & 822293 & 6.232 & 7.3903 & TST & & \\
\hline CHEMBL234659 & 822293 & 8.77 & 7.4491 & TST & & \\
\hline CHEMBL234662 & 822293 & 6.921 & 7.1127 & TST & & \\
\hline CHEMBL 2037005 & 822293 & 5.141 & 6.6848 & TST & & \\
\hline CHEMBL 264385 & 822293 & \multicolumn{3}{|c|}{5.013999999999999} & 5.7715 & TST \\
\hline CHEMBL 2037006 & 822293 & 5.152 & 7.0584 & TST & & \\
\hline CHEMBL81592 & 822293 & 5.352 & 6.7704 & TST & & \\
\hline CHEMBL 2037007 & 822293 & 5.295 & 6.6999 & TST & & \\
\hline CHEMBL345721 & 822293 & 5.699 & 5.9933 & TRN & & \\
\hline CHEMBL2037008 & 822293 & 5.824 & 6.5558 & TRN & & \\
\hline CHEMBL148774 & 822293 & \multicolumn{3}{|c|}{5.3870000000000005} & 5.7237 & TRN \\
\hline CHEMBL2037009 & 822293 & 6.796 & 6.4909 & TRN & & \\
\hline CHEMBL202515 & 822293 & 5.59 & 5.3297 & TRN & & \\
\hline CHEMBL201880 & 822293 & 6.652 & 5.7028 & TRN & & \\
\hline CHEMBL202140 & 822293 & 5.118 & 5.4072 & TRN & & \\
\hline CHEMBL360246 & 822293 & 5.301 & 5.1415 & TRN & & \\
\hline CHEMBL 2037010 & 822293 & 5.42 & 5.8228 & TRN & & \\
\hline CHEMBL181656 & 822293 & 5.405 & 7.1095 & TST & & \\
\hline CHEMBL182884 & 822293 & 5.857 & 6.6411 & TST & & \\
\hline CHEMBL367891 & 822293 & 4.979 & 4.9955 & TRN & & \\
\hline CHEMBL 367549 & 822293 & 5.638 & 5.7873 & TRN & & \\
\hline CHEMBL2037079 & 822293 & \multicolumn{3}{|c|}{5.1610000000000005} & 5.483 & Tार \\
\hline CHEMBL363532 & 822293 & \multicolumn{3}{|c|}{5.6339999999999995} & 6.7574 & TST \\
\hline CHEMBL181644 & 822293 & 5.822 & 6.9196 & TST & & \\
\hline CHEMBL182230 & 822293 & 5.385 & 6.9838 & TST & & \\
\hline CHEMBL435343 & 822293 & \multicolumn{3}{|c|}{5.3870000000000005} & 5.7277 & TKIV \\
\hline CHEMBL180504 & 822293 & 5.125 & 6.9617 & TST & & \\
\hline CHEMBL232395 & 822293 & \multicolumn{3}{|c|}{6.8660000000000005} & 7.0761 & TST \\
\hline CHEMBL391479 & 822293 & 6.504 & 7.2751 & TST & & \\
\hline CHEMBL 2037080 & 822293 & \multicolumn{3}{|c|}{6.587000000000001} & 7.0329 & TST \\
\hline CHEMBL 2037078 & 822293 & \multicolumn{3}{|c|}{6.428999999999999} & 7.3212 & TST \\
\hline CHEMBL360368 & 822293 & \multicolumn{3}{|c|}{5.803999999999999} & 6.8259 & TST \\
\hline CHEMBL391478 & 822293 & 7.699 & 7.6094 & TST & & \\
\hline CHEMBL2037081 & 822293 & 6.05 & 7.3463 & TST & & \\
\hline CHEMBL425766 & 822293 & 6.188 & 5.4978 & TRN & & \\
\hline CHEMBL201581 & 822293 & 5.501 & 5.2875 & TRN & & \\
\hline CHEMBL369725 & 822293 & 4.854 & 5.4591 & TRN & & \\
\hline CHEMBL201036 & 822293 & 5.269 & 6.1297 & TRN & & \\
\hline
\end{tabular}




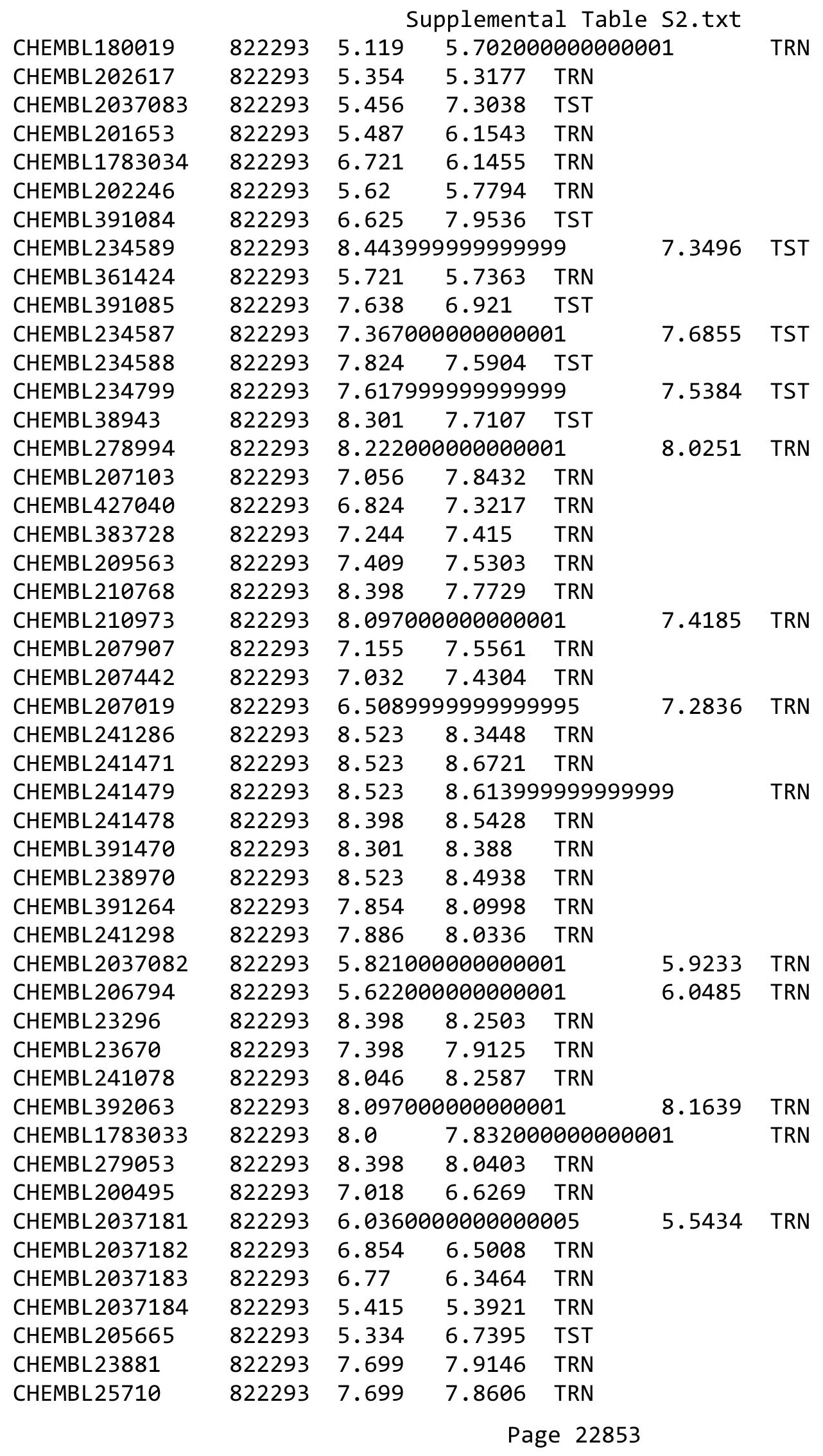




\begin{tabular}{|c|c|c|c|c|c|c|}
\hline & & \multicolumn{5}{|c|}{ Supplemental Table S2.txt } \\
\hline CHEMBL491039 & 822293 & 3.409 & 6.9305 & TST & & \\
\hline CHEMBL491237 & 822293 & \multicolumn{3}{|c|}{4.468999999999999} & 6.8595 & TST \\
\hline CHEMBL235143 & 822293 & 8.523 & 8.0608 & TST & & \\
\hline CHEMBL393939 & 822293 & 8.398 & 7.8864 & TRN & & \\
\hline CHEMBL238357 & 822293 & 8.301 & 7.8909 & TST & & \\
\hline CHEMBL 237518 & 822293 & 8.301 & 8.0979 & TRN & & \\
\hline CHEMBL392717 & 822293 & 8.523 & 8.1703 & TRN & & \\
\hline CHEMBL237086 & 822293 & \multicolumn{3}{|c|}{8.222000000000001} & 8.1364 & TRN \\
\hline CHEMBL 237710 & 822293 & 7.495 & 8.2642 & TRN & & \\
\hline CHEMBL236876 & 822293 & 8.398 & 8.3393 & TRN & & \\
\hline CHEMBL 237484 & 822293 & 8.523 & 7.8876 & TST & & \\
\hline CHEMBL393938 & 822293 & 8.523 & 8.2406 & TRN & & \\
\hline CHEMBL 237084 & 822293 & 7.398 & 8.2964 & TRN & & \\
\hline CHEMBL401236 & 822293 & 8.301 & 8.0689 & TST & & \\
\hline CHEMBL 236218 & 822293 & 8.046 & 7.8764 & TST & & \\
\hline CHEMBL399217 & 822293 & 8.301 & 7.81 & TST & & \\
\hline CHEMBL 237085 & 822293 & 8.398 & 8.2185 & TRN & & \\
\hline CHEMBL485087 & 822293 & 7.886 & 7.9081 & TRN & & \\
\hline CHEMBL495904 & 822293 & \multicolumn{3}{|c|}{8.222000000000001} & 7.9782 & TRN \\
\hline CHEMBL495905 & 822293 & 8.0 & 8.0259 & TRN & & \\
\hline CHEMBL498172 & 822293 & 7.699 & 8.047 & TRN & & \\
\hline CHEMBL525552 & 822293 & 6.801 & 7.4768 & TRN & & \\
\hline CHEMBL525366 & 822293 & 8.0 & 7.9188 & TRN & & \\
\hline CHEMBL498171 & 822293 & 8.0 & 7.7076 & TRN & & \\
\hline CHEMBL496733 & 822293 & \multicolumn{3}{|c|}{7.2010000000000005} & 7.9749 & TRN \\
\hline CHEMBL522575 & 822293 & 8.0 & 7.7098 & TRN & & \\
\hline CHEMBL519345 & 822293 & 7.602 & 7.8544 & TRN & & \\
\hline CHEMBL522619 & 822293 & 8.301 & 8.0852 & TRN & & \\
\hline CHEMBL485088 & 822293 & \multicolumn{3}{|c|}{8.097000000000001} & 8.0513 & I KIV \\
\hline CHEMBL484266 & 822293 & \multicolumn{3}{|c|}{8.097000000000001} & 7.9705 & TRN \\
\hline CHEMBL496116 & 822293 & 7.495 & 7.4405 & TRN & & \\
\hline CHEMBL496744 & 822293 & \multicolumn{3}{|c|}{8.222000000000001} & 8.1334 & 110 \\
\hline CHEMBL484467 & 822293 & 8.301 & 8.0854 & TRN & & \\
\hline CHEMBL497789 & 822293 & 7.886 & 7.7003 & TRN & & \\
\hline CHEMBL497991 & 822293 & 7.886 & 7.6613 & TRN & & \\
\hline CHEMBL520827 & 822293 & 7.886 & 7.9915 & TRN & & \\
\hline CHEMBL522577 & 822293 & 7.796 & 8.1967 & TRN & & \\
\hline CHEMBL522224 & 822293 & 8.398 & 7.9259 & TRN & & \\
\hline CHEMBL496136 & 822293 & 8.398 & 8.0322 & TRN & & \\
\hline CHEMBL496534 & 822293 & 7.796 & 7.9147 & TRN & & \\
\hline CHEMBL498401 & 822293 & 8.0 & 7.9703 & TRN & & \\
\hline CHEMBL496743 & 822293 & 7.699 & 7.9262 & TRN & & \\
\hline CHEMBL524829 & 822293 & 8.0 & 7.7166 & TRN & & \\
\hline CHEMBL496726 & 822293 & 7.602 & 7.909 & TRN & & \\
\hline CHEMBL498608 & 822293 & 7.796 & 7.9775 & TRN & & \\
\hline CHEMBL496933 & 822293 & 7.796 & 8.1576 & TRN & & \\
\hline CHEMBL 3288978 & 1364398 & 4.2007 & 3.7701 & TRN & & \\
\hline CHEMBL 3289009 & 1364398 & 7.4559 & 7.3354 & TRN & & \\
\hline
\end{tabular}


Supplemental Table S2.txt

\begin{tabular}{|c|c|c|c|c|}
\hline CHEMBL 3288995 & 1364398 & 4.2007 & 5.3977 & TRN \\
\hline CHEMBL3288991 & 1364398 & 4.2007 & 4.3322 & TRN \\
\hline CHEMBL3288985 & 1364398 & 4.2007 & 4.1847 & TRN \\
\hline CHEMBL 3288967 & 1364398 & 4.2007 & 4.5058 & TRN \\
\hline CHEMBL3288961 & 1364398 & 5.1549 & 5.0057 & TRN \\
\hline CHEMBL 3289007 & 1364398 & 6.3665 & 6.4406 & TRN \\
\hline CHEMBL 3288973 & 1364398 & 7.3468 & 6.7215 & TRN \\
\hline CHEMBL 3288980 & 1364398 & 4.2007 & 4.063 & TRN \\
\hline CHEMBL 3289003 & 1364398 & 7.2924 & 7.2002 & TRN \\
\hline CHEMBL3288996 & 1364398 & 4.2007 & 4.6355 & TRN \\
\hline CHEMBL3288966 & 1364398 & 6.2596 & 2.1568 & TST \\
\hline CHEMBL 3288988 & 1364398 & 5.9208 & 5.9875 & TRN \\
\hline CHEMBL3288969 & 1364398 & 4.2007 & \multicolumn{2}{|c|}{ 4.0089999999999995 } \\
\hline CHEMBL 3288977 & 1364398 & 4.2007 & 4.2208 & TRN \\
\hline CHEMBL3289004 & 1364398 & 4.2007 & 6.3024 & TST \\
\hline CHEMBL3288992 & 1364398 & 4.2007 & 4.1371 & TRN \\
\hline CHEMBL1173704 & 1364398 & 6.6778 & 2.4656 & TST \\
\hline CHEMBL 3289000 & 1364398 & 4.2007 & 4.9501 & TST \\
\hline CHEMBL 3288962 & 1364398 & 4.2007 & 4.5116 & TRN \\
\hline CHEMBL3288979 & 1364398 & 4.2007 & 3.7477 & TRN \\
\hline CHEMBL3288998 & 1364398 & 4.2007 & 4.3427 & TRN \\
\hline CHEMBL1803018 & 1364398 & 6.9208 & 3.7095 & TST \\
\hline CHEMBL1802987 & 1364398 & 7.0223 & 3.638 & TST \\
\hline CHEMBL3288975 & 1364398 & 4.2007 & 4.6759 & TRN \\
\hline CHEMBL 3288974 & 1364398 & 5.699 & 5.5223 & TRN \\
\hline CHEMBL3288989 & 1364398 & 4.2007 & 4.2169 & TRN \\
\hline CHEMBL 3288990 & 1364398 & 6.3565 & 5.6884 & TRN \\
\hline CHEMBL3289010 & 1364398 & 7.301 & 7.3524 & TRN \\
\hline CHEMBL 3288965 & 1364398 & 7.3665 & 3.5856 & TST \\
\hline CHEMBL 3289005 & 1364398 & 6.7212 & \multicolumn{2}{|c|}{6.986000000000001} \\
\hline CHEMBL3288984 & 1364398 & 4.2007 & 5.1302 & TRN \\
\hline CHEMBL 3288986 & 1364398 & 4.2007 & 4.5109 & TRN \\
\hline CHEMBL 3288982 & 1364398 & 6.3665 & 6.5846 & TRN \\
\hline CHEMBL 3288993 & 1364398 & 4.2007 & 4.4994 & TRN \\
\hline CHEMBL 3288970 & 1364398 & 5.4949 & 5.1511 & TRN \\
\hline CHEMBL3288994 & 1364398 & 7.1675 & 6.8974 & TRN \\
\hline CHEMBL3288971 & 1364398 & 4.2007 & 3.9663 & TRN \\
\hline CHEMBL 3288964 & 1364398 & 7.0706 & 3.8682 & TST \\
\hline CHEMBL3288999 & 1364398 & 5.4437 & 6.0406 & TRN \\
\hline CHEMBL 3288981 & 1364398 & 6.0915 & 6.3188 & TRN \\
\hline CHEMBL3288987 & 1364398 & 4.2007 & 3.8844 & TRN \\
\hline CHEMBL3289008 & 1364398 & 6.0362 & 5.9966 & TRN \\
\hline CHEMBL3288997 & 1364398 & 5.3372 & 5.4304 & TST \\
\hline CHEMBL3288976 & 1364398 & 6.4815 & 5.5159 & TRN \\
\hline CHEMBL1802986 & 1364398 & 7.284 & 4.0121 & TST \\
\hline CHEMBL3289006 & 1364398 & 7.301 & 7.2092 & TRN \\
\hline CHEMBL3288968 & 1364398 & 4.2007 & 3.3545 & TST \\
\hline CHEMBL 3288963 & 1364398 & 6.5686 & 2.1612 & TST \\
\hline
\end{tabular}

Page 22855 
Supplemental Table S2.txt

\begin{tabular}{lllll} 
CHEMBL3288983 & 1364398 & 6.7959 & 6.9801 & TRN \\
CHEMBL3289001 & 1364398 & 6.0915 & 5.2432 & TST \\
CHEMBL3289002 & 1364398 & 6.5376 & 5.6684 & TRN \\
CHEMBL3288972 & 1364398 & 6.4089 & 4.4618 & TST \\
CHEMBL55647 & 924 & 7.9481 & 6.8771 & TST \\
CHEMBL56851 & 924 & 6.63 & 6.5735 & TRN \\
CHEMBL299253 & 924 & 8.0278 & 7.6909 & TST \\
CHEMBL440118 & 924 & 6.6052 & 6.8956 & TRN \\
CHEMBL431354 & 924 & 6.56 & 6.4359 & TRN \\
CHEMBL58930 & 924 & 6.902 & 6.9106 & TRN \\
CHEMBL292399 & 924 & 5.0 & 5.6827 & TST \\
CHEMBL57097 & 924 & 7.0 & 7.2569 & TRN \\
CHEMBL293539 & 924 & 7.9183 & 7.6282 & TRN \\
CHEMBL56558 & 924 & 5.0 & 4.4541 & TST \\
CHEMBL57425 & 924 & 6.2226 & 6.5438 & TRN \\
CHEMBL57797 & 924 & 4.0 & 5.9204 & TST \\
CHEMBL294705 & 924 & 6.3988 & 5.1609 & TST \\
CHEMBL57593 & 924 & 8.3726 & 8.4755 & TRN \\
CHEMBL293111 & 924 & 6.8933 & 6.735 & TRN \\
CHEMBL57540 & 924 & 8.4157 & 7.9911 & TST \\
CHEMBL293734 & 924 & 7.0685 & 7.0257 & TRN \\
CHEMBL57364 & 924 & 8.9626 & 9.1055 & TRN \\
CHEMBL55655 & 924 & 5.0 & 4.9838 & TRN \\
CHEMBL301019 & 924 & 7.8716 & 7.6631 & TRN \\
CHEMBL294023 & 924 & 5.0 & 5.6774 & TRN \\
CHEMBL56150 & 924 & 7.7029 & 8.0914 & TRN \\
CHEMBL294646 & 924 & 5.0 & 5.2677 & TRN \\
CHEMBL59315 & 924 & 8.8665 & 8.9885 & TRN \\
CHEMBL56620 & 924 & 5.0 & 5.1015 & TRN \\
CHEMBL56899 & 924 & 7.2061 & 7.2023 & TRN \\
CHEMBL408034 & 924 & 5.0 & 4.6445 & TRN \\
CHEMBL291908 & 924 & 7.596 & 7.4207 & TRN \\
CHEMBL294868 & 924 & 5.0 & 5.0644 & TRN \\
CHEMBL57868 & 924 & 7.5281 & 7.5644 & TRN \\
CHEMBL57546 & 924 & 6.8153 & 6.7624 & TRN \\
CHEMBL55319 & 924 & 6.397 & 6.5216 & TRN \\
CHEMBL57859 & 924 & 8.6326 & 9.2183 & TRN \\
CHEMBL58384 & 924 & 6.095 & 6.15 & TRN \\
CHEMBL57098 & 924 & 5.0 & 4.7983 & TRN \\
CHEMBL57882 & 924 & 6.7951 & 6.1704 & TRN \\
CHEMBL56869 & 924 & 8.8894 & 8.8137 & TRN \\
CHEMBL59033 & 924 & 5.0 & 4.9176 & TST \\
CHEMBL13647 & 924 & 9.0969 & 8.5868 & TRN \\
CHEMBL292672 & 924 & 6.3452 & 5.4691 & TST \\
CHEMBL5568479 & 924 & 5.0 & 4.2315 & TST \\
& 924 & 5.0 & 5.7884 & TRN \\
\hline
\end{tabular}

Page 22856 


\begin{tabular}{|c|c|c|c|c|c|}
\hline \multicolumn{6}{|c|}{ Supplemental Table S2.txt } \\
\hline CHEMBL59262 & 924 & 7.5825 & 7.2095 & TRN & \\
\hline CHEMBL59149 & 924 & 7.1577 & 6.9099 & TRN & \\
\hline CHEMBL 293980 & 924 & 7.9179 & 7.6139 & TRN & \\
\hline CHEMBL56439 & 924 & 5.0 & 5.4681 & TST & \\
\hline CHEMBL58476 & 924 & 7.2814 & 7.1107 & TRN & \\
\hline CHEMBL417939 & 924 & 6.5861 & 6.78 & TST & \\
\hline CHEMBL55790 & 924 & 6.3638 & 5.3288 & TST & \\
\hline CHEMBL292366 & 924 & 7.0369 & 6.3634 & TST & \\
\hline CHEMBL 300152 & 924 & 6.6841 & 6.2311 & TST & \\
\hline CHEMBL 298808 & 924 & 5.6265 & 5.7581 & TRN & \\
\hline CHEMBL60699 & 924 & 5.0 & 4.9894 & TRN & \\
\hline CHEMBL56805 & 924 & 7.5805 & 7.6242 & TRN & \\
\hline CHEMBL431357 & 924 & 5.0 & 4.9561 & TST & \\
\hline CHEMBL57317 & 924 & 6.9825 & 7.1066 & TRN & \\
\hline CHEMBL299691 & 924 & 7.4872 & 7.5246 & TRN & \\
\hline CHEMBL 292686 & 924 & 7.5867 & 7.3759 & TRN & \\
\hline CHEMBL298595 & 924 & 9.4685 & 9.248 & TRN & \\
\hline CHEMBL60583 & 924 & 9.2676 & 9.4056 & TRN & \\
\hline CHEMBL 292637 & 924 & 5.0 & 5.0335 & TRN & \\
\hline CHEMBL56804 & 924 & 8.9208 & 8.868 & TRN & \\
\hline CHEMBL56292 & 924 & 8.2798 & 8.325 & TRN & \\
\hline CHEMBL56403 & 924 & 7.1818 & 7.0683 & TRN & \\
\hline CHEMBL56878 & 924 & 8.3904 & 8.8881 & TST & \\
\hline CHEMBL 293968 & 924 & 7.4472 & 7.58899 & 99999999995 & TRN \\
\hline CHEMBL301224 & 924 & 7.7587 & 7.4122 & TRN & \\
\hline CHEMBL57747 & 924 & 8.0851 & 7.8489 & TRN & \\
\hline CHEMBL 294235 & 924 & 6.5882 & 6.2419 & TRN & \\
\hline CHEMBL556313 & 924 & 7.2147 & 7.7765 & TRN & \\
\hline CHEMBL56438 & 924 & 7.4437 & 7.1635 & TRN & \\
\hline CHEMBL55654 & 924 & 6.8702 & 6.8938 & TRN & \\
\hline CHEMBL431943 & 924 & 7.6996 & 8.2573 & TRN & \\
\hline CHEMBL57168 & 924 & 7.2629 & 7.3554 & TRN & \\
\hline CHEMBL61204 & 924 & 6.2793 & 4.8777 & TST & \\
\hline CHEMBL57999 & 924 & 8.4724 & 8.2032 & TRN & \\
\hline CHEMBL55460 & 924 & 6.1445 & 4.7969 & TST & \\
\hline CHEMBL 299022 & 924 & 8.27 & 8.2561 & TRN & \\
\hline CHEMBL 299454 & 924 & 8.9747 & 8.8018 & TRN & \\
\hline CHEMBL1590743 & 752506 & 5.1935 & 5.2247 & TST & \\
\hline CHEMBL2369306 & 752506 & 4.013 & 4.9878 & TRN & \\
\hline CHEMBL1350780 & 752506 & 5.6451 & 6.0199 & TRN & \\
\hline CHEMBL1499306 & 752506 & 5.3286 & 5.3467 & TRN & \\
\hline CHEMBL1720876 & 752506 & 5.2231 & 5.7859 & TST & \\
\hline CHEMBL1342053 & 752506 & 5.2996 & 5.2028 & TRN & \\
\hline CHEMBL3195273 & 752506 & 5.8837 & 6.1347 & TRN & \\
\hline CHEMBL1559226 & 752506 & 5.1241 & 5.1409 & TRN & \\
\hline CHEMBL1602693 & 752506 & 5.1585 & 5.4861 & TST & \\
\hline CHEMBL57013 & 752506 & 5.8077 & 5.2823 & TST & \\
\hline CHEMBL1531328 & 752506 & 5.6453 & 5.5948 & TST & \\
\hline
\end{tabular}




\begin{tabular}{|c|c|c|c|c|c|}
\hline \multicolumn{6}{|c|}{ Supplemental Table S2.txt } \\
\hline CHEMBL1393664 & 752506 & 4.9119 & 4.6549 & TRN & \\
\hline CHEMBL3194415 & 752506 & 5.3049 & 5.2487 & TRN & \\
\hline CHEMBL598679 & 752506 & 5.4046 & 5.3015 & TRN & \\
\hline CHEMBL1981538 & 752506 & 6.1118 & 5.7424 & TRN & \\
\hline CHEMBL3198503 & 752506 & 5.9834 & 5.7323 & TRN & \\
\hline CHEMBL1439036 & 752506 & 5.5834 & 5.44600 & 0000000001 & TST \\
\hline CHEMBL1165723 & 752506 & 5.1167 & 5.3843 & TRN & \\
\hline CHEMBL1366838 & 752506 & 5.6602 & 4.9992 & TST & \\
\hline CHEMBL2001712 & 752506 & 5.3087 & 5.28 & TRN & \\
\hline CHEMBL1974506 & 752506 & 5.8024 & 5.98 & TRN & \\
\hline CHEMBL1407614 & 752506 & 5.3813 & 4.9188 & TRN & \\
\hline CHEMBL1464042 & 752506 & 5.3298 & 4.9623 & TRN & \\
\hline CHEMBL1215474 & 752506 & 5.3761 & 5.4667 & TRN & \\
\hline CHEMBL1513705 & 752506 & 5.3986 & 5.059 & TST & \\
\hline CHEMBL1487183 & 752506 & 5.6463 & 5.4127 & TST & \\
\hline CHEMBL1456635 & 752506 & 5.415 & 4.8886 & TRN & \\
\hline CHEMBL1529203 & 752506 & 5.1813 & 5.4336 & TRN & \\
\hline CHEMBL1736253 & 752506 & 4.8398 & 5.3143 & TRN & \\
\hline CHEMBL1526174 & 752506 & 5.7617 & 5.5514 & TRN & \\
\hline CHEMBL1544797 & 752506 & 5.3735 & 5.4682 & TRN & \\
\hline CHEMBL1966824 & 752506 & 5.3239 & 5.3388 & TST & \\
\hline CHEMBL3208249 & 752506 & 5.7231 & 5.8338 & TRN & \\
\hline CHEMBL1309059 & 752506 & 5.7701 & 5.666 & TRN & \\
\hline CHEMBL599255 & 752506 & 5.4433 & 5.4819 & TRN & \\
\hline CHEMBL3192817 & 752506 & 5.7445 & 5.5966 & TRN & \\
\hline CHEMBL1532068 & 752506 & 6.3201 & 6.2615 & TRN & \\
\hline CHEMBL1576905 & 752506 & 5.1847 & 5.3167 & TRN & \\
\hline CHEMBL1341995 & 752506 & 5.3305 & 5.2045 & TRN & \\
\hline CHEMBL1986611 & 752506 & 5.043 & 5.2105 & TRN & \\
\hline CHEMBL1485450 & 752506 & 5.3184 & 5.3641 & TRN & \\
\hline CHEMBL1472908 & 752506 & 5.56 & 5.313 & TST & \\
\hline CHEMBL601137 & 752506 & 5.8604 & 5.92399 & 99999999995 & TRN \\
\hline CHEMBL1426637 & 752506 & 2.585 & 5.5521 & TST & \\
\hline CHEMBL1312087 & 752506 & 5.4102 & 5.7454 & TRN & \\
\hline CHEMBL1493059 & 752506 & 5.0281 & 4.8193 & TRN & \\
\hline CHEMBL1566205 & 752506 & 5.4493 & 5.3706 & TRN & \\
\hline CHEMBL602969 & 752506 & 5.6704 & 5.1465 & TST & \\
\hline CHEMBL1982032 & 752506 & 5.6385 & 5.6817 & TST & \\
\hline CHEMBL1972217 & 752506 & 5.4201 & 5.7494 & TRN & \\
\hline CHEMBL1437997 & 752506 & 5.2427 & 5.1754 & TRN & \\
\hline CHEMBL1428823 & 752506 & 4.5686 & 5.1631 & TRN & \\
\hline CHEMBL1971144 & 752506 & 5.7665 & 6.1822 & TRN & \\
\hline CHEMBL1523610 & 752506 & 5.5877 & 4.8938 & TRN & \\
\hline CHEMBL1329726 & 752506 & 5.4471 & 4.954 & TRN & \\
\hline CHEMBL 3192547 & 752506 & 5.9034 & 5.8583 & TRN & \\
\hline CHEMBL1399663 & 752506 & 5.3148 & 5.2756 & TST & \\
\hline CHEMBL3192035 & 752506 & 5.5571 & 5.8313 & TRN & \\
\hline CHEMBL3192299 & 752506 & 5.5711 & 5.8803 & TRN & \\
\hline
\end{tabular}

Page 22858 
Supplemental Table S2.txt

\begin{tabular}{|c|c|c|c|c|}
\hline 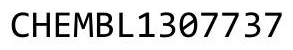 & & & & \\
\hline 929 & 506 & 1627 & & \\
\hline AEMBL1985759 & 2506 & 0127 & 1635 & \\
\hline HEMBL1885024 & 52506 & 2218 & 8594 & \\
\hline 274 & 2506 & 2524 & 998 & \\
\hline IEMBL13 & 2506 & 1944 & 2813 & \\
\hline AEMBL586031 & 52506 & .0381 & .8067 & \\
\hline HEMBL3196747 & 52506 & 5955 & 63 & \\
\hline HEMBL1497024 & 52506 & 3161 & 88 & \\
\hline EMBL1421071 & 52506 & 767 & & \\
\hline IEMBL1348935 & 52506 & 471 & 552 & \\
\hline HEMBL1598493 & 52506 & 1627 & 2508 & \\
\hline HEMBL1325192 & 52506 & 31 & 5044 & RN \\
\hline AEMBL1428012 & 52506 & & 7797 & \\
\hline IEMBL1376732 & 52506 & & 1898 & \\
\hline EMBL1340089 & 52506 & & 2863 & \\
\hline AEMBL3191835 & 52506 & & 1501 & \\
\hline AEMBL1613298 & 52506 & & 182 & \\
\hline L1314867 & 36 & & 282 & \\
\hline L3191933 & $\partial 6$ & & 3093 & \\
\hline L1734695 & 506 & & 3785 & \\
\hline L1411646 & 52506 & & 5887 & \\
\hline AEMBL1483740 & & & & RN \\
\hline EMBL14 & 06 & & 55 & \\
\hline 299 & $\partial 6$ & & 95 & RIV \\
\hline 142 & 06 & & 166 & RN \\
\hline L1337074 & 52506 & & 9542 & RN \\
\hline HEMBL1979106 & & & & RN \\
\hline AEMBL1348954 & 52506 & & 196 & ST \\
\hline 933 & $\partial 6$ & & 566 & RN \\
\hline 784 & $\partial 6$ & 65 & 93 & RN \\
\hline AEMBL582073 & & & 3887 & RN \\
\hline AEMBL1406616 & & & 532 & RN \\
\hline AEMBL1407228 & 52506 & & 272 & ST \\
\hline 979 & 26 & & 137 & RN \\
\hline 56 & 96 & & 944 & RN \\
\hline HEMBL1981797 & 52506 & & 1046 & ST \\
\hline AEMBL1386049 & 52506 & & 865 & RN \\
\hline AEMBL15 & 52506 & & 346 & ST \\
\hline 329 & 26 & & 762 & RIN \\
\hline 343 & 06 & & 059 & RN \\
\hline AEMBL1549574 & 52506 & 572 & 0623 & RN \\
\hline IEMBL1301325 & 52506 & & 904 & RN \\
\hline HEIMDL & 752506 & & 051 & SI \\
\hline & & & 1902 & SI \\
\hline HEMBL 319 & 52506 & & 5.5478 & RN \\
\hline 2354875 & 52506 & & 5.7434 & RN \\
\hline CHEMBL1609391 & 752506 & 306 & 4.8197 & TST \\
\hline
\end{tabular}

Page 22859 


\begin{tabular}{|c|c|}
\hline CHEMBL1526230 & 752506 \\
\hline CHEMBL585656 & 752506 \\
\hline CHEMBL3212034 & 752506 \\
\hline CHEMBL1598631 & 752506 \\
\hline CHEMBL1542560 & 752506 \\
\hline CHEMBL1366987 & 752506 \\
\hline CHEMBL469424 & 752506 \\
\hline CHEMBL1361461 & 752506 \\
\hline CHEMBL1481281 & 752506 \\
\hline CHEMBL1503945 & 752506 \\
\hline CHEMBL1494441 & 752506 \\
\hline CHEMBL479187 & 752506 \\
\hline CHEMBL1725096 & 752506 \\
\hline CHEMBL1385616 & 752506 \\
\hline CHEMBL1453089 & 752506 \\
\hline CHEMBL530049 & 752506 \\
\hline CHEMBL3189409 & 752506 \\
\hline CHEMBL1488923 & 752506 \\
\hline CHEMBL1612840 & 752506 \\
\hline CHEMBL1489769 & 752506 \\
\hline CHEMBL1474113 & 752506 \\
\hline CHEMBL1475749 & 752506 \\
\hline CHEMBL1995645 & 752506 \\
\hline CHEMBL1494117 & 752506 \\
\hline CHEMBL1591445 & 752506 \\
\hline CHEMBL1383777 & 752506 \\
\hline CHEMBL1345336 & 752506 \\
\hline CHEMBL1590661 & 752506 \\
\hline CHEMBL1586169 & 752506 \\
\hline CHEMBL3189810 & 752506 \\
\hline CHEMBL1584364 & 752506 \\
\hline CHEMBL1421010 & 752506 \\
\hline CHEMBL1501102 & 752506 \\
\hline CHEMBL1483235 & 752506 \\
\hline CHEMBL1313978 & 752506 \\
\hline CHEMBL1505372 & 752506 \\
\hline CHEMBL1492585 & 752506 \\
\hline CHEMBL 2095095 & 752506 \\
\hline CHEMBL1525735 & 752506 \\
\hline CHEMBL1466593 & 752506 \\
\hline CHEMBL1506527 & 752506 \\
\hline CHEMBL1454614 & 752506 \\
\hline CHEMBL1475691 & 752506 \\
\hline CHEMBL1470603 & 752506 \\
\hline CHEMBL1443454 & 752506 \\
\hline CHEMBL1500188 & 752506 \\
\hline CHEMBL1508790 & 752506 \\
\hline CHEMBL1399492 & 752506 \\
\hline
\end{tabular}

Supplemental Table S2.txt
$\begin{array}{lll}5.8505 & 5.3002 & \text { TRN }\end{array}$
$\begin{array}{llll}5.6619 & 5.9628 & \text { TRN }\end{array}$
$\begin{array}{lll}2.585 & 4.7841 & \text { TRN }\end{array}$

$\begin{array}{lll}5.6914 & 4.9195 & \text { TST }\end{array}$

$\begin{array}{llll}5.0487 & 5.2559 & \text { TRN }\end{array}$

$\begin{array}{lll}5.7196 & 5.6297 & \text { TST }\end{array}$

$\begin{array}{lll}5.0901 & 5.1693 & \text { TST }\end{array}$

$5.2959 \quad 5.7283$ TRN

$\begin{array}{lll}5.3002 & 5.1084 & \text { TRN }\end{array}$

4.94855 .0391 TRN

$\begin{array}{lll}5.6702 & 5.5137 & \text { TRN }\end{array}$

$\begin{array}{llll}4.9935 & 4.7586 & \text { TRN }\end{array}$

$\begin{array}{lll}5.5127 & 5.2717 \quad \text { TRN }\end{array}$

$\begin{array}{lll}4.8775 & 5.341 & \text { TST }\end{array}$

$\begin{array}{lll}5.1665 & 5.4803 & \text { TRN }\end{array}$

$\begin{array}{llll}5.9278 & 5.9234 & \text { TRN }\end{array}$

$\begin{array}{lll}5.2018 & 5.091 & \text { TRN }\end{array}$

$\begin{array}{lll}5.8864 & 5.9288 & \text { TRN }\end{array}$

$\begin{array}{lll}5.3172 & 5.052 & \text { TRN }\end{array}$

$\begin{array}{lll}5.5784 & 5.1621 & \text { TST }\end{array}$

$\begin{array}{lll}6.1852 & 5.0234 & \text { TRN }\end{array}$

$\begin{array}{lll}5.7565 & 4.8604 & \text { TST }\end{array}$

$\begin{array}{lll}5.4358 & 5.67 \quad \text { TRN }\end{array}$

$\begin{array}{lll}5.6817 & 5.1629 & \text { TST }\end{array}$

$\begin{array}{lll}5.1046 & 5.1632 & \text { TRN }\end{array}$

$\begin{array}{lll}5.4608 & 5.3943 & \text { TRN }\end{array}$

$\begin{array}{lll}5.7778 & 5.0039 & \text { TST }\end{array}$

$\begin{array}{llll}5.6544 & 5.5837 & \text { TRN }\end{array}$

$\begin{array}{llll}5.4427 & 5.6577 & \text { TRN }\end{array}$

$\begin{array}{lll}5.4802 & 5.4057 & \text { TRN }\end{array}$

$\begin{array}{lll}7.71 & 5.7729 & \text { TRN }\end{array}$

$\begin{array}{lll}5.1295 & 4.7887 & \text { TST }\end{array}$

$\begin{array}{llll}5.5096 & 5.3524 & \text { TRN }\end{array}$

$\begin{array}{llll}5.4118 & 5.6677 & \text { TRN }\end{array}$

$\begin{array}{lll}5.3371 & 5.2507 & \text { TRN }\end{array}$

$\begin{array}{lll}2.585 & 5.254 & \text { TRN }\end{array}$

$\begin{array}{lll}7.71 & 7.1432 & \text { TRN }\end{array}$

$6.0422 \quad 5.8113$ TRN

$5.4318 \quad 5.1186$ TRN

$5.1051 \quad 5.1589$ TST

$5.1846 \quad 5.4705$ TRN

$\begin{array}{lll}5.3261 & 5.553999999999999 & \text { TRN }\end{array}$

$2.585 \quad 4.9226$ TST

2.5854 .1762 TRN

$\begin{array}{lll}5.39 & 4.9986 & \text { TRN }\end{array}$

$\begin{array}{lll}7.71 & 6.3302 & \text { TRN }\end{array}$

$\begin{array}{lll}5.1394 & 4.921 & \text { TRN }\end{array}$

5.60525 .5958 TRN

Page 22860 


\begin{tabular}{|c|c|c|c|c|c|c|}
\hline & & & & & & \\
\hline CHEMBL2001316 & 752506 & 5.4281 & 5.3802 & TRN & & \\
\hline CHEMBL3196451 & 752506 & 6.143 & 5.9302 & TRN & & \\
\hline CHEMBL1501432 & 752506 & 5.5444 & 5.9415 & TRN & & \\
\hline CHEMBL1700319 & 752506 & 2.585 & 4.1726 & TRN & & \\
\hline CHEMBL1510390 & 752506 & 4.2081 & 4.6134 & TRN & & \\
\hline CHEMBL1564801 & 752506 & 5.3206 & 4.8303 & TRN & & \\
\hline CHEMBL1318943 & 752506 & 5.2485 & 5.3074 & TRN & & \\
\hline CHEMBL1606291 & 752506 & 5.9622 & 6.0839 & TRN & & \\
\hline CHEMBL582491 & 752506 & 4.4791 & 5.2747 & TRN & & \\
\hline CHEMBL1705009 & 752506 & 5.399 & 4.9546 & TRN & & \\
\hline CHEMBL1301699 & 752506 & 2.585 & 4.8638 & TST & & \\
\hline CHEMBL1432186 & 752506 & 5.7459 & 5.5976 & TRN & & \\
\hline CHEMBL1464024 & 752506 & 5.3226 & 5.45700 & 0000000001 & & TRN \\
\hline CHEMBL1302886 & 752506 & 2.585 & 4.5685 & TRN & & \\
\hline CHEMBL1460315 & 752506 & 5.5782 & 5.79200 & 0000000001 & & TRN \\
\hline CHEMBL 2094652 & 752506 & 4.4752 & 5.7415 & TRN & & \\
\hline CHEMBL1572967 & 752506 & 5.1342 & 4.9281 & TRN & & \\
\hline CHEMBL1437208 & 752506 & 5.09399 & э9999999 & 99 & 5.3426 & TRN \\
\hline CHEMBL1470633 & 752506 & 5.8462 & 5.3971 & TRN & & \\
\hline CHEMBL1459746 & 752506 & 5.3886 & 5.6051 & TRN & & \\
\hline CHEMBL1417809 & 752506 & 5.5879 & 5.8616 & TRN & & \\
\hline CHEMBL1543599 & 752506 & 6.0726 & 5.3939 & TRN & & \\
\hline CHEMBL1334743 & 752506 & 5.1792 & 4.996 & TRN & & \\
\hline CHEMBL1369200 & 752506 & 5.46700 & 00000000 & 005 & 5.2158 & TRN \\
\hline CHEMBL1503066 & 752506 & 5.3445 & 5.0614 & TRN & & \\
\hline CHEMBL 3214238 & 752506 & 4.8499 & 5.1714 & TRN & & \\
\hline CHEMBL1581627 & 752506 & 5.58299 & 99999999 & & 5.686 & TRN \\
\hline CHEMBL1606557 & 752506 & 5.1606 & 5.2185 & TRN & & \\
\hline CHEMBL1449103 & 752506 & 4.2096 & 4.8337 & TRN & & \\
\hline CHEMBL1482513 & 752506 & 5.2461 & 5.5984 & TST & & \\
\hline CHEMBL1403744 & 752506 & 5.901 & 4.9035 & TST & & \\
\hline CHEMBL1383624 & 752506 & 5.0989 & 5.1621 & TST & & \\
\hline CHEMBL1535252 & 752506 & 5.1253 & 5.2547 & TRN & & \\
\hline CHEMBL1993788 & 752506 & 5.4135 & 5.2424 & TRN & & \\
\hline CHEMBL563512 & 752506 & 4.3696 & 5.3888 & TST & & \\
\hline CHEMBL1469642 & 752506 & 2.585 & 4.6676 & TRN & & \\
\hline CHEMBL580609 & 752506 & 5.1663 & 6.0123 & TRN & & \\
\hline CHEMBL1462457 & 752506 & 5.1012 & 5.2503 & TRN & & \\
\hline CHEMBL1343131 & 752506 & 5.0632 & 5.1625 & TRN & & \\
\hline CHEMBL1464433 & 752506 & 5.4833 & 5.1709 & TRN & & \\
\hline CHEMBL3190941 & 752506 & 5.5478 & 5.6618 & TST & & \\
\hline CHEMBL1534042 & 752506 & 5.5361 & 5.3463 & TRN & & \\
\hline CHEMBL3145303 & 752506 & 6.4045 & 6.5845 & TRN & & \\
\hline CHEMBL 3194088 & 752506 & 5.2474 & 4.845 & TRN & & \\
\hline CHEMBL1434450 & 752506 & 5.26399 & و9999999 & & 4.7729 & TST \\
\hline CHEMBL1379600 & 752506 & 5.0326 & 5.09699 & 9999999 & & TRN \\
\hline CHEMBL1482663 & 752506 & 5.2989 & 5.1967 & TST & & \\
\hline CHEMBL1986025 & 752506 & 6.0383 & 5.6781 & TRN & & \\
\hline
\end{tabular}


Supplemental Table S2.txt

\begin{tabular}{|c|c|c|c|c|}
\hline . & & 7932 & & \\
\hline & & .1732 & & \\
\hline 10001 & 06 & & & \\
\hline AEMBL 50 & 2506 & & & \\
\hline AEMBL1972249 & 52506 & & & \\
\hline HEMBL1349631 & 52506 & .8844 & 7503 & \\
\hline HEMBL15 & 506 & & 665 & \\
\hline IFMBI 15 & & & & \\
\hline AEMBL3189393 & 52506 & 18 & & \\
\hline HEMBL1482193 & 52506 & 11 & .9075 & \\
\hline HEMBL1338690 & 52506 & & 2963 & \\
\hline IEMBL15 & 506 & & 812 & \\
\hline IEMBL1: & & & & \\
\hline HEMBL19ऽ & 52506 & & 5.1252 & \\
\hline AEMBL141 & 506 & & 302 & \\
\hline IEMBL13 & 52506 & 36 & $\partial 314$ & \\
\hline AEMBL19 & 06 & & 084 & \\
\hline HEMBL14 & & & & \\
\hline AEMBL13 & 506 & & 9175 & \\
\hline IEMBL15 & 06 & & & \\
\hline $\mathrm{E} \in \mathrm{MB} \mathrm{B}$ & 06 & & & \\
\hline AEMBL3] & $\partial 6$ & & & 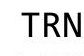 \\
\hline AEMBL16 & $\partial 6$ & & 84 & \\
\hline AEMBL59 & 506 & & 957 & \\
\hline JEMBL13 & & & & v \\
\hline HEMBL1C & 06 & & 553 & 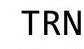 \\
\hline HEMBL31 & 6 & & 74 & RN \\
\hline HFMBI 24 & 06 & & 83 & \\
\hline HEMBL156 & & & & in \\
\hline HEMBL134 & & & 372 & 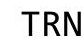 \\
\hline HEMBL1C & 06 & & 826 & RIV \\
\hline HEMBL2 & 6 & & 66 & ST \\
\hline 9 & $\partial 6$ & & 881 & RN \\
\hline HEMBL136 & 52506 & & 3968 & is \\
\hline HEMBL1413424 & 52506 & & 9685 & TRN \\
\hline HEMBL15 & 506 & & 939 & \\
\hline HEMPI 2 & & & 46 & RIV \\
\hline & & & 611 & RN \\
\hline HEMBL1544186 & 52506 & & & TRN \\
\hline AEMBL14 & 52506 & & 135 & TRN \\
\hline HEMBL17 & 52506 & & 3711 & \\
\hline HEMBL19 & & & 5.2664 & TRN \\
\hline HEMBL170 & 52506 & & 4.8955 & IST \\
\hline AEMBL1344292 & 52506 & & 5.2541 & TRN \\
\hline MBL1S & 06 & & 5.7267 & $n$ \\
\hline HEMBL19 & 66 & & .5181 & \\
\hline CHEMBL578716 & 52506 & & 5.6135 & \\
\hline CHEMBL170730 & 752506 & 5.2721 & 5.2698 & ГRN \\
\hline
\end{tabular}

Page 22862 


\begin{tabular}{ll} 
CHEMBL1544409 & 752506 \\
CHEMBL1560290 & 752506 \\
CHEMBL1440862 & 752506 \\
CHEMBL1347533 & 752506 \\
CHEMBL1437888 & 752506 \\
CHEMBL3194214 & 752506 \\
CHEMBL530361 & 752506 \\
CHEMBL1968316 & 752506 \\
CHEMBL1425921 & 752506 \\
CHEMBL1471752 & 752506 \\
CHEMBL1372292 & 752506 \\
CHEMBL1478826 & 752506 \\
CHEMBL1315169 & 752506 \\
CHEMBL1602800 & 752506 \\
CHEMBL1442500 & 752506 \\
CHEMBL1412039 & 752506 \\
CHEMBL566283 & 752506 \\
CHEMBL1557298 & 752506 \\
CHEMBL1379149 & 752506 \\
CHEMBL3197716 & 752506 \\
CHEMBL3208260 & 752506 \\
CHEMBL1573112 & 752506 \\
CHEMBL1418948 & 752506 \\
CHEMBL1717930 & 752506 \\
CHEMBL3191106 & 752506 \\
CHEMBL1555499 & 752506 \\
CHEMBL1380801 & 752506 \\
CHEMBL1452090 & 752506 \\
CHEMBL1468344 & 752506 \\
CHEMBL1310341 & 752506 \\
CHEMBL591412 & 752506 \\
CHEMBL2004417 & 752506 \\
CHEMEMBL1718568 & 752506 \\
CHEMBL3199198 & 752506 \\
CHEMBL3189323 & 752506 \\
CHEMBL1384373 & 752506 \\
CHEMBL1319643 & 752506 \\
CHEMBL1348853 & 752506 \\
CHEMBL1413931 & 752506 \\
CHEMBL3189344 & 752506 \\
CHEMBL1561237 & 752506 \\
CHEMBL1498681 & 752506 \\
\hline
\end{tabular}

Supplemental Table S2.txt

$\begin{array}{llll}5.6024 & 5.1556 & \text { TST } & \\ 5.5291 & 5.1211 & \text { TRN } & \\ 7.71 & 6.0378 & \text { TRN } & \\ 5.2598 & 5.5025 & \text { TRN } & \\ 5.1358 & 4.9175 & \text { TST } & \\ 5.5919 & 5.582000000000001 & \text { TRN }\end{array}$

$\begin{array}{lll}5.6031 & 5.3886 & \text { TRN }\end{array}$

$\begin{array}{lll}4.3576 & 5.2201 & \text { TRN }\end{array}$

5.44175 .5582 TRN

$\begin{array}{lll}5.025 & 4.3803 & \text { TRN }\end{array}$

$\begin{array}{llll}5.965 & 5.3298 & \text { TRN }\end{array}$

5.68615 .5461 TRN

$\begin{array}{lll}5.3321 & 5.3201 & \text { TRN }\end{array}$

$\begin{array}{llll}5.4653 & 5.3983 & \text { TRN }\end{array}$

$\begin{array}{lll}5.4627 & 5.5508 & \text { TRN }\end{array}$

$\begin{array}{lll}5.4473 & 5.3841 & \text { TRN }\end{array}$

$5.1115 \quad 5.0826$ TRN

$\begin{array}{lll}4.9842 & 5.1489 & \text { TRN }\end{array}$

$\begin{array}{lll}5.3341 & 5.3197 & \text { TRN }\end{array}$

6.08655 .5142 TRN

$\begin{array}{llll}2.585 & 4.7858 & \text { TRN }\end{array}$

$\begin{array}{lll}5.1826 & 4.9273 & \text { TRN }\end{array}$

$\begin{array}{llll}4.7926 & 4.6739 & \text { TST }\end{array}$

$5.3053 \quad 5.3881$ TRN

$\begin{array}{lll}6.2 & 5.597 & \text { TRN }\end{array}$

$\begin{array}{lll}5.6588 & 5.5863 & \text { TRN }\end{array}$

$5.2125 \quad 5.4687$ TRN

$\begin{array}{lll}5.257000000000001 & 5.568 & \text { TRN }\end{array}$

$5.4679 \quad 5.1142$ TRN

$5.4954 \quad 5.0426$ TRN

$\begin{array}{lll}5.9416 & 6.0794 & \text { TRN }\end{array}$

$\begin{array}{lll}6.3162 & 6.1269 & \text { TRN }\end{array}$

$\begin{array}{lll}5.0752 & 5.641 & \text { TRN }\end{array}$

$6.2378 \quad 5.3249$ TRN

$\begin{array}{lll}5.284 & 5.8 & \text { TRN }\end{array}$

$5.1092 \quad 5.1474$ TRN

$5.7199 \quad 5.6083$ TRN

$\begin{array}{llll}5.0942 & 4.7886 & \text { TRN }\end{array}$

$5.2882 \quad 5.3313$ TRN

6.05595 .7559 TRN

$\begin{array}{lll}5.1022 & 5.537000000000001 & \text { TRN }\end{array}$

$4.731 \quad 4.9574$ TRN

$\begin{array}{lll}5.287000000000001 & 5.617000000000001 & \text { TRN }\end{array}$

$5.6745 \quad 5.7051$ TRN

$4.5648 \quad 5.1719$ TRN

$5.5577 \quad 5.2772$ TST

$5.4288 \quad 5.8147 \quad$ TRN

5.09195 .1795 TRN

Page 22863 


\begin{tabular}{ll} 
CHEMBL1611650 & 752506 \\
CHEMBL124006 & 752506 \\
CHEMBL1538410 & 752506 \\
CHEMBL1326163 & 752506 \\
CHEMBL1438881 & 752506 \\
CHEMBL3197259 & 752506 \\
CHEMBL1516510 & 752506 \\
CHEMBL1542809 & 752506 \\
CHEMBL1530315 & 752506 \\
CHEMBL1468672 & 752506 \\
CHEMBL1478673 & 752506 \\
CHEMBL1400298 & 752506 \\
CHEMBL3196698 & 752506 \\
CHEMBL1458182 & 752506 \\
CHEMBL1544743 & 752506 \\
CHEMBL455284 & 752506 \\
CHEMBL2003651 & 752506 \\
CHEMBL1319488 & 752506 \\
CHEMBL592316 & 752506 \\
CHEMBL1533366 & 752506 \\
CHEMBL1597627 & 752506 \\
CHEMBL3198557 & 752506 \\
CHEMBL3193805 & 752506 \\
CHEMBL1579644 & 752506 \\
CHEMBL1575392 & 752506 \\
CHEMBL1512573 & 752506 \\
CHEMBL1532242 & 752506 \\
CHEMBL1335704 & 752506 \\
CHEMBL1370471 & 752506 \\
CHEMBL1981200 & 752506 \\
CHEMBL1448627 & 752506 \\
CHEMEMBL & \\
CHEMBL1338339 & 752506 \\
CHEMBL1547025 & 752506 \\
CHEMBL1508593 & 752506 \\
CHEMBL546170 & 752506 \\
CHEMBL1565115 & 752506 \\
CHEMBL1499935 & 752506 \\
CHEMBL1393940 & 752506 \\
CHEMBL1521758 & 752506 \\
CHEMBL1357277 & 752506 \\
CHEMBL544584 & 752506 \\
\hline
\end{tabular}

Supplemental Table S2.txt
$\begin{array}{lll}5.6209 & 5.1074 & \text { TRN }\end{array}$
$6.2732 \quad 5.2308$ TRN
$5.3956 \quad 5.2764$ TRN
$4.5482 \quad 5.0973$ TRN
6.60856 .3503 TRN
$\begin{array}{lll}5.9083 & 6.2989999999999995 & \text { TRN }\end{array}$
$5.1029 \quad 5.4748$ TRN

5.61145 .1955 TRN

$\begin{array}{lll}5.0963 & 5.1908 \text { TRN }\end{array}$

$5.5638 \quad 5.4157 \quad$ TRN

$2.9208 \quad 4.9317$ TRN

6.127000000000001

$5.2997 \quad 5.0149$ TRN

$\begin{array}{lll}2.585 & 4.8125 & \text { TST }\end{array}$

$5.5859 \quad 5.2171$ TRN

$\begin{array}{lll}7.71 & 6.5137 \quad \text { TRN }\end{array}$

5.582999999999999

$\begin{array}{lll}5.9161 & 5.5157 & \text { TRN }\end{array}$

$5.617999999999999 \quad$ TRN

$5.2825 \quad 5.0307$ TRN

$\begin{array}{lll}5.4163 & 5.3882 & \text { TRN }\end{array}$

$\begin{array}{lll}5.6598 & 5.9339 & \text { TRN }\end{array}$

$\begin{array}{lll}4.8265 & 5.6217 & \text { TRN }\end{array}$

$\begin{array}{lll}5.4453 & 5.6792 & \text { TRN }\end{array}$

$\begin{array}{lll}5.6323 & 5.0379 & \text { TRN }\end{array}$

$\begin{array}{llll}4.9416 & 4.7967 & \text { TRN }\end{array}$

$\begin{array}{llll}5.2047 & 4.6414 & \text { TRN }\end{array}$

$\begin{array}{lll}2.585 & 4.8568 & \text { TRN }\end{array}$

$\begin{array}{llll}4.2428 & 5.3568 & \text { TRN }\end{array}$

$5.6659 \quad 5.6994$ TRN

$\begin{array}{lll}5.5011 & 6.0297 & \text { TRN }\end{array}$

$\begin{array}{lll}5.6631 & 5.5722 & \text { TST }\end{array}$

$\begin{array}{lll}2.585 & 5.1252 & \text { TRN }\end{array}$

$\begin{array}{lll}5.119 & 5.2196 & \text { TRN }\end{array}$

$\begin{array}{lll}5.2648 & 5.1154 & \text { TST }\end{array}$

$\begin{array}{lll}5.9311 & 5.5755 & \text { TRN }\end{array}$

5.50175 .4263 TRN

5.247999999999999

$\begin{array}{lll}4.8778 & 5.1634 & \text { TRN }\end{array}$

5.9493 TRN

$\begin{array}{lll}5.1178 & 4.9812 & \text { TRN }\end{array}$

$\begin{array}{llll}5.5011 & 5.3069 & \text { TST }\end{array}$

$\begin{array}{lll}5.582000000000001 & 5.6071 & \text { TRN }\end{array}$

$\begin{array}{llll}5.0683 & 4.8266 & \text { TRN }\end{array}$

$5.4562 \quad 5.4865$ TRN

$4.8752 \quad 5.8103$ TST

$5.4122 \quad 5.5361$ TRN

$\begin{array}{lll}5.529 & 5.4324 & \text { TRN }\end{array}$

$5.6657 \quad 5.9887 \quad$ TRN

5.57995 .5827 TRN

4.8818 TRN

Page 22864 
Supplemental Table S2.txt

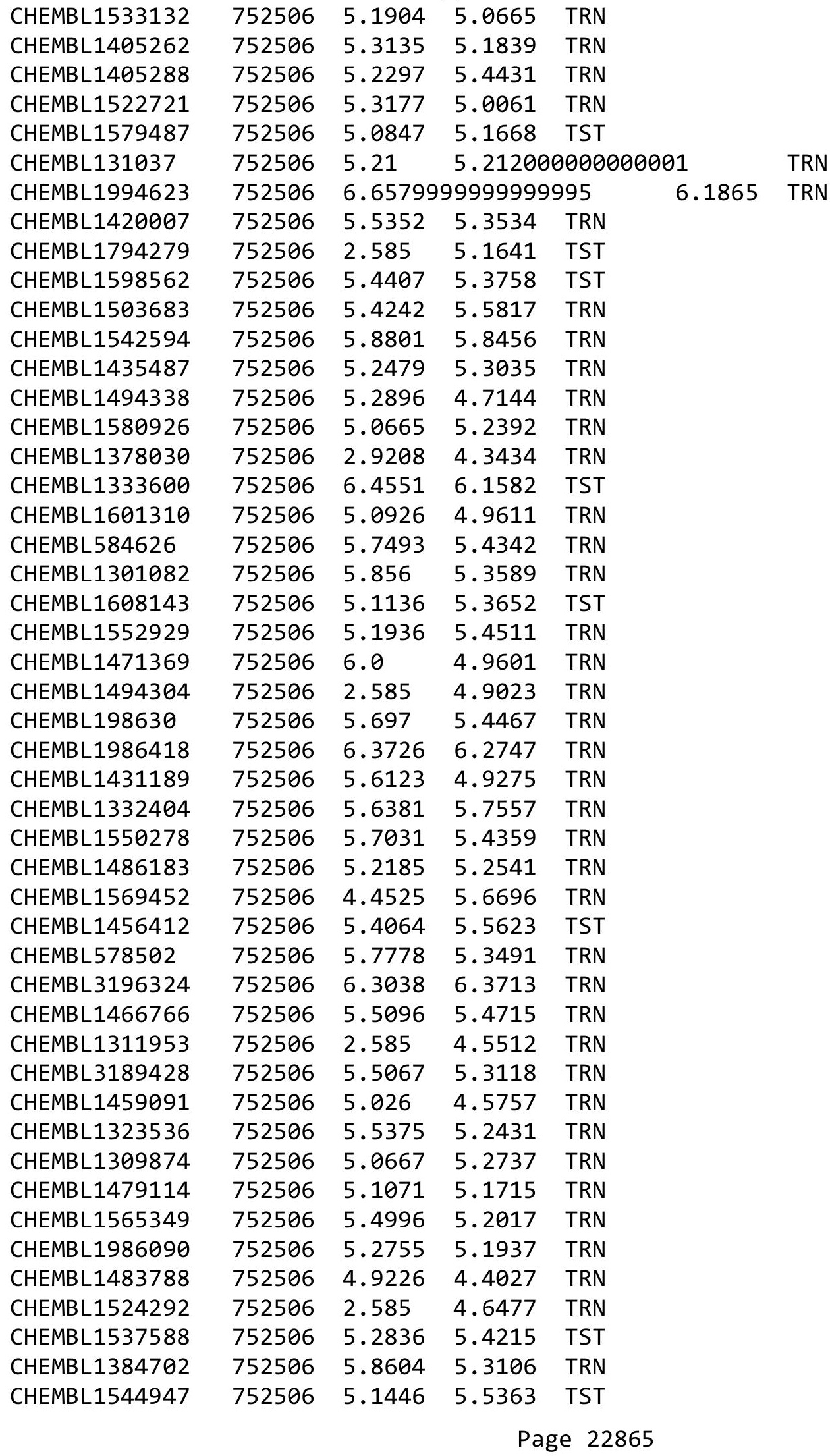




\begin{tabular}{|c|c|c|c|c|c|}
\hline & & \\
\hline CHEMBL1968732 & 752506 & 5.1646 & 5.4867 & TRN & \\
\hline CHEMBL1367466 & 752506 & 5.4848 & 5.1482 & TRN & \\
\hline CHEMBL3197931 & 752506 & 5.4501 & 5.6315 & TRN & \\
\hline CHEMBL1462076 & 752506 & 5.3622 & 5.3968 & TRN & \\
\hline CHEMBL1519239 & 752506 & 5.6189 & 5.4553 & TRN & \\
\hline CHEMBL1416089 & 752506 & 5.244 & 5.3477 & TRN & \\
\hline CHEMBL1980657 & 752506 & 5.4244 & 5.8238 & TRN & \\
\hline CHEMBL586135 & 752506 & 6.2218 & 6.4994 & TRN & \\
\hline CHEMBL1497918 & 752506 & 5.1061 & 5.4102 & TRN & \\
\hline CHEMBL1306583 & 752506 & 5.1129 & 4.8169 & TRN & \\
\hline CHEMBL1606145 & 752506 & 5.2655 & 5.4357 & TRN & \\
\hline CHEMBL1789998 & 752506 & 6.6568 & 6.3795 & TRN & \\
\hline CHEMBL1538398 & 752506 & 4.1929 & 5.4766 & TST & \\
\hline CHEMBL1794134 & 752506 & 5.6221 & 5.8489 & TRN & \\
\hline CHEMBL1577266 & 752506 & 5.2153 & 5.0667 & TST & \\
\hline CHEMBL585591 & 752506 & 6.6386 & 6.8011 & TRN & \\
\hline CHEMBL1369287 & 752506 & 5.1511 & 5.5096 & TST & \\
\hline CHEMBL1699408 & 752506 & 5.0212 & 5.4108 & TRN & \\
\hline CHEMBL1452585 & 752506 & 4.8339 & 5.391 & TST & \\
\hline CHEMBL1318350 & 752506 & 7.71 & 7.2447 & TRN & \\
\hline CHEMBL1717265 & 752506 & 5.2844 & 5.1911 & TRN & \\
\hline CHEMBL1531512 & 752506 & 5.1309 & 5.5317 & TST & \\
\hline CHEMBL1334062 & 752506 & 6.3557 & 5.74100 & 00000000005 & TRN \\
\hline CHEMBL547285 & 752506 & 6.2717 & 6.1501 & TRN & \\
\hline CHEMBL1542936 & 752506 & 5.5924 & 5.4374 & TRN & \\
\hline CHEMBL1316978 & 752506 & 5.75700 & 00000000 & 5.0208 & TRN \\
\hline CHEMBL1476017 & 752506 & 5.2215 & 5.7885 & TST & \\
\hline CHEMBL1591383 & 752506 & 5.267 & 5.1899 & TRN & \\
\hline CHEMBL1313469 & 752506 & 4.542 & 5.0027 & TST & \\
\hline CHEMBL3145296 & 752506 & 6.0468 & 5.8785 & TRN & \\
\hline CHEMBL1999960 & 752506 & 5.5859 & 5.2393 & TRN & \\
\hline CHEMBL3209306 & 752506 & 5.8074 & 6.1093 & TRN & \\
\hline CHEMBL1361675 & 752506 & 4.9439 & 5.001 & TST & \\
\hline CHEMBL1339245 & 752506 & 5.5532 & 5.6158 & TRN & \\
\hline CHEMBL1460522 & 752506 & 5.3393 & 5.4071 & TRN & \\
\hline CHEMBL1610706 & 752506 & 5.379 & 5.0682 & TRN & \\
\hline CHEMBL1419822 & 752506 & 5.1329 & 5.0821 & TRN & \\
\hline CHEMBL1538392 & 752506 & 5.2732 & 4.4437 & TRN & \\
\hline CHEMBL1595766 & 752506 & 5.3669 & 4.8498 & TRN & \\
\hline CHEMBL338474 & 752506 & 5.6444 & 5.6399 & TST & \\
\hline CHEMBL1484487 & 752506 & 5.3859 & 5.8746 & TRN & \\
\hline CHEMBL1469568 & 752506 & 4.9614 & 4.9636 & TST & \\
\hline CHEMBL1300956 & 752506 & 5.6153 & 5.4707 & TRN & \\
\hline CHEMBL1309091 & 752506 & 6.0523 & 5.7892 & TRN & \\
\hline CHEMBL 3196980 & 752506 & 4.9974 & 5.3248 & TRN & \\
\hline CHEMBL1600684 & 752506 & 5.0588 & 5.4616 & TRN & \\
\hline CHEMBL1329148 & 752506 & 4.852 & 5.1645 & TST & \\
\hline CHEMBL1420742 & 752506 & 5.2291 & 4.7997 & TST & \\
\hline
\end{tabular}

Page 22866 


\begin{tabular}{|c|c|c|c|c|c|c|}
\hline & & \multicolumn{5}{|c|}{ Supplemental Table s2.txt } \\
\hline CHEMBL1517752 & 752506 & 5.6094 & 5.1417 & TRN & & \\
\hline CHEMBL1347339 & 752506 & 5.4669 & 5.3051 & TRN & & \\
\hline CHEMBL3199820 & 752506 & 5.6684 & 5.9057 & TRN & & \\
\hline CHEMBL1461209 & 752506 & 6.0008 & 5.9162 & TRN & & \\
\hline CHEMBL1366319 & 752506 & 5.8077 & 5.5206 & TRN & & \\
\hline CHEMBL1316193 & 752506 & 5.688 & 6.2234 & TRN & & \\
\hline CHEMBL1518765 & 752506 & \multicolumn{3}{|c|}{5.297999999999999} & 5.0406 & TRN \\
\hline CHEMBL1456725 & 752506 & 2.585 & 5.1432 & TST & & \\
\hline CHEMBL1485023 & 752506 & 5.25 & 5.1895 & TRN & & \\
\hline CHEMBL1974389 & 752506 & 5.6676 & 5.4365 & TST & & \\
\hline CHEMBL1333664 & 752506 & 4.5496 & 4.891 & TST & & \\
\hline CHEMBL1463714 & 752506 & 5.5707 & 5.1755 & TRN & & \\
\hline CHEMBL586029 & 752506 & 5.2041 & 5.2223 & TRN & & \\
\hline CHEMBL1580472 & 752506 & 5.4646 & 5.5497 & TRN & & \\
\hline CHEMBL1525432 & 752506 & 4.5379 & 4.7654 & TRN & & \\
\hline CHEMBL1393820 & 752506 & 5.4421 & 5.9755 & TRN & & \\
\hline CHEMBL1990783 & 752506 & 5.9245 & 5.8942 & TRN & & \\
\hline CHEMBL 2002465 & 752506 & 5.5784 & 5.4775 & TRN & & \\
\hline CHEMBL1582088 & 752506 & 5.5484 & 5.6658 & TRN & & \\
\hline CHEMBL1404846 & 752506 & 2.585 & 4.7664 & TRN & & \\
\hline CHEMBL1444481 & 752506 & 4.7402 & 4.5216 & TRN & & \\
\hline CHEMBL1564201 & 752506 & 5.0542 & 4.7673 & TRN & & \\
\hline CHEMBL1973050 & 752506 & 5.5715 & 5.2517 & TRN & & \\
\hline CHEMBL3194563 & 752506 & 6.0438 & 5.7104 & TRN & & \\
\hline CHEMBL3208365 & 752506 & 5.5698 & 5.4255 & TST & & \\
\hline CHEMBL1478310 & 752506 & 5.9855 & 5.5982 & TRN & & \\
\hline CHEMBL1509727 & 752506 & 5.315 & 5.6944 & TRN & & \\
\hline CHEMBL1332450 & 752506 & 5.6164 & 6.0509 & TRN & & \\
\hline CHEMBL 3194640 & 752506 & 5.224 & 5.6388 & TRN & & \\
\hline CHEMBL1427969 & 752506 & 5.6494 & 4.9135 & TST & & \\
\hline CHEMBL1527828 & 752506 & 5.4368 & 5.1319 & TRN & & \\
\hline CHEMBL1405975 & 752506 & \multicolumn{3}{|c|}{5.257999999999999} & 5.5547 & TST \\
\hline CHEMBL1794087 & 752506 & 4.8645 & 5.0554 & TRN & & \\
\hline CHEMBL1499501 & 752506 & 5.5902 & 5.6981 & TST & & \\
\hline CHEMBL1532828 & 752506 & 5.5569 & 5.7746 & TRN & & \\
\hline CHEMBL1509896 & 752506 & 5.5974 & 5.3952 & TRN & & \\
\hline CHEMBL1343952 & 752506 & 5.1754 & 5.1986 & TRN & & \\
\hline CHEMBL1608578 & 752506 & 4.7547 & 4.6373 & TRN & & \\
\hline CHEMBL1711510 & 752506 & 2.585 & 4.7148 & TRN & & \\
\hline CHEMBL1579599 & 752506 & 5.4438 & 5.4124 & TRN & & \\
\hline CHEMBL1529190 & 752506 & 5.7109 & 5.724 & TRN & & \\
\hline CHEMBL1315704 & 752506 & 5.0548 & 4.7684 & TRN & & \\
\hline CHEMBL1608942 & 752506 & 5.2904 & 5.0548 & TRN & & \\
\hline CHEMBL1333387 & 752506 & 5.2738 & 5.1358 & TRN & & \\
\hline CHEMBL2006154 & 752506 & 5.4671 & 5.17 & TRN & & \\
\hline CHEMBL601768 & 752506 & \multicolumn{3}{|c|}{6.3389999999999995} & 6.2756 & TRN \\
\hline CHEMBL589238 & 752506 & 5.9776 & 5.4706 & TRN & & \\
\hline CHEMBL1482951 & 752506 & 5.5021 & 5.438 & TST & & \\
\hline
\end{tabular}




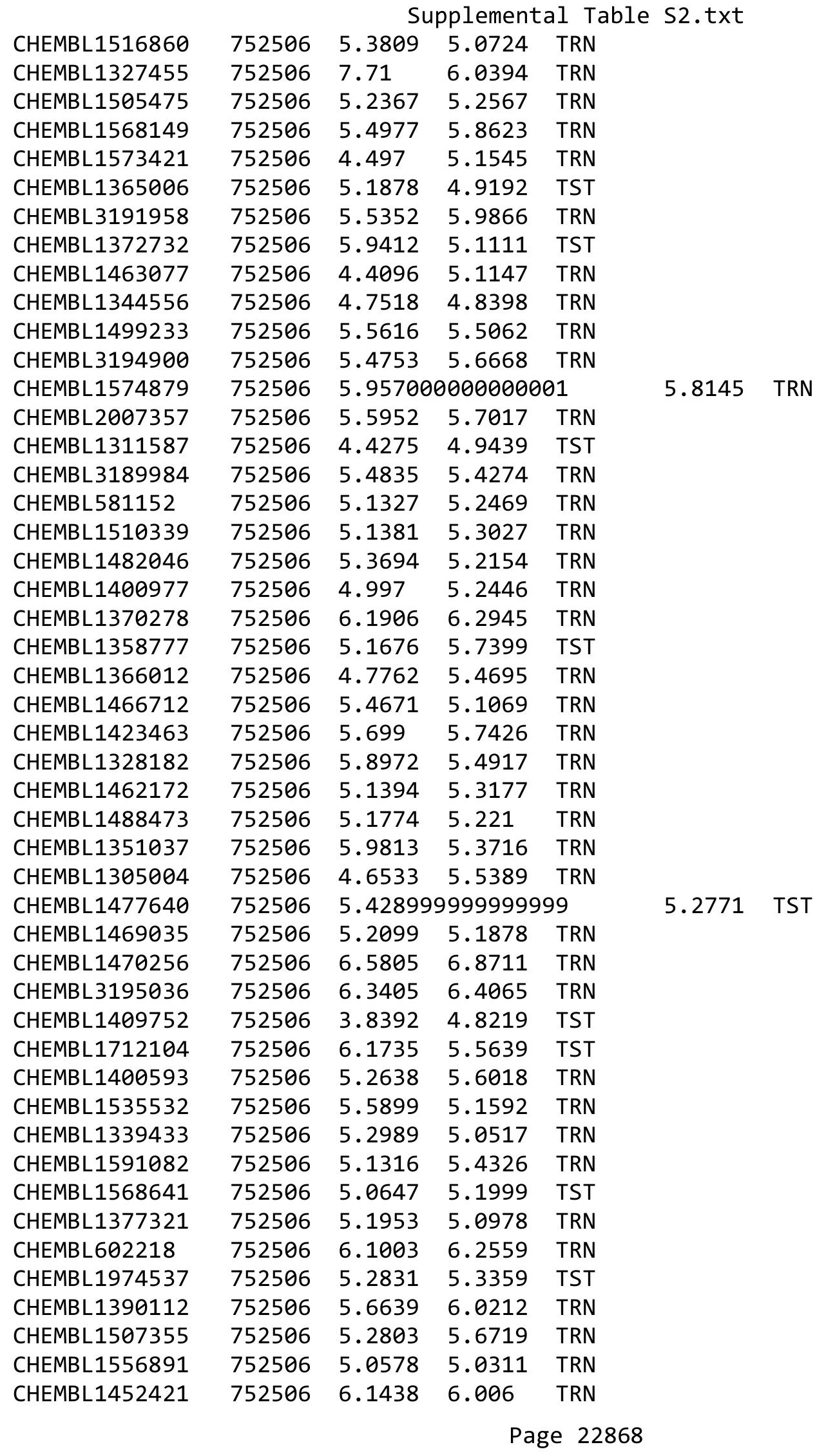




\begin{tabular}{|c|c|c|c|c|c|c|}
\hline & & & pplement & al Table & $52 . t x t$ & \\
\hline CHEMBL1454611 & 752506 & 5.4761 & 6.0543 & TRN & & \\
\hline CHEMBL604321 & 752506 & 5.9872 & 5.80200 & 00000000 & 305 & TRN \\
\hline CHEMBL 3198754 & 752506 & 6.1266 & 5.942 & TRN & & \\
\hline CHEMBL1981570 & 752506 & 5.4169 & 5.86 & TRN & & \\
\hline CHEMBL 3190849 & 752506 & 5.1725 & 5.2346 & TRN & & \\
\hline CHEMBL1442280 & 752506 & 6.022 & 6.0544 & TRN & & \\
\hline CHEMBL1544371 & 752506 & 5.7528 & 5.7757 & TRN & & \\
\hline CHEMBL1324032 & 752506 & 5.4904 & 5.2109 & TST & & \\
\hline CHEMBL1702299 & 752506 & 5.0942 & 4.9742 & TST & & \\
\hline CHEMBL3196457 & 752506 & 5.5766 & 5.29200 & 00000000 & & TRN \\
\hline CHEMBL1986741 & 752506 & 5.1969 & 5.0679 & TRN & & \\
\hline CHEMBL1530707 & 752506 & 5.435 & 5.2704 & TST & & \\
\hline CHEMBL1300612 & 752506 & 5.5271 & 5.2391 & TRN & & \\
\hline CHEMBL1982569 & 752506 & 6.046 & 6.2184 & TRN & & \\
\hline CHEMBL1978354 & 752506 & 5.5177 & 5.4822 & TRN & & \\
\hline CHEMBL578515 & 752506 & 5.4931 & 5.2318 & TRN & & \\
\hline CHEMBL1365622 & 752506 & 4.9523 & 5.2542 & TRN & & \\
\hline CHEMBL1545435 & 752506 & 5.1375 & 4.7254 & TRN & & \\
\hline CHEMBL1511219 & 752506 & 5.9488 & 6.0726 & TRN & & \\
\hline CHEMBL 3197275 & 752506 & 5.0488 & 5.0967 & TRN & & \\
\hline CHEMBL1420404 & 752506 & 5.3191 & 5.0915 & TRN & & \\
\hline CHEMBL1403755 & 752506 & 5.23799 & 99999999 & 995 & 5.1659 & TRN \\
\hline CHEMBL1443900 & 752506 & 5.4185 & 5.1228 & TST & & \\
\hline CHEMBL1598465 & 752506 & 5.1273 & 4.9165 & TST & & \\
\hline CHEMBL1587031 & 752506 & 5.1358 & 4.7466 & TRN & & \\
\hline CHEMBL1432721 & 752506 & 5.5258 & 5.2777 & TRN & & \\
\hline CHEMBL1714867 & 752506 & 5.4911 & 5.5679 & TRN & & \\
\hline CHEMBL1984190 & 752506 & 5.7991 & 5.8041 & TRN & & \\
\hline CHEMBL1794083 & 752506 & 2.585 & 5.3804 & TST & & \\
\hline CHEMBL1403484 & 752506 & 5.5458 & 5.8362 & TRN & & \\
\hline CHEMBL577102 & 752506 & 5.1442 & 5.0286 & TRN & & \\
\hline CHEMBL1606583 & 752506 & 5.7007 & 6.1296 & TRN & & \\
\hline CHEMBL1368384 & 752506 & 5.439 & 5.0145 & TRN & & \\
\hline CHEMBL1329016 & 752506 & 5.1874 & 4.8956 & TST & & \\
\hline CHEMBL1424596 & 752506 & 5.3563 & 5.0358 & TRN & & \\
\hline CHEMBL1501632 & 752506 & 5.3598 & 5.2456 & TRN & & \\
\hline CHEMBL1998716 & 752506 & 5.0391 & 5.4117 & TRN & & \\
\hline CHEMBL1568827 & 752506 & 5.57299 & 99999999 & 995 & 5.3931 & TRN \\
\hline CHEMBL 3193989 & 752506 & 5.7696 & 6.02 & TRN & & \\
\hline CHEMBL1717082 & 752506 & 5.4547 & 5.1402 & TST & & \\
\hline CHEMBL1501236 & 752506 & 5.2431 & 5.539 & TRN & & \\
\hline CHEMBL1338667 & 752506 & 5.7169 & 4.9505 & TRN & & \\
\hline CHEMBL1478187 & 752506 & 4.8884 & 5.2017 & TRN & & \\
\hline CHEMBL1435517 & 752506 & 4.848 & 5.1588 & TRN & & \\
\hline CHEMBL1701527 & 752506 & 5.3011 & 5.2428 & TST & & \\
\hline CHEMBL1449018 & 752506 & 5.1586 & 4.9873 & TRN & & \\
\hline CHEMBL1427516 & 752506 & 2.585 & 4.9452 & TST & & \\
\hline CHEMBL1328118 & 752506 & 5.13299 & 9999999 & 99 & 5.0328 & TRN \\
\hline
\end{tabular}




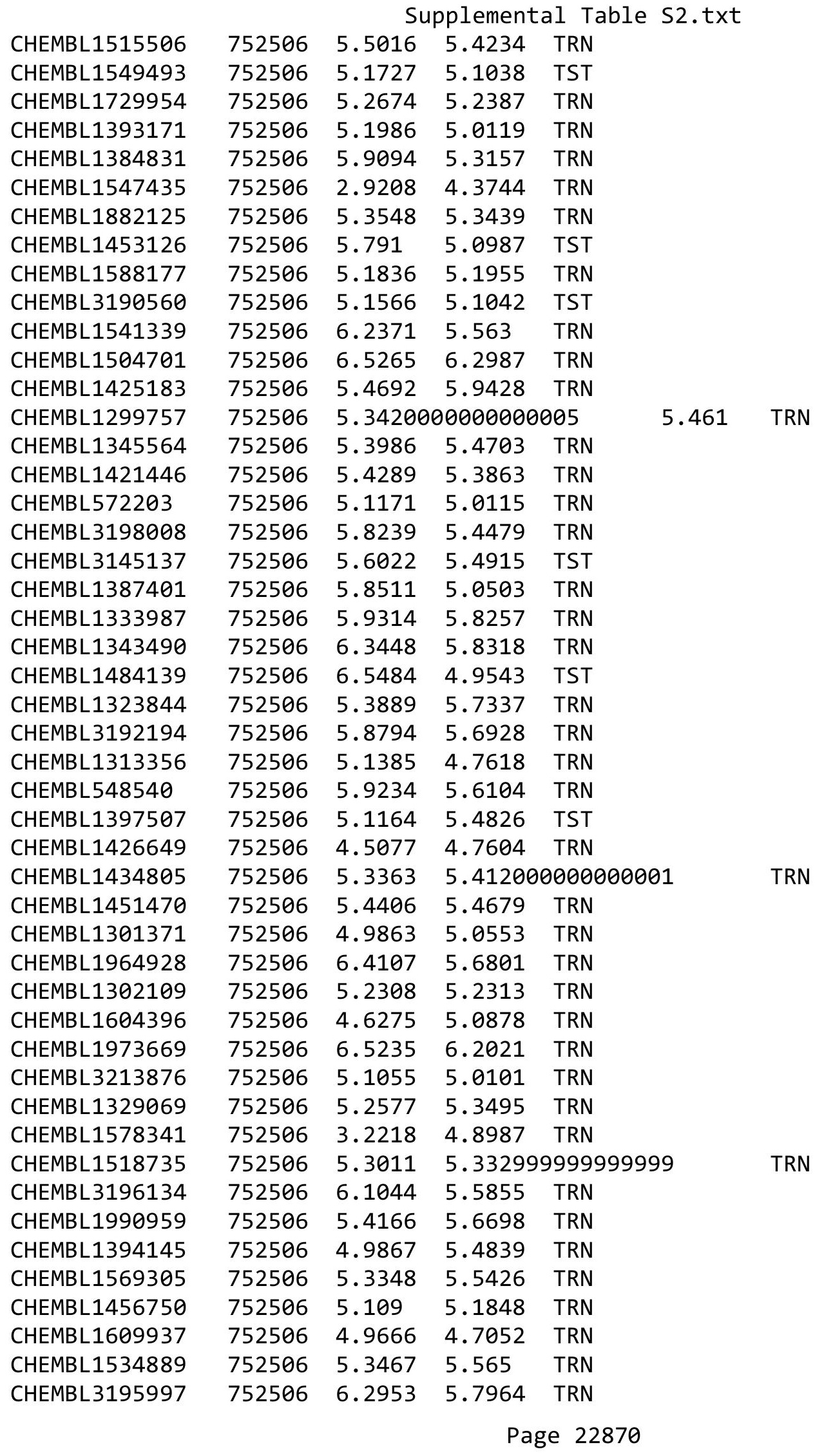




\begin{tabular}{|c|c|c|c|c|c|c|c|}
\hline & & & & & & & \\
\hline CHEMBL1312953 & 752506 & 6.0281 & 6.1412 & TRN & & & \\
\hline CHEMBL3192713 & 752506 & 5.2209 & 5.2336 & TST & & & \\
\hline CHEMBL1374384 & 752506 & 4.6891 & 4.921 & TRN & & & \\
\hline CHEMBL1309573 & 752506 & 5.565 & 6.2207 & TRN & & & \\
\hline CHEMBL1998184 & 752506 & 5.166 & 5.2421 & TRN & & & \\
\hline CHEMBL1424697 & 752506 & 5.282 & 5.5116 & TRN & & & \\
\hline CHEMBL 2002008 & 752506 & 6.0636 & 5.8167 & TRN & & & \\
\hline CHEMBL1467678 & 752506 & 5.6183 & 5.5833 & TST & & & \\
\hline CHEMBL1352223 & 752506 & 5.2819 & 4.8371 & TST & & & \\
\hline CHEMBL1589457 & 752506 & 5.4958 & 4.9905 & TRN & & & \\
\hline CHEMBL1404792 & 752506 & 7.71 & 7.4969 & TRN & & & \\
\hline CHEMBL1348057 & 752506 & 5.1864 & 5.2499 & TRN & & & \\
\hline CHEMBL3190868 & 752506 & 6.2526 & 6.2785 & TRN & & & \\
\hline CHEMBL1407169 & 752506 & 5.0975 & 5.4764 & TST & & & \\
\hline CHEMBL1448592 & 752506 & 5.9851 & 5.9501 & TRN & & & \\
\hline CHEMBL1541725 & 752506 & 5.4481 & 5.3332 & TRN & & & \\
\hline CHEMBL1301313 & 752506 & 5.2489 & 4.8467 & TRN & & & \\
\hline CHEMBL1384942 & 752506 & 5.2715 & 5.5154 & TRN & & & \\
\hline CHEMBL1404277 & 752506 & 5.42399 & 99999999 & 995 & 5.0758 & TST & \\
\hline CHEMBL 578512 & 752506 & 6.2027 & 6.2902 & TRN & & & \\
\hline CHEMBL1468750 & 752506 & 5.4053 & 5.3436 & TRN & & & \\
\hline CHEMBL600060 & 752506 & 5.59399 & 99999999 & & 5.79200 & 0000000001 & TRN \\
\hline CHEMBL1378034 & 752506 & 5.1489 & 4.9906 & TRN & & & \\
\hline CHEMBL1487952 & 752506 & 5.17399 & 99999999 & 995 & 5.2468 & TRN & \\
\hline CHEMBL1322082 & 752506 & 5.0469 & 5.7715 & TST & & & \\
\hline CHEMBL1874620 & 752506 & 5.765 & 5.7469 & TRN & & & \\
\hline CHEMBL1398961 & 752506 & 4.9842 & 5.1508 & TRN & & & \\
\hline CHEMBL1512033 & 752506 & 2.585 & 4.9983 & TST & & & \\
\hline CHEMBL3196976 & 752506 & 5.7174 & 5.4793 & TST & & & \\
\hline CHEMBL1502410 & 752506 & 4.8398 & 5.2796 & TRN & & & \\
\hline CHEMBL1359252 & 752506 & 5.0453 & 5.1707 & TRN & & & \\
\hline CHEMBL1529622 & 752506 & 4.8642 & 4.8409 & TST & & & \\
\hline CHEMBL1382022 & 752506 & 3.2218 & 4.3938 & TRN & & & \\
\hline CHEMBL1346771 & 752506 & 5.0735 & 5.7752 & TRN & & & \\
\hline CHEMBL1317513 & 752506 & 5.7773 & 5.8583 & TRN & & & \\
\hline CHEMBL3197912 & 752506 & 5.6164 & 5.82100 & 0000000001 & & TRN & \\
\hline CHEMBL1402496 & 752506 & 5.087 & 4.8532 & TST & & & \\
\hline CHEMBL1347861 & 752506 & 5.6964 & 5.3124 & TRN & & & \\
\hline CHEMBL1473642 & 752506 & 5.3892 & 4.9855 & TST & & & \\
\hline CHEMBL1487065 & 752506 & 5.115 & 5.0753 & TRN & & & \\
\hline CHEMBL1447711 & 752506 & 5.2334 & 5.1346 & TRN & & & \\
\hline CHEMBL1524734 & 752506 & 5.9329 & 5.4492 & TRN & & & \\
\hline CHEMBL1461738 & 752506 & 5.1227 & 5.3128 & TRN & & & \\
\hline CHEMBL1331851 & 752506 & 5.6702 & 5.619 & TRN & & & \\
\hline CHEMBL3189394 & 752506 & 5.4022 & 5.505 & TRN & & & \\
\hline CHEMBL1486109 & 752506 & 5.4195 & 5.5945 & TRN & & & \\
\hline CHEMBL1453469 & 752506 & 5.2446 & 4.7301 & TRN & & & \\
\hline CHEMBL199868 & 752506 & 6.1952 & 6.2371 & TRN & & & \\
\hline
\end{tabular}

Page 22871 
Supplemental Table S2.txt

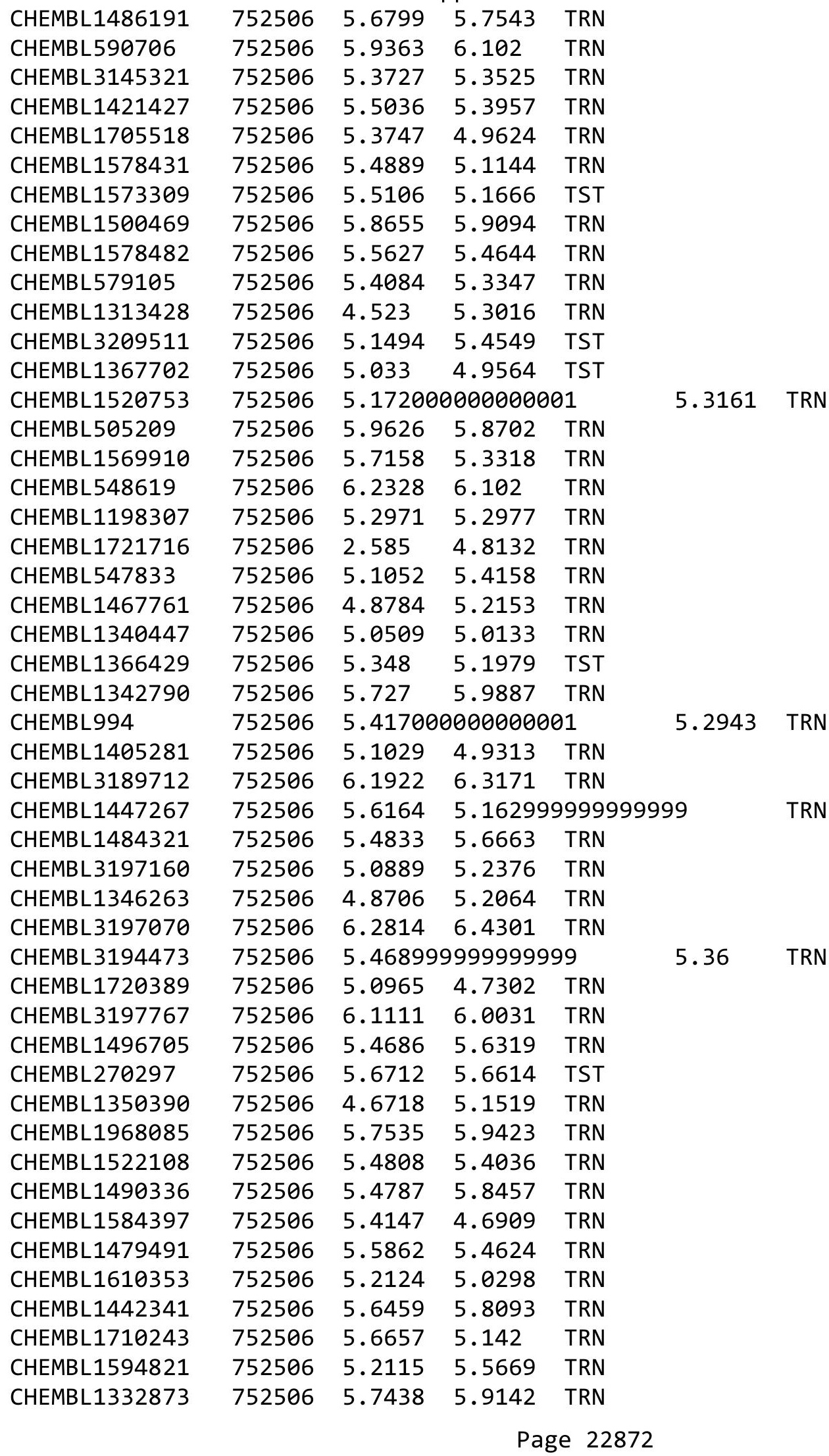


Supplemental Table S2.txt

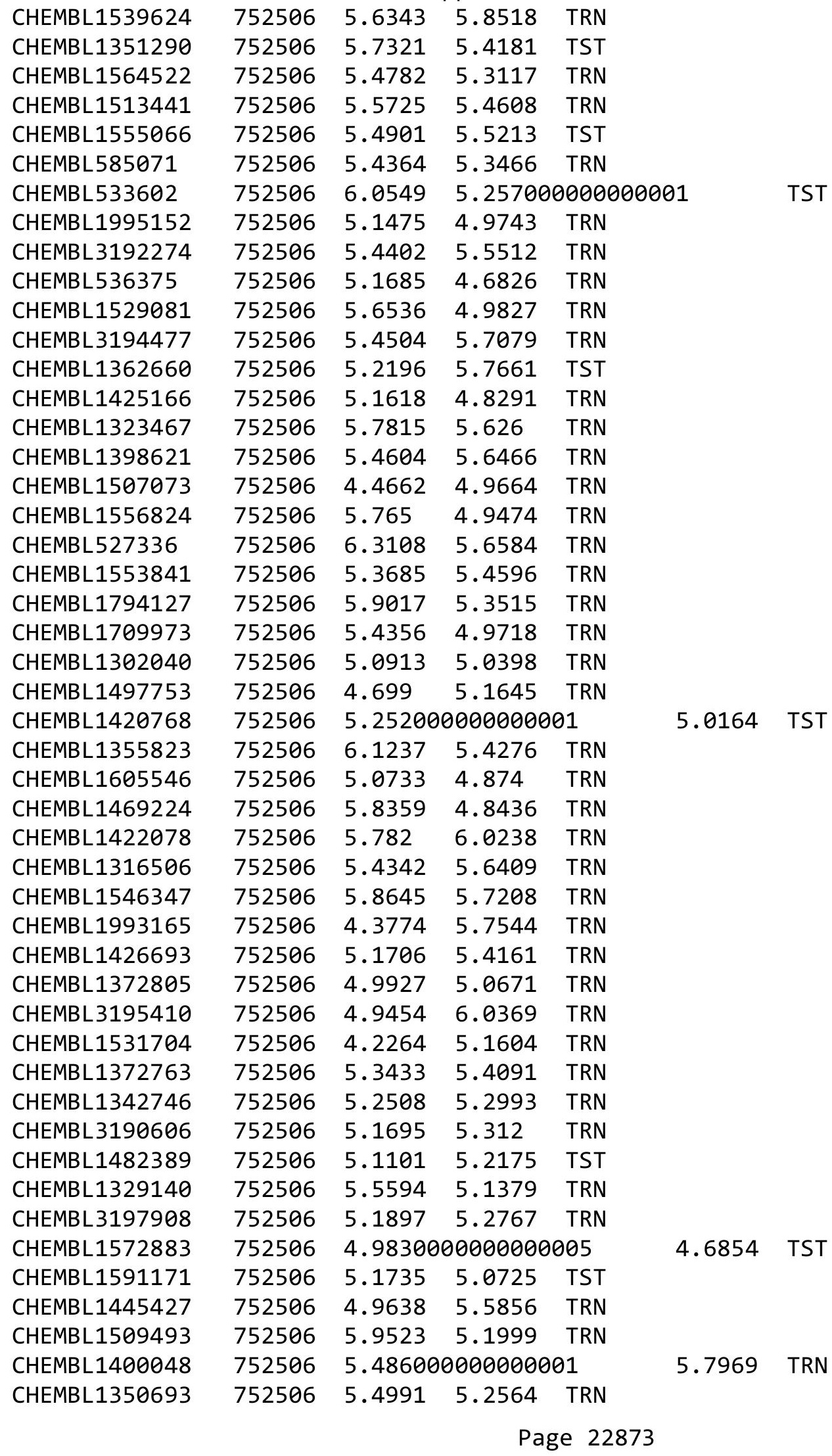




\begin{tabular}{|c|c|c|c|c|c|}
\hline & & & oplement & al lable s & \\
\hline CHEMBL3213034 & 752506 & 5.5986 & 6.0064 & TRN & \\
\hline CHEMBL1790002 & 752506 & 5.3694 & 5.65600 & $\partial 000000001$ & TRN \\
\hline CHEMBL1502586 & 752506 & 5.4494 & 5.2967 & TRN & \\
\hline CHEMBL1971379 & 752506 & 5.521 & 5.6094 & TRN & \\
\hline CHEMBL123 & 752506 & 5.6728 & 5.9687 & TST & \\
\hline CHEMBL1437516 & 752506 & 5.6761 & 5.7746 & TRN & \\
\hline CHEMBL1439210 & 752506 & 5.5935 & 5.6529 & TRN & \\
\hline CHEMBL1534387 & 752506 & 5.8655 & 5.4088 & TRN & \\
\hline CHEMBL1459468 & 752506 & 5.7734 & 6.0074 & TRN & \\
\hline CHEMBL1596419 & 752506 & 2.585 & 5.1274 & TST & \\
\hline CHEMBL1586371 & 752506 & 5.9562 & 5.88200 & 0000000001 & TRN \\
\hline CHEMBL1471580 & 752506 & 5.4143 & 5.206 & TRN & \\
\hline CHEMBL1998606 & 752506 & 6.2338 & 5.7948 & TRN & \\
\hline CHEMBL3198028 & 752506 & 2.585 & 5.109 & TRN & \\
\hline CHEMBL1512675 & 752506 & 5.4003 & 4.8844 & TRN & \\
\hline CHEMBL1472117 & 752506 & 5.3757 & 5.2958 & TST & \\
\hline CHEMBL1987419 & 752506 & 5.6535 & 6.0233 & TRN & \\
\hline CHEMBL1464071 & 752506 & 5.5144 & 5.3582 & TRN & \\
\hline CHEMBL1603308 & 752506 & 2.585 & 4.9945 & TST & \\
\hline CHEMBL1332756 & 752506 & 6.2832 & 6.2908 & TRN & \\
\hline CHEMBL1540891 & 752506 & 5.7881 & 5.222 & TRN & \\
\hline CHEMBL1571290 & 752506 & 6.0 & 5.6954 & TRN & \\
\hline CHEMBL1335827 & 752506 & 4.8274 & 5.1014 & TRN & \\
\hline CHEMBL1457690 & 752506 & 5.6815 & 5.7235 & TRN & \\
\hline CHEMBL1699099 & 752506 & 4.9492 & 4.7892 & TRN & \\
\hline CHEMBL1442546 & 752506 & 5.1892 & 4.9554 & TST & \\
\hline CHEMBL1390247 & 752506 & 4.8834 & 5.6838 & TST & \\
\hline CHEMBL1501376 & 752506 & 5.1699 & 4.6995 & TRN & \\
\hline CHEMBL1413470 & 752506 & 6.1046 & 5.5326 & TRN & \\
\hline CHEMBL1543714 & 752506 & 5.2067 & 5.421 & TRN & \\
\hline CHEMBL1347084 & 752506 & 2.585 & 5.3561 & TST & \\
\hline CHEMBL1735624 & 752506 & 5.3669 & 5.4356 & TRN & \\
\hline CHEMBL1985667 & 752506 & 5.3807 & 5.5853 & TRN & \\
\hline CHEMBL1999630 & 752506 & 5.3584 & 5.67700 & 00000000005 & TRN \\
\hline CHEMBL3192725 & 752506 & 5.1633 & 5.4247 & TRN & \\
\hline CHEMBL1566334 & 752506 & 5.2728 & 4.5845 & TRN & \\
\hline CHEMBL578944 & 752506 & 6.1989 & 5.4748 & TRN & \\
\hline CHEMBL530499 & 752506 & 5.8492 & 5.75200 & 0000000001 & TRN \\
\hline CHEMBL1387510 & 752506 & 5.4832 & 6.0342 & TRN & \\
\hline CHEMBL590665 & 752506 & 6.3743 & 6.2355 & TRN & \\
\hline CHEMBL1370884 & 752506 & 5.474 & 5.3512 & TRN & \\
\hline CHEMBL1482438 & 752506 & 5.3788 & 5.4058 & TRN & \\
\hline CHEMBL1424307 & 752506 & 4.8962 & 5.3853 & TRN & \\
\hline CHEMBL1559473 & 752506 & 5.1942 & 4.7743 & TST & \\
\hline CHEMBL1495725 & 752506 & 4.9183 & 4.6609 & TRN & \\
\hline CHEMBL1581410 & 752506 & 5.3643 & 5.2657 & TRN & \\
\hline CHEMBL1314461 & 752506 & 5.2734 & 5.1111 & TRN & \\
\hline CHEMBL1560061 & 752506 & 5.8477 & 4.8806 & TRN & \\
\hline
\end{tabular}




\begin{tabular}{|c|c|c|c|c|c|c|}
\hline & & \multicolumn{5}{|c|}{ Supplemental Table S2.txt } \\
\hline CHEMBL3199550 & 752506 & 5.8248 & 5.3543 & TRN & & \\
\hline CHEMBL3197238 & 752506 & 5.3127 & 5.6096 & TRN & & \\
\hline CHEMBL417727 & 752506 & 5.9751 & 6.046 & TRN & & \\
\hline CHEMBL1358184 & 752506 & 5.5188 & 5.1098 & TRN & & \\
\hline CHEMBL 3210428 & 752506 & 5.3908 & 5.0763 & TRN & & \\
\hline CHEMBL3199335 & 752506 & 5.334 & 5.4599 & TRN & & \\
\hline CHEMBL469036 & 752506 & 5.5245 & 5.0708 & TST & & \\
\hline CHEMBL3194022 & 752506 & 5.1974 & 5.5701 & TRN & & \\
\hline CHEMBL1391518 & 752506 & 5.4656 & 5.62799 & 999999999 & & TRN \\
\hline CHEMBL1420676 & 752506 & 2.585 & 4.8816 & TRN & & \\
\hline CHEMBL1306983 & 752506 & 5.5967 & 5.4424 & TRN & & \\
\hline CHEMBL1585527 & 752506 & 5.4678 & 5.9824 & TRN & & \\
\hline CHEMBL601335 & 752506 & 6.0 & 5.6615 & TRN & & \\
\hline CHEMBL1434767 & 752506 & 5.819 & 5.1809 & TRN & & \\
\hline CHEMBL1519450 & 752506 & 6.1872 & 5.8637 & TRN & & \\
\hline CHEMBL1543839 & 752506 & 5.2699 & 4.9807 & TRN & & \\
\hline CHEMBL1600855 & 752506 & 5.3147 & 5.2509 & TST & & \\
\hline CHEMBL1502020 & 752506 & 5.6054 & 5.5607 & TRN & & \\
\hline CHEMBL1981408 & 752506 & 5.7036 & 6.1626 & TRN & & \\
\hline CHEMBL478501 & 752506 & 4.8268 & 5.1411 & TST & & \\
\hline CHEMBL1603029 & 752506 & 5.1238 & 4.9905 & TST & & \\
\hline CHEMBL2006168 & 752506 & 6.3889 & 5.5726 & TRN & & \\
\hline CHEMBL3199362 & 752506 & 5.433 & 5.3832 & TRN & & \\
\hline CHEMBL1394624 & 752506 & 5.8024 & 5.5241 & TRN & & \\
\hline CHEMBL1471716 & 752506 & 5.2982 & 4.7087 & TRN & & \\
\hline CHEMBL1716494 & 752506 & 4.819 & 5.1854 & TRN & & \\
\hline CHEMBL1565460 & 752506 & 5.7978 & 5.3572 & TRN & & \\
\hline CHEMBL1417242 & 752506 & 5.3573 & 5.5598 & TRN & & \\
\hline CHEMBL3194807 & 752506 & 5.5583 & 5.6827 & TRN & & \\
\hline CHEMBL1602142 & 752506 & 4.9508 & 5.3518 & TRN & & \\
\hline CHEMBL1488371 & 752506 & 5.4509 & 5.4146 & TRN & & \\
\hline CHEMBL1568848 & 752506 & 5.3813 & 5.4248 & TST & & \\
\hline CHEMBL359374 & 752506 & 5.1301 & 4.9779 & TRN & & \\
\hline CHEMBL1606685 & 752506 & 5.05399 & 79999999 & 99 & 5.3584 & TRN \\
\hline CHEMBL1521492 & 752506 & 5.3973 & 5.5289 & TRN & & \\
\hline CHEMBL1465485 & 752506 & 5.4825 & 5.1973 & TRN & & \\
\hline CHEMBL1598785 & 752506 & 6.1778 & 6.1789 & TRN & & \\
\hline CHEMBL3191510 & 752506 & 6.1529 & 5.0992 & TRN & & \\
\hline CHEMBL1477969 & 752506 & 5.5348 & 4.8243 & TRN & & \\
\hline CHEMBL1362503 & 752506 & 4.6015 & 4.9184 & TST & & \\
\hline CHEMBL2001739 & 752506 & 5.3635 & 5.5889 & TRN & & \\
\hline CHEMBL1479947 & 752506 & 5.3428 & 5.4139 & TRN & & \\
\hline CHEMBL3195749 & 752506 & 5.6603 & 5.7396 & TRN & & \\
\hline CHEMBL1311879 & 752506 & 6.4261 & 6.0285 & TRN & & \\
\hline CHEMBL1442155 & 752506 & 6.0816 & 5.9636 & TRN & & \\
\hline CHEMBL528791 & 752506 & 5.2375 & 4.5982 & TRN & & \\
\hline CHEMBL3199286 & 752506 & 7.71 & 6.631 & TRN & & \\
\hline CHEMBL1523792 & 752506 & 5.9187 & 5.3656 & TRN & & \\
\hline
\end{tabular}

Page 22875 


\begin{tabular}{|c|c|c|c|c|c|c|}
\hline & & \multicolumn{5}{|c|}{ Supplemental Table S2.txt } \\
\hline CHEMBL3210935 & 752506 & 2.585 & 5.0195 & TRN & & \\
\hline CHEMBL1447306 & 752506 & 5.11 & 5.2429 & TRN & & \\
\hline CHEMBL1487619 & 752506 & 5.7231 & 5.5481 & TRN & & \\
\hline CHEMBL1370513 & 752506 & 6.0654 & 6.0129 & TRN & & \\
\hline CHEMBL1584502 & 752506 & 5.129 & 4.6487 & TRN & & \\
\hline CHEMBL1990598 & 752506 & 5.7994 & 5.2423 & TRN & & \\
\hline CHEMBL1492936 & 752506 & 6.4583 & 6.0332 & TRN & & \\
\hline CHEMBL1553590 & 752506 & 5.1737 & 5.3268 & TRN & & \\
\hline CHEMBL1965376 & 752506 & 5.3843 & 5.4692 & TRN & & \\
\hline CHEMBL1534358 & 752506 & 6.2009 & 5.5698 & TST & & \\
\hline CHEMBL601146 & 752506 & 6.0 & 5.7773 & TRN & & \\
\hline CHEMBL3189217 & 752506 & 5.4115 & 5.4847 & TST & & \\
\hline CHEMBL1315948 & 752506 & 5.4371 & 5.4294 & TRN & & \\
\hline CHEMBL1525275 & 752506 & 5.1455 & 4.9716 & TST & & \\
\hline CHEMBL1487901 & 752506 & 5.2371 & 5.3691 & TST & & \\
\hline CHEMBL3212029 & 752506 & 6.00700 & 30000000 & 01 & 5.7305 & TRN \\
\hline CHEMBL1562839 & 752506 & 5.153 & 5.3346 & TRN & & \\
\hline CHEMBL1990786 & 752506 & 5.7062 & 5.5325 & TRN & & \\
\hline CHEMBL1552591 & 752506 & 5.4707 & 5.8345 & TRN & & \\
\hline CHEMBL1566610 & 752506 & 6.5051 & 5.6532 & TST & & \\
\hline CHEMBL1514680 & 752506 & 5.4667 & 5.0725 & TST & & \\
\hline CHEMBL1365585 & 752506 & 5.1418 & 5.1544 & TRN & & \\
\hline CHEMBL1388595 & 752506 & 5.1338 & 5.5606 & TRN & & \\
\hline CHEMBL1964464 & 752506 & 5.9784 & 6.1868 & TRN & & \\
\hline CHEMBL1405964 & 752506 & 4.6891 & 4.8563 & TST & & \\
\hline CHEMBL1470728 & 752506 & 5.7233 & 5.7605 & TST & & \\
\hline CHEMBL3190669 & 752506 & 5.506 & 5.7507 & TRN & & \\
\hline CHEMBL1564958 & 752506 & 5.8598 & 5.7584 & TRN & & \\
\hline CHEMBL1366727 & 752506 & 5.4289 & 5.1325 & TRN & & \\
\hline CHEMBL1486943 & 752506 & 5.1571 & 5.2224 & TRN & & \\
\hline CHEMBL3190181 & 752506 & 6.0952 & 5.8477 & TRN & & \\
\hline CHEMBL 1544718 & 752506 & 5.2263 & 4.9837 & TRN & & \\
\hline CHEMBL1347858 & 752506 & 5.4139 & 5.2541 & TRN & & \\
\hline CHEMBL1278035 & 752506 & 5.1941 & 5.0621 & TRN & & \\
\hline CHEMBL1544103 & 752506 & 5.9714 & 5.9887 & TRN & & \\
\hline CHEMBL1336823 & 752506 & 5.1668 & 5.2119 & TST & & \\
\hline CHEMBL1324944 & 752506 & 5.9523 & 5.6204 & TRN & & \\
\hline CHEMBL1330556 & 752506 & 5.7948 & 5.3705 & TRN & & \\
\hline CHEMBL1964614 & 752506 & 6.0988 & 5.9165 & TRN & & \\
\hline CHEMBL1308404 & 752506 & 5.2812 & 5.4239 & TRN & & \\
\hline CHEMBL1558285 & 752506 & 6.2203 & 6.5849 & TRN & & \\
\hline CHEMBL1424665 & 752506 & 5.9307 & 6.0206 & TRN & & \\
\hline CHEMBL1572019 & 752506 & 4.9212 & 4.504 & TRN & & \\
\hline CHEMBL1587630 & 752506 & 5.5268 & 5.2747 & TRN & & \\
\hline CHEMBL592068 & 752506 & 5.5229 & 5.3809 & TRN & & \\
\hline CHEMBL1336647 & 752506 & 5.1255 & 5.3964 & TRN & & \\
\hline CHEMBL1549975 & 752506 & 4.9602 & 5.4093 & TRN & & \\
\hline CHEMBL1504345 & 752506 & 4.9374 & 5.0105 & TRN & & \\
\hline
\end{tabular}




\begin{tabular}{|c|c|c|c|c|c|c|}
\hline & & \multicolumn{5}{|c|}{ Supplemental Table S2.txt } \\
\hline CHEMBL1446283 & 752506 & 2.585 & 4.6801 & TST & & \\
\hline CHEMBL1536193 & 752506 & 3.6334 & 4.7147 & TST & & \\
\hline CHEMBL1585538 & 752506 & 5.1535 & 5.6655 & TRN & & \\
\hline CHEMBL1550862 & 752506 & 5.3751 & 5.3608 & TRN & & \\
\hline CHEMBL1525720 & 752506 & 5.6951 & 5.5401 & TRN & & \\
\hline CHEMBL1442114 & 752506 & 5.2958 & 5.5031 & TRN & & \\
\hline CHEMBL1391048 & 752506 & 4.8592 & 5.2659 & TRN & & \\
\hline CHEMBL1564542 & 752506 & 5.11100 & 00000000 & $\partial 1$ & 4.5546 & TRN \\
\hline CHEMBL1352313 & 752506 & 5.7131 & 5.1245 & TST & & \\
\hline CHEMBL1550406 & 752506 & 5.1413 & 4.8273 & TRN & & \\
\hline CHEMBL 2000340 & 752506 & 5.0439 & 4.8873 & TST & & \\
\hline CHEMBL1996724 & 752506 & 5.3737 & 5.8879 & TRN & & \\
\hline CHEMBL3199639 & 752506 & 5.8055 & 6.0112 & TRN & & \\
\hline CHEMBL1526479 & 752506 & 5.2758 & 5.2692 & TRN & & \\
\hline CHEMBL1345159 & 752506 & 5.2306 & 5.4702 & TST & & \\
\hline CHEMBL1371706 & 752506 & 5.6273 & 5.6166 & TRN & & \\
\hline CHEMBL1713269 & 752506 & 4.6148 & 4.9237 & TRN & & \\
\hline CHEMBL1381963 & 752506 & 5.4026 & 5.4544 & TRN & & \\
\hline CHEMBL1431608 & 752506 & 2.585 & 5.2875 & TRN & & \\
\hline CHEMBL1418230 & 752506 & 5.2173 & 5.2204 & TRN & & \\
\hline CHEMBL3192939 & 752506 & 5.5569 & 5.5602 & TST & & \\
\hline CHEMBL 2094567 & 752506 & 6.5566 & 6.643 & TRN & & \\
\hline CHEMBL533226 & 752506 & 5.404 & 5.4106 & TRN & & \\
\hline CHEMBL1608985 & 752506 & 5.4605 & 5.4493 & TRN & & \\
\hline CHEMBL1515360 & 752506 & 5.1355 & 4.8704 & TST & & \\
\hline CHEMBL1703391 & 752506 & 5.1697 & 5.1433 & TRN & & \\
\hline CHEMBL3197433 & 752506 & 6.2716 & 5.9351 & TRN & & \\
\hline CHEMBL1377849 & 752506 & 5.6688 & 5.3615 & TRN & & \\
\hline CHEMBL1568474 & 752506 & 5.2967 & 5.1178 & TRN & & \\
\hline CHEMBL1527341 & 752506 & 5.9817 & 5.7553 & TRN & & \\
\hline CHEMBL1567571 & 752506 & 5.9759 & 5.5669 & TRN & & \\
\hline CHEMBL1492208 & 752506 & 5.8499 & 5.5652 & TRN & & \\
\hline CHEMBL1394105 & 752506 & 6.4298 & 5.4755 & TRN & & \\
\hline CHEMBL1472304 & 752506 & 5.4068 & 5.319 & TRN & & \\
\hline CHEMBL1980600 & 752506 & 5.3969 & 5.6375 & TRN & & \\
\hline CHEMBL1426340 & 752506 & 6.0224 & 5.9853 & TRN & & \\
\hline CHEMBL1431928 & 752506 & 5.3682 & 5.2924 & TRN & & \\
\hline CHEMBL1969593 & 752506 & 5.2687 & 5.3033 & TRN & & \\
\hline CHEMBL 3189245 & 752506 & 5.8533 & 6.1966 & TRN & & \\
\hline CHEMBL1974180 & 752506 & 5.6763 & 5.6504 & TRN & & \\
\hline CHEMBL530291 & 752506 & 5.6906 & 6.7386 & TRN & & \\
\hline CHEMBL393287 & 752506 & 5.1116 & 5.3544 & TRN & & \\
\hline CHEMBL582030 & 752506 & 5.4455 & 5.7321 & TRN & & \\
\hline CHEMBL609606 & 752506 & 6.6245 & 6.7431 & TRN & & \\
\hline CHEMBL1580083 & 752506 & 5.1123 & 5.3834 & TRN & & \\
\hline CHEMBL1735244 & 752506 & 5.4088 & 5.1521 & TRN & & \\
\hline CHEMBL1340713 & 752506 & 5.3991 & 5.6885 & TRN & & \\
\hline CHEMBL1439867 & 752506 & 5.3237 & 5.5908 & TRN & & \\
\hline
\end{tabular}


Supplemental Table S2.txt

\begin{tabular}{|c|c|}
\hline 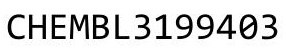 & \\
\hline CHEMBL1567944 & Je \\
\hline HEMBL1988268 & \\
\hline HEMBL1385633 & \\
\hline HEMBL1345865 & \\
\hline HEMBL1338304 & (52) \\
\hline HEMBL1462872 & 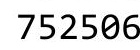 \\
\hline HEMBL1464619 & 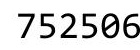 \\
\hline AEMBL1490481 & 52 \\
\hline HEMBL1306287 & \\
\hline HEMBL1595632 & 7525 \\
\hline HEMBL3197550 & 525 \\
\hline HEMBL1596655 & 12, \\
\hline HEMBL3189325 & 752 \\
\hline CHEMBL581471 & \\
\hline HEMBL1558160 & 525 \\
\hline HEMBL1343392 & \\
\hline HEMBL1439300 & 1525 \\
\hline HEMBL1536608 & 752 \\
\hline CHEMBL1716313 & 52 \\
\hline CHEMBL374350 & 525 \\
\hline CHEMBL3213254 & \\
\hline HEMBL1338677 & 7525 \\
\hline HEMBL1401057 & 752 \\
\hline CHEMBL1425525 & 752 \\
\hline CHEMBL1499250 & 52 \\
\hline CHEMBL1530557 & 7525 \\
\hline HEMBL1603204 & 7525 \\
\hline HEMBL1993889 & 752 \\
\hline CHEMBL1483746 & 752 \\
\hline CHEMBL1613688 & 525 \\
\hline CHEMBL600862 & 7525 \\
\hline HEMBL 3189405 & 52 \\
\hline HEMBL1470135 & 752 \\
\hline CHEMBL1308088 & 52 \\
\hline CHEMBL1702140 & 7525 \\
\hline CHEMBL1487136 & 7525 \\
\hline CHEMBL1531 & $5<5$ \\
\hline CHEMBL1570497 & 752 \\
\hline CHEMBL1990582 & 752 \\
\hline CHEMBL 3191831 & 7525 \\
\hline CHEMBL1465527 & 7525 \\
\hline CHEMBL1339398 & 752 \\
\hline CHEMBL1509085 & 7525 \\
\hline CHEMBL117804 & 7525 \\
\hline CHEMBL1535120 & 752 \\
\hline CHEMBL1452840 & 752 \\
\hline CHEMBL1476734 & \\
\hline
\end{tabular}
6.2852
5.7908 TRN
$\begin{array}{lll}5.6287 & 6.3248 & \text { TST }\end{array}$
$5.2962 \quad 5.2783$ TRN
$\begin{array}{lll}5.643 & 5.0603 & \text { TST }\end{array}$
$5.2267 \quad 5.4455$ TRN
$\begin{array}{lll}5.3321 & 5.407 & \text { TRN }\end{array}$
$\begin{array}{lll}5.1271 & 4.8378 & \text { TRN }\end{array}$
$\begin{array}{lll}4.074 & 5.0759 & \text { TRN }\end{array}$
$5.3509 \quad 5.0549$ TRN
$5.1187 \quad 5.2466 \quad$ TRN
5.40315 .4162 TST
$5.5488 \quad 5.4556 \quad$ TRN
$5.1129 \quad 5.3284$ TST
$6.016 \quad 5.989$ TRN
$\begin{array}{lll}5.565 & 4.9267 & \text { TRN }\end{array}$
$5.4298 \quad 5.4419$ TST
$\begin{array}{llll}5.2587 & 4.9129 & \text { TRN }\end{array}$
$\begin{array}{lll}5.476 & 4.6833 & \text { TRN }\end{array}$
$\begin{array}{lll}5.1978 & 4.9772 & \text { TRN }\end{array}$
$\begin{array}{lll}5.5941 & 5.2448 & \text { TRN }\end{array}$
$\begin{array}{lll}5.0952 & 5.0832 & \text { TST }\end{array}$
$5.3673 \quad 5.3143$ TST
$\begin{array}{lll}5.6594 & 6.1106 & \text { TRN }\end{array}$
$6.0264 \quad 5.5536$ TRN
$5.3451 \quad 4.9341$ TST
$4.959 \quad 5.2284$ TRN
$5.3421 \quad 5.0764$ TRN
$6.3673 \quad 6.0395$ TRN
$\begin{array}{lll}5.2937 & 4.588 \quad \text { TRN }\end{array}$
$5.3979 \quad 5.2553$ TRN
$\begin{array}{lll}7.71 & 5.7637 & \text { TST }\end{array}$
$6.4207 \quad 6.3839$ TRN
$\begin{array}{lll}6.024 & 5.8907 \text { TRN }\end{array}$
$5.5678 \quad 5.3322$ TRN
$5.5461 \quad 5.4547$ TRN
$\begin{array}{lll}5.371 & 4.9481 & \text { TST }\end{array}$
$6.6191 \quad 5.8571 \quad$ TST
$5.7312 \quad 5.6016 \quad$ TRN
$5.11835 .1370000000000005 \quad$ TRN
6.20316 .3487 TRN
$5.9122 \quad 5.5714$ TRN
$5.0186 \quad 5.0586$ TST
$5.4487 \quad 5.0738 \quad$ TST
$5.5093 \quad 5.0925$ TRN
$\begin{array}{lll}5.9788 & 5.8739 & \text { TRN }\end{array}$
$\begin{array}{llll}2.585 & 4.4974 & \text { TRN }\end{array}$
$6.0645 \quad 5.4332$ TST
$5.2818 \quad 5.0782$ TRN

Page 22878 


\begin{tabular}{|c|c|c|c|c|c|c|}
\hline \multicolumn{7}{|c|}{ 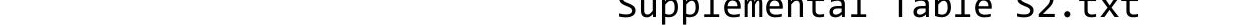 } \\
\hline CHEMBL3191079 & 752506 & 5.2891 & 5.3669 & TRN & & \\
\hline CHEMBL1208858 & 752506 & 5.5909 & 5.3824 & TST & & \\
\hline CHEMBL1387688 & 752506 & 5.3117 & 4.8728 & TST & & \\
\hline CHEMBL1996376 & 752506 & 5.4865 & 5.7066 & TRN & & \\
\hline CHEMBL1429632 & 752506 & 5.99100 & 00000000 & 205 & 5.5085 & TRN \\
\hline CHEMBL1582018 & 752506 & 5.8761 & 5.7079 & TRN & & \\
\hline CHEMBL1451659 & 752506 & 4.8874 & 4.9514 & TST & & \\
\hline CHEMBL1997659 & 752506 & 5.5794 & 5.5141 & TRN & & \\
\hline CHEMBL1516440 & 752506 & 5.9751 & 5.4428 & TRN & & \\
\hline CHEMBL1698464 & 752506 & 5.3539 & 5.2709 & TRN & & \\
\hline CHEMBL1542862 & 752506 & 5.6196 & 5.4213 & TRN & & \\
\hline CHEMBL503363 & 752506 & 5.0958 & 5.0468 & TST & & \\
\hline CHEMBL1563483 & 752506 & 5.4885 & 5.3851 & TST & & \\
\hline CHEMBL1372692 & 752506 & 4.9788 & 4.9611 & TRN & & \\
\hline CHEMBL1526864 & 752506 & 4.9987 & 5.2209 & TST & & \\
\hline CHEMBL1371864 & 752506 & 5.2363 & 5.1358 & TRN & & \\
\hline CHEMBL1610227 & 752506 & 4.8459 & 4.8437 & TRN & & \\
\hline CHEMBL1471779 & 752506 & 4.8894 & 5.1507 & TRN & & \\
\hline CHEMBL1588264 & 752506 & 5.2115 & 5.3068 & TRN & & \\
\hline CHEMBL1604139 & 752506 & 5.3621 & 5.3265 & TRN & & \\
\hline CHEMBL1381135 & 752506 & 5.0755 & 5.0307 & TRN & & \\
\hline CHEMBL1421347 & 752506 & 6.0718 & 5.1331 & TST & & \\
\hline CHEMBL1474135 & 752506 & 4.6893 & 4.8359 & TST & & \\
\hline CHEMBL1573697 & 752506 & 5.6153 & 5.5342 & TRN & & \\
\hline CHEMBL1468306 & 752506 & 5.3814 & 5.2687 & TRN & & \\
\hline CHEMBL1382827 & 752506 & 5.4358 & 5.4779 & TRN & & \\
\hline CHEMBL1575588 & 752506 & 5.6472 & 5.3377 & TRN & & \\
\hline CHEMBL1325149 & 752506 & 5.9401 & 5.4236 & TRN & & \\
\hline CHEMBL1969300 & 752506 & 5.5575 & 5.4993 & TRN & & \\
\hline CHEMBL1547818 & 752506 & 5.1534 & 5.4996 & TRN & & \\
\hline CHEMBL1402899 & 752506 & 4.9927 & 5.2744 & TST & & \\
\hline CHEMBL1432378 & 752506 & 5.2615 & 5.194 & TRN & & \\
\hline CHEMBL1417731 & 752506 & 5.9055 & 5.4584 & TRN & & \\
\hline CHEMBL3195226 & 752506 & 5.5572 & 5.8492 & TRN & & \\
\hline CHEMBL1542693 & 752506 & 5.5227 & 5.2301 & TRN & & \\
\hline CHEMBL1484167 & 752506 & 6.2128 & 6.2879 & TRN & & \\
\hline CHEMBL1432707 & 752506 & 5.5677 & 5.5858 & TRN & & \\
\hline CHEMBL581880 & 752506 & 5.8983 & 5.71700 & 0000000000 & 05 & TRN \\
\hline CHEMBL1600776 & 752506 & 5.6706 & 5.3088 & TRN & & \\
\hline CHEMBL1517325 & 752506 & 5.8274 & 6.2606 & TRN & & \\
\hline CHEMBL1898721 & 752506 & 5.3349 & 5.5494 & TRN & & \\
\hline CHEMBL568092 & 752506 & 6.53299 & 99999999 & 995 & 6.102 & TRN \\
\hline CHEMBL3213251 & 752506 & 4.3511 & 4.8793 & TRN & & \\
\hline CHEMBL1490308 & 752506 & 5.4332 & 4.883 & TST & & \\
\hline CHEMBL3195760 & 752506 & 5.76 & 6.3894 & TRN & & \\
\hline CHEMBL533293 & 752506 & 6.5445 & 6.3537 & TRN & & \\
\hline CHEMBL1406208 & 752506 & 5.7737 & 5.6023 & TRN & & \\
\hline CHEMBL1447947 & 752506 & 2.585 & 4.7959 & TST & & \\
\hline
\end{tabular}




\begin{tabular}{|c|c|c|c|c|c|}
\hline \multirow[b]{2}{*}{ CHEMBL1478501 } & \multirow[b]{2}{*}{752506} & \multicolumn{4}{|c|}{ Supplemental Table s2.txt } \\
\hline & & \multicolumn{2}{|c|}{$5.1534 \quad 4.8367$} & \multicolumn{2}{|c|}{ TST } \\
\hline CHEMBL1457209 & 752506 & 4.7894 & 5.4109 & TST & \\
\hline CHEMBL1415844 & 752506 & \multicolumn{3}{|c|}{5.452999999999999} & TRN \\
\hline CHEMBL3191713 & 752506 & 7.71 & 6.7614 & TRN & \\
\hline CHEMBL2006997 & 752506 & 5.6124 & 5.4561 & TRN & \\
\hline CHEMBL1362557 & 752506 & 4.7113 & 5.1441 & TST & \\
\hline CHEMBL1446199 & 752506 & 4.3582 & 4.7275 & TST & \\
\hline CHEMBL1353317 & 752506 & 5.3436 & 5.2057 & TRN & \\
\hline CHEMBL1439624 & 752506 & 5.586 & 5.8455 & TRN & \\
\hline CHEMBL1604690 & 752506 & 4.9931 & 5.1598 & TRN & \\
\hline CHEMBL1326728 & 752506 & 4.9212 & 4.9303 & TRN & \\
\hline CHEMBL1987894 & 752506 & 6.0084 & 6.2774 & TRN & \\
\hline CHEMBL1465255 & 752506 & 5.4031 & 5.0928 & TRN & \\
\hline CHEMBL1379329 & 752506 & 5.6319 & 5.3031 & TRN & \\
\hline CHEMBL1304004 & 752506 & 5.1966 & 5.494 & TRN & \\
\hline CHEMBL1395907 & 752506 & 5.3027 & 5.7924 & TRN & \\
\hline CHEMBL1336541 & 752506 & 5.5885 & 5.3274 & TRN & \\
\hline CHEMBL1551228 & 752506 & 5.439 & 4.9102 & TRN & \\
\hline CHEMBL3193507 & 752506 & 5.3587 & 5.0284 & TRN & \\
\hline CHEMBL3197928 & 752506 & 5.7552 & 5.4367 & TRN & \\
\hline CHEMBL1565674 & 752506 & 5.1047 & 5.2815 & TRN & \\
\hline CHEMBL1572685 & 752506 & 5.1807 & 5.4754 & TST & \\
\hline CHEMBL1333193 & 752506 & 5.5414 & 5.4821 & TST & \\
\hline CHEMBL1517141 & 752506 & 5.3129 & 5.7246 & TRN & \\
\hline CHEMBL1304363 & 752506 & 6.1195 & 6.0935 & TRN & \\
\hline CHEMBL1513972 & 752506 & 5.1322 & 5.4544 & TST & \\
\hline CHEMBL1382853 & 752506 & 5.3882 & 5.0216 & TRN & \\
\hline CHEMBL1342248 & 752506 & 5.2793 & 5.2579 & TRN & \\
\hline CHEMBL1353481 & 752506 & 5.1669 & 5.3404 & TRN & \\
\hline CHEMBL1341927 & 752506 & 5.1791 & 4.7584 & TRN & \\
\hline CHEMBL1994877 & 752506 & 5.6121 & 5.6775 & TRN & \\
\hline CHEMBL1424729 & 752506 & 5.0954 & 5.6777 & TRN & \\
\hline CHEMBL1469709 & 752506 & 5.1137 & 4.6474 & TRN & \\
\hline CHEMBL1466186 & 752506 & 5.1457 & 5.1576 & TRN & \\
\hline CHEMBL1979195 & 752506 & 5.5082 & 5.4801 & TRN & \\
\hline CHEMBL1412583 & 752506 & 5.3742 & 5.1 & TST & \\
\hline CHEMBL1304383 & 752506 & 5.3545 & 4.9324 & TRN & \\
\hline CHEMBL1979747 & 752506 & 5.3164 & 5.74299 & 9999999999 & TRN \\
\hline CHEMBL1552224 & 752506 & 4.1914 & 5.1821 & TST & \\
\hline CHEMBL3198659 & 752506 & 5.1374 & 5.1401 & TRN & \\
\hline CHEMBL1714817 & 752506 & 6.0 & 5.0544 & TRN & \\
\hline CHEMBL1722214 & 752506 & 2.585 & 4.81800 & 20000000005 & TRN \\
\hline CHEMBL1581949 & 752506 & 5.5158 & 5.1867 & TRN & \\
\hline CHEMBL3194778 & 752506 & 5.7231 & 6.0932 & TRN & \\
\hline CHEMBL1361509 & 752506 & 5.1816 & 4.6136 & TRN & \\
\hline CHEMBL1410424 & 752506 & 5.0982 & 5.0904 & TRN & \\
\hline CHEMBL1413669 & 752506 & 4.8256 & 5.0251 & TRN & \\
\hline CHEMBL86104 & 752506 & 5.7042 & 5.8375 & TRN & \\
\hline
\end{tabular}


Supplemental Table S2.txt

\begin{tabular}{|c|c|c|c|c|c|c|}
\hline CHEMBL1335703 & 752506 & 4.9722 & 5.8639 & TRN & & \\
\hline CHEMBL1347196 & 752506 & 5.0634 & 5.1968 & TST & & \\
\hline CHEMBL1986678 & 752506 & 5.7445 & 5.7882 & TRN & & \\
\hline CHEMBL1425736 & 752506 & 5.1785 & 5.2762 & TST & & \\
\hline CHEMBL1558462 & 752506 & 5.0933 & 5.118 & TRN & & \\
\hline CHEMBL1380914 & 752506 & 5.0482 & 4.6322 & TRN & & \\
\hline CHEMBL1551950 & 752506 & 5.5784 & 5.0578 & TST & & \\
\hline CHEMBL1569044 & 752506 & 2.9208 & 4.6688 & TRN & & \\
\hline CHEMBL1496396 & 752506 & 5.2932 & 5.0741 & TRN & & \\
\hline CHEMBL3197126 & 752506 & 6.0248 & 5.6297 & TRN & & \\
\hline CHEMBL1320566 & 752506 & 5.3112 & 5.2557 & TRN & & \\
\hline CHEMBL1314143 & 752506 & 2.585 & 4.8969 & TST & & \\
\hline CHEMBL1608392 & 752506 & 5.1758 & 4.9355 & TRN & & \\
\hline CHEMBL3198720 & 752506 & \multicolumn{3}{|c|}{5.8629999999999995} & 6.1756 & TRN \\
\hline CHEMBL1422155 & 752506 & 5.0839 & 5.7749 & TRN & & \\
\hline CHEMBL1469885 & 752506 & 5.4991 & 5.5738 & TRN & & \\
\hline CHEMBL19980 & 752506 & 6.0 & 6.0373 & TST & & \\
\hline CHEMBL1470905 & 752506 & 5.3127 & 5.2371 & TST & & \\
\hline CHEMBL1359321 & 752506 & 5.3106 & 5.1561 & TRN & & \\
\hline CHEMBL1535361 & 752506 & 5.4182 & 5.5671 & TRN & & \\
\hline CHEMBL3194518 & 752506 & 6.4012 & 5.4265 & TRN & & \\
\hline CHEMBL1541595 & 752506 & 4.6747 & 5.4485 & TRN & & \\
\hline CHEMBL3145285 & 752506 & 5.848 & 5.8255 & TRN & & \\
\hline CHEMBL3194562 & 752506 & 5.58 & 5.8618 & TRN & & \\
\hline CHEMBL1449204 & 752506 & 5.1413 & 4.6632 & TRN & & \\
\hline CHEMBL1409554 & 752506 & 5.5616 & 5.7107 & TRN & & \\
\hline CHEMBL581677 & 752506 & 5.0833 & 5.2273 & TRN & & \\
\hline CHEMBL1593888 & 752506 & \multicolumn{3}{|c|}{5.752000000000001} & 5.5693 & TRN \\
\hline CHEMBL1479181 & 752506 & 4.8931 & 5.1129 & TRN & & \\
\hline CHEMBL 2005246 & 752506 & 5.7711 & 6.0338 & TRN & & \\
\hline CHEMBL1433124 & 752506 & 5.5564 & 5.5649 & TRN & & \\
\hline CHEMBL375781 & 752506 & 7.71 & 5.9339 & TRN & & \\
\hline CHEMBL1697895 & 752506 & 2.585 & 4.9597 & TST & & \\
\hline CHEMBL1560235 & 752506 & 2.585 & 4.785 & TRN & & \\
\hline CHEMBL1386653 & 752506 & 5.0945 & 4.8406 & TRN & & \\
\hline CHEMBL1430381 & 752506 & 5.0483 & 4.9224 & TRN & & \\
\hline CHEMBL601400 & 752506 & 2.585 & 5.1413 & TST & & \\
\hline CHEMBL1441340 & 752506 & 5.1404 & 5.3021 & TRN & & \\
\hline CHEMBL3191879 & 752506 & 5.6321 & 5.4761 & TRN & & \\
\hline CHEMBL1979800 & 752506 & 6.0646 & 5.7037 & TRN & & \\
\hline CHEMBL1369945 & 752506 & 5.3179 & 5.3641 & TRN & & \\
\hline CHEMBL1410479 & 752506 & 5.1316 & 5.2616 & TRN & & \\
\hline CHEMBL1393615 & 752506 & 5.1513 & 5.5978 & TRN & & \\
\hline CHEMBL1544114 & 752506 & 5.6767 & 5.9314 & TRN & & \\
\hline CHEMBL1518578 & 752506 & 4.8573 & 4.7866 & TRN & & \\
\hline CHEMBL1414806 & 752506 & 5.1709 & 5.2253 & TRN & & \\
\hline CHEMBL1430872 & 752506 & 5.3085 & 4.9842 & TRN & & \\
\hline CHEMBL1386058 & 752506 & 7.71 & 5.9197 & TRN & & \\
\hline
\end{tabular}

Page 22881 


\begin{tabular}{|c|c|c|c|c|c|}
\hline & & \multicolumn{4}{|c|}{ Supplemental Table S2.txt } \\
\hline CHEMBL1706537 & 752506 & 2.585 & 4.8616 & TRN & \\
\hline CHEMBL1584754 & 752506 & 5.5988 & 5.7636 & TST & \\
\hline CHEMBL1488001 & 752506 & 5.178 & 5.2599 & TRN & \\
\hline CHEMBL3199539 & 752506 & 5.8114 & 5.9007 & TRN & \\
\hline CHEMBL1363219 & 752506 & 6.1874 & 4.3452 & TST & \\
\hline CHEMBL1970836 & 752506 & 5.7147 & 5.6034 & TRN & \\
\hline CHEMBL3191453 & 752506 & 6.4992 & 6.2253 & TRN & \\
\hline CHEMBL1401931 & 752506 & 5.2264 & 5.2348 & TRN & \\
\hline CHEMBL3193474 & 752506 & 5.4393 & 5.2627 & TRN & \\
\hline CHEMBL1505192 & 752506 & 5.5552 & 6.0693 & TRN & \\
\hline CHEMBL78150 & 752506 & 6.0323 & 5.381 & TRN & \\
\hline CHEMBL1439384 & 752506 & 5.2094 & 5.0929 & TRN & \\
\hline CHEMBL1563766 & 752506 & 5.5039 & 5.846 & TRN & \\
\hline CHEMBL1309888 & 752506 & 5.1096 & 4.9476 & TST & \\
\hline CHEMBL1423935 & 752506 & 5.5567 & 5.4277 & TRN & \\
\hline CHEMBL1996281 & 752506 & 5.6544 & 5.8561 & TRN & \\
\hline CHEMBL1318526 & 752506 & 5.9401 & 5.4 & TRN & \\
\hline CHEMBL1471980 & 752506 & 5.0135 & 4.8923 & TST & \\
\hline CHEMBL1401821 & 752506 & 5.4215 & 5.5011 & TRN & \\
\hline CHEMBL1489273 & 752506 & 5.4549 & 5.354 & TRN & \\
\hline CHEMBL1585768 & 752506 & 4.3184 & 4.9234 & TRN & \\
\hline CHEMBL3194195 & 752506 & 5.5131 & 5.0246 & TRN & \\
\hline CHEMBL3145322 & 752506 & 5.1344 & 5.4645 & TRN & \\
\hline CHEMBL3145293 & 752506 & 5.4431 & 5.26 & TRN & \\
\hline CHEMBL1414571 & 752506 & 5.9416 & 5.1146 & TST & \\
\hline CHEMBL1563943 & 752506 & 6.6341 & 5.7221 & TRN & \\
\hline CHEMBL1728201 & 752506 & 2.585 & 4.8285 & TST & \\
\hline CHEMBL1988210 & 752506 & 4.9905 & 5.7651 & TRN & \\
\hline CHEMBL1585332 & 752506 & 5.2158 & 4.816 & TRN & \\
\hline CHEMBL1324755 & 752506 & 5.96899 & 79999999 & 6.0099 & TRN \\
\hline CHEMBL1976225 & 752506 & 5.6931 & 5.5428 & TRN & \\
\hline CHEMBL 1455060 & 752506 & 5.1983 & 4.9977 & TRN & \\
\hline CHEMBL1342423 & 752506 & 5.4681 & 6.0001 & TRN & \\
\hline CHEMBL1595329 & 752506 & 4.9245 & 4.7982 & TST & \\
\hline CHEMBL1562606 & 752506 & 5.7399 & 5.48799 & 99999999995 & TRN \\
\hline CHEMBL1563198 & 752506 & 5.2339 & 4.5306 & TRN & \\
\hline CHEMBL1794168 & 752506 & 2.585 & 4.2392 & TRN & \\
\hline CHEMBL1391313 & 752506 & 2.585 & 5.1319 & TST & \\
\hline CHEMBL1484306 & 752506 & 5.183 & 4.937 & TST & \\
\hline CHEMBL1379737 & 752506 & 5.2282 & 5.2366 & TRN & \\
\hline CHEMBL1412605 & 752506 & 4.4678 & 4.9357 & TST & \\
\hline CHEMBL1533447 & 752506 & 4.9352 & 4.9144 & TRN & \\
\hline CHEMBL1487720 & 752506 & 5.3226 & 4.7012 & TRN & \\
\hline CHEMBL3211356 & 752506 & 5.6619 & 5.8844 & TRN & \\
\hline CHEMBL1428995 & 752506 & 5.4827 & 4.8369 & TRN & \\
\hline CHEMBL1317657 & 752506 & 5.3835 & 5.6417 & TST & \\
\hline CHEMBL1464666 & 752506 & 5.5455 & 5.5894 & TRN & \\
\hline CHEMBL3195531 & 752506 & 5.4267 & 5.5512 & TRN & \\
\hline
\end{tabular}


Supplemental Table S2.txt

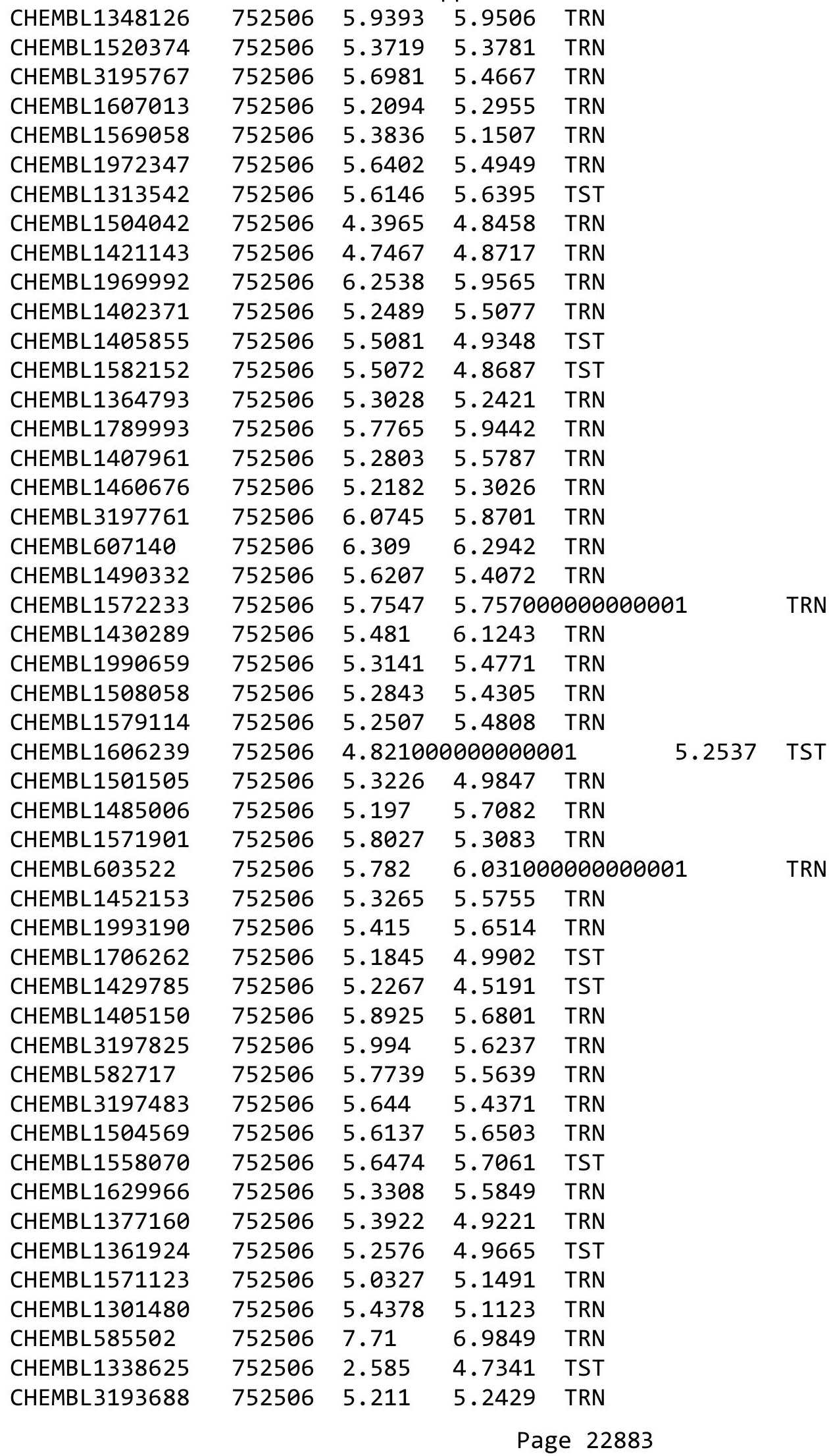




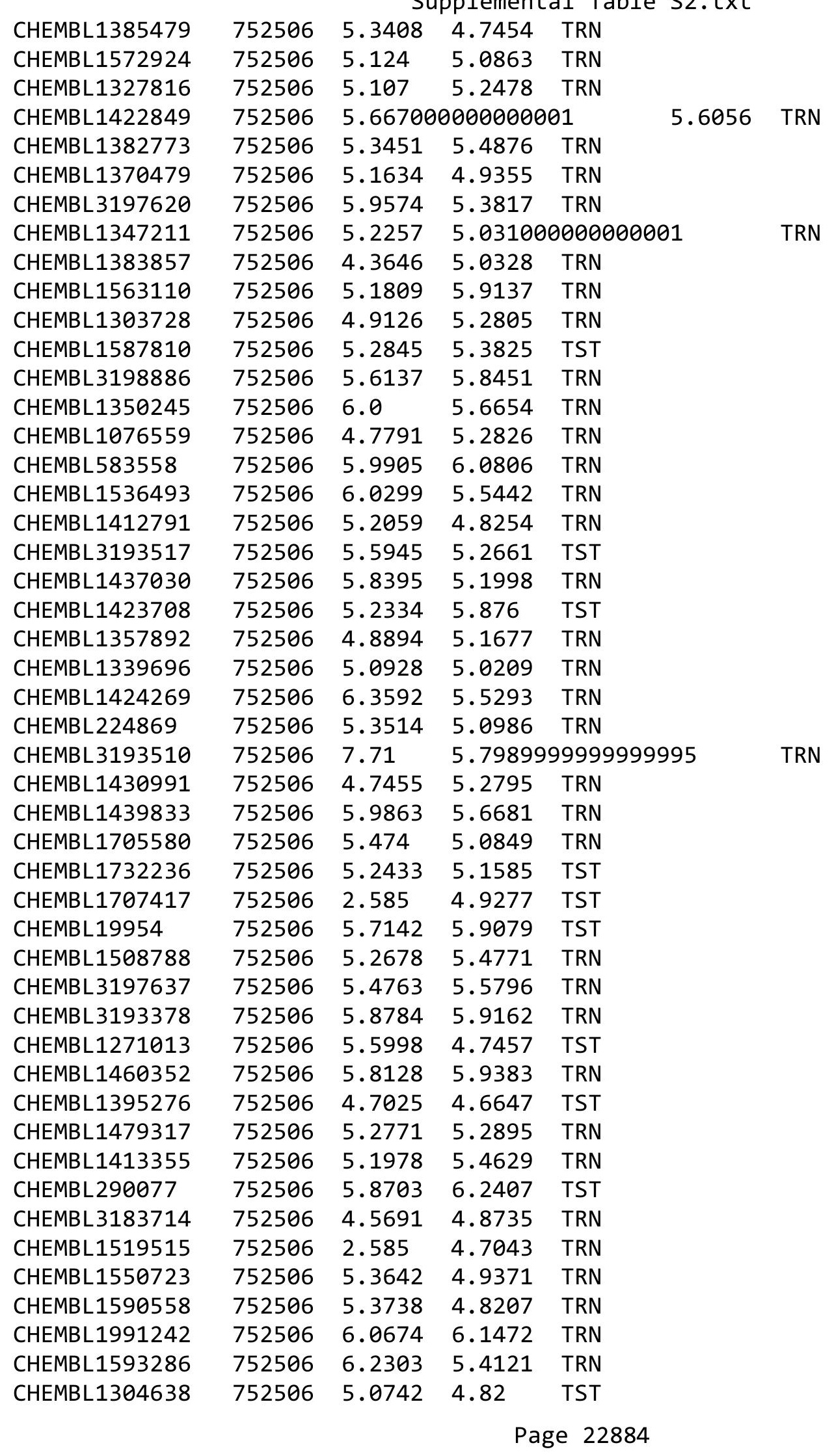




\begin{tabular}{|c|c|c|c|c|c|c|}
\hline & & & & & & \\
\hline CHEMBL1419381 & 752506 & 5.5685 & 5.5928 & TRN & & \\
\hline CHEMBL1511795 & 752506 & 5.1263 & 5.1867 & TRN & & \\
\hline CHEMBL1383315 & 752506 & 5.4247 & 5.2397 & TRN & & \\
\hline CHEMBL1501558 & 752506 & 5.5759 & 5.4619 & TRN & & \\
\hline CHEMBL1524322 & 752506 & 5.3602 & 5.4166 & TST & & \\
\hline CHEMBL1362508 & 752506 & 4.6745 & 4.7978 & TRN & & \\
\hline CHEMBL1582999 & 752506 & 5.1125 & 5.0055 & TRN & & \\
\hline CHEMBL1443312 & 752506 & 5.2187 & 5.4052 & TRN & & \\
\hline CHEMBL1571208 & 752506 & 5.1171 & 4.9215 & TRN & & \\
\hline CHEMBL1548492 & 752506 & 6.2233 & 6.1737 & TRN & & \\
\hline CHEMBL3195691 & 752506 & 5.6855 & 5.63299 & 99999999 & & TRN \\
\hline CHEMBL 3145304 & 752506 & 5.2986 & 5.476 & TRN & & \\
\hline CHEMBL130596 & 752506 & 2.585 & 5.0644 & TST & & \\
\hline CHEMBL1720152 & 752506 & 5.6455 & 5.5586 & TRN & & \\
\hline CHEMBL1368428 & 752506 & 5.6302 & 5.7715 & TRN & & \\
\hline CHEMBL1587263 & 752506 & 5.4819 & 5.1022 & TST & & \\
\hline CHEMBL1522655 & 752506 & 5.1619 & 4.8878 & TRN & & \\
\hline CHEMBL1547979 & 752506 & 5.83799 & 99999999 & 99 & 5.7201 & TRN \\
\hline CHEMBL1461508 & 752506 & 5.1632 & 5.3826 & TST & & \\
\hline CHEMBL1375740 & 752506 & 5.51399 & 99999999 & 99 & 5.7656 & TRN \\
\hline CHEMBL1483562 & 752506 & 5.4323 & 5.215 & TRN & & \\
\hline CHEMBL1454819 & 752506 & 5.1481 & 5.189 & TRN & & \\
\hline CHEMBL1705384 & 752506 & 5.093 & 4.9621 & TST & & \\
\hline CHEMBL3194816 & 752506 & 5.3309 & 5.5036 & TRN & & \\
\hline CHEMBL2002162 & 752506 & 5.0957 & 5.2565 & TST & & \\
\hline CHEMBL3193702 & 752506 & 5.3429 & 5.5332 & TRN & & \\
\hline CHEMBL463175 & 752506 & 5.4695 & 5.2432 & TST & & \\
\hline CHEMBL1417967 & 752506 & 5.6469 & 5.0982 & TRN & & \\
\hline CHEMBL2003806 & 752506 & 5.5859 & 5.4641 & TRN & & \\
\hline CHEMBL1567335 & 752506 & 5.4424 & 5.0008 & TRN & & \\
\hline CHEMBL1369594 & 752506 & 5.4303 & 5.1194 & TRN & & \\
\hline CHEMBL456295 & 752506 & 5.4757 & 5.0623 & TRN & & \\
\hline CHEMBL1523997 & 752506 & 5.6366 & 5.5001 & TRN & & \\
\hline CHEMBL1380630 & 752506 & 5.8962 & 5.4335 & TRN & & \\
\hline CHEMBL1567294 & 752506 & 6.1334 & 5.9818 & TRN & & \\
\hline CHEMBL3198618 & 752506 & 5.5547 & 5.7159 & TRN & & \\
\hline CHEMBL1971033 & 752506 & 5.4395 & 5.7628 & TRN & & \\
\hline CHEMBL1320669 & 752506 & 6.1107 & 5.114 & TST & & \\
\hline CHEMBL1468954 & 752506 & 5.1856 & 5.3281 & TRN & & \\
\hline CHEMBL1604546 & 752506 & 5.1701 & 5.3334 & TST & & \\
\hline CHEMBL1405279 & 752506 & 5.1056 & 5.5983 & TRN & & \\
\hline CHEMBL1343966 & 752506 & 5.9285 & 5.4941 & TRN & & \\
\hline CHEMBL1307801 & 752506 & 5.141 & 5.334 & TRN & & \\
\hline CHEMBL602718 & 752506 & 5.9326 & 6.0174 & TRN & & \\
\hline CHEMBL1502251 & 752506 & 5.3785 & 4.9167 & TST & & \\
\hline CHEMBL1394270 & 752506 & 5.6696 & 5.763 & TRN & & \\
\hline CHEMBL1418631 & 752506 & 5.6649 & 5.6752 & TRN & & \\
\hline CHEMBL1501506 & 752506 & 5.67899 & 99999999 & 99 & 5.8298 & TST \\
\hline
\end{tabular}




\begin{tabular}{|c|c|c|c|c|c|c|}
\hline & & \multicolumn{5}{|c|}{ Supplemental Table S2.txt } \\
\hline CHEMBL1603844 & 752506 & 4.9519 & 5.1218 & TST & & \\
\hline CHEMBL1468192 & 752506 & 5.1095 & 5.2877 & TRN & & \\
\hline CHEMBL1377607 & 752506 & 5.7153 & 5.3571 & TST & & \\
\hline CHEMBL1573351 & 752506 & 5.21299 & 9999999 & 99 & 5.1435 & TRN \\
\hline CHEMBL1342448 & 752506 & 5.8419 & 4.877 & TST & & \\
\hline CHEMBL1554027 & 752506 & 5.1273 & 5.131 & TRN & & \\
\hline CHEMBL1343853 & 752506 & 4.9598 & 4.8549 & TRN & & \\
\hline CHEMBL1599520 & 752506 & 5.3141 & 5.2605 & TRN & & \\
\hline CHEMBL1998863 & 752506 & 5.9905 & 5.9183 & TRN & & \\
\hline CHEMBL1994034 & 752506 & 5.9112 & 6.0194 & TRN & & \\
\hline CHEMBL1430227 & 752506 & 5.4864 & 5.3297 & TRN & & \\
\hline CHEMBL1330307 & 752506 & 5.5538 & 5.9311 & TRN & & \\
\hline CHEMBL1429774 & 752506 & 5.7036 & 5.9347 & TRN & & \\
\hline CHEMBL1469029 & 752506 & 5.5119 & 5.2739 & TRN & & \\
\hline CHEMBL1483479 & 752506 & 5.4638 & 5.1277 & TRN & & \\
\hline CHEMBL1535134 & 752506 & 5.4065 & 4.9404 & TRN & & \\
\hline CHEMBL3196163 & 752506 & 5.8633 & 6.1891 & TRN & & \\
\hline CHEMBL1699199 & 752506 & 6.1433 & 5.9569 & TRN & & \\
\hline CHEMBL1325226 & 752506 & 5.4283 & 5.5022 & TRN & & \\
\hline CHEMBL1347347 & 752506 & 5.2313 & 5.3144 & TRN & & \\
\hline CHEMBL1566174 & 752506 & 4.5256 & 5.0711 & TRN & & \\
\hline CHEMBL1352607 & 752506 & 5.5427 & 5.2307 & TRN & & \\
\hline CHEMBL1449336 & 752506 & 6.2429 & 5.6175 & TRN & & \\
\hline CHEMBL1471734 & 752506 & 5.3152 & 5.2631 & TRN & & \\
\hline CHEMBL1457902 & 752506 & 5.4483 & 5.4435 & TRN & & \\
\hline CHEMBL1387181 & 752506 & 6.4104 & 5.7931 & TRN & & \\
\hline CHEMBL1534781 & 752506 & 5.362 & 4.9766 & TRN & & \\
\hline CHEMBL1533321 & 752506 & 5.3839 & 5.2642 & TRN & & \\
\hline CHEMBL1402539 & 752506 & 5.3703 & 5.3911 & TRN & & \\
\hline CHEMBL3198581 & 752506 & 5.1527 & 5.7057 & TRN & & \\
\hline CHEMBL1376777 & 752506 & 5.1978 & 5.3523 & TRN & & \\
\hline CHEMBL1438978 & 752506 & 5.3799 & 5.249 & TRN & & \\
\hline CHEMBL1383414 & 752506 & 5.9176 & 5.5331 & TRN & & \\
\hline CHEMBL1443775 & 752506 & 5.296 & 5.6215 & TRN & & \\
\hline CHEMBL1732074 & 752506 & 7.71 & 5.8011 & TST & & \\
\hline CHEMBL1563650 & 752506 & 5.7142 & 5.2648 & TRN & & \\
\hline CHEMBL602987 & 752506 & 5.415 & 5.5458 & TRN & & \\
\hline CHEMBL3194186 & 752506 & 5.6499 & 5.2494 & TST & & \\
\hline CHEMBL1377316 & 752506 & 5.4124 & 5.4929 & TRN & & \\
\hline CHEMBL577662 & 752506 & 5.9978 & 6.215 & TRN & & \\
\hline CHEMBL1313222 & 752506 & 5.4286 & 5.1768 & TRN & & \\
\hline CHEMBL1976567 & 752506 & 5.4559 & 5.0441 & TRN & & \\
\hline CHEMBL1422453 & 752506 & 5.7174 & 5.9838 & TRN & & \\
\hline CHEMBL1730863 & 752506 & 5.1906 & 5.0151 & TST & & \\
\hline CHEMBL1561764 & 752506 & 5.1807 & 5.1589 & TRN & & \\
\hline CHEMBL1467386 & 752506 & 5.3805 & 4.8393 & TST & & \\
\hline CHEMBL1426792 & 752506 & 5.2588 & 4.8619 & TST & & \\
\hline CHEMBL1526165 & 752506 & 5.1532 & 5.2953 & TST & & \\
\hline
\end{tabular}




\begin{tabular}{|c|c|c|c|c|c|}
\hline \multirow[b]{2}{*}{ CHEMBL1552445 } & \\
\hline & 752506 & 5.1283 & 5.2057 & TRN & \\
\hline CHEMBL1725628 & 752506 & 5.42 & 5.0764 & TST & \\
\hline CHEMBL1355233 & 752506 & 5.3811 & 5.3328 & TST & \\
\hline CHEMBL147514 & 752506 & 5.3365 & 5.1866 & TST & \\
\hline CHEMBL1504112 & 752506 & 2.585 & 4.7866 & TRN & \\
\hline CHEMBL1492752 & 752506 & 5.8431 & 5.9304 & TST & \\
\hline CHEMBL1546374 & 752506 & 6.3852 & \multicolumn{2}{|c|}{6.0889999999999995} & TRN \\
\hline CHEMBL609438 & 752506 & 5.9642 & 6.1897 & TRN & \\
\hline CHEMBL1529991 & 752506 & 5.2403 & 5.1857 & TST & \\
\hline CHEMBL1321398 & 752506 & 5.6182 & 5.4394 & TST & \\
\hline CHEMBL3191808 & 752506 & 6.4375 & 6.465 & TRN & \\
\hline CHEMBL1321527 & 752506 & 5.1071 & 4.8286 & TRN & \\
\hline CHEMBL1577606 & 752506 & 5.3508 & 5.5927 & TRN & \\
\hline CHEMBL 2007422 & 752506 & 6.4936 & 5.9094 & TRN & \\
\hline CHEMBL1531172 & 752506 & 5.1451 & 5.7256 & TRN & \\
\hline CHEMBL1497139 & 752506 & 5.1369 & 4.785 & TST & \\
\hline CHEMBL1716540 & 752506 & 5.4857 & 5.0968 & TST & \\
\hline CHEMBL2003602 & 752506 & 5.6249 & 5.2615 & TRN & \\
\hline CHEMBL 2004056 & 752506 & 5.0301 & \multicolumn{2}{|c|}{5.1339999999999995} & TRN \\
\hline CHEMBL3189599 & 752506 & 5.6054 & 5.5258 & TRN & \\
\hline CHEMBL 3208223 & 752506 & 4.4881 & 5.2282 & TRN & \\
\hline CHEMBL1310221 & 752506 & 5.6576 & 5.375 & TRN & \\
\hline CHEMBL1540999 & 752506 & 2.585 & 4.9737 & TST & \\
\hline CHEMBL1969707 & 752506 & 5.7345 & 5.5448 & TRN & \\
\hline CHEMBL1385055 & 752506 & 5.0984 & 4.7721 & TRN & \\
\hline CHEMBL 2007601 & 752506 & 5.3912 & 5.92 & TRN & \\
\hline CHEMBL1548761 & 752506 & 5.4149 & 5.1503 & TRN & \\
\hline CHEMBL1485865 & 752506 & 5.6792 & 5.3268 & TRN & \\
\hline CHEMBL1349146 & 752506 & 6.1189 & 5.9524 & TRN & \\
\hline CHEMBL1393829 & 752506 & 6.0645 & 6.0301 & TRN & \\
\hline CHEMBL1344025 & 752506 & 5.4725 & 5.4257 & TRN & \\
\hline CHEMBL1382628 & 752506 & 5.2675 & 5.5208 & TRN & \\
\hline CHEMBL1981898 & 752506 & 5.7378 & 6.2801 & TRN & \\
\hline CHEMBL1393813 & 752506 & 5.5394 & \multicolumn{2}{|c|}{5.537999999999999} & TRN \\
\hline CHEMBL1586660 & 752506 & 5.1834 & 5.2093 & TRN & \\
\hline CHEMBL1723286 & 752506 & 5.1474 & 4.7404 & TRN & \\
\hline CHEMBL1982774 & 752506 & 6.1606 & 5.9177 & TRN & \\
\hline CHEMBL1516692 & 752506 & 5.5321 & 5.0049 & TRN & \\
\hline CHEMBL478791 & 752506 & 5.476 & 4.7907 & TST & \\
\hline CHEMBL1390785 & 752506 & 5.7809 & \multicolumn{2}{|c|}{5.542000000000001} & TRN \\
\hline CHEMBL1387462 & 752506 & 5.1287 & 5.2592 & TRN & \\
\hline CHEMBL1703510 & 752506 & 5.2643 & 5.6052 & TRN & \\
\hline CHEMBL1440795 & 752506 & 4.4746 & 4.8954 & TRN & \\
\hline CHEMBL1728771 & 752506 & 4.5196 & 4.8511 & TRN & \\
\hline CHEMBL1393691 & 752506 & 2.585 & 4.6967 & TRN & \\
\hline CHEMBL1701327 & 752506 & 5.232 & 5.1977 & TRN & \\
\hline CHEMBL1368008 & 752506 & 5.5262 & 5.5396 & TRN & \\
\hline CHEMBL1733223 & 752506 & 5.079 & 5.1264 & TRN & \\
\hline & & & & 22887 & \\
\hline
\end{tabular}




\begin{tabular}{|c|c|c|c|c|c|c|}
\hline & & & & & & \\
\hline CHEMBL1711914 & 752506 & 5.2508 & 4.9535 & TRN & & \\
\hline CHEMBL592600 & 752506 & 6.3061 & 6.3021 & TRN & & \\
\hline CHEMBL1968859 & 752506 & 5.92700 & 00000000 & 205 & 5.9036 & TRN \\
\hline CHEMBL1533431 & 752506 & 5.0341 & 5.3985 & TRN & & \\
\hline CHEMBL3198723 & 752506 & 5.26399 & 99999999 & 99 & 5.3543 & TRN \\
\hline CHEMBL579919 & 752506 & 5.5127 & 5.3056 & TRN & & \\
\hline CHEMBL1332013 & 752506 & 5.1138 & 5.5397 & TRN & & \\
\hline CHEMBL1700791 & 752506 & 5.3624 & 4.797 & TRN & & \\
\hline CHEMBL3190786 & 752506 & 5.4526 & 5.8688 & TRN & & \\
\hline CHEMBL1466260 & 752506 & 5.2759 & 5.6062 & TRN & & \\
\hline CHEMBL1998940 & 752506 & 4.7652 & 5.3542 & TST & & \\
\hline CHEMBL1376794 & 752506 & 5.1978 & 4.8444 & TRN & & \\
\hline CHEMBL1429861 & 752506 & 5.7486 & 5.32100 & 0000000001 & & TRN \\
\hline CHEMBL1589062 & 752506 & 5.1589 & 5.4015 & TST & & \\
\hline CHEMBL3191855 & 752506 & 6.228 & 5.8608 & TRN & & \\
\hline CHEMBL1393625 & 752506 & 5.3556 & 4.8819 & TST & & \\
\hline CHEMBL3190261 & 752506 & 5.7825 & 5.4274 & TRN & & \\
\hline CHEMBL3190986 & 752506 & 5.7093 & 5.6434 & TRN & & \\
\hline CHEMBL1562926 & 752506 & 6.1687 & 5.7114 & TRN & & \\
\hline CHEMBL3196962 & 752506 & 5.3114 & 5.3089 & TRN & & \\
\hline CHEMBL 2006840 & 752506 & 5.71399 & 99999999 & 995 & 5.7743 & TRN \\
\hline CHEMBL1306079 & 752506 & 5.1904 & 4.8043 & TST & & \\
\hline CHEMBL51931 & 752506 & 5.9944 & 5.9523 & TRN & & \\
\hline CHEMBL1988072 & 752506 & 5.8063 & 5.5477 & TRN & & \\
\hline CHEMBL1594475 & 752506 & 6.0527 & 6.1915 & TRN & & \\
\hline CHEMBL1561133 & 752506 & 5.1348 & 4.4645 & TRN & & \\
\hline CHEMBL1430718 & 752506 & 5.3276 & 5.2433 & TRN & & \\
\hline CHEMBL3199020 & 752506 & 5.6698 & 5.8159 & TRN & & \\
\hline CHEMBL84010 & 752506 & 5.4012 & 5.6741 & TRN & & \\
\hline CHEMBL494255 & 752506 & 5.1067 & 5.32600 & 0000000000 & 05 & TST \\
\hline CHEMBL1729758 & 752506 & 5.1351 & 5.5852 & TST & & \\
\hline CHEMBL1574982 & 752506 & 5.3983 & 5.0672 & TRN & & \\
\hline CHEMBL1522373 & 752506 & 5.3939 & 5.5541 & TRN & & \\
\hline CHEMBL1339270 & 752506 & 5.7493 & 5.9296 & TRN & & \\
\hline CHEMBL1374714 & 752506 & 4.7069 & 5.2968 & TRN & & \\
\hline CHEMBL1478237 & 752506 & 5.4833 & 5.3692 & TRN & & \\
\hline CHEMBL2006607 & 752506 & 5.8752 & 5.2214 & TRN & & \\
\hline CHEMBL1425438 & 752506 & 5.7493 & 5.0787 & TRN & & \\
\hline CHEMBL1419943 & 752506 & 5.17700 & 20000000 & 205 & 4.8812 & TRN \\
\hline CHEMBL3199737 & 752506 & 5.7513 & 5.2191 & TRN & & \\
\hline CHEMBL1458338 & 752506 & 5.05399 & 99999999 & 99 & 5.6043 & TRN \\
\hline CHEMBL585827 & 752506 & 6.2118 & 6.0847 & TRN & & \\
\hline CHEMBL3198896 & 752506 & 5.5342 & 5.6945 & TST & & \\
\hline CHEMBL1325823 & 752506 & 5.4324 & 5.1573 & TRN & & \\
\hline CHEMBL1506317 & 752506 & 5.5597 & 5.2994 & TRN & & \\
\hline CHEMBL1487312 & 752506 & 2.585 & 4.255 & TRN & & \\
\hline CHEMBL1348582 & 752506 & 5.3059 & 5.5477 & TRN & & \\
\hline CHEMBL1527447 & 752506 & 5.2662 & 4.787 & TST & & \\
\hline
\end{tabular}




\begin{tabular}{|c|c|c|c|c|c|}
\hline & & \multicolumn{4}{|c|}{ Supplemental Table S2.txt } \\
\hline CHEMBL1579923 & 752506 & 5.3194 & 5.3035 & TRN & \\
\hline CHEMBL1526966 & 752506 & 5.1066 & 4.9584 & TRN & \\
\hline CHEMBL1512403 & 752506 & 5.567 & 5.4778 & TRN & \\
\hline CHEMBL1490169 & 752506 & 5.4131 & 5.1497 & TST & \\
\hline CHEMBL1436964 & 752506 & 5.2531 & 5.0493 & TRN & \\
\hline CHEMBL1425701 & 752506 & 4.8277 & 4.9706 & TRN & \\
\hline CHEMBL1364485 & 752506 & 5.1305 & 4.7811 & TRN & \\
\hline CHEMBL3192555 & 752506 & 6.3932 & 6.1257 & TRN & \\
\hline CHEMBL1383372 & 752506 & 2.585 & 4.2388 & TRN & \\
\hline CHEMBL1977877 & 752506 & 6.2829 & 6.1559 & TRN & \\
\hline CHEMBL 3145280 & 752506 & 5.6931 & 5.9307 & TRN & \\
\hline CHEMBL1489294 & 752506 & 5.3437 & 5.3147 & TRN & \\
\hline CHEMBL1594623 & 752506 & 2.585 & 5.1997 & TST & \\
\hline CHEMBL3197024 & 752506 & 5.9133 & 5.8282 & TRN & \\
\hline CHEMBL532160 & 752506 & 5.4149 & 5.2645 & TRN & \\
\hline CHEMBL1555483 & 752506 & 5.2855 & 5.4363 & TRN & \\
\hline CHEMBL1310691 & 752506 & 4.4693 & 4.9592 & TRN & \\
\hline CHEMBL1984876 & 752506 & 6.5018 & 6.5583 & TRN & \\
\hline CHEMBL1514530 & 752506 & 6.3226 & 6.204 & TRN & \\
\hline CHEMBL3183210 & 752506 & 5.6966 & 5.4307 & TRN & \\
\hline CHEMBL1400965 & 752506 & 6.5714 & 6.6083 & TRN & \\
\hline CHEMBL3195091 & 752506 & 6.0787 & 6.0469 & TRN & \\
\hline CHEMBL3196139 & 752506 & \multicolumn{3}{|c|}{6.127999999999999} & TRN \\
\hline CHEMBL65374 & 752506 & 5.4357 & 5.315 & TRN & \\
\hline CHEMBL1721483 & 752506 & 2.585 & 4.9942 & TST & \\
\hline CHEMBL3192911 & 752506 & 4.7135 & 4.6875 & TRN & \\
\hline CHEMBL3198332 & 752506 & 6.26 & 6.4205 & TRN & \\
\hline CHEMBL1558183 & 752506 & 4.6953 & 5.4055 & TRN & \\
\hline CHEMBL1306838 & 752506 & 5.1545 & 4.8763 & TRN & \\
\hline CHEMBL1601325 & 752506 & 5.2118 & 4.5986 & TST & \\
\hline CHEMBL1479483 & 752506 & 5.2507 & 4.9239 & TRN & \\
\hline CHEMBL1541973 & 752506 & 5.3555 & 5.42299 & 9999999999 & TRN \\
\hline CHEMBL3195322 & 752506 & 5.8918 & 5.5722 & TRN & \\
\hline CHEMBL1532575 & 752506 & 4.727 & 5.0602 & TRN & \\
\hline CHEMBL1546316 & 752506 & 4.4327 & 4.4951 & TST & \\
\hline CHEMBL1374947 & 752506 & 5.5261 & 5.4097 & TRN & \\
\hline CHEMBL1502014 & 752506 & 5.6878 & 5.76 & TST & \\
\hline CHEMBL1587891 & 752506 & 4.9602 & 5.2826 & TRN & \\
\hline CHEMBL1427991 & 752506 & 5.5063 & 5.143 & TRN & \\
\hline CHEMBL1468075 & 752506 & 5.355 & 5.2936 & TRN & \\
\hline CHEMBL1389740 & 752506 & 5.0878 & 5.2218 & TRN & \\
\hline CHEMBL1698970 & 752506 & 5.181 & 5.0866 & TRN & \\
\hline CHEMBL1964943 & 752506 & 5.504 & 5.3022 & TRN & \\
\hline CHEMBL1980322 & 752506 & 5.7731 & 5.7697 & TRN & \\
\hline CHEMBL1323248 & 752506 & 5.0962 & 4.9988 & TRN & \\
\hline CHEMBL1994179 & 752506 & 5.5136 & 5.8305 & TRN & \\
\hline CHEMBL1460004 & 752506 & 5.4085 & 5.5146 & TRN & \\
\hline \multirow[t]{2}{*}{ CHEMBL3193481 } & 752506 & 5.1861 & 5.25899 & 99999999995 & TRN \\
\hline & & \multicolumn{4}{|c|}{ Page 22889} \\
\hline
\end{tabular}




\begin{tabular}{|c|c|c|c|c|c|c|}
\hline & & \multicolumn{5}{|c|}{ Supplemental Table S2.txt } \\
\hline CHEMBL1558065 & 752506 & 5.4035 & 5.9819 & TRN & & \\
\hline CHEMBL1506300 & 752506 & 5.0929 & 4.8517 & TRN & & \\
\hline CHEMBL1510454 & 752506 & 5.2763 & 5.1733 & TRN & & \\
\hline CHEMBL1422481 & 752506 & 4.8989 & 5.3423 & TST & & \\
\hline CHEMBL1440300 & 752506 & 5.6832 & 5.5908 & TRN & & \\
\hline CHEMBL1335915 & 752506 & 5.1555 & 5.0623 & TRN & & \\
\hline CHEMBL1543865 & 752506 & 5.2072 & 5.1381 & TRN & & \\
\hline CHEMBL1463877 & 752506 & 5.149 & 5.5228 & TRN & & \\
\hline CHEMBL1518085 & 752506 & 5.7873 & 5.7384 & TRN & & \\
\hline CHEMBL1536018 & 752506 & 5.4129 & 5.4092 & TRN & & \\
\hline CHEMBL590927 & 752506 & 6.1571 & 6.0183 & TRN & & \\
\hline CHEMBL1569989 & 752506 & 5.6214 & 6.0711 & TRN & & \\
\hline CHEMBL1597217 & 752506 & 5.3403 & 5.2059 & TRN & & \\
\hline CHEMBL1308687 & 752506 & 5.4293 & 5.3065 & TRN & & \\
\hline CHEMBL1535055 & 752506 & 5.8256 & 5.1775 & TRN & & \\
\hline CHEMBL1439207 & 752506 & 5.4254 & 5.2922 & TRN & & \\
\hline CHEMBL1519651 & 752506 & 5.4127 & 5.2066 & TRN & & \\
\hline CHEMBL1456848 & 752506 & 5.3951 & 5.1907 & TRN & & \\
\hline CHEMBL1606390 & 752506 & 5.3413 & 5.1318 & TRN & & \\
\hline CHEMBL1308879 & 752506 & 5.289 & 5.0117 & TRN & & \\
\hline CHEMBL1455877 & 752506 & 5.6676 & 5.7166 & TRN & & \\
\hline CHEMBL1459140 & 752506 & 5.5112 & 5.4103 & TRN & & \\
\hline CHEMBL1384771 & 752506 & 5.2542 & 5.1255 & TST & & \\
\hline CHEMBL1469102 & 752506 & 5.3272 & 4.9332 & TRN & & \\
\hline CHEMBL1995378 & 752506 & 5.572 & 5.2312 & TRN & & \\
\hline CHEMBL1347586 & 752506 & 5.0683 & 4.59 & TST & & \\
\hline CHEMBL1407572 & 752506 & 5.2683 & 5.5929 & TST & & \\
\hline CHEMBL 3197639 & 752506 & 4.96899 & 999999999 & 99 & 5.1789 & TRN \\
\hline CHEMBL1347156 & 752506 & 5.8847 & 5.4346 & TRN & & \\
\hline CHEMBL 2006122 & 752506 & 5.1491 & 5.0192 & TRN & & \\
\hline CHEMBL1987461 & 752506 & 6.0824 & 6.2071 & TRN & & \\
\hline CHEMBL1360343 & 752506 & 4.93 & 4.5949 & TRN & & \\
\hline CHEMBL1525567 & 752506 & 5.153 & 5.0177 & TRN & & \\
\hline CHEMBL117966 & 752506 & 5.5203 & 5.4514 & TRN & & \\
\hline CHEMBL1337570 & 752506 & 5.3413 & 5.0345 & TRN & & \\
\hline CHEMBL3191817 & 752506 & 5.6334 & 5.6224 & TRN & & \\
\hline CHEMBL1491847 & 752506 & 5.4234 & 5.5391 & TST & & \\
\hline CHEMBL1452711 & 752506 & 5.4825 & 5.602 & TRN & & \\
\hline CHEMBL528694 & 752506 & 6.5376 & 6.0806 & TRN & & \\
\hline CHEMBL1473233 & 752506 & 5.5837 & 5.1639 & TRN & & \\
\hline CHEMBL1990093 & 752506 & 6.045 & 5.5232 & TRN & & \\
\hline CHEMBL1583292 & 752506 & 5.7964 & 5.652 & TST & & \\
\hline CHEMBL1794128 & 752506 & 2.585 & 4.7427 & TRN & & \\
\hline CHEMBL1366622 & 752506 & 5.8462 & 5.7472 & TRN & & \\
\hline CHEMBL 3190712 & 752506 & 6.0814 & 5.6435 & TRN & & \\
\hline CHEMBL3196364 & 752506 & 6.1799 & 6.1593 & TRN & & \\
\hline CHEMBL 3184551 & 752506 & 4.5574 & 4.729 & TRN & & \\
\hline CHEMBL1525597 & 752506 & 5.2935 & 5.5929 & TRN & & \\
\hline
\end{tabular}




\begin{tabular}{|c|c|c|c|c|c|}
\hline & & & & & \\
\hline CHEMBL1375155 & 752506 & 5.484 & 5.185 & TST & \\
\hline CHEMBL493863 & 752506 & 5.5022 & 5.2458 & TRN & \\
\hline CHEMBL1370434 & 752506 & 5.1497 & 5.0724 & TST & \\
\hline CHEMBL1583914 & 752506 & 5.5092 & 5.1461 & TRN & \\
\hline CHEMBL1444205 & 752506 & 5.3475 & 4.9223 & TRN & \\
\hline CHEMBL1544664 & 752506 & 5.0111 & 4.8467 & TRN & \\
\hline CHEMBL1387923 & 752506 & 5.3429 & 5.4242 & TRN & \\
\hline CHEMBL1602905 & 752506 & 5.4984 & 5.1298 & TRN & \\
\hline CHEMBL1455229 & 752506 & 5.7902 & 5.5452 & TRN & \\
\hline CHEMBL1326441 & 752506 & 4.9855 & 4.8774 & TRN & \\
\hline CHEMBL1525220 & 752506 & 5.9948 & 5.1024 & TRN & \\
\hline CHEMBL3145305 & 752506 & 5.7025 & 5.6899 & TRN & \\
\hline CHEMBL3196633 & 752506 & 6.1741 & 5.4294 & TRN & \\
\hline CHEMBL2006909 & 752506 & 5.5248 & 5.3746 & TRN & \\
\hline CHEMBL1560784 & 752506 & 5.4731 & 5.4187 & TST & \\
\hline CHEMBL1309960 & 752506 & 5.4587 & 5.3268 & TRN & \\
\hline CHEMBL1339737 & 752506 & 5.5049 & 6.102 & TRN & \\
\hline CHEMBL1504710 & 752506 & 2.585 & 4.9825 & TRN & \\
\hline CHEMBL3195551 & 752506 & 5.5049 & 5.5182 & TRN & \\
\hline CHEMBL3194752 & 752506 & 5.33700 & 000000006 & 5.6266 & TRN \\
\hline CHEMBL1492667 & 752506 & 4.8794 & 5.0934 & TRN & \\
\hline CHEMBL1988657 & 752506 & 6.1474 & 6.1476 & TRN & \\
\hline CHEMBL1524240 & 752506 & 5.3879 & 5.1957 & TRN & \\
\hline CHEMBL1344225 & 752506 & 6.0682 & 5.8729 & TRN & \\
\hline CHEMBL3193650 & 752506 & 6.2043 & 5.581 & TRN & \\
\hline CHEMBL1306343 & 752506 & 6.0852 & 6.0104 & TRN & \\
\hline CHEMBL1300092 & 752506 & 2.585 & 5.221 & TST & \\
\hline CHEMBL1416856 & 752506 & 5.4651 & 5.9499 & TST & \\
\hline CHEMBL1310822 & 752506 & 4.5077 & 4.524 & TRN & \\
\hline CHEMBL1310468 & 752506 & 5.2151 & 5.0426 & TRN & \\
\hline CHEMBL1307519 & 752506 & 5.0147 & 4.9214 & TST & \\
\hline CHEMBL1365290 & 752506 & 5.3161 & 4.8671 & TRN & \\
\hline CHEMBL1726720 & 752506 & 4.9893 & 4.7663 & TRN & \\
\hline CHEMBL1498146 & 752506 & 5.187 & 5.1321 & TRN & \\
\hline CHEMBL1488126 & 752506 & 5.1655 & 5.4168 & TRN & \\
\hline CHEMBL598270 & 752506 & 5.3671 & 5.4798 & TST & \\
\hline CHEMBL1609490 & 752506 & 5.4731 & 5.5039 & TRN & \\
\hline CHEMBL581860 & 752506 & 4.8726 & 5.3021 & TRN & \\
\hline CHEMBL1983243 & 752506 & 5.3177 & 5.7263 & TRN & \\
\hline CHEMBL 3212271 & 752506 & 5.7335 & 6.3791 & TRN & \\
\hline CHEMBL1978733 & 752506 & 5.0999 & 5.3858 & TRN & \\
\hline CHEMBL1473052 & 752506 & 5.2352 & 5.0545 & TST & \\
\hline CHEMBL1313410 & 752506 & 5.1406 & 5.08899 & 99999999995 & TST \\
\hline CHEMBL1394557 & 752506 & 5.4024 & 4.9033 & TRN & \\
\hline CHEMBL1451348 & 752506 & 5.4082 & 4.9828 & TRN & \\
\hline CHEMBL1465648 & 752506 & 2.9208 & 4.8729 & TST & \\
\hline CHEMBL1528306 & 752506 & 4.8289 & 5.1163 & TST & \\
\hline CHEMBL583351 & 752506 & 5.5075 & 5.7155 & TRN & \\
\hline
\end{tabular}




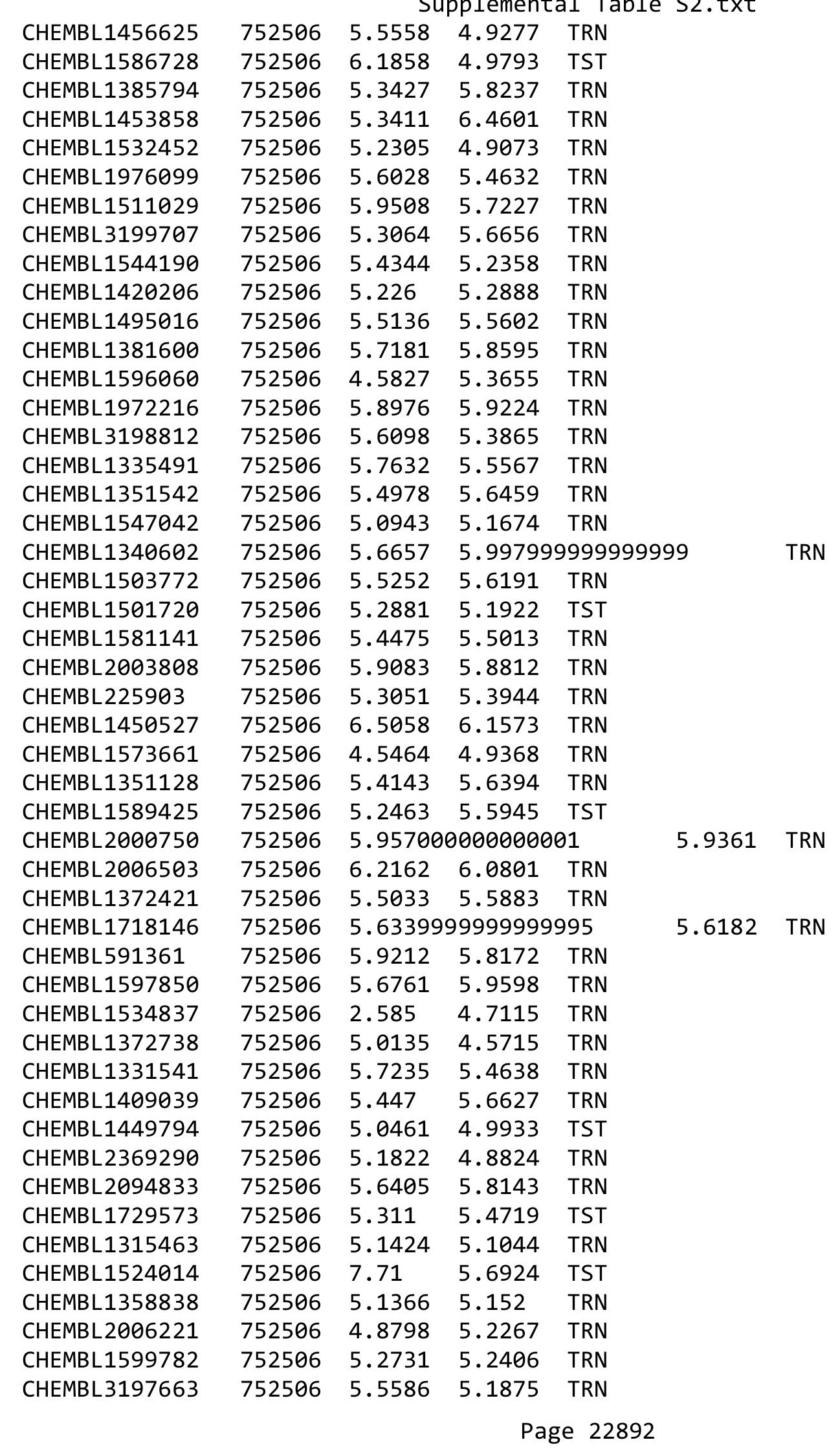




\begin{tabular}{ll} 
CHEMBL1517493 & 752506 \\
CHEMBL1497081 & 752506 \\
CHEMBL3191770 & 752506 \\
CHEMBL1381673 & 752506 \\
CHEMBL1483847 & 752506 \\
CHEMBL1995715 & 752506 \\
CHEMBL1529236 & 752506 \\
CHEMBL1412396 & 752506 \\
CHEMBL1324027 & 752506 \\
CHEMBL1996749 & 752506 \\
CHEMBL1326118 & 752506 \\
CHEMBL1479010 & 752506 \\
CHEMBL3195933 & 752506 \\
CHEMBL1588869 & 752506 \\
CHEMBL1509219 & 752506 \\
CHEMBL1385558 & 752506 \\
CHEMBL1500686 & 752506 \\
CHEMBL1335944 & 752506 \\
CHEMBL1457825 & 752506 \\
CHEMBL582444 & 752506 \\
CHEMBL1444307 & 752506 \\
CHEMBL2004809 & 752506 \\
CHEMBL1330113 & 752506 \\
CHEMBL1335846 & 752506 \\
CHEMBL1420037 & 752506 \\
CHEMBL602620 & 752506 \\
CHEMBL1428868 & 752506 \\
CHEMBL1588275 & 752506 \\
CHEMBL3190690 & 752506 \\
CHEMEMBL1994078 & 752506 \\
CHEMBL1348332 & 752506 \\
CHEMBL1441681 & 752506 \\
CHEMBL1405947 & 752506 \\
CHEMBL1535955 & 752506 \\
CHEMBL3213027 & 752506 \\
CHEMBL1331809 & 752506 \\
CHEMBL1305077 & 752506 \\
CHEMBL1733782 & 752506 \\
CHEMBL1305011 & 752506 \\
CHEMBL1534657 & 752506 \\
CHEMBL1577983 & 752506 \\
CHEMBL1340698 & 752506 \\
\hline
\end{tabular}

Supplemental Table S2.txt

$\begin{array}{ll}4.5735 & 4.7493\end{array}$

$\begin{array}{lll}5.1914 & 4.828 & \text { TST }\end{array}$

5.66845 .8041 TRN

$\begin{array}{llll}5.2311 & 4.9975 & \text { TRN }\end{array}$

$\begin{array}{lll}5.4093 & 5.4972 & \text { TRN }\end{array}$

$\begin{array}{lll}6.3178 & 5.3609 & \text { TRN }\end{array}$

4.77295 .2446 TRN

$\begin{array}{lll}5.1914 & 5.1417 & \text { TRN }\end{array}$

$\begin{array}{llll}5.2687 & 5.5643 & \text { TRN }\end{array}$

$\begin{array}{llll}6.4522 & 6.1037 & \text { TRN }\end{array}$

$\begin{array}{lll}5.0883 & 4.9213 & \text { TRN }\end{array}$

$\begin{array}{lll}5.3023 & 5.148 \quad \text { TRN }\end{array}$

$\begin{array}{lll}5.4731 & 5.4409 & \text { TRN }\end{array}$

$\begin{array}{llll}4.8486 & 4.9088 & \text { TRN }\end{array}$

$\begin{array}{llll}3.9531 & 4.6389 & \text { TRN }\end{array}$

$\begin{array}{llll}5.4994 & 5.0295 & \text { TRN }\end{array}$

$\begin{array}{llll}5.3666 & 5.0888 & \text { TRN }\end{array}$

$2.9208 \quad 4.5376 \quad$ TRN

$\begin{array}{lll}4.64 & 4.9843 & \text { TST }\end{array}$

$\begin{array}{lll}5.0854 & 5.0918 & \text { TST }\end{array}$

$\begin{array}{lll}4.6253 & 4.8792 & \text { TRN }\end{array}$

$\begin{array}{lll}5.5902 & 5.4461 & \text { TRN }\end{array}$

$\begin{array}{llll}5.3698 & 5.4221 & \text { TRN }\end{array}$

6.41795 .8422 TRN

$\begin{array}{lll}6.3002 & 5.7503 & \text { TRN }\end{array}$

$4.8435 \quad 5.1831$ TRN

$\begin{array}{llll}4.0032 & 4.5396 & \text { TST }\end{array}$

$\begin{array}{llll}5.1472 & 5.2335 & \text { TRN }\end{array}$

$\begin{array}{llll}6.0032 & 5.3368 & \text { TRN }\end{array}$

$\begin{array}{lll}5.3803 & 5.2554 & \text { TRN }\end{array}$

$\begin{array}{lll}5.0169 & 4.9227 & \text { TST }\end{array}$

$\begin{array}{llll}5.3121 & 5.1998 & \text { TRN }\end{array}$

$\begin{array}{lll}5.8428 & 5.9917 & \text { TRN }\end{array}$

5.28395 .6645 TRN

$\begin{array}{lll}5.4483 & 4.9729 & \text { TST }\end{array}$

$\begin{array}{llll}5.0533 & 4.9398 & \text { TRN }\end{array}$

2.5854 .6572 TRN

$\begin{array}{lll}5.7368 & 5.377000000000001 & \text { TRN }\end{array}$

$\begin{array}{llll}5.3565 & 4.8732 & \text { TRN }\end{array}$

$\begin{array}{lll}5.4035 & 5.3236 & \text { TRN }\end{array}$

$\begin{array}{lll}5.5706 & 5.4082 & \text { TRN }\end{array}$

$\begin{array}{lll}6.0075 & 5.642 & \text { TST }\end{array}$

$\begin{array}{llll}5.3553 & 5.3308 & \text { TRN }\end{array}$

$\begin{array}{lll}5.5399 & 5.1924 & \text { TST }\end{array}$

$\begin{array}{lll}5.6525 & 5.1816 & \text { TRN }\end{array}$

$\begin{array}{llll}5.2998 & 5.2566 & \text { TRN }\end{array}$

$\begin{array}{lll}5.6505 & 4.9974 & \text { TST }\end{array}$

5.38635 .4463 TRN

Page 22893 


\begin{tabular}{|c|c|c|c|c|c|c|}
\hline \\
\hline CHEMBL1534478 & 752506 & 4.08 & 4.8065 & TRN & & \\
\hline CHEMBL1527664 & 752506 & 4.852 & 5.1996 & TST & & \\
\hline CHEMBL2131919 & 752506 & 5.1207 & 5.3359 & TRN & & \\
\hline CHEMBL1311226 & 752506 & 5.3637 & 5.6612 & TRN & & \\
\hline CHEMBL1481849 & 752506 & 5.4445 & 5.5382 & TST & & \\
\hline CHEMBL1588339 & 752506 & 5.3633 & 5.1924 & TRN & & \\
\hline CHEMBL601933 & 752506 & 6.3187 & 6.102 & TRN & & \\
\hline CHEMBL1565189 & 752506 & 5.3722 & 5.5828 & TRN & & \\
\hline CHEMBL1445414 & 752506 & 5.1232 & 5.2009 & TRN & & \\
\hline CHEMBL1496004 & 752506 & 5.6853 & 5.5872 & TRN & & \\
\hline CHEMBL3189714 & 752506 & 6.3838 & 6.023 & TRN & & \\
\hline CHEMBL1356472 & 752506 & 5.5258 & 6.1671 & TRN & & \\
\hline CHEMBL1587181 & 752506 & 5.2337 & 5.2899 & TST & & \\
\hline CHEMBL1333334 & 752506 & 6.013 & 4.7469 & TRN & & \\
\hline CHEMBL1571682 & 752506 & 5.3683 & 4.9797 & TRN & & \\
\hline CHEMBL1327954 & 752506 & 5.49700 & 20000000 & $\partial 1$ & 5.066 & TRN \\
\hline CHEMBL3191846 & 752506 & 5.5732 & 5.9315 & TRN & & \\
\hline CHEMBL1565005 & 752506 & 5.5664 & 5.3946 & TRN & & \\
\hline CHEMBL1364308 & 752506 & 4.8884 & 5.3051 & TRN & & \\
\hline CHEMBL1444381 & 752506 & 4.4295 & 5.1703 & TRN & & \\
\hline CHEMBL580918 & 752506 & 7.71 & 6.8693 & TRN & & \\
\hline CHEMBL1393379 & 752506 & 5.3544 & 4.7066 & TRN & & \\
\hline CHEMBL1385113 & 752506 & 4.511 & 4.5164 & TRN & & \\
\hline CHEMBL1499544 & 752506 & 5.5498 & 4.9556 & TST & & \\
\hline CHEMBL1498886 & 752506 & 5.7696 & 5.1404 & TRN & & \\
\hline CHEMBL1492261 & 752506 & 5.1927 & 4.5116 & TRN & & \\
\hline CHEMBL1303810 & 752506 & 5.3219 & 5.0262 & TRN & & \\
\hline CHEMBL1582859 & 752506 & 5.1401 & 4.7612 & TRN & & \\
\hline CHEMBL1329757 & 752506 & 5.3232 & 5.2946 & TRN & & \\
\hline CHEMBL1420187 & 752506 & 5.1684 & 5.2684 & TRN & & \\
\hline CHEMBL 2005895 & 752506 & 5.5884 & 5.8049 & TRN & & \\
\hline CHEMBL1714133 & 752506 & 5.4583 & 4.9948 & TRN & & \\
\hline CHEMBL1344875 & 752506 & 5.2171 & 5.0002 & TRN & & \\
\hline CHEMBL1485727 & 752506 & 6.0821 & 5.4075 & TRN & & \\
\hline CHEMBL3193422 & 752506 & 5.8851 & 5.8106 & TRN & & \\
\hline CHEMBL1277149 & 752506 & 5.0725 & 5.1763 & TRN & & \\
\hline CHEMBL602828 & 752506 & 5.8268 & 6.0105 & TRN & & \\
\hline CHEMBL1481162 & 752506 & 5.5053 & 5.1192 & TRN & & \\
\hline CHEMBL3190911 & 752506 & 5.9801 & 5.6253 & TRN & & \\
\hline CHEMBL1531502 & 752506 & 2.9208 & 4.8721 & TRN & & \\
\hline CHEMBL1569585 & 752506 & 5.8 & 5.3851 & TRN & & \\
\hline CHEMBL1526462 & 752506 & 5.3299 & 5.008 & TST & & \\
\hline CHEMBL1322853 & 752506 & 5.3097 & 4.9456 & TRN & & \\
\hline CHEMBL3214014 & 752506 & 2.585 & 5.2864 & TST & & \\
\hline CHEMBL1588349 & 752506 & 5.2624 & 5.6309 & TRN & & \\
\hline CHEMBL1985479 & 752506 & 5.4371 & 5.2573 & TRN & & \\
\hline CHEMBL576208 & 752506 & 5.697 & 5.0961 & TRN & & \\
\hline CHEMBL1337741 & 752506 & 2.585 & 4.8113 & TRN & & \\
\hline
\end{tabular}




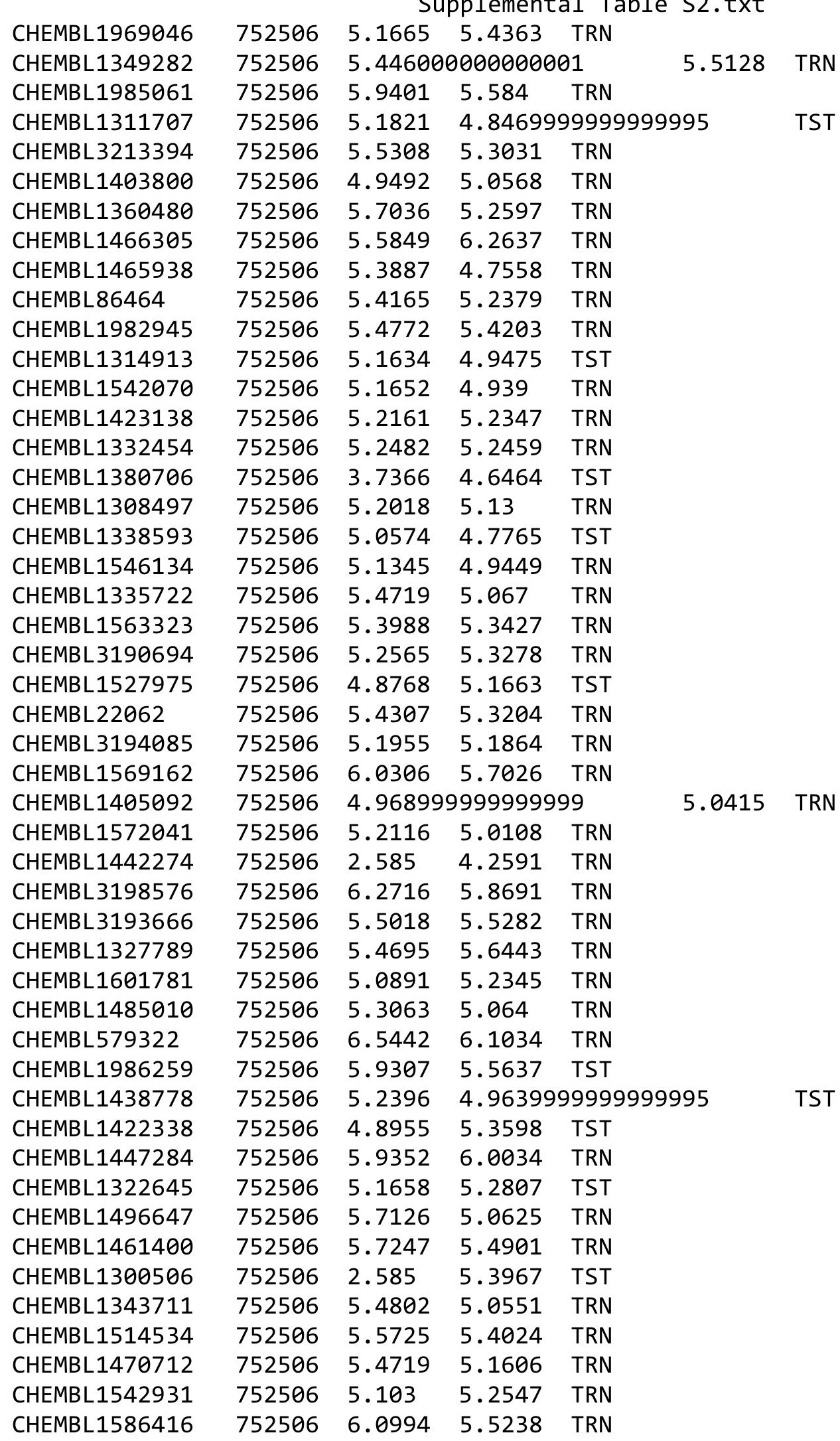

Page 22895 
Supplemental Table S2.txt

\begin{tabular}{|c|c|c|c|c|c|}
\hline CHEMBL1491222 & 752506 & 5.8948 & 6.2271 & TRN & \\
\hline CHEMBL1503651 & 752506 & 5.3073 & 5.82 & TST & \\
\hline CHEMBL1308648 & 752506 & 5.5964 & 4.998 & TST & \\
\hline CHEMBL1316480 & 752506 & 5.1632 & 5.1879 & TRN & \\
\hline CHEMBL580340 & 752506 & 5.6796 & 5.0517 & TRN & \\
\hline CHEMBL1310479 & 752506 & 5.8122 & 5.8785 & TRN & \\
\hline CHEMBL3193835 & 752506 & 6.261 & 6.0944 & TRN & \\
\hline CHEMBL1528242 & 752506 & 4.9296 & 5.7292 & TRN & \\
\hline CHEMBL1730785 & 752506 & 5.1142 & 5.1453 & TRN & \\
\hline CHEMBL1364184 & 752506 & 4.3961 & 5.1587 & TST & \\
\hline CHEMBL1448732 & 752506 & 5.3964 & 5.187 & TRN & \\
\hline CHEMBL1701004 & 752506 & 5.1665 & 4.7392 & TRN & \\
\hline CHEMBL1405453 & 752506 & 6.1105 & 5.345 & TRN & \\
\hline CHEMBL591370 & 752506 & 5.2752 & 5.2377 & TRN & \\
\hline CHEMBL3197988 & 752506 & 2.585 & 5.3101 & TRN & \\
\hline CHEMBL1572498 & 752506 & 5.3994 & 5.3083 & TRN & \\
\hline CHEMBL1595884 & 752506 & 5.40600 & 00000006 & 1 & 5.1931 \\
\hline CHEMBL1366271 & 752506 & 5.0645 & 5.1211 & TRN & \\
\hline CHEMBL3192616 & 752506 & 5.994 & 5.8112 & TRN & \\
\hline CHEMBL1582705 & 752506 & 2.585 & 4.5845 & TRN & \\
\hline CHEMBL3196495 & 752506 & 5.2023 & 4.7757 & TRN & \\
\hline CHEMBL1569724 & 752506 & 5.4874 & 4.7144 & TST & \\
\hline CHEMBL3192855 & 752506 & 6.2325 & 6.0675 & TRN & \\
\hline CHEMBL1551233 & 752506 & 5.1299 & 5.4598 & TST & \\
\hline CHEMBL2094789 & 752506 & 5.6548 & 5.0328 & TST & \\
\hline CHEMBL3211531 & 752506 & 5.4932 & 5.2026 & TRN & \\
\hline CHEMBL1388369 & 752506 & 5.5411 & 5.4998 & TRN & \\
\hline CHEMBL1359871 & 752506 & 5.6178 & 5.763 & TRN & \\
\hline CHEMBL1528481 & 752506 & 6.051 & 5.5948 & TRN & \\
\hline CHEMBL3197314 & 752506 & 6.42 & 5.6739 & TRN & \\
\hline CHEMBL1430757 & 752506 & 5.4332 & 5.6108 & TRN & \\
\hline CHEMBL1482296 & 752506 & 5.6613 & 5.3041 & TRN & \\
\hline CHEMBL1728912 & 752506 & 6.0629 & 6.0708 & TRN & \\
\hline CHEMBL1306267 & 752506 & 5.6438 & 5.8374 & TRN & \\
\hline CHEMBL 3145088 & 752506 & 6.0228 & 5.5273 & TRN & \\
\hline CHEMBL1580073 & 752506 & 5.4395 & 5.3591 & TST & \\
\hline CHEMBL1588046 & 752506 & 5.5366 & 5.7356 & TRN & \\
\hline CHEMBL1568189 & 752506 & 5.1464 & 5.0829 & TRN & \\
\hline CHEMBL3197091 & 752506 & 5.6002 & 5.7809 & TRN & \\
\hline CHEMBL1586256 & 752506 & 2.585 & 4.7912 & TRN & \\
\hline CHEMBL600100 & 752506 & 6.4897 & 5.9276 & TRN & \\
\hline CHEMBL1460585 & 752506 & 4.2147 & 5.2075 & TRN & \\
\hline CHEMBL1423660 & 752506 & 6.1489 & 6.1103 & TRN & \\
\hline CHEMBL1347534 & 752506 & 5.391 & 5.2826 & TST & \\
\hline CHEMBL1394121 & 752506 & 5.0604 & 5.1806 & TRN & \\
\hline CHEMBL1415127 & 752506 & 5.2415 & 5.3489 & TRN & \\
\hline CHEMBL3195241 & 752506 & 6.1144 & 6.5195 & TRN & \\
\hline CHEMBL1487460 & 752506 & 5.465 & 5.4528 & TRN & \\
\hline
\end{tabular}




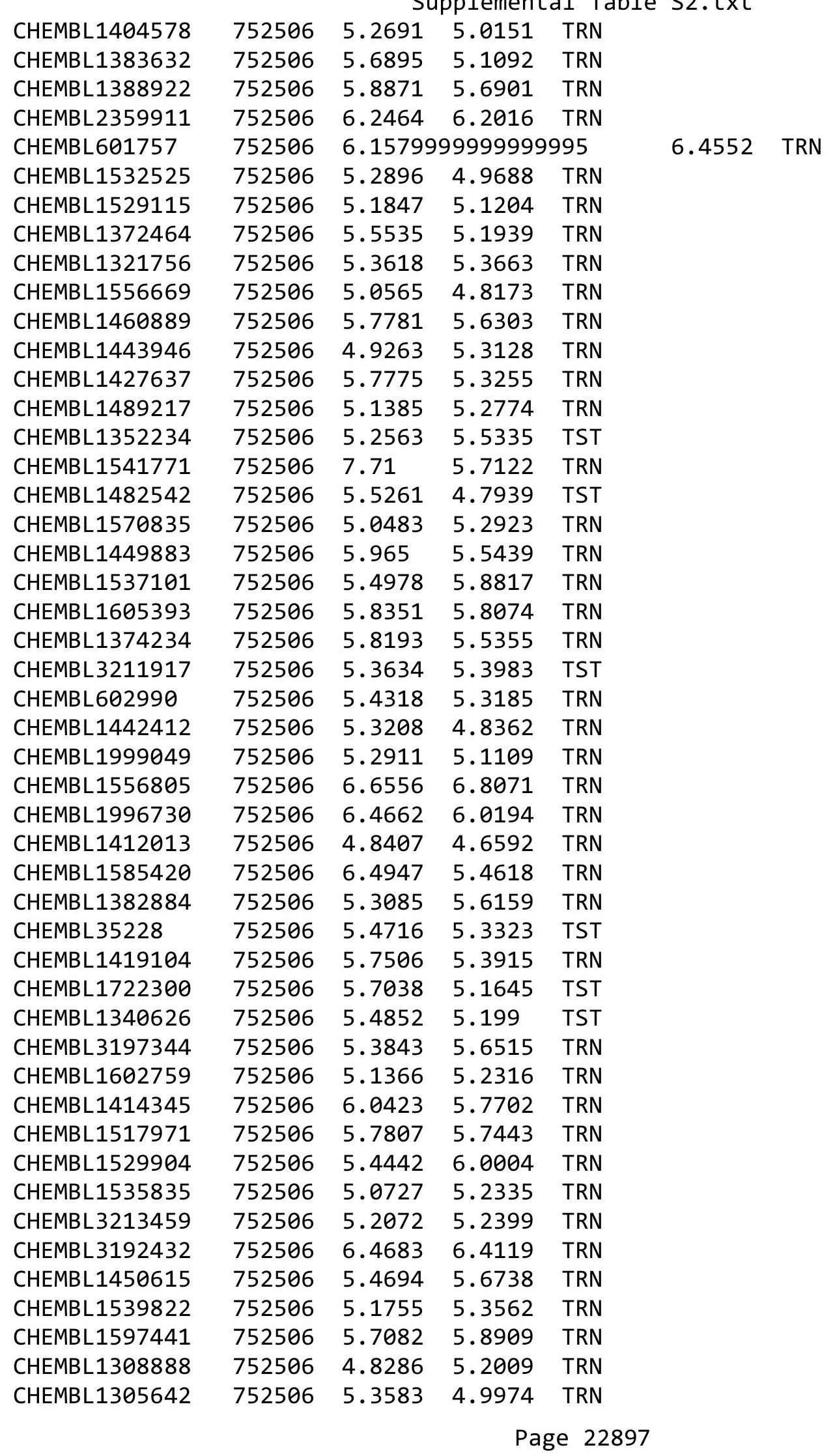


Supplemental Table S2.txt

\begin{tabular}{|c|c|c|c|c|c|c|}
\hline CHEMBL1352011 & 752506 & 5.6799 & 5.6306 & TRN & & \\
\hline CHEMBL1983939 & 752506 & 6.1082 & 6.0093 & TRN & & \\
\hline CHEMBL1369965 & 752506 & 5.1117 & 5.1831 & TRN & & \\
\hline CHEMBL1384167 & 752506 & 5.5193 & 5.5905 & TRN & & \\
\hline CHEMBL1583382 & 752506 & 6.2047 & 5.5596 & TRN & & \\
\hline CHEMBL1376868 & 752506 & 5.4313 & 5.1084 & TRN & & \\
\hline CHEMBL1525074 & 752506 & 5.0841 & 4.9105 & TRN & & \\
\hline CHEMBL1457669 & 752506 & 5.0754 & 4.7959 & TST & & \\
\hline CHEMBL1467999 & 752506 & 5.6073 & 5.0808 & TRN & & \\
\hline CHEMBL1377336 & 752506 & 5.1547 & 4.6587 & TRN & & \\
\hline CHEMBL586465 & 752506 & 5.9481 & 5.9562 & TRN & & \\
\hline CHEMBL1387069 & 752506 & 4.8066 & 4.7567 & TRN & & \\
\hline CHEMBL3191962 & 752506 & 6.2064 & 6.1978 & TRN & & \\
\hline CHEMBL1308223 & 752506 & 5.5577 & 5.0589 & TRN & & \\
\hline CHEMBL1304232 & 752506 & 4.542 & 5.4181 & TST & & \\
\hline CHEMBL1408788 & 752506 & 5.4419 & 5.3938 & TRN & & \\
\hline CHEMBL3199665 & 752506 & 6.066 & 5.8512 & TRN & & \\
\hline CHEMBL1561181 & 752506 & 5.0619 & 5.1447 & TRN & & \\
\hline CHEMBL1328510 & 752506 & 6.0 & 5.5913 & TRN & & \\
\hline CHEMBL1991431 & 752506 & 5.5516 & 5.9012 & TRN & & \\
\hline CHEMBL1428415 & 752506 & 5.2777 & 5.3561 & TRN & & \\
\hline CHEMBL1555271 & 752506 & 6.2003 & 6.348 & TRN & & \\
\hline CHEMBL1387162 & 752506 & 5.5421 & 5.0032 & TRN & & \\
\hline CHEMBL1509790 & 752506 & 5.0951 & 5.3335 & TRN & & \\
\hline CHEMBL1312088 & 752506 & 5.3739 & 5.1026 & TRN & & \\
\hline CHEMBL1392542 & 752506 & 4.6131 & 4.84399 & 9999999999 & & TST \\
\hline CHEMBL1342473 & 752506 & 5.3888 & 5.3256 & TRN & & \\
\hline CHEMBL1568179 & 752506 & 4.9069 & 5.2307 & TST & & \\
\hline CHEMBL1725453 & 752506 & \multicolumn{3}{|c|}{5.547000000000001} & 5.4041 & TRN \\
\hline CHEMBL1597655 & 752506 & 5.7385 & 5.6212 & TRN & & \\
\hline CHEMBL1519374 & 752506 & 5.4481 & 5.3689 & TRN & & \\
\hline CHEMBL1608727 & 752506 & 5.7383 & 5.7693 & TRN & & \\
\hline CHEMBL1338004 & 752506 & 5.5318 & 5.4262 & TRN & & \\
\hline CHEMBL3192049 & 752506 & 5.1314 & 5.0257 & TRN & & \\
\hline CHEMBL3210267 & 752506 & 5.3763 & 5.8875 & TRN & & \\
\hline CHEMBL1501752 & 752506 & 5.1604 & 5.0315 & TRN & & \\
\hline CHEMBL1707745 & 752506 & 5.4678 & 5.5697 & TRN & & \\
\hline CHEMBL1611162 & 752506 & \multicolumn{3}{|c|}{5.3629999999999995} & 4.7957 & TRN \\
\hline CHEMBL1311052 & 752506 & \multicolumn{3}{|c|}{5.162000000000001} & 5.1391 & TRN \\
\hline CHEMBL3190804 & 752506 & 5.8011 & 6.1395 & TRN & & \\
\hline CHEMBL1351750 & 752506 & \multicolumn{3}{|c|}{5.1610000000000005} & 5.2072 & TRN \\
\hline CHEMBL1388482 & 752506 & 5.3238 & 4.988 & TRN & & \\
\hline CHEMBL3194449 & 752506 & 6.0466 & 5.80399 & 9999999999 & & TRN \\
\hline CHEMBL3194964 & 752506 & 5.9512 & 5.8011 & TRN & & \\
\hline CHEMBL1365411 & 752506 & 5.1404 & 5.2132 & TRN & & \\
\hline CHEMBL1455542 & 752506 & 5.3984 & 5.1258 & TRN & & \\
\hline CHEMBL1406419 & 752506 & 5.1395 & 5.0535 & TRN & & \\
\hline CHEMBL3211808 & 752506 & 5.2754 & 5.4901 & TRN & & \\
\hline
\end{tabular}

Page 22898 


\begin{tabular}{|c|c|c|c|c|c|c|}
\hline & & \multicolumn{5}{|c|}{ Supplemental Table S2.txt } \\
\hline CHEMBL 3191087 & 752506 & 5.5309 & 5.6036 & TRN & & \\
\hline CHEMBL1419659 & 752506 & 5.2377 & 5.6813 & TRN & & \\
\hline CHEMBL239275 & 752506 & 5.7719 & 5.6699 & TRN & & \\
\hline CHEMBL1443802 & 752506 & 5.1388 & 5.1044 & TRN & & \\
\hline CHEMBL1308313 & 752506 & 5.649 & 5.5778 & TRN & & \\
\hline CHEMBL1442145 & 752506 & 5.6021 & 5.6441 & TRN & & \\
\hline CHEMBL1308783 & 752506 & 5.1393 & 5.7587 & TRN & & \\
\hline CHEMBL1345789 & 752506 & 4.5217 & 4.5731 & TRN & & \\
\hline CHEMBL1457068 & 752506 & \multicolumn{3}{|c|}{5.5360000000000005} & 4.8908 & TRN \\
\hline CHEMBL1381793 & 752506 & 5.2414 & 5.018 & TST & & \\
\hline CHEMBL588038 & 752506 & 6.2674 & 5.0459 & TST & & \\
\hline CHEMBL1348102 & 752506 & 4.9038 & 5.3559 & TST & & \\
\hline CHEMBL1345709 & 752506 & 4.5144 & 4.715 & TRN & & \\
\hline CHEMBL1492096 & 752506 & 5.5408 & 5.8004 & TRN & & \\
\hline CHEMBL1301723 & 752506 & 5.1309 & 4.8343 & TST & & \\
\hline CHEMBL3194969 & 752506 & \multicolumn{3}{|c|}{5.752000000000001} & 6.0016 & TRN \\
\hline CHEMBL1536406 & 752506 & 5.1288 & 4.8357 & TRN & & \\
\hline CHEMBL1327509 & 752506 & 5.1824 & 5.4194 & TRN & & \\
\hline CHEMBL3192415 & 752506 & 5.6014 & 4.9939 & TRN & & \\
\hline CHEMBL1887153 & 752506 & 6.0799 & 6.2338 & TRN & & \\
\hline CHEMBL1416171 & 752506 & 5.5632 & 5.2117 & TST & & \\
\hline CHEMBL1462451 & 752506 & 5.0588 & 5.1081 & TST & & \\
\hline CHEMBL578675 & 752506 & 5.1005 & 4.9617 & TRN & & \\
\hline CHEMBL1520740 & 752506 & 5.2242 & 5.1968 & TRN & & \\
\hline CHEMBL1507840 & 752506 & 4.845 & 4.5351 & TRN & & \\
\hline CHEMBL1379262 & 752506 & 5.1534 & 4.8252 & TRN & & \\
\hline CHEMBL1309391 & 752506 & 5.433 & 5.3081 & TST & & \\
\hline CHEMBL1468577 & 752506 & 5.34 & 5.3953 & TRN & & \\
\hline CHEMBL1864040 & 752506 & 5.5827 & 5.6327 & TRN & & \\
\hline CHEMBL1277150 & 752506 & 5.0909 & 5.0996 & TRN & & \\
\hline CHEMBL1424443 & 752506 & 5.1576 & 5.1241 & TRN & & \\
\hline CHEMBL1324011 & 752506 & 5.8891 & 6.0042 & TRN & & \\
\hline CHEMBL1318651 & 752506 & 5.5563 & 5.7824 & TRN & & \\
\hline CHEMBL1224757 & 752506 & 5.5167 & 5.584 & TRN & & \\
\hline CHEMBL1375045 & 752506 & 5.5274 & 5.4139 & TST & & \\
\hline CHEMBL1498509 & 752506 & 5.9825 & 5.9098 & TRN & & \\
\hline CHEMBL1993194 & 752506 & 7.71 & 6.4015 & TRN & & \\
\hline CHEMBL 2003567 & 752506 & 5.4721 & 5.9843 & TRN & & \\
\hline CHEMBL1505604 & 752506 & 5.6828 & 5.8855 & TST & & \\
\hline CHEMBL1530911 & 752506 & 5.8821 & 5.1809 & TST & & \\
\hline CHEMBL1361283 & 752506 & 5.1778 & 5.7545 & TST & & \\
\hline CHEMBL1308329 & 752506 & 4.6232 & 5.1491 & TST & & \\
\hline CHEMBL3191789 & 752506 & 5.1321 & 4.6863 & TST & & \\
\hline CHEMBL1542654 & 752506 & 5.6596 & 5.3402 & TST & & \\
\hline CHEMBL1358020 & 752506 & 5.4815 & 4.974 & TST & & \\
\hline CHEMBL1408115 & 752506 & 5.98799 & 99999999 & 995 & 5.3983 & TST \\
\hline CHEMBL1592917 & 752506 & 5.1881 & 5.5105 & TST & & \\
\hline CHEMBL1548173 & 752506 & 6.0 & 4.9465 & TST & & \\
\hline
\end{tabular}




\begin{tabular}{|c|c|c|c|c|}
\hline & & & olement & \\
\hline CHEMBL 3192490 & 752506 & 2.585 & 5.0463 & TST \\
\hline CHEMBL1317160 & 752506 & 5.631 & 5.0926 & TST \\
\hline CHEMBL1558433 & 752506 & 5.1096 & 5.4747 & TST \\
\hline CHEMBL1563176 & 752506 & 5.1461 & 4.6043 & TST \\
\hline CHEMBL1458403 & 752506 & 5.1368 & 4.5255 & TST \\
\hline CHEMBL1422381 & 752506 & 5.2413 & 4.9601 & TST \\
\hline CHEMBL3197396 & 752506 & 6.224 & 5.7172 & TST \\
\hline CHEMBL1479393 & 752506 & 5.1684 & 5.3229 & TST \\
\hline CHEMBL 1413680 & 752506 & 5.3613 & 5.1551 & TST \\
\hline CHEMBL1388509 & 752506 & 5.05 & 5.3656 & TST \\
\hline CHEMBL 3194618 & 752506 & 5.5136 & 5.4048 & TST \\
\hline CHEMBL1325908 & 752506 & 4.8935 & 5.3204 & TST \\
\hline CHEMBL1574218 & 752506 & 5.0959 & 5.3547 & TST \\
\hline CHEMBL548615 & 752506 & 5.9859 & 6.0197 & TST \\
\hline CHEMBL1600447 & 752506 & 5.1993 & 5.0648 & TST \\
\hline CHEMBL 3189247 & 752506 & 5.2375 & 6.2655 & TST \\
\hline CHEMBL3196181 & 752506 & 5.9948 & 6.1561 & TST \\
\hline CHEMBL 3196754 & 752506 & 6.3643 & 6.0502 & TST \\
\hline CHEMBL592124 & 752506 & 5.1005 & 5.8807 & TST \\
\hline CHEMBL1410436 & 752506 & 5.1667 & 5.2271 & TST \\
\hline CHEMBL1461052 & 752506 & 2.585 & 4.9288 & TST \\
\hline CHEMBL1491637 & 752506 & 5.5933 & 5.5659 & TST \\
\hline CHEMBL1983104 & 752506 & 5.0901 & 4.7699 & TST \\
\hline CHEMBL 1450446 & 752506 & 5.2525 & 4.8287 & TST \\
\hline CHEMBL1328271 & 752506 & 4.6868 & 5.2131 & TST \\
\hline CHEMBL1520694 & 752506 & 5.5433 & 5.2961 & TST \\
\hline CHEMBL1564403 & 752506 & 5.425 & 5.1274 & TST \\
\hline CHEMBL1550934 & 752506 & 5.7479 & 5.8241 & TST \\
\hline CHEMBL1607143 & 752506 & 5.4148 & 5.277 & TST \\
\hline CHEMBL1332054 & 752506 & 5.2078 & 5.5299 & TST \\
\hline CHEMBL1582997 & 752506 & 5.2336 & 5.2035 & TST \\
\hline CHEMBL 3194513 & 752506 & 5.7435 & 5.6395 & TST \\
\hline CHEMBL1505866 & 752506 & 5.2104 & 5.3347 & TST \\
\hline CHEMBL1429703 & 752506 & 5.2556 & 5.5639 & TST \\
\hline CHEMBL1519955 & 752506 & 6.2984 & 5.9119 & TST \\
\hline CHEMBL1531308 & 752506 & 5.2138 & 4.6817 & TST \\
\hline CHEMBL1493221 & 752506 & 5.1445 & 4.7888 & TST \\
\hline CHEMBL1533459 & 752506 & 5.7416 & 5.8066 & TST \\
\hline CHEMBL1602792 & 752506 & 5.3634 & 5.2237 & TST \\
\hline CHEMBL 3194760 & 752506 & 6.0688 & 5.2147 & TST \\
\hline CHEMBL1343525 & 752506 & 5.0566 & 5.4249 & TST \\
\hline CHEMBL1327172 & 752506 & 5.6284 & 5.6506 & TST \\
\hline CHEMBL3191242 & 752506 & 6.0545 & 5.9521 & TST \\
\hline CHEMBL1391287 & 752506 & 5.5211 & 5.7168 & TST \\
\hline CHEMBL1610180 & 752506 & 5.4173 & 5.0641 & TST \\
\hline CHEMBL1415184 & 752506 & 6.6649 & 5.6452 & TST \\
\hline CHEMBL120734 & 752506 & 5.4987 & 6.0594 & TST \\
\hline CHEMBL1331849 & 752506 & 3.9416 & 4.9874 & TST \\
\hline
\end{tabular}


Supplemental Table S2.txt

\begin{tabular}{|c|c|c|c|c|}
\hline-1 & & & זונד & \\
\hline HEMBL1989294 & 52506 & .0921 & 6.1083 & \\
\hline & 06 & & & \\
\hline EMPI 12 & 2506 & 9 & & \\
\hline EMBL581346 & 52506 & 876 & & \\
\hline IEMBL1533399 & 52506 & 4237 & 0185 & \\
\hline HEMBL89445 & 52506 & .71 & 1032 & \\
\hline 243 & 506 & & 7788 & \\
\hline EMBL1507162 & 52506 & & 9717 & \\
\hline IEMBL1712452 & 52506 & 2397 & 7467 & \\
\hline IEMBL1994211 & 52506 & 6297 & 4898 & \\
\hline EMBL1428566 & 52506 & 92 & 398 & \\
\hline 132 & & & & \\
\hline EMBL1 & 52506 & 6 & 854 & \\
\hline EMBL1380193 & 52506 & 94 & 8219 & \\
\hline 733891 & 52506 & .4627 & 2055 & \\
\hline 36467 & 506 & 2 & 428 & \\
\hline 56686 & 06 & & 275 & \\
\hline 928 & 506 & & 2112 & \\
\hline EMBL1 & 506 & 85 & 757 & S \\
\hline 205 & 506 & 42 & 12 & \\
\hline 53 & 506 & 3 & 2723 & \\
\hline 007 & 36 & & 3977 & \\
\hline 459 & & & & \\
\hline EMBL1 & 06 & 352 & 3 & $S$ \\
\hline 31 & 26 & 5 & 1 & \\
\hline 39 & 6 & 4 & 5 & \\
\hline 9 & & & 45 & \\
\hline 88 & & & & ST \\
\hline EME & $\partial 6$ & & 57 & S \\
\hline 394 & 06 & 72 & 572 & \\
\hline 0 & $\partial 6$ & & $\partial 8$ & \\
\hline & & & & ST \\
\hline EMBL373784 & & & 62 & \\
\hline EMBL3 & 52506 & 561 & 987 & ST \\
\hline EMBL & 506 & 44 & 002 & \\
\hline & 36 & & & \\
\hline & & & 6.3002 & ST \\
\hline IEMBL1539155 & 52506 & 55 & 3442 & $\mathrm{~S}$ \\
\hline 65083 & 52506 & & & $S$ \\
\hline 95409 & 52506 & & 785 & 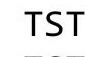 \\
\hline & & & & S \\
\hline EMBL1478220 & 52506 & 5.2463 & 1677 & $\mathrm{~S}$ \\
\hline EMBL607309 & 52506 & 429 & .3312 & S \\
\hline & 2506 & & & \\
\hline HEMBL1464261 & 506 & & 1877 & \\
\hline 12 & 52506 & & 5.5988 & \\
\hline CHEMBL1440293 & 752506 & 5.1301 & 4.9111 & TS \\
\hline
\end{tabular}

Page 22901 
Supplemental Table S2.txt

\begin{tabular}{|c|c|c|c|c|c|c|}
\hline CHEMBL1462318 & 752506 & 4.871 & 5.5322 & TST & & \\
\hline CHEMBL3190594 & 752506 & 6.4366 & 6.0713 & TST & & \\
\hline CHEMBL1610300 & 752506 & 5.3866 & 5.459 & TST & & \\
\hline CHEMBL1547232 & 752506 & 5.3534 & 5.0058 & TST & & \\
\hline CHEMBL581868 & 752506 & 5.7846 & 5.9436 & TST & & \\
\hline CHEMBL1458022 & 752506 & 5.3533 & 5.1637 & TST & & \\
\hline CHEMBL 2138014 & 752506 & 5.5417 & 5.5073 & TST & & \\
\hline CHEMBL487356 & 752506 & 5.5284 & 5.3189 & TST & & \\
\hline CHEMBL1600257 & 752506 & 4.8233 & 4.6225 & TST & & \\
\hline CHEMBL1476358 & 752506 & 5.4044 & 5.3624 & TST & & \\
\hline CHEMBL1520536 & 752506 & 5.1261 & 4.7885 & TST & & \\
\hline CHEMBL 3197127 & 752506 & 5.8342 & 5.7632 & TST & & \\
\hline CHEMBL1367897 & 752506 & 2.9208 & 4.7741 & TST & & \\
\hline CHEMBL1412700 & 752506 & 4.8456 & 5.2852 & TST & & \\
\hline CHEMBL 3193844 & 752506 & 6.0837 & 6.2773 & TST & & \\
\hline CHEMBL1611369 & 752506 & 5.5406 & 4.9113 & TST & & \\
\hline CHEMBL1362088 & 752506 & 5.7421 & 5.806 & TST & & \\
\hline CHEMBL1352999 & 752506 & 2.9208 & 5.5318 & TST & & \\
\hline CHEMBL1471088 & 752506 & 5.3165 & 5.0406 & TST & & \\
\hline CHEMBL1376759 & 752506 & \multicolumn{3}{|c|}{5.1770000000000005} & 5.1448 & TST \\
\hline CHEMBL1360097 & 752506 & 5.106 & 5.1162 & TST & & \\
\hline CHEMBL1605536 & 752506 & 5.4707 & 4.9994 & TST & & \\
\hline CHEMBL1343814 & 752506 & 5.9076 & 5.1927 & TST & & \\
\hline CHEMBL1538748 & 752506 & 5.1971 & 5.6962 & TST & & \\
\hline CHEMBL1346694 & 752506 & 5.3748 & 5.1957 & TST & & \\
\hline CHEMBL1349075 & 752506 & 5.9038 & 5.6481 & TST & & \\
\hline CHEMBL1451112 & 752506 & 5.037 & 5.0682 & TST & & \\
\hline CHEMBL1519558 & 752506 & 5.8083 & 5.2301 & TST & & \\
\hline CHEMBL1570257 & 752506 & 5.4896 & 5.4351 & TST & & \\
\hline CHEMBL1557619 & 752506 & 5.6251 & 5.3678 & TST & & \\
\hline CHEMBL1370977 & 752506 & 5.3266 & 5.5606 & TST & & \\
\hline CHEMBL1383333 & 752506 & 5.7071 & 5.7081 & TST & & \\
\hline CHEMBL1524678 & 752506 & 5.3541 & 5.0251 & TST & & \\
\hline CHEMBL1582794 & 752506 & 5.7655 & 5.3827 & TST & & \\
\hline CHEMBL1347469 & 752506 & 5.8604 & 5.615 & TST & & \\
\hline CHEMBL 3190293 & 752506 & 5.6637 & 5.7289 & TST & & \\
\hline CHEMBL 2141549 & 752506 & 5.3625 & 5.0017 & TST & & \\
\hline CHEMBL1472228 & 752506 & 4.4343 & 4.9073 & TST & & \\
\hline CHEMBL1583964 & 752506 & 5.1737 & 5.0355 & TST & & \\
\hline CHEMBL1555532 & 752506 & 5.445 & 5.1691 & TST & & \\
\hline CHEMBL1329129 & 752506 & 5.9763 & 5.7897 & TST & & \\
\hline CHEMBL 3197504 & 752506 & 4.978 & 5.3556 & TST & & \\
\hline CHEMBL1385323 & 752506 & 5.2912 & 4.4791 & TST & & \\
\hline CHEMBL1401402 & 752506 & 5.3939 & 5.5689 & TST & & \\
\hline CHEMBL 3190989 & 752506 & 5.5114 & 5.6699 & TST & & \\
\hline CHEMBL 3199549 & 752506 & 4.8297 & 5.1413 & TST & & \\
\hline CHEMBL1539180 & 752506 & 5.1553 & 5.3446 & TST & & \\
\hline CHEMBL1588832 & 752506 & 5.1832 & 5.3847 & TST & & \\
\hline
\end{tabular}

Page 22902 


\begin{tabular}{|c|c|c|c|c|c|}
\hline \multirow[b]{2}{*}{ CHEMBL1335650 } & & \multicolumn{4}{|c|}{ Supplemental Table S2.txt } \\
\hline & 752506 & 2.9208 & 4.864 & TST & \\
\hline CHEMBL1881714 & 752506 & 6.1449 & \multicolumn{2}{|c|}{5.452999999999999} & \multirow{2}{*}{$\begin{array}{l}\text { TST } \\
\text { TST }\end{array}$} \\
\hline CHEMBL1446412 & 752506 & \multicolumn{3}{|c|}{5.542999999999999} & \\
\hline CHEMBL578487 & 752506 & 6.3851 & 5.697 & TST & \\
\hline CHEMBL479107 & 752506 & 5.2858 & 5.0912 & TST & \\
\hline CHEMBL1489033 & 752506 & 5.2587 & 5.0024 & TST & \\
\hline CHEMBL1889837 & 752506 & 5.086 & 5.1508 & TST & \\
\hline CHEMBL1545542 & 752506 & 5.1034 & 5.5442 & TST & \\
\hline CHEMBL1611686 & 752506 & 5.7233 & 5.8188 & TST & \\
\hline CHEMBL1983418 & 752506 & 6.3018 & 5.7711 & TST & \\
\hline CHEMBL1351173 & 752506 & 5.7528 & \multicolumn{2}{|c|}{5.513999999999999} & TST \\
\hline CHEMBL1457139 & 752506 & 5.7091 & 5.92 & TST & \\
\hline CHEMBL 317115 & 752506 & 5.1647 & 5.6794 & TST & \\
\hline CHEMBL1304016 & 752506 & 5.2068 & 5.1452 & TST & \\
\hline CHEMBL1563221 & 752506 & 4.93 & 5.0401 & TST & \\
\hline CHEMBL1413844 & 752506 & 4.5011 & 5.1586 & TST & \\
\hline CHEMBL1315053 & 752506 & 5.7404 & 5.4368 & TST & \\
\hline CHEMBL1794140 & 752506 & 5.2391 & 5.0448 & TST & \\
\hline CHEMBL1341999 & 752506 & 5.3209 & 5.5077 & TST & \\
\hline CHEMBL600121 & 752506 & 5.5556 & 5.8983 & TST & \\
\hline CHEMBL1981103 & 752506 & 5.1803 & 5.2509 & TST & \\
\hline CHEMBL1336197 & 752506 & 5.4519 & 5.2961 & TST & \\
\hline CHEMBL1727380 & 752506 & 5.6912 & 5.7847 & TST & \\
\hline CHEMBL1607327 & 752506 & 2.585 & 4.7989 & TST & \\
\hline CHEMBL1392025 & 752506 & 5.1756 & 5.4428 & TST & \\
\hline CHEMBL3196351 & 752506 & 5.7206 & \multicolumn{2}{|c|}{5.1739999999999995} & TST \\
\hline CHEMBL1601942 & 752506 & 5.1433 & 5.3685 & TST & \\
\hline CHEMBL3196499 & 752506 & 5.7724 & 5.692 & TST & \\
\hline CHEMBL1710575 & 752506 & 5.3493 & 5.1932 & TST & \\
\hline CHEMBL1474014 & 752506 & 5.25 & 5.4811 & TST & \\
\hline CHEMBL1409903 & 752506 & 5.3928 & 4.902 & TST & \\
\hline CHEMBL1309127 & 752506 & 5.9755 & 5.9985 & TST & \\
\hline CHEMBL1506290 & 752506 & 2.585 & 5.2474 & TST & \\
\hline CHEMBL1412002 & 752506 & 6.2037 & 6.1172 & TST & \\
\hline CHEMBL1520479 & 752506 & 5.2556 & 4.996 & TST & \\
\hline CHEMBL213580 & 752506 & 5.1475 & 4.9909 & TST & \\
\hline CHEMBL1603001 & 752506 & 6.0446 & 6.0844 & TST & \\
\hline CHEMBL1401026 & 752506 & 5.4814 & 5.0033 & TST & \\
\hline CHEMBL 3196726 & 752506 & 6.0387 & 5.5055 & TST & \\
\hline CHEMBL179509 & 303659 & 7.2757 & 7.6633 & TRN & \\
\hline CHEMBL366468 & 303659 & 8.0969 & 7.8802 & TRN & \\
\hline CHEMBL 362620 & 303659 & 7.6198 & \multicolumn{2}{|c|}{7.832000000000001} & TRN \\
\hline CHEMBL369093 & 303659 & 5.0 & 4.9801 & TST & \\
\hline CHEMBL180417 & 303659 & 6.6198 & 6.9065 & TRN & \\
\hline CHEMBL175475 & 303659 & 8.4089 & 8.4433 & TRN & \\
\hline CHEMBL179414 & 303659 & 8.9586 & 8.8872 & TRN & \\
\hline CHEMBL178242 & 303659 & 7.5229 & 7.6145 & TRN & \\
\hline CHEMBL178508 & 303659 & 6.5528 & 6.8639 & TRN & \\
\hline & & & & 22903 & \\
\hline
\end{tabular}




\begin{tabular}{|c|c|c|c|c|c|}
\hline \multicolumn{6}{|c|}{ Supplemental Table S2.txt } \\
\hline CHEMBL362485 & 303659 & 8.6198 & 8.2602 & TRN & \\
\hline CHEMBL362014 & 303659 & 6.585 & 6.5106 & TST & \\
\hline CHEMBL179475 & 303659 & 8.7696 & 8.5383 & TRN & \\
\hline CHEMBL366471 & 303659 & 7.7447 & 7.7841 & TRN & \\
\hline CHEMBL179555 & 303659 & 5.0 & 4.9152 & TST & \\
\hline CHEMBL362409 & 303659 & 7.6383 & 8.0392 & TRN & \\
\hline CHEMBL178837 & 303659 & 7.2924 & 7.0662 & TRN & \\
\hline CHEMBL360966 & 303659 & 7.4202 & 7.1717 & TRN & \\
\hline CHEMBL179924 & 303659 & 7.3979 & 7.5633 & TRN & \\
\hline CHEMBL360733 & 303659 & 7.7447 & 8.0362 & TRN & \\
\hline CHEMBL360562 & 303659 & 5.0 & 5.8861 & TRN & \\
\hline CHEMBL180215 & 303659 & 6.3372 & 6.2404 & TST & \\
\hline CHEMBL359613 & 303659 & 7.3872 & 7.3404 & TST & \\
\hline CHEMBL179664 & 303659 & 6.6021 & 6.4058 & TRN & \\
\hline CHEMBL178303 & 303659 & 7.301 & 6.9599 & TST & \\
\hline CHEMBL368905 & 303659 & 6.8239 & 7.0143 & TRN & \\
\hline CHEMBL178992 & 303659 & 7.7212 & 7.2441 & TRN & \\
\hline CHEMBL178738 & 303659 & 7.7447 & 7.6793 & TRN & \\
\hline CHEMBL179712 & 303659 & 8.5528 & 8.703 & TRN & \\
\hline CHEMBL360122 & 303659 & 9.0 & 9.0591 & TRN & \\
\hline CHEMBL361200 & 303659 & 7.585 & 7.71399 & 99999999995 & TRN \\
\hline CHEMBL360311 & 303659 & 7.699 & 7.4257 & TRN & \\
\hline CHEMBL361561 & 303659 & 7.0044 & 7.0176 & TRN & \\
\hline CHEMBL440558 & 303659 & 7.6778 & 7.8899 & TRN & \\
\hline CHEMBL179700 & 303659 & 7.8861 & 7.2692 & TRN & \\
\hline CHEMBL178677 & 303659 & 9.1487 & 8.8977 & TRN & \\
\hline CHEMBL178942 & 303659 & 7.8861 & 7.9512 & TRN & \\
\hline CHEMBL179769 & 303659 & 7.1549 & 7.0607 & TRN & \\
\hline CHEMBL179474 & 303659 & 8.6778 & 8.8349 & TRN & \\
\hline CHEMBL361015 & 303659 & 8.1079 & 8.0669 & TRN & \\
\hline CHEMBL179558 & 303659 & 8.6383 & 8.5044 & TRN & \\
\hline CHEMBL180416 & 303659 & 8.6198 & 8.3867 & TRN & \\
\hline CHEMBL175886 & 303659 & 8.0 & 8.03399 & 9999999999 & TRN \\
\hline CHEMBL359638 & 303659 & 5.301 & 5.3993 & TRN & \\
\hline CHEMBL178710 & 303659 & 7.8239 & 8.1418 & TRN & \\
\hline CHEMBL178670 & 303659 & 7.6198 & 7.1898 & TRN & \\
\hline CHEMBL179699 & 303659 & 7.7447 & 7.5846 & TRN & \\
\hline CHEMBL179737 & 303659 & 7.3565 & 6.9869 & TRN & \\
\hline CHEMBL 360345 & 303659 & 6.7696 & 6.12 & TST & \\
\hline CHEMBL361129 & 303659 & 8.8539 & 8.9268 & TRN & \\
\hline CHEMBL360036 & 303659 & 7.0506 & 7.1851 & TST & \\
\hline CHEMBL359906 & 303659 & 8.1487 & 7.8659 & TRN & \\
\hline CHEMBL179810 & 303659 & 6.699 & 6.7889 & TRN & \\
\hline CHEMBL178856 & 303659 & 7.7212 & 7.6967 & TST & \\
\hline CHEMBL13662 & 303659 & 6.0706 & 5.8084 & TST & \\
\hline CHEMBL359545 & 303659 & 7.9208 & 8.2729 & TRN & \\
\hline CHEMBL179048 & 303659 & 6.2351 & 7.0347 & TRN & \\
\hline CHEMBL68712 & 303659 & 7.699 & 7.81 & TRN & \\
\hline
\end{tabular}




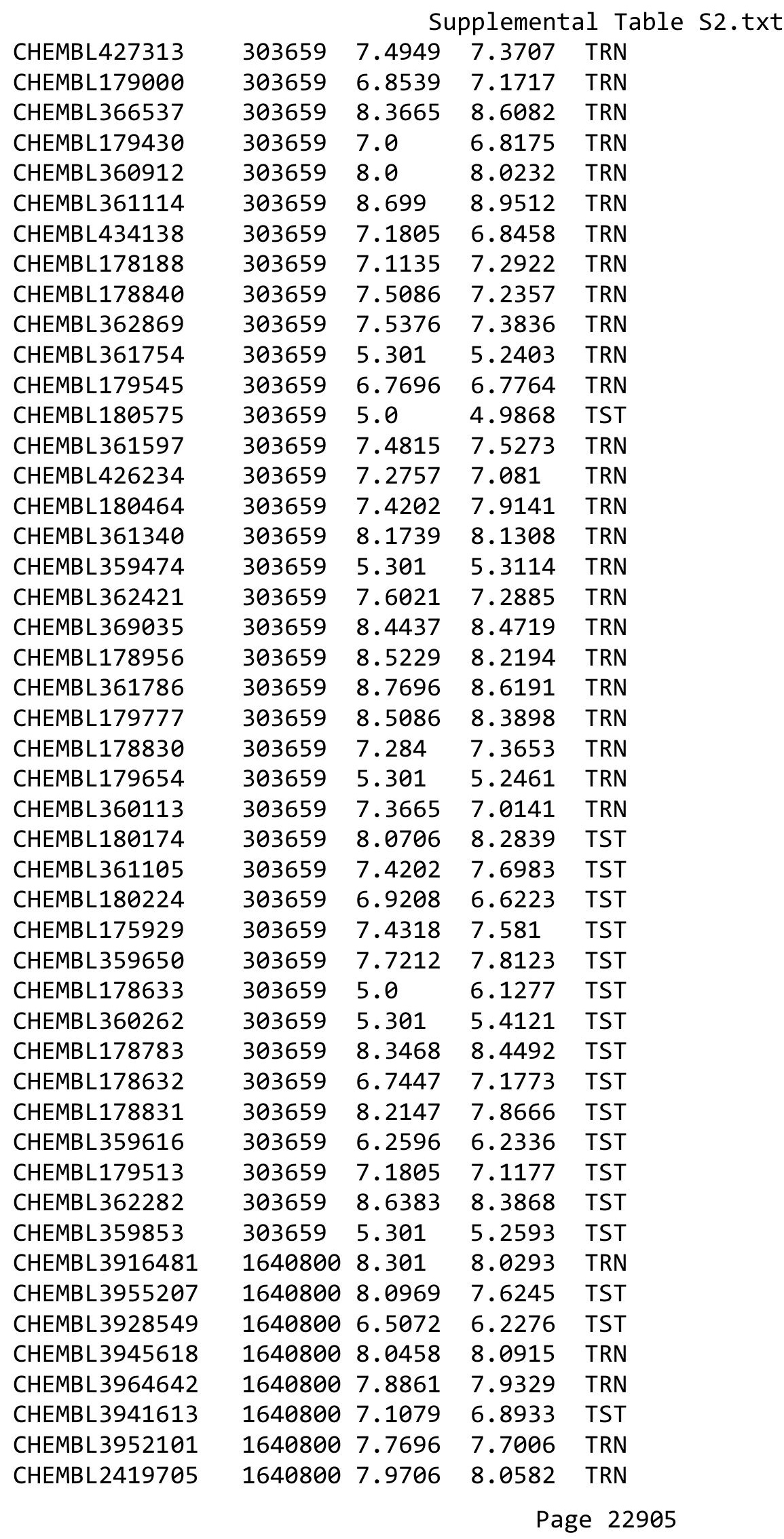


Supplemental Table S2.txt

\begin{tabular}{|c|c|c|c|c|}
\hline CHEMBL3985156 & 1640800 & 7.6383 & 7.7679 & TRN \\
\hline CHEMBL 2419698 & 1640800 & 8.1249 & 8.2973 & TRN \\
\hline CHEMBL3940683 & 1640800 & 7.8539 & 7.9381 & TRN \\
\hline CHEMBL3933577 & 1640800 & 7.8539 & 7.8913 & TRN \\
\hline CHEMBL3940284 & 1640800 & 6.0 & 6.5401 & TRN \\
\hline CHEMBL3960803 & 1640800 & 7.7447 & 7.7572 & TRN \\
\hline CHEMBL3968547 & 1640800 & 7.3665 & 7.4111 & TRN \\
\hline CHEMBL3919581 & 1640800 & 6.0 & 6.3977 & TRN \\
\hline CHEMBL3914416 & 1640800 & 7.4949 & 7.7187 & TRN \\
\hline CHEMBL2419704 & 1640800 & 7.2441 & 7.2846 & TRN \\
\hline CHEMBL3944401 & 1640800 & 7.9208 & 7.9819 & TRN \\
\hline CHEMBL3903427 & 1640800 & 7.5376 & 7.5631 & TRN \\
\hline CHEMBL3983088 & 1640800 & 7.9914 & 8.0527 & TRN \\
\hline CHEMBL 3913243 & 1640800 & 7.7959 & 7.8594 & TRN \\
\hline CHEMBL3943283 & 1640800 & 7.7447 & 7.6834 & TRN \\
\hline CHEMBL3935111 & 1640800 & 7.9208 & 8.0504 & TRN \\
\hline CHEMBL3965278 & 1640800 & 7.8539 & 7.6766 & TRN \\
\hline CHEMBL3928915 & 1640800 & 8.0 & 7.9895 & TRN \\
\hline CHEMBL3937250 & 1640800 & 7.6778 & 7.8739 & TRN \\
\hline CHEMBL3932754 & 1640800 & 6.9586 & 7.4542 & TRN \\
\hline CHEMBL3933643 & 1640800 & 6.4134 & 5.688 & TST \\
\hline CHEMBL3895038 & 1640800 & 8.6021 & 8.0093 & TST \\
\hline CHEMBL3922251 & 1640800 & 7.7212 & 7.8233 & TRN \\
\hline CHEMBL 3949450 & 1640800 & 6.7696 & 6.62299 & و999999999 \\
\hline CHEMBL3969046 & 1640800 & 6.0888 & 5.9611 & TST \\
\hline CHEMBL3901978 & 1640800 & 7.699 & 7.6532 & TRN \\
\hline CHEMBL 3977049 & 1640800 & 7.7447 & 7.8874 & TRN \\
\hline CHEMBL3939009 & 1640800 & 7.699 & 7.6486 & TRN \\
\hline CHEMBL3973611 & 1640800 & 6.8477 & 6.7558 & TST \\
\hline CHEMBL 2419699 & 1640800 & 7.7959 & 7.7362 & TRN \\
\hline CHEMBL3987175 & 1640800 & 7.4034 & 7.19799 & 99999999995 \\
\hline CHEMBL3978546 & 1640800 & 7.3665 & 7.0559 & TST \\
\hline CHEMBL3935482 & 1640800 & 7.3768 & 7.3305 & TRN \\
\hline CHEMBL 3986246 & 1640800 & 7.9208 & 7.8448 & TRN \\
\hline CHEMBL 2419701 & 1640800 & 7.7447 & 7.636 & TRN \\
\hline CHEMBL3930358 & 1640800 & 6.6126 & 6.1536 & TST \\
\hline CHEMBL3902386 & 1640800 & 7.4089 & 6.9936 & TST \\
\hline CHEMBL 2419700 & 1640800 & 7.5086 & 7.5299 & TRN \\
\hline CHEMBL3967549 & 1640800 & 7.9208 & 7.8504 & TRN \\
\hline CHEMBL3956527 & 1640800 & 8.2218 & 8.023 & TRN \\
\hline CHEMBL3907294 & 1640800 & 7.699 & 7.4219 & TRN \\
\hline CHEMBL3942389 & 1640800 & 6.1409 & 6.0784 & TRN \\
\hline CHEMBL3949925 & 1640800 & 6.7258 & 6.1194 & TST \\
\hline CHEMBL3898270 & 1640800 & 7.8861 & 7.0513 & TRN \\
\hline CHEMBL 3907810 & 1640800 & 4.5058 & 4.2879 & TRN \\
\hline CHEMBL3942774 & 1640800 & 6.4522 & 6.5484 & TRN \\
\hline CHEMBL3978051 & 1640800 & 6.1192 & 6.534 & TST \\
\hline CHEMBL3944854 & 1640800 & 7.9208 & 7.737 & TRN \\
\hline
\end{tabular}

Page 22906 
Supplemental Table S2.txt

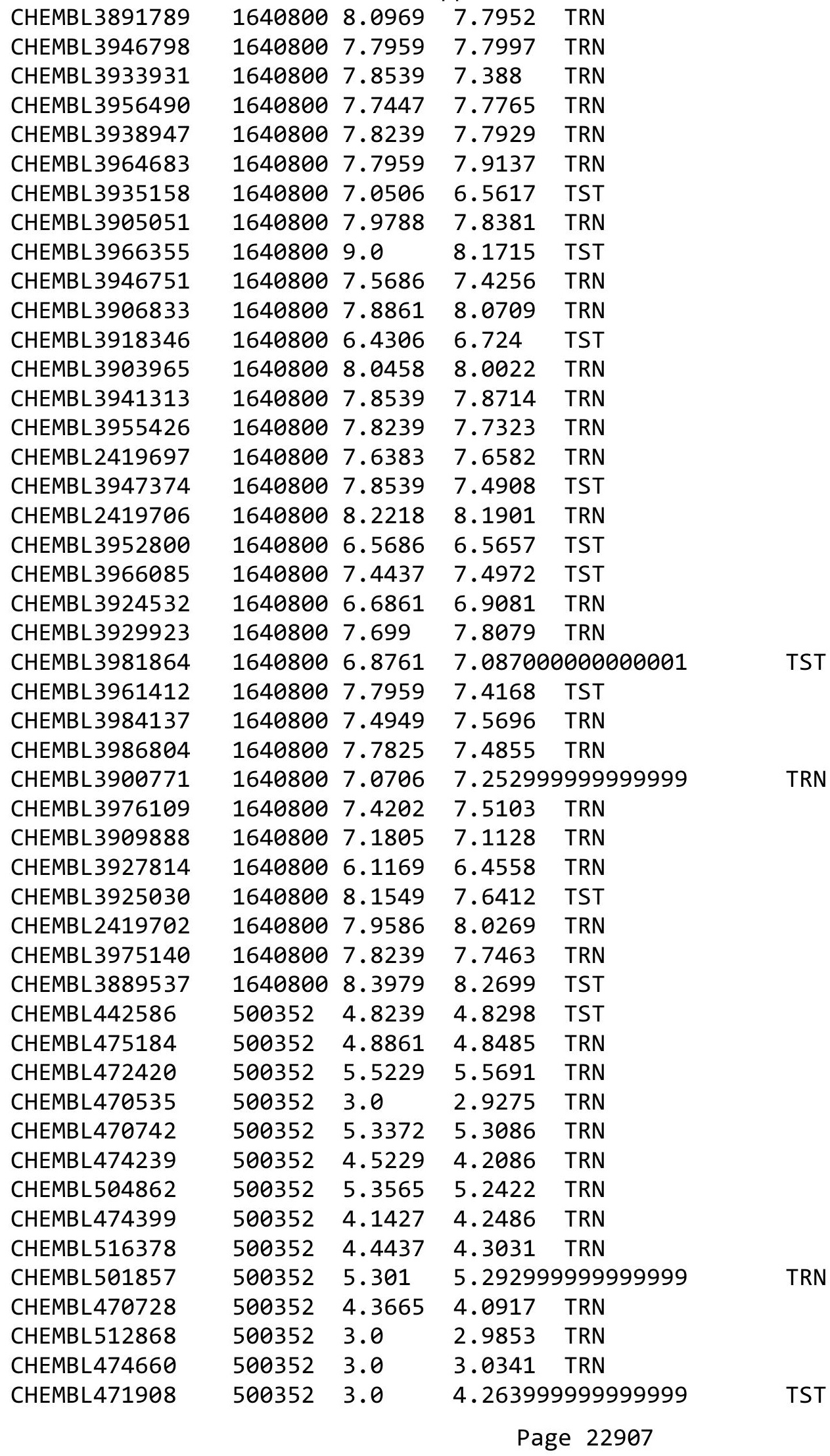




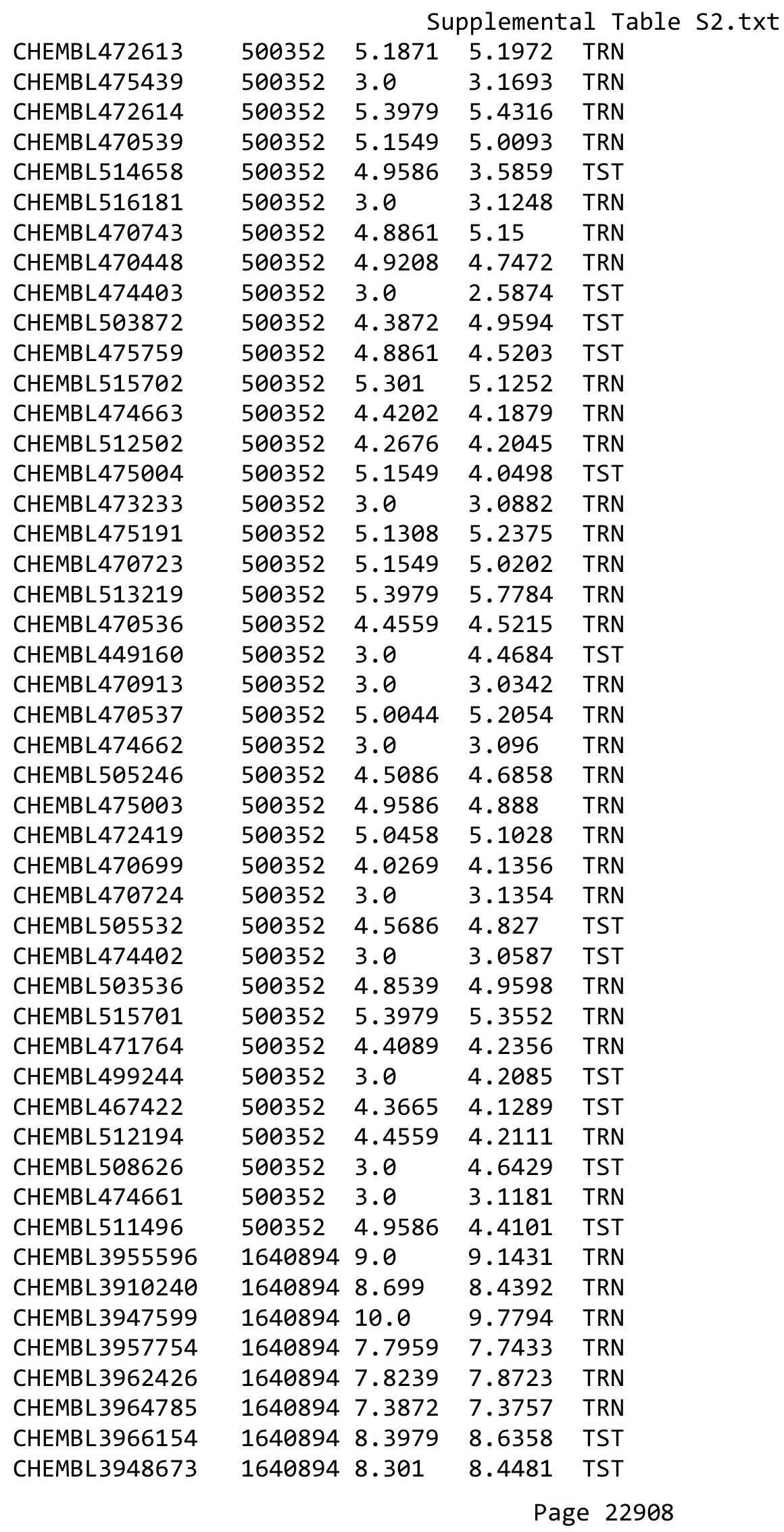


Supplemental Table S2.txt

\begin{tabular}{|c|c|c|c|c|}
\hline HEMBL & 540894 & & & \\
\hline HEMBL3893218 & 640894 & 7.9586 & 3.0677 & \\
\hline 77 & & & & \\
\hline HEMBL3924860 & 0894 & 10.0 & & Ne \\
\hline AEMBL3932648 & 540894 & 699 & 5722 & \\
\hline HEMBL3964465 & 640894 & 8.3979 & 5984 & \\
\hline HEMBL 389 & 894 & 9.0 & 832 & \\
\hline IEMBL 395 & 894 & 9 & & $\mathrm{RN}$ \\
\hline AEMBL3973784 & 640894 & 6.1101 & 0207 & \\
\hline HEMBL3944823 & 640894 & 99 & 7553 & \\
\hline HEMBL3977413 & 640894 & 979 & 4227 & \\
\hline IEMBL391 & 394 & 076 & 526 & \\
\hline AEMBL39 & & & & RN \\
\hline HEMBL396 & 894 & 7.5229 & 9862 & \\
\hline AEMBL398 & 640894 & & 427 & \\
\hline AEMBL3937 & 64 & 9. & 7111 & \\
\hline HEMBL39 & 34 & 7. & 013 & RN \\
\hline HEMBL39 & & 9 . & & \\
\hline HEMBL 394 & 94 & & 2859 & \\
\hline HEMBL393 & 94 & & & $T$ \\
\hline AEMBL & 04 & 8 & 966 & NIV \\
\hline HEMBL39 & 34 & 9. & 728 & $\mathrm{RN}$ \\
\hline HEMBL39 & & & 321 & \\
\hline HFMRI 395 & & & & \\
\hline HEMBL 397 & & & & $\cdots$ \\
\hline HEMBL39 & 64 & & 014 & KIV \\
\hline HEMBL3 & 4 & & 27 & RN \\
\hline$H F M B I=$ & 4 & 97 & 365 & \\
\hline HEMBL397 & & & 1915 & IRIV \\
\hline HEMBL 3961 & 54 & & 974 & IRIV \\
\hline HEMBL 393 & 64 & & 372 & RN \\
\hline HEMBL & $T$ & & 11 & RN \\
\hline HEMBL & & 8 & 995 & $\mathrm{RN}$ \\
\hline HEMBL3903434 & 64 & 9 & 224 & IRN \\
\hline HEMBL3922637 & 6408 & & 297 & TRN \\
\hline HEMBL 38 & 64 & & 896 & TRN \\
\hline HFMRI $=$ & & & 56 & $\Gamma \mathrm{RN}$ \\
\hline HEMBL3 & & & 111 & TST \\
\hline HEMBL3948002 & 640894 & 9. & $\partial 267$ & TST \\
\hline HEMBL 395 & 6408 & & 4647 & TST \\
\hline HEMBL39 & 640894 & 7 & 4159 & $g u^{2}$ \\
\hline CHEMBL3891196 & & & & TRN \\
\hline HEMBL3972303 & 1640894 & 7.6383 & 852 & RN \\
\hline HEMBL3892340 & 640894 & 9. & 1928 & TR \\
\hline MBL3 & & & 2033 & $\mathrm{~N}$ \\
\hline HEMBL 39 & 640 & & 2137 & \\
\hline CHEMBL39465 & 6408 & .2218 & .1786 & \\
\hline LHEMBL3918307 & 164089 & 7.0862 & 7.7934 & ГST \\
\hline
\end{tabular}

Page 22909 
Supplemental Table S2.txt

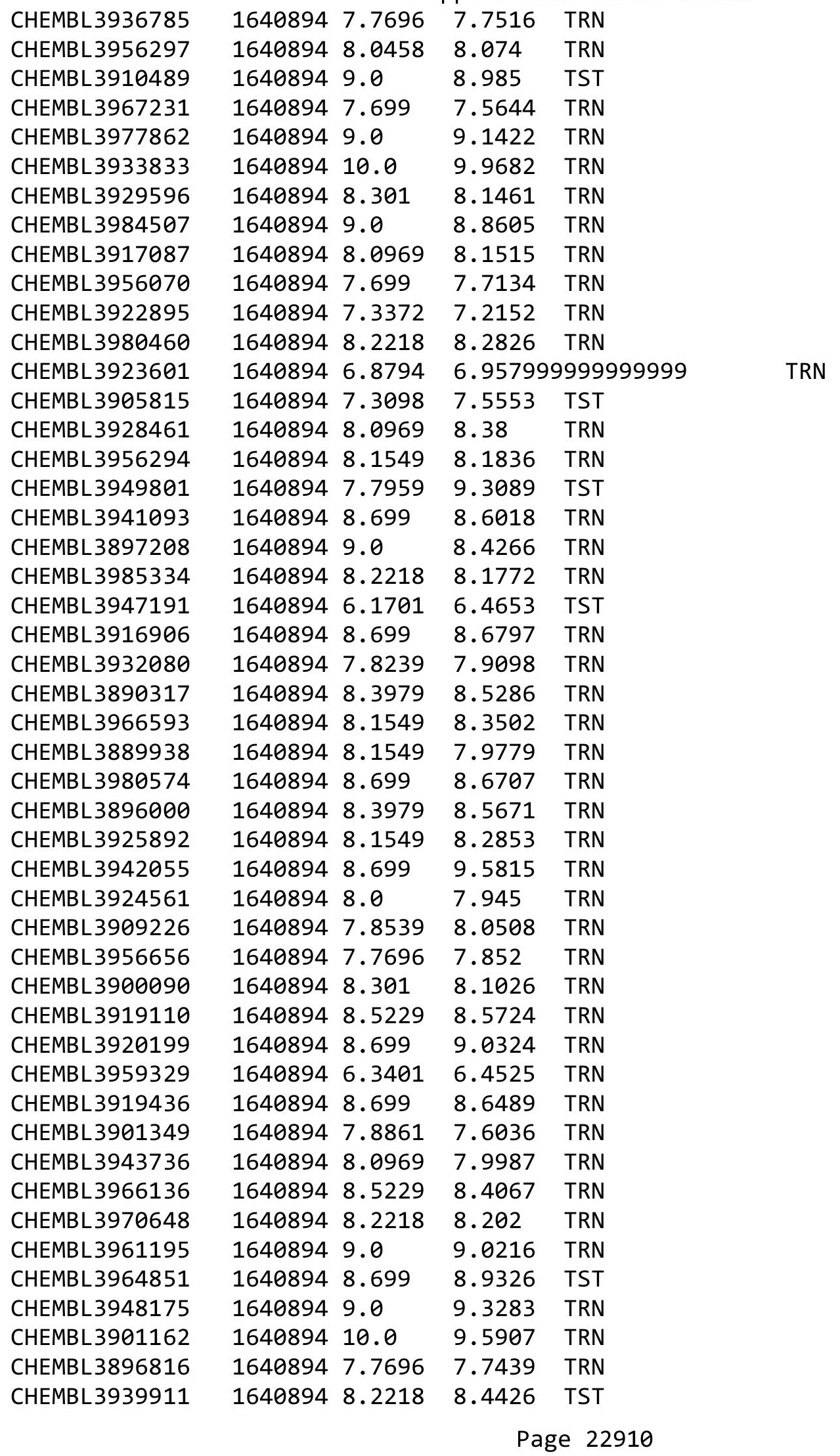




$$
\text { Supplemental Table S2.txt }
$$

\begin{tabular}{|c|c|c|c|c|c|}
\hline CHEMBL 3891084 & 1640894 & 8.699 & 9.0337 & TRN & \\
\hline CHEMBL3951313 & 1640894 & 6.0899 & 6.1083 & TRN & \\
\hline CHEMBL3986244 & 1640894 & 8.301 & 8.1385 & TRN & \\
\hline CHEMBL 3943804 & 1640894 & 6.5702 & 6.4997 & TST & \\
\hline CHEMBL3909385 & 1640894 & 8.301 & 8.5053 & TRN & \\
\hline CHEMBL3951558 & 1640894 & 8.301 & 8.2885 & TRN & \\
\hline CHEMBL 3941002 & 1640894 & 10.0 & 9.8362 & TRN & \\
\hline CHEMBL 3954844 & 1640894 & 8.1549 & 7.9007 & TRN & \\
\hline CHEMBL3964995 & 1640894 & 8.699 & 8.7137 & TRN & \\
\hline CHEMBL3976547 & 1640894 & 9.0 & 8.942 & TRN & \\
\hline CHEMBL3910507 & 1640894 & 9.0 & 9.0494 & TRN & \\
\hline CHEMBL 3933143 & 1640894 & 8.5229 & 8.3588 & TST & \\
\hline CHEMBL3972697 & 1640894 & 8.3979 & 8.6395 & TRN & \\
\hline CHEMBL3974562 & 1640894 & 10.0 & \multicolumn{2}{|c|}{9.652000000000001} & TST \\
\hline CHEMBL3985502 & 1640894 & 7.4815 & 7.5468 & TRN & \\
\hline CHEMBL3948570 & 1640894 & 10.0 & 9.9205 & TRN & \\
\hline CHEMBL3961662 & 1640894 & 8.1549 & 8.3431 & TRN & \\
\hline CHEMBL3985604 & 1640894 & 10.0 & 9.6962 & TRN & \\
\hline CHEMBL3944218 & 1640894 & 8.699 & 8.5473 & TRN & \\
\hline CHEMBL3904950 & 1640894 & 8.699 & 8.6312 & TRN & \\
\hline CHEMBL3901165 & 1640894 & 10.0 & 8.7431 & TST & \\
\hline CHEMBL3973082 & 1640894 & 8.3979 & \multicolumn{2}{|c|}{8.591000000000001} & TRN \\
\hline CHEMBL 3950774 & 1640894 & 8.699 & 8.8441 & TRN & \\
\hline CHEMBL3945948 & 1640894 & 8.301 & 8.1664 & TRN & \\
\hline CHEMBL 3906042 & 1640894 & 8.2218 & 8.4362 & TRN & \\
\hline CHEMBL3962236 & 1640894 & 9.0 & 8.7122 & TST & \\
\hline CHEMBL3916260 & 1640894 & 8.0969 & 7.7927 & TST & \\
\hline CHEMBL3919552 & 1640894 & 8.3979 & 8.3906 & TST & \\
\hline CHEMBL3977140 & 1640894 & 9.0 & 8.9729 & TST & \\
\hline CHEMBL3926917 & 1640894 & 8.2218 & 8.2653 & TST & \\
\hline CHEMBL3951727 & 1640894 & 8.699 & 9.0041 & TST & \\
\hline CHEMBL3962697 & 1640894 & 8.301 & 8.3822 & TST & \\
\hline CHEMBL 3975489 & 1640894 & 8.699 & 8.8497 & TST & \\
\hline CHEMBL3919818 & 1640894 & 10.0 & 9.8459 & TST & \\
\hline CHEMBL3946980 & 1640894 & 8.2218 & 8.1585 & TST & \\
\hline CHEMBL3970908 & 1640894 & 8.699 & 8.5566 & TST & \\
\hline CHEMBL3946431 & 1640894 & 8.5229 & 9.061 & TST & \\
\hline CHEMBL3978469 & 1640894 & 8.2218 & 8.8918 & TST & \\
\hline CHEMBL3934910 & 1640894 & 9.0 & 9.5782 & TST & \\
\hline CHEMBL3967258 & 1640894 & 8.5229 & 8.3902 & TST & \\
\hline CHEMBL3934169 & 1640894 & 9.0 & 9.1368 & TST & \\
\hline CHEMBL393919 & 448691 & 4.585 & 4.4176 & TRN & \\
\hline CHEMBL428903 & 448691 & 5.5686 & 4.6146 & TST & \\
\hline CHEMBL237528 & 448691 & 4.9208 & 4.0093 & TRN & \\
\hline CHEMBL392316 & 448691 & 4.3372 & 4.3637 & TST & \\
\hline CHEMBL429451 & 448691 & 4.7959 & 4.8262 & TRN & \\
\hline CHEMBL396638 & 448691 & 5.6778 & 4.8937 & TST & \\
\hline CHEMBL237483 & 448691 & 4.6021 & 4.2741 & TST & \\
\hline
\end{tabular}

Page 22911 


\begin{tabular}{|c|c|c|c|c|c|}
\hline \multicolumn{6}{|c|}{ Supplemental Table s2.txt } \\
\hline CHEMBL394075 & 448691 & 5.2676 & 4.769 & TRN & \\
\hline CHEMBL 235147 & 448691 & 4.1871 & 4.1082 & TRN & \\
\hline CHEMBL237935 & 448691 & 4.7447 & 4.4123 & TRN & \\
\hline CHEMBL238367 & 448691 & 4.301 & 4.461 & TRN & \\
\hline CHEMBL398980 & 448691 & 4.284 & 4.468 & TRN & \\
\hline CHEMBL 237504 & 448691 & 3.6576 & 4.8881 & TRN & \\
\hline CHEMBL238149 & 448691 & 5.1249 & 4.6085 & TRN & \\
\hline CHEMBL237478 & 448691 & 3.5391 & 3.6224 & TRN & \\
\hline CHEMBL 238345 & 448691 & 6.0 & 5.4143 & TRN & \\
\hline CHEMBL237698 & 448691 & 4.5686 & 4.5593 & TRN & \\
\hline CHEMBL236847 & 448691 & 4.5686 & 4.4903 & TST & \\
\hline CHEMBL 235138 & 448691 & 4.3279 & 4.9837 & TST & \\
\hline CHEMBL392315 & 448691 & 4.3665 & 4.8241 & TRN & \\
\hline CHEMBL237911 & 448691 & 4.5686 & 4.7633 & TST & \\
\hline CHEMBL 236002 & 448691 & 4.0269 & 4.6804 & TRN & \\
\hline CHEMBL 237530 & 448691 & 4.5229 & 4.03600 & 00000000005 & TRN \\
\hline CHEMBL394394 & 448691 & 4.2596 & 4.612 & TRN & \\
\hline CHEMBL237315 & 448691 & 4.585 & 4.2973 & TRN & \\
\hline CHEMBL 238369 & 448691 & 4.2291 & 4.2711 & TRN & \\
\hline CHEMBL393553 & 448691 & 4.5376 & 4.8222 & TRN & \\
\hline CHEMBL 236450 & 448691 & 4.9586 & 4.3237 & TST & \\
\hline CHEMBL 236003 & 448691 & 4.4202 & 4.2326 & TST & \\
\hline CHEMBL398777 & 448691 & 4.1079 & 4.6598 & TRN & \\
\hline CHEMBL393557 & 448691 & 4.2147 & 4.391 & TRN & \\
\hline CHEMBL393350 & 448691 & 4.7212 & 4.9237 & TRN & \\
\hline CHEMBL237689 & 448691 & 4.6021 & 4.8609 & TRN & \\
\hline CHEMBL237069 & 448691 & 4.6576 & 4.8114 & TRN & \\
\hline CHEMBL 237291 & 448691 & 4.6576 & 4.8155 & TRN & \\
\hline CHEMBL393994 & 448691 & 4.8539 & 4.8504 & TRN & \\
\hline CHEMBL235140 & 448691 & 4.6576 & 4.8709 & TRN & \\
\hline CHEMBL391823 & 448691 & 4.6198 & 4.895 & TRN & \\
\hline CHEMBL 235798 & 448691 & 4.2757 & 4.3581 & TRN & \\
\hline CHEMBL 236649 & 448691 & 4.6198 & 4.4794 & TRN & \\
\hline CHEMBL 236645 & 448691 & 4.3979 & 4.4556 & TRN & \\
\hline CHEMBL237052 & 448691 & 4.3279 & 4.3703 & TRN & \\
\hline CHEMBL391707 & 448691 & 4.4815 & 4.144 & TRN & \\
\hline CHEMBL 237688 & 448691 & 3.8794 & 4.5762 & TRN & \\
\hline CHEMBL235616 & 448691 & 4.6021 & 4.7515 & TRN & \\
\hline CHEMBL 237912 & 448691 & 4.4437 & 4.7998 & TRN & \\
\hline CHEMBL 238180 & 448691 & 3.8827 & 4.1804 & TST & \\
\hline CHEMBL438672 & 448691 & 4.6778 & 4.4237 & TRN & \\
\hline CHEMBL237079 & 448691 & 4.7959 & 4.1681 & TST & \\
\hline CHEMBL392094 & 448691 & 4.7212 & 4.4084 & TST & \\
\hline CHEMBL 236447 & 448691 & 4.1675 & 4.0837 & TRN & \\
\hline CHEMBL445669 & 448691 & 4.3372 & 4.8832 & TRN & \\
\hline CHEMBL 236640 & 448691 & 4.5528 & 4.8241 & TRN & \\
\hline CHEMBL235617 & 448691 & 4.6198 & 4.6768 & TRN & \\
\hline CHEMBL 235582 & 448691 & 6.0 & 5.33299 & 9999999999 & TRN \\
\hline & & & & 22912 & \\
\hline
\end{tabular}




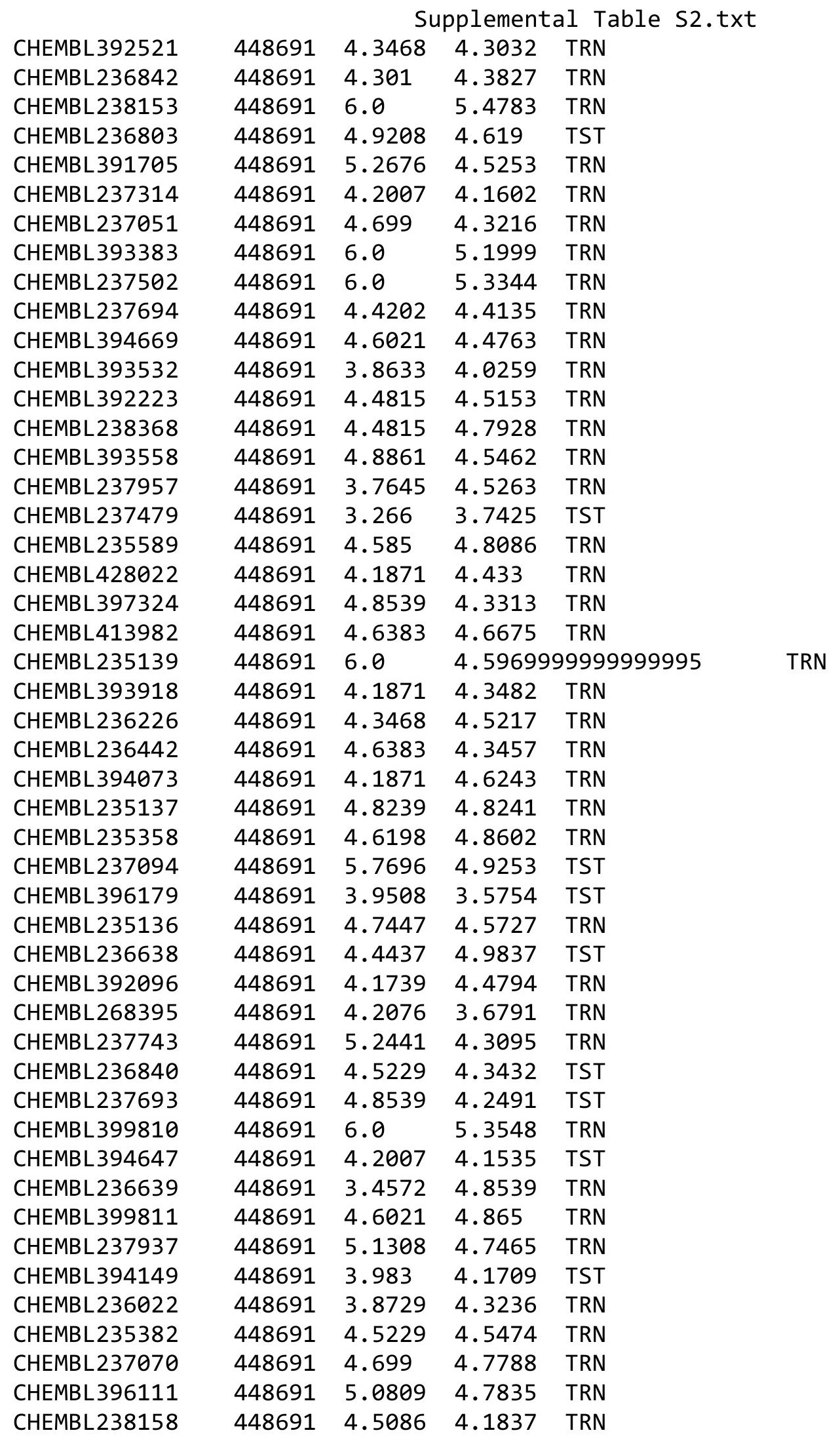

Page 22913 


\begin{tabular}{|c|c|c|c|c|c|}
\hline & & \multicolumn{4}{|c|}{ Supplemental Table s2.txt } \\
\hline CHEMBL394667 & 448691 & 3.8327 & 5.0733 & TRN & \\
\hline CHEMBL238159 & 448691 & 5.0 & 4.8703 & TRN & \\
\hline CHEMBL237719 & 448691 & 4.2924 & 4.2472 & TRN & \\
\hline CHEMBL238353 & 448691 & 4.2441 & 4.0299 & TRN & \\
\hline CHEMBL396655 & 448691 & 3.8962 & 4.1902 & TRN & \\
\hline CHEMBL235356 & 448691 & 5.4318 & 4.7794 & TST & \\
\hline CHEMBL235590 & 448691 & 3.6904 & 4.28600 & 00000000005 & TRN \\
\hline CHEMBL235815 & 448691 & 5.041 & 4.422 & TRN & \\
\hline CHEMBL237920 & 448691 & 6.0 & 5.3611 & TRN & \\
\hline CHEMBL391706 & 448691 & 5.2676 & 4.4176 & TRN & \\
\hline CHEMBL393125 & 448691 & 4.7212 & 4.4132 & TRN & \\
\hline CHEMBL237687 & 448691 & 4.2007 & 4.3827 & TRN & \\
\hline CHEMBL396598 & 448691 & 4.3098 & 4.4141 & TRN & \\
\hline CHEMBL237290 & 448691 & 3.6038 & 4.4025 & TRN & \\
\hline CHEMBL235627 & 448691 & 4.3188 & 4.4485 & TST & \\
\hline CHEMBL429269 & 448691 & 4.0044 & 4.0055 & TRN & \\
\hline CHEMBL238342 & 448691 & 6.0 & 5.2234 & TRN & \\
\hline CHEMBL429983 & 448691 & 5.0315 & 4.2 & TRN & \\
\hline CHEMBL235176 & 448691 & 4.6383 & 4.8031 & TRN & \\
\hline CHEMBL238144 & 448691 & 4.7959 & 4.761 & TRN & \\
\hline CHEMBL394645 & 448691 & 3.6968 & 4.7428 & TRN & \\
\hline CHEMBL236630 & 448691 & 4.4949 & 4.4176 & TRN & \\
\hline CHEMBL238135 & 448691 & 4.6576 & 4.5879 & TRN & \\
\hline CHEMBL235359 & 448691 & 4.284 & 4.495 & TRN & \\
\hline CHEMBL237930 & 448691 & 4.3565 & 4.6302 & TRN & \\
\hline CHEMBL235797 & 448691 & 3.8729 & 4.1386 & TRN & \\
\hline CHEMBL235592 & 448691 & 3.6421 & 3.9843 & TRN & \\
\hline CHEMBL393755 & 448691 & 4.4318 & 4.2136 & TST & \\
\hline CHEMBL235802 & 448691 & 4.301 & 4.1339 & TRN & \\
\hline CHEMBL235162 & 448691 & 4.2441 & 4.3002 & TRN & \\
\hline CHEMBL393382 & 448691 & 3.7905 & 4.0899 & TRN & \\
\hline CHEMBL391944 & 448691 & 3.9172 & 4.7665 & TRN & \\
\hline CHEMBL238154 & 448691 & 6.0 & 5.3191 & TRN & \\
\hline CHEMBL236629 & 448691 & 3.9747 & 3.635 & TST & \\
\hline CHEMBL393568 & 448691 & 3.556 & 4.3901 & TRN & \\
\hline CHEMBL396303 & 448691 & 4.3565 & 4.0376 & TRN & \\
\hline CHEMBL237299 & 448691 & 4.5376 & 4.1938 & TST & \\
\hline CHEMBL394074 & 448691 & 5.0915 & 4.6936 & TRN & \\
\hline CHEMBL410179 & 448691 & 4.3768 & 4.4176 & TRN & \\
\hline CHEMBL393753 & 448691 & 4.4089 & 4.4782 & TRN & \\
\hline CHEMBL238134 & 448691 & 4.5686 & 4.4788 & TRN & \\
\hline CHEMBL237702 & 448691 & 6.0 & 5.4023 & TST & \\
\hline CHEMBL237714 & 448691 & 4.0969 & 4.7539 & TST & \\
\hline CHEMBL394646 & 448691 & 4.1079 & 4.7138 & TST & \\
\hline CHEMBL396341 & 448691 & 4.3468 & 4.3928 & TST & \\
\hline CHEMBL237919 & 448691 & 6.0 & 5.25200 & 0000000001 & TST \\
\hline CHEMBL236443 & 448691 & 4.7696 & 4.6128 & TST & \\
\hline CHEMBL393552 & 448691 & 4.5686 & 4.6002 & TST & \\
\hline
\end{tabular}




\begin{tabular}{|c|c|c|c|c|c|}
\hline \multirow[b]{2}{*}{ CHEMBL237910 } & \multicolumn{5}{|c|}{ Supplemental Table S2.txt } \\
\hline & 448691 & 4.5686 & 4.4794 & TST & \\
\hline CHEMBL393359 & 448691 & 4.2366 & 4.3877 & TST & \\
\hline CHEMBL237692 & 448691 & 4.9208 & 4.4271 & TST & \\
\hline CHEMBL438334 & 448691 & 4.4202 & 4.8241 & TST & \\
\hline CHEMBL236626 & 448691 & 4.585 & 4.2574 & TST & \\
\hline CHEMBL 236841 & 448691 & 4.7959 & 4.9837 & TST & \\
\hline CHEMBL399624 & 448691 & 4.7696 & 4.7696 & TST & \\
\hline CHEMBL3678431 & 1528633 & 6.9208 & 6.9196 & TRN & \\
\hline CHEMBL3678316 & 1528633 & 7.1079 & 6.733 & TRN & \\
\hline CHEMBL3678323 & 1528633 & 6.9208 & 6.9526 & TRN & \\
\hline CHEMBL 3678451 & 1528633 & 6.0809 & 6.1518 & TRN & \\
\hline CHEMBL3683286 & 1528633 & 6.0 & 6.937 & TRN & \\
\hline CHEMBL3678437 & 1528633 & 7.7447 & 7.222 & TRN & \\
\hline CHEMBL 3678434 & 1528633 & 7.2218 & 7.7973 & TRN & \\
\hline CHEMBL3678356 & 1528633 & 8.0315 & 7.4742 & TRN & \\
\hline CHEMBL3678495 & 1528633 & 6.7212 & 6.9872 & TRN & \\
\hline CHEMBL3678377 & 1528633 & 6.0362 & 6.3641 & TRN & \\
\hline CHEMBL3678330 & 1528633 & 7.1249 & 6.6526 & TST & \\
\hline CHEMBL 3678378 & 1528633 & 6.699 & 6.2917 & TRN & \\
\hline CHEMBL3683277 & 1528633 & 6.7959 & 6.92899 & 9999999999 & TST \\
\hline CHEMBL3678358 & 1528633 & 7.7696 & 7.0178 & TRN & \\
\hline CHEMBL3678450 & 1528633 & 5.6819 & 6.2151 & TRN & \\
\hline CHEMBL3678476 & 1528633 & 7.0506 & 7.0671 & TRN & \\
\hline CHEMBL3970675 & 1528633 & 8.0458 & 7.4213 & TRN & \\
\hline CHEMBL3678361 & 1528633 & 8.0315 & 7.2745 & TRN & \\
\hline CHEMBL3678435 & 1528633 & 8.3665 & 8.0314 & TRN & \\
\hline CHEMBL 3678314 & 1528633 & 7.1549 & 6.6902 & TRN & \\
\hline CHEMBL 3678386 & 1528633 & 7.4089 & 7.0565 & TRN & \\
\hline CHEMBL3678395 & 1528633 & 8.2924 & 8.096 & TRN & \\
\hline CHEMBL3678486 & 1528633 & 8.3872 & 7.9038 & TRN & \\
\hline CHEMBL3678308 & 1528633 & 7.7959 & 7.9048 & TRN & \\
\hline CHEMBL3964676 & 1528633 & 6.3188 & 7.2069 & TST & \\
\hline CHEMBL3678436 & 1528633 & 7.3979 & 7.0362 & TRN & \\
\hline CHEMBL3678307 & 1528633 & 6.0 & 7.2086 & TRN & \\
\hline CHEMBL3956790 & 1528633 & 6.9208 & 7.0115 & TST & \\
\hline CHEMBL 3678370 & 1528633 & 6.0269 & 6.9434 & TST & \\
\hline CHEMBL 3678408 & 1528633 & 7.3979 & 6.9752 & TRN & \\
\hline CHEMBL 3683274 & 1528633 & 7.5528 & 6.8583 & TST & \\
\hline CHEMBL 3678321 & 1528633 & 7.7696 & 6.8006 & TRN & \\
\hline CHEMBL3678477 & 1528633 & 5.6021 & 6.0047 & TRN & \\
\hline CHEMBL 3683272 & 1528633 & 6.0 & 7.2953 & TST & \\
\hline CHEMBL 3678360 & 1528633 & 6.0809 & 7.4504 & TST & \\
\hline CHEMBL3678332 & 1528633 & 7.1805 & 6.8011 & TRN & \\
\hline CHEMBL3678496 & 1528633 & 7.8539 & 7.6288 & TRN & \\
\hline CHEMBL3678462 & 1528633 & 7.7959 & 7.00700 & 0000000001 & TRN \\
\hline CHEMBL 3678445 & 1528633 & 6.2076 & 6.2425 & TRN & \\
\hline CHEMBL3678485 & 1528633 & 7.6778 & 6.8969 & TRN & \\
\hline CHEMBL 3678444 & 1528633 & 7.301 & 7.1451 & TRN & \\
\hline & & & & 22915 & \\
\hline
\end{tabular}


Supplemental Table S2.txt

\begin{tabular}{|c|c|c|c|c|c|}
\hline CHEMBL3934746 & 1528633 & 6.7959 & 7.5354 & TST & \\
\hline CHEMBL 3678484 & 1528633 & 7.0177 & 6.4543 & TRN & \\
\hline CHEMBL3678365 & 1528633 & 6.8861 & 7.2791 & TRN & \\
\hline CHEMBL3678405 & 1528633 & 6.4949 & 6.7344 & TRN & \\
\hline CHEMBL3678465 & 1528633 & 8.2518 & 7.4141 & TRN & \\
\hline CHEMBL3678313 & 1528633 & 7.2596 & 6.79899 & 99999999995 & TRN \\
\hline CHEMBL3678382 & 1528633 & 6.0915 & 6.3746 & TRN & \\
\hline CHEMBL 3678410 & 1528633 & 6.699 & 6.9605 & TRN & \\
\hline CHEMBL3678375 & 1528633 & 6.3188 & 6.5812 & TRN & \\
\hline CHEMBL3678492 & 1528633 & 7.5376 & 6.9948 & TST & \\
\hline CHEMBL 3678331 & 1528633 & 7.9586 & 7.4094 & TRN & \\
\hline CHEMBL3678373 & 1528633 & 7.3188 & 6.8973 & TRN & \\
\hline CHEMBL 3678394 & 1528633 & 7.699 & 8.0654 & TRN & \\
\hline CHEMBL 3678426 & 1528633 & 7.2596 & 6.9583 & TST & \\
\hline CHEMBL3678438 & 1528633 & 7.3468 & 7.9916 & TRN & \\
\hline CHEMBL3678363 & 1528633 & 6.8239 & 6.354 & TRN & \\
\hline CHEMBL3968561 & 1528633 & 6.0 & 7.3617 & TRN & \\
\hline CHEMBL3678463 & 1528633 & 7.1938 & 7.3273 & TRN & \\
\hline CHEMBL 3678427 & 1528633 & 7.2218 & 7.7053 & TST & \\
\hline CHEMBL3678362 & 1528633 & 5.9318 & 6.8556 & TST & \\
\hline CHEMBL3678366 & 1528633 & 6.9586 & 7.0219 & TRN & \\
\hline CHEMBL3678467 & 1528633 & 6.1739 & 6.3061 & TRN & \\
\hline CHEMBL3678379 & 1528633 & 6.1249 & 6.4881 & TRN & \\
\hline CHEMBL 3678502 & 1528633 & 6.7959 & 6.274 & TRN & \\
\hline CHEMBL3678310 & 1528633 & 6.3468 & 6.57 & TST & \\
\hline CHEMBL3678413 & 1528633 & 6.7696 & 6.8076 & TRN & \\
\hline CHEMBL3678372 & 1528633 & 6.8539 & 6.7472 & TRN & \\
\hline CHEMBL 3678315 & 1528633 & 7.1024 & 7.0045 & TST & \\
\hline CHEMBL 3678420 & 1528633 & 6.6778 & 6.9074 & TRN & \\
\hline CHEMBL3678359 & 1528633 & 5.699 & 7.1658 & TST & \\
\hline CHEMBL3678482 & 1528633 & 6.6576 & 6.2448 & TRN & \\
\hline CHEMBL 3678344 & 1528633 & 6.0 & 6.8597 & TRN & \\
\hline CHEMBL3678369 & 1528633 & 6.7696 & 6.5894 & TRN & \\
\hline CHEMBL3678392 & 1528633 & 7.9208 & 7.8212 & TRN & \\
\hline CHEMBL 3678328 & 1528633 & 7.2596 & \multicolumn{2}{|c|}{6.622000000000001} & TRN \\
\hline CHEMBL3678350 & 1528633 & 8.2441 & 7.5469 & TRN & \\
\hline CHEMBL 3678371 & 1528633 & 7.3565 & 6.6354 & TRN & \\
\hline CHEMBL 3678334 & 1528633 & 6.8239 & 6.7243 & TRN & \\
\hline CHEMBL 3683283 & 1528633 & 7.0177 & 7.0183 & TST & \\
\hline CHEMBL 3678347 & 1528633 & 8.0132 & 7.6135 & TRN & \\
\hline CHEMBL3678335 & 1528633 & 7.0 & 7.2816 & TRN & \\
\hline CHEMBL3678414 & 1528633 & 7.3768 & 7.2793 & TRN & \\
\hline CHEMBL3678374 & 1528633 & 6.7696 & 6.7591 & TRN & \\
\hline CHEMBL 3678472 & 1528633 & 5.6021 & 6.075 & TRN & \\
\hline CHEMBL 3678487 & 1528633 & 7.5229 & 6.9562 & TRN & \\
\hline CHEMBL3678396 & 1528633 & 7.8861 & 8.0197 & TRN & \\
\hline CHEMBL3678480 & 1528633 & 6.1249 & 6.5435 & TRN & \\
\hline CHEMBL3678399 & 1528633 & 7.3565 & 7.65 & TRN & \\
\hline
\end{tabular}


Supplemental Table S2.txt

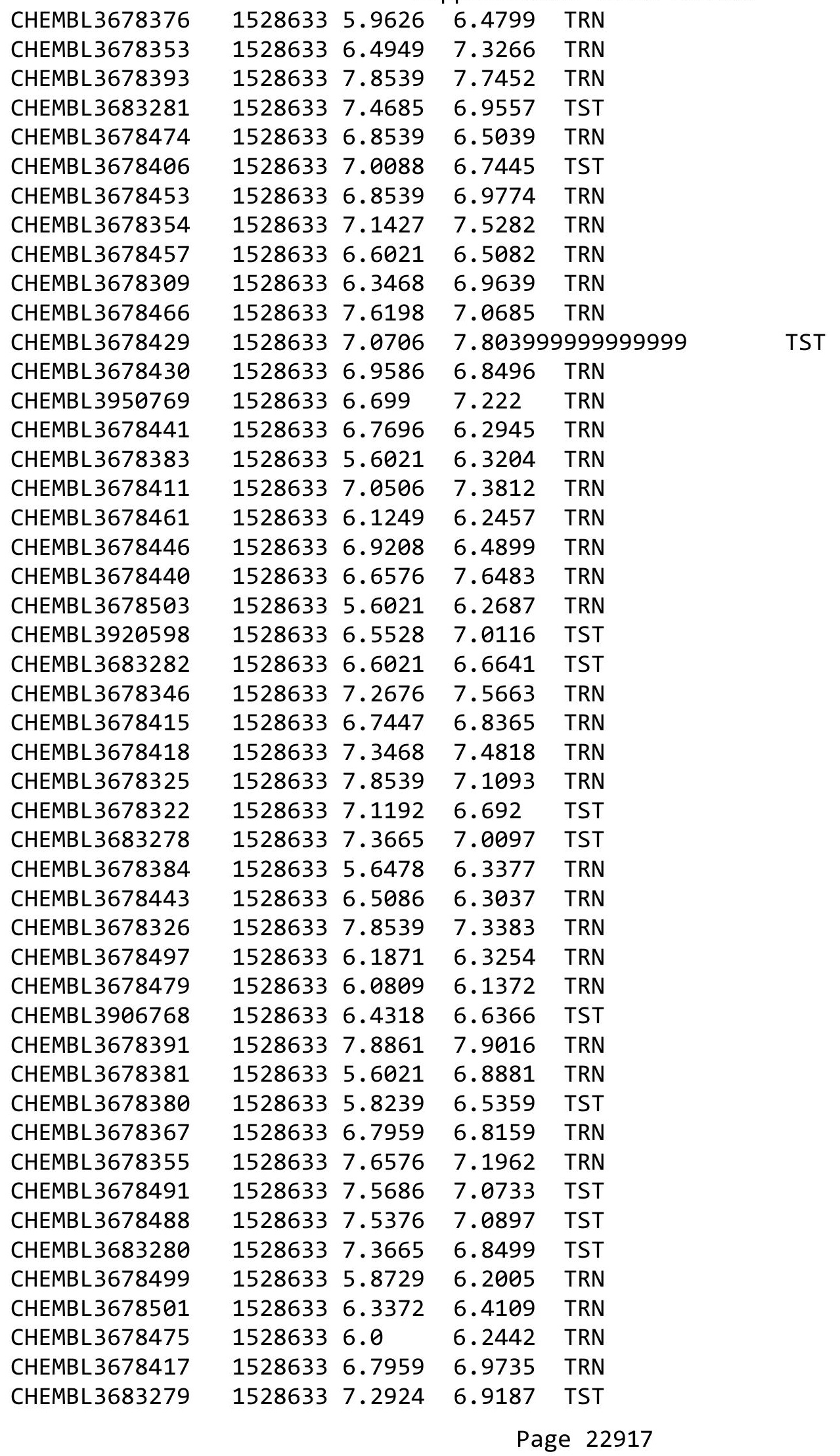


Supplemental Table S2.txt

\begin{tabular}{|c|c|c|c|c|}
\hline CHEMBL 3678460 & 1528633 & 6.0809 & 6.2561 & TRN \\
\hline CHEMBL3678454 & 1528633 & 6.585 & 6.7436 & TRN \\
\hline CHEMBL3678389 & 1528633 & 7.8861 & 7.979 & TRN \\
\hline CHEMBL3678459 & 1528633 & 6.0809 & 6.204 & TRN \\
\hline CHEMBL3678481 & 1528633 & 6.8239 & 6.2767 & TRN \\
\hline CHEMBL3678500 & 1528633 & 6.4685 & 6.3903 & TRN \\
\hline CHEMBL3683271 & 1528633 & 6.2076 & 6.188 & TRN \\
\hline CHEMBL3896027 & 1528633 & 8.3188 & 6.8855 & TRN \\
\hline CHEMBL 3678452 & 1528633 & 6.1249 & 6.1984 & TRN \\
\hline CHEMBL3678489 & 1528633 & 7.6383 & 7.0369 & TST \\
\hline CHEMBL 3678403 & 1528633 & 7.3098 & 7.1392 & TRN \\
\hline CHEMBL 3678320 & 1528633 & 8.0362 & 7.3127 & TRN \\
\hline CHEMBL 3678468 & 1528633 & 6.7959 & 6.8508 & TRN \\
\hline CHEMBL3978580 & 1528633 & 7.1079 & 7.261 & TRN \\
\hline CHEMBL 3678318 & 1528633 & 8.5686 & 7.0623 & TST \\
\hline CHEMBL3678409 & 1528633 & 6.7696 & 6.8947 & TRN \\
\hline CHEMBL3678428 & 1528633 & 7.0862 & 7.0132 & TST \\
\hline CHEMBL3678469 & 1528633 & 6.2757 & 6.4581 & TRN \\
\hline CHEMBL3678439 & 1528633 & 7.9208 & 7.8845 & TRN \\
\hline CHEMBL3678493 & 1528633 & 7.1739 & 7.0651 & TST \\
\hline CHEMBL3678364 & 1528633 & 7.6021 & 6.8257 & TRN \\
\hline CHEMBL3678368 & 1528633 & 6.1871 & 6.3925 & TRN \\
\hline CHEMBL3678432 & 1528633 & 7.3872 & 6.8597 & TRN \\
\hline CHEMBL3678433 & 1528633 & 7.4685 & 7.1383 & TRN \\
\hline CHEMBL3678348 & 1528633 & 7.5229 & 7.7629 & TST \\
\hline CHEMBL3678498 & 1528633 & 6.1249 & 6.484 & TRN \\
\hline CHEMBL3678387 & 1528633 & 7.8539 & 8.0349 & TRN \\
\hline CHEMBL3678473 & 1528633 & 5.6021 & 5.9152 & TRN \\
\hline CHEMBL 3678400 & 1528633 & 6.3872 & 6.8937 & TST \\
\hline CHEMBL3678456 & 1528633 & 6.2366 & 6.54799 & 9999999999 \\
\hline CHEMBL3678390 & 1528633 & 7.5686 & 8.182 & TRN \\
\hline CHEMBL 3678458 & 1528633 & 6.4815 & 6.2336 & TRN \\
\hline CHEMBL3678419 & 1528633 & 6.9586 & 6.8923 & TRN \\
\hline CHEMBL 3678449 & 1528633 & 6.2076 & 6.353 & TRN \\
\hline CHEMBL3678421 & 1528633 & 6.5229 & 6.8847 & TRN \\
\hline CHEMBL3678422 & 1528633 & 6.0809 & 6.9749 & TRN \\
\hline CHEMBL3678357 & 1528633 & 7.4318 & 7.0504 & TRN \\
\hline CHEMBL 3678442 & 1528633 & 6.5086 & 6.3907 & TRN \\
\hline CHEMBL3678416 & 1528633 & 6.9586 & 7.0688 & TRN \\
\hline CHEMBL3678397 & 1528633 & 8.1249 & 7.79 & TRN \\
\hline CHEMBL3683276 & 1528633 & 7.6198 & 7.1486 & TST \\
\hline CHEMBL 3678470 & 1528633 & 6.6383 & 6.6703 & TRN \\
\hline CHEMBL3639772 & 1528633 & 7.1192 & 6.9984 & TRN \\
\hline CHEMBL 3678324 & 1528633 & 7.5686 & 7.3345 & TST \\
\hline CHEMBL 3678447 & 1528633 & 6.6778 & 6.5963 & TRN \\
\hline CHEMBL 3678448 & 1528633 & 6.2076 & 6.6459 & TRN \\
\hline CHEMBL3678398 & 1528633 & 7.8239 & 7.9095 & TRN \\
\hline CHEMBL 3678312 & 1528633 & 8.5229 & 7.2419 & TST \\
\hline
\end{tabular}


Supplemental Table S2.txt

\begin{tabular}{|c|c|c|c|c|}
\hline CHEMBL 3678478 & 1528633 & 5.8962 & 6.3178 & TRN \\
\hline CHEMBL 3941955 & 1528633 & 7.3665 & 7.6228 & TST \\
\hline CHEMBL 3678494 & 1528633 & 6.9586 & 6.9167 & TRN \\
\hline CHEMBL 3925953 & 1528633 & 7.1308 & 6.6554 & TST \\
\hline CHEMBL 3678404 & 1528633 & 7.4559 & 7.6215 & TST \\
\hline CHEMBL 3894981 & 1528633 & 8.0757 & 6.8185 & TST \\
\hline CHEMBL 3678388 & 1528633 & 7.0177 & 7.6757 & TRN \\
\hline CHEMBL 3678311 & 1528633 & 6.4559 & 6.3858 & TRN \\
\hline CHEMBL 3678464 & 1528633 & 7.7696 & 7.0696 & TST \\
\hline CHEMBL 3678471 & 1528633 & 6.7959 & 6.9015 & TRN \\
\hline CHEMBL 3969870 & 1528633 & 7.7212 & 7.2441 & TST \\
\hline CHEMBL 3678455 & 1528633 & 6.4685 & 7.2072 & TRN \\
\hline CHEMBL 3942050 & 1528633 & 7.2757 & 7.1845 & TST \\
\hline CHEMBL 3914052 & 1528633 & 8.2366 & 7.1313 & TST \\
\hline CHEMBL 3678423 & 1528633 & 7.0177 & 7.2637 & TRN \\
\hline CHEMBL 3678317 & 1528633 & 7.4318 & 7.04 & TST \\
\hline CHEMBL 3678483 & 1528633 & 6.6778 & 6.4166 & TST \\
\hline CHEMBL 3678329 & 1528633 & 7.3279 & 7.0643 & TRN \\
\hline CHEMBL 3968364 & 1528633 & 7.1135 & 6.9127 & TST \\
\hline CHEMBL 3678412 & 1528633 & 6.8861 & 6.8927 & TRN \\
\hline CHEMBL 3678490 & 1528633 & 7.5086 & 7.015 & TST \\
\hline CHEMBL1574689 & 688363 & 5.2072 & 5.2061 & TRN \\
\hline CHEMBL1383592 & 688363 & 5.1304 & 5.1171 & TRN \\
\hline CHEMBL1545971 & 688363 & 5.232 & 5.2165 & TRN \\
\hline CHEMBL1404069 & 688363 & 6.1349 & 6.1428 & TRN \\
\hline CHEMBL1432676 & 688363 & 5.21 & 5.7631 & TST \\
\hline CHEMBL1385608 & 688363 & 5.7833 & 4.399 & TST \\
\hline CHEMBL1428935 & 688363 & 5.5137 & 5.2665 & TST \\
\hline CHEMBL1308461 & 688363 & 5.2391 & 5.232 & TRN \\
\hline CHEMBL1370128 & 688363 & 3.4559 & 3.4502 & TRN \\
\hline CHEMBL 3214137 & 688363 & 5.1892 & 5.1903 & TRN \\
\hline CHEMBL1366620 & 688363 & 5.21399 & 999999999 & 5.2187 \\
\hline CHEMBL1527817 & 688363 & 5.0609 & 5.3578 & TST \\
\hline CHEMBL1439981 & 688363 & 5.4503 & 5.4532 & TRN \\
\hline CHEMBL1522356 & 688363 & 5.1622 & 5.1594 & TRN \\
\hline CHEMBL1398754 & 688363 & 6.3686 & 6.4006 & TRN \\
\hline CHEMBL 1342128 & 688363 & 4.738 & 4.7482 & TRN \\
\hline CHEMBL1353428 & 688363 & 5.8058 & 5.8048 & TRN \\
\hline CHEMBL1351633 & 688363 & 5.4559 & 5.4597 & TRN \\
\hline CHEMBL1310577 & 688363 & 5.0355 & 5.0316 & TRN \\
\hline CHEMBL1349920 & 688363 & 4.7488 & 4.7487 & TRN \\
\hline CHEMBL 3213775 & 688363 & 4.7881 & 4.7791 & TRN \\
\hline CHEMBL 3197426 & 688363 & 5.3436 & 5.3458 & TRN \\
\hline CHEMBL1439255 & 688363 & 4.8222 & 4.818000 & 00000000005 \\
\hline CHEMBL1528149 & 688363 & 3.4559 & 4.2021 & TST \\
\hline CHEMBL1311646 & 688363 & 4.6872 & 4.6904 & TRN \\
\hline CHEMBL 3211272 & 688363 & 5.2951 & 5.2951 & TRN \\
\hline CHEMBL1391119 & 688363 & 4.8761 & 6.2074 & TST \\
\hline
\end{tabular}




\begin{tabular}{|c|c|c|c|c|c|}
\hline \multirow[b]{2}{*}{ CHEMBL1377743 } & \multicolumn{5}{|c|}{ Supplemental Table S2.txt } \\
\hline & 688363 & 4.8492 & 4.8446 & TRN & \\
\hline CHEMBL1453832 & 688363 & 3.4559 & 3.4647 & TRN & \\
\hline CHEMBL1427860 & 688363 & 6.5258 & 6.4886 & TRN & \\
\hline CHEMBL1311570 & 688363 & 5.0936 & 5.1027 & TRN & \\
\hline CHEMBL 1455508 & 688363 & 3.4559 & 3.4552 & TRN & \\
\hline CHEMBL1480648 & 688363 & 5.1444 & 5.1434 & TRN & \\
\hline CHEMBL1573504 & 688363 & 3.4559 & 3.4597 & TRN & \\
\hline CHEMBL1990096 & 688363 & 5.1002 & 5.101 & TRN & \\
\hline CHEMBL1308845 & 688363 & 5.2884 & 5.29200 & 0000000001 & TRN \\
\hline CHEMBL1610409 & 688363 & 5.0922 & 5.0978 & TRN & \\
\hline CHEMBL417727 & 688363 & 5.3721 & 4.6927 & TST & \\
\hline CHEMBL1319576 & 688363 & 3.4559 & 3.45300 & 00000000003 & TRN \\
\hline CHEMBL1608982 & 688363 & 5.407 & 4.9221 & TST & \\
\hline CHEMBL1423799 & 688363 & 5.2845 & 5.2913 & TRN & \\
\hline CHEMBL1426022 & 688363 & 5.3582 & 5.3553 & TRN & \\
\hline CHEMBL1493277 & 688363 & 5.3217 & 5.3247 & TRN & \\
\hline CHEMBL1456185 & 688363 & 3.4559 & 3.4485 & TRN & \\
\hline CHEMBL1365319 & 688363 & 5.3427 & 5.3514 & TRN & \\
\hline CHEMBL1507807 & 688363 & 4.8213 & 4.8146 & TRN & \\
\hline CHEMBL1457093 & 688363 & 5.0145 & 5.0049 & TRN & \\
\hline CHEMBL1387309 & 688363 & 4.8318 & 4.82600 & 00000000005 & TRN \\
\hline CHEMBL1353075 & 688363 & 5.1 & 5.0938 & TRN & \\
\hline CHEMBL1537995 & 688363 & 5.1556 & 5.1612 & TRN & \\
\hline CHEMBL1335124 & 688363 & 5.0938 & 5.095 & TRN & \\
\hline CHEMBL1389702 & 688363 & 4.64 & 3.8431 & TST & \\
\hline CHEMBL1499276 & 688363 & 5.2713 & 5.2691 & TRN & \\
\hline CHEMBL1446166 & 688363 & 4.9961 & 4.9985 & TRN & \\
\hline CHEMBL1341841 & 688363 & 4.9821 & 4.9835 & TRN & \\
\hline CHEMBL1539256 & 688363 & 4.8315 & 4.8303 & TRN & \\
\hline CHEMBL1579872 & 688363 & 4.8925 & 4.8971 & TRN & \\
\hline CHEMBL1350415 & 688363 & 4.8339 & 4.8353 & TRN & \\
\hline CHEMBL1468490 & 688363 & 5.2425 & 4.48600 & 0000000001 & TST \\
\hline CHEMBL1342925 & 688363 & 5.0861 & 5.0884 & TRN & \\
\hline CHEMBL1585652 & 688363 & 5.7047 & 5.7113 & TRN & \\
\hline CHEMBL1386511 & 688363 & 4.7404 & 4.7342 & TRN & \\
\hline CHEMBL1570844 & 688363 & $5.3610 e$ & 00000000 & 5.3572 & TRN \\
\hline CHEMBL1599610 & 688363 & 5.2939 & 5.2828 & TRN & \\
\hline CHEMBL1511420 & 688363 & 4.7089 & 4.7028 & TRN & \\
\hline CHEMBL1423382 & 688363 & 5.3851 & 5.3903 & TRN & \\
\hline CHEMBL1468302 & 688363 & 5.3668 & 5.3617 & TRN & \\
\hline CHEMBL1471779 & 688363 & 5.1004 & 5.0984 & TRN & \\
\hline CHEMBL3190644 & 688363 & 5.3047 & 5.3115 & TRN & \\
\hline CHEMBL1462447 & 688363 & 3.4559 & 3.4556 & TRN & \\
\hline CHEMBL1453776 & 688363 & 3.4559 & 3.4655 & TRN & \\
\hline CHEMBL1560529 & 688363 & 3.4559 & 3.4586 & TRN & \\
\hline CHEMBL3194054 & 688363 & 5.4498 & 5.4563 & TRN & \\
\hline CHEMBL1509886 & 688363 & 5.0514 & 5.0506 & TRN & \\
\hline CHEMBL262083 & 688363 & 5.3252 & 3.9235 & TST & \\
\hline
\end{tabular}




\begin{tabular}{|c|c|c|c|c|c|}
\hline \multicolumn{6}{|c|}{ Supplemental Table S2.txt } \\
\hline CHEMBL3195229 & 688363 & 5.0419 & 5.03 & TRN & \\
\hline CHEMBL3199632 & 688363 & 5.0074 & 4.9984 & TRN & \\
\hline CHEMBL1393538 & 688363 & 4.8794 & 4.8864 & TRN & \\
\hline CHEMBL1427504 & 688363 & 5.2172 & 5.227 & TRN & \\
\hline CHEMBL1585445 & 688363 & 5.3718 & 5.3645 & TRN & \\
\hline CHEMBL1580409 & 688363 & 3.9208 & 3.9149 & TRN & \\
\hline CHEMBL1467233 & 688363 & 3.4559 & 3.4455 & TRN & \\
\hline CHEMBL1534058 & 688363 & 3.4559 & 3.4525 & TRN & \\
\hline CHEMBL1379143 & 688363 & 4.8447 & 4.3542 & TST & \\
\hline CHEMBL1345334 & 688363 & 5.2592 & 5.2536 & TRN & \\
\hline CHEMBL1402158 & 688363 & 5.2584 & 5.2689 & TRN & \\
\hline CHEMBL1327690 & 688363 & 4.7918 & 4.8021 & TRN & \\
\hline CHEMBL1603366 & 688363 & 4.9987 & 5.0028 & TRN & \\
\hline CHEMBL1543306 & 688363 & 6.6576 & 6.6568 & TRN & \\
\hline CHEMBL1329549 & 688363 & 5.5303 & 5.5301 & TRN & \\
\hline CHEMBL1531745 & 688363 & 5.1903 & 5.2037 & TRN & \\
\hline CHEMBL1427745 & 688363 & 5.2793 & 4.0977 & TST & \\
\hline CHEMBL3195213 & 688363 & 3.4559 & 3.4507 & TRN & \\
\hline CHEMBL1300782 & 688363 & 3.4559 & 3.4681 & TRN & \\
\hline CHEMBL1870697 & 688363 & 3.4559 & 3.4663 & TRN & \\
\hline CHEMBL1600727 & 688363 & 4.7615 & 4.7596 & TRN & \\
\hline CHEMBL1360426 & 688363 & 5.2204 & 5.2078 & TRN & \\
\hline CHEMBL1348426 & 688363 & 5.0964 & 5.1017 & TRN & \\
\hline CHEMBL1312703 & 688363 & 5.3644 & 5.3648 & TRN & \\
\hline CHEMBL1419096 & 688363 & 4.8239 & 4.828 & TRN & \\
\hline CHEMBL1364371 & 688363 & 4.7572 & 4.8888 & TST & \\
\hline CHEMBL1426896 & 688363 & 5.296 & 5.1224 & TST & \\
\hline CHEMBL1502859 & 688363 & 3.4559 & 4.8188 & TST & \\
\hline CHEMBL1453672 & 688363 & 5.1566 & 5.3054 & TST & \\
\hline CHEMBL1493500 & 688363 & 4.7612 & 5.8872 & TST & \\
\hline CHEMBL1559259 & 688363 & 5.5035 & 5.396 & TST & \\
\hline CHEMBL1563162 & 688363 & 4.863 & 4.4691 & TST & \\
\hline CHEMBL564979 & 688363 & 5.0052 & 4.6559 & TST & \\
\hline CHEMBL1973629 & 688363 & 3.4559 & 5.01399 & 9999999999 & TST \\
\hline CHEMBL1312713 & 688363 & 5.1582 & 4.751 & TST & \\
\hline CHEMBL3208997 & 688363 & 5.3788 & 5.1603 & TST & \\
\hline CHEMBL1568243 & 688363 & 5.3051 & 4.709 & TST & \\
\hline CHEMBL1483730 & 688363 & 4.9194 & 4.9135 & TST & \\
\hline CHEMBL1487131 & 688363 & 5.3366 & 5.0349 & TST & \\
\hline CHEMBL1359694 & 688363 & 5.0888 & 5.1814 & TST & \\
\hline CHEMBL1431004 & 688363 & 5.2578 & 4.4859 & TST & \\
\hline CHEMBL1389982 & 688363 & 5.282 & 4.6254 & TST & \\
\hline CHEMBL3928672 & 1637364 & 5.0 & 5.4963 & TRN & \\
\hline CHEMBL3910913 & 1637364 & 3.699 & 4.4435 & TRN & \\
\hline CHEMBL3970708 & 1637364 & 5.0 & 4.8666 & TRN & \\
\hline CHEMBL3928473 & 1637364 & 3.699 & 4.8297 & TRN & \\
\hline CHEMBL3954820 & 1637364 & 5.0 & 4.8432 & TST & \\
\hline CHEMBL3890459 & 1637364 & 5.9996 & 5.8561 & TRN & \\
\hline
\end{tabular}

Page 22921 
Supplemental Table S2.txt

\begin{tabular}{|c|c|c|c|c|c|}
\hline CHEMBL3942912 & 1637364 & 3.699 & 3.7893 & TRN & \\
\hline CHEMBL 3898653 & 1637364 & 5.9996 & 5.7216 & TRN & \\
\hline CHEMBL3926226 & 1637364 & 3.3979 & \multicolumn{2}{|c|}{3.7110000000000003} & TRN \\
\hline CHEMBL 3900173 & 1637364 & 5.0 & 4.646 & TRN & \\
\hline CHEMBL 3950225 & 1637364 & 5.9996 & 5.8361 & TST & \\
\hline CHEMBL3913350 & 1637364 & 3.699 & 3.8339 & TRN & \\
\hline CHEMBL3917767 & 1637364 & 3.3979 & 3.1668 & TST & \\
\hline CHEMBL 3987017 & 1637364 & 6.9957 & 5.3973 & TRN & \\
\hline CHEMBL3906293 & 1637364 & 3.3979 & 2.1688 & TRN & \\
\hline CHEMBL 3893985 & 1637364 & 5.9996 & 6.0226 & TRN & \\
\hline CHEMBL 3985240 & 1637364 & 5.9996 & 5.6817 & TRN & \\
\hline CHEMBL3946950 & 1637364 & 3.699 & 4.0089 & TRN & \\
\hline CHEMBL 3917923 & 1637364 & 5.0 & 4.8546 & TRN & \\
\hline CHEMBL 3899421 & 1637364 & 3.699 & 3.7986 & TST & \\
\hline CHEMBL 3898507 & 1637364 & 5.0 & 4.394 & TRN & \\
\hline CHEMBL 3960918 & 1637364 & 5.0 & 4.5358 & TRN & \\
\hline CHEMBL3922882 & 1637364 & 5.0 & 4.449 & TRN & \\
\hline CHEMBL 3902680 & 1637364 & 5.9996 & 5.2935 & TRN & \\
\hline CHEMBL 3967274 & 1637364 & 3.699 & 4.7098 & TST & \\
\hline CHEMBL 3896659 & 1637364 & 5.9996 & 6.1011 & TRN & \\
\hline CHEMBL 3901154 & 1637364 & 3.699 & 4.687 & TST & \\
\hline CHEMBL3936822 & 1637364 & 3.699 & 4.9826 & TST & \\
\hline CHEMBL3896539 & 1637364 & 5.9996 & 4.6543 & TRN & \\
\hline CHEMBL3909719 & 1637364 & 3.699 & 3.534 & TRN & \\
\hline CHEMBL3906136 & 1637364 & 5.0 & 3.4406 & TST & \\
\hline CHEMBL 3920188 & 1637364 & 5.9996 & 6.0521 & TRN & \\
\hline CHEMBL3933805 & 1637364 & 3.3979 & 3.2671 & TRN & \\
\hline CHEMBL3906566 & 1637364 & 5.9996 & 3.592 & TST & \\
\hline CHEMBL 3954078 & 1637364 & 3.699 & 4.8679 & TRN & \\
\hline CHEMBL3984431 & 1637364 & 5.0 & 4.5912 & TRN & \\
\hline CHEMBL 3941254 & 1637364 & 3.699 & 3.3672 & TST & \\
\hline CHEMBL3928770 & 1637364 & 3.699 & 4.8466 & TRN & \\
\hline CHEMBL3912492 & 1637364 & 5.0 & 5.436 & TRN & \\
\hline CHEMBL 3911748 & 1637364 & 5.0 & 4.2471 & TST & \\
\hline CHEMBL3973095 & 1637364 & 3.699 & 5.1296 & TRN & \\
\hline CHEMBL 3956748 & 1637364 & 3.699 & 5.38200 & 3000000001 & TRN \\
\hline CHEMBL 3973489 & 1637364 & 5.0 & 5.5741 & TRN & \\
\hline CHEMBL3968900 & 1637364 & 5.9996 & 6.2153 & TRN & \\
\hline CHEMBL3947169 & 1637364 & 5.0 & 4.6142 & TRN & \\
\hline CHEMBL 3938941 & 1637364 & 5.0 & 4.4071 & TRN & \\
\hline CHEMBL 3944565 & 1637364 & 5.0 & 5.0476 & TRN & \\
\hline CHEMBL 3968729 & 1637364 & 5.0 & 4.6767 & TRN & \\
\hline CHEMBL3909606 & 1637364 & 5.0 & 4.3873 & TRN & \\
\hline CHEMBL 3896220 & 1637364 & 3.699 & 5.1823 & TST & \\
\hline CHEMBL 3905635 & 1637364 & 5.0 & 5.037 & TRN & \\
\hline CHEMBL 3974293 & 1637364 & 3.3979 & 3.5135 & TST & \\
\hline CHEMBL 3907887 & 1637364 & 3.699 & 4.1932 & TRN & \\
\hline CHEMBL 3980202 & 1637364 & 3.699 & 4.5877 & TRN & \\
\hline
\end{tabular}

Page 22922 
Supplemental Table S2.txt

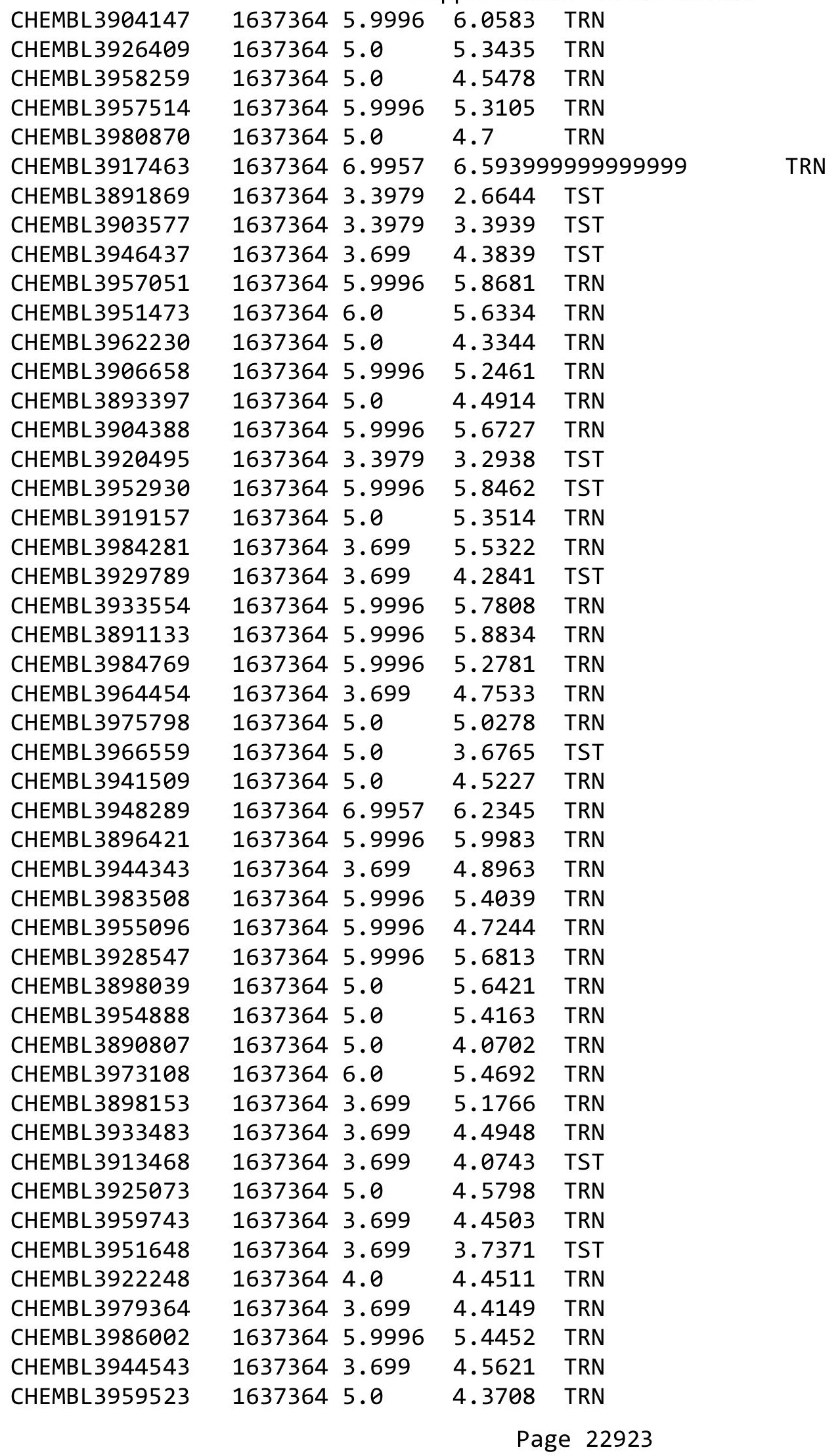


Supplemental Table S2.txt

\begin{tabular}{|c|c|c|c|c|c|}
\hline CHEMBL3983333 & 1637364 & 3.3979 & 3.4372 & TST & \\
\hline CHEMBL3912237 & 1637364 & 5.0 & 4.7271 & TRN & \\
\hline CHEMBL3893815 & 1637364 & 5.9996 & 5.7273 & TRN & \\
\hline CHEMBL3987146 & 1637364 & 5.9996 & 5.9281 & TRN & \\
\hline CHEMBL3945227 & 1637364 & 5.0 & 5.0885 & TRN & \\
\hline CHEMBL3898456 & 1637364 & 5.9996 & 4.8041 & TST & \\
\hline CHEMBL3985527 & 1637364 & 3.699 & 4.2707 & TRN & \\
\hline CHEMBL3908186 & 1637364 & 3.699 & 4.9245 & TST & \\
\hline CHEMBL3913682 & 1637364 & 3.699 & 3.8355 & TST & \\
\hline CHEMBL3985688 & 1637364 & 5.9996 & 5.6346 & TRN & \\
\hline CHEMBL3935523 & 1637364 & 3.3979 & 2.2062 & TST & \\
\hline CHEMBL3889494 & 1637364 & 5.0 & 4.9135 & TRN & \\
\hline CHEMBL3902279 & 1637364 & 3.699 & 3.681 & TRN & \\
\hline CHEMBL3963844 & 1637364 & 5.0 & 4.3491 & TRN & \\
\hline CHEMBL3890629 & 1637364 & 5.9996 & 5.57700 & 0000000001 & TRN \\
\hline CHEMBL3895025 & 1637364 & 3.699 & 4.1844 & TRN & \\
\hline CHEMBL3918269 & 1637364 & 3.699 & 4.445 & TST & \\
\hline CHEMBL3952979 & 1637364 & 5.9996 & 5.5623 & TRN & \\
\hline CHEMBL3979485 & 1637364 & 5.0 & 5.7637 & TRN & \\
\hline CHEMBL3922931 & 1637364 & 5.0 & 5.0383 & TRN & \\
\hline CHEMBL3984791 & 1637364 & 3.699 & 4.7125 & TST & \\
\hline CHEMBL3973841 & 1637364 & 5.9996 & 5.6153 & TRN & \\
\hline CHEMBL3916202 & 1637364 & 5.0 & 5.2015 & TRN & \\
\hline CHEMBL3964615 & 1637364 & 5.0 & 4.4496 & TRN & \\
\hline CHEMBL3890529 & 1637364 & 3.699 & 4.239 & TRN & \\
\hline CHEMBL3904961 & 1637364 & 3.699 & 4.2571 & TRN & \\
\hline CHEMBL3951746 & 1637364 & 3.3979 & 3.3862 & TST & \\
\hline CHEMBL3938549 & 1637364 & 3.699 & 4.4252 & TRN & \\
\hline CHEMBL3914054 & 1637364 & 3.699 & 4.1214 & TRN & \\
\hline CHEMBL3918386 & 1637364 & 5.9996 & 4.7186 & TRN & \\
\hline CHEMBL3963906 & 1637364 & 3.699 & 4.2026 & TRN & \\
\hline CHEMBL1620574 & 1637364 & 3.3979 & 2.8343 & TST & \\
\hline CHEMBL3981786 & 1637364 & 3.699 & 4.3921 & TRN & \\
\hline CHEMBL3911311 & 1637364 & 5.0 & 3.3508 & TST & \\
\hline CHEMBL3931432 & 1637364 & 5.0 & 5.1044 & TRN & \\
\hline CHEMBL3933662 & 1637364 & 5.9996 & 5.7527 & TRN & \\
\hline CHEMBL3943124 & 1637364 & 5.0 & 5.3812 & TST & \\
\hline CHEMBL3890479 & 1637364 & 6.9957 & 5.3305 & TRN & \\
\hline CHEMBL3962174 & 1637364 & 5.0 & 5.9399 & TRN & \\
\hline CHEMBL3947909 & 1637364 & 5.9996 & 4.9466 & TRN & \\
\hline CHEMBL3907157 & 1637364 & 5.9996 & 4.6459 & TST & \\
\hline CHEMBL3890510 & 1637364 & 6.0 & 3.9311 & TST & \\
\hline CHEMBL3943382 & 1637364 & 3.699 & 5.4011 & TRN & \\
\hline CHEMBL3905390 & 1637364 & 5.9996 & 5.6091 & TST & \\
\hline CHEMBL3968845 & 1637364 & 5.0 & 4.6605 & TST & \\
\hline CHEMBL3910851 & 1637364 & 6.9957 & 6.218 & TRN & \\
\hline CHEMBL3986666 & 1637364 & 5.9996 & 5.8176 & TRN & \\
\hline CHEMBL3975590 & 1637364 & 3.699 & 4.4444 & TRN & \\
\hline
\end{tabular}


Supplemental Table S2.txt

\begin{tabular}{|c|c|c|c|c|}
\hline CHEMBL3979855 & 1637364 & 3.699 & 4.3204 & TRN \\
\hline CHEMBL3985317 & 1637364 & 5.0 & 4.0138 & TRN \\
\hline CHEMBL 3932053 & 1637364 & 3.699 & 3.8819 & TST \\
\hline CHEMBL 3948740 & 1637364 & 5.9996 & 4.7193 & TRN \\
\hline CHEMBL 3978769 & 1637364 & 5.0 & 5.4562 & TST \\
\hline CHEMBL 3922397 & 1637364 & 5.0 & 5.056 & TRN \\
\hline CHEMBL3919197 & 1637364 & 3.699 & 4.6758 & TST \\
\hline CHEMBL 3934870 & 1637364 & 3.3979 & 3.02699 & 99999999997 \\
\hline CHEMBL 3927193 & 1637364 & 3.3979 & 3.8052 & TST \\
\hline CHEMBL 3971820 & 1637364 & 3.3979 & 2.4834 & TST \\
\hline CHEMBL 3980355 & 1637364 & 3.3979 & 3.4593 & TST \\
\hline CHEMBL 3946358 & 1637364 & 3.3979 & 2.2029 & TST \\
\hline CHEMBL3955392 & 1637364 & 5.9996 & 5.3742 & TRN \\
\hline CHEMBL3926114 & 1637364 & 5.9996 & 5.7423 & TRN \\
\hline CHEMBL 3890752 & 1637364 & 3.699 & 5.3481 & TST \\
\hline CHEMBL3973363 & 1637364 & 5.0 & 4.686 & TRN \\
\hline CHEMBL3912990 & 1637364 & 5.0 & 4.397 & TRN \\
\hline CHEMBL 3966974 & 1637364 & 5.9996 & 5.9742 & TRN \\
\hline CHEMBL3938994 & 1637364 & 3.3979 & 3.5791 & TST \\
\hline CHEMBL 3980173 & 1637364 & 5.9996 & 4.6132 & TRN \\
\hline CHEMBL3891681 & 1637364 & 3.699 & 5.54 & TRN \\
\hline CHEMBL3959839 & 1637364 & 3.699 & 4.2662 & TRN \\
\hline CHEMBL 3895648 & 1637364 & 5.9996 & 5.4975 & TRN \\
\hline CHEMBL3937654 & 1637364 & 6.9957 & 6.1491 & TRN \\
\hline CHEMBL 3960239 & 1637364 & 5.0 & 4.6037 & TRN \\
\hline CHEMBL3913480 & 1637364 & 3.699 & 4.8182 & TRN \\
\hline CHEMBL3929075 & 1637364 & 5.9996 & 5.8863 & TRN \\
\hline CHEMBL3910325 & 1637364 & 3.699 & 4.7164 & TRN \\
\hline CHEMBL3902727 & 1637364 & 5.0 & 4.5514 & TST \\
\hline CHEMBL 3960602 & 1637364 & 5.9996 & 5.9427 & TRN \\
\hline CHEMBL3921023 & 1637364 & 5.9996 & 4.6101 & TRN \\
\hline CHEMBL 3963298 & 1637364 & 5.9996 & 6.3933 & TRN \\
\hline CHEMBL3902197 & 1637364 & 3.699 & 3.79100 & 00000000004 \\
\hline CHEMBL3896778 & 1637364 & 5.0 & 4.8283 & TRN \\
\hline CHEMBL3892258 & 1637364 & 5.9996 & 5.3817 & TRN \\
\hline CHEMBL3925527 & 1637364 & 5.9996 & 5.8135 & TRN \\
\hline CHEMBL 3936288 & 1637364 & 5.0 & 5.6317 & TRN \\
\hline CHEMBL3962652 & 1637364 & 5.0 & 3.9568 & TST \\
\hline CHEMBL 3943410 & 1637364 & 5.9996 & 5.2964 & TRN \\
\hline CHEMBL3891724 & 1637364 & 5.9996 & 5.0131 & TST \\
\hline CHEMBL3915327 & 1637364 & 3.699 & 4.7561 & TRN \\
\hline CHEMBL 3923632 & 1637364 & 5.0 & 5.9155 & TRN \\
\hline CHEMBL3916638 & 1637364 & 5.9996 & 4.5676 & TST \\
\hline CHEMBL3965164 & 1637364 & 5.9996 & 5.5254 & TRN \\
\hline CHEMBL3950383 & 1637364 & 3.3979 & 2.4978 & TST \\
\hline CHEMBL3923543 & 1637364 & 5.9996 & 5.5938 & TRN \\
\hline CHEMBL 3925818 & 1637364 & 5.0 & 5.7218 & TRN \\
\hline CHEMBL3915701 & 1637364 & 5.0 & 4.6124 & TRN \\
\hline
\end{tabular}


Supplemental Table S2.txt

\begin{tabular}{|c|c|c|c|c|c|}
\hline CHEMBL3922558 & 1637364 & 3.699 & 4.7247 & TST & \\
\hline CHEMBL3928965 & 1637364 & 5.9996 & \multicolumn{2}{|c|}{6.257999999999999} & TRN \\
\hline CHEMBL3929274 & 1637364 & 5.0 & 4.3547 & TRN & \\
\hline CHEMBL3910579 & 1637364 & 5.0 & 4.7201 & TRN & \\
\hline CHEMBL3943205 & 1637364 & 6.9957 & 6.4394 & TRN & \\
\hline CHEMBL3910540 & 1637364 & 5.9996 & 5.1272 & TRN & \\
\hline CHEMBL3909902 & 1637364 & 3.3979 & 3.5118 & TST & \\
\hline CHEMBL3959460 & 1637364 & 5.0 & 5.3105 & TRN & \\
\hline CHEMBL3970543 & 1637364 & 5.9996 & 5.9894 & TRN & \\
\hline CHEMBL3916819 & 1637364 & 3.699 & 4.2558 & TST & \\
\hline CHEMBL3901267 & 1637364 & 5.0 & 4.5473 & TRN & \\
\hline CHEMBL3952615 & 1637364 & 3.699 & 4.9616 & TRN & \\
\hline CHEMBL3966235 & 1637364 & 3.699 & 4.3587 & TRN & \\
\hline CHEMBL3949952 & 1637364 & 3.699 & 4.6676 & TRN & \\
\hline CHEMBL3956160 & 1637364 & 5.9996 & 5.7848 & TRN & \\
\hline CHEMBL3983821 & 1637364 & 5.0 & 4.8901 & TRN & \\
\hline CHEMBL3899273 & 1637364 & 3.699 & 5.3468 & TRN & \\
\hline CHEMBL3985432 & 1637364 & 5.0 & 4.5594 & TST & \\
\hline CHEMBL3963520 & 1637364 & 6.9957 & 6.4418 & TRN & \\
\hline CHEMBL3897143 & 1637364 & 5.0 & 5.7001 & TRN & \\
\hline CHEMBL3924960 & 1637364 & 5.0 & 4.8531 & TRN & \\
\hline CHEMBL3938367 & 1637364 & 3.3979 & 3.7956 & TST & \\
\hline CHEMBL3958159 & 1637364 & 5.9996 & \multicolumn{2}{|c|}{6.0089999999999995} & TRN \\
\hline CHEMBL3895763 & 1637364 & 5.9996 & 6.0538 & TRN & \\
\hline CHEMBL1625915 & 1637364 & 3.699 & 3.7273 & TRN & \\
\hline CHEMBL3977275 & 1637364 & 3.699 & 4.3944 & TRN & \\
\hline CHEMBL 3905430 & 1637364 & 5.0 & 4.4204 & TRN & \\
\hline CHEMBL3970115 & 1637364 & 3.699 & 4.6843 & TRN & \\
\hline CHEMBL3927051 & 1637364 & 6.0 & 5.2377 & TRN & \\
\hline CHEMBL3926039 & 1637364 & 3.699 & 4.1334 & TRN & \\
\hline CHEMBL3909796 & 1637364 & 5.9996 & 5.9468 & TRN & \\
\hline CHEMBL3941649 & 1637364 & 5.0 & 4.4116 & TRN & \\
\hline CHEMBL 3982868 & 1637364 & 5.0 & 2.6887 & TST & \\
\hline CHEMBL3955377 & 1637364 & 3.3979 & 3.6861 & TST & \\
\hline CHEMBL 3892082 & 1637364 & 3.699 & 4.3286 & TST & \\
\hline CHEMBL3979171 & 1637364 & 5.9996 & 5.854 & TST & \\
\hline CHEMBL3974877 & 1637364 & 3.699 & 4.8307 & TRN & \\
\hline CHEMBL3896996 & 1637364 & 5.0 & 4.0574 & TRN & \\
\hline CHEMBL3909355 & 1637364 & 5.0 & 5.0148 & TRN & \\
\hline CHEMBL3946966 & 1637364 & 3.699 & 3.9649 & TRN & \\
\hline CHEMBL3958390 & 1637364 & 5.0 & 4.5226 & TRN & \\
\hline CHEMBL3913886 & 1637364 & 3.699 & 3.8314 & TRN & \\
\hline CHEMBL3891026 & 1637364 & 3.699 & 4.2563 & TRN & \\
\hline CHEMBL3897685 & 1637364 & 3.699 & 4.3 & TRN & \\
\hline CHEMBL 3889794 & 1637364 & 5.0 & 3.9344 & TST & \\
\hline CHEMBL3966491 & 1637364 & 5.9996 & 5.9287 & TRN & \\
\hline CHEMBL3948117 & 1637364 & 5.0 & 5.2922 & TST & \\
\hline CHEMBL3940292 & 1637364 & 5.9996 & 5.3905 & TRN & \\
\hline
\end{tabular}

Page 22926 
Supplemental Table S2.txt

\begin{tabular}{|c|c|c|c|c|c|}
\hline CHEMBL3907356 & 1637364 & 5.9996 & 5.4568 & TRN & \\
\hline CHEMBL3917581 & 1637364 & 5.0 & 5.5588 & TRN & \\
\hline CHEMBL3975063 & 1637364 & 5.0 & 5.4873 & TST & \\
\hline CHEMBL3944765 & 1637364 & 3.3979 & 2.3165 & TST & \\
\hline CHEMBL3927355 & 1637364 & 5.9996 & 6.0559 & TRN & \\
\hline CHEMBL3907657 & 1637364 & 3.699 & 3.7172 & TST & \\
\hline CHEMBL3969694 & 1637364 & 5.0 & 4.1874 & TST & \\
\hline CHEMBL3893934 & 1637364 & 5.9996 & 6.095 & TRN & \\
\hline CHEMBL3953561 & 1637364 & 5.9996 & \multicolumn{2}{|c|}{5.3629999999999995} & TRN \\
\hline CHEMBL3985573 & 1637364 & 3.699 & 4.3497 & TRN & \\
\hline CHEMBL3904336 & 1637364 & 5.0 & 4.9209 & TRN & \\
\hline CHEMBL3979843 & 1637364 & 5.0 & 5.0984 & TRN & \\
\hline CHEMBL3891414 & 1637364 & 5.0 & 4.752 & TRN & \\
\hline CHEMBL3955389 & 1637364 & 5.0 & 4.5494 & TRN & \\
\hline CHEMBL3901231 & 1637364 & 5.9996 & 6.4202 & TRN & \\
\hline CHEMBL3911947 & 1637364 & 5.0 & 6.0688 & TRN & \\
\hline CHEMBL3941290 & 1637364 & 5.9996 & 5.2682 & TRN & \\
\hline CHEMBL3916066 & 1637364 & 5.0 & 4.4351 & TRN & \\
\hline CHEMBL3898318 & 1637364 & 6.9957 & 6.0723 & TRN & \\
\hline CHEMBL3982286 & 1637364 & 5.0 & 4.1484 & TRN & \\
\hline CHEMBL3893221 & 1637364 & 5.0 & 5.56 & TRN & \\
\hline CHEMBL3899100 & 1637364 & 5.9996 & 6.055 & TRN & \\
\hline CHEMBL3921352 & 1637364 & 5.9996 & 5.0443 & TRN & \\
\hline CHEMBL3935766 & 1637364 & 3.699 & 4.3237 & TRN & \\
\hline CHEMBL 3916222 & 1637364 & 5.0 & \multicolumn{2}{|c|}{5.053999999999999} & TRN \\
\hline CHEMBL 3977569 & 1637364 & 5.0 & 5.7314 & TRN & \\
\hline CHEMBL3956209 & 1637364 & 5.9996 & 4.9711 & TRN & \\
\hline CHEMBL3924231 & 1637364 & 5.9996 & 5.6841 & TRN & \\
\hline CHEMBL 3890412 & 1637364 & 3.699 & 4.3354 & TRN & \\
\hline CHEMBL3940342 & 1637364 & 5.0 & 4.4647 & TRN & \\
\hline CHEMBL 3982230 & 1637364 & 3.699 & 4.3618 & TRN & \\
\hline CHEMBL3982639 & 1637364 & 5.0 & \multicolumn{2}{|c|}{5.122000000000001} & TRN \\
\hline CHEMBL3906591 & 1637364 & 5.9996 & 5.3911 & TRN & \\
\hline CHEMBL3957350 & 1637364 & 3.699 & 4.246 & TST & \\
\hline CHEMBL3899907 & 1637364 & 5.9996 & 5.4467 & TRN & \\
\hline CHEMBL3910665 & 1637364 & 3.699 & 4.2224 & TRN & \\
\hline CHEMBL 3941426 & 1637364 & 5.9996 & 4.5274 & TST & \\
\hline CHEMBL3947051 & 1637364 & 3.3979 & 3.7439 & TST & \\
\hline CHEMBL3965210 & 1637364 & 5.9996 & 6.2423 & TRN & \\
\hline CHEMBL3959156 & 1637364 & 3.699 & 4.2797 & TRN & \\
\hline CHEMBL3956921 & 1637364 & 3.3979 & 2.5513 & TST & \\
\hline CHEMBL 3893239 & 1637364 & 3.699 & 3.7933 & TST & \\
\hline CHEMBL 3980343 & 1637364 & 5.9996 & 5.4566 & TRN & \\
\hline CHEMBL 3938821 & 1637364 & 3.699 & 3.9724 & TST & \\
\hline CHEMBL 3926304 & 1637364 & 3.699 & 5.1284 & TRN & \\
\hline CHEMBL 3890473 & 1637364 & 3.699 & 3.1248 & TRN & \\
\hline CHEMBL3913586 & 1637364 & 6.0 & 5.1499 & TRN & \\
\hline \multirow[t]{2}{*}{ CHEMBL1626013 } & 1637364 & 3.3979 & \multicolumn{2}{|c|}{3.4810000000000003} & TST \\
\hline & & & & 22927 & \\
\hline
\end{tabular}


Supplemental Table S2.txt

\begin{tabular}{|c|c|c|c|c|}
\hline CHEMBL3970011 & 1637364 & 5.9996 & 6.0744 & TRN \\
\hline CHEMBL3918772 & 1637364 & 5.0 & 5.0917 & TRN \\
\hline CHEMBL3962471 & 1637364 & 3.699 & 4.3745 & TRN \\
\hline CHEMBL3920305 & 1637364 & 5.0 & 5.6681 & TST \\
\hline CHEMBL3906316 & 1637364 & 3.699 & 3.6978 & TRN \\
\hline CHEMBL3966398 & 1637364 & 3.699 & 4.7342 & TRN \\
\hline CHEMBL3965311 & 1637364 & 5.9996 & 4.8945 & TRN \\
\hline CHEMBL3919677 & 1637364 & 6.0 & 5.1047 & TRN \\
\hline CHEMBL3954212 & 1637364 & 3.699 & 3.8192 & TST \\
\hline CHEMBL3935690 & 1637364 & 5.9996 & 5.2757 & TRN \\
\hline CHEMBL3924519 & 1637364 & 3.699 & 4.5557 & TRN \\
\hline CHEMBL3889999 & 1637364 & 3.699 & 4.34399 & 9999999999 \\
\hline CHEMBL 3943231 & 1637364 & 3.699 & 4.2473 & TRN \\
\hline CHEMBL3983062 & 1637364 & 3.699 & 3.7442 & TRN \\
\hline CHEMBL3944433 & 1637364 & 3.3979 & 3.0961 & TST \\
\hline CHEMBL 3962444 & 1637364 & 5.9996 & 6.5661 & TRN \\
\hline CHEMBL3935211 & 1637364 & 3.3979 & 3.4191 & TST \\
\hline CHEMBL 3956242 & 1637364 & 6.9957 & 6.7221 & TRN \\
\hline CHEMBL3976295 & 1637364 & 5.9996 & 6.0578 & TRN \\
\hline CHEMBL2419599 & 1528666 & 7.6778 & 7.394 & TRN \\
\hline CHEMBL3699922 & 1528666 & 7.699 & 7.5333 & TRN \\
\hline CHEMBL 2419609 & 1528666 & 7.6162 & 7.6188 & TRN \\
\hline CHEMBL3699896 & 1528666 & 7.7447 & 8.0926 & TRN \\
\hline CHEMBL3699918 & 1528666 & 8.0506 & 8.1244 & TRN \\
\hline CHEMBL3699898 & 1528666 & 7.0969 & 7.2371 & TRN \\
\hline CHEMBL3699826 & 1528666 & 7.2076 & 6.9474 & TRN \\
\hline CHEMBL3699929 & 1528666 & 8.1871 & 8.0283 & TRN \\
\hline CHEMBL3699889 & 1528666 & 7.7696 & 7.9327 & TRN \\
\hline CHEMBL3699901 & 1528666 & 7.3372 & 7.4181 & TRN \\
\hline CHEMBL3699893 & 1528666 & 8.2366 & 8.0046 & TRN \\
\hline CHEMBL3699862 & 1528666 & 7.1739 & 7.2009 & TRN \\
\hline CHEMBL3699869 & 1528666 & 7.5376 & 7.9506 & TST \\
\hline CHEMBL2419606 & 1528666 & 7.301 & 7.8433 & TST \\
\hline CHEMBL 3699830 & 1528666 & 7.1079 & 7.5249 & TRN \\
\hline CHEMBL 3699828 & 1528666 & 7.1367 & 7.2447 & TRN \\
\hline CHEMBL3699858 & 1528666 & 6.8125 & 6.7356 & TST \\
\hline CHEMBL 3699884 & 1528666 & 7.3665 & 7.1611 & TRN \\
\hline CHEMBL2419591 & 1528666 & 7.6383 & 7.5396 & TRN \\
\hline CHEMBL3699876 & 1528666 & 7.5229 & 7.4825 & TRN \\
\hline CHEMBL3699835 & 1528666 & 6.1884 & 6.2307 & TST \\
\hline CHEMBL2419592 & 1528666 & 7.5686 & 7.4743 & TRN \\
\hline CHEMBL3699905 & 1528666 & 6.6799 & 6.8541 & TRN \\
\hline CHEMBL2419594 & 1528666 & 7.7212 & 7.6327 & TRN \\
\hline CHEMBL3699891 & 1528666 & 6.6556 & \multicolumn{2}{|c|}{6.928999999999999} \\
\hline CHEMBL 2419589 & 1528666 & 8.1308 & 7.932 & TRN \\
\hline CHEMBL3699887 & 1528666 & 6.7959 & 7.0742 & TRN \\
\hline CHEMBL3699912 & 1528666 & 6.6596 & 6.6994 & TRN \\
\hline CHEMBL 3699879 & 1528666 & 7.3279 & 7.1136 & TRN \\
\hline
\end{tabular}

Page 22928 
Supplemental Table S2.txt

\begin{tabular}{|c|c|c|c|c|}
\hline CHEMBL3699899 & 1528666 & 6.8097 & 6.6094 & TRN \\
\hline CHEMBL3699823 & 1528666 & 6.3799 & 6.2761 & TRN \\
\hline CHEMBL3699925 & 1528666 & 7.6198 & 7.9004 & TRN \\
\hline CHEMBL 3699900 & 1528666 & 6.6655 & 6.9732 & TRN \\
\hline CHEMBL 2419595 & 1528666 & 7.1079 & \multicolumn{2}{|c|}{7.077999999999999} \\
\hline CHEMBL 3699927 & 1528666 & 7.7696 & 7.8173 & TRN \\
\hline CHEMBL3699919 & 1528666 & 6.295 & 6.7164 & TRN \\
\hline CHEMBL 3699864 & 1528666 & 6.4389 & \multicolumn{2}{|c|}{6.712999999999999} \\
\hline CHEMBL 3699861 & 1528666 & 6.3125 & 6.8 & TST \\
\hline CHEMBL3699892 & 1528666 & 6.7328 & 6.9109 & TRN \\
\hline CHEMBL 2419596 & 1528666 & 7.699 & 7.5592 & TRN \\
\hline CHEMBL3699854 & 1528666 & 6.8013 & 6.9763 & TRN \\
\hline CHEMBL3699908 & 1528666 & 7.1871 & 7.0649 & TRN \\
\hline CHEMBL 3699865 & 1528666 & 6.4828 & 6.8405 & TST \\
\hline CHEMBL3699850 & 1528666 & 6.1624 & 6.2822 & TRN \\
\hline CHEMBL 3699843 & 1528666 & 7.1427 & 7.5302 & TST \\
\hline CHEMBL3699836 & 1528666 & 6.3947 & 6.1485 & TST \\
\hline CHEMBL3699924 & 1528666 & 7.7696 & 7.8036 & TRN \\
\hline CHEMBL2419598 & 1528666 & 8.2518 & 7.9041 & TRN \\
\hline CHEMBL3699930 & 1528666 & 8.0458 & 8.0135 & TRN \\
\hline CHEMBL3699894 & 1528666 & 7.5528 & 7.4286 & TRN \\
\hline CHEMBL3699848 & 1528666 & 5.9031 & 5.7825 & TRN \\
\hline CHEMBL3699897 & 1528666 & 7.1024 & 7.1321 & TRN \\
\hline CHEMBL3699860 & 1528666 & 6.9355 & 7.0459 & TST \\
\hline CHEMBL 3699831 & 1528666 & 7.3665 & 7.2463 & TRN \\
\hline CHEMBL3699852 & 1528666 & 6.9172 & 7.0144 & TRN \\
\hline CHEMBL3699923 & 1528666 & 6.4789 & 6.5833 & TRN \\
\hline CHEMBL3699880 & 1528666 & 7.6778 & 7.5024 & TRN \\
\hline CHEMBL3699870 & 1528666 & 7.585 & 7.324 & TST \\
\hline CHEMBL3699909 & 1528666 & 6.8861 & 6.9095 & TRN \\
\hline CHEMBL3699914 & 1528666 & 8.2147 & 7.9456 & TRN \\
\hline CHEMBL3699873 & 1528666 & 7.6778 & 7.8679 & TST \\
\hline CHEMBL3699845 & 1528666 & 5.8297 & 5.5027 & TST \\
\hline CHEMBL 3699885 & 1528666 & 7.0269 & 7.0958 & TRN \\
\hline CHEMBL 3699920 & 1528666 & 5.317 & 5.82700 & 0000000001 \\
\hline CHEMBL3699867 & 1528666 & 6.7852 & 6.3765 & TST \\
\hline CHEMBL3699926 & 1528666 & 7.3279 & 7.4573 & TRN \\
\hline CHEMBL3699829 & 1528666 & 7.0506 & 7.1594 & TRN \\
\hline CHEMBL3699895 & 1528666 & 7.3188 & 7.3279 & TRN \\
\hline CHEMBL 3699868 & 1528666 & 7.1675 & 7.5292 & TST \\
\hline CHEMBL3699917 & 1528666 & 7.5686 & 7.7018 & TRN \\
\hline CHEMBL 2419593 & 1528666 & 7.7447 & 7.6404 & TRN \\
\hline CHEMBL3699834 & 1528666 & 7.2076 & 6.7995 & TRN \\
\hline CHEMBL3699913 & 1528666 & 8.1249 & 8.0563 & TRN \\
\hline CHEMBL3699827 & 1528666 & 6.7959 & 6.7339 & TRN \\
\hline CHEMBL3699825 & 1528666 & 7.6383 & 7.6095 & TRN \\
\hline CHEMBL 3699844 & 1528666 & 6.1824 & 6.04 & TRN \\
\hline CHEMBL3699875 & 1528666 & 8.0706 & 7.6477 & TRN \\
\hline
\end{tabular}

Page 22929 
Supplemental Table S2.txt

\begin{tabular}{|c|c|c|c|c|c|}
\hline CHEMBL 3699883 & 1528666 & 6.9101 & 7.0769 & TRN & \\
\hline CHEMBL 3699871 & 1528666 & 8.1805 & 7.8741 & TST & \\
\hline CHEMBL2419600 & 1528666 & 8.2518 & 8.227 & TRN & \\
\hline CHEMBL3699915 & 1528666 & 7.8239 & \multicolumn{2}{|c|}{7.8229999999999995} & TRN \\
\hline CHEMBL 3699833 & 1528666 & 6.5702 & 6.1514 & TRN & \\
\hline CHEMBL 3699878 & 1528666 & 7.0555 & 7.2202 & TRN & \\
\hline CHEMBL 3699903 & 1528666 & 7.7696 & 7.9657 & TRN & \\
\hline CHEMBL 3699851 & 1528666 & 6.5867 & 6.746 & TST & \\
\hline CHEMBL 3699849 & 1528666 & 6.2069 & 5.945 & TRN & \\
\hline CHEMBL3699906 & 1528666 & 6.6198 & 6.5626 & TRN & \\
\hline CHEMBL 2419597 & 1528666 & 7.8539 & 7.8092 & TRN & \\
\hline CHEMBL 3699841 & 1528666 & 6.6003 & 6.6994 & TST & \\
\hline CHEMBL 3699866 & 1528666 & 6.1831 & 6.8007 & TST & \\
\hline CHEMBL 3699877 & 1528666 & 7.8239 & 7.8328 & TRN & \\
\hline CHEMBL3699910 & 1528666 & 6.9788 & 7.1759 & TRN & \\
\hline CHEMBL 2419590 & 1528666 & 7.1079 & 6.8543 & TRN & \\
\hline CHEMBL 3699840 & 1528666 & 6.8827 & 6.7863 & TST & \\
\hline CHEMBL 3699824 & 1528666 & 5.4067 & 5.4902 & TRN & \\
\hline CHEMBL 3699832 & 1528666 & 6.644 & 6.6318 & TRN & \\
\hline CHEMBL 3699928 & 1528666 & 6.3063 & 6.3526 & TRN & \\
\hline CHEMBL3699863 & 1528666 & 6.52 & 6.5227 & TST & \\
\hline CHEMBL 3699888 & 1528666 & 6.5918 & 6.4891 & TRN & \\
\hline CHEMBL 3699882 & 1528666 & 6.8268 & 7.0296 & TRN & \\
\hline CHEMBL 3699842 & 1528666 & 6.9281 & 6.9003 & TST & \\
\hline CHEMBL 3639987 & 1528666 & 6.7878 & 6.7593 & TRN & \\
\hline CHEMBL3699853 & 1528666 & 6.5287 & 6.6605 & TST & \\
\hline CHEMBL 3699859 & 1528666 & 6.2815 & 6.5569 & TST & \\
\hline CHEMBL 3699856 & 1528666 & 7.0088 & 7.2745 & TRN & \\
\hline CHEMBL 3699855 & 1528666 & 7.4815 & \multicolumn{2}{|c|}{7.513999999999999} & TRN \\
\hline CHEMBL 3699921 & 1528666 & 7.5376 & 7.8035 & TRN & \\
\hline CHEMBL3699904 & 1528666 & 6.4647 & 6.4293 & TRN & \\
\hline CHEMBL 3699911 & 1528666 & 7.2076 & 7.3041 & TRN & \\
\hline CHEMBL3699839 & 1528666 & 5.6904 & 5.6798 & TST & \\
\hline CHEMBL 3699907 & 1528666 & 6.6126 & 6.6902 & TRN & \\
\hline CHEMBL 3699846 & 1528666 & 6.4737 & 6.3699 & TRN & \\
\hline CHEMBL3699838 & 1528666 & 7.4559 & 7.194 & TST & \\
\hline CHEMBL 3699881 & 1528666 & 8.1308 & 8.0033 & TST & \\
\hline CHEMBL 3699857 & 1528666 & 6.7471 & 6.45 & TST & \\
\hline CHEMBL 3699916 & 1528666 & 8.4685 & 8.3754 & TRN & \\
\hline CHEMBL 2419608 & 1528666 & 7.5686 & 7.3495 & TST & \\
\hline CHEMBL3699890 & 1528666 & 5.8729 & 6.0887 & TRN & \\
\hline CHEMBL3699902 & 1528666 & 6.7122 & 6.7325 & TRN & \\
\hline CHEMBL3699837 & 1528666 & 7.0555 & 6.6425 & TST & \\
\hline CHEMBL3699872 & 1528666 & 7.4437 & 7.5233 & TRN & \\
\hline CHEMBL 3699847 & 1528666 & 6.2083 & 6.2217 & TST & \\
\hline CHEMBL3699874 & 1528666 & 7.5229 & 7.4405 & TRN & \\
\hline CHEMBL3699886 & 1528666 & 8.0757 & 7.87 & TRN & \\
\hline CHEMBL3907042 & 1639645 & 7.6021 & 7.7367 & TRN & \\
\hline
\end{tabular}

Page 22930 
Supplemental Table S2.txt

\begin{tabular}{|c|c|c|c|c|c|}
\hline CHEMBL 3898863 & 1639645 & 7.6021 & 7.2354 & TRN & \\
\hline CHEMBL3933134 & 1639645 & 7.6021 & 7.0389 & TST & \\
\hline CHEMBL3909461 & 1639645 & 7.6021 & 7.7 & TRN & \\
\hline CHEMBL3903866 & 1639645 & 7.6021 & 7.6148 & TST & \\
\hline CHEMBL3951002 & 1639645 & 7.6021 & 7.7436 & TRN & \\
\hline CHEMBL3898780 & 1639645 & 6.6021 & 7.1221 & TRN & \\
\hline CHEMBL3946116 & 1639645 & 6.6021 & 7.1824 & TRN & \\
\hline CHEMBL 3914814 & 1639645 & 7.6021 & 7.2291 & TST & \\
\hline CHEMBL3910989 & 1639645 & 7.6021 & 7.1668 & TRN & \\
\hline CHEMBL3927527 & 1639645 & 7.6021 & 7.7461 & TRN & \\
\hline CHEMBL3948809 & 1639645 & 7.6021 & 7.4844 & TRN & \\
\hline CHEMBL3902796 & 1639645 & 7.6021 & 7.584 & TRN & \\
\hline CHEMBL3898691 & 1639645 & 6.6021 & 6.8613 & TRN & \\
\hline CHEMBL3930437 & 1639645 & 7.6021 & 7.1542 & TST & \\
\hline CHEMBL3984255 & 1639645 & 7.6021 & 7.7428 & TST & \\
\hline CHEMBL466397 & 1639645 & 7.6021 & 7.6905 & TST & \\
\hline CHEMBL507714 & 1639645 & 7.6021 & 7.2078 & TRN & \\
\hline CHEMBL3955439 & 1639645 & 7.6021 & 7.5422 & TRN & \\
\hline CHEMBL3976571 & 1639645 & 7.6021 & 7.4806 & TRN & \\
\hline CHEMBL3975048 & 1639645 & 5.0 & 6.4977 & TST & \\
\hline CHEMBL3943489 & 1639645 & 7.6021 & 7.3297 & TRN & \\
\hline CHEMBL3972228 & 1639645 & 7.6021 & 7.7411 & TRN & \\
\hline CHEMBL 3908084 & 1639645 & 7.6021 & 7.7693 & TST & \\
\hline CHEMBL3905410 & 1639645 & 7.6021 & 7.2812 & TRN & \\
\hline CHEMBL3918216 & 1639645 & 6.6021 & 6.8742 & TRN & \\
\hline CHEMBL3968197 & 1639645 & 6.6021 & 7.0872 & TST & \\
\hline CHEMBL3953421 & 1639645 & 7.6021 & 7.7415 & TRN & \\
\hline CHEMBL3936093 & 1639645 & 7.6021 & 7.0912 & TRN & \\
\hline CHEMBL3920487 & 1639645 & 6.6021 & 7.0515 & TRN & \\
\hline CHEMBL 3894234 & 1639645 & 7.6021 & 7.4291 & TRN & \\
\hline CHEMBL3954082 & 1639645 & 7.6021 & 7.5854 & TRN & \\
\hline CHEMBL3899043 & 1639645 & 6.6021 & 6.9666 & TRN & \\
\hline CHEMBL 3937247 & 1639645 & 7.6021 & 7.5344 & TRN & \\
\hline CHEMBL3930103 & 1639645 & 7.6021 & 7.7513 & TRN & \\
\hline CHEMBL3930497 & 1639645 & 7.6021 & 7.1092 & TRN & \\
\hline CHEMBL3920947 & 1639645 & 7.6021 & 7.0651 & TRN & \\
\hline CHEMBL3968247 & 1639645 & 6.6021 & 6.7648 & TRN & \\
\hline CHEMBL3934152 & 1639645 & 7.6021 & 7.4276 & TRN & \\
\hline CHEMBL3969290 & 1639645 & 7.6021 & 7.5361 & TRN & \\
\hline CHEMBL3950746 & 1639645 & 7.6021 & 7.76200 & 00000000005 & TRN \\
\hline CHEMBL3961740 & 1639645 & 6.6021 & 7.1803 & TRN & \\
\hline CHEMBL3953680 & 1639645 & 7.6021 & 7.5591 & TRN & \\
\hline CHEMBL3971235 & 1639645 & 7.6021 & 7.505 & TRN & \\
\hline CHEMBL3915699 & 1639645 & 7.6021 & 7.8318 & TRN & \\
\hline CHEMBL3921580 & 1639645 & 6.6021 & 7.0076 & TRN & \\
\hline CHEMBL3927744 & 1639645 & 7.6021 & 7.178 & TRN & \\
\hline CHEMBL3951885 & 1639645 & 7.6021 & 7.7711 & TRN & \\
\hline CHEMBL3934556 & 1639645 & 7.6021 & 7.2798 & TRN & \\
\hline
\end{tabular}

Page 22931 
Supplemental Table S2.txt

\begin{tabular}{|c|c|c|c|c|}
\hline CHEMBL3957456 & 1639645 & 7.6021 & 7.5231 & TRN \\
\hline CHEMBL3907857 & 1639645 & 6.6021 & 7.1987 & TST \\
\hline CHEMBL3915154 & 1639645 & 7.6021 & 7.4146 & TRN \\
\hline CHEMBL 3896361 & 1639645 & 7.6021 & 7.3068 & TRN \\
\hline CHEMBL3913169 & 1639645 & 6.6021 & 6.6021 & TRN \\
\hline CHEMBL3980159 & 1639645 & 7.6021 & 7.0695 & TST \\
\hline CHEMBL 3973742 & 1639645 & 7.6021 & 7.7199 & TRN \\
\hline CHEMBL3968940 & 1639645 & 7.6021 & 7.231 & TRN \\
\hline CHEMBL3984698 & 1639645 & 6.6021 & 7.0156 & TST \\
\hline CHEMBL3986972 & 1639645 & 7.6021 & 7.7528 & TST \\
\hline CHEMBL3911054 & 1639645 & 6.6021 & 6.9114 & TRN \\
\hline CHEMBL 3982401 & 1639645 & 7.6021 & 7.7591 & TRN \\
\hline CHEMBL 3892197 & 1639645 & 6.6021 & 7.1882 & TST \\
\hline CHEMBL447639 & 1639645 & 7.6021 & 7.1062 & TRN \\
\hline CHEMBL3950255 & 1639645 & 7.6021 & 7.249 & TRN \\
\hline CHEMBL3979973 & 1639645 & 7.6021 & 7.4852 & TRN \\
\hline CHEMBL3952960 & 1639645 & 7.6021 & 7.2999 & TRN \\
\hline CHEMBL3979137 & 1639645 & 7.6021 & 7.1327 & TRN \\
\hline CHEMBL3951670 & 1639645 & 7.6021 & 7.2819 & TRN \\
\hline CHEMBL3907119 & 1639645 & 7.6021 & 7.0939 & TRN \\
\hline CHEMBL3949909 & 1639645 & 7.6021 & 7.7819 & TRN \\
\hline CHEMBL3904450 & 1639645 & 7.6021 & 7.2344 & TRN \\
\hline CHEMBL3893349 & 1639645 & 6.6021 & 6.7799 & TST \\
\hline CHEMBL3941932 & 1639645 & 7.6021 & 7.7739 & TRN \\
\hline CHEMBL 3934864 & 1639645 & 6.6021 & \multicolumn{2}{|c|}{6.9670000000000005} \\
\hline CHEMBL 3899525 & 1639645 & 7.6021 & 6.7279 & TRN \\
\hline CHEMBL 3981549 & 1639645 & 7.6021 & 7.2832 & TRN \\
\hline CHEMBL 3898274 & 1639645 & 7.6021 & 7.4224 & TST \\
\hline CHEMBL 3945814 & 1639645 & 7.6021 & 7.4947 & TRN \\
\hline CHEMBL 3896056 & 1639645 & 5.0 & 6.4755 & TST \\
\hline CHEMBL3915202 & 1639645 & 7.6021 & 7.478 & TRN \\
\hline CHEMBL3974124 & 1639645 & 6.6021 & 7.1841 & TST \\
\hline CHEMBL3957736 & 1639645 & 6.6021 & 6.8612 & TRN \\
\hline CHEMBL3919927 & 1639645 & 7.6021 & 7.7291 & TRN \\
\hline CHEMBL 3937417 & 1639645 & 7.6021 & 7.5015 & TRN \\
\hline CHEMBL3952208 & 1639645 & 6.6021 & 7.4711 & TRN \\
\hline CHEMBL3951411 & 1639645 & 7.6021 & 7.5272 & TRN \\
\hline CHEMBL3967147 & 1639645 & 7.6021 & 7.7411 & TST \\
\hline CHEMBL 3918940 & 1639645 & 7.6021 & 7.7154 & TST \\
\hline CHEMBL506862 & 1639645 & 7.6021 & 7.0508 & TRN \\
\hline CHEMBL3956400 & 1639645 & 7.6021 & 7.1832 & TST \\
\hline CHEMBL3970170 & 1639645 & 7.6021 & 7.7374 & TRN \\
\hline CHEMBL3918624 & 1639645 & 7.6021 & 7.1509 & TRN \\
\hline CHEMBL 3983732 & 1639645 & 6.6021 & 7.2114 & TST \\
\hline CHEMBL3915209 & 1639645 & 7.6021 & 7.1305 & TRN \\
\hline CHEMBL3972006 & 1639645 & 7.6021 & 7.7767 & TST \\
\hline CHEMBL3937659 & 1639645 & 6.6021 & 7.0178 & TRN \\
\hline CHEMBL 3896094 & 1639645 & 7.6021 & 7.3602 & TRN \\
\hline
\end{tabular}

Page 22932 
Supplemental Table S2.txt

\begin{tabular}{|c|c|c|c|c|c|}
\hline CHEMBL3896003 & 1639645 & 5.0 & 6.244 & TRN & \\
\hline CHEMBL3908294 & 1639645 & 6.6021 & 6.9261 & TRN & \\
\hline CHEMBL3917108 & 1639645 & 6.6021 & 6.8518 & TRN & \\
\hline CHEMBL3930141 & 1639645 & 7.6021 & 7.4782 & TRN & \\
\hline CHEMBL3918852 & 1639645 & 6.6021 & 7.0504 & TRN & \\
\hline CHEMBL3950296 & 1639645 & 7.6021 & 7.3962 & TRN & \\
\hline CHEMBL3971673 & 1639645 & 7.6021 & 7.5417 & TRN & \\
\hline CHEMBL3913651 & 1639645 & 7.6021 & 7.5388 & TRN & \\
\hline CHEMBL3967372 & 1639645 & 7.6021 & 7.7779 & TRN & \\
\hline CHEMBL 3950784 & 1639645 & 7.6021 & 7.7295 & TRN & \\
\hline CHEMBL3938801 & 1639645 & 7.6021 & 7.5307 & TRN & \\
\hline CHEMBL3912500 & 1639645 & 7.6021 & 7.697 & TRN & \\
\hline CHEMBL3910640 & 1639645 & 7.6021 & 7.5196 & TRN & \\
\hline CHEMBL3948450 & 1639645 & 7.6021 & 7.5288 & TRN & \\
\hline CHEMBL 3901948 & 1639645 & 7.6021 & 7.4914 & TRN & \\
\hline CHEMBL3976565 & 1639645 & 7.6021 & 7.7609 & TRN & \\
\hline CHEMBL3953464 & 1639645 & 7.6021 & \multicolumn{2}{|c|}{7.593999999999999} & TRN \\
\hline CHEMBL3913225 & 1639645 & 5.0 & 7.2791 & TRN & \\
\hline CHEMBL3905860 & 1639645 & 7.6021 & 7.756 & TRN & \\
\hline CHEMBL3986506 & 1639645 & 6.6021 & 7.0182 & TST & \\
\hline CHEMBL3890964 & 1639645 & 7.6021 & 7.7378 & TST & \\
\hline CHEMBL3891415 & 1639645 & 7.6021 & 7.3063 & TST & \\
\hline CHEMBL3934156 & 1639645 & 7.6021 & 7.5285 & TST & \\
\hline CHEMBL3896493 & 1639645 & 7.6021 & 7.7139 & TST & \\
\hline CHEMBL 3940222 & 1639645 & 6.6021 & 6.3038 & TRN & \\
\hline CHEMBL 3944498 & 1639645 & 6.6021 & 6.6959 & TRN & \\
\hline CHEMBL3923001 & 1639645 & 7.6021 & 7.4912 & TRN & \\
\hline CHEMBL3949038 & 1639645 & 7.6021 & 7.6832 & TST & \\
\hline CHEMBL3942170 & 1639645 & 6.6021 & 7.1427 & TRN & \\
\hline CHEMBL3912542 & 1639645 & 7.6021 & 7.4617 & TRN & \\
\hline CHEMBL3969511 & 1639645 & 7.6021 & 7.3184 & TST & \\
\hline CHEMBL3957642 & 1639645 & 6.6021 & 7.0585 & TST & \\
\hline CHEMBL3896138 & 1639645 & 7.6021 & 7.7923 & TRN & \\
\hline CHEMBL3972920 & 1639645 & 7.6021 & 7.7361 & TST & \\
\hline CHEMBL 3894895 & 1639645 & 7.6021 & 7.6438 & TRN & \\
\hline CHEMBL3946368 & 1639645 & 7.6021 & 7.7596 & TRN & \\
\hline CHEMBL 3937303 & 1639645 & 7.6021 & 7.6481 & TST & \\
\hline CHEMBL3927429 & 1639645 & 7.6021 & 7.1873 & TRN & \\
\hline CHEMBL3889680 & 1639645 & 5.0 & 6.7757 & TST & \\
\hline CHEMBL3947685 & 1639645 & 7.6021 & 7.2075 & TRN & \\
\hline CHEMBL3973792 & 1639645 & 7.6021 & 7.581 & TRN & \\
\hline CHEMBL3950325 & 1639645 & 7.6021 & 7.5099 & TRN & \\
\hline CHEMBL3963196 & 1639645 & 7.6021 & 7.7938 & TST & \\
\hline CHEMBL2335657 & 943500 & 5.1421 & 4.8855 & TRN & \\
\hline CHEMBL2336122 & 943500 & 4.284 & 5.1791 & TRN & \\
\hline CHEMBL 2336588 & 943500 & 4.6882 & 5.1229 & TRN & \\
\hline CHEMBL 2335650 & 943500 & 5.1029 & 5.1297 & TRN & \\
\hline CHEMBL 2335670 & 943500 & 5.0773 & 5.3502 & TRN & \\
\hline
\end{tabular}

Page 22933 


\begin{tabular}{|c|c|c|c|c|c|}
\hline & & \multicolumn{4}{|c|}{ Supplemental Table S2.txt } \\
\hline CHEMBL 2335666 & 943500 & 4.8996 & 4.8748 & TRN & \\
\hline CHEMBL 2336127 & 943500 & 5.3215 & 5.3975 & TRN & \\
\hline CHEMBL 2336126 & 943500 & 4.9586 & 5.2466 & TRN & \\
\hline CHEMBL 2336128 & 943500 & 5.5317 & 5.4156 & TRN & \\
\hline CHEMBL 2336117 & 943500 & 5.4012 & 5.215 & TRN & \\
\hline CHEMBL 2335652 & 943500 & 4.4802 & 4.9827 & TRN & \\
\hline CHEMBL 2336608 & 943500 & 5.2967 & 4.44 & TRN & \\
\hline CHEMBL 2335676 & 943500 & 5.4067 & 5.5873 & TRN & \\
\hline CHEMBL 2336106 & 943500 & 5.1249 & 5.2721 & TRN & \\
\hline CHEMBL2336609 & 943500 & 5.1007 & 4.3326 & TRN & \\
\hline CHEMBL 2336110 & 943500 & 4.0386 & 3.7879 & TRN & \\
\hline CHEMBL2336596 & 943500 & 5.3261 & 4.0003 & TST & \\
\hline CHEMBL 2335668 & 943500 & 5.5086 & 5.3521 & TRN & \\
\hline CHEMBL 2336107 & 943500 & 5.4881 & 5.1735 & TRN & \\
\hline CHEMBL 2335660 & 943500 & 4.9281 & 4.8196 & TRN & \\
\hline CHEMBL 2336593 & 943500 & 5.5768 & 5.1522 & TST & \\
\hline CHEMBL2335651 & 943500 & 5.433 & 5.3621 & TRN & \\
\hline CHEMBL 2336096 & 943500 & 5.6716 & 5.2365 & TRN & \\
\hline CHEMBL 2335681 & 943500 & 5.5114 & 5.57299 & 99999999995 & TRN \\
\hline CHEMBL 2335658 & 943500 & 3.0 & 4.5739 & TRN & \\
\hline CHEMBL2336112 & 943500 & 3.0 & 3.8037 & TRN & \\
\hline CHEMBL 2336113 & 943500 & 5.2269 & 4.2747 & TRN & \\
\hline CHEMBL 2336094 & 943500 & 4.8729 & 4.9121 & TRN & \\
\hline CHEMBL 2335647 & 943500 & 5.5867 & 5.2683 & TRN & \\
\hline CHEMBL 2335682 & 943500 & 5.6576 & 5.2618 & TRN & \\
\hline CHEMBL1477081 & 943500 & 6.0506 & 4.6464 & TST & \\
\hline CHEMBL 2335674 & 943500 & 4.9747 & 5.5711 & TRN & \\
\hline CHEMBL 2335673 & 943500 & 5.3325 & 5.426 & TRN & \\
\hline CHEMBL 2335667 & 943500 & 4.6968 & 4.7593 & TRN & \\
\hline CHEMBL 2335672 & 943500 & 5.5918 & 5.516 & TRN & \\
\hline CHEMBL 2335648 & 943500 & 4.9914 & 4.9748 & TRN & \\
\hline CHEMBL2336095 & 943500 & 5.5302 & 5.3629 & TRN & \\
\hline CHEMBL 2336100 & 943500 & 3.0 & 5.2709 & TST & \\
\hline CHEMBL2336587 & 943500 & 4.6819 & 4.725 & TRN & \\
\hline CHEMBL 2336591 & 943500 & 5.4609 & 5.3284 & TST & \\
\hline CHEMBL 2335664 & 943500 & 4.3809 & 4.7744 & TRN & \\
\hline CHEMBL2336105 & 943500 & 5.1124 & 5.2856 & TRN & \\
\hline CHEMBL 2336602 & 943500 & 3.0 & 5.322 & TST & \\
\hline CHEMBL2336607 & 943500 & 4.2976 & 4.072 & TRN & \\
\hline CHEMBL 2336120 & 943500 & 5.6421 & 5.2861 & TRN & \\
\hline CHEMBL 2336594 & 943500 & 4.9066 & 4.8164 & TST & \\
\hline CHEMBL2335659 & 943500 & 4.6216 & 4.9616 & TRN & \\
\hline CHEMBL 2336131 & 943500 & 5.3152 & 5.0447 & TRN & \\
\hline CHEMBL 2336092 & 943500 & 4.7773 & 5.2111 & TRN & \\
\hline CHEMBL 2336604 & 943500 & 4.1469 & 4.138 & TRN & \\
\hline CHEMBL 2335665 & 943500 & 4.9666 & 4.9955 & TRN & \\
\hline CHEMBL2335653 & 943500 & 5.1062 & 5.3892 & TRN & \\
\hline CHEMBL2336119 & 943500 & 5.5003 & 5.4058 & TRN & \\
\hline
\end{tabular}




\begin{tabular}{|c|c|c|c|c|c|c|}
\hline \multirow[b]{2}{*}{ CHEMBL2336129 } & \multicolumn{6}{|c|}{ Supplemental Table S2.txt } \\
\hline & 943500 & 5.4056 & 5.0673 & TRN & & \\
\hline CHEMBL 2335649 & 943500 & 5.066 & 5.2235 & TRN & & \\
\hline CHEMBL2336109 & 943500 & 3.0 & 3.7007 & TRN & & \\
\hline CHEMBL2335662 & 943500 & 4.6055 & 4.63 & TRN & & \\
\hline CHEMBL2336118 & 943500 & 5.2027 & 5.3839 & TRN & & \\
\hline CHEMBL2336111 & 943500 & 5.0292 & 4.2192 & TST & & \\
\hline CHEMBL2335680 & 943500 & 5.4023 & 5.5644 & TRN & & \\
\hline CHEMBL 2336124 & 943500 & 5.4134 & 5.3155 & TRN & & \\
\hline CHEMBL2336605 & 943500 & 4.1469 & 4.1183 & TST & & \\
\hline CHEMBL2335654 & 943500 & 5.1851 & 5.2621 & TRN & & \\
\hline CHEMBL2335678 & 943500 & 5.3372 & 5.6392 & TRN & & \\
\hline CHEMBL2336101 & 943500 & 3.0 & 4.9618 & TST & & \\
\hline CHEMBL2336099 & 943500 & 5.7077 & 5.4985 & TRN & & \\
\hline CHEMBL 2336115 & 943500 & 5.025 & 4.2299 & TST & & \\
\hline CHEMBL2336599 & 943500 & 5.4698 & 5.0074 & TST & & \\
\hline CHEMBL2336098 & 943500 & 4.6737 & 4.9269 & TRN & & \\
\hline CHEMBL2336600 & 943500 & 6.0915 & 5.0421 & TST & & \\
\hline CHEMBL2335679 & 943500 & 5.5376 & 5.3279 & TRN & & \\
\hline CHEMBL 2335675 & 943500 & 5.6326 & 5.3749 & TRN & & \\
\hline CHEMBL2335655 & 943500 & 5.2441 & 5.0773 & TRN & & \\
\hline CHEMBL2335669 & 943500 & 5.32700 & j000000e & 01 & $\begin{array}{l}5 \quad 3771 \\
\end{array}$ & TRN \\
\hline CHEMBL2336121 & 943500 & 5.7595 & 5.403 & TRN & & \\
\hline CHEMBL 2336102 & 943500 & 3.0 & 4.9837 & TST & & \\
\hline CHEMBL 2335656 & 943500 & 5.2832 & 4.8477 & TRN & & \\
\hline CHEMBL2336114 & 943500 & 4.8386 & 4.0949 & TST & & \\
\hline CHEMBL2336598 & 943500 & 5.3904 & 5.2651 & TST & & \\
\hline CHEMBL2336601 & 943500 & 5.1694 & 4.7774 & TST & & \\
\hline CHEMBL2336597 & 943500 & 5.2027 & 5.0558 & TST & & \\
\hline CHEMBL2336108 & 943500 & 6.0315 & 4.3965 & TST & & \\
\hline CHEMBL2336589 & 943500 & 5.5243 & 4.3702 & TST & & \\
\hline CHEMBL2336592 & 943500 & 5.5045 & 5.4942 & TST & & \\
\hline CHEMBL2335661 & 943500 & 5.1772 & 4.7069 & TRN & & \\
\hline CHEMBL2336595 & 943500 & 5.699 & 4.3074 & TST & & \\
\hline CHEMBL 2336125 & 943500 & 5.5045 & 5.4895 & TRN & & \\
\hline CHEMBL2336097 & 943500 & 5.4841 & 5.093 & TRN & & \\
\hline CHEMBL2335663 & 943500 & 5.1343 & 5.234 & TRN & & \\
\hline CHEMBL2336606 & 943500 & 5.0545 & 4.5489 & TST & & \\
\hline CHEMBL2335671 & 943500 & 5.3546 & 5.5796 & TRN & & \\
\hline CHEMBL2336123 & 943500 & 5.3686 & 5.4301 & TRN & & \\
\hline CHEMBL2336130 & 943500 & 4.8041 & 5.0434 & TRN & & \\
\hline CHEMBL 2336603 & 943500 & 5.0391 & 5.1924 & TST & & \\
\hline CHEMBL 2336104 & 943500 & 4.9172 & 5.0132 & TRN & & \\
\hline CHEMBL2336116 & 943500 & 5.6162 & 5.2715 & TRN & & \\
\hline CHEMBL2336093 & 943500 & 5.6536 & 5.2461 & TRN & & \\
\hline CHEMBL 2336590 & 943500 & 5.3565 & 4.0116 & TST & & \\
\hline CHEMBL2336103 & 943500 & 5.0545 & 5.0461 & TRN & & \\
\hline CHEMBL2335677 & 943500 & 5.699 & 5.4541 & TRN & & \\
\hline CHEMBL1485064 & 688379 & 3.9278 & 4.7681 & TRN & & \\
\hline
\end{tabular}

Page 22935 


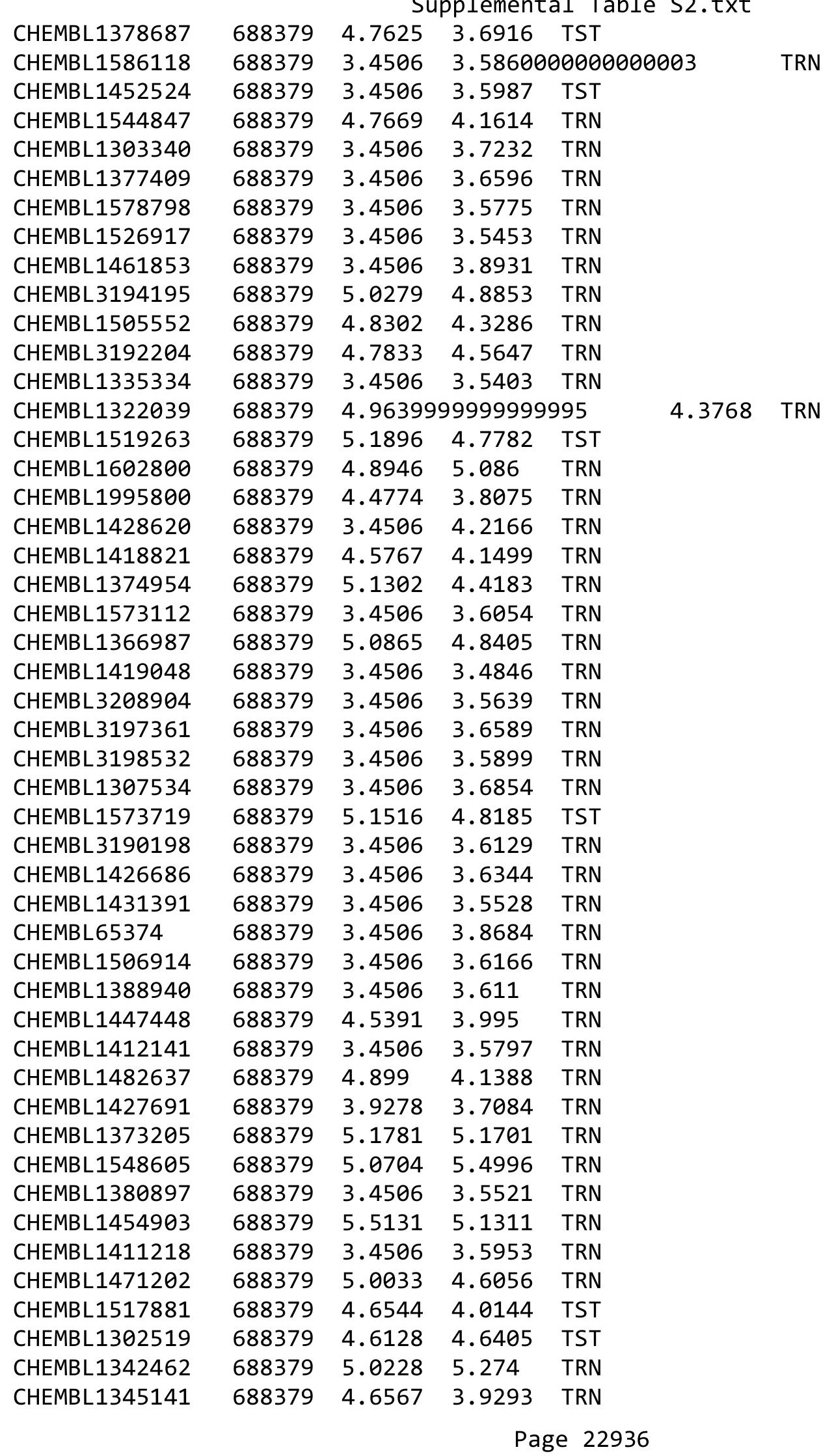


Supplemental Table S2.txt

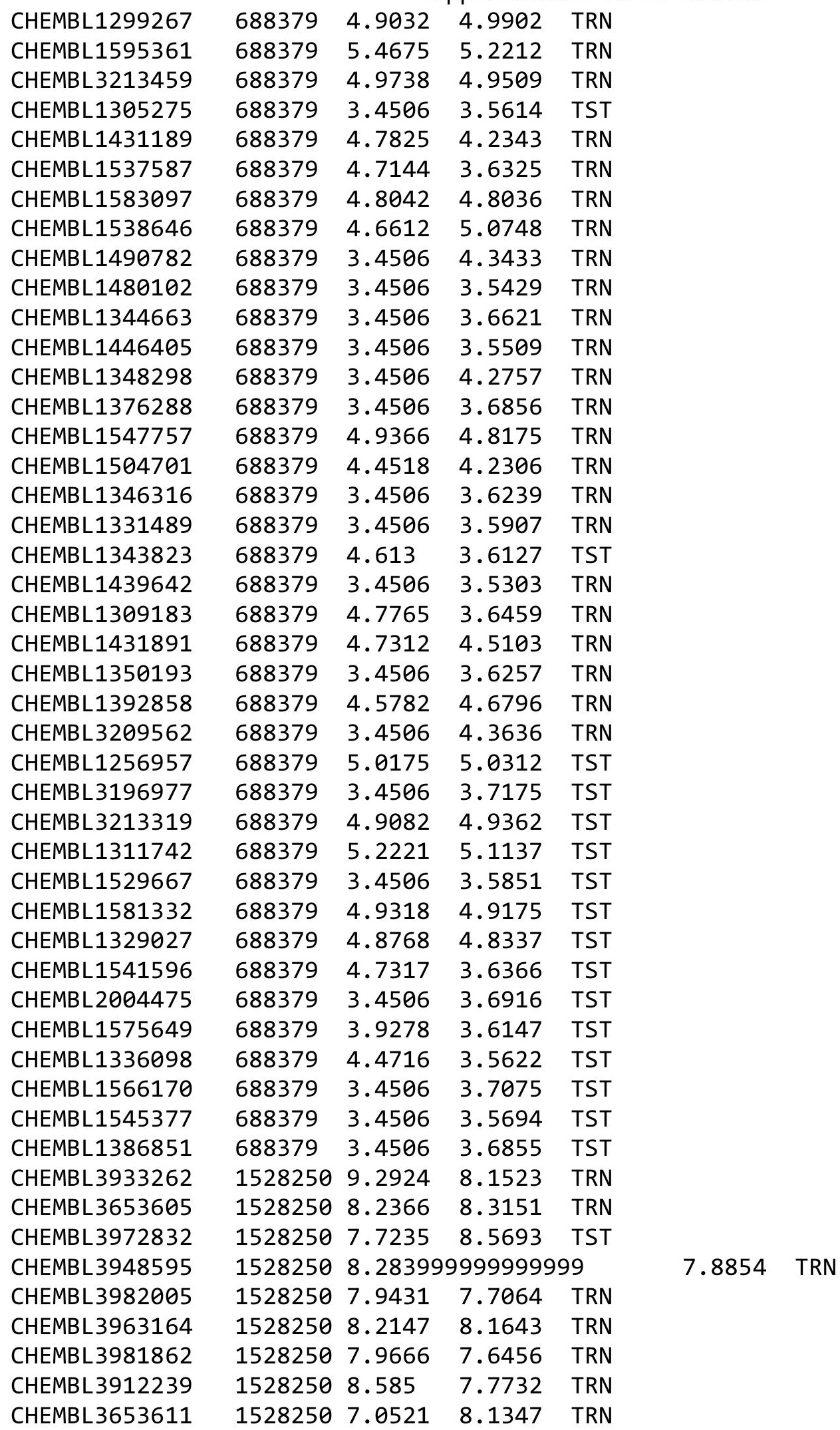

Page 22937 
Supplemental Table S2.txt

\begin{tabular}{|c|c|c|c|c|}
\hline HEM & 28250 & 699 & 3697 & \\
\hline & 528250 & 7.7878 & 562 & \\
\hline & & & & \\
\hline AEMBL3961797 & 8250 & 9862 & & \\
\hline AEMBL3653613 & 528250 & 6.0 & 7059 & \\
\hline HEMBL3980192 & 528250 & 7.1637 & 8218 & \\
\hline & 50 & 986 & 206 & \\
\hline IFMPI = & & & 1919 & \\
\hline HEMBL392 & 250 & 5528 & 2025 & \\
\hline HEMBL3974176 & 528250 & 6.066 & 1917 & \\
\hline HEMBL3939132 & 528250 & 8.1871 & .1707 & \\
\hline IEMBL3C & 50 & 167 & 8311 & \\
\hline AEMBL3S & & & 3185 & \\
\hline HEMBL3653633 & 50 & 8.1805 & 3941 & \\
\hline HEMBL397 & 50 & 8.1249 & 5567 & \\
\hline AEMBL365 & שנ & 269 & 7245 & \\
\hline AEMBL3S & 0 & 272 & 593 & \\
\hline HEMBL36 & & 989 & & \\
\hline AEMBL3S & & 3915 & 1078 & \\
\hline IEMBL36 & & 8 & & \\
\hline HEMBL= & ש & 6 & .79 & - \\
\hline AEMBL & 30 & - & 11 & 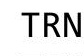 \\
\hline AEMBL & & & .76 & \\
\hline AFMRI & & & 361 & \\
\hline AEMBL36 & & & & 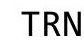 \\
\hline HEMBL & 0 & & 686 & II \\
\hline HEMBL & & & 507 & RN \\
\hline HFMBI : & 50 & & 081 & \\
\hline HEMBL3E & & 383 & & TIV \\
\hline HEMBL36536 & & 7. & & 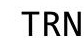 \\
\hline HEMBL & & 8 & 484 & RIV \\
\hline HEMBL; & & 77 & & RN \\
\hline HEMP & 50 & 8 & & \\
\hline HEMBL3922903 & & 07 & 133 & IRN \\
\hline HEMBL 397718 & 50 & 7.684 & 058 & TRN \\
\hline HEMBL3 & & 198 & 351 & \\
\hline HᄃMD - & & & 35 & RN \\
\hline HEMBL3 & & & 556 & IRN \\
\hline HEMBL3924726 & 50 & 8.0969 & 5211 & TRN \\
\hline EMBL & 50 & 366 & & RN \\
\hline HEMBL36 & & 676 & 208 & \\
\hline HEMBL3 3 & & & 7.5749 & RN \\
\hline HEMBL38 & & 7.5969 & 8.2105 & RN \\
\hline AEMBL3970852 & 250 & 7.8928 & 7373 & TRN \\
\hline 1. & & 2464 & 7.7249 & ב \\
\hline HEMBL3 & & & 8.5675 & \\
\hline HEMBL 39 & & .7696 & 7.8788 & \\
\hline HEMBL3985761 & 1528250 & 7.3696 & 7.2387 & \\
\hline
\end{tabular}

Page 22938 
Supplemental Table S2.txt

\begin{tabular}{|c|c|c|c|c|c|}
\hline CHEMBL 3653577 & 1528250 & 7.7932 & 8.3158 & TRN & \\
\hline CHEMBL3930191 & 1528250 & 8.6383 & 8.1901 & TRN & \\
\hline CHEMBL3976066 & 1528250 & 8.1805 & 7.7547 & TST & \\
\hline CHEMBL 3934294 & 1528250 & 7.3372 & 7.653 & TRN & \\
\hline CHEMBL3965334 & 1528250 & 7.8447 & 8.4479 & TST & \\
\hline CHEMBL 3951484 & 1528250 & 8.9208 & 8.6354 & TRN & \\
\hline CHEMBL 3973274 & 1528250 & 7.75200 & 000000000 & & 7.461 \\
\hline CHEMBL 3653587 & 1528250 & 7.8268 & 8.207 & TRN & \\
\hline CHEMBL 3653533 & 1528250 & 8.5686 & 8.3603 & TRN & \\
\hline CHEMBL3972669 & 1528250 & 7.7167 & 7.9878 & TRN & \\
\hline CHEMBL 3981272 & 1528250 & 7.317 & 7.7064 & TRN & \\
\hline CHEMBL3653595 & 1528250 & 6.5901 & 7.5446 & TRN & \\
\hline CHEMBL3980866 & 1528250 & 7.9469 & 7.4871 & TST & \\
\hline CHEMBL 3653532 & 1528250 & 7.7375 & 8.2459 & TST & \\
\hline CHEMBL3979614 & 1528250 & 7.8539 & 7.682 & TRN & \\
\hline CHEMBL3905532 & 1528250 & 8.3565 & 7.9556 & TRN & \\
\hline CHEMBL3964448 & 1528250 & 8.2924 & 8.016 & TRN & \\
\hline CHEMBL3973098 & 1528250 & 8.3468 & 8.0478 & TRN & \\
\hline CHEMBL3949097 & 1528250 & 7.5575 & 8.0067 & TRN & \\
\hline CHEMBL3905995 & 1528250 & 6.7235 & 7.6244 & TST & \\
\hline CHEMBL3916946 & 1528250 & 8.6021 & 8.8288 & TRN & \\
\hline CHEMBL3957717 & 1528250 & 8.3279 & 7.5436 & TST & \\
\hline CHEMBL3971909 & 1528250 & 5.6891 & 7.7214 & TST & \\
\hline CHEMBL 3650228 & 1528250 & 7.6345 & 8.2344 & TRN & \\
\hline CHEMBL 3937322 & 1528250 & 8.3372 & 8.2089 & TRN & \\
\hline CHEMBL3965703 & 1528250 & 8.2007 & 7.653 & TST & \\
\hline CHEMBL 3984814 & 1528250 & 7.433 & 7.0842 & TST & \\
\hline CHEMBL 3901818 & 1528250 & 8.1871 & 7.6022 & TST & \\
\hline CHEMBL 3653604 & 1528250 & 7.7852 & 8.2834 & TRN & \\
\hline CHEMBL3896595 & 1528250 & 8.6198 & 8.5152 & TRN & \\
\hline CHEMBL3970396 & 1528250 & 7.6498 & 6.7925 & TRN & \\
\hline CHEMBL 3934233 & 1528250 & 7.5045 & 7.1739 & TRN & \\
\hline CHEMBL 3927741 & 1528250 & 7.9136 & 8.6958 & TST & \\
\hline CHEMBL 3653588 & 1528250 & 8.1938 & 8.3022 & TRN & \\
\hline CHEMBL 3653616 & 1528250 & 7.9957 & 7.7204 & TRN & \\
\hline CHEMBL3962208 & 1528250 & 8.8861 & 8.1255 & TRN & \\
\hline CHEMBL3913370 & 1528250 & 8.7959 & 8.3223 & TRN & \\
\hline CHEMBL 3653620 & 1528250 & 8.301 & 7.8004 & TRN & \\
\hline CHEMBL3907659 & 1528250 & 7.8386 & 7.7918 & TRN & \\
\hline CHEMBL3986441 & 1528250 & 8.6021 & 7.9102 & TRN & \\
\hline CHEMBL 3903242 & 1528250 & 8.699 & 8.0899 & TRN & \\
\hline CHEMBL3964776 & 1528250 & 7.4437 & 8.1534 & TRN & \\
\hline CHEMBL3961104 & 1528250 & 7.7878 & 7.9397 & TST & \\
\hline CHEMBL3933113 & 1528250 & 8.7696 & 7.9288 & TST & \\
\hline CHEMBL3939143 & 1528250 & 7.5719 & 7.5466 & TST & \\
\hline CHEMBL3954072 & 1528250 & 7.4318 & 7.1425 & TST & \\
\hline CHEMBL 3944872 & 1528250 & 8.7696 & 8.7109 & TRN & \\
\hline CHEMBL 3945924 & 1528250 & 7.6904 & 7.8716 & TRN & \\
\hline
\end{tabular}

Page 22939 
Supplemental Table S2.txt

\begin{tabular}{|c|c|c|c|c|}
\hline CHEMBL3653572 & 1528250 & 7.6635 & 7.3425 & TST \\
\hline CHEMBL 3650229 & 1528250 & 7.2358 & 8.0148 & TST \\
\hline CHEMBL3938291 & 1528250 & 8.5686 & 8.0536 & TRN \\
\hline CHEMBL 3653580 & 1528250 & 8.1249 & 8.0857 & TRN \\
\hline CHEMBL3960968 & 1528250 & 8.3979 & 8.26 & TRN \\
\hline CHEMBL3923274 & 1528250 & 8.3188 & 8.1331 & TRN \\
\hline CHEMBL3911594 & 1528250 & 8.1871 & 7.7012 & TRN \\
\hline CHEMBL3968629 & 1528250 & 8.0269 & 7.7642 & TST \\
\hline CHEMBL3986759 & 1528250 & 8.3468 & 7.9023 & TRN \\
\hline CHEMBL3935245 & 1528250 & 7.6498 & 7.04899 & 99999999995 \\
\hline CHEMBL3918807 & 1528250 & 7.6596 & 7.8074 & TST \\
\hline CHEMBL3968837 & 1528250 & 9.1024 & 8.2959 & TRN \\
\hline CHEMBL 3653584 & 1528250 & 8.7959 & 8.3477 & TRN \\
\hline CHEMBL3957134 & 1528250 & 8.8239 & 8.3444 & TST \\
\hline CHEMBL 3942545 & 1528250 & 8.0809 & 8.4268 & TST \\
\hline CHEMBL3931846 & 1528250 & 7.2284 & 7.0291 & TST \\
\hline CHEMBL3905542 & 1528250 & 7.1385 & 7.7077 & TST \\
\hline CHEMBL 3922763 & 1528250 & 7.9101 & 7.9179 & TST \\
\hline CHEMBL3653598 & 1528250 & 6.0 & 7.2251 & TRN \\
\hline CHEMBL 3927253 & 1528250 & 9.2924 & 8.4446 & TRN \\
\hline CHEMBL 3653601 & 1528250 & 6.0 & 7.3748 & TRN \\
\hline CHEMBL3981590 & 1528250 & 7.3054 & 8.2563 & TRN \\
\hline CHEMBL3930145 & 1528250 & 7.6904 & 7.3041 & TST \\
\hline CHEMBL3969065 & 1528250 & 8.699 & 8.0908 & TRN \\
\hline CHEMBL3958549 & 1528250 & 7.5591 & 7.4236 & TST \\
\hline CHEMBL 3902985 & 1528250 & 8.7959 & 7.9035 & TRN \\
\hline CHEMBL3653610 & 1528250 & 6.0381 & 8.0525 & TRN \\
\hline CHEMBL3960708 & 1528250 & 8.4559 & 7.8375 & TRN \\
\hline CHEMBL3899292 & 1640356 & 6.8069 & 6.1808 & TRN \\
\hline CHEMBL3981833 & 1640356 & 7.3565 & 6.2381 & TRN \\
\hline CHEMBL3986565 & 1640356 & 5.5444 & 6.8204 & TST \\
\hline CHEMBL3970476 & 1640356 & 6.0 & 6.1045 & TRN \\
\hline CHEMBL3911266 & 1640356 & 7.8539 & 6.8569 & TST \\
\hline CHEMBL3977387 & 1640356 & 6.4318 & 6.692 & TST \\
\hline CHEMBL3112857 & 1640356 & 7.2757 & 7.5825 & TRN \\
\hline CHEMBL3944470 & 1640356 & 7.5086 & 6.7633 & TRN \\
\hline CHEMBL3961677 & 1640356 & 7.6576 & 7.263 & TRN \\
\hline CHEMBL3917496 & 1640356 & 6.0 & 6.5641 & TRN \\
\hline CHEMBL3968336 & 1640356 & 6.0 & 6.1825 & TRN \\
\hline CHEMBL3964685 & 1640356 & 6.0 & 6.2349 & TRN \\
\hline CHEMBL3959404 & 1640356 & 6.0 & 6.1427 & TRN \\
\hline CHEMBL3918391 & 1640356 & 6.0 & 6.1844 & TRN \\
\hline CHEMBL3943531 & 1640356 & 7.2924 & 7.2065 & TST \\
\hline CHEMBL3112853 & 1640356 & 8.0458 & 7.7137 & TRN \\
\hline CHEMBL3917798 & 1640356 & 6.0 & 6.4565 & TRN \\
\hline CHEMBL3930747 & 1640356 & 6.284 & 6.3712 & TRN \\
\hline CHEMBL 3954012 & 1640356 & 5.8755 & \multicolumn{2}{|c|}{6.417999999999999} \\
\hline CHEMBL3922944 & 1640356 & 6.0 & 5.9641 & TRN \\
\hline
\end{tabular}




\begin{tabular}{|c|c|c|c|c|}
\hline \multicolumn{5}{|c|}{ Supplemental Table S2.txt } \\
\hline CHEMBL3964814 & 1640356 & 6.0 & 6.4135 & TRN \\
\hline CHEMBL3112862 & 1640356 & 6.0 & 6.6259 & TST \\
\hline CHEMBL3950222 & 1640356 & 7.585 & 7.1601 & TST \\
\hline CHEMBL3930708 & 1640356 & 6.0 & 6.5884 & TRN \\
\hline CHEMBL3922497 & 1640356 & 6.9957 & 7.0136 & TRN \\
\hline CHEMBL 3935564 & 1640356 & 6.0 & 6.1191 & TST \\
\hline CHEMBL 3893813 & 1640356 & 7.5229 & 6.7119 & TRN \\
\hline CHEMBL3927896 & 1640356 & 7.2007 & 7.0829 & TRN \\
\hline CHEMBL3893392 & 1640356 & 6.0 & 5.6832 & TRN \\
\hline CHEMBL3917877 & 1640356 & 6.0 & 5.7673 & TRN \\
\hline CHEMBL3908338 & 1640356 & 7.6198 & 6.3078 & TRN \\
\hline CHEMBL3936766 & 1640356 & 7.2218 & 6.7045 & TRN \\
\hline CHEMBL3908806 & 1640356 & 6.9914 & 6.4408 & TRN \\
\hline CHEMBL3890826 & 1640356 & 6.0 & 6.4684 & TRN \\
\hline CHEMBL3939903 & 1640356 & 6.0 & 6.0037 & TRN \\
\hline CHEMBL 3914007 & 1640356 & 6.0 & 5.9683 & TRN \\
\hline CHEMBL3908482 & 1640356 & 6.0 & 5.9542 & TRN \\
\hline CHEMBL3916147 & 1640356 & 6.0 & 6.2512 & TRN \\
\hline CHEMBL3952768 & 1640356 & 6.0 & 6.9691 & TRN \\
\hline CHEMBL3983824 & 1640356 & 6.8962 & 7.1346 & TST \\
\hline CHEMBL3930892 & 1640356 & 6.9547 & 6.7533 & TRN \\
\hline CHEMBL3953697 & 1640356 & 7.6383 & 7.1765 & TRN \\
\hline CHEMBL3904288 & 1640356 & 6.8097 & 7.1352 & TST \\
\hline CHEMBL 3890103 & 1640356 & 6.0 & 6.26 & TRN \\
\hline CHEMBL3965878 & 1640356 & 6.0 & 5.8319 & TRN \\
\hline CHEMBL3896311 & 1640356 & 6.0 & 5.7168 & TRN \\
\hline CHEMBL3932244 & 1640356 & 6.8827 & 7.2344 & TST \\
\hline CHEMBL3930072 & 1640356 & 6.0 & 6.9741 & TRN \\
\hline CHEMBL3978959 & 1640356 & 6.0 & 6.21899 & 9999999999 \\
\hline CHEMBL3932198 & 1640356 & 6.0 & 5.7109 & TRN \\
\hline CHEMBL3956312 & 1640356 & 6.8013 & 6.6615 & TRN \\
\hline CHEMBL3893381 & 1640356 & 6.7077 & 6.8023 & TST \\
\hline CHEMBL3928308 & 1640356 & 6.0 & 6.4444 & TRN \\
\hline CHEMBL3925163 & 1640356 & 6.0 & 5.97 & TRN \\
\hline CHEMBL3937641 & 1640356 & 6.0 & 5.8177 & TRN \\
\hline CHEMBL3936162 & 1640356 & 6.9747 & 6.9003 & TST \\
\hline CHEMBL3914529 & 1640356 & 7.4318 & 6.9809 & TRN \\
\hline CHEMBL3931282 & 1640356 & 7.4949 & 7.3616 & TRN \\
\hline CHEMBL3910203 & 1640356 & 6.0 & 6.0306 & TRN \\
\hline CHEMBL3910755 & 1640356 & 6.0 & 6.4258 & TRN \\
\hline CHEMBL3961321 & 1640356 & 6.6126 & 6.761 & TST \\
\hline CHEMBL3916280 & 1640356 & 6.0 & 6.4832 & TRN \\
\hline CHEMBL3950856 & 1640356 & 7.2518 & 6.6693 & TRN \\
\hline CHEMBL3974771 & 1640356 & 7.6198 & 7.2942 & TST \\
\hline CHEMBL3938410 & 1640356 & 5.5229 & 6.9623 & TST \\
\hline CHEMBL3971065 & 1640356 & 6.0 & 5.897 & TRN \\
\hline CHEMBL3971261 & 1640356 & 7.3768 & 7.4679 & TRN \\
\hline CHEMBL3970127 & 1640356 & 8.699 & 7.1809 & TRN \\
\hline
\end{tabular}


Supplemental Table S2.txt

\begin{tabular}{|c|c|c|c|c|c|}
\hline CHEMBL3112854 & 1640356 & 7.2676 & 7.4639 & TRN & \\
\hline CHEMBL3984868 & 1640356 & 6.0 & 6.545 & TRN & \\
\hline CHEMBL3901730 & 1640356 & 6.0 & 5.565 & TRN & \\
\hline CHEMBL3974610 & 1640356 & 6.0 & 6.0605 & TRN & \\
\hline CHEMBL3916531 & 1640356 & 7.4815 & 7.121 & TRN & \\
\hline CHEMBL3982597 & 1640356 & 6.0 & 5.8533 & TRN & \\
\hline CHEMBL 3897578 & 1640356 & 7.4559 & 6.697 & TST & \\
\hline CHEMBL3896167 & 1640356 & 6.0278 & 6.5207 & TRN & \\
\hline CHEMBL3981254 & 1640356 & 7.284 & 6.5866 & TST & \\
\hline CHEMBL3112858 & 1640356 & 7.0269 & 7.4329 & TRN & \\
\hline CHEMBL3937375 & 1640356 & 7.5376 & 6.4334 & TST & \\
\hline CHEMBL3913066 & 1640356 & 6.0 & 6.2908 & TRN & \\
\hline CHEMBL3925391 & 1640356 & 7.9586 & 7.4198 & TRN & \\
\hline CHEMBL3971967 & 1640356 & 8.3979 & 7.865 & TRN & \\
\hline CHEMBL3970508 & 1640356 & 7.2441 & 6.4562 & TST & \\
\hline CHEMBL3972428 & 1640356 & 6.0 & 6.2639 & TST & \\
\hline CHEMBL3112859 & 1640356 & 6.7773 & 6.6649 & TRN & \\
\hline CHEMBL 3112860 & 1640356 & 6.5654 & 6.6628 & TRN & \\
\hline CHEMBL3112855 & 1640356 & 7.6198 & 7.6712 & TRN & \\
\hline CHEMBL3964324 & 1640356 & 6.0 & 6.1206 & TRN & \\
\hline CHEMBL3900870 & 1640356 & 9.0 & 8.5625 & TRN & \\
\hline CHEMBL3918242 & 1640356 & 6.0 & 6.04299 & 9999999999 & TRN \\
\hline CHEMBL3923121 & 1640356 & 6.0 & 6.5432 & TRN & \\
\hline CHEMBL3893924 & 1640356 & 6.0 & 6.6987 & TRN & \\
\hline CHEMBL3907424 & 1640356 & 6.0 & 6.6784 & TRN & \\
\hline CHEMBL3934544 & 1640356 & 7.3468 & 6.4198 & TST & \\
\hline CHEMBL3947247 & 1640356 & 6.0 & 6.7961 & TST & \\
\hline CHEMBL3931890 & 1640356 & 6.0 & 7.0401 & TRN & \\
\hline CHEMBL3112856 & 1640356 & 7.1805 & 7.8465 & TRN & \\
\hline CHEMBL3951881 & 1640356 & 6.0 & 6.0006 & TRN & \\
\hline CHEMBL3985936 & 1640356 & 6.5867 & 6.6049 & TRN & \\
\hline CHEMBL3905243 & 1640356 & 6.0 & 6.114 & TRN & \\
\hline CHEMBL3945651 & 1640356 & 7.585 & 6.79899 & 99999999995 & TST \\
\hline CHEMBL3943810 & 1640356 & 7.9208 & 6.5347 & TST & \\
\hline CHEMBL3940961 & 1640356 & 6.0 & 6.3559 & TRN & \\
\hline CHEMBL3921269 & 1640356 & 7.3565 & 6.9102 & TRN & \\
\hline CHEMBL3112865 & 1640356 & 7.6778 & 7.409 & TST & \\
\hline CHEMBL3926375 & 1640356 & 7.9208 & 6.7415 & TST & \\
\hline CHEMBL3945090 & 1640356 & 6.0 & 6.3216 & TRN & \\
\hline CHEMBL3896158 & 1640356 & 6.0 & 5.7732 & TRN & \\
\hline CHEMBL36525 & 47497 & 5.1427 & 5.0635 & TRN & \\
\hline CHEMBL34488 & 47497 & 7.4318 & 7.348 & TRN & \\
\hline CHEMBL33478 & 47497 & 7.6778 & 7.5821 & TRN & \\
\hline CHEMBL35189 & 47497 & 5.8996 & 5.8735 & TST & \\
\hline CHEMBL34998 & 47497 & 6.8861 & 7.1231 & TRN & \\
\hline CHEMBL284071 & 47497 & 6.6108 & 6.4665 & TRN & \\
\hline CHEMBL34424 & 47497 & 4.9031 & 5.1886 & TRN & \\
\hline CHEMBL35043 & 47497 & 6.4437 & 6.4523 & TRN & \\
\hline
\end{tabular}




\begin{tabular}{|c|c|c|c|c|}
\hline & & \multicolumn{3}{|c|}{ Supplemental Table S } \\
\hline CHEMBL6685 & 47497 & 7.2596 & 7.0076 & TST \\
\hline CHEMBL286831 & 47497 & 6.6198 & 6.4661 & TRN \\
\hline CHEMBL35805 & 47497 & 6.6778 & 6.7334 & TRN \\
\hline CHEMBL33648 & 47497 & 6.6198 & 6.6333 & TRN \\
\hline CHEMBL6784 & 47497 & 4.7447 & 5.3654 & TST \\
\hline CHEMBL35496 & 47497 & 6.6576 & 6.5228 & TRN \\
\hline CHEMBL1795055 & 47497 & 6.0 & 6.0088 & TRN \\
\hline CHEMBL268177 & 47497 & 5.2218 & 5.6727 & TST \\
\hline CHEMBL35265 & 47497 & 6.301 & 6.4439 & TRN \\
\hline CHEMBL2112275 & 47497 & 6.4559 & 6.1823 & TRN \\
\hline CHEMBL 36322 & 47497 & 7.1192 & 7.1065 & TRN \\
\hline CHEMBL32308 & 47497 & 7.3872 & 7.3971 & TRN \\
\hline CHEMBL32732 & 47497 & 6.7447 & 6.728 & TRN \\
\hline CHEMBL 289401 & 47497 & 7.3565 & 7.2186 & TRN \\
\hline CHEMBL33088 & 47497 & 6.3925 & 6.6365 & TST \\
\hline CHEMBL36452 & 47497 & 6.0458 & 5.9803 & TRN \\
\hline CHEMBL287316 & 47497 & 7.1024 & 7.0939 & TRN \\
\hline CHEMBL34647 & 47497 & 6.1487 & 6.7007 & TST \\
\hline CHEMBL435541 & 47497 & 6.1938 & 6.4523 & TRN \\
\hline CHEMBL 286666 & 47497 & 5.1278 & 5.2586 & TRN \\
\hline CHEMBL6919 & 47497 & 4.6198 & 5.2222 & TST \\
\hline CHEMBL34012 & 47497 & 6.0177 & 5.9843 & TRN \\
\hline CHEMBL432282 & 47497 & 4.6882 & 4.9348 & TST \\
\hline CHEMBL34473 & 47497 & 5.2111 & 5.2586 & TRN \\
\hline CHEMBL34086 & 47497 & 6.6383 & 6.7287 & TRN \\
\hline CHEMBL34319 & 47497 & 6.9101 & 6.8979 & TRN \\
\hline CHEMBL284610 & 47497 & 6.5607 & 6.6596 & TST \\
\hline CHEMBL 286587 & 47497 & 5.9208 & 6.004 & TST \\
\hline CHEMBL286300 & 47497 & 4.9031 & 4.7788 & TRN \\
\hline CHEMBL 286338 & 47497 & 6.8861 & 6.9234 & TRN \\
\hline CHEMBL 290348 & 47497 & 7.0605 & 7.1538 & TRN \\
\hline CHEMBL418051 & 47497 & 5.0915 & 4.954 & TRN \\
\hline CHEMBL34646 & 47497 & 6.284 & 6.6096 & TST \\
\hline CHEMBL154106 & 47497 & 6.0 & 7.0004 & TST \\
\hline CHEMBL432669 & 47497 & 7.0706 & 7.0435 & TRN \\
\hline CHEMBL34608 & 47497 & 4.9393 & 5.3711 & TRN \\
\hline CHEMBL286449 & 47497 & 6.4202 & 6.4051 & TRN \\
\hline CHEMBL32982 & 47497 & 7.1024 & 7.1143 & TRN \\
\hline CHEMBL35710 & 47497 & 6.6676 & 6.8375 & TST \\
\hline CHEMBL 287470 & 47497 & 6.3872 & 6.2472 & TRN \\
\hline CHEMBL32160 & 47497 & 6.699 & 6.6883 & TRN \\
\hline CHEMBL35595 & 47497 & 4.5686 & 4.9347 & TST \\
\hline CHEMBL35421 & 47497 & 6.5719 & 6.4647 & TRN \\
\hline CHEMBL 284500 & 47497 & 7.4815 & 7.5821 & TRN \\
\hline CHEMBL36334 & 47497 & 7.301 & 7.272 & TRN \\
\hline CHEMBL34314 & 47497 & 7.2676 & 6.7116 & TRN \\
\hline CHEMBL36567 & 47497 & 5.9914 & 5.86100 & 0000000001 \\
\hline CHEMBL285590 & 47497 & 6.8097 & 6.7334 & TRN \\
\hline
\end{tabular}




\begin{tabular}{|c|c|c|c|c|c|c|}
\hline & & \multicolumn{5}{|c|}{ Supplemental Table s2.txt } \\
\hline CHEMBL34582 & 47497 & 5.9788 & 5.7987 & TRN & & \\
\hline CHEMBL6753 & 47497 & 5.0315 & 5.646 & TST & & \\
\hline CHEMBL284617 & 47497 & 7.2366 & 7.3229 & TRN & & \\
\hline CHEMBL285688 & 47497 & 7.0506 & 6.8979 & TRN & & \\
\hline CHEMBL32208 & 47497 & 7.3665 & 7.3229 & TRN & & \\
\hline CHEMBL266240 & 47497 & 5.0757 & 5.7709 & TST & & \\
\hline CHEMBL408856 & 47497 & 6.0 & 7.0554 & TRN & & \\
\hline CHEMBL36252 & 47497 & 7.1805 & 6.9946 & TST & & \\
\hline CHEMBL 285788 & 47497 & 6.6021 & 6.626 & TRN & & \\
\hline CHEMBL286297 & 47497 & 6.2596 & 6.4051 & TRN & & \\
\hline CHEMBL286999 & 47497 & 6.0 & 5.9784 & TST & & \\
\hline CHEMBL37958 & 47497 & 7.2076 & 7.0589 & TRN & & \\
\hline CHEMBL34262 & 47497 & 7.0315 & 7.0966 & TRN & & \\
\hline CHEMBL35338 & 47497 & 6.8697 & 6.728 & TRN & & \\
\hline CHEMBL285516 & 47497 & 6.9914 & 7.0527 & TRN & & \\
\hline CHEMBL34016 & 47497 & 6.0 & 5.2778 & TRN & & \\
\hline CHEMBL35907 & 47497 & 6.4437 & 6.5372 & TRN & & \\
\hline CHEMBL 34354 & 47497 & 6.4622 & 6.6568 & TRN & & \\
\hline CHEMBL 32848 & 47497 & 7.1192 & 7.0861 & TRN & & \\
\hline CHEMBL 35503 & 47497 & 6.6021 & 6.7854 & TST & & \\
\hline CHEMBL34768 & 47497 & 7.0177 & 7.0939 & TRN & & \\
\hline CHEMBL35061 & 47497 & 6.6778 & 6.5782 & TRN & & \\
\hline CHEMBL415466 & 47497 & 7.4437 & 7.5737 & TRN & & \\
\hline CHEMBL 36390 & 47497 & 6.5229 & 6.5855 & TRN & & \\
\hline CHEMBL34809 & 47497 & 6.0 & 6.1711 & TRN & & \\
\hline CHEMBL33963 & 47497 & 6.3372 & 6.269 & TRN & & \\
\hline CHEMBL284711 & 47497 & $6.7570 e$ & 30000000 & 01 & 6.5033 & TRN \\
\hline CHEMBL34371 & 47497 & 6.0 & 5.9731 & TRN & & \\
\hline CHEMBL 35240 & 47497 & 6.9788 & 6.9234 & TRN & & \\
\hline CHEMBL34770 & 47497 & 6.38206 & 30000000 & 01 & 6.3823 & TRN \\
\hline CHEMBL286669 & 47497 & 6.475 & 6.4439 & TRN & & \\
\hline CHEMBL35695 & 47497 & 5.2007 & 5.2778 & TRN & & \\
\hline CHEMBL284061 & 47497 & 7.3665 & 7.348 & TRN & & \\
\hline CHEMBL 289672 & 47497 & 5.0655 & 5.0801 & TRN & & \\
\hline CHEMBL35410 & 47497 & 5.0 & 5.1203 & TRN & & \\
\hline CHEMBL6852 & 47497 & 4.6021 & 4.7659 & TST & & \\
\hline CHEMBL32949 & 47497 & 5.0362 & 4.954 & TRN & & \\
\hline CHEMBL284354 & 47497 & 7.6383 & 7.6473 & TRN & & \\
\hline CHEMBL 36283 & 47497 & 5.3979 & 5.5624 & TRN & & \\
\hline CHEMBL285266 & 47497 & 6.3468 & 6.4523 & TRN & & \\
\hline CHEMBL35746 & 47497 & 6.1549 & 6.4935 & TRN & & \\
\hline CHEMBL34782 & 47497 & 7.3279 & 7.2236 & TRN & & \\
\hline CHEMBL264608 & 47497 & 6.0 & 5.5624 & TRN & & \\
\hline CHEMBL285239 & 47497 & 5.0506 & 5.1831 & TRN & & \\
\hline CHEMBL286602 & 47497 & 5.2518 & 5.1831 & TRN & & \\
\hline CHEMBL32157 & 47497 & 7.2518 & 7.21200 & 0000000001 & & TRN \\
\hline CHEMBL35385 & 47497 & 6.5376 & 6.4523 & TRN & & \\
\hline CHEMBL34899 & 47497 & 7.3098 & 7.2525 & TRN & & \\
\hline
\end{tabular}




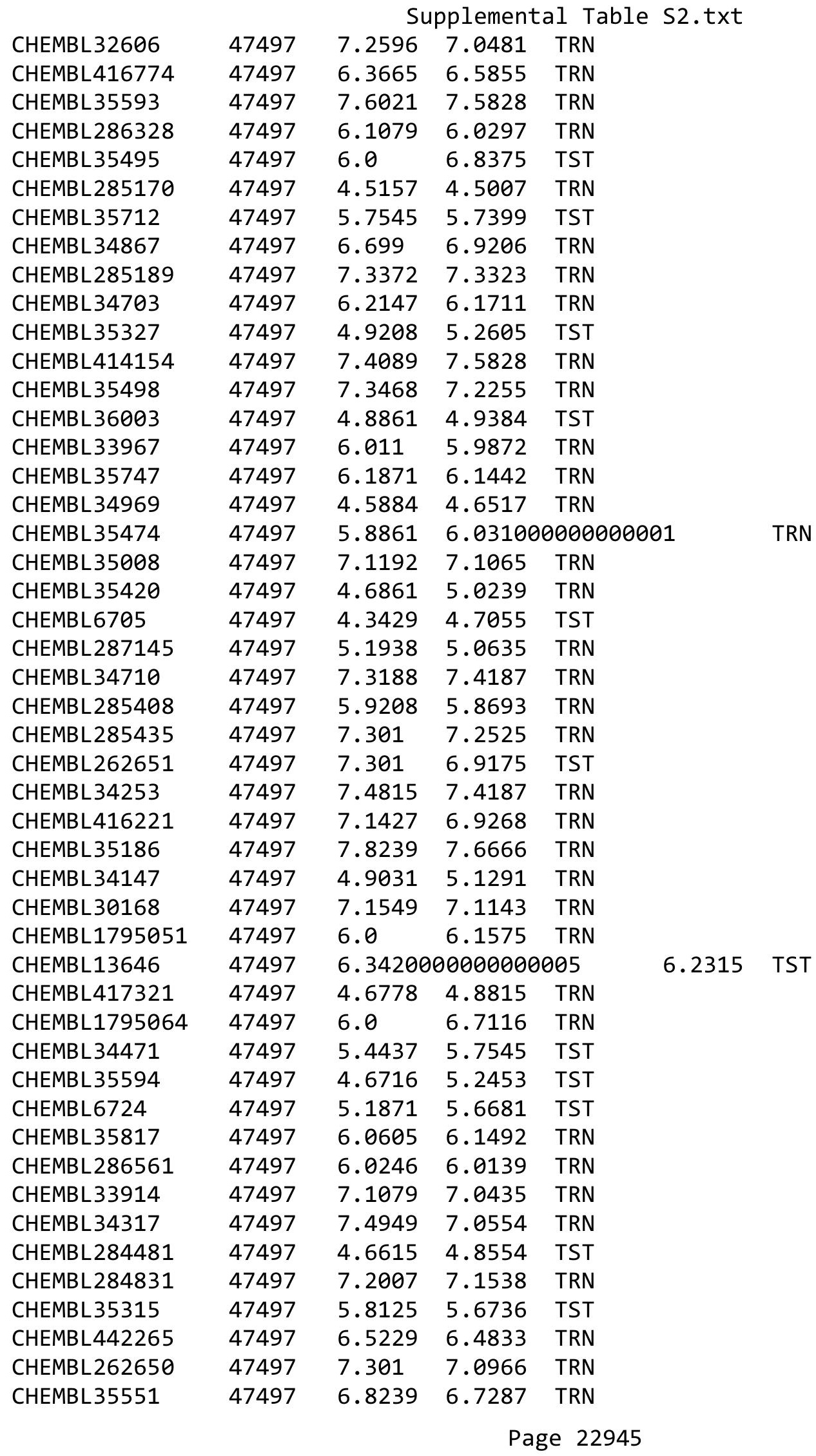




\begin{tabular}{|c|c|c|c|c|c|}
\hline \multirow[b]{2}{*}{ CHEMBL34829 } & \multicolumn{5}{|c|}{ Supplemental Table S2.txt } \\
\hline & 47497 & 4.7959 & 4.7788 & TRN & \\
\hline CHEMBL 35262 & 47497 & 6.5376 & 6.1575 & TRN & \\
\hline CHEMBL286131 & 47497 & 7.5229 & 7.6666 & TRN & \\
\hline CHEMBL 284398 & 47497 & 6.8097 & 6.6883 & TRN & \\
\hline CHEMBL284732 & 47497 & 7.284 & 7.2281 & TRN & \\
\hline CHEMBL35021 & 47497 & 6.0706 & 6.269 & TRN & \\
\hline CHEMBL34013 & 47497 & 5.0 & 4.9613 & TRN & \\
\hline CHEMBL32096 & 47497 & 6.5376 & 6.3435 & TRN & \\
\hline CHEMBL 34520 & 47497 & 6.2882 & 6.3898 & TRN & \\
\hline CHEMBL34073 & 47497 & 6.0458 & 6.0088 & TRN & \\
\hline CHEMBL 289647 & 47497 & 6.6198 & 6.5372 & TRN & \\
\hline CHEMBL418402 & 47497 & 7.3665 & 7.2951 & TRN & \\
\hline CHEMBL416410 & 47497 & 6.9586 & 7.0527 & TRN & \\
\hline CHEMBL 285962 & 47497 & 5.1163 & 4.9613 & TRN & \\
\hline CHEMBL 286586 & 47497 & 7.6021 & 7.5737 & TRN & \\
\hline CHEMBL7092 & 47497 & 5.0088 & 5.3744 & TST & \\
\hline CHEMBL35194 & 47497 & 5.9586 & 6.03700 & 0000000001 & TRN \\
\hline CHEMBL284118 & 47497 & 5.9208 & 5.9034 & TRN & \\
\hline CHEMBL 286549 & 47497 & 4.9208 & 4.8512 & TRN & \\
\hline CHEMBL1795065 & 47497 & 6.0 & 6.9946 & TST & \\
\hline CHEMBL 289888 & 47497 & 7.2076 & 7.0004 & TST & \\
\hline CHEMBL 286445 & 47497 & 6.6478 & 6.5932 & TRN & \\
\hline CHEMBL 285531 & 47497 & 6.3979 & 6.4473 & TST & \\
\hline CHEMBL32165 & 47497 & 6.6478 & 6.4935 & TRN & \\
\hline CHEMBL35050 & 47497 & 6.3468 & 6.1525 & TRN & \\
\hline CHEMBL6853 & 47497 & 5.0809 & 5.45799 & 9999999999 & TST \\
\hline CHEMBL34546 & 47497 & 6.0 & 6.5932 & TST & \\
\hline CHEMBL36017 & 47497 & 4.4855 & 4.8618 & TST & \\
\hline CHEMBL 2112274 & 47497 & 7.3979 & 7.5864 & TST & \\
\hline CHEMBL35528 & 47497 & 5.2676 & 5.0801 & TRN & \\
\hline CHEMBL35227 & 47497 & 7.4089 & 7.6473 & TRN & \\
\hline CHEMBL 269628 & 47497 & 5.2147 & 6.0888 & TST & \\
\hline CHEMBL36451 & 47497 & 6.5376 & 6.6205 & TST & \\
\hline CHEMBL 35118 & 47497 & 7.1549 & 6.7116 & TST & \\
\hline CHEMBL262389 & 47497 & 5.0088 & 4.8512 & TRN & \\
\hline CHEMBL34696 & 47497 & 4.6383 & 4.6488 & TRN & \\
\hline CHEMBL 284694 & 47497 & 5.426 & 5.5346 & TRN & \\
\hline CHEMBL417497 & 47497 & 6.3665 & 6.3636 & TRN & \\
\hline CHEMBL35132 & 47497 & 6.2924 & 6.3786 & TRN & \\
\hline CHEMBL35484 & 47497 & 6.1192 & 6.1457 & TRN & \\
\hline CHEMBL32198 & 47497 & 5.4559 & 5.6504 & TRN & \\
\hline CHEMBL32836 & 47497 & 5.3872 & 5.5346 & TRN & \\
\hline CHEMBL431112 & 47497 & 6.9031 & 6.9206 & TST & \\
\hline CHEMBL35532 & 47497 & 6.2147 & 6.414 & TRN & \\
\hline CHEMBL408857 & 47497 & 6.4881 & 6.37799 & 9999999999 & TRN \\
\hline CHEMBL34852 & 47497 & 7.5229 & 7.5828 & TRN & \\
\hline CHEMBL35113 & 47497 & 6.6021 & 6.3866 & TST & \\
\hline CHEMBL418047 & 47497 & 7.1871 & 7.2775 & TRN & \\
\hline
\end{tabular}




\begin{tabular}{|c|c|c|c|c|c|c|}
\hline & & \multicolumn{5}{|c|}{ Supplemental Table S2.txt } \\
\hline CHEMBL36253 & 47497 & 6.2076 & 6.4385 & TRN & & \\
\hline CHEMBL 7204 & 47497 & 4.1051 & 4.5424 & TST & & \\
\hline CHEMBL7087 & 47497 & 4.6778 & 5.0465 & TST & & \\
\hline CHEMBL 2112276 & 47497 & 7.4089 & 7.0766 & TRN & & \\
\hline CHEMBL 32735 & 47497 & 5.4622 & 5.6768 & TST & & \\
\hline CHEMBL 286108 & 47497 & 6.5528 & 6.6382 & TST & & \\
\hline CHEMBL35698 & 47497 & 5.0223 & 5.1291 & TRN & & \\
\hline CHEMBL284165 & 47497 & 7.1871 & 7.1231 & TRN & & \\
\hline CHEMBL287117 & 47497 & 7.301 & 7.0025 & TST & & \\
\hline CHEMBL37730 & 47497 & 7.3188 & 7.01 & TRN & & \\
\hline CHEMBL265674 & 47497 & 5.0655 & 5.4662 & TST & & \\
\hline CHEMBL34711 & 47497 & 6.6021 & 6.4332 & TST & & \\
\hline CHEMBL35653 & 47497 & 6.4202 & 6.4107 & TRN & & \\
\hline CHEMBL418599 & 47497 & 6.6778 & 6.9268 & TRN & & \\
\hline CHEMBL 34974 & 47497 & 6.2924 & 6.37799 & 9999999999 & & TRN \\
\hline CHEMBL36447 & 47497 & 6.9208 & 7.0861 & TST & & \\
\hline CHEMBL33904 & 47497 & 5.4815 & 5.6419 & TRN & & \\
\hline CHEMBL 285238 & 47497 & 4.6383 & 4.9308 & TST & & \\
\hline CHEMBL3729962 & 1537607 & 6.24700 & 00000000 & 01 & 6.1386 & TRN \\
\hline CHEMBL 3727965 & 1537607 & 7.0194 & 7.1122 & TRN & & \\
\hline CHEMBL3729067 & 1537607 & 3.5229 & 1.5972 & TST & & \\
\hline CHEMBL3730866 & 1537607 & 5.2495 & 5.2189 & TRN & & \\
\hline CHEMBL3731108 & 1537607 & 6.2457 & 6.2322 & TRN & & \\
\hline CHEMBL3728013 & 1537607 & 6.9634 & 6.7251 & TRN & & \\
\hline CHEMBL3729253 & 1537607 & 7.0647 & 7.1254 & TRN & & \\
\hline CHEMBL3730129 & 1537607 & 3.5229 & 3.3979 & TRN & & \\
\hline CHEMBL 3727848 & 1537607 & 3.5229 & 3.6309 & TRN & & \\
\hline CHEMBL 3728008 & 1537607 & 6.8216 & 6.9941 & TRN & & \\
\hline CHEMBL3731102 & 1537607 & 6.9776 & 6.8714 & TRN & & \\
\hline CHEMBL 3730755 & 1537607 & 5.4963 & 5.4633 & TRN & & \\
\hline CHEMBL 3727781 & 1537607 & 7.4166 & 7.4128 & TRN & & \\
\hline CHEMBL 3730469 & 1537607 & 7.9776 & 7.9905 & TRN & & \\
\hline CHEMBL3732951 & 1537607 & 5.2778 & 5.1928 & TRN & & \\
\hline CHEMBL 3730494 & 1537607 & 7.17899 & 99999999 & 99 & 7.1518 & TRN \\
\hline CHEMBL3729033 & 1537607 & 3.5229 & 3.4597 & TRN & & \\
\hline CHEMBL3730410 & 1537607 & 5.62 & 5.5236 & TRN & & \\
\hline CHEMBL 3728491 & 1537607 & 3.5229 & 3.5582 & TRN & & \\
\hline CHEMBL3732091 & 1537607 & 3.5229 & 2.1279 & TST & & \\
\hline CHEMBL 3733272 & 1537607 & 7.1353 & 7.1836 & TRN & & \\
\hline CHEMBL3729435 & 1537607 & 5.4669 & 5.5842 & TRN & & \\
\hline CHEMBL3728620 & 1537607 & 7.6066 & 6.7583 & TRN & & \\
\hline CHEMBL 3732266 & 1537607 & 6.3349 & 6.3707 & TRN & & \\
\hline CHEMBL3729340 & 1537607 & 3.5229 & 5.0828 & TST & & \\
\hline CHEMBL3730431 & 1537607 & 8.3054 & 8.3128 & TRN & & \\
\hline CHEMBL3731766 & 1537607 & 6.83299 & 99999999 & 99 & 6.8559 & TRN \\
\hline CHEMBL3729432 & 1537607 & 3.5229 & 3.4748 & TRN & & \\
\hline CHEMBL 3729892 & 1537607 & 5.0577 & 5.0941 & TRN & & \\
\hline CHEMBL 3728153 & 1537607 & 6.2261 & 6.7583 & TRN & & \\
\hline
\end{tabular}


Supplemental Table S2.txt

\begin{tabular}{|c|c|c|c|c|c|c|}
\hline CHEMBL 3728202 & 1537607 & 3.5229 & 1.5296 & TST & & \\
\hline CHEMBL3730981 & 1537607 & 4.7773 & 4.7975 & TRN & & \\
\hline CHEMBL3728728 & 1537607 & 5.6017 & 5.6233 & TRN & & \\
\hline CHEMBL3728417 & 1537607 & 3.5229 & 3.5728 & TRN & & \\
\hline CHEMBL3731476 & 1537607 & 7.4772 & 7.5544 & TRN & & \\
\hline CHEMBL3730270 & 1537607 & 7.2598 & 7.3433 & TRN & & \\
\hline CHEMBL 3727827 & 1537607 & \multicolumn{3}{|c|}{5.486000000000001} & 5.5769 & TRN \\
\hline CHEMBL3727477 & 1537607 & 3.5229 & 4.3951 & TST & & \\
\hline CHEMBL3727768 & 1537607 & 6.1694 & 6.044 & TRN & & \\
\hline CHEMBL3729143 & 1537607 & \multicolumn{3}{|c|}{7.122000000000001} & 7.0705 & TRN \\
\hline CHEMBL 3731542 & 1537607 & 5.6334 & 7.1623 & TST & & \\
\hline CHEMBL3728563 & 1537607 & 5.0379 & 6.1762 & TST & & \\
\hline CHEMBL3731160 & 1537607 & 7.6478 & 7.3483 & TRN & & \\
\hline CHEMBL3730518 & 1537607 & 3.5229 & 3.2641 & TST & & \\
\hline CHEMBL3732678 & 1537607 & 6.8216 & 6.8158 & TRN & & \\
\hline CHEMBL 3732510 & 1537607 & 3.5229 & 2.8202 & TST & & \\
\hline CHEMBL3727816 & 1537607 & 5.1605 & 5.1069 & TRN & & \\
\hline CHEMBL3732594 & 1537607 & 3.5229 & 3.6575 & TST & & \\
\hline CHEMBL3728073 & 1537607 & 7.0302 & 7.0487 & TRN & & \\
\hline CHEMBL3728653 & 1537607 & 6.2105 & 6.1939 & TRN & & \\
\hline CHEMBL3728147 & 1537607 & 3.5229 & 4.6253 & TST & & \\
\hline CHEMBL3730719 & 1537607 & 5.511 & 5.5483 & TRN & & \\
\hline CHEMBL3732797 & 1537607 & 5.6029 & 5.98 & TRN & & \\
\hline CHEMBL3730712 & 1537607 & 6.2642 & 6.218 & TRN & & \\
\hline CHEMBL3732786 & 1537607 & 7.4381 & 7.4394 & TRN & & \\
\hline CHEMBL3732817 & 1537607 & 5.5294 & 5.6629 & TRN & & \\
\hline CHEMBL3731050 & 1537607 & 7.0672 & 7.1171 & TRN & & \\
\hline CHEMBL3729385 & 1537607 & 3.5229 & 2.5874 & TST & & \\
\hline CHEMBL3732187 & 1537607 & 3.5229 & 3.4902 & TRN & & \\
\hline CHEMBL3731888 & 1537607 & 5.2352 & 5.2835 & TRN & & \\
\hline CHEMBL3730794 & 1537607 & 3.5229 & 5.9595 & TST & & \\
\hline CHEMBL3731170 & 1537607 & 7.4216 & 7.4477 & TRN & & \\
\hline CHEMBL3732437 & 1537607 & 6.9957 & 6.9739 & TRN & & \\
\hline CHEMBL3728638 & 1537607 & 6.2371 & 6.3906 & TRN & & \\
\hline CHEMBL3728113 & 1537607 & 3.5229 & 3.4952 & TST & & \\
\hline CHEMBL3731072 & 1537607 & 5.0252 & 6.4879 & TST & & \\
\hline CHEMBL3729647 & 1537607 & 3.5229 & 4.6785 & TST & & \\
\hline CHEMBL3732953 & 1537607 & 3.5229 & 3.8536 & TST & & \\
\hline CHEMBL3732890 & 1537607 & 6.9066 & 6.9149 & TRN & & \\
\hline CHEMBL3731960 & 1537607 & 3.5229 & 4.1876 & TST & & \\
\hline CHEMBL127912 & 62137 & 9.3372 & 9.2154 & TRN & & \\
\hline CHEMBL129465 & 62137 & 9.1308 & 9.244 & TRN & & \\
\hline CHEMBL338552 & 62137 & 9.2291 & 9.4974 & TRN & & \\
\hline CHEMBL126280 & 62137 & 9.1938 & 9.2197 & TRN & & \\
\hline CHEMBL129035 & 62137 & 8.4437 & 9.0976 & TRN & & \\
\hline CHEMBL126780 & 62137 & 8.7447 & 8.7626 & TRN & & \\
\hline CHEMBL127114 & 62137 & 7.8097 & 8.0086 & TST & & \\
\hline CHEMBL341299 & 62137 & 9.2218 & 8.9486 & TRN & & \\
\hline
\end{tabular}

Page 22948 


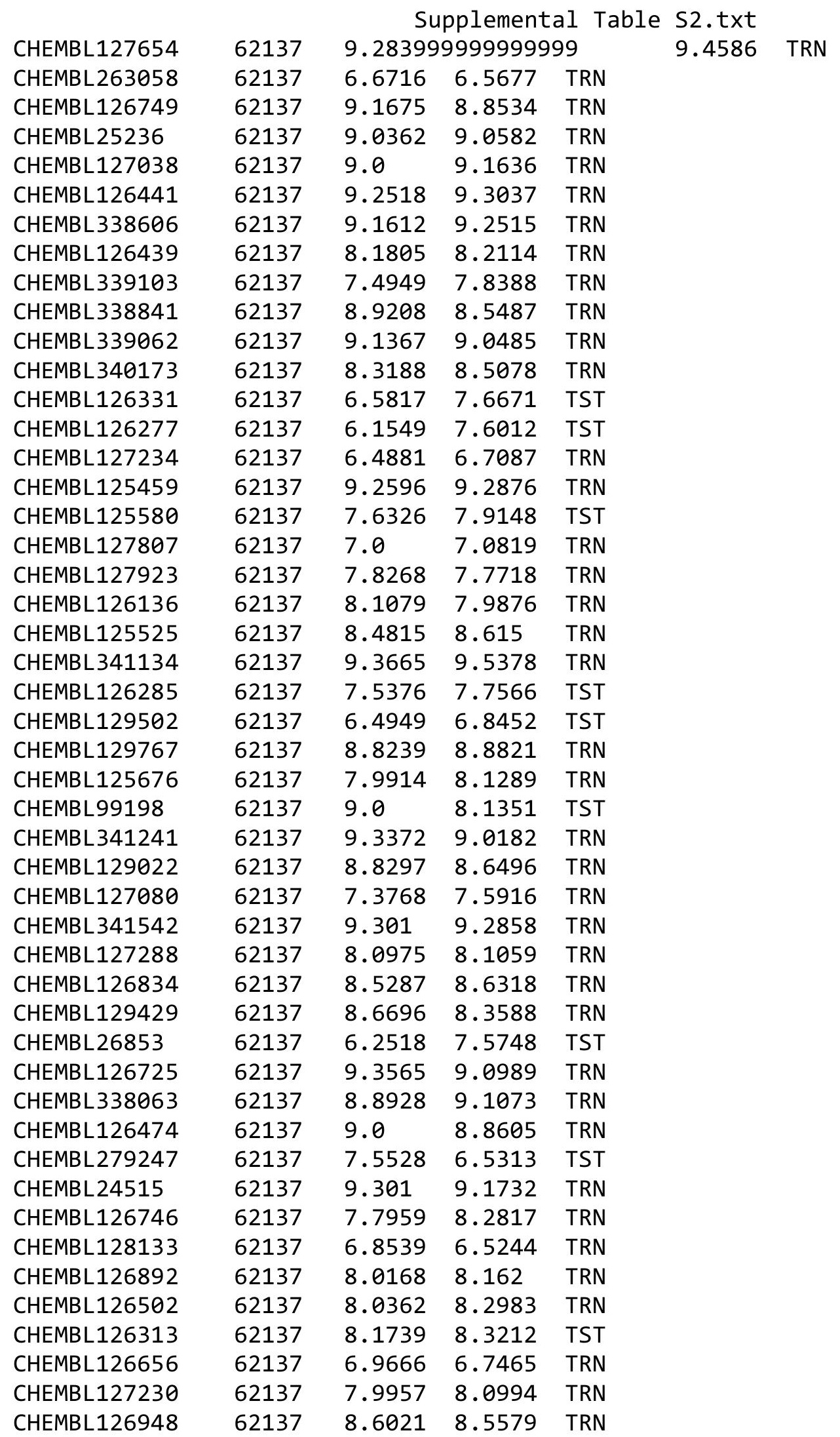

Page 22949 


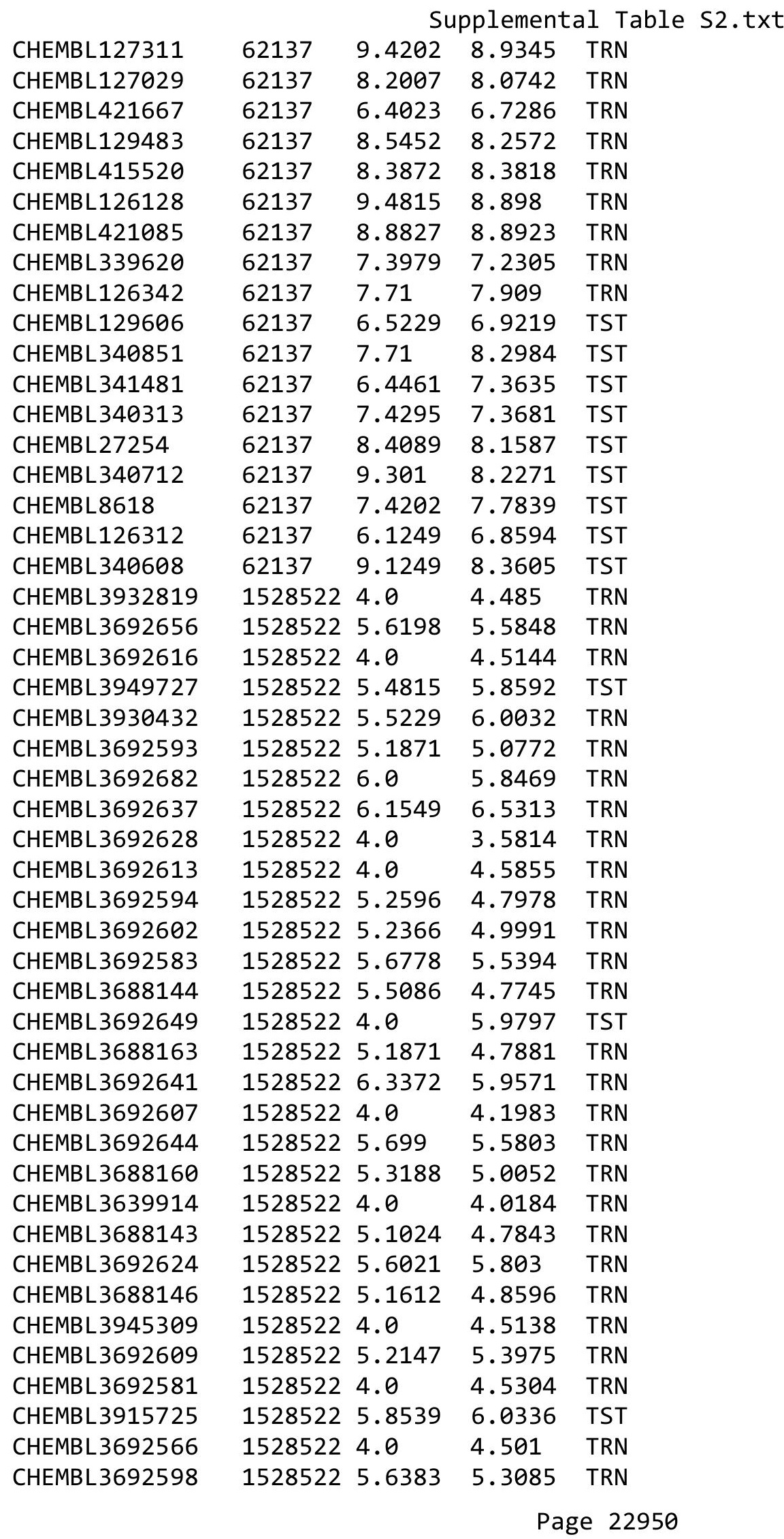


Supplemental Table S2.txt

\begin{tabular}{|c|c|c|c|c|c|}
\hline CHEMBL3944406 & 1528522 & 5.4318 & 5.6926 & TRN & \\
\hline CHEMBL3688158 & 1528522 & 4.0 & 4.3389 & TRN & \\
\hline CHEMBL3692627 & 1528522 & 6.0 & 5.5237 & TRN & \\
\hline CHEMBL3692574 & 1528522 & 4.0 & 3.9873 & TRN & \\
\hline CHEMBL3692646 & 1528522 & 5.041 & 5.2444 & TST & \\
\hline CHEMBL3692587 & 1528522 & 5.0 & 4.8931 & TRN & \\
\hline CHEMBL3688159 & 1528522 & 5.2441 & 5.1775 & TRN & \\
\hline CHEMBL3692651 & 1528522 & 6.0 & 5.9259 & TRN & \\
\hline CHEMBL3692614 & 1528522 & 5.1549 & 5.2094 & TRN & \\
\hline CHEMBL3940445 & 1528522 & 5.6198 & 5.1928 & TST & \\
\hline CHEMBL3692608 & 1528522 & 4.0 & 4.194 & TRN & \\
\hline CHEMBL3688140 & 1528522 & 4.0 & 3.9642 & TRN & \\
\hline CHEMBL3688161 & 1528522 & 5.2218 & 4.5494 & TRN & \\
\hline CHEMBL 3692610 & 1528522 & 5.0655 & 4.6773 & TRN & \\
\hline CHEMBL3932719 & 1528522 & 5.6198 & 5.9198 & TST & \\
\hline CHEMBL3692690 & 1528522 & 5.4685 & 5.5921 & TRN & \\
\hline CHEMBL3692620 & 1528522 & 4.0 & \multicolumn{2}{|c|}{3.6630000000000003} & TRN \\
\hline CHEMBL 3688156 & 1528522 & 4.0 & 4.0947 & TRN & \\
\hline CHEMBL 3688147 & 1528522 & 5.1192 & 4.9905 & TST & \\
\hline CHEMBL3692643 & 1528522 & 6.3565 & \multicolumn{2}{|c|}{6.622000000000001} & TRN \\
\hline CHEMBL3692600 & 1528522 & 4.0 & 4.3715 & TRN & \\
\hline CHEMBL3688150 & 1528522 & 5.0506 & 5.07 & TRN & \\
\hline CHEMBL 3688164 & 1528522 & 5.4949 & 4.8916 & TRN & \\
\hline CHEMBL 3688145 & 1528522 & 5.4949 & 5.4323 & TRN & \\
\hline CHEMBL3692638 & 1528522 & 6.1135 & 5.9531 & TRN & \\
\hline CHEMBL3692579 & 1528522 & 4.0 & 4.5403 & TST & \\
\hline CHEMBL3692576 & 1528522 & 5.3372 & 5.4681 & TST & \\
\hline CHEMBL3890376 & 1528522 & 5.1249 & 5.2279 & TST & \\
\hline CHEMBL 3688149 & 1528522 & 5.2518 & 4.9053 & TRN & \\
\hline CHEMBL3692591 & 1528522 & 4.0 & 3.7642 & TRN & \\
\hline CHEMBL3935456 & 1528522 & 5.1739 & 4.7113 & TST & \\
\hline CHEMBL3692632 & 1528522 & 5.1938 & 5.8113 & TST & \\
\hline CHEMBL 3688165 & 1528522 & 4.0 & 4.0767 & TRN & \\
\hline CHEMBL3918370 & 1528522 & 5.585 & 5.99 & TST & \\
\hline CHEMBL3692601 & 1528522 & 5.3372 & 5.4738 & TRN & \\
\hline CHEMBL3692599 & 1528522 & 4.0 & 4.195 & TRN & \\
\hline CHEMBL3934360 & 1528522 & 5.2676 & 4.8617 & TST & \\
\hline CHEMBL3692570 & 1528522 & 4.0 & 4.5249 & TRN & \\
\hline CHEMBL3692648 & 1528522 & 5.041 & 5.2989 & TST & \\
\hline CHEMBL3977713 & 1528522 & 4.0 & 5.379 & TST & \\
\hline CHEMBL3688162 & 1528522 & 4.0 & 3.6406 & TRN & \\
\hline CHEMBL3692630 & 1528522 & 6.3979 & 6.3148 & TST & \\
\hline CHEMBL3941794 & 1528522 & 4.0 & 4.3281 & TRN & \\
\hline CHEMBL3692615 & 1528522 & 4.0 & 4.2573 & TRN & \\
\hline CHEMBL3692595 & 1528522 & 4.0 & 4.2474 & TRN & \\
\hline CHEMBL3692677 & 1528522 & 4.0 & 4.3092 & TRN & \\
\hline CHEMBL3692578 & 1528522 & 4.0 & 3.5722 & TRN & \\
\hline CHEMBL3692629 & 1528522 & 5.1612 & 5.135 & TRN & \\
\hline
\end{tabular}


Supplemental Table S2.txt

\begin{tabular}{|c|c|c|c|c|}
\hline CHEMBL 3688154 & 1528522 & 4.0 & 4.1872 & TRN \\
\hline CHEMBL 3692668 & 1528522 & 4.0 & 4.0197 & TRN \\
\hline CHEMBL3692645 & 1528522 & 6.2366 & 6.21899 & 999999999 \\
\hline CHEMBL 3910908 & 1528522 & 5.041 & 5.1746 & TST \\
\hline CHEMBL3692582 & 1528522 & 5.4815 & 5.2693 & TRN \\
\hline CHEMBL3692612 & 1528522 & 5.4089 & 4.9337 & TRN \\
\hline CHEMBL3692611 & 1528522 & 4.0 & 3.8714 & TRN \\
\hline CHEMBL3692571 & 1528522 & 4.0 & 4.3879 & TRN \\
\hline CHEMBL3688142 & 1528522 & 4.0 & 4.6956 & TRN \\
\hline CHEMBL3692580 & 1528522 & 5.2441 & 5.2349 & TST \\
\hline CHEMBL 3688153 & 1528522 & 4.0 & 3.9661 & TRN \\
\hline CHEMBL 3907512 & 1528522 & 5.4949 & 5.2578 & TST \\
\hline CHEMBL3692654 & 1528522 & 4.0 & 5.2142 & TST \\
\hline CHEMBL3688155 & 1528522 & 5.1675 & 4.8973 & TRN \\
\hline CHEMBL3692597 & 1528522 & 5.1487 & 4.8392 & TRN \\
\hline CHEMBL3692567 & 1528522 & 4.0 & 4.454 & TRN \\
\hline CHEMBL3943688 & 1528522 & 5.5086 & 5.5641 & TRN \\
\hline CHEMBL3692604 & 1528522 & 5.2757 & 5.3153 & TRN \\
\hline CHEMBL3692592 & 1528522 & 5.1675 & 5.1261 & TRN \\
\hline CHEMBL3692623 & 1528522 & 4.0 & 4.2658 & TRN \\
\hline CHEMBL3692596 & 1528522 & 5.6576 & 5.3567 & TRN \\
\hline CHEMBL3692688 & 1528522 & 5.585 & 5.8834 & TRN \\
\hline CHEMBL3692633 & 1528522 & 5.0044 & 5.1111 & TST \\
\hline CHEMBL3692585 & 1528522 & 4.0 & 4.6797 & TRN \\
\hline CHEMBL3692639 & 1528522 & 6.3279 & 6.8744 & TST \\
\hline CHEMBL3692605 & 1528522 & 5.1675 & 5.1107 & TRN \\
\hline CHEMBL3692653 & 1528522 & 4.0 & 4.8044 & TST \\
\hline CHEMBL3980730 & 1528522 & 5.3279 & 4.9543 & TST \\
\hline CHEMBL3692590 & 1528522 & 4.0 & 3.8962 & TRN \\
\hline CHEMBL3692584 & 1528522 & 5.3188 & 5.8274 & TRN \\
\hline CHEMBL3688151 & 1528522 & 5.3872 & 5.05699 & 9999999995 \\
\hline CHEMBL3692569 & 1528522 & 4.0 & 4.1628 & TRN \\
\hline CHEMBL3692647 & 1528522 & 5.2076 & 5.9137 & TST \\
\hline CHEMBL3692650 & 1528522 & 5.5086 & 5.7518 & TST \\
\hline CHEMBL3692573 & 1528522 & 4.0 & 4.0287 & TRN \\
\hline CHEMBL3692642 & 1528522 & 6.1308 & 6.8359 & TST \\
\hline CHEMBL3688148 & 1528522 & 5.2596 & 5.1688 & TRN \\
\hline CHEMBL3692635 & 1528522 & 4.0 & 5.7028 & TST \\
\hline CHEMBL3951915 & 1528522 & 4.0 & 4.4897 & TST \\
\hline CHEMBL3692572 & 1528522 & 4.0 & 4.4834 & TRN \\
\hline CHEMBL3952684 & 1528522 & 5.6383 & 5.5612 & TRN \\
\hline CHEMBL3692575 & 1528522 & 5.4089 & 4.8691 & TRN \\
\hline CHEMBL3692603 & 1528522 & 5.0809 & 4.8448 & TRN \\
\hline CHEMBL3692625 & 1528522 & 5.2924 & 4.9323 & TRN \\
\hline CHEMBL3692631 & 1528522 & 5.3565 & 6.2275 & TST \\
\hline CHEMBL3692691 & 1528522 & 5.7447 & 5.4468 & TRN \\
\hline CHEMBL3897135 & 1528522 & 5.5229 & 5.6539 & TST \\
\hline CHEMBL3692588 & 1528522 & 4.0 & 4.1616 & TRN \\
\hline
\end{tabular}


Supplemental Table S2.txt

\begin{tabular}{|c|c|c|c|c|c|}
\hline CHEMBL3692568 & 1528522 & 5.1518 & 5.3922 & TRN & \\
\hline CHEMBL3688141 & 1528522 & 5.4949 & 4.8901 & TRN & \\
\hline CHEMBL3958525 & 1528522 & 5.5229 & 5.7794 & TRN & \\
\hline CHEMBL332924 & 47386 & 4.6198 & 4.396 & TST & \\
\hline CHEMBL117023 & 47386 & 5.3468 & 4.5694 & TRN & \\
\hline CHEMBL115426 & 47386 & 5.1249 & 4.4472 & TST & \\
\hline CHEMBL117450 & 47386 & 4.8239 & 4.3838 & TRN & \\
\hline CHEMBL3142935 & 47386 & 4.1612 & 4.2673 & TST & \\
\hline CHEMBL115630 & 47386 & 5.3979 & 4.6002 & TRN & \\
\hline CHEMBL441280 & 47386 & 5.3979 & 5.2505 & TRN & \\
\hline CHEMBL116429 & 47386 & 4.8539 & 5.3773 & TRN & \\
\hline CHEMBL115757 & 47386 & 5.3979 & 5.4514 & TRN & \\
\hline CHEMBL115957 & 47386 & 4.7212 & 4.5183 & TST & \\
\hline CHEMBL 324834 & 47386 & 4.3468 & 4.4025 & TRN & \\
\hline CHEMBL333388 & 47386 & 5.3979 & 4.5563 & TRN & \\
\hline CHEMBL411658 & 47386 & 3.4685 & 4.1798 & TRN & \\
\hline CHEMBL118025 & 47386 & 5.8861 & 5.6014 & TRN & \\
\hline CHEMBL117801 & 47386 & 4.6383 & 4.5938 & TST & \\
\hline CHEMBL116623 & 47386 & 3.0 & 4.581 & TRN & \\
\hline CHEMBL331850 & 47386 & 5.0315 & 5.6803 & TRN & \\
\hline CHEMBL117255 & 47386 & 4.2596 & 4.341 & TRN & \\
\hline CHEMBL325401 & 47386 & 5.4685 & 4.6955 & TRN & \\
\hline CHEMBL333878 & 47386 & 2.3979 & 3.6772 & TRN & \\
\hline CHEMBL 326725 & 47386 & 3.5686 & 3.9739 & TRN & \\
\hline CHEMBL444594 & 47386 & 4.8861 & 5.5526 & TRN & \\
\hline CHEMBL325147 & 47386 & 5.6198 & 5.5828 & TRN & \\
\hline CHEMBL420872 & 47386 & 5.2218 & 5.3874 & TRN & \\
\hline CHEMBL118907 & 47386 & 4.6383 & 4.5671 & TST & \\
\hline CHEMBL116264 & 47386 & 6.3979 & 4.6612 & TST & \\
\hline CHEMBL331383 & 47386 & 4.8539 & 4.5256 & TST & \\
\hline CHEMBL117508 & 47386 & 4.7696 & 4.7774 & TRN & \\
\hline CHEMBL117232 & 47386 & 4.301 & 4.0576 & TRN & \\
\hline CHEMBL432443 & 47386 & 5.5229 & 5.3682 & TRN & \\
\hline CHEMBL 331322 & 47386 & 3.8239 & 5.3773 & TRN & \\
\hline CHEMBL116458 & 47386 & 6.301 & 5.4246 & TRN & \\
\hline CHEMBL118908 & 47386 & 5.8239 & 4.76699 & 99999999995 & TRN \\
\hline CHEMBL419590 & 47386 & 5.3372 & 5.4164 & TRN & \\
\hline CHEMBL116863 & 47386 & 5.0969 & 5.6876 & TRN & \\
\hline CHEMBL115701 & 47386 & 5.9208 & 5.7099 & TRN & \\
\hline CHEMBL3142936 & 47386 & 4.6021 & 4.5183 & TST & \\
\hline CHEMBL432433 & 47386 & 4.5086 & 3.8894 & TRN & \\
\hline CHEMBL116036 & 47386 & 5.301 & 5.3773 & TRN & \\
\hline CHEMBL117336 & 47386 & 5.8861 & 5.8825 & TRN & \\
\hline CHEMBL 2370490 & 47386 & 4.6576 & 4.5863 & TRN & \\
\hline CHEMBL119622 & 47386 & 6.699 & 5.797006 & 0000000001 & TRN \\
\hline CHEMBL116477 & 47386 & 5.5229 & 5.5042 & TRN & \\
\hline CHEMBL325223 & 47386 & 5.585 & 5.3773 & TRN & \\
\hline CHEMBL116894 & 47386 & 5.4815 & 5.6317 & TRN & \\
\hline
\end{tabular}




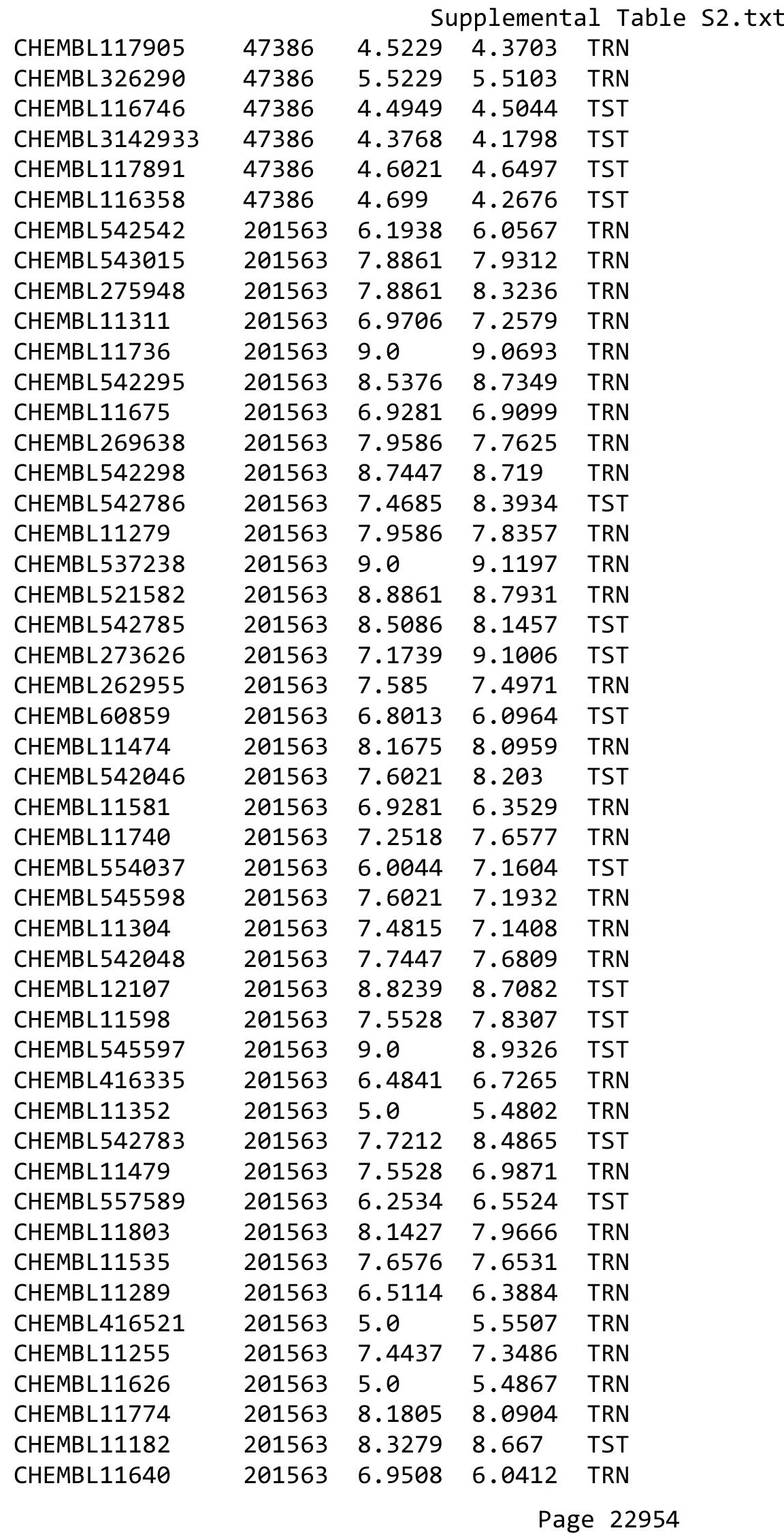




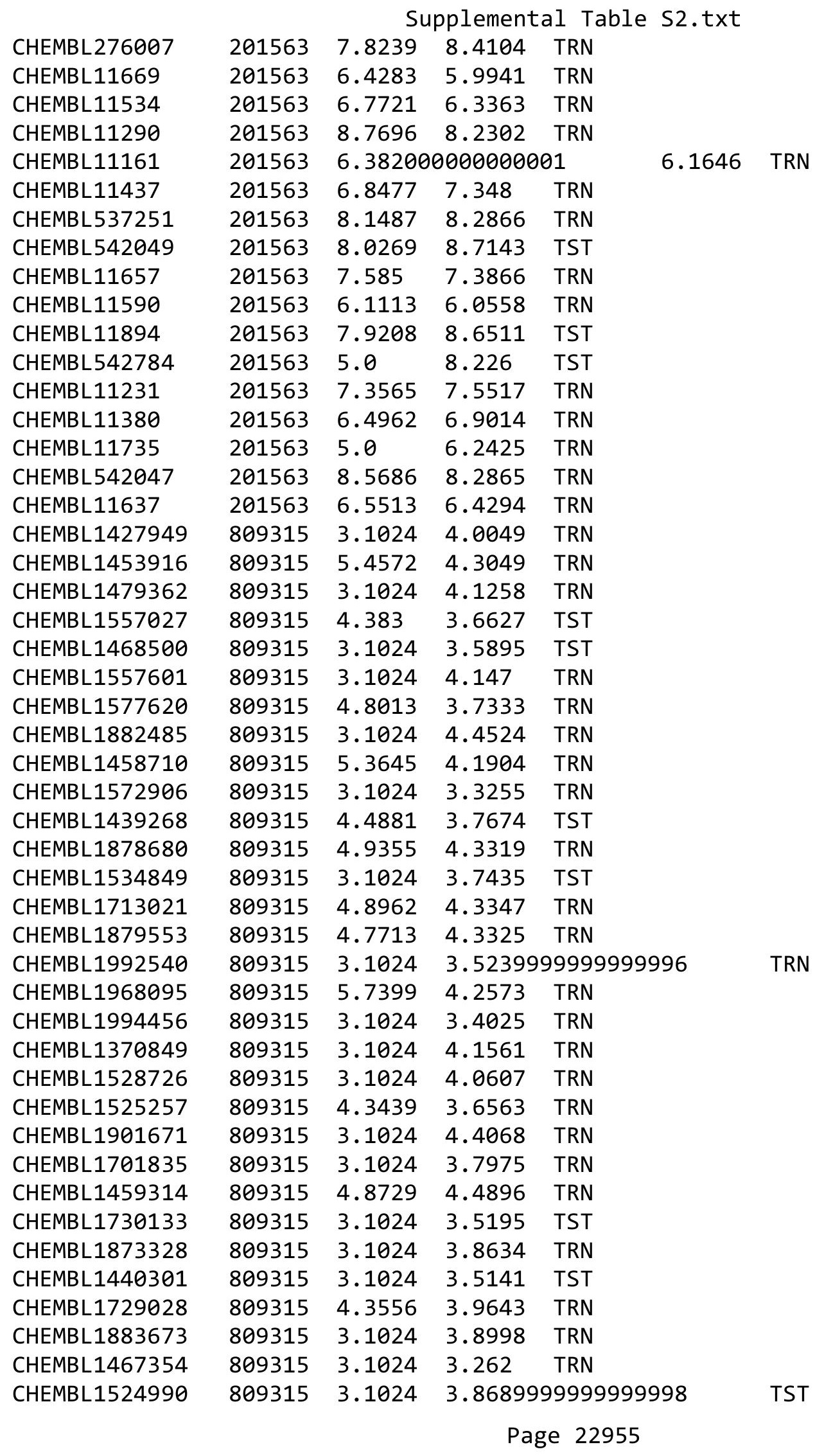


Supplemental Table S2.txt

\begin{tabular}{|c|c|c|c|c|c|c|}
\hline CHEMBL1462924 & 809315 & 3.1024 & 3.7358 & TRN & & \\
\hline CHEMBL1408688 & 809315 & 3.1024 & 3.8214 & TST & & \\
\hline CHEMBL1722488 & 809315 & 4.9318 & 3.8062 & TRN & & \\
\hline CHEMBL1529401 & 809315 & 3.1024 & 3.7113 & TST & & \\
\hline CHEMBL1491564 & 809315 & 3.1024 & 3.654 & TRN & & \\
\hline CHEMBL1725294 & 809315 & 3.1024 & 4.4318 & TRN & & \\
\hline CHEMBL1399390 & 809315 & 3.1024 & 4.0323 & TRN & & \\
\hline CHEMBL1491734 & 809315 & 4.7375 & 3.6905 & TST & & \\
\hline CHEMBL1324195 & 809315 & 3.1024 & 3.7019 & TRN & & \\
\hline CHEMBL1346308 & 809315 & 3.1024 & 3.6148 & TRN & & \\
\hline CHEMBL1884334 & 809315 & 5.8297 & 4.6078 & TRN & & \\
\hline CHEMBL1494757 & 809315 & 5.1537 & 3.7972 & TRN & & \\
\hline CHEMBL1902783 & 809315 & 5.21399 & 99999999 & 995 & 4.0362 & TRN \\
\hline CHEMBL1589231 & 809315 & 3.1024 & 3.4418 & TRN & & \\
\hline CHEMBL1558744 & 809315 & 3.1024 & 3.9517 & TRN & & \\
\hline CHEMBL1901953 & 809315 & 5.34200 & 00000000 & 305 & 4.2069 & TRN \\
\hline CHEMBL1431520 & 809315 & 5.38399 & 99999999 & 995 & 4.3482 & TRN \\
\hline CHEMBL1971872 & 809315 & 3.1024 & 3.5063 & TRN & & \\
\hline CHEMBL1496105 & 809315 & 3.1024 & 3.798 & TRN & & \\
\hline CHEMBL1892639 & 809315 & 3.1024 & 4.4842 & TRN & & \\
\hline CHEMBL1712090 & 809315 & 3.1024 & 4.3298 & TRN & & \\
\hline CHEMBL 2004928 & 809315 & 3.1024 & 3.5736 & TRN & & \\
\hline CHEMBL1427663 & 809315 & 3.1024 & 3.2532 & TRN & & \\
\hline CHEMBL1343685 & 809315 & 5.3615 & 4.8137 & TRN & & \\
\hline CHEMBL1891270 & 809315 & 3.1024 & 4.1572 & TRN & & \\
\hline CHEMBL1887146 & 809315 & 3.1024 & 3.6885 & TRN & & \\
\hline CHEMBL1482332 & 809315 & 3.1024 & 3.9146 & TRN & & \\
\hline CHEMBL1346278 & 809315 & 4.7235 & 3.9641 & TRN & & \\
\hline CHEMBL1719240 & 809315 & 3.1024 & 4.2546 & TRN & & \\
\hline CHEMBL1880451 & 809315 & 3.1024 & 3.3507 & TST & & \\
\hline CHEMBL1735332 & 809315 & 4.6289 & 4.3755 & TRN & & \\
\hline CHEMBL1319264 & 809315 & 4.9234 & 4.4884 & TRN & & \\
\hline CHEMBL1505748 & 809315 & 4.7986 & 3.8127 & TRN & & \\
\hline CHEMBL1515432 & 809315 & 3.1024 & 3.5116 & TST & & \\
\hline CHEMBL1880887 & 809315 & 3.1024 & 4.4897 & TRN & & \\
\hline CHEMBL1894456 & 809315 & 5.1656 & 4.522 & TRN & & \\
\hline CHEMBL1888730 & 809315 & 4.8225 & 4.3878 & TRN & & \\
\hline CHEMBL1397395 & 809315 & 3.1024 & 3.2524 & TRN & & \\
\hline CHEMBL1993796 & 809315 & 5.2204 & 4.1488 & TRN & & \\
\hline CHEMBL1393504 & 809315 & 3.1024 & 3.6487 & TRN & & \\
\hline CHEMBL1975051 & 809315 & 3.1024 & 4.0065 & TRN & & \\
\hline CHEMBL1870332 & 809315 & 3.1024 & 4.1803 & TRN & & \\
\hline CHEMBL1731522 & 809315 & 3.1024 & 3.7463 & TRN & & \\
\hline CHEMBL1718652 & 809315 & 5.2588 & 3.8276 & TRN & & \\
\hline CHEMBL1888908 & 809315 & 3.1024 & 4.6006 & TRN & & \\
\hline CHEMBL1513925 & 809315 & 3.1024 & 3.4113 & TST & & \\
\hline CHEMBL1880473 & 809315 & 4.9208 & 3.9795 & TRN & & \\
\hline CHEMBL1721546 & 809315 & 3.1024 & 4.0024 & TST & & \\
\hline
\end{tabular}


Supplemental Table S2.txt

\begin{tabular}{|c|c|c|c|c|}
\hline CHEMBL1904672 & 809315 & 4.942 & 4.2219 & TRN \\
\hline CHEMBL1611803 & 809315 & 3.1024 & 3.8032 & TST \\
\hline CHEMBL1969010 & 809315 & 4.3152 & 4.4933 & TRN \\
\hline CHEMBL1549839 & 809315 & 3.1024 & 3.7177 & TRN \\
\hline CHEMBL1550633 & 809315 & 5.064 & 3.7839 & TST \\
\hline CHEMBL1428783 & 809315 & 4.6216 & 4.3848 & TRN \\
\hline CHEMBL1580989 & 809315 & 4.5784 & 4.0974 & TRN \\
\hline CHEMBL1550224 & 809315 & 5.0706 & 4.4591 & TRN \\
\hline CHEMBL1987344 & 809315 & 3.1024 & 3.6188 & TST \\
\hline CHEMBL1475866 & 809315 & 4.8539 & 3.739 & TRN \\
\hline CHEMBL1598940 & 809315 & 3.1024 & 3.8196 & TRN \\
\hline CHEMBL1340521 & 809315 & 3.1024 & $3.91300 e$ & 30000000003 \\
\hline CHEMBL1456690 & 809315 & 4.1568 & 3.2229 & TRN \\
\hline CHEMBL1708119 & 809315 & 3.1024 & 3.2136 & TRN \\
\hline CHEMBL1564224 & 809315 & 4.6957 & 3.6932 & TRN \\
\hline CHEMBL1714762 & 809315 & 4.4023 & 3.2666 & TRN \\
\hline CHEMBL1489418 & 809315 & 3.1024 & 4.1187 & TST \\
\hline CHEMBL1601471 & 809315 & 4.1035 & 4.5747 & TRN \\
\hline CHEMBL1725784 & 809315 & 5.4622 & 3.2278 & TRN \\
\hline CHEMBL1500468 & 809315 & 3.1024 & 3.5703 & TRN \\
\hline CHEMBL1602676 & 809315 & 4.8601 & 4.2306 & TRN \\
\hline CHEMBL1376482 & 809315 & 3.1024 & 3.3879 & TST \\
\hline CHEMBL1503376 & 809315 & 5.3726 & 4.8835 & TRN \\
\hline CHEMBL1486891 & 809315 & 5.3747 & 4.0541 & TRN \\
\hline CHEMBL1883315 & 809315 & 3.1024 & 3.318 & TST \\
\hline CHEMBL1516099 & 809315 & 3.1024 & 3.4935 & TRN \\
\hline CHEMBL1966961 & 809315 & 5.4776 & 3.3568 & TRN \\
\hline CHEMBL1330873 & 809315 & 3.1024 & 3.7059 & TRN \\
\hline CHEMBL1422847 & 809315 & 5.1244 & 3.6927 & TRN \\
\hline CHEMBL1982896 & 809315 & 3.1024 & 3.3532 & TRN \\
\hline CHEMBL1405103 & 809315 & 3.1024 & 3.3444 & TRN \\
\hline CHEMBL1557060 & 809315 & 3.1024 & 3.7823 & TRN \\
\hline CHEMBL1555363 & 809315 & 3.1024 & 3.1082 & TRN \\
\hline CHEMBL1863958 & 809315 & 3.1024 & 3.9104 & TRN \\
\hline CHEMBL1999984 & 809315 & 4.5058 & 4.1024 & TRN \\
\hline CHEMBL1723414 & 809315 & 3.1024 & 3.7799 & TRN \\
\hline CHEMBL1421091 & 809315 & \multicolumn{3}{|c|}{4.9830000000000005} \\
\hline CHEMBL1985895 & 809315 & 3.1024 & 4.0659 & TST \\
\hline CHEMBL1880550 & 809315 & 5.7986 & 4.242 & TRN \\
\hline CHEMBL1877015 & 809315 & 3.1024 & 4.2169 & TRN \\
\hline CHEMBL1506609 & 809315 & 3.1024 & 3.6674 & TRN \\
\hline CHEMBL1337268 & 809315 & 4.383 & 3.8413 & TRN \\
\hline CHEMBL1905593 & 809315 & 5.3872 & 4.5925 & TRN \\
\hline CHEMBL1575370 & 809315 & 3.1024 & 2.8588 & TRN \\
\hline CHEMBL1412745 & 809315 & 3.1024 & 3.5283 & TRN \\
\hline CHEMBL1588387 & 809315 & 4.6198 & 3.784 & TRN \\
\hline CHEMBL1700311 & 809315 & 3.1024 & 3.9265 & TRN \\
\hline CHEMBL1981303 & 809315 & 3.1024 & 3.6555 & TST \\
\hline
\end{tabular}


Supplemental Table S2.txt

\begin{tabular}{|c|c|c|c|c|}
\hline CHEMBL1891615 & 809315 & 3.1024 & 3.4514 & TST \\
\hline CHEMBL1450049 & 809315 & 5.2668 & 3.5965 & TRN \\
\hline CHEMBL1967640 & 809315 & 5.0386 & 4.3066 & TRN \\
\hline CHEMBL1731294 & 809315 & 3.1024 & 3.1407 & TST \\
\hline CHEMBL1396713 & 809315 & 3.1024 & 3.6525 & TST \\
\hline CHEMBL1969457 & 809315 & 4.9626 & 3.7542 & TST \\
\hline CHEMBL1900738 & 809315 & 4.6882 & 4.2206 & TRN \\
\hline CHEMBL1438732 & 809315 & 3.1024 & 3.7933 & TRN \\
\hline CHEMBL1558069 & 809315 & 3.1024 & 3.7317 & TRN \\
\hline CHEMBL1525055 & 809315 & 5.3439 & 4.2301 & TRN \\
\hline CHEMBL1393529 & 809315 & 3.1024 & 3.2589 & TRN \\
\hline CHEMBL1301826 & 809315 & 3.1024 & 3.7225 & TRN \\
\hline CHEMBL1448654 & 809315 & 5.4921 & 3.9988 & TRN \\
\hline CHEMBL1397022 & 809315 & 4.4815 & 3.792 & TRN \\
\hline CHEMBL1867718 & 809315 & 4.8894 & 4.2279 & TRN \\
\hline CHEMBL1364287 & 809315 & 4.9083 & 4.7296 & TRN \\
\hline CHEMBL1512072 & 809315 & 3.1024 & 4.1966 & TRN \\
\hline CHEMBL1400446 & 809315 & 3.1024 & 3.3227 & TRN \\
\hline CHEMBL1975458 & 809315 & 3.1024 & 4.1228 & TRN \\
\hline CHEMBL1423148 & 809315 & 4.3089 & 3.5705 & TRN \\
\hline CHEMBL1497342 & 809315 & 4.4306 & 3.6792 & TRN \\
\hline CHEMBL1571998 & 809315 & 3.1024 & 3.7891 & TRN \\
\hline CHEMBL1532425 & 809315 & 3.1024 & 3.673 & TST \\
\hline CHEMBL1605288 & 809315 & 5.4437 & 4.4036 & TRN \\
\hline CHEMBL1588014 & 809315 & 3.1024 & 3.5686 & TRN \\
\hline CHEMBL1581308 & 809315 & 3.1024 & 3.711006 & 30000000003 \\
\hline CHEMBL1307703 & 809315 & 5.399 & 4.4492 & TRN \\
\hline CHEMBL1463893 & 809315 & 3.1024 & 4.2607 & TST \\
\hline CHEMBL1893210 & 809315 & 5.2111 & 4.5982 & TRN \\
\hline CHEMBL1311274 & 809315 & 3.1024 & 4.1901 & TRN \\
\hline CHEMBL1877908 & 809315 & 3.1024 & 4.329 & TRN \\
\hline CHEMBL 2004144 & 809315 & 3.1024 & 3.9445 & TRN \\
\hline CHEMBL1559375 & 809315 & 4.8633 & 3.9705 & TRN \\
\hline CHEMBL1403619 & 809315 & 3.1024 & 3.568 & TRN \\
\hline CHEMBL1497909 & 809315 & 3.1024 & 3.9695 & TRN \\
\hline CHEMBL1730650 & 809315 & 3.1024 & 3.4681 & TRN \\
\hline CHEMBL1429513 & 809315 & 4.6778 & $4.15300 e$ & 00000000005 \\
\hline CHEMBL1563287 & 809315 & 3.1024 & 3.4477 & TRN \\
\hline CHEMBL1450838 & 809315 & 4.3851 & 3.2739 & TRN \\
\hline CHEMBL1711830 & 809315 & 3.1024 & 4.1711 & TRN \\
\hline CHEMBL1442453 & 809315 & 3.1024 & 4.0985 & TRN \\
\hline CHEMBL1733950 & 809315 & 3.1024 & 3.3638 & TRN \\
\hline CHEMBL2003436 & 809315 & 3.1024 & 3.4656 & TRN \\
\hline CHEMBL1557268 & 809315 & 3.1024 & 3.3542 & TRN \\
\hline CHEMBL1865969 & 809315 & 3.1024 & 3.2503 & TST \\
\hline CHEMBL1879523 & 809315 & 3.1024 & 3.7046 & TST \\
\hline CHEMBL1595051 & 809315 & 3.1024 & 3.9355 & TRN \\
\hline CHEMBL1476641 & 809315 & 3.1024 & 3.1921 & TRN \\
\hline
\end{tabular}

Page 22958 


\begin{tabular}{|c|c|c|c|c|c|}
\hline \multicolumn{6}{|c|}{ Supplemental Table S2.txt } \\
\hline CHEMBL1547685 & 809315 & 5.06 & 4.3044 & TRN & \\
\hline CHEMBL1443753 & 809315 & 3.1024 & 3.8828 & TRN & \\
\hline CHEMBL1586524 & 809315 & 3.1024 & 3.2419 & TRN & \\
\hline CHEMBL1999359 & 809315 & 3.1024 & 4.0717 & TRN & \\
\hline CHEMBL1879313 & 809315 & 5.059 & 4.0068 & TRN & \\
\hline CHEMBL1595618 & 809315 & 3.1024 & 3.6407 & TRN & \\
\hline CHEMBL1991618 & 809315 & 3.1024 & 3.9835 & TST & \\
\hline CHEMBL1601300 & 809315 & 5.7352 & 4.0297 & TST & \\
\hline CHEMBL 1367230 & 809315 & 3.1024 & 4.1688 & TST & \\
\hline CHEMBL1474526 & 809315 & 4.5498 & 3.2686 & TST & \\
\hline CHEMBL1880968 & 809315 & 5.4841 & 3.918 & TST & \\
\hline CHEMBL1987094 & 809315 & 3.1024 & 4.0215 & TST & \\
\hline CHEMBL1545153 & 809315 & 4.9158 & 4.1974 & TST & \\
\hline CHEMBL1395840 & 809315 & 3.1024 & 3.4731 & TST & \\
\hline CHEMBL 2001262 & 809315 & 3.1024 & 3.6792 & TST & \\
\hline CHEMBL1480223 & 809315 & 4.5591 & 3.9786 & TST & \\
\hline CHEMBL 2006274 & 809315 & 3.1024 & 3.5385 & TST & \\
\hline CHEMBL1540513 & 809315 & 3.1024 & 4.2458 & TST & \\
\hline CHEMBL1385111 & 809315 & 5.0 & 4.3429 & TST & \\
\hline CHEMBL1423858 & 809315 & 3.1024 & 3.5036 & TST & \\
\hline CHEMBL1979976 & 809315 & 4.3161 & 4.226 & TST & \\
\hline CHEMBL1341199 & 809315 & 3.1024 & 3.3571 & TST & \\
\hline CHEMBL1512150 & 809315 & 3.1024 & 3.4039 & TST & \\
\hline CHEMBL1580522 & 809315 & 3.1024 & 3.8763 & TST & \\
\hline CHEMBL1530972 & 809315 & 3.1024 & 4.2527 & TST & \\
\hline CHEMBL1707466 & 809315 & 4.6716 & 4.3292 & TST & \\
\hline CHEMBL3890952 & 1638332 & 6.6 & 6.4708 & TST & \\
\hline CHEMBL3986031 & 1638332 & 6.7 & 6.3211 & TRN & \\
\hline CHEMBL 3950244 & 1638332 & 7.4 & 6.8658 & TST & \\
\hline CHEMBL3936313 & 1638332 & 6.9 & 6.63399 & 99999999995 & TRN \\
\hline CHEMBL 3975361 & 1638332 & 6.9 & 7.1962 & TRN & \\
\hline CHEMBL3972891 & 1638332 & 8.35 & 7.2302 & TRN & \\
\hline CHEMBL3936030 & 1638332 & 6.3 & 6.6332 & TST & \\
\hline CHEMBL3926339 & 1638332 & 6.9 & 6.3476 & TST & \\
\hline CHEMBL3981280 & 1638332 & 6.5 & 6.9119 & TRN & \\
\hline CHEMBL3978906 & 1638332 & 6.65 & 6.8651 & TST & \\
\hline CHEMBL3936387 & 1638332 & 6.95 & 6.56 & TST & \\
\hline CHEMBL3939149 & 1638332 & 6.1 & 6.6332 & TST & \\
\hline CHEMBL3975672 & 1638332 & 6.7 & 6.8325 & TRN & \\
\hline CHEMBL3978163 & 1638332 & 7.0 & 7.1033 & TRN & \\
\hline CHEMBL3914902 & 1638332 & 7.3 & 7.2321 & TRN & \\
\hline CHEMBL3924729 & 1638332 & 6.7 & 7.1114 & TST & \\
\hline CHEMBL3922595 & 1638332 & 7.1 & 6.5492 & TST & \\
\hline CHEMBL3962216 & 1638332 & 6.9 & 6.6854 & TST & \\
\hline CHEMBL3900518 & 1638332 & 7.0 & 6.6854 & TST & \\
\hline CHEMBL3903238 & 1638332 & 7.3 & 6.9197 & TST & \\
\hline CHEMBL3913118 & 1638332 & 6.1 & 6.8179 & TST & \\
\hline CHEMBL3964255 & 1638332 & 7.34 & 6.5058 & TRN & \\
\hline
\end{tabular}




\begin{tabular}{|c|c|c|c|c|c|}
\hline \multicolumn{6}{|c|}{ semental } \\
\hline CHEMBL3950900 & 1638332 & 6.87 & 7.6937 & TST & \\
\hline CHEMBL3948263 & 1638332 & 7.68 & 7.5331 & TST & \\
\hline CHEMBL3955287 & 1638332 & 6.85 & 6.55200 & 00000000005 & TST \\
\hline CHEMBL3952672 & 1638332 & 7.5 & 7.0889 & TRN & \\
\hline CHEMBL3967281 & 1638332 & 7.5 & 7.4645 & TRN & \\
\hline CHEMBL3962344 & 1638332 & 7.6 & 7.2107 & TST & \\
\hline CHEMBL3978115 & 1638332 & 7.5 & 7.3096 & TRN & \\
\hline CHEMBL3968950 & 1638332 & 7.8 & 7.4665 & TRN & \\
\hline CHEMBL3920558 & 1638332 & 7.7 & 7.1265 & TRN & \\
\hline CHEMBL3923266 & 1638332 & 7.3 & 7.6937 & TST & \\
\hline CHEMBL3910676 & 1638332 & 7.4 & 7.3625 & TST & \\
\hline CHEMBL3913347 & 1638332 & 7.9 & 7.3636 & TST & \\
\hline CHEMBL3906068 & 1638332 & 8.0 & 7.4537 & TST & \\
\hline CHEMBL3908892 & 1638332 & 7.6 & 7.2703 & TST & \\
\hline CHEMBL3958090 & 1638332 & 7.5 & 6.8512 & TST & \\
\hline CHEMBL3969947 & 1638332 & 5.5 & 6.0855 & TST & \\
\hline CHEMBL3946862 & 1638332 & 7.9 & 7.4463 & TST & \\
\hline CHEMBL3949556 & 1638332 & 7.7 & 7.3625 & TST & \\
\hline CHEMBL3909026 & 1638332 & 7.5 & 7.1487 & TST & \\
\hline CHEMBL3911750 & 1638332 & 7.7 & 7.2901 & TST & \\
\hline CHEMBL3932568 & 1638332 & 7.5 & 7.0869 & TST & \\
\hline CHEMBL3935259 & 1638332 & 7.8 & 7.1934 & TST & \\
\hline CHEMBL3976345 & 1638332 & 7.3 & 7.1659 & TRN & \\
\hline CHEMBL 3897251 & 1638332 & 7.55 & 6.8702 & TRN & \\
\hline CHEMBL3908412 & 1638332 & 7.65 & 6.8702 & TRN & \\
\hline CHEMBL3957021 & 1638332 & 7.45 & 7.0176 & TRN & \\
\hline CHEMBL3965836 & 1638332 & 7.4 & 7.1659 & TRN & \\
\hline CHEMBL3953888 & 1638332 & 7.35 & 7.0176 & TRN & \\
\hline CHEMBL3904443 & 1638332 & 7.45 & 6.9876 & TRN & \\
\hline CHEMBL3901739 & 1638332 & 7.3 & 6.9876 & TRN & \\
\hline CHEMBL3979206 & 1638332 & 7.7 & 7.3311 & TRN & \\
\hline CHEMBL 3969300 & 1638332 & 6.9 & 6.6123 & TRN & \\
\hline CHEMBL3918931 & 1638332 & 7.1 & 6.6931 & TRN & \\
\hline CHEMBL3916168 & 1638332 & 6.3 & 6.7171 & TRN & \\
\hline CHEMBL 3973218 & 1638332 & 6.9 & 6.46899 & 9999999999 & TRN \\
\hline CHEMBL3907955 & 1638332 & 6.35 & 6.71299 & 9999999999 & TRN \\
\hline CHEMBL3906665 & 1638332 & 7.0 & 6.7277 & TRN & \\
\hline CHEMBL3986076 & 1638332 & 4.0 & 6.5023 & TST & \\
\hline CHEMBL3964147 & 1638332 & 7.2 & 6.6188 & TRN & \\
\hline CHEMBL 3954142 & 1638332 & 7.4 & 7.0684 & TRN & \\
\hline CHEMBL3987020 & 1638332 & 8.0 & 7.506 & TRN & \\
\hline CHEMBL 3940806 & 1638332 & 4.0 & 5.4489 & TST & \\
\hline CHEMBL3969936 & 1638332 & 6.6 & 6.3956 & TRN & \\
\hline CHEMBL3978946 & 1638332 & 6.7 & 6.4629 & TRN & \\
\hline CHEMBL 3986344 & 1638332 & 6.5 & 6.7408 & TST & \\
\hline CHEMBL 3902724 & 1638332 & 5.3 & 6.2216 & TST & \\
\hline CHEMBL 3920001 & 1638332 & 6.3 & 6.6931 & TRN & \\
\hline CHEMBL3938343 & 1638332 & 6.3 & 6.6365 & TRN & \\
\hline
\end{tabular}




\begin{tabular}{|c|c|c|c|c|c|}
\hline \multirow{3}{*}{$\begin{array}{l}\text { CHEMBL } 3973838 \\
\text { CHEMBL } 3921165\end{array}$} & \multirow[b]{2}{*}{1638332} & \multicolumn{4}{|c|}{ Supplemental Table S2.txt } \\
\hline & & 5.6 & 6.4689 & 9999999999 & TRN \\
\hline & 1638332 & 6.25 & 7.0684 & TRN & \\
\hline CHEMBL3934345 & 1638332 & 6.0 & 6.7277 & TRN & \\
\hline CHEMBL3931639 & 1638332 & 6.5 & 6.6634 & TRN & \\
\hline CHEMBL3950017 & 1638332 & 5.5 & 6.6634 & TRN & \\
\hline CHEMBL3947345 & 1638332 & 7.9 & 7.506 & TRN & \\
\hline CHEMBL3940623 & 1638332 & 6.8 & 6.4966 & TRN & \\
\hline CHEMBL3943265 & 1638332 & 4.0 & 4.9778 & TRN & \\
\hline CHEMBL3895518 & 1638332 & 7.5 & 7.0039 & TRN & \\
\hline CHEMBL3905218 & 1638332 & 5.8 & 6.6188 & TRN & \\
\hline CHEMBL3954659 & 1638332 & 5.8 & 5.7153 & TRN & \\
\hline CHEMBL3908976 & 1638332 & 4.0 & 7.1599 & TST & \\
\hline CHEMBL3986598 & 1638332 & 7.07 & 7.2241 & TRN & \\
\hline CHEMBL3891538 & 1638332 & 7.1 & 7.0815 & TRN & \\
\hline CHEMBL3929745 & 1638332 & 7.2 & 7.2241 & TRN & \\
\hline CHEMBL3950815 & 1638332 & 5.3 & 4.9626 & TRN & \\
\hline CHEMBL3917684 & 1638332 & 4.0 & 5.9898 & TRN & \\
\hline CHEMBL3944662 & 1638332 & 4.0 & 5.7395 & TRN & \\
\hline CHEMBL3896696 & 1638332 & 4.0 & 5.9122 & TRN & \\
\hline CHEMBL3964543 & 1638332 & 6.6 & 6.4966 & TRN & \\
\hline CHEMBL3903230 & 1638332 & 7.5 & 7.4936 & TST & \\
\hline CHEMBL3921641 & 1638332 & 7.6 & 7.5634 & TST & \\
\hline CHEMBL3970997 & 1638332 & 8.4 & 7.3311 & TRN & \\
\hline CHEMBL3968241 & 1638332 & 8.6 & 5.7799 & TRN & \\
\hline CHEMBL3909990 & 1638332 & 8.1 & 7.5244 & TRN & \\
\hline CHEMBL3951502 & 1638332 & 4.0 & 7.4443 & TRN & \\
\hline CHEMBL3979250 & 1638332 & 6.6 & 6.1107 & TRN & \\
\hline CHEMBL3981652 & 1638332 & 6.7 & 6.7493 & TRN & \\
\hline CHEMBL3946911 & 1638332 & 6.7 & 6.5064 & TRN & \\
\hline CHEMBL3949616 & 1638332 & 5.9 & 5.7861 & TRN & \\
\hline CHEMBL3985316 & 1638332 & 7.0 & 7.1481 & TST & \\
\hline CHEMBL3897301 & 1638332 & 6.9 & 7.1388 & TRN & \\
\hline CHEMBL3932620 & 1638332 & 8.4 & 6.1802 & TRN & \\
\hline CHEMBL3935315 & 1638332 & 7.4 & 6.9166 & TRN & \\
\hline CHEMBL3916805 & 1638332 & 5.8 & 5.7123 & TRN & \\
\hline CHEMBL3919537 & 1638332 & 4.0 & 5.9251 & TRN & \\
\hline CHEMBL3914102 & 1638332 & 4.0 & 5.5887 & TRN & \\
\hline CHEMBL3923362 & 1638332 & 4.0 & 4.5124 & TRN & \\
\hline CHEMBL3956990 & 1638332 & 4.0 & 4.5124 & TRN & \\
\hline CHEMBL3954388 & 1638332 & 4.0 & 7.4558 & TRN & \\
\hline CHEMBL3911722 & 1638332 & 4.0 & 7.5354 & TRN & \\
\hline CHEMBL3908997 & 1638332 & 7.5 & 7.5244 & TRN & \\
\hline CHEMBL3972691 & 1638332 & 7.4 & 7.4443 & TRN & \\
\hline CHEMBL3960838 & 1638332 & 8.7 & 7.1972 & TRN & \\
\hline CHEMBL3933814 & 1638332 & 7.8 & 6.5437 & TRN & \\
\hline CHEMBL3931110 & 1638332 & 4.0 & 5.8371 & TST & \\
\hline CHEMBL3903052 & 1638332 & 6.2 & 6.6115 & TRN & \\
\hline CHEMBL3905716 & 1638332 & 7.5 & 7.1435 & TRN & \\
\hline
\end{tabular}




\begin{tabular}{|c|c|c|c|c|}
\hline & & & pplement & al $\mathrm{Ta}$ \\
\hline CHEMBL3962012 & 1638332 & 7.17 & 6.9439 & TRN \\
\hline CHEMBL3953809 & 1638332 & 4.0 & 6.3131 & TST \\
\hline CHEMBL3986393 & 1638332 & 4.0 & 6.5278 & TST \\
\hline CHEMBL3891308 & 1638332 & 8.2 & 7.5749 & TRN \\
\hline CHEMBL3941108 & 1638332 & 7.1 & 7.18 & TRN \\
\hline CHEMBL3950597 & 1638332 & 5.6 & 6.7164 & TRN \\
\hline CHEMBL3895308 & 1638332 & 6.1 & 6.7687 & TRN \\
\hline CHEMBL3897976 & 1638332 & 6.1 & 6.836 & TRN \\
\hline CHEMBL3935894 & 1638332 & 6.0 & 7.2205 & TRN \\
\hline CHEMBL3926192 & 1638332 & 6.5 & 6.8493 & TRN \\
\hline CHEMBL3908728 & 1638332 & 6.5 & 6.5465 & TRN \\
\hline CHEMBL3972753 & 1638332 & 7.4 & 7.2187 & TST \\
\hline CHEMBL3950116 & 1638332 & 4.0 & 7.3233 & TRN \\
\hline CHEMBL3926955 & 1638332 & 7.3 & 6.8632 & TRN \\
\hline CHEMBL3890799 & 1638332 & 7.3 & 6.9556 & TRN \\
\hline CHEMBL3985868 & 1638332 & 7.6 & 7.1396 & TRN \\
\hline CHEMBL3926527 & 1638332 & 8.9 & 7.0501 & TRN \\
\hline CHEMBL3918424 & 1638332 & 6.9 & 6.9278 & TRN \\
\hline CHEMBL3895338 & 1638332 & 8.1 & 6.728 & TRN \\
\hline CHEMBL3892607 & 1638332 & 7.25 & 6.8761 & TRN \\
\hline CHEMBL3954472 & 1638332 & 7.2 & 7.056 & TRN \\
\hline CHEMBL3951816 & 1638332 & 7.6 & 7.1107 & TRN \\
\hline CHEMBL 3979252 & 1638332 & 7.8 & 7.4669 & TRN \\
\hline CHEMBL 3940439 & 1638332 & 8.4 & 7.3186 & TRN \\
\hline CHEMBL3930643 & 1638332 & 8.1 & 7.3701 & TRN \\
\hline CHEMBL3976660 & 1638332 & 8.6 & 7.3421 & TRN \\
\hline CHEMBL3982724 & 1638332 & 8.3 & 7.1568 & TRN \\
\hline CHEMBL3942614 & 1638332 & 4.0 & 7.7118 & TRN \\
\hline CHEMBL3932191 & 1638332 & 6.9 & 6.9492 & TRN \\
\hline CHEMBL3981204 & 1638332 & 6.8 & 6.6713 & TRN \\
\hline CHEMBL3983692 & 1638332 & 7.7 & 7.2061 & TRN \\
\hline CHEMBL3921195 & 1638332 & 6.7 & 6.8087 & TRN \\
\hline CHEMBL3943152 & 1638332 & 7.7 & 6.99 & TRN \\
\hline CHEMBL3965393 & 1638332 & 4.0 & 6.6417 & TRN \\
\hline CHEMBL3970565 & 1638332 & 7.2 & 6.8883 & TRN \\
\hline CHEMBL3965282 & 1638332 & 9.2 & 7.0559 & TRN \\
\hline CHEMBL3943229 & 1638332 & 7.3 & 6.4505 & TRN \\
\hline CHEMBL 3940580 & 1638332 & 7.9 & 7.019 & TRN \\
\hline CHEMBL3911951 & 1638332 & 7.53 & 7.2887 & TRN \\
\hline CHEMBL3909231 & 1638332 & 4.0 & 7.4028 & TST \\
\hline CHEMBL3956501 & 1638332 & 4.0 & 7.5803 & TRN \\
\hline CHEMBL3947060 & 1638332 & 5.8 & 7.2752 & TRN \\
\hline CHEMBL3928899 & 1638332 & 6.5 & 6.3168 & TRN \\
\hline CHEMBL 3979858 & 1638332 & 7.1 & 6.7929 & TRN \\
\hline CHEMBL 3983258 & 1638332 & 8.2 & 6.778 & TRN \\
\hline CHEMBL3985915 & 1638332 & 7.6 & 7.2529 & TRN \\
\hline CHEMBL3937928 & 1638332 & 8.6 & 7.5683 & TRN \\
\hline CHEMBL 3945874 & 1638332 & 7.8 & 6.9267 & TRN \\
\hline
\end{tabular}




\begin{tabular}{|c|c|c|c|c|c|}
\hline CHEMBL3960033 & 1638332 & 7.5 & \multicolumn{2}{|c|}{6.9879999999999995} & TRN \\
\hline CHEMBL 3902600 & 1638332 & 7.7 & 7.159 & TRN & \\
\hline CHEMBL3958849 & 1638332 & 7.1 & 6.8615 & TRN & \\
\hline CHEMBL3961536 & 1638332 & 8.0 & 7.2655 & TRN & \\
\hline CHEMBL3901000 & 1638332 & 8.0 & 6.2273 & TRN & \\
\hline CHEMBL3957349 & 1642025 & 7.6576 & 7.7204 & TRN & \\
\hline CHEMBL3937626 & 1642025 & 6.0 & 6.1688 & TRN & \\
\hline CHEMBL3963075 & 1642025 & 7.8861 & 7.9618 & TST & \\
\hline CHEMBL3951991 & 1642025 & 6.0 & 6.0725 & TRN & \\
\hline CHEMBL3951691 & 1642025 & 7.6383 & 7.6231 & TRN & \\
\hline CHEMBL3979279 & 1642025 & 6.0 & 6.0278 & TRN & \\
\hline CHEMBL3910184 & 1642025 & 8.3979 & 8.3988 & TRN & \\
\hline CHEMBL3928453 & 1642025 & 7.5376 & \multicolumn{2}{|c|}{7.202000000000001} & TRN \\
\hline CHEMBL3982966 & 1642025 & 8.699 & 8.6841 & TRN & \\
\hline CHEMBL 3979242 & 1642025 & 8.301 & 8.2162 & TRN & \\
\hline CHEMBL3912331 & 1642025 & 6.0 & 6.1276 & TRN & \\
\hline CHEMBL3959630 & 1642025 & 7.7212 & 7.8288 & TRN & \\
\hline CHEMBL3974023 & 1642025 & 9.0 & 9.0146 & TRN & \\
\hline CHEMBL3897260 & 1642025 & 7.5686 & 7.3871 & TRN & \\
\hline CHEMBL3968880 & 1642025 & 8.699 & 8.6378 & TRN & \\
\hline CHEMBL3913755 & 1642025 & 6.0 & 5.9865 & TRN & \\
\hline CHEMBL3897225 & 1642025 & 7.6021 & 7.2141 & TRN & \\
\hline CHEMBL3909589 & 1642025 & 8.301 & 8.3368 & TST & \\
\hline CHEMBL3897013 & 1642025 & 8.699 & 8.6859 & TRN & \\
\hline CHEMBL3957690 & 1642025 & 7.7212 & 7.7234 & TRN & \\
\hline CHEMBL3940558 & 1642025 & 8.301 & 7.6801 & TST & \\
\hline CHEMBL3959433 & 1642025 & 6.0 & 5.4235 & TST & \\
\hline CHEMBL3912265 & 1642025 & 9.301 & 9.3111 & TRN & \\
\hline CHEMBL3934188 & 1642025 & 8.0458 & 8.5224 & TRN & \\
\hline CHEMBL3894596 & 1642025 & 6.0 & 7.6615 & TST & \\
\hline CHEMBL3922606 & 1642025 & 7.7959 & 8.3941 & TRN & \\
\hline CHEMBL3972345 & 1642025 & 6.0 & 7.0856 & TST & \\
\hline CHEMBL3972898 & 1642025 & 7.4202 & 7.4528 & TRN & \\
\hline CHEMBL3967283 & 1642025 & 6.0 & 6.0688 & TRN & \\
\hline CHEMBL3986662 & 1642025 & 8.3979 & 8.3986 & TRN & \\
\hline CHEMBL3895755 & 1642025 & 6.0 & 6.0988 & TRN & \\
\hline CHEMBL3921073 & 1642025 & 8.301 & 8.2387 & TRN & \\
\hline CHEMBL3978312 & 1642025 & 8.5229 & 8.461 & TRN & \\
\hline CHEMBL3969549 & 1642025 & 6.0 & 5.7056 & TST & \\
\hline CHEMBL3954457 & 1642025 & 8.2218 & 7.2075 & TST & \\
\hline CHEMBL3958808 & 1642025 & 7.7696 & 7.8787 & TRN & \\
\hline CHEMBL3955531 & 1642025 & 6.0 & 5.9235 & TRN & \\
\hline CHEMBL3917864 & 1642025 & 9.0 & 9.408 & TRN & \\
\hline CHEMBL3966105 & 1642025 & 7.7959 & 7.515 & TST & \\
\hline CHEMBL3968173 & 1642025 & 8.699 & 8.6366 & TRN & \\
\hline CHEMBL3904039 & 1642025 & 6.0 & 7.8536 & TST & \\
\hline CHEMBL3942861 & 1642025 & 8.0969 & 7.9733 & TRN & \\
\hline CHEMBL3967088 & 1642025 & 8.301 & 8.1962 & TRN & \\
\hline
\end{tabular}


Supplemental Table S2.txt

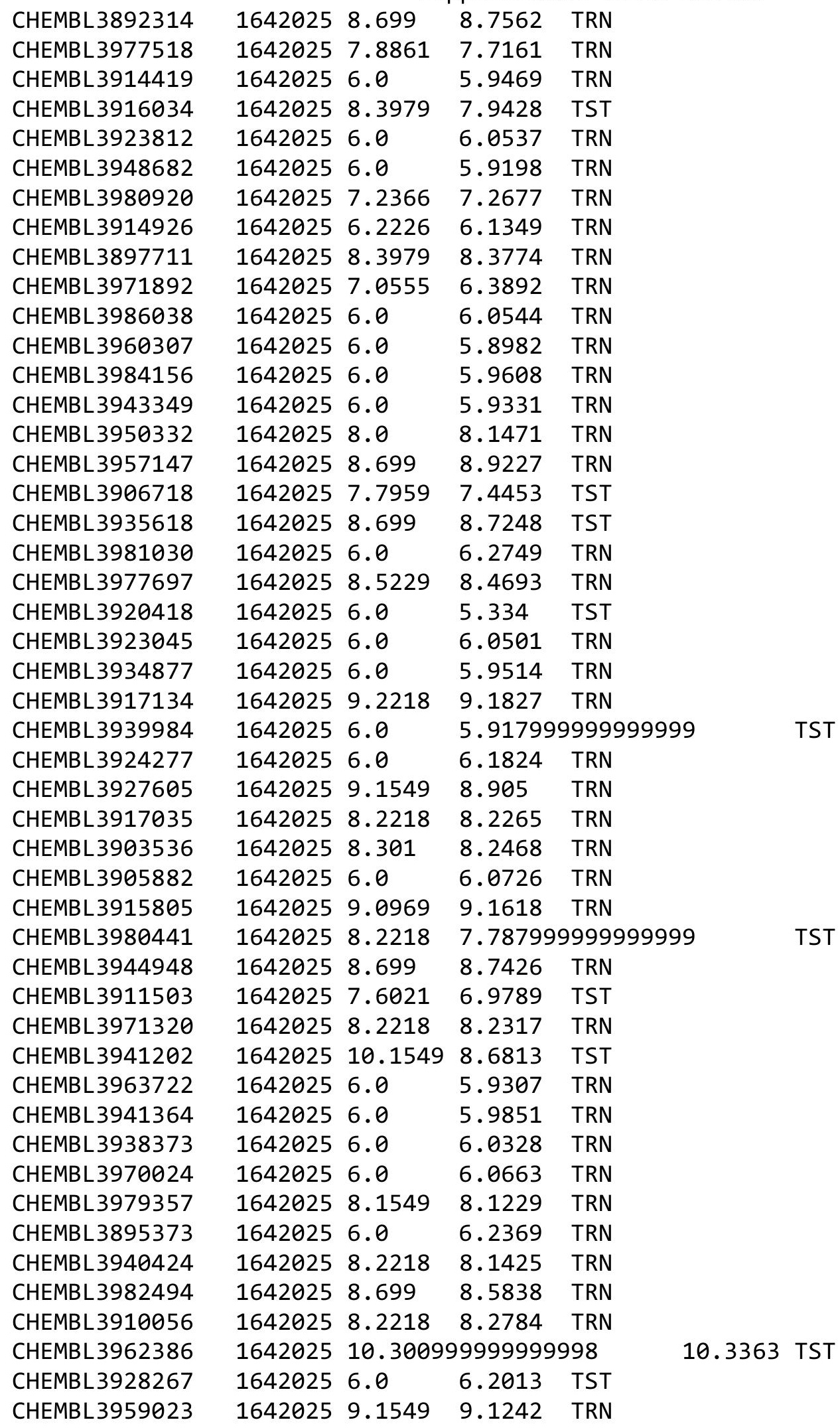

Page 22964 


\begin{tabular}{|c|c|c|c|c|c|}
\hline \multicolumn{6}{|c|}{ Supplemental Table S2.txt } \\
\hline CHEMBL3908048 & 1642025 & 9.0 & 8.9111 & TRN & \\
\hline CHEMBL3984667 & 1642025 & 7.5376 & 6.5941 & TST & \\
\hline CHEMBL 3974480 & 1642025 & 8.301 & 8.3252 & TRN & \\
\hline CHEMBL 3891708 & 1642025 & 8.2218 & 8.0632 & TRN & \\
\hline CHEMBL3962537 & 1642025 & 8.3979 & 8.3657 & TRN & \\
\hline CHEMBL 3932108 & 1642025 & 6.0 & 6.1919 & TRN & \\
\hline CHEMBL 3914858 & 1642025 & 6.0 & 5.9189 & TRN & \\
\hline CHEMBL3963053 & 1642025 & 8.2218 & 7.5445 & TST & \\
\hline CHEMBL3907309 & 1642025 & 8.301 & 7.9005 & TST & \\
\hline CHEMBL3960643 & 1642025 & 6.0 & 6.1408 & TRN & \\
\hline CHEMBL 3927391 & 1642025 & 6.0 & 5.9338 & TRN & \\
\hline CHEMBL3981489 & 1642025 & 8.301 & 7.9006 & TST & \\
\hline CHEMBL 3900020 & 1642025 & 9.0 & 8.8977 & TRN & \\
\hline CHEMBL3960403 & 1642025 & 6.0 & 5.8882 & TRN & \\
\hline CHEMBL3893379 & 1642025 & 8.0969 & 8.1727 & TRN & \\
\hline CHEMBL 3939728 & 1642025 & 8.2218 & 8.1058 & TRN & \\
\hline CHEMBL3973945 & 1642025 & 8.3979 & 8.724 & TRN & \\
\hline CHEMBL3906135 & 1642025 & 9.301 & 7.6722 & TST & \\
\hline CHEMBL3901569 & 1642025 & 6.0 & 6.2597 & TRN & \\
\hline CHEMBL3941469 & 1642025 & 8.301 & 6.8208 & TST & \\
\hline CHEMBL3972715 & 1642025 & 8.0969 & 7.9104 & TRN & \\
\hline CHEMBL3932494 & 1642025 & 6.0 & 5.8433 & TRN & \\
\hline CHEMBL3925151 & 1642025 & 9.2218 & 8.5758 & TST & \\
\hline CHEMBL3916210 & 1642025 & 8.2218 & 8.206 & TRN & \\
\hline CHEMBL3913388 & 1642025 & 6.0 & 6.2359 & TRN & \\
\hline CHEMBL3908927 & 1642025 & 8.3979 & 8.4708 & TRN & \\
\hline CHEMBL 3899281 & 1642025 & 6.0 & 5.2701 & TST & \\
\hline CHEMBL 3894591 & 1642025 & 8.301 & 8.1576 & TRN & \\
\hline CHEMBL3916138 & 1642025 & 6.0 & 4.7469 & TST & \\
\hline CHEMBL 3889987 & 1642025 & 9.0 & 9.0137 & TRN & \\
\hline CHEMBL3903415 & 1642025 & 8.2218 & 8.1686 & TRN & \\
\hline CHEMBL3902593 & 1642025 & 8.5229 & 8.5491 & TRN & \\
\hline CHEMBL3928962 & 1642025 & 8.1549 & 8.2171 & TRN & \\
\hline CHEMBL3931521 & 1642025 & 8.1549 & 7.83 & TST & \\
\hline CHEMBL3939218 & 1642025 & 6.0 & 6.8021 & TST & \\
\hline CHEMBL3904885 & 1642025 & 6.0 & 5.6297 & TST & \\
\hline CHEMBL 3900971 & 1642025 & 7.8239 & 7.4783 & TRN & \\
\hline CHEMBL 3918867 & 1642025 & 6.0 & 6.1736 & TRN & \\
\hline CHEMBL3961679 & 1642025 & 8.2218 & 8.1679 & TRN & \\
\hline CHEMBL3918977 & 1642025 & 6.0 & 5.1781 & TST & \\
\hline CHEMBL3930581 & 1642025 & 8.3979 & 8.2256 & TRN & \\
\hline CHEMBL3949877 & 1642025 & 6.0 & 6.11799 & 9999999999 & TRN \\
\hline CHEMBL 3983426 & 1642025 & 8.3979 & 8.3662 & TRN & \\
\hline CHEMBL 3890003 & 1642025 & 7.6383 & 7.4094 & TST & \\
\hline CHEMBL 3895925 & 1642025 & 6.0 & 5.6716 & TST & \\
\hline CHEMBL3947974 & 1642025 & 9.0 & 9.0067 & TRN & \\
\hline CHEMBL 3951673 & 1642025 & 8.699 & 8.5094 & TRN & \\
\hline CHEMBL 3946254 & 1642515 & 6.8401 & 6.3976 & TRN & \\
\hline
\end{tabular}

Page 22965 


$$
\text { Supplemental Table S2.txt }
$$

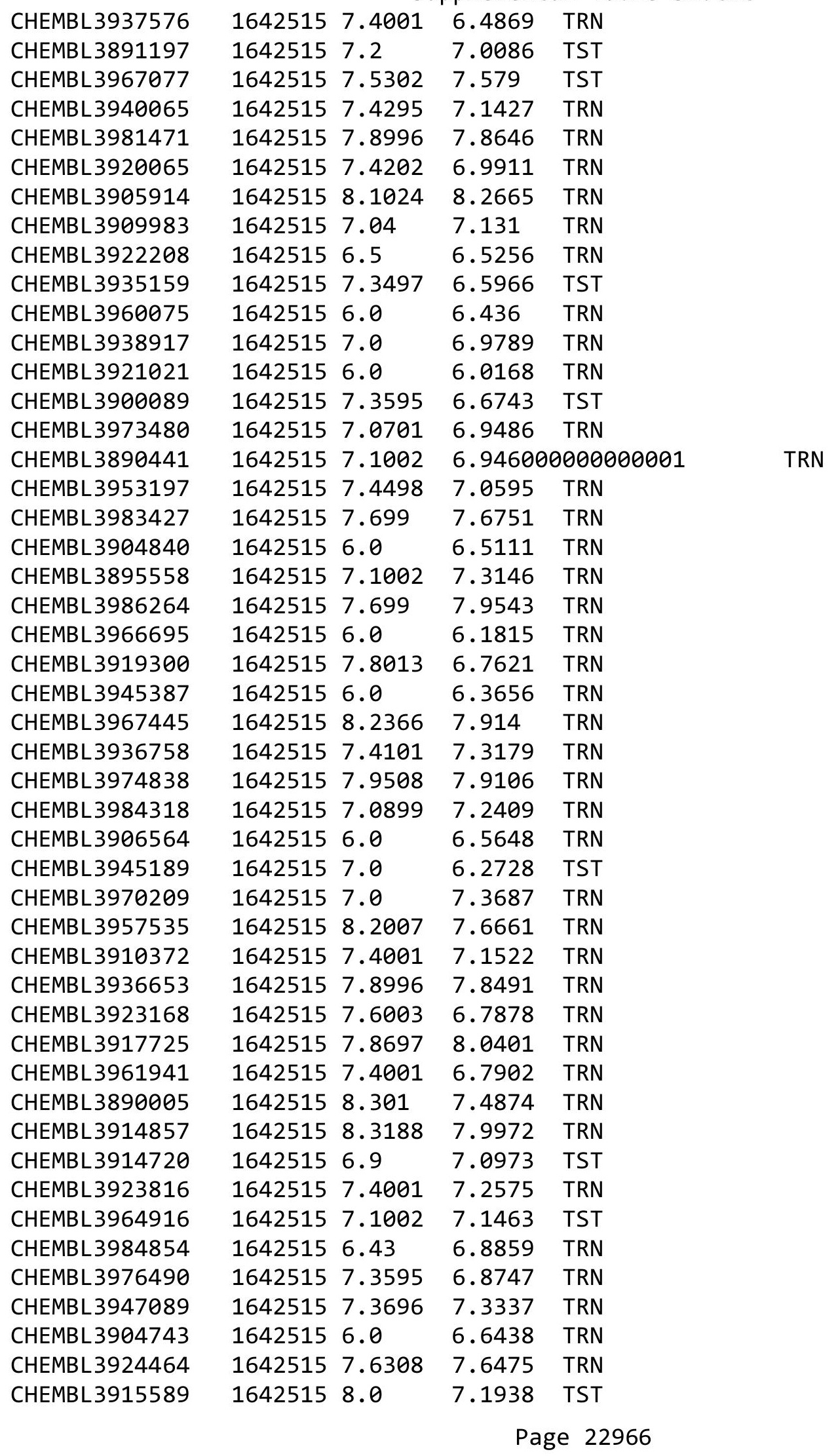


Supplemental Table S2.txt

\begin{tabular}{|c|c|c|c|c|c|}
\hline CHEMBL3946826 & 1642515 & 7.2596 & 7.1226 & TRN & \\
\hline CHEMBL3964243 & 1642515 & 7.3002 & 7.5413 & TST & \\
\hline CHEMBL3950699 & 1642515 & 6.0 & 6.2043 & TRN & \\
\hline CHEMBL3946989 & 1642515 & 6.0 & 6.5961 & TRN & \\
\hline CHEMBL3943500 & 1642515 & 7.1002 & 6.695 & TST & \\
\hline CHEMBL3896271 & 1642515 & 6.7501 & 6.8552 & TST & \\
\hline CHEMBL3947891 & 1642515 & 6.0 & 6.9729 & TRN & \\
\hline CHEMBL3946132 & 1642515 & 7.1002 & 6.7545 & TST & \\
\hline CHEMBL3906045 & 1642515 & 6.43 & 6.5414 & TST & \\
\hline CHEMBL3956614 & 1642515 & 6.4 & 6.9436 & TRN & \\
\hline CHEMBL3961280 & 1642515 & 8.2007 & 8.0665 & TST & \\
\hline CHEMBL3938984 & 1642515 & 7.5003 & 7.1166 & TRN & \\
\hline CHEMBL3934656 & 1642515 & 7.8013 & 8.022 & TRN & \\
\hline CHEMBL3933252 & 1642515 & 7.5302 & 7.1865 & TST & \\
\hline CHEMBL3923235 & 1642515 & 7.4001 & 7.545 & TRN & \\
\hline CHEMBL3916735 & 1642515 & 6.4 & 6.3559 & TRN & \\
\hline CHEMBL3928756 & 1642515 & 6.6 & 6.9116 & TRN & \\
\hline CHEMBL3936619 & 1642515 & 6.0 & 6.4515 & TRN & \\
\hline CHEMBL3949272 & 1642515 & 7.3002 & 7.0665 & TRN & \\
\hline CHEMBL3907793 & 1642515 & 7.3002 & 7.3481 & TRN & \\
\hline CHEMBL3960245 & 1642515 & 6.76 & 6.4068 & TST & \\
\hline CHEMBL3954936 & 1642515 & 7.699 & 7.7836 & TRN & \\
\hline CHEMBL3932188 & 1642515 & 7.699 & 6.6324 & TRN & \\
\hline CHEMBL3973475 & 1642515 & 7.7399 & 7.6545 & TRN & \\
\hline CHEMBL3913899 & 1642515 & 6.9 & 6.7904 & TRN & \\
\hline CHEMBL3934050 & 1642515 & 6.6 & 6.8023 & TST & \\
\hline CHEMBL3919664 & 1642515 & 6.0 & 6.4342 & TRN & \\
\hline CHEMBL3921656 & 1642515 & 7.3002 & 8.0358 & TST & \\
\hline CHEMBL3954268 & 1642515 & 6.6 & 6.7023 & TRN & \\
\hline CHEMBL3963279 & 1642515 & 7.8013 & 7.9122 & TRN & \\
\hline CHEMBL3948603 & 1642515 & 7.4001 & 6.7966 & TRN & \\
\hline CHEMBL3896213 & 1642515 & 7.6108 & 7.5177 & TST & \\
\hline CHEMBL3969399 & 1642515 & 7.4001 & 7.7276 & TRN & \\
\hline CHEMBL3897237 & 1642515 & 6.0 & 6.1329 & TRN & \\
\hline CHEMBL3938026 & 1642515 & 7.4401 & 7.0987 & TRN & \\
\hline CHEMBL3912077 & 1642515 & 7.0 & 7.7486 & TRN & \\
\hline CHEMBL3943013 & 1642515 & 7.0301 & 6.856 & TRN & \\
\hline CHEMBL3938418 & 1642515 & 6.0 & 5.8917 & TRN & \\
\hline CHEMBL3980994 & 1642515 & 6.5 & 6.3309 & TRN & \\
\hline CHEMBL3979405 & 1642515 & 7.699 & $7.45200 t$ & 0000000001 & TRN \\
\hline CHEMBL 3942250 & 1642515 & 7.1002 & 6.7692 & TRN & \\
\hline CHEMBL3891750 & 1642515 & 6.7001 & 6.492006 & 0000000001 & TST \\
\hline CHEMBL3975084 & 1642515 & 7.6003 & 7.1699 & TRN & \\
\hline CHEMBL3926483 & 1642515 & 7.3002 & 7.8891 & TRN & \\
\hline CHEMBL3955511 & 1642515 & 6.6 & 7.2299 & TST & \\
\hline CHEMBL3906207 & 1642515 & 8.0 & 7.33899 & 99999999995 & TST \\
\hline CHEMBL3945419 & 1642515 & 7.3002 & 6.8367 & TRN & \\
\hline CHEMBL3954147 & 1642515 & 7.5003 & 6.5094 & TRN & \\
\hline
\end{tabular}


Supplemental Table S2.txt

\begin{tabular}{|c|c|c|c|c|}
\hline CHEMBL3928620 & 1642515 & 6.6 & 7.0008 & TST \\
\hline CHEMBL3953783 & 1642515 & 7.1002 & 7.4012 & TRN \\
\hline CHEMBL 3900625 & 1642515 & 6.0 & 6.0498 & TRN \\
\hline CHEMBL3891830 & 1642515 & 6.3 & 7.0585 & TRN \\
\hline CHEMBL3914545 & 1642515 & 6.0 & 6.3017 & TRN \\
\hline CHEMBL 3970054 & 1642515 & 6.7399 & 7.2528 & TRN \\
\hline CHEMBL3984595 & 1642515 & 6.8 & \multicolumn{2}{|c|}{7.0520000000000005} \\
\hline CHEMBL 3965542 & 1642515 & 6.4 & 5.5615 & TST \\
\hline CHEMBL 3962858 & 1642515 & 6.0 & 6.2825 & TRN \\
\hline CHEMBL3899670 & 1642515 & 7.9393 & 7.9665 & TST \\
\hline CHEMBL 3931652 & 1642515 & 7.0 & 7.2944 & TRN \\
\hline CHEMBL 3928785 & 1642515 & 7.3595 & 7.2227 & TRN \\
\hline CHEMBL 3951020 & 1642515 & 6.0 & 6.46 & TRN \\
\hline CHEMBL 3897182 & 1642515 & 7.8013 & 7.2515 & TST \\
\hline CHEMBL3916556 & 1642515 & 7.8013 & 7.1415 & TST \\
\hline CHEMBL3921541 & 1642515 & 6.2 & 6.7669 & TST \\
\hline CHEMBL3897781 & 1642515 & 7.5003 & 7.6146 & TST \\
\hline CHEMBL3906194 & 1642515 & 6.6 & 6.8187 & TRN \\
\hline CHEMBL 3948827 & 1642515 & 5.7 & 5.6981 & TRN \\
\hline CHEMBL3965629 & 1642515 & 7.0 & 7.1953 & TST \\
\hline CHEMBL3952152 & 1642515 & 7.58 & 7.2347 & TST \\
\hline CHEMBL3942735 & 1642515 & 7.8508 & 7.5445 & TRN \\
\hline CHEMBL3961849 & 1642515 & 7.6003 & 7.4045 & TRN \\
\hline CHEMBL 3941856 & 1642515 & 6.6 & 7.1155 & TRN \\
\hline CHEMBL3904138 & 1642515 & 8.041 & 7.9926 & TRN \\
\hline CHEMBL3950911 & 1642515 & 6.0 & 5.8901 & TRN \\
\hline CHEMBL3946102 & 1642515 & 6.0 & 6.6819 & TRN \\
\hline CHEMBL3903983 & 1642515 & 7.699 & 7.3948 & TST \\
\hline CHEMBL3915469 & 1642515 & 6.0 & 6.5959 & TRN \\
\hline CHEMBL3909675 & 1642515 & 7.5003 & 7.4364 & TRN \\
\hline CHEMBL3964371 & 1642515 & 6.4 & 5.8365 & TRN \\
\hline CHEMBL3918171 & 1642515 & 6.0 & 6.1041 & TRN \\
\hline CHEMBL3906769 & 1642515 & 7.1198 & 7.4356 & TRN \\
\hline CHEMBL 3911481 & 1642515 & 7.8508 & 7.3997 & TRN \\
\hline CHEMBL3920897 & 1642515 & 7.9318 & 7.6946 & TRN \\
\hline CHEMBL3981370 & 1642515 & 7.4001 & 6.7028 & TRN \\
\hline CHEMBL3951030 & 1642515 & 6.0 & 6.3122 & TRN \\
\hline CHEMBL3933125 & 1642515 & 6.0 & 6.1399 & TRN \\
\hline CHEMBL 3911413 & 1642515 & 6.0 & 6.2383 & TRN \\
\hline CHEMBL3890561 & 1642515 & 6.0 & 7.0094 & TRN \\
\hline CHEMBL3967385 & 1642515 & 6.0 & 6.1554 & TRN \\
\hline CHEMBL3954397 & 1642515 & 7.5003 & 7.3332 & TRN \\
\hline CHEMBL3935995 & 1642515 & 7.8297 & 7.5855 & TRN \\
\hline CHEMBL3951416 & 1642515 & 6.3 & 6.5737 & TRN \\
\hline CHEMBL3975636 & 1642515 & 6.8 & 6.8615 & TRN \\
\hline CHEMBL3928215 & 1642515 & 7.6308 & 7.4262 & TRN \\
\hline CHEMBL3978377 & 1642515 & 6.56 & 6.6195 & TST \\
\hline CHEMBL3931778 & 1642515 & 6.44 & 7.3133 & TST \\
\hline
\end{tabular}




\begin{tabular}{|c|c|c|c|c|c|}
\hline \multicolumn{6}{|c|}{ Supplemental Table s2.txt } \\
\hline CHEMBL3928889 & 1642515 & 6.0 & 6.2861 & TRN & \\
\hline CHEMBL3952160 & 1642515 & 7.2 & 7.0878 & TST & \\
\hline CHEMBL3923377 & 1642515 & 7.6498 & 6.4124 & TST & \\
\hline CHEMBL3968133 & 1642515 & 7.8013 & 7.9024 & TRN & \\
\hline CHEMBL 3925273 & 1642515 & 8.4949 & 7.4212 & TST & \\
\hline CHEMBL3980931 & 1642515 & 6.0 & 6.2678 & TRN & \\
\hline CHEMBL3976605 & 1642515 & 7.0 & 6.7328 & TST & \\
\hline CHEMBL 3955703 & 1642515 & 7.1198 & 7.2502 & TRN & \\
\hline CHEMBL3956010 & 1642515 & 7.06 & \multicolumn{2}{|c|}{6.9270000000000005} & TRN \\
\hline CHEMBL3904251 & 1642515 & 7.4001 & 7.1911 & TRN & \\
\hline CHEMBL3936551 & 1642515 & 6.0 & 6.2007 & TRN & \\
\hline CHEMBL3947197 & 1642515 & 7.8996 & 7.5824 & TRN & \\
\hline CHEMBL3901985 & 1642515 & 7.2403 & 7.4671 & TST & \\
\hline CHEMBL 3925568 & 1642515 & 6.0 & 6.3191 & TRN & \\
\hline CHEMBL3889556 & 1642515 & 8.2291 & 8.0787 & TRN & \\
\hline CHEMBL3915054 & 1642515 & 6.2 & 6.6667 & TRN & \\
\hline CHEMBL3901310 & 1642515 & 7.0701 & 6.7784 & TRN & \\
\hline CHEMBL3911143 & 1642515 & 6.0 & 6.2461 & TRN & \\
\hline CHEMBL 3946841 & 1642515 & 7.4001 & 7.3881 & TST & \\
\hline CHEMBL3951380 & 1642515 & 7.5003 & 7.1447 & TRN & \\
\hline CHEMBL3935464 & 1642515 & 7.1002 & 6.7669 & TST & \\
\hline CHEMBL3891612 & 1642515 & 7.6003 & 6.1652 & TRN & \\
\hline CHEMBL3952765 & 1642515 & 7.3497 & \multicolumn{2}{|c|}{6.9110000000000005} & TRN \\
\hline CHEMBL 3938002 & 1642515 & 7.0 & 6.5548 & TST & \\
\hline CHEMBL3907060 & 1642515 & 7.2197 & 6.9707 & TRN & \\
\hline CHEMBL3924602 & 1642515 & 6.13 & 6.0433 & TST & \\
\hline CHEMBL3964899 & 1642515 & 7.4401 & 7.9809 & TRN & \\
\hline CHEMBL3966375 & 1642515 & 7.3799 & \multicolumn{2}{|c|}{ 7. 361000000000001} & TST \\
\hline CHEMBL 3950348 & 1642515 & 5.86 & 6.6542 & TRN & \\
\hline CHEMBL3898553 & 1642515 & 7.1002 & 7.2303 & TRN & \\
\hline CHEMBL 3914354 & 1642515 & 6.9 & 7.2608 & TST & \\
\hline CHEMBL3890699 & 1642515 & 8.6383 & 8.2028 & TRN & \\
\hline CHEMBL3947652 & 1642515 & 6.5 & 6.7612 & TRN & \\
\hline CHEMBL3902545 & 1642515 & 7.1302 & 6.8931 & TRN & \\
\hline CHEMBL3898513 & 1642515 & 7.7399 & 7.8883 & TRN & \\
\hline CHEMBL3980975 & 1642515 & 6.1 & 6.8381 & TST & \\
\hline CHEMBL3891835 & 1642515 & 7.2 & 7.4623 & TRN & \\
\hline CHEMBL3978440 & 1642515 & 6.71 & 6.0288 & TRN & \\
\hline CHEMBL3672954 & 1528170 & 6.0 & 5.9336 & TRN & \\
\hline CHEMBL3672991 & 1528170 & 6.0 & 6.1181 & TRN & \\
\hline CHEMBL3959004 & 1528170 & 6.5112 & 6.8946 & TST & \\
\hline CHEMBL3889470 & 1528170 & 8.4202 & 8.4596 & TRN & \\
\hline CHEMBL3672989 & 1528170 & 6.0 & 6.1116 & TRN & \\
\hline CHEMBL3937657 & 1528170 & 7.7447 & 7.7276 & TRN & \\
\hline CHEMBL3974007 & 1528170 & 8.3279 & 8.4122 & TRN & \\
\hline CHEMBL3942310 & 1528170 & 7.3468 & 7.2476 & TST & \\
\hline CHEMBL3673035 & 1528170 & 6.0 & 7.062 & TST & \\
\hline CHEMBL3672996 & 1528170 & 6.0 & 5.8642 & TRN & \\
\hline
\end{tabular}


Supplemental Table S2.txt

\begin{tabular}{|c|c|c|c|c|}
\hline HEMB & 528170 & 6.7897 & & $\cdots$ \\
\hline 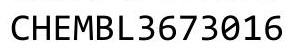 & 528170 & 6.0 & & \\
\hline HFMRI & 28170 & 8.9586 & & \\
\hline 672979 & 70 & 6.0 & & \\
\hline AEMBL3898424 & 528170 & 8.6021 & 5721 & \\
\hline 983785 & 528170 & 8.7959 & 87 & \\
\hline HEMBL: & 528170 & 6.0 & & \\
\hline AEMBL3 & 170 & 7.6402 & 77 & \\
\hline HEMBL3672986 & 528170 & 6.0 & 6.0024 & \\
\hline HEMBL3952952 & 528170 & 6.018 & 1848 & \\
\hline HEMBL 3673004 & 170 & 8.5528 & & \\
\hline HEMBL3 & 170 & 6.0 & & ST \\
\hline HEMBL & & 8.3979 & & \\
\hline HEMBL3920284 & 528170 & 7.1844 & 55 & INIV \\
\hline HEMBL3944115 & 170 & 6.1203 & & \\
\hline HEMBL3 & 70 & 6.4351 & & RIV \\
\hline HEMBL & 70 & 6. & & RN \\
\hline HEMBL; & 70 & 6.0 & & ST \\
\hline HEMBL3 & 70 & 8.5686 & & \\
\hline AEMBL3 & 70 & 6.5761 & & I KIV \\
\hline HEMBL; & $\theta$ & 086 & & RI \\
\hline HEM & 70 & 207 & & RN \\
\hline HEMBL & 70 & 6. & & RN \\
\hline HEMBL3 & 70 & 6 . & & IRN \\
\hline AEMBL3 & & 021 & 48 & IRN \\
\hline HEMBL3 & 70 & 291 & & 「RN \\
\hline HEM & 70 & 214 & & RN \\
\hline HEME & 70 & 6. & & IST \\
\hline HEMBL3 & & 6 & & $\Gamma \mathrm{RN}$ \\
\hline HEMBL3672952 & 70 & 6. & 52 & TRN \\
\hline AEMBL. & & 6 & & 「RN \\
\hline HFM & 70 & & & 「RN \\
\hline וסMF & & 7. & & 「RN \\
\hline HEMBL3 & 70 & 6 . & & 「RN \\
\hline HEMBL 3673044 & 70 & 6 & & ГRN \\
\hline AEMRI & 0 & 8. & 82 & ГST \\
\hline 8 & 70 & 35 & & TRN \\
\hline HEMBL3 & & 7.6055 & & TRN \\
\hline HEMBL3 & 70 & 6. & & $\Gamma R$ \\
\hline AEMBL & & & & TST \\
\hline HEMBL3 & & 8 & & TRN \\
\hline HEMBL3 & 70 & 6.0 & 86 & TRN \\
\hline HEMBL3 & 170 & 8.44 & & ГRN \\
\hline HEMBL3 & 70 & 8.0458 & & $\Gamma R$ \\
\hline CHEMPI 3007 & & 7.6364 & & $|د|$ \\
\hline HEMBL 3970300 & 152 & 6.371 & 5.8802 & ית \\
\hline HEMBL 3672973 & 170 & 6.0 & 5.5163 & ST \\
\hline CHEMBL3673026 & 1528170 & 6.0 & 6.2627 & $\Gamma$ \\
\hline
\end{tabular}

Page 22970 


$$
\text { Supplemental Table S2.txt }
$$

\begin{tabular}{|c|c|c|c|c|c|}
\hline CHEMBL 3962712 & 1528170 & 6.5791 & 6.4886 & TST & \\
\hline CHEMBL 3911357 & 1528170 & 8.0655 & 8.0229 & TRN & \\
\hline CHEMBL 3673028 & 1528170 & 9.1549 & 7.1734 & TST & \\
\hline CHEMBL 3672994 & 1528170 & 6.0 & 6.0815 & TRN & \\
\hline CHEMBL3968339 & 1528170 & 8.7447 & 8.6524 & TRN & \\
\hline CHEMBL 3941658 & 1528170 & 7.8013 & 7.1304 & TST & \\
\hline CHEMBL 3672982 & 1528170 & 6.9194 & 6.6717 & TRN & \\
\hline CHEMBL3672997 & 1528170 & 6.0 & 5.9462 & TRN & \\
\hline CHEMBL 3935738 & 1528170 & 7.8182 & 7.6492 & TRN & \\
\hline CHEMBL3959892 & 1528170 & 8.1192 & 8.0309 & TRN & \\
\hline CHEMBL 3672967 & 1528170 & 6.0 & 5.9332 & TST & \\
\hline CHEMBL 3914844 & 1528170 & 6.1632 & 5.8536 & TST & \\
\hline CHEMBL 3969821 & 1528170 & 8.4202 & 8.4369 & TRN & \\
\hline CHEMBL 3673012 & 1528170 & 6.0 & 5.847 & TRN & \\
\hline CHEMBL 3893232 & 1528170 & 7.0278 & 7.1525 & TST & \\
\hline CHEMBL3673034 & 1528170 & 6.0 & 5.7293 & TST & \\
\hline CHEMBL 3673042 & 1528170 & 6.0 & 6.1261 & TRN & \\
\hline CHEMBL 3673014 & 1528170 & 6.0 & 6.0154 & TRN & \\
\hline CHEMBL 3970091 & 1528170 & 7.2328 & 7.0607 & TRN & \\
\hline CHEMBL 3672987 & 1528170 & 6.0 & 6.1168 & TRN & \\
\hline CHEMBL 3672980 & 1528170 & 7.71899 & 799999999 & 7.824 & TRN \\
\hline CHEMBL 3672948 & 1528170 & 6.0 & 5.9425 & TRN & \\
\hline CHEMBL 3673025 & 1528170 & 6.0 & 6.4243 & TST & \\
\hline CHEMBL3672946 & 1528170 & 6.0 & 5.8742 & TST & \\
\hline CHEMBL 3672977 & 1528170 & 6.0 & 5.6406 & TRN & \\
\hline CHEMBL 3672998 & 1528170 & 8.4559 & 8.4036 & TRN & \\
\hline CHEMBL 3672984 & 1528170 & 5.3991 & 5.7032 & TRN & \\
\hline CHEMBL 3973594 & 1528170 & 7.3242 & 7.3491 & TST & \\
\hline CHEMBL3673022 & 1528170 & 6.0 & \multicolumn{2}{|c|}{6.077999999999999} & TRN \\
\hline CHEMBL3672999 & 1528170 & 6.0 & 5.9295 & TRN & \\
\hline CHEMBL 3672962 & 1528170 & 6.0 & 6.9329 & TST & \\
\hline CHEMBL 3907918 & 1528170 & 6.2378 & 6.3536 & TRN & \\
\hline CHEMBL1576762 & 737632 & 2.4559 & 4.7234 & TRN & \\
\hline CHEMBL1503050 & 737632 & 4.6563 & 4.7512 & TRN & \\
\hline CHEMBL1524257 & 737632 & 5.2267 & 5.3642 & TRN & \\
\hline CHEMBL1478303 & 737632 & 4.0889 & 3.7904 & TST & \\
\hline CHEMBL1497153 & 737632 & 4.0548 & 4.6109 & TRN & \\
\hline CHEMBL1716317 & 737632 & 4.0182 & 4.1539 & TRN & \\
\hline CHEMBL1370068 & 737632 & 3.7655 & 4.6265 & TRN & \\
\hline CHEMBL1553368 & 737632 & 8.8239 & 6.9468 & TRN & \\
\hline CHEMBL1980844 & 737632 & 4.4588 & 4.2071 & TST & \\
\hline CHEMBL1326833 & 737632 & 5.8066 & 5.9208 & TRN & \\
\hline CHEMBL1334412 & 737632 & 4.2136 & 4.5166 & TRN & \\
\hline CHEMBL255881 & 737632 & 4.3408 & 4.0358 & TRN & \\
\hline CHEMBL1732315 & 737632 & 4.2006 & \multicolumn{2}{|c|}{4.696000000000001} & TRN \\
\hline CHEMBL1412077 & 737632 & 6.2426 & 6.233 & TRN & \\
\hline CHEMBL1583907 & 737632 & 4.567 & 4.4174 & TST & \\
\hline CHEMBL1304092 & 737632 & 4.8522 & 4.6638 & TRN & \\
\hline
\end{tabular}


Supplemental Table S2.txt

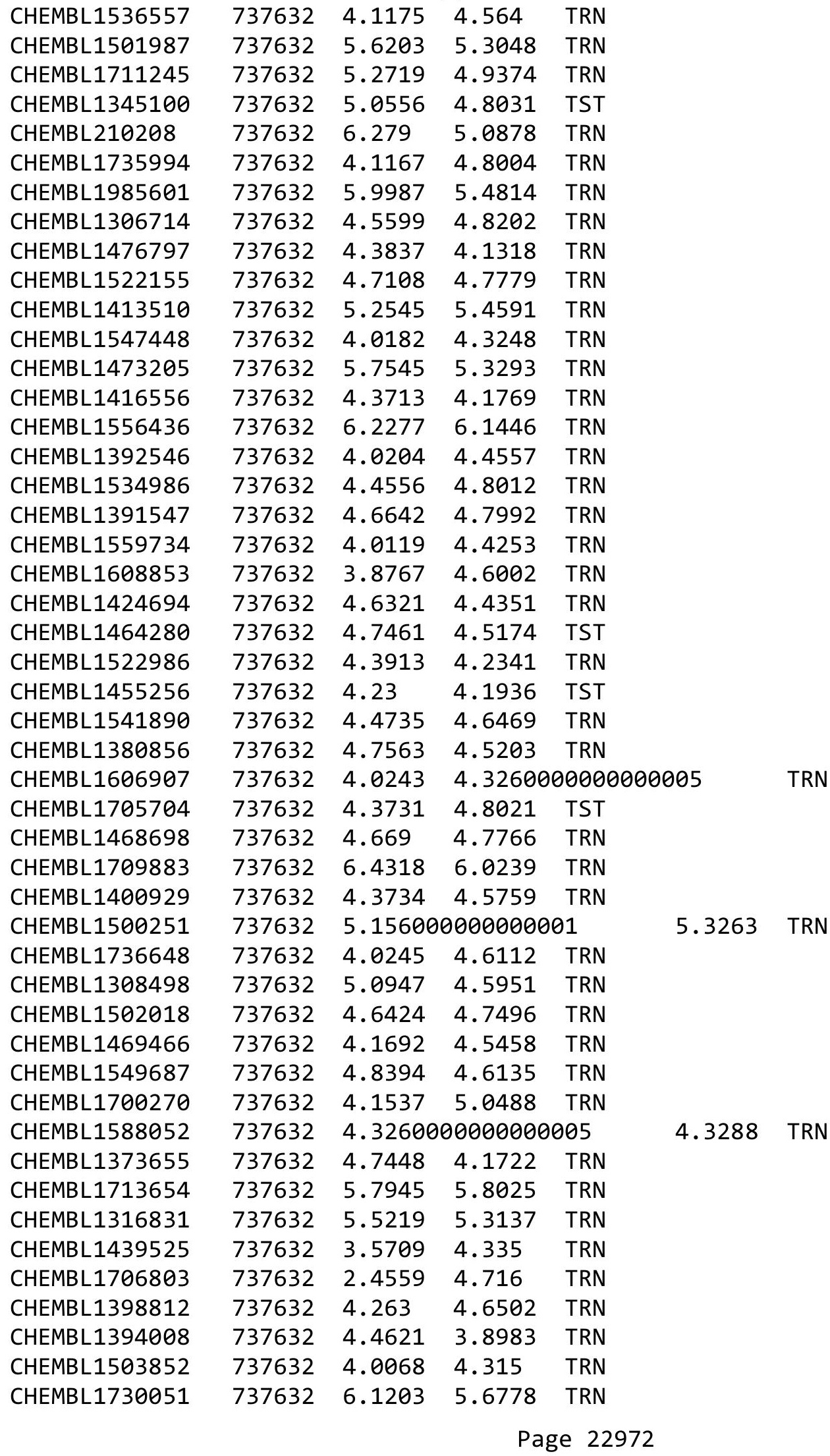


Supplemental Table S2.txt

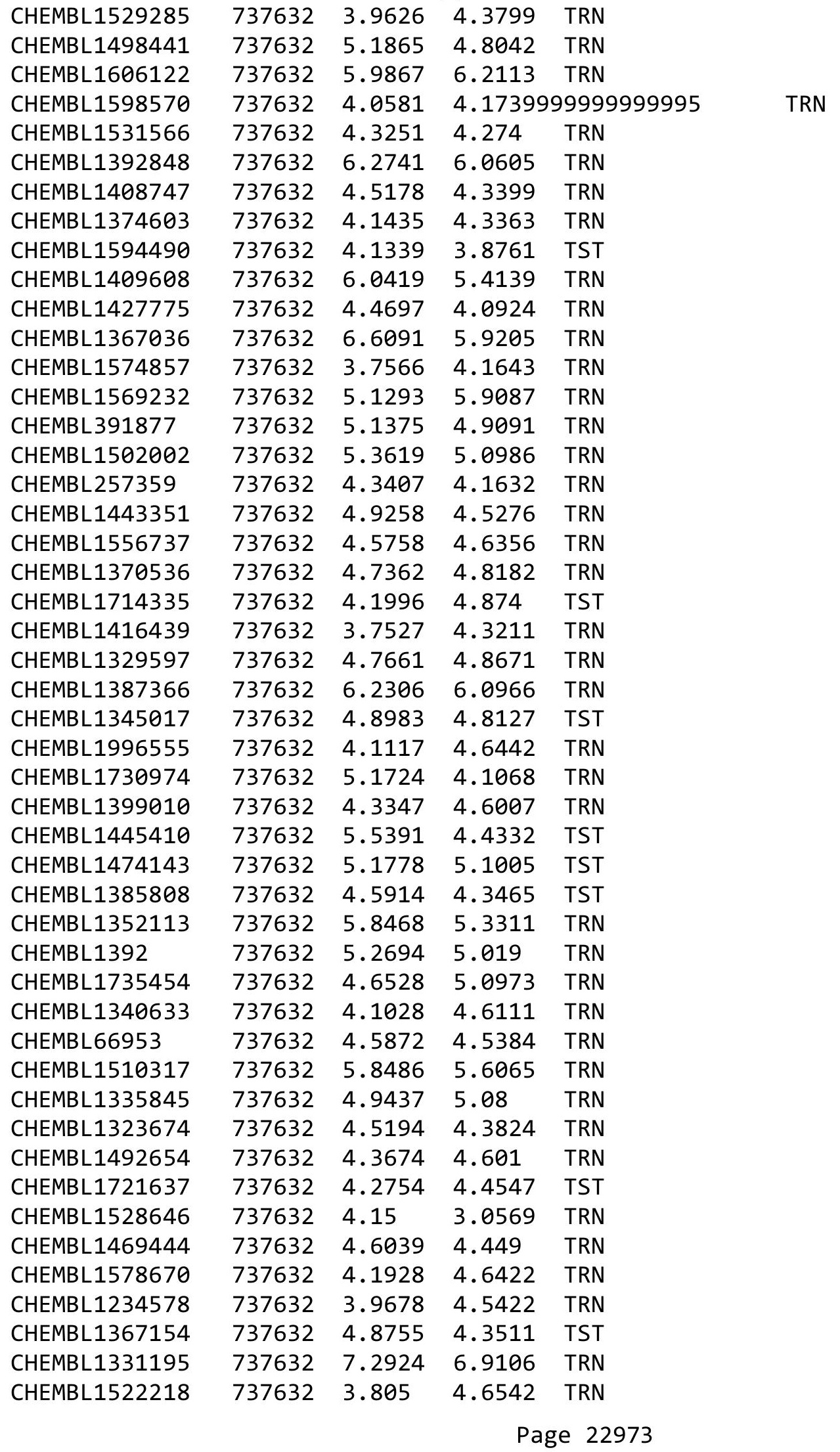




\begin{tabular}{|c|c|c|c|c|c|c|}
\hline \multirow[b]{2}{*}{ CHEMBL1303641 } & & \multicolumn{5}{|c|}{ Supplemental Table S2.txt } \\
\hline & 737632 & 6.279 & 6.2804 & TRN & & \\
\hline CHEMBL1556531 & 737632 & 4.1189 & 4.3467 & TRN & & \\
\hline CHEMBL1544136 & 737632 & 4.718 & 4.9477 & TRN & & \\
\hline CHEMBL1528814 & 737632 & \multicolumn{3}{|c|}{4.446000000000001} & 4.5283 & TRN \\
\hline CHEMBL1725771 & 737632 & 5.223 & 5.4232 & TRN & & \\
\hline CHEMBL1448906 & 737632 & 5.1702 & 5.0594 & TRN & & \\
\hline CHEMBL1385512 & 737632 & 5.2396 & 4.9246 & TRN & & \\
\hline CHEMBL1601846 & 737632 & 4.7235 & 5.1618 & TRN & & \\
\hline CHEMBL69612 & 737632 & 4.1462 & 4.2672 & TRN & & \\
\hline CHEMBL1522563 & 737632 & 5.8864 & 5.812 & TRN & & \\
\hline CHEMBL1550323 & 737632 & 4.6967 & 4.2704 & TRN & & \\
\hline CHEMBL201289 & 737632 & 4.5349 & 4.4836 & TRN & & \\
\hline CHEMBL1730473 & 737632 & 3.738 & 4.2913 & TRN & & \\
\hline CHEMBL1609006 & 737632 & 3.7937 & 4.6042 & TRN & & \\
\hline CHEMBL1533230 & 737632 & 4.4004 & 4.4593 & TST & & \\
\hline CHEMBL1313968 & 737632 & 4.8093 & 4.971 & TRN & & \\
\hline CHEMBL1548506 & 737632 & 4.9941 & 4.3641 & TST & & \\
\hline CHEMBL1401891 & 737632 & 5.2924 & 4.9345 & TST & & \\
\hline CHEMBL1509989 & 737632 & 5.0933 & 4.5922 & TST & & \\
\hline CHEMBL1545832 & 737632 & 4.7842 & 4.2978 & TRN & & \\
\hline CHEMBL1501132 & 737632 & 4.629 & 4.1391 & TRN & & \\
\hline CHEMBL1445654 & 737632 & 3.7658 & 4.8956 & TST & & \\
\hline CHEMBL1429070 & 737632 & 5.4418 & 5.3242 & TRN & & \\
\hline CHEMBL1345866 & 737632 & 5.4676 & 5.0577 & TRN & & \\
\hline CHEMBL1421993 & 737632 & 4.9992 & 4.8477 & TRN & & \\
\hline CHEMBL1399913 & 737632 & 3.6908 & 4.8527 & TRN & & \\
\hline CHEMBL1539325 & 737632 & 4.1474 & 4.5263 & TST & & \\
\hline CHEMBL1386802 & 737632 & \multicolumn{3}{|c|}{5.6129999999999995} & 4.6164 & TRN \\
\hline CHEMBL1575701 & 737632 & 5.3991 & 5.012 & TRN & & \\
\hline CHEMBL1719807 & 737632 & 4.5108 & 4.4655 & TRN & & \\
\hline CHEMBL1608727 & 737632 & 4.8993 & 4.2932 & TRN & & \\
\hline CHEMBL1332509 & 737632 & 3.8945 & 4.6957 & TRN & & \\
\hline CHEMBL1492044 & 737632 & 7.3768 & 4.9404 & TRN & & \\
\hline CHEMBL1374066 & 737632 & 5.0951 & 4.7663 & TRN & & \\
\hline CHEMBL1508847 & 737632 & 4.5384 & 4.2195 & TRN & & \\
\hline CHEMBL1372920 & 737632 & 5.7138 & 5.5426 & TRN & & \\
\hline CHEMBL1346055 & 737632 & 4.0613 & 4.3677 & TRN & & \\
\hline CHEMBL1709562 & 737632 & 5.1948 & 5.0112 & TRN & & \\
\hline CHEMBL1451725 & 737632 & 4.2873 & 4.8219 & TST & & \\
\hline CHEMBL1460470 & 737632 & 4.9954 & 4.5524 & TRN & & \\
\hline CHEMBL1504675 & 737632 & 4.4645 & 3.9828 & TRN & & \\
\hline CHEMBL1398964 & 737632 & 5.6426 & 3.9551 & TRN & & \\
\hline CHEMBL1713905 & 737632 & 6.0448 & 5.9894 & TRN & & \\
\hline CHEMBL1501577 & 737632 & 4.5023 & 4.45 & TRN & & \\
\hline CHEMBL1732657 & 737632 & 5.6889 & 5.1225 & TRN & & \\
\hline CHEMBL1430473 & 737632 & 5.2997 & 4.4961 & TRN & & \\
\hline CHEMBL1612106 & 737632 & 4.0253 & 3.786 & TRN & & \\
\hline CHEMBL1718985 & 737632 & 4.1138 & 4.7262 & TRN & & \\
\hline
\end{tabular}

Page 22974 


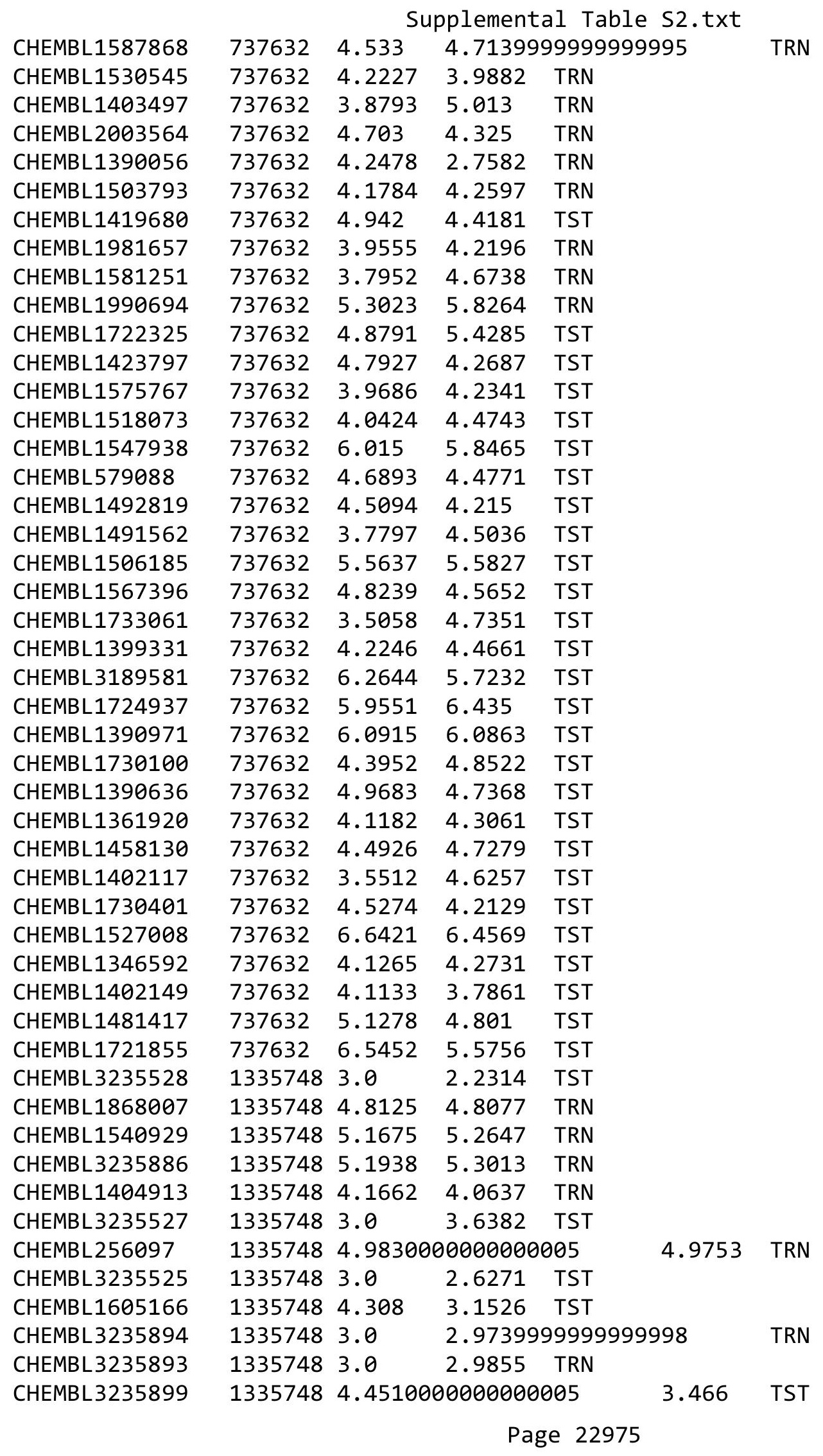


Supplemental Table S2.txt

\begin{tabular}{|c|c|c|c|c|c|c|}
\hline CHEMBL 2030281 & 1335748 & 5.4437 & 5.3971 & TRN & & \\
\hline CHEMBL 3235896 & 1335748 & 3.0 & 2.9949 & TRN & & \\
\hline CHEMBL1331211 & 1335748 & 4.8327 & 4.9671 & TRN & & \\
\hline CHEMBL 3235890 & 1335748 & 4.2557 & 4.2486 & TRN & & \\
\hline CHEMBL1335844 & 1335748 & 4.2132 & 4.2582 & TRN & & \\
\hline CHEMBL3235901 & 1335748 & 5.5376 & 5.4811 & TRN & & \\
\hline CHEMBL3235883 & 1335748 & 3.0 & 3.0532 & TRN & & \\
\hline CHEMBL 3235892 & 1335748 & 3.0 & 3.0652 & TRN & & \\
\hline CHEMBL 3235881 & 1335748 & 4.6234 & 4.6047 & TRN & & \\
\hline CHEMBL1481999 & 1335748 & 4.1238 & 4.1376 & TRN & & \\
\hline CHEMBL3235526 & 1335748 & 4.109 & 3.6315 & TST & & \\
\hline CHEMBL3235888 & 1335748 & 5.5086 & 5.4837 & TRN & & \\
\hline CHEMBL 3235889 & 1335748 & 3.0 & 2.9894 & TRN & & \\
\hline CHEMBL256098 & 1335748 & 4.3224 & 4.3952 & TRN & & \\
\hline CHEMBL3235884 & 1335748 & 3.0 & 2.9783 & TRN & & \\
\hline CHEMBL 2030270 & 1335748 & 4.4365 & 4.4117 & TRN & & \\
\hline CHEMBL3183104 & 1335748 & 3.0 & 2.9355 & TRN & & \\
\hline CHEMBL 3235902 & 1335748 & 5.4437 & 5.5142 & TRN & & \\
\hline CHEMBL3235885 & 1335748 & 3.0 & 3.0494 & TRN & & \\
\hline CHEMBL3235891 & 1335748 & 3.0 & 2.9772 & TRN & & \\
\hline CHEMBL3235529 & 1335748 & 4.40300 & 00000000 & 305 & 3.1210000000000004 & TST \\
\hline CHEMBL3187250 & 1335748 & 5.3768 & 5.3021 & TRN & & \\
\hline CHEMBL 3235882 & 1335748 & 3.0 & 2.9855 & TRN & & \\
\hline CHEMBL1564699 & 1335748 & 4.8153 & 4.7464 & TRN & & \\
\hline CHEMBL1888104 & 1335748 & 4.52 & 4.5036 & TRN & & \\
\hline CHEMBL3235530 & 1335748 & 3.0 & 2.9417 & TRN & & \\
\hline CHEMBL 3188402 & 1335748 & 4.9136 & 4.8836 & TRN & & \\
\hline CHEMBL 3235895 & 1335748 & 5.1079 & 5.0975 & TRN & & \\
\hline CHEMBL3235898 & 1335748 & 4.8182 & 3.3367 & TST & & \\
\hline CHEMBL 3235879 & 1335748 & 3.0 & 3.0522 & TRN & & \\
\hline CHEMBL 3235897 & 1335748 & 3.0 & 4.5487 & TST & & \\
\hline CHEMBL3235522 & 1335748 & 4.3675 & 4.3539 & TST & & \\
\hline CHEMBL 3235880 & 1335748 & 3.0 & 3.0143 & TRN & & \\
\hline CHEMBL3185602 & 1335748 & 4.7235 & 4.7483 & TRN & & \\
\hline CHEMBL 3235903 & 1335748 & 4.6799 & 4.6645 & TRN & & \\
\hline CHEMBL3235900 & 1335748 & 4.5302 & 5.2399 & TST & & \\
\hline CHEMBL1334970 & 1335748 & 4.5391 & 4.5246 & TRN & & \\
\hline CHEMBL 3235523 & 1335748 & 3.0 & 3.9258 & TST & & \\
\hline CHEMBL3235887 & 1335748 & 4.8827 & 4.7761 & TRN & & \\
\hline CHEMBL401743 & 1335748 & 3.0 & 4.6062 & TST & & \\
\hline CHEMBL1497487 & 1335748 & 3.0 & 3.0685 & TRN & & \\
\hline CHEMBL3235524 & 1335748 & 3.0 & 2.2761 & TST & & \\
\hline CHEMBL3679354 & 1528416 & 8.7959 & 8.0075 & TRN & & \\
\hline CHEMBL3679356 & 1528416 & 7.4437 & 7.3982 & TRN & & \\
\hline CHEMBL 3684154 & 1528416 & 8.5086 & 8.2952 & TRN & & \\
\hline CHEMBL3674339 & 1528416 & 7.7212 & 7.6056 & TRN & & \\
\hline CHEMBL3684197 & 1528416 & 5.5086 & 6.5739 & TST & & \\
\hline CHEMBL3679362 & 1528416 & 8.7696 & 7.9383 & TRN & & \\
\hline
\end{tabular}

Page 22976 
Supplemental Table S2.txt

\begin{tabular}{|c|c|c|c|c|c|}
\hline CHEMBL 3674287 & 1528416 & 7.8539 & 8.0019 & TRN & \\
\hline CHEMBL3674356 & 1528416 & 8.8861 & 6.6057 & TST & \\
\hline CHEMBL3679332 & 1528416 & 8.1612 & 8.4253 & TRN & \\
\hline CHEMBL3639830 & 1528416 & 6.0 & 7.5015 & TRN & \\
\hline CHEMBL3674246 & 1528416 & 8.4318 & 8.0588 & TRN & \\
\hline CHEMBL 3674173 & 1528416 & 8.4685 & 8.0473 & TRN & \\
\hline CHEMBL3674299 & 1528416 & 7.2218 & \multicolumn{2}{|c|}{7.718999999999999} & TRN \\
\hline CHEMBL3679189 & 1528416 & 6.2366 & 6.4755 & TRN & \\
\hline CHEMBL 3684163 & 1528416 & 8.699 & 7.8782 & TRN & \\
\hline CHEMBL3674285 & 1528416 & 7.4559 & 8.2339 & TST & \\
\hline CHEMBL3679222 & 1528416 & 8.8239 & 8.118 & TRN & \\
\hline CHEMBL3684204 & 1528416 & 6.2596 & 6.8108 & TST & \\
\hline CHEMBL 3684224 & 1528416 & 8.0 & 8.4313 & TRN & \\
\hline CHEMBL 3684158 & 1528416 & 7.4559 & 6.9552 & TRN & \\
\hline CHEMBL3679305 & 1528416 & 9.0655 & 7.5206 & TRN & \\
\hline CHEMBL3674160 & 1528416 & 8.4437 & 8.0995 & TRN & \\
\hline CHEMBL3679335 & 1528416 & 8.6198 & 8.4444 & TRN & \\
\hline CHEMBL 3674180 & 1528416 & 6.0 & 7.3938 & TRN & \\
\hline CHEMBL 3684225 & 1528416 & 7.4559 & 7.7368 & TRN & \\
\hline CHEMBL3684277 & 1528416 & 8.1549 & 7.1612 & TRN & \\
\hline CHEMBL3674224 & 1528416 & 8.3979 & 8.0224 & TRN & \\
\hline CHEMBL3679370 & 1528416 & 8.8239 & 8.2682 & TRN & \\
\hline CHEMBL3684190 & 1528416 & 6.7696 & \multicolumn{2}{|c|}{7.632000000000001} & TST \\
\hline CHEMBL 3679264 & 1528416 & 8.4685 & 7.85 & TRN & \\
\hline CHEMBL3679299 & 1528416 & 6.0809 & 7.4574 & TRN & \\
\hline CHEMBL3674197 & 1528416 & 7.6778 & 7.8512 & TRN & \\
\hline CHEMBL3674327 & 1528416 & 8.0915 & 8.0041 & TRN & \\
\hline CHEMBL 3674344 & 1528416 & 8.5376 & 7.477 & TRN & \\
\hline CHEMBL 3679258 & 1528416 & 8.6778 & 8.0088 & TRN & \\
\hline CHEMBL3684133 & 1528416 & 8.3098 & 8.3211 & TRN & \\
\hline CHEMBL 3684241 & 1528416 & 9.1805 & 7.9483 & TRN & \\
\hline CHEMBL 3674308 & 1528416 & 8.6198 & 9.0363 & TRN & \\
\hline CHEMBL3679353 & 1528416 & 6.0 & 7.3988 & TRN & \\
\hline CHEMBL 3679315 & 1528416 & 8.2518 & 8.6452 & TRN & \\
\hline CHEMBL 3674220 & 1528416 & 7.4559 & 8.0004 & TRN & \\
\hline CHEMBL3679282 & 1528416 & 8.1079 & 7.5938 & TRN & \\
\hline CHEMBL3679187 & 1528416 & 8.2441 & 7.6588 & TRN & \\
\hline CHEMBL3684127 & 1528416 & 8.585 & 8.0495 & TRN & \\
\hline CHEMBL 3679347 & 1528416 & 8.2441 & 7.9926 & TRN & \\
\hline CHEMBL3679262 & 1528416 & 8.0088 & 7.5681 & TRN & \\
\hline CHEMBL3684214 & 1528416 & 6.699 & 6.7111 & TST & \\
\hline CHEMBL3639781 & 1528416 & 8.4559 & 8.079 & TRN & \\
\hline CHEMBL3674241 & 1528416 & 8.0362 & 7.8346 & TRN & \\
\hline CHEMBL3679330 & 1528416 & 8.1871 & 8.4936 & TRN & \\
\hline CHEMBL 3674305 & 1528416 & 7.8539 & 7.9889 & TRN & \\
\hline CHEMBL3679375 & 1528416 & 8.2757 & 8.0035 & TRN & \\
\hline CHEMBL3684181 & 1528416 & 6.0 & 7.8267 & TRN & \\
\hline CHEMBL3679260 & 1528416 & 8.7959 & 8.2143 & TRN & \\
\hline
\end{tabular}




\begin{tabular}{|c|c|c|c|c|c|}
\hline \multicolumn{6}{|c|}{ Supplemental Table S2.txt } \\
\hline CHEMBL 3679248 & 1528416 & 8.0 & 7.7733 & TRN & \\
\hline CHEMBL 3674353 & 1528416 & 6.0 & 7.2004 & TRN & \\
\hline CHEMBL 3679270 & 1528416 & 8.5528 & 8.1249 & TRN & \\
\hline CHEMBL 3684255 & 1528416 & 8.4949 & 8.4438 & TRN & \\
\hline CHEMBL 3679313 & 1528416 & 8.3279 & 7.8577 & TRN & \\
\hline CHEMBL 3674214 & 1528416 & 7.699 & 8.196 & TRN & \\
\hline CHEMBL 3968390 & 1528416 & 8.3979 & 7.6838 & TST & \\
\hline CHEMBL 3674182 & 1528416 & 8.3565 & 8.551 & TRN & \\
\hline CHEMBL 3679164 & 1528416 & 8.0 & 7.7914 & TRN & \\
\hline CHEMBL 3674192 & 1528416 & 6.0 & 7.9294 & TRN & \\
\hline CHEMBL 3684195 & 1528416 & 7.0132 & 6.989 & TST & \\
\hline CHEMBL 3674351 & 1528416 & 8.1549 & 7.6645 & TRN & \\
\hline CHEMBL 3674177 & 1528416 & 6.0 & 6.7547 & TRN & \\
\hline CHEMBL 3674284 & 1528416 & 7.3665 & 8.2388 & TST & \\
\hline CHEMBL3674162 & 1528416 & 6.0 & 7.2274 & TRN & \\
\hline CHEMBL 3679291 & 1528416 & 8.0 & 7.7269 & TST & \\
\hline CHEMBL 3679235 & 1528416 & 8.2007 & 8.1724 & TRN & \\
\hline CHEMBL 3679341 & 1528416 & 8.4815 & 8.0014 & TST & \\
\hline CHEMBL 3684149 & 1528416 & 8.5086 & 8.0272 & TRN & \\
\hline CHEMBL3684126 & 1528416 & 8.4685 & 7.9252 & TRN & \\
\hline CHEMBL 3940345 & 1528416 & 7.7959 & 7.7892 & TST & \\
\hline CHEMBL 3679283 & 1528416 & 7.8861 & 7.96700 & 00000000005 & TRN \\
\hline CHEMBL 3679308 & 1528416 & 7.301 & 7.5556 & TRN & \\
\hline CHEMBL 3679217 & 1528416 & 8.5528 & 7.9646 & TRN & \\
\hline CHEMBL 3679225 & 1528416 & 8.3768 & 8.7891 & TRN & \\
\hline CHEMBL 3679346 & 1528416 & 8.5229 & 6.7441 & TRN & \\
\hline CHEMBL 3684176 & 1528416 & 8.3665 & 7.7584 & TRN & \\
\hline CHEMBL 3684216 & 1528416 & 8.2076 & 8.11399 & 9999999999 & TRN \\
\hline CHEMBL 3679360 & 1528416 & 6.0 & 7.8322 & TRN & \\
\hline CHEMBL 3674219 & 1528416 & 8.2596 & 8.2346 & TRN & \\
\hline CHEMBL 3679220 & 1528416 & 7.8539 & 7.5771 & TRN & \\
\hline CHEMBL 3679287 & 1528416 & 8.5229 & 8.307 & TRN & \\
\hline CHEMBL 3679230 & 1528416 & 9.1367 & 8.1159 & TRN & \\
\hline CHEMBL 3684177 & 1528416 & 6.0 & 8.0735 & TRN & \\
\hline CHEMBL 3674198 & 1528416 & 9.0969 & 8.6804 & TRN & \\
\hline CHEMBL 3679209 & 1528416 & 8.5086 & 7.5903 & TRN & \\
\hline CHEMBL 3684205 & 1528416 & 7.9586 & 8.4664 & TRN & \\
\hline CHEMBL3684196 & 1528416 & 5.3768 & 6.6104 & TST & \\
\hline CHEMBL 3679344 & 1528416 & 8.7212 & 8.0862 & TRN & \\
\hline CHEMBL 3674315 & 1528416 & 7.2924 & 8.7005 & TST & \\
\hline CHEMBL 3679218 & 1528416 & 6.0 & 7.4829 & TRN & \\
\hline CHEMBL 3674325 & 1528416 & 6.1805 & 7.7992 & TST & \\
\hline CHEMBL3674296 & 1528416 & 7.6576 & 7.5861 & TST & \\
\hline CHEMBL 3679334 & 1528416 & 8.4437 & 8.666 & TRN & \\
\hline CHEMBL3679184 & 1528416 & 7.3979 & 7.9376 & TRN & \\
\hline CHEMBL 3679232 & 1528416 & 8.4437 & 7.8696 & TRN & \\
\hline CHEMBL3684182 & 1528416 & 8.7447 & 7.7113 & TRN & \\
\hline CHEMBL3679183 & 1528416 & 7.7212 & 7.7254 & TRN & \\
\hline
\end{tabular}


Supplemental Table S2.txt

\begin{tabular}{|c|c|c|c|c|c|}
\hline CHEMBL3639831 & 1528416 & 6.9586 & \multicolumn{2}{|c|}{7.2010000000000005} & TST \\
\hline CHEMBL3679279 & 1528416 & 6.0 & 7.2147 & TRN & \\
\hline CHEMBL3674165 & 1528416 & 7.585 & 7.1911 & TRN & \\
\hline CHEMBL3679180 & 1528416 & 7.1135 & 6.8639 & TRN & \\
\hline CHEMBL3679302 & 1528416 & 7.9586 & 7.6986 & TRN & \\
\hline CHEMBL 3679246 & 1528416 & 6.0 & 7.6499 & TRN & \\
\hline CHEMBL3679245 & 1528416 & 8.3768 & 8.5406 & TRN & \\
\hline CHEMBL 3684193 & 1528416 & 8.8539 & 8.2756 & TRN & \\
\hline CHEMBL3684187 & 1528416 & 7.7212 & 7.5864 & TRN & \\
\hline CHEMBL3679213 & 1528416 & 6.2007 & 7.3428 & TRN & \\
\hline CHEMBL3679254 & 1528416 & 7.6198 & 8.2328 & TRN & \\
\hline CHEMBL3674342 & 1528416 & 5.8539 & 7.631 & TST & \\
\hline CHEMBL 3679163 & 1528416 & 8.6198 & 7.6702 & TRN & \\
\hline CHEMBL 3684134 & 1528416 & 7.8239 & 7.9268 & TRN & \\
\hline CHEMBL 3674290 & 1528416 & 7.2366 & 7.2123 & TST & \\
\hline CHEMBL3684206 & 1528416 & 7.7447 & 7.3262 & TRN & \\
\hline CHEMBL3674291 & 1528416 & 8.3565 & 7.9087 & TRN & \\
\hline CHEMBL 3674307 & 1528416 & 8.1079 & 8.4541 & TST & \\
\hline CHEMBL3684272 & 1528416 & 7.6576 & 7.9081 & TRN & \\
\hline CHEMBL3679355 & 1528416 & 8.3872 & 7.6586 & TRN & \\
\hline CHEMBL3679342 & 1528416 & 7.4559 & 7.2511 & TRN & \\
\hline CHEMBL3684274 & 1528416 & 8.7212 & 8.0081 & TST & \\
\hline CHEMBL3674200 & 1528416 & 8.7696 & 8.5813 & TRN & \\
\hline CHEMBL3679175 & 1528416 & 6.9586 & 8.5305 & TST & \\
\hline CHEMBL 3674286 & 1528416 & 7.3098 & 7.8105 & TRN & \\
\hline CHEMBL 3674278 & 1528416 & 8.2076 & 7.8089 & TRN & \\
\hline CHEMBL3684213 & 1528416 & 5.4685 & 6.8738 & TRN & \\
\hline CHEMBL3674318 & 1528416 & 7.9586 & 8.6153 & TST & \\
\hline CHEMBL3674236 & 1528416 & 6.0 & 7.8084 & TRN & \\
\hline CHEMBL 3674314 & 1528416 & 7.699 & 7.2335 & TRN & \\
\hline CHEMBL3679192 & 1528416 & 5.2924 & 5.8799 & TRN & \\
\hline CHEMBL3679336 & 1528416 & 8.3979 & 8.0424 & TRN & \\
\hline CHEMBL3674184 & 1528416 & 8.0 & 8.7679 & TST & \\
\hline CHEMBL3679314 & 1528416 & 7.9208 & 7.7561 & TRN & \\
\hline CHEMBL 3684251 & 1528416 & 6.6576 & 6.9495 & TRN & \\
\hline CHEMBL3684244 & 1528416 & 8.0362 & 8.1751 & TRN & \\
\hline CHEMBL3684221 & 1528416 & 6.4685 & 6.1216 & TRN & \\
\hline CHEMBL3674243 & 1528416 & 7.8539 & 7.4971 & TRN & \\
\hline CHEMBL3684254 & 1528416 & 8.7696 & 8.5967 & TRN & \\
\hline CHEMBL 3684280 & 1528416 & 8.1024 & 7.4304 & TRN & \\
\hline CHEMBL3679278 & 1528416 & 8.0088 & 7.4927 & TRN & \\
\hline CHEMBL3679321 & 1528416 & 8.585 & 7.8943 & TRN & \\
\hline CHEMBL3674282 & 1528416 & 8.4089 & 8.218 & TRN & \\
\hline CHEMBL3679311 & 1528416 & 8.4949 & 7.7848 & TRN & \\
\hline CHEMBL3679215 & 1528416 & 7.0506 & 8.1766 & TST & \\
\hline CHEMBL3969903 & 1528416 & 8.3665 & 7.8457 & TST & \\
\hline CHEMBL 3679174 & 1528416 & 8.6198 & 7.7198 & TRN & \\
\hline CHEMBL3679309 & 1528416 & 8.7959 & 7.9753 & TRN & \\
\hline
\end{tabular}

Page 22979 
Supplemental Table S2.txt

\begin{tabular}{|c|c|c|c|c|c|}
\hline CHEMBL 3684265 & 1528416 & 6.8861 & 7.232 & TRN & \\
\hline CHEMBL 3679345 & 1528416 & 8.2596 & 7.9575 & TRN & \\
\hline CHEMBL3679240 & 1528416 & 8.6383 & 7.5422 & TST & \\
\hline CHEMBL 3674247 & 1528416 & 8.4685 & 8.1841 & TRN & \\
\hline CHEMBL3679178 & 1528416 & 8.4202 & 7.28799 & 9999999999 & TST \\
\hline CHEMBL3674188 & 1528416 & 6.0 & 7.4027 & TRN & \\
\hline CHEMBL3674187 & 1528416 & 8.7212 & 8.1843 & TRN & \\
\hline CHEMBL 3684248 & 1528416 & 8.283999 & 99999999 & 8.0035 & \\
\hline CHEMBL 3674170 & 1528416 & 8.4685 & 8.3294 & TST & \\
\hline CHEMBL3639731 & 1528416 & 8.2924 & 8.48 & TST & \\
\hline CHEMBL 3674213 & 1528416 & 6.0 & 8.1446 & TRN & \\
\hline CHEMBL3684174 & 1528416 & 8.5686 & 8.4993 & TRN & \\
\hline CHEMBL 3674273 & 1528416 & 8.3872 & 8.5452 & TST & \\
\hline CHEMBL 3679300 & 1528416 & 6.5376 & 7.8896 & TRN & \\
\hline CHEMBL3684263 & 1528416 & 8.7959 & 7.7986 & TRN & \\
\hline CHEMBL 3674349 & 1528416 & 8.3098 & 7.8882 & TST & \\
\hline CHEMBL3679340 & 1528416 & 8.0362 & 7.8507 & TRN & \\
\hline CHEMBL 3674239 & 1528416 & 8.3372 & 8.1426 & TRN & \\
\hline CHEMBL 3679250 & 1528416 & 7.9586 & 8.173 & TRN & \\
\hline CHEMBL3973589 & 1528416 & 6.0 & 7.926 & TST & \\
\hline CHEMBL 3674266 & 1528416 & 8.5376 & 6.7301 & TST & \\
\hline CHEMBL3674201 & 1528416 & 8.5376 & 8.1134 & TRN & \\
\hline CHEMBL 3674283 & 1528416 & 7.2518 & 7.9132 & TST & \\
\hline CHEMBL 3674253 & 1528416 & 8.0757 & 7.5511 & TRN & \\
\hline CHEMBL3674346 & 1528416 & 8.6778 & 8.40899 & 9999999999 & \\
\hline CHEMBL3679337 & 1528416 & 6.0 & 8.1781 & TRN & \\
\hline CHEMBL 3674338 & 1528416 & 6.0 & 6.9808 & TRN & \\
\hline CHEMBL 3674316 & 1528416 & 6.041 & 7.8721 & TST & \\
\hline CHEMBL3679210 & 1528416 & 6.0 & 7.4639 & TRN & \\
\hline CHEMBL 3674249 & 1528416 & 8.7447 & 8.2316 & TRN & \\
\hline CHEMBL 3684207 & 1528416 & 8.7212 & 7.9354 & TRN & \\
\hline CHEMBL 3674300 & 1528416 & 7.8539 & 7.6573 & TST & \\
\hline CHEMBL3679185 & 1528416 & 7.699 & 6.8959 & TRN & \\
\hline CHEMBL3674365 & 1528416 & 8.5229 & 8.3995 & TRN & \\
\hline CHEMBL3679366 & 1528416 & 8.7696 & 8.5012 & TRN & \\
\hline CHEMBL3679303 & 1528416 & 7.5229 & 7.565 & TRN & \\
\hline CHEMBL3679195 & 1528416 & 8.0 & 7.1141 & TRN & \\
\hline CHEMBL 3674174 & 1528416 & 6.0 & 7.2786 & TRN & \\
\hline CHEMBL3684286 & 1528416 & 7.3279 & 7.8399 & TRN & \\
\hline CHEMBL 3684232 & 1528416 & 8.5686 & 8.2073 & TRN & \\
\hline CHEMBL3684208 & 1528416 & 7.3979 & 7.8137 & TRN & \\
\hline CHEMBL3679207 & 1528416 & 6.0 & 7.8707 & TRN & \\
\hline CHEMBL3679322 & 1528416 & 8.8239 & 7.7758 & TRN & \\
\hline CHEMBL 3674268 & 1528416 & 6.0 & 7.2556 & TRN & \\
\hline CHEMBL 3684234 & 1528416 & 7.9586 & 7.9656 & TST & \\
\hline CHEMBL3684266 & 1528416 & 7.1308 & 7.6698 & TST & \\
\hline CHEMBL 3679301 & 1528416 & 7.8539 & 8.0276 & TRN & \\
\hline CHEMBL3684128 & 1528416 & 7.8539 & 7.8577 & TRN & \\
\hline
\end{tabular}

Page 22980 
Supplemental Table S2.txt

\begin{tabular}{|c|c|c|c|c|c|}
\hline CHEMBL 3674206 & 1528416 & 8.6576 & 8.6236 & TRN & \\
\hline CHEMBL3679186 & 1528416 & 6.0 & 7.2837 & TRN & \\
\hline CHEMBL 3684220 & 1528416 & 8.0315 & 7.8743 & TRN & \\
\hline CHEMBL 3679247 & 1528416 & 8.1805 & 7.7828 & TRN & \\
\hline CHEMBL 3679348 & 1528416 & 8.4685 & 8.3424 & TRN & \\
\hline CHEMBL 3674319 & 1528416 & 8.2924 & 8.9644 & TST & \\
\hline CHEMBL3679280 & 1528416 & 7.4815 & 7.1187 & TRN & \\
\hline CHEMBL 3674208 & 1528416 & 8.0605 & 8.3894 & TST & \\
\hline CHEMBL 3684278 & 1528416 & 7.7447 & 7.9007 & TRN & \\
\hline CHEMBL3679293 & 1528416 & 7.9208 & 8.0871 & TRN & \\
\hline CHEMBL 3674265 & 1528416 & 8.699 & 8.8123 & TST & \\
\hline CHEMBL3679223 & 1528416 & 8.8861 & 8.2336 & TRN & \\
\hline CHEMBL 3674311 & 1528416 & 7.0809 & 7.1378 & TRN & \\
\hline CHEMBL 3679307 & 1528416 & 7.7959 & \multicolumn{2}{|c|}{7.9270000000000005} & TRN \\
\hline CHEMBL 3684132 & 1528416 & 6.0 & 7.7379 & TRN & \\
\hline CHEMBL 3684144 & 1528416 & 7.8861 & 7.6071 & TRN & \\
\hline CHEMBL 3674154 & 1528416 & 7.6778 & 6.3752 & TRN & \\
\hline CHEMBL 3684211 & 1528416 & 6.0 & 7.8943 & TRN & \\
\hline CHEMBL 3684151 & 1528416 & 8.7696 & 7.9089 & TRN & \\
\hline CHEMBL 3684200 & 1528416 & 8.7959 & 7.9855 & TRN & \\
\hline CHEMBL3674293 & 1528416 & 8.4559 & 8.2803 & TRN & \\
\hline CHEMBL 3674309 & 1528416 & 6.2007 & 8.1331 & TST & \\
\hline CHEMBL 3684185 & 1528416 & 7.7696 & 7.6613 & TRN & \\
\hline CHEMBL 3684231 & 1528416 & 8.0555 & 8.0871 & TRN & \\
\hline CHEMBL 3674179 & 1528416 & 7.6383 & 7.2631 & TRN & \\
\hline CHEMBL 3674156 & 1528416 & 8.6198 & 6.4964 & TST & \\
\hline CHEMBL 3674262 & 1528416 & 8.7696 & 7.9422 & TRN & \\
\hline CHEMBL 3674347 & 1528416 & 7.3372 & 7.5279 & TST & \\
\hline CHEMBL 3674254 & 1528416 & 7.7959 & 8.0556 & TST & \\
\hline CHEMBL 3674263 & 1528416 & 8.1675 & 8.4431 & TST & \\
\hline CHEMBL 3684210 & 1528416 & 7.7447 & \multicolumn{2}{|c|}{7.787999999999999} & TRN \\
\hline CHEMBL 3684160 & 1528416 & 6.0 & 7.6037 & TRN & \\
\hline CHEMBL 3684223 & 1528416 & 8.5376 & 8.5884 & TRN & \\
\hline CHEMBL 3679167 & 1528416 & 7.8239 & 7.2877 & TRN & \\
\hline CHEMBL 3674190 & 1528416 & 6.0 & 7.6834 & TRN & \\
\hline CHEMBL3971452 & 1528416 & 8.2441 & 7.5435 & TST & \\
\hline CHEMBL 3674332 & 1528416 & 5.8539 & 7.8962 & TST & \\
\hline CHEMBL 3684186 & 1528416 & 8.2924 & 7.7639 & TRN & \\
\hline CHEMBL 3674321 & 1528416 & 7.8239 & 7.4378 & TRN & \\
\hline CHEMBL 3684168 & 1528416 & 7.7959 & 8.1267 & TRN & \\
\hline CHEMBL3679236 & 1528416 & 8.2924 & 8.3925 & TRN & \\
\hline CHEMBL 3684162 & 1528416 & 7.7959 & 7.5452 & TRN & \\
\hline CHEMBL 3674340 & 1528416 & 7.8539 & 8.0691 & TRN & \\
\hline CHEMBL 3684236 & 1528416 & 8.1938 & \multicolumn{2}{|c|}{7.6610000000000005} & TRN \\
\hline CHEMBL 3684219 & 1528416 & 8.4089 & 8.2229 & TRN & \\
\hline CHEMBL3679173 & 1528416 & 7.6021 & 7.6987 & TRN & \\
\hline CHEMBL 3674218 & 1528416 & 7.9586 & 8.3617 & TRN & \\
\hline CHEMBL3679298 & 1528416 & 8.1612 & 7.8258 & TRN & \\
\hline
\end{tabular}

Page 22981 
Supplemental Table S2.txt

\begin{tabular}{|c|c|c|c|c|c|}
\hline CHEMBL 3684243 & 1528416 & 5.4685 & 6.8373 & TRN & \\
\hline CHEMBL 3684260 & 1528416 & 8.6198 & 8.315 & TRN & \\
\hline CHEMBL3684289 & 1528416 & 7.0969 & 7.0581 & TRN & \\
\hline CHEMBL3679179 & 1528416 & 7.1938 & 7.1774 & TRN & \\
\hline CHEMBL 3674303 & 1528416 & 8.585 & 7.6287 & TRN & \\
\hline CHEMBL 3684209 & 1528416 & 8.5528 & 8.6403 & TRN & \\
\hline CHEMBL3679170 & 1528416 & 6.0 & 8.0052 & TRN & \\
\hline CHEMBL 3674191 & 1528416 & 8.301 & 8.0384 & TRN & \\
\hline CHEMBL 3679194 & 1528416 & 8.6021 & \multicolumn{2}{|c|}{7.8260000000000005} & TRN \\
\hline CHEMBL 3679253 & 1528416 & 8.9586 & 7.6542 & TRN & \\
\hline CHEMBL 3679333 & 1528416 & 8.4949 & 8.5887 & TRN & \\
\hline CHEMBL 3684270 & 1528416 & 8.3188 & 7.9839 & TRN & \\
\hline CHEMBL 3674298 & 1528416 & 8.7447 & 8.4499 & TST & \\
\hline CHEMBL 3674280 & 1528416 & 7.7212 & 8.1875 & TRN & \\
\hline CHEMBL 3684135 & 1528416 & 8.2676 & \multicolumn{2}{|c|}{8.072000000000001} & TRN \\
\hline CHEMBL 3679324 & 1528416 & 8.8539 & 7.9822 & TRN & \\
\hline CHEMBL3679319 & 1528416 & 8.0757 & 8.1627 & TRN & \\
\hline CHEMBL 3684253 & 1528416 & 8.3565 & 7.4235 & TRN & \\
\hline CHEMBL 3679237 & 1528416 & 8.6576 & 7.9151 & TRN & \\
\hline CHEMBL 3684141 & 1528416 & 7.6778 & 6.5289 & TRN & \\
\hline CHEMBL3679259 & 1528416 & 8.5086 & 7.8309 & TRN & \\
\hline CHEMBL 3684201 & 1528416 & 6.0 & 7.5524 & TRN & \\
\hline CHEMBL3679288 & 1528416 & 6.8539 & 7.5116 & TRN & \\
\hline CHEMBL 3674257 & 1528416 & 7.9586 & 7.7237 & TRN & \\
\hline CHEMBL 3674313 & 1528416 & 7.1805 & 7.6088 & TRN & \\
\hline CHEMBL 3684252 & 1528416 & 7.6778 & 7.9137 & TST & \\
\hline CHEMBL 3684281 & 1528416 & 8.0177 & 7.5592 & TRN & \\
\hline CHEMBL3684233 & 1528416 & 8.1024 & 7.8317 & TRN & \\
\hline CHEMBL 3684287 & 1528416 & 5.9208 & 7.0694 & TST & \\
\hline CHEMBL 3679257 & 1528416 & 8.6383 & 8.471 & TRN & \\
\hline CHEMBL3674336 & 1528416 & 8.2518 & 8.0868 & TST & \\
\hline CHEMBL 3684283 & 1528416 & 7.1938 & 7.2164 & TRN & \\
\hline CHEMBL 3684264 & 1528416 & 7.0 & 7.5832 & TST & \\
\hline CHEMBL 3684271 & 1528416 & 8.5229 & 7.7222 & TRN & \\
\hline CHEMBL 3977004 & 1528416 & 8.1739 & 7.879 & TST & \\
\hline CHEMBL3674210 & 1528416 & 7.9208 & 7.7758 & TST & \\
\hline CHEMBL 3674258 & 1528416 & 8.4202 & 8.2953 & TRN & \\
\hline CHEMBL 3679289 & 1528416 & 8.4815 & 8.199 & TST & \\
\hline CHEMBL 3684279 & 1528416 & 7.7212 & 7.1489 & TRN & \\
\hline CHEMBL 3679255 & 1528416 & 8.8239 & 7.7779 & TRN & \\
\hline CHEMBL 3679351 & 1528416 & 8.585 & 8.7056 & TRN & \\
\hline CHEMBL 3674360 & 1528416 & 8.5528 & 7.7553 & TRN & \\
\hline CHEMBL 3674276 & 1528416 & 8.5686 & 7.8119 & TRN & \\
\hline CHEMBL 3684125 & 1528416 & 7.8861 & \multicolumn{2}{|c|}{8.318999999999999} & TRN \\
\hline CHEMBL 3684256 & 1528416 & 7.0 & 6.3831 & TST & \\
\hline CHEMBL 3684202 & 1528416 & 8.6893 & 8.1129 & TRN & \\
\hline CHEMBL 3679374 & 1528416 & 8.2076 & 8.2077 & TRN & \\
\hline CHEMBL 3684166 & 1528416 & 8.8239 & 7.6041 & TRN & \\
\hline
\end{tabular}

Page 22982 
Supplemental Table S2.txt

\begin{tabular}{|c|c|c|c|c|}
\hline CHEMBL 3684146 & 1528416 & 8.0555 & 8.2149 & TRN \\
\hline CHEMBL3684145 & 1528416 & 8.2596 & 7.6999 & TRN \\
\hline CHEMBL 3674252 & 1528416 & 8.1192 & 7.2835 & TRN \\
\hline CHEMBL3674199 & 1528416 & 8.3372 & 8.2901 & TRN \\
\hline CHEMBL3679208 & 1528416 & 8.7447 & 8.0034 & TRN \\
\hline CHEMBL3684150 & 1528416 & 8.2366 & 7.9683 & TRN \\
\hline CHEMBL3674267 & 1528416 & 8.6576 & 7.0675 & TST \\
\hline CHEMBL 3674215 & 1528416 & 8.5686 & 8.5675 & TRN \\
\hline CHEMBL 3679292 & 1528416 & 8.4089 & 8.5554 & TRN \\
\hline CHEMBL3679244 & 1528416 & 8.3565 & 8.6825 & TRN \\
\hline CHEMBL3684229 & 1528416 & 7.7959 & 7.4759 & TST \\
\hline CHEMBL3674275 & 1528416 & 7.8861 & 8.1848 & TST \\
\hline CHEMBL 3679243 & 1528416 & 8.0862 & 7.7514 & TRN \\
\hline CHEMBL 3679343 & 1528416 & 8.3665 & 8.2889 & TRN \\
\hline CHEMBL3674166 & 1528416 & 6.0 & 7.1116 & TRN \\
\hline CHEMBL 3674348 & 1528416 & 7.4437 & 7.5115 & TST \\
\hline CHEMBL3679304 & 1528416 & 7.9586 & 8.2032 & TRN \\
\hline CHEMBL 3674264 & 1528416 & 8.041 & 8.1151 & TST \\
\hline CHEMBL 3679214 & 1528416 & 8.5086 & 8.3524 & TRN \\
\hline CHEMBL3679318 & 1528416 & 7.9208 & 7.7983 & TRN \\
\hline CHEMBL3684226 & 1528416 & 8.5528 & 7.7296 & TST \\
\hline CHEMBL3679323 & 1528416 & 8.5229 & 7.7226 & TRN \\
\hline CHEMBL3679182 & 1528416 & 7.7447 & 7.9701 & TRN \\
\hline CHEMBL 3679350 & 1528416 & 8.6576 & 8.4914 & TRN \\
\hline CHEMBL3679296 & 1528416 & 7.8539 & 7.4864 & TRN \\
\hline CHEMBL 3684273 & 1528416 & 7.4685 & 7.782 & TRN \\
\hline CHEMBL3684153 & 1528416 & 8.7447 & 8.0335 & TRN \\
\hline CHEMBL3921375 & 1528416 & 7.9586 & 7.7966 & TST \\
\hline CHEMBL 3674259 & 1528416 & 7.7696 & 7.1726 & TRN \\
\hline CHEMBL3674186 & 1528416 & 8.8861 & 8.8808 & TST \\
\hline CHEMBL3679234 & 1528416 & 8.699 & 8.1303 & TRN \\
\hline CHEMBL3674322 & 1528416 & 7.9586 & 7.0569 & TRN \\
\hline CHEMBL3684172 & 1528416 & 8.6778 & 8.1347 & TST \\
\hline CHEMBL3679162 & 1528416 & 8.8539 & 7.03299 & 99999999995 \\
\hline CHEMBL 3684269 & 1528416 & 8.5086 & 8.0047 & TRN \\
\hline CHEMBL3674363 & 1528416 & 8.8539 & 8.0345 & TRN \\
\hline CHEMBL 3674250 & 1528416 & 6.0 & 7.9199 & TRN \\
\hline CHEMBL3679317 & 1528416 & 6.0 & 7.907 & TRN \\
\hline CHEMBL 3679266 & 1528416 & 7.5686 & 8.0453 & TRN \\
\hline CHEMBL 3679327 & 1528416 & 8.7696 & 8.4283 & TST \\
\hline CHEMBL3674292 & 1528416 & 8.3979 & 8.2448 & TRN \\
\hline CHEMBL 3674272 & 1528416 & 6.0 & 8.3199 & TST \\
\hline CHEMBL 3684165 & 1528416 & 6.0 & 7.5261 & TRN \\
\hline CHEMBL 3679211 & 1528416 & 8.3768 & 8.2397 & TRN \\
\hline CHEMBL3674261 & 1528416 & 8.0458 & 8.4695 & TST \\
\hline CHEMBL 3674350 & 1528416 & 6.0 & 7.3694 & TRN \\
\hline CHEMBL 3674317 & 1528416 & 7.7959 & 8.6049 & TST \\
\hline CHEMBL 3900783 & 1528416 & 8.1249 & 7.6246 & TST \\
\hline
\end{tabular}

Page 22983 
Supplemental Table S2.txt

\begin{tabular}{|c|c|c|c|c|c|}
\hline CHEMBL 3684188 & 1528416 & 8.2676 & 7.7039 & TRN & \\
\hline CHEMBL 3674279 & 1528416 & 8.4318 & 8.6937 & TST & \\
\hline CHEMBL3679196 & 1528416 & 6.9586 & 7.7069 & TRN & \\
\hline CHEMBL 3674335 & 1528416 & 8.1612 & 8.165 & TRN & \\
\hline CHEMBL 3674196 & 1528416 & 8.4318 & 8.5161 & TST & \\
\hline CHEMBL 3674306 & 1528416 & 7.1612 & 8.7084 & TST & \\
\hline CHEMBL3679316 & 1528416 & 8.0809 & 8.2903 & TRN & \\
\hline CHEMBL 3684258 & 1528416 & 8.7696 & 7.0049 & TRN & \\
\hline CHEMBL3674289 & 1528416 & 7.7447 & 7.9283 & TRN & \\
\hline CHEMBL 3684227 & 1528416 & 7.2596 & 7.4258 & TRN & \\
\hline CHEMBL 3674223 & 1528416 & 8.1612 & 8.2259 & TRN & \\
\hline CHEMBL 3674216 & 1528416 & 7.8861 & 8.2321 & TRN & \\
\hline CHEMBL 3684198 & 1528416 & 6.1135 & 7.2419 & TST & \\
\hline CHEMBL3679281 & 1528416 & 8.0506 & 8.0816 & TRN & \\
\hline CHEMBL 3674234 & 1528416 & 8.3768 & 8.4402 & TRN & \\
\hline CHEMBL3679201 & 1528416 & 8.5229 & 7.751 & TRN & \\
\hline CHEMBL3674158 & 1528416 & 7.7447 & 6.6498 & TST & \\
\hline CHEMBL 3679202 & 1528416 & 8.0809 & 7.6176 & TRN & \\
\hline CHEMBL3674271 & 1528416 & 8.2291 & \multicolumn{2}{|c|}{7.5360000000000005} & TRN \\
\hline CHEMBL 3679251 & 1528416 & 8.7959 & 8.1911 & TRN & \\
\hline CHEMBL3679290 & 1528416 & 7.6198 & 7.8659 & TST & \\
\hline CHEMBL 3679364 & 1528416 & 8.5376 & 8.1959 & TRN & \\
\hline CHEMBL3684259 & 1528416 & 7.7696 & 6.9647 & TRN & \\
\hline CHEMBL3674331 & 1528416 & 7.2676 & 6.6909 & TST & \\
\hline CHEMBL 3674202 & 1528416 & 7.8861 & 6.7172 & TST & \\
\hline CHEMBL3684129 & 1528416 & 8.0605 & 7.8376 & TRN & \\
\hline CHEMBL 3684143 & 1528416 & 8.699 & 8.4035 & TRN & \\
\hline CHEMBL3674205 & 1528416 & 8.2147 & 8.4005 & TRN & \\
\hline CHEMBL 3679200 & 1528416 & 5.6778 & 5.8579 & TRN & \\
\hline CHEMBL 3679267 & 1528416 & 8.1192 & 7.7928 & TRN & \\
\hline CHEMBL3679241 & 1528416 & 8.2596 & 8.1282 & TRN & \\
\hline CHEMBL 3639780 & 1528416 & 7.6778 & 7.4757 & TRN & \\
\hline CHEMBL3684215 & 1528416 & 6.0757 & 6.7818 & TRN & \\
\hline CHEMBL3679190 & 1528416 & 8.2518 & 8.1013 & TRN & \\
\hline CHEMBL3674269 & 1528416 & 8.0044 & 7.9417 & TRN & \\
\hline CHEMBL3679191 & 1528416 & 6.0 & 7.7381 & TRN & \\
\hline CHEMBL 3942248 & 1528416 & 8.2076 & 8.0429 & TST & \\
\hline CHEMBL3684136 & 1528416 & 8.6778 & 8.3233 & TRN & \\
\hline CHEMBL 3674172 & 1528416 & 8.1549 & 7.7722 & TRN & \\
\hline CHEMBL 3674320 & 1528416 & 8.8239 & 6.4526 & TST & \\
\hline CHEMBL3951305 & 1528416 & 9.0 & 8.1615 & TST & \\
\hline CHEMBL 3679252 & 1528416 & 6.8239 & 8.2929 & TRN & \\
\hline CHEMBL3674343 & 1528416 & 6.0 & 7.8537 & TRN & \\
\hline CHEMBL3674161 & 1528416 & 8.3979 & 8.7189 & TST & \\
\hline CHEMBL3679181 & 1528416 & 6.0 & 8.0823 & TRN & \\
\hline CHEMBL 3674225 & 1528416 & 8.3372 & 7.2734 & TST & \\
\hline CHEMBL 3679328 & 1528416 & 8.9586 & 7.9719 & TST & \\
\hline CHEMBL3962984 & 1528416 & 7.9586 & 8.2026 & TST & \\
\hline
\end{tabular}


Supplemental Table S2.txt

\begin{tabular}{|c|c|c|c|c|}
\hline . & & 8.7447 & & \\
\hline & 528416 & 7.6778 & .9989 & \\
\hline 274 & & 2007 & & \\
\hline AEMBL & & 6198 & & \\
\hline AEMBL3679193 & 528416 & 6.0 & 3706 & \\
\hline HEMBL3684203 & 528416 & 8.6383 & 8927 & \\
\hline 221 & 16 & & 256 & \\
\hline 140 & 528416 & & & \\
\hline AEMBL3674330 & 528416 & 7. & 5961 & \\
\hline HEMBL3684138 & 528416 & 8.7212 & $\partial 001$ & \\
\hline HEMBL3902874 & 528416 & 8.5686 & 5451 & \\
\hline IEMBL & 28 & 383 & 324 & \\
\hline IEMBL: & & & & \\
\hline HEMBL36 & 528416 & 6.0 & 7.3153 & \\
\hline AEMBL36 & 16 & 8 & 4697 & \\
\hline AEMBL36 & 528 & 98 & 3194 & \\
\hline AEMBL & 6 & & 022 & \\
\hline HEMBL & 6 & & 31 & \\
\hline HEMBL3 & 16 & & 2343 & \\
\hline AEMBL3 & 16 & & & \\
\hline HEMBL & 6 & 872 & 41 & RIV \\
\hline AEMBL & 6 & & 45 & RN \\
\hline AEMBL & 6 & 09 & & \\
\hline 362 & & 565 & 5846 & \\
\hline IEMBL36 & & & & $1=2$. \\
\hline HEMBL; & 6 & 8 . & 232 & 1 \\
\hline HEMBL & 6 & & 95 & Niv \\
\hline HFMBI : & 16 & 39 & 27 & $C T$ \\
\hline HEMBL36 & & 8 . & & is \\
\hline HEMBL 3679 & 6 & 24 & & I RN \\
\hline HEMBL3 & 6 & & 7447 & RN \\
\hline HEMBL & 6 & & $\partial 2$ & RN \\
\hline 65 & 16 & 8 & 69 & 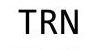 \\
\hline HEMBL3674328 & & & 5089 & IRN \\
\hline HEMBL3684139 & $52 \varepsilon$ & 685 & 3001 & TRN \\
\hline HEMBL36 & 6 & 1 & 352 & ST \\
\hline HFMRI & 6 & & 53 & $\Gamma \mathrm{RN}$ \\
\hline HEMBL; & & & 3633 & IRN \\
\hline HEMBL3679221 & 16 & & 4323 & TRN \\
\hline IEMBL3 & 6 & & 3259 & TST \\
\hline HEMBL36 & 6 & 18 & 888 & RN \\
\hline CHEMBL 36 & 6 & & & RN \\
\hline HEMBL36 & 16 & 8.7447 & 8.5993 & TRN \\
\hline AEMBL3674333 & 528 & 8. & 731 & TR \\
\hline 13 & & & 7.7537 & ב \\
\hline HEMBL36 & -5 & 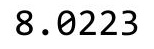 & .0206 & \\
\hline CHEMBL368413] & 5284 & & 7.9721 & \\
\hline CHEMBL3679295 & 1528416 & 7.6021 & 7.6246 & RN \\
\hline
\end{tabular}

Page 22985 
Supplemental Table S2.txt

\begin{tabular}{|c|c|c|c|c|}
\hline IE & & & 27 & $\mathrm{~T}$ \\
\hline & 528416 & & & \\
\hline & 16 & 959 & & \\
\hline AEMB & 28416 & 6.0 & 164 & \\
\hline AEMBL3674329 & 528416 & 1079 & 9372 & \\
\hline HEMBL3674230 & 528416 & 8.3372 & 0426 & \\
\hline 1228 & 16 & 739 & & \\
\hline 240 & 16 & 809 & & \\
\hline HEMBL3684152 & 528416 & 8.5528 & & \\
\hline HEMBL3674304 & 528416 & 7.0269 & .9222 & \\
\hline AEMBL3674195 & 528416 & 8.6576 & 7.7 & \\
\hline IEMBL: & 16 & 959 & & \\
\hline AEMBL & & 861 & & \\
\hline HEMBL3674326 & 528 & 7.1427 & & \\
\hline AEMBL36 & 16 & 2676 & & \\
\hline AEMBL 36 & 528 & 366 & 7.7 & \\
\hline AEMBL & 6 & 757 & & \\
\hline HEMBL & 6 & 367 & & \\
\hline HEMBL36 & 16 & 1427 & & \\
\hline AEMBL36 & 6 & 5 & & RN \\
\hline AEMIBL & 16 & 8 & 23 & \\
\hline AEMBL & 0 & 36 & & \\
\hline AEMBL & & 7 & & \\
\hline 323 & & & & מח \\
\hline AEMBL36 & 6 & & & NIV \\
\hline HEMBL & 16 & r & & SI \\
\hline HEMBL. & 6 & & & RN \\
\hline $\mathrm{AFMB}$ & 16 & & & RN \\
\hline HEMBL36 & & & & ו \\
\hline HEMBL3674227 & 52 & 49 & 56 & IRN \\
\hline HEMBL36 & 6 & 212 & 16 & \\
\hline AFMB & 6 & 33 & & Niv \\
\hline HEMBL. & & & 42 & ST \\
\hline HEMBL3679212 & & 8 . & & RN \\
\hline HEMBL3674240 & 52 & 7.7212 & 12 & RN \\
\hline HEMBL3C & 6 & 18 & & \\
\hline HFMRI & 6 & & & RN \\
\hline HEMBL & & & & RN \\
\hline HEMBL3674235 & 16 & 239 & & RN \\
\hline IEMBL3 & 6 & & & RN \\
\hline HEMBL36 & 6 & & 24 & \\
\hline CHEMBL3679168 & & & & RN \\
\hline HEMBL3679320 & 16 & 198 & 8.4472 & RN \\
\hline AEMBL3679203 & 528 & 8.5686 & 7.9575 & ГRN \\
\hline EMBL3 & & 559 & & \\
\hline CHEMBL3674233 & & .7696 & & \\
\hline LHEMBL 3679310 & 5284 & & 8.2656 & \\
\hline THEMBL3679238 & 1528416 & 8.6021 & 8.0181 & ГST \\
\hline
\end{tabular}

Page 22986 
Supplemental Table S2.txt

\begin{tabular}{|c|c|c|c|c|c|}
\hline CHEMBL3674157 & 1528416 & 7.5229 & 6.9678 & TST & \\
\hline CHEMBL3679352 & 1528416 & 8.3279 & 7.6466 & TRN & \\
\hline CHEMBL 3674288 & 1528416 & 8.9586 & 8.6215 & TRN & \\
\hline CHEMBL 3938946 & 1528416 & 8.4949 & 8.0133 & TST & \\
\hline CHEMBL3674155 & 1528416 & 6.0 & 7.0324 & TRN & \\
\hline CHEMBL 3674226 & 1528416 & 8.6778 & 7.8015 & TRN & \\
\hline CHEMBL3674231 & 1528416 & 8.301 & 8.013 & TRN & \\
\hline CHEMBL 3674171 & 1528416 & 7.9586 & 7.9384 & TRN & \\
\hline CHEMBL3684261 & 1528416 & 8.3279 & 7.8824 & TRN & \\
\hline CHEMBL3674341 & 1528416 & 8.1249 & 7.6411 & TST & \\
\hline CHEMBL3684191 & 1528416 & 6.0862 & 7.5195 & TST & \\
\hline CHEMBL3679171 & 1528416 & 7.7696 & 7.6113 & TRN & \\
\hline CHEMBL 3674358 & 1528416 & 7.7696 & 8.5355 & TST & \\
\hline CHEMBL3684242 & 1528416 & 7.4437 & 7.7337 & TST & \\
\hline CHEMBL3674181 & 1528416 & 8.2757 & 8.7564 & TST & \\
\hline CHEMBL3679357 & 1528416 & 7.2596 & 7.4915 & TRN & \\
\hline CHEMBL3684156 & 1528416 & 6.0 & 7.9062 & TRN & \\
\hline CHEMBL 3684247 & 1528416 & 8.6383 & 8.14299 & 9999999999 & TRN \\
\hline CHEMBL3674302 & 1528416 & 8.6021 & 8.3667 & TST & \\
\hline CHEMBL 3674248 & 1528416 & 7.0223 & 7.5089 & TRN & \\
\hline CHEMBL3684130 & 1528416 & 8.5376 & 8.4004 & TRN & \\
\hline CHEMBL 3674255 & 1528416 & 6.0 & 8.2348 & TST & \\
\hline CHEMBL 3944105 & 1528416 & 6.0 & 7.8041 & TST & \\
\hline CHEMBL3918698 & 1528416 & 7.5528 & 7.6372 & TST & \\
\hline CHEMBL 3674324 & 1528416 & 8.0862 & 8.0953 & TST & \\
\hline CHEMBL3674183 & 1528416 & 8.7959 & 9.0825 & TST & \\
\hline CHEMBL3674232 & 1528416 & 8.6576 & 8.3983 & TRN & \\
\hline CHEMBL3679166 & 1528416 & 6.0 & 7.8813 & TRN & \\
\hline CHEMBL3674176 & 1528416 & 7.1739 & 7.0156 & TST & \\
\hline CHEMBL3674295 & 1528416 & 7.4437 & 7.8477 & TST & \\
\hline CHEMBL3684267 & 1528416 & 9.0269 & 7.9547 & TRN & \\
\hline CHEMBL 3684180 & 1528416 & 8.5686 & 8.1092 & TRN & \\
\hline CHEMBL3684159 & 1528416 & 7.585 & 7.7621 & TRN & \\
\hline CHEMBL 3684238 & 1528416 & 8.699 & 8.1009 & TST & \\
\hline CHEMBL3679373 & 1528416 & 8.6383 & 7.8806 & TST & \\
\hline CHEMBL3679286 & 1528416 & 8.3979 & 8.2087 & TRN & \\
\hline CHEMBL3684199 & 1528416 & 6.0315 & 7.3047 & TST & \\
\hline CHEMBL3679172 & 1528416 & 8.0555 & 8.0514 & TRN & \\
\hline CHEMBL3679261 & 1528416 & 6.0 & 7.9649 & TRN & \\
\hline CHEMBL 3684230 & 1528416 & 8.4559 & 7.5625 & TST & \\
\hline CHEMBL3674294 & 1528416 & 7.3665 & 7.5238 & TST & \\
\hline CHEMBL3684173 & 1528416 & 9.0458 & 8.2628 & TST & \\
\hline CHEMBL3679306 & 1528416 & 7.7447 & 7.6598 & TRN & \\
\hline CHEMBL 3674354 & 1528416 & 8.4949 & \multicolumn{2}{|c|}{7.6979999999999995} & TRN \\
\hline CHEMBL3684282 & 1528416 & 7.8239 & 7.9535 & TRN & \\
\hline CHEMBL 3684284 & 1528416 & 7.7696 & 8.1611 & TST & \\
\hline CHEMBL3684285 & 1528416 & 8.2076 & 8.2867 & TST & \\
\hline CHEMBL3679263 & 1528416 & 8.4559 & 7.9232 & TRN & \\
\hline
\end{tabular}

Page 22987 
Supplemental Table S2.txt

\begin{tabular}{|c|c|c|c|c|}
\hline the & 8416 & 8.2596 & & \\
\hline & 528416 & 7.4089 & .6349 & \\
\hline 75 & 16 & & & \\
\hline AEMBL & & 8861 & & \\
\hline AEMBL3679233 & 528416 & 528 & & \\
\hline HEMBL3684235 & 528416 & 7.3979 & 64 & \\
\hline 325 & 16 & 8.8861 & & \\
\hline 193 & 16 & & & \\
\hline AEMBL36 & 528416 & & & \\
\hline HEMBL3679165 & 528416 & 188 & .0944 & \\
\hline HEMBL3679359 & 528416 & 6.0 & 49 & \\
\hline IEMBL3 & 528 & 18 & 45 & \\
\hline IEMBL: & & & & \\
\hline HEMBL36 & 528416 & 6 . & & \\
\hline AEMBL36 & 16 & & & \\
\hline AEMBL36 & 528 & 12 & 46 & \\
\hline AEMBL3 & 6 & & 82 & \\
\hline HEMBL36 & 6 & & 55 & \\
\hline HEMBL3S & 16 & & & \\
\hline IEMBL36 & 6 & & & \\
\hline HEMBL= & 6 & & 22 & 15 \\
\hline AEMBL & 6 & & & SI \\
\hline HEMBL & 6 & & & \\
\hline 352 & & & & \\
\hline AEMBL36 & & & & I RIV \\
\hline HEMBL3 & 6 & & 3 & RN \\
\hline HEMBL & 6 & & & No \\
\hline HFMBI : & 16 & & & \\
\hline AEMBL36 & & & & is \\
\hline HEMBL3679297 & 6 & & & $\Gamma \mathrm{RN}$ \\
\hline HEMBL36 & 6 & & & RN \\
\hline HEMBL & 6 & 6 & & RN \\
\hline AEMBL & 6 & & & $\mathrm{RN}$ \\
\hline HEMBL3674297 & & & & IS \\
\hline HEMBL3674189 & 52 & & 6. & TRN \\
\hline HEMBL36 & 6 & & 7. & RN \\
\hline HFMRI & 6 & & 7. & IRIV \\
\hline HEMBL & & & & ST \\
\hline HEMBL3679176 & 16 & 7. & & TRN \\
\hline IEMBL36 & 6 & & & TST \\
\hline HEMBL36 & 6 & & & \\
\hline CHEMBL 36 & 6 & & & RIV \\
\hline HEMBL36 & 16 & & & RN \\
\hline AEMBL3684250 & 528 & 7.9 & 24 & TST \\
\hline 12 & 16 & & & is \\
\hline HEMBL1 & & & & \\
\hline HEMBL12 & 77423 & 5.6383 & 5.6802 & \\
\hline HEMBL124071 & 177423 & 6.6778 & 6.9898 & ГRN \\
\hline
\end{tabular}

Page 22988 


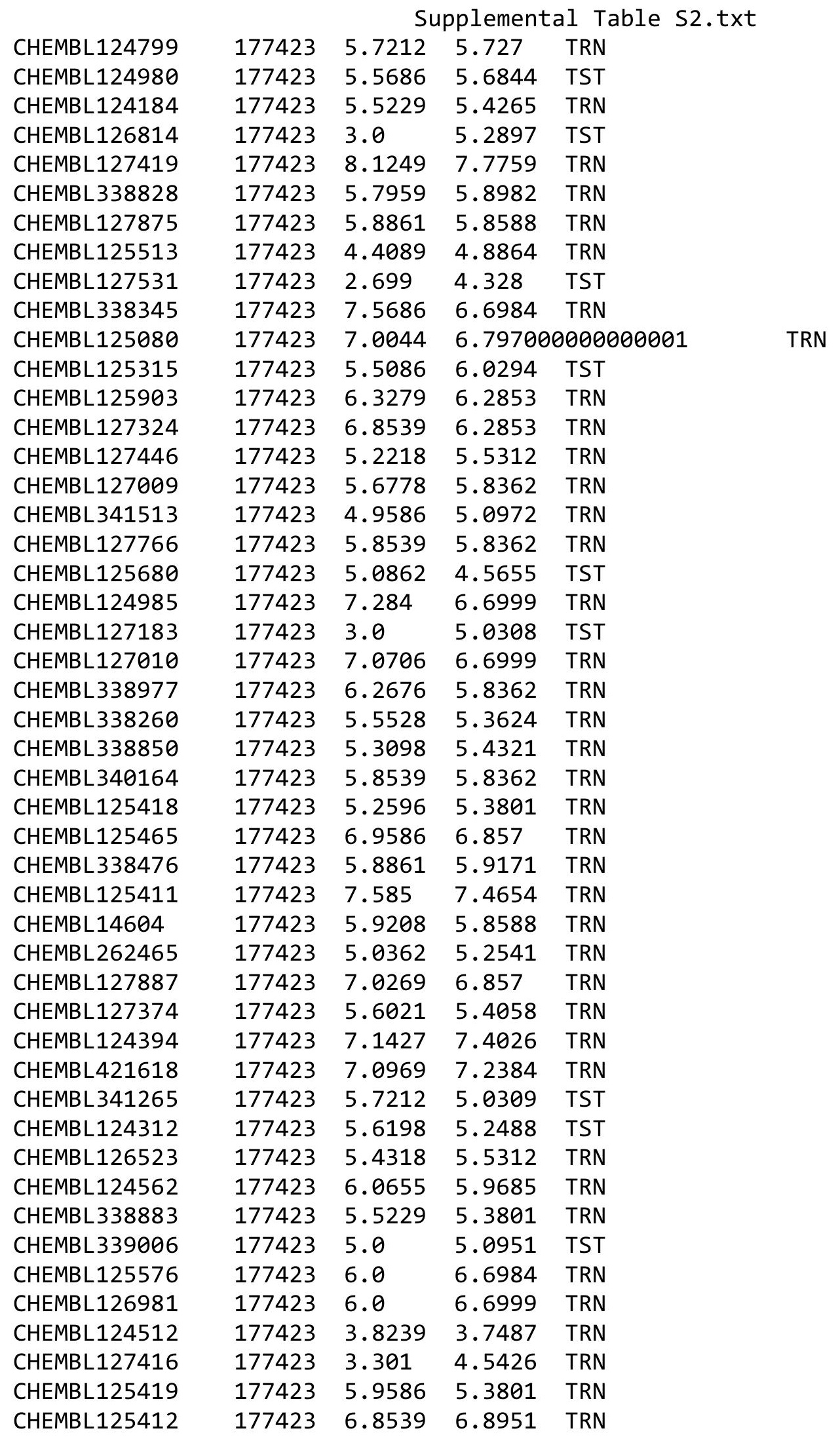

Page 22989 


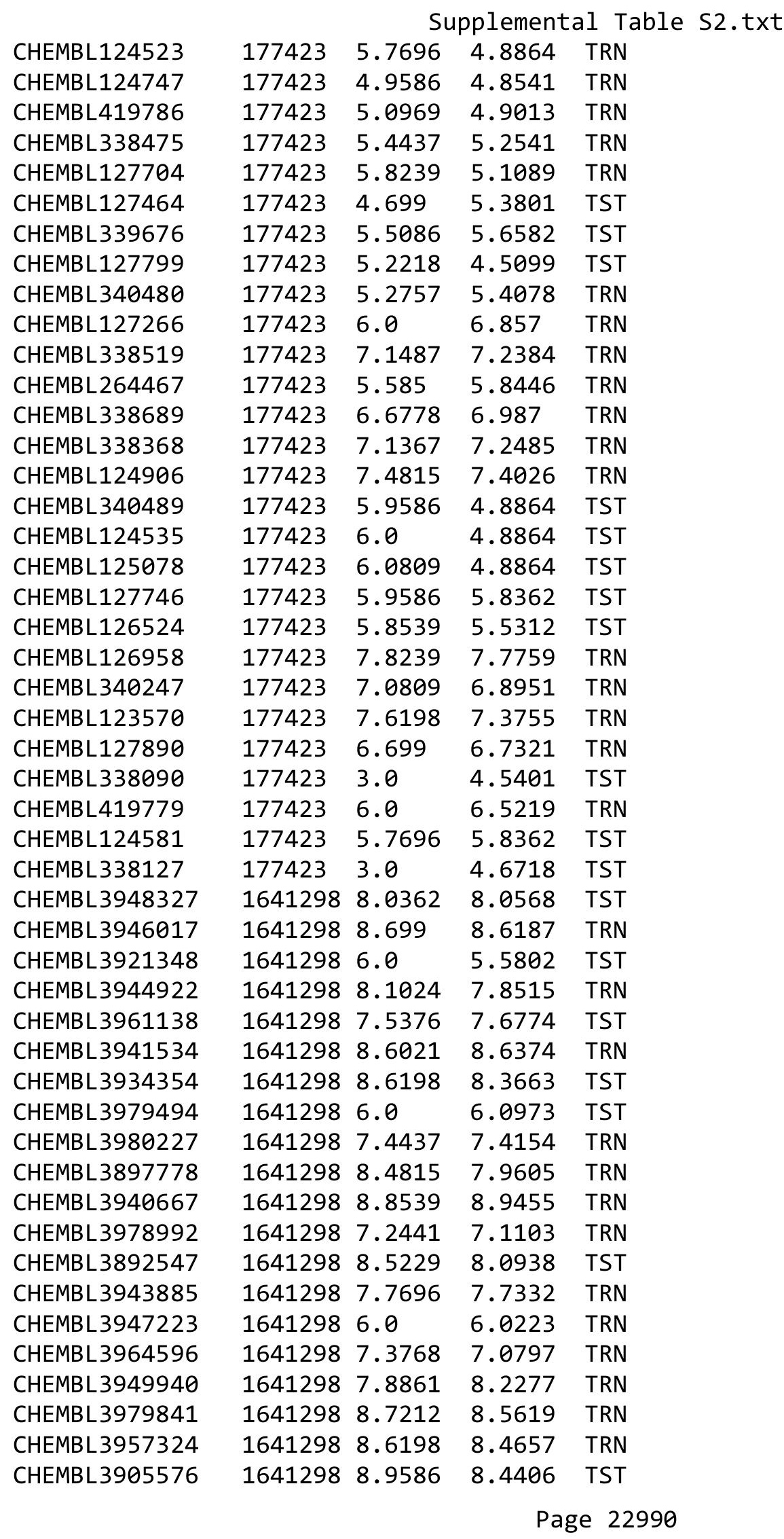




\begin{tabular}{|c|c|c|c|c|}
\hline \multicolumn{5}{|c|}{ Supplemental Table S2.txt } \\
\hline CHEMBL3944919 & 1641298 & 6.0 & 5.5869 & TRN \\
\hline CHEMBL3965623 & 1641298 & 8.6021 & 8.6591 & TRN \\
\hline CHEMBL3914699 & 1641298 & 7.8239 & 7.8227 & TRN \\
\hline CHEMBL3935971 & 1641298 & 6.8761 & 7.1029 & TRN \\
\hline CHEMBL3889715 & 1641298 & 8.0362 & 8.1316 & TRN \\
\hline CHEMBL3959037 & 1641298 & 8.585 & 8.4719 & TRN \\
\hline CHEMBL3955135 & 1641298 & 7.2218 & 7.1603 & TRN \\
\hline CHEMBL3898643 & 1641298 & 8.1739 & 8.2295 & TRN \\
\hline CHEMBL3926257 & 1641298 & 8.6778 & 8.7292 & TRN \\
\hline CHEMBL3922467 & 1641298 & 7.8861 & 7.3632 & TST \\
\hline CHEMBL3929278 & 1641298 & 6.0 & 5.8448 & TRN \\
\hline CHEMBL3937069 & 1641298 & 7.8539 & 7.9906 & TRN \\
\hline CHEMBL3946180 & 1641298 & 8.0458 & 8.3089 & TST \\
\hline CHEMBL3907098 & 1641298 & 8.5086 & 8.4675 & TRN \\
\hline CHEMBL3909145 & 1641298 & 7.7447 & 7.6676 & TRN \\
\hline CHEMBL3913576 & 1641298 & 8.585 & 8.7249 & TRN \\
\hline CHEMBL3893685 & 1641298 & 8.5528 & 8.7035 & TRN \\
\hline CHEMBL3950066 & 1641298 & 8.041 & 8.15 & TRN \\
\hline CHEMBL3899309 & 1641298 & 8.6778 & 8.8127 & TRN \\
\hline CHEMBL3898617 & 1641298 & 9.0 & 9.0554 & TRN \\
\hline CHEMBL3891479 & 1641298 & 8.6198 & 8.7658 & TRN \\
\hline CHEMBL3921952 & 1641298 & 7.8239 & 8.2362 & TST \\
\hline CHEMBL 3923884 & 1641298 & 8.3565 & 8.2819 & TRN \\
\hline CHEMBL3962111 & 1641298 & 7.1612 & 7.2092 & TST \\
\hline CHEMBL3949178 & 1641298 & 6.0 & 5.9034 & TRN \\
\hline CHEMBL3957221 & 1641298 & 7.8539 & 7.8658 & TRN \\
\hline CHEMBL3941558 & 1641298 & 8.3979 & 8.6356 & TRN \\
\hline CHEMBL3953790 & 1641298 & 8.6778 & 8.756 & TRN \\
\hline CHEMBL3953262 & 1641298 & 8.1871 & 7.8237 & TST \\
\hline CHEMBL3985657 & 1641298 & 8.6576 & 8.5063 & TRN \\
\hline CHEMBL3906694 & 1641298 & 7.3768 & 7.641 & TRN \\
\hline CHEMBL3924755 & 1641298 & 7.9586 & 7.745 & TST \\
\hline CHEMBL3933285 & 1641298 & 8.4559 & 8.3937 & TRN \\
\hline CHEMBL3956927 & 1641298 & 8.2366 & 8.0305 & TRN \\
\hline CHEMBL3889552 & 1641298 & 8.0969 & 7.7861 & TST \\
\hline CHEMBL3901053 & 1641298 & 7.9586 & 8.0485 & TRN \\
\hline CHEMBL3915250 & 1641298 & 7.1612 & 7.4498 & TST \\
\hline CHEMBL3915092 & 1641298 & 8.3565 & 8.3781 & TRN \\
\hline CHEMBL3925056 & 1641298 & 8.5376 & 8.5151 & TRN \\
\hline CHEMBL3925952 & 1641298 & 8.4089 & 8.2262 & TRN \\
\hline CHEMBL3980421 & 1641298 & 8.1192 & 8.1254 & TRN \\
\hline CHEMBL3929661 & 1641298 & 7.2676 & 7.6776 & TST \\
\hline CHEMBL3909804 & 1641298 & 8.0757 & 8.2134 & TST \\
\hline CHEMBL3970235 & 1641298 & 7.8539 & 7.8617 & TRN \\
\hline CHEMBL3958746 & 1641298 & 8.3979 & 8.264 & TRN \\
\hline CHEMBL3918578 & 1641298 & 7.2441 & 7.0396 & TRN \\
\hline CHEMBL3895806 & 1641298 & 7.699 & 7.5464 & TRN \\
\hline CHEMBL3930550 & 1641298 & 8.3468 & 8.1856 & TRN \\
\hline
\end{tabular}


Supplemental Table S2.txt

\begin{tabular}{|c|c|c|c|c|}
\hline 106 & 541298 & & & \\
\hline HEMBL3945962 & 641298 & & & \\
\hline & 541298 & & & \\
\hline IEMBL 391 & 641298 & 4089 & & \\
\hline HEMBL396 & 541298 & 528 & & \\
\hline AEMBL3903413 & 641298 & 8.699 & .59 & \\
\hline AEMBL 393 & 298 & 549 & & \\
\hline EMBL & & & & \\
\hline HEMBL396 & 641298 & 7.7696 & & \\
\hline HEMBL393 & 641298 & 8.0 & 594 & \\
\hline AEMBL390 & 298 & 8.2441 & & \\
\hline IEMBL39 & 298 & 85 & & \\
\hline EMBL & 298 & & & \\
\hline IEMBL394 & 298 & 8.9586 & & \\
\hline IEMBL391 & 298 & 3239 & & \\
\hline IEMBL391 & 98 & 2757 & 88 & \\
\hline EMBL & 98 & 539 & 77 & \\
\hline EMBL & 8 & & & \\
\hline IEMBL395 & 298 & 959 & & RN \\
\hline IEMBL: & 298 & 576 & & \\
\hline IEMBL & 88 & 47 & & \\
\hline EMB & 88 & & & \\
\hline EMB & 98 & 12 & & (1) \\
\hline IEMBL39 & 298 & 383 & & \\
\hline IEMBL392 & 98 & 5 & & RIN \\
\hline EMBL & 98 & 212 & & \\
\hline EMB & 88 & $\partial 98$ & & \\
\hline EMB & 98 & 861 & & RN \\
\hline IEMBL39e & 298 & & & \\
\hline IEMBL390 & 98 & 8 & & RN \\
\hline IEMBL392 & 64 & & & RI \\
\hline 6 & 8 & 49 & & Niv \\
\hline & 98 & & & RN \\
\hline IEMBL395 & 298 & 0 & & RI \\
\hline AEMBL3896939 & 98 & & 31 & KI \\
\hline JEMBL398 & 16 & & 31 & 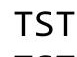 \\
\hline 6 & & & & ST \\
\hline & & 49 & & ST \\
\hline AEMBL393 & 298 & 8.7959 & 966 & RN \\
\hline EMBL. & 298 & & & RN \\
\hline AEMBL396 & 98 & & & RN \\
\hline HEMBL394 & & & & RN \\
\hline AEMBL391 & & 8.7696 & & $\mathrm{RN}$ \\
\hline AEMBL394 & 298 & 7.1024 & 527 & ST \\
\hline 53 & 98 & & & $\mathrm{ni}$ \\
\hline CHEMBL394 & & . & & \\
\hline CHEMBL394 & 641298 & 7.3565 & 7.8038 & \\
\hline CHEMBL3972569 & 164129 & 8.5528 & 8.5894 & $\mathrm{R}$ \\
\hline
\end{tabular}

Page 22992 
Supplemental Table S2.txt

\begin{tabular}{|c|c|c|c|c|}
\hline HEMB I & 541298 & & & \\
\hline HEMPI 2092052 & 641298 & 6.0 & 6.0959 & \\
\hline & 298 & 861 & & \\
\hline HEMBL395 & 298 & 6.0 & 2664 & S \\
\hline HEMBL394 & 641298 & 6778 & 5641 & \\
\hline HEMBL3962512 & 641298 & 7.4949 & 8229 & \\
\hline 37 & 98 & 9.2218 & 9803 & \\
\hline |FMRI: & & & & \\
\hline AEMBL39 & 298 & 7.7696 & 5655 & \\
\hline HEMBL 397 & 298 & 8.4815 & 6676 & \\
\hline HEMBL 397 & 298 & 7.1487 & & \\
\hline IEMBL39 & 298 & 685 & 517 & \\
\hline AEMBL3E & & & & \\
\hline HEMBL 396 & 298 & 8.8861 & 0423 & \\
\hline AEMBL38 & 298 & 8.6198 & 7402 & \\
\hline AEMBL395 & 62 & 8.5686 & 5016 & \\
\hline AEMBL3S & 98 & 871 & 146 & \\
\hline HEMBL3S & & .757 & 55 & \\
\hline HEMBL3S & 298 & 6.0 & 8855 & \\
\hline AEMBL3S & & 212 & & \\
\hline HEIMBLSS & 98 & 249 & 299 & RN \\
\hline HEMBL: & & 665 & & +2 \\
\hline HEMBL & & 861 & & \\
\hline HEMBL39 & 298 & 6.0 & & \\
\hline HEMBL 397 & & 229 & & N \\
\hline HEMBL3S & 98 & 7. & 021 & $\cdots$ \\
\hline HEMBL & 98 & 96 & 67 & RN \\
\hline$H F M B I=$ & 98 & 18 & 46 & \\
\hline HEMBL3 & & 8.1549 & & iv \\
\hline HEMBL 394 & & 8.7212 & & 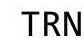 \\
\hline HEMBL3S & 98 & 757 & 449 & RN \\
\hline HEMBL; & 88 & 76 & & RN \\
\hline AEMBL & & 39 & 691 & $\mathrm{~N}$ \\
\hline HEMBL 389 & 98 & 9. & & IRN \\
\hline HEMBL 396018 & 6 & 8.3665 & 4384 & TRN \\
\hline HEMBL3S & 298 & 6.6478 & 37 & ST \\
\hline HFMRI 3 & & 72 & & RN \\
\hline HEMBL3 & & 586 & 226 & ST \\
\hline HEMBL391 & 98 & 7.1308 & 5985 & $\Gamma \mathrm{RN}$ \\
\hline AEMBL39 & & 8.5229 & 5682 & $\Gamma \mathrm{RN}$ \\
\hline HEMBL39 & 98 & 188 & 4822 & \\
\hline CHEMBL 39 & & 8.9208 & 3.8739 & ST \\
\hline HEMBL389 & & 7.8239 & 8.2365 & RN \\
\hline HEMBL 393 & 298 & 7.1487 & 3873 & TRN \\
\hline 1. & & & & \\
\hline HEMBL39 & & 1202 & 2819 & \\
\hline CHEMBL 392 & & 8.5376 & .3823 & \\
\hline CHEMBL3924024 & 164129 & 8.0362 & 7.5346 & ST \\
\hline
\end{tabular}

Page 22993 


$$
\text { Supplemental Table S2.txt }
$$

\begin{tabular}{|c|c|c|c|c|c|c|}
\hline CHEMBL 3940680 & 1641298 & 7.8239 & 7.5395 & TRN & & \\
\hline CHEMBL 3892378 & 1641298 & 8.6383 & 7.7652 & TST & & \\
\hline CHEMBL3915462 & 1641298 & 9.0458 & 8.8442 & TRN & & \\
\hline CHEMBL3940626 & 1641298 & 8.0 & 7.9868 & TRN & & \\
\hline CHEMBL 3974115 & 1641298 & 8.3188 & 8.0851 & TST & & \\
\hline CHEMBL 3929078 & 1641298 & 7.9208 & 7.9569 & TST & & \\
\hline CHEMBL3929736 & 1641298 & 8.1427 & 8.0463 & TRN & & \\
\hline CHEMBL3979979 & 1641298 & 7.8861 & 7.9525 & TST & & \\
\hline CHEMBL 3939646 & 1641298 & 8.1024 & 7.8787 & TRN & & \\
\hline CHEMBL3971096 & 1641298 & 8.4815 & 8.0691 & TST & & \\
\hline CHEMBL 3938321 & 1641298 & 8.5376 & 8.2591 & TST & & \\
\hline CHEMBL 3943078 & 1641298 & 8.7959 & 8.5781 & TRN & & \\
\hline CHEMBL 3954661 & 1641298 & 8.5528 & 8.6372 & TRN & & \\
\hline CHEMBL 3961272 & 1641298 & 8.3468 & 8.0779 & TRN & & \\
\hline CHEMBL3911912 & 1641298 & 8.1024 & 8.1049 & TRN & & \\
\hline CHEMBL 3932686 & 1641298 & 7.8539 & 8.0878 & TRN & & \\
\hline CHEMBL 3929280 & 1641298 & 8.6198 & 7.7624 & TST & & \\
\hline CHEMBL 3982221 & 1641298 & 8.6778 & 8.9992 & TRN & & \\
\hline CHEMBL 3951818 & 1641298 & 8.7959 & 8.854 & TRN & & \\
\hline CHEMBL 3944776 & 1641298 & 8.699 & 8.651 & TRN & & \\
\hline CHEMBL 3952955 & 1641298 & 8.6198 & 8.3561 & TRN & & \\
\hline CHEMBL 3951314 & 1641298 & 7.8239 & 7.6868 & TRN & & \\
\hline CHEMBL 3970132 & 1641298 & 8.3279 & 8.4324 & TRN & & \\
\hline CHEMBL3968106 & 1641298 & 8.8239 & 8.8987 & TRN & & \\
\hline CHEMBL 3909420 & 1641298 & 8.7696 & 8.2208 & TST & & \\
\hline CHEMBL 3906381 & 1641298 & 8.3872 & 8.3394 & TST & & \\
\hline CHEMBL3951957 & 1641298 & 7.6778 & 7.683 & TST & & \\
\hline CHEMBL 3903608 & 1641298 & 8.2441 & 8.3605 & TRN & & \\
\hline CHEMBL 3918127 & 1641298 & 8.6198 & 8.4904 & TRN & & \\
\hline CHEMBL 3189714 & 688213 & 3.158 & 3.2251 & TRN & & \\
\hline CHEMBL1531790 & 688213 & 5.1739 & 5.3544 & TRN & & \\
\hline CHEMBL1588187 & 688213 & 4.1124 & 3.8568 & TRN & & \\
\hline CHEMBL1470135 & 688213 & 3.158 & 3.4206 & TRN & & \\
\hline CHEMBL1542790 & 688213 & 5.4338 & 4.9673 & TRN & & \\
\hline CHEMBL1403448 & 688213 & 5.21399 & 799999999 & 995 & 5.233 & TRN \\
\hline CHEMBL1531090 & 688213 & 4.9226 & 4.8373 & TRN & & \\
\hline CHEMBL1583898 & 688213 & 3.158 & 3.2631 & TRN & & \\
\hline CHEMBL 255881 & 688213 & 5.9714 & 3.8887 & TST & & \\
\hline CHEMBL1468758 & 688213 & 3.158 & 3.5106 & TRN & & \\
\hline CHEMBL1363966 & 688213 & 3.158 & 4.5945 & TST & & \\
\hline CHEMBL1537500 & 688213 & 4.6445 & 4.6875 & TST & & \\
\hline CHEMBL1327038 & 688213 & 5.4566 & 4.9284 & TRN & & \\
\hline CHEMBL1577214 & 688213 & 4.6521 & 5.0638 & TST & & \\
\hline CHEMBL1968356 & 688213 & 4.5901 & 4.9725 & TRN & & \\
\hline CHEMBL1528600 & 688213 & 5.3712 & 4.9172 & TRN & & \\
\hline CHEMBL1499183 & 688213 & 4.7484 & 5.0792 & TRN & & \\
\hline CHEMBL1386091 & 688213 & 5.3459 & 5.3852 & TRN & & \\
\hline CHEMBL1428762 & 688213 & 4.3322 & 4.6441 & TRN & & \\
\hline
\end{tabular}

Page 22994 


\begin{tabular}{|c|c|c|c|c|c|c|}
\hline & & \multicolumn{5}{|c|}{ Supplemental Table S2.txt } \\
\hline CHEMBL1567756 & 688213 & 3.158 & 3.1948 & TRN & & \\
\hline CHEMBL1996902 & 688213 & 5.1258 & 4.864 & TRN & & \\
\hline CHEMBL261692 & 688213 & 5.0567 & 5.1849 & TST & & \\
\hline CHEMBL1548265 & 688213 & 3.158 & 3.2792 & TRN & & \\
\hline CHEMBL1386978 & 688213 & 4.9205 & 4.643 & TRN & & \\
\hline CHEMBL1498705 & 688213 & 4.8827 & 5.1195 & TRN & & \\
\hline CHEMBL1576374 & 688213 & 4.8371 & 4.4013 & TRN & & \\
\hline CHEMBL1313009 & 688213 & 3.158 & 3.1539 & TRN & & \\
\hline CHEMBL1584932 & 688213 & 4.5901 & 4.3594 & TRN & & \\
\hline CHEMBL1574619 & 688213 & 5.5538 & 4.3726 & TST & & \\
\hline CHEMBL1466516 & 688213 & 3.158 & 4.1157 & TRN & & \\
\hline CHEMBL1331799 & 688213 & 3.158 & 3.8241 & TRN & & \\
\hline CHEMBL1459901 & 688213 & 5.3319 & 4.6654 & TST & & \\
\hline CHEMBL1376484 & 688213 & 4.1124 & 3.8722 & TST & & \\
\hline CHEMBL1466539 & 688213 & 5.2525 & 4.6283 & TST & & \\
\hline CHEMBL1498729 & 688213 & 5.5751 & 5.4189 & TRN & & \\
\hline CHEMBL1327816 & 688213 & 3.158 & 3.6157 & TRN & & \\
\hline CHEMBL1313195 & 688213 & 5.6447 & 4.1722 & TST & & \\
\hline CHEMBL1339786 & 688213 & 3.158 & 3.9599 & TRN & & \\
\hline CHEMBL1543513 & 688213 & 3.158 & 3.4565 & TRN & & \\
\hline CHEMBL511499 & 688213 & 5.0646 & 4.7536 & TST & & \\
\hline CHEMBL3189172 & 688213 & 4.5501 & 4.6074 & TST & & \\
\hline CHEMBL3196625 & 688213 & 4.6786 & 3.9178 & TST & & \\
\hline CHEMBL1706577 & 688213 & 5.6472 & 5.6187 & TRN & & \\
\hline CHEMBL1613444 & 688213 & 3.158 & 4.9833 & TST & & \\
\hline CHEMBL1497274 & 688213 & 5.2992 & 4.4426 & TRN & & \\
\hline CHEMBL1307211 & 688213 & 4.2461 & 4.5139 & TRN & & \\
\hline CHEMBL1351180 & 688213 & 5.671 & 5.3497 & TRN & & \\
\hline CHEMBL1497316 & 688213 & 5.0128 & 4.256 & TRN & & \\
\hline CHEMBL1576310 & 688213 & 5.2331 & 4.5409 & TRN & & \\
\hline CHEMBL1305250 & 688213 & 5.3888 & 4.7662 & TRN & & \\
\hline CHEMBL1328311 & 688213 & 5.3685 & 5.4072 & TRN & & \\
\hline CHEMBL3199451 & 688213 & 5.5024 & 5.1947 & TRN & & \\
\hline CHEMBL492267 & 688213 & 5.17299 & 79999999 & 99 & 4.7664 & TRN \\
\hline CHEMBL1391809 & 688213 & 3.158 & 3.3742 & TRN & & \\
\hline CHEMBL1331178 & 688213 & 5.0665 & 3.7219 & TST & & \\
\hline CHEMBL1399844 & 688213 & 3.158 & 4.4506 & TST & & \\
\hline CHEMBL1384281 & 688213 & 6.5406 & 6.6741 & TRN & & \\
\hline CHEMBL1502065 & 688213 & 5.1915 & 5.1871 & TRN & & \\
\hline CHEMBL1482891 & 688213 & 4.5901 & 4.292 & TRN & & \\
\hline CHEMBL1313045 & 688213 & 3.158 & 3.2755 & TRN & & \\
\hline CHEMBL454173 & 688213 & 5.1598 & 3.6056 & TST & & \\
\hline CHEMBL1349451 & 688213 & 5.0427 & 4.9078 & TRN & & \\
\hline CHEMBL3197990 & 688213 & 5.5022 & 5.6765 & TRN & & \\
\hline CHEMBL1349382 & 688213 & 5.6024 & 5.3438 & TRN & & \\
\hline CHEMBL1421068 & 688213 & 4.7632 & 4.6984 & TRN & & \\
\hline CHEMBL1447467 & 688213 & 5.6674 & 5.41 & TRN & & \\
\hline CHEMBL1596723 & 688213 & 4.6031 & 4.5395 & TRN & & \\
\hline
\end{tabular}




\begin{tabular}{|c|c|c|c|c|}
\hline & & & oplement & al $\mathrm{T}$ \\
\hline CHEMBL1503392 & 688213 & 4.3215 & 3.8663 & TRN \\
\hline CHEMBL1323696 & 688213 & 5.8784 & 5.5884 & TRN \\
\hline CHEMBL1401938 & 688213 & 5.2802 & 5.4729 & TRN \\
\hline CHEMBL1469476 & 688213 & 3.158 & 3.5437 & TRN \\
\hline CHEMBL3196959 & 688213 & 5.2593 & 5.8212 & TRN \\
\hline CHEMBL1986591 & 688213 & 5.5906 & 4.755 & TRN \\
\hline CHEMBL1341067 & 688213 & 4.3311 & 4.7455 & TRN \\
\hline CHEMBL1300005 & 688213 & 3.158 & 5.4288 & TST \\
\hline CHEMBL1533366 & 688213 & 3.158 & 3.572 & TRN \\
\hline CHEMBL1468599 & 688213 & 3.158 & 3.1296 & TRN \\
\hline CHEMBL1570763 & 688213 & 5.1159 & 5.6063 & TRN \\
\hline CHEMBL 2002223 & 688213 & 5.7496 & 6.0093 & TRN \\
\hline CHEMBL1409126 & 688213 & 4.7852 & 5.0325 & TST \\
\hline CHEMBL3198219 & 688213 & 3.158 & 3.5083 & TRN \\
\hline CHEMBL1521351 & 688213 & 3.158 & 2.8197 & TRN \\
\hline CHEMBL1422628 & 688213 & 3.158 & 3.9258 & TRN \\
\hline CHEMBL1345665 & 688213 & 4.3794 & 4.125 & TRN \\
\hline CHEMBL3199005 & 688213 & 4.9747 & 4.0338 & TRN \\
\hline CHEMBL1577281 & 688213 & 5.6552 & 5.8259 & TRN \\
\hline CHEMBL1432402 & 688213 & 3.158 & 3.1489 & TRN \\
\hline CHEMBL1369422 & 688213 & 5.568 & 5.1879 & TRN \\
\hline CHEMBL1533978 & 688213 & 4.1124 & 3.3937 & TRN \\
\hline CHEMBL1452997 & 688213 & 3.158 & 3.8346 & TRN \\
\hline CHEMBL1320591 & 688213 & 3.158 & 3.1347 & TST \\
\hline CHEMBL1452574 & 688213 & 3.158 & 3.9257 & TRN \\
\hline CHEMBL1392806 & 688213 & 5.8389 & 6.0712 & TRN \\
\hline CHEMBL1470433 & 688213 & 3.158 & 3.4859 & TRN \\
\hline CHEMBL1303547 & 688213 & 5.1171 & 5.2425 & TRN \\
\hline CHEMBL1413819 & 688213 & 5.2486 & 4.6872 & TRN \\
\hline CHEMBL1452509 & 688213 & 3.158 & 3.2236 & TRN \\
\hline CHEMBL1336563 & 688213 & 3.158 & 3.8464 & TRN \\
\hline CHEMBL1488628 & 688213 & 5.2194 & 5.205 & TRN \\
\hline CHEMBL1492266 & 688213 & 5.4791 & 5.9893 & TRN \\
\hline CHEMBL1364528 & 688213 & 5.3468 & 4.851 & TRN \\
\hline CHEMBL1342206 & 688213 & 3.158 & 4.0328 & TRN \\
\hline CHEMBL1482979 & 688213 & 5.4242 & 5.3077 & TRN \\
\hline CHEMBL1714669 & 688213 & 5.5772 & 5.2308 & TRN \\
\hline CHEMBL1565236 & 688213 & 5.187 & 5.6834 & TRN \\
\hline CHEMBL1526645 & 688213 & 5.274 & 5.0083 & TRN \\
\hline CHEMBL 3208943 & 688213 & 3.158 & 3.2504 & TRN \\
\hline CHEMBL1704267 & 688213 & 5.6977 & 6.1572 & TRN \\
\hline CHEMBL1347829 & 688213 & 5.7217 & 5.6412 & TRN \\
\hline CHEMBL1388603 & 688213 & 5.8033 & 5.1547 & TRN \\
\hline CHEMBL1387238 & 688213 & 3.158 & 3.6544 & TRN \\
\hline CHEMBL1427801 & 688213 & 5.3234 & 5.5481 & TRN \\
\hline CHEMBL417727 & 688213 & 3.158 & 4.3982 & TRN \\
\hline CHEMBL1604871 & 688213 & 3.158 & 3.1615 & TRN \\
\hline CHEMBL3197885 & 688213 & 5.1975 & 5.2906 & TRN \\
\hline
\end{tabular}




\begin{tabular}{|c|c|c|c|c|c|}
\hline & & \multicolumn{4}{|c|}{ Supplemental Table S2.txt } \\
\hline CHEMBL1329712 & 688213 & 3.158 & 4.1359 & TRN & \\
\hline CHEMBL1456621 & 688213 & 5.1801 & 4.235 & TRN & \\
\hline CHEMBL1539325 & 688213 & 5.2816 & 4.2682 & TST & \\
\hline CHEMBL1329801 & 688213 & 4.9923 & 5.0927 & TRN & \\
\hline CHEMBL1432963 & 688213 & 5.7387 & 5.3468 & TRN & \\
\hline CHEMBL1363851 & 688213 & 5.225 & 4.8481 & TRN & \\
\hline CHEMBL512649 & 688213 & 4.9809 & 4.7653 & TST & \\
\hline CHEMBL3192969 & 688213 & 5.7115 & 5.3304 & TRN & \\
\hline CHEMBL1319919 & 688213 & 3.158 & 2.8453 & TRN & \\
\hline CHEMBL1969704 & 688213 & 3.158 & 3.2507 & TRN & \\
\hline CHEMBL1498987 & 688213 & 3.6364 & 3.5935 & TRN & \\
\hline CHEMBL1536594 & 688213 & 5.3479 & 5.5015 & TRN & \\
\hline CHEMBL1390871 & 688213 & 4.6264 & 4.1385 & TST & \\
\hline CHEMBL1402735 & 688213 & 3.158 & 3.1161 & TRN & \\
\hline CHEMBL1507343 & 688213 & 5.0113 & 5.3083 & TRN & \\
\hline CHEMBL1380059 & 688213 & 5.5789 & 5.3093 & TST & \\
\hline CHEMBL1402456 & 688213 & 3.158 & 2.7381 & TRN & \\
\hline CHEMBL3190626 & 688213 & 4.9374 & 4.9098 & TST & \\
\hline CHEMBL3189853 & 688213 & 5.4231 & 5.58 & TRN & \\
\hline CHEMBL1594483 & 688213 & 4.8617 & 4.5591 & TRN & \\
\hline CHEMBL1374203 & 688213 & 3.158 & 2.4534 & TRN & \\
\hline CHEMBL1431555 & 688213 & 3.158 & 3.0982 & TRN & \\
\hline CHEMBL1459977 & 688213 & 3.158 & 3.1801 & TRN & \\
\hline CHEMBL1427609 & 688213 & 4.5901 & 4.0974 & TRN & \\
\hline CHEMBL1462307 & 688213 & 4.794 & 4.223 & TRN & \\
\hline CHEMBL1973729 & 688213 & 3.158 & 4.0553 & TST & \\
\hline CHEMBL1467405 & 688213 & 5.5075 & 5.3272 & TRN & \\
\hline CHEMBL1558223 & 688213 & 4.5754 & 5.1522 & TRN & \\
\hline CHEMBL1344542 & 688213 & 4.9978 & 4.8898 & TST & \\
\hline CHEMBL1370120 & 688213 & 5.6813 & 5.4101 & TRN & \\
\hline CHEMBL1468746 & 688213 & 5.7196 & 5.3272 & TRN & \\
\hline CHEMBL 3194875 & 688213 & 3.158 & 3.6409 & TRN & \\
\hline CHEMBL3198948 & 688213 & 5.0369 & 4.796 & TST & \\
\hline CHEMBL1453834 & 688213 & 3.6364 & 3.2964 & TRN & \\
\hline CHEMBL1332391 & 688213 & 3.158 & 2.9565 & TRN & \\
\hline CHEMBL1387110 & 688213 & 5.1722 & 5.2392 & TRN & \\
\hline CHEMBL1581750 & 688213 & 5.1113 & 5.3659 & TRN & \\
\hline CHEMBL1422472 & 688213 & 3.158 & 2.95300 & 00000000003 & TRN \\
\hline CHEMBL1971613 & 688213 & 5.3658 & 5.4385 & TRN & \\
\hline CHEMBL1388620 & 688213 & 3.158 & 3.7603 & TRN & \\
\hline CHEMBL1372905 & 688213 & 4.5216 & 4.2495 & TRN & \\
\hline CHEMBL1323013 & 688213 & 5.3126 & 4.5666 & TRN & \\
\hline CHEMBL422471 & 688213 & 5.1896 & 4.9861 & TRN & \\
\hline CHEMBL1488460 & 688213 & 3.158 & 3.6919 & TRN & \\
\hline CHEMBL1581059 & 688213 & 3.158 & 3.0664 & TRN & \\
\hline CHEMBL1598471 & 688213 & 4.8979 & 5.0175 & TST & \\
\hline CHEMBL1469742 & 688213 & 5.6119 & 5.3123 & TRN & \\
\hline CHEMBL1506606 & 688213 & 3.158 & 4.5859 & TST & \\
\hline
\end{tabular}




\begin{tabular}{|c|c|c|c|c|c|}
\hline \multicolumn{6}{|c|}{ Supplemental Table S2.txt } \\
\hline CHEMBL580819 & 688213 & 5.2986 & 5.1175 & TRN & \\
\hline CHEMBL1350854 & 688213 & 5.6728 & 5.2867 & TRN & \\
\hline CHEMBL3197958 & 688213 & 5.1799 & 4.9514 & TRN & \\
\hline CHEMBL1306004 & 688213 & 3.158 & 3.216 & TRN & \\
\hline CHEMBL1575547 & 688213 & 4.6996 & 5.1123 & TRN & \\
\hline CHEMBL1538815 & 688213 & 4.569 & 5.1329 & TRN & \\
\hline CHEMBL1501744 & 688213 & 3.158 & 3.7194 & TRN & \\
\hline CHEMBL1417890 & 688213 & 4.9352 & 4.6237 & TRN & \\
\hline CHEMBL1334484 & 688213 & 5.5345 & 5.8194 & TRN & \\
\hline CHEMBL1581188 & 688213 & 3.158 & 4.1667 & TRN & \\
\hline CHEMBL1353989 & 688213 & 4.5901 & 4.2284 & TRN & \\
\hline CHEMBL1346314 & 688213 & 5.6256 & 5.0279 & TST & \\
\hline CHEMBL374632 & 688213 & 5.6338 & 5.6802 & TRN & \\
\hline CHEMBL578585 & 688213 & 5.1781 & 4.2497 & TRN & \\
\hline CHEMBL600336 & 688213 & 5.4008 & 5.7237 & TRN & \\
\hline CHEMBL1414554 & 688213 & 5.6517 & 5.8755 & TRN & \\
\hline CHEMBL1491961 & 688213 & 4.8318 & 5.038 & TST & \\
\hline CHEMBL1546584 & 688213 & 3.158 & 3.2285 & TRN & \\
\hline CHEMBL3197709 & 688213 & 3.158 & 3.4929 & TRN & \\
\hline CHEMBL1549437 & 688213 & 3.6364 & 3.1484 & TRN & \\
\hline CHEMBL341473 & 688213 & 5.5485 & 5.6292 & TRN & \\
\hline CHEMBL1598666 & 688213 & 4.9041 & 4.6498 & TRN & \\
\hline CHEMBL 2006503 & 688213 & 3.158 & 3.0343 & TRN & \\
\hline CHEMBL1337717 & 688213 & 5.3991 & 5.2461 & TRN & \\
\hline CHEMBL1361703 & 688213 & 5.237 & 5.2078 & TRN & \\
\hline CHEMBL1586048 & 688213 & 3.158 & 3.5427 & TRN & \\
\hline CHEMBL1408947 & 688213 & 3.158 & 4.4228 & TST & \\
\hline CHEMBL1302158 & 688213 & 5.5658 & 4.6293 & TST & \\
\hline CHEMBL1471739 & 688213 & 3.158 & 3.0926 & TST & \\
\hline CHEMBL1380296 & 688213 & 4.5901 & 3.5725 & TST & \\
\hline CHEMBL1331912 & 688213 & 3.158 & 4.4458 & TST & \\
\hline CHEMBL1549732 & 688213 & 4.8184 & 3.9031 & TST & \\
\hline CHEMBL1492553 & 688213 & 5.2261 & 4.0711 & TST & \\
\hline CHEMBL1424837 & 688213 & 4.8817 & 4.73300 & 00000000005 & TST \\
\hline CHEMBL1360493 & 688213 & 5.2601 & 5.265 & TST & \\
\hline CHEMBL1543789 & 688213 & 3.158 & 4.4724 & TST & \\
\hline CHEMBL1550490 & 688213 & 3.158 & 3.8315 & TST & \\
\hline CHEMBL1406232 & 688213 & 3.158 & 5.106 & TST & \\
\hline CHEMBL1500600 & 688213 & 5.9062 & 5.5856 & TST & \\
\hline CHEMBL1456712 & 688213 & 5.4183 & 4.7904 & TST & \\
\hline CHEMBL1345945 & 688213 & 4.9914 & 5.8488 & TST & \\
\hline CHEMBL1342667 & 688213 & 3.158 & 3.6888 & TST & \\
\hline CHEMBL1345770 & 688213 & 5.8133 & 5.0026 & TST & \\
\hline CHEMBL1492243 & 688213 & 4.7406 & 5.0873 & TST & \\
\hline CHEMBL51931 & 688213 & 3.158 & 4.4137 & TST & \\
\hline CHEMBL1587782 & 688213 & 5.0334 & 4.5759 & TST & \\
\hline CHEMBL1988401 & 688213 & 4.8011 & 5.3573 & TST & \\
\hline CHEMBL3213958 & 688362 & 3.0004 & 3.7037 & TRN & \\
\hline
\end{tabular}

Page 22998 


\begin{tabular}{|c|c|c|c|c|}
\hline & & & pplement & al $\mathrm{T}$ \\
\hline CHEMBL1368995 & 688362 & 4.2534 & 3.0027 & TRN \\
\hline CHEMBL1556273 & 688362 & 3.0004 & 3.6676 & TRN \\
\hline CHEMBL1340701 & 688362 & 3.0004 & 3.3985 & TRN \\
\hline CHEMBL1362075 & 688362 & 3.0004 & 2.9885 & TRN \\
\hline CHEMBL1302946 & 688362 & 3.0004 & 3.4101 & TRN \\
\hline CHEMBL1539483 & 688362 & 3.0004 & 3.0963 & TRN \\
\hline CHEMBL1311684 & 688362 & 3.0004 & 3.0493 & TRN \\
\hline CHEMBL1386322 & 688362 & 3.0004 & 3.8259 & TRN \\
\hline CHEMBL1360300 & 688362 & 3.0004 & 2.9266 & TRN \\
\hline CHEMBL1534915 & 688362 & 4.9957 & 3.5823 & TST \\
\hline CHEMBL 3189343 & 688362 & 3.0004 & 3.3309 & TST \\
\hline CHEMBL1529932 & 688362 & 5.5452 & 5.3274 & TRN \\
\hline CHEMBL1976754 & 688362 & 3.0004 & 3.281 & TRN \\
\hline CHEMBL3193915 & 688362 & 3.0004 & 3.3858 & TRN \\
\hline CHEMBL3195874 & 688362 & 3.0004 & 3.0342 & TRN \\
\hline CHEMBL1417829 & 688362 & 3.0004 & 4.1209 & TRN \\
\hline CHEMBL1439775 & 688362 & 3.0004 & 3.0156 & TRN \\
\hline CHEMBL1383807 & 688362 & 3.0004 & 3.2707 & TRN \\
\hline CHEMBL1504364 & 688362 & 3.0004 & 3.4665 & TRN \\
\hline CHEMBL1325487 & 688362 & 4.8013 & 3.8954 & TST \\
\hline CHEMBL1518885 & 688362 & 3.0004 & 3.0598 & TRN \\
\hline CHEMBL1605701 & 688362 & 5.3125 & 4.2729 & TRN \\
\hline CHEMBL1516984 & 688362 & 3.0004 & 3.3001 & TRN \\
\hline CHEMBL1484384 & 688362 & 3.0004 & 3.2308 & TRN \\
\hline CHEMBL 240331 & 688362 & 5.0182 & 5.7761 & TRN \\
\hline CHEMBL1469835 & 688362 & 4.1349 & 3.4053 & TRN \\
\hline CHEMBL1569933 & 688362 & 3.0004 & 3.4241 & TST \\
\hline CHEMBL1404792 & 688362 & 4.9245 & 4.249 & TST \\
\hline CHEMBL1486430 & 688362 & 5.5072 & 5.6073 & TRN \\
\hline CHEMBL1501233 & 688362 & 3.0004 & 3.2027 & TRN \\
\hline CHEMBL1446839 & 688362 & 3.0004 & 3.3269 & TRN \\
\hline CHEMBL1353223 & 688362 & 3.0004 & 3.0658 & TRN \\
\hline CHEMBL1579256 & 688362 & 3.0004 & 3.2778 & TRN \\
\hline CHEMBL1351147 & 688362 & 3.0004 & 3.0037 & TRN \\
\hline CHEMBL1314070 & 688362 & 3.0004 & 2.8454 & TRN \\
\hline CHEMBL1374814 & 688362 & 3.0004 & 3.3131 & TRN \\
\hline CHEMBL1543857 & 688362 & 3.0004 & 3.109 & TRN \\
\hline CHEMBL1565449 & 688362 & 3.0004 & 2.8781 & TRN \\
\hline CHEMBL3194926 & 688362 & 5.1403 & 3.4878 & TRN \\
\hline CHEMBL1338476 & 688362 & 3.0004 & 3.1197 & TRN \\
\hline CHEMBL1382264 & 688362 & 3.0004 & 3.0899 & TRN \\
\hline CHEMBL1452132 & 688362 & 4.4498 & 3.8107 & TRN \\
\hline CHEMBL1604999 & 688362 & 3.0004 & 2.7887 & TRN \\
\hline CHEMBL3213607 & 688362 & 3.0004 & 3.0328 & TRN \\
\hline CHEMBL1489460 & 688362 & 3.0004 & 2.7588 & TRN \\
\hline CHEMBL1563943 & 688362 & 3.0004 & 3.1064 & TRN \\
\hline CHEMBL1338487 & 688362 & 4.9066 & 4.1816 & TRN \\
\hline CHEMBL1334710 & 688362 & 5.3716 & 5.56 & TRN \\
\hline
\end{tabular}




\begin{tabular}{|c|c|c|c|c|}
\hline & & & pplement & al $\mathrm{T}$ \\
\hline CHEMBL1375712 & 688362 & 3.0004 & 3.635 & TRN \\
\hline CHEMBL1489864 & 688362 & 5.1152 & 3.7722 & TRN \\
\hline CHEMBL1535276 & 688362 & 3.0004 & 3.3417 & TRN \\
\hline CHEMBL1991234 & 688362 & 5.3036 & 5.5183 & TST \\
\hline CHEMBL1980031 & 688362 & 4.2848 & 3.6161 & TRN \\
\hline CHEMBL1321811 & 688362 & 5.2048 & 3.8151 & TST \\
\hline CHEMBL1458324 & 688362 & 3.0004 & 3.0023 & TRN \\
\hline CHEMBL1499077 & 688362 & 5.6968 & 4.0182 & TRN \\
\hline CHEMBL1388509 & 688362 & 3.0004 & 3.6577 & TST \\
\hline CHEMBL1585024 & 688362 & 3.0004 & 3.4153 & TRN \\
\hline CHEMBL1607428 & 688362 & 5.4737 & 4.271 & TST \\
\hline CHEMBL1567438 & 688362 & 3.0004 & 3.0101 & TRN \\
\hline CHEMBL1307682 & 688362 & 4.5498 & 4.5353 & TRN \\
\hline CHEMBL1504545 & 688362 & 3.0004 & 3.3734 & TRN \\
\hline CHEMBL1439696 & 688362 & 4.9914 & 5.3872 & TRN \\
\hline CHEMBL1382072 & 688362 & 3.0004 & 3.475 & TRN \\
\hline CHEMBL1585156 & 688362 & 4.5258 & 4.8024 & TST \\
\hline CHEMBL1568713 & 688362 & 3.0004 & 3.2802 & TST \\
\hline CHEMBL1452494 & 688362 & 3.0004 & 2.8889 & TRN \\
\hline CHEMBL1428640 & 688362 & 4.3635 & 3.1557 & TST \\
\hline CHEMBL610508 & 688362 & 5.7375 & 5.9218 & TRN \\
\hline CHEMBL1489035 & 688362 & 3.0004 & 2.9568 & TRN \\
\hline CHEMBL1365257 & 688362 & 3.0004 & 3.1622 & TRN \\
\hline CHEMBL1605622 & 688362 & 3.0004 & 3.7304 & TST \\
\hline CHEMBL1460225 & 688362 & 4.3143 & 4.1986 & TST \\
\hline CHEMBL1386914 & 688362 & 3.0004 & 2.9513 & TRN \\
\hline CHEMBL1572577 & 688362 & 3.0004 & 3.6642 & TRN \\
\hline CHEMBL1533351 & 688362 & 4.1945 & 3.2793 & TST \\
\hline CHEMBL1503962 & 688362 & 4.8239 & 4.0784 & TRN \\
\hline CHEMBL1373923 & 688362 & 3.0004 & 3.5677 & TRN \\
\hline CHEMBL1462208 & 688362 & 3.0004 & 3.3444 & TRN \\
\hline CHEMBL1379607 & 688362 & 3.0004 & 3.0616 & TRN \\
\hline CHEMBL1492221 & 688362 & 3.0004 & 2.8116 & TRN \\
\hline CHEMBL1304445 & 688362 & 5.3872 & 5.7994 & TST \\
\hline CHEMBL1391336 & 688362 & 4.1249 & 3.3969 & TRN \\
\hline CHEMBL1970286 & 688362 & 5.1343 & 3.5948 & TRN \\
\hline CHEMBL1393701 & 688362 & 3.0004 & 3.1795 & TRN \\
\hline CHEMBL1320577 & 688362 & 3.0004 & 3.3738 & TRN \\
\hline CHEMBL1343762 & 688362 & 3.0004 & 2.8191 & TRN \\
\hline CHEMBL1407614 & 688362 & 4.5607 & 3.5806 & TRN \\
\hline CHEMBL1340638 & 688362 & 5.2396 & 3.9574 & TRN \\
\hline CHEMBL1586301 & 688362 & 3.0004 & 2.9572 & TRN \\
\hline CHEMBL1526624 & 688362 & 5.8182 & 5.6225 & TRN \\
\hline CHEMBL1372826 & 688362 & 3.0004 & 3.2637 & TRN \\
\hline CHEMBL358546 & 688362 & 4.9547 & 5.6683 & TRN \\
\hline CHEMBL1350396 & 688362 & 4.7375 & 4.1056 & TRN \\
\hline CHEMBL1403606 & 688362 & 3.0004 & 3.0065 & TST \\
\hline CHEMBL1531156 & 688362 & 4.9101 & 4.1407 & TRN \\
\hline
\end{tabular}




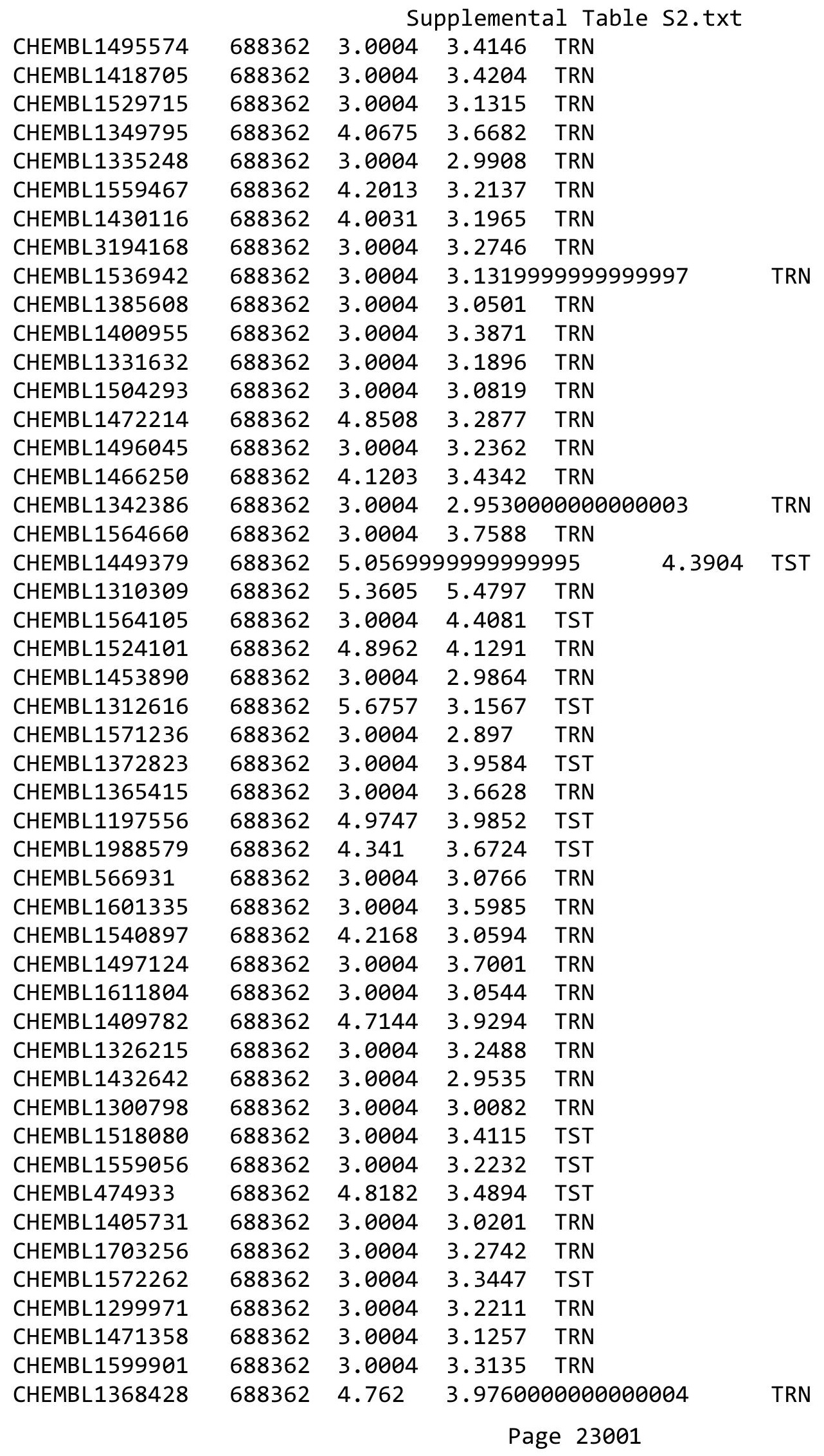





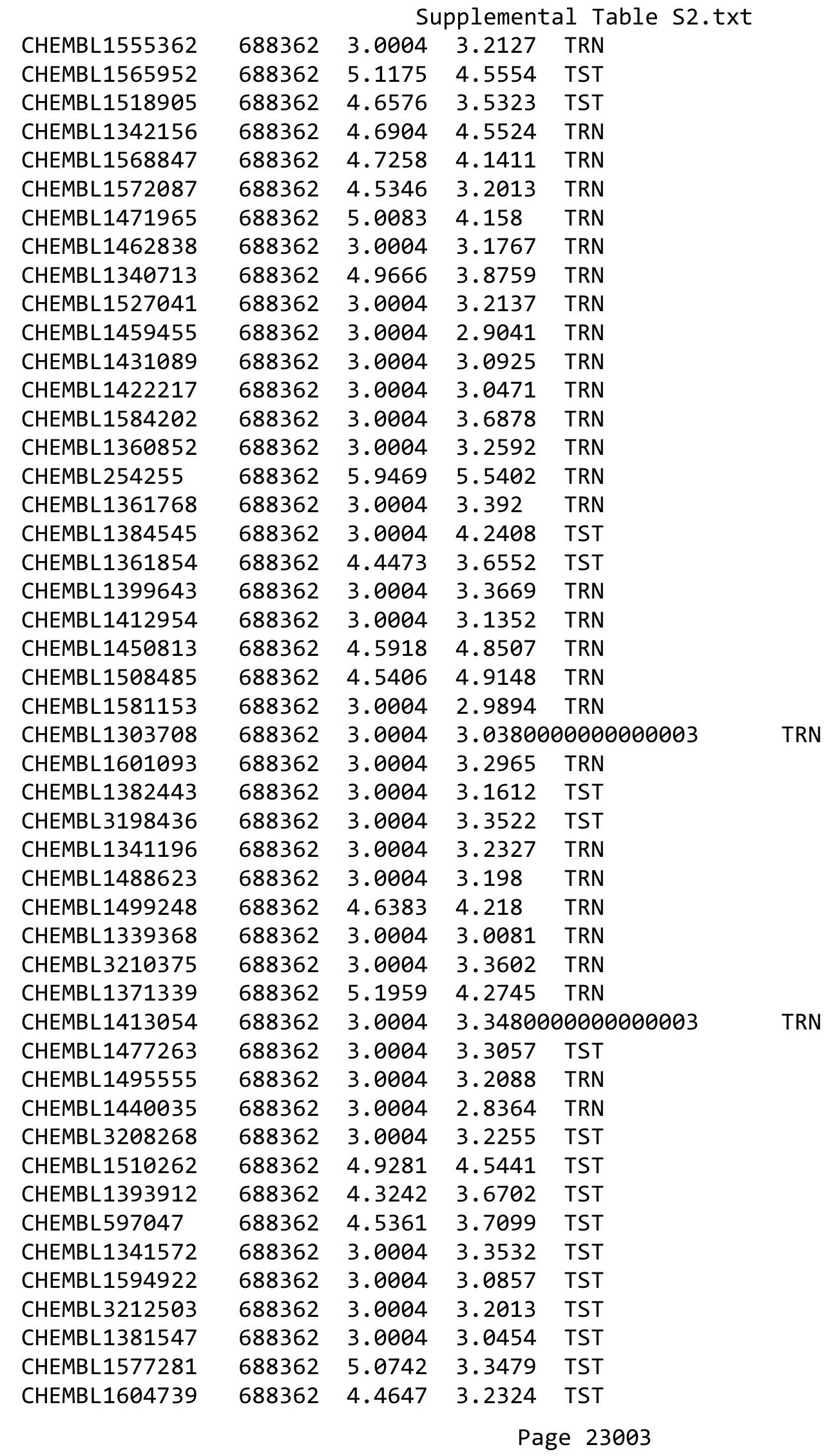




\begin{tabular}{|c|c|c|c|c|c|}
\hline \multicolumn{6}{|c|}{ Supplemental Table S2.txt } \\
\hline CHEMBL1409540 & 688362 & 3.0004 & 2.8257 & TST & \\
\hline CHEMBL1600647 & 688362 & 4.4437 & 5.1562 & TST & \\
\hline CHEMBL1439674 & 688362 & 3.0004 & 3.66399 & 99999999997 & TST \\
\hline CHEMBL1550080 & 688362 & 3.0004 & 3.5482 & TST & \\
\hline CHEMBL1580182 & 688362 & 3.0004 & 2.8224 & TST & \\
\hline CHEMBL1718423 & 688362 & 4.3737 & 3.7289 & TST & \\
\hline CHEMBL1325006 & 688362 & 4.9872 & 3.2966 & TST & \\
\hline CHEMBL1403530 & 688362 & 3.0004 & 3.10699 & 99999999998 & TST \\
\hline CHEMBL1425463 & 688362 & 3.0004 & 3.0687 & TST & \\
\hline CHEMBL1501751 & 688362 & 3.0004 & 3.1323 & TST & \\
\hline CHEMBL1578082 & 688362 & 4.3575 & 3.537 & TST & \\
\hline CHEMBL1561520 & 688362 & 3.0004 & 2.906 & TST & \\
\hline CHEMBL1586234 & 688362 & 3.0004 & 2.8956 & TST & \\
\hline CHEMBL 2142817 & 1301435 & 5.0026 & 4.4075 & TRN & \\
\hline CHEMBL1902247 & 1301435 & 4.8765 & 4.9676 & TRN & \\
\hline CHEMBL1553553 & 1301435 & 3.284 & 4.0527 & TRN & \\
\hline CHEMBL1458038 & 1301435 & 4.4505 & 4.0935 & TRN & \\
\hline CHEMBL1406361 & 1301435 & 3.284 & 3.5054 & TRN & \\
\hline CHEMBL1369200 & 1301435 & 4.8348 & 4.909 & TRN & \\
\hline CHEMBL1546172 & 1301435 & 4.9974 & 5.1091 & TST & \\
\hline CHEMBL1559713 & 1301435 & 4.4204 & 4.2296 & TRN & \\
\hline CHEMBL 3185444 & 1301435 & 4.7185 & 4.6361 & TRN & \\
\hline CHEMBL1408307 & 1301435 & 4.4056 & 4.4536 & TRN & \\
\hline CHEMBL1311094 & 1301435 & 4.8207 & 4.3218 & TRN & \\
\hline CHEMBL1299714 & 1301435 & 3.284 & 3.6553 & TRN & \\
\hline CHEMBL93109 & 1301435 & 4.2898 & 3.944 & TRN & \\
\hline CHEMBL1713163 & 1301435 & 4.7688 & 4.789 & TST & \\
\hline CHEMBL 2139564 & 1301435 & 4.8665 & 5.0009 & TST & \\
\hline CHEMBL1332512 & 1301435 & 3.284 & 4.1742 & TRN & \\
\hline CHEMBL1488923 & 1301435 & 5.6904 & 5.2137 & TRN & \\
\hline CHEMBL1462900 & 1301435 & 4.8742 & 5.82299 & 99999999995 & TRN \\
\hline CHEMBL1479234 & 1301435 & 4.5714 & 4.2288 & TRN & \\
\hline CHEMBL1550664 & 1301435 & 3.284 & 3.5182 & TRN & \\
\hline CHEMBL1581094 & 1301435 & 3.284 & 3.9508 & TRN & \\
\hline CHEMBL1595582 & 1301435 & 3.284 & 4.2335 & TRN & \\
\hline CHEMBL1600275 & 1301435 & 5.0762 & 4.2821 & TRN & \\
\hline CHEMBL3185534 & 1301435 & 4.5789 & 4.274 & TST & \\
\hline CHEMBL1329798 & 1301435 & 3.284 & 3.6563 & TRN & \\
\hline CHEMBL1302266 & 1301435 & 4.7075 & 4.2197 & TRN & \\
\hline CHEMBL1503463 & 1301435 & 3.284 & 4.0342 & TRN & \\
\hline CHEMBL3184701 & 1301435 & 3.284 & 4.5384 & TST & \\
\hline CHEMBL1545865 & 1301435 & 3.284 & 3.6976 & TRN & \\
\hline CHEMBL1895744 & 1301435 & 4.8342 & 4.4074 & TRN & \\
\hline CHEMBL1534441 & 1301435 & 4.4229 & 4.0551 & TRN & \\
\hline CHEMBL 2131028 & 1301435 & 4.6722 & 4.6784 & TST & \\
\hline CHEMBL1597669 & 1301435 & 3.284 & 3.7371 & TRN & \\
\hline CHEMBL1440781 & 1301435 & 4.8523 & 3.9713 & TRN & \\
\hline CHEMBL1379390 & 1301435 & 4.5203 & 4.145 & TRN & \\
\hline
\end{tabular}


Supplemental Table S2.txt

\begin{tabular}{|c|c|c|c|c|}
\hline CHEMBL2362144 & 1301435 & 5.7055 & 5.1357 & TRN \\
\hline CHEMBL 2355520 & 1301435 & 4.8595 & 4.6067 & TRN \\
\hline CHEMBL3185466 & 1301435 & 5.0726 & 4.8756 & TST \\
\hline CHEMBL1421442 & 1301435 & 4.3425 & 4.4798 & TRN \\
\hline CHEMBL251717 & 1301435 & 4.6287 & 3.5587 & TRN \\
\hline CHEMBL1570216 & 1301435 & 3.284 & 3.4807 & TRN \\
\hline CHEMBL3188484 & 1301435 & 4.4564 & 4.0507 & TST \\
\hline CHEMBL1535375 & 1301435 & 5.062 & 4.9602 & TST \\
\hline CHEMBL1313954 & 1301435 & 4.3003 & 3.48 & TRN \\
\hline CHEMBL1604245 & 1301435 & 4.4603 & 3.7458 & TRN \\
\hline CHEMBL1373197 & 1301435 & 3.284 & 4.3517 & TST \\
\hline CHEMBL1337227 & 1301435 & 5.1146 & 5.2605 & TRN \\
\hline CHEMBL 3187662 & 1301435 & 4.6075 & 4.5008 & TST \\
\hline CHEMBL1454840 & 1301435 & 4.5098 & 4.4667 & TRN \\
\hline CHEMBL1496788 & 1301435 & 4.9961 & 5.2215 & TRN \\
\hline CHEMBL1479010 & 1301435 & 5.3197 & 4.9137 & TRN \\
\hline CHEMBL1556786 & 1301435 & 3.284 & 3.7158 & TRN \\
\hline CHEMBL1384167 & 1301435 & 5.3439 & 5.5399 & TRN \\
\hline CHEMBL1486874 & 1301435 & 3.284 & 3.4833 & TRN \\
\hline CHEMBL1416853 & 1301435 & 3.284 & 4.0063 & TST \\
\hline CHEMBL1479296 & 1301435 & 4.2938 & 3.7889 & TRN \\
\hline CHEMBL3182996 & 1301435 & 4.6962 & 3.7997 & TST \\
\hline CHEMBL1900154 & 1301435 & 4.6761 & 4.5947 & TRN \\
\hline CHEMBL1588387 & 1301435 & 4.4429 & 3.7249 & TRN \\
\hline CHEMBL1561956 & 1301435 & 4.4237 & 3.5709 & TRN \\
\hline CHEMBL1611128 & 1301435 & 3.284 & 3.4804 & TRN \\
\hline CHEMBL591598 & 1301435 & 4.4692 & 4.9751 & TRN \\
\hline CHEMBL1396619 & 1301435 & 5.2907 & 3.8865 & TRN \\
\hline CHEMBL1301480 & 1301435 & 4.9618 & 4.8007 & TRN \\
\hline CHEMBL1303404 & 1301435 & 3.284 & 3.9723 & TRN \\
\hline CHEMBL1588716 & 1301435 & 4.4664 & 3.9395 & TRN \\
\hline CHEMBL3188477 & 1301435 & 4.6165 & 3.8134 & TST \\
\hline CHEMBL1456521 & 1301435 & 4.422 & 3.8489 & TRN \\
\hline CHEMBL 3184385 & 1301435 & 4.5693 & 4.4159 & TRN \\
\hline CHEMBL1714393 & 1301435 & 3.284 & 3.8621 & TRN \\
\hline CHEMBL1533657 & 1301435 & 4.8655 & 4.4861 & TST \\
\hline CHEMBL1878940 & 1301435 & 4.8187 & 4.9825 & TST \\
\hline CHEMBL1343831 & 1301435 & 3.284 & 3.8824 & TRN \\
\hline CHEMBL2358899 & 1301435 & 6.0 & 5.1684 & TST \\
\hline CHEMBL1380459 & 1301435 & 4.6457 & 4.1892 & TRN \\
\hline CHEMBL3188935 & 1301435 & 5.118 & 4.9914 & TST \\
\hline CHEMBL1277151 & 1301435 & 4.3534 & 4.3813 & TRN \\
\hline CHEMBL1505044 & 1301435 & 4.7219 & 4.9221 & TRN \\
\hline CHEMBL1511219 & 1301435 & 5.5986 & 4.9602 & TRN \\
\hline CHEMBL1610429 & 1301435 & 3.284 & \multicolumn{2}{|c|}{3.6010000000000004} \\
\hline CHEMBL137586 & 1301435 & 3.284 & 3.819 & TRN \\
\hline CHEMBL1895747 & 1301435 & 4.823 & 4.2816 & TST \\
\hline CHEMBL1579644 & 1301435 & 5.4841 & 4.9937 & TST \\
\hline
\end{tabular}

Page 23005 
Supplemental Table S2.txt

\begin{tabular}{|c|c|c|c|c|}
\hline & & & 8 & \\
\hline CHЕMPI $171005 ?$ & 301435 & 5.6716 & & \\
\hline IEMBL: & & 84 & 476 & \\
\hline IEMBL1482964 & 301435 & 84 & 144 & \\
\hline AEMBL1399193 & 301435 & 1013 & 8315 & \\
\hline AEMBL13. & 5 & 152 & 569 & \\
\hline r & & 838 & & \\
\hline IEMBL 2130868 & 35 & 3.284 & & \\
\hline IEMBL1379493 & 30 & 4.7071 & 358 & \\
\hline AEMBL598885 & 5 & 4.5106 & 324 & \\
\hline AEMBL13] & 5 & 3.284 & 18 & \\
\hline 83 & 5 & & & \\
\hline IEMBL156 & 30 & 3.284 & 651 & \\
\hline AEMBL135 & 30 & 5.0565 & 609 & \\
\hline 26 & & 4.6923 & 46 & \\
\hline 84 & 5 & 226 & & \\
\hline 62 & 30 & 87 & & \\
\hline IEMBL 509 & 130 & 726 & & \\
\hline 761 & 5 & & & \\
\hline 44 & & 7.2396 & 49 & \\
\hline 4 & 5 & 34 & & \\
\hline & 5 & & & \\
\hline 97 & 5 & 249 & & \\
\hline 69 & & 916 & & \\
\hline & & & & \\
\hline 34 & 136 & 7 & & \\
\hline 86 & 5 & 5 . & & \\
\hline & & 545 & & \\
\hline & & & & \\
\hline & 5 & & & \\
\hline & 5 & & & \\
\hline & 5 & & & \\
\hline & & 72 & & \\
\hline & 5 & & & \\
\hline 203 & 5 & 4. & & \\
\hline & $13 \mathrm{~K}$ & 3.2 & & \\
\hline & & & & \\
\hline & & & & \\
\hline 370 & 130 & 209 & & \\
\hline & 136 & & $\partial 2$ & \\
\hline & 130 & & & \\
\hline 73 & 130 & 929 & & \\
\hline 884 & 130 & 3.284 & & $\mathrm{R}$ \\
\hline 336 & 130 & 5.399 & 94 & \\
\hline & 130 & 4.3505 & & \\
\hline 08 & 130 & & & \\
\hline CHEMBL1392228 & 130 & 4.7701 & 4.4485 & \\
\hline CHEMBL1392611 & 1301435 & 4.4756 & 4.3567 & \\
\hline
\end{tabular}

Page 23006 
Supplemental Table S2.txt

\begin{tabular}{|c|c|c|c|c|}
\hline CHEMBL1587117 & 1301435 & 4.6637 & 3.9847 & TRN \\
\hline CHEMBL1500923 & 1301435 & 3.284 & 3.2596 & TRN \\
\hline CHEMBL1487964 & 1301435 & 3.284 & 4.2676 & TRN \\
\hline CHEMBL1366417 & 1301435 & 3.284 & 4.0508 & TRN \\
\hline CHEMBL1350432 & 1301435 & 5.055 & 4.9085 & TST \\
\hline CHEMBL3182316 & 1301435 & 4.7778 & 4.0366 & TRN \\
\hline CHEMBL1309228 & 1301435 & 5.2118 & 4.9489 & TRN \\
\hline CHEMBL1490041 & 1301435 & 5.1232 & 5.3192 & TRN \\
\hline CHEMBL1891068 & 1301435 & 4.6792 & 4.7688 & TST \\
\hline CHEMBL1997132 & 1301435 & 4.6564 & 4.7479 & TRN \\
\hline CHEMBL1530972 & 1301435 & 3.284 & 4.35 & TRN \\
\hline CHEMBL 2356186 & 1301435 & 6.0857 & 5.38399 & 99999999995 \\
\hline CHEMBL1595274 & 1301435 & 3.284 & 3.5414 & TRN \\
\hline CHEMBL1539359 & 1301435 & 4.6256 & 4.8171 & TRN \\
\hline CHEMBL1573261 & 1301435 & 3.284 & 4.2845 & TST \\
\hline CHEMBL1542378 & 1301435 & 4.5969 & 4.4013 & TRN \\
\hline CHEMBL 2148124 & 1301435 & 5.2941 & 4.8977 & TRN \\
\hline CHEMBL1455421 & 1301435 & 4.9266 & 4.7413 & TRN \\
\hline CHEMBL199194 & 1301435 & 4.3857 & 4.1692 & TRN \\
\hline CHEMBL1468323 & 1301435 & 3.284 & 3.6521 & TRN \\
\hline CHEMBL 2355651 & 1301435 & 5.2916 & 4.9582 & TRN \\
\hline CHEMBL3183087 & 1301435 & 5.2233 & 4.1429 & TST \\
\hline CHEMBL3187781 & 1301435 & 4.4936 & 3.9031 & TST \\
\hline CHEMBL1494214 & 1301435 & 5.015 & 4.8189 & TRN \\
\hline CHEMBL1896073 & 1301435 & 4.8019 & 4.9367 & TRN \\
\hline CHEMBL1978733 & 1301435 & 5.3645 & 5.2626 & TRN \\
\hline CHEMBL3183439 & 1301435 & 5.1169 & 3.8745 & TST \\
\hline CHEMBL1872364 & 1301435 & 4.721 & 4.4042 & TRN \\
\hline CHEMBL1991779 & 1301435 & 5.3768 & 5.2269 & TRN \\
\hline CHEMBL1356042 & 1301435 & 3.284 & 4.3716 & TST \\
\hline CHEMBL1903021 & 1301435 & 5.0013 & 4.9556 & TRN \\
\hline CHEMBL1586425 & 1301435 & 5.0665 & 5.1819 & TRN \\
\hline CHEMBL1546205 & 1301435 & 5.1349 & 5.42299 & 9999999999 \\
\hline CHEMBL1579071 & 1301435 & 4.4517 & 4.4689 & TRN \\
\hline CHEMBL1409101 & 1301435 & 3.284 & 3.8176 & TRN \\
\hline CHEMBL1522279 & 1301435 & 3.284 & 4.6577 & TRN \\
\hline CHEMBL1309142 & 1301435 & 3.284 & 3.7592 & TRN \\
\hline CHEMBL1448943 & 1301435 & 4.6584 & 4.1424 & TRN \\
\hline CHEMBL1897363 & 1301435 & 4.724 & 4.7217 & TRN \\
\hline CHEMBL3183027 & 1301435 & 6.0 & 4.881 & TST \\
\hline CHEMBL1502192 & 1301435 & 3.284 & 4.0221 & TRN \\
\hline CHEMBL1595632 & 1301435 & 5.224 & 5.1141 & TRN \\
\hline CHEMBL1382538 & 1301435 & 3.284 & 4.2642 & TRN \\
\hline CHEMBL1438758 & 1301435 & 4.5522 & 3.5463 & TRN \\
\hline CHEMBL1422720 & 1301435 & 4.8864 & 4.5805 & TRN \\
\hline CHEMBL1386609 & 1301435 & 3.284 & 4.2184 & TRN \\
\hline CHEMBL1430096 & 1301435 & 4.6496 & 4.6681 & TRN \\
\hline CHEMBL1896918 & 1301435 & 4.474 & 4.4465 & TST \\
\hline
\end{tabular}


Supplemental Table S2.txt

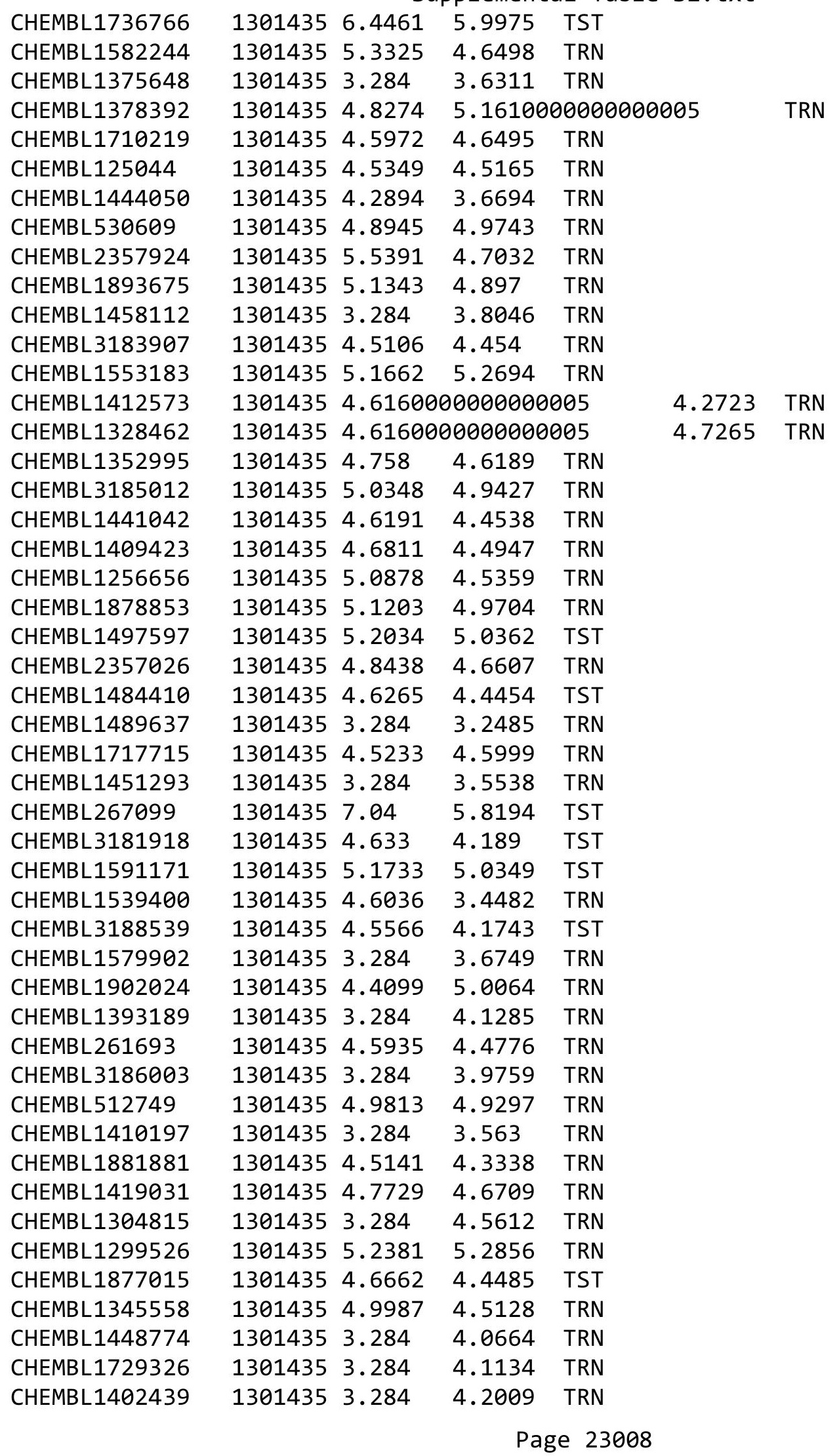


Supplemental Table S2.txt

\begin{tabular}{|c|c|c|c|c|c|}
\hline CHEMBL1486546 & 1301435 & 4.9292 & 5.3109 & TRN & \\
\hline CHEMBL1396351 & 1301435 & 5.1035 & 5.1351 & TRN & \\
\hline CHEMBL3188673 & 1301435 & 4.5539 & 4.8423 & TRN & \\
\hline CHEMBL429335 & 1301435 & 3.284 & 4.2811 & TRN & \\
\hline CHEMBL2136405 & 1301435 & 4.6371 & 4.3467 & TST & \\
\hline CHEMBL1901846 & 1301435 & 3.284 & 3.9119 & TRN & \\
\hline CHEMBL3185372 & 1301435 & 3.284 & 4.5602 & TST & \\
\hline CHEMBL1608301 & 1301435 & 4.3638 & 4.1088 & TRN & \\
\hline CHEMBL1537106 & 1301435 & 4.9539 & 4.9522 & TRN & \\
\hline CHEMBL1474280 & 1301435 & 3.284 & 3.7614 & TRN & \\
\hline CHEMBL1442242 & 1301435 & 4.4553 & 4.5177 & TST & \\
\hline CHEMBL3187793 & 1301435 & 4.7165 & 4.865 & TST & \\
\hline CHEMBL1573883 & 1301435 & 3.284 & 4.3173 & TRN & \\
\hline CHEMBL1892565 & 1301435 & 4.4433 & 4.7757 & TRN & \\
\hline CHEMBL1531169 & 1301435 & 5.1096 & 4.7828 & TRN & \\
\hline CHEMBL1884029 & 1301435 & 4.5916 & 4.3094 & TRN & \\
\hline CHEMBL1342147 & 1301435 & 4.4456 & 4.4445 & TRN & \\
\hline CHEMBL2359034 & 1301435 & 4.6066 & 4.6992 & TRN & \\
\hline CHEMBL1213608 & 1301435 & 3.284 & 3.7678 & TRN & \\
\hline CHEMBL252403 & 1301435 & 4.5017 & 4.1806 & TRN & \\
\hline CHEMBL3185532 & 1301435 & 4.4152 & 3.9512 & TRN & \\
\hline CHEMBL1421770 & 1301435 & 4.7585 & 4.4603 & TRN & \\
\hline CHEMBL1428452 & 1301435 & 3.284 & 3.8048 & TRN & \\
\hline CHEMBL1374009 & 1301435 & 4.5117 & \multicolumn{2}{|c|}{3.7030000000000003} & TRN \\
\hline CHEMBL 3183001 & 1301435 & 6.0 & 4.8845 & TRN & \\
\hline CHEMBL 3183827 & 1301435 & 4.3639 & 4.0762 & TST & \\
\hline CHEMBL 2359997 & 1301435 & 5.0915 & 4.8455 & TRN & \\
\hline CHEMBL1878022 & 1301435 & 3.284 & 3.9852 & TRN & \\
\hline CHEMBL1355823 & 1301435 & 5.6289 & 4.7846 & TRN & \\
\hline CHEMBL1374367 & 1301435 & 4.4029 & 3.9479 & TST & \\
\hline CHEMBL1342393 & 1301435 & 4.6158 & 4.5726 & TRN & \\
\hline CHEMBL 3186452 & 1301435 & 4.4935 & 4.5707 & TST & \\
\hline CHEMBL2354885 & 1301435 & 3.284 & 4.4184 & TST & \\
\hline CHEMBL1373664 & 1301435 & 3.284 & 3.6443 & TRN & \\
\hline CHEMBL1325658 & 1301435 & 3.284 & 4.1473 & TRN & \\
\hline CHEMBL1520753 & 1301435 & 5.066 & 5.3108 & TRN & \\
\hline CHEMBL 1435056 & 1301435 & 3.284 & 3.9296 & TST & \\
\hline CHEMBL 3187125 & 1301435 & 3.284 & 3.9086 & TRN & \\
\hline CHEMBL1866397 & 1301435 & 4.6857 & 4.3784 & TST & \\
\hline CHEMBL 3185075 & 1301435 & 4.4322 & 4.3033 & TST & \\
\hline CHEMBL1459468 & 1301435 & 5.8894 & 4.9868 & TRN & \\
\hline CHEMBL1519965 & 1301435 & 5.5086 & 5.1306 & TRN & \\
\hline CHEMBL1483331 & 1301435 & 4.9352 & 4.6655 & TST & \\
\hline CHEMBL3187367 & 1301435 & 3.284 & 4.4137 & TST & \\
\hline CHEMBL607553 & 1301435 & 5.1192 & 5.2204 & TRN & \\
\hline CHEMBL3186236 & 1301435 & 4.6264 & 4.4167 & TRN & \\
\hline CHEMBL1484344 & 1301435 & 3.284 & 3.9636 & TRN & \\
\hline CHEMBL610198 & 1301435 & 5.1238 & 5.2937 & TRN & \\
\hline
\end{tabular}

Page 23009 
Supplemental Table S2.txt

\begin{tabular}{|c|c|c|c|c|c|}
\hline CHEMBL1309463 & 1301435 & 5.1518 & 4.1671 & TRN & \\
\hline CHEMBL1712850 & 1301435 & 5.1445 & 5.3064 & TRN & \\
\hline CHEMBL1573994 & 1301435 & 4.9311 & 5.1091 & TRN & \\
\hline CHEMBL1366321 & 1301435 & 3.284 & 3.7859 & TRN & \\
\hline CHEMBL367376 & 1301435 & 6.7696 & 6.2787 & TST & \\
\hline CHEMBL1481861 & 1301435 & 4.3453 & 3.9049 & TRN & \\
\hline CHEMBL1540513 & 1301435 & 3.284 & 3.7814 & TRN & \\
\hline CHEMBL1880578 & 1301435 & 4.3153 & 3.8516 & TRN & \\
\hline CHEMBL3184207 & 1301435 & 6.0 & 5.2708 & TRN & \\
\hline CHEMBL3183033 & 1301435 & 4.7484 & 4.5111 & TST & \\
\hline CHEMBL1591445 & 1301435 & 4.5426 & 4.6111 & TRN & \\
\hline CHEMBL1575970 & 1301435 & 4.5948 & 3.8674 & TRN & \\
\hline CHEMBL1454738 & 1301435 & 4.7537 & 4.6106 & TRN & \\
\hline CHEMBL3186645 & 1301435 & 4.9076 & 4.7571 & TST & \\
\hline CHEMBL1455137 & 1301435 & 5.3615 & 5.2925 & TST & \\
\hline CHEMBL1405344 & 1301435 & 4.9003 & 4.4713 & TST & \\
\hline CHEMBL1896333 & 1301435 & 4.33899 & 99999999 & 4.3717 & TRN \\
\hline CHEMBL1872338 & 1301435 & 4.862 & 4.7423 & TRN & \\
\hline CHEMBL3185154 & 1301435 & 6.0 & 4.828 & TST & \\
\hline CHEMBL1521051 & 1301435 & 3.284 & 3.3423 & TRN & \\
\hline CHEMBL1397452 & 1301435 & 4.5309 & 4.08899 & 99999999995 & TRN \\
\hline CHEMBL1725682 & 1301435 & 3.284 & 4.0349 & TST & \\
\hline CHEMBL1488730 & 1301435 & 3.284 & 3.56 & TRN & \\
\hline CHEMBL1505604 & 1301435 & 5.5751 & 5.2489 & TRN & \\
\hline CHEMBL1394527 & 1301435 & 4.4302 & 3.7208 & TRN & \\
\hline CHEMBL1329974 & 1301435 & 4.7537 & 5.0685 & TRN & \\
\hline CHEMBL1463659 & 1301435 & 5.5017 & 5.2776 & TRN & \\
\hline CHEMBL2359013 & 1301435 & 5.4089 & 4.7589 & TRN & \\
\hline CHEMBL1312318 & 1301435 & 3.284 & 3.4803 & TRN & \\
\hline CHEMBL1325945 & 1301435 & 5.2182 & 5.086 & TRN & \\
\hline CHEMBL3183869 & 1301435 & 4.3185 & 4.3869 & TST & \\
\hline CHEMBL1602614 & 1301435 & 4.5771 & 4.043 & TRN & \\
\hline CHEMBL595840 & 1301435 & 3.284 & 4.3481 & TRN & \\
\hline CHEMBL2359853 & 1301435 & 4.6349 & 4.4145 & TRN & \\
\hline CHEMBL1386689 & 1301435 & 3.284 & 3.7802 & TRN & \\
\hline CHEMBL3186317 & 1301435 & 5.1002 & 5.0688 & TRN & \\
\hline CHEMBL1383534 & 1301435 & 4.5891 & 4.1876 & TRN & \\
\hline CHEMBL1402010 & 1301435 & 5.2684 & 4.9826 & TRN & \\
\hline CHEMBL3187962 & 1301435 & 4.4037 & 4.2342 & TST & \\
\hline CHEMBL3187897 & 1301435 & 4.6149 & 4.4034 & TRN & \\
\hline CHEMBL1427265 & 1301435 & 3.284 & 4.1151 & TRN & \\
\hline CHEMBL1315401 & 1301435 & 4.4079 & 4.5203 & TST & \\
\hline CHEMBL3187701 & 1301435 & 4.3572 & 4.3199 & TST & \\
\hline CHEMBL1868520 & 1301435 & 4.5698 & 4.5874 & TRN & \\
\hline CHEMBL1734568 & 1301435 & 3.284 & 4.4597 & TST & \\
\hline CHEMBL3188025 & 1301435 & 4.452 & 3.9714 & TST & \\
\hline CHEMBL1453723 & 1301435 & 4.3574 & 4.3704 & TRN & \\
\hline CHEMBL1486109 & 1301435 & 5.4202 & 5.1137 & TRN & \\
\hline
\end{tabular}

Page 23010 
Supplemental Table S2.txt

\begin{tabular}{|c|c|c|c|c|c|}
\hline CHEMBL1456099 & 1301435 & 3.284 & 4.2109 & TRN & \\
\hline CHEMBL1597627 & 1301435 & 5.3019 & 4.8017 & TRN & \\
\hline CHEMBL1363706 & 1301435 & 4.7314 & 4.6892 & TRN & \\
\hline CHEMBL 213580 & 1301435 & 5.058 & 5.1594 & TRN & \\
\hline CHEMBL1493204 & 1301435 & 4.3358 & 3.9109 & TRN & \\
\hline CHEMBL1597705 & 1301435 & 4.7755 & 4.6235 & TRN & \\
\hline CHEMBL1601647 & 1301435 & 3.284 & 3.8119 & TRN & \\
\hline CHEMBL 2136235 & 1301435 & 4.5921 & \multicolumn{2}{|c|}{4.7410000000000005} & TST \\
\hline CHEMBL 3187031 & 1301435 & 4.6135 & 4.6039 & TRN & \\
\hline CHEMBL1995376 & 1301435 & 5.6819 & 4.7091 & TRN & \\
\hline CHEMBL1442326 & 1301435 & 3.284 & 4.1734 & TRN & \\
\hline CHEMBL1544685 & 1301435 & 3.284 & 3.8439 & TRN & \\
\hline CHEMBL1361072 & 1301435 & 5.0985 & 4.6927 & TST & \\
\hline CHEMBL1606999 & 1301435 & 3.284 & 3.5748 & TRN & \\
\hline CHEMBL1572605 & 1301435 & 3.284 & 4.338 & TST & \\
\hline CHEMBL1468355 & 1301435 & 4.4833 & 4.3883 & TRN & \\
\hline CHEMBL1898104 & 1301435 & 4.9706 & 4.3871 & TRN & \\
\hline CHEMBL 2133546 & 1301435 & 4.6297 & 4.6387 & TRN & \\
\hline CHEMBL1527400 & 1301435 & 5.2076 & 5.166 & TRN & \\
\hline CHEMBL1409883 & 1301435 & 5.3526 & \multicolumn{2}{|c|}{5.167999999999999} & TRN \\
\hline CHEMBL1981570 & 1301435 & 5.2823 & 5.5463 & TRN & \\
\hline CHEMBL1478962 & 1301435 & 3.284 & 3.4672 & TRN & \\
\hline CHEMBL3182923 & 1301435 & 3.3279 & 4.045 & TST & \\
\hline CHEMBL1486329 & 1301435 & 4.5714 & 4.9844 & TRN & \\
\hline CHEMBL1446234 & 1301435 & 4.9442 & 4.6286 & TST & \\
\hline CHEMBL3182459 & 1301435 & 4.7031 & 4.4109 & TRN & \\
\hline CHEMBL1484208 & 1301435 & 5.1379 & 5.3088 & TRN & \\
\hline CHEMBL1391313 & 1301435 & 3.284 & \multicolumn{2}{|c|}{3.6719999999999997} & TRN \\
\hline CHEMBL1303280 & 1301435 & 4.7254 & 4.5499 & TRN & \\
\hline CHEMBL1563176 & 1301435 & 5.1733 & 4.9262 & TST & \\
\hline CHEMBL1390421 & 1301435 & 3.284 & 3.6104 & TRN & \\
\hline CHEMBL 2139358 & 1301435 & 4.5265 & 4.0615 & TRN & \\
\hline CHEMBL1325451 & 1301435 & 4.8022 & 4.7923 & TRN & \\
\hline CHEMBL1309573 & 1301435 & 5.4473 & 5.0305 & TRN & \\
\hline CHEMBL473735 & 1301435 & 4.5465 & 4.1378 & TRN & \\
\hline CHEMBL1473464 & 1301435 & 3.284 & 4.0332 & TRN & \\
\hline CHEMBL1517002 & 1301435 & 3.284 & 3.6007 & TRN & \\
\hline CHEMBL 2362612 & 1301435 & 4.967 & 4.5288 & TRN & \\
\hline CHEMBL1463529 & 1301435 & 4.8881 & 4.8437 & TRN & \\
\hline CHEMBL1540839 & 1301435 & 4.6994 & 4.3641 & TRN & \\
\hline CHEMBL1974563 & 1301435 & 3.284 & 4.3512 & TST & \\
\hline CHEMBL1360928 & 1301435 & 4.4983 & 4.3811 & TRN & \\
\hline CHEMBL1404547 & 1301435 & 4.8407 & 4.8009 & TRN & \\
\hline CHEMBL1359120 & 1301435 & 4.841 & 4.738 & TRN & \\
\hline CHEMBL1876725 & 1301435 & 5.1057 & 4.8385 & TRN & \\
\hline CHEMBL1868562 & 1301435 & 4.8392 & 4.8045 & TRN & \\
\hline CHEMBL1517072 & 1301435 & 3.284 & 4.229 & TRN & \\
\hline CHEMBL1437083 & 1301435 & 5.0339 & 5.2674 & TRN & \\
\hline
\end{tabular}


Supplemental Table S2.txt

\begin{tabular}{|c|c|c|c|c|}
\hline HEMBL & & 3.284 & 4.2596 & בו \\
\hline & & 3.284 & & \\
\hline HFMRI & 35 & 284 & & \\
\hline HEMBL3188377 & 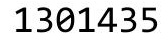 & 3834 & 7862 & \\
\hline AEMBL1576166 & 301435 & 4175 & 9242 & \\
\hline HEMBL3188780 & $301<$ & 3279 & 2364 & \\
\hline HEMBL & . & 3974 & 114 & \\
\hline AEMBL1 & . & 5255 & 367 & \\
\hline HEMBL1439384 & 301435 & 5.1141 & 1327 & \\
\hline HEMBL1720155 & 3014 & 1616 & 4041 & \\
\hline HEMBL1 & 301 & & & \\
\hline AEMBL & 30 & & 303 & \\
\hline HEMBL1 & 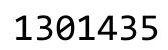 & & & \\
\hline HEMBL2354532 & 301 & 195 & 2506 & \\
\hline HEMBL 318 & 301 & 502 & & \\
\hline HEMBL3 & 30 & 68 & 968 & \\
\hline HEMBLI & D & 05 & & \\
\hline HEMBL1 & 30 & 525 & & \\
\hline HEMBL3 & 30 & & 368 & \\
\hline HEMBL138 & & & 385 & I KIV \\
\hline HEMBL: & 30 & & 74 & RIN \\
\hline HEMBL & 36 & & & MIV \\
\hline HEMBL & 30 & & & \\
\hline HEMBL1 & & 655 & & IST \\
\hline AEMBL2. & 30 & 3 . & 58 & RN \\
\hline HEMBL1 & 30 & 84 & 85 & RI \\
\hline HEMBL & & 22 & & $\mathrm{RN}$ \\
\hline HEME & & 24 & & RN \\
\hline AEMBL1 & & & & IRN \\
\hline HEMBL 236 & 301 & & 326 & RN \\
\hline HEMBL 2 & 30 & 49 & 312 & ST \\
\hline HFM & 20 & & & ST \\
\hline נ & & & & TRN \\
\hline HEMBL1 & 30 & & & 「RN \\
\hline HEMBL1317 & 30 & 66 & 695 & ГRN \\
\hline AEMRI & 30 & & 46 & RN \\
\hline 1 & & & & RN \\
\hline HEMBL3 & & 941 & 5277 & TST \\
\hline HEMBL1 & 30 & & & TRN \\
\hline 5 & ש2 & & & RN \\
\hline HEMBL2 & 20 & 52 & & TRN \\
\hline HEMBL1 & & 377 & & 「RN \\
\hline HEMBL190 & 30 & 5.1163 & 3169 & $\Gamma R$ \\
\hline HEMBL1 & 30 & & & TR \\
\hline 9 & & & & \\
\hline HEMBL 213 & 130 & 4.737 & & \\
\hline CHEMBL199 & 130 & 4.39 & 4.9678 & \\
\hline CHEMBL1542560 & 1301435 & 4.856 & 4.8544 & \\
\hline
\end{tabular}

Page 23012 
Supplemental Table S2.txt

\begin{tabular}{|c|c|c|c|c|}
\hline CHEMBL1569984 & 1301435 & 3.284 & 4.0045 & TRN \\
\hline CHEMBL1521269 & 1301435 & 4.4768 & 4.3266 & TRN \\
\hline CHEMBL405317 & 1301435 & 5.2612 & 5.2697 & TRN \\
\hline CHEMBL1717333 & 1301435 & 5.1068 & 4.83899 & \\
\hline CHEMBL1472108 & 1301435 & 4.9606 & 4.9242 & TRN \\
\hline CHEMBL1710184 & 1301435 & 5.0424 & 5.1708 & TRN \\
\hline CHEMBL 2132785 & 1301435 & 3.284 & 3.8546 & TST \\
\hline CHEMBL1899585 & 1301435 & 4.7791 & 5.2599 & TRN \\
\hline CHEMBL414890 & 1301435 & 5.2 & 5.1989 & TST \\
\hline CHEMBL1516047 & 1301435 & 4.5229 & 3.8419 & TRN \\
\hline CHEMBL1481616 & 1301435 & 3.284 & 3.9479 & TRN \\
\hline CHEMBL3182522 & 1301435 & 4.7552 & 5.3353 & TRN \\
\hline CHEMBL 2004445 & 1301435 & 4.7395 & 4.3888 & TST \\
\hline CHEMBL3185621 & 1301435 & 4.4459 & 4.4664 & TRN \\
\hline CHEMBL1564490 & 1301435 & 3.284 & 4.1683 & TRN \\
\hline CHEMBL 3185003 & 1301435 & 4.6582 & 4.5578 & TRN \\
\hline CHEMBL486569 & 1301435 & 4.5369 & 4.3674 & TRN \\
\hline CHEMBL1607086 & 1301435 & 3.284 & 4.0915 & TRN \\
\hline CHEMBL1527433 & 1301435 & 4.5634 & 4.312 & TRN \\
\hline CHEMBL1597322 & 1301435 & 3.284 & 3.8597 & TRN \\
\hline CHEMBL1555066 & 1301435 & 5.061 & 4.9794 & TRN \\
\hline CHEMBL1488712 & 1301435 & 4.8697 & 4.5998 & TRN \\
\hline CHEMBL1470676 & 1301435 & 3.284 & 3.6558 & TRN \\
\hline CHEMBL1460869 & 1301435 & 5.2269 & 4.6719 & TRN \\
\hline CHEMBL 286593 & 1301435 & 4.6706 & 5.2501 & TRN \\
\hline CHEMBL3189242 & 1301435 & 3.284 & 3.573 & TRN \\
\hline CHEMBL1448153 & 1301435 & 3.284 & 4.2452 & TRN \\
\hline CHEMBL3184527 & 1301435 & 5.1079 & 4.9967 & TST \\
\hline CHEMBL1336419 & 1301435 & 3.284 & 4.1614 & TST \\
\hline CHEMBL1432977 & 1301435 & 3.284 & 3.8402 & TST \\
\hline CHEMBL1367759 & 1301435 & 3.284 & 4.4573 & TRN \\
\hline CHEMBL3185699 & 1301435 & 3.284 & 4.1847 & TST \\
\hline CHEMBL 2144728 & 1301435 & 6.109 & 5.3431 & TST \\
\hline CHEMBL1548672 & 1301435 & 3.284 & 3.4157 & TRN \\
\hline CHEMBL1351908 & 1301435 & 4.6426 & 3.9918 & TRN \\
\hline CHEMBL1500112 & 1301435 & 4.5891 & 4.1828 & TRN \\
\hline CHEMBL1732332 & 1301435 & 8.301 & 5.7625 & TST \\
\hline CHEMBL1601310 & 1301435 & 5.1925 & 5.2325 & TRN \\
\hline CHEMBL1310496 & 1301435 & 3.284 & 3.716 & TRN \\
\hline CHEMBL1707441 & 1301435 & 5.0635 & 4.9037 & TST \\
\hline CHEMBL1577174 & 1301435 & 4.7249 & 4.2362 & TRN \\
\hline CHEMBL1733824 & 1301435 & 4.5403 & 4.493 & TST \\
\hline CHEMBL1461730 & 1301435 & 3.284 & 3.7027 & TRN \\
\hline CHEMBL1373194 & 1301435 & 4.362 & 4.5021 & TRN \\
\hline CHEMBL 3186502 & 1301435 & 4.32 & 3.863 & TST \\
\hline CHEMBL1315275 & 1301435 & 3.284 & 3.7283 & TRN \\
\hline CHEMBL1536196 & 1301435 & 3.284 & 4.2973 & TST \\
\hline CHEMBL1488020 & 1301435 & 4.6772 & 4.0747 & TRN \\
\hline
\end{tabular}

Page 23013 
Supplemental Table S2.txt

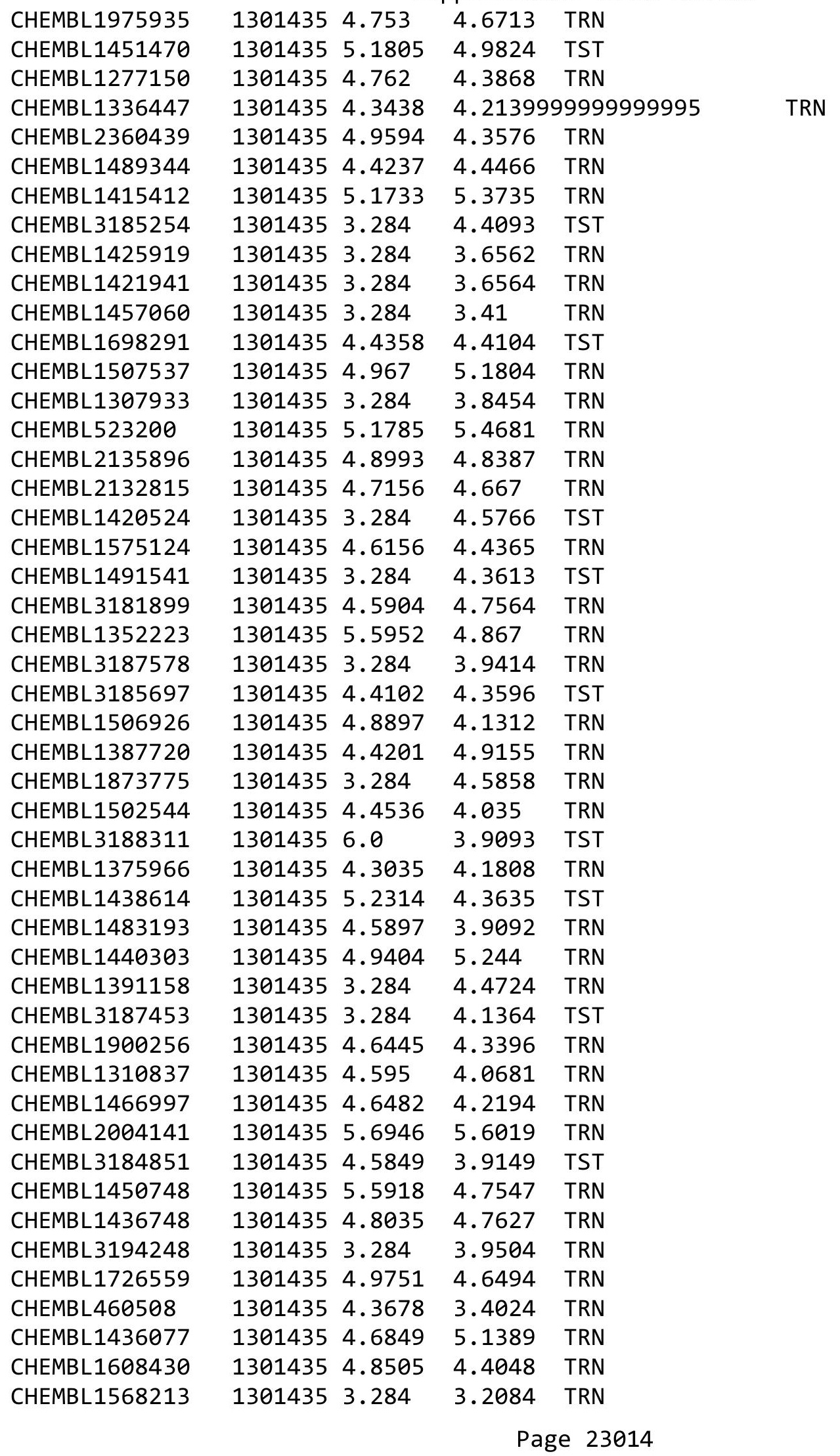


Supplemental Table S2.txt

\begin{tabular}{|c|c|c|c|c|}
\hline 23 & S143015 & 3.284 & & 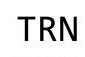 \\
\hline HEMBL1309466 & & 3.284 & 3.9655 & \\
\hline 3371 & 01 & 099 & & \\
\hline AEMBL134 & & 284 & & \\
\hline AEMBL1607801 & 301435 & 409 & 1667 & \\
\hline HEMBL1489293 & 301435 & 4.5364 & 6221 & \\
\hline AEMBL3. & 301 & 929 & 999 & \\
\hline EMBL] & & 5.585 & & RN \\
\hline AEMBL14S & 30 & 3.284 & 032 & CT \\
\hline HEMBL148 & 30 & 7016 & 0829 & $\Gamma \mathrm{RN}$ \\
\hline HEMBL17 & 30 & 2899 & 8913 & \\
\hline EMBL1 & 0 & 84 & 194 & $\mathrm{RN}$ \\
\hline EMBL 2 & & 683 & & \\
\hline AEMBL153 & 30 & 4.8539 & 6063 & PN \\
\hline AEMBL318 & 30 & 84 & 3053 & וد \\
\hline AEMBL1 & te & 84 & 21 & IIV \\
\hline AEMBL1 & $3 t$ & 84 & 404 & ST \\
\hline AEMBL1 & 36 & 726 & 025 & \\
\hline AEMBL318 & 36 & 4.7442 & 45 & \\
\hline IEMBL13 & & 55 & & alv \\
\hline IEMBL1 & & & 271 & RIV \\
\hline IEMBL2 & S & 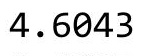 & & RN \\
\hline EMBL: & 5 & & 541 & RN \\
\hline 26 & & & 8333 & RN \\
\hline IEMBL15 & & & & I KIV \\
\hline IEMBL? & 3( & 2 & 17 & RN \\
\hline IEMBL & 36 & & & RN \\
\hline FMB & 5 & & 96 & RN \\
\hline IEMBL1 & & & & TRN \\
\hline AEMBL15 & & & & TRN \\
\hline IEMBL1 & & 4 & & 「RN \\
\hline AEMBL & 36 & & 42 & RN \\
\hline EMBL1 & & 55 & 169 & ST \\
\hline AEMBL318 & & & 5076 & TRN \\
\hline AEMBL161€ & 20 & 84 & 4382 & TST \\
\hline AEMBL1 & $36-2$ & $\partial 79$ & 863 & TRN \\
\hline 1 & 5 & & & $\Gamma \mathrm{RN}$ \\
\hline HEMBL1 & & 31 & 933 & RN \\
\hline IEMBL130 & 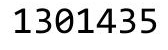 & 3.284 & 2891 & TRN \\
\hline EMBL130 & 30 & 556 & 1049 & TRN \\
\hline EMBL1 & 30 & 99 & 821 & TST \\
\hline HEMBL3 & & & & TST \\
\hline HEMBL151 & & 975 & 959 & ГST \\
\hline EMBL187 & 30 & 4.3631 & 2768 & TST \\
\hline רDI & & & 5916 & TST \\
\hline HEMBL1 & & & & KIN \\
\hline HEMBL142 & & & .8781 & SI \\
\hline CHEMBL3183209 & 1301435 & 4.3546 & 4.2767 & $S T$ \\
\hline
\end{tabular}

Page 23015 


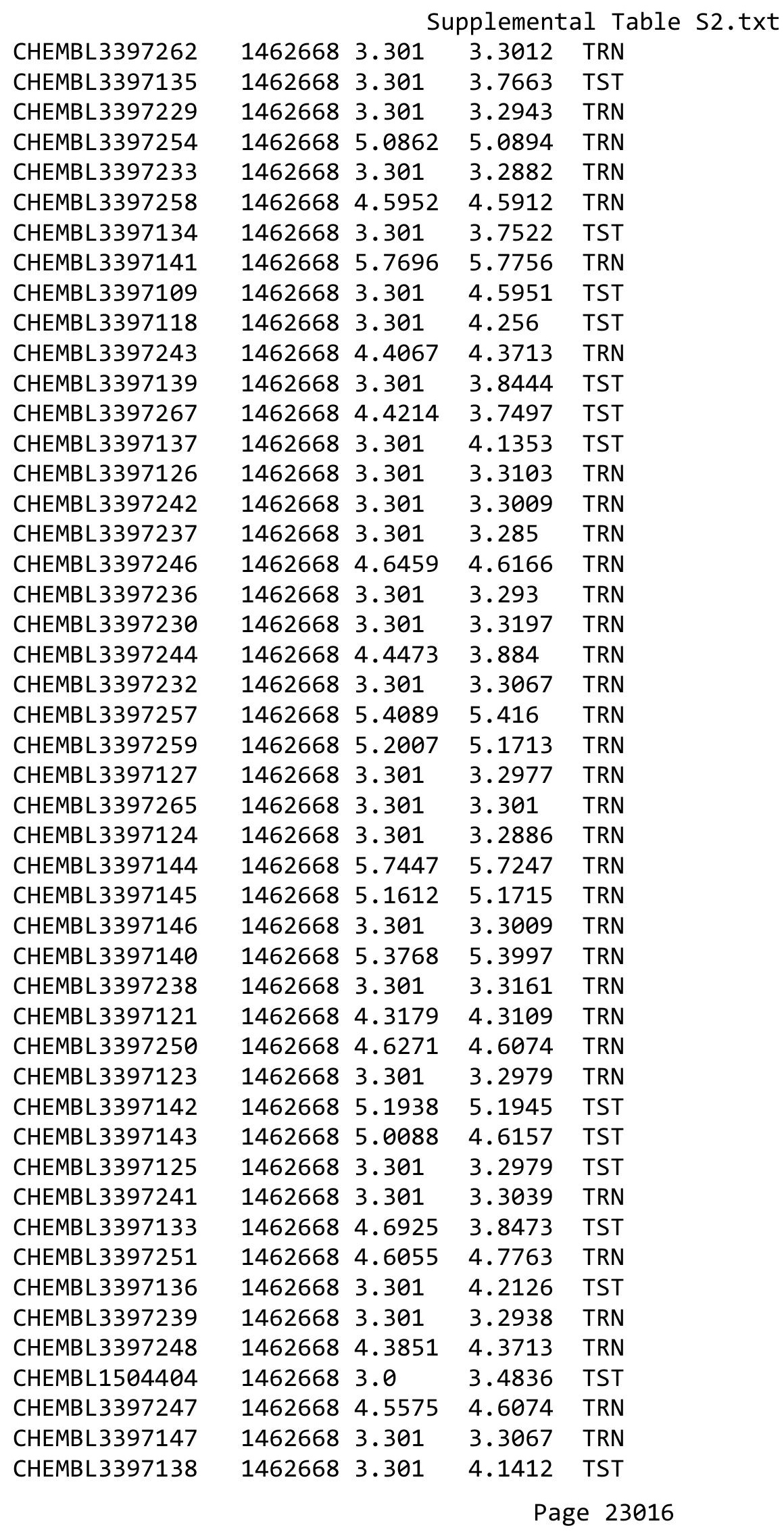




\begin{tabular}{|c|c|c|c|c|}
\hline \multicolumn{5}{|c|}{ Supplemental Table S2.txt } \\
\hline CHEMBL3397122 & 1462668 & 3.301 & 4.5869 & TST \\
\hline CHEMBL 3397255 & 1462668 & 4.9318 & 4.7763 & TRN \\
\hline CHEMBL3397264 & 1462668 & 3.301 & 3.2957 & TRN \\
\hline CHEMBL 3397253 & 1462668 & 5.2518 & 5.2587 & TRN \\
\hline CHEMBL3397260 & 1462668 & 3.301 & 3.3072 & TRN \\
\hline CHEMBL 3397228 & 1462668 & 3.301 & 3.2882 & TRN \\
\hline CHEMBL 3397234 & 1462668 & 3.301 & 3.2967 & TRN \\
\hline CHEMBL3397266 & 1462668 & 3.301 & 3.3069 & TRN \\
\hline CHEMBL 3397249 & 1462668 & 3.301 & 3.884 & TRN \\
\hline CHEMBL3397245 & 1462668 & 4.8041 & 4.834 & TRN \\
\hline CHEMBL 3397263 & 1462668 & 3.301 & 3.3042 & TRN \\
\hline CHEMBL3397231 & 1462668 & 3.301 & 3.2967 & TRN \\
\hline CHEMBL3397119 & 1462668 & 3.301 & 4.3537 & TST \\
\hline CHEMBL3397261 & 1462668 & 3.301 & 3.3009 & TRN \\
\hline CHEMBL3397120 & 1462668 & 4.4559 & 4.18 & TST \\
\hline CHEMBL 3397240 & 1462668 & 3.301 & 3.3364 & TRN \\
\hline CHEMBL3397256 & 1462668 & 5.0458 & 5.0196 & TRN \\
\hline CHEMBL3397252 & 1462668 & 4.6402 & 4.6498 & TRN \\
\hline CHEMBL3397235 & 1462668 & 3.301 & 3.2938 & TRN \\
\hline CHEMBL3120175 & 1292758 & 6.1439 & 6.9979 & TRN \\
\hline CHEMBL 3120941 & 1292758 & 7.3372 & 7.4049 & TRN \\
\hline CHEMBL3121166 & 1292758 & 5.8312 & 5.7526 & TRN \\
\hline CHEMBL 3120945 & 1292758 & 6.7352 & 7.0323 & TRN \\
\hline CHEMBL3121057 & 1292758 & 7.9586 & 8.0903 & TRN \\
\hline CHEMBL3121082 & 1292758 & 5.8969 & 6.1717 & TRN \\
\hline CHEMBL 3121060 & 1292758 & 6.9031 & 6.8465 & TRN \\
\hline CHEMBL 3121048 & 1292758 & 7.9281 & 8.0933 & TRN \\
\hline CHEMBL3120905 & 1292758 & 6.4377 & 6.3887 & TRN \\
\hline CHEMBL3121190 & 1292758 & 4.0 & 4.1329 & TST \\
\hline CHEMBL3120910 & 1292758 & 6.8996 & 5.7376 & TST \\
\hline CHEMBL3120914 & 1292758 & 5.2007 & 5.2534 & TST \\
\hline CHEMBL 3120920 & 1292758 & 6.5952 & 7.2009 & TRN \\
\hline CHEMBL 3120924 & 1292758 & 7.6198 & 7.4148 & TRN \\
\hline CHEMBL3121064 & 1292758 & 7.5376 & 8.1949 & TRN \\
\hline CHEMBL3120928 & 1292758 & 6.4413 & 6.8575 & TRN \\
\hline CHEMBL3121182 & 1292758 & 8.2441 & 7.7642 & TRN \\
\hline CHEMBL 3121062 & 1292758 & 8.6576 & 7.9979 & TRN \\
\hline CHEMBL3120923 & 1292758 & 5.7383 & 6.0379 & TRN \\
\hline CHEMBL3121186 & 1292758 & 7.9586 & 8.2147 & TRN \\
\hline CHEMBL3120906 & 1292758 & 6.1367 & 5.5151 & TST \\
\hline CHEMBL3120939 & 1292758 & 7.9066 & 7.8917 & TRN \\
\hline CHEMBL3121191 & 1292758 & 4.0 & 4.993 & TST \\
\hline CHEMBL 3121043 & 1292758 & 8.301 & 8.1976 & TRN \\
\hline CHEMBL3121077 & 1292758 & 7.3665 & 7.8372 & TRN \\
\hline CHEMBL2311191 & 1292758 & 8.6198 & 8.0295 & TRN \\
\hline CHEMBL 3121067 & 1292758 & 7.699 & 7.279 & TRN \\
\hline CHEMBL3120911 & 1292758 & 6.2118 & 6.2835 & TST \\
\hline CHEMBL3121046 & 1292758 & 7.4949 & 7.5205 & TRN \\
\hline
\end{tabular}


Supplemental Table S2.txt

\begin{tabular}{|c|c|c|c|c|}
\hline CHEMBL 3120916 & 1292758 & 7.041 & 7.2191 & TST \\
\hline CHEMBL 3121034 & 1292758 & 7.3188 & 7.7647 & TST \\
\hline CHEMBL 3121081 & 1292758 & 6.2874 & 6.2436 & TRN \\
\hline CHEMBL 3121074 & 1292758 & 7.6198 & 7.6612 & TRN \\
\hline CHEMBL3120918 & 1292758 & 6.8239 & 6.8523 & TST \\
\hline CHEMBL 3121037 & 1292758 & 6.5452 & 8.3403 & TST \\
\hline CHEMBL 3121071 & 1292758 & 7.3768 & 6.9631 & TRN \\
\hline CHEMBL 3121083 & 1292758 & 5.1241 & 5.241006 & 00000000005 \\
\hline CHEMBL 3120927 & 1292758 & 7.3372 & 7.5942 & TRN \\
\hline CHEMBL3120944 & 1292758 & 7.0132 & 6.6466 & TRN \\
\hline CHEMBL 3121185 & 1292758 & 7.699 & 7.7739 & TRN \\
\hline CHEMBL 3121188 & 1292758 & 7.1871 & 7.1388 & TRN \\
\hline CHEMBL 3121040 & 1292758 & 7.4949 & 7.6087 & TRN \\
\hline CHEMBL 3121041 & 1292758 & 8.5086 & 8.6471 & TRN \\
\hline CHEMBL3121169 & 1292758 & 7.75700 & 000000000 & 7.5845 \\
\hline CHEMBL 3121183 & 1292758 & 8.1135 & 8.1563 & TRN \\
\hline CHEMBL3121056 & 1292758 & 6.7799 & 7.2159 & TRN \\
\hline CHEMBL 3120946 & 1292758 & 7.1549 & 7.0372 & TRN \\
\hline CHEMBL 3120942 & 1292758 & 6.857 & 6.699 & TRN \\
\hline CHEMBL 3121069 & 1292758 & 6.9508 & 7.1582 & TRN \\
\hline CHEMBL 3120937 & 1292758 & 7.4815 & 6.7872 & TRN \\
\hline CHEMBL 3121065 & 1292758 & 8.3872 & 8.3233 & TRN \\
\hline CHEMBL 3120904 & 1292758 & 4.0 & 6.1444 & TST \\
\hline CHEMBL 3121054 & 1292758 & 7.6778 & 7.4324 & TRN \\
\hline CHEMBL 3121053 & 1292758 & 6.8069 & 7.1524 & TRN \\
\hline CHEMBL 3121035 & 1292758 & 7.4202 & 7.9272 & TRN \\
\hline CHEMBL 3121070 & 1292758 & 8.0362 & 7.6663 & TRN \\
\hline CHEMBL 3121078 & 1292758 & 7.8861 & 8.1196 & TRN \\
\hline CHEMBL 3121084 & 1292758 & 5.5005 & 5.1343 & TRN \\
\hline CHEMBL 3120919 & 1292758 & 7.7212 & 7.8261 & TRN \\
\hline CHEMBL 3120932 & 1292758 & 7.0132 & 7.8273 & TRN \\
\hline CHEMBL 3120922 & 1292758 & 7.3565 & 7.2551 & TRN \\
\hline CHEMBL 3120907 & 1292758 & 7.6778 & 6.6807 & TST \\
\hline CHEMBL 3121073 & 1292758 & 8.1367 & 7.8901 & TRN \\
\hline CHEMBL 3120948 & 1292758 & 7.2676 & 7.4327 & TRN \\
\hline CHEMBL3121061 & 1292758 & 7.3468 & 7.7536 & TRN \\
\hline CHEMBL 3121047 & 1292758 & 8.1871 & 8.0933 & TRN \\
\hline CHEMBL 3121068 & 1292758 & 7.6576 & 7.5612 & TRN \\
\hline CHEMBL 3120935 & 1292758 & 8.2366 & 8.0923 & TRN \\
\hline CHEMBL 3121168 & 1292758 & 5.6286 & 5.4234 & TRN \\
\hline CHEMBL 3121052 & 1292758 & 7.1135 & 7.2035 & TRN \\
\hline CHEMBL 3121045 & 1292758 & 8.5528 & 7.7991 & TRN \\
\hline CHEMBL 3120925 & 1292758 & 6.0773 & 6.3047 & TRN \\
\hline CHEMBL 3121066 & 1292758 & 8.3979 & 8.2257 & TRN \\
\hline CHEMBL 3121167 & 1292758 & 8.699 & 8.1976 & TRN \\
\hline CHEMBL 3120913 & 1292758 & 5.6714 & 5.0847 & TST \\
\hline CHEMBL 3121055 & 1292758 & 6.7122 & 6.767 & TRN \\
\hline CHEMBL 3120174 & 1292758 & 5.4921 & 6.0261 & TRN \\
\hline
\end{tabular}


Supplemental Table S2.txt

\begin{tabular}{|c|c|c|c|c|}
\hline ILT & & & & \\
\hline & & 7.9208 & 7.9234 & \\
\hline 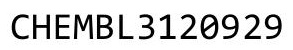 & & & & \\
\hline IEMBL & & & & \\
\hline AEMBL3121076 & 292758 & 7.9208 & 8997 & \\
\hline HEMBL3121189 & 58 & 18 & 9004 & \\
\hline 21059 & & 8.0 & 6129 & \\
\hline 21042 & & 51 & 7503 & גו \\
\hline HEMBL3121049 & 292758 & 7.284 & 3195 & \\
\hline HEMBL3121085 & 292758 & 4.6021 & 5047 & \\
\hline HEMBL3121051 & 0 & 7.9586 & 7872 & \\
\hline 1039 & & & 8279 & \\
\hline AEMBL & & & 494 & \\
\hline HEMBL3121075 & 58 & 7.3468 & 182 & \\
\hline AEMBL3121058 & & & & \\
\hline HEMBL; & 8 & & 24 & RN \\
\hline AEMBL & & & 375 & 年 \\
\hline 20915 & & & 209 & \\
\hline 20938 & 58 & & 3442 & \\
\hline AEMBL3120943 & & & & I KIV \\
\hline AEMBL. & 8 & & 15 & ГRN \\
\hline HEMBL & & & & ונכ \\
\hline 0926 & & & 462 & ST \\
\hline 20940 & & & 935 & $S$ \\
\hline AEMBL3 & & 8. & 42 & ISI \\
\hline HEMBL3 & 58 & & 196 & IST \\
\hline HEME & & & 42 & ST \\
\hline 921 & & & 66 & $T S T$ \\
\hline AEMBL3 & & & & $|S|$ \\
\hline AEMBL3121038 & 8 & 7. & 16 & ГST \\
\hline 21044 & & & 672 & IST \\
\hline JEN & & & 86 & ГST \\
\hline & & & 845 & TST \\
\hline HEMBL3 & & & & TST \\
\hline HEMBL1098210 & & & 182 & ГRN \\
\hline ICMPI & & & 08 & TRN \\
\hline 10 & & & & $\mathrm{RN}$ \\
\hline HEMBL1 & & & 7.7332 & TST \\
\hline HEMBL1 & & & 3472 & TRN \\
\hline 209 & & & 227 & RN \\
\hline HEMBL: & & & & TRN \\
\hline HEMBL: & & & 726 & 「RN \\
\hline HEMBL1099070 & & & 1917 & TRN \\
\hline HEMBL1 & & & & TR \\
\hline 0 & & & & RN \\
\hline HEMBL1097880 & & 8.6 & 8.0744 & \\
\hline HEMBL1097857 & 25 & 7.75 & 7.3551 & \\
\hline CHEMBL1095091 & 629725 & 6.5045 & 6.4692 & IR \\
\hline
\end{tabular}

Page 23019 


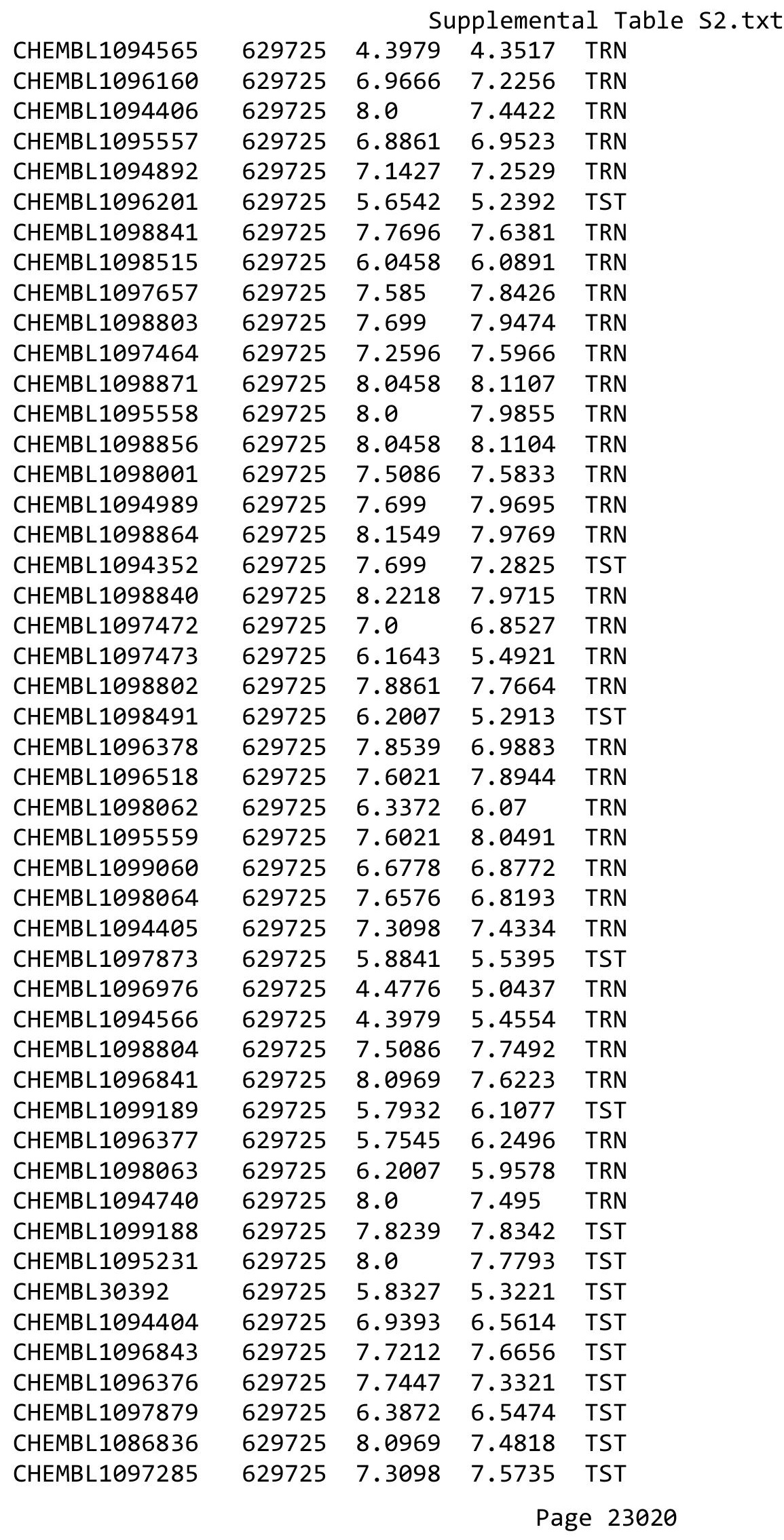




\begin{tabular}{|c|c|c|c|c|c|}
\hline & & \multicolumn{4}{|c|}{ Supplemental Table S2.txt } \\
\hline CHEMBL1095532 & 629725 & 7.1612 & 7.4192 & TST & \\
\hline CHEMBL1412448 & 688549 & 4.5 & 4.7244 & TRN & \\
\hline CHEMBL1501458 & 688549 & 4.9 & 4.981 & TST & \\
\hline CHEMBL1302571 & 688549 & 5.0 & 5.2212 & TRN & \\
\hline CHEMBL1402153 & 688549 & 4.6 & 4.8642 & TRN & \\
\hline CHEMBL3197234 & 688549 & 4.9 & 4.727 & TRN & \\
\hline CHEMBL1611300 & 688549 & 4.9 & 4.8825 & TRN & \\
\hline CHEMBL1358973 & 688549 & 5.1 & 5.0033 & TRN & \\
\hline CHEMBL1431928 & 688549 & 5.0 & 5.0588 & TRN & \\
\hline CHEMBL1349869 & 688549 & 4.8 & 5.0728 & TRN & \\
\hline CHEMBL1396127 & 688549 & 4.8 & 4.7146 & TRN & \\
\hline CHEMBL1336237 & 688549 & 4.9 & 5.0062 & TRN & \\
\hline CHEMBL1404777 & 688549 & 4.8 & 5.3531 & TRN & \\
\hline CHEMBL1438667 & 688549 & 4.7 & 5.0389 & TRN & \\
\hline CHEMBL1536007 & 688549 & 4.7 & 5.2452 & TRN & \\
\hline CHEMBL1585568 & 688549 & 5.55 & 4.9843 & TST & \\
\hline CHEMBL1368371 & 688549 & 4.45 & 4.9119 & TRN & \\
\hline CHEMBL1599168 & 688549 & 4.9 & 5.077 & TRN & \\
\hline CHEMBL1367262 & 688549 & 4.45 & 4.5521 & TRN & \\
\hline CHEMBL1406156 & 688549 & 4.5 & 4.9974 & TRN & \\
\hline CHEMBL1529847 & 688549 & 4.5 & 5.0746 & TRN & \\
\hline CHEMBL1476125 & 688549 & 4.9 & 4.9321 & TRN & \\
\hline CHEMBL1593763 & 688549 & 6.1 & 5.8574 & TRN & \\
\hline CHEMBL1316269 & 688549 & 4.9 & 5.0955 & TRN & \\
\hline CHEMBL1513820 & 688549 & 5.0 & 5.0239 & TRN & \\
\hline CHEMBL1612172 & 688549 & 4.5 & 4.7681 & TRN & \\
\hline CHEMBL1473551 & 688549 & 4.8 & 4.9144 & TRN & \\
\hline CHEMBL1549783 & 688549 & 8.301 & 5.047 & TRN & \\
\hline CHEMBL1503461 & 688549 & 6.7001 & 5.3761 & TST & \\
\hline CHEMBL1592561 & 688549 & 4.8 & 5.0937 & TRN & \\
\hline CHEMBL1310041 & 688549 & 4.9 & 5.0394 & TRN & \\
\hline CHEMBL1461288 & 688549 & 8.301 & 5.2295 & TST & \\
\hline CHEMBL1325093 & 688549 & 4.5 & 4.7288 & TST & \\
\hline CHEMBL1369085 & 688549 & 4.5 & 5.0058 & TRN & \\
\hline CHEMBL1533147 & 688549 & 4.5 & 5.425 & TRN & \\
\hline CHEMBL1603459 & 688549 & 4.7 & 4.4215 & TST & \\
\hline CHEMBL 271023 & 688549 & 4.8 & 5.1653 & TST & \\
\hline CHEMBL1581798 & 688549 & 4.7 & 4.6537 & TRN & \\
\hline CHEMBL1256390 & 688549 & 4.5 & 5.4926 & TST & \\
\hline CHEMBL1421751 & 688549 & 4.5 & 5.4651 & TST & \\
\hline CHEMBL1505620 & 688549 & 5.15 & 4.97199 & 99999999995 & TRN \\
\hline CHEMBL2369223 & 688549 & 4.75 & 4.9887 & TST & \\
\hline CHEMBL1309656 & 688549 & 5.1 & 5.1043 & TST & \\
\hline CHEMBL1358212 & 688549 & 4.6 & 4.3431 & TRN & \\
\hline CHEMBL1452641 & 688549 & 5.0 & 5.1085 & TRN & \\
\hline CHEMBL149322 & 688549 & 5.1 & 5.0987 & TRN & \\
\hline CHEMBL1413840 & 688549 & 5.0 & 5.2317 & TRN & \\
\hline CHEMBL1512857 & 688549 & 4.45 & 4.9561 & TRN & \\
\hline
\end{tabular}




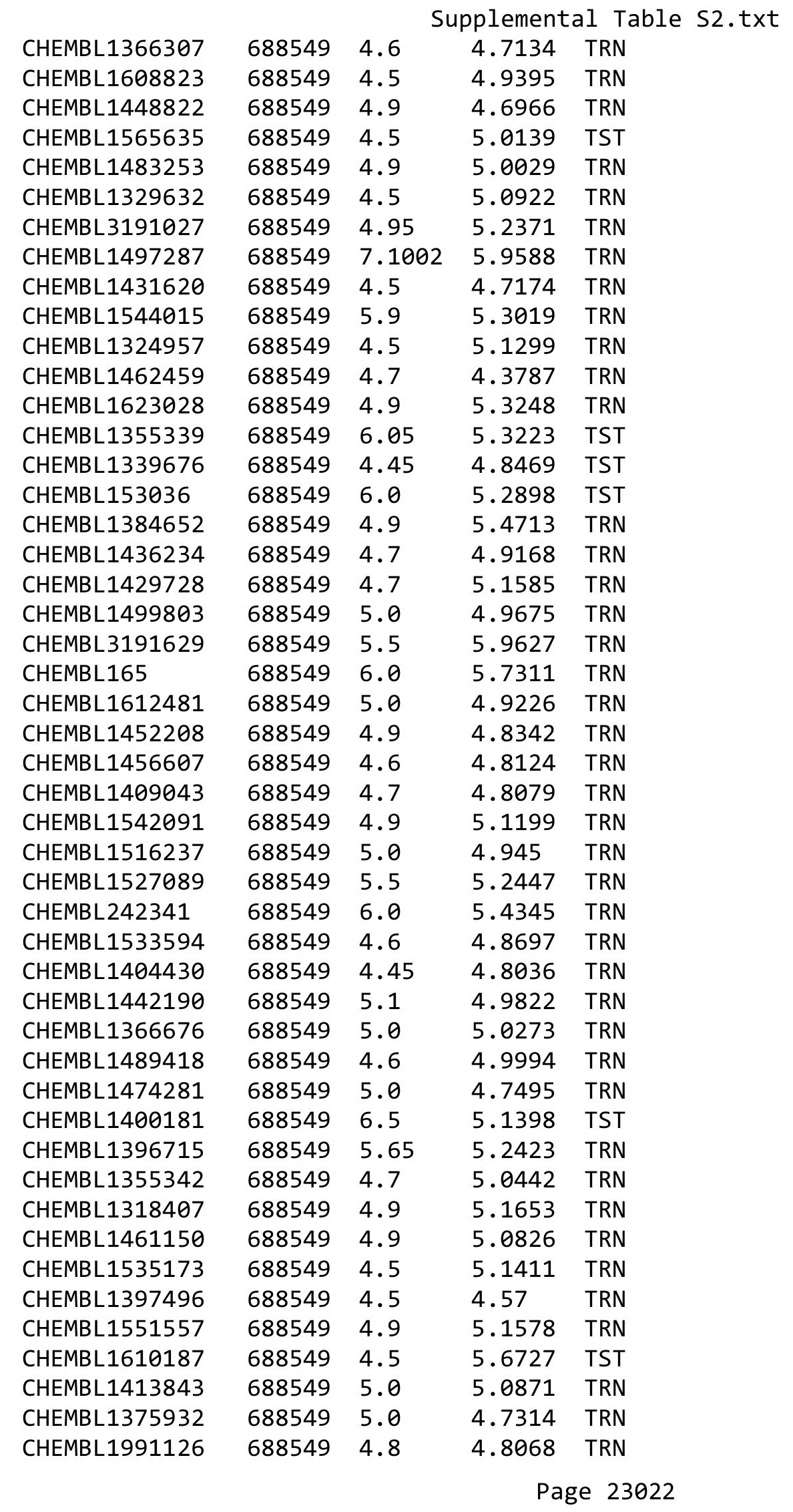




\begin{tabular}{|c|c|c|c|c|c|}
\hline \multicolumn{6}{|c|}{ Supplemental Table S2.txt } \\
\hline CHEMBL1380508 & 688549 & 5.95 & 5.4285 & TRN & \\
\hline CHEMBL1545628 & 688549 & 4.9 & 4.7136 & TRN & \\
\hline CHEMBL1590953 & 688549 & 4.9 & 5.0318 & TRN & \\
\hline CHEMBL1305287 & 688549 & 5.3 & 5.1299 & TRN & \\
\hline CHEMBL1317959 & 688549 & 4.5 & 4.7157 & TRN & \\
\hline CHEMBL1422097 & 688549 & 5.05 & 5.1239 & TRN & \\
\hline CHEMBL1595100 & 688549 & 4.9 & 5.1102 & TRN & \\
\hline CHEMBL1503124 & 688549 & 4.9 & 5.0466 & TRN & \\
\hline CHEMBL1556431 & 688549 & 4.9 & 4.5589 & TRN & \\
\hline CHEMBL1459538 & 688549 & 5.0 & 4.8224 & TRN & \\
\hline CHEMBL1357626 & 688549 & 5.4 & 5.24799 & 9999999999 & TRN \\
\hline CHEMBL1579130 & 688549 & 7.8996 & 5.5895 & TST & \\
\hline CHEMBL1507341 & 688549 & 8.2007 & 5.2148 & TST & \\
\hline CHEMBL1437226 & 688549 & 4.6 & 4.6232 & TRN & \\
\hline CHEMBL1397140 & 688549 & 5.1 & 4.76399 & 9999999999 & TST \\
\hline CHEMBL1554058 & 688549 & 4.9 & 4.7595 & TRN & \\
\hline CHEMBL462576 & 688549 & 6.6 & 5.5681 & TST & \\
\hline CHEMBL1592695 & 688549 & 4.9 & 5.1115 & TRN & \\
\hline CHEMBL1440279 & 688549 & 4.6 & 4.9101 & TRN & \\
\hline CHEMBL601952 & 688549 & 4.8 & 5.1438 & TRN & \\
\hline CHEMBL222334 & 688549 & 4.9 & 5.3384 & TST & \\
\hline CHEMBL1398925 & 688549 & 5.0 & 4.954 & TRN & \\
\hline CHEMBL1578661 & 688549 & 4.9 & 5.1363 & TST & \\
\hline CHEMBL1463381 & 688549 & 4.8 & 5.1293 & TST & \\
\hline CHEMBL1602945 & 688549 & 4.5 & 4.9548 & TRN & \\
\hline CHEMBL1439954 & 688549 & 4.5 & 5.1284 & TRN & \\
\hline CHEMBL1580343 & 688549 & 4.5 & 4.999 & TRN & \\
\hline CHEMBL1472817 & 688549 & 5.7 & 5.5075 & TRN & \\
\hline CHEMBL1473907 & 688549 & 5.0 & 4.8967 & TST & \\
\hline CHEMBL1310986 & 688549 & 5.1 & 5.0552 & TST & \\
\hline CHEMBL1600209 & 688549 & 4.5 & 4.681 & TRN & \\
\hline CHEMBL1315886 & 688549 & 4.95 & 5.0412 & TRN & \\
\hline CHEMBL1551280 & 688549 & 4.5 & 5.0546 & TRN & \\
\hline CHEMBL1483191 & 688549 & 5.0 & 5.1378 & TRN & \\
\hline CHEMBL1476219 & 688549 & 4.8 & 4.8653 & TRN & \\
\hline CHEMBL1592694 & 688549 & 4.45 & 4.7142 & TRN & \\
\hline CHEMBL1467568 & 688549 & 6.1 & 5.1779 & TST & \\
\hline CHEMBL1572197 & 688549 & 4.9 & 5.3015 & TRN & \\
\hline CHEMBL1412828 & 688549 & 4.9 & 4.8525 & TRN & \\
\hline CHEMBL1605595 & 688549 & 4.5 & 4.6531 & TRN & \\
\hline CHEMBL1582610 & 688549 & 5.4 & 5.3149 & TST & \\
\hline CHEMBL1597315 & 688549 & 4.6 & 4.5785 & TRN & \\
\hline CHEMBL1516342 & 688549 & 4.9 & 4.7997 & TST & \\
\hline CHEMBL1468924 & 688549 & 4.5 & 4.9594 & TRN & \\
\hline CHEMBL371561 & 688549 & 8.2007 & 5.0369 & TST & \\
\hline CHEMBL1093246 & 688549 & 4.6 & 5.3154 & TRN & \\
\hline CHEMBL1559740 & 688549 & 4.6 & 4.6056 & TRN & \\
\hline CHEMBL35482 & 688549 & 5.1 & 5.4888 & TRN & \\
\hline
\end{tabular}




\begin{tabular}{|c|c|c|c|c|}
\hline & & & & \\
\hline CHEMBL1356830 & 688549 & 4.8 & 4.9501 & TRN \\
\hline CHEMBL1563855 & 688549 & 5.3 & 5.0877 & TRN \\
\hline CHEMBL1518450 & 688549 & 5.0 & 4.7924 & TRN \\
\hline CHEMBL1324999 & 688549 & 5.0 & 4.8647 & TRN \\
\hline CHEMBL1425542 & 688549 & 4.9 & 5.0509 & TRN \\
\hline CHEMBL1416951 & 688549 & 5.0 & 5.1961 & TRN \\
\hline CHEMBL1371789 & 688549 & 5.3 & 5.0791 & TRN \\
\hline CHEMBL1560217 & 688549 & 4.5 & 4.4445 & TRN \\
\hline CHEMBL1482543 & 688549 & 5.0 & 4.9854 & TRN \\
\hline CHEMBL1302596 & 688549 & 4.9 & 4.8138 & TRN \\
\hline CHEMBL1608433 & 688549 & 4.5 & 5.0346 & TRN \\
\hline CHEMBL1481616 & 688549 & 5.3 & 5.2148 & TRN \\
\hline CHEMBL1395970 & 688549 & 4.5 & 4.651 & TRN \\
\hline CHEMBL1414760 & 688549 & 4.5 & 4.7237 & TRN \\
\hline CHEMBL1592241 & 688549 & 5.3 & 4.9259 & TRN \\
\hline CHEMBL1319106 & 688549 & 4.5 & 4.3938 & TRN \\
\hline CHEMBL1312255 & 688549 & 4.8 & 4.914 & TRN \\
\hline CHEMBL1457225 & 688549 & 4.9 & 4.7257 & TRN \\
\hline CHEMBL1486934 & 688549 & 4.5 & 4.8661 & TRN \\
\hline CHEMBL1373889 & 688549 & 5.0 & 5.296 & TRN \\
\hline CHEMBL1535202 & 688549 & 4.5 & 4.9494 & TRN \\
\hline CHEMBL1354521 & 688549 & 4.95 & 4.5004 & TRN \\
\hline CHEMBL1412539 & 688549 & 5.0 & 4.9594 & TRN \\
\hline CHEMBL229359 & 688549 & 4.8 & 4.987 & TRN \\
\hline CHEMBL1545467 & 688549 & 4.9 & 5.5335 & TST \\
\hline CHEMBL1596675 & 688549 & 4.5 & 5.1335 & TST \\
\hline CHEMBL1388344 & 688549 & 5.0 & 5.0297 & TRN \\
\hline CHEMBL1434092 & 688549 & 4.6 & 4.867 & TRN \\
\hline CHEMBL260451 & 688549 & 5.4 & 5.0741 & TRN \\
\hline CHEMBL1586297 & 688549 & 5.0 & 5.1889 & TST \\
\hline CHEMBL1593821 & 688549 & 4.6 & 4.8167 & TRN \\
\hline CHEMBL1609356 & 688549 & 6.8 & 5.3937 & TST \\
\hline CHEMBL1404601 & 688549 & 5.0 & 4.5163 & TRN \\
\hline CHEMBL1554119 & 688549 & 4.9 & 4.7039 & TRN \\
\hline CHEMBL3192101 & 688549 & 5.0 & 5.2127 & TRN \\
\hline CHEMBL1314376 & 688549 & 5.6 & 5.0179 & TRN \\
\hline CHEMBL1320504 & 688549 & 5.0 & 5.2643 & TRN \\
\hline CHEMBL1421565 & 688549 & 4.85 & 5.0048 & TRN \\
\hline CHEMBL1356290 & 688549 & 4.95 & 4.9751 & TRN \\
\hline CHEMBL1610470 & 688549 & 4.8 & 5.0985 & TRN \\
\hline CHEMBL1453953 & 688549 & 5.0 & 5.0284 & TRN \\
\hline CHEMBL336467 & 688549 & 4.5 & 4.7862 & TST \\
\hline CHEMBL1349500 & 688549 & 4.9 & 5.2954 & TRN \\
\hline CHEMBL1377592 & 688549 & 4.6 & 4.7791 & TRN \\
\hline CHEMBL1411866 & 688549 & 4.9 & 4.8273 & TRN \\
\hline CHEMBL1222385 & 688549 & 5.2 & 4.6216 & TRN \\
\hline CHEMBL 289277 & 688549 & 4.5 & 5.1932 & TST \\
\hline CHEMBL1415560 & 688549 & 5.0 & 4.6911 & TRN \\
\hline
\end{tabular}




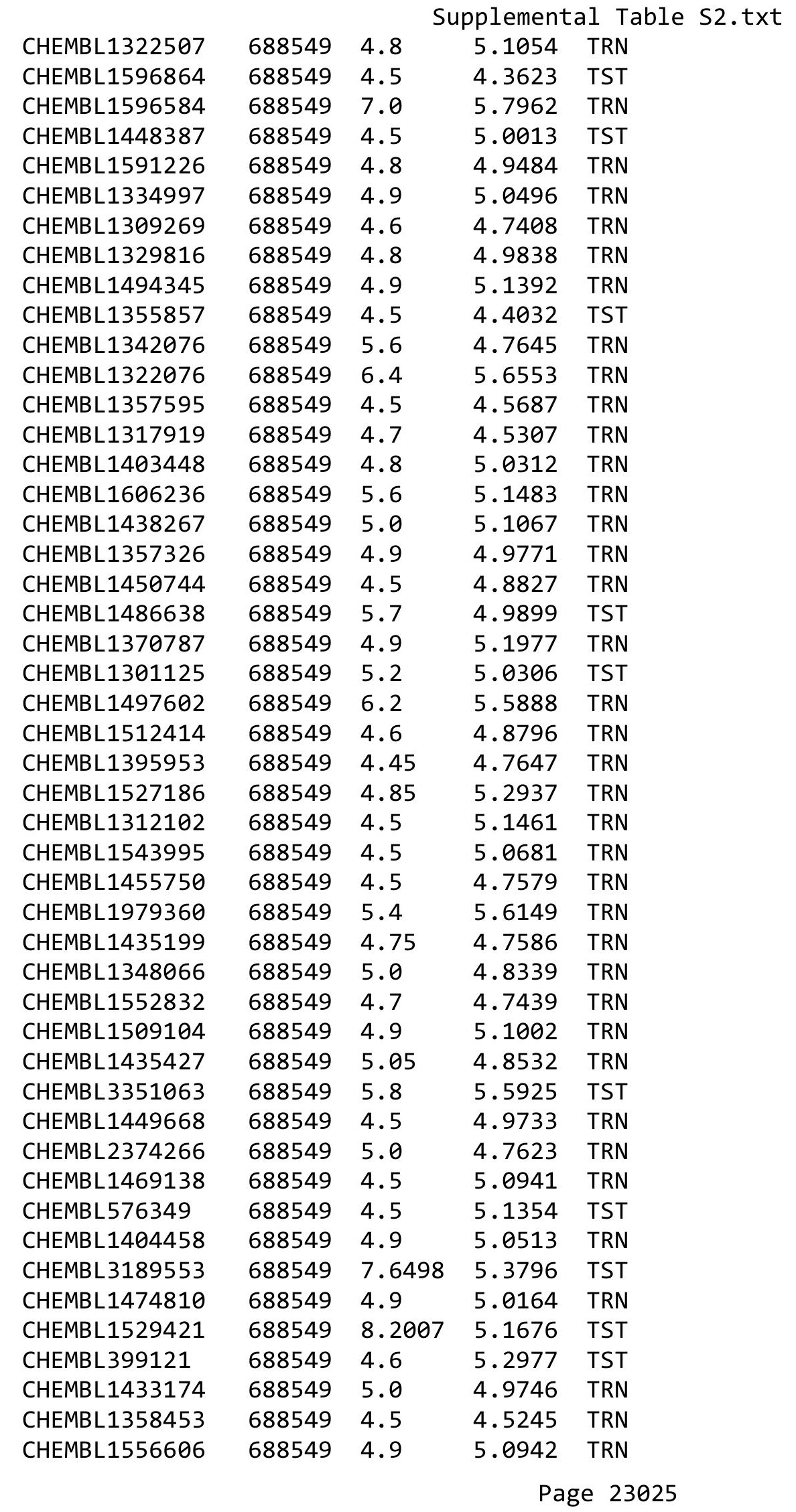




\begin{tabular}{|c|c|c|c|c|c|}
\hline \multicolumn{6}{|c|}{ Supplemental Table S2.txt } \\
\hline CHEMBL1337912 & 688549 & 4.9 & 4.8471 & TRN & \\
\hline CHEMBL1322960 & 688549 & 4.8 & 4.7485 & TRN & \\
\hline CHEMBL1514761 & 688549 & 5.5 & 5.4849 & TRN & \\
\hline CHEMBL1551670 & 688549 & 4.8 & 5.3793 & TRN & \\
\hline CHEMBL1586111 & 688549 & 5.7 & 5.2605 & TRN & \\
\hline CHEMBL1396475 & 688549 & 4.9 & 4.9029 & TRN & \\
\hline CHEMBL1496452 & 688549 & 4.8 & 4.9606 & TRN & \\
\hline CHEMBL578420 & 688549 & 5.6 & 5.7328 & TRN & \\
\hline CHEMBL1410508 & 688549 & 4.5 & 5.1022 & TST & \\
\hline CHEMBL1556792 & 688549 & 4.7 & 4.4925 & TRN & \\
\hline CHEMBL1398308 & 688549 & 4.5 & 5.0411 & TRN & \\
\hline CHEMBL1313647 & 688549 & 4.9 & 5.0384 & TST & \\
\hline CHEMBL1441205 & 688549 & 6.1 & 5.2007 & TRN & \\
\hline CHEMBL261693 & 688549 & 6.3 & 5.4845 & TST & \\
\hline CHEMBL1570993 & 688549 & 5.2 & 5.4347 & TST & \\
\hline CHEMBL1545566 & 688549 & 4.9 & 5.074 & TRN & \\
\hline CHEMBL221137 & 688549 & 4.9 & 5.1965 & TST & \\
\hline CHEMBL1316314 & 688549 & 4.5 & 5.1182 & TST & \\
\hline CHEMBL1324329 & 688549 & 4.5 & 4.4934 & TST & \\
\hline CHEMBL1471945 & 688549 & 5.0 & 4.6402 & TST & \\
\hline CHEMBL1555208 & 688549 & 4.5 & 4.762 & TRN & \\
\hline CHEMBL1409586 & 688549 & 4.5 & 4.8965 & TST & \\
\hline CHEMBL1455181 & 688549 & 4.7 & 5.37299 & & TRN \\
\hline CHEMBL1360809 & 688549 & 4.6 & 4.4793 & TRN & \\
\hline CHEMBL1334550 & 688549 & 4.6 & 4.96 & TRN & \\
\hline CHEMBL1327089 & 688549 & 5.0 & 4.8771 & TRN & \\
\hline CHEMBL1532543 & 688549 & 4.7 & 4.8473 & TRN & \\
\hline CHEMBL465843 & 688549 & 6.0 & 5.7661 & TRN & \\
\hline CHEMBL1350251 & 688549 & 4.9 & 5.2444 & TRN & \\
\hline CHEMBL 3214270 & 688549 & 8.0 & 5.6841 & TST & \\
\hline CHEMBL1370575 & 688549 & 4.7 & 5.1553 & TRN & \\
\hline CHEMBL1307167 & 688549 & 4.5 & 4.9326 & TRN & \\
\hline CHEMBL1507389 & 688549 & 4.5 & 4.9361 & TRN & \\
\hline CHEMBL1560024 & 688549 & 4.45 & 5.0851 & TRN & \\
\hline CHEMBL1534030 & 688549 & 5.0 & 4.8398 & TRN & \\
\hline CHEMBL1410792 & 688549 & 5.1 & 5.2376 & TRN & \\
\hline CHEMBL1598912 & 688549 & 4.95 & 5.0309 & TRN & \\
\hline CHEMBL1370834 & 688549 & 4.6 & 5.02 & TRN & \\
\hline CHEMBL1439403 & 688549 & 5.6 & 5.2593 & TRN & \\
\hline CHEMBL1495889 & 688549 & 4.9 & 4.7025 & TRN & \\
\hline CHEMBL1464782 & 688549 & 8.0 & 5.4726 & TRN & \\
\hline CHEMBL1410408 & 688549 & 4.9 & 5.2736 & TRN & \\
\hline CHEMBL1601309 & 688549 & 5.0 & 5.3145 & TRN & \\
\hline CHEMBL1513963 & 688549 & 4.9 & 5.396 & TRN & \\
\hline CHEMBL1397156 & 688549 & 4.8 & 4.8254 & TRN & \\
\hline CHEMBL1582803 & 688549 & 5.2 & 5.152 & TST & \\
\hline CHEMBL1592147 & 688549 & 5.45 & 5.1045 & TRN & \\
\hline CHEMBL1551969 & 688549 & 4.5 & 4.7526 & TRN & \\
\hline
\end{tabular}




\begin{tabular}{|c|c|c|c|c|c|}
\hline \multicolumn{6}{|c|}{ Supplemental Table S2.txt } \\
\hline CHEMBL 3145108 & 688549 & 4.6 & 4.8395 & TRN & \\
\hline CHEMBL1315605 & 688549 & 4.8 & 5.1556 & TRN & \\
\hline CHEMBL1475635 & 688549 & 4.9 & 4.4357 & TRN & \\
\hline CHEMBL574181 & 688549 & 5.8 & 4.9661 & TRN & \\
\hline CHEMBL1532668 & 688549 & 4.8 & 5.6502 & TST & \\
\hline CHEMBL3195761 & 688549 & 6.1 & 5.6755 & TRN & \\
\hline CHEMBL1417809 & 688549 & 7.2 & 5.1426 & TST & \\
\hline CHEMBL1302523 & 688549 & 4.5 & 4.4214 & TRN & \\
\hline CHEMBL1443342 & 688549 & 4.5 & 4.9543 & TST & \\
\hline CHEMBL1490104 & 688549 & 5.0 & 5.0744 & TRN & \\
\hline CHEMBL1500106 & 688549 & 5.0 & 5.0732 & TRN & \\
\hline CHEMBL1256686 & 688549 & 5.4 & 5.4134 & TST & \\
\hline CHEMBL1515065 & 688549 & 5.5 & 5.7625 & TRN & \\
\hline CHEMBL1458873 & 688549 & 4.9 & 4.9606 & TRN & \\
\hline CHEMBL1335945 & 688549 & 4.9 & 5.0198 & TST & \\
\hline CHEMBL1383728 & 688549 & 4.7 & 5.3485 & TST & \\
\hline CHEMBL1403789 & 688549 & 4.8 & 5.1677 & TRN & \\
\hline CHEMBL1465527 & 688549 & 4.6 & 5.1346 & TST & \\
\hline CHEMBL1409276 & 688549 & 5.0 & 5.1577 & TST & \\
\hline CHEMBL1590410 & 688549 & 5.7 & 5.4328 & TRN & \\
\hline CHEMBL1481781 & 688549 & 4.5 & 4.9895 & TRN & \\
\hline CHEMBL1413422 & 688549 & 4.7 & 5.0298 & TST & \\
\hline CHEMBL1553468 & 688549 & 4.9 & 4.8008 & TRN & \\
\hline CHEMBL1494270 & 688549 & 4.5 & 4.5456 & TRN & \\
\hline CHEMBL1453276 & 688549 & 7.15 & 5.475 & TST & \\
\hline CHEMBL1479545 & 688549 & 4.5 & 4.938 & TRN & \\
\hline CHEMBL1592201 & 688549 & 5.5 & 5.5374 & TRN & \\
\hline CHEMBL1366347 & 688549 & 5.35 & 5.2834 & TRN & \\
\hline CHEMBL1518990 & 688549 & 4.8 & 4.8008 & TRN & \\
\hline CHEMBL1553369 & 688549 & 4.5 & 4.8245 & TRN & \\
\hline CHEMBL1526240 & 688549 & 5.3 & 5.5164 & TST & \\
\hline CHEMBL1363246 & 688549 & 5.0 & 5.3451 & TRN & \\
\hline CHEMBL1531173 & 688549 & 4.9 & 4.81800 & 00000000005 & TRN \\
\hline CHEMBL1376258 & 688549 & 4.9 & 5.0614 & TRN & \\
\hline CHEMBL1483161 & 688549 & 4.45 & 4.7016 & TST & \\
\hline CHEMBL1482103 & 688549 & 5.3 & 5.1386 & TRN & \\
\hline CHEMBL1374542 & 688549 & 5.5 & 4.8103 & TRN & \\
\hline CHEMBL1413793 & 688549 & 4.8 & 4.9296 & TRN & \\
\hline CHEMBL1442502 & 688549 & 4.9 & 4.9721 & TRN & \\
\hline CHEMBL1372519 & 688549 & 4.5 & 4.9091 & TRN & \\
\hline CHEMBL1592872 & 688549 & 4.9 & 4.8185 & TRN & \\
\hline CHEMBL1560395 & 688549 & 4.8 & 4.3753 & TRN & \\
\hline CHEMBL1594517 & 688549 & 4.9 & 5.0053 & TRN & \\
\hline CHEMBL1547250 & 688549 & 4.5 & 5.0508 & TRN & \\
\hline CHEMBL1415756 & 688549 & 4.8 & 4.898 & TRN & \\
\hline CHEMBL3191552 & 688549 & 5.2 & 5.229 & TST & \\
\hline CHEMBL1569086 & 688549 & 4.9 & 4.7913 & TRN & \\
\hline CHEMBL1554428 & 688549 & 4.6 & 4.8845 & TRN & \\
\hline
\end{tabular}




\begin{tabular}{|c|c|c|c|c|c|}
\hline \multicolumn{6}{|c|}{ Supplemental Table S2.txt } \\
\hline CHEMBL1327335 & 688549 & 5.0 & 4.7655 & TRN & \\
\hline CHEMBL1333076 & 688549 & 4.5 & 4.8925 & TRN & \\
\hline CHEMBL1345494 & 688549 & 4.9 & 5.2607 & TST & \\
\hline CHEMBL1395837 & 688549 & 4.65 & 4.7078 & TRN & \\
\hline CHEMBL3197122 & 688549 & 7.2 & 6.0579 & TST & \\
\hline CHEMBL1554888 & 688549 & 4.6 & 4.4669 & TRN & \\
\hline CHEMBL1466028 & 688549 & 5.1 & 4.9843 & TRN & \\
\hline CHEMBL1477057 & 688549 & 4.8 & 4.7386 & TRN & \\
\hline CHEMBL1521428 & 688549 & 4.7 & 4.8426 & TRN & \\
\hline CHEMBL1364980 & 688549 & 4.5 & 5.0632 & TRN & \\
\hline CHEMBL1332007 & 688549 & 4.5 & 4.9857 & TRN & \\
\hline CHEMBL1409244 & 688549 & 4.7 & 4.9976 & TRN & \\
\hline CHEMBL1399702 & 688549 & 4.7 & 4.8161 & TRN & \\
\hline CHEMBL1360800 & 688549 & 4.85 & 5.2696 & TST & \\
\hline CHEMBL1314366 & 688549 & 4.85 & 5.4225 & TRN & \\
\hline CHEMBL1574638 & 688549 & 4.8 & 4.7202 & TRN & \\
\hline CHEMBL1371801 & 688549 & 5.2 & 5.0398 & TRN & \\
\hline CHEMBL1484713 & 688549 & 4.6 & 5.0011 & TST & \\
\hline CHEMBL1554455 & 688549 & 4.5 & 4.6888 & TRN & \\
\hline CHEMBL600554 & 688549 & 4.6 & 4.9956 & TRN & \\
\hline CHEMBL1469246 & 688549 & 4.8 & $5.3020 e$ & 00000000005 & TRN \\
\hline CHEMBL1562431 & 688549 & 5.4 & 5.2439 & TST & \\
\hline CHEMBL1504575 & 688549 & 4.9 & 5.0893 & TRN & \\
\hline CHEMBL1395736 & 688549 & 4.45 & 4.7524 & TRN & \\
\hline CHEMBL1346315 & 688549 & 4.5 & 4.77 & TRN & \\
\hline CHEMBL68534 & 688549 & 4.9 & 4.8952 & TRN & \\
\hline CHEMBL1317040 & 688549 & 5.5 & 5.1899 & TST & \\
\hline CHEMBL1406922 & 688549 & 4.7 & 4.2971 & TRN & \\
\hline CHEMBL1565613 & 688549 & 4.5 & 4.4617 & TRN & \\
\hline CHEMBL1551354 & 688549 & 4.8 & 4.92 & TRN & \\
\hline CHEMBL1467411 & 688549 & 5.0 & 5.1144 & TRN & \\
\hline CHEMBL3210159 & 688549 & 4.5 & 4.6963 & TST & \\
\hline CHEMBL1565840 & 688549 & 5.25 & 5.2158 & TRN & \\
\hline CHEMBL1590378 & 688549 & 6.0 & 5.6089 & TST & \\
\hline CHEMBL1306666 & 688549 & 5.4 & 4.8923 & TRN & \\
\hline CHEMBL3208361 & 688549 & 4.9 & 4.8473 & TST & \\
\hline CHEMBL1437502 & 688549 & 5.7 & 5.1821 & TRN & \\
\hline CHEMBL1567985 & 688549 & 4.8 & 5.2801 & TRN & \\
\hline CHEMBL601140 & 688549 & 4.7 & 5.0231 & TRN & \\
\hline CHEMBL10284 & 688549 & 4.9 & 5.1642 & TST & \\
\hline CHEMBL1394511 & 688549 & 4.45 & 4.6195 & TRN & \\
\hline CHEMBL3189867 & 688549 & 4.5 & 6.1298 & TST & \\
\hline CHEMBL1574027 & 688549 & 5.2 & 4.8849 & TRN & \\
\hline CHEMBL1332454 & 688549 & 4.6 & 4.7757 & TRN & \\
\hline CHEMBL1437067 & 688549 & 4.5 & 5.0723 & TRN & \\
\hline CHEMBL1571157 & 688549 & 4.9 & 5.025 & TRN & \\
\hline CHEMBL1526722 & 688549 & 4.8 & 4.9878 & TRN & \\
\hline CHEMBL1445230 & 688549 & 4.9 & 5.1521 & TST & \\
\hline
\end{tabular}




\begin{tabular}{|c|c|c|c|c|}
\hline & & & oplement & al $\mathrm{Ta}$ \\
\hline CHEMBL1512550 & 688549 & 6.5 & 5.4762 & TRN \\
\hline CHEMBL1440703 & 688549 & 5.5 & 5.0522 & TST \\
\hline CHEMBL1548291 & 688549 & 4.5 & 5.003 & TST \\
\hline CHEMBL1556566 & 688549 & 5.0 & 5.653 & TST \\
\hline CHEMBL1581345 & 688549 & 4.9 & 4.7108 & TRN \\
\hline CHEMBL1338469 & 688549 & 4.5 & 5.2908 & TRN \\
\hline CHEMBL1408650 & 688549 & 7.699 & 5.0341 & TST \\
\hline CHEMBL246957 & 688549 & 5.4 & 5.0239 & TST \\
\hline CHEMBL1513511 & 688549 & 4.5 & 4.7477 & TRN \\
\hline CHEMBL1526191 & 688549 & 7.6003 & 5.1276 & TRN \\
\hline CHEMBL1591258 & 688549 & 4.5 & 5.16 & TRN \\
\hline CHEMBL1462244 & 688549 & 5.1 & 5.0748 & TRN \\
\hline CHEMBL1368212 & 688549 & 5.3 & 5.3295 & TRN \\
\hline CHEMBL3213953 & 688549 & 5.95 & 5.4456 & TRN \\
\hline CHEMBL1531896 & 688549 & 4.9 & 5.3029 & TST \\
\hline CHEMBL1353922 & 688549 & 5.1 & 4.9901 & TRN \\
\hline CHEMBL1346382 & 688549 & 5.2 & 4.909 & TRN \\
\hline CHEMBL1561100 & 688549 & 4.45 & 4.6703 & TRN \\
\hline CHEMBL1349014 & 688549 & 4.5 & 4.8032 & TRN \\
\hline CHEMBL1554801 & 688549 & 5.0 & 4.5245 & TRN \\
\hline CHEMBL1591114 & 688549 & 4.5 & 4.3023 & TRN \\
\hline CHEMBL1416089 & 688549 & 4.5 & 4.7885 & TRN \\
\hline CHEMBL1542576 & 688549 & 5.6 & 4.9608 & TRN \\
\hline CHEMBL1528802 & 688549 & 4.5 & 4.8882 & TRN \\
\hline CHEMBL1489960 & 688549 & 4.6 & 5.0812 & TRN \\
\hline CHEMBL1498470 & 688549 & 4.95 & 5.0222 & TRN \\
\hline CHEMBL1512331 & 688549 & 4.8 & 4.8461 & TRN \\
\hline CHEMBL78150 & 688549 & 5.0 & 4.9696 & TST \\
\hline CHEMBL1366460 & 688549 & 5.2 & 4.8739 & TRN \\
\hline CHEMBL1393877 & 688549 & 4.8 & 5.083 & TRN \\
\hline CHEMBL1351688 & 688549 & 6.5 & 4.9176 & TST \\
\hline CHEMBL1608293 & 688549 & 4.9 & 5.0491 & TRN \\
\hline CHEMBL227959 & 688549 & 4.5 & 4.85 & TRN \\
\hline CHEMBL1552181 & 688549 & 4.6 & 4.7509 & TRN \\
\hline CHEMBL1571760 & 688549 & 5.0 & 5.0046 & TRN \\
\hline CHEMBL1342112 & 688549 & 5.0 & 4.7635 & TRN \\
\hline CHEMBL300814 & 688549 & 5.6 & 5.1823 & TRN \\
\hline CHEMBL393287 & 688549 & 4.9 & 4.8976 & TRN \\
\hline CHEMBL1592591 & 688549 & 4.5 & 4.6571 & TST \\
\hline CHEMBL1398864 & 688549 & 4.9 & 4.851 & TRN \\
\hline CHEMBL1522172 & 688549 & 4.9 & 4.5873 & TRN \\
\hline CHEMBL1519203 & 688549 & 8.3979 & 4.9857 & TRN \\
\hline CHEMBL1408045 & 688549 & 6.2 & 6.0046 & TRN \\
\hline CHEMBL1437005 & 688549 & 5.6 & 5.4223 & TRN \\
\hline CHEMBL1316255 & 688549 & 5.1 & 4.8689 & TRN \\
\hline CHEMBL1256995 & 688549 & 4.7 & 5.4235 & TST \\
\hline CHEMBL1485563 & 688549 & 4.5 & 5.2254 & TST \\
\hline CHEMBL1590383 & 688549 & 4.7 & 4.507 & TST \\
\hline
\end{tabular}




\begin{tabular}{|c|c|c|c|c|c|}
\hline \multicolumn{6}{|c|}{ Supplemental Table S2.txt } \\
\hline CHEMBL1442780 & 688549 & 5.3 & 5.274 & TRN & \\
\hline CHEMBL600572 & 688549 & 4.5 & 5.0165 & TRN & \\
\hline CHEMBL1601412 & 688549 & 4.9 & 4.8352 & TRN & \\
\hline CHEMBL406557 & 688549 & 4.9 & 4.9651 & TRN & \\
\hline CHEMBL1363322 & 688549 & 4.5 & 5.1688 & TRN & \\
\hline CHEMBL1406016 & 688549 & 4.5 & 4.8101 & TRN & \\
\hline CHEMBL1511197 & 688549 & 5.0 & 4.7637 & TRN & \\
\hline CHEMBL1395582 & 688549 & 4.7 & 4.6806 & TST & \\
\hline CHEMBL1538094 & 688549 & 7.1002 & 5.9682 & TRN & \\
\hline CHEMBL1481939 & 688549 & 5.5 & 4.9197 & TRN & \\
\hline CHEMBL 242385 & 688549 & 4.9 & 5.2888 & TRN & \\
\hline CHEMBL1488141 & 688549 & 5.0 & 5.2298 & TRN & \\
\hline CHEMBL1459884 & 688549 & 5.0 & 4.963 & TRN & \\
\hline CHEMBL1364407 & 688549 & 4.6 & 4.6814 & TRN & \\
\hline CHEMBL1330138 & 688549 & 4.5 & 5.0769 & TRN & \\
\hline CHEMBL1328137 & 688549 & 4.45 & 5.4466 & TRN & \\
\hline CHEMBL1512692 & 688549 & 4.5 & 4.4838 & TRN & \\
\hline CHEMBL1571426 & 688549 & 4.85 & 5.3491 & TRN & \\
\hline CHEMBL1311351 & 688549 & 4.7 & 5.2562 & TST & \\
\hline CHEMBL1413837 & 688549 & 8.2007 & 6.1515 & TRN & \\
\hline CHEMBL1326299 & 688549 & 4.8 & 4.953 & TRN & \\
\hline CHEMBL1589821 & 688549 & 4.7 & 4.8421 & TRN & \\
\hline CHEMBL1579548 & 688549 & 4.55 & 4.7244 & TRN & \\
\hline CHEMBL1591115 & 688549 & 4.8 & 4.7767 & TRN & \\
\hline CHEMBL1513185 & 688549 & 5.2 & 4.8216 & TRN & \\
\hline CHEMBL1357058 & 688549 & 4.45 & 4.8658 & TRN & \\
\hline CHEMBL1578956 & 688549 & 5.1 & 5.0553 & TRN & \\
\hline CHEMBL1521215 & 688549 & 5.2 & 4.8739 & TRN & \\
\hline CHEMBL1433083 & 688549 & 4.9 & 4.8686 & TRN & \\
\hline CHEMBL1509287 & 688549 & 4.9 & 4.7091 & TRN & \\
\hline CHEMBL1600210 & 688549 & 5.1 & 5.2365 & TRN & \\
\hline CHEMBL1548380 & 688549 & 8.301 & 5.4037 & TST & \\
\hline CHEMBL52387 & 688549 & 5.0 & 5.2407 & TST & \\
\hline CHEMBL1534193 & 688549 & 6.0 & 5.0697 & TRN & \\
\hline CHEMBL1317472 & 688549 & 4.9 & 4.6172 & TRN & \\
\hline CHEMBL1613718 & 688549 & 4.65 & 4.4639 & TRN & \\
\hline CHEMBL1530113 & 688549 & 4.5 & 5.035 & TRN & \\
\hline CHEMBL1611321 & 688549 & 4.8 & 4.9157 & TRN & \\
\hline CHEMBL1337500 & 688549 & 4.6 & 5.3181 & TST & \\
\hline CHEMBL1354129 & 688549 & 4.8 & 4.7435 & TRN & \\
\hline CHEMBL1553813 & 688549 & 5.25 & 5.57600 & 00000000005 & TRN \\
\hline CHEMBL1394691 & 688549 & 5.0 & 4.8225 & TRN & \\
\hline CHEMBL1592769 & 688549 & 4.7 & 5.6944 & TRN & \\
\hline CHEMBL1495306 & 688549 & 5.1 & 4.7736 & TRN & \\
\hline CHEMBL 3190958 & 688549 & 5.0 & 5.3036 & TRN & \\
\hline CHEMBL192627 & 688549 & 5.3 & 5.4057 & TST & \\
\hline CHEMBL 2068217 & 688549 & 5.4 & 5.5446 & TST & \\
\hline CHEMBL1446715 & 688549 & 4.8 & 4.9757 & TRN & \\
\hline
\end{tabular}




\begin{tabular}{|c|c|c|c|c|c|}
\hline \multicolumn{6}{|c|}{ Supplemental Table s2.txt } \\
\hline CHEMBL1481190 & 688549 & 4.45 & 4.7865 & TRN & \\
\hline CHEMBL1336396 & 688549 & 4.9 & 4.877 & TST & \\
\hline CHEMBL1437035 & 688549 & 5.6 & 5.5149 & TRN & \\
\hline CHEMBL1412137 & 688549 & 5.5 & 5.1795 & TRN & \\
\hline CHEMBL1434348 & 688549 & 4.45 & 4.5755 & TRN & \\
\hline CHEMBL1567020 & 688549 & 4.9 & 5.6309 & TST & \\
\hline CHEMBL1416488 & 688549 & 4.7 & 4.8815 & TRN & \\
\hline CHEMBL1384533 & 688549 & 5.0 & 4.8589 & TRN & \\
\hline CHEMBL1300592 & 688549 & 4.45 & 4.769 & TRN & \\
\hline CHEMBL1494263 & 688549 & 4.95 & 4.8028 & TRN & \\
\hline CHEMBL1366458 & 688549 & 4.8 & 4.842 & TRN & \\
\hline CHEMBL1396595 & 688549 & 4.5 & 5.0266 & TRN & \\
\hline CHEMBL1396076 & 688549 & 5.1 & 4.9396 & TRN & \\
\hline CHEMBL1456299 & 688549 & 4.5 & 5.0551 & TRN & \\
\hline CHEMBL1355474 & 688549 & 4.5 & 4.6719 & TRN & \\
\hline CHEMBL1343568 & 688549 & 4.7 & 5.0574 & TRN & \\
\hline CHEMBL1315194 & 688549 & 4.5 & 5.1693 & TST & \\
\hline CHEMBL1401242 & 688549 & 4.95 & 4.7246 & TRN & \\
\hline CHEMBL1594868 & 688549 & 4.95 & 4.8296 & TRN & \\
\hline CHEMBL1410321 & 688549 & 4.9 & 4.9029 & TRN & \\
\hline CHEMBL1320489 & 688549 & 4.5 & 4.8505 & TRN & \\
\hline CHEMBL1300779 & 688549 & 5.0 & 5.0854 & TRN & \\
\hline CHEMBL1377304 & 688549 & 5.0 & 5.1516 & TRN & \\
\hline CHEMBL1512956 & 688549 & 4.45 & 5.1696 & TRN & \\
\hline CHEMBL1602281 & 688549 & 4.5 & 4.6338 & TRN & \\
\hline CHEMBL1476045 & 688549 & 4.8 & 4.7652 & TRN & \\
\hline CHEMBL560020 & 688549 & 4.5 & 5.0799 & TST & \\
\hline CHEMBL1394591 & 688549 & 4.95 & 5.7791 & TST & \\
\hline CHEMBL 2001111 & 688549 & 7.699 & 5.8091 & TRN & \\
\hline CHEMBL1451905 & 688549 & 4.9 & 5.0854 & TRN & \\
\hline CHEMBL1368802 & 688549 & 4.5 & 4.7974 & TRN & \\
\hline CHEMBL1512059 & 688549 & 4.6 & 4.6098 & TRN & \\
\hline CHEMBL1550510 & 688549 & 4.7 & 4.7751 & TST & \\
\hline CHEMBL1474556 & 688549 & 4.5 & 4.8487 & TST & \\
\hline CHEMBL1483375 & 688549 & 8.0 & 5.4913 & TRN & \\
\hline CHEMBL1468664 & 688549 & 7.6498 & 5.5683 & TRN & \\
\hline CHEMBL1337548 & 688549 & 4.5 & 4.8064 & TRN & \\
\hline CHEMBL1434603 & 688549 & 5.25 & 4.9312 & TRN & \\
\hline CHEMBL1534136 & 688549 & 4.9 & 4.9161 & TRN & \\
\hline CHEMBL3193353 & 688549 & 5.55 & 5.3768 & TST & \\
\hline CHEMBL1299756 & 688549 & 4.9 & 5.0199 & TRN & \\
\hline CHEMBL1610810 & 688549 & 4.9 & 4.933 & TRN & \\
\hline CHEMBL1492028 & 688549 & 5.45 & 5.3487 & TST & \\
\hline CHEMBL1401187 & 688549 & 5.0 & 4.9695 & TRN & \\
\hline CHEMBL1463839 & 688549 & 5.6 & 5.1203 & TRN & \\
\hline CHEMBL1451924 & 688549 & 4.8 & 5.04899 & 99999999995 & TRN \\
\hline CHEMBL1568981 & 688549 & 5.2 & 4.9695 & TRN & \\
\hline CHEMBL1466948 & 688549 & 5.1 & 5.0873 & TRN & \\
\hline
\end{tabular}




\begin{tabular}{|c|c|c|c|c|}
\hline \multicolumn{5}{|c|}{ Supplemental Tabl } \\
\hline CHEMBL1982674 & 688549 & 7.3002 & 5.7372 & TST \\
\hline CHEMBL1322702 & 688549 & 4.9 & 5.3573 & TRN \\
\hline CHEMBL465226 & 688549 & 4.9 & 5.5279 & TST \\
\hline CHEMBL1592284 & 688549 & 4.95 & 4.6141 & TRN \\
\hline CHEMBL1359529 & 688549 & 4.9 & 4.8388 & TRN \\
\hline CHEMBL1435462 & 688549 & 4.6 & 4.6011 & TRN \\
\hline CHEMBL1336496 & 688549 & 4.8 & 4.9089 & TRN \\
\hline CHEMBL1091971 & 688549 & 5.7 & 5.4956 & TST \\
\hline CHEMBL1437245 & 688549 & 4.5 & 4.6142 & TRN \\
\hline CHEMBL1606431 & 688549 & 4.5 & 4.824 & TRN \\
\hline CHEMBL3196534 & 688549 & 4.7 & 4.7626 & TRN \\
\hline CHEMBL1526339 & 688549 & 4.9 & 4.9652 & TRN \\
\hline CHEMBL1553528 & 688549 & 4.9 & 5.0758 & TRN \\
\hline CHEMBL1484299 & 688549 & 5.2 & 5.1001 & TST \\
\hline CHEMBL1582199 & 688549 & 7.0501 & 5.4584 & TST \\
\hline CHEMBL1398684 & 688549 & 4.7 & 4.762 & TRN \\
\hline CHEMBL1513774 & 688549 & 4.7 & 4.9806 & TRN \\
\hline CHEMBL524407 & 688549 & 4.8 & 4.7122 & TRN \\
\hline CHEMBL1587932 & 688549 & 4.9 & 4.382 & TRN \\
\hline CHEMBL1496115 & 688549 & 4.6 & 4.8671 & TRN \\
\hline CHEMBL1310825 & 688549 & 4.9 & 4.8846 & TST \\
\hline CHEMBL1494038 & 688549 & 4.5 & 4.7216 & TST \\
\hline CHEMBL1578877 & 688549 & 4.9 & 5.0015 & TRN \\
\hline CHEMBL1400530 & 688549 & 4.7 & 4.9565 & TRN \\
\hline CHEMBL1350152 & 688549 & 5.3 & 5.2313 & TRN \\
\hline CHEMBL261113 & 688549 & 4.9 & 5.3843 & TRN \\
\hline CHEMBL1556616 & 688549 & 4.9 & 4.9407 & TRN \\
\hline CHEMBL1505212 & 688549 & 5.0 & 4.7463 & TRN \\
\hline CHEMBL346516 & 688549 & 4.5 & 5.5952 & TST \\
\hline CHEMBL1338803 & 688549 & 4.5 & 5.0355 & TRN \\
\hline CHEMBL1575034 & 688549 & 5.2 & 5.1761 & TRN \\
\hline CHEMBL1438452 & 688549 & 5.1 & 4.8029 & TRN \\
\hline CHEMBL1425330 & 688549 & 4.9 & 5.4991 & TRN \\
\hline CHEMBL1608208 & 688549 & 4.5 & 4.9798 & TRN \\
\hline CHEMBL1311136 & 688549 & 4.9 & 5.0334 & TRN \\
\hline CHEMBL1401010 & 688549 & 4.8 & 5.1059 & TRN \\
\hline CHEMBL1197976 & 688549 & 4.7 & 4.7244 & TRN \\
\hline CHEMBL3186408 & 688549 & 6.0 & 5.7958 & TST \\
\hline CHEMBL1453210 & 688549 & 4.9 & 4.6415 & TRN \\
\hline CHEMBL1399271 & 688549 & 4.9 & 5.1488 & TRN \\
\hline CHEMBL1394916 & 688549 & 4.9 & 4.8532 & TRN \\
\hline CHEMBL1479966 & 688549 & 4.8 & 4.9899 & TRN \\
\hline CHEMBL3189279 & 688549 & 7.2 & 5.8388 & TRN \\
\hline CHEMBL1529777 & 688549 & 4.9 & 4.7506 & TRN \\
\hline CHEMBL1474989 & 688549 & 4.5 & 4.5994 & TRN \\
\hline CHEMBL1558607 & 688549 & 4.5 & 5.0938 & TRN \\
\hline CHEMBL1398653 & 688549 & 4.9 & 5.193 & TRN \\
\hline CHEMBL1572743 & 688549 & 5.4 & 4.787 & TRN \\
\hline
\end{tabular}




\begin{tabular}{|c|c|c|c|c|c|}
\hline & & \\
\hline CHEMBL1360872 & 688549 & 4.9 & 4.6403 & TRN & \\
\hline CHEMBL1474277 & 688549 & 4.5 & 5.0698 & TST & \\
\hline CHEMBL1401402 & 688549 & 4.9 & 4.8399 & TRN & \\
\hline CHEMBL1403956 & 688549 & 5.0 & 5.2165 & TRN & \\
\hline CHEMBL589101 & 688549 & 4.5 & 4.5479 & TRN & \\
\hline CHEMBL1324136 & 688549 & 4.95 & 5.0341 & TRN & \\
\hline CHEMBL1355871 & 688549 & 6.1 & 5.2871 & TRN & \\
\hline CHEMBL 3214164 & 688549 & 5.4 & 5.2085 & TRN & \\
\hline CHEMBL1590348 & 688549 & 4.45 & 4.5794 & TRN & \\
\hline CHEMBL1396853 & 688549 & 4.45 & 4.9051 & TRN & \\
\hline CHEMBL1605897 & 688549 & 4.95 & 5.0615 & TRN & \\
\hline CHEMBL1324157 & 688549 & 5.0 & 5.2118 & TRN & \\
\hline CHEMBL1513621 & 688549 & 4.6 & 4.76399 & 9999999999 & TRN \\
\hline CHEMBL1566877 & 688549 & 5.5 & 5.812 & TRN & \\
\hline CHEMBL1568497 & 688549 & 4.7 & 4.7323 & TST & \\
\hline CHEMBL1424528 & 688549 & 4.9 & 5.4201 & TST & \\
\hline CHEMBL1590608 & 688549 & 5.85 & 5.7191 & TRN & \\
\hline CHEMBL1456523 & 688549 & 5.0 & 5.0323 & TRN & \\
\hline CHEMBL1476409 & 688549 & 5.2 & 5.3136 & TRN & \\
\hline CHEMBL1435221 & 688549 & 6.5 & 5.8607 & TRN & \\
\hline CHEMBL1306114 & 688549 & 4.7 & 5.2917 & TRN & \\
\hline CHEMBL1417503 & 688549 & 4.5 & 5.0489 & TRN & \\
\hline CHEMBL1551185 & 688549 & 4.6 & 4.8297 & TRN & \\
\hline CHEMBL1551835 & 688549 & 4.6 & 4.8549 & TST & \\
\hline CHEMBL1312502 & 688549 & 4.9 & 4.6136 & TRN & \\
\hline CHEMBL1547422 & 688549 & 4.7 & 5.2419 & TST & \\
\hline CHEMBL1397308 & 688549 & 4.5 & 5.4726 & TST & \\
\hline CHEMBL1993826 & 688549 & 5.55 & 5.1884 & TST & \\
\hline CHEMBL1574597 & 688549 & 4.5 & 4.6881 & TRN & \\
\hline CHEMBL1369506 & 688549 & 5.0 & 5.2689 & TRN & \\
\hline CHEMBL1542068 & 688549 & 5.1 & 5.3165 & TRN & \\
\hline CHEMBL1494024 & 688549 & 4.8 & 5.1746 & TST & \\
\hline CHEMBL1478130 & 688549 & 4.5 & 4.7552 & TRN & \\
\hline CHEMBL1304367 & 688549 & 5.9 & 5.0214 & TRN & \\
\hline CHEMBL1344123 & 688549 & 4.9 & 5.2003 & TRN & \\
\hline CHEMBL1365525 & 688549 & 4.5 & 4.3722 & TRN & \\
\hline CHEMBL1331418 & 688549 & 5.0 & 4.6197 & TRN & \\
\hline CHEMBL1372938 & 688549 & 4.8 & 4.9774 & TST & \\
\hline CHEMBL1474432 & 688549 & 4.5 & 4.9408 & TST & \\
\hline CHEMBL1318165 & 688549 & 5.35 & 5.3141 & TRN & \\
\hline CHEMBL1326644 & 688549 & 5.0 & 4.8878 & TRN & \\
\hline CHEMBL1601364 & 688549 & 5.0 & 4.7699 & TRN & \\
\hline CHEMBL1316880 & 688549 & 4.9 & 5.6555 & TRN & \\
\hline CHEMBL1528626 & 688549 & 5.0 & 5.0093 & TRN & \\
\hline CHEMBL1543238 & 688549 & 5.8 & 5.1608 & TRN & \\
\hline CHEMBL1972346 & 688549 & 4.9 & 5.4579 & TRN & \\
\hline CHEMBL 1552887 & 688549 & 4.5 & 4.813 & TST & \\
\hline CHEMBL1408676 & 688549 & 5.0 & 4.6467 & TRN & \\
\hline & & & & 23033 & \\
\hline
\end{tabular}




\begin{tabular}{|c|c|c|c|c|c|}
\hline \multirow[b]{2}{*}{ CHEMBL1608078 } & \multirow{2}{*}{688549} & \\
\hline & & 4.5 & 5.2637 & TST & \\
\hline CHEMBL1399528 & 688549 & 4.6 & 4.8227 & TRN & \\
\hline CHEMBL1494069 & 688549 & 5.5 & 4.7667 & TRN & \\
\hline CHEMBL1600646 & 688549 & 4.9 & 5.1825 & TRN & \\
\hline CHEMBL1590820 & 688549 & 4.7 & 4.7854 & TRN & \\
\hline CHEMBL1500966 & 688549 & 4.5 & 4.8961 & TRN & \\
\hline CHEMBL1465350 & 688549 & 5.5 & 5.7058 & TST & \\
\hline CHEMBL1477629 & 688549 & 4.45 & 4.6835 & TRN & \\
\hline CHEMBL1482509 & 688549 & 4.7 & 5.0431 & TRN & \\
\hline CHEMBL1314926 & 688549 & 5.25 & 5.3697 & TRN & \\
\hline CHEMBL1522486 & 688549 & 5.0 & 5.4002 & TRN & \\
\hline CHEMBL1544962 & 688549 & 5.0 & 5.1725 & TRN & \\
\hline CHEMBL1454749 & 688549 & 4.5 & 4.6049 & TRN & \\
\hline CHEMBL1299495 & 688549 & 4.5 & 4.8899 & TRN & \\
\hline CHEMBL1397081 & 688549 & 4.45 & 5.477 & TRN & \\
\hline CHEMBL1441988 & 688549 & 4.9 & 4.8139 & TRN & \\
\hline CHEMBL1605613 & 688549 & 4.9 & 5.2198 & TRN & \\
\hline CHEMBL1449372 & 688549 & 4.7 & 4.9905 & TRN & \\
\hline CHEMBL1433701 & 688549 & 4.5 & 4.3955 & TRN & \\
\hline CHEMBL1374097 & 688549 & 5.1 & 5.1367 & TRN & \\
\hline CHEMBL1395020 & 688549 & 5.1 & 4.8988 & TRN & \\
\hline CHEMBL1377694 & 688549 & 4.45 & 5.28799 & 9999999999 & TRN \\
\hline CHEMBL1582368 & 688549 & 4.8 & 4.9598 & TRN & \\
\hline CHEMBL1591941 & 688549 & 4.9 & 4.8066 & TRN & \\
\hline CHEMBL1388744 & 688549 & 4.7 & 4.7771 & TRN & \\
\hline CHEMBL1457577 & 688549 & 4.9 & 5.4414 & TST & \\
\hline CHEMBL1449971 & 688549 & 4.6 & 4.3764 & TST & \\
\hline CHEMBL1478874 & 688549 & 4.5 & 5.2406 & TRN & \\
\hline CHEMBL1552501 & 688549 & 5.3 & 4.9551 & TRN & \\
\hline CHEMBL1334962 & 688549 & 5.0 & 5.092 & TST & \\
\hline CHEMBL1464956 & 688549 & 4.8 & 4.6376 & TRN & \\
\hline CHEMBL1358554 & 688549 & 5.0 & 4.7934 & TRN & \\
\hline CHEMBL1539867 & 688549 & 4.8 & 5.0184 & TRN & \\
\hline CHEMBL1590296 & 688549 & 7.6003 & 5.4219 & TRN & \\
\hline CHEMBL1473106 & 688549 & 4.5 & 4.7842 & TRN & \\
\hline CHEMBL1613592 & 688549 & 5.45 & 5.8415 & TST & \\
\hline CHEMBL1457612 & 688549 & 4.45 & 4.59399 & 9999999999 & TRN \\
\hline CHEMBL1481147 & 688549 & 5.1 & 5.0758 & TRN & \\
\hline CHEMBL 2374055 & 688549 & 4.5 & 5.3182 & TST & \\
\hline CHEMBL1440291 & 688549 & 4.6 & 4.8661 & TRN & \\
\hline CHEMBL1372214 & 688549 & 4.9 & 4.9978 & TRN & \\
\hline CHEMBL1554253 & 688549 & 4.8 & 4.5672 & TRN & \\
\hline CHEMBL1404107 & 688549 & 5.1 & 4.6728 & TRN & \\
\hline CHEMBL1426679 & 688549 & 4.9 & 5.1909 & TRN & \\
\hline CHEMBL1437726 & 688549 & 5.2 & 4.8424 & TRN & \\
\hline CHEMBL1504492 & 688549 & 4.7 & 4.8302 & TRN & \\
\hline CHEMBL1335003 & 688549 & 4.6 & 4.9199 & TRN & \\
\hline CHEMBL1337084 & 688549 & 4.9 & 4.9601 & TST & \\
\hline & & & & 23034 & \\
\hline
\end{tabular}




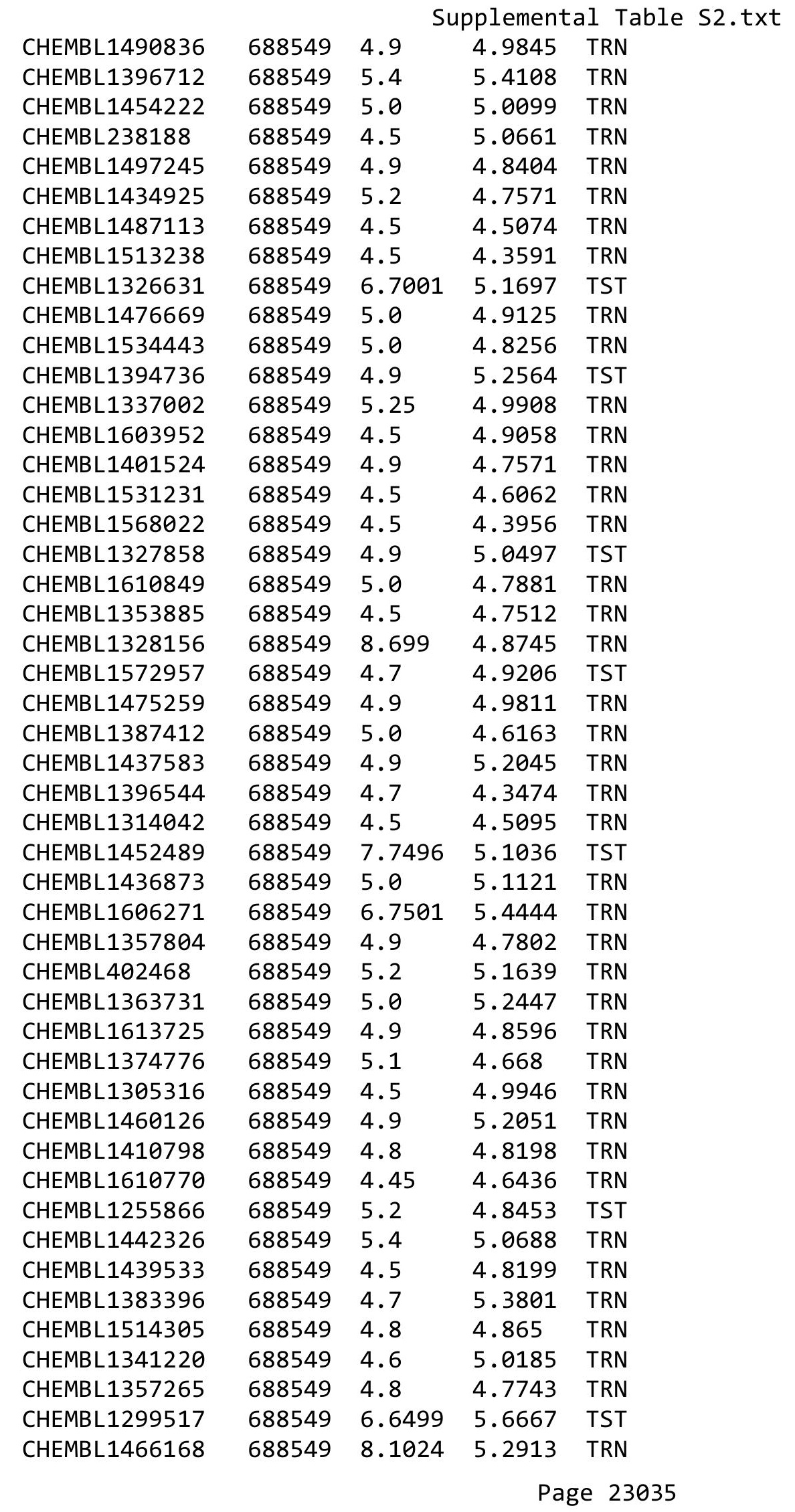




\begin{tabular}{|c|c|c|c|c|}
\hline \multicolumn{5}{|c|}{ Supplemental Table S2.txt } \\
\hline CHEMBL1438512 & 688549 & 5.1 & 4.8187 & TRN \\
\hline CHEMBL1452348 & 688549 & 4.9 & 5.4893 & TRN \\
\hline CHEMBL1368506 & 688549 & 4.85 & 5.3462 & TRN \\
\hline CHEMBL1588726 & 688549 & 4.8 & 4.9507 & TRN \\
\hline CHEMBL1406161 & 688549 & 4.9 & 4.6807 & TRN \\
\hline CHEMBL1560154 & 688549 & 4.5 & 4.7717 & TRN \\
\hline CHEMBL1406283 & 688549 & 4.7 & 4.9799 & TRN \\
\hline CHEMBL63426 & 688549 & 4.5 & 4.94 & TST \\
\hline CHEMBL1488592 & 688549 & 4.9 & 5.0137 & TRN \\
\hline CHEMBL1595693 & 688549 & 4.5 & 5.2962 & TRN \\
\hline CHEMBL1448827 & 688549 & 4.6 & 5.5815 & TRN \\
\hline CHEMBL1553773 & 688549 & 4.7 & 4.8229 & TRN \\
\hline CHEMBL1481031 & 688549 & 5.4 & 5.1188 & TRN \\
\hline CHEMBL1476611 & 688549 & 4.9 & 4.9487 & TRN \\
\hline CHEMBL1376624 & 688549 & 4.5 & 5.2825 & TRN \\
\hline CHEMBL600347 & 688549 & 4.9 & 4.6519 & TRN \\
\hline CHEMBL1527485 & 688549 & 4.5 & 4.7406 & TRN \\
\hline CHEMBL1586846 & 688549 & 4.95 & 4.7721 & TRN \\
\hline CHEMBL1319960 & 688549 & 4.5 & 5.2195 & TRN \\
\hline CHEMBL1474827 & 688549 & 5.55 & 5.1083 & TRN \\
\hline CHEMBL1402332 & 688549 & 4.7 & 4.9784 & TRN \\
\hline CHEMBL1554087 & 688549 & 5.4 & 5.6355 & TRN \\
\hline CHEMBL1369663 & 688549 & 7.2503 & 5.2195 & TRN \\
\hline CHEMBL1452714 & 688549 & 5.0 & 5.2991 & TRN \\
\hline CHEMBL1515602 & 688549 & 4.7 & 4.6302 & TRN \\
\hline CHEMBL1468661 & 688549 & 4.95 & 4.7817 & TRN \\
\hline CHEMBL1418494 & 688549 & 4.9 & 4.7946 & TRN \\
\hline CHEMBL1370322 & 688549 & 4.7 & 5.2712 & TST \\
\hline CHEMBL1456683 & 688549 & 5.1 & 4.9555 & TRN \\
\hline CHEMBL1437162 & 688549 & 4.9 & 4.623 & TRN \\
\hline CHEMBL1368561 & 688549 & 5.1 & 5.1874 & TRN \\
\hline CHEMBL1336039 & 688549 & 4.9 & 5.0407 & TRN \\
\hline CHEMBL1968978 & 688549 & 4.95 & 5.079 & TRN \\
\hline CHEMBL1416417 & 688549 & 5.2 & 4.9399 & TST \\
\hline CHEMBL1359181 & 688549 & 4.5 & 4.6588 & TST \\
\hline CHEMBL1591622 & 688549 & 4.8 & 4.7761 & TRN \\
\hline CHEMBL3196538 & 688549 & 5.0 & 5.1434 & TRN \\
\hline CHEMBL1375585 & 688549 & 4.5 & 5.4852 & TRN \\
\hline CHEMBL1547823 & 688549 & 4.8 & 5.0273 & TRN \\
\hline CHEMBL1373914 & 688549 & 5.0 & 5.0973 & TRN \\
\hline CHEMBL1372890 & 688549 & 5.1 & 5.2005 & TRN \\
\hline CHEMBL1436840 & 688549 & 4.95 & 5.0544 & TRN \\
\hline CHEMBL1440713 & 688549 & 4.8 & 5.0688 & TST \\
\hline CHEMBL1437722 & 688549 & 5.2 & 4.5922 & TRN \\
\hline CHEMBL1412647 & 688549 & 8.0 & 5.0682 & TST \\
\hline CHEMBL1446849 & 688549 & 4.9 & 5.2008 & TRN \\
\hline CHEMBL1486828 & 688549 & 4.9 & 4.9713 & TRN \\
\hline CHEMBL1512137 & 688549 & 4.7 & 4.9907 & TRN \\
\hline
\end{tabular}




\begin{tabular}{|c|c|c|c|c|c|}
\hline \\
\hline CHEMBL1488054 & 688549 & 4.8 & 5.2843 & TRN & \\
\hline CHEMBL1320023 & 688549 & 5.25 & 5.0354 & TRN & \\
\hline CHEMBL1372850 & 688549 & 5.5 & 5.2477 & TST & \\
\hline CHEMBL1362998 & 688549 & 4.9 & 4.5565 & TRN & \\
\hline CHEMBL1447576 & 688549 & 4.5 & 4.6799 & TRN & \\
\hline CHEMBL225313 & 688549 & 4.9 & 5.17399 & 99999999995 & TST \\
\hline CHEMBL1354951 & 688549 & 4.5 & 4.6914 & TST & \\
\hline CHEMBL1476172 & 688549 & 5.5 & 5.3157 & TRN & \\
\hline CHEMBL1427685 & 688549 & 4.5 & 4.7485 & TST & \\
\hline CHEMBL1321914 & 688549 & 4.9 & 4.8526 & TRN & \\
\hline CHEMBL1502721 & 688549 & 4.9 & 4.7729 & TRN & \\
\hline CHEMBL1397952 & 688549 & 5.65 & 5.438 & TRN & \\
\hline CHEMBL1495071 & 688549 & 4.5 & 4.9403 & TST & \\
\hline CHEMBL1596996 & 688549 & 4.9 & 4.1981 & TST & \\
\hline CHEMBL1356882 & 688549 & 4.5 & 5.0405 & TRN & \\
\hline CHEMBL1593648 & 688549 & 5.1 & 5.3295 & TRN & \\
\hline CHEMBL1525394 & 688549 & 4.5 & 4.4825 & TRN & \\
\hline CHEMBL1594042 & 688549 & 5.05 & 4.93 & TRN & \\
\hline CHEMBL607253 & 688549 & 5.25 & 5.8794 & TST & \\
\hline CHEMBL1494788 & 688549 & 4.7 & 4.8887 & TRN & \\
\hline CHEMBL1370379 & 688549 & 4.6 & 5.3647 & TRN & \\
\hline CHEMBL3207635 & 688549 & 4.95 & 5.3154 & TRN & \\
\hline CHEMBL1593338 & 688549 & 4.8 & 4.897 & TRN & \\
\hline CHEMBL1442682 & 688549 & 4.8 & 4.9072 & TRN & \\
\hline CHEMBL1511557 & 688549 & 5.0 & 5.1889 & TRN & \\
\hline CHEMBL1554073 & 688549 & 4.6 & 5.17299 & 9999999999 & TRN \\
\hline CHEMBL1604705 & 688549 & 4.9 & 5.1731 & TRN & \\
\hline CHEMBL198759 & 688549 & 5.7 & 5.2666 & TST & \\
\hline CHEMBL1308223 & 688549 & 6.6 & 5.3272 & TRN & \\
\hline CHEMBL1519969 & 688549 & 5.6 & 5.8277 & TRN & \\
\hline CHEMBL1334486 & 688549 & 4.9 & 5.2277 & TRN & \\
\hline CHEMBL1411257 & 688549 & 4.9 & 5.3083 & TRN & \\
\hline CHEMBL1448284 & 688549 & 5.2 & 4.981 & TRN & \\
\hline CHEMBL1565932 & 688549 & 4.8 & 4.9202 & TRN & \\
\hline CHEMBL1451916 & 688549 & 4.9 & 4.8809 & TRN & \\
\hline CHEMBL1531978 & 688549 & 4.9 & 4.7012 & TRN & \\
\hline CHEMBL1527993 & 688549 & 4.7 & 4.7761 & TST & \\
\hline CHEMBL1447280 & 688549 & 5.3 & 4.8397 & TRN & \\
\hline CHEMBL1591133 & 688549 & 4.5 & 5.2852 & TRN & \\
\hline CHEMBL1213966 & 688549 & 4.9 & 5.0463 & TRN & \\
\hline CHEMBL1444859 & 688549 & 4.5 & 4.72 & TRN & \\
\hline CHEMBL1415760 & 688549 & 4.7 & 4.407 & TRN & \\
\hline CHEMBL1456417 & 688549 & 4.6 & 5.2211 & TRN & \\
\hline CHEMBL1573511 & 688549 & 5.0 & 5.1529 & TRN & \\
\hline CHEMBL1369161 & 688549 & 6.1 & 5.6422 & TRN & \\
\hline CHEMBL1417702 & 688549 & 4.7 & 5.3961 & TRN & \\
\hline CHEMBL1477337 & 688549 & 4.7 & 5.018 & TRN & \\
\hline CHEMBL1515137 & 688549 & 4.6 & 4.9205 & TST & \\
\hline
\end{tabular}




\begin{tabular}{|c|c|c|c|c|c|}
\hline \multicolumn{6}{|c|}{ Supplemental Table S2.txt } \\
\hline CHEMBL1452426 & 688549 & 5.5 & 5.3184 & TRN & \\
\hline CHEMBL2373651 & 688549 & 4.8 & 5.3465 & TST & \\
\hline CHEMBL1326787 & 688549 & 4.5 & 4.999 & TRN & \\
\hline CHEMBL374632 & 688549 & 6.5 & 5.6161 & TRN & \\
\hline CHEMBL564201 & 688549 & 4.9 & 5.4747 & TRN & \\
\hline CHEMBL1553303 & 688549 & 5.0 & 5.4082 & TRN & \\
\hline CHEMBL1451087 & 688549 & 4.5 & 5.0715 & TST & \\
\hline CHEMBL1322635 & 688549 & 4.8 & 4.8658 & TRN & \\
\hline CHEMBL1478843 & 688549 & 7.5003 & 5.1467 & TST & \\
\hline CHEMBL1580578 & 688549 & 5.6 & 5.13700 & 00000000005 & TRN \\
\hline CHEMBL1475164 & 688549 & 5.3 & 4.933 & TRN & \\
\hline CHEMBL1576907 & 688549 & 8.301 & 5.5561 & TRN & \\
\hline CHEMBL1404678 & 688549 & 4.9 & 5.2019 & TRN & \\
\hline CHEMBL1422405 & 688549 & 4.45 & 4.7896 & TRN & \\
\hline CHEMBL1431763 & 688549 & 4.6 & 4.768 & TRN & \\
\hline CHEMBL1514596 & 688549 & 5.3 & 4.6879 & TRN & \\
\hline CHEMBL1353069 & 688549 & 4.7 & 4.9611 & TRN & \\
\hline CHEMBL1341112 & 688549 & 4.45 & 4.8019 & TRN & \\
\hline CHEMBL1354577 & 688549 & 5.0 & 4.9227 & TRN & \\
\hline CHEMBL1479106 & 688549 & 4.9 & 4.9026 & TRN & \\
\hline CHEMBL1356854 & 688549 & 5.6 & 4.8766 & TRN & \\
\hline CHEMBL1303653 & 688549 & 4.5 & 4.9447 & TRN & \\
\hline CHEMBL1435275 & 688549 & 4.75 & 5.5024 & TRN & \\
\hline CHEMBL1558119 & 688549 & 4.9 & 4.6572 & TRN & \\
\hline CHEMBL1499069 & 688549 & 4.8 & 4.7457 & TRN & \\
\hline CHEMBL1548265 & 688549 & 4.9 & 4.8701 & TRN & \\
\hline CHEMBL1463540 & 688549 & 4.5 & 4.9989 & TRN & \\
\hline CHEMBL1481412 & 688549 & 4.5 & 5.0578 & TRN & \\
\hline CHEMBL1325702 & 688549 & 4.9 & 4.9611 & TRN & \\
\hline CHEMBL1516772 & 688549 & 4.5 & 4.5898 & TRN & \\
\hline CHEMBL504598 & 688549 & 4.7 & 5.0351 & TRN & \\
\hline CHEMBL1607122 & 688549 & 4.9 & 5.0612 & TST & \\
\hline CHEMBL1394378 & 688549 & 4.9 & 4.8876 & TRN & \\
\hline CHEMBL117 & 688549 & 6.0 & 5.3486 & TRN & \\
\hline CHEMBL1481384 & 688549 & 4.9 & 5.2433 & TRN & \\
\hline CHEMBL1501724 & 688549 & 4.9 & 5.4306 & TRN & \\
\hline CHEMBL1531299 & 688549 & 5.6 & 5.1758 & TRN & \\
\hline CHEMBL1356682 & 688549 & 5.2 & 5.2634 & TRN & \\
\hline CHEMBL1595798 & 688549 & 4.5 & 4.6873 & TST & \\
\hline CHEMBL1436858 & 688549 & 5.0 & 5.1871 & TRN & \\
\hline CHEMBL1395894 & 688549 & 5.0 & 5.0563 & TRN & \\
\hline CHEMBL1566132 & 688549 & 8.301 & 5.5173 & TST & \\
\hline CHEMBL1417800 & 688549 & 4.9 & 5.3114 & TRN & \\
\hline CHEMBL1507850 & 688549 & 5.2 & 5.6482 & TRN & \\
\hline CHEMBL1394601 & 688549 & 4.9 & 4.7032 & TST & \\
\hline CHEMBL1395842 & 688549 & 7.2 & 5.2338 & TRN & \\
\hline CHEMBL1596602 & 688549 & 4.5 & 4.633 & TRN & \\
\hline CHEMBL1316756 & 688549 & 4.5 & 5.3392 & TRN & \\
\hline
\end{tabular}




\begin{tabular}{|c|c|c|c|c|c|}
\hline & & \multicolumn{4}{|c|}{ Supplemental Table S2.txt } \\
\hline CHEMBL1395100 & 688549 & 4.8 & 4.3853 & TRN & \\
\hline CHEMBL1528874 & 688549 & 4.9 & 4.7546 & TRN & \\
\hline CHEMBL1476492 & 688549 & 5.5 & 5.2091 & TRN & \\
\hline CHEMBL1380008 & 688549 & 5.3 & 4.9177 & TRN & \\
\hline CHEMBL1727680 & 688549 & 5.3 & 5.5772 & TST & \\
\hline CHEMBL1555267 & 688549 & 4.7 & 5.5119 & TST & \\
\hline CHEMBL1348675 & 688549 & 4.8 & 5.2126 & TRN & \\
\hline CHEMBL1329566 & 688549 & 4.9 & 4.838 & TRN & \\
\hline CHEMBL1331685 & 688549 & 4.6 & 4.843 & TRN & \\
\hline CHEMBL3194665 & 688549 & 4.8 & 5.2507 & TRN & \\
\hline CHEMBL1331857 & 688549 & 4.7 & \multicolumn{2}{|c|}{5.257999999999999} & TRN \\
\hline CHEMBL1399493 & 688549 & 5.1 & 4.8909 & TRN & \\
\hline CHEMBL1357996 & 688549 & 4.85 & 4.9615 & TRN & \\
\hline CHEMBL1535127 & 688549 & 6.5 & 5.1346 & TST & \\
\hline CHEMBL3192608 & 688549 & 4.9 & 5.1122 & TRN & \\
\hline CHEMBL1308000 & 688549 & 4.5 & 4.4535 & TRN & \\
\hline CHEMBL1380000 & 688549 & 4.6 & 5.4075 & TRN & \\
\hline CHEMBL1577389 & 688549 & 4.9 & 4.9684 & TRN & \\
\hline CHEMBL1356824 & 688549 & 4.9 & 4.8141 & TRN & \\
\hline CHEMBL1493739 & 688549 & 6.9 & 5.1551 & TST & \\
\hline CHEMBL1477769 & 688549 & 4.8 & 4.9246 & TRN & \\
\hline CHEMBL1397353 & 688549 & 4.9 & 4.9741 & TRN & \\
\hline CHEMBL1492524 & 688549 & 5.2 & 4.9703 & TRN & \\
\hline CHEMBL1472668 & 688549 & 4.5 & 4.8766 & TRN & \\
\hline CHEMBL 277127 & 688549 & 4.5 & 4.8343 & TRN & \\
\hline CHEMBL1551417 & 688549 & 4.8 & 5.1387 & TRN & \\
\hline CHEMBL1329033 & 688549 & 4.5 & 4.9202 & TRN & \\
\hline CHEMBL1340325 & 688549 & 4.9 & 4.9874 & TRN & \\
\hline CHEMBL1331573 & 688549 & 4.6 & 4.9997 & TRN & \\
\hline CHEMBL1436312 & 688549 & 5.4 & 5.1033 & TRN & \\
\hline CHEMBL1583650 & 688549 & 5.0 & 5.1452 & TRN & \\
\hline CHEMBL1563519 & 688549 & 5.25 & 5.2248 & TRN & \\
\hline CHEMBL1528565 & 688549 & 4.8 & 4.9026 & TST & \\
\hline CHEMBL1214345 & 688549 & 4.9 & 4.8848 & TRN & \\
\hline CHEMBL1555441 & 688549 & 4.5 & 4.9887 & TRN & \\
\hline CHEMBL1363622 & 688549 & 4.5 & 4.497 & TRN & \\
\hline CHEMBL1326645 & 688549 & 4.75 & 5.2243 & TRN & \\
\hline CHEMBL528807 & 688549 & 4.85 & 4.784 & TRN & \\
\hline CHEMBL1422346 & 688549 & 4.95 & 5.2378 & TRN & \\
\hline CHEMBL1490048 & 688549 & 4.6 & 4.7899 & TRN & \\
\hline CHEMBL1592975 & 688549 & 4.5 & 5.7094 & TST & \\
\hline CHEMBL1555040 & 688549 & 4.9 & 4.598 & TRN & \\
\hline CHEMBL1445232 & 688549 & 4.5 & 4.4921 & TRN & \\
\hline CHEMBL1544147 & 688549 & 4.95 & 5.0186 & TRN & \\
\hline CHEMBL1415119 & 688549 & 4.5 & 4.4242 & TRN & \\
\hline CHEMBL1435638 & 688549 & 4.5 & 4.6183 & TRN & \\
\hline CHEMBL1433049 & 688549 & 8.0506 & 5.2154 & TST & \\
\hline CHEMBL1329410 & 688549 & 4.7 & 5.0004 & TRN & \\
\hline
\end{tabular}




\begin{tabular}{|c|c|c|c|c|c|}
\hline \multicolumn{6}{|c|}{ Supplemental Table s2.txt } \\
\hline CHEMBL1361514 & 688549 & 4.7 & 4.6678 & TRN & \\
\hline CHEMBL1396384 & 688549 & 4.6 & 4.6405 & TRN & \\
\hline CHEMBL1436623 & 688549 & 4.9 & 4.9142 & TRN & \\
\hline CHEMBL1561989 & 688549 & 4.5 & 4.638 & TRN & \\
\hline CHEMBL406120 & 688549 & 4.7 & 4.9632 & TRN & \\
\hline CHEMBL596674 & 688549 & 4.7 & 5.1049 & TRN & \\
\hline CHEMBL1524192 & 688549 & 5.0 & 4.9299 & TRN & \\
\hline CHEMBL1342330 & 688549 & 4.5 & 4.8719 & TST & \\
\hline CHEMBL1592791 & 688549 & 4.75 & 4.7299 & TRN & \\
\hline CHEMBL1400508 & 688549 & 4.9 & 5.0563 & TRN & \\
\hline CHEMBL1438868 & 688549 & 5.0 & 5.1931 & TRN & \\
\hline CHEMBL1585637 & 688549 & 4.9 & 4.9306 & TRN & \\
\hline CHEMBL1435961 & 688549 & 5.2 & 5.0962 & TRN & \\
\hline CHEMBL1553807 & 688549 & 5.35 & 5.4428 & TRN & \\
\hline CHEMBL131921 & 688549 & 4.9 & $5.1720 e$ & 0000000001 & TRN \\
\hline CHEMBL1552783 & 688549 & 4.9 & 4.7174 & TRN & \\
\hline CHEMBL1593453 & 688549 & 4.7 & 4.6407 & TRN & \\
\hline CHEMBL1362096 & 688549 & 4.5 & 4.9577 & TST & \\
\hline CHEMBL1437883 & 688549 & 5.3 & 4.7566 & TRN & \\
\hline CHEMBL1534672 & 688549 & 4.65 & 4.5953 & TRN & \\
\hline CHEMBL1389753 & 688549 & 4.8 & 4.9619 & TST & \\
\hline CHEMBL328710 & 688549 & 5.0 & 5.1369 & TST & \\
\hline CHEMBL1594961 & 688549 & 5.5 & 5.3261 & TRN & \\
\hline CHEMBL186366 & 688549 & 5.0 & 5.0817 & TRN & \\
\hline CHEMBL52 & 688549 & 4.6 & 5.0017 & TRN & \\
\hline CHEMBL1513360 & 688549 & 4.5 & $5.3720 e$ & 0000000001 & TRN \\
\hline CHEMBL1475301 & 688549 & 4.9 & 5.2154 & TRN & \\
\hline CHEMBL1423466 & 688549 & 4.8 & 5.1847 & TRN & \\
\hline CHEMBL1383627 & 688549 & 6.5 & $5.2010 e$ & 00000000005 & TRN \\
\hline CHEMBL 274619 & 688549 & 7.3002 & 5.7346 & TST & \\
\hline CHEMBL1475630 & 688549 & 5.0 & 5.1985 & TRN & \\
\hline CHEMBL1372591 & 688549 & 4.9 & 5.147 & TST & \\
\hline CHEMBL1412825 & 688549 & 5.1 & 5.2926 & TRN & \\
\hline CHEMBL1431063 & 688549 & 4.5 & 5.0159 & TRN & \\
\hline CHEMBL1477139 & 688549 & 4.7 & 5.2928 & TRN & \\
\hline CHEMBL1410350 & 688549 & 4.65 & 5.1083 & TRN & \\
\hline CHEMBL1561796 & 688549 & 4.5 & 4.7306 & TRN & \\
\hline CHEMBL1362013 & 688549 & 5.7 & 5.2416 & TRN & \\
\hline CHEMBL1468382 & 688549 & 6.2 & 5.4091 & TRN & \\
\hline CHEMBL1972280 & 688549 & 7.8013 & 5.4493 & TST & \\
\hline CHEMBL1357128 & 688549 & 4.9 & 4.2368 & TRN & \\
\hline CHEMBL1317032 & 688549 & 5.0 & 5.0667 & TRN & \\
\hline CHEMBL326312 & 688549 & 7.3002 & 5.1686 & TRN & \\
\hline CHEMBL1580467 & 688549 & 4.55 & 4.8146 & TRN & \\
\hline CHEMBL1520028 & 688549 & 4.8 & 4.9967 & TST & \\
\hline CHEMBL1336136 & 688549 & 4.7 & 5.3142 & TRN & \\
\hline CHEMBL1552089 & 688549 & 4.65 & 4.7284 & TRN & \\
\hline CHEMBL1301630 & 688549 & 4.9 & 4.7931 & TRN & \\
\hline
\end{tabular}




\begin{tabular}{|c|c|c|c|c|}
\hline & & & & al T \\
\hline CHEMBL1534248 & 688549 & 4.6 & 5.5547 & TST \\
\hline CHEMBL1583952 & 688549 & 5.0 & 4.9702 & TRN \\
\hline CHEMBL1424968 & 688549 & 4.6 & 4.5964 & TRN \\
\hline CHEMBL1486073 & 688549 & 4.7 & 4.8792 & TRN \\
\hline CHEMBL1575028 & 688549 & 4.9 & 5.17299 & 9999999999 \\
\hline CHEMBL1513090 & 688549 & 4.5 & 5.0441 & TRN \\
\hline CHEMBL1506017 & 688549 & 5.0 & 4.8437 & TRN \\
\hline CHEMBL1487869 & 688549 & 4.9 & 4.9747 & TRN \\
\hline CHEMBL1524128 & 688549 & 5.4 & 4.9502 & TST \\
\hline CHEMBL1601294 & 688549 & 4.9 & 4.8248 & TRN \\
\hline CHEMBL1338466 & 688549 & 4.55 & 4.8839 & TST \\
\hline CHEMBL1540513 & 688549 & 4.6 & 4.7331 & TRN \\
\hline CHEMBL1520216 & 688549 & 4.5 & 4.8828 & TRN \\
\hline CHEMBL1370555 & 688549 & 5.1 & 4.9781 & TRN \\
\hline CHEMBL1317831 & 688549 & 4.6 & 4.7222 & TRN \\
\hline CHEMBL1491866 & 688549 & 4.7 & 5.2862 & TRN \\
\hline CHEMBL1526543 & 688549 & 4.5 & 5.2402 & TST \\
\hline CHEMBL1496577 & 688549 & 4.45 & 4.835 & TRN \\
\hline CHEMBL1512964 & 688549 & 4.5 & 5.0652 & TRN \\
\hline CHEMBL1349067 & 688549 & 4.9 & 5.1229 & TRN \\
\hline CHEMBL1414645 & 688549 & 4.9 & 4.7772 & TRN \\
\hline CHEMBL1384345 & 688549 & 8.1024 & 5.2768 & TST \\
\hline CHEMBL1350157 & 688549 & 4.9 & 5.0257 & TRN \\
\hline CHEMBL1369231 & 688549 & 4.9 & 5.4331 & TRN \\
\hline CHEMBL3190499 & 688549 & 4.9 & 5.0146 & TRN \\
\hline CHEMBL1408430 & 688549 & 4.9 & 5.1983 & TRN \\
\hline CHEMBL1565120 & 688549 & 4.8 & 4.9052 & TST \\
\hline CHEMBL1554254 & 688549 & 4.65 & 4.5214 & TRN \\
\hline CHEMBL1427303 & 688549 & 6.2 & 5.1118 & TRN \\
\hline CHEMBL 3190040 & 688549 & 4.7 & 4.8725 & TRN \\
\hline CHEMBL1573195 & 688549 & 4.8 & 4.9039 & TRN \\
\hline CHEMBL1331875 & 688549 & 5.6 & 5.2939 & TRN \\
\hline CHEMBL408563 & 688549 & 5.1 & 5.222 & TRN \\
\hline CHEMBL1554305 & 688549 & 5.0 & 4.813 & TRN \\
\hline CHEMBL1344112 & 688549 & 4.7 & 4.792 & TRN \\
\hline CHEMBL1521607 & 688549 & 4.5 & 5.182 & TRN \\
\hline CHEMBL1591968 & 688549 & 4.7 & 4.9681 & TRN \\
\hline CHEMBL1434124 & 688549 & 5.0 & 4.3286 & TRN \\
\hline CHEMBL1448584 & 688549 & 5.8 & 5.1629 & TRN \\
\hline CHEMBL1328811 & 688549 & 5.0 & 4.7417 & TRN \\
\hline CHEMBL 3190751 & 688549 & 4.9 & 5.0056 & TRN \\
\hline CHEMBL1478086 & 688549 & 5.2 & 5.0478 & TRN \\
\hline CHEMBL1320008 & 688549 & 5.1 & 5.3471 & TRN \\
\hline CHEMBL1534577 & 688549 & 4.8 & 5.0386 & TRN \\
\hline CHEMBL1419335 & 688549 & 4.5 & 4.5369 & TRN \\
\hline CHEMBL1495345 & 688549 & 4.9 & 4.7592 & TRN \\
\hline CHEMBL21241 & 688549 & 4.5 & 4.9762 & TST \\
\hline CHEMBL1344731 & 688549 & 4.7 & 4.8626 & TST \\
\hline
\end{tabular}




\begin{tabular}{|c|c|c|c|c|}
\hline \multicolumn{5}{|c|}{ Supplemental Table S2.txt } \\
\hline CHEMBL1516908 & 688549 & 4.9 & 5.0418 & TRN \\
\hline CHEMBL1375274 & 688549 & 4.5 & 5.1815 & TST \\
\hline CHEMBL1372571 & 688549 & 4.9 & 4.6067 & TRN \\
\hline CHEMBL1603131 & 688549 & 5.15 & 5.1431 & TST \\
\hline CHEMBL1513844 & 688549 & 4.8 & 4.6656 & TST \\
\hline CHEMBL1587880 & 688549 & 4.9 & 5.1679 & TRN \\
\hline CHEMBL 3199262 & 688549 & 4.9 & 5.1215 & TRN \\
\hline CHEMBL1549241 & 688549 & 4.6 & 5.0415 & TRN \\
\hline CHEMBL1415749 & 688549 & 5.45 & 5.0728 & TST \\
\hline CHEMBL1430185 & 688549 & 4.7 & 4.9231 & TRN \\
\hline CHEMBL1438451 & 688549 & 4.9 & 4.8782 & TRN \\
\hline CHEMBL1434380 & 688549 & 4.65 & 5.0042 & TRN \\
\hline CHEMBL1338737 & 688549 & 4.45 & 4.754 & TRN \\
\hline CHEMBL1338517 & 688549 & 4.5 & 5.2865 & TRN \\
\hline CHEMBL1394918 & 688549 & 4.85 & 4.7064 & TRN \\
\hline CHEMBL329872 & 688549 & 4.9 & 5.0504 & TRN \\
\hline CHEMBL1313648 & 688549 & 4.8 & 4.8968 & TRN \\
\hline CHEMBL1412549 & 688549 & 4.5 & 4.6804 & TRN \\
\hline CHEMBL1328462 & 688549 & 4.5 & 4.4557 & TRN \\
\hline CHEMBL1500078 & 688549 & 4.5 & 5.3798 & TRN \\
\hline CHEMBL410484 & 688549 & 5.3 & 4.9483 & TRN \\
\hline CHEMBL1456016 & 688549 & 4.8 & 4.9372 & TST \\
\hline CHEMBL1437230 & 688549 & 4.6 & 4.7524 & TRN \\
\hline CHEMBL1586875 & 688549 & 4.8 & 4.8605 & TRN \\
\hline CHEMBL571087 & 688549 & 5.0 & 5.1561 & TRN \\
\hline CHEMBL1375672 & 688549 & 5.3 & 5.3632 & TRN \\
\hline CHEMBL1344586 & 688549 & 4.6 & 5.4426 & TST \\
\hline CHEMBL1520236 & 688549 & 4.7 & 5.1199 & TRN \\
\hline CHEMBL1589556 & 688549 & 4.5 & 4.93 & TRN \\
\hline CHEMBL1436947 & 688549 & 4.65 & 4.6539 & TRN \\
\hline CHEMBL1329768 & 688549 & 5.0 & 4.8457 & TRN \\
\hline CHEMBL1423492 & 688549 & 4.8 & 5.3162 & TST \\
\hline CHEMBL1603890 & 688549 & 4.7 & 4.5275 & TST \\
\hline CHEMBL1354491 & 688549 & 4.6 & 4.5717 & TRN \\
\hline CHEMBL1485868 & 688549 & 5.35 & 5.5791 & TRN \\
\hline CHEMBL1449728 & 688549 & 7.6003 & 5.3599 & TST \\
\hline CHEMBL1357243 & 688549 & 4.9 & 4.9238 & TRN \\
\hline CHEMBL1304798 & 688549 & 5.0 & 5.0361 & TRN \\
\hline CHEMBL1570716 & 688549 & 4.8 & 5.0406 & TST \\
\hline CHEMBL1422107 & 688549 & 4.95 & 5.1124 & TRN \\
\hline CHEMBL1380174 & 688549 & 5.75 & 5.206 & TST \\
\hline CHEMBL1514951 & 688549 & 5.6 & 5.2131 & TRN \\
\hline CHEMBL1550909 & 688549 & 5.5 & 5.2202 & TRN \\
\hline CHEMBL1590663 & 688549 & 4.7 & 4.9633 & TRN \\
\hline CHEMBL1569926 & 688549 & 8.0 & 5.0938 & TRN \\
\hline CHEMBL1610972 & 688549 & 5.0 & 5.1829 & TST \\
\hline CHEMBL1516303 & 688549 & 5.0 & 4.967 & TRN \\
\hline CHEMBL1358264 & 688549 & 4.5 & 4.5668 & TRN \\
\hline
\end{tabular}




\begin{tabular}{|c|c|c|c|c|}
\hline \multicolumn{5}{|c|}{ Supplemental Table S2.txt } \\
\hline CHEMBL1600851 & 688549 & 5.4 & 5.2329 & TRN \\
\hline CHEMBL1317931 & 688549 & 6.0 & 5.9009 & TST \\
\hline CHEMBL1344611 & 688549 & 4.7 & 4.5988 & TRN \\
\hline CHEMBL1485139 & 688549 & 4.6 & 4.8122 & TRN \\
\hline CHEMBL1548720 & 688549 & 4.6 & 4.9117 & TRN \\
\hline CHEMBL1476131 & 688549 & 4.8 & 5.0388 & TRN \\
\hline CHEMBL1311346 & 688549 & 5.2 & 5.2158 & TST \\
\hline CHEMBL1592325 & 688549 & 5.25 & 5.2311 & TRN \\
\hline CHEMBL1376244 & 688549 & 4.9 & 4.7233 & TRN \\
\hline CHEMBL1309678 & 688549 & 4.5 & 4.8639 & TRN \\
\hline CHEMBL1512312 & 688549 & 5.4 & 5.2437 & TRN \\
\hline CHEMBL1440056 & 688549 & 5.0 & 5.3951 & TST \\
\hline CHEMBL3144916 & 688549 & 5.0 & 5.1206 & TST \\
\hline CHEMBL1567639 & 688549 & 4.7 & 5.0291 & TRN \\
\hline CHEMBL1518946 & 688549 & 5.55 & 4.9437 & TRN \\
\hline CHEMBL1433718 & 688549 & 4.7 & 4.6888 & TRN \\
\hline CHEMBL1557564 & 688549 & 5.1 & 4.7623 & TRN \\
\hline CHEMBL1324618 & 688549 & 4.7 & 5.0826 & TRN \\
\hline CHEMBL1316171 & 688549 & 5.2 & 4.7983 & TRN \\
\hline CHEMBL1526748 & 688549 & 4.5 & 4.9238 & TRN \\
\hline CHEMBL1408542 & 688549 & 5.2 & 5.8268 & TRN \\
\hline CHEMBL1475818 & 688549 & 5.3 & 5.152 & TRN \\
\hline CHEMBL1515004 & 688549 & 5.0 & 4.6533 & TRN \\
\hline CHEMBL445969 & 688549 & 5.8 & 5.0517 & TST \\
\hline CHEMBL1333386 & 688549 & 4.9 & 4.8413 & TRN \\
\hline CHEMBL1551923 & 688549 & 4.9 & 4.8524 & TRN \\
\hline CHEMBL1595162 & 688549 & 4.9 & 5.0217 & TRN \\
\hline CHEMBL1315202 & 688549 & 4.7 & 4.9205 & TRN \\
\hline CHEMBL1612499 & 688549 & 6.2 & 5.3421 & TRN \\
\hline CHEMBL1333767 & 688549 & 4.5 & 4.5275 & TRN \\
\hline CHEMBL1589324 & 688549 & 5.1 & 5.1248 & TRN \\
\hline CHEMBL1317587 & 688549 & 4.5 & 4.6573 & TRN \\
\hline CHEMBL1446914 & 688549 & 4.9 & 5.0505 & TRN \\
\hline CHEMBL1316980 & 688549 & 5.7 & 5.4988 & TRN \\
\hline CHEMBL1343768 & 688549 & 4.9 & 5.484 & TRN \\
\hline CHEMBL3191772 & 688549 & 4.9 & 5.2688 & TRN \\
\hline CHEMBL1568306 & 688549 & 5.0 & 4.9906 & TRN \\
\hline CHEMBL1419996 & 688549 & 5.0 & 4.933 & TST \\
\hline CHEMBL1516173 & 688549 & 4.9 & 5.0487 & TRN \\
\hline CHEMBL1498591 & 688549 & 4.8 & 5.0607 & TRN \\
\hline CHEMBL1523699 & 688549 & 4.5 & 4.8036 & TST \\
\hline CHEMBL1407161 & 688549 & 4.8 & 4.9352 & TRN \\
\hline CHEMBL1316447 & 688549 & 4.5 & 5.0785 & TRN \\
\hline CHEMBL1610636 & 688549 & 4.8 & 5.1801 & TRN \\
\hline CHEMBL1551502 & 688549 & 5.1 & 5.1082 & TRN \\
\hline CHEMBL1554626 & 688549 & 4.5 & 4.8236 & TRN \\
\hline CHEMBL1590398 & 688549 & 4.9 & 4.6984 & TRN \\
\hline CHEMBL54804 & 688549 & 5.0 & 5.7185 & TST \\
\hline
\end{tabular}




\begin{tabular}{|c|c|c|c|c|}
\hline \multicolumn{5}{|c|}{ Supplemental Table S2.txt } \\
\hline CHEMBL1429150 & 688549 & 4.5 & 4.437 & TRN \\
\hline CHEMBL1477695 & 688549 & 4.5 & 4.6167 & TRN \\
\hline CHEMBL1435958 & 688549 & 4.5 & 4.7031 & TST \\
\hline CHEMBL1605762 & 688549 & 4.9 & 4.9731 & TRN \\
\hline CHEMBL1580240 & 688549 & 4.9 & 4.9517 & TRN \\
\hline CHEMBL1446201 & 688549 & 4.7 & 4.9637 & TRN \\
\hline CHEMBL592712 & 688549 & 4.6 & 4.481 & TRN \\
\hline CHEMBL1537329 & 688549 & 4.9 & 5.1284 & TRN \\
\hline CHEMBL1470294 & 688549 & 4.7 & 5.0662 & TRN \\
\hline CHEMBL1311144 & 688549 & 4.65 & 4.7571 & TRN \\
\hline CHEMBL1396184 & 688549 & 4.95 & 5.0482 & TRN \\
\hline CHEMBL1398282 & 688549 & 4.9 & 4.8092 & TRN \\
\hline CHEMBL1509936 & 688549 & 4.7 & 5.2984 & TST \\
\hline CHEMBL1345146 & 688549 & 4.8 & 4.7816 & TST \\
\hline CHEMBL1595927 & 688549 & 4.6 & 4.8492 & TRN \\
\hline CHEMBL1495025 & 688549 & 4.9 & 5.1453 & TST \\
\hline CHEMBL1603889 & 688549 & 4.45 & 4.8132 & TRN \\
\hline CHEMBL28 & 688549 & 5.3 & 5.5323 & TRN \\
\hline CHEMBL1477059 & 688549 & 5.2 & 4.955 & TRN \\
\hline CHEMBL1322090 & 688549 & 4.5 & 4.9442 & TRN \\
\hline CHEMBL1435120 & 688549 & 4.6 & 5.0127 & TRN \\
\hline CHEMBL1369611 & 688549 & 4.5 & 4.7869 & TST \\
\hline CHEMBL1357076 & 688549 & 4.9 & 4.7238 & TRN \\
\hline CHEMBL1515160 & 688549 & 4.5 & 4.5358 & TRN \\
\hline CHEMBL1502259 & 688549 & 4.7 & 4.8693 & TRN \\
\hline CHEMBL1597839 & 688549 & 4.9 & 4.96 & TRN \\
\hline CHEMBL1597278 & 688549 & 4.6 & 4.9001 & TRN \\
\hline CHEMBL1368674 & 688549 & 4.9 & 4.997 & TRN \\
\hline CHEMBL1414183 & 688549 & 4.9 & 5.1872 & TRN \\
\hline CHEMBL1476353 & 688549 & 4.5 & 4.6346 & TRN \\
\hline CHEMBL1397191 & 688549 & 4.9 & 4.9224 & TRN \\
\hline CHEMBL1363772 & 688549 & 4.9 & 4.7208 & TRN \\
\hline CHEMBL1433489 & 688549 & 4.5 & 5.5931 & TST \\
\hline CHEMBL1503636 & 688549 & 4.9 & 4.8488 & TRN \\
\hline CHEMBL1519019 & 688549 & 5.0 & 4.8451 & TRN \\
\hline CHEMBL1320735 & 688549 & 4.6 & 4.8789 & TRN \\
\hline CHEMBL1590116 & 688549 & 7.6003 & 5.6806 & TST \\
\hline CHEMBL1529256 & 688549 & 5.0 & 5.2086 & TST \\
\hline CHEMBL1370563 & 688549 & 4.8 & 5.0384 & TST \\
\hline CHEMBL1347477 & 688549 & 5.5 & 5.3275 & TRN \\
\hline CHEMBL 3199273 & 688549 & 7.0501 & 5.1058 & TST \\
\hline CHEMBL 1357087 & 688549 & 4.8 & 4.9415 & TRN \\
\hline CHEMBL1414391 & 688549 & 5.05 & 4.6747 & TRN \\
\hline CHEMBL1465810 & 688549 & 6.2 & 5.4474 & TST \\
\hline CHEMBL1410215 & 688549 & 4.45 & 5.1106 & TRN \\
\hline CHEMBL1604734 & 688549 & 4.5 & 4.9809 & TRN \\
\hline CHEMBL1526331 & 688549 & 4.9 & 5.2384 & TRN \\
\hline CHEMBL1578425 & 688549 & 4.7 & 4.7438 & TRN \\
\hline
\end{tabular}




\begin{tabular}{|c|c|c|c|c|c|}
\hline \multicolumn{6}{|c|}{ Supplemental Table s2.txt } \\
\hline CHEMBL1356312 & 688549 & 4.5 & 4.5778 & TRN & \\
\hline CHEMBL1354416 & 688549 & 4.6 & 4.7618 & TRN & \\
\hline CHEMBL1208858 & 688549 & 4.5 & 5.2307 & TST & \\
\hline CHEMBL1468847 & 688549 & 4.5 & 4.9226 & TST & \\
\hline CHEMBL1476179 & 688549 & 4.9 & 4.5941 & TRN & \\
\hline CHEMBL1420628 & 688549 & 5.0 & 4.9996 & TRN & \\
\hline CHEMBL1309260 & 688549 & 5.0 & 5.1396 & TRN & \\
\hline CHEMBL1478852 & 688549 & 4.5 & 5.1508 & TRN & \\
\hline CHEMBL1572707 & 688549 & 4.8 & 5.2675 & TRN & \\
\hline CHEMBL1514097 & 688549 & 5.9 & 5.2225 & TRN & \\
\hline CHEMBL1447402 & 688549 & 4.7 & \multicolumn{2}{|c|}{4.4030000000000005} & TRN \\
\hline CHEMBL1606585 & 688549 & 4.7 & 4.8806 & TRN & \\
\hline CHEMBL1485418 & 688549 & 4.9 & 4.8094 & TRN & \\
\hline CHEMBL1414943 & 688549 & 5.4 & 5.5028 & TRN & \\
\hline CHEMBL405760 & 688549 & 4.5 & \multicolumn{2}{|c|}{5.0969999999999995} & TRN \\
\hline CHEMBL1592972 & 688549 & 4.7 & 4.5963 & TST & \\
\hline CHEMBL 1476656 & 688549 & 4.9 & 4.6991 & TRN & \\
\hline CHEMBL1529989 & 688549 & 5.1 & 5.1325 & TRN & \\
\hline CHEMBL1596486 & 688549 & 5.0 & 4.9612 & TRN & \\
\hline CHEMBL1361552 & 688549 & 4.9 & 5.0977 & TRN & \\
\hline CHEMBL1301968 & 688549 & 5.35 & 4.8484 & TRN & \\
\hline CHEMBL1491435 & 688549 & 5.4 & 5.0057 & TST & \\
\hline CHEMBL1326968 & 688549 & 4.9 & 4.8961 & TRN & \\
\hline CHEMBL1553157 & 688549 & 4.9 & 4.7748 & TRN & \\
\hline CHEMBL1531398 & 688549 & 4.5 & 5.1971 & TRN & \\
\hline CHEMBL1512190 & 688549 & 5.0 & 4.8847 & TRN & \\
\hline CHEMBL1448941 & 688549 & 4.6 & 4.8105 & TRN & \\
\hline CHEMBL1416737 & 688549 & 4.85 & 5.0154 & TRN & \\
\hline CHEMBL1430893 & 688549 & 4.9 & 4.7226 & TRN & \\
\hline CHEMBL1356025 & 688549 & 4.9 & 4.7716 & TRN & \\
\hline CHEMBL1349063 & 688549 & 6.2 & 5.6593 & TRN & \\
\hline CHEMBL1480224 & 688549 & 5.15 & 5.1454 & TRN & \\
\hline CHEMBL1398533 & 688549 & 4.9 & 4.6091 & TRN & \\
\hline CHEMBL1561807 & 688549 & 4.7 & 4.993 & TRN & \\
\hline CHEMBL1610180 & 688549 & 4.5 & 5.1608 & TRN & \\
\hline CHEMBL1542863 & 688549 & 5.9 & 4.4302 & TST & \\
\hline CHEMBL1331738 & 688549 & 4.9 & 4.7573 & TRN & \\
\hline CHEMBL1328223 & 688549 & 5.5 & 5.2344 & TRN & \\
\hline CHEMBL1593774 & 688549 & 4.5 & 4.8021 & TRN & \\
\hline CHEMBL1491228 & 688549 & 4.9 & 5.0366 & TRN & \\
\hline CHEMBL1516545 & 688549 & 4.9 & 5.5657 & TST & \\
\hline CHEMBL1448023 & 688549 & 5.0 & 4.8724 & TRN & \\
\hline CHEMBL1512706 & 688549 & 5.3 & 5.0281 & TRN & \\
\hline CHEMBL1514071 & 688549 & 4.9 & 4.7835 & TRN & \\
\hline CHEMBL1497019 & 688549 & 6.2 & 5.2236 & TRN & \\
\hline CHEMBL1415176 & 688549 & 4.5 & 4.8142 & TRN & \\
\hline CHEMBL1444724 & 688549 & 5.0 & 4.7995 & TRN & \\
\hline CHEMBL1394193 & 688549 & 4.8 & 5.0494 & TRN & \\
\hline
\end{tabular}




\begin{tabular}{|c|c|c|c|c|c|}
\hline \multicolumn{6}{|c|}{ Supplemental Table S2.txt } \\
\hline CHEMBL1529033 & 688549 & 4.9 & 5.0037 & TRN & \\
\hline CHEMBL1601474 & 688549 & 4.45 & 4.9039 & TRN & \\
\hline CHEMBL1332306 & 688549 & 4.9 & 5.2744 & TRN & \\
\hline CHEMBL1357982 & 688549 & 5.0 & $4.7410 e$ & 00000000005 & TST \\
\hline CHEMBL1323445 & 688549 & 4.9 & 4.9248 & TRN & \\
\hline CHEMBL1567235 & 688549 & 4.9 & 4.944 & TRN & \\
\hline CHEMBL1532222 & 688549 & 8.301 & 5.3716 & TRN & \\
\hline CHEMBL1384330 & 688549 & 4.5 & 4.9356 & TST & \\
\hline CHEMBL1476773 & 688549 & 4.45 & 4.7316 & TRN & \\
\hline CHEMBL1436786 & 688549 & 4.5 & 4.6308 & TST & \\
\hline CHEMBL1500421 & 688549 & 4.8 & 4.987 & TRN & \\
\hline CHEMBL1316037 & 688549 & 5.8 & 5.1369 & TRN & \\
\hline CHEMBL1375781 & 688549 & 4.8 & 5.0561 & TST & \\
\hline CHEMBL1417660 & 688549 & 4.8 & 4.6287 & TRN & \\
\hline CHEMBL1507092 & 688549 & 5.0 & 4.7476 & TRN & \\
\hline CHEMBL1602759 & 688549 & 4.9 & 4.8305 & TRN & \\
\hline CHEMBL258893 & 688549 & 5.3 & 5.0724 & TST & \\
\hline CHEMBL1515054 & 688549 & 6.3 & 5.2941 & TRN & \\
\hline CHEMBL1439644 & 688549 & 5.0 & 5.2133 & TRN & \\
\hline CHEMBL1538584 & 688549 & 7.8996 & 5.5866 & TST & \\
\hline CHEMBL1593915 & 688549 & 4.7 & 5.0665 & TRN & \\
\hline CHEMBL123 & 688549 & 6.0 & 5.4777 & TST & \\
\hline CHEMBL1427909 & 688549 & 4.7 & 5.0804 & TRN & \\
\hline CHEMBL1445555 & 688549 & 8.4949 & 5.0534 & TST & \\
\hline CHEMBL1512997 & 688549 & 4.5 & 5.0465 & TRN & \\
\hline CHEMBL1333339 & 688549 & 5.0 & 5.3072 & TRN & \\
\hline CHEMBL1367788 & 688549 & 4.9 & 5.1193 & TRN & \\
\hline CHEMBL85194 & 688549 & 4.6 & 4.7587 & TRN & \\
\hline CHEMBL1555613 & 688549 & 4.95 & 4.9959 & TRN & \\
\hline CHEMBL1359868 & 688549 & 4.9 & 4.7561 & TRN & \\
\hline CHEMBL1506407 & 688549 & 5.0 & 5.102 & TRN & \\
\hline CHEMBL1574845 & 688549 & 4.8 & 5.1548 & TRN & \\
\hline CHEMBL1531320 & 688549 & 5.0 & 5.3433 & TRN & \\
\hline CHEMBL1354381 & 688549 & 4.45 & 4.8799 & TRN & \\
\hline CHEMBL1530307 & 688549 & 7.699 & 5.314 & TRN & \\
\hline CHEMBL1409836 & 688549 & 4.9 & 5.1001 & TRN & \\
\hline CHEMBL1436405 & 688549 & 4.9 & 4.6094 & TRN & \\
\hline CHEMBL1611513 & 688549 & 4.7 & 4.4007 & TRN & \\
\hline CHEMBL1552968 & 688549 & 4.9 & 5.1195 & TRN & \\
\hline CHEMBL1555342 & 688549 & 4.85 & 5.37299 & 9999999999 & TRN \\
\hline CHEMBL1521563 & 688549 & 4.9 & 4.8893 & TRN & \\
\hline CHEMBL34450 & 688549 & 4.6 & 5.0633 & TST & \\
\hline CHEMBL1317719 & 688549 & 4.7 & 4.8514 & TST & \\
\hline CHEMBL117966 & 688549 & 6.05 & 5.2213 & TRN & \\
\hline CHEMBL1368675 & 688549 & 5.0 & 5.2695 & TRN & \\
\hline CHEMBL1322995 & 688549 & 4.8 & 4.5718 & TRN & \\
\hline CHEMBL1590606 & 688549 & 4.8 & 5.7456 & TRN & \\
\hline CHEMBL1576580 & 688549 & 4.5 & 4.8286 & TRN & \\
\hline
\end{tabular}




\begin{tabular}{|c|c|c|c|c|c|}
\hline & & \multicolumn{4}{|c|}{ Supplemental Table S2.txt } \\
\hline CHEMBL1375273 & 688549 & 5.1 & 4.9391 & TRN & \\
\hline CHEMBL1337816 & 688549 & 4.8 & 4.7567 & TRN & \\
\hline CHEMBL1314857 & 688549 & 4.8 & 5.0944 & TRN & \\
\hline CHEMBL1513957 & 688549 & 4.6 & 4.5305 & TST & \\
\hline CHEMBL1593674 & 688549 & 4.7 & 4.5775 & TST & \\
\hline CHEMBL554041 & 688549 & 4.8 & 5.5886 & TST & \\
\hline CHEMBL1555873 & 688549 & 5.2 & 4.8651 & TRN & \\
\hline CHEMBL428258 & 688549 & 4.6 & 5.1557 & TRN & \\
\hline CHEMBL1314527 & 688549 & 4.65 & 4.2987 & TRN & \\
\hline CHEMBL1355964 & 688549 & 5.45 & 4.9435 & TRN & \\
\hline CHEMBL1320607 & 688549 & 4.9 & 5.1749 & TRN & \\
\hline CHEMBL1609743 & 688549 & 4.8 & 5.0337 & TRN & \\
\hline CHEMBL1388233 & 688549 & 4.9 & 4.937 & TRN & \\
\hline CHEMBL1360895 & 688549 & 4.7 & 5.3026 & TRN & \\
\hline CHEMBL1394547 & 688549 & 4.5 & 5.2873 & TRN & \\
\hline CHEMBL405317 & 688549 & 5.8 & 5.7393 & TRN & \\
\hline CHEMBL1563821 & 688549 & 4.45 & 4.8827 & TRN & \\
\hline CHEMBL1518016 & 688549 & 5.0 & 4.97199 & 99999999995 & TRN \\
\hline CHEMBL3194991 & 688549 & 4.95 & 4.9821 & TRN & \\
\hline CHEMBL1436726 & 688549 & 4.5 & 5.61600 & 00000000005 & TST \\
\hline CHEMBL1593522 & 688549 & 4.45 & 4.7798 & TRN & \\
\hline CHEMBL1561128 & 688549 & 4.9 & 4.9266 & TRN & \\
\hline CHEMBL375126 & 688549 & 4.8 & 4.993 & TST & \\
\hline CHEMBL1342911 & 688549 & 4.7 & 4.9784 & TRN & \\
\hline CHEMBL1604166 & 688549 & 5.0 & 5.0863 & TRN & \\
\hline CHEMBL1411492 & 688549 & 4.5 & 4.8589 & TRN & \\
\hline CHEMBL441282 & 688549 & 4.5 & 4.5664 & TRN & \\
\hline CHEMBL1446548 & 688549 & 4.5 & 4.5785 & TRN & \\
\hline CHEMBL1533477 & 688549 & 4.9 & 5.3231 & TRN & \\
\hline CHEMBL 3192555 & 688549 & 5.5 & 5.3436 & TST & \\
\hline CHEMBL1351707 & 688549 & 4.7 & 5.0785 & TRN & \\
\hline CHEMBL1415527 & 688549 & 5.1 & 5.0306 & TRN & \\
\hline CHEMBL1423121 & 688549 & 4.7 & 5.1001 & TRN & \\
\hline CHEMBL1356104 & 688549 & 5.2 & 5.4355 & TRN & \\
\hline CHEMBL1363516 & 688549 & 4.6 & 4.7249 & TRN & \\
\hline CHEMBL1330978 & 688549 & 5.45 & 5.4997 & TRN & \\
\hline CHEMBL1526702 & 688549 & 4.6 & 5.1662 & TRN & \\
\hline CHEMBL1613230 & 688549 & 4.6 & 4.5314 & TRN & \\
\hline CHEMBL1520422 & 688549 & 4.8 & 5.2597 & TST & \\
\hline CHEMBL1592458 & 688549 & 4.7 & 4.502 & TRN & \\
\hline CHEMBL1309655 & 688549 & 5.0 & 4.9213 & TRN & \\
\hline CHEMBL1526148 & 688549 & 4.5 & 4.6466 & TRN & \\
\hline CHEMBL1421398 & 688549 & 5.1 & 4.9925 & TRN & \\
\hline CHEMBL1500986 & 688549 & 5.0 & 4.9242 & TRN & \\
\hline CHEMBL1412556 & 688549 & 4.9 & 5.249 & TRN & \\
\hline CHEMBL1552414 & 688549 & 4.95 & 4.6551 & TRN & \\
\hline CHEMBL1455996 & 688549 & 4.9 & 5.0101 & TRN & \\
\hline CHEMBL1355216 & 688549 & 4.9 & 5.3256 & TST & \\
\hline
\end{tabular}




\begin{tabular}{|c|c|c|c|c|c|}
\hline \multicolumn{6}{|c|}{ Supplemental Table S2.txt } \\
\hline CHEMBL1336155 & 688549 & 5.4 & 5.5532 & TST & \\
\hline CHEMBL1471358 & 688549 & 4.5 & 5.0211 & TRN & \\
\hline CHEMBL597035 & 688549 & 4.6 & 4.9347 & TST & \\
\hline CHEMBL1496471 & 688549 & 6.8 & 5.3971 & TRN & \\
\hline CHEMBL1562298 & 688549 & 4.7 & 5.0947 & TRN & \\
\hline CHEMBL1455689 & 688549 & 5.1 & 4.7717 & TRN & \\
\hline CHEMBL1313788 & 688549 & 4.9 & 5.19600 & 0000000001 & TRN \\
\hline CHEMBL1479215 & 688549 & 5.6 & 5.3708 & TST & \\
\hline CHEMBL1401679 & 688549 & 4.5 & 5.2259 & TRN & \\
\hline CHEMBL1379048 & 688549 & 4.5 & 5.0568 & TST & \\
\hline CHEMBL1514379 & 688549 & 4.9 & 4.7713 & TRN & \\
\hline CHEMBL1392905 & 688549 & 4.5 & 4.907 & TRN & \\
\hline CHEMBL1332709 & 688549 & 6.0 & 5.186 & TRN & \\
\hline CHEMBL3214154 & 688549 & 8.0 & 5.2931 & TRN & \\
\hline CHEMBL1500474 & 688549 & 4.9 & 4.7385 & TRN & \\
\hline CHEMBL1602693 & 688549 & 4.5 & 5.0081 & TST & \\
\hline CHEMBL1520905 & 688549 & 4.5 & 4.8433 & TRN & \\
\hline CHEMBL1490987 & 688549 & 4.6 & 4.4102 & TRN & \\
\hline CHEMBL1602649 & 688549 & 4.5 & 4.7159 & TRN & \\
\hline CHEMBL 29878 & 688549 & 7.3002 & 4.9127 & TRN & \\
\hline CHEMBL1587568 & 688549 & 4.9 & 5.1412 & TRN & \\
\hline CHEMBL1551751 & 688549 & 4.45 & 4.9617 & TRN & \\
\hline CHEMBL1518540 & 688549 & 4.6 & 5.1184 & TRN & \\
\hline CHEMBL3210869 & 688549 & 4.9 & 5.3648 & TST & \\
\hline CHEMBL1333387 & 688549 & 4.8 & 5.0077 & TRN & \\
\hline CHEMBL1560956 & 688549 & 4.9 & 4.9176 & TRN & \\
\hline CHEMBL1518691 & 688549 & 6.4 & 4.9883 & TRN & \\
\hline CHEMBL1400731 & 688549 & 4.6 & 4.8204 & TRN & \\
\hline CHEMBL1524101 & 688549 & 6.8 & 4.7526 & TST & \\
\hline CHEMBL1386456 & 688549 & 4.9 & 4.4203 & TRN & \\
\hline CHEMBL1471899 & 688549 & 5.4 & 5.0515 & TRN & \\
\hline CHEMBL1557820 & 688549 & 4.8 & 4.5085 & TST & \\
\hline CHEMBL1517187 & 688549 & 4.6 & 5.3089 & TST & \\
\hline CHEMBL1304513 & 688549 & 7.8013 & 4.7872 & TRN & \\
\hline CHEMBL1557947 & 688549 & 4.45 & 4.5921 & TRN & \\
\hline CHEMBL1544093 & 688549 & 4.5 & 4.6256 & TRN & \\
\hline CHEMBL1516388 & 688549 & 4.7 & 5.6704 & TST & \\
\hline CHEMBL1439176 & 688549 & 6.4 & 5.4485 & TST & \\
\hline CHEMBL1320917 & 688549 & 5.4 & 4.7834 & TRN & \\
\hline CHEMBL1336482 & 688549 & 4.7 & 4.89199 & 99999999995 & TRN \\
\hline CHEMBL1475346 & 688549 & 4.5 & 4.3264 & TRN & \\
\hline CHEMBL1404118 & 688549 & 4.8 & 4.9357 & TRN & \\
\hline CHEMBL1342753 & 688549 & 4.45 & 5.2051 & TRN & \\
\hline CHEMBL1403123 & 688549 & 4.45 & 5.0424 & TRN & \\
\hline CHEMBL1518774 & 688549 & 4.9 & 5.1657 & TRN & \\
\hline CHEMBL1405806 & 688549 & 4.9 & 5.1442 & TRN & \\
\hline CHEMBL3212912 & 688549 & 4.8 & 4.87 & TST & \\
\hline CHEMBL1489769 & 688549 & 4.9 & 5.5368 & TST & \\
\hline
\end{tabular}




\begin{tabular}{|c|c|c|c|c|c|}
\hline \multicolumn{6}{|c|}{ Supplemental Table S2.txt } \\
\hline CHEMBL1554727 & 688549 & 4.9 & 5.2133 & TRN & \\
\hline CHEMBL1389449 & 688549 & 4.8 & 4.8709 & TRN & \\
\hline CHEMBL1441891 & 688549 & 4.6 & 4.885 & TRN & \\
\hline CHEMBL1547108 & 688549 & 5.0 & 5.3043 & TRN & \\
\hline CHEMBL1474403 & 688549 & 5.6 & 5.2478 & TRN & \\
\hline CHEMBL1334170 & 688549 & 4.8 & 4.7918 & TST & \\
\hline CHEMBL1604458 & 688549 & 7.8013 & 5.7382 & TST & \\
\hline CHEMBL1551874 & 688549 & 4.9 & 4.4938 & TRN & \\
\hline CHEMBL1478691 & 688549 & 5.1 & 5.15799 & 99999999995 & TRN \\
\hline CHEMBL1299403 & 688549 & 5.0 & 5.1562 & TRN & \\
\hline CHEMBL1487634 & 688549 & 4.5 & 4.5461 & TRN & \\
\hline CHEMBL1456514 & 688549 & 4.7 & 5.1384 & TRN & \\
\hline CHEMBL1560213 & 688549 & 4.7 & 5.0194 & TRN & \\
\hline CHEMBL1591231 & 688549 & 4.6 & 4.5637 & TRN & \\
\hline CHEMBL1456079 & 688549 & 4.6 & 4.8542 & TRN & \\
\hline CHEMBL1315457 & 688549 & 4.5 & 5.2912 & TST & \\
\hline CHEMBL1488499 & 688549 & 5.3 & 4.6672 & TRN & \\
\hline CHEMBL1551349 & 688549 & 4.5 & 4.6612 & TRN & \\
\hline CHEMBL1362727 & 688549 & 4.7 & 4.8713 & TRN & \\
\hline CHEMBL1531927 & 688549 & 4.8 & 5.1039 & TRN & \\
\hline CHEMBL1397447 & 688549 & 4.6 & 5.14 & TRN & \\
\hline CHEMBL3209431 & 688549 & 7.699 & 5.1626 & TST & \\
\hline CHEMBL1592366 & 688549 & 4.5 & 5.5742 & TRN & \\
\hline CHEMBL1381662 & 688549 & 8.301 & 5.1655 & TST & \\
\hline CHEMBL1442840 & 688549 & 4.8 & 5.206 & TRN & \\
\hline CHEMBL1437612 & 688549 & 4.6 & 4.6832 & TST & \\
\hline CHEMBL1553108 & 688549 & 4.6 & 4.7553 & TRN & \\
\hline CHEMBL1557378 & 688549 & 4.6 & 4.9207 & TRN & \\
\hline CHEMBL1555336 & 688549 & 4.85 & 4.6263 & TRN & \\
\hline CHEMBL1566498 & 688549 & 5.7 & 5.6969 & TRN & \\
\hline CHEMBL1493785 & 688549 & 5.0 & 5.3343 & TRN & \\
\hline CHEMBL1456663 & 688549 & 7.1002 & 5.1275 & TST & \\
\hline CHEMBL1373783 & 688549 & 4.9 & 4.9446 & TRN & \\
\hline CHEMBL1584661 & 688549 & 5.0 & 5.0129 & TRN & \\
\hline CHEMBL1454612 & 688549 & 4.5 & 5.2165 & TRN & \\
\hline CHEMBL1377784 & 688549 & 5.0 & 5.1472 & TRN & \\
\hline CHEMBL1387610 & 688549 & 6.2 & 5.4815 & TRN & \\
\hline CHEMBL1445286 & 688549 & 4.8 & 5.1328 & TRN & \\
\hline CHEMBL1464144 & 688549 & 5.1 & 5.1561 & TRN & \\
\hline CHEMBL1403263 & 688549 & 4.5 & 5.1551 & TRN & \\
\hline CHEMBL1458074 & 688549 & 5.0 & 4.7868 & TRN & \\
\hline CHEMBL1454544 & 688549 & 5.0 & 4.7084 & TRN & \\
\hline CHEMBL1476964 & 688549 & 4.5 & 4.5536 & TST & \\
\hline CHEMBL1488685 & 688549 & 4.85 & 4.7763 & TRN & \\
\hline CHEMBL1384832 & 688549 & 4.8 & 5.2558 & TRN & \\
\hline CHEMBL1330071 & 688549 & 4.9 & 5.4165 & TRN & \\
\hline CHEMBL1573861 & 688549 & 4.9 & 5.2116 & TRN & \\
\hline CHEMBL1592400 & 688549 & 4.45 & 4.7057 & TRN & \\
\hline
\end{tabular}




\begin{tabular}{|c|c|c|c|c|}
\hline \multicolumn{5}{|c|}{ Supplemental Table S2.txt } \\
\hline CHEMBL1493037 & 688549 & 4.6 & 4.7495 & TST \\
\hline CHEMBL1301287 & 688549 & 5.5 & 5.3101 & TRN \\
\hline CHEMBL1335327 & 688549 & 4.6 & 4.8785 & TRN \\
\hline CHEMBL1392208 & 688549 & 4.8 & 5.0222 & TRN \\
\hline CHEMBL1352741 & 688549 & 5.6 & 5.1303 & TRN \\
\hline CHEMBL1473362 & 688549 & 4.8 & 5.0198 & TRN \\
\hline CHEMBL1323139 & 688549 & 4.8 & 5.0101 & TST \\
\hline CHEMBL1505809 & 688549 & 5.1 & 5.0208 & TRN \\
\hline CHEMBL1316550 & 688549 & 5.0 & 4.6932 & TRN \\
\hline CHEMBL1377287 & 688549 & 4.9 & 4.8765 & TRN \\
\hline CHEMBL1394209 & 688549 & 4.9 & 4.4848 & TRN \\
\hline CHEMBL1512208 & 688549 & 4.5 & 4.9116 & TST \\
\hline CHEMBL1466730 & 688549 & 6.45 & 5.0307 & TST \\
\hline CHEMBL1428003 & 688549 & 4.75 & 4.547 & TRN \\
\hline CHEMBL1598627 & 688549 & 5.5 & 5.7409 & TRN \\
\hline CHEMBL587849 & 688549 & 5.4 & 5.2785 & TST \\
\hline CHEMBL1340343 & 688549 & 4.5 & 5.3264 & TRN \\
\hline CHEMBL1433666 & 688549 & 4.9 & 4.7529 & TRN \\
\hline CHEMBL1568287 & 688549 & 4.8 & 4.6889 & TRN \\
\hline CHEMBL1387673 & 688549 & 4.5 & 5.1697 & TRN \\
\hline CHEMBL1476215 & 688549 & 4.65 & 5.3466 & TRN \\
\hline CHEMBL1583267 & 688549 & 5.1 & 4.9757 & TRN \\
\hline CHEMBL1398721 & 688549 & 4.9 & 4.5876 & TRN \\
\hline CHEMBL1551719 & 688549 & 4.5 & 4.6327 & TRN \\
\hline CHEMBL1401545 & 688549 & 5.0 & 5.2003 & TRN \\
\hline CHEMBL1356126 & 688549 & 4.9 & 5.048 & TRN \\
\hline CHEMBL1356580 & 688549 & 4.9 & 5.0805 & TRN \\
\hline CHEMBL1354867 & 688549 & 4.5 & 5.1569 & TRN \\
\hline CHEMBL 3145245 & 688549 & 4.45 & 6.0029 & TRN \\
\hline CHEMBL1490146 & 688549 & 4.8 & 4.9704 & TRN \\
\hline CHEMBL1396242 & 688549 & 4.8 & 4.7817 & TRN \\
\hline CHEMBL296586 & 688549 & 4.5 & 5.1062 & TST \\
\hline CHEMBL1355230 & 688549 & 4.9 & 4.9585 & TRN \\
\hline CHEMBL1594135 & 688549 & 4.7 & 4.3758 & TRN \\
\hline CHEMBL1428325 & 688549 & 4.9 & 4.9195 & TRN \\
\hline CHEMBL1552965 & 688549 & 4.5 & 5.0499 & TRN \\
\hline CHEMBL1445650 & 688549 & 5.35 & 5.0391 & TRN \\
\hline CHEMBL582444 & 688549 & 4.9 & 5.1205 & TST \\
\hline CHEMBL1312478 & 688549 & 4.9 & 4.8882 & TRN \\
\hline CHEMBL1574816 & 688549 & 4.9 & 4.3297 & TRN \\
\hline CHEMBL1300475 & 688549 & 7.6003 & 5.432 & TST \\
\hline CHEMBL1557753 & 688549 & 4.65 & 5.2064 & TRN \\
\hline CHEMBL1375367 & 688549 & 5.0 & 4.4393 & TRN \\
\hline CHEMBL1474791 & 688549 & 4.9 & 4.8689 & TRN \\
\hline CHEMBL1411473 & 688549 & 4.9 & 4.6886 & TRN \\
\hline CHEMBL1373287 & 688549 & 4.7 & 4.8349 & TST \\
\hline CHEMBL1389037 & 688549 & 4.9 & 4.8654 & TRN \\
\hline CHEMBL1553367 & 688549 & 5.4 & 5.2441 & TST \\
\hline
\end{tabular}




\begin{tabular}{|c|c|c|c|c|c|}
\hline \\
\hline CHEMBL1409293 & 688549 & 4.5 & 4.5989 & TRN & \\
\hline CHEMBL1522114 & 688549 & 5.0 & 4.7959 & TRN & \\
\hline CHEMBL1325376 & 688549 & 4.5 & 4.747 & TRN & \\
\hline CHEMBL1371030 & 688549 & 5.45 & 5.7942 & TRN & \\
\hline CHEMBL265686 & 688549 & 6.5 & 5.6634 & TRN & \\
\hline CHEMBL1592540 & 688549 & 5.5 & 5.19 & TRN & \\
\hline CHEMBL1439014 & 688549 & 4.9 & 4.7076 & TRN & \\
\hline CHEMBL1365104 & 688549 & 4.8 & 4.5202 & TRN & \\
\hline CHEMBL1397876 & 688549 & 4.7 & 5.0251 & TRN & \\
\hline CHEMBL1492074 & 688549 & 4.6 & 4.7168 & TRN & \\
\hline CHEMBL1522038 & 688549 & 4.5 & 4.9089 & TRN & \\
\hline CHEMBL1554496 & 688549 & 4.8 & 5.4073 & TST & \\
\hline CHEMBL1541834 & 688549 & 4.9 & 5.2721 & TRN & \\
\hline CHEMBL1437749 & 688549 & 5.45 & 5.1885 & TRN & \\
\hline CHEMBL1415806 & 688549 & 4.45 & 5.2443 & TRN & \\
\hline CHEMBL1568805 & 688549 & 4.5 & 4.9691 & TRN & \\
\hline CHEMBL1368942 & 688549 & 4.7 & 4.926 & TST & \\
\hline CHEMBL1540682 & 688549 & 5.4 & 4.8816 & TST & \\
\hline CHEMBL75267 & 688549 & 4.9 & 5.0028 & TRN & \\
\hline CHEMBL1360786 & 688549 & 4.5 & 4.4502 & TRN & \\
\hline CHEMBL1435853 & 688549 & 5.4 & 5.231 & TRN & \\
\hline CHEMBL1606319 & 688549 & 4.9 & 5.0388 & TRN & \\
\hline CHEMBL1375580 & 688549 & 4.9 & 5.5339 & TRN & \\
\hline CHEMBL1438256 & 688549 & 4.7 & 4.8505 & TRN & \\
\hline CHEMBL310798 & 688549 & 4.5 & 4.9829 & TST & \\
\hline CHEMBL1495688 & 688549 & 5.5 & 5.211 & TRN & \\
\hline CHEMBL578636 & 688549 & 4.9 & 4.7671 & TRN & \\
\hline CHEMBL1366321 & 688549 & 4.9 & 5.0432 & TRN & \\
\hline CHEMBL1519404 & 688549 & 4.8 & 4.7957 & TRN & \\
\hline CHEMBL1475369 & 688549 & 5.0 & 4.7229 & TRN & \\
\hline CHEMBL1555009 & 688549 & 4.7 & 4.7287 & TRN & \\
\hline CHEMBL1315325 & 688549 & 5.25 & 4.5931 & TRN & \\
\hline CHEMBL1330639 & 688549 & 5.25 & 5.3943 & TST & \\
\hline CHEMBL1574969 & 688549 & 5.5 & 5.1512 & TRN & \\
\hline CHEMBL1594065 & 688549 & 5.5 & 4.7138 & TRN & \\
\hline CHEMBL1588968 & 688549 & 4.7 & 4.8538 & TRN & \\
\hline CHEMBL1394662 & 688549 & 4.85 & 5.0323 & TRN & \\
\hline CHEMBL1368573 & 688549 & 5.3 & 5.06806 & 20000000005 & TRN \\
\hline CHEMBL1370071 & 688549 & 5.4 & 5.0466 & TRN & \\
\hline CHEMBL1413124 & 688549 & 4.9 & 4.8364 & TRN & \\
\hline CHEMBL1576508 & 688549 & 5.0 & 5.21 & TST & \\
\hline CHEMBL1552571 & 688549 & 5.0 & 5.2606 & TRN & \\
\hline CHEMBL1590235 & 688549 & 5.5 & 4.7649 & TRN & \\
\hline CHEMBL1255936 & 688549 & 4.9 & 5.0475 & TST & \\
\hline CHEMBL1412795 & 688549 & 4.9 & 5.0871 & TRN & \\
\hline CHEMBL1300237 & 688549 & 4.9 & 5.0394 & TRN & \\
\hline CHEMBL1453291 & 688549 & 4.9 & 5.3165 & TRN & \\
\hline CHEMBL1551677 & 688549 & 4.5 & 5.078 & TRN & \\
\hline & & & & 23051 & \\
\hline
\end{tabular}




\begin{tabular}{|c|c|c|c|c|}
\hline \multicolumn{5}{|c|}{ lemental T } \\
\hline CHEMBL1564477 & 688549 & 4.6 & 4.9849 & TRN \\
\hline CHEMBL1434127 & 688549 & 5.1 & 4.8816 & TRN \\
\hline CHEMBL1585521 & 688549 & 5.0 & 4.9422 & TRN \\
\hline CHEMBL1356424 & 688549 & 4.5 & 4.4346 & TRN \\
\hline CHEMBL1461275 & 688549 & 5.0 & 5.5024 & TRN \\
\hline CHEMBL1356771 & 688549 & 4.6 & 4.5788 & TRN \\
\hline CHEMBL1410491 & 688549 & 4.9 & 5.0925 & TST \\
\hline CHEMBL1533566 & 688549 & 5.0 & 4.8723 & TRN \\
\hline CHEMBL1373090 & 688549 & 4.45 & 5.1669 & TRN \\
\hline CHEMBL1516339 & 688549 & 6.0 & 5.5105 & TRN \\
\hline CHEMBL1552299 & 688549 & 5.4 & 5.1985 & TRN \\
\hline CHEMBL1546623 & 688549 & 4.7 & 4.9212 & TRN \\
\hline CHEMBL1366544 & 688549 & 5.0 & 5.2949 & TST \\
\hline CHEMBL1491541 & 688549 & 4.5 & 5.029 & TRN \\
\hline CHEMBL1495412 & 688549 & 4.55 & 5.5577 & TST \\
\hline CHEMBL1563727 & 688549 & 4.8 & 5.0989 & TRN \\
\hline CHEMBL233194 & 688549 & 5.05 & 5.2331 & TRN \\
\hline CHEMBL1415790 & 688549 & 4.9 & 5.0579 & TRN \\
\hline CHEMBL1516925 & 688549 & 4.9 & 4.8761 & TRN \\
\hline CHEMBL1529092 & 688549 & 5.1 & 5.0085 & TRN \\
\hline CHEMBL1597445 & 688549 & 4.7 & 5.1487 & TST \\
\hline CHEMBL1613650 & 688549 & 4.5 & 5.5573 & TRN \\
\hline CHEMBL1473246 & 688549 & 4.8 & 4.9908 & TRN \\
\hline CHEMBL 236614 & 688549 & 4.9 & 5.0264 & TRN \\
\hline CHEMBL1397609 & 688549 & 4.5 & 4.9074 & TST \\
\hline CHEMBL1508424 & 688549 & 4.9 & 5.3176 & TRN \\
\hline CHEMBL539648 & 688549 & 8.1024 & 5.4001 & TST \\
\hline CHEMBL1299529 & 688549 & 4.7 & 5.1926 & TRN \\
\hline CHEMBL1600964 & 688549 & 4.95 & 4.827 & TRN \\
\hline CHEMBL1573026 & 688549 & 6.4 & 5.1355 & TST \\
\hline CHEMBL1395862 & 688549 & 5.0 & 5.1696 & TRN \\
\hline CHEMBL1355201 & 688549 & 4.8 & 4.6311 & TRN \\
\hline CHEMBL 1435450 & 688549 & 4.5 & 4.9068 & TRN \\
\hline CHEMBL1502512 & 688549 & 4.6 & 4.3833 & TST \\
\hline CHEMBL1342109 & 688549 & 4.9 & 4.6257 & TRN \\
\hline CHEMBL1358801 & 688549 & 4.9 & 4.8403 & TRN \\
\hline CHEMBL1556227 & 688549 & 4.5 & 4.8537 & TRN \\
\hline CHEMBL1405454 & 688549 & 4.9 & 5.2324 & TRN \\
\hline CHEMBL429023 & 688549 & 4.9 & 5.5022 & TRN \\
\hline CHEMBL1524206 & 688549 & 6.35 & 5.2205 & TRN \\
\hline CHEMBL1445486 & 688549 & 4.9 & 4.7132 & TRN \\
\hline CHEMBL1482365 & 688549 & 4.8 & 4.9311 & TRN \\
\hline CHEMBL1504969 & 688549 & 4.5 & 5.3742 & TST \\
\hline CHEMBL1562057 & 688549 & 4.5 & 5.2607 & TST \\
\hline CHEMBL1528196 & 688549 & 5.5 & 5.5633 & TRN \\
\hline CHEMBL1313548 & 688549 & 4.7 & 4.9497 & TRN \\
\hline CHEMBL1427801 & 688549 & 5.25 & 5.631 & TRN \\
\hline CHEMBL1381824 & 688549 & 5.1 & 4.9541 & TRN \\
\hline
\end{tabular}




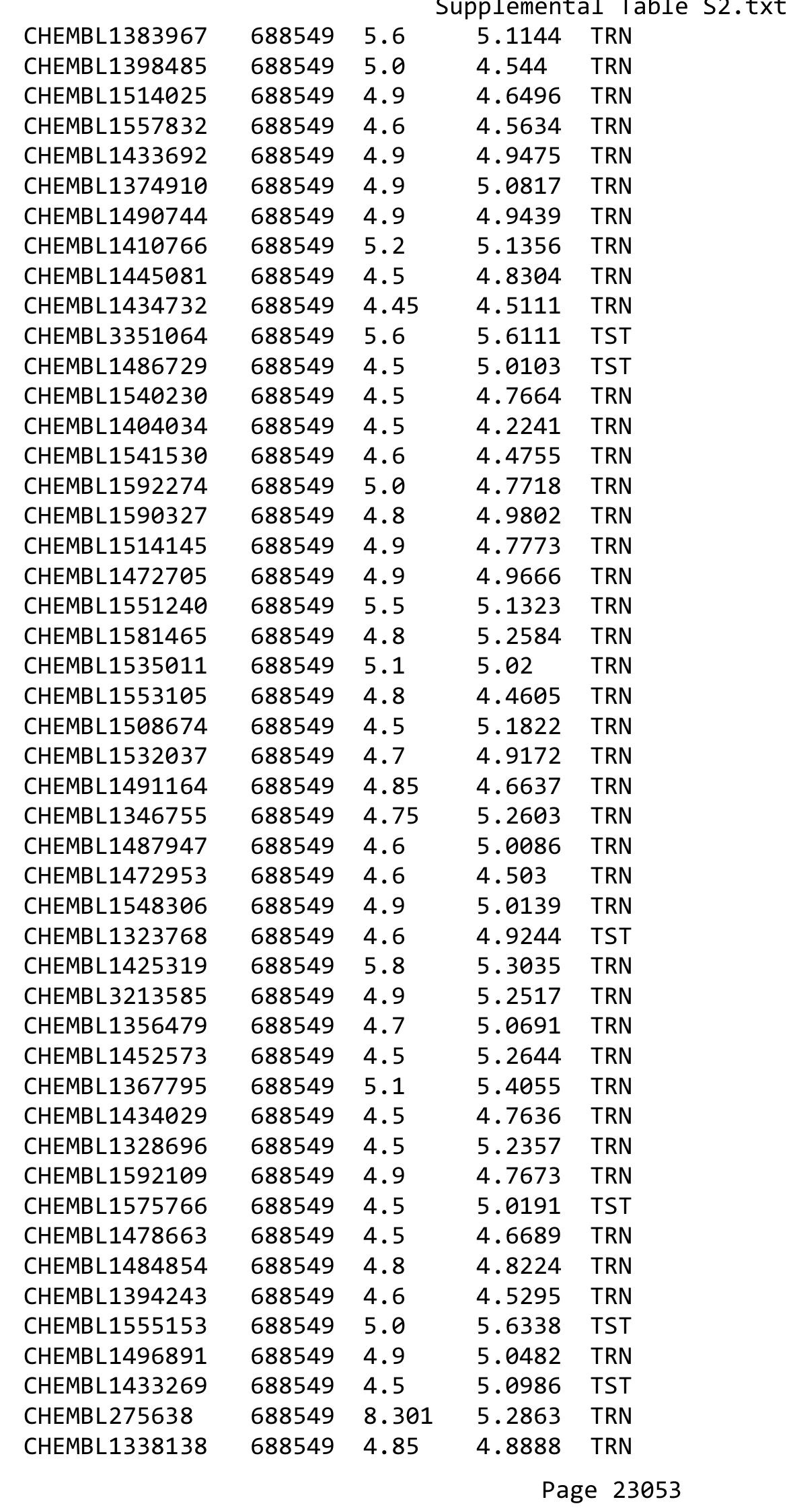




\begin{tabular}{|c|c|c|c|c|c|}
\hline \\
\hline CHEMBL407864 & 688549 & 4.9 & 5.0636 & TRN & \\
\hline CHEMBL1528453 & 688549 & 4.9 & 5.1052 & TRN & \\
\hline CHEMBL1579151 & 688549 & 4.9 & 5.2138 & TST & \\
\hline CHEMBL1475327 & 688549 & 4.6 & 4.7078 & TRN & \\
\hline CHEMBL 2374027 & 688549 & 4.9 & 5.1402 & TST & \\
\hline CHEMBL1475922 & 688549 & 4.7 & 4.887 & TRN & \\
\hline CHEMBL1520944 & 688549 & 5.1 & 4.9551 & TRN & \\
\hline CHEMBL1477778 & 688549 & 4.6 & 4.5148 & TRN & \\
\hline CHEMBL1591942 & 688549 & 4.5 & 4.8385 & TRN & \\
\hline CHEMBL1477819 & 688549 & 4.6 & 4.5508 & TRN & \\
\hline CHEMBL1528247 & 688549 & 5.0 & 4.8494 & TRN & \\
\hline CHEMBL1320569 & 688549 & 5.0 & 4.9971 & TST & \\
\hline CHEMBL1451153 & 688549 & 5.5 & 5.1205 & TRN & \\
\hline CHEMBL1437388 & 688549 & 4.5 & 4.7377 & TRN & \\
\hline CHEMBL1358196 & 688549 & 5.2 & 5.4938 & TRN & \\
\hline CHEMBL1400126 & 688549 & 4.7 & 5.3526 & TRN & \\
\hline CHEMBL1570711 & 688549 & 4.7 & 4.9147 & TRN & \\
\hline CHEMBL1385176 & 688549 & 4.9 & 5.1891 & TRN & \\
\hline CHEMBL1372701 & 688549 & 4.8 & 5.0542 & TRN & \\
\hline CHEMBL1559814 & 688549 & 6.8 & 5.586 & TRN & \\
\hline CHEMBL1612696 & 688549 & 4.6 & 4.8755 & TRN & \\
\hline CHEMBL1482420 & 688549 & 4.45 & 4.961 & TRN & \\
\hline CHEMBL1531863 & 688549 & 8.1024 & 5.3926 & TST & \\
\hline CHEMBL1333156 & 688549 & 4.9 & 4.7349 & TRN & \\
\hline CHEMBL1332346 & 688549 & 4.7 & 4.8515 & TST & \\
\hline CHEMBL1557392 & 688549 & 4.5 & 4.8529 & TRN & \\
\hline CHEMBL1314798 & 688549 & 4.45 & 5.3293 & TRN & \\
\hline CHEMBL1592596 & 688549 & 5.65 & 5.4327 & TRN & \\
\hline CHEMBL1567790 & 688549 & 4.65 & 4.6909 & TRN & \\
\hline CHEMBL1411594 & 688549 & 4.9 & 4.7789 & TRN & \\
\hline CHEMBL1338800 & 688549 & 5.0 & 4.9823 & TRN & \\
\hline CHEMBL1327810 & 688549 & 4.9 & 4.77800 & 00000000005 & TRN \\
\hline CHEMBL515505 & 688549 & 5.3 & 5.4829 & TST & \\
\hline CHEMBL1539765 & 688549 & 4.5 & 5.0758 & TST & \\
\hline CHEMBL1435212 & 688549 & 5.0 & 5.1108 & TRN & \\
\hline CHEMBL1577459 & 688549 & 4.9 & 4.9041 & TRN & \\
\hline CHEMBL536950 & 688549 & 4.6 & 5.1381 & TST & \\
\hline CHEMBL1473452 & 688549 & 5.35 & 5.1602 & TRN & \\
\hline CHEMBL 2373615 & 688549 & 5.3 & 5.2646 & TST & \\
\hline CHEMBL1432063 & 688549 & 5.0 & 4.8522 & TRN & \\
\hline CHEMBL1566838 & 688549 & 5.3 & 5.1378 & TRN & \\
\hline CHEMBL1309430 & 688549 & 4.6 & 5.3404 & TRN & \\
\hline CHEMBL1568359 & 688549 & 4.7 & 5.1861 & TRN & \\
\hline CHEMBL1538973 & 688549 & 4.6 & 5.0809 & TRN & \\
\hline CHEMBL1389304 & 688549 & 4.8 & 5.0404 & TRN & \\
\hline CHEMBL1515664 & 688549 & 4.6 & 4.6 & TRN & \\
\hline CHEMBL1456099 & 688549 & 5.0 & 5.0629 & TRN & \\
\hline CHEMBL1447960 & 688549 & 4.5 & 4.9799 & TRN & \\
\hline
\end{tabular}




\begin{tabular}{|c|c|c|c|c|c|}
\hline \multicolumn{6}{|c|}{ Supplemental Table S2.txt } \\
\hline CHEMBL1521069 & 688549 & 4.5 & 5.2012 & TST & \\
\hline CHEMBL1452710 & 688549 & 4.5 & 5.0008 & TRN & \\
\hline CHEMBL1594015 & 688549 & 4.5 & 4.8115 & TRN & \\
\hline CHEMBL1584502 & 688549 & 4.5 & 4.9685 & TRN & \\
\hline CHEMBL1498728 & 688549 & 5.0 & 5.4929 & TRN & \\
\hline CHEMBL1553046 & 688549 & 4.5 & 4.5659 & TRN & \\
\hline CHEMBL1534435 & 688549 & 4.85 & 5.3493 & TST & \\
\hline CHEMBL1489306 & 688549 & 4.5 & 4.8337 & TRN & \\
\hline CHEMBL1555658 & 688549 & 4.6 & 4.8194 & TRN & \\
\hline CHEMBL1319214 & 688549 & 4.8 & 4.966 & TST & \\
\hline CHEMBL1473004 & 688549 & 4.6 & 4.8199 & TRN & \\
\hline CHEMBL1519624 & 688549 & 4.5 & 5.0108 & TRN & \\
\hline CHEMBL1567904 & 688549 & 4.45 & 4.5324 & TRN & \\
\hline CHEMBL1593631 & 688549 & 4.6 & 5.506 & TRN & \\
\hline CHEMBL1418013 & 688549 & 5.1 & 5.3395 & TRN & \\
\hline CHEMBL1437584 & 688549 & 4.9 & 5.4196 & TRN & \\
\hline CHEMBL1408476 & 688549 & 4.9 & 4.9433 & TRN & \\
\hline CHEMBL1435814 & 688549 & 4.9 & 5.0092 & TRN & \\
\hline CHEMBL1571058 & 688549 & 5.0 & 4.8476 & TRN & \\
\hline CHEMBL1386546 & 688549 & 4.9 & 5.2458 & TRN & \\
\hline CHEMBL1394881 & 688549 & 4.65 & 4.4646 & TRN & \\
\hline CHEMBL1356146 & 688549 & 4.5 & 4.3391 & TRN & \\
\hline CHEMBL1380684 & 688549 & 6.0 & 5.8412 & TST & \\
\hline CHEMBL1414873 & 688549 & 4.5 & 4.5414 & TRN & \\
\hline CHEMBL1567282 & 688549 & 4.5 & 4.7664 & TRN & \\
\hline CHEMBL53898 & 688549 & 4.6 & 5.2024 & TRN & \\
\hline CHEMBL1553510 & 688549 & 4.5 & 4.5699 & TRN & \\
\hline CHEMBL1325479 & 688549 & 4.5 & 4.5616 & TRN & \\
\hline CHEMBL1444626 & 688549 & 5.0 & 5.1476 & TRN & \\
\hline CHEMBL1485697 & 688549 & 4.8 & 5.1315 & TRN & \\
\hline CHEMBL1355245 & 688549 & 4.8 & 4.6927 & TRN & \\
\hline CHEMBL 3189854 & 688549 & 4.9 & 5.3525 & TRN & \\
\hline CHEMBL1481791 & 688549 & 4.5 & 4.8816 & TRN & \\
\hline CHEMBL1532428 & 688549 & 4.5 & 5.002 & TRN & \\
\hline CHEMBL1299346 & 688549 & 6.9 & 5.006 & TST & \\
\hline CHEMBL1357688 & 688549 & 6.0 & 5.3149 & TRN & \\
\hline CHEMBL1390531 & 688549 & 4.9 & 5.039 & TRN & \\
\hline CHEMBL1323007 & 688549 & 4.7 & 4.8098 & TST & \\
\hline CHEMBL1390578 & 688549 & 4.5 & 4.71899 & 9999999999 & TRN \\
\hline CHEMBL1597436 & 688549 & 4.9 & 4.7148 & TRN & \\
\hline CHEMBL1608086 & 688549 & 4.95 & 5.1853 & TRN & \\
\hline CHEMBL1439977 & 688549 & 4.5 & 4.823 & TRN & \\
\hline CHEMBL1569172 & 688549 & 4.6 & 5.1789 & TRN & \\
\hline CHEMBL1521269 & 688549 & 4.7 & 4.8234 & TRN & \\
\hline CHEMBL1376210 & 688549 & 5.1 & 5.0222 & TRN & \\
\hline CHEMBL1374191 & 688549 & 8.2007 & 5.3822 & TRN & \\
\hline CHEMBL1518405 & 688549 & 4.7 & 4.9681 & TRN & \\
\hline CHEMBL1486922 & 688549 & 5.0 & 5.1511 & TRN & \\
\hline
\end{tabular}




\begin{tabular}{|c|c|c|c|c|c|}
\hline & & \multicolumn{4}{|c|}{ Supplemental Table S2.txt } \\
\hline CHEMBL1443946 & 688549 & 4.5 & 4.8069 & TRN & \\
\hline CHEMBL1560503 & 688549 & 4.45 & 4.4906 & TRN & \\
\hline CHEMBL1405493 & 688549 & 4.9 & 4.7473 & TRN & \\
\hline CHEMBL1422597 & 688549 & 4.9 & 5.5606 & TRN & \\
\hline CHEMBL1604350 & 688549 & 4.9 & 4.5141 & TRN & \\
\hline CHEMBL1325515 & 688549 & 4.8 & 4.8918 & TRN & \\
\hline CHEMBL1509595 & 688549 & 4.9 & 4.8372 & TRN & \\
\hline CHEMBL1490183 & 688549 & 5.0 & 4.8924 & TRN & \\
\hline CHEMBL1607908 & 688549 & 4.5 & 5.5348 & TRN & \\
\hline CHEMBL1369635 & 688549 & 4.9 & 4.9011 & TRN & \\
\hline CHEMBL1415442 & 688549 & 4.7 & 4.6313 & TRN & \\
\hline CHEMBL1313754 & 688549 & 4.5 & 4.7075 & TST & \\
\hline CHEMBL1412283 & 688549 & 5.0 & 4.8935 & TRN & \\
\hline CHEMBL1418567 & 688549 & 4.7 & 4.9187 & TRN & \\
\hline CHEMBL1386737 & 688549 & 8.301 & 5.0716 & TRN & \\
\hline CHEMBL1604715 & 688549 & 4.9 & 5.1654 & TRN & \\
\hline CHEMBL1422468 & 688549 & 5.0 & 5.0387 & TRN & \\
\hline CHEMBL1378830 & 688549 & 4.9 & 5.171 & TRN & \\
\hline CHEMBL1367806 & 688549 & 4.9 & 4.8914 & TRN & \\
\hline CHEMBL1440798 & 688549 & 4.9 & 4.8921 & TRN & \\
\hline CHEMBL1592575 & 688549 & 4.9 & 4.9883 & TRN & \\
\hline CHEMBL1601973 & 688549 & 6.4 & 5.4392 & TRN & \\
\hline CHEMBL3392050 & 688549 & 6.0 & 5.3536 & TST & \\
\hline CHEMBL1365553 & 688549 & 4.9 & 5.2408 & TST & \\
\hline CHEMBL1563695 & 688549 & 5.0 & 4.833 & TRN & \\
\hline CHEMBL481577 & 688549 & 4.5 & 4.8284 & TRN & \\
\hline CHEMBL1576870 & 688549 & 4.9 & 4.9972 & TRN & \\
\hline CHEMBL1477877 & 688549 & 6.0 & 5.6176 & TRN & \\
\hline CHEMBL1399553 & 688549 & 5.0 & 5.5347 & TST & \\
\hline CHEMBL1315535 & 688549 & 4.45 & 4.4373 & TRN & \\
\hline CHEMBL1551039 & 688549 & 5.1 & 4.9594 & TRN & \\
\hline CHEMBL1473541 & 688549 & 4.5 & 4.5624 & TRN & \\
\hline CHEMBL1427637 & 688549 & 5.3 & 5.0683 & TST & \\
\hline CHEMBL1595264 & 688549 & 5.1 & 5.0396 & TRN & \\
\hline CHEMBL1362432 & 688549 & 5.0 & 5.024 & TRN & \\
\hline CHEMBL1441357 & 688549 & 4.5 & 5.2438 & TRN & \\
\hline CHEMBL1331486 & 688549 & 5.2 & 4.9181 & TST & \\
\hline CHEMBL1417302 & 688549 & 4.5 & 4.7596 & TRN & \\
\hline CHEMBL1352792 & 688549 & 4.8 & 5.0265 & TRN & \\
\hline CHEMBL1439717 & 688549 & 4.9 & 4.8389 & TST & \\
\hline CHEMBL1591135 & 688549 & 4.9 & 4.5805 & TRN & \\
\hline CHEMBL1469212 & 688549 & 4.8 & 4.9238 & TRN & \\
\hline CHEMBL587884 & 688549 & 6.5 & 5.3855 & TST & \\
\hline CHEMBL1418230 & 688549 & 4.7 & $5.0760 e$ & 00000000005 & TRN \\
\hline CHEMBL1406602 & 688549 & 4.5 & 4.7258 & TRN & \\
\hline CHEMBL1512720 & 688549 & 4.85 & 4.436 & TST & \\
\hline CHEMBL1394244 & 688549 & 4.45 & 4.8317 & TRN & \\
\hline CHEMBL1613723 & 688549 & 4.5 & 5.1125 & TRN & \\
\hline
\end{tabular}




\begin{tabular}{|c|c|c|c|c|}
\hline \multicolumn{5}{|c|}{ Supplemental Table S2.txt } \\
\hline CHEMBL1498956 & 688549 & 4.5 & 4.8401 & TRN \\
\hline CHEMBL1568361 & 688549 & 4.5 & 5.1562 & TRN \\
\hline CHEMBL1317058 & 688549 & 4.5 & 5.0622 & TST \\
\hline CHEMBL1593616 & 688549 & 4.9 & 5.2917 & TRN \\
\hline CHEMBL1375955 & 688549 & 4.5 & 4.3972 & TRN \\
\hline CHEMBL1374788 & 688549 & 5.45 & 5.1146 & TST \\
\hline CHEMBL1567220 & 688549 & 5.3 & 5.3336 & TRN \\
\hline CHEMBL1450380 & 688549 & 4.5 & 4.8584 & TRN \\
\hline CHEMBL1555114 & 688549 & 5.7 & 5.5549 & TRN \\
\hline CHEMBL1461196 & 688549 & 4.5 & 5.1678 & TRN \\
\hline CHEMBL1599118 & 688549 & 4.5 & 4.5903 & TRN \\
\hline CHEMBL1382277 & 688549 & 4.5 & 4.5936 & TRN \\
\hline CHEMBL1523468 & 688549 & 4.8 & 5.1527 & TRN \\
\hline CHEMBL1512156 & 688549 & 4.7 & 5.232 & TST \\
\hline CHEMBL1397459 & 688549 & 4.8 & 5.018 & TRN \\
\hline CHEMBL1984604 & 688549 & 4.7 & 5.1351 & TRN \\
\hline CHEMBL1318114 & 688549 & 4.6 & 4.6719 & TRN \\
\hline CHEMBL1610384 & 688549 & 4.5 & 4.7351 & TRN \\
\hline CHEMBL1440562 & 688549 & 4.8 & 4.9315 & TRN \\
\hline CHEMBL 542493 & 688549 & 4.9 & 5.3255 & TST \\
\hline CHEMBL1491272 & 688549 & 4.9 & 4.9463 & TRN \\
\hline CHEMBL1552443 & 688549 & 4.45 & 5.2226 & TRN \\
\hline CHEMBL1440188 & 688549 & 5.0 & 4.9198 & TRN \\
\hline CHEMBL1449173 & 688549 & 4.95 & 5.1099 & TRN \\
\hline CHEMBL1434613 & 688549 & 4.5 & 5.08 & TST \\
\hline CHEMBL1393260 & 688549 & 4.9 & 5.1046 & TST \\
\hline CHEMBL1314693 & 688549 & 4.9 & 4.8275 & TRN \\
\hline CHEMBL1584578 & 688549 & 4.7 & 4.8894 & TST \\
\hline CHEMBL1477550 & 688549 & 4.95 & 5.0322 & TRN \\
\hline CHEMBL1347099 & 688549 & 5.4 & 4.9373 & TRN \\
\hline CHEMBL1415141 & 688549 & 4.9 & 4.8373 & TRN \\
\hline CHEMBL1327646 & 688549 & 5.5 & 5.1713 & TRN \\
\hline CHEMBL1304015 & 688549 & 4.8 & 4.9733 & TRN \\
\hline CHEMBL1491340 & 688549 & 4.9 & 5.7485 & TST \\
\hline CHEMBL1372649 & 688549 & 4.7 & 4.801 & TRN \\
\hline CHEMBL1423811 & 688549 & 4.9 & 4.8598 & TRN \\
\hline CHEMBL1568028 & 688549 & 4.9 & 4.7881 & TRN \\
\hline CHEMBL1488710 & 688549 & 6.1 & 5.42 & TRN \\
\hline CHEMBL1180 & 688549 & 4.7 & 5.1461 & TST \\
\hline CHEMBL1401707 & 688549 & 4.9 & 5.1263 & TRN \\
\hline CHEMBL1575720 & 688549 & 4.6 & 5.0513 & TRN \\
\hline CHEMBL1412695 & 688549 & 5.4 & 5.0864 & TRN \\
\hline CHEMBL1323927 & 688549 & 4.8 & 4.7573 & TRN \\
\hline CHEMBL1519975 & 688549 & 5.5 & 5.1777 & TRN \\
\hline CHEMBL 260028 & 688549 & 5.3 & 5.454 & TRN \\
\hline CHEMBL1317124 & 688549 & 4.5 & 5.0132 & TST \\
\hline CHEMBL1554106 & 688549 & 4.9 & 5.0217 & TRN \\
\hline CHEMBL1493497 & 688549 & 5.3 & 5.0817 & TRN \\
\hline
\end{tabular}




\begin{tabular}{|c|c|c|c|c|c|}
\hline \multicolumn{6}{|c|}{ Supplemental Table S2.txt } \\
\hline CHEMBL1501793 & 688549 & 4.45 & 5.0983 & TST & \\
\hline CHEMBL1358610 & 688549 & 4.65 & 4.8111 & TST & \\
\hline CHEMBL1599306 & 688549 & 5.0 & 5.2901 & TRN & \\
\hline CHEMBL1370707 & 688549 & 7.0 & 5.0245 & TST & \\
\hline CHEMBL1375479 & 688549 & 4.9 & 5.3684 & TRN & \\
\hline CHEMBL1493117 & 688549 & 4.7 & 5.0745 & TST & \\
\hline CHEMBL1527850 & 688549 & 4.95 & 5.0329 & TRN & \\
\hline CHEMBL1434953 & 688549 & 5.65 & 5.3199 & TST & \\
\hline CHEMBL1398683 & 688549 & 4.5 & 5.0386 & TST & \\
\hline CHEMBL1325198 & 688549 & 4.8 & 4.5834 & TRN & \\
\hline CHEMBL1419320 & 688549 & 4.7 & 4.9726 & TST & \\
\hline CHEMBL1518624 & 688549 & 4.5 & 4.871 & TRN & \\
\hline CHEMBL1358433 & 688549 & 4.6 & 4.635 & TRN & \\
\hline CHEMBL1537051 & 688549 & 4.8 & 5.1705 & TRN & \\
\hline CHEMBL1555511 & 688549 & 4.45 & 5.5358 & TRN & \\
\hline CHEMBL1335587 & 688549 & 4.45 & 4.581 & TRN & \\
\hline CHEMBL1601128 & 688549 & 4.55 & 4.9469 & TRN & \\
\hline CHEMBL1350119 & 688549 & 5.0 & 4.9103 & TRN & \\
\hline CHEMBL1384088 & 688549 & 6.4 & 5.5023 & TRN & \\
\hline CHEMBL1328299 & 688549 & 4.9 & 4.5752 & TRN & \\
\hline CHEMBL1455630 & 688549 & 4.9 & 4.9026 & TRN & \\
\hline CHEMBL1557062 & 688549 & 5.3 & 4.9954 & TRN & \\
\hline CHEMBL1325877 & 688549 & 4.5 & 4.6616 & TRN & \\
\hline CHEMBL1571463 & 688549 & 4.7 & 4.66 & TRN & \\
\hline CHEMBL1437286 & 688549 & 4.7 & 4.709 & TRN & \\
\hline CHEMBL1376023 & 688549 & 4.6 & 4.6914 & TRN & \\
\hline CHEMBL1573615 & 688549 & 4.65 & 4.6561 & TRN & \\
\hline CHEMBL1318858 & 688549 & 7.5003 & 5.5257 & TRN & \\
\hline CHEMBL1340008 & 688549 & 6.4 & 5.3933 & TRN & \\
\hline CHEMBL1371504 & 688549 & 5.2 & 5.2876 & TRN & \\
\hline CHEMBL1317531 & 688549 & 4.7 & 4.63899 & 9999999999 & TRN \\
\hline CHEMBL1364048 & 688549 & 8.301 & 6.0722 & TRN & \\
\hline CHEMBL1330568 & 688549 & 4.9 & 4.7803 & TST & \\
\hline CHEMBL48449 & 688549 & 6.0 & 5.8569 & TST & \\
\hline CHEMBL1597594 & 688549 & 5.1 & 5.1183 & TRN & \\
\hline CHEMBL1566730 & 688549 & 5.0 & 5.2625 & TRN & \\
\hline CHEMBL1335967 & 688549 & 4.9 & 4.6974 & TRN & \\
\hline CHEMBL 30432 & 688549 & 4.5 & 4.9551 & TST & \\
\hline CHEMBL1407907 & 688549 & 6.5 & 4.8565 & TRN & \\
\hline CHEMBL1371531 & 688549 & 4.9 & 4.6664 & TRN & \\
\hline CHEMBL1503644 & 688549 & 5.0 & 5.0436 & TRN & \\
\hline CHEMBL1453260 & 688549 & 4.5 & 4.7523 & TRN & \\
\hline CHEMBL1339429 & 688549 & 4.9 & 4.8796 & TRN & \\
\hline CHEMBL1403048 & 688549 & 4.7 & 5.2089 & TRN & \\
\hline CHEMBL1445766 & 688549 & 6.9 & 5.245 & TRN & \\
\hline CHEMBL1565133 & 688549 & 4.9 & 4.8829 & TST & \\
\hline CHEMBL1504505 & 688549 & 4.5 & 4.5136 & TRN & \\
\hline CHEMBL1338425 & 688549 & 4.5 & 4.7985 & TRN & \\
\hline
\end{tabular}




\begin{tabular}{|c|c|c|c|c|c|}
\hline CHEMBL1515192 & 688549 & 4.9 & 5.41799 & d & TRN \\
\hline CHEMBL1610783 & 688549 & 5.0 & 5.0126 & TRN & \\
\hline CHEMBL1551199 & 688549 & 5.3 & 5.2405 & TRN & \\
\hline CHEMBL1412672 & 688549 & 4.6 & 4.4237 & TRN & \\
\hline CHEMBL1323889 & 688549 & 5.4 & 5.5682 & TRN & \\
\hline CHEMBL1515418 & 688549 & 4.6 & 4.2263 & TRN & \\
\hline CHEMBL1378961 & 688549 & 4.5 & 4.346 & TRN & \\
\hline CHEMBL1503576 & 688549 & 4.5 & 5.4408 & TST & \\
\hline CHEMBL1455056 & 688549 & 4.5 & 4.93 & TRN & \\
\hline CHEMBL1331148 & 688549 & 4.6 & 5.2771 & TST & \\
\hline CHEMBL1443752 & 688549 & 5.0 & 5.0382 & TST & \\
\hline CHEMBL1387162 & 688549 & 4.7 & 4.7133 & TST & \\
\hline CHEMBL1356208 & 688549 & 4.45 & 4.5807 & TRN & \\
\hline CHEMBL528165 & 688549 & 4.9 & 5.2082 & TST & \\
\hline CHEMBL462314 & 688549 & 5.2 & 5.4925 & TST & \\
\hline CHEMBL1366712 & 688549 & 5.4 & 5.3516 & TRN & \\
\hline CHEMBL1597519 & 688549 & 4.9 & 4.43 & TRN & \\
\hline CHEMBL1460356 & 688549 & 4.5 & 5.1186 & TRN & \\
\hline CHEMBL1330273 & 688549 & 5.8 & 5.6575 & TRN & \\
\hline CHEMBL1576363 & 688549 & 4.7 & 4.8701 & TRN & \\
\hline CHEMBL1322563 & 688549 & 4.5 & 4.9621 & TRN & \\
\hline CHEMBL1563333 & 688549 & 4.9 & 4.8688 & TRN & \\
\hline CHEMBL1406081 & 688549 & 4.5 & 4.8854 & TRN & \\
\hline CHEMBL1368684 & 688549 & 4.75 & 4.8357 & TRN & \\
\hline CHEMBL1545280 & 688549 & 4.5 & 4.7037 & TRN & \\
\hline CHEMBL1535606 & 688549 & 4.5 & 5.0378 & TST & \\
\hline CHEMBL1439787 & 688549 & 5.3 & 5.5022 & TRN & \\
\hline CHEMBL1531919 & 688549 & 4.5 & 4.7319 & TRN & \\
\hline CHEMBL1557964 & 688549 & 4.5 & 5.404 & TST & \\
\hline CHEMBL1362247 & 688549 & 4.9 & 4.9279 & TRN & \\
\hline CHEMBL1333833 & 688549 & 4.9 & 4.819 & TRN & \\
\hline CHEMBL1439805 & 688549 & 5.45 & 5.4665 & TRN & \\
\hline CHEMBL1476071 & 688549 & 4.9 & 5.7768 & TRN & \\
\hline CHEMBL1523729 & 688549 & 5.4 & 5.4666 & TRN & \\
\hline CHEMBL1442969 & 688549 & 4.8 & 4.9772 & TST & \\
\hline CHEMBL1512279 & 688549 & 5.6 & 5.0208 & TRN & \\
\hline CHEMBL1468597 & 688549 & 4.8 & 4.8599 & TRN & \\
\hline CHEMBL1505916 & 688549 & 4.7 & 4.6868 & TRN & \\
\hline CHEMBL1360605 & 688549 & 4.9 & 5.2749 & TRN & \\
\hline CHEMBL1561897 & 688549 & 4.8 & 4.7416 & TRN & \\
\hline CHEMBL1569543 & 688549 & 4.7 & 4.8582 & TRN & \\
\hline CHEMBL1495849 & 688549 & 5.0 & 5.1889 & TRN & \\
\hline CHEMBL1588285 & 688549 & 4.75 & 5.3245 & TRN & \\
\hline CHEMBL1371452 & 688549 & 4.9 & 4.7563 & TRN & \\
\hline CHEMBL1403744 & 688549 & 4.8 & 4.8453 & TST & \\
\hline CHEMBL1473693 & 688549 & 7.8013 & 5.5013 & TRN & \\
\hline CHEMBL1585988 & 688549 & 6.0 & 4.8943 & TRN & \\
\hline \multirow[t]{2}{*}{ CHEMBL1488204 } & 688549 & 4.9 & 5.1453 & TRN & \\
\hline & & \multicolumn{4}{|c|}{ Page 23059} \\
\hline
\end{tabular}




\begin{tabular}{|c|c|c|c|c|c|}
\hline \multicolumn{6}{|c|}{ Supplemental Table S2.txt } \\
\hline CHEMBL1428196 & 688549 & 5.2 & 5.2019 & TRN & \\
\hline CHEMBL1518159 & 688549 & 5.3 & 5.1256 & TRN & \\
\hline CHEMBL1552670 & 688549 & 5.2 & 5.1869 & TRN & \\
\hline CHEMBL1582505 & 688549 & 4.6 & 5.3192 & TST & \\
\hline CHEMBL184074 & 688549 & 4.5 & 4.9473 & TST & \\
\hline CHEMBL1537967 & 688549 & 5.0 & 4.9217 & TRN & \\
\hline CHEMBL1429821 & 688549 & 6.0 & 5.4182 & TST & \\
\hline CHEMBL1315394 & 688549 & 4.8 & 4.7254 & TRN & \\
\hline CHEMBL1506065 & 688549 & 4.9 & 5.2169 & TRN & \\
\hline CHEMBL293749 & 688549 & 5.0 & 5.1044 & TRN & \\
\hline CHEMBL1597357 & 688549 & 4.5 & 4.7143 & TRN & \\
\hline CHEMBL1377702 & 688549 & 4.9 & 5.0451 & TRN & \\
\hline CHEMBL1474468 & 688549 & 5.3 & 4.93 & TRN & \\
\hline CHEMBL1393096 & 688549 & 4.6 & 4.4496 & TRN & \\
\hline CHEMBL1340370 & 688549 & 6.25 & 5.8038 & TRN & \\
\hline CHEMBL1317572 & 688549 & 6.2 & 5.745 & TRN & \\
\hline CHEMBL1096400 & 688549 & 4.9 & 5.1063 & TRN & \\
\hline CHEMBL1973647 & 688549 & 4.45 & 5.0187 & TRN & \\
\hline CHEMBL1417381 & 688549 & 4.8 & 4.9037 & TRN & \\
\hline CHEMBL3194619 & 688549 & 4.5 & 5.3186 & TST & \\
\hline CHEMBL1353630 & 688549 & 5.05 & 5.2722 & TRN & \\
\hline CHEMBL1497932 & 688549 & 5.5 & 5.1556 & TRN & \\
\hline CHEMBL1475211 & 688549 & 4.45 & 5.0132 & TRN & \\
\hline CHEMBL1522726 & 688549 & 5.0 & 5.1771 & TRN & \\
\hline CHEMBL1523920 & 688549 & 4.9 & 4.8368 & TRN & \\
\hline CHEMBL1315622 & 688549 & 4.8 & 5.0077 & TRN & \\
\hline CHEMBL1604951 & 688549 & 5.25 & 4.7851 & TRN & \\
\hline CHEMBL1569635 & 688549 & 5.0 & 5.0223 & TRN & \\
\hline CHEMBL1532930 & 688549 & 4.9 & 5.1607 & TRN & \\
\hline CHEMBL1451237 & 688549 & 5.0 & 5.0054 & TRN & \\
\hline CHEMBL1599294 & 688549 & 4.7 & 4.7433 & TRN & \\
\hline CHEMBL1608159 & 688549 & 4.9 & 5.1534 & TRN & \\
\hline CHEMBL1473218 & 688549 & 5.6 & 5.0736 & TRN & \\
\hline CHEMBL1403565 & 688549 & 4.8 & 5.1885 & TRN & \\
\hline CHEMBL1514570 & 688549 & 4.5 & 4.38899 & 9999999999 & TRN \\
\hline CHEMBL1512931 & 688549 & 4.6 & 4.6219 & TRN & \\
\hline CHEMBL1375970 & 688549 & 4.5 & 4.5747 & TRN & \\
\hline CHEMBL1398139 & 688549 & 4.5 & 4.6073 & TRN & \\
\hline CHEMBL528256 & 688549 & 4.5 & 4.9983 & TRN & \\
\hline CHEMBL1324079 & 688549 & 4.8 & 5.1558 & TRN & \\
\hline CHEMBL1429438 & 688549 & 4.7 & 5.1363 & TRN & \\
\hline CHEMBL1331363 & 688549 & 5.0 & 4.9412 & TRN & \\
\hline CHEMBL1412866 & 688549 & 4.9 & 4.7303 & TRN & \\
\hline CHEMBL1214525 & 688549 & 4.8 & 4.8435 & TRN & \\
\hline CHEMBL1316536 & 688549 & 4.8 & 5.056 & TRN & \\
\hline CHEMBL1395162 & 688549 & 4.9 & 4.8309 & TRN & \\
\hline CHEMBL1368503 & 688549 & 4.5 & 4.7933 & TRN & \\
\hline CHEMBL1214519 & 688549 & 5.2 & 5.0827 & TRN & \\
\hline
\end{tabular}




\begin{tabular}{|c|c|c|c|c|}
\hline \multicolumn{5}{|c|}{ Supplemental Table S2.txt } \\
\hline CHEMBL524222 & 688549 & 4.5 & 4.4825 & TRN \\
\hline CHEMBL1567202 & 688549 & 4.75 & 4.7663 & TRN \\
\hline CHEMBL1593115 & 688549 & 4.5 & 4.4658 & TRN \\
\hline CHEMBL1514677 & 688549 & 5.7 & 5.2724 & TRN \\
\hline CHEMBL1393934 & 688549 & 4.95 & 5.0126 & TRN \\
\hline CHEMBL1471476 & 688549 & 4.9 & 5.1367 & TRN \\
\hline CHEMBL559612 & 688549 & 4.9 & 4.8579 & TST \\
\hline CHEMBL1417994 & 688549 & 4.85 & 4.8846 & TRN \\
\hline CHEMBL1351624 & 688549 & 4.6 & 4.7786 & TRN \\
\hline CHEMBL1325991 & 688549 & 4.9 & 4.8006 & TRN \\
\hline CHEMBL1316226 & 688549 & 6.1 & 5.7526 & TRN \\
\hline CHEMBL195008 & 688549 & 4.5 & 4.9339 & TST \\
\hline CHEMBL1365615 & 688549 & 5.3 & 5.3003 & TRN \\
\hline CHEMBL1484528 & 688549 & 5.0 & 4.8247 & TRN \\
\hline CHEMBL1483444 & 688549 & 5.0 & 5.1083 & TRN \\
\hline CHEMBL1341192 & 688549 & 4.8 & 4.9718 & TRN \\
\hline CHEMBL1531413 & 688549 & 4.9 & 5.1577 & TRN \\
\hline CHEMBL1490200 & 688549 & 4.9 & 4.6748 & TRN \\
\hline CHEMBL1438637 & 688549 & 4.6 & 4.6819 & TRN \\
\hline CHEMBL1605499 & 688549 & 4.9 & 5.188 & TST \\
\hline CHEMBL1434038 & 688549 & 5.5 & 5.0477 & TRN \\
\hline CHEMBL1593142 & 688549 & 4.5 & 4.9511 & TRN \\
\hline CHEMBL1364598 & 688549 & 4.5 & 4.9716 & TRN \\
\hline CHEMBL1410437 & 688549 & 4.8 & 4.8532 & TRN \\
\hline CHEMBL1516995 & 688549 & 4.7 & 4.716 & TRN \\
\hline CHEMBL1429330 & 688549 & 5.4 & 5.1868 & TRN \\
\hline CHEMBL1475763 & 688549 & 5.0 & 5.1397 & TRN \\
\hline CHEMBL1317848 & 688549 & 4.85 & 4.7558 & TRN \\
\hline CHEMBL1318988 & 688549 & 5.0 & 5.0774 & TRN \\
\hline CHEMBL1397914 & 688549 & 4.7 & 5.0035 & TRN \\
\hline CHEMBL1518080 & 688549 & 4.9 & 4.9747 & TST \\
\hline CHEMBL1367954 & 688549 & 4.5 & 4.7672 & TRN \\
\hline CHEMBL1472696 & 688549 & 4.8 & 4.5476 & TRN \\
\hline CHEMBL1449838 & 688549 & 5.6 & 5.1997 & TST \\
\hline CHEMBL1506451 & 688549 & 4.5 & 4.7494 & TRN \\
\hline CHEMBL1530594 & 688549 & 4.5 & 5.1234 & TRN \\
\hline CHEMBL1375660 & 688549 & 4.8 & 4.7363 & TRN \\
\hline CHEMBL1397517 & 688549 & 5.0 & 5.1181 & TRN \\
\hline CHEMBL1300280 & 688549 & 4.9 & 4.8713 & TRN \\
\hline CHEMBL1515132 & 688549 & 4.6 & 5.4962 & TST \\
\hline CHEMBL1448856 & 688549 & 4.9 & 4.6475 & TRN \\
\hline CHEMBL1564109 & 688549 & 4.9 & 4.913 & TRN \\
\hline CHEMBL1370909 & 688549 & 4.9 & 4.8206 & TRN \\
\hline CHEMBL1334916 & 688549 & 4.9 & 5.0495 & TRN \\
\hline CHEMBL1519715 & 688549 & 4.45 & 5.2119 & TRN \\
\hline CHEMBL1402538 & 688549 & 4.5 & 4.9432 & TRN \\
\hline CHEMBL192509 & 688549 & 4.9 & 5.6888 & TRN \\
\hline CHEMBL1376571 & 688549 & 4.5 & 4.3109 & TRN \\
\hline
\end{tabular}




\begin{tabular}{|c|c|c|c|c|c|}
\hline \multirow{2}{*}{ CHEMBL1555692 } & \multirow{2}{*}{688549} & \\
\hline & & 5.0 & 4.9718 & TRN & \\
\hline CHEMBL3194052 & 688549 & 5.3 & 5.6012 & TRN & \\
\hline CHEMBL1494088 & 688549 & 5.0 & 4.8356 & TRN & \\
\hline CHEMBL1585117 & 688549 & 4.9 & 5.3754 & TRN & \\
\hline CHEMBL1376974 & 688549 & 6.0 & 5.5891 & TST & \\
\hline CHEMBL1598457 & 688549 & 5.2 & 4.8894 & TRN & \\
\hline CHEMBL 237253 & 688549 & 4.8 & 5.042 & TRN & \\
\hline CHEMBL66953 & 688549 & 5.0 & 5.2551 & TST & \\
\hline CHEMBL1428417 & 688549 & 4.5 & 4.4224 & TRN & \\
\hline CHEMBL1395127 & 688549 & 6.0 & 5.3983 & TST & \\
\hline CHEMBL1409287 & 688549 & 4.9 & 5.2038 & TRN & \\
\hline CHEMBL1590297 & 688549 & 4.9 & 4.7573 & TRN & \\
\hline CHEMBL1256484 & 688549 & 5.0 & 4.8716 & TRN & \\
\hline CHEMBL1457868 & 688549 & 4.5 & 5.039 & TRN & \\
\hline CHEMBL1315331 & 688549 & 5.5 & 5.3511 & TRN & \\
\hline CHEMBL1527336 & 688549 & 7.0 & 5.3482 & TRN & \\
\hline CHEMBL1306522 & 688549 & 5.0 & 4.831 & TRN & \\
\hline CHEMBL1366140 & 688549 & 4.7 & 5.0581 & TRN & \\
\hline CHEMBL1607711 & 688549 & 8.0 & 5.1354 & TST & \\
\hline CHEMBL570345 & 688549 & 4.5 & 4.8261 & TRN & \\
\hline CHEMBL1545965 & 688549 & 5.05 & 4.8653 & TRN & \\
\hline CHEMBL1524853 & 688549 & 4.9 & 6.1221 & TST & \\
\hline CHEMBL1314550 & 688549 & 4.85 & 4.8183 & TRN & \\
\hline CHEMBL543467 & 688549 & 4.5 & 4.897 & TST & \\
\hline CHEMBL1603200 & 688549 & 6.2 & 4.6451 & TRN & \\
\hline CHEMBL1472778 & 688549 & 4.8 & 4.9051 & TRN & \\
\hline CHEMBL1319873 & 688549 & 4.8 & 4.9368 & TRN & \\
\hline CHEMBL1354555 & 688549 & 4.75 & 4.9477 & TRN & \\
\hline CHEMBL1529126 & 688549 & 4.9 & 4.715 & TRN & \\
\hline CHEMBL1402249 & 688549 & 4.7 & 4.9455 & TST & \\
\hline CHEMBL1410534 & 688549 & 4.8 & 5.1162 & TRN & \\
\hline CHEMBL1612538 & 688549 & 4.9 & 4.686 & TRN & \\
\hline CHEMBL1357853 & 688549 & 4.75 & 5.044 & TRN & \\
\hline CHEMBL1610876 & 688549 & 4.7 & 4.92399 & 99999999995 & TRN \\
\hline CHEMBL1596986 & 688549 & 5.0 & 4.8596 & TRN & \\
\hline CHEMBL1605497 & 688549 & 4.9 & 4.9281 & TRN & \\
\hline CHEMBL1457178 & 688549 & 4.5 & 5.0467 & TRN & \\
\hline CHEMBL1407248 & 688549 & 5.0 & 5.1826 & TRN & \\
\hline CHEMBL1434057 & 688549 & 4.5 & 5.2244 & TRN & \\
\hline CHEMBL1496409 & 688549 & 4.6 & 4.941 & TRN & \\
\hline CHEMBL1597164 & 688549 & 4.7 & 4.8536 & TRN & \\
\hline CHEMBL1580990 & 688549 & 4.5 & 4.3696 & TRN & \\
\hline CHEMBL1477136 & 688549 & 4.8 & 4.425 & TRN & \\
\hline CHEMBL1318486 & 688549 & 4.75 & 4.9349 & TRN & \\
\hline CHEMBL1368219 & 688549 & 4.9 & 5.1751 & TRN & \\
\hline CHEMBL1463274 & 688549 & 5.45 & 5.3173 & TRN & \\
\hline CHEMBL1384800 & 688549 & 4.9 & 5.0823 & TRN & \\
\hline CHEMBL1589931 & 688549 & 4.5 & 5.5495 & TRN & \\
\hline & & & & 23062 & \\
\hline
\end{tabular}




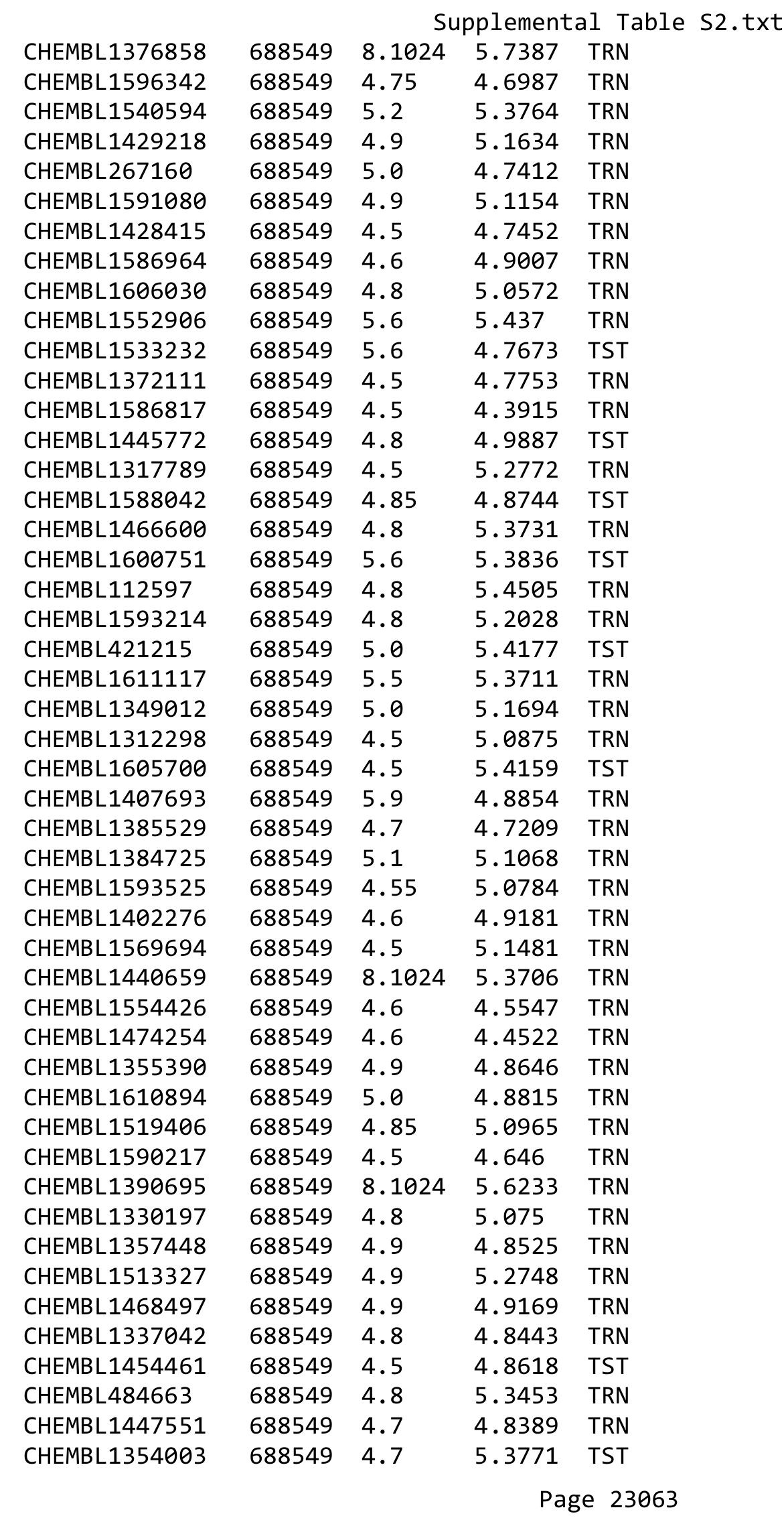




\begin{tabular}{|c|c|c|c|c|c|}
\hline \multicolumn{6}{|c|}{ Supplemental Table s2.txt } \\
\hline CHEMBL1473394 & 688549 & 4.9 & 4.7048 & TRN & \\
\hline CHEMBL1317100 & 688549 & 4.6 & 5.29 & TST & \\
\hline CHEMBL1540114 & 688549 & 4.9 & 4.8296 & TRN & \\
\hline CHEMBL1351715 & 688549 & 4.5 & 5.1123 & TRN & \\
\hline CHEMBL259103 & 688549 & 5.1 & 5.3521 & TRN & \\
\hline CHEMBL1582714 & 688549 & 8.2007 & 5.0453 & TST & \\
\hline CHEMBL1328481 & 688549 & 4.5 & 5.0755 & TST & \\
\hline CHEMBL1399847 & 688549 & 4.5 & 4.8343 & TRN & \\
\hline CHEMBL1452098 & 688549 & 5.8 & 4.9447 & TRN & \\
\hline CHEMBL1314978 & 688549 & 4.8 & 4.887 & TRN & \\
\hline CHEMBL1592615 & 688549 & 4.5 & 4.7173 & TRN & \\
\hline CHEMBL1414871 & 688549 & 4.8 & 4.7382 & TRN & \\
\hline CHEMBL1436182 & 688549 & 4.8 & 5.1188 & TRN & \\
\hline CHEMBL1363326 & 688549 & 4.45 & 4.7627 & TRN & \\
\hline CHEMBL1570135 & 688549 & 4.7 & 4.4314 & TRN & \\
\hline CHEMBL1334708 & 688549 & 4.5 & 5.0995 & TRN & \\
\hline CHEMBL1385673 & 688549 & 5.0 & 5.1005 & TRN & \\
\hline CHEMBL1573832 & 688549 & 4.9 & 5.311 & TRN & \\
\hline CHEMBL1327128 & 688549 & 4.5 & 4.2683 & TRN & \\
\hline CHEMBL1328466 & 688549 & 4.8 & 5.0316 & TRN & \\
\hline CHEMBL1608066 & 688549 & 4.9 & 5.0223 & TRN & \\
\hline CHEMBL1578649 & 688549 & 4.5 & 5.0368 & TRN & \\
\hline CHEMBL1594720 & 688549 & 4.5 & 4.4942 & TRN & \\
\hline CHEMBL 89445 & 688549 & 4.7 & 5.5381 & TRN & \\
\hline CHEMBL1329712 & 688549 & 4.5 & 4.7615 & TRN & \\
\hline CHEMBL1427979 & 688549 & 5.1 & 5.2434 & TRN & \\
\hline CHEMBL1377546 & 688549 & 4.7 & 4.9148 & TRN & \\
\hline CHEMBL1412815 & 688549 & 4.5 & 4.7414 & TRN & \\
\hline CHEMBL1420031 & 688549 & 4.5 & 4.5415 & TRN & \\
\hline CHEMBL1417553 & 688549 & 4.5 & 5.0425 & TST & \\
\hline CHEMBL356688 & 688549 & 4.8 & 4.9866 & TST & \\
\hline CHEMBL1362849 & 688549 & 4.9 & 4.8903 & TRN & \\
\hline CHEMBL1496635 & 688549 & 4.45 & 4.8712 & TST & \\
\hline CHEMBL1541876 & 688549 & 4.5 & 4.8154 & TRN & \\
\hline CHEMBL1319810 & 688549 & 4.8 & 4.6884 & TRN & \\
\hline CHEMBL1305222 & 688549 & 6.5 & 5.1421 & TST & \\
\hline CHEMBL1501719 & 688549 & 6.4 & 5.3049 & TST & \\
\hline CHEMBL1568597 & 688549 & 4.6 & 4.8647 & TRN & \\
\hline CHEMBL1339671 & 688549 & 5.0 & 4.7098 & TST & \\
\hline CHEMBL1335318 & 688549 & 4.5 & 4.74100 & 00000000005 & TRN \\
\hline CHEMBL1521545 & 688549 & 4.5 & 4.8776 & TRN & \\
\hline CHEMBL1555689 & 688549 & 4.9 & 4.6131 & TRN & \\
\hline CHEMBL1436125 & 688549 & 4.6 & 4.744 & TRN & \\
\hline CHEMBL1363534 & 688549 & 4.45 & 5.2365 & TRN & \\
\hline CHEMBL1331926 & 688549 & 4.8 & 4.9412 & TRN & \\
\hline CHEMBL1314894 & 688549 & 4.6 & 4.4143 & TRN & \\
\hline CHEMBL1530882 & 688549 & 5.3 & 5.1728 & TST & \\
\hline CHEMBL1512483 & 688549 & 5.0 & 5.0787 & TRN & \\
\hline
\end{tabular}




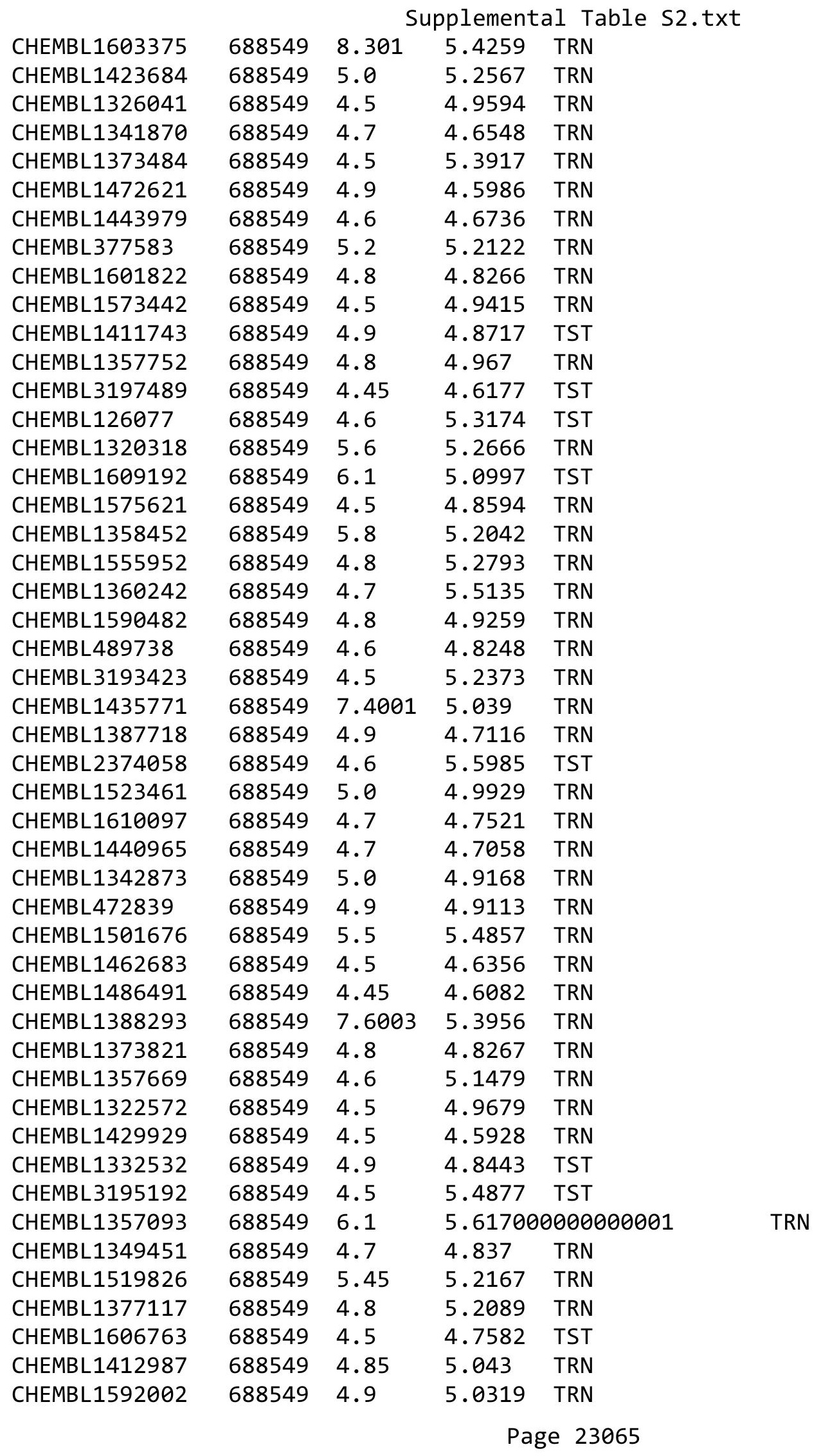




\begin{tabular}{|c|c|c|c|c|}
\hline \multicolumn{5}{|c|}{ Supplemental Tabl } \\
\hline CHEMBL1451162 & 688549 & 4.85 & 4.8567 & TRN \\
\hline CHEMBL1525989 & 688549 & 5.5 & 5.0369 & TST \\
\hline CHEMBL1378350 & 688549 & 4.7 & 5.2804 & TRN \\
\hline CHEMBL406835 & 688549 & 5.6 & 5.2203 & TRN \\
\hline CHEMBL1604546 & 688549 & 4.6 & 5.1773 & TST \\
\hline CHEMBL1407150 & 688549 & 5.5 & 5.0751 & TRN \\
\hline CHEMBL1378383 & 688549 & 5.6 & 5.0752 & TST \\
\hline CHEMBL1365045 & 688549 & 4.7 & 4.467 & TRN \\
\hline CHEMBL1424253 & 688549 & 4.5 & 4.8709 & TRN \\
\hline CHEMBL1464553 & 688549 & 6.0 & 4.9025 & TST \\
\hline CHEMBL1554338 & 688549 & 4.5 & 4.3165 & TRN \\
\hline CHEMBL1350237 & 688549 & 6.05 & 5.0166 & TRN \\
\hline CHEMBL1290347 & 688549 & 4.9 & 5.0351 & TRN \\
\hline CHEMBL1405928 & 688549 & 4.85 & 4.9361 & TRN \\
\hline CHEMBL1393129 & 688549 & 5.8 & 5.5432 & TRN \\
\hline CHEMBL1416732 & 688549 & 5.3 & 4.977 & TRN \\
\hline CHEMBL1255837 & 688549 & 6.0 & 5.7528 & TST \\
\hline CHEMBL1475403 & 688549 & 4.9 & 5.5849 & TRN \\
\hline CHEMBL1436104 & 688549 & 4.7 & 5.2468 & TRN \\
\hline CHEMBL1558099 & 688549 & 4.8 & 5.0094 & TRN \\
\hline CHEMBL1402362 & 688549 & 4.8 & 5.2992 & TRN \\
\hline CHEMBL1473756 & 688549 & 5.0 & 5.0583 & TRN \\
\hline CHEMBL1354529 & 688549 & 4.6 & 5.2275 & TRN \\
\hline CHEMBL1403324 & 688549 & 5.7 & 5.7939 & TRN \\
\hline CHEMBL1556372 & 688549 & 5.0 & 5.0235 & TRN \\
\hline CHEMBL1336746 & 688549 & 4.95 & 5.0067 & TRN \\
\hline CHEMBL1482872 & 688549 & 4.9 & 4.935 & TRN \\
\hline CHEMBL1591304 & 688549 & 7.0 & 5.0507 & TRN \\
\hline CHEMBL1358724 & 688549 & 4.7 & 5.3217 & TST \\
\hline CHEMBL1571810 & 688549 & 8.301 & 5.2321 & TRN \\
\hline CHEMBL150 & 688549 & 6.0 & 5.5531 & TRN \\
\hline CHEMBL1324774 & 688549 & 4.5 & 5.285 & TST \\
\hline CHEMBL1369691 & 688549 & 4.8 & 4.9138 & TRN \\
\hline CHEMBL1475715 & 688549 & 4.9 & 4.8568 & TRN \\
\hline CHEMBL1488608 & 688549 & 5.2 & 5.2346 & TRN \\
\hline CHEMBL1486449 & 688549 & 6.05 & 5.2416 & TRN \\
\hline CHEMBL1404398 & 688549 & 5.7 & 5.3954 & TRN \\
\hline CHEMBL1373107 & 688549 & 4.9 & 5.0359 & TRN \\
\hline CHEMBL1371435 & 688549 & 4.5 & 5.1248 & TRN \\
\hline CHEMBL1488584 & 688549 & 4.6 & 5.2154 & TRN \\
\hline CHEMBL1394302 & 688549 & 4.5 & 4.6309 & TRN \\
\hline CHEMBL1576840 & 688549 & 5.5 & 4.8206 & TRN \\
\hline CHEMBL1515290 & 688549 & 5.5 & 5.1647 & TST \\
\hline CHEMBL1409817 & 688549 & 4.9 & 5.1336 & TRN \\
\hline CHEMBL1393017 & 688549 & 4.9 & 4.9444 & TRN \\
\hline CHEMBL1398801 & 688549 & 4.9 & 5.1488 & TRN \\
\hline CHEMBL1396898 & 688549 & 5.0 & 5.1847 & TRN \\
\hline CHEMBL1335581 & 688549 & 5.2 & 4.7078 & TRN \\
\hline
\end{tabular}




\begin{tabular}{|c|c|c|c|c|}
\hline \multicolumn{5}{|c|}{ Supplemental Table S2.txt } \\
\hline CHEMBL1564151 & 688549 & 4.5 & 5.075 & TRN \\
\hline CHEMBL1355647 & 688549 & 5.0 & 5.1817 & TRN \\
\hline CHEMBL1579254 & 688549 & 5.0 & 5.1949 & TRN \\
\hline CHEMBL1373846 & 688549 & 8.0 & 5.5006 & TRN \\
\hline CHEMBL1443386 & 688549 & 5.0 & 5.1478 & TST \\
\hline CHEMBL1409297 & 688549 & 5.0 & 4.8619 & TRN \\
\hline CHEMBL1577933 & 688549 & 8.0506 & 5.4341 & TRN \\
\hline CHEMBL1597432 & 688549 & 5.2 & 5.1101 & TRN \\
\hline CHEMBL1597750 & 688549 & 4.9 & 4.7791 & TRN \\
\hline CHEMBL1594897 & 688549 & 5.0 & 4.9922 & TRN \\
\hline CHEMBL1355145 & 688549 & 4.5 & 4.5754 & TRN \\
\hline CHEMBL498770 & 688549 & 4.9 & 4.8765 & TST \\
\hline CHEMBL1337987 & 688549 & 4.65 & 4.6753 & TRN \\
\hline CHEMBL1301138 & 688549 & 6.45 & 5.2765 & TRN \\
\hline CHEMBL1599945 & 688549 & 4.5 & 4.3353 & TRN \\
\hline CHEMBL1402956 & 688549 & 4.7 & 5.0727 & TST \\
\hline CHEMBL1404876 & 688549 & 4.7 & 4.7218 & TRN \\
\hline CHEMBL1612493 & 688549 & 4.9 & 4.9232 & TRN \\
\hline CHEMBL1450676 & 688549 & 5.7 & 5.3032 & TRN \\
\hline CHEMBL1497004 & 688549 & 5.1 & 5.2585 & TRN \\
\hline CHEMBL1570250 & 688549 & 4.5 & 4.7348 & TRN \\
\hline CHEMBL1213769 & 688549 & 5.0 & 5.082 & TRN \\
\hline CHEMBL1493192 & 688549 & 5.6 & 5.2099 & TRN \\
\hline CHEMBL1365820 & 688549 & 4.6 & 4.8756 & TRN \\
\hline CHEMBL234583 & 688549 & 5.0 & 4.849 & TRN \\
\hline CHEMBL1407077 & 688549 & 5.1 & 4.8185 & TRN \\
\hline CHEMBL1435381 & 688549 & 4.5 & 5.3089 & TST \\
\hline CHEMBL1338121 & 688549 & 5.0 & 5.0619 & TRN \\
\hline CHEMBL 265715 & 688549 & 5.6 & 5.0956 & TRN \\
\hline CHEMBL1406630 & 688549 & 4.8 & 4.7108 & TRN \\
\hline CHEMBL1355802 & 688549 & 6.4 & 5.8889 & TRN \\
\hline CHEMBL1611998 & 688549 & 4.8 & 4.9358 & TRN \\
\hline CHEMBL 263376 & 688549 & 7.4001 & 5.2095 & TRN \\
\hline CHEMBL1318769 & 688549 & 5.0 & 4.5671 & TRN \\
\hline CHEMBL1465770 & 688549 & 8.0 & 5.4975 & TRN \\
\hline CHEMBL1609807 & 688549 & 4.5 & 5.0689 & TST \\
\hline CHEMBL1534168 & 688549 & 4.6 & 4.8158 & TRN \\
\hline CHEMBL1395080 & 688549 & 5.0 & 5.0512 & TRN \\
\hline CHEMBL1440504 & 688549 & 4.7 & 4.8201 & TRN \\
\hline CHEMBL1526910 & 688549 & 4.8 & 4.9932 & TRN \\
\hline CHEMBL1376633 & 688549 & 4.7 & 4.7318 & TST \\
\hline CHEMBL1578969 & 688549 & 6.95 & 5.7294 & TRN \\
\hline CHEMBL1517345 & 688549 & 4.5 & 4.9124 & TRN \\
\hline CHEMBL1371410 & 688549 & 4.9 & 4.9542 & TST \\
\hline CHEMBL1394829 & 688549 & 4.9 & 5.2517 & TST \\
\hline CHEMBL1545040 & 688549 & 4.9 & 4.6491 & TRN \\
\hline CHEMBL1364003 & 688549 & 4.5 & 5.0994 & TRN \\
\hline CHEMBL1396497 & 688549 & 5.0 & 4.8709 & TRN \\
\hline
\end{tabular}




\begin{tabular}{|c|c|c|c|c|c|}
\hline \multicolumn{6}{|c|}{ Supplemental Table S2.txt } \\
\hline CHEMBL1560136 & 688549 & 4.7 & 4.6784 & TRN & \\
\hline CHEMBL1418703 & 688549 & 4.5 & 4.4665 & TRN & \\
\hline CHEMBL1390671 & 688549 & 5.0 & 4.6648 & TRN & \\
\hline CHEMBL1598888 & 688549 & 4.95 & 5.3552 & TRN & \\
\hline CHEMBL1381270 & 688549 & 4.9 & 4.9832 & TRN & \\
\hline CHEMBL1486734 & 688549 & 4.6 & 4.6445 & TRN & \\
\hline CHEMBL1410714 & 688549 & 4.9 & 5.6375 & TRN & \\
\hline CHEMBL1579821 & 688549 & 4.5 & 5.1639 & TST & \\
\hline CHEMBL1356019 & 688549 & 4.9 & 4.6384 & TRN & \\
\hline CHEMBL99408 & 688549 & 4.5 & 5.5592 & TRN & \\
\hline CHEMBL1554658 & 688549 & 4.9 & 4.6768 & TRN & \\
\hline CHEMBL187266 & 688549 & 4.9 & 5.4548 & TST & \\
\hline CHEMBL1412712 & 688549 & 4.6 & 4.8202 & TRN & \\
\hline CHEMBL1521689 & 688549 & 4.5 & 5.5271 & TRN & \\
\hline CHEMBL1475488 & 688549 & 4.5 & 5.6834 & TST & \\
\hline CHEMBL1408968 & 688549 & 4.6 & 4.8642 & TRN & \\
\hline CHEMBL1581154 & 688549 & 4.8 & 5.3669 & TRN & \\
\hline CHEMBL1473833 & 688549 & 4.5 & 5.1327 & TRN & \\
\hline CHEMBL1557423 & 688549 & 5.6 & 5.0699 & TRN & \\
\hline CHEMBL1534227 & 688549 & 4.5 & 5.0556 & TRN & \\
\hline CHEMBL1311219 & 688549 & 4.8 & 4.8963 & TRN & \\
\hline CHEMBL1503705 & 688549 & 7.9508 & 5.6581 & TRN & \\
\hline CHEMBL1370676 & 688549 & 4.7 & 5.1166 & TRN & \\
\hline CHEMBL1404682 & 688549 & 4.5 & 4.6743 & TRN & \\
\hline CHEMBL1404372 & 688549 & 5.0 & 4.9412 & TST & \\
\hline CHEMBL1308955 & 688549 & 4.5 & 5.2226 & TRN & \\
\hline CHEMBL1380247 & 688549 & 5.95 & 5.3244 & TRN & \\
\hline CHEMBL1395966 & 688549 & 5.0 & 4.663 & TRN & \\
\hline CHEMBL1317673 & 688549 & 4.5 & 4.6968 & TRN & \\
\hline CHEMBL1532008 & 688549 & 4.5 & 4.3459 & TRN & \\
\hline CHEMBL1501153 & 688549 & 4.5 & 5.7713 & TST & \\
\hline CHEMBL1314180 & 688549 & 4.65 & 4.7964 & TRN & \\
\hline CHEMBL1475572 & 688549 & 4.5 & 5.1399 & TRN & \\
\hline CHEMBL1314250 & 688549 & 4.5 & 5.78299 & 99999999995 & TRN \\
\hline CHEMBL1522332 & 688549 & 4.5 & 4.2376 & TRN & \\
\hline CHEMBL1320525 & 688549 & 5.0 & 5.0383 & TST & \\
\hline CHEMBL1561456 & 688549 & 4.8 & 4.87 & TRN & \\
\hline CHEMBL1329715 & 688549 & 5.0 & 5.1357 & TRN & \\
\hline CHEMBL1597158 & 688549 & 4.9 & 4.4243 & TRN & \\
\hline CHEMBL1462694 & 688549 & 4.8 & 4.9693 & TRN & \\
\hline CHEMBL1554951 & 688549 & 5.15 & 5.193 & TRN & \\
\hline CHEMBL1362127 & 688549 & 4.5 & 4.9464 & TRN & \\
\hline CHEMBL1436458 & 688549 & 4.5 & 4.9463 & TRN & \\
\hline CHEMBL1595336 & 688549 & 5.5 & 5.1942 & TRN & \\
\hline CHEMBL1412832 & 688549 & 4.6 & 4.3984 & TRN & \\
\hline CHEMBL1395287 & 688549 & 8.2007 & 5.0417 & TRN & \\
\hline CHEMBL1356310 & 688549 & 4.5 & 5.1728 & TRN & \\
\hline CHEMBL1393735 & 688549 & 4.6 & 5.1665 & TRN & \\
\hline
\end{tabular}




\begin{tabular}{|c|c|c|c|c|}
\hline \multicolumn{5}{|c|}{ Supplemental Table S2.txt } \\
\hline CHEMBL102714 & 688549 & 4.9 & 5.1118 & TST \\
\hline CHEMBL1395660 & 688549 & 4.6 & 4.6766 & TRN \\
\hline CHEMBL1455472 & 688549 & 4.8 & 5.3716 & TRN \\
\hline CHEMBL1439324 & 688549 & 4.8 & 5.0262 & TRN \\
\hline CHEMBL457504 & 688549 & 4.8 & 5.2958 & TST \\
\hline CHEMBL1515037 & 688549 & 4.65 & 4.9918 & TRN \\
\hline CHEMBL1540894 & 688549 & 4.9 & 5.1725 & TRN \\
\hline CHEMBL1485379 & 688549 & 4.8 & 5.1875 & TRN \\
\hline CHEMBL1536491 & 688549 & 4.9 & 4.7487 & TRN \\
\hline CHEMBL1513894 & 688549 & 5.0 & 5.038 & TRN \\
\hline CHEMBL291536 & 688549 & 4.5 & 4.9682 & TRN \\
\hline CHEMBL1567968 & 688549 & 4.7 & 4.7605 & TRN \\
\hline CHEMBL1394808 & 688549 & 5.0 & 4.9075 & TRN \\
\hline CHEMBL3190765 & 688549 & 4.9 & 5.2008 & TST \\
\hline CHEMBL1548093 & 688549 & 4.9 & 5.0186 & TRN \\
\hline CHEMBL1535746 & 688549 & 5.4 & 5.2599 & TRN \\
\hline CHEMBL1383282 & 688549 & 4.8 & 4.8896 & TST \\
\hline CHEMBL1609409 & 688549 & 5.0 & 4.9902 & TRN \\
\hline CHEMBL1189 & 688549 & 8.1024 & 5.5016 & TST \\
\hline CHEMBL1315927 & 688549 & 4.5 & 4.8631 & TST \\
\hline CHEMBL1353893 & 688549 & 4.8 & 4.7471 & TST \\
\hline CHEMBL1309802 & 688549 & 5.5 & 4.8242 & TRN \\
\hline CHEMBL447876 & 688549 & 5.5 & 5.4987 & TST \\
\hline CHEMBL1545294 & 688549 & 4.9 & 4.9712 & TST \\
\hline CHEMBL1395912 & 688549 & 5.0 & 4.7671 & TRN \\
\hline CHEMBL1525495 & 688549 & 4.65 & 4.3009 & TRN \\
\hline CHEMBL1514529 & 688549 & 4.9 & 5.153 & TRN \\
\hline CHEMBL1319286 & 688549 & 4.5 & 4.4836 & TRN \\
\hline CHEMBL1329446 & 688549 & 5.0 & 5.184 & TRN \\
\hline CHEMBL1328170 & 688549 & 4.6 & 5.0039 & TST \\
\hline CHEMBL468167 & 688549 & 5.4 & 5.319 & TST \\
\hline CHEMBL1598907 & 688549 & 4.9 & 5.2236 & TRN \\
\hline CHEMBL1462631 & 688549 & 4.7 & 4.7423 & TRN \\
\hline CHEMBL1402846 & 688549 & 5.0 & 4.8816 & TRN \\
\hline CHEMBL1590315 & 688549 & 4.7 & 4.8291 & TRN \\
\hline CHEMBL1414269 & 688549 & 4.9 & 5.0138 & TRN \\
\hline CHEMBL1422105 & 688549 & 5.2 & 5.0546 & TRN \\
\hline CHEMBL1588811 & 688549 & 4.5 & 5.4589 & TRN \\
\hline CHEMBL1555531 & 688549 & 4.9 & 5.376 & TRN \\
\hline CHEMBL1578294 & 688549 & 4.5 & 4.5711 & TRN \\
\hline CHEMBL1537372 & 688549 & 6.4 & 5.0187 & TRN \\
\hline CHEMBL1535245 & 688549 & 5.1 & 4.9237 & TRN \\
\hline CHEMBL1511313 & 688549 & 4.5 & 4.5731 & TRN \\
\hline CHEMBL1516188 & 688549 & 5.1 & 4.9687 & TRN \\
\hline CHEMBL1343612 & 688549 & 4.6 & 5.1385 & TRN \\
\hline CHEMBL1516290 & 688549 & 4.5 & 5.1855 & TRN \\
\hline CHEMBL1319919 & 688549 & 4.9 & 4.8016 & TRN \\
\hline CHEMBL1318128 & 688549 & 5.55 & 4.9761 & TRN \\
\hline
\end{tabular}




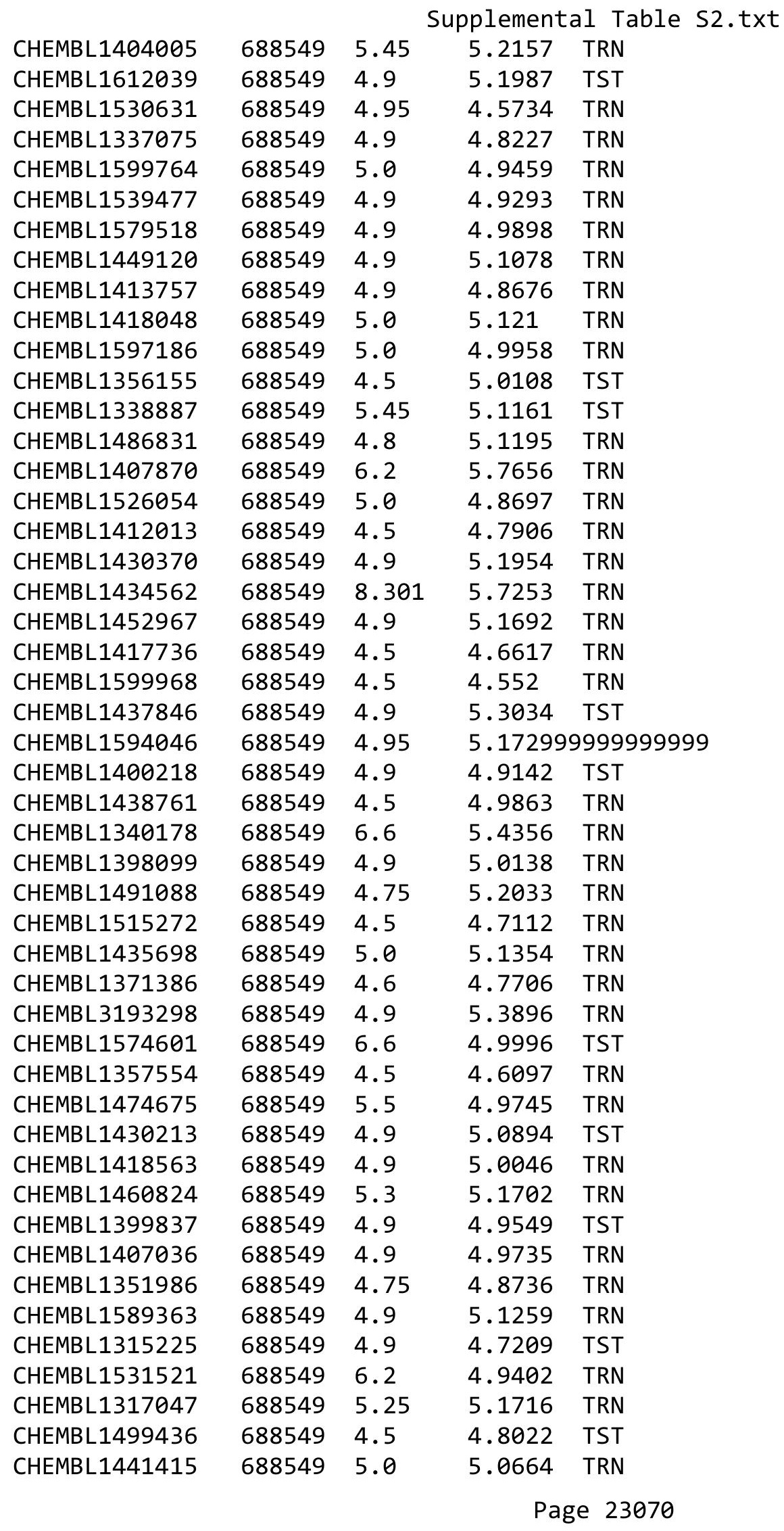

TRN 


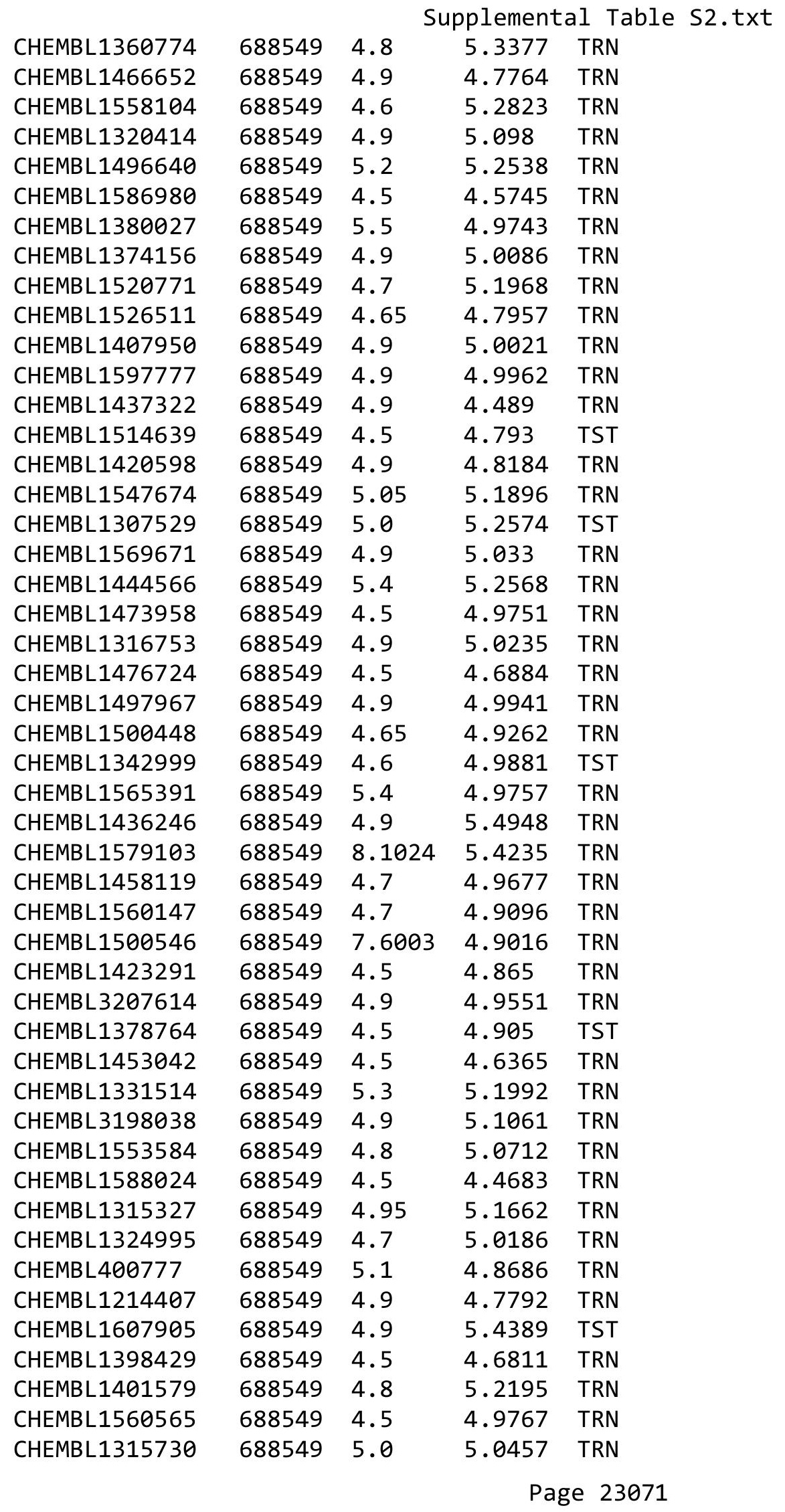




\begin{tabular}{|c|c|c|c|c|c|}
\hline & & & & & \\
\hline CHEMBL1595564 & 688549 & 4.6 & 4.8178 & TST & \\
\hline CHEMBL1396899 & 688549 & 4.6 & 4.831 & TRN & \\
\hline CHEMBL1970272 & 688549 & 5.1 & 4.9521 & TST & \\
\hline CHEMBL1588219 & 688549 & 4.9 & 4.9775 & TRN & \\
\hline CHEMBL1361615 & 688549 & 4.7 & 4.9039 & TRN & \\
\hline CHEMBL1575411 & 688549 & 5.0 & 5.1634 & TRN & \\
\hline CHEMBL1484454 & 688549 & 5.5 & 5.0546 & TRN & \\
\hline CHEMBL1449490 & 688549 & 4.5 & 4.9008 & TST & \\
\hline CHEMBL1534496 & 688549 & 4.9 & 5.1129 & TRN & \\
\hline CHEMBL1562153 & 688549 & 4.5 & 4.9363 & TRN & \\
\hline CHEMBL1503880 & 688549 & 5.5 & 5.5912 & TRN & \\
\hline CHEMBL1367304 & 688549 & 4.6 & 5.00899 & 99999999995 & TRN \\
\hline CHEMBL1552376 & 688549 & 4.45 & 4.8552 & TRN & \\
\hline CHEMBL1474369 & 688549 & 5.4 & 5.2042 & TRN & \\
\hline CHEMBL1553421 & 688549 & 4.7 & 5.1584 & TST & \\
\hline CHEMBL1305312 & 688549 & 4.5 & 4.7103 & TRN & \\
\hline CHEMBL243652 & 688549 & 4.6 & 5.1931 & TST & \\
\hline CHEMBL1436656 & 688549 & 5.6 & 4.9127 & TRN & \\
\hline CHEMBL1550877 & 688549 & 4.7 & 5.17200 & 0000000001 & TST \\
\hline CHEMBL1413202 & 688549 & 4.6 & 5.3016 & TRN & \\
\hline CHEMBL1316265 & 688549 & 4.5 & 4.934 & TRN & \\
\hline CHEMBL1424915 & 688549 & 4.9 & 4.9413 & TRN & \\
\hline CHEMBL1550003 & 688549 & 5.35 & 5.0189 & TST & \\
\hline CHEMBL1370224 & 688549 & 4.9 & 5.2036 & TRN & \\
\hline CHEMBL1445576 & 688549 & 4.5 & 4.695 & TRN & \\
\hline CHEMBL1494966 & 688549 & 4.65 & 5.24799 & 9999999999 & TST \\
\hline CHEMBL1311481 & 688549 & 4.5 & 4.8062 & TRN & \\
\hline CHEMBL1522852 & 688549 & 4.8 & 5.2927 & TST & \\
\hline CHEMBL1526035 & 688549 & 5.5 & 5.2952 & TRN & \\
\hline CHEMBL1351997 & 688549 & 4.65 & 4.9713 & TRN & \\
\hline CHEMBL1477172 & 688549 & 4.8 & 4.637 & TRN & \\
\hline CHEMBL1453366 & 688549 & 4.9 & 5.3416 & TST & \\
\hline CHEMBL1436272 & 688549 & 4.5 & 4.7479 & TRN & \\
\hline CHEMBL1597836 & 688549 & 4.9 & 4.6257 & TRN & \\
\hline CHEMBL1417779 & 688549 & 8.1024 & 5.4309 & TRN & \\
\hline CHEMBL1609655 & 688549 & 4.9 & 4.9054 & TRN & \\
\hline CHEMBL448741 & 688549 & 4.5 & 5.23 & TST & \\
\hline CHEMBL1460641 & 688549 & 6.6 & 5.3225 & TRN & \\
\hline CHEMBL1093507 & 688549 & 4.8 & 5.0291 & TRN & \\
\hline CHEMBL1391217 & 688549 & 4.5 & 5.0838 & TST & \\
\hline CHEMBL1474863 & 688549 & 5.5 & 4.9888 & TRN & \\
\hline CHEMBL1524845 & 688549 & 4.9 & 4.7172 & TRN & \\
\hline CHEMBL1436307 & 688549 & 4.9 & 5.2968 & TRN & \\
\hline CHEMBL277500 & 688549 & 8.3979 & 5.4468 & TST & \\
\hline CHEMBL1446827 & 688549 & 5.6 & 5.3139 & TRN & \\
\hline CHEMBL1376370 & 688549 & 5.35 & 5.0867 & TRN & \\
\hline CHEMBL1393339 & 688549 & 4.9 & 4.8122 & TRN & \\
\hline CHEMBL 2002776 & 688549 & 5.3 & 5.4053 & TRN & \\
\hline & & & & 23072 & \\
\hline
\end{tabular}




\begin{tabular}{|c|c|c|c|c|c|}
\hline & & & & & \\
\hline CHEMBL1602456 & 688549 & 5.0 & 4.7942 & TRN & \\
\hline CHEMBL429711 & 688549 & 5.1 & 5.1563 & TST & \\
\hline CHEMBL1411570 & 688549 & 4.9 & 4.9934 & TRN & \\
\hline CHEMBL1356364 & 688549 & 4.8 & 5.0541 & TRN & \\
\hline CHEMBL1437602 & 688549 & 4.9 & 4.9099 & TRN & \\
\hline CHEMBL1318468 & 688549 & 4.8 & 4.6185 & TRN & \\
\hline CHEMBL1569981 & 688549 & 4.95 & 4.7627 & TRN & \\
\hline CHEMBL1517100 & 688549 & 6.5 & 5.29799 & 9999999999 & TRN \\
\hline CHEMBL1323217 & 688549 & 4.5 & 4.7254 & TRN & \\
\hline CHEMBL1519341 & 688549 & 4.5 & 4.4961 & TRN & \\
\hline CHEMBL1321262 & 688549 & 4.85 & 4.9039 & TRN & \\
\hline CHEMBL1590533 & 688549 & 4.9 & 5.07600 & 00000000005 & TRN \\
\hline CHEMBL1435900 & 688549 & 4.8 & 5.6392 & TRN & \\
\hline CHEMBL3199587 & 688549 & 5.75 & 5.8344 & TST & \\
\hline CHEMBL3192112 & 688549 & 7.4001 & 5.399 & TST & \\
\hline CHEMBL1541000 & 688549 & 4.9 & 4.7475 & TRN & \\
\hline CHEMBL1585105 & 688549 & 5.0 & 4.8785 & TRN & \\
\hline CHEMBL1475496 & 688549 & 4.6 & 4.6199 & TRN & \\
\hline CHEMBL1522813 & 688549 & 4.6 & 5.0172 & TRN & \\
\hline CHEMBL1356293 & 688549 & 4.5 & 5.2696 & TRN & \\
\hline CHEMBL1606813 & 688549 & 4.5 & 5.0544 & TRN & \\
\hline CHEMBL1428659 & 688549 & 5.1 & 4.9558 & TRN & \\
\hline CHEMBL1499041 & 688549 & 5.0 & 4.7777 & TRN & \\
\hline CHEMBL1377384 & 688549 & 5.3 & 5.3447 & TRN & \\
\hline CHEMBL1514965 & 688549 & 7.0 & 5.063 & TST & \\
\hline CHEMBL1488251 & 688549 & 5.0 & 4.7994 & TRN & \\
\hline CHEMBL1425453 & 688549 & 5.65 & 5.2123 & TST & \\
\hline CHEMBL1416104 & 688549 & 4.5 & 4.9903 & TRN & \\
\hline CHEMBL1373823 & 688549 & 4.9 & 5.1946 & TRN & \\
\hline CHEMBL1339835 & 688549 & 4.9 & 4.8342 & TRN & \\
\hline CHEMBL1535988 & 688549 & 5.1 & 5.2132 & TRN & \\
\hline CHEMBL1290316 & 688549 & 5.0 & 5.3449 & TRN & \\
\hline CHEMBL1483226 & 688549 & 4.9 & 5.016 & TRN & \\
\hline CHEMBL1510906 & 688549 & 4.5 & 5.1964 & TST & \\
\hline CHEMBL18115 & 688549 & 6.0 & 4.8867 & TRN & \\
\hline CHEMBL1555898 & 688549 & 4.5 & 4.7629 & TRN & \\
\hline CHEMBL1460155 & 688549 & 4.9 & 5.0801 & TRN & \\
\hline CHEMBL1444359 & 688549 & 4.8 & 5.0568 & TRN & \\
\hline CHEMBL1348181 & 688549 & 4.9 & 4.9507 & TRN & \\
\hline CHEMBL1331122 & 688549 & 5.2 & 5.2712 & TST & \\
\hline CHEMBL1565416 & 688549 & 4.9 & 5.145 & TRN & \\
\hline CHEMBL1543924 & 688549 & 4.9 & 4.8024 & TST & \\
\hline CHEMBL1403950 & 688549 & 5.0 & 4.94 & TRN & \\
\hline CHEMBL1515357 & 688549 & 4.85 & 5.08899 & 99999999995 & TRN \\
\hline CHEMBL1601947 & 688549 & 4.9 & 4.9356 & TRN & \\
\hline CHEMBL1451617 & 688549 & 5.0 & 4.739 & TRN & \\
\hline CHEMBL1574088 & 688549 & 4.7 & 4.7063 & TRN & \\
\hline CHEMBL1435570 & 688549 & 4.8 & 5.0483 & TST & \\
\hline & & & & 23073 & \\
\hline
\end{tabular}




\begin{tabular}{|c|c|c|c|c|}
\hline & & & pplement & al $\mathrm{T}$ \\
\hline CHEMBL1585127 & 688549 & 5.0 & 4.8675 & TRN \\
\hline CHEMBL1316795 & 688549 & 4.9 & 4.9365 & TRN \\
\hline CHEMBL1529957 & 688549 & 4.9 & 5.084 & TRN \\
\hline CHEMBL1422481 & 688549 & 4.9 & 5.0834 & TRN \\
\hline CHEMBL1605242 & 688549 & 6.7501 & 5.2061 & TRN \\
\hline CHEMBL1474458 & 688549 & 4.6 & 4.4273 & TRN \\
\hline CHEMBL1472609 & 688549 & 4.5 & 4.4385 & TRN \\
\hline CHEMBL1541001 & 688549 & 4.9 & 4.9026 & TRN \\
\hline CHEMBL460517 & 688549 & 5.0 & 5.3592 & TRN \\
\hline CHEMBL1566891 & 688549 & 5.0 & 4.8439 & TRN \\
\hline CHEMBL1360064 & 688549 & 4.9 & 4.9427 & TRN \\
\hline CHEMBL1387290 & 688549 & 5.1 & 4.6935 & TRN \\
\hline CHEMBL1363696 & 688549 & 4.9 & 5.7732 & TRN \\
\hline CHEMBL1528999 & 688549 & 4.5 & 4.9745 & TRN \\
\hline CHEMBL1329375 & 688549 & 4.9 & 5.1113 & TRN \\
\hline CHEMBL1420358 & 688549 & 4.7 & 4.8313 & TRN \\
\hline CHEMBL1450386 & 688549 & 4.8 & 5.1638 & TRN \\
\hline CHEMBL1355421 & 688549 & 4.5 & 4.3988 & TST \\
\hline CHEMBL1492436 & 688549 & 4.5 & 4.8376 & TRN \\
\hline CHEMBL1526488 & 688549 & 5.0 & 4.8521 & TRN \\
\hline CHEMBL1588060 & 688549 & 4.8 & 5.0117 & TRN \\
\hline CHEMBL1534503 & 688549 & 4.5 & 4.5597 & TRN \\
\hline CHEMBL1531582 & 688549 & 4.5 & 4.4934 & TST \\
\hline CHEMBL1358102 & 688549 & 4.7 & 4.9184 & TRN \\
\hline CHEMBL1473317 & 688549 & 5.0 & 4.9734 & TRN \\
\hline CHEMBL3194824 & 688549 & 7.6498 & 5.8456 & TRN \\
\hline CHEMBL1306806 & 688549 & 6.1 & 5.6768 & TST \\
\hline CHEMBL1572836 & 688549 & 4.9 & 4.649 & TRN \\
\hline CHEMBL1479295 & 688549 & 4.8 & 4.8706 & TRN \\
\hline CHEMBL1401486 & 688549 & 4.9 & 4.4354 & TRN \\
\hline CHEMBL1475081 & 688549 & 4.9 & 4.7747 & TRN \\
\hline CHEMBL 1457100 & 688549 & 4.5 & 4.9079 & TST \\
\hline CHEMBL1324662 & 688549 & 4.6 & 4.9806 & TST \\
\hline CHEMBL1327584 & 688549 & 4.5 & 4.8131 & TRN \\
\hline CHEMBL1483007 & 688549 & 4.5 & 4.6452 & TRN \\
\hline CHEMBL1565727 & 688549 & 8.301 & 5.2017 & TRN \\
\hline CHEMBL1417844 & 688549 & 4.45 & 5.0977 & TRN \\
\hline CHEMBL1553965 & 688549 & 5.4 & 5.0661 & TRN \\
\hline CHEMBL1591261 & 688549 & 4.8 & 4.5514 & TRN \\
\hline CHEMBL1607304 & 688549 & 4.8 & 5.0238 & TRN \\
\hline CHEMBL1428274 & 688549 & 4.7 & 5.3846 & TRN \\
\hline CHEMBL1397921 & 688549 & 5.0 & 4.698 & TRN \\
\hline CHEMBL1512211 & 688549 & 4.7 & 4.8381 & TRN \\
\hline CHEMBL1539240 & 688549 & 5.0 & 5.2542 & TRN \\
\hline CHEMBL3193533 & 688549 & 4.45 & 5.3132 & TRN \\
\hline CHEMBL180162 & 688549 & 4.9 & 5.1399 & TRN \\
\hline CHEMBL1555165 & 688549 & 4.5 & 4.9624 & TRN \\
\hline CHEMBL1398633 & 688549 & 4.9 & 4.7203 & TRN \\
\hline
\end{tabular}




\begin{tabular}{|c|c|c|c|c|}
\hline \multicolumn{5}{|c|}{ Supplemental Table S2.txt } \\
\hline CHEMBL1497878 & 688549 & 4.8 & 4.8046 & TRN \\
\hline CHEMBL1364383 & 688549 & 5.25 & 5.3884 & TRN \\
\hline CHEMBL1476020 & 688549 & 4.6 & 4.6719 & TRN \\
\hline CHEMBL1501302 & 688549 & 4.5 & 4.5804 & TRN \\
\hline CHEMBL150924 & 688549 & 5.0 & 5.0062 & TRN \\
\hline CHEMBL1530698 & 688549 & 5.5 & 5.2482 & TRN \\
\hline CHEMBL1357553 & 688549 & 4.9 & 4.8442 & TST \\
\hline CHEMBL1393672 & 688549 & 4.9 & 5.4323 & TST \\
\hline CHEMBL 88272 & 688549 & 4.4 & 4.727 & TST \\
\hline CHEMBL1474475 & 688549 & 4.6 & 4.4349 & TRN \\
\hline CHEMBL1317327 & 688549 & 4.5 & 4.8257 & TST \\
\hline CHEMBL1454742 & 688549 & 4.5 & 5.5919 & TST \\
\hline CHEMBL1473421 & 688549 & 6.15 & 5.0096 & TRN \\
\hline CHEMBL1588326 & 688549 & 5.0 & 5.21899 & 9999999999 \\
\hline CHEMBL1480826 & 688549 & 5.5 & 4.8875 & TRN \\
\hline CHEMBL1371746 & 688549 & 5.1 & 5.0302 & TRN \\
\hline CHEMBL1594052 & 688549 & 4.8 & 4.8262 & TRN \\
\hline CHEMBL1526301 & 688549 & 4.65 & 4.7305 & TRN \\
\hline CHEMBL1565756 & 688549 & 4.7 & 4.9075 & TST \\
\hline CHEMBL1389630 & 688549 & 4.75 & 4.9123 & TRN \\
\hline CHEMBL1549966 & 688549 & 4.8 & 4.9132 & TRN \\
\hline CHEMBL1482575 & 688549 & 4.9 & 4.9212 & TST \\
\hline CHEMBL1525773 & 688549 & 4.8 & 4.9657 & TRN \\
\hline CHEMBL1591337 & 688549 & 4.6 & 4.8374 & TRN \\
\hline CHEMBL1469857 & 688549 & 4.45 & 5.1277 & TRN \\
\hline CHEMBL1514806 & 688549 & 4.8 & 4.459 & TRN \\
\hline CHEMBL85139 & 688549 & 4.9 & 5.3554 & TRN \\
\hline CHEMBL1608241 & 688549 & 4.45 & 4.5136 & TRN \\
\hline CHEMBL1579133 & 688549 & 6.7001 & 5.146 & TRN \\
\hline CHEMBL86676 & 688549 & 4.5 & 5.0385 & TST \\
\hline CHEMBL1602608 & 688549 & 5.0 & 4.9326 & TRN \\
\hline CHEMBL1355345 & 688549 & 5.5 & 4.8111 & TRN \\
\hline CHEMBL1464549 & 688549 & 5.2 & 4.7677 & TRN \\
\hline CHEMBL3209382 & 688549 & 4.9 & 5.5206 & TRN \\
\hline CHEMBL1494432 & 688549 & 4.7 & 4.6613 & TRN \\
\hline CHEMBL3191141 & 688549 & 5.5 & 5.4042 & TRN \\
\hline CHEMBL1441523 & 688549 & 4.9 & 4.8072 & TRN \\
\hline CHEMBL1368091 & 688549 & 4.85 & 4.7611 & TRN \\
\hline CHEMBL1459688 & 688549 & 5.4 & 5.1049 & TRN \\
\hline CHEMBL1366697 & 688549 & 5.0 & 5.3687 & TRN \\
\hline CHEMBL1413940 & 688549 & 4.45 & 4.552 & TRN \\
\hline CHEMBL1488889 & 688549 & 4.6 & 5.3108 & TST \\
\hline CHEMBL1438073 & 688549 & 4.7 & 4.7051 & TRN \\
\hline CHEMBL1409241 & 688549 & 4.9 & 4.8576 & TRN \\
\hline CHEMBL1525442 & 688549 & 5.0 & 5.1672 & TST \\
\hline CHEMBL1561192 & 688549 & 7.8996 & 5.3754 & TRN \\
\hline CHEMBL1300414 & 688549 & 4.6 & 5.2002 & TST \\
\hline CHEMBL1535794 & 688549 & 4.8 & 4.9199 & TRN \\
\hline
\end{tabular}




\begin{tabular}{|c|c|c|c|c|c|}
\hline \multicolumn{6}{|c|}{ Supplemental Table S2.txt } \\
\hline CHEMBL1352436 & 688549 & 4.9 & 5.0258 & TRN & \\
\hline CHEMBL1436369 & 688549 & 4.75 & 4.559 & TRN & \\
\hline CHEMBL259615 & 688549 & 6.0 & 5.0438 & TRN & \\
\hline CHEMBL1480144 & 688549 & 5.0 & 4.6296 & TRN & \\
\hline CHEMBL1601738 & 688549 & 5.1 & 4.9544 & TRN & \\
\hline CHEMBL549321 & 688549 & 4.8 & 4.6693 & TRN & \\
\hline CHEMBL1442562 & 688549 & 4.9 & 4.8748 & TRN & \\
\hline CHEMBL1409944 & 688549 & 4.85 & 5.2122 & TRN & \\
\hline CHEMBL1434637 & 688549 & 4.5 & 5.0627 & TRN & \\
\hline CHEMBL1445118 & 688549 & 4.7 & 5.0703 & TRN & \\
\hline CHEMBL1426830 & 688549 & 5.1 & 5.0634 & TRN & \\
\hline CHEMBL1330184 & 688549 & 4.5 & 4.6464 & TRN & \\
\hline CHEMBL1402541 & 688549 & 4.9 & 5.2229 & TRN & \\
\hline CHEMBL3213501 & 688549 & 4.9 & 5.3944 & TST & \\
\hline CHEMBL303846 & 688549 & 5.0 & 5.2939 & TST & \\
\hline CHEMBL1374200 & 688549 & 4.85 & 5.0764 & TST & \\
\hline CHEMBL1596966 & 688549 & 4.5 & 5.0751 & TRN & \\
\hline CHEMBL1306756 & 688549 & 6.15 & 5.5702 & TRN & \\
\hline CHEMBL1523589 & 688549 & 5.9 & 5.4989 & TRN & \\
\hline CHEMBL1355197 & 688549 & 4.85 & 4.9536 & TRN & \\
\hline CHEMBL3199576 & 688549 & 4.9 & 5.4079 & TST & \\
\hline CHEMBL1603687 & 688549 & 4.5 & 5.4275 & TST & \\
\hline CHEMBL1514871 & 688549 & 4.9 & 5.318 & TRN & \\
\hline CHEMBL1323729 & 688549 & 4.6 & 4.9212 & TRN & \\
\hline CHEMBL1352138 & 688549 & 4.8 & 4.3622 & TST & \\
\hline CHEMBL1530828 & 688549 & 4.6 & 5.1913 & TRN & \\
\hline CHEMBL1501971 & 688549 & 4.5 & 4.8727 & TRN & \\
\hline CHEMBL 282731 & 688549 & 8.2007 & 5.3395 & TRN & \\
\hline CHEMBL1339717 & 688549 & 4.9 & 4.8201 & TRN & \\
\hline CHEMBL1333430 & 688549 & 5.0 & 4.908 & TRN & \\
\hline CHEMBL1357544 & 688549 & 4.5 & 5.2505 & TRN & \\
\hline CHEMBL1370516 & 688549 & 4.7 & 4.3916 & TRN & \\
\hline CHEMBL1563483 & 688549 & 4.7 & 5.472 & TST & \\
\hline CHEMBL3210494 & 688549 & 4.45 & 5.1715 & TST & \\
\hline CHEMBL1601416 & 688549 & 4.9 & 5.11100 & 0000000001 & TRN \\
\hline CHEMBL1606088 & 688549 & 5.0 & 5.3606 & TRN & \\
\hline CHEMBL1419597 & 688549 & 5.0 & 5.0649 & TRN & \\
\hline CHEMBL1326916 & 688549 & 5.5 & 5.0418 & TRN & \\
\hline CHEMBL1592735 & 688549 & 4.9 & 4.9715 & TRN & \\
\hline CHEMBL1581335 & 688549 & 4.5 & 5.0899 & TRN & \\
\hline CHEMBL1591928 & 688549 & 6.45 & 5.2755 & TRN & \\
\hline CHEMBL1454897 & 688549 & 4.7 & 4.6638 & TRN & \\
\hline CHEMBL1482470 & 688549 & 4.5 & 4.8748 & TST & \\
\hline CHEMBL1530084 & 688549 & 4.8 & 5.082 & TRN & \\
\hline CHEMBL1324142 & 688549 & 4.6 & 4.8273 & TRN & \\
\hline CHEMBL1593118 & 688549 & 4.9 & 4.8004 & TRN & \\
\hline CHEMBL1384347 & 688549 & 6.1 & 5.3368 & TRN & \\
\hline CHEMBL1398793 & 688549 & 5.2 & 4.8105 & TRN & \\
\hline
\end{tabular}




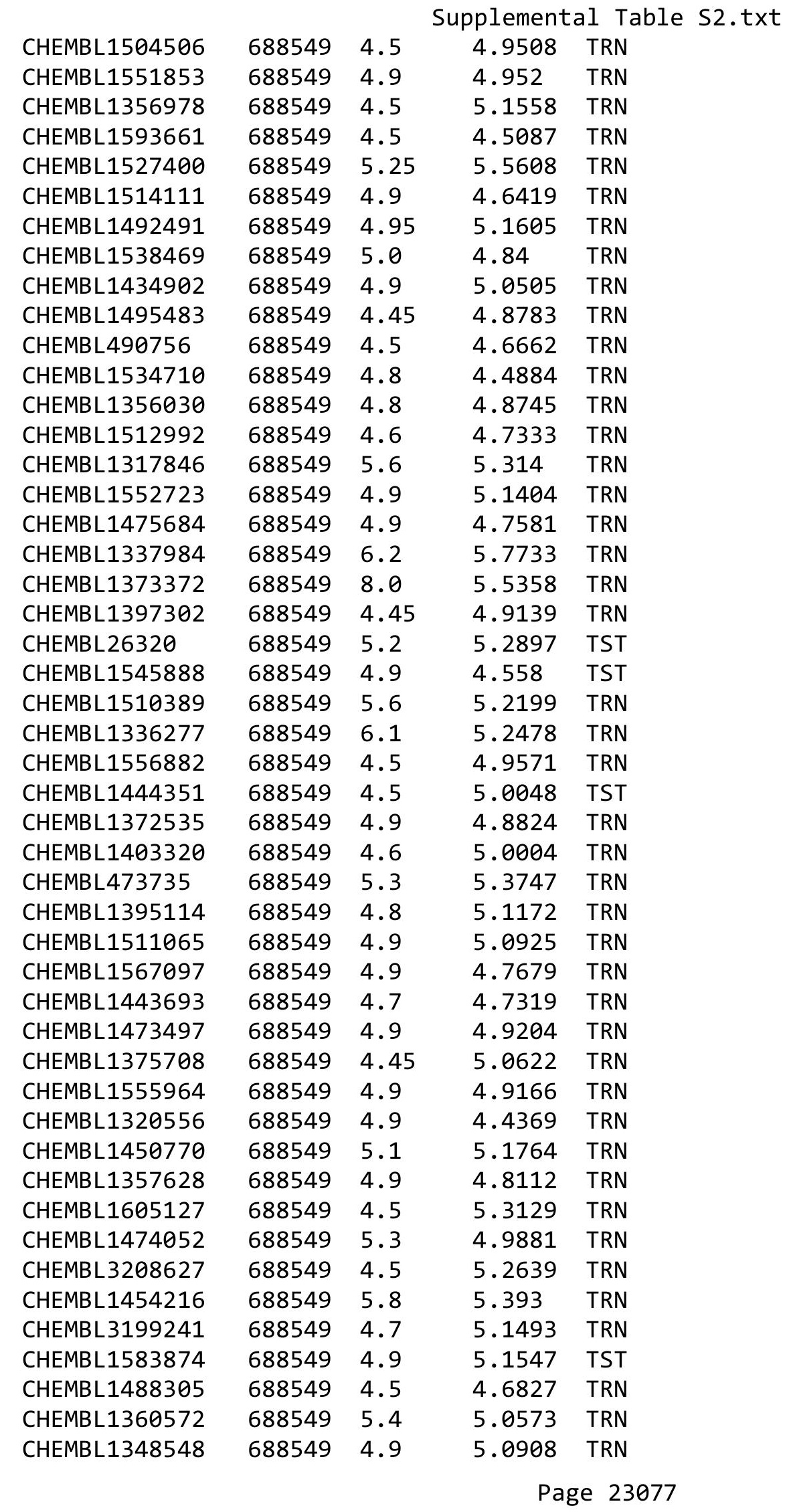




\begin{tabular}{|c|c|c|c|c|c|}
\hline \multirow{2}{*}{\multicolumn{2}{|c|}{ CHEMBL1376817 }} & \\
\hline & & 4.6 & 4.8837 & TRN & \\
\hline CHEMBL1409032 & 688549 & 5.0 & 5.1213 & TRN & \\
\hline CHEMBL1574539 & 688549 & 5.0 & 5.0297 & TRN & \\
\hline CHEMBL1521005 & 688549 & 5.0 & 5.0404 & TRN & \\
\hline CHEMBL1378006 & 688549 & 5.7 & 5.2168 & TRN & \\
\hline CHEMBL1560639 & 688549 & 5.5 & 5.3591 & TRN & \\
\hline CHEMBL1519352 & 688549 & 4.7 & 4.8916 & TRN & \\
\hline CHEMBL210868 & 688549 & 4.6 & 5.1198 & TST & \\
\hline CHEMBL1552079 & 688549 & 5.1 & 5.1666 & TRN & \\
\hline CHEMBL1481651 & 688549 & 5.3 & \multicolumn{2}{|c|}{5.167000000000001} & TRN \\
\hline CHEMBL1441934 & 688549 & 4.5 & 4.954 & TST & \\
\hline CHEMBL1584849 & 688549 & 7.7496 & 5.6248 & TST & \\
\hline CHEMBL1438339 & 688549 & 4.9 & 5.3215 & TST & \\
\hline CHEMBL1467999 & 688549 & 4.9 & 4.8161 & TRN & \\
\hline CHEMBL1595518 & 688549 & 4.5 & 4.6927 & TRN & \\
\hline CHEMBL1422586 & 688549 & 4.7 & 5.3415 & TRN & \\
\hline CHEMBL1411550 & 688549 & 4.5 & 4.852 & TRN & \\
\hline CHEMBL 274844 & 688549 & 4.5 & 5.4201 & TST & \\
\hline CHEMBL1552023 & 688549 & 4.9 & 5.1844 & TRN & \\
\hline CHEMBL1338443 & 688549 & 5.3 & 4.8834 & TRN & \\
\hline CHEMBL1527661 & 688549 & 5.0 & 4.8916 & TRN & \\
\hline CHEMBL239009 & 688549 & 4.5 & 4.6323 & TRN & \\
\hline CHEMBL1606419 & 688549 & 4.6 & 5.1549 & TRN & \\
\hline CHEMBL1455025 & 688549 & 5.1 & 5.4248 & TRN & \\
\hline CHEMBL1589137 & 688549 & 4.5 & 5.3026 & TRN & \\
\hline CHEMBL1355548 & 688549 & 4.9 & 5.2728 & TRN & \\
\hline CHEMBL1611263 & 688549 & 5.45 & 5.2594 & TRN & \\
\hline CHEMBL1315145 & 688549 & 4.8 & 4.8096 & TRN & \\
\hline CHEMBL1398171 & 688549 & 4.7 & 5.0381 & TRN & \\
\hline CHEMBL1546068 & 688549 & 4.5 & 4.9257 & TST & \\
\hline CHEMBL1323790 & 688549 & 4.7 & 4.8487 & TRN & \\
\hline CHEMBL1604017 & 688549 & 4.5 & 4.6038 & TST & \\
\hline CHEMBL1305583 & 688549 & 8.301 & 5.505 & TRN & \\
\hline CHEMBL1513145 & 688549 & 5.1 & 4.8112 & TRN & \\
\hline CHEMBL1474256 & 688549 & 4.5 & 4.5462 & TRN & \\
\hline CHEMBL1324524 & 688549 & 4.9 & 4.8521 & TRN & \\
\hline CHEMBL1375958 & 688549 & 4.9 & 5.3689 & TRN & \\
\hline CHEMBL1474341 & 688549 & 5.8 & \multicolumn{2}{|c|}{5.236000000000001} & TRN \\
\hline CHEMBL 2003172 & 688549 & 5.0 & 5.07 & TRN & \\
\hline CHEMBL1413831 & 688549 & 4.6 & 5.1598 & TRN & \\
\hline CHEMBL1549823 & 688549 & 5.2 & 5.1392 & TRN & \\
\hline CHEMBL1549097 & 688549 & 4.9 & 4.8536 & TRN & \\
\hline CHEMBL 236388 & 688549 & 6.2 & 5.0092 & TRN & \\
\hline CHEMBL 259139 & 688549 & 4.45 & 4.864 & TST & \\
\hline CHEMBL1332688 & 688549 & 4.8 & 5.2923 & TRN & \\
\hline CHEMBL1488129 & 688549 & 4.6 & 4.9494 & TRN & \\
\hline CHEMBL1611005 & 688549 & 4.6 & 5.0108 & TRN & \\
\hline \multirow[t]{2}{*}{ CHEMBL1544951 } & 688549 & 4.8 & 4.8998 & TST & \\
\hline & & \multicolumn{4}{|c|}{ Page 23078} \\
\hline
\end{tabular}




\begin{tabular}{|c|c|c|c|c|c|}
\hline \\
\hline CHEMBL1608009 & 688549 & 4.8 & 5.3257 & TRN & \\
\hline CHEMBL1425624 & 688549 & 4.5 & 4.8723 & TRN & \\
\hline CHEMBL1516856 & 688549 & 4.8 & 4.8234 & TRN & \\
\hline CHEMBL1299399 & 688549 & 4.8 & 4.6066 & TRN & \\
\hline CHEMBL323542 & 688549 & 4.9 & 5.4176 & TST & \\
\hline CHEMBL1457597 & 688549 & 5.0 & 4.8516 & TRN & \\
\hline CHEMBL1447501 & 688549 & 4.5 & 4.9316 & TRN & \\
\hline CHEMBL1379900 & 688549 & 4.5 & 4.8918 & TRN & \\
\hline CHEMBL1330058 & 688549 & 5.3 & 5.4689 & TRN & \\
\hline CHEMBL1401878 & 688549 & 4.5 & 5.2078 & TRN & \\
\hline CHEMBL1522810 & 688549 & 4.8 & 4.8531 & TRN & \\
\hline CHEMBL1461491 & 688549 & 4.5 & 5.1911 & TST & \\
\hline CHEMBL64239 & 688549 & 4.9 & 5.0741 & TRN & \\
\hline CHEMBL1515472 & 688549 & 4.85 & 5.0646 & TRN & \\
\hline CHEMBL1446802 & 688549 & 4.5 & 4.875 & TRN & \\
\hline CHEMBL528712 & 688549 & 4.9 & 4.774 & TRN & \\
\hline CHEMBL1571874 & 688549 & 4.8 & 4.4947 & TST & \\
\hline CHEMBL1362424 & 688549 & 5.2 & 5.5003 & TRN & \\
\hline CHEMBL1533540 & 688549 & 4.45 & 4.5885 & TRN & \\
\hline CHEMBL1466714 & 688549 & 4.9 & 4.6144 & TRN & \\
\hline CHEMBL1434051 & 688549 & 4.75 & 4.8165 & TRN & \\
\hline CHEMBL1515749 & 688549 & 4.6 & 5.2448 & TRN & \\
\hline CHEMBL1451208 & 688549 & 8.0 & 5.273 & TST & \\
\hline CHEMBL1455537 & 688549 & 4.5 & 5.1261 & TRN & \\
\hline CHEMBL1494905 & 688549 & 5.0 & 5.1777 & TRN & \\
\hline CHEMBL1524276 & 688549 & 5.2 & 5.2826 & TRN & \\
\hline CHEMBL1527382 & 688549 & 4.95 & 4.7285 & TRN & \\
\hline CHEMBL3190400 & 688549 & 5.3 & 5.3977 & TRN & \\
\hline CHEMBL1455438 & 688549 & 4.6 & 4.8835 & TRN & \\
\hline CHEMBL1442632 & 688549 & 5.0 & 4.8988 & TRN & \\
\hline CHEMBL1318033 & 688549 & 4.6 & 4.5186 & TST & \\
\hline CHEMBL1343389 & 688549 & 4.8 & 5.3241 & TST & \\
\hline CHEMBL1567510 & 688549 & 5.0 & 4.72199 & 99999999995 & TRN \\
\hline CHEMBL586946 & 688549 & 4.5 & 5.3597 & TST & \\
\hline CHEMBL1564928 & 688549 & 4.7 & 5.21899 & 9999999999 & TRN \\
\hline CHEMBL1491288 & 688549 & 5.2 & 4.9788 & TRN & \\
\hline CHEMBL1609203 & 688549 & 4.6 & 4.4533 & TRN & \\
\hline CHEMBL1525901 & 688549 & 4.7 & 4.9605 & TST & \\
\hline CHEMBL1591740 & 688549 & 4.8 & 4.855 & TRN & \\
\hline CHEMBL1438593 & 688549 & 4.5 & 4.9763 & TST & \\
\hline CHEMBL1435819 & 688549 & 4.9 & 5.1301 & TST & \\
\hline CHEMBL1448090 & 688549 & 4.8 & 4.8865 & TRN & \\
\hline CHEMBL1352955 & 688549 & 5.0 & 4.8423 & TRN & \\
\hline CHEMBL429335 & 688549 & 5.1 & 5.4264 & TRN & \\
\hline CHEMBL16751 & 688549 & 4.8 & 5.135 & TRN & \\
\hline CHEMBL1370293 & 688549 & 4.9 & 5.6422 & TRN & \\
\hline CHEMBL1357389 & 688549 & 4.8 & 5.0838 & TRN & \\
\hline CHEMBL1453691 & 688549 & 5.0 & 4.9517 & TRN & \\
\hline
\end{tabular}




\begin{tabular}{|c|c|c|c|c|c|}
\hline & & & & & \\
\hline CHEMBL1417788 & 688549 & 5.0 & 5.0516 & TRN & \\
\hline CHEMBL1527663 & 688549 & 4.5 & 5.0997 & TRN & \\
\hline CHEMBL1512426 & 688549 & 4.9 & 5.2689 & TST & \\
\hline CHEMBL1484934 & 688549 & 5.3 & 4.7992 & TRN & \\
\hline CHEMBL1518205 & 688549 & 4.9 & 4.8289 & TRN & \\
\hline CHEMBL1412726 & 688549 & 4.6 & 5.3299 & TRN & \\
\hline CHEMBL1433507 & 688549 & 4.7 & 5.5086 & TRN & \\
\hline CHEMBL1390863 & 688549 & 4.9 & 4.8273 & TRN & \\
\hline CHEMBL1375390 & 688549 & 4.9 & 5.1339 & TST & \\
\hline CHEMBL599088 & 688549 & 4.8 & 4.755 & TST & \\
\hline CHEMBL1333047 & 688549 & 5.5 & 5.4009 & TRN & \\
\hline CHEMBL1327424 & 688549 & 4.5 & 4.9834 & TRN & \\
\hline CHEMBL1590360 & 688549 & 5.2 & 5.3421 & TRN & \\
\hline CHEMBL1424917 & 688549 & 5.0 & 4.7656 & TST & \\
\hline CHEMBL1398931 & 688549 & 4.5 & 4.8403 & TRN & \\
\hline CHEMBL1395004 & 688549 & 4.9 & 5.0047 & TRN & \\
\hline CHEMBL1391746 & 688549 & 4.9 & 4.7707 & TRN & \\
\hline CHEMBL1378724 & 688549 & 4.8 & 5.0077 & TRN & \\
\hline CHEMBL1548616 & 688549 & 4.8 & 4.637 & TRN & \\
\hline CHEMBL1514773 & 688549 & 5.4 & 4.9198 & TRN & \\
\hline CHEMBL1454845 & 688549 & 4.5 & 4.558 & TRN & \\
\hline CHEMBL1386201 & 688549 & 6.2 & 5.1119 & TRN & \\
\hline CHEMBL1552900 & 688549 & 5.5 & 4.9084 & TRN & \\
\hline CHEMBL1356515 & 688549 & 4.6 & 4.9798 & TRN & \\
\hline CHEMBL1424062 & 688549 & 4.95 & 5.0179 & TRN & \\
\hline CHEMBL1444575 & 688549 & 4.8 & 4.6839 & TRN & \\
\hline CHEMBL1379600 & 688549 & 4.5 & 4.7023 & TRN & \\
\hline CHEMBL1529784 & 688549 & 5.6 & 5.5761 & TRN & \\
\hline CHEMBL1420443 & 688549 & 8.1024 & 5.3632 & TRN & \\
\hline CHEMBL1417981 & 688549 & 4.7 & 4.5384 & TST & \\
\hline CHEMBL1591644 & 688549 & 4.5 & 4.6917 & TRN & \\
\hline CHEMBL1453071 & 688549 & 4.9 & 5.2556 & TST & \\
\hline CHEMBL1513351 & 688549 & 4.6 & 4.6735 & TRN & \\
\hline CHEMBL1480801 & 688549 & 5.6 & 4.75899 & 99999999995 & TRN \\
\hline CHEMBL1360816 & 688549 & 4.5 & 4.9906 & TRN & \\
\hline CHEMBL1395137 & 688549 & 4.5 & 4.6119 & TRN & \\
\hline CHEMBL1514885 & 688549 & 4.5 & 4.9718 & TST & \\
\hline CHEMBL1396641 & 688549 & 4.9 & 4.9024 & TRN & \\
\hline CHEMBL1362737 & 688549 & 4.9 & 4.853 & TRN & \\
\hline CHEMBL222409 & 688549 & 4.6 & 4.919 & TST & \\
\hline CHEMBL1357850 & 688549 & 4.6 & 4.726 & TRN & \\
\hline CHEMBL 36028 & 688549 & 5.0 & 5.1212 & TST & \\
\hline CHEMBL1464608 & 688549 & 4.9 & 4.8392 & TRN & \\
\hline CHEMBL1396203 & 688549 & 4.6 & 4.855 & TRN & \\
\hline CHEMBL1601908 & 688549 & 5.1 & 4.89199 & 99999999995 & TRN \\
\hline CHEMBL1435271 & 688549 & 4.6 & 4.7672 & TRN & \\
\hline CHEMBL1592831 & 688549 & 4.5 & 5.0723 & TRN & \\
\hline CHEMBL1464550 & 688549 & 4.7 & 4.9788 & TRN & \\
\hline & & & & 23080 & \\
\hline
\end{tabular}




\begin{tabular}{|c|c|c|c|c|}
\hline \multicolumn{5}{|c|}{ Supplemental Table S2.txt } \\
\hline CHEMBL1451936 & 688549 & 4.5 & 4.7833 & TRN \\
\hline CHEMBL1526325 & 688549 & 4.6 & 4.7484 & TRN \\
\hline CHEMBL1567682 & 688549 & 4.9 & 5.2388 & TRN \\
\hline CHEMBL1440636 & 688549 & 5.95 & 5.3724 & TRN \\
\hline CHEMBL1376919 & 688549 & 5.4 & 5.3831 & TRN \\
\hline CHEMBL1352280 & 688549 & 4.9 & 4.7014 & TRN \\
\hline CHEMBL1314932 & 688549 & 5.0 & 5.0218 & TRN \\
\hline CHEMBL 212242 & 688549 & 4.9 & 5.1363 & TRN \\
\hline CHEMBL1402683 & 688549 & 4.5 & 5.1998 & TRN \\
\hline CHEMBL1513260 & 688549 & 5.0 & 4.7912 & TRN \\
\hline CHEMBL1728023 & 688549 & 6.0 & 5.2228 & TRN \\
\hline CHEMBL1516879 & 688549 & 5.3 & 5.206 & TRN \\
\hline CHEMBL530361 & 688549 & 4.6 & 5.0978 & TRN \\
\hline CHEMBL1531294 & 688549 & 4.8 & 4.7408 & TST \\
\hline CHEMBL1593037 & 688549 & 5.65 & 5.505 & TRN \\
\hline CHEMBL72365 & 688549 & 4.9 & 4.9228 & TST \\
\hline CHEMBL1304530 & 688549 & 8.1024 & 5.2555 & TRN \\
\hline CHEMBL1482541 & 688549 & 5.1 & 4.8265 & TRN \\
\hline CHEMBL1368118 & 688549 & 5.1 & 4.9735 & TRN \\
\hline CHEMBL1555091 & 688549 & 4.5 & 4.2816 & TRN \\
\hline CHEMBL1315721 & 688549 & 4.9 & 5.3909 & TRN \\
\hline CHEMBL1307919 & 688549 & 6.0 & 5.4231 & TRN \\
\hline CHEMBL1611354 & 688549 & 4.7 & 5.3823 & TRN \\
\hline CHEMBL1450497 & 688549 & 5.3 & 5.9176 & TRN \\
\hline CHEMBL444376 & 688549 & 5.0 & 5.0899 & TRN \\
\hline CHEMBL1394538 & 688549 & 4.8 & 5.0856 & TRN \\
\hline CHEMBL1333686 & 688549 & 6.1 & 5.3394 & TRN \\
\hline CHEMBL1386036 & 688549 & 4.8 & 5.0027 & TRN \\
\hline CHEMBL1428001 & 688549 & 5.8 & 5.4563 & TRN \\
\hline CHEMBL1566113 & 688549 & 4.9 & 4.956 & TRN \\
\hline CHEMBL1409336 & 688549 & 4.6 & 4.3595 & TRN \\
\hline CHEMBL1477025 & 688549 & 4.8 & 4.4301 & TRN \\
\hline CHEMBL1527303 & 688549 & 4.45 & 4.8196 & TST \\
\hline CHEMBL1376723 & 688549 & 4.5 & 4.8304 & TST \\
\hline CHEMBL1362994 & 688549 & 4.5 & 4.6651 & TRN \\
\hline CHEMBL1529975 & 688549 & 5.0 & 5.1436 & TST \\
\hline CHEMBL310310 & 688549 & 6.0 & 5.3479 & TST \\
\hline CHEMBL1496296 & 688549 & 4.9 & 5.3 & TRN \\
\hline CHEMBL405358 & 688549 & 4.7 & 5.0873 & TST \\
\hline CHEMBL1597067 & 688549 & 4.9 & 4.4898 & TRN \\
\hline CHEMBL1512711 & 688549 & 5.1 & 5.1292 & TRN \\
\hline CHEMBL1365081 & 688549 & 4.9 & 4.9195 & TRN \\
\hline CHEMBL1404446 & 688549 & 7.0 & 5.6353 & TRN \\
\hline CHEMBL1353747 & 688549 & 4.9 & 5.081 & TRN \\
\hline CHEMBL1965461 & 688549 & 5.0 & 5.181 & TST \\
\hline CHEMBL1436069 & 688549 & 4.5 & 4.9857 & TRN \\
\hline CHEMBL1348813 & 688549 & 4.6 & 4.4671 & TRN \\
\hline CHEMBL448515 & 688549 & 4.5 & 5.3994 & TST \\
\hline
\end{tabular}




\begin{tabular}{|c|c|c|c|c|}
\hline \multicolumn{5}{|c|}{ Supplemental Table S2.txt } \\
\hline CHEMBL 3194325 & 688549 & 4.9 & 5.3439 & TRN \\
\hline CHEMBL1397603 & 688549 & 4.8 & 4.9267 & TRN \\
\hline CHEMBL1341254 & 688549 & 4.7 & 5.0141 & TST \\
\hline CHEMBL1554462 & 688549 & 4.7 & 5.0861 & TRN \\
\hline CHEMBL1573345 & 688549 & 4.5 & 4.349 & TRN \\
\hline CHEMBL1516098 & 688549 & 5.0 & 4.8119 & TRN \\
\hline CHEMBL1329237 & 688549 & 4.8 & 4.9096 & TST \\
\hline CHEMBL1488400 & 688549 & 4.5 & 5.0461 & TRN \\
\hline CHEMBL1489337 & 688549 & 5.1 & 5.0165 & TRN \\
\hline CHEMBL1378425 & 688549 & 4.5 & 5.2185 & TRN \\
\hline CHEMBL1346595 & 688549 & 4.5 & 4.6376 & TRN \\
\hline CHEMBL1595178 & 688549 & 7.1002 & 4.86 & TRN \\
\hline CHEMBL1359956 & 688549 & 5.45 & 5.0442 & TRN \\
\hline CHEMBL1414599 & 688549 & 4.7 & 5.2652 & TRN \\
\hline CHEMBL1483381 & 688549 & 4.9 & 4.752 & TRN \\
\hline CHEMBL1554531 & 688549 & 4.9 & 5.0616 & TRN \\
\hline CHEMBL1528470 & 688549 & 4.8 & 4.9253 & TST \\
\hline CHEMBL1560148 & 688549 & 6.8 & 5.2157 & TRN \\
\hline CHEMBL1487735 & 688549 & 4.9 & 4.5259 & TRN \\
\hline CHEMBL1572552 & 688549 & 4.45 & 4.6442 & TRN \\
\hline CHEMBL1528373 & 688549 & 4.5 & 4.8278 & TRN \\
\hline CHEMBL1515860 & 688549 & 4.8 & 5.2105 & TRN \\
\hline CHEMBL1318799 & 688549 & 5.0 & 4.8614 & TST \\
\hline CHEMBL1356623 & 688549 & 5.4 & 5.2123 & TRN \\
\hline CHEMBL1497693 & 688549 & 4.9 & 4.8345 & TRN \\
\hline CHEMBL1558496 & 688549 & 8.2007 & 5.7167 & TRN \\
\hline CHEMBL1603866 & 688549 & 4.9 & 5.0812 & TRN \\
\hline CHEMBL1591263 & 688549 & 4.5 & 5.3713 & TST \\
\hline CHEMBL1478339 & 688549 & 4.95 & 4.7383 & TRN \\
\hline CHEMBL1359251 & 688549 & 4.65 & 4.7803 & TRN \\
\hline CHEMBL1440950 & 688549 & 4.5 & 5.2232 & TRN \\
\hline CHEMBL1488418 & 688549 & 4.7 & 4.666 & TRN \\
\hline CHEMBL1516492 & 688549 & 5.2 & 5.2179 & TRN \\
\hline CHEMBL1542791 & 688549 & 5.0 & 4.8163 & TRN \\
\hline CHEMBL1429472 & 688549 & 4.8 & 5.5072 & TST \\
\hline CHEMBL1590214 & 688549 & 7.5003 & 5.39 & TST \\
\hline CHEMBL1185172 & 688549 & 4.65 & 4.6627 & TRN \\
\hline CHEMBL1474836 & 688549 & 5.7 & 5.3344 & TRN \\
\hline CHEMBL1589640 & 688549 & 4.45 & 4.5104 & TRN \\
\hline CHEMBL1513326 & 688549 & 4.45 & 4.3379 & TRN \\
\hline CHEMBL1418067 & 688549 & 4.5 & 4.8379 & TRN \\
\hline CHEMBL17127 & 688549 & 4.5 & $4.8180 e$ & 00000000005 \\
\hline CHEMBL1568200 & 688549 & 4.6 & 4.9822 & TST \\
\hline CHEMBL1311772 & 688549 & 4.8 & 4.8993 & TRN \\
\hline CHEMBL 3209753 & 688549 & 7.0501 & 5.5851 & TRN \\
\hline CHEMBL1478 & 688549 & 4.5 & 5.6753 & TST \\
\hline CHEMBL1307720 & 688549 & 5.5 & 5.13 & TRN \\
\hline CHEMBL1434786 & 688549 & 5.0 & 5.0224 & TRN \\
\hline
\end{tabular}

TRN 


\begin{tabular}{|c|c|c|c|c|}
\hline \multicolumn{5}{|c|}{ Supplemental Table S2.txt } \\
\hline CHEMBL1383022 & 688549 & 5.3 & 5.0557 & TRN \\
\hline CHEMBL261118 & 688549 & 5.6 & 5.1086 & TRN \\
\hline CHEMBL1355387 & 688549 & 4.7 & 5.0192 & TRN \\
\hline CHEMBL1593293 & 688549 & 5.1 & 4.9907 & TRN \\
\hline CHEMBL1331128 & 688549 & 8.3979 & 5.3242 & TST \\
\hline CHEMBL1378090 & 688549 & 4.8 & 5.1953 & TST \\
\hline CHEMBL1377867 & 688549 & 4.9 & 4.8766 & TRN \\
\hline CHEMBL1442681 & 688549 & 4.7 & 4.7569 & TRN \\
\hline CHEMBL1469736 & 688549 & 4.5 & 4.4728 & TRN \\
\hline CHEMBL1468183 & 688549 & 4.65 & 5.3491 & TST \\
\hline CHEMBL1493577 & 688549 & 5.0 & 4.5444 & TRN \\
\hline CHEMBL1486465 & 688549 & 6.4 & 5.5534 & TRN \\
\hline CHEMBL1612774 & 688549 & 4.9 & 4.7344 & TST \\
\hline CHEMBL1566071 & 688549 & 4.6 & 4.7274 & TRN \\
\hline CHEMBL1321050 & 688549 & 5.5 & 5.2609 & TRN \\
\hline CHEMBL1552177 & 688549 & 4.45 & 4.4843 & TRN \\
\hline CHEMBL1374828 & 688549 & 4.8 & 5.1249 & TRN \\
\hline CHEMBL1381938 & 688549 & 4.8 & 4.981 & TRN \\
\hline CHEMBL1511994 & 688549 & 5.45 & 5.347 & TRN \\
\hline CHEMBL1316070 & 688549 & 5.1 & 5.3699 & TRN \\
\hline CHEMBL375270 & 688549 & 4.8 & 5.7123 & TRN \\
\hline CHEMBL1373043 & 688549 & 4.8 & 5.1211 & TRN \\
\hline CHEMBL1372601 & 688549 & 5.1 & 4.7107 & TRN \\
\hline CHEMBL1553321 & 688549 & 4.6 & 4.5806 & TRN \\
\hline CHEMBL1585531 & 688549 & 4.8 & 4.8231 & TRN \\
\hline CHEMBL1454850 & 688549 & 4.7 & 5.0915 & TRN \\
\hline CHEMBL1400651 & 688549 & 4.5 & 5.0349 & TRN \\
\hline CHEMBL1503016 & 688549 & 4.9 & 4.7107 & TRN \\
\hline CHEMBL1435593 & 688549 & 4.5 & 4.4988 & TRN \\
\hline CHEMBL1325395 & 688549 & 5.5 & 5.3539 & TRN \\
\hline CHEMBL1565957 & 688549 & 4.6 & 5.1181 & TRN \\
\hline CHEMBL1357266 & 688549 & 5.25 & 5.0776 & TRN \\
\hline CHEMBL1558691 & 688549 & 4.8 & 5.1724 & TRN \\
\hline CHEMBL1476813 & 688549 & 5.0 & 4.9116 & TRN \\
\hline CHEMBL1396894 & 688549 & 4.5 & 4.5725 & TRN \\
\hline CHEMBL1476851 & 688549 & 6.0 & 5.3956 & TRN \\
\hline CHEMBL1504209 & 688549 & 4.7 & 5.4068 & TST \\
\hline CHEMBL1451343 & 688549 & 4.5 & 5.06 & TRN \\
\hline CHEMBL1306036 & 688549 & 5.1 & 5.665 & TRN \\
\hline CHEMBL1597569 & 688549 & 4.9 & 4.6297 & TRN \\
\hline CHEMBL1522362 & 688549 & 6.0 & 5.2117 & TRN \\
\hline CHEMBL1321943 & 688549 & 4.9 & 4.9465 & TRN \\
\hline CHEMBL1455814 & 688549 & 5.0 & 4.8797 & TRN \\
\hline CHEMBL1368261 & 688549 & 4.9 & 5.4636 & TST \\
\hline CHEMBL1523844 & 688549 & 4.5 & 4.6803 & TRN \\
\hline CHEMBL1369668 & 688549 & 6.45 & 5.8455 & TRN \\
\hline CHEMBL 264931 & 688549 & 5.0 & 5.5028 & TRN \\
\hline CHEMBL1528536 & 688549 & 4.8 & 4.7404 & TST \\
\hline
\end{tabular}




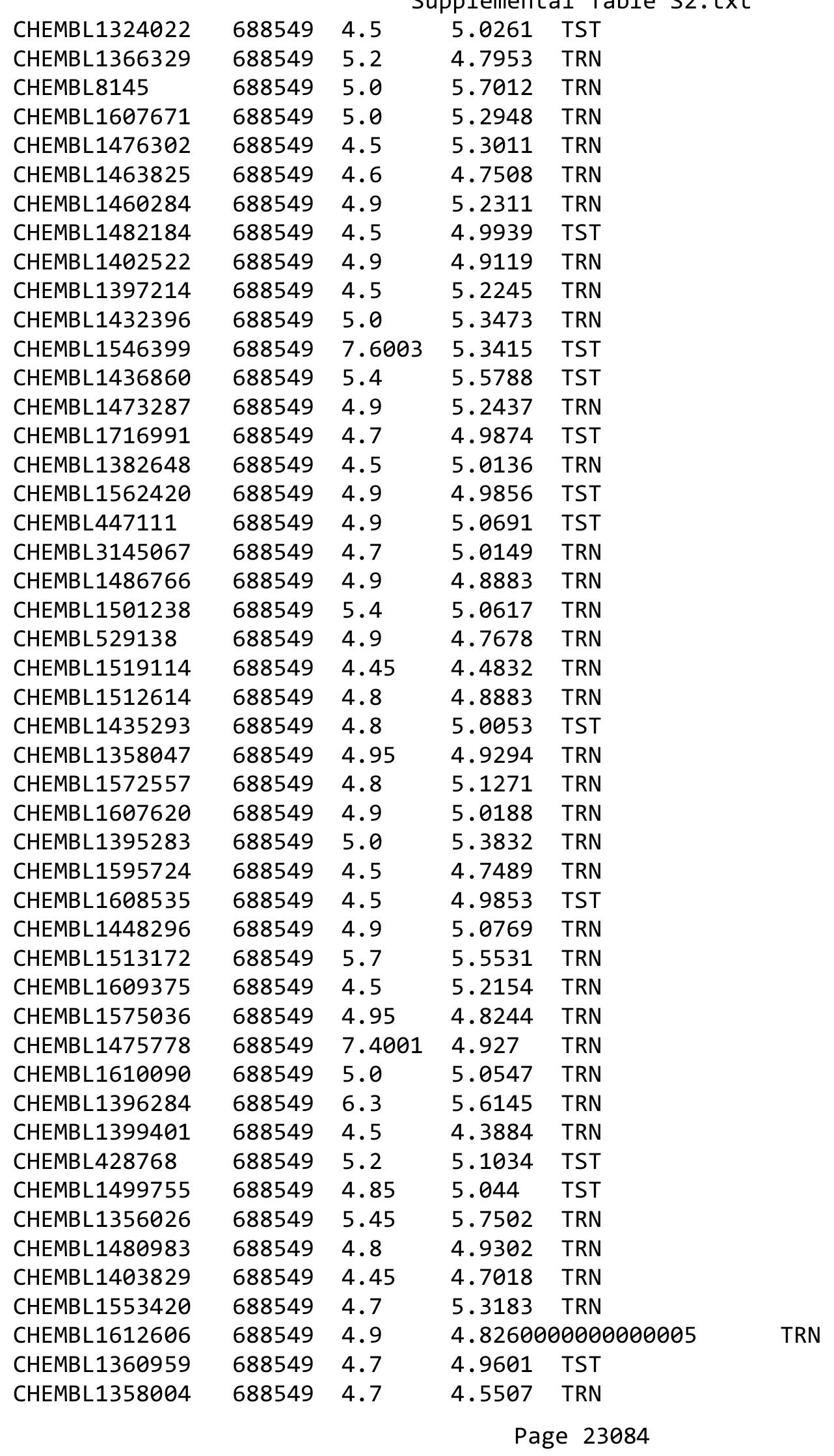




\begin{tabular}{|c|c|c|c|c|c|}
\hline \multicolumn{6}{|c|}{ Supplemental Table S2.txt } \\
\hline CHEMBL1402807 & 688549 & 5.8 & 4.9875 & TRN & \\
\hline CHEMBL1371865 & 688549 & 4.8 & 5.0926 & TRN & \\
\hline CHEMBL1375824 & 688549 & 4.7 & 4.8449 & TRN & \\
\hline CHEMBL1429633 & 688549 & 4.9 & 5.1344 & TRN & \\
\hline CHEMBL1486507 & 688549 & 4.8 & 5.0038 & TRN & \\
\hline CHEMBL1321680 & 688549 & 4.5 & 5.434 & TST & \\
\hline CHEMBL1489659 & 688549 & 4.5 & 4.8216 & TST & \\
\hline CHEMBL1592110 & 688549 & 4.8 & 4.8928 & TRN & \\
\hline CHEMBL1597994 & 688549 & 5.6 & 4.8713 & TRN & \\
\hline CHEMBL1437217 & 688549 & 4.5 & 4.3784 & TRN & \\
\hline CHEMBL1551859 & 688549 & 7.6003 & 5.6938 & TRN & \\
\hline CHEMBL1603681 & 688549 & 4.9 & 4.6363 & TRN & \\
\hline CHEMBL1496424 & 688549 & 5.1 & 5.4839 & TST & \\
\hline CHEMBL1315493 & 688549 & 4.95 & 4.7176 & TRN & \\
\hline CHEMBL15901 & 688549 & 8.1024 & 5.3086 & TRN & \\
\hline CHEMBL1530097 & 688549 & 4.5 & 5.2853 & TRN & \\
\hline CHEMBL3196123 & 688549 & 5.1 & 5.6127 & TRN & \\
\hline CHEMBL1335169 & 688549 & 5.0 & 4.8965 & TRN & \\
\hline CHEMBL1336110 & 688549 & 4.5 & 4.6039 & TRN & \\
\hline CHEMBL1504089 & 688549 & 4.8 & 5.0099 & TRN & \\
\hline CHEMBL1526316 & 688549 & 4.9 & 4.9431 & TRN & \\
\hline CHEMBL1432711 & 688549 & 4.5 & 4.8001 & TRN & \\
\hline CHEMBL1321669 & 688549 & 7.8013 & 5.194 & TRN & \\
\hline CHEMBL1515243 & 688549 & 5.3 & 5.2572 & TRN & \\
\hline CHEMBL1561980 & 688549 & 4.5 & 4.8922 & TRN & \\
\hline CHEMBL1358788 & 688549 & 5.0 & 5.0397 & TRN & \\
\hline CHEMBL1357509 & 688549 & 7.0 & 5.9909 & TRN & \\
\hline CHEMBL1314507 & 688549 & 5.0 & 4.9762 & TRN & \\
\hline CHEMBL1486128 & 688549 & 5.5 & 5.5331 & TRN & \\
\hline CHEMBL374107 & 688549 & 5.0 & 5.1918 & TST & \\
\hline CHEMBL1395520 & 688549 & 4.8 & 4.9314 & TRN & \\
\hline CHEMBL1347243 & 688549 & 4.5 & 5.2175 & TRN & \\
\hline CHEMBL1430353 & 688549 & 4.6 & 5.0791 & TRN & \\
\hline CHEMBL1555163 & 688549 & 4.6 & 5.1378 & TRN & \\
\hline CHEMBL1371671 & 688549 & 4.5 & 4.7639 & 9999999999 & TRN \\
\hline CHEMBL1472666 & 688549 & 4.9 & 4.766 & TRN & \\
\hline CHEMBL1325279 & 688549 & 6.1 & 5.3759 & TRN & \\
\hline CHEMBL1558388 & 688549 & 5.0 & 5.1346 & TRN & \\
\hline CHEMBL1437419 & 688549 & 5.2 & 5.274 & TRN & \\
\hline CHEMBL1524804 & 688549 & 4.5 & 4.6236 & TRN & \\
\hline CHEMBL1607194 & 688549 & 4.9 & 5.0203 & TRN & \\
\hline CHEMBL3199613 & 688549 & 5.5 & 5.2831 & TST & \\
\hline CHEMBL1488515 & 688549 & 4.7 & 5.2916 & TST & \\
\hline CHEMBL408850 & 688549 & 5.1 & 5.1597 & TRN & \\
\hline CHEMBL1526810 & 688549 & 4.8 & 4.8958 & TRN & \\
\hline CHEMBL260213 & 688549 & 5.6 & 5.1603 & TRN & \\
\hline CHEMBL1563741 & 688549 & 4.6 & 5.0197 & TRN & \\
\hline CHEMBL1598227 & 688549 & 8.301 & 5.8641 & TRN & \\
\hline
\end{tabular}




\begin{tabular}{|c|c|c|c|c|}
\hline \multicolumn{5}{|c|}{ Supplemental Table S2.txt } \\
\hline CHEMBL1352298 & 688549 & 4.7 & 4.8479 & TRN \\
\hline CHEMBL1432420 & 688549 & 5.2 & 4.7663 & TRN \\
\hline CHEMBL201325 & 688549 & 4.8 & 5.0529 & TRN \\
\hline CHEMBL 274839 & 688549 & 6.5 & 5.9576 & TRN \\
\hline CHEMBL1584720 & 688549 & 4.5 & 4.5191 & TRN \\
\hline CHEMBL1608876 & 688549 & 4.6 & 4.8293 & TRN \\
\hline CHEMBL1567236 & 688549 & 4.9 & 4.9065 & TST \\
\hline CHEMBL1401895 & 688549 & 6.7001 & 5.0119 & TRN \\
\hline CHEMBL1441710 & 688549 & 4.8 & 5.1833 & TST \\
\hline CHEMBL1404188 & 688549 & 4.6 & 5.16 & TRN \\
\hline CHEMBL1328894 & 688549 & 4.9 & 4.8786 & TRN \\
\hline CHEMBL137498 & 688549 & 5.0 & 5.1358 & TRN \\
\hline CHEMBL1609759 & 688549 & 5.0 & 4.833 & TRN \\
\hline CHEMBL1536041 & 688549 & 4.6 & 4.4967 & TRN \\
\hline CHEMBL1557170 & 688549 & 6.3 & 5.0747 & TST \\
\hline CHEMBL1455349 & 688549 & 5.4 & 5.2683 & TRN \\
\hline CHEMBL1590087 & 688549 & 5.0 & 5.106 & TRN \\
\hline CHEMBL1394351 & 688549 & 5.5 & 5.4021 & TST \\
\hline CHEMBL39878 & 688549 & 4.5 & 4.8602 & TRN \\
\hline CHEMBL1462451 & 688549 & 4.6 & 5.3842 & TST \\
\hline CHEMBL1409202 & 688549 & 4.5 & 5.205 & TRN \\
\hline CHEMBL1541840 & 688549 & 4.5 & 4.4305 & TRN \\
\hline CHEMBL1406859 & 688549 & 5.0 & 5.2001 & TRN \\
\hline CHEMBL1403254 & 688549 & 6.9 & 5.1343 & TRN \\
\hline CHEMBL1457783 & 688549 & 5.0 & 5.2628 & TST \\
\hline CHEMBL1405548 & 688549 & 4.9 & 5.0386 & TRN \\
\hline CHEMBL1372307 & 688549 & 6.1 & 5.7745 & TRN \\
\hline CHEMBL1521239 & 688549 & 4.8 & 4.9866 & TRN \\
\hline CHEMBL1354280 & 688549 & 4.6 & 4.3432 & TRN \\
\hline CHEMBL1554915 & 688549 & 5.2 & 5.0406 & TRN \\
\hline CHEMBL1571018 & 688549 & 5.3 & 5.0675 & TRN \\
\hline CHEMBL 275311 & 688549 & 4.4 & 5.4059 & TST \\
\hline CHEMBL1469885 & 688549 & 4.45 & 4.6923 & TST \\
\hline CHEMBL1595237 & 688549 & 4.45 & 4.4006 & TRN \\
\hline CHEMBL1315021 & 688549 & 4.45 & 4.5596 & TRN \\
\hline CHEMBL1399937 & 688549 & 4.6 & 4.9801 & TRN \\
\hline CHEMBL1402959 & 688549 & 5.0 & 4.7442 & TRN \\
\hline CHEMBL1553106 & 688549 & 4.75 & 5.0689 & TRN \\
\hline CHEMBL1526044 & 688549 & 5.4 & 5.2432 & TRN \\
\hline CHEMBL1406466 & 688549 & 4.8 & 5.4596 & TRN \\
\hline CHEMBL1587655 & 688549 & 4.7 & 4.4069 & TST \\
\hline CHEMBL1404788 & 688549 & 5.6 & 5.0009 & TRN \\
\hline CHEMBL1255755 & 688549 & 4.9 & 5.3249 & TRN \\
\hline CHEMBL1320792 & 688549 & 4.6 & 4.8095 & TRN \\
\hline CHEMBL3192873 & 688549 & 5.05 & 5.7009 & TRN \\
\hline CHEMBL1313936 & 688549 & 5.3 & 5.0303 & TRN \\
\hline CHEMBL1474701 & 688549 & 4.5 & 5.3737 & TST \\
\hline CHEMBL 242384 & 688549 & 5.2 & 5.1979 & TRN \\
\hline
\end{tabular}




\begin{tabular}{|c|c|c|c|c|}
\hline & & & pplement & al $\mathrm{Ta}$ \\
\hline CHEMBL1579415 & 688549 & 4.6 & 5.2089 & TRN \\
\hline CHEMBL1532190 & 688549 & 4.8 & 4.9125 & TRN \\
\hline CHEMBL1321606 & 688549 & 4.5 & 4.4004 & TRN \\
\hline CHEMBL1328077 & 688549 & 4.65 & 5.0068 & TRN \\
\hline CHEMBL1605955 & 688549 & 4.95 & 5.3159 & TRN \\
\hline CHEMBL1370149 & 688549 & 6.4 & 5.449 & TST \\
\hline CHEMBL1591131 & 688549 & 5.0 & 4.9865 & TRN \\
\hline CHEMBL1514512 & 688549 & 4.9 & 5.1638 & TST \\
\hline CHEMBL1370019 & 688549 & 4.5 & 4.7856 & TRN \\
\hline CHEMBL1465257 & 688549 & 5.0 & 5.6354 & TRN \\
\hline CHEMBL1443672 & 688549 & 4.65 & 4.9822 & TRN \\
\hline CHEMBL1491327 & 688549 & 5.4 & 5.1357 & TRN \\
\hline CHEMBL151 & 688549 & 6.0 & 5.5025 & TRN \\
\hline CHEMBL1378442 & 688549 & 4.8 & 4.8852 & TRN \\
\hline CHEMBL1360916 & 688549 & 4.6 & 5.4523 & TST \\
\hline CHEMBL1320935 & 688549 & 4.5 & 5.08 & TRN \\
\hline CHEMBL1321245 & 688549 & 4.8 & 4.9159 & TRN \\
\hline CHEMBL1412478 & 688549 & 4.9 & 4.8452 & TRN \\
\hline CHEMBL1567019 & 688549 & 4.8 & 4.8556 & TRN \\
\hline CHEMBL1559088 & 688549 & 4.45 & 4.534 & TRN \\
\hline CHEMBL191015 & 688549 & 5.0 & 4.9354 & TRN \\
\hline CHEMBL1395485 & 688549 & 4.9 & 4.9128 & TRN \\
\hline CHEMBL1495094 & 688549 & 4.6 & 5.1261 & TRN \\
\hline CHEMBL119841 & 688549 & 4.6 & 4.8558 & TRN \\
\hline CHEMBL1471225 & 688549 & 5.3 & 4.9332 & TRN \\
\hline CHEMBL1399521 & 688549 & 5.4 & 5.2472 & TRN \\
\hline CHEMBL1338892 & 688549 & 4.5 & 5.3119 & TRN \\
\hline CHEMBL1462542 & 688549 & 8.301 & 5.4564 & TRN \\
\hline CHEMBL1475047 & 688549 & 6.1 & 5.3537 & TRN \\
\hline CHEMBL1476373 & 688549 & 4.5 & 5.2864 & TRN \\
\hline CHEMBL3199093 & 688549 & 5.0 & 5.3799 & TRN \\
\hline CHEMBL1406119 & 688549 & 4.7 & 4.763 & TST \\
\hline CHEMBL1513346 & 688549 & 4.6 & 4.9024 & TRN \\
\hline CHEMBL1516624 & 688549 & 4.8 & 4.8336 & TRN \\
\hline CHEMBL1422539 & 688549 & 4.7 & 4.6111 & TRN \\
\hline CHEMBL1396322 & 688549 & 4.6 & 4.8077 & TRN \\
\hline CHEMBL1562496 & 688549 & 4.8 & 5.0602 & TRN \\
\hline CHEMBL1580983 & 688549 & 6.5 & 5.4488 & TRN \\
\hline CHEMBL1434098 & 688549 & 4.5 & 4.8998 & TRN \\
\hline CHEMBL1509254 & 688549 & 7.4001 & 5.1433 & TRN \\
\hline CHEMBL1519387 & 688549 & 4.8 & 5.1329 & TRN \\
\hline CHEMBL1505118 & 688549 & 5.0 & 5.2473 & TST \\
\hline CHEMBL1333673 & 688549 & 5.45 & 5.1635 & TRN \\
\hline CHEMBL1374552 & 688549 & 4.5 & 4.4684 & TST \\
\hline CHEMBL1316178 & 688549 & 4.8 & 5.5216 & TST \\
\hline CHEMBL1514271 & 688549 & 4.8 & 4.8492 & TRN \\
\hline CHEMBL1531257 & 688549 & 4.9 & 5.1986 & TST \\
\hline CHEMBL1464103 & 688549 & 4.9 & 5.0944 & TST \\
\hline
\end{tabular}




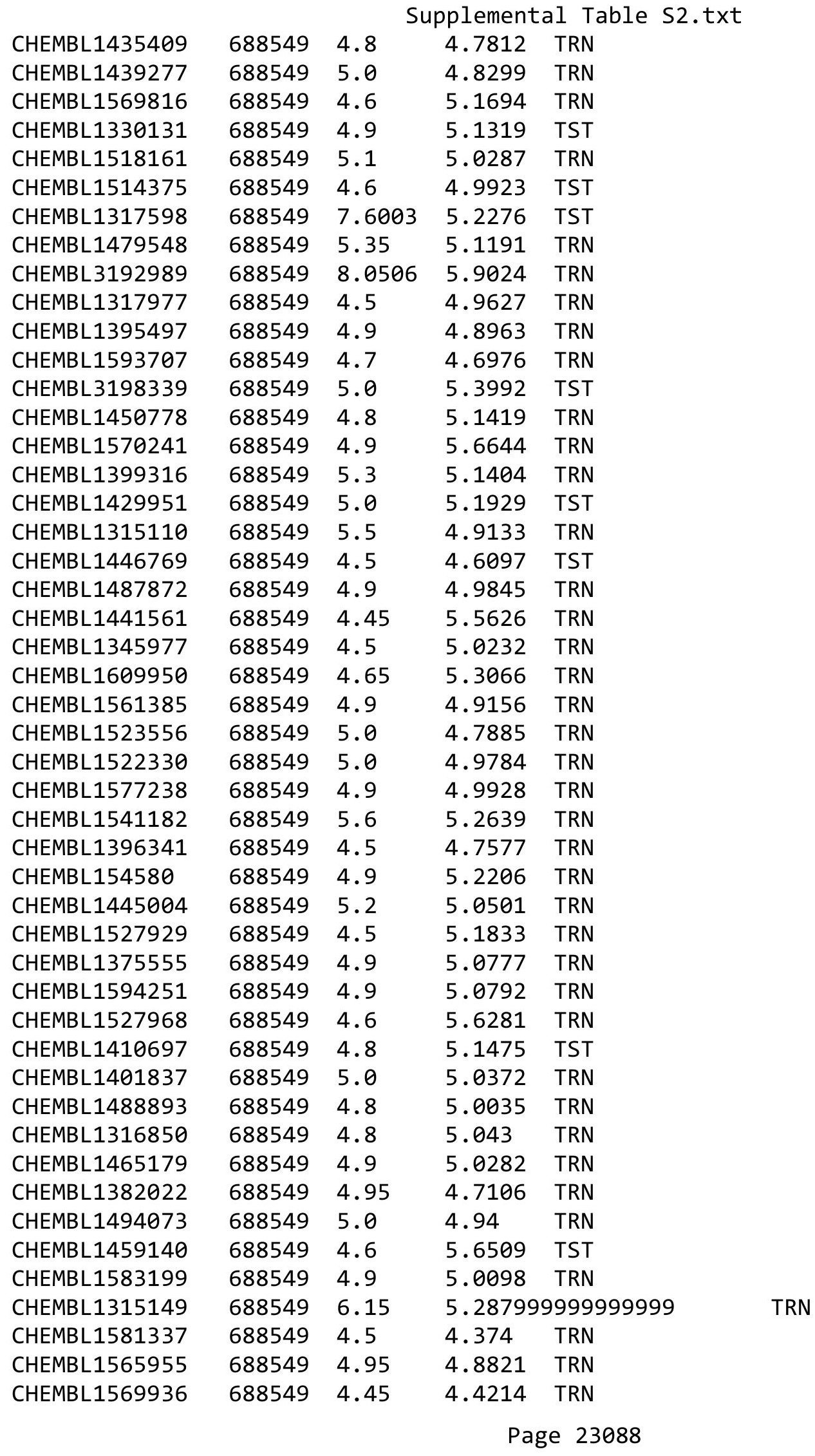




\begin{tabular}{|c|c|c|c|c|}
\hline \multicolumn{5}{|c|}{ Supplemental Table S2.txt } \\
\hline CHEMBL1324998 & 688549 & 5.9 & 4.619 & TRN \\
\hline CHEMBL1434937 & 688549 & 4.9 & 4.8778 & TRN \\
\hline CHEMBL1603779 & 688549 & 4.7 & 4.8781 & TRN \\
\hline CHEMBL1425743 & 688549 & 4.9 & 4.6224 & TRN \\
\hline CHEMBL1397569 & 688549 & 4.5 & 4.2587 & TRN \\
\hline CHEMBL1541487 & 688549 & 4.5 & 4.596 & TRN \\
\hline CHEMBL 308688 & 688549 & 4.8 & 5.3109 & TRN \\
\hline CHEMBL1606451 & 688549 & 5.0 & 4.7746 & TRN \\
\hline CHEMBL1328538 & 688549 & 4.5 & 4.3441 & TRN \\
\hline CHEMBL1485405 & 688549 & 4.6 & 4.4887 & TRN \\
\hline CHEMBL1612049 & 688549 & 5.0 & 4.7188 & TRN \\
\hline CHEMBL1539876 & 688549 & 4.9 & 4.7393 & TRN \\
\hline CHEMBL1513762 & 688549 & 6.0 & 5.2247 & TRN \\
\hline CHEMBL1582419 & 688549 & 5.0 & 5.0102 & TRN \\
\hline CHEMBL1381855 & 688549 & 4.95 & 5.3132 & TRN \\
\hline CHEMBL580381 & 688549 & 5.3 & 5.1392 & TRN \\
\hline CHEMBL1593164 & 688549 & 4.6 & 4.9637 & TRN \\
\hline CHEMBL1372514 & 688549 & 5.0 & 5.0939 & TRN \\
\hline CHEMBL1447542 & 688549 & 4.8 & 4.8849 & TRN \\
\hline CHEMBL1514377 & 688549 & 5.0 & 4.8044 & TRN \\
\hline CHEMBL 265943 & 688549 & 5.0 & 5.0566 & TRN \\
\hline CHEMBL1302503 & 688549 & 4.6 & 5.3305 & TST \\
\hline CHEMBL1544907 & 688549 & 4.9 & 5.1107 & TRN \\
\hline CHEMBL257856 & 688549 & 6.6 & 5.0984 & TRN \\
\hline CHEMBL1484097 & 688549 & 4.8 & 4.9011 & TRN \\
\hline CHEMBL1356652 & 688549 & 4.6 & 4.968 & TRN \\
\hline CHEMBL1373699 & 688549 & 4.6 & 4.8701 & TST \\
\hline CHEMBL1444402 & 688549 & 8.2007 & 5.2007 & TRN \\
\hline CHEMBL1410947 & 688549 & 4.8 & 4.596 & TRN \\
\hline CHEMBL1446049 & 688549 & 5.1 & 5.0314 & TRN \\
\hline CHEMBL1551915 & 688549 & 4.8 & 4.9904 & TST \\
\hline CHEMBL1409101 & 688549 & 5.1 & 5.1343 & TRN \\
\hline CHEMBL1400868 & 688549 & 4.9 & 4.8254 & TRN \\
\hline CHEMBL1543972 & 688549 & 8.2007 & 5.5442 & TRN \\
\hline CHEMBL1570156 & 688549 & 4.9 & 5.1069 & TST \\
\hline CHEMBL416657 & 688549 & 5.2 & 4.6854 & TST \\
\hline CHEMBL1435104 & 688549 & 4.9 & 4.7763 & TRN \\
\hline CHEMBL1405788 & 688549 & 4.45 & 4.8676 & TRN \\
\hline CHEMBL3191307 & 688549 & 4.9 & 5.2216 & TRN \\
\hline CHEMBL1527704 & 688549 & 4.45 & 4.8613 & TRN \\
\hline CHEMBL1370731 & 688549 & 4.7 & 5.3317 & TRN \\
\hline CHEMBL 2374044 & 688549 & 4.7 & 5.2863 & TST \\
\hline CHEMBL1409658 & 688549 & 4.8 & 5.0937 & TRN \\
\hline CHEMBL1602956 & 688549 & 4.5 & 5.225 & TRN \\
\hline CHEMBL1343178 & 688549 & 5.2 & 4.7455 & TRN \\
\hline CHEMBL1529007 & 688549 & 5.4 & 5.2005 & TRN \\
\hline CHEMBL1371989 & 688549 & 5.4 & 4.8497 & TRN \\
\hline CHEMBL1315083 & 688549 & 4.8 & 4.7975 & TRN \\
\hline
\end{tabular}




\begin{tabular}{|c|c|c|c|c|}
\hline \multicolumn{5}{|c|}{ Supplemental Table S2.txt } \\
\hline CHEMBL1375336 & 688549 & 4.5 & 4.6693 & TRN \\
\hline CHEMBL1524355 & 688549 & 5.1 & 5.1806 & TRN \\
\hline CHEMBL1256178 & 688549 & 4.7 & 5.3135 & TST \\
\hline CHEMBL1423635 & 688549 & 8.0506 & 4.7972 & TRN \\
\hline CHEMBL1605605 & 688549 & 6.0 & 5.2587 & TRN \\
\hline CHEMBL1484852 & 688549 & 4.5 & 5.4537 & TRN \\
\hline CHEMBL1307028 & 688549 & 4.9 & 5.2375 & TRN \\
\hline CHEMBL1331097 & 688549 & 4.9 & 4.9356 & TRN \\
\hline CHEMBL1514409 & 688549 & 5.0 & 4.936 & TRN \\
\hline CHEMBL1505273 & 688549 & 5.0 & 5.1014 & TST \\
\hline CHEMBL1548237 & 688549 & 4.95 & 5.0446 & TRN \\
\hline CHEMBL1594512 & 688549 & 7.6003 & 4.9153 & TRN \\
\hline CHEMBL1339243 & 688549 & 4.5 & 4.9149 & TRN \\
\hline CHEMBL1576166 & 688549 & 5.8 & 5.325 & TRN \\
\hline CHEMBL1319623 & 688549 & 4.6 & 4.6945 & TRN \\
\hline CHEMBL1503002 & 688549 & 4.8 & 5.1942 & TRN \\
\hline CHEMBL1590761 & 688549 & 5.4 & 5.0959 & TRN \\
\hline CHEMBL1487251 & 688549 & 4.5 & 4.4772 & TRN \\
\hline CHEMBL1394550 & 688549 & 4.9 & 4.7079 & TRN \\
\hline CHEMBL1468900 & 688549 & 4.8 & 4.851 & TRN \\
\hline CHEMBL1396098 & 688549 & 5.0 & 5.0754 & TRN \\
\hline CHEMBL1518629 & 688549 & 4.9 & 4.9348 & TRN \\
\hline CHEMBL563919 & 688549 & 5.6 & 5.4497 & TRN \\
\hline CHEMBL1483180 & 688549 & 4.9 & 5.2214 & TRN \\
\hline CHEMBL1491986 & 688549 & 7.0 & 5.6117 & TRN \\
\hline CHEMBL578512 & 688549 & 6.1 & 5.4844 & TRN \\
\hline CHEMBL1553700 & 688549 & 4.6 & 4.9329 & TRN \\
\hline CHEMBL1445545 & 688549 & 4.5 & 4.6494 & TRN \\
\hline CHEMBL1327038 & 688549 & 5.0 & 4.5536 & TRN \\
\hline CHEMBL1601032 & 688549 & 4.9 & 5.1949 & TRN \\
\hline CHEMBL1455957 & 688549 & 4.5 & 5.2269 & TST \\
\hline CHEMBL1596724 & 688549 & 4.5 & 4.7871 & TRN \\
\hline CHEMBL1513142 & 688549 & 5.25 & 5.266 & TRN \\
\hline CHEMBL1488035 & 688549 & 6.2 & 5.0579 & TRN \\
\hline CHEMBL1399096 & 688549 & 4.7 & 5.1862 & TST \\
\hline CHEMBL1363484 & 688549 & 4.5 & 5.035 & TRN \\
\hline CHEMBL1595747 & 688549 & 5.2 & 5.3231 & TRN \\
\hline CHEMBL1499489 & 688549 & 4.9 & 4.6665 & TRN \\
\hline CHEMBL1607281 & 688549 & 4.9 & 4.819 & TRN \\
\hline CHEMBL1573553 & 688549 & 5.5 & 5.2488 & TRN \\
\hline CHEMBL1335173 & 688549 & 4.9 & 4.783 & TRN \\
\hline CHEMBL1487271 & 688549 & 4.6 & 4.4159 & TRN \\
\hline CHEMBL1396485 & 688549 & 5.4 & 5.2094 & TRN \\
\hline CHEMBL1567951 & 688549 & 4.7 & 4.9744 & TRN \\
\hline CHEMBL1437759 & 688549 & 4.6 & 4.762 & TRN \\
\hline CHEMBL1321501 & 688549 & 8.2007 & 5.5312 & TRN \\
\hline CHEMBL1602652 & 688549 & 4.9 & 5.4027 & TRN \\
\hline CHEMBL1457164 & 688549 & 4.85 & 5.396 & TRN \\
\hline
\end{tabular}




\begin{tabular}{|c|c|c|c|c|c|}
\hline \\
\hline CHEMBL1598184 & 688549 & 4.9 & 4.7785 & TRN & \\
\hline CHEMBL1370891 & 688549 & 4.5 & 5.1239 & TST & \\
\hline CHEMBL1373194 & 688549 & 5.3 & 5.1104 & TRN & \\
\hline CHEMBL111951 & 688549 & 5.0 & 5.0522 & TRN & \\
\hline CHEMBL1384654 & 688549 & 4.9 & 5.1395 & TRN & \\
\hline CHEMBL1398240 & 688549 & 4.5 & 5.2063 & TRN & \\
\hline CHEMBL1389438 & 688549 & 5.4 & 5.3113 & TRN & \\
\hline CHEMBL1576565 & 688549 & 4.9 & 5.0102 & TRN & \\
\hline CHEMBL1314906 & 688549 & 4.5 & 4.725 & TRN & \\
\hline CHEMBL1600749 & 688549 & 4.9 & 5.1862 & TRN & \\
\hline CHEMBL435392 & 688549 & 4.8 & 4.792 & TRN & \\
\hline CHEMBL1378444 & 688549 & 5.0 & 4.879 & TRN & \\
\hline CHEMBL1396193 & 688549 & 4.45 & 4.7346 & TRN & \\
\hline CHEMBL1531073 & 688549 & 5.0 & 4.9748 & TRN & \\
\hline CHEMBL1317817 & 688549 & 4.9 & 4.7292 & TRN & \\
\hline CHEMBL1389480 & 688549 & 7.0501 & 4.9172 & TST & \\
\hline CHEMBL1611948 & 688549 & 5.5 & 5.3294 & TRN & \\
\hline CHEMBL1505569 & 688549 & 4.8 & 4.9169 & TRN & \\
\hline CHEMBL1524798 & 688549 & 5.3 & 5.3484 & TRN & \\
\hline CHEMBL1386220 & 688549 & 5.5 & 5.1554 & TST & \\
\hline CHEMBL1590160 & 688549 & 5.6 & 5.2865 & TRN & \\
\hline CHEMBL1425262 & 688549 & 7.5003 & 5.5321 & TRN & \\
\hline CHEMBL1605182 & 688549 & 5.0 & 4.6972 & TRN & \\
\hline CHEMBL310396 & 688549 & 4.5 & 5.1566 & TST & \\
\hline CHEMBL1597191 & 688549 & 4.85 & 4.8576 & TRN & \\
\hline CHEMBL1314196 & 688549 & 4.9 & 4.9182 & TRN & \\
\hline CHEMBL1368085 & 688549 & 4.5 & 5.1138 & TRN & \\
\hline CHEMBL1335271 & 688549 & 4.6 & 4.7121 & TRN & \\
\hline CHEMBL1314438 & 688549 & 5.0 & 4.65600 & 0000000001 & TRN \\
\hline CHEMBL1584466 & 688549 & 5.0 & 5.3073 & TRN & \\
\hline CHEMBL1313933 & 688549 & 4.8 & 4.7033 & TRN & \\
\hline CHEMBL1374302 & 688549 & 4.5 & 4.7093 & TST & \\
\hline CHEMBL1476863 & 688549 & 4.8 & 4.8901 & TRN & \\
\hline CHEMBL1481221 & 688549 & 4.8 & 4.7686 & TRN & \\
\hline CHEMBL1370884 & 688549 & 4.9 & 4.9389 & TRN & \\
\hline CHEMBL3199152 & 688549 & 4.9 & 5.2397 & TRN & \\
\hline CHEMBL1417829 & 688549 & 4.5 & 4.8379 & TRN & \\
\hline CHEMBL1394421 & 688549 & 4.5 & 4.468 & TRN & \\
\hline CHEMBL1329301 & 688549 & 6.5 & 4.9222 & TRN & \\
\hline CHEMBL1522587 & 688549 & 4.7 & 5.57799 & 9999999999 & TRN \\
\hline CHEMBL1394458 & 688549 & 5.25 & 5.295 & TRN & \\
\hline CHEMBL1525518 & 688549 & 4.45 & 5.2484 & TRN & \\
\hline CHEMBL1475873 & 688549 & 4.9 & 4.963 & TRN & \\
\hline CHEMBL1390237 & 688549 & 4.8 & 5.1094 & TST & \\
\hline CHEMBL1338463 & 688549 & 4.9 & 4.888 & TRN & \\
\hline CHEMBL1476431 & 688549 & 5.0 & 4.8097 & TRN & \\
\hline CHEMBL1399651 & 688549 & 5.2 & 4.6606 & TRN & \\
\hline CHEMBL1554520 & 688549 & 4.7 & 4.6707 & TRN & \\
\hline
\end{tabular}




\begin{tabular}{|c|c|c|c|c|c|}
\hline \multicolumn{6}{|c|}{ Supplemental Table S2.txt } \\
\hline CHEMBL1595912 & 688549 & 4.6 & 4.7991 & TRN & \\
\hline CHEMBL1416275 & 688549 & 5.65 & 5.4906 & TRN & \\
\hline CHEMBL1545361 & 688549 & 4.5 & 4.4369 & TRN & \\
\hline CHEMBL501701 & 688549 & 4.9 & 5.2241 & TST & \\
\hline CHEMBL1375371 & 688549 & 5.0 & 5.1823 & TRN & \\
\hline CHEMBL1577977 & 688549 & 5.5 & 4.9998 & TST & \\
\hline CHEMBL1608018 & 688549 & 4.5 & 4.8419 & TRN & \\
\hline CHEMBL1398260 & 688549 & 5.7 & 5.8342 & TST & \\
\hline CHEMBL1516183 & 688549 & 5.7 & 5.2929 & TRN & \\
\hline CHEMBL1521327 & 688549 & 5.0 & 4.6924 & TRN & \\
\hline CHEMBL1486765 & 688549 & 4.7 & 4.6877 & TRN & \\
\hline CHEMBL1458840 & 688549 & 4.6 & 4.46899 & 9999999999 & TRN \\
\hline CHEMBL1401145 & 688549 & 6.0 & 5.4252 & TRN & \\
\hline CHEMBL1980204 & 688549 & 4.5 & 5.1385 & TST & \\
\hline CHEMBL407501 & 688549 & 4.9 & 5.2518 & TRN & \\
\hline CHEMBL1477930 & 688549 & 5.25 & 5.1118 & TRN & \\
\hline CHEMBL1479020 & 688549 & 4.9 & 4.7962 & TRN & \\
\hline CHEMBL1381044 & 688549 & 4.9 & 5.1105 & TRN & \\
\hline CHEMBL1325327 & 688549 & 4.9 & 5.3971 & TRN & \\
\hline CHEMBL1487152 & 688549 & 4.9 & 4.8323 & TRN & \\
\hline CHEMBL1518846 & 688549 & 5.4 & 5.2889 & TRN & \\
\hline CHEMBL1558210 & 688549 & 8.1024 & 5.1753 & TRN & \\
\hline CHEMBL1514452 & 688549 & 4.65 & 5.317 & TRN & \\
\hline CHEMBL1492957 & 688549 & 4.8 & 4.976 & TRN & \\
\hline CHEMBL1552620 & 688549 & 4.9 & 5.4406 & TRN & \\
\hline CHEMBL1455520 & 688549 & 6.6 & 5.49799 & 9999999999 & TRN \\
\hline CHEMBL1406206 & 688549 & 8.0 & 5.2113 & TRN & \\
\hline CHEMBL1452502 & 688549 & 4.8 & 4.7627 & TRN & \\
\hline CHEMBL1493178 & 688549 & 5.8 & 5.107 & TRN & \\
\hline CHEMBL1498876 & 688549 & 4.9 & 5.1037 & TRN & \\
\hline CHEMBL1579153 & 688549 & 4.9 & 5.0965 & TRN & \\
\hline CHEMBL1513285 & 688549 & 4.95 & 5.2309 & TRN & \\
\hline CHEMBL1600347 & 688549 & 4.5 & 4.8947 & TST & \\
\hline CHEMBL3195220 & 688549 & 4.45 & 5.7013 & TRN & \\
\hline CHEMBL1436438 & 688549 & 5.0 & 5.1138 & TRN & \\
\hline CHEMBL23327 & 688549 & 5.0 & 5.1023 & TST & \\
\hline CHEMBL547833 & 688549 & 4.5 & 4.9179 & TRN & \\
\hline CHEMBL1392200 & 688549 & 4.8 & 5.0215 & TRN & \\
\hline CHEMBL1464445 & 688549 & 5.75 & 5.4469 & TRN & \\
\hline CHEMBL1318060 & 688549 & 5.6 & 5.7302 & TRN & \\
\hline CHEMBL1323978 & 688549 & 4.8 & 4.8249 & TRN & \\
\hline CHEMBL1442642 & 688549 & 4.5 & 5.1248 & TRN & \\
\hline CHEMBL1596955 & 688549 & 4.8 & 4.7228 & TRN & \\
\hline CHEMBL1354729 & 688549 & 8.301 & 5.1273 & TRN & \\
\hline CHEMBL1554303 & 688549 & 4.5 & 5.2561 & TRN & \\
\hline CHEMBL1573665 & 688549 & 4.9 & 4.8862 & TRN & \\
\hline CHEMBL1358288 & 688549 & 5.5 & 4.9317 & TRN & \\
\hline CHEMBL1526991 & 688549 & 5.0 & 4.8374 & TRN & \\
\hline
\end{tabular}




\begin{tabular}{|c|c|c|c|c|c|}
\hline \multicolumn{6}{|c|}{ Supplemental Table s2.txt } \\
\hline CHEMBL1313242 & 688549 & 5.2 & 5.1153 & TRN & \\
\hline CHEMBL1345047 & 688549 & 4.8 & 5.2796 & TRN & \\
\hline CHEMBL1440902 & 688549 & 4.5 & 4.3825 & TRN & \\
\hline CHEMBL1335708 & 688549 & 8.301 & 5.2702 & TRN & \\
\hline CHEMBL1305169 & 688549 & 4.95 & 4.9718 & TRN & \\
\hline CHEMBL1993627 & 688549 & 5.4 & 5.4704 & TRN & \\
\hline CHEMBL 1480310 & 688549 & 4.9 & 5.1702 & TRN & \\
\hline CHEMBL1563942 & 688549 & 4.5 & 4.8968 & TRN & \\
\hline CHEMBL1562200 & 688549 & 5.4 & 5.1731 & TRN & \\
\hline CHEMBL1256291 & 688549 & 4.8 & 5.4287 & TST & \\
\hline CHEMBL1431130 & 688549 & 5.0 & 4.8445 & TST & \\
\hline CHEMBL1475918 & 688549 & 4.7 & 4.6099 & TRN & \\
\hline CHEMBL1484911 & 688549 & 4.45 & 4.6943 & TRN & \\
\hline CHEMBL 3198449 & 688549 & 7.4001 & 5.4251 & TST & \\
\hline CHEMBL1565595 & 688549 & 4.8 & 5.3701 & TST & \\
\hline CHEMBL1498264 & 688549 & 5.1 & 5.0715 & TST & \\
\hline CHEMBL1440011 & 688549 & 4.5 & 4.8328 & TRN & \\
\hline CHEMBL1526095 & 688549 & 4.85 & 5.2403 & TRN & \\
\hline CHEMBL1560690 & 688549 & 5.1 & 5.1167 & TRN & \\
\hline CHEMBL1555315 & 688549 & 5.0 & 5.3254 & TRN & \\
\hline CHEMBL1407683 & 688549 & 4.8 & 5.0832 & TRN & \\
\hline CHEMBL1332494 & 688549 & 5.25 & 5.04899 & 99999999995 & TRN \\
\hline CHEMBL1372732 & 688549 & 4.7 & 4.8878 & TST & \\
\hline CHEMBL1330251 & 688549 & 4.7 & 5.0842 & TST & \\
\hline CHEMBL1427103 & 688549 & 4.7 & 5.1881 & TRN & \\
\hline CHEMBL1388206 & 688549 & 4.9 & 5.0545 & TST & \\
\hline CHEMBL1554449 & 688549 & 4.7 & 4.5915 & TRN & \\
\hline CHEMBL1557018 & 688549 & 4.6 & 4.8587 & TRN & \\
\hline CHEMBL1435124 & 688549 & 4.45 & 5.4049 & TRN & \\
\hline CHEMBL46703 & 688549 & 4.7 & 5.0965 & TRN & \\
\hline CHEMBL1596756 & 688549 & 4.5 & 4.705 & TRN & \\
\hline CHEMBL550826 & 688549 & 4.5 & 4.5723 & TRN & \\
\hline CHEMBL1353113 & 688549 & 5.0 & 5.2134 & TRN & \\
\hline CHEMBL1407292 & 688549 & 5.6 & 5.3503 & TRN & \\
\hline CHEMBL1558887 & 688549 & 4.9 & 4.6891 & TRN & \\
\hline CHEMBL1435605 & 688549 & 5.0 & 5.1132 & TRN & \\
\hline CHEMBL1492780 & 688549 & 4.9 & 4.9741 & TRN & \\
\hline CHEMBL1356667 & 688549 & 4.5 & 4.9552 & TRN & \\
\hline CHEMBL1333985 & 688549 & 4.9 & 4.9292 & TRN & \\
\hline CHEMBL1322696 & 688549 & 4.5 & 4.623 & TRN & \\
\hline CHEMBL1523890 & 688549 & 4.8 & 4.7717 & TRN & \\
\hline CHEMBL1354905 & 688549 & 4.9 & 5.1417 & TRN & \\
\hline CHEMBL1431561 & 688549 & 4.9 & 5.0995 & TRN & \\
\hline CHEMBL1488131 & 688549 & 4.5 & 5.1446 & TST & \\
\hline CHEMBL1435683 & 688549 & 4.8 & 5.0383 & TRN & \\
\hline CHEMBL1437358 & 688549 & 4.8 & 4.7011 & TRN & \\
\hline CHEMBL1540711 & 688549 & 5.0 & 4.8481 & TRN & \\
\hline CHEMBL1470934 & 688549 & 4.9 & 5.0725 & TRN & \\
\hline
\end{tabular}




\begin{tabular}{|c|c|c|c|c|}
\hline \multicolumn{5}{|c|}{ Supplemental Table S2.txt } \\
\hline CHEMBL1552496 & 688549 & 4.7 & 4.6797 & TRN \\
\hline CHEMBL448847 & 688549 & 4.9 & 5.3812 & TST \\
\hline CHEMBL1314323 & 688549 & 4.9 & 4.7065 & TRN \\
\hline CHEMBL1301126 & 688549 & 4.6 & 4.8245 & TRN \\
\hline CHEMBL134291 & 688549 & 4.9 & 5.1056 & TRN \\
\hline CHEMBL1314864 & 688549 & 4.6 & 4.7801 & TRN \\
\hline CHEMBL1456222 & 688549 & 5.5 & 5.0492 & TRN \\
\hline CHEMBL1503922 & 688549 & 4.5 & 4.7404 & TRN \\
\hline CHEMBL1356766 & 688549 & 5.0 & 4.618 & TST \\
\hline CHEMBL1532569 & 688549 & 4.8 & 4.7488 & TRN \\
\hline CHEMBL1395771 & 688549 & 4.9 & 4.7798 & TRN \\
\hline CHEMBL1355643 & 688549 & 4.9 & 5.0584 & TRN \\
\hline CHEMBL1513622 & 688549 & 4.9 & 4.9007 & TRN \\
\hline CHEMBL1476900 & 688549 & 4.8 & 4.7409 & TRN \\
\hline CHEMBL1342739 & 688549 & 5.9 & 5.2276 & TRN \\
\hline CHEMBL1605974 & 688549 & 4.55 & 4.6183 & TRN \\
\hline CHEMBL1418018 & 688549 & 5.4 & 5.2023 & TRN \\
\hline CHEMBL273386 & 688549 & 4.7 & 5.6629 & TRN \\
\hline CHEMBL1591202 & 688549 & 5.4 & 5.4308 & TRN \\
\hline CHEMBL1558930 & 688549 & 4.9 & 4.7398 & TRN \\
\hline CHEMBL1514746 & 688549 & 4.9 & 4.9732 & TRN \\
\hline CHEMBL1518945 & 688549 & 4.5 & 4.877 & TRN \\
\hline CHEMBL1303635 & 688549 & 4.5 & 4.6087 & TRN \\
\hline CHEMBL1518168 & 688549 & 8.1024 & 5.3338 & TRN \\
\hline CHEMBL1364512 & 688549 & 4.7 & 4.8841 & TRN \\
\hline CHEMBL1524244 & 688549 & 4.5 & 4.8468 & TRN \\
\hline CHEMBL1565734 & 688549 & 4.6 & 4.4628 & TRN \\
\hline CHEMBL1358556 & 688549 & 4.5 & 5.0173 & TRN \\
\hline CHEMBL 303579 & 688549 & 5.4 & 5.3801 & TRN \\
\hline CHEMBL1327990 & 688549 & 4.9 & 4.828 & TRN \\
\hline CHEMBL1328281 & 688549 & 4.9 & 4.529 & TRN \\
\hline CHEMBL1555137 & 688549 & 4.5 & 5.8271 & TRN \\
\hline CHEMBL508779 & 688549 & 6.1 & 5.1728 & TST \\
\hline CHEMBL1557474 & 688549 & 5.1 & 5.1213 & TRN \\
\hline CHEMBL1317118 & 688549 & 4.6 & 4.708 & TRN \\
\hline CHEMBL1324509 & 688549 & 4.6 & 4.9166 & TRN \\
\hline CHEMBL3212690 & 688549 & 4.7 & 5.3093 & TST \\
\hline CHEMBL1495613 & 688549 & 4.5 & 5.1659 & TRN \\
\hline CHEMBL1480147 & 688549 & 4.7 & 4.8939 & TRN \\
\hline CHEMBL 1441400 & 688549 & 5.1 & 4.8938 & TRN \\
\hline CHEMBL1390081 & 688549 & 4.9 & 5.1322 & TRN \\
\hline CHEMBL1417353 & 688549 & 4.9 & 5.121 & TRN \\
\hline CHEMBL1543562 & 688549 & 4.5 & 5.2252 & TRN \\
\hline CHEMBL1444261 & 688549 & 5.1 & 4.8158 & TRN \\
\hline CHEMBL1353568 & 688549 & 4.6 & 4.829 & TST \\
\hline CHEMBL1381063 & 688549 & 4.9 & 4.9719 & TRN \\
\hline CHEMBL530149 & 688549 & 5.0 & 5.169 & TRN \\
\hline CHEMBL34704 & 688549 & 4.5 & 5.0005 & TST \\
\hline
\end{tabular}




\begin{tabular}{|c|c|c|c|c|}
\hline \multicolumn{5}{|c|}{ Supplemental Table S2.txt } \\
\hline CHEMBL1535257 & 688549 & 4.5 & 4.8567 & TRN \\
\hline CHEMBL1591989 & 688549 & 4.7 & 5.0797 & TRN \\
\hline CHEMBL1457311 & 688549 & 4.9 & 4.8824 & TRN \\
\hline CHEMBL1320219 & 688549 & 4.8 & 4.6191 & TRN \\
\hline CHEMBL3198440 & 688549 & 4.95 & 5.0878 & TRN \\
\hline CHEMBL1173475 & 688549 & 5.6 & 5.575 & TRN \\
\hline CHEMBL1386457 & 688549 & 4.8 & 5.1094 & TRN \\
\hline CHEMBL1355715 & 688549 & 5.7 & 4.5792 & TST \\
\hline CHEMBL1517172 & 688549 & 4.5 & 4.9467 & TST \\
\hline CHEMBL1543167 & 688549 & 4.9 & 4.7402 & TRN \\
\hline CHEMBL1406702 & 688549 & 5.9 & 5.4708 & TRN \\
\hline CHEMBL1400703 & 688549 & 6.5 & 5.3013 & TRN \\
\hline CHEMBL1601333 & 688549 & 4.5 & 5.4404 & TST \\
\hline CHEMBL1597573 & 688549 & 4.45 & 5.3953 & TRN \\
\hline CHEMBL1479449 & 688549 & 5.0 & 4.8424 & TRN \\
\hline CHEMBL1403849 & 688549 & 5.0 & 4.9835 & TRN \\
\hline CHEMBL1337527 & 688549 & 5.8 & 5.5047 & TRN \\
\hline CHEMBL1516460 & 688549 & 4.9 & 5.0783 & TST \\
\hline CHEMBL1299654 & 688549 & 6.6 & 5.4843 & TST \\
\hline CHEMBL1331263 & 688549 & 5.1 & 4.9156 & TRN \\
\hline CHEMBL1590279 & 688549 & 4.5 & 4.4318 & TRN \\
\hline CHEMBL1336004 & 688549 & 4.5 & 4.8839 & TRN \\
\hline CHEMBL1451814 & 688549 & 4.5 & 4.684 & TRN \\
\hline CHEMBL1414360 & 688549 & 5.4 & 4.7377 & TRN \\
\hline CHEMBL1566939 & 688549 & 4.9 & 5.004 & TRN \\
\hline CHEMBL1354831 & 688549 & 4.85 & 4.8681 & TRN \\
\hline CHEMBL1412669 & 688549 & 4.8 & 4.9101 & TRN \\
\hline CHEMBL1552807 & 688549 & 5.9 & 4.9224 & TRN \\
\hline CHEMBL1353451 & 688549 & 4.9 & 5.0851 & TRN \\
\hline CHEMBL1435923 & 688549 & 5.3 & 5.3768 & TST \\
\hline CHEMBL1314968 & 688549 & 4.9 & 4.7562 & TRN \\
\hline CHEMBL1400609 & 688549 & 4.9 & 4.8808 & TRN \\
\hline CHEMBL1315072 & 688549 & 4.5 & 5.0095 & TRN \\
\hline CHEMBL1397598 & 688549 & 4.7 & 5.4926 & TRN \\
\hline CHEMBL1558175 & 688549 & 5.85 & 4.8566 & TST \\
\hline CHEMBL1483427 & 688549 & 4.9 & 4.8495 & TRN \\
\hline CHEMBL1554964 & 688549 & 5.2 & 4.9324 & TRN \\
\hline CHEMBL1386926 & 688549 & 4.8 & 5.2629 & TRN \\
\hline CHEMBL1315998 & 688549 & 5.0 & 5.0 & TRN \\
\hline CHEMBL1412416 & 688549 & 4.9 & 4.95 & TRN \\
\hline CHEMBL1449204 & 688549 & 4.5 & 4.6021 & TRN \\
\hline CHEMBL1502228 & 688549 & 4.9 & 4.5965 & TRN \\
\hline CHEMBL1417719 & 688549 & 4.9 & 4.8135 & TRN \\
\hline CHEMBL1457192 & 688549 & 5.0 & 4.8374 & TRN \\
\hline CHEMBL1334234 & 688549 & 5.8 & 5.1883 & TRN \\
\hline CHEMBL1599477 & 688549 & 4.7 & 4.7427 & TRN \\
\hline CHEMBL1477856 & 688549 & 4.5 & 4.7633 & TRN \\
\hline CHEMBL1597711 & 688549 & 4.5 & 4.7545 & TRN \\
\hline
\end{tabular}




\begin{tabular}{|c|c|c|c|c|c|}
\hline \multicolumn{6}{|c|}{ Supplemental Table S2.txt } \\
\hline CHEMBL1444124 & 688549 & 5.5 & 5.02 & TRN & \\
\hline CHEMBL1372997 & 688549 & 4.8 & 5.5843 & TST & \\
\hline CHEMBL1561214 & 688549 & 6.35 & 5.0051 & TST & \\
\hline CHEMBL1499966 & 688549 & 4.75 & 5.0559 & TRN & \\
\hline CHEMBL1314812 & 688549 & 4.5 & 4.8796 & TRN & \\
\hline CHEMBL1396034 & 688549 & 4.5 & 4.792 & TRN & \\
\hline CHEMBL1335397 & 688549 & 5.7 & 5.1894 & TRN & \\
\hline CHEMBL1567913 & 688549 & 5.5 & 5.072 & TST & \\
\hline CHEMBL1597827 & 688549 & 4.6 & 5.2034 & TST & \\
\hline CHEMBL1409173 & 688549 & 6.1 & 5.2621 & TRN & \\
\hline CHEMBL1374004 & 688549 & 5.9 & 5.6619 & TRN & \\
\hline CHEMBL343732 & 688549 & 4.6 & 4.6919 & TST & \\
\hline CHEMBL1536413 & 688549 & 4.6 & 5.3229 & TRN & \\
\hline CHEMBL1513122 & 688549 & 4.5 & 4.9265 & TRN & \\
\hline CHEMBL1508699 & 688549 & 4.7 & 4.9207 & TRN & \\
\hline CHEMBL1467405 & 688549 & 6.1 & 5.6903 & TRN & \\
\hline CHEMBL1445388 & 688549 & 4.6 & 5.0257 & TRN & \\
\hline CHEMBL1374990 & 688549 & 4.5 & 5.1754 & TST & \\
\hline CHEMBL1445850 & 688549 & 5.4 & 5.2596 & TRN & \\
\hline CHEMBL1358598 & 688549 & 4.5 & 4.6685 & TRN & \\
\hline CHEMBL1489209 & 688549 & 5.0 & 4.9079 & TRN & \\
\hline CHEMBL1383189 & 688549 & 4.5 & 5.2635 & TRN & \\
\hline CHEMBL1594589 & 688549 & 4.45 & 4.5913 & TRN & \\
\hline CHEMBL1401099 & 688549 & 4.9 & 5.2271 & TRN & \\
\hline CHEMBL1412731 & 688549 & 4.5 & 4.8046 & TRN & \\
\hline CHEMBL1407250 & 688549 & 4.8 & 4.9475 & TRN & \\
\hline CHEMBL1513406 & 688549 & 5.0 & 4.7628 & TRN & \\
\hline CHEMBL3193405 & 688549 & 4.95 & 5.5862 & TRN & \\
\hline CHEMBL1439295 & 688549 & 4.9 & 4.9186 & TRN & \\
\hline CHEMBL1523199 & 688549 & 5.1 & 5.0632 & TRN & \\
\hline CHEMBL1343248 & 688549 & 5.0 & 5.1173 & TRN & \\
\hline CHEMBL1553645 & 688549 & 4.45 & 4.7414 & TRN & \\
\hline CHEMBL1594817 & 688549 & 4.9 & 5.1583 & TRN & \\
\hline CHEMBL1413823 & 688549 & 5.6 & 5.05699 & 99999999995 & TRN \\
\hline CHEMBL1327079 & 688549 & 5.0 & 4.9019 & TRN & \\
\hline CHEMBL1432657 & 688549 & 4.8 & 4.8197 & TRN & \\
\hline CHEMBL1600397 & 688549 & 4.8 & 5.0219 & TST & \\
\hline CHEMBL1489126 & 688549 & 4.7 & 4.8268 & TRN & \\
\hline CHEMBL1576748 & 688549 & 4.9 & 5.0486 & TRN & \\
\hline CHEMBL 3196267 & 688549 & 4.9 & 4.9987 & TST & \\
\hline CHEMBL1396810 & 688549 & 4.5 & 4.5982 & TRN & \\
\hline CHEMBL1441350 & 688549 & 5.0 & 5.007 & TRN & \\
\hline CHEMBL1572391 & 688549 & 4.9 & 4.72 & TRN & \\
\hline CHEMBL1362278 & 688549 & 5.2 & 5.1798 & TRN & \\
\hline CHEMBL1609218 & 688549 & 7.699 & 4.953 & TRN & \\
\hline CHEMBL1326949 & 688549 & 4.5 & 4.6198 & TRN & \\
\hline CHEMBL1396817 & 688549 & 4.9 & 4.534 & TRN & \\
\hline CHEMBL 242383 & 688549 & 5.1 & 5.2487 & TRN & \\
\hline
\end{tabular}




\begin{tabular}{|c|c|c|c|c|c|}
\hline \\
\hline CHEMBL1556955 & 688549 & 4.7 & 4.6107 & TRN & \\
\hline CHEMBL1412344 & 688549 & 4.8 & 4.978 & TRN & \\
\hline CHEMBL1475856 & 688549 & 4.5 & 4.9537 & TRN & \\
\hline CHEMBL1514781 & 688549 & 5.0 & 5.2737 & TRN & \\
\hline CHEMBL1519146 & 688549 & 4.8 & 5.17399 & 99999999995 & TRN \\
\hline CHEMBL1403562 & 688549 & 4.9 & 5.021 & TRN & \\
\hline CHEMBL1491000 & 688549 & 4.9 & 4.8089 & TRN & \\
\hline CHEMBL1534413 & 688549 & 5.0 & 4.8428 & TRN & \\
\hline CHEMBL1418702 & 688549 & 6.6 & 5.0153 & TST & \\
\hline CHEMBL1537418 & 688549 & 4.9 & 5.0323 & TRN & \\
\hline CHEMBL1546818 & 688549 & 4.5 & 4.863 & TRN & \\
\hline CHEMBL1569027 & 688549 & 4.9 & 5.0595 & TRN & \\
\hline CHEMBL1437262 & 688549 & 4.5 & 4.965 & TST & \\
\hline CHEMBL1378195 & 688549 & 4.9 & 5.0169 & TRN & \\
\hline CHEMBL1466653 & 688549 & 7.4001 & 5.6547 & TRN & \\
\hline CHEMBL1442492 & 688549 & 4.7 & 5.0229 & TST & \\
\hline CHEMBL1357974 & 688549 & 5.2 & 5.0811 & TRN & \\
\hline CHEMBL1354484 & 688549 & 4.8 & 4.3824 & TRN & \\
\hline CHEMBL1363415 & 688549 & 4.9 & 4.9228 & TRN & \\
\hline CHEMBL1611872 & 688549 & 5.0 & 4.7706 & TST & \\
\hline CHEMBL1349674 & 688549 & 7.1002 & 5.1347 & TST & \\
\hline CHEMBL1316947 & 688549 & 4.8 & 4.9017 & TRN & \\
\hline CHEMBL1537599 & 688549 & 4.6 & 5.0679 & TRN & \\
\hline CHEMBL1414363 & 688549 & 5.0 & 4.6357 & TRN & \\
\hline CHEMBL1344911 & 688549 & 4.6 & 4.5146 & TRN & \\
\hline CHEMBL1522344 & 688549 & 4.6 & 4.8179 & TRN & \\
\hline CHEMBL1552485 & 688549 & 4.5 & 4.9333 & TRN & \\
\hline CHEMBL1434517 & 688549 & 4.5 & 4.6704 & TRN & \\
\hline CHEMBL1575456 & 688549 & 5.2 & 5.41799 & 9999999999 & TST \\
\hline CHEMBL1561360 & 688549 & 4.8 & 4.8099 & TRN & \\
\hline CHEMBL1512179 & 688549 & 4.45 & 4.78 & TRN & \\
\hline CHEMBL1397782 & 688549 & 4.5 & 5.1364 & TST & \\
\hline CHEMBL1354776 & 688549 & 5.0 & 5.3849 & TRN & \\
\hline CHEMBL1481687 & 688549 & 4.6 & 5.6078 & TST & \\
\hline CHEMBL1470714 & 688549 & 4.9 & 4.9559 & TRN & \\
\hline CHEMBL1519005 & 688549 & 5.0 & 5.0557 & TRN & \\
\hline CHEMBL1384151 & 688549 & 4.8 & 5.1326 & TRN & \\
\hline CHEMBL1437139 & 688549 & 6.2 & 5.7275 & TST & \\
\hline CHEMBL1414371 & 688549 & 4.9 & 5.2546 & TRN & \\
\hline CHEMBL1409118 & 688549 & 5.75 & 5.0036 & TRN & \\
\hline CHEMBL1576059 & 688549 & 4.8 & 4.8706 & TRN & \\
\hline CHEMBL1601379 & 688549 & 5.0 & 5.1853 & TRN & \\
\hline CHEMBL1552684 & 688549 & 4.6 & 4.8214 & TST & \\
\hline CHEMBL1356913 & 688549 & 4.6 & 4.8904 & TRN & \\
\hline CHEMBL1328253 & 688549 & 4.8 & 4.9734 & TRN & \\
\hline CHEMBL1552586 & 688549 & 4.8 & 4.7691 & TRN & \\
\hline CHEMBL1308898 & 688549 & 4.8 & 4.8258 & TRN & \\
\hline CHEMBL1370316 & 688549 & 5.4 & 5.1487 & TRN & \\
\hline
\end{tabular}




\begin{tabular}{|c|c|c|c|c|}
\hline \multicolumn{5}{|c|}{ Supplemental Table S2.txt } \\
\hline CHEMBL1517627 & 688549 & 4.6 & 4.5115 & TRN \\
\hline CHEMBL470671 & 688549 & 6.2 & 5.0032 & TRN \\
\hline CHEMBL1591689 & 688549 & 5.0 & 4.8477 & TRN \\
\hline CHEMBL56731 & 688549 & 4.9 & 4.8121 & TRN \\
\hline CHEMBL1408864 & 688549 & 5.0 & 4.9012 & TRN \\
\hline CHEMBL1373852 & 688549 & 5.1 & 4.5208 & TRN \\
\hline CHEMBL1409447 & 688549 & 4.6 & 5.0455 & TRN \\
\hline CHEMBL1475122 & 688549 & 5.7 & 5.1709 & TRN \\
\hline CHEMBL1317046 & 688549 & 4.6 & 4.5286 & TRN \\
\hline CHEMBL1372889 & 688549 & 6.7001 & 6.2754 & TRN \\
\hline CHEMBL1371479 & 688549 & 4.9 & 5.0186 & TRN \\
\hline CHEMBL1508357 & 688549 & 5.0 & 5.186 & TRN \\
\hline CHEMBL1522243 & 688549 & 4.7 & 5.2887 & TRN \\
\hline CHEMBL1330722 & 688549 & 4.5 & 4.6774 & TRN \\
\hline CHEMBL1407038 & 688549 & 4.7 & 4.9482 & TRN \\
\hline CHEMBL1575305 & 688549 & 6.25 & 5.6338 & TRN \\
\hline CHEMBL1508377 & 688549 & 4.9 & 5.0537 & TRN \\
\hline CHEMBL1555204 & 688549 & 4.7 & 5.0712 & TST \\
\hline CHEMBL1564871 & 688549 & 4.5 & 5.0627 & TRN \\
\hline CHEMBL1531563 & 688549 & 4.6 & 5.4674 & TRN \\
\hline CHEMBL1488661 & 688549 & 5.3 & 4.5579 & TRN \\
\hline CHEMBL1552880 & 688549 & 4.5 & 4.9048 & TRN \\
\hline CHEMBL1330095 & 688549 & 5.0 & 4.7713 & TRN \\
\hline CHEMBL1525243 & 688549 & 4.85 & 4.843 & TRN \\
\hline CHEMBL1371175 & 688549 & 4.9 & 4.7799 & TRN \\
\hline CHEMBL1365070 & 688549 & 4.9 & 4.8494 & TRN \\
\hline CHEMBL1590072 & 688549 & 4.8 & 4.8684 & TRN \\
\hline CHEMBL1403030 & 688549 & 5.5 & 5.1162 & TRN \\
\hline CHEMBL1380362 & 688549 & 6.5501 & 5.3858 & TST \\
\hline CHEMBL1337274 & 688549 & 5.1 & 5.0221 & TST \\
\hline CHEMBL1365154 & 688549 & 4.5 & 4.7404 & TRN \\
\hline CHEMBL424581 & 688549 & 4.7 & 4.8003 & TRN \\
\hline CHEMBL1334344 & 688549 & 4.5 & 4.886 & TRN \\
\hline CHEMBL1433710 & 688549 & 5.5 & 5.2891 & TRN \\
\hline CHEMBL1365367 & 688549 & 5.0 & 4.6991 & TST \\
\hline CHEMBL1489706 & 688549 & 4.5 & 4.6371 & TRN \\
\hline CHEMBL1445958 & 688549 & 4.75 & 4.2471 & TRN \\
\hline CHEMBL116438 & 688549 & 4.8 & 5.3235 & TRN \\
\hline CHEMBL1317538 & 688549 & 4.7 & 5.0263 & TRN \\
\hline CHEMBL1490017 & 688549 & 5.5 & 4.9012 & TRN \\
\hline CHEMBL 259331 & 688549 & 5.6 & 5.1039 & TRN \\
\hline CHEMBL1435408 & 688549 & 5.25 & 5.0398 & TRN \\
\hline CHEMBL3195747 & 688549 & 5.3 & 5.7143 & TRN \\
\hline CHEMBL1354879 & 688549 & 5.25 & 5.3088 & TRN \\
\hline CHEMBL1591979 & 688549 & 4.5 & 4.9504 & TRN \\
\hline CHEMBL1548327 & 688549 & 4.8 & 5.0177 & TST \\
\hline CHEMBL1538798 & 688549 & 4.6 & 4.9311 & TRN \\
\hline CHEMBL1592483 & 688549 & 4.6 & 4.5512 & TRN \\
\hline
\end{tabular}




\begin{tabular}{|c|c|c|c|c|c|}
\hline \multicolumn{6}{|c|}{ Supplemental Table S2.txt } \\
\hline CHEMBL1315978 & 688549 & 5.2 & 5.1907 & TRN & \\
\hline CHEMBL1495242 & 688549 & 5.0 & 5.0006 & TST & \\
\hline CHEMBL1514672 & 688549 & 4.9 & 4.9841 & TRN & \\
\hline CHEMBL1536294 & 688549 & 8.1024 & 5.1011 & TST & \\
\hline CHEMBL1581755 & 688549 & 7.4001 & 5.1218 & TST & \\
\hline CHEMBL1322588 & 688549 & 4.45 & 5.0369 & TRN & \\
\hline CHEMBL1452896 & 688549 & 4.5 & 4.82 & TRN & \\
\hline CHEMBL1385545 & 688549 & 5.0 & 4.6729 & TST & \\
\hline CHEMBL 260342 & 688549 & 5.2 & 5.2547 & TRN & \\
\hline CHEMBL1513915 & 688549 & 4.45 & 5.2402 & TRN & \\
\hline CHEMBL3197626 & 688549 & 4.95 & 5.2991 & TRN & \\
\hline CHEMBL1357673 & 688549 & 4.5 & 4.8671 & TRN & \\
\hline CHEMBL3213515 & 688549 & 4.8 & 5.3479 & TST & \\
\hline CHEMBL1415598 & 688549 & 5.3 & 5.2491 & TRN & \\
\hline CHEMBL1365927 & 688549 & 4.5 & 4.6288 & TRN & \\
\hline CHEMBL1442201 & 688549 & 6.2 & 5.0553 & TRN & \\
\hline CHEMBL1328930 & 688549 & 4.9 & 4.7329 & TRN & \\
\hline CHEMBL1375740 & 688549 & 5.9 & 5.3813 & TRN & \\
\hline CHEMBL1593003 & 688549 & 4.85 & 4.7031 & TRN & \\
\hline CHEMBL1374507 & 688549 & 4.5 & 5.2007 & TRN & \\
\hline CHEMBL1492655 & 688549 & 4.9 & 4.7072 & TRN & \\
\hline CHEMBL1464645 & 688549 & 6.3 & 5.7172 & TRN & \\
\hline CHEMBL1483062 & 688549 & 8.0 & 5.7107 & TRN & \\
\hline CHEMBL1449350 & 688549 & 4.7 & 4.8162 & TRN & \\
\hline CHEMBL1436148 & 688549 & 4.8 & 4.4195 & TRN & \\
\hline CHEMBL1407095 & 688549 & 4.8 & 4.96899 & 9999999999 & TRN \\
\hline CHEMBL1552997 & 688549 & 4.9 & 5.224 & TST & \\
\hline CHEMBL1429512 & 688549 & 4.45 & 4.8857 & TRN & \\
\hline CHEMBL1395139 & 688549 & 4.8 & 5.1247 & TRN & \\
\hline CHEMBL1395010 & 688549 & 4.5 & 5.0599 & TRN & \\
\hline CHEMBL1537169 & 688549 & 4.8 & 4.6716 & TRN & \\
\hline CHEMBL1376163 & 688549 & 5.0 & 4.8925 & TST & \\
\hline CHEMBL1382714 & 688549 & 6.7001 & 5.0986 & TRN & \\
\hline CHEMBL1315098 & 688549 & 5.0 & 4.9357 & TRN & \\
\hline CHEMBL1322642 & 688549 & 5.4 & 5.2857 & TRN & \\
\hline CHEMBL1475255 & 688549 & 5.0 & 5.0462 & TRN & \\
\hline CHEMBL1256740 & 688549 & 6.0 & 5.1646 & TST & \\
\hline CHEMBL1600535 & 688549 & 4.9 & 4.9631 & TST & \\
\hline CHEMBL406119 & 688549 & 4.5 & 5.0728 & TRN & \\
\hline CHEMBL1590288 & 688549 & 5.5 & 5.221 & TRN & \\
\hline CHEMBL1577902 & 688549 & 5.0 & 5.0775 & TRN & \\
\hline CHEMBL1537857 & 688549 & 4.9 & 4.4456 & TRN & \\
\hline CHEMBL1493507 & 688549 & 4.8 & 4.6738 & TRN & \\
\hline CHEMBL1452108 & 688549 & 4.9 & 5.1949 & TRN & \\
\hline CHEMBL1478719 & 688549 & 7.4001 & 5.3713 & TRN & \\
\hline CHEMBL1506076 & 688549 & 4.8 & 5.1316 & TRN & \\
\hline CHEMBL1472108 & 688549 & 4.5 & 4.7324 & TST & \\
\hline CHEMBL1448223 & 688549 & 4.9 & 5.1094 & TRN & \\
\hline
\end{tabular}




\begin{tabular}{|c|c|c|c|c|}
\hline \multicolumn{5}{|c|}{ Supplemental Table S2.txt } \\
\hline CHEMBL1413419 & 688549 & 5.0 & 5.1167 & TRN \\
\hline CHEMBL1463435 & 688549 & 4.9 & 4.9548 & TRN \\
\hline CHEMBL1548335 & 688549 & 4.7 & 5.0842 & TRN \\
\hline CHEMBL1591556 & 688549 & 6.0 & 5.7933 & TST \\
\hline CHEMBL1330033 & 688549 & 4.95 & 4.5247 & TRN \\
\hline CHEMBL1491944 & 688549 & 4.9 & 5.0409 & TRN \\
\hline CHEMBL1314436 & 688549 & 5.5 & 5.4621 & TRN \\
\hline CHEMBL1331383 & 688549 & 4.9 & 5.0795 & TRN \\
\hline CHEMBL1472867 & 688549 & 5.0 & 5.2146 & TRN \\
\hline CHEMBL1352911 & 688549 & 5.0 & 4.8798 & TRN \\
\hline CHEMBL1472513 & 688549 & 4.6 & 5.0569 & TRN \\
\hline CHEMBL1521128 & 688549 & 4.45 & 4.4474 & TRN \\
\hline CHEMBL1421232 & 688549 & 4.9 & 5.2375 & TRN \\
\hline CHEMBL1371774 & 688549 & 4.5 & 4.5741 & TRN \\
\hline CHEMBL1412891 & 688549 & 5.0 & 4.7576 & TRN \\
\hline CHEMBL1593009 & 688549 & 4.5 & 5.2041 & TRN \\
\hline CHEMBL1403379 & 688549 & 4.7 & 4.7978 & TRN \\
\hline CHEMBL1479909 & 688549 & 4.8 & 4.3641 & TRN \\
\hline CHEMBL1325495 & 688549 & 4.7 & 4.7885 & TRN \\
\hline CHEMBL1413671 & 688549 & 5.3 & 5.0607 & TRN \\
\hline CHEMBL3196464 & 688549 & 5.0 & 5.0106 & TRN \\
\hline CHEMBL1370448 & 688549 & 4.9 & 5.1416 & TRN \\
\hline CHEMBL1521950 & 688549 & 4.7 & 4.7286 & TRN \\
\hline CHEMBL1543893 & 688549 & 4.5 & 4.8404 & TRN \\
\hline CHEMBL1590419 & 688549 & 4.5 & 4.6116 & TRN \\
\hline CHEMBL1377517 & 688549 & 4.5 & 4.9262 & TRN \\
\hline CHEMBL1574383 & 688549 & 4.7 & 5.0829 & TRN \\
\hline CHEMBL1351907 & 688549 & 4.5 & 5.376 & TST \\
\hline CHEMBL1335490 & 688549 & 5.0 & 4.8594 & TRN \\
\hline CHEMBL587620 & 688549 & 4.7 & 4.7246 & TRN \\
\hline CHEMBL3198641 & 688549 & 8.0506 & 5.2462 & TRN \\
\hline CHEMBL573524 & 688549 & 4.5 & 5.1499 & TRN \\
\hline CHEMBL1607093 & 688549 & 4.7 & 5.3705 & TRN \\
\hline CHEMBL1256911 & 688549 & 5.0 & 5.0046 & TST \\
\hline CHEMBL1367834 & 688549 & 5.05 & 4.8048 & TRN \\
\hline CHEMBL1440954 & 688549 & 4.8 & 5.0312 & TRN \\
\hline CHEMBL 1488003 & 688549 & 4.8 & 4.6092 & TST \\
\hline CHEMBL1586489 & 688549 & 4.5 & 4.9419 & TST \\
\hline CHEMBL1314650 & 688549 & 4.45 & 5.2066 & TST \\
\hline CHEMBL1609927 & 688549 & 4.7 & 4.9134 & TRN \\
\hline CHEMBL1473242 & 688549 & 4.75 & 4.6888 & TRN \\
\hline CHEMBL1469059 & 688549 & 5.3 & 6.1467 & TRN \\
\hline CHEMBL1319037 & 688549 & 5.0 & 5.027 & TRN \\
\hline CHEMBL1512746 & 688549 & 4.7 & 4.7933 & TST \\
\hline CHEMBL1314762 & 688549 & 4.8 & 4.6131 & TRN \\
\hline CHEMBL365374 & 688549 & 4.6 & 4.7858 & TRN \\
\hline CHEMBL1360143 & 688549 & 4.9 & 4.8855 & TRN \\
\hline CHEMBL1525639 & 688549 & 4.7 & 4.9216 & TRN \\
\hline
\end{tabular}




\begin{tabular}{|c|c|c|c|c|}
\hline \multicolumn{5}{|c|}{ Supplemental Table S2.txt } \\
\hline CHEMBL1590587 & 688549 & 4.8 & 5.039 & TRN \\
\hline CHEMBL3208365 & 688549 & 6.0 & 5.0657 & TRN \\
\hline CHEMBL1442813 & 688549 & 4.9 & 5.3019 & TRN \\
\hline CHEMBL1449854 & 688549 & 4.7 & 4.6574 & TRN \\
\hline CHEMBL1538545 & 688549 & 4.6 & 5.3685 & TST \\
\hline CHEMBL1492671 & 688549 & 6.4 & 5.5688 & TRN \\
\hline CHEMBL1579072 & 688549 & 5.35 & 4.7059 & TRN \\
\hline CHEMBL1491561 & 688549 & 5.05 & 5.0304 & TST \\
\hline CHEMBL1433040 & 688549 & 4.9 & 5.0275 & TRN \\
\hline CHEMBL1501480 & 688549 & 5.3 & 5.2281 & TRN \\
\hline CHEMBL1389307 & 688549 & 5.0 & 5.2412 & TRN \\
\hline CHEMBL1394587 & 688549 & 4.9 & 4.9551 & TRN \\
\hline CHEMBL1569243 & 688549 & 5.0 & 4.9139 & TRN \\
\hline CHEMBL1436280 & 688549 & 5.6 & 5.0542 & TRN \\
\hline CHEMBL1434392 & 688549 & 4.75 & 4.5205 & TRN \\
\hline CHEMBL1373007 & 688549 & 5.1 & 5.1124 & TST \\
\hline CHEMBL1547159 & 688549 & 4.9 & 5.2443 & TST \\
\hline CHEMBL1449069 & 688549 & 4.5 & 4.4147 & TRN \\
\hline CHEMBL1476419 & 688549 & 5.0 & 4.7005 & TRN \\
\hline CHEMBL1458271 & 688549 & 5.1 & 5.4191 & TRN \\
\hline CHEMBL1515468 & 688549 & 4.8 & 5.1798 & TRN \\
\hline CHEMBL1395477 & 688549 & 4.6 & 4.9709 & TRN \\
\hline CHEMBL1594218 & 688549 & 4.9 & 5.1516 & TRN \\
\hline CHEMBL1523911 & 688549 & 4.5 & 4.6275 & TST \\
\hline CHEMBL1343219 & 688549 & 4.8 & 4.6519 & TST \\
\hline CHEMBL1367089 & 688549 & 4.8 & 4.9642 & TRN \\
\hline CHEMBL1458755 & 688549 & 5.0 & 5.0993 & TRN \\
\hline CHEMBL1608213 & 688549 & 5.4 & 5.2608 & TRN \\
\hline CHEMBL1548075 & 688549 & 4.85 & 5.0399 & TRN \\
\hline CHEMBL1550150 & 688549 & 8.3468 & 5.8131 & TRN \\
\hline CHEMBL1610124 & 688549 & 5.0 & 5.0788 & TRN \\
\hline CHEMBL1485895 & 688549 & 4.5 & 4.8153 & TRN \\
\hline CHEMBL1538503 & 688549 & 4.6 & 4.6101 & TRN \\
\hline CHEMBL194594 & 688549 & 5.2 & 5.0544 & TRN \\
\hline CHEMBL1559944 & 688549 & 5.2 & 5.1748 & TRN \\
\hline CHEMBL1308610 & 688549 & 4.5 & 4.6897 & TRN \\
\hline CHEMBL1608441 & 688549 & 4.6 & 4.6199 & TRN \\
\hline CHEMBL1397030 & 688549 & 4.5 & 4.5195 & TRN \\
\hline CHEMBL1318029 & 688549 & 5.4 & 5.2343 & TRN \\
\hline CHEMBL1362654 & 688549 & 4.5 & 4.7619 & TRN \\
\hline CHEMBL1536647 & 688549 & 4.7 & 5.0186 & TRN \\
\hline CHEMBL1355803 & 688549 & 5.7 & 5.1661 & TRN \\
\hline CHEMBL1553483 & 688549 & 5.0 & 4.9902 & TRN \\
\hline CHEMBL1499336 & 688549 & 6.4 & 5.3367 & TRN \\
\hline CHEMBL1327253 & 688549 & 4.5 & 5.1181 & TRN \\
\hline CHEMBL1356670 & 688549 & 4.55 & 4.7511 & TRN \\
\hline CHEMBL1356407 & 688549 & 4.7 & 4.9099 & TRN \\
\hline CHEMBL3196400 & 688549 & 4.8 & 5.1706 & TRN \\
\hline
\end{tabular}




\begin{tabular}{|c|c|c|c|c|c|}
\hline & & \\
\hline CHEMBL1377126 & 688549 & 4.8 & 4.7081 & TRN & \\
\hline CHEMBL1299969 & 688549 & 4.5 & 5.0271 & TRN & \\
\hline CHEMBL1451504 & 688549 & 4.7 & 4.8701 & TRN & \\
\hline CHEMBL1455934 & 688549 & 5.3 & 4.572 & TRN & \\
\hline CHEMBL1373256 & 688549 & 4.9 & 4.9239 & TRN & \\
\hline CHEMBL47940 & 688549 & 4.6 & 4.7577 & TST & \\
\hline CHEMBL1304398 & 688549 & 5.0 & 4.9253 & TRN & \\
\hline CHEMBL1464620 & 688549 & 4.9 & 5.1263 & TRN & \\
\hline CHEMBL1552152 & 688549 & 4.5 & 4.9517 & TRN & \\
\hline CHEMBL168105 & 688549 & 7.8996 & 5.3887 & TST & \\
\hline CHEMBL1404459 & 688549 & 4.7 & 4.849 & TRN & \\
\hline CHEMBL1586958 & 688549 & 4.95 & 5.2932 & TST & \\
\hline CHEMBL1471444 & 688549 & 4.5 & 4.8346 & TRN & \\
\hline CHEMBL1365810 & 688549 & 4.8 & 4.8662 & TRN & \\
\hline CHEMBL1346072 & 688549 & 4.8 & 5.0485 & TRN & \\
\hline CHEMBL1401668 & 688549 & 5.0 & 4.7007 & TRN & \\
\hline CHEMBL1256660 & 688549 & 4.7 & 4.8951 & TST & \\
\hline CHEMBL1493496 & 688549 & 4.9 & 4.7867 & TST & \\
\hline CHEMBL1335568 & 688549 & 4.9 & 4.9973 & TRN & \\
\hline CHEMBL1538729 & 688549 & 7.3002 & 5.5133 & TRN & \\
\hline CHEMBL1386099 & 688549 & 4.9 & 5.3587 & TRN & \\
\hline CHEMBL1373113 & 688549 & 4.9 & 4.9267 & TST & \\
\hline CHEMBL1339255 & 688549 & 4.6 & 5.1578 & TRN & \\
\hline CHEMBL1541830 & 688549 & 4.6 & 5.2771 & TST & \\
\hline CHEMBL1434344 & 688549 & 4.95 & 4.7309 & TRN & \\
\hline CHEMBL428789 & 688549 & 4.8 & 5.1178 & TRN & \\
\hline CHEMBL1536842 & 688549 & 4.5 & 4.6474 & TRN & \\
\hline CHEMBL1533655 & 688549 & 4.7 & 5.2488 & TRN & \\
\hline CHEMBL239276 & 688549 & 4.5 & 5.3145 & TRN & \\
\hline CHEMBL1437060 & 688549 & 4.9 & 4.5373 & TRN & \\
\hline CHEMBL1440334 & 688549 & 4.9 & 4.8472 & TRN & \\
\hline CHEMBL1342074 & 688549 & 4.5 & 4.6904 & TRN & \\
\hline CHEMBL1560215 & 688549 & 5.0 & 5.0679 & TRN & \\
\hline CHEMBL1353929 & 688549 & 4.5 & 5.1816 & TRN & \\
\hline CHEMBL1597099 & 688549 & 4.5 & 4.6453 & TRN & \\
\hline CHEMBL1475907 & 688549 & 4.5 & 5.13399 & 99999999995 & TRN \\
\hline CHEMBL 2374259 & 688549 & 4.9 & 5.1523 & TST & \\
\hline CHEMBL192566 & 688549 & 4.6 & 5.6039 & TST & \\
\hline CHEMBL1314890 & 688549 & 4.5 & 5.2806 & TRN & \\
\hline CHEMBL1208903 & 688549 & 4.9 & 5.0561 & TRN & \\
\hline CHEMBL1365850 & 688549 & 4.9 & 5.2717 & TRN & \\
\hline CHEMBL1567587 & 688549 & 4.8 & 5.0701 & TRN & \\
\hline CHEMBL1481085 & 688549 & 4.7 & 4.1569 & TRN & \\
\hline CHEMBL1518166 & 688549 & 4.7 & 4.7399 & TRN & \\
\hline CHEMBL1519770 & 688549 & 4.8 & 5.2069 & TRN & \\
\hline CHEMBL1613331 & 688549 & 4.9 & 4.8728 & TRN & \\
\hline CHEMBL 1318348 & 688549 & 4.9 & 4.8757 & TRN & \\
\hline CHEMBL8260 & 688549 & 5.4 & 5.4872 & TRN & \\
\hline & & & & 23102 & \\
\hline
\end{tabular}




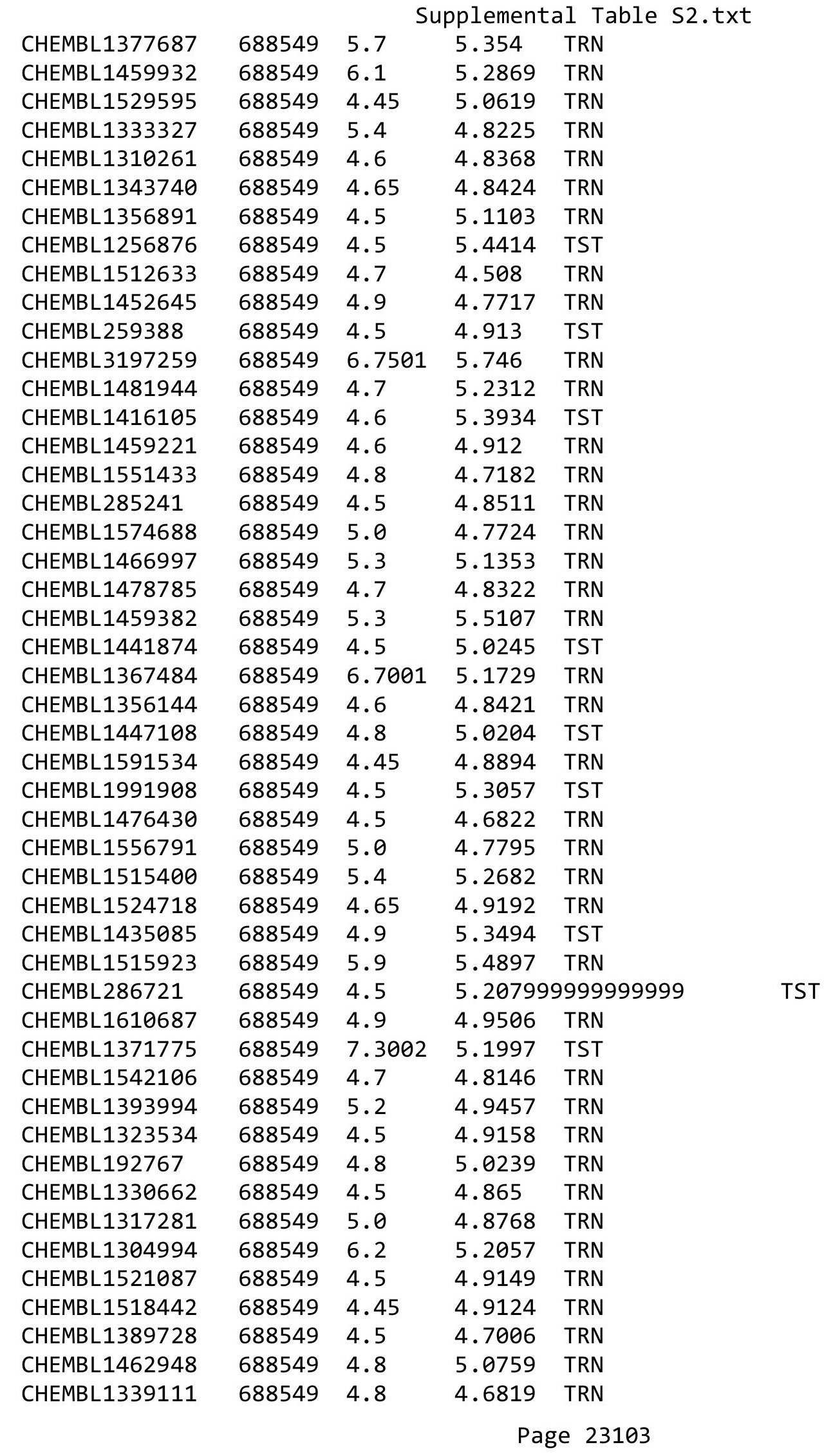




\begin{tabular}{|c|c|c|c|c|}
\hline \multicolumn{5}{|c|}{ Supplemental Table S2.txt } \\
\hline CHEMBL1310308 & 688549 & 4.5 & 5.1158 & TRN \\
\hline CHEMBL1465414 & 688549 & 4.7 & 4.7831 & TRN \\
\hline CHEMBL1440316 & 688549 & 4.6 & 4.7995 & TRN \\
\hline CHEMBL1315579 & 688549 & 4.7 & 5.4621 & TRN \\
\hline CHEMBL601757 & 688549 & 5.95 & 5.4656 & TRN \\
\hline CHEMBL1520957 & 688549 & 4.6 & 5.1485 & TRN \\
\hline CHEMBL1256869 & 688549 & 4.8 & 5.2534 & TRN \\
\hline CHEMBL1435883 & 688549 & 4.5 & 4.461 & TRN \\
\hline CHEMBL1490042 & 688549 & 4.5 & 5.0086 & TRN \\
\hline CHEMBL1397645 & 688549 & 4.9 & 4.6156 & TRN \\
\hline CHEMBL1315177 & 688549 & 4.95 & 4.65 & TRN \\
\hline CHEMBL1581158 & 688549 & 4.5 & 5.2253 & TST \\
\hline CHEMBL1606495 & 688549 & 4.5 & 4.8654 & TRN \\
\hline CHEMBL1356395 & 688549 & 5.6 & 5.8752 & TST \\
\hline CHEMBL227726 & 688549 & 4.9 & 4.9817 & TRN \\
\hline CHEMBL1315580 & 688549 & 4.9 & 5.0218 & TRN \\
\hline CHEMBL1561495 & 688549 & 8.2007 & 5.1699 & TRN \\
\hline CHEMBL1573365 & 688549 & 4.5 & 5.1952 & TST \\
\hline CHEMBL1463272 & 688549 & 4.85 & 5.0554 & TRN \\
\hline CHEMBL1501898 & 688549 & 4.5 & 4.8623 & TST \\
\hline CHEMBL1419647 & 688549 & 4.7 & 4.9847 & TRN \\
\hline CHEMBL1357558 & 688549 & 4.7 & 4.8659 & TST \\
\hline CHEMBL1569618 & 688549 & 5.9 & 5.2995 & TRN \\
\hline CHEMBL1978643 & 688549 & 5.1 & 5.2025 & TST \\
\hline CHEMBL1346516 & 688549 & 4.6 & 5.0053 & TRN \\
\hline CHEMBL1579060 & 688549 & 4.9 & 4.6347 & TRN \\
\hline CHEMBL1390831 & 688549 & 4.9 & 4.8317 & TRN \\
\hline CHEMBL1574361 & 688549 & 5.25 & 5.2892 & TRN \\
\hline CHEMBL1381538 & 688549 & 5.3 & 5.4785 & TRN \\
\hline CHEMBL1593290 & 688549 & 4.9 & 4.8718 & TRN \\
\hline CHEMBL1357901 & 688549 & 5.0 & 4.8811 & TRN \\
\hline CHEMBL1329458 & 688549 & 4.9 & 4.8681 & TRN \\
\hline CHEMBL1551774 & 688549 & 4.5 & 4.9147 & TRN \\
\hline CHEMBL75035 & 688549 & 4.5 & 5.2093 & TST \\
\hline CHEMBL1516763 & 688549 & 4.8 & 4.8575 & TRN \\
\hline CHEMBL1401648 & 688549 & 4.8 & 4.9471 & TRN \\
\hline CHEMBL1429106 & 688549 & 4.9 & 4.9878 & TST \\
\hline CHEMBL1338240 & 688549 & 4.8 & 5.182 & TRN \\
\hline CHEMBL1545556 & 688549 & 6.4 & 5.4894 & TRN \\
\hline CHEMBL1571643 & 688549 & 5.4 & 4.9406 & TRN \\
\hline CHEMBL1592098 & 688549 & 8.2007 & 5.2952 & TRN \\
\hline CHEMBL1513833 & 688549 & 4.8 & 4.5328 & TRN \\
\hline CHEMBL1366061 & 688549 & 4.5 & 4.692 & TRN \\
\hline CHEMBL1489041 & 688549 & 4.5 & 4.3344 & TRN \\
\hline CHEMBL1425445 & 688549 & 6.6 & 5.5134 & TRN \\
\hline CHEMBL1398454 & 688549 & 5.1 & 4.6603 & TRN \\
\hline CHEMBL578523 & 688549 & 4.7 & 5.5064 & TRN \\
\hline CHEMBL1316820 & 688549 & 4.6 & 4.8738 & TRN \\
\hline
\end{tabular}




\begin{tabular}{|c|c|c|c|c|c|}
\hline \multicolumn{6}{|c|}{ Supplemental Table S2.txt } \\
\hline CHEMBL1306181 & 688549 & 4.5 & 4.5409 & TRN & \\
\hline CHEMBL16312 & 688549 & 4.6 & 5.0786 & TRN & \\
\hline CHEMBL337173 & 688549 & 5.5 & 5.4306 & TST & \\
\hline CHEMBL1382491 & 688549 & 4.7 & 4.5718 & TRN & \\
\hline CHEMBL1553674 & 688549 & 4.75 & 4.5341 & TRN & \\
\hline CHEMBL1612609 & 688549 & 5.0 & 4.997 & TRN & \\
\hline CHEMBL1365865 & 688549 & 4.6 & 5.2467 & TRN & \\
\hline CHEMBL1414129 & 688549 & 4.9 & 4.7151 & TRN & \\
\hline CHEMBL1317601 & 688549 & 4.5 & 4.4089 & TRN & \\
\hline CHEMBL1364404 & 688549 & 6.1 & 5.285 & TRN & \\
\hline CHEMBL1497557 & 688549 & 5.1 & 4.7535 & TRN & \\
\hline CHEMBL1450973 & 688549 & 5.9 & 5.3276 & TRN & \\
\hline CHEMBL452409 & 688549 & 5.0 & 5.1025 & TRN & \\
\hline CHEMBL1302822 & 688549 & 4.6 & 5.0343 & TRN & \\
\hline CHEMBL1493184 & 688549 & 4.9 & 4.7322 & TRN & \\
\hline CHEMBL1377982 & 688549 & 6.5501 & 5.3407 & TRN & \\
\hline CHEMBL1499632 & 688549 & 4.9 & 5.3113 & TRN & \\
\hline CHEMBL1483591 & 688549 & 5.25 & 4.6419 & TRN & \\
\hline CHEMBL1546037 & 688549 & 4.9 & 4.7182 & TST & \\
\hline CHEMBL1607701 & 688549 & 5.2 & 4.8873 & TRN & \\
\hline CHEMBL1474627 & 688549 & 4.5 & 5.077 & TST & \\
\hline CHEMBL1592256 & 688549 & 4.9 & 5.1633 & TRN & \\
\hline CHEMBL1323354 & 688549 & 4.9 & 5.13399 & 99999999995 & TRN \\
\hline CHEMBL1425250 & 688549 & 4.85 & 5.1491 & TST & \\
\hline CHEMBL1494027 & 688549 & 5.25 & 5.5492 & TRN & \\
\hline CHEMBL1366470 & 688549 & 5.0 & 5.4033 & TRN & \\
\hline CHEMBL1377119 & 688549 & 4.9 & 5.0047 & TRN & \\
\hline CHEMBL1546956 & 688549 & 5.0 & 4.9926 & TRN & \\
\hline CHEMBL1504945 & 688549 & 4.9 & 4.9574 & TRN & \\
\hline CHEMBL1561254 & 688549 & 4.8 & 5.0239 & TST & \\
\hline CHEMBL1361722 & 688549 & 4.7 & 4.9131 & TRN & \\
\hline CHEMBL1589937 & 688549 & 4.5 & 5.0228 & TRN & \\
\hline CHEMBL1435100 & 688549 & 5.0 & 5.0523 & TRN & \\
\hline CHEMBL1395184 & 688549 & 4.6 & 5.47 & TRN & \\
\hline CHEMBL1323791 & 688549 & 4.8 & 5.3113 & TRN & \\
\hline CHEMBL1513190 & 688549 & 4.9 & 4.7382 & TST & \\
\hline CHEMBL1449209 & 688549 & 4.7 & 4.6607 & TRN & \\
\hline CHEMBL1359760 & 688549 & 4.8 & 4.8004 & TST & \\
\hline CHEMBL1437765 & 688549 & 4.9 & 4.9032 & TRN & \\
\hline CHEMBL1604007 & 688549 & 4.45 & 5.4157 & TST & \\
\hline CHEMBL1456630 & 688549 & 5.7 & 5.1799 & TRN & \\
\hline CHEMBL1444884 & 688549 & 5.5 & 5.1677 & TRN & \\
\hline CHEMBL1603268 & 688549 & 6.5 & 5.3556 & TRN & \\
\hline CHEMBL1377782 & 688549 & 4.9 & 4.6381 & TRN & \\
\hline CHEMBL1566148 & 688549 & 4.9 & 5.1101 & TST & \\
\hline CHEMBL1332808 & 688549 & 4.45 & 5.1789 & TRN & \\
\hline CHEMBL1377307 & 688549 & 5.1 & 4.8962 & TRN & \\
\hline CHEMBL1398957 & 688549 & 4.9 & 4.8951 & TRN & \\
\hline
\end{tabular}




\begin{tabular}{|c|c|c|c|c|c|}
\hline \\
\hline CHEMBL1579643 & 688549 & 4.9 & 5.0842 & TRN & \\
\hline CHEMBL1559245 & 688549 & 4.9 & 4.9812 & TRN & \\
\hline CHEMBL1416809 & 688549 & 4.8 & 5.0028 & TRN & \\
\hline CHEMBL1448066 & 688549 & 5.0 & 4.7668 & TRN & \\
\hline CHEMBL1474773 & 688549 & 4.65 & 5.3968 & TRN & \\
\hline CHEMBL1302314 & 688549 & 4.8 & 4.8157 & TRN & \\
\hline CHEMBL1369899 & 688549 & 4.5 & 4.63399 & 99999999995 & TRN \\
\hline CHEMBL1334260 & 688549 & 7.9508 & 5.2027 & TRN & \\
\hline CHEMBL1314850 & 688549 & 4.8 & 4.9319 & TRN & \\
\hline CHEMBL1417180 & 688549 & 4.6 & 4.7354 & TRN & \\
\hline CHEMBL1453649 & 688549 & 4.9 & 4.6624 & TRN & \\
\hline CHEMBL1435001 & 688549 & 5.0 & 4.829 & TRN & \\
\hline CHEMBL1455160 & 688549 & 4.8 & 5.1347 & TRN & \\
\hline CHEMBL1358179 & 688549 & 4.5 & 4.3604 & TRN & \\
\hline CHEMBL1553780 & 688549 & 4.9 & 4.8753 & TRN & \\
\hline CHEMBL18686 & 688549 & 5.0 & 5.4625 & TST & \\
\hline CHEMBL1368165 & 688549 & 4.95 & 5.2457 & TST & \\
\hline CHEMBL1510369 & 688549 & 4.9 & 4.9397 & TRN & \\
\hline CHEMBL1513400 & 688549 & 4.5 & 4.8111 & TRN & \\
\hline CHEMBL1474479 & 688549 & 4.8 & 5.2316 & TRN & \\
\hline CHEMBL1446073 & 688549 & 4.8 & 4.565 & TRN & \\
\hline CHEMBL1472875 & 688549 & 4.7 & 5.1146 & TRN & \\
\hline CHEMBL1533112 & 688549 & 5.1 & 5.1533 & TRN & \\
\hline CHEMBL578890 & 688549 & 4.45 & 4.6806 & TRN & \\
\hline CHEMBL1466068 & 688549 & 4.5 & 4.8547 & TRN & \\
\hline CHEMBL1451375 & 688549 & 5.0 & 5.1191 & TRN & \\
\hline CHEMBL1411054 & 688549 & 4.5 & 4.6904 & TRN & \\
\hline CHEMBL1579773 & 688549 & 5.0 & 5.3344 & TRN & \\
\hline CHEMBL1411665 & 688549 & 4.9 & 5.1264 & TRN & \\
\hline CHEMBL3209194 & 688549 & 8.2007 & 5.1377 & TST & \\
\hline CHEMBL1516550 & 688549 & 5.85 & 5.4666 & TRN & \\
\hline CHEMBL1409320 & 688549 & 4.9 & 4.9941 & TST & \\
\hline CHEMBL1449964 & 688549 & 5.0 & 5.6435 & TRN & \\
\hline CHEMBL3194854 & 688549 & 5.0 & 5.0638 & TRN & \\
\hline CHEMBL 24983 & 688549 & 4.9 & 5.05399 & 9999999999 & TST \\
\hline CHEMBL1471008 & 688549 & 5.0 & 4.9373 & TRN & \\
\hline CHEMBL1335446 & 688549 & 4.7 & 5.0071 & TRN & \\
\hline CHEMBL1599340 & 688549 & 5.6 & 5.3414 & TRN & \\
\hline CHEMBL1592221 & 688549 & 4.5 & 4.9486 & TRN & \\
\hline CHEMBL1477366 & 688549 & 4.8 & 4.9168 & TRN & \\
\hline CHEMBL1485582 & 688549 & 4.85 & 5.0069 & TRN & \\
\hline CHEMBL1435278 & 688549 & 4.5 & 4.9605 & TRN & \\
\hline CHEMBL1453801 & 688549 & 5.1 & 4.93199 & 99999999995 & TRN \\
\hline CHEMBL1397045 & 688549 & 5.1 & 5.1044 & TRN & \\
\hline CHEMBL1366350 & 688549 & 4.6 & 5.1486 & TRN & \\
\hline CHEMBL 3144890 & 688549 & 4.8 & 4.8232 & TST & \\
\hline CHEMBL1390641 & 688549 & 4.9 & 5.2294 & TRN & \\
\hline CHEMBL1572383 & 688549 & 7.8013 & 5.1904 & TRN & \\
\hline
\end{tabular}





\begin{tabular}{|c|c|c|c|c|c|}
\hline \multirow{3}{*}{$\begin{array}{l}\text { CHEMBL1329228 } \\
\text { CHEMBL1378063 }\end{array}$} & \multirow{3}{*}{$\begin{array}{l}688549 \\
688549\end{array}$} & \multicolumn{4}{|c|}{ Supplemental Table S2.txt } \\
\hline & & 5.0 & \multicolumn{2}{|c|}{4.946000000000001} & TRN \\
\hline & & 4.9 & 5.033 & TRN & \\
\hline CHEMBL1357947 & 688549 & 4.9 & 4.6176 & TRN & \\
\hline CHEMBL1347274 & 688549 & 4.7 & 5.0746 & TRN & \\
\hline CHEMBL1443872 & 688549 & 4.9 & 5.4885 & TST & \\
\hline CHEMBL1327227 & 688549 & 4.6 & 4.8656 & TRN & \\
\hline CHEMBL1449127 & 688549 & 7.6498 & 5.0766 & TRN & \\
\hline CHEMBL1330459 & 688549 & 6.0 & 5.3037 & TRN & \\
\hline CHEMBL1526437 & 688549 & 5.0 & 5.1251 & TRN & \\
\hline CHEMBL1436355 & 688549 & 4.9 & 4.7853 & TRN & \\
\hline CHEMBL1564573 & 688549 & 4.7 & 4.5635 & TRN & \\
\hline CHEMBL1332434 & 688549 & 4.5 & 4.7905 & TST & \\
\hline CHEMBL1512786 & 688549 & 4.8 & 4.9097 & TRN & \\
\hline CHEMBL1552938 & 688549 & 4.45 & 4.9167 & TRN & \\
\hline CHEMBL1594063 & 688549 & 4.85 & 4.556 & TRN & \\
\hline CHEMBL1554101 & 688549 & 4.6 & 4.8295 & TRN & \\
\hline CHEMBL1476313 & 688549 & 4.9 & 4.4961 & TRN & \\
\hline CHEMBL1396734 & 688549 & 4.8 & 4.7797 & TRN & \\
\hline CHEMBL1513560 & 688549 & 4.6 & 4.9335 & TRN & \\
\hline CHEMBL1583101 & 688549 & 4.5 & 4.7179 & TRN & \\
\hline CHEMBL1531549 & 688549 & 4.8 & 5.0124 & TRN & \\
\hline CHEMBL1319510 & 688549 & 4.5 & 4.7117 & TRN & \\
\hline CHEMBL1433508 & 688549 & 4.6 & 5.2813 & TRN & \\
\hline CHEMBL1493139 & 688549 & 4.9 & 4.9074 & TRN & \\
\hline CHEMBL1455403 & 688549 & 4.6 & 4.8695 & TRN & \\
\hline CHEMBL1549387 & 688549 & 8.2007 & 5.3435 & TRN & \\
\hline CHEMBL1313979 & 688549 & 5.7 & 5.2237 & TRN & \\
\hline CHEMBL1478012 & 688549 & 4.45 & 4.3427 & TRN & \\
\hline CHEMBL1506175 & 688549 & 4.9 & 4.9601 & TRN & \\
\hline CHEMBL1399912 & 688549 & 4.9 & 5.0241 & TRN & \\
\hline CHEMBL1570047 & 688549 & 5.1 & 4.829 & TRN & \\
\hline CHEMBL1302618 & 688549 & 4.9 & 4.8222 & TRN & \\
\hline CHEMBL1364763 & 688549 & 4.9 & 4.9996 & TRN & \\
\hline CHEMBL1554736 & 688549 & 4.45 & 4.8186 & TRN & \\
\hline CHEMBL1398221 & 688549 & 5.0 & 4.6519 & TRN & \\
\hline CHEMBL1491745 & 688549 & 4.9 & 4.8214 & TST & \\
\hline CHEMBL1315059 & 688549 & 5.5 & 5.1579 & TRN & \\
\hline CHEMBL1573636 & 688549 & 4.9 & 5.1456 & TRN & \\
\hline CHEMBL1457356 & 688549 & 5.0 & 4.827 & TRN & \\
\hline CHEMBL1310144 & 688549 & 6.0 & 5.4662 & TRN & \\
\hline CHEMBL512749 & 688549 & 5.4 & 5.3998 & TRN & \\
\hline CHEMBL1475283 & 688549 & 4.45 & 5.3662 & TRN & \\
\hline CHEMBL1584746 & 688549 & 4.6 & 5.026 & TST & \\
\hline CHEMBL1557782 & 688549 & 4.6 & 4.4217 & TRN & \\
\hline CHEMBL1437252 & 688549 & 5.5 & 5.1999 & TRN & \\
\hline CHEMBL1331601 & 688549 & 4.7 & 5.0772 & TST & \\
\hline CHEMBL1448124 & 688549 & 5.0 & 4.5935 & TRN & \\
\hline CHEMBL1571217 & 688549 & 5.5 & 5.2365 & TRN & \\
\hline
\end{tabular}




\begin{tabular}{|c|c|c|c|c|c|}
\hline \multicolumn{6}{|c|}{ Supplemental Table S2.txt } \\
\hline CHEMBL1400144 & 688549 & 4.95 & 5.0265 & TRN & \\
\hline CHEMBL1372129 & 688549 & 4.5 & 4.7278 & TRN & \\
\hline CHEMBL1411836 & 688549 & 4.6 & 5.6287 & TRN & \\
\hline CHEMBL1496611 & 688549 & 4.5 & 4.9308 & TRN & \\
\hline CHEMBL1354317 & 688549 & 5.1 & 5.1269 & TRN & \\
\hline CHEMBL1449065 & 688549 & 4.9 & 4.5038 & TRN & \\
\hline CHEMBL1335529 & 688549 & 5.5 & 5.0436 & TST & \\
\hline CHEMBL1548867 & 688549 & 4.9 & 4.8028 & TRN & \\
\hline CHEMBL1316402 & 688549 & 5.0 & 5.0062 & TRN & \\
\hline CHEMBL1358376 & 688549 & 4.9 & 4.7884 & TRN & \\
\hline CHEMBL546137 & 688549 & 4.9 & 4.7664 & TRN & \\
\hline CHEMBL1554164 & 688549 & 5.5 & 5.4803 & TRN & \\
\hline CHEMBL1400942 & 688549 & 4.6 & 5.3413 & TRN & \\
\hline CHEMBL1460357 & 688549 & 5.0 & 5.1268 & TRN & \\
\hline CHEMBL1441574 & 688549 & 8.2007 & 5.3036 & TST & \\
\hline CHEMBL1256816 & 688549 & 4.5 & 4.9733 & TST & \\
\hline CHEMBL1375753 & 688549 & 4.5 & 4.5783 & TRN & \\
\hline CHEMBL1556666 & 688549 & 4.6 & 4.8077 & TRN & \\
\hline CHEMBL1472916 & 688549 & 5.0 & 4.7348 & TRN & \\
\hline CHEMBL3207541 & 688549 & 4.7 & 5.2198 & TRN & \\
\hline CHEMBL1474151 & 688549 & 5.0 & 4.9095 & TRN & \\
\hline CHEMBL1559605 & 688549 & 4.95 & 4.7775 & TRN & \\
\hline CHEMBL1359389 & 688549 & 4.9 & 4.8818 & TRN & \\
\hline CHEMBL1498547 & 688549 & 5.5 & 5.0217 & TRN & \\
\hline CHEMBL1394759 & 688549 & 4.7 & 5.2437 & TRN & \\
\hline CHEMBL1456625 & 688549 & 4.5 & 4.7346 & TRN & \\
\hline CHEMBL3197115 & 688549 & 5.0 & 4.84399 & & TRN \\
\hline CHEMBL 8080 & 688549 & 5.1 & 5.4008 & TST & \\
\hline CHEMBL1399793 & 688549 & 5.25 & 4.6973 & TRN & \\
\hline CHEMBL1453505 & 688549 & 5.0 & 5.3563 & TRN & \\
\hline CHEMBL1453741 & 688549 & 5.1 & 5.0417 & TRN & \\
\hline CHEMBL1308850 & 688549 & 4.8 & 5.1694 & TST & \\
\hline CHEMBL1612880 & 688549 & 4.6 & 5.0351 & TRN & \\
\hline CHEMBL1450751 & 688549 & 4.9 & 4.9592 & TRN & \\
\hline CHEMBL1325462 & 688549 & 4.6 & 4.868 & TRN & \\
\hline CHEMBL1590284 & 688549 & 4.8 & 4.7393 & TRN & \\
\hline CHEMBL601770 & 688549 & 5.3 & 5.5183 & TRN & \\
\hline CHEMBL1556879 & 688549 & 4.5 & 5.2278 & TRN & \\
\hline CHEMBL1440408 & 688549 & 4.9 & 4.7357 & TRN & \\
\hline CHEMBL1370256 & 688549 & 4.45 & 5.1336 & TRN & \\
\hline CHEMBL1493134 & 688549 & 4.9 & 5.45 & TST & \\
\hline CHEMBL1439783 & 688549 & 4.5 & 4.6657 & TRN & \\
\hline CHEMBL1344349 & 688549 & 5.3 & 5.6166 & TST & \\
\hline CHEMBL1551672 & 688549 & 4.9 & 5.112 & TRN & \\
\hline CHEMBL3196369 & 688549 & 4.45 & 5.2515 & TRN & \\
\hline CHEMBL1376268 & 688549 & 4.9 & 5.1563 & TRN & \\
\hline CHEMBL1406753 & 688549 & 5.0 & 4.9458 & TRN & \\
\hline CHEMBL1315684 & 688549 & 4.5 & 4.4733 & TRN & \\
\hline
\end{tabular}




\begin{tabular}{|c|c|c|c|c|}
\hline & & & pplement & al $\mathrm{Ta}$ \\
\hline CHEMBL1315373 & 688549 & 5.0 & 4.6763 & TRN \\
\hline CHEMBL1398505 & 688549 & 5.1 & 5.0898 & TRN \\
\hline CHEMBL1553504 & 688549 & 4.6 & 5.1821 & TRN \\
\hline CHEMBL1475660 & 688549 & 5.4 & 5.1204 & TRN \\
\hline CHEMBL1376627 & 688549 & 4.5 & 5.2531 & TRN \\
\hline CHEMBL1474766 & 688549 & 4.5 & 4.505 & TRN \\
\hline CHEMBL1425943 & 688549 & 4.45 & 4.7331 & TST \\
\hline CHEMBL1404519 & 688549 & 5.4 & 5.4812 & TST \\
\hline CHEMBL1530679 & 688549 & 8.301 & 5.2999 & TRN \\
\hline CHEMBL1436178 & 688549 & 4.5 & 4.7722 & TST \\
\hline CHEMBL1525752 & 688549 & 4.9 & 5.376 & TRN \\
\hline CHEMBL1378375 & 688549 & 5.0 & 4.8698 & TRN \\
\hline CHEMBL3198373 & 688549 & 5.1 & 4.9816 & TRN \\
\hline CHEMBL1445543 & 688549 & 5.0 & 4.8185 & TRN \\
\hline CHEMBL1456236 & 688549 & 4.5 & 4.8455 & TST \\
\hline CHEMBL1353661 & 688549 & 4.9 & 4.8586 & TRN \\
\hline CHEMBL1502031 & 688549 & 4.7 & 5.0091 & TRN \\
\hline CHEMBL491991 & 688549 & 5.5 & 5.3864 & TRN \\
\hline CHEMBL1337235 & 688549 & 4.9 & 4.4477 & TRN \\
\hline CHEMBL1526013 & 688549 & 4.8 & 5.1152 & TRN \\
\hline CHEMBL1604405 & 688549 & 4.45 & 4.7342 & TRN \\
\hline CHEMBL1310637 & 688549 & 4.9 & 4.7632 & TRN \\
\hline CHEMBL1454417 & 688549 & 4.6 & 4.7857 & TRN \\
\hline CHEMBL1356974 & 688549 & 5.7 & 5.0348 & TRN \\
\hline CHEMBL1320173 & 688549 & 4.55 & 4.302 & TRN \\
\hline CHEMBL1556966 & 688549 & 5.7 & 5.4072 & TST \\
\hline CHEMBL1409629 & 688549 & 5.0 & 5.296 & TRN \\
\hline CHEMBL1569817 & 688549 & 4.9 & 5.3683 & TRN \\
\hline CHEMBL1435102 & 688549 & 4.5 & 5.1827 & TRN \\
\hline CHEMBL1553324 & 688549 & 4.5 & 4.8463 & TRN \\
\hline CHEMBL1476790 & 688549 & 4.9 & 4.6398 & TRN \\
\hline CHEMBL1339724 & 688549 & 4.7 & 5.341 & TRN \\
\hline CHEMBL1440123 & 688549 & 4.9 & 4.908 & TRN \\
\hline CHEMBL1309450 & 688549 & 5.45 & 5.3355 & TST \\
\hline CHEMBL1318141 & 688549 & 4.9 & 5.1597 & TRN \\
\hline CHEMBL131199 & 688549 & 5.6 & 5.2271 & TST \\
\hline CHEMBL58033 & 688549 & 4.9 & 5.4629 & TST \\
\hline CHEMBL1371600 & 688549 & 5.0 & 4.9704 & TRN \\
\hline CHEMBL1317932 & 688549 & 5.3 & 5.0094 & TST \\
\hline CHEMBL1568787 & 688549 & 4.9 & 4.9834 & TRN \\
\hline CHEMBL509256 & 688549 & 6.1 & 5.1255 & TRN \\
\hline CHEMBL1339702 & 688549 & 5.0 & 4.8498 & TRN \\
\hline CHEMBL1464555 & 688549 & 5.3 & 5.271 & TRN \\
\hline CHEMBL1418410 & 688549 & 5.0 & 4.8268 & TRN \\
\hline CHEMBL1394513 & 688549 & 4.7 & 5.555 & TRN \\
\hline CHEMBL1316891 & 688549 & 4.7 & 4.598 & TRN \\
\hline CHEMBL1256697 & 688549 & 4.7 & 4.867 & TST \\
\hline CHEMBL1472083 & 688549 & 4.8 & 4.7822 & TRN \\
\hline
\end{tabular}




\begin{tabular}{|c|c|c|c|c|c|}
\hline \\
\hline CHEMBL282489 & 688549 & 4.8 & 5.1494 & TST & \\
\hline CHEMBL1433988 & 688549 & 4.5 & 4.854 & TST & \\
\hline CHEMBL1597728 & 688549 & 5.0 & 4.9933 & TRN & \\
\hline CHEMBL3199462 & 688549 & 5.0 & 5.4541 & TRN & \\
\hline CHEMBL1405215 & 688549 & 4.7 & 5.3416 & TRN & \\
\hline CHEMBL1610184 & 688549 & 4.5 & 4.5814 & TRN & \\
\hline CHEMBL1357293 & 688549 & 4.7 & 4.8713 & TRN & \\
\hline CHEMBL3213348 & 688549 & 7.6498 & 5.3247 & TRN & \\
\hline CHEMBL1461992 & 688549 & 4.6 & 4.8147 & TRN & \\
\hline CHEMBL1428456 & 688549 & 4.8 & 5.0846 & TRN & \\
\hline CHEMBL1531926 & 688549 & 4.7 & 5.1802 & TRN & \\
\hline CHEMBL1372857 & 688549 & 4.9 & 5.1865 & TRN & \\
\hline CHEMBL1222382 & 688549 & 4.5 & 5.03100 & 0000000001 & TRN \\
\hline CHEMBL1590777 & 688549 & 4.6 & 4.726 & TRN & \\
\hline CHEMBL1433630 & 688549 & 5.0 & 5.6167 & TRN & \\
\hline CHEMBL1443912 & 688549 & 5.1 & 5.0063 & TRN & \\
\hline CHEMBL1315148 & 688549 & 4.6 & 4.6382 & TRN & \\
\hline CHEMBL1607320 & 688549 & 4.7 & 4.8375 & TRN & \\
\hline CHEMBL1435463 & 688549 & 4.9 & 4.8186 & TRN & \\
\hline CHEMBL1513479 & 688549 & 4.6 & 5.0482 & TRN & \\
\hline CHEMBL1612125 & 688549 & 5.0 & 5.1023 & TRN & \\
\hline CHEMBL1475049 & 688549 & 6.1 & 5.2084 & TRN & \\
\hline CHEMBL2007403 & 688549 & 4.8 & 5.084 & TRN & \\
\hline CHEMBL555689 & 688549 & 5.7 & 4.9246 & TRN & \\
\hline CHEMBL1593141 & 688549 & 4.95 & 4.9449 & TRN & \\
\hline CHEMBL1606734 & 688549 & 6.1 & 5.3193 & TRN & \\
\hline CHEMBL1433548 & 688549 & 4.7 & 4.8544 & TRN & \\
\hline CHEMBL1452501 & 688549 & 5.0 & 5.9178 & TST & \\
\hline CHEMBL1406814 & 688549 & 4.9 & 5.5039 & TRN & \\
\hline CHEMBL1494495 & 688549 & 5.3 & 5.1971 & TRN & \\
\hline CHEMBL1356402 & 688549 & 5.7 & 5.7169 & TRN & \\
\hline CHEMBL1565909 & 688549 & 5.0 & 4.7492 & TRN & \\
\hline CHEMBL1422296 & 688549 & 5.4 & 5.475 & TST & \\
\hline CHEMBL1305427 & 688549 & 4.5 & 5.278 & TRN & \\
\hline CHEMBL1473755 & 688549 & 5.3 & 4.78 & TRN & \\
\hline CHEMBL3210742 & 688549 & 4.9 & 5.3434 & TST & \\
\hline CHEMBL1475180 & 688549 & 4.5 & 4.5506 & TRN & \\
\hline CHEMBL1465620 & 688549 & 4.7 & 5.007 & TRN & \\
\hline CHEMBL1543164 & 688549 & 4.6 & 4.9246 & TRN & \\
\hline CHEMBL1474557 & 688549 & 4.5 & 5.2905 & TRN & \\
\hline CHEMBL1405423 & 688549 & 5.2 & 5.3338 & TRN & \\
\hline CHEMBL1330965 & 688549 & 5.0 & 5.0179 & TRN & \\
\hline CHEMBL1593152 & 688549 & 7.699 & 5.2897 & TRN & \\
\hline CHEMBL1370571 & 688549 & 4.5 & 4.6589 & TRN & \\
\hline CHEMBL119171 & 688549 & 5.1 & 5.3509 & TRN & \\
\hline CHEMBL1329631 & 688549 & 4.9 & 5.1254 & TRN & \\
\hline CHEMBL1388271 & 688549 & 4.6 & 5.0147 & TRN & \\
\hline CHEMBL1550642 & 688549 & 4.6 & 4.7656 & TRN & \\
\hline
\end{tabular}




\begin{tabular}{|c|c|c|c|c|}
\hline \multicolumn{5}{|c|}{ Supplemental Table S2.txt } \\
\hline CHEMBL1523460 & 688549 & 4.9 & 4.8076 & TRN \\
\hline CHEMBL1390986 & 688549 & 4.8 & 5.0872 & TRN \\
\hline CHEMBL1370087 & 688549 & 5.6 & 5.7591 & TRN \\
\hline CHEMBL1351261 & 688549 & 5.85 & 5.2469 & TRN \\
\hline CHEMBL1611710 & 688549 & 4.7 & 4.9794 & TRN \\
\hline CHEMBL1339794 & 688549 & 6.5 & 4.3205 & TST \\
\hline CHEMBL1435351 & 688549 & 5.0 & 5.3044 & TST \\
\hline CHEMBL1482179 & 688549 & 4.7 & 5.2003 & TRN \\
\hline CHEMBL1526751 & 688549 & 4.5 & 4.5955 & TRN \\
\hline CHEMBL1507418 & 688549 & 5.6 & 4.9145 & TRN \\
\hline CHEMBL1574308 & 688549 & 4.9 & 4.7096 & TRN \\
\hline CHEMBL1557305 & 688549 & 4.6 & 4.7579 & TRN \\
\hline CHEMBL1368062 & 688549 & 4.9 & 5.3494 & TRN \\
\hline CHEMBL1427430 & 688549 & 4.5 & 4.8354 & TRN \\
\hline CHEMBL1606291 & 688549 & 5.9 & 5.4904 & TRN \\
\hline CHEMBL1607713 & 688549 & 5.0 & 4.9916 & TRN \\
\hline CHEMBL1519258 & 688549 & 4.8 & 5.2086 & TRN \\
\hline CHEMBL1546185 & 688549 & 4.9 & 4.9521 & TRN \\
\hline CHEMBL1342182 & 688549 & 4.8 & 5.2389 & TST \\
\hline CHEMBL1327046 & 688549 & 4.7 & 4.6219 & TRN \\
\hline CHEMBL1592650 & 688549 & 4.6 & 4.1844 & TRN \\
\hline CHEMBL1256737 & 688549 & 6.0 & 5.2171 & TST \\
\hline CHEMBL1480704 & 688549 & 4.9 & 5.0085 & TRN \\
\hline CHEMBL1472981 & 688549 & 4.5 & 5.2637 & TRN \\
\hline CHEMBL1336166 & 688549 & 4.9 & 4.7972 & TRN \\
\hline CHEMBL1468832 & 688549 & 8.301 & 5.3045 & TRN \\
\hline CHEMBL1490276 & 688549 & 4.6 & 5.1943 & TRN \\
\hline CHEMBL1475648 & 688549 & 7.4001 & 5.2824 & TRN \\
\hline CHEMBL1606608 & 688549 & 8.0 & 4.9412 & TRN \\
\hline CHEMBL1309497 & 688549 & 5.0 & 4.8737 & TRN \\
\hline CHEMBL1356135 & 688549 & 5.1 & 4.8695 & TRN \\
\hline CHEMBL1321310 & 688549 & 5.1 & 4.8118 & TRN \\
\hline CHEMBL1346348 & 688549 & 6.5 & 5.13299 & 9999999999 \\
\hline CHEMBL1474085 & 688549 & 4.5 & 4.6718 & TRN \\
\hline CHEMBL66654 & 688549 & 6.0 & 5.2729 & TST \\
\hline CHEMBL1363294 & 688549 & 4.5 & 4.6818 & TST \\
\hline CHEMBL3304020 & 688549 & 5.7 & 5.6813 & TST \\
\hline CHEMBL3196607 & 688549 & 4.45 & 5.3834 & TRN \\
\hline CHEMBL497781 & 688549 & 4.6 & 4.9966 & TRN \\
\hline CHEMBL1338787 & 688549 & 5.0 & 5.087 & TRN \\
\hline CHEMBL1482564 & 688549 & 4.75 & 4.9485 & TRN \\
\hline CHEMBL3208847 & 688549 & 5.7 & 5.5957 & TRN \\
\hline CHEMBL1554098 & 688549 & 6.0 & 5.518 & TST \\
\hline CHEMBL1611260 & 688549 & 4.7 & 5.3317 & TRN \\
\hline CHEMBL1354693 & 688549 & 4.7 & 4.4788 & TRN \\
\hline CHEMBL1464293 & 688549 & 5.0 & 4.8841 & TRN \\
\hline CHEMBL3197851 & 688549 & 4.9 & 5.0562 & TST \\
\hline CHEMBL1381882 & 688549 & 4.8 & 4.9605 & TRN \\
\hline
\end{tabular}




\begin{tabular}{|c|c|c|c|c|}
\hline \multicolumn{5}{|c|}{ Supplemental Table S2.txt } \\
\hline CHEMBL3198370 & 688549 & 4.8 & 4.8265 & TRN \\
\hline CHEMBL1355600 & 688549 & 4.9 & 5.0763 & TRN \\
\hline CHEMBL1500621 & 688549 & 6.5 & 5.0074 & TRN \\
\hline CHEMBL1486089 & 688549 & 5.4 & 5.1839 & TRN \\
\hline CHEMBL1446696 & 688549 & 4.8 & 4.7683 & TRN \\
\hline CHEMBL1525916 & 688549 & 4.6 & 4.5172 & TRN \\
\hline CHEMBL1376120 & 688549 & 5.0 & 4.669 & TRN \\
\hline CHEMBL1592342 & 688549 & 4.9 & 5.2458 & TRN \\
\hline CHEMBL1561350 & 688549 & 5.6 & 5.2171 & TRN \\
\hline CHEMBL104728 & 688549 & 5.15 & 5.0803 & TST \\
\hline CHEMBL1433827 & 688549 & 4.5 & 4.4855 & TRN \\
\hline CHEMBL1335489 & 688549 & 5.0 & 5.0372 & TRN \\
\hline CHEMBL1436942 & 688549 & 4.8 & 4.7589 & TRN \\
\hline CHEMBL1489425 & 688549 & 4.9 & 5.2573 & TST \\
\hline CHEMBL1356822 & 688549 & 7.6003 & 5.1804 & TRN \\
\hline CHEMBL1407116 & 688549 & 4.7 & 4.6841 & TRN \\
\hline CHEMBL1466793 & 688549 & 5.45 & 5.1224 & TRN \\
\hline CHEMBL1480128 & 688549 & 4.9 & 4.5338 & TRN \\
\hline CHEMBL1436415 & 688549 & 4.8 & 4.7141 & TRN \\
\hline CHEMBL1429038 & 688549 & 4.5 & 4.4766 & TRN \\
\hline CHEMBL1516105 & 688549 & 4.6 & 5.2033 & TRN \\
\hline CHEMBL1408808 & 688549 & 5.2 & 5.6571 & TST \\
\hline CHEMBL1491521 & 688549 & 8.0 & 5.3511 & TST \\
\hline CHEMBL1301766 & 688549 & 4.5 & 5.4565 & TST \\
\hline CHEMBL138297 & 688549 & 8.1024 & 5.6914 & TST \\
\hline CHEMBL1308582 & 688549 & 5.1 & 4.9766 & TRN \\
\hline CHEMBL1394226 & 688549 & 4.5 & 4.8252 & TRN \\
\hline CHEMBL1386871 & 688549 & 4.9 & 5.0065 & TRN \\
\hline CHEMBL1520243 & 688549 & 4.45 & 5.2307 & TRN \\
\hline CHEMBL1551748 & 688549 & 4.7 & 4.7646 & TRN \\
\hline CHEMBL1518592 & 688549 & 4.9 & 4.7525 & TRN \\
\hline CHEMBL1337661 & 688549 & 4.5 & 5.3668 & TRN \\
\hline CHEMBL1315812 & 688549 & 5.2 & 4.6827 & TRN \\
\hline CHEMBL1559914 & 688549 & 5.5 & 5.1732 & TRN \\
\hline CHEMBL1585268 & 688549 & 4.6 & 5.2079 & TST \\
\hline CHEMBL1489556 & 688549 & 6.5 & 5.2077 & TRN \\
\hline CHEMBL1523206 & 688549 & 4.7 & 4.5801 & TST \\
\hline CHEMBL1368640 & 688549 & 7.7496 & 5.3662 & TRN \\
\hline CHEMBL1524669 & 688549 & 4.9 & 5.0214 & TRN \\
\hline CHEMBL1591117 & 688549 & 4.7 & 4.883 & TRN \\
\hline CHEMBL1477014 & 688549 & 4.6 & 4.9692 & TRN \\
\hline CHEMBL1340371 & 688549 & 4.5 & 5.3602 & TRN \\
\hline CHEMBL1594652 & 688549 & 4.5 & 5.2218 & TRN \\
\hline CHEMBL1439893 & 688549 & 4.9 & 4.9937 & TRN \\
\hline CHEMBL1514681 & 688549 & 4.9 & 4.6434 & TRN \\
\hline CHEMBL1451402 & 688549 & 4.95 & 4.9374 & TRN \\
\hline CHEMBL 275516 & 688549 & 4.9 & 5.4757 & TST \\
\hline CHEMBL1518698 & 688549 & 4.5 & 4.6458 & TRN \\
\hline
\end{tabular}




\begin{tabular}{|c|c|c|c|c|c|}
\hline \multicolumn{6}{|c|}{ Supplemental Table S2.txt } \\
\hline CHEMBL1458833 & 688549 & 4.65 & 5.1685 & TST & \\
\hline CHEMBL1606127 & 688549 & 6.8 & 5.7437 & TRN & \\
\hline CHEMBL1471326 & 688549 & 5.0 & 5.1901 & TRN & \\
\hline CHEMBL1537435 & 688549 & 5.7 & 5.1186 & TRN & \\
\hline CHEMBL1607223 & 688549 & 4.9 & 4.949 & TRN & \\
\hline CHEMBL1503780 & 688549 & 5.5 & 5.1939 & TRN & \\
\hline CHEMBL1451103 & 688549 & 5.3 & 5.2549 & TRN & \\
\hline CHEMBL582715 & 688549 & 5.0 & 4.7448 & TRN & \\
\hline CHEMBL1549365 & 688549 & 7.8508 & 5.6891 & TRN & \\
\hline CHEMBL1378198 & 688549 & 4.45 & 4.6711 & TRN & \\
\hline CHEMBL1512119 & 688549 & 4.9 & 5.0749 & TRN & \\
\hline CHEMBL1347879 & 688549 & 4.9 & 5.13399 & 99999999995 & TRN \\
\hline CHEMBL355496 & 688549 & 4.9 & 5.1882 & TST & \\
\hline CHEMBL1512257 & 688549 & 4.7 & 4.7372 & TRN & \\
\hline CHEMBL1484176 & 688549 & 4.5 & 4.7109 & TST & \\
\hline CHEMBL1393189 & 688549 & 4.9 & 4.8635 & TST & \\
\hline CHEMBL1554292 & 688549 & 6.1 & 5.1812 & TRN & \\
\hline CHEMBL1517401 & 688549 & 4.7 & 5.6126 & TST & \\
\hline CHEMBL1528768 & 688549 & 4.5 & 4.6375 & TRN & \\
\hline CHEMBL1450703 & 688549 & 4.7 & 4.7088 & TRN & \\
\hline CHEMBL1401717 & 688549 & 5.0 & 5.0134 & TST & \\
\hline CHEMBL1358604 & 688549 & 4.6 & 4.6349 & TRN & \\
\hline CHEMBL1608756 & 688549 & 8.0 & 5.4213 & TRN & \\
\hline CHEMBL14276 & 688549 & 4.6 & 5.0337 & TRN & \\
\hline CHEMBL1413999 & 688549 & 4.9 & 4.8485 & TRN & \\
\hline CHEMBL1434258 & 688549 & 4.9 & 4.9592 & TRN & \\
\hline CHEMBL1473740 & 688549 & 4.6 & 5.0332 & TRN & \\
\hline CHEMBL1583096 & 688549 & 4.5 & 5.045 & TST & \\
\hline CHEMBL1318220 & 688549 & 4.7 & 5.5767 & TST & \\
\hline CHEMBL1504882 & 688549 & 4.5 & 5.2031 & TRN & \\
\hline CHEMBL1397888 & 688549 & 4.5 & 5.2225 & TST & \\
\hline CHEMBL1407052 & 688549 & 5.0 & 4.872 & TRN & \\
\hline CHEMBL1304213 & 688549 & 4.5 & 5.1169 & TRN & \\
\hline CHEMBL1611819 & 688549 & 4.6 & 4.7093 & TRN & \\
\hline CHEMBL1598419 & 688549 & 4.9 & 5.2215 & TRN & \\
\hline CHEMBL3198291 & 688549 & 5.1 & 4.9639 & TRN & \\
\hline CHEMBL1488667 & 688549 & 5.0 & 5.1059 & TRN & \\
\hline CHEMBL1555938 & 688549 & 4.5 & 4.5004 & TRN & \\
\hline CHEMBL1320081 & 688549 & 4.9 & 4.9737 & TRN & \\
\hline CHEMBL1591505 & 688549 & 5.0 & 4.9652 & TRN & \\
\hline CHEMBL1538363 & 688549 & 4.5 & 4.82600 & 00000000005 & TRN \\
\hline CHEMBL1373443 & 688549 & 4.9 & 4.8854 & TRN & \\
\hline CHEMBL1358478 & 688549 & 5.0 & 5.0049 & TST & \\
\hline CHEMBL 1447750 & 688549 & 4.9 & 4.7034 & TRN & \\
\hline CHEMBL1330463 & 688549 & 4.5 & 5.0551 & TRN & \\
\hline CHEMBL1451740 & 688549 & 4.5 & 5.0169 & TRN & \\
\hline CHEMBL261123 & 688549 & 5.3 & 5.2797 & TRN & \\
\hline CHEMBL1363915 & 688549 & 4.8 & 4.7085 & TRN & \\
\hline
\end{tabular}




\begin{tabular}{|c|c|c|c|c|c|}
\hline & & & & & \\
\hline CHEMBL1515130 & 688549 & 5.0 & 5.0926 & TRN & \\
\hline CHEMBL1447419 & 688549 & 5.2 & 4.9681 & TRN & \\
\hline CHEMBL1590010 & 688549 & 4.5 & 5.072 & TST & \\
\hline CHEMBL1463869 & 688549 & 4.9 & 4.9106 & TRN & \\
\hline CHEMBL1332602 & 688549 & 4.9 & 4.9674 & TRN & \\
\hline CHEMBL225513 & 688549 & 4.8 & 5.0938 & TRN & \\
\hline CHEMBL1552437 & 688549 & 4.95 & 5.2827 & TRN & \\
\hline CHEMBL1354327 & 688549 & 4.6 & 4.3497 & TRN & \\
\hline CHEMBL1608077 & 688549 & 4.8 & 4.9262 & TRN & \\
\hline CHEMBL1359337 & 688549 & 5.5 & 5.05699 & 99999999995 & TRN \\
\hline CHEMBL1570673 & 688549 & 4.5 & 4.7973 & TST & \\
\hline CHEMBL1470754 & 688549 & 4.9 & 5.1543 & TRN & \\
\hline CHEMBL1316928 & 688549 & 4.5 & 4.3259 & TRN & \\
\hline CHEMBL1362329 & 688549 & 4.7 & 4.6686 & TRN & \\
\hline CHEMBL1610601 & 688549 & 5.0 & 5.1397 & TRN & \\
\hline CHEMBL1515169 & 688549 & 4.8 & 5.307 & TRN & \\
\hline CHEMBL1457999 & 688549 & 4.95 & 5.5334 & TRN & \\
\hline CHEMBL1491064 & 688549 & 4.5 & 5.2234 & TST & \\
\hline CHEMBL375629 & 688549 & 4.5 & 4.9325 & TST & \\
\hline CHEMBL1563222 & 688549 & 4.9 & 5.2676 & TRN & \\
\hline CHEMBL1367899 & 688549 & 4.5 & 4.8808 & TRN & \\
\hline CHEMBL294018 & 688549 & 5.1 & 5.3974 & TST & \\
\hline CHEMBL1338958 & 688549 & 4.5 & 4.6598 & TST & \\
\hline CHEMBL1599964 & 688549 & 4.5 & 5.2937 & TST & \\
\hline CHEMBL1500193 & 688549 & 4.9 & 4.7059 & TRN & \\
\hline CHEMBL492010 & 688549 & 5.0 & 4.9678 & TRN & \\
\hline CHEMBL1330157 & 688549 & 5.0 & 4.5747 & TRN & \\
\hline CHEMBL1396032 & 688549 & 5.0 & 4.9334 & TRN & \\
\hline CHEMBL1504324 & 688549 & 5.0 & 4.7139 & 99999999995 & TST \\
\hline CHEMBL1315725 & 688549 & 5.5 & 5.5162 & TST & \\
\hline CHEMBL1320019 & 688549 & 4.45 & 4.9482 & TRN & \\
\hline CHEMBL1468103 & 688549 & 4.8 & 5.1719 & TRN & \\
\hline CHEMBL1975191 & 688549 & 6.6 & 5.4679 & TRN & \\
\hline CHEMBL1589567 & 688549 & 4.7 & 4.9437 & TRN & \\
\hline CHEMBL1376804 & 688549 & 5.4 & 5.0049 & TRN & \\
\hline CHEMBL3145107 & 688549 & 5.0 & 4.9178 & TRN & \\
\hline CHEMBL 1437275 & 688549 & 4.9 & 4.9009 & TRN & \\
\hline CHEMBL1613610 & 688549 & 4.5 & 4.8298 & TRN & \\
\hline CHEMBL1349964 & 688549 & 4.9 & 5.0045 & TST & \\
\hline CHEMBL1542674 & 688549 & 4.9 & 4.8077 & TST & \\
\hline CHEMBL1424036 & 688549 & 4.8 & 4.8837 & TRN & \\
\hline CHEMBL1466749 & 688549 & 4.9 & 4.6831 & TRN & \\
\hline CHEMBL1339706 & 688549 & 4.7 & 5.0414 & TRN & \\
\hline CHEMBL1593939 & 688549 & 4.9 & 4.8223 & TRN & \\
\hline CHEMBL1403351 & 688549 & 4.6 & 4.9771 & TRN & \\
\hline CHEMBL1363210 & 688549 & 4.9 & 5.0566 & TRN & \\
\hline CHEMBL1331895 & 688549 & 5.4 & 5.222 & TRN & \\
\hline CHEMBL1408789 & 688549 & 4.9 & 4.7588 & TRN & \\
\hline & & & & 23115 & \\
\hline
\end{tabular}




\begin{tabular}{|c|c|c|c|c|}
\hline & & & ient & al Ta \\
\hline CHEMBL1549880 & 688549 & 4.9 & 4.8888 & TST \\
\hline CHEMBL1611939 & 688549 & 4.9 & 4.8366 & TRN \\
\hline CHEMBL1585034 & 688549 & 5.0 & 4.7655 & TRN \\
\hline CHEMBL1373012 & 688549 & 4.8 & 4.7832 & TRN \\
\hline CHEMBL1561854 & 688549 & 4.5 & 5.0965 & TRN \\
\hline CHEMBL1314161 & 688549 & 5.0 & 4.808 & TRN \\
\hline CHEMBL1356550 & 688549 & 4.6 & 5.4971 & TST \\
\hline CHEMBL1347831 & 688549 & 5.8 & 4.9927 & TRN \\
\hline CHEMBL1364432 & 688549 & 4.8 & 4.7472 & TRN \\
\hline CHEMBL1591810 & 688549 & 4.6 & 4.6002 & TRN \\
\hline CHEMBL1413055 & 688549 & 4.9 & 4.9199 & TRN \\
\hline CHEMBL1356761 & 688549 & 4.5 & 4.6544 & TRN \\
\hline CHEMBL1535354 & 688549 & 4.6 & 4.8277 & TRN \\
\hline CHEMBL1358743 & 688549 & 5.8 & 5.5112 & TST \\
\hline CHEMBL1405585 & 688549 & 4.7 & 4.831 & TRN \\
\hline CHEMBL1467490 & 688549 & 4.6 & 4.9258 & TRN \\
\hline CHEMBL1321398 & 688549 & 4.6 & 5.0256 & TST \\
\hline CHEMBL1397648 & 688549 & 4.9 & 4.4367 & TRN \\
\hline CHEMBL1312486 & 688549 & 4.8 & 4.8785 & TRN \\
\hline CHEMBL1523200 & 688549 & 4.7 & 4.8406 & TRN \\
\hline CHEMBL1496715 & 688549 & 8.0 & 5.0096 & TST \\
\hline CHEMBL1316352 & 688549 & 4.7 & 5.388 & TRN \\
\hline CHEMBL1561928 & 688549 & 5.0 & 4.9691 & TRN \\
\hline CHEMBL1432550 & 688549 & 4.7 & 4.6647 & TRN \\
\hline CHEMBL1590202 & 688549 & 4.8 & 4.7825 & TRN \\
\hline CHEMBL1441600 & 688549 & 4.5 & 5.0235 & TRN \\
\hline CHEMBL1325637 & 688549 & 4.9 & 5.0013 & TST \\
\hline CHEMBL1329024 & 688549 & 5.5 & 5.4882 & TRN \\
\hline CHEMBL1512694 & 688549 & 4.9 & 4.8949 & TRN \\
\hline CHEMBL1513654 & 688549 & 4.9 & 5.1385 & TST \\
\hline CHEMBL1515852 & 688549 & 6.0 & 5.278 & TRN \\
\hline CHEMBL1427972 & 688549 & 5.6 & 5.4016 & TRN \\
\hline CHEMBL1397627 & 688549 & 4.9 & 4.8883 & TRN \\
\hline CHEMBL1396547 & 688549 & 4.8 & 4.8213 & TST \\
\hline CHEMBL1522191 & 688549 & 4.9 & 4.7758 & TRN \\
\hline CHEMBL1595869 & 688549 & 4.5 & 4.9579 & TRN \\
\hline CHEMBL1414379 & 688549 & 5.2 & 5.0665 & TRN \\
\hline CHEMBL1453743 & 688549 & 4.5 & 4.4885 & TRN \\
\hline CHEMBL1413556 & 688549 & 6.0 & 5.3959 & TRN \\
\hline CHEMBL1329927 & 688549 & 4.7 & 5.059 & TST \\
\hline CHEMBL1474024 & 688549 & 5.3 & 5.2638 & TRN \\
\hline CHEMBL1549411 & 688549 & 5.0 & 5.0616 & TRN \\
\hline CHEMBL1483489 & 688549 & 4.5 & 5.047 & TRN \\
\hline CHEMBL1569751 & 688549 & 4.9 & 4.945 & TRN \\
\hline CHEMBL1386623 & 688549 & 4.7 & 4.8236 & TRN \\
\hline CHEMBL3192709 & 688549 & 5.45 & 5.2967 & TRN \\
\hline CHEMBL1373521 & 688549 & 5.0 & 4.7798 & TRN \\
\hline CHEMBL1370387 & 688549 & 4.5 & 4.5454 & TRN \\
\hline
\end{tabular}




\begin{tabular}{|c|c|c|c|c|c|}
\hline \\
\hline CHEMBL1307970 & 688549 & 4.7 & 5.2464 & TST & \\
\hline CHEMBL3192857 & 688549 & 4.5 & 4.9182 & TST & \\
\hline CHEMBL1595221 & 688549 & 4.8 & 5.103 & TST & \\
\hline CHEMBL1365677 & 688549 & 4.9 & 4.8135 & TRN & \\
\hline CHEMBL1510416 & 688549 & 4.9 & 5.0569 & TRN & \\
\hline CHEMBL1976304 & 688549 & 4.75 & 4.6454 & TST & \\
\hline CHEMBL1550809 & 688549 & 4.9 & 5.0335 & TRN & \\
\hline CHEMBL1518609 & 688549 & 4.5 & 5.3016 & TRN & \\
\hline CHEMBL1540848 & 688549 & 4.9 & 4.7599 & TRN & \\
\hline CHEMBL3189329 & 688549 & 4.7 & 5.2922 & TST & \\
\hline CHEMBL1532162 & 688549 & 5.4 & 5.0996 & TRN & \\
\hline CHEMBL1444446 & 688549 & 5.0 & 5.188 & TRN & \\
\hline CHEMBL1310000 & 688549 & 5.0 & 4.9741 & TRN & \\
\hline CHEMBL1564231 & 688549 & 4.9 & 4.5548 & TRN & \\
\hline CHEMBL140 & 688549 & 4.4 & 5.3098 & TRN & \\
\hline CHEMBL1482864 & 688549 & 4.5 & 5.1423 & TRN & \\
\hline CHEMBL1521574 & 688549 & 5.3 & 4.9926 & TRN & \\
\hline CHEMBL1354859 & 688549 & 4.45 & 4.865 & TRN & \\
\hline CHEMBL1337040 & 688549 & 5.0 & 5.193 & TST & \\
\hline CHEMBL1494622 & 688549 & 4.8 & 5.2964 & TST & \\
\hline CHEMBL1410152 & 688549 & 5.1 & 5.1859 & TRN & \\
\hline CHEMBL1590790 & 688549 & 5.5 & 5.0102 & TRN & \\
\hline CHEMBL1435894 & 688549 & 4.45 & 4.7303 & TRN & \\
\hline CHEMBL1594929 & 688549 & 4.5 & 5.007 & TRN & \\
\hline CHEMBL1519230 & 688549 & 8.301 & 5.7838 & TRN & \\
\hline CHEMBL1389366 & 688549 & 5.35 & 5.49 & TRN & \\
\hline CHEMBL1311501 & 688549 & 4.9 & 5.0159 & TRN & \\
\hline CHEMBL1395781 & 688549 & 4.8 & 4.828 & TRN & \\
\hline CHEMBL1366926 & 688549 & 4.9 & 4.8861 & TRN & \\
\hline CHEMBL1332967 & 688549 & 4.9 & 4.9784 & TRN & \\
\hline CHEMBL1553845 & 688549 & 4.6 & 5.3229 & TRN & \\
\hline CHEMBL1523780 & 688549 & 4.8 & 4.8204 & TRN & \\
\hline CHEMBL1511217 & 688549 & 5.1 & 5.3509 & TRN & \\
\hline CHEMBL3216928 & 688549 & 4.7 & 5.0957 & TST & \\
\hline CHEMBL1395207 & 688549 & 4.8 & 4.8046 & TRN & \\
\hline CHEMBL1357026 & 688549 & 4.5 & 5.24200 & 0000000001 & TRN \\
\hline CHEMBL1424069 & 688549 & 4.7 & 4.9846 & TRN & \\
\hline CHEMBL1334574 & 688549 & 5.1 & 4.8307 & TST & \\
\hline CHEMBL1347975 & 688549 & 4.7 & 4.7399 & TRN & \\
\hline CHEMBL1552395 & 688549 & 4.5 & 4.5029 & TRN & \\
\hline CHEMBL1411897 & 688549 & 4.5 & 4.9159 & TST & \\
\hline CHEMBL1569133 & 688549 & 5.5 & 5.0461 & TRN & \\
\hline CHEMBL1445596 & 688549 & 5.0 & 4.9095 & TRN & \\
\hline CHEMBL1568343 & 688549 & 5.1 & 5.1893 & TRN & \\
\hline CHEMBL1511969 & 688549 & 5.4 & 5.0493 & TRN & \\
\hline CHEMBL 1605555 & 688549 & 4.9 & 5.3576 & TRN & \\
\hline CHEMBL1367325 & 688549 & 6.3 & 5.495 & TRN & \\
\hline CHEMBL1471728 & 688549 & 4.8 & 5.0072 & TRN & \\
\hline
\end{tabular}




\begin{tabular}{|c|c|c|c|c|c|}
\hline \multicolumn{6}{|c|}{ Supplemental Table S2.txt } \\
\hline CHEMBL597251 & 688549 & 4.6 & 4.5519 & TST & \\
\hline CHEMBL1440544 & 688549 & 4.9 & 4.907 & TST & \\
\hline CHEMBL1592493 & 688549 & 6.0 & 5.20700 & 0000000001 & TRN \\
\hline CHEMBL1520707 & 688549 & 4.5 & 5.2344 & TRN & \\
\hline CHEMBL1967837 & 688549 & 4.5 & 5.1578 & TRN & \\
\hline CHEMBL1330642 & 688549 & 4.9 & 5.4672 & TRN & \\
\hline CHEMBL1554400 & 688549 & 5.8 & 5.1777 & TRN & \\
\hline CHEMBL1493396 & 688549 & 4.9 & 5.0565 & TST & \\
\hline CHEMBL1524752 & 688549 & 4.9 & 5.2334 & TRN & \\
\hline CHEMBL1326785 & 688549 & 4.8 & 4.8891 & TRN & \\
\hline CHEMBL1464497 & 688549 & 4.6 & 4.9721 & TRN & \\
\hline CHEMBL1338853 & 688549 & 4.5 & 5.2737 & TRN & \\
\hline CHEMBL1402941 & 688549 & 5.0 & 4.7296 & TRN & \\
\hline CHEMBL1523446 & 688549 & 5.0 & 5.0335 & TST & \\
\hline CHEMBL1397179 & 688549 & 4.9 & 4.8852 & TRN & \\
\hline CHEMBL1478321 & 688549 & 4.5 & 4.5697 & TRN & \\
\hline CHEMBL1354513 & 688549 & 5.25 & 4.8855 & TRN & \\
\hline CHEMBL352865 & 688549 & 6.0 & 4.9221 & TRN & \\
\hline CHEMBL1494324 & 688549 & 4.9 & 5.0894 & TRN & \\
\hline CHEMBL1315180 & 688549 & 4.8 & 4.8293 & TRN & \\
\hline CHEMBL1578061 & 688549 & 4.45 & 4.9529 & TST & \\
\hline CHEMBL1371455 & 688549 & 5.0 & 4.8485 & TRN & \\
\hline CHEMBL1605879 & 688549 & 4.9 & 4.9544 & TRN & \\
\hline CHEMBL388757 & 688549 & 5.2 & 5.1437 & TRN & \\
\hline CHEMBL1505658 & 688549 & 5.0 & 4.7729 & TRN & \\
\hline CHEMBL1474777 & 688549 & 4.85 & 4.79899 & 99999999995 & TRN \\
\hline CHEMBL1466087 & 688549 & 4.9 & 5.1703 & TRN & \\
\hline CHEMBL354676 & 688549 & 5.0 & 5.1508 & TRN & \\
\hline CHEMBL1476242 & 688549 & 4.9 & 5.0187 & TRN & \\
\hline CHEMBL1355733 & 688549 & 5.25 & 5.2193 & TRN & \\
\hline CHEMBL1557640 & 688549 & 4.6 & 4.8724 & TST & \\
\hline CHEMBL1515830 & 688549 & 4.9 & 4.5622 & TRN & \\
\hline CHEMBL1383658 & 688549 & 4.6 & 5.0823 & TRN & \\
\hline CHEMBL1394495 & 688549 & 4.5 & 5.0292 & TRN & \\
\hline CHEMBL1424065 & 688549 & 6.0 & 5.4216 & TRN & \\
\hline CHEMBL1357307 & 688549 & 5.7 & 5.3801 & TRN & \\
\hline CHEMBL1347369 & 688549 & 4.8 & 4.7916 & TRN & \\
\hline CHEMBL1527817 & 688549 & 4.5 & 4.8071 & TST & \\
\hline CHEMBL1501547 & 688549 & 5.0 & 4.6099 & TRN & \\
\hline CHEMBL1364051 & 688549 & 4.6 & 4.9398 & TRN & \\
\hline CHEMBL1363938 & 688549 & 4.9 & 4.79899 & 99999999995 & TRN \\
\hline CHEMBL1324462 & 688549 & 4.5 & 4.8577 & TRN & \\
\hline CHEMBL1330699 & 688549 & 5.5 & 4.9403 & TRN & \\
\hline CHEMBL1594867 & 688549 & 5.0 & 5.308 & TRN & \\
\hline CHEMBL1467184 & 688549 & 4.9 & 4.9816 & TRN & \\
\hline CHEMBL1551997 & 688549 & 5.25 & 4.7907 & TRN & \\
\hline CHEMBL1374450 & 688549 & 4.5 & 5.4933 & TRN & \\
\hline CHEMBL1488393 & 688549 & 6.5 & 5.2611 & TRN & \\
\hline
\end{tabular}




\begin{tabular}{|c|c|c|c|c|c|}
\hline CHEMBL1541257 & 688549 & 4.9 & \multicolumn{2}{|c|}{ 4.7010000000000005 } & \multirow[t]{2}{*}{ TST } \\
\hline CHEMBL1532790 & 688549 & 4.9 & 4.9215 & TRN & \\
\hline CHEMBL1449954 & 688549 & 4.9 & 4.7213 & TRN & \\
\hline CHEMBL1397197 & 688549 & 5.0 & 4.7743 & TRN & \\
\hline CHEMBL1444358 & 688549 & 4.8 & 4.8493 & TRN & \\
\hline CHEMBL1407986 & 688549 & 4.5 & 4.8625 & TRN & \\
\hline CHEMBL1519059 & 688549 & 5.0 & 5.2605 & TRN & \\
\hline CHEMBL1398504 & 688549 & 4.9 & 4.5233 & TRN & \\
\hline CHEMBL1495493 & 688549 & 4.9 & 5.043 & TRN & \\
\hline CHEMBL1213834 & 688549 & 5.6 & 5.1465 & TRN & \\
\hline CHEMBL1509691 & 688549 & 4.9 & 4.7718 & TRN & \\
\hline CHEMBL1352987 & 688549 & 4.9 & 5.0205 & TRN & \\
\hline CHEMBL1436403 & 688549 & 5.0 & 5.0808 & TRN & \\
\hline CHEMBL1335426 & 688549 & 8.1024 & 5.9449 & TRN & \\
\hline CHEMBL1320593 & 688549 & 4.8 & 5.2257 & TRN & \\
\hline CHEMBL1514555 & 688549 & 4.9 & 5.0368 & TRN & \\
\hline CHEMBL1526982 & 688549 & 4.8 & 5.0003 & TRN & \\
\hline CHEMBL1341815 & 688549 & 4.6 & 4.8168 & TST & \\
\hline CHEMBL 3197622 & 688549 & 5.0 & 5.0725 & TRN & \\
\hline CHEMBL1555356 & 688549 & 5.4 & 5.0454 & TRN & \\
\hline CHEMBL1572372 & 688549 & 4.9 & 4.8855 & TRN & \\
\hline CHEMBL137648 & 688549 & 4.6 & 5.0779 & TST & \\
\hline CHEMBL1384594 & 688549 & 4.9 & 4.739 & TRN & \\
\hline CHEMBL1524331 & 688549 & 5.5 & 5.1237 & TST & \\
\hline CHEMBL1488625 & 688549 & 4.9 & 4.7951 & TST & \\
\hline CHEMBL1425614 & 688549 & 4.8 & 5.0447 & TRN & \\
\hline CHEMBL405914 & 688549 & 6.3 & 5.3868 & TRN & \\
\hline CHEMBL1327935 & 688549 & 5.15 & 5.1954 & TRN & \\
\hline CHEMBL1305429 & 688549 & 4.9 & 4.8209 & TRN & \\
\hline CHEMBL1451302 & 688549 & 5.3 & 5.3039 & TST & \\
\hline CHEMBL1736254 & 688549 & 5.4 & 5.4225 & TST & \\
\hline CHEMBL514612 & 688549 & 5.0 & 5.0679 & TRN & \\
\hline CHEMBL1374258 & 688549 & 5.5 & 4.9752 & TRN & \\
\hline CHEMBL1516370 & 688549 & 4.7 & 5.0381 & TRN & \\
\hline CHEMBL1516887 & 688549 & 4.9 & 5.0516 & TRN & \\
\hline CHEMBL1448242 & 688549 & 4.45 & 4.9028 & TRN & \\
\hline CHEMBL1496228 & 688549 & 5.0 & 5.0058 & TRN & \\
\hline CHEMBL1712082 & 688549 & 5.6 & 5.7986 & TST & \\
\hline CHEMBL1530272 & 688549 & 4.7 & 4.96399 & 99999999995 & TRN \\
\hline CHEMBL1429722 & 688549 & 5.1 & 4.9442 & TRN & \\
\hline CHEMBL1533107 & 688549 & 5.0 & 5.0402 & TRN & \\
\hline CHEMBL1435700 & 688549 & 5.0 & 5.0781 & TRN & \\
\hline CHEMBL1407552 & 688549 & 5.0 & 5.4055 & TRN & \\
\hline CHEMBL1611559 & 688549 & 4.5 & 4.7244 & TRN & \\
\hline CHEMBL1556254 & 688549 & 4.95 & 5.1148 & TRN & \\
\hline CHEMBL1302380 & 688549 & 5.5 & 5.3544 & TRN & \\
\hline CHEMBL1512253 & 688549 & 4.8 & 4.9505 & TRN & \\
\hline CHEMBL1584460 & 688549 & 4.9 & 5.0084 & TRN & \\
\hline & & & & 23119 & \\
\hline
\end{tabular}




\begin{tabular}{|c|c|c|c|c|c|}
\hline \multicolumn{6}{|c|}{ Supplemental Table S2.txt } \\
\hline CHEMBL1408951 & 688549 & 4.45 & 4.654 & TRN & \\
\hline CHEMBL1357497 & 688549 & 4.9 & 4.9559 & TST & \\
\hline CHEMBL3138730 & 688549 & 6.2 & 5.8336 & TST & \\
\hline CHEMBL1442939 & 688549 & 4.5 & 4.4053 & TRN & \\
\hline CHEMBL1447829 & 688549 & 4.5 & 4.7724 & TRN & \\
\hline CHEMBL1477249 & 688549 & 4.7 & 5.1376 & TRN & \\
\hline CHEMBL1601695 & 688549 & 4.9 & 4.4834 & TRN & \\
\hline CHEMBL1356773 & 688549 & 4.5 & 4.4723 & TRN & \\
\hline CHEMBL1524482 & 688549 & 4.7 & 5.3339 & TRN & \\
\hline CHEMBL1491542 & 688549 & 5.0 & 4.9338 & TRN & \\
\hline CHEMBL1594643 & 688549 & 7.5003 & 5.6207 & TRN & \\
\hline CHEMBL1346883 & 688549 & 4.45 & 4.9114 & TRN & \\
\hline CHEMBL1399459 & 688549 & 4.85 & 4.6357 & TRN & \\
\hline CHEMBL1559360 & 688549 & 5.4 & 5.0046 & TRN & \\
\hline CHEMBL1526223 & 688549 & 4.7 & 5.0537 & TST & \\
\hline CHEMBL1565686 & 688549 & 5.0 & 5.2316 & TRN & \\
\hline CHEMBL1589812 & 688549 & 5.6 & 5.1685 & TRN & \\
\hline CHEMBL1457610 & 688549 & 6.4 & 5.2296 & TST & \\
\hline CHEMBL1393698 & 688549 & 4.7 & 4.78100 & 2000000001 & TRN \\
\hline CHEMBL1348248 & 688549 & 7.4001 & 5.6003 & TRN & \\
\hline CHEMBL1551012 & 688549 & 4.7 & 4.8922 & TRN & \\
\hline CHEMBL1606367 & 688549 & 4.45 & 5.2232 & TRN & \\
\hline CHEMBL1320977 & 688549 & 4.9 & 5.2623 & TRN & \\
\hline CHEMBL1481756 & 688549 & 7.4001 & 5.0072 & TST & \\
\hline CHEMBL1389724 & 688549 & 5.0 & 5.0542 & TRN & \\
\hline CHEMBL1514784 & 688549 & 7.4001 & 5.2239 & TRN & \\
\hline CHEMBL1521694 & 688549 & 5.5 & 5.0705 & TRN & \\
\hline CHEMBL1374179 & 688549 & 4.6 & 5.0397 & TRN & \\
\hline CHEMBL1380056 & 688549 & 5.0 & 4.9852 & TRN & \\
\hline CHEMBL1394568 & 688549 & 4.7 & 4.8419 & TRN & \\
\hline CHEMBL1428148 & 688549 & 4.5 & 4.6662 & TRN & \\
\hline CHEMBL1401945 & 688549 & 4.9 & 4.7325 & TRN & \\
\hline CHEMBL1368609 & 688549 & 4.65 & 4.373 & TST & \\
\hline CHEMBL1442619 & 688549 & 4.9 & 4.5611 & TRN & \\
\hline CHEMBL1409504 & 688549 & 4.9 & 4.7152 & TRN & \\
\hline CHEMBL1358182 & 688549 & 4.8 & 4.5927 & TRN & \\
\hline CHEMBL1438100 & 688549 & 5.0 & 5.1234 & TRN & \\
\hline CHEMBL1351638 & 688549 & 4.8 & 4.8238 & TRN & \\
\hline CHEMBL1323093 & 688549 & 4.8 & 4.6424 & TRN & \\
\hline CHEMBL1547049 & 688549 & 4.8 & 4.8234 & TRN & \\
\hline CHEMBL1594100 & 688549 & 4.95 & 4.9132 & TRN & \\
\hline CHEMBL1356664 & 688549 & 5.45 & 5.0375 & TRN & \\
\hline CHEMBL1590804 & 688549 & 5.0 & 4.9225 & TRN & \\
\hline CHEMBL1355882 & 688549 & 4.85 & 4.88899 & 9999999999 & TRN \\
\hline CHEMBL1437484 & 688549 & 5.0 & 4.95100 & 00000000005 & TRN \\
\hline CHEMBL1547533 & 688549 & 4.8 & 5.4535 & TRN & \\
\hline CHEMBL600103 & 688549 & 4.9 & 5.3261 & TRN & \\
\hline CHEMBL1502184 & 688549 & 5.1 & 4.7416 & TRN & \\
\hline
\end{tabular}




\begin{tabular}{|c|c|c|c|c|c|}
\hline & & & & & \\
\hline CHEMBL1335707 & 688549 & 4.8 & 5.0808 & TRN & \\
\hline CHEMBL3208765 & 688549 & 4.6 & 5.0917 & TRN & \\
\hline CHEMBL1519261 & 688549 & 4.8 & 4.6559 & TRN & \\
\hline CHEMBL1515952 & 688549 & 5.9 & 5.2255 & TRN & \\
\hline CHEMBL1327069 & 688549 & 7.5498 & 5.3349 & TST & \\
\hline CHEMBL1539118 & 688549 & 4.5 & 4.8343 & TRN & \\
\hline CHEMBL1299689 & 688549 & 5.4 & 5.7545 & TST & \\
\hline CHEMBL1472148 & 688549 & 5.6 & 5.00899 & 99999999995 & TST \\
\hline CHEMBL1429637 & 688549 & 5.0 & 5.2819 & TRN & \\
\hline CHEMBL1416470 & 688549 & 4.9 & 4.5993 & TRN & \\
\hline CHEMBL1468774 & 688549 & 4.7 & 5.0976 & TRN & \\
\hline CHEMBL1473481 & 688549 & 4.9 & 4.47199 & 99999999995 & TRN \\
\hline CHEMBL1439391 & 688549 & 5.0 & 4.9556 & TRN & \\
\hline CHEMBL3199915 & 688549 & 5.0 & 5.2486 & TST & \\
\hline CHEMBL1374617 & 688549 & 4.6 & 5.2843 & TRN & \\
\hline CHEMBL1507474 & 688549 & 5.0 & 4.8619 & TRN & \\
\hline CHEMBL1514888 & 688549 & 4.8 & 4.756 & TRN & \\
\hline CHEMBL1611737 & 688549 & 6.0 & 5.8697 & TRN & \\
\hline CHEMBL1417970 & 688549 & 4.5 & 4.4819 & TRN & \\
\hline CHEMBL1593678 & 688549 & 4.6 & 4.6559 & TRN & \\
\hline CHEMBL1339310 & 688549 & 4.75 & 4.6015 & TRN & \\
\hline CHEMBL1361147 & 688549 & 4.9 & 5.2633 & TRN & \\
\hline CHEMBL1536265 & 688549 & 8.1024 & 5.3462 & TRN & \\
\hline CHEMBL1558155 & 688549 & 4.8 & 4.8893 & TST & \\
\hline CHEMBL3199301 & 688549 & 4.8 & 4.7156 & TRN & \\
\hline CHEMBL1362964 & 688549 & 4.9 & 5.2617 & TRN & \\
\hline CHEMBL1403041 & 688549 & 5.0 & 5.0841 & TRN & \\
\hline CHEMBL1472468 & 688549 & 4.9 & 4.9227 & TRN & \\
\hline CHEMBL1522769 & 688549 & 4.9 & 5.4353 & TRN & \\
\hline CHEMBL1353544 & 688549 & 5.05 & 4.9454 & TST & \\
\hline CHEMBL1402510 & 688549 & 5.2 & 5.7442 & TRN & \\
\hline CHEMBL1613308 & 688549 & 4.9 & 5.043 & TRN & \\
\hline CHEMBL1608194 & 688549 & 5.8 & 5.0958 & TRN & \\
\hline CHEMBL18879 & 688549 & 4.6 & 5.2373 & TST & \\
\hline CHEMBL1346587 & 688549 & 4.5 & 4.8003 & TRN & \\
\hline CHEMBL16685 & 688549 & 5.0 & 5.2982 & TRN & \\
\hline CHEMBL1596442 & 688549 & 4.5 & 4.9437 & TRN & \\
\hline CHEMBL1475099 & 688549 & 4.7 & 5.0392 & TST & \\
\hline CHEMBL1320434 & 688549 & 4.8 & 5.0909 & TST & \\
\hline CHEMBL1583496 & 688549 & 4.9 & 4.9099 & TRN & \\
\hline CHEMBL1446100 & 688549 & 8.1024 & 5.479 & TRN & \\
\hline CHEMBL1416355 & 688549 & 5.6 & 5.0262 & TRN & \\
\hline CHEMBL1563581 & 688549 & 5.9 & 4.9743 & TRN & \\
\hline CHEMBL1568767 & 688549 & 4.6 & 4.6157 & TRN & \\
\hline CHEMBL1437451 & 688549 & 4.8 & 4.9061 & TRN & \\
\hline CHEMBL1373803 & 688549 & 5.85 & 5.2033 & TRN & \\
\hline CHEMBL1551846 & 688549 & 4.8 & 5.2107 & TRN & \\
\hline CHEMBL1311755 & 688549 & 4.5 & 4.456 & TRN & \\
\hline & & & & 23121 & \\
\hline
\end{tabular}




\begin{tabular}{|c|c|c|c|c|c|}
\hline \multicolumn{6}{|c|}{ Supplemental Table S2.txt } \\
\hline CHEMBL1421605 & 688549 & 4.7 & 4.7554 & TRN & \\
\hline CHEMBL1477803 & 688549 & 4.6 & 4.4662 & TRN & \\
\hline CHEMBL1407754 & 688549 & 4.8 & 4.6331 & TRN & \\
\hline CHEMBL1317352 & 688549 & 4.6 & 4.4613 & TRN & \\
\hline CHEMBL1382030 & 688549 & 4.9 & 5.1474 & TRN & \\
\hline CHEMBL98350 & 688549 & 5.0 & 5.1533 & TST & \\
\hline CHEMBL1521937 & 688549 & 4.9 & 4.9369 & TRN & \\
\hline CHEMBL1578302 & 688549 & 5.0 & 4.8894 & TRN & \\
\hline CHEMBL1434727 & 688549 & 4.5 & 4.7515 & TRN & \\
\hline CHEMBL1413739 & 688549 & 8.301 & 5.2294 & TRN & \\
\hline CHEMBL1355966 & 688549 & 4.9 & 4.9993 & TRN & \\
\hline CHEMBL1435458 & 688549 & 4.8 & 4.6637 & TRN & \\
\hline CHEMBL1410173 & 688549 & 4.9 & 4.8314 & TRN & \\
\hline CHEMBL1471950 & 688549 & 6.3 & 5.4829 & TST & \\
\hline CHEMBL1593151 & 688549 & 4.9 & 4.8875 & TRN & \\
\hline CHEMBL465339 & 688549 & 4.7 & 5.4577 & TRN & \\
\hline CHEMBL1595800 & 688549 & 4.8 & 5.085 & TRN & \\
\hline CHEMBL1493226 & 688549 & 4.9 & 4.9752 & TST & \\
\hline CHEMBL1403125 & 688549 & 4.8 & 4.9061 & TRN & \\
\hline CHEMBL1554855 & 688549 & 4.9 & 4.5363 & TRN & \\
\hline CHEMBL1399887 & 688549 & 5.3 & 4.88399 & 99999999995 & TRN \\
\hline CHEMBL483137 & 688549 & 5.0 & 5.0529 & TRN & \\
\hline CHEMBL86931 & 688549 & 4.5 & 5.1783 & TST & \\
\hline CHEMBL1491767 & 688549 & 4.9 & 4.775 & TRN & \\
\hline CHEMBL1606292 & 688549 & 4.8 & 4.7258 & TST & \\
\hline CHEMBL602575 & 688549 & 6.7001 & 5.8772 & TST & \\
\hline CHEMBL1300881 & 688549 & 4.7 & 4.4514 & TRN & \\
\hline CHEMBL1410233 & 688549 & 4.9 & 4.9444 & TRN & \\
\hline CHEMBL1394861 & 688549 & 4.8 & 5.0629 & TRN & \\
\hline CHEMBL1325661 & 688549 & 4.45 & 4.5614 & TRN & \\
\hline CHEMBL1558761 & 688549 & 4.8 & 5.0625 & TRN & \\
\hline CHEMBL1326206 & 688549 & 4.5 & 4.8547 & TRN & \\
\hline CHEMBL1518190 & 688549 & 4.8 & 5.3759 & TST & \\
\hline CHEMBL1600947 & 688549 & 5.5 & 5.0435 & TRN & \\
\hline CHEMBL1590492 & 688549 & 4.9 & 5.3437 & TRN & \\
\hline CHEMBL1570213 & 688549 & 5.0 & 5.1525 & TRN & \\
\hline CHEMBL1418216 & 688549 & 4.9 & 4.7392 & TRN & \\
\hline CHEMBL1568558 & 688549 & 5.0 & 5.0378 & TRN & \\
\hline CHEMBL3198047 & 688549 & 4.8 & 4.8852 & TST & \\
\hline CHEMBL1406781 & 688549 & 4.45 & 4.4483 & TRN & \\
\hline CHEMBL1554923 & 688549 & 5.3 & 5.2386 & TRN & \\
\hline CHEMBL1600282 & 688549 & 4.7 & 5.1697 & TRN & \\
\hline CHEMBL1317586 & 688549 & 4.6 & 4.8781 & TRN & \\
\hline CHEMBL1403669 & 688549 & 4.55 & 5.3581 & TRN & \\
\hline CHEMBL1356998 & 688549 & 4.5 & 5.0125 & TRN & \\
\hline CHEMBL1560612 & 688549 & 4.9 & 4.7529 & TRN & \\
\hline CHEMBL1437014 & 688549 & 5.15 & 4.8498 & TRN & \\
\hline CHEMBL1553996 & 688549 & 4.5 & 4.8828 & TRN & \\
\hline
\end{tabular}




\begin{tabular}{|c|c|c|c|c|c|}
\hline \multicolumn{6}{|c|}{ preme } \\
\hline CHEMBL1356628 & 688549 & 4.5 & 5.018 & TST & \\
\hline CHEMBL1334159 & 688549 & 8.301 & 5.4221 & TST & \\
\hline CHEMBL1440005 & 688549 & 4.5 & 5.1322 & TST & \\
\hline CHEMBL1452817 & 688549 & 5.7 & 5.2115 & TRN & \\
\hline CHEMBL1395128 & 688549 & 5.6 & 5.6187 & TST & \\
\hline CHEMBL 259784 & 688549 & 5.9 & 5.3919 & TRN & \\
\hline CHEMBL1336975 & 688549 & 4.6 & 4.7768 & TRN & \\
\hline CHEMBL472929 & 688549 & 4.9 & 4.9724 & TRN & \\
\hline CHEMBL1407850 & 688549 & 5.0 & 4.9532 & TRN & \\
\hline CHEMBL1463731 & 688549 & 5.0 & 5.0538 & TRN & \\
\hline CHEMBL1580789 & 688549 & 4.8 & 5.0624 & TST & \\
\hline CHEMBL515248 & 688549 & 4.8 & 5.1408 & TST & \\
\hline CHEMBL1513968 & 688549 & 4.9 & 4.6319 & TRN & \\
\hline CHEMBL1549879 & 688549 & 4.9 & 4.9618 & TRN & \\
\hline CHEMBL1601632 & 688549 & 6.5 & 5.1612 & TST & \\
\hline CHEMBL1341531 & 688549 & 5.0 & 5.0045 & TRN & \\
\hline CHEMBL1437736 & 688549 & 4.95 & 5.2007 & TRN & \\
\hline CHEMBL1354262 & 688549 & 4.8 & 4.7197 & TRN & \\
\hline CHEMBL1376795 & 688549 & 4.9 & 4.8054 & TRN & \\
\hline CHEMBL1320149 & 688549 & 4.8 & 5.1818 & TRN & \\
\hline CHEMBL1360620 & 688549 & 6.7001 & 5.9393 & TST & \\
\hline CHEMBL1339432 & 688549 & 5.0 & 5.1707 & TRN & \\
\hline CHEMBL1600930 & 688549 & 5.0 & 5.0959 & TRN & \\
\hline CHEMBL1442465 & 688549 & 4.5 & 4.3857 & TRN & \\
\hline CHEMBL287689 & 688549 & 5.3 & 5.1936 & TST & \\
\hline CHEMBL1394944 & 688549 & 5.4 & 4.9766 & TRN & \\
\hline CHEMBL1434695 & 688549 & 5.3 & 5.0682 & TRN & \\
\hline CHEMBL1451013 & 688549 & 5.3 & 5.7149 & TST & \\
\hline CHEMBL1453607 & 688549 & 5.1 & 5.0854 & TRN & \\
\hline CHEMBL1488285 & 688549 & 4.55 & 4.3804 & TRN & \\
\hline CHEMBL1355340 & 688549 & 5.1 & 5.273 & TRN & \\
\hline CHEMBL1453606 & 688549 & 5.0 & 5.24200 & 0000000001 & TRN \\
\hline CHEMBL1398842 & 688549 & 8.2007 & 5.5072 & TRN & \\
\hline CHEMBL1357934 & 688549 & 4.9 & 4.7536 & TRN & \\
\hline CHEMBL1394980 & 688549 & 4.95 & 4.5843 & TRN & \\
\hline CHEMBL1475348 & 688549 & 4.95 & 4.7972 & TRN & \\
\hline CHEMBL1594699 & 688549 & 4.9 & 4.7448 & TRN & \\
\hline CHEMBL1441326 & 688549 & 4.7 & 4.9376 & TST & \\
\hline CHEMBL1487324 & 688549 & 7.8013 & 5.7956 & TRN & \\
\hline CHEMBL1552511 & 688549 & 4.7 & 4.6276 & TRN & \\
\hline CHEMBL1363142 & 688549 & 5.0 & 4.78600 & 00000000005 & TST \\
\hline CHEMBL1324347 & 688549 & 4.8 & 4.9742 & TRN & \\
\hline CHEMBL1433736 & 688549 & 4.8 & 5.3512 & TRN & \\
\hline CHEMBL1328771 & 688549 & 4.5 & 5.3248 & TST & \\
\hline CHEMBL1302850 & 688549 & 4.5 & 5.6262 & TST & \\
\hline CHEMBL1306822 & 688549 & 4.8 & 4.3577 & TST & \\
\hline CHEMBL3211017 & 688549 & 7.699 & 5.9134 & TRN & \\
\hline CHEMBL1474347 & 688549 & 4.5 & 5.1599 & TRN & \\
\hline
\end{tabular}




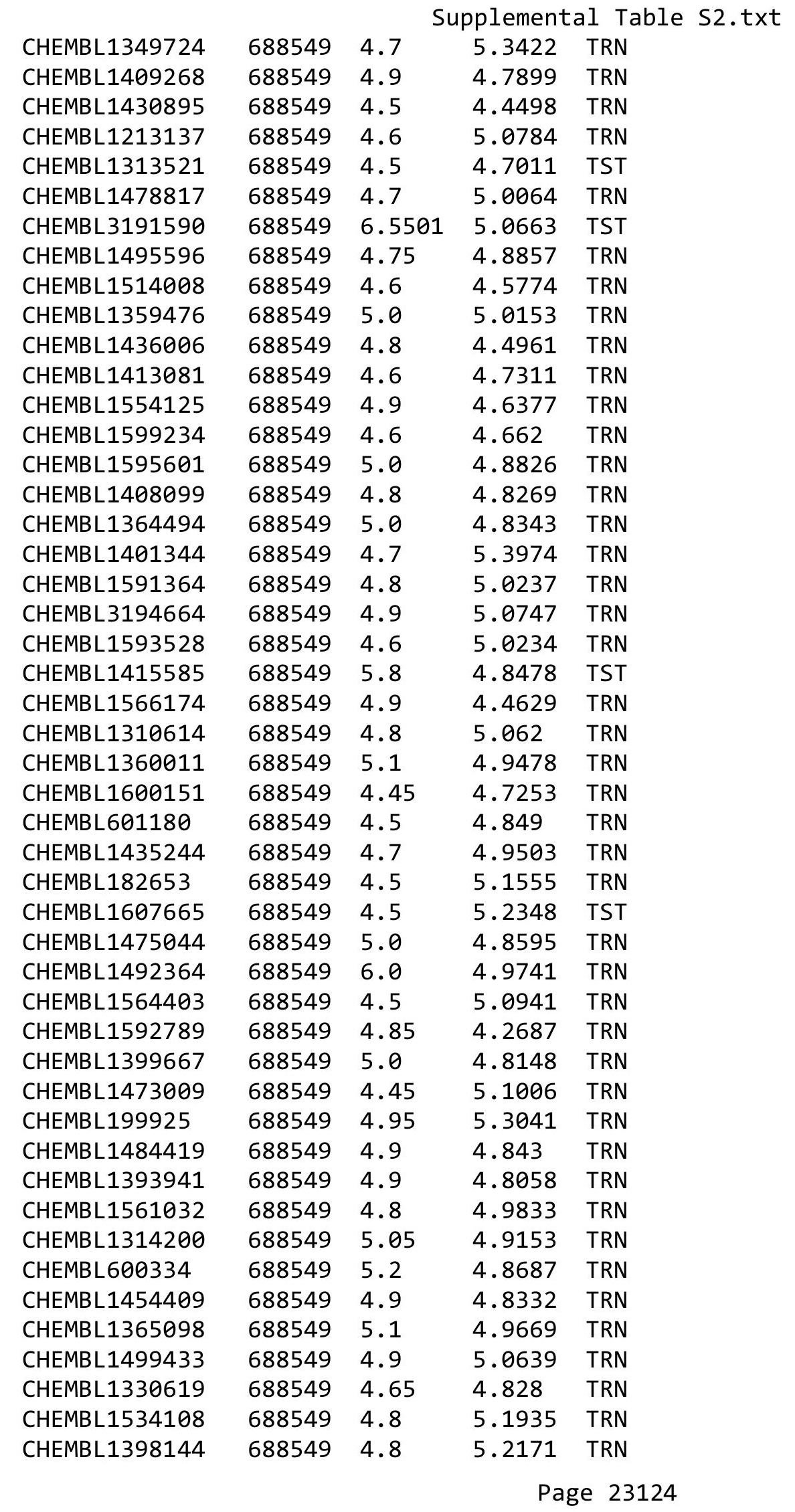




\begin{tabular}{|c|c|c|c|c|c|}
\hline & & & & & \\
\hline CHEMBL1608065 & 688549 & 4.9 & 5.0234 & TRN & \\
\hline CHEMBL1538370 & 688549 & 5.55 & 4.7672 & TST & \\
\hline CHEMBL43612 & 688549 & 5.0 & 5.2051 & TST & \\
\hline CHEMBL1488720 & 688549 & 4.7 & 5.3255 & TRN & \\
\hline CHEMBL1356919 & 688549 & 4.9 & 4.8701 & TRN & \\
\hline CHEMBL1352023 & 688549 & 4.7 & 4.9787 & TRN & \\
\hline CHEMBL1409420 & 688549 & 4.95 & 5.2622 & TRN & \\
\hline CHEMBL1366392 & 688549 & 5.2 & 4.7898 & TRN & \\
\hline CHEMBL1590286 & 688549 & 4.8 & 5.1263 & TRN & \\
\hline CHEMBL1551186 & 688549 & 6.0 & 5.67399 & 99999999995 & TRN \\
\hline CHEMBL1313622 & 688549 & 4.45 & 4.7961 & TST & \\
\hline CHEMBL1476510 & 688549 & 5.65 & 5.3197 & TRN & \\
\hline CHEMBL1587117 & 688549 & 5.6 & 5.9563 & TRN & \\
\hline CHEMBL1444259 & 688549 & 5.3 & 5.3923 & TRN & \\
\hline CHEMBL1497853 & 688549 & 4.5 & 4.6134 & TRN & \\
\hline CHEMBL472930 & 688549 & 4.5 & 5.0609 & TRN & \\
\hline CHEMBL1311173 & 688549 & 4.6 & 5.0963 & TRN & \\
\hline CHEMBL1479386 & 688549 & 5.0 & 5.3481 & TRN & \\
\hline CHEMBL1370779 & 688549 & 6.3 & 5.1841 & TRN & \\
\hline CHEMBL1322828 & 688549 & 4.9 & 4.8248 & TRN & \\
\hline CHEMBL1400251 & 688549 & 4.7 & 5.0178 & TRN & \\
\hline CHEMBL1523579 & 688549 & 5.0 & 4.8266 & TRN & \\
\hline CHEMBL1552542 & 688549 & 4.5 & 4.4432 & TRN & \\
\hline CHEMBL1489395 & 688549 & 4.45 & 4.3802 & TRN & \\
\hline CHEMBL259422 & 688549 & 6.1 & 5.2496 & TRN & \\
\hline CHEMBL1257130 & 688549 & 4.9 & 5.2747 & TST & \\
\hline CHEMBL1496625 & 688549 & 4.5 & 4.6012 & TRN & \\
\hline CHEMBL1433513 & 688549 & 4.6 & 5.5242 & TRN & \\
\hline CHEMBL1610732 & 688549 & 4.45 & 4.9563 & TRN & \\
\hline CHEMBL1412927 & 688549 & 5.2 & 5.2487 & TRN & \\
\hline CHEMBL1604118 & 688549 & 4.7 & 4.9875 & TRN & \\
\hline CHEMBL1345845 & 688549 & 5.6 & 5.4167 & TRN & \\
\hline CHEMBL1344115 & 688549 & 4.8 & 5.2443 & TST & \\
\hline CHEMBL1486352 & 688549 & 4.6 & 5.2411 & TRN & \\
\hline CHEMBL1394738 & 688549 & 4.5 & 5.2636 & TST & \\
\hline CHEMBL1566928 & 688549 & 4.9 & 5.0162 & TRN & \\
\hline CHEMBL1501170 & 688549 & 4.6 & 5.2866 & TRN & \\
\hline CHEMBL1432324 & 688549 & 5.0 & 4.8273 & TRN & \\
\hline CHEMBL1333530 & 688549 & 5.0 & 5.1893 & TRN & \\
\hline CHEMBL1311597 & 688549 & 4.8 & 4.8948 & TST & \\
\hline CHEMBL1345505 & 688549 & 5.0 & 5.2236 & TRN & \\
\hline CHEMBL1553690 & 688549 & 8.1024 & 5.5225 & TRN & \\
\hline CHEMBL1606513 & 688549 & 5.0 & 4.8522 & TRN & \\
\hline CHEMBL1524793 & 688549 & 4.6 & 4.7933 & TRN & \\
\hline CHEMBL1518418 & 688549 & 5.0 & 5.6223 & TST & \\
\hline CHEMBL1593564 & 688549 & 5.7 & 5.6333 & TRN & \\
\hline CHEMBL6291 & 688549 & 4.5 & 5.2336 & TST & \\
\hline CHEMBL323356 & 688549 & 4.8 & 4.7953 & TRN & \\
\hline
\end{tabular}




\begin{tabular}{|c|c|c|c|c|}
\hline \multicolumn{5}{|c|}{ Supplemental Table S2.txt } \\
\hline CHEMBL1605632 & 688549 & 5.1 & 4.7871 & TST \\
\hline CHEMBL1311534 & 688549 & 4.9 & 5.0683 & TRN \\
\hline CHEMBL1445787 & 688549 & 4.45 & 5.1617 & TRN \\
\hline CHEMBL1349305 & 688549 & 4.7 & 5.1595 & TRN \\
\hline CHEMBL1505797 & 688549 & 4.6 & 5.1203 & TRN \\
\hline CHEMBL1407498 & 688549 & 4.5 & 5.2819 & TRN \\
\hline CHEMBL1407420 & 688549 & 8.301 & 5.8585 & TRN \\
\hline CHEMBL1515691 & 688549 & 4.6 & 5.4559 & TST \\
\hline CHEMBL1209196 & 688549 & 4.5 & 5.0539 & TST \\
\hline CHEMBL1551255 & 688549 & 4.6 & 4.905 & TRN \\
\hline CHEMBL1510051 & 688549 & 7.8508 & 4.8962 & TST \\
\hline CHEMBL1410012 & 688549 & 4.8 & 4.7823 & TRN \\
\hline CHEMBL1308419 & 688549 & 4.7 & 4.8947 & TRN \\
\hline CHEMBL1496180 & 688549 & 4.9 & 5.1847 & TRN \\
\hline CHEMBL1331053 & 688549 & 8.2007 & 5.0255 & TRN \\
\hline CHEMBL1452558 & 688549 & 4.9 & 4.8919 & TRN \\
\hline CHEMBL1546299 & 688549 & 4.8 & 5.0602 & TRN \\
\hline CHEMBL1364829 & 688549 & 5.2 & 5.0129 & TRN \\
\hline CHEMBL1316622 & 688549 & 4.5 & 5.0749 & TRN \\
\hline CHEMBL1490465 & 688549 & 5.0 & 5.0763 & TRN \\
\hline CHEMBL1396824 & 688549 & 4.9 & 5.2523 & TRN \\
\hline CHEMBL1589101 & 688549 & 5.75 & 5.0392 & TST \\
\hline CHEMBL1512222 & 688549 & 4.8 & 4.6585 & TRN \\
\hline CHEMBL1462011 & 688549 & 4.9 & 4.8984 & TRN \\
\hline CHEMBL1339120 & 688549 & 4.9 & 5.2928 & TRN \\
\hline CHEMBL1525468 & 688549 & 4.8 & 5.1454 & TRN \\
\hline CHEMBL1601358 & 688549 & 4.75 & 5.2471 & TST \\
\hline CHEMBL1419082 & 688549 & 5.5 & 5.1372 & TRN \\
\hline CHEMBL 29898 & 688549 & 5.3 & 5.4134 & TST \\
\hline CHEMBL1343304 & 688549 & 6.7501 & 4.9625 & TST \\
\hline CHEMBL1486519 & 688549 & 4.8 & 4.8956 & TRN \\
\hline CHEMBL1486647 & 688549 & 7.2 & 5.0152 & TRN \\
\hline CHEMBL1454793 & 688549 & 4.9 & 4.9311 & TRN \\
\hline CHEMBL1436826 & 688549 & 4.9 & 5.2892 & TST \\
\hline CHEMBL1604123 & 688549 & 4.9 & 5.1284 & TRN \\
\hline CHEMBL1459660 & 688549 & 5.45 & 4.724 & TRN \\
\hline CHEMBL1396785 & 688549 & 4.7 & 4.9024 & TRN \\
\hline CHEMBL1373577 & 688549 & 4.8 & 5.3195 & TST \\
\hline CHEMBL1578888 & 688549 & 4.8 & 4.6575 & TRN \\
\hline CHEMBL1540341 & 688549 & 4.7 & 5.0862 & TRN \\
\hline CHEMBL1547504 & 688549 & 4.9 & 4.9216 & TRN \\
\hline CHEMBL1352323 & 688549 & 8.2007 & 5.2796 & TRN \\
\hline CHEMBL1527008 & 688549 & 4.9 & 5.0437 & TRN \\
\hline CHEMBL1454247 & 688549 & 5.0 & 5.246 & TRN \\
\hline CHEMBL1532931 & 688549 & 5.3 & 4.9075 & TRN \\
\hline CHEMBL1438626 & 688549 & 4.8 & 4.9311 & TRN \\
\hline CHEMBL1518622 & 688549 & 4.9 & 4.7325 & TRN \\
\hline CHEMBL1441573 & 688549 & 4.9 & 4.883 & TRN \\
\hline
\end{tabular}




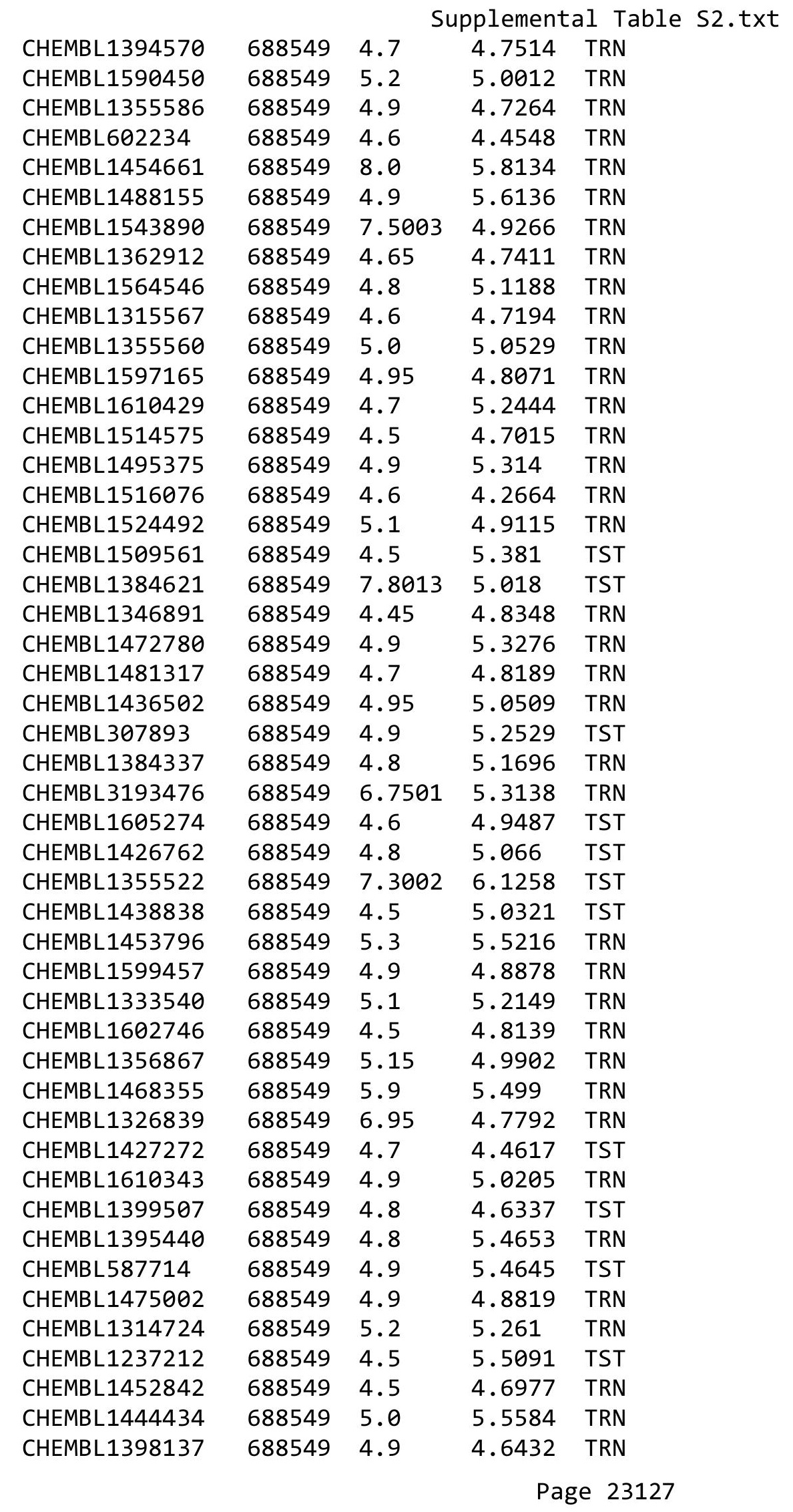




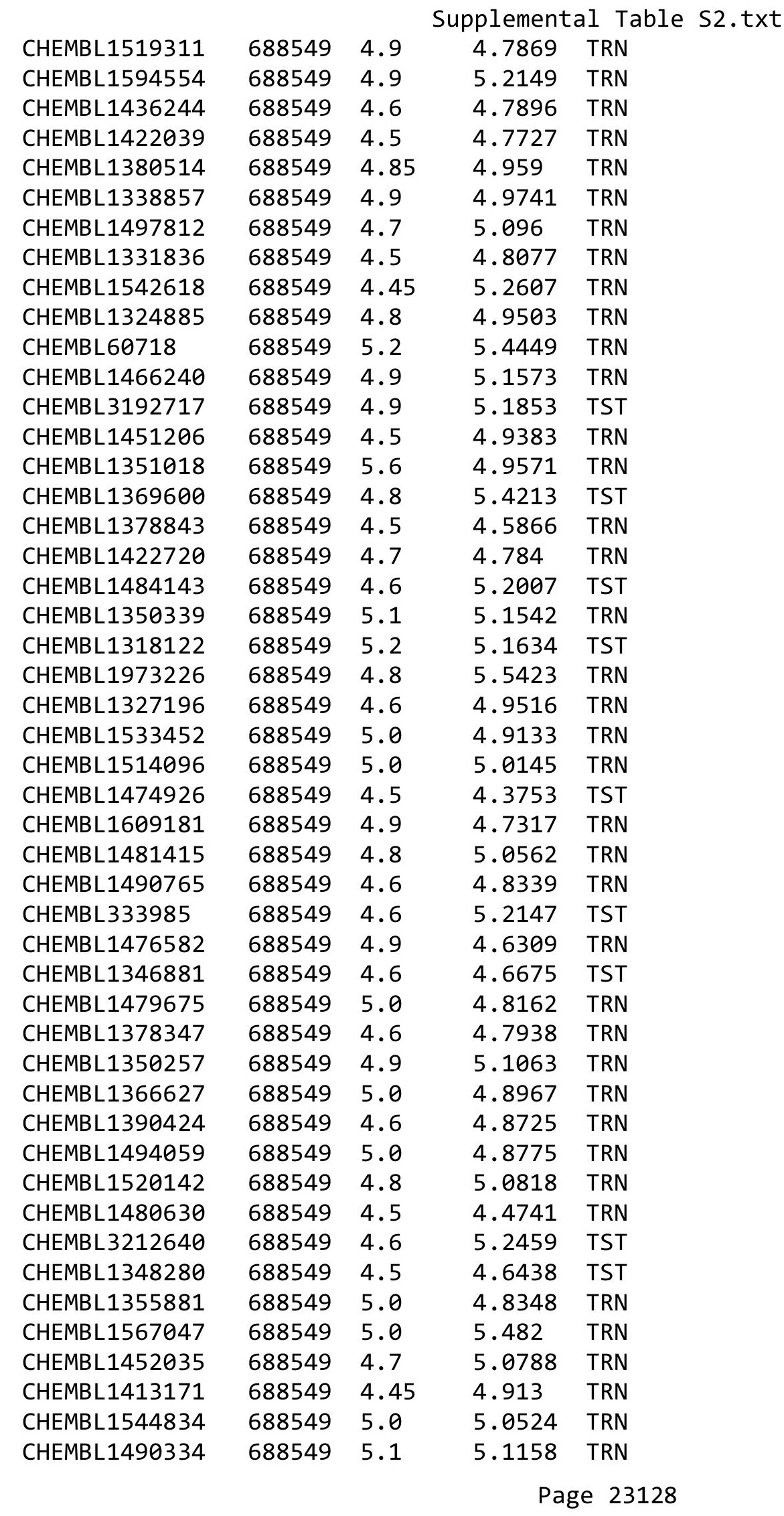




\begin{tabular}{|c|c|c|c|c|}
\hline \multicolumn{5}{|c|}{ Supplemental Table S2.txt } \\
\hline CHEMBL1361203 & 688549 & 5.6 & 4.6249 & TRN \\
\hline CHEMBL1350956 & 688549 & 4.7 & 4.9885 & TRN \\
\hline CHEMBL1331076 & 688549 & 4.8 & 5.0066 & TRN \\
\hline CHEMBL1591673 & 688549 & 5.7 & 5.1725 & TRN \\
\hline CHEMBL1362919 & 688549 & 5.0 & 5.0053 & TRN \\
\hline CHEMBL1329594 & 688549 & 4.5 & 4.6728 & TRN \\
\hline CHEMBL1396586 & 688549 & 4.8 & 4.645 & TRN \\
\hline CHEMBL1328681 & 688549 & 6.0 & 5.9213 & TST \\
\hline CHEMBL1334995 & 688549 & 4.45 & 5.1759 & TRN \\
\hline CHEMBL1587788 & 688549 & 4.9 & 5.2705 & TRN \\
\hline CHEMBL1379970 & 688549 & 6.6 & 6.2813 & TRN \\
\hline CHEMBL1553148 & 688549 & 5.0 & 4.9567 & TRN \\
\hline CHEMBL1593747 & 688549 & 4.55 & 5.1801 & TRN \\
\hline CHEMBL1603482 & 688549 & 5.25 & 5.1816 & TRN \\
\hline CHEMBL1531322 & 688549 & 4.9 & 5.3688 & TST \\
\hline CHEMBL270299 & 688549 & 4.8 & 4.8475 & TST \\
\hline CHEMBL1330326 & 688549 & 4.5 & 4.7101 & TRN \\
\hline CHEMBL1514491 & 688549 & 5.0 & 5.1854 & TRN \\
\hline CHEMBL1398700 & 688549 & 4.9 & 4.9455 & TRN \\
\hline CHEMBL1372902 & 688549 & 4.5 & 5.0786 & TRN \\
\hline CHEMBL1598734 & 688549 & 4.8 & 4.9256 & TRN \\
\hline CHEMBL1492980 & 688549 & 4.9 & 5.0 & TRN \\
\hline CHEMBL1393143 & 688549 & 4.5 & 4.6668 & TRN \\
\hline CHEMBL1565441 & 688549 & 4.9 & 4.8322 & TRN \\
\hline CHEMBL1473949 & 688549 & 4.7 & 5.2889 & TRN \\
\hline CHEMBL1364375 & 688549 & 4.5 & 4.9313 & TRN \\
\hline CHEMBL1367121 & 688549 & 4.45 & 5.0156 & TRN \\
\hline CHEMBL1501652 & 688549 & 5.0 & 4.9279 & TST \\
\hline CHEMBL1548028 & 688549 & 4.5 & 5.2393 & TST \\
\hline CHEMBL1602645 & 688549 & 4.45 & 4.9212 & TRN \\
\hline CHEMBL1521924 & 688549 & 5.0 & 5.1291 & TRN \\
\hline CHEMBL1463808 & 688549 & 5.8 & 5.3747 & TRN \\
\hline CHEMBL1420595 & 688549 & 4.95 & 4.9111 & TST \\
\hline CHEMBL1322597 & 688549 & 4.9 & 5.345 & TRN \\
\hline CHEMBL580421 & 688549 & 5.9 & 5.6068 & TST \\
\hline CHEMBL1586973 & 688549 & 4.9 & 5.1027 & TRN \\
\hline CHEMBL1319419 & 688549 & 4.9 & 4.5634 & TRN \\
\hline CHEMBL1496110 & 688549 & 4.8 & 4.9731 & TRN \\
\hline CHEMBL1396271 & 688549 & 4.7 & 4.6292 & TRN \\
\hline CHEMBL1361775 & 688549 & 5.1 & 4.8266 & TRN \\
\hline CHEMBL1529046 & 688549 & 4.5 & 4.8817 & TRN \\
\hline CHEMBL1312534 & 688549 & 4.5 & 4.9973 & TRN \\
\hline CHEMBL1436251 & 688549 & 5.2 & 4.8856 & TRN \\
\hline CHEMBL1435324 & 688549 & 4.9 & 4.7611 & TRN \\
\hline CHEMBL1319405 & 688549 & 5.1 & 4.8118 & TRN \\
\hline CHEMBL1349216 & 688549 & 4.6 & 4.7108 & TRN \\
\hline CHEMBL1520322 & 688549 & 4.5 & 4.7741 & TRN \\
\hline CHEMBL1552326 & 688549 & 5.5 & 4.9185 & TRN \\
\hline
\end{tabular}




\begin{tabular}{|c|c|c|c|c|c|}
\hline & & & & & \\
\hline CHEMBL1375797 & 688549 & 4.5 & 4.7622 & TRN & \\
\hline CHEMBL1524927 & 688549 & 4.7 & 5.1217 & TST & \\
\hline CHEMBL1550768 & 688549 & 4.8 & 4.6926 & TRN & \\
\hline CHEMBL1564932 & 688549 & 4.8 & 4.9988 & TST & \\
\hline CHEMBL1558843 & 688549 & 4.9 & 4.6501 & TRN & \\
\hline CHEMBL1356051 & 688549 & 6.3 & 5.8584 & TRN & \\
\hline CHEMBL1300493 & 688549 & 5.3 & 5.0634 & TRN & \\
\hline CHEMBL294009 & 688549 & 4.8 & 5.0464 & TRN & \\
\hline CHEMBL1499681 & 688549 & 4.9 & 4.8491 & TRN & \\
\hline CHEMBL1435119 & 688549 & 4.9 & 4.75899 & & TRN \\
\hline CHEMBL1595322 & 688549 & 4.5 & 4.7843 & TRN & \\
\hline CHEMBL1413282 & 688549 & 4.9 & 4.8724 & TRN & \\
\hline CHEMBL25236 & 688549 & 5.0 & 5.0468 & TRN & \\
\hline CHEMBL1374497 & 688549 & 8.0 & 4.9686 & TRN & \\
\hline CHEMBL1322078 & 688549 & 4.5 & 4.8281 & TST & \\
\hline CHEMBL1447088 & 688549 & 4.5 & 4.6543 & TST & \\
\hline CHEMBL1417225 & 688549 & 4.7 & 4.9085 & TRN & \\
\hline CHEMBL1524365 & 688549 & 4.6 & 5.2431 & TRN & \\
\hline CHEMBL1572026 & 688549 & 4.7 & 5.1332 & TRN & \\
\hline CHEMBL1446987 & 688549 & 5.0 & 4.9783 & TRN & \\
\hline CHEMBL1597951 & 688549 & 4.5 & 5.0999 & TRN & \\
\hline CHEMBL1359775 & 688549 & 4.8 & 4.6068 & TST & \\
\hline CHEMBL1445595 & 688549 & 4.9 & 4.9063 & TRN & \\
\hline CHEMBL1565641 & 688549 & 4.8 & 4.7488 & TRN & \\
\hline CHEMBL1300612 & 688549 & 5.45 & 5.0899 & TRN & \\
\hline CHEMBL1554144 & 688549 & 4.9 & 4.9144 & TRN & \\
\hline CHEMBL1553227 & 688549 & 4.95 & 4.8496 & TRN & \\
\hline CHEMBL1082160 & 688549 & 5.0 & 5.1021 & TRN & \\
\hline CHEMBL1488604 & 688549 & 5.0 & 4.8819 & TRN & \\
\hline CHEMBL1592684 & 688549 & 5.5 & 5.2602 & TRN & \\
\hline CHEMBL1417496 & 688549 & 4.75 & 4.8466 & TRN & \\
\hline CHEMBL1479306 & 688549 & 4.9 & 5.5912 & TRN & \\
\hline CHEMBL16223 & 688549 & 5.2 & 4.7978 & TRN & \\
\hline CHEMBL1604833 & 688549 & 4.8 & 4.8989 & TRN & \\
\hline CHEMBL1389857 & 688549 & 4.7 & 4.9787 & TRN & \\
\hline CHEMBL1517284 & 688549 & 4.5 & 5.2707 & TRN & \\
\hline CHEMBL1381498 & 688549 & 5.0 & 4.8877 & TST & \\
\hline CHEMBL408653 & 688549 & 5.3 & 5.5013 & TRN & \\
\hline CHEMBL456446 & 688549 & 5.0 & 5.1696 & TRN & \\
\hline CHEMBL1489082 & 688549 & 4.5 & 5.7152 & TRN & \\
\hline CHEMBL1530274 & 688549 & 5.0 & 4.91 & TST & \\
\hline CHEMBL1395275 & 688549 & 5.3 & 5.1229 & TRN & \\
\hline CHEMBL1607804 & 688549 & 5.05 & 4.785 & TRN & \\
\hline CHEMBL1433947 & 688549 & 5.55 & 5.1066 & TRN & \\
\hline CHEMBL3197885 & 688549 & 4.9 & 5.3515 & TRN & \\
\hline CHEMBL1545160 & 688549 & 4.8 & 4.7349 & TRN & \\
\hline CHEMBL546257 & 688549 & 6.0 & 5.0602 & TRN & \\
\hline CHEMBL1406956 & 688549 & 5.05 & 5.1517 & TST & \\
\hline
\end{tabular}




\begin{tabular}{|c|c|c|c|c|c|}
\hline & & & & & \\
\hline CHEMBL 3190220 & 688549 & 4.5 & 5.0463 & TST & \\
\hline CHEMBL1327137 & 688549 & 4.6 & 5.0603 & TRN & \\
\hline CHEMBL1400406 & 688549 & 5.7 & 5.0147 & TRN & \\
\hline CHEMBL1353194 & 688549 & 4.5 & 4.6533 & TRN & \\
\hline CHEMBL 288174 & 688549 & 4.5 & 4.9095 & TST & \\
\hline CHEMBL1328480 & 688549 & 5.2 & 5.2043 & TST & \\
\hline CHEMBL1596698 & 688549 & 5.4 & 5.5622 & TRN & \\
\hline CHEMBL1367076 & 688549 & 4.9 & 4.9285 & TRN & \\
\hline CHEMBL1536079 & 688549 & 4.6 & 5.2947 & TRN & \\
\hline CHEMBL1422845 & 688549 & 6.4 & 5.6141 & TST & \\
\hline CHEMBL1333254 & 688549 & 4.9 & $4.9830 e$ & 00000000005 & TRN \\
\hline CHEMBL1519929 & 688549 & 4.9 & 4.582 & TRN & \\
\hline CHEMBL1363883 & 688549 & 5.3 & 5.9238 & TST & \\
\hline CHEMBL1593342 & 688549 & 4.8 & 5.0131 & TRN & \\
\hline CHEMBL1609140 & 688549 & 5.5 & 5.2082 & TRN & \\
\hline CHEMBL1373463 & 688549 & 4.5 & 4.4084 & TRN & \\
\hline CHEMBL1588966 & 688549 & 4.5 & 5.2066 & TRN & \\
\hline CHEMBL1604193 & 688549 & 4.55 & 4.6929 & TRN & \\
\hline CHEMBL1337337 & 688549 & 4.8 & 4.7137 & TRN & \\
\hline CHEMBL1506356 & 688549 & 4.5 & 5.2062 & TRN & \\
\hline CHEMBL3192589 & 688549 & 4.7 & 4.6226 & TRN & \\
\hline CHEMBL1572924 & 688549 & 5.95 & 4.9869 & TRN & \\
\hline CHEMBL1513463 & 688549 & 4.8 & 5.5173 & TST & \\
\hline CHEMBL1602496 & 688549 & 4.8 & 5.0851 & TRN & \\
\hline CHEMBL1534744 & 688549 & 4.6 & 5.1578 & TRN & \\
\hline CHEMBL429095 & 688549 & 6.2 & 5.3957 & TST & \\
\hline CHEMBL 397785 & 688549 & 4.6 & 5.0382 & TRN & \\
\hline CHEMBL1568288 & 688549 & 4.5 & 4.7239 & TRN & \\
\hline CHEMBL 276727 & 688549 & 5.2 & 5.3815 & TST & \\
\hline CHEMBL3208592 & 688549 & 4.5 & 5.0376 & TRN & \\
\hline CHEMBL1336709 & 688549 & 4.5 & 5.0628 & TRN & \\
\hline CHEMBL3190579 & 688549 & 4.7 & 4.8975 & TRN & \\
\hline CHEMBL1448399 & 688549 & 5.0 & $5.3020 e$ & j0000000005 & TRN \\
\hline CHEMBL1300317 & 688549 & 4.5 & 4.5737 & TST & \\
\hline CHEMBL1445067 & 688549 & 4.8 & 4.725 & TRN & \\
\hline CHEMBL1513884 & 688549 & 4.9 & 4.9109 & TRN & \\
\hline CHEMBL1304919 & 688549 & 5.9 & 4.7835 & TRN & \\
\hline CHEMBL1569585 & 688549 & 5.5 & 5.2167 & TST & \\
\hline CHEMBL1356510 & 688549 & 4.9 & 5.9146 & TRN & \\
\hline CHEMBL1435533 & 688549 & 5.55 & 5.019 & TRN & \\
\hline CHEMBL1518894 & 688549 & 4.45 & 4.8578 & TRN & \\
\hline CHEMBL1424345 & 688549 & 4.6 & 5.3774 & TRN & \\
\hline CHEMBL1499384 & 688549 & 5.0 & 5.3233 & TRN & \\
\hline CHEMBL1404162 & 688549 & 4.8 & 4.4324 & TRN & \\
\hline CHEMBL1573196 & 688549 & 4.9 & 5.05399 & 9999999999 & TRN \\
\hline CHEMBL1336808 & 688549 & 5.0 & 4.9941 & TRN & \\
\hline CHEMBL1484038 & 688549 & 4.9 & 4.7726 & TRN & \\
\hline CHEMBL1431659 & 688549 & 4.9 & 4.8878 & TRN & \\
\hline & & & & 23131 & \\
\hline
\end{tabular}




\begin{tabular}{|c|c|c|c|c|}
\hline & & & pplemen & al $\mathrm{T}$ \\
\hline CHEMBL1368274 & 688549 & 4.5 & 4.8427 & TRN \\
\hline CHEMBL1416927 & 688549 & 5.5 & 5.226 & TRN \\
\hline CHEMBL1355278 & 688549 & 5.5 & 5.0967 & TRN \\
\hline CHEMBL1432070 & 688549 & 4.9 & 4.9786 & TRN \\
\hline CHEMBL1416902 & 688549 & 4.7 & 4.9173 & TRN \\
\hline CHEMBL1431577 & 688549 & 4.9 & 5.0653 & TRN \\
\hline CHEMBL1478870 & 688549 & 4.5 & 4.3642 & TRN \\
\hline CHEMBL1490452 & 688549 & 4.9 & 5.2445 & TRN \\
\hline CHEMBL1425919 & 688549 & 5.3 & 5.1585 & TRN \\
\hline CHEMBL1477380 & 688549 & 5.25 & 5.2931 & TRN \\
\hline CHEMBL1567793 & 688549 & 4.6 & 5.0024 & TRN \\
\hline CHEMBL1367094 & 688549 & 4.6 & 4.9231 & TRN \\
\hline CHEMBL1426732 & 688549 & 6.2 & 5.1562 & TRN \\
\hline CHEMBL 2006154 & 688549 & 4.6 & 5.0486 & TST \\
\hline CHEMBL1385107 & 688549 & 4.5 & 4.997 & TRN \\
\hline CHEMBL1433556 & 688549 & 4.9 & 4.8242 & TRN \\
\hline CHEMBL1490643 & 688549 & 4.5 & 5.0018 & TRN \\
\hline CHEMBL1309056 & 688549 & 4.7 & 4.9091 & TRN \\
\hline CHEMBL1554039 & 688549 & 5.0 & 4.8101 & TRN \\
\hline CHEMBL1591472 & 688549 & 4.9 & 4.9172 & TRN \\
\hline CHEMBL1541773 & 688549 & 6.05 & 5.3776 & TRN \\
\hline CHEMBL1373848 & 688549 & 4.5 & 4.8935 & TRN \\
\hline CHEMBL1415927 & 688549 & 4.7 & 4.9975 & TST \\
\hline CHEMBL1353522 & 688549 & 4.5 & 5.0922 & TST \\
\hline CHEMBL1378851 & 688549 & 4.5 & 4.546 & TST \\
\hline CHEMBL1358044 & 688549 & 4.7 & 5.4081 & TRN \\
\hline CHEMBL1442768 & 688549 & 5.45 & 4.9537 & TRN \\
\hline CHEMBL1571032 & 688549 & 4.45 & 4.559 & TRN \\
\hline CHEMBL1447019 & 688549 & 4.5 & 5.3347 & TRN \\
\hline CHEMBL1610691 & 688549 & 5.6 & 5.479 & TRN \\
\hline CHEMBL1495392 & 688549 & 4.7 & 5.0344 & TST \\
\hline CHEMBL1385229 & 688549 & 8.1024 & 5.4376 & TST \\
\hline CHEMBL1596612 & 688549 & 5.5 & 5.0081 & TRN \\
\hline CHEMBL1593951 & 688549 & 4.5 & 4.6834 & TRN \\
\hline CHEMBL1514827 & 688549 & 5.45 & 5.3177 & TRN \\
\hline CHEMBL1450120 & 688549 & 4.9 & 4.9241 & TRN \\
\hline CHEMBL1364157 & 688549 & 4.8 & 5.2733 & TRN \\
\hline CHEMBL1967431 & 688549 & 5.9 & 5.1544 & TRN \\
\hline CHEMBL1521741 & 688549 & 5.25 & 5.0939 & TRN \\
\hline CHEMBL1609978 & 688549 & 4.7 & 5.074 & TRN \\
\hline CHEMBL1610968 & 688549 & 5.0 & 4.7575 & TRN \\
\hline CHEMBL1433544 & 688549 & 4.75 & 4.6829 & TRN \\
\hline CHEMBL1512969 & 688549 & 5.3 & 4.9258 & TRN \\
\hline CHEMBL1324882 & 688549 & 5.0 & 4.8492 & TST \\
\hline CHEMBL1300386 & 688549 & 4.7 & 4.7911 & TST \\
\hline CHEMBL 7644 & 688549 & 5.4 & 5.5799 & TST \\
\hline CHEMBL3194422 & 688549 & 5.4 & 5.2827 & TRN \\
\hline CHEMBL1562777 & 688549 & 5.9 & 5.6055 & TRN \\
\hline
\end{tabular}




\begin{tabular}{|c|c|c|c|c|c|}
\hline & & & & & \\
\hline CHEMBL1576290 & 688549 & 4.5 & 4.9275 & TRN & \\
\hline CHEMBL1455387 & 688549 & 5.0 & 4.8104 & TRN & \\
\hline CHEMBL1413716 & 688549 & 4.9 & 4.8693 & TRN & \\
\hline CHEMBL1489449 & 688549 & 4.6 & 4.7137 & TRN & \\
\hline CHEMBL1555128 & 688549 & 5.2 & 5.23 & TRN & \\
\hline CHEMBL1470420 & 688549 & 4.9 & 4.8023 & TRN & \\
\hline CHEMBL1359723 & 688549 & 5.4 & 5.0567 & TRN & \\
\hline CHEMBL1354551 & 688549 & 4.7 & 4.9165 & TST & \\
\hline CHEMBL1514141 & 688549 & 5.6 & 5.2751 & TRN & \\
\hline CHEMBL1516211 & 688549 & 4.6 & 5.0334 & TRN & \\
\hline CHEMBL323197 & 688549 & 6.0 & 5.3166 & TRN & \\
\hline CHEMBL1365239 & 688549 & 4.8 & 4.7517 & TRN & \\
\hline CHEMBL1610028 & 688549 & 4.5 & 5.0519 & TRN & \\
\hline CHEMBL1474691 & 688549 & 4.5 & 4.4224 & TRN & \\
\hline CHEMBL1991885 & 688549 & 4.5 & 5.3249 & TRN & \\
\hline CHEMBL1610565 & 688549 & 4.7 & 4.5732 & TRN & \\
\hline CHEMBL1382209 & 688549 & 4.8 & 4.9257 & TRN & \\
\hline CHEMBL1417896 & 688549 & 4.6 & 5.2287 & TRN & \\
\hline CHEMBL1355854 & 688549 & 4.5 & 4.545 & TRN & \\
\hline CHEMBL1395156 & 688549 & 4.9 & 4.9361 & TRN & \\
\hline CHEMBL1342148 & 688549 & 5.0 & 4.8754 & TRN & \\
\hline CHEMBL1366856 & 688549 & 4.8 & 4.7261 & TRN & \\
\hline CHEMBL1535546 & 688549 & 4.6 & 4.7295 & TRN & \\
\hline CHEMBL1541466 & 688549 & 8.1024 & 5.7013 & TRN & \\
\hline CHEMBL1401359 & 688549 & 4.9 & 5.0628 & TRN & \\
\hline CHEMBL1487859 & 688549 & 4.9 & 4.9878 & TRN & \\
\hline CHEMBL1553380 & 688549 & 4.7 & 5.00899 & 99999999995 & TRN \\
\hline CHEMBL1435261 & 688549 & 4.9 & 5.7477 & TST & \\
\hline CHEMBL1436024 & 688549 & 4.7 & 5.1424 & TRN & \\
\hline CHEMBL1500220 & 688549 & 4.9 & 4.715 & TRN & \\
\hline CHEMBL1389540 & 688549 & 4.9 & 4.9348 & TRN & \\
\hline CHEMBL1474684 & 688549 & 4.5 & 4.9201 & TST & \\
\hline CHEMBL1453336 & 688549 & 7.4001 & 5.5381 & TRN & \\
\hline CHEMBL1593285 & 688549 & 4.65 & 4.4758 & TRN & \\
\hline CHEMBL1572980 & 688549 & 5.7 & 5.6179 & TRN & \\
\hline CHEMBL1356094 & 688549 & 5.9 & 5.1383 & TST & \\
\hline CHEMBL1541441 & 688549 & 4.55 & 4.8992 & TST & \\
\hline CHEMBL1572195 & 688549 & 4.5 & 4.9273 & TST & \\
\hline CHEMBL1571730 & 688549 & 4.6 & 5.1393 & TRN & \\
\hline CHEMBL1329661 & 688549 & 4.5 & 4.7191 & TRN & \\
\hline CHEMBL1382028 & 688549 & 5.2 & 5.1264 & TRN & \\
\hline CHEMBL1360431 & 688549 & 4.9 & 4.8487 & TRN & \\
\hline CHEMBL1356738 & 688549 & 4.9 & 4.8227 & TRN & \\
\hline CHEMBL1595219 & 688549 & 4.6 & 4.7569 & TRN & \\
\hline CHEMBL1526649 & 688549 & 4.7 & 4.8454 & TRN & \\
\hline CHEMBL1514262 & 688549 & 5.0 & 5.0778 & TST & \\
\hline CHEMBL319244 & 688549 & 4.5 & 5.1056 & TRN & \\
\hline CHEMBL1530319 & 688549 & 4.5 & 5.2775 & TRN & \\
\hline & & & & 23133 & \\
\hline
\end{tabular}




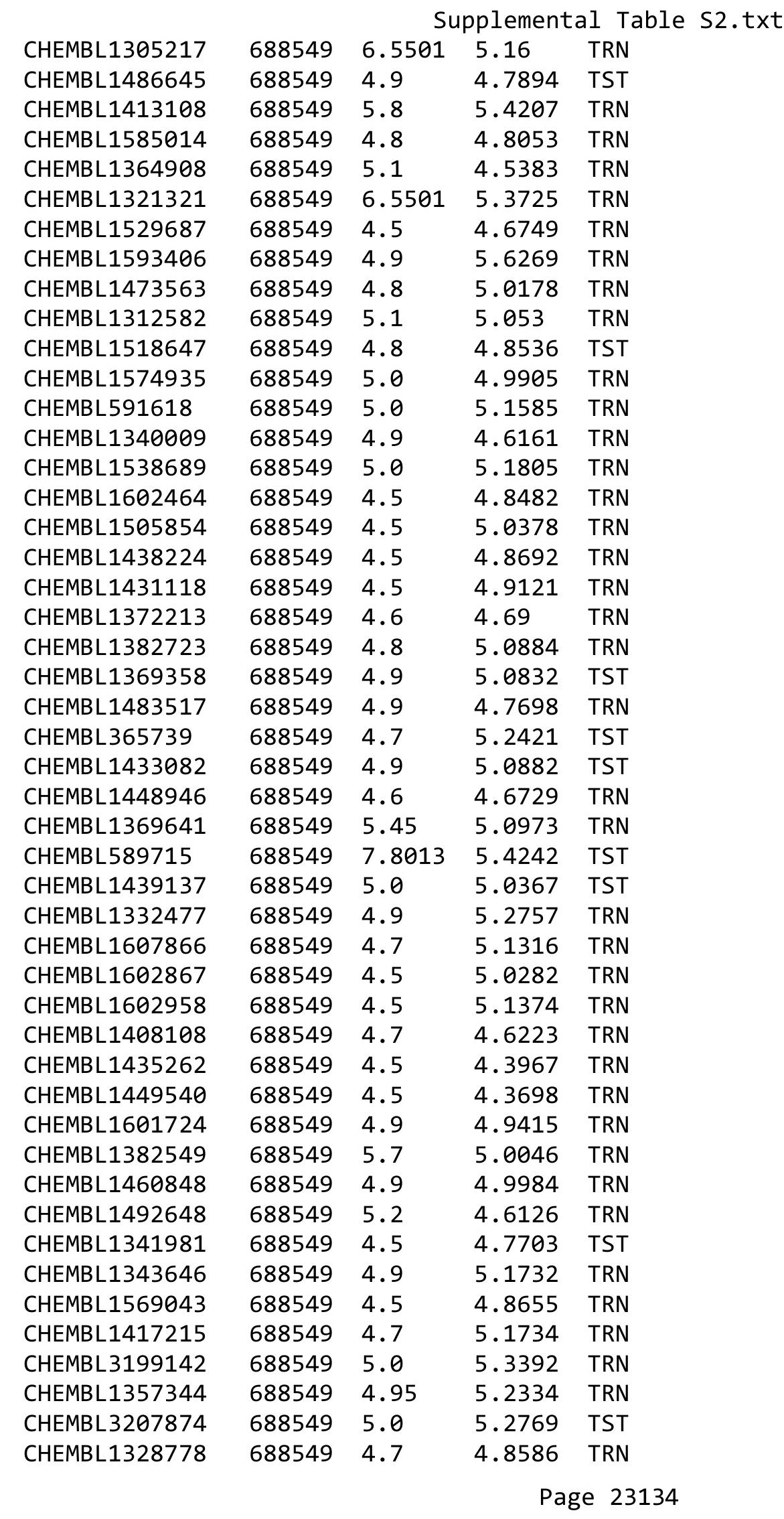




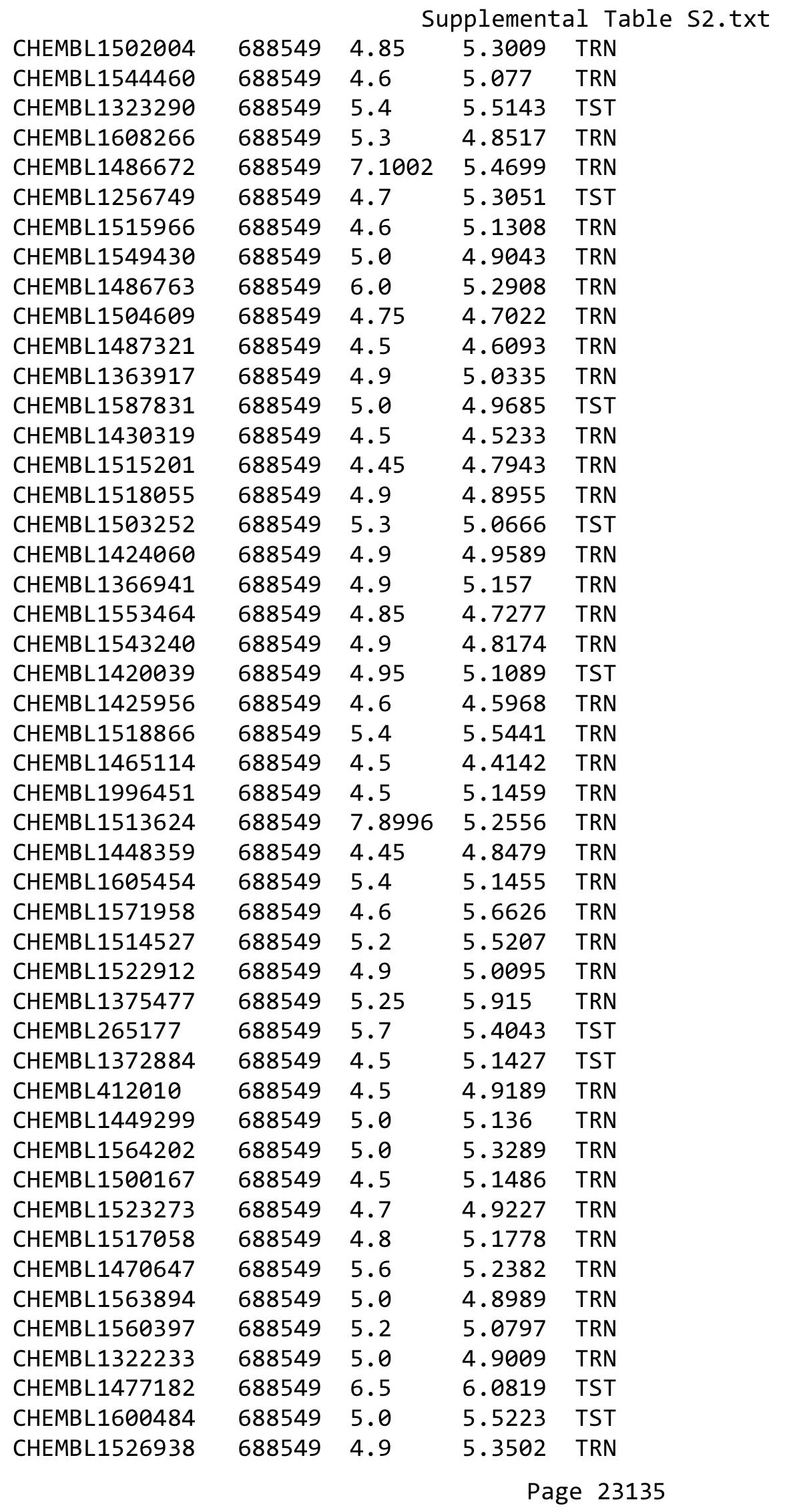




\begin{tabular}{|c|c|c|c|c|c|}
\hline \multirow{2}{*}{ CHEMBL1354442 } & \multirow{2}{*}{688549} & \\
\hline & & 5.4 & 4.7187 & \multicolumn{2}{|l|}{ TRN } \\
\hline CHEMBL1489045 & 688549 & 5.0 & 4.9246 & \multicolumn{2}{|l|}{ TRN } \\
\hline CHEMBL29097 & 688549 & 4.5 & 4.6527 & \multicolumn{2}{|l|}{ TST } \\
\hline CHEMBL1362562 & 688549 & 4.7 & 4.6393 & \multicolumn{2}{|l|}{ TRN } \\
\hline CHEMBL1482873 & 688549 & 4.5 & 4.9432 & \multicolumn{2}{|l|}{ TRN } \\
\hline CHEMBL1350167 & 688549 & 4.5 & 4.6648 & \multicolumn{2}{|l|}{ TRN } \\
\hline CHEMBL1356313 & 688549 & 4.45 & 5.2012 & \multicolumn{2}{|l|}{ TRN } \\
\hline CHEMBL1456175 & 688549 & 4.6 & 4.8167 & \multicolumn{2}{|l|}{ TST } \\
\hline CHEMBL1378049 & 688549 & 4.7 & 4.7735 & \multicolumn{2}{|l|}{ TRN } \\
\hline CHEMBL1339035 & 688549 & 4.5 & 5.1851 & \multicolumn{2}{|l|}{ TST } \\
\hline CHEMBL1364729 & 688549 & 4.5 & 5.056 & \multicolumn{2}{|l|}{ TST } \\
\hline CHEMBL1551080 & 688549 & 4.5 & 4.5655 & \multicolumn{2}{|l|}{ TRN } \\
\hline CHEMBL1439781 & 688549 & 4.7 & 5.0729 & \multicolumn{2}{|l|}{ TRN } \\
\hline CHEMBL1587744 & 688549 & 5.2 & 4.9856 & \multicolumn{2}{|l|}{ TRN } \\
\hline CHEMBL1570216 & 688549 & 5.0 & 5.5424 & \multicolumn{2}{|l|}{ TRN } \\
\hline CHEMBL1347687 & 688549 & 5.2 & 4.965 & \multicolumn{2}{|l|}{ TRN } \\
\hline CHEMBL1552332 & 688549 & 5.1 & 5.0407 & \multicolumn{2}{|l|}{ TRN } \\
\hline CHEMBL1566778 & 688549 & 4.8 & 5.1236 & \multicolumn{2}{|l|}{ TRN } \\
\hline CHEMBL1605430 & 688549 & 4.8 & 4.8909 & TRN & \\
\hline CHEMBL1415516 & 688549 & 4.7 & 4.617 & TRN & \\
\hline CHEMBL1500235 & 688549 & 4.7 & 5.1829 & TRN & \\
\hline CHEMBL1530387 & 688549 & 5.0 & 4.8512 & TST & \\
\hline CHEMBL1509700 & 688549 & 5.7 & 5.1554 & TST & \\
\hline CHEMBL1604894 & 688549 & 5.4 & 5.3908 & TRN & \\
\hline CHEMBL1329798 & 688549 & 5.3 & 5.8596 & TRN & \\
\hline CHEMBL1402105 & 688549 & 4.9 & 5.0573 & TRN & \\
\hline CHEMBL1477213 & 688549 & 4.5 & 4.791 & TRN & \\
\hline CHEMBL1358378 & 688549 & 4.5 & 5.2221 & TST & \\
\hline CHEMBL1318620 & 688549 & 4.5 & 4.9635 & TRN & \\
\hline CHEMBL1401953 & 688549 & 4.9 & 5.1169 & TRN & \\
\hline CHEMBL1321597 & 688549 & 5.0 & 5.3372 & TRN & \\
\hline CHEMBL1474284 & 688549 & 5.0 & 5.0682 & TRN & \\
\hline CHEMBL1339052 & 688549 & 5.0 & 4.7477 & TRN & \\
\hline CHEMBL1411288 & 688549 & 4.7 & 4.956 & TRN & \\
\hline CHEMBL1566340 & 688549 & 4.9 & 5.1912 & TRN & \\
\hline CHEMBL1328073 & 688549 & 4.8 & 4.9646 & TRN & \\
\hline CHEMBL1447547 & 688549 & 4.9 & 4.7321 & TRN & \\
\hline CHEMBL1587270 & 688549 & 4.9 & 4.8892 & TRN & \\
\hline CHEMBL1510399 & 688549 & 5.0 & 4.9097 & TRN & \\
\hline CHEMBL1448453 & 688549 & 5.0 & 4.8538 & TRN & \\
\hline CHEMBL1519214 & 688549 & 4.7 & 4.7711 & TRN & \\
\hline CHEMBL1397745 & 688549 & 4.9 & 5.2563 & TRN & \\
\hline CHEMBL1555188 & 688549 & 4.9 & 4.7948 & TRN & \\
\hline CHEMBL1412163 & 688549 & 4.5 & 5.3735 & TST & \\
\hline CHEMBL1448181 & 688549 & 4.5 & 4.7351 & TRN & \\
\hline CHEMBL1568897 & 688549 & 4.8 & 4.6635 & TRN & \\
\hline CHEMBL1514431 & 688549 & 5.0 & $4.9910 €$ & 00000000005 & TRN \\
\hline CHEMBL1606549 & 688549 & 4.7 & 5.1122 & TRN & \\
\hline & & & & 23136 & \\
\hline
\end{tabular}




\begin{tabular}{|c|c|c|c|c|c|}
\hline & & & & & \\
\hline CHEMBL1359157 & 688549 & 4.5 & 4.9459 & TST & \\
\hline CHEMBL1256656 & 688549 & 6.0 & 5.0003 & TST & \\
\hline CHEMBL1433814 & 688549 & 4.6 & 4.9046 & TST & \\
\hline CHEMBL1420106 & 688549 & 5.0 & 4.9235 & TST & \\
\hline CHEMBL1528905 & 688549 & 5.0 & 4.888 & TST & \\
\hline CHEMBL1485101 & 688549 & 4.9 & 5.2332 & TST & \\
\hline CHEMBL1480522 & 688549 & 5.1 & 5.0791 & TST & \\
\hline CHEMBL1383533 & 688549 & 4.9 & 4.798 & TST & \\
\hline CHEMBL1588229 & 688549 & 4.8 & 4.9321 & TST & \\
\hline CHEMBL1534640 & 688549 & 7.1002 & 4.9361 & TST & \\
\hline CHEMBL1412114 & 688549 & 4.6 & 4.6572 & TST & \\
\hline CHEMBL1513594 & 688549 & 5.5 & 4.8355 & TST & \\
\hline CHEMBL1513619 & 688549 & 6.1 & 5.2647 & TST & \\
\hline CHEMBL1513342 & 688549 & 4.9 & 5.12200 & 0000000001 & TST \\
\hline CHEMBL1422535 & 688549 & 4.9 & 4.9279 & TST & \\
\hline CHEMBL1450476 & 688549 & 4.7 & 4.5976 & TST & \\
\hline CHEMBL1608430 & 688549 & 5.6 & 5.0221 & TST & \\
\hline CHEMBL1483183 & 688549 & 4.9 & 4.8638 & TST & \\
\hline CHEMBL1477241 & 688549 & 4.9 & 5.0915 & TST & \\
\hline CHEMBL 252722 & 688549 & 5.0 & 5.1002 & TST & \\
\hline CHEMBL1409561 & 688549 & 4.5 & 4.574 & TST & \\
\hline CHEMBL1427423 & 688549 & 4.6 & 4.7722 & TST & \\
\hline CHEMBL250711 & 688549 & 4.9 & 4.7655 & TST & \\
\hline CHEMBL1590107 & 688549 & 4.8 & 4.4977 & TST & \\
\hline CHEMBL1507260 & 688549 & 4.6 & 5.3869 & TST & \\
\hline CHEMBL1542533 & 688549 & 5.3 & 4.7939 & TST & \\
\hline CHEMBL1518001 & 688549 & 5.3 & 5.0486 & TST & \\
\hline CHEMBL1386323 & 688549 & 5.4 & 5.0548 & TST & \\
\hline CHEMBL1385434 & 688549 & 4.5 & 5.4852 & TST & \\
\hline CHEMBL1319015 & 688549 & 4.8 & 4.8136 & TST & \\
\hline CHEMBL1521729 & 688549 & 4.5 & 5.2146 & TST & \\
\hline CHEMBL2374050 & 688549 & 6.0 & 5.8235 & TST & \\
\hline CHEMBL1455729 & 688549 & 5.5 & 5.745 & TST & \\
\hline CHEMBL606675 & 688549 & 4.5 & 5.0189 & TST & \\
\hline CHEMBL1565462 & 688549 & 4.5 & 4.922 & TST & \\
\hline CHEMBL1433850 & 688549 & 4.9 & 4.8353 & TST & \\
\hline CHEMBL1558940 & 688549 & 4.5 & 5.0532 & TST & \\
\hline CHEMBL1356931 & 688549 & 4.5 & 4.647 & TST & \\
\hline CHEMBL1475470 & 688549 & 5.0 & 4.5264 & TST & \\
\hline CHEMBL1489223 & 688549 & 4.5 & 5.3426 & TST & \\
\hline CHEMBL1324391 & 688549 & 5.45 & 5.4123 & TST & \\
\hline CHEMBL1418196 & 688549 & 4.7 & 4.7627 & TST & \\
\hline CHEMBL1314454 & 688549 & 5.9 & 5.194 & TST & \\
\hline CHEMBL1450119 & 688549 & 4.8 & 5.2936 & TST & \\
\hline CHEMBL1557195 & 688549 & 4.8 & 4.2822 & TST & \\
\hline CHEMBL1359628 & 688549 & 5.2 & 5.1874 & TST & \\
\hline CHEMBL1390196 & 688549 & 4.7 & 5.2854 & TST & \\
\hline CHEMBL1355963 & 688549 & 6.0 & 5.7536 & TST & \\
\hline & & & & 23137 & \\
\hline
\end{tabular}




\begin{tabular}{|c|c|c|c|c|}
\hline \multicolumn{5}{|c|}{ Supplemental Table S2.txt } \\
\hline CHEMBL1336575 & 688549 & 4.5 & 4.8835 & TST \\
\hline CHEMBL520107 & 688549 & 4.5 & 4.6659 & TST \\
\hline CHEMBL1576551 & 688549 & 4.45 & 4.9707 & TST \\
\hline CHEMBL186526 & 688549 & 4.9 & 5.1086 & TST \\
\hline CHEMBL1419997 & 688549 & 5.0 & 4.9757 & TST \\
\hline CHEMBL1435798 & 688549 & 4.5 & 5.1829 & TST \\
\hline CHEMBL1564660 & 688549 & 4.6 & 4.8259 & TST \\
\hline CHEMBL1506436 & 688549 & 5.3 & 5.2521 & TST \\
\hline CHEMBL1214410 & 688549 & 5.0 & 4.7946 & TST \\
\hline CHEMBL1534295 & 688549 & 4.5 & 4.9183 & TST \\
\hline CHEMBL1559473 & 688549 & 4.5 & 4.8933 & TST \\
\hline CHEMBL1599634 & 688549 & 4.75 & 4.4734 & TST \\
\hline CHEMBL1356739 & 688549 & 5.65 & 5.3692 & TST \\
\hline CHEMBL1310612 & 688549 & 5.1 & 5.4902 & TST \\
\hline CHEMBL1429873 & 688549 & 4.6 & 4.9605 & TST \\
\hline CHEMBL1354569 & 688549 & 4.7 & 4.6543 & TST \\
\hline CHEMBL388931 & 688549 & 5.8 & 5.1811 & TST \\
\hline CHEMBL1443354 & 688549 & 4.8 & 5.1476 & TST \\
\hline CHEMBL1489944 & 688549 & 4.9 & 5.0278 & TST \\
\hline CHEMBL1381205 & 688549 & 5.0 & 4.7695 & TST \\
\hline CHEMBL1382628 & 688549 & 4.8 & 4.976 & TST \\
\hline CHEMBL1528739 & 688549 & 5.55 & 4.9332 & TST \\
\hline CHEMBL1595524 & 688549 & 4.6 & 4.7774 & TST \\
\hline CHEMBL1476764 & 688549 & 5.0 & 4.5835 & TST \\
\hline CHEMBL1436181 & 688549 & 4.6 & 4.8876 & TST \\
\hline CHEMBL428496 & 688549 & 5.6 & 5.7056 & TST \\
\hline CHEMBL1323755 & 688549 & 4.5 & 5.0028 & TST \\
\hline CHEMBL1600154 & 688549 & 5.0 & 5.0804 & TST \\
\hline CHEMBL1325980 & 688549 & 4.7 & 5.0293 & TST \\
\hline CHEMBL1356780 & 688549 & 4.9 & 5.4182 & TST \\
\hline CHEMBL1524371 & 688549 & 4.5 & 5.1423 & TST \\
\hline CHEMBL1197859 & 688549 & 5.0 & 4.6866 & TST \\
\hline CHEMBL1520782 & 688549 & 7.1002 & 5.1022 & TST \\
\hline CHEMBL1526774 & 688549 & 4.85 & 4.6666 & TST \\
\hline CHEMBL1368418 & 688549 & 4.5 & 4.8702 & TST \\
\hline CHEMBL1594941 & 688549 & 7.3002 & 5.2503 & TST \\
\hline CHEMBL1531352 & 688549 & 4.9 & 5.1397 & TST \\
\hline CHEMBL1593018 & 688549 & 4.7 & 4.8331 & TST \\
\hline CHEMBL1466554 & 688549 & 4.7 & 5.0887 & TST \\
\hline CHEMBL1490766 & 688549 & 4.8 & 5.2187 & TST \\
\hline CHEMBL1603509 & 688549 & 4.9 & 5.0496 & TST \\
\hline CHEMBL1372212 & 688549 & 4.45 & 4.8922 & TST \\
\hline CHEMBL1323968 & 688549 & 5.05 & 5.3224 & TST \\
\hline CHEMBL500996 & 688549 & 4.9 & 5.3547 & TST \\
\hline CHEMBL1450337 & 688549 & 4.8 & 4.9195 & TST \\
\hline CHEMBL1481978 & 688549 & 5.0 & 4.8664 & TST \\
\hline CHEMBL1554221 & 688549 & 4.9 & 4.7673 & TST \\
\hline CHEMBL1487466 & 688549 & 5.1 & 5.0458 & TST \\
\hline
\end{tabular}




\begin{tabular}{|c|c|c|c|c|c|}
\hline \multicolumn{6}{|c|}{ Supplemental Table S2.txt } \\
\hline CHEMBL1404816 & 688549 & 4.9 & 4.4958 & TST & \\
\hline CHEMBL1355928 & 688549 & 5.5 & 4.9582 & TST & \\
\hline CHEMBL1517102 & 688549 & 4.5 & 4.7767 & TST & \\
\hline CHEMBL1413504 & 688549 & 4.55 & 5.3368 & TST & \\
\hline CHEMBL1560969 & 688549 & 6.5 & 5.6273 & TST & \\
\hline CHEMBL1495119 & 688549 & 4.6 & 4.9313 & TST & \\
\hline CHEMBL 296348 & 688549 & 7.8013 & 5.0065 & TST & \\
\hline CHEMBL1473759 & 688549 & 5.4 & 5.6316 & TST & \\
\hline CHEMBL1488481 & 688549 & 5.1 & 5.0992 & TST & \\
\hline CHEMBL1333664 & 688549 & 4.7 & 4.9862 & TST & \\
\hline CHEMBL1304625 & 688549 & 4.9 & 5.1713 & TST & \\
\hline CHEMBL1504482 & 688549 & 4.5 & 5.2903 & TST & \\
\hline CHEMBL1369185 & 688549 & 4.9 & 5.2447 & TST & \\
\hline CHEMBL1482799 & 688549 & 4.8 & 4.6067 & TST & \\
\hline CHEMBL1356524 & 688549 & 4.5 & 5.0597 & TST & \\
\hline CHEMBL1594647 & 688549 & 4.9 & 5.2431 & TST & \\
\hline CHEMBL1555014 & 688549 & 4.9 & 4.9149 & TST & \\
\hline CHEMBL1410865 & 688549 & 4.5 & 5.16299 & 9999999999 & TST \\
\hline CHEMBL1475937 & 688549 & 4.9 & 4.7073 & TST & \\
\hline CHEMBL601968 & 688549 & 4.9 & 4.9849 & TST & \\
\hline CHEMBL1440788 & 688549 & 4.85 & 5.087 & TST & \\
\hline CHEMBL1373404 & 688549 & 4.6 & 4.7905 & TST & \\
\hline CHEMBL1485604 & 688549 & 4.5 & 4.4488 & TST & \\
\hline CHEMBL1314398 & 688549 & 5.0 & 5.0942 & TST & \\
\hline CHEMBL1543742 & 688549 & 4.65 & 4.8646 & TST & \\
\hline CHEMBL460515 & 688549 & 4.9 & 4.8461 & TST & \\
\hline CHEMBL1439566 & 688549 & 7.0 & 5.6586 & TST & \\
\hline CHEMBL1410006 & 688549 & 6.1 & 5.3618 & TST & \\
\hline CHEMBL1358237 & 688549 & 4.9 & 5.3756 & TST & \\
\hline CHEMBL3190150 & 688549 & 4.8 & 5.1202 & TST & \\
\hline CHEMBL1317744 & 688549 & 4.8 & 4.8317 & TST & \\
\hline CHEMBL1437927 & 688549 & 4.95 & 4.8823 & TST & \\
\hline CHEMBL1464055 & 688549 & 8.1024 & 5.1863 & TST & \\
\hline CHEMBL1610740 & 688549 & 4.9 & 5.4357 & TST & \\
\hline CHEMBL1370437 & 688549 & 5.3 & 5.1745 & TST & \\
\hline CHEMBL1369639 & 688549 & 4.9 & 5.092 & TST & \\
\hline CHEMBL1569989 & 688549 & 5.4 & 5.6437 & TST & \\
\hline CHEMBL1439041 & 688549 & 4.8 & 4.7897 & TST & \\
\hline CHEMBL1369740 & 688549 & 4.9 & 5.0988 & TST & \\
\hline CHEMBL1606230 & 688549 & 4.9 & 5.1186 & TST & \\
\hline CHEMBL1472693 & 688549 & 4.9 & 4.8206 & TST & \\
\hline CHEMBL1978424 & 688549 & 5.0 & 5.1357 & TST & \\
\hline CHEMBL1485627 & 688549 & 5.3 & 5.13 & TST & \\
\hline CHEMBL1314431 & 688549 & 4.5 & 4.3388 & TST & \\
\hline CHEMBL1331907 & 688549 & 4.7 & 5.1909 & TST & \\
\hline CHEMBL170408 & 688549 & 8.4949 & 4.9928 & TST & \\
\hline CHEMBL1358681 & 688549 & 4.7 & 4.5911 & TST & \\
\hline CHEMBL1396455 & 688549 & 4.6 & 4.3825 & TST & \\
\hline
\end{tabular}




\begin{tabular}{|c|c|c|c|c|c|}
\hline \\
\hline CHEMBL1531362 & 688549 & 4.6 & 5.0323 & TST & \\
\hline CHEMBL1480392 & 688549 & 4.8 & 5.0496 & TST & \\
\hline CHEMBL1515006 & 688549 & 4.75 & 5.4622 & TST & \\
\hline CHEMBL1518385 & 688549 & 8.0 & 5.3374 & TST & \\
\hline CHEMBL1431131 & 688549 & 4.9 & 4.873 & TST & \\
\hline CHEMBL1600906 & 688549 & 4.9 & 4.9028 & TST & \\
\hline CHEMBL1315095 & 688549 & 4.9 & 4.8699 & TST & \\
\hline CHEMBL1377235 & 688549 & 4.5 & 5.8901 & TST & \\
\hline CHEMBL1479550 & 688549 & 4.8 & 5.2607 & TST & \\
\hline CHEMBL297784 & 688549 & 6.0 & 5.2002 & TST & \\
\hline CHEMBL1497939 & 688549 & 6.3 & 5.6906 & TST & \\
\hline CHEMBL1401409 & 688549 & 4.9 & 5.0401 & TST & \\
\hline CHEMBL1507162 & 688549 & 4.7 & 4.7085 & TST & \\
\hline CHEMBL1473574 & 688549 & 5.7 & 5.0288 & TST & \\
\hline CHEMBL1386337 & 688549 & 4.5 & 5.0339 & TST & \\
\hline CHEMBL1514941 & 688549 & 5.0 & 5.5396 & TST & \\
\hline CHEMBL1527656 & 688549 & 5.0 & 4.99100 & 00000000005 & TST \\
\hline CHEMBL1513793 & 688549 & 5.0 & 5.2806 & TST & \\
\hline CHEMBL1336006 & 688549 & 5.4 & 5.0771 & TST & \\
\hline CHEMBL1412319 & 688549 & 5.2 & 5.36 & TST & \\
\hline CHEMBL1540520 & 688549 & 4.7 & 4.6893 & TST & \\
\hline CHEMBL1362869 & 688549 & 5.1 & 4.7061 & TST & \\
\hline CHEMBL1438469 & 688549 & 5.0 & 5.4174 & TST & \\
\hline CHEMBL1393648 & 688549 & 4.9 & 5.2832 & TST & \\
\hline CHEMBL1474624 & 688549 & 4.5 & 4.7632 & TST & \\
\hline CHEMBL1328533 & 688549 & 4.8 & 4.9648 & TST & \\
\hline CHEMBL1357140 & 688549 & 5.4 & 4.9659 & TST & \\
\hline CHEMBL1514498 & 688549 & 4.5 & 4.4848 & TST & \\
\hline CHEMBL1499845 & 688549 & 7.6498 & 4.7393 & TST & \\
\hline CHEMBL1475971 & 688549 & 5.2 & 4.7787 & TST & \\
\hline CHEMBL1366718 & 688549 & 4.9 & 5.2975 & TST & \\
\hline CHEMBL1579531 & 688549 & 6.5 & 5.2634 & TST & \\
\hline CHEMBL1498407 & 688549 & 4.5 & 4.9873 & TST & \\
\hline CHEMBL1494331 & 688549 & 4.8 & 5.0815 & TST & \\
\hline CHEMBL1395732 & 688549 & 4.5 & 4.7805 & TST & \\
\hline CHEMBL1452128 & 688549 & 5.0 & 4.8305 & TST & \\
\hline CHEMBL1503330 & 688549 & 8.1024 & 4.7949 & TST & \\
\hline CHEMBL1381328 & 688549 & 5.5 & 5.25299 & 9999999999 & TST \\
\hline CHEMBL1474489 & 688549 & 5.7 & 4.5389 & TST & \\
\hline CHEMBL1415140 & 688549 & 4.5 & 4.9771 & TST & \\
\hline CHEMBL1593752 & 688549 & 4.6 & 4.9721 & TST & \\
\hline CHEMBL1491438 & 688549 & 4.5 & 4.8376 & TST & \\
\hline CHEMBL1173823 & 688549 & 4.5 & 5.1113 & TST & \\
\hline CHEMBL1592589 & 688549 & 4.9 & 4.9487 & TST & \\
\hline CHEMBL1591406 & 688549 & 6.0 & 5.2131 & TST & \\
\hline CHEMBL1513241 & 688549 & 4.8 & 4.5489 & TST & \\
\hline CHEMBL1359371 & 688549 & 4.9 & 5.1747 & TST & \\
\hline CHEMBL1441480 & 688549 & 4.5 & 4.4619 & TST & \\
\hline
\end{tabular}




\begin{tabular}{|c|c|c|c|c|}
\hline \multicolumn{5}{|c|}{ Supplemental Table S2.txt } \\
\hline CHEMBL1341736 & 688549 & 4.45 & 5.2828 & TST \\
\hline CHEMBL 1605575 & 688549 & 4.8 & 5.0625 & TST \\
\hline CHEMBL1508694 & 688549 & 5.1 & 5.1863 & TST \\
\hline CHEMBL1459485 & 688549 & 4.5 & 4.2774 & TST \\
\hline CHEMBL1540025 & 688549 & 4.5 & 4.5597 & TST \\
\hline CHEMBL1326725 & 688549 & 4.5 & 4.648 & TST \\
\hline CHEMBL1346466 & 688549 & 4.9 & 5.0696 & TST \\
\hline CHEMBL1325504 & 688549 & 4.5 & 4.3687 & TST \\
\hline CHEMBL1397427 & 688549 & 4.7 & 4.9155 & TST \\
\hline CHEMBL1553370 & 688549 & 4.9 & 4.9286 & TST \\
\hline CHEMBL1355454 & 688549 & 4.5 & \multicolumn{2}{|c|}{4.946000000000001} \\
\hline CHEMBL1440282 & 688549 & 4.7 & 4.8299 & TST \\
\hline CHEMBL1318943 & 688549 & 5.3 & 5.1749 & TST \\
\hline CHEMBL1514486 & 688549 & 5.0 & 5.3531 & TST \\
\hline CHEMBL1477081 & 688549 & 5.4 & 5.3748 & TST \\
\hline CHEMBL1609446 & 688549 & 5.3 & 5.4176 & TST \\
\hline CHEMBL1338161 & 688549 & 4.6 & 5.2798 & TST \\
\hline CHEMBL1474861 & 688549 & 4.5 & 5.0254 & TST \\
\hline CHEMBL1531920 & 688549 & 4.45 & 4.503 & TST \\
\hline CHEMBL1400825 & 688549 & 4.6 & 4.6895 & TST \\
\hline CHEMBL1535951 & 688549 & 4.6 & 5.1262 & TST \\
\hline CHEMBL1519385 & 688549 & 4.45 & 5.1218 & TST \\
\hline CHEMBL1309799 & 688549 & 4.85 & 5.2332 & TST \\
\hline CHEMBL1610268 & 688549 & 4.9 & 5.2306 & TST \\
\hline CHEMBL1307575 & 688549 & 4.55 & 4.8775 & TST \\
\hline CHEMBL15192 & 688549 & 5.3 & 5.3949 & TST \\
\hline CHEMBL1321484 & 688549 & 4.45 & 4.8475 & TST \\
\hline CHEMBL1396228 & 688549 & 4.65 & 4.7245 & TST \\
\hline CHEMBL1552051 & 688549 & 4.9 & 4.8118 & TST \\
\hline CHEMBL1368218 & 688549 & 5.3 & 5.0416 & TST \\
\hline CHEMBL181633 & 688549 & 4.5 & 5.3222 & TST \\
\hline CHEMBL3194970 & 688549 & 4.6 & 5.3407 & TST \\
\hline CHEMBL1405122 & 688549 & 7.699 & 6.0494 & TST \\
\hline CHEMBL393136 & 688549 & 4.5 & 4.9214 & TST \\
\hline CHEMBL1518381 & 688549 & 4.8 & 5.2768 & TST \\
\hline CHEMBL259421 & 688549 & 5.6 & 4.9657 & TST \\
\hline CHEMBL1455239 & 688549 & 5.4 & 5.2226 & TST \\
\hline CHEMBL1553869 & 688549 & 4.9 & 4.8905 & TST \\
\hline CHEMBL1460920 & 688549 & 4.9 & 5.1708 & TST \\
\hline CHEMBL1317358 & 688549 & 4.9 & 4.8675 & TST \\
\hline CHEMBL1551155 & 688549 & 4.8 & 4.4846 & TST \\
\hline CHEMBL 1606755 & 688549 & 4.9 & 5.2323 & TST \\
\hline CHEMBL1536936 & 688549 & 6.05 & 5.3912 & TST \\
\hline CHEMBL1436334 & 688549 & 5.6 & 5.3464 & TST \\
\hline CHEMBL1515562 & 688549 & 5.0 & 5.1748 & TST \\
\hline CHEMBL1579696 & 688549 & 4.8 & 4.9189 & TST \\
\hline CHEMBL1512098 & 688549 & 5.15 & 4.824 & TST \\
\hline CHEMBL1599199 & 688549 & 5.2 & 5.5643 & TST \\
\hline
\end{tabular}




\begin{tabular}{|c|c|c|c|c|}
\hline & & & upplement & al Table S \\
\hline CHEMBL1594116 & 688549 & 4.6 & 5.0638 & TST \\
\hline CHEMBL1529733 & 688549 & 4.9 & 5.0718 & TST \\
\hline CHEMBL1438621 & 688549 & 5.0 & 4.5476 & TST \\
\hline CHEMBL1506771 & 688549 & 5.2 & 4.9247 & TST \\
\hline CHEMBL1560476 & 688549 & 8.0 & 5.1048 & TST \\
\hline CHEMBL597744 & 688549 & 5.1 & 5.2647 & TST \\
\hline CHEMBL1553745 & 688549 & 5.8 & 5.7047 & TST \\
\hline CHEMBL1343554 & 688549 & 4.9 & 5.6018 & TST \\
\hline CHEMBL20963 & 688549 & 4.6 & 4.8729 & TST \\
\hline CHEMBL1371242 & 688549 & 4.9 & 5.0751 & TST \\
\hline CHEMBL1373222 & 688549 & 5.1 & 5.2577 & TST \\
\hline CHEMBL1543818 & 688549 & 5.9 & 5.3298 & TST \\
\hline CHEMBL1300967 & 688549 & 4.5 & 4.7545 & TST \\
\hline CHEMBL1499545 & 688549 & 6.1 & 5.2931 & TST \\
\hline CHEMBL1593827 & 688549 & 4.5 & 4.4388 & TST \\
\hline CHEMBL1396684 & 688549 & 6.0 & 5.4899 & TST \\
\hline CHEMBL1358039 & 688549 & 4.6 & 4.6288 & TST \\
\hline CHEMBL1478440 & 688549 & 4.9 & 4.9015 & TST \\
\hline CHEMBL1527624 & 688549 & 4.8 & 5.3672 & TST \\
\hline CHEMBL1532568 & 688549 & 4.7 & 4.9007 & TST \\
\hline CHEMBL1303340 & 688549 & 6.05 & 5.9526 & TST \\
\hline CHEMBL1310104 & 688549 & 4.9 & 4.7275 & TST \\
\hline CHEMBL1406438 & 688549 & 4.6 & 4.6848 & TST \\
\hline CHEMBL1516585 & 688549 & 4.5 & 4.5856 & TST \\
\hline CHEMBL1496341 & 688549 & 4.8 & 4.591 & TST \\
\hline CHEMBL 242171 & 688549 & 4.9 & 5.2367 & TST \\
\hline CHEMBL1402233 & 688549 & 5.0 & 4.9141 & TST \\
\hline CHEMBL1402759 & 688549 & 4.5 & 4.6908 & TST \\
\hline CHEMBL602970 & 688549 & 5.0 & 5.0733 & TST \\
\hline CHEMBL1404773 & 688549 & 4.5 & 5.2163 & TST \\
\hline CHEMBL1590140 & 688549 & 5.65 & 5.3447 & TST \\
\hline CHEMBL1358908 & 688549 & 6.5 & 5.51 & TST \\
\hline CHEMBL1482054 & 688549 & 4.5 & 4.7841 & TST \\
\hline CHEMBL1377351 & 688549 & 4.45 & 5.2244 & TST \\
\hline CHEMBL1445393 & 688549 & 5.65 & 5.6089 & TST \\
\hline CHEMBL1592716 & 688549 & 5.3 & 4.926 & TST \\
\hline CHEMBL1255867 & 688549 & 4.9 & 5.1958 & TST \\
\hline CHEMBL1325260 & 688549 & 4.7 & 5.1635 & TST \\
\hline CHEMBL1775009 & 688549 & 5.3 & 5.0658 & TST \\
\hline CHEMBL199194 & 688549 & 6.0 & 5.3163 & TST \\
\hline CHEMBL1514320 & 688549 & 4.9 & $5.0310 e$ & 0000000001 \\
\hline CHEMBL1451058 & 688549 & 5.2 & 5.152 & TST \\
\hline CHEMBL1377820 & 688549 & 5.1 & 4.8777 & TST \\
\hline CHEMBL1432762 & 688549 & 4.95 & 4.9049 & TST \\
\hline CHEMBL1303457 & 688549 & 4.95 & 5.2719 & TST \\
\hline CHEMBL1605540 & 688549 & 5.0 & 5.114 & TST \\
\hline CHEMBL1434411 & 688549 & 4.5 & 4.4853 & TST \\
\hline CHEMBL1343727 & 688549 & 4.7 & 5.0574 & TST \\
\hline
\end{tabular}




\begin{tabular}{|c|c|c|c|c|}
\hline \multicolumn{5}{|c|}{ Supplemental Table S2.txt } \\
\hline CHEMBL1437268 & 688549 & 5.2 & 5.4193 & TST \\
\hline CHEMBL1449808 & 688549 & 5.7 & 4.8582 & TST \\
\hline CHEMBL1319432 & 688549 & 5.0 & 5.0457 & TST \\
\hline CHEMBL1477253 & 688549 & 4.5 & 4.9436 & TST \\
\hline CHEMBL1321836 & 688549 & 5.1 & 5.0159 & TST \\
\hline CHEMBL1449750 & 688549 & 5.0 & 4.8457 & TST \\
\hline CHEMBL1492738 & 688549 & 5.0 & 5.0063 & TST \\
\hline CHEMBL1346857 & 688549 & 4.9 & 5.1001 & TST \\
\hline CHEMBL1314036 & 688549 & 4.45 & 4.7074 & TST \\
\hline CHEMBL65 & 688549 & 7.6003 & 6.0099 & TST \\
\hline CHEMBL1425650 & 688549 & 5.45 & 5.2311 & TST \\
\hline CHEMBL1525987 & 688549 & 4.8 & 5.5813 & TST \\
\hline CHEMBL1316301 & 688549 & 5.2 & 5.1319 & TST \\
\hline CHEMBL1325549 & 688549 & 4.5 & 5.0685 & TST \\
\hline CHEMBL411085 & 688549 & 4.9 & 4.7699 & TST \\
\hline CHEMBL1573012 & 688549 & 4.8 & 5.0577 & TST \\
\hline CHEMBL1351433 & 688549 & 5.5 & 5.2046 & TST \\
\hline CHEMBL1482231 & 688549 & 4.8 & 4.7716 & TST \\
\hline CHEMBL1598938 & 688549 & 4.75 & 4.7256 & TST \\
\hline CHEMBL1465340 & 688549 & 4.5 & 5.1544 & TST \\
\hline CHEMBL1487415 & 688549 & 5.0 & 4.8761 & TST \\
\hline CHEMBL3209388 & 688549 & 8.3468 & 5.7723 & TST \\
\hline CHEMBL1531627 & 688549 & 4.6 & 5.5124 & TST \\
\hline CHEMBL1333907 & 688549 & 5.0 & 5.1836 & TST \\
\hline CHEMBL1305122 & 688549 & 4.45 & 4.8629 & TST \\
\hline CHEMBL1361016 & 688549 & 4.6 & 4.7348 & TST \\
\hline CHEMBL1494309 & 688549 & 4.8 & 4.9192 & TST \\
\hline CHEMBL1541839 & 688549 & 6.4 & 4.9806 & TST \\
\hline CHEMBL1553192 & 688549 & 5.1 & 4.5673 & TST \\
\hline CHEMBL1377224 & 688549 & 4.9 & 5.1152 & TST \\
\hline CHEMBL1455316 & 688549 & 4.6 & 5.0458 & TST \\
\hline CHEMBL1527282 & 688549 & 4.9 & 5.0703 & TST \\
\hline CHEMBL1346468 & 688549 & 4.9 & 5.0209 & TST \\
\hline CHEMBL1501554 & 688549 & 4.6 & 4.7636 & TST \\
\hline CHEMBL1555401 & 688549 & 6.5 & 5.8983 & TST \\
\hline CHEMBL1603853 & 688549 & 5.6 & 5.5165 & TST \\
\hline CHEMBL 1464080 & 688549 & 4.7 & 4.9107 & TST \\
\hline CHEMBL1598438 & 688549 & 4.7 & 4.4874 & TST \\
\hline CHEMBL1398497 & 688549 & 4.7 & 4.9072 & TST \\
\hline CHEMBL1582912 & 688549 & 4.8 & 5.0534 & TST \\
\hline CHEMBL1409884 & 688549 & 5.3 & 5.1772 & TST \\
\hline CHEMBL 1375780 & 688549 & 4.8 & 4.9761 & TST \\
\hline CHEMBL1568666 & 688549 & 4.7 & 5.2388 & TST \\
\hline CHEMBL1367553 & 688549 & 4.95 & 5.1073 & TST \\
\hline CHEMBL1605478 & 688549 & 5.0 & 5.1756 & TST \\
\hline CHEMBL1358092 & 688549 & 4.5 & 4.9356 & TST \\
\hline CHEMBL1553236 & 688549 & 4.45 & 4.8886 & TST \\
\hline CHEMBL1550087 & 688549 & 5.0 & 4.7682 & TST \\
\hline
\end{tabular}




\begin{tabular}{|c|c|c|c|c|}
\hline & & & pplement & \\
\hline CHEMBL1519979 & 688549 & 4.6 & 4.9052 & TST \\
\hline CHEMBL104264 & 688549 & 4.6 & 5.0699 & TST \\
\hline CHEMBL546597 & 688549 & 4.5 & 4.8118 & TST \\
\hline CHEMBL1365570 & 688549 & 5.1 & 5.0791 & TST \\
\hline CHEMBL1530958 & 688549 & 4.7 & 5.5937 & TST \\
\hline CHEMBL1516021 & 688549 & 5.9 & 5.0467 & TST \\
\hline CHEMBL1457402 & 688549 & 4.9 & 5.065 & TST \\
\hline CHEMBL1433891 & 688549 & 4.85 & 5.0011 & TST \\
\hline CHEMBL1545634 & 688549 & 6.1 & 5.4048 & TST \\
\hline CHEMBL1325149 & 688549 & 5.5 & 5.2625 & TST \\
\hline CHEMBL1359216 & 688549 & 6.05 & 5.307 & TST \\
\hline CHEMBL1333734 & 688549 & 4.9 & 4.6092 & TST \\
\hline CHEMBL1579513 & 688549 & 4.9 & 4.9119 & TST \\
\hline CHEMBL3196791 & 688549 & 4.45 & 5.6056 & TST \\
\hline CHEMBL1591493 & 688549 & 4.5 & 5.5324 & TST \\
\hline CHEMBL1570219 & 688549 & 4.9 & 5.0089 & TST \\
\hline CHEMBL1606417 & 688549 & 4.8 & 4.6153 & TST \\
\hline CHEMBL1607465 & 688549 & 4.5 & 5.2755 & TST \\
\hline CHEMBL1476411 & 688549 & 5.25 & 4.7303 & TST \\
\hline CHEMBL1554931 & 688549 & 4.9 & 4.867 & TST \\
\hline CHEMBL1302365 & 688549 & 5.0 & 5.1922 & TST \\
\hline CHEMBL1408656 & 688549 & 4.5 & 4.8705 & TST \\
\hline CHEMBL1559782 & 688549 & 4.6 & 4.9351 & TST \\
\hline CHEMBL1413019 & 688549 & 4.7 & 4.8973 & TST \\
\hline CHEMBL1521586 & 688549 & 5.55 & 5.1317 & TST \\
\hline CHEMBL1367968 & 688549 & 4.5 & 5.1752 & TST \\
\hline CHEMBL1564031 & 688549 & 4.5 & 4.5565 & TST \\
\hline CHEMBL1426379 & 688549 & 4.5 & 4.9313 & TST \\
\hline CHEMBL1575967 & 688549 & 4.5 & 5.1893 & TST \\
\hline CHEMBL1528265 & 688549 & 4.5 & 4.8085 & TST \\
\hline CHEMBL1499524 & 688549 & 6.1 & 5.4954 & TST \\
\hline CHEMBL1557788 & 688549 & 4.5 & 4.7836 & TST \\
\hline CHEMBL1372744 & 688549 & 4.5 & 4.5746 & TST \\
\hline CHEMBL1524484 & 688549 & 6.5 & 5.5587 & TST \\
\hline CHEMBL1476762 & 688549 & 4.7 & 5.1825 & TST \\
\hline CHEMBL320247 & 688549 & 5.3 & 5.0334 & TST \\
\hline CHEMBL1412761 & 688549 & 4.5 & 5.2761 & TST \\
\hline CHEMBL1472652 & 688549 & 5.1 & 4.9827 & TST \\
\hline CHEMBL1440478 & 688549 & 4.9 & 5.2075 & TST \\
\hline CHEMBL1539502 & 688549 & 5.4 & 5.3474 & TST \\
\hline CHEMBL1501431 & 688549 & 4.5 & 4.8947 & TST \\
\hline CHEMBL1518566 & 688549 & 4.6 & 4.7598 & TST \\
\hline CHEMBL1581560 & 688549 & 5.0 & 4.9171 & TST \\
\hline CHEMBL1411211 & 688549 & 4.75 & 5.0842 & TST \\
\hline CHEMBL44 & 688549 & 5.0 & 5.5395 & TST \\
\hline CHEMBL1394362 & 688549 & 4.5 & 4.6398 & TST \\
\hline CHEMBL1397186 & 688549 & 4.7 & 4.7316 & TST \\
\hline CHEMBL1450286 & 688549 & 4.95 & 5.2168 & TST \\
\hline
\end{tabular}




\begin{tabular}{|c|c|c|c|c|}
\hline \multicolumn{5}{|c|}{ Supplemental Table S2.txt } \\
\hline CHEMBL 3198964 & 688549 & 4.9 & 5.2768 & TST \\
\hline CHEMBL1451926 & 688549 & 5.0 & 4.8957 & TST \\
\hline CHEMBL1443124 & 688549 & 4.9 & 4.9572 & TST \\
\hline CHEMBL1318900 & 688549 & 5.65 & 4.3725 & TST \\
\hline CHEMBL3194140 & 688549 & 8.0 & 5.4256 & TST \\
\hline CHEMBL1327501 & 688549 & 4.9 & 4.8832 & TST \\
\hline CHEMBL1304647 & 688549 & 5.35 & 5.2343 & TST \\
\hline CHEMBL1544832 & 688549 & 4.6 & 5.1391 & TST \\
\hline CHEMBL1330852 & 688549 & 4.95 & 5.0071 & TST \\
\hline CHEMBL1371093 & 688549 & 4.7 & 4.891 & TST \\
\hline CHEMBL1370549 & 688549 & 5.0 & 4.8098 & TST \\
\hline CHEMBL1433832 & 688549 & 4.6 & 4.76 & TST \\
\hline CHEMBL1492461 & 688549 & 4.7 & 5.1712 & TST \\
\hline CHEMBL1404450 & 688549 & 4.7 & 5.4597 & TST \\
\hline CHEMBL1406513 & 688549 & 5.1 & 4.954 & TST \\
\hline CHEMBL1610241 & 688549 & 4.6 & 5.3238 & TST \\
\hline CHEMBL1354290 & 688549 & 5.0 & 4.7954 & TST \\
\hline CHEMBL1555823 & 688549 & 5.5 & 5.0959 & TST \\
\hline CHEMBL1605488 & 688549 & 4.7 & 5.1156 & TST \\
\hline CHEMBL1591595 & 688549 & 4.45 & 5.0217 & TST \\
\hline CHEMBL1534466 & 688549 & 4.8 & 5.0073 & TST \\
\hline CHEMBL1412054 & 688549 & 4.9 & 5.1264 & TST \\
\hline CHEMBL1321323 & 688549 & 4.45 & 4.7738 & TST \\
\hline CHEMBL1495505 & 688549 & 5.0 & 5.2448 & TST \\
\hline CHEMBL1437197 & 688549 & 4.7 & 5.1317 & TST \\
\hline CHEMBL1365444 & 688549 & 4.5 & 4.9814 & TST \\
\hline CHEMBL1436583 & 688549 & 4.7 & 4.9529 & TST \\
\hline CHEMBL1561450 & 688549 & 8.1024 & 4.8595 & TST \\
\hline CHEMBL1482664 & 688549 & 4.45 & 5.0399 & TST \\
\hline CHEMBL1388376 & 688549 & 4.5 & 5.4409 & TST \\
\hline CHEMBL1374420 & 688549 & 8.301 & 5.2887 & TST \\
\hline CHEMBL1316156 & 688549 & 4.5 & 4.8593 & TST \\
\hline CHEMBL1421833 & 688549 & 5.9 & 5.3408 & TST \\
\hline CHEMBL1361869 & 688549 & 4.6 & 4.8262 & TST \\
\hline CHEMBL1324842 & 688549 & 5.8 & 5.0923 & TST \\
\hline CHEMBL1593545 & 688549 & 4.8 & 4.9499 & TST \\
\hline CHEMBL3192913 & 688549 & 5.0 & 4.9258 & TST \\
\hline CHEMBL1558102 & 688549 & 4.9 & 5.0646 & TST \\
\hline CHEMBL1539301 & 688549 & 4.9 & 5.2076 & TST \\
\hline CHEMBL1593924 & 688549 & 4.9 & 4.865 & TST \\
\hline CHEMBL3193799 & 688549 & 4.9 & 5.2666 & TST \\
\hline CHEMBL 259805 & 688549 & 5.7 & 5.3667 & TST \\
\hline CHEMBL1371014 & 688549 & 4.8 & 5.2325 & TST \\
\hline CHEMBL1597921 & 688549 & 4.9 & 4.9011 & TST \\
\hline CHEMBL1422210 & 688549 & 4.9 & 4.9403 & TST \\
\hline CHEMBL1543947 & 688549 & 4.5 & 4.5784 & TST \\
\hline CHEMBL1570788 & 688549 & 4.8 & 5.0515 & TST \\
\hline CHEMBL1600780 & 688549 & 4.4 & 4.5787 & TST \\
\hline
\end{tabular}




\begin{tabular}{|c|c|c|c|c|c|}
\hline \multirow[b]{2}{*}{ CHEMBL3190834 } & \multirow{2}{*}{688549} & \multicolumn{4}{|c|}{ ble Sz. } \\
\hline & & 4.9 & 5.3259 & TST & \\
\hline CHEMBL1256914 & 688549 & 4.5 & \multicolumn{2}{|c|}{5.0089999999999995} & TST \\
\hline CHEMBL1591718 & 688549 & 5.4 & 4.9714 & TST & \\
\hline CHEMBL1477937 & 688549 & 4.5 & 5.2605 & TST & \\
\hline CHEMBL1594175 & 688549 & 6.5 & 5.5702 & TST & \\
\hline CHEMBL1321213 & 688549 & 5.0 & 4.9275 & TST & \\
\hline CHEMBL1350574 & 688549 & 7.699 & 5.2275 & TST & \\
\hline CHEMBL1347716 & 688549 & 4.6 & 4.8245 & TST & \\
\hline CHEMBL1598906 & 688549 & 6.25 & 5.8336 & TST & \\
\hline CHEMBL1472809 & 688549 & 4.5 & 4.6586 & TST & \\
\hline CHEMBL1342119 & 688549 & 5.3 & 4.993 & TST & \\
\hline CHEMBL 260560 & 688549 & 5.0 & 5.1233 & TST & \\
\hline CHEMBL1979948 & 688549 & 4.5 & 5.4016 & TST & \\
\hline CHEMBL1361294 & 688549 & 4.6 & 4.9617 & TST & \\
\hline CHEMBL1255733 & 688549 & 5.7 & 5.5858 & TST & \\
\hline CHEMBL1403488 & 688549 & 4.5 & 4.5756 & TST & \\
\hline CHEMBL1427823 & 688549 & 5.1 & 4.7857 & TST & \\
\hline CHEMBL582473 & 688549 & 4.9 & 4.7033 & TST & \\
\hline CHEMBL404313 & 688549 & 4.5 & 5.5469 & TST & \\
\hline CHEMBL1519056 & 688549 & 4.7 & 5.0613 & TST & \\
\hline CHEMBL1533227 & 688549 & 6.2 & 5.1301 & TST & \\
\hline CHEMBL1597643 & 688549 & 4.7 & 5.0459 & TST & \\
\hline CHEMBL1397959 & 688549 & 4.7 & 4.6914 & TST & \\
\hline CHEMBL1433343 & 688549 & 5.0 & 4.9812 & TST & \\
\hline CHEMBL1476639 & 688549 & 4.95 & 4.8376 & TST & \\
\hline CHEMBL1436250 & 688549 & 4.9 & 4.7587 & TST & \\
\hline CHEMBL3199594 & 688549 & 5.2 & 5.5818 & TST & \\
\hline CHEMBL1434180 & 688549 & 4.7 & 4.4442 & TST & \\
\hline CHEMBL1450878 & 688549 & 4.9 & 4.9164 & TST & \\
\hline CHEMBL530049 & 688549 & 4.8 & 5.0775 & TST & \\
\hline CHEMBL1348360 & 688549 & 4.65 & 5.3169 & TST & \\
\hline CHEMBL1369528 & 688549 & 5.2 & 5.073 & TST & \\
\hline CHEMBL1567403 & 688549 & 4.5 & 4.8198 & TST & \\
\hline CHEMBL1610977 & 688549 & 4.9 & 5.0047 & TST & \\
\hline CHEMBL1381784 & 688549 & 4.8 & 5.3538 & TST & \\
\hline CHEMBL3213303 & 688549 & 4.9 & 4.9373 & TST & \\
\hline CHEMBL1395731 & 688549 & 4.9 & 5.1454 & TST & \\
\hline CHEMBL1496103 & 688549 & 4.5 & 4.417 & TST & \\
\hline CHEMBL1374746 & 688549 & 5.2 & 5.1137 & TST & \\
\hline CHEMBL1369782 & 688549 & 6.25 & 5.3326 & TST & \\
\hline CHEMBL1477267 & 688549 & 5.2 & 5.3422 & TST & \\
\hline CHEMBL1554153 & 688549 & 5.55 & 4.8718 & TST & \\
\hline CHEMBL569088 & 688549 & 4.5 & 4.6459 & TST & \\
\hline CHEMBL1549844 & 688549 & 8.2007 & 5.6992 & TST & \\
\hline CHEMBL1506246 & 688549 & 4.5 & 4.8064 & TST & \\
\hline CHEMBL1477031 & 688549 & 4.95 & 5.2093 & TST & \\
\hline CHEMBL1520523 & 688549 & 4.45 & 4.6497 & TST & \\
\hline CHEMBL 274438 & 688549 & 4.5 & 5.3027 & TST & \\
\hline & & & & e 23146 & \\
\hline
\end{tabular}




\begin{tabular}{|c|c|c|c|c|c|}
\hline \\
\hline CHEMBL1517068 & 688549 & 4.9 & 4.9214 & TST & \\
\hline CHEMBL1436476 & 688549 & 4.55 & 4.8763 & TST & \\
\hline CHEMBL1441225 & 688549 & 4.5 & 4.8829 & TST & \\
\hline CHEMBL1354701 & 688549 & 4.5 & 4.2956 & TST & \\
\hline CHEMBL1362198 & 688549 & 5.0 & 5.3576 & TST & \\
\hline CHEMBL1444953 & 688549 & 5.0 & 4.9985 & TST & \\
\hline CHEMBL1448086 & 688549 & 4.9 & 4.8472 & TST & \\
\hline CHEMBL1374108 & 688549 & 4.9 & 5.1004 & TST & \\
\hline CHEMBL1521403 & 688549 & 4.5 & 4.6003 & TST & \\
\hline CHEMBL1609183 & 688549 & 4.9 & 5.0684 & TST & \\
\hline CHEMBL1473819 & 688549 & 5.0 & 4.971 & TST & \\
\hline CHEMBL1301175 & 688549 & 4.9 & 5.1243 & TST & \\
\hline CHEMBL1316470 & 688549 & 4.5 & 5.4751 & TST & \\
\hline CHEMBL1319095 & 688549 & 5.0 & 5.205 & TST & \\
\hline CHEMBL1311916 & 688549 & 6.3 & 5.4143 & TST & \\
\hline CHEMBL1418548 & 688549 & 4.8 & 5.007 & TST & \\
\hline CHEMBL1367331 & 688549 & 4.9 & 5.2288 & TST & \\
\hline CHEMBL1435475 & 688549 & 4.5 & 5.0495 & TST & \\
\hline CHEMBL1437166 & 688549 & 4.9 & 5.1596 & TST & \\
\hline CHEMBL475335 & 688549 & 4.5 & 5.2129 & TST & \\
\hline CHEMBL1613541 & 688549 & 8.2007 & 5.21700 & j0000000005 & TST \\
\hline CHEMBL1351105 & 688549 & 4.8 & 5.4595 & TST & \\
\hline CHEMBL1588503 & 688549 & 5.0 & 4.7501 & TST & \\
\hline CHEMBL1560366 & 688549 & 4.5 & 4.6602 & TST & \\
\hline CHEMBL1518672 & 688549 & 5.0 & 5.065 & TST & \\
\hline CHEMBL1372039 & 688549 & 4.9 & 4.7155 & TST & \\
\hline CHEMBL1325619 & 688549 & 4.85 & 4.5146 & TST & \\
\hline CHEMBL1320103 & 688549 & 4.6 & 4.7772 & TST & \\
\hline CHEMBL1354564 & 688549 & 4.5 & 4.5337 & TST & \\
\hline CHEMBL1360037 & 688549 & 4.9 & 5.044 & TST & \\
\hline CHEMBL1317325 & 688549 & 4.9 & 5.1267 & TST & \\
\hline CHEMBL1433819 & 688549 & 4.45 & 4.6368 & TST & \\
\hline CHEMBL1356399 & 688549 & 4.7 & 5.0058 & TST & \\
\hline CHEMBL1333766 & 688549 & 5.0 & 5.0235 & TST & \\
\hline CHEMBL1356125 & 688549 & 4.5 & 4.8188 & TST & \\
\hline CHEMBL1611241 & 688549 & 4.8 & 5.4534 & TST & \\
\hline CHEMBL3193065 & 688549 & 4.6 & 5.2091 & TST & \\
\hline CHEMBL1356020 & 688549 & 4.7 & 4.8925 & TST & \\
\hline CHEMBL1413931 & 688549 & 4.8 & 4.615 & TST & \\
\hline CHEMBL1337846 & 688549 & 5.0 & 5.2232 & TST & \\
\hline CHEMBL1594545 & 688549 & 4.7 & 4.9124 & TST & \\
\hline CHEMBL1603850 & 688549 & 4.5 & 5.12200 & 0000000001 & TST \\
\hline CHEMBL1396463 & 688549 & 4.5 & 4.4951 & TST & \\
\hline CHEMBL1318014 & 688549 & 4.6 & 4.7102 & TST & \\
\hline CHEMBL 1487567 & 688549 & 4.6 & 4.5034 & TST & \\
\hline CHEMBL1330972 & 688549 & 5.8 & 5.1763 & TST & \\
\hline CHEMBL1574769 & 688549 & 4.9 & 5.0499 & TST & \\
\hline CHEMBL1553366 & 688549 & 4.6 & 4.5912 & TST & \\
\hline
\end{tabular}




\begin{tabular}{|c|c|c|c|c|c|}
\hline \multirow[b]{2}{*}{ CHEMBL 3192283} & \multicolumn{5}{|c|}{ Supplemental Table S2.txt } \\
\hline & 688549 & 7.8013 & 5.4175 & TST & \\
\hline CHEMBL1388947 & 688549 & 4.9 & 4.7567 & TST & \\
\hline CHEMBL1572191 & 688549 & 4.9 & 4.6658 & TST & \\
\hline CHEMBL1364205 & 688549 & 4.9 & 4.8512 & TST & \\
\hline CHEMBL1351610 & 688549 & 4.9 & 4.7633 & TST & \\
\hline CHEMBL1461857 & 688549 & 5.3 & 4.9978 & TST & \\
\hline CHEMBL1554622 & 688549 & 4.6 & 4.7224 & TST & \\
\hline CHEMBL1492954 & 688549 & 4.9 & 5.1479 & TST & \\
\hline CHEMBL1366181 & 688549 & 4.7 & 5.1899 & TST & \\
\hline CHEMBL1350224 & 688549 & 8.0506 & 5.3865 & TST & \\
\hline CHEMBL 1374260 & 688549 & 4.8 & 4.8592 & TST & \\
\hline CHEMBL1445710 & 688549 & 4.45 & 4.67899 & 9999999999 & TST \\
\hline CHEMBL1407945 & 688549 & 4.8 & 4.6447 & TST & \\
\hline CHEMBL1383822 & 688549 & 5.65 & 5.0622 & TST & \\
\hline CHEMBL1361506 & 688549 & 5.4 & 4.9713 & TST & \\
\hline CHEMBL1529948 & 688549 & 4.5 & 4.9828 & TST & \\
\hline CHEMBL1397552 & 688549 & 4.7 & 4.9841 & TST & \\
\hline CHEMBL1439033 & 688549 & 5.0 & 5.4183 & TST & \\
\hline CHEMBL1513494 & 688549 & 4.5 & 5.0343 & TST & \\
\hline CHEMBL1573866 & 688549 & 5.0 & 4.8865 & TST & \\
\hline CHEMBL1354621 & 688549 & 5.6 & 5.0753 & TST & \\
\hline CHEMBL1579670 & 688549 & 5.3 & 5.4013 & TST & \\
\hline CHEMBL1964290 & 809227 & 4.6 & 5.1931 & TRN & \\
\hline CHEMBL213505 & 809227 & 8.5 & 7.7796 & TRN & \\
\hline CHEMBL202721 & 809227 & 4.5 & 5.6462 & TRN & \\
\hline CHEMBL1987034 & 809227 & 8.4 & 8.2009 & TRN & \\
\hline CHEMBL1980435 & 809227 & 6.7 & 6.4912 & TRN & \\
\hline CHEMBL377383 & 809227 & 4.6 & 4.6055 & TRN & \\
\hline CHEMBL 2005886 & 809227 & 7.3 & 7.0619 & TRN & \\
\hline CHEMBL481491 & 809227 & 4.6 & 5.2812 & TST & \\
\hline CHEMBL1682345 & 809227 & 4.6 & 5.1514 & TRN & \\
\hline CHEMBL1973142 & 809227 & 5.7 & 5.3549 & TRN & \\
\hline CHEMBL388311 & 809227 & 7.6 & 8.157 & TRN & \\
\hline CHEMBL1973145 & 809227 & 8.1 & 7.83 & TRN & \\
\hline CHEMBL1982924 & 809227 & 6.4 & 6.812 & TRN & \\
\hline CHEMBL 2005936 & 809227 & 4.6 & 5.1606 & TRN & \\
\hline CHEMBL1807515 & 809227 & 7.2 & 7.62299 & 9999999999 & TRN \\
\hline CHEMBL1964948 & 809227 & 4.5 & 4.4905 & TRN & \\
\hline CHEMBL1971141 & 809227 & 8.0 & 6.3071 & TRN & \\
\hline CHEMBL1995813 & 809227 & 6.5 & 7.2246 & TRN & \\
\hline CHEMBL1979718 & 809227 & 4.6 & 5.3049 & TRN & \\
\hline CHEMBL206236 & 809227 & 4.6 & 4.9229 & TRN & \\
\hline CHEMBL523823 & 809227 & 4.6 & 4.3259 & TST & \\
\hline CHEMBL1973178 & 809227 & 8.9 & 8.7234 & TRN & \\
\hline CHEMBL1987430 & 809227 & 4.5 & 4.5551 & TRN & \\
\hline CHEMBL 244378 & 809227 & 6.7 & 7.1261 & TRN & \\
\hline CHEMBL1988778 & 809227 & 8.5 & 9.1848 & TRN & \\
\hline CHEMBL2001957 & 809227 & 4.6 & 4.6453 & TRN & \\
\hline
\end{tabular}




\begin{tabular}{|c|c|c|c|c|}
\hline \multicolumn{5}{|c|}{ Supplemental Table S2.txt } \\
\hline CHEMBL1969372 & 809227 & 4.6 & 4.9842 & TRN \\
\hline CHEMBL1993413 & 809227 & 4.6 & 5.3505 & TRN \\
\hline CHEMBL1990583 & 809227 & 6.6 & 6.2832 & TRN \\
\hline CHEMBL1986943 & 809227 & 7.9 & 7.9002 & TRN \\
\hline CHEMBL289959 & 809227 & 3.6 & 4.2012 & TRN \\
\hline CHEMBL 2006263 & 809227 & 4.6 & 4.9532 & TST \\
\hline CHEMBL1993584 & 809227 & 4.6 & 4.7706 & TRN \\
\hline CHEMBL1986263 & 809227 & 6.6 & 7.0413 & TRN \\
\hline CHEMBL 2000114 & 809227 & 5.9 & 5.4601 & TRN \\
\hline CHEMBL210618 & 809227 & 4.6 & 4.5014 & TRN \\
\hline CHEMBL1986265 & 809227 & 4.5 & 4.8936 & TRN \\
\hline CHEMBL1971172 & 809227 & 6.6 & 6.7696 & TRN \\
\hline CHEMBL1975647 & 809227 & 4.6 & 5.3194 & TRN \\
\hline CHEMBL1968380 & 809227 & 4.6 & 4.677 & TRN \\
\hline CHEMBL1964644 & 809227 & 4.6 & 4.4259 & TRN \\
\hline CHEMBL1991734 & 809227 & 6.4 & 5.4456 & TST \\
\hline CHEMBL1981782 & 809227 & 4.6 & 4.7411 & TRN \\
\hline CHEMBL1977681 & 809227 & 6.8 & 6.1199 & TRN \\
\hline CHEMBL1990912 & 809227 & 4.6 & 5.0049 & TRN \\
\hline CHEMBL1991782 & 809227 & 3.2 & 3.5771 & TRN \\
\hline CHEMBL1983348 & 809227 & 5.7 & 5.9935 & TRN \\
\hline CHEMBL1995592 & 809227 & 6.2 & 5.9001 & TST \\
\hline CHEMBL 1974480 & 809227 & 6.2 & 5.2751 & TRN \\
\hline CHEMBL 2006493 & 809227 & 4.6 & 4.4409 & TST \\
\hline CHEMBL1986177 & 809227 & 4.5 & 4.8524 & TRN \\
\hline CHEMBL1983449 & 809227 & 4.6 & 4.7427 & TRN \\
\hline CHEMBL1992323 & 809227 & 4.6 & 4.4224 & TRN \\
\hline CHEMBL1969735 & 809227 & 4.6 & 4.6736 & TRN \\
\hline CHEMBL 2003524 & 809227 & 4.6 & 5.1701 & TST \\
\hline CHEMBL 2002649 & 809227 & 7.1 & 6.5946 & TRN \\
\hline CHEMBL1983589 & 809227 & 7.5 & 6.8143 & TRN \\
\hline CHEMBL1989423 & 809227 & 5.4 & 4.4017 & TST \\
\hline CHEMBL1985367 & 809227 & 4.5 & 5.4424 & TST \\
\hline CHEMBL1996510 & 809227 & 4.5 & 5.0724 & TST \\
\hline CHEMBL437747 & 809227 & 5.8 & 5.3446 & TRN \\
\hline CHEMBL 2005718 & 809227 & 7.1 & 6.8489 & TRN \\
\hline CHEMBL 2001584 & 809227 & 4.5 & 4.4991 & TRN \\
\hline CHEMBL507936 & 809227 & 7.3 & 7.7186 & TRN \\
\hline CHEMBL1971227 & 809227 & 5.7 & 4.6902 & TST \\
\hline CHEMBL104264 & 809227 & 4.6 & 5.0811 & TST \\
\hline CHEMBL1967998 & 809227 & 7.4 & 7.6375 & TRN \\
\hline CHEMBL1994321 & 809227 & 8.2 & 8.0762 & TRN \\
\hline CHEMBL1978562 & 809227 & 6.2 & 5.2455 & TST \\
\hline CHEMBL1997129 & 809227 & 6.1 & 6.0906 & TRN \\
\hline CHEMBL1984788 & 809227 & 6.0 & 5.4352 & TRN \\
\hline CHEMBL451964 & 809227 & 4.6 & 4.5106 & TRN \\
\hline CHEMBL1964307 & 809227 & 8.4 & 7.7913 & TRN \\
\hline CHEMBL1989471 & 809227 & 5.5 & 5.5587 & TST \\
\hline
\end{tabular}




\begin{tabular}{|c|c|c|c|c|}
\hline & & & upplemen & al $\mathrm{T}$ \\
\hline CHEMBL2002099 & 809227 & 4.5 & 4.5534 & TRN \\
\hline CHEMBL 2000508 & 809227 & 4.6 & 4.2217 & TRN \\
\hline CHEMBL1971694 & 809227 & 4.6 & 4.6773 & TST \\
\hline CHEMBL 2001547 & 809227 & 4.6 & 4.494 & TRN \\
\hline CHEMBL 210928 & 809227 & 4.6 & 4.3704 & TRN \\
\hline CHEMBL1978195 & 809227 & 4.5 & 4.3256 & TRN \\
\hline CHEMBL1994361 & 809227 & 4.6 & 4.4418 & TRN \\
\hline CHEMBL1986603 & 809227 & 4.6 & 4.738 & TST \\
\hline CHEMBL1972840 & 809227 & 6.4 & 5.5095 & TRN \\
\hline CHEMBL 2003286 & 809227 & 4.6 & 4.2987 & TRN \\
\hline CHEMBL1979318 & 809227 & 6.5 & 5.0465 & TRN \\
\hline CHEMBL206382 & 809227 & 4.6 & 4.5873 & TRN \\
\hline CHEMBL1998585 & 809227 & 8.7 & 8.0341 & TRN \\
\hline CHEMBL127898 & 809227 & 6.2 & 4.7565 & TST \\
\hline CHEMBL519697 & 809227 & 5.8 & 4.8769 & TST \\
\hline CHEMBL 2004934 & 809227 & 4.6 & 4.7009 & TRN \\
\hline CHEMBL1987261 & 809227 & 8.0 & 6.5966 & TRN \\
\hline CHEMBL 2000652 & 809227 & 9.0 & 8.785 & TRN \\
\hline CHEMBL1977619 & 809227 & 3.6 & 3.9335 & TST \\
\hline CHEMBL1996345 & 809227 & 4.5 & 4.6418 & TST \\
\hline CHEMBL1975128 & 809227 & 6.0 & 5.3968 & TRN \\
\hline CHEMBL 2004025 & 809227 & 4.5 & 5.5934 & TST \\
\hline CHEMBL1996048 & 809227 & 4.6 & 5.2047 & TST \\
\hline CHEMBL461876 & 809227 & 4.6 & 4.6472 & TST \\
\hline CHEMBL1965033 & 809227 & 6.9 & 5.831 & TRN \\
\hline CHEMBL 2001485 & 809227 & 8.4 & 7.4268 & TRN \\
\hline CHEMBL504950 & 809227 & 4.6 & 5.2384 & TRN \\
\hline CHEMBL1997335 & 809227 & 5.6 & 4.9113 & TRN \\
\hline CHEMBL1966425 & 809227 & 5.7 & 5.9369 & TRN \\
\hline CHEMBL1984363 & 809227 & 9.0 & 7.6553 & TRN \\
\hline CHEMBL1978099 & 809227 & 7.8 & 7.3095 & TRN \\
\hline CHEMBL1977041 & 809227 & 8.3 & 7.8462 & TRN \\
\hline CHEMBL1968070 & 809227 & 4.6 & 5.2407 & TRN \\
\hline CHEMBL1988608 & 809227 & 4.6 & 5.16 & TRN \\
\hline CHEMBL184847 & 809227 & 4.6 & 6.5351 & TRN \\
\hline CHEMBL1984367 & 809227 & 6.6 & 6.2186 & TRN \\
\hline CHEMBL1985723 & 809227 & 7.9 & 6.9484 & TRN \\
\hline CHEMBL 226898 & 809227 & 5.8 & 5.5854 & TRN \\
\hline CHEMBL1982563 & 809227 & 4.6 & 4.6988 & TRN \\
\hline CHEMBL539474 & 809227 & 4.6 & 5.6496 & TST \\
\hline CHEMBL575824 & 809227 & 4.6 & 5.1823 & TRN \\
\hline CHEMBL1973868 & 809227 & 4.5 & 4.0882 & TRN \\
\hline CHEMBL1972462 & 809227 & 4.5 & 4.194 & TRN \\
\hline CHEMBL1977128 & 809227 & 6.3 & 6.1927 & TRN \\
\hline CHEMBL1970074 & 809227 & 7.7 & 7.9837 & TRN \\
\hline CHEMBL1965702 & 809227 & 7.7 & 7.5178 & TRN \\
\hline CHEMBL1986970 & 809227 & 4.6 & 4.8999 & TRN \\
\hline CHEMBL1958401 & 809227 & 4.6 & 5.0438 & TRN \\
\hline
\end{tabular}




\begin{tabular}{|c|c|c|c|c|c|}
\hline \multirow[b]{2}{*}{ CHEMBL1984044 } & \multirow{2}{*}{809227} & \\
\hline & & 6.0 & 5.1797 & TRN & \\
\hline CHEMBL 2003456 & 809227 & 7.1 & 5.3477 & TRN & \\
\hline CHEMBL1966816 & 809227 & 6.7 & 5.3958 & TRN & \\
\hline CHEMBL1972584 & 809227 & 6.4 & 6.4888 & TRN & \\
\hline CHEMBL 2002992 & 809227 & 4.5 & 4.18199 & 99999999995 & TRN \\
\hline CHEMBL560813 & 809227 & 4.6 & 5.2388 & TRN & \\
\hline CHEMBL1982700 & 809227 & 4.5 & 4.2639 & TST & \\
\hline CHEMBL1968791 & 809227 & 8.0 & 7.5965 & TRN & \\
\hline CHEMBL326282 & 809227 & 5.6 & 4.4813 & TST & \\
\hline CHEMBL1977634 & 809227 & 4.5 & 4.4497 & TRN & \\
\hline CHEMBL1992732 & 809227 & 4.6 & 4.6401 & TST & \\
\hline CHEMBL1971186 & 809227 & 4.6 & 4.60800 & 00000000005 & TRN \\
\hline CHEMBL 2003482 & 809227 & 4.6 & 4.5311 & TRN & \\
\hline CHEMBL1976872 & 809227 & 3.6 & 4.1995 & TRN & \\
\hline CHEMBL 2006456 & 809227 & 7.9 & 7.5208 & TRN & \\
\hline CHEMBL1969156 & 809227 & 5.0 & 4.6156 & TST & \\
\hline CHEMBL1973211 & 809227 & 8.1 & 8.0405 & TRN & \\
\hline CHEMBL1984700 & 809227 & 4.6 & 4.4481 & TRN & \\
\hline CHEMBL 2007151 & 809227 & 8.0 & 7.28100 & 0000000001 & TRN \\
\hline CHEMBL1998953 & 809227 & 5.9 & 5.3305 & TRN & \\
\hline CHEMBL1971606 & 809227 & 4.5 & 4.4488 & TRN & \\
\hline CHEMBL1972125 & 809227 & 4.6 & 4.6339 & TRN & \\
\hline CHEMBL1461728 & 809227 & 4.6 & 4.7165 & TRN & \\
\hline CHEMBL1976134 & 809227 & 6.5 & 5.6623 & TRN & \\
\hline CHEMBL1965131 & 809227 & 5.6 & 5.1473 & TRN & \\
\hline CHEMBL1972158 & 809227 & 5.8 & 5.2759 & TRN & \\
\hline CHEMBL1981215 & 809227 & 4.5 & 4.6667 & TRN & \\
\hline CHEMBL1974457 & 809227 & 4.6 & 4.8251 & TRN & \\
\hline CHEMBL2006580 & 809227 & 6.2 & 5.0699 & TRN & \\
\hline CHEMBL1999414 & 809227 & 7.2 & 7.895 & TRN & \\
\hline CHEMBL1967336 & 809227 & 4.5 & 4.5291 & TRN & \\
\hline CHEMBL2006581 & 809227 & 4.6 & 5.1286 & TRN & \\
\hline CHEMBL1979855 & 809227 & 4.6 & 4.4574 & TRN & \\
\hline CHEMBL1970340 & 809227 & 5.0 & 3.9396 & TRN & \\
\hline CHEMBL1967992 & 809227 & 4.5 & 4.612 & TRN & \\
\hline CHEMBL2005186 & 809227 & 4.6 & 5.4153 & TRN & \\
\hline CHEMBL 2006450 & 809227 & 4.6 & 4.871 & TRN & \\
\hline CHEMBL1975534 & 809227 & 5.9 & 4.7336 & TRN & \\
\hline CHEMBL1966703 & 809227 & 4.6 & 4.6 & TST & \\
\hline CHEMBL2001987 & 809227 & 4.5 & 4.5706 & TRN & \\
\hline CHEMBL1969561 & 809227 & 4.6 & 4.8232 & TRN & \\
\hline CHEMBL1994555 & 809227 & 4.5 & 4.606 & TST & \\
\hline CHEMBL1975121 & 809227 & 4.5 & 4.3802 & TRN & \\
\hline CHEMBL1983640 & 809227 & 7.7 & 8.1765 & TRN & \\
\hline CHEMBL1997023 & 809227 & 4.6 & 4.4441 & TST & \\
\hline CHEMBL1964687 & 809227 & 7.5 & 7.8342 & TRN & \\
\hline CHEMBL1971943 & 809227 & 4.8 & 5.3413 & TRN & \\
\hline CHEMBL1999918 & 809227 & 4.6 & 4.8571 & TRN & \\
\hline & & & & 23151 & \\
\hline
\end{tabular}




\begin{tabular}{|c|c|c|c|c|c|}
\hline & & & & & \\
\hline CHEMBL1988537 & 809227 & 6.0 & 5.0783 & TST & \\
\hline CHEMBL1969049 & 809227 & 4.6 & 4.6924 & TRN & \\
\hline CHEMBL 2005828 & 809227 & 8.8 & 7.9487 & TRN & \\
\hline CHEMBL 2002240 & 809227 & 5.7 & 4.7001 & TRN & \\
\hline CHEMBL1980178 & 809227 & 7.3 & 7.2829 & TRN & \\
\hline CHEMBL1998611 & 809227 & 6.1 & 5.0155 & TRN & \\
\hline CHEMBL485556 & 809227 & 6.3 & 5.2436 & TST & \\
\hline CHEMBL1975900 & 809227 & 4.6 & 4.7042 & TRN & \\
\hline CHEMBL 255822 & 809227 & 4.6 & 4.3975 & TRN & \\
\hline CHEMBL1972221 & 809227 & 4.6 & 4.4323 & TRN & \\
\hline CHEMBL2006778 & 809227 & 7.3 & 7.1045 & TRN & \\
\hline CHEMBL 378627 & 809227 & 4.6 & 4.3754 & TRN & \\
\hline CHEMBL1996979 & 809227 & 7.2 & 6.8437 & TRN & \\
\hline CHEMBL1997025 & 809227 & 4.6 & 5.4303 & TRN & \\
\hline CHEMBL1968406 & 809227 & 8.7 & 7.9781 & TRN & \\
\hline CHEMBL1998545 & 809227 & 4.6 & 4.7719 & TRN & \\
\hline CHEMBL1986869 & 809227 & 4.6 & 4.3832 & TRN & \\
\hline CHEMBL1975923 & 809227 & 4.8 & 4.7647 & TST & \\
\hline CHEMBL 2005449 & 809227 & 5.7 & 6.3823 & TRN & \\
\hline CHEMBL1987998 & 809227 & 4.5 & 4.8773 & TRN & \\
\hline CHEMBL1682558 & 809227 & 4.6 & 4.5246 & TRN & \\
\hline CHEMBL1990496 & 809227 & 4.6 & 5.0707 & TRN & \\
\hline CHEMBL242865 & 809227 & 4.5 & 5.5814 & TRN & \\
\hline CHEMBL1997623 & 809227 & 8.3 & 8.0314 & TRN & \\
\hline CHEMBL 2002479 & 809227 & 6.4 & 5.7826 & TRN & \\
\hline CHEMBL1472492 & 809227 & 5.9 & 5.4017 & TST & \\
\hline CHEMBL1993166 & 809227 & 4.6 & 4.7328 & TRN & \\
\hline CHEMBL1967094 & 809227 & 6.5 & 6.2698 & TRN & \\
\hline CHEMBL1966035 & 809227 & 4.6 & 4.8506 & TRN & \\
\hline CHEMBL1965437 & 809227 & 5.6 & 6.3426 & TRN & \\
\hline CHEMBL 2003341 & 809227 & 4.6 & 4.4441 & TRN & \\
\hline CHEMBL1992645 & 809227 & 4.6 & 4.3853 & TST & \\
\hline CHEMBL1982992 & 809227 & 4.6 & 5.4467 & TRN & \\
\hline CHEMBL1998110 & 809227 & 4.5 & 4.3712 & TRN & \\
\hline CHEMBL1999590 & 809227 & 6.1 & 5.0362 & TST & \\
\hline CHEMBL1981079 & 809227 & 4.8 & 4.7835 & TRN & \\
\hline CHEMBL1978166 & 809227 & 7.3 & 7.595 & TRN & \\
\hline CHEMBL1972276 & 809227 & 4.6 & 4.8207 & TRN & \\
\hline CHEMBL1980489 & 809227 & 4.6 & 4.7149 & TRN & \\
\hline CHEMBL 2000832 & 809227 & 5.7 & 5.5075 & TRN & \\
\hline CHEMBL1967116 & 809227 & 8.9 & 8.1512 & TRN & \\
\hline CHEMBL1990590 & 809227 & 4.5 & 4.7082 & TRN & \\
\hline CHEMBL513846 & 809227 & 5.7 & 5.1202 & TRN & \\
\hline CHEMBL1970709 & 809227 & 4.6 & 4.4947 & TRN & \\
\hline CHEMBL1965660 & 809227 & 4.9 & 5.09399 & 9999999999 & TRN \\
\hline CHEMBL1992125 & 809227 & 6.0 & 6.1472 & TRN & \\
\hline CHEMBL1985309 & 809227 & 5.9 & 5.0623 & TRN & \\
\hline CHEMBL1998112 & 809227 & 4.6 & 5.5632 & TRN & \\
\hline & & & & 23152 & \\
\hline
\end{tabular}




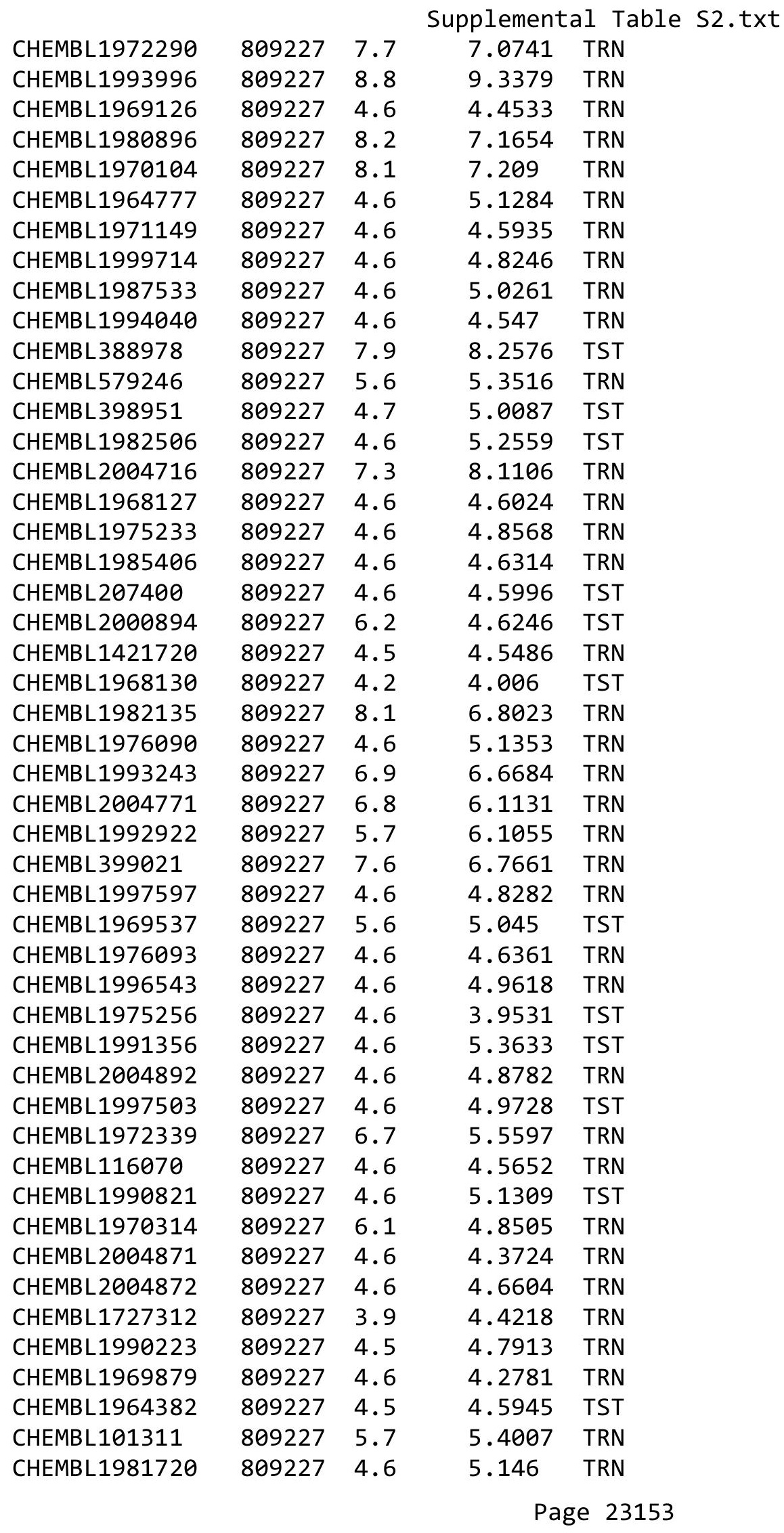




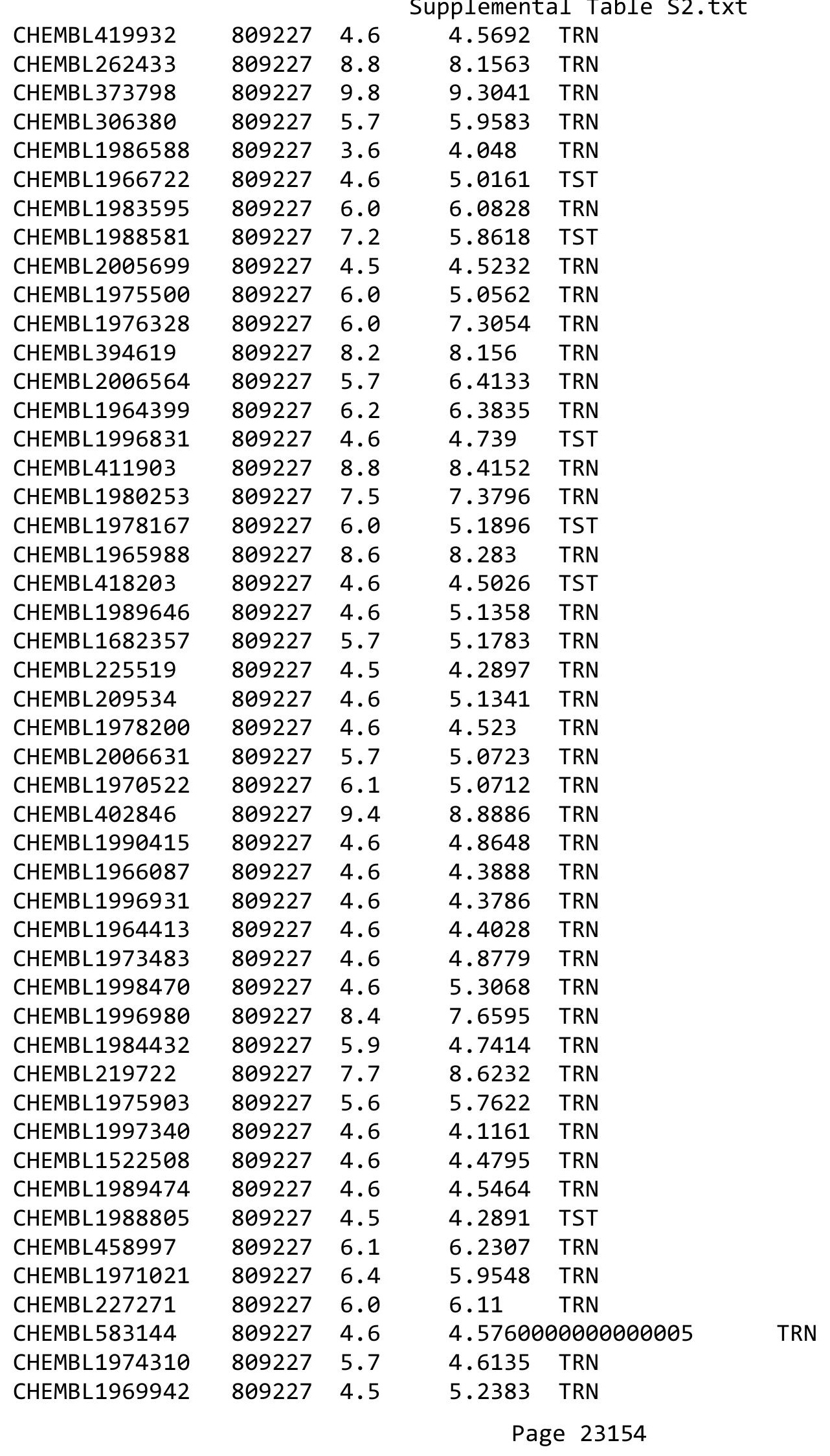

Supplemental Table S2.txt 


\begin{tabular}{|c|c|c|c|c|c|}
\hline CHEMBL1978567 & 809227 & 4.5 & 4.3712 & TRN & \\
\hline CHEMBL1982660 & 809227 & 4.7 & 5.7829 & 99999999995 & TRN \\
\hline CHEMBL1994693 & 809227 & 8.1 & 7.4804 & TRN & \\
\hline CHEMBL1982957 & 809227 & 7.5 & 7.1722 & TRN & \\
\hline CHEMBL1725279 & 809227 & 7.3 & 6.8283 & TST & \\
\hline CHEMBL2002346 & 809227 & 6.6 & 7.2988 & TRN & \\
\hline CHEMBL1975138 & 809227 & 4.6 & 5.0159 & TST & \\
\hline CHEMBL424872 & 809227 & 4.7 & 4.7411 & TRN & \\
\hline CHEMBL1971947 & 809227 & 7.5 & 8.168 & TRN & \\
\hline CHEMBL412142 & 809227 & 4.6 & 4.6846 & TST & \\
\hline CHEMBL1980704 & 809227 & 4.6 & 4.7195 & TST & \\
\hline CHEMBL2003271 & 809227 & 4.6 & 4.7352 & TRN & \\
\hline CHEMBL1972365 & 809227 & 6.1 & 5.117 & TST & \\
\hline CHEMBL1966808 & 809227 & 4.6 & 4.2517 & TRN & \\
\hline CHEMBL1996255 & 809227 & 9.1 & 9.1692 & TRN & \\
\hline CHEMBL 2004447 & 809227 & 4.6 & 4.6296 & TRN & \\
\hline CHEMBL1992231 & 809227 & 6.3 & 5.9738 & TRN & \\
\hline CHEMBL1983111 & 809227 & 6.9 & 6.9276 & TST & \\
\hline CHEMBL1973860 & 809227 & 4.6 & 4.4232 & TRN & \\
\hline CHEMBL260135 & 809227 & 4.6 & 5.2485 & TRN & \\
\hline CHEMBL 220241 & 809227 & 5.8 & 5.1396 & TRN & \\
\hline CHEMBL1988141 & 809227 & 6.5 & 5.4052 & TST & \\
\hline CHEMBL1982610 & 809227 & 4.6 & 4.9258 & TST & \\
\hline CHEMBL1977134 & 809227 & 7.3 & 7.7517 & TRN & \\
\hline CHEMBL1999496 & 809227 & 4.6 & 5.1613 & TRN & \\
\hline CHEMBL2006933 & 809227 & 4.6 & 5.0201 & TST & \\
\hline CHEMBL1985206 & 809227 & 6.9 & 4.4732 & TST & \\
\hline CHEMBL 375293 & 809227 & 5.9 & 5.8531 & TST & \\
\hline CHEMBL1991078 & 809227 & 4.9 & 6.7552 & TRN & \\
\hline CHEMBL1987359 & 809227 & 4.6 & 4.6731 & TST & \\
\hline CHEMBL1977749 & 809227 & 4.5 & 4.8288 & TST & \\
\hline CHEMBL2000685 & 809227 & 4.6 & 4.9726 & TRN & \\
\hline CHEMBL 2001613 & 809227 & 4.1 & 4.3302 & TRN & \\
\hline CHEMBL1997275 & 809227 & 5.8 & 5.9527 & TRN & \\
\hline CHEMBL1993904 & 809227 & 5.8 & 5.6068 & TRN & \\
\hline CHEMBL1994438 & 809227 & 7.8 & 7.3009 & TRN & \\
\hline CHEMBL1980376 & 809227 & 4.2 & 4.6466 & TRN & \\
\hline CHEMBL1967513 & 809227 & 4.5 & 4.3889 & 9999999999 & TRN \\
\hline CHEMBL 2000724 & 809227 & 4.5 & 4.7362 & TRN & \\
\hline CHEMBL1985311 & 809227 & 8.0 & 8.7295 & TRN & \\
\hline CHEMBL1982413 & 809227 & 6.3 & 5.0364 & TRN & \\
\hline CHEMBL1969502 & 809227 & 5.9 & 6.0688 & TRN & \\
\hline CHEMBL1965910 & 809227 & 7.5 & 6.8824 & TRN & \\
\hline CHEMBL1682553 & 809227 & 4.6 & 4.8136 & TRN & \\
\hline CHEMBL1971430 & 809227 & 4.6 & 5.3315 & TRN & \\
\hline CHEMBL1983963 & 809227 & 8.8 & 8.8133 & TRN & \\
\hline CHEMBL1997764 & 809227 & 6.8 & 6.6295 & TRN & \\
\hline \multirow[t]{2}{*}{ CHEMBL 2000271} & 809227 & 5.7 & 5.9345 & TRN & \\
\hline & & \multicolumn{4}{|c|}{ Page 23155} \\
\hline
\end{tabular}




\begin{tabular}{|c|c|c|c|c|}
\hline & & & ipplement & al Table S \\
\hline CHEMBL562488 & 809227 & 4.7 & 4.1712 & TRN \\
\hline CHEMBL1981792 & 809227 & 5.9 & 4.5637 & TRN \\
\hline CHEMBL1987535 & 809227 & 4.5 & 4.9554 & TRN \\
\hline CHEMBL1985092 & 809227 & 4.6 & 5.7058 & TRN \\
\hline CHEMBL2004692 & 809227 & 4.6 & 4.3323 & TST \\
\hline CHEMBL1981410 & 809227 & 7.0 & 6.8246 & TRN \\
\hline CHEMBL 2002586 & 809227 & 4.5 & 4.5706 & TRN \\
\hline CHEMBL1987815 & 809227 & 4.5 & 3.802 & TST \\
\hline CHEMBL1996234 & 809227 & 4.6 & 5.5341 & TRN \\
\hline CHEMBL383264 & 809227 & 4.5 & 5.6315 & TRN \\
\hline CHEMBL 2007421 & 809227 & 6.5 & \multicolumn{2}{|c|}{6.071000000000001} \\
\hline CHEMBL1991434 & 809227 & 4.6 & 4.6671 & TST \\
\hline CHEMBL1967544 & 809227 & 4.6 & 5.0752 & TRN \\
\hline CHEMBL1973138 & 809227 & 4.5 & 4.457 & TRN \\
\hline CHEMBL 223367 & 809227 & 4.6 & 5.4603 & TST \\
\hline CHEMBL1992673 & 809227 & 4.5 & 4.6491 & TRN \\
\hline CHEMBL340384 & 809227 & 6.5 & 5.3249 & TST \\
\hline CHEMBL1969151 & 809227 & 5.8 & 7.5022 & TRN \\
\hline CHEMBL1996587 & 809227 & 4.6 & 4.6928 & TRN \\
\hline CHEMBL1993335 & 809227 & 7.0 & 5.7582 & TST \\
\hline CHEMBL1988692 & 809227 & 6.8 & 5.8194 & TRN \\
\hline CHEMBL 2007574 & 809227 & 4.5 & 5.9015 & TRN \\
\hline CHEMBL1964804 & 809227 & 4.6 & 5.2131 & TRN \\
\hline CHEMBL443962 & 809227 & 5.6 & 5.4632 & TST \\
\hline CHEMBL2000354 & 809227 & 4.6 & 4.9026 & TRN \\
\hline CHEMBL1965507 & 809227 & 5.0 & 5.4514 & TRN \\
\hline CHEMBL 274064 & 809227 & 4.6 & 5.0405 & TRN \\
\hline CHEMBL1998680 & 809227 & 4.5 & 4.4971 & TRN \\
\hline CHEMBL1967564 & 809227 & 4.6 & 4.5253 & TRN \\
\hline CHEMBL592030 & 809227 & 4.9 & 5.0816 & TST \\
\hline CHEMBL 2000071 & 809227 & 5.8 & 6.0885 & TRN \\
\hline CHEMBL1979176 & 809227 & 4.6 & 5.1854 & TRN \\
\hline CHEMBL1970317 & 809227 & 8.9 & 7.4621 & TRN \\
\hline CHEMBL1985491 & 809227 & 8.6 & 8.8855 & TRN \\
\hline CHEMBL2002613 & 809227 & 5.9 & 6.1171 & TRN \\
\hline CHEMBL 2000408 & 809227 & 4.6 & 4.5086 & TRN \\
\hline CHEMBL 248757 & 809227 & 4.6 & 5.6844 & TST \\
\hline CHEMBL1978014 & 809227 & 4.6 & 4.8332 & TRN \\
\hline CHEMBL1997007 & 809227 & 4.5 & 4.7662 & TRN \\
\hline CHEMBL1994538 & 809227 & 4.6 & 4.8026 & TRN \\
\hline CHEMBL1975490 & 809227 & 6.0 & 5.7685 & TRN \\
\hline CHEMBL1964444 & 809227 & 6.6 & 4.9731 & TRN \\
\hline CHEMBL 2002690 & 809227 & 4.5 & 5.3538 & TRN \\
\hline CHEMBL 2006567 & 809227 & 4.6 & 4.4682 & TRN \\
\hline CHEMBL1986139 & 809227 & 4.6 & 4.9787 & TRN \\
\hline CHEMBL 383527 & 809227 & 4.6 & 4.6935 & TRN \\
\hline CHEMBL1980540 & 809227 & 4.6 & 4.7067 & TRN \\
\hline CHEMBL 278041 & 809227 & 4.6 & 4.2266 & TRN \\
\hline
\end{tabular}




\begin{tabular}{|c|c|c|c|c|}
\hline & & & ement & al Ta \\
\hline CHEMBL1979883 & 809227 & 8.3 & 7.9779 & TRN \\
\hline CHEMBL1984162 & 809227 & 7.4 & 7.9764 & TRN \\
\hline CHEMBL1998432 & 809227 & 8.9 & 7.6193 & TRN \\
\hline CHEMBL491758 & 809227 & 7.1 & 7.114 & TRN \\
\hline CHEMBL1986590 & 809227 & 6.2 & 6.0258 & TRN \\
\hline CHEMBL549730 & 809227 & 4.6 & 4.6124 & TRN \\
\hline CHEMBL1682360 & 809227 & 4.6 & 4.4726 & TRN \\
\hline CHEMBL1970189 & 809227 & 4.6 & 4.6533 & TRN \\
\hline CHEMBL1870106 & 809227 & 4.5 & 4.466 & TRN \\
\hline CHEMBL1996791 & 809227 & 4.6 & 4.8594 & TRN \\
\hline CHEMBL371206 & 809227 & 7.8 & 7.7043 & TRN \\
\hline CHEMBL1974664 & 809227 & 6.5 & 6.2171 & TST \\
\hline CHEMBL1998477 & 809227 & 5.6 & 5.1574 & TRN \\
\hline CHEMBL406845 & 809227 & 4.6 & 4.8759 & TRN \\
\hline CHEMBL1974288 & 809227 & 4.6 & 4.8226 & TRN \\
\hline CHEMBL1984296 & 809227 & 4.5 & 4.919 & TST \\
\hline CHEMBL196363 & 809227 & 9.1 & 8.371 & TRN \\
\hline CHEMBL1996837 & 809227 & 3.6 & 3.8465 & TRN \\
\hline CHEMBL1190711 & 809227 & 7.4 & 5.6154 & TRN \\
\hline CHEMBL1990346 & 809227 & 4.6 & 5.0952 & TRN \\
\hline CHEMBL1968705 & 809227 & 4.6 & 5.2085 & TRN \\
\hline CHEMBL1991410 & 809227 & 4.6 & 4.9244 & TRN \\
\hline CHEMBL1964441 & 809227 & 7.9 & 7.697 & TRN \\
\hline CHEMBL546797 & 809227 & 4.5 & 5.1045 & TRN \\
\hline CHEMBL404367 & 809227 & 8.6 & 8.7122 & TRN \\
\hline CHEMBL1966343 & 809227 & 4.6 & 4.8592 & TRN \\
\hline CHEMBL1978271 & 809227 & 4.5 & 4.4823 & TRN \\
\hline CHEMBL1967887 & 809227 & 4.6 & 5.2264 & TRN \\
\hline CHEMBL 2007266 & 809227 & 7.1 & 7.6029 & TRN \\
\hline CHEMBL 2000568 & 809227 & 4.8 & 5.2186 & TRN \\
\hline CHEMBL1994308 & 809227 & 4.5 & 4.8845 & TRN \\
\hline CHEMBL1980161 & 809227 & 5.6 & 4.5076 & TST \\
\hline CHEMBL 2007097 & 809227 & 4.4 & 4.0562 & TRN \\
\hline CHEMBL1988717 & 809227 & 8.7 & 8.5136 & TRN \\
\hline CHEMBL1974328 & 809227 & 4.8 & 5.9731 & TRN \\
\hline CHEMBL509032 & 809227 & 7.4 & 6.9766 & TRN \\
\hline CHEMBL 243298 & 809227 & 7.5 & 6.6673 & TRN \\
\hline CHEMBL143703 & 809227 & 5.5 & 4.7299 & TRN \\
\hline CHEMBL1973808 & 809227 & 4.6 & 4.617 & TRN \\
\hline CHEMBL 2000429 & 809227 & 4.6 & 4.3702 & TRN \\
\hline CHEMBL1972576 & 809227 & 4.6 & 5.0275 & TRN \\
\hline CHEMBL1990254 & 809227 & 4.6 & 4.744 & TRN \\
\hline CHEMBL1992342 & 809227 & 4.6 & 4.8999 & TRN \\
\hline CHEMBL 2002202 & 809227 & 4.1 & 4.3426 & TRN \\
\hline CHEMBL1988173 & 809227 & 4.6 & 5.2165 & TST \\
\hline CHEMBL1973013 & 809227 & 4.5 & 5.4794 & TST \\
\hline CHEMBL1164265 & 809227 & 6.9 & 4.6887 & TST \\
\hline CHEMBL535331 & 809227 & 5.7 & 5.3267 & TRN \\
\hline
\end{tabular}




\begin{tabular}{|c|c|c|c|c|c|}
\hline \multirow[b]{2}{*}{ CHEMBL1989805 } & \multirow[b]{2}{*}{809227} & \\
\hline & & 4.6 & 4.4269 & TST & \\
\hline CHEMBL1966204 & 809227 & 7.1 & 6.2969 & TRN & \\
\hline CHEMBL1965423 & 809227 & 4.6 & 4.5524 & TRN & \\
\hline CHEMBL1983025 & 809227 & 7.7 & 7.6795 & TRN & \\
\hline CHEMBL1975927 & 809227 & 6.5 & 6.8222 & TRN & \\
\hline CHEMBL 205415 & 809227 & 4.7 & 4.802 & TRN & \\
\hline CHEMBL1977135 & 809227 & 4.6 & 4.885 & TRN & \\
\hline CHEMBL2001920 & 809227 & 6.8 & 4.7635 & TST & \\
\hline CHEMBL 2002322 & 809227 & 4.6 & 4.2982 & TRN & \\
\hline CHEMBL1997119 & 809227 & 4.9 & 4.5542 & TST & \\
\hline CHEMBL1980904 & 809227 & 8.5 & \multicolumn{2}{|c|}{8.902000000000001} & TRN \\
\hline CHEMBL1977138 & 809227 & 4.5 & 5.7828 & TST & \\
\hline CHEMBL2002323 & 809227 & 4.6 & 4.5122 & TST & \\
\hline CHEMBL1241473 & 809227 & 7.7 & 7.7143 & TRN & \\
\hline CHEMBL1978448 & 809227 & 4.6 & 5.0903 & TST & \\
\hline CHEMBL1972258 & 809227 & 4.6 & 4.5615 & TRN & \\
\hline CHEMBL2004513 & 809227 & 6.2 & 5.2759 & TRN & \\
\hline CHEMBL1980329 & 809227 & 4.5 & 6.17 & TRN & \\
\hline CHEMBL 2004515 & 809227 & 4.6 & 4.968 & TRN & \\
\hline CHEMBL2001257 & 809227 & 6.4 & 7.3224 & TRN & \\
\hline CHEMBL1992042 & 809227 & 4.5 & 5.2145 & TST & \\
\hline CHEMBL 2005548 & 809227 & 4.6 & 4.6793 & TRN & \\
\hline CHEMBL271441 & 809227 & 9.3 & 9.5087 & TRN & \\
\hline CHEMBL1992536 & 809227 & 4.6 & 4.9377 & TRN & \\
\hline CHEMBL21156 & 809227 & 4.5 & 4.4747 & TST & \\
\hline CHEMBL1992740 & 809227 & 4.6 & 4.5016 & TRN & \\
\hline CHEMBL1994724 & 809227 & 4.5 & 4.3879 & TRN & \\
\hline CHEMBL1989267 & 809227 & 6.3 & 6.0899 & TRN & \\
\hline CHEMBL2002373 & 809227 & 4.6 & 4.761 & TRN & \\
\hline CHEMBL439340 & 809227 & 4.6 & 4.5387 & TRN & \\
\hline CHEMBL2006188 & 809227 & 4.6 & 4.5296 & TRN & \\
\hline CHEMBL1970290 & 809227 & 4.5 & 5.222 & TRN & \\
\hline CHEMBL1967531 & 809227 & 8.5 & 7.2779 & TRN & \\
\hline CHEMBL1970913 & 809227 & 4.6 & 4.4225 & TRN & \\
\hline CHEMBL1973893 & 809227 & 4.6 & 4.484 & TRN & \\
\hline CHEMBL1997534 & 809227 & 4.6 & 4.9587 & TRN & \\
\hline CHEMBL1993877 & 809227 & 5.7 & 5.4949 & TRN & \\
\hline CHEMBL1985095 & 809227 & 5.9 & 5.0754 & TST & \\
\hline CHEMBL1996500 & 809227 & 4.5 & 4.4015 & TRN & \\
\hline CHEMBL273187 & 809227 & 10.0 & 10.0979 & 99999999999 & TRN \\
\hline CHEMBL1973363 & 809227 & 5.5 & 5.3912 & TRN & \\
\hline CHEMBL1991180 & 809227 & 4.6 & 4.6034 & TST & \\
\hline CHEMBL1989708 & 809227 & 7.9 & 7.9365 & TRN & \\
\hline CHEMBL1682540 & 809227 & 4.6 & 4.8931 & TRN & \\
\hline CHEMBL1976420 & 809227 & 4.8 & 4.885 & TST & \\
\hline CHEMBL1986979 & 809227 & 9.1 & 9.3639 & TRN & \\
\hline CHEMBL413779 & 809227 & 4.6 & 5.5403 & TST & \\
\hline CHEMBL1994864 & 809227 & 4.6 & 4.765 & TRN & \\
\hline & & & & 3158 & \\
\hline
\end{tabular}




\begin{tabular}{|c|c|c|c|c|c|}
\hline \\
\hline CHEMBL1981744 & 809227 & 4.5 & 4.448 & TRN & \\
\hline CHEMBL2002446 & 809227 & 8.8 & 7.6533 & TST & \\
\hline CHEMBL497151 & 809227 & 4.6 & 4.6699 & TRN & \\
\hline CHEMBL 2000029 & 809227 & 4.5 & 4.9506 & TRN & \\
\hline CHEMBL1973961 & 809227 & 4.7 & 4.632 & TRN & \\
\hline CHEMBL246970 & 809227 & 4.6 & 5.0179 & TRN & \\
\hline CHEMBL340921 & 809227 & 4.6 & 4.9625 & TST & \\
\hline CHEMBL1994977 & 809227 & 4.5 & 4.4083 & TRN & \\
\hline CHEMBL373598 & 809227 & 4.6 & 5.4948 & TST & \\
\hline CHEMBL2001149 & 809227 & 4.5 & 4.1097 & TRN & \\
\hline CHEMBL1999718 & 809227 & 4.6 & 4.3744 & TRN & \\
\hline CHEMBL1987073 & 809227 & 6.5 & 6.0462 & TRN & \\
\hline CHEMBL1276446 & 809227 & 8.5 & 7.5066 & TST & \\
\hline CHEMBL 2005478 & 809227 & 7.1 & 5.4813 & TST & \\
\hline CHEMBL1996646 & 809227 & 6.9 & 6.9963 & TRN & \\
\hline CHEMBL1995712 & 809227 & 6.9 & 7.2171 & TRN & \\
\hline CHEMBL1979773 & 809227 & 4.5 & 4.7026 & TRN & \\
\hline CHEMBL1977346 & 809227 & 6.0 & 5.5854 & TRN & \\
\hline CHEMBL 2003657 & 809227 & 4.6 & 4.5486 & TRN & \\
\hline CHEMBL1971649 & 809227 & 8.0 & 7.0247 & TRN & \\
\hline CHEMBL1996702 & 809227 & 4.5 & 5.0469 & TRN & \\
\hline CHEMBL 2007124 & 809227 & 4.5 & 5.7852 & TRN & \\
\hline CHEMBL 2006439 & 809227 & 5.0 & 7.0893 & TRN & \\
\hline CHEMBL1985681 & 809227 & 7.0 & 5.6132 & TST & \\
\hline CHEMBL1969190 & 809227 & 7.4 & 7.6127 & TRN & \\
\hline CHEMBL1973937 & 809227 & 7.4 & 8.5055 & TRN & \\
\hline CHEMBL1991674 & 809227 & 6.0 & 6.7044 & TRN & \\
\hline CHEMBL1982711 & 809227 & 4.6 & 5.0474 & TRN & \\
\hline CHEMBL1984842 & 809227 & 4.6 & 4.2147 & TRN & \\
\hline CHEMBL 2004118 & 809227 & 4.5 & 5.0917 & TRN & \\
\hline CHEMBL1682346 & 809227 & 4.6 & 5.5373 & TRN & \\
\hline CHEMBL 2007044 & 809227 & 5.6 & 4.8786 & TST & \\
\hline CHEMBL 2001998 & 809227 & 7.0 & 5.5768 & TST & \\
\hline CHEMBL1994241 & 809227 & 5.9 & 6.0045 & TRN & \\
\hline CHEMBL 223460 & 809227 & 4.6 & 5.4652 & TST & \\
\hline CHEMBL1998829 & 809227 & 6.1 & 6.1181 & TRN & \\
\hline CHEMBL50894 & 809227 & 4.6 & 4.7579 & TRN & \\
\hline CHEMBL1995211 & 809227 & 4.5 & 5.46 & TRN & \\
\hline CHEMBL1988838 & 809227 & 7.8 & 7.8375 & TRN & \\
\hline CHEMBL1981725 & 809227 & 8.3 & 7.9115 & TRN & \\
\hline CHEMBL1982753 & 809227 & 7.0 & 5.3954 & TRN & \\
\hline CHEMBL375284 & 809227 & 8.4 & 8.1398 & TRN & \\
\hline CHEMBL2006299 & 809227 & 4.5 & $4.7860 e$ & 00000000005 & TRN \\
\hline CHEMBL1972346 & 809227 & 4.7 & 4.7361 & TST & \\
\hline CHEMBL1980562 & 809227 & 7.8 & 7.5081 & TRN & \\
\hline CHEMBL1965169 & 809227 & 4.5 & 5.0952 & TST & \\
\hline CHEMBL1081312 & 809227 & 4.5 & 5.5199 & TRN & \\
\hline CHEMBL1965170 & 809227 & 8.0 & 8.1891 & TRN & \\
\hline & & & & 23159 & \\
\hline
\end{tabular}




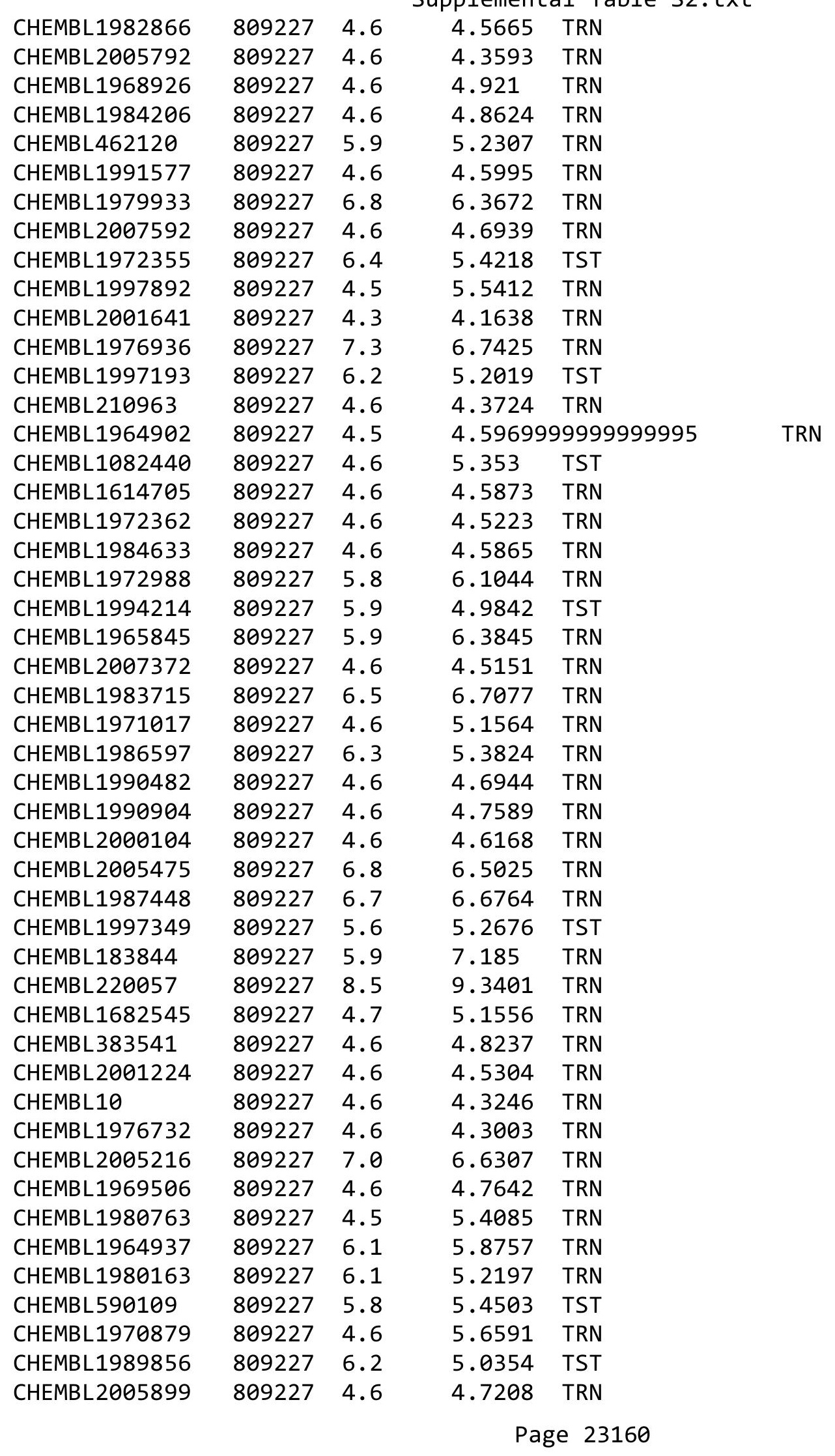




\begin{tabular}{|c|c|c|c|c|c|}
\hline \\
\hline CHEMBL1682552 & 809227 & 4.6 & 4.7254 & TRN & \\
\hline CHEMBL259850 & 809227 & 4.6 & 4.3858 & TRN & \\
\hline CHEMBL 2007479 & 809227 & 4.5 & 4.5106 & TRN & \\
\hline CHEMBL1986851 & 809227 & 6.1 & 7.8373 & TRN & \\
\hline CHEMBL229799 & 809227 & 6.8 & 6.5719 & TRN & \\
\hline CHEMBL105739 & 809227 & 8.3 & 7.7307 & TRN & \\
\hline CHEMBL1682359 & 809227 & 4.6 & 4.3939 & TRN & \\
\hline CHEMBL1972220 & 809227 & 7.9 & 7.9923 & TRN & \\
\hline CHEMBL379300 & 809227 & 6.5 & 6.2717 & TRN & \\
\hline CHEMBL203673 & 809227 & 4.6 & 4.8718 & TRN & \\
\hline CHEMBL1973720 & 809227 & 8.2 & 7.5837 & TRN & \\
\hline CHEMBL1969523 & 809227 & 6.3 & 6.8222 & TRN & \\
\hline CHEMBL207995 & 809227 & 5.8 & 4.9382 & TRN & \\
\hline CHEMBL 2001923 & 809227 & 4.6 & 4.6452 & TRN & \\
\hline CHEMBL1986781 & 809227 & 4.6 & 4.45 & TRN & \\
\hline CHEMBL1983070 & 809227 & 4.5 & 5.1076 & TRN & \\
\hline CHEMBL526133 & 809227 & 4.6 & 5.2902 & TRN & \\
\hline CHEMBL2003514 & 809227 & 4.5 & 4.2417 & TRN & \\
\hline CHEMBL1966836 & 809227 & 8.6 & 8.6609 & TRN & \\
\hline CHEMBL1989043 & 809227 & 4.5 & 4.8559 & TRN & \\
\hline CHEMBL1979057 & 809227 & 5.8 & 5.9534 & TRN & \\
\hline CHEMBL1981045 & 809227 & 4.6 & 4.7003 & TRN & \\
\hline CHEMBL1975418 & 809227 & 5.6 & 5.1994 & TRN & \\
\hline CHEMBL1992796 & 809227 & 4.6 & 5.4116 & TRN & \\
\hline CHEMBL1164180 & 809227 & 5.9 & 5.2085 & TST & \\
\hline CHEMBL223257 & 809227 & 4.6 & 5.3355 & TST & \\
\hline CHEMBL1999428 & 809227 & 6.5 & 5.4678 & TRN & \\
\hline CHEMBL1967560 & 809227 & 4.6 & 4.5986 & TRN & \\
\hline CHEMBL1997611 & 809227 & 4.5 & 4.5305 & TST & \\
\hline CHEMBL211378 & 809227 & 7.8 & 7.915 & TRN & \\
\hline CHEMBL1982465 & 809227 & 8.2 & 7.84399 & 9999999999 & TRN \\
\hline CHEMBL 2001751 & 809227 & 7.5 & 7.4594 & TRN & \\
\hline CHEMBL 2003420 & 809227 & 4.6 & 4.7358 & TRN & \\
\hline CHEMBL1984586 & 809227 & 8.3 & 7.0074 & TRN & \\
\hline CHEMBL1999774 & 809227 & 4.6 & 4.78 & TST & \\
\hline CHEMBL272938 & 809227 & 9.4 & 9.6835 & TRN & \\
\hline CHEMBL1972659 & 809227 & 4.6 & 4.6527 & TST & \\
\hline CHEMBL 2002723 & 809227 & 5.7 & 5.0421 & TST & \\
\hline CHEMBL1973395 & 809227 & 4.6 & 5.888 & TRN & \\
\hline CHEMBL1987143 & 809227 & 5.3 & 4.7679 & TST & \\
\hline CHEMBL1970217 & 809227 & 4.6 & 4.845 & TRN & \\
\hline CHEMBL1971801 & 809227 & 4.6 & 5.02 & TRN & \\
\hline CHEMBL1968850 & 809227 & 4.6 & $5.3270 e$ & 0000000001 & TRN \\
\hline CHEMBL 2005528 & 809227 & 4.6 & 4.9391 & TST & \\
\hline CHEMBL1984686 & 809227 & 4.5 & 4.319 & TRN & \\
\hline CHEMBL185569 & 809227 & 8.1 & 8.3421 & TRN & \\
\hline CHEMBL1969843 & 809227 & 4.6 & 4.4113 & TRN & \\
\hline CHEMBL 2007002 & 809227 & 4.6 & 5.2612 & TRN & \\
\hline & & & & 23161 & \\
\hline
\end{tabular}




\begin{tabular}{|c|c|c|c|c|}
\hline & & & 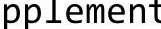 & al Ta \\
\hline CHEMBL1987007 & 809227 & 7.0 & 5.9179 & TRN \\
\hline CHEMBL1973793 & 809227 & 4.5 & 5.3367 & TST \\
\hline CHEMBL1969588 & 809227 & 7.4 & 8.3174 & TRN \\
\hline CHEMBL1984711 & 809227 & 6.7 & 6.6652 & TRN \\
\hline CHEMBL1992073 & 809227 & 4.5 & 4.85 & TRN \\
\hline CHEMBL484390 & 809227 & 4.6 & 4.9235 & TST \\
\hline CHEMBL1979252 & 809227 & 4.6 & 4.8165 & TRN \\
\hline CHEMBL1986143 & 809227 & 4.5 & 4.5942 & TRN \\
\hline CHEMBL1972934 & 809227 & 4.6 & 4.2391 & TRN \\
\hline CHEMBL2007559 & 809227 & 4.5 & 4.3586 & TRN \\
\hline CHEMBL1992581 & 809227 & 5.5 & 6.0968 & TRN \\
\hline CHEMBL1682341 & 809227 & 4.6 & 4.9259 & TRN \\
\hline CHEMBL 2004290 & 809227 & 6.9 & 7.8104 & TRN \\
\hline CHEMBL1986499 & 809227 & 5.8 & 5.1739 & TRN \\
\hline CHEMBL1972937 & 809227 & 4.6 & 4.8676 & TRN \\
\hline CHEMBL1972250 & 809227 & 6.6 & 5.0102 & TST \\
\hline CHEMBL 2000393 & 809227 & 6.6 & 6.0837 & TST \\
\hline CHEMBL403402 & 809227 & 9.0 & 9.432 & TRN \\
\hline CHEMBL1983573 & 809227 & 4.5 & 4.6762 & TST \\
\hline CHEMBL 2004311 & 809227 & 7.6 & 6.7855 & TRN \\
\hline CHEMBL1992634 & 809227 & 7.6 & 6.6596 & TRN \\
\hline CHEMBL1242373 & 809227 & 8.7 & 7.8103 & TRN \\
\hline CHEMBL1984847 & 809227 & 4.5 & 4.5468 & TST \\
\hline CHEMBL316264 & 809227 & 4.6 & 4.3291 & TRN \\
\hline CHEMBL1988075 & 809227 & 8.4 & 7.7703 & TRN \\
\hline CHEMBL1996576 & 809227 & 4.5 & 4.8845 & TST \\
\hline CHEMBL1991678 & 809227 & 4.5 & 4.3173 & TRN \\
\hline CHEMBL2001239 & 809227 & 4.6 & 5.5104 & TRN \\
\hline CHEMBL1988594 & 809227 & 4.6 & 5.3895 & TRN \\
\hline CHEMBL 2001288 & 809227 & 6.0 & 4.899 & TRN \\
\hline CHEMBL1992363 & 809227 & 7.8 & 6.5451 & TRN \\
\hline CHEMBL1999811 & 809227 & 5.6 & 5.2366 & TRN \\
\hline CHEMBL1965495 & 809227 & 6.0 & 6.2071 & TRN \\
\hline CHEMBL235157 & 809227 & 4.5 & 4.7584 & TST \\
\hline CHEMBL1985074 & 809227 & 4.6 & 4.9492 & TST \\
\hline CHEMBL 2000481 & 809227 & 4.6 & 5.5568 & TRN \\
\hline CHEMBL1982874 & 809227 & 4.6 & 4.6333 & TRN \\
\hline CHEMBL1991725 & 809227 & 5.9 & 5.7546 & TRN \\
\hline CHEMBL1992242 & 809227 & 6.9 & 6.6379 & TRN \\
\hline CHEMBL1982271 & 809227 & 8.1 & 7.5349 & TRN \\
\hline CHEMBL 2007296 & 809227 & 4.6 & 4.5181 & TRN \\
\hline CHEMBL 208637 & 809227 & 4.6 & 4.3189 & TRN \\
\hline CHEMBL2004159 & 809227 & 4.5 & 4.6843 & TRN \\
\hline CHEMBL396523 & 809227 & 6.9 & 7.0016 & TRN \\
\hline CHEMBL1978371 & 809227 & 5.6 & 4.921 & TST \\
\hline CHEMBL1970203 & 809227 & 6.4 & 5.2744 & TRN \\
\hline CHEMBL1986530 & 809227 & 4.6 & 5.0736 & TST \\
\hline CHEMBL440084 & 809227 & 4.5 & 4.6673 & TRN \\
\hline
\end{tabular}




\begin{tabular}{|c|c|c|c|c|c|}
\hline & & & & & \\
\hline CHEMBL1999321 & 809227 & 4.6 & 5.6072 & TRN & \\
\hline CHEMBL1968590 & 809227 & 7.5 & 6.9555 & TRN & \\
\hline CHEMBL385478 & 809227 & 7.4 & 7.7209 & TRN & \\
\hline CHEMBL1999749 & 809227 & 6.3 & 5.8131 & TRN & \\
\hline CHEMBL 2005375 & 809227 & 4.6 & 4.54899 & 99999999995 & TRN \\
\hline CHEMBL1984191 & 809227 & 6.3 & 4.7954 & TRN & \\
\hline CHEMBL1983006 & 809227 & 4.6 & 4.8924 & TRN & \\
\hline CHEMBL1971029 & 809227 & 8.1 & 7.7333 & TRN & \\
\hline CHEMBL394790 & 809227 & 8.7 & 7.6517 & TRN & \\
\hline CHEMBL226471 & 809227 & 4.6 & 4.8742 & TRN & \\
\hline CHEMBL1974702 & 809227 & 4.6 & 4.3577 & TRN & \\
\hline CHEMBL1996111 & 809227 & 4.6 & 4.9542 & TRN & \\
\hline CHEMBL1966175 & 809227 & 4.5 & 4.6219 & TRN & \\
\hline CHEMBL1965589 & 809227 & 4.6 & 4.7181 & TRN & \\
\hline CHEMBL 2007375 & 809227 & 4.5 & 4.6477 & TRN & \\
\hline CHEMBL1998193 & 809227 & 4.6 & 4.7518 & TRN & \\
\hline CHEMBL379975 & 809227 & 4.8 & 4.5337 & TRN & \\
\hline CHEMBL474432 & 809227 & 4.6 & 6.5631 & TST & \\
\hline CHEMBL1965387 & 809227 & 7.2 & 7.0673 & TRN & \\
\hline CHEMBL2001539 & 809227 & 4.8 & 3.8279 & TST & \\
\hline CHEMBL1997041 & 809227 & 4.6 & 4.8868 & TRN & \\
\hline CHEMBL1988153 & 809227 & 5.9 & 4.6353 & TRN & \\
\hline CHEMBL550418 & 809227 & 4.5 & 4.1895 & TRN & \\
\hline CHEMBL1986666 & 809227 & 7.2 & 6.7091 & TRN & \\
\hline CHEMBL1971289 & 809227 & 4.5 & 4.4574 & TRN & \\
\hline CHEMBL1999556 & 809227 & 5.7 & 5.2949 & TRN & \\
\hline CHEMBL1988437 & 809227 & 4.8 & 6.0889 & TST & \\
\hline CHEMBL1968245 & 809227 & 4.6 & 4.8452 & TRN & \\
\hline CHEMBL1979577 & 809227 & 8.5 & 8.134 & TRN & \\
\hline CHEMBL1998121 & 809227 & 4.6 & 5.2583 & TRN & \\
\hline CHEMBL1233887 & 809227 & 4.5 & 4.9126 & TST & \\
\hline CHEMBL1991800 & 809227 & 4.6 & 4.4512 & TRN & \\
\hline CHEMBL52387 & 809227 & 4.6 & 5.3964 & TST & \\
\hline CHEMBL379835 & 809227 & 4.6 & 4.721 & TST & \\
\hline CHEMBL1979357 & 809227 & 4.6 & 4.687 & TRN & \\
\hline CHEMBL1980802 & 809227 & 4.6 & 5.184 & TST & \\
\hline CHEMBL1996649 & 809227 & 6.6 & 7.5336 & TRN & \\
\hline CHEMBL1996817 & 809227 & 7.6 & 7.1153 & TRN & \\
\hline CHEMBL1979554 & 809227 & 4.6 & 4.833 & TRN & \\
\hline CHEMBL1993962 & 809227 & 4.8 & 4.6711 & TST & \\
\hline CHEMBL1986756 & 809227 & 4.5 & 4.4179 & TRN & \\
\hline CHEMBL409349 & 809227 & 8.6 & 8.8338 & TRN & \\
\hline CHEMBL 2004355 & 809227 & 4.6 & 4.9289 & TRN & \\
\hline CHEMBL468280 & 809227 & 4.6 & 4.3227 & TST & \\
\hline CHEMBL1990884 & 809227 & 6.1 & 6.4785 & TRN & \\
\hline CHEMBL 3109278 & 809227 & 8.8 & 7.1497 & TRN & \\
\hline CHEMBL 256835 & 809227 & 4.6 & 4.6723 & TRN & \\
\hline CHEMBL1980142 & 809227 & 4.6 & 4.6227 & TRN & \\
\hline & & & & 23163 & \\
\hline
\end{tabular}




\begin{tabular}{|c|c|c|c|c|}
\hline & & & pplement & \\
\hline CHEMBL41783 & 809227 & 4.6 & 4.4237 & TRN \\
\hline CHEMBL 2004438 & 809227 & 7.0 & 6.9634 & TRN \\
\hline CHEMBL 2006276 & 809227 & 4.6 & 4.9171 & TRN \\
\hline CHEMBL191003 & 809227 & 4.7 & 5.5556 & TRN \\
\hline CHEMBL271381 & 809227 & 7.3 & 8.0861 & TRN \\
\hline CHEMBL 2006785 & 809227 & 4.6 & 4.5312 & TRN \\
\hline CHEMBL1973359 & 809227 & 5.6 & 5.0318 & TST \\
\hline CHEMBL1994638 & 809227 & 9.0 & 9.335 & TRN \\
\hline CHEMBL1995740 & 809227 & 4.6 & 4.2798 & TRN \\
\hline CHEMBL1985888 & 809227 & 8.8 & 9.0909 & TRN \\
\hline CHEMBL1996390 & 809227 & 4.6 & 4.6812 & TRN \\
\hline CHEMBL1990162 & 809227 & 6.5 & 6.3229 & TRN \\
\hline CHEMBL1992220 & 809227 & 8.0 & 7.5846 & TRN \\
\hline CHEMBL1979690 & 809227 & 7.5 & 7.5142 & TRN \\
\hline CHEMBL 234085 & 809227 & 4.7 & 4.112 & TRN \\
\hline CHEMBL1995832 & 809227 & 4.6 & 4.5329 & TRN \\
\hline CHEMBL1969042 & 809227 & 6.4 & 5.8135 & TRN \\
\hline CHEMBL 2000345 & 809227 & 6.3 & 5.989 & TRN \\
\hline CHEMBL1999931 & 809227 & 6.6 & 6.7297 & TRN \\
\hline CHEMBL1976376 & 809227 & 6.0 & 6.0067 & TRN \\
\hline CHEMBL1991640 & 809227 & 4.6 & 5.2104 & TST \\
\hline CHEMBL1983575 & 809227 & 4.5 & 6.0673 & TRN \\
\hline CHEMBL1968868 & 809227 & 4.5 & 4.4703 & TRN \\
\hline CHEMBL1375418 & 809227 & 4.6 & 5.1975 & TRN \\
\hline CHEMBL 302449 & 809227 & 7.5 & 7.1074 & TST \\
\hline CHEMBL 2007064 & 809227 & 6.5 & 7.1895 & TRN \\
\hline CHEMBL1981047 & 809227 & 4.7 & 6.2912 & TRN \\
\hline CHEMBL229968 & 809227 & 7.0 & 6.2197 & TRN \\
\hline CHEMBL1976196 & 809227 & 4.5 & 4.1675 & TST \\
\hline CHEMBL1976240 & 809227 & 4.6 & 4.6802 & TRN \\
\hline CHEMBL1987948 & 809227 & 7.4 & 7.3231 & TRN \\
\hline CHEMBL1997197 & 809227 & 4.5 & 4.4605 & TRN \\
\hline CHEMBL1983630 & 809227 & 4.1 & 4.501 & TRN \\
\hline CHEMBL1968151 & 809227 & 4.6 & 4.1118 & TRN \\
\hline CHEMBL1979093 & 809227 & 7.4 & 8.2367 & TRN \\
\hline CHEMBL1381197 & 809227 & 6.1 & 5.3138 & TRN \\
\hline CHEMBL1987009 & 809227 & 6.8 & 6.8405 & TRN \\
\hline CHEMBL379218 & 809227 & 6.2 & 5.9545 & TRN \\
\hline CHEMBL 2003817 & 809227 & 4.6 & 4.9011 & TRN \\
\hline CHEMBL336961 & 809227 & 4.6 & 5.0375 & TRN \\
\hline CHEMBL1994830 & 809227 & 4.6 & 4.6262 & TRN \\
\hline CHEMBL1987054 & 809227 & 7.2 & 7.6602 & TRN \\
\hline CHEMBL1970083 & 809227 & 7.8 & 7.5274 & TRN \\
\hline CHEMBL 226403 & 809227 & 4.7 & 4.7625 & TRN \\
\hline CHEMBL 2005631 & 809227 & 8.8 & 7.9045 & TRN \\
\hline CHEMBL1994938 & 809227 & 7.2 & 6.7196 & TRN \\
\hline CHEMBL1977223 & 809227 & 4.6 & 5.3767 & TRN \\
\hline CHEMBL1995765 & 809227 & 4.8 & 4.4777 & TST \\
\hline
\end{tabular}




\begin{tabular}{|c|c|c|c|c|}
\hline & & & pplement & \\
\hline CHEMBL1976290 & 809227 & 4.0 & 4.3232 & TRN \\
\hline CHEMBL1966279 & 809227 & 4.6 & 5.3982 & TRN \\
\hline CHEMBL1236126 & 809227 & 4.6 & 5.075 & TST \\
\hline CHEMBL1997846 & 809227 & 4.7 & 6.1464 & TRN \\
\hline CHEMBL1984760 & 809227 & 4.5 & 4.9335 & TRN \\
\hline CHEMBL2004419 & 809227 & 4.6 & 4.4925 & TRN \\
\hline CHEMBL1991728 & 809227 & 5.7 & 4.7627 & TRN \\
\hline CHEMBL360847 & 809227 & 4.5 & 4.9689 & TST \\
\hline CHEMBL1995811 & 809227 & 4.7 & 5.1409 & TRN \\
\hline CHEMBL1975787 & 809227 & 4.6 & 4.8438 & TRN \\
\hline CHEMBL2002407 & 809227 & 4.6 & 5.2361 & TRN \\
\hline CHEMBL1972489 & 809227 & 4.6 & 4.5937 & TRN \\
\hline CHEMBL1994074 & 809227 & 7.0 & 5.8119 & TRN \\
\hline CHEMBL1992937 & 809227 & 4.7 & 5.2292 & TST \\
\hline CHEMBL451401 & 809227 & 4.9 & 4.2668 & TRN \\
\hline CHEMBL1968930 & 809227 & 9.1 & 6.9825 & TRN \\
\hline CHEMBL1985566 & 809227 & 4.6 & 4.897 & TRN \\
\hline CHEMBL536151 & 809227 & 6.1 & 5.0837 & TST \\
\hline CHEMBL1986328 & 809227 & 4.6 & 4.5879 & TST \\
\hline CHEMBL95692 & 809227 & 4.6 & 4.675 & TRN \\
\hline CHEMBL1090356 & 809227 & 7.8 & 7.6158 & TRN \\
\hline CHEMBL2002450 & 809227 & 4.1 & 4.4588 & TRN \\
\hline CHEMBL1976455 & 809227 & 4.9 & 5.0051 & TRN \\
\hline CHEMBL261849 & 809227 & 4.5 & 5.5207 & TST \\
\hline CHEMBL1983923 & 809227 & 8.4 & 6.7605 & TRN \\
\hline CHEMBL1983534 & 809227 & 5.9 & 5.2363 & TRN \\
\hline CHEMBL1982361 & 809227 & 4.6 & 4.8871 & TRN \\
\hline CHEMBL1999112 & 809227 & 4.6 & 4.6872 & TST \\
\hline CHEMBL2000801 & 809227 & 8.0 & 6.4385 & TRN \\
\hline CHEMBL1982122 & 809227 & 4.6 & 4.9795 & TRN \\
\hline CHEMBL1682546 & 809227 & 4.6 & 5.0315 & TRN \\
\hline CHEMBL1991395 & 809227 & 4.6 & 4.5927 & TRN \\
\hline CHEMBL1971245 & 809227 & 7.3 & 6.2415 & TST \\
\hline CHEMBL1987648 & 809227 & 4.6 & 4.4991 & TST \\
\hline CHEMBL1996780 & 809227 & 4.6 & 4.695 & TST \\
\hline CHEMBL1972142 & 809227 & 6.7 & 5.9318 & TST \\
\hline CHEMBL1966514 & 809227 & 7.8 & 7.6928 & TST \\
\hline CHEMBL2003638 & 809227 & 6.3 & 6.0058 & TST \\
\hline CHEMBL 296586 & 809227 & 5.8 & 5.4575 & TST \\
\hline CHEMBL1996066 & 809227 & 8.5 & 6.1628 & TST \\
\hline CHEMBL1983393 & 809227 & 4.5 & 5.1032 & TST \\
\hline CHEMBL516429 & 809227 & 6.6 & 5.8673 & TST \\
\hline CHEMBL1970806 & 809227 & 4.6 & 4.4508 & TST \\
\hline CHEMBL1993722 & 809227 & 5.8 & 7.021 & TST \\
\hline CHEMBL2006674 & 809227 & 4.5 & 5.0885 & TST \\
\hline CHEMBL1984236 & 809227 & 6.6 & 4.7688 & TST \\
\hline CHEMBL1992371 & 809227 & 4.5 & 4.6534 & TST \\
\hline CHEMBL 202635 & 809227 & 5.6 & 4.797 & TST \\
\hline
\end{tabular}




\begin{tabular}{|c|c|c|c|c|}
\hline & & & 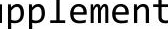 & al Tabl \\
\hline CHEMBL1375640 & 809227 & 4.6 & 4.9275 & TST \\
\hline CHEMBL1979970 & 809227 & 4.6 & 4.4872 & TST \\
\hline CHEMBL2002599 & 809227 & 4.5 & 4.4935 & TST \\
\hline CHEMBL 249282 & 809227 & 5.9 & 4.8141 & TST \\
\hline CHEMBL 2004637 & 809227 & 4.5 & 5.0813 & TST \\
\hline CHEMBL1993374 & 809227 & 4.5 & 4.9137 & TST \\
\hline CHEMBL1969264 & 809227 & 4.6 & 5.2307 & TST \\
\hline CHEMBL1973711 & 809227 & 5.8 & 4.9616 & TST \\
\hline CHEMBL 2006237 & 809227 & 4.6 & 5.1448 & TST \\
\hline CHEMBL1999506 & 809227 & 4.5 & 4.5207 & TST \\
\hline CHEMBL1967720 & 809227 & 9.0 & 7.9879 & TST \\
\hline CHEMBL 2005509 & 809227 & 8.0 & 7.7543 & TST \\
\hline CHEMBL1572266 & 809227 & 4.6 & 4.5839 & TST \\
\hline CHEMBL1991138 & 809227 & 6.2 & 6.2894 & TST \\
\hline CHEMBL1969755 & 809227 & 4.6 & 4.6415 & TST \\
\hline CHEMBL1972820 & 809227 & 4.6 & 4.5559 & TST \\
\hline CHEMBL1605605 & 809227 & 4.5 & 4.0905 & TST \\
\hline CHEMBL1989029 & 809227 & 8.2 & 6.1074 & TST \\
\hline CHEMBL514499 & 809227 & 7.3 & 6.45700 & 0000000001 \\
\hline CHEMBL1970352 & 809227 & 4.5 & 4.6364 & TST \\
\hline CHEMBL1965631 & 809227 & 4.6 & 5.3831 & TST \\
\hline CHEMBL1980144 & 809227 & 4.6 & 4.9787 & TST \\
\hline CHEMBL1991188 & 809227 & 4.6 & 4.6485 & TST \\
\hline CHEMBL1980167 & 809227 & 5.6 & 4.8214 & TST \\
\hline CHEMBL1972849 & 809227 & 4.6 & 4.3565 & TST \\
\hline CHEMBL 377408 & 809227 & 4.7 & 5.1019 & TST \\
\hline CHEMBL1986855 & 809227 & 8.4 & 7.391 & TST \\
\hline CHEMBL215152 & 809227 & 6.5 & 5.9577 & TST \\
\hline CHEMBL231209 & 809227 & 8.4 & 7.3413 & TST \\
\hline CHEMBL1976220 & 809227 & 8.9 & 7.8788 & TST \\
\hline CHEMBL 2006765 & 809227 & 4.5 & 5.4313 & TST \\
\hline CHEMBL 259922 & 809227 & 4.6 & 5.099 & TST \\
\hline CHEMBL1997617 & 809227 & 8.8 & 7.5612 & TST \\
\hline CHEMBL1969301 & 809227 & 6.0 & 5.1384 & TST \\
\hline CHEMBL1982383 & 809227 & 6.5 & 4.9902 & TST \\
\hline CHEMBL17370 & 809227 & 4.6 & 4.4931 & TST \\
\hline CHEMBL1980246 & 809227 & 4.5 & 5.2575 & TST \\
\hline CHEMBL 374044 & 809227 & 9.0 & 9.8159 & TST \\
\hline CHEMBL1987910 & 809227 & 7.9 & 6.7078 & TST \\
\hline CHEMBL1983932 & 809227 & 7.0 & 5.7391 & TST \\
\hline CHEMBL1983980 & 809227 & 6.3 & 5.3205 & TST \\
\hline CHEMBL1999484 & 809227 & 6.5 & 6.5725 & TST \\
\hline CHEMBL404366 & 809227 & 9.8 & 9.0926 & TST \\
\hline CHEMBL1966069 & 809227 & 4.6 & 4.7187 & TST \\
\hline CHEMBL1986899 & 809227 & 5.9 & 5.5006 & TST \\
\hline CHEMBL1991285 & 809227 & 6.4 & 5.2785 & TST \\
\hline CHEMBL1997822 & 809227 & 6.1 & 6.8032 & TST \\
\hline CHEMBL1985690 & 809227 & 5.7 & 6.1729 & TST \\
\hline
\end{tabular}




\begin{tabular}{|c|c|c|c|c|c|c|}
\hline & & & & & & \\
\hline CHEMBL243088 & 809227 & 6.6 & 7.0122 & TST & & \\
\hline CHEMBL1984038 & 809227 & 4.6 & 4.7406 & TST & & \\
\hline CHEMBL1974416 & 809227 & 6.4 & 6.5043 & TST & & \\
\hline CHEMBL1993661 & 809227 & 7.5 & 7.5384 & TST & & \\
\hline CHEMBL2004615 & 809227 & 6.0 & 4.5235 & TST & & \\
\hline CHEMBL1997872 & 809227 & 6.8 & 5.1829 & TST & & \\
\hline CHEMBL1097003 & 614756 & 7.9208 & 4.1321 & TST & & \\
\hline CHEMBL1093745 & 614756 & 4.2596 & 4.3451 & TRN & & \\
\hline CHEMBL1089723 & 614756 & 4.8539 & 4.8771 & TRN & & \\
\hline CHEMBL1077244 & 614756 & 1.0 & 1.0589 & TRN & & \\
\hline CHEMBL1082235 & 614756 & 6.45100 & 00000000 & 205 & 5.4003 & TRN \\
\hline CHEMBL1077243 & 614756 & 4.0088 & 4.2673 & TRN & & \\
\hline CHEMBL1084683 & 614756 & 5.2598 & 5.1268 & TRN & & \\
\hline CHEMBL1086640 & 614756 & 6.71 & 6.6883 & TRN & & \\
\hline CHEMBL1086176 & 614756 & 5.6092 & 6.2395 & TST & & \\
\hline CHEMBL1095038 & 614756 & 5.5385 & 5.5488 & TRN & & \\
\hline CHEMBL1085920 & 614756 & 4.7751 & 5.3463 & TRN & & \\
\hline CHEMBL1077282 & 614756 & 4.9769 & 5.5947 & TRN & & \\
\hline CHEMBL1083837 & 614756 & 3.0 & 3.8254 & TRN & & \\
\hline CHEMBL1097694 & 614756 & 4.8539 & 4.5399 & TRN & & \\
\hline CHEMBL1077218 & 614756 & 4.9586 & 4.9921 & TRN & & \\
\hline CHEMBL1091081 & 614756 & 4.7447 & 3.8147 & TRN & & \\
\hline CHEMBL1086174 & 614756 & 5.8925 & 4.7399 & TRN & & \\
\hline CHEMBL1091082 & 614756 & 4.6576 & 4.7495 & TRN & & \\
\hline CHEMBL1093390 & 614756 & 4.2518 & 4.2764 & TRN & & \\
\hline CHEMBL1093747 & 614756 & 5.301 & 5.1715 & TRN & & \\
\hline CHEMBL1083209 & 614756 & 5.9634 & 5.8467 & TRN & & \\
\hline CHEMBL1077270 & 614756 & 3.0 & 3.7563 & TRN & & \\
\hline CHEMBL1086175 & 614756 & 5.8687 & 5.96200 & 0000000001 & & TRN \\
\hline CHEMBL1086781 & 614756 & 6.585 & 5.1948 & TST & & \\
\hline CHEMBL1086639 & 614756 & 7.0269 & 7.3398 & TRN & & \\
\hline CHEMBL1095039 & 614756 & 5.4193 & 5.3789 & TRN & & \\
\hline CHEMBL1083528 & 614756 & 4.6014 & 5.3113 & TST & & \\
\hline CHEMBL1095040 & 614756 & 5.1549 & 4.6065 & TRN & & \\
\hline CHEMBL1085918 & 614756 & 4.9629 & 4.9549 & TRN & & \\
\hline CHEMBL1085927 & 614756 & 5.9266 & 5.6806 & TRN & & \\
\hline CHEMBL1082236 & 614756 & 7.5686 & 7.8163 & TRN & & \\
\hline CHEMBL1086426 & 614756 & 3.0 & 3.6678 & TRN & & \\
\hline CHEMBL1086782 & 614756 & 6.1798 & 5.3152 & TRN & & \\
\hline CHEMBL1093079 & 614756 & 4.3098 & 3.6211 & TRN & & \\
\hline CHEMBL1084134 & 614756 & 5.9281 & 5.5645 & TRN & & \\
\hline CHEMBL1088618 & 614756 & 7.2596 & 7.3338 & TRN & & \\
\hline CHEMBL1089722 & 614756 & 4.2596 & 6.115 & TST & & \\
\hline CHEMBL1084692 & 614756 & 4.7669 & 4.8021 & TRN & & \\
\hline CHEMBL1091083 & 614756 & 4.6383 & 5.0806 & TRN & & \\
\hline CHEMBL1086425 & 614756 & 3.0 & 2.9041 & TRN & & \\
\hline CHEMBL1086427 & 614756 & 8.2218 & 4.6121 & TST & & \\
\hline CHEMBL1093746 & 614756 & 2.7645 & 3.3511 & TRN & & \\
\hline
\end{tabular}

Page 23167 


\begin{tabular}{|c|c|c|c|c|c|c|}
\hline \multicolumn{7}{|c|}{ Supplemental Table S2.txt } \\
\hline CHEMBL1084681 & 614756 & 5.3003 & 5.0381 & TRN & & \\
\hline CHEMBL1092802 & 614756 & 3.8268 & 4.0791 & TRN & & \\
\hline CHEMBL1083208 & 614756 & 6.0292 & 6.2486 & TRN & & \\
\hline CHEMBL1077258 & 614756 & 5.1448 & 5.0254 & TRN & & \\
\hline CHEMBL1085919 & 614756 & 4.912 & 4.7727 & TRN & & \\
\hline CHEMBL1077233 & 614756 & 4.301 & 5.2925 & TRN & & \\
\hline CHEMBL1084684 & 614756 & 5.0693 & 5.2022 & TST & & \\
\hline CHEMBL1084682 & 614756 & 5.2666 & 5.211 & TRN & & \\
\hline CHEMBL1077260 & 614756 & 5.38299 & 9999999 & 99 & 5.4888 & TST \\
\hline CHEMBL1095366 & 614756 & 5.0 & 5.5891 & TST & & \\
\hline CHEMBL1084693 & 614756 & 4.6876 & 4.7524 & TST & & \\
\hline CHEMBL1077213 & 614756 & 4.9208 & 3.4462 & TST & & \\
\hline CHEMBL1086638 & 614756 & 7.1192 & 5.3658 & TST & & \\
\hline CHEMBL1082237 & 614756 & 7.3565 & 5.8752 & TST & & \\
\hline CHEMBL1095041 & 614756 & 5.0969 & 4.976 & TST & & \\
\hline CHEMBL1086780 & 614756 & 6.7033 & 6.1014 & TST & & \\
\hline CHEMBL3667454 & 1528556 & 7.1549 & 7.1406 & TRN & & \\
\hline CHEMBL 3667472 & 1528556 & 9.3979 & 9.3936 & TRN & & \\
\hline CHEMBL 3667461 & 1528556 & $7.8210 e$ & 0000000 & $\partial 1$ & 7.6452 & TST \\
\hline CHEMBL3667485 & 1528556 & 8.8539 & 8.8319 & TRN & & \\
\hline CHEMBL3672463 & 1528556 & 8.0506 & 8.7541 & TST & & \\
\hline CHEMBL 3672475 & 1528556 & 8.0132 & 8.0388 & TRN & & \\
\hline CHEMBL 3672458 & 1528556 & 8.8239 & 9.022 & TST & & \\
\hline CHEMBL 3667477 & 1528556 & 8.8539 & 8.8714 & TRN & & \\
\hline CHEMBL 3672467 & 1528556 & 8.8239 & 9.1529 & TST & & \\
\hline CHEMBL3667479 & 1528556 & 7.9431 & 8.2753 & TST & & \\
\hline CHEMBL3667459 & 1528556 & 7.3979 & 7.407 & TRN & & \\
\hline CHEMBL 3667464 & 1528556 & 6.5458 & 6.5308 & TRN & & \\
\hline CHEMBL3672469 & 1528556 & 8.0506 & 8.0587 & TRN & & \\
\hline CHEMBL 3672454 & 1528556 & 9.2218 & 9.2203 & TRN & & \\
\hline CHEMBL3672459 & 1528556 & 8.8539 & 8.9992 & TST & & \\
\hline CHEMBL3667466 & 1528556 & 9.0458 & 9.0593 & TRN & & \\
\hline CHEMBL3667457 & 1528556 & 6.8286 & 6.8395 & TRN & & \\
\hline CHEMBL 3672451 & 1528556 & 9.3979 & 9.4194 & TRN & & \\
\hline CHEMBL3667482 & 1528556 & 8.2518 & 8.2486 & TRN & & \\
\hline CHEMBL3672452 & 1528556 & 8.8239 & 8.8187 & TRN & & \\
\hline CHEMBL3667476 & 1528556 & 9.3979 & 9.3979 & TRN & & \\
\hline CHEMBL 3672468 & 1528556 & 8.1805 & 8.7515 & TST & & \\
\hline CHEMBL 3667473 & 1528556 & 8.8239 & 8.8207 & TRN & & \\
\hline CHEMBL3667462 & 1528556 & 7.6799 & 7.6952 & TRN & & \\
\hline CHEMBL3667480 & 1528556 & 8.8539 & 8.9251 & TST & & \\
\hline CHEMBL3667481 & 1528556 & 8.8239 & 8.8273 & TRN & & \\
\hline CHEMBL3672453 & 1528556 & 9.3979 & 9.3766 & TRN & & \\
\hline CHEMBL 3672472 & 1528556 & 9.5229 & 9.4834 & TRN & & \\
\hline CHEMBL 3667455 & 1528556 & 6.9586 & 6.9661 & TRN & & \\
\hline CHEMBL 3667471 & 1528556 & 9.1549 & 9.1282 & TRN & & \\
\hline CHEMBL 3667463 & 1528556 & 7.2434 & 7.2433 & TRN & & \\
\hline CHEMBL3667468 & 1528556 & 8.7447 & 8.7306 & TRN & & \\
\hline
\end{tabular}


Supplemental Table S2.txt

\begin{tabular}{|c|c|c|c|c|}
\hline 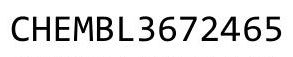 & & & & \\
\hline HEMBL3672461 & & 8.0655 & 8.5769 & \\
\hline & & & & \\
\hline 72464 & 56 & 31 & 23 & \\
\hline AEMBL3672457 & 528556 & 8.1249 & 1203 & \\
\hline AEMBL3667478 & 528556 & 9.699 & .9673 & \\
\hline HEMBL3667456 & 528 & 7.1549 & .1454 & \\
\hline IEMBL3 & $2 \varepsilon$ & 4815 & .4722 & \\
\hline EMBL3 & 528 & 9.2218 & .2354 & \\
\hline AEMBL3667475 & 528556 & 8.8239 & 8.8568 & \\
\hline AEMBL3667483 & 528 & 8.1487 & .1617 & \\
\hline HEMBL 366 & 528 & 9.0 & .981 & \\
\hline HEMBL; & & 9 & & \\
\hline HEMBL & 528 & 3539 & 3.8388 & \\
\hline AEMBL3672450 & 528 & 8.1079 & .1228 & \\
\hline AEMBL366 & $0<c$ & 7.3979 & 20 & \\
\hline AEMBL & 2 & 239 & 87 & \\
\hline HEMBL & 6 & 739 & & \\
\hline HEMBL & 52 & 01 & & \\
\hline HEMBL36 & $\because 6$ & 539 & & RN \\
\hline $\mathrm{E} / \mathrm{MBL} 36$ & $D<c$ & 8. & 8.1202 & NIV \\
\hline HEMBL3 & 22 & 979 & 43 & RIN \\
\hline HEMBL & 6 & & & \\
\hline 9 & 56 & 79 & & RN \\
\hline IEMBL36 & & 979 & & ST \\
\hline $\mathrm{EEMB} 36$ & 52 & 9.301 & 9.2971 & RIN \\
\hline HEMBL31 & 29 & 3. & .3003 & RN \\
\hline HEMBL3 & & 35 & & \\
\hline HEM & & & & RN \\
\hline IEMBL3 & & & & RN \\
\hline HEMBL311; & 96 & 5.4202 & 62 & RN \\
\hline HEMBL311; & 29 & 6 . & 07 & RN \\
\hline HEMBL3. & & & & RN \\
\hline 0 & & & & ST \\
\hline HEMBL 3113 & 296 & 861 & 81 & RN \\
\hline IEMBL31 & 96 & 4. & 88 & ST \\
\hline HEMBL3113 & 200 & $\partial 07$ & 07 & RN \\
\hline & & & & RN \\
\hline HEMBL311 & & 5.2076 & 35 & RN \\
\hline HEMBL 31 & 290 & 6.2924 & 55 & RN \\
\hline HEMBL31 & 99 & 9 & 96 & \\
\hline HEMBL3113 & & & & \\
\hline HEMBL31 & & & & RN \\
\hline HEMBL3113 & 290553 & 39 & 5.8652 & RN \\
\hline AEMBL 311 & 29055 & 3.3979 & 384 & F \\
\hline & & & & \\
\hline HEMBL3 & - & - & 5.2793 & \\
\hline 311338 & & 3979 & 3.3303 & \\
\hline
\end{tabular}

Page 23169 
Supplemental Table S2.txt

\begin{tabular}{|c|c|c|c|c|c|}
\hline CHEMBL 3113204 & 1290553 & 5.3468 & 5.4275 & TRN & \\
\hline CHEMBL 3113387 & 1290553 & 4.7212 & \multicolumn{2}{|c|}{4.736000000000001} & TRN \\
\hline CHEMBL 3113178 & 1290553 & 6.301 & 6.1944 & TRN & \\
\hline CHEMBL 3113202 & 1290553 & 5.6383 & 5.6942 & TRN & \\
\hline CHEMBL3113197 & 1290553 & 6.7959 & 6.7784 & TRN & \\
\hline CHEMBL3113383 & 1290553 & 3.3979 & 3.9404 & TST & \\
\hline CHEMBL1596118 & 1290553 & 5.2924 & 5.4245 & TRN & \\
\hline CHEMBL3113166 & 1290553 & 6.1024 & 6.2374 & TST & \\
\hline CHEMBL3113154 & 1290553 & 3.3979 & 3.4912 & TRN & \\
\hline CHEMBL3113152 & 1290553 & 5.6576 & 5.6861 & TRN & \\
\hline CHEMBL3113161 & 1290553 & 3.3979 & 3.4138 & TRN & \\
\hline CHEMBL3113189 & 1290553 & 5.1549 & 5.1129 & TRN & \\
\hline CHEMBL 3113180 & 1290553 & 6.4815 & 6.4932 & TRN & \\
\hline CHEMBL3113155 & 1290553 & 3.3979 & 3.4332 & TRN & \\
\hline CHEMBL 3113374 & 1290553 & 5.2518 & 5.6381 & TST & \\
\hline CHEMBL3113200 & 1290553 & 5.7959 & 5.6962 & TRN & \\
\hline CHEMBL3113369 & 1290553 & 5.8861 & 5.9312 & TST & \\
\hline CHEMBL 3113162 & 1290553 & 3.3979 & 3.3519 & TRN & \\
\hline CHEMBL 3113198 & 1290553 & 6.6576 & 6.6388 & TRN & \\
\hline CHEMBL 3113193 & 1290553 & 6.7447 & 6.7614 & TRN & \\
\hline CHEMBL3113191 & 1290553 & 6.4089 & 6.4216 & TRN & \\
\hline CHEMBL3113185 & 1290553 & 5.4318 & 5.4075 & TRN & \\
\hline CHEMBL 3113158 & 1290553 & 4.6576 & 4.712 & TRN & \\
\hline CHEMBL3113371 & 1290553 & 5.6383 & 5.5356 & TST & \\
\hline CHEMBL3113151 & 1290553 & 4.8861 & 4.7798 & TRN & \\
\hline CHEMBL 3113384 & 1290553 & 3.3979 & 2.8343 & TST & \\
\hline CHEMBL3113156 & 1290553 & 3.3979 & 3.4026 & TRN & \\
\hline CHEMBL 3113168 & 1290553 & 6.4559 & 6.4706 & TRN & \\
\hline CHEMBL3113169 & 1290553 & 6.6198 & 6.6925 & TRN & \\
\hline CHEMBL3113379 & 1290553 & 3.3979 & 3.3894 & TRN & \\
\hline CHEMBL3113368 & 1290553 & 5.5376 & 5.9648 & TST & \\
\hline CHEMBL3113199 & 1290553 & 5.3468 & 5.415 & TRN & \\
\hline CHEMBL3113196 & 1290553 & 5.9586 & 5.9772 & TRN & \\
\hline CHEMBL 3113378 & 1290553 & 3.3979 & \multicolumn{2}{|c|}{3.4530000000000003} & TRN \\
\hline CHEMBL3113366 & 1290553 & 5.2757 & 5.3099 & TRN & \\
\hline CHEMBL3113375 & 1290553 & 3.3979 & 3.4491 & TRN & \\
\hline CHEMBL 3113372 & 1290553 & 5.6576 & 5.9902 & TST & \\
\hline CHEMBL3113373 & 1290553 & 5.6021 & 5.4761 & TST & \\
\hline CHEMBL 3113190 & 1290553 & 4.9208 & 4.9303 & TRN & \\
\hline CHEMBL3113195 & 1290553 & 6.1192 & 6.1643 & TRN & \\
\hline CHEMBL3113181 & 1290553 & 5.8861 & 5.8395 & TRN & \\
\hline CHEMBL3113187 & 1290553 & 5.301 & 5.3077 & TRN & \\
\hline CHEMBL3113385 & 1290553 & 3.3979 & 3.4581 & TRN & \\
\hline CHEMBL3113186 & 1290553 & 5.3979 & 4.9012 & TST & \\
\hline CHEMBL 3113183 & 1290553 & 5.4559 & 5.4423 & TRN & \\
\hline CHEMBL 3113171 & 1290553 & 5.5229 & 5.943 & TST & \\
\hline CHEMBL3113367 & 1290553 & 5.2007 & 4.7452 & TST & \\
\hline CHEMBL3113163 & 1290553 & 3.3979 & 2.7317 & TST & \\
\hline
\end{tabular}

Page 23170 
Supplemental Table S2.txt

\begin{tabular}{|c|c|c|c|c|}
\hline CHEMBL3113184 & 290553 & 4.9586 & 4.8327 & TST \\
\hline HEMBL 3113167 & 290553 & 6.2441 & 6.0116 & \\
\hline HEMBL 3113203 & 290553 & 5.3768 & 4.9838 & \\
\hline HEMBL3113192 & 290553 & 6.585 & 2755 & \\
\hline HEMBL174052 & 03638 & 7.7959 & 7.7183 & \\
\hline HEMBL173881 & 03638 & 5.4202 & 5.7699 & \\
\hline HEMBL90308 & 03638 & 6.8539 & 3.8388 & ST \\
\hline HEMBL91417 & 03638 & 7.6021 & 4.4799 & \\
\hline HEMBL178071 & 03638 & 7.2596 & 7.1334 & \\
\hline HEMBL177471 & 03638 & 6.3098 & 6.4455 & \\
\hline HEMBL177757 & 03638 & 8.6576 & 7.6705 & \\
\hline HEMBL174951 & 03638 & 5.5229 & .6296 & \\
\hline HEMBL176173 & 03638 & 8.0 & 3.1321 & \\
\hline HEMBL177488 & 303638 & 7.1079 & 7.1235 & \\
\hline HEMBL177495 & 03638 & 5.4815 & 4.8833 & \\
\hline HEMBL178432 & 03638 & 6.0269 & 6.3236 & \\
\hline HEMBL175694 & 303638 & 7.6778 & 5705 & RIV \\
\hline HEMBL176166 & 303638 & 7.3279 & 7.3136 & \\
\hline HEMBL36655 & 03638 & 4.8477 & 4.7306 & \\
\hline HEMBL426410 & 03638 & 6. & 47 & \\
\hline HEMBL173992 & 03638 & 539 & 53 & KIV \\
\hline HEMBL1 & 38 & & 969 & ST \\
\hline HEMBL37044 & 303638 & 5.8539 & 936 & \\
\hline HEMBL174397 & 03638 & 8.0 & 1103 & TRN \\
\hline HEMBL175021 & 03638 & 098 & 5705 & IRI \\
\hline HEMBL177714 & 03638 & 55 & 98 & 「RN \\
\hline HEMBL $285 €$ & 38 & 18 & 95 & ST \\
\hline HEMBL367307 & 03638 & 8.2518 & 8.2728 & TRN \\
\hline HEMBL177694 & 03638 & 5.3665 & 12 & ISI \\
\hline HEMBL174396 & 03638 & 6.2147 & 6.2204 & TRN \\
\hline HEMBL 368284 & 03638 & 3372 & 8.3841 & TRN \\
\hline CHEMBL177729 & 38 & 66 & .71 & RN \\
\hline CHEMBL177728 & 38 & 6.699 & 6.7251 & TRN \\
\hline HEMBL177681 & 03638 & 4.3188 & 4 & TRN \\
\hline HEMBL 90258 & 303638 & 6.8861 & 3.8388 & TST \\
\hline HEMBL178640 & 303638 & 506 & 1239 & TRN \\
\hline CHEMBL177708 & 38 & 8. & 21 & ГRN \\
\hline CHEMBL366671 & 303638 & 7.5086 & 7.5878 & TRN \\
\hline CHEMBL426232 & 03638 & 7.9586 & 7.9926 & TRN \\
\hline CHEMBL425684 & 303638 & 208 & 6. & ГRN \\
\hline CHEMBL362061 & 303638 & 7.7447 & 7.9186 & TRN \\
\hline CHEMBL367859 & 303638 & 7.699 & 7.6272 & TRN \\
\hline CHEMBL426230 & 303638 & 7.7447 & 7.6653 & TRN \\
\hline CHEMBL177577 & 03638 & 8.3279 & 8.1321 & TRN \\
\hline CHEMBL1 & 303 & 4.8794 & 4.9426 & T \\
\hline CHEMBL413727 & 303638 & 6.7696 & 4.4799 & \\
\hline CHEMBL369547 & 303638 & 7.2147 & 7.3449 & ГRN \\
\hline CHEMBL176324 & 303638 & 7.6383 & 7.4027 & 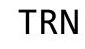 \\
\hline
\end{tabular}

Page 23171 


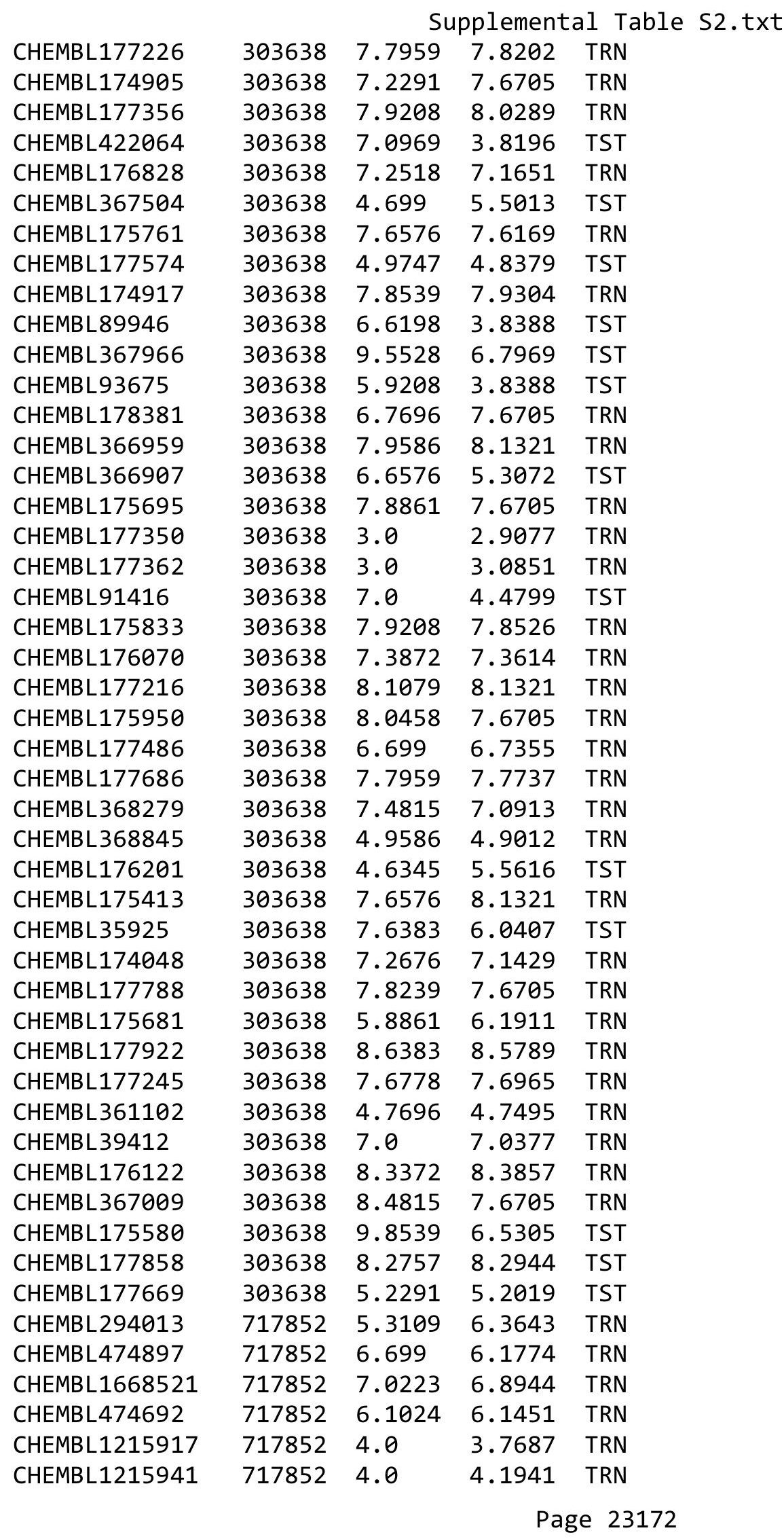




\begin{tabular}{|c|c|c|c|c|c|}
\hline \multirow[b]{2}{*}{ CHEMBL303479 } & \multicolumn{5}{|c|}{ Supplemental Table S2.txt } \\
\hline & 717852 & 7.6517 & \multicolumn{2}{|c|}{7.803999999999999} & TRN \\
\hline CHEMBL599071 & 717852 & 5.311 & 5.1503 & TRN & \\
\hline CHEMBL498297 & 717852 & 6.0017 & 5.4061 & TRN & \\
\hline CHEMBL1668519 & 717852 & 6.5686 & 6.443 & TST & \\
\hline CHEMBL264521 & 717852 & 5.7156 & 6.3831 & TRN & \\
\hline CHEMBL1215944 & 717852 & 5.6819 & 5.2212 & TRN & \\
\hline CHEMBL1668509 & 717852 & 5.6778 & 4.6941 & TRN & \\
\hline CHEMBL19847 & 717852 & 9.0 & 8.8274 & TRN & \\
\hline CHEMBL306529 & 717852 & 8.0223 & 7.8654 & TRN & \\
\hline CHEMBL 259462 & 717852 & 6.0 & 5.8578 & TRN & \\
\hline CHEMBL 271839 & 717852 & 7.5528 & \multicolumn{2}{|c|}{7.1579999999999995} & TRN \\
\hline CHEMBL1668504 & 717852 & 5.8471 & 5.8805 & TRN & \\
\hline CHEMBL1668395 & 717852 & 7.3768 & 8.2051 & TRN & \\
\hline CHEMBL570907 & 717852 & 6.8827 & 6.7762 & TRN & \\
\hline CHEMBL511150 & 717852 & 6.3279 & 6.5922 & TRN & \\
\hline CHEMBL188 & 717852 & 7.8761 & \multicolumn{2}{|c|}{7.872999999999999} & TRN \\
\hline CHEMBL381689 & 717852 & 5.5391 & 5.9731 & TRN & \\
\hline CHEMBL1215916 & 717852 & 4.0 & 4.1735 & TRN & \\
\hline CHEMBL 73711 & 717852 & 5.7174 & 5.6035 & TRN & \\
\hline CHEMBL593434 & 717852 & 6.2518 & 5.6815 & TST & \\
\hline CHEMBL1216000 & 717852 & 4.0 & 4.0686 & TRN & \\
\hline CHEMBL1215964 & 717852 & 4.0 & 5.146 & TRN & \\
\hline CHEMBL472856 & 717852 & 5.4685 & 6.1045 & TRN & \\
\hline CHEMBL408430 & 717852 & 5.301 & 5.8364 & TRN & \\
\hline CHEMBL1215919 & 717852 & 4.0 & 4.4043 & TRN & \\
\hline CHEMBL570690 & 717852 & 6.1487 & 6.1398 & TRN & \\
\hline CHEMBL597438 & 717852 & 5.7001 & 5.7171 & TRN & \\
\hline CHEMBL 258242 & 717852 & 6.5086 & 6.5434 & TRN & \\
\hline CHEMBL1668512 & 717852 & 6.8861 & 6.8074 & TRN & \\
\hline CHEMBL201571 & 717852 & 7.3768 & 5.8016 & TRN & \\
\hline CHEMBL108085 & 717852 & 9.301 & 8.8245 & TRN & \\
\hline CHEMBL371214 & 717852 & 6.1694 & 6.9566 & TRN & \\
\hline CHEMBL1668518 & 717852 & 4.0 & 5.9999 & TRN & \\
\hline CHEMBL 385508 & 717852 & 6.0 & 6.0529 & TRN & \\
\hline CHEMBL381492 & 717852 & 7.9318 & 7.4376 & TRN & \\
\hline CHEMBL 2179724 & 717852 & 5.0 & 6.4436 & TST & \\
\hline CHEMBL523577 & 717852 & 4.0 & 4.5045 & TRN & \\
\hline CHEMBL 272203 & 717852 & 8.2518 & 5.7321 & TST & \\
\hline CHEMBL1215898 & 717852 & 6.2924 & 4.5322 & TRN & \\
\hline CHEMBL1215908 & 717852 & 4.0 & 3.9811 & TRN & \\
\hline CHEMBL502276 & 717852 & 5.9136 & 5.3724 & TRN & \\
\hline CHEMBL1215942 & 717852 & 4.0 & 4.7344 & TRN & \\
\hline CHEMBL571777 & 717852 & 6.6576 & 6.6801 & TRN & \\
\hline CHEMBL1215977 & 717852 & 4.0 & 4.8383 & TRN & \\
\hline CHEMBL596579 & 717852 & 5.6021 & 5.9715 & TST & \\
\hline CHEMBL411631 & 717852 & 7.3468 & 7.0813 & TRN & \\
\hline CHEMBL306764 & 717852 & 6.4168 & 7.2892 & TRN & \\
\hline CHEMBL1354658 & 717852 & 7.3161 & 6.0836 & TST & \\
\hline
\end{tabular}




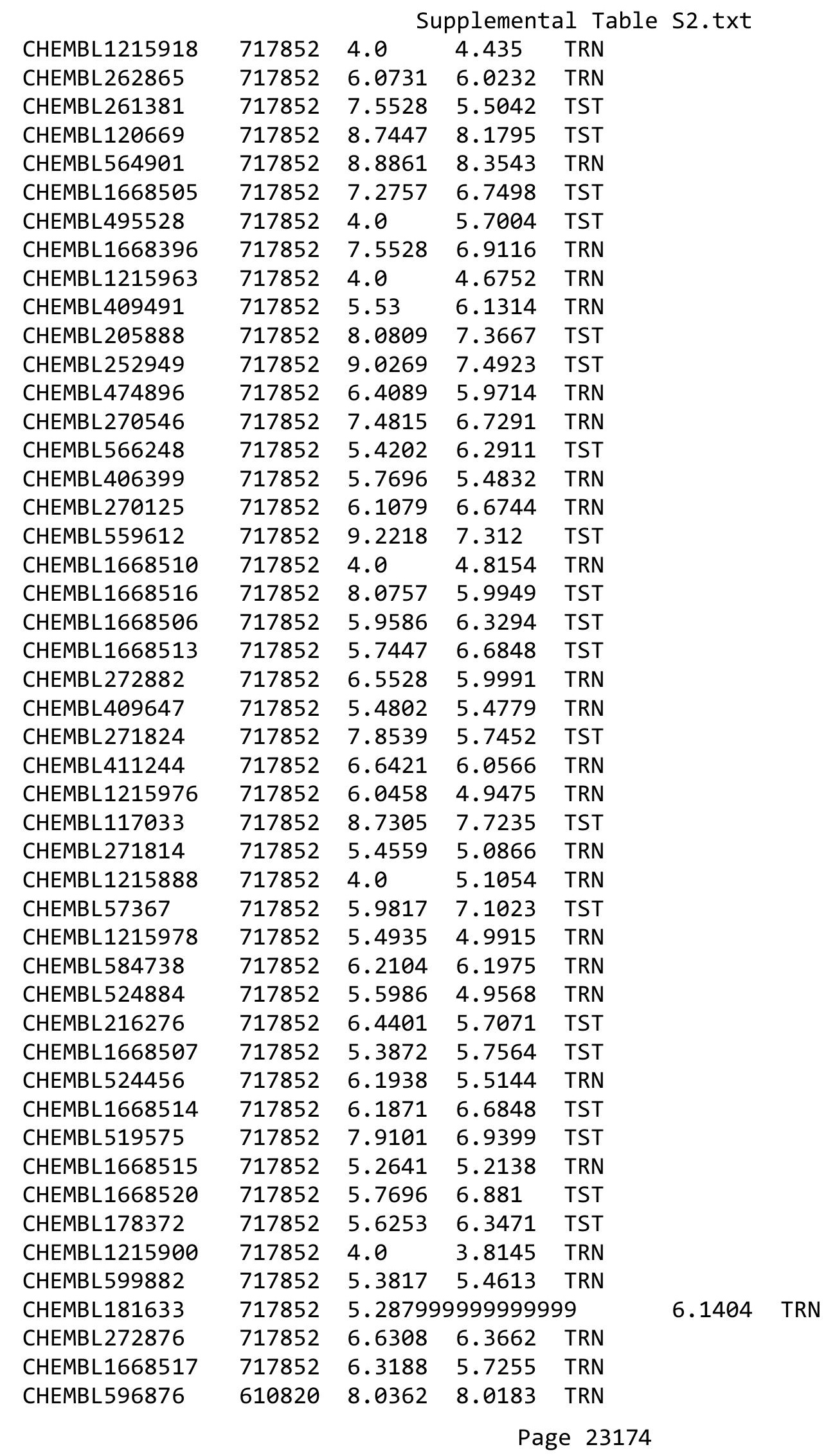




CHEMBL597229
CHEMBL597430
CHEMBL598557
CHEMBL591447
CHEMBL597940
CHEMBL597924
CHEMBL608147
CHEMBL597216
CHEMBL591825
CHEMBL609315
CHEMBL596617
CHEMBL599180
CHEMBL591826
CHEMBL232782
CHEMBL598047
CHEMBL609024
CHEMBL597923
CHEMBL596874
CHEMBL597087
CHEMBL597131
CHEMBL597029
CHEMBL598243
CHEMBL598245
CHEMBL597294
CHEMBL597086
CHEMBL592635
CHEMBL599470
CHEMBL597295
CHEMBL599469
CHEMBL592771
CHEMBL604388
CHEMBL597431
CHEMBL610214
CHEMBL599179
CHEMBL599381
CHEMBL5 597088
CHEMBL598764
CHEMBL597064
CHEMBL596658
CHEMBL605005
CHEMBL599488
CHEMBL598572

Supplemental Table S2.txt

$\begin{array}{llll}610820 & 9.3665 & 8.9927 & \text { TRN } \\ 610820 & 9.6021 & 8.9927 & \text { TRN } \\ 610820 & 9.1871 & 9.0136 & \text { TRN } \\ 610820 & 7.9208 & 7.8103 & \text { TRN } \\ 610820 & 9.4559 & 9.0136 & \text { TRN } \\ 610820 & 6.4685 & 6.5565 & \text { TRN } \\ 610820 & 8.6778 & 9.1787 & \text { TRN } \\ 610820 & 8.3098 & 8.3167 & \text { TST } \\ 610820 & 8.0362 & 7.562 & \text { TRN } \\ 610820 & 6.6778 & 6.9631 & \text { TST } \\ 610820 & 8.6198 & 8.9927 & \text { TRN } \\ 610820 & 6.0915 & 6.0517 & \text { TST } \\ 610820 & 6.9208 & 6.994 & \text { TRN } \\ 610820 & 8.7696 & 7.6039 & \text { TST } \\ 610820 & 8.7447 & 8.6521 & \text { TRN } \\ 610820 & 7.8239 & 7.562 & \text { TRN } \\ 610820 & 9.0 & 8.4621 & \text { TRN } \\ 610820 & 7.9208 & 7.9259 & \text { TRN } \\ 610820 & 7.5528 & 7.7339 & \text { TST } \\ 610820 & 6.2441 & 8.3922 & \text { TST } \\ 610820 & 7.7212 & 7.562 & \text { TRN } \\ 610820 & 8.0706 & 7.9747 & \text { TRN } \\ 610820 & 8.0969 & 8.9927 & \text { TRN } \\ 610820 & 8.0757 & 8.3167 & \text { TST } \\ 610820 & 7.5528 & 7.2196 & \text { TST } \\ 610820 & 8.0315 & 7.7703 & \text { TRN } \\ 610820 & 7.0915 & 7.0992 & \text { TRN } \\ 610820 & 8.6198 & 8.3167 & \text { TST } \\ 610820 & 6.5376 & 6.5372 & \text { TRN } \\ 610820 & 8.8539 & 8.4621 & \text { TRN } \\ 610820 & 7.9208 & 8.0158 & \text { TRN } \\ 610820 & 9.4559 & 8.9927 & \text { TRN } \\ 610820 & 8.1871 & 9.1787 & \text { TRN } \\ 610820 & 5.8861 & 5.8175 & \text { TST } \\ 610820 & 8.0655 & 8.4621 & \text { TRN } \\ 610820 & 8.6576 & 8.3167 & \text { TST } \\ 610820 & 9.8239 & 9.0136 & \text { TRN } \\ 610820 & 7.9208 & 8.3263 & \text { TRN } \\ 610820 & 9.6021 & 9.1787 & \text { TRN } \\ 610820 & 8.6383 & 9.0136 & \text { TRN } \\ 610820 & 7.8861 & 7.562 & \text { TRN } \\ 610820 & 8.2676 & 8.4621 & \text { TRN } \\ 610820 & 9.3979 & 9.1787 & \text { TRN } \\ 610820 & 7.3372 & 7.2973 & \text { TRN } \\ 610820 & 7.5528 & 7.562 & \text { TRN } \\ 610820 & 7.8539 & 7.9363 & \text { TRN } \\ & 9.699 & 9.1787 & \text { TRN }\end{array}$

Page 23175 


\begin{tabular}{|c|c|c|c|c|}
\hline & & & & \\
\hline MBL598139 & 610820 & 586 & 71 & TST \\
\hline CHEMBL598545 & 610820 & 7.5376 & 7.6936 & \\
\hline AEMBL590243 & 10820 & 6.1487 & 562 & \\
\hline HEMBL598558 & 510820 & 9.4559 & 9.0136 & \\
\hline CHEMBL599276 & 10820 & 7.8861 & 7.9532 & \\
\hline CHEMBL597647 & 10820 & 9.5686 & 9.1787 & \\
\hline HEMBL597030 & 610820 & 8.1135 & 6937 & \\
\hline HEMBL598556 & 610820 & 9.0969 & 9.0136 & \\
\hline CHEMBL591682 & 610820 & 6.1367 & 6.2318 & \\
\hline HEMBL596877 & 10820 & 8.2147 & 8.66 & \\
\hline CHEMBL586217 & 20 & 468 & 9927 & \\
\hline HEMBL598048 & 610820 & 8.6383 & 9.1787 & \\
\hline CHEMBL599489 & 610 & 7.2924 & 7.2633 & \\
\hline CHEMBL596875 & $61 €$ & 8.0605 & 39 & \\
\hline HEMBL: & 20 & 147 & 31 & \\
\hline CHEMBL & 610 & 778 & & \\
\hline CHEMBL & 20 & 372 & 973 & \\
\hline CHEMBL598046 & 61 & 576 & 88 & \\
\hline CHEMBL: & 610 & 07 & 41 & \\
\hline CHEMBL & 20 & 76 & & \\
\hline CHEMBL & 20 & 78 & & \\
\hline CHEMBL: & 20 & 239 & 63 & \\
\hline CHEMBL597729 & 61 & 09 & & \\
\hline CHEMBL: & 0 & 79 & 76 & \\
\hline CHEMBL & 20 & & 67 & \\
\hline CHEMBL & & 55 & 27 & \\
\hline CHEMBL: & 20 & & & 10 \\
\hline CHEMBL599181 & 61 & 86 & 521 & TS \\
\hline CHEMBL592772 & 610820 & 8.7447 & 621 & 15 \\
\hline CHEMBL3 & 166 & 539 & 538 & $\mathrm{TR}$ \\
\hline CHEMBL & 66 & & & 11 \\
\hline CHEMBL3125273 & 166 & 72 & 08 & 15 \\
\hline CHEMBL3125253 & 1296166 & 8.5229 & 33 & $\mathrm{TP}$ \\
\hline CHEMBL3 & 166 & 5 . & & in \\
\hline CHEMBL3 & 66 & 7. & 581 & TS \\
\hline CHEMBL & 66 & & & $\mathrm{TR}$ \\
\hline CHEMBL3125267 & 1296166 & 586 & 505 & $\mathrm{TR}$ \\
\hline CHEMBL3125263 & 1296166 & 7.6576 & 572 & TR \\
\hline CHEMBL3 & 166 & 29 & & In \\
\hline CHEMBL3 & 166 & 372 & 875 & $\mathrm{TR}$ \\
\hline CHEMBL3125236 & 1296166 & 7.0969 & 7.0972 & $\mathrm{TR}$ \\
\hline CHEMBL3125252 & 1296166 & 8.1549 & 8.1557 & $\mathrm{TR}$ \\
\hline CHEMBL3125244 & 1296166 & 7.9586 & & $\mathrm{TR}$ \\
\hline CHEMBL3125286 & 1296166 & 7.699 & 7.6984 & $R$ \\
\hline CHEMBL3125249 & 1296166 & 7.6021 & 7.5998 & $\mathrm{TR}$ \\
\hline CHEMBL3125285 & 1296166 & 7.6576 & 7.6568 & $\mathrm{TR}$ \\
\hline CHEMBL3125272 & 1296166 & 7.4685 & 7.4678 & TR \\
\hline CHEMBL 3125284 & 1296166 & 6.7696 & 6.7699 & $r R$ \\
\hline
\end{tabular}

Page 23176 
Supplemental Table S2.txt

\begin{tabular}{|c|c|c|c|c|c|}
\hline CHEMBL 3125265 & 1296166 & 7.8239 & 7.8244 & TRN & \\
\hline CHEMBL 3125271 & 1296166 & 7.1308 & 7.58 & TST & \\
\hline CHEMBL3125240 & 1296166 & 8.301 & 8.3011 & TRN & \\
\hline CHEMBL3125269 & 1296166 & 5.0 & 4.9994 & TRN & \\
\hline CHEMBL3125257 & 1296166 & 7.4949 & 7.4943 & TRN & \\
\hline CHEMBL3125256 & 1296166 & 8.3979 & 8.3976 & TRN & \\
\hline CHEMBL 3125255 & 1296166 & 8.301 & 8.3009 & TRN & \\
\hline CHEMBL3125282 & 1296166 & 7.6778 & 7.6777 & TRN & \\
\hline CHEMBL3125277 & 1296166 & 6.9208 & 6.6622 & TST & \\
\hline CHEMBL3125235 & 1296166 & 8.699 & 8.6991 & TRN & \\
\hline CHEMBL 3125274 & 1296166 & 6.6676 & 6.6684 & TRN & \\
\hline CHEMBL 3125243 & 1296166 & 7.6576 & 7.6579 & TRN & \\
\hline CHEMBL3125259 & 1296166 & 8.301 & 8.3007 & TRN & \\
\hline CHEMBL3125260 & 1296166 & 8.1549 & 8.1611 & TRN & \\
\hline CHEMBL 3125258 & 1296166 & 7.7696 & 7.7702 & TRN & \\
\hline CHEMBL3125264 & 1296166 & 5.0 & 5.0001 & TRN & \\
\hline CHEMBL3125242 & 1296166 & 8.0458 & 8.0461 & TRN & \\
\hline CHEMBL3125275 & 1296166 & 5.8894 & 5.8893 & TRN & \\
\hline CHEMBL3125103 & 1296166 & 8.3979 & 8.4 & TRN & \\
\hline CHEMBL 3125270 & 1296166 & 8.3979 & 8.3939 & TRN & \\
\hline CHEMBL3125266 & 1296166 & 8.5229 & 8.5293 & TRN & \\
\hline CHEMBL 3125251 & 1296166 & 8.0458 & 8.0449 & TRN & \\
\hline CHEMBL 3125241 & 1296166 & 7.3768 & 7.3764 & TRN & \\
\hline CHEMBL3125246 & 1296166 & 7.4559 & 7.9089 & TST & \\
\hline CHEMBL 3125102 & 1296166 & 8.3979 & 8.3928 & TRN & \\
\hline CHEMBL 3125279 & 1296166 & 7.9208 & 7.9248 & TRN & \\
\hline CHEMBL3125281 & 1296166 & 7.3372 & 7.3381 & TRN & \\
\hline CHEMBL 3125101 & 1296166 & 8.699 & 8.1574 & TST & \\
\hline CHEMBL3125247 & 1296166 & 8.2218 & \multicolumn{2}{|c|}{8.222000000000001} & TRN \\
\hline CHEMBL 3125248 & 1296166 & 6.9508 & 5.142 & TST & \\
\hline CHEMBL 3125268 & 1296166 & 5.0 & 8.01 & TST & \\
\hline CHEMBL 3125262 & 1296166 & 7.6778 & 7.9922 & TST & \\
\hline CHEMBL3125104 & 1296166 & 8.5229 & 8.2607 & TST & \\
\hline CHEMBL3125250 & 1296166 & 7.7447 & 7.7948 & TST & \\
\hline CHEMBL 3125278 & 1296166 & 6.3565 & 6.6843 & TST & \\
\hline CHEMBL3125237 & 1296166 & 7.3468 & 6.849 & TST & \\
\hline CHEMBL3125238 & 1296166 & 7.3979 & 6.1336 & TST & \\
\hline CHEMBL3954838 & 1637646 & 5.301 & 5.8588 & TRN & \\
\hline CHEMBL371198 & 1637646 & 4.301 & 4.5125 & TRN & \\
\hline CHEMBL 373300 & 1637646 & 6.0783 & 4.8928 & TRN & \\
\hline CHEMBL1908963 & 1637646 & 4.301 & 4.3326 & TRN & \\
\hline CHEMBL3942419 & 1637646 & 4.301 & 4.5747 & TST & \\
\hline CHEMBL372712 & 1637646 & 4.301 & 4.2599 & TRN & \\
\hline CHEMBL189579 & 1637646 & 5.3002 & 4.6418 & TST & \\
\hline CHEMBL364029 & 1637646 & 4.301 & 4.4531 & TRN & \\
\hline CHEMBL189308 & 1637646 & 4.301 & 4.0643 & TST & \\
\hline CHEMBL 3953207 & 1637646 & 4.301 & 4.3741 & TRN & \\
\hline CHEMBL3895953 & 1637646 & 6.7471 & 6.1586 & TRN & \\
\hline
\end{tabular}

Page 23177 
Supplemental Table S2.txt

\begin{tabular}{|c|c|c|c|c|c|}
\hline CHEMBL189317 & 1637646 & 4.301 & 4.4236 & TRN & \\
\hline CHEMBL3907135 & 1637646 & 4.301 & 4.5615 & TST & \\
\hline CHEMBL3970752 & 1637646 & 4.301 & 6.15 & TRN & \\
\hline CHEMBL189745 & 1637646 & 4.301 & 4.5606 & TRN & \\
\hline CHEMBL3931560 & 1637646 & 5.5018 & 6.3116 & TRN & \\
\hline CHEMBL3976143 & 1637646 & 5.2181 & 4.8352 & TRN & \\
\hline CHEMBL3895532 & 1637646 & 4.301 & 4.6472 & TST & \\
\hline CHEMBL190332 & 1637646 & 4.301 & 4.4395 & TRN & \\
\hline CHEMBL3960034 & 1637646 & 4.301 & 4.0001 & TRN & \\
\hline CHEMBL425546 & 1637646 & 4.301 & 4.5542 & TST & \\
\hline CHEMBL3901003 & 1637646 & 6.6326 & 6.0095 & TRN & \\
\hline CHEMBL359761 & 1637646 & 4.301 & 4.2979 & TST & \\
\hline CHEMBL189848 & 1637646 & 4.301 & 4.3208 & TRN & \\
\hline CHEMBL191138 & 1637646 & 4.301 & 4.2431 & TRN & \\
\hline CHEMBL3928814 & 1637646 & 5.3925 & 4.7081 & TRN & \\
\hline CHEMBL360675 & 1637646 & 4.301 & 6.1959 & TRN & \\
\hline CHEMBL3905466 & 1637646 & 6.857 & 6.4962 & TRN & \\
\hline CHEMBL3984345 & 1637646 & 7.0969 & 5.8054 & TRN & \\
\hline CHEMBL189543 & 1637646 & 4.301 & 4.4539 & TRN & \\
\hline CHEMBL370295 & 1637646 & 4.301 & 4.2127 & TRN & \\
\hline CHEMBL3935761 & 1637646 & 7.2291 & 6.4777 & TRN & \\
\hline CHEMBL3979462 & 1637646 & 4.301 & 4.721999 & 99999999995 & TST \\
\hline CHEMBL 3983877 & 1637646 & 7.0757 & 6.2764 & TST & \\
\hline CHEMBL190627 & 1637646 & 4.301 & 4.2677 & TRN & \\
\hline CHEMBL 3907408 & 1637646 & 4.301 & 4.681 & TRN & \\
\hline CHEMBL3895697 & 1637646 & 6.2549 & 6.2287 & TRN & \\
\hline CHEMBL3941758 & 1637646 & 5.8761 & 5.7917 & TRN & \\
\hline CHEMBL 3945479 & 1637646 & 4.301 & 4.7269 & TRN & \\
\hline CHEMBL3973692 & 1637646 & 7.3665 & 6.5954 & TRN & \\
\hline CHEMBL189732 & 1637646 & 4.301 & 4.0731 & TST & \\
\hline CHEMBL 3962672 & 1637646 & 4.301 & 4.3027 & TRN & \\
\hline CHEMBL189937 & 1637646 & 6.3575 & 6.1026 & TRN & \\
\hline CHEMBL 3958430 & 1637646 & 6.2636 & 5.7864 & TRN & \\
\hline CHEMBL364317 & 1637646 & 7.6198 & 6.6027 & TRN & \\
\hline CHEMBL 365339 & 1637646 & 4.301 & 4.8063 & TRN & \\
\hline CHEMBL3950533 & 1637646 & 5.2255 & 6.0513 & TRN & \\
\hline CHEMBL192060 & 1637646 & 5.6021 & 4.8766 & TRN & \\
\hline CHEMBL3971207 & 1637646 & 4.301 & 6.3511 & TRN & \\
\hline CHEMBL3964646 & 1637646 & 7.0223 & 6.5574 & TRN & \\
\hline CHEMBL 3920898 & 1637646 & 5.7305 & 5.7863 & TRN & \\
\hline CHEMBL140272 & 1637646 & 7.6778 & 5.8057 & TST & \\
\hline CHEMBL3977079 & 1637646 & 4.301 & 4.3938 & TRN & \\
\hline CHEMBL 3897354 & 1637646 & 6.6882 & 6.2339 & TRN & \\
\hline CHEMBL3968467 & 1637646 & 4.301 & 4.5174 & TRN & \\
\hline CHEMBL190804 & 1637646 & 4.301 & 4.3611 & TRN & \\
\hline CHEMBL3903712 & 1637646 & 4.301 & 4.5263 & TRN & \\
\hline CHEMBL3952178 & 1637646 & 4.301 & 4.666 & TRN & \\
\hline CHEMBL3927156 & 1637646 & 6.8477 & 6.4195 & TRN & \\
\hline
\end{tabular}




\begin{tabular}{|c|c|c|c|c|c|}
\hline \multicolumn{6}{|c|}{ Supplemental Table S2.txt } \\
\hline CHEMBL189490 & 1637646 & 4.301 & 4.2194 & TRN & \\
\hline CHEMBL190302 & 1637646 & 4.301 & 4.1916 & TST & \\
\hline CHEMBL3918866 & 1637646 & 5.4202 & 4.5614 & TST & \\
\hline CHEMBL189978 & 1637646 & 4.301 & 4.1862 & TRN & \\
\hline CHEMBL192749 & 1637646 & 4.301 & 4.1148 & TRN & \\
\hline CHEMBL 3893248 & 1637646 & 4.301 & 4.4586 & TST & \\
\hline CHEMBL193184 & 1637646 & 4.301 & 4.0867 & TST & \\
\hline CHEMBL3960859 & 1637646 & 6.9245 & 6.5277 & TST & \\
\hline CHEMBL193177 & 1637646 & 4.301 & 4.2737 & TST & \\
\hline CHEMBL33891 & 809261 & 4.7 & 3.9219 & TRN & \\
\hline CHEMBL1983573 & 809261 & 3.0 & 3.1999 & TRN & \\
\hline CHEMBL 2004311 & 809261 & 3.0 & 4.0331 & TRN & \\
\hline CHEMBL 2000568 & 809261 & 3.0 & 2.9806 & TRN & \\
\hline CHEMBL1975175 & 809261 & 3.0 & 4.0022 & TST & \\
\hline CHEMBL1992634 & 809261 & 3.0 & 3.3531 & TRN & \\
\hline CHEMBL1242373 & 809261 & 3.0 & 4.2455 & TRN & \\
\hline CHEMBL1090363 & 809261 & 6.2 & 4.3928 & TRN & \\
\hline CHEMBL1986869 & 809261 & 3.0 & 2.7745 & TRN & \\
\hline CHEMBL 2004033 & 809261 & 5.5 & 2.9764 & TST & \\
\hline CHEMBL2001239 & 809261 & 5.5 & 4.3352 & TRN & \\
\hline CHEMBL1971534 & 809261 & 3.0 & 2.779 & TRN & \\
\hline CHEMBL143703 & 809261 & 3.0 & 3.3621 & TRN & \\
\hline CHEMBL1988594 & 809261 & 3.0 & 3.9417 & TRN & \\
\hline CHEMBL 2005886 & 809261 & 3.0 & 3.2981 & TRN & \\
\hline CHEMBL235157 & 809261 & 3.0 & 2.8345 & TRN & \\
\hline CHEMBL1976878 & 809261 & 5.7 & 4.9358 & TRN & \\
\hline CHEMBL481491 & 809261 & 3.0 & 2.6986 & TST & \\
\hline CHEMBL 2002479 & 809261 & 3.0 & 4.3358 & TRN & \\
\hline CHEMBL1992242 & 809261 & 3.0 & 3.7033 & TRN & \\
\hline CHEMBL1976673 & 809261 & 3.0 & 2.61 & TRN & \\
\hline CHEMBL 2000137 & 809261 & 3.0 & 4.069 & TRN & \\
\hline CHEMBL1992645 & 809261 & 3.0 & 3.1603 & TST & \\
\hline CHEMBL1973013 & 809261 & 3.0 & 3.4187 & TRN & \\
\hline CHEMBL1999749 & 809261 & 3.0 & 3.7997 & TRN & \\
\hline CHEMBL1989834 & 809261 & 3.0 & 3.1965 & TRN & \\
\hline CHEMBL1981079 & 809261 & 3.0 & 3.6042 & TST & \\
\hline CHEMBL1983634 & 809261 & 6.0 & 4.3096 & TRN & \\
\hline CHEMBL1998834 & 809261 & 3.0 & 2.8331 & TRN & \\
\hline CHEMBL1965423 & 809261 & 3.0 & 3.2365 & TRN & \\
\hline CHEMBL 2000832 & 809261 & 5.5 & 3.8969 & TRN & \\
\hline CHEMBL1993073 & 809261 & 5.7 & 3.9586 & TRN & \\
\hline CHEMBL1990590 & 809261 & 3.0 & 3.2893 & TRN & \\
\hline CHEMBL1990583 & 809261 & 3.0 & 4.1659 & TRN & \\
\hline CHEMBL1992125 & 809261 & 3.0 & 4.3498 & TRN & \\
\hline CHEMBL1996111 & 809261 & 3.0 & 2.969 & TRN & \\
\hline CHEMBL289959 & 809261 & 3.0 & 3.91399 & 99999999997 & TRN \\
\hline CHEMBL1980896 & 809261 & 3.0 & 3.8454 & TRN & \\
\hline CHEMBL1975208 & 809261 & 3.0 & 3.0556 & TST & \\
\hline
\end{tabular}




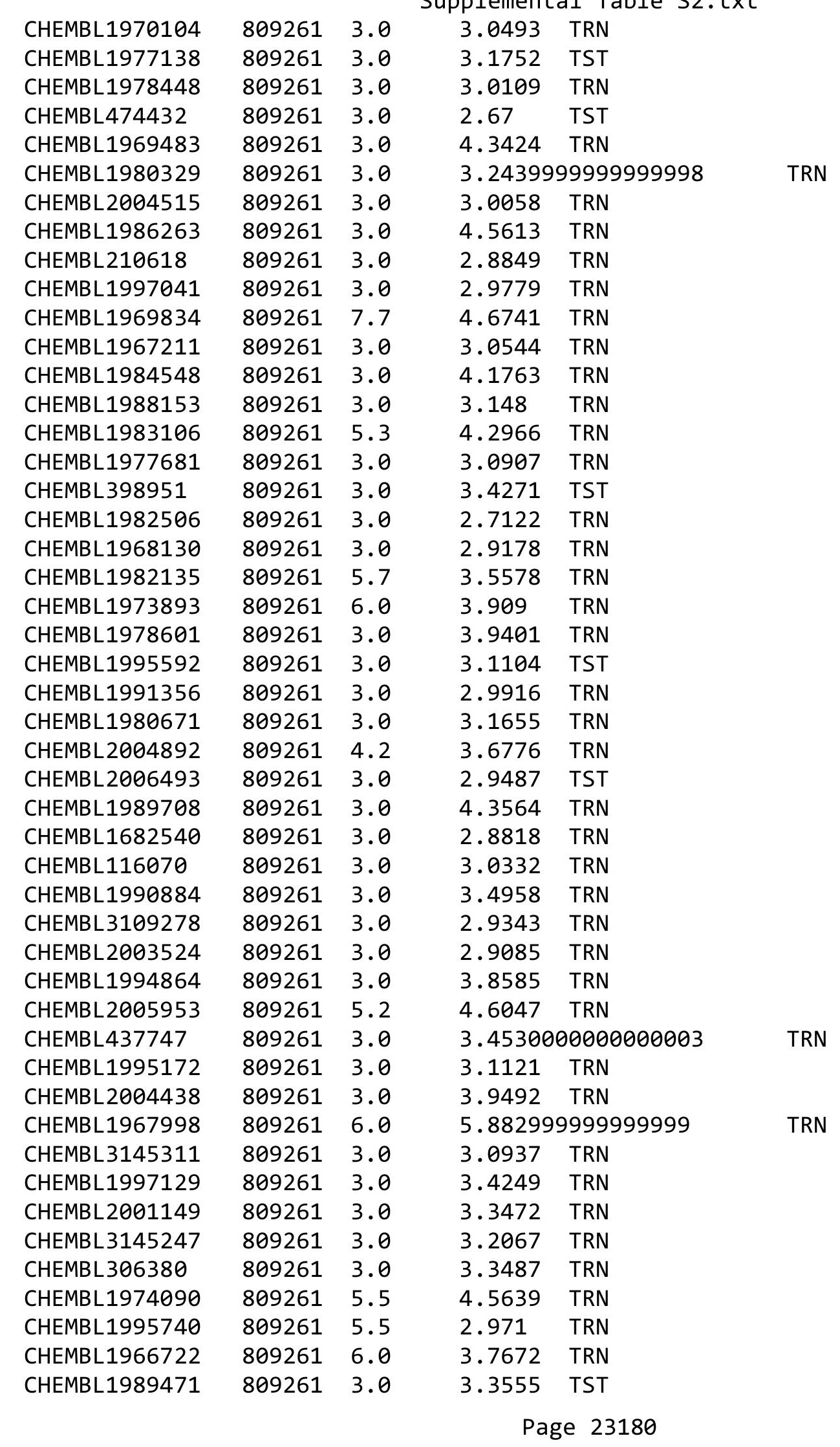




\begin{tabular}{|c|c|c|c|c|c|}
\hline \multicolumn{6}{|c|}{ Supplemental Table S2.txt } \\
\hline CHEMBL1992723 & 809261 & 3.0 & 2.987 & TRN & \\
\hline CHEMBL210928 & 809261 & 3.0 & 2.7748 & TRN & \\
\hline CHEMBL1995068 & 809261 & 5.4 & 4.2734 & TRN & \\
\hline CHEMBL1977148 & 809261 & 3.0 & 3.6362 & TRN & \\
\hline CHEMBL1973937 & 809261 & 6.0 & 4.5823 & TRN & \\
\hline CHEMBL1966842 & 809261 & 3.0 & 4.2426 & TRN & \\
\hline CHEMBL1991186 & 809261 & 3.0 & 3.8406 & TRN & \\
\hline CHEMBL1682357 & 809261 & 3.0 & 3.2084 & TRN & \\
\hline CHEMBL1989505 & 809261 & 3.0 & 4.0859 & TRN & \\
\hline CHEMBL262623 & 809261 & 3.0 & 3.2965 & TRN & \\
\hline CHEMBL1986658 & 809261 & 3.0 & 3.6991 & TRN & \\
\hline CHEMBL1967875 & 809261 & 3.0 & 2.9579 & TST & \\
\hline CHEMBL1970522 & 809261 & 3.0 & 2.8165 & TRN & \\
\hline CHEMBL1988622 & 809261 & 3.0 & 2.8221 & TRN & \\
\hline CHEMBL519697 & 809261 & 3.0 & 3.3868 & TST & \\
\hline CHEMBL 2007064 & 809261 & 3.0 & 2.8343 & TRN & \\
\hline CHEMBL1983846 & 809261 & 3.0 & 4.1938 & TRN & \\
\hline CHEMBL50894 & 809261 & 5.0 & 3.2405 & TRN & \\
\hline CHEMBL1983630 & 809261 & 3.0 & 3.1855 & TRN & \\
\hline CHEMBL1994669 & 809261 & 3.0 & 4.1332 & TRN & \\
\hline CHEMBL1981725 & 809261 & 6.3 & 5.2697 & TRN & \\
\hline CHEMBL1522508 & 809261 & 3.0 & 3.7268 & TRN & \\
\hline CHEMBL1973795 & 809261 & 3.0 & 2.9863 & TRN & \\
\hline CHEMBL1978099 & 809261 & 3.0 & 4.9334 & TRN & \\
\hline CHEMBL1970083 & 809261 & 3.0 & 3.9219 & TRN & \\
\hline CHEMBL184847 & 809261 & 4.7 & 3.7503 & TRN & \\
\hline CHEMBL1393571 & 809261 & 3.0 & 3.0394 & TRN & \\
\hline CHEMBL1974310 & 809261 & 3.0 & 2.8187 & TRN & \\
\hline CHEMBL1984367 & 809261 & 3.0 & 3.0755 & TRN & \\
\hline CHEMBL 243749 & 809261 & 7.1 & 4.5255 & TRN & \\
\hline CHEMBL 2005631 & 809261 & 6.3 & 4.4429 & TRN & \\
\hline CHEMBL 2006836 & 809261 & 3.0 & 3.285 & TST & \\
\hline CHEMBL3145328 & 809261 & 5.7 & 3.4079 & TRN & \\
\hline CHEMBL1982563 & 809261 & 3.0 & 3.3449 & TRN & \\
\hline CHEMBL399530 & 809261 & 3.0 & 2.9469 & TRN & \\
\hline CHEMBL1972365 & 809261 & 3.0 & 3.2710 & 00000000004 & TRN \\
\hline CHEMBL1997193 & 809261 & 3.0 & 3.187 & TST & \\
\hline CHEMBL1973860 & 809261 & 3.0 & 2.6929 & TST & \\
\hline CHEMBL1972489 & 809261 & 3.0 & 3.6237 & TRN & \\
\hline CHEMBL1974803 & 809261 & 5.5 & 3.6121 & TRN & \\
\hline CHEMBL1994074 & 809261 & 3.0 & 2.988 & TRN & \\
\hline CHEMBL 2004544 & 809261 & 3.0 & 3.1751 & TRN & \\
\hline CHEMBL244627 & 809261 & 3.0 & 3.3162 & TRN & \\
\hline CHEMBL451401 & 809261 & 3.0 & 2.8133 & TRN & \\
\hline CHEMBL1989569 & 809261 & 3.0 & 3.1539 & TRN & \\
\hline CHEMBL 2006715 & 809261 & 3.0 & 4.865 & TRN & \\
\hline CHEMBL 2005475 & 809261 & 3.0 & 3.0016 & TRN & \\
\hline CHEMBL 2002450 & 809261 & 3.0 & 3.0108 & TRN & \\
\hline
\end{tabular}




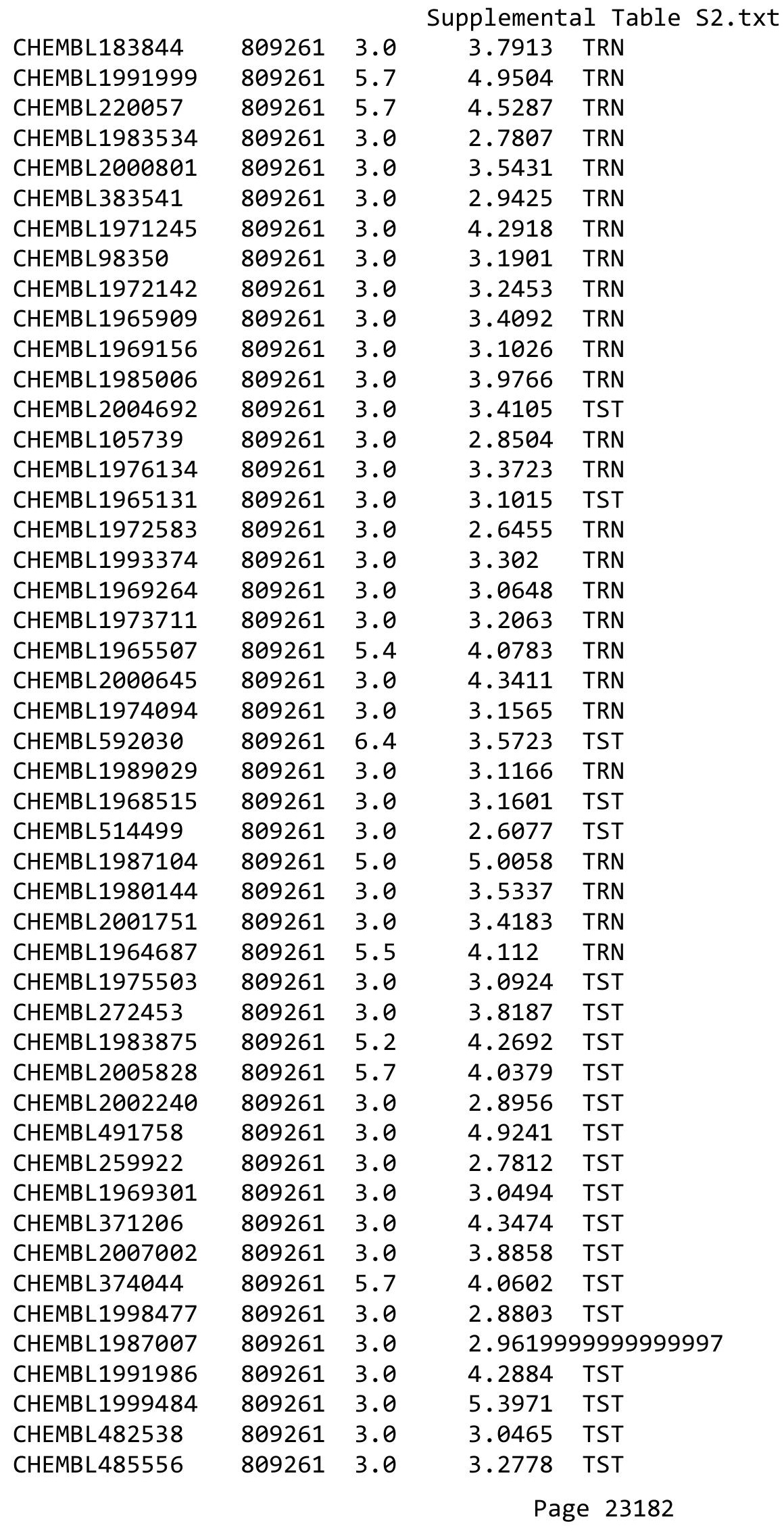




\begin{tabular}{|c|c|c|c|c|}
\hline & & & pplement & al $\mathrm{T}$ \\
\hline CHEMBL1973399 & 809261 & 3.0 & 2.9494 & TST \\
\hline CHEMBL1987881 & 809261 & 4.5 & 4.4887 & TST \\
\hline CHEMBL1997822 & 809261 & 3.0 & 3.4504 & TST \\
\hline CHEMBL1966578 & 809261 & 3.0 & 3.0375 & TST \\
\hline CHEMBL 243088 & 809261 & 7.3 & 4.4645 & TST \\
\hline CHEMBL1993661 & 809261 & 3.0 & 4.6963 & TST \\
\hline CHEMBL1682341 & 809261 & 3.0 & 3.0658 & TST \\
\hline CHEMBL1968406 & 809261 & 5.4 & 4.157 & TST \\
\hline CHEMBL1986684 & 809261 & 3.0 & 2.7761 & TST \\
\hline CHEMBL524040 & 552254 & 8.5229 & 8.5119 & TRN \\
\hline CHEMBL522533 & 552254 & 7.8861 & 7.8178 & TRN \\
\hline CHEMBL525924 & 552254 & 8.3665 & 8.3583 & TRN \\
\hline CHEMBL428429 & 552254 & 7.4318 & 8.879 & TST \\
\hline CHEMBL496714 & 552254 & 9.0088 & 8.7735 & TST \\
\hline CHEMBL494638 & 552254 & 9.0 & 8.9637 & TRN \\
\hline CHEMBL495889 & 552254 & 9.0088 & 9.0193 & TRN \\
\hline CHEMBL525360 & 552254 & 8.585 & 8.7873 & TST \\
\hline CHEMBL525003 & 552254 & 8.5686 & 8.5315 & TRN \\
\hline CHEMBL494180 & 552254 & 9.4685 & 9.475 & TRN \\
\hline CHEMBL522572 & 552254 & 8.0088 & 8.9926 & TST \\
\hline CHEMBL 257149 & 552254 & 8.8861 & 8.8061 & TST \\
\hline CHEMBL256777 & 552254 & 8.1079 & 9.0372 & TST \\
\hline CHEMBL497554 & 552254 & 7.8539 & 8.8304 & TST \\
\hline CHEMBL494822 & 552254 & 7.9208 & 9.4696 & TST \\
\hline CHEMBL498353 & 552254 & 8.0315 & 8.0423 & TRN \\
\hline CHEMBL493801 & 552254 & 7.585 & 7.5785 & TRN \\
\hline CHEMBL496294 & 552254 & 8.699 & 8.6928 & TRN \\
\hline CHEMBL498352 & 552254 & 8.301 & 8.2879 & TRN \\
\hline CHEMBL524623 & 552254 & 8.4089 & 8.5869 & TST \\
\hline CHEMBL521688 & 552254 & 9.0 & 8.9551 & TRN \\
\hline CHEMBL524824 & 552254 & 8.699 & 8.7018 & TRN \\
\hline CHEMBL497960 & 552254 & 8.0 & 8.0061 & TRN \\
\hline CHEMBL495690 & 552254 & 7.9586 & 8.1267 & TRN \\
\hline CHEMBL508147 & 552254 & 8.8239 & 8.6943 & TRN \\
\hline CHEMBL494637 & 552254 & 8.4559 & 8.4726 & TRN \\
\hline CHEMBL525361 & 552254 & 7.9586 & 7.9562 & TRN \\
\hline CHEMBL497122 & 552254 & 8.7696 & 8.779 & TRN \\
\hline CHEMBL495691 & 552254 & 7.1675 & 7.1554 & TRN \\
\hline CHEMBL494819 & 552254 & 8.5686 & 8.5684 & TRN \\
\hline CHEMBL525606 & 552254 & 8.6576 & 8.6758 & TRN \\
\hline CHEMBL497951 & 552254 & 9.0 & 9.0668 & TRN \\
\hline CHEMBL498153 & 552254 & 8.1612 & 8.9401 & TST \\
\hline CHEMBL523177 & 552254 & 8.7696 & 8.8012 & TRN \\
\hline CHEMBL496307 & 552254 & 9.0088 & 8.9961 & TRN \\
\hline CHEMBL522066 & 552254 & 9.0 & 9.0055 & TRN \\
\hline CHEMBL497558 & 552254 & 7.8539 & 7.9007 & TRN \\
\hline CHEMBL497748 & 552254 & 9.5528 & 9.5953 & TRN \\
\hline CHEMBL521536 & 552254 & 9.0088 & 8.9863 & TRN \\
\hline
\end{tabular}




\begin{tabular}{|c|c|c|c|c|c|}
\hline \multicolumn{6}{|c|}{ Supplemental Table S2.txt } \\
\hline CHEMBL497121 & 552254 & 9.0 & 9.0282 & TRN & \\
\hline CHEMBL522701 & 552254 & 9.0 & 8.9711 & TRN & \\
\hline CHEMBL498351 & 552254 & 8.4202 & 8.3907 & TRN & \\
\hline CHEMBL497555 & 552254 & 8.6778 & 8.68 & TRN & \\
\hline CHEMBL523414 & 552254 & 9.0 & 8.9777 & TRN & \\
\hline CHEMBL496095 & 552254 & 9.0 & 8.992 & TRN & \\
\hline CHEMBL494206 & 552254 & 8.7447 & 8.74 & TRN & \\
\hline CHEMBL496495 & 552254 & 7.9586 & 8.0061 & TRN & \\
\hline CHEMBL494639 & 552254 & 7.3565 & 7.3337 & TRN & \\
\hline CHEMBL496097 & 552254 & 8.5229 & 8.5301 & TRN & \\
\hline CHEMBL494809 & 552254 & 8.6383 & 8.5106 & TST & \\
\hline CHEMBL496096 & 552254 & 8.699 & 8.8881 & TST & \\
\hline CHEMBL496295 & 552254 & 8.6576 & 8.9878 & TST & \\
\hline CHEMBL339328 & 841979 & 6.0 & 5.9564 & TRN & \\
\hline CHEMBL127424 & 841979 & 4.0 & 4.3464 & TRN & \\
\hline CHEMBL127354 & 841979 & 5.8239 & 5.9502 & TRN & \\
\hline CHEMBL 303080 & 841979 & 4.0 & 4.5601 & TST & \\
\hline CHEMBL125577 & 841979 & 5.8539 & 5.7734 & TRN & \\
\hline CHEMBL125086 & 841979 & 5.8539 & 5.7774 & TRN & \\
\hline CHEMBL126769 & 841979 & 5.7696 & 5.7828 & TRN & \\
\hline CHEMBL434253 & 841979 & 5.3872 & 5.5699 & TRN & \\
\hline CHEMBL126645 & 841979 & 4.0 & 4.1776 & TRN & \\
\hline CHEMBL127893 & 841979 & 5.9208 & 5.777 & TRN & \\
\hline CHEMBL443033 & 841979 & 6.0969 & 5.9353 & TRN & \\
\hline CHEMBL64950 & 841979 & 5.7959 & 5.0412 & TRN & \\
\hline CHEMBL420520 & 841979 & 4.0 & 4.7676 & TRN & \\
\hline CHEMBL126483 & 841979 & 5.8239 & 5.8506 & TRN & \\
\hline CHEMBL126996 & 841979 & 5.4437 & 5.615 & TRN & \\
\hline CHEMBL333127 & 841979 & 4.0 & 3.9597 & TRN & \\
\hline CHEMBL126974 & 841979 & 5.9208 & 5.6945 & TRN & \\
\hline CHEMBL340257 & 841979 & 5.2147 & 5.4689 & TRN & \\
\hline CHEMBL 304929 & 841979 & 6.0458 & 5.4879 & TRN & \\
\hline CHEMBL67008 & 841979 & 5.4437 & 4.21399 & 99999999995 & TRN \\
\hline CHEMBL127292 & 841979 & 5.4685 & 5.777 & TRN & \\
\hline CHEMBL127458 & 841979 & 6.0809 & 6.0042 & TRN & \\
\hline CHEMBL341121 & 841979 & 6.0177 & 5.7844 & TRN & \\
\hline CHEMBL 2089325 & 841979 & 5.7825 & 4.4796 & TST & \\
\hline CHEMBL417403 & 841979 & 5.7696 & 4.4734 & TST & \\
\hline CHEMBL419776 & 841979 & 6.0315 & 5.7411 & TRN & \\
\hline CHEMBL 294769 & 841979 & 5.3468 & 4.4451 & TRN & \\
\hline CHEMBL126466 & 841979 & 6.0605 & 5.956 & TRN & \\
\hline CHEMBL 2086878 & 841979 & 6.8239 & 4.3707 & TST & \\
\hline CHEMBL340660 & 841979 & 5.4559 & 5.5813 & TRN & \\
\hline CHEMBL338375 & 841979 & 6.6576 & 6.4991 & TRN & \\
\hline CHEMBL 2086884 & 841979 & 5.6126 & 4.6414 & TST & \\
\hline CHEMBL129591 & 841979 & 6.301 & 6.1795 & TRN & \\
\hline CHEMBL338427 & 841979 & 4.0 & 4.2857 & TRN & \\
\hline CHEMBL 341075 & 841979 & 5.585 & 5.6931 & TRN & \\
\hline
\end{tabular}




\begin{tabular}{|c|c|c|c|c|}
\hline & & & oplement & al $\mathrm{T}$ \\
\hline CHEMBL126187 & 841979 & 5.2757 & 5.3665 & TRN \\
\hline CHEMBL125861 & 841979 & 6.4089 & 6.0393 & TRN \\
\hline CHEMBL129713 & 841979 & 5.8539 & 5.886 & TRN \\
\hline CHEMBL339339 & 841979 & 4.0 & 4.4641 & TRN \\
\hline CHEMBL127935 & 841979 & 5.3565 & 5.1082 & TRN \\
\hline CHEMBL125527 & 841979 & 5.8539 & 5.909 & TRN \\
\hline CHEMBL340617 & 841979 & 4.0 & 4.1003 & TRN \\
\hline CHEMBL63450 & 841979 & 4.0 & 4.1008 & TRN \\
\hline CHEMBL65704 & 841979 & 5.6778 & 4.9144 & TRN \\
\hline CHEMBL 2088848 & 841979 & 6.1135 & 5.6921 & TRN \\
\hline CHEMBL126653 & 841979 & 5.3979 & 5.4822 & TRN \\
\hline CHEMBL 303318 & 841979 & 4.0 & 4.1261 & TST \\
\hline CHEMBL65038 & 841979 & 4.0 & 4.5625 & TRN \\
\hline CHEMBL64643 & 841979 & 4.0 & 4.5345 & TST \\
\hline CHEMBL1230742 & 841979 & 5.4559 & 4.8183 & TST \\
\hline CHEMBL29197 & 841979 & 6.0 & 4.5544 & TRN \\
\hline CHEMBL341010 & 841979 & 4.0 & 4.5228 & TRN \\
\hline CHEMBL127948 & 841979 & 5.7696 & 5.7364 & TRN \\
\hline CHEMBL62997 & 841979 & 5.6576 & 4.5172 & TST \\
\hline CHEMBL126233 & 841979 & 4.0 & 4.2808 & TRN \\
\hline CHEMBL126310 & 841979 & 5.7447 & 5.7491 & TRN \\
\hline CHEMBL35820 & 841979 & 5.7696 & 4.149 & TRN \\
\hline CHEMBL 2086883 & 841979 & 5.2306 & 4.7182 & TST \\
\hline CHEMBL 205792 & 841979 & 6.2441 & 4.7792 & TST \\
\hline CHEMBL 2086880 & 841979 & 6.4815 & 4.5272 & TST \\
\hline CHEMBL 2086876 & 841979 & 6.6021 & 4.5396 & TST \\
\hline CHEMBL62848 & 841979 & 4.0 & 4.4829 & TST \\
\hline CHEMBL67906 & 841979 & 4.0 & 3.9425 & TRN \\
\hline CHEMBL63787 & 841979 & 4.0 & 3.9398 & TRN \\
\hline CHEMBL63244 & 841979 & 5.6198 & 5.1677 & TRN \\
\hline CHEMBL340114 & 841979 & 4.0 & 4.6512 & TRN \\
\hline CHEMBL340622 & 841979 & 4.0 & 4.328 & TRN \\
\hline CHEMBL127223 & 841979 & 6.4089 & 6.1665 & TRN \\
\hline CHEMBL340714 & 841979 & 6.2147 & 5.7921 & TRN \\
\hline CHEMBL126456 & 841979 & 5.1938 & 6.1528 & TRN \\
\hline CHEMBL125515 & 841979 & 5.3468 & 5.5744 & TRN \\
\hline CHEMBL338472 & 841979 & 6.3188 & 6.0742 & TRN \\
\hline CHEMBL64297 & 841979 & 5.5686 & 4.4727 & TST \\
\hline CHEMBL 2086881 & 841979 & 5.4609 & 4.4452 & TST \\
\hline CHEMBL 2086877 & 841979 & 5.6517 & 4.5465 & TST \\
\hline CHEMBL2089326 & 841979 & 6.4949 & 4.6638 & TST \\
\hline CHEMBL63605 & 841979 & 4.0 & 5.186 & TRN \\
\hline CHEMBL2059273 & 841979 & 6.0458 & 4.3678 & TST \\
\hline CHEMBL123678 & 841979 & 6.0809 & 5.7986 & TRN \\
\hline CHEMBL125526 & 841979 & 5.301 & 5.5255 & TRN \\
\hline CHEMBL64351 & 841979 & 5.8239 & 4.4562 & TST \\
\hline CHEMBL 338218 & 841979 & 6.3768 & 6.2535 & TRN \\
\hline CHEMBL126890 & 841979 & 4.0 & 4.0288 & TRN \\
\hline
\end{tabular}




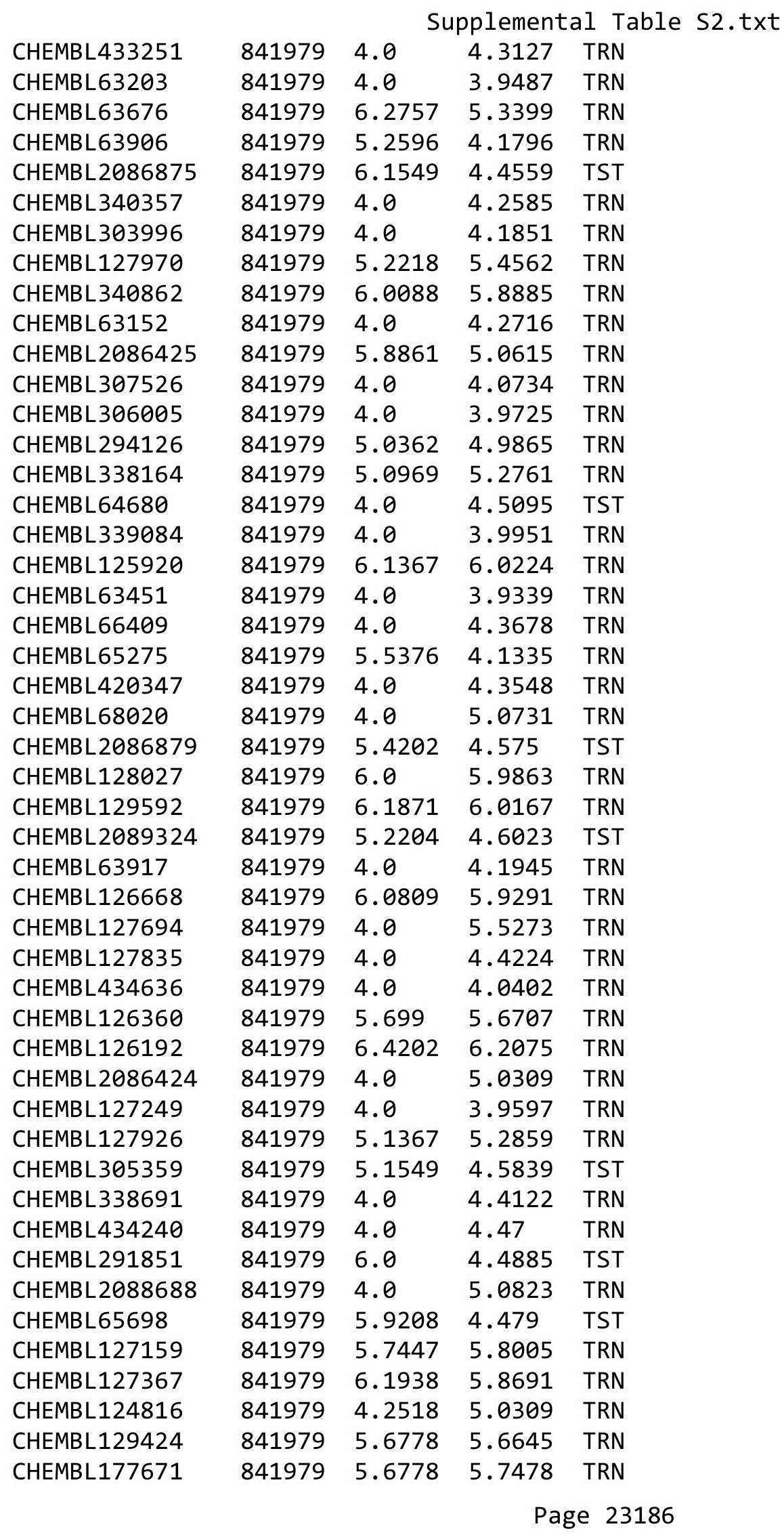




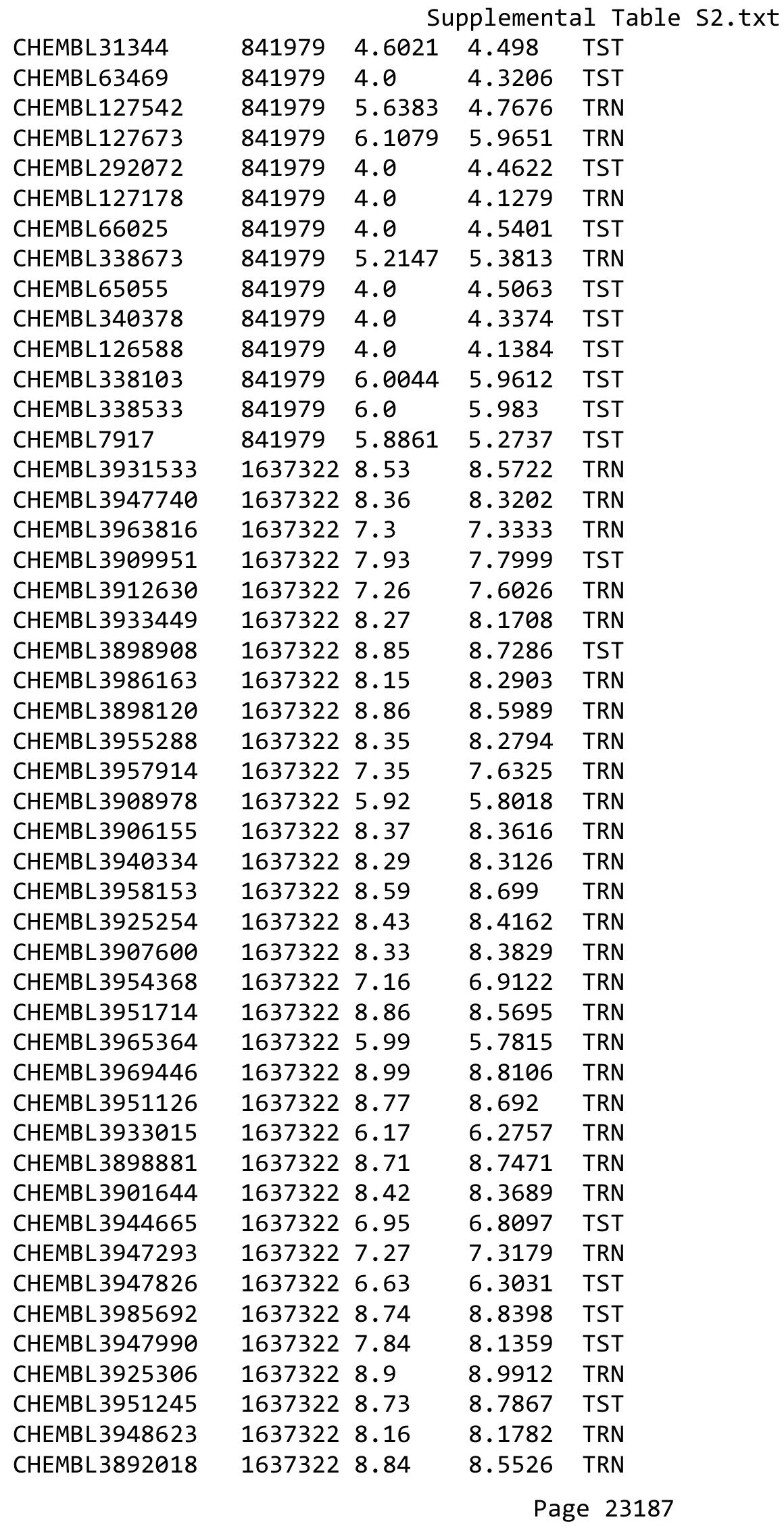




\begin{tabular}{|c|c|c|c|c|}
\hline & & & pplement & al $\mathrm{Ta}$ \\
\hline CHEMBL3987037 & 1637322 & 8.66 & 8.6039 & TRN \\
\hline CHEMBL3921313 & 1637322 & 8.51 & 8.1619 & TRN \\
\hline CHEMBL3927327 & 1637322 & 8.53 & 8.4013 & TRN \\
\hline CHEMBL3976280 & 1637322 & 8.73 & 8.9009 & TRN \\
\hline CHEMBL 3973820 & 1637322 & 8.16 & 8.2997 & TRN \\
\hline CHEMBL3918011 & 1637322 & 7.76 & 7.8523 & TRN \\
\hline CHEMBL3915235 & 1637322 & 8.04 & 8.1776 & TRN \\
\hline CHEMBL3965673 & 1637322 & 5.0 & 5.3087 & TRN \\
\hline CHEMBL3968094 & 1637322 & 7.67 & 7.5056 & TRN \\
\hline CHEMBL3918751 & 1637322 & 8.76 & 8.6474 & TRN \\
\hline CHEMBL 3956164 & 1637322 & 8.09 & 8.3127 & TRN \\
\hline CHEMBL3908829 & 1637322 & 8.32 & 8.5383 & TRN \\
\hline CHEMBL3911573 & 1637322 & 8.78 & 8.6282 & TRN \\
\hline CHEMBL3969879 & 1637322 & 7.72 & 7.6159 & TRN \\
\hline CHEMBL 3972564 & 1637322 & 6.84 & 6.9701 & TRN \\
\hline CHEMBL 3927875 & 1637322 & 9.01 & 8.7992 & TRN \\
\hline CHEMBL3930634 & 1637322 & 6.54 & 6.6697 & TRN \\
\hline CHEMBL3901627 & 1637322 & 8.56 & 8.3993 & TST \\
\hline CHEMBL3904329 & 1637322 & 8.35 & 8.6214 & TRN \\
\hline CHEMBL3969408 & 1637322 & 5.86 & 5.8208 & TRN \\
\hline CHEMBL3985853 & 1637322 & 8.66 & 8.7248 & TRN \\
\hline CHEMBL3908326 & 1637322 & 8.7 & 8.6356 & TRN \\
\hline CHEMBL3918092 & 1637322 & 9.12 & 9.2014 & TRN \\
\hline CHEMBL3964675 & 1637322 & 8.72 & 8.5126 & TRN \\
\hline CHEMBL3955706 & 1637322 & 8.62 & 8.7104 & TRN \\
\hline CHEMBL3937533 & 1637322 & 8.66 & 8.4686 & TRN \\
\hline CHEMBL3962814 & 1637322 & 8.27 & 8.4602 & TRN \\
\hline CHEMBL3931674 & 1637322 & 8.2 & 8.2376 & TRN \\
\hline CHEMBL3976219 & 1637322 & 8.22 & 8.2203 & TRN \\
\hline CHEMBL3924872 & 1637322 & 7.88 & 7.7333 & TRN \\
\hline CHEMBL 3908529 & 1637322 & 8.45 & 8.2296 & TRN \\
\hline CHEMBL3962805 & 1637322 & 8.35 & 8.2819 & TRN \\
\hline CHEMBL3960128 & 1637322 & 7.73 & 7.7487 & TST \\
\hline CHEMBL3909565 & 1637322 & 8.75 & 8.574 & TRN \\
\hline CHEMBL3948321 & 1637322 & 8.8 & 8.6204 & TRN \\
\hline CHEMBL3985750 & 1637322 & 8.54 & 8.4121 & TRN \\
\hline CHEMBL3983115 & 1637322 & 8.41 & 8.4147 & TRN \\
\hline CHEMBL3926311 & 1637322 & 7.78 & 7.722 & TRN \\
\hline CHEMBL3926406 & 1637322 & 8.57 & 8.626 & TRN \\
\hline CHEMBL3979490 & 1637322 & 9.21 & 8.8556 & TST \\
\hline CHEMBL 3898355 & 1637322 & 8.76 & 8.5836 & TST \\
\hline CHEMBL 3940725 & 1637322 & 7.96 & 7.7116 & TRN \\
\hline CHEMBL3973531 & 1637322 & 8.3 & 8.3185 & TRN \\
\hline CHEMBL3913757 & 1637322 & 8.81 & 8.7242 & TRN \\
\hline CHEMBL3961210 & 1637322 & 8.79 & 8.6718 & TRN \\
\hline CHEMBL3936765 & 1637322 & 6.13 & 6.4063 & TRN \\
\hline CHEMBL3951156 & 1637322 & 8.1 & 8.1985 & TRN \\
\hline CHEMBL3979170 & 1637322 & 8.71 & 8.7911 & TST \\
\hline
\end{tabular}




\begin{tabular}{|c|c|c|c|c|c|}
\hline \multicolumn{6}{|c|}{ Supplemental Table S2.txt } \\
\hline CHEMBL3921618 & 1637322 & 9.29 & 9.1556 & TRN & \\
\hline CHEMBL3969815 & 1637322 & 8.78 & 8.8375 & TRN & \\
\hline CHEMBL3961872 & 1637322 & 8.75 & 8.8496 & TST & \\
\hline CHEMBL 3985222 & 1637322 & 8.97 & 8.9284 & TRN & \\
\hline CHEMBL 3974664 & 1637322 & 8.46 & 8.5185 & TRN & \\
\hline CHEMBL3972173 & 1637322 & 7.83 & 7.9234 & TRN & \\
\hline CHEMBL3919173 & 1637322 & 9.25 & 9.1006 & TRN & \\
\hline CHEMBL3956737 & 1637322 & 6.28 & 6.4009 & TRN & \\
\hline CHEMBL3966022 & 1637322 & 8.14 & 8.2535 & TRN & \\
\hline CHEMBL3968499 & 1637322 & 9.02 & 9.0034 & TRN & \\
\hline CHEMBL3912505 & 1637322 & 7.11 & 6.5848 & TRN & \\
\hline CHEMBL 3915158 & 1637322 & 6.1 & 6.17 & TRN & \\
\hline CHEMBL3950262 & 1637322 & 8.12 & 7.9953 & TRN & \\
\hline CHEMBL3949470 & 1637322 & 8.6 & 8.5923 & TRN & \\
\hline CHEMBL3893008 & 1637322 & 8.62 & 8.5964 & TRN & \\
\hline CHEMBL 3889493 & 1637322 & 8.04 & 8.2224 & TRN & \\
\hline CHEMBL3984548 & 1637322 & 8.46 & 8.3748 & TRN & \\
\hline CHEMBL3920908 & 1637322 & 8.43 & 8.3218 & TST & \\
\hline CHEMBL3939278 & 1637322 & 8.66 & 8.6307 & TRN & \\
\hline CHEMBL 3974693 & 1637322 & 8.41 & 8.4371 & TRN & \\
\hline CHEMBL3972208 & 1637322 & 6.39 & 6.2179 & TRN & \\
\hline CHEMBL3950907 & 1637322 & 8.06 & 8.1729 & TRN & \\
\hline CHEMBL3931421 & 1637322 & 9.07 & 9.0633 & TRN & \\
\hline CHEMBL3923296 & 1637322 & 8.75 & 8.8149 & TRN & \\
\hline CHEMBL 3918495 & 1637322 & 8.33 & 8.5925 & TRN & \\
\hline CHEMBL 3945369 & 1637322 & 6.1 & 6.2675 & TRN & \\
\hline CHEMBL3961267 & 1637322 & 7.65 & 7.62700 & 0000000001 & TRN \\
\hline CHEMBL3984039 & 1637322 & 8.87 & 9.1434 & TRN & \\
\hline CHEMBL3928627 & 1637322 & 7.01 & 6.9709 & TST & \\
\hline CHEMBL 3908877 & 1637322 & 8.62 & 8.5992 & TST & \\
\hline CHEMBL 3907488 & 1637322 & 7.81 & 7.8789 & TST & \\
\hline CHEMBL 3929803 & 1637322 & 8.25 & 8.4449 & TRN & \\
\hline CHEMBL 3970430 & 1637322 & 8.86 & 8.9889 & TRN & \\
\hline CHEMBL3969475 & 1637322 & 8.61 & 8.6778 & TRN & \\
\hline CHEMBL 3963728 & 1637322 & 6.16 & 6.3303 & TST & \\
\hline CHEMBL 3944224 & 1637322 & 8.19 & 8.2725 & TRN & \\
\hline CHEMBL3909318 & 1637322 & 8.42 & 8.4397 & TRN & \\
\hline CHEMBL 3982668 & 1637322 & 8.06 & 8.2223 & TRN & \\
\hline CHEMBL3980232 & 1637322 & 8.93 & 8.8038 & TST & \\
\hline CHEMBL 3937633 & 1637322 & 8.85 & 8.854 & TRN & \\
\hline CHEMBL 3955563 & 1637322 & 8.97 & 8.9416 & TRN & \\
\hline CHEMBL3890607 & 1637322 & 8.43 & 8.6037 & TRN & \\
\hline CHEMBL3893373 & 1637322 & 8.15 & 8.0718 & TRN & \\
\hline CHEMBL3954298 & 1637322 & 8.67 & 8.5629 & TRN & \\
\hline CHEMBL 3900620 & 1637322 & 8.69 & 8.4393 & TRN & \\
\hline CHEMBL3983996 & 1637322 & 8.85 & 8.7896 & TRN & \\
\hline CHEMBL3935124 & 1637322 & 7.97 & 7.9098 & TRN & \\
\hline CHEMBL3973645 & 1637322 & 6.58 & 6.4813 & TST & \\
\hline
\end{tabular}




\begin{tabular}{|c|c|c|c|c|c|}
\hline \multicolumn{6}{|c|}{ Supplemental Table S2.txt } \\
\hline CHEMBL3971073 & 1637322 & 7.78 & 8.0217 & TRN & \\
\hline CHEMBL3957264 & 1637322 & 8.81 & 8.8827 & TRN & \\
\hline CHEMBL3969096 & 1637322 & 7.57 & 7.6738 & TRN & \\
\hline CHEMBL3905212 & 1637322 & 8.39 & 8.0951 & TST & \\
\hline CHEMBL 3897034 & 1637322 & 8.04 & 7.9353 & TRN & \\
\hline CHEMBL3979885 & 1637322 & 8.47 & 8.19700 & 0000000001 & TRN \\
\hline CHEMBL3982334 & 1637322 & 6.88 & 7.1647 & TRN & \\
\hline CHEMBL3919730 & 1637322 & 9.14 & 9.05 & TRN & \\
\hline CHEMBL3922453 & 1637322 & 8.85 & 8.7505 & TRN & \\
\hline CHEMBL3959345 & 1637322 & 8.82 & 8.794 & TRN & \\
\hline CHEMBL3959201 & 1637322 & 8.47 & 8.135 & TST & \\
\hline CHEMBL3915233 & 1637322 & 7.37 & 7.619 & TRN & \\
\hline CHEMBL3912569 & 1637322 & 9.06 & 9.0887 & TRN & \\
\hline CHEMBL3975954 & 1637322 & 8.51 & 8.564 & TRN & \\
\hline CHEMBL3966748 & 1637322 & 9.21 & 8.9945 & TST & \\
\hline CHEMBL3929648 & 1637322 & 8.24 & 8.1158 & TRN & \\
\hline CHEMBL3926964 & 1637322 & 6.56 & 6.4188 & TRN & \\
\hline CHEMBL3891619 & 1637322 & 7.94 & 8.07200 & 0000000001 & TRN \\
\hline CHEMBL3986661 & 1637322 & 8.05 & 7.8369 & TRN & \\
\hline CHEMBL3943043 & 1637322 & 8.91 & 8.7813 & TRN & \\
\hline CHEMBL3904745 & 1637322 & 8.55 & 8.4803 & TRN & \\
\hline CHEMBL 3965614 & 1637322 & 8.68 & 8.4465 & TRN & \\
\hline CHEMBL3968009 & 1637322 & 8.86 & 8.8583 & TST & \\
\hline CHEMBL3906122 & 1637322 & 8.38 & 8.3342 & TST & \\
\hline CHEMBL3900268 & 1637322 & 6.64 & 6.8686 & TRN & \\
\hline CHEMBL3951728 & 1637322 & 8.07 & 7.9693 & TRN & \\
\hline CHEMBL3962554 & 1637322 & 8.34 & 8.2339 & TRN & \\
\hline CHEMBL3913970 & 1637322 & 8.43 & 8.4702 & TST & \\
\hline CHEMBL3972979 & 1637322 & 8.98 & 8.8601 & TRN & \\
\hline CHEMBL3975447 & 1637322 & 9.01 & 8.994 & TRN & \\
\hline CHEMBL3911516 & 1637322 & 8.51 & 8.2633 & TRN & \\
\hline CHEMBL3958756 & 1637322 & 7.49 & 7.4146 & TRN & \\
\hline CHEMBL3956120 & 1637322 & 8.07 & 7.9628 & TRN & \\
\hline CHEMBL3907551 & 1637322 & 6.45 & 6.4324 & TRN & \\
\hline CHEMBL3904777 & 1637322 & 7.91 & 8.0308 & TST & \\
\hline CHEMBL3975007 & 1637322 & 7.3 & 7.1897 & TRN & \\
\hline CHEMBL3972517 & 1637322 & 8.74 & 8.7621 & TRN & \\
\hline CHEMBL3928956 & 1637322 & 6.83 & 7.0559 & TRN & \\
\hline CHEMBL3919270 & 1637322 & 7.65 & 7.5989 & TRN & \\
\hline CHEMBL3941705 & 1637322 & 7.87 & 7.8038 & TRN & \\
\hline CHEMBL3982570 & 1637322 & 7.47 & 7.4301 & TRN & \\
\hline CHEMBL3920007 & 1637322 & 8.62 & 8.4568 & TRN & \\
\hline CHEMBL3922698 & 1637322 & 8.92 & 8.8611 & TRN & \\
\hline CHEMBL3957533 & 1637322 & 8.41 & 8.4751 & TRN & \\
\hline CHEMBL3969373 & 1637322 & 8.64 & 8.7495 & TRN & \\
\hline CHEMBL3905485 & 1637322 & 8.94 & 8.9401 & TRN & \\
\hline CHEMBL3904674 & 1637322 & 9.26 & 9.2571 & TRN & \\
\hline CHEMBL3945845 & 1637322 & 8.14 & 8.3035 & TRN & \\
\hline
\end{tabular}




\begin{tabular}{|c|c|c|c|c|c|}
\hline \\
\hline CHEMBL3951694 & 1637322 & 8.96 & 8.8284 & TRN & \\
\hline CHEMBL3929914 & 1637322 & 8.68 & 8.5148 & TST & \\
\hline CHEMBL3971277 & 1637322 & 8.8 & 9.054 & TRN & \\
\hline CHEMBL3891892 & 1637322 & 8.96 & 8.7989 & TRN & \\
\hline CHEMBL3985498 & 1637322 & 7.96 & 7.8989 & TRN & \\
\hline CHEMBL3912831 & 1637322 & 8.63 & 8.6866 & TRN & \\
\hline CHEMBL3931154 & 1637322 & 8.46 & 8.4881 & TRN & \\
\hline CHEMBL3893718 & 1637322 & 8.23 & 8.5909 & TRN & \\
\hline CHEMBL3973321 & 1637322 & 8.12 & 8.2623 & TRN & \\
\hline CHEMBL3960327 & 1637322 & 8.52 & 8.559 & TRN & \\
\hline CHEMBL3956571 & 1637322 & 7.91 & 8.06200 & 0000000001 & TRN \\
\hline CHEMBL3907314 & 1637322 & 9.35 & 9.0143 & TRN & \\
\hline CHEMBL3904561 & 1637322 & 8.47 & 8.7489 & TST & \\
\hline CHEMBL3945264 & 1637322 & 8.66 & 8.8074 & TRN & \\
\hline CHEMBL3942594 & 1637322 & 8.43 & 8.5407 & TRN & \\
\hline CHEMBL3915268 & 1637322 & 8.85 & 8.9624 & TRN & \\
\hline CHEMBL3925081 & 1637322 & 8.58 & 8.699 & TRN & \\
\hline CHEMBL3959849 & 1637322 & 8.55 & 8.7534 & TST & \\
\hline CHEMBL3962549 & 1637322 & 7.75 & 7.92899 & 9999999999 & TRN \\
\hline CHEMBL3966626 & 1637322 & 7.2 & 7.0801 & TRN & \\
\hline CHEMBL3969192 & 1637322 & 7.21 & 6.7851 & TRN & \\
\hline CHEMBL3975986 & 1637322 & 6.41 & 6.3079 & TRN & \\
\hline CHEMBL3979996 & 1637322 & 6.62 & 6.5417 & TRN & \\
\hline CHEMBL 3891474 & 1637322 & 8.14 & 8.4813 & TST & \\
\hline CHEMBL3892135 & 1637322 & 8.74 & 8.8203 & TRN & \\
\hline CHEMBL3969824 & 1637322 & 8.54 & 8.6648 & TRN & \\
\hline CHEMBL3932285 & 1637322 & 8.72 & 8.6559 & TRN & \\
\hline CHEMBL3922586 & 1637322 & 8.73 & 8.7144 & TRN & \\
\hline CHEMBL3901682 & 1637322 & 6.94 & 6.9165 & TRN & \\
\hline CHEMBL3927733 & 1637322 & 8.52 & 8.3573 & TRN & \\
\hline CHEMBL3976053 & 1637322 & 8.7 & 8.6079 & TST & \\
\hline CHEMBL 3973587 & 1637322 & 8.15 & 8.3592 & TRN & \\
\hline CHEMBL3936828 & 1637322 & 8.49 & 8.5684 & TRN & \\
\hline CHEMBL3934039 & 1637322 & 7.9 & 7.9777 & TRN & \\
\hline CHEMBL3981418 & 1637322 & 8.91 & 8.7974 & TST & \\
\hline CHEMBL3972694 & 1637322 & 7.94 & 8.0833 & TST & \\
\hline CHEMBL3921457 & 1637322 & 8.66 & 8.606 & TST & \\
\hline CHEMBL3918739 & 1637322 & 8.9 & 8.6711 & TRN & \\
\hline CHEMBL3968793 & 1637322 & 7.91 & 8.0795 & TRN & \\
\hline CHEMBL3966305 & 1637322 & 8.93 & 8.936 & TST & \\
\hline CHEMBL3891115 & 1637322 & 6.81 & 6.7532 & TST & \\
\hline CHEMBL3979662 & 1637322 & 6.91 & 6.692 & TST & \\
\hline CHEMBL3983387 & 1637322 & 8.56 & 8.3986 & TST & \\
\hline CHEMBL3986068 & 1637322 & 8.65 & 8.8683 & TRN & \\
\hline CHEMBL3916975 & 1637322 & 8.79 & 8.5946 & TRN & \\
\hline CHEMBL3919709 & 1637322 & 9.06 & 8.4152 & TRN & \\
\hline CHEMBL3975791 & 1637322 & 9.04 & 8.4152 & TRN & \\
\hline CHEMBL3963323 & 1637322 & 8.58 & 8.5904 & TRN & \\
\hline
\end{tabular}




\begin{tabular}{|c|c|c|c|c|}
\hline \multicolumn{5}{|c|}{ Supplemental Table S2.txt } \\
\hline CHEMBL3945373 & 1637322 & 8.74 & 8.6263 & TRN \\
\hline CHEMBL3893344 & 1637322 & 8.61 & 8.5726 & TRN \\
\hline CHEMBL3896052 & 1637322 & 8.69 & 8.6354 & TRN \\
\hline CHEMBL3947361 & 1637322 & 8.54 & 8.6547 & TRN \\
\hline CHEMBL3944739 & 1637322 & 7.98 & 7.8118 & TST \\
\hline CHEMBL3909551 & 1637322 & 8.63 & 8.6139 & TRN \\
\hline CHEMBL3899692 & 1637322 & 8.77 & 8.5107 & TRN \\
\hline CHEMBL3961400 & 1637322 & 8.54 & 8.7362 & TRN \\
\hline CHEMBL3958708 & 1637322 & 8.74 & 8.61 & TRN \\
\hline CHEMBL3974080 & 1637322 & 7.6 & 7.5387 & TRN \\
\hline CHEMBL3921197 & 1637322 & 9.08 & 8.995 & TST \\
\hline CHEMBL 3898568 & 1637322 & 8.44 & 8.5663 & TRN \\
\hline CHEMBL3924422 & 1637322 & 8.24 & 8.1809 & TRN \\
\hline CHEMBL3959193 & 1637322 & 7.76 & 7.9526 & TRN \\
\hline CHEMBL 3936087 & 1637322 & 8.58 & 8.8352 & TRN \\
\hline CHEMBL 3893070 & 1637322 & 8.31 & 8.1442 & TRN \\
\hline CHEMBL3977904 & 1637322 & 8.02 & 7.8842 & TST \\
\hline CHEMBL 3904441 & 1637322 & 8.39 & 8.2919 & TRN \\
\hline CHEMBL3945159 & 1637322 & 9.11 & 9.1577 & TRN \\
\hline CHEMBL3915021 & 1637322 & 7.88 & 8.0287 & TST \\
\hline CHEMBL3892776 & 1637322 & 8.32 & 8.7286 & TRN \\
\hline CHEMBL3981077 & 1637322 & 8.06 & 7.8989 & TST \\
\hline CHEMBL3930819 & 1637322 & 7.91 & 8.0341 & TRN \\
\hline CHEMBL 3926082 & 1637322 & 8.82 & 9.099 & TST \\
\hline CHEMBL3970423 & 1637322 & 8.9 & 8.682 & TRN \\
\hline CHEMBL3950089 & 1637322 & 8.95 & 8.971 & TRN \\
\hline CHEMBL3959573 & 1637322 & 8.82 & 9.0842 & TRN \\
\hline CHEMBL3912310 & 1637322 & 8.25 & 8.2724 & TRN \\
\hline CHEMBL3914955 & 1637322 & 8.57 & 8.3156 & TRN \\
\hline CHEMBL3973263 & 1637322 & 8.35 & 8.6168 & TRN \\
\hline CHEMBL3975714 & 1637322 & 7.92 & 7.9691 & TRN \\
\hline CHEMBL3933707 & 1637322 & 8.9 & 8.8053 & TRN \\
\hline CHEMBL3950069 & 1637322 & 8.67 & 8.5826 & TRN \\
\hline CHEMBL3979013 & 1637322 & 9.21 & 8.9981 & TRN \\
\hline CHEMBL3942811 & 1637322 & 8.17 & 8.1981 & TRN \\
\hline CHEMBL3940175 & 1637322 & 8.79 & 8.7974 & TST \\
\hline CHEMBL3968038 & 1637322 & 7.8 & 7.9474 & TRN \\
\hline CHEMBL3965640 & 1637322 & 8.33 & 8.0657 & TRN \\
\hline CHEMBL3928393 & 1637322 & 8.99 & 8.9702 & TST \\
\hline CHEMBL3918704 & 1637322 & 8.5 & 8.2429 & TRN \\
\hline CHEMBL3947189 & 1637322 & 8.74 & 8.8671 & TRN \\
\hline CHEMBL3944438 & 1637322 & 8.71 & 8.4044 & TRN \\
\hline CHEMBL3964574 & 1637322 & 8.91 & 9.0239 & TRN \\
\hline CHEMBL3942328 & 1637322 & 8.99 & 8.8926 & TRN \\
\hline CHEMBL3951847 & 1637322 & 8.22 & 8.4051 & TRN \\
\hline CHEMBL3930298 & 1637322 & 7.56 & 7.9453 & TST \\
\hline CHEMBL3891464 & 1637322 & 8.25 & 8.1925 & TRN \\
\hline CHEMBL3950910 & 1637322 & 8.9 & 8.7308 & TRN \\
\hline
\end{tabular}




\begin{tabular}{|c|c|c|c|c|c|}
\hline \multicolumn{6}{|c|}{ pplemental Table S } \\
\hline CHEMBL3901420 & 1637322 & 8.08 & 8.3067 & TRN & \\
\hline CHEMBL3905866 & 1637322 & 8.86 & 8.9129 & TRN & \\
\hline CHEMBL3903198 & 1637322 & 8.31 & 8.1048 & TRN & \\
\hline CHEMBL3943933 & 1637322 & 7.77 & 7.9152 & TRN & \\
\hline CHEMBL3925077 & 1637322 & 7.95 & 8.3768 & TRN & \\
\hline CHEMBL3946674 & 1637322 & 8.37 & 8.3434 & TRN & \\
\hline CHEMBL3931790 & 1637322 & 8.74 & 8.8113 & TRN & \\
\hline CHEMBL3934487 & 1637322 & 8.53 & 8.3092 & TRN & \\
\hline CHEMBL3893786 & 1637322 & 8.76 & 8.9552 & TRN & \\
\hline CHEMBL3917141 & 1637322 & 8.71 & 8.7133 & TRN & \\
\hline CHEMBL 3941700 & 1637322 & 8.75 & 8.8502 & TRN & \\
\hline CHEMBL3969665 & 1637322 & 8.18 & 8.2069 & TST & \\
\hline CHEMBL3981076 & 1637322 & 8.01 & 8.0088 & TRN & \\
\hline CHEMBL3983529 & 1637322 & 8.44 & 8.40299 & 9999999999 & TRN \\
\hline CHEMBL3935457 & 1637322 & 8.64 & 8.6204 & TRN & \\
\hline CHEMBL3905048 & 1637322 & 8.44 & 8.5934 & TRN & \\
\hline CHEMBL3925610 & 1637322 & 8.21 & 8.1561 & TST & \\
\hline CHEMBL3928261 & 1637322 & 8.57 & 8.5205 & TRN & \\
\hline CHEMBL3985259 & 1637322 & 7.97 & 8.1004 & TST & \\
\hline CHEMBL 3890205 & 1637322 & 7.28 & 7.3204 & TST & \\
\hline CHEMBL3944610 & 1637322 & 8.76 & 8.522 & TRN & \\
\hline CHEMBL3944320 & 1637322 & 8.63 & 8.5611 & TRN & \\
\hline CHEMBL3979908 & 1637322 & 7.25 & 7.4927 & TRN & \\
\hline CHEMBL3934355 & 1637322 & 7.92 & 8.0755 & TRN & \\
\hline CHEMBL3919750 & 1637322 & 7.76 & 8.0263 & TRN & \\
\hline CHEMBL3969112 & 1637322 & 8.53 & 8.5405 & TRN & \\
\hline CHEMBL3966560 & 1637322 & 8.32 & 8.1063 & TRN & \\
\hline CHEMBL3910444 & 1637322 & 8.62 & 9.0198 & TRN & \\
\hline CHEMBL3907642 & 1637322 & 8.52 & 8.4175 & TRN & \\
\hline CHEMBL3973929 & 1637322 & 8.7 & 8.6468 & TRN & \\
\hline CHEMBL3972617 & 1637322 & 8.14 & 7.9456 & TRN & \\
\hline CHEMBL3908149 & 1637322 & 8.73 & 8.9 & TRN & \\
\hline CHEMBL3943080 & 1637322 & 7.48 & 7.7379 & TRN & \\
\hline CHEMBL 3904294 & 1637322 & 8.33 & 8.3871 & TRN & \\
\hline CHEMBL3907063 & 1637322 & 8.14 & 8.3003 & TRN & \\
\hline CHEMBL3896623 & 1637322 & 8.31 & 8.5607 & TRN & \\
\hline CHEMBL3893950 & 1637322 & 8.14 & 8.4061 & TRN & \\
\hline CHEMBL3955745 & 1637322 & 7.88 & 7.9691 & TRN & \\
\hline CHEMBL3953117 & 1637322 & 7.82 & 8.2413 & TST & \\
\hline CHEMBL3951360 & 1637322 & 8.39 & 8.5035 & TRN & \\
\hline CHEMBL3930158 & 1637322 & 7.5 & 7.6062 & TRN & \\
\hline CHEMBL3911746 & 1637322 & 8.0 & 8.182 & TST & \\
\hline CHEMBL3917295 & 1637322 & 8.37 & 8.4782 & TRN & \\
\hline CHEMBL3902110 & 1637322 & 8.1 & 8.0588 & TRN & \\
\hline CHEMBL3904814 & 1637322 & 7.0 & 7.1868 & TST & \\
\hline CHEMBL3911948 & 1637322 & 7.18 & 7.5212 & TST & \\
\hline CHEMBL3928239 & 1637322 & 8.57 & 8.5041 & TRN & \\
\hline CHEMBL3979028 & 1637322 & 7.77 & 7.9872 & TRN & \\
\hline
\end{tabular}




\begin{tabular}{|c|c|c|c|c|}
\hline \multicolumn{5}{|c|}{ Supplemental Table S2.txt } \\
\hline CHEMBL 3890378 & 1637322 & 8.62 & 8.7504 & TRN \\
\hline CHEMBL 3932363 & 1637322 & 8.25 & 8.5529 & 9999999999 \\
\hline CHEMBL3932756 & 1637322 & 8.43 & 8.5164 & TRN \\
\hline CHEMBL3919479 & 1637322 & 8.76 & 8.9139 & TRN \\
\hline CHEMBL3968818 & 1637322 & 8.76 & 8.7026 & TRN \\
\hline CHEMBL3966316 & 1637322 & 7.49 & 7.5479 & TRN \\
\hline CHEMBL 3940940 & 1637322 & 7.85 & 8.2154 & TST \\
\hline CHEMBL3982107 & 1637322 & 8.32 & 8.5849 & TRN \\
\hline CHEMBL 3979670 & 1637322 & 8.54 & 8.7113 & TRN \\
\hline CHEMBL3911738 & 1637322 & 7.99 & 8.0854 & TRN \\
\hline CHEMBL3951090 & 1637322 & 8.01 & 8.1047 & TRN \\
\hline CHEMBL3960571 & 1637322 & 8.71 & 8.5937 & TRN \\
\hline CHEMBL3949508 & 1637322 & 7.76 & 7.8364 & TRN \\
\hline CHEMBL3901612 & 1637322 & 8.64 & 8.6905 & TRN \\
\hline CHEMBL3974206 & 1637322 & 8.78 & 8.5827 & TST \\
\hline CHEMBL3889711 & 1637322 & 8.74 & 8.2567 & TRN \\
\hline CHEMBL 3927585 & 1637322 & 8.12 & 8.2068 & TRN \\
\hline CHEMBL3946103 & 1637322 & 8.71 & 8.4228 & TRN \\
\hline CHEMBL3936421 & 1637322 & 8.15 & 7.9473 & TRN \\
\hline CHEMBL3901119 & 1637322 & 9.12 & 8.7706 & TST \\
\hline CHEMBL3919884 & 1637322 & 8.66 & 8.6309 & TST \\
\hline CHEMBL3942606 & 1637322 & 8.85 & 8.4331 & TST \\
\hline CHEMBL3945277 & 1637322 & 8.82 & 8.7521 & TRN \\
\hline CHEMBL 3897523 & 1637322 & 8.57 & 8.2289 & TRN \\
\hline CHEMBL 3907327 & 1637322 & 8.39 & 7.9972 & TRN \\
\hline CHEMBL3956579 & 1637322 & 8.26 & 8.1044 & TST \\
\hline CHEMBL3959260 & 1637322 & 8.1 & 8.2391 & TRN \\
\hline CHEMBL3890852 & 1637322 & 8.32 & 8.4382 & TST \\
\hline CHEMBL 3893642 & 1637322 & 8.6 & 8.7526 & TRN \\
\hline CHEMBL3950156 & 1637322 & 8.38 & 8.2773 & TRN \\
\hline CHEMBL3952866 & 1637322 & 8.15 & 8.0083 & TST \\
\hline CHEMBL3925114 & 1637322 & 8.83 & 8.7122 & TRN \\
\hline CHEMBL3897155 & 1637322 & 8.53 & 8.4801 & TST \\
\hline CHEMBL3937972 & 1637322 & 9.01 & 8.7553 & TRN \\
\hline CHEMBL3935177 & 1637322 & 8.1 & 7.9866 & TRN \\
\hline CHEMBL3962492 & 1637322 & 8.6 & 8.6395 & TRN \\
\hline CHEMBL3903823 & 1637322 & 8.17 & 8.2547 & TRN \\
\hline CHEMBL3964096 & 1637322 & 9.04 & 8.8597 & TST \\
\hline CHEMBL 3948755 & 1637322 & 8.11 & 7.941 & TST \\
\hline CHEMBL3892155 & 1637322 & 8.45 & 8.4663 & TRN \\
\hline CHEMBL3987162 & 1637322 & 7.55 & 7.5937 & TRN \\
\hline CHEMBL3921441 & 1637322 & 8.79 & 8.7471 & TRN \\
\hline CHEMBL3905015 & 1637322 & 7.42 & 7.5809 & TRN \\
\hline CHEMBL 3921817 & 1637322 & 9.11 & 8.8401 & TRN \\
\hline CHEMBL3927219 & 1637322 & 7.88 & 8.0795 & TRN \\
\hline CHEMBL 3902434 & 1637322 & 8.49 & 8.4648 & TRN \\
\hline CHEMBL3927158 & 1637322 & 7.24 & 7.3597 & TRN \\
\hline CHEMBL3985182 & 1637322 & 7.98 & 7.8807 & TRN \\
\hline
\end{tabular}


Supplemental Table S2.txt

\begin{tabular}{|c|c|c|c|c|}
\hline HEMBL3933442 & 1637322 & 8.22 & 8.2573 & TRN \\
\hline CHEMBL 3934080 & 1637322 & 8.8 & 8.8314 & \\
\hline HEMBL3895443 & 637322 & 8.38 & 2229 & \\
\hline HEMBL 3904736 & 637322 & 6.36 & 6607 & $2 \mathrm{~N}$ \\
\hline HEMBL3914473 & 637322 & 6.88 & .9414 & 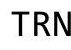 \\
\hline HEMBL3898926 & 637322 & 7.96 & 7.971 & \\
\hline HEMBL3952277 & 637322 & 8.81 & 8.6439 & \\
\hline HEMBL3926245 & 1637322 & 7.73 & 7.8542 & ST \\
\hline HEMBL3978617 & 1637322 & 8.72 & 8.4648 & RN \\
\hline HEMBL 3966071 & 1637322 & 8.8 & 8.6899 & ST \\
\hline CHEMBL3966200 & 1637322 & 8.58 & 8.5069 & RN \\
\hline HEMBL 3940672 & 1637322 & 8.57 & 8.2772 & ST \\
\hline HEMBL 3979328 & 1637322 & 8.8 & .6249 & RN \\
\hline HEMBL 3983918 & 1637322 & 9.12 & 8.84 & ST \\
\hline CHEMBL 3975193 & 1637322 & 8.08 & 7.9583 & RN \\
\hline HEMBL 3924172 & 1637322 & 8.84 & 8.5582 & $\mathrm{RN}$ \\
\hline HEMBL3921469 & 1637322 & 8.93 & 8.762 & RN \\
\hline CHEMBL 3900551 & 1637322 & 6.59 & 6.4869 & RN \\
\hline HEMBL 3897783 & 1637322 & 8.73 & 8.8102 & RN \\
\hline CHEMBL3891525 & 1637322 & 8.56 & 8.5149 & RN \\
\hline CHEMBL3935838 & 1637322 & 8.19 & 8.044 & ST \\
\hline CHEMBL3977010 & 1637322 & 8.51 & 8.6111 & RN \\
\hline CHEMBL3967761 & 1637322 & 8.7 & 8.7459 & RN \\
\hline CHEMBL3893556 & 1637322 & 7.31 & 7.336 & RN \\
\hline CHEMBL 3896249 & 1637322 & 9.17 & 8.8541 & RN \\
\hline HEMBL3952789 & 1637322 & 8.19 & 8.0052 & RN \\
\hline CHEMBL3955385 & 1637322 & 7.77 & 7.5978 & TRN \\
\hline CHEMBL 3977708 & 1637322 & 8.18 & 8.3016 & TRN \\
\hline CHEMBL3980069 & 1637322 & 9.44 & 9.1928 & RN \\
\hline CHEMBL3946938 & 1637322 & 8.62 & 8.699 & TRN \\
\hline HEMBL 3941337 & 1637322 & 6.87 & 6.6651 & TRN \\
\hline CHEMBL 3983585 & 1637322 & 6.92 & 6.7169 & RN \\
\hline CHEMBL3918638 & 1637322 & 9.34 & 8.4152 & TRN \\
\hline CHEMBL3920637 & 1637322 & 8.42 & 8.4059 & TRN \\
\hline CHEMBL3917908 & 1637322 & 8.85 & 8.8923 & TRN \\
\hline CHEMBL3980712 & 1637322 & 6.58 & 6.6696 & TRN \\
\hline CHEMBL 3978349 & 1637322 & 8.26 & 8.055 & ST \\
\hline CHEMBL3976721 & 1637322 & 7.55 & 7.5212 & TRN \\
\hline CHEMBL3974273 & 1637322 & 7.48 & 7.6227 & TRN \\
\hline CHEMBL3898255 & 1637322 & 7.31 & 7.5073 & TST \\
\hline CHEMBL 3927794 & 1637322 & 7.26 & 7.4203 & TST \\
\hline CHEMBL3953833 & 1637322 & 8.58 & 8.2213 & TRN \\
\hline CHEMBL3964043 & 1637322 & 8.72 & 8.6935 & TRN \\
\hline CHEMBL3945658 & 1637322 & 7.12 & 7.0986 & TRN \\
\hline CHEMBL3948306 & 1637322 & 6.65 & 6.6863 & RN \\
\hline CHEMBL3984035 & 1637322 & 8.23 & 7.9494 & ISI \\
\hline CHEMBL3986725 & 1637322 & 8.04 & 7.9117 & TST \\
\hline CHEMBL3896142 & 1637322 & 8.87 & 8.4343 & TST \\
\hline
\end{tabular}

Page 23195 


\begin{tabular}{|c|c|c|c|c|c|}
\hline \multicolumn{6}{|c|}{ pplementa1 } \\
\hline CHEMBL3908707 & 1637322 & 8.85 & 8.6396 & TRN & \\
\hline CHEMBL3941227 & 1637322 & 8.06 & 7.9831 & TST & \\
\hline CHEMBL3943917 & 1637322 & 8.21 & 8.1791 & TRN & \\
\hline CHEMBL3979972 & 1637322 & 8.11 & 7.9003 & TRN & \\
\hline CHEMBL3982399 & 1637322 & 8.22 & 8.3589 & TRN & \\
\hline CHEMBL3932817 & 1637322 & 8.09 & 8.1744 & TST & \\
\hline CHEMBL3930088 & 1637322 & 8.0 & 7.8499 & TST & \\
\hline CHEMBL3972445 & 1637322 & 7.04 & 6.6667 & TRN & \\
\hline CHEMBL3969747 & 1637322 & 7.39 & 7.4262 & TST & \\
\hline CHEMBL3918426 & 1637322 & 8.75 & 8.4819 & TST & \\
\hline CHEMBL3906938 & 1637322 & 7.98 & 8.1728 & TRN & \\
\hline CHEMBL3956028 & 1637322 & 6.87 & 6.7763 & TRN & \\
\hline CHEMBL3964762 & 1637322 & 8.19 & 8.1801 & TRN & \\
\hline CHEMBL3948234 & 1637322 & 8.6 & 8.1133 & TST & \\
\hline CHEMBL3932022 & 1637322 & 8.74 & 8.4644 & TST & \\
\hline CHEMBL3957473 & 1637322 & 8.81 & 8.5897 & TRN & \\
\hline CHEMBL3950496 & 1637322 & 8.41 & 8.4091 & TRN & \\
\hline CHEMBL3902961 & 1637322 & 8.78 & 8.6446 & TRN & \\
\hline CHEMBL3905633 & 1637322 & 7.84 & 7.9845 & TST & \\
\hline CHEMBL3937212 & 1637322 & 7.9 & 8.0438 & TST & \\
\hline CHEMBL3966929 & 1637322 & 8.0 & 8.0795 & TRN & \\
\hline CHEMBL 3922100 & 1637322 & 8.4 & 8.3381 & TST & \\
\hline CHEMBL3906284 & 1637322 & 8.4 & 8.7471 & TRN & \\
\hline CHEMBL 3921787 & 1637322 & 7.28 & 7.2212 & TRN & \\
\hline CHEMBL3951171 & 1637322 & 8.66 & 8.6592 & TRN & \\
\hline CHEMBL3983694 & 1637322 & 8.05 & 8.1174 & TRN & \\
\hline CHEMBL3981207 & 1637322 & 7.69 & 8.0478 & TRN & \\
\hline CHEMBL3986631 & 1637322 & 7.08 & 7.3458 & TRN & \\
\hline CHEMBL3969667 & 1637322 & 8.18 & 8.0666 & TRN & \\
\hline CHEMBL3933908 & 1637322 & 7.9 & 8.08 & TRN & \\
\hline CHEMBL3936673 & 1637322 & 7.56 & 7.7901 & TRN & \\
\hline CHEMBL3980417 & 1637322 & 8.62 & 8.59799 & 9999999999 & TRN \\
\hline CHEMBL3921190 & 1637322 & 8.75 & 8.5773 & TRN & \\
\hline CHEMBL 3920274 & 1637322 & 6.56 & 6.5651 & TST & \\
\hline CHEMBL3953771 & 1637322 & 7.9 & 8.1843 & TST & \\
\hline CHEMBL3950292 & 1637322 & 7.81 & 8.0136 & TRN & \\
\hline CHEMBL3959787 & 1637322 & 7.15 & 7.0137 & TRN & \\
\hline CHEMBL3986861 & 1637322 & 8.15 & 7.9108 & TST & \\
\hline CHEMBL3891816 & 1637322 & 7.78 & 7.3736 & TST & \\
\hline CHEMBL3927140 & 1637322 & 8.5 & 8.4776 & TRN & \\
\hline CHEMBL3929849 & 1637322 & 7.21 & 7.4004 & TRN & \\
\hline CHEMBL3966941 & 1637322 & 7.53 & 7.4893 & TST & \\
\hline CHEMBL3939018 & 1637322 & 8.26 & 8.5344 & TST & \\
\hline CHEMBL3912757 & 1637322 & 7.55 & 7.7245 & TRN & \\
\hline CHEMBL3915450 & 1637322 & 7.42 & 7.709 & TRN & \\
\hline CHEMBL3956493 & 1637322 & 8.29 & 8.3196 & TRN & \\
\hline CHEMBL3964931 & 1637322 & 7.9 & 7.79899 & 99999999995 & TRN \\
\hline CHEMBL3918956 & 1637322 & 7.58 & 7.7561 & TRN & \\
\hline & & & & 23196 & \\
\hline
\end{tabular}




\begin{tabular}{|c|c|c|c|c|c|}
\hline \multicolumn{6}{|c|}{ Supplemental Table s2.txt } \\
\hline CHEMBL3894754 & 1637322 & 8.16 & 8.2376 & TRN & \\
\hline CHEMBL3963296 & 1637322 & 7.71 & 7.5798 & TRN & \\
\hline CHEMBL3890187 & 1637322 & 7.04 & 6.8629 & TST & \\
\hline CHEMBL3978313 & 1637322 & 7.89 & 7.8029 & TRN & \\
\hline CHEMBL3889604 & 1637322 & 7.73 & 7.7568 & TRN & \\
\hline CHEMBL3939332 & 1637322 & 8.05 & 8.03 & TRN & \\
\hline CHEMBL3912250 & 1637322 & 7.58 & 7.4034 & TRN & \\
\hline CHEMBL3901265 & 1637322 & 8.25 & 8.1393 & TRN & \\
\hline CHEMBL3903973 & 1637322 & 8.86 & 8.9157 & TRN & \\
\hline CHEMBL3957928 & 1637322 & 7.35 & 7.5072 & TRN & \\
\hline CHEMBL3960591 & 1637322 & 7.48 & 7.8809 & TST & \\
\hline CHEMBL3899721 & 1637322 & 6.96 & 7.1971 & TRN & \\
\hline CHEMBL3934772 & 1637322 & 7.65 & 7.7705 & TRN & \\
\hline CHEMBL3909752 & 1637322 & 7.25 & 7.6756 & TRN & \\
\hline CHEMBL3906945 & 1637322 & 7.74 & 7.7876 & TRN & \\
\hline CHEMBL3954396 & 1637322 & 8.75 & 8.8704 & TRN & \\
\hline CHEMBL3944937 & 1637322 & 6.79 & 7.0765 & TRN & \\
\hline CHEMBL3895267 & 1637322 & 8.81 & 8.5886 & TRN & \\
\hline CHEMBL3892529 & 1637322 & 8.86 & 8.6876 & TRN & \\
\hline CHEMBL3935597 & 1637322 & 9.03 & 9.0108 & TRN & \\
\hline CHEMBL3932893 & 1637322 & 7.13 & 6.8776 & TST & \\
\hline CHEMBL3952706 & 1637322 & 7.36 & 7.6928 & TST & \\
\hline CHEMBL3939860 & 1637322 & 8.08 & 8.3621 & TST & \\
\hline CHEMBL3976275 & 1637322 & 8.76 & 8.5645 & TRN & \\
\hline CHEMBL3978754 & 1637322 & 8.73 & 8.8135 & TST & \\
\hline CHEMBL3942716 & 1637322 & 8.28 & 8.478 & TRN & \\
\hline CHEMBL3982718 & 1637322 & 7.82 & 7.7779 & TRN & \\
\hline CHEMBL3892005 & 1637322 & 7.54 & 7.785 & TST & \\
\hline CHEMBL3894762 & 1637322 & 8.81 & 8.6256 & TST & \\
\hline CHEMBL3896514 & 1637322 & 7.79 & 7.6848 & TST & \\
\hline CHEMBL3906253 & 1637322 & 7.69 & 7.9557 & TRN & \\
\hline CHEMBL3946877 & 1637322 & 6.45 & 6.9349 & TST & \\
\hline CHEMBL 3944241 & 1637322 & 7.29 & 7.5742 & TST & \\
\hline CHEMBL3947664 & 1637322 & 7.98 & 8.3301 & TRN & \\
\hline CHEMBL3899151 & 1637322 & 8.73 & 8.59799 & 9999999999 & TRN \\
\hline CHEMBL3960877 & 1637322 & 9.0 & 8.9759 & TST & \\
\hline CHEMBL3958209 & 1637322 & 8.86 & 9.1716 & TRN & \\
\hline CHEMBL3933492 & 1637322 & 5.1 & 4.9501 & TRN & \\
\hline CHEMBL3982416 & 1637322 & 5.3 & 5.5392 & TRN & \\
\hline CHEMBL3984969 & 1637322 & 5.7 & 5.5589 & TRN & \\
\hline CHEMBL3953206 & 1637322 & 6.0 & 6.3309 & TRN & \\
\hline CHEMBL3946591 & 1637322 & 7.17 & 7.4327 & TST & \\
\hline CHEMBL3942179 & 1637322 & 7.41 & 7.5689 & TRN & \\
\hline CHEMBL3930685 & 1637322 & 6.8 & 6.7707 & TST & \\
\hline CHEMBL3910555 & 1637322 & 8.38 & 8.1012 & TRN & \\
\hline CHEMBL3918036 & 1637322 & 6.46 & 6.2042 & TRN & \\
\hline CHEMBL3926088 & 1637322 & 6.36 & 6.1343 & TRN & \\
\hline CHEMBL3948043 & 1637322 & 6.98 & 8.4152 & TRN & \\
\hline
\end{tabular}




\begin{tabular}{|c|c|c|c|c|}
\hline \multicolumn{5}{|c|}{ Supplemental Table S2.txt } \\
\hline CHEMBL 3972657 & 1637322 & 7.26 & 7.0781 & TST \\
\hline CHEMBL 3918892 & 1637322 & 6.77 & 6.2941 & TST \\
\hline CHEMBL3966660 & 1637322 & 7.09 & 6.9279 & TST \\
\hline CHEMBL 3899891 & 1637322 & 7.62 & 7.516 & TST \\
\hline CHEMBL 3890118 & 1637322 & 7.78 & 7.7801 & TST \\
\hline CHEMBL3950169 & 1637322 & 8.48 & 8.283 & TST \\
\hline CHEMBL 3952885 & 1637322 & 6.87 & 6.7882 & TST \\
\hline CHEMBL 3890870 & 1637322 & 7.1 & 7.5276 & TST \\
\hline CHEMBL3893659 & 1637322 & 5.0 & 5.4241 & TST \\
\hline CHEMBL3928923 & 1637322 & 7.7 & 7.3319 & TST \\
\hline CHEMBL 3938712 & 1637322 & 6.92 & 6.9072 & TST \\
\hline CHEMBL 3975295 & 1637322 & 7.21 & 6.6703 & TST \\
\hline CHEMBL 3977791 & 1637322 & 6.83 & 6.7438 & TST \\
\hline CHEMBL 3916904 & 1637322 & 6.66 & 6.4368 & TST \\
\hline CHEMBL3974131 & 1637322 & 6.76 & 6.645 & TST \\
\hline CHEMBL3925322 & 1637322 & 7.19 & 6.6695 & TST \\
\hline CHEMBL 3922592 & 1637322 & 5.0 & 5.9723 & TST \\
\hline CHEMBL3985007 & 1637322 & 6.8 & 6.4678 & TST \\
\hline CHEMBL3982466 & 1637322 & 5.0 & 5.2968 & TST \\
\hline CHEMBL3910921 & 1637322 & 8.0 & 7.7524 & TST \\
\hline CHEMBL3908141 & 1637322 & 5.0 & 5.67 & TST \\
\hline CHEMBL 3971947 & 1637322 & 7.04 & 7.4469 & TST \\
\hline CHEMBL3960102 & 1637322 & 6.59 & 6.4011 & TST \\
\hline CHEMBL3891736 & 1637322 & 7.39 & 7.3653 & TST \\
\hline CHEMBL3932123 & 1637322 & 6.98 & 7.0936 & TST \\
\hline CHEMBL3952488 & 1637322 & 7.76 & 7.5977 & TST \\
\hline CHEMBL 3679718 & 1527815 & 5.2924 & 5.5493 & TRN \\
\hline CHEMBL3684410 & 1527815 & 5.7447 & 5.6226 & TRN \\
\hline CHEMBL 3684351 & 1527815 & 6.585 & 6.8355 & TRN \\
\hline CHEMBL 3684427 & 1527815 & 6.9208 & 6.5993 & TRN \\
\hline CHEMBL 3684348 & 1527815 & 6.8239 & 6.5152 & TRN \\
\hline CHEMBL 3684442 & 1527815 & 5.4949 & 5.5197 & TRN \\
\hline CHEMBL 3684381 & 1527815 & 5.1938 & 5.107 & TRN \\
\hline CHEMBL 3684430 & 1527815 & 6.8539 & 6.8997 & TRN \\
\hline CHEMBL3684530 & 1527815 & 5.8539 & 6.541 & TST \\
\hline CHEMBL 3684508 & 1527815 & 6.3372 & 6.3654 & TRN \\
\hline CHEMBL 3684479 & 1527815 & 6.1805 & 6.3905 & TRN \\
\hline CHEMBL3684503 & 1527815 & 5.9208 & 6.4832 & TRN \\
\hline CHEMBL 3679725 & 1527815 & 4.5528 & 5.0299 & TRN \\
\hline CHEMBL3684426 & 1527815 & 6.8239 & 6.7881 & TRN \\
\hline CHEMBL3684446 & 1527815 & 5.8861 & 5.8132 & TRN \\
\hline CHEMBL3684406 & 1527815 & 6.699 & 6.6419 & TRN \\
\hline CHEMBL3684390 & 1527815 & 5.7212 & 5.6822 & TRN \\
\hline CHEMBL 3684403 & 1527815 & 5.1739 & 5.4022 & TRN \\
\hline CHEMBL3684535 & 1527815 & 5.0315 & 5.9525 & TST \\
\hline CHEMBL3679731 & 1527815 & 5.7447 & 5.9804 & TRN \\
\hline CHEMBL 3684511 & 1527815 & 6.6778 & 5.6234 & TST \\
\hline CHEMBL3684391 & 1527815 & 5.3188 & 5.347 & TRN \\
\hline
\end{tabular}


Supplemental Table S2.txt

\begin{tabular}{|c|c|c|c|c|c|}
\hline CHEMBL 3684474 & 1527815 & 6.4815 & 6.3112 & TRN & \\
\hline CHEMBL3684461 & 1527815 & 5.7447 & 5.4465 & TRN & \\
\hline CHEMBL3684468 & 1527815 & 5.699 & 5.7974 & TRN & \\
\hline CHEMBL 3684431 & 1527815 & 6.5086 & 6.5995 & TRN & \\
\hline CHEMBL 3684439 & 1527815 & 6.6021 & 7.0752 & TRN & \\
\hline CHEMBL 3679727 & 1527815 & 5.0915 & 5.405 & TRN & \\
\hline CHEMBL 3684482 & 1527815 & 6.041 & 6.0403 & TRN & \\
\hline CHEMBL3679712 & 1527815 & 4.8861 & 5.1333 & TRN & \\
\hline CHEMBL3684525 & 1527815 & 6.0177 & 6.1719 & TRN & \\
\hline CHEMBL 3684448 & 1527815 & 5.6576 & 5.8491 & TRN & \\
\hline CHEMBL 3684490 & 1527815 & 5.9208 & 6.076006 & 00000000005 & TRN \\
\hline CHEMBL 3684467 & 1527815 & 5.1612 & 5.7226 & TRN & \\
\hline CHEMBL 3684357 & 1527815 & 5.2757 & 5.5998 & TRN & \\
\hline CHEMBL 3684424 & 1527815 & 6.8539 & 6.6883 & TRN & \\
\hline CHEMBL3684396 & 1527815 & 5.4685 & 5.4786 & TRN & \\
\hline CHEMBL 3684404 & 1527815 & 5.2366 & 5.1546 & TRN & \\
\hline CHEMBL3639832 & 1527815 & 6.9208 & 6.766 & TRN & \\
\hline CHEMBL 3684526 & 1527815 & 6.301 & 6.5377 & TRN & \\
\hline CHEMBL 3684488 & 1527815 & 6.1549 & 6.1963 & TRN & \\
\hline CHEMBL 3684432 & 1527815 & 5.9586 & 6.2652 & TRN & \\
\hline CHEMBL 3684469 & 1527815 & 5.5229 & 5.5891 & TRN & \\
\hline CHEMBL3679716 & 1527815 & 5.3279 & 5.6272 & TRN & \\
\hline CHEMBL 3679730 & 1527815 & 5.4559 & 5.4104 & TRN & \\
\hline CHEMBL 3684374 & 1527815 & 6.3098 & 5.7917 & TST & \\
\hline CHEMBL3684516 & 1527815 & 6.1805 & 5.6911 & TST & \\
\hline CHEMBL3684339 & 1527815 & 6.1675 & 5.9994 & TRN & \\
\hline CHEMBL 3684466 & 1527815 & 5.5686 & 5.4532 & TRN & \\
\hline CHEMBL 3684435 & 1527815 & 6.3188 & 6.5555 & TRN & \\
\hline CHEMBL3684536 & 1527815 & 5.2147 & 5.7741 & TRN & \\
\hline CHEMBL3684338 & 1527815 & 6.7959 & 6.8788 & TRN & \\
\hline CHEMBL 3684537 & 1527815 & 7.0177 & 7.0083 & TRN & \\
\hline CHEMBL 3684370 & 1527815 & 7.1192 & 6.8154 & TRN & \\
\hline CHEMBL 3684531 & 1527815 & 6.8539 & 6.5218 & TRN & \\
\hline CHEMBL 3684388 & 1527815 & 5.3565 & 5.5459 & TST & \\
\hline CHEMBL3684372 & 1527815 & 6.1612 & \multicolumn{2}{|c|}{5.8229999999999995} & TRN \\
\hline CHEMBL3684440 & 1527815 & 5.7696 & 6.0477 & TRN & \\
\hline CHEMBL 3684414 & 1527815 & 6.9208 & 6.6566 & TRN & \\
\hline CHEMBL 3684507 & 1527815 & 6.4685 & 6.2185 & TRN & \\
\hline CHEMBL 3684450 & 1527815 & 5.2218 & \multicolumn{2}{|c|}{5.377999999999999} & TRN \\
\hline CHEMBL3684379 & 1527815 & 5.3468 & 5.1864 & TRN & \\
\hline CHEMBL 3684475 & 1527815 & 6.1427 & 6.2296 & TRN & \\
\hline CHEMBL 3684401 & 1527815 & 5.5528 & 5.3501 & TRN & \\
\hline CHEMBL3684452 & 1527815 & 5.5376 & 5.4369 & TRN & \\
\hline CHEMBL 3684470 & 1527815 & 5.3768 & 5.4971 & TRN & \\
\hline CHEMBL 3684429 & 1527815 & 6.6576 & 6.8141 & TRN & \\
\hline CHEMBL 3684413 & 1527815 & 6.6198 & 6.7386 & TRN & \\
\hline CHEMBL 3684473 & 1527815 & 5.7447 & 5.6973 & TRN & \\
\hline CHEMBL 3684344 & 1527815 & 6.1549 & 5.9419 & TRN & \\
\hline
\end{tabular}

Page 23199 
Supplemental Table S2.txt

\begin{tabular}{|c|c|c|c|c|}
\hline HEM & 527815 & & & \\
\hline & & 5.0809 & & \\
\hline 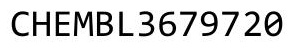 & 315 & & & \\
\hline HEMBL & 7815 & & & 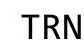 \\
\hline AEMBL3684458 & 527815 & 757 & & \\
\hline HEMBL3684453 & 527815 & 5.3098 & 4537 & \\
\hline HEMBL & 15 & 29 & & \\
\hline IFMBI 368 & & & & \\
\hline HEMBL3684371 & 815 & 6.1079 & 5916 & \\
\hline HEMBL368 & 527815 & 447 & 3351 & \\
\hline HEMBL 368 & 815 & 5.3279 & 628 & \\
\hline AEMBL36 & 815 & 23 & & \\
\hline AEMBL & & & & \\
\hline HEMBL 36 & 815 & 6.1192 & 5.2733 & \\
\hline HEMBL368 & 815 & 7. & 709 & \\
\hline HEMBL368 & 15 & 79 & 554 & \\
\hline AEMBL3 & 5 & & & RN \\
\hline HEMBL36 & & & & \\
\hline HEMBL36 & 315 & & & \\
\hline AEMBL36 & & & & \\
\hline AEMBL & 15 & & & ונד \\
\hline HEMBL3 & & & & 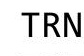 \\
\hline HEMBL & & & & \\
\hline HFMRI & & & & \\
\hline HEMBL 368 & & & & N \\
\hline HEMBL & 15 & & 99 & RN \\
\hline HEMBL & & & & ST \\
\hline HFMBI : & 15 & & & \\
\hline HEMBL36 & & & & RIV \\
\hline HEMBL 368 & & & & I RIV \\
\hline HEMBL36 & & & & RN \\
\hline HEMBL & & & & RN \\
\hline HEMBL & 5 & & & RN \\
\hline HEMBL 368 & & & & IRN \\
\hline HEMBL 3684 & -2 & & & TRN \\
\hline HEMBL36 & & & & \\
\hline HFMRI & & & 16 & RIV \\
\hline HEMBL & & & & RN \\
\hline HEMBL368 & 15 & 5.7212 & 57 & $\Gamma \mathrm{RN}$ \\
\hline AEMBL36 & -8 & & & RN \\
\hline HEMBL36 & & & 21 & \\
\hline CHEMBL 36 & & & 5.2059 & RIV \\
\hline HEMBL368 & 15 & 85 & 6.22 & RN \\
\hline HEMBL368 & 815 & 5.284 & 5.5214 & TRN \\
\hline $\mathrm{MPI}=$ & & & & \\
\hline HEMBL 36 & & & & \\
\hline CHEMBL368 & & - & 5.7541 & \\
\hline CHEMBL3684477 & 1527815 & 6.3565 & 6.3238 & \\
\hline
\end{tabular}

Page 23200 
Supplemental Table S2.txt

\begin{tabular}{|c|c|c|c|c|}
\hline CHEMBL 3679724 & 1527815 & 4.6383 & 5.2947 & TRN \\
\hline CHEMBL 3684528 & 1527815 & 6.8861 & 6.307 & TRN \\
\hline CHEMBL3684457 & 1527815 & 5.6383 & 5.7067 & TRN \\
\hline CHEMBL 3684529 & 1527815 & 5.301 & 6.6999 & TST \\
\hline CHEMBL 3684481 & 1527815 & 5.9208 & 5.9581 & TRN \\
\hline CHEMBL3684486 & 1527815 & 6.1135 & 6.2226 & TRN \\
\hline CHEMBL 3684420 & 1527815 & 6.9208 & 6.0507 & TRN \\
\hline CHEMBL3639833 & 1527815 & 5.4685 & 5.5825 & TRN \\
\hline CHEMBL 3684400 & 1527815 & 5.6021 & 5.1524 & TST \\
\hline CHEMBL 3684532 & 1527815 & 6.3098 & 6.2618 & TRN \\
\hline CHEMBL 3684409 & 1527815 & 6.699 & 6.5053 & TRN \\
\hline CHEMBL 3684397 & 1527815 & 5.2366 & 5.03 & TRN \\
\hline CHEMBL 3679728 & 1527815 & 5.6576 & 5.6164 & TRN \\
\hline CHEMBL 3684353 & 1527815 & 6.4437 & 6.41100 & 00000000005 \\
\hline CHEMBL3684359 & 1527815 & 6.6198 & 6.1306 & TRN \\
\hline CHEMBL 3684437 & 1527815 & 5.7212 & 5.4857 & TRN \\
\hline CHEMBL 3684412 & 1527815 & 6.0969 & 6.3828 & TRN \\
\hline CHEMBL 3684454 & 1527815 & 5.7212 & 5.6315 & TRN \\
\hline CHEMBL 3684494 & 1527815 & 5.6778 & 5.8316 & TST \\
\hline CHEMBL 3684500 & 1527815 & 7.3188 & 6.0373 & TST \\
\hline CHEMBL 3684443 & 1527815 & 5.4685 & 5.3365 & TRN \\
\hline CHEMBL 3684337 & 1527815 & 6.0969 & 5.6807 & TST \\
\hline CHEMBL 3684402 & 1527815 & 5.8539 & 5.9068 & TRN \\
\hline CHEMBL 3679714 & 1527815 & 5.6778 & 5.8123 & TRN \\
\hline CHEMBL 3684514 & 1527815 & 6.1938 & 6.398 & TRN \\
\hline CHEMBL 3684335 & 1527815 & 7.0809 & 5.7757 & TST \\
\hline CHEMBL 3684462 & 1527815 & 5.2757 & 5.4183 & TRN \\
\hline CHEMBL 3684407 & 1527815 & 5.9586 & 6.4072 & TRN \\
\hline CHEMBL 3684492 & 1527815 & 6.1549 & 6.2884 & TRN \\
\hline CHEMBL 3684534 & 1527815 & 5.284 & 5.1994 & TRN \\
\hline CHEMBL 3684377 & 1527815 & 5.5528 & 5.5584 & TRN \\
\hline CHEMBL 3679711 & 1527815 & 5.2007 & 5.2656 & TST \\
\hline CHEMBL 3684433 & 1527815 & 6.8861 & 6.5528 & TRN \\
\hline CHEMBL 3684364 & 1527815 & 5.7447 & 5.9968 & TRN \\
\hline CHEMBL 3684484 & 1527815 & 6.2757 & 6.181 & TRN \\
\hline CHEMBL3679726 & 1527815 & 5.1427 & 4.8754 & TRN \\
\hline CHEMBL 3684478 & 1527815 & 5.2218 & 5.2928 & TRN \\
\hline CHEMBL 3679710 & 1527815 & 5.5528 & 4.9258 & TRN \\
\hline CHEMBL 3684355 & 1527815 & 6.6383 & 7.004 & TRN \\
\hline CHEMBL 3684445 & 1527815 & 5.4685 & 5.2593 & TRN \\
\hline CHEMBL3679713 & 1527815 & 5.1024 & 5.1233 & TST \\
\hline CHEMBL 3684527 & 1527815 & 5.8539 & 6.1624 & TRN \\
\hline CHEMBL 3684356 & 1527815 & 5.7212 & 6.6114 & TRN \\
\hline CHEMBL3684366 & 1527815 & 6.9586 & 6.5995 & TRN \\
\hline CHEMBL3684505 & 1527815 & 5.9586 & 5.5172 & TST \\
\hline CHEMBL 3684491 & 1527815 & 6.1249 & 5.9887 & TRN \\
\hline CHEMBL 3684449 & 1527815 & 6.0044 & 5.8521 & TRN \\
\hline CHEMBL 3684496 & 1527815 & 6.301 & 5.8566 & TST \\
\hline
\end{tabular}


Supplemental Table S2.txt

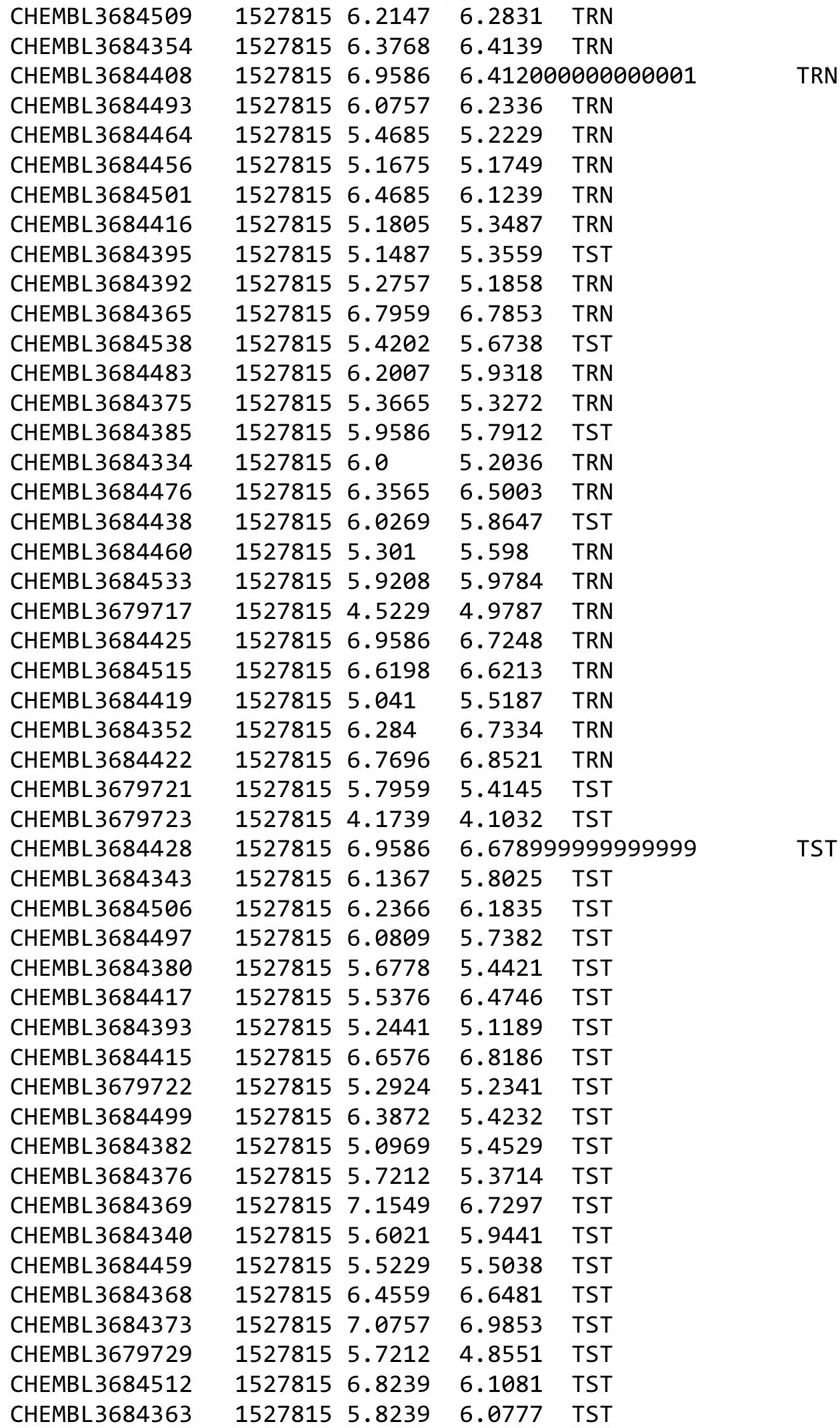

Page 23202 
Supplemental Table S2.txt

\begin{tabular}{|c|c|c|c|c|c|c|}
\hline CHEMBL3684485 & 1527815 & 5.9208 & 6.2036 & TST & & \\
\hline CHEMBL3684362 & 1527815 & 6.1871 & 6.2362 & TST & & \\
\hline CHEMBL3684398 & 1527815 & 5.2596 & 4.8134 & TST & & \\
\hline CHEMBL 3684411 & 1527815 & 6.8539 & 6.4896 & TST & & \\
\hline CHEMBL3684489 & 1527815 & 6.0269 & 5.6527 & TST & & \\
\hline CHEMBL3684455 & 1527815 & 6.1024 & 6.0531 & TST & & \\
\hline CHEMBL 3684378 & 1527815 & 5.3565 & 5.2071 & TST & & \\
\hline CHEMBL 3684502 & 1527815 & 7.1367 & 6.4594 & TST & & \\
\hline CHEMBL192566 & 954935 & 6.8589 & 7.5723 & TST & & \\
\hline CHEMBL92309 & 954935 & 2.2011 & 2.3673 & TST & & \\
\hline CHEMBL191334 & 954935 & 5.3552 & 5.3305 & TRN & & \\
\hline CHEMBL1186585 & 954935 & 4.9721 & 4.9987 & TRN & & \\
\hline CHEMBL573107 & 954935 & 4.3897 & 4.4093 & TRN & & \\
\hline CHEMBL1242367 & 954935 & 3.6821 & 3.6969 & TRN & & \\
\hline CHEMBL 2005886 & 954935 & 5.9518 & 5.9382 & TRN & & \\
\hline CHEMBL1357247 & 954935 & 3.7901 & 3.8098 & TRN & & \\
\hline CHEMBL9470 & 954935 & 5.7704 & 5.2066 & TST & & \\
\hline CHEMBL1256459 & 954935 & 6.6287 & 6.6632 & TRN & & \\
\hline CHEMBL3349342 & 954935 & 4.0955 & 4.0908 & TRN & & \\
\hline CHEMBL180127 & 954935 & 3.9522 & 3.9622 & TRN & & \\
\hline CHEMBL1673039 & 954935 & 4.7508 & 4.6867 & TRN & & \\
\hline CHEMBL393929 & 954935 & 5.2236 & 5.2315 & TRN & & \\
\hline CHEMBL483847 & 954935 & 3.8939 & 3.8922 & TRN & & \\
\hline CHEMBL 240954 & 954935 & 4.5917 & 3.6518 & TST & & \\
\hline CHEMBL1788116 & 954935 & 5.0386 & 5.0674 & TRN & & \\
\hline CHEMBL373751 & 954935 & 3.319 & 3.4056 & TRN & & \\
\hline CHEMBL65 & 954935 & 7.9763 & 7.9774 & TRN & & \\
\hline CHEMBL379300 & 954935 & 5.7496 & 5.7343 & TRN & & \\
\hline CHEMBL514499 & 954935 & \multicolumn{3}{|c|}{6.797999999999999} & 6.7199 & TRN \\
\hline CHEMBL 2363137 & 954935 & 5.3142 & 5.2982 & TRN & & \\
\hline CHEMBL102714 & 954935 & 3.8372 & 3.8237 & TRN & & \\
\hline CHEMBL259181 & 954935 & 3.4079 & 3.4063 & TRN & & \\
\hline CHEMBL3199475 & 954935 & 3.6026 & 3.5959 & TRN & & \\
\hline CHEMBL1190711 & 954935 & 3.8703 & 3.8544 & TRN & & \\
\hline CHEMBL 258844 & 954935 & 3.8764 & 3.8484 & TRN & & \\
\hline CHEMBL512504 & 954935 & 4.1512 & 4.1461 & TRN & & \\
\hline CHEMBL 2137530 & 954935 & 4.9544 & 4.9942 & TRN & & \\
\hline CHEMBL135561 & 954935 & \multicolumn{3}{|c|}{ 4.1739999999999995 } & 4.1604 & TRN \\
\hline CHEMBL 202721 & 954935 & 5.2081 & 5.2575 & TRN & & \\
\hline CHEMBL379975 & 954935 & 3.7485 & 3.7196 & TRN & & \\
\hline CHEMBL1404918 & 954935 & 2.9695 & 2.8949 & TRN & & \\
\hline CHEMBL1643959 & 954935 & 3.5682 & 3.5601 & TRN & & \\
\hline CHEMBL 217354 & 954935 & 6.6701 & 6.6701 & TRN & & \\
\hline CHEMBL399530 & 954935 & 3.2569 & 3.2724 & TRN & & \\
\hline CHEMBL392695 & 954935 & 4.5746 & 4.6375 & TRN & & \\
\hline CHEMBL188678 & 954935 & 4.3963 & 4.3809 & TRN & & \\
\hline CHEMBL 2134202 & 954935 & 4.7293 & 4.7223 & TRN & & \\
\hline CHEMBL449158 & 954935 & 7.0851 & 7.0156 & TST & & \\
\hline
\end{tabular}




\begin{tabular}{|c|c|c|c|c|c|}
\hline \multicolumn{6}{|c|}{ Supplemental Table S2.txt } \\
\hline CHEMBL189584 & 954935 & 5.0024 & 5.0003 & TRN & \\
\hline CHEMBL515416 & 954935 & 4.4239 & 4.4849 & TRN & \\
\hline CHEMBL558642 & 954935 & 4.069 & 4.0772 & TRN & \\
\hline CHEMBL 210618 & 954935 & 3.6531 & 3.6928 & TRN & \\
\hline CHEMBL1230020 & 954935 & 3.3862 & 3.3683 & TRN & \\
\hline CHEMBL472940 & 954935 & 2.7805 & 2.8282 & TRN & \\
\hline CHEMBL1909414 & 954935 & 3.2462 & 3.1673 & TRN & \\
\hline CHEMBL255342 & 954935 & 3.386 & 3.3506 & TRN & \\
\hline CHEMBL 3186408 & 954935 & 3.5711 & 3.6686 & TST & \\
\hline CHEMBL209148 & 954935 & 4.5755 & 4.4797 & TRN & \\
\hline CHEMBL585951 & 954935 & 5.7066 & 5.6815 & TRN & \\
\hline CHEMBL 220241 & 954935 & 3.8916 & 3.9044 & TRN & \\
\hline CHEMBL 577784 & 954935 & 3.75100 & 0000000 & 3.8314 & TRN \\
\hline CHEMBL300389 & 954935 & 6.8696 & 6.8944 & TRN & \\
\hline CHEMBL 222102 & 954935 & 3.2858 & 3.7858 & TST & \\
\hline CHEMBL 2144069 & 954935 & 4.5327 & 4.9731 & TST & \\
\hline CHEMBL1516890 & 954935 & 3.7954 & 4.0819 & TST & \\
\hline CHEMBL1970879 & 954935 & 5.8543 & 4.4897 & TST & \\
\hline CHEMBL 3392440 & 954935 & 3.7209 & 3.6393 & TST & \\
\hline CHEMBL 221137 & 954935 & 4.1707 & 4.2543 & TST & \\
\hline CHEMBL 213100 & 954935 & 6.4471 & 5.2852 & TST & \\
\hline CHEMBL412142 & 954935 & 4.5271 & 4.5539 & TST & \\
\hline CHEMBL1590308 & 954935 & 4.2179 & 3.5619 & TST & \\
\hline CHEMBL509032 & 954935 & 6.0051 & 5.6996 & TST & \\
\hline CHEMBL483849 & 954935 & 0.8762 & 1.4798 & TST & \\
\hline CHEMBL524659 & 552584 & 5.699 & 5.0651 & TRN & \\
\hline CHEMBL504837 & 552584 & 5.3372 & 5.2256 & TRN & \\
\hline CHEMBL501266 & 552584 & 2.9031 & 3.4819 & TRN & \\
\hline CHEMBL527080 & 552584 & 4.5086 & 4.5952 & TRN & \\
\hline CHEMBL524509 & 552584 & 4.5086 & 4.3357 & TRN & \\
\hline CHEMBL525431 & 552584 & 4.0706 & 4.6065 & TRN & \\
\hline CHEMBL498954 & 552584 & 2.6021 & 3.1102 & TST & \\
\hline CHEMBL526130 & 552584 & 4.1675 & 4.1966 & TRN & \\
\hline CHEMBL503983 & 552584 & 6.0 & 5.7719 & TRN & \\
\hline CHEMBL 2372282 & 552584 & 4.7959 & 3.9368 & TRN & \\
\hline CHEMBL507807 & 552584 & 5.2076 & 5.2422 & TRN & \\
\hline CHEMBL506848 & 552584 & 2.9031 & 5.3255 & TRN & \\
\hline CHEMBL526300 & 552584 & 4.7959 & 4.90300 & 00000000005 & TRN \\
\hline CHEMBL508377 & 552584 & 5.3468 & 5.2029 & TRN & \\
\hline CHEMBL525587 & 552584 & 2.9031 & 3.0141 & TRN & \\
\hline CHEMBL527072 & 552584 & 4.2218 & 4.5357 & TRN & \\
\hline CHEMBL499501 & 552584 & 2.9031 & 3.6534 & TRN & \\
\hline CHEMBL450322 & 552584 & 4.7959 & 4.4561 & TRN & \\
\hline CHEMBL508126 & 552584 & 5.4318 & 3.3234 & TRN & \\
\hline CHEMBL524483 & 552584 & 4.0177 & 3.8669 & TRN & \\
\hline CHEMBL508398 & 552584 & 4.0915 & 4.208 & TRN & \\
\hline CHEMBL525060 & 552584 & 4.5229 & 3.9302 & TRN & \\
\hline CHEMBL501031 & 552584 & 4.0458 & 4.3445 & TRN & \\
\hline
\end{tabular}




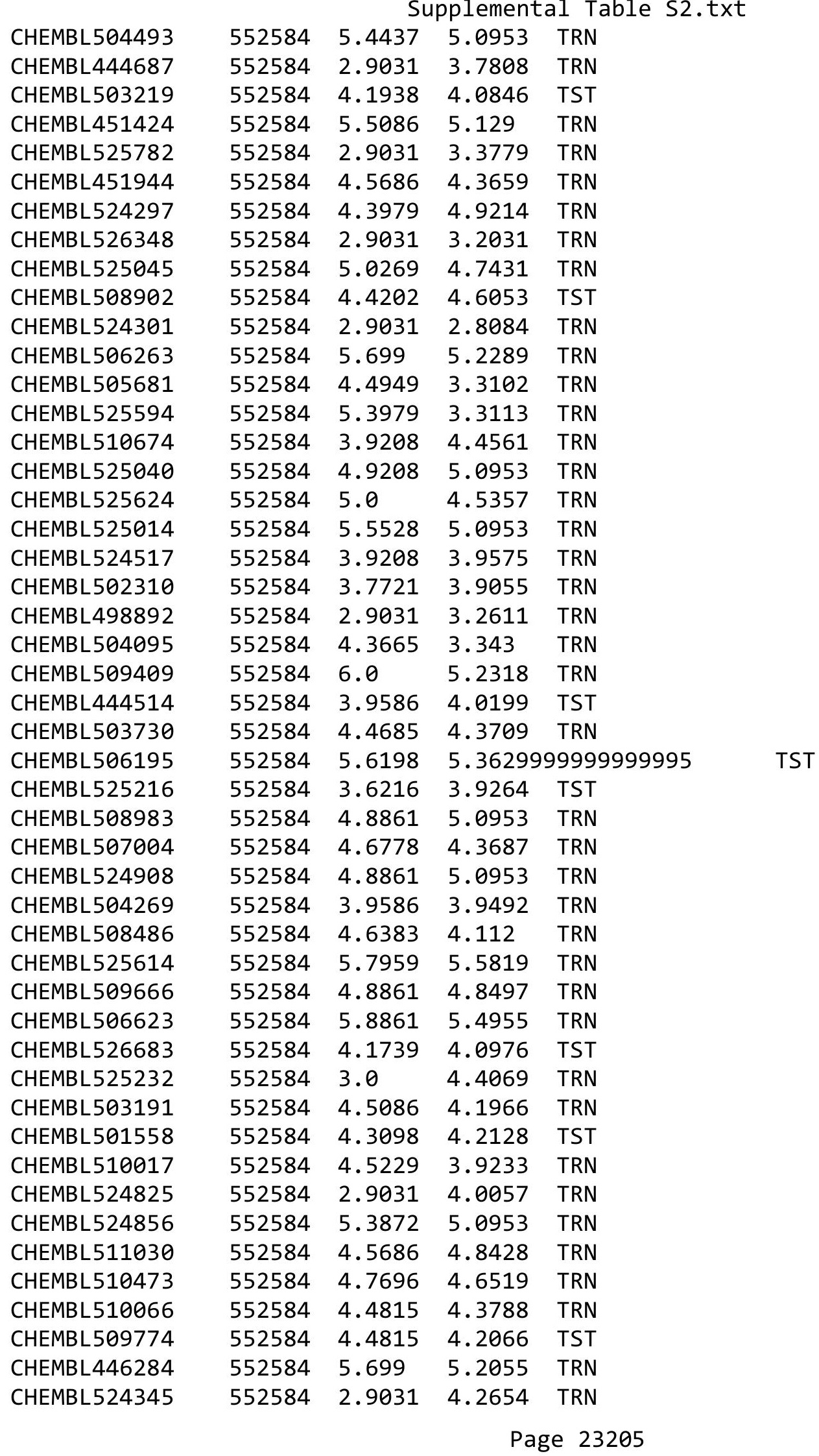




\begin{tabular}{|c|c|c|c|c|c|}
\hline \\
\hline CHEMBL508704 & 552584 & 4.0 & 4.3788 & TRN & \\
\hline CHEMBL525088 & 552584 & 4.2441 & 5.3419 & TRN & \\
\hline CHEMBL500441 & 552584 & 4.6383 & 4.66 & TST & \\
\hline CHEMBL442891 & 552584 & 2.9031 & 3.3643 & TRN & \\
\hline CHEMBL486090 & 552584 & 6.1938 & 5.5794 & TST & \\
\hline CHEMBL499121 & 552584 & 4.4318 & 4.886 & TST & \\
\hline CHEMBL505603 & 552584 & 4.2218 & 4.24 & TRN & \\
\hline CHEMBL444490 & 552584 & 2.6021 & 5.4007 & TRN & \\
\hline CHEMBL505790 & 552584 & 5.0915 & 5.0953 & TRN & \\
\hline CHEMBL526373 & 552584 & 5.7959 & 5.033 & TRN & \\
\hline CHEMBL505689 & 552584 & 4.0605 & \multicolumn{2}{|c|}{4.361000000000001} & TRN \\
\hline CHEMBL525636 & 552584 & 5.7696 & 5.2081 & TRN & \\
\hline CHEMBL505899 & 552584 & 6.0458 & 5.5589 & TRN & \\
\hline CHEMBL499790 & 552584 & 4.4815 & 4.2204 & TST & \\
\hline CHEMBL525583 & 552584 & 5.6576 & 5.3077 & TST & \\
\hline CHEMBL499946 & 552584 & 2.9031 & 3.4101 & TRN & \\
\hline CHEMBL526174 & 552584 & 6.2076 & 5.9356 & TST & \\
\hline CHEMBL526499 & 552584 & 5.2007 & 4.9739 & TRN & \\
\hline CHEMBL507073 & 552584 & 3.9208 & 3.9104 & TRN & \\
\hline CHEMBL507649 & 552584 & 5.3872 & 5.0227 & TRN & \\
\hline CHEMBL510233 & 552584 & 4.0969 & 4.5062 & TRN & \\
\hline CHEMBL501283 & 552584 & 4.0969 & 4.2092 & TRN & \\
\hline CHEMBL524692 & 552584 & 2.9031 & 3.1149 & TRN & \\
\hline CHEMBL505622 & 552584 & 5.4318 & 5.1501 & TRN & \\
\hline CHEMBL525635 & 552584 & 5.3665 & 5.2289 & TRN & \\
\hline CHEMBL504266 & 552584 & 5.6198 & 5.0986 & TRN & \\
\hline CHEMBL510720 & 552584 & 3.8239 & 4.4699 & TRN & \\
\hline CHEMBL504919 & 552584 & 4.7959 & 4.8596 & TRN & \\
\hline CHEMBL503673 & 552584 & 5.8861 & 5.5755 & TRN & \\
\hline CHEMBL504423 & 552584 & 5.6778 & 5.7507 & TRN & \\
\hline CHEMBL524718 & 552584 & 4.5686 & 4.7702 & TRN & \\
\hline CHEMBL526381 & 552584 & 5.6383 & 5.3873 & TST & \\
\hline CHEMBL503489 & 552584 & 5.4949 & 5.4591 & TRN & \\
\hline CHEMBL501094 & 552584 & 4.3468 & 4.7616 & TRN & \\
\hline CHEMBL506740 & 552584 & 4.4949 & 4.3986 & TRN & \\
\hline CHEMBL443697 & 552584 & 6.2441 & 5.7958 & TRN & \\
\hline CHEMBL524661 & 552584 & 2.9031 & 3.346 & TRN & \\
\hline CHEMBL524877 & 552584 & 2.9031 & 3.68399 & 99999999997 & TRN \\
\hline CHEMBL504336 & 552584 & 4.9208 & 4.9322 & TRN & \\
\hline CHEMBL503205 & 552584 & 4.0655 & 4.208 & TRN & \\
\hline CHEMBL502045 & 552584 & 2.9031 & 3.7583 & TRN & \\
\hline CHEMBL499664 & 552584 & 4.1612 & 4.3616 & TRN & \\
\hline CHEMBL508564 & 552584 & 5.8539 & 5.0953 & TRN & \\
\hline CHEMBL527054 & 552584 & 3.9706 & 3.8691 & TRN & \\
\hline CHEMBL 207341 & 552584 & 4.6198 & 4.3511 & TRN & \\
\hline CHEMBL506645 & 552584 & 2.9031 & 3.5763 & TRN & \\
\hline CHEMBL499766 & 552584 & 5.699 & 5.1442 & TRN & \\
\hline CHEMBL500788 & 552584 & 4.585 & 4.4447 & TRN & \\
\hline
\end{tabular}




\begin{tabular}{|c|c|c|c|c|}
\hline \multicolumn{5}{|c|}{ Supplemental T } \\
\hline CHEMBL500475 & 552584 & 6.2757 & & \\
\hline HEMBL506261 & 52584 & 0969 & 4501 & \\
\hline HEMBL510716 & 52584 & 5.7696 & 0238 & \\
\hline HEMBL526336 & 52584 & .0458 & 7317 & \\
\hline HEMBL508221 & & 5229 & & \\
\hline HEMBL502881 & 52584 & 3.9136 & 3.5016 & \\
\hline HEMBL501035 & 52584 & 2.9031 & 2.9144 & \\
\hline HEMBL508454 & 584 & 2.9031 & 5.1273 & \\
\hline HEMBL5C & 584 & 4.699 & 4.3687 & \\
\hline HEMBL5 & & 362 & & \\
\hline HEMBL505501 & 52584 & 4.8861 & 4.7232 & \\
\hline HEMBL525018 & 52584 & 5.3468 & 5.2289 & \\
\hline HEMBL508 & 584 & 4.1487 & 4.2654 & \\
\hline HEMBL5 & & 539 & & \\
\hline HEMBL: & & 696 & & \\
\hline HEMBL5 & 84 & 5.3098 & & \\
\hline HEMBL5 & 84 & 5.2596 & & \\
\hline HEMBL5 & 84 & 4.4437 & 66 & \\
\hline HEMBL & & 85 & & \\
\hline HEMBL & & 441 & & \\
\hline HEMBL: & & 696 & & \\
\hline HEMBL5 & & 089 & & \\
\hline CHEMBLS & 84 & 4.0 & 741 & \\
\hline HEMBL & & 3. & 86 & \\
\hline LHEMBL & & 6 . & & \\
\hline CHEMBL5 & & & & \\
\hline HEMBL4 & & & & \\
\hline CHEMBL5 & & 031 & 89 & \\
\hline HEMBL & & & & \\
\hline CHEMBL & & 223 & & \\
\hline CHEMBL 5 & & 212 & & \\
\hline CHEMBL 5 & & 208 & & \\
\hline CHEMBL5 & & 949 & & \\
\hline CHEMBL & & 768 & 19 & \\
\hline CHEMBL. & 51 & 871 & 57 & \\
\hline CHEMBL3940238 & 1571 & 8.0458 & 577 & \\
\hline CHEMBL3 & 1571 & 6.8729 & & \\
\hline CHEMBL & & 547 & & \\
\hline CHEMBL3 & 51 & 7. & 38 & \\
\hline CHEMBL3 & 571 & 7.2757 & 1867 & \\
\hline CHEMBL3928156 & 1641571 & 6.684 & 6.7428 & \\
\hline CHEMBL39813. & 1641571 & 7.1871 & & \\
\hline CHEMBL3 & & 6.4522 & & \\
\hline CHEMBL 3 & 571 & 7.0757 & 7.0505 & \\
\hline CHEMBL39 & 1571 & 5.4202 & 5.4359 & \\
\hline CHEMBL3930428 & 1641571 & 6.8356 & 6.9621 & \\
\hline CHEMBL390787€ & 1641571 & 6.0605 & 6.0896 & \\
\hline EMBL 3946423 & 1641571 & 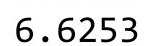 & 5.6637 & \\
\hline
\end{tabular}

Page 23207 
Supplemental Table S2.txt

\begin{tabular}{|c|c|c|c|c|c|c|}
\hline CHEMBL3965859 & 1641571 & 7.3872 & \multicolumn{3}{|c|}{7.292999999999999} & TRN \\
\hline CHEMBL3934185 & 1641571 & 6.6383 & 6.7482 & TRN & & \\
\hline CHEMBL3903185 & 1641571 & 5.99100 & 00000000 & 005 & 7.1001 & TST \\
\hline CHEMBL3977377 & 1641571 & 7.7959 & 7.8484 & TRN & & \\
\hline CHEMBL3898816 & 1641571 & 6.8894 & 5.7653 & TST & & \\
\hline CHEMBL3935842 & 1641571 & 6.4101 & 6.4675 & TRN & & \\
\hline CHEMBL3930525 & 1641571 & 7.2441 & 7.2805 & TRN & & \\
\hline CHEMBL3937131 & 1641571 & 7.5376 & 7.54206 & 0000000001 & & TRN \\
\hline CHEMBL3956441 & 1641571 & 8.2218 & 8.2598 & TRN & & \\
\hline CHEMBL3954046 & 1641571 & 5.5834 & 5.6208 & TRN & & \\
\hline CHEMBL3916785 & 1641571 & 7.3279 & 7.414 & TRN & & \\
\hline CHEMBL3934744 & 1641571 & 7.5528 & 7.3136 & TRN & & \\
\hline CHEMBL3971841 & 1641571 & 5.7812 & 5.7343 & TRN & & \\
\hline CHEMBL3899892 & 1641571 & 7.5686 & 7.5823 & TRN & & \\
\hline CHEMBL3914811 & 1641571 & 6.9281 & 7.112 & TRN & & \\
\hline CHEMBL3925061 & 1641571 & 6.6289 & 6.5548 & TRN & & \\
\hline CHEMBL3932318 & 1641571 & 6.6271 & 6.7115 & TRN & & \\
\hline CHEMBL3924741 & 1641571 & 6.5952 & 6.6625 & TRN & & \\
\hline CHEMBL3941436 & 1641571 & 6.224 & 6.2788 & TRN & & \\
\hline CHEMBL3904374 & 1641571 & 6.295 & 6.2252 & TRN & & \\
\hline CHEMBL3982244 & 1641571 & 6.6478 & 7.1748 & TST & & \\
\hline CHEMBL3903258 & 1641571 & 6.8125 & 6.7845 & TRN & & \\
\hline CHEMBL3939125 & 1641571 & 8.3979 & 8.3745 & TRN & & \\
\hline CHEMBL3970371 & 1641571 & 7.7212 & 7.7233 & TRN & & \\
\hline CHEMBL3975373 & 1641571 & 6.1057 & 6.3104 & TRN & & \\
\hline CHEMBL3930216 & 1641571 & 7.7696 & 8.2659 & TST & & \\
\hline CHEMBL3949463 & 1641571 & 6.5272 & 6.4569 & TRN & & \\
\hline CHEMBL3954630 & 1641571 & 7.5229 & 7.499 & TRN & & \\
\hline CHEMBL3972713 & 1641571 & 6.7375 & 6.6316 & TRN & & \\
\hline CHEMBL3899918 & 1641571 & 6.7447 & 6.7731 & TRN & & \\
\hline CHEMBL3950449 & 1641571 & 6.1163 & 5.9989 & TRN & & \\
\hline CHEMBL3890034 & 1641571 & 6.6968 & 6.6919 & TRN & & \\
\hline CHEMBL3986090 & 1641571 & 6.7545 & 6.6965 & TRN & & \\
\hline CHEMBL3940263 & 1641571 & 6.4214 & 6.4611 & TRN & & \\
\hline CHEMBL3966888 & 1641571 & 7.2007 & 7.1845 & TRN & & \\
\hline CHEMBL3983991 & 1641571 & 5.0448 & 7.2002 & TST & & \\
\hline CHEMBL3895270 & 1641571 & 8.699 & 8.6029 & TRN & & \\
\hline CHEMBL3945060 & 1641571 & 6.5421 & 6.5189 & TRN & & \\
\hline CHEMBL3985381 & 1641571 & 7.5528 & 7.5563 & TRN & & \\
\hline CHEMBL3916741 & 1641571 & 5.7375 & 5.7408 & TRN & & \\
\hline CHEMBL3953789 & 1641571 & 6.4647 & 6.5098 & TRN & & \\
\hline CHEMBL3892255 & 1641571 & 6.6073 & 6.6331 & TRN & & \\
\hline CHEMBL3890903 & 1641571 & 7.1367 & 7.1029 & TRN & & \\
\hline CHEMBL3951547 & 1641571 & 7.8861 & 7.8781 & TRN & & \\
\hline CHEMBL3922326 & 1641571 & 7.8239 & 7.7093 & TRN & & \\
\hline CHEMBL3922489 & 1641571 & 8.699 & 8.7299 & TRN & & \\
\hline CHEMBL3959151 & 1641571 & 6.3261 & 6.5035 & TRN & & \\
\hline CHEMBL3986532 & 1641571 & 6.4949 & 6.9262 & TST & & \\
\hline
\end{tabular}


Supplemental Table S2.txt

\begin{tabular}{|c|c|c|c|c|}
\hline W & 541571 & & & \\
\hline & 641571 & 6.1772 & & \\
\hline & & 021 & & \\
\hline IEMBL & & 2218 & & \\
\hline HEMBL396 & 571 & & & \\
\hline HEMBL3922730 & 641571 & 6.3401 & 4186 & \\
\hline HEMBL393 & 571 & & & \\
\hline IFMRI 380 & & & & \\
\hline AEMBL3981762 & 571 & 3979 & & \\
\hline HEMBL 394 & 571 & 229 & 485 & \\
\hline HEMBL3903587 & 571 & 7.6021 & & \\
\hline IEMBL38 & 51 & 35 & & \\
\hline AEMBL3S & & & & \\
\hline HEMBL393 & 571 & 6.2262 & & \\
\hline HEMBL391 & 571 & 559 & & \\
\hline AEMBL392 & 71 & 56 & & \\
\hline AEMBL39 & 71 & 24 & & \\
\hline HEMBL39 & & 26 & & \\
\hline HEMBL392 & & 7.0269 & & \\
\hline AEMBL39 & & & & \\
\hline HEIMBLSS & 1 & & 11 & I RIV \\
\hline AEMBL: & & 34 & & RN \\
\hline AEMBL & & & & \\
\hline 568 & & 768 & & \\
\hline AEMBL3 & & & & TST \\
\hline HEMBL3 & 11 & & & RN \\
\hline AEMBL & & 6 & & RN \\
\hline HFMBI 36 & & 55 & & \\
\hline HEMBL3S & & & & $1=2+3$ \\
\hline HEMBL39122 & & & & is \\
\hline HEMBL3S & 71 & & & TST \\
\hline HEMBL & & 38 & & ST \\
\hline AEMBL; & & 7. & & TT \\
\hline HEMBL393. & & 7. & & is \\
\hline HEMBL3893455 & 71 & 7.2924 & & TST \\
\hline HEMBL 393 & & 98 & 31 & ГST \\
\hline HFMRI 3 & & & & \\
\hline HEMBL1e & & & & TRN \\
\hline HEMBL3949207 & 99 & 229 & & TRN \\
\hline AEMBL3969302 & & & & TRN \\
\hline HEMBL10 & 99 & 29 & 25 & \\
\hline CHEMBL108 & & & & RN \\
\hline HEMBL3968786 & 599 & 5.2815 & 3.5064 & ГST \\
\hline AEMBL1076723 & 599 & 3.5229 & 139 & TR \\
\hline MRI 1 & & & & RIN \\
\hline HEMBL3S & & & & \\
\hline LHEMBL1087909 & & & 5.3032 & \\
\hline CHEMBL3931810 & 1640599 & 4.4949 & 3.9159 & ГRN \\
\hline
\end{tabular}

Page 23209 
Supplemental Table S2.txt

\begin{tabular}{|c|c|c|c|c|c|c|}
\hline CHEMBL3913491 & 1640599 & 7.0706 & 5.2097 & TRN & & \\
\hline CHEMBL1081654 & 1640599 & 3.5229 & 3.2047 & TRN & & \\
\hline CHEMBL1088178 & 1640599 & 5.7011 & 4.823 & TRN & & \\
\hline CHEMBL1082869 & 1640599 & 7.2076 & 5.8551 & TRN & & \\
\hline CHEMBL3973776 & 1640599 & 3.699 & 4.3238 & TST & & \\
\hline CHEMBL1086158 & 1640599 & 5.8827 & 5.8301 & TRN & & \\
\hline CHEMBL1087770 & 1640599 & 3.5229 & 2.8869 & TRN & & \\
\hline CHEMBL3936796 & 1640599 & 6.1765 & 4.1558 & TST & & \\
\hline CHEMBL1080382 & 1640599 & 5.4855 & 5.0011 & TRN & & \\
\hline CHEMBL3959287 & 1640599 & 3.699 & 4.5419 & TST & & \\
\hline CHEMBL1080383 & 1640599 & 3.699 & 4.6307 & TRN & & \\
\hline CHEMBL1087142 & 1640599 & 3.5229 & 3.815 & TRN & & \\
\hline CHEMBL1088177 & 1640599 & 4.3233 & 5.0946 & TRN & & \\
\hline CHEMBL1080865 & 1640599 & 6.3809 & 4.4131 & TRN & & \\
\hline CHEMBL1080384 & 1640599 & 6.5867 & 5.5845 & TRN & & \\
\hline CHEMBL1076708 & 1640599 & 3.5229 & 3.8269 & TRN & & \\
\hline CHEMBL1081645 & 1640599 & 4.0 & 4.3447 & TRN & & \\
\hline CHEMBL3982822 & 1640599 & 3.699 & 3.2705 & TST & & \\
\hline CHEMBL1087282 & 1640599 & 3.5229 & 3.39 & TRN & & \\
\hline CHEMBL3892174 & 1640599 & 3.699 & 4.6843 & TRN & & \\
\hline CHEMBL3898098 & 1640599 & 3.699 & 4.5308 & TRN & & \\
\hline CHEMBL1081655 & 1640599 & 3.5229 & 3.1533 & TRN & & \\
\hline CHEMBL1087139 & 1640599 & 3.5229 & 3.3472 & TRN & & \\
\hline CHEMBL3890236 & 1640599 & 3.699 & 4.0231 & TRN & & \\
\hline CHEMBL3958821 & 1640599 & 3.699 & 4.319 & TRN & & \\
\hline CHEMBL3984678 & 1640599 & 5.4815 & 5.5884 & TRN & & \\
\hline CHEMBL1080684 & 1640599 & 3.699 & 3.9847 & TRN & & \\
\hline CHEMBL1080881 & 1640599 & 5.6326 & 4.3057 & TRN & & \\
\hline CHEMBL1088176 & 1640599 & 3.5229 & 4.3409 & TRN & & \\
\hline CHEMBL3914872 & 1640599 & 3.699 & 4.6233 & TRN & & \\
\hline CHEMBL 3899042 & 1640599 & 2.3107 & 4.1827 & TRN & & \\
\hline CHEMBL1090423 & 1640599 & \multicolumn{3}{|c|}{2.9610000000000003} & 4.5908 & TRN \\
\hline CHEMBL3968014 & 1640599 & 3.699 & 4.3454 & TRN & & \\
\hline CHEMBL1087911 & 1640599 & \multicolumn{3}{|c|}{ 2.9939999999999998 } & 4.14 & TST \\
\hline CHEMBL3918272 & 1640599 & 6.6271 & 4.4929 & TST & & \\
\hline CHEMBL1081646 & 1640599 & 5.6345 & 3.2949 & TST & & \\
\hline CHEMBL3904549 & 1640599 & 6.1096 & 4.3849 & TST & & \\
\hline CHEMBL3930934 & 1640599 & 3.5229 & 3.1696 & TST & & \\
\hline CHEMBL1086157 & 1640599 & \multicolumn{3}{|c|}{5.247999999999999} & 5.1872 & TST \\
\hline CHEMBL1080864 & 1640599 & 3.699 & 4.6636 & TST & & \\
\hline CHEMBL3914648 & 1640599 & 3.699 & 4.6707 & TST & & \\
\hline CHEMBL3715107 & 1536508 & 4.1267 & 4.0073 & TRN & & \\
\hline CHEMBL1491180 & 1536508 & 4.0269 & 4.213 & TRN & & \\
\hline CHEMBL3715266 & 1536508 & 4.2269 & 4.2767 & TRN & & \\
\hline CHEMBL3717389 & 1536508 & 6.9281 & 6.9507 & TRN & & \\
\hline CHEMBL3717917 & 1536508 & 3.327 & 5.51399 & 9999999999 & & TST \\
\hline CHEMBL3717869 & 1536508 & 4.327 & 4.5088 & TRN & & \\
\hline CHEMBL3715429 & 1536508 & 5.327006 & 0000000 & & 5.0366 & TRN \\
\hline
\end{tabular}


Supplemental Table S2.txt

\begin{tabular}{|c|c|c|c|c|c|}
\hline CHEMBL3715535 & 1536508 & 4.4271 & 4.7743 & TRN & \\
\hline CHEMBL3714984 & 1536508 & 5.3768 & 5.8091 & TRN & \\
\hline CHEMBL3718273 & 1536508 & 5.5768 & 5.3972 & TRN & \\
\hline CHEMBL3717700 & 1536508 & 4.2269 & 4.5682 & TRN & \\
\hline CHEMBL3715001 & 1536508 & 5.0768 & 5.3588 & TRN & \\
\hline CHEMBL 3716540 & 1536508 & 6.1267 & 5.8393 & TRN & \\
\hline CHEMBL 3716878 & 1536508 & 4.4271 & 4.6491 & TRN & \\
\hline CHEMBL3716987 & 1536508 & 4.5272 & 4.4868 & TRN & \\
\hline CHEMBL3715235 & 1536508 & 7.284 & 6.9819 & TRN & \\
\hline CHEMBL3716980 & 1536508 & 7.0269 & 7.1453 & TRN & \\
\hline CHEMBL 3715345 & 1536508 & 6.1267 & 5.944 & TRN & \\
\hline CHEMBL3714789 & 1536508 & 3.8268 & 4.0039 & TRN & \\
\hline CHEMBL3719257 & 1536508 & 5.6757 & 5.9274 & TRN & \\
\hline CHEMBL3714999 & 1536508 & 5.5272 & 5.33299 & & TRN \\
\hline CHEMBL3715166 & 1536508 & 5.0269 & 4.4845 & TST & \\
\hline CHEMBL3716813 & 1536508 & 5.2765 & 5.4687 & TRN & \\
\hline CHEMBL3718373 & 1536508 & 5.3768 & 5.3683 & TRN & \\
\hline CHEMBL3718514 & 1536508 & 5.2765 & 5.3152 & TRN & \\
\hline CHEMBL3718114 & 1536508 & 5.0269 & 4.6636 & TRN & \\
\hline CHEMBL3714926 & 1536508 & 5.5768 & 5.6211 & TRN & \\
\hline CHEMBL3716901 & 1536508 & 4.4271 & 4.4972 & TRN & \\
\hline CHEMBL3717211 & 1536508 & 6.7258 & 6.6772 & TRN & \\
\hline CHEMBL3715750 & 1536508 & 4.8268 & 4.9169 & TRN & \\
\hline CHEMBL3715526 & 1536508 & 6.2765 & 5.9107 & TST & \\
\hline CHEMBL1479446 & 1536508 & 7.3279 & 5.9274 & TRN & \\
\hline CHEMBL3719015 & 1536508 & 4.8268 & 4.9721 & TRN & \\
\hline CHEMBL 3716394 & 1536508 & 5.7258 & 5.1503 & TRN & \\
\hline CHEMBL3715203 & 1536508 & 5.7773 & 5.4773 & TRN & \\
\hline CHEMBL3717071 & 1536508 & 5.9747 & 5.8579 & TRN & \\
\hline CHEMBL3716978 & 1536508 & 5.2269 & 5.3651 & TRN & \\
\hline CHEMBL3715101 & 1536508 & 5.1765 & 4.7274 & TRN & \\
\hline CHEMBL 3716260 & 1536508 & 5.2269 & 5.3189 & TRN & \\
\hline CHEMBL3719197 & 1536508 & 6.1765 & 6.5851 & TRN & \\
\hline CHEMBL3716696 & 1536508 & 3.9281 & 3.8768 & TRN & \\
\hline CHEMBL3715792 & 1536508 & 3.7258 & 4.4981 & TST & \\
\hline CHEMBL3718895 & 1536508 & 4.5272 & 4.7578 & TST & \\
\hline CHEMBL3718498 & 1536508 & 5.1267 & 5.2034 & TRN & \\
\hline CHEMBL3718664 & 1536508 & 6.1267 & 6.5387 & TRN & \\
\hline CHEMBL3717718 & 1536508 & 5.0269 & 4.0128 & TST & \\
\hline CHEMBL3715105 & 1536508 & 5.5272 & 5.629 & TRN & \\
\hline CHEMBL3716811 & 1536508 & 5.5768 & 5.5641 & TRN & \\
\hline CHEMBL3717089 & 1536508 & 6.5768 & 6.4438 & TRN & \\
\hline CHEMBL3718178 & 1536508 & 5.2269 & 4.7394 & TRN & \\
\hline CHEMBL3716462 & 1536508 & 5.9747 & 6.2951 & TRN & \\
\hline CHEMBL3717734 & 1536508 & 4.327 & 4.4424 & TRN & \\
\hline CHEMBL3717803 & 1536508 & 5.3768 & 5.4384 & TRN & \\
\hline CHEMBL3716488 & 1536508 & 5.2765 & 5.0596 & TRN & \\
\hline CHEMBL 3715244 & 1536508 & 5.5768 & 5.7494 & TRN & \\
\hline
\end{tabular}

Page 23211 
Supplemental Table S2.txt

\begin{tabular}{|c|c|c|c|c|c|c|}
\hline CHEMBL3718384 & 1536508 & 5.8761 & 5.5722 & TRN & & \\
\hline CHEMBL 3716581 & 1536508 & 5.1267 & 5.6477 & TRN & & \\
\hline CHEMBL3719295 & 1536508 & 5.6271 & 5.8004 & TRN & & \\
\hline CHEMBL3715184 & 1536508 & 3.9281 & 4.1607 & TRN & & \\
\hline CHEMBL3716596 & 1536508 & 5.5768 & 5.7494 & TRN & & \\
\hline CHEMBL3717439 & 1536508 & 3.9281 & 3.8724 & TST & & \\
\hline CHEMBL3718735 & 1536508 & 5.0269 & 4.7571 & TRN & & \\
\hline CHEMBL3718557 & 1536508 & \multicolumn{3}{|c|}{5.327000000000001} & 5.4311 & TRN \\
\hline CHEMBL3718400 & 1536508 & 7.1739 & 7.0579 & TRN & & \\
\hline CHEMBL3718061 & 1536508 & 5.7773 & 5.8202 & TRN & & \\
\hline CHEMBL3715676 & 1536508 & 4.9281 & 5.2798 & TST & & \\
\hline CHEMBL3715346 & 1536508 & 4.2269 & 4.8726 & TRN & & \\
\hline CHEMBL3718975 & 1536508 & 4.1267 & 3.8071 & TST & & \\
\hline CHEMBL3717485 & 1536508 & 4.0269 & 4.6668 & TRN & & \\
\hline CHEMBL3716061 & 1536508 & 3.8268 & 3.4999 & TST & & \\
\hline CHEMBL3715901 & 1536508 & 5.3768 & 5.1479 & TRN & & \\
\hline CHEMBL 3717047 & 1536508 & 6.1765 & 5.8146 & TRN & & \\
\hline CHEMBL 3714858 & 1536508 & 5.9747 & 6.1153 & TRN & & \\
\hline CHEMBL3715040 & 1536508 & 5.5272 & 5.5755 & TRN & & \\
\hline CHEMBL3716871 & 1536508 & 5.5768 & 5.1171 & TRN & & \\
\hline CHEMBL3718077 & 1536508 & 5.8268 & 5.7981 & TRN & & \\
\hline CHEMBL 3719005 & 1536508 & 5.1267 & 5.0967 & TRN & & \\
\hline CHEMBL3715462 & 1536508 & 5.2765 & 5.6787 & TRN & & \\
\hline CHEMBL3715489 & 1536508 & 5.7773 & 5.5206 & TRN & & \\
\hline CHEMBL3715615 & 1536508 & \multicolumn{3}{|c|}{5.327000000000001} & 5.6488 & TST \\
\hline CHEMBL3716563 & 1536508 & 5.2269 & 5.0977 & TRN & & \\
\hline CHEMBL3717723 & 1536508 & 5.7258 & 5.9691 & TRN & & \\
\hline CHEMBL3718612 & 1536508 & 5.2269 & 5.0664 & TRN & & \\
\hline CHEMBL3714976 & 1536508 & 5.6778 & 5.5936 & TRN & & \\
\hline CHEMBL 3718740 & 1536508 & 5.6271 & 5.6214 & TRN & & \\
\hline CHEMBL3718728 & 1536508 & 5.7258 & 5.581 & TRN & & \\
\hline CHEMBL3716990 & 1536508 & 5.1267 & 5.4383 & TRN & & \\
\hline CHEMBL3716976 & 1536508 & \multicolumn{3}{|c|}{5.327000000000001} & 5.237 & TRN \\
\hline CHEMBL3716169 & 1536508 & 3.8268 & 5.2216 & TST & & \\
\hline CHEMBL3718054 & 1536508 & 5.1765 & 5.103 & TRN & & \\
\hline CHEMBL3715539 & 1536508 & \multicolumn{3}{|c|}{5.327000000000001} & 5.6645 & TRN \\
\hline CHEMBL3716450 & 1536508 & 5.8794 & 5.8009 & TRN & & \\
\hline CHEMBL 3716352 & 1536508 & 3.7282 & 3.5665 & TRN & & \\
\hline CHEMBL3715551 & 1536508 & 5.4763 & 5.3205 & TRN & & \\
\hline CHEMBL3716127 & 1536508 & 5.2765 & 5.2349 & TRN & & \\
\hline CHEMBL3715097 & 1536508 & 5.4271 & 5.5499 & TRN & & \\
\hline CHEMBL3718470 & 1536508 & 5.1765 & 4.6901 & TRN & & \\
\hline CHEMBL3715081 & 1536508 & 7.3279 & 7.0407 & TRN & & \\
\hline CHEMBL3715139 & 1536508 & 5.4271 & 5.8041 & TRN & & \\
\hline CHEMBL3717683 & 1536508 & 5.6271 & 5.9882 & TST & & \\
\hline CHEMBL3717553 & 1536508 & 6.4763 & 6.1502 & TRN & & \\
\hline CHEMBL 3716829 & 1536508 & 5.2765 & 5.1913 & TST & & \\
\hline CHEMBL3718643 & 1536508 & 5.0768 & 5.4141 & TRN & & \\
\hline
\end{tabular}


Supplemental Table S2.txt

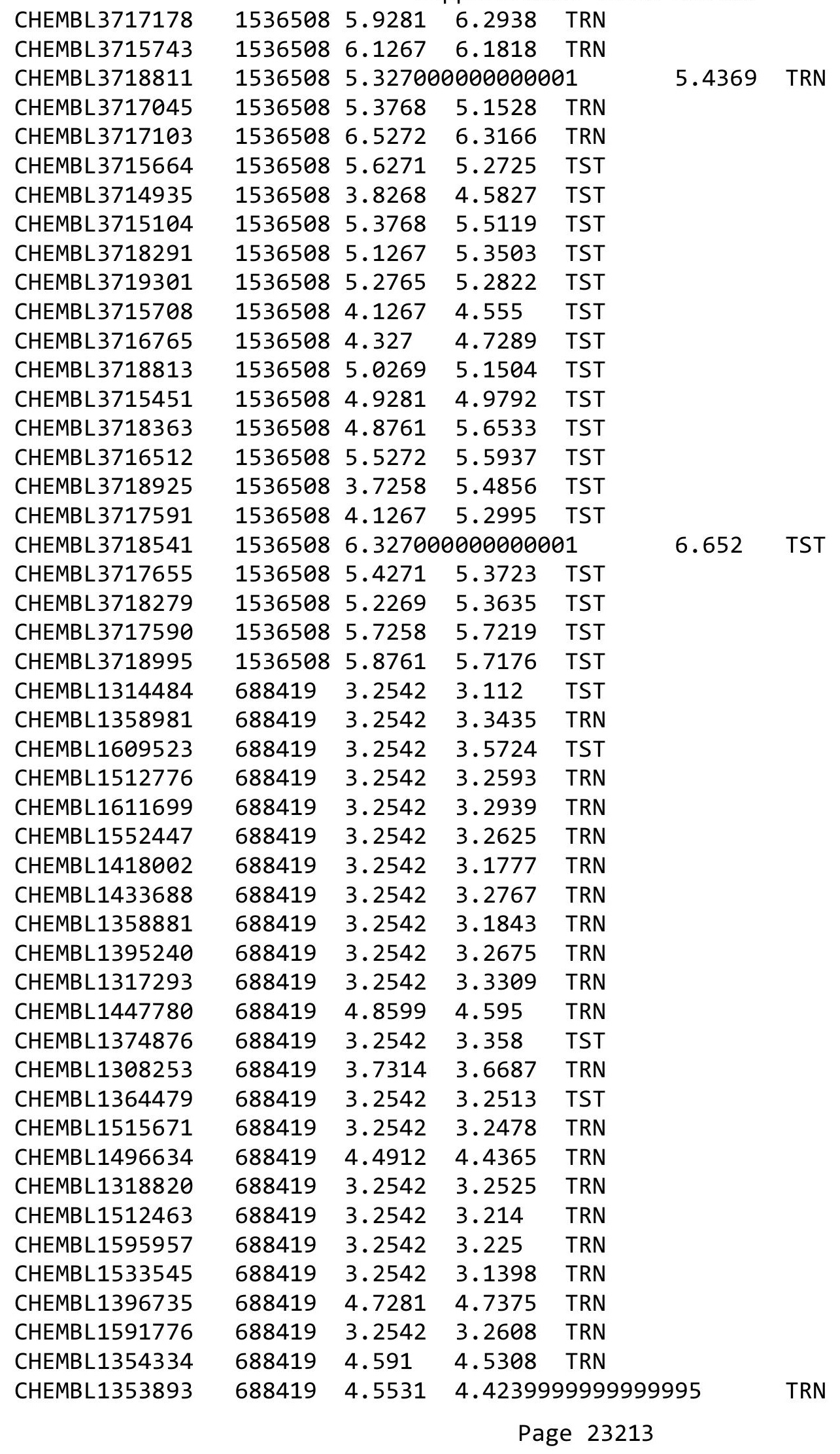




\begin{tabular}{|c|c|c|c|c|c|c|}
\hline & & \multicolumn{5}{|c|}{ Supplemental Table S2.txt } \\
\hline CHEMBL1552162 & 688419 & 3.7314 & 3.6838 & TRN & & \\
\hline CHEMBL1409647 & 688419 & 3.2542 & 3.3328 & TRN & & \\
\hline CHEMBL1479764 & 688419 & 4.396 & 4.3098 & TRN & & \\
\hline CHEMBL1599377 & 688419 & 3.2542 & 3.3165 & TST & & \\
\hline CHEMBL1299252 & 688419 & 4.6639 & 2.8686 & TST & & \\
\hline CHEMBL1433992 & 688419 & 3.2542 & 3.3312 & TRN & & \\
\hline CHEMBL1397522 & 688419 & 3.2542 & 3.2998 & TRN & & \\
\hline CHEMBL1561785 & 688419 & 3.2542 & 2.4275 & TST & & \\
\hline CHEMBL1553082 & 688419 & 3.2542 & 3.2378 & TRN & & \\
\hline CHEMBL1416019 & 688419 & 3.2542 & 3.2145 & TRN & & \\
\hline CHEMBL1316131 & 688419 & 3.2542 & 3.3541 & TST & & \\
\hline CHEMBL1596671 & 688419 & 3.2542 & 3.1683 & TST & & \\
\hline CHEMBL1434360 & 688419 & 3.2542 & 3.2443 & TRN & & \\
\hline CHEMBL1324820 & 688419 & 4.9147 & 2.812 & TST & & \\
\hline CHEMBL1514516 & 688419 & 3.2542 & 3.4359 & TRN & & \\
\hline CHEMBL1424535 & 688419 & 4.5224 & 4.6952 & TRN & & \\
\hline CHEMBL1374466 & 688419 & 3.2542 & 3.6467 & TST & & \\
\hline CHEMBL1528098 & 688419 & 3.2542 & 2.9661 & TST & & \\
\hline CHEMBL1515498 & 688419 & 4.7793 & 4.78 & TRN & & \\
\hline CHEMBL1513873 & 688419 & 3.2542 & 3.2152 & TRN & & \\
\hline CHEMBL1453184 & 688419 & 3.2542 & 3.2947 & TRN & & \\
\hline CHEMBL1371918 & 688419 & 3.7314 & 4.0445 & TRN & & \\
\hline CHEMBL1356059 & 688419 & 3.2542 & 3.177 & TRN & & \\
\hline CHEMBL1522122 & 688419 & 3.2542 & 3.2791 & TRN & & \\
\hline CHEMBL1394803 & 688419 & 3.2542 & 2.4457 & TST & & \\
\hline CHEMBL1555130 & 688419 & 3.2542 & 3.228 & TRN & & \\
\hline CHEMBL1355238 & 688419 & 4.8658 & 4.9645 & TRN & & \\
\hline CHEMBL1435340 & 688419 & 3.2542 & 3.2501 & TST & & \\
\hline CHEMBL1374198 & 688419 & 3.2542 & 3.2023 & TRN & & \\
\hline CHEMBL1081637 & 809036 & 4.8794 & 4.6586 & TRN & & \\
\hline CHEMBL1321728 & 809036 & 4.7986 & 4.356 & TRN & & \\
\hline CHEMBL1340521 & 809036 & 4.8928 & 4.5789 & TRN & & \\
\hline CHEMBL1999984 & 809036 & 4.8477 & 4.5981 & TRN & & \\
\hline CHEMBL1723682 & 809036 & 4.76699 & 99999999 & 995 & 4.5189 & TRN \\
\hline CHEMBL1555363 & 809036 & 6.0209 & 4.7843 & TRN & & \\
\hline CHEMBL1455943 & 809036 & 4.6038 & 4.0914 & TRN & & \\
\hline CHEMBL1973603 & 809036 & 5.2441 & 4.5792 & TRN & & \\
\hline CHEMBL1352633 & 809036 & 4.4295 & 4.3789 & TRN & & \\
\hline CHEMBL1395840 & 809036 & 5.3665 & 4.7634 & TRN & & \\
\hline CHEMBL1352043 & 809036 & 3.1024 & 4.7605 & TRN & & \\
\hline CHEMBL 2006274 & 809036 & 4.5935 & 4.5098 & TRN & & \\
\hline CHEMBL1595428 & 809036 & 4.4921 & 4.4924 & TRN & & \\
\hline CHEMBL1731294 & 809036 & 5.7258 & 4.8009 & TRN & & \\
\hline CHEMBL1365163 & 809036 & 3.1024 & 4.5284 & TRN & & \\
\hline CHEMBL1582353 & 809036 & 3.1024 & 4.5926 & TRN & & \\
\hline CHEMBL1730810 & 809036 & 4.3116 & 4.4824 & TST & & \\
\hline CHEMBL1584577 & 809036 & 3.1024 & 4.5812 & TRN & & \\
\hline CHEMBL1984924 & 809036 & 3.1024 & 4.5322 & TRN & & \\
\hline
\end{tabular}

Page 23214 


\begin{tabular}{|c|c|c|c|c|c|c|}
\hline & & \multicolumn{5}{|c|}{ Supplemental Table S2.txt } \\
\hline CHEMBL1461430 & 809036 & 3.1024 & 4.4458 & TRN & & \\
\hline CHEMBL1891356 & 809036 & 3.1024 & 4.505 & TRN & & \\
\hline CHEMBL1423858 & 809036 & 5.1805 & 4.5618 & TRN & & \\
\hline CHEMBL1986319 & 809036 & 4.6737 & 4.5699 & TRN & & \\
\hline CHEMBL1475866 & 809036 & 4.6615 & 4.4983 & TRN & & \\
\hline CHEMBL1409280 & 809036 & \multicolumn{3}{|c|}{5.247999999999999} & 4.1618 & TRN \\
\hline CHEMBL1566701 & 809036 & 4.4078 & 4.4902 & TST & & \\
\hline CHEMBL1545864 & 809036 & 4.9872 & 4.7034 & TRN & & \\
\hline CHEMBL1989527 & 809036 & 4.8013 & 4.4972 & TRN & & \\
\hline CHEMBL1375247 & 809036 & 4.7932 & 4.5094 & TRN & & \\
\hline CHEMBL1589231 & 809036 & 5.0867 & 4.5654 & TRN & & \\
\hline CHEMBL1507163 & 809036 & 4.2899 & 4.3929 & TST & & \\
\hline CHEMBL1467701 & 809036 & 4.5817 & 4.6133 & TRN & & \\
\hline CHEMBL1867143 & 809036 & 5.2125 & 4.0541 & TRN & & \\
\hline CHEMBL1721561 & 809036 & 4.5607 & 4.4636 & TRN & & \\
\hline CHEMBL1557566 & 809036 & 3.1024 & 4.4828 & TRN & & \\
\hline CHEMBL1587670 & 809036 & 3.1024 & 4.4874 & TRN & & \\
\hline CHEMBL1901953 & 809036 & 4.7235 & 4.5036 & TRN & & \\
\hline CHEMBL1476695 & 809036 & 3.1024 & 4.5936 & TRN & & \\
\hline CHEMBL1982896 & 809036 & 4.8327 & 4.477 & TRN & & \\
\hline CHEMBL1731097 & 809036 & 4.7144 & 4.0468 & TST & & \\
\hline CHEMBL1503607 & 809036 & 5.1355 & 4.5844 & TST & & \\
\hline CHEMBL1575293 & 809036 & 4.3851 & 4.4216 & TRN & & \\
\hline CHEMBL1497333 & 809036 & 3.1024 & 4.6803 & TRN & & \\
\hline CHEMBL1319484 & 809036 & 3.1024 & 4.0788 & TRN & & \\
\hline CHEMBL1699788 & 809036 & 3.1024 & 4.6252 & TRN & & \\
\hline CHEMBL1890635 & 809036 & 5.1221 & 4.0807 & TST & & \\
\hline CHEMBL1965579 & 809036 & 3.1024 & 4.4816 & TRN & & \\
\hline CHEMBL1882358 & 809036 & 4.8297 & 4.0837 & TRN & & \\
\hline CHEMBL1478646 & 809036 & 3.1024 & 4.004 & TRN & & \\
\hline CHEMBL1502371 & 809036 & 4.3116 & 4.4397 & TRN & & \\
\hline CHEMBL1412745 & 809036 & 4.8697 & 4.5235 & TRN & & \\
\hline CHEMBL1987906 & 809036 & 3.1024 & 4.4347 & TST & & \\
\hline CHEMBL1880473 & 809036 & 4.9136 & 4.4405 & TRN & & \\
\hline CHEMBL1727505 & 809036 & 4.3565 & 4.5966 & TRN & & \\
\hline CHEMBL1468409 & 809036 & 4.1726 & 4.3425 & TRN & & \\
\hline CHEMBL1965758 & 809036 & 3.1024 & 4.5909 & TRN & & \\
\hline CHEMBL1487042 & 809036 & 3.1024 & 4.5781 & TRN & & \\
\hline CHEMBL 2006569 & 809036 & 3.1024 & 4.5784 & TRN & & \\
\hline CHEMBL1699180 & 809036 & 4.4413 & 4.4503 & TST & & \\
\hline CHEMBL1883523 & 809036 & 4.7645 & 4.5426 & TRN & & \\
\hline CHEMBL1323843 & 809036 & 3.1024 & 4.4896 & TRN & & \\
\hline CHEMBL1495663 & 809036 & 4.71 & 4.6996 & TRN & & \\
\hline CHEMBL1863958 & 809036 & 4.6326 & 4.4998 & TRN & & \\
\hline CHEMBL1314090 & 809036 & 4.4685 & 4.4677 & TST & & \\
\hline CHEMBL1351484 & 809036 & 4.7905 & 4.6307 & TRN & & \\
\hline CHEMBL1380024 & 809036 & 4.8894 & 4.4716 & TRN & & \\
\hline CHEMBL1391456 & 809036 & 3.1024 & 4.0754 & TRN & & \\
\hline
\end{tabular}




\begin{tabular}{|c|c|c|c|c|c|c|}
\hline & & \multicolumn{5}{|c|}{ Supplemental Table S2.txt } \\
\hline CHEMBL1710294 & 809036 & 5.4214 & 4.5274 & TRN & & \\
\hline CHEMBL1493942 & 809036 & 4.8601 & 4.0653 & TST & & \\
\hline CHEMBL1476641 & 809036 & 5.0605 & 4.5861 & TRN & & \\
\hline CHEMBL1513847 & 809036 & 4.3372 & 4.4349 & TRN & & \\
\hline CHEMBL1497909 & 809036 & \multicolumn{3}{|c|}{5.2620000000000005} & 4.7033 & TRN \\
\hline CHEMBL1538976 & 809036 & 5.0372 & 4.0193 & TRN & & \\
\hline CHEMBL1877908 & 809036 & 5.1649 & 4.5525 & TRN & & \\
\hline CHEMBL1984056 & 809036 & 3.1024 & 4.0773 & TRN & & \\
\hline CHEMBL1722673 & 809036 & 4.5918 & 4.6218 & TST & & \\
\hline CHEMBL1714762 & 809036 & 5.3862 & 4.7137 & TRN & & \\
\hline CHEMBL1301152 & 809036 & 4.6421 & 4.6216 & TST & & \\
\hline CHEMBL1322917 & 809036 & 3.1024 & 4.4684 & TRN & & \\
\hline CHEMBL1420497 & 809036 & 4.9788 & 4.5887 & TRN & & \\
\hline CHEMBL1307821 & 809036 & 4.5258 & 4.5302 & TRN & & \\
\hline CHEMBL1880968 & 809036 & 4.7471 & 4.516 & TRN & & \\
\hline CHEMBL1450084 & 809036 & 4.4935 & 4.4671 & TST & & \\
\hline CHEMBL1990248 & 809036 & 4.9066 & 4.0438 & TST & & \\
\hline CHEMBL1564425 & 809036 & 4.6073 & 4.0822 & TRN & & \\
\hline CHEMBL1564224 & 809036 & 4.7258 & 4.476 & TRN & & \\
\hline CHEMBL 2000259 & 809036 & 3.1024 & 4.5457 & TRN & & \\
\hline CHEMBL1354360 & 809036 & 3.1024 & 4.648 & TRN & & \\
\hline CHEMBL1586524 & 809036 & 4.6198 & 4.3729 & TRN & & \\
\hline CHEMBL1532425 & 809036 & 4.8268 & 4.5985 & TRN & & \\
\hline CHEMBL1580005 & 809036 & 4.8697 & 4.0736 & TRN & & \\
\hline CHEMBL1381720 & 809036 & 5.3143 & 4.0742 & TRN & & \\
\hline CHEMBL1328052 & 809036 & 4.5421 & 4.5039 & TRN & & \\
\hline CHEMBL1905593 & 809036 & 5.1739 & 4.6029 & TRN & & \\
\hline CHEMBL1881477 & 809036 & 3.1024 & 4.6894 & TRN & & \\
\hline CHEMBL1503702 & 809036 & 4.3116 & 4.3604 & TRN & & \\
\hline CHEMBL1584639 & 809036 & 4.7328 & 4.4743 & TRN & & \\
\hline CHEMBL1427949 & 809036 & 5.21899 & 99999999 & 99 & 4.6106 & TRN \\
\hline CHEMBL1390969 & 809036 & 4.3716 & 4.4578 & TRN & & \\
\hline CHEMBL1358434 & 809036 & 4.8013 & 4.0259 & TRN & & \\
\hline CHEMBL1525257 & 809036 & 4.8268 & 4.5562 & TRN & & \\
\hline CHEMBL1376482 & 809036 & 4.9245 & 4.6123 & TST & & \\
\hline CHEMBL1470755 & 809036 & 4.6596 & 4.4886 & TRN & & \\
\hline CHEMBL1987094 & 809036 & 4.8297 & 4.545 & TRN & & \\
\hline CHEMBL1393529 & 809036 & 5.4145 & 4.6806 & TRN & & \\
\hline CHEMBL1470504 & 809036 & 3.1024 & 4.551 & TRN & & \\
\hline CHEMBL1865969 & 809036 & 4.6778 & 4.6159 & TST & & \\
\hline CHEMBL1702908 & 809036 & 3.1024 & 4.8055 & TRN & & \\
\hline CHEMBL1346308 & 809036 & 5.066 & 4.6762 & TRN & & \\
\hline CHEMBL1305255 & 809036 & 5.1733 & 4.6098 & TRN & & \\
\hline CHEMBL1975051 & 809036 & 4.8697 & 4.5574 & TRN & & \\
\hline CHEMBL1481069 & 809036 & 4.5214 & 4.3102 & TRN & & \\
\hline CHEMBL1966886 & 809036 & 4.8297 & 4.5262 & TRN & & \\
\hline CHEMBL1523527 & 809036 & 4.8996 & 3.9352 & TRN & & \\
\hline CHEMBL1413178 & 809036 & 4.9747 & 4.5478 & TST & & \\
\hline
\end{tabular}




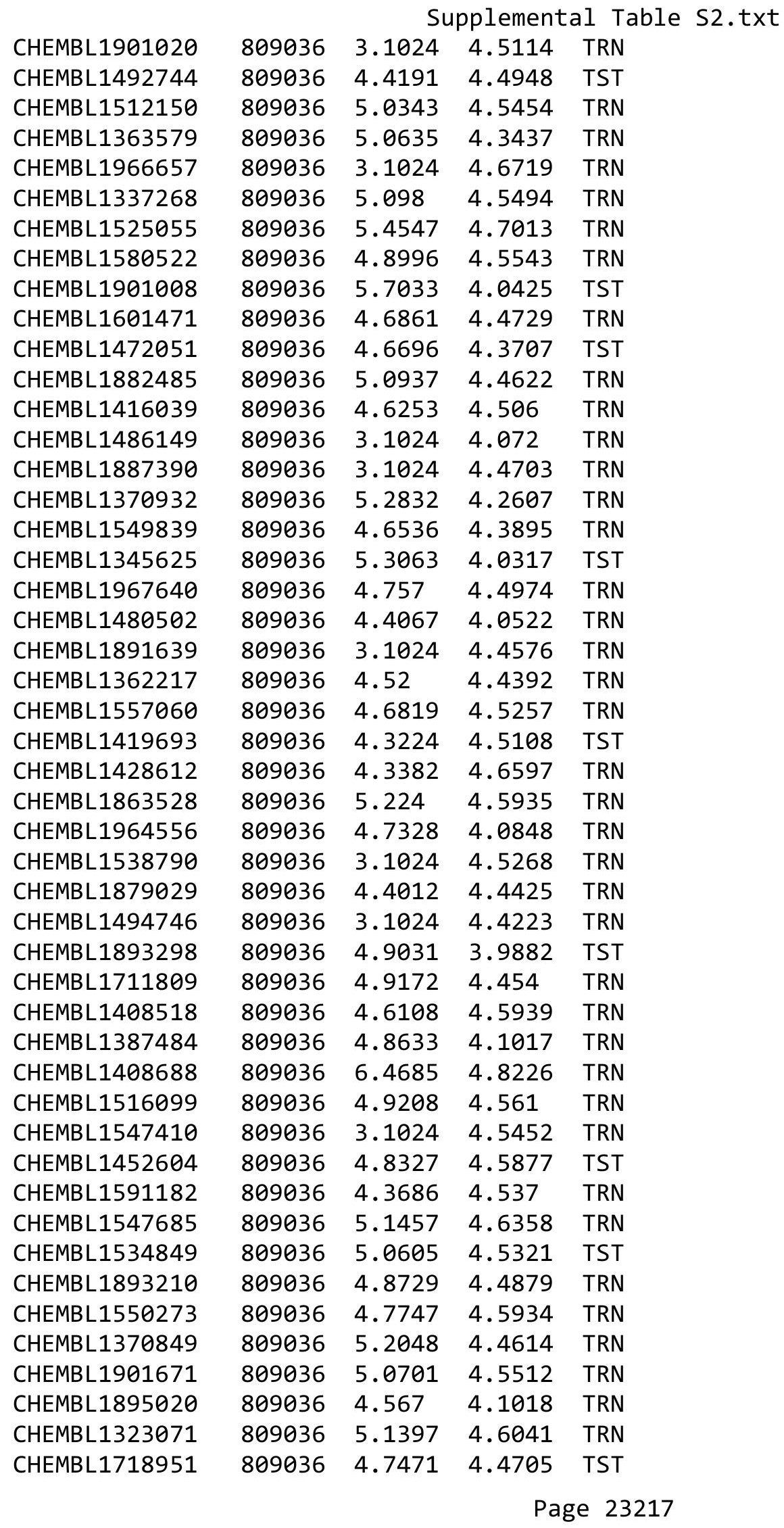




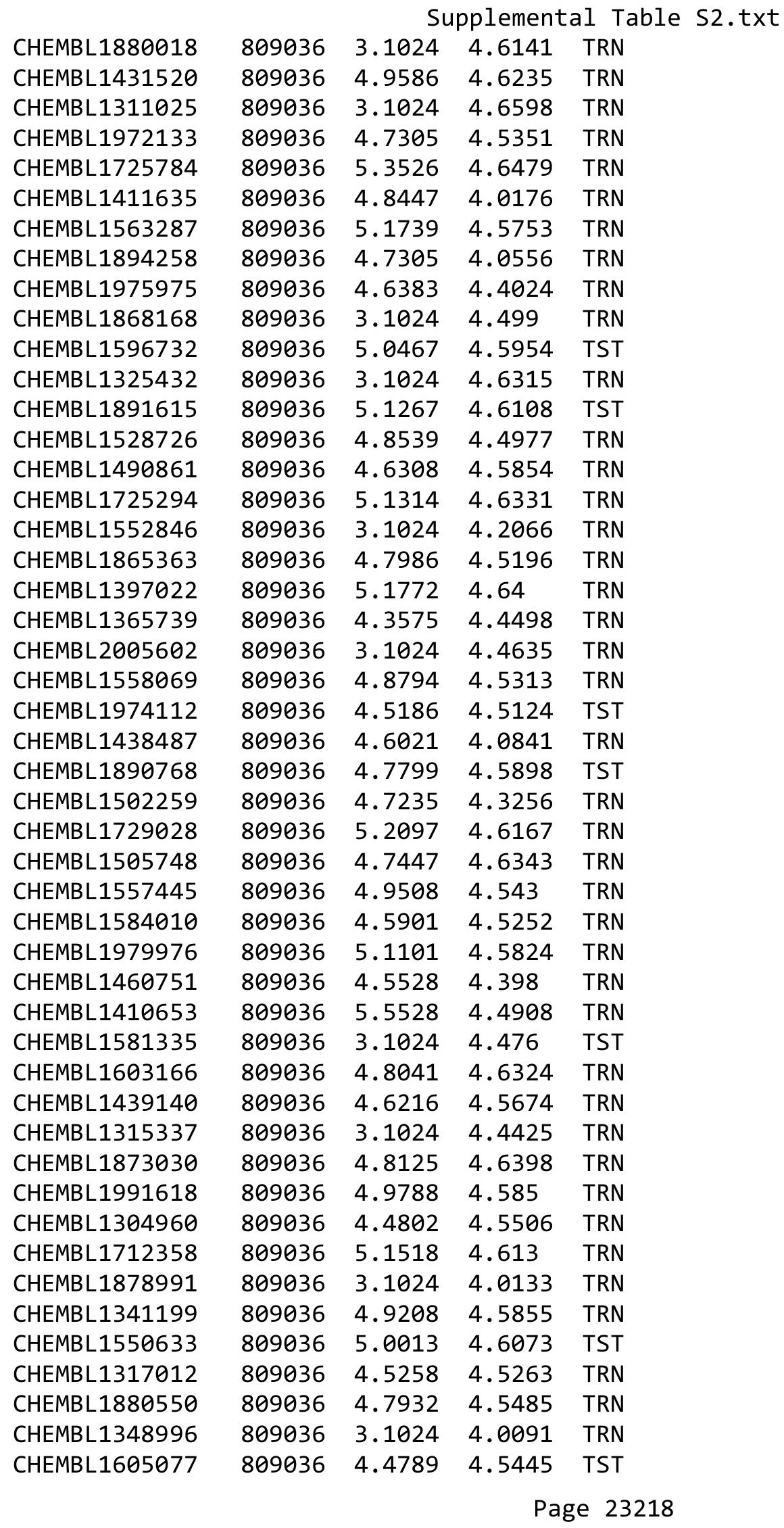




\begin{tabular}{|c|c|c|c|c|c|c|}
\hline & & \multicolumn{5}{|c|}{ Supplemental Table s2.txt } \\
\hline CHEMBL1971872 & 809036 & 4.684 & 4.5622 & TRN & & \\
\hline CHEMBL1307703 & 809036 & 5.0088 & 4.6494 & TRN & & \\
\hline CHEMBL1975458 & 809036 & 5.5784 & 4.7049 & TRN & & \\
\hline CHEMBL1420862 & 809036 & 3.1024 & 4.622 & TRN & & \\
\hline CHEMBL1719240 & 809036 & 5.2314 & 4.6682 & TRN & & \\
\hline CHEMBL2006310 & 809036 & 3.1024 & 4.064 & TST & & \\
\hline CHEMBL 2000633 & 809036 & 3.1024 & 4.1138 & TRN & & \\
\hline CHEMBL1309310 & 809036 & 4.7235 & 4.1008 & TRN & & \\
\hline CHEMBL1308563 & 809036 & 4.7167 & 4.623 & TRN & & \\
\hline CHEMBL1328045 & 809036 & 4.7852 & 4.106 & TRN & & \\
\hline CHEMBL250574 & 809036 & 3.1024 & 4.5583 & TST & & \\
\hline CHEMBL1511397 & 809036 & 5.0762 & 4.0179 & TST & & \\
\hline CHEMBL1382123 & 809036 & 4.8729 & 4.4952 & TRN & & \\
\hline CHEMBL1364287 & 809036 & 4.9626 & 4.6287 & TRN & & \\
\hline CHEMBL1557763 & 809036 & 3.1024 & 4.6426 & TRN & & \\
\hline CHEMBL1879313 & 809036 & 4.6383 & 4.3896 & TRN & & \\
\hline CHEMBL1321703 & 809036 & 3.1024 & 4.0977 & TRN & & \\
\hline CHEMBL1540513 & 809036 & 5.0605 & 4.6999 & TRN & & \\
\hline CHEMBL1727940 & 809036 & 3.1024 & 4.4151 & TRN & & \\
\hline CHEMBL1990418 & 809036 & 4.6655 & 4.4801 & TST & & \\
\hline CHEMBL1896933 & 809036 & 3.1024 & 4.4663 & TRN & & \\
\hline CHEMBL1480223 & 809036 & 4.82100 & j000000e & 01 & 4.5192 & TRN \\
\hline CHEMBL1531618 & 809036 & 4.6556 & 4.0777 & TRN & & \\
\hline CHEMBL1467641 & 809036 & 5.1624 & 4.4707 & TRN & & \\
\hline CHEMBL1878613 & 809036 & 4.9586 & 4.4189 & TRN & & \\
\hline CHEMBL2361002 & 809036 & 5.0768 & 4.0208 & TST & & \\
\hline CHEMBL1870332 & 809036 & 4.8013 & 4.5398 & TRN & & \\
\hline CHEMBL1414819 & 809036 & 4.4881 & 4.4478 & TRN & & \\
\hline CHEMBL1423034 & 809036 & 4.6402 & 4.6251 & TRN & & \\
\hline CHEMBL1429513 & 809036 & 5.0985 & 4.476 & TRN & & \\
\hline CHEMBL1719740 & 809036 & 3.1024 & 4.0631 & TRN & & \\
\hline CHEMBL1726305 & 809036 & 4.8386 & 4.6997 & TRN & & \\
\hline CHEMBL1989592 & 809036 & 4.9281 & 4.5322 & TRN & & \\
\hline CHEMBL1470073 & 809036 & 4.6234 & 4.0103 & TRN & & \\
\hline CHEMBL1467354 & 809036 & 4.5834 & 4.4342 & TRN & & \\
\hline CHEMBL1427466 & 809036 & 4.7328 & 4.5949 & TRN & & \\
\hline CHEMBL1878680 & 809036 & 4.9914 & 4.4747 & TRN & & \\
\hline CHEMBL1571998 & 809036 & 5.0841 & 4.6323 & TRN & & \\
\hline CHEMBL596836 & 809036 & 3.1024 & 4.5288 & TST & & \\
\hline CHEMBL1562798 & 809036 & 4.6676 & 4.5626 & TST & & \\
\hline CHEMBL1369225 & 809036 & 4.6882 & 4.4926 & TST & & \\
\hline CHEMBL1588014 & 809036 & 5.0773 & 4.5705 & TRN & & \\
\hline CHEMBL1457134 & 809036 & 4.7852 & 4.5924 & TRN & & \\
\hline CHEMBL1725168 & 809036 & 4.5452 & 4.4601 & TRN & & \\
\hline CHEMBL1390768 & 809036 & 3.1024 & 4.0711 & TST & & \\
\hline CHEMBL1879523 & 809036 & 4.8729 & 4.5591 & TST & & \\
\hline CHEMBL1529401 & 809036 & 4.7033 & 4.4749 & TST & & \\
\hline CHEMBL1586992 & 809036 & 4.52 & 4.5313 & TRN & & \\
\hline
\end{tabular}


Supplemental Table S2.txt

\begin{tabular}{|c|c|c|c|c|c|c|}
\hline CHEMBL2004928 & 809036 & 5.7878 & 4.6894 & TRN & & \\
\hline CHEMBL1393504 & 809036 & 4.8182 & 4.5806 & TRN & & \\
\hline CHEMBL590457 & 809036 & 3.1024 & 4.6557 & TST & & \\
\hline CHEMBL1375050 & 809036 & 3.1024 & 4.4914 & TRN & & \\
\hline CHEMBL1450838 & 809036 & 4.5834 & 4.4402 & TRN & & \\
\hline CHEMBL1701835 & 809036 & 5.0237 & 4.4919 & TRN & & \\
\hline CHEMBL1438663 & 809036 & 4.8386 & 3.9891 & TST & & \\
\hline CHEMBL1489418 & 809036 & 4.7986 & 4.5871 & TST & & \\
\hline CHEMBL1892639 & 809036 & 4.8477 & 4.5596 & TRN & & \\
\hline CHEMBL1379359 & 809036 & 4.684 & 4.5218 & TRN & & \\
\hline CHEMBL1880468 & 809036 & 4.8827 & 4.3647 & TRN & & \\
\hline CHEMBL1565318 & 809036 & 4.4921 & 4.4338 & TRN & & \\
\hline CHEMBL1583472 & 809036 & 4.71899 & 79999999 & 99 & 4.5072 & TRN \\
\hline CHEMBL1580989 & 809036 & 5.0438 & 4.5169 & TRN & & \\
\hline CHEMBL1385597 & 809036 & 4.6216 & 4.4449 & TRN & & \\
\hline CHEMBL 2002517 & 809036 & 4.5528 & 4.5128 & TRN & & \\
\hline CHEMBL1479362 & 809036 & 4.7423 & 4.5784 & TRN & & \\
\hline CHEMBL1456690 & 809036 & 4.6517 & 4.5981 & TRN & & \\
\hline CHEMBL1985895 & 809036 & 4.7595 & 4.5031 & TRN & & \\
\hline CHEMBL1550224 & 809036 & 4.8477 & 4.6139 & TRN & & \\
\hline CHEMBL1575354 & 809036 & 4.6091 & 4.5987 & TRN & & \\
\hline CHEMBL1512072 & 809036 & 4.8729 & 4.5651 & TRN & & \\
\hline CHEMBL1596782 & 809036 & 4.9066 & 4.4247 & TRN & & \\
\hline CHEMBL1865197 & 809036 & 3.1024 & 4.3545 & TRN & & \\
\hline CHEMBL1870365 & 809036 & 4.8761 & 4.0877 & TRN & & \\
\hline CHEMBL1701510 & 809036 & 5.4034 & 4.1092 & TST & & \\
\hline CHEMBL1427663 & 809036 & 4.762 & 4.511 & TST & & \\
\hline CHEMBL1605288 & 809036 & 4.8356 & 4.6664 & TRN & & \\
\hline CHEMBL1334334 & 809036 & 4.5719 & 4.4538 & TRN & & \\
\hline CHEMBL1343368 & 809036 & 4.341 & 4.0784 & TRN & & \\
\hline CHEMBL1703524 & 809036 & 3.1024 & 4.7488 & TRN & & \\
\hline CHEMBL 2003436 & 809036 & 5.0467 & 4.6287 & TRN & & \\
\hline CHEMBL1588387 & 809036 & 4.9872 & 4.5499 & TRN & & \\
\hline CHEMBL1577144 & 809036 & 3.1024 & 4.1195 & TRN & & \\
\hline CHEMBL1330873 & 809036 & 4.5935 & 4.4585 & TRN & & \\
\hline CHEMBL1435228 & 809036 & 4.8239 & 4.0036 & TRN & & \\
\hline CHEMBL1599015 & 809036 & 4.3439 & 4.6646 & TRN & & \\
\hline CHEMBL1311027 & 809036 & 4.3497 & 4.2508 & TRN & & \\
\hline CHEMBL1598940 & 809036 & 5.5622 & 4.7978 & TRN & & \\
\hline CHEMBL1714625 & 809036 & 5.04 & 4.55 & TST & & \\
\hline CHEMBL1556578 & 809036 & 4.7595 & 4.6839 & TRN & & \\
\hline CHEMBL1975660 & 809036 & 4.8697 & 4.5383 & TST & & \\
\hline CHEMBL1416321 & 809036 & 3.1024 & 4.6405 & TRN & & \\
\hline CHEMBL1309409 & 809036 & 4.5361 & 4.4243 & TST & & \\
\hline CHEMBL1714180 & 809036 & 4.3429 & 4.4869 & TST & & \\
\hline CHEMBL1579612 & 809036 & 3.1024 & 4.0469 & TRN & & \\
\hline CHEMBL1735332 & 809036 & 4.7852 & 4.4777 & TRN & & \\
\hline CHEMBL1447188 & 809036 & 4.8633 & 4.0522 & TRN & & \\
\hline
\end{tabular}

Page 23220 


\begin{tabular}{|c|c|c|c|c|c|}
\hline \multirow[b]{2}{*}{ CHEMBL1440686 } & \multicolumn{5}{|c|}{ Supplemental Table S2.txt } \\
\hline & 809036 & 4.9355 & 4.2917 & TRN & \\
\hline CHEMBL1562838 & 809036 & 5.0526 & 4.0859 & TRN & \\
\hline CHEMBL1587637 & 809036 & 5.1192 & 4.0524 & TRN & \\
\hline CHEMBL1547898 & 809036 & 5.1085 & 4.60800 & 00000000005 & TRN \\
\hline CHEMBL1868534 & 809036 & 4.9547 & 4.5992 & TST & \\
\hline CHEMBL1496105 & 809036 & 4.8894 & 4.5593 & TRN & \\
\hline CHEMBL1611803 & 809036 & 4.6676 & 4.4994 & TST & \\
\hline CHEMBL1974351 & 809036 & 4.9101 & 4.461 & TST & \\
\hline CHEMBL1345140 & 809036 & 3.1024 & 4.1158 & TRN & \\
\hline CHEMBL1534533 & 809036 & 4.567 & 4.4941 & TRN & \\
\hline CHEMBL1570212 & 809036 & 5.4634 & 4.6372 & TRN & \\
\hline CHEMBL1372519 & 809036 & 3.1024 & 4.5886 & TRN & \\
\hline CHEMBL1448193 & 809036 & 4.7144 & 4.0001 & TST & \\
\hline CHEMBL1544440 & 809036 & 5.0386 & 4.5823 & TRN & \\
\hline CHEMBL1459314 & 809036 & 5.0615 & 4.6423 & TRN & \\
\hline CHEMBL1430891 & 809036 & 3.1024 & 4.5652 & TRN & \\
\hline CHEMBL1981305 & 809036 & 3.1024 & 4.6563 & TRN & \\
\hline CHEMBL1968095 & 809036 & 5.0645 & 4.6018 & TRN & \\
\hline CHEMBL1526033 & 809036 & 4.7375 & 4.6067 & TRN & \\
\hline CHEMBL1867718 & 809036 & 4.7447 & 4.5396 & TRN & \\
\hline CHEMBL1721546 & 809036 & 4.8239 & 4.4937 & TST & \\
\hline CHEMBL1277891 & 809036 & 4.8729 & 4.5583 & TRN & \\
\hline CHEMBL1379420 & 809036 & 4.4145 & 4.4188 & TRN & \\
\hline CHEMBL1887146 & 809036 & 4.7932 & 4.5042 & TRN & \\
\hline CHEMBL1506609 & 809036 & 5.3726 & 4.6936 & TRN & \\
\hline CHEMBL1872827 & 809036 & 3.1024 & 4.0391 & TRN & \\
\hline CHEMBL1992359 & 809036 & 4.6676 & 4.6649 & TRN & \\
\hline CHEMBL1900738 & 809036 & 4.757 & 4.4655 & TST & \\
\hline CHEMBL1524400 & 809036 & 4.466 & 4.4721 & TRN & \\
\hline CHEMBL1578365 & 809036 & 4.5498 & 4.5106 & TRN & \\
\hline CHEMBL1384547 & 809036 & 4.8539 & 4.1385 & TRN & \\
\hline CHEMBL1574359 & 809036 & 4.5317 & 4.5571 & TRN & \\
\hline CHEMBL1400446 & 809036 & 4.9706 & 4.6522 & TRN & \\
\hline CHEMBL1884334 & 809036 & 5.0453 & 4.4964 & TRN & \\
\hline CHEMBL1416156 & 809036 & 4.58 & 4.0338 & TRN & \\
\hline CHEMBL1879553 & 809036 & 4.4413 & 4.3485 & TRN & \\
\hline CHEMBL 1703276 & 809036 & 4.6126 & 4.5518 & TST & \\
\hline CHEMBL1311933 & 809036 & 4.3215 & 4.3741 & TST & \\
\hline CHEMBL1477801 & 809036 & 4.475 & 4.3806 & TST & \\
\hline CHEMBL1575370 & 809036 & 5.0424 & 4.5959 & TST & \\
\hline CHEMBL1441149 & 809036 & 3.1024 & 4.6195 & TRN & \\
\hline CHEMBL1319264 & 809036 & 4.6326 & 4.6377 & TRN & \\
\hline CHEMBL1324722 & 809036 & 4.5719 & 4.5453 & TRN & \\
\hline CHEMBL1730650 & 809036 & 5.4789 & 4.6097 & TRN & \\
\hline CHEMBL1711830 & 809036 & 5.0778 & 4.5539 & TRN & \\
\hline CHEMBL1885453 & 809036 & 4.9318 & 4.6439 & TRN & \\
\hline CHEMBL1612775 & 809036 & 4.6576 & 4.4079 & TRN & \\
\hline CHEMBL1494757 & 809036 & 5.0443 & 4.6397 & TRN & \\
\hline
\end{tabular}

Page 23221 


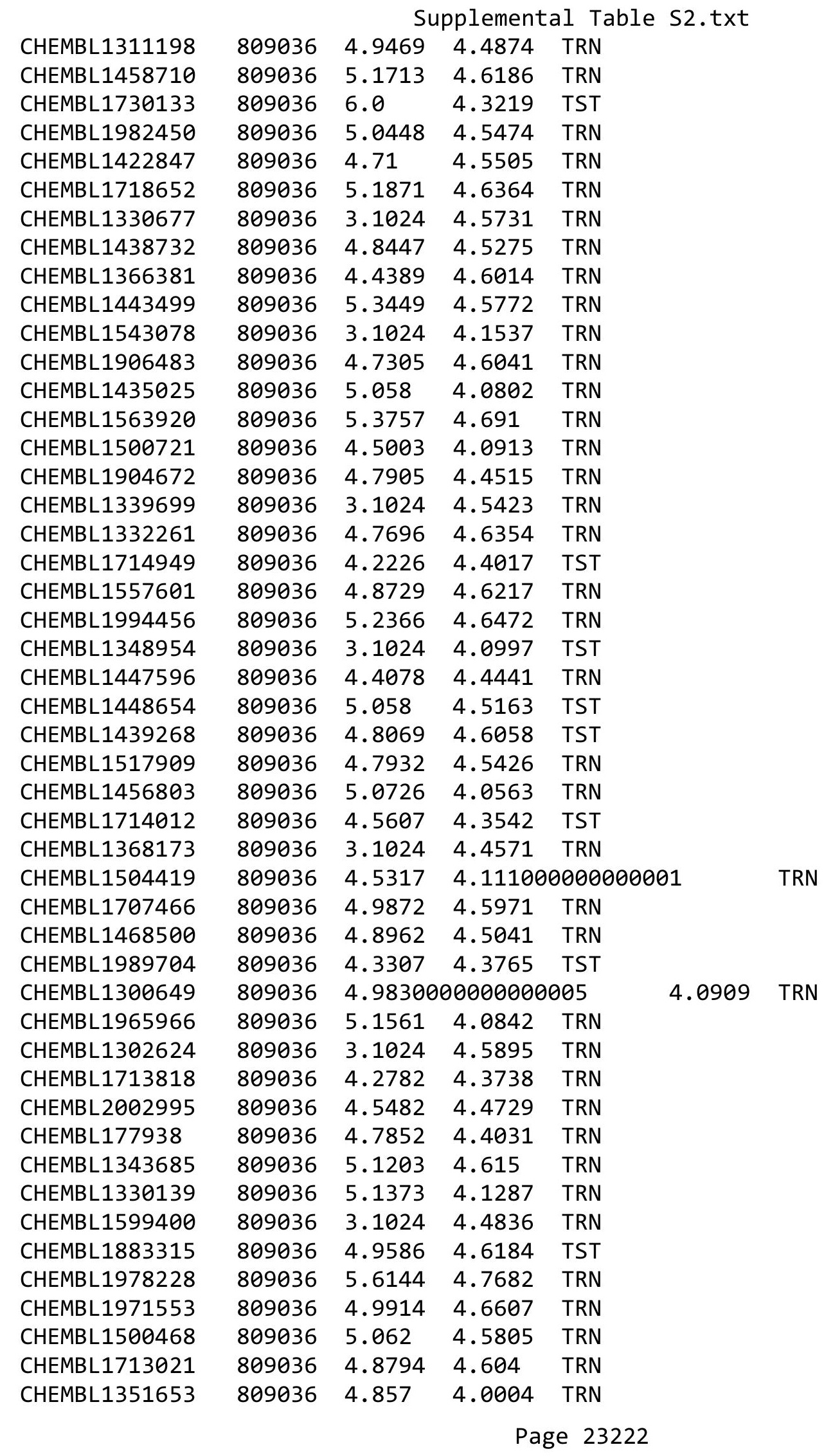




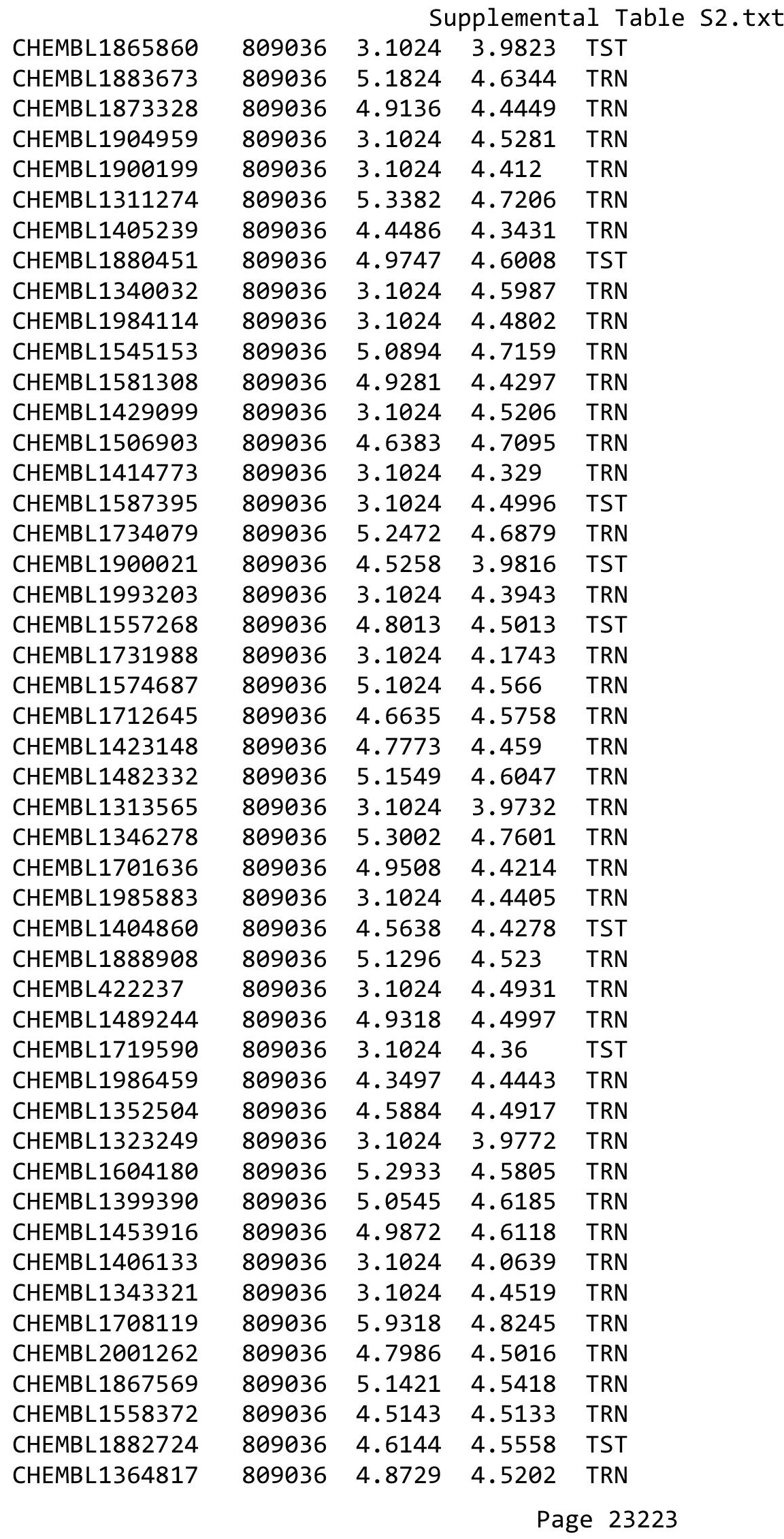




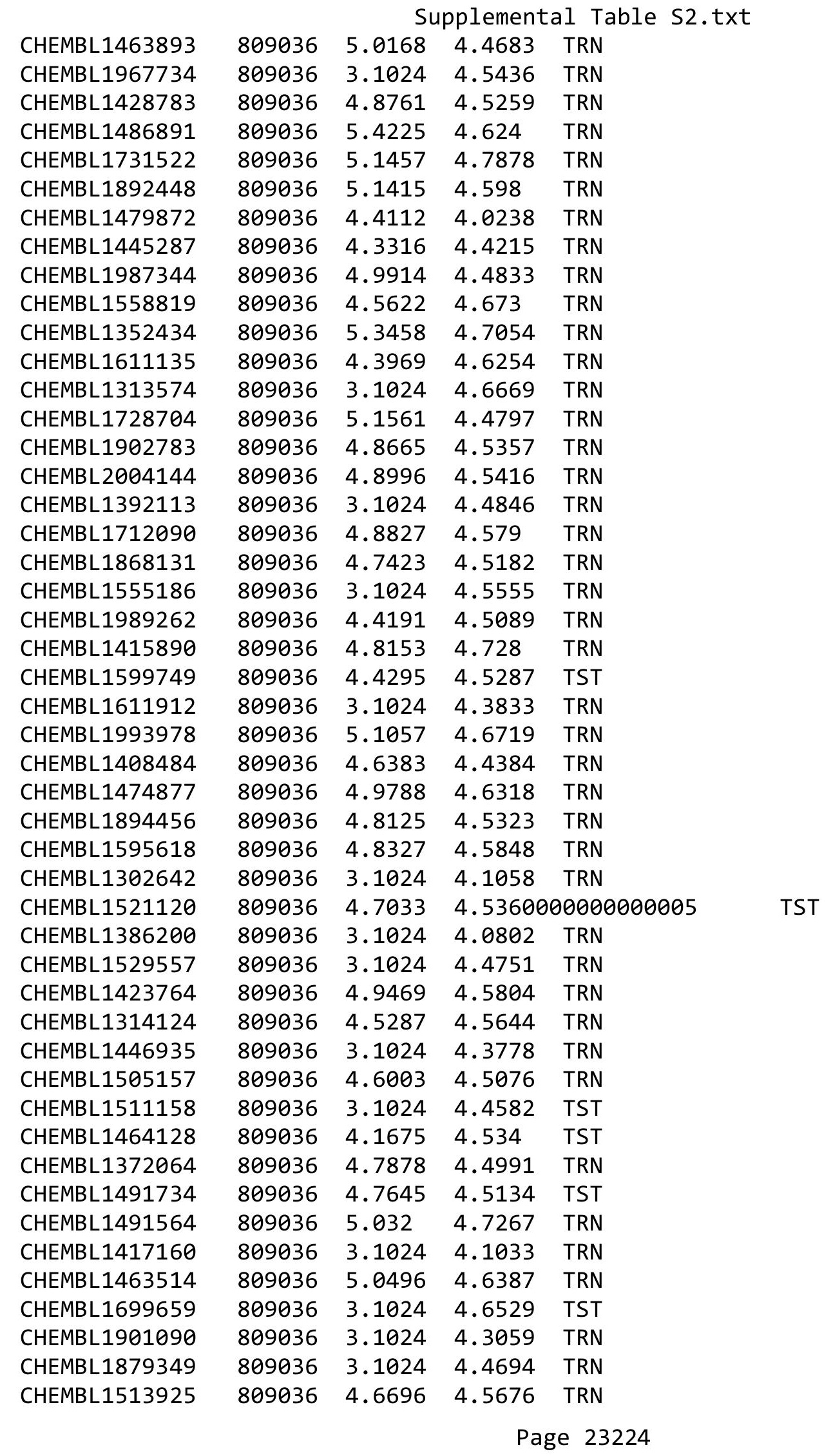




\begin{tabular}{|c|c|c|c|c|}
\hline \multicolumn{5}{|c|}{ Supplemental Table s2.txt } \\
\hline CHEMBL1985765 & 809036 & 3.1024 & 4.5356 & TRN \\
\hline CHEMBL1723903 & 809036 & 4.3546 & 4.4153 & TRN \\
\hline CHEMBL1530211 & 809036 & 3.1024 & 4.3347 & TST \\
\hline CHEMBL1729533 & 809036 & 6.6198 & 4.6352 & TRN \\
\hline CHEMBL1982071 & 809036 & 4.9469 & 4.5405 & TRN \\
\hline CHEMBL1440301 & 809036 & 5.279 & 4.5918 & TRN \\
\hline CHEMBL1554786 & 809036 & 4.699 & 4.6979 & TRN \\
\hline CHEMBL1341668 & 809036 & 4.6234 & 4.5453 & TST \\
\hline CHEMBL1385111 & 809036 & 4.8928 & 4.4731 & TRN \\
\hline CHEMBL1698139 & 809036 & 3.1024 & 4.4431 & TST \\
\hline CHEMBL1510895 & 809036 & 3.1024 & 4.5584 & TRN \\
\hline CHEMBL1410428 & 809036 & 3.1024 & 4.5708 & TST \\
\hline CHEMBL1372308 & 809036 & 4.4989 & 4.0902 & TST \\
\hline CHEMBL1579167 & 809036 & 3.1024 & 4.6061 & TRN \\
\hline CHEMBL1410280 & 809036 & 4.4342 & 4.4133 & TRN \\
\hline CHEMBL1312157 & 809036 & 4.5114 & 4.0824 & TRN \\
\hline CHEMBL1443753 & 809036 & 5.4306 & 4.55 & TRN \\
\hline CHEMBL1345381 & 809036 & 3.1024 & 4.7116 & TRN \\
\hline CHEMBL1503376 & 809036 & 4.9508 & 4.6013 & TRN \\
\hline CHEMBL1468363 & 809036 & 4.9469 & 4.6708 & TRN \\
\hline CHEMBL1475242 & 809036 & 3.1024 & 4.1416 & TRN \\
\hline CHEMBL1995169 & 809036 & 5.4572 & 4.0732 & TRN \\
\hline CHEMBL1602676 & 809036 & 5.1403 & 4.5572 & TRN \\
\hline CHEMBL1992540 & 809036 & 5.4535 & 4.671 & TRN \\
\hline CHEMBL1723414 & 809036 & 5.2284 & 4.6821 & TRN \\
\hline CHEMBL1405103 & 809036 & 4.8041 & 4.5262 & TRN \\
\hline CHEMBL1548262 & 809036 & 4.8477 & 4.5141 & TRN \\
\hline CHEMBL1881568 & 809036 & 3.1024 & 4.0879 & TRN \\
\hline CHEMBL1558744 & 809036 & 4.9172 & 4.4816 & TRN \\
\hline CHEMBL1906351 & 809036 & 3.1024 & 4.591 & TRN \\
\hline CHEMBL1497342 & 809036 & 4.8356 & 4.5179 & TRN \\
\hline CHEMBL1993796 & 809036 & 4.9172 & 4.5994 & TRN \\
\hline CHEMBL1595051 & 809036 & 5.1221 & 4.6401 & TRN \\
\hline CHEMBL1369130 & 809036 & 5.1096 & 4.648 & TRN \\
\hline CHEMBL1459757 & 809036 & 5.1918 & 4.0909 & TRN \\
\hline CHEMBL1310005 & 809036 & 4.5884 & 4.5569 & TRN \\
\hline CHEMBL1459641 & 809036 & 4.9706 & 4.5279 & TRN \\
\hline CHEMBL1966961 & 809036 & 5.0975 & 4.5971 & TRN \\
\hline CHEMBL1524990 & 809036 & 4.7375 & 4.5177 & TST \\
\hline CHEMBL1456075 & 809036 & 4.9508 & 4.5616 & TRN \\
\hline CHEMBL1863599 & 809036 & 4.6073 & 4.4027 & TST \\
\hline CHEMBL1985708 & 809036 & 4.6757 & 4.5057 & TRN \\
\hline CHEMBL1728872 & 809036 & 3.1024 & 4.6179 & TRN \\
\hline CHEMBL249301 & 809036 & 4.5607 & 4.5584 & TRN \\
\hline CHEMBL1487964 & 809036 & 5.2557 & 4.7099 & TST \\
\hline CHEMBL1515432 & 809036 & 5.0491 & 4.6109 & TST \\
\hline CHEMBL1463672 & 809036 & 4.7167 & 4.0266 & TST \\
\hline CHEMBL1700439 & 809036 & 4.5452 & 4.5782 & TRN \\
\hline
\end{tabular}




\begin{tabular}{|c|c|c|c|c|c|c|}
\hline & & \multicolumn{5}{|c|}{ Supplemental Table S2.txt } \\
\hline CHEMBL1994259 & 809036 & 4.9508 & 4.5555 & TRN & & \\
\hline CHEMBL1721460 & 809036 & 4.4389 & 4.3859 & TST & & \\
\hline CHEMBL1733950 & 809036 & 5.8761 & 4.7865 & TRN & & \\
\hline CHEMBL1981303 & 809036 & 4.9706 & 4.5714 & TST & & \\
\hline CHEMBL1474526 & 809036 & 5.3809 & 4.8606 & TRN & & \\
\hline CHEMBL1570792 & 809036 & \multicolumn{3}{|c|}{4.9830000000000005} & 4.5799 & TRN \\
\hline CHEMBL1415357 & 809036 & 4.5884 & 4.4823 & TRN & & \\
\hline CHEMBL1588045 & 809036 & 4.5331 & 4.5313 & TRN & & \\
\hline CHEMBL1732017 & 809036 & 5.1979 & 4.6915 & TRN & & \\
\hline CHEMBL1878617 & 809036 & 4.7959 & 4.4961 & TST & & \\
\hline CHEMBL1999359 & 809036 & 4.7282 & 4.605 & TST & & \\
\hline CHEMBL1396713 & 809036 & 5.0531 & 4.6174 & TST & & \\
\hline CHEMBL1987417 & 809036 & 3.1024 & 4.5202 & TST & & \\
\hline CHEMBL1507187 & 809036 & 3.1024 & 4.1063 & TST & & \\
\hline CHEMBL1572906 & 809036 & 4.7328 & 4.4967 & TST & & \\
\hline CHEMBL1316999 & 809036 & 4.8447 & 4.0338 & TST & & \\
\hline CHEMBL1557027 & 809036 & 4.9245 & 4.5233 & TST & & \\
\hline CHEMBL1969457 & 809036 & 4.7959 & 4.5184 & TST & & \\
\hline CHEMBL 1604372 & 809036 & 3.1024 & 4.3008 & TST & & \\
\hline CHEMBL1559375 & 809036 & 4.7852 & 4.5215 & TST & & \\
\hline CHEMBL1969010 & 809036 & 4.51 & 4.4273 & TST & & \\
\hline CHEMBL1301826 & 809036 & 4.757 & 4.4397 & TST & & \\
\hline CHEMBL1722488 & 809036 & 5.2351 & 4.6703 & TST & & \\
\hline CHEMBL 1880887 & 809036 & 5.0565 & 4.085 & TST & & \\
\hline CHEMBL1472228 & 809036 & 4.8268 & 4.1249 & TST & & \\
\hline CHEMBL3391736 & 809036 & 4.6576 & 4.0995 & TST & & \\
\hline CHEMBL1374250 & 809036 & 5.109 & 4.7051 & TST & & \\
\hline CHEMBL1379578 & 809036 & 3.1024 & 4.4192 & TST & & \\
\hline CHEMBL 1367230 & 809036 & 4.8125 & 4.5217 & TST & & \\
\hline CHEMBL1402745 & 809036 & 4.6073 & 4.417 & TST & & \\
\hline CHEMBL1450049 & 809036 & 4.5544 & 4.5171 & TST & & \\
\hline CHEMBL1509007 & 809036 & 3.1024 & 4.5577 & TST & & \\
\hline CHEMBL1507325 & 809036 & 5.1397 & 4.4308 & TST & & \\
\hline CHEMBL1324195 & 809036 & 5.5045 & 4.8263 & TST & & \\
\hline CHEMBL1442453 & 809036 & 4.6635 & 4.5103 & TST & & \\
\hline CHEMBL1418287 & 809036 & 5.0259 & 3.9248 & TST & & \\
\hline CHEMBL1584903 & 809036 & 3.1024 & 4.4312 & TST & & \\
\hline CHEMBL56897 & 809036 & 6.0223 & 4.6742 & TST & & \\
\hline CHEMBL1421091 & 809036 & 4.6198 & 4.6602 & TST & & \\
\hline CHEMBL1699961 & 809036 & 5.1361 & 4.4208 & TST & & \\
\hline CHEMBL1528882 & 809036 & 4.9469 & 4.5831 & TST & & \\
\hline CHEMBL1507647 & 809036 & 4.9281 & 4.5143 & TST & & \\
\hline CHEMBL1976625 & 809036 & 4.383 & 4.4625 & TST & & \\
\hline CHEMBL1891270 & 809036 & 4.9957 & 4.599 & TST & & \\
\hline CHEMBL1700311 & 809036 & 4.7799 & 4.5092 & TST & & \\
\hline CHEMBL1462924 & 809036 & 4.5784 & 4.4714 & TST & & \\
\hline CHEMBL1723920 & 809036 & 3.1024 & 4.3249 & TST & & \\
\hline CHEMBL1728949 & 809036 & 3.1024 & 4.078 & TST & & \\
\hline
\end{tabular}




\begin{tabular}{|c|c|c|c|c|c|c|c|}
\hline \multicolumn{7}{|c|}{ Supplemental Table S2.txt } & \\
\hline CHEMBL1503062 & 809036 & 4.4622 & 4.4382 & TST & & & \\
\hline CHEMBL1903425 & 809036 & 4.3391 & 4.5192 & TST & & & \\
\hline CHEMBL3391749 & 809036 & \multicolumn{3}{|c|}{4.9830000000000005} & 4.5941 & TST & \\
\hline CHEMBL1577620 & 809036 & 5.5171 & 4.8263 & TST & & & \\
\hline CHEMBL1306971 & 809036 & 5.7122 & 4.38 & TST & & & \\
\hline CHEMBL1414448 & 809036 & 4.3737 & 4.4232 & TST & & & \\
\hline CHEMBL1897646 & 809036 & 4.567 & 4.5126 & TST & & & \\
\hline CHEMBL1549006 & 809036 & 4.1512 & 4.4267 & TST & & & \\
\hline CHEMBL1601300 & 809036 & 4.6716 & 4.507 & TST & & & \\
\hline CHEMBL1888730 & 809036 & 4.8069 & 4.473 & TST & & & \\
\hline CHEMBL601822 & 809036 & 4.3516 & 4.5304 & TST & & & \\
\hline CHEMBL1300822 & 809036 & 4.6253 & 4.0761 & TST & & & \\
\hline CHEMBL1980827 & 809036 & \multicolumn{3}{|c|}{4.821000000000001} & 4.5209 & TST & \\
\hline CHEMBL1474285 & 809036 & 4.585 & 4.5035 & TST & & & \\
\hline CHEMBL1419223 & 809036 & 4.9136 & 4.5113 & TST & & & \\
\hline CHEMBL1877015 & 809036 & 4.8508 & 4.5319 & TST & & & \\
\hline CHEMBL1530972 & 809036 & 5.0783 & 4.6005 & TST & & & \\
\hline CHEMBL1403619 & 809036 & 5.0 & 4.5912 & TST & & & \\
\hline CHEMBL1529285 & 737034 & 5.3344 & 5.3196 & TRN & & & \\
\hline CHEMBL1461815 & 737034 & 4.3033 & 4.8816 & TRN & & & \\
\hline CHEMBL1332050 & 737034 & 4.9367 & \multicolumn{3}{|c|}{4.986000000000001} & TRN & \\
\hline CHEMBL3196910 & 737034 & 3.0 & 4.1825 & TRN & & & \\
\hline CHEMBL1993780 & 737034 & 5.767 & 5.6301 & TRN & & & \\
\hline CHEMBL1982652 & 737034 & 3.0 & 4.2155 & TRN & & & \\
\hline CHEMBL1482554 & 737034 & 5.5498 & 5.4241 & TRN & & & \\
\hline CHEMBL1438520 & 737034 & 5.1537 & 5.1636 & TRN & & & \\
\hline CHEMBL1411344 & 737034 & 5.1308 & 5.5109 & TRN & & & \\
\hline CHEMBL1302524 & 737034 & 5.4237 & 6.0253 & TRN & & & \\
\hline CHEMBL1983083 & 737034 & 5.0083 & 4.8997 & TRN & & & \\
\hline CHEMBL1373248 & 737034 & 4.9614 & 5.2724 & TRN & & & \\
\hline CHEMBL1566786 & 737034 & 5.2284 & 5.6552 & TRN & & & \\
\hline CHEMBL1986073 & 737034 & 4.8768 & 4.5682 & TRN & & & \\
\hline CHEMBL1359782 & 737034 & 5.2161 & 5.1192 & TRN & & & \\
\hline CHEMBL1359842 & 737034 & 4.4592 & 4.5608 & TRN & & & \\
\hline CHEMBL1410616 & 737034 & 4.7395 & 4.9062 & TRN & & & \\
\hline CHEMBL1535723 & 737034 & \multicolumn{3}{|c|}{5.2139999999999995} & 5.2479 & 9999999999 & TRN \\
\hline CHEMBL1320866 & 737034 & 4.512 & 4.5912 & TRN & & & \\
\hline CHEMBL1362933 & 737034 & 5.5686 & 5.0116 & TST & & & \\
\hline CHEMBL 2006639 & 737034 & 4.4542 & 4.5861 & TRN & & & \\
\hline CHEMBL1498353 & 737034 & 4.8265 & 4.9512 & TRN & & & \\
\hline CHEMBL1612112 & 737034 & 6.0555 & 5.6035 & TRN & & & \\
\hline CHEMBL1379448 & 737034 & 5.7399 & 5.7638 & TRN & & & \\
\hline CHEMBL3209659 & 737034 & 4.5167 & 4.4902 & TRN & & & \\
\hline CHEMBL 3212364 & 737034 & 5.7852 & 6.0412 & TRN & & & \\
\hline CHEMBL1610416 & 737034 & 4.4046 & 5.4656 & TRN & & & \\
\hline CHEMBL 3190368 & 737034 & 5.2104 & 5.8809 & TRN & & & \\
\hline CHEMBL1501971 & 737034 & 4.4672 & 4.0946 & TRN & & & \\
\hline CHEMBL1461928 & 737034 & 5.6144 & 5.1338 & TRN & & & \\
\hline
\end{tabular}

Page 23227 


\begin{tabular}{|c|c|c|c|c|c|}
\hline \multirow[b]{2}{*}{ CHEMBL1529471 } & \multicolumn{5}{|c|}{ Supplemental Table S2.txt } \\
\hline & 737034 & 6.0088 & 6.0443 & TRN & \\
\hline CHEMBL1426692 & 737034 & 6.0655 & 5.70700 & 0000000001 & TRN \\
\hline CHEMBL1336615 & 737034 & 4.4613 & 4.5954 & TRN & \\
\hline CHEMBL1373210 & 737034 & 5.091 & 4.8415 & TRN & \\
\hline CHEMBL1586805 & 737034 & 5.5607 & 4.8979 & TRN & \\
\hline CHEMBL1454039 & 737034 & 3.0 & 3.8591 & TRN & \\
\hline CHEMBL1463714 & 737034 & 5.0218 & 5.3882 & TST & \\
\hline CHEMBL1543789 & 737034 & 5.4841 & 5.0888 & TRN & \\
\hline CHEMBL1585923 & 737034 & 5.1965 & 5.9093 & TRN & \\
\hline CHEMBL1340834 & 737034 & 5.857 & 5.6609 & TRN & \\
\hline CHEMBL1510003 & 737034 & 5.059 & 4.8649 & TRN & \\
\hline CHEMBL1459044 & 737034 & 5.4425 & 4.9677 & TRN & \\
\hline CHEMBL2005973 & 737034 & 5.7305 & 5.3093 & TRN & \\
\hline CHEMBL1323245 & 737034 & 5.2628 & 5.5276 & TRN & \\
\hline CHEMBL1484688 & 737034 & 4.132 & 5.2182 & TST & \\
\hline CHEMBL1303182 & 737034 & 4.2472 & 4.4166 & TRN & \\
\hline CHEMBL1438598 & 737034 & 4.8551 & 5.0591 & TRN & \\
\hline CHEMBL1375094 & 737034 & 4.8401 & 4.7736 & TRN & \\
\hline CHEMBL1599723 & 737034 & $5.0680 e$ & 00000000 & 5.4445 & TRN \\
\hline CHEMBL1612095 & 737034 & 4.4165 & 4.3178 & TRN & \\
\hline CHEMBL1377632 & 737034 & 5.6696 & 5.0939 & TRN & \\
\hline CHEMBL1382616 & 737034 & 5.0031 & 5.2385 & TRN & \\
\hline CHEMBL2004928 & 737034 & 5.0516 & 5.1985 & TRN & \\
\hline CHEMBL1598762 & 737034 & 6.3768 & 5.7954 & TRN & \\
\hline CHEMBL1558779 & 737034 & 5.0035 & 4.5885 & TRN & \\
\hline CHEMBL1495592 & 737034 & 5.6861 & 5.44799 & 99999999995 & TRN \\
\hline CHEMBL399293 & 737034 & 5.2197 & 5.303 & TST & \\
\hline CHEMBL1384567 & 737034 & 5.3862 & 4.6158 & TRN & \\
\hline CHEMBL3214310 & 737034 & 5.9208 & 5.67399 & 99999999995 & TRN \\
\hline CHEMBL1446626 & 737034 & 5.8125 & 5.5691 & TRN & \\
\hline CHEMBL 3190558 & 737034 & 6.4559 & 5.7859 & TRN & \\
\hline CHEMBL1392313 & 737034 & 4.9318 & 5.5154 & TRN & \\
\hline CHEMBL1255778 & 737034 & 5.7799 & 5.3211 & TST & \\
\hline CHEMBL1580543 & 737034 & 4.34 & 4.7214 & TRN & \\
\hline CHEMBL1481493 & 737034 & 5.5452 & 5.3313 & TRN & \\
\hline CHEMBL1386161 & 737034 & 5.2434 & 5.0566 & TRN & \\
\hline CHEMBL1443688 & 737034 & 5.1858 & 5.1103 & TRN & \\
\hline CHEMBL3144884 & 737034 & 5.3893 & 5.17 & TST & \\
\hline CHEMBL3194119 & 737034 & 4.9948 & 4.7202 & TRN & \\
\hline CHEMBL3856088 & 737034 & 5.4828 & 4.8286 & TRN & \\
\hline CHEMBL1904459 & 737034 & 5.2062 & 5.2774 & TRN & \\
\hline CHEMBL3199008 & 737034 & 5.2857 & 5.5143 & TRN & \\
\hline CHEMBL3191627 & 737034 & 5.3072 & 5.3293 & TRN & \\
\hline CHEMBL1499798 & 737034 & 4.8159 & 4.8913 & TRN & \\
\hline CHEMBL1346456 & 737034 & 5.5391 & 5.7557 & TRN & \\
\hline CHEMBL1463486 & 737034 & 4.0146 & 4.5111 & TRN & \\
\hline CHEMBL1987816 & 737034 & 4.9859 & 5.1073 & TRN & \\
\hline CHEMBL1306575 & 737034 & 5.0004 & 5.1706 & TRN & \\
\hline
\end{tabular}




\begin{tabular}{|c|c|c|c|c|c|c|}
\hline & & \multicolumn{5}{|c|}{ Supplemental Table S2.txt } \\
\hline CHEMBL1981243 & 737034 & 5.1331 & 5.1973 & TRN & & \\
\hline CHEMBL1562713 & 737034 & 5.5622 & 5.0037 & TST & & \\
\hline CHEMBL1405311 & 737034 & 5.3125 & 5.3141 & TRN & & \\
\hline CHEMBL1384282 & 737034 & 3.0 & 3.7326 & TRN & & \\
\hline CHEMBL1431007 & 737034 & 4.6552 & 5.1096 & TRN & & \\
\hline CHEMBL1516834 & 737034 & 5.7352 & 5.0635 & TRN & & \\
\hline CHEMBL1307317 & 737034 & 5.9281 & 5.4545 & TRN & & \\
\hline CHEMBL1502931 & 737034 & 4.6946 & 4.3881 & TRN & & \\
\hline CHEMBL1704267 & 737034 & 5.6421 & 5.5752 & TRN & & \\
\hline CHEMBL1309157 & 737034 & 5.1884 & 5.2444 & TRN & & \\
\hline CHEMBL 3210000 & 737034 & 4.1718 & 5.3224 & TRN & & \\
\hline CHEMBL579088 & 737034 & 5.3799 & 5.3287 & TST & & \\
\hline CHEMBL299853 & 737034 & 5.8327 & 5.5082 & TRN & & \\
\hline CHEMBL1507875 & 737034 & 3.0 & 4.4053 & TST & & \\
\hline CHEMBL1430381 & 737034 & 4.6123 & 4.5471 & TRN & & \\
\hline CHEMBL1522941 & 737034 & 5.9508 & 5.1287 & TRN & & \\
\hline CHEMBL1402046 & 737034 & 4.4202 & 4.5626 & TRN & & \\
\hline CHEMBL3198784 & 737034 & 5.4306 & 4.8593 & TRN & & \\
\hline CHEMBL1471026 & 737034 & 4.7174 & 4.2588 & TRN & & \\
\hline CHEMBL1417141 & 737034 & 3.0 & 4.9459 & TST & & \\
\hline CHEMBL1457300 & 737034 & 5.129 & 4.6428 & TRN & & \\
\hline CHEMBL1550429 & 737034 & 5.4425 & 5.81 & TRN & & \\
\hline CHEMBL1446164 & 737034 & 4.5732 & 4.9107 & TRN & & \\
\hline CHEMBL1430309 & 737034 & 5.1198 & 5.1142 & TRN & & \\
\hline CHEMBL1991440 & 737034 & 4.78600 & 00000000 & 205 & 5.2375 & TRN \\
\hline CHEMBL1994935 & 737034 & 5.4763 & 5.1828 & TRN & & \\
\hline CHEMBL1986785 & 737034 & 4.4612 & 4.6564 & TST & & \\
\hline CHEMBL1469245 & 737034 & 5.2118 & 4.761 & TRN & & \\
\hline CHEMBL1422763 & 737034 & 5.0246 & 5.2256 & TRN & & \\
\hline CHEMBL3198174 & 737034 & 5.4237 & 5.3419 & TRN & & \\
\hline CHEMBL1456300 & 737034 & 4.4888 & 4.7989 & TRN & & \\
\hline CHEMBL3192298 & 737034 & 4.668 & 5.1642 & TRN & & \\
\hline CHEMBL1997990 & 737034 & 6.1612 & 5.9222 & TRN & & \\
\hline CHEMBL1530474 & 737034 & 4.6904 & 4.6309 & TRN & & \\
\hline CHEMBL1503523 & 737034 & 5.7282 & 4.6997 & TRN & & \\
\hline CHEMBL1484595 & 737034 & 4.9446 & 5.3112 & TRN & & \\
\hline CHEMBL1535921 & 737034 & 4.4562 & 3.9548 & TRN & & \\
\hline CHEMBL1508847 & 737034 & 5.9508 & 5.718 & TRN & & \\
\hline CHEMBL1539939 & 737034 & 4.529 & 4.5914 & TRN & & \\
\hline CHEMBL3902037 & 737034 & 4.8739 & 4.8258 & TRN & & \\
\hline CHEMBL1478433 & 737034 & 4.4621 & 4.5734 & TRN & & \\
\hline CHEMBL1509755 & 737034 & 5.0921 & 5.1362 & TRN & & \\
\hline CHEMBL1365071 & 737034 & 4.382 & 4.2905 & TRN & & \\
\hline CHEMBL1550415 & 737034 & 4.7744 & 4.8848 & TRN & & \\
\hline CHEMBL1560561 & 737034 & 3.0 & 5.0943 & TST & & \\
\hline CHEMBL1382281 & 737034 & 3.0 & 4.0609 & TST & & \\
\hline CHEMBL1403970 & 737034 & 5.2976 & 4.7311 & TST & & \\
\hline CHEMBL1368944 & 737034 & 4.1065 & 3.8415 & TST & & \\
\hline
\end{tabular}




\begin{tabular}{|c|c|c|c|c|c|c|}
\hline \multirow[b]{2}{*}{ CHEMBL1440415 } & & \multicolumn{5}{|c|}{ Supplemental Table S2.txt } \\
\hline & 737034 & 5.3615 & 5.3611 & TRN & & \\
\hline CHEMBL1564367 & 737034 & 4.6794 & 4.8332 & TRN & & \\
\hline CHEMBL1489711 & 737034 & \multicolumn{3}{|c|}{5.2139999999999995} & 3.9188 & TRN \\
\hline CHEMBL3192969 & 737034 & 5.2132 & 5.2689 & TRN & & \\
\hline CHEMBL3192738 & 737034 & 5.0691 & 5.0805 & TRN & & \\
\hline CHEMBL1486559 & 737034 & 4.337 & 4.5668 & TRN & & \\
\hline CHEMBL1888528 & 737034 & 5.7959 & 5.7867 & TRN & & \\
\hline CHEMBL1550788 & 737034 & 5.2725 & 5.9215 & TRN & & \\
\hline CHEMBL1342081 & 737034 & 4.8219 & 5.0242 & TRN & & \\
\hline CHEMBL1313637 & 737034 & 4.3836 & 4.6645 & TST & & \\
\hline CHEMBL1505277 & 737034 & 4.2287 & 4.7323 & TRN & & \\
\hline CHEMBL1427763 & 737034 & 5.1475 & 4.7835 & TST & & \\
\hline CHEMBL1359301 & 737034 & 4.8844 & 4.8985 & TRN & & \\
\hline CHEMBL3235881 & 737034 & 5.2581 & 5.1228 & TRN & & \\
\hline CHEMBL1376622 & 737034 & 5.4547 & 5.3327 & TRN & & \\
\hline CHEMBL175434 & 737034 & 5.6757 & 5.5692 & TRN & & \\
\hline CHEMBL1444958 & 737034 & 5.6402 & 5.3739 & TRN & & \\
\hline CHEMBL1486131 & 737034 & \multicolumn{3}{|c|}{5.3839999999999995} & 5.1475 & TRN \\
\hline CHEMBL1599965 & 737034 & 5.2403 & 5.737 & TRN & & \\
\hline CHEMBL1456876 & 737034 & 4.4182 & 4.9583 & TRN & & \\
\hline CHEMBL3195729 & 737034 & 3.0 & 4.6236 & TRN & & \\
\hline CHEMBL1374955 & 737034 & 5.0937 & 4.8202 & TRN & & \\
\hline CHEMBL1606907 & 737034 & 5.8356 & 5.9594 & TRN & & \\
\hline CHEMBL1966168 & 737034 & 5.8125 & 4.9824 & TRN & & \\
\hline CHEMBL1874620 & 737034 & 5.8508 & 5.6206 & TRN & & \\
\hline CHEMBL1582771 & 737034 & 6.0044 & 5.7588 & TRN & & \\
\hline CHEMBL474786 & 737034 & 4.8013 & 4.3415 & TRN & & \\
\hline CHEMBL1519443 & 737034 & 4.5402 & 4.8001 & TRN & & \\
\hline CHEMBL1480877 & 737034 & 4.4402 & 4.024 & TRN & & \\
\hline CHEMBL3195531 & 737034 & 6.0044 & 5.4914 & TRN & & \\
\hline CHEMBL1405362 & 737034 & 4.2236 & 4.7161 & TST & & \\
\hline CHEMBL1419733 & 737034 & 5.1296 & 5.12799 & 9999999999 & & TRN \\
\hline CHEMBL1374929 & 737034 & 4.5654 & 4.6865 & TRN & & \\
\hline CHEMBL1508715 & 737034 & 4.0435 & 3.6857 & TRN & & \\
\hline CHEMBL1372651 & 737034 & 5.2798 & 5.3001 & TRN & & \\
\hline CHEMBL3144970 & 737034 & 5.1018 & 5.1757 & TST & & \\
\hline CHEMBL1376311 & 737034 & 5.2882 & 5.37299 & 9999999999 & & TRN \\
\hline CHEMBL1319597 & 737034 & 4.8033 & 5.0866 & TRN & & \\
\hline CHEMBL3194407 & 737034 & 5.2823 & 5.6713 & TRN & & \\
\hline CHEMBL 1478270 & 737034 & 4.5481 & 4.5384 & TST & & \\
\hline CHEMBL1530147 & 737034 & 6.0655 & 5.8738 & TRN & & \\
\hline CHEMBL1996724 & 737034 & 5.8729 & 5.8842 & TRN & & \\
\hline CHEMBL1539024 & 737034 & 5.1403 & 5.3186 & TRN & & \\
\hline CHEMBL1352201 & 737034 & 4.4331 & 4.1611 & TRN & & \\
\hline CHEMBL1372921 & 737034 & 4.7875 & 4.5949 & TRN & & \\
\hline CHEMBL1318643 & 737034 & 5.0996 & 4.8105 & TST & & \\
\hline CHEMBL1488474 & 737034 & 5.8962 & 5.8987 & TRN & & \\
\hline CHEMBL551842 & 737034 & 5.1858 & 5.1821 & TST & & \\
\hline
\end{tabular}


Supplemental Table S2.txt

\begin{tabular}{|c|c|c|c|c|c|}
\hline CHEMBL1370278 & 737034 & 5.0017 & 5.2446 & TST & \\
\hline CHEMBL1575869 & 737034 & 6.0506 & 5.7715 & TRN & \\
\hline CHEMBL3925157 & 737034 & 5.2211 & 4.9683 & TRN & \\
\hline CHEMBL1391798 & 737034 & 4.6562 & 5.7032 & TST & \\
\hline CHEMBL1972235 & 737034 & 4.09699 & 9999999 & 4.7334 & TST \\
\hline CHEMBL3192436 & 737034 & 5.2807 & 5.4769 & TRN & \\
\hline CHEMBL1447137 & 737034 & 5.2749 & 5.5246 & TRN & \\
\hline CHEMBL1422658 & 737034 & 4.8456 & 5.0431 & TST & \\
\hline CHEMBL1985987 & 737034 & 6.1308 & 5.0753 & TRN & \\
\hline CHEMBL1562142 & 737034 & 4.7775 & 5.2101 & TST & \\
\hline CHEMBL1380562 & 737034 & 4.3443 & 4.4237 & TST & \\
\hline CHEMBL1423198 & 737034 & 5.5086 & 5.2319 & TRN & \\
\hline CHEMBL1384094 & 737034 & 5.2807 & 5.3005 & TRN & \\
\hline CHEMBL1529300 & 737034 & 4.3801 & 5.1468 & TRN & \\
\hline CHEMBL1526750 & 737034 & 4.3428 & 4.1987 & TRN & \\
\hline CHEMBL1393615 & 737034 & 4.9112 & 5.17299 & 9999999999 & TRN \\
\hline CHEMBL1401747 & 737034 & 6.2757 & 6.0712 & TRN & \\
\hline CHEMBL1604012 & 737034 & 5.5513 & 5.6865 & TRN & \\
\hline CHEMBL 2000877 & 737034 & 5.8601 & 5.0294 & TRN & \\
\hline CHEMBL1577412 & 737034 & 4.8962 & 5.6227 & TST & \\
\hline CHEMBL1328224 & 737034 & 5.3862 & 5.042 & TST & \\
\hline CHEMBL1481301 & 737034 & 5.7905 & 4.9175 & TRN & \\
\hline CHEMBL1595121 & 737034 & 5.3107 & 5.2845 & TRN & \\
\hline CHEMBL1381243 & 737034 & 5.5528 & 5.2051 & TRN & \\
\hline CHEMBL1565522 & 737034 & 3.0 & 5.1215 & TST & \\
\hline CHEMBL1967744 & 737034 & 4.8116 & 4.4839 & TRN & \\
\hline CHEMBL1448854 & 737034 & 5.2418 & 4.7246 & TRN & \\
\hline CHEMBL1536518 & 737034 & 4.3328 & 4.29899 & 99999999995 & \\
\hline CHEMBL 1482585 & 737034 & 5.3382 & 5.08 & TRN & \\
\hline CHEMBL1501032 & 737034 & 5.3188 & 4.6925 & TST & \\
\hline CHEMBL1302463 & 737034 & 5.2351 & 5.3273 & TRN & \\
\hline CHEMBL3196826 & 737034 & 4.8993 & 5.3632 & TRN & \\
\hline CHEMBL1984130 & 737034 & 4.7481 & 4.2771 & TRN & \\
\hline CHEMBL1421587 & 737034 & 4.3451 & 4.7439 & TRN & \\
\hline CHEMBL1341103 & 737034 & 4.4743 & 4.3206 & TRN & \\
\hline CHEMBL1508839 & 737034 & 5.0287 & 4.8532 & TRN & \\
\hline CHEMBL1522351 & 737034 & 5.7447 & 5.3546 & TRN & \\
\hline CHEMBL1459404 & 737034 & 4.409 & 3.5912 & TST & \\
\hline CHEMBL1369200 & 737034 & 5.0985 & 4.3698 & TRN & \\
\hline CHEMBL1455361 & 737034 & 5.3768 & 5.2272 & TRN & \\
\hline CHEMBL1518098 & 737034 & 6.2676 & 5.0432 & TST & \\
\hline CHEMBL1526929 & 737034 & 3.0 & 4.143 & TRN & \\
\hline CHEMBL1976388 & 737034 & 4.5462 & 4.1019 & TRN & \\
\hline CHEMBL1453859 & 737034 & 4.3861 & 4.2686 & TRN & \\
\hline CHEMBL1514705 & 737034 & 4.6805 & 4.5806 & TRN & \\
\hline CHEMBL1530190 & 737034 & 4.524 & 4.6701 & TRN & \\
\hline CHEMBL1488623 & 737034 & 4.311 & 4.5894 & TRN & \\
\hline CHEMBL1335254 & 737034 & 5.5622 & 5.4238 & TRN & \\
\hline
\end{tabular}

Page 23231 


\begin{tabular}{|c|c|c|c|c|}
\hline \multicolumn{5}{|c|}{ Supplemental Table S2.txt } \\
\hline CHEMBL1371827 & 737034 & 3.0 & 3.8372 & TRN \\
\hline CHEMBL 3190792 & 737034 & 5.4841 & 5.6143 & TRN \\
\hline CHEMBL3208517 & 737034 & 4.3423 & 4.8149 & TRN \\
\hline CHEMBL1458609 & 737034 & 5.0232 & 4.5121 & TRN \\
\hline CHEMBL1981464 & 737034 & 5.6271 & 5.604 & TST \\
\hline CHEMBL1520133 & 737034 & 5.7825 & 4.8973 & TRN \\
\hline CHEMBL1376540 & 737034 & 6.0605 & 5.3302 & TRN \\
\hline CHEMBL1372052 & 737034 & 4.4603 & 5.8436 & TST \\
\hline CHEMBL1973307 & 737034 & 4.0859 & 4.8445 & TRN \\
\hline CHEMBL1605867 & 737034 & 5.2487 & 5.0293 & TRN \\
\hline CHEMBL1466971 & 737034 & 4.2955 & 5.6347 & TST \\
\hline CHEMBL1547006 & 737034 & 3.0 & 3.5503 & TRN \\
\hline CHEMBL1429046 & 737034 & 4.5242 & 5.3269 & TRN \\
\hline CHEMBL1380374 & 737034 & 4.3739 & 4.5689 & TRN \\
\hline CHEMBL1443090 & 737034 & 5.1433 & 4.9415 & TRN \\
\hline CHEMBL1598935 & 737034 & 5.6459 & 5.3602 & TRN \\
\hline CHEMBL1380889 & 737034 & 3.0 & 3.7418 & TRN \\
\hline CHEMBL1306068 & 737034 & 4.3002 & 4.2624 & TRN \\
\hline CHEMBL 2002465 & 737034 & 5.2984 & 5.635 & TRN \\
\hline CHEMBL1466235 & 737034 & 5.4067 & 4.8175 & TRN \\
\hline CHEMBL1530670 & 737034 & 5.2588 & 4.8686 & TRN \\
\hline CHEMBL3195265 & 737034 & 5.4989 & 5.5791 & TRN \\
\hline CHEMBL1519030 & 737034 & 4.9772 & 4.8716 & TST \\
\hline CHEMBL1571756 & 737034 & 4.4013 & 4.1223 & TRN \\
\hline CHEMBL1599175 & 737034 & 4.8739 & 5.4013 & TRN \\
\hline CHEMBL1379048 & 737034 & 5.6655 & 5.3627 & TST \\
\hline CHEMBL1562466 & 737034 & 5.51 & 5.2264 & TRN \\
\hline CHEMBL3189845 & 737034 & 6.0 & 5.7166 & TRN \\
\hline CHEMBL1573910 & 737034 & 5.1824 & 5.5473 & TRN \\
\hline CHEMBL1407306 & 737034 & 4.7765 & 4.2984 & TST \\
\hline CHEMBL1890400 & 737034 & 4.7744 & 4.9141 & TRN \\
\hline CHEMBL1381436 & 737034 & 5.1518 & 5.1619 & TRN \\
\hline CHEMBL1470194 & 737034 & 3.0 & 4.1747 & TRN \\
\hline CHEMBL1091723 & 737034 & 5.9393 & 5.6767 & TRN \\
\hline CHEMBL1531500 & 737034 & 4.7435 & 4.9715 & TRN \\
\hline CHEMBL1471146 & 737034 & 4.4419 & 4.8493 & TRN \\
\hline CHEMBL1361703 & 737034 & 5.266 & 5.0012 & TRN \\
\hline CHEMBL1449334 & 737034 & 5.5361 & 5.6902 & TRN \\
\hline CHEMBL3198816 & 737034 & 5.1158 & 5.4797 & TRN \\
\hline CHEMBL3196108 & 737034 & 6.1675 & 6.0354 & TRN \\
\hline CHEMBL1468795 & 737034 & 4.9412 & 5.1343 & TRN \\
\hline CHEMBL1312212 & 737034 & 5.6676 & 5.4919 & TRN \\
\hline CHEMBL1423032 & 737034 & 5.1871 & 5.0229 & TRN \\
\hline CHEMBL1420406 & 737034 & 4.2716 & 4.55399 & 9999999999 \\
\hline CHEMBL1365961 & 737034 & 4.1961 & 5.3066 & TST \\
\hline CHEMBL1999473 & 737034 & 4.9614 & 5.5694 & TRN \\
\hline CHEMBL1340344 & 737034 & 5.5391 & 5.4683 & TRN \\
\hline CHEMBL1308139 & 737034 & 4.2108 & 4.1777 & TRN \\
\hline
\end{tabular}

TRN

Page 23232 


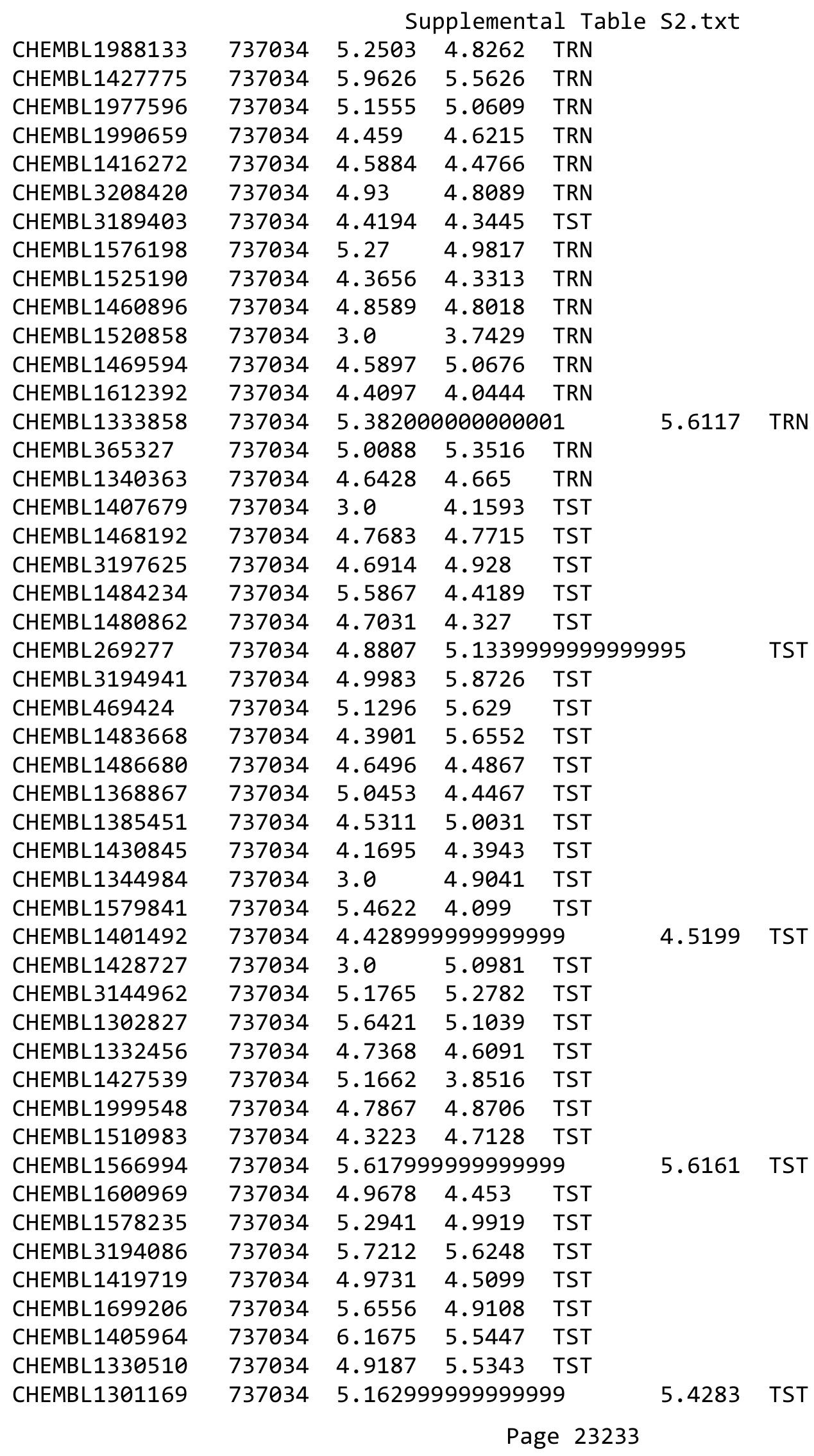


Supplemental Table S2.txt

\begin{tabular}{|c|c|c|c|c|c|c|}
\hline CHEMBL1418005 & 737034 & 5.9172 & 4.9971 & TST & & \\
\hline CHEMBL1560775 & 737034 & 5.5867 & 5.8755 & TST & & \\
\hline CHEMBL1373688 & 737034 & $4.31800 e$ & 30000000 & 305 & 4.7951 & TST \\
\hline CHEMBL3213641 & 737034 & 4.6556 & 5.4301 & TST & & \\
\hline CHEMBL1455522 & 737034 & 5.1046 & 5.3097 & TST & & \\
\hline CHEMBL1461225 & 737034 & 5.8013 & 5.7164 & TST & & \\
\hline CHEMBL1481234 & 737034 & 3.0 & 4.5766 & TST & & \\
\hline CHEMBL1471715 & 737034 & 4.7734 & 5.2435 & TST & & \\
\hline CHEMBL3904978 & 1640908 & 9.6778 & 8.7062 & TRN & & \\
\hline CHEMBL3967754 & 1640908 & 7.7352 & 9.0223 & TRN & & \\
\hline CHEMBL3922587 & 1640908 & 8.7212 & 8.7605 & TRN & & \\
\hline CHEMBL3949948 & 1640908 & 7.8928 & 7.5697 & TRN & & \\
\hline CHEMBL3904866 & 1640908 & 8.2366 & 7.9216 & TRN & & \\
\hline CHEMBL3967191 & 1640908 & 8.3768 & 7.9967 & TRN & & \\
\hline CHEMBL3978973 & 1640908 & 8.6021 & 8.0191 & TRN & & \\
\hline CHEMBL3954786 & 1640908 & 9.2676 & 8.9357 & TRN & & \\
\hline CHEMBL3905161 & 1640908 & 8.9666 & 8.8999 & TRN & & \\
\hline CHEMBL3926385 & 1640908 & 6.1249 & 7.4592 & TST & & \\
\hline CHEMBL3906186 & 1640908 & 9.301 & 8.4703 & TRN & & \\
\hline CHEMBL3982203 & 1640908 & 7.9747 & 8.242 & TRN & & \\
\hline CHEMBL3970392 & 1640908 & 8.9586 & 8.9718 & TRN & & \\
\hline CHEMBL3934159 & 1640908 & 9.4089 & 8.6465 & TRN & & \\
\hline CHEMBL3959540 & 1640908 & 7.7747 & 7.6586 & TST & & \\
\hline CHEMBL3955691 & 1640908 & 7.2168 & 7.4844 & TST & & \\
\hline CHEMBL3945473 & 1640908 & 8.9208 & 8.7347 & TRN & & \\
\hline CHEMBL3899392 & 1640908 & 7.1367 & 9.1678 & TST & & \\
\hline CHEMBL3936818 & 1640908 & 8.0088 & 8.3161 & TRN & & \\
\hline CHEMBL3944289 & 1640908 & 7.8827 & 7.7289 & TRN & & \\
\hline CHEMBL3905571 & 1640908 & 7.5129 & 7.2471 & TST & & \\
\hline CHEMBL3973737 & 1640908 & 9.1135 & 9.0533 & TRN & & \\
\hline CHEMBL3895161 & 1640908 & 6.1249 & 7.8499 & TRN & & \\
\hline CHEMBL3955538 & 1640908 & 8.699 & 8.297 & TRN & & \\
\hline CHEMBL 3912270 & 1640908 & 8.8539 & 8.4842 & TRN & & \\
\hline CHEMBL3931733 & 1640908 & 9.8539 & 10.105 & TRN & & \\
\hline CHEMBL3952655 & 1640908 & 7.5157 & 7.7005 & TST & & \\
\hline CHEMBL3934608 & 1640908 & 8.8861 & 9.2819 & TRN & & \\
\hline CHEMBL3976236 & 1640908 & 9.1249 & 8.8448 & TRN & & \\
\hline CHEMBL3975668 & 1640908 & 7.8601 & 8.0144 & TRN & & \\
\hline CHEMBL 3960405 & 1640908 & 11.0 & 10.5343 & TRN & & \\
\hline CHEMBL3945301 & 1640908 & 8.9626 & 8.7733 & TRN & & \\
\hline CHEMBL3958268 & 1640908 & 7.7212 & 8.6942 & TRN & & \\
\hline CHEMBL3938983 & 1640908 & 8.699 & 8.3392 & TRN & & \\
\hline CHEMBL3890836 & 1640908 & 10.1675 & 8.9657 & TRN & & \\
\hline CHEMBL3972719 & 1640908 & 10.5686 & 10.3495 & TRN & & \\
\hline CHEMBL3947583 & 1640908 & 8.9586 & 8.7971 & TRN & & \\
\hline CHEMBL3936634 & 1640908 & 9.6778 & 8.3911 & TRN & & \\
\hline CHEMBL3949922 & 1640908 & 6.1249 & 7.9414 & TST & & \\
\hline CHEMBL 3955247 & 1640908 & 10.6383 & 11.0548 & TRN & & \\
\hline
\end{tabular}

Page 23234 
Supplemental Table S2.txt

\begin{tabular}{|c|c|c|c|c|}
\hline CHEMBL 3890431 & 1640908 & 8.9586 & 8.0476 & TRN \\
\hline CHEMBL 3892748 & 1640908 & 8.8239 & 8.8028 & TRN \\
\hline CHEMBL 3890395 & 1640908 & 8.9208 & 8.9286 & TRN \\
\hline CHEMBL 3919734 & 1640908 & 6.1249 & 7.4663 & TRN \\
\hline CHEMBL3946887 & 1640908 & 8.9208 & 8.8512 & TRN \\
\hline CHEMBL 3942245 & 1640908 & 7.0555 & 8.4396 & TRN \\
\hline CHEMBL 3946076 & 1640908 & 7.2076 & 10.1519 & TST \\
\hline CHEMBL3978832 & 1640908 & 9.2076 & 8.6724 & TRN \\
\hline CHEMBL 3943073 & 1640908 & 7.8861 & 7.7396 & TRN \\
\hline CHEMBL 3982870 & 1640908 & 8.9208 & 8.8894 & TRN \\
\hline CHEMBL 3948455 & 1640908 & 6.0372 & 7.298999 & 99999999995 \\
\hline CHEMBL 3898312 & 1640908 & 6.0 & 8.0477 & TST \\
\hline CHEMBL 3956689 & 1640908 & 9.1675 & 8.6408 & TRN \\
\hline CHEMBL 3957122 & 1640908 & 9.8539 & 8.9784 & TST \\
\hline CHEMBL3929872 & 1640908 & 9.4318 & 8.7909 & TRN \\
\hline CHEMBL 3954931 & 1640908 & 9.3768 & 8.751 & TRN \\
\hline CHEMBL3967410 & 1640908 & 9.0862 & 10.1579 & TRN \\
\hline CHEMBL 3902562 & 1640908 & 8.8539 & 8.7338 & TRN \\
\hline CHEMBL 3937162 & 1640908 & 9.4318 & 8.7688 & TRN \\
\hline CHEMBL 3958142 & 1640908 & 10.1367 & 10.9378 & TRN \\
\hline CHEMBL 3911724 & 1640908 & 6.9066 & 7.1235 & TST \\
\hline CHEMBL3928666 & 1640908 & 7.8665 & 7.7816 & TRN \\
\hline CHEMBL 3927304 & 1640908 & 9.0757 & 9.0175 & TRN \\
\hline CHEMBL 3942605 & 1640908 & 8.2218 & 8.756 & TST \\
\hline CHEMBL 3914246 & 1640908 & 11.5229 & 9.4016 & TRN \\
\hline CHEMBL 3950949 & 1640908 & 8.5376 & 8.0687 & TRN \\
\hline CHEMBL 3924344 & 1640908 & 7.4572 & 7.3835 & TST \\
\hline CHEMBL 3934377 & 1640908 & 6.0 & 8.2783 & TRN \\
\hline CHEMBL 3926763 & 1640908 & 6.0 & 8.8164 & TRN \\
\hline CHEMBL 3926785 & 1640908 & 9.3098 & 8.4678 & TRN \\
\hline CHEMBL 3944299 & 1640908 & 8.5086 & 8.7335 & TRN \\
\hline CHEMBL 3970286 & 1640908 & 8.4815 & 9.888 & TST \\
\hline CHEMBL 3976016 & 1640908 & 7.8729 & 8.037 & TRN \\
\hline CHEMBL 3955203 & 1640908 & 7.7375 & 7.4895 & TRN \\
\hline CHEMBL 3948155 & 1640908 & 8.5528 & 8.2542 & TRN \\
\hline CHEMBL 3907625 & 1640908 & 6.1249 & 7.4625 & TRN \\
\hline CHEMBL 3935322 & 1640908 & 8.6778 & 8.3045 & TRN \\
\hline CHEMBL 3937884 & 1640908 & 7.4112 & 7.9893 & TRN \\
\hline CHEMBL 3896176 & 1640908 & 10.2518 & 10.4939 & TRN \\
\hline CHEMBL 3890466 & 1640908 & 7.6003 & 7.3502 & TST \\
\hline CHEMBL 3963411 & 1640908 & 8.8861 & 8.7501 & TRN \\
\hline CHEMBL 3959504 & 1640908 & 8.4089 & 7.8644 & TRN \\
\hline CHEMBL 3937178 & 1640908 & 11.3979 & 11.2665 & TRN \\
\hline CHEMBL 3948898 & 1640908 & 9.2366 & 8.7081 & TRN \\
\hline CHEMBL 3943266 & 1640908 & 6.0 & 7.3821 & TST \\
\hline CHEMBL 3920330 & 1640908 & 7.4202 & 8.9891 & TRN \\
\hline CHEMBL 3980754 & 1640908 & 11.69900 & 00000006 & 11.4701 \\
\hline CHEMBL 3963698 & 1640908 & 9.0555 & 8.627 & TRN \\
\hline
\end{tabular}


Supplemental Table S2.txt

\begin{tabular}{|c|c|c|c|c|c|}
\hline CHEMBL 3968402 & 1640908 & 7.2351 & 7.1837 & TST & \\
\hline CHEMBL3959469 & 1640908 & 8.3768 & 8.9552 & TRN & \\
\hline CHEMBL3983406 & 1640908 & 10.5528 & 11.1717 & TRN & \\
\hline CHEMBL3971216 & 1640908 & 8.7959 & 8.4555 & TRN & \\
\hline CHEMBL3910671 & 1640908 & 11.6990 & 000000000 & 10.7613 & TRN \\
\hline CHEMBL3968426 & 1640908 & 6.0 & 8.647 & TRN & \\
\hline CHEMBL3897275 & 1640908 & 10.0706 & 9.0492 & TRN & \\
\hline CHEMBL3965475 & 1640908 & 8.0044 & 7.4976 & TRN & \\
\hline CHEMBL3908257 & 1640908 & 8.2757 & 8.4846 & TST & \\
\hline CHEMBL3974865 & 1640908 & 8.7696 & 8.4707 & TST & \\
\hline CHEMBL 3963624 & 1640908 & 7.8477 & 7.9146 & TST & \\
\hline CHEMBL 3895140 & 1640908 & 9.9586 & 10.3778 & TST & \\
\hline CHEMBL3917692 & 1640908 & 8.0458 & 8.3375 & TST & \\
\hline CHEMBL3939301 & 1640908 & 8.5086 & 8.3548 & TST & \\
\hline CHEMBL3950983 & 1640908 & 6.6055 & 8.5682 & TST & \\
\hline CHEMBL3952913 & 1640908 & 8.2218 & 7.7009 & TST & \\
\hline CHEMBL3911911 & 1640908 & 8.7696 & 8.1146 & TST & \\
\hline CHEMBL 3678259 & 1528469 & 5.2882 & 5.1955 & TRN & \\
\hline CHEMBL3678183 & 1528469 & 7.5229 & 7.6194 & TRN & \\
\hline CHEMBL 3678218 & 1528469 & 7.1549 & 7.2823 & TRN & \\
\hline CHEMBL 3678253 & 1528469 & 5.8386 & 5.9882 & TRN & \\
\hline CHEMBL3678167 & 1528469 & 6.4559 & 6.4051 & TRN & \\
\hline CHEMBL3639770 & 1528469 & 7.2676 & 7.282999 & 99999999995 & TRN \\
\hline CHEMBL3678264 & 1528469 & 5.9393 & 6.1405 & TRN & \\
\hline CHEMBL3683069 & 1528469 & 6.0269 & 5.8411 & TRN & \\
\hline CHEMBL 3678239 & 1528469 & 7.5086 & 7.4277 & TRN & \\
\hline CHEMBL 3678186 & 1528469 & 5.8239 & 6.9092 & TST & \\
\hline CHEMBL3683096 & 1528469 & 7.2366 & 7.4618 & TRN & \\
\hline CHEMBL3678279 & 1528469 & 6.8239 & 7.2862 & TST & \\
\hline CHEMBL 3678207 & 1528469 & 7.699 & 7.4185 & TRN & \\
\hline CHEMBL 3678241 & 1528469 & 6.9788 & 7.0662 & TRN & \\
\hline CHEMBL3678208 & 1528469 & 7.1938 & 7.0357 & TRN & \\
\hline CHEMBL3678251 & 1528469 & 6.3768 & 6.6716 & TRN & \\
\hline CHEMBL3683065 & 1528469 & 4.757 & 6.0283 & TST & \\
\hline CHEMBL 3678246 & 1528469 & 5.4498 & 7.1367 & TST & \\
\hline CHEMBL3678181 & 1528469 & 4.9208 & 5.7638 & TST & \\
\hline CHEMBL 3678229 & 1528469 & 7.1612 & 7.0878 & TRN & \\
\hline CHEMBL 3678268 & 1528469 & 7.7212 & \multicolumn{2}{|c|}{7.792000000000001} & TRN \\
\hline CHEMBL 3678165 & 1528469 & 7.2676 & 7.2009 & TRN & \\
\hline CHEMBL 3678205 & 1528469 & 7.1675 & 7.6669 & TRN & \\
\hline CHEMBL 3683077 & 1528469 & 5.8386 & 5.9447 & TRN & \\
\hline CHEMBL 3678267 & 1528469 & 6.5452 & 6.6 & TRN & \\
\hline CHEMBL3678190 & 1528469 & 6.4685 & 6.6189 & TRN & \\
\hline CHEMBL3678216 & 1528469 & 7.3279 & 7.4928 & TRN & \\
\hline CHEMBL 3683079 & 1528469 & 4.8239 & 6.2131 & TST & \\
\hline CHEMBL 3678274 & 1528469 & 8.1549 & 8.2343 & TRN & \\
\hline CHEMBL 3678280 & 1528469 & 4.7212 & 6.6985 & TST & \\
\hline CHEMBL 3678215 & 1528469 & 7.0269 & 6.9959 & TRN & \\
\hline
\end{tabular}

Page 23236 
Supplemental Table S2.txt

\begin{tabular}{|c|c|c|c|c|c|}
\hline CHEMBL 3678220 & 1528469 & 5.1612 & 5.2277 & TRN & \\
\hline CHEMBL3678209 & 1528469 & 7.1938 & 7.1998 & TRN & \\
\hline CHEMBL 3678240 & 1528469 & 6.0 & 6.6499 & TRN & \\
\hline CHEMBL 3683094 & 1528469 & 7.9586 & 6.9677 & TST & \\
\hline CHEMBL3683072 & 1528469 & 5.2366 & 5.5825 & TRN & \\
\hline CHEMBL3678225 & 1528469 & 7.7447 & 7.5974 & TRN & \\
\hline CHEMBL 3678224 & 1528469 & 7.4685 & 7.5734 & TRN & \\
\hline CHEMBL 3678184 & 1528469 & 6.0742 & 6.6308 & TST & \\
\hline CHEMBL 3678265 & 1528469 & 5.4498 & 5.2716 & TRN & \\
\hline CHEMBL3678172 & 1528469 & 7.0315 & 6.974 & TRN & \\
\hline CHEMBL3678164 & 1528469 & 5.9626 & 6.0367 & TRN & \\
\hline CHEMBL3678213 & 1528469 & 7.7212 & 7.6252 & TRN & \\
\hline CHEMBL3683091 & 1528469 & 7.3565 & 6.9155 & TST & \\
\hline CHEMBL 3678252 & 1528469 & 6.8697 & 7.1926 & TRN & \\
\hline CHEMBL3678171 & 1528469 & 6.4815 & 6.6497 & TRN & \\
\hline CHEMBL3678217 & 1528469 & 7.5229 & 7.4086 & TRN & \\
\hline CHEMBL3683066 & 1528469 & 5.8539 & 6.7138 & TST & \\
\hline CHEMBL 3678260 & 1528469 & 6.8097 & 6.6545 & TRN & \\
\hline CHEMBL 3678242 & 1528469 & 7.585 & 7.5237 & TRN & \\
\hline CHEMBL3678193 & 1528469 & 7.9586 & 8.0342 & TRN & \\
\hline CHEMBL3678187 & 1528469 & 7.2366 & 7.1832 & TRN & \\
\hline CHEMBL3683073 & 1528469 & 4.6778 & 6.3817 & TST & \\
\hline CHEMBL 3678263 & 1528469 & 6.4815 & 6.4926 & TRN & \\
\hline CHEMBL3678211 & 1528469 & 5.5686 & 5.7194 & TRN & \\
\hline CHEMBL 3678179 & 1528469 & 7.8539 & 7.8837 & TRN & \\
\hline CHEMBL3678180 & 1528469 & 5.7447 & 5.6487 & TST & \\
\hline CHEMBL 3683085 & 1528469 & 5.3372 & 5.2695 & TRN & \\
\hline CHEMBL 3678235 & 1528469 & 5.2861 & 5.6948 & TRN & \\
\hline CHEMBL3683081 & 1528469 & 6.1851 & 6.3315 & TRN & \\
\hline CHEMBL 3683076 & 1528469 & 4.8979 & 6.789 & TST & \\
\hline CHEMBL 3678277 & 1528469 & 6.0 & 6.2903 & TST & \\
\hline CHEMBL 3678200 & 1528469 & 7.2924 & 7.3197 & TRN & \\
\hline CHEMBL 3683078 & 1528469 & 5.5157 & 5.4007 & TRN & \\
\hline CHEMBL3678178 & 1528469 & 7.1192 & \multicolumn{2}{|c|}{7.0520000000000005} & TRN \\
\hline CHEMBL 3678198 & 1528469 & 6.3279 & 6.2808 & TRN & \\
\hline CHEMBL 3683075 & 1528469 & 5.585 & 6.8128 & TST & \\
\hline CHEMBL3678197 & 1528469 & 4.9208 & 4.8895 & TRN & \\
\hline CHEMBL 3678189 & 1528469 & 5.0155 & 4.9498 & TRN & \\
\hline CHEMBL3678169 & 1528469 & 6.6108 & 6.6566 & TRN & \\
\hline CHEMBL 3678250 & 1528469 & 7.585 & 7.7121 & TRN & \\
\hline CHEMBL3678281 & 1528469 & 5.3768 & 6.3702 & TST & \\
\hline CHEMBL3678249 & 1528469 & 7.7959 & 7.6629 & TRN & \\
\hline CHEMBL 3678175 & 1528469 & 6.9747 & 6.8709 & TRN & \\
\hline CHEMBL3683064 & 1528469 & 6.3143 & \multicolumn{2}{|c|}{6.832000000000001} & TST \\
\hline CHEMBL 3678278 & 1528469 & 4.8539 & 6.4871 & TST & \\
\hline CHEMBL3683098 & 1528469 & 5.585 & 6.3758 & TST & \\
\hline CHEMBL3678196 & 1528469 & 7.0223 & 6.9137 & TRN & \\
\hline CHEMBL3678245 & 1528469 & 5.5528 & 7.8984 & TST & \\
\hline
\end{tabular}

Page 23237 
Supplemental Table S2.txt

\begin{tabular}{|c|c|c|c|c|c|}
\hline CHEMBL 3678247 & 1528469 & 7.5686 & 7.6548 & TRN & \\
\hline CHEMBL 3678191 & 1528469 & 7.3565 & 7.1461 & TRN & \\
\hline CHEMBL3683080 & 1528469 & 7.1079 & 7.1229 & TRN & \\
\hline CHEMBL 3678258 & 1528469 & 6.5229 & 6.6223 & TRN & \\
\hline CHEMBL 3678185 & 1528469 & 7.0 & 7.2883 & TST & \\
\hline CHEMBL 3678256 & 1528469 & 6.3979 & 6.1902 & TST & \\
\hline CHEMBL 3678170 & 1528469 & 7.301 & 7.3392 & TRN & \\
\hline CHEMBL 3683074 & 1528469 & 5.7825 & 6.2824 & TST & \\
\hline CHEMBL 3639819 & 1528469 & 6.4815 & 6.1537 & TRN & \\
\hline CHEMBL 3678237 & 1528469 & 7.2676 & 7.1565 & TRN & \\
\hline CHEMBL 3678174 & 1528469 & 7.2518 & 7.407 & TRN & \\
\hline CHEMBL 3678266 & 1528469 & 6.4089 & 6.3114 & TRN & \\
\hline CHEMBL 3678221 & 1528469 & 7.4949 & 7.355 & TRN & \\
\hline CHEMBL 3678214 & 1528469 & 7.0605 & 6.9718 & TRN & \\
\hline CHEMBL 3678254 & 1528469 & 5.8539 & 5.87299 & 9999999999 & TRN \\
\hline CHEMBL 3678204 & 1528469 & 6.585 & 6.6466 & TRN & \\
\hline CHEMBL3683097 & 1528469 & 8.699 & 8.2162 & TRN & \\
\hline CHEMBL 3678232 & 1528469 & 7.8861 & 8.0029 & TRN & \\
\hline CHEMBL 3678188 & 1528469 & 5.9586 & 5.8464 & TRN & \\
\hline CHEMBL 3683093 & 1528469 & 8.301 & 7.8474 & TST & \\
\hline CHEMBL 3678282 & 1528469 & 6.4498 & 6.0088 & TRN & \\
\hline CHEMBL3678199 & 1528469 & 6.9957 & 7.0343 & TRN & \\
\hline CHEMBL 3678210 & 1528469 & 6.8697 & 6.8457 & TRN & \\
\hline CHEMBL 3678226 & 1528469 & 6.9666 & 6.8107 & TRN & \\
\hline CHEMBL 3678269 & 1528469 & 6.0506 & 6.0519 & TRN & \\
\hline CHEMBL 3678276 & 1528469 & 5.9412 & 6.4389 & TST & \\
\hline CHEMBL 3678233 & 1528469 & 7.0362 & 6.9937 & TRN & \\
\hline CHEMBL 3678231 & 1528469 & 6.9508 & 6.9071 & TRN & \\
\hline CHEMBL 3678192 & 1528469 & 7.5528 & 7.641 & TRN & \\
\hline CHEMBL 3678275 & 1528469 & 6.3116 & 6.3765 & TST & \\
\hline CHEMBL 3678238 & 1528469 & 7.5376 & 7.7705 & TRN & \\
\hline CHEMBL 3683089 & 1528469 & 5.1805 & 5.1583 & TRN & \\
\hline CHEMBL3678206 & 1528469 & 6.4202 & 5.7342 & TST & \\
\hline CHEMBL3683095 & 1528469 & 7.284 & 6.6096 & TST & \\
\hline CHEMBL 3678248 & 1528469 & 7.9208 & 7.7635 & TRN & \\
\hline CHEMBL3678177 & 1528469 & 7.1871 & 7.2024 & TRN & \\
\hline CHEMBL 3678173 & 1528469 & 7.8539 & 7.8671 & TRN & \\
\hline CHEMBL 3678273 & 1528469 & 9.0 & 8.9085 & TRN & \\
\hline CHEMBL 3678255 & 1528469 & 5.4622 & 5.9866 & TRN & \\
\hline CHEMBL 3683090 & 1528469 & 5.0757 & 5.0572 & TRN & \\
\hline CHEMBL 3678272 & 1528469 & 8.2218 & 8.2357 & TRN & \\
\hline CHEMBL 3683088 & 1528469 & 5.7825 & 6.7819 & TST & \\
\hline CHEMBL 3683070 & 1528469 & 5.2924 & 6.9432 & TST & \\
\hline CHEMBL 3683087 & 1528469 & 6.3468 & 6.7908 & TST & \\
\hline CHEMBL 3678222 & 1528469 & 6.8996 & 7.5894 & TST & \\
\hline CHEMBL3683068 & 1528469 & 6.2518 & 6.6178 & TST & \\
\hline CHEMBL 3678182 & 1528469 & 5.2218 & 4.7884 & TST & \\
\hline CHEMBL 3683083 & 1528469 & 6.2111 & 6.0184 & TRN & \\
\hline
\end{tabular}


Supplemental Table S2.txt

\begin{tabular}{|c|c|c|c|c|}
\hline CHEMBL 3678223 & 1528469 & 6.9469 & 7.7011 & TST \\
\hline CHEMBL 3678203 & 1528469 & 7.3979 & 7.4718 & TRN \\
\hline CHEMBL 3678219 & 1528469 & 7.1612 & 7.2286 & TRN \\
\hline CHEMBL 3683086 & 1528469 & 5.4202 & 5.4209 & TRN \\
\hline CHEMBL3678212 & 1528469 & 7.6198 & \multicolumn{2}{|c|}{7.382000000000001} \\
\hline CHEMBL 3678270 & 1528469 & 8.5229 & 8.3444 & TRN \\
\hline CHEMBL 3683084 & 1528469 & 5.301 & 5.2279 & TRN \\
\hline CHEMBL 3678236 & 1528469 & 7.2924 & 6.8137 & TRN \\
\hline CHEMBL 3678243 & 1528469 & 7.3372 & 7.3681 & TRN \\
\hline CHEMBL3678257 & 1528469 & 6.1278 & 6.0461 & TRN \\
\hline CHEMBL 3678202 & 1528469 & 6.1612 & 5.9583 & TRN \\
\hline CHEMBL 3678195 & 1528469 & 6.6882 & 6.6826 & TRN \\
\hline CHEMBL 3683071 & 1528469 & 5.8239 & 5.9913 & TST \\
\hline CHEMBL 3678261 & 1528469 & 6.9208 & 6.3881 & TRN \\
\hline CHEMBL3678201 & 1528469 & 7.1612 & 6.8826 & TRN \\
\hline CHEMBL 3683092 & 1528469 & 8.0 & 7.4429 & TST \\
\hline CHEMBL 3678176 & 1528469 & 6.9747 & 6.8395 & TRN \\
\hline CHEMBL 3683099 & 1528469 & 5.857 & 5.9716 & TRN \\
\hline CHEMBL 3678227 & 1528469 & 6.9706 & 6.9427 & TRN \\
\hline CHEMBL 3678166 & 1528469 & 4.8697 & \multicolumn{2}{|c|}{5.212000000000001} \\
\hline CHEMBL 3678262 & 1528469 & \multicolumn{3}{|c|}{$4.7669999999999995 \quad 4.779$} \\
\hline CHEMBL3678271 & 1528469 & 7.7959 & 8.0261 & TRN \\
\hline CHEMBL 3678168 & 1528469 & 7.4089 & 7.4444 & TRN \\
\hline CHEMBL 3683082 & 1528469 & 5.475 & 5.8704 & TRN \\
\hline CHEMBL 3678244 & 1528469 & 7.3372 & 7.4257 & TRN \\
\hline CHEMBL 3678228 & 1528469 & 7.4318 & 7.2881 & TRN \\
\hline CHEMBL 3678230 & 1528469 & 7.5229 & 7.629 & TRN \\
\hline CHEMBL 3694144 & 1528067 & 8.699 & 9.0612 & TRN \\
\hline CHEMBL 3694069 & 1528067 & 8.1549 & 8.2523 & TRN \\
\hline CHEMBL 3694063 & 1528067 & 8.0458 & 8.2077 & TRN \\
\hline CHEMBL 3694043 & 1528067 & 8.3979 & 8.7172 & TRN \\
\hline CHEMBL 3641242 & 1528067 & 8.5229 & 8.0452 & TST \\
\hline CHEMBL 3641245 & 1528067 & 5.0 & 4.8289 & TRN \\
\hline CHEMBL 3694200 & 1528067 & 10.0 & 9.9812 & TRN \\
\hline CHEMBL 3641164 & 1528067 & 8.0969 & 8.6718 & TST \\
\hline CHEMBL 3641178 & 1528067 & 9.0 & 9.2246 & TST \\
\hline CHEMBL 3641230 & 1528067 & 9.0 & 9.0442 & TRN \\
\hline CHEMBL3639399 & 1528067 & 7.7696 & \multicolumn{2}{|c|}{7.502000000000001} \\
\hline CHEMBL 3641220 & 1528067 & 9.0 & 8.5554 & TRN \\
\hline CHEMBL 3697871 & 1528067 & 7.2518 & 7.4944 & TRN \\
\hline CHEMBL 3641044 & 1528067 & 10.0 & 9.6794 & TRN \\
\hline CHEMBL 3641103 & 1528067 & 7.8861 & 8.2755 & TRN \\
\hline CHEMBL 3641217 & 1528067 & 6.8894 & 7.5501 & TST \\
\hline CHEMBL 3641197 & 1528067 & 9.0 & 9.2659 & TST \\
\hline CHEMBL 3694213 & 1528067 & 9.0 & 9.4693 & TRN \\
\hline CHEMBL 3689901 & 1528067 & 7.585 & 8.5845 & TRN \\
\hline CHEMBL 3643289 & 1528067 & 6.2255 & 6.0241 & TRN \\
\hline CHEMBL 3697804 & 1528067 & 4.8239 & 4.492 & TRN \\
\hline
\end{tabular}


Supplemental Table S2.txt

\begin{tabular}{|c|c|c|c|c|}
\hline CHEMBL3643287 & 1528067 & 5.0 & 6.5176 & TST \\
\hline CHEMBL3694074 & 1528067 & 8.3979 & 9.0492 & TST \\
\hline CHEMBL3694031 & 1528067 & 8.5229 & 8.2253 & TRN \\
\hline CHEMBL3694125 & 1528067 & 6.2628 & 6.9778 & TST \\
\hline CHEMBL 3641110 & 1528067 & 8.3979 & 8.2589 & TRN \\
\hline CHEMBL3641152 & 1528067 & 7.9208 & 7.6985 & TRN \\
\hline CHEMBL3694176 & 1528067 & 8.699 & 9.2122 & TRN \\
\hline CHEMBL3643295 & 1528067 & 8.699 & 8.0492 & TST \\
\hline CHEMBL3694098 & 1528067 & 8.301 & 8.3591 & TRN \\
\hline CHEMBL3641222 & 1528067 & 8.5229 & 8.1814 & TRN \\
\hline CHEMBL3694136 & 1528067 & 8.3979 & 8.185 & TRN \\
\hline CHEMBL3694143 & 1528067 & 8.2218 & 8.5526 & TRN \\
\hline CHEMBL3694042 & 1528067 & 8.1549 & 8.2106 & TRN \\
\hline CHEMBL3697902 & 1528067 & 8.699 & 8.9256 & TST \\
\hline CHEMBL3697838 & 1528067 & 8.1549 & 8.3355 & TRN \\
\hline CHEMBL3697935 & 1528067 & 8.3979 & 8.6796 & TRN \\
\hline CHEMBL3697813 & 1528067 & 6.0778 & 6.3589 & TRN \\
\hline CHEMBL3694099 & 1528067 & 8.5229 & 9.1806 & TST \\
\hline CHEMBL3697868 & 1528067 & 7.2596 & 7.5346 & TRN \\
\hline CHEMBL3641192 & 1528067 & 7.7447 & 7.307 & TRN \\
\hline CHEMBL3697836 & 1528067 & 7.6778 & 8.3995 & TRN \\
\hline CHEMBL3697897 & 1528067 & 7.699 & 6.8134 & TST \\
\hline CHEMBL3643297 & 1528067 & 8.301 & 7.7793 & TST \\
\hline CHEMBL3697767 & 1528067 & 6.767 & 6.915 & TRN \\
\hline CHEMBL 3697747 & 1528067 & 4.0 & 4.5298 & TST \\
\hline CHEMBL3641144 & 1528067 & 8.5229 & 8.7667 & TRN \\
\hline CHEMBL3641123 & 1528067 & 8.5229 & 8.6662 & TRN \\
\hline CHEMBL3641075 & 1528067 & 8.5229 & 8.6058 & TRN \\
\hline CHEMBL3694080 & 1528067 & 8.5229 & 8.7644 & TRN \\
\hline CHEMBL3643288 & 1528067 & 5.699 & 5.9354 & TRN \\
\hline CHEMBL3694065 & 1528067 & 10.0 & 9.2334 & TRN \\
\hline CHEMBL3641223 & 1528067 & 8.0458 & 7.8687 & TST \\
\hline CHEMBL 3641141 & 1528067 & 8.3979 & 8.6836 & TRN \\
\hline CHEMBL3689903 & 1528067 & 8.1549 & 8.4212 & TRN \\
\hline CHEMBL 3697722 & 1528067 & 10.0 & 9.7565 & TRN \\
\hline CHEMBL3641189 & 1528067 & 7.4815 & 7.4083 & TST \\
\hline CHEMBL3641132 & 1528067 & 8.5229 & 8.7953 & TRN \\
\hline CHEMBL3641080 & 1528067 & 8.3979 & 8.7846 & TRN \\
\hline CHEMBL3697914 & 1528067 & 8.0969 & 7.2723 & TST \\
\hline CHEMBL3641077 & 1528067 & 8.3979 & 8.2571 & TRN \\
\hline CHEMBL3641232 & 1528067 & 8.301 & 8.7195 & TRN \\
\hline CHEMBL3641149 & 1528067 & 6.9747 & 8.31899 & 9999999999 \\
\hline CHEMBL3694032 & 1528067 & 7.2676 & 7.9386 & TST \\
\hline CHEMBL3694216 & 1528067 & 8.3979 & 8.6853 & TRN \\
\hline CHEMBL 3694204 & 1528067 & 8.5229 & 8.5865 & TRN \\
\hline CHEMBL3641117 & 1528067 & 8.0969 & 8.0829 & TRN \\
\hline CHEMBL3697858 & 1528067 & 6.699 & 8.147 & TST \\
\hline CHEMBL3697733 & 1528067 & 4.699 & 5.3068 & TST \\
\hline
\end{tabular}


Supplemental Table S2.txt

\begin{tabular}{|c|c|c|c|c|}
\hline 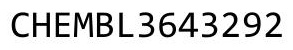 & & 5.0 & 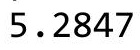 & \\
\hline CHEMBL & 528067 & 5.699 & & \\
\hline HEMBL3697864 & 528067 & 8.699 & 4158 & \\
\hline HEMBL3694124 & 528067 & 5.6494 & 8224 & \\
\hline HEMBL3697928 & 528067 & 10.0 & 0641 & \\
\hline AEMBL3689927 & 528067 & 7.8861 & .4987 & \\
\hline HEMBL3697750 & 528067 & 8.3979 & .8546 & \\
\hline HEMBL3694106 & 528067 & 6.0123 & .222 & \\
\hline HEMBL3641052 & 528067 & 8.1549 & .4398 & \\
\hline IEMBL 369 & 528067 & .5229 & 2107 & \\
\hline AEMBL3697892 & 528067 & 10.0 & 4757 & \\
\hline HEMBL3641206 & 528067 & 8.0458 & 7.9954 & \\
\hline HEMBL3697900 & 528067 & 10.0 & 3489 & \\
\hline HEMBL3694 & 528067 & 10.0 & 153 & \\
\hline IEMBL 369 & 528067 & 10.0 & 136 & \\
\hline AEMBL 369 & 528067 & 6.2434 & 229 & \\
\hline HEMBL3697917 & .528067 & 8.1549 & 7535 & \\
\hline HEMBL3694081 & 528067 & 8.3979 & 3027 & \\
\hline HEMBL364 & 528067 & 7.8239 & 01 & \\
\hline 46 & 528067 & 7.585 & 686 & \\
\hline AEMBL36 & 528067 & 7.9586 & & \\
\hline HEMBL3697826 & .528067 & 8.301 & 8063 & \\
\hline HEMBL 364 & 528067 & 9.0 & 52 & \\
\hline HEMBL369 & .528067 & 6.7033 & 7691 & \\
\hline 01 & 528067 & 9.0 & 236 & \\
\hline 36 & 528067 & 8.699 & 543 & \\
\hline HEMBL363 & 528067 & 7.6383 & & \\
\hline AEMBL3694212 & 528067 & 8.699 & 885 & \\
\hline AEMBL 3694 & 528067 & 5.0 & 7413 & \\
\hline 11 & 528067 & 8.3979 & 204 & \\
\hline 60 & 528067 & 8.1549 & 521 & \\
\hline HEMBL 369 & 528067 & 8.699 & 292 & \\
\hline HEMBL 3641118 & 528067 & 9.0 & 09 & \\
\hline HEMBL 364 & 528067 & 8.5229 & 581 & \\
\hline 37 & 528067 & 8.699 & & \\
\hline 19 & 67 & 99 & 256 & RN \\
\hline HEMBL3697851 & 528067 & 8.3979 & 703 & $\mathrm{RN}$ \\
\hline AEMBL3694115 & 528067 & 5.6515 & 743 & \\
\hline HEMBL36 & 1528067 & 8.699 & 366 & RI \\
\hline 29 & .528067 & 8. & 17 & \\
\hline & 67 & 8.5229 & 3001 & ST \\
\hline AEMBL3641210 & 528067 & 8.5229 & 9253 & ST \\
\hline HEMBL 369 & 528067 & 10.0 & & TST \\
\hline HEMBL 364 & 1528067 & 8.5229 & & \\
\hline HEMBL 36 & .528067 & 3.8239 & & \\
\hline HEMBL3694187 & 528067 & 8.3979 & 7437 & RN \\
\hline HEMBL3694123 & 528067 & 6.6383 & .3455 & \\
\hline CHEMBL 3641065 & 1528067 & 8.3979 & 8.5152 & \\
\hline
\end{tabular}

Page 23241 


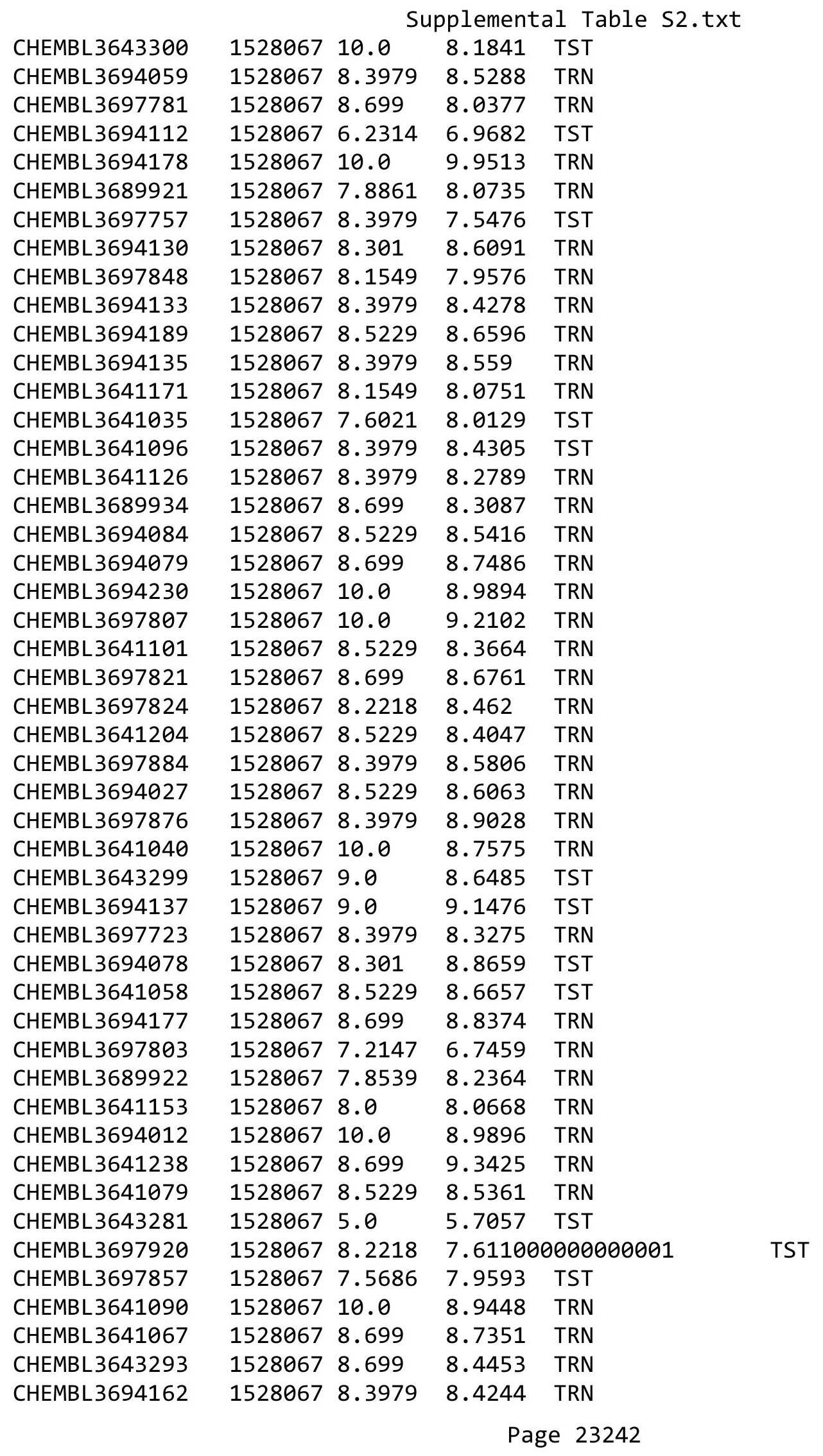


Supplemental Table S2.txt

\begin{tabular}{|c|c|c|c|c|c|}
\hline CHEMBL3641172 & 1528067 & 8.3979 & 8.5839 & TRN & \\
\hline CHEMBL3694152 & 1528067 & 8.3979 & 9.238 & TRN & \\
\hline CHEMBL3697875 & 1528067 & 8.0 & 8.0759 & TRN & \\
\hline CHEMBL3694095 & 1528067 & 9.0 & 8.3591 & TRN & \\
\hline CHEMBL3694033 & 1528067 & 9.0 & 8.8827 & TRN & \\
\hline CHEMBL3689920 & 1528067 & 7.6576 & 7.7004 & TRN & \\
\hline CHEMBL3697737 & 1528067 & 3.8239 & 4.7631 & TRN & \\
\hline CHEMBL3697758 & 1528067 & 3.8239 & 5.1511 & TST & \\
\hline CHEMBL3697913 & 1528067 & 8.301 & 7.6987 & TST & \\
\hline CHEMBL3641078 & 1528067 & 8.0969 & 8.1808 & TRN & \\
\hline CHEMBL3641066 & 1528067 & 6.5654 & 8.2012 & TRN & \\
\hline CHEMBL3641157 & 1528067 & 7.9208 & 7.3541 & TST & \\
\hline CHEMBL3694140 & 1528067 & 8.699 & 8.1473 & TRN & \\
\hline CHEMBL3694148 & 1528067 & 8.1549 & 8.3211 & TRN & \\
\hline CHEMBL 3641050 & 1528067 & 10.0 & 9.0872 & TRN & \\
\hline CHEMBL3697725 & 1528067 & 4.1549 & 5.2328 & TST & \\
\hline CHEMBL3641196 & 1528067 & 10.0 & 9.4314 & TST & \\
\hline CHEMBL 3694142 & 1528067 & 9.0 & 7.973 & TRN & \\
\hline CHEMBL3694047 & 1528067 & 7.3872 & 7.8916 & TRN & \\
\hline CHEMBL 3694014 & 1528067 & 10.0 & 9.2032 & TRN & \\
\hline CHEMBL3694128 & 1528067 & 5.3798 & 5.76 & TRN & \\
\hline CHEMBL3694109 & 1528067 & 6.3458 & 6.54299 & 9999999999 & TRN \\
\hline CHEMBL3641243 & 1528067 & 7.2291 & 7.3888 & TRN & \\
\hline CHEMBL3641193 & 1528067 & 7.5686 & 7.1322 & TST & \\
\hline CHEMBL 3697785 & 1528067 & 8.2218 & 8.4816 & TRN & \\
\hline CHEMBL3641145 & 1528067 & 6.2351 & 7.0501 & TRN & \\
\hline CHEMBL3639929 & 1528067 & 7.3468 & 7.6594 & TRN & \\
\hline CHEMBL3689935 & 1528067 & 8.3979 & 8.4285 & TST & \\
\hline CHEMBL3641128 & 1528067 & 9.0 & 8.4261 & TST & \\
\hline CHEMBL 3697879 & 1528067 & 8.0969 & 8.7577 & TRN & \\
\hline CHEMBL 3697845 & 1528067 & 8.3979 & 8.3925 & TRN & \\
\hline CHEMBL3694201 & 1528067 & 8.5229 & 8.6444 & TRN & \\
\hline CHEMBL3689917 & 1528067 & 8.5229 & 8.3862 & TRN & \\
\hline CHEMBL3641031 & 1528067 & 8.2218 & 8.3518 & TRN & \\
\hline CHEMBL3641088 & 1528067 & 8.699 & 9.0938 & TRN & \\
\hline CHEMBL3641213 & 1528067 & 7.8861 & 8.1236 & TRN & \\
\hline CHEMBL3641239 & 1528067 & 8.3979 & 8.4833 & TRN & \\
\hline CHEMBL3694172 & 1528067 & 9.0 & 9.4635 & TRN & \\
\hline CHEMBL3694199 & 1528067 & 8.5229 & 8.8551 & TRN & \\
\hline CHEMBL 3697874 & 1528067 & 8.2218 & 8.8745 & TRN & \\
\hline CHEMBL 3643284 & 1528067 & 7.3098 & 5.1849 & TST & \\
\hline CHEMBL3689933 & 1528067 & 8.699 & 8.6646 & TRN & \\
\hline CHEMBL 3694120 & 1528067 & 5.7383 & 5.8224 & TRN & \\
\hline CHEMBL 3641082 & 1528067 & 8.699 & \multicolumn{2}{|c|}{8.966000000000001} & TRN \\
\hline CHEMBL3641111 & 1528067 & 8.699 & 8.9599 & TRN & \\
\hline CHEMBL3641151 & 1528067 & 9.0 & 8.6077 & TRN & \\
\hline CHEMBL 3694225 & 1528067 & 8.0458 & 8.1305 & TRN & \\
\hline CHEMBL 3694052 & 1528067 & 7.8239 & 7.4586 & TST & \\
\hline
\end{tabular}


Supplemental Table S2.txt

\begin{tabular}{|c|c|c|c|c|c|}
\hline CHEMBL 3689923 & 1528067 & 8.0458 & 8.1968 & TRN & \\
\hline CHEMBL3694202 & 1528067 & 8.301 & 8.7545 & TRN & \\
\hline CHEMBL3641089 & 1528067 & 10.0 & 9.0989 & TRN & \\
\hline CHEMBL 3697782 & 1528067 & 5.9492 & 6.4727 & TRN & \\
\hline CHEMBL3697809 & 1528067 & 7.8239 & 8.4363 & TRN & \\
\hline CHEMBL 3694121 & 1528067 & 7.0555 & 6.2329 & TRN & \\
\hline CHEMBL 3641046 & 1528067 & 9.0 & 8.9835 & TRN & \\
\hline CHEMBL 3641057 & 1528067 & 8.1549 & 8.7197 & TST & \\
\hline CHEMBL 3697883 & 1528067 & 9.0 & 9.2606 & TRN & \\
\hline CHEMBL3641205 & 1528067 & 8.2218 & 7.3344 & TST & \\
\hline CHEMBL 3697731 & 1528067 & 3.8239 & 4.6878 & TRN & \\
\hline CHEMBL3694097 & 1528067 & 8.699 & 8.7449 & TRN & \\
\hline CHEMBL3697863 & 1528067 & 8.699 & 8.812999 & 9999999999 & TRN \\
\hline CHEMBL 3694164 & 1528067 & 8.3979 & 8.3224 & TRN & \\
\hline CHEMBL3697872 & 1528067 & 6.3546 & 7.4442 & TST & \\
\hline CHEMBL 3697727 & 1528067 & 7.7696 & 7.8459 & TST & \\
\hline CHEMBL 3641148 & 1528067 & 8.2218 & 8.1918 & TRN & \\
\hline CHEMBL3697937 & 1528067 & 8.3979 & 8.5935 & TRN & \\
\hline CHEMBL3689918 & 1528067 & 7.2441 & 7.459 & TRN & \\
\hline CHEMBL3689919 & 1528067 & 7.301 & 7.4344 & TRN & \\
\hline CHEMBL3697801 & 1528067 & 7.6383 & 7.4046 & TST & \\
\hline CHEMBL 3641134 & 1528067 & 10.0 & 8.861 & TST & \\
\hline CHEMBL3697916 & 1528067 & 5.699 & 6.7509 & TST & \\
\hline CHEMBL3697778 & 1528067 & 8.3979 & 8.462 & TRN & \\
\hline CHEMBL 3697818 & 1528067 & 8.699 & 8.7867 & TRN & \\
\hline CHEMBL3694223 & 1528067 & 8.2218 & 8.2768 & TRN & \\
\hline CHEMBL 3641055 & 1528067 & 10.0 & 8.7678 & TST & \\
\hline CHEMBL3641125 & 1528067 & 10.0 & 9.6454 & TRN & \\
\hline CHEMBL 3641200 & 1528067 & 8.699 & 9.158 & TST & \\
\hline CHEMBL 3641140 & 1528067 & 8.5229 & 8.8193 & TRN & \\
\hline CHEMBL 3641227 & 1528067 & 8.699 & 8.5884 & TRN & \\
\hline CHEMBL 3697834 & 1528067 & 7.8861 & 8.1431 & TRN & \\
\hline CHEMBL3694219 & 1528067 & 8.5229 & 8.715 & TRN & \\
\hline CHEMBL 3641113 & 1528067 & 8.699 & 8.8556 & TST & \\
\hline CHEMBL 3697934 & 1528067 & 9.0 & 9.1166 & TRN & \\
\hline CHEMBL3697815 & 1528067 & 7.4815 & 7.9535 & TRN & \\
\hline CHEMBL 3689944 & 1528067 & 7.6778 & 8.1125 & TST & \\
\hline CHEMBL 3694146 & 1528067 & 8.0969 & 8.418 & TRN & \\
\hline CHEMBL 3641094 & 1528067 & 9.0 & 9.1016 & TRN & \\
\hline CHEMBL3697799 & 1528067 & 6.5702 & 5.9562 & TRN & \\
\hline CHEMBL 3697907 & 1528067 & 9.0 & 8.8895 & TST & \\
\hline CHEMBL3694057 & 1528067 & 8.1549 & 7.9881 & TRN & \\
\hline CHEMBL3694150 & 1528067 & 8.5229 & 8.1011 & TRN & \\
\hline CHEMBL3641137 & 1528067 & 8.5229 & 8.86 & TST & \\
\hline CHEMBL3697823 & 1528067 & 7.0555 & 6.7731 & TRN & \\
\hline CHEMBL3694195 & 1528067 & 10.0 & 10.0841 & TRN & \\
\hline CHEMBL3694116 & 1528067 & 6.4976 & 6.7812 & TST & \\
\hline CHEMBL 3697882 & 1528067 & 7.3872 & 7.7019 & TST & \\
\hline
\end{tabular}

Page 23244 
Supplemental Table S2.txt

\begin{tabular}{|c|c|c|c|c|}
\hline HEMBL & 528067 & & 8.217 & $\cdots$ \\
\hline HEMBL 3641042 & 528067 & 8.5229 & 8.7342 & \\
\hline HFMBI & 28067 & 9.0 & & \\
\hline AEMBL369 & 28067 & & & \\
\hline HEMBL3694206 & 528067 & 10.0 & 8072 & \\
\hline HEMBL3697776 & 528067 & 8.2218 & .3301 & \\
\hline AEMBL & 28067 & 8.301 & .726 & \\
\hline HEMBL369 & 28067 & & & DN \\
\hline HEMBL3694087 & 528067 & 8.301 & 9328 & \\
\hline HEMBL3641131 & 528067 & 10.0 & 4101 & \\
\hline HEMBL 364 & 528067 & & 8561 & \\
\hline AEMBL & 528067 & 5. & 8992 & ST \\
\hline HEMBL3 & 8067 & & 4245 & \\
\hline HEMBL3641122 & 528067 & 9.0 & 7239 & $\mid$ \\
\hline HEMBL 369 & 528067 & 7.32 & & I nIV \\
\hline HEMBL3 & 8067 & 8 . & 7129 & 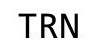 \\
\hline HEMBL & 28067 & & & RN \\
\hline HEMBL & 528067 & & & $\mathrm{RN}$ \\
\hline HEMBL3 & 528067 & 9 . & 4779 & w \\
\hline HEMBL 364 & 528067 & 5 & & 131 \\
\hline HEMBL & 67 & 6 & 46 & RN \\
\hline HEM & 67 & & 35 & RN \\
\hline AEMBL & 528067 & 7. & - & $\mathrm{RN}$ \\
\hline HEMBL3 & 528067 & 7. & & I RIV \\
\hline HEMBL369 & 3067 & & & | \\
\hline HEMBL3 & 8067 & 8 & 3 & 「RN \\
\hline HEME & 3067 & 9. & & RN \\
\hline HFMP & 3067 & 7. & 736 & RN \\
\hline HEMBL3 & 67 & & 75 & IRIN \\
\hline AEMBL369 & 528067 & 8. & 4715 & TRN \\
\hline HEMBL & 8067 & 8 & 53 & ST \\
\hline HFM & 57 & & & 「RN \\
\hline (15MP & & & & TST \\
\hline HEMBL3 & 28067 & 8.522 & 779 & TRN \\
\hline HEMBL369 & 528067 & 9 & 394 & ГRN \\
\hline AFMRI: & 3067 & & & TRN \\
\hline 0 & 57 & & & ГRN \\
\hline HEMBL3 & & 9. & 3853 & TRN \\
\hline HEMBL3 & 528067 & 5.69 & 33 & TST \\
\hline TIDL & 3067 & 9 & & 「RN \\
\hline HEMBL3 & 528067 & 8 . & 23 & TRN \\
\hline HEMBL3 & 528067 & 8.699 & 458 & RN \\
\hline HEMBL3 & 528067 & 8.2 & 5962 & ГRN \\
\hline HEMBL3 & 528067 & 7. & & TR \\
\hline CHFMRI 369 & $6 /$ & & & RN \\
\hline HEMBL3 & 1528067 & 10.0 & & \\
\hline HEMBL 36 & 1528067 & 7.8861 & 7095 & RN \\
\hline CHEMBL3697850 & 1528067 & 8.699 & 9.0474 & TRN \\
\hline
\end{tabular}

Page 23245 


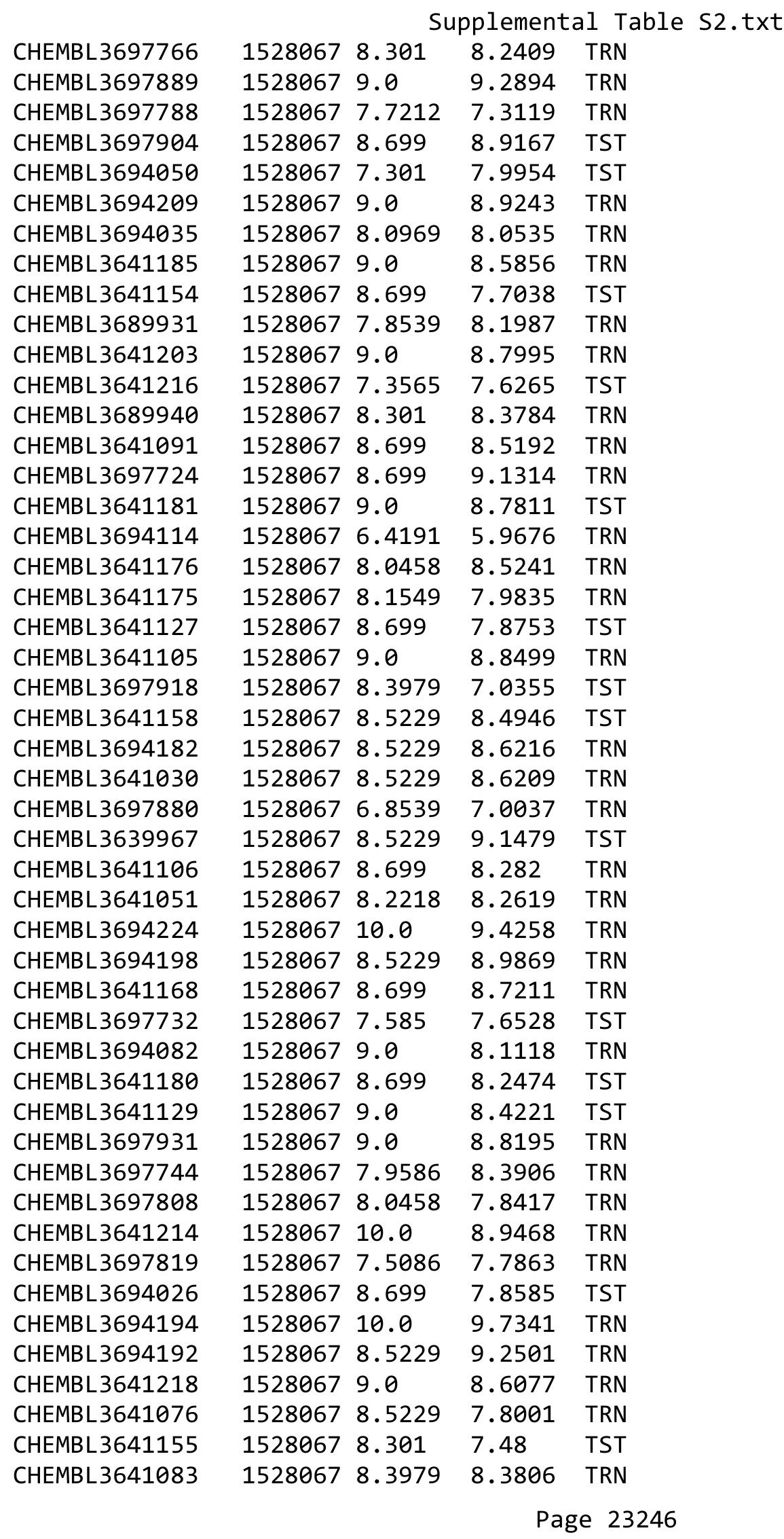




\begin{tabular}{|c|c|c|c|c|c|}
\hline \multicolumn{6}{|c|}{ Supplemental Table S2.txt } \\
\hline CHEMBL3697860 & 1528067 & 10.0 & 9.5533 & TRN & \\
\hline CHEMBL 3694129 & 1528067 & 5.9435 & 6.7233 & TST & \\
\hline CHEMBL3641207 & 1528067 & 9.0 & 8.936 & TRN & \\
\hline CHEMBL 3641085 & 1528067 & 9.0 & 9.0166 & TRN & \\
\hline CHEMBL3641162 & 1528067 & 10.0 & 8.5579 & TST & \\
\hline CHEMBL3697796 & 1528067 & 7.3979 & 6.6495 & TRN & \\
\hline CHEMBL3694036 & 1528067 & 7.7212 & 7.8936 & TRN & \\
\hline CHEMBL3689928 & 1528067 & 7.8239 & 7.8356 & TRN & \\
\hline CHEMBL 3694060 & 1528067 & 7.3979 & 7.9481 & TRN & \\
\hline CHEMBL3694221 & 1528067 & 8.301 & 8.1801 & TRN & \\
\hline CHEMBL 3694018 & 1528067 & 10.0 & 9.4637 & TRN & \\
\hline CHEMBL 3697761 & 1528067 & 4.0 & 4.492 & TRN & \\
\hline CHEMBL 3643296 & 1528067 & 8.3979 & 8.3015 & TRN & \\
\hline CHEMBL 3641124 & 1528067 & 8.301 & 8.4491 & TRN & \\
\hline CHEMBL3689912 & 1528067 & 8.3979 & 8.869 & TRN & \\
\hline CHEMBL 3694186 & 1528067 & 8.5229 & 8.4415 & TRN & \\
\hline CHEMBL3694220 & 1528067 & 8.1549 & 8.3217 & TRN & \\
\hline CHEMBL3689909 & 1528067 & 9.0 & 8.9189 & TRN & \\
\hline CHEMBL 3641056 & 1528067 & 8.699 & 7.5206 & TST & \\
\hline CHEMBL3697843 & 1528067 & 9.0 & 9.1434 & TRN & \\
\hline CHEMBL3694168 & 1528067 & 8.699 & 8.6423 & TRN & \\
\hline CHEMBL 3641133 & 1528067 & 8.699 & 8.6293 & TST & \\
\hline CHEMBL 3697820 & 1528067 & 8.5229 & 7.6486 & TRN & \\
\hline CHEMBL 3694183 & 1528067 & 8.699 & 8.4731 & TRN & \\
\hline CHEMBL3641166 & 1528067 & 9.0 & 8.9216 & TRN & \\
\hline CHEMBL 3697855 & 1528067 & 7.301 & 7.16100 & 00000000005 & TRN \\
\hline CHEMBL 3697746 & 1528067 & 6.0128 & 6.4458 & TRN & \\
\hline CHEMBL3694184 & 1528067 & 8.699 & 8.5122 & TRN & \\
\hline CHEMBL 3697798 & 1528067 & 8.0969 & 7.4724 & TST & \\
\hline CHEMBL3689911 & 1528067 & 8.699 & 8.5527 & TRN & \\
\hline CHEMBL 3697861 & 1528067 & 8.5229 & 8.0163 & TRN & \\
\hline CHEMBL3641190 & 1528067 & 7.1308 & 6.806 & TST & \\
\hline CHEMBL 3694090 & 1528067 & 8.0969 & 8.3387 & TRN & \\
\hline CHEMBL3694208 & 1528067 & 10.0 & 9.2845 & TST & \\
\hline CHEMBL3694028 & 1528067 & 8.1549 & 8.1843 & TRN & \\
\hline CHEMBL3697754 & 1528067 & 4.699 & 4.8089 & TRN & \\
\hline CHEMBL3697927 & 1528067 & 8.699 & 8.5693 & TST & \\
\hline CHEMBL 3641170 & 1528067 & 7.7447 & 8.4579 & TRN & \\
\hline CHEMBL3641188 & 1528067 & 7.5528 & 7.4965 & TST & \\
\hline CHEMBL3643283 & 1528067 & 5.0 & 4.8909 & TST & \\
\hline CHEMBL 3641092 & 1528067 & 8.3979 & 8.4278 & TST & \\
\hline CHEMBL3641026 & 1528067 & 8.699 & 8.703 & TRN & \\
\hline CHEMBL 3639887 & 1528067 & 8.0458 & 8.1742 & TRN & \\
\hline CHEMBL3694101 & 1528067 & 8.301 & 8.269 & TRN & \\
\hline CHEMBL3641059 & 1528067 & 8.2218 & 7.934 & TRN & \\
\hline CHEMBL 3694061 & 1528067 & 7.8861 & 8.1078 & TRN & \\
\hline CHEMBL3694111 & 1528067 & 5.0 & 6.0516 & TRN & \\
\hline CHEMBL3697866 & 1528067 & 9.0 & 9.3287 & TRN & \\
\hline
\end{tabular}




\begin{tabular}{|c|c|c|c|c|c|}
\hline \multicolumn{6}{|c|}{ Supplemental Table S2.txt } \\
\hline CHEMBL3694169 & 1528067 & 9.0 & 9.0823 & TRN & \\
\hline CHEMBL3694016 & 1528067 & 9.0 & 8.9682 & TRN & \\
\hline CHEMBL3694088 & 1528067 & 8.699 & 8.8776 & TRN & \\
\hline CHEMBL 3697756 & 1528067 & 4.699 & 4.8292 & TRN & \\
\hline CHEMBL3697919 & 1528067 & 8.0969 & 7.4235 & TST & \\
\hline CHEMBL3694021 & 1528067 & 10.0 & 9.1792 & TRN & \\
\hline CHEMBL3697865 & 1528067 & 10.0 & 9.5652 & TRN & \\
\hline CHEMBL3694179 & 1528067 & 8.699 & 8.5066 & TRN & \\
\hline CHEMBL3641037 & 1528067 & 9.0 & 9.5596 & TRN & \\
\hline CHEMBL3694068 & 1528067 & 8.699 & 8.5102 & TRN & \\
\hline CHEMBL3641121 & 1528067 & 8.3979 & 8.8414 & TST & \\
\hline CHEMBL 3697760 & 1528067 & 7.2518 & 6.8656 & TRN & \\
\hline CHEMBL3697741 & 1528067 & 7.2291 & 7.3018 & TST & \\
\hline CHEMBL3697909 & 1528067 & 8.699 & 8.6438 & TST & \\
\hline CHEMBL3641183 & 1528067 & 10.0 & 8.7281 & TST & \\
\hline CHEMBL3641202 & 1528067 & 10.0 & 9.173 & TRN & \\
\hline CHEMBL3697783 & 1528067 & 8.699 & 8.7036 & TRN & \\
\hline CHEMBL3697793 & 1528067 & 9.0 & 8.1487 & TRN & \\
\hline CHEMBL3697769 & 1528067 & 7.8239 & 8.1104 & TRN & \\
\hline CHEMBL3641169 & 1528067 & 8.5229 & 8.5752 & TRN & \\
\hline CHEMBL3641167 & 1528067 & 7.7696 & 8.6684 & TRN & \\
\hline CHEMBL3697728 & 1528067 & 6.6108 & 6.9551 & TRN & \\
\hline CHEMBL3641186 & 1528067 & 8.5229 & 8.1212 & TST & \\
\hline CHEMBL 3697800 & 1528067 & 5.699 & 4.6192 & TRN & \\
\hline CHEMBL3697764 & 1528067 & 6.5331 & 6.6575 & TRN & \\
\hline CHEMBL3689925 & 1528067 & 7.1549 & 7.2655 & TRN & \\
\hline CHEMBL3694013 & 1528067 & 10.0 & 9.1602 & TRN & \\
\hline CHEMBL3694104 & 1528067 & 9.0 & 8.8257 & TRN & \\
\hline CHEMBL3689924 & 1528067 & 8.5229 & 8.4446 & TRN & \\
\hline CHEMBL3641221 & 1528067 & 8.5229 & 8.3402 & TST & \\
\hline CHEMBL3641165 & 1528067 & 8.3979 & 7.8597 & TRN & \\
\hline CHEMBL 3697740 & 1528067 & 4.699 & 5.3057 & TRN & \\
\hline CHEMBL3641047 & 1528067 & 9.0 & 9.3233 & TRN & \\
\hline CHEMBL3694156 & 1528067 & 9.0 & 8.4534 & TRN & \\
\hline CHEMBL3641195 & 1528067 & 9.0 & 7.37 & TST & \\
\hline CHEMBL3697873 & 1528067 & 7.7696 & 8.2262 & TRN & \\
\hline CHEMBL3697852 & 1528067 & 6.9431 & 7.432 & TRN & \\
\hline CHEMBL3643302 & 1528067 & 7.8861 & 7.3727 & TST & \\
\hline CHEMBL 3694215 & 1528067 & 10.0 & 8.844 & TRN & \\
\hline CHEMBL3697786 & 1528067 & 8.3979 & 7.8681 & TST & \\
\hline CHEMBL3641064 & 1528067 & 8.2218 & 8.815 & TRN & \\
\hline CHEMBL3694048 & 1528067 & 7.301 & 7.4708 & TRN & \\
\hline CHEMBL3694025 & 1528067 & 10.0 & 8.9068 & TRN & \\
\hline CHEMBL3694181 & 1528067 & 8.5229 & 9.31299 & 9999999999 & TRN \\
\hline CHEMBL3697772 & 1528067 & 6.9957 & 6.8307 & TRN & \\
\hline CHEMBL3694024 & 1528067 & 8.5229 & 8.4833 & TRN & \\
\hline CHEMBL3697829 & 1528067 & 8.5229 & 8.0847 & TRN & \\
\hline CHEMBL3697832 & 1528067 & 9.0 & 9.4182 & TRN & \\
\hline
\end{tabular}


Supplemental Table S2.txt

\begin{tabular}{|c|c|c|c|c|}
\hline CHEMBL3697910 & 1528067 & 7.8539 & 8.288 & TRN \\
\hline CHEMBL3641198 & 1528067 & 9.0 & 9.9547 & TST \\
\hline CHEMBL3641173 & 1528067 & 7.6383 & 8.3314 & TRN \\
\hline CHEMBL 3694207 & 1528067 & 8.699 & 9.177 & TRN \\
\hline CHEMBL3694139 & 1528067 & 7.9586 & 8.0587 & TRN \\
\hline CHEMBL3697777 & 1528067 & 7.5376 & 8.1309 & TRN \\
\hline CHEMBL3641209 & 1528067 & 8.2218 & 8.2824 & TST \\
\hline CHEMBL3694132 & 1528067 & 8.2218 & 8.3903 & TRN \\
\hline CHEMBL 3641161 & 1528067 & 8.3979 & 8.8009 & TRN \\
\hline CHEMBL3694131 & 1528067 & 8.0969 & 8.185 & TRN \\
\hline CHEMBL3641098 & 1528067 & 8.3979 & 8.4256 & TRN \\
\hline CHEMBL3641160 & 1528067 & 8.699 & 8.9087 & TRN \\
\hline CHEMBL3694053 & 1528067 & 8.699 & 8.1213 & TRN \\
\hline CHEMBL3641071 & 1528067 & 8.699 & 8.4001 & TRN \\
\hline CHEMBL3697753 & 1528067 & 7.9586 & 7.4603 & TRN \\
\hline CHEMBL3697830 & 1528067 & 6.5622 & 7.8595 & TST \\
\hline CHEMBL3697856 & 1528067 & 8.699 & 8.2857 & TRN \\
\hline CHEMBL3694166 & 1528067 & 9.0 & 8.9293 & TRN \\
\hline CHEMBL3697771 & 1528067 & 8.699 & 8.1116 & TRN \\
\hline CHEMBL3697894 & 1528067 & 10.0 & 9.6189 & TST \\
\hline CHEMBL3641108 & 1528067 & 8.699 & 8.6085 & TRN \\
\hline CHEMBL3694228 & 1528067 & 8.3979 & 8.5042 & TRN \\
\hline CHEMBL3697827 & 1528067 & 5.8539 & 7.57100 & 0000000001 \\
\hline CHEMBL3641043 & 1528067 & 9.0 & 9.6261 & TRN \\
\hline CHEMBL 3694045 & 1528067 & 8.0 & 8.3702 & TRN \\
\hline CHEMBL3694067 & 1528067 & 8.699 & 8.9496 & TRN \\
\hline CHEMBL3694190 & 1528067 & 8.5229 & 8.6216 & TRN \\
\hline CHEMBL3903788 & 1528067 & 5.1549 & 4.6462 & TST \\
\hline CHEMBL 3641241 & 1528067 & 7.8861 & 7.8395 & TRN \\
\hline CHEMBL 3694227 & 1528067 & 10.0 & 8.9263 & TST \\
\hline CHEMBL3694062 & 1528067 & 8.0458 & 7.9332 & TST \\
\hline CHEMBL3694119 & 1528067 & 5.7014 & 5.5347 & TRN \\
\hline CHEMBL3697839 & 1528067 & 9.0 & 9.4865 & TRN \\
\hline CHEMBL 3643301 & 1528067 & 7.5229 & 7.0666 & TST \\
\hline CHEMBL 3641025 & 1528067 & 9.0 & 8.372 & TRN \\
\hline CHEMBL3697854 & 1528067 & 8.3979 & 8.6748 & TRN \\
\hline CHEMBL3694034 & 1528067 & 8.699 & 8.6052 & TRN \\
\hline CHEMBL3694076 & 1528067 & 8.0458 & 8.1401 & TRN \\
\hline CHEMBL3697789 & 1528067 & 10.0 & 8.6334 & TRN \\
\hline CHEMBL3694096 & 1528067 & 9.0 & 8.7554 & TRN \\
\hline CHEMBL3697862 & 1528067 & 7.8539 & 8.2968 & TRN \\
\hline CHEMBL3697923 & 1528067 & 8.3979 & 8.997 & TRN \\
\hline CHEMBL3694214 & 1528067 & 10.0 & 10.5226 & TRN \\
\hline CHEMBL3639400 & 1528067 & 7.1871 & 6.6553 & TRN \\
\hline CHEMBL3694071 & 1528067 & 8.5229 & 8.5981 & TRN \\
\hline CHEMBL3694231 & 1528067 & 9.0 & 9.44 & TRN \\
\hline CHEMBL3697721 & 1528067 & 8.699 & 8.5874 & TRN \\
\hline CHEMBL3697911 & 1528067 & 8.699 & 9.1361 & TRN \\
\hline
\end{tabular}




\begin{tabular}{|c|c|c|c|c|}
\hline \multicolumn{5}{|c|}{ Supplemental Table S2.txt } \\
\hline CHEMBL3641097 & 1528067 & 9.0 & 8.8834 & TRN \\
\hline CHEMBL3689916 & 1528067 & 9.0 & 8.5093 & TRN \\
\hline CHEMBL 3694145 & 1528067 & 7.699 & 8.0151 & TRN \\
\hline CHEMBL 3697844 & 1528067 & 8.301 & 8.2661 & TRN \\
\hline CHEMBL 3697749 & 1528067 & 4.0 & 4.5195 & TST \\
\hline CHEMBL 3697840 & 1528067 & 7.7696 & 8.3317 & TST \\
\hline CHEMBL3694039 & 1528067 & 6.1701 & 6.8377 & TST \\
\hline CHEMBL 3694015 & 1528067 & 9.0 & 8.9824 & TRN \\
\hline CHEMBL 3689905 & 1528067 & 7.1675 & 7.8075 & TST \\
\hline CHEMBL3694072 & 1528067 & 8.1549 & 8.5541 & TRN \\
\hline CHEMBL3694044 & 1528067 & 8.0458 & 7.8173 & TRN \\
\hline CHEMBL3697765 & 1528067 & 8.0969 & 8.021 & TRN \\
\hline CHEMBL3694075 & 1528067 & 8.699 & 8.9523 & TRN \\
\hline CHEMBL 3694083 & 1528067 & 8.5229 & 8.2807 & TRN \\
\hline CHEMBL3641029 & 1528067 & 8.699 & 8.6056 & TRN \\
\hline CHEMBL3697717 & 1528067 & 10.0 & 10.1608 & TRN \\
\hline CHEMBL 3641226 & 1528067 & 7.1427 & 7.2651 & TST \\
\hline CHEMBL3697752 & 1528067 & 8.699 & 9.3443 & TRN \\
\hline CHEMBL 3641087 & 1528067 & 8.699 & 8.0219 & TST \\
\hline CHEMBL3694030 & 1528067 & 8.699 & 9.0341 & TRN \\
\hline CHEMBL3697729 & 1528067 & 3.8239 & 4.6373 & TRN \\
\hline CHEMBL3697921 & 1528067 & 5.8539 & 5.3643 & TST \\
\hline CHEMBL3697930 & 1528067 & 10.0 & 8.9096 & TST \\
\hline CHEMBL3697792 & 1528067 & 7.5376 & 6.7358 & TRN \\
\hline CHEMBL3697877 & 1528067 & 7.2518 & 7.8832 & TRN \\
\hline CHEMBL3697735 & 1528067 & 3.8239 & 4.7737 & TRN \\
\hline CHEMBL 3643290 & 1528067 & 6.2832 & 5.2541 & TST \\
\hline CHEMBL3697922 & 1528067 & 10.0 & 8.8669 & TRN \\
\hline CHEMBL 3697825 & 1528067 & 5.0 & 7.0546 & TST \\
\hline CHEMBL3694158 & 1528067 & 8.699 & 8.5534 & TRN \\
\hline CHEMBL3689937 & 1528067 & 8.2218 & 8.4712 & TRN \\
\hline CHEMBL 3641159 & 1528067 & 9.0 & 8.4565 & TST \\
\hline CHEMBL3694149 & 1528067 & 10.0 & 8.6749 & TRN \\
\hline CHEMBL3694218 & 1528067 & 10.0 & 10.1543 & TRN \\
\hline CHEMBL3697912 & 1528067 & 9.0 & 8.9609 & TRN \\
\hline CHEMBL3641093 & 1528067 & 8.699 & 9.1571 & TRN \\
\hline CHEMBL 3694064 & 1528067 & 8.699 & 8.849 & TRN \\
\hline CHEMBL3641114 & 1528067 & 8.5229 & 7.4351 & TST \\
\hline CHEMBL 3694092 & 1528067 & 8.699 & 8.5551 & TRN \\
\hline CHEMBL3694155 & 1528067 & 9.0 & 9.0334 & TST \\
\hline CHEMBL3697759 & 1528067 & 8.5229 & 8.7617 & TRN \\
\hline CHEMBL 3697822 & 1528067 & 8.2218 & 8.6694 & TRN \\
\hline CHEMBL3697791 & 1528067 & 6.3372 & 6.4706 & TRN \\
\hline CHEMBL 3641139 & 1528067 & 8.5229 & 8.9695 & TRN \\
\hline CHEMBL3641036 & 1528067 & 8.0458 & 8.2081 & TST \\
\hline CHEMBL3641150 & 1528067 & 8.3979 & 8.3452 & TRN \\
\hline CHEMBL 3641049 & 1528067 & 8.301 & 8.1844 & TRN \\
\hline CHEMBL3689908 & 1528067 & 8.5229 & 8.8102 & TRN \\
\hline
\end{tabular}


Supplemental Table S2.txt

\begin{tabular}{|c|c|c|c|c|}
\hline 891 & יל & 0 & 749 & תבני \\
\hline HEMBL3697748 & 528067 & 4.699 & 4154 & \\
\hline AEMBL3689914 & 528067 & 9.0 & 3455 & \\
\hline 913 & 28067 & 8.5229 & & \\
\hline IEMBL3697784 & 28067 & 605 & 852 & \\
\hline AEMBL3641048 & 528067 & 7.9208 & $\partial 195$ & \\
\hline AEMBL3689926 & 528067 & 7.0809 & .2241 & \\
\hline HEMBL3694196 & 528067 & & 5441 & \\
\hline AEMBL36 & 528067 & 7.4949 & 3698 & \\
\hline IEMBL3 & 528067 & 6.9208 & 7588 & \\
\hline AEMBL3641211 & 528067 & 9.0 & 9304 & \\
\hline AEMBL3697903 & 528067 & 8.5229 & 3547 & \\
\hline AEMBL3694049 & 528067 & 7.0915 & 58 & \\
\hline AEMBL & 528067 & 9.0 & & \\
\hline AEMBL & 528067 & 9.0 & & \\
\hline AEMBL3 & 528067 & 8.699 & 79 & \\
\hline AEMBL3694141 & 528067 & & & \\
\hline IEMBL & 528067 & 9.0 & 75 & \\
\hline HEMBL & 3067 & 7.69 & 45 & \\
\hline AEMBL & 528067 & 8.0 & & \\
\hline AEMBL & 528067 & 8.301 & & \\
\hline HEMBL369 & 528067 & & & \\
\hline AEMBL & 528067 & 8.2 & 54 & \\
\hline 61 & 067 & 8.301 & & \\
\hline 939 & 3067 & 8 . & & \\
\hline 932 & 067 & 7.9208 & & \\
\hline IEMBL3694103 & 528067 & 8.699 & & \\
\hline 846 & 3067 & & & \\
\hline 197 & 5 & 7. & & \\
\hline 07 & 067 & 8 . & & \\
\hline HEMBL; & 067 & 8.699 & & \\
\hline HEMBL3641199 & 528067 & 9.0 & 243 & TS \\
\hline 08 & 067 & & & \\
\hline 16 & 57 & 7 & & KIV \\
\hline & 067 & 6.7905 & & \\
\hline AEMBL3641032 & 528067 & 8.301 & & $\mathrm{R}$ \\
\hline AEMBL3697739 & 528067 & 3.8239 & & ST \\
\hline & 528067 & & & \\
\hline 54 & 57 & 8. & 62 & $\mathrm{RN}$ \\
\hline & 528067 & 8.699 & 641 & $\mathrm{RN}$ \\
\hline AEMBL3694122 & 528067 & 6.0783 & & $\mathrm{R}$ \\
\hline AEMBL3641184 & 528067 & & & R \\
\hline 187 & 528067 & 8.699 & & \\
\hline CHEMBI & 528067 & 8.699 & 121 & $R$ \\
\hline AEMBL3697780 & 528067 & 7.8239 & 7.8416 & TS \\
\hline AEMBL3694102 & 528067 & 8.699 & 8.6873 & $\Gamma R$ \\
\hline & .528067 & 3.301 & & \\
\hline & & & & \\
\hline
\end{tabular}

Page 23251 


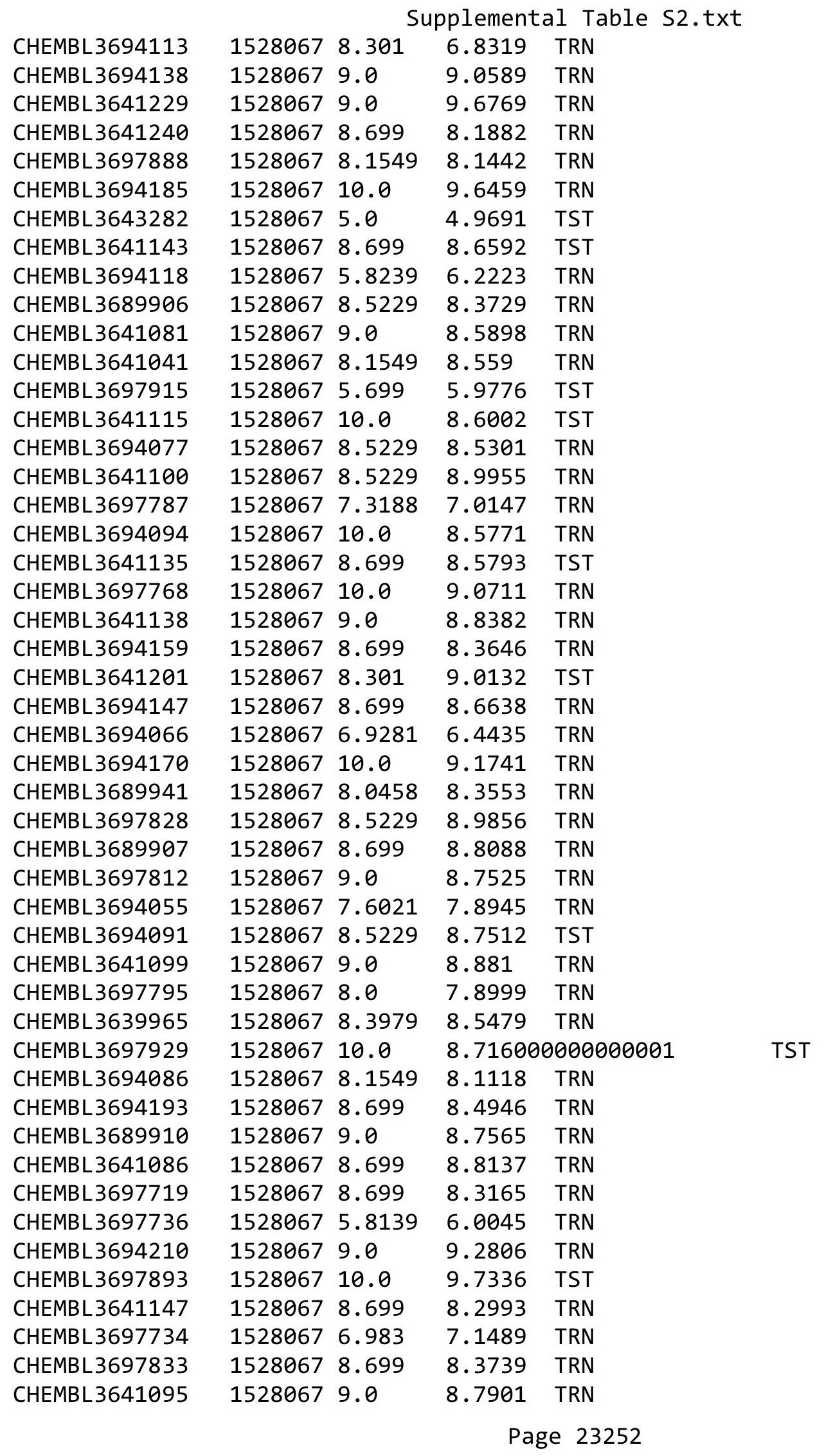


Supplemental Table S2.txt

\begin{tabular}{|c|c|c|c|c|}
\hline HEM & 528067 & & & mive \\
\hline & 528067 & 6.7144 & 8089 & \\
\hline AFMRI & 28067 & 549 & 567 & \\
\hline IEMBL369 & 28067 & 10.0 & 2205 & \\
\hline AEMBL3697762 & 528067 & 5229 & 4402 & \\
\hline HEMBL3697794 & 528067 & 8. & .9248 & \\
\hline 75 & 28067 & 9.0 & 1644 & \\
\hline AEMBL 36 & 28067 & & 1119 & 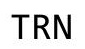 \\
\hline HEMBL 364 & 528067 & 7.3098 & .9134 & \\
\hline HEMBL369 & 528067 & 10.0 & .0266 & \\
\hline HEMBL369 & 528067 & 5.5406 & 5.9156 & \\
\hline AEMBL & 528067 & & 7853 & \\
\hline HEMBL; & 8067 & & 9395 & \\
\hline HEMBL 363 & 528067 & 8.3979 & .3293 & \\
\hline AEMBL369 & 528067 & 7.6383 & & \\
\hline AEMBL3 & 8067 & 9. & 5443 & Niv \\
\hline AEMBL & 3067 & & 049 & RN \\
\hline HEMBL & 8067 & 10.0 & 3732 & \\
\hline HEMBI 3 & 528067 & & 5123 & \\
\hline AEMBL3 & 3067 & 8 & 3616 & RIV \\
\hline HEMBL & 67 & & 036 & RN \\
\hline HEM & 67 & & 731 & Triv \\
\hline AEMBL & 3067 & 7.8539 & 7.2203 & ST \\
\hline HEMBL3 & 528067 & 9.0 & 072 & RN \\
\hline HEMBL369 & 67 & 7. & & SI \\
\hline HEMBL3 & 067 & 7 & 38 & ST \\
\hline HEM & 67 & & 38 & ST \\
\hline 02 & 67 & 239 & 497 & ST \\
\hline AEMBL3 & 67 & & & IST \\
\hline AEMBL36 & 528067 & 8. & 37 & TRN \\
\hline AEMBL & 3067 & 979 & 59 & ST \\
\hline 3 & 57 & 8 & & RN \\
\hline נ & & & 8.2235 & RN \\
\hline HEMBL3 & 28067 & 8.5229 & & RN \\
\hline HEMBL369 & 528067 & 652 & 403 & RN \\
\hline JEMPI & 67 & 9 & 89 & RN \\
\hline 3 & 57 & 8. & 23 & RN \\
\hline HEMBL3 & & & & TRN \\
\hline HEMBL3 & 528067 & & 3145 & ST \\
\hline 49 & 067 & & 97 & RN \\
\hline HEMBL3 & 3067 & 8 . & 315 & ST \\
\hline & 67 & 7.2366 & 3.0152 & RN \\
\hline AEMBL3 & 3067 & 7.8539 & .5822 & RN \\
\hline HEMBL3 & 528067 & 7. & & $R$ \\
\hline$y$ & & 539 & & \\
\hline HEMBL3 & 528067 & 10.0 & 9.0119 & \\
\hline HEMBL3 & .528067 & 7.0223 & 5.4387 & RN \\
\hline CHEMBL3697847 & 1528067 & 6.9393 & 7.1098 & TRN \\
\hline
\end{tabular}

Page 23253 


$$
\text { Supplemental Table S2.txt }
$$

\begin{tabular}{|c|c|c|c|c|c|}
\hline CHEMBL 3641074 & 1528067 & 8.0969 & 8.4776 & TRN & \\
\hline CHEMBL 3697885 & 1528067 & 10.0 & 9.2914 & TRN & \\
\hline CHEMBL3697774 & 1528067 & 8.301 & 8.2294 & TRN & \\
\hline CHEMBL 3641034 & 1528067 & 8.0 & 8.3877 & TST & \\
\hline CHEMBL 3697870 & 1528067 & 6.5346 & 6.4696 & TRN & \\
\hline CHEMBL3694205 & 1528067 & 8.699 & 8.6207 & TRN & \\
\hline CHEMBL 3694217 & 1528067 & 8.699 & 8.9929 & TRN & \\
\hline CHEMBL 3641053 & 1528067 & 10.0 & 9.1539 & TRN & \\
\hline CHEMBL 3641215 & 1528067 & 7.9208 & 8.3366 & TRN & \\
\hline CHEMBL3697742 & 1528067 & 7.7959 & 7.3401 & TST & \\
\hline CHEMBL 3697837 & 1528067 & 7.4437 & 7.9917 & TRN & \\
\hline CHEMBL 3641104 & 1528067 & 8.2218 & 8.0549 & TRN & \\
\hline CHEMBL 3689942 & 1528067 & 8.3979 & 8.4902 & TRN & \\
\hline CHEMBL 3641102 & 1528067 & 8.3979 & 9.0403 & TRN & \\
\hline CHEMBL3641182 & 1528067 & 8.699 & 8.6621 & TRN & \\
\hline CHEMBL 3697810 & 1528067 & 5.585 & 7.3281 & TST & \\
\hline CHEMBL 3643294 & 1528067 & 8.5229 & 8.6863 & TRN & \\
\hline CHEMBL3694157 & 1528067 & 8.2218 & 9.2534 & TRN & \\
\hline CHEMBL 3641109 & 1528067 & 8.301 & 8.7119 & TRN & \\
\hline CHEMBL 3697773 & 1528067 & 7.3872 & 7.1098 & TRN & \\
\hline CHEMBL3694175 & 1528067 & 8.699 & 8.6574 & TRN & \\
\hline CHEMBL 3697859 & 1528067 & 8.0458 & 8.8882 & TRN & \\
\hline CHEMBL 3641028 & 1528067 & 8.5229 & 8.7693 & TRN & \\
\hline CHEMBL 3641219 & 1528067 & 6.6556 & 7.4432 & TST & \\
\hline CHEMBL 3689929 & 1528067 & 7.4559 & 8.0871 & TRN & \\
\hline CHEMBL 3697925 & 1528067 & 8.699 & 8.7788 & TRN & \\
\hline CHEMBL3697905 & 1528067 & 8.5229 & 9.0706 & TST & \\
\hline CHEMBL3689936 & 1528067 & 8.3979 & 8.0178 & TRN & \\
\hline CHEMBL 3641063 & 1528067 & 8.699 & 8.7599 & TRN & \\
\hline CHEMBL 3697881 & 1528067 & 8.699 & 8.7508 & TRN & \\
\hline CHEMBL 3641224 & 1528067 & 8.699 & 8.3559 & TRN & \\
\hline CHEMBL 3641027 & 1528067 & 8.3979 & 9.1902 & TST & \\
\hline CHEMBL 3694058 & 1528067 & 8.1549 & 8.0072 & TRN & \\
\hline CHEMBL3694126 & 1528067 & 7.8861 & 6.8464 & TRN & \\
\hline CHEMBL 3694038 & 1528067 & 8.5229 & 8.3267 & TRN & \\
\hline CHEMBL 3694089 & 1528067 & 7.6198 & \multicolumn{2}{|c|}{8.027000000000001} & TRN \\
\hline CHEMBL 3641142 & 1528067 & 10.0 & 9.1852 & TRN & \\
\hline CHEMBL 3641084 & 1528067 & 8.699 & 8.7193 & TRN & \\
\hline CHEMBL3694191 & 1528067 & 8.699 & 9.1853 & TRN & \\
\hline CHEMBL 3694100 & 1528067 & 8.3979 & 9.0698 & TRN & \\
\hline CHEMBL 3641073 & 1528067 & 7.8861 & 7.9918 & TRN & \\
\hline CHEMBL3701957 & 1528586 & 7.1524 & 7.061 & TRN & \\
\hline CHEMBL3641725 & 1528586 & 8.2218 & 8.3076 & TRN & \\
\hline CHEMBL 3641740 & 1528586 & 8.5086 & 7.7525 & TRN & \\
\hline CHEMBL3701911 & 1528586 & 8.2596 & 7.3419 & TRN & \\
\hline CHEMBL 3701952 & 1528586 & 8.9208 & 9.2988 & TRN & \\
\hline CHEMBL 3641750 & 1528586 & 8.0506 & 7.8384 & TRN & \\
\hline CHEMBL3701934 & 1528586 & 8.0177 & 8.0827 & TRN & \\
\hline
\end{tabular}


Supplemental Table S2.txt

\begin{tabular}{|c|c|c|c|c|c|}
\hline CHEMBL3701936 & 1528586 & 6.8887 & 7.0985 & TRN & \\
\hline CHEMBL3641759 & 1528586 & 8.4949 & 8.8459 & TRN & \\
\hline CHEMBL3641746 & 1528586 & 6.0 & 6.5022 & TRN & \\
\hline CHEMBL3641749 & 1528586 & 7.6364 & 8.2441 & TRN & \\
\hline CHEMBL3701903 & 1528586 & 6.9126 & 7.4322 & TST & \\
\hline CHEMBL3641694 & 1528586 & 7.4134 & 6.947999 & 99999999995 & TST \\
\hline CHEMBL3701980 & 1528586 & 7.7905 & 7.2924 & TRN & \\
\hline CHEMBL3641695 & 1528586 & 6.0 & 6.4431 & TRN & \\
\hline CHEMBL3701982 & 1528586 & 8.8239 & 9.0179 & TRN & \\
\hline CHEMBL3701997 & 1528586 & 9.0969 & 8.5602 & TRN & \\
\hline CHEMBL 3640008 & 1528586 & 9.0969 & 8.5363 & TRN & \\
\hline CHEMBL3641726 & 1528586 & 6.8193 & 5.1132 & TRN & \\
\hline CHEMBL3641715 & 1528586 & 6.0 & 7.3854 & TST & \\
\hline CHEMBL3701931 & 1528586 & 7.4473 & 7.0792 & TRN & \\
\hline CHEMBL3641760 & 1528586 & 8.3279 & 7.7648 & TRN & \\
\hline CHEMBL3641732 & 1528586 & 7.8416 & 7.7052 & TRN & \\
\hline CHEMBL3701901 & 1528586 & 5.36799 & 999999999 & 6.3296 & TST \\
\hline CHEMBL3701933 & 1528586 & 8.3768 & 8.5363 & TRN & \\
\hline CHEMBL 3641702 & 1528586 & 6.0 & 6.0965 & TRN & \\
\hline CHEMBL3701943 & 1528586 & 9.1549 & 8.9651 & TRN & \\
\hline CHEMBL3701930 & 1528586 & 7.3449 & 7.8844 & TRN & \\
\hline CHEMBL3701990 & 1528586 & 7.6402 & 7.0169 & TRN & \\
\hline CHEMBL3701923 & 1528586 & 7.9245 & 7.2801 & TRN & \\
\hline CHEMBL 3702000 & 1528586 & 6.0 & 6.617999 & 9999999999 & TRN \\
\hline CHEMBL3641736 & 1528586 & 6.8601 & 6.9254 & TRN & \\
\hline CHEMBL 3641734 & 1528586 & 8.699 & 8.1034 & TRN & \\
\hline CHEMBL3701953 & 1528586 & 9.0969 & 8.886000 & 0000000001 & TRN \\
\hline CHEMBL3701906 & 1528586 & 6.0 & 6.7223 & TRN & \\
\hline CHEMBL3701955 & 1528586 & 7.4295 & 7.8921 & TRN & \\
\hline CHEMBL3701946 & 1528586 & 8.9208 & 9.1929 & TRN & \\
\hline CHEMBL3701969 & 1528586 & 6.2811 & 7.0099 & TRN & \\
\hline CHEMBL3701921 & 1528586 & 7.426 & 7.5989 & TRN & \\
\hline CHEMBL3641731 & 1528586 & 8.0757 & 7.3292 & TRN & \\
\hline CHEMBL 3641723 & 1528586 & 8.3565 & 7.5725 & TRN & \\
\hline CHEMBL3701998 & 1528586 & 6.0 & 6.3259 & TRN & \\
\hline CHEMBL3641717 & 1528586 & 7.9586 & 7.7102 & TRN & \\
\hline CHEMBL3641713 & 1528586 & 6.0 & 7.1241 & TST & \\
\hline CHEMBL3641728 & 1528586 & 8.3665 & 8.2166 & TRN & \\
\hline CHEMBL3641710 & 1528586 & 6.0 & 6.0485 & TRN & \\
\hline CHEMBL3641743 & 1528586 & 6.0 & 6.6298 & TRN & \\
\hline CHEMBL3641758 & 1528586 & 8.5229 & 8.6076 & TRN & \\
\hline CHEMBL3701994 & 1528586 & 6.0 & 6.4961 & TRN & \\
\hline CHEMBL3641698 & 1528586 & 6.0 & 6.4786 & TRN & \\
\hline CHEMBL3701904 & 1528586 & 6.0 & 7.626 & TRN & \\
\hline CHEMBL3641748 & 1528586 & 7.3778 & 7.7838 & TRN & \\
\hline CHEMBL3701922 & 1528586 & 7.289 & 7.0942 & TRN & \\
\hline CHEMBL3702013 & 1528586 & 8.1024 & 7.4093 & TST & \\
\hline \multirow[t]{2}{*}{ CHEMBL3702019 } & 1528586 & 6.0 & 5.83899 & 99999999995 & TRN \\
\hline & & \multicolumn{4}{|c|}{ Page 23255} \\
\hline
\end{tabular}


Supplemental Table S2.txt

\begin{tabular}{|c|c|c|c|c|c|}
\hline CHEMBL 3702018 & 1528586 & 8.2366 & 8.8585 & TRN & \\
\hline CHEMBL 3701941 & 1528586 & 8.6383 & 7.9048 & TRN & \\
\hline CHEMBL 3641724 & 1528586 & 8.0555 & 8.0546 & TRN & \\
\hline CHEMBL 3701974 & 1528586 & 7.8508 & 7.2281 & TRN & \\
\hline CHEMBL3701913 & 1528586 & 7.9136 & 6.9065 & TRN & \\
\hline CHEMBL 3641699 & 1528586 & 8.3372 & 7.4381 & TST & \\
\hline CHEMBL 3701960 & 1528586 & 7.2284 & 7.402 & TRN & \\
\hline CHEMBL 3701940 & 1528586 & 6.568 & 6.0363 & TRN & \\
\hline CHEMBL 3641700 & 1528586 & 6.0 & 6.1428 & TRN & \\
\hline CHEMBL 3701925 & 1528586 & 8.699 & 8.7 & TST & \\
\hline CHEMBL 3701978 & 1528586 & 8.3279 & 8.3922 & TRN & \\
\hline CHEMBL 3641733 & 1528586 & 8.0269 & 7.9738 & TRN & \\
\hline CHEMBL 3641751 & 1528586 & 8.0969 & 7.9634 & TRN & \\
\hline CHEMBL 3641735 & 1528586 & 7.2604 & 7.129 & TRN & \\
\hline CHEMBL 3701981 & 1528586 & 9.2218 & 9.3409 & TRN & \\
\hline CHEMBL 3641704 & 1528586 & 6.0 & 6.2347 & TRN & \\
\hline CHEMBL 3641706 & 1528586 & 6.0 & 6.7415 & TRN & \\
\hline CHEMBL 3701944 & 1528586 & 8.2147 & 8.0112 & TRN & \\
\hline CHEMBL 3701942 & 1528586 & 7.5702 & 7.5171 & TRN & \\
\hline CHEMBL 3701907 & 1528586 & 9.301 & 8.4435 & TRN & \\
\hline CHEMBL 3641761 & 1528586 & 8.3768 & 9.0488 & TRN & \\
\hline CHEMBL 3641752 & 1528586 & 8.4949 & 8.2726 & TRN & \\
\hline CHEMBL 3641757 & 1528586 & 8.3665 & 8.1541 & TRN & \\
\hline CHEMBL 3701926 & 1528586 & 7.3585 & 7.3298 & TRN & \\
\hline CHEMBL 3701979 & 1528586 & 8.585 & 8.7469 & TRN & \\
\hline CHEMBL 3641738 & 1528586 & 8.7959 & 8.4474 & TRN & \\
\hline CHEMBL 3641729 & 1528586 & 8.3279 & 7.9098 & TRN & \\
\hline CHEMBL 3701966 & 1528586 & 8.1308 & 7.4822 & TRN & \\
\hline CHEMBL 3701924 & 1528586 & 7.9066 & 7.9844 & TRN & \\
\hline CHEMBL 3701912 & 1528586 & 7.5751 & 7.7931 & TRN & \\
\hline CHEMBL 3701956 & 1528586 & 8.6383 & 7.8657 & TRN & \\
\hline CHEMBL 3701918 & 1528586 & 6.0 & 6.0409 & TRN & \\
\hline CHEMBL 3701959 & 1528586 & 7.6536 & 7.5383 & TST & \\
\hline CHEMBL 3701963 & 1528586 & 8.5686 & 8.8899 & TRN & \\
\hline CHEMBL 3701988 & 1528586 & 7.7077 & 7.8727 & TRN & \\
\hline CHEMBL3701999 & 1528586 & 6.0 & 6.2936 & TRN & \\
\hline CHEMBL 3701932 & 1528586 & 7.3279 & 7.0405 & TRN & \\
\hline CHEMBL 3701945 & 1528586 & 9.0969 & 8.7931 & TRN & \\
\hline CHEMBL 3641753 & 1528586 & 8.6576 & 8.9827 & TRN & \\
\hline CHEMBL 3641722 & 1528586 & 6.0 & 6.7752 & TRN & \\
\hline CHEMBL 3701905 & 1528586 & 6.0 & 6.456 & TRN & \\
\hline CHEMBL 3701927 & 1528586 & 6.5588 & 7.6156 & TST & \\
\hline CHEMBL 3701900 & 1528586 & 7.1308 & 7.1135 & TST & \\
\hline CHEMBL 3701972 & 1528586 & 8.0177 & 8.0813 & TRN & \\
\hline CHEMBL 3701977 & 1528586 & 6.9586 & 6.404 & TRN & \\
\hline CHEMBL 3701928 & 1528586 & 6.0 & 6.4059 & TRN & \\
\hline CHEMBL 3641739 & 1528586 & \multicolumn{3}{|c|}{6.962999999999999} & 7.2558 \\
\hline CHEMBL 3641708 & 1528586 & 6.0 & 8.0053 & TRN & \\
\hline
\end{tabular}


Supplemental Table S2.txt

\begin{tabular}{|c|c|c|c|c|}
\hline CHEMBL3702012 & 1528586 & 7.6737 & 6.1251 & TST \\
\hline CHEMBL3701929 & 1528586 & 8.2924 & 8.2547 & TRN \\
\hline CHEMBL3641718 & 1528586 & 6.0 & 6.3322 & TRN \\
\hline CHEMBL3701916 & 1528586 & 6.0 & 5.9911 & TRN \\
\hline CHEMBL3641712 & 1528586 & 8.2147 & 7.4653 & TRN \\
\hline CHEMBL3641756 & 1528586 & 8.301 & 8.0643 & TRN \\
\hline CHEMBL3701965 & 1528586 & 6.6637 & 7.0707 & TST \\
\hline CHEMBL3701902 & 1528586 & 7.8041 & 7.7906 & TST \\
\hline CHEMBL 3641707 & 1528586 & 6.2217 & 7.4901 & TST \\
\hline CHEMBL3701939 & 1528586 & 8.585 & 8.0029 & TRN \\
\hline CHEMBL3701950 & 1528586 & 7.4401 & 7.7799 & TST \\
\hline CHEMBL3641691 & 1528586 & 6.0 & 6.5859 & TRN \\
\hline CHEMBL3701917 & 1528586 & 8.2676 & 7.0592 & TRN \\
\hline CHEMBL3641692 & 1528586 & 6.0 & 6.3239 & TRN \\
\hline CHEMBL3701951 & 1528586 & 9.301 & 9.1984 & TRN \\
\hline CHEMBL3641742 & 1528586 & 6.0 & 6.2517 & TRN \\
\hline CHEMBL3641755 & 1528586 & 8.585 & 7.9065 & TRN \\
\hline CHEMBL3701962 & 1528586 & 6.4285 & 7.0044 & TRN \\
\hline CHEMBL3701973 & 1528586 & 8.2291 & 7.9874 & TRN \\
\hline CHEMBL3701954 & 1528586 & 6.1322 & 6.2618 & TRN \\
\hline CHEMBL3701938 & 1528586 & 8.3979 & 8.2883 & TRN \\
\hline CHEMBL3701948 & 1528586 & 7.5751 & 7.7561 & TST \\
\hline CHEMBL 3702011 & 1528586 & 8.9586 & 7.7691 & TST \\
\hline CHEMBL3701986 & 1528586 & 6.0 & 6.5893 & TRN \\
\hline CHEMBL3701970 & 1528586 & 7.9281 & 7.4438 & TRN \\
\hline CHEMBL3641730 & 1528586 & 8.2366 & 8.334 & TRN \\
\hline CHEMBL3701964 & 1528586 & 7.8827 & 7.63299 & 9999999999 \\
\hline CHEMBL3701935 & 1528586 & 7.5406 & 7.6759 & TRN \\
\hline CHEMBL3701975 & 1528586 & 8.6198 & 9.0811 & TRN \\
\hline CHEMBL3701908 & 1528586 & 7.7423 & 8.0955 & TRN \\
\hline CHEMBL3701909 & 1528586 & 8.8239 & 8.6359 & TRN \\
\hline CHEMBL3701947 & 1528586 & 6.9144 & 7.8675 & TST \\
\hline CHEMBL 3701985 & 1528586 & 6.0 & 6.4443 & TRN \\
\hline CHEMBL3641719 & 1528586 & 6.0 & 6.0586 & TRN \\
\hline CHEMBL3701961 & 1528586 & 9.301 & 9.469 & TRN \\
\hline CHEMBL3701920 & 1528586 & 6.0 & 6.3139 & TST \\
\hline CHEMBL 3641741 & 1528586 & 9.0 & 9.1091 & TST \\
\hline CHEMBL3701915 & 1528586 & 7.5591 & 6.7392 & TST \\
\hline CHEMBL3641703 & 1528586 & 7.8729 & 7.9736 & TST \\
\hline CHEMBL3641697 & 1528586 & 6.3783 & 7.2306 & TST \\
\hline CHEMBL3701958 & 1528586 & 8.3098 & 7.9817 & TST \\
\hline CHEMBL3702010 & 1528586 & 8.4202 & 6.3252 & TST \\
\hline CHEMBL 3702020 & 1528586 & 6.0 & 6.8525 & TST \\
\hline CHEMBL 3641754 & 1528586 & 8.4202 & 8.2299 & TST \\
\hline CHEMBL3701987 & 1528586 & 7.857 & 7.4959 & TST \\
\hline CHEMBL3701976 & 1528586 & 8.2757 & 7.5692 & TST \\
\hline CHEMBL3701919 & 1528586 & 7.3439 & 7.9279 & TST \\
\hline CHEMBL3701996 & 1528586 & 6.0 & 5.9634 & TST \\
\hline
\end{tabular}




\begin{tabular}{|c|c|c|c|c|c|}
\hline \multicolumn{6}{|c|}{ Supplemental Table S2.txt } \\
\hline CHEMBL3701989 & 1528586 & 6.0 & 7.7559 & TST & \\
\hline CHEMBL3641727 & 1528586 & 8.5528 & 8.0235 & TST & \\
\hline CHEMBL3701983 & 1528586 & 8.8539 & 9.1791 & TST & \\
\hline CHEMBL3701971 & 1528586 & 7.767 & 7.4574 & TST & \\
\hline CHEMBL3701910 & 1528586 & 8.8239 & 8.1191 & TST & \\
\hline CHEMBL3701914 & 1528586 & 6.0 & 6.2482 & TST & \\
\hline CHEMBL3701949 & 1528586 & 8.301 & 7.891 & TST & \\
\hline CHEMBL1964290 & 809258 & 4.1 & 4.8752 & TRN & \\
\hline CHEMBL1230164 & 809258 & 5.3 & 5.1018 & TRN & \\
\hline CHEMBL 2003768 & 809258 & 4.1 & 3.7326 & TRN & \\
\hline CHEMBL213505 & 809258 & 6.9 & 7.0726 & TRN & \\
\hline CHEMBL202721 & 809258 & 7.5 & 5.7516 & TRN & \\
\hline CHEMBL1987034 & 809258 & 6.5 & 6.6419 & TRN & \\
\hline CHEMBL1980435 & 809258 & 5.9 & 6.1557 & TRN & \\
\hline CHEMBL 377383 & 809258 & 4.1 & 3.8984 & TRN & \\
\hline CHEMBL 2005886 & 809258 & 7.3 & 6.7157 & TRN & \\
\hline CHEMBL481491 & 809258 & 6.1 & 5.0591 & TST & \\
\hline CHEMBL1973142 & 809258 & 5.2 & 5.0644 & TRN & \\
\hline CHEMBL1973145 & 809258 & 4.1 & 5.9232 & TRN & \\
\hline CHEMBL1982924 & 809258 & 5.6 & 6.5157 & TRN & \\
\hline CHEMBL 2005936 & 809258 & 5.6 & 5.3929 & TRN & \\
\hline CHEMBL1807515 & 809258 & 7.6 & 6.6681 & TRN & \\
\hline CHEMBL1964948 & 809258 & 7.6 & 5.3032 & TRN & \\
\hline CHEMBL1971141 & 809258 & 4.1 & 5.0343 & TRN & \\
\hline CHEMBL1995813 & 809258 & 6.6 & 6.6996 & TRN & \\
\hline CHEMBL206236 & 809258 & 4.1 & 4.1711 & TRN & \\
\hline CHEMBL244378 & 809258 & 7.0 & 6.6437 & TRN & \\
\hline CHEMBL 2001957 & 809258 & 5.5 & 4.7215 & TRN & \\
\hline CHEMBL1969372 & 809258 & 4.1 & 4.8395 & TRN & \\
\hline CHEMBL1993413 & 809258 & 4.4 & 5.5239 & TRN & \\
\hline CHEMBL1986943 & 809258 & 7.1 & 7.20700 & 0000000001 & TRN \\
\hline CHEMBL 2006263 & 809258 & 4.1 & 4.8112 & TST & \\
\hline CHEMBL1993584 & 809258 & 4.1 & 4.8736 & TRN & \\
\hline CHEMBL1986263 & 809258 & 6.5 & 5.9325 & TRN & \\
\hline CHEMBL 2000114 & 809258 & 6.1 & 5.4882 & TRN & \\
\hline CHEMBL210618 & 809258 & 4.1 & 3.8744 & TRN & \\
\hline CHEMBL1971172 & 809258 & 6.3 & 6.3517 & TRN & \\
\hline CHEMBL1975647 & 809258 & 4.1 & 4.8499 & TRN & \\
\hline CHEMBL1968380 & 809258 & 4.1 & 4.0665 & TRN & \\
\hline CHEMBL1964644 & 809258 & 4.1 & 4.189 & TRN & \\
\hline CHEMBL1981782 & 809258 & 4.1 & 4.2257 & TRN & \\
\hline CHEMBL1977681 & 809258 & 6.3 & 5.5817 & TRN & \\
\hline CHEMBL1990912 & 809258 & 5.1 & 5.0298 & TRN & \\
\hline CHEMBL1988163 & 809258 & 6.8 & 6.8356 & TRN & \\
\hline CHEMBL 2006493 & 809258 & 4.1 & 3.9903 & TST & \\
\hline CHEMBL1996923 & 809258 & 4.1 & 3.9474 & TST & \\
\hline CHEMBL1983449 & 809258 & 4.1 & 3.7555 & TRN & \\
\hline CHEMBL1992323 & 809258 & 4.1 & 3.85 & TRN & \\
\hline
\end{tabular}




\begin{tabular}{|c|c|c|c|c|c|}
\hline \\
\hline CHEMBL1969735 & 809258 & 5.9 & 4.7908 & TRN & \\
\hline CHEMBL 2002649 & 809258 & 6.8 & 6.1064 & TRN & \\
\hline CHEMBL1983589 & 809258 & 7.2 & 7.1067 & TRN & \\
\hline CHEMBL 2005718 & 809258 & 6.7 & 6.6392 & TRN & \\
\hline CHEMBL1995172 & 809258 & 5.3 & 4.4197 & TST & \\
\hline CHEMBL1994321 & 809258 & 8.1 & 7.8005 & TRN & \\
\hline CHEMBL1997129 & 809258 & 6.9 & 6.473 & TRN & \\
\hline CHEMBL1984788 & 809258 & 6.2 & 5.0941 & TRN & \\
\hline CHEMBL1996604 & 809258 & 5.2 & 4.5931 & TRN & \\
\hline CHEMBL 2000508 & 809258 & 4.1 & 4.9422 & TRN & \\
\hline CHEMBL1971694 & 809258 & 4.1 & 4.0084 & TST & \\
\hline CHEMBL 2001547 & 809258 & 4.1 & 4.6135 & TRN & \\
\hline CHEMBL210928 & 809258 & 4.1 & 3.8935 & TRN & \\
\hline CHEMBL1986603 & 809258 & 4.1 & 5.0257 & TST & \\
\hline CHEMBL1977148 & 809258 & 7.6 & 7.8926 & TRN & \\
\hline CHEMBL1966842 & 809258 & 7.0 & 6.9434 & TRN & \\
\hline CHEMBL 2003286 & 809258 & 4.1 & 4.2683 & TRN & \\
\hline CHEMBL1992306 & 809258 & 5.9 & 5.9042 & TRN & \\
\hline CHEMBL 2001668 & 809258 & 4.1 & 4.4195 & TST & \\
\hline CHEMBL1979318 & 809258 & 4.1 & 4.0263 & TST & \\
\hline CHEMBL206382 & 809258 & 4.1 & 3.8403 & TRN & \\
\hline CHEMBL1998585 & 809258 & 7.6 & 7.5478 & TRN & \\
\hline CHEMBL519697 & 809258 & 5.7 & 4.7838 & TST & \\
\hline CHEMBL 2004934 & 809258 & 4.1 & 4.1975 & TRN & \\
\hline CHEMBL1987261 & 809258 & 6.0 & 6.523 & TRN & \\
\hline CHEMBL1981947 & 809258 & 5.3 & 5.2783 & TST & \\
\hline CHEMBL1975128 & 809258 & 6.0 & 5.5257 & TRN & \\
\hline CHEMBL1996048 & 809258 & 6.8 & 5.9421 & TST & \\
\hline CHEMBL1970369 & 809258 & 4.1 & 4.0495 & TRN & \\
\hline CHEMBL461876 & 809258 & 4.1 & 4.3965 & TRN & \\
\hline CHEMBL1984363 & 809258 & 6.0 & 6.1908 & TRN & \\
\hline CHEMBL1978099 & 809258 & 5.5 & 5.501 & TRN & \\
\hline CHEMBL1988608 & 809258 & 4.1 & 4.2061 & TRN & \\
\hline CHEMBL184847 & 809258 & 6.1 & 5.86799 & 9999999999 & TRN \\
\hline CHEMBL1984367 & 809258 & 4.1 & 5.7161 & TRN & \\
\hline CHEMBL1985723 & 809258 & 6.3 & 6.6572 & TRN & \\
\hline CHEMBL178737 & 809258 & 4.1 & 4.7055 & TST & \\
\hline CHEMBL226898 & 809258 & 7.1 & 6.7984 & TRN & \\
\hline CHEMBL1982563 & 809258 & 5.7 & 4.8321 & TRN & \\
\hline CHEMBL539474 & 809258 & 5.1 & 4.8346 & TST & \\
\hline CHEMBL575824 & 809258 & 4.1 & 4.7647 & TRN & \\
\hline CHEMBL1977128 & 809258 & 5.8 & 5.8068 & TRN & \\
\hline CHEMBL1974803 & 809258 & 5.6 & 4.7557 & TST & \\
\hline CHEMBL1970074 & 809258 & 6.0 & 5.9854 & TRN & \\
\hline CHEMBL1965702 & 809258 & 6.3 & 6.4695 & TRN & \\
\hline CHEMBL1986970 & 809258 & 4.1 & 4.9641 & TRN & \\
\hline CHEMBL 2005112 & 809258 & 4.1 & 4.6701 & TST & \\
\hline CHEMBL1958401 & 809258 & 4.1 & 4.724 & TRN & \\
\hline & & & & 23259 & \\
\hline
\end{tabular}




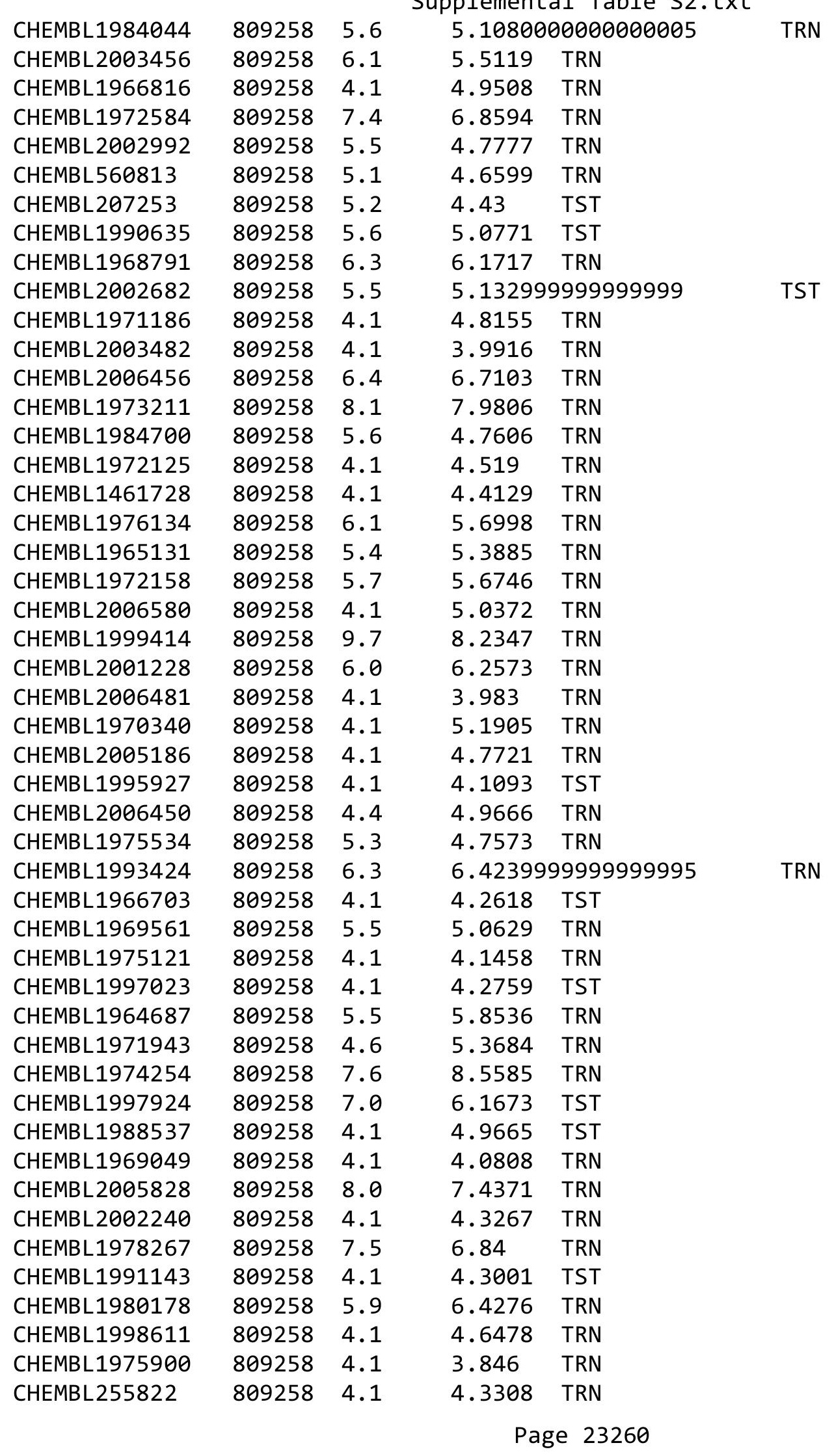




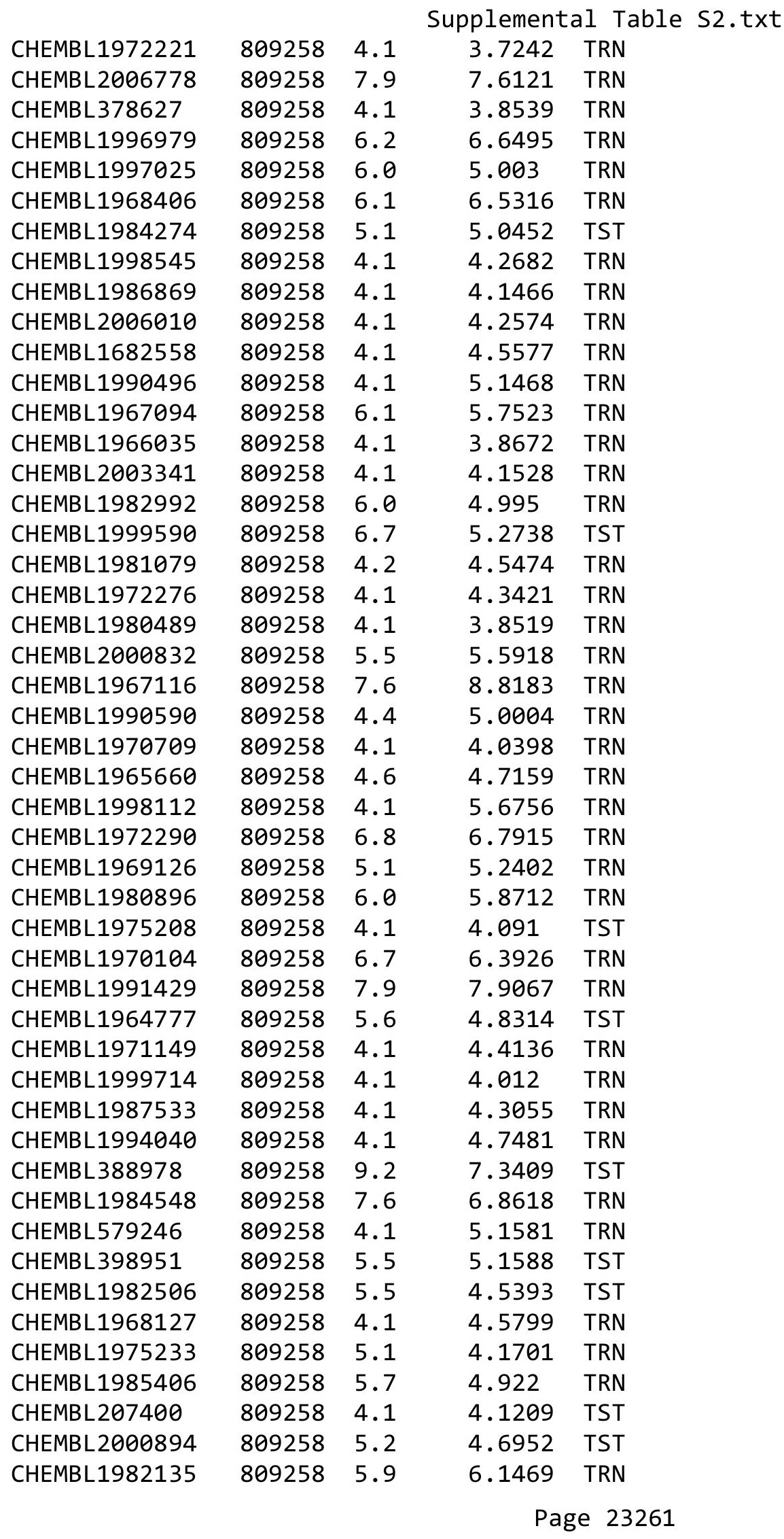




\begin{tabular}{|c|c|c|c|c|c|}
\hline \\
\hline CHEMBL1976090 & 809258 & 4.1 & 5.0262 & TRN & \\
\hline CHEMBL1993243 & 809258 & 6.9 & 7.3021 & TRN & \\
\hline CHEMBL1992922 & 809258 & 6.4 & 6.5254 & TRN & \\
\hline CHEMBL1997597 & 809258 & 4.1 & 4.0998 & TRN & \\
\hline CHEMBL1969537 & 809258 & 4.1 & 4.8154 & TST & \\
\hline CHEMBL1976093 & 809258 & 4.1 & 4.4689 & TRN & \\
\hline CHEMBL 210032 & 809258 & 5.1 & 4.42399 & 99999999995 & TRN \\
\hline CHEMBL1975256 & 809258 & 4.1 & 4.1009 & TST & \\
\hline CHEMBL508928 & 809258 & 8.2 & 7.6068 & TRN & \\
\hline CHEMBL1991356 & 809258 & 4.1 & 4.6958 & TST & \\
\hline CHEMBL1983309 & 809258 & 5.5 & 4.7071 & TRN & \\
\hline CHEMBL 2004892 & 809258 & 4.1 & 3.9666 & TRN & \\
\hline CHEMBL1999126 & 809258 & 5.6 & 4.7282 & TST & \\
\hline CHEMBL1997503 & 809258 & 5.4 & 5.2169 & TST & \\
\hline CHEMBL1972339 & 809258 & 6.6 & 6.2193 & TRN & \\
\hline CHEMBL116070 & 809258 & 4.1 & 4.2384 & TST & \\
\hline CHEMBL1990821 & 809258 & 6.3 & 5.0606 & TST & \\
\hline CHEMBL1970314 & 809258 & 4.1 & 4.785 & TRN & \\
\hline CHEMBL 2004871 & 809258 & 5.2 & 4.5808 & TRN & \\
\hline CHEMBL2004872 & 809258 & 4.1 & 4.1556 & TRN & \\
\hline CHEMBL1727312 & 809258 & 4.1 & 4.0135 & TRN & \\
\hline CHEMBL1969879 & 809258 & 4.1 & 4.0937 & TRN & \\
\hline CHEMBL1971463 & 809258 & 5.7 & 4.6252 & TRN & \\
\hline CHEMBL1981720 & 809258 & 5.6 & 4.9285 & TRN & \\
\hline CHEMBL419932 & 809258 & 4.1 & 4.4749 & TRN & \\
\hline CHEMBL262433 & 809258 & 7.1 & 6.937 & TRN & \\
\hline CHEMBL 306380 & 809258 & 4.1 & 5.5487 & TRN & \\
\hline CHEMBL1966722 & 809258 & 5.9 & 5.2256 & TST & \\
\hline CHEMBL1983595 & 809258 & 5.6 & 5.7306 & TRN & \\
\hline CHEMBL1975500 & 809258 & 5.7 & 5.3472 & TRN & \\
\hline CHEMBL394619 & 809258 & 7.0 & 7.0816 & TRN & \\
\hline CHEMBL1996831 & 809258 & 5.7 & 4.4843 & TST & \\
\hline CHEMBL411903 & 809258 & 7.5 & 7.2263 & TRN & \\
\hline CHEMBL1980253 & 809258 & 6.4 & 6.7237 & TRN & \\
\hline CHEMBL1965988 & 809258 & 8.2 & 7.7631 & TRN & \\
\hline CHEMBL418203 & 809258 & 6.0 & 4.6738 & TST & \\
\hline CHEMBL1989646 & 809258 & 4.1 & 5.0078 & TRN & \\
\hline CHEMBL225519 & 809258 & 4.7 & 4.6566 & TRN & \\
\hline CHEMBL1978200 & 809258 & 4.1 & 4.6994 & TRN & \\
\hline CHEMBL2006631 & 809258 & 4.1 & 4.5612 & TRN & \\
\hline CHEMBL1970522 & 809258 & 4.1 & 4.5744 & TRN & \\
\hline CHEMBL402846 & 809258 & 6.8 & 6.7441 & TRN & \\
\hline CHEMBL1990415 & 809258 & 5.1 & 4.5389 & TRN & \\
\hline CHEMBL1966087 & 809258 & 4.1 & 3.9633 & TRN & \\
\hline CHEMBL1964692 & 809258 & 8.3 & 7.3208 & TRN & \\
\hline CHEMBL1996931 & 809258 & 4.1 & 4.1517 & TRN & \\
\hline CHEMBL1964413 & 809258 & 4.1 & 4.0726 & TRN & \\
\hline CHEMBL1973483 & 809258 & 4.1 & 4.7338 & TRN & \\
\hline & & & & 23262 & \\
\hline
\end{tabular}




\begin{tabular}{|c|c|c|c|c|c|}
\hline & & & & & \\
\hline CHEMBL1998470 & 809258 & 5.4 & 5.2814 & TRN & \\
\hline CHEMBL1996980 & 809258 & 7.1 & 7.0839 & TRN & \\
\hline CHEMBL1970735 & 809258 & 5.6 & 4.1401 & TRN & \\
\hline CHEMBL1997340 & 809258 & 4.1 & 3.9832 & TRN & \\
\hline CHEMBL1994669 & 809258 & 8.3 & 7.0289 & TRN & \\
\hline CHEMBL2004365 & 809258 & 5.9 & 5.0341 & TST & \\
\hline CHEMBL1522508 & 809258 & 4.1 & 4.3113 & TRN & \\
\hline CHEMBL1989474 & 809258 & 4.1 & 4.5192 & TRN & \\
\hline CHEMBL1090360 & 809258 & 8.3 & 7.8917 & TRN & \\
\hline CHEMBL210887 & 809258 & 5.9 & 5.1066 & TST & \\
\hline CHEMBL458997 & 809258 & 5.3 & 5.29899 & 99999999995 & TRN \\
\hline CHEMBL1971021 & 809258 & 4.1 & 4.9128 & TRN & \\
\hline CHEMBL227271 & 809258 & 6.1 & 6.9347 & TRN & \\
\hline CHEMBL583144 & 809258 & 4.1 & 4.2236 & TRN & \\
\hline CHEMBL1974310 & 809258 & 6.1 & 5.1911 & TST & \\
\hline CHEMBL1982660 & 809258 & 4.4 & 5.0499 & TRN & \\
\hline CHEMBL1994693 & 809258 & 6.7 & 6.7514 & TRN & \\
\hline CHEMBL1982957 & 809258 & 4.1 & 6.33 & TRN & \\
\hline CHEMBL1975138 & 809258 & 6.2 & 5.2922 & TST & \\
\hline CHEMBL424872 & 809258 & 4.1 & 3.9189 & TRN & \\
\hline CHEMBL2006836 & 809258 & 4.1 & 4.4788 & TST & \\
\hline CHEMBL412142 & 809258 & 4.1 & 4.0888 & TST & \\
\hline CHEMBL1980704 & 809258 & 4.1 & 4.4099 & TST & \\
\hline CHEMBL2003271 & 809258 & 5.4 & 5.3264 & TRN & \\
\hline CHEMBL1966808 & 809258 & 4.1 & 4.276 & TST & \\
\hline CHEMBL2004447 & 809258 & 4.1 & 4.0042 & TST & \\
\hline CHEMBL1992231 & 809258 & 4.4 & 5.113 & TRN & \\
\hline CHEMBL1983111 & 809258 & 7.6 & 6.3214 & TST & \\
\hline CHEMBL1973860 & 809258 & 4.1 & 4.6714 & TRN & \\
\hline CHEMBL1977713 & 809258 & 4.1 & 4.3032 & TRN & \\
\hline CHEMBL260135 & 809258 & 4.1 & 4.3622 & TRN & \\
\hline CHEMBL220241 & 809258 & 5.8 & 5.2343 & TRN & \\
\hline CHEMBL2004544 & 809258 & 5.4 & 4.6686 & TST & \\
\hline CHEMBL1982610 & 809258 & 4.1 & 4.4015 & TST & \\
\hline CHEMBL1989569 & 809258 & 5.5 & 5.0785 & TRN & \\
\hline CHEMBL1999496 & 809258 & 4.1 & 4.2299 & TRN & \\
\hline CHEMBL375293 & 809258 & 5.4 & 4.9958 & TST & \\
\hline CHEMBL1988300 & 809258 & 6.2 & 6.88399 & 99999999995 & TRN \\
\hline CHEMBL1991078 & 809258 & 6.3 & 6.6323 & TRN & \\
\hline CHEMBL1994438 & 809258 & 6.6 & 6.8762 & TRN & \\
\hline CHEMBL 2000724 & 809258 & 4.4 & 4.8746 & TRN & \\
\hline CHEMBL1989265 & 809258 & 4.1 & 4.1442 & TST & \\
\hline CHEMBL 2004647 & 809258 & 4.1 & 4.3533 & TST & \\
\hline CHEMBL1969502 & 809258 & 6.2 & 5.9345 & TRN & \\
\hline CHEMBL1682553 & 809258 & 4.1 & 4.4747 & TRN & \\
\hline CHEMBL1971430 & 809258 & 5.4 & 4.9695 & TRN & \\
\hline CHEMBL1983963 & 809258 & 6.6 & 7.2038 & TRN & \\
\hline CHEMBL1997764 & 809258 & 6.3 & 6.3015 & TRN & \\
\hline & & & & 23263 & \\
\hline
\end{tabular}




\begin{tabular}{|c|c|c|c|c|c|}
\hline \multirow[b]{2}{*}{ CHEMBL1985092 } & \multirow[b]{2}{*}{809258} & \\
\hline & & 6.4 & 5.6237 & TRN & \\
\hline CHEMBL 2004692 & 809258 & 4.1 & 4.2439 & TST & \\
\hline CHEMBL1981410 & 809258 & 6.9 & 6.3189 & TRN & \\
\hline CHEMBL1996234 & 809258 & 6.5 & 5.7385 & TRN & \\
\hline CHEMBL383264 & 809258 & 8.3 & 5.0368 & TRN & \\
\hline CHEMBL1991434 & 809258 & 4.1 & 4.522 & TRN & \\
\hline CHEMBL1967544 & 809258 & 4.1 & 4.5961 & TRN & \\
\hline CHEMBL223367 & 809258 & 6.5 & 5.0372 & TST & \\
\hline CHEMBL340384 & 809258 & 5.6 & 5.0829 & TST & \\
\hline CHEMBL1969151 & 809258 & 6.8 & 6.8678 & TRN & \\
\hline CHEMBL1996587 & 809258 & 4.1 & 4.9735 & TRN & \\
\hline CHEMBL1964804 & 809258 & 4.1 & 4.3151 & TRN & \\
\hline CHEMBL443962 & 809258 & 5.6 & 4.9517 & TST & \\
\hline CHEMBL 2000354 & 809258 & 5.9 & 4.9039 & TRN & \\
\hline CHEMBL1965507 & 809258 & 4.7 & 7.0017 & TRN & \\
\hline CHEMBL274064 & 809258 & 6.3 & 5.2385 & TRN & \\
\hline CHEMBL1967564 & 809258 & 4.1 & 4.1292 & TRN & \\
\hline CHEMBL592030 & 809258 & 6.8 & 5.8795 & TST & \\
\hline CHEMBL 2000071 & 809258 & 6.6 & 6.6824 & TRN & \\
\hline CHEMBL1979176 & 809258 & 5.3 & 4.4933 & TRN & \\
\hline CHEMBL1970317 & 809258 & 8.8 & 8.8187 & TRN & \\
\hline CHEMBL 2002613 & 809258 & 4.4 & 5.7174 & TRN & \\
\hline CHEMBL 2000408 & 809258 & 5.8 & 4.8511 & TRN & \\
\hline CHEMBL248757 & 809258 & 7.3 & 5.1426 & TST & \\
\hline CHEMBL1978014 & 809258 & 4.1 & 4.5084 & TRN & \\
\hline CHEMBL1994538 & 809258 & 4.1 & 4.3429 & TRN & \\
\hline CHEMBL1983195 & 809258 & 4.1 & 4.9345 & TST & \\
\hline CHEMBL1964444 & 809258 & 5.9 & 5.3921 & TRN & \\
\hline CHEMBL1989957 & 809258 & 4.1 & 4.7633 & TRN & \\
\hline CHEMBL1986139 & 809258 & 4.1 & 4.621 & TRN & \\
\hline CHEMBL1980540 & 809258 & 4.1 & 4.3752 & TRN & \\
\hline CHEMBL1979883 & 809258 & 8.2 & 7.9724 & TRN & \\
\hline CHEMBL1984162 & 809258 & 6.6 & $7.1770 e$ & 20000000005 & TRN \\
\hline CHEMBL1997051 & 809258 & 7.0 & 6.7397 & TRN & \\
\hline CHEMBL1998432 & 809258 & 6.5 & 6.8181 & TRN & \\
\hline CHEMBL491758 & 809258 & 6.4 & 5.3416 & TRN & \\
\hline CHEMBL549730 & 809258 & 4.1 & 3.5371 & TRN & \\
\hline CHEMBL1970189 & 809258 & 5.1 & 3.8625 & TST & \\
\hline CHEMBL1870106 & 809258 & 4.4 & 4.5364 & TRN & \\
\hline CHEMBL1996791 & 809258 & 4.1 & 4.7906 & TRN & \\
\hline CHEMBL371206 & 809258 & 8.2 & 6.9849 & TRN & \\
\hline CHEMBL1974664 & 809258 & 4.1 & 5.5111 & TST & \\
\hline CHEMBL1974288 & 809258 & 4.1 & 4.4343 & TRN & \\
\hline CHEMBL196363 & 809258 & 7.1 & 7.347 & TRN & \\
\hline CHEMBL1190711 & 809258 & 4.1 & 5.8528 & TRN & \\
\hline CHEMBL1968705 & 809258 & 6.0 & 5.2681 & TRN & \\
\hline CHEMBL1991410 & 809258 & 4.4 & 5.2057 & TRN & \\
\hline CHEMBL404367 & 809258 & 6.9 & 6.8264 & TRN & \\
\hline & & & & 3264 & \\
\hline
\end{tabular}




\begin{tabular}{|c|c|c|c|c|}
\hline \multicolumn{5}{|c|}{ Supplemental Table S2.txt } \\
\hline CHEMBL1966343 & 809258 & 5.1 & 4.3542 & TRN \\
\hline CHEMBL1978271 & 809258 & 4.4 & 5.2402 & TRN \\
\hline CHEMBL1967887 & 809258 & 4.1 & 5.6383 & TRN \\
\hline CHEMBL2000568 & 809258 & 7.0 & 5.4232 & TRN \\
\hline CHEMBL2000335 & 809258 & 7.6 & 7.7414 & TRN \\
\hline CHEMBL1977604 & 809258 & 4.1 & 4.1391 & TST \\
\hline CHEMBL1974328 & 809258 & 7.7 & 6.2595 & TRN \\
\hline CHEMBL509032 & 809258 & 7.1 & 6.1503 & TRN \\
\hline CHEMBL243298 & 809258 & 4.4 & 5.5053 & TRN \\
\hline CHEMBL1973808 & 809258 & 4.1 & 4.0745 & TRN \\
\hline CHEMBL2000429 & 809258 & 5.8 & 4.8227 & TRN \\
\hline CHEMBL1972576 & 809258 & 7.0 & 7.2813 & TRN \\
\hline CHEMBL1992555 & 809258 & 4.1 & 4.6112 & TST \\
\hline CHEMBL1992342 & 809258 & 4.1 & 3.9521 & TRN \\
\hline CHEMBL1988173 & 809258 & 6.4 & 5.2999 & TST \\
\hline CHEMBL1164265 & 809258 & 7.2 & 5.5282 & TST \\
\hline CHEMBL535331 & 809258 & 5.4 & 4.9698 & TRN \\
\hline CHEMBL1989805 & 809258 & 4.1 & 4.8952 & TST \\
\hline CHEMBL1966204 & 809258 & 6.2 & 6.1681 & TRN \\
\hline CHEMBL1965423 & 809258 & 5.9 & 5.8191 & TRN \\
\hline CHEMBL1982980 & 809258 & 5.9 & 4.9141 & TST \\
\hline CHEMBL1983025 & 809258 & 6.8 & 7.3618 & TRN \\
\hline CHEMBL 205415 & 809258 & 4.1 & 4.5352 & TRN \\
\hline CHEMBL1977135 & 809258 & 5.1 & 4.3383 & TRN \\
\hline CHEMBL 2001920 & 809258 & 5.3 & 4.7832 & TRN \\
\hline CHEMBL1241473 & 809258 & 7.0 & 6.8147 & TRN \\
\hline CHEMBL1978448 & 809258 & 5.8 & 4.667 & TST \\
\hline CHEMBL 2004513 & 809258 & 4.1 & 4.4882 & TRN \\
\hline CHEMBL1972258 & 809258 & 4.1 & 3.8611 & TRN \\
\hline CHEMBL1969483 & 809258 & 6.4 & 6.7137 & TRN \\
\hline CHEMBL2001257 & 809258 & 7.3 & 7.4936 & TRN \\
\hline CHEMBL1992536 & 809258 & 4.1 & 3.7861 & TRN \\
\hline CHEMBL1992740 & 809258 & 4.1 & 3.9905 & TRN \\
\hline CHEMBL2002373 & 809258 & 5.9 & 4.6547 & TRN \\
\hline CHEMBL439340 & 809258 & 4.1 & 4.4183 & TRN \\
\hline CHEMBL2006188 & 809258 & 4.1 & 4.0893 & TRN \\
\hline CHEMBL1967531 & 809258 & 8.1 & 7.7496 & TRN \\
\hline CHEMBL1970913 & 809258 & 4.1 & 4.2516 & TRN \\
\hline CHEMBL1973893 & 809258 & 4.1 & 3.839 & TRN \\
\hline CHEMBL1995736 & 809258 & 5.3 & 4.8214 & TRN \\
\hline CHEMBL1997534 & 809258 & 6.5 & 5.5435 & TRN \\
\hline CHEMBL1996500 & 809258 & 5.8 & 4.6521 & TRN \\
\hline CHEMBL1985095 & 809258 & 6.2 & 5.9868 & TST \\
\hline CHEMBL1998551 & 809258 & 4.1 & 4.9158 & TRN \\
\hline CHEMBL1977374 & 809258 & 4.1 & 4.9017 & TRN \\
\hline CHEMBL1682540 & 809258 & 4.1 & 4.0813 & TRN \\
\hline CHEMBL1976420 & 809258 & 4.7 & 5.4305 & TST \\
\hline CHEMBL1994864 & 809258 & 4.1 & 3.8718 & TRN \\
\hline
\end{tabular}




\begin{tabular}{|c|c|c|c|c|}
\hline & & & pplement & al $\mathrm{Ta}$ \\
\hline CHEMBL 2002446 & 809258 & 6.3 & 5.905 & TST \\
\hline CHEMBL497151 & 809258 & 5.5 & 4.9029 & TST \\
\hline CHEMBL1973961 & 809258 & 5.7 & 4.7709 & TRN \\
\hline CHEMBL 246970 & 809258 & 6.6 & 5.3574 & TRN \\
\hline CHEMBL340921 & 809258 & 4.1 & 4.6103 & TST \\
\hline CHEMBL1994977 & 809258 & 4.4 & 5.1971 & TRN \\
\hline CHEMBL1999718 & 809258 & 4.1 & 3.9774 & TRN \\
\hline CHEMBL1987073 & 809258 & 5.7 & 5.7225 & TRN \\
\hline CHEMBL 2000078 & 809258 & 6.3 & 6.8672 & TRN \\
\hline CHEMBL1995712 & 809258 & 5.8 & 6.29 & TRN \\
\hline CHEMBL1979773 & 809258 & 9.1 & 5.4706 & TRN \\
\hline CHEMBL1977346 & 809258 & 5.3 & 4.7468 & TRN \\
\hline CHEMBL1971649 & 809258 & 6.2 & 5.7516 & TRN \\
\hline CHEMBL 2005482 & 809258 & 6.4 & 7.5109 & TRN \\
\hline CHEMBL1997909 & 809258 & 6.6 & 6.4567 & TRN \\
\hline CHEMBL1998435 & 809258 & 4.1 & 4.1556 & TRN \\
\hline CHEMBL2006439 & 809258 & 4.7 & 6.157 & TRN \\
\hline CHEMBL2006156 & 809258 & 5.1 & 5.1162 & TST \\
\hline CHEMBL1969190 & 809258 & 7.8 & 7.4234 & TRN \\
\hline CHEMBL1973937 & 809258 & 6.9 & 6.7653 & TRN \\
\hline CHEMBL1991674 & 809258 & 7.0 & 7.0539 & TRN \\
\hline CHEMBL1982711 & 809258 & 6.6 & 6.1124 & TRN \\
\hline CHEMBL1987982 & 809258 & 5.1 & 4.6693 & TST \\
\hline CHEMBL 2007044 & 809258 & 4.1 & 5.1908 & TST \\
\hline CHEMBL1994241 & 809258 & 7.1 & 5.6606 & TST \\
\hline CHEMBL223460 & 809258 & 6.4 & 4.9548 & TST \\
\hline CHEMBL1998829 & 809258 & 6.0 & 6.0594 & TRN \\
\hline CHEMBL50894 & 809258 & 7.1 & 5.8582 & TST \\
\hline CHEMBL1988838 & 809258 & 5.7 & 5.9556 & TRN \\
\hline CHEMBL1981725 & 809258 & 8.4 & 7.4755 & TRN \\
\hline CHEMBL1980562 & 809258 & 6.8 & 6.7818 & TRN \\
\hline CHEMBL1081312 & 809258 & 5.9 & 5.8672 & TRN \\
\hline CHEMBL1982866 & 809258 & 4.1 & 4.4015 & TRN \\
\hline CHEMBL1968926 & 809258 & 5.9 & 4.5392 & TRN \\
\hline CHEMBL462120 & 809258 & 4.1 & 4.5073 & TST \\
\hline CHEMBL1979933 & 809258 & 4.4 & 5.2716 & TRN \\
\hline CHEMBL 2007592 & 809258 & 4.1 & 4.7149 & TST \\
\hline CHEMBL1976936 & 809258 & 7.0 & 7.0819 & TRN \\
\hline CHEMBL210963 & 809258 & 4.1 & 3.7509 & TRN \\
\hline CHEMBL1082440 & 809258 & 5.7 & 5.381 & TST \\
\hline CHEMBL1614705 & 809258 & 4.1 & 4.6233 & TRN \\
\hline CHEMBL1984633 & 809258 & 4.1 & 3.9235 & TRN \\
\hline CHEMBL1972988 & 809258 & 4.4 & 5.3553 & TRN \\
\hline CHEMBL 2007372 & 809258 & 4.1 & 4.5311 & TRN \\
\hline CHEMBL1965845 & 809258 & 6.0 & 6.0026 & TRN \\
\hline CHEMBL 2006715 & 809258 & 7.9 & 7.8131 & TRN \\
\hline CHEMBL1990482 & 809258 & 4.1 & 4.4887 & TRN \\
\hline CHEMBL1990904 & 809258 & 5.4 & 5.1302 & TRN \\
\hline
\end{tabular}




\begin{tabular}{|c|c|c|c|c|c|}
\hline & & & & & \\
\hline CHEMBL1987448 & 809258 & 6.8 & 6.3481 & TRN & \\
\hline CHEMBL 2005475 & 809258 & 5.8 & 5.6935 & TRN & \\
\hline CHEMBL1997349 & 809258 & 4.1 & 5.1098 & TST & \\
\hline CHEMBL183844 & 809258 & 4.1 & 5.4388 & TRN & \\
\hline CHEMBL220057 & 809258 & 5.8 & 6.6747 & TRN & \\
\hline CHEMBL1682545 & 809258 & 4.1 & 4.5153 & TRN & \\
\hline CHEMBL 383541 & 809258 & 4.1 & 4.5053 & TRN & \\
\hline CHEMBL 2001224 & 809258 & 4.1 & 3.9116 & TRN & \\
\hline CHEMBL10 & 809258 & 4.1 & 4.9227 & TRN & \\
\hline CHEMBL1976732 & 809258 & 4.1 & 4.9426 & TRN & \\
\hline CHEMBL2005216 & 809258 & 6.7 & 7.0225 & TRN & \\
\hline CHEMBL1969506 & 809258 & 4.1 & 4.1766 & TRN & \\
\hline CHEMBL1964937 & 809258 & 5.7 & 6.0278 & TRN & \\
\hline CHEMBL1980163 & 809258 & 4.1 & 4.4484 & TRN & \\
\hline CHEMBL2005899 & 809258 & 4.1 & 3.9631 & TRN & \\
\hline CHEMBL1682552 & 809258 & 4.1 & 4.1771 & TRN & \\
\hline CHEMBL1972568 & 809258 & 4.1 & 3.8983 & TRN & \\
\hline CHEMBL1986851 & 809258 & 8.9 & 8.1481 & TRN & \\
\hline CHEMBL229799 & 809258 & 6.6 & 7.2774 & TRN & \\
\hline CHEMBL1971223 & 809258 & 4.4 & 5.2143 & TRN & \\
\hline CHEMBL105739 & 809258 & 6.3 & 5.9669 & TRN & \\
\hline CHEMBL 379300 & 809258 & 7.2 & 6.831 & TRN & \\
\hline CHEMBL1973720 & 809258 & 7.3 & 7.0243 & TRN & \\
\hline CHEMBL1969523 & 809258 & 6.5 & 5.4054 & TRN & \\
\hline CHEMBL1988995 & 809258 & 4.1 & 4.8569 & TRN & \\
\hline CHEMBL1986781 & 809258 & 4.1 & 4.7919 & TRN & \\
\hline CHEMBL1983070 & 809258 & 4.4 & 5.4689 & TRN & \\
\hline CHEMBL526133 & 809258 & 4.1 & 4.6399 & TRN & \\
\hline CHEMBL1979057 & 809258 & 6.0 & 5.7909 & TRN & \\
\hline CHEMBL387971 & 809258 & 6.1 & 5.4822 & TST & \\
\hline CHEMBL1164180 & 809258 & 6.3 & 5.4738 & TST & \\
\hline CHEMBL1999428 & 809258 & 4.1 & 4.4145 & TRN & \\
\hline CHEMBL1967560 & 809258 & 4.1 & 3.9886 & TRN & \\
\hline CHEMBL 211378 & 809258 & 5.5 & 6.1129 & TRN & \\
\hline CHEMBL1516890 & 809258 & 6.7 & $6.3210 e$ & 2000000001 & TRN \\
\hline CHEMBL1982465 & 809258 & 7.8 & 7.8638 & TRN & \\
\hline CHEMBL 2001751 & 809258 & 7.2 & 7.6852 & TRN & \\
\hline CHEMBL1984586 & 809258 & 7.6 & 7.2765 & TRN & \\
\hline CHEMBL1972659 & 809258 & 4.1 & 4.4055 & TST & \\
\hline CHEMBL 272453 & 809258 & 7.2 & 6.6795 & TRN & \\
\hline CHEMBL1970217 & 809258 & 4.1 & 4.2063 & TRN & \\
\hline CHEMBL 2005528 & 809258 & 4.1 & 4.4904 & TST & \\
\hline CHEMBL185569 & 809258 & 5.2 & 6.1571 & TRN & \\
\hline CHEMBL1969843 & 809258 & 4.1 & $4.0360 e$ & 30000000005 & TRN \\
\hline CHEMBL2007002 & 809258 & 5.6 & 5.82299 & 99999999995 & TRN \\
\hline CHEMBL1987007 & 809258 & 4.1 & 5.2246 & TRN & \\
\hline CHEMBL1984711 & 809258 & 5.2 & 5.164 & TRN & \\
\hline CHEMBL484390 & 809258 & 5.6 & 4.7005 & TST & \\
\hline & & & & 23267 & \\
\hline
\end{tabular}




\begin{tabular}{|c|c|c|c|c|}
\hline \multicolumn{5}{|c|}{ Supplemental Table S2.txt } \\
\hline CHEMBL1979252 & 809258 & 4.1 & 3.9797 & TRN \\
\hline CHEMBL1986499 & 809258 & 5.2 & 5.6446 & TRN \\
\hline CHEMBL1972937 & 809258 & 4.1 & 4.28100 & 0000000001 \\
\hline CHEMBL 2000393 & 809258 & 5.9 & 5.9941 & TST \\
\hline CHEMBL1089101 & 809258 & 5.6 & 5.0367 & TRN \\
\hline CHEMBL2004311 & 809258 & 6.2 & 5.5759 & TRN \\
\hline CHEMBL1992634 & 809258 & 7.3 & 6.6745 & TRN \\
\hline CHEMBL1242373 & 809258 & 6.3 & 6.2751 & TRN \\
\hline CHEMBL56543 & 809258 & 5.7 & 4.8275 & TRN \\
\hline CHEMBL1984847 & 809258 & 4.4 & 5.3357 & TRN \\
\hline CHEMBL316264 & 809258 & 4.1 & 4.5244 & TRN \\
\hline CHEMBL1988076 & 809258 & 7.0 & 6.6294 & TRN \\
\hline CHEMBL1991678 & 809258 & 4.1 & 4.8207 & TRN \\
\hline CHEMBL2001239 & 809258 & 4.1 & 5.5174 & TST \\
\hline CHEMBL1988594 & 809258 & 6.4 & 7.2552 & TRN \\
\hline CHEMBL 2001288 & 809258 & 5.2 & 4.2837 & TRN \\
\hline CHEMBL1992363 & 809258 & 6.9 & 6.7822 & TRN \\
\hline CHEMBL1999811 & 809258 & 5.5 & 5.1947 & TST \\
\hline CHEMBL235157 & 809258 & 4.4 & 4.6539 & TST \\
\hline CHEMBL1985074 & 809258 & 4.1 & 4.3725 & TST \\
\hline CHEMBL1982874 & 809258 & 6.1 & 5.937 & TRN \\
\hline CHEMBL 2000481 & 809258 & 6.3 & 5.6565 & TRN \\
\hline CHEMBL1991725 & 809258 & 4.1 & 4.8913 & TRN \\
\hline CHEMBL1992242 & 809258 & 4.1 & 4.9349 & TRN \\
\hline CHEMBL1982271 & 809258 & 7.4 & 6.9911 & TRN \\
\hline CHEMBL 2007296 & 809258 & 4.1 & 4.3364 & TRN \\
\hline CHEMBL396523 & 809258 & 7.1 & 6.4216 & TRN \\
\hline CHEMBL 208637 & 809258 & 4.1 & 4.0489 & TRN \\
\hline CHEMBL1970203 & 809258 & 6.9 & 7.0311 & TRN \\
\hline CHEMBL1986530 & 809258 & 6.4 & 5.001 & TST \\
\hline CHEMBL1968590 & 809258 & 6.7 & 7.1077 & TRN \\
\hline CHEMBL 2007336 & 809258 & 6.0 & 5.0352 & TRN \\
\hline CHEMBL2005375 & 809258 & 4.1 & 3.9478 & TRN \\
\hline CHEMBL1984191 & 809258 & 5.7 & 4.8804 & TRN \\
\hline CHEMBL1972183 & 809258 & 4.1 & 4.1203 & TST \\
\hline CHEMBL1971029 & 809258 & 7.0 & 6.8651 & TRN \\
\hline CHEMBL 394790 & 809258 & 7.3 & 7.2943 & TRN \\
\hline CHEMBL226471 & 809258 & 6.2 & 5.5194 & TRN \\
\hline CHEMBL1974702 & 809258 & 4.1 & 4.0867 & TRN \\
\hline CHEMBL1996111 & 809258 & 5.7 & 4.9871 & TRN \\
\hline CHEMBL1965589 & 809258 & 4.1 & 4.6559 & TRN \\
\hline CHEMBL379975 & 809258 & 8.4 & 6.2094 & TST \\
\hline CHEMBL474432 & 809258 & 6.4 & 5.3373 & TST \\
\hline CHEMBL1988153 & 809258 & 5.7 & 4.6282 & TST \\
\hline CHEMBL1986666 & 809258 & 5.6 & 5.8068 & TRN \\
\hline CHEMBL1988437 & 809258 & 6.6 & 6.4415 & TST \\
\hline CHEMBL1998121 & 809258 & 5.4 & 4.8687 & TRN \\
\hline CHEMBL1979577 & 809258 & 7.7 & 7.7579 & TRN \\
\hline
\end{tabular}

TRN 


\begin{tabular}{|c|c|c|c|c|c|}
\hline & & & & & \\
\hline CHEMBL1233887 & 809258 & 4.4 & 4.6997 & TST & \\
\hline CHEMBL1991800 & 809258 & 5.5 & 4.9097 & TRN & \\
\hline CHEMBL52387 & 809258 & 4.1 & 4.3745 & TST & \\
\hline CHEMBL 379835 & 809258 & 4.1 & 4.2709 & TST & \\
\hline CHEMBL1996649 & 809258 & 9.7 & 8.1292 & TRN & \\
\hline CHEMBL1979357 & 809258 & 4.1 & 4.2489 & TRN & \\
\hline CHEMBL1996817 & 809258 & 6.8 & 6.9398 & TRN & \\
\hline CHEMBL3197315 & 809258 & 4.1 & 4.3934 & TST & \\
\hline CHEMBL468280 & 809258 & 4.1 & 4.0759 & TST & \\
\hline CHEMBL1990884 & 809258 & 5.4 & $5.1270 e$ & 0000000001 & TRN \\
\hline CHEMBL3109278 & 809258 & 7.8 & 7.0663 & TRN & \\
\hline CHEMBL 256835 & 809258 & 6.6 & 5.1904 & TRN & \\
\hline CHEMBL1974998 & 809258 & 4.4 & 5.3051 & TRN & \\
\hline CHEMBL1980142 & 809258 & 4.1 & 4.1626 & TRN & \\
\hline CHEMBL41783 & 809258 & 4.1 & 4.0277 & TRN & \\
\hline CHEMBL2006276 & 809258 & 4.1 & 4.4795 & TRN & \\
\hline CHEMBL 271381 & 809258 & 7.5 & 6.7574 & TRN & \\
\hline CHEMBL 2006785 & 809258 & 4.1 & 4.3255 & TRN & \\
\hline CHEMBL1995740 & 809258 & 5.2 & 4.4123 & TRN & \\
\hline CHEMBL1990162 & 809258 & 5.7 & 5.8135 & TRN & \\
\hline CHEMBL1992220 & 809258 & 7.5 & 7.209 & TRN & \\
\hline CHEMBL 234085 & 809258 & 4.1 & 3.9891 & TRN & \\
\hline CHEMBL1995832 & 809258 & 5.9 & 4.8481 & TRN & \\
\hline CHEMBL1998414 & 809258 & 4.1 & 4.507 & TRN & \\
\hline CHEMBL1969042 & 809258 & 6.7 & 5.5832 & TRN & \\
\hline CHEMBL 2000345 & 809258 & 7.1 & 5.6336 & TST & \\
\hline CHEMBL1999931 & 809258 & 7.5 & 6.5501 & TRN & \\
\hline CHEMBL1375418 & 809258 & 5.4 & 4.7071 & TRN & \\
\hline CHEMBL 2007064 & 809258 & 4.1 & 5.8059 & TRN & \\
\hline CHEMBL1981047 & 809258 & 7.8 & 6.46399 & 99999999995 & TRN \\
\hline CHEMBL229968 & 809258 & 6.8 & 7.0876 & TRN & \\
\hline CHEMBL1976240 & 809258 & 4.1 & 4.4 & TRN & \\
\hline CHEMBL1987948 & 809258 & 6.3 & 6.24 & TRN & \\
\hline CHEMBL1979093 & 809258 & 7.7 & 7.3895 & TRN & \\
\hline CHEMBL1968151 & 809258 & 4.1 & 4.2212 & TST & \\
\hline CHEMBL1987009 & 809258 & 6.2 & 6.1292 & TRN & \\
\hline CHEMBL 379218 & 809258 & 6.1 & 6.8604 & TRN & \\
\hline CHEMBL 2003817 & 809258 & 4.1 & 4.3244 & TRN & \\
\hline CHEMBL1994830 & 809258 & 4.1 & 4.3942 & TST & \\
\hline CHEMBL226403 & 809258 & 4.2 & 5.3458 & TRN & \\
\hline CHEMBL1994938 & 809258 & 7.3 & 7.4969 & TRN & \\
\hline CHEMBL1977223 & 809258 & 5.5 & 4.8051 & TRN & \\
\hline CHEMBL1236126 & 809258 & 4.1 & 4.6373 & TST & \\
\hline CHEMBL1966279 & 809258 & 5.9 & 5.6206 & TRN & \\
\hline CHEMBL1997846 & 809258 & 5.9 & 6.5233 & TRN & \\
\hline CHEMBL2004419 & 809258 & 4.1 & 5.2169 & TRN & \\
\hline CHEMBL 2007073 & 809258 & 4.4 & 5.1852 & TRN & \\
\hline CHEMBL1995811 & 809258 & 6.1 & 5.5087 & TRN & \\
\hline & & & & 23269 & \\
\hline
\end{tabular}




\begin{tabular}{|c|c|c|c|c|c|}
\hline \multicolumn{6}{|c|}{ Supplemental Table S2.txt } \\
\hline CHEMBL1972489 & 809258 & 4.1 & 4.2384 & TRN & \\
\hline CHEMBL1994074 & 809258 & 6.5 & 5.4518 & TRN & \\
\hline CHEMBL1992937 & 809258 & 5.9 & 4.8874 & TST & \\
\hline CHEMBL1968930 & 809258 & 6.9 & 6.6006 & TRN & \\
\hline CHEMBL1972119 & 809258 & 4.1 & 4.2332 & TRN & \\
\hline CHEMBL1986328 & 809258 & 4.1 & 4.8556 & TST & \\
\hline CHEMBL95692 & 809258 & 5.8 & 4.9276 & TRN & \\
\hline CHEMBL1090356 & 809258 & 7.2 & 7.2615 & TRN & \\
\hline CHEMBL1976455 & 809258 & 4.1 & 4.8091 & TRN & \\
\hline CHEMBL1983923 & 809258 & 7.0 & 5.6721 & TST & \\
\hline CHEMBL1983534 & 809258 & 4.1 & 4.6462 & TRN & \\
\hline CHEMBL1982361 & 809258 & 4.1 & 4.0451 & TRN & \\
\hline CHEMBL1999112 & 809258 & 6.2 & 5.2482 & TST & \\
\hline CHEMBL1982122 & 809258 & 4.1 & 4.91100 & 00000000005 & TRN \\
\hline CHEMBL 2000801 & 809258 & 4.1 & 5.2369 & TRN & \\
\hline CHEMBL1682546 & 809258 & 4.1 & 4.2088 & TRN & \\
\hline CHEMBL1991395 & 809258 & 5.2 & 4.756 & TRN & \\
\hline CHEMBL1971245 & 809258 & 5.7 & 5.3877 & TRN & \\
\hline CHEMBL1972142 & 809258 & 6.2 & 5.9608 & TRN & \\
\hline CHEMBL1966514 & 809258 & 8.4 & 8.0355 & TRN & \\
\hline CHEMBL 2003638 & 809258 & 6.4 & 6.3439 & TRN & \\
\hline CHEMBL1996066 & 809258 & 4.1 & 5.6281 & TST & \\
\hline CHEMBL1972152 & 809258 & 4.1 & 4.6578 & TST & \\
\hline CHEMBL1993722 & 809258 & 6.4 & 6.5387 & TRN & \\
\hline CHEMBL1970806 & 809258 & 4.1 & 4.3326 & TST & \\
\hline CHEMBL1375640 & 809258 & 5.2 & 4.7131 & TST & \\
\hline CHEMBL1979970 & 809258 & 4.1 & 3.9366 & TRN & \\
\hline CHEMBL249282 & 809258 & 4.1 & 5.2379 & TST & \\
\hline CHEMBL 2006237 & 809258 & 4.1 & 4.1321 & TRN & \\
\hline CHEMBL 2005509 & 809258 & 7.5 & 7.181 & TST & \\
\hline CHEMBL1991138 & 809258 & 5.6 & 5.3663 & TST & \\
\hline CHEMBL1969755 & 809258 & 4.1 & 4.2506 & TST & \\
\hline CHEMBL1605605 & 809258 & 4.1 & 4.3597 & TST & \\
\hline CHEMBL1972820 & 809258 & 4.1 & 4.3173 & TST & \\
\hline CHEMBL1989029 & 809258 & 5.8 & 5.6548 & TST & \\
\hline CHEMBL392642 & 809258 & 6.6 & 5.2602 & TST & \\
\hline CHEMBL514499 & 809258 & 6.7 & 5.3716 & TST & \\
\hline CHEMBL1965631 & 809258 & 5.4 & 4.7473 & TST & \\
\hline CHEMBL1980144 & 809258 & 6.7 & 6.932 & TST & \\
\hline CHEMBL1991188 & 809258 & 4.1 & 4.1721 & TST & \\
\hline CHEMBL1972849 & 809258 & 4.1 & 5.0496 & TST & \\
\hline CHEMBL377408 & 809258 & 5.6 & 4.6669 & TST & \\
\hline CHEMBL1986855 & 809258 & 7.3 & 7.07100 & 0000000001 & TST \\
\hline CHEMBL215152 & 809258 & 7.7 & 5.7988 & TST & \\
\hline CHEMBL231209 & 809258 & 7.3 & 7.2465 & TST & \\
\hline CHEMBL1975357 & 809258 & 4.1 & 4.6046 & TST & \\
\hline CHEMBL1976220 & 809258 & 7.4 & 7.2488 & TST & \\
\hline CHEMBL259922 & 809258 & 4.1 & 5.0656 & TST & \\
\hline
\end{tabular}




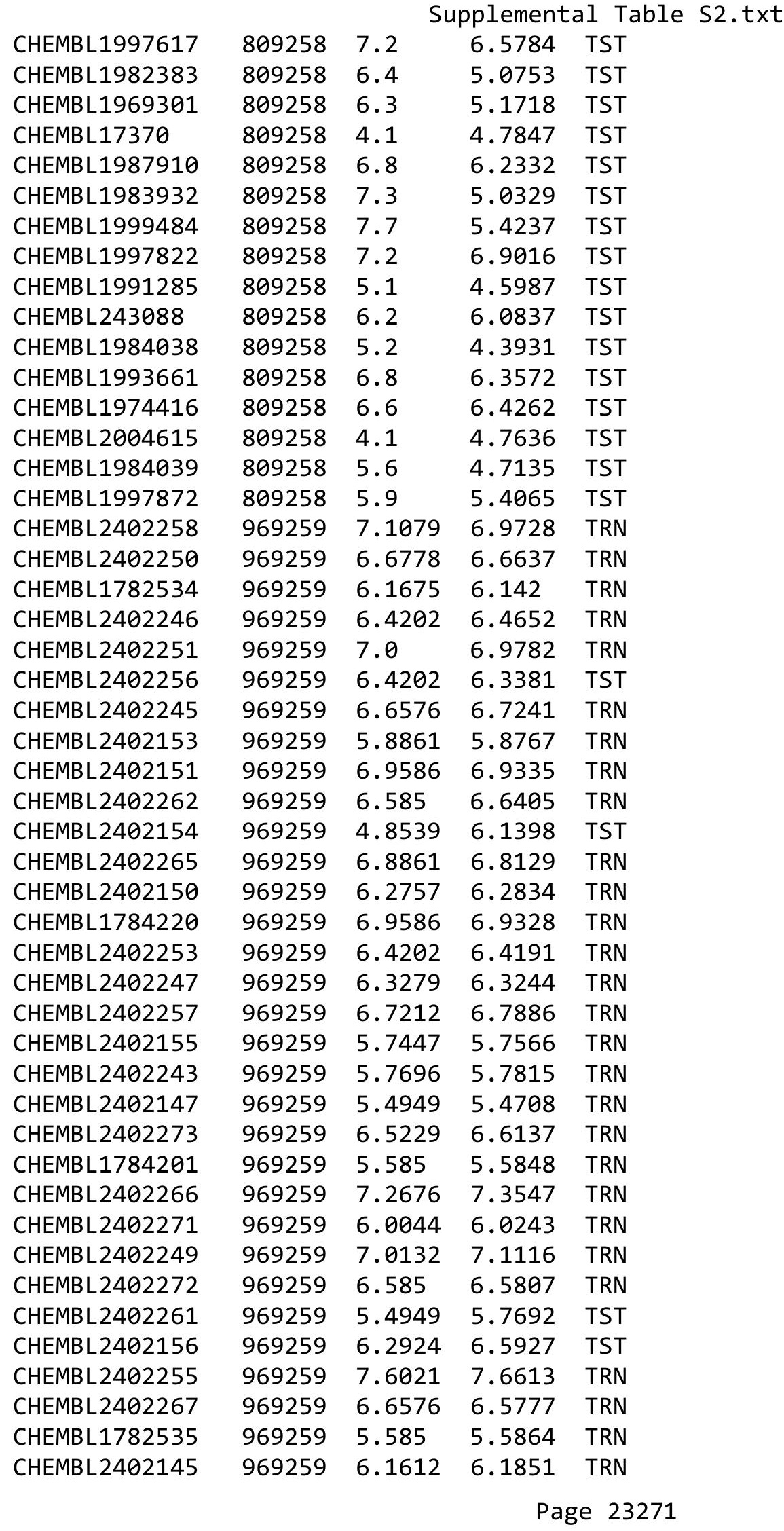




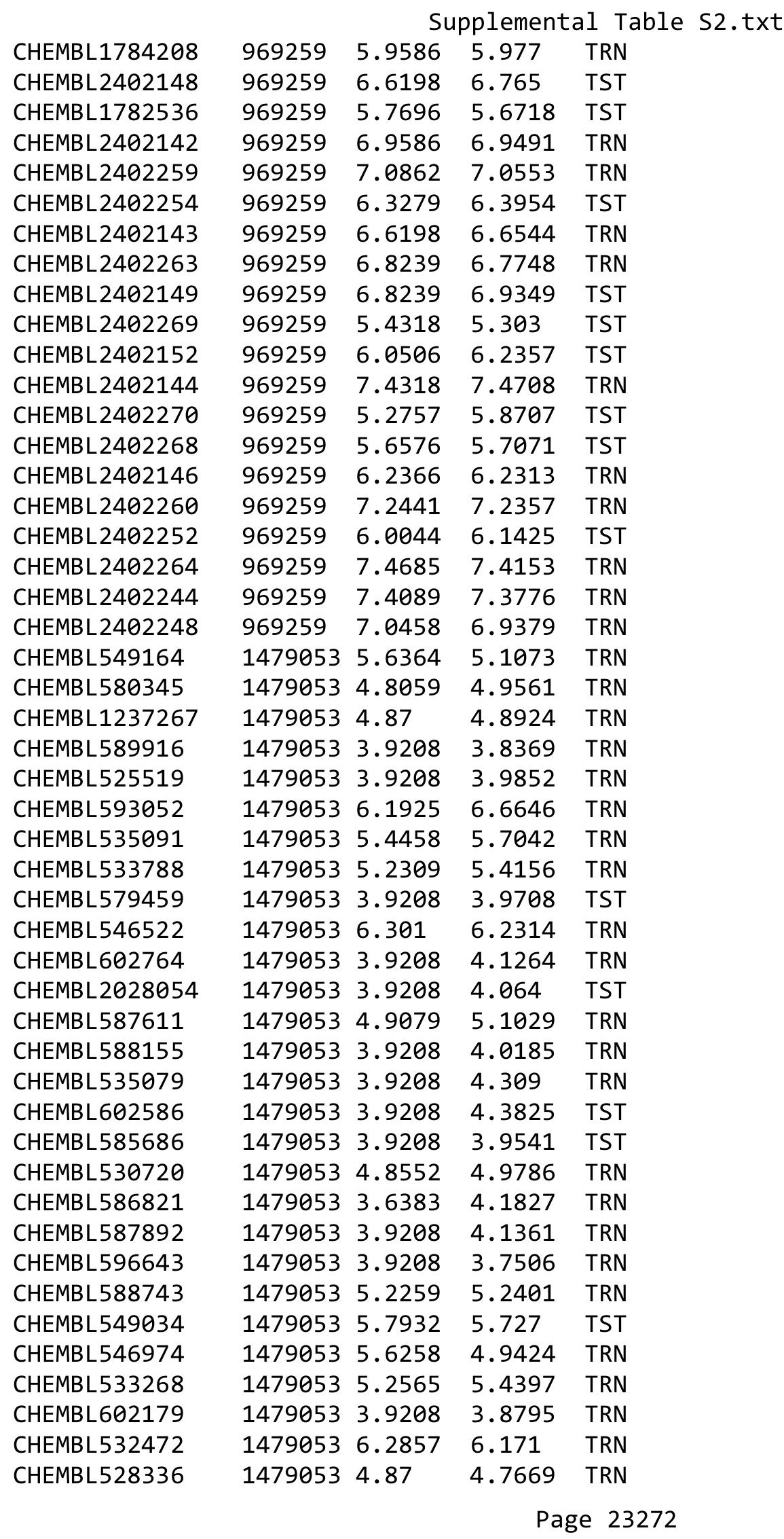


Supplemental Table S2.txt

\begin{tabular}{|c|c|c|c|c|}
\hline CHEMBL549075 & 479053 & 4.9935 & 5.1092 & TRN \\
\hline HEMBL526981 & 479053 & 3.9208 & 3.8707 & TRN \\
\hline HEMBI 532647 & 9053 & 4.9587 & 2451 & $2 \mathrm{~N}$ \\
\hline HEMBL546355 & 9053 & 2189 & 1732 & \\
\hline HEMBL532079 & 479053 & 3.9208 & .9015 & KIN \\
\hline HEMBL580199 & 479053 & 5.1056 & 5.2301 & \\
\hline HEMBL12 & 479053 & 3.9208 & .7825 & RN \\
\hline HEMBL529099 & 479053 & 5.1571 & 5.188 & PN \\
\hline HEMBL579802 & 1479053 & 5.012 & 5.0837 & TRN \\
\hline HEMBL581874 & 479053 & 3.9208 & 3.9342 & ГRN \\
\hline HEMBL597444 & 479053 & 3.9208 & 3.92 & RN \\
\hline HEMBL5 & 1479053 & 4.87 & 4.7691 & RN \\
\hline HEMBL5 & 479053 & 5.6153 & 5.318 & \\
\hline HEMBL527234 & 1479053 & 3.9208 & 3.7552 & TRN \\
\hline HEMBL580307 & 479053 & 6.2526 & 6.4372 & TRN \\
\hline HEMBL 6 & 4790 & 3. & 3.9384 & KIN \\
\hline HEMBL 5 & 53 & 5 . & 7757 & RN \\
\hline HEMBL5 & 479053 & 5.3568 & 5.3656 & IST \\
\hline HEMBL5 & 479053 & 5.3408 & 5.1956 & TRN \\
\hline HEMBL582400 & & 5.6 & 5.5996 & I KIV \\
\hline HEMBL 5 & 4 & 5 . & $\partial 152$ & RN \\
\hline HEMBL5 & 14 & 3. & 3.9398 & 「RN \\
\hline HEMBL 2 & 9053 & 3.9208 & 3.7421 & TRN \\
\hline HEMBL5 & 9053 & 4.87 & 4.9862 & TRN \\
\hline HEMBL6 & 053 & 3.5 & 3.8863 & TRN \\
\hline HEMBL 5 & 47 & 5 . & 5.5354 & TRN \\
\hline HEMBL5 & 053 & 3 . & 7613 & 「RN \\
\hline HEMBL5 & 053 & 3. & 3.8326 & TRN \\
\hline HEMBL 5 & & 3. & 1208 & TRN \\
\hline HEMBL600356 & 47905 & 3.9208 & 4.0201 & TST \\
\hline HEMBL5 & 905 & 5 . & 4.9974 & TRN \\
\hline THEMBL & 3 & 5 . & 186 & TRN \\
\hline HEMBL5 & & & 5.4729 & TRN \\
\hline HEMBL5 & 479053 & 3.92 & 4.0331 & TRN \\
\hline HEMBL532141 & 47905 & 3.9208 & 3.8902 & TRN \\
\hline HEMBL 5 & 99 & 5 . & 5.4212 & TRN \\
\hline CHEMBLS & & 5 . & 279 & TRN \\
\hline CHEMBL580539 & 1479053 & 5.6885 & 5.8645 & TRN \\
\hline CHEMBL 5 & 47905 & 3.9208 & 3.8446 & TRN \\
\hline CHEMBL5 & 905 & 5 . & 9818 & TRN \\
\hline CHEMBL 6 & 1479053 & 3.5 & 4.2012 & TRN \\
\hline CHEMBL6 & 1479053 & 3.9208 & 4.0822 & TRN \\
\hline CHEMBL161678 & 1479053 & 3.9208 & 3.9902 & TRN \\
\hline CHEMBL 5 & 147905 & 5.0463 & 5.1957 & $\mathrm{TR}$ \\
\hline CHEMBL3 & 147905 & & 4.2366 & KIV \\
\hline CHEMBL5 & 1479053 & 3.9208 & 3.9282 & T. \\
\hline CHEMBL529372 & 1479053 & 5.4122 & 5.6457 & RN \\
\hline CHEMBL578294 & 1479053 & 5.2479 & 5.2606 & TRN \\
\hline
\end{tabular}

Page 23273 
Supplemental Table S2.txt

\begin{tabular}{|c|c|c|c|c|}
\hline LHEMBL529823 & 479053 & 5.2991 & 5.0363 & TRN \\
\hline HEMBL1623897 & 479053 & 3.9208 & 3.8289 & \\
\hline HEMBL 582010 & 9053 & 5.2303 & 3717 & \\
\hline HEMBL533079 & 9053 & 6749 & 8002 & \\
\hline HEMBL 587083 & 479053 & 3.9208 & 0118 & \\
\hline HEMBL 580876 & 479053 & 3.9208 & .8713 & \\
\hline HEMBL534123 & 9053 & 5.4766 & .2686 & \\
\hline HEMBL600132 & 479053 & 5.171 & 5966 & $C T$ \\
\hline HEMBL530399 & 479053 & 4.9722 & 5.0127 & RIN \\
\hline HEMBL1619026 & 479053 & 3.9208 & 8105 & TRN \\
\hline HEMBL590944 & 4790 & 3.9208 & 4.0141 & \\
\hline HEMBL5 & 9053 & 6.7799 & 5402 & RN \\
\hline HEMBL5 & 9053 & 3.9208 & 1798 & \\
\hline HEMBL605281 & 479053 & 3.9208 & 3.7739 & TRN \\
\hline HEMBL1237217 & & 5.1663 & 1356 & TST \\
\hline HEMBL 5 & 4 & 46 & 4.8892 & KIN \\
\hline HEMBL 5 & & 5.9034 & 507 & RN \\
\hline HEMBL 6 & 053 & 3.9208 & 583 & TRN \\
\hline HEMBL5 & 9053 & 5.9622 & 343 & I RIV \\
\hline HEMBL 588855 & & 3.9208 & 313 & n \\
\hline HEMBL5 & 47 & 36 & 54 & 1 \\
\hline HEMBL: & & 208 & 81 & ГST \\
\hline HEMBL5 & 053 & 3.9208 & 844 & TST \\
\hline HEMBL 5 & 053 & 3945 & 3545 & TRN \\
\hline HEMBL528734 & & 3.9208 & 345 & IRI \\
\hline HEMBL6 & 47 & 208 & 24 & 「RN \\
\hline HEMBL & & 208 & 55 & RN \\
\hline HEMBL5 & 53 & 208 & 194 & TRN \\
\hline HEMBL 5 & & 097 & & IRIN \\
\hline HEMBL580381 & 47905 & 3.9208 & 3343 & TRN \\
\hline HEMBL 6 & 0 & 208 & 34 & IST \\
\hline HEMBL & & 51 & 1987 & TRN \\
\hline HEMBL5 & & 08 & & TRN \\
\hline HEMBL526627 & 905 & 5.6817 & & TRN \\
\hline HEMBL2028047 & 47905 & 3.9208 & 3023 & TRN \\
\hline HEMBL $\epsilon$ & 995 & 796 & 37 & TRN \\
\hline HEM & & 77 & 91 & TRN \\
\hline HEMBL524746 & 1479053 & 5.3716 & & TRN \\
\hline HEMBL5 & 905 & 429 & 1603 & TRN \\
\hline HEMBL5 & 905 & 325 & 554 & TRN \\
\hline HEMBL5 & 14790 & 05 & 1963 & TRN \\
\hline CHEMBL5 & 90 & 3.9208 & 3.7652 & TRN \\
\hline CHEMBL590674 & 1479053 & 3.9208 & 3.9617 & TRN \\
\hline CHEMBL 5 & 7905 & 5.4215 & 808 & $\mathrm{TR}$ \\
\hline CHEMBL5 & ביבי & & & IRN \\
\hline HEMBL 5 & 147905 & 5.8242 & 5.8931 & \\
\hline CHEMBL532363 & 1479053 & 4.87 & 5.1978 & RN \\
\hline CHEMBL603686 & 1479053 & 3.9208 & 3.8713 & 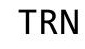 \\
\hline
\end{tabular}

Page 23274 
Supplemental Table S2.txt

\begin{tabular}{|c|c|c|c|c|c|}
\hline CHEMBL533284 & 1479053 & 5.2918 & 5.3103 & TRN & \\
\hline CHEMBL587802 & 1479053 & 5.3471 & 4.9436 & TRN & \\
\hline CHEMBL582552 & 1479053 & 3.9208 & 3.9617 & TRN & \\
\hline CHEMBL1738986 & 1479053 & 3.9208 & 3.8462 & TRN & \\
\hline CHEMBL577011 & 1479053 & 3.9208 & 3.8534 & TRN & \\
\hline CHEMBL600174 & 1479053 & 3.9208 & 3.8576 & TST & \\
\hline CHEMBL596652 & 1479053 & 3.9208 & 3.8284 & TRN & \\
\hline CHEMBL533598 & 1479053 & 3.9208 & 3.9535 & TRN & \\
\hline CHEMBL581475 & 1479053 & 3.9208 & 3.8136 & TRN & \\
\hline CHEMBL547476 & 1479053 & 3.9208 & 3.9487 & TRN & \\
\hline CHEMBL528245 & 1479053 & 3.9208 & 3.8552 & TRN & \\
\hline CHEMBL1615697 & 1479053 & 3.9208 & 4.006 & TST & \\
\hline CHEMBL582286 & 1479053 & 3.9208 & 3.8135 & TRN & \\
\hline CHEMBL1437888 & 1479053 & 5.171 & 4.997 & TST & \\
\hline CHEMBL535029 & 1479053 & 5.2303 & 4.9988 & TRN & \\
\hline CHEMBL583682 & 1479053 & 3.9208 & 3.8115 & TRN & \\
\hline CHEMBL582393 & 1479053 & 5.2123 & 5.4903 & TRN & \\
\hline CHEMBL587208 & 1479053 & 5.5324 & \multicolumn{2}{|c|}{5.207000000000001} & TRN \\
\hline CHEMBL584829 & 1479053 & 3.9208 & 4.0201 & TRN & \\
\hline CHEMBL 2028059 & 1479053 & 3.9208 & 3.8375 & TST & \\
\hline CHEMBL533085 & 1479053 & 5.0433 & 5.0479 & TST & \\
\hline CHEMBL470514 & 1479053 & 3.9208 & 4.2838 & TRN & \\
\hline CHEMBL535659 & 1479053 & 5.3664 & 5.2763 & TRN & \\
\hline CHEMBL529348 & 1479053 & 3.9208 & 3.8588 & TRN & \\
\hline CHEMBL525462 & 1479053 & 4.87 & 4.8537 & TRN & \\
\hline CHEMBL586234 & 1479053 & 6.0462 & 5.4737 & TRN & \\
\hline CHEMBL589922 & 1479053 & 3.9208 & 3.8406 & TRN & \\
\hline CHEMBL534797 & 1479053 & 5.0225 & 5.034 & TRN & \\
\hline CHEMBL582666 & 1479053 & 5.171 & 4.9092 & TRN & \\
\hline CHEMBL547825 & 1479053 & 3.9208 & 4.1234 & TRN & \\
\hline CHEMBL1545915 & 1479053 & 3.9208 & 3.8855 & TST & \\
\hline CHEMBL531060 & 1479053 & 3.9208 & 4.1608 & TRN & \\
\hline CHEMBL106772 & 1479053 & 5.3472 & 5.2835 & TRN & \\
\hline CHEMBL527419 & 1479053 & 4.9411 & 4.2833 & TST & \\
\hline CHEMBL601528 & 1479053 & 3.9208 & 3.9305 & TRN & \\
\hline CHEMBL528694 & 1479053 & 5.6953 & 5.6107 & TRN & \\
\hline CHEMBL589946 & 1479053 & 3.9208 & 3.8612 & TRN & \\
\hline CHEMBL592550 & 1479053 & 3.9208 & 3.84 & TRN & \\
\hline CHEMBL588379 & 1479053 & 5.4795 & 5.0088 & TRN & \\
\hline CHEMBL546661 & 1479053 & 5.7476 & 4.6487 & TRN & \\
\hline CHEMBL533252 & 1479053 & 5.1891 & 4.9851 & TRN & \\
\hline CHEMBL579760 & 1479053 & 3.9208 & 4.1274 & TRN & \\
\hline CHEMBL527131 & 1479053 & 3.9208 & 3.8188 & TRN & \\
\hline CHEMBL590182 & 1479053 & 3.9208 & 3.7363 & TRN & \\
\hline CHEMBL524784 & 1479053 & 3.9208 & 4.0039 & TRN & \\
\hline CHEMBL607975 & 1479053 & 3.9208 & 4.1594 & TRN & \\
\hline CHEMBL602312 & 1479053 & 5.171 & 4.963 & TRN & \\
\hline CHEMBL548061 & 1479053 & 5.7627 & 5.2396 & TRN & \\
\hline
\end{tabular}

Page 23275 
Supplemental Table S2.txt

\begin{tabular}{|c|c|c|c|c|}
\hline CHEMBL546383 & 1479053 & 5.1568 & 5.1634 & TRN \\
\hline CHEMBL591890 & 1479053 & 3.9208 & 4.0689 & TST \\
\hline CHEMBL580757 & 1479053 & 3.9208 & 3.8792 & TRN \\
\hline CHEMBL528032 & 1479053 & 5.2942 & 5.1458 & TRN \\
\hline CHEMBL533195 & 1479053 & 5.43 & 5.4022 & TST \\
\hline CHEMBL581860 & 1479053 & 3.9208 & 4.5295 & TRN \\
\hline CHEMBL1237255 & 1479053 & 3.9208 & 4.0999 & TRN \\
\hline CHEMBL582356 & 1479053 & 5.4389 & 5.232 & TRN \\
\hline CHEMBL586937 & 1479053 & 5.4101 & 5.4211 & TRN \\
\hline CHEMBL532254 & 1479053 & 5.9935 & 5.5879 & TST \\
\hline CHEMBL548005 & 1479053 & 5.7905 & 5.7434 & TRN \\
\hline CHEMBL590888 & 1479053 & 3.9208 & 4.0424 & TRN \\
\hline CHEMBL607308 & 1479053 & 3.9208 & 4.0526 & TRN \\
\hline CHEMBL549080 & 1479053 & 5.3021 & 5.2255 & TRN \\
\hline CHEMBL587980 & 1479053 & 4.9968 & 5.2516 & TRN \\
\hline CHEMBL546912 & 1479053 & 5.1963 & 5.3999 & TRN \\
\hline CHEMBL535557 & 1479053 & 4.87 & 5.3027 & TRN \\
\hline CHEMBL546994 & 1479053 & 3.9208 & 3.8665 & TRN \\
\hline CHEMBL529990 & 1479053 & 5.8419 & 5.6669 & TRN \\
\hline CHEMBL588253 & 1479053 & 5.4706 & 5.6531 & TRN \\
\hline CHEMBL529792 & 1479053 & 6.0443 & 5.4154 & TST \\
\hline CHEMBL591183 & 1479053 & 5.1837 & 5.1618 & TRN \\
\hline CHEMBL548545 & 1479053 & 5.5255 & 5.3975 & TRN \\
\hline CHEMBL525710 & 1479053 & 5.1291 & 5.2957 & TRN \\
\hline CHEMBL577014 & 1479053 & 3.9208 & 4.0271 & TRN \\
\hline CHEMBL580043 & 1479053 & 5.3518 & 5.3899 & TRN \\
\hline CHEMBL586130 & 1479053 & 5.2104 & \multicolumn{2}{|c|}{5.2010000000000005} \\
\hline CHEMBL582079 & 1479053 & 3.9208 & 3.8838 & TRN \\
\hline CHEMBL586298 & 1479053 & 5.9031 & 6.3498 & TRN \\
\hline CHEMBL547614 & 1479053 & 3.9208 & 3.9457 & TST \\
\hline CHEMBL601580 & 1479053 & 5.171 & 4.9269 & TRN \\
\hline CHEMBL599885 & 1479053 & 3.9208 & 3.8331 & TRN \\
\hline CHEMBL532270 & 1479053 & 5.7742 & 5.6346 & TRN \\
\hline CHEMBL549210 & 1479053 & 3.9208 & 3.7781 & TRN \\
\hline CHEMBL 2028052 & 1479053 & 3.9208 & 4.0918 & TRN \\
\hline CHEMBL600706 & 1479053 & 3.9208 & 3.8881 & TRN \\
\hline CHEMBL580534 & 1479053 & 5.0126 & 5.0309 & TRN \\
\hline CHEMBL580140 & 1479053 & 3.9208 & 4.1116 & TRN \\
\hline CHEMBL530402 & 1479053 & 5.1838 & 5.0706 & TRN \\
\hline CHEMBL527906 & 1479053 & 5.4579 & 5.6297 & TRN \\
\hline CHEMBL582070 & 1479053 & 3.9208 & 4.1667 & TRN \\
\hline CHEMBL532148 & 1479053 & 5.0436 & 4.9132 & TRN \\
\hline CHEMBL548111 & 1479053 & 5.1651 & 5.1825 & TRN \\
\hline CHEMBL588259 & 1479053 & 6.71 & 6.6918 & TRN \\
\hline CHEMBL525826 & 1479053 & 3.9208 & 4.1566 & TRN \\
\hline CHEMBL601122 & 1479053 & 5.171 & 4.8217 & TRN \\
\hline CHEMBL1485159 & 1479053 & 3.9208 & 4.0485 & TRN \\
\hline CHEMBL601825 & 1479053 & 3.9208 & 3.8596 & TRN \\
\hline
\end{tabular}

Page 23276 
Supplemental Table S2.txt

\begin{tabular}{|c|c|c|c|c|}
\hline CHEMBL533399 & 1479053 & 3.9208 & 4.295 & TST \\
\hline CHEMBL529968 & 1479053 & 3.9208 & 3.9339 & TRN \\
\hline CHEMBL546955 & 1479053 & 5.7916 & 5.751 & TRN \\
\hline CHEMBL536627 & 1479053 & 3.6383 & 3.9909 & TRN \\
\hline CHEMBL528533 & 1479053 & 3.9208 & 4.8366 & TRN \\
\hline CHEMBL535498 & 1479053 & 5.3891 & 5.5235 & TRN \\
\hline CHEMBL534875 & 1479053 & 5.21399 & 999999999 & 5.3281 \\
\hline CHEMBL580567 & 1479053 & 5.2177 & 5.1694 & TRN \\
\hline CHEMBL525506 & 1479053 & 5.7585 & 5.7079 & TRN \\
\hline CHEMBL317364 & 1479053 & 3.9208 & 3.8011 & TRN \\
\hline CHEMBL1623028 & 1479053 & 3.9208 & 4.0887 & TRN \\
\hline CHEMBL588184 & 1479053 & 5.2321 & 5.2924 & TRN \\
\hline CHEMBL547443 & 1479053 & 3.9208 & 3.9902 & TRN \\
\hline CHEMBL524764 & 1479053 & 5.3027 & 5.3497 & TRN \\
\hline CHEMBL587410 & 1479053 & 3.9208 & 4.0077 & TST \\
\hline CHEMBL545822 & 1479053 & 5.2301 & 5.2136 & TRN \\
\hline CHEMBL533564 & 1479053 & 5.1741 & 5.3891 & TST \\
\hline CHEMBL1740701 & 1479053 & 3.9208 & 3.9288 & TRN \\
\hline CHEMBL527374 & 1479053 & 5.3932 & 5.5803 & TRN \\
\hline CHEMBL531046 & 1479053 & 5.7873 & 5.3834 & TST \\
\hline CHEMBL529140 & 1479053 & 6.1284 & 6.3132 & TRN \\
\hline CHEMBL526064 & 1479053 & 5.1979 & 5.2501 & TRN \\
\hline CHEMBL547266 & 1479053 & 3.9208 & 4.6035 & TRN \\
\hline CHEMBL588636 & 1479053 & 5.4442 & 5.2489 & TST \\
\hline CHEMBL529773 & 1479053 & 3.9208 & 3.896000 & 30000000004 \\
\hline CHEMBL598279 & 1479053 & 5.3303 & 5.0811 & TRN \\
\hline CHEMBL528480 & 1479053 & 5.7572 & 5.598 & TRN \\
\hline CHEMBL533283 & 1479053 & 5.4512 & 5.5926 & TRN \\
\hline CHEMBL592123 & 1479053 & 5.171 & 5.1769 & TRN \\
\hline CHEMBL586135 & 1479053 & 4.8148 & 4.6858 & TRN \\
\hline CHEMBL528508 & 1479053 & 5.3356 & 5.5498 & TRN \\
\hline CHEMBL 2028063 & 1479053 & 3.9208 & 4.7856 & TRN \\
\hline CHEMBL601325 & 1479053 & 3.9208 & 4.012 & TST \\
\hline CHEMBL548076 & 1479053 & 5.1879 & 5.4963 & TRN \\
\hline CHEMBL536393 & 1479053 & 3.9208 & 3.7589 & TRN \\
\hline CHEMBL602211 & 1479053 & 3.9208 & 4.055 & TRN \\
\hline CHEMBL582072 & 1479053 & 3.9208 & 3.9259 & TRN \\
\hline CHEMBL581358 & 1479053 & 5.4712 & 5.3527 & TRN \\
\hline CHEMBL587120 & 1479053 & 6.2798 & 6.1361 & TRN \\
\hline CHEMBL602552 & 1479053 & 3.9208 & 3.9727 & TST \\
\hline CHEMBL546799 & 1479053 & 3.9208 & 3.8208 & TRN \\
\hline CHEMBL529612 & 1479053 & 4.87 & 5.1396 & TRN \\
\hline CHEMBL531938 & 1479053 & 5.3476 & 5.1639 & TRN \\
\hline CHEMBL526944 & 1479053 & 5.4013 & 5.5491 & TRN \\
\hline CHEMBL587090 & 1479053 & 5.9767 & 5.6652 & TST \\
\hline CHEMBL 2028055 & 1479053 & 3.9208 & 3.8453 & TRN \\
\hline CHEMBL579809 & 1479053 & 5.3029 & 5.3044 & TRN \\
\hline CHEMBL533883 & 1479053 & 5.8928 & 5.6625 & TST \\
\hline
\end{tabular}


Supplemental Table S2.txt

\begin{tabular}{|c|c|c|c|c|c|}
\hline CHEMBL590919 & 1479053 & 3.9208 & 4.4487 & TRN & \\
\hline CHEMBL531829 & 1479053 & 5.2766 & 5.0266 & TST & \\
\hline CHEMBL548918 & 1479053 & 5.4209 & 5.2343 & TRN & \\
\hline CHEMBL609628 & 1479053 & 5.171 & 4.7878 & TRN & \\
\hline CHEMBL588732 & 1479053 & 3.9208 & 3.8132 & TRN & \\
\hline CHEMBL206540 & 1479053 & 3.9208 & 3.8746 & TRN & \\
\hline CHEMBL600549 & 1479053 & 3.9208 & 3.9169 & TST & \\
\hline CHEMBL529984 & 1479053 & 3.9208 & 3.9975 & TRN & \\
\hline CHEMBL535680 & 1479053 & 5.3407 & 5.4107 & TRN & \\
\hline CHEMBL530989 & 1479053 & 5.1302 & 5.0299 & TRN & \\
\hline CHEMBL586553 & 1479053 & 5.2933 & 5.1886 & TRN & \\
\hline CHEMBL530513 & 1479053 & 5.6293 & 5.5995 & TRN & \\
\hline CHEMBL588939 & 1479053 & 5.2506 & 5.3095 & TRN & \\
\hline CHEMBL547184 & 1479053 & 5.216 & 5.0397 & TST & \\
\hline CHEMBL548432 & 1479053 & 5.4815 & 5.2872 & TRN & \\
\hline CHEMBL124006 & 1479053 & 6.0814 & 5.5988 & TRN & \\
\hline CHEMBL609156 & 1479053 & 3.9208 & 3.8775 & TRN & \\
\hline CHEMBL528437 & 1479053 & 3.9208 & 3.8164 & TRN & \\
\hline CHEMBL529603 & 1479053 & 3.9208 & 3.9853 & TRN & \\
\hline CHEMBL 2028043 & 1479053 & 3.9208 & 3.9652 & TRN & \\
\hline CHEMBL547140 & 1479053 & 5.7185 & 5.7689 & TRN & \\
\hline CHEMBL582767 & 1479053 & 3.9208 & 4.94 & TST & \\
\hline CHEMBL525486 & 1479053 & 3.9208 & 3.9938 & TRN & \\
\hline CHEMBL586471 & 1479053 & 5.1354 & 4.8301 & TST & \\
\hline CHEMBL584676 & 1479053 & 3.9208 & 3.8127 & TRN & \\
\hline CHEMBL475813 & 1479053 & 3.9208 & 4.0626 & TRN & \\
\hline CHEMBL532570 & 1479053 & 5.9003 & 5.6683 & TRN & \\
\hline CHEMBL546309 & 1479053 & 5.7126 & 5.8343 & TRN & \\
\hline CHEMBL529225 & 1479053 & 5.0486 & 4.9225 & TRN & \\
\hline CHEMBL524580 & 1479053 & 5.8058 & 5.9173 & TRN & \\
\hline CHEMBL579920 & 1479053 & 5.0623 & 5.1997 & TRN & \\
\hline CHEMBL527904 & 1479053 & 5.8199 & 6.3989 & TRN & \\
\hline CHEMBL528761 & 1479053 & 5.244 & \multicolumn{2}{|c|}{5.5360000000000005} & TRN \\
\hline CHEMBL529957 & 1479053 & 4.87 & 5.1042 & TRN & \\
\hline CHEMBL534441 & 1479053 & 5.0472 & 4.9512 & TRN & \\
\hline CHEMBL 2028042 & 1479053 & 3.9208 & 3.7927 & TRN & \\
\hline CHEMBL588011 & 1479053 & 5.0814 & 4.9823 & TST & \\
\hline CHEMBL588020 & 1479053 & 6.5114 & 5.8619 & TRN & \\
\hline CHEMBL582634 & 1479053 & 5.443 & 5.2838 & TRN & \\
\hline CHEMBL353161 & 1479053 & 5.0586 & 4.966 & TRN & \\
\hline CHEMBL536421 & 1479053 & 3.9208 & 3.7553 & TRN & \\
\hline CHEMBL 2028048 & 1479053 & 3.9208 & 3.9133 & TRN & \\
\hline CHEMBL587344 & 1479053 & 5.4765 & 5.5801 & TRN & \\
\hline CHEMBL580914 & 1479053 & 6.5768 & 6.3114 & TRN & \\
\hline CHEMBL547269 & 1479053 & 3.9208 & 3.8338 & TRN & \\
\hline CHEMBL599886 & 1479053 & 3.9208 & 3.7836 & TST & \\
\hline CHEMBL586656 & 1479053 & 5.6269 & 5.7168 & TRN & \\
\hline CHEMBL583555 & 1479053 & 3.9208 & 4.0617 & TST & \\
\hline
\end{tabular}


Supplemental Table S2.txt

\begin{tabular}{|c|c|c|c|c|c|}
\hline CHEMBL588318 & 1479053 & 5.5719 & 5.1571 & TRN & \\
\hline CHEMBL547448 & 1479053 & 4.9197 & 5.1523 & TRN & \\
\hline CHEMBL547795 & 1479053 & 5.6855 & 5.6376 & TRN & \\
\hline CHEMBL590933 & 1479053 & 5.171 & 4.8927 & TRN & \\
\hline CHEMBL588859 & 1479053 & 3.9208 & 3.9626 & TRN & \\
\hline CHEMBL587288 & 1479053 & 3.9208 & 3.9134 & TRN & \\
\hline CHEMBL590159 & 1479053 & 3.9208 & 3.8381 & TRN & \\
\hline CHEMBL586632 & 1479053 & 5.6282 & 5.6161 & TRN & \\
\hline CHEMBL537082 & 1479053 & 5.0767 & 4.8175 & TST & \\
\hline CHEMBL586704 & 1479053 & 3.9208 & 3.8381 & TRN & \\
\hline CHEMBL548372 & 1479053 & 5.2591 & 5.4996 & TRN & \\
\hline CHEMBL580654 & 1479053 & 3.9208 & \multicolumn{2}{|c|}{3.7319999999999998} & TRN \\
\hline CHEMBL546211 & 1479053 & 4.87 & 5.0525 & TRN & \\
\hline CHEMBL588673 & 1479053 & 5.2209 & 4.9165 & TST & \\
\hline CHEMBL533333 & 1479053 & 5.4414 & 5.8009 & TRN & \\
\hline CHEMBL530139 & 1479053 & 5.4703 & 5.4893 & TRN & \\
\hline CHEMBL527902 & 1479053 & 5.3892 & \multicolumn{2}{|c|}{5.3020000000000005} & TRN \\
\hline CHEMBL598369 & 1479053 & 3.9208 & 3.7999 & TRN & \\
\hline CHEMBL584841 & 1479053 & 3.9208 & 3.951 & TRN & \\
\hline CHEMBL533999 & 1479053 & 3.9208 & 3.9351 & TRN & \\
\hline CHEMBL536671 & 1479053 & 5.4887 & 5.0868 & TRN & \\
\hline CHEMBL534612 & 1479053 & 3.9208 & 3.8414 & TRN & \\
\hline CHEMBL581489 & 1479053 & 3.9208 & 3.8355 & TRN & \\
\hline CHEMBL581065 & 1479053 & 5.8008 & 5.2784 & TST & \\
\hline CHEMBL534214 & 1479053 & 4.87 & 5.2816 & TRN & \\
\hline CHEMBL533931 & 1479053 & 5.5887 & 5.3949 & TRN & \\
\hline CHEMBL536166 & 1479053 & 6.2168 & 6.3989 & TRN & \\
\hline CHEMBL592044 & 1479053 & 3.9208 & 4.3613 & TRN & \\
\hline CHEMBL584015 & 1479053 & 5.171 & 5.0153 & TRN & \\
\hline CHEMBL532890 & 1479053 & 5.2278 & \multicolumn{2}{|c|}{5.202000000000001} & TST \\
\hline CHEMBL580249 & 1479053 & 3.9208 & 3.7481 & TRN & \\
\hline CHEMBL529452 & 1479053 & 6.5817 & 5.7576 & TRN & \\
\hline CHEMBL2028050 & 1479053 & 5.3116 & 5.2485 & TRN & \\
\hline CHEMBL2028045 & 1479053 & 3.9208 & 3.969 & TRN & \\
\hline CHEMBL530438 & 1479053 & 3.9208 & 3.9714 & TRN & \\
\hline CHEMBL525308 & 1479053 & 4.9126 & 5.3656 & TRN & \\
\hline CHEMBL586031 & 1479053 & 3.9208 & 3.9632 & TST & \\
\hline CHEMBL531529 & 1479053 & 5.7693 & 5.3488 & TRN & \\
\hline CHEMBL586695 & 1479053 & 5.1174 & 5.2796 & TRN & \\
\hline CHEMBL533855 & 1479053 & 3.9208 & 3.8905 & TRN & \\
\hline CHEMBL601806 & 1479053 & 3.9208 & 3.9182 & TST & \\
\hline CHEMBL586026 & 1479053 & 3.9208 & 4.1048 & TST & \\
\hline CHEMBL549003 & 1479053 & 5.4141 & \multicolumn{2}{|c|}{5.6129999999999995} & TRN \\
\hline CHEMBL533941 & 1479053 & 5.5173 & 5.3122 & TRN & \\
\hline CHEMBL527213 & 1479053 & 5.3614 & 5.365 & TRN & \\
\hline CHEMBL468963 & 1479053 & 6.2343 & 6.5172 & TRN & \\
\hline CHEMBL532987 & 1479053 & 3.9208 & 3.8215 & TRN & \\
\hline CHEMBL546770 & 1479053 & 5.558 & 5.1462 & TRN & \\
\hline
\end{tabular}


Supplemental Table S2.txt

\begin{tabular}{|c|c|c|c|c|c|}
\hline CHEMBL588566 & 1479053 & 5.5776 & 5.3523 & TRN & \\
\hline CHEMBL526243 & 1479053 & 6.1555 & \multicolumn{2}{|c|}{6.452000000000001} & TRN \\
\hline CHEMBL106525 & 1479053 & 5.2303 & 5.1116 & TRN & \\
\hline CHEMBL580967 & 1479053 & 5.4383 & 5.4642 & TRN & \\
\hline CHEMBL578952 & 1479053 & 3.9208 & 3.76 & TRN & \\
\hline CHEMBL549208 & 1479053 & 3.9208 & 3.9527 & TST & \\
\hline CHEMBL588727 & 1479053 & 5.4267 & 5.5725 & TRN & \\
\hline CHEMBL532762 & 1479053 & 5.2527 & 5.2387 & TRN & \\
\hline CHEMBL592786 & 1479053 & 3.9208 & 4.0333 & TRN & \\
\hline CHEMBL527221 & 1479053 & 3.6383 & 4.093 & TRN & \\
\hline CHEMBL532525 & 1479053 & 3.9208 & 3.7952 & TRN & \\
\hline CHEMBL338094 & 1479053 & 3.9208 & 3.7809 & TRN & \\
\hline CHEMBL586888 & 1479053 & 3.9208 & 3.8025 & TRN & \\
\hline CHEMBL535323 & 1479053 & 5.3265 & 5.3602 & TRN & \\
\hline CHEMBL536685 & 1479053 & 5.1394 & 4.9999 & TRN & \\
\hline CHEMBL532103 & 1479053 & 5.3928 & 5.4172 & TRN & \\
\hline CHEMBL531695 & 1479053 & 5.6249 & 5.4121 & TST & \\
\hline CHEMBL529924 & 1479053 & 5.4045 & 5.2125 & TRN & \\
\hline CHEMBL2021322 & 1479053 & 3.9208 & 3.8949 & TRN & \\
\hline CHEMBL170758 & 1479053 & 5.8292 & 5.5909 & TRN & \\
\hline CHEMBL536892 & 1479053 & 5.324 & 5.4186 & TRN & \\
\hline CHEMBL581135 & 1479053 & 6.5867 & 6.7415 & TRN & \\
\hline CHEMBL601566 & 1479053 & 3.9208 & 4.0716 & TRN & \\
\hline CHEMBL606159 & 1479053 & 3.9208 & 3.7965 & TRN & \\
\hline CHEMBL533070 & 1479053 & 4.87 & 5.0311 & TRN & \\
\hline CHEMBL586095 & 1479053 & 5.2878 & 5.4598 & TRN & \\
\hline CHEMBL609036 & 1479053 & 3.9208 & 4.1028 & TRN & \\
\hline CHEMBL586078 & 1479053 & 3.9208 & 3.8553 & TRN & \\
\hline CHEMBL580496 & 1479053 & 4.9226 & 5.1185 & TRN & \\
\hline CHEMBL 2028064 & 1479053 & 3.9208 & 4.0844 & TRN & \\
\hline CHEMBL533377 & 1479053 & 5.6373 & 5.4742 & TRN & \\
\hline CHEMBL588127 & 1479053 & 5.3021 & 5.2249 & TRN & \\
\hline CHEMBL602413 & 1479053 & 5.171 & 5.0031 & TRN & \\
\hline CHEMBL586933 & 1479053 & 3.9208 & 3.7479 & TRN & \\
\hline CHEMBL 2028056 & 1479053 & 3.9208 & 4.03600 & 00000000005 & TRN \\
\hline CHEMBL529919 & 1479053 & 3.9208 & 3.8742 & TRN & \\
\hline CHEMBL591362 & 1479053 & 5.171 & 5.0891 & TRN & \\
\hline CHEMBL587968 & 1479053 & 5.8505 & 5.7811 & TRN & \\
\hline CHEMBL532597 & 1479053 & 3.9208 & 4.106 & TST & \\
\hline CHEMBL535077 & 1479053 & 6.9172 & 6.8815 & TRN & \\
\hline CHEMBL591887 & 1479053 & 3.9208 & 3.9646 & TRN & \\
\hline CHEMBL548901 & 1479053 & 3.9208 & 3.9643 & TRN & \\
\hline CHEMBL582478 & 1479053 & 5.171 & 5.0428 & TRN & \\
\hline CHEMBL578933 & 1479053 & 3.9208 & 3.8159 & TRN & \\
\hline CHEMBL592125 & 1479053 & 3.9208 & 3.9407 & TRN & \\
\hline CHEMBL580159 & 1479053 & 3.9208 & 3.8764 & TRN & \\
\hline CHEMBL537153 & 1479053 & 5.2804 & 5.1316 & TRN & \\
\hline CHEMBL549093 & 1479053 & 5.2237 & 5.5089 & TRN & \\
\hline
\end{tabular}

Page 23280 
Supplemental Table S2.txt

\begin{tabular}{|c|c|c|c|c|c|}
\hline CHEMBL587028 & 1479053 & 4.9356 & 5.1794 & TRN & \\
\hline CHEMBL580699 & 1479053 & 5.2258 & 5.1356 & TST & \\
\hline CHEMBL580474 & 1479053 & 5.2106 & 5.3522 & TRN & \\
\hline CHEMBL534288 & 1479053 & 3.9208 & 3.8145 & TRN & \\
\hline CHEMBL597857 & 1479053 & 3.9208 & 3.8498 & TRN & \\
\hline CHEMBL600305 & 1479053 & 3.9208 & 3.9149 & TRN & \\
\hline CHEMBL532958 & 1479053 & 4.8151 & 4.9282 & TRN & \\
\hline CHEMBL586175 & 1479053 & 5.0114 & 5.2463 & TRN & \\
\hline CHEMBL339050 & 1479053 & 5.4873 & 5.3744 & TRN & \\
\hline CHEMBL585983 & 1479053 & 3.9208 & 3.9737 & TRN & \\
\hline CHEMBL10835 & 1479053 & 3.9208 & 3.9761 & TRN & \\
\hline CHEMBL529640 & 1479053 & 3.9208 & 3.9295 & TRN & \\
\hline CHEMBL547367 & 1479053 & 5.5027 & 5.1539 & TST & \\
\hline CHEMBL601348 & 1479053 & 3.9208 & 4.0541 & TST & \\
\hline CHEMBL578508 & 1479053 & 3.9208 & 3.933006 & 30000000003 & TRN \\
\hline CHEMBL534283 & 1479053 & 3.9208 & 4.2765 & TRN & \\
\hline CHEMBL586109 & 1479053 & 5.2057 & 5.2558 & TRN & \\
\hline CHEMBL547552 & 1479053 & 5.5926 & 5.5087 & TRN & \\
\hline CHEMBL590435 & 1479053 & 3.9208 & 3.8611 & TRN & \\
\hline CHEMBL590686 & 1479053 & 3.9208 & 3.8458 & TRN & \\
\hline CHEMBL547488 & 1479053 & 3.9208 & 3.8999 & TRN & \\
\hline CHEMBL 2028046 & 1479053 & 3.9208 & 3.8614 & TRN & \\
\hline CHEMBL526587 & 1479053 & 3.9208 & 3.9359 & TRN & \\
\hline CHEMBL531184 & 1479053 & 5.0355 & 5.1475 & TRN & \\
\hline CHEMBL580353 & 1479053 & 3.9208 & 4.1571 & TRN & \\
\hline CHEMBL527620 & 1479053 & 3.9208 & 3.8316 & TRN & \\
\hline CHEMBL587759 & 1479053 & 3.6383 & 3.7164 & TRN & \\
\hline CHEMBL533017 & 1479053 & 3.9208 & 3.88199 & 99999999997 & TRN \\
\hline CHEMBL535556 & 1479053 & 3.9208 & 4.0536 & TRN & \\
\hline CHEMBL534374 & 1479053 & 5.5043 & 5.5557 & TST & \\
\hline CHEMBL527132 & 1479053 & 5.6688 & 4.9906 & TST & \\
\hline CHEMBL601378 & 1479053 & 5.171 & 4.9119 & TRN & \\
\hline CHEMBL528063 & 1479053 & 4.87 & 5.1543 & TRN & \\
\hline CHEMBL548406 & 1479053 & 5.7913 & 5.5955 & TRN & \\
\hline CHEMBL531849 & 1479053 & 4.9558 & 5.3407 & TST & \\
\hline CHEMBL588501 & 1479053 & 5.171 & 5.0056 & TRN & \\
\hline CHEMBL1744512 & 1479053 & 3.9208 & 3.8461 & TRN & \\
\hline CHEMBL577874 & 1479053 & 3.9208 & 3.8882 & TRN & \\
\hline CHEMBL600488 & 1479053 & 3.9208 & 3.9401 & TRN & \\
\hline CHEMBL587612 & 1479053 & 6.059 & 6.3797 & TRN & \\
\hline CHEMBL579535 & 1479053 & 5.2901 & 5.3593 & TRN & \\
\hline CHEMBL597248 & 1479053 & 3.9208 & 4.2427 & TRN & \\
\hline CHEMBL546544 & 1479053 & 5.1505 & 4.9579 & TRN & \\
\hline CHEMBL1567944 & 1479053 & 3.6383 & 4.4673 & TRN & \\
\hline CHEMBL526818 & 1479053 & 4.87 & 5.0981 & TRN & \\
\hline CHEMBL579457 & 1479053 & 5.1132 & 4.9895 & TRN & \\
\hline CHEMBL577012 & 1479053 & 3.9208 & 3.9215 & TRN & \\
\hline CHEMBL547869 & 1479053 & 3.6383 & 4.6912 & TST & \\
\hline
\end{tabular}


Supplemental Table S2.txt

\begin{tabular}{|c|c|c|c|c|c|}
\hline CHEMBL585431 & 1479053 & 3.9208 & 3.8555 & TST & \\
\hline CHEMBL92137 & 1479053 & 5.1086 & 5.1136 & TRN & \\
\hline CHEMBL2028068 & 1479053 & 3.9208 & 4.04 & TST & \\
\hline CHEMBL589733 & 1479053 & 5.171 & 4.6923 & TRN & \\
\hline CHEMBL581349 & 1479053 & 3.9208 & 3.9173 & TRN & \\
\hline CHEMBL548721 & 1479053 & 5.228 & 5.3232 & TRN & \\
\hline CHEMBL592332 & 1479053 & 3.9208 & 3.9021 & TRN & \\
\hline CHEMBL584655 & 1479053 & 3.9208 & 3.8809 & TRN & \\
\hline CHEMBL584240 & 1479053 & 3.9208 & 3.8597 & TRN & \\
\hline CHEMBL582486 & 1479053 & 3.9208 & 3.8912 & TST & \\
\hline CHEMBL602127 & 1479053 & 3.9208 & 3.9648 & TRN & \\
\hline CHEMBL601612 & 1479053 & 3.9208 & 3.9807 & TRN & \\
\hline CHEMBL537379 & 1479053 & 5.329 & 5.4044 & TRN & \\
\hline CHEMBL548338 & 1479053 & 3.9208 & 4.0086 & TST & \\
\hline CHEMBL546472 & 1479053 & 5.1479 & 4.8962 & TRN & \\
\hline CHEMBL546632 & 1479053 & 5.4532 & 5.1765 & TRN & \\
\hline CHEMBL531611 & 1479053 & 3.9208 & 3.951 & TRN & \\
\hline CHEMBL548469 & 1479053 & 4.9325 & 4.4917 & TRN & \\
\hline CHEMBL319952 & 1479053 & 3.9208 & 3.9274 & TRN & \\
\hline CHEMBL604323 & 1479053 & 3.9208 & 4.061 & TRN & \\
\hline CHEMBL598263 & 1479053 & 6.4868 & 5.9698 & TST & \\
\hline CHEMBL586962 & 1479053 & 3.9208 & 4.0776 & TRN & \\
\hline CHEMBL577445 & 1479053 & 3.9208 & 3.89300 & 00000000002 & TRN \\
\hline CHEMBL581187 & 1479053 & 3.9208 & 3.99 & TRN & \\
\hline CHEMBL581702 & 1479053 & 6.7878 & 6.8733 & TRN & \\
\hline CHEMBL1594640 & 1479053 & 3.9208 & 4.0476 & TRN & \\
\hline CHEMBL532155 & 1479053 & 3.9208 & 4.033 & TRN & \\
\hline CHEMBL546871 & 1479053 & 5.3516 & 4.8985 & TRN & \\
\hline CHEMBL591128 & 1479053 & 3.9208 & 3.8177 & TRN & \\
\hline CHEMBL581225 & 1479053 & 3.9208 & 3.9966 & TST & \\
\hline CHEMBL585622 & 1479053 & 5.171 & 5.1309 & TRN & \\
\hline CHEMBL591147 & 1479053 & 3.9208 & 3.8632 & TRN & \\
\hline CHEMBL530149 & 1479053 & 3.9208 & 4.0639 & TRN & \\
\hline CHEMBL547442 & 1479053 & 5.3961 & 5.3362 & TRN & \\
\hline CHEMBL531744 & 1479053 & 5.6182 & 5.5455 & TRN & \\
\hline CHEMBL586186 & 1479053 & 5.3472 & 5.3034 & TRN & \\
\hline CHEMBL590680 & 1479053 & 3.9208 & 3.8514 & TRN & \\
\hline CHEMBL533110 & 1479053 & 3.6383 & 3.8644 & TRN & \\
\hline CHEMBL527400 & 1479053 & 5.28 & 5.3586 & TRN & \\
\hline CHEMBL586687 & 1479053 & 5.2234 & 5.6099 & TRN & \\
\hline CHEMBL547193 & 1479053 & 3.9208 & 4.1367 & TRN & \\
\hline CHEMBL528350 & 1479053 & 4.9776 & 5.0246 & TRN & \\
\hline CHEMBL529055 & 1479053 & 5.1086 & 5.1857 & TRN & \\
\hline CHEMBL582119 & 1479053 & 3.9208 & 3.9953 & TST & \\
\hline CHEMBL580812 & 1479053 & 5.2706 & 5.2871 & TRN & \\
\hline CHEMBL580252 & 1479053 & 5.2989 & 5.2079 & TST & \\
\hline CHEMBL535514 & 1479053 & 3.9208 & 3.8745 & TRN & \\
\hline CHEMBL582610 & 1479053 & 5.3119 & 5.4343 & TRN & \\
\hline
\end{tabular}


Supplemental Table S2.txt

\begin{tabular}{|c|c|c|c|c|c|}
\hline CHEMBL528564 & 1479053 & 5.4106 & 5.438 & TRN & \\
\hline CHEMBL588599 & 1479053 & 4.87 & 5.1958 & TRN & \\
\hline CHEMBL601786 & 1479053 & 3.9208 & 3.9511 & TRN & \\
\hline CHEMBL534384 & 1479053 & 5.4112 & 5.2093 & TRN & \\
\hline CHEMBL536424 & 1479053 & 5.1922 & 5.2587 & TRN & \\
\hline CHEMBL537576 & 1479053 & 5.5114 & 5.4654 & TRN & \\
\hline CHEMBL582495 & 1479053 & 3.9208 & 3.995 & TST & \\
\hline CHEMBL608855 & 1479053 & 3.9208 & 3.8564 & TST & \\
\hline CHEMBL546162 & 1479053 & 5.171 & 4.621 & TRN & \\
\hline CHEMBL532775 & 1479053 & 5.4426 & 5.2498 & TRN & \\
\hline CHEMBL589060 & 1479053 & 3.9208 & 3.8631 & TRN & \\
\hline CHEMBL592338 & 1479053 & 3.9208 & 3.8839 & TRN & \\
\hline CHEMBL537071 & 1479053 & 3.9208 & 3.9057 & TRN & \\
\hline CHEMBL601814 & 1479053 & 3.9208 & 3.8111 & TRN & \\
\hline CHEMBL545880 & 1479053 & 3.9208 & 3.9158 & TRN & \\
\hline CHEMBL579443 & 1479053 & 3.9208 & 3.9004 & TRN & \\
\hline CHEMBL591393 & 1479053 & 3.9208 & 4.7547 & TRN & \\
\hline CHEMBL548388 & 1479053 & 5.38200 & 00000006 & 1 & 5.0026 \\
\hline CHEMBL 2028041 & 1479053 & 3.9208 & 4.1141 & TST & \\
\hline CHEMBL527541 & 1479053 & 5.171 & 4.8722 & TRN & \\
\hline CHEMBL1459149 & 1479053 & 3.9208 & 4.0564 & TST & \\
\hline CHEMBL579893 & 1479053 & 5.6476 & 5.4686 & TRN & \\
\hline CHEMBL530073 & 1479053 & 5.2093 & 5.4281 & TRN & \\
\hline CHEMBL527911 & 1479053 & 5.8804 & 5.7168 & TRN & \\
\hline CHEMBL579331 & 1479053 & 3.9208 & 3.9501 & TRN & \\
\hline CHEMBL587420 & 1479053 & 3.6383 & 4.3553 & TRN & \\
\hline CHEMBL580516 & 1479053 & 3.9208 & 4.896 & TST & \\
\hline CHEMBL261095 & 1479053 & 3.9208 & 3.8074 & TRN & \\
\hline CHEMBL537087 & 1479053 & 3.9208 & 4.3063 & TRN & \\
\hline CHEMBL 2028060 & 1479053 & 3.9208 & 3.9525 & TRN & \\
\hline CHEMBL534151 & 1479053 & 5.6655 & 5.5745 & TST & \\
\hline CHEMBL525149 & 1479053 & 6.6882 & 6.7729 & TRN & \\
\hline CHEMBL588481 & 1479053 & 3.9208 & 3.9761 & TRN & \\
\hline CHEMBL597855 & 1479053 & 3.9208 & 3.855 & TRN & \\
\hline CHEMBL587989 & 1479053 & 3.9208 & 3.8929 & TST & \\
\hline CHEMBL581240 & 1479053 & 3.9208 & 3.8508 & TRN & \\
\hline CHEMBL587022 & 1479053 & 3.9208 & 3.8899 & TST & \\
\hline CHEMBL602366 & 1479053 & 3.9208 & 4.0349 & TST & \\
\hline CHEMBL602946 & 1479053 & 5.171 & 4.4323 & TRN & \\
\hline CHEMBL580388 & 1479053 & 3.9208 & 4.1048 & TST & \\
\hline CHEMBL527593 & 1479053 & 3.9208 & 3.9482 & TST & \\
\hline CHEMBL 2028051 & 1479053 & 3.9208 & 3.8596 & TRN & \\
\hline CHEMBL606531 & 1479053 & 3.9208 & 3.9313 & TRN & \\
\hline CHEMBL592344 & 1479053 & 3.9208 & 3.7632 & TRN & \\
\hline CHEMBL584237 & 1479053 & 3.9208 & 3.8831 & TRN & \\
\hline CHEMBL548334 & 1479053 & 3.9208 & 3.9049 & TST & \\
\hline CHEMBL585966 & 1479053 & 3.9208 & 3.8619 & TRN & \\
\hline CHEMBL589224 & 1479053 & 3.9208 & 3.8906 & TST & \\
\hline
\end{tabular}


Supplemental Table S2.txt

\begin{tabular}{|c|c|c|c|c|c|}
\hline CHEMBL546826 & 1479053 & 5.2885 & 5.3585 & TRN & \\
\hline CHEMBL592808 & 1479053 & 3.9208 & 3.9061 & TRN & \\
\hline CHEMBL525106 & 1479053 & 3.9208 & 4.0071 & TRN & \\
\hline CHEMBL528043 & 1479053 & 5.5809 & 5.2771 & TRN & \\
\hline CHEMBL529385 & 1479053 & 3.9208 & 4.0484 & TRN & \\
\hline CHEMBL526234 & 1479053 & 5.3858 & 5.54200 & 0000000001 & TRN \\
\hline CHEMBL535475 & 1479053 & 6.1643 & 5.9286 & TRN & \\
\hline CHEMBL581077 & 1479053 & 5.1455 & 5.2936 & TRN & \\
\hline CHEMBL535730 & 1479053 & 3.9208 & 4.0059 & TST & \\
\hline CHEMBL536676 & 1479053 & 5.23 & 5.2983 & TRN & \\
\hline CHEMBL529081 & 1479053 & 3.6383 & 3.9543 & TRN & \\
\hline CHEMBL591641 & 1479053 & 3.9208 & 3.8665 & TRN & \\
\hline CHEMBL547775 & 1479053 & 5.4844 & 5.409 & TRN & \\
\hline CHEMBL528794 & 1479053 & 4.9713 & 5.0804 & TRN & \\
\hline CHEMBL537564 & 1479053 & 5.919 & 5.5964 & TRN & \\
\hline CHEMBL577440 & 1479053 & 3.9208 & 4.0339 & TRN & \\
\hline CHEMBL548589 & 1479053 & 5.1977 & 5.1446 & TRN & \\
\hline CHEMBL590212 & 1479053 & 3.9208 & 4.056 & TRN & \\
\hline CHEMBL589951 & 1479053 & 3.9208 & 3.9348 & TRN & \\
\hline CHEMBL530308 & 1479053 & 3.9208 & 3.8812 & TST & \\
\hline CHEMBL601957 & 1479053 & 3.9208 & 3.9764 & TRN & \\
\hline CHEMBL580275 & 1479053 & 5.3392 & 5.454 & TRN & \\
\hline CHEMBL532015 & 1479053 & 3.9208 & 3.909 & TST & \\
\hline CHEMBL587825 & 1479053 & 3.9208 & 4.0483 & TRN & \\
\hline CHEMBL524973 & 1479053 & 3.9208 & 4.2627 & TRN & \\
\hline CHEMBL582430 & 1479053 & 5.4218 & 5.4226 & TRN & \\
\hline CHEMBL547715 & 1479053 & 5.1086 & 5.2831 & TRN & \\
\hline CHEMBL 2028067 & 1479053 & 3.9208 & 4.1397 & TST & \\
\hline CHEMBL532699 & 1479053 & 5.9385 & 6.0262 & TRN & \\
\hline CHEMBL536112 & 1479053 & 5.8771 & 5.5926 & TST & \\
\hline CHEMBL580149 & 1479053 & 5.2555 & 5.1651 & TST & \\
\hline CHEMBL587824 & 1479053 & 5.3106 & 5.2175 & TST & \\
\hline CHEMBL586093 & 1479053 & 5.5784 & 5.4501 & TRN & \\
\hline CHEMBL533808 & 1479053 & 5.3575 & 5.0931 & TRN & \\
\hline CHEMBL1460047 & 1479053 & 3.9208 & 4.1845 & TST & \\
\hline CHEMBL548422 & 1479053 & 5.4288 & 5.3019 & TRN & \\
\hline CHEMBL580819 & 1479053 & 3.9208 & 3.8217 & TRN & \\
\hline CHEMBL526210 & 1479053 & 6.059 & \multicolumn{2}{|c|}{5.821000000000001} & TST \\
\hline CHEMBL534190 & 1479053 & 3.9208 & 3.9114 & TRN & \\
\hline CHEMBL598881 & 1479053 & 3.9208 & 4.023 & TST & \\
\hline CHEMBL589205 & 1479053 & 3.9208 & 3.859 & TRN & \\
\hline CHEMBL578030 & 1479053 & 3.9208 & 4.209 & TRN & \\
\hline CHEMBL536165 & 1479053 & 3.6383 & 3.9098 & TRN & \\
\hline CHEMBL537778 & 1479053 & 3.9208 & 3.895 & TRN & \\
\hline CHEMBL601534 & 1479053 & 3.9208 & 4.11 & TST & \\
\hline CHEMBL546565 & 1479053 & 5.143 & 5.2382 & TRN & \\
\hline CHEMBL580809 & 1479053 & 5.0453 & 5.1092 & TST & \\
\hline CHEMBL596852 & 1479053 & 5.171 & 4.7935 & TRN & \\
\hline
\end{tabular}


Supplemental Table S2.txt

\begin{tabular}{|c|c|c|c|c|}
\hline CHEMBL579790 & 479053 & 5.3901 & 5.5094 & TRN \\
\hline HEMBL533389 & 479053 & 3.6383 & 3.9911 & \\
\hline HEMBL 5 & 9053 & 3.9208 & 7776 & \\
\hline HEMBL529435 & 9053 & $\partial 498$ & 2072 & \\
\hline HEMBL 526800 & 479053 & 3.9208 & .8215 & \\
\hline HEMBL 531880 & 479053 & 5.1575 & .2128 & \\
\hline HEMBL530531 & 479053 & 3.9208 & .2278 & \\
\hline HEMBL 2028044 & 1479053 & 3.9208 & 3.9581 & DN \\
\hline HEMBL534671 & 1479053 & 5.4786 & 5.2388 & \\
\hline HEMBL531222 & 479053 & 3.9208 & 3.8805 & \\
\hline HEMBL528447 & 479053 & 5.0627 & 4.9884 & \\
\hline HEMBL5 & 479053 & 5.2893 & .2196 & RN \\
\hline HEMBL5 & 9053 & 3.9208 & 3.9572 & \\
\hline HEMBL581933 & 1479053 & 5.3442 & 5.3175 & \\
\hline HEMBL6C & 179953 & 3.9208 & 3.8284 & \\
\hline HEMBL5 & 4 & 208 & 3.8056 & NIV \\
\hline HEMBL 5 & 3 & 5.4888 & .4262 & RN \\
\hline HEMBL5 & 479053 & 5.5768 & 5.6127 & $\mathrm{RN}$ \\
\hline HEMBL2 & 9053 & 4.9456 & 4.7489 & IRN \\
\hline HEMBL2 & & 3.9208 & 3.9891 & . \\
\hline HEMBL5 & 4 & 08 & 764 & RIN \\
\hline HEMBL5 & & 53 & 001 & RN \\
\hline HEMBL 2 & 9053 & 3.9208 & 3.9298 & TRN \\
\hline HEMBL5 & 9053 & 3.9208 & 9101 & $1 \mathrm{~K}$ \\
\hline HEMBL532464 & כש & 6.8633 & 6.8802 & IRN \\
\hline HEMBL5 & 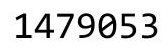 & 4.9325 & 4.9703 & 「RN \\
\hline HEMBL & J & 08 & 602 & RN \\
\hline HEMBL5 & 253 & 237 & 5.2721 & TRN \\
\hline HEMBL 5 & & 5.6546 & 264 & IRIN \\
\hline HEMBL533000 & 47905 & 5.5274 & 5.2433 & TRN \\
\hline HEMBL 5 & 9053 & 237 & 5.3263 & TRN \\
\hline HEMBL: & 3 & 16 & 5 . & TST \\
\hline HEMBL5 & & 741 & 5.0757 & TRN \\
\hline HEMBL597262 & 479053 & 3.9208 & 3.9409 & TRN \\
\hline HEMBL532801 & 479053 & 5.5574 & 5.5614 & TRN \\
\hline HEMBL 5 & $9 a$ & 153 & 692 & TRN \\
\hline CHEMBL & & 65 & 398 & TRN \\
\hline CHEMBL5 & 1479053 & 4.9736 & 5.0573 & TRN \\
\hline HEMBL5 & 479053 & 5.171 & 5.0194 & TRN \\
\hline HEMBL 5 & 905 & 3.9208 & 617 & TST \\
\hline CHEMBL 5 & 14790 & 5.5563 & 5.4573 & TRN \\
\hline CHEMBL 5 & 1479053 & 3.9208 & 3.8559 & TRN \\
\hline CHEMBL602940 & 1479053 & 3.9208 & 4.1253 & TST \\
\hline CHEMBL 6 & 147905 & 3.9208 & 8808 & $\mathrm{TR}$ \\
\hline CHEMBL5 & 147905 & 08 & 3.7492 & IRN \\
\hline HEMBL6 & 147905 & 3.9208 & 3.9787 & \\
\hline CHEMBL582180 & 1479053 & 3.9208 & 3.8393 & ГRN \\
\hline CHEMBL514409 & 1479053 & 5.8716 & 5.4366 & . \\
\hline
\end{tabular}

Page 23285 
Supplemental Table S2.txt

\begin{tabular}{|c|c|c|c|c|c|}
\hline CHEMBL581771 & 1479053 & 5.0386 & 4.8323 & TRN & \\
\hline CHEMBL581359 & 1479053 & 5.1484 & 5.0614 & TRN & \\
\hline CHEMBL49055 & 1479053 & 5.171 & 5.0601 & TRN & \\
\hline CHEMBL547387 & 1479053 & 5.1184 & 5.166 & TRN & \\
\hline CHEMBL586375 & 1479053 & 5.7192 & 5.6869 & TRN & \\
\hline CHEMBL535921 & 1479053 & 5.4219 & \multicolumn{2}{|c|}{5.537000000000001} & TRN \\
\hline CHEMBL534803 & 1479053 & 5.1046 & 5.2415 & TRN & \\
\hline CHEMBL546792 & 1479053 & 5.4183 & 5.4515 & TRN & \\
\hline CHEMBL548126 & 1479053 & 5.1662 & 5.1553 & TRN & \\
\hline CHEMBL170760 & 1479053 & 6.2083 & 5.7291 & TRN & \\
\hline CHEMBL604389 & 1479053 & 3.9208 & 4.0009 & TRN & \\
\hline CHEMBL600906 & 1479053 & 3.9208 & 3.9369 & TRN & \\
\hline CHEMBL547127 & 1479053 & 5.3405 & 5.2186 & TRN & \\
\hline CHEMBL548861 & 1479053 & 5.4761 & 5.3887 & TRN & \\
\hline CHEMBL589920 & 1479053 & 3.9208 & 4.4623 & TST & \\
\hline CHEMBL586253 & 1479053 & 5.1582 & 5.289 & TRN & \\
\hline CHEMBL533921 & 1479053 & 3.9208 & 4.0917 & TRN & \\
\hline CHEMBL591395 & 1479053 & 3.9208 & 3.9241 & TRN & \\
\hline CHEMBL1198307 & 1479053 & 5.171 & 5.0451 & TRN & \\
\hline CHEMBL592305 & 1479053 & 3.9208 & 3.8706 & TST & \\
\hline CHEMBL586442 & 1479053 & 3.9208 & 3.7895 & TRN & \\
\hline CHEMBL584235 & 1479053 & 3.9208 & 3.8737 & TRN & \\
\hline CHEMBL586178 & 1479053 & 3.9208 & 4.0931 & TRN & \\
\hline CHEMBL530217 & 1479053 & 5.4713 & 5.2003 & TRN & \\
\hline CHEMBL 600030 & 1479053 & 3.9208 & \multicolumn{2}{|c|}{3.8560000000000003} & TRN \\
\hline CHEMBL528458 & 1479053 & 3.6383 & 3.8532 & TRN & \\
\hline CHEMBL580264 & 1479053 & 5.2125 & 5.2529 & TRN & \\
\hline CHEMBL581191 & 1479053 & 5.3252 & 5.2886 & TRN & \\
\hline CHEMBL548002 & 1479053 & 5.5859 & 5.3523 & TRN & \\
\hline CHEMBL532560 & 1479053 & 3.9208 & 3.9575 & TRN & \\
\hline CHEMBL533770 & 1479053 & 4.8834 & 5.2301 & TRN & \\
\hline CHEMBL580188 & 1479053 & 3.9208 & 3.7668 & TRN & \\
\hline CHEMBL600904 & 1479053 & 3.9208 & \multicolumn{2}{|c|}{3.8310000000000004} & $\mathrm{TRT}$ \\
\hline CHEMBL529874 & 1479053 & 3.9208 & 3.8002 & TST & \\
\hline CHEMBL532907 & 1479053 & 5.5283 & 5.3998 & TRN & \\
\hline CHEMBL532808 & 1479053 & 5.8336 & 5.8178 & TRN & \\
\hline CHEMBL1237253 & 1479053 & 3.6383 & 4.6747 & TRN & \\
\hline CHEMBL587104 & 1479053 & 3.9208 & 3.7966 & TRN & \\
\hline CHEMBL531170 & 1479053 & 6.1101 & 6.1141 & TRN & \\
\hline CHEMBL533981 & 1479053 & 5.1231 & 5.2422 & TRN & \\
\hline CHEMBL528147 & 1479053 & 5.3824 & 5.4293 & TST & \\
\hline CHEMBL605751 & 1479053 & 3.9208 & 3.9357 & TRN & \\
\hline CHEMBL579315 & 1479053 & 3.9208 & 3.9248 & TST & \\
\hline CHEMBL536161 & 1479053 & 5.1276 & 5.067 & TST & \\
\hline CHEMBL586255 & 1479053 & 5.2113 & 5.1824 & TST & \\
\hline CHEMBL586344 & 1479053 & 3.9208 & 3.9928 & TST & \\
\hline CHEMBL532650 & 1479053 & 6.247999 & 99999999 & 6.1401 & SI \\
\hline CHEMBL526987 & 1479053 & 5.2357 & 5.3117 & TST & \\
\hline
\end{tabular}


Supplemental Table S2.txt

\begin{tabular}{|c|c|c|c|c|}
\hline HEMBL611070 & 1479053 & 3.9208 & 4.0281 & TST \\
\hline CHEMBL524606 & 1479053 & 5.2544 & 5.3485 & \\
\hline HEMBL 532060 & 479053 & 5.3558 & & \\
\hline AEMBL587923 & 479053 & 3.9208 & 4457 & \\
\hline HEMBL530649 & 479053 & 5.4589 & 5264 & \\
\hline HEMBL587153 & 479053 & 6.5031 & 6.3965 & \\
\hline AEMBL588752 & 479053 & 4.7761 & 4826 & \\
\hline AEMBL 547180 & 479053 & 5.4135 & & \\
\hline HEMBL 603945 & 479053 & 3.9208 & 3.9576 & \\
\hline HEMBL530291 & 479053 & 6.5143 & 6646 & \\
\hline HEMBL580580 & 1479053 & 5.8456 & 5.2569 & \\
\hline AEMBL17 & 479053 & 5.5914 & 656 & \\
\hline HEMBL 57 & 1479053 & 3.9208 & & \\
\hline HEMBL 532510 & 1479053 & 3.9208 & 3.8899 & \\
\hline HEMBL588516 & 479053 & 3.9208 & & \\
\hline HEMBL52 & 1479053 & 3.9208 & 553 & \\
\hline HEMBL5 & 053 & 3.9208 & 02 & \\
\hline HEMBL6 & 479053 & 3.9208 & 895 & \\
\hline AEMBL600374 & 1479053 & 3.9208 & 03 & \\
\hline HEMBL 54 & 053 & 7.1805 & 957 & \\
\hline HEMBL 58 & 147 & 5.3376 & 83 & \\
\hline HEMBL5 & 147 & 5.2871 & 03 & \\
\hline HEMBL5 & 1479053 & 5.6794 & 2141 & \\
\hline IEMBL58 & 1479053 & 4.9325 & & \\
\hline HEMBL581619 & 253 & 5.2061 & & ST \\
\hline HEMBL587485 & 053 & 3.9208 & 78 & \\
\hline HEMBL5 & 147 & 4.6624 & 31 & \\
\hline AEMBLS & 053 & 3.9208 & 363 & \\
\hline AEMBL60 & 053 & 5.171 & & \\
\hline HEMBL 2028057 & 479053 & 3.9208 & 166 & TST \\
\hline HEMBL5 & 3 & 6.0405 & 66 & \\
\hline HEMBL: & 33 & 89 & 81 & \\
\hline AEMBL52 & 147 & 3.9208 & & \\
\hline JEMBL45 & 1479053 & 3.9208 & 19 & ST \\
\hline HEMBL $52 \angle$ & 479053 & 5.3086 & 3054 & TS1 \\
\hline AEMBL5 & 479053 & 5.3476 & 82 & \\
\hline CHEMBL & 147 & 3. & 61 & \\
\hline CHEMBL589723 & 1479053 & 3.9208 & 3.9304 & ST \\
\hline HEMBL 36 & 479053 & 5.8697 & 475 & S \\
\hline HEMBL 5 & 479053 & 6.1986 & & TST \\
\hline CHEMBL54 & 1479053 & 5.3394 & 5.2747 & \\
\hline CHEMBL 58 & 1479053 & 3.9208 & 3.9156 & ST \\
\hline CHEMBL547136 & 1479053 & 5.5171 & 5.4928 & ST 1 \\
\hline CHEMBL 53: & 479053 & 5.148 & 385 & S \\
\hline CHEMBL: & 1479053 & 3.9208 & & \\
\hline CHEMBL587371 & 1479053 & 3.9208 & 3.898 & \\
\hline CHEMBL527691 & 1479053 & 5.0994 & 5.1565 & \\
\hline CHEMBL529064 & 1479053 & 5.1165 & 5.0165 & TS \\
\hline
\end{tabular}

Page 23287 


\begin{tabular}{|c|c|c|c|c|c|}
\hline & & & & & \\
\hline CHEMBL586700 & 1479053 & 5.5426 & 5.13200 & 0000000001 & TST \\
\hline CHEMBL526110 & 1479053 & 6.7721 & 6.5825 & TST & \\
\hline CHEMBL529312 & 1479053 & 5.1788 & 5.2597 & TST & \\
\hline CHEMBL528186 & 1479053 & 5.2403 & 5.3569 & TST & \\
\hline CHEMBL533429 & 1479053 & 5.4679 & 5.1049 & TST & \\
\hline CHEMBL527390 & 1479053 & 5.4574 & 5.5527 & TST & \\
\hline CHEMBL529822 & 1479053 & 5.8348 & 5.6612 & TST & \\
\hline CHEMBL2028058 & 1479053 & 3.9208 & 3.9751 & TST & \\
\hline CHEMBL533776 & 1479053 & 5.5455 & 5.4104 & TST & \\
\hline CHEMBL549067 & 1479053 & 5.4728 & 5.3995 & TST & \\
\hline CHEMBL549241 & 1479053 & 5.206 & 5.3594 & TST & \\
\hline CHEMBL582420 & 1479053 & 3.9208 & 3.8035 & TST & \\
\hline CHEMBL580730 & 1479053 & 5.3488 & 5.2081 & TST & \\
\hline CHEMBL548482 & 1479053 & 3.6383 & 4.0316 & TST & \\
\hline CHEMBL596856 & 1479053 & 3.9208 & 4.2022 & TST & \\
\hline CHEMBL580698 & 1479053 & 5.5337 & 5.5711 & TST & \\
\hline CHEMBL531393 & 1479053 & 5.1318 & 5.2427 & TST & \\
\hline CHEMBL587029 & 1479053 & 6.6925 & 6.2678 & TST & \\
\hline CHEMBL528705 & 1479053 & 6.0501 & 5.5108 & TST & \\
\hline CHEMBL530223 & 1479053 & 3.9208 & 3.8664 & TST & \\
\hline CHEMBL586310 & 1479053 & 3.9208 & 3.9363 & TST & \\
\hline CHEMBL1237214 & 1479053 & 5.7642 & 5.5352 & TST & \\
\hline CHEMBL590914 & 1479053 & 3.9208 & 3.9962 & TST & \\
\hline CHEMBL95606 & 1479053 & 3.9208 & 4.0483 & TST & \\
\hline CHEMBL537505 & 1479053 & 3.9208 & 3.7602 & TST & \\
\hline CHEMBL525879 & 1479053 & 5.2646 & 5.4644 & TST & \\
\hline CHEMBL536115 & 1479053 & 6.1463 & 5.9154 & TST & \\
\hline CHEMBL589236 & 1479053 & 3.9208 & 3.9 & TST & \\
\hline CHEMBL 2028066 & 1479053 & 3.9208 & 4.0202 & TST & \\
\hline CHEMBL586942 & 1479053 & 5.2953 & 5.1706 & TST & \\
\hline CHEMBL529424 & 1479053 & 3.6383 & 3.7701 & TST & \\
\hline CHEMBL532879 & 1479053 & 3.9208 & 4.0025 & TST & \\
\hline CHEMBL353621 & 1479053 & 6.1403 & 6.3486 & TST & \\
\hline CHEMBL494669 & 1479053 & 3.9208 & 4.0705 & TST & \\
\hline CHEMBL593290 & 1479053 & 6.3747 & 6.0114 & TST & \\
\hline CHEMBL2028049 & 1479053 & 3.9208 & 3.9668 & TST & \\
\hline CHEMBL601771 & 1479053 & 3.9208 & 3.8661 & TST & \\
\hline CHEMBL332200 & 45427 & 6.6882 & 6.655 & TRN & \\
\hline CHEMBL 331727 & 45427 & 7.1612 & 7.1834 & TRN & \\
\hline CHEMBL122951 & 45427 & 7.4089 & 7.4073 & TRN & \\
\hline CHEMBL121777 & 45427 & 6.9101 & 6.9617 & TST & \\
\hline CHEMBL122395 & 45427 & 7.1192 & 7.1387 & TRN & \\
\hline CHEMBL6784 & 45427 & 6.3468 & 6.8871 & TST & \\
\hline CHEMBL331527 & 45427 & 8.2218 & 8.1563 & TRN & \\
\hline CHEMBL122349 & 45427 & 7.4559 & 7.5061 & TRN & \\
\hline CHEMBL331738 & 45427 & 7.4089 & 7.4084 & TRN & \\
\hline CHEMBL123877 & 45427 & 7.1079 & 7.1469 & TRN & \\
\hline CHEMBL122817 & 45427 & 7.1938 & 7.1882 & TRN & \\
\hline
\end{tabular}




\begin{tabular}{|c|c|c|c|c|}
\hline & & & oplement & al $\mathrm{Ta}$ \\
\hline CHEMBL2112600 & 45427 & 7.5686 & 7.6257 & TST \\
\hline CHEMBL123603 & 45427 & 7.0506 & 7.1391 & TST \\
\hline CHEMBL124046 & 45427 & 6.8125 & 6.8106 & TRN \\
\hline CHEMBL332527 & 45427 & 6.8097 & 6.9138 & TST \\
\hline CHEMBL332586 & 45427 & 6.8356 & 6.8293 & TRN \\
\hline CHEMBL6853 & 45427 & 6.7447 & 7.2495 & TST \\
\hline CHEMBL122870 & 45427 & 7.1549 & 7.1833 & TRN \\
\hline CHEMBL268177 & 45427 & 6.9031 & 7.0787 & TST \\
\hline CHEMBL332648 & 45427 & 8.0969 & 8.1142 & TRN \\
\hline CHEMBL331386 & 45427 & 8.0 & 7.9546 & TRN \\
\hline CHEMBL6705 & 45427 & 5.8827 & 6.5839 & TST \\
\hline CHEMBL332225 & 45427 & 7.2218 & 7.2153 & TRN \\
\hline CHEMBL122767 & 45427 & 6.6289 & 6.6577 & TRN \\
\hline CHEMBL 266240 & 45427 & 6.7959 & 7.0278 & TST \\
\hline CHEMBL122762 & 45427 & 6.5229 & 6.4878 & TRN \\
\hline CHEMBL123652 & 45427 & 7.1308 & 7.1135 & TRN \\
\hline CHEMBL332549 & 45427 & 6.6108 & 6.5829 & TRN \\
\hline CHEMBL123065 & 45427 & 7.3768 & 7.3365 & TRN \\
\hline CHEMBL122074 & 45427 & 7.2676 & 7.2765 & TRN \\
\hline CHEMBL340569 & 45427 & 7.1427 & 7.3081 & TRN \\
\hline CHEMBL124399 & 45427 & 7.1308 & 7.0786 & TRN \\
\hline CHEMBL269122 & 45427 & 7.301 & 7.2775 & TRN \\
\hline CHEMBL122795 & 45427 & 7.2218 & 7.171 & TRN \\
\hline CHEMBL123066 & 45427 & 6.6108 & 6.6327 & TRN \\
\hline CHEMBL287117 & 45427 & 7.8239 & 7.8392 & TRN \\
\hline CHEMBL122336 & 45427 & 6.7447 & 6.8789 & TST \\
\hline CHEMBL332220 & 45427 & 8.0458 & 8.0694 & TRN \\
\hline CHEMBL123398 & 45427 & 7.2924 & 7.2659 & TRN \\
\hline CHEMBL7092 & 45427 & 6.4949 & 7.1287 & TST \\
\hline CHEMBL333692 & 45427 & 7.3872 & 7.4241 & TRN \\
\hline CHEMBL121927 & 45427 & 6.6882 & 6.7106 & TRN \\
\hline CHEMBL122756 & 45427 & 7.2596 & 7.2535 & TRN \\
\hline CHEMBL6724 & 45427 & 7.1805 & 7.125 & TST \\
\hline CHEMBL122573 & 45427 & 7.1549 & 7.1342 & TRN \\
\hline CHEMBL121782 & 45427 & 7.2147 & 7.2125 & TRN \\
\hline CHEMBL13646 & 45427 & 6.9031 & 6.8509 & TRN \\
\hline CHEMBL122390 & 45427 & 7.6383 & 7.6142 & TRN \\
\hline CHEMBL334088 & 45427 & 7.2076 & 7.1825 & TRN \\
\hline CHEMBL122781 & 45427 & 7.3468 & 7.3339 & TRN \\
\hline CHEMBL122961 & 45427 & 7.1367 & 7.1345 & TRN \\
\hline CHEMBL122749 & 45427 & 7.2218 & 7.2221 & TRN \\
\hline CHEMBL331697 & 45427 & 8.2218 & 8.2282 & TRN \\
\hline CHEMBL330755 & 45427 & 7.9586 & 8.0611 & TRN \\
\hline CHEMBL6685 & 45427 & 7.7696 & 7.728 & TRN \\
\hline CHEMBL6852 & 45427 & 5.6576 & 6.7581 & TST \\
\hline CHEMBL2112599 & 45427 & 7.4559 & 7.5161 & TST \\
\hline CHEMBL122176 & 45427 & 7.1249 & 7.1362 & TRN \\
\hline CHEMBL123827 & 45427 & 7.1805 & 7.1938 & TRN \\
\hline
\end{tabular}




\begin{tabular}{|c|c|c|c|c|c|c|}
\hline & & \multicolumn{5}{|c|}{ Supplemental Table S2.txt } \\
\hline CHEMBL332744 & 45427 & 7.3468 & 7.3725 & TRN & & \\
\hline CHEMBL121364 & 45427 & 7.1549 & 7.1787 & TST & & \\
\hline CHEMBL124224 & 45427 & 7.1549 & 7.1269 & TRN & & \\
\hline CHEMBL 7204 & 45427 & 5.4928 & 6.6994 & TST & & \\
\hline CHEMBL121696 & 45427 & 7.3979 & 7.3498 & TRN & & \\
\hline CHEMBL 268439 & 45427 & 8.301 & 8.3341 & TRN & & \\
\hline CHEMBL125776 & 45427 & 7.2076 & 7.1886 & TRN & & \\
\hline CHEMBL124168 & 45427 & 7.1612 & 7.1751 & TRN & & \\
\hline CHEMBL 331331 & 45427 & 7.0655 & 7.1127 & TRN & & \\
\hline CHEMBL13630 & 45427 & 9.0969 & 8.3146 & TST & & \\
\hline CHEMBL 341002 & 45427 & 7.5229 & 7.3653 & TST & & \\
\hline CHEMBL 7087 & 45427 & 5.6108 & 6.6496 & TST & & \\
\hline CHEMBL125980 & 45427 & 7.1487 & 7.1333 & TRN & & \\
\hline CHEMBL122484 & 45427 & \multicolumn{3}{|c|}{6.757000000000001} & 6.7418 & TRN \\
\hline CHEMBL123599 & 45427 & 7.8239 & 7.8363 & TRN & & \\
\hline CHEMBL 333874 & 45427 & 8.0 & 8.0337 & TST & & \\
\hline CHEMBL125338 & 45427 & 7.2076 & 7.2562 & TRN & & \\
\hline CHEMBL123482 & 45427 & 7.2441 & 7.2658 & TRN & & \\
\hline CHEMBL122838 & 45427 & 7.1549 & 7.1381 & TRN & & \\
\hline CHEMBL122953 & 45427 & 7.1871 & 7.1927 & TRN & & \\
\hline CHEMBL419604 & 45427 & 8.301 & 8.3052 & TRN & & \\
\hline CHEMBL123982 & 45427 & 6.5528 & 6.5465 & TRN & & \\
\hline CHEMBL 332222 & 45427 & 7.8539 & 7.6036 & TRN & & \\
\hline CHEMBL 338513 & 45427 & 7.1024 & 7.1036 & TRN & & \\
\hline CHEMBL122394 & 45427 & 6.8239 & 6.9405 & TST & & \\
\hline CHEMBL14182 & 45427 & 7.2757 & 7.289 & TRN & & \\
\hline CHEMBL 332221 & 45427 & 7.9208 & 7.9269 & TRN & & \\
\hline CHEMBL121662 & 45427 & 7.2596 & 7.282 & TRN & & \\
\hline CHEMBL 340503 & 45427 & 7.1938 & 7.3452 & TRN & & \\
\hline CHEMBL124165 & 45427 & 6.8539 & 6.8801 & TRN & & \\
\hline CHEMBL 333954 & 45427 & 7.0655 & 7.1588 & TST & & \\
\hline CHEMBL123047 & 45427 & 7.3565 & 7.2273 & TST & & \\
\hline CHEMBL 122720 & 45427 & 7.8239 & 7.8029 & TRN & & \\
\hline CHEMBL 123108 & 45427 & 7.9208 & 7.7612 & TRN & & \\
\hline CHEMBL 331002 & 45427 & 6.6198 & 6.6522 & TRN & & \\
\hline CHEMBL332119 & 45427 & 7.2076 & 7.2198 & TRN & & \\
\hline CHEMBL6919 & 45427 & 6.2518 & 6.8451 & TST & & \\
\hline CHEMBL123539 & 45427 & 8.0458 & 8.0244 & TRN & & \\
\hline CHEMBL125729 & 45427 & 7.3372 & 7.3646 & TRN & & \\
\hline CHEMBL123535 & 45427 & 6.8239 & 6.9774 & TST & & \\
\hline CHEMBL 265674 & 45427 & 6.2676 & 7.1391 & TST & & \\
\hline CHEMBL331932 & 45427 & 6.71 & 6.7039 & TRN & & \\
\hline CHEMBL121726 & 45427 & 7.1938 & 7.1817 & TRN & & \\
\hline CHEMBL 269628 & 45427 & \multicolumn{3}{|c|}{6.757000000000001} & 7.1308 & TST \\
\hline CHEMBL6633 & 45427 & 6.8125 & 6.7471 & TRN & & \\
\hline CHEMBL451190 & 45427 & 8.0458 & 8.102 & TRN & & \\
\hline CHEMBL123116 & 45427 & 6.9508 & 6.99 & TST & & \\
\hline CHEMBL541990 & 45427 & 7.5229 & 7.5421 & TRN & & \\
\hline
\end{tabular}




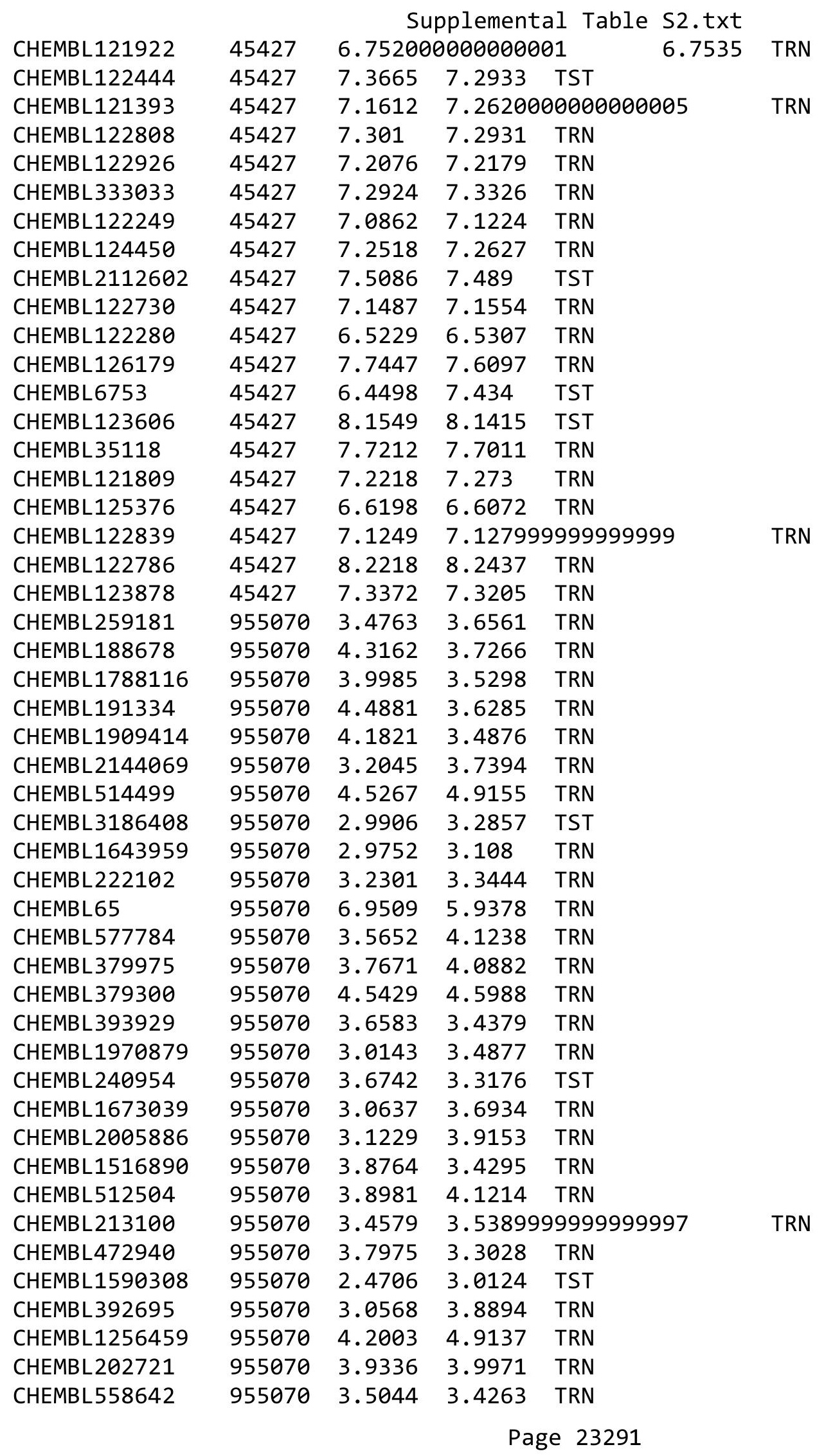




\begin{tabular}{|c|c|c|c|c|c|c|}
\hline & & \multicolumn{5}{|c|}{ Supplemental Table s2.txt } \\
\hline CHEMBL1230020 & 955070 & 3.2706 & 3.4577 & TRN & & \\
\hline CHEMBL210618 & 955070 & 3.1395 & 3.1318 & TRN & & \\
\hline CHEMBL483847 & 955070 & 3.9617 & 3.4332 & TRN & & \\
\hline CHEMBL2363137 & 955070 & 3.8005 & 3.7851 & TRN & & \\
\hline CHEMBL1357247 & 955070 & 2.4997 & 2.8542 & TRN & & \\
\hline CHEMBL3199475 & 955070 & 3.4148 & 3.655 & TRN & & \\
\hline CHEMBL221137 & 955070 & 3.9214 & 3.7874 & TST & & \\
\hline CHEMBL92309 & 955070 & 2.7261 & 2.7802 & TST & & \\
\hline CHEMBL 209148 & 955070 & 2.8586 & 3.5412 & TRN & & \\
\hline CHEMBL3349342 & 955070 & 3.7782 & 3.8751 & TRN & & \\
\hline CHEMBL180127 & 955070 & 2.9365 & 3.4318 & TRN & & \\
\hline CHEMBL483849 & 955070 & 2.6253 & 2.4558 & TRN & & \\
\hline CHEMBL573107 & 955070 & 4.4703 & 4.0885 & TRN & & \\
\hline CHEMBL 373751 & 955070 & 3.0694 & 3.1816 & TRN & & \\
\hline CHEMBL515416 & 955070 & 3.8131 & 3.6093 & TRN & & \\
\hline CHEMBL509032 & 955070 & 3.4448 & 4.0869 & TRN & & \\
\hline CHEMBL1190711 & 955070 & 5.3041 & 4.0609 & TRN & & \\
\hline CHEMBL102714 & 955070 & 3.75 & 3.2239 & TRN & & \\
\hline CHEMBL189584 & 955070 & 4.4802 & 3.8329 & TRN & & \\
\hline CHEMBL449158 & 955070 & 6.66 & 4.93199 & 9999999999 & 95 & TST \\
\hline CHEMBL 220241 & 955070 & 3.4426 & 3.7371 & TRN & & \\
\hline CHEMBL135561 & 955070 & 4.2006 & 3.5886 & TRN & & \\
\hline CHEMBL585951 & 955070 & 5.7829 & 4.5738 & TST & & \\
\hline CHEMBL192566 & 955070 & 5.9954 & 5.657 & TST & & \\
\hline CHEMBL9470 & 955070 & 6.0863 & 4.3831 & TST & & \\
\hline CHEMBL1404918 & 955070 & 3.3081 & 2.8141 & TST & & \\
\hline CHEMBL 300389 & 955070 & 5.9377 & 4.8695 & TST & & \\
\hline CHEMBL 258844 & 955070 & 3.1906 & 3.5469 & TST & & \\
\hline CHEMBL1242367 & 955070 & 3.1802 & 3.395 & TST & & \\
\hline CHEMBL412142 & 955070 & 3.2881 & 3.3709 & TST & & \\
\hline CHEMBL3392440 & 955070 & 3.41300 & 00000000 & 003 & 3.3197 & TST \\
\hline CHEMBL3982721 & 1528726 & 6.6021 & 6.6161 & TRN & & \\
\hline CHEMBL3929459 & 1528726 & 5.78700 & 30000000 & 01 & 6.0627 & TRN \\
\hline CHEMBL3904368 & 1528726 & 6.6383 & 6.6963 & TRN & & \\
\hline CHEMBL3889527 & 1528726 & 6.7747 & 6.4663 & TRN & & \\
\hline CHEMBL3905230 & 1528726 & 7.0809 & 5.544 & TST & & \\
\hline CHEMBL3928836 & 1528726 & 6.11799 & 79999999 & 99 & 6.1666 & TRN \\
\hline CHEMBL3966192 & 1528726 & 5.7126 & 6.2717 & TRN & & \\
\hline CHEMBL3953681 & 1528726 & 5.8187 & 5.9053 & TRN & & \\
\hline CHEMBL3917555 & 1528726 & 6.0 & 6.4389 & TRN & & \\
\hline CHEMBL3700604 & 1528726 & $5.8210 €$ & 30000000 & 01 & 6.4116 & TST \\
\hline CHEMBL3914382 & 1528726 & 6.6696 & 6.1782 & TRN & & \\
\hline CHEMBL3700597 & 1528726 & 5.3398 & 6.24700 & 0000000001 & & TST \\
\hline CHEMBL3889784 & 1528726 & 6.585 & 6.5174 & TRN & & \\
\hline CHEMBL3926272 & 1528726 & 7.1739 & 6.3997 & TRN & & \\
\hline CHEMBL3977157 & 1528726 & 6.4711 & 6.5121 & TRN & & \\
\hline CHEMBL3967181 & 1528726 & 6.5952 & 6.8118 & TRN & & \\
\hline CHEMBL3945150 & 1528726 & 5.6828 & 5.8464 & TRN & & \\
\hline
\end{tabular}




\begin{tabular}{|c|c|c|c|c|c|c|}
\hline \multicolumn{7}{|c|}{ Supplemental Table S2.txt } \\
\hline CHEMBL3946618 & 1528726 & 6.0 & 6.4048 & TRN & & \\
\hline CHEMBL 3964435 & 1528726 & 7.1192 & 6.5927 & TRN & & \\
\hline CHEMBL3910032 & 1528726 & 6.4112 & 6.0005 & TRN & & \\
\hline CHEMBL 3951301 & 1528726 & 5.82100 & 00000000 & 01 & 5.9704 & TRN \\
\hline CHEMBL 3972107 & 1528726 & 6.1844 & 6.2208 & TRN & & \\
\hline CHEMBL3932102 & 1528726 & 6.9747 & 6.3565 & TRN & & \\
\hline CHEMBL 3962656 & 1528726 & 6.7852 & 6.3511 & TRN & & \\
\hline CHEMBL 3898704 & 1528726 & 6.0 & 6.3436 & TRN & & \\
\hline CHEMBL 3895180 & 1528726 & 5.8548 & 6.2356 & TRN & & \\
\hline CHEMBL3897032 & 1528726 & 6.75700 & 30000000 & 01 & 5.4214 & TST \\
\hline CHEMBL3910253 & 1528726 & 6.3242 & 5.9686 & TRN & & \\
\hline CHEMBL3904746 & 1528726 & 6.5243 & 6.7232 & TRN & & \\
\hline CHEMBL 3978344 & 1528726 & 6.7328 & 6.9503 & TRN & & \\
\hline CHEMBL 3921260 & 1528726 & 6.7399 & 6.4403 & TRN & & \\
\hline CHEMBL 3957824 & 1528726 & 5.6251 & 5.6737 & TRN & & \\
\hline CHEMBL3924382 & 1528726 & 5.6243 & 6.0203 & TRN & & \\
\hline CHEMBL3908683 & 1528726 & 7.041 & 6.7475 & TRN & & \\
\hline CHEMBL3931916 & 1528726 & 5.9957 & 6.4094 & TRN & & \\
\hline CHEMBL3918859 & 1528726 & 7.0269 & 7.0463 & TRN & & \\
\hline CHEMBL3970249 & 1528726 & 5.8111 & 6.0267 & TRN & & \\
\hline CHEMBL3700616 & 1528726 & 6.0 & 5.9725 & TST & & \\
\hline CHEMBL 3983854 & 1528726 & 5.6123 & 6.1738 & TRN & & \\
\hline CHEMBL3959025 & 1528726 & 6.4776 & 6.3941 & TRN & & \\
\hline CHEMBL 3977824 & 1528726 & 6.4283 & 6.5537 & TRN & & \\
\hline CHEMBL 3900484 & 1528726 & 6.1192 & 6.2658 & TRN & & \\
\hline CHEMBL3890623 & 1528726 & 7.3979 & 5.7009 & TST & & \\
\hline CHEMBL3985159 & 1528726 & 6.1593 & 6.1581 & TRN & & \\
\hline CHEMBL3900779 & 1528726 & 5.8579 & 5.6674 & TRN & & \\
\hline CHEMBL 3913797 & 1528726 & 5.5758 & 5.8848 & TRN & & \\
\hline CHEMBL 3904776 & 1528726 & 6.8665 & 6.6 & TRN & & \\
\hline CHEMBL3982571 & 1528726 & 5.527 & 5.3022 & TRN & & \\
\hline CHEMBL 3959408 & 1528726 & 6.1029 & 6.3721 & TRN & & \\
\hline CHEMBL3978965 & 1528726 & 5.2314 & 5.8093 & TRN & & \\
\hline CHEMBL 3975549 & 1528726 & 6.4685 & 5.9833 & TRN & & \\
\hline CHEMBL3899029 & 1528726 & 6.5482 & 6.5872 & TRN & & \\
\hline CHEMBL 3932271 & 1528726 & 6.3768 & 5.8345 & TRN & & \\
\hline CHEMBL 3954964 & 1528726 & 6.7055 & 6.5759 & TRN & & \\
\hline CHEMBL3931686 & 1528726 & 6.5003 & 6.7399 & TRN & & \\
\hline CHEMBL 3964373 & 1528726 & 5.8035 & 5.9613 & TRN & & \\
\hline CHEMBL 3944963 & 1528726 & 6.6556 & 6.0908 & TRN & & \\
\hline CHEMBL3928257 & 1528726 & 5.5586 & 5.6817 & TRN & & \\
\hline CHEMBL 3946707 & 1528726 & 7.1135 & 6.82799 & 9999999999 & & TRN \\
\hline CHEMBL3954572 & 1528726 & 5.6859 & 5.8149 & TRN & & \\
\hline CHEMBL 3704153 & 1528726 & 7.1612 & 6.4942 & TRN & & \\
\hline CHEMBL3982867 & 1528726 & 6.475 & 6.3709 & TRN & & \\
\hline CHEMBL3889712 & 1528726 & 5.8094 & 6.3969 & TRN & & \\
\hline CHEMBL 3700600 & 1528726 & 6.0721 & 6.3935 & TST & & \\
\hline CHEMBL 3914664 & 1528726 & 6.6198 & 6.3293 & TRN & & \\
\hline
\end{tabular}

Page 23293 
Supplemental Table S2.txt

\begin{tabular}{|c|c|c|c|c|c|}
\hline CHEMBL3945785 & 1528726 & 6.6144 & 6.8703 & TRN & \\
\hline CHEMBL3700598 & 1528726 & 6.1599 & 6.086 & TST & \\
\hline CHEMBL3925059 & 1528726 & 6.3382 & 6.3595 & TRN & \\
\hline CHEMBL 3700594 & 1528726 & 6.0 & 5.6058 & TST & \\
\hline CHEMBL3915382 & 1528726 & 6.1785 & 6.1405 & TRN & \\
\hline CHEMBL3909841 & 1528726 & 5.87 & 5.8617 & TRN & \\
\hline CHEMBL3909141 & 1528726 & 6.2733 & 6.0109 & TRN & \\
\hline CHEMBL 3932788 & 1528726 & 6.9626 & 5.9758 & TST & \\
\hline CHEMBL 3974132 & 1528726 & 5.5879 & 5.7696 & TST & \\
\hline CHEMBL3968446 & 1528726 & 5.6741 & 6.3091 & TRN & \\
\hline CHEMBL3965656 & 1528726 & 5.6712 & 5.7973 & TRN & \\
\hline CHEMBL3960507 & 1528726 & 6.2557 & 5.8901 & TRN & \\
\hline CHEMBL3940939 & 1528726 & 7.1549 & 5.8556 & TST & \\
\hline CHEMBL3965819 & 1528726 & 5.3953 & 6.58899 & 99999999995 & TST \\
\hline CHEMBL3896095 & 1528726 & 6.0 & 6.3108 & TRN & \\
\hline CHEMBL3968654 & 1528726 & 5.4198 & 6.4389 & TRN & \\
\hline CHEMBL3937060 & 1528726 & 5.7698 & 5.8382 & TRN & \\
\hline CHEMBL3934941 & 1528726 & 5.909 & 6.1217 & TRN & \\
\hline CHEMBL3700658 & 1528726 & 6.1759 & 5.7766 & TRN & \\
\hline CHEMBL3949351 & 1528726 & 5.8213 & 6.7215 & TST & \\
\hline CHEMBL3909567 & 1528726 & 6.7496 & 5.4723 & TST & \\
\hline CHEMBL3700618 & 1528726 & 5.4548 & 5.7089 & TST & \\
\hline CHEMBL3913372 & 1528726 & 7.0605 & 6.6607 & TRN & \\
\hline CHEMBL3928157 & 1528726 & 6.3645 & 6.0768 & TRN & \\
\hline CHEMBL 3972179 & 1528726 & 5.5449 & 5.7735 & TRN & \\
\hline CHEMBL3917052 & 1528726 & 6.1593 & 5.9616 & TRN & \\
\hline CHEMBL3890811 & 1528726 & 6.0 & 6.3866 & TRN & \\
\hline CHEMBL3957173 & 1528726 & 7.0177 & 6.4995 & TRN & \\
\hline CHEMBL3971615 & 1528726 & \multicolumn{3}{|c|}{5.6770000000000005} & TRN \\
\hline CHEMBL 3913593 & 1528726 & 6.7545 & 6.0087 & TST & \\
\hline CHEMBL 3948103 & 1528726 & 5.8277 & 6.0469 & TST & \\
\hline CHEMBL 3957248 & 1528726 & 5.8557 & 5.6173 & TRN & \\
\hline CHEMBL3949309 & 1528726 & 5.8327 & 6.0592 & TRN & \\
\hline CHEMBL 3932282 & 1528726 & 5.8435 & 5.8074 & TST & \\
\hline CHEMBL3947079 & 1528726 & 5.8897 & 5.6219 & TST & \\
\hline CHEMBL3930107 & 1528726 & 6.0 & 6.3301 & TRN & \\
\hline CHEMBL3902614 & 1528726 & 6.3936 & 6.3896 & TRN & \\
\hline CHEMBL3976923 & 1528726 & 5.901 & 5.7697 & TRN & \\
\hline CHEMBL3700599 & 1528726 & 5.9237 & 6.6182 & TST & \\
\hline CHEMBL3911845 & 1528726 & 6.1765 & 5.6635 & TRN & \\
\hline CHEMBL 3977080 & 1528726 & 5.5959 & 6.0181 & TRN & \\
\hline CHEMBL 3895363 & 1528726 & 7.0655 & 6.3327 & TRN & \\
\hline CHEMBL3926672 & 1528726 & 6.064 & 5.974 & TRN & \\
\hline CHEMBL3949705 & 1528726 & 6.0 & 6.4417 & TRN & \\
\hline CHEMBL3700622 & 1528726 & 5.8729 & 5.5502 & TST & \\
\hline CHEMBL3928362 & 1528726 & 6.8069 & 6.4665 & TRN & \\
\hline CHEMBL3935736 & 1528726 & 5.6505 & 5.794 & TRN & \\
\hline CHEMBL3934439 & 1528726 & 6.2434 & 5.8792 & TST & \\
\hline
\end{tabular}


Supplemental Table S2.txt

\begin{tabular}{|c|c|c|c|c|c|}
\hline CHEMBL3975581 & 1528726 & 6.15799 & و999999 & 995 & \multirow[t]{2}{*}{114} \\
\hline CHEMBL 3700620 & 1528726 & 5.9523 & 5.8665 & TST & \\
\hline CHEMBL3700603 & 1528726 & 5.8706 & 7.1128 & TST & \\
\hline CHEMBL3949337 & 1528726 & 5.8256 & 6.0767 & TRN & \\
\hline CHEMBL 3897282 & 1528726 & 5.9285 & 5.9969 & TRN & \\
\hline CHEMBL 3900788 & 1528726 & 6.7305 & 6.4597 & TRN & \\
\hline CHEMBL3953913 & 1528726 & 6.2557 & 5.9406 & TRN & \\
\hline CHEMBL3912924 & 1528726 & 6.5622 & 6.6546 & TRN & \\
\hline CHEMBL 3905473 & 1528726 & 6.2041 & 5.7393 & TST & \\
\hline CHEMBL 3955781 & 1528726 & 5.9382 & 5.8133 & TRN & \\
\hline CHEMBL3978928 & 1528726 & 6.8761 & 6.4245 & TRN & \\
\hline CHEMBL 3960049 & 1528726 & 6.6946 & 5.4943 & TST & \\
\hline CHEMBL 3898578 & 1528726 & 6.5317 & 6.7793 & TRN & \\
\hline CHEMBL 3983030 & 1528726 & 6.7033 & 6.6962 & TRN & \\
\hline CHEMBL3946604 & 1528726 & 6.0565 & 5.8213 & TRN & \\
\hline CHEMBL3958443 & 1528726 & 6.9957 & 6.3389 & TRN & \\
\hline CHEMBL 3937774 & 1528726 & 7.2291 & 6.8654 & TRN & \\
\hline CHEMBL 3941114 & 1528726 & 6.7305 & 5.775 & TST & \\
\hline CHEMBL 3964374 & 1528726 & 7.2147 & 5.9059 & TST & \\
\hline CHEMBL3961519 & 1528726 & 6.5607 & 6.7008 & TRN & \\
\hline CHEMBL3971952 & 1528726 & 6.4413 & 6.3841 & TRN & \\
\hline CHEMBL 3978245 & 1528726 & 6.8697 & 7.1411 & TRN & \\
\hline CHEMBL 3976025 & 1528726 & 6.8268 & 5.4968 & TST & \\
\hline CHEMBL 3978771 & 1528726 & 6.9747 & 6.7364 & TRN & \\
\hline CHEMBL3933615 & 1528726 & 6.4401 & 6.4167 & TRN & \\
\hline CHEMBL3969374 & 1528726 & 6.7471 & 6.894 & TRN & \\
\hline CHEMBL 3983687 & 1528726 & 5.2546 & 5.6448 & TRN & \\
\hline CHEMBL 3983483 & 1528726 & 5.6629 & 5.7683 & TRN & \\
\hline CHEMBL3700619 & 1528726 & 5.4579 & 5.6883 & TST & \\
\hline CHEMBL 3941135 & 1528726 & 5.9527 & 6.5244 & TRN & \\
\hline CHEMBL3939596 & 1528726 & 5.6358 & 5.7767 & TRN & \\
\hline CHEMBL 3937569 & 1528726 & 6.3089 & 6.1172 & TRN & \\
\hline CHEMBL 3978410 & 1528726 & 5.6107 & 5.8264 & TRN & \\
\hline CHEMBL3946155 & 1528726 & 6.6162 & 6.7465 & TRN & \\
\hline CHEMBL 3922281 & 1528726 & 6.3002 & 6.5404 & TRN & \\
\hline CHEMBL3902202 & 1528726 & 5.2193 & 6.0831 & TRN & \\
\hline CHEMBL 3976950 & 1528726 & 6.2 & 5.9901 & TRN & \\
\hline CHEMBL3933956 & 1528726 & 7.4437 & 6.8892 & TRN & \\
\hline CHEMBL3922839 & 1528726 & 5.2269 & 5.4637 & TRN & \\
\hline CHEMBL 3922291 & 1528726 & 6.3757 & 6.1002 & TRN & \\
\hline CHEMBL3900976 & 1528726 & 5.2137 & 6.0304 & TRN & \\
\hline CHEMBL3963091 & 1528726 & 5.8283 & 5.852 & TST & \\
\hline CHEMBL3923339 & 1528726 & 6.8601 & 6.1968 & TRN & \\
\hline CHEMBL3966892 & 1528726 & 6.6778 & 6.0357 & TRN & \\
\hline CHEMBL3926986 & 1528726 & 5.7528 & 7.0033 & TST & \\
\hline CHEMBL3974569 & 1528726 & 5.4528 & 5.501 & TST & \\
\hline CHEMBL 3986378 & 1528726 & 6.4001 & 6.0167 & TST & \\
\hline CHEMBL 3900294 & 1528726 & 6.8268 & 5.5076 & TST & \\
\hline
\end{tabular}


Supplemental Table S2.txt

\begin{tabular}{|c|c|c|c|c|}
\hline CHEMBL 3941356 & 1528726 & 6.4248 & 6.4024 & TST \\
\hline CHEMBL 3946264 & 1528726 & 5.8353 & 6.3692 & TST \\
\hline CHEMBL 3963238 & 1528726 & 6.5935 & 6.0938 & TST \\
\hline CHEMBL 3961442 & 1528726 & 7.1249 & 6.1689 & TST \\
\hline CHEMBL 3937788 & 1528726 & 5.9706 & 6.2638 & TST \\
\hline CHEMBL 3700609 & 1528726 & 6.0921 & 6.6932 & TST \\
\hline CHEMBL96347 & 63683 & \multicolumn{2}{|c|}{6.247999999999999} & 6.2164 \\
\hline CHEMBL431286 & 63683 & 7.9626 & 8.0737 & TRN \\
\hline CHEMBL419148 & 63683 & 4.0 & 3.9813 & TRN \\
\hline CHEMBL96746 & 63683 & 7.5719 & 7.6105 & TRN \\
\hline CHEMBL450628 & 63683 & 5.7496 & 5.7642 & TRN \\
\hline CHEMBL422068 & 63683 & 7.4377 & 7.4833 & TRN \\
\hline CHEMBL 329132 & 63683 & 5.0953 & 5.36 & TST \\
\hline CHEMBL406551 & 63683 & 7.5406 & 7.5033 & TRN \\
\hline CHEMBL96463 & 63683 & 5.4522 & 5.4635 & TRN \\
\hline CHEMBL 317510 & 63683 & 7.295 & 7.2401 & TRN \\
\hline CHEMBL318086 & 63683 & 7.6021 & 7.6271 & TRN \\
\hline CHEMBL96831 & 63683 & 5.4389 & 6.0682 & TST \\
\hline CHEMBL 95013 & 63683 & 7.3242 & 7.3399 & TRN \\
\hline CHEMBL328073 & 63683 & 6.9788 & 7.1401 & TST \\
\hline CHEMBL415010 & 63683 & 7.9547 & 7.9638 & TRN \\
\hline CHEMBL96154 & 63683 & \multicolumn{2}{|c|}{7.617999999999999} & 7.6069 \\
\hline CHEMBL93820 & 63683 & 7.7328 & 7.7207 & TRN \\
\hline CHEMBL421184 & 63683 & 5.0 & 4.976 & TRN \\
\hline CHEMBL94964 & 63683 & 7.1831 & 7.51 & TST \\
\hline CHEMBL94212 & 63683 & 7.7773 & 7.8545 & TRN \\
\hline CHEMBL 264625 & 63683 & 4.0 & 4.8427 & TST \\
\hline CHEMBL94602 & 63683 & 5.8327 & 5.7632 & TRN \\
\hline CHEMBL 318270 & 63683 & 6.1844 & \multicolumn{2}{|c|}{6.1770000000000005} \\
\hline CHEMBL316851 & 63683 & \multicolumn{3}{|c|}{6.617999999999999} \\
\hline CHEMBL94766 & 63683 & 7.5969 & 7.6084 & TRN \\
\hline CHEMBL314755 & 63683 & 7.3036 & 7.3507 & TRN \\
\hline CHEMBL94488 & 63683 & 6.4067 & 6.4507 & TRN \\
\hline CHEMBL 313870 & 63683 & 6.9136 & 6.9131 & TRN \\
\hline CHEMBL96325 & 63683 & 5.5017 & 5.5947 & TRN \\
\hline CHEMBL317981 & 63683 & 4.0 & 4.0207 & TRN \\
\hline CHEMBL94769 & 63683 & 6.1278 & 6.5647 & TST \\
\hline CHEMBL 330425 & 63683 & 6.7352 & 6.6863 & TRN \\
\hline CHEMBL 95095 & 63683 & 7.3072 & 7.269 & TRN \\
\hline CHEMBL94810 & 63683 & 7.399 & 7.3512 & TRN \\
\hline CHEMBL330104 & 63683 & 8.1805 & 8.1258 & TRN \\
\hline CHEMBL440507 & 63683 & 5.4318 & 5.181 & TST \\
\hline CHEMBL316878 & 63683 & 7.6498 & 7.3882 & TRN \\
\hline CHEMBL 94934 & 63683 & 7.4789 & 7.4236 & TRN \\
\hline CHEMBL 96614 & 63683 & 6.6021 & 6.5099 & TST \\
\hline CHEMBL 96723 & 63683 & 7.4802 & 7.4829 & TRN \\
\hline CHEMBL316629 & 63683 & 7.0255 & 7.0008 & TRN \\
\hline CHEMBL 318683 & 63683 & 5.0339 & 5.1426 & TST \\
\hline
\end{tabular}




\begin{tabular}{|c|c|c|c|c|c|c|}
\hline & & \multicolumn{5}{|c|}{ Supplemental Table s2.txt } \\
\hline CHEMBL96506 & 63683 & 7.6478 & 7.6562 & TRN & & \\
\hline CHEMBL94438 & 63683 & 7.4828 & 7.5096 & TRN & & \\
\hline CHEMBL 329744 & 63683 & 7.1331 & 6.7785 & TST & & \\
\hline CHEMBL419879 & 63683 & 7.1385 & 7.1605 & TRN & & \\
\hline CHEMBL317589 & 63683 & 7.5935 & 7.6061 & TRN & & \\
\hline CHEMBL96171 & 63683 & 7.6676 & 7.6551 & TRN & & \\
\hline CHEMBL96125 & 63683 & 5.7423 & 5.0739 & TST & & \\
\hline CHEMBL96318 & 63683 & 7.0565 & 7.0753 & TRN & & \\
\hline CHEMBL96387 & 63683 & 7.1255 & 7.1142 & TRN & & \\
\hline CHEMBL328878 & 63683 & 6.9666 & 6.9521 & TRN & & \\
\hline CHEMBL96303 & 63683 & 7.8665 & 7.9475 & TRN & & \\
\hline CHEMBL314946 & 63683 & 7.2596 & 7.3088 & TRN & & \\
\hline CHEMBL330045 & 63683 & 6.1481 & 5.86 & TST & & \\
\hline CHEMBL 96520 & 63683 & 5.0232 & 4.8606 & TST & & \\
\hline CHEMBL433173 & 63683 & 7.3206 & 7.3341 & TRN & & \\
\hline CHEMBL330135 & 63683 & 8.1487 & 8.0601 & TRN & & \\
\hline CHEMBL96422 & 63683 & 7.5114 & 7.5144 & TRN & & \\
\hline CHEMBL93084 & 63683 & 7.3036 & 7.2856 & TRN & & \\
\hline CHEMBL 327976 & 63683 & 7.6696 & 7.6567 & TRN & & \\
\hline CHEMBL420435 & 63683 & 7.4841 & 7.4876 & TRN & & \\
\hline CHEMBL419136 & 63683 & 7.8097 & 7.8253 & TRN & & \\
\hline CHEMBL94446 & 63683 & 6.2725 & 6.2749 & TRN & & \\
\hline CHEMBL94962 & 63683 & 6.9245 & 6.9077 & TRN & & \\
\hline CHEMBL 313867 & 63683 & 6.2534 & 6.2017 & TRN & & \\
\hline CHEMBL91926 & 63683 & \multicolumn{3}{|c|}{7.327000000000001} & 7.2926 & TRN \\
\hline CHEMBL319007 & 63683 & 7.8069 & 7.7181 & TRN & & \\
\hline CHEMBL 329943 & 63683 & 7.0862 & 7.1584 & TRN & & \\
\hline CHEMBL431460 & 63683 & 7.0958 & 7.1061 & TRN & & \\
\hline CHEMBL 96313 & 63683 & 7.1068 & 7.0659 & TRN & & \\
\hline CHEMBL314511 & 63683 & 4.0 & 4.896 & TST & & \\
\hline CHEMBL96331 & 63683 & 5.1057 & 6.1169 & TST & & \\
\hline CHEMBL 2112377 & 63683 & 6.5834 & 6.1792 & TST & & \\
\hline CHEMBL94606 & 63683 & 6.015 & 5.94600 & 0000000001 & & TST \\
\hline CHEMBL 96351 & 63683 & 5.2518 & 4.5484 & TST & & \\
\hline CHEMBL96193 & 63683 & 6.129 & 6.3261 & TST & & \\
\hline CHEMBL94752 & 63683 & 6.8153 & 6.8185 & TRN & & \\
\hline CHEMBL316453 & 63683 & 7.0615 & 7.15600 & 0000000001 & & TRN \\
\hline CHEMBL330354 & 63683 & 7.4789 & 7.3965 & TRN & & \\
\hline CHEMBL330629 & 63683 & 5.2027 & 5.0941 & TST & & \\
\hline CHEMBL318247 & 63683 & 6.9626 & 6.9298 & TRN & & \\
\hline CHEMBL329477 & 63683 & 7.0778 & 7.2551 & TRN & & \\
\hline CHEMBL329251 & 63683 & \multicolumn{3}{|c|}{7.752000000000001} & 7.7508 & TRN \\
\hline CHEMBL 327823 & 63683 & 5.109 & 4.5771 & TST & & \\
\hline CHEMBL95017 & 63683 & 7.8827 & 7.8819 & TRN & & \\
\hline CHEMBL316301 & 63683 & 7.153 & 7.1387 & TRN & & \\
\hline CHEMBL 94580 & 63683 & 7.8794 & 7.87299 & 9999999999 & & TRN \\
\hline CHEMBL96906 & 63683 & 6.3251 & 6.3006 & TRN & & \\
\hline CHEMBL431087 & 63683 & 7.1624 & 7.1018 & TRN & & \\
\hline
\end{tabular}




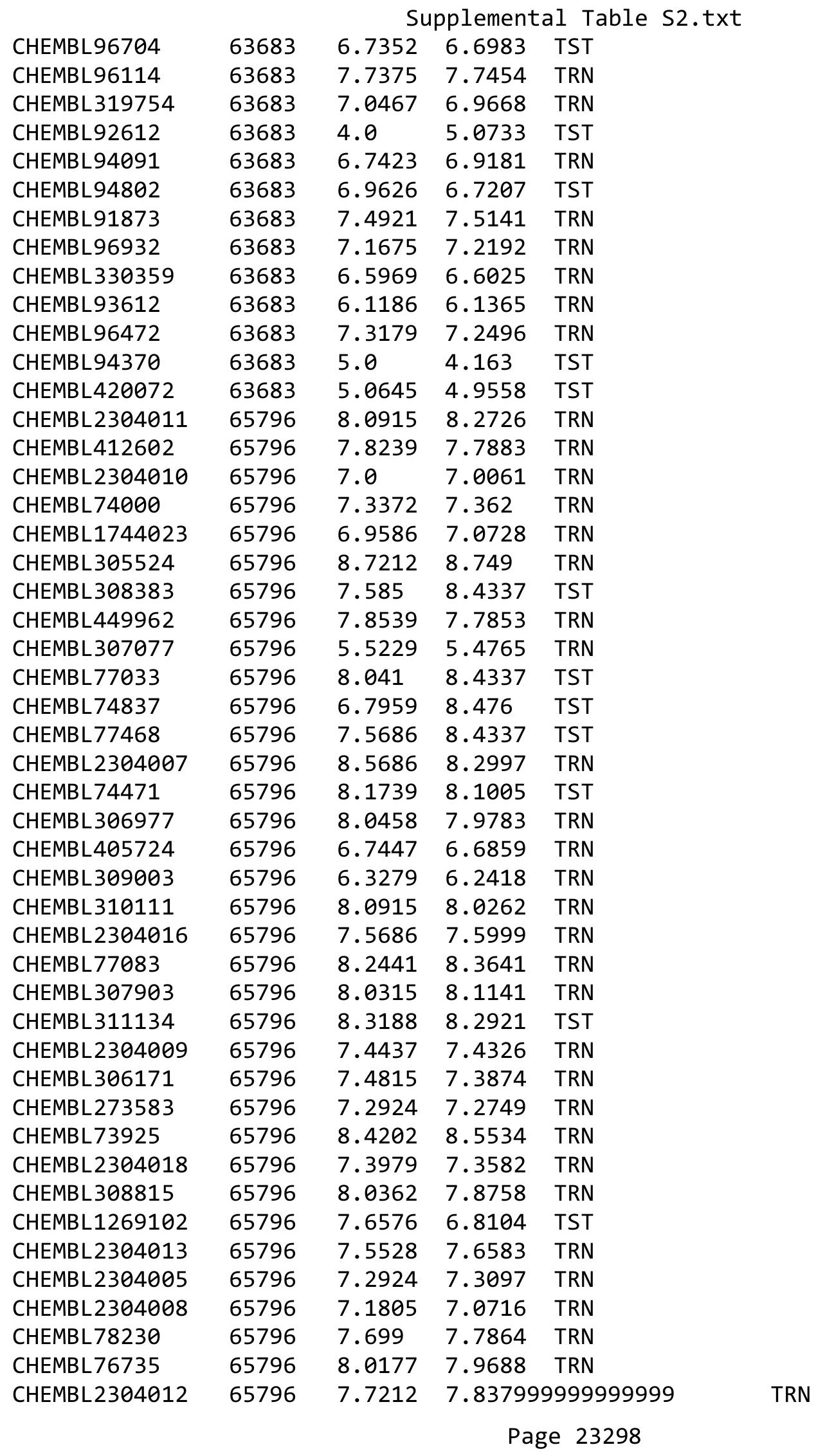




\begin{tabular}{|c|c|c|c|c|c|}
\hline \multicolumn{6}{|c|}{ Supplemental Table S2.txt } \\
\hline CHEMBL 78023 & 65796 & 6.0915 & 6.1684 & TRN & \\
\hline CHEMBL2304006 & 65796 & 8.3098 & 7.5862 & TST & \\
\hline CHEMBL72891 & 65796 & 8.6198 & 8.6673 & TRN & \\
\hline CHEMBL 306123 & 65796 & 5.699 & 5.7963 & TRN & \\
\hline CHEMBL2304015 & 65796 & 8.7447 & 8.129 & TST & \\
\hline CHEMBL308621 & 65796 & 8.5528 & 7.8616 & TST & \\
\hline CHEMBL307936 & 65796 & 9.0 & 8.8224 & TRN & \\
\hline CHEMBL311384 & 65796 & 7.6778 & 7.7193 & TRN & \\
\hline CHEMBL 305650 & 65796 & 8.4202 & 7.996 & TST & \\
\hline CHEMBL308403 & 65796 & 8.699 & 8.5789 & TRN & \\
\hline CHEMBL424422 & 65796 & 8.2518 & 8.1516 & TRN & \\
\hline CHEMBL2304014 & 65796 & 5.6576 & 6.1769 & TST & \\
\hline CHEMBL308584 & 65796 & 8.0969 & 8.3393 & TRN & \\
\hline CHEMBL77853 & 65796 & 8.0088 & 8.0312 & TRN & \\
\hline CHEMBL2304017 & 65796 & 4.6383 & 5.8891 & TST & \\
\hline CHEMBL 3718776 & 1536985 & 4.8239 & 4.7436 & TRN & \\
\hline CHEMBL3718019 & 1536985 & 5.4437 & 5.5332 & TRN & \\
\hline CHEMBL3716396 & 1536985 & 6.0 & 6.012006 & 00000000005 & TRN \\
\hline CHEMBL3718758 & 1536985 & 3.0 & 3.7039 & TRN & \\
\hline CHEMBL3715412 & 1536985 & 6.3768 & 6.3587 & TRN & \\
\hline CHEMBL3714773 & 1536985 & 5.5229 & 5.1743 & TRN & \\
\hline CHEMBL 3715533 & 1536985 & 5.9586 & 5.8625 & TRN & \\
\hline CHEMBL3717470 & 1536985 & 6.0 & 5.945 & TRN & \\
\hline CHEMBL3718956 & 1536985 & 4.699 & 4.9464 & TRN & \\
\hline CHEMBL3718368 & 1536985 & 6.0809 & 5.4181 & TST & \\
\hline CHEMBL3716309 & 1536985 & 5.1805 & 5.2272 & TRN & \\
\hline CHEMBL 3717532 & 1536985 & 5.6021 & 6.0338 & TRN & \\
\hline CHEMBL 3719067 & 1536985 & 6.1024 & 6.0879 & TRN & \\
\hline CHEMBL 3716048 & 1536985 & 5.3279 & 5.5494 & TRN & \\
\hline CHEMBL3717191 & 1536985 & 6.1427 & 5.8958 & TRN & \\
\hline CHEMBL 3715388 & 1536985 & 6.4949 & 6.2019 & TST & \\
\hline CHEMBL3716598 & 1536985 & 4.6778 & 5.5033 & TST & \\
\hline CHEMBL3718730 & 1536985 & 5.5686 & 5.724 & TRN & \\
\hline CHEMBL3718407 & 1536985 & 6.0269 & 6.3218 & TRN & \\
\hline CHEMBL3716143 & 1536985 & 4.8539 & 5.1667 & TST & \\
\hline CHEMBL3717059 & 1536985 & 4.6383 & 4.2019 & TRN & \\
\hline CHEMBL3718636 & 1536985 & 5.4949 & 5.6866 & TRN & \\
\hline CHEMBL3715360 & 1536985 & 5.8239 & 6.141 & TRN & \\
\hline CHEMBL3715121 & 1536985 & 4.8861 & 4.7263 & TRN & \\
\hline CHEMBL3715032 & 1536985 & 5.7959 & 5.6382 & TRN & \\
\hline CHEMBL3716727 & 1536985 & 5.2076 & 5.1422 & TRN & \\
\hline CHEMBL 3717174 & 1536985 & 5.6198 & 5.6969 & TRN & \\
\hline CHEMBL3714893 & 1536985 & 4.5376 & 4.1408 & TRN & \\
\hline CHEMBL3715919 & 1536985 & 5.2596 & 5.6151 & TRN & \\
\hline CHEMBL 3717234 & 1536985 & 5.6198 & 5.32299 & 99999999995 & TRN \\
\hline CHEMBL3716635 & 1536985 & 6.1427 & 6.1553 & TRN & \\
\hline CHEMBL 3716044 & 1536985 & 6.3768 & 6.58799 & 9999999999 & TRN \\
\hline CHEMBL3718439 & 1536985 & 6.2147 & 6.2111 & TRN & \\
\hline
\end{tabular}




\begin{tabular}{|c|c|c|c|c|}
\hline \multicolumn{5}{|c|}{ Supplemental Table S2.txt } \\
\hline CHEMBL 3719148 & 1536985 & 6.0 & 5.1549 & TRN \\
\hline CHEMBL 3715259 & 1536985 & 5.585 & 5.8864 & TRN \\
\hline CHEMBL3718105 & 1536985 & 5.6778 & 5.5584 & TRN \\
\hline CHEMBL 3716274 & 1536985 & 5.3665 & 5.1505 & TRN \\
\hline CHEMBL3719157 & 1536985 & 4.2218 & 4.2428 & TRN \\
\hline CHEMBL3719302 & 1536985 & 4.3768 & 4.5172 & TRN \\
\hline CHEMBL 3718783 & 1536985 & 6.9208 & 6.4547 & TRN \\
\hline CHEMBL 3717200 & 1536985 & 5.1249 & 5.0875 & TRN \\
\hline CHEMBL3718661 & 1536985 & 5.3665 & 5.1316 & TRN \\
\hline CHEMBL3717368 & 1536985 & 3.0 & 3.4191 & TRN \\
\hline CHEMBL3715494 & 1536985 & 5.0458 & 5.0903 & TRN \\
\hline CHEMBL 3718268 & 1536985 & 6.1192 & 5.6517 & TST \\
\hline CHEMBL 3717295 & 1536985 & 6.3768 & 6.1847 & TST \\
\hline CHEMBL 3716544 & 1536985 & 6.0605 & 6.0211 & TST \\
\hline CHEMBL3716839 & 1536985 & 4.9208 & 4.8804 & TST \\
\hline CHEMBL3717063 & 1536985 & 6.4949 & 6.0147 & TST \\
\hline CHEMBL3718575 & 1536985 & 4.7959 & 5.4199 & TST \\
\hline CHEMBL 3717030 & 1536985 & 6.0 & 5.559 & TST \\
\hline CHEMBL3716900 & 1536985 & 3.0 & 4.7211 & TST \\
\hline CHEMBL3716936 & 1536985 & 5.1308 & 5.2647 & TST \\
\hline CHEMBL3715825 & 1536985 & 6.0269 & 5.2753 & TST \\
\hline CHEMBL 3126883 & 1294964 & 3.0 & 3.4861 & TRN \\
\hline CHEMBL 3127047 & 1294964 & 3.0 & 4.2004 & TST \\
\hline CHEMBL3126892 & 1294964 & 3.0 & 3.0885 & TRN \\
\hline CHEMBL 3127055 & 1294964 & 3.0 & 3.9583 & TST \\
\hline CHEMBL 3126876 & 1294964 & 3.0 & 2.9972 & TRN \\
\hline CHEMBL 3126893 & 1294964 & 3.0 & 3.0271 & TRN \\
\hline CHEMBL 3126872 & 1294964 & 3.0 & 3.3384 & TST \\
\hline CHEMBL3126889 & 1294964 & 4.1051 & 3.8575 & TRN \\
\hline CHEMBL 3126885 & 1294964 & 3.0 & 3.0348 & TRN \\
\hline CHEMBL 3126878 & 1294964 & 3.0 & 3.5101 & TRN \\
\hline CHEMBL 3126873 & 1294964 & 3.0 & 2.8651 & TRN \\
\hline CHEMBL 3127061 & 1294964 & 3.0 & 2.911 & TRN \\
\hline CHEMBL 3127053 & 1294964 & 3.0 & 2.7875 & TRN \\
\hline CHEMBL 3124960 & 1294964 & 3.0 & 2.742 & TRN \\
\hline CHEMBL3126910 & 1294964 & 3.0 & 3.3301 & TRN \\
\hline CHEMBL3126895 & 1294964 & 4.0372 & 4.0241 & TRN \\
\hline CHEMBL 3126888 & 1294964 & 3.0 & 3.0122 & TRN \\
\hline CHEMBL3126896 & 1294964 & 3.0 & 3.5237 & TST \\
\hline CHEMBL3126901 & 1294964 & 3.0 & 2.7271 & TRN \\
\hline CHEMBL3127066 & 1294964 & 4.5317 & 4.4055 & TRN \\
\hline CHEMBL3126907 & 1294964 & 4.0376 & 3.904 & TST \\
\hline CHEMBL3126914 & 1294964 & 5.8416 & 4.8227 & TST \\
\hline CHEMBL 3126870 & 1294964 & 3.0 & 3.2336 & TRN \\
\hline CHEMBL1269812 & 1294964 & 7.0458 & 5.3199 & TST \\
\hline CHEMBL3126899 & 1294964 & 3.0 & 3.7281 & TRN \\
\hline CHEMBL3126866 & 1294964 & 4.0472 & 3.3799 & TRN \\
\hline CHEMBL3126887 & 1294964 & 3.0 & 2.9082 & TRN \\
\hline
\end{tabular}




\begin{tabular}{|c|c|c|c|c|}
\hline \multicolumn{5}{|c|}{ Supplemental Table S2.txt } \\
\hline CHEMBL1814768 & 1294964 & 4.4045 & 4.1974 & TRN \\
\hline CHEMBL3127052 & 1294964 & 3.0 & 2.8883 & TRN \\
\hline CHEMBL3126882 & 1294964 & 3.0 & 2.6944 & TRN \\
\hline CHEMBL3126912 & 1294964 & 3.0 & 3.2501 & TRN \\
\hline CHEMBL 3127044 & 1294964 & 4.6126 & 3.787 & TST \\
\hline CHEMBL 3126897 & 1294964 & 3.0 & 3.2805 & TST \\
\hline CHEMBL3127068 & 1294964 & 4.1232 & 4.1586 & TRN \\
\hline CHEMBL3126868 & 1294964 & 3.0 & 3.4023 & TRN \\
\hline CHEMBL3126911 & 1294964 & 3.0 & 3.6868 & TRN \\
\hline CHEMBL3127049 & 1294964 & 4.1314 & 4.7936 & TRN \\
\hline CHEMBL 3126898 & 1294964 & 4.0097 & 3.6445 & TST \\
\hline CHEMBL 3126865 & 1294964 & 4.0665 & 3.839 & TST \\
\hline CHEMBL3127058 & 1294964 & 4.0419 & 4.417 & TRN \\
\hline CHEMBL3126915 & 1294964 & 4.8761 & 3.9206 & TST \\
\hline CHEMBL3126913 & 1294964 & 4.0737 & 4.152 & TRN \\
\hline CHEMBL 3127060 & 1294964 & 3.0 & 2.9707 & TRN \\
\hline CHEMBL3126886 & 1294964 & 3.0 & 3.1113 & TRN \\
\hline CHEMBL3126904 & 1294964 & 3.0 & 3.2592 & TRN \\
\hline CHEMBL3126871 & 1294964 & 4.644 & 4.3505 & TRN \\
\hline CHEMBL 3127048 & 1294964 & 4.2007 & 3.7735 & TST \\
\hline CHEMBL3126905 & 1294964 & 4.4425 & 4.6853 & TST \\
\hline CHEMBL3126890 & 1294964 & 3.0 & 2.9354 & TRN \\
\hline CHEMBL3127065 & 1294964 & 5.7696 & 5.4148 & TRN \\
\hline CHEMBL3127064 & 1294964 & 3.0 & 3.6694 & TST \\
\hline CHEMBL3127045 & 1294964 & 3.0 & 3.4727 & TRN \\
\hline CHEMBL3127062 & 1294964 & 3.0 & 2.9168 & TRN \\
\hline CHEMBL3126874 & 1294964 & 4.065 & 3.4885 & TRN \\
\hline CHEMBL3126908 & 1294964 & 6.2147 & 5.2711 & TRN \\
\hline CHEMBL 3127063 & 1294964 & 4.1232 & 3.8084 & TRN \\
\hline CHEMBL3126880 & 1294964 & 3.0 & 3.1004 & TRN \\
\hline CHEMBL3126879 & 1294964 & 3.0 & 2.8439 & TRN \\
\hline CHEMBL3126909 & 1294964 & 4.0074 & 3.5609 & TRN \\
\hline CHEMBL3126877 & 1294964 & 3.0 & 3.0187 & TRN \\
\hline CHEMBL3126906 & 1294964 & 4.2351 & 4.0536 & TST \\
\hline CHEMBL3127050 & 1294964 & 3.0 & 3.3057 & TRN \\
\hline CHEMBL3126875 & 1294964 & 3.0 & 3.1038 & TRN \\
\hline CHEMBL 3127054 & 1294964 & 4.15 & 3.6041 & TRN \\
\hline CHEMBL403715 & 1294964 & 3.0 & 3.6426 & TST \\
\hline CHEMBL3126900 & 1294964 & 3.0 & 3.0022 & TRN \\
\hline CHEMBL319177 & 1294964 & 3.0 & 2.9916 & TST \\
\hline CHEMBL3126894 & 1294964 & 3.0 & 3.0745 & TRN \\
\hline CHEMBL3127051 & 1294964 & 3.0 & 2.9561 & TRN \\
\hline CHEMBL3126902 & 1294964 & 3.0 & 2.7372 & TRN \\
\hline CHEMBL3127056 & 1294964 & 3.0 & 3.4677 & TST \\
\hline CHEMBL1814767 & 1294964 & 4.4377 & 4.5023 & TRN \\
\hline CHEMBL3126869 & 1294964 & 3.0 & 3.1801 & TRN \\
\hline CHEMBL 3127067 & 1294964 & 4.3645 & 4.167 & TRN \\
\hline CHEMBL3127059 & 1294964 & 3.0 & 3.1281 & TRN \\
\hline
\end{tabular}


Supplemental Table S2.txt

\begin{tabular}{|c|c|c|c|c|}
\hline CHEMBL3127057 & 1294964 & 3.0 & 3.1439 & TST \\
\hline CHEMBL 3126884 & 294964 & 3.0 & 2.9549 & \\
\hline HEMBL 3126881 & 294964 & 3.0 & .7738 & \\
\hline HEMBL3127046 & 294964 & 4.1831 & 4.5923 & RN \\
\hline HEMBL3126891 & 294964 & 3.0 & .0084 & N \\
\hline HEMBL3126903 & 294964 & 3.0 & .6124 & \\
\hline HEMBL3126867 & 294964 & 3.0 & 3064 & \\
\hline HEMBL 284708 & 24012 & 7.7696 & 7.7799 & \\
\hline HEMBL 36307 & 124012 & 7.6021 & 7.6281 & RN \\
\hline HEMBL290865 & 24012 & 7.8539 & 7.8903 & N \\
\hline HEMBL38216 & 24012 & 6.4908 & 6.4797 & \\
\hline HEMBL 37871 & 24012 & 7.3979 & 7.2651 & \\
\hline HEMBL 37504 & 24 & 7.3979 & 7.3852 & \\
\hline HEMBL 34184 & 124012 & 8.0969 & 8.1104 & RN \\
\hline HEMBL35409 & 24012 & 5.7423 & 5.6683 & \\
\hline HEMBL422940 & 246 & 6.3872 & 6.4851 & RN \\
\hline HEMBL 284760 & 24 & 7.2757 & 7.2695 & RN \\
\hline HEMBL 38321 & 124 & 7.6021 & 7.58 & \\
\hline HEMBL 285905 & 124012 & 6.2924 & 7.6476 & \\
\hline HEMBL 38335 & 24 & 6.4089 & 6.3663 & N \\
\hline HEMBL 287754 & 24 & 5.3969 & 5.3845 & RN \\
\hline HEMBL3\& & 24 & 7.301 & 7.3436 & RN \\
\hline HEMBL 37 & 124 & 6.3468 & 39 & RN \\
\hline HEMBL38184 & 124 & 7.2441 & 7.2299 & N \\
\hline LHEMBL 37548 & 24 & 6.2676 & 6.2667 & TRN \\
\hline HEMBL 37487 & 24 & 7.5229 & 7.8265 & RN \\
\hline HEMBL3 3 & 124 & 6.7696 & 6.8073 & $\Gamma \mathrm{RN}$ \\
\hline IHEMBL35029 & 12 & 7.4559 & 7.4482 & IRN \\
\hline LHEMBL287959 & 124 & 7.1192 & 7.1 & TRN \\
\hline CHEMBL37911 & 24 & 7.8861 & 7.8839 & TRN \\
\hline HEMBL 33906 & 24 & 7.3279 & 7.3489 & ГRN \\
\hline HEMBL 2S & 124 & 7.2596 & 7.2884 & TRN \\
\hline CHEMBL35598 & 2 & 8.0969 & 8.0781 & TRN \\
\hline CHEMBL 37493 & 24 & 7.9208 & 7.9198 & TRN \\
\hline HEMBL 290017 & 24012 & 7.6198 & 7.3429 & TRN \\
\hline CHEMBL289134 & 24 & 6.2984 & 6.2749 & TRN \\
\hline CHEMBL $2 \varepsilon$ & 124 & 8.1549 & 8.1032 & TRN \\
\hline CHEMBL286371 & 124 & 6.1811 & 6.4473 & TRN \\
\hline CHEMBL430731 & 124012 & 6.5935 & 7.4393 & TST \\
\hline CHEMBL35988 & 24 & 6.7375 & 6.7663 & TRN \\
\hline CHEMBL37927 & 124 & 7.2441 & 7.2817 & TRN \\
\hline CHEMBL417687 & 124012 & 7.7696 & 7.7226 & TRN \\
\hline CHEMBL35019 & 124 & 5.6536 & 6.9511 & TST \\
\hline CHEMBL 36664 & 124012 & 8.0969 & 8.1013 & TRN \\
\hline CHEMBL3 & 246 & 7.2441 & 7.0251 & I KIV \\
\hline CHEMBL34704 & 124012 & 7.1549 & 7.2197 & \\
\hline CHEMBL 38260 & 124012 & 7.2757 & 7.2666 & RIN \\
\hline CHEMBL417693 & 124012 & 7.2757 & 7.2886 & $\Gamma \mathrm{RN}$ \\
\hline
\end{tabular}

Page 23302 


\begin{tabular}{|c|c|c|c|c|}
\hline \multicolumn{5}{|c|}{ Supplemental Table S2.txt } \\
\hline CHEMBL38195 & 124012 & 7.7696 & 7.7688 & TRN \\
\hline CHEMBL285661 & 124012 & 6.1662 & 6.8354 & TST \\
\hline CHEMBL35379 & 124012 & 7.3565 & 7.3275 & TRN \\
\hline CHEMBL37646 & 124012 & 6.0315 & 7.1216 & TST \\
\hline CHEMBL286239 & 124012 & 6.4815 & 7.6351 & TST \\
\hline CHEMBL34072 & 124012 & 7.6021 & 7.1682 & TST \\
\hline CHEMBL35579 & 124012 & 6.4685 & 6.9666 & TST \\
\hline CHEMBL265999 & 124012 & 5.6817 & 8.2428 & TST \\
\hline CHEMBL284774 & 124012 & 6.8539 & 6.7772 & TST \\
\hline CHEMBL34601 & 124012 & 7.2518 & 6.9435 & TST \\
\hline CHEMBL418230 & 124012 & 7.0044 & 7.641 & TST \\
\hline CHEMBL 2152602 & 851435 & 3.0 & 3.1275 & TRN \\
\hline CHEMBL562474 & 851435 & 3.0 & 3.1702 & TRN \\
\hline CHEMBL572123 & 851435 & 4.1427 & 3.9594 & TRN \\
\hline CHEMBL 2152619 & 851435 & 3.0 & 3.0429 & TRN \\
\hline CHEMBL551010 & 851435 & 4.2366 & 4.3665 & TRN \\
\hline CHEMBL549853 & 851435 & 4.2366 & 3.7206 & TRN \\
\hline CHEMBL 2152614 & 851435 & 2.5229 & 2.8077 & TRN \\
\hline CHEMBL 2152604 & 851435 & 3.0 & 2.9581 & TRN \\
\hline CHEMBL 2152577 & 851435 & 3.0 & 2.3384 & TRN \\
\hline CHEMBL 2152601 & 851435 & 3.0 & 2.9829 & TRN \\
\hline CHEMBL 2152571 & 851435 & 4.0315 & 3.8315 & TRN \\
\hline CHEMBL 2152598 & 851435 & 3.0 & 3.3976 & TST \\
\hline CHEMBL540468 & 851435 & 4.284 & 4.1979 & TRN \\
\hline CHEMBL 2152623 & 851435 & 3.0 & 3.0972 & TRN \\
\hline CHEMBL 2152612 & 851435 & 2.5229 & 2.8147 & TRN \\
\hline CHEMBL2152569 & 851435 & 3.0 & 3.523 & TRN \\
\hline CHEMBL 2152572 & 851435 & 4.2518 & 3.9328 & TRN \\
\hline CHEMBL 2152596 & 851435 & 3.0 & 3.1467 & TRN \\
\hline CHEMBL 2152624 & 851435 & 3.0 & 3.1677 & TRN \\
\hline CHEMBL 2152592 & 851435 & 3.0 & 2.9566 & TRN \\
\hline CHEMBL2152595 & 851435 & 3.0 & 3.3157 & TRN \\
\hline CHEMBL 2152622 & 851435 & 3.0 & 2.968 & TRN \\
\hline CHEMBL 2152617 & 851435 & 3.0 & 2.8426 & TRN \\
\hline CHEMBL2152599 & 851435 & 3.0 & 3.069 & TRN \\
\hline CHEMBL2152600 & 851435 & 3.0 & 2.8471 & TRN \\
\hline CHEMBL 2152597 & 851435 & 3.0 & 3.1493 & TST \\
\hline CHEMBL2152625 & 851435 & 3.0 & 3.0782 & TRN \\
\hline CHEMBL551610 & 851435 & 4.1079 & 4.0131 & TST \\
\hline CHEMBL 2152605 & 851435 & 3.0 & 2.8178 & TRN \\
\hline CHEMBL2151055 & 851435 & 3.0 & 2.9128 & TRN \\
\hline CHEMBL561194 & 851435 & 4.2518 & 4.0611 & TRN \\
\hline CHEMBL2152610 & 851435 & 3.6778 & 3.0551 & TST \\
\hline CHEMBL 2152587 & 851435 & 4.1249 & 3.5895 & TST \\
\hline CHEMBL 2152603 & 851435 & 3.0 & 2.9534 & TRN \\
\hline CHEMBL224864 & 851435 & 4.5229 & 3.2939 & TST \\
\hline CHEMBL 2152582 & 851435 & 3.0 & 3.3859 & TRN \\
\hline CHEMBL 2152606 & 851435 & 3.0 & 3.2312 & TRN \\
\hline
\end{tabular}




\begin{tabular}{|c|c|c|c|c|c|}
\hline \multirow[b]{2}{*}{ CHEMBL561596 } & \multicolumn{5}{|c|}{ Supplemental Table S2.txt } \\
\hline & 851435 & 4.2218 & 4.0158 & TRN & \\
\hline CHEMBL 2152616 & 851435 & 3.0 & 3.0082 & TRN & \\
\hline CHEMBL2152626 & 851435 & 3.0 & 3.0198 & TRN & \\
\hline CHEMBL560337 & 851435 & 4.1675 & 4.1373 & TRN & \\
\hline CHEMBL2152591 & 851435 & 3.0 & 2.9596 & TRN & \\
\hline CHEMBL2152594 & 851435 & 3.0 & 2.8107 & TRN & \\
\hline CHEMBL 2152615 & 851435 & 3.0 & 2.9382 & TRN & \\
\hline CHEMBL2152608 & 851435 & 3.0 & 3.3762 & TRN & \\
\hline CHEMBL 2152628 & 851435 & 3.0 & 2.9601 & TRN & \\
\hline CHEMBL23832 & 851435 & 4.1675 & 4.2424 & TRN & \\
\hline CHEMBL2152620 & 851435 & 3.0 & 2.9421 & TRN & \\
\hline CHEMBL2152593 & 851435 & 3.0 & 2.8755 & TRN & \\
\hline CHEMBL2152579 & 851435 & 3.0 & 3.0277 & TRN & \\
\hline CHEMBL558854 & 851435 & 4.1871 & 4.0746 & TRN & \\
\hline CHEMBL 2152590 & 851435 & 3.0 & 3.2455 & TRN & \\
\hline CHEMBL2152586 & 851435 & 3.0 & 3.6147 & TST & \\
\hline CHEMBL2152618 & 851435 & 3.0 & 3.08699 & 99999999997 & TRN \\
\hline CHEMBL 2152585 & 851435 & 3.0 & 3.7433 & TST & \\
\hline CHEMBL 2152621 & 851435 & 3.0 & 3.022 & TRN & \\
\hline CHEMBL 2152576 & 851435 & 3.0 & 2.85699 & 99999999998 & TRN \\
\hline CHEMBL 2152611 & 851435 & 2.5229 & 3.1264 & TST & \\
\hline CHEMBL 2152573 & 851435 & 3.0 & 3.6343 & TST & \\
\hline CHEMBL 2152627 & 851435 & 3.0 & 2.9322 & TST & \\
\hline CHEMBL 2152568 & 851435 & 3.0 & 3.2726 & TST & \\
\hline CHEMBL2152609 & 851435 & 3.0 & 3.2937 & TST & \\
\hline CHEMBL562473 & 851435 & 3.0 & 3.7719 & TST & \\
\hline CHEMBL 2152584 & 851435 & 3.0 & 3.7668 & TST & \\
\hline CHEMBL 2152607 & 851435 & 3.0 & 3.0966 & TST & \\
\hline CHEMBL2152613 & 851435 & 3.0 & 2.8643 & TST & \\
\hline CHEMBL 2059515 & 829947 & 9.7 & 9.7703 & TRN & \\
\hline CHEMBL2059516 & 829947 & 8.9 & 8.967 & TRN & \\
\hline CHEMBL 2059517 & 829947 & 8.6 & 8.5563 & TRN & \\
\hline CHEMBL 2059518 & 829947 & 8.9 & 8.9669 & TRN & \\
\hline CHEMBL2059519 & 829947 & 8.5 & 8.4724 & TRN & \\
\hline CHEMBL 2059520 & 829947 & 8.5 & 8.4802 & TRN & \\
\hline CHEMBL2059521 & 829947 & 8.4 & 8.4197 & TRN & \\
\hline CHEMBL 2059522 & 829947 & 8.3 & 8.2667 & TRN & \\
\hline CHEMBL2059523 & 829947 & 6.2 & 8.4153 & TST & \\
\hline CHEMBL 2059524 & 829947 & 5.6 & 5.9394 & TST & \\
\hline CHEMBL 2059525 & 829947 & 4.0 & 3.9531 & TRN & \\
\hline CHEMBL2059526 & 829947 & 4.0 & 4.0192 & TRN & \\
\hline CHEMBL 2059527 & 829947 & 8.8 & 8.8094 & TRN & \\
\hline CHEMBL2057232 & 829947 & 9.0 & 8.9823 & TRN & \\
\hline CHEMBL 2059528 & 829947 & 7.6 & 7.5082 & TRN & \\
\hline CHEMBL 2059529 & 829947 & 7.5 & 7.5319 & TRN & \\
\hline CHEMBL 2059663 & 829947 & 7.5 & 7.4058 & TRN & \\
\hline CHEMBL 2059664 & 829947 & 6.2 & 6.1675 & TRN & \\
\hline CHEMBL2059665 & 829947 & 4.5 & 4.5317 & TRN & \\
\hline
\end{tabular}




\begin{tabular}{|c|c|c|c|c|}
\hline \multicolumn{5}{|c|}{ Supplemental Table S2.txt } \\
\hline CHEMBL 2059666 & 829947 & 4.5 & 4.5454 & TRN \\
\hline CHEMBL 2059667 & 829947 & 4.5 & 4.5572 & TRN \\
\hline CHEMBL2059668 & 829947 & 4.5 & 4.4896 & TRN \\
\hline CHEMBL 2059669 & 829947 & 8.4 & 8.3248 & TRN \\
\hline CHEMBL2059670 & 829947 & 8.7 & 8.9171 & TRN \\
\hline CHEMBL2059671 & 829947 & 8.9 & 8.833 & TRN \\
\hline CHEMBL 2059672 & 829947 & 8.3 & 8.3607 & TRN \\
\hline CHEMBL2059673 & 829947 & 4.5 & 8.1767 & TST \\
\hline CHEMBL 2059674 & 829947 & 6.9 & 9.3064 & TST \\
\hline CHEMBL2059675 & 829947 & 8.7 & 7.9255 & TST \\
\hline CHEMBL2059676 & 829947 & 8.3 & 9.0737 & TST \\
\hline CHEMBL 2059677 & 829947 & 7.6 & 7.4516 & TRN \\
\hline CHEMBL2059678 & 829947 & 6.6 & 6.603 & TRN \\
\hline CHEMBL 2059679 & 829947 & 6.4 & 6.4872 & TRN \\
\hline CHEMBL2059680 & 829947 & 6.8 & 6.7767 & TRN \\
\hline CHEMBL 2059681 & 829947 & 8.0 & 7.9846 & TRN \\
\hline CHEMBL2059682 & 829947 & 7.0 & 6.972 & TRN \\
\hline CHEMBL2059683 & 829947 & 10.8 & 10.8294 & TRN \\
\hline CHEMBL 2059684 & 829947 & 10.7 & 10.7198 & TRN \\
\hline CHEMBL2059685 & 829947 & 7.8 & 7.8504 & TRN \\
\hline CHEMBL 2059686 & 829947 & 9.6 & 9.4798 & TRN \\
\hline CHEMBL2059687 & 829947 & 10.0 & 9.8739 & TRN \\
\hline CHEMBL 2059688 & 829947 & 9.6 & 9.6399 & TRN \\
\hline CHEMBL2059689 & 829947 & 8.4 & 8.4955 & TRN \\
\hline CHEMBL2057282 & 829947 & 9.8 & 8.9861 & TST \\
\hline CHEMBL 2057283 & 829947 & 9.6 & 8.8477 & TST \\
\hline CHEMBL 2057284 & 829947 & 8.1 & 9.3071 & TST \\
\hline CHEMBL 2057285 & 829947 & 9.1 & 9.9358 & TST \\
\hline CHEMBL 2057286 & 829947 & 9.1 & 9.6855 & TST \\
\hline CHEMBL 2057287 & 829947 & 6.7 & 8.7568 & TST \\
\hline CHEMBL 2057288 & 829947 & 5.8 & 9.385 & TST \\
\hline CHEMBL481943 & 487985 & 5.4473 & 5.8663 & TST \\
\hline CHEMBL482113 & 487985 & 4.6383 & 4.5985 & TRN \\
\hline CHEMBL481952 & 487985 & 5.7825 & 6.0003 & TST \\
\hline CHEMBL519621 & 487985 & 6.3615 & 6.3865 & TRN \\
\hline CHEMBL452471 & 487985 & 5.3116 & 5.2605 & TRN \\
\hline CHEMBL10 & 487985 & 5.6383 & 5.3465 & TST \\
\hline CHEMBL520280 & 487985 & 4.8297 & 4.6898 & TRN \\
\hline CHEMBL519628 & 487985 & 5.2848 & 5.3305 & TRN \\
\hline CHEMBL481912 & 487985 & 5.2262 & 5.2487 & TRN \\
\hline CHEMBL522362 & 487985 & 4.0778 & 4.1306 & TRN \\
\hline CHEMBL481919 & 487985 & 6.2062 & 6.2366 & TRN \\
\hline CHEMBL481950 & 487985 & 5.1952 & 5.9016 & TST \\
\hline CHEMBL113419 & 487985 & 5.063 & 5.1067 & TRN \\
\hline CHEMBL481315 & 487985 & 4.279 & 4.2957 & TRN \\
\hline CHEMBL481749 & 487985 & 5.7747 & 5.7407 & TRN \\
\hline CHEMBL524015 & 487985 & 4.3546 & 4.2576 & TRN \\
\hline CHEMBL480963 & 487985 & 4.9508 & 4.9974 & TRN \\
\hline
\end{tabular}




\begin{tabular}{|c|c|c|c|c|c|}
\hline & & & & & \\
\hline CHEMBL518962 & 487985 & 4.3605 & 4.3169 & TRN & \\
\hline CHEMBL519624 & 487985 & 5.129 & 5.1772 & TRN & \\
\hline CHEMBL109383 & 487985 & 4.2933 & 4.2894 & TRN & \\
\hline CHEMBL111403 & 487985 & 4.5243 & 4.5855 & TRN & \\
\hline CHEMBL481316 & 487985 & 4.6536 & 4.7072 & TRN & \\
\hline CHEMBL494879 & 487985 & 5.5513 & 6.0355 & TST & \\
\hline CHEMBL481926 & 487985 & 5.3429 & 5.3291 & TRN & \\
\hline CHEMBL482279 & 487985 & 5.3335 & 5.4681 & TRN & \\
\hline CHEMBL111364 & 487985 & 5.3635 & 5.5296 & TRN & \\
\hline CHEMBL523880 & 487985 & 5.4056 & 5.38399 & 99999999995 & TRN \\
\hline CHEMBL516460 & 487985 & 6.0 & 4.9728 & TST & \\
\hline CHEMBL521265 & 487985 & 4.4191 & 4.3696 & TRN & \\
\hline CHEMBL521250 & 487985 & 6.3575 & 6.3877 & TRN & \\
\hline CHEMBL494665 & 487985 & 4.1457 & 4.1867 & TRN & \\
\hline CHEMBL481965 & 487985 & 4.2882 & 4.2744 & TRN & \\
\hline CHEMBL493870 & 487985 & 4.3615 & 4.3885 & TRN & \\
\hline CHEMBL494871 & 487985 & 5.5735 & 5.8895 & TST & \\
\hline CHEMBL506320 & 487985 & 5.2062 & 5.2412 & TRN & \\
\hline CHEMBL481911 & 487985 & 4.5719 & 4.6146 & TRN & \\
\hline CHEMBL481766 & 487985 & 6.1549 & 6.1736 & TRN & \\
\hline CHEMBL482087 & 487985 & 6.3391 & 6.34399 & 9999999999 & TRN \\
\hline CHEMBL482112 & 487985 & 5.0066 & 5.0475 & TRN & \\
\hline CHEMBL109352 & 487985 & 5.2924 & 5.2874 & TST & \\
\hline CHEMBL521091 & 487985 & 6.3809 & 6.3867 & TRN & \\
\hline CHEMBL480958 & 487985 & 6.6216 & 6.6103 & TRN & \\
\hline CHEMBL480962 & 487985 & 6.6968 & 6.6687 & TRN & \\
\hline CHEMBL479416 & 487985 & 4.5528 & 4.5256 & TRN & \\
\hline CHEMBL494666 & 487985 & 6.1726 & 6.1899 & TRN & \\
\hline CHEMBL481706 & 487985 & 4.6737 & 5.3507 & TST & \\
\hline CHEMBL516761 & 487985 & 4.618 & 4.5351 & TRN & \\
\hline CHEMBL481882 & 487985 & 5.2581 & 5.3494 & TRN & \\
\hline CHEMBL480981 & 487985 & 4.7595 & 5.6697 & TST & \\
\hline CHEMBL480956 & 487985 & 4.3536 & 4.3648 & TRN & \\
\hline CHEMBL481944 & 487985 & 5.2306 & 6.0581 & TST & \\
\hline CHEMBL481951 & 487985 & 4.5528 & 5.7841 & TST & \\
\hline CHEMBL519617 & 487985 & 4.8386 & 4.8778 & TRN & \\
\hline CHEMBL518964 & 487985 & 5.399 & 5.4767 & TRN & \\
\hline CHEMBL494901 & 487985 & 4.7747 & 4.2812 & TST & \\
\hline CHEMBL481100 & 487985 & 6.1675 & 6.0852 & TRN & \\
\hline CHEMBL480952 & 487985 & 6.2882 & 6.3044 & TRN & \\
\hline CHEMBL521111 & 487985 & 4.9393 & 5.5572 & TST & \\
\hline CHEMBL516607 & 487985 & 6.4134 & 6.4316 & TRN & \\
\hline CHEMBL481116 & 487985 & 5.9747 & 5.8925 & TRN & \\
\hline CHEMBL480951 & 487985 & 5.6904 & 5.6784 & TRN & \\
\hline CHEMBL479810 & 487985 & 5.6144 & 5.5517 & TRN & \\
\hline CHEMBL493669 & 487985 & 6.4559 & 6.2952 & TRN & \\
\hline CHEMBL481705 & 487985 & 4.9136 & 4.7932 & TRN & \\
\hline CHEMBL482111 & 487985 & 5.5331 & 5.7094 & TRN & \\
\hline
\end{tabular}




\begin{tabular}{|c|c|c|c|c|}
\hline \multicolumn{5}{|c|}{ Supplemental Table S2.txt } \\
\hline CHEMBL480957 & 487985 & 4.7375 & 4.2061 & TST \\
\hline CHEMBL482086 & 487985 & 6.4413 & 6.4283 & TRN \\
\hline CHEMBL521417 & 487985 & 4.4157 & 4.3144 & TRN \\
\hline CHEMBL481883 & 487985 & 5.3645 & 5.3733 & TRN \\
\hline CHEMBL454698 & 487985 & 4.3696 & 4.0005 & TST \\
\hline CHEMBL479985 & 487985 & 4.3497 & 4.3516 & TRN \\
\hline CHEMBL481698 & 487985 & 4.2557 & 4.2454 & TRN \\
\hline CHEMBL481765 & 487985 & 6.7773 & 6.6285 & TRN \\
\hline CHEMBL521692 & 487985 & 4.4437 & 4.4731 & TST \\
\hline CHEMBL111456 & 487985 & 5.9586 & 4.5433 & TST \\
\hline CHEMBL481942 & 487985 & 5.0048 & 5.756 & TST \\
\hline CHEMBL3719061 & 1537067 & 6.0 & 6.8139 & TST \\
\hline CHEMBL3716361 & 1537067 & 7.0 & 6.0934 & TRN \\
\hline CHEMBL 3718458 & 1537067 & 7.0 & 7.4994 & TRN \\
\hline CHEMBL3719035 & 1537067 & 8.0 & 7.5906 & TRN \\
\hline CHEMBL3718053 & 1537067 & 6.0 & 6.2302 & TRN \\
\hline CHEMBL3719333 & 1537067 & 8.0 & 6.7833 & TST \\
\hline CHEMBL 3716746 & 1537067 & 8.0 & 8.1536 & TRN \\
\hline CHEMBL3715288 & 1537067 & 7.0 & 6.3884 & TRN \\
\hline CHEMBL3717864 & 1537067 & 7.0 & 6.9749 & TRN \\
\hline CHEMBL3719250 & 1537067 & 7.0 & 7.1143 & TRN \\
\hline CHEMBL3719210 & 1537067 & 7.0 & 6.9715 & TRN \\
\hline CHEMBL3719004 & 1537067 & 8.0 & 6.8961 & TRN \\
\hline CHEMBL3719351 & 1537067 & 8.0 & 7.6326 & TRN \\
\hline CHEMBL3717613 & 1537067 & 8.0 & 7.3041 & TRN \\
\hline CHEMBL3716032 & 1537067 & 7.0 & 7.0791 & TRN \\
\hline CHEMBL3718682 & 1537067 & 6.0 & 6.4709 & TST \\
\hline CHEMBL3716536 & 1537067 & 5.0 & 6.1963 & TRN \\
\hline CHEMBL3717668 & 1537067 & 7.0 & 6.4679 & TRN \\
\hline CHEMBL3715794 & 1537067 & 7.0 & 7.4734 & TRN \\
\hline CHEMBL3717799 & 1537067 & 8.0 & 7.7735 & TRN \\
\hline CHEMBL 3717445 & 1537067 & 6.0 & 6.3232 & TRN \\
\hline CHEMBL3716735 & 1537067 & 7.0 & 7.0439 & TRN \\
\hline CHEMBL3718277 & 1537067 & 7.0 & 6.6827 & TRN \\
\hline CHEMBL3716620 & 1537067 & 6.0 & 6.5628 & TRN \\
\hline CHEMBL3714923 & 1537067 & 7.0 & 6.8982 & TRN \\
\hline CHEMBL3716104 & 1537067 & 7.0 & 6.7379 & TRN \\
\hline CHEMBL3718886 & 1537067 & 7.0 & 6.6339 & TST \\
\hline CHEMBL 3715252 & 1537067 & 6.0 & 6.4095 & TRN \\
\hline CHEMBL3716338 & 1537067 & 7.0 & 7.1439 & TRN \\
\hline CHEMBL3715284 & 1537067 & 6.0 & 6.3857 & TRN \\
\hline CHEMBL3716305 & 1537067 & 7.0 & 6.7181 & TRN \\
\hline CHEMBL3716039 & 1537067 & 7.0 & 6.4752 & TST \\
\hline CHEMBL3716109 & 1537067 & 7.0 & 7.1539 & TRN \\
\hline CHEMBL 3718554 & 1537067 & 6.0 & 6.0666 & TRN \\
\hline CHEMBL3718946 & 1537067 & 7.0 & 7.12 & TRN \\
\hline CHEMBL3715158 & 1537067 & 7.0 & 6.5471 & TRN \\
\hline CHEMBL 3718200 & 1537067 & 7.0 & 7.8636 & TRN \\
\hline
\end{tabular}




\begin{tabular}{|c|c|c|c|c|}
\hline & & & $\begin{array}{c}5 \\
\end{array}$ & \\
\hline CHEMBL3718908 & 1537067 & 6.0 & 6.7426 & TRN \\
\hline CHEMBL3716176 & 1537067 & 8.0 & 7.5541 & TRN \\
\hline CHEMBL3715598 & 1537067 & 8.0 & 6.5488 & TRN \\
\hline CHEMBL3716335 & 1537067 & 7.0 & 6.6425 & TST \\
\hline CHEMBL3716827 & 1537067 & 7.0 & 6.6649 & TRN \\
\hline CHEMBL3717459 & 1537067 & 8.0 & 7.7739 & TRN \\
\hline CHEMBL3716944 & 1537067 & 6.0 & 6.7507 & TRN \\
\hline CHEMBL3719335 & 1537067 & 6.0 & 6.437 & TRN \\
\hline CHEMBL3716153 & 1537067 & 7.0 & 6.1213 & TST \\
\hline CHEMBL3715103 & 1537067 & 6.0 & 6.8685 & TRN \\
\hline CHEMBL 3715425 & 1537067 & 6.0 & 5.8557 & TRN \\
\hline CHEMBL 3715724 & 1537067 & 7.0 & 6.3039 & TRN \\
\hline CHEMBL3714889 & 1537067 & 8.0 & 7.6421 & TRN \\
\hline CHEMBL3717696 & 1537067 & 5.0 & 5.8647 & TRN \\
\hline CHEMBL 3717934 & 1537067 & 7.0 & 6.598 & TRN \\
\hline CHEMBL 3718145 & 1537067 & 7.0 & 6.0326 & TRN \\
\hline CHEMBL3715258 & 1537067 & 6.0 & 6.4158 & TRN \\
\hline CHEMBL3719338 & 1537067 & 7.0 & 7.42 & TRN \\
\hline CHEMBL 3717764 & 1537067 & 8.0 & 7.1339 & TRN \\
\hline CHEMBL 3717254 & 1537067 & 7.0 & 6.7437 & TRN \\
\hline CHEMBL3715512 & 1537067 & 8.0 & 7.5948 & TRN \\
\hline CHEMBL 3717154 & 1537067 & 5.0 & 6.0172 & TRN \\
\hline CHEMBL3716094 & 1537067 & 6.0 & 6.3171 & TRN \\
\hline CHEMBL3718069 & 1537067 & 7.0 & 6.6939 & TRN \\
\hline CHEMBL 3714831 & 1537067 & 6.0 & 6.274 & TRN \\
\hline CHEMBL 3718844 & 1537067 & 6.0 & 6.5112 & TRN \\
\hline CHEMBL3718383 & 1537067 & 8.0 & 7.4645 & TRN \\
\hline CHEMBL3715175 & 1537067 & 7.0 & 6.7435 & TRN \\
\hline CHEMBL3716404 & 1537067 & 8.0 & 7.0663 & TRN \\
\hline CHEMBL3716693 & 1537067 & 7.0 & 6.5766 & TRN \\
\hline CHEMBL3715176 & 1537067 & 7.0 & 6.5648 & TST \\
\hline CHEMBL3718953 & 1537067 & 6.0 & 6.1021 & TRN \\
\hline CHEMBL 3717280 & 1537067 & 6.0 & 6.6124 & TRN \\
\hline CHEMBL3719261 & 1537067 & 6.0 & 6.2289 & TRN \\
\hline CHEMBL3716115 & 1537067 & 6.0 & 5.892 & TRN \\
\hline CHEMBL3719348 & 1537067 & 8.0 & 7.6575 & TRN \\
\hline CHEMBL 3718460 & 1537067 & 6.0 & 5.9471 & TRN \\
\hline CHEMBL 3718040 & 1537067 & 5.0 & 6.1669 & TRN \\
\hline CHEMBL 3717657 & 1537067 & 5.0 & 6.015 & TRN \\
\hline CHEMBL 3715439 & 1537067 & 7.0 & 6.1943 & TRN \\
\hline CHEMBL3719344 & 1537067 & 8.0 & 7.8124 & TRN \\
\hline CHEMBL3719376 & 1537067 & 6.0 & 6.303 & TRN \\
\hline CHEMBL3717058 & 1537067 & 6.0 & 6.2224 & TST \\
\hline CHEMBL3719093 & 1537067 & 6.0 & 6.8035 & TRN \\
\hline CHEMBL 3716330 & 1537067 & 7.0 & 6.0348 & TRN \\
\hline CHEMBL3716772 & 1537067 & 6.0 & 6.7224 & TRN \\
\hline CHEMBL 3717385 & 1537067 & 6.0 & 6.7729 & TRN \\
\hline CHEMBL 3718604 & 1537067 & 7.0 & 7.1417 & TRN \\
\hline
\end{tabular}




\begin{tabular}{|c|c|c|c|c|}
\hline & & & ient & al Ta \\
\hline CHEMBL3716425 & 1537067 & 6.0 & 6.3563 & TRN \\
\hline CHEMBL3719008 & 1537067 & 7.0 & 6.476 & TRN \\
\hline CHEMBL3717054 & 1537067 & 6.0 & 6.5189 & TST \\
\hline CHEMBL3714971 & 1537067 & 7.0 & 7.19 & TRN \\
\hline CHEMBL3716199 & 1537067 & 6.0 & 6.4639 & TST \\
\hline CHEMBL3718902 & 1537067 & 7.0 & 6.4984 & TRN \\
\hline CHEMBL3715624 & 1537067 & 7.0 & 6.5198 & TRN \\
\hline CHEMBL3716010 & 1537067 & 7.0 & 6.6355 & TRN \\
\hline CHEMBL3716186 & 1537067 & 7.0 & 6.6348 & TRN \\
\hline CHEMBL3717073 & 1537067 & 6.0 & 6.6357 & TRN \\
\hline CHEMBL 3715410 & 1537067 & 6.0 & 5.8818 & TRN \\
\hline CHEMBL3717609 & 1537067 & 7.0 & 7.1927 & TRN \\
\hline CHEMBL 3714905 & 1537067 & 6.0 & 7.1886 & TRN \\
\hline CHEMBL3717813 & 1537067 & 6.0 & 6.455 & TRN \\
\hline CHEMBL 3716227 & 1537067 & 6.0 & 6.6584 & TRN \\
\hline CHEMBL 3718673 & 1537067 & 6.0 & 6.5305 & TST \\
\hline CHEMBL3716949 & 1537067 & 6.0 & 6.2567 & TRN \\
\hline CHEMBL 3718856 & 1537067 & 7.0 & 6.6315 & TRN \\
\hline CHEMBL 3718648 & 1537067 & 6.0 & 6.2625 & TRN \\
\hline CHEMBL3714953 & 1537067 & 7.0 & 7.6167 & TRN \\
\hline CHEMBL 3717947 & 1537067 & 6.0 & 6.4235 & TRN \\
\hline CHEMBL 3718478 & 1537067 & 6.0 & 6.6092 & TRN \\
\hline CHEMBL 3718121 & 1537067 & 6.0 & 6.1825 & TRN \\
\hline CHEMBL 3715044 & 1537067 & 8.0 & 6.6674 & TST \\
\hline CHEMBL 3715241 & 1537067 & 6.0 & 7.0465 & TST \\
\hline CHEMBL 3716340 & 1537067 & 7.0 & 6.5473 & TRN \\
\hline CHEMBL3716018 & 1537067 & 5.0 & 6.4061 & TST \\
\hline CHEMBL3714939 & 1537067 & 7.0 & 6.2851 & TST \\
\hline CHEMBL3718130 & 1537067 & 6.0 & 6.8214 & TST \\
\hline CHEMBL3717539 & 1537067 & 7.0 & 6.5331 & TRN \\
\hline CHEMBL3718319 & 1537067 & 8.0 & 7.3259 & TST \\
\hline CHEMBL3715902 & 1537067 & 6.0 & 6.2377 & TRN \\
\hline CHEMBL 3718683 & 1537067 & 7.0 & 7.6416 & TRN \\
\hline CHEMBL3715972 & 1537067 & 8.0 & 7.8662 & TRN \\
\hline CHEMBL 3715379 & 1537067 & 7.0 & 6.5174 & TST \\
\hline CHEMBL3716663 & 1537067 & 7.0 & 6.6954 & TRN \\
\hline CHEMBL 3717444 & 1537067 & 5.0 & 6.3403 & TRN \\
\hline CHEMBL 3716022 & 1537067 & 6.0 & 6.7094 & TRN \\
\hline CHEMBL 3718070 & 1537067 & 6.0 & 5.944 & TRN \\
\hline CHEMBL 3715085 & 1537067 & 7.0 & 6.1805 & TRN \\
\hline CHEMBL3717579 & 1537067 & 8.0 & 7.9177 & TRN \\
\hline CHEMBL 3718078 & 1537067 & 6.0 & 6.6333 & TRN \\
\hline CHEMBL 3718587 & 1537067 & 6.0 & 5.926 & TST \\
\hline CHEMBL3717962 & 1537067 & 7.0 & 7.362 & TST \\
\hline CHEMBL 3716629 & 1537067 & 7.0 & 7.2328 & TST \\
\hline CHEMBL3717499 & 1537067 & 7.0 & 6.2016 & TRN \\
\hline CHEMBL3716047 & 1537067 & 6.0 & 6.4958 & TRN \\
\hline CHEMBL 3717293 & 1537067 & 6.0 & 6.6636 & TST \\
\hline
\end{tabular}




\begin{tabular}{|c|c|c|c|c|c|}
\hline & & & & & \\
\hline CHEMBL3716145 & 1537067 & 7.0 & 7.1128 & TST & \\
\hline CHEMBL3716256 & 1537067 & 6.0 & 6.0783 & TST & \\
\hline CHEMBL3715251 & 1537067 & 7.0 & 6.6472 & TST & \\
\hline CHEMBL 3717031 & 1537067 & 7.0 & 6.485 & TRN & \\
\hline CHEMBL 3714867 & 1537067 & 7.0 & 5.94799 & 99999999995 & TST \\
\hline CHEMBL3715771 & 1537067 & 8.0 & 7.6442 & TRN & \\
\hline CHEMBL3716377 & 1537067 & 7.0 & 6.3627 & TRN & \\
\hline CHEMBL3719313 & 1537067 & 7.0 & 7.185 & TST & \\
\hline CHEMBL3719124 & 1537067 & 7.0 & 7.00899 & 99999999995 & TRN \\
\hline CHEMBL3715313 & 1537067 & 8.0 & 7.0409 & TST & \\
\hline CHEMBL3717365 & 1537067 & 6.0 & 6.7668 & TST & \\
\hline CHEMBL3718685 & 1537067 & 7.0 & 7.126 & TST & \\
\hline CHEMBL3714988 & 1537067 & 6.0 & 6.3953 & TST & \\
\hline CHEMBL3715189 & 1537067 & 6.0 & 6.1742 & TRN & \\
\hline CHEMBL 3715774 & 1537067 & 7.0 & 6.3322 & TRN & \\
\hline CHEMBL3719305 & 1537067 & 8.0 & 6.8278 & TRN & \\
\hline CHEMBL3716924 & 1537067 & 8.0 & 7.7039 & TRN & \\
\hline CHEMBL3716196 & 1537067 & 6.0 & 6.5387 & TST & \\
\hline CHEMBL3715649 & 1537067 & 7.0 & 7.0182 & TST & \\
\hline CHEMBL3716401 & 1537067 & 6.0 & 5.9885 & TST & \\
\hline CHEMBL3717837 & 1537067 & 6.0 & 6.3163 & TRN & \\
\hline CHEMBL3715721 & 1537067 & 6.0 & 6.693 & TRN & \\
\hline CHEMBL3716770 & 1537067 & 7.0 & 6.8296 & TRN & \\
\hline CHEMBL 3718057 & 1537067 & 6.0 & 6.2686 & TST & \\
\hline CHEMBL 3715757 & 1537067 & 8.0 & 7.8305 & TRN & \\
\hline CHEMBL 3717132 & 1537067 & 7.0 & 6.7107 & TRN & \\
\hline CHEMBL3717988 & 1537067 & 7.0 & 6.9712 & TRN & \\
\hline CHEMBL3715061 & 1537067 & 6.0 & 6.9675 & TRN & \\
\hline CHEMBL 3717184 & 1537067 & 6.0 & 5.8181 & TRN & \\
\hline CHEMBL 3718430 & 1537067 & 7.0 & 6.8726 & TRN & \\
\hline CHEMBL3717901 & 1537067 & 6.0 & 6.38899 & 9999999999 & TST \\
\hline CHEMBL3717812 & 1537067 & 7.0 & 6.6843 & TRN & \\
\hline CHEMBL 3715484 & 1537067 & 6.0 & 7.0457 & TST & \\
\hline CHEMBL3715964 & 1537067 & 8.0 & 8.3668 & TRN & \\
\hline CHEMBL 3716983 & 1537067 & 7.0 & 6.5435 & TRN & \\
\hline CHEMBL3715921 & 1537067 & 5.0 & 6.1691 & TST & \\
\hline CHEMBL 3717631 & 1537067 & 7.0 & 6.9958 & TST & \\
\hline CHEMBL3715129 & 1537067 & 7.0 & 6.4073 & TRN & \\
\hline CHEMBL 3718091 & 1537067 & 6.0 & 6.2154 & TRN & \\
\hline CHEMBL 3717986 & 1537067 & 7.0 & 7.3105 & TRN & \\
\hline CHEMBL 3717147 & 1537067 & 6.0 & 6.5979 & TST & \\
\hline CHEMBL3718006 & 1537067 & 6.0 & 6.5064 & TRN & \\
\hline CHEMBL3718698 & 1537067 & 7.0 & 7.7409 & TRN & \\
\hline CHEMBL 3718467 & 1537067 & 7.0 & 6.0438 & TST & \\
\hline CHEMBL 3715440 & 1537067 & 6.0 & 6.2166 & TRN & \\
\hline CHEMBL 3717623 & 1537067 & 7.0 & 6.6939 & TRN & \\
\hline CHEMBL 3717940 & 1537067 & 8.0 & 7.4665 & TRN & \\
\hline CHEMBL3718907 & 1537067 & 6.0 & 6.6677 & TRN & \\
\hline & & & & 23310 & \\
\hline
\end{tabular}




\begin{tabular}{|c|c|c|c|c|}
\hline & & & $n t$ & $a \perp 1 a$ \\
\hline CHEMBL 3718441 & 1537067 & 7.0 & 7.0535 & TST \\
\hline CHEMBL3717603 & 1537067 & 6.0 & 6.0829 & TRN \\
\hline CHEMBL3714957 & 1537067 & 7.0 & 7.0123 & TRN \\
\hline CHEMBL3715403 & 1537067 & 7.0 & 7.1206 & TRN \\
\hline CHEMBL3719387 & 1537067 & 6.0 & 6.8205 & TRN \\
\hline CHEMBL3716477 & 1537067 & 7.0 & 6.1235 & TST \\
\hline CHEMBL3715859 & 1537067 & 6.0 & 6.7106 & TST \\
\hline CHEMBL3714845 & 1537067 & 7.0 & 6.2711 & TRN \\
\hline CHEMBL 3716891 & 1537067 & 6.0 & 6.4831 & TRN \\
\hline CHEMBL3715820 & 1537067 & 7.0 & 6.4524 & TRN \\
\hline CHEMBL3718337 & 1537067 & 7.0 & 6.8863 & TRN \\
\hline CHEMBL3717554 & 1537067 & 6.0 & 6.3793 & TRN \\
\hline CHEMBL3719272 & 1537067 & 6.0 & 6.5275 & TRN \\
\hline CHEMBL3717913 & 1537067 & 7.0 & 6.8024 & TST \\
\hline CHEMBL3716982 & 1537067 & 6.0 & 6.2055 & TRN \\
\hline CHEMBL3714793 & 1537067 & 7.0 & 6.3651 & TRN \\
\hline CHEMBL3717836 & 1537067 & 8.0 & 7.6542 & TRN \\
\hline CHEMBL3714966 & 1537067 & 7.0 & 6.7305 & TRN \\
\hline CHEMBL3716262 & 1537067 & 6.0 & 6.5423 & TST \\
\hline CHEMBL3718591 & 1537067 & 7.0 & 6.4761 & TRN \\
\hline CHEMBL3715357 & 1537067 & 7.0 & 6.5185 & TST \\
\hline CHEMBL 3717171 & 1537067 & 7.0 & 6.9436 & TRN \\
\hline CHEMBL 3717621 & 1537067 & 6.0 & 6.3081 & TRN \\
\hline CHEMBL3715609 & 1537067 & 6.0 & 7.1943 & TRN \\
\hline CHEMBL3719162 & 1537067 & 7.0 & 7.0162 & TST \\
\hline CHEMBL3716961 & 1537067 & 7.0 & 6.8571 & TRN \\
\hline CHEMBL3719359 & 1537067 & 7.0 & 6.7059 & TRN \\
\hline CHEMBL3718896 & 1537067 & 6.0 & 7.3686 & TST \\
\hline CHEMBL3715369 & 1537067 & 7.0 & 6.5832 & TRN \\
\hline CHEMBL3716584 & 1537067 & 7.0 & 6.7112 & TRN \\
\hline CHEMBL3717205 & 1537067 & 7.0 & 6.971 & TST \\
\hline CHEMBL3715858 & 1537067 & 7.0 & 6.6592 & TRN \\
\hline CHEMBL3717827 & 1537067 & 8.0 & 7.6533 & TRN \\
\hline CHEMBL3715102 & 1537067 & 6.0 & 5.9591 & TRN \\
\hline CHEMBL3715735 & 1537067 & 7.0 & 6.7792 & TRN \\
\hline CHEMBL3716084 & 1537067 & 6.0 & 6.13 & TST \\
\hline CHEMBL3717659 & 1537067 & 7.0 & 6.9491 & TRN \\
\hline CHEMBL3716895 & 1537067 & 7.0 & 6.8567 & TST \\
\hline CHEMBL 3716278 & 1537067 & 6.0 & 6.1846 & TRN \\
\hline CHEMBL 3717757 & 1537067 & 6.0 & 6.1135 & TST \\
\hline CHEMBL3715888 & 1537067 & 7.0 & 6.2314 & TST \\
\hline CHEMBL3717052 & 1537067 & 8.0 & 6.5524 & TRN \\
\hline CHEMBL3716710 & 1537067 & 6.0 & 6.489 & TRN \\
\hline CHEMBL 3719029 & 1537067 & 7.0 & 6.3144 & TRN \\
\hline CHEMBL3715842 & 1537067 & 8.0 & 7.8363 & TRN \\
\hline CHEMBL3716468 & 1537067 & 7.0 & 6.1922 & TST \\
\hline CHEMBL 3715714 & 1537067 & 6.0 & 7.7909 & TST \\
\hline CHEMBL3717049 & 1537067 & 7.0 & 6.796 & TRN \\
\hline
\end{tabular}




\begin{tabular}{|c|c|c|c|c|c|c|}
\hline \multicolumn{7}{|c|}{ splemental lable s2.txt } \\
\hline CHEMBL3715049 & 1537067 & 8.0 & 8.3346 & TRN & & \\
\hline CHEMBL3716740 & 1537067 & 8.0 & 7.5591 & TRN & & \\
\hline CHEMBL3715271 & 1537067 & 7.0 & 6.3595 & TST & & \\
\hline CHEMBL3717712 & 1537067 & 6.0 & 6.6854 & TST & & \\
\hline CHEMBL3718135 & 1537067 & 7.0 & 7.0313 & TRN & & \\
\hline CHEMBL3974098 & 1640360 & 7.9208 & 7.2524 & TRN & & \\
\hline CHEMBL3953258 & 1640360 & 8.301 & 8.706 & TST & & \\
\hline CHEMBL3907522 & 1640360 & 8.0 & 8.1041 & TRN & & \\
\hline CHEMBL3899691 & 1640360 & 8.301 & 8.0823 & TRN & & \\
\hline CHEMBL3937990 & 1640360 & 9.0 & 9.2345 & TRN & & \\
\hline CHEMBL3909153 & 1640360 & 7.4089 & 7.9677 & TRN & & \\
\hline CHEMBL3894752 & 1640360 & 7.7212 & 6.9433 & TRN & & \\
\hline CHEMBL3925040 & 1640360 & 8.0969 & 8.1778 & TRN & & \\
\hline CHEMBL3915318 & 1640360 & 8.5229 & 8.5185 & TRN & & \\
\hline CHEMBL3901920 & 1640360 & 6.75700 & t00000006 & 01 & 6.9451 & TRN \\
\hline CHEMBL3980879 & 1640360 & 7.2147 & 7.3682 & TRN & & \\
\hline CHEMBL3946316 & 1640360 & 8.699 & 8.0959 & TRN & & \\
\hline CHEMBL3955154 & 1640360 & 6.0 & 7.1269 & TST & & \\
\hline CHEMBL3954389 & 1640360 & 9.0 & 9.1017 & TRN & & \\
\hline CHEMBL3890738 & 1640360 & 8.1549 & 7.5769 & TRN & & \\
\hline CHEMBL3955422 & 1640360 & 6.3747 & 6.3018 & TRN & & \\
\hline CHEMBL3952098 & 1640360 & 10.3009 & 99999999 & 998 & 9.8415 & TRN \\
\hline CHEMBL3931330 & 1640360 & 8.1549 & 7.6077 & TRN & & \\
\hline CHEMBL 3916862 & 1640360 & 8.2218 & 7.9978 & TRN & & \\
\hline CHEMBL3953329 & 1640360 & 7.2757 & 7.8068 & TRN & & \\
\hline CHEMBL 3942837 & 1640360 & 9.0 & 8.6169 & TST & & \\
\hline CHEMBL3941046 & 1640360 & 8.1549 & $8.22200 t$ & 0000000001 & & TRN \\
\hline CHEMBL3955874 & 1640360 & 6.0 & 5.3472 & TRN & & \\
\hline CHEMBL 3912027 & 1640360 & 7.7212 & 7.8134 & TRN & & \\
\hline CHEMBL3946792 & 1640360 & 10.3009 & 79999999 & 998 & 9.8398 & TRN \\
\hline CHEMBL3913050 & 1640360 & 9.0 & 9.164 & TRN & & \\
\hline CHEMBL3961917 & 1640360 & 7.5686 & 8.3336 & TST & & \\
\hline CHEMBL3941611 & 1640360 & 6.0 & 8.5259 & TST & & \\
\hline CHEMBL3944382 & 1640360 & 10.3009 & 99999999 & 998 & 9.2656 & TRN \\
\hline CHEMBL3983414 & 1640360 & 7.5229 & 7.6819 & TRN & & \\
\hline CHEMBL3956296 & 1640360 & 8.301 & 6.7201 & TST & & \\
\hline CHEMBL3933540 & 1640360 & 8.0 & 7.8203 & TRN & & \\
\hline CHEMBL3922293 & 1640360 & 8.3979 & 7.7602 & TRN & & \\
\hline CHEMBL3933350 & 1640360 & 6.0 & 6.5006 & TRN & & \\
\hline CHEMBL3955380 & 1640360 & 9.0 & 9.1854 & TST & & \\
\hline CHEMBL3918365 & 1640360 & 7.7959 & 7.9314 & TRN & & \\
\hline CHEMBL3898421 & 1640360 & 8.2218 & 7.8056 & TRN & & \\
\hline CHEMBL3931269 & 1640360 & 10.3009 & 99999999 & 998 & 8.1038 & TST \\
\hline CHEMBL3893918 & 1640360 & 7.9208 & 8.1516 & TRN & & \\
\hline CHEMBL3920743 & 1640360 & 6.8508 & 6.9934 & TRN & & \\
\hline CHEMBL 3973436 & 1640360 & 7.6778 & 7.0685 & TRN & & \\
\hline CHEMBL3982026 & 1640360 & 7.3279 & 6.9203 & TRN & & \\
\hline CHEMBL3936679 & 1640360 & 7.9586 & 8.0434 & TRN & & \\
\hline
\end{tabular}


Supplemental Table S2.txt

\begin{tabular}{|c|c|c|c|c|}
\hline CHEMBL 3909748 & 1640360 & 7.699 & 7.7551 & TRN \\
\hline CHEMBL 3984267 & 1640360 & 6.6055 & 8.3415 & TST \\
\hline CHEMBL 3969554 & 1640360 & 8.0458 & 8.2487 & TRN \\
\hline CHEMBL 3911140 & 1640360 & 8.1549 & 7.8448 & TRN \\
\hline CHEMBL 3971202 & 1640360 & 6.0 & 8.3847 & TST \\
\hline CHEMBL 3951592 & 1640360 & 7.9586 & 7.4497 & TRN \\
\hline CHEMBL 3985106 & 1640360 & 6.3915 & 7.202006 & 0000000001 \\
\hline CHEMBL 3966898 & 1640360 & 8.0458 & 7.5767 & TRN \\
\hline CHEMBL 3933393 & 1640360 & 7.1079 & 7.9437 & TRN \\
\hline CHEMBL 3946722 & 1640360 & 8.0 & 8.1378 & TRN \\
\hline CHEMBL 3894265 & 1640360 & 8.3979 & 8.2239 & TRN \\
\hline CHEMBL 3976840 & 1640360 & 7.1487 & 7.7216 & TRN \\
\hline CHEMBL 3898340 & 1640360 & 7.9208 & 8.4689 & TRN \\
\hline CHEMBL 3905965 & 1640360 & 6.9914 & 8.2899 & TRN \\
\hline CHEMBL 3964007 & 1640360 & 4.0 & 5.9046 & TRN \\
\hline CHEMBL 3936268 & 1640360 & 8.3979 & 8.6764 & TRN \\
\hline CHEMBL 3977871 & 1640360 & 7.7696 & 8.6663 & TST \\
\hline CHEMBL 3924403 & 1640360 & 9.0 & 9.3852 & TRN \\
\hline CHEMBL 3933885 & 1640360 & 9.0 & 8.7572 & TRN \\
\hline CHEMBL 3942066 & 1640360 & 7.0605 & 6.9893 & TST \\
\hline CHEMBL 3889646 & 1640360 & 6.0 & 8.2812 & TST \\
\hline CHEMBL 3962140 & 1640360 & 8.5229 & 8.8782 & TST \\
\hline CHEMBL 3926505 & 1640360 & 6.9547 & 7.3578 & TST \\
\hline CHEMBL 3956289 & 1640360 & 8.301 & 7.8965 & TRN \\
\hline CHEMBL 3949746 & 1640360 & 9.0 & 8.0526 & TST \\
\hline CHEMBL 3892940 & 1640360 & 8.3979 & 8.4511 & TRN \\
\hline CHEMBL 3942532 & 1640360 & 8.9208 & 8.5951 & TRN \\
\hline CHEMBL 3900470 & 1640360 & 8.5229 & 9.6181 & TST \\
\hline CHEMBL 3943445 & 1640360 & 7.0132 & 7.558 & TRN \\
\hline CHEMBL 3985225 & 1640360 & 8.3979 & 8.0074 & TRN \\
\hline CHEMBL 3953214 & 1640360 & 7.6576 & 7.5086 & TRN \\
\hline CHEMBL 3937432 & 1640360 & 8.2218 & 9.0058 & TST \\
\hline CHEMBL3931055 & 1640360 & 8.3979 & 8.4464 & TRN \\
\hline CHEMBL 3972974 & 1640360 & 8.3979 & 7.9199 & TRN \\
\hline CHEMBL 3963342 & 1640360 & 8.5229 & 8.2403 & TRN \\
\hline CHEMBL3920975 & 1640360 & 8.0 & 7.9749 & TRN \\
\hline CHEMBL 3958406 & 1640360 & 8.5229 & 7.7484 & TRN \\
\hline CHEMBL 3980747 & 1640360 & 8.3979 & 8.5196 & TRN \\
\hline CHEMBL 3922960 & 1640360 & 6.6799 & 7.1856 & TRN \\
\hline CHEMBL 3918528 & 1640360 & 7.3979 & 8.0898 & TRN \\
\hline CHEMBL 3940496 & 1640360 & 8.4685 & 8.1364 & TRN \\
\hline CHEMBL 3918090 & 1640360 & 7.4089 & 7.50799 & 9999999999 \\
\hline CHEMBL 3942919 & 1640360 & 9.0 & 8.5317 & TRN \\
\hline CHEMBL 3906189 & 1640360 & 9.0 & 9.4793 & TST \\
\hline CHEMBL 3935467 & 1640360 & 8.1549 & 7.8965 & TRN \\
\hline CHEMBL 3959614 & 1640360 & 6.9508 & 6.8216 & TRN \\
\hline CHEMBL 3924655 & 1640360 & 8.1938 & 7.9205 & TRN \\
\hline CHEMBL 3919233 & 1640360 & 6.0 & 6.1579 & TRN \\
\hline
\end{tabular}


Supplemental Table S2.txt

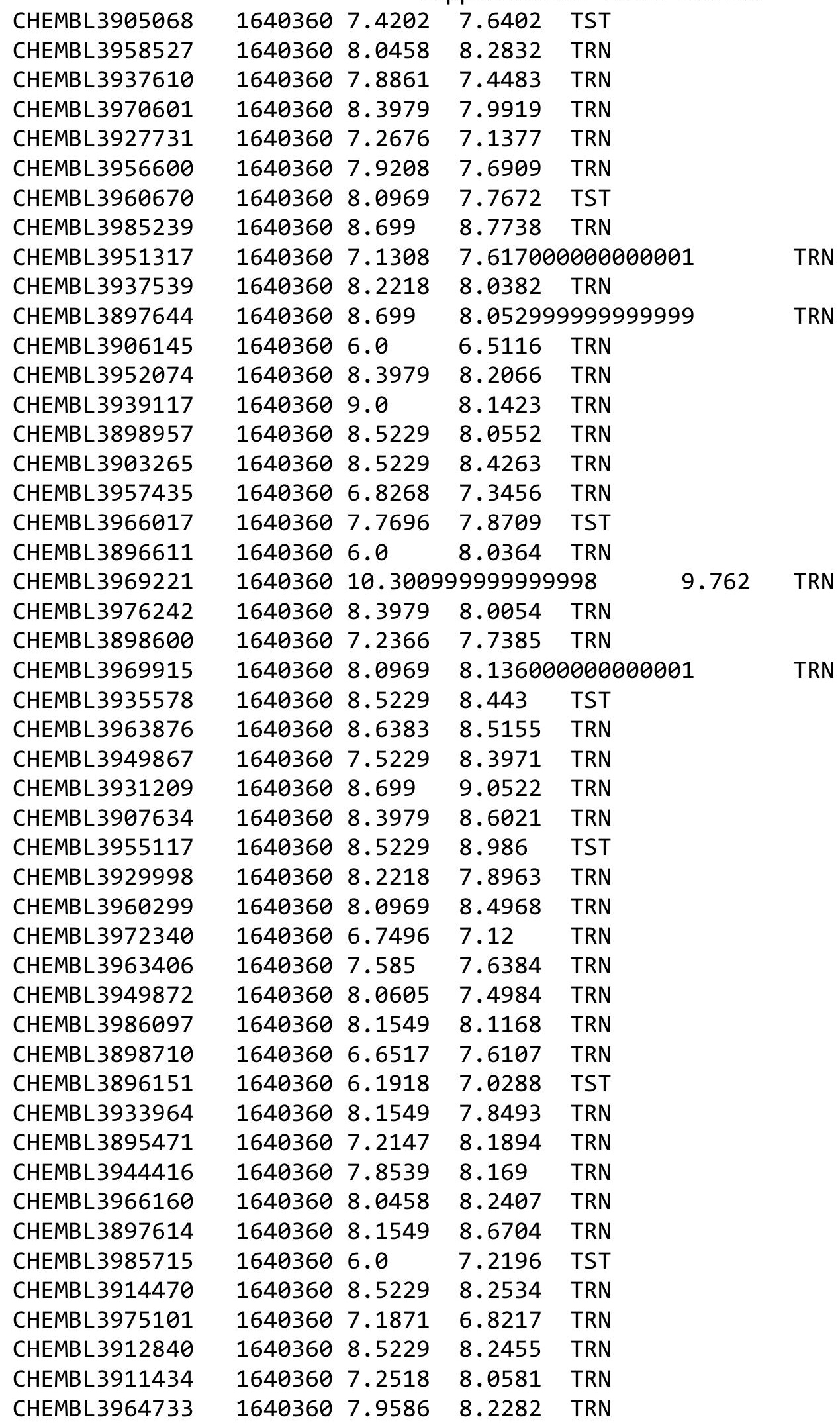

Page 23314 


\begin{tabular}{|c|c|c|c|c|c|c|}
\hline \multicolumn{7}{|c|}{ Supplemental Table S2.txt } \\
\hline CHEMBL3936339 & 1640360 & 7.7212 & 7.8797 & TRN & & \\
\hline CHEMBL 3981578 & 1640360 & 8.699 & 8.0059 & TST & & \\
\hline CHEMBL3936887 & 1640360 & 9.0 & 9.6021 & TRN & & \\
\hline CHEMBL 3923226 & 1640360 & 6.8239 & 7.7718 & TRN & & \\
\hline CHEMBL3905224 & 1640360 & 6.0 & 8.3167 & TST & & \\
\hline CHEMBL3937723 & 1640360 & 6.6778 & 7.3817 & TRN & & \\
\hline CHEMBL3960797 & 1640360 & 10.3009 & 79999999 & 998 & 9.8042 & TRN \\
\hline CHEMBL3936865 & 1640360 & 7.0 & 6.4386 & TRN & & \\
\hline CHEMBL3986599 & 1640360 & 6.8601 & 7.3468 & TRN & & \\
\hline CHEMBL3894214 & 1640360 & 8.2218 & 8.4571 & TRN & & \\
\hline CHEMBL 3984297 & 1640360 & 8.3979 & 8.4701 & TRN & & \\
\hline CHEMBL3930847 & 1640360 & 7.8539 & 8.6817 & TST & & \\
\hline CHEMBL3955640 & 1640360 & 7.041 & 7.2424 & TRN & & \\
\hline CHEMBL3971222 & 1640360 & 7.5528 & 7.6156 & TRN & & \\
\hline CHEMBL3974105 & 1640360 & 8.699 & 9.3118 & TST & & \\
\hline CHEMBL 3910052 & 1640360 & 9.0 & 9.5387 & TRN & & \\
\hline CHEMBL3980909 & 1640360 & 7.301 & 7.126 & TRN & & \\
\hline CHEMBL3968208 & 1640360 & 8.2218 & 8.5056 & TRN & & \\
\hline CHEMBL3939570 & 1640360 & 6.8697 & 6.6211 & TST & & \\
\hline CHEMBL3963983 & 1640360 & 7.2441 & 7.1567 & TRN & & \\
\hline CHEMBL3942558 & 1640360 & 8.1549 & 8.4779 & TRN & & \\
\hline CHEMBL3906587 & 1640360 & 8.3979 & 8.4358 & TRN & & \\
\hline CHEMBL3962992 & 1640360 & 8.0458 & 8.3351 & TRN & & \\
\hline CHEMBL3964325 & 1640360 & 7.4949 & 7.66700 & 0000000001 & & TRN \\
\hline CHEMBL3958337 & 1640360 & 7.4949 & 8.2278 & TST & & \\
\hline CHEMBL 3913318 & 1640360 & 7.5686 & 7.5045 & TRN & & \\
\hline CHEMBL3979977 & 1640360 & 6.1739 & 5.9046 & TRN & & \\
\hline CHEMBL 3905848 & 1640360 & 7.8539 & 8.56899 & 9999999999 & & TST \\
\hline CHEMBL 3932634 & 1640360 & 6.0 & 8.5403 & TST & & \\
\hline CHEMBL3969611 & 1640360 & 8.0458 & 7.9203 & TST & & \\
\hline CHEMBL3907627 & 1640360 & 8.699 & 8.3452 & TST & & \\
\hline CHEMBL3974724 & 1640360 & 8.5229 & 8.3284 & TRN & & \\
\hline CHEMBL 3899736 & 1640360 & 6.0 & 6.0464 & TRN & & \\
\hline CHEMBL3979915 & 1640360 & 7.6198 & 7.4452 & TRN & & \\
\hline CHEMBL3894330 & 1640360 & 8.0605 & 8.5683 & TRN & & \\
\hline CHEMBL3901446 & 1640360 & 8.28399 & 99999999 & & 7.8091 & TRN \\
\hline CHEMBL3939848 & 1640360 & 10.3009 & 79999999 & 998 & 9.3127 & TST \\
\hline CHEMBL3940964 & 1640360 & 8.3665 & 7.9704 & TRN & & \\
\hline CHEMBL3953374 & 1640360 & 6.0 & 8.0603 & TST & & \\
\hline CHEMBL3946669 & 1640360 & 10.3009 & 99999999 & 998 & 9.3901 & TRN \\
\hline CHEMBL3903141 & 1640360 & 6.9872 & 7.8684 & TRN & & \\
\hline CHEMBL3948336 & 1640360 & 7.6383 & 7.2888 & TRN & & \\
\hline CHEMBL3900073 & 1640360 & 8.3979 & 8.0476 & TRN & & \\
\hline CHEMBL3984630 & 1640360 & 6.7212 & 5.9046 & TRN & & \\
\hline CHEMBL3910149 & 1640360 & 6.0 & 7.4299 & TRN & & \\
\hline CHEMBL3891236 & 1640360 & 8.1549 & 7.9026 & TRN & & \\
\hline CHEMBL3919613 & 1640360 & 7.5376 & 7.2978 & TRN & & \\
\hline CHEMBL3984956 & 1640360 & 7.7212 & 7.2781 & TRN & & \\
\hline
\end{tabular}


Supplemental Table S2.txt

\begin{tabular}{|c|c|c|c|c|c|c|}
\hline CHEMBL3978374 & 1640360 & 7.6778 & 7.0599 & TRN & & \\
\hline CHEMBL3961953 & 1640360 & 8.699 & 8.5669 & TST & & \\
\hline CHEMBL3943431 & 1640360 & 10.30099 & 99999999 & 998 & 10.0223 & TRN \\
\hline CHEMBL 3897017 & 1640360 & 8.3979 & 8.458 & TRN & & \\
\hline CHEMBL3964554 & 1640360 & 7.7447 & 7.7447 & TST & & \\
\hline CHEMBL3956557 & 1640360 & 7.8239 & 7.3869 & TRN & & \\
\hline CHEMBL3941332 & 1640360 & 7.4559 & 7.1013 & TST & & \\
\hline CHEMBL3961951 & 1640360 & 7.0809 & 7.6187 & TRN & & \\
\hline CHEMBL3926660 & 1640360 & 7.8539 & 7.3406 & TST & & \\
\hline CHEMBL3901613 & 1640360 & 6.0 & 6.9115 & TST & & \\
\hline CHEMBL3951021 & 1640360 & 7.9208 & 8.79 & TST & & \\
\hline CHEMBL3894982 & 1640360 & 8.1549 & 8.0996 & TST & & \\
\hline CHEMBL3902229 & 1640360 & 9.0 & 9.067 & TST & & \\
\hline CHEMBL3921052 & 1640360 & 8.2218 & 7.9024 & TRN & & \\
\hline CHEMBL3900257 & 1640360 & 8.699 & 8.1844 & TRN & & \\
\hline CHEMBL3956639 & 1640360 & 6.0 & 8.7534 & TST & & \\
\hline CHEMBL3945116 & 1640360 & 6.7545 & 6.9893 & TRN & & \\
\hline CHEMBL3983041 & 1640360 & 8.0969 & 8.2936 & TRN & & \\
\hline CHEMBL3893003 & 1640360 & 7.6021 & 7.8392 & TST & & \\
\hline CHEMBL3964386 & 1640360 & 8.5229 & 8.7922 & TRN & & \\
\hline CHEMBL3914842 & 1640360 & 8.5229 & 8.7909 & TST & & \\
\hline CHEMBL3923486 & 1640360 & 7.3565 & 7.63399 & 99999999 & 995 & TRN \\
\hline CHEMBL3924342 & 1640360 & 6.8633 & 6.9238 & TRN & & \\
\hline CHEMBL3927389 & 1640360 & 8.301 & 7.9597 & TST & & \\
\hline CHEMBL3920015 & 1640360 & 7.9208 & 8.5503 & TRN & & \\
\hline CHEMBL3908736 & 1640360 & 8.2218 & 7.4394 & TRN & & \\
\hline CHEMBL3966035 & 1640360 & 7.8861 & 7.1936 & TRN & & \\
\hline CHEMBL3950971 & 1640360 & 8.5229 & 8.454 & TRN & & \\
\hline CHEMBL3920623 & 1640360 & 7.8239 & 7.855 & TST & & \\
\hline CHEMBL3965398 & 1640360 & 8.301 & 8.1308 & TRN & & \\
\hline CHEMBL3913909 & 1640360 & 8.1549 & 7.3903 & TST & & \\
\hline CHEMBL3938655 & 1640360 & 6.6108 & 7.3121 & TRN & & \\
\hline CHEMBL3970130 & 1640360 & 6.567 & 8.4249 & TST & & \\
\hline CHEMBL3915368 & 1640360 & 9.0 & 8.5741 & TST & & \\
\hline CHEMBL3952583 & 1640360 & 7.9586 & 7.8432 & TST & & \\
\hline CHEMBL3965137 & 1640360 & 8.0 & 7.1325 & TRN & & \\
\hline CHEMBL3946929 & 1640360 & 6.0 & 8.6489 & TST & & \\
\hline CHEMBL3930197 & 1640360 & 8.3979 & 9.1348 & TST & & \\
\hline CHEMBL3903825 & 1640360 & 7.0506 & 7.1312 & TRN & & \\
\hline CHEMBL3934611 & 1640360 & 8.1549 & 7.9384 & TRN & & \\
\hline CHEMBL3909126 & 1640360 & 9.0 & 8.8842 & TRN & & \\
\hline CHEMBL3891553 & 1640360 & 10.30099 & 99999999 & 998 & 9.193 & TRN \\
\hline CHEMBL3957515 & 1640360 & 8.2218 & 8.3651 & TRN & & \\
\hline CHEMBL370286 & 304333 & 4.718999 & 99999999؛ & 99 & 4.7282 & TRN \\
\hline CHEMBL193282 & 304333 & 6.9208 & 6.9071 & TRN & & \\
\hline CHEMBL195869 & 304333 & 5.3372 & 5.3662 & TRN & & \\
\hline CHEMBL362972 & 304333 & 3.301 & 3.3034 & TRN & & \\
\hline CHEMBL364456 & 304333 & 5.4318 & 5.4297 & TRN & & \\
\hline
\end{tabular}




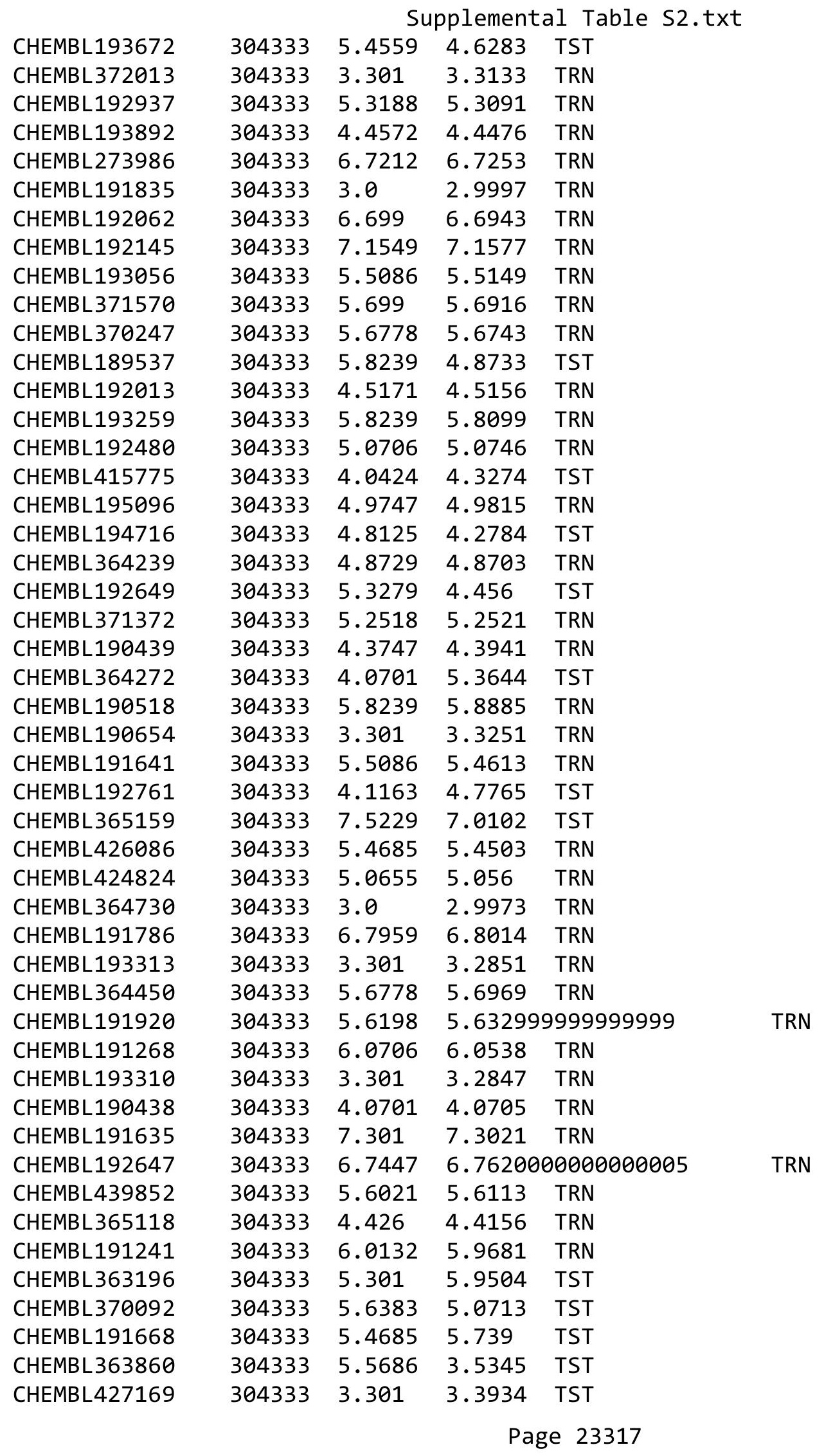


Supplemental Table S2.txt

\begin{tabular}{|c|c|c|c|c|c|}
\hline CHEMBL191601 & 304333 & 5.5528 & 5.602 & TST & \\
\hline CHEMBL 241708 & 1453986 & 6.9066 & 6.9365 & TRN & \\
\hline CHEMBL378528 & 1453986 & 6.9586 & 6.9179 & TRN & \\
\hline CHEMBL377337 & 1453986 & 6.0362 & 5.7513 & TRN & \\
\hline CHEMBL209194 & 1453986 & 6.0757 & 5.7339 & TRN & \\
\hline CHEMBL240623 & 1453986 & 6.9855 & 7.4122 & TRN & \\
\hline CHEMBL3326773 & 1453986 & 4.8837 & 5.1645 & TRN & \\
\hline CHEMBL3325885 & 1453986 & 3.8729 & 3.4761 & TRN & \\
\hline CHEMBL246441 & 1453986 & 7.7447 & 7.9748 & TRN & \\
\hline CHEMBL241713 & 1453986 & 6.817 & 6.8593 & TRN & \\
\hline CHEMBL332892 & 1453986 & 2.8356 & 2.3511 & TST & \\
\hline CHEMBL3325979 & 1453986 & 2.1347 & 2.0671 & TRN & \\
\hline CHEMBL239374 & 1453986 & 7.4283 & 7.4181 & TRN & \\
\hline CHEMBL1213083 & 1453986 & 5.6925 & 5.489 & TST & \\
\hline CHEMBL3326384 & 1453986 & 5.118 & 5.5316 & TST & \\
\hline CHEMBL1173475 & 1453986 & 4.8604 & 5.4527 & TST & \\
\hline CHEMBL391998 & 1453986 & 7.0132 & 6.9366 & TRN & \\
\hline CHEMBL240621 & 1453986 & 6.734 & 7.1577 & TRN & \\
\hline CHEMBL3326783 & 1453986 & 5.1391 & 4.9268 & TRN & \\
\hline CHEMBL3326781 & 1453986 & 4.7411 & 4.6593 & TRN & \\
\hline CHEMBL3325980 & 1453986 & 2.0382 & 4.1072 & TST & \\
\hline CHEMBL 246440 & 1453986 & 8.0044 & 7.9013 & TRN & \\
\hline CHEMBL211759 & 1453986 & 6.4202 & 6.3363 & TRN & \\
\hline CHEMBL164 & 1453986 & 5.3261 & 5.1206 & TST & \\
\hline CHEMBL377104 & 1453986 & 7.4089 & 7.2616 & TRN & \\
\hline CHEMBL208866 & 1453986 & 5.9208 & 5.7678 & TRN & \\
\hline CHEMBL1450008 & 1453986 & 4.5536 & 5.0025 & TST & \\
\hline CHEMBL3326774 & 1453986 & 3.838 & 5.3922 & TST & \\
\hline CHEMBL3325886 & 1453986 & 3.7282 & 3.1354 & TST & \\
\hline CHEMBL3325974 & 1453986 & 3.0035 & 4.3023 & TST & \\
\hline CHEMBL3326776 & 1453986 & 5.2097 & 5.37799 & 9999999999 & TS \\
\hline CHEMBL393276 & 1453986 & 7.5229 & 7.3023 & TRN & \\
\hline CHEMBL378999 & 1453986 & 7.3979 & 7.1465 & TRN & \\
\hline CHEMBL3325973 & 1453986 & 3.2132 & 3.425 & TRN & \\
\hline CHEMBL208662 & 1453986 & 6.5376 & 6.5834 & TRN & \\
\hline CHEMBL394234 & 1453986 & 7.9508 & 7.6554 & TRN & \\
\hline CHEMBL1162521 & 1453986 & 2.8041 & 3.2213 & TST & \\
\hline CHEMBL211113 & 1453986 & 4.699 & 5.33299 & 9999999999 & TRN \\
\hline CHEMBL3325462 & 1453986 & 4.963 & 5.0735 & TRN & \\
\hline CHEMBL208977 & 1453986 & 4.699 & 4.7167 & TRN & \\
\hline CHEMBL3326779 & 1453986 & 3.8604 & 5.487 & TST & \\
\hline CHEMBL379156 & 1453986 & 7.4815 & 6.9307 & TRN & \\
\hline CHEMBL1945352 & 1453986 & \multicolumn{2}{|c|}{3.6180000000000003} & 4.7641 & TST \\
\hline CHEMBL246857 & 1453986 & 7.6799 & 7.6572 & TRN & \\
\hline CHEMBL3325884 & 1453986 & 7.5376 & 7.1074 & TRN & \\
\hline CHEMBL3325976 & 1453986 & 2.6131 & 4.2626 & TST & \\
\hline CHEMBL211768 & 1453986 & 7.2518 & 7.2051 & TRN & \\
\hline CHEMBL2064327 & 1453986 & 4.7411 & 4.7656 & TRN & \\
\hline
\end{tabular}

Page 23318 
Supplemental Table S2.txt

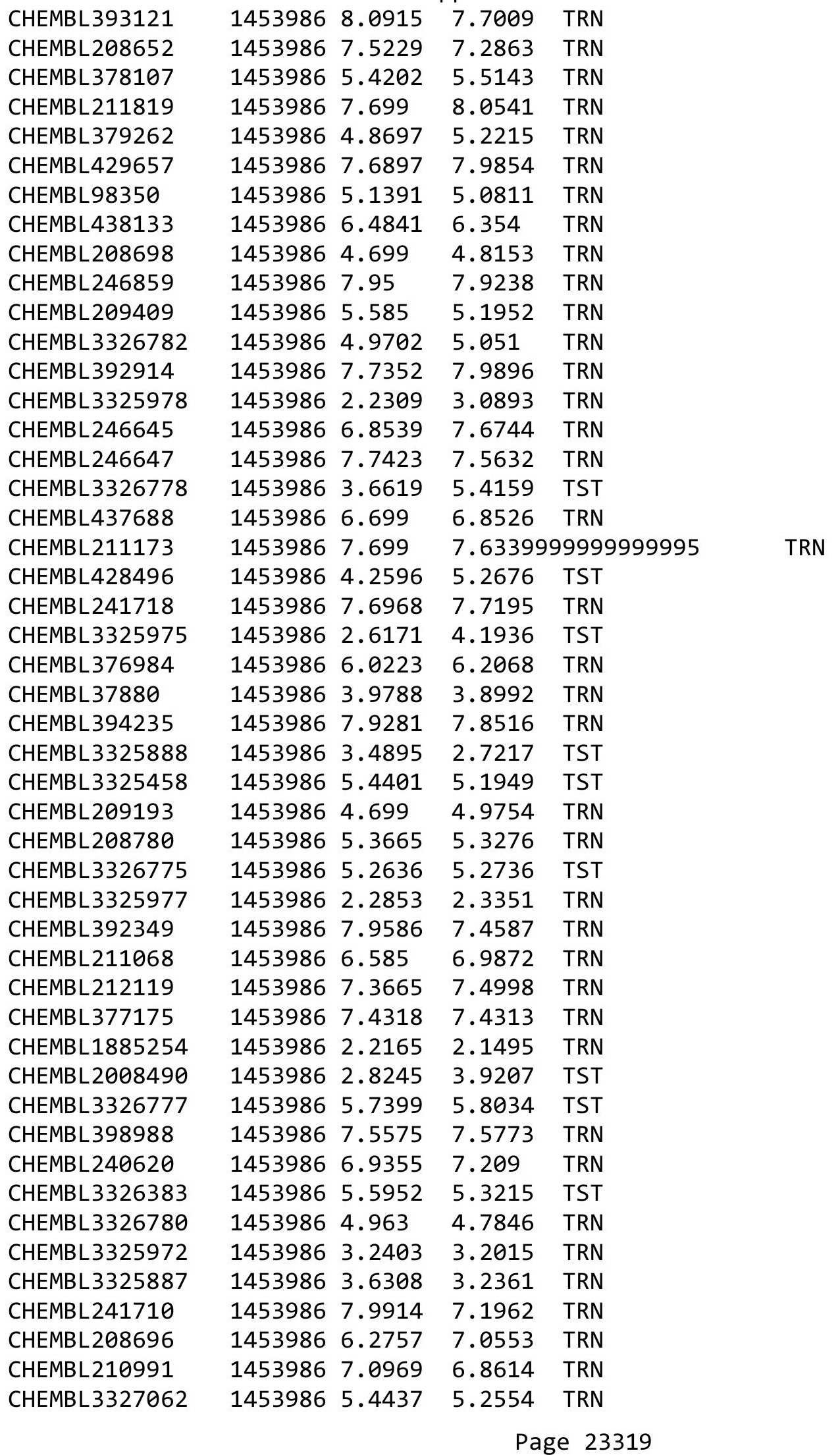




\begin{tabular}{|c|c|c|c|c|c|}
\hline \multicolumn{6}{|c|}{ Supplemental Table S2.txt } \\
\hline CHEMBL211112 & 1453986 & 6.0 & 5.8865 & TRN & \\
\hline CHEMBL154750 & 158358 & 3.301 & 3.3613 & TRN & \\
\hline CHEMBL150809 & 158358 & 3.301 & 3.4464 & TST & \\
\hline CHEMBL150816 & 158358 & 3.301 & 3.0743 & TST & \\
\hline CHEMBL436465 & 158358 & 3.301 & 3.2807 & TRN & \\
\hline CHEMBL356237 & 158358 & 4.7959 & 4.8887 & TRN & \\
\hline CHEMBL150568 & 158358 & 6.0655 & 6.1886 & TRN & \\
\hline CHEMBL153682 & 158358 & 4.6198 & 4.7312 & TRN & \\
\hline CHEMBL356679 & 158358 & 4.6021 & 4.3343 & TRN & \\
\hline CHEMBL358447 & 158358 & 3.301 & 3.4231 & TST & \\
\hline CHEMBL345970 & 158358 & 4.5229 & 4.4945 & TRN & \\
\hline CHEMBL152934 & 158358 & 5.3565 & 5.34399 & 9999999999 & TRN \\
\hline CHEMBL345730 & 158358 & 4.6383 & 4.5383 & TRN & \\
\hline CHEMBL151956 & 158358 & 5.1675 & 5.124 & TRN & \\
\hline CHEMBL 356027 & 158358 & 3.301 & 3.2562 & TRN & \\
\hline CHEMBL 359055 & 158358 & 4.8861 & 5.0723 & TRN & \\
\hline CHEMBL153624 & 158358 & 4.301 & 4.3293 & TRN & \\
\hline CHEMBL153106 & 158358 & 5.6778 & 5.6558 & TRN & \\
\hline CHEMBL149573 & 158358 & 3.301 & 3.3189 & TRN & \\
\hline CHEMBL405050 & 158358 & 3.301 & 3.278 & TRN & \\
\hline CHEMBL155093 & 158358 & 4.7212 & 4.5273 & TRN & \\
\hline CHEMBL435677 & 158358 & 4.7959 & 4.7528 & TRN & \\
\hline CHEMBL355950 & 158358 & 3.301 & 3.3716 & TRN & \\
\hline CHEMBL153084 & 158358 & 5.6021 & 5.5897 & TRN & \\
\hline CHEMBL149635 & 158358 & 3.301 & 3.4005 & TRN & \\
\hline CHEMBL150575 & 158358 & 3.301 & 3.3114 & TRN & \\
\hline CHEMBL150504 & 158358 & 5.0315 & 4.8977 & TRN & \\
\hline CHEMBL149746 & 158358 & 3.301 & 3.8274 & TST & \\
\hline CHEMBL348706 & 158358 & 5.4202 & 5.4396 & TRN & \\
\hline CHEMBL450929 & 158358 & 5.0 & 5.0571 & TRN & \\
\hline CHEMBL150790 & 158358 & 3.301 & 3.3558 & TRN & \\
\hline CHEMBL 356228 & 158358 & 3.301 & 3.9556 & TST & \\
\hline CHEMBL151537 & 158358 & 3.301 & 3.7433 & TST & \\
\hline CHEMBL150912 & 158358 & 3.301 & 4.0988 & TST & \\
\hline CHEMBL347769 & 158358 & 3.301 & 3.2598 & TRN & \\
\hline CHEMBL357368 & 158358 & 3.301 & 3.2989 & TRN & \\
\hline CHEMBL153365 & 158358 & 3.301 & 3.2916 & TRN & \\
\hline CHEMBL155505 & 158358 & 5.4437 & 5.4935 & TRN & \\
\hline CHEMBL348189 & 158358 & 3.301 & 3.3084 & TRN & \\
\hline CHEMBL 357347 & 158358 & 3.301 & 3.3388 & TRN & \\
\hline CHEMBL345775 & 158358 & 3.301 & 3.2716 & TRN & \\
\hline CHEMBL152521 & 158358 & 3.301 & 3.2572 & TRN & \\
\hline CHEMBL347547 & 158358 & 3.301 & 3.1431 & TST & \\
\hline CHEMBL153571 & 158358 & 3.301 & 3.3199 & TRN & \\
\hline CHEMBL150573 & 158358 & 4.3279 & 4.274 & TRN & \\
\hline CHEMBL153812 & 158358 & 3.301 & 3.3655 & TRN & \\
\hline CHEMBL 76202 & 158358 & 6.3665 & 6.2917 & TRN & \\
\hline CHEMBL150765 & 158358 & 3.301 & 3.2416 & TRN & \\
\hline
\end{tabular}




\begin{tabular}{|c|c|c|c|c|}
\hline \multicolumn{5}{|c|}{ Supplementa] } \\
\hline HEMBL153208 & 158358 & 4.7959 & 4.8582 & $\mathrm{TR}$ \\
\hline HEMBL 358384 & 58358 & 5.0757 & 5.0218 & \\
\hline HEMBL35 & & & & \\
\hline HEMBL152995 & 58358 & 4.6383 & & \\
\hline HEMBL1 & 58358 & 3.301 & 2708 & \\
\hline HEMBL150579 & 58358 & 3.301 & 3.2941 & \\
\hline HEMBL153526 & 58358 & 4.4318 & 4.4495 & \\
\hline HEMBL1 & 58358 & 3.301 & 3.5613 & \\
\hline HEMBL3: & 58358 & 4.7959 & 4.9997 & \\
\hline HEMBL3 & 58358 & 6.1549 & 6.1682 & \\
\hline HEMBL150899 & 58358 & 3.301 & 3.2439 & \\
\hline HEMBL1 & 58358 & 3.301 & 3.2505 & \\
\hline HEMB & 58 & 4.3979 & 4.4069 & \\
\hline HEMBL1 & 58358 & 5.2676 & 5.2638 & \\
\hline HEMBL] & 58358 & 3.301 & 3.2674 & \\
\hline HEMBL1 & 58 & 09 & & \\
\hline HEMB & 58 & 4.8861 & 4.8854 & \\
\hline HEMBL: & 58 & 28 & 4.5019 & RN \\
\hline HEMBL- & 58 & 86 & 4.9334 & - MN \\
\hline HEMB & 58 & & 5.565 & Tा \\
\hline 527 & 58 & 3. & & TRN \\
\hline CHEME & 58 & 4.8861 & 4.8 & RIV \\
\hline CHEME & 58 & 4. & $4 . \epsilon$ & TRN \\
\hline 00 & 58 & 3.301 & 2.7348 & TST \\
\hline HEMBL & 58 & 3. & & in \\
\hline HEMBL1 & 58 & 4. & & TRI \\
\hline 381 & 58 & & 67 & RN \\
\hline 145 & 58 & 3.301 & 3.2 & TRN \\
\hline HEME & 58 & 3. & 3.8 & TST \\
\hline HEMBL4 & 58 & 5 . & & TRN \\
\hline HEMBL3 & 58358 & 5 . & 5. & TRN \\
\hline 29 & & & & TRN \\
\hline 53 & 58 & 3. & 3. & TRN \\
\hline 169 & & & 179 & TRN \\
\hline HEMBL359358 & 58358 & & 2.8394 & TST \\
\hline 455 & 58 & 5 . & & TST \\
\hline CHEMB & 58 & 6 . & 6. & TST \\
\hline CHEME & 58 & 3. & 3.5 & TST \\
\hline CHEMBL1 & 58358 & 3.301 & 3.9181 & TST \\
\hline CHEMBL3 & 58358 & 3.301 & 4.3595 & TST \\
\hline CHEMB & 58 & & 4. & TST \\
\hline CHEMBL: & 58358 & 3.301 & 3.8249 & TST \\
\hline CHEMBL3 & 58358 & 4.6021 & 5.0284 & TST \\
\hline CHEMBL346870 & 58358 & 5.2518 & 4.7582 & TST \\
\hline CHEMBL310080 & 58358 & 5.0315 & 4.4719 & TST \\
\hline CHEMBL3 & 1575200 & 6.7375 & 6.8166 & TRN \\
\hline CHEMBL3 & 1575200 & 7.0088 & 6.5688 & TST \\
\hline CHEMBL3799000 & 1575200 & 6.3851 & 6.1408 & TRI \\
\hline
\end{tabular}

Page 23321 
Supplemental Table S2.txt

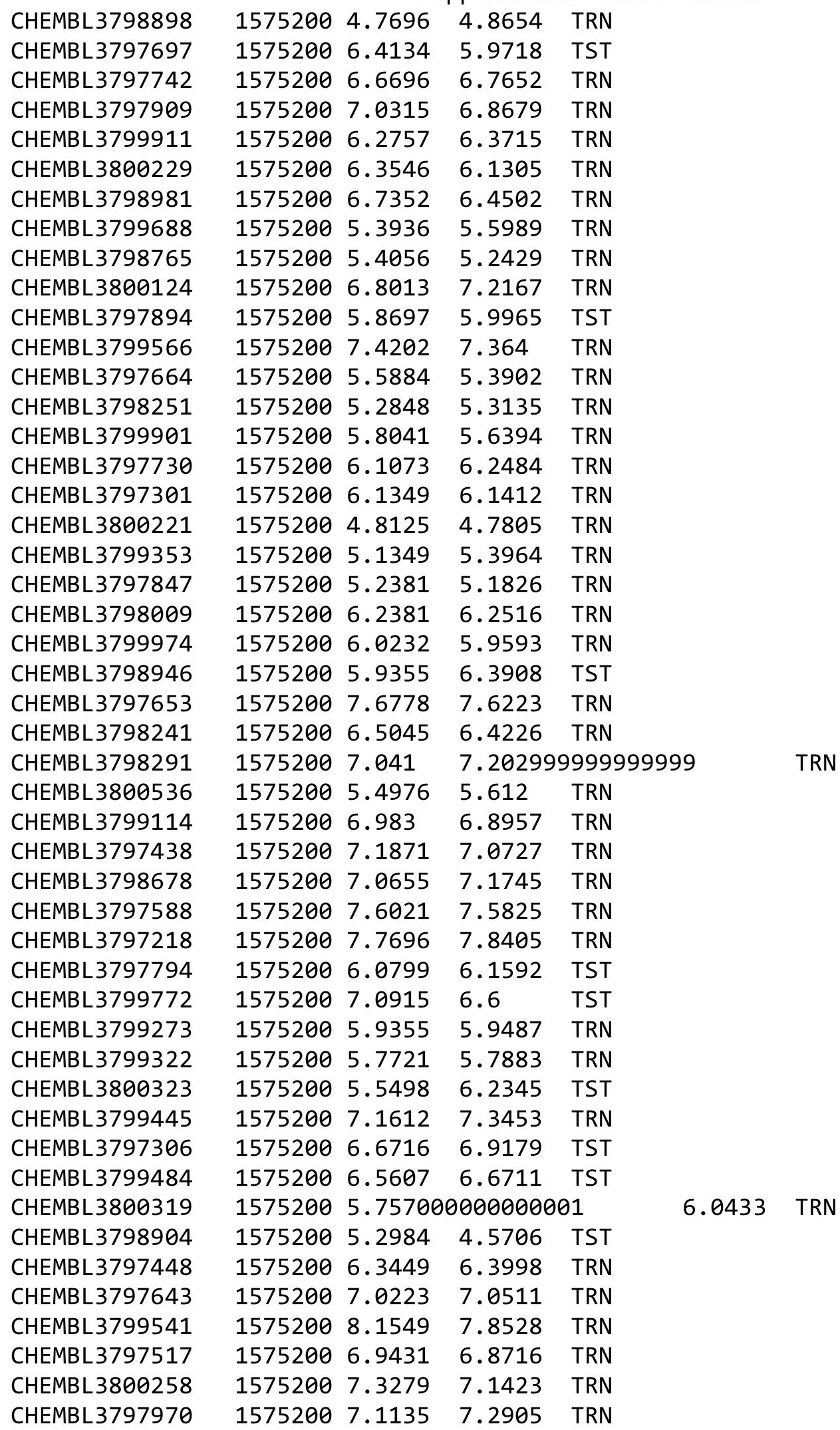

Page 23322 
Supplemental Table S2.txt

\begin{tabular}{|c|c|c|c|c|}
\hline Th & & 6.7447 & & \\
\hline O'М & 575200 & 6.5482 & 6.1585 & \\
\hline ITN & 200 & & & \\
\hline HEMBL 379889 & 5200 & 626 & & \\
\hline AEMBL3797564 & 575200 & 555 & 9685 & \\
\hline HEMBL1233881 & 54927 & 7.0044 & 8026 & \\
\hline HEMBL12 & & & 1886 & \\
\hline IEMBL12 & & 851 & & \\
\hline AEMBL1241391 & 54927 & & 1045 & \\
\hline HEMBL1242289 & 54927 & & 2566 & \\
\hline HEMBL1241271 & 54927 & 4.0 & 0729 & \\
\hline IEMBL12 & 27 & & 364 & \\
\hline IEMBL12 & & & & \\
\hline AEMBL1241241 & 27 & & 6423 & \\
\hline AEMBL12 & 27 & 98 & 5027 & \\
\hline AEMBL1 & 27 & 08 & 5786 & \\
\hline AEMBL12 & & & 144 & \\
\hline HEMBL12 & & & 575 & \\
\hline AEMBL12 & & 596 & 5.4469 & \\
\hline AEMBL12 & & & 998 & \\
\hline AEMBL1 & 7 & 6 & 806 & RIV \\
\hline AEMBL12 & & & 476 & 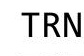 \\
\hline HEMBL12 & & & 031 & \\
\hline AEMBL12 & & & 307 & \\
\hline AEMBL12 & & & & I NIV \\
\hline HEMBL1 & & & 22 & II \\
\hline HEMBL1 & & & 82 & וכ \\
\hline HFMBI 1 & & & 25 & \\
\hline AEMBL1 & & & & RIV \\
\hline HEMBL1242032 & & 86 & & IRIV \\
\hline HEMBL1 & & J & 647 & ST \\
\hline HEMBL1 & & & 751 & RN \\
\hline HEMBL1 & & 239 & 374 & RN \\
\hline HEMBL1242845 & & & 983 & is \\
\hline HEMBL1242294 & & 012 & 3868 & TRN \\
\hline HEMBL1 & & 66 & 538 & $\mathrm{RN}$ \\
\hline HEMRI 1 & & 1 & 988 & RN \\
\hline HEMBL1 & & & 1942 & RN \\
\hline HEMBL1242377 & 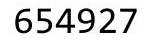 & 21 & 9993 & $\Gamma \mathrm{RN}$ \\
\hline AEMBL12 & & & & ГRN \\
\hline HEMBL1 & & 757 & 421 & \\
\hline HEMBL12 & & & & IST \\
\hline HEMBL1242028 & & 3279 & 1124 & $\Gamma \mathrm{RN}$ \\
\hline HEMBL1242024 & 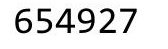 & 85 & & ГRN \\
\hline MBL12 & & 4 & 4089 & I \\
\hline HEMBL12 & & & .7548 & \\
\hline HEMBL124 & & 4.3979 & .1853 & \\
\hline LHEMBL1242848 & 654927 & 5.3261 & 5.4512 & ГRN \\
\hline
\end{tabular}

Page 23323 
Supplemental Table S2.txt

\begin{tabular}{|c|c|c|c|c|c|}
\hline CHEMBL1242660 & 654927 & 5.5229 & 5.4894 & TRN & \\
\hline CHEMBL1241587 & 654927 & 5.301 & 4.9663 & TST & \\
\hline CHEMBL1242111 & 654927 & 5.3958 & 5.4799 & TRN & \\
\hline CHEMBL1241484 & 654927 & 5.3372 & 5.4066 & TRN & \\
\hline CHEMBL1242200 & 654927 & 4.0 & 4.803 & TRN & \\
\hline CHEMBL1242113 & 654927 & 4.0 & 4.9724 & TRN & \\
\hline CHEMBL1242114 & 654927 & 5.4089 & 5.6359 & TRN & \\
\hline CHEMBL1242031 & 654927 & 5.3098 & 6.1129 & TRN & \\
\hline CHEMBL1242852 & 654927 & 4.8861 & 4.9729 & TST & \\
\hline CHEMBL1242110 & 654927 & 5.556 & 5.6849 & TRN & \\
\hline CHEMBL1241483 & 654927 & 4.8861 & 5.2768 & TRN & \\
\hline CHEMBL1240553 & 654927 & 5.2924 & 5.106 & TRN & \\
\hline CHEMBL1241679 & 654927 & 5.1427 & 4.6908 & TRN & \\
\hline CHEMBL1241490 & 654927 & 5.2441 & 5.2258 & TRN & \\
\hline CHEMBL1241579 & 654927 & 6.0 & 5.504 & TRN & \\
\hline CHEMBL1242846 & 654927 & 5.3098 & 5.5872 & TST & \\
\hline CHEMBL1241948 & 654927 & 5.3098 & 5.3984 & TRN & \\
\hline CHEMBL1242288 & 654927 & 4.7447 & 4.6308 & TRN & \\
\hline CHEMBL1242201 & 654927 & 4.0 & 5.3255 & TRN & \\
\hline CHEMBL1242026 & 654927 & 4.9208 & 5.2731 & TRN & \\
\hline CHEMBL1242027 & 654927 & 5.4559 & 5.6301 & TRN & \\
\hline CHEMBL1241943 & 654927 & 4.0 & 3.6933 & TRN & \\
\hline CHEMBL1242295 & 654927 & 5.0088 & 5.3046 & TRN & \\
\hline CHEMBL1241770 & 654927 & 4.0 & 3.9204 & TRN & \\
\hline CHEMBL1081312 & 654927 & 7.2218 & 6.4834 & TRN & \\
\hline CHEMBL1241485 & 654927 & 5.0315 & 5.3126 & TRN & \\
\hline CHEMBL1241439 & 654927 & 5.5528 & 5.0744 & TST & \\
\hline CHEMBL1242112 & 654927 & 6.0605 & 5.6955 & TRN & \\
\hline CHEMBL1241583 & 654927 & 5.3565 & 4.8067 & TRN & \\
\hline CHEMBL1240545 & 654927 & 5.4559 & 4.7638 & TRN & \\
\hline CHEMBL1241492 & 654927 & 4.8539 & 4.7665 & TRN & \\
\hline CHEMBL1230790 & 654927 & 5.585 & 5.58899 & 99999999995 & TRN \\
\hline CHEMBL1242381 & 654927 & 5.0458 & 4.967 & TRN & \\
\hline CHEMBL1242198 & 654927 & 5.4318 & 5.8203 & TRN & \\
\hline CHEMBL1242656 & 654927 & 5.3915 & 5.5032 & TRN & \\
\hline CHEMBL1242025 & 654927 & 4.5086 & 2.9498 & TST & \\
\hline CHEMBL1242378 & 654927 & 6.0 & 5.9165 & TRN & \\
\hline CHEMBL1241773 & 654927 & 5.4685 & 5.5625 & TRN & \\
\hline CHEMBL1242567 & 654927 & 4.6198 & 5.1182 & TRN & \\
\hline CHEMBL1241588 & 654927 & 5.041 & 4.3322 & TST & \\
\hline CHEMBL1241945 & 654927 & 6.6778 & 5.9781 & TRN & \\
\hline CHEMBL1241487 & 654927 & 5.6308 & 5.3363 & TRN & \\
\hline CHEMBL1241684 & 654927 & 4.9208 & 5.5801 & TST & \\
\hline CHEMBL1242202 & 654927 & 5.1079 & 5.1902 & TRN & \\
\hline CHEMBL1242199 & 654927 & 5.1314 & 5.5314 & TRN & \\
\hline CHEMBL1242030 & 654927 & 5.699 & 5.1485 & TRN & \\
\hline CHEMBL1241859 & 654927 & 4.0 & 4.0428 & TRN & \\
\hline CHEMBL1241858 & 654927 & 4.0 & 3.4131 & TRN & \\
\hline
\end{tabular}




\begin{tabular}{|c|c|c|c|c|c|c|}
\hline \multicolumn{7}{|c|}{ Supplemental Table S2.txt } \\
\hline CHEMBL1242659 & 654927 & 4.0 & 4.9154 & TRN & & \\
\hline CHEMBL1242751 & 654927 & 5.4437 & 4.7553 & TST & & \\
\hline CHEMBL1242662 & 654927 & 5.1308 & 5.1157 & TST & & \\
\hline CHEMBL1241390 & 654927 & 4.8539 & 4.8545 & TST & & \\
\hline CHEMBL1242666 & 654927 & 5.3768 & 5.6737 & TST & & \\
\hline CHEMBL1242657 & 654927 & 6.0 & 5.2162 & TST & & \\
\hline CHEMBL1242752 & 654927 & 5.3979 & 5.5182 & TST & & \\
\hline CHEMBL1233882 & 654927 & 8.0969 & 6.4736 & TST & & \\
\hline CHEMBL1242290 & 654927 & 5.2291 & 5.5543 & TST & & \\
\hline CHEMBL1241674 & 654927 & 6.3893 & 5.1784 & TST & & \\
\hline CHEMBL1241582 & 654927 & 5.2924 & 5.0122 & TST & & \\
\hline CHEMBL1230020 & 954623 & 5.2089 & 5.2068 & TRN & & \\
\hline CHEMBL92309 & 954623 & 3.9006 & 3.2101 & TST & & \\
\hline CHEMBL1516890 & 954623 & 3.8729 & 3.8563 & TRN & & \\
\hline CHEMBL3349342 & 954623 & 4.4647 & 4.49100 & 00000 & 005 & TRN \\
\hline CHEMBL3392440 & 954623 & 3.714 & 3.65 & TRN & & \\
\hline CHEMBL 255342 & 954623 & 3.56600 & 00000000 & 003 & 3.5372 & TRN \\
\hline CHEMBL 2144069 & 954623 & 5.3141 & 5.3339 & TRN & & \\
\hline CHEMBL 258844 & 954623 & 4.5535 & 4.54899 & 99999 & 995 & TRN \\
\hline CHEMBL221137 & 954623 & 5.45200 & 00000000 & 01 & 4.8136 & TST \\
\hline CHEMBL188678 & 954623 & 4.8617 & 4.8183 & TRN & & \\
\hline CHEMBL392695 & 954623 & 5.0167 & 5.0983 & TRN & & \\
\hline CHEMBL1788116 & 954623 & 5.4345 & 5.4342 & TRN & & \\
\hline CHEMBL509032 & 954623 & 5.5761 & 5.4809 & TRN & & \\
\hline CHEMBL1970879 & 954623 & 5.3367 & 5.3291 & TRN & & \\
\hline CHEMBL1590308 & 954623 & 4.8823 & 3.2526 & TST & & \\
\hline CHEMBL393929 & 954623 & 5.50299 & 99999999 & 99 & 5.5292 & TRN \\
\hline CHEMBL1186585 & 954623 & 4.1478 & 4.073 & TRN & & \\
\hline CHEMBL65 & 954623 & 8.8233 & 8.7789 & TRN & & \\
\hline CHEMBL 9470 & 954623 & 7.0677 & 6.1231 & TST & & \\
\hline CHEMBL515416 & 954623 & 4.5729 & 4.561 & TRN & & \\
\hline CHEMBL192566 & 954623 & 8.7001 & 9.6773 & TST & & \\
\hline CHEMBL 222102 & 954623 & 4.0292 & 4.0905 & TRN & & \\
\hline CHEMBL135561 & 954623 & 4.5856 & 4.6058 & TRN & & \\
\hline CHEMBL3186408 & 954623 & 4.669 & 3.7953 & TST & & \\
\hline CHEMBL472940 & 954623 & 2.6605 & 2.6554 & TRN & & \\
\hline CHEMBL180127 & 954623 & 4.9586 & 4.9152 & TRN & & \\
\hline CHEMBL191334 & 954623 & 3.4118 & 3.4104 & TRN & & \\
\hline CHEMBL1190711 & 954623 & 5.0142 & 5.0738 & TRN & & \\
\hline CHEMBL558642 & 954623 & 4.8077 & 4.7721 & TRN & & \\
\hline CHEMBL 217354 & 954623 & 6.8126 & 6.8503 & TRN & & \\
\hline CHEMBL412142 & 954623 & 4.1186 & 4.1211 & TRN & & \\
\hline CHEMBL102714 & 954623 & 3.38 & 3.3797 & TRN & & \\
\hline CHEMBL573107 & 954623 & 5.6508 & 5.6649 & TRN & & \\
\hline CHEMBL 220241 & 954623 & 4.6368 & 4.6346 & TRN & & \\
\hline CHEMBL585951 & 954623 & 6.9342 & 6.9437 & TRN & & \\
\hline CHEMBL 2363137 & 954623 & 5.4321 & 5.465 & TRN & & \\
\hline CHEMBL 259181 & 954623 & 5.4511 & 5.4847 & TRN & & \\
\hline
\end{tabular}




\begin{tabular}{|c|c|c|c|c|c|c|}
\hline & & \multicolumn{5}{|c|}{ Supplemental Table S2.txt } \\
\hline CHEMBL 2134202 & 954623 & 3.3941 & 3.5652 & TRN & & \\
\hline CHEMBL 2005886 & 954623 & 5.4054 & 5.4476 & TRN & & \\
\hline CHEMBL1357247 & 954623 & 4.0815 & 4.0802 & TRN & & \\
\hline CHEMBL209148 & 954623 & 4.5936 & 4.5761 & TRN & & \\
\hline CHEMBL379975 & 954623 & 5.8087 & 5.7933 & TRN & & \\
\hline CHEMBL514499 & 954623 & 7.7129 & 7.6724 & TRN & & \\
\hline CHEMBL1643959 & 954623 & 3.4605 & 3.4122 & TRN & & \\
\hline CHEMBL 2137530 & 954623 & 5.0918 & 5.0821 & TRN & & \\
\hline CHEMBL300389 & 954623 & 7.2518 & 7.2479 & TRN & & \\
\hline CHEMBL189584 & 954623 & 3.9652 & 3.9228 & TRN & & \\
\hline CHEMBL213100 & 954623 & 4.6205 & 4.6074 & TRN & & \\
\hline CHEMBL483847 & 954623 & 3.9659 & 3.9436 & TRN & & \\
\hline CHEMBL 399530 & 954623 & 3.7176 & 3.7004 & TRN & & \\
\hline CHEMBL1673039 & 954623 & 4.9 & 4.925 & TRN & & \\
\hline CHEMBL512504 & 954623 & 4.1757 & 4.1721 & TRN & & \\
\hline CHEMBL1256459 & 954623 & 7.3345 & 7.3689 & TRN & & \\
\hline CHEMBL449158 & 954623 & 6.3107 & 7.6002 & TST & & \\
\hline CHEMBL483849 & 954623 & 1.7918 & 1.4779 & TST & & \\
\hline CHEMBL 373751 & 954623 & 3.1612 & 3.1793 & TRN & & \\
\hline CHEMBL577784 & 954623 & 5.7083 & 5.6639 & TST & & \\
\hline CHEMBL240954 & 954623 & 3.5377 & 3.3495 & TST & & \\
\hline CHEMBL1404918 & 954623 & 3.3595 & 2.7324 & TST & & \\
\hline CHEMBL3199475 & 954623 & 3.6365 & 4.1423 & TST & & \\
\hline CHEMBL 379300 & 954623 & 6.7878 & 6.4317 & TST & & \\
\hline CHEMBL1909414 & 954623 & 3.799 & 3.9542 & TST & & \\
\hline CHEMBL1242367 & 954623 & 4.4894 & 4.4248 & TST & & \\
\hline CHEMBL 202721 & 954623 & 5.311 & 5.1232 & TST & & \\
\hline CHEMBL210618 & 954623 & 3.2284 & 3.9216 & TST & & \\
\hline CHEMBL1242367 & 954936 & 4.2383 & 4.1311 & TRN & & \\
\hline CHEMBL102714 & 954936 & 5.0448 & 4.9601 & TRN & & \\
\hline CHEMBL472940 & 954936 & 3.9301 & 4.0089 & TRN & & \\
\hline CHEMBL573107 & 954936 & 6.0728 & 5.8758 & TRN & & \\
\hline CHEMBL 3392440 & 954936 & 3.93600 & 30000000 & 204 & 3.8792 & TRN \\
\hline CHEMBL 209148 & 954936 & 4.093 & 3.9206 & TRN & & \\
\hline CHEMBL412142 & 954936 & 3.4041 & 3.569 & TRN & & \\
\hline CHEMBL202721 & 954936 & 5.8803 & 5.8129 & TRN & & \\
\hline CHEMBL392695 & 954936 & 5.3625 & 5.2946 & TRN & & \\
\hline CHEMBL 379300 & 954936 & 6.3624 & 6.1138 & TRN & & \\
\hline CHEMBL189584 & 954936 & 3.6021 & 3.6046 & TRN & & \\
\hline CHEMBL373751 & 954936 & 3.2772 & 3.3365 & TRN & & \\
\hline CHEMBL 222102 & 954936 & 3.7148 & 4.2128 & TRN & & \\
\hline CHEMBL1643959 & 954936 & 3.5151 & 3.42199 & 99999 & 97 & TRN \\
\hline CHEMBL 2144069 & 954936 & 3.8662 & 4.0936 & TRN & & \\
\hline CHEMBL65 & 954936 & 7.4637 & 7.5264 & TRN & & \\
\hline CHEMBL483847 & 954936 & 3.9898 & 4.0592 & TRN & & \\
\hline CHEMBL1673039 & 954936 & 4.7201 & 4.6856 & TRN & & \\
\hline CHEMBL1970879 & 954936 & 3.8672 & 3.8524 & TRN & & \\
\hline CHEMBL393929 & 954936 & 5.1288 & 4.9833 & TRN & & \\
\hline
\end{tabular}

Page 23326 


\begin{tabular}{|c|c|c|c|c|c|}
\hline \multirow{2}{*}{ CHEMBL512504 } & \multirow[b]{2}{*}{954936} & \\
\hline & & 5.4071 & \multicolumn{2}{|c|}{5.2829999999999995} & \multirow[t]{2}{*}{ TRN } \\
\hline CHEMBL210618 & 954936 & 3.4999 & 3.3318 & TRN & \\
\hline CHEMBL1230020 & 954936 & 4.5973 & 4.5487 & TRN & \\
\hline CHEMBL1516890 & 954936 & 3.9552 & 4.2543 & TRN & \\
\hline CHEMBL135561 & 954936 & 4.1743 & 4.396 & TRN & \\
\hline CHEMBL258844 & 954936 & 4.5317 & 4.3895 & TRN & \\
\hline CHEMBL300389 & 954936 & 6.8339 & 6.813 & TRN & \\
\hline CHEMBL577784 & 954936 & 5.6342 & 5.9277 & TRN & \\
\hline CHEMBL 2363137 & 954936 & 4.6124 & 4.5853 & TRN & \\
\hline CHEMBL2134202 & 954936 & 4.1473 & 4.3336 & TRN & \\
\hline CHEMBL2005886 & 954936 & 4.141 & 3.9788 & TRN & \\
\hline CHEMBL514499 & 954936 & 6.4691 & 6.426 & TRN & \\
\hline CHEMBL259181 & 954936 & 4.4256 & 4.3608 & TRN & \\
\hline CHEMBL483849 & 954936 & 1.6865 & 2.7781 & TST & \\
\hline CHEMBL3349342 & 954936 & 4.2643 & 4.4372 & TRN & \\
\hline CHEMBL558642 & 954936 & 4.3067 & 4.1802 & TRN & \\
\hline CHEMBL379975 & 954936 & 5.8362 & 6.0127 & TRN & \\
\hline CHEMBL213100 & 954936 & 4.3308 & 4.4582 & TRN & \\
\hline CHEMBL188678 & 954936 & 5.1743 & 5.0415 & TRN & \\
\hline CHEMBL3199475 & 954936 & 4.3927 & 4.3042 & TRN & \\
\hline CHEMBL192566 & 954936 & 7.6167 & 7.107 & TST & \\
\hline CHEMBL1186585 & 954936 & 4.8877 & \multicolumn{2}{|c|}{4.718999999999999} & TRN \\
\hline CHEMBL1590308 & 954936 & 3.161 & 3.6266 & TST & \\
\hline CHEMBL 255342 & 954936 & 4.2003 & 4.2194 & TRN & \\
\hline CHEMBL1788116 & 954936 & 4.4954 & 4.4299 & TRN & \\
\hline CHEMBL3186408 & 954936 & 3.7844 & 3.8137 & TST & \\
\hline CHEMBL1357247 & 954936 & 3.3945 & 3.3488 & TRN & \\
\hline CHEMBL221137 & 954936 & 4.37 & 4.6448 & TST & \\
\hline CHEMBL515416 & 954936 & 4.1587 & 4.1363 & TRN & \\
\hline CHEMBL449158 & 954936 & 6.2896 & 6.1775 & TST & \\
\hline CHEMBL217354 & 954936 & 6.3582 & 6.5162 & TRN & \\
\hline CHEMBL180127 & 954936 & 4.6898 & 4.5859 & TRN & \\
\hline CHEMBL509032 & 954936 & 5.0507 & 5.0433 & TRN & \\
\hline CHEMBL1256459 & 954936 & 6.0664 & 6.1012 & TRN & \\
\hline CHEMBL1404918 & 954936 & 2.9144 & 3.3221 & TST & \\
\hline CHEMBL585951 & 954936 & 6.1108 & 5.6138 & TST & \\
\hline CHEMBL1909414 & 954936 & 3.4041 & 3.9127 & TST & \\
\hline CHEMBL1190711 & 954936 & 5.0982 & 4.9904 & TST & \\
\hline CHEMBL220241 & 954936 & 5.6634 & \multicolumn{2}{|c|}{4.6160000000000005} & TST \\
\hline CHEMBL9470 & 954936 & 4.1858 & 5.5872 & TST & \\
\hline CHEMBL191334 & 954936 & 3.3891 & 4.465 & TST & \\
\hline CHEMBL92309 & 954936 & 3.3078 & 3.0081 & TST & \\
\hline CHEMBL2137530 & 954936 & 4.931 & 5.1999 & TST & \\
\hline CHEMBL 240954 & 954936 & 3.5835 & 3.8904 & TST & \\
\hline CHEMBL 399530 & 954936 & 4.5023 & 4.7837 & TST & \\
\hline CHEMBL338401 & 52672 & 3.6021 & 3.676 & TRN & \\
\hline CHEMBL126600 & 52672 & 7.301 & 7.5011 & TRN & \\
\hline \multirow[t]{2}{*}{ CHEMBL339246 } & 52672 & 6.4685 & 5.9398 & TRN & \\
\hline & & \multicolumn{4}{|c|}{ Page 23327} \\
\hline
\end{tabular}




\begin{tabular}{|c|c|c|c|c|c|}
\hline \multicolumn{6}{|c|}{ Supplemental Table S2.txt } \\
\hline CHEMBL126405 & 52672 & 4.9003 & 4.5165 & TRN & \\
\hline CHEMBL127083 & 52672 & 5.0 & 5.7193 & TST & \\
\hline CHEMBL129107 & 52672 & 5.3686 & 5.6544 & TRN & \\
\hline CHEMBL125352 & 52672 & 5.0 & 4.8999 & TRN & \\
\hline CHEMBL126549 & 52672 & 8.5229 & 8.6225 & TRN & \\
\hline CHEMBL126328 & 52672 & 8.3979 & 8.3641 & TRN & \\
\hline CHEMBL126788 & 52672 & 5.0 & 4.9781 & TRN & \\
\hline CHEMBL129475 & 52672 & 6.8239 & 7.0777 & TRN & \\
\hline CHEMBL339070 & 52672 & 5.7595 & 5.8826 & TRN & \\
\hline CHEMBL340741 & 52672 & 6.1675 & 6.1529 & TRN & \\
\hline CHEMBL126908 & 52672 & 7.6021 & 7.8831 & TRN & \\
\hline CHEMBL340904 & 52672 & 8.5229 & 6.9642 & TST & \\
\hline CHEMBL129584 & 52672 & 3.6021 & 4.0301 & TRN & \\
\hline CHEMBL48796 & 52672 & 7.585 & 7.6559 & TRN & \\
\hline CHEMBL125351 & 52672 & 5.0 & 5.1302 & TRN & \\
\hline CHEMBL125731 & 52672 & 6.4559 & 6.7775 & TRN & \\
\hline CHEMBL129466 & 52672 & 5.0 & 5.0661 & TRN & \\
\hline CHEMBL126458 & 52672 & 5.7352 & 5.9167 & TRN & \\
\hline CHEMBL126630 & 52672 & 8.301 & 8.0781 & TRN & \\
\hline CHEMBL300936 & 52672 & 8.5229 & 8.5514 & TRN & \\
\hline CHEMBL125401 & 52672 & 7.699 & 7.5686 & TRN & \\
\hline CHEMBL126710 & 52672 & 5.0 & 5.1079 & TRN & \\
\hline CHEMBL126934 & 52672 & 5.0 & 5.0584 & TRN & \\
\hline CHEMBL340012 & 52672 & 7.301 & 7.3375 & TRN & \\
\hline CHEMBL130020 & 52672 & 5.0 & 5.0773 & TRN & \\
\hline CHEMBL339925 & 52672 & 5.0 & 5.3173 & TRN & \\
\hline CHEMBL129471 & 52672 & 8.2218 & 8.0385 & TRN & \\
\hline CHEMBL129763 & 52672 & 5.0 & 4.8407 & TRN & \\
\hline CHEMBL129716 & 52672 & 6.699 & 6.7971 & TRN & \\
\hline CHEMBL129563 & 52672 & 5.0 & 7.3567 & TST & \\
\hline CHEMBL341286 & 52672 & 5.0 & 6.4428 & TST & \\
\hline CHEMBL126997 & 52672 & 8.699 & 8.7248 & TRN & \\
\hline CHEMBL420143 & 52672 & 7.0458 & 7.2384 & TRN & \\
\hline CHEMBL340794 & 52672 & 7.9586 & 7.7665 & TRN & \\
\hline CHEMBL340796 & 52672 & 3.6021 & 3.2202 & TRN & \\
\hline CHEMBL129555 & 52672 & 6.4437 & 6.5418 & TRN & \\
\hline CHEMBL 295136 & 52672 & 8.301 & 7.5114 & TRN & \\
\hline CHEMBL126782 & 52672 & 6.8539 & 6.9105 & TRN & \\
\hline CHEMBL129213 & 52672 & 3.6021 & 3.50699 & 99999999997 & TRN \\
\hline CHEMBL127929 & 52672 & 6.7696 & 6.3943 & TRN & \\
\hline CHEMBL126459 & 52672 & 5.0 & 6.0916 & TST & \\
\hline CHEMBL126993 & 52672 & 8.301 & 8.13600 & 0000000001 & TST \\
\hline CHEMBL340332 & 52672 & 5.0 & 4.9653 & TST & \\
\hline CHEMBL435992 & 52672 & 6.6021 & 6.7905 & TST & \\
\hline CHEMBL340400 & 52672 & 3.6021 & 5.4915 & TST & \\
\hline CHEMBL129532 & 52672 & 5.0 & 5.379 & TST & \\
\hline CHEMBL263955 & 52672 & 7.7696 & 7.2378 & TST & \\
\hline CHEMBL129396 & 52672 & 8.301 & 8.1458 & TST & \\
\hline
\end{tabular}




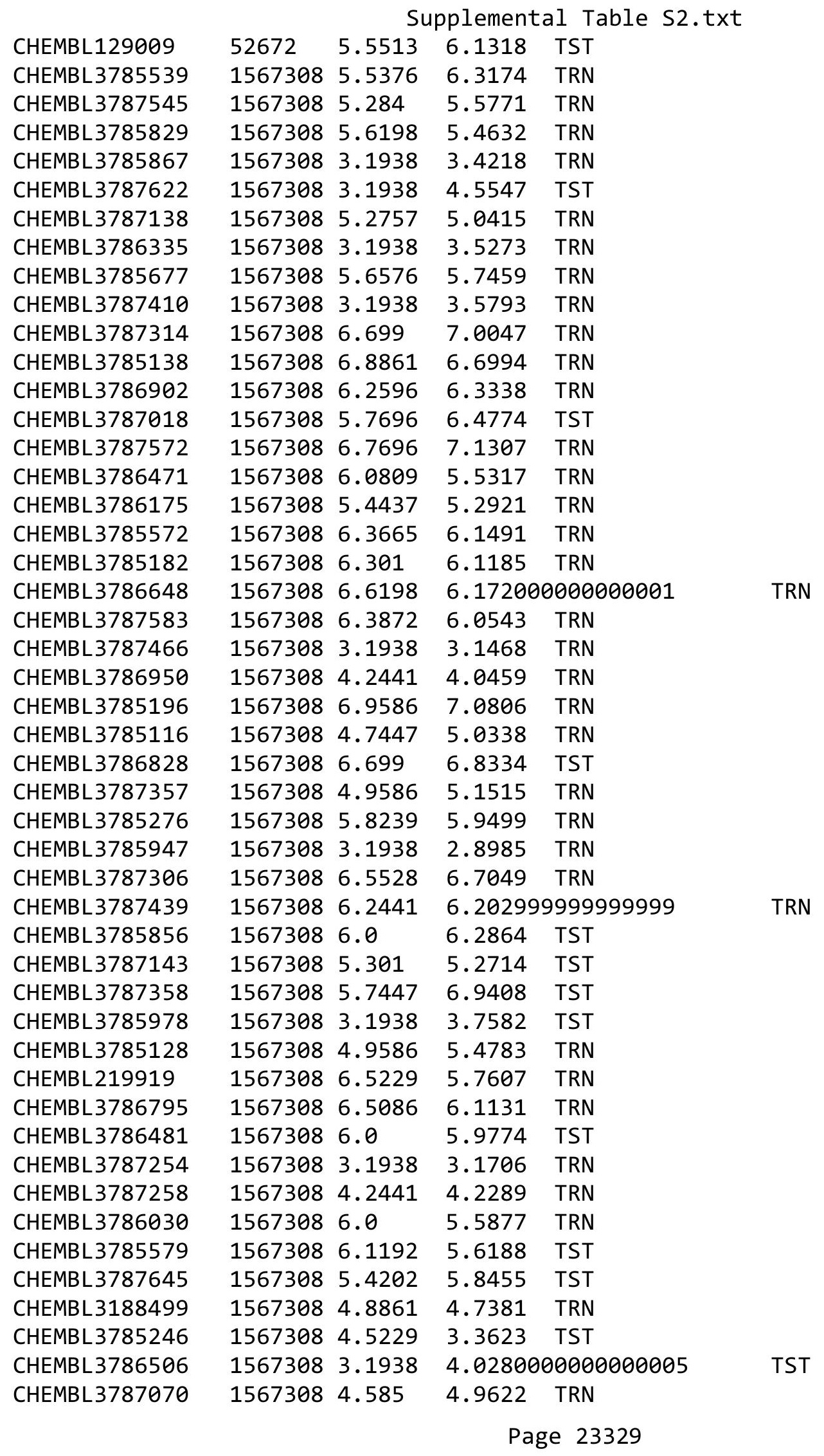


Supplemental Table S2.txt

\begin{tabular}{|c|c|c|c|c|c|c|}
\hline CHEMBL3786301 & 1567308 & 6.6383 & 6.9478 & TST & & \\
\hline CHEMBL3786138 & 1567308 & 6.4949 & 6.5046 & TRN & & \\
\hline CHEMBL3786151 & 1567308 & 6.301 & 6.2452 & TRN & & \\
\hline CHEMBL 3786741 & 1567308 & 5.8539 & 6.2438 & TRN & & \\
\hline CHEMBL3785985 & 1567308 & 6.8539 & 6.6789 & TRN & & \\
\hline CHEMBL1404918 & 954508 & 3.1886 & 3.1769 & TRN & & \\
\hline CHEMBL240954 & 954508 & \multicolumn{3}{|c|}{4.2010000000000005} & 3.3753 & TST \\
\hline CHEMBL483849 & 954508 & 3.0811 & 2.4098 & TST & & \\
\hline CHEMBL1643959 & 954508 & 3.721 & 3.9037 & TRN & & \\
\hline CHEMBL514499 & 954508 & 7.7657 & 7.8541 & TRN & & \\
\hline CHEMBL180127 & 954508 & 4.4018 & 4.6487 & TRN & & \\
\hline CHEMBL3392440 & 954508 & 3.9684 & 3.8735 & TRN & & \\
\hline CHEMBL1256459 & 954508 & 7.8145 & 7.8859 & TRN & & \\
\hline CHEMBL1673039 & 954508 & 5.3295 & 5.2043 & TRN & & \\
\hline CHEMBL 222102 & 954508 & 3.6589 & 3.6364 & TRN & & \\
\hline CHEMBL1970879 & 954508 & 5.4609 & 5.3436 & TRN & & \\
\hline CHEMBL210618 & 954508 & 3.3739 & 3.2576 & TRN & & \\
\hline CHEMBL 2137530 & 954508 & 4.5628 & 4.9117 & TRN & & \\
\hline CHEMBL393929 & 954508 & 4.3025 & 4.1642 & TRN & & \\
\hline CHEMBL 9470 & 954508 & 6.5682 & 6.3709 & TST & & \\
\hline CHEMBL1190711 & 954508 & 5.5583 & 5.6086 & TRN & & \\
\hline CHEMBL 2144069 & 954508 & \multicolumn{3}{|c|}{7.4239999999999995} & 7.6473 & TRN \\
\hline CHEMBL379300 & 954508 & 6.8659 & 6.6981 & TRN & & \\
\hline CHEMBL392695 & 954508 & 6.1694 & 5.9538 & TRN & & \\
\hline CHEMBL558642 & 954508 & 5.8014 & 5.4589 & TRN & & \\
\hline CHEMBL 213100 & 954508 & 4.4156 & 4.6496 & TRN & & \\
\hline CHEMBL1186585 & 954508 & 4.3425 & 4.2208 & TRN & & \\
\hline CHEMBL 2363137 & 954508 & \multicolumn{3}{|c|}{5.656000000000001} & 5.7238 & \\
\hline CHEMBL 217354 & 954508 & 7.819 & 7.7692 & TRN & & \\
\hline CHEMBL3349342 & 954508 & 5.8572 & 5.65 & TRN & & \\
\hline CHEMBL92309 & 954508 & 2.6096 & 3.3177 & TST & & \\
\hline CHEMBL189584 & 954508 & 4.2396 & 4.0856 & TRN & & \\
\hline CHEMBL65 & 954508 & 8.3737 & 8.5613 & TRN & & \\
\hline CHEMBL259181 & 954508 & 5.4724 & 5.7875 & TRN & & \\
\hline CHEMBL1590308 & 954508 & 3.2663 & 3.6635 & TST & & \\
\hline CHEMBL512504 & 954508 & 4.0755 & 4.1736 & TRN & & \\
\hline CHEMBL1357247 & 954508 & 3.1782 & 3.1338 & TRN & & \\
\hline CHEMBL577784 & 954508 & 5.1696 & 5.5644 & TRN & & \\
\hline CHEMBL515416 & 954508 & 4.2447 & 4.364 & TRN & & \\
\hline CHEMBL3186408 & 954508 & 5.1556 & 4.0648 & TST & & \\
\hline CHEMBL 2005886 & 954508 & 5.9982 & 5.8276 & TRN & & \\
\hline CHEMBL202721 & 954508 & 6.1509 & 6.1777 & TRN & & \\
\hline CHEMBL379975 & 954508 & 5.4611 & 5.3708 & TRN & & \\
\hline CHEMBL 2134202 & 954508 & 3.8238 & 3.9466 & TRN & & \\
\hline CHEMBL220241 & 954508 & 4.9761 & 5.0776 & TRN & & \\
\hline CHEMBL221137 & 954508 & 5.6975 & 5.4407 & TST & & \\
\hline CHEMBL472940 & 954508 & 5.277 & 5.2014 & TRN & & \\
\hline CHEMBL573107 & 954508 & 5.3253 & 5.3438 & TRN & & \\
\hline
\end{tabular}

Page 23330 
Supplemental Table S2.txt

\begin{tabular}{|c|c|c|c|c|}
\hline CHEMBL1230020 & 954508 & 3.7095 & 3.7373 & TRN \\
\hline CHEMBL1516890 & 954508 & 3.9752 & 3.8626 & TRN \\
\hline CHEMBL509032 & 954508 & 5.8241 & 5.9349 & TRN \\
\hline CHEMBL258844 & 954508 & 4.7112 & 4.6195 & TRN \\
\hline CHEMBL188678 & 954508 & 4.2552 & 4.3296 & TRN \\
\hline CHEMBL483847 & 954508 & 3.8547 & 3.9086 & TRN \\
\hline CHEMBL373751 & 954508 & 3.6634 & 3.7754 & TRN \\
\hline CHEMBL1242367 & 954508 & 5.3261 & 5.0591 & TRN \\
\hline CHEMBL585951 & 954508 & 6.9301 & 6.4582 & TRN \\
\hline CHEMBL399530 & 954508 & 5.0771 & 4.9598 & TRN \\
\hline CHEMBL192566 & 954508 & 8.7932 & 9.155 & TST \\
\hline CHEMBL300389 & 954508 & 6.9418 & 6.7184 & TRN \\
\hline CHEMBL135561 & 954508 & 4.175 & 4.4475 & TRN \\
\hline CHEMBL412142 & 954508 & 3.9285 & 3.8658 & TST \\
\hline CHEMBL255342 & 954508 & 2.9976 & 3.53 & TST \\
\hline CHEMBL449158 & 954508 & 6.6464 & 6.8981 & TST \\
\hline CHEMBL1788116 & 954508 & 5.6364 & 4.7508 & TST \\
\hline CHEMBL1909414 & 954508 & 4.7074 & 4.0568 & TST \\
\hline CHEMBL191334 & 954508 & 5.4511 & 4.3891 & TST \\
\hline CHEMBL102714 & 954508 & 3.2677 & 3.4413 & TST \\
\hline CHEMBL209148 & 954508 & 5.0537 & 5.1675 & TST \\
\hline CHEMBL3199475 & 954508 & 3.8765 & 5.1246 & TST \\
\hline CHEMBL25236 & 425700 & 7.41 & 7.3487 & TRN \\
\hline CHEMBL220700 & 425700 & 7.62 & 7.35 & TRN \\
\hline CHEMBL346692 & 425700 & 5.77 & 6.2868 & TRN \\
\hline CHEMBL376020 & 425700 & 7.24 & 7.3997 & TRN \\
\hline CHEMBL376445 & 425700 & 5.51 & 6.3018 & TRN \\
\hline CHEMBL221681 & 425700 & 7.77 & 7.2854 & TRN \\
\hline CHEMBL139926 & 425700 & 7.03 & 6.331 & TRN \\
\hline CHEMBL124444 & 425700 & 7.52 & 7.3249 & TRN \\
\hline CHEMBL218368 & 425700 & 6.82 & 7.2643 & TRN \\
\hline CHEMBL218318 & 425700 & 7.35 & 7.4163 & TRN \\
\hline CHEMBL221397 & 425700 & 7.51 & 7.2775 & TRN \\
\hline CHEMBL59725 & 425700 & 6.47 & 6.3541 & TRN \\
\hline CHEMBL424294 & 425700 & 7.82 & 7.3454 & TRN \\
\hline CHEMBL374749 & 425700 & 6.62 & 6.4992 & TRN \\
\hline CHEMBL221549 & 425700 & 6.77 & 6.9381 & TRN \\
\hline CHEMBL219274 & 425700 & 6.55 & 6.4642 & TRN \\
\hline CHEMBL218203 & 425700 & 6.7 & 6.4987 & TRN \\
\hline CHEMBL218150 & 425700 & 6.22 & 6.2425 & TRN \\
\hline CHEMBL218638 & 425700 & 7.4 & 7.3576 & TRN \\
\hline CHEMBL218444 & 425700 & 7.8 & 7.24100 & 20000000005 \\
\hline CHEMBL210955 & 425700 & 8.54 & 7.0606 & TRN \\
\hline CHEMBL210405 & 425700 & 9.0 & 7.3428 & TST \\
\hline CHEMBL210404 & 425700 & 9.36 & 7.7121 & TST \\
\hline CHEMBL425057 & 425700 & 8.59 & 7.3237 & TST \\
\hline CHEMBL310843 & 425700 & 8.66 & 7.0407 & TST \\
\hline CHEMBL160952 & 425700 & 8.91 & 6.8711 & TST \\
\hline
\end{tabular}




\begin{tabular}{|c|c|c|c|c|c|}
\hline \multicolumn{6}{|c|}{ plemental } \\
\hline CHEMBL423247 & 425700 & 8.57 & 6.9752 & TST & \\
\hline CHEMBL 218787 & 425700 & 8.3 & 6.9456 & TST & \\
\hline CHEMBL345357 & 425700 & 7.71 & 6.9573 & TST & \\
\hline CHEMBL 7927 & 425700 & 8.64 & 7.11 & TST & \\
\hline CHEMBL344677 & 425700 & 8.05 & 7.46700 & 00000000005 & TRN \\
\hline CHEMBL342060 & 425700 & 7.17 & 7.4382 & TRN & \\
\hline CHEMBL143352 & 425700 & 7.06 & 7.5658 & TRN & \\
\hline CHEMBL139600 & 425700 & 7.17 & 7.5745 & TRN & \\
\hline CHEMBL141845 & 425700 & 9.17 & 7.7312 & TRN & \\
\hline CHEMBL140968 & 425700 & 7.11 & 7.4494 & TRN & \\
\hline CHEMBL142020 & 425700 & 6.89 & 7.4737 & TRN & \\
\hline CHEMBL357684 & 425700 & 7.39 & 7.5275 & TRN & \\
\hline CHEMBL139722 & 425700 & 7.52 & 7.6108 & TRN & \\
\hline CHEMBL218151 & 425700 & 6.2 & 6.3618 & TRN & \\
\hline CHEMBL221129 & 425700 & 7.4 & 7.2529 & TRN & \\
\hline CHEMBL 386986 & 425700 & 7.12 & 7.2765 & TRN & \\
\hline CHEMBL217981 & 425700 & 7.38 & 7.2473 & TRN & \\
\hline CHEMBL 385289 & 425700 & 7.04 & 7.2741 & TRN & \\
\hline CHEMBL 218351 & 425700 & 6.89 & 7.1067 & TRN & \\
\hline CHEMBL 220754 & 425700 & 6.57 & 7.0741 & TRN & \\
\hline CHEMBL 221866 & 425700 & 6.54 & 6.4823 & TRN & \\
\hline CHEMBL437525 & 425700 & 6.55 & 7.0982 & TRN & \\
\hline CHEMBL 218607 & 425700 & 6.52 & 7.1149 & TRN & \\
\hline CHEMBL425285 & 425700 & 6.66 & 6.33299 & 9999999999 & Tाt \\
\hline CHEMBL221587 & 425700 & 6.8 & 7.0712 & TRN & \\
\hline CHEMBL 221897 & 425700 & 6.6 & 6.2773 & TRN & \\
\hline CHEMBL221843 & 425700 & 6.01 & 7.1045 & TRN & \\
\hline CHEMBL 373873 & 425700 & 6.55 & 6.2996 & TRN & \\
\hline CHEMBL267014 & 425700 & 9.21 & 6.8873 & TST & \\
\hline CHEMBL 221814 & 425700 & 8.49 & 7.3048 & TST & \\
\hline CHEMBL 221600 & 425700 & 9.23 & 7.3448 & TST & \\
\hline CHEMBL377200 & 425700 & 8.28 & 7.3468 & TST & \\
\hline CHEMBL 208018 & 425700 & 9.0 & 7.3003 & TST & \\
\hline CHEMBL210717 & 425700 & 9.15 & 7.2162 & TST & \\
\hline CHEMBL437490 & 425700 & 8.54 & 7.2905 & TST & \\
\hline CHEMBL135561 & 954727 & 4.3406 & 4.4742 & TRN & \\
\hline CHEMBL3349342 & 954727 & 5.25799 & 99999999 & 4.9749 & TRN \\
\hline CHEMBL 3392440 & 954727 & 4.5321 & 4.4339 & TRN & \\
\hline CHEMBL221137 & 954727 & 4.9713 & 4.8124 & TST & \\
\hline CHEMBL 258844 & 954727 & 4.6542 & 4.6306 & TRN & \\
\hline CHEMBL180127 & 954727 & 3.7005 & 3.7412 & TRN & \\
\hline CHEMBL514499 & 954727 & 7.6442 & 7.5584 & TRN & \\
\hline CHEMBL1643959 & 954727 & 3.238 & 3.1145 & TRN & \\
\hline CHEMBL1357247 & 954727 & 3.9447 & 3.7761 & TRN & \\
\hline CHEMBL102714 & 954727 & 4.6463 & 4.8453 & TRN & \\
\hline CHEMBL 220241 & 954727 & 3.721 & 3.8193 & TRN & \\
\hline CHEMBL1909414 & 954727 & 3.6536 & 3.7087 & TRN & \\
\hline CHEMBL1186585 & 954727 & 4.6974 & 4.6536 & TRN & \\
\hline
\end{tabular}

Page 23332 


\begin{tabular}{|c|c|c|c|c|c|}
\hline \multicolumn{6}{|c|}{ Supplemental Table S2.txt } \\
\hline CHEMBL449158 & 954727 & 6.914 & 7.5804 & TST & \\
\hline CHEMBL1516890 & 954727 & 4.7334 & 4.6724 & TRN & \\
\hline CHEMBL1190711 & 954727 & 4.9143 & 5.0402 & TRN & \\
\hline CHEMBL393929 & 954727 & 4.2799 & 4.4168 & TRN & \\
\hline CHEMBL65 & 954727 & 8.4598 & 8.5262 & TRN & \\
\hline CHEMBL 2134202 & 954727 & 4.2451 & 4.2868 & TRN & \\
\hline CHEMBL217354 & 954727 & 7.4027 & 7.586 & TRN & \\
\hline CHEMBL3186408 & 954727 & 4.2217 & 3.4073 & TST & \\
\hline CHEMBL 210618 & 954727 & 3.5163 & 3.4903 & TRN & \\
\hline CHEMBL188678 & 954727 & 5.0785 & 5.1184 & TRN & \\
\hline CHEMBL202721 & 954727 & 5.5546 & 5.6633 & TRN & \\
\hline CHEMBL379300 & 954727 & 6.8884 & 6.8146 & TRN & \\
\hline CHEMBL515416 & 954727 & 4.8345 & 4.7763 & TRN & \\
\hline CHEMBL412142 & 954727 & 3.5818 & 3.6523 & TRN & \\
\hline CHEMBL509032 & 954727 & 5.6957 & 5.6586 & TRN & \\
\hline CHEMBL1590308 & 954727 & 3.0282 & 3.0454 & TST & \\
\hline CHEMBL472940 & 954727 & 3.2061 & 3.2799 & TRN & \\
\hline CHEMBL 2005886 & 954727 & 4.5611 & 4.9201 & TRN & \\
\hline CHEMBL379975 & 954727 & 5.8232 & 5.7945 & TRN & \\
\hline CHEMBL1788116 & 954727 & 4.9156 & 4.8279 & TRN & \\
\hline CHEMBL1230020 & 954727 & 4.9994 & 4.8468 & TRN & \\
\hline CHEMBL483849 & 954727 & 3.0866 & 1.7315 & TST & \\
\hline CHEMBL585951 & 954727 & 6.6876 & 6.5258 & TRN & \\
\hline CHEMBL192566 & 954727 & 7.7406 & 9.2824 & TST & \\
\hline CHEMBL 213100 & 954727 & 6.3348 & 6.3581 & TRN & \\
\hline CHEMBL92309 & 954727 & 3.0424 & 2.7413 & TST & \\
\hline CHEMBL240954 & 954727 & 3.6858 & 3.7193 & TST & \\
\hline CHEMBL9470 & 954727 & 6.3973 & 5.9271 & TST & \\
\hline CHEMBL373751 & 954727 & 3.3251 & 3.3257 & TRN & \\
\hline CHEMBL399530 & 954727 & 4.6986 & 4.6143 & TRN & \\
\hline CHEMBL255342 & 954727 & 3.4474 & 3.6108 & TRN & \\
\hline CHEMBL483847 & 954727 & 4.2007 & 4.0645 & TRN & \\
\hline CHEMBL573107 & 954727 & 4.0927 & 4.19600 & 0000000001 & TRN \\
\hline CHEMBL209148 & 954727 & 4.545 & 4.38399 & 99999999995 & TRN \\
\hline CHEMBL191334 & 954727 & 5.595 & 5.6037 & TRN & \\
\hline CHEMBL577784 & 954727 & 6.0067 & 5.9321 & TRN & \\
\hline CHEMBL3199475 & 954727 & 3.8101 & 3.7741 & TRN & \\
\hline CHEMBL189584 & 954727 & 3.8998 & 3.8254 & TRN & \\
\hline CHEMBL512504 & 954727 & 3.9474 & 3.8245 & TRN & \\
\hline CHEMBL 222102 & 954727 & 4.0227 & 4.0833 & TRN & \\
\hline CHEMBL1256459 & 954727 & 8.007 & 7.9748 & TRN & \\
\hline CHEMBL1673039 & 954727 & 3.8667 & 3.9858 & TRN & \\
\hline CHEMBL558642 & 954727 & 5.0437 & 5.0632 & TRN & \\
\hline CHEMBL 2137530 & 954727 & 5.0599 & 5.0639 & TRN & \\
\hline CHEMBL 2144069 & 954727 & 3.8384 & 4.9862 & TST & \\
\hline CHEMBL259181 & 954727 & 5.5893 & 4.6422 & TST & \\
\hline CHEMBL392695 & 954727 & 6.0949 & 5.4563 & TST & \\
\hline CHEMBL1242367 & 954727 & 3.6846 & 3.6183 & TST & \\
\hline
\end{tabular}




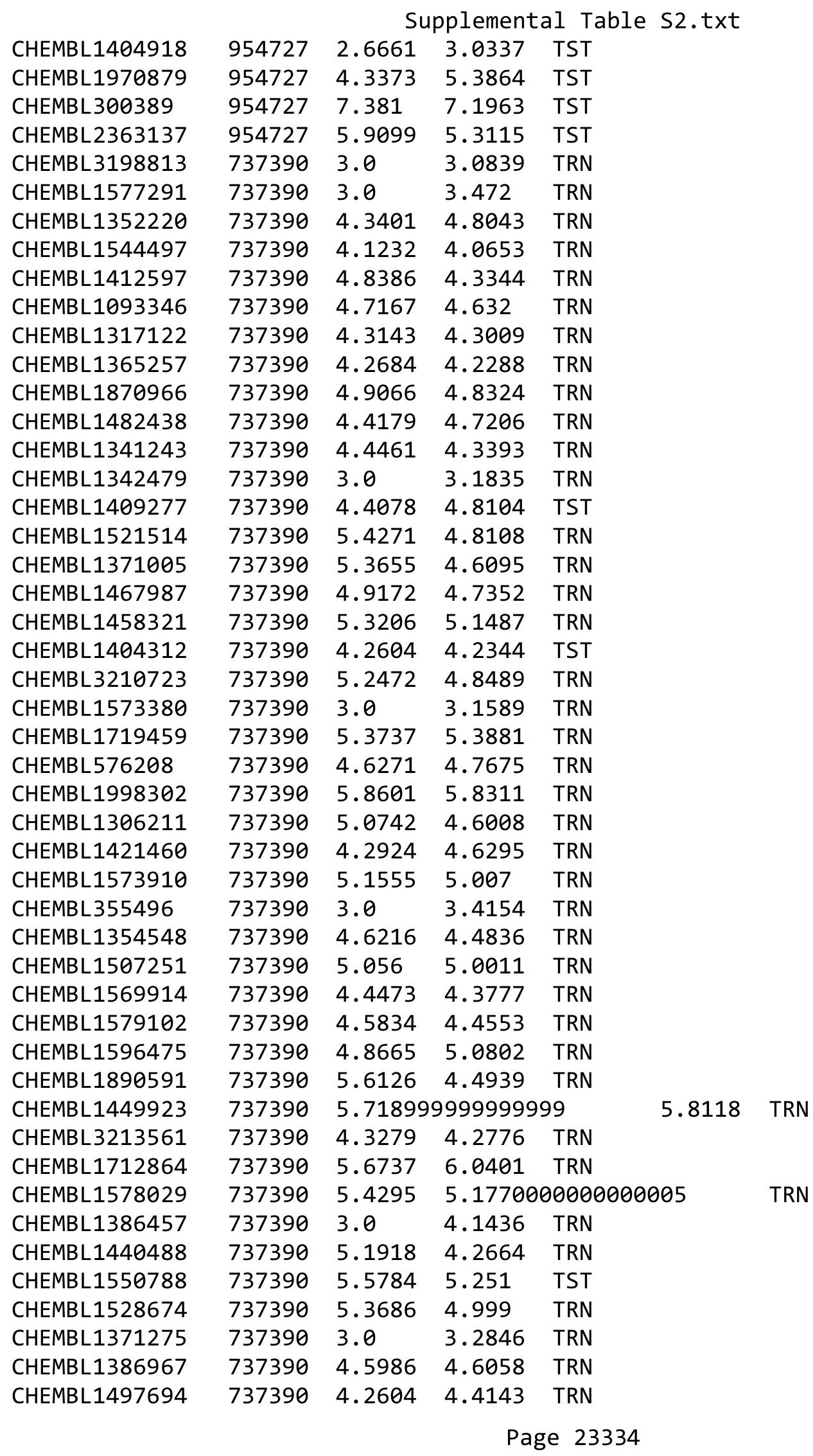


Supplemental Table S2.txt

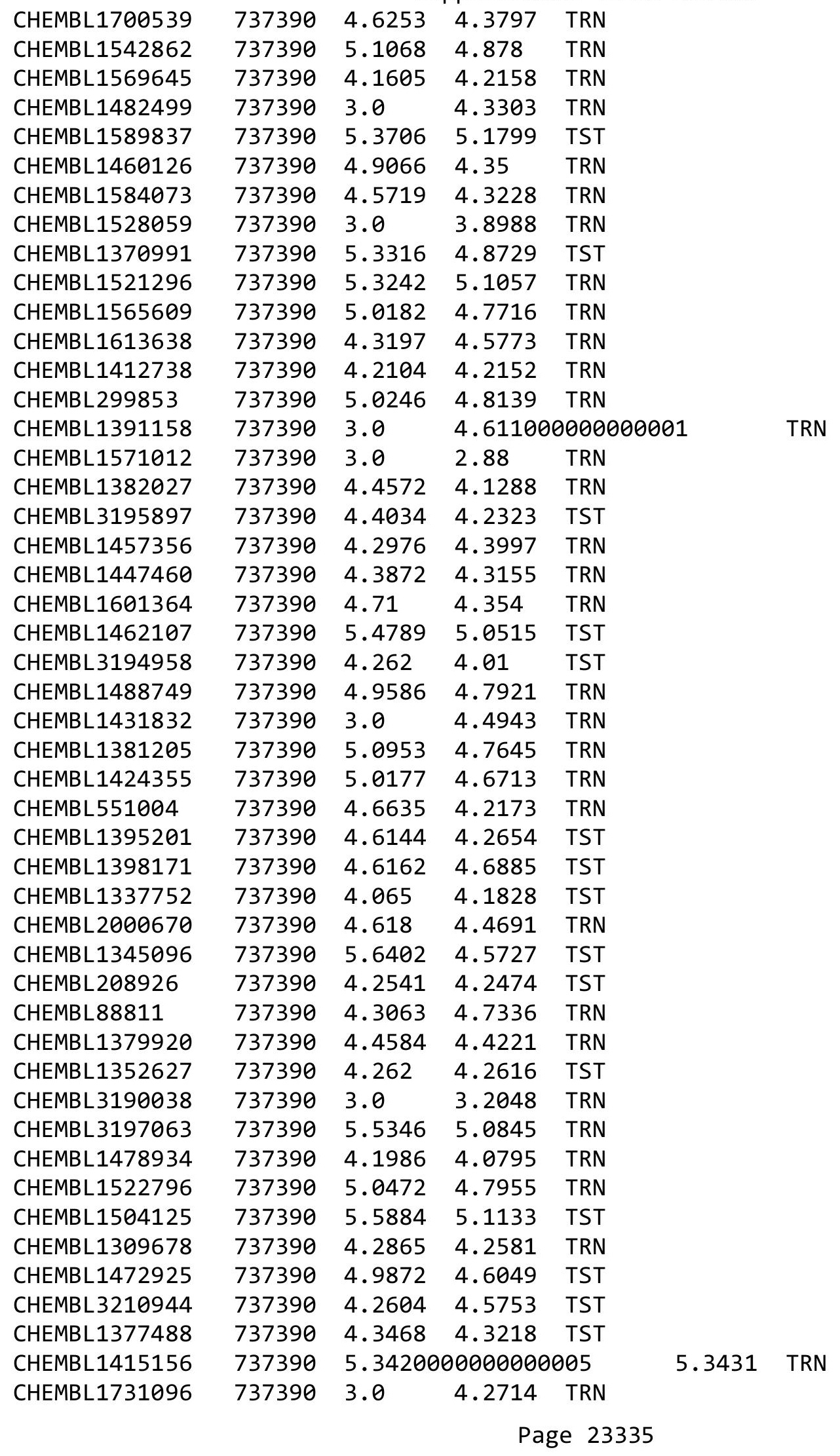




\begin{tabular}{|c|c|c|c|c|c|c|}
\hline & & \multicolumn{5}{|c|}{ Supplemental Table S2.txt } \\
\hline CHEMBL1343309 & 737390 & 3.0 & 3.3882 & TRN & & \\
\hline CHEMBL1523036 & 737390 & 4.6946 & 4.4034 & TRN & & \\
\hline CHEMBL1361268 & 737390 & 4.6003 & 3.3025 & TRN & & \\
\hline CHEMBL1449597 & 737390 & 3.0 & 3.3786 & TRN & & \\
\hline CHEMBL3199870 & 737390 & \multicolumn{3}{|c|}{4.821000000000001} & 4.6992 & TRN \\
\hline CHEMBL1522470 & 737390 & 4.6253 & 4.3678 & TRN & & \\
\hline CHEMBL63883 & 737390 & 3.0 & 3.8257 & TRN & & \\
\hline CHEMBL1535290 & 737390 & 4.6021 & 4.2165 & TRN & & \\
\hline CHEMBL1312888 & 737390 & 3.0 & 3.2791 & TRN & & \\
\hline CHEMBL1531764 & 737390 & 4.4559 & 4.2034 & TRN & & \\
\hline CHEMBL1387558 & 737390 & 4.0083 & 3.9606 & TRN & & \\
\hline CHEMBL1707033 & 737390 & 5.6108 & 6.0316 & TRN & & \\
\hline CHEMBL1439396 & 737390 & 3.0 & 3.3079 & TRN & & \\
\hline CHEMBL1546423 & 737390 & 4.7696 & 4.4982 & TRN & & \\
\hline CHEMBL1309254 & 737390 & 3.0 & 4.5254 & TST & & \\
\hline CHEMBL1600286 & 737390 & 5.341 & 4.8552 & TRN & & \\
\hline CHEMBL233119 & 737390 & 3.0 & 3.3795 & TRN & & \\
\hline CHEMBL1313683 & 737390 & 5.0083 & 4.4583 & TRN & & \\
\hline CHEMBL1698189 & 737390 & 3.0 & 3.0332 & TRN & & \\
\hline CHEMBL1389725 & 737390 & 4.082 & 4.5638 & TRN & & \\
\hline CHEMBL1892270 & 737390 & 3.0 & 3.0731 & TRN & & \\
\hline CHEMBL1500091 & 737390 & 4.757 & 4.4235 & TST & & \\
\hline CHEMBL3199687 & 737390 & 3.0 & 4.8619 & TST & & \\
\hline CHEMBL1525722 & 737390 & 4.4908 & 4.4293 & TRN & & \\
\hline CHEMBL1967857 & 737390 & 5.5817 & 5.279 & TST & & \\
\hline CHEMBL1428614 & 737390 & 4.3686 & 4.4991 & TRN & & \\
\hline CHEMBL1595804 & 737390 & 4.9957 & 4.4913 & TRN & & \\
\hline CHEMBL1328084 & 737390 & 4.9393 & 4.7142 & TRN & & \\
\hline CHEMBL1392424 & 737390 & 4.3468 & 4.2769 & TRN & & \\
\hline CHEMBL1714407 & 737390 & 4.5884 & 4.1503 & TRN & & \\
\hline CHEMBL1427898 & 737390 & 3.0 & 4.3935 & TRN & & \\
\hline CHEMBL1598139 & 737390 & 4.6395 & 4.3671 & TRN & & \\
\hline CHEMBL1969992 & 737390 & 3.0 & 3.1226 & TST & & \\
\hline CHEMBL1421377 & 737390 & 5.6904 & 5.0335 & TST & & \\
\hline CHEMBL1319034 & 737390 & 3.0 & 2.947 & TRN & & \\
\hline CHEMBL3196451 & 737390 & 6.6126 & 6.0978 & TRN & & \\
\hline CHEMBL1575677 & 737390 & 3.0 & 3.4471 & TRN & & \\
\hline CHEMBL1500164 & 737390 & 3.0 & 4.1416 & TRN & & \\
\hline CHEMBL3191524 & 737390 & 4.248 & 4.2025 & TRN & & \\
\hline CHEMBL1515340 & 737390 & 3.0 & 3.2113 & TRN & & \\
\hline CHEMBL1732672 & 737390 & 4.6126 & 4.5231 & TRN & & \\
\hline CHEMBL1506756 & 737390 & 5.3161 & 5.1013 & TRN & & \\
\hline CHEMBL546865 & 737390 & 3.0 & 2.9253 & TRN & & \\
\hline CHEMBL1379892 & 737390 & \multicolumn{3}{|c|}{5.2620000000000005} & 4.6529 & TRN \\
\hline CHEMBL1405401 & 737390 & 3.0 & 2.9517 & TRN & & \\
\hline CHEMBL1432044 & 737390 & 5.5031 & 3.1885 & TRN & & \\
\hline CHEMBL1338489 & 737390 & 5.2262 & 4.5797 & TRN & & \\
\hline \multirow[t]{2}{*}{ CHEMBL3190081 } & 737390 & 3.0 & 4.1695 & TRN & & \\
\hline & & \multicolumn{5}{|c|}{ Page 23336} \\
\hline
\end{tabular}




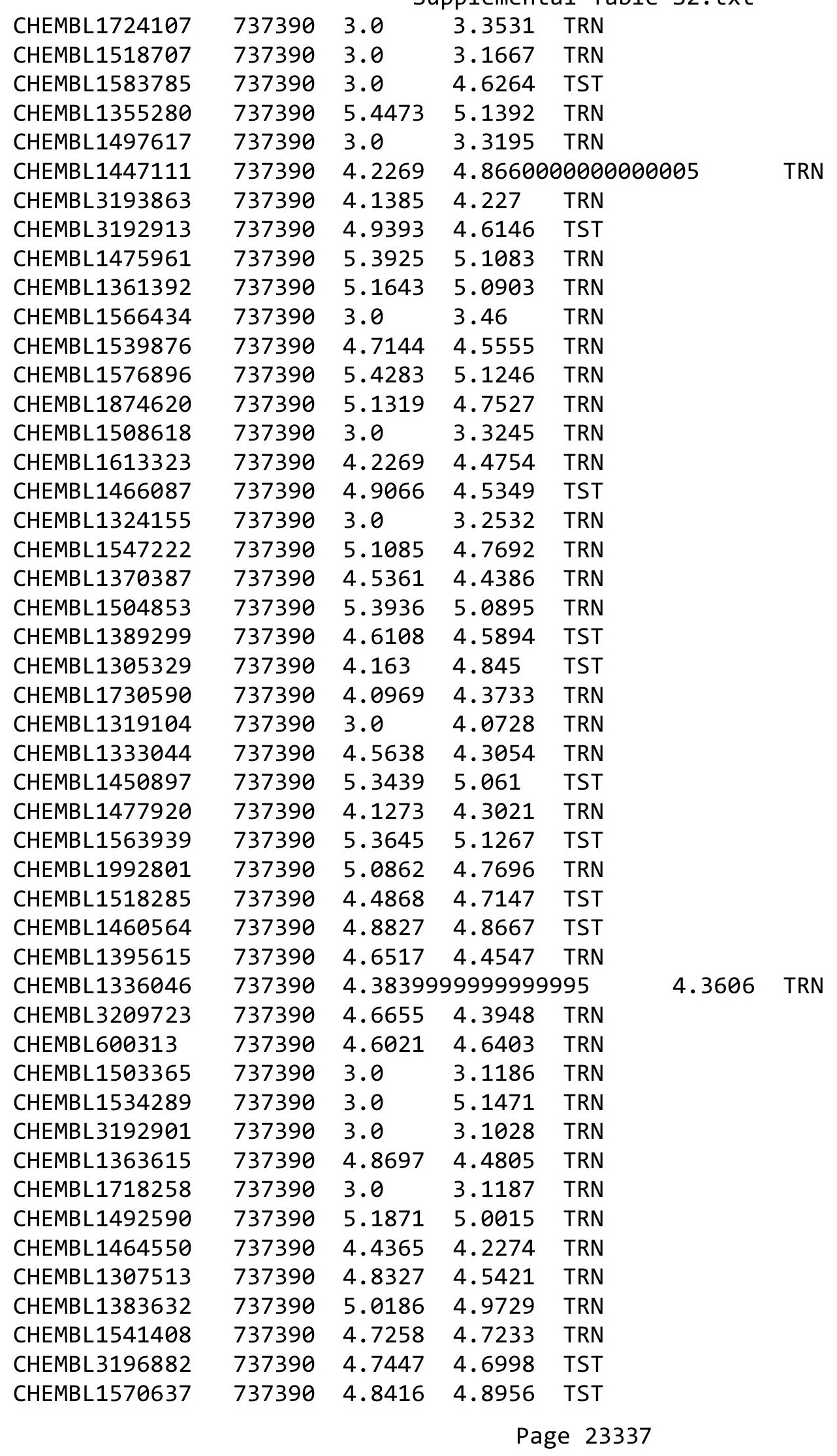




\begin{tabular}{|c|c|c|c|c|c|}
\hline & & \multicolumn{4}{|c|}{ Supplemental Table S2.txt } \\
\hline CHEMBL236899 & 737390 & 4.8097 & 4.8322 & TRN & \\
\hline CHEMBL1517624 & 737390 & 5.0079 & 4.1853 & TRN & \\
\hline CHEMBL1387749 & 737390 & 4.5258 & 4.2075 & TRN & \\
\hline CHEMBL1604600 & 737390 & 4.6904 & 4.5519 & TST & \\
\hline CHEMBL1309946 & 737390 & 4.1878 & 4.8239 & TRN & \\
\hline CHEMBL1348741 & 737390 & 4.8125 & 4.6014 & TRN & \\
\hline CHEMBL3144856 & 737390 & 5.0799 & 4.9012 & TST & \\
\hline CHEMBL1480369 & 737390 & 3.0 & 3.2927 & TRN & \\
\hline CHEMBL1435486 & 737390 & 3.0 & 3.5053 & TRN & \\
\hline CHEMBL3195749 & 737390 & 4.3851 & 5.6464 & TRN & \\
\hline CHEMBL1597726 & 737390 & 4.6126 & 4.4735 & TST & \\
\hline CHEMBL3209654 & 737390 & 3.0 & 5.121 & TST & \\
\hline CHEMBL1374950 & 737390 & 4.8268 & 4.5594 & TRN & \\
\hline CHEMBL1432131 & 737390 & 4.9626 & 3.1684 & TRN & \\
\hline CHEMBL 2000196 & 737390 & 5.4609 & 5.256 & TST & \\
\hline CHEMBL1500694 & 737390 & 4.5638 & 4.2156 & TRN & \\
\hline CHEMBL1904348 & 737390 & 4.0615 & 4.895 & TST & \\
\hline CHEMBL3197446 & 737390 & 4.7669 & 99999999 & 4.6615 & TRI \\
\hline CHEMBL1484459 & 737390 & 3.0 & 3.1368 & TRN & \\
\hline CHEMBL1426692 & 737390 & 4.9747 & 4.581 & TST & \\
\hline CHEMBL1464949 & 737390 & 5.4168 & 5.1835 & TRN & \\
\hline CHEMBL1556089 & 737390 & 4.2782 & 4.0616 & TRN & \\
\hline CHEMBL1493528 & 737390 & 4.7696 & 4.8637 & TRN & \\
\hline CHEMBL1548872 & 737390 & 5.3143 & 4.9125 & TST & \\
\hline CHEMBL1426042 & 737390 & 3.0 & 3.0731 & TRN & \\
\hline CHEMBL1429243 & 737390 & 4.5918 & 4.5873 & TRN & \\
\hline CHEMBL1506031 & 737390 & 4.9914 & 4.6197 & TST & \\
\hline CHEMBL1719113 & 737390 & 5.6144 & 4.8839 & TST & \\
\hline CHEMBL1398836 & 737390 & 4.5622 & 4.3371 & TRN & \\
\hline CHEMBL340701 & 737390 & 5.4461 & 5.0548 & TRN & \\
\hline CHEMBL1367313 & 737390 & 4.6234 & 4.6073 & TRN & \\
\hline CHEMBL1519816 & 737390 & 3.0 & 4.1711 & TRN & \\
\hline CHEMBL1582309 & 737390 & 4.3556 & 4.3468 & TRN & \\
\hline CHEMBL1606065 & 737390 & 4.2226 & 4.3419 & TRN & \\
\hline CHEMBL1475673 & 737390 & 3.0 & 3.1292 & TRN & \\
\hline CHEMBL3197805 & 737390 & 5.2684 & 5.1574 & TST & \\
\hline CHEMBL1308385 & 737390 & 5.0419 & 4.6739 & TRN & \\
\hline CHEMBL1458444 & 737390 & 5.3635 & 5.1785 & TRN & \\
\hline CHEMBL1304247 & 737390 & 4.3179 & 4.0927 & TST & \\
\hline CHEMBL1321156 & 737390 & 4.2757 & 4.19300 & 00000000005 & TRI \\
\hline CHEMBL1475128 & 737390 & 5.8153 & 5.4507 & TRN & \\
\hline CHEMBL1708975 & 737390 & 4.1605 & 4.3406 & TRN & \\
\hline CHEMBL1365104 & 737390 & 4.8297 & 4.5825 & TST & \\
\hline CHEMBL1595926 & 737390 & 5.0205 & 4.7679 & TRN & \\
\hline CHEMBL1510959 & 737390 & 4.7375 & 4.8678 & TST & \\
\hline CHEMBL412603 & 737390 & 4.7905 & 4.2894 & TRN & \\
\hline CHEMBL3208275 & 737390 & 3.0 & 3.4042 & TRN & \\
\hline CHEMBL1469091 & 737390 & 5.2175 & 4.8854 & TST & \\
\hline
\end{tabular}




\begin{tabular}{|c|c|c|c|c|c|}
\hline \multicolumn{6}{|c|}{ Supplemental Table S2.txt } \\
\hline CHEMBL1440766 & 737390 & 3.0 & 2.8866 & TRN & \\
\hline CHEMBL1341119 & 737390 & 4.7122 & 4.5642 & TRN & \\
\hline CHEMBL1379048 & 737390 & 5.3883 & 4.7684 & TST & \\
\hline CHEMBL1408715 & 737390 & 4.9706 & 4.6099 & TRN & \\
\hline CHEMBL1319768 & 737390 & 3.0 & 4.2474 & TRN & \\
\hline CHEMBL1980744 & 737390 & 4.8477 & 4.9718 & TRN & \\
\hline CHEMBL1422087 & 737390 & 5.1209 & 4.8616 & TST & \\
\hline CHEMBL1410437 & 737390 & 4.4023 & 4.6068 & TRN & \\
\hline CHEMBL1569920 & 737390 & 5.5735 & 4.8713 & TST & \\
\hline CHEMBL1412585 & 737390 & 4.3458 & 4.3117 & TRN & \\
\hline CHEMBL1538518 & 737390 & 4.2636 & 4.2299 & TST & \\
\hline CHEMBL1875040 & 737390 & 3.0 & 4.6152 & TRN & \\
\hline CHEMBL1412678 & 737390 & 4.9431 & 4.6005 & TRN & \\
\hline CHEMBL1301421 & 737390 & 3.0 & 3.9367 & TRN & \\
\hline CHEMBL1503246 & 737390 & 4.7909 & 4.2237 & TRN & \\
\hline CHEMBL1719382 & 737390 & 3.0 & 3.0884 & TRN & \\
\hline CHEMBL1372677 & 737390 & 4.1506 & 4.0414 & TRN & \\
\hline CHEMBL1605528 & 737390 & 4.6478 & 4.6106 & TRN & \\
\hline CHEMBL1489745 & 737390 & 5.27 & 5.0543 & TRN & \\
\hline CHEMBL1443965 & 737390 & 4.9136 & 4.5219 & TRN & \\
\hline CHEMBL1424024 & 737390 & 4.3585 & 4.2818 & TRN & \\
\hline CHEMBL1542876 & 737390 & 4.433 & 4.3094 & TST & \\
\hline CHEMBL1504679 & 737390 & 4.6144 & 4.4818 & TST & \\
\hline CHEMBL1309184 & 737390 & 4.1878 & 4.3264 & TRN & \\
\hline CHEMBL1522941 & 737390 & 5.2197 & 5.1338 & TRN & \\
\hline CHEMBL1434792 & 737390 & 5.4034 & 5.1654 & TRN & \\
\hline CHEMBL3196108 & 737390 & 5.1238 & 5.0114 & TRN & \\
\hline CHEMBL3196452 & 737390 & 4.9706 & 4.5179 & TRN & \\
\hline CHEMBL 1483444 & 737390 & 4.5317 & 4.175 & TST & \\
\hline CHEMBL1588557 & 737390 & 5.0555 & 4.56800 & 00000000005 & TRN \\
\hline CHEMBL1504945 & 737390 & 4.5258 & 4.3063 & TRN & \\
\hline CHEMBL442925 & 737390 & 4.4056 & 4.6446 & TRN & \\
\hline CHEMBL1373577 & 737390 & 4.6655 & 4.6967 & TRN & \\
\hline CHEMBL1432894 & 737390 & 3.0 & 4.0721 & TRN & \\
\hline CHEMBL1975547 & 737390 & 5.3893 & 5.0189 & TRN & \\
\hline CHEMBL1401768 & 737390 & 4.1555 & 4.1453 & TRN & \\
\hline CHEMBL1336070 & 737390 & 4.3449 & 4.4727 & TRN & \\
\hline CHEMBL1412627 & 737390 & 4.7235 & 4.2286 & TRN & \\
\hline CHEMBL3213606 & 737390 & 4.3757 & 4.3551 & TRN & \\
\hline CHEMBL1387710 & 737390 & 4.8633 & 4.4026 & TST & \\
\hline CHEMBL1402386 & 737390 & 3.0 & 4.529 & TRN & \\
\hline CHEMBL1513162 & 737390 & 4.5735 & 4.6146 & TRN & \\
\hline CHEMBL1581330 & 737390 & 3.0 & 3.2224 & TRN & \\
\hline CHEMBL1470135 & 737390 & 4.8928 & 4.8196 & TRN & \\
\hline CHEMBL1462381 & 737390 & 4.382 & 4.4753 & TRN & \\
\hline CHEMBL1413787 & 737390 & 3.0 & 4.3128 & TRN & \\
\hline CHEMBL1323994 & 737390 & 4.5361 & 4.417 & TST & \\
\hline CHEMBL1328930 & 737390 & 4.6696 & 4.4154 & TRN & \\
\hline
\end{tabular}




\begin{tabular}{|c|c|c|c|c|c|c|c|}
\hline \multicolumn{7}{|c|}{ Supplemental Table S2.txt } & \\
\hline CHEMBL1501990 & 737390 & 5.3575 & 5.13 & TRN & & & \\
\hline CHEMBL1349748 & 737390 & 5.61799 & 99999999 & & 5.1701 & TST & \\
\hline CHEMBL1506796 & 737390 & 5.7258 & 5.3524 & TRN & & & \\
\hline CHEMBL1332928 & 737390 & 4.752 & 4.7197 & TST & & & \\
\hline CHEMBL1560459 & 737390 & 4.0867 & 4.313 & TST & & & \\
\hline CHEMBL1493516 & 737390 & 4.8962 & 4.529 & TRN & & & \\
\hline CHEMBL1354754 & 737390 & 5.2175 & 5.0899 & TRN & & & \\
\hline CHEMBL1385557 & 737390 & 3.0 & 3.1088 & TST & & & \\
\hline CHEMBL1573287 & 737390 & 3.0 & 4.3444 & TRN & & & \\
\hline CHEMBL1380580 & 737390 & 5.5129 & 4.9616 & TRN & & & \\
\hline CHEMBL1479657 & 737390 & 5.5513 & 4.8729 & TRN & & & \\
\hline CHEMBL1397706 & 737390 & 4.9706 & 4.4678 & TST & & & \\
\hline CHEMBL1380030 & 737390 & 4.4763 & 4.42399 & 999999999 & 995 & TRN & \\
\hline CHEMBL1528847 & 737390 & 4.8633 & 4.1856 & TRN & & & \\
\hline CHEMBL3194419 & 737390 & 3.0 & 3.0791 & TRN & & & \\
\hline CHEMBL1520808 & 737390 & 4.618 & 4.3235 & TRN & & & \\
\hline CHEMBL1351535 & 737390 & 3.0 & 3.1735 & TRN & & & \\
\hline CHEMBL3193227 & 737390 & 3.0 & 3.0675 & TRN & & & \\
\hline CHEMBL3209143 & 737390 & 4.6289 & 4.4448 & TRN & & & \\
\hline CHEMBL1584930 & 737390 & 3.0 & 4.724 & TRN & & & \\
\hline CHEMBL1353712 & 737390 & 4.71899 & 99999999 & 99 & 4.4830 & 0000000005 & TRN \\
\hline CHEMBL1315825 & 737390 & 4.6364 & 4.4893 & TRN & & & \\
\hline CHEMBL1528211 & 737390 & 4.5031 & 4.2313 & TRN & & & \\
\hline CHEMBL1501910 & 737390 & 4.5834 & 4.3031 & TRN & & & \\
\hline CHEMBL1602108 & 737390 & 4.5607 & 4.3971 & TRN & & & \\
\hline CHEMBL1605599 & 737390 & 4.7595 & 4.9658 & TRN & & & \\
\hline CHEMBL546170 & 737390 & 3.0 & 4.9218 & TRN & & & \\
\hline CHEMBL1507938 & 737390 & 4.7258 & 4.2963 & TRN & & & \\
\hline CHEMBL1430214 & 737390 & 4.3458 & 4.2723 & TRN & & & \\
\hline CHEMBL1421263 & 737390 & 3.0 & 4.5579 & TST & & & \\
\hline CHEMBL1516968 & 737390 & 4.2396 & 4.1464 & TRN & & & \\
\hline CHEMBL1444349 & 737390 & 5.0453 & 4.4884 & TST & & & \\
\hline CHEMBL1364988 & 737390 & 5.6968 & 4.9446 & TRN & & & \\
\hline CHEMBL3211987 & 737390 & 3.0 & 4.2896 & TRN & & & \\
\hline CHEMBL1343697 & 737390 & 4.8827 & 4.6933 & TST & & & \\
\hline CHEMBL1471498 & 737390 & 5.3036 & 5.4302 & TRN & & & \\
\hline CHEMBL 3199034 & 737390 & 4.2588 & 4.2597 & TRN & & & \\
\hline CHEMBL3197982 & 737390 & 5.7595 & 4.9492 & TRN & & & \\
\hline CHEMBL1505544 & 737390 & 4.8761 & 4.8902 & TRN & & & \\
\hline CHEMBL1898479 & 737390 & 4.7645 & 4.871 & TRN & & & \\
\hline CHEMBL1165723 & 737390 & 4.9957 & 4.7459 & TRN & & & \\
\hline CHEMBL1457057 & 737390 & 5.0516 & 4.9094 & TRN & & & \\
\hline CHEMBL1461427 & 737390 & 3.0 & 2.9439 & TRN & & & \\
\hline CHEMBL1537846 & 737390 & 4.5702 & 4.328 & TRN & & & \\
\hline CHEMBL1988699 & 737390 & 4.6198 & 4.1242 & TRN & & & \\
\hline CHEMBL1342248 & 737390 & 4.9914 & 4.5503 & TRN & & & \\
\hline CHEMBL1405940 & 737390 & 5.0248 & 4.2122 & TRN & & & \\
\hline CHEMBL1322521 & 737390 & 4.8386 & 4.4223 & TRN & & & \\
\hline
\end{tabular}




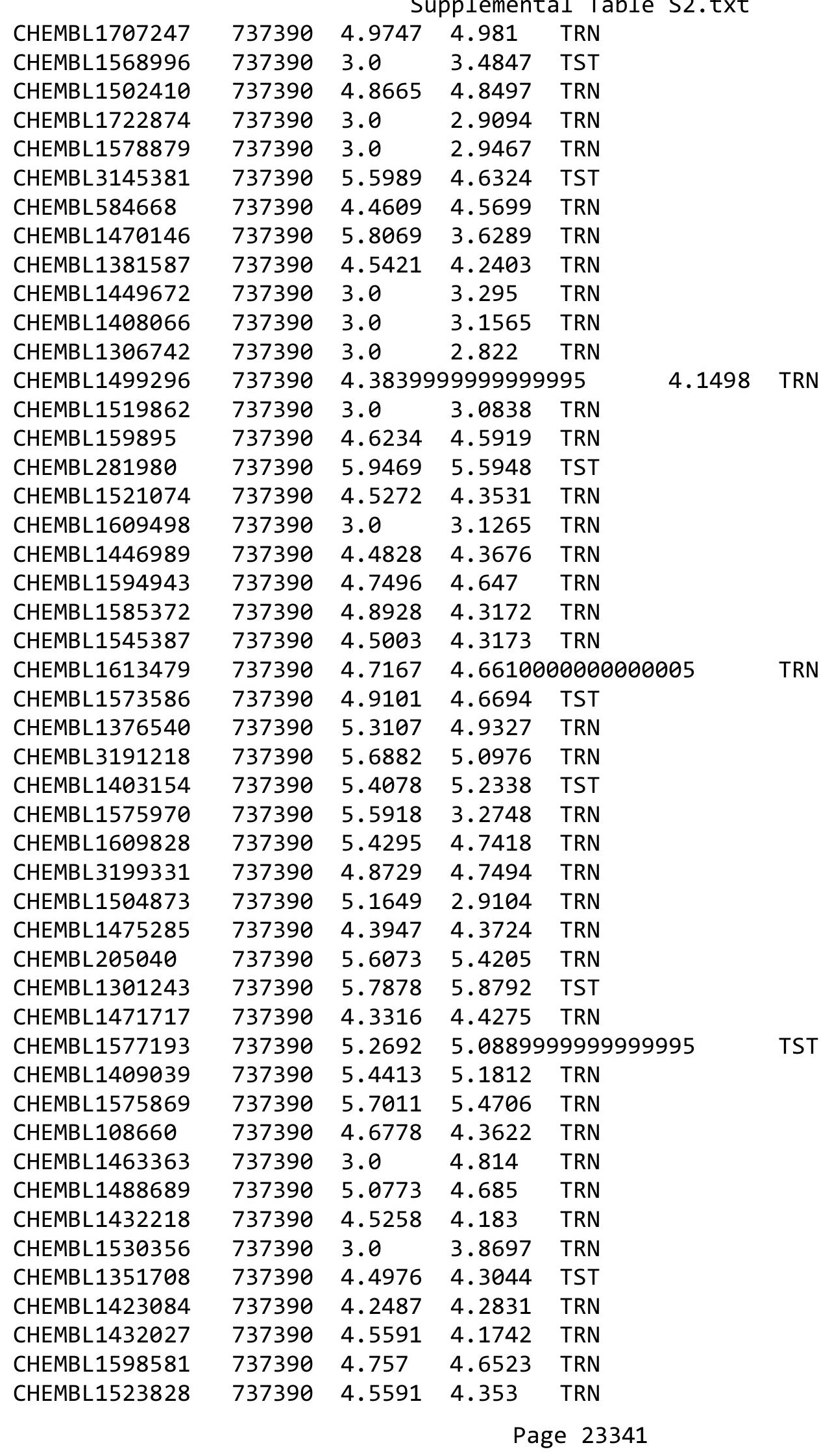


Supplemental Table S2.txt

\begin{tabular}{|c|c|c|c|c|}
\hline HEN & & & & \\
\hline HEMBL1465938 & 37390 & 5.0273 & 5.0115 & \\
\hline 98 & 90 & & 1078 & \\
\hline AEMBL1563187 & 7390 & & 1351 & \\
\hline AEMBL3197545 & 37390 & 596 & 1553 & \\
\hline HEMBL3190751 & 37390 & 672 & 1955 & \\
\hline HEMBL1322948 & 7390 & & .742 & \\
\hline IEMBL1427194 & 7390 & & & \\
\hline AEMBL1372256 & 37390 & & 316 & \\
\hline HEMBL1427991 & 7390 & & 7127 & \\
\hline AEMBL3145370 & 7390 & & 5074 & \\
\hline EMBL14 & 7390 & & 165 & \\
\hline IEMBL15 & & & & \\
\hline HEMBL510279 & 37390 & 761 & 8557 & \\
\hline AEMBL1344555 & 390 & 3. & 063 & \\
\hline AEMBL15 & 7390 & 3 & 3799 & \\
\hline AEMBL1563664 & 390 & & 173 & \\
\hline HEMBL1381216 & 90 & & 837 & \\
\hline HEMBL3196057 & 37390 & $3 .+2>$ & 8455 & \\
\hline AEMBL13e & 90 & & & \\
\hline HEMBL 14 & 90 & 2 & 378 & KIV \\
\hline AEMBL19 & 90 & & & 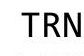 \\
\hline HEMBL15 & 90 & & 068 & \\
\hline AEMBL1480814 & 390 & & 724 & \\
\hline AEMBL15 & & & & (3) \\
\hline AEMBL14 & 90 & & 742 & RN \\
\hline HEMBL14 & 90 & & 33 & ST \\
\hline AFMBI 13 & 90 & & 68 & \\
\hline HEMBL 31 & & & 944 & IRIV \\
\hline HEMBL1996376 & & & & ISI \\
\hline HEMBL13 & 90 & & 113 & ST \\
\hline HEMBL1 & 90 & & 991 & RN \\
\hline 21 & 90 & & 114 & RN \\
\hline HEMBL1425406 & & & 5837 & IRN \\
\hline HEMBL1585064 & 37390 & & 3646 & ГRN \\
\hline HEMBL1342723 & 390 & & 592 & RN \\
\hline HFMRI 15 & 90 & 3 & & RN \\
\hline HEMBL1530147 & & & 252 & RN \\
\hline HEMBL3208696 & 37390 & & 144 & TRN \\
\hline JEMBL14 & 90 & & 571 & $\Gamma \mathrm{RN}$ \\
\hline HEMBL3193011 & 90 & 31 & 3603 & \\
\hline CHEMBL1379918 & & & 1.7363 & TRN \\
\hline HEMBL1495016 & 37390 & & 1309 & RN \\
\hline AEMBL1515473 & 37390 & 7 & & RN \\
\hline MBL31S & 90 & & 155 & \\
\hline HEMBL15€ & 37390 &. & 709 & \\
\hline CHEMBL3191871 & 37390 & 3.0 & 3048 & \\
\hline CHEMBL1605940 & 737390 & 5.4056 & 4.9066 & RN \\
\hline
\end{tabular}

Page 23342 


\begin{tabular}{|c|c|c|c|c|c|c|}
\hline \multicolumn{7}{|c|}{ Supplemental Table S2.txt } \\
\hline CHEMBL1392845 & 737390 & 3.0 & 3.0203 & TST & & \\
\hline CHEMBL1417815 & 737390 & 5.6861 & 5.62799 & 999999999 & & TRN \\
\hline CHEMBL1499090 & 737390 & 4.9355 & 4.6196 & TRN & & \\
\hline CHEMBL1303887 & 737390 & 5.2933 & 4.8901 & TST & & \\
\hline CHEMBL1529509 & 737390 & 4.6055 & 4.3054 & TST & & \\
\hline CHEMBL1966622 & 737390 & 3.0 & 3.0155 & TRN & & \\
\hline CHEMBL3214026 & 737390 & 4.3288 & 4.3933 & TRN & & \\
\hline CHEMBL1718271 & 737390 & 4.7905 & 4.5325 & TRN & & \\
\hline CHEMBL1560329 & 737390 & 3.0 & 4.4857 & TRN & & \\
\hline CHEMBL1598920 & 737390 & 3.0 & 3.1791 & TRN & & \\
\hline CHEMBL1494979 & 737390 & 3.0 & 4.6789 & TRN & & \\
\hline CHEMBL1568641 & 737390 & 4.6459 & 4.5098 & TRN & & \\
\hline CHEMBL3189672 & 737390 & 3.0 & 4.7186 & TRN & & \\
\hline CHEMBL1584379 & 737390 & 3.0 & 5.4883 & TRN & & \\
\hline CHEMBL570468 & 737390 & 4.3449 & 4.5441 & TRN & & \\
\hline CHEMBL1373107 & 737390 & 4.38399 & 99999999 & 995 & 4.5962 & TRN \\
\hline CHEMBL3190318 & 737390 & 3.0 & 3.313 & TRN & & \\
\hline CHEMBL 3145048 & 737390 & 4.4498 & 4.3352 & TST & & \\
\hline CHEMBL1307406 & 737390 & 5.475 & 5.2269 & TRN & & \\
\hline CHEMBL1484644 & 737390 & 5.4685 & 4.8291 & TRN & & \\
\hline CHEMBL1407802 & 737390 & 4.6459 & 4.467 & TRN & & \\
\hline CHEMBL1380540 & 737390 & 3.0 & 3.3626 & TRN & & \\
\hline CHEMBL1703849 & 737390 & 3.0 & 3.2646 & TRN & & \\
\hline CHEMBL1533086 & 737390 & 5.0555 & 4.6183 & TRN & & \\
\hline CHEMBL1427637 & 737390 & 4.8297 & 4.71899 & 999999999 & & TST \\
\hline CHEMBL3197065 & 737390 & 4.8928 & 4.5644 & TRN & & \\
\hline CHEMBL1463829 & 737390 & 5.3605 & 5.1253 & TRN & & \\
\hline CHEMBL1460321 & 737390 & 4.6144 & 4.1352 & TRN & & \\
\hline CHEMBL1485847 & 737390 & 3.0 & 3.1411 & TRN & & \\
\hline CHEMBL1468761 & 737390 & 4.5302 & 4.4884 & TRN & & \\
\hline CHEMBL1394975 & 737390 & 4.8041 & 4.4749 & TRN & & \\
\hline CHEMBL1418096 & 737390 & 5.5768 & 5.3795 & TRN & & \\
\hline CHEMBL1469986 & 737390 & 4.1593 & 4.0827 & TST & & \\
\hline CHEMBL1534545 & 737390 & 4.295 & 4.4077 & TRN & & \\
\hline CHEMBL1372464 & 737390 & 3.0 & 2.9538 & TRN & & \\
\hline CHEMBL1392754 & 737390 & 4.5171 & 4.2369 & TST & & \\
\hline CHEMBL1392564 & 737390 & 4.7077 & 4.5533 & TRN & & \\
\hline CHEMBL1389833 & 737390 & 4.5436 & 4.2806 & TRN & & \\
\hline CHEMBL1501843 & 737390 & 4.4179 & 4.5339 & TST & & \\
\hline CHEMBL1471358 & 737390 & 4.618 & 4.3569 & TRN & & \\
\hline CHEMBL1701182 & 737390 & 5.3768 & 5.1802 & TRN & & \\
\hline CHEMBL1428684 & 737390 & 4.6925 & 4.4015 & TRN & & \\
\hline CHEMBL1530113 & 737390 & 4.3188 & 4.1419 & TRN & & \\
\hline CHEMBL1531037 & 737390 & 4.2076 & 4.6044 & TRN & & \\
\hline CHEMBL336718 & 737390 & 3.0 & 4.5089 & TRN & & \\
\hline CHEMBL1400093 & 737390 & 4.9281 & 4.6541 & TST & & \\
\hline CHEMBL3193861 & 737390 & 3.0 & 4.0372 & TRN & & \\
\hline CHEMBL3191962 & 737390 & 5.8761 & 5.4312 & TST & & \\
\hline
\end{tabular}




\begin{tabular}{|c|c|c|c|c|c|}
\hline \multicolumn{6}{|c|}{ Supplemental Table S2.txt } \\
\hline CHEMBL1613216 & 737390 & 5.4935 & 4.5306 & TRN & \\
\hline CHEMBL1384143 & 737390 & 3.0 & 3.2272 & TRN & \\
\hline CHEMBL1421255 & 737390 & 5.8239 & 5.4 & TRN & \\
\hline CHEMBL1982945 & 737390 & 4.8386 & 4.84699 & 99999999995 & TRN \\
\hline CHEMBL1532623 & 737390 & 4.8327 & 4.5069 & TRN & \\
\hline CHEMBL1407928 & 737390 & 4.2336 & 4.3064 & TST & \\
\hline CHEMBL1591913 & 737390 & 5.2495 & 5.1786 & TRN & \\
\hline CHEMBL1708850 & 737390 & 4.5452 & 4.4465 & TST & \\
\hline CHEMBL1306782 & 737390 & 4.762 & 4.617 & TRN & \\
\hline CHEMBL1570824 & 737390 & 4.02 & 4.5754 & TRN & \\
\hline CHEMBL1381872 & 737390 & 4.9626 & 4.5958 & TRN & \\
\hline CHEMBL1717238 & 737390 & 3.0 & 4.7942 & TRN & \\
\hline CHEMBL1463739 & 737390 & 4.1203 & 4.2461 & TRN & \\
\hline CHEMBL1988780 & 737390 & 5.7258 & 5.5439 & TST & \\
\hline CHEMBL1582665 & 737390 & 4.5086 & 4.4636 & TRN & \\
\hline CHEMBL3210366 & 737390 & 5.0711 & 5.0222 & TRN & \\
\hline CHEMBL1322449 & 737390 & 4.3605 & 4.341 & TRN & \\
\hline CHEMBL1441265 & 737390 & 4.5952 & 4.7537 & TRN & \\
\hline CHEMBL 2369298 & 737390 & 3.0 & 3.91399 & 99999999997 & TST \\
\hline CHEMBL1479061 & 737390 & 3.0 & 3.2078 & TRN & \\
\hline CHEMBL1511922 & 737390 & 4.0635 & 4.351 & TRN & \\
\hline CHEMBL1569446 & 737390 & 4.7471 & 4.797 & TRN & \\
\hline CHEMBL1329446 & 737390 & 5.1385 & 4.68199 & 99999999995 & TRN \\
\hline CHEMBL1535900 & 737390 & 3.0 & 3.2708 & TRN & \\
\hline CHEMBL1342938 & 737390 & 3.0 & 3.2547 & TRN & \\
\hline CHEMBL1314088 & 737390 & 3.0 & 3.1978 & TRN & \\
\hline CHEMBL3195102 & 737390 & 5.6144 & 5.2753 & TRN & \\
\hline CHEMBL1307207 & 737390 & 5.0516 & 4.897 & TRN & \\
\hline CHEMBL1336877 & 737390 & 4.0942 & 4.15600 & 0000000001 & TRN \\
\hline CHEMBL1970753 & 737390 & 4.6596 & 4.3859 & TRN & \\
\hline CHEMBL1365705 & 737390 & 4.6402 & 4.3624 & TRN & \\
\hline CHEMBL1545955 & 737390 & 3.0 & 3.1547 & TRN & \\
\hline CHEMBL1320578 & 737390 & 5.1791 & 4.3298 & TST & \\
\hline CHEMBL1608383 & 737390 & 4.0227 & 4.079 & TST & \\
\hline CHEMBL1504289 & 737390 & 4.9914 & 4.626 & TRN & \\
\hline CHEMBL1361810 & 737390 & 4.9747 & 4.7021 & TRN & \\
\hline CHEMBL1406151 & 737390 & 4.5045 & 4.2762 & TRN & \\
\hline CHEMBL1322261 & 737390 & 4.4168 & 4.1567 & TST & \\
\hline CHEMBL1472212 & 737390 & 5.0031 & 4.3571 & TRN & \\
\hline CHEMBL494082 & 737390 & 5.2941 & 5.2151 & TRN & \\
\hline CHEMBL1395570 & 737390 & 4.2749 & 4.6735 & TRN & \\
\hline CHEMBL602561 & 737390 & 4.5702 & 4.5857 & TRN & \\
\hline CHEMBL1542961 & 737390 & 4.3625 & 4.3992 & TRN & \\
\hline CHEMBL1527802 & 737390 & 4.5072 & 4.4475 & TRN & \\
\hline CHEMBL1489817 & 737390 & 4.8962 & 4.6355 & TRN & \\
\hline CHEMBL1472308 & 737390 & 4.4425 & 4.3646 & TST & \\
\hline CHEMBL1864348 & 737390 & 4.6556 & 4.8871 & TRN & \\
\hline CHEMBL1093717 & 737390 & 4.2013 & 4.4865 & TRN & \\
\hline
\end{tabular}




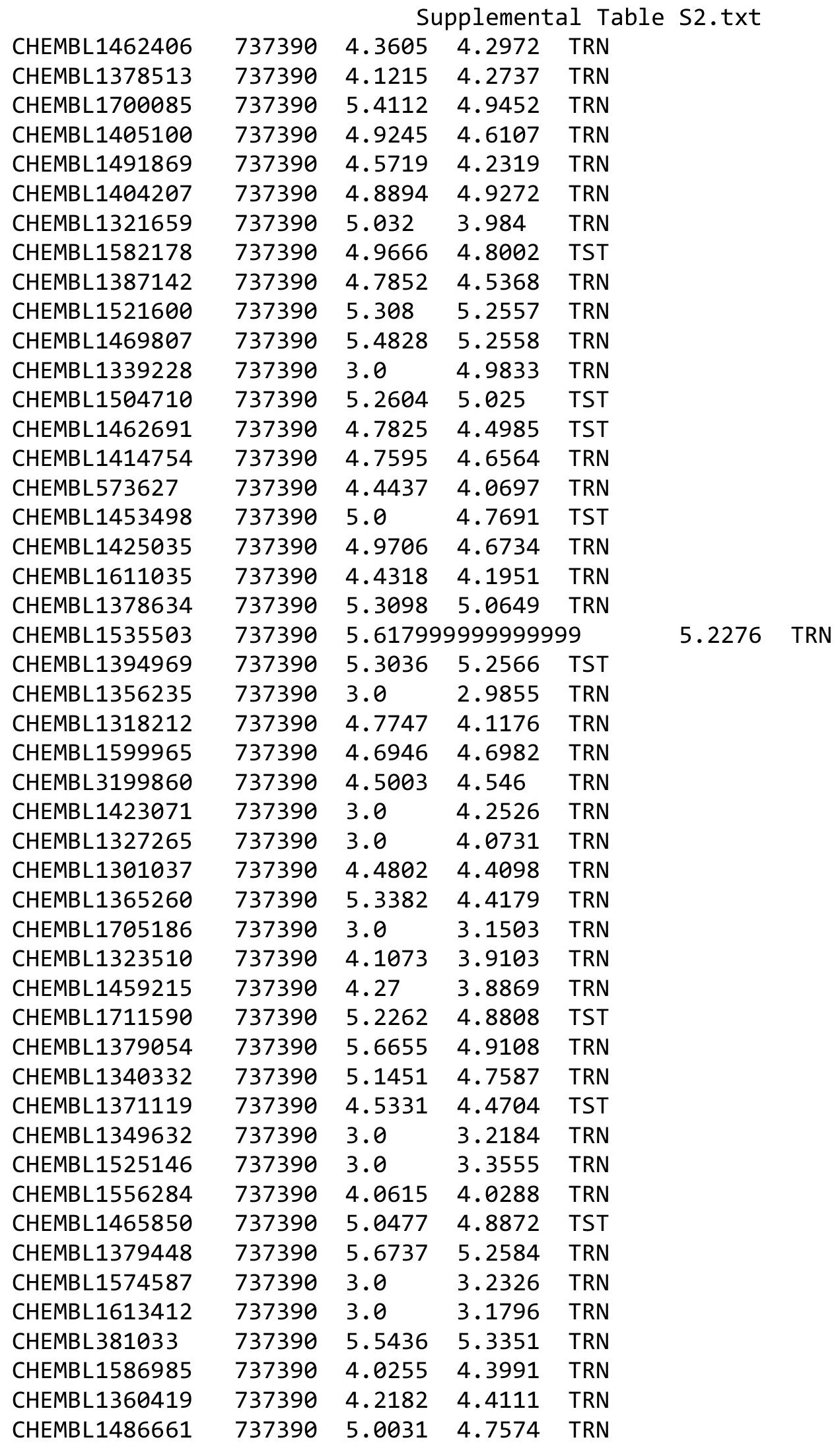

Page 23345 
Supplemental Table S2.txt

\begin{tabular}{|c|c|c|c|c|c|}
\hline CHEMBL1969046 & 737390 & 5.7496 & 5.7385 & TRN & \\
\hline CHEMBL1392911 & 737390 & 5.5622 & 5.1597 & TRN & \\
\hline CHEMBL484663 & 737390 & 4.9355 & 3.8469 & TRN & \\
\hline CHEMBL1498118 & 737390 & 3.0 & 3.2962 & TST & \\
\hline CHEMBL1964664 & 737390 & 4.1319 & 4.5196 & TRN & \\
\hline CHEMBL1559546 & 737390 & 4.1831 & 4.4223 & TRN & \\
\hline CHEMBL1491894 & 737390 & 4.6615 & 4.6396 & TRN & \\
\hline CHEMBL3189585 & 737390 & 4.0429 & 4.0077 & TRN & \\
\hline CHEMBL1532037 & 737390 & 4.7959 & 4.5953 & TRN & \\
\hline CHEMBL1732501 & 737390 & 4.3072 & 4.5656 & TST & \\
\hline CHEMBL1478825 & 737390 & 5.1209 & 5.1 & TRN & \\
\hline CHEMBL1480646 & 737390 & 4.6882 & 4.2125 & TRN & \\
\hline CHEMBL1563249 & 737390 & 4.0985 & 4.4679 & TRN & \\
\hline CHEMBL378903 & 737390 & 3.0 & 4.3771 & TRN & \\
\hline CHEMBL1438722 & 737390 & 5.6402 & 5.0935 & TRN & \\
\hline CHEMBL1559500 & 737390 & 4.9626 & 4.4946 & TRN & \\
\hline CHEMBL428789 & 737390 & 4.618 & 4.2786 & TRN & \\
\hline CHEMBL1409773 & 737390 & 4.5702 & 4.5377 & TRN & \\
\hline CHEMBL1393780 & 737390 & 4.7905 & 4.6353 & TRN & \\
\hline CHEMBL1475973 & 737390 & 4.6478 & 4.1701 & TRN & \\
\hline CHEMBL 1378542 & 737390 & 3.0 & 3.1923 & TRN & \\
\hline CHEMBL1525161 & 737390 & 3.0 & 4.7897 & TRN & \\
\hline CHEMBL1535487 & 737390 & 3.0 & 3.264 & TRN & \\
\hline CHEMBL1431732 & 737390 & 3.0 & 3.8672 & TRN & \\
\hline CHEMBL1322894 & 737390 & 4.8794 & 4.5424 & TRN & \\
\hline CHEMBL1405247 & 737390 & 4.4449 & 4.665 & TST & \\
\hline CHEMBL1542356 & 737390 & 3.0 & 4.9314 & TRN & \\
\hline CHEMBL1560004 & 737390 & 3.0 & 4.6195 & TRN & \\
\hline CHEMBL 1540987 & 737390 & 4.0501 & 4.6956 & TRN & \\
\hline CHEMBL1337075 & 737390 & 3.0 & 4.8087 & TRN & \\
\hline CHEMBL1556319 & 737390 & 5.433 & 4.6611 & TRN & \\
\hline CHEMBL1479973 & 737390 & 3.0 & 4.2932 & TRN & \\
\hline CHEMBL1539910 & 737390 & 4.4841 & 4.4123 & TRN & \\
\hline CHEMBL1332602 & 737390 & 4.3449 & 3.96199 & 99999999997 & TRN \\
\hline CHEMBL1539398 & 737390 & 3.0 & 5.0249 & TRN & \\
\hline CHEMBL1536129 & 737390 & 4.0975 & 4.229 & TRN & \\
\hline CHEMBL1342873 & 737390 & 4.6271 & 4.4639 & TRN & \\
\hline CHEMBL1604550 & 737390 & 5.4724 & 4.9924 & TRN & \\
\hline CHEMBL1411203 & 737390 & 3.0 & 4.629 & TRN & \\
\hline CHEMBL1609787 & 737390 & 3.0 & 4.8635 & TRN & \\
\hline CHEMBL1402456 & 737390 & 6.0462 & 5.5646 & TRN & \\
\hline CHEMBL3210574 & 737390 & 3.0 & 3.2183 & TST & \\
\hline CHEMBL1319534 & 737390 & 3.0 & 3.0136 & TRN & \\
\hline CHEMBL1560993 & 737390 & 4.6819 & 4.7143 & TST & \\
\hline CHEMBL1545215 & 737390 & 3.0 & 3.1572 & TRN & \\
\hline CHEMBL1438627 & 737390 & 4.8729 & 4.8883 & TRN & \\
\hline CHEMBL1426867 & 737390 & 4.7645 & 4.5161 & TRN & \\
\hline CHEMBL1302524 & 737390 & 5.2226 & 4.9372 & TRN & \\
\hline
\end{tabular}

Page 23346 


\begin{tabular}{|c|c|c|c|c|c|c|}
\hline \multicolumn{7}{|c|}{ Supplemental Table s2.txt } \\
\hline CHEMBL1447830 & 737390 & 3.0 & 3.315 & TRN & & \\
\hline CHEMBL1501135 & 737390 & 4.6073 & 4.8266 & TST & & \\
\hline CHEMBL1584557 & 737390 & 3.0 & 4.0789 & TST & & \\
\hline CHEMBL1534143 & 737390 & 4.6144 & 3.0083 & TRN & & \\
\hline CHEMBL1314677 & 737390 & 5.27 & 5.0003 & TRN & & \\
\hline CHEMBL1313386 & 737390 & 3.0 & 4.0809 & TRN & & \\
\hline CHEMBL1447078 & 737390 & 4.3958 & 4.5271 & TST & & \\
\hline CHEMBL1390831 & 737390 & 4.5884 & 4.3518 & TRN & & \\
\hline CHEMBL1550291 & 737390 & 4.4776 & 4.2664 & TRN & & \\
\hline CHEMBL1492642 & 737390 & 5.4045 & 5.2508 & TRN & & \\
\hline CHEMBL1422056 & 737390 & 4.6676 & 4.8402 & TST & & \\
\hline CHEMBL1999511 & 737390 & 4.4559 & 4.4409 & TRN & & \\
\hline CHEMBL3192666 & 737390 & 3.0 & 3.3371 & TST & & \\
\hline CHEMBL3193997 & 737390 & 5.0731 & 4.6504 & TRN & & \\
\hline CHEMBL3194932 & 737390 & 3.0 & 4.1365 & TRN & & \\
\hline CHEMBL1413278 & 737390 & 3.0 & 3.4499 & TRN & & \\
\hline CHEMBL1429870 & 737390 & 4.666 & 4.6361 & TRN & & \\
\hline CHEMBL1542328 & 737390 & 5.7375 & 5.2491 & TRN & & \\
\hline CHEMBL1498679 & 737390 & 4.7122 & 4.5212 & TRN & & \\
\hline CHEMBL1544489 & 737390 & 5.61799 & 99999999 & 99 & 4.9208 & TRN \\
\hline CHEMBL1352443 & 737390 & 3.0 & 4.6708 & TRN & & \\
\hline CHEMBL1483847 & 737390 & 4.6055 & 4.478 & TRN & & \\
\hline CHEMBL1329140 & 737390 & 5.0716 & 5.1229 & TRN & & \\
\hline CHEMBL1408395 & 737390 & 4.8477 & 4.6578 & TST & & \\
\hline CHEMBL1490171 & 737390 & 4.7328 & 4.6897 & TST & & \\
\hline CHEMBL1888528 & 737390 & 4.7258 & 4.8026 & TST & & \\
\hline CHEMBL1487632 & 737390 & 4.3556 & 4.2137 & TST & & \\
\hline CHEMBL1490198 & 737390 & 4.8239 & 4.6157 & TST & & \\
\hline CHEMBL1414729 & 737390 & 3.0 & 3.2201 & TST & & \\
\hline CHEMBL1521051 & 737390 & 5.3054 & 4.9394 & TST & & \\
\hline CHEMBL1468876 & 737390 & 3.0 & 3.2077 & TST & & \\
\hline CHEMBL1507023 & 737390 & 3.0 & 4.329 & TST & & \\
\hline CHEMBL1532928 & 737390 & 4.1487 & 4.8506 & TST & & \\
\hline CHEMBL1405521 & 737390 & 3.0 & 2.9709 & TST & & \\
\hline CHEMBL1473428 & 737390 & 5.2549 & 4.9746 & TST & & \\
\hline CHEMBL1342287 & 737390 & 3.0 & 4.4377 & TST & & \\
\hline CHEMBL3195061 & 737390 & 4.7282 & 4.5594 & TST & & \\
\hline CHEMBL1714229 & 737390 & 4.5867 & 4.3359 & TST & & \\
\hline CHEMBL1582494 & 737390 & 4.5112 & 3.222 & TST & & \\
\hline CHEMBL1379026 & 737390 & 5.2976 & 4.7593 & TST & & \\
\hline CHEMBL1556240 & 737390 & 5.2226 & 4.6734 & TST & & \\
\hline CHEMBL1439751 & 737390 & 3.0 & 3.091 & TST & & \\
\hline CHEMBL1338502 & 737390 & 3.0 & 3.9724 & TST & & \\
\hline CHEMBL1586401 & 737390 & 3.0 & 4.7767 & TST & & \\
\hline CHEMBL1477061 & 737390 & 5.3372 & 5.4274 & TST & & \\
\hline CHEMBL 3194361 & 737390 & 5.1918 & 4.9858 & TST & & \\
\hline CHEMBL1494975 & 737390 & 3.0 & 4.8513 & TST & & \\
\hline CHEMBL3196248 & 737390 & 4.2062 & 4.2129 & TST & & \\
\hline
\end{tabular}


Supplemental Table S2.txt

\begin{tabular}{|c|c|c|c|c|c|}
\hline CHEMBL1376622 & 737390 & 5.6498 & 5.4534 & TST & \\
\hline CHEMBL392680 & 737390 & 4.8729 & 4.8007 & TST & \\
\hline CHEMBL1313107 & 737390 & 4.1537 & 4.09 & TST & \\
\hline CHEMBL1329906 & 737390 & 4.4949 & 4.5481 & TST & \\
\hline CHEMBL1558497 & 737390 & 4.5784 & 4.4453 & TST & \\
\hline CHEMBL1519485 & 737390 & 4.6925 & 4.4034 & TST & \\
\hline CHEMBL1564015 & 737390 & 4.6345 & 4.4766 & TST & \\
\hline CHEMBL1486728 & 737390 & 3.0 & 3.1898 & TST & \\
\hline CHEMBL3191048 & 737390 & 4.8041 & 4.8096 & TST & \\
\hline CHEMBL1610992 & 737390 & 4.3696 & 4.4982 & TST & \\
\hline CHEMBL1523355 & 737390 & 4.5544 & 4.4048 & TST & \\
\hline CHEMBL1369984 & 737390 & 3.0 & 4.573 & TST & \\
\hline CHEMBL1564777 & 737390 & 4.9706 & 4.6123 & TST & \\
\hline CHEMBL3191759 & 737390 & 3.0 & 2.924 & TST & \\
\hline CHEMBL3197208 & 737390 & 4.9318 & 4.96899 & 9999999999 & TST \\
\hline CHEMBL576846 & 737390 & 3.0 & 2.9852 & TST & \\
\hline CHEMBL1304004 & 737390 & 3.0 & 4.0063 & TST & \\
\hline CHEMBL1449493 & 737390 & 4.5186 & 4.5062 & TST & \\
\hline CHEMBL1375292 & 737390 & 4.8447 & 4.6317 & TST & \\
\hline CHEMBL 241862 & 737390 & 4.9747 & 4.8385 & TST & \\
\hline CHEMBL3198259 & 737390 & 4.5901 & 4.7101 & TST & \\
\hline CHEMBL595840 & 737390 & 5.5072 & 5.0818 & TST & \\
\hline CHEMBL1333579 & 737390 & 5.2161 & 3.1921 & TST & \\
\hline CHEMBL1586735 & 737390 & 4.6326 & 4.4655 & TST & \\
\hline CHEMBL1463989 & 737390 & 4.6383 & 4.4678 & TST & \\
\hline CHEMBL1509368 & 737390 & 4.5498 & 4.3469 & TST & \\
\hline CHEMBL1965415 & 737390 & 4.7878 & 4.7712 & TST & \\
\hline CHEMBL1568555 & 737390 & 4.7011 & 4.7663 & TST & \\
\hline CHEMBL175434 & 737390 & 5.3045 & 5.2438 & TST & \\
\hline CHEMBL3209095 & 737390 & 3.0 & 4.7747 & TST & \\
\hline CHEMBL1491232 & 737390 & 3.0 & 4.0606 & TST & \\
\hline CHEMBL431426 & 37359 & 4.0 & 5.0742 & TRN & \\
\hline CHEMBL103198 & 37359 & 4.0 & 5.4224 & TST & \\
\hline CHEMBL328610 & 37359 & 4.0 & 4.2352 & TRN & \\
\hline CHEMBL318094 & 37359 & 5.1938 & 5.13899 & 9999999999 & TRN \\
\hline CHEMBL100959 & 37359 & 4.0 & 4.0736 & TRN & \\
\hline CHEMBL100864 & 37359 & 4.0 & 4.3037 & TRN & \\
\hline CHEMBL323347 & 37359 & 4.0 & 5.3876 & TRN & \\
\hline CHEMBL100866 & 37359 & 5.0706 & 4.4456 & TRN & \\
\hline CHEMBL102298 & 37359 & 6.0555 & 5.6966 & TRN & \\
\hline CHEMBL321305 & 37359 & 4.0 & 4.1417 & TRN & \\
\hline CHEMBL432004 & 37359 & 4.0 & 4.2102 & TRN & \\
\hline CHEMBL103166 & 37359 & 4.0 & 4.4255 & TRN & \\
\hline CHEMBL328169 & 37359 & 5.1427 & 5.0836 & TRN & \\
\hline CHEMBL330418 & 37359 & 5.0315 & 5.1618 & TRN & \\
\hline CHEMBL103699 & 37359 & 5.0969 & 5.0614 & TRN & \\
\hline CHEMBL 321129 & 37359 & 6.3372 & 5.7468 & TRN & \\
\hline CHEMBL100897 & 37359 & 5.5686 & 5.6807 & TRN & \\
\hline
\end{tabular}




\begin{tabular}{|c|c|c|c|c|c|c|}
\hline \multicolumn{7}{|c|}{ Supplemental Table S2.txt } \\
\hline CHEMBL101115 & 37359 & 5.5686 & 5.2133 & TRN & & \\
\hline CHEMBL328407 & 37359 & 5.6021 & 4.4174 & TST & & \\
\hline CHEMBL328386 & 37359 & 5.7959 & 5.176 & TRN & & \\
\hline CHEMBL319567 & 37359 & 6.4202 & 5.4103 & TRN & & \\
\hline CHEMBL100816 & 37359 & 4.0 & 5.3175 & TST & & \\
\hline CHEMBL101304 & 37359 & 6.8239 & 5.6084 & TRN & & \\
\hline CHEMBL100398 & 37359 & 4.0 & 4.9225 & TRN & & \\
\hline CHEMBL102485 & 37359 & 4.0 & 4.9195 & TRN & & \\
\hline CHEMBL103827 & 37359 & 6.699 & 4.4921 & TRN & & \\
\hline CHEMBL319426 & 37359 & 5.3872 & 5.1738 & TRN & & \\
\hline CHEMBL101329 & 37359 & 6.0458 & 5.4612 & TRN & & \\
\hline CHEMBL327961 & 37359 & 5.5686 & 5.2347 & TRN & & \\
\hline CHEMBL322460 & 37359 & 5.75700 & 00000000 & & 4.6411 & TRN \\
\hline CHEMBL103793 & 37359 & 4.0 & 5.1692 & TRN & & \\
\hline CHEMBL101065 & 37359 & 4.0 & 5.51399 & 9999999999 & & TRN \\
\hline CHEMBL319621 & 37359 & 4.0 & 4.1665 & TRN & & \\
\hline CHEMBL321805 & 37359 & 4.0 & 4.2616 & TRN & & \\
\hline CHEMBL318983 & 37359 & 4.0 & 4.1859 & TRN & & \\
\hline CHEMBL101192 & 37359 & 6.5086 & 5.1294 & TRN & & \\
\hline CHEMBL100817 & 37359 & 4.0 & 5.3048 & TST & & \\
\hline CHEMBL 327940 & 37359 & 4.0 & 5.2859 & TST & & \\
\hline CHEMBL101169 & 37359 & 5.3468 & 4.5413 & TRN & & \\
\hline CHEMBL319785 & 37359 & 4.0 & 5.0897 & TRN & & \\
\hline CHEMBL319146 & 37359 & 5.4437 & 5.1847 & TRN & & \\
\hline CHEMBL103351 & 37359 & 4.0 & 4.9803 & TRN & & \\
\hline CHEMBL319320 & 37359 & 5.2924 & 5.2264 & TRN & & \\
\hline CHEMBL103244 & 37359 & 4.0 & 5.3998 & TST & & \\
\hline CHEMBL103835 & 37359 & 6.1675 & 5.3477 & TRN & & \\
\hline CHEMBL329036 & 37359 & 4.0 & 5.4052 & TRN & & \\
\hline CHEMBL317695 & 37359 & 4.0 & 5.1116 & TST & & \\
\hline CHEMBL328845 & 37359 & 4.0 & 5.0447 & TST & & \\
\hline CHEMBL422070 & 37359 & 4.0 & 5.0692 & TST & & \\
\hline CHEMBL99696 & 37359 & 5.7447 & 5.3079 & TST & & \\
\hline CHEMBL103453 & 37359 & 5.284 & 5.586 & TST & & \\
\hline CHEMBL103717 & 37359 & 4.0 & 5.102 & TST & & \\
\hline CHEMBL320617 & 37359 & 4.0 & 5.175 & TST & & \\
\hline CHEMBL317415 & 37359 & 6.3279 & 4.9572 & TST & & \\
\hline CHEMBL3701546 & 1528055 & 6.3372 & 6.4093 & TRN & & \\
\hline CHEMBL 3641366 & 1528055 & 6.0 & 7.3588 & TRN & & \\
\hline CHEMBL3701437 & 1528055 & 5.9547 & 6.53700 & 0000000001 & & TST \\
\hline CHEMBL3641422 & 1528055 & 7.0655 & 7.0302 & TRN & & \\
\hline CHEMBL3698143 & 1528055 & 6.7959 & 6.7347 & TRN & & \\
\hline CHEMBL3641296 & 1528055 & 6.8761 & 6.2263 & TRN & & \\
\hline CHEMBL3701439 & 1528055 & 6.6819 & 6.5993 & TST & & \\
\hline CHEMBL3701624 & 1528055 & 5.6981 & 5.9846 & TST & & \\
\hline CHEMBL3698046 & 1528055 & 6.8539 & 6.8137 & TRN & & \\
\hline CHEMBL 3643637 & 1528055 & 6.289 & 6.9682 & TRN & & \\
\hline CHEMBL 3701527 & 1528055 & 7.0506 & 6.8982 & TRN & & \\
\hline
\end{tabular}

Page 23349 
Supplemental Table S2.txt

\begin{tabular}{|c|c|c|c|c|c|c|}
\hline CHEMBL 3701523 & 1528055 & 6.6478 & 6.7709 & TRN & & \\
\hline CHEMBL 3701419 & 1528055 & 6.6421 & 6.5299 & TRN & & \\
\hline CHEMBL3701576 & 1528055 & 7.0315 & 6.8667 & TRN & & \\
\hline CHEMBL 3698043 & 1528055 & 6.0 & 6.0313 & TRN & & \\
\hline CHEMBL3641398 & 1528055 & 6.3605 & 6.5882 & TRN & & \\
\hline CHEMBL 3641412 & 1528055 & 7.1427 & 6.8473 & TRN & & \\
\hline CHEMBL 3641274 & 1528055 & 5.6794 & 7.0009 & TST & & \\
\hline CHEMBL 3701541 & 1528055 & 7.0809 & 6.5106 & TRN & & \\
\hline CHEMBL 3641350 & 1528055 & 7.5528 & 7.0891 & TRN & & \\
\hline CHEMBL3641458 & 1528055 & 6.6778 & 7.0516 & TST & & \\
\hline CHEMBL 3641288 & 1528055 & 5.8817 & 6.2956 & TRN & & \\
\hline CHEMBL 3701448 & 1528055 & 6.3261 & 6.2622 & TRN & & \\
\hline CHEMBL 3701515 & 1528055 & 6.75200 & 000000000 & 11 & 6.416 & TRN \\
\hline CHEMBL 3701595 & 1528055 & 5.0297 & 5.8709 & TRN & & \\
\hline CHEMBL3698038 & 1528055 & 6.7696 & 6.6246 & TRN & & \\
\hline CHEMBL 3701436 & 1528055 & 5.607 & 6.5335 & TST & & \\
\hline CHEMBL 3643534 & 1528055 & 7.2596 & 7.0128 & TRN & & \\
\hline CHEMBL 3701429 & 1528055 & 6.4078 & 6.6682 & TRN & & \\
\hline CHEMBL 3698136 & 1528055 & 6.6253 & 6.869 & TRN & & \\
\hline CHEMBL3698050 & 1528055 & 7.1192 & 7.1384 & TRN & & \\
\hline CHEMBL 3641434 & 1528055 & 6.7399 & 6.7798 & TST & & \\
\hline CHEMBL 3641372 & 1528055 & 6.0 & 6.2688 & TRN & & \\
\hline CHEMBL 3698140 & 1528055 & 7.0862 & 6.5106 & TRN & & \\
\hline CHEMBL 3641370 & 1528055 & 6.1791 & 5.8688 & TRN & & \\
\hline CHEMBL 3641453 & 1528055 & 6.6655 & 6.0773 & TRN & & \\
\hline CHEMBL 3698072 & 1528055 & 7.1871 & 6.7592 & TRN & & \\
\hline CHEMBL 3698147 & 1528055 & 6.9355 & 6.5459 & TRN & & \\
\hline CHEMBL 3701615 & 1528055 & 6.1494 & 6.5934 & TRN & & \\
\hline CHEMBL 3698088 & 1528055 & 6.2526 & 6.2486 & TRN & & \\
\hline CHEMBL 3641460 & 1528055 & \multicolumn{3}{|c|}{6.2620000000000005} & 6.336 & TRN \\
\hline CHEMBL 3643585 & 1528055 & 6.2314 & 6.2877 & TRN & & \\
\hline CHEMBL 3643564 & 1528055 & 6.6345 & 6.3851 & TRN & & \\
\hline CHEMBL 3641310 & 1528055 & 6.7799 & 6.5275 & TRN & & \\
\hline CHEMBL 3701504 & 1528055 & 6.1643 & 6.2685 & TRN & & \\
\hline CHEMBL 3643596 & 1528055 & 6.0 & 6.0888 & TRN & & \\
\hline CHEMBL 3701588 & 1528055 & 6.5003 & 6.0172 & TRN & & \\
\hline CHEMBL 3701547 & 1528055 & 6.4123 & 6.3266 & TRN & & \\
\hline CHEMBL 3643614 & 1528055 & 6.9547 & 6.8879 & TRN & & \\
\hline CHEMBL 3643542 & 1528055 & 6.0 & 6.3021 & TRN & & \\
\hline CHEMBL 3701589 & 1528055 & 6.0424 & 6.9549 & TST & & \\
\hline CHEMBL 3641334 & 1528055 & 6.0 & 6.0952 & TRN & & \\
\hline CHEMBL 3698135 & 1528055 & 6.71 & 6.4821 & TRN & & \\
\hline CHEMBL 3643505 & 1528055 & 6.4547 & 6.1101 & TST & & \\
\hline CHEMBL 3701440 & 1528055 & 6.9355 & 6.9717 & TRN & & \\
\hline CHEMBL 3643591 & 1528055 & 6.0 & 6.2765 & TRN & & \\
\hline CHEMBL 3701610 & 1528055 & 5.9602 & 6.7786 & TST & & \\
\hline CHEMBL 3643610 & 1528055 & 7.04 & 7.1403 & TRN & & \\
\hline CHEMBL 3701468 & 1528055 & 6.3161 & 6.3804 & TRN & & \\
\hline
\end{tabular}


Supplemental Table S2.txt

\begin{tabular}{|c|c|c|c|c|c|}
\hline CHEMBL 3701418 & 1528055 & 6.7773 & 6.3573 & TRN & \\
\hline CHEMBL 3643604 & 1528055 & 6.8297 & 6.43 & TRN & \\
\hline CHEMBL3641255 & 1528055 & 6.0675 & 6.1721 & TST & \\
\hline CHEMBL 3641352 & 1528055 & 7.2924 & 6.6416 & TRN & \\
\hline CHEMBL3643607 & 1528055 & 6.2321 & 6.2179 & TRN & \\
\hline CHEMBL 3701623 & 1528055 & 5.6525 & 5.7516 & TRN & \\
\hline CHEMBL 3701457 & 1528055 & 6.4989 & 6.426 & TRN & \\
\hline CHEMBL3641332 & 1528055 & 6.0996 & 6.2694 & TRN & \\
\hline CHEMBL 3641449 & 1528055 & 5.965 & 6.5238 & TRN & \\
\hline CHEMBL 3641383 & 1528055 & 6.0 & 6.438 & TRN & \\
\hline CHEMBL 3698045 & 1528055 & 6.3565 & 6.5594 & TRN & \\
\hline CHEMBL 3641301 & 1528055 & 6.4123 & 6.1938 & TRN & \\
\hline CHEMBL 3698156 & 1528055 & 6.0595 & 6.1864 & TRN & \\
\hline CHEMBL 3643529 & 1528055 & 8.2749 & 7.0545 & TRN & \\
\hline CHEMBL 3641261 & 1528055 & 6.0237 & 5.8466 & TRN & \\
\hline CHEMBL 3643512 & 1528055 & 7.1186 & 6.5297 & TRN & \\
\hline CHEMBL3698073 & 1528055 & 7.0269 & 7.1804 & TRN & \\
\hline CHEMBL 3701502 & 1528055 & 6.4365 & 6.2405 & TRN & \\
\hline CHEMBL 3641382 & 1528055 & 7.2441 & 6.4733 & TRN & \\
\hline CHEMBL 3701491 & 1528055 & 6.6536 & \multicolumn{2}{|c|}{6.507000000000001} & TRN \\
\hline CHEMBL 3698057 & 1528055 & 6.2255 & 6.0575 & TST & \\
\hline CHEMBL3701469 & 1528055 & 6.4089 & 5.8124 & TRN & \\
\hline CHEMBL 3641416 & 1528055 & 7.3468 & 7.1096 & TRN & \\
\hline CHEMBL 3641326 & 1528055 & 7.2757 & 7.2725 & TRN & \\
\hline CHEMBL 3641259 & 1528055 & 6.3335 & 5.8493 & TRN & \\
\hline CHEMBL 3641264 & 1528055 & 6.0182 & 6.3087 & TRN & \\
\hline CHEMBL3643527 & 1528055 & 7.056 & 6.9204 & TRN & \\
\hline CHEMBL 3698071 & 1528055 & 6.0862 & 6.0254 & TRN & \\
\hline CHEMBL 3641419 & 1528055 & 6.9788 & 7.1426 & TRN & \\
\hline CHEMBL 3641442 & 1528055 & 6.0 & 6.4496 & TRN & \\
\hline CHEMBL3701427 & 1528055 & 6.9914 & 6.4714 & TRN & \\
\hline CHEMBL 3643507 & 1528055 & 6.3516 & 6.3602 & TRN & \\
\hline CHEMBL 3640003 & 1528055 & 6.6364 & 6.2883 & TRN & \\
\hline CHEMBL 3643630 & 1528055 & 6.0159 & 6.0868 & TRN & \\
\hline CHEMBL 3701423 & 1528055 & 6.4078 & 6.2108 & TRN & \\
\hline CHEMBL3701421 & 1528055 & 6.6234 & 6.1526 & TST & \\
\hline CHEMBL3643552 & 1528055 & 6.0 & 6.079 & TRN & \\
\hline CHEMBL 3641463 & 1528055 & 6.9626 & 6.5825 & TST & \\
\hline CHEMBL 3701445 & 1528055 & 6.3747 & 6.4882 & TRN & \\
\hline CHEMBL 3643628 & 1528055 & 6.7773 & \multicolumn{2}{|c|}{6.827999999999999} & TRN \\
\hline CHEMBL 3643627 & 1528055 & 6.5498 & 7.0467 & TRN & \\
\hline CHEMBL3701505 & 1528055 & 6.6383 & 6.4869 & TRN & \\
\hline CHEMBL3701636 & 1528055 & 6.6596 & 6.2615 & TRN & \\
\hline CHEMBL3701538 & 1528055 & 7.0132 & 6.9551 & TRN & \\
\hline CHEMBL 3698123 & 1528055 & 6.0985 & 6.4097 & TRN & \\
\hline CHEMBL3701533 & 1528055 & 6.9586 & 6.6526 & TRN & \\
\hline CHEMBL3701602 & 1528055 & 6.7721 & 6.2346 & TRN & \\
\hline CHEMBL3701426 & 1528055 & 6.2426 & 6.7308 & TRN & \\
\hline
\end{tabular}


Supplemental Table S2.txt

\begin{tabular}{|c|c|c|c|c|}
\hline CHEMBL3643571 & 1528055 & 7.27 & 6.8412 & TRN \\
\hline CHEMBL3698047 & 1528055 & 6.9393 & 6.7825 & TRN \\
\hline CHEMBL3701476 & 1528055 & 5.9197 & 6.0563 & TRN \\
\hline CHEMBL3698067 & 1528055 & 6.1656 & 6.2456 & TST \\
\hline CHEMBL 3641338 & 1528055 & 6.2218 & 6.4269 & TRN \\
\hline CHEMBL3643619 & 1528055 & 6.8097 & 6.9322 & TRN \\
\hline CHEMBL3643550 & 1528055 & 6.0 & 6.0386 & TRN \\
\hline CHEMBL3701551 & 1528055 & 6.6055 & 6.7768 & TRN \\
\hline CHEMBL3643561 & 1528055 & 6.4868 & 6.3853 & TRN \\
\hline CHEMBL3701558 & 1528055 & 6.0 & 6.5166 & TRN \\
\hline CHEMBL 3701424 & 1528055 & 6.3665 & 6.5352 & TRN \\
\hline CHEMBL3641256 & 1528055 & 6.5045 & 6.079 & TRN \\
\hline CHEMBL 3643644 & 1528055 & 6.2373 & 6.86 & TRN \\
\hline CHEMBL 3701488 & 1528055 & 6.699 & 6.5757 & TRN \\
\hline CHEMBL 3643636 & 1528055 & 6.0535 & 6.7591 & TST \\
\hline CHEMBL3698089 & 1528055 & 6.1244 & 6.1419 & TRN \\
\hline CHEMBL3643608 & 1528055 & 6.9136 & 6.5583 & TRN \\
\hline CHEMBL3701613 & 1528055 & 6.1898 & 6.4234 & TRN \\
\hline CHEMBL3701495 & 1528055 & 6.8013 & 6.947 & TRN \\
\hline CHEMBL3701630 & 1528055 & 5.8085 & 5.9181 & TRN \\
\hline CHEMBL 3641408 & 1528055 & 7.301 & 7.1503 & TRN \\
\hline CHEMBL 3643623 & 1528055 & 7.4089 & 6.7165 & TST \\
\hline CHEMBL3701586 & 1528055 & 5.2378 & 6.0751 & TST \\
\hline CHEMBL 3643590 & 1528055 & 6.0 & 6.5029 & TRN \\
\hline CHEMBL 3641440 & 1528055 & 6.0 & 6.2448 & TRN \\
\hline CHEMBL 3698151 & 1528055 & 6.8928 & 6.619 & TRN \\
\hline CHEMBL 3701480 & 1528055 & 6.8386 & 6.3824 & TRN \\
\hline CHEMBL3641336 & 1528055 & 6.7932 & 6.7492 & TRN \\
\hline CHEMBL 3641284 & 1528055 & 6.0 & 6.3571 & TRN \\
\hline CHEMBL3643581 & 1528055 & 6.7122 & 6.599 & TRN \\
\hline CHEMBL 3698146 & 1528055 & 5.9805 & 6.2491 & TRN \\
\hline CHEMBL3978997 & 1528055 & 6.7747 & 6.25200 & 3000000001 \\
\hline CHEMBL 3639424 & 1528055 & 7.2182 & 6.8053 & TRN \\
\hline CHEMBL3698131 & 1528055 & 6.9318 & 6.5173 & TRN \\
\hline CHEMBL3701489 & 1528055 & 6.1226 & 6.1749 & TRN \\
\hline CHEMBL 3641380 & 1528055 & 7.4949 & 7.2299 & TRN \\
\hline CHEMBL 3698141 & 1528055 & 6.7471 & 6.5304 & TRN \\
\hline CHEMBL3643613 & 1528055 & 7.2161 & 7.2043 & TRN \\
\hline CHEMBL3641268 & 1528055 & 6.1427 & 6.2535 & TRN \\
\hline CHEMBL3698031 & 1528055 & 6.9431 & 6.9497 & TRN \\
\hline CHEMBL 3643576 & 1528055 & 6.6904 & 6.5533 & TST \\
\hline CHEMBL3641397 & 1528055 & 6.0 & 6.7324 & TST \\
\hline CHEMBL3643643 & 1528055 & 6.4711 & 6.5684 & TRN \\
\hline CHEMBL3701443 & 1528055 & 7.0655 & 6.5742 & TRN \\
\hline CHEMBL 3701486 & 1528055 & 6.2652 & 6.254 & TRN \\
\hline CHEMBL 3641415 & 1528055 & 7.0 & 7.0086 & TRN \\
\hline CHEMBL3698099 & 1528055 & 6.8665 & 6.3543 & TRN \\
\hline CHEMBL3641319 & 1528055 & 7.0044 & 6.6367 & TRN \\
\hline
\end{tabular}

Page 23352 
Supplemental Table S2.txt

\begin{tabular}{|c|c|c|c|c|c|c|}
\hline CHEMBL3641413 & 1528055 & 7.3098 & 7.2735 & TRN & & \\
\hline CHEMBL3641320 & 1528055 & 6.16299 & 79999999 & & 6.2076 & TRN \\
\hline CHEMBL3701577 & 1528055 & 6.7825 & 6.6219 & TRN & & \\
\hline CHEMBL3698049 & 1528055 & 7.5686 & 6.8776 & TRN & & \\
\hline CHEMBL3698149 & 1528055 & 6.2557 & 6.6199 & TRN & & \\
\hline CHEMBL3643528 & 1528055 & 6.7986 & 6.841 & TRN & & \\
\hline CHEMBL3641428 & 1528055 & 6.0 & 6.2334 & TRN & & \\
\hline CHEMBL3641275 & 1528055 & 6.24799 & 99999999 & 99 & 7.2584 & \\
\hline CHEMBL3701568 & 1528055 & 6.0 & 6.2614 & TRN & & \\
\hline CHEMBL3643633 & 1528055 & 6.7235 & 6.4772 & TST & & \\
\hline CHEMBL3701631 & 1528055 & 5.7964 & 6.2565 & TRN & & \\
\hline CHEMBL3641249 & 1528055 & 5.5675 & 6.0058 & TRN & & \\
\hline CHEMBL3643611 & 1528055 & 7.289 & 7.475 & TRN & & \\
\hline CHEMBL 3641465 & 1528055 & 6.0 & 6.6161 & TRN & & \\
\hline CHEMBL3701509 & 1528055 & 6.8447 & 6.5159 & TRN & & \\
\hline CHEMBL3643577 & 1528055 & 6.2104 & 6.3263 & TST & & \\
\hline CHEMBL3641355 & 1528055 & 7.4559 & 6.8603 & TRN & & \\
\hline CHEMBL3643617 & 1528055 & 6.3686 & 6.6269 & TRN & & \\
\hline CHEMBL3701471 & 1528055 & 6.1314 & 6.2061 & TRN & & \\
\hline CHEMBL3701600 & 1528055 & 5.2952 & 6.1661 & TRN & & \\
\hline CHEMBL3698064 & 1528055 & 6.7773 & 6.7799 & TST & & \\
\hline CHEMBL3701498 & 1528055 & 5.841 & 6.7282 & TST & & \\
\hline CHEMBL3698075 & 1528055 & 6.9872 & 6.3543 & TRN & & \\
\hline CHEMBL3701473 & 1528055 & 5.6562 & 6.0301 & TRN & & \\
\hline CHEMBL 3698150 & 1528055 & 6.4271 & 6.8051 & TRN & & \\
\hline CHEMBL3641364 & 1528055 & 7.2924 & 7.4944 & TRN & & \\
\hline CHEMBL3701607 & 1528055 & 6.6364 & 6.3855 & TST & & \\
\hline CHEMBL3643510 & 1528055 & 6.7696 & 6.4919 & TST & & \\
\hline CHEMBL3641342 & 1528055 & 6.3645 & 6.1043 & TRN & & \\
\hline CHEMBL 3641357 & 1528055 & 7.3468 & 6.8493 & TRN & & \\
\hline CHEMBL3641426 & 1528055 & 7.4202 & 7.1679 & TRN & & \\
\hline CHEMBL3641297 & 1528055 & 6.5157 & 6.1706 & TRN & & \\
\hline CHEMBL3701446 & 1528055 & 6.6596 & 6.5964 & TRN & & \\
\hline CHEMBL3701579 & 1528055 & 6.0 & 6.332006 & 0000000001 & & \\
\hline CHEMBL3641461 & 1528055 & 6.8601 & 7.3459 & TRN & & \\
\hline CHEMBL3641248 & 1528055 & 6.71 & 6.2828 & TRN & & \\
\hline CHEMBL3701529 & 1528055 & 6.699 & 6.9325 & TRN & & \\
\hline CHEMBL3641430 & 1528055 & 6.3969 & 6.1377 & TRN & & \\
\hline CHEMBL3641356 & 1528055 & 7.3565 & 6.9714 & TRN & & \\
\hline CHEMBL3701482 & 1528055 & 6.5287 & 6.2438 & TRN & & \\
\hline CHEMBL3698103 & 1528055 & 5.3883 & 6.2935 & TST & & \\
\hline CHEMBL3643640 & 1528055 & 6.8665 & 6.854 & TRN & & \\
\hline CHEMBL3641265 & 1528055 & 5.6405 & 6.3258 & TRN & & \\
\hline CHEMBL3701420 & 1528055 & 6.4609 & 6.6641 & TST & & \\
\hline CHEMBL 3641252 & 1528055 & 5.9289 & 6.0781 & TRN & & \\
\hline CHEMBL3698129 & 1528055 & 6.3316 & 6.2675 & TRN & & \\
\hline CHEMBL3641385 & 1528055 & 7.6021 & 7.4599 & TRN & & \\
\hline CHEMBL 3643578 & 1528055 & 6.2612 & 6.6527 & TST & & \\
\hline
\end{tabular}


Supplemental Table S2.txt

\begin{tabular}{|c|c|c|c|c|}
\hline CHEMBL3698138 & 1528055 & 6.7423 & 6.7104 & TRN \\
\hline CHEMBL3698098 & 1528055 & 6.8153 & 6.4463 & TRN \\
\hline CHEMBL3641272 & 1528055 & 6.6946 & 6.4643 & TST \\
\hline CHEMBL3701474 & 1528055 & 7.0862 & 6.6445 & TRN \\
\hline CHEMBL3643606 & 1528055 & 6.52 & 6.1468 & TRN \\
\hline CHEMBL3701567 & 1528055 & 6.0 & 6.556 & TRN \\
\hline CHEMBL3698144 & 1528055 & 6.6536 & 6.6253 & TRN \\
\hline CHEMBL3701553 & 1528055 & 6.0 & 6.4887 & TRN \\
\hline CHEMBL3641401 & 1528055 & 6.5901 & 6.6725 & TRN \\
\hline CHEMBL3641454 & 1528055 & 6.0334 & 5.9582 & TST \\
\hline CHEMBL3698056 & 1528055 & 6.4449 & 6.102 & TST \\
\hline CHEMBL3641403 & 1528055 & 6.2916 & 6.6973 & TST \\
\hline CHEMBL3701514 & 1528055 & 6.8356 & 6.6583 & TRN \\
\hline CHEMBL3701580 & 1528055 & 6.0 & 6.5297 & TRN \\
\hline CHEMBL3701485 & 1528055 & 6.2034 & 6.1657 & TRN \\
\hline CHEMBL3643566 & 1528055 & 6.8182 & 6.5001 & TRN \\
\hline CHEMBL3701536 & 1528055 & 6.0278 & 6.4448 & TRN \\
\hline CHEMBL3641417 & 1528055 & 6.5143 & 6.6205 & TRN \\
\hline CHEMBL3701422 & 1528055 & 6.7423 & 6.0374 & TST \\
\hline CHEMBL3701617 & 1528055 & 5.8499 & 6.0747 & TRN \\
\hline CHEMBL3698092 & 1528055 & 6.1918 & 6.9758 & TRN \\
\hline CHEMBL 3643544 & 1528055 & 6.6091 & 6.5247 & TRN \\
\hline CHEMBL3698155 & 1528055 & 6.4609 & 6.2638 & TRN \\
\hline CHEMBL3641435 & 1528055 & 6.7471 & 6.6005 & TRN \\
\hline CHEMBL3701552 & 1528055 & 6.0 & 6.5203 & TRN \\
\hline CHEMBL3701548 & 1528055 & 6.3045 & 6.7259 & TRN \\
\hline CHEMBL3698137 & 1528055 & 6.4828 & 6.593 & TRN \\
\hline CHEMBL3698042 & 1528055 & 5.7305 & 6.2989 & TST \\
\hline CHEMBL3641250 & 1528055 & 6.5243 & 6.2866 & TRN \\
\hline CHEMBL3701450 & 1528055 & 6.3747 & 6.1802 & TRN \\
\hline CHEMBL3698087 & 1528055 & 6.6716 & 6.5808 & TRN \\
\hline CHEMBL3701499 & 1528055 & 6.8697 & 6.975 & TRN \\
\hline CHEMBL3701605 & 1528055 & 6.8069 & 6.0476 & TRN \\
\hline CHEMBL3698106 & 1528055 & 7.6778 & 7.2706 & TRN \\
\hline CHEMBL3701534 & 1528055 & 6.7545 & 6.7422 & TRN \\
\hline CHEMBL3641411 & 1528055 & 6.9431 & 6.9519 & TRN \\
\hline CHEMBL3701459 & 1528055 & 6.0742 & 6.0877 & TRN \\
\hline CHEMBL3698069 & 1528055 & 5.9821 & 5.8693 & TRN \\
\hline CHEMBL3641456 & 1528055 & 6.7595 & 6.7644 & TST \\
\hline CHEMBL3641427 & 1528055 & 6.6517 & 6.5734 & TRN \\
\hline CHEMBL3701449 & 1528055 & 6.5575 & 6.2815 & TRN \\
\hline CHEMBL3641257 & 1528055 & 5.9842 & 6.3231 & TRN \\
\hline CHEMBL3641260 & 1528055 & 5.8471 & 5.935 & TRN \\
\hline CHEMBL3701458 & 1528055 & 5.6953 & 5.9583 & TRN \\
\hline CHEMBL3701431 & 1528055 & 6.1549 & 6.3367 & TST \\
\hline CHEMBL3701454 & 1528055 & 6.2733 & 6.61600 & 00000000005 \\
\hline CHEMBL3698059 & 1528055 & 6.7986 & 6.0651 & TST \\
\hline CHEMBL3643615 & 1528055 & 6.8539 & 6.9668 & TRN \\
\hline
\end{tabular}


Supplemental Table S2.txt

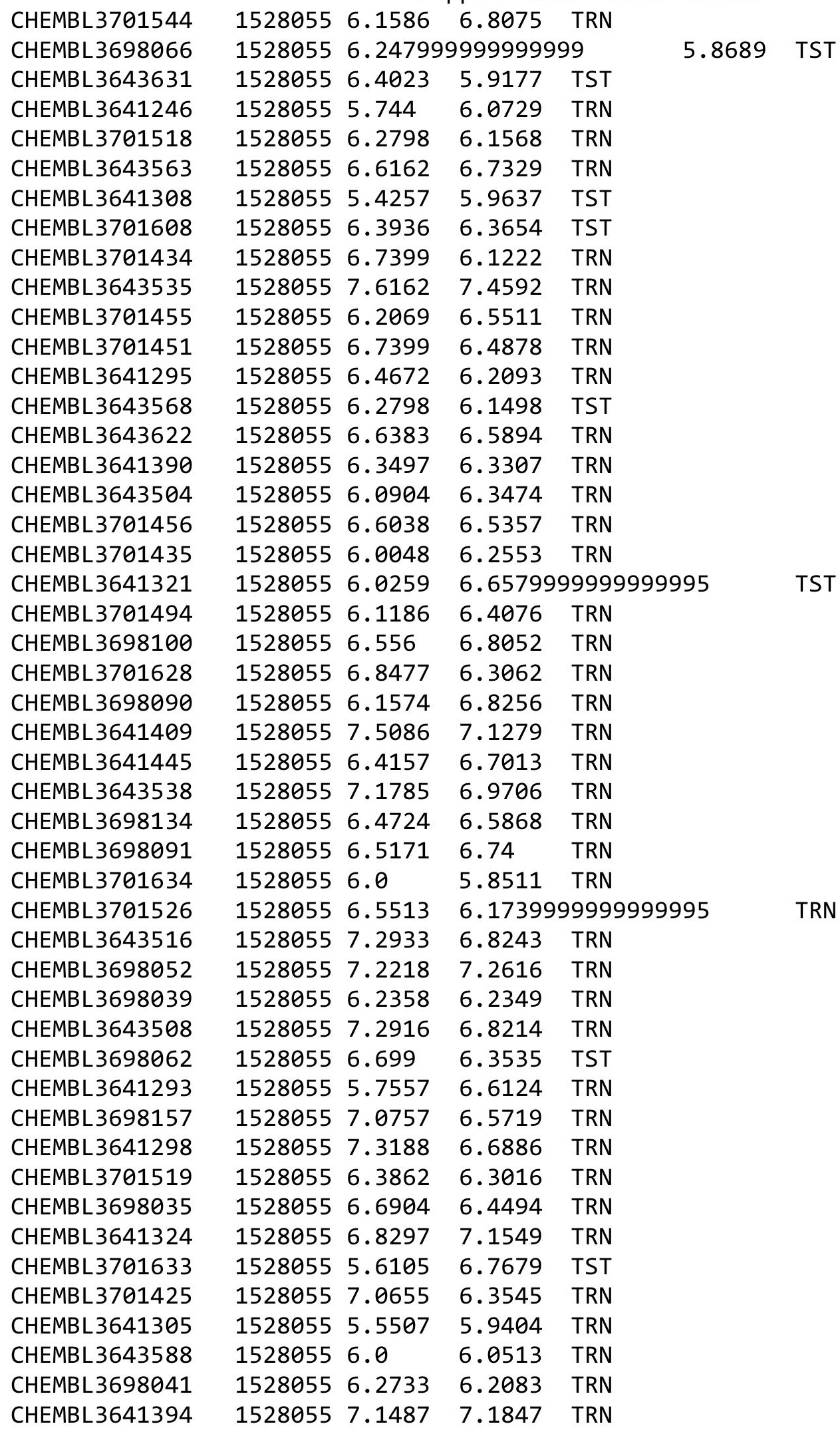

Page 23355 
Supplemental Table S2.txt

\begin{tabular}{|c|c|c|c|c|c|}
\hline CHEMBL3643641 & 1528055 & 6.6596 & 6.726 & TRN & \\
\hline CHEMBL3701575 & 1528055 & 6.4989 & 6.6837 & TRN & \\
\hline CHEMBL3698104 & 1528055 & 7.1739 & 7.112 & TRN & \\
\hline CHEMBL3641420 & 1528055 & 7.0757 & 6.947 & TRN & \\
\hline CHEMBL3641262 & 1528055 & 5.4022 & 5.7209 & TRN & \\
\hline CHEMBL3701616 & 1528055 & 6.3585 & 6.2246 & TRN & \\
\hline CHEMBL3701555 & 1528055 & 6.0 & 6.1294 & TRN & \\
\hline CHEMBL3643517 & 1528055 & 7.0168 & 7.1496 & TRN & \\
\hline CHEMBL3701516 & 1528055 & 6.0101 & 6.3556 & TRN & \\
\hline CHEMBL3701496 & 1528055 & 6.6234 & 6.9279 & TRN & \\
\hline CHEMBL3641353 & 1528055 & 6.3615 & 6.1068 & TRN & \\
\hline CHEMBL3698120 & 1528055 & 6.0 & 6.4009 & TRN & \\
\hline CHEMBL3641389 & 1528055 & 6.699 & 6.545 & TRN & \\
\hline CHEMBL 3643520 & 1528055 & 7.0899 & 6.9707 & TRN & \\
\hline CHEMBL3643506 & 1528055 & 6.7721 & 5.9606 & TST & \\
\hline CHEMBL3641436 & 1528055 & 6.0 & 6.0878 & TRN & \\
\hline CHEMBL3698095 & 1528055 & 6.644 & 6.5993 & TRN & \\
\hline CHEMBL3641361 & 1528055 & 7.3768 & 7.0789 & TRN & \\
\hline CHEMBL3641278 & 1528055 & 6.5768 & 6.1724 & TRN & \\
\hline CHEMBL 3641343 & 1528055 & 5.6017 & 6.4442 & TST & \\
\hline CHEMBL3643541 & 1528055 & 6.1568 & 6.1156 & TRN & \\
\hline CHEMBL3643583 & 1528055 & 6.7932 & 7.0161 & TRN & \\
\hline CHEMBL3641341 & 1528055 & 6.1568 & 6.2215 & TRN & \\
\hline CHEMBL3641444 & 1528055 & 6.4306 & 6.8171 & TRN & \\
\hline CHEMBL3641368 & 1528055 & 5.9512 & 5.885 & TRN & \\
\hline CHEMBL3701517 & 1528055 & 6.3947 & 6.3645 & TRN & \\
\hline CHEMBL3701512 & 1528055 & 6.8069 & 6.6069 & TRN & \\
\hline CHEMBL3701464 & 1528055 & 6.0 & 6.2809 & TRN & \\
\hline CHEMBL 3698110 & 1528055 & 6.5654 & 6.5906 & TRN & \\
\hline CHEMBL3643626 & 1528055 & 6.5591 & 6.4571 & TST & \\
\hline CHEMBL3641251 & 1528055 & 6.5376 & 6.2869 & TRN & \\
\hline CHEMBL3641299 & 1528055 & 7.1487 & 6.8075 & TRN & \\
\hline CHEMBL3698130 & 1528055 & 6.1871 & 6.1964 & TRN & \\
\hline CHEMBL3698036 & 1528055 & 7.0706 & \multicolumn{2}{|c|}{6.906000000000001} & TRN \\
\hline CHEMBL3641307 & 1528055 & 6.2941 & 6.5006 & TST & \\
\hline CHEMBL3641269 & 1528055 & 6.3507 & 6.1863 & TRN & \\
\hline CHEMBL3643624 & 1528055 & 6.3625 & 7.2747 & TST & \\
\hline CHEMBL 3643524 & 1528055 & 7.567 & 7.2744 & TRN & \\
\hline CHEMBL3641266 & 1528055 & 6.0214 & 6.2047 & TRN & \\
\hline CHEMBL3641457 & 1528055 & 6.1986 & 6.7316 & TST & \\
\hline CHEMBL3643632 & 1528055 & 6.1986 & 6.1631 & TST & \\
\hline CHEMBL3701606 & 1528055 & 6.8386 & 6.5477 & TRN & \\
\hline CHEMBL3643621 & 1528055 & 6.1662 & 6.2491 & TRN & \\
\hline CHEMBL3643612 & 1528055 & 7.1107 & 7.1132 & TRN & \\
\hline CHEMBL3641424 & 1528055 & 7.0915 & 7.0482 & TRN & \\
\hline CHEMBL3698033 & 1528055 & 6.9431 & 6.9165 & TRN & \\
\hline CHEMBL3641462 & 1528055 & 6.4342 & 6.9509 & TRN & \\
\hline CHEMBL3701500 & 1528055 & 6.6778 & 7.0048 & TRN & \\
\hline
\end{tabular}

Page 23356 
Supplemental Table S2.txt

\begin{tabular}{|c|c|c|c|c|}
\hline 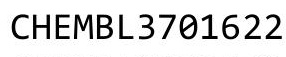 & & & & \\
\hline HEMBL3639402 & 528055 & 6.7878 & 6.6287 & \\
\hline HEMBL3 & 28055 & 6.7773 & 66 & \\
\hline & & 6.8268 & & \\
\hline AEMBL3 & 28055 & 9914 & 44 & \\
\hline AEMBL3698105 & 528055 & 7.2757 & .9875 & \\
\hline HEMBL3698109 & 528055 & 6.7423 & .7144 & \\
\hline HEMBL3641316 & 528055 & 6.2573 & 3286 & \\
\hline HEMBL36 & 28055 & 1871 & 0512 & \\
\hline IEMBL37 & & & 1185 & \\
\hline HEMBL3641425 & 528055 & 7.1805 & 6.8969 & \\
\hline HEMBL3701525 & 528055 & 6.5436 & 5.1267 & \\
\hline HEMBL3698085 & .528055 & 45 & 2109 & \\
\hline HEMBL37 & 528055 & 84 & 167 & \\
\hline AEMBL36 & 528055 & & 598 & \\
\hline HEMBL3701478 & 528055 & 6.3536 & 0288 & \\
\hline HEMBL3698029 & 528055 & & & \\
\hline HEMBL37 & 528055 & & 33 & \\
\hline HEM & 5280 & & 209 & \\
\hline HEM & 5 & & 349 & \\
\hline HEMBL3698125 & 528055 & 6.0 & 7611 & \\
\hline AEMBL3643584 & 5000 & 6. & & \\
\hline HEMBL37 & 5280 & 4. & 21 & KIN \\
\hline HEN & 528055 & & 88 & \\
\hline HEM & 55 & & & \\
\hline L364 & 528055 & & & iv \\
\hline AEMBL3641464 & 52 & & & r \\
\hline HEMBL37 & 5286 & & & SI \\
\hline HEN & 52 & & & RN \\
\hline 145 & 55 & 6 . & 271 & RN \\
\hline AEMBL3698148 & & & & IRN \\
\hline AEMBL3698107 & 5280 & 6. & 32 & ГRN \\
\hline AEMBL3 & 055 & 51 & & RN \\
\hline 7 & 528 & 11 & 41 & RN \\
\hline 3 & 5 & 6 . & 04 & $\mathrm{RN}$ \\
\hline HEMBL370 & 528055 & 6 & 5972 & TRN \\
\hline AEMBL3641455 & 528055 & 6 & & TST \\
\hline & & & & RN \\
\hline 6 & 5 & 4 & & RIN \\
\hline HEMBL3643565 & 528055 & & & ST \\
\hline AEMBL3641300 & 528055 & 179 & 8584 & ГST \\
\hline AEMBL3 & 52805 & & 805 & RN \\
\hline & 500 & & 7.0762 & \\
\hline HEMBL36 & 528055 & & & \\
\hline HEMBL 36 & 1528055 & 49 & 1549 & ST \\
\hline HEMBL 364 & 52805 & 5.4 & 9897 & RN \\
\hline תב וסחזM & & & & \\
\hline CHEN & 52805 & & & \\
\hline
\end{tabular}

Page 23357 
Supplemental Table S2.txt

\begin{tabular}{|c|c|c|c|c|c|}
\hline CHEMBL3641348 & 1528055 & 6.2573 & 6.3196 & TRN & \\
\hline CHEMBL3643605 & 1528055 & 6.5622 & 6.6702 & TRN & \\
\hline CHEMBL3701590 & 1528055 & 6.1129 & 6.1049 & TRN & \\
\hline CHEMBL3643599 & 1528055 & 7.2757 & 6.8685 & TST & \\
\hline CHEMBL 3701442 & 1528055 & 6.8327 & \multicolumn{2}{|c|}{6.332000000000001} & TRN \\
\hline CHEMBL3641289 & 1528055 & 6.0 & 6.6603 & TRN & \\
\hline CHEMBL3641344 & 1528055 & 6.0 & 6.4213 & TRN & \\
\hline CHEMBL3698111 & 1528055 & 7.1938 & 7.0702 & TRN & \\
\hline CHEMBL3701574 & 1528055 & 6.0329 & 6.3253 & TRN & \\
\hline CHEMBL3701560 & 1528055 & 6.0 & 6.1359 & TRN & \\
\hline CHEMBL3643634 & 1528055 & 6.3036 & 6.2037 & TST & \\
\hline CHEMBL3698108 & 1528055 & 6.7077 & 6.9072 & TRN & \\
\hline CHEMBL3643620 & 1528055 & 6.7825 & 6.8932 & TRN & \\
\hline CHEMBL3641294 & 1528055 & 6.4724 & 6.6056 & TRN & \\
\hline CHEMBL 3643556 & 1528055 & 6.4737 & 6.4427 & TST & \\
\hline CHEMBL3643616 & 1528055 & 6.7595 & 6.6402 & TRN & \\
\hline CHEMBL3701510 & 1528055 & 6.857 & 6.6059 & TRN & \\
\hline CHEMBL3641400 & 1528055 & 7.1079 & 7.0204 & TRN & \\
\hline CHEMBL3701465 & 1528055 & 5.5947 & 5.9563 & TRN & \\
\hline CHEMBL3701585 & 1528055 & 6.5391 & 6.3814 & TRN & \\
\hline CHEMBL3641450 & 1528055 & 5.7009 & 6.4463 & TRN & \\
\hline CHEMBL3698112 & 1528055 & 7.3468 & 7.2658 & TRN & \\
\hline CHEMBL3698063 & 1528055 & 6.9957 & 6.3574 & TST & \\
\hline CHEMBL3643580 & 1528055 & 6.5817 & 6.6428 & TRN & \\
\hline CHEMBL3641282 & 1528055 & 6.0 & 6.7021 & TRN & \\
\hline CHEMBL3701614 & 1528055 & 7.1938 & 6.2577 & TRN & \\
\hline CHEMBL3698093 & 1528055 & 5.7755 & 6.8369 & TRN & \\
\hline CHEMBL3641312 & 1528055 & 5.7016 & 6.2504 & TRN & \\
\hline CHEMBL3698101 & 1528055 & 6.6021 & 6.7768 & TRN & \\
\hline CHEMBL 3643526 & 1528055 & 6.5436 & 6.9222 & TRN & \\
\hline CHEMBL3701521 & 1528055 & 6.4622 & 6.3027 & TRN & \\
\hline CHEMBL3641291 & 1528055 & 7.1024 & 6.6053 & TRN & \\
\hline CHEMBL3701432 & 1528055 & 6.1549 & 6.3087 & TST & \\
\hline CHEMBL3641285 & 1528055 & 6.4855 & 6.4007 & TRN & \\
\hline CHEMBL3641358 & 1528055 & 6.0 & 6.1952 & TRN & \\
\hline CHEMBL3701578 & 1528055 & 6.0 & 6.0565 & TRN & \\
\hline CHEMBL3698132 & 1528055 & 7.1805 & 6.7302 & TRN & \\
\hline CHEMBL3701611 & 1528055 & 6.0 & 6.2557 & TRN & \\
\hline CHEMBL3698027 & 1528055 & 7.8861 & 7.3035 & TRN & \\
\hline CHEMBL3701438 & 1528055 & 6.8097 & 6.7917 & TRN & \\
\hline CHEMBL3701417 & 1528055 & 7.0655 & 6.5216 & TRN & \\
\hline CHEMBL3641339 & 1528055 & 5.7701 & 6.2427 & TRN & \\
\hline CHEMBL3643549 & 1528055 & 6.6126 & 6.3021 & TRN & \\
\hline CHEMBL3701524 & 1528055 & 6.5406 & 6.6408 & TRN & \\
\hline CHEMBL3641386 & 1528055 & 6.0 & 7.0991 & TRN & \\
\hline CHEMBL3643515 & 1528055 & 6.2426 & 6.4301 & TST & \\
\hline CHEMBL3701493 & 1528055 & 5.4726 & 6.24700 & 0000000001 & TST \\
\hline CHEMBL3701507 & 1528055 & 6.4202 & 6.3403 & TRN & \\
\hline
\end{tabular}


Supplemental Table S2.txt

\begin{tabular}{|c|c|c|c|c|c|}
\hline CHEMBL3643532 & 1528055 & 7.6144 & 7.6493 & TRN & \\
\hline CHEMBL3643629 & 1528055 & 6.4698 & 6.00799 & 9999999999 & TRN \\
\hline CHEMBL3701483 & 1528055 & 6.5031 & 6.5203 & TRN & \\
\hline CHEMBL 3641365 & 1528055 & 7.3768 & 7.3861 & TRN & \\
\hline CHEMBL3643573 & 1528055 & 6.2565 & 6.3075 & TST & \\
\hline CHEMBL 3641267 & 1528055 & 6.21399 & 99999999 & 6.2492 & (17) \\
\hline CHEMBL3701612 & 1528055 & 6.2358 & 6.2844 & TRN & \\
\hline CHEMBL 3641270 & 1528055 & 6.7077 & 6.4526 & TST & \\
\hline CHEMBL 3701503 & 1528055 & 6.4413 & 6.33 & TRN & \\
\hline CHEMBL3701543 & 1528055 & 6.9914 & 6.794 & TRN & \\
\hline CHEMBL 3698128 & 1528055 & 6.2321 & 6.3696 & TRN & \\
\hline CHEMBL 3641378 & 1528055 & 6.0 & 6.8634 & TRN & \\
\hline CHEMBL 3698061 & 1528055 & 6.8761 & 6.23600 & 0000000001 & \\
\hline CHEMBL 3698083 & 1528055 & 5.9574 & 6.1587 & TRN & \\
\hline CHEMBL3641279 & 1528055 & 6.0 & 5.8115 & TST & \\
\hline CHEMBL 3698122 & 1528055 & 6.1898 & 6.1061 & TRN & \\
\hline CHEMBL3701618 & 1528055 & 5.6536 & 5.9555 & TRN & \\
\hline CHEMBL 3643513 & 1528055 & 6.0 & 6.1811 & TRN & \\
\hline CHEMBL 3641306 & 1528055 & 6.6326 & 6.5471 & TRN & \\
\hline CHEMBL3701632 & 1528055 & 5.4753 & 6.1978 & TST & \\
\hline CHEMBL 3643543 & 1528055 & 6.0 & 6.2431 & TRN & \\
\hline CHEMBL3641391 & 1528055 & 6.3778 & 6.4969 & TRN & \\
\hline CHEMBL 3698065 & 1528055 & 6.9066 & 6.2816 & TST & \\
\hline CHEMBL 3641258 & 1528055 & 5.9784 & 5.8786 & TRN & \\
\hline CHEMBL 3701532 & 1528055 & 6.6108 & 6.2194 & TRN & \\
\hline CHEMBL 3641407 & 1528055 & 6.8827 & 7.2652 & TRN & \\
\hline CHEMBL 3641281 & 1528055 & 6.5317 & 6.5982 & TRN & \\
\hline CHEMBL 3643519 & 1528055 & 6.0835 & \multicolumn{2}{|c|}{6.547000000000001} & \\
\hline CHEMBL3639969 & 1528055 & 6.0 & 6.5934 & TRN & \\
\hline CHEMBL3701540 & 1528055 & 6.9508 & 6.586 & TRN & \\
\hline CHEMBL 3698154 & 1528055 & 7.1612 & 6.8444 & TRN & \\
\hline CHEMBL 3701571 & 1528055 & 7.4318 & 6.8915 & TRN & \\
\hline CHEMBL 3701481 & 1528055 & 6.4012 & 6.3451 & TRN & \\
\hline CHEMBL 3701587 & 1528055 & 5.3043 & 6.1943 & TRN & \\
\hline CHEMBL3641277 & 1528055 & 7.1871 & 7.1758 & TRN & \\
\hline CHEMBL3641313 & 1528055 & 6.3363 & 6.2408 & TRN & \\
\hline CHEMBL 3698158 & 1528055 & 6.9508 & 6.5549 & TRN & \\
\hline CHEMBL3641346 & 1528055 & 5.7978 & \multicolumn{2}{|c|}{6.452999999999999} & \\
\hline CHEMBL 3641392 & 1528055 & 6.4214 & 6.3245 & TRN & \\
\hline CHEMBL3641315 & 1528055 & 6.0 & 6.8618 & TRN & \\
\hline CHEMBL3641345 & 1528055 & 6.067 & 5.8737 & TRN & \\
\hline CHEMBL 3641406 & 1528055 & 7.4437 & 7.4417 & TRN & \\
\hline CHEMBL 3643558 & 1528055 & 7.4295 & 6.7935 & TST & \\
\hline CHEMBL 3641421 & 1528055 & 6.8327 & 6.5227 & TRN & \\
\hline CHEMBL3643511 & 1528055 & 6.3233 & 6.3912 & TST & \\
\hline CHEMBL 3643603 & 1528055 & 6.7773 & 6.2691 & TRN & \\
\hline CHEMBL3641311 & 1528055 & 6.7471 & 6.6162 & TRN & \\
\hline CHEMBL3701597 & 1528055 & 5.1716 & 6.1934 & TRN & \\
\hline
\end{tabular}


Supplemental Table S2.txt

\begin{tabular}{|c|c|c|c|c|}
\hline CHEMBL 3641371 & 1528055 & 6.0 & 6.0932 & TRN \\
\hline CHEMBL 3701441 & 1528055 & 9.1637 & 7.1198 & TRN \\
\hline CHEMBL3641369 & 1528055 & 6.1993 & 6.0082 & TRN \\
\hline CHEMBL3701621 & 1528055 & 5.4779 & 6.4594 & TRN \\
\hline CHEMBL3701599 & 1528055 & 6.8013 & 6.5235 & TST \\
\hline CHEMBL 3698034 & 1528055 & 6.9431 & 6.558 & TRN \\
\hline CHEMBL 3641381 & 1528055 & 7.6198 & 7.0621 & TRN \\
\hline CHEMBL3701545 & 1528055 & 6.5702 & 6.5327 & TRN \\
\hline CHEMBL3643586 & 1528055 & 6.0414 & 6.5759 & TRN \\
\hline CHEMBL3698068 & 1528055 & 5.8706 & 5.9585 & TRN \\
\hline CHEMBL 3643618 & 1528055 & 7.1035 & 7.296 & TRN \\
\hline CHEMBL 3701549 & 1528055 & 6.6091 & 6.6407 & TRN \\
\hline CHEMBL3701556 & 1528055 & 6.0 & 6.3731 & TRN \\
\hline CHEMBL 3643582 & 1528055 & 7.0857 & 6.7315 & TRN \\
\hline CHEMBL 3698032 & 1528055 & 6.9431 & 7.0547 & TRN \\
\hline CHEMBL 3641292 & 1528055 & 6.4841 & 6.6783 & TST \\
\hline CHEMBL 3643530 & 1528055 & 6.8069 & 6.9223 & TRN \\
\hline CHEMBL 3639401 & 1528055 & 6.4157 & 6.6262 & TST \\
\hline CHEMBL 3641414 & 1528055 & 7.1427 & 6.8951 & TRN \\
\hline CHEMBL3698079 & 1528055 & 6.1772 & 6.0282 & TST \\
\hline CHEMBL3701626 & 1528055 & 5.4069 & 6.0472 & TST \\
\hline CHEMBL 3641354 & 1528055 & 7.7212 & 7.6293 & TRN \\
\hline CHEMBL3701539 & 1528055 & 6.7747 & 6.6848 & TRN \\
\hline CHEMBL 3643557 & 1528055 & 5.8383 & 6.2762 & TST \\
\hline CHEMBL 3641452 & 1528055 & 6.3799 & 6.4707 & TRN \\
\hline CHEMBL3643523 & 1528055 & 6.6552 & 7.1185 & TRN \\
\hline CHEMBL 3641396 & 1528055 & 6.1186 & 6.2376 & TRN \\
\hline CHEMBL 3701470 & 1528055 & 6.6676 & 6.1428 & TRN \\
\hline CHEMBL3701430 & 1528055 & 5.7064 & 6.4729 & TRN \\
\hline CHEMBL3701433 & 1528055 & 5.5825 & 6.2913 & TRN \\
\hline CHEMBL3641302 & 1528055 & 6.0438 & 6.0603 & TRN \\
\hline CHEMBL 3641329 & 1528055 & 6.5436 & 5.7581 & TRN \\
\hline CHEMBL 3698117 & 1528055 & 6.0 & 6.8656 & TRN \\
\hline CHEMBL 3641247 & 1528055 & 6.6676 & 6.411006 & 00000000005 \\
\hline CHEMBL3701609 & 1528055 & 6.0635 & 6.3716 & TST \\
\hline CHEMBL 3643635 & 1528055 & 5.9385 & 6.5889 & TRN \\
\hline CHEMBL3701592 & 1528055 & 6.5817 & 6.562 & TST \\
\hline CHEMBL 3698114 & 1528055 & 6.9101 & 6.5553 & TRN \\
\hline CHEMBL 3643540 & 1528055 & 6.4449 & 7.0316 & TST \\
\hline CHEMBL 3641399 & 1528055 & 6.1733 & 6.3062 & TRN \\
\hline CHEMBL 3641360 & 1528055 & 7.3279 & 7.1807 & TRN \\
\hline CHEMBL 3643537 & 1528055 & 6.3585 & 6.5293 & TRN \\
\hline CHEMBL 3641393 & 1528055 & 6.9586 & 6.3006 & TRN \\
\hline CHEMBL 3643625 & 1528055 & 6.4191 & 7.0815 & TST \\
\hline CHEMBL 3698037 & 1528055 & 7.284 & 6.8453 & TRN \\
\hline CHEMBL 3701513 & 1528055 & 6.8697 & 6.4398 & TRN \\
\hline CHEMBL 3641323 & 1528055 & 6.3665 & 6.5147 & TRN \\
\hline CHEMBL 3701416 & 1528055 & 6.0287 & 6.1722 & TRN \\
\hline
\end{tabular}

Page 23360 
Supplemental Table S2.txt

\begin{tabular}{|c|c|c|c|c|c|}
\hline CHEMBL3643560 & 1528055 & 6.7235 & 6.6046 & TRN & \\
\hline CHEMBL 3643587 & 1528055 & 6.7212 & 6.7965 & TRN & \\
\hline CHEMBL3701535 & 1528055 & 6.7447 & 6.7534 & TRN & \\
\hline CHEMBL3698082 & 1528055 & 6.4547 & 6.1917 & TRN & \\
\hline CHEMBL3641337 & 1528055 & 6.4737 & 6.3384 & TRN & \\
\hline CHEMBL3641431 & 1528055 & 6.5376 & 6.2562 & TRN & \\
\hline CHEMBL3701461 & 1528055 & 5.90799 & 79999999 & 6.2275 & TST \\
\hline CHEMBL3701629 & 1528055 & 5.5577 & 6.093 & TST & \\
\hline CHEMBL 3701444 & 1528055 & 7.4202 & 6.6476 & TRN & \\
\hline CHEMBL3698077 & 1528055 & 7.2518 & \multicolumn{2}{|c|}{6.917000000000001} & TRN \\
\hline CHEMBL3641322 & 1528055 & 7.4949 & 7.2028 & TRN & \\
\hline CHEMBL3641253 & 1528055 & 5.54899 & 79999999 & 5.9132 & TRN \\
\hline CHEMBL3641318 & 1528055 & 7.0362 & 6.8974 & TST & \\
\hline CHEMBL 3698070 & 1528055 & 6.3429 & 6.0704 & TRN & \\
\hline CHEMBL3698113 & 1528055 & 7.9586 & 7.4379 & TRN & \\
\hline CHEMBL3701542 & 1528055 & 6.1618 & 6.6737 & TRN & \\
\hline CHEMBL3701581 & 1528055 & 6.0 & 6.0604 & TRN & \\
\hline CHEMBL 3698051 & 1528055 & 7.1192 & 6.5259 & TRN & \\
\hline CHEMBL3641377 & 1528055 & 7.3188 & 7.1724 & TRN & \\
\hline CHEMBL3641395 & 1528055 & 6.4271 & 6.8658 & TST & \\
\hline CHEMBL3698097 & 1528055 & 7.1871 & 7.2039 & TRN & \\
\hline CHEMBL3641402 & 1528055 & 6.7077 & 6.5996 & TRN & \\
\hline CHEMBL3698096 & 1528055 & 7.585 & 7.3415 & TRN & \\
\hline CHEMBL3698074 & 1528055 & 6.9547 & 7.0266 & TRN & \\
\hline CHEMBL3701484 & 1528055 & 6.3372 & 6.2991 & TRN & \\
\hline CHEMBL3701452 & 1528055 & 6.4522 & 6.6829 & TRN & \\
\hline CHEMBL3641351 & 1528055 & 7.1675 & 6.8756 & TRN & \\
\hline CHEMBL 3701479 & 1528055 & 5.9767 & 6.1092 & TRN & \\
\hline CHEMBL3641459 & 1528055 & 6.7282 & 6.5862 & TST & \\
\hline CHEMBL3643522 & 1528055 & 6.4962 & 6.5795 & TRN & \\
\hline CHEMBL3701593 & 1528055 & 6.7033 & 6.2847 & TST & \\
\hline CHEMBL3698139 & 1528055 & 6.567 & 6.3248 & TRN & \\
\hline CHEMBL3641317 & 1528055 & 5.8136 & 6.2634 & TRN & \\
\hline CHEMBL3641314 & 1528055 & 6.3045 & 6.4486 & TRN & \\
\hline CHEMBL3698115 & 1528055 & 6.0 & 6.4015 & TRN & \\
\hline CHEMBL3701497 & 1528055 & 6.5768 & 6.7073 & TRN & \\
\hline CHEMBL3643531 & 1528055 & 7.1931 & 6.9269 & TST & \\
\hline CHEMBL3701472 & 1528055 & 6.3251 & 6.237 & TRN & \\
\hline CHEMBL3641376 & 1528055 & 6.9136 & 6.6013 & TRN & \\
\hline CHEMBL3701601 & 1528055 & 6.0 & 6.425 & TRN & \\
\hline CHEMBL3643539 & 1528055 & 6.7496 & 7.2599 & TST & \\
\hline CHEMBL3643601 & 1528055 & 6.9914 & 6.672006 & 0000000001 & TST \\
\hline CHEMBL3643533 & 1528055 & 6.4461 & 7.1171 & TST & \\
\hline CHEMBL 3701537 & 1528055 & 6.0339 & 6.4366 & TRN & \\
\hline CHEMBL3701603 & 1528055 & 6.6696 & 6.8162 & TST & \\
\hline CHEMBL3643521 & 1528055 & 6.0915 & 6.03100 & 0000000001 & TRN \\
\hline CHEMBL3641276 & 1528055 & 6.1349 & 7.3163 & TST & \\
\hline CHEMBL3701591 & 1528055 & 6.7375 & 6.6651 & TRN & \\
\hline
\end{tabular}


Supplemental Table S2.txt

\begin{tabular}{|c|c|c|c|c|}
\hline CHEMBL3698153 & 1528055 & 6.6073 & 6.4047 & TRN \\
\hline CHEMBL3701572 & 1528055 & 6.0 & 6.4426 & TRN \\
\hline CHEMBL3701466 & 1528055 & 6.2815 & 6.0015 & TRN \\
\hline CHEMBL3698133 & 1528055 & 6.8327 & 6.6673 & TRN \\
\hline CHEMBL3641418 & 1528055 & 6.8861 & 6.5619 & TRN \\
\hline CHEMBL3643638 & 1528055 & 6.4868 & 6.8039 & TRN \\
\hline CHEMBL3698152 & 1528055 & 6.8508 & 6.75799 & 9999999999 \\
\hline CHEMBL3643639 & 1528055 & 7.0 & 6.4368 & TRN \\
\hline CHEMBL3698060 & 1528055 & 6.8665 & 6.3934 & TST \\
\hline CHEMBL3641374 & 1528055 & 6.0 & 6.7145 & TRN \\
\hline CHEMBL3641423 & 1528055 & 6.4789 & 6.7036 & TRN \\
\hline CHEMBL3698055 & 1528055 & 6.9136 & 7.0488 & TRN \\
\hline CHEMBL3643555 & 1528055 & 6.3625 & 6.56 & TST \\
\hline CHEMBL 3698053 & 1528055 & 7.2676 & 7.1524 & TRN \\
\hline CHEMBL 3643575 & 1528055 & 6.6144 & 6.8035 & TST \\
\hline CHEMBL3641273 & 1528055 & 7.6198 & 7.1048 & TST \\
\hline CHEMBL3643589 & 1528055 & 6.0 & 6.1913 & TRN \\
\hline CHEMBL3698028 & 1528055 & 8.0 & 7.2632 & TST \\
\hline CHEMBL 3643562 & 1528055 & 6.9245 & 6.524 & TST \\
\hline CHEMBL3701625 & 1528055 & 5.3503 & 5.6283 & TST \\
\hline CHEMBL3701594 & 1528055 & 3.301 & 6.1128 & TST \\
\hline CHEMBL3701501 & 1528055 & 6.6345 & 6.841 & TST \\
\hline CHEMBL3698040 & 1528055 & 6.2426 & 6.0937 & TST \\
\hline CHEMBL 3701598 & 1528055 & 5.4012 & 6.3038 & TST \\
\hline CHEMBL3643525 & 1528055 & 7.3261 & 7.3456 & TST \\
\hline CHEMBL3643567 & 1528055 & 6.8996 & 6.0246 & TST \\
\hline CHEMBL3641304 & 1528055 & 6.1512 & 6.0175 & TST \\
\hline CHEMBL3701428 & 1528055 & 7.041 & 6.291 & TST \\
\hline CHEMBL 3701522 & 1528055 & 6.2076 & 6.1873 & TST \\
\hline CHEMBL 3698142 & 1528055 & 6.6635 & 6.3934 & TST \\
\hline CHEMBL3698086 & 1528055 & 7.0088 & 6.5547 & TST \\
\hline CHEMBL 3643554 & 1528055 & 5.9731 & 6.3369 & TST \\
\hline CHEMBL3698124 & 1528055 & 6.2118 & 6.1238 & TST \\
\hline CHEMBL3698054 & 1528055 & 7.0757 & 7.1642 & TST \\
\hline CHEMBL 3698076 & 1528055 & 6.7447 & 6.2671 & TST \\
\hline CHEMBL3698080 & 1528055 & 7.0757 & 7.0836 & TST \\
\hline CHEMBL3701596 & 1528055 & 5.515 & 5.9166 & TST \\
\hline CHEMBL3701477 & 1528055 & 6.9281 & 6.5354 & TST \\
\hline CHEMBL3701627 & 1528055 & 6.5186 & 6.4436 & TST \\
\hline CHEMBL 3641388 & 1528055 & 6.9031 & 6.5609 & TST \\
\hline CHEMBL3643509 & 1528055 & 6.8125 & 6.5266 & TST \\
\hline CHEMBL3641466 & 1528055 & 8.251 & 6.869 & TST \\
\hline CHEMBL3701490 & 1528055 & 6.2644 & 6.3585 & TST \\
\hline CHEMBL3643518 & 1528055 & 7.0491 & 6.605 & TST \\
\hline CHEMBL 3701604 & 1528055 & 7.0605 & 6.221 & TST \\
\hline CHEMBL3698102 & 1528055 & 6.8539 & 6.7506 & TST \\
\hline CHEMBL 3643574 & 1528055 & 6.6271 & 6.6997 & TST \\
\hline CHEMBL 3701463 & 1528055 & 6.2403 & 6.3005 & TST \\
\hline
\end{tabular}


Supplemental Table S2.txt

\begin{tabular}{|c|c|c|c|c|}
\hline 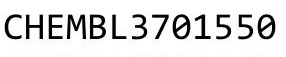 & 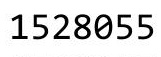 & 5778 & & \\
\hline CHEMBL3643569 & .528055 & 6.4895 & 2253 & \\
\hline HEMBL3641303 & 528055 & 6.7212 & & \\
\hline 42 & 年 & 3013 & & \\
\hline EMBL36 & 528055 & 3386 & & \\
\hline AEMBL3643572 & 528055 & 6.983 & 5101 & \\
\hline HEMBL3701520 & 528055 & 5.8626 & 4723 & \\
\hline HEMBL 364 & 528055 & & 716 & \\
\hline IEMBL369 & 528055 & 7.5229 & 9583 & \\
\hline IEMBL & 528055 & 6.0 & 3204 & \\
\hline HEMBL364 & 528055 & 6.2204 & 3646 & \\
\hline HEMBL369 & 528055 & 6.5638 & 7194 & \\
\hline HEMBL37€ & 5280 & 9957 & 5766 & \\
\hline AEMBL; & 528055 & 6.3706 & 3314 & \\
\hline AEMBL & 528055 & 6.8508 & 5355 & \\
\hline JEMBL 364 & 528055 & 6.0 & 6.8329 & \\
\hline HEMBL364 & 528055 & 901 & 3079 & \\
\hline HEMBL 37 & 528 & & 3074 & \\
\hline HEMBL & 528 & 472 & 5688 & \\
\hline AEMB & 528055 & 6.5969 & 6.0959 & \\
\hline IEMBL 364 & 528055 & & 5158 & \\
\hline HEMBL369 & 528 & 8 & & \\
\hline HEMBL 37 & 528 & & & \\
\hline AEMBL & - & & & \\
\hline IEMB & 301 & 6.0 & 348 & \\
\hline IEMBL19] & 10 & 5.2668 & & \\
\hline HEMBL186 & 1 & & & \\
\hline AEMBL172 & 301 & & & \\
\hline HEMBL & 1 & 8 & & \\
\hline IEMB & 1 & 95 & 87 & \\
\hline IEMBL145 & 犭1 & & & \\
\hline HEMBL 213 & s & 575 & 301 & \\
\hline IEMBL & 30 & & & RI \\
\hline 7 & & & 95 & \\
\hline IEMBL15 & & & & \\
\hline IEMBL136 & 90 & 5.0501 & 5001 & \\
\hline AEMBL15 & 301 & 5.3575 & 2245 & \\
\hline 1 & & & & \\
\hline 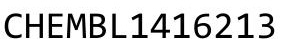 & 1 & 51 & 05 & \\
\hline AEMBL & & & & \\
\hline AEMBL318 & 01501 & 6.3401 & 6.0754 & \\
\hline HEMBL: & 2015 & 5 & 83 & \\
\hline CHEMBL318 & & & & \\
\hline CHEMBL190 & 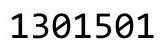 & 5.3686 & 5.5186 & \\
\hline CHEMBL 213 & 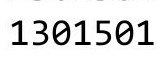 & 5.301 & 5.7265 & $\mathrm{R} \mid$ \\
\hline HEMBL 213 & 30150 & 7983 & .6519 & \\
\hline CHEMBL 318 & 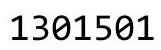 & & & \\
\hline CHEMBL196 & & & & \\
\hline
\end{tabular}

Page 23363 
Supplemental Table S2.txt

\begin{tabular}{|c|c|c|c|c|}
\hline AEMBL 2137234 & 301501 & 4.9825 & & \\
\hline HEMBL1876686 & & 5.1249 & 5.3129 & \\
\hline & & & & \\
\hline IEMBL236 & 501 & 6.0 & & \\
\hline AEMBL1 & 301501 & 7011 & & \\
\hline HEMBL2355724 & 301501 & 4.9718 & $\partial 17$ & \\
\hline AEMBL & 501 & & & \\
\hline EMBL & & & & \\
\hline AEMBL 2 & 501 & 9983 & & RN \\
\hline AEMBL1 & 301501 & 5.2104 & 203 & ST \\
\hline AEMBL: & 301501 & 5.3161 & & \\
\hline IEMBL: & 01 & .1337 & & \\
\hline IEMBL & 01 & & & \\
\hline AEMBL & 501 & 0128 & & \\
\hline AEMBL & 301501 & 6.025 & & \\
\hline AEMBL: & 01 & 5143 & & \\
\hline AEMBL & $\partial 1$ & 27 & & \\
\hline AEMBL & $\partial 1$ & & & \\
\hline AEMBL & 01 & 6.3261 & & \\
\hline IEMBL & 01 & 5.05 & & \\
\hline |EMB| & 01 & 9 & & \\
\hline EMB & $\partial 1$ & 6 & & \\
\hline IEMB & $\partial 1$ & & & \\
\hline 47 & $\partial 1$ & & & \\
\hline IEMBL & $\partial 1$ & & & KN \\
\hline AEMBL & 01 & 8 & & \\
\hline IEMBL & 1 & 6 & & \\
\hline EME & 01 & 29 & & KIV \\
\hline IEMBL & $\partial 1$ & 7.71 & & \\
\hline AEMBL & 301 & 5.6091 & & RN \\
\hline IEMBL & $\partial 1$ & .0044 & & $\mathrm{RI}$ \\
\hline 09 & 31 & 8 & & . \\
\hline 7 & $\partial 1$ & 96 & & מת \\
\hline AEMBL & 301 & 5.4401 & & \\
\hline HEMBL: & 301501 & 4.7956 & & S \\
\hline IEMBL & $\partial 1$ & .4271 & 62 & RI \\
\hline 5 & 1 & 22 & & 年 \\
\hline & 1 & & & RI \\
\hline AEMBL: & 301501 & 5.1163 & & RI \\
\hline IEMBL & 301501 & 5.0306 & & \\
\hline AEMBL & 301501 & . 3391 & & \\
\hline HEMBL & 1301 & 5.9747 & & \\
\hline HEMBL & 301501 & 4.9935 & & RI \\
\hline EMBL & 301501 & 7.71 & & $\mathrm{R}$ \\
\hline 64 & 301 & 18 & & \\
\hline CHEMBL 1 & 1301501 & .0241 & & \\
\hline CHEMBL3 & 301501 & . 3197 & 5.7172 & \\
\hline CHEMBL528791 & 1301501 & 5.1931 & 5.4368 & $\mathbf{R}$ \\
\hline
\end{tabular}

Page 23364 
Supplemental Table S2.txt

\begin{tabular}{|c|c|c|c|c|c|}
\hline CHEMBL3185199 & 1301501 & 6.3635 & 5.8976 & TRN & \\
\hline CHEMBL1332013 & 1301501 & 5.0605 & 5.4516 & TRN & \\
\hline CHEMBL3182213 & 1301501 & 6.0 & 5.8857 & TRN & \\
\hline CHEMBL3183291 & 1301501 & 5.6108 & 5.5856 & TRN & \\
\hline CHEMBL1928491 & 1301501 & 5.4145 & 5.3786 & TRN & \\
\hline CHEMBL 3183608 & 1301501 & 6.2692 & 5.6958 & TRN & \\
\hline CHEMBL 2140610 & 1301501 & 4.9333 & 5.603 & TRN & \\
\hline CHEMBL 2136180 & 1301501 & 5.0926 & 6.0803 & TRN & \\
\hline CHEMBL 3188935 & 1301501 & 7.71 & 5.8292 & TRN & \\
\hline CHEMBL1569003 & 1301501 & 5.2534 & 5.5146 & TRN & \\
\hline CHEMBL1548185 & 1301501 & 4.8658 & 5.4881 & TRN & \\
\hline CHEMBL1389957 & 1301501 & 6.0788 & 5.5077 & TRN & \\
\hline CHEMBL1986418 & 1301501 & 5.6596 & 5.527 & TRN & \\
\hline CHEMBL1332439 & 1301501 & 5.0458 & \multicolumn{2}{|c|}{5.212000000000001} & TRN \\
\hline CHEMBL1531450 & 1301501 & 4.8179 & 5.2659 & TRN & \\
\hline CHEMBL1439325 & 1301501 & 6.2503 & 5.3248 & TST & \\
\hline CHEMBL1433238 & 1301501 & 5.8125 & 5.3843 & TRN & \\
\hline CHEMBL 3189023 & 1301501 & 6.5952 & 6.0641 & TRN & \\
\hline CHEMBL1412265 & 1301501 & 5.4815 & 5.5592 & TST & \\
\hline CHEMBL3183382 & 1301501 & 6.3019 & 5.9017 & TRN & \\
\hline CHEMBL 2139303 & 1301501 & 6.0 & 5.8567 & TRN & \\
\hline CHEMBL1566089 & 1301501 & 5.7282 & 5.3498 & TRN & \\
\hline CHEMBL1461192 & 1301501 & 5.8861 & 5.6642 & TRN & \\
\hline CHEMBL2138809 & 1301501 & 4.5409 & 5.445 & TRN & \\
\hline CHEMBL 2143548 & 1301501 & 4.7411 & 5.659 & TRN & \\
\hline CHEMBL3185630 & 1301501 & 5.032 & 5.852 & TRN & \\
\hline CHEMBL1574404 & 1301501 & 5.6144 & 5.2443 & TRN & \\
\hline CHEMBL3182079 & 1301501 & 4.9905 & 5.6379 & TRN & \\
\hline CHEMBL 2132699 & 1301501 & 5.0872 & 5.9973 & TRN & \\
\hline CHEMBL3184718 & 1301501 & 5.8477 & 5.7309 & TST & \\
\hline CHEMBL1573112 & 1301501 & 5.1349 & 5.2387 & TRN & \\
\hline CHEMBL528694 & 1301501 & 6.2984 & 5.3608 & TST & \\
\hline CHEMBL2141366 & 1301501 & 5.2668 & 5.6912 & TRN & \\
\hline CHEMBL2143154 & 1301501 & 6.3363 & 5.7466 & TRN & \\
\hline CHEMBL2132619 & 1301501 & 4.7474 & 6.0169 & TRN & \\
\hline CHEMBL1416062 & 1301501 & 5.9666 & 5.6649 & TST & \\
\hline CHEMBL2130699 & 1301501 & 6.0 & 5.8497 & TRN & \\
\hline CHEMBL3183887 & 1301501 & 5.0182 & 5.9423 & TRN & \\
\hline CHEMBL1367183 & 1301501 & 5.3969 & 5.2955 & TRN & \\
\hline CHEMBL2361807 & 1301501 & 6.0996 & 5.9826 & TRN & \\
\hline CHEMBL530361 & 1301501 & 5.1244 & 5.2206 & TRN & \\
\hline CHEMBL1505827 & 1301501 & 5.0958 & 5.279 & TRN & \\
\hline CHEMBL2355140 & 1301501 & 5.6757 & 5.8853 & TRN & \\
\hline CHEMBL3184609 & 1301501 & 4.9974 & 5.6594 & TRN & \\
\hline CHEMBL1529272 & 1301501 & 5.1605 & 5.4038 & TST & \\
\hline CHEMBL1540672 & 1301501 & 5.1911 & 5.3424 & TRN & \\
\hline CHEMBL3182337 & 1301501 & 6.0 & 5.8498 & TRN & \\
\hline CHEMBL3188165 & 1301501 & 4.4621 & 5.6587 & TRN & \\
\hline
\end{tabular}


Supplemental Table S2.txt

\begin{tabular}{|c|c|c|c|c|c|c|}
\hline CHEMBL 3186497 & 1301501 & 5.3726 & 5.9881 & TRN & & \\
\hline CHEMBL 2130729 & 1301501 & 6.3429 & 5.5472 & TRN & & \\
\hline CHEMBL 3187044 & 1301501 & 5.0114 & 5.4545 & TRN & & \\
\hline CHEMBL1507676 & 1301501 & 5.15 & 5.1297 & TRN & & \\
\hline CHEMBL 3183816 & 1301501 & 7.71 & 5.6565 & TRN & & \\
\hline CHEMBL 3187410 & 1301501 & 5.4473 & 5.9206 & TRN & & \\
\hline CHEMBL1477013 & 1301501 & 5.9788 & 5.6703 & TRN & & \\
\hline CHEMBL3185719 & 1301501 & 5.0301 & 6.0965 & TRN & & \\
\hline CHEMBL1343392 & 1301501 & 5.3925 & 5.0858 & TRN & & \\
\hline CHEMBL3184167 & 1301501 & 6.3251 & 5.5202 & TRN & & \\
\hline CHEMBL 2136684 & 1301501 & 6.2993 & 5.8819 & TRN & & \\
\hline CHEMBL1872760 & 1301501 & 5.3768 & 5.3154 & TST & & \\
\hline CHEMBL1544478 & 1301501 & 4.7138 & 5.2193 & TRN & & \\
\hline CHEMBL1572491 & 1301501 & 4.743 & 5.5689 & TST & & \\
\hline CHEMBL1605224 & 1301501 & 5.75200 & 00000000 & 1 & 5.4268 & TRN \\
\hline CHEMBL1526851 & 1301501 & 5.8827 & 5.3393 & TST & & \\
\hline CHEMBL1415594 & 1301501 & 5.9914 & 5.4365 & TRN & & \\
\hline CHEMBL 3186771 & 1301501 & 6.0 & 5.7239 & TRN & & \\
\hline CHEMBL 3187003 & 1301501 & 6.2993 & 5.9075 & TRN & & \\
\hline CHEMBL1333226 & 1301501 & 5.3665 & 5.2796 & TRN & & \\
\hline CHEMBL1446051 & 1301501 & 5.6536 & 5.688 & TRN & & \\
\hline CHEMBL1481347 & 1301501 & 5.7447 & 5.4 & TRN & & \\
\hline CHEMBL1529190 & 1301501 & 5.6861 & 5.441 & TRN & & \\
\hline CHEMBL 2136465 & 1301501 & 6.0 & 5.5441 & TRN & & \\
\hline CHEMBL1710136 & 1301501 & 5.4473 & 5.2204 & TST & & \\
\hline CHEMBL 3188711 & 1301501 & 5.5867 & 5.8348 & TRN & & \\
\hline CHEMBL1489294 & 1301501 & 4.9961 & 5.1997 & TST & & \\
\hline CHEMBL 3184209 & 1301501 & 5.0259 & 5.5731 & TRN & & \\
\hline CHEMBL1465527 & 1301501 & 5.3883 & 5.2774 & TRN & & \\
\hline CHEMBL 3187278 & 1301501 & 5.7399 & 5.8406 & TRN & & \\
\hline CHEMBL1369945 & 1301501 & 5.2612 & 5.3503 & TST & & \\
\hline CHEMBL 3186560 & 1301501 & 5.0325 & 5.671 & TRN & & \\
\hline CHEMBL 3191048 & 1301501 & 5.1261 & 5.3836 & TRN & & \\
\hline CHEMBL1474759 & 1301501 & 5.066 & 5.6541 & TST & & \\
\hline CHEMBL 2144728 & 1301501 & 4.9722 & 5.6215 & TRN & & \\
\hline CHEMBL 3185728 & 1301501 & 5.8268 & 5.7405 & TRN & & \\
\hline CHEMBL1562164 & 1301501 & 5.5622 & 5.4665 & TRN & & \\
\hline CHEMBL 3186438 & 1301501 & 6.38200 & 20000000 & 1 & 5.8162 & TRN \\
\hline CHEMBL 3188072 & 1301501 & 4.9759 & 5.7873 & TRN & & \\
\hline CHEMBL1458479 & 1301501 & 7.71 & 5.9006 & TRN & & \\
\hline CHEMBL 3185340 & 1301501 & 6.3072 & 5.9338 & TRN & & \\
\hline CHEMBL1483699 & 1301501 & 5.0701 & 5.4523 & TRN & & \\
\hline CHEMBL 2359502 & 1301501 & 6.0 & 6.0336 & TRN & & \\
\hline CHEMBL 3184382 & 1301501 & 6.0 & 5.5852 & TRN & & \\
\hline CHEMBL 2140957 & 1301501 & 6.0 & 5.9511 & TRN & & \\
\hline CHEMBL 2136504 & 1301501 & 5.0783 & 5.7118 & TRN & & \\
\hline CHEMBL1504701 & 1301501 & 7.71 & 5.6049 & TRN & & \\
\hline CHEMBL1327251 & 1301501 & 5.4225 & 5.4009 & TST & & \\
\hline
\end{tabular}

Page 23366 
Supplemental Table S2.txt

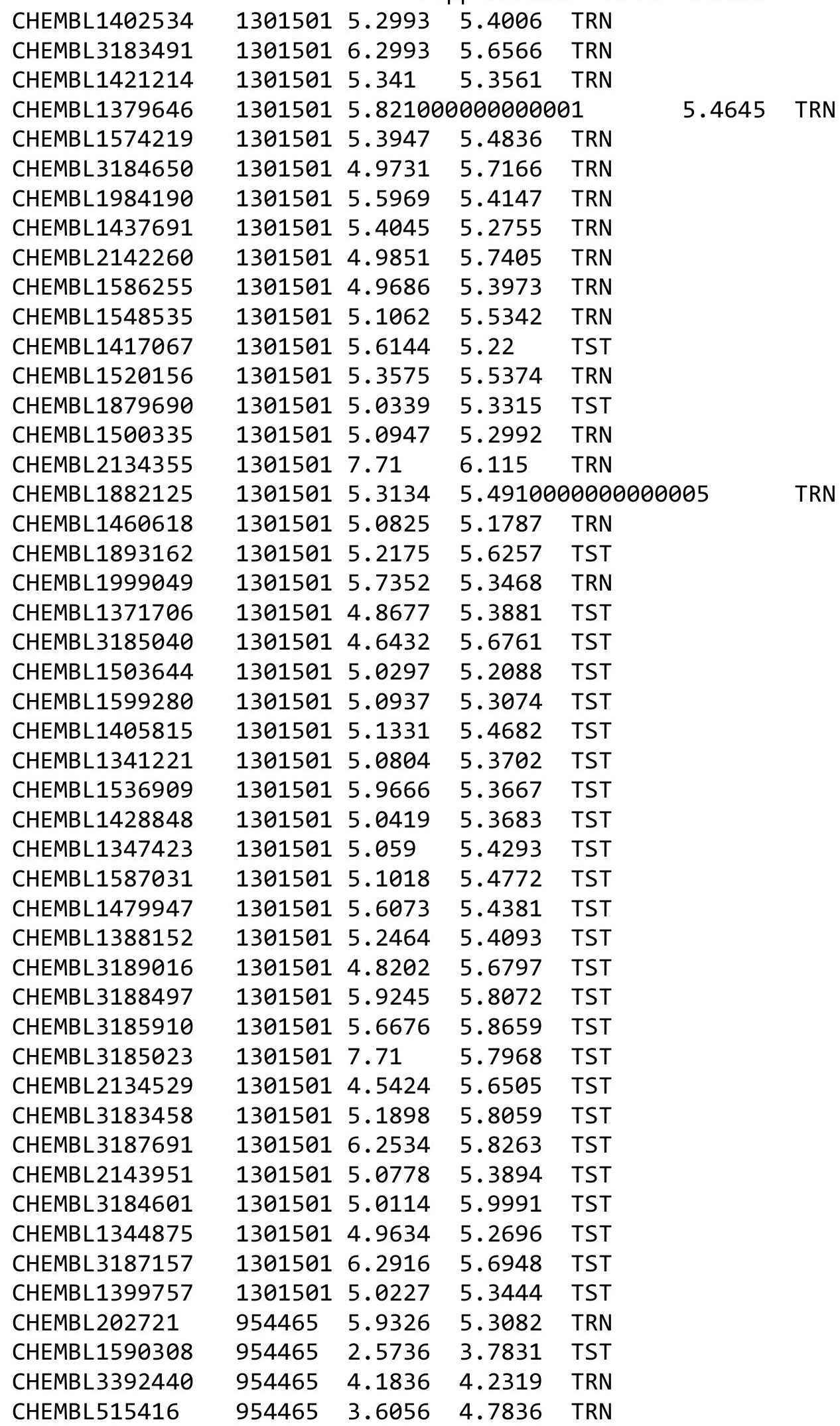

Page 23367 


\begin{tabular}{|c|c|c|c|c|c|}
\hline \multicolumn{6}{|c|}{ Supplemental Table S2.txt } \\
\hline CHEMBL92309 & 954465 & 3.9006 & 3.3482 & TST & \\
\hline CHEMBL514499 & 954465 & 6.8598 & 7.0855 & TRN & \\
\hline CHEMBL1673039 & 954465 & 5.0963 & 5.1148 & TRN & \\
\hline CHEMBL1242367 & 954465 & 4.8163 & 4.5167 & TRN & \\
\hline CHEMBL 240954 & 954465 & 4.3865 & 4.0487 & TST & \\
\hline CHEMBL 2005886 & 954465 & 5.2831 & 5.649 & TRN & \\
\hline CHEMBL393929 & 954465 & 3.98 & 4.2326 & TRN & \\
\hline CHEMBL373751 & 954465 & 3.0537 & 4.0447 & TRN & \\
\hline CHEMBL1190711 & 954465 & 5.9759 & 5.3773 & TRN & \\
\hline CHEMBL512504 & 954465 & 3.6894 & 5.1598 & TRN & \\
\hline CHEMBL483847 & 954465 & 4.3374 & 4.5388 & TRN & \\
\hline CHEMBL258844 & 954465 & 5.5592 & 4.6869 & TRN & \\
\hline CHEMBL412142 & 954465 & 5.38299 & 99999999 & 4.3668 & TRN \\
\hline CHEMBL220241 & 954465 & 4.2343 & 5.0712 & TRN & \\
\hline CHEMBL1970879 & 954465 & 3.3074 & 4.954 & TRN & \\
\hline CHEMBL188678 & 954465 & 5.1107 & 4.7663 & TRN & \\
\hline CHEMBL2363137 & 954465 & 4.9895 & 5.0876 & TRN & \\
\hline CHEMBL210618 & 954465 & 3.0862 & 3.7888 & TRN & \\
\hline CHEMBL3199475 & 954465 & 5.41 & 4.7157 & TRN & \\
\hline CHEMBL483849 & 954465 & 3.7455 & 2.65100 & 00000000002 & TRN \\
\hline CHEMBL192566 & 954465 & 8.2133 & 8.2553 & TST & \\
\hline CHEMBL1404918 & 954465 & 2.9863 & 3.2665 & TRN & \\
\hline CHEMBL585951 & 954465 & 6.3711 & 6.3835 & TRN & \\
\hline CHEMBL509032 & 954465 & 5.773 & 5.8267 & TRN & \\
\hline CHEMBL3349342 & 954465 & 5.614 & 5.4183 & TRN & \\
\hline CHEMBL102714 & 954465 & 4.6225 & 3.928 & TRN & \\
\hline CHEMBL573107 & 954465 & 5.007 & 5.4046 & TRN & \\
\hline CHEMBL259181 & 954465 & 4.8044 & 4.822 & TRN & \\
\hline CHEMBL1788116 & 954465 & 5.6359 & 4.7128 & TRN & \\
\hline CHEMBL558642 & 954465 & 5.5579 & 4.4925 & TRN & \\
\hline CHEMBL1516890 & 954465 & 4.0946 & 4.3597 & TRN & \\
\hline CHEMBL209148 & 954465 & 4.9966 & 4.8576 & TRN & \\
\hline CHEMBL222102 & 954465 & 4.357 & 4.1507 & TRN & \\
\hline CHEMBL379300 & 954465 & 5.2079 & 6.5251 & TRN & \\
\hline CHEMBL1357247 & 954465 & 3.4268 & 3.4939 & TRN & \\
\hline CHEMBL191334 & 954465 & 5.9791 & 4.6528 & TRN & \\
\hline CHEMBL449158 & 954465 & 6.0176 & 7.0058 & TST & \\
\hline CHEMBL379975 & 954465 & 5.0913 & 5.2882 & TRN & \\
\hline CHEMBL472940 & 954465 & 3.1428 & 4.003 & TRN & \\
\hline CHEMBL577784 & 954465 & 6.4414 & 5.5187 & TRN & \\
\hline CHEMBL2144069 & 954465 & 6.1335 & 5.3209 & TRN & \\
\hline CHEMBL221137 & 954465 & 3.552 & 5.001 & TST & \\
\hline CHEMBL65 & 954465 & 9.3556 & 8.3083 & TRN & \\
\hline CHEMBL135561 & 954465 & 3.9915 & 4.7483 & TRN & \\
\hline CHEMBL1230020 & 954465 & 3.2983 & 4.3722 & TRN & \\
\hline CHEMBL3186408 & 954465 & 4.4396 & 4.1831 & TST & \\
\hline CHEMBL180127 & 954465 & 4.9739 & 4.5165 & TRN & \\
\hline CHEMBL9470 & 954465 & 6.9948 & 6.03799 & 9999999999 & \\
\hline
\end{tabular}




\begin{tabular}{|c|c|c|c|c|c|}
\hline \multicolumn{6}{|c|}{ Supplemental Table S2.txt } \\
\hline CHEMBL392695 & 954465 & 4.9413 & 5.3647 & TST & \\
\hline CHEMBL 300389 & 954465 & 7.1018 & 6.9362 & TST & \\
\hline CHEMBL1256459 & 954465 & 6.0058 & 7.1795 & TST & \\
\hline CHEMBL213100 & 954465 & 3.9527 & 5.237 & TST & \\
\hline CHEMBL189584 & 954465 & 5.5037 & 4.9282 & TST & \\
\hline CHEMBL1643959 & 954465 & 4.4463 & 4.0572 & TST & \\
\hline CHEMBL1909414 & 954465 & 5.7776 & 4.3416 & TST & \\
\hline CHEMBL1312928 & 809037 & 3.9223 & 3.6717 & TRN & \\
\hline CHEMBL1368708 & 809037 & 4.8568 & 4.8122 & TRN & \\
\hline CHEMBL 3304020 & 809037 & 5.8305 & 4.8788 & TRN & \\
\hline CHEMBL 2028187 & 809037 & 3.4452 & 4.0298 & TST & \\
\hline CHEMBL1307972 & 809037 & 5.1748 & 4.261 & TRN & \\
\hline CHEMBL59530 & 809037 & 3.446 & 4.9111 & TST & \\
\hline CHEMBL1713127 & 809037 & 4.621 & 4.2007 & TRN & \\
\hline CHEMBL1339694 & 809037 & 3.4454 & 3.6898 & TRN & \\
\hline CHEMBL1529280 & 809037 & 4.6199 & 4.4406 & TRN & \\
\hline CHEMBL1438505 & 809037 & 4.9671 & 4.8449 & TRN & \\
\hline CHEMBL494325 & 809037 & 5.2249 & 5.1196 & TRN & \\
\hline CHEMBL1993707 & 809037 & 3.4452 & 4.6298 & TRN & \\
\hline CHEMBL1385327 & 809037 & 5.0723 & 5.2416 & TRN & \\
\hline CHEMBL1980848 & 809037 & 4.6378 & 4.6148 & TRN & \\
\hline CHEMBL1490392 & 809037 & 4.4946 & 4.6975 & TRN & \\
\hline CHEMBL1352064 & 809037 & 4.8156 & 4.8873 & TRN & \\
\hline CHEMBL 2007313 & 809037 & 5.3007 & 5.0395 & TRN & \\
\hline CHEMBL1610875 & 809037 & 4.7984 & 5.5231 & TRN & \\
\hline CHEMBL1511754 & 809037 & 4.8045 & 4.3735 & TRN & \\
\hline CHEMBL1544409 & 809037 & 5.1576 & 4.5096 & TRN & \\
\hline CHEMBL1462756 & 809037 & 4.7808 & 4.7817 & TRN & \\
\hline CHEMBL1995641 & 809037 & 3.4453 & 3.8917 & TRN & \\
\hline CHEMBL1562983 & 809037 & 3.4453 & 4.84399 & 9999999999 & TRN \\
\hline CHEMBL576412 & 809037 & 4.6611 & 4.4219 & TRN & \\
\hline CHEMBL1487959 & 809037 & 3.4452 & 3.9506 & TRN & \\
\hline CHEMBL1515941 & 809037 & 4.6831 & 5.2458 & TRN & \\
\hline CHEMBL1612809 & 809037 & 3.4453 & 4.0079 & TRN & \\
\hline CHEMBL1549657 & 809037 & 4.6939 & 4.4777 & TRN & \\
\hline CHEMBL1396943 & 809037 & 3.4452 & 3.9508 & TRN & \\
\hline CHEMBL1475299 & 809037 & 4.686 & 5.165 & TRN & \\
\hline CHEMBL1494091 & 809037 & 5.0802 & 4.5897 & TRN & \\
\hline CHEMBL1480880 & 809037 & 3.9224 & 4.9638 & TRN & \\
\hline CHEMBL1549424 & 809037 & 3.4453 & 3.8122 & TRN & \\
\hline CHEMBL1380143 & 809037 & 5.0724 & 5.0213 & TRN & \\
\hline CHEMBL1378385 & 809037 & 4.9539 & 4.753 & TRN & \\
\hline CHEMBL1972216 & 809037 & 4.9668 & 4.4485 & TRN & \\
\hline CHEMBL1464490 & 809037 & 3.4452 & 3.7205 & TRN & \\
\hline CHEMBL1347672 & 809037 & 4.5376 & 4.5863 & TRN & \\
\hline CHEMBL1372451 & 809037 & 3.4456 & 4.0932 & TRN & \\
\hline CHEMBL1546346 & 809037 & 3.4449 & 4.3722 & TST & \\
\hline CHEMBL1965433 & 809037 & 4.9348 & 4.323 & TRN & \\
\hline
\end{tabular}




\begin{tabular}{|c|c|c|c|c|c|}
\hline & & \multicolumn{4}{|c|}{ Supplemental Table S2.txt } \\
\hline CHEMBL1304187 & 809037 & 3.4452 & 3.5925 & TRN & \\
\hline CHEMBL 2001670 & 809037 & 3.4448 & 3.8104 & TRN & \\
\hline CHEMBL2004809 & 809037 & 5.124 & 4.6577 & TRN & \\
\hline CHEMBL1453780 & 809037 & 4.6997 & 4.7778 & TRN & \\
\hline CHEMBL1399772 & 809037 & 5.4953 & 5.1583 & TRN & \\
\hline CHEMBL1983418 & 809037 & 5.065 & 4.3047 & TRN & \\
\hline CHEMBL1540237 & 809037 & 4.9777 & 4.4662 & TRN & \\
\hline CHEMBL428909 & 809037 & 4.8463 & 4.69600 & 2000000001 & TRN \\
\hline CHEMBL1967019 & 809037 & 4.8106 & 4.7002 & TRN & \\
\hline CHEMBL2373711 & 809037 & 5.0941 & 4.8366 & TST & \\
\hline CHEMBL1708715 & 809037 & 4.7915 & 4.3702 & TST & \\
\hline CHEMBL1418980 & 809037 & 4.7917 & 4.7875 & TRN & \\
\hline CHEMBL1380630 & 809037 & 4.9254 & 4.8183 & TRN & \\
\hline CHEMBL1488229 & 809037 & 3.4453 & 3.6358 & TRN & \\
\hline CHEMBL1972217 & 809037 & 5.0261 & 4.9315 & TRN & \\
\hline CHEMBL1302818 & 809037 & 3.4452 & 3.6868 & TRN & \\
\hline CHEMBL1341317 & 809037 & 5.0313 & 4.8209 & TRN & \\
\hline CHEMBL1719626 & 809037 & 4.9123 & 4.9792 & TST & \\
\hline CHEMBL1882211 & 809037 & 5.1031 & 4.8653 & TRN & \\
\hline CHEMBL1337807 & 809037 & 3.4452 & 3.9358 & TRN & \\
\hline CHEMBL1411648 & 809037 & 4.8937 & 4.7554 & TRN & \\
\hline CHEMBL1976374 & 809037 & 4.6597 & 3.9673 & TRN & \\
\hline CHEMBL1413003 & 809037 & 4.7541 & 4.774 & TRN & \\
\hline CHEMBL1508267 & 809037 & 4.9583 & 5.0679 & TST & \\
\hline CHEMBL1300713 & 809037 & 4.9413 & 4.8378 & TRN & \\
\hline CHEMBL1595937 & 809037 & 4.8482 & 4.4277 & TRN & \\
\hline CHEMBL1329069 & 809037 & 5.2247 & 4.9326 & TRN & \\
\hline CHEMBL1383315 & 809037 & 5.4006 & 5.2044 & TRN & \\
\hline CHEMBL1866510 & 809037 & 4.3996 & 4.3621 & TRN & \\
\hline CHEMBL565657 & 809037 & 4.7033 & 4.1708 & TST & \\
\hline CHEMBL1517605 & 809037 & 4.8727 & 4.9475 & TRN & \\
\hline CHEMBL1585705 & 809037 & 5.0238 & 4.249 & TRN & \\
\hline CHEMBL1736199 & 809037 & 5.1887 & 4.1858 & TRN & \\
\hline CHEMBL587564 & 809037 & 3.4455 & 4.1347 & TRN & \\
\hline CHEMBL3195049 & 809037 & 4.9524 & 4.4833 & TRN & \\
\hline CHEMBL1479201 & 809037 & 4.8722 & 4.5832 & TST & \\
\hline CHEMBL1717403 & 809037 & 4.8944 & 5.1734 & TRN & \\
\hline CHEMBL1555905 & 809037 & 4.9803 & 4.7279 & TST & \\
\hline CHEMBL1706512 & 809037 & 4.5333 & 4.3189 & TRN & \\
\hline CHEMBL1985010 & 809037 & 3.4456 & 3.8922 & TRN & \\
\hline CHEMBL1525654 & 809037 & 4.6243 & 4.47199 & 99999999995 & TRN \\
\hline CHEMBL479368 & 809037 & 5.3214 & 4.9873 & TRN & \\
\hline CHEMBL1611106 & 809037 & 4.7959 & 5.0178 & TRN & \\
\hline CHEMBL1469961 & 809037 & 4.9056 & 4.9916 & TRN & \\
\hline CHEMBL1339283 & 809037 & 3.4452 & 4.2662 & TRN & \\
\hline CHEMBL1528660 & 809037 & 3.4455 & 4.2606 & TRN & \\
\hline CHEMBL1903362 & 809037 & 4.8407 & 4.4309 & TST & \\
\hline CHEMBL1484503 & 809037 & 4.5305 & 4.0541 & TRN & \\
\hline
\end{tabular}


Supplemental Table S2.txt

\begin{tabular}{|c|c|c|c|c|}
\hline 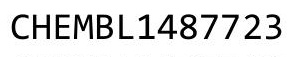 & & 2 & & \\
\hline HEMBL1507740 & 037 & 4452 & 5696 & \\
\hline HEMBL15 & 09037 & 6814 & & \\
\hline 164 & 037 & 721 & 069 & \\
\hline EMBL1: & 037 & 452 & 7189 & \\
\hline AEMBL1600535 & 09037 & 1042 & 8157 & \\
\hline HEMBL1699187 & 09037 & 4.8761 & 4.4771 & \\
\hline HEMBL14€ & 09037 & 452 & 3845 & \\
\hline EMBL13 & 037 & 267 & .3054 & \\
\hline IEMBL15 & 337 & & 2097 & \\
\hline HEMBL1413178 & 09037 & 556 & 9327 & \\
\hline HEMBL1502 & 09037 & 4.9153 & 4.6417 & \\
\hline HEMBL1397 & 09037 & & 3898 & \\
\hline HEMBL135 & 037 & & 25 & \\
\hline HEMBL13 & 37 & & 4783 & \\
\hline HEMBL151 & 09037 & 661 & 7528 & \\
\hline HEMBL199. & 09037 & 17 & 337 & \\
\hline HEMBL139 & 37 & 13 & 261 & \\
\hline HEMBL 141 & & & & \\
\hline AEMBL14 & 37 & 625 & 334 & \\
\hline HEMBL19 & 09037 & 582 & 587 & \\
\hline HEMBL156 & 37 & & & \\
\hline HEMBL14 & 37 & 99 & 972 & \\
\hline HEMBL14 & & & 56 & RN \\
\hline HEM & 37 & 25 & & RN \\
\hline AEMBL153 & 09037 & & & RN \\
\hline HEMBL142 & 29037 & 65 & 015 & ГRN \\
\hline HEMBL14 & 337 & 88 & 633 & $\mathrm{RN}$ \\
\hline HEME & & & & RN \\
\hline HEMBL17 & 37 & 05 & 43 & RN \\
\hline HEMBL132 & 37 & & & $\mathrm{R}$ \\
\hline HEMBL1967149 & 29037 & & & RN \\
\hline HEMBL13 & 037 & & 919 & 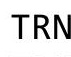 \\
\hline$A F M$ & & & & RN \\
\hline HEMBL131 & & & & RN \\
\hline HEMBL144 & 09037 & & 293 & RN \\
\hline HEMBL1368216 & 29037 & 453 & 361 & RN \\
\hline 155 & 37 & 52 & 911 & RIV \\
\hline 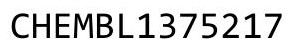 & & 91 & & RN \\
\hline HEMBL 356 & & & & RN \\
\hline HEMBL2000559 & 9037 & 33 & 855 & ST \\
\hline HEMBL 189 & 37 & 39 & 012 & RI \\
\hline HEMBL141 & & & & \\
\hline HEMBL198 & & & 3636 & RN \\
\hline HEMBL2001316 & & .9517 & 8199 & RN \\
\hline HEMBL147: & 09037 & 051 & 954 & \\
\hline CHEMBL173095 & & & & \\
\hline ז & & & & \\
\hline
\end{tabular}

Page 23371 


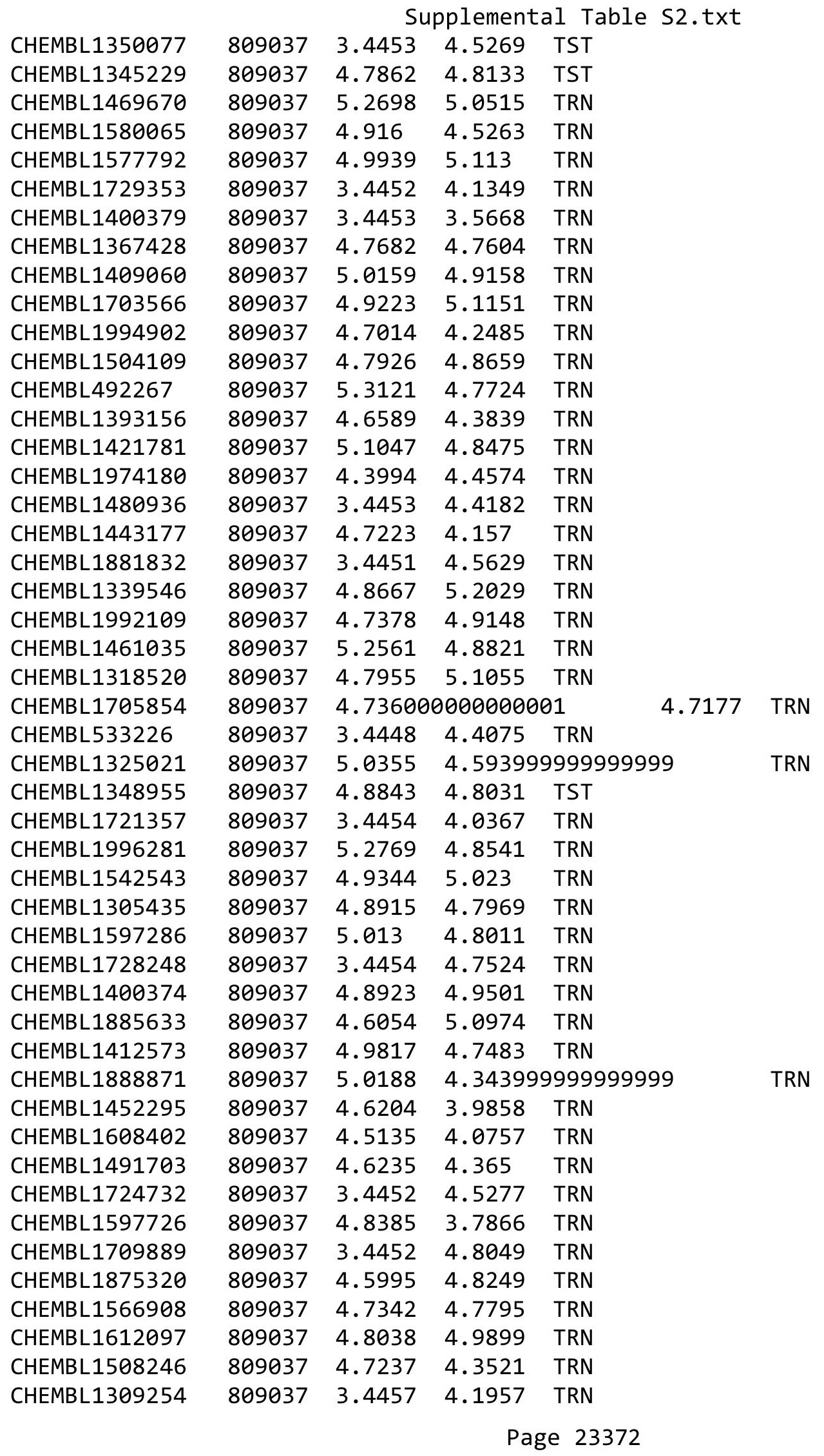




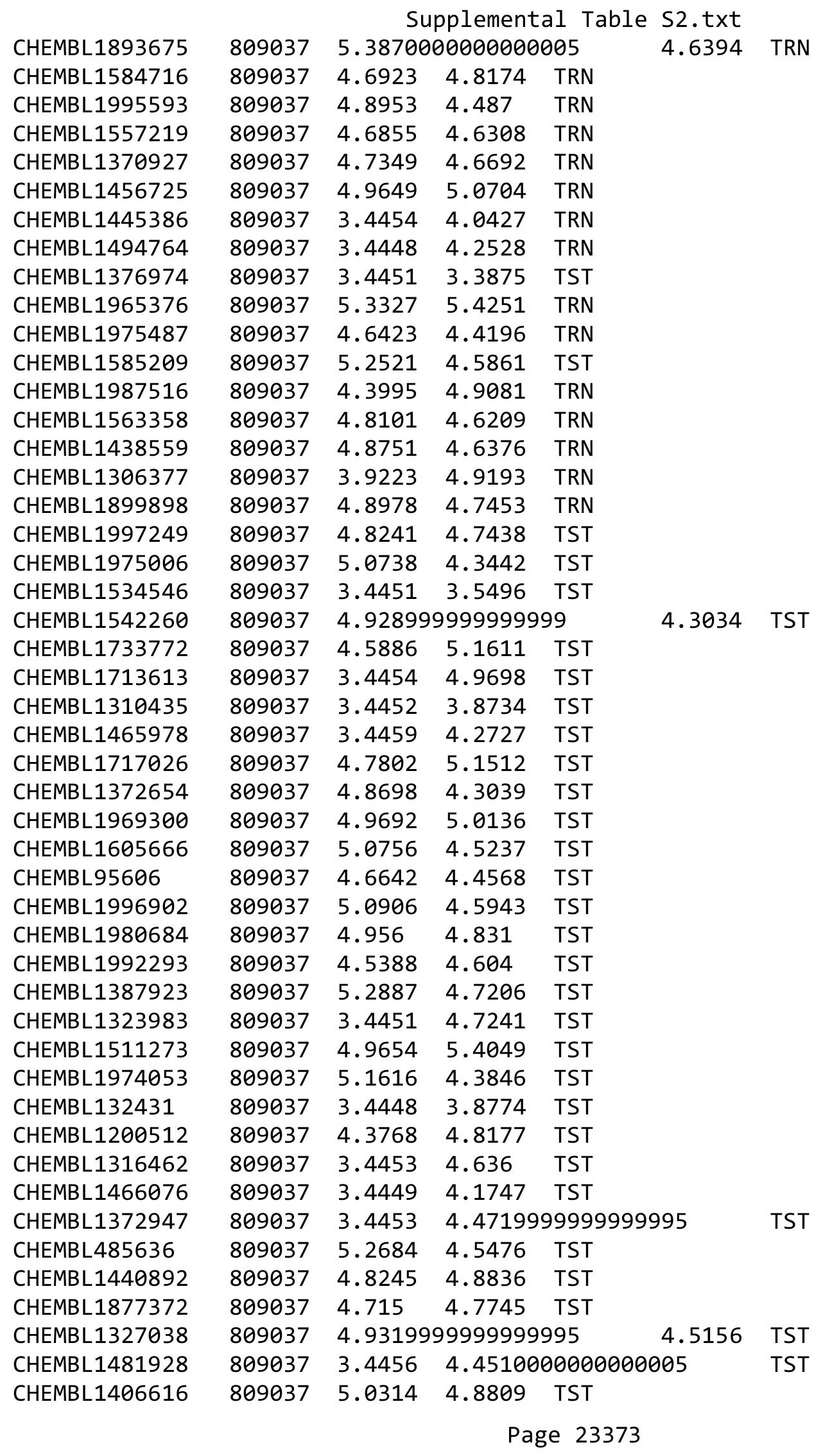




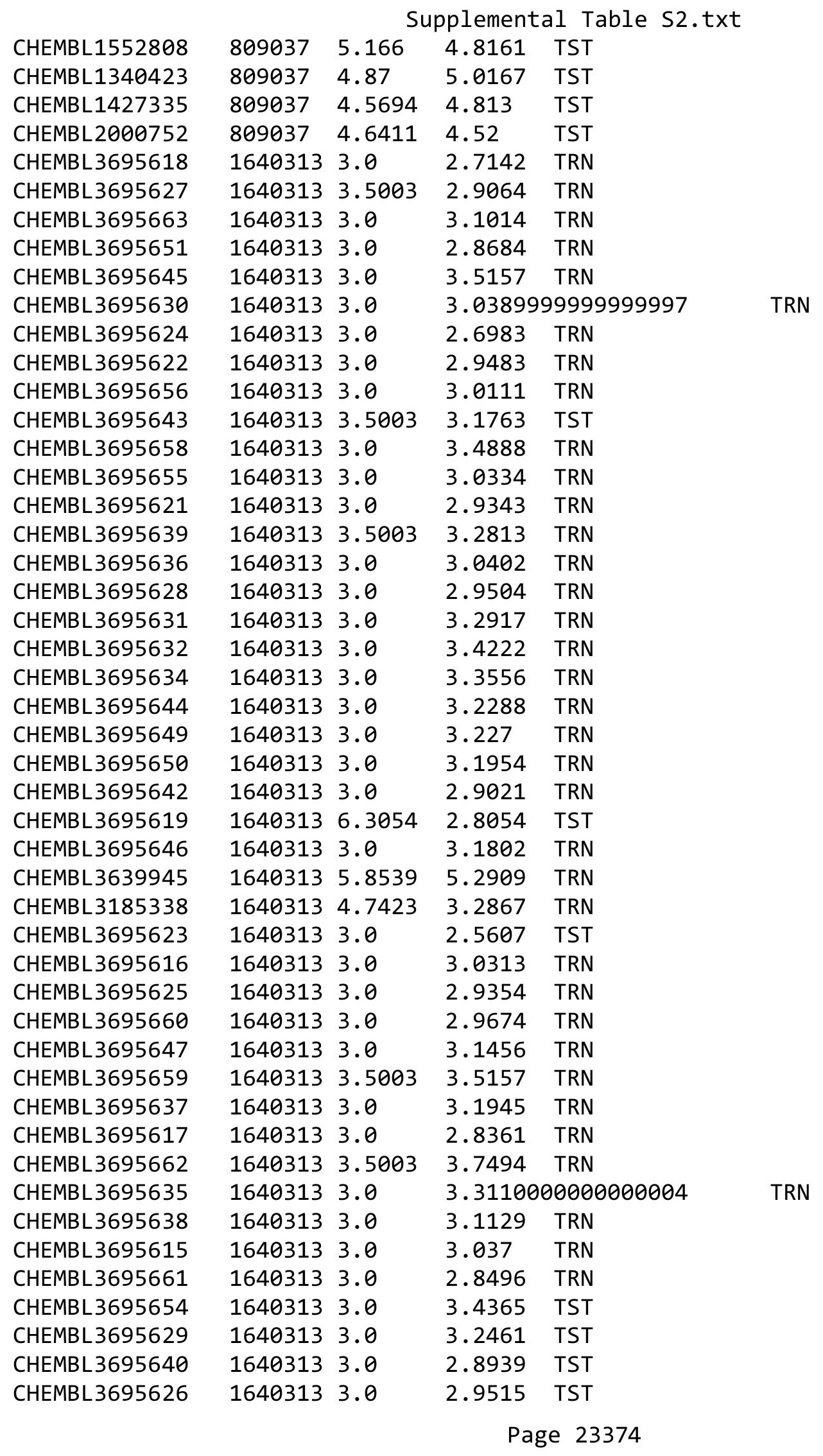


Supplemental Table S2.txt

\begin{tabular}{|c|c|c|c|c|c|}
\hline CHEMBL3695652 & 1640313 & 3.5003 & 3.1338 & TST & \\
\hline CHEMBL3695633 & 1640313 & 3.0 & 3.0991 & TST & \\
\hline CHEMBL3695648 & 1640313 & 3.0 & 3.0947 & TST & \\
\hline CHEMBL3695641 & 1640313 & 3.0 & 3.0924 & TST & \\
\hline CHEMBL3695620 & 1640313 & 3.5003 & 2.8783 & TST & \\
\hline CHEMBL3695653 & 1640313 & 3.0 & 3.0712 & TST & \\
\hline CHEMBL3913779 & 1528121 & 8.1849 & 7.5823 & TST & \\
\hline CHEMBL3958842 & 1528121 & 8.66 & 8.5164 & TRN & \\
\hline CHEMBL 3658762 & 1528121 & 8.9465 & 8.5919 & TST & \\
\hline CHEMBL3658745 & 1528121 & 8.1731 & 7.301 & TRN & \\
\hline CHEMBL 3658783 & 1528121 & 8.5931 & 8.1376 & TRN & \\
\hline CHEMBL3662984 & 1528121 & 9.5334 & 8.799 & TRN & \\
\hline CHEMBL3927859 & 1528121 & 8.6275 & 8.3968 & TRN & \\
\hline CHEMBL3952847 & 1528121 & 7.5036 & 7.5095 & TRN & \\
\hline CHEMBL 3654844 & 1528121 & 6.0 & 7.3189 & TRN & \\
\hline CHEMBL3959697 & 1528121 & 8.2618 & 8.2474 & TST & \\
\hline CHEMBL3968532 & 1528121 & 8.6336 & 8.9297 & TRN & \\
\hline CHEMBL3951012 & 1528121 & 6.0 & 8.5223 & TRN & \\
\hline CHEMBL3658848 & 1528121 & 6.0 & 7.3813 & TRN & \\
\hline CHEMBL3663031 & 1528121 & 8.3974 & 7.5342 & TRN & \\
\hline CHEMBL3936319 & 1528121 & 8.0066 & 8.6869 & TRN & \\
\hline CHEMBL3658650 & 1528121 & 6.0 & 7.4975 & TRN & \\
\hline CHEMBL3931175 & 1528121 & 8.9311 & 9.0285 & TRN & \\
\hline CHEMBL3662976 & 1528121 & 8.4807 & 8.6954 & TRN & \\
\hline CHEMBL 3977443 & 1528121 & 7.5714 & 7.8238 & TRN & \\
\hline CHEMBL3920678 & 1528121 & 9.4868 & 8.6544 & TRN & \\
\hline CHEMBL3942342 & 1528121 & 8.4443 & 8.7074 & TRN & \\
\hline CHEMBL3663077 & 1528121 & 8.8225 & 8.0282 & TRN & \\
\hline CHEMBL3953225 & 1528121 & 7.9547 & 8.378 & TRN & \\
\hline CHEMBL 3924849 & 1528121 & 8.9194 & 8.1224 & TST & \\
\hline CHEMBL3938440 & 1528121 & 7.6185 & 8.2536 & TRN & \\
\hline CHEMBL 3654704 & 1528121 & 9.6105 & 8.9492 & TRN & \\
\hline CHEMBL3654690 & 1528121 & 7.22 & 7.2431 & TRN & \\
\hline CHEMBL 3658698 & 1528121 & 8.5147 & 7.3863 & TRN & \\
\hline CHEMBL3654736 & 1528121 & 7.5259 & 7.51399 & 9999999999 & TRN \\
\hline CHEMBL3662967 & 1528121 & 8.9212 & 8.6475 & TRN & \\
\hline CHEMBL 3937572 & 1528121 & 8.757 & 8.2391 & TRN & \\
\hline CHEMBL3662961 & 1528121 & 9.0631 & 7.6675 & TST & \\
\hline CHEMBL3949165 & 1528121 & 8.4951 & 8.1649 & TST & \\
\hline CHEMBL3906763 & 1528121 & 9.1359 & 8.3112 & TST & \\
\hline CHEMBL3658746 & 1528121 & 8.2035 & 9.2536 & TST & \\
\hline CHEMBL 3889764 & 1528121 & 8.4403 & 8.4638 & TRN & \\
\hline CHEMBL3662966 & 1528121 & 8.4364 & 8.4965 & TRN & \\
\hline CHEMBL3970082 & 1528121 & 6.9326 & 7.7563 & TRN & \\
\hline CHEMBL3654711 & 1528121 & 9.6 & 8.3974 & TRN & \\
\hline CHEMBL3663035 & 1528121 & 9.6326 & 7.6947 & TRN & \\
\hline CHEMBL3957611 & 1528121 & 8.4441 & 9.1869 & TRN & \\
\hline CHEMBL 3658697 & 1528121 & 6.0 & 7.6947 & TRN & \\
\hline
\end{tabular}


Supplemental Table S2.txt

\begin{tabular}{|c|c|c|c|c|c|}
\hline CHEMBL3966356 & 1528121 & 9.6007 & 8.6577 & TRN & \\
\hline CHEMBL3919806 & 1528121 & 9.4363 & 8.8297 & TRN & \\
\hline CHEMBL3654801 & 1528121 & 7.3999 & 8.1029 & TST & \\
\hline CHEMBL3658706 & 1528121 & 6.0 & 7.7654 & TRN & \\
\hline CHEMBL3916987 & 1528121 & 8.1718 & 7.9308 & TST & \\
\hline CHEMBL3658838 & 1528121 & 9.2314 & 8.7378 & TRN & \\
\hline CHEMBL3980585 & 1528121 & 8.7567 & 8.0784 & TRN & \\
\hline CHEMBL3663060 & 1528121 & 8.506 & 8.7765 & TST & \\
\hline CHEMBL 3654674 & 1528121 & 8.6996 & 7.8544 & TRN & \\
\hline CHEMBL3654787 & 1528121 & 6.5969 & 7.7991 & TST & \\
\hline CHEMBL3662953 & 1528121 & 8.8145 & 7.9099 & TRN & \\
\hline CHEMBL3921892 & 1528121 & 9.7359 & 9.1371 & TST & \\
\hline CHEMBL3654773 & 1528121 & 7.401 & 7.7078 & TST & \\
\hline CHEMBL3654786 & 1528121 & 7.3743 & 7.7438 & TST & \\
\hline CHEMBL3951190 & 1528121 & 7.8794 & 7.4335 & TRN & \\
\hline CHEMBL3921154 & 1528121 & 9.1245 & 8.189 & TST & \\
\hline CHEMBL3658808 & 1528121 & 8.4277 & 8.3699 & TRN & \\
\hline CHEMBL3663039 & 1528121 & 8.8857 & 8.3058 & TRN & \\
\hline CHEMBL3658757 & 1528121 & 7.8589 & 8.8278 & TRN & \\
\hline CHEMBL3658732 & 1528121 & 8.5538 & 8.98899 & 9999999999 & TRN \\
\hline CHEMBL3926295 & 1528121 & 8.3481 & 7.8465 & TST & \\
\hline CHEMBL3658717 & 1528121 & 7.5197 & 7.4687 & TRN & \\
\hline CHEMBL3663034 & 1528121 & 9.7135 & 7.7334 & TRN & \\
\hline CHEMBL3922252 & 1528121 & 8.8716 & 8.7038 & TRN & \\
\hline CHEMBL3658689 & 1528121 & 6.0 & 8.022 & TRN & \\
\hline CHEMBL 3654830 & 1528121 & 6.9834 & 7.6985 & TRN & \\
\hline CHEMBL3937028 & 1528121 & 7.6286 & 8.3232 & TRN & \\
\hline CHEMBL3974855 & 1528121 & 8.0463 & 8.3594 & TRN & \\
\hline CHEMBL3920793 & 1528121 & 9.5706 & 9.2415 & TST & \\
\hline CHEMBL3946876 & 1528121 & 8.1131 & 8.05 & TRN & \\
\hline CHEMBL 3658842 & 1528121 & 8.9133 & 8.6898 & TRN & \\
\hline CHEMBL3973344 & 1528121 & 7.8681 & 8.0333 & TST & \\
\hline CHEMBL3968484 & 1528121 & 8.7535 & 8.12 & TRN & \\
\hline CHEMBL 3658846 & 1528121 & 6.4246 & 8.2603 & TRN & \\
\hline CHEMBL3658804 & 1528121 & 9.5103 & 8.8866 & TRN & \\
\hline CHEMBL3913287 & 1528121 & 7.9215 & 8.1835 & TRN & \\
\hline CHEMBL3663106 & 1528121 & 6.1892 & 7.1486 & TST & \\
\hline CHEMBL3654729 & 1528121 & 8.2687 & 7.7238 & TRN & \\
\hline CHEMBL3658826 & 1528121 & 6.0 & 8.2667 & TRN & \\
\hline CHEMBL 3658768 & 1528121 & 7.9559 & 7.3684 & TRN & \\
\hline CHEMBL3959300 & 1528121 & 7.3465 & 8.5725 & TRN & \\
\hline CHEMBL3658771 & 1528121 & 8.2422 & 7.357 & TRN & \\
\hline CHEMBL3663043 & 1528121 & 8.6859 & 8.1565 & TRN & \\
\hline CHEMBL3935557 & 1528121 & 7.643 & 8.0592 & TRN & \\
\hline CHEMBL 3654745 & 1528121 & 7.9241 & 8.8608 & TRN & \\
\hline CHEMBL 3658791 & 1528121 & 8.8371 & 8.4627 & TRN & \\
\hline CHEMBL3951781 & 1528121 & 7.1555 & 7.2919 & TRN & \\
\hline CHEMBL3940290 & 1528121 & $8.9020 e$ & 30000006 & 8.4323 & TST \\
\hline
\end{tabular}


Supplemental Table S2.txt

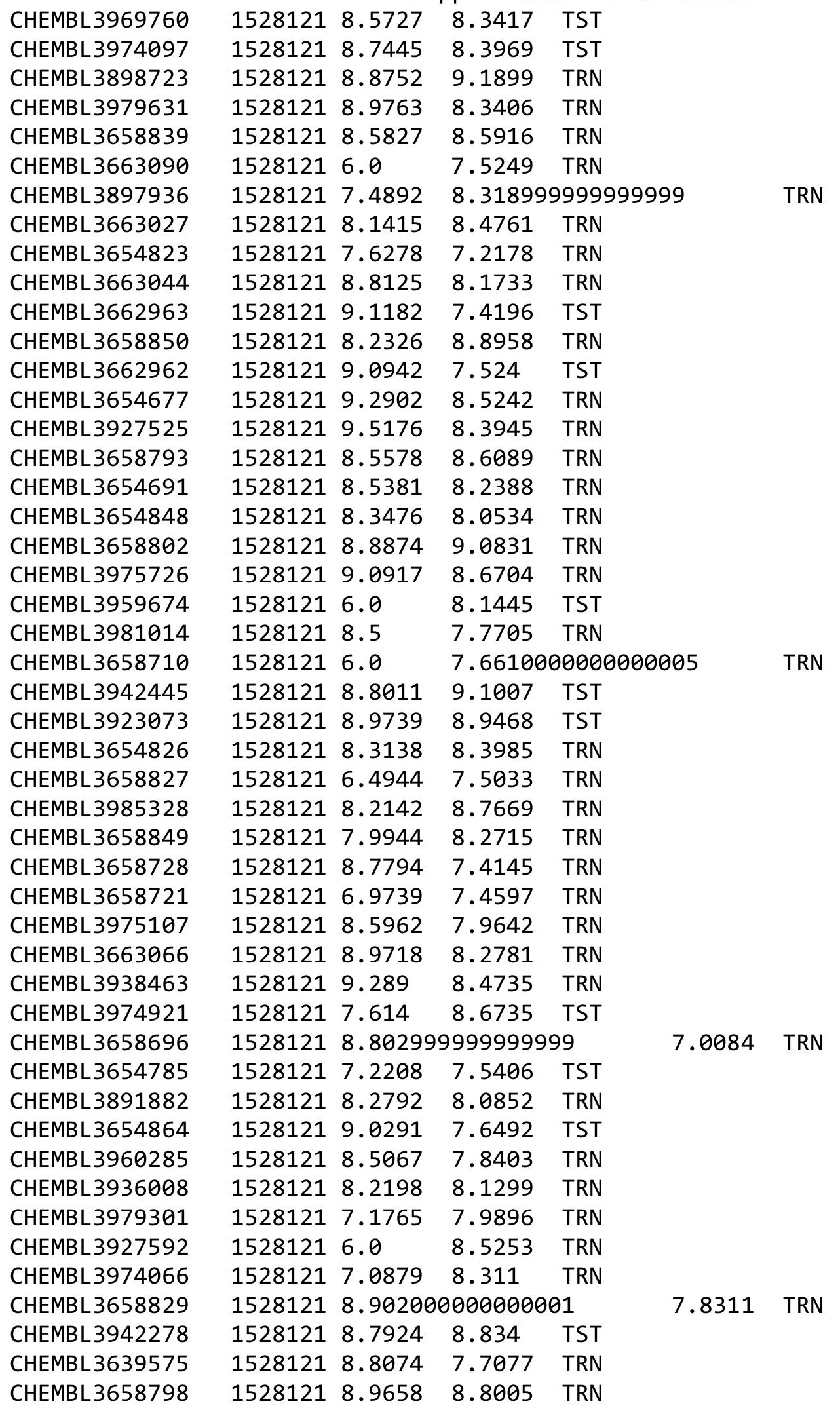


Supplemental Table S2.txt

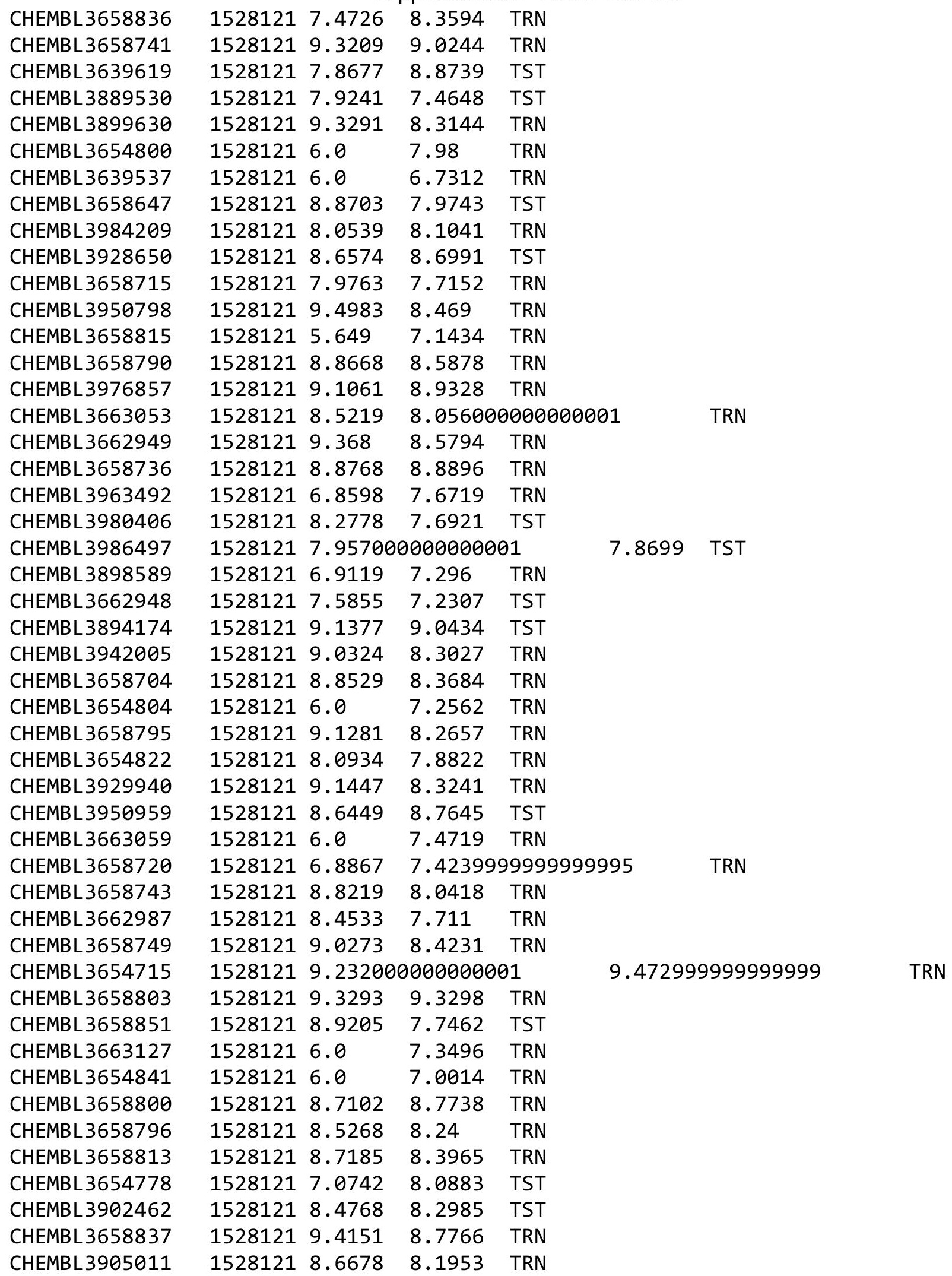

Page 23378 
Supplemental Table S2.txt

\begin{tabular}{|c|c|c|c|c|}
\hline HEMBL & & 545 & 8 & \\
\hline HFMRI 3658917 & 528121 & 9.5133 & o 9946 & \\
\hline HEMBL & & 6.0 & 761 & \\
\hline AEMBL3663028 & 528121 & 8.8523 & 0261 & \\
\hline HEMBL3906704 & 528121 & 8.734 & 2683 & \\
\hline HEMBL 366 & 121 & 9.2507 & 338 & \\
\hline AEMBL: & & 6.8626 & & \\
\hline HEMBL & 121 & 6.0 & 6932 & \\
\hline HEMBL3930833 & 528121 & 9.6276 & 6871 & \\
\hline HEMBL3658774 & 528121 & 8.5774 & 8.4868 & \\
\hline AEMBL3 & 121 & .7945 & 239 & \\
\hline HEMBL; & & & & \\
\hline HEMBL3 & 121 & 9.3241 & 8381 & \\
\hline HEMBL3 & 21 & 9.3567 & 4335 & \\
\hline HEMBL365 & 21 & 8.5622 & 5158 & \\
\hline AEMBL & 21 & 881 & 326 & \\
\hline AEMBL & & & & RN \\
\hline HEMBL; & 21 & 3615 & 595 & \\
\hline HEMBL3 & 21 & 7595 & & \\
\hline AEMBL3 & 21 & 9.1495 & 11 & KIV \\
\hline AEMBL & 1 & 59 & & RN \\
\hline AEMBL & & & & RIV \\
\hline HEMBL & 21 & 658 & 108 & \\
\hline HEMBL & & 694 & & \\
\hline AEMBL 3 & 21 & 313 & 98 & $R N$ \\
\hline AEMBL: & 21 & 62 & 48 & ST \\
\hline AEM & & & & $\mathrm{RN}$ \\
\hline HEMPI & & & & Due \\
\hline IEMBL: & & & & RN \\
\hline HEMBL 36 & 21 & & 356 & 「RN \\
\hline AEMBL & 21 & 99 & & $\mathrm{RN}$ \\
\hline AFM & & & & RN \\
\hline & & & & RN \\
\hline AEMBL3 & & & & RN \\
\hline HEMBL36 & 21 & 7.8881 & .72 & ГST \\
\hline$A F M B I=$ & 1 & 49 & & IST \\
\hline & & & & ST \\
\hline HEMBL3 & & & & TRN \\
\hline AEMBL 3658 & 21 & 6.5974 & 23 & $\Gamma R$ \\
\hline EMBL; & 21 & 141 & & IST \\
\hline HEMBL3 & 1 & 175 & & TST \\
\hline HEMBL3 & & & & TRN \\
\hline HEMBL3 & & 9.5177 & 5824 & TST \\
\hline AEMBL36 & 52 & 824 & 23 & TR \\
\hline MBL: & & 243 & & IST \\
\hline HEMBL 3 & 52 & .8716 & 7.8265 & \\
\hline CHEMBL 3 & 21 & .3645 & 8.7942 & \\
\hline CHEMBL3658825 & 1528121 & 8.8002 & 7.8894 & \\
\hline
\end{tabular}

Page 23379 
Supplemental Table S2.txt

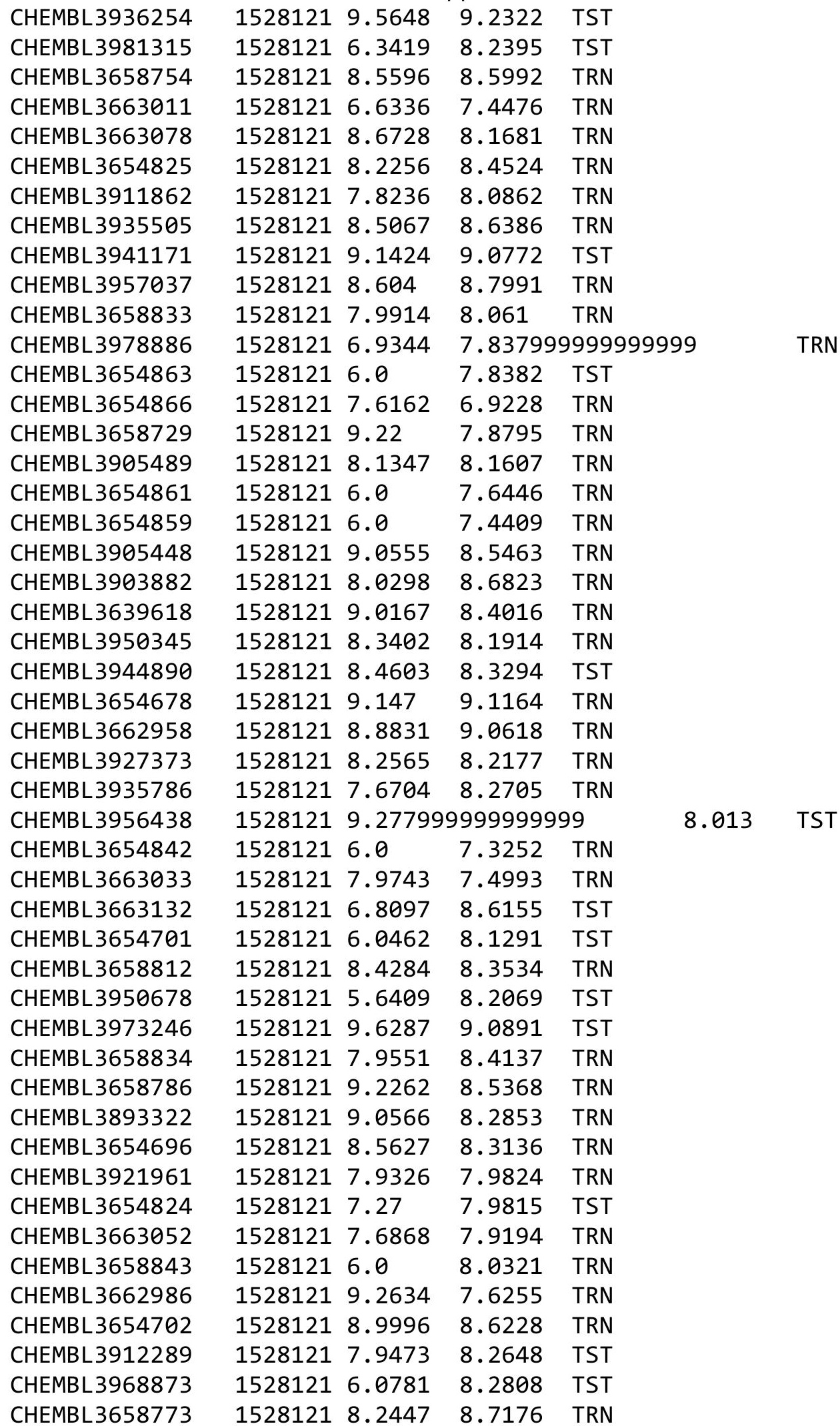

Page 23380 
Supplemental Table S2.txt

\begin{tabular}{|c|c|c|c|c|}
\hline CHEMBL3663051 & 1528121 & 7.4955 & 7.7257 & TRN \\
\hline CHEMBL 3654777 & 1528121 & 7.9496 & 8.2398 & TST \\
\hline CHEMBL 3892537 & 1528121 & 8.2684 & 8.2982 & TRN \\
\hline CHEMBL3662996 & 1528121 & 6.5146 & 7.7224 & TRN \\
\hline CHEMBL3654832 & 1528121 & 6.0 & \multicolumn{2}{|c|}{7.327000000000001} \\
\hline CHEMBL 3975068 & 1528121 & 8.4288 & 8.355 & TST \\
\hline CHEMBL3984351 & 1528121 & 9.3931 & 9.2217 & TRN \\
\hline CHEMBL3909961 & 1528121 & 6.2466 & 7.2473 & TRN \\
\hline CHEMBL 3957789 & 1528121 & 6.9876 & 7.1167 & TST \\
\hline CHEMBL3658758 & 1528121 & 9.0706 & 8.3586 & TRN \\
\hline CHEMBL3948555 & 1528121 & 8.4173 & 8.2763 & TST \\
\hline CHEMBL 3658748 & 1528121 & 7.6071 & 7.8133 & TRN \\
\hline CHEMBL 3654744 & 1528121 & 9.4168 & 7.3275 & TST \\
\hline CHEMBL 3917364 & 1528121 & 9.5902 & 8.9013 & TRN \\
\hline CHEMBL3944730 & 1528121 & 7.9551 & 8.3704 & TRN \\
\hline CHEMBL3925897 & 1528121 & 8.1148 & 7.8741 & TRN \\
\hline CHEMBL3658816 & 1528121 & 8.7891 & 8.3055 & TRN \\
\hline CHEMBL 3663083 & 1528121 & 6.0 & 7.6968 & TRN \\
\hline CHEMBL3911112 & 1528121 & 8.7196 & 8.8038 & TRN \\
\hline CHEMBL3920790 & 1528121 & 6.6002 & 7.9643 & TRN \\
\hline CHEMBL3894949 & 1528121 & 9.7991 & 8.2988 & TRN \\
\hline CHEMBL3658751 & 1528121 & 8.3541 & 8.1591 & TRN \\
\hline CHEMBL3891758 & 1528121 & 7.5524 & 8.9549 & TRN \\
\hline CHEMBL3950468 & 1528121 & 8.1953 & 7.5731 & TST \\
\hline CHEMBL 3893873 & 1528121 & 6.9739 & 8.2014 & TRN \\
\hline CHEMBL3654865 & 1528121 & 8.2304 & 7.6187 & TRN \\
\hline CHEMBL3658691 & 1528121 & 6.0 & 7.6158 & TRN \\
\hline CHEMBL3654821 & 1528121 & 7.8687 & 7.6949 & TRN \\
\hline CHEMBL3658752 & 1528121 & 8.1765 & 7.8666 & TRN \\
\hline CHEMBL 3658787 & 1528121 & 8.5931 & 8.4385 & TRN \\
\hline CHEMBL 3897708 & 1528121 & 8.7086 & 8.1775 & TRN \\
\hline CHEMBL3663010 & 1528121 & 9.3705 & 7.7601 & TRN \\
\hline CHEMBL 3658814 & 1528121 & 8.6688 & 8.2683 & TRN \\
\hline CHEMBL3953172 & 1528121 & 8.838 & 8.5023 & TST \\
\hline CHEMBL3924564 & 1528121 & 9.0267 & 7.5814 & TRN \\
\hline CHEMBL3654849 & 1528121 & 9.0024 & 8.7864 & TRN \\
\hline CHEMBL3662974 & 1528121 & 8.2853 & 8.76 & TRN \\
\hline CHEMBL3658739 & 1528121 & 7.8945 & 7.6793 & TRN \\
\hline CHEMBL3658797 & 1528121 & 8.9423 & 8.6654 & TRN \\
\hline CHEMBL 3654684 & 1528121 & 7.8196 & 8.5409 & TRN \\
\hline CHEMBL3964198 & 1528121 & 8.6821 & 8.6936 & TST \\
\hline CHEMBL3910296 & 1528121 & 8.3433 & 7.62 & TST \\
\hline CHEMBL3935687 & 1528121 & 6.3 & 7.2984 & TST \\
\hline CHEMBL3906072 & 1528121 & 7.6659 & 8.3028 & TRN \\
\hline CHEMBL3896273 & 1528121 & 7.3009 & 8.0283 & TRN \\
\hline CHEMBL3658701 & 1528121 & 9.4777 & 7.4049 & TRN \\
\hline CHEMBL3658744 & 1528121 & 8.2092 & 7.1283 & TRN \\
\hline CHEMBL3658785 & 1528121 & 8.2661 & 8.4378 & TRN \\
\hline
\end{tabular}


Supplemental Table S2.txt

\begin{tabular}{|c|c|c|c|c|}
\hline 9 & 528121 & & & \\
\hline & 528121 & 8.2662 & & \\
\hline 396 & 28121 & 9278 & & \\
\hline AEMBL & 121 & 3 & & \\
\hline AEMBL3658841 & 528121 & 5194 & 6291 & \\
\hline HEMBL390 & 528121 & 9.4747 & 8.5452 & \\
\hline HEMBL & 28121 & & & \\
\hline AEMBL 366 & & & & \\
\hline HEMBL3658703 & 528121 & 8.9876 & 8.4313 & \\
\hline HEMBL3654693 & 528121 & 7.848 & .4762 & \\
\hline HEMBL; & 21 & 7.15 & & \\
\hline HEMBL: & 121 & & & \\
\hline HEMBL3 & & & & \\
\hline HEMBL3952195 & 528121 & 8.3385 & & \\
\hline AEMBL3658756 & 121 & & & \\
\hline HEMBL3 & -1 & 8 . & & \\
\hline HEMBL & 21 & & & r \\
\hline HEMBL; & 21 & & & \\
\hline HEMBL365 & 21 & & & \\
\hline HEMBL365 & & 8 . & & niv \\
\hline HEMBL & 1 & & & ГRN \\
\hline HEM & 1 & & & MIV \\
\hline HEMBL & 1 & & & \\
\hline HEMBL3 & & & & I RIV \\
\hline HEMBL 394 & 1 & 8. & & I RN \\
\hline HEMBL 363 & $\mathbf{1}$ & & & RN \\
\hline HFM & & & & KIV \\
\hline 23 & & 8 . & & RN \\
\hline AEMBL3 & & & & IRN \\
\hline AEMBL 365 & 1 & 7. & 71 & ГST \\
\hline HEMBL & 21 & & & TRN \\
\hline $15 \mathrm{M}$ & & & & \\
\hline 5 & & 6. & & TST \\
\hline HEMBL 398 & & & & TST \\
\hline HEMBL 3658 & 21 & & & ГRN \\
\hline AFMRI: & 21 & & 71 & ГST \\
\hline 5 & & & & TRN \\
\hline HEMBL36 & & 8.9722 & & TRN \\
\hline HEMBL 366 & 21 & 6. & & $\Gamma R$ \\
\hline LITSL & & & & R \\
\hline HEMBL3 & & & 71 & TRN \\
\hline HEMBL3 & & 8 . & 016 & 「RN \\
\hline HEMBL 366 & & & .7183 & {$[R$} \\
\hline HEMBL 365 & 152 & & & TR \\
\hline 3 & & & & $\mathrm{~T}$ \\
\hline HEMBL365 & 152 & & 7.9536 & \\
\hline CHEMBL 365 & 21 & 6.9017 & 7.9997 & \\
\hline CHEMBL3931192 & 1528121 & 7.9952 & 8.3373 & \\
\hline
\end{tabular}

Page 23382 
Supplemental Table S2.txt

\begin{tabular}{|c|c|c|c|c|c|c|}
\hline CHEMBL3973791 & 1528121 & 9.3197 & 8.4071 & TST & & \\
\hline CHEMBL3957711 & 1528121 & 9.0847 & 8.1111 & TST & & \\
\hline CHEMBL3956733 & 1528121 & 8.7347 & 8.7002 & TRN & & \\
\hline CHEMBL 3658824 & 1528121 & 6.4484 & 8.2611 & TRN & & \\
\hline CHEMBL3935667 & 1528121 & 8.731 & 8.2397 & TST & & \\
\hline CHEMBL 3658654 & 1528121 & 6.0 & 7.75200 & 000000000 & & TRN \\
\hline CHEMBL3927661 & 1528121 & 9.4768 & 8.34100 & 000000000 & & TRN \\
\hline CHEMBL 3658781 & 1528121 & 8.5611 & 8.5032 & TRN & & \\
\hline CHEMBL 3658840 & 1528121 & 8.221 & 8.3938 & TRN & & \\
\hline CHEMBL 3658765 & 1528121 & 7.6981 & 8.4575 & TST & & \\
\hline CHEMBL 3658759 & 1528121 & 8.1158 & 8.3018 & TRN & & \\
\hline CHEMBL3663073 & 1528121 & 8.3587 & 8.0442 & TRN & & \\
\hline CHEMBL 3658646 & 1528121 & 6.0 & 7.6208 & TRN & & \\
\hline CHEMBL 3654683 & 1528121 & 8.4067 & 9.1408 & TRN & & \\
\hline CHEMBL3662991 & 1528121 & 8.9439 & 9.2945 & TST & & \\
\hline CHEMBL 3658709 & 1528121 & 7.7291 & 7.404 & TRN & & \\
\hline CHEMBL3658792 & 1528121 & 8.9519 & 8.76700 & 000000000 & & 17 \\
\hline CHEMBL3957466 & 1528121 & 9.127 & 8.2564 & TRN & & \\
\hline CHEMBL3654709 & 1528121 & 8.9991 & 8.7136 & TRN & & \\
\hline CHEMBL3654851 & 1528121 & 7.6151 & 8.2244 & TRN & & \\
\hline CHEMBL3929464 & 1528121 & 8.0394 & 8.1591 & TST & & \\
\hline CHEMBL3920394 & 1528121 & 8.0825 & 7.9722 & TST & & \\
\hline CHEMBL3654686 & 1528121 & 8.6774 & 8.0023 & TRN & & \\
\hline CHEMBL3956229 & 1528121 & 8.3808 & 7.9858 & TRN & & \\
\hline CHEMBL 3658763 & 1528121 & 8.6851 & 8.4157 & TST & & \\
\hline CHEMBL 3658772 & 1528121 & 8.6992 & 8.7156 & TRN & & \\
\hline CHEMBL3703711 & 1528121 & 9.46600 & 00000000 & 31 & 7.5773 & \\
\hline CHEMBL 3658794 & 1528121 & 8.5989 & 8.8236 & TRN & & \\
\hline CHEMBL 3658683 & 1528121 & 8.7135 & 8.9848 & TRN & & \\
\hline CHEMBL3654692 & 1528121 & 8.3485 & 7.4339 & TRN & & \\
\hline CHEMBL 3654707 & 1528121 & 9.3862 & 8.65299 & 999999999 & & . \\
\hline CHEMBL 3895418 & 1528121 & 8.461 & 8.2316 & TRN & & \\
\hline CHEMBL 3662977 & 1528121 & 9.4473 & 7.7877 & TRN & & \\
\hline CHEMBL 3893178 & 1528121 & 9.5267 & 9.327 & TRN & & \\
\hline CHEMBL3908314 & 1528121 & 8.8921 & 9.3071 & TST & & \\
\hline CHEMBL3662981 & 1528121 & 9.2627 & 8.7403 & TRN & & \\
\hline CHEMBL 3654813 & 1528121 & 7.364 & 8.1338 & TRN & & \\
\hline CHEMBL 3658830 & 1528121 & 8.0647 & 7.6463 & TRN & & \\
\hline CHEMBL 3658705 & 1528121 & 8.2162 & 7.2014 & TRN & & \\
\hline CHEMBL 3654783 & 1528121 & 8.6426 & 7.5578 & TST & & \\
\hline CHEMBL3927336 & 1528121 & 8.5929 & 8.149 & TST & & \\
\hline CHEMBL 3654828 & 1528121 & 7.0362 & 7.3144 & TST & & \\
\hline CHEMBL 3899094 & 1528121 & 8.1855 & 8.1887 & TRN & & \\
\hline CHEMBL 3658742 & 1528121 & 7.2545 & 7.4459 & TST & & \\
\hline CHEMBL3658761 & 1528121 & 7.318 & 8.5454 & TRN & & \\
\hline CHEMBL3929971 & 1528121 & 6.1164 & 7.7409 & TRN & & \\
\hline CHEMBL3658799 & 1528121 & 8.6694 & 8.4301 & TRN & & \\
\hline CHEMBL 3905409 & 1528121 & 6.2442 & 7.6999 & TST & & \\
\hline
\end{tabular}

Page 23383 


\begin{tabular}{|c|c|c|c|c|c|c|}
\hline & & \multicolumn{5}{|c|}{ Supplemental Table S2.txt } \\
\hline CHEMBL3658639 & 1528121 & 8.5518 & 7.809 & TRN & & \\
\hline CHEMBL 3654815 & 1528121 & 7.82100 & 00000000 & 01 & 7.1791 & TRN \\
\hline CHEMBL3948896 & 1528121 & 8.3616 & 7.6028 & TRN & & \\
\hline CHEMBL 3654847 & 1528121 & 8.6092 & 8.1514 & TRN & & \\
\hline CHEMBL3948768 & 1528121 & 8.5745 & 8.1698 & TRN & & \\
\hline CHEMBL 3654854 & 1528121 & 7.5891 & 7.8115 & TRN & & \\
\hline CHEMBL3967379 & 1528121 & 9.51 & 9.1841 & TRN & & \\
\hline CHEMBL3911111 & 1528121 & 9.1725 & 9.6775 & TRN & & \\
\hline CHEMBL 3658747 & 1528121 & 7.8765 & 6.8193 & TRN & & \\
\hline CHEMBL3920613 & 1528121 & 8.6123 & 8.1242 & TRN & & \\
\hline CHEMBL 3897336 & 1528121 & 6.4215 & 7.1472 & TRN & & \\
\hline CHEMBL 3658685 & 1528121 & 6.0 & 6.8243 & TRN & & \\
\hline CHEMBL 3658734 & 1528121 & 8.8401 & 7.978 & TRN & & \\
\hline CHEMBL3969123 & 1528121 & 8.1135 & 8.9415 & TRN & & \\
\hline CHEMBL3658713 & 1528121 & 6.0 & 7.4932 & TRN & & \\
\hline CHEMBL 3663133 & 1528121 & 6.75799 & 79999999 & 99 & 7.0594 & TST \\
\hline CHEMBL3945436 & 1528121 & 9.0666 & 8.3973 & TRN & & \\
\hline CHEMBL3654846 & 1528121 & 8.7755 & 8.0231 & TRN & & \\
\hline CHEMBL3654728 & 1528121 & 7.8219 & 8.0345 & TRN & & \\
\hline CHEMBL3967249 & 1528121 & 8.7452 & 8.5921 & TRN & & \\
\hline CHEMBL 3658817 & 1528121 & 6.0 & 7.4979 & TRN & & \\
\hline CHEMBL3654699 & 1528121 & 8.2536 & 8.8017 & TRN & & \\
\hline CHEMBL3898535 & 1528121 & 8.4843 & 8.2026 & TRN & & \\
\hline CHEMBL3944385 & 1528121 & 9.2195 & 8.4969 & TRN & & \\
\hline CHEMBL3936322 & 1528121 & 9.2501 & 9.2601 & TRN & & \\
\hline CHEMBL 3658760 & 1528121 & 8.0724 & 7.1691 & TRN & & \\
\hline CHEMBL2408790 & 1528121 & 9.5441 & 8.0512 & TST & & \\
\hline CHEMBL 3945543 & 1528121 & 9.177 & 8.7753 & TST & & \\
\hline CHEMBL3899267 & 1528121 & 9.4465 & 8.6603 & TRN & & \\
\hline CHEMBL3921119 & 1528121 & 7.2513 & 9.1852 & TRN & & \\
\hline CHEMBL3654827 & 1528121 & 7.5916 & 7.683 & TRN & & \\
\hline CHEMBL3944625 & 1528121 & 7.8395 & 8.30299 & 9999999999 & & TRN \\
\hline CHEMBL 3662951 & 1528121 & 9.2164 & 8.7286 & TRN & & \\
\hline CHEMBL3658638 & 1528121 & 7.0381 & 6.7691 & TRN & & \\
\hline CHEMBL3654687 & 1528121 & 7.4869 & 7.5639 & TRN & & \\
\hline CHEMBL3899498 & 1528121 & 8.7187 & 8.9911 & TRN & & \\
\hline CHEMBL3654798 & 1528121 & 9.1459 & 7.6687 & TST & & \\
\hline CHEMBL3663075 & 1528121 & 8.2154 & 8.4464 & TRN & & \\
\hline CHEMBL3958692 & 1528121 & 7.7062 & 8.2604 & TST & & \\
\hline CHEMBL3930606 & 1528121 & 7.8668 & 8.1602 & TRN & & \\
\hline CHEMBL 3957839 & 1528121 & 8.7937 & 7.8243 & TRN & & \\
\hline CHEMBL3662965 & 1528121 & 8.5127 & 8.329 & TRN & & \\
\hline CHEMBL3941763 & 1528121 & 8.0792 & 7.4866 & TST & & \\
\hline CHEMBL3658716 & 1528121 & 7.0365 & 7.5805 & TRN & & \\
\hline CHEMBL3663111 & 1528121 & 8.2668 & 8.8019 & TST & & \\
\hline CHEMBL3662983 & 1528121 & 7.8972 & 7.7846 & TRN & & \\
\hline CHEMBL3658831 & 1528121 & 8.9183 & 8.3139 & TRN & & \\
\hline CHEMBL3958065 & 1528121 & 7.2522 & 8.7696 & TST & & \\
\hline
\end{tabular}


Supplemental Table S2.txt

\begin{tabular}{|c|c|c|c|c|c|}
\hline CHEMBL 3654712 & 1528121 & 6.8965 & 8.3801 & TRN & \\
\hline CHEMBL3940710 & 1528121 & 7.8333 & 7.5947 & TST & \\
\hline CHEMBL3905471 & 1528121 & 7.9237 & 8.0965 & TRN & \\
\hline CHEMBL3658755 & 1528121 & 7.6533 & 8.4597 & TRN & \\
\hline CHEMBL3982912 & 1528121 & 8.3529 & 9.2105 & TRN & \\
\hline CHEMBL3958667 & 1528121 & 8.9784 & 8.9752 & TRN & \\
\hline CHEMBL3663041 & 1528121 & 7.51 & 8.1198 & TRN & \\
\hline CHEMBL3654703 & 1528121 & 9.184 & 9.0585 & TRN & \\
\hline CHEMBL3941369 & 1528121 & 9.2715 & 8.6127 & TRN & \\
\hline CHEMBL3979326 & 1528121 & 8.3107 & 8.126 & TRN & \\
\hline CHEMBL3658832 & 1528121 & 8.3854 & 8.4484 & TRN & \\
\hline CHEMBL3944034 & 1528121 & 7.7208 & 7.442 & TST & \\
\hline CHEMBL3654867 & 1528121 & 6.0 & 8.3393 & TRN & \\
\hline CHEMBL3654685 & 1528121 & 8.7757 & 7.6882 & TST & \\
\hline CHEMBL3654853 & 1528121 & 8.8016 & 8.2516 & TRN & \\
\hline CHEMBL3662970 & 1528121 & 8.5424 & 8.5771 & TRN & \\
\hline CHEMBL3654819 & 1528121 & 7.6641 & 8.0185 & TRN & \\
\hline CHEMBL3943819 & 1528121 & 5.706 & 7.1911 & TST & \\
\hline CHEMBL3893894 & 1528121 & 9.5016 & 9.221 & TST & \\
\hline CHEMBL3941820 & 1528121 & 7.2187 & 7.5612 & TST & \\
\hline CHEMBL3920564 & 1528121 & 6.7144 & 7.2823 & TRN & \\
\hline CHEMBL3654706 & 1528121 & 7.4557 & 8.5289 & TRN & \\
\hline CHEMBL3912609 & 1528121 & 8.3457 & 8.1986 & TST & \\
\hline CHEMBL3968054 & 1528121 & 9.0321 & 9.5021 & TST & \\
\hline CHEMBL3971147 & 1528121 & 6.2148 & 7.6128 & TST & \\
\hline CHEMBL3895416 & 1528121 & 6.3389 & 7.1565 & TRN & \\
\hline CHEMBL3658641 & 1528121 & 8.2267 & 7.7548 & TRN & \\
\hline CHEMBL 3654705 & 1528121 & 8.1858 & 7.7924 & TRN & \\
\hline CHEMBL3654688 & 1528121 & 8.0043 & 7.7249 & TRN & \\
\hline CHEMBL3662960 & 1528121 & 8.8677 & 8.0178 & TST & \\
\hline CHEMBL3969484 & 1528121 & 9.1557 & 8.7568 & TRN & \\
\hline CHEMBL3658735 & 1528121 & 7.2294 & 8.46 & TRN & \\
\hline CHEMBL 3658750 & 1528121 & 8.3059 & 8.1996 & TRN & \\
\hline CHEMBL3944640 & 1528121 & 7.9702 & 7.7848 & TST & \\
\hline CHEMBL3658648 & 1528121 & 7.3629 & 8.3025 & TST & \\
\hline CHEMBL3654770 & 1528121 & 7.6295 & 8.1852 & TST & \\
\hline CHEMBL3658724 & 1528121 & 9.423 & 8.6518 & TRN & \\
\hline CHEMBL3897662 & 1528121 & 7.8348 & 8.3896 & TST & \\
\hline CHEMBL3654814 & 1528121 & 7.2812 & 8.0187 & TRN & \\
\hline CHEMBL3981811 & 1528121 & 7.5965 & 8.2101 & TRN & \\
\hline CHEMBL3662952 & 1528121 & 8.8505 & 7.7753 & TRN & \\
\hline CHEMBL3663058 & 1528121 & 8.4185 & 7.9338 & TRN & \\
\hline CHEMBL3969978 & 1528121 & 9.2552 & 8.641 & TRN & \\
\hline CHEMBL 3948976 & 1528121 & 7.5824 & 8.4102 & TRN & \\
\hline CHEMBL3654668 & 1528121 & 9.4065 & 8.0568 & TRN & \\
\hline CHEMBL3969928 & 1528121 & 8.93700 & 0000000 & 01 & 8.6317 \\
\hline CHEMBL3970628 & 1528121 & 7.9842 & 8.3872 & TRN & \\
\hline CHEMBL3662968 & 1528121 & 8.5318 & 8.2661 & TRN & \\
\hline
\end{tabular}

Page 23385 
Supplemental Table S2.txt

\begin{tabular}{|c|c|c|c|c|c|}
\hline CHEMBL3658801 & 1528121 & 8.1807 & 8.2916 & TRN & \\
\hline CHEMBL 3654743 & 1528121 & 8.2045 & 9.0715 & TST & \\
\hline CHEMBL3662950 & 1528121 & 8.3626 & 8.1388 & TRN & \\
\hline CHEMBL3985185 & 1528121 & 8.3391 & 8.9739 & TST & \\
\hline CHEMBL3654809 & 1528121 & 6.0 & 7.2732 & TRN & \\
\hline CHEMBL3658810 & 1528121 & 8.5815 & 8.5985 & TRN & \\
\hline CHEMBL3662947 & 1528121 & 8.8499 & 8.8033 & TRN & \\
\hline CHEMBL3654839 & 1528121 & 8.7552 & 8.3154 & TST & \\
\hline CHEMBL3981326 & 1528121 & 7.8735 & 7.6175 & TST & \\
\hline CHEMBL3896475 & 1528121 & 8.6139 & 8.2152 & TRN & \\
\hline CHEMBL3936631 & 1528121 & 9.2208 & 8.3247 & TRN & \\
\hline CHEMBL3654695 & 1528121 & 7.7972 & 8.7006 & TRN & \\
\hline CHEMBL3955600 & 1528121 & 7.1787 & 8.3193 & TST & \\
\hline CHEMBL3979007 & 1528121 & 8.8271 & 8.5854 & TST & \\
\hline CHEMBL3663022 & 1528121 & 6.0 & 7.5204 & TRN & \\
\hline CHEMBL3662988 & 1528121 & 8.5262 & 8.3726 & TRN & \\
\hline CHEMBL3982116 & 1528121 & 7.4624 & 8.2938 & TST & \\
\hline CHEMBL 3654689 & 1528121 & 6.3181 & 7.6796 & TST & \\
\hline CHEMBL3948042 & 1528121 & 8.2103 & 8.0164 & TRN & \\
\hline CHEMBL3974324 & 1528121 & 8.3123 & 8.4711 & TST & \\
\hline CHEMBL 3654700 & 1528121 & 8.98299 & 999999999 & 8.0553 & TRN \\
\hline CHEMBL3967333 & 1528121 & 9.6511 & 9.3098 & TRN & \\
\hline CHEMBL3663065 & 1528121 & 9.2147 & 8.1915 & TRN & \\
\hline CHEMBL 3890498 & 1528121 & 7.1513 & 8.626 & TST & \\
\hline CHEMBL3911918 & 1528121 & 7.0615 & 8.258 & TST & \\
\hline CHEMBL 2408789 & 1528121 & 9.6893 & 7.7764 & TRN & \\
\hline CHEMBL 3663080 & 1528121 & 8.6588 & 8.1311 & TRN & \\
\hline CHEMBL3946196 & 1528121 & 8.5134 & 8.9137 & TST & \\
\hline CHEMBL3942955 & 1528121 & 7.6073 & 7.1749 & TRN & \\
\hline CHEMBL3940358 & 1528121 & 9.2932 & 9.0847 & TST & \\
\hline CHEMBL3922284 & 1528121 & 8.1688 & 8.259 & TRN & \\
\hline CHEMBL3658789 & 1528121 & 8.2468 & 8.4531 & TRN & \\
\hline CHEMBL3658807 & 1528121 & 8.9523 & 8.9854 & TRN & \\
\hline CHEMBL3662964 & 1528121 & 7.9363 & 8.1102 & TRN & \\
\hline CHEMBL3941068 & 1528121 & 7.1419 & 7.7737 & TRN & \\
\hline CHEMBL3658809 & 1528121 & 8.4814 & 8.5586 & TRN & \\
\hline CHEMBL3663115 & 1528121 & 8.4352 & 7.7551 & TRN & \\
\hline CHEMBL3654721 & 1528121 & 7.9901 & 7.485 & TRN & \\
\hline CHEMBL3663074 & 1528121 & 9.0971 & 9.056000 & 0000000001 & TST \\
\hline CHEMBL3662985 & 1528121 & 7.2721 & 7.4586 & TRN & \\
\hline CHEMBL 3662980 & 1528121 & 9.4456 & 8.7567 & TRN & \\
\hline CHEMBL3941389 & 1528121 & 8.1749 & 8.7245 & TST & \\
\hline CHEMBL3663037 & 1528121 & 6.0 & 8.0625 & TRN & \\
\hline CHEMBL3907735 & 1528121 & 9.1262 & 8.2943 & TST & \\
\hline CHEMBL3893199 & 1528121 & 9.2506 & 9.3448 & TRN & \\
\hline CHEMBL3973667 & 1528121 & 7.3514 & 8.702 & TRN & \\
\hline CHEMBL 3658770 & 1528121 & 8.9727 & 7.7618 & TRN & \\
\hline CHEMBL3658727 & 1528121 & 6.0 & 8.3141 & TST & \\
\hline
\end{tabular}


Supplemental Table S2.txt

\begin{tabular}{|c|c|c|c|c|c|}
\hline CHEMBL3658805 & 1528121 & 9.0887 & 8.9842 & TRN & \\
\hline CHEMBL3658753 & 1528121 & 8.3865 & 7.8921 & TRN & \\
\hline CHEMBL3654694 & 1528121 & 9.0296 & 8.5891 & TRN & \\
\hline CHEMBL 3658740 & 1528121 & 9.2355 & 8.3401 & TRN & \\
\hline CHEMBL3663040 & 1528121 & 6.0 & 7.8847 & TRN & \\
\hline CHEMBL3658714 & 1528121 & 8.1825 & 7.653 & TRN & \\
\hline CHEMBL3658730 & 1528121 & 9.4688 & 9.4704 & TRN & \\
\hline CHEMBL 2408788 & 1528121 & 9.07 & 8.7378 & TRN & \\
\hline CHEMBL3654817 & 1528121 & 8.4194 & 7.8973 & TRN & \\
\hline CHEMBL3663068 & 1528121 & 9.7983 & 9.6497 & TRN & \\
\hline CHEMBL3955579 & 1528121 & 8.4382 & 8.0262 & TRN & \\
\hline CHEMBL3662972 & 1528121 & 8.6297 & 8.6054 & TRN & \\
\hline CHEMBL3662957 & 1528121 & 9.0187 & 7.818 & TST & \\
\hline CHEMBL3658822 & 1528121 & 6.7967 & 7.816 & TST & \\
\hline CHEMBL3658733 & 1528121 & 8.8505 & 7.9429 & TST & \\
\hline CHEMBL3663036 & 1528121 & 9.0377 & 7.7125 & TST & \\
\hline CHEMBL3654799 & 1528121 & 9.0135 & 7.5118 & TST & \\
\hline CHEMBL540825 & 202725 & 5.1249 & \multicolumn{2}{|c|}{5.031000000000001} & TRN \\
\hline CHEMBL558816 & 202725 & 7.3279 & 7.8339 & TST & \\
\hline CHEMBL543404 & 202725 & 7.0605 & 7.0012 & TRN & \\
\hline CHEMBL545049 & 202725 & 7.0458 & 7.0468 & TRN & \\
\hline CHEMBL542209 & 202725 & 6.6946 & 6.9802 & TRN & \\
\hline CHEMBL557637 & 202725 & 6.6676 & 6.8695 & TRN & \\
\hline CHEMBL543557 & 202725 & 6.4841 & 5.9555 & TST & \\
\hline CHEMBL545280 & 202725 & 7.4949 & 7.6113 & TRN & \\
\hline CHEMBL545511 & 202725 & 7.9208 & 7.755 & TRN & \\
\hline CHEMBL540308 & 202725 & 6.0 & 5.8804 & TRN & \\
\hline CHEMBL552660 & 202725 & 5.5686 & 5.7788 & TRN & \\
\hline CHEMBL543400 & 202725 & 7.1308 & 7.0383 & TRN & \\
\hline CHEMBL554661 & 202725 & 7.0605 & 7.0193 & TRN & \\
\hline CHEMBL545050 & 202725 & 7.3279 & 6.0945 & TST & \\
\hline CHEMBL543403 & 202725 & 5.6842 & 5.6886 & TRN & \\
\hline CHEMBL553280 & 202725 & 7.284 & 7.3035 & TRN & \\
\hline CHEMBL545743 & 202725 & 6.8327 & 6.9482 & TST & \\
\hline CHEMBL545747 & 202725 & 7.4089 & 7.1547 & TRN & \\
\hline CHEMBL553610 & 202725 & 7.1938 & 6.901 & TST & \\
\hline CHEMBL540051 & 202725 & 6.7471 & 6.7948 & TRN & \\
\hline CHEMBL554396 & 202725 & 6.7375 & 7.4182 & TST & \\
\hline CHEMBL543642 & 202725 & 6.475 & 6.4319 & TRN & \\
\hline CHEMBL554435 & 202725 & 7.7212 & 8.215 & TST & \\
\hline CHEMBL536101 & 202725 & 6.0 & 6.1743 & TRN & \\
\hline CHEMBL554210 & 202725 & 7.8539 & 7.8334 & TRN & \\
\hline CHEMBL543168 & 202725 & 7.3872 & 7.3788 & TRN & \\
\hline CHEMBL545517 & 202725 & 7.284 & 7.40600 & 0000000001 & TRN \\
\hline CHEMBL545514 & 202725 & 6.8794 & 6.9438 & TRN & \\
\hline CHEMBL544578 & 202725 & 6.5157 & 6.6008 & TRN & \\
\hline CHEMBL544586 & 202725 & 6.0 & 6.1634 & TRN & \\
\hline CHEMBL539539 & 202725 & 6.0 & 5.4375 & TST & \\
\hline
\end{tabular}


Supplemental Table S2.txt

\begin{tabular}{|c|c|c|c|c|}
\hline CHEMBL540052 & 202725 & 6.9872 & 7.0323 & TRN \\
\hline CHEMBL542703 & 202725 & 6.3893 & 6.7023 & TST \\
\hline CHEMBL542699 & 202725 & 7.0809 & 7.0961 & TRN \\
\hline CHEMBL539775 & 202725 & 7.0655 & \multicolumn{2}{|c|}{6.837000000000001} \\
\hline CHEMBL540827 & 202725 & 6.0 & 5.975 & TRN \\
\hline CHEMBL539284 & 202725 & 7.1024 & 7.4787 & TST \\
\hline CHEMBL545516 & 202725 & 7.9208 & 7.4901 & TST \\
\hline CHEMBL542934 & 202725 & 7.0315 & 6.8581 & TRN \\
\hline CHEMBL558220 & 202725 & 7.585 & 7.8504 & TST \\
\hline CHEMBL539028 & 202725 & 7.2924 & 7.0485 & TRN \\
\hline CHEMBL555656 & 202725 & 6.0 & 5.8801 & TRN \\
\hline CHEMBL542205 & 202725 & 7.0 & 6.9853 & TRN \\
\hline CHEMBL543167 & 202725 & 7.4949 & 7.5601 & TRN \\
\hline CHEMBL542642 & 202725 & 6.0 & 5.9753 & TRN \\
\hline CHEMBL543881 & 202725 & 7.1805 & 7.1239 & TRN \\
\hline CHEMBL554050 & 202725 & 7.7212 & 7.6265 & TRN \\
\hline CHEMBL554167 & 202725 & 7.2596 & 6.8655 & TST \\
\hline CHEMBL557432 & 202725 & 7.2147 & 7.2517 & TRN \\
\hline CHEMBL553582 & 202725 & 7.2291 & 7.2004 & TRN \\
\hline CHEMBL541580 & 202725 & 6.4609 & 6.3098 & TST \\
\hline CHEMBL543880 & 202725 & 7.7696 & 7.9294 & TRN \\
\hline CHEMBL538770 & 202725 & 6.6968 & 6.7873 & TRN \\
\hline CHEMBL1347923 & 688161 & 4.4 & 4.8945 & TRN \\
\hline CHEMBL1490867 & 688161 & 5.5 & 4.9304 & TRN \\
\hline CHEMBL1534731 & 688161 & 5.3 & 5.0755 & TRN \\
\hline CHEMBL1495740 & 688161 & 4.6 & 4.9447 & TRN \\
\hline CHEMBL1519435 & 688161 & 4.5 & 4.8777 & TRN \\
\hline CHEMBL1437158 & 688161 & 4.9 & 5.0967 & TRN \\
\hline CHEMBL1330516 & 688161 & 5.6 & 4.9251 & TRN \\
\hline CHEMBL246957 & 688161 & 5.5 & 4.9489 & TST \\
\hline CHEMBL3190186 & 688161 & 5.0 & 4.9131 & TRN \\
\hline CHEMBL1608005 & 688161 & 4.8 & 4.9689 & TRN \\
\hline CHEMBL1572280 & 688161 & 4.5 & 4.9459 & TST \\
\hline CHEMBL1407573 & 688161 & 4.4 & 4.8724 & TRN \\
\hline CHEMBL1415772 & 688161 & 5.0 & 4.883 & TRN \\
\hline CHEMBL1452917 & 688161 & 4.6 & 5.1282 & TST \\
\hline CHEMBL1510035 & 688161 & 4.6 & 5.2382 & TRN \\
\hline CHEMBL1508182 & 688161 & 4.7 & 5.2969 & TST \\
\hline CHEMBL1336927 & 688161 & 4.7 & 4.7779 & TRN \\
\hline CHEMBL228792 & 688161 & 4.6 & 4.8618 & TRN \\
\hline CHEMBL1457994 & 688161 & 5.5 & 4.9051 & TRN \\
\hline CHEMBL1407574 & 688161 & 4.8 & 4.8094 & TRN \\
\hline CHEMBL267476 & 688161 & 6.8 & 4.8377 & TRN \\
\hline CHEMBL1431956 & 688161 & 5.2 & 4.8406 & TRN \\
\hline CHEMBL1332208 & 688161 & 4.8 & 4.8199 & TRN \\
\hline CHEMBL1344214 & 688161 & 4.4 & 4.9901 & TRN \\
\hline CHEMBL1384436 & 688161 & 4.6 & 4.8063 & TRN \\
\hline CHEMBL1410058 & 688161 & 4.7 & 4.8495 & TRN \\
\hline
\end{tabular}




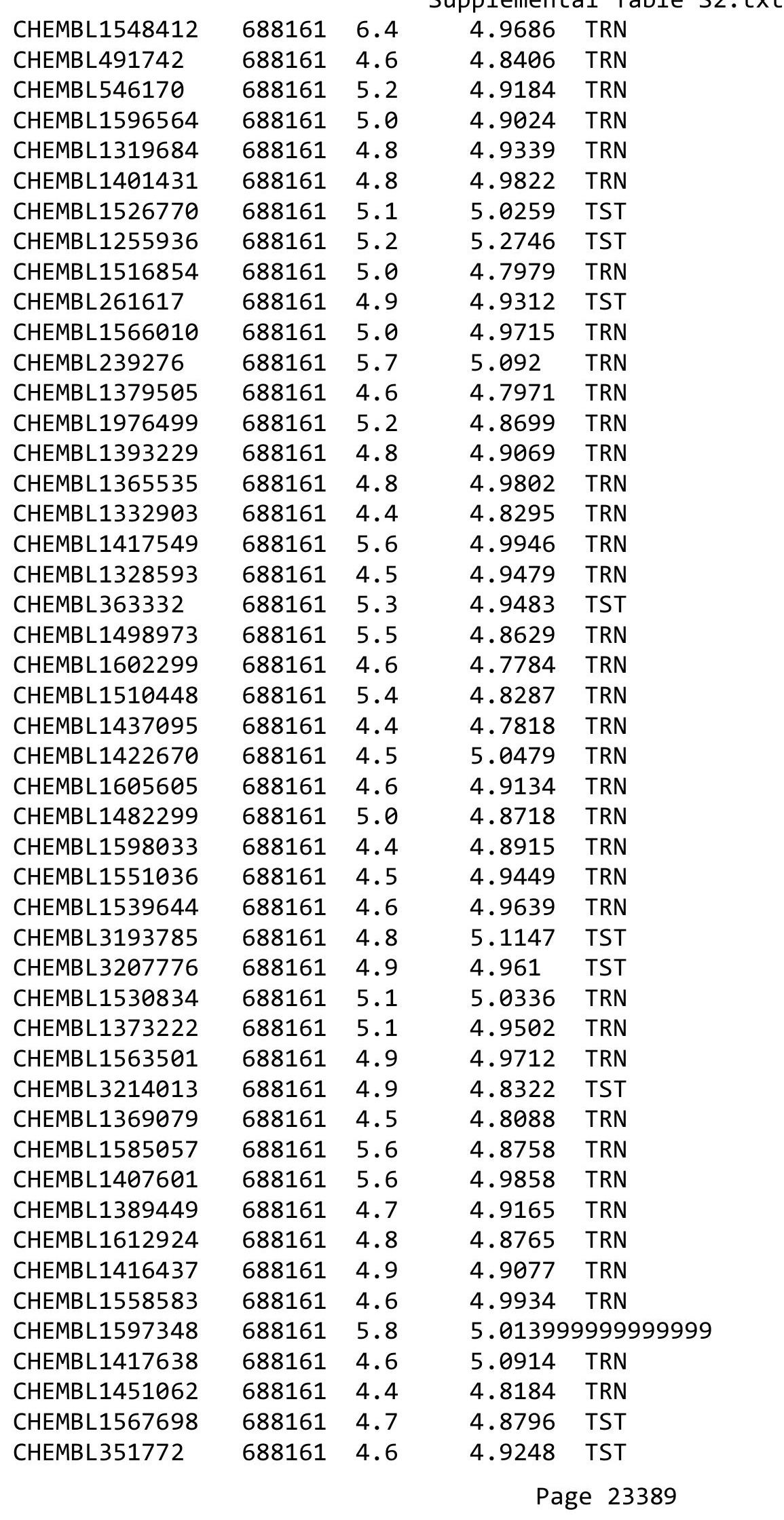

TRN 


\begin{tabular}{|c|c|c|c|c|c|}
\hline \multicolumn{6}{|c|}{ Supplemental Table S2.txt } \\
\hline CHEMBL587849 & 688161 & 5.5 & 5.0863 & TRN & \\
\hline CHEMBL1331363 & 688161 & 5.0 & 4.829 & TRN & \\
\hline CHEMBL1411390 & 688161 & 4.6 & 4.9165 & TRN & \\
\hline CHEMBL 3192857 & 688161 & 5.2 & 4.942 & TST & \\
\hline CHEMBL1380582 & 688161 & 4.7 & 4.9074 & TRN & \\
\hline CHEMBL1608618 & 688161 & 4.4 & 4.864 & TRN & \\
\hline CHEMBL1501540 & 688161 & 4.6 & 4.9816 & TRN & \\
\hline CHEMBL1508377 & 688161 & 4.5 & 4.9224 & TRN & \\
\hline CHEMBL1310575 & 688161 & 4.6 & 4.9664 & TRN & \\
\hline CHEMBL1585074 & 688161 & 4.6 & 4.9527 & TRN & \\
\hline CHEMBL1429381 & 688161 & 5.0 & 4.8619 & TRN & \\
\hline CHEMBL1345273 & 688161 & 4.6 & 4.8241 & TRN & \\
\hline CHEMBL1485785 & 688161 & 4.5 & 4.9293 & TRN & \\
\hline CHEMBL1434106 & 688161 & 4.7 & 4.9609 & TRN & \\
\hline CHEMBL1400386 & 688161 & 4.6 & 5.4545 & TST & \\
\hline CHEMBL1478652 & 688161 & 5.0 & 5.0756 & TRN & \\
\hline CHEMBL1415598 & 688161 & 4.8 & 4.879 & TRN & \\
\hline CHEMBL1571970 & 688161 & 7.8996 & 4.9295 & TRN & \\
\hline CHEMBL1497581 & 688161 & 4.7 & 4.8082 & TRN & \\
\hline CHEMBL1576456 & 688161 & 5.1 & 4.9248 & TRN & \\
\hline CHEMBL1419791 & 688161 & 4.8 & 4.8891 & TRN & \\
\hline CHEMBL1399506 & 688161 & 4.7 & 4.9314 & TRN & \\
\hline CHEMBL1438230 & 688161 & 4.5 & 4.8998 & TRN & \\
\hline CHEMBL1550802 & 688161 & 5.4 & 4.9547 & TRN & \\
\hline CHEMBL1404231 & 688161 & 4.8 & 5.2441 & TRN & \\
\hline CHEMBL1374504 & 688161 & 4.6 & 4.939 & TRN & \\
\hline CHEMBL1593850 & 688161 & 4.6 & 4.8497 & TST & \\
\hline CHEMBL1463276 & 688161 & 4.6 & 4.9162 & TRN & \\
\hline CHEMBL1543402 & 688161 & 4.5 & 4.7914 & TRN & \\
\hline CHEMBL1401227 & 688161 & 4.5 & 4.9978 & TRN & \\
\hline CHEMBL1491809 & 688161 & 4.9 & 4.9118 & TRN & \\
\hline CHEMBL1441444 & 688161 & 4.6 & 4.9538 & TRN & \\
\hline CHEMBL3192376 & 688161 & 5.1 & 4.8469 & TRN & \\
\hline CHEMBL1341830 & 688161 & 5.0 & 4.9857 & TRN & \\
\hline CHEMBL1448896 & 688161 & 5.5 & 4.93199 & 99999999995 & TRN \\
\hline CHEMBL1613623 & 688161 & 5.4 & 4.8005 & TRN & \\
\hline CHEMBL1409737 & 688161 & 5.7 & 4.9393 & TRN & \\
\hline CHEMBL1485434 & 688161 & 5.0 & 5.1766 & TRN & \\
\hline CHEMBL1587160 & 688161 & 4.6 & 4.9612 & TRN & \\
\hline CHEMBL1311609 & 688161 & 4.5 & 4.9499 & TRN & \\
\hline CHEMBL1448530 & 688161 & 4.7 & 4.8062 & TRN & \\
\hline CHEMBL1368596 & 688161 & 4.4 & 4.8999 & TRN & \\
\hline CHEMBL1476741 & 688161 & 4.5 & 5.2817 & TRN & \\
\hline CHEMBL1338606 & 688161 & 5.5 & 4.9086 & TRN & \\
\hline CHEMBL1611618 & 688161 & 5.1 & 4.8643 & TRN & \\
\hline CHEMBL1544631 & 688161 & 5.5 & 4.9277 & TRN & \\
\hline CHEMBL1497812 & 688161 & 4.6 & 4.8487 & TRN & \\
\hline CHEMBL336161 & 688161 & 4.8 & 5.0208 & TST & \\
\hline
\end{tabular}




\begin{tabular}{|c|c|c|c|c|c|}
\hline \multicolumn{6}{|c|}{ Supplemental Table S2.txt } \\
\hline CHEMBL311489 & 688161 & 5.4 & 5.023 & TRN & \\
\hline CHEMBL1428196 & 688161 & 4.8 & 4.8238 & TRN & \\
\hline CHEMBL418068 & 688161 & 4.9 & 5.07 & TRN & \\
\hline CHEMBL1362829 & 688161 & 4.8 & 5.1109 & TST & \\
\hline CHEMBL1515352 & 688161 & 9.0 & 4.9369 & TRN & \\
\hline CHEMBL1595437 & 688161 & 6.0 & 4.9063 & TRN & \\
\hline CHEMBL1403934 & 688161 & 5.5 & 4.8687 & TRN & \\
\hline CHEMBL1378830 & 688161 & 5.0 & 4.8808 & TRN & \\
\hline CHEMBL1488392 & 688161 & 4.7 & 4.7835 & TRN & \\
\hline CHEMBL1554664 & 688161 & 4.5 & 4.7558 & TRN & \\
\hline CHEMBL1368851 & 688161 & 4.5 & 5.0043 & TRN & \\
\hline CHEMBL1332761 & 688161 & 4.7 & 4.9339 & TRN & \\
\hline CHEMBL1410399 & 688161 & 5.6 & 5.3854 & TRN & \\
\hline CHEMBL1432430 & 688161 & 4.4 & 4.9581 & TRN & \\
\hline CHEMBL1583671 & 688161 & 4.4 & 4.8804 & TRN & \\
\hline CHEMBL1562602 & 688161 & 5.5 & 4.9845 & TRN & \\
\hline CHEMBL1421495 & 688161 & 5.2 & 4.8449 & TRN & \\
\hline CHEMBL3194525 & 688161 & 4.7 & 4.879 & TRN & \\
\hline CHEMBL1438341 & 688161 & 4.6 & 4.9317 & TRN & \\
\hline CHEMBL1388319 & 688161 & 4.6 & 4.9421 & TRN & \\
\hline CHEMBL1399493 & 688161 & 4.6 & 4.868 & TRN & \\
\hline CHEMBL1409762 & 688161 & 6.0 & 5.17200 & 0000000001 & TST \\
\hline CHEMBL1447013 & 688161 & 4.7 & 4.9887 & TRN & \\
\hline CHEMBL1366858 & 688161 & 4.6 & 5.2177 & TRN & \\
\hline CHEMBL1430213 & 688161 & 4.5 & 4.7735 & TRN & \\
\hline CHEMBL1389294 & 688161 & 8.0 & 5.0285 & TRN & \\
\hline CHEMBL1566730 & 688161 & 4.5 & 4.9485 & TRN & \\
\hline CHEMBL6291 & 688161 & 4.7 & 4.8006 & TST & \\
\hline CHEMBL1382202 & 688161 & 5.8 & 5.2865 & TRN & \\
\hline CHEMBL1575830 & 688161 & 4.8 & 4.8572 & TRN & \\
\hline CHEMBL1482442 & 688161 & 4.7 & 4.8569 & TRN & \\
\hline CHEMBL1305427 & 688161 & 4.7 & 5.13200 & 0000000001 & TST \\
\hline CHEMBL 76904 & 688161 & 5.4 & 5.3618 & TRN & \\
\hline CHEMBL1528265 & 688161 & 4.6 & 4.9164 & TRN & \\
\hline CHEMBL1410347 & 688161 & 5.0 & 4.8494 & TRN & \\
\hline CHEMBL1307923 & 688161 & 5.6 & 5.0189 & TRN & \\
\hline CHEMBL1356395 & 688161 & 5.3 & 5.0549 & TST & \\
\hline CHEMBL1550366 & 688161 & 5.3 & 5.1772 & TST & \\
\hline CHEMBL1379593 & 688161 & 4.4 & 5.0248 & TRN & \\
\hline CHEMBL 222993 & 688161 & 5.4 & 5.2647 & TST & \\
\hline CHEMBL1323290 & 688161 & 5.1 & 5.0898 & TST & \\
\hline CHEMBL1419169 & 688161 & 4.8 & 4.9426 & TRN & \\
\hline CHEMBL1347431 & 688161 & 4.6 & 4.981 & TRN & \\
\hline CHEMBL1387552 & 688161 & 8.0 & 4.9293 & TRN & \\
\hline CHEMBL1314376 & 688161 & 5.0 & 4.9837 & TRN & \\
\hline CHEMBL1363915 & 688161 & 4.4 & 4.9197 & TRN & \\
\hline CHEMBL1341295 & 688161 & 4.8 & 4.9183 & TRN & \\
\hline CHEMBL1528842 & 688161 & 4.7 & 5.0814 & TRN & \\
\hline
\end{tabular}




\begin{tabular}{|c|c|c|c|c|}
\hline \multicolumn{5}{|c|}{ Supplemental Table S2.txt } \\
\hline CHEMBL1476139 & 688161 & 4.6 & 4.8329 & TRN \\
\hline CHEMBL1334320 & 688161 & 4.6 & 4.85 & TRN \\
\hline CHEMBL1490297 & 688161 & 4.7 & 4.9056 & TRN \\
\hline CHEMBL1503576 & 688161 & 5.3 & 4.9097 & TST \\
\hline CHEMBL1552095 & 688161 & 4.9 & 5.0404 & TST \\
\hline CHEMBL1410321 & 688161 & 5.5 & 5.1049 & TRN \\
\hline CHEMBL1570008 & 688161 & 4.7 & 4.9008 & TRN \\
\hline CHEMBL1339424 & 688161 & 4.6 & 4.9135 & TRN \\
\hline CHEMBL1478868 & 688161 & 5.7 & 4.8964 & TST \\
\hline CHEMBL1340325 & 688161 & 4.5 & 4.8849 & TRN \\
\hline CHEMBL1539793 & 688161 & 4.6 & 4.9264 & TRN \\
\hline CHEMBL1600989 & 688161 & 4.8 & 4.8567 & TRN \\
\hline CHEMBL1538241 & 688161 & 4.5 & 4.9367 & TRN \\
\hline CHEMBL1333512 & 688161 & 5.4 & 4.9522 & TRN \\
\hline CHEMBL1453510 & 688161 & 4.5 & 4.9044 & TRN \\
\hline CHEMBL1407088 & 688161 & 4.6 & 4.8509 & TRN \\
\hline CHEMBL1409287 & 688161 & 4.8 & 4.9065 & TRN \\
\hline CHEMBL1484038 & 688161 & 4.9 & 4.9196 & TRN \\
\hline CHEMBL470671 & 688161 & 4.5 & 4.8495 & TRN \\
\hline CHEMBL1577661 & 688161 & 5.1 & 4.9546 & TRN \\
\hline CHEMBL1517986 & 688161 & 4.4 & 5.0892 & TRN \\
\hline CHEMBL1591908 & 688161 & 6.7001 & 4.9359 & TRN \\
\hline CHEMBL1353230 & 688161 & 5.8 & 4.9516 & TRN \\
\hline CHEMBL1489244 & 688161 & 5.0 & 4.8301 & TRN \\
\hline CHEMBL1559159 & 688161 & 4.5 & 4.9347 & TRN \\
\hline CHEMBL1328210 & 688161 & 4.4 & 4.9226 & TRN \\
\hline CHEMBL1335327 & 688161 & 4.6 & 4.9645 & TRN \\
\hline CHEMBL1606407 & 688161 & 4.5 & 4.9959 & TST \\
\hline CHEMBL333985 & 688161 & 4.8 & 4.8 & TST \\
\hline CHEMBL1483676 & 688161 & 4.8 & 4.8833 & TRN \\
\hline CHEMBL1556067 & 688161 & 4.8 & 4.8891 & TRN \\
\hline CHEMBL1576580 & 688161 & 4.9 & 5.0137 & TRN \\
\hline CHEMBL480626 & 688161 & 6.0 & 5.1546 & TRN \\
\hline CHEMBL1500265 & 688161 & 5.5 & 5.0339 & TRN \\
\hline CHEMBL1316292 & 688161 & 4.6 & 4.7438 & TRN \\
\hline CHEMBL1415790 & 688161 & 4.4 & 4.8689 & TRN \\
\hline CHEMBL460366 & 688161 & 5.1 & 5.1717 & TRN \\
\hline CHEMBL1361042 & 688161 & 4.9 & 4.9591 & TRN \\
\hline CHEMBL1368885 & 688161 & 4.9 & 4.8823 & TRN \\
\hline CHEMBL1379798 & 688161 & 5.8 & 4.871 & TRN \\
\hline CHEMBL1375636 & 688161 & 4.5 & 4.8411 & TRN \\
\hline CHEMBL1364109 & 688161 & 4.6 & 4.8777 & TRN \\
\hline CHEMBL 29726 & 688161 & 4.9 & 4.9898 & TST \\
\hline CHEMBL1519261 & 688161 & 4.6 & 4.865 & TRN \\
\hline CHEMBL1449133 & 688161 & 5.0 & 4.9045 & TST \\
\hline CHEMBL1427685 & 688161 & 4.7 & 4.8412 & TRN \\
\hline CHEMBL1605104 & 688161 & 4.5 & 4.8295 & TRN \\
\hline CHEMBL1440703 & 688161 & 5.0 & 4.9366 & TRN \\
\hline
\end{tabular}




\begin{tabular}{|c|c|c|c|c|}
\hline \multicolumn{5}{|c|}{ Supplemental Table S2.txt } \\
\hline CHEMBL1448399 & 688161 & 4.8 & 4.9194 & TRN \\
\hline CHEMBL1451787 & 688161 & 4.8 & 4.9875 & TRN \\
\hline CHEMBL1343536 & 688161 & 4.6 & 4.8539 & TRN \\
\hline CHEMBL294649 & 688161 & 4.8 & $4.9060 e$ & 0000000001 \\
\hline CHEMBL1452992 & 688161 & 4.8 & 4.8991 & TRN \\
\hline CHEMBL1352072 & 688161 & 4.7 & 4.8036 & TRN \\
\hline CHEMBL1567017 & 688161 & 4.7 & 4.8581 & TRN \\
\hline CHEMBL1328327 & 688161 & 4.9 & 4.8641 & TRN \\
\hline CHEMBL1543601 & 688161 & 5.4 & 4.9433 & TRN \\
\hline CHEMBL1581403 & 688161 & 4.6 & 5.0381 & TRN \\
\hline CHEMBL1383055 & 688161 & 4.4 & 5.0352 & TRN \\
\hline CHEMBL1372640 & 688161 & 4.6 & 4.8584 & TRN \\
\hline CHEMBL1436980 & 688161 & 5.1 & 4.9047 & TRN \\
\hline CHEMBL374107 & 688161 & 8.4949 & 5.0296 & TST \\
\hline CHEMBL1390126 & 688161 & 4.9 & 4.963 & TRN \\
\hline CHEMBL1453299 & 688161 & 4.9 & 5.3065 & TRN \\
\hline CHEMBL1393628 & 688161 & 5.0 & 4.7819 & TRN \\
\hline CHEMBL1561598 & 688161 & 4.5 & 5.0245 & TRN \\
\hline CHEMBL3196182 & 688161 & 4.7 & 4.944 & TST \\
\hline CHEMBL1342645 & 688161 & 4.8 & 4.9187 & TST \\
\hline CHEMBL1354119 & 688161 & 4.5 & 4.9783 & TRN \\
\hline CHEMBL1301670 & 688161 & 4.4 & 4.8799 & TRN \\
\hline CHEMBL1518405 & 688161 & 4.4 & 4.8957 & TRN \\
\hline CHEMBL1375430 & 688161 & 4.4 & 4.8733 & TRN \\
\hline CHEMBL1308667 & 688161 & 4.5 & 4.8415 & TRN \\
\hline CHEMBL1501236 & 688161 & 5.3 & 4.898 & TRN \\
\hline CHEMBL1565492 & 688161 & 8.2007 & 4.9493 & TRN \\
\hline CHEMBL1334275 & 688161 & 6.1 & 4.9438 & TRN \\
\hline CHEMBL25424 & 688161 & 4.9 & 5.0243 & TST \\
\hline CHEMBL1335945 & 688161 & 5.6 & 5.2393 & TST \\
\hline CHEMBL1535801 & 688161 & 4.6 & 4.7795 & TRN \\
\hline CHEMBL1607229 & 688161 & 4.9 & 4.9012 & TRN \\
\hline CHEMBL388676 & 688161 & 6.0 & 5.6157 & TST \\
\hline CHEMBL1306004 & 688161 & 4.5 & 4.7592 & TRN \\
\hline CHEMBL1508675 & 688161 & 5.5 & 4.8269 & TRN \\
\hline CHEMBL1469456 & 688161 & 4.5 & 4.9543 & TRN \\
\hline CHEMBL1200471 & 688161 & 6.7001 & 5.2304 & TST \\
\hline CHEMBL1444983 & 688161 & 4.9 & 4.996 & TRN \\
\hline CHEMBL1368811 & 688161 & 5.4 & 4.9552 & TST \\
\hline CHEMBL1304097 & 688161 & 4.6 & 4.9406 & TRN \\
\hline CHEMBL192627 & 688161 & 6.8 & 5.527 & TST \\
\hline CHEMBL1331920 & 688161 & 5.2 & 4.8465 & TRN \\
\hline CHEMBL3193930 & 688161 & 4.8 & 4.9949 & TRN \\
\hline CHEMBL1313353 & 688161 & 4.6 & 4.8566 & TRN \\
\hline CHEMBL1592213 & 688161 & 4.8 & 4.8677 & TRN \\
\hline CHEMBL1583564 & 688161 & 4.4 & 4.9345 & TRN \\
\hline CHEMBL1453050 & 688161 & 4.8 & 4.9078 & TRN \\
\hline CHEMBL1402925 & 688161 & 4.4 & 4.7815 & TRN \\
\hline
\end{tabular}

TRN 


\begin{tabular}{|c|c|c|c|c|}
\hline \multicolumn{5}{|c|}{ Supplemental Table S2.txt } \\
\hline CHEMBL1497983 & 688161 & 4.9 & 4.8759 & TRN \\
\hline CHEMBL1580990 & 688161 & 5.5 & 5.1069 & TRN \\
\hline CHEMBL1559654 & 688161 & 5.0 & 4.9568 & TRN \\
\hline CHEMBL1558927 & 688161 & 4.6 & 4.975 & TRN \\
\hline CHEMBL1366915 & 688161 & 4.6 & 4.9217 & TRN \\
\hline CHEMBL1424060 & 688161 & 4.6 & 4.8845 & TRN \\
\hline CHEMBL251904 & 688161 & 4.8 & 4.9535 & TRN \\
\hline CHEMBL1453592 & 688161 & 4.6 & 4.7742 & TRN \\
\hline CHEMBL1378707 & 688161 & 5.3 & 4.9681 & TRN \\
\hline CHEMBL1317009 & 688161 & 5.0 & 4.7814 & TRN \\
\hline CHEMBL1334536 & 688161 & 4.8 & 4.928 & TST \\
\hline CHEMBL1441612 & 688161 & 5.1 & 5.2722 & TRN \\
\hline CHEMBL1419235 & 688161 & 4.6 & 4.871 & TRN \\
\hline CHEMBL65 & 688161 & 4.4 & 5.2969 & TST \\
\hline CHEMBL1325390 & 688161 & 5.1 & 5.166 & TST \\
\hline CHEMBL1459411 & 688161 & 4.6 & 4.8217 & TRN \\
\hline CHEMBL1396384 & 688161 & 4.5 & 4.7525 & TRN \\
\hline CHEMBL1317066 & 688161 & 4.6 & 4.7863 & TRN \\
\hline CHEMBL1331148 & 688161 & 4.8 & 4.9266 & TST \\
\hline CHEMBL1568116 & 688161 & 4.8 & 4.9335 & TRN \\
\hline CHEMBL1359769 & 688161 & 4.5 & 4.992 & TRN \\
\hline CHEMBL1402174 & 688161 & 4.7 & 4.8059 & TRN \\
\hline CHEMBL1592835 & 688161 & 4.7 & 4.8694 & TRN \\
\hline CHEMBL 2006039 & 688161 & 5.9 & 5.2046 & TRN \\
\hline CHEMBL1532252 & 688161 & 4.7 & 4.9472 & TRN \\
\hline CHEMBL1320816 & 688161 & 4.4 & 4.8174 & TRN \\
\hline CHEMBL1334614 & 688161 & 4.6 & 4.8959 & TRN \\
\hline CHEMBL1441723 & 688161 & 4.9 & 4.9007 & TRN \\
\hline CHEMBL1180496 & 688161 & 4.6 & 4.8667 & TRN \\
\hline CHEMBL1381236 & 688161 & 4.7 & 4.9907 & TST \\
\hline CHEMBL1571560 & 688161 & 5.4 & 5.1484 & TRN \\
\hline CHEMBL1453954 & 688161 & 4.5 & 5.1514 & TRN \\
\hline CHEMBL1529257 & 688161 & 4.9 & 4.9858 & TRN \\
\hline CHEMBL1328369 & 688161 & 5.2 & 5.2413 & TRN \\
\hline CHEMBL1416389 & 688161 & 5.4 & 4.9465 & TRN \\
\hline CHEMBL1337451 & 688161 & 5.0 & 4.745 & TRN \\
\hline CHEMBL1455538 & 688161 & 4.8 & 4.8982 & TRN \\
\hline CHEMBL1313917 & 688161 & 4.6 & 4.8933 & TRN \\
\hline CHEMBL1422046 & 688161 & 4.6 & 4.8422 & TRN \\
\hline CHEMBL1329054 & 688161 & 4.8 & 4.7744 & TRN \\
\hline CHEMBL1530777 & 688161 & 4.5 & 4.8803 & TST \\
\hline CHEMBL1488756 & 688161 & 4.8 & 4.919 & TRN \\
\hline CHEMBL126077 & 688161 & 5.9 & 4.9946 & TST \\
\hline CHEMBL1438937 & 688161 & 7.8996 & 4.9543 & TST \\
\hline CHEMBL1457981 & 688161 & 4.6 & 5.3976 & TRN \\
\hline CHEMBL1419335 & 688161 & 6.9 & 5.5487 & TRN \\
\hline CHEMBL1365850 & 688161 & 4.8 & 5.0625 & TRN \\
\hline CHEMBL1527567 & 688161 & 5.6 & 4.9038 & TRN \\
\hline
\end{tabular}




\begin{tabular}{|c|c|c|c|c|}
\hline \multicolumn{5}{|c|}{ Supplemental Table S2.txt } \\
\hline CHEMBL25719 & 688161 & 5.1 & 4.9817 & TST \\
\hline CHEMBL1331280 & 688161 & 4.8 & 4.9935 & TRN \\
\hline CHEMBL1497676 & 688161 & 4.8 & 4.9519 & TRN \\
\hline CHEMBL1613220 & 688161 & 4.4 & 4.8756 & TRN \\
\hline CHEMBL1790030 & 688161 & 8.2007 & 4.9258 & TST \\
\hline CHEMBL1528170 & 688161 & 4.7 & 4.8559 & TRN \\
\hline CHEMBL1337494 & 688161 & 5.5 & 5.0126 & TRN \\
\hline CHEMBL1613376 & 688161 & 4.4 & 4.885 & TRN \\
\hline CHEMBL1357674 & 688161 & 6.1 & 4.9512 & TST \\
\hline CHEMBL1449018 & 688161 & 5.5 & 5.3236 & TRN \\
\hline CHEMBL1467596 & 688161 & 5.5 & 4.8731 & TRN \\
\hline CHEMBL1303479 & 688161 & 4.5 & 4.9467 & TST \\
\hline CHEMBL1256686 & 688161 & 5.8 & 5.3069 & TST \\
\hline CHEMBL 3207440 & 688161 & 4.5 & 4.9297 & TRN \\
\hline CHEMBL1399445 & 688161 & 4.9 & 4.802 & TRN \\
\hline CHEMBL1389592 & 688161 & 4.4 & 4.8554 & TRN \\
\hline CHEMBL1480742 & 688161 & 4.8 & 4.8701 & TRN \\
\hline CHEMBL1558287 & 688161 & 4.4 & 4.8992 & TRN \\
\hline CHEMBL 3194691 & 688161 & 5.6 & 4.9886 & TST \\
\hline CHEMBL1511671 & 688161 & 5.1 & 4.9001 & TRN \\
\hline CHEMBL1333056 & 688161 & 6.0 & 4.8438 & TST \\
\hline CHEMBL1388246 & 688161 & 5.2 & 4.9719 & TST \\
\hline CHEMBL1608411 & 688161 & 4.5 & 4.9178 & TRN \\
\hline CHEMBL1577487 & 688161 & 4.8 & 4.8459 & TRN \\
\hline CHEMBL1566869 & 688161 & 4.8 & 4.9043 & TST \\
\hline CHEMBL1459071 & 688161 & 4.4 & 4.9028 & TRN \\
\hline CHEMBL1569712 & 688161 & 4.9 & 4.8332 & TRN \\
\hline CHEMBL1456047 & 688161 & 4.5 & 4.8944 & TRN \\
\hline CHEMBL1489392 & 688161 & 4.9 & 5.0198 & TST \\
\hline CHEMBL1478258 & 688161 & 4.6 & 4.9321 & TRN \\
\hline CHEMBL1592651 & 688161 & 5.1 & 4.8603 & TRN \\
\hline CHEMBL397442 & 688161 & 4.8 & 5.1886 & TRN \\
\hline CHEMBL1457355 & 688161 & 4.4 & 4.8519 & TRN \\
\hline CHEMBL1405922 & 688161 & 4.4 & 4.8463 & TRN \\
\hline CHEMBL1600176 & 688161 & 4.5 & 4.9086 & TRN \\
\hline CHEMBL1537558 & 688161 & 5.4 & 4.886 & TRN \\
\hline CHEMBL1482799 & 688161 & 5.4 & 4.9007 & TRN \\
\hline CHEMBL1457788 & 688161 & 4.8 & 4.8595 & TRN \\
\hline CHEMBL1392532 & 688161 & 4.7 & 4.9683 & TRN \\
\hline CHEMBL1549590 & 688161 & 4.4 & 4.8094 & TRN \\
\hline CHEMBL1497269 & 688161 & 4.8 & 4.8135 & TRN \\
\hline CHEMBL1373923 & 688161 & 5.1 & 4.9791 & TST \\
\hline CHEMBL1374456 & 688161 & 4.8 & 4.8916 & TRN \\
\hline CHEMBL1528202 & 688161 & 5.3 & 4.8048 & TRN \\
\hline CHEMBL1544635 & 688161 & 4.6 & 4.758 & TRN \\
\hline CHEMBL1362978 & 688161 & 4.7 & 4.8981 & TRN \\
\hline CHEMBL1371297 & 688161 & 4.5 & 4.8841 & TRN \\
\hline CHEMBL1363362 & 688161 & 4.4 & 4.7366 & TRN \\
\hline
\end{tabular}




\begin{tabular}{|c|c|c|c|c|}
\hline & & & pplement & $\mathrm{a} \perp \mathrm{Ta}$ \\
\hline CHEMBL1490600 & 688161 & 4.8 & 5.0032 & TST \\
\hline CHEMBL1338469 & 688161 & 4.6 & 4.9446 & TRN \\
\hline CHEMBL1450838 & 688161 & 5.1 & 5.0607 & TRN \\
\hline CHEMBL1509059 & 688161 & 4.5 & 4.8866 & TRN \\
\hline CHEMBL567331 & 688161 & 4.5 & 4.7728 & TRN \\
\hline CHEMBL1383927 & 688161 & 6.3 & 5.4742 & TRN \\
\hline CHEMBL1447718 & 688161 & 4.5 & 4.877 & TRN \\
\hline CHEMBL1541733 & 688161 & 4.9 & 4.8855 & TRN \\
\hline CHEMBL1434848 & 688161 & 5.0 & 5.0154 & TRN \\
\hline CHEMBL137648 & 688161 & 4.8 & 4.9756 & TST \\
\hline CHEMBL1598438 & 688161 & 4.6 & 4.8763 & TRN \\
\hline CHEMBL1371781 & 688161 & 4.6 & 4.7926 & TRN \\
\hline CHEMBL1451789 & 688161 & 4.5 & 4.9292 & TRN \\
\hline CHEMBL1445061 & 688161 & 4.4 & 4.8949 & TST \\
\hline CHEMBL1478440 & 688161 & 4.6 & 4.8502 & TRN \\
\hline CHEMBL1322176 & 688161 & 5.1 & 4.9102 & TRN \\
\hline CHEMBL1313141 & 688161 & 4.8 & 4.9748 & TRN \\
\hline CHEMBL1570846 & 688161 & 6.0 & 4.9457 & TRN \\
\hline CHEMBL1373659 & 688161 & 4.6 & 4.7845 & TRN \\
\hline CHEMBL1468798 & 688161 & 4.5 & 4.904 & TRN \\
\hline CHEMBL1607080 & 688161 & 4.6 & 4.9087 & TRN \\
\hline CHEMBL1312849 & 688161 & 4.6 & 4.8773 & TRN \\
\hline CHEMBL1554098 & 688161 & 6.0 & 4.9803 & TST \\
\hline CHEMBL1607792 & 688161 & 4.7 & 4.8899 & TRN \\
\hline CHEMBL1325819 & 688161 & 5.1 & 4.9623 & TRN \\
\hline CHEMBL1414469 & 688161 & 4.6 & 4.9116 & TRN \\
\hline CHEMBL1519365 & 688161 & 4.7 & 4.9986 & TRN \\
\hline CHEMBL1335502 & 688161 & 5.2 & 4.7467 & TRN \\
\hline CHEMBL1462011 & 688161 & 4.9 & 4.8676 & TRN \\
\hline CHEMBL1530581 & 688161 & 5.7 & 5.2895 & TRN \\
\hline CHEMBL1417610 & 688161 & 4.8 & 4.8975 & TRN \\
\hline CHEMBL1452208 & 688161 & 4.5 & 4.8566 & TRN \\
\hline CHEMBL3189931 & 688161 & 4.6 & 4.9254 & TRN \\
\hline CHEMBL1536129 & 688161 & 5.2 & 4.9569 & TRN \\
\hline CHEMBL1346172 & 688161 & 5.5 & 5.0644 & TRN \\
\hline CHEMBL1440750 & 688161 & 4.5 & 4.9769 & TRN \\
\hline CHEMBL457504 & 688161 & 4.5 & 4.94 & TRN \\
\hline CHEMBL1509321 & 688161 & 6.9 & 4.8917 & TRN \\
\hline CHEMBL1460841 & 688161 & 4.5 & 4.9299 & TRN \\
\hline CHEMBL1341593 & 688161 & 5.0 & 4.8755 & TRN \\
\hline CHEMBL15192 & 688161 & 4.8 & 4.9353 & TST \\
\hline CHEMBL3145067 & 688161 & 6.0 & 4.9357 & TRN \\
\hline CHEMBL462576 & 688161 & 6.0 & 4.9921 & TST \\
\hline CHEMBL1441575 & 688161 & 4.6 & 4.8905 & TRN \\
\hline CHEMBL1377847 & 688161 & 5.3 & 4.8554 & TRN \\
\hline CHEMBL67535 & 688161 & 5.5 & 4.9619 & TRN \\
\hline CHEMBL1376158 & 688161 & 5.3 & 4.8731 & TRN \\
\hline CHEMBL1552194 & 688161 & 4.4 & 4.8375 & TRN \\
\hline
\end{tabular}




\begin{tabular}{|c|c|c|c|c|c|}
\hline \multicolumn{6}{|c|}{ Supplemental Table S2.txt } \\
\hline CHEMBL1333655 & 688161 & 5.1 & 5.2597 & TRN & \\
\hline CHEMBL2374259 & 688161 & 6.0 & 4.9734 & TST & \\
\hline CHEMBL1310198 & 688161 & 4.5 & 4.8509 & TRN & \\
\hline CHEMBL1593134 & 688161 & 5.2 & 4.828 & TRN & \\
\hline CHEMBL1481000 & 688161 & 4.4 & 4.8888 & TST & \\
\hline CHEMBL1528250 & 688161 & 4.7 & 4.913 & TRN & \\
\hline CHEMBL1587972 & 688161 & 4.4 & 4.9186 & TRN & \\
\hline CHEMBL452241 & 688161 & 6.1 & 4.882 & TRN & \\
\hline CHEMBL225513 & 688161 & 4.9 & \multicolumn{2}{|c|}{5.207000000000001} & TRN \\
\hline CHEMBL1509822 & 688161 & 4.8 & 4.8561 & TRN & \\
\hline CHEMBL1430559 & 688161 & 5.1 & 4.9232 & TST & \\
\hline CHEMBL1528418 & 688161 & 5.4 & 4.8185 & TRN & \\
\hline CHEMBL1477766 & 688161 & 4.5 & 4.9 & TRN & \\
\hline CHEMBL1310392 & 688161 & 5.9 & 4.9189 & TST & \\
\hline CHEMBL1381438 & 688161 & 4.5 & 4.9585 & TRN & \\
\hline CHEMBL1339209 & 688161 & 4.8 & 4.8264 & TRN & \\
\hline CHEMBL1496083 & 688161 & 4.8 & 4.9332 & TRN & \\
\hline CHEMBL1515004 & 688161 & 4.6 & 5.0136 & TRN & \\
\hline CHEMBL1318914 & 688161 & 6.4 & 4.9096 & TRN & \\
\hline CHEMBL1375781 & 688161 & 7.5003 & 4.9774 & TRN & \\
\hline CHEMBL1485289 & 688161 & 4.6 & 4.8962 & TST & \\
\hline CHEMBL1560437 & 688161 & 4.6 & 4.8388 & TRN & \\
\hline CHEMBL1526497 & 688161 & 5.5 & 5.3079 & TRN & \\
\hline CHEMBL1529609 & 688161 & 5.5 & 5.1071 & TST & \\
\hline CHEMBL1477786 & 688161 & 4.6 & 4.8995 & TRN & \\
\hline CHEMBL1323023 & 688161 & 5.5 & 4.8703 & TRN & \\
\hline CHEMBL1592571 & 688161 & 4.4 & 4.9308 & TRN & \\
\hline CHEMBL1405719 & 688161 & 5.1 & 4.8357 & TRN & \\
\hline CHEMBL1470281 & 688161 & 4.9 & 5.0857 & TST & \\
\hline CHEMBL3190396 & 688161 & 4.6 & 4.9398 & TRN & \\
\hline CHEMBL1430352 & 688161 & 4.5 & 4.9014 & TRN & \\
\hline CHEMBL1303670 & 688161 & 4.5 & 4.9407 & TRN & \\
\hline CHEMBL1712082 & 688161 & 5.4 & 5.1026 & TST & \\
\hline CHEMBL1414873 & 688161 & 5.3 & 5.09699 & 99999999995 & TRN \\
\hline CHEMBL1605172 & 688161 & 4.7 & 5.4459 & TRN & \\
\hline CHEMBL1482852 & 688161 & 4.9 & 4.8373 & TRN & \\
\hline CHEMBL3199173 & 688161 & 5.5 & 4.9323 & TRN & \\
\hline CHEMBL1603627 & 688161 & 6.5 & 4.9019 & TRN & \\
\hline CHEMBL1554246 & 688161 & 4.8 & 4.9037 & TRN & \\
\hline CHEMBL1304950 & 688161 & 5.8 & 4.7749 & TRN & \\
\hline CHEMBL1459182 & 688161 & 6.2 & 4.8708 & TRN & \\
\hline CHEMBL419045 & 688161 & 4.7 & 4.8641 & TST & \\
\hline CHEMBL3192690 & 688161 & 5.3 & 5.3055 & TRN & \\
\hline CHEMBL1426630 & 688161 & 4.6 & 4.9263 & TRN & \\
\hline CHEMBL1430173 & 688161 & 4.4 & 4.9408 & TRN & \\
\hline CHEMBL1327833 & 688161 & 5.1 & 4.8038 & TRN & \\
\hline CHEMBL1524890 & 688161 & 5.2 & 4.9573 & TRN & \\
\hline CHEMBL1508238 & 688161 & 4.9 & 4.8606 & TRN & \\
\hline
\end{tabular}




\begin{tabular}{|c|c|c|c|c|}
\hline & & & & al lable \\
\hline CHEMBL1610375 & 688161 & 4.8 & 4.8179 & TRN \\
\hline CHEMBL1519586 & 688161 & 4.5 & $4.9460 e$ & 0000000001 \\
\hline CHEMBL3197685 & 688161 & 4.6 & 4.8239 & TRN \\
\hline CHEMBL 3212141 & 688161 & 4.4 & 4.9773 & TST \\
\hline CHEMBL530038 & 688161 & 4.8 & 4.8854 & TRN \\
\hline CHEMBL1501343 & 688161 & 4.7 & 4.9042 & TRN \\
\hline CHEMBL1300405 & 688161 & 4.4 & 4.8337 & TRN \\
\hline CHEMBL1456042 & 688161 & 4.8 & 4.8317 & TRN \\
\hline CHEMBL1334368 & 688161 & 4.6 & 4.8746 & TRN \\
\hline CHEMBL1594217 & 688161 & 4.8 & 4.9368 & TST \\
\hline CHEMBL1547832 & 688161 & 4.8 & 4.8347 & TRN \\
\hline CHEMBL1409676 & 688161 & 5.5 & 5.0455 & TRN \\
\hline CHEMBL1542745 & 688161 & 4.9 & 5.096 & TRN \\
\hline CHEMBL1590902 & 688161 & 4.9 & 5.1328 & TST \\
\hline CHEMBL1324375 & 688161 & 4.6 & 4.8432 & TRN \\
\hline CHEMBL1365823 & 688161 & 4.6 & 4.9437 & TRN \\
\hline CHEMBL1518035 & 688161 & 4.4 & 4.8613 & TRN \\
\hline CHEMBL1348178 & 688161 & 4.4 & 4.9942 & TRN \\
\hline CHEMBL1448387 & 688161 & 5.3 & 5.6946 & TST \\
\hline CHEMBL33884 & 688161 & 4.8 & 4.916 & TRN \\
\hline CHEMBL1442969 & 688161 & 4.5 & 4.8714 & TRN \\
\hline CHEMBL1351991 & 688161 & 5.4 & 4.9546 & TRN \\
\hline CHEMBL1598104 & 688161 & 4.8 & 4.8134 & TRN \\
\hline CHEMBL1387705 & 688161 & 4.4 & 4.8786 & TRN \\
\hline CHEMBL13791 & 688161 & 4.7 & 4.8957 & TST \\
\hline CHEMBL1314388 & 688161 & 4.6 & 4.7827 & TRN \\
\hline CHEMBL1448182 & 688161 & 4.8 & 4.824 & TRN \\
\hline CHEMBL1317306 & 688161 & 5.0 & 4.9443 & TRN \\
\hline CHEMBL1400296 & 688161 & 4.4 & 4.9183 & TRN \\
\hline CHEMBL349384 & 688161 & 4.9 & 4.9888 & TST \\
\hline CHEMBL1310219 & 688161 & 4.7 & 4.9044 & TRN \\
\hline CHEMBL1327681 & 688161 & 4.6 & 4.7998 & TRN \\
\hline CHEMBL 286204 & 688161 & 4.4 & 4.8808 & TRN \\
\hline CHEMBL479014 & 688161 & 4.9 & 5.0812 & TST \\
\hline CHEMBL1534488 & 688161 & 4.8 & 5.1101 & TRN \\
\hline CHEMBL1410039 & 688161 & 5.3 & 4.9749 & TRN \\
\hline CHEMBL1308260 & 688161 & 4.7 & 4.9036 & TRN \\
\hline CHEMBL1451494 & 688161 & 5.4 & 4.8876 & TRN \\
\hline CHEMBL1546583 & 688161 & 4.9 & 4.8838 & TRN \\
\hline CHEMBL1370753 & 688161 & 5.4 & 4.881 & TRN \\
\hline CHEMBL1577137 & 688161 & 7.0 & 4.8562 & TRN \\
\hline CHEMBL1434645 & 688161 & 4.4 & 5.0733 & TST \\
\hline CHEMBL 307893 & 688161 & 5.0 & 5.2236 & TST \\
\hline CHEMBL1566378 & 688161 & 4.4 & 4.8865 & TRN \\
\hline CHEMBL1733605 & 688161 & 4.4 & 4.8592 & TRN \\
\hline CHEMBL1424917 & 688161 & 5.5 & 5.1291 & TRN \\
\hline CHEMBL1584091 & 688161 & 4.4 & 4.8986 & TRN \\
\hline CHEMBL1586914 & 688161 & 4.7 & 4.8199 & TRN \\
\hline
\end{tabular}

TRN 


\begin{tabular}{|c|c|c|c|c|c|}
\hline & & & & & \\
\hline CHEMBL 3207744 & 688161 & 4.5 & 5.0445 & TST & \\
\hline CHEMBL1515852 & 688161 & 4.6 & 4.8485 & TRN & \\
\hline CHEMBL1384101 & 688161 & 4.8 & 4.8149 & TRN & \\
\hline CHEMBL1315257 & 688161 & 4.7 & 4.891 & TRN & \\
\hline CHEMBL1391676 & 688161 & 4.7 & 5.3069 & TRN & \\
\hline CHEMBL1562802 & 688161 & 4.9 & 4.8565 & TRN & \\
\hline CHEMBL1440651 & 688161 & 4.4 & 4.923 & TRN & \\
\hline CHEMBL1461931 & 688161 & 4.7 & 5.01699 & 99999999995 & TRN \\
\hline CHEMBL1545294 & 688161 & 4.4 & 4.8084 & TRN & \\
\hline CHEMBL1556579 & 688161 & 5.1 & 4.9313 & TRN & \\
\hline CHEMBL1597911 & 688161 & 4.5 & 4.9567 & TST & \\
\hline CHEMBL1604283 & 688161 & 6.0 & 5.0507 & TST & \\
\hline CHEMBL1314469 & 688161 & 5.3 & 4.9827 & TST & \\
\hline CHEMBL1324889 & 688161 & 4.5 & 4.7791 & TRN & \\
\hline CHEMBL1602599 & 688161 & 5.1 & 4.8956 & TRN & \\
\hline CHEMBL1366297 & 688161 & 4.5 & 5.0161 & TRN & \\
\hline CHEMBL549321 & 688161 & 4.6 & 4.9918 & TRN & \\
\hline CHEMBL1391416 & 688161 & 4.7 & 4.8718 & TRN & \\
\hline CHEMBL98350 & 688161 & 4.4 & 4.9657 & TRN & \\
\hline CHEMBL1518190 & 688161 & 4.5 & 4.8574 & TST & \\
\hline CHEMBL3145017 & 688161 & 4.6 & 5.1343 & TST & \\
\hline CHEMBL1406204 & 688161 & 4.6 & 4.8505 & TRN & \\
\hline CHEMBL1371207 & 688161 & 4.6 & 4.854 & TRN & \\
\hline CHEMBL1352368 & 688161 & 4.6 & 4.8817 & TRN & \\
\hline CHEMBL1502203 & 688161 & 4.8 & 5.1293 & TRN & \\
\hline CHEMBL1370817 & 688161 & 4.9 & 4.8499 & TRN & \\
\hline CHEMBL1553721 & 688161 & 4.8 & 5.4523 & TRN & \\
\hline CHEMBL487894 & 688161 & 6.0 & 4.9881 & TRN & \\
\hline CHEMBL1581714 & 688161 & 4.5 & 4.7966 & TRN & \\
\hline CHEMBL1473754 & 688161 & 6.5 & 4.9518 & TRN & \\
\hline CHEMBL1341665 & 688161 & 4.7 & 5.1151 & TST & \\
\hline CHEMBL1453291 & 688161 & 6.1 & 4.8178 & TRN & \\
\hline CHEMBL1438663 & 688161 & 4.6 & 4.9019 & TRN & \\
\hline CHEMBL1554531 & 688161 & 5.5 & 4.9398 & TRN & \\
\hline CHEMBL1477329 & 688161 & 4.9 & 4.8867 & TRN & \\
\hline CHEMBL1504428 & 688161 & 5.4 & 4.9404 & TRN & \\
\hline CHEMBL1557008 & 688161 & 4.5 & 4.9441 & TRN & \\
\hline CHEMBL1443218 & 688161 & 4.8 & 4.9491 & TRN & \\
\hline CHEMBL1531761 & 688161 & 5.3 & 4.8788 & TRN & \\
\hline CHEMBL1353227 & 688161 & 4.5 & 4.9585 & TRN & \\
\hline CHEMBL1311205 & 688161 & 5.1 & 4.9773 & TST & \\
\hline CHEMBL 2373284 & 688161 & 5.3 & 5.0418 & TST & \\
\hline CHEMBL404845 & 688161 & 4.5 & 5.1674 & TST & \\
\hline CHEMBL 1403830 & 688161 & 4.5 & 5.0375 & TRN & \\
\hline CHEMBL112816 & 688161 & 5.3 & 4.9775 & TRN & \\
\hline CHEMBL1468811 & 688161 & 4.9 & 5.3048 & TRN & \\
\hline CHEMBL1361234 & 688161 & 4.9 & 4.9366 & TRN & \\
\hline CHEMBL1511539 & 688161 & 4.4 & 5.0111 & TRN & \\
\hline & & & & 23399 & \\
\hline
\end{tabular}




\begin{tabular}{|c|c|c|c|c|}
\hline \multicolumn{5}{|c|}{ Supplemental Table S2.txt } \\
\hline CHEMBL1483698 & 688161 & 4.8 & 5.0179 & TRN \\
\hline CHEMBL3193049 & 688161 & 5.6 & 4.9307 & TRN \\
\hline CHEMBL1374081 & 688161 & 4.5 & 4.813 & TRN \\
\hline CHEMBL1482809 & 688161 & 4.5 & 4.7496 & TRN \\
\hline CHEMBL1362160 & 688161 & 4.9 & 4.8922 & TRN \\
\hline CHEMBL1527943 & 688161 & 4.7 & 5.0253 & TRN \\
\hline CHEMBL1439770 & 688161 & 4.8 & 4.7957 & TRN \\
\hline CHEMBL1417927 & 688161 & 4.6 & 4.9867 & TRN \\
\hline CHEMBL1606020 & 688161 & 5.3 & 4.9367 & TRN \\
\hline CHEMBL1470090 & 688161 & 4.7 & 4.8834 & TRN \\
\hline CHEMBL1582610 & 688161 & 4.7 & 5.2061 & TRN \\
\hline CHEMBL1349787 & 688161 & 4.9 & 4.9148 & TRN \\
\hline CHEMBL1442635 & 688161 & 4.6 & 4.8126 & TRN \\
\hline CHEMBL1340418 & 688161 & 4.6 & 4.8914 & TRN \\
\hline CHEMBL1574081 & 688161 & 5.1 & 4.9143 & TRN \\
\hline CHEMBL1333783 & 688161 & 4.9 & 4.9472 & TRN \\
\hline CHEMBL1330186 & 688161 & 4.7 & 5.0145 & TRN \\
\hline CHEMBL240331 & 688161 & 5.2 & 4.9455 & TRN \\
\hline CHEMBL1363566 & 688161 & 5.0 & 4.9187 & TRN \\
\hline CHEMBL1457915 & 688161 & 4.6 & 4.8387 & TST \\
\hline CHEMBL1417302 & 688161 & 4.7 & 4.9543 & TRN \\
\hline CHEMBL1473252 & 688161 & 5.0 & 5.0033 & TST \\
\hline CHEMBL1579120 & 688161 & 4.9 & 4.9148 & TRN \\
\hline CHEMBL1301917 & 688161 & 4.6 & 4.963 & TRN \\
\hline CHEMBL1531919 & 688161 & 4.6 & 4.8827 & TRN \\
\hline CHEMBL1402577 & 688161 & 5.2 & 4.7935 & TRN \\
\hline CHEMBL1513643 & 688161 & 5.5 & 5.2206 & TST \\
\hline CHEMBL1564986 & 688161 & 4.6 & 4.8658 & TRN \\
\hline CHEMBL1542674 & 688161 & 5.0 & 4.783 & TRN \\
\hline CHEMBL1497385 & 688161 & 4.7 & 4.9224 & TST \\
\hline CHEMBL1335392 & 688161 & 4.4 & 4.8651 & TRN \\
\hline CHEMBL1344226 & 688161 & 6.0 & 4.9134 & TRN \\
\hline CHEMBL1608535 & 688161 & 4.9 & 5.1408 & TST \\
\hline CHEMBL1386456 & 688161 & 4.6 & 4.869 & TRN \\
\hline CHEMBL1509090 & 688161 & 4.7 & 4.8299 & TRN \\
\hline CHEMBL1538195 & 688161 & 4.6 & 4.9655 & TRN \\
\hline CHEMBL1539114 & 688161 & 4.6 & 4.7804 & TRN \\
\hline CHEMBL1502576 & 688161 & 4.7 & 4.8833 & TRN \\
\hline CHEMBL1583499 & 688161 & 6.4 & 4.9359 & TRN \\
\hline CHEMBL1592444 & 688161 & 4.5 & 4.9782 & TST \\
\hline CHEMBL1563307 & 688161 & 4.8 & 4.8981 & TST \\
\hline CHEMBL1532349 & 688161 & 5.0 & 4.8386 & TRN \\
\hline CHEMBL1522250 & 688161 & 4.4 & 4.9644 & TST \\
\hline CHEMBL1490628 & 688161 & 7.0 & 5.4655 & TRN \\
\hline CHEMBL1329850 & 688161 & 4.9 & 5.2674 & TRN \\
\hline CHEMBL490744 & 688161 & 4.7 & 4.7938 & TRN \\
\hline CHEMBL1504719 & 688161 & 4.8 & 4.942 & TRN \\
\hline CHEMBL1256697 & 688161 & 4.7 & 5.0766 & TRN \\
\hline
\end{tabular}




\begin{tabular}{|c|c|c|c|c|}
\hline & & & oplement & al $\mathrm{T}$ \\
\hline CHEMBL1390901 & 688161 & 4.9 & 5.2223 & TRN \\
\hline CHEMBL1603477 & 688161 & 4.5 & 4.8833 & TRN \\
\hline CHEMBL3198962 & 688161 & 5.0 & 4.9865 & TRN \\
\hline CHEMBL1587578 & 688161 & 4.6 & 4.8811 & TRN \\
\hline CHEMBL1502229 & 688161 & 4.5 & 4.8918 & TST \\
\hline CHEMBL1325403 & 688161 & 5.0 & 4.8152 & TRN \\
\hline CHEMBL1319525 & 688161 & 4.5 & 4.8021 & TRN \\
\hline CHEMBL1314828 & 688161 & 5.0 & 5.1027 & TST \\
\hline CHEMBL1463280 & 688161 & 4.6 & 5.0185 & TRN \\
\hline CHEMBL1568136 & 688161 & 5.1 & 4.885 & TRN \\
\hline CHEMBL1387925 & 688161 & 5.5 & 4.8546 & TRN \\
\hline CHEMBL1401424 & 688161 & 4.6 & 5.1078 & TRN \\
\hline CHEMBL1256484 & 688161 & 5.3 & 5.3546 & TRN \\
\hline CHEMBL1542791 & 688161 & 7.2 & 4.7649 & TRN \\
\hline CHEMBL1320319 & 688161 & 4.6 & 5.1493 & TRN \\
\hline CHEMBL1331937 & 688161 & 5.3 & 5.1419 & TST \\
\hline CHEMBL43612 & 688161 & 5.7 & 5.0915 & TRN \\
\hline CHEMBL1359428 & 688161 & 4.9 & 4.9169 & TRN \\
\hline CHEMBL1401971 & 688161 & 4.4 & 4.8856 & TRN \\
\hline CHEMBL1446519 & 688161 & 4.4 & 4.9926 & TST \\
\hline CHEMBL321820 & 688161 & 4.7 & 4.9786 & TST \\
\hline CHEMBL1357676 & 688161 & 4.6 & 4.9418 & TRN \\
\hline CHEMBL1596886 & 688161 & 4.8 & 4.8878 & TRN \\
\hline CHEMBL1606662 & 688161 & 4.9 & 5.0455 & TRN \\
\hline CHEMBL1368207 & 688161 & 4.9 & 4.936 & TST \\
\hline CHEMBL1432324 & 688161 & 5.5 & 4.8223 & TRN \\
\hline CHEMBL1512359 & 688161 & 5.7 & 4.9849 & TST \\
\hline CHEMBL1585410 & 688161 & 4.7 & 4.9407 & TRN \\
\hline CHEMBL1445418 & 688161 & 4.5 & 4.8598 & TRN \\
\hline CHEMBL1347617 & 688161 & 4.7 & 5.1062 & TRN \\
\hline CHEMBL1329994 & 688161 & 4.7 & 4.9184 & TRN \\
\hline CHEMBL1329383 & 688161 & 4.5 & 4.8588 & TRN \\
\hline CHEMBL1535312 & 688161 & 4.8 & 4.8743 & TRN \\
\hline CHEMBL1538109 & 688161 & 4.9 & 4.9249 & TRN \\
\hline CHEMBL28319 & 688161 & 4.4 & 5.0802 & TRN \\
\hline CHEMBL1505491 & 688161 & 4.6 & 4.9849 & TRN \\
\hline CHEMBL1509915 & 688161 & 8.2007 & 4.9395 & TRN \\
\hline CHEMBL1332890 & 688161 & 4.6 & 4.8744 & TRN \\
\hline CHEMBL1397369 & 688161 & 5.5 & 5.0922 & TST \\
\hline CHEMBL1372111 & 688161 & 4.6 & 4.8165 & TRN \\
\hline CHEMBL1505145 & 688161 & 4.4 & 4.9702 & TRN \\
\hline CHEMBL1459934 & 688161 & 4.8 & 4.7995 & TRN \\
\hline CHEMBL1556896 & 688161 & 4.6 & 5.0128 & TRN \\
\hline CHEMBL1415126 & 688161 & 4.5 & 4.8498 & TRN \\
\hline CHEMBL1303139 & 688161 & 5.9 & 5.5827 & TRN \\
\hline CHEMBL1480465 & 688161 & 4.8 & 4.8972 & TRN \\
\hline CHEMBL1486574 & 688161 & 4.7 & 5.0491 & TRN \\
\hline CHEMBL1421271 & 688161 & 4.9 & 4.8393 & TRN \\
\hline
\end{tabular}




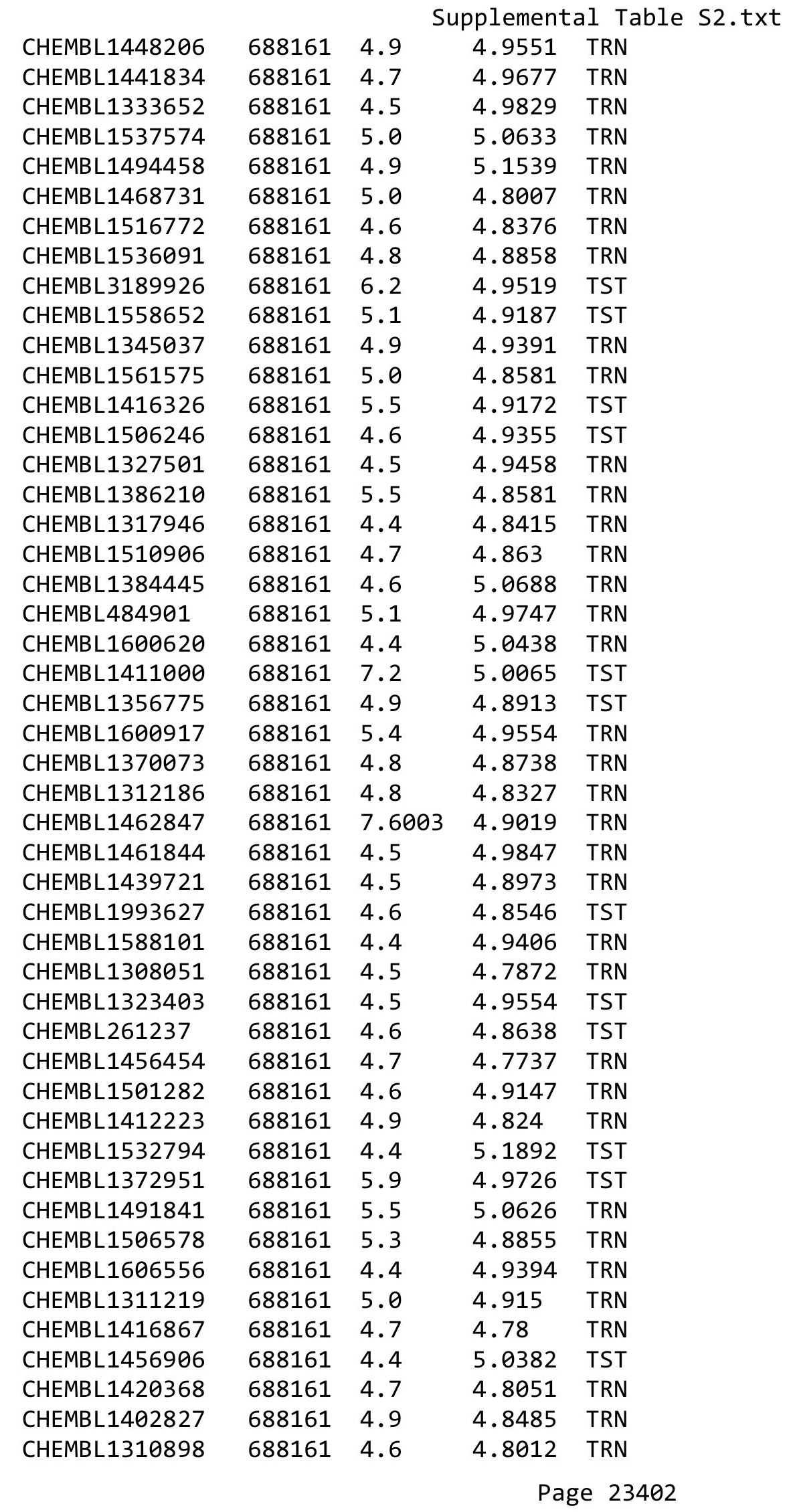




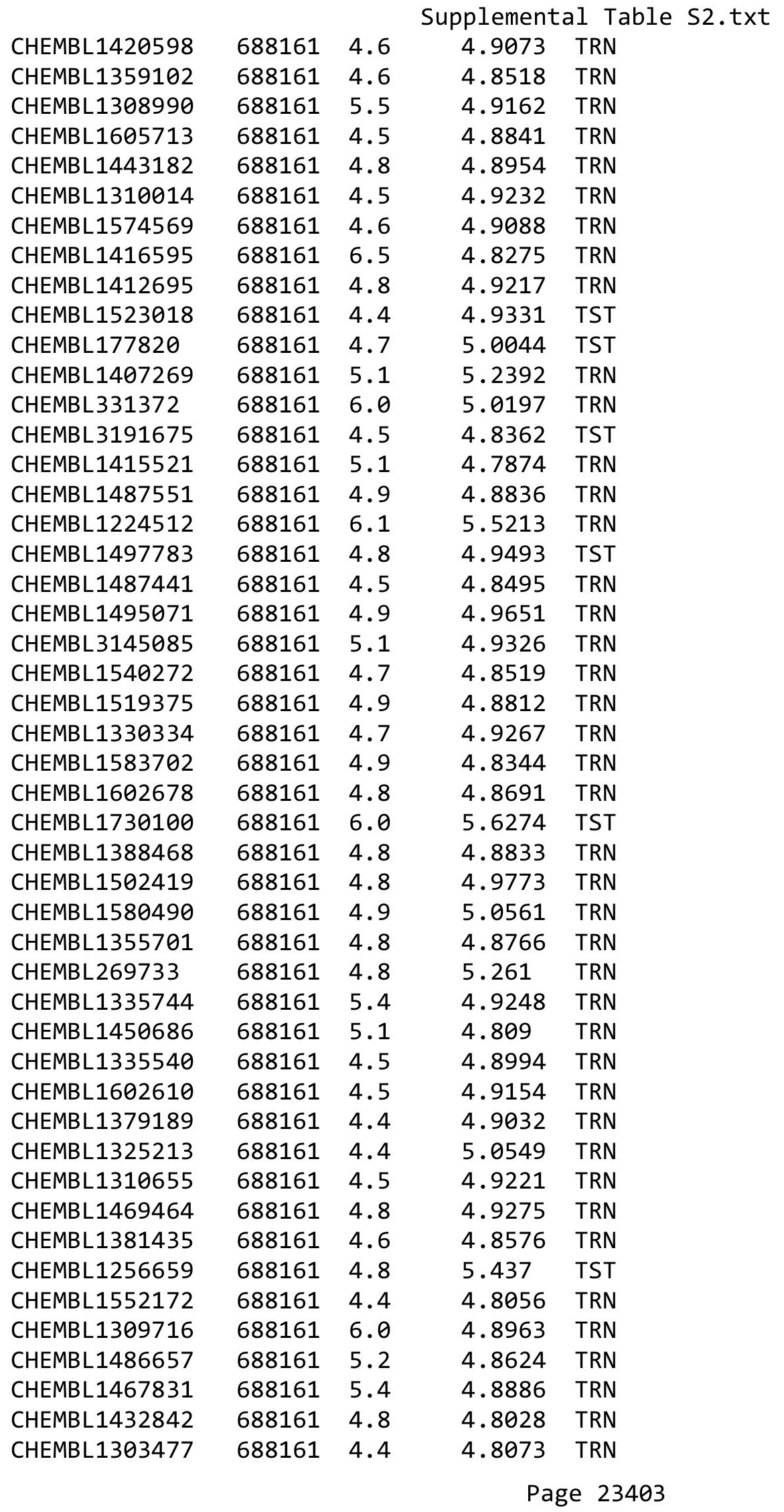




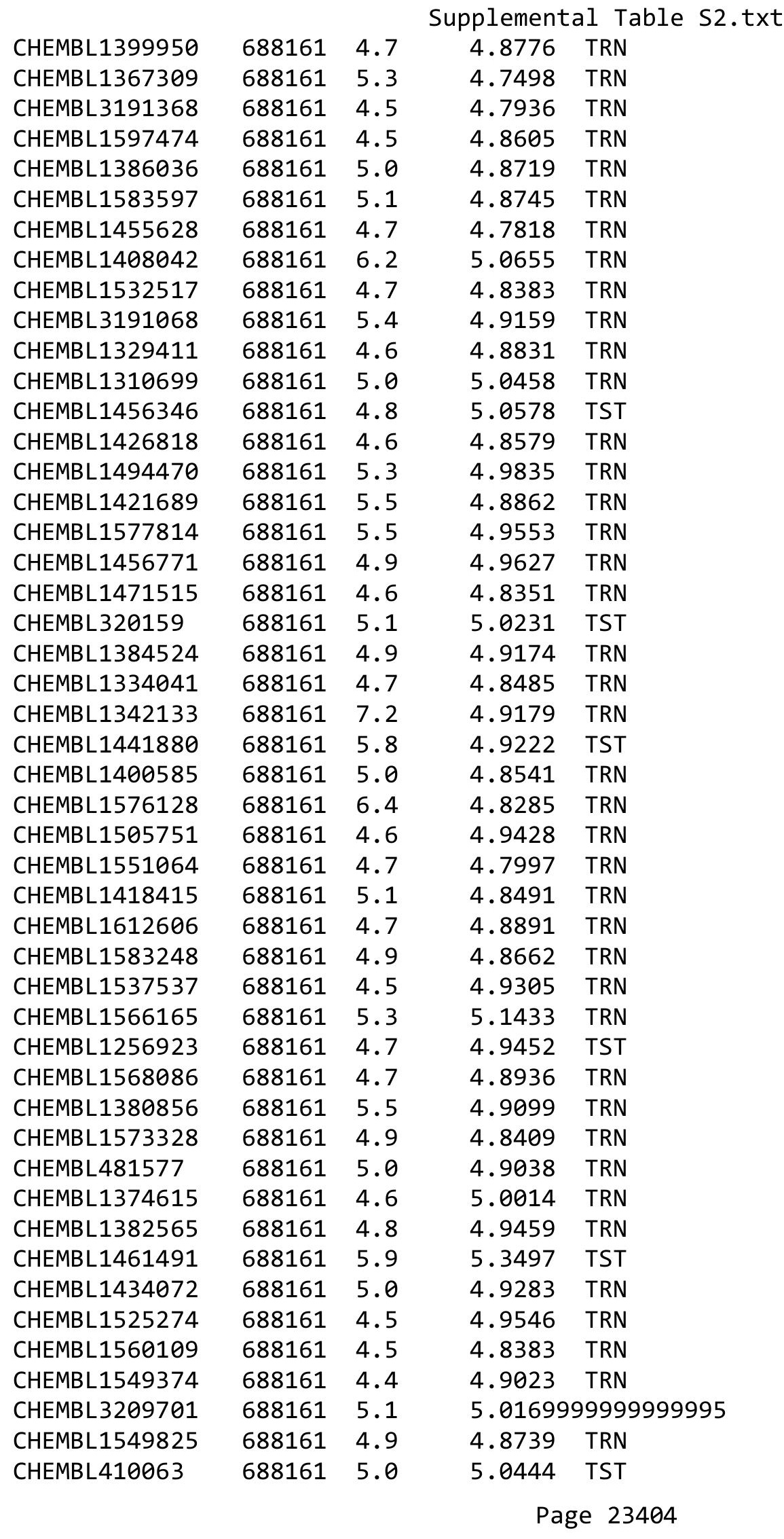




\begin{tabular}{|c|c|c|c|c|c|}
\hline \multicolumn{6}{|c|}{ Supplemental Table S2.txt } \\
\hline CHEMBL1580372 & 688161 & 4.5 & 4.8109 & TRN & \\
\hline CHEMBL1340322 & 688161 & 4.6 & 4.8204 & TRN & \\
\hline CHEMBL1536864 & 688161 & 4.6 & 4.8632 & TRN & \\
\hline CHEMBL1315609 & 688161 & 4.4 & 4.8515 & TRN & \\
\hline CHEMBL1386050 & 688161 & 4.4 & 4.8961 & TRN & \\
\hline CHEMBL1470371 & 688161 & 5.5 & 4.8237 & TRN & \\
\hline CHEMBL1566838 & 688161 & 4.5 & 4.8946 & TRN & \\
\hline CHEMBL1308058 & 688161 & 5.3 & 4.8471 & TRN & \\
\hline CHEMBL1335880 & 688161 & 4.9 & 4.7871 & TRN & \\
\hline CHEMBL1595221 & 688161 & 4.9 & 4.9296 & TRN & \\
\hline CHEMBL1568597 & 688161 & 4.7 & 4.9615 & TRN & \\
\hline CHEMBL1532397 & 688161 & 4.8 & 4.851 & TRN & \\
\hline CHEMBL1301192 & 688161 & 7.6003 & 4.9492 & TRN & \\
\hline CHEMBL1417897 & 688161 & 4.4 & 4.8836 & TRN & \\
\hline CHEMBL1554362 & 688161 & 4.9 & 4.9353 & TST & \\
\hline CHEMBL1368261 & 688161 & 5.0 & 4.9723 & TST & \\
\hline CHEMBL1304445 & 688161 & 5.4 & 5.0431 & TRN & \\
\hline CHEMBL1473099 & 688161 & 5.1 & 4.9469 & TRN & \\
\hline CHEMBL62 & 688161 & 4.8 & 5.3494 & TST & \\
\hline CHEMBL1544909 & 688161 & 4.5 & 4.8732 & TRN & \\
\hline CHEMBL1535587 & 688161 & 4.6 & 4.979 & TRN & \\
\hline CHEMBL1607991 & 688161 & 5.2 & 5.28799 & 9999999999 & TRN \\
\hline CHEMBL1324113 & 688161 & 4.6 & 4.8679 & TRN & \\
\hline CHEMBL1548408 & 688161 & 4.8 & 4.9293 & TRN & \\
\hline CHEMBL1505224 & 688161 & 4.4 & 5.0102 & TRN & \\
\hline CHEMBL1477693 & 688161 & 6.6 & 4.8739 & TRN & \\
\hline CHEMBL1564824 & 688161 & 4.9 & 4.9515 & TRN & \\
\hline CHEMBL1605965 & 688161 & 4.6 & 4.9728 & TRN & \\
\hline CHEMBL1371869 & 688161 & 4.9 & 5.0728 & TST & \\
\hline CHEMBL1517430 & 688161 & 4.5 & 4.8103 & TRN & \\
\hline CHEMBL1408033 & 688161 & 4.8 & 4.9118 & TRN & \\
\hline CHEMBL1576324 & 688161 & 4.6 & 5.1611 & TRN & \\
\hline CHEMBL1448019 & 688161 & 4.6 & 4.9328 & TRN & \\
\hline CHEMBL1469024 & 688161 & 4.9 & 4.9358 & TRN & \\
\hline CHEMBL1370417 & 688161 & 4.9 & 4.9046 & TST & \\
\hline CHEMBL1585343 & 688161 & 4.4 & 5.0759 & TRN & \\
\hline CHEMBL1455073 & 688161 & 5.5 & 5.2292 & TST & \\
\hline CHEMBL1597827 & 688161 & 5.6 & 5.062 & TRN & \\
\hline CHEMBL1602058 & 688161 & 4.6 & 4.9459 & TRN & \\
\hline CHEMBL1377184 & 688161 & 4.7 & 4.88899 & 9999999999 & TRN \\
\hline CHEMBL1518110 & 688161 & 4.9 & 4.7724 & TRN & \\
\hline CHEMBL1978101 & 688161 & 4.8 & 5.1049 & TRN & \\
\hline CHEMBL1604679 & 688161 & 5.0 & 4.9912 & TRN & \\
\hline CHEMBL1473434 & 688161 & 4.5 & 4.7593 & TRN & \\
\hline CHEMBL1526851 & 688161 & 5.8 & 5.3258 & TRN & \\
\hline CHEMBL1308769 & 688161 & 4.5 & 4.9422 & TRN & \\
\hline CHEMBL1499545 & 688161 & 4.7 & 4.8461 & TST & \\
\hline CHEMBL1452945 & 688161 & 5.1 & 4.9309 & TRN & \\
\hline
\end{tabular}




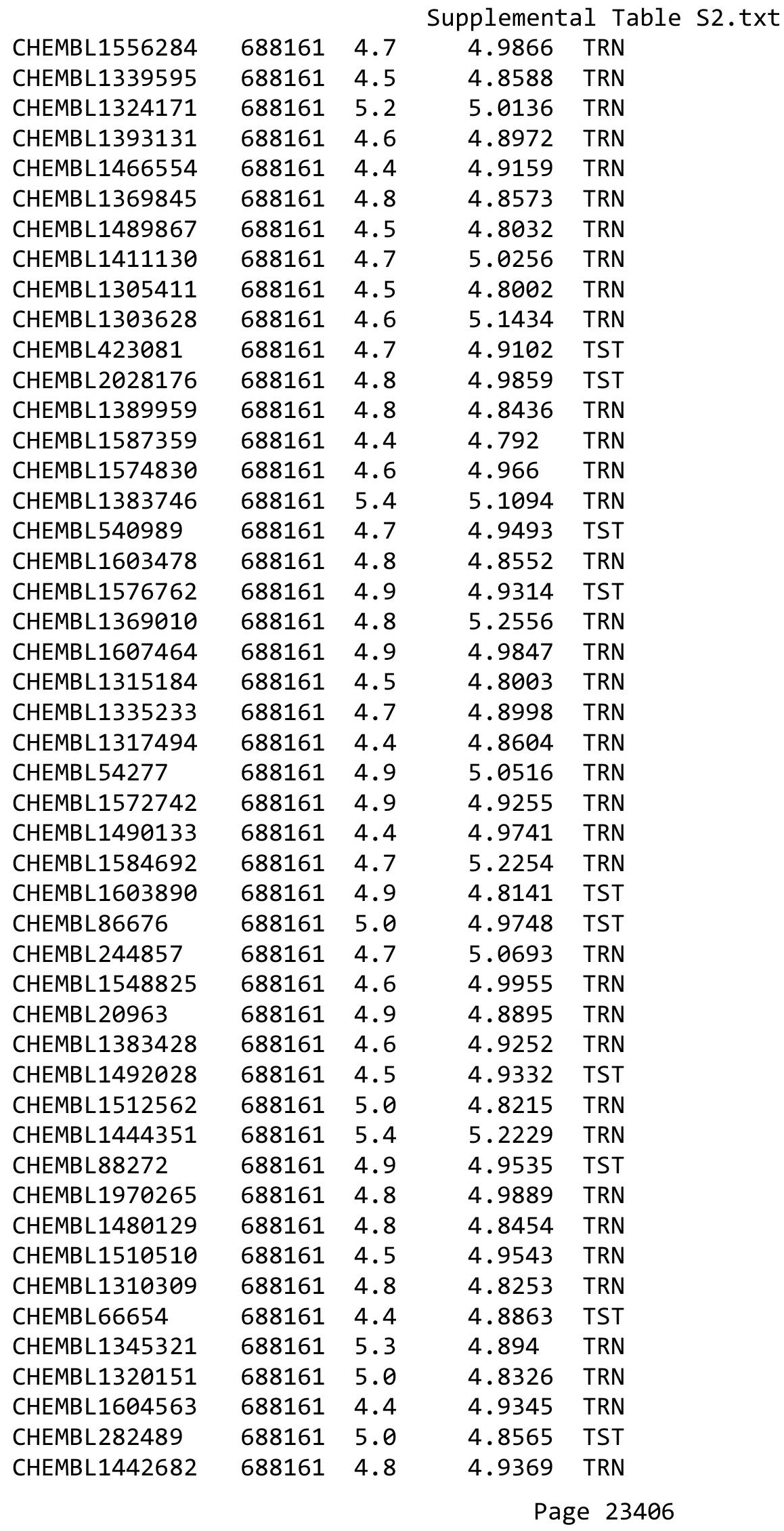




\begin{tabular}{|c|c|c|c|c|}
\hline & & & pplement & $\mathrm{a} \perp \mathrm{Ta}$ \\
\hline CHEMBL1546919 & 688161 & 6.2 & 4.8877 & TRN \\
\hline CHEMBL1331907 & 688161 & 4.6 & 4.8243 & TRN \\
\hline CHEMBL186526 & 688161 & 4.8 & 4.9494 & TRN \\
\hline CHEMBL1577952 & 688161 & 5.0 & 4.8735 & TRN \\
\hline CHEMBL1551139 & 688161 & 4.6 & 4.8445 & TRN \\
\hline CHEMBL1489926 & 688161 & 4.6 & 4.8464 & TRN \\
\hline CHEMBL1352121 & 688161 & 4.9 & 5.0028 & TRN \\
\hline CHEMBL1477253 & 688161 & 5.5 & 4.9589 & TRN \\
\hline CHEMBL1360999 & 688161 & 4.4 & 4.785 & TRN \\
\hline CHEMBL1471093 & 688161 & 5.2 & 4.9544 & TRN \\
\hline CHEMBL1517197 & 688161 & 4.6 & 4.8829 & TRN \\
\hline CHEMBL1455200 & 688161 & 4.9 & 4.8621 & TRN \\
\hline CHEMBL1510257 & 688161 & 4.6 & 4.9328 & TRN \\
\hline CHEMBL1323351 & 688161 & 4.4 & 4.9299 & TRN \\
\hline CHEMBL1489528 & 688161 & 4.6 & 4.8599 & TRN \\
\hline CHEMBL1563085 & 688161 & 4.4 & 4.7825 & TRN \\
\hline CHEMBL1328128 & 688161 & 5.8 & 4.905 & TRN \\
\hline CHEMBL1336386 & 688161 & 5.5 & 5.0672 & TRN \\
\hline CHEMBL1307495 & 688161 & 5.0 & 4.8953 & TRN \\
\hline CHEMBL221137 & 688161 & 5.3 & 4.8238 & TST \\
\hline CHEMBL1317461 & 688161 & 4.4 & 4.7642 & TRN \\
\hline CHEMBL1338892 & 688161 & 4.4 & 4.9483 & TRN \\
\hline CHEMBL1319407 & 688161 & 4.4 & 4.9919 & TRN \\
\hline CHEMBL1336793 & 688161 & 4.6 & 5.1093 & TRN \\
\hline CHEMBL1543115 & 688161 & 4.4 & 5.0277 & TRN \\
\hline CHEMBL1579490 & 688161 & 4.9 & 4.9316 & TRN \\
\hline CHEMBL1329235 & 688161 & 5.5 & 4.9795 & TRN \\
\hline CHEMBL1439137 & 688161 & 4.7 & 4.9022 & TST \\
\hline CHEMBL1486659 & 688161 & 5.5 & 5.371 & TRN \\
\hline CHEMBL1345107 & 688161 & 5.4 & 4.8911 & TRN \\
\hline CHEMBL1329004 & 688161 & 4.5 & 5.0012 & TST \\
\hline CHEMBL1503006 & 688161 & 5.6 & 4.8738 & TRN \\
\hline CHEMBL1576666 & 688161 & 4.6 & 4.8996 & TRN \\
\hline CHEMBL1455446 & 688161 & 5.5 & 4.9273 & TRN \\
\hline CHEMBL1575954 & 688161 & 4.7 & 4.9109 & TRN \\
\hline CHEMBL1450564 & 688161 & 4.5 & 4.8118 & TRN \\
\hline CHEMBL1528960 & 688161 & 4.4 & 4.8955 & TRN \\
\hline CHEMBL1331734 & 688161 & 5.0 & 5.4625 & TST \\
\hline CHEMBL1393750 & 688161 & 4.6 & 4.8789 & TRN \\
\hline CHEMBL1502089 & 688161 & 4.6 & 4.9604 & TST \\
\hline CHEMBL 32503 & 688161 & 4.8 & 5.8357 & TRN \\
\hline CHEMBL1523235 & 688161 & 4.4 & 4.9515 & TRN \\
\hline CHEMBL1412344 & 688161 & 4.4 & 4.8379 & TRN \\
\hline CHEMBL1409613 & 688161 & 4.9 & 4.802 & TRN \\
\hline CHEMBL1574614 & 688161 & 4.6 & 4.9912 & TST \\
\hline CHEMBL1337991 & 688161 & 4.7 & 4.9354 & TRN \\
\hline CHEMBL1363890 & 688161 & 4.5 & 4.9174 & TRN \\
\hline CHEMBL1362221 & 688161 & 5.2 & 5.3129 & TRN \\
\hline
\end{tabular}




\begin{tabular}{|c|c|c|c|c|}
\hline \multicolumn{5}{|c|}{ Supplemental Table s2.tx } \\
\hline CHEMBL1441016 & 688161 & 4.4 & 4.928 & TRN \\
\hline CHEMBL1608377 & 688161 & 4.6 & 4.9277 & TRN \\
\hline CHEMBL1577586 & 688161 & 4.6 & 4.937 & TST \\
\hline CHEMBL1330853 & 688161 & 5.6 & 4.8953 & TRN \\
\hline CHEMBL1332952 & 688161 & 4.4 & 4.9057 & TRN \\
\hline CHEMBL1529788 & 688161 & 5.4 & 5.1666 & TRN \\
\hline CHEMBL24510 & 688161 & 6.0 & 4.8709 & TST \\
\hline CHEMBL210868 & 688161 & 4.5 & 4.9787 & TRN \\
\hline CHEMBL1531305 & 688161 & 4.6 & 4.8614 & TRN \\
\hline CHEMBL1430584 & 688161 & 4.9 & 5.3318 & TRN \\
\hline CHEMBL1395864 & 688161 & 5.1 & 5.0722 & TST \\
\hline CHEMBL1329790 & 688161 & 4.4 & 4.9972 & TRN \\
\hline CHEMBL1545566 & 688161 & 5.0 & 5.0867 & TRN \\
\hline CHEMBL 9225 & 688161 & 4.9 & 4.9498 & TRN \\
\hline CHEMBL1369384 & 688161 & 4.8 & 5.0018 & TST \\
\hline CHEMBL1385107 & 688161 & 5.5 & 4.9199 & TRN \\
\hline CHEMBL1544780 & 688161 & 5.0 & 4.9145 & TRN \\
\hline CHEMBL1467552 & 688161 & 5.5 & 4.9076 & TRN \\
\hline CHEMBL1445792 & 688161 & 5.9 & 5.0063 & TST \\
\hline CHEMBL1348232 & 688161 & 4.8 & 4.8854 & TRN \\
\hline CHEMBL1402285 & 688161 & 5.2 & 4.9166 & TRN \\
\hline CHEMBL1422008 & 688161 & 4.4 & 4.9707 & TRN \\
\hline CHEMBL1302307 & 688161 & 4.8 & 4.9007 & TRN \\
\hline CHEMBL1529360 & 688161 & 5.5 & 4.8807 & TRN \\
\hline CHEMBL1501471 & 688161 & 5.4 & 4.827 & TRN \\
\hline CHEMBL1503420 & 688161 & 4.5 & 4.9933 & TRN \\
\hline CHEMBL1558724 & 688161 & 4.5 & 5.069 & TRN \\
\hline CHEMBL1301760 & 688161 & 4.6 & 4.9093 & TRN \\
\hline CHEMBL275938 & 688161 & 6.0 & 5.3128 & TRN \\
\hline CHEMBL1576973 & 688161 & 4.6 & 4.8914 & TST \\
\hline CHEMBL1370718 & 688161 & 5.0 & 5.2026 & TRN \\
\hline CHEMBL1379793 & 688161 & 4.4 & 4.978 & TRN \\
\hline CHEMBL1549880 & 688161 & 4.8 & 4.851 & TRN \\
\hline CHEMBL1376577 & 688161 & 4.9 & 5.0797 & TRN \\
\hline CHEMBL1403803 & 688161 & 4.4 & 4.8636 & TRN \\
\hline CHEMBL1526750 & 688161 & 4.8 & 4.8075 & TRN \\
\hline CHEMBL 2374368 & 688161 & 5.6 & 4.9648 & TST \\
\hline CHEMBL1313635 & 688161 & 4.9 & 4.7801 & TRN \\
\hline CHEMBL1388790 & 688161 & 4.9 & 4.9624 & TRN \\
\hline CHEMBL1481785 & 688161 & 4.8 & 4.9388 & TRN \\
\hline CHEMBL1547674 & 688161 & 4.8 & 4.8407 & TRN \\
\hline CHEMBL1406513 & 688161 & 4.5 & 4.9083 & TRN \\
\hline CHEMBL3198728 & 688161 & 4.4 & 4.9096 & TST \\
\hline CHEMBL1462031 & 688161 & 4.4 & 4.8126 & TRN \\
\hline CHEMBL1590818 & 688161 & 4.7 & 4.8934 & TRN \\
\hline CHEMBL8739 & 688161 & 6.9 & 4.8754 & TRN \\
\hline CHEMBL1596266 & 688161 & 4.6 & 4.9753 & TRN \\
\hline CHEMBL1301069 & 688161 & 5.0 & 4.8815 & TRN \\
\hline
\end{tabular}




\begin{tabular}{|c|c|c|c|c|}
\hline \multicolumn{5}{|c|}{ Supplemental Table s2.txt } \\
\hline CHEMBL1978364 & 688161 & 4.8 & 4.8683 & TRN \\
\hline CHEMBL1415053 & 688161 & 5.2 & 5.3121 & TST \\
\hline CHEMBL1578304 & 688161 & 4.9 & 4.8429 & TRN \\
\hline CHEMBL1504057 & 688161 & 4.7 & 4.9333 & TRN \\
\hline CHEMBL1480282 & 688161 & 4.4 & 4.9075 & TRN \\
\hline CHEMBL1403709 & 688161 & 4.6 & 4.8218 & TRN \\
\hline CHEMBL1322866 & 688161 & 4.7 & 4.9143 & TRN \\
\hline CHEMBL1542963 & 688161 & 5.5 & 5.0131 & TRN \\
\hline CHEMBL1433405 & 688161 & 6.0 & 4.9625 & TST \\
\hline CHEMBL16807 & 688161 & 4.7 & 5.0329 & TRN \\
\hline CHEMBL1335446 & 688161 & 4.4 & 4.9577 & TRN \\
\hline CHEMBL 8565 & 688161 & 4.7 & 5.3811 & TST \\
\hline CHEMBL1304455 & 688161 & 4.6 & 5.0376 & TRN \\
\hline CHEMBL1365545 & 688161 & 4.6 & 5.0187 & TRN \\
\hline CHEMBL1382476 & 688161 & 5.0 & 5.2313 & TRN \\
\hline CHEMBL1583874 & 688161 & 5.1 & 4.9792 & TRN \\
\hline CHEMBL1446502 & 688161 & 5.3 & 4.8909 & TRN \\
\hline CHEMBL 21241 & 688161 & 4.4 & 5.0033 & TST \\
\hline CHEMBL1408384 & 688161 & 4.8 & 4.9207 & TRN \\
\hline CHEMBL1461478 & 688161 & 4.8 & 4.9756 & TRN \\
\hline CHEMBL 213432 & 688161 & 4.6 & 4.8268 & TRN \\
\hline CHEMBL1544354 & 688161 & 5.3 & 5.0561 & TST \\
\hline CHEMBL1491767 & 688161 & 4.4 & 5.1362 & TRN \\
\hline CHEMBL1390198 & 688161 & 7.5003 & 4.89 & TRN \\
\hline CHEMBL1351983 & 688161 & 5.5 & 4.9929 & TRN \\
\hline CHEMBL1312571 & 688161 & 5.5 & 5.0788 & TRN \\
\hline CHEMBL1256984 & 688161 & 5.6 & 4.8576 & TST \\
\hline CHEMBL592106 & 688161 & 4.5 & 4.905 & TRN \\
\hline CHEMBL1568684 & 688161 & 4.7 & 4.8804 & TRN \\
\hline CHEMBL1399873 & 688161 & 4.6 & 5.1021 & TRN \\
\hline CHEMBL1480102 & 688161 & 5.0 & 5.1597 & TRN \\
\hline CHEMBL1468635 & 688161 & 4.5 & 4.8171 & TRN \\
\hline CHEMBL1502967 & 688161 & 4.6 & 4.9053 & TRN \\
\hline CHEMBL1489456 & 688161 & 4.9 & 4.8721 & TRN \\
\hline CHEMBL1560507 & 688161 & 4.8 & 4.8027 & TRN \\
\hline CHEMBL1466511 & 688161 & 8.2007 & 4.9495 & TST \\
\hline CHEMBL1390573 & 688161 & 4.8 & 4.9056 & TRN \\
\hline CHEMBL1605126 & 688161 & 4.9 & 4.8395 & TRN \\
\hline CHEMBL1609908 & 688161 & 5.5 & 4.8882 & TRN \\
\hline CHEMBL3195192 & 688161 & 4.8 & 4.9353 & TST \\
\hline CHEMBL1431830 & 688161 & 5.3 & 4.8856 & TRN \\
\hline CHEMBL 273094 & 688161 & 4.6 & 4.912 & TST \\
\hline CHEMBL1463264 & 688161 & 4.5 & 4.8535 & TRN \\
\hline CHEMBL1527563 & 688161 & 5.3 & $4.9060 e$ & 0000000001 \\
\hline CHEMBL1543949 & 688161 & 4.9 & 4.9126 & TST \\
\hline CHEMBL1598108 & 688161 & 4.7 & 4.8561 & TRN \\
\hline CHEMBL1300887 & 688161 & 4.8 & 4.975 & TST \\
\hline CHEMBL1486897 & 688161 & 5.1 & 4.989 & TRN \\
\hline
\end{tabular}

TRN 


\begin{tabular}{|c|c|c|c|c|}
\hline \multicolumn{5}{|c|}{ Supplemental Table S2.txt } \\
\hline CHEMBL602807 & 688161 & 5.2 & 5.3462 & TRN \\
\hline CHEMBL1373558 & 688161 & 5.4 & 4.8564 & TRN \\
\hline CHEMBL1418094 & 688161 & 5.5 & 5.1336 & TST \\
\hline CHEMBL1526277 & 688161 & 4.4 & 4.9201 & TRN \\
\hline CHEMBL1578498 & 688161 & 5.2 & 4.9122 & TRN \\
\hline CHEMBL1388376 & 688161 & 4.6 & 5.0124 & TST \\
\hline CHEMBL1302845 & 688161 & 4.6 & 4.7919 & TRN \\
\hline CHEMBL1362547 & 688161 & 4.8 & 5.0273 & TRN \\
\hline CHEMBL1387047 & 688161 & 4.9 & 4.8209 & TRN \\
\hline CHEMBL1558418 & 688161 & 5.2 & 5.0626 & TRN \\
\hline CHEMBL1329969 & 688161 & 4.4 & 4.9557 & TRN \\
\hline CHEMBL1495091 & 688161 & 4.5 & 4.928 & TRN \\
\hline CHEMBL1430893 & 688161 & 4.8 & 4.8239 & TRN \\
\hline CHEMBL 247484 & 688161 & 5.6 & 5.245 & TRN \\
\hline CHEMBL1329881 & 688161 & 4.9 & 4.9379 & TRN \\
\hline CHEMBL484663 & 688161 & 5.4 & 4.9873 & TRN \\
\hline CHEMBL94990 & 688161 & 4.7 & 4.9871 & TRN \\
\hline CHEMBL601952 & 688161 & 5.5 & 4.9372 & TRN \\
\hline CHEMBL1299346 & 688161 & 4.8 & 4.8188 & TRN \\
\hline CHEMBL1561544 & 688161 & 4.9 & 5.0621 & TST \\
\hline CHEMBL1372421 & 688161 & 5.8 & 4.8843 & TRN \\
\hline CHEMBL1588408 & 688161 & 4.7 & 4.9538 & TST \\
\hline CHEMBL1325774 & 688161 & 5.0 & 4.8693 & TST \\
\hline CHEMBL1328466 & 688161 & 4.5 & 4.9099 & TRN \\
\hline CHEMBL1370807 & 688161 & 5.3 & 4.882 & TRN \\
\hline CHEMBL1339446 & 688161 & 4.8 & 5.11 & TRN \\
\hline CHEMBL1466712 & 688161 & 5.7 & 4.8492 & TRN \\
\hline CHEMBL393287 & 688161 & 5.6 & 4.7761 & TRN \\
\hline CHEMBL1402163 & 688161 & 4.6 & 4.8308 & TRN \\
\hline CHEMBL1329017 & 688161 & 4.9 & 4.9322 & TRN \\
\hline CHEMBL1423060 & 688161 & 4.5 & 4.7468 & TRN \\
\hline CHEMBL1357151 & 688161 & 6.0 & 4.8372 & TST \\
\hline CHEMBL1433489 & 688161 & 4.8 & 5.0152 & TRN \\
\hline CHEMBL1352480 & 688161 & 4.6 & 4.9197 & TRN \\
\hline CHEMBL1573315 & 688161 & 4.6 & 4.8931 & TRN \\
\hline CHEMBL1448885 & 688161 & 4.6 & 4.834 & TRN \\
\hline CHEMBL1586107 & 688161 & 4.6 & 4.8116 & TRN \\
\hline CHEMBL450493 & 688161 & 4.5 & 4.8959 & TRN \\
\hline CHEMBL1327203 & 688161 & 5.5 & 5.0045 & TRN \\
\hline CHEMBL1608171 & 688161 & 4.6 & 4.8418 & TRN \\
\hline CHEMBL1600399 & 688161 & 4.5 & 5.1087 & TRN \\
\hline CHEMBL 90472 & 688161 & 4.8 & 4.8813 & TST \\
\hline CHEMBL68423 & 688161 & 4.8 & 4.8248 & TST \\
\hline CHEMBL1328324 & 688161 & 4.5 & 4.9001 & TST \\
\hline CHEMBL1484278 & 688161 & 4.6 & 4.9387 & TRN \\
\hline CHEMBL1320546 & 688161 & 4.6 & 4.9159 & TRN \\
\hline CHEMBL1309430 & 688161 & 8.1024 & 4.9451 & TST \\
\hline CHEMBL1462683 & 688161 & 4.8 & 4.9315 & TRN \\
\hline
\end{tabular}




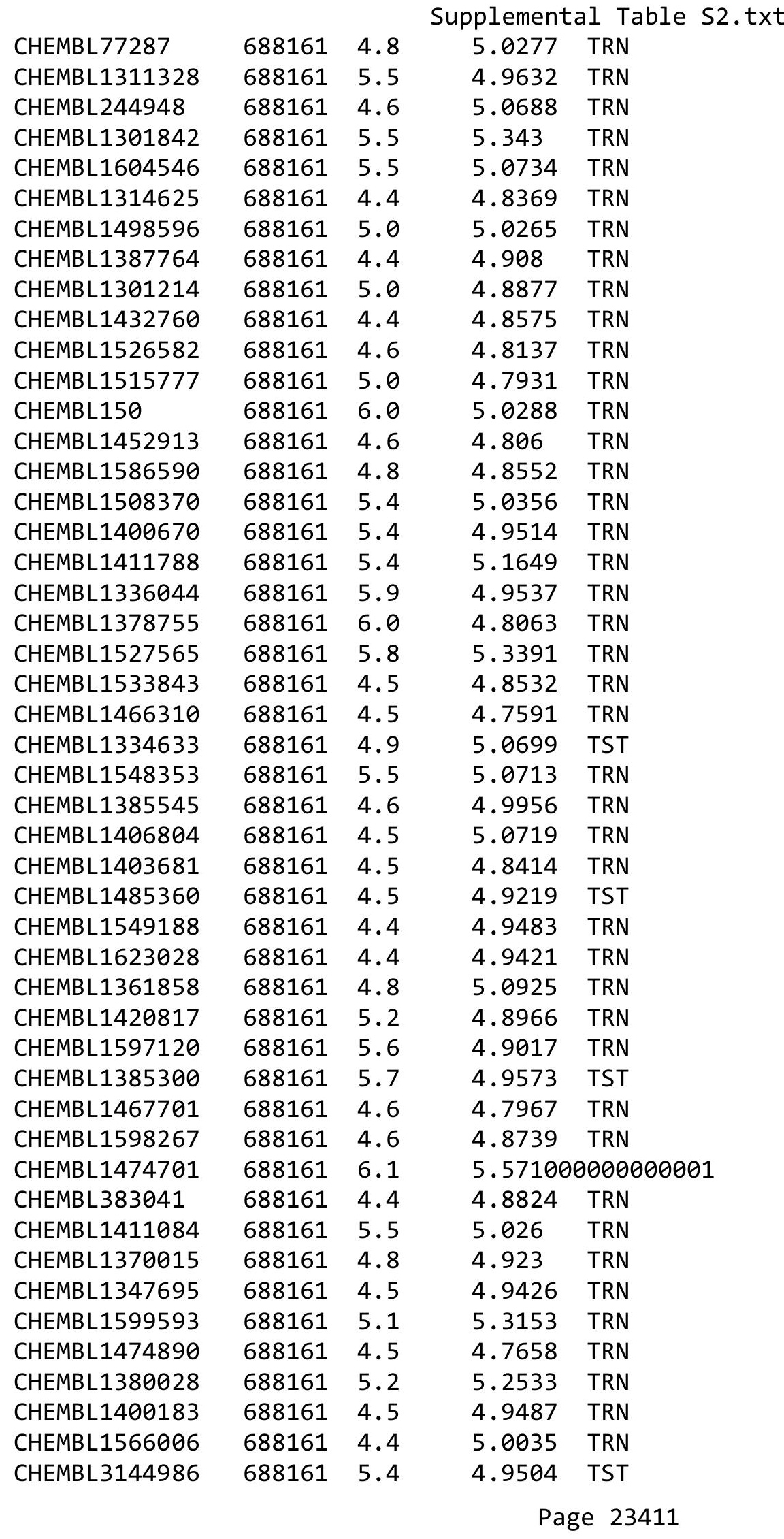




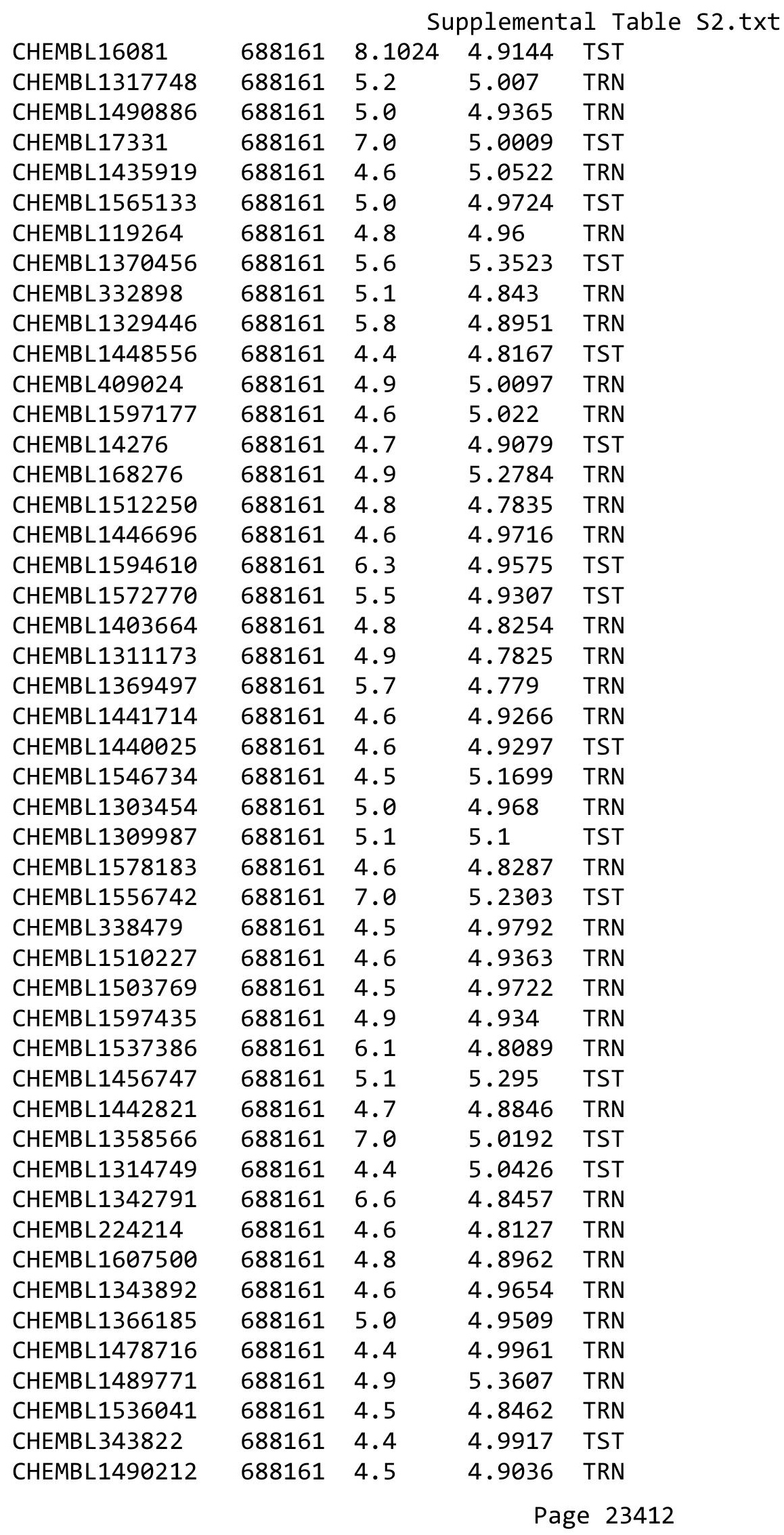




\begin{tabular}{|c|c|c|c|c|c|}
\hline & & & & & \\
\hline CHEMBL559612 & 688161 & 4.9 & 5.0371 & TST & \\
\hline CHEMBL1533766 & 688161 & 4.8 & 4.8294 & TRN & \\
\hline CHEMBL1578418 & 688161 & 4.4 & 4.9414 & TRN & \\
\hline CHEMBL1568268 & 688161 & 4.8 & 4.8447 & TRN & \\
\hline CHEMBL1350275 & 688161 & 4.5 & 4.8118 & TRN & \\
\hline CHEMBL1383004 & 688161 & 5.0 & 4.97199 & 99999999995 & TRN \\
\hline CHEMBL1373868 & 688161 & 5.0 & 4.8532 & TRN & \\
\hline CHEMBL1575967 & 688161 & 4.8 & 4.9474 & TRN & \\
\hline CHEMBL1583045 & 688161 & 4.8 & 4.8949 & TRN & \\
\hline CHEMBL1367944 & 688161 & 4.8 & 4.9028 & TRN & \\
\hline CHEMBL1429064 & 688161 & 4.6 & 4.8923 & TRN & \\
\hline CHEMBL577635 & 688161 & 4.5 & 5.1134 & TST & \\
\hline CHEMBL1321173 & 688161 & 5.2 & 4.8633 & TRN & \\
\hline CHEMBL1322656 & 688161 & 4.9 & 4.9442 & TRN & \\
\hline CHEMBL1256836 & 688161 & 4.4 & 5.0042 & TST & \\
\hline CHEMBL1482002 & 688161 & 4.7 & 4.814 & TRN & \\
\hline CHEMBL1376296 & 688161 & 4.9 & 4.7774 & TRN & \\
\hline CHEMBL1609468 & 688161 & 4.5 & 5.2196 & TST & \\
\hline CHEMBL 3211878 & 688161 & 4.7 & 4.8989 & TRN & \\
\hline CHEMBL1319625 & 688161 & 4.6 & 4.8439 & TRN & \\
\hline CHEMBL259331 & 688161 & 4.4 & 4.9385 & TST & \\
\hline CHEMBL1368562 & 688161 & 5.5 & 4.9421 & TRN & \\
\hline CHEMBL1550351 & 688161 & 4.7 & 4.916 & TRN & \\
\hline CHEMBL1407598 & 688161 & 6.0 & 4.8509 & TRN & \\
\hline CHEMBL1716991 & 688161 & 4.8 & 5.1175 & TRN & \\
\hline CHEMBL1596872 & 688161 & 5.9 & 4.9684 & TRN & \\
\hline CHEMBL1601188 & 688161 & 4.8 & 4.9242 & TRN & \\
\hline CHEMBL1421142 & 688161 & 4.5 & 4.8861 & TRN & \\
\hline CHEMBL1371792 & 688161 & 4.8 & 5.5044 & TRN & \\
\hline CHEMBL1563498 & 688161 & 5.5 & 4.8736 & TRN & \\
\hline CHEMBL1598188 & 688161 & 5.0 & 4.8915 & TRN & \\
\hline CHEMBL1465069 & 688161 & 4.5 & 4.9708 & TRN & \\
\hline CHEMBL1609807 & 688161 & 4.8 & 4.9518 & TRN & \\
\hline CHEMBL1309248 & 688161 & 5.1 & 4.8714 & TRN & \\
\hline CHEMBL1327243 & 688161 & 4.9 & 4.9722 & TST & \\
\hline CHEMBL1306907 & 688161 & 4.9 & 5.1389 & TRN & \\
\hline CHEMBL1322563 & 688161 & 5.7 & 4.9213 & TRN & \\
\hline CHEMBL1322319 & 688161 & 6.3 & 5.0196 & TST & \\
\hline CHEMBL1532745 & 688161 & 4.6 & 4.9243 & TRN & \\
\hline CHEMBL1513077 & 688161 & 5.1 & 5.0337 & TRN & \\
\hline CHEMBL1305316 & 688161 & 4.5 & 5.0169 & TRN & \\
\hline CHEMBL82949 & 688161 & 4.7 & 4.8932 & TRN & \\
\hline CHEMBL3207743 & 688161 & 4.4 & 4.9812 & TST & \\
\hline CHEMBL1372249 & 688161 & 4.7 & 4.8387 & TRN & \\
\hline CHEMBL1336787 & 688161 & 4.6 & $4.8610 e$ & $\partial 000000001$ & TRN \\
\hline CHEMBL1487137 & 688161 & 5.2 & 4.8712 & TRN & \\
\hline CHEMBL1437929 & 688161 & 4.6 & 4.7788 & TRN & \\
\hline CHEMBL1519748 & 688161 & 4.9 & 4.9705 & TRN & \\
\hline & & & & 23413 & \\
\hline
\end{tabular}




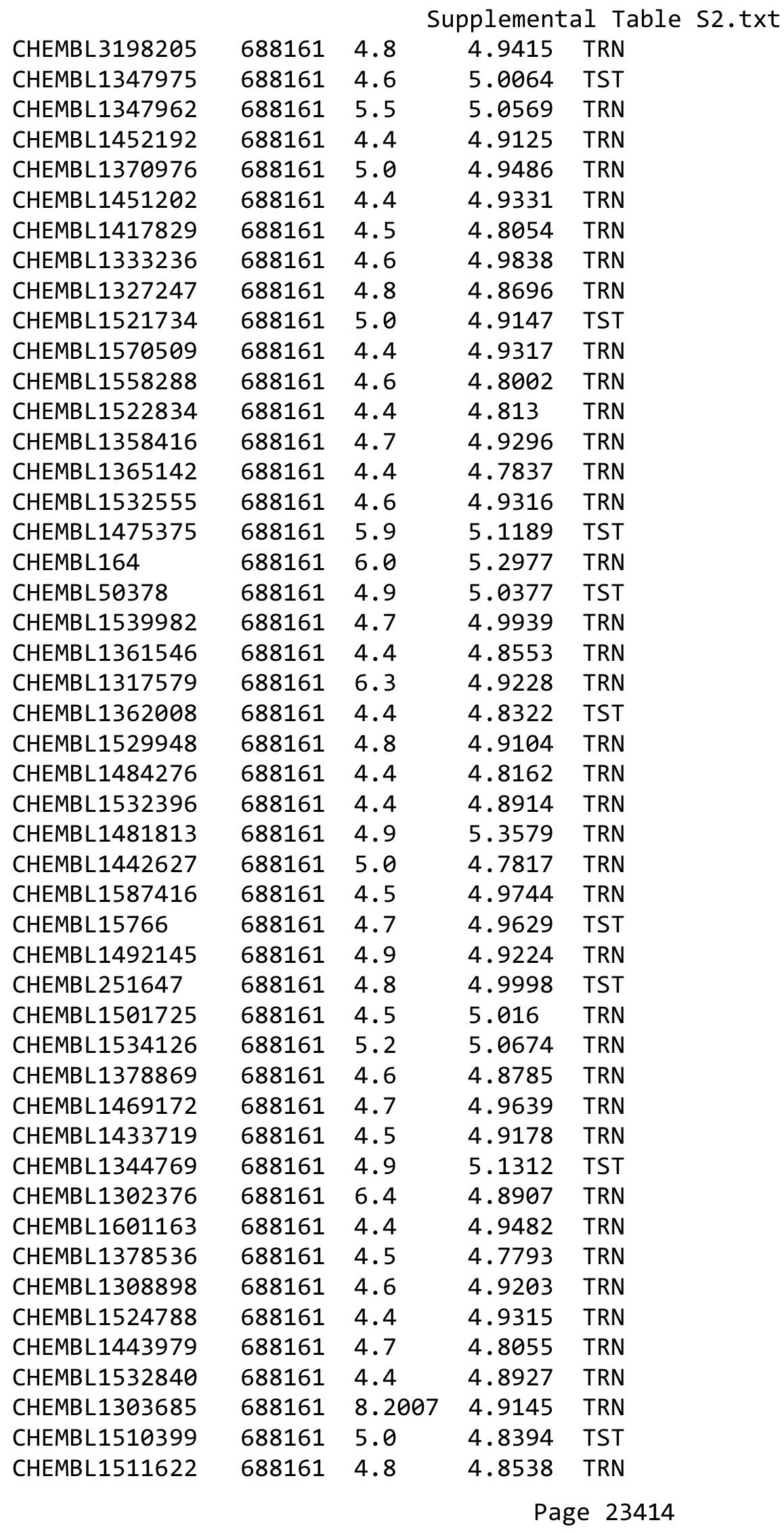




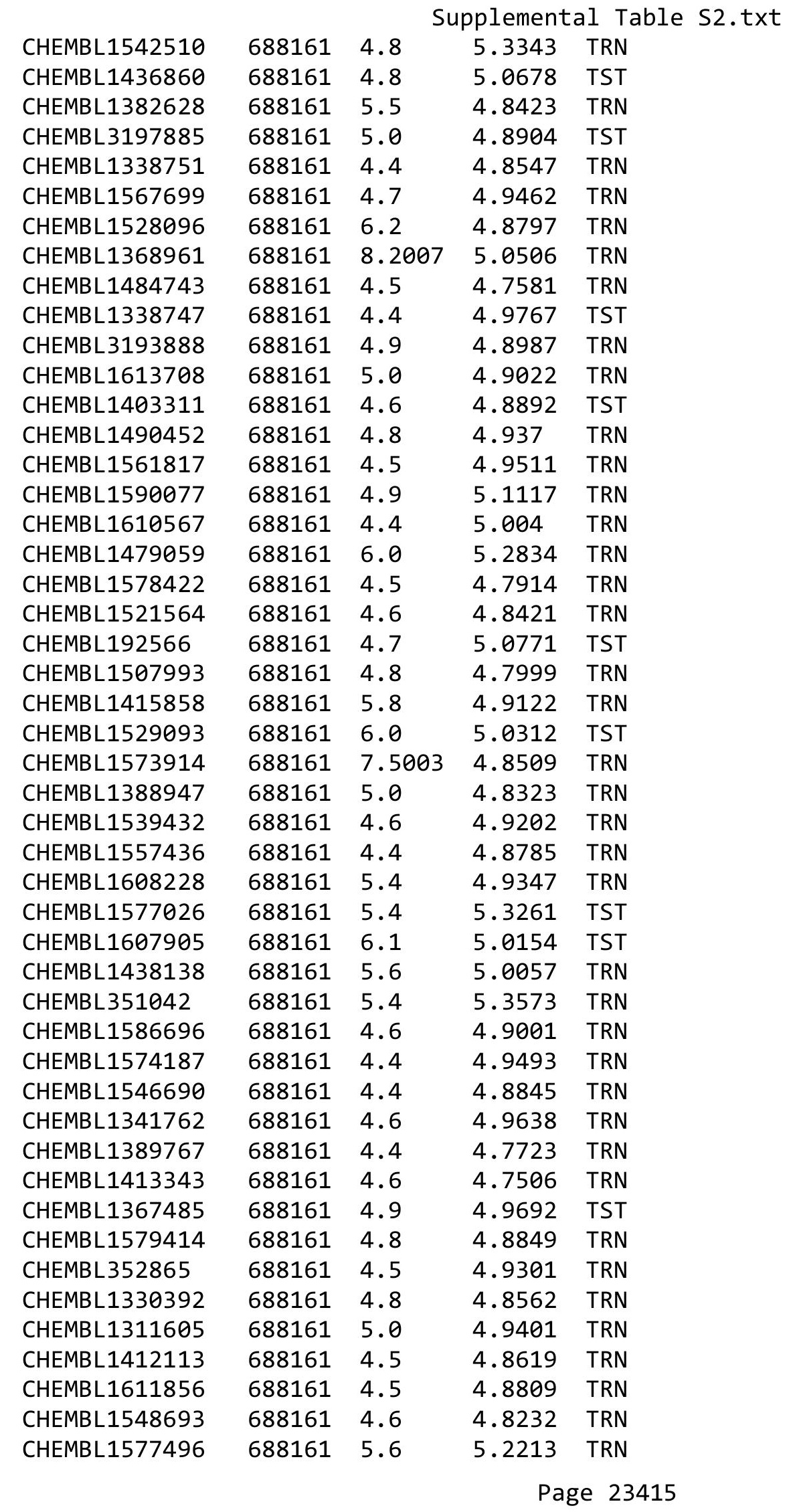




\begin{tabular}{|c|c|c|c|c|c|}
\hline & & & & & \\
\hline CHEMBL1438788 & 688161 & 4.6 & 4.8142 & TRN & \\
\hline CHEMBL1314890 & 688161 & 4.7 & 4.9911 & TRN & \\
\hline CHEMBL169233 & 688161 & 6.2 & 4.9471 & TST & \\
\hline CHEMBL1317982 & 688161 & 4.8 & 4.8008 & TRN & \\
\hline CHEMBL1519490 & 688161 & 6.3 & 5.0372 & TST & \\
\hline CHEMBL1579130 & 688161 & 4.8 & 4.9125 & TST & \\
\hline CHEMBL1468925 & 688161 & 4.8 & 4.8799 & TRN & \\
\hline CHEMBL1434325 & 688161 & 4.9 & 4.97199 & 99999999995 & TRN \\
\hline CHEMBL1487801 & 688161 & 5.8 & 5.3932 & TRN & \\
\hline CHEMBL1404918 & 688161 & 5.5 & 5.0408 & TST & \\
\hline CHEMBL1343514 & 688161 & 4.4 & 4.8988 & TRN & \\
\hline CHEMBL522600 & 688161 & 4.6 & 4.9655 & TRN & \\
\hline CHEMBL1553173 & 688161 & 4.6 & 4.9568 & TRN & \\
\hline CHEMBL1390244 & 688161 & 5.4 & 4.8468 & TRN & \\
\hline CHEMBL1534131 & 688161 & 5.1 & 5.1866 & TST & \\
\hline CHEMBL1364521 & 688161 & 4.5 & 4.8128 & TRN & \\
\hline CHEMBL1464963 & 688161 & 4.6 & 4.8819 & TRN & \\
\hline CHEMBL1346222 & 688161 & 4.9 & 4.7954 & TRN & \\
\hline CHEMBL 88402 & 688161 & 4.8 & 4.9335 & TRN & \\
\hline CHEMBL1414830 & 688161 & 5.6 & 4.9249 & TST & \\
\hline CHEMBL539947 & 688161 & 4.7 & 4.9786 & TRN & \\
\hline CHEMBL1375958 & 688161 & 4.8 & 5.019 & TRN & \\
\hline CHEMBL1529151 & 688161 & 5.3 & 4.8314 & TRN & \\
\hline CHEMBL1323883 & 688161 & 4.9 & 5.1425 & TST & \\
\hline CHEMBL1339018 & 688161 & 4.7 & 4.9427 & TRN & \\
\hline CHEMBL1353885 & 688161 & 6.1 & 4.8459 & TRN & \\
\hline CHEMBL300814 & 688161 & 4.8 & 5.1053 & TRN & \\
\hline CHEMBL1602127 & 688161 & 4.6 & 4.9406 & TST & \\
\hline CHEMBL1584284 & 688161 & 4.4 & 4.797 & TRN & \\
\hline CHEMBL1470252 & 688161 & 4.4 & 5.026 & TRN & \\
\hline CHEMBL1358297 & 688161 & 4.7 & 4.968 & TST & \\
\hline CHEMBL1471352 & 688161 & 4.9 & 5.2392 & TRN & \\
\hline CHEMBL1383257 & 688161 & 4.6 & 4.9133 & TRN & \\
\hline CHEMBL1349305 & 688161 & 5.4 & 4.8678 & TRN & \\
\hline CHEMBL1506683 & 688161 & 4.9 & 4.9535 & TRN & \\
\hline CHEMBL1471021 & 688161 & 4.5 & 4.9383 & TRN & \\
\hline CHEMBL333536 & 688161 & 4.4 & 4.9023 & TST & \\
\hline CHEMBL541585 & 688161 & 4.8 & 5.4143 & TST & \\
\hline CHEMBL1606181 & 688161 & 4.9 & 4.8914 & TRN & \\
\hline CHEMBL1562104 & 688161 & 4.8 & 5.2816 & TST & \\
\hline CHEMBL1557648 & 688161 & 4.9 & 4.8688 & TRN & \\
\hline CHEMBL1347133 & 688161 & 4.6 & 4.9147 & TRN & \\
\hline CHEMBL1313935 & 688161 & 4.4 & 4.9383 & TRN & \\
\hline CHEMBL1406745 & 688161 & 5.8 & 4.8212 & TRN & \\
\hline CHEMBL1541834 & 688161 & 5.5 & 4.9474 & TRN & \\
\hline CHEMBL1340725 & 688161 & 4.5 & 4.766 & TRN & \\
\hline CHEMBL1410746 & 688161 & 4.9 & 4.9826 & TRN & \\
\hline CHEMBL1321988 & 688161 & 4.6 & 4.9247 & TST & \\
\hline & & & & 23416 & \\
\hline
\end{tabular}




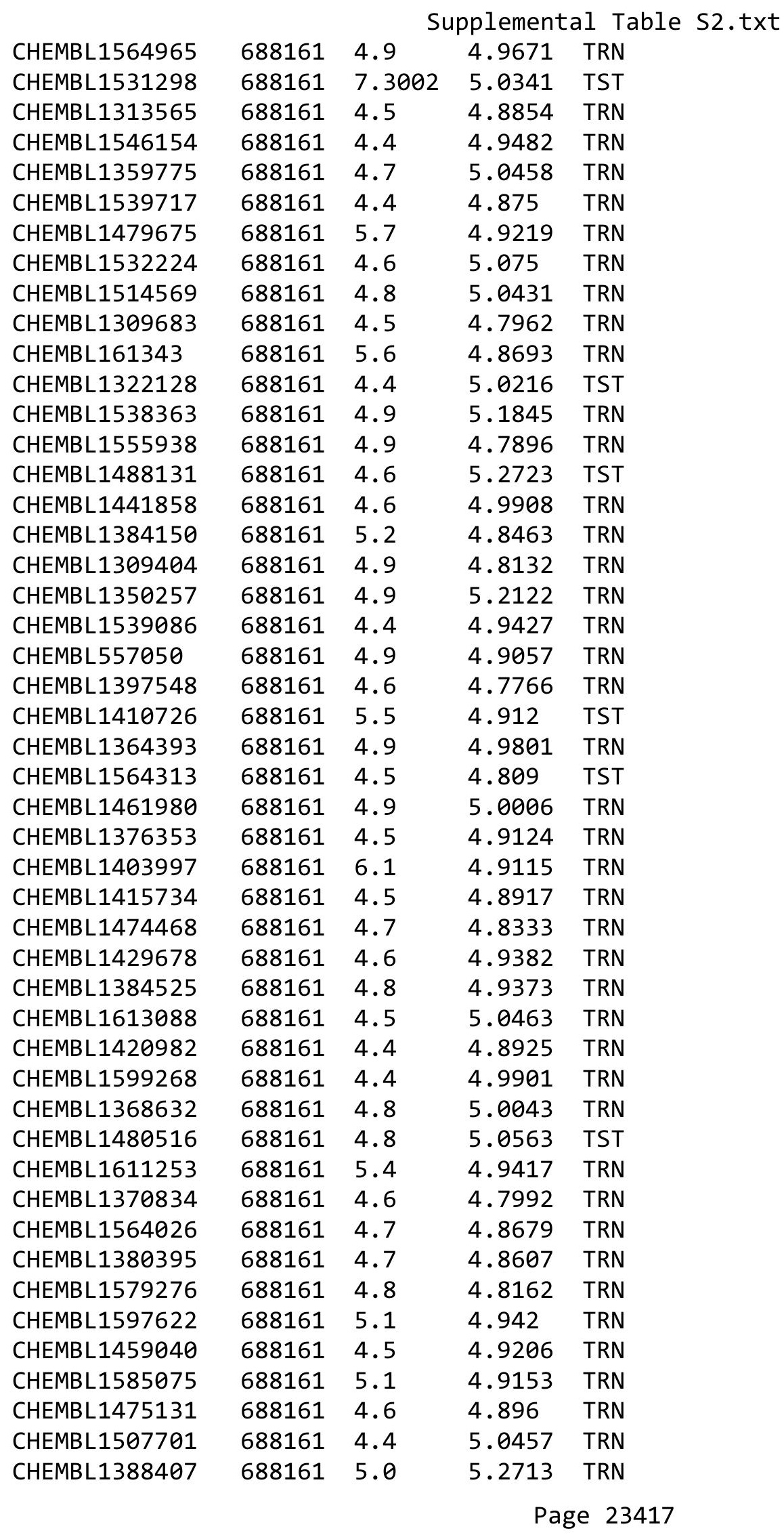




\begin{tabular}{|c|c|c|c|c|c|}
\hline & & \multicolumn{4}{|c|}{ Supplemental Table S2.txt } \\
\hline CHEMBL1599992 & 688161 & 5.2 & 4.8751 & TRN & \\
\hline CHEMBL1436063 & 688161 & 5.8 & 4.9164 & TST & \\
\hline CHEMBL1357018 & 688161 & 4.6 & 4.8116 & TRN & \\
\hline CHEMBL1588599 & 688161 & 4.5 & 4.9286 & TRN & \\
\hline CHEMBL1382462 & 688161 & 4.5 & 4.9358 & TRN & \\
\hline CHEMBL1427752 & 688161 & 5.6 & 5.4323 & TRN & \\
\hline CHEMBL1416009 & 688161 & 5.7 & 5.2883 & TST & \\
\hline CHEMBL1412373 & 688161 & 5.4 & 4.9408 & TRN & \\
\hline CHEMBL3196509 & 688161 & 4.9 & 4.8929 & TRN & \\
\hline CHEMBL1547450 & 688161 & 4.7 & 4.92899 & 9999999999 & TRN \\
\hline CHEMBL1417558 & 688161 & 5.0 & 4.7683 & TRN & \\
\hline CHEMBL1478276 & 688161 & 4.8 & 4.9235 & TRN & \\
\hline CHEMBL1509003 & 688161 & 4.8 & 4.8548 & TRN & \\
\hline CHEMBL1413758 & 688161 & 4.8 & 4.8976 & TRN & \\
\hline CHEMBL1352425 & 688161 & 4.4 & 4.9257 & TRN & \\
\hline CHEMBL1417892 & 688161 & 4.6 & 4.9228 & TRN & \\
\hline CHEMBL1578948 & 688161 & 4.6 & 4.7809 & TRN & \\
\hline CHEMBL1584420 & 688161 & 4.5 & 5.0002 & TRN & \\
\hline CHEMBL1453322 & 688161 & 4.5 & 5.0262 & TST & \\
\hline CHEMBL1524927 & 688161 & 4.9 & 5.073 & TST & \\
\hline CHEMBL3207664 & 688161 & 4.4 & 4.8406 & TST & \\
\hline CHEMBL1495004 & 688161 & 4.5 & 4.7754 & TRN & \\
\hline CHEMBL1426154 & 688161 & 4.4 & 4.9203 & TST & \\
\hline CHEMBL1490178 & 688161 & 5.4 & 4.967 & TRN & \\
\hline CHEMBL1471520 & 688161 & 4.6 & 4.96 & TRN & \\
\hline CHEMBL1602170 & 688161 & 4.6 & 4.8031 & TRN & \\
\hline CHEMBL1471436 & 688161 & 4.6 & 4.8491 & TRN & \\
\hline CHEMBL1386609 & 688161 & 5.0 & 4.8739 & TRN & \\
\hline CHEMBL1398335 & 688161 & 5.5 & 5.0558 & TST & \\
\hline CHEMBL1390160 & 688161 & 4.6 & 4.8529 & TRN & \\
\hline CHEMBL1379571 & 688161 & 5.3 & 4.7758 & TRN & \\
\hline CHEMBL1373113 & 688161 & 4.4 & 4.8601 & TRN & \\
\hline CHEMBL1511524 & 688161 & 7.6003 & 4.9208 & TRN & \\
\hline CHEMBL1419096 & 688161 & 5.5 & 4.8818 & TRN & \\
\hline CHEMBL1489349 & 688161 & 4.7 & 4.8551 & TRN & \\
\hline CHEMBL1571018 & 688161 & 4.6 & 4.7777 & TRN & \\
\hline CHEMBL1492194 & 688161 & 4.7 & 4.9091 & TRN & \\
\hline CHEMBL331385 & 688161 & 4.8 & 4.9493 & TRN & \\
\hline CHEMBL1611496 & 688161 & 4.4 & 4.8328 & TRN & \\
\hline CHEMBL1378170 & 688161 & 5.5 & 4.912 & TRN & \\
\hline CHEMBL1572533 & 688161 & 4.8 & 4.8977 & TRN & \\
\hline CHEMBL1348813 & 688161 & 5.6 & 5.0551 & TRN & \\
\hline CHEMBL1417770 & 688161 & 4.8 & 5.0432 & TRN & \\
\hline CHEMBL1329699 & 688161 & 5.1 & 4.8784 & TRN & \\
\hline CHEMBL1345570 & 688161 & 4.5 & 4.8913 & TRN & \\
\hline CHEMBL89445 & 688161 & 5.1 & 4.8765 & TRN & \\
\hline CHEMBL1354529 & 688161 & 4.6 & 4.973 & TRN & \\
\hline CHEMBL1507183 & 688161 & 5.8 & 5.3712 & TRN & \\
\hline
\end{tabular}




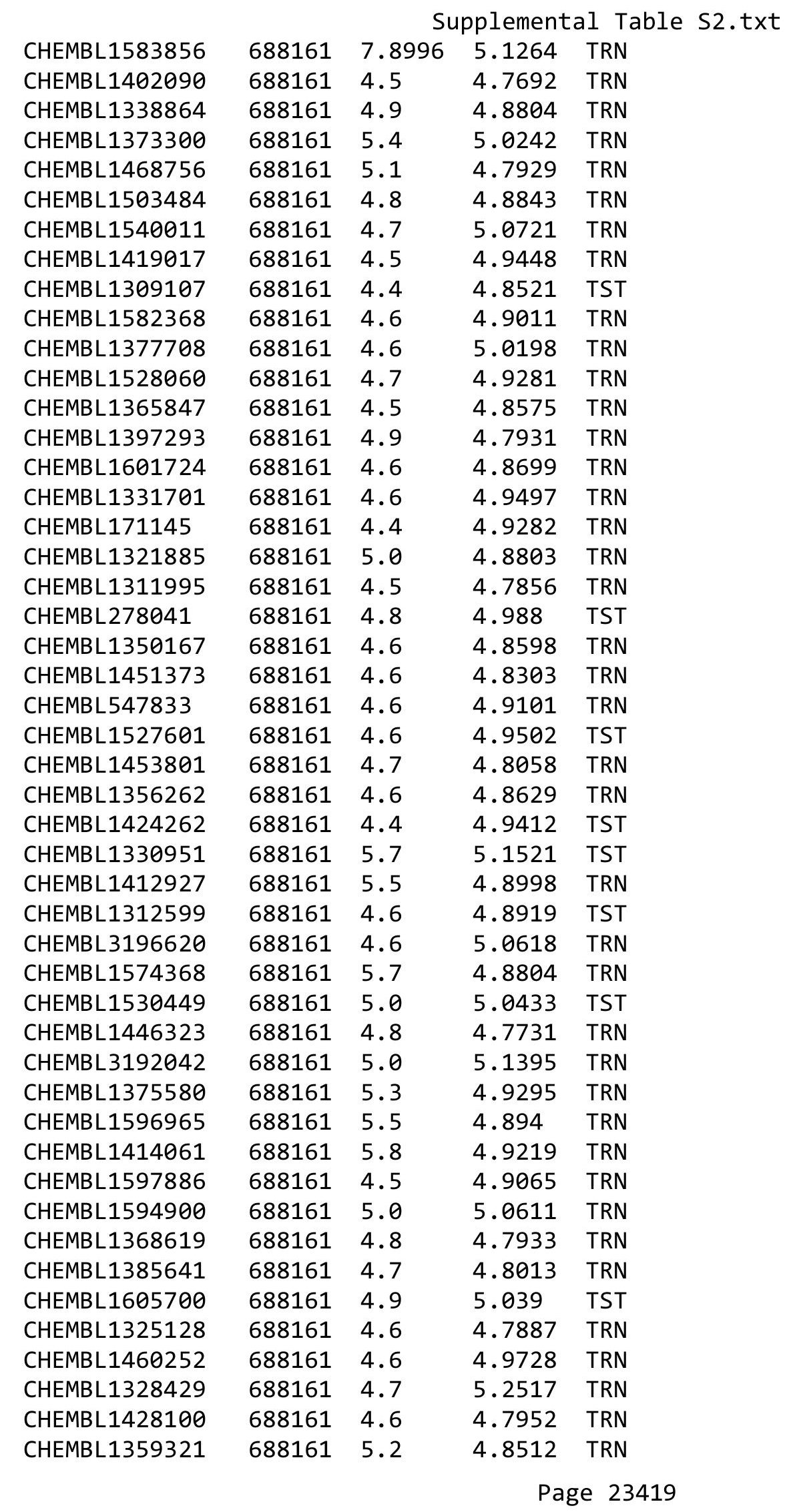




\begin{tabular}{|c|c|c|c|c|}
\hline \multicolumn{5}{|c|}{ Supplemental Table S2.txt } \\
\hline CHEMBL1561663 & 688161 & 4.6 & 4.8526 & TRN \\
\hline CHEMBL1337197 & 688161 & 4.6 & 4.8949 & TRN \\
\hline CHEMBL1590397 & 688161 & 4.6 & 4.8842 & TRN \\
\hline CHEMBL1509933 & 688161 & 4.8 & 4.8734 & TRN \\
\hline CHEMBL1506932 & 688161 & 4.8 & 4.9302 & TRN \\
\hline CHEMBL1597569 & 688161 & 4.5 & 4.9064 & TRN \\
\hline CHEMBL78573 & 688161 & 5.2 & $5.2870 €$ & 0000000001 \\
\hline CHEMBL1512440 & 688161 & 5.6 & 5.1722 & TST \\
\hline CHEMBL1449334 & 688161 & 5.7 & 5.2806 & TRN \\
\hline CHEMBL1371427 & 688161 & 4.4 & 4.9222 & TRN \\
\hline CHEMBL1430160 & 688161 & 4.6 & 4.8278 & TRN \\
\hline CHEMBL1568090 & 688161 & 5.6 & 4.8248 & TRN \\
\hline CHEMBL1424952 & 688161 & 5.5 & 4.7676 & TRN \\
\hline CHEMBL1439504 & 688161 & 4.5 & 4.7759 & TRN \\
\hline CHEMBL1412354 & 688161 & 4.7 & 5.1419 & TST \\
\hline CHEMBL530049 & 688161 & 5.6 & 5.0866 & TRN \\
\hline CHEMBL1447719 & 688161 & 5.3 & 4.9517 & TRN \\
\hline CHEMBL1561474 & 688161 & 7.8013 & 5.0265 & TST \\
\hline CHEMBL1546299 & 688161 & 4.9 & 4.8915 & TRN \\
\hline CHEMBL 279731 & 688161 & 4.7 & 5.0713 & TST \\
\hline CHEMBL1342861 & 688161 & 4.4 & 4.9356 & TRN \\
\hline CHEMBL1373611 & 688161 & 5.5 & 4.9142 & TST \\
\hline CHEMBL 222409 & 688161 & 4.9 & 4.9814 & TRN \\
\hline CHEMBL1555438 & 688161 & 4.7 & 5.0129 & TRN \\
\hline CHEMBL1476262 & 688161 & 4.5 & 5.0361 & TST \\
\hline CHEMBL1558000 & 688161 & 4.8 & 4.8817 & TRN \\
\hline CHEMBL1545559 & 688161 & 4.9 & 5.1291 & TRN \\
\hline CHEMBL1310614 & 688161 & 4.6 & 4.8359 & TRN \\
\hline CHEMBL1336421 & 688161 & 4.8 & 4.8649 & TRN \\
\hline CHEMBL1471358 & 688161 & 4.7 & 4.8373 & TRN \\
\hline CHEMBL1484160 & 688161 & 4.7 & 5.1361 & TRN \\
\hline CHEMBL1529652 & 688161 & 4.8 & 4.8079 & TRN \\
\hline CHEMBL1585192 & 688161 & 4.5 & 4.9085 & TST \\
\hline CHEMBL1970272 & 688161 & 5.0 & 4.935 & TRN \\
\hline CHEMBL1501434 & 688161 & 4.7 & 4.9283 & TRN \\
\hline CHEMBL1411897 & 688161 & 5.8 & 5.3464 & TST \\
\hline CHEMBL1312848 & 688161 & 4.7 & 5.06 & TRN \\
\hline CHEMBL1390346 & 688161 & 4.9 & 4.814 & TRN \\
\hline CHEMBL1255832 & 688161 & 5.0 & 4.99 & TRN \\
\hline CHEMBL1581387 & 688161 & 4.6 & 4.8772 & TRN \\
\hline CHEMBL1411761 & 688161 & 4.8 & 4.8272 & TRN \\
\hline CHEMBL 3198987 & 688161 & 4.6 & 4.9336 & TRN \\
\hline CHEMBL294264 & 688161 & 6.0 & 5.1073 & TRN \\
\hline CHEMBL1477191 & 688161 & 5.4 & 4.8822 & TRN \\
\hline CHEMBL1459673 & 688161 & 4.7 & 4.9687 & TRN \\
\hline CHEMBL1307165 & 688161 & 4.5 & 4.942 & TRN \\
\hline CHEMBL1338657 & 688161 & 4.7 & 4.9772 & TRN \\
\hline CHEMBL1545476 & 688161 & 5.1 & 4.9056 & TRN \\
\hline
\end{tabular}




\begin{tabular}{|c|c|c|c|c|}
\hline \multicolumn{5}{|c|}{ Supplemental Table S2.txt } \\
\hline CHEMBL1076555 & 688161 & 5.0 & 4.989 & TRN \\
\hline CHEMBL1521090 & 688161 & 6.7001 & 4.8577 & TRN \\
\hline CHEMBL1331977 & 688161 & 5.5 & 4.8228 & TRN \\
\hline CHEMBL1409564 & 688161 & 4.4 & 4.824 & TRN \\
\hline CHEMBL1426641 & 688161 & 4.7 & 4.862 & TRN \\
\hline CHEMBL1533940 & 688161 & 5.4 & 5.2432 & TRN \\
\hline CHEMBL1397552 & 688161 & 4.7 & 4.9241 & TST \\
\hline CHEMBL1401860 & 688161 & 4.5 & 4.9738 & TRN \\
\hline CHEMBL1468844 & 688161 & 4.4 & 4.9194 & TST \\
\hline CHEMBL1517965 & 688161 & 5.8 & 4.9683 & TST \\
\hline CHEMBL1521232 & 688161 & 4.5 & 4.9064 & TRN \\
\hline CHEMBL1541707 & 688161 & 4.8 & 4.8692 & TRN \\
\hline CHEMBL1488115 & 688161 & 4.5 & 4.8249 & TRN \\
\hline CHEMBL1370480 & 688161 & 4.6 & 5.0991 & TRN \\
\hline CHEMBL605003 & 688161 & 5.1 & 5.0201 & TRN \\
\hline CHEMBL1381323 & 688161 & 5.2 & 5.346 & TRN \\
\hline CHEMBL405358 & 688161 & 4.9 & 4.9569 & TST \\
\hline CHEMBL1488104 & 688161 & 5.2 & 4.8355 & TRN \\
\hline CHEMBL47814 & 688161 & 4.8 & 4.8102 & TRN \\
\hline CHEMBL1396236 & 688161 & 5.4 & 5.1074 & TST \\
\hline CHEMBL3190165 & 688161 & 4.7 & 5.0637 & TST \\
\hline CHEMBL1512763 & 688161 & 5.2 & 4.91 & TST \\
\hline CHEMBL1459258 & 688161 & 5.1 & 5.2876 & TRN \\
\hline CHEMBL554041 & 688161 & 4.4 & 4.9717 & TST \\
\hline CHEMBL1299799 & 688161 & 4.7 & 4.8798 & TRN \\
\hline CHEMBL1552720 & 688161 & 4.7 & 4.8389 & TRN \\
\hline CHEMBL1540836 & 688161 & 4.7 & 5.0648 & TRN \\
\hline CHEMBL3192945 & 688161 & 5.1 & 5.1151 & TRN \\
\hline CHEMBL1354961 & 688161 & 6.2 & 5.1139 & TST \\
\hline CHEMBL1411054 & 688161 & 4.6 & 4.9494 & TRN \\
\hline CHEMBL1456676 & 688161 & 4.8 & 5.2926 & TST \\
\hline CHEMBL1431174 & 688161 & 5.5 & 5.4485 & TRN \\
\hline CHEMBL1501726 & 688161 & 4.9 & 4.9244 & TRN \\
\hline CHEMBL1490159 & 688161 & 4.6 & 4.8831 & TRN \\
\hline CHEMBL1424069 & 688161 & 4.8 & 4.902 & TRN \\
\hline CHEMBL1320440 & 688161 & 7.699 & 4.9401 & TRN \\
\hline CHEMBL1588006 & 688161 & 4.4 & 4.91 & TRN \\
\hline CHEMBL1191361 & 688161 & 4.9 & 4.9208 & TST \\
\hline CHEMBL1599054 & 688161 & 4.8 & 4.9291 & TRN \\
\hline CHEMBL1351658 & 688161 & 4.8 & 4.9711 & TST \\
\hline CHEMBL1512328 & 688161 & 5.4 & 5.015 & TST \\
\hline CHEMBL1567191 & 688161 & 5.2 & 5.1113 & TST \\
\hline CHEMBL1409330 & 688161 & 4.5 & 4.8448 & TRN \\
\hline CHEMBL1490654 & 688161 & 4.7 & 4.9179 & TST \\
\hline CHEMBL1304456 & 688161 & 4.6 & 4.849 & TST \\
\hline CHEMBL516616 & 688161 & 5.6 & 5.2248 & TRN \\
\hline CHEMBL1485262 & 688161 & 5.5 & 4.8492 & TRN \\
\hline CHEMBL1307319 & 688161 & 4.5 & 5.1351 & TRN \\
\hline
\end{tabular}




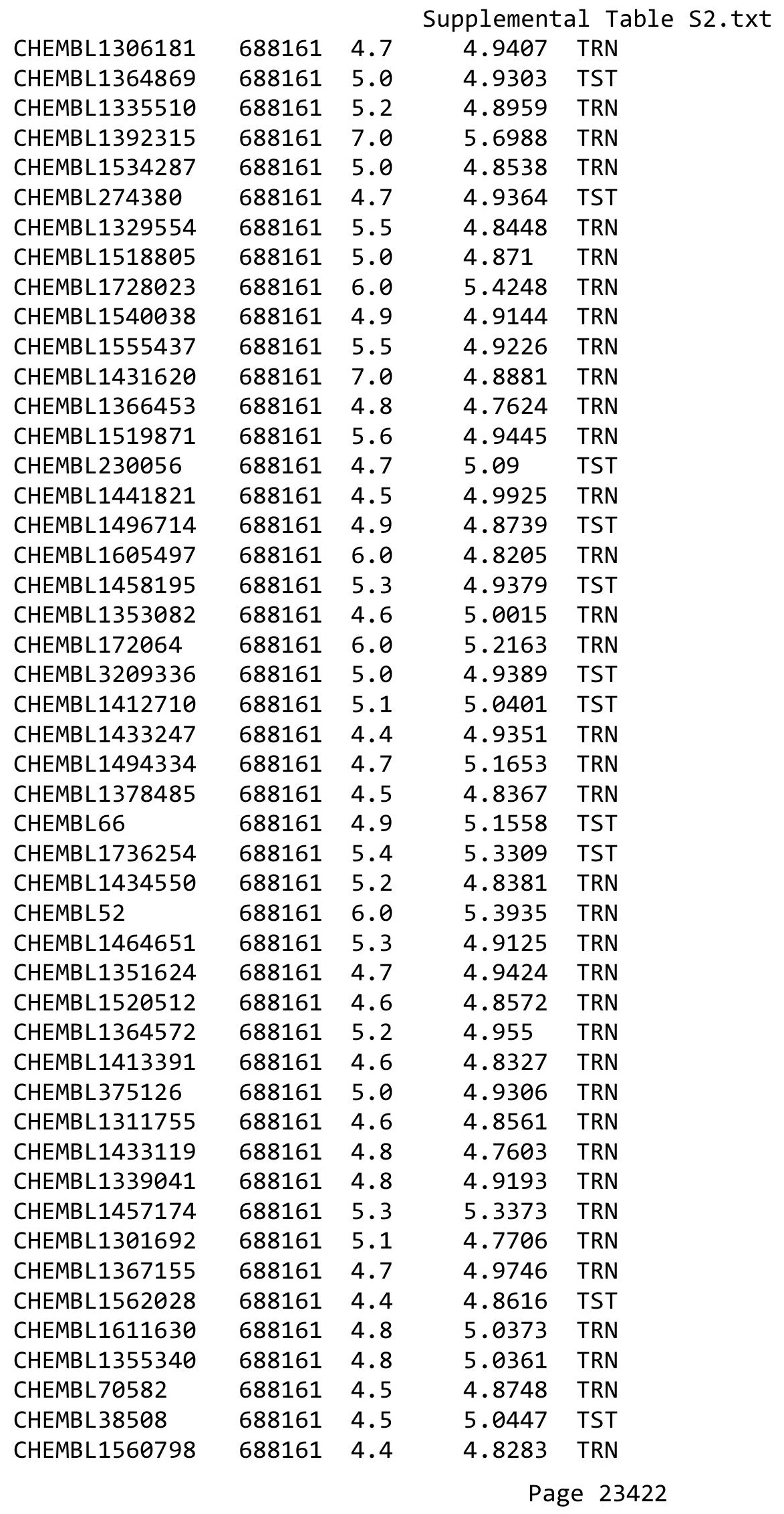




\begin{tabular}{|c|c|c|c|c|}
\hline \multicolumn{5}{|c|}{ Supplemental Table S2.txt } \\
\hline CHEMBL1401560 & 688161 & 5.2 & 4.9025 & TRN \\
\hline CHEMBL1415573 & 688161 & 4.4 & 4.9106 & TST \\
\hline CHEMBL1377449 & 688161 & 4.5 & 5.1231 & TRN \\
\hline CHEMBL1512075 & 688161 & 4.5 & 5.0281 & TST \\
\hline CHEMBL1327552 & 688161 & 4.7 & 4.8867 & TRN \\
\hline CHEMBL1352427 & 688161 & 4.5 & 4.8344 & TRN \\
\hline CHEMBL1413699 & 688161 & 7.699 & 4.8812 & TRN \\
\hline CHEMBL1489081 & 688161 & 5.8 & 4.8649 & TRN \\
\hline CHEMBL1448849 & 688161 & 4.8 & 4.9376 & TRN \\
\hline CHEMBL1336287 & 688161 & 4.9 & 5.0337 & TRN \\
\hline CHEMBL1391427 & 688161 & 4.6 & 5.0203 & TRN \\
\hline CHEMBL264666 & 688161 & 5.2 & 4.8871 & TST \\
\hline CHEMBL1569668 & 688161 & 4.4 & 4.8127 & TRN \\
\hline CHEMBL1418459 & 688161 & 4.6 & 4.8934 & TRN \\
\hline CHEMBL1391181 & 688161 & 4.4 & 5.0475 & TRN \\
\hline CHEMBL1435319 & 688161 & 4.7 & 5.075 & TST \\
\hline CHEMBL1407940 & 688161 & 4.6 & 4.8522 & TST \\
\hline CHEMBL1611224 & 688161 & 4.5 & 4.9335 & TRN \\
\hline CHEMBL500812 & 688161 & 5.1 & 5.0189 & TRN \\
\hline CHEMBL1509328 & 688161 & 4.6 & 4.8685 & TRN \\
\hline CHEMBL1459532 & 688161 & 4.6 & 4.8409 & TRN \\
\hline CHEMBL1360345 & 688161 & 5.4 & 5.4861 & TRN \\
\hline CHEMBL1582129 & 688161 & 4.9 & 4.8427 & TRN \\
\hline CHEMBL1470619 & 688161 & 4.5 & 4.9764 & TRN \\
\hline CHEMBL1396377 & 688161 & 4.4 & 4.7741 & TRN \\
\hline CHEMBL1214274 & 688161 & 6.5 & 5.1677 & TRN \\
\hline CHEMBL1574985 & 688161 & 4.5 & 4.8534 & TRN \\
\hline CHEMBL1510394 & 688161 & 7.0 & 5.5677 & TRN \\
\hline CHEMBL1326646 & 688161 & 4.9 & 5.1342 & TRN \\
\hline CHEMBL1512539 & 688161 & 4.9 & 4.9134 & TRN \\
\hline CHEMBL222519 & 688161 & 6.0 & 5.3096 & TRN \\
\hline CHEMBL1558651 & 688161 & 4.4 & 4.8814 & TRN \\
\hline CHEMBL1511442 & 688161 & 4.9 & 4.9779 & TRN \\
\hline CHEMBL1447573 & 688161 & 4.4 & 4.9217 & TRN \\
\hline CHEMBL1323167 & 688161 & 7.8013 & 5.0224 & TRN \\
\hline CHEMBL 285480 & 688161 & 4.4 & 5.1408 & TRN \\
\hline CHEMBL490718 & 688161 & 4.6 & 4.8497 & TRN \\
\hline CHEMBL1561130 & 688161 & 4.5 & 4.8692 & TRN \\
\hline CHEMBL1520292 & 688161 & 4.7 & 4.9147 & TRN \\
\hline CHEMBL1407137 & 688161 & 4.7 & 4.8554 & TRN \\
\hline CHEMBL1572599 & 688161 & 4.5 & 4.9193 & TRN \\
\hline CHEMBL1588513 & 688161 & 4.4 & 5.005 & TRN \\
\hline CHEMBL1466229 & 688161 & 4.6 & 4.8922 & TST \\
\hline CHEMBL1443574 & 688161 & 4.8 & 4.8127 & TRN \\
\hline CHEMBL1346468 & 688161 & 4.4 & 4.9542 & TRN \\
\hline CHEMBL1608410 & 688161 & 5.2 & 4.9696 & TST \\
\hline CHEMBL1595973 & 688161 & 4.7 & 4.7826 & TRN \\
\hline CHEMBL1423690 & 688161 & 6.3 & 5.5187 & TRN \\
\hline
\end{tabular}




\begin{tabular}{|c|c|c|c|c|c|}
\hline \multicolumn{6}{|c|}{ Supplemental Table S2.txt } \\
\hline CHEMBL1530492 & 688161 & 5.0 & 4.8574 & TRN & \\
\hline CHEMBL1351038 & 688161 & 5.0 & 4.8473 & TRN & \\
\hline CHEMBL1340515 & 688161 & 5.3 & 4.84399 & 9999999999 & TST \\
\hline CHEMBL83154 & 688161 & 4.5 & 4.8708 & TRN & \\
\hline CHEMBL3208365 & 688161 & 5.4 & 4.9109 & TRN & \\
\hline CHEMBL1523375 & 688161 & 4.6 & 4.9135 & TRN & \\
\hline CHEMBL1325511 & 688161 & 6.4 & 5.1558 & TRN & \\
\hline CHEMBL577455 & 688161 & 5.0 & 5.0345 & TST & \\
\hline CHEMBL1466260 & 688161 & 5.0 & 4.8741 & TRN & \\
\hline CHEMBL3194422 & 688161 & 4.9 & 4.8974 & TRN & \\
\hline CHEMBL1406186 & 688161 & 4.8 & 4.9403 & TRN & \\
\hline CHEMBL1315288 & 688161 & 4.6 & 4.9735 & TST & \\
\hline CHEMBL1439893 & 688161 & 5.0 & 5.0717 & TRN & \\
\hline CHEMBL1345910 & 688161 & 4.5 & 4.9543 & TRN & \\
\hline CHEMBL1402138 & 688161 & 6.3 & 4.7789 & TRN & \\
\hline CHEMBL1378329 & 688161 & 4.9 & 4.9092 & TRN & \\
\hline CHEMBL3195623 & 688161 & 4.8 & 4.8595 & TRN & \\
\hline CHEMBL1399727 & 688161 & 4.7 & 4.9037 & TRN & \\
\hline CHEMBL3194875 & 688161 & 4.5 & 4.8863 & TST & \\
\hline CHEMBL1555665 & 688161 & 4.9 & 4.9864 & TRN & \\
\hline CHEMBL1406119 & 688161 & 4.8 & 4.8752 & TRN & \\
\hline CHEMBL1609381 & 688161 & 5.5 & 4.8704 & TST & \\
\hline CHEMBL1357247 & 688161 & 4.7 & 5.0011 & TST & \\
\hline CHEMBL1594707 & 688161 & 4.6 & 5.1771 & TRN & \\
\hline CHEMBL1586326 & 688161 & 4.9 & 4.8792 & TRN & \\
\hline CHEMBL1526784 & 688161 & 7.8996 & 4.8939 & TRN & \\
\hline CHEMBL1550430 & 688161 & 4.8 & 4.9324 & TRN & \\
\hline CHEMBL1413795 & 688161 & 5.0 & 4.9649 & TST & \\
\hline CHEMBL1326569 & 688161 & 4.8 & 5.1072 & TRN & \\
\hline CHEMBL1451939 & 688161 & 5.2 & 4.8485 & TRN & \\
\hline CHEMBL1548008 & 688161 & 4.5 & 4.8084 & TRN & \\
\hline CHEMBL1538676 & 688161 & 4.7 & 4.7795 & TRN & \\
\hline CHEMBL 253570 & 688161 & 5.4 & 5.33299 & 9999999999 & TRN \\
\hline CHEMBL1350197 & 688161 & 5.1 & 4.9021 & TRN & \\
\hline CHEMBL1508385 & 688161 & 4.6 & 4.7956 & TRN & \\
\hline CHEMBL1548414 & 688161 & 4.9 & 4.9956 & TST & \\
\hline CHEMBL1499656 & 688161 & 5.1 & 4.9432 & TRN & \\
\hline CHEMBL1375274 & 688161 & 5.5 & 4.9412 & TRN & \\
\hline CHEMBL1583283 & 688161 & 4.6 & 4.9096 & TRN & \\
\hline CHEMBL1526578 & 688161 & 5.5 & 5.1832 & TST & \\
\hline CHEMBL1604645 & 688161 & 5.7 & 4.9031 & TRN & \\
\hline CHEMBL1441762 & 688161 & 4.6 & 4.9449 & TST & \\
\hline CHEMBL1336807 & 688161 & 5.2 & 4.9619 & TRN & \\
\hline CHEMBL1404006 & 688161 & 8.1024 & 4.9395 & TRN & \\
\hline CHEMBL1483325 & 688161 & 4.5 & 4.8946 & TRN & \\
\hline CHEMBL1384684 & 688161 & 4.6 & 4.8698 & TRN & \\
\hline CHEMBL1430319 & 688161 & 4.5 & 5.0461 & TRN & \\
\hline CHEMBL1093246 & 688161 & 4.9 & 5.2336 & TRN & \\
\hline
\end{tabular}




\begin{tabular}{|c|c|c|c|c|c|}
\hline \multicolumn{6}{|c|}{ Supplemental Table s2.txt } \\
\hline CHEMBL411481 & 688161 & 4.6 & 4.9368 & TRN & \\
\hline CHEMBL1312986 & 688161 & 5.7 & 4.9453 & TRN & \\
\hline CHEMBL1432915 & 688161 & 5.0 & 4.915 & TRN & \\
\hline CHEMBL1454803 & 688161 & 5.1 & 5.1563 & TRN & \\
\hline CHEMBL63426 & 688161 & 5.1 & 4.9171 & TST & \\
\hline CHEMBL1304349 & 688161 & 6.5 & 4.926 & TRN & \\
\hline CHEMBL1510117 & 688161 & 4.5 & 4.8731 & TRN & \\
\hline CHEMBL1593288 & 688161 & 4.5 & 4.9451 & TRN & \\
\hline CHEMBL1400768 & 688161 & 4.8 & 4.9114 & TRN & \\
\hline CHEMBL1500716 & 688161 & 4.8 & 4.8867 & TRN & \\
\hline CHEMBL1529114 & 688161 & 4.5 & 4.7482 & TRN & \\
\hline CHEMBL407734 & 688161 & 4.9 & 4.8827 & TRN & \\
\hline CHEMBL1493415 & 688161 & 4.6 & 4.9204 & TRN & \\
\hline CHEMBL1550241 & 688161 & 4.9 & 4.9814 & TRN & \\
\hline CHEMBL1345083 & 688161 & 5.4 & 4.9095 & TRN & \\
\hline CHEMBL1576291 & 688161 & 4.7 & 5.2436 & TRN & \\
\hline CHEMBL1414946 & 688161 & 6.3 & 4.9623 & TRN & \\
\hline CHEMBL1395997 & 688161 & 4.5 & 4.9108 & TRN & \\
\hline CHEMBL1386920 & 688161 & 4.9 & 4.9564 & TST & \\
\hline CHEMBL1597496 & 688161 & 4.7 & 4.92399 & 99999999995 & TRN \\
\hline CHEMBL1449836 & 688161 & 5.2 & 5.06800 & 00000000005 & TRN \\
\hline CHEMBL1366759 & 688161 & 4.4 & 4.8608 & TRN & \\
\hline CHEMBL1304359 & 688161 & 5.7 & 5.5094 & TRN & \\
\hline CHEMBL1462467 & 688161 & 5.3 & 4.8824 & TRN & \\
\hline CHEMBL1422696 & 688161 & 4.8 & 5.1289 & TRN & \\
\hline CHEMBL1322879 & 688161 & 5.4 & 5.0007 & TRN & \\
\hline CHEMBL1461989 & 688161 & 4.5 & 4.9086 & TRN & \\
\hline CHEMBL1608949 & 688161 & 4.6 & 4.8785 & TRN & \\
\hline CHEMBL1515355 & 688161 & 4.5 & 4.7994 & TRN & \\
\hline CHEMBL1500106 & 688161 & 4.5 & 4.7648 & TRN & \\
\hline CHEMBL1456734 & 688161 & 5.5 & 4.918 & TRN & \\
\hline CHEMBL408049 & 688161 & 4.4 & 4.953 & TST & \\
\hline CHEMBL210276 & 688161 & 4.7 & 4.919 & TRN & \\
\hline CHEMBL1447473 & 688161 & 4.6 & 4.9186 & TRN & \\
\hline CHEMBL1580879 & 688161 & 4.6 & 4.9175 & TRN & \\
\hline CHEMBL1567359 & 688161 & 4.6 & 4.8737 & TST & \\
\hline CHEMBL1559553 & 688161 & 4.9 & 4.8054 & TRN & \\
\hline CHEMBL1526649 & 688161 & 5.0 & 4.8839 & TRN & \\
\hline CHEMBL1412265 & 688161 & 5.3 & 4.9945 & TRN & \\
\hline CHEMBL1334083 & 688161 & 4.4 & 4.8061 & TRN & \\
\hline CHEMBL1518642 & 688161 & 4.6 & 4.9446 & TRN & \\
\hline CHEMBL 1455212 & 688161 & 4.6 & 4.8863 & TRN & \\
\hline CHEMBL1358503 & 688161 & 4.7 & 4.8973 & TRN & \\
\hline CHEMBL1370387 & 688161 & 4.8 & 4.9487 & TRN & \\
\hline CHEMBL1454461 & 688161 & 4.7 & 4.955 & TRN & \\
\hline CHEMBL1570765 & 688161 & 5.5 & 4.8921 & TRN & \\
\hline CHEMBL1421279 & 688161 & 5.9 & 4.9841 & TRN & \\
\hline CHEMBL1591323 & 688161 & 4.4 & 5.0892 & TST & \\
\hline
\end{tabular}




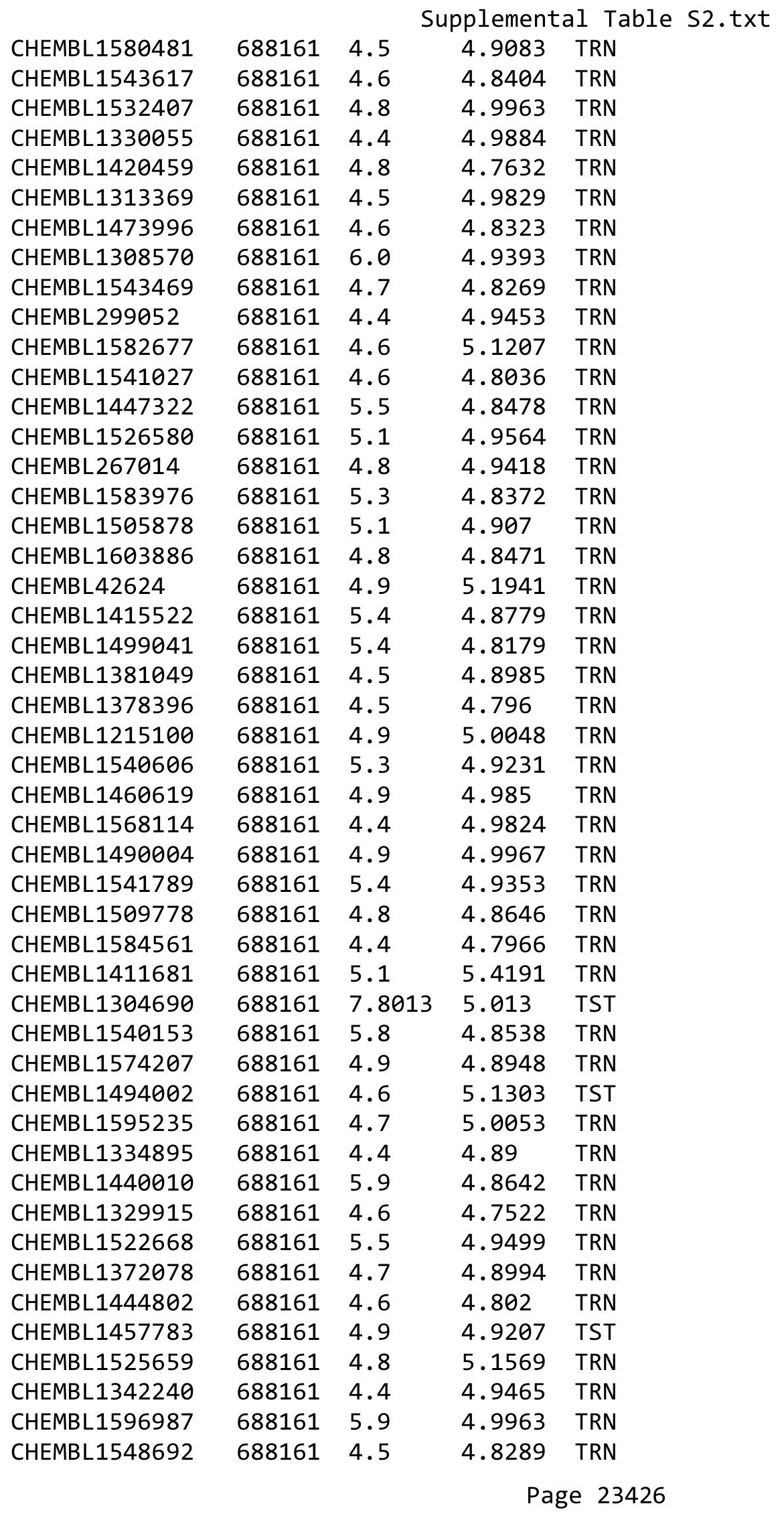




\begin{tabular}{|c|c|c|c|c|c|}
\hline \multicolumn{6}{|c|}{ Supplemental Table s2.txt } \\
\hline CHEMBL1601757 & 688161 & 4.8 & 4.8263 & TRN & \\
\hline CHEMBL1435188 & 688161 & 4.5 & 5.0351 & TST & \\
\hline CHEMBL28626 & 688161 & 4.8 & 5.2894 & TRN & \\
\hline CHEMBL1401847 & 688161 & 5.4 & 5.0248 & TST & \\
\hline CHEMBL1497927 & 688161 & 4.4 & 4.7439 & TRN & \\
\hline CHEMBL584520 & 688161 & 4.6 & 4.9223 & TST & \\
\hline CHEMBL1587655 & 688161 & 4.9 & 4.7438 & TRN & \\
\hline CHEMBL1604692 & 688161 & 7.3002 & 4.91 & TRN & \\
\hline CHEMBL1435409 & 688161 & 4.5 & 4.827 & TRN & \\
\hline CHEMBL1405153 & 688161 & 4.7 & 4.8148 & TRN & \\
\hline CHEMBL571087 & 688161 & 4.6 & 5.0763 & TRN & \\
\hline CHEMBL1312863 & 688161 & 4.5 & 4.8854 & TRN & \\
\hline CHEMBL1352161 & 688161 & 4.9 & $5.1270 e$ & $\partial 000000001$ & TST \\
\hline CHEMBL1481566 & 688161 & 4.4 & 4.8831 & TRN & \\
\hline CHEMBL1456741 & 688161 & 5.2 & 5.0185 & TST & \\
\hline CHEMBL1355896 & 688161 & 4.5 & 4.7427 & TRN & \\
\hline CHEMBL1548828 & 688161 & 5.0 & 4.8943 & TRN & \\
\hline CHEMBL1312427 & 688161 & 4.6 & 4.9241 & TRN & \\
\hline CHEMBL1470492 & 688161 & 5.6 & 5.6104 & TRN & \\
\hline CHEMBL1554960 & 688161 & 4.7 & 4.8773 & TRN & \\
\hline CHEMBL1329505 & 688161 & 4.4 & 4.8241 & TRN & \\
\hline CHEMBL39878 & 688161 & 6.6 & 4.9519 & TRN & \\
\hline CHEMBL1374801 & 688161 & 4.5 & 4.888 & TRN & \\
\hline CHEMBL1560296 & 688161 & 4.9 & 4.9142 & TRN & \\
\hline CHEMBL1321876 & 688161 & 4.9 & 4.7952 & TRN & \\
\hline CHEMBL1586973 & 688161 & 5.1 & 5.0341 & TRN & \\
\hline CHEMBL1575442 & 688161 & 5.0 & 4.8693 & TRN & \\
\hline CHEMBL1317860 & 688161 & 5.4 & 5.0088 & TRN & \\
\hline CHEMBL471005 & 688161 & 5.4 & 5.2738 & TST & \\
\hline CHEMBL1467787 & 688161 & 4.6 & 4.8948 & TRN & \\
\hline CHEMBL1450936 & 688161 & 4.9 & 4.9178 & TRN & \\
\hline CHEMBL153036 & 688161 & 4.9 & 4.9723 & TRN & \\
\hline CHEMBL1317076 & 688161 & 4.8 & 5.0547 & TST & \\
\hline CHEMBL1413408 & 688161 & 5.0 & 4.8505 & TRN & \\
\hline CHEMBL1404660 & 688161 & 4.5 & 4.9096 & TRN & \\
\hline CHEMBL1498126 & 688161 & 5.7 & 4.8995 & TRN & \\
\hline CHEMBL1452607 & 688161 & 4.5 & 4.8643 & TRN & \\
\hline CHEMBL1547361 & 688161 & 5.5 & 4.8317 & TRN & \\
\hline CHEMBL1517017 & 688161 & 4.7 & 4.9896 & TRN & \\
\hline CHEMBL1303766 & 688161 & 4.8 & 4.8229 & TRN & \\
\hline CHEMBL1612117 & 688161 & 4.5 & 4.8778 & TRN & \\
\hline CHEMBL1452045 & 688161 & 4.9 & 4.8909 & TRN & \\
\hline CHEMBL1460835 & 688161 & 7.6003 & 4.8478 & TRN & \\
\hline CHEMBL1372751 & 688161 & 5.5 & 4.9563 & TRN & \\
\hline CHEMBL111654 & 688161 & 4.5 & 4.8959 & TRN & \\
\hline CHEMBL1360944 & 688161 & 4.9 & 4.9804 & TST & \\
\hline CHEMBL1323944 & 688161 & 4.8 & 4.8489 & TRN & \\
\hline CHEMBL1489707 & 688161 & 4.6 & 4.8457 & TRN & \\
\hline
\end{tabular}




\begin{tabular}{|c|c|c|c|c|c|}
\hline \multicolumn{6}{|c|}{ Supplemental Table S2.txt } \\
\hline CHEMBL1396202 & 688161 & 4.5 & 4.9399 & TRN & \\
\hline CHEMBL16410 & 688161 & 4.9 & 4.8988 & TST & \\
\hline CHEMBL1460491 & 688161 & 5.4 & 4.9973 & TRN & \\
\hline CHEMBL1474016 & 688161 & 5.5 & 4.9473 & TRN & \\
\hline CHEMBL1982713 & 688161 & 4.9 & 4.9176 & TRN & \\
\hline CHEMBL1500636 & 688161 & 4.6 & 4.8001 & TRN & \\
\hline CHEMBL1354502 & 688161 & 4.9 & 4.8772 & TRN & \\
\hline CHEMBL1489758 & 688161 & 5.1 & 5.4255 & TST & \\
\hline CHEMBL1558496 & 688161 & 4.5 & 5.0395 & TRN & \\
\hline CHEMBL293749 & 688161 & 5.2 & 4.9428 & TRN & \\
\hline CHEMBL1403500 & 688161 & 7.5003 & 4.965 & TRN & \\
\hline CHEMBL1556277 & 688161 & 5.4 & 5.1558 & TRN & \\
\hline CHEMBL1351018 & 688161 & 5.4 & 5.0637 & TRN & \\
\hline CHEMBL1598247 & 688161 & 5.0 & 4.8673 & TRN & \\
\hline CHEMBL1611312 & 688161 & 4.9 & 5.0177 & TST & \\
\hline CHEMBL1561241 & 688161 & 5.8 & 4.913 & TRN & \\
\hline CHEMBL534084 & 688161 & 4.8 & 5.0179 & TRN & \\
\hline CHEMBL1506668 & 688161 & 5.9 & 5.194 & TRN & \\
\hline CHEMBL1363873 & 688161 & 4.5 & 5.0659 & TRN & \\
\hline CHEMBL 78150 & 688161 & 5.4 & 4.9254 & TRN & \\
\hline CHEMBL1504284 & 688161 & 5.3 & 5.3582 & TRN & \\
\hline CHEMBL3196079 & 688161 & 4.6 & 5.0002 & TRN & \\
\hline CHEMBL1384308 & 688161 & 4.5 & 4.9037 & TRN & \\
\hline CHEMBL1503681 & 688161 & 4.7 & 4.9017 & TST & \\
\hline CHEMBL1582589 & 688161 & 4.4 & 4.9109 & TRN & \\
\hline CHEMBL532641 & 688161 & 4.4 & 4.8706 & TRN & \\
\hline CHEMBL1355835 & 688161 & 4.6 & 4.8605 & TRN & \\
\hline CHEMBL1576154 & 688161 & 4.6 & 4.9421 & TRN & \\
\hline CHEMBL1560136 & 688161 & 4.6 & 4.8319 & TRN & \\
\hline CHEMBL1566174 & 688161 & 4.4 & 4.9119 & TRN & \\
\hline CHEMBL1328748 & 688161 & 4.4 & 5.0746 & TST & \\
\hline CHEMBL1441062 & 688161 & 4.5 & 4.9325 & TRN & \\
\hline CHEMBL1515691 & 688161 & 4.6 & 5.0439 & TST & \\
\hline CHEMBL1584901 & 688161 & 4.5 & 4.9583 & TST & \\
\hline CHEMBL1504149 & 688161 & 4.8 & 4.8466 & TRN & \\
\hline CHEMBL1516118 & 688161 & 4.6 & 4.8149 & TRN & \\
\hline CHEMBL1472926 & 688161 & 4.4 & 4.7748 & TRN & \\
\hline CHEMBL1549861 & 688161 & 5.7 & 4.9111 & TRN & \\
\hline CHEMBL1569694 & 688161 & 4.4 & 4.9135 & TRN & \\
\hline CHEMBL1452049 & 688161 & 4.5 & 4.9162 & TRN & \\
\hline CHEMBL1543187 & 688161 & 4.5 & 4.9304 & TRN & \\
\hline CHEMBL1549413 & 688161 & 5.1 & 5.0088 & TRN & \\
\hline CHEMBL 224282 & 688161 & 5.0 & 5.16299 & э999999999 & TRN \\
\hline CHEMBL1495785 & 688161 & 4.5 & 4.9439 & TRN & \\
\hline CHEMBL1418219 & 688161 & 4.7 & 4.9614 & TRN & \\
\hline CHEMBL1532515 & 688161 & 5.0 & 4.8509 & TRN & \\
\hline CHEMBL1368239 & 688161 & 4.8 & 4.8824 & TRN & \\
\hline CHEMBL1551729 & 688161 & 4.6 & 4.8154 & TRN & \\
\hline
\end{tabular}




\begin{tabular}{|c|c|c|c|c|}
\hline \multicolumn{5}{|c|}{ Supplemental Table S2.txt } \\
\hline CHEMBL1586310 & 688161 & 4.6 & 5.2498 & TRN \\
\hline CHEMBL1466151 & 688161 & 5.1 & 4.7963 & TRN \\
\hline CHEMBL1548028 & 688161 & 4.8 & 4.8973 & TRN \\
\hline CHEMBL1529766 & 688161 & 4.9 & 5.0788 & TRN \\
\hline CHEMBL1406638 & 688161 & 6.9 & 4.9032 & TRN \\
\hline CHEMBL3392062 & 688161 & 4.6 & 4.8416 & TST \\
\hline CHEMBL1367412 & 688161 & 4.7 & 4.8659 & TRN \\
\hline CHEMBL1500457 & 688161 & 4.4 & 4.9297 & TST \\
\hline CHEMBL343732 & 688161 & 4.5 & 4.9077 & TRN \\
\hline CHEMBL1340479 & 688161 & 5.3 & 5.7805 & TST \\
\hline CHEMBL1552540 & 688161 & 4.8 & 4.9553 & TRN \\
\hline CHEMBL1509585 & 688161 & 5.1 & 5.2232 & TRN \\
\hline CHEMBL1494832 & 688161 & 4.5 & 4.8751 & TRN \\
\hline CHEMBL1497718 & 688161 & 4.5 & 4.8524 & TRN \\
\hline CHEMBL1480546 & 688161 & 4.6 & 4.921 & TRN \\
\hline CHEMBL1301162 & 688161 & 4.4 & 4.9188 & TRN \\
\hline CHEMBL1440782 & 688161 & 6.2 & 4.9272 & TRN \\
\hline CHEMBL1314644 & 688161 & 6.3 & 4.9998 & TRN \\
\hline CHEMBL1385713 & 688161 & 5.4 & 4.9014 & TRN \\
\hline CHEMBL1590598 & 688161 & 4.6 & 4.8143 & TRN \\
\hline CHEMBL129795 & 688161 & 4.6 & 5.0066 & TRN \\
\hline CHEMBL1411230 & 688161 & 5.3 & 4.9144 & TRN \\
\hline CHEMBL1432647 & 688161 & 4.5 & 4.9302 & TST \\
\hline CHEMBL1384725 & 688161 & 4.6 & 4.9528 & TRN \\
\hline CHEMBL1451209 & 688161 & 4.9 & 4.8832 & TRN \\
\hline CHEMBL1337654 & 688161 & 5.9 & 5.0406 & TRN \\
\hline CHEMBL1449350 & 688161 & 4.6 & 4.7558 & TRN \\
\hline CHEMBL1574133 & 688161 & 4.4 & 4.8006 & TRN \\
\hline CHEMBL1421442 & 688161 & 5.6 & 4.8612 & TRN \\
\hline CHEMBL1372528 & 688161 & 6.4 & 4.9241 & TRN \\
\hline CHEMBL1550045 & 688161 & 4.4 & 5.0619 & TRN \\
\hline CHEMBL1540853 & 688161 & 4.5 & 4.8822 & TRN \\
\hline CHEMBL1978817 & 688161 & 7.1002 & 5.0895 & TRN \\
\hline CHEMBL1567730 & 688161 & 5.6 & 4.8148 & TRN \\
\hline CHEMBL1431853 & 688161 & 4.6 & 5.1713 & TRN \\
\hline CHEMBL1464517 & 688161 & 4.8 & 4.8668 & TRN \\
\hline CHEMBL1310073 & 688161 & 4.8 & 4.8423 & TRN \\
\hline CHEMBL1401398 & 688161 & 4.4 & 4.819 & TRN \\
\hline CHEMBL1364873 & 688161 & 4.4 & 4.8156 & TRN \\
\hline CHEMBL1505151 & 688161 & 5.0 & 4.8786 & TRN \\
\hline CHEMBL1458486 & 688161 & 6.6 & 4.8068 & TRN \\
\hline CHEMBL1435908 & 688161 & 5.1 & 5.0031 & TST \\
\hline CHEMBL38288 & 688161 & 4.8 & 4.9158 & TRN \\
\hline CHEMBL36296 & 688161 & 6.1 & 5.0701 & TRN \\
\hline CHEMBL323197 & 688161 & 4.6 & 5.0762 & TRN \\
\hline CHEMBL1585641 & 688161 & 4.9 & 4.8653 & TRN \\
\hline CHEMBL1575051 & 688161 & 4.8 & 4.9583 & TRN \\
\hline CHEMBL1385193 & 688161 & 4.8 & 4.9713 & TRN \\
\hline
\end{tabular}




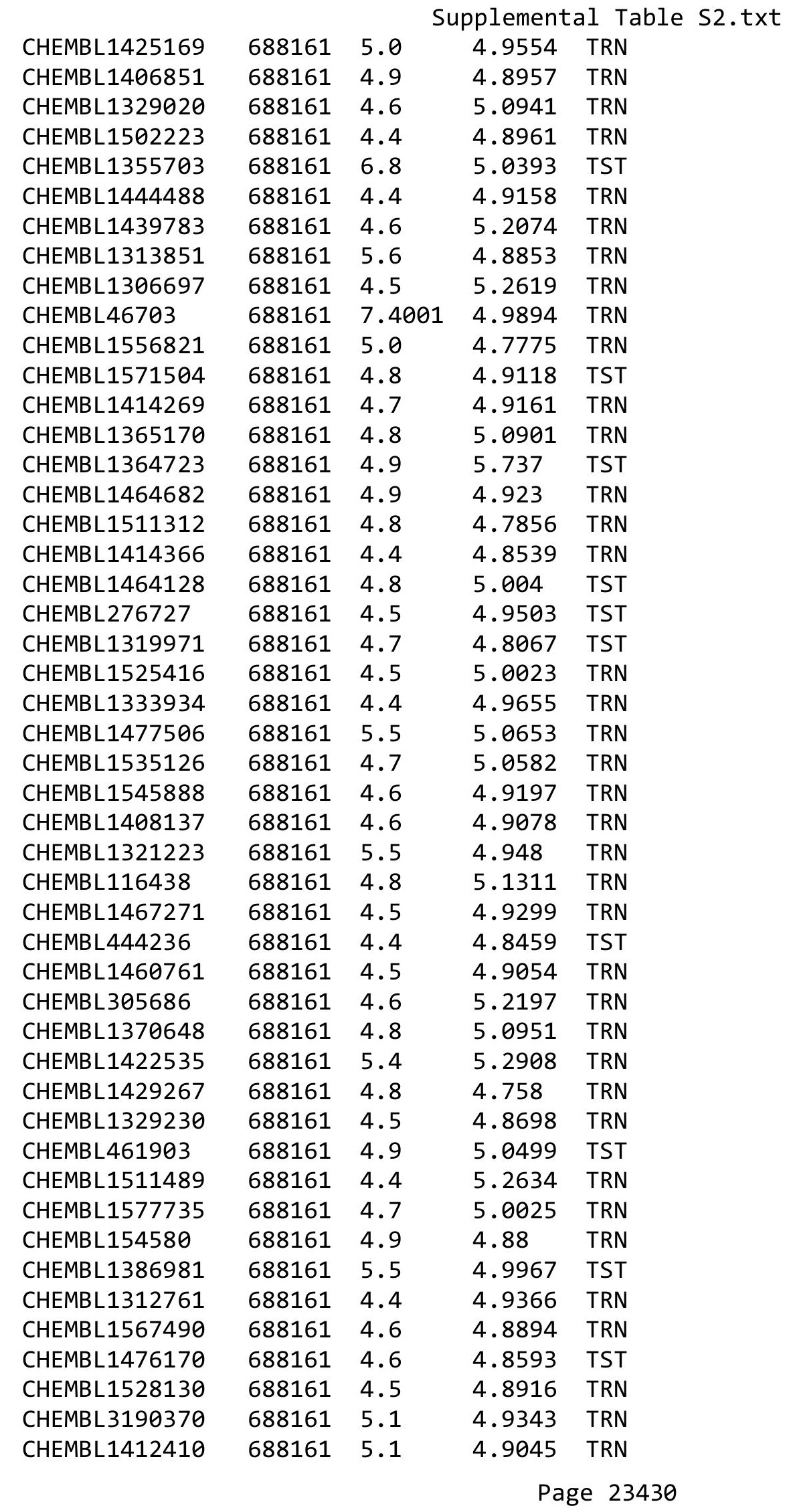




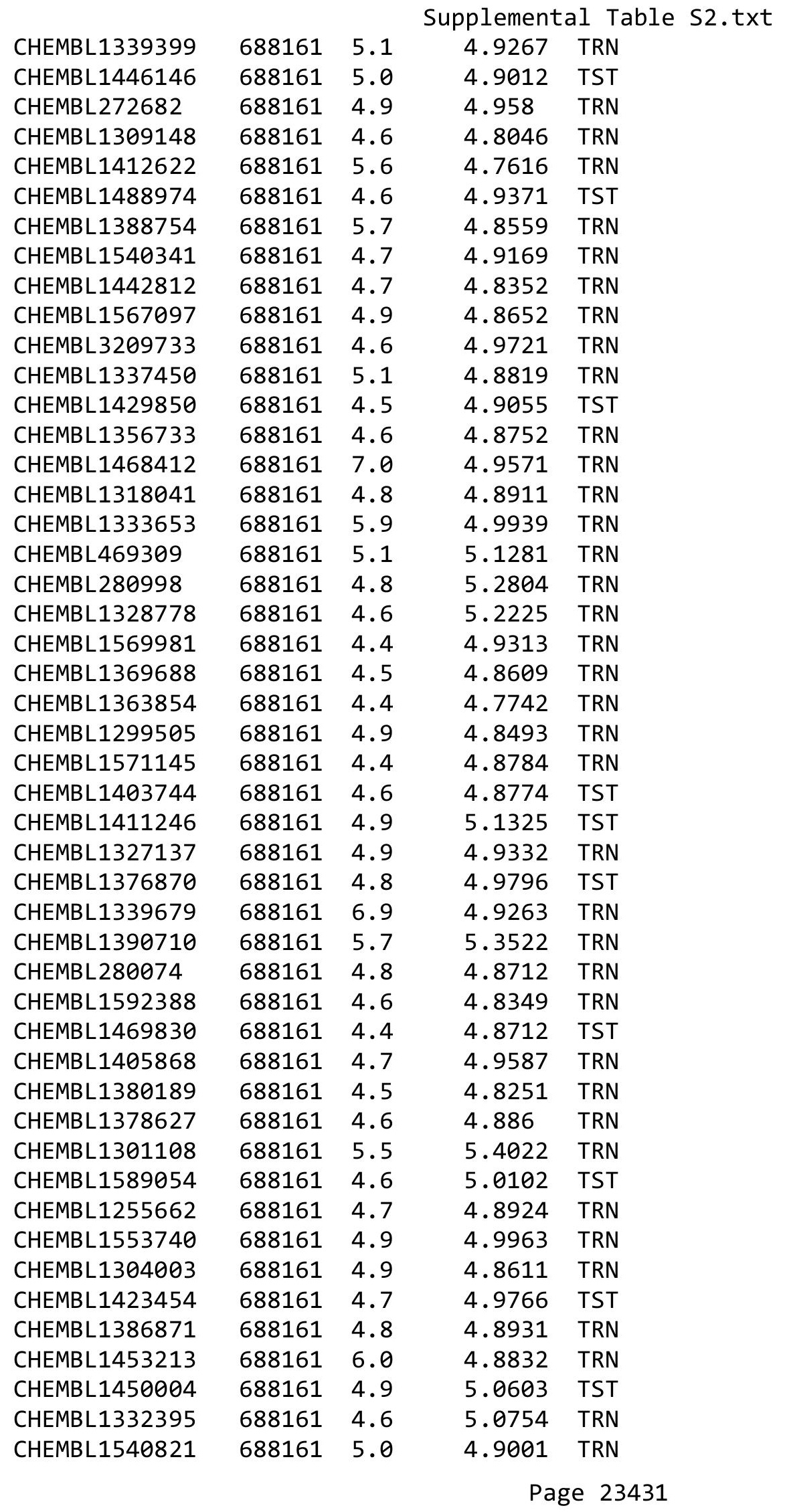




\begin{tabular}{|c|c|c|c|c|c|}
\hline \multicolumn{6}{|c|}{ Supplemental Table S2.txt } \\
\hline CHEMBL1524664 & 688161 & 4.7 & 4.9127 & TRN & \\
\hline CHEMBL1493465 & 688161 & 4.5 & 5.0436 & TRN & \\
\hline CHEMBL85811 & 688161 & 5.4 & 5.1935 & TRN & \\
\hline CHEMBL1429873 & 688161 & 5.4 & 4.8629 & TRN & \\
\hline CHEMBL1444092 & 688161 & 4.8 & 4.8955 & TRN & \\
\hline CHEMBL1374457 & 688161 & 5.6 & 5.003 & TRN & \\
\hline CHEMBL1424468 & 688161 & 4.7 & 4.7797 & TRN & \\
\hline CHEMBL1516632 & 688161 & 4.9 & 4.8704 & TRN & \\
\hline CHEMBL1495812 & 688161 & 6.8 & 4.8283 & TRN & \\
\hline CHEMBL1487093 & 688161 & 4.9 & 4.8789 & TRN & \\
\hline CHEMBL1790009 & 688161 & 6.5 & 4.9578 & TST & \\
\hline CHEMBL1605033 & 688161 & 4.7 & 5.0012 & TRN & \\
\hline CHEMBL1539220 & 688161 & 4.4 & 4.85800 & 00000000005 & TRN \\
\hline CHEMBL1336392 & 688161 & 7.2 & 4.9077 & TRN & \\
\hline CHEMBL1574004 & 688161 & 4.6 & 4.9396 & TRN & \\
\hline CHEMBL1626177 & 688161 & 4.7 & 5.0401 & TST & \\
\hline CHEMBL1313253 & 688161 & 4.9 & 4.8935 & TRN & \\
\hline CHEMBL1527631 & 688161 & 5.2 & 4.9238 & TRN & \\
\hline CHEMBL1499016 & 688161 & 4.6 & 4.7419 & TRN & \\
\hline CHEMBL1418843 & 688161 & 4.9 & 4.9384 & TRN & \\
\hline CHEMBL1565852 & 688161 & 4.4 & 4.9016 & TRN & \\
\hline CHEMBL1564253 & 688161 & 4.8 & 5.1761 & TST & \\
\hline CHEMBL1494876 & 688161 & 5.1 & 4.8824 & TRN & \\
\hline CHEMBL1595761 & 688161 & 4.6 & 4.7318 & TRN & \\
\hline CHEMBL1331836 & 688161 & 4.8 & 4.8996 & TRN & \\
\hline CHEMBL1358274 & 688161 & 5.2 & 4.9134 & TRN & \\
\hline CHEMBL1562166 & 688161 & 5.6 & 4.922 & TRN & \\
\hline CHEMBL1347588 & 688161 & 4.8 & 4.9938 & TRN & \\
\hline CHEMBL1568805 & 688161 & 7.2 & 4.8837 & TRN & \\
\hline CHEMBL1506843 & 688161 & 4.7 & 4.8033 & TRN & \\
\hline CHEMBL1489171 & 688161 & 5.4 & 4.9369 & TRN & \\
\hline CHEMBL1370313 & 688161 & 4.5 & 4.955 & TRN & \\
\hline CHEMBL1365517 & 688161 & 4.7 & 4.9019 & TRN & \\
\hline CHEMBL1568498 & 688161 & 5.3 & 4.8436 & TRN & \\
\hline CHEMBL1498384 & 688161 & 4.6 & 4.9181 & TRN & \\
\hline CHEMBL1591258 & 688161 & 4.8 & 4.9308 & TRN & \\
\hline CHEMBL1453208 & 688161 & 4.7 & 4.9238 & TRN & \\
\hline CHEMBL1572104 & 688161 & 4.7 & 4.8943 & TRN & \\
\hline CHEMBL1578546 & 688161 & 4.8 & 4.9243 & TRN & \\
\hline CHEMBL 284104 & 688161 & 6.0 & 4.8492 & TRN & \\
\hline CHEMBL258465 & 688161 & 4.8 & 4.8203 & TST & \\
\hline CHEMBL1333071 & 688161 & 4.6 & 4.8141 & TRN & \\
\hline CHEMBL220845 & 688161 & 5.4 & 5.5659 & TRN & \\
\hline CHEMBL1423898 & 688161 & 5.8 & 4.9217 & TRN & \\
\hline CHEMBL530280 & 688161 & 4.6 & 4.8794 & TRN & \\
\hline CHEMBL1384368 & 688161 & 5.9 & 4.9098 & TRN & \\
\hline CHEMBL3189947 & 688161 & 4.5 & 4.8391 & TST & \\
\hline CHEMBL1524520 & 688161 & 4.5 & 4.864 & TRN & \\
\hline
\end{tabular}




\begin{tabular}{|c|c|c|c|c|c|}
\hline \multicolumn{6}{|c|}{ Supplemental Table S2.txt } \\
\hline CHEMBL1447501 & 688161 & 4.5 & 4.8994 & TRN & \\
\hline CHEMBL1518866 & 688161 & 4.5 & 4.9001 & TRN & \\
\hline CHEMBL1485078 & 688161 & 5.6 & 4.8712 & TRN & \\
\hline CHEMBL1433187 & 688161 & 4.8 & 4.9045 & TRN & \\
\hline CHEMBL1361733 & 688161 & 6.0 & 4.9921 & TRN & \\
\hline CHEMBL1441397 & 688161 & 4.6 & 4.905 & TRN & \\
\hline CHEMBL1432354 & 688161 & 5.5 & 4.8938 & TRN & \\
\hline CHEMBL1446065 & 688161 & 4.6 & 4.8671 & TRN & \\
\hline CHEMBL1423568 & 688161 & 4.8 & 4.8239 & TRN & \\
\hline CHEMBL1560337 & 688161 & 4.7 & 4.8912 & TRN & \\
\hline CHEMBL1601153 & 688161 & 4.9 & 4.7514 & TRN & \\
\hline CHEMBL1563871 & 688161 & 4.4 & 4.8804 & TRN & \\
\hline CHEMBL1493571 & 688161 & 5.4 & 4.9981 & TRN & \\
\hline CHEMBL1434198 & 688161 & 4.7 & 4.8399 & TRN & \\
\hline CHEMBL1440715 & 688161 & 4.5 & 4.9017 & TRN & \\
\hline CHEMBL1338095 & 688161 & 4.4 & 4.7915 & TRN & \\
\hline CHEMBL1364030 & 688161 & 4.6 & 4.9494 & TRN & \\
\hline CHEMBL1339794 & 688161 & 4.6 & 5.0322 & TRN & \\
\hline CHEMBL1589797 & 688161 & 4.6 & 4.8481 & TST & \\
\hline CHEMBL1455664 & 688161 & 4.4 & 4.9516 & TRN & \\
\hline CHEMBL3191344 & 688161 & 4.7 & 4.9881 & TRN & \\
\hline CHEMBL1571874 & 688161 & 4.6 & 4.9898 & TST & \\
\hline CHEMBL1533424 & 688161 & 5.4 & 5.0017 & TRN & \\
\hline CHEMBL1515961 & 688161 & 5.4 & 5.13899 & 7999999999 & TRN \\
\hline CHEMBL1491340 & 688161 & 4.6 & 5.025 & TST & \\
\hline CHEMBL1519622 & 688161 & 4.6 & 4.9326 & TRN & \\
\hline CHEMBL1572060 & 688161 & 5.6 & 4.9106 & TRN & \\
\hline CHEMBL1478694 & 688161 & 4.5 & 4.9095 & TRN & \\
\hline CHEMBL1407952 & 688161 & 5.4 & 4.931 & TRN & \\
\hline CHEMBL1566177 & 688161 & 4.9 & 4.9791 & TRN & \\
\hline CHEMBL1585708 & 688161 & 4.6 & 4.8958 & TRN & \\
\hline CHEMBL1465650 & 688161 & 4.4 & 4.896 & TST & \\
\hline CHEMBL1518503 & 688161 & 5.5 & 5.2886 & TRN & \\
\hline CHEMBL1309515 & 688161 & 4.5 & 4.9212 & TRN & \\
\hline CHEMBL1613631 & 688161 & 4.9 & 4.8727 & TRN & \\
\hline CHEMBL1539103 & 688161 & 4.7 & 4.8143 & TRN & \\
\hline CHEMBL1496596 & 688161 & 4.8 & 5.0626 & TRN & \\
\hline CHEMBL1496062 & 688161 & 5.5 & 5.245 & TRN & \\
\hline CHEMBL1455993 & 688161 & 4.9 & 5.0791 & TRN & \\
\hline CHEMBL1566696 & 688161 & 4.5 & 5.125 & TRN & \\
\hline CHEMBL1497427 & 688161 & 4.9 & 4.7424 & TRN & \\
\hline CHEMBL1504418 & 688161 & 4.4 & 4.8449 & TRN & \\
\hline CHEMBL580421 & 688161 & 4.8 & 4.9434 & TRN & \\
\hline CHEMBL1518966 & 688161 & 5.3 & 4.8587 & TRN & \\
\hline CHEMBL1576068 & 688161 & 4.6 & 4.8287 & TRN & \\
\hline CHEMBL1394738 & 688161 & 4.9 & 4.9221 & TST & \\
\hline CHEMBL1495845 & 688161 & 4.8 & 4.9014 & TRN & \\
\hline CHEMBL1548490 & 688161 & 4.9 & 4.9033 & TRN & \\
\hline
\end{tabular}




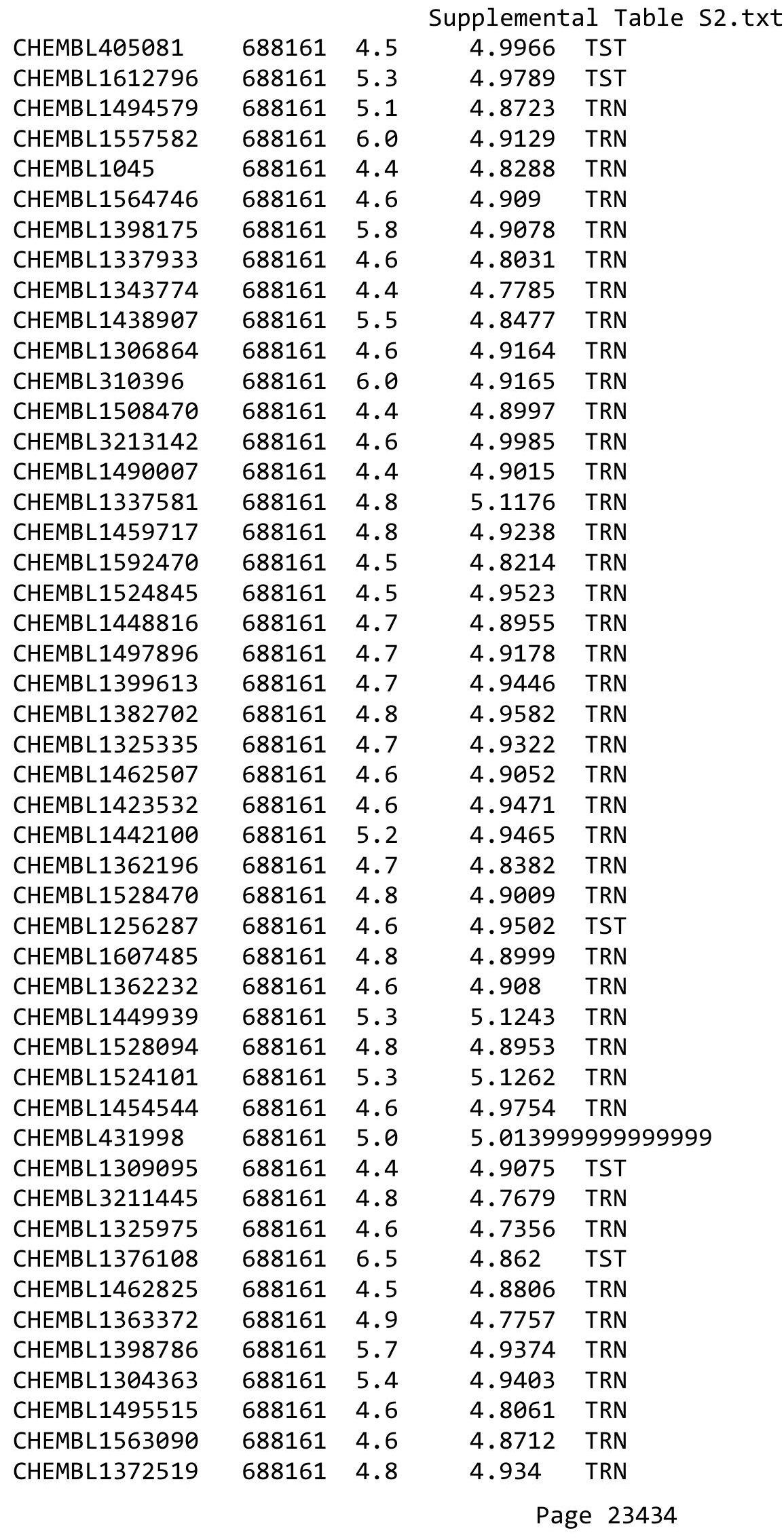




\begin{tabular}{|c|c|c|c|c|}
\hline \multicolumn{5}{|c|}{ Supplemental Table S2.txt } \\
\hline CHEMBL1301020 & 688161 & 4.8 & 5.3443 & TRN \\
\hline CHEMBL1340563 & 688161 & 4.9 & 5.1883 & TRN \\
\hline CHEMBL1455912 & 688161 & 5.4 & 5.7128 & TRN \\
\hline CHEMBL1544852 & 688161 & 5.4 & 4.9449 & TRN \\
\hline CHEMBL1572855 & 688161 & 4.8 & 4.8374 & TRN \\
\hline CHEMBL1332016 & 688161 & 4.6 & 5.1934 & TRN \\
\hline CHEMBL1500377 & 688161 & 4.6 & 4.838 & TRN \\
\hline CHEMBL1606460 & 688161 & 4.8 & 4.9723 & TST \\
\hline CHEMBL1504362 & 688161 & 5.0 & 4.8828 & TRN \\
\hline CHEMBL1528688 & 688161 & 5.6 & 5.3649 & TST \\
\hline CHEMBL1443320 & 688161 & 5.1 & 4.9169 & TRN \\
\hline CHEMBL1520849 & 688161 & 4.8 & 4.8665 & TRN \\
\hline CHEMBL1498077 & 688161 & 4.8 & 4.8881 & TST \\
\hline CHEMBL1386096 & 688161 & 5.5 & 4.9704 & TST \\
\hline CHEMBL1302381 & 688161 & 4.5 & 5.0341 & TRN \\
\hline CHEMBL1561554 & 688161 & 5.4 & 4.9417 & TRN \\
\hline CHEMBL1301505 & 688161 & 4.8 & 4.8236 & TRN \\
\hline CHEMBL1361413 & 688161 & 5.7 & 4.9596 & TRN \\
\hline CHEMBL126804 & 688161 & 5.0 & 5.0132 & TRN \\
\hline CHEMBL1416274 & 688161 & 4.8 & 4.9209 & TRN \\
\hline CHEMBL 368700 & 688161 & 5.1 & 4.981 & TST \\
\hline CHEMBL1469865 & 688161 & 5.5 & 5.0744 & TRN \\
\hline CHEMBL1568111 & 688161 & 4.4 & 4.8467 & TRN \\
\hline CHEMBL1579570 & 688161 & 4.8 & 4.933 & TRN \\
\hline CHEMBL1331476 & 688161 & 5.1 & 4.9344 & TST \\
\hline CHEMBL1337364 & 688161 & 5.5 & 5.3255 & TRN \\
\hline CHEMBL1360725 & 688161 & 4.9 & 4.9622 & TST \\
\hline CHEMBL1580240 & 688161 & 6.7001 & 4.9524 & TRN \\
\hline CHEMBL1376529 & 688161 & 4.4 & 4.8192 & TRN \\
\hline CHEMBL1456081 & 688161 & 4.8 & 4.9485 & TRN \\
\hline CHEMBL1341867 & 688161 & 4.5 & 4.8544 & TRN \\
\hline CHEMBL1602465 & 688161 & 4.5 & 4.8715 & TRN \\
\hline CHEMBL468590 & 688161 & 5.0 & 4.94 & TST \\
\hline CHEMBL1389510 & 688161 & 4.6 & 4.8326 & TRN \\
\hline CHEMBL1589300 & 688161 & 5.6 & 5.0917 & TRN \\
\hline CHEMBL1342780 & 688161 & 4.4 & 4.8931 & TRN \\
\hline CHEMBL1348930 & 688161 & 4.5 & 4.9252 & TRN \\
\hline CHEMBL1569012 & 688161 & 4.6 & 5.0923 & TRN \\
\hline CHEMBL1548983 & 688161 & 8.1024 & 4.7904 & TRN \\
\hline CHEMBL1384489 & 688161 & 4.8 & 4.8944 & TRN \\
\hline CHEMBL1571688 & 688161 & 5.4 & 4.9298 & TRN \\
\hline CHEMBL1366732 & 688161 & 4.6 & 4.8391 & TRN \\
\hline CHEMBL1324015 & 688161 & 7.0 & 4.9605 & TST \\
\hline CHEMBL1487285 & 688161 & 4.9 & 4.9618 & TRN \\
\hline CHEMBL1423571 & 688161 & 4.7 & 5.1465 & TRN \\
\hline CHEMBL1556608 & 688161 & 4.9 & 4.7503 & TRN \\
\hline CHEMBL1532361 & 688161 & 5.5 & 4.8056 & TRN \\
\hline CHEMBL1580957 & 688161 & 4.5 & 4.9613 & TST \\
\hline
\end{tabular}




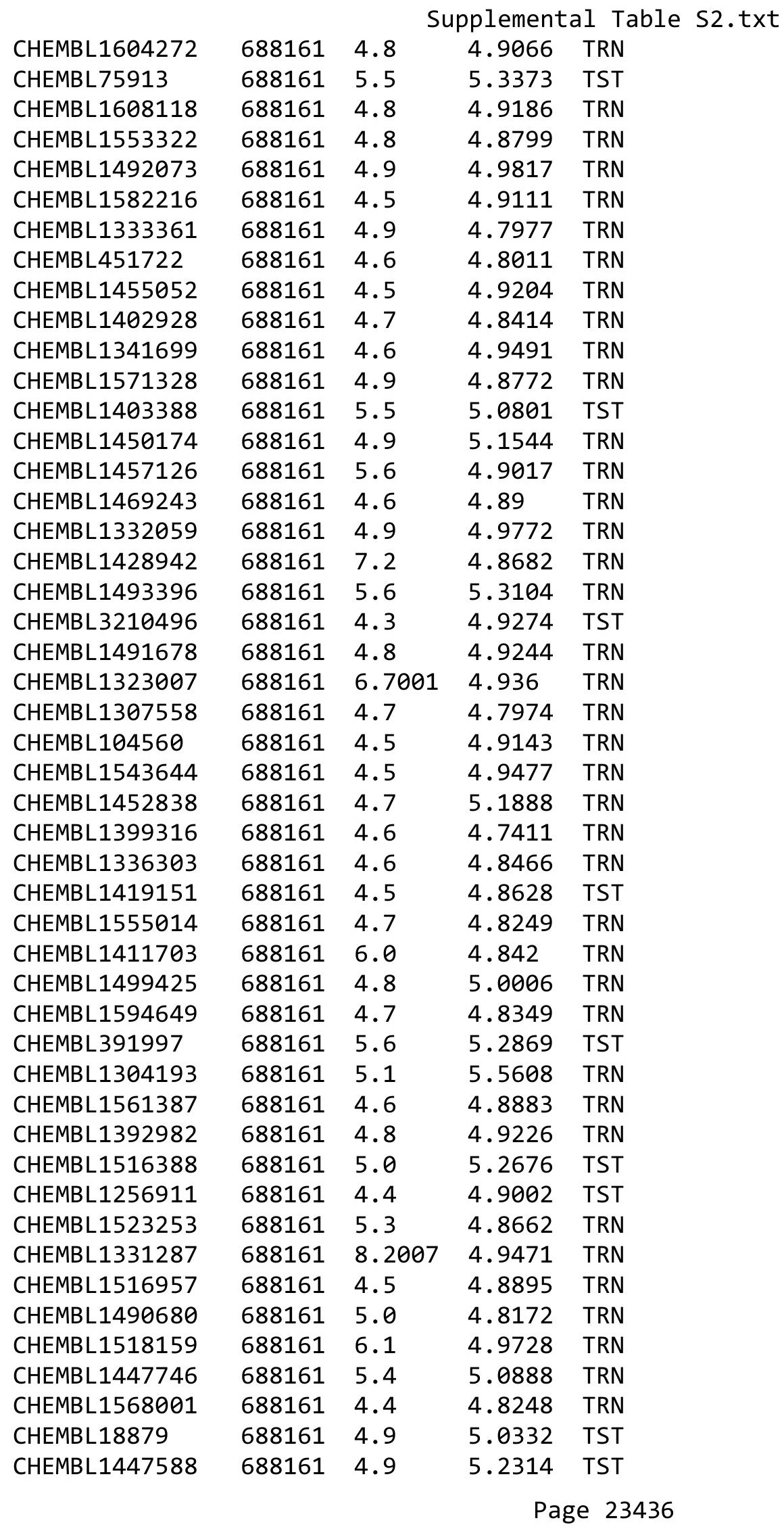




\begin{tabular}{|c|c|c|c|c|c|}
\hline \multicolumn{6}{|c|}{ Supplemental Table S2.txt } \\
\hline CHEMBL1416105 & 688161 & 6.8 & 5.0055 & TRN & \\
\hline CHEMBL1453347 & 688161 & 5.6 & 4.9143 & TST & \\
\hline CHEMBL1446716 & 688161 & 5.5 & 5.0242 & TRN & \\
\hline CHEMBL1529438 & 688161 & 4.5 & 4.9669 & TST & \\
\hline CHEMBL1449328 & 688161 & 4.9 & 4.8422 & TRN & \\
\hline CHEMBL1321470 & 688161 & 5.8 & 4.9732 & TST & \\
\hline CHEMBL461431 & 688161 & 5.3 & 5.396 & TRN & \\
\hline CHEMBL1577317 & 688161 & 4.4 & 4.8408 & TRN & \\
\hline CHEMBL1373680 & 688161 & 5.2 & \multicolumn{2}{|c|}{4.861000000000001} & TRN \\
\hline CHEMBL1445576 & 688161 & 4.8 & 4.9668 & TRN & \\
\hline CHEMBL1604473 & 688161 & 4.5 & 4.9309 & TRN & \\
\hline CHEMBL1480032 & 688161 & 5.5 & 5.0147 & TST & \\
\hline CHEMBL1339527 & 688161 & 5.6 & 4.9112 & TRN & \\
\hline CHEMBL1370036 & 688161 & 4.6 & 4.7654 & TRN & \\
\hline CHEMBL 3212742 & 688161 & 4.5 & 4.9659 & TST & \\
\hline CHEMBL1604523 & 688161 & 4.5 & 5.0656 & TST & \\
\hline CHEMBL1332074 & 688161 & 4.4 & 4.9725 & TRN & \\
\hline CHEMBL1386370 & 688161 & 4.4 & 5.0403 & TRN & \\
\hline CHEMBL1609128 & 688161 & 4.9 & 5.0663 & TRN & \\
\hline CHEMBL1486510 & 688161 & 4.7 & 4.8487 & TRN & \\
\hline CHEMBL1606656 & 688161 & 4.6 & 4.9665 & TST & \\
\hline CHEMBL2002522 & 688161 & 5.1 & 4.9677 & TRN & \\
\hline CHEMBL1544460 & 688161 & 4.5 & 4.9447 & TRN & \\
\hline CHEMBL1518206 & 688161 & 5.5 & 4.8145 & TRN & \\
\hline CHEMBL1321088 & 688161 & 5.5 & 4.915 & TRN & \\
\hline CHEMBL1469528 & 688161 & 4.5 & 4.9145 & TRN & \\
\hline CHEMBL1504505 & 688161 & 4.4 & 4.8843 & TRN & \\
\hline CHEMBL1430935 & 688161 & 5.0 & 4.9841 & TRN & \\
\hline CHEMBL1419702 & 688161 & 4.4 & 4.8856 & TRN & \\
\hline CHEMBL1428775 & 688161 & 4.5 & 5.0558 & TST & \\
\hline CHEMBL1416218 & 688161 & 4.8 & 5.0899 & TST & \\
\hline CHEMBL1566105 & 688161 & 7.1002 & 5.3899 & TST & \\
\hline CHEMBL1371349 & 688161 & 5.4 & 4.9083 & TRN & \\
\hline CHEMBL1416666 & 688161 & 6.9 & 4.8525 & TRN & \\
\hline CHEMBL516075 & 688161 & 4.5 & 4.7386 & TRN & \\
\hline CHEMBL1550751 & 688161 & 4.6 & 4.8675 & TRN & \\
\hline CHEMBL1511695 & 688161 & 4.5 & 4.9156 & TRN & \\
\hline CHEMBL1311973 & 688161 & 6.3 & 4.9231 & TRN & \\
\hline CHEMBL1344136 & 688161 & 4.9 & 4.8258 & TRN & \\
\hline CHEMBL1423560 & 688161 & 4.6 & 4.9423 & TRN & \\
\hline CHEMBL1501151 & 688161 & 5.2 & 5.3276 & TRN & \\
\hline CHEMBL1487976 & 688161 & 4.6 & 4.9139 & TRN & \\
\hline CHEMBL1348342 & 688161 & 4.7 & 5.1146 & TRN & \\
\hline CHEMBL1408153 & 688161 & 4.4 & 4.904 & TRN & \\
\hline CHEMBL1320183 & 688161 & 5.0 & 4.871 & TRN & \\
\hline CHEMBL1532971 & 688161 & 5.1 & 4.8828 & TRN & \\
\hline CHEMBL1313601 & 688161 & 6.8 & 4.9129 & TRN & \\
\hline \multirow[t]{2}{*}{ CHEMBL1594299 } & 688161 & 5.0 & $5.2520 e$ & 2000000001 & TRN \\
\hline & & \multicolumn{4}{|c|}{ Page 23437} \\
\hline
\end{tabular}




\begin{tabular}{|c|c|c|c|c|}
\hline \multicolumn{5}{|c|}{ Supplemental Table s2.txt } \\
\hline CHEMBL1347028 & 688161 & 5.2 & 5.2793 & TRN \\
\hline CHEMBL 3197540 & 688161 & 4.4 & 4.8773 & TRN \\
\hline CHEMBL1594149 & 688161 & 4.8 & 5.1335 & TST \\
\hline CHEMBL1473149 & 688161 & 6.5 & 4.9436 & TRN \\
\hline CHEMBL1440291 & 688161 & 4.5 & 4.8504 & TRN \\
\hline CHEMBL1470675 & 688161 & 4.7 & 4.7779 & TRN \\
\hline CHEMBL1482404 & 688161 & 4.8 & 4.909 & TRN \\
\hline CHEMBL1463066 & 688161 & 4.9 & 5.3149 & TRN \\
\hline CHEMBL1541596 & 688161 & 4.7 & 4.9381 & TRN \\
\hline CHEMBL1318447 & 688161 & 4.9 & 4.8516 & TRN \\
\hline CHEMBL1496243 & 688161 & 5.3 & 4.9509 & TRN \\
\hline CHEMBL1543818 & 688161 & 4.7 & 4.8068 & TRN \\
\hline CHEMBL1383229 & 688161 & 4.6 & 4.9686 & TST \\
\hline CHEMBL490913 & 688161 & 4.6 & 4.7861 & TRN \\
\hline CHEMBL1510449 & 688161 & 5.0 & 4.9393 & TRN \\
\hline CHEMBL1491628 & 688161 & 5.4 & 4.9095 & TST \\
\hline CHEMBL260311 & 688161 & 5.6 & 4.8868 & TRN \\
\hline CHEMBL1329616 & 688161 & 4.6 & 4.90600 & 0000000001 \\
\hline CHEMBL1573365 & 688161 & 4.4 & 5.1151 & TST \\
\hline CHEMBL 7033 & 688161 & 4.7 & 4.837 & TRN \\
\hline CHEMBL1470366 & 688161 & 5.1 & 4.9389 & TRN \\
\hline CHEMBL491909 & 688161 & 4.6 & 4.8228 & TRN \\
\hline CHEMBL1407483 & 688161 & 4.9 & 5.4888 & TST \\
\hline CHEMBL1414563 & 688161 & 5.5 & 5.3035 & TRN \\
\hline CHEMBL1550525 & 688161 & 4.6 & 4.9161 & TST \\
\hline CHEMBL1556861 & 688161 & 4.6 & 4.8617 & TRN \\
\hline CHEMBL1336709 & 688161 & 4.5 & 4.7894 & TRN \\
\hline CHEMBL1418522 & 688161 & 5.0 & 4.8247 & TRN \\
\hline CHEMBL1410147 & 688161 & 6.3 & 5.1788 & TST \\
\hline CHEMBL1319120 & 688161 & 4.9 & 4.79 & TRN \\
\hline CHEMBL1453953 & 688161 & 4.6 & 4.7865 & TRN \\
\hline CHEMBL1459280 & 688161 & 4.9 & 5.1798 & TRN \\
\hline CHEMBL237253 & 688161 & 4.5 & 4.9142 & TRN \\
\hline CHEMBL1377260 & 688161 & 8.1024 & 4.959 & TST \\
\hline CHEMBL1580276 & 688161 & 4.4 & 4.994 & TRN \\
\hline CHEMBL 29898 & 688161 & 6.6 & 5.1879 & TRN \\
\hline CHEMBL1417749 & 688161 & 4.8 & 4.8899 & TST \\
\hline CHEMBL1479236 & 688161 & 4.8 & 4.8749 & TRN \\
\hline CHEMBL1371188 & 688161 & 4.8 & 4.856 & TRN \\
\hline CHEMBL1421517 & 688161 & 4.5 & 4.8867 & TRN \\
\hline CHEMBL1314291 & 688161 & 4.6 & 4.7743 & TRN \\
\hline CHEMBL80941 & 688161 & 4.9 & 5.3748 & TST \\
\hline CHEMBL1416115 & 688161 & 4.8 & 4.9684 & TRN \\
\hline CHEMBL1575730 & 688161 & 4.5 & 4.9012 & TRN \\
\hline CHEMBL1452561 & 688161 & 6.0 & 5.4136 & TRN \\
\hline CHEMBL1605613 & 688161 & 4.4 & 4.8113 & TRN \\
\hline CHEMBL1514431 & 688161 & 4.5 & 4.8442 & TRN \\
\hline CHEMBL1461578 & 688161 & 4.4 & 4.9124 & TRN \\
\hline
\end{tabular}




\begin{tabular}{|c|c|c|c|c|}
\hline & & & pplement & $\mathrm{a} \perp \mathrm{Ta}$ \\
\hline CHEMBL1541719 & 688161 & 4.4 & 4.9265 & TRN \\
\hline CHEMBL1299193 & 688161 & 4.6 & 4.8591 & TRN \\
\hline CHEMBL1592542 & 688161 & 6.6 & 5.2469 & TST \\
\hline CHEMBL1531592 & 688161 & 6.0 & 4.8726 & TRN \\
\hline CHEMBL1447023 & 688161 & 4.5 & 4.9075 & TRN \\
\hline CHEMBL466401 & 688161 & 4.6 & 4.8364 & TRN \\
\hline CHEMBL1566062 & 688161 & 4.4 & 4.9208 & TRN \\
\hline CHEMBL1565171 & 688161 & 4.7 & 4.9312 & TRN \\
\hline CHEMBL1551068 & 688161 & 4.7 & 4.7386 & TRN \\
\hline CHEMBL1367565 & 688161 & 4.4 & 4.9604 & TRN \\
\hline CHEMBL1596090 & 688161 & 4.8 & 4.8083 & TRN \\
\hline CHEMBL1583943 & 688161 & 4.4 & 4.8938 & TRN \\
\hline CHEMBL1352005 & 688161 & 4.8 & 4.8977 & TRN \\
\hline CHEMBL1335881 & 688161 & 4.9 & 4.9768 & TST \\
\hline CHEMBL1546310 & 688161 & 4.9 & 5.0518 & TRN \\
\hline CHEMBL1581335 & 688161 & 5.5 & 4.9278 & TRN \\
\hline CHEMBL1517431 & 688161 & 6.2 & 4.8687 & TRN \\
\hline CHEMBL1322220 & 688161 & 4.5 & 4.8063 & TRN \\
\hline CHEMBL1320502 & 688161 & 5.9 & 4.958 & TRN \\
\hline CHEMBL3190751 & 688161 & 4.6 & 4.9056 & TRN \\
\hline CHEMBL1539824 & 688161 & 4.5 & 4.8592 & TRN \\
\hline CHEMBL1607269 & 688161 & 4.4 & 4.8979 & TRN \\
\hline CHEMBL1492764 & 688161 & 4.5 & 4.9063 & TRN \\
\hline CHEMBL1404880 & 688161 & 4.6 & 4.9919 & TRN \\
\hline CHEMBL1361262 & 688161 & 5.1 & 4.9906 & TRN \\
\hline CHEMBL1316357 & 688161 & 4.7 & 4.7323 & TRN \\
\hline CHEMBL1300503 & 688161 & 4.7 & 4.8667 & TST \\
\hline CHEMBL1368505 & 688161 & 4.6 & 4.9771 & TRN \\
\hline CHEMBL1348151 & 688161 & 4.6 & 4.9222 & TRN \\
\hline CHEMBL1517187 & 688161 & 4.7 & 5.0446 & TST \\
\hline CHEMBL1608758 & 688161 & 4.7 & 4.9867 & TRN \\
\hline CHEMBL1484657 & 688161 & 4.6 & 4.8762 & TRN \\
\hline CHEMBL1431145 & 688161 & 4.7 & 5.1678 & TRN \\
\hline CHEMBL1996451 & 688161 & 4.6 & 4.9495 & TRN \\
\hline CHEMBL1531668 & 688161 & 4.7 & 4.8795 & TST \\
\hline CHEMBL1394981 & 688161 & 4.5 & 5.0399 & TRN \\
\hline CHEMBL1302960 & 688161 & 4.7 & 5.1116 & TRN \\
\hline CHEMBL1496744 & 688161 & 5.1 & 4.878 & TRN \\
\hline CHEMBL1384172 & 688161 & 5.7 & 5.0299 & TRN \\
\hline CHEMBL1306790 & 688161 & 4.5 & 4.9684 & TRN \\
\hline CHEMBL1478187 & 688161 & 4.6 & 4.9553 & TRN \\
\hline CHEMBL1450545 & 688161 & 5.1 & 4.9627 & TST \\
\hline CHEMBL1325377 & 688161 & 4.8 & 4.9212 & TRN \\
\hline CHEMBL1599015 & 688161 & 4.6 & 4.7587 & TRN \\
\hline CHEMBL3196987 & 688161 & 4.6 & 4.9034 & TRN \\
\hline CHEMBL1446896 & 688161 & 5.0 & 4.9261 & TRN \\
\hline CHEMBL1451874 & 688161 & 4.4 & 4.9999 & TRN \\
\hline CHEMBL1606077 & 688161 & 4.8 & 4.9055 & TRN \\
\hline
\end{tabular}




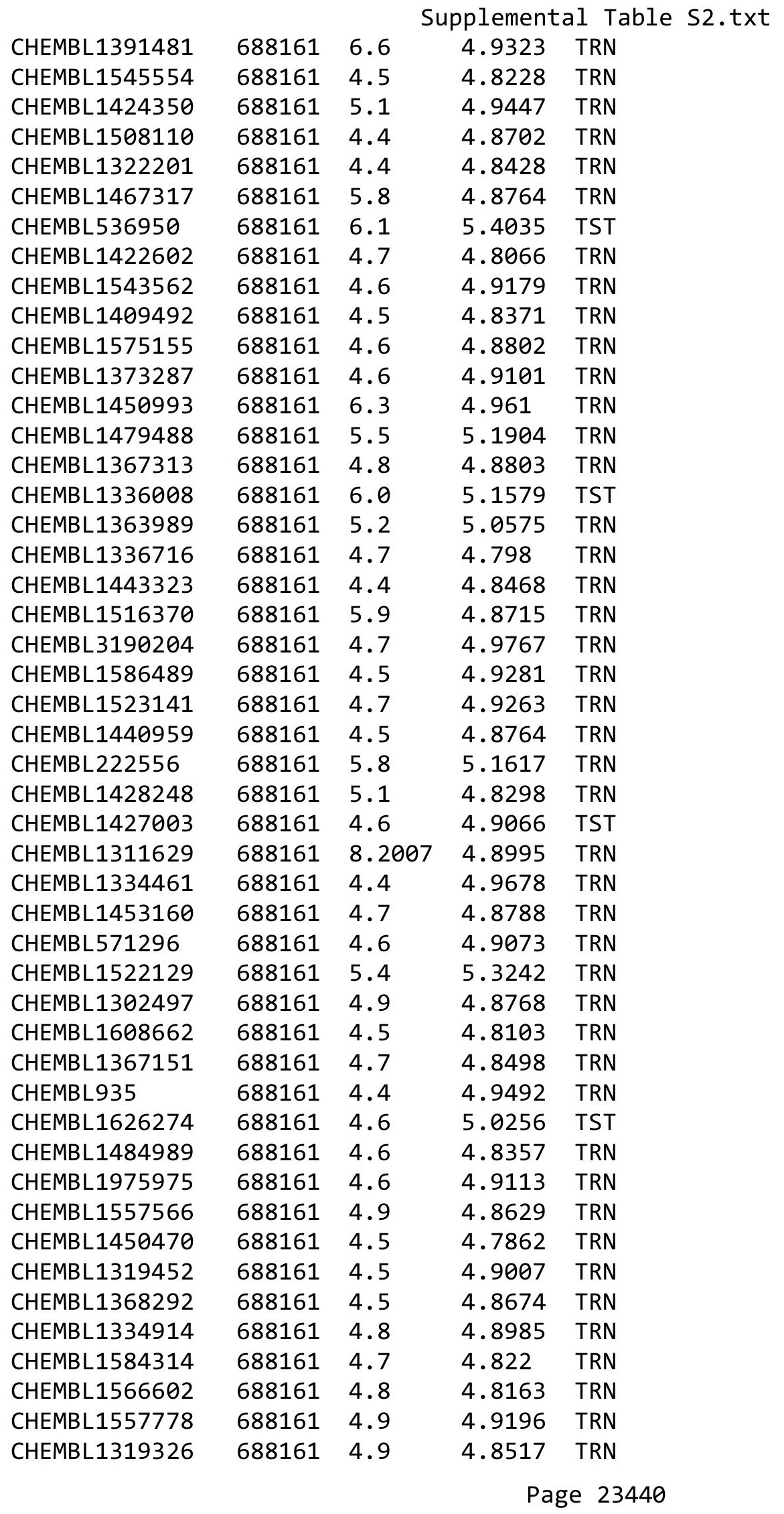




\begin{tabular}{|c|c|c|c|c|c|}
\hline \multirow{2}{*}{ CHEMBL1336714 } & \multirow{2}{*}{688161} & \multirow[b]{2}{*}{4.6} & \\
\hline & & & 4.9524 & TRN & \\
\hline CHEMBL1597812 & 688161 & 4.7 & 5.0345 & TST & \\
\hline CHEMBL1493034 & 688161 & 4.7 & 4.8036 & TRN & \\
\hline CHEMBL1508235 & 688161 & 5.7 & 4.7984 & TRN & \\
\hline CHEMBL1567402 & 688161 & 5.1 & 5.1617 & TRN & \\
\hline CHEMBL1404511 & 688161 & 4.6 & 4.8589 & TRN & \\
\hline CHEMBL1474185 & 688161 & 4.5 & 4.9105 & TRN & \\
\hline CHEMBL1554888 & 688161 & 4.7 & 4.8551 & TRN & \\
\hline CHEMBL1981243 & 688161 & 4.6 & 4.8445 & TRN & \\
\hline CHEMBL3213883 & 688161 & 5.4 & 5.1225 & TST & \\
\hline CHEMBL1565212 & 688161 & 5.4 & 4.8792 & TRN & \\
\hline CHEMBL1393205 & 688161 & 4.8 & 4.9363 & TRN & \\
\hline CHEMBL1349061 & 688161 & 5.5 & 4.9333 & TRN & \\
\hline CHEMBL1593717 & 688161 & 5.0 & 5.0314 & TST & \\
\hline CHEMBL1536945 & 688161 & 5.3 & 4.9134 & TRN & \\
\hline CHEMBL1585829 & 688161 & 4.8 & 4.8539 & TRN & \\
\hline CHEMBL1428932 & 688161 & 5.7 & 4.9363 & TRN & \\
\hline CHEMBL1589562 & 688161 & 4.9 & 4.9009 & TRN & \\
\hline CHEMBL1314288 & 688161 & 4.8 & 4.9239 & 99999999995 & TRN \\
\hline CHEMBL3199353 & 688161 & 5.2 & 4.9099 & TRN & \\
\hline CHEMBL1538976 & 688161 & 5.5 & 4.7902 & TRN & \\
\hline CHEMBL1599249 & 688161 & 4.5 & 4.9002 & TRN & \\
\hline CHEMBL1531620 & 688161 & 5.0 & 4.9387 & TST & \\
\hline CHEMBL 29097 & 688161 & 4.9 & 4.8195 & TST & \\
\hline CHEMBL1555494 & 688161 & 4.8 & 4.8772 & TRN & \\
\hline CHEMBL80155 & 688161 & 4.5 & 4.9425 & TRN & \\
\hline CHEMBL1564364 & 688161 & 4.8 & 4.966 & TRN & \\
\hline CHEMBL52347 & 688161 & 4.6 & 5.1411 & TRN & \\
\hline CHEMBL1558692 & 688161 & 4.8 & 4.9725 & TST & \\
\hline CHEMBL151797 & 688161 & 4.7 & 4.9898 & TRN & \\
\hline CHEMBL1464266 & 688161 & 5.3 & 4.9583 & TRN & \\
\hline CHEMBL1337243 & 688161 & 4.4 & 4.8606 & TRN & \\
\hline CHEMBL1359691 & 688161 & 4.6 & 4.8608 & TRN & \\
\hline CHEMBL1375337 & 688161 & 4.6 & 4.936 & TRN & \\
\hline CHEMBL1328941 & 688161 & 5.0 & 5.103 & TRN & \\
\hline CHEMBL1482262 & 688161 & 4.6 & 4.7902 & TRN & \\
\hline CHEMBL1381016 & 688161 & 4.6 & 4.9674 & TST & \\
\hline CHEMBL1527282 & 688161 & 4.5 & 4.9742 & TRN & \\
\hline CHEMBL1422702 & 688161 & 4.6 & 4.7765 & TRN & \\
\hline CHEMBL1609748 & 688161 & 5.1 & 5.1272 & TRN & \\
\hline CHEMBL1399136 & 688161 & 4.7 & 4.8332 & TRN & \\
\hline CHEMBL1488280 & 688161 & 5.0 & 4.763 & TRN & \\
\hline CHEMBL1364346 & 688161 & 5.5 & 4.8636 & TRN & \\
\hline CHEMBL3199462 & 688161 & 5.8 & 4.9234 & TRN & \\
\hline CHEMBL1339376 & 688161 & 4.8 & 4.9518 & TRN & \\
\hline CHEMBL544115 & 688161 & 4.8 & 5.43 & TST & \\
\hline CHEMBL1358570 & 688161 & 5.4 & 5.1057 & TST & \\
\hline CHEMBL1526240 & 688161 & 4.7 & 5.0947 & TST & \\
\hline & & & & 23441 & \\
\hline
\end{tabular}




\begin{tabular}{|c|c|c|c|c|c|}
\hline & & & & & \\
\hline CHEMBL1582009 & 688161 & 5.4 & 4.8286 & TRN & \\
\hline CHEMBL1336808 & 688161 & 5.3 & 4.8919 & 99999999995 & TRN \\
\hline CHEMBL1547457 & 688161 & 4.9 & 4.8618 & TRN & \\
\hline CHEMBL1598490 & 688161 & 4.6 & 4.923 & TRN & \\
\hline CHEMBL1521130 & 688161 & 4.8 & 4.8807 & TRN & \\
\hline CHEMBL572189 & 688161 & 4.4 & 4.8783 & TRN & \\
\hline CHEMBL1303198 & 688161 & 4.9 & 4.8297 & TRN & \\
\hline CHEMBL1378655 & 688161 & 4.8 & 5.1386 & TRN & \\
\hline CHEMBL1698288 & 688161 & 5.4 & 4.9384 & TST & \\
\hline CHEMBL1385254 & 688161 & 4.4 & 4.8206 & TRN & \\
\hline CHEMBL1374249 & 688161 & 4.6 & 4.9067 & TRN & \\
\hline CHEMBL1554974 & 688161 & 4.9 & 4.9188 & TRN & \\
\hline CHEMBL1385926 & 688161 & 4.6 & 4.8886 & TRN & \\
\hline CHEMBL25308 & 688161 & 4.8 & 4.9783 & TST & \\
\hline CHEMBL1552854 & 688161 & 4.6 & 4.828 & TRN & \\
\hline CHEMBL1600347 & 688161 & 4.6 & 5.0583 & TRN & \\
\hline CHEMBL1557772 & 688161 & 4.9 & 4.9018 & TRN & \\
\hline CHEMBL1466155 & 688161 & 4.8 & 4.7769 & TRN & \\
\hline CHEMBL1514398 & 688161 & 6.2 & 4.9939 & TST & \\
\hline CHEMBL1495381 & 688161 & 4.5 & 4.9757 & TST & \\
\hline CHEMBL1542518 & 688161 & 4.6 & 4.8284 & TRN & \\
\hline CHEMBL1577170 & 688161 & 4.4 & 4.9108 & TRN & \\
\hline CHEMBL1558214 & 688161 & 4.4 & 4.9153 & TRN & \\
\hline CHEMBL1585158 & 688161 & 4.8 & 4.8838 & TRN & \\
\hline CHEMBL1502286 & 688161 & 4.5 & 5.0121 & TRN & \\
\hline CHEMBL1343695 & 688161 & 4.5 & 4.8835 & TRN & \\
\hline CHEMBL1355970 & 688161 & 4.4 & 4.8392 & TRN & \\
\hline CHEMBL1460401 & 688161 & 4.6 & 5.1854 & TRN & \\
\hline CHEMBL1373746 & 688161 & 5.6 & 4.8679 & TRN & \\
\hline CHEMBL1348502 & 688161 & 4.9 & 4.8564 & TRN & \\
\hline CHEMBL24983 & 688161 & 4.9 & 5.1001 & TST & \\
\hline CHEMBL578585 & 688161 & 4.8 & 4.8207 & TRN & \\
\hline CHEMBL566933 & 688161 & 5.3 & 5.187 & TRN & \\
\hline CHEMBL1606330 & 688161 & 4.8 & 4.9492 & TRN & \\
\hline CHEMBL1566512 & 688161 & 5.5 & 5.379 & TRN & \\
\hline CHEMBL1235157 & 688161 & 4.5 & 4.8408 & TST & \\
\hline CHEMBL 245121 & 688161 & 5.7 & 4.8761 & TST & \\
\hline CHEMBL1315457 & 688161 & 4.4 & 4.8457 & TST & \\
\hline CHEMBL1590095 & 688161 & 4.4 & 4.7482 & TRN & \\
\hline CHEMBL105310 & 688161 & 4.7 & 4.9987 & TRN & \\
\hline CHEMBL1481914 & 688161 & 5.6 & 5.1001 & TRN & \\
\hline CHEMBL1519768 & 688161 & 5.0 & 4.806 & TST & \\
\hline CHEMBL1393088 & 688161 & 4.4 & 4.937 & TRN & \\
\hline CHEMBL1443376 & 688161 & 4.9 & 4.9228 & TST & \\
\hline CHEMBL1419223 & 688161 & 4.8 & 4.7641 & TRN & \\
\hline CHEMBL1353353 & 688161 & 4.9 & 4.836 & TRN & \\
\hline CHEMBL1583517 & 688161 & 4.4 & 4.8977 & TRN & \\
\hline CHEMBL1362572 & 688161 & 4.6 & 4.8429 & TRN & \\
\hline
\end{tabular}




\begin{tabular}{|c|c|c|c|c|c|}
\hline & & \multicolumn{4}{|c|}{ Supplemental Table S2.txt } \\
\hline CHEMBL1594134 & 688161 & 4.4 & 4.8701 & TRN & \\
\hline CHEMBL1533037 & 688161 & 4.5 & 4.9162 & TRN & \\
\hline CHEMBL1551643 & 688161 & 5.7 & 5.1343 & TST & \\
\hline CHEMBL1559772 & 688161 & 4.4 & 4.8214 & TRN & \\
\hline CHEMBL1359447 & 688161 & 5.3 & 5.1488 & TST & \\
\hline CHEMBL1607951 & 688161 & 5.1 & 4.9147 & TRN & \\
\hline CHEMBL1451433 & 688161 & 5.1 & 4.8968 & TRN & \\
\hline CHEMBL1346737 & 688161 & 4.6 & 5.0428 & TRN & \\
\hline CHEMBL1419549 & 688161 & 4.6 & 4.9089 & TRN & \\
\hline CHEMBL1530548 & 688161 & 4.8 & 4.8191 & TRN & \\
\hline CHEMBL1565244 & 688161 & 4.6 & \multicolumn{2}{|c|}{4.9430000000000005} & TRN \\
\hline CHEMBL1603991 & 688161 & 5.6 & 5.2825 & TRN & \\
\hline CHEMBL1418088 & 688161 & 5.6 & 4.982 & TRN & \\
\hline CHEMBL1569825 & 688161 & 4.7 & 4.9333 & TRN & \\
\hline CHEMBL1363313 & 688161 & 5.1 & 4.8179 & TRN & \\
\hline CHEMBL1534376 & 688161 & 4.9 & 4.8044 & TRN & \\
\hline CHEMBL1474681 & 688161 & 4.5 & 4.9297 & TRN & \\
\hline CHEMBL453376 & 688161 & 5.4 & 5.0318 & TST & \\
\hline CHEMBL1325732 & 688161 & 5.3 & 5.0335 & TST & \\
\hline CHEMBL1427756 & 688161 & 5.4 & 4.7559 & TRN & \\
\hline CHEMBL1460713 & 688161 & 4.9 & 4.9147 & TRN & \\
\hline CHEMBL1372808 & 688161 & 4.7 & 4.9783 & TRN & \\
\hline CHEMBL1578064 & 688161 & 4.8 & 4.9689 & TRN & \\
\hline CHEMBL358546 & 688161 & 5.3 & 5.0089 & TRN & \\
\hline CHEMBL1434057 & 688161 & 4.9 & 4.9226 & TRN & \\
\hline CHEMBL 258893 & 688161 & 4.7 & 4.9203 & TST & \\
\hline CHEMBL1349514 & 688161 & 4.6 & 4.7985 & TRN & \\
\hline CHEMBL1510416 & 688161 & 5.0 & 4.944 & TRN & \\
\hline CHEMBL1520491 & 688161 & 4.5 & 4.8692 & TRN & \\
\hline CHEMBL1328025 & 688161 & 6.8 & 4.9037 & TRN & \\
\hline CHEMBL1479248 & 688161 & 4.9 & 4.8257 & TRN & \\
\hline CHEMBL1431996 & 688161 & 4.9 & 4.7979 & TRN & \\
\hline CHEMBL1497318 & 688161 & 4.4 & 4.8263 & TST & \\
\hline CHEMBL1322078 & 688161 & 4.6 & 4.9333 & TRN & \\
\hline CHEMBL1330543 & 688161 & 4.6 & 4.7821 & TRN & \\
\hline CHEMBL1528726 & 688161 & 4.7 & 5.2474 & TRN & \\
\hline CHEMBL1386272 & 688161 & 4.8 & 4.8704 & TRN & \\
\hline CHEMBL1349721 & 688161 & 4.5 & 4.9056 & TRN & \\
\hline CHEMBL44 & 688161 & 6.0 & 5.1216 & TRN & \\
\hline CHEMBL1308738 & 688161 & 5.3 & 4.8955 & TRN & \\
\hline CHEMBL1475951 & 688161 & 4.8 & 4.8599 & TRN & \\
\hline CHEMBL1361308 & 688161 & 5.7 & 4.8748 & TRN & \\
\hline CHEMBL1999166 & 688161 & 4.6 & 4.9078 & TST & \\
\hline CHEMBL1463899 & 688161 & 7.8013 & 4.9649 & TST & \\
\hline CHEMBL530963 & 688161 & 4.9 & 4.871 & TRN & \\
\hline CHEMBL1479366 & 688161 & 4.9 & 4.9548 & TRN & \\
\hline CHEMBL1418460 & 688161 & 4.5 & 4.8537 & TST & \\
\hline CHEMBL592712 & 688161 & 4.8 & 4.7854 & TRN & \\
\hline
\end{tabular}




\begin{tabular}{|c|c|c|c|c|c|}
\hline \multicolumn{6}{|c|}{ Supplemental Table S2.txt } \\
\hline CHEMBL1521813 & 688161 & 4.5 & 5.0228 & TRN & \\
\hline CHEMBL1378991 & 688161 & 4.5 & 4.8955 & TRN & \\
\hline CHEMBL1474209 & 688161 & 5.9 & 5.0348 & TRN & \\
\hline CHEMBL1373244 & 688161 & 5.0 & 4.7549 & TRN & \\
\hline CHEMBL1441079 & 688161 & 4.5 & 4.8933 & TRN & \\
\hline CHEMBL1605399 & 688161 & 4.6 & 4.7669 & TRN & \\
\hline CHEMBL1532838 & 688161 & 5.0 & 4.8759 & TRN & \\
\hline CHEMBL1492428 & 688161 & 5.0 & 5.2466 & TRN & \\
\hline CHEMBL17127 & 688161 & 4.7 & 4.8928 & TRN & \\
\hline CHEMBL1364003 & 688161 & 4.7 & 4.7745 & TRN & \\
\hline CHEMBL1299891 & 688161 & 4.4 & 5.0501 & TRN & \\
\hline CHEMBL 1463540 & 688161 & 4.6 & 4.9308 & TST & \\
\hline CHEMBL1467839 & 688161 & 4.6 & 4.8683 & TRN & \\
\hline CHEMBL1301720 & 688161 & 5.5 & 4.909 & TRN & \\
\hline CHEMBL1360434 & 688161 & 4.6 & 4.8635 & TRN & \\
\hline CHEMBL1569027 & 688161 & 4.4 & 4.8953 & TRN & \\
\hline CHEMBL1427637 & 688161 & 4.8 & 4.9596 & TRN & \\
\hline CHEMBL1317924 & 688161 & 4.4 & 4.9571 & TRN & \\
\hline CHEMBL1446731 & 688161 & 5.5 & 4.909 & TRN & \\
\hline CHEMBL1407317 & 688161 & 5.5 & 4.9396 & TRN & \\
\hline CHEMBL1556512 & 688161 & 5.6 & 4.7899 & TRN & \\
\hline CHEMBL1375570 & 688161 & 4.6 & 4.8619 & TST & \\
\hline CHEMBL1530927 & 688161 & 4.6 & 4.8745 & TRN & \\
\hline CHEMBL566531 & 688161 & 4.8 & 5.1457 & TRN & \\
\hline CHEMBL1498575 & 688161 & 4.8 & 4.775 & TRN & \\
\hline CHEMBL1347378 & 688161 & 4.7 & 4.8743 & TRN & \\
\hline CHEMBL1475541 & 688161 & 4.5 & 4.8236 & TRN & \\
\hline CHEMBL1474633 & 688161 & 4.7 & 4.9451 & TRN & \\
\hline CHEMBL1352852 & 688161 & 4.8 & 4.8755 & TRN & \\
\hline CHEMBL1360942 & 688161 & 5.6 & 5.1299 & TST & \\
\hline CHEMBL1392390 & 688161 & 4.5 & 4.7758 & TRN & \\
\hline CHEMBL1304961 & 688161 & 4.7 & 5.0554 & TST & \\
\hline CHEMBL1398609 & 688161 & 5.1 & 4.9906 & TST & \\
\hline CHEMBL1299783 & 688161 & 6.0 & 4.9175 & TRN & \\
\hline CHEMBL1309126 & 688161 & 4.8 & 4.8491 & TRN & \\
\hline CHEMBL140 & 688161 & 6.0 & 5.3071 & TRN & \\
\hline CHEMBL1331335 & 688161 & 4.4 & 4.8332 & TRN & \\
\hline CHEMBL1321811 & 688161 & 4.6 & 4.8577 & TRN & \\
\hline CHEMBL1602211 & 688161 & 4.8 & 4.9792 & TRN & \\
\hline CHEMBL1326192 & 688161 & 4.9 & 4.8888 & TRN & \\
\hline CHEMBL1425945 & 688161 & 4.9 & 4.8734 & TRN & \\
\hline CHEMBL3145107 & 688161 & 5.5 & 4.9122 & TRN & \\
\hline CHEMBL1573269 & 688161 & 4.7 & 4.82600 & 00000000005 & TRN \\
\hline CHEMBL1564572 & 688161 & 4.8 & 4.7893 & TRN & \\
\hline CHEMBL1340820 & 688161 & 4.9 & 4.9577 & TRN & \\
\hline CHEMBL1379324 & 688161 & 4.4 & 5.02 & TST & \\
\hline CHEMBL1493884 & 688161 & 4.8 & 5.5956 & TRN & \\
\hline CHEMBL1479404 & 688161 & 4.5 & 4.9133 & TRN & \\
\hline
\end{tabular}




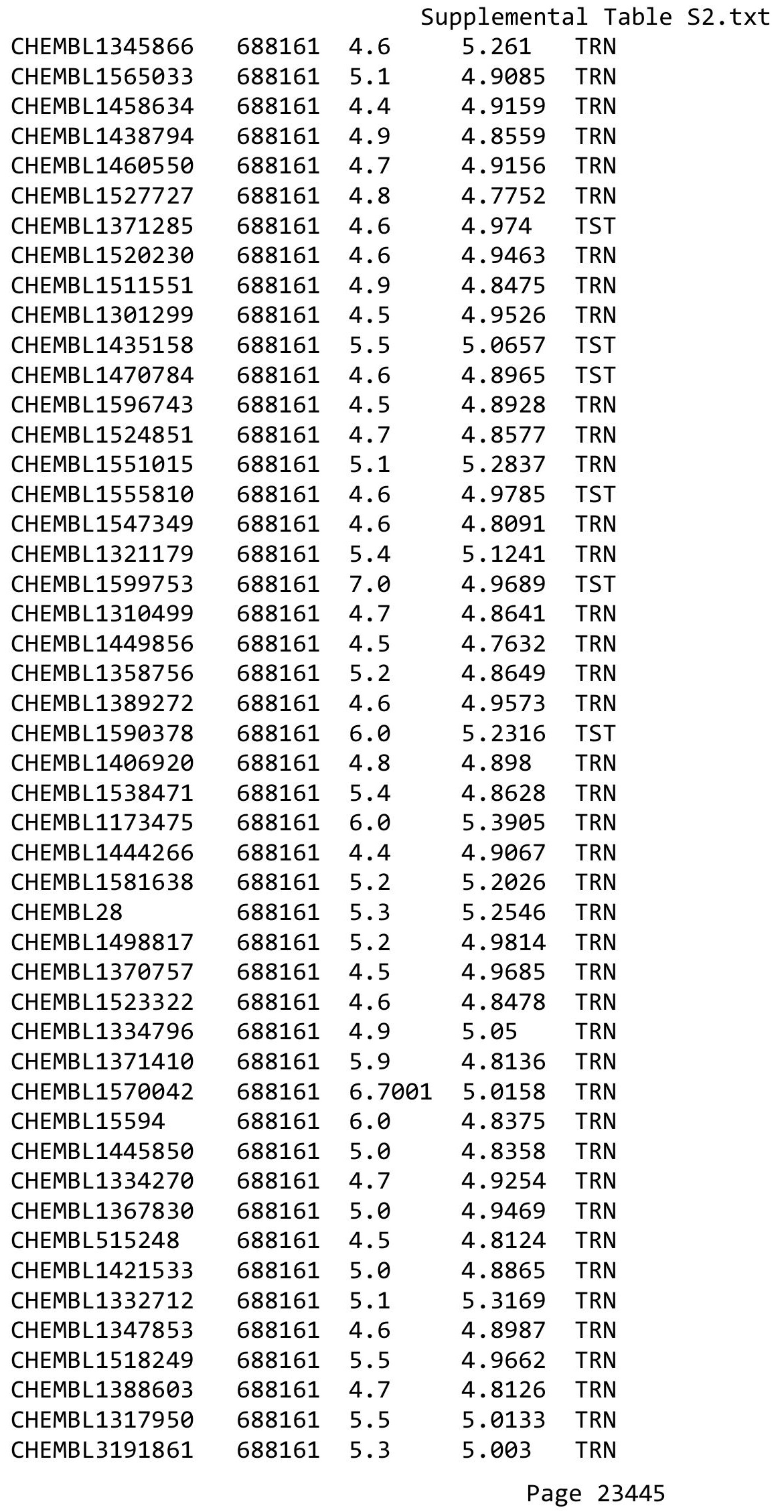




\begin{tabular}{|c|c|c|c|c|c|}
\hline \multicolumn{6}{|c|}{ Supplemental Table S2.txt } \\
\hline CHEMBL1523911 & 688161 & 4.5 & 4.9019 & TRN & \\
\hline CHEMBL1326295 & 688161 & 5.9 & 4.9572 & TRN & \\
\hline CHEMBL337173 & 688161 & 4.4 & 5.0063 & TRN & \\
\hline CHEMBL1329526 & 688161 & 4.7 & 4.7638 & TRN & \\
\hline CHEMBL1435381 & 688161 & 4.4 & 5.0446 & TST & \\
\hline CHEMBL1521490 & 688161 & 4.6 & 4.7994 & TRN & \\
\hline CHEMBL1558822 & 688161 & 5.1 & 4.9018 & TRN & \\
\hline CHEMBL1482369 & 688161 & 5.0 & 4.8492 & TRN & \\
\hline CHEMBL1345225 & 688161 & 4.7 & 4.8657 & TRN & \\
\hline CHEMBL3196681 & 688161 & 5.6 & 4.9055 & TST & \\
\hline CHEMBL1482983 & 688161 & 4.8 & 4.9082 & TRN & \\
\hline CHEMBL370152 & 688161 & 4.6 & 5.0508 & TST & \\
\hline CHEMBL1411449 & 688161 & 5.5 & 4.9172 & TRN & \\
\hline CHEMBL1341450 & 688161 & 4.4 & 5.0614 & TRN & \\
\hline CHEMBL1579143 & 688161 & 4.9 & 5.3541 & TRN & \\
\hline CHEMBL1348345 & 688161 & 5.3 & 5.0508 & TRN & \\
\hline CHEMBL1442006 & 688161 & 5.1 & 4.9445 & TRN & \\
\hline CHEMBL1331809 & 688161 & 5.7 & 5.3781 & TRN & \\
\hline CHEMBL1543554 & 688161 & 4.5 & 4.7852 & TRN & \\
\hline CHEMBL313737 & 688161 & 5.5 & 4.9707 & TST & \\
\hline CHEMBL1368067 & 688161 & 4.9 & 4.8855 & TRN & \\
\hline CHEMBL1391294 & 688161 & 4.5 & 4.9247 & TRN & \\
\hline CHEMBL1605701 & 688161 & 5.0 & 5.0968 & TRN & \\
\hline CHEMBL1600749 & 688161 & 4.7 & 4.8413 & TRN & \\
\hline CHEMBL1381328 & 688161 & 5.4 & 4.8618 & TRN & \\
\hline CHEMBL1575053 & 688161 & 5.1 & 4.8923 & TRN & \\
\hline CHEMBL1587288 & 688161 & 4.7 & 4.817 & TRN & \\
\hline CHEMBL1573083 & 688161 & 4.5 & 4.7956 & TRN & \\
\hline CHEMBL1605749 & 688161 & 5.0 & 4.8326 & TRN & \\
\hline CHEMBL1707818 & 688161 & 4.8 & 5.0925 & TRN & \\
\hline CHEMBL1363398 & 688161 & 4.8 & 5.1176 & TRN & \\
\hline CHEMBL1462139 & 688161 & 4.4 & 4.76399 & & TRN \\
\hline CHEMBL1425330 & 688161 & 4.8 & 4.9089 & TRN & \\
\hline CHEMBL177611 & 688161 & 4.6 & 4.9246 & TRN & \\
\hline CHEMBL1346140 & 688161 & 5.5 & 5.0162 & TRN & \\
\hline CHEMBL1425003 & 688161 & 4.9 & 5.2398 & TRN & \\
\hline CHEMBL1549452 & 688161 & 5.0 & 5.39 & TRN & \\
\hline CHEMBL1611800 & 688161 & 5.0 & 4.922 & TST & \\
\hline CHEMBL1319806 & 688161 & 4.7 & 4.9568 & TRN & \\
\hline CHEMBL1588727 & 688161 & 5.3 & 4.7893 & TRN & \\
\hline CHEMBL1459530 & 688161 & 4.5 & 5.6637 & TRN & \\
\hline CHEMBL1423479 & 688161 & 5.7 & 5.0536 & TST & \\
\hline CHEMBL1489804 & 688161 & 4.4 & 4.8788 & TRN & \\
\hline CHEMBL3196107 & 688161 & 4.6 & 4.9441 & TRN & \\
\hline CHEMBL1442372 & 688161 & 4.9 & 4.8793 & TRN & \\
\hline CHEMBL1348265 & 688161 & 5.2 & 4.953 & TST & \\
\hline CHEMBL1440157 & 688161 & 4.4 & 4.7967 & TRN & \\
\hline CHEMBL1448781 & 688161 & 5.5 & 4.9902 & TST & \\
\hline
\end{tabular}




\begin{tabular}{|c|c|c|c|c|}
\hline \multicolumn{5}{|c|}{ Supplemental Table S2.txt } \\
\hline CHEMBL1307438 & 688161 & 6.1 & 4.9232 & TRN \\
\hline CHEMBL1575787 & 688161 & 4.6 & 5.1135 & TRN \\
\hline CHEMBL1394169 & 688161 & 4.6 & 4.8564 & TRN \\
\hline CHEMBL 3196407 & 688161 & 5.4 & 5.0632 & TRN \\
\hline CHEMBL1558613 & 688161 & 4.5 & 4.8378 & TRN \\
\hline CHEMBL1314768 & 688161 & 7.3002 & 5.0611 & TST \\
\hline CHEMBL 373137 & 688161 & 4.6 & 4.9194 & TRN \\
\hline CHEMBL1407051 & 688161 & 4.6 & 5.0145 & TRN \\
\hline CHEMBL1474302 & 688161 & 4.4 & 4.902 & TRN \\
\hline CHEMBL22373 & 688161 & 4.5 & 4.9292 & TST \\
\hline CHEMBL1484665 & 688161 & 4.8 & 4.8571 & TRN \\
\hline CHEMBL416657 & 688161 & 4.5 & 4.7823 & TST \\
\hline CHEMBL1459569 & 688161 & 4.6 & 4.8716 & TRN \\
\hline CHEMBL1516005 & 688161 & 4.5 & 4.8926 & TRN \\
\hline CHEMBL1374476 & 688161 & 5.4 & 5.0342 & TRN \\
\hline CHEMBL1306666 & 688161 & 5.6 & 4.8925 & TRN \\
\hline CHEMBL1536690 & 688161 & 4.5 & 4.8726 & TRN \\
\hline CHEMBL1412617 & 688161 & 5.3 & 5.002 & TRN \\
\hline CHEMBL1412605 & 688161 & 4.8 & 4.9045 & TRN \\
\hline CHEMBL441282 & 688161 & 5.0 & 5.2104 & TST \\
\hline CHEMBL1350226 & 688161 & 4.8 & 4.9418 & TRN \\
\hline CHEMBL1388233 & 688161 & 4.7 & 4.9045 & TRN \\
\hline CHEMBL1578233 & 688161 & 4.7 & 4.7495 & TRN \\
\hline CHEMBL1362888 & 688161 & 4.9 & 4.8741 & TRN \\
\hline CHEMBL1324212 & 688161 & 4.4 & 4.8434 & TRN \\
\hline CHEMBL1317932 & 688161 & 5.5 & 4.979 & TRN \\
\hline CHEMBL1460877 & 688161 & 5.6 & 5.0138 & TRN \\
\hline CHEMBL1555314 & 688161 & 4.7 & 4.8062 & TRN \\
\hline CHEMBL1381553 & 688161 & 5.2 & 4.8859 & TRN \\
\hline CHEMBL1563270 & 688161 & 4.5 & 4.936 & TRN \\
\hline CHEMBL1469735 & 688161 & 5.5 & 4.9107 & TRN \\
\hline CHEMBL1380257 & 688161 & 4.4 & 4.9129 & TST \\
\hline CHEMBL1452397 & 688161 & 4.5 & 4.9348 & TRN \\
\hline CHEMBL1551049 & 688161 & 4.4 & 4.9078 & TRN \\
\hline CHEMBL1449373 & 688161 & 5.5 & 5.4607 & TRN \\
\hline CHEMBL1519762 & 688161 & 4.6 & 4.9814 & TRN \\
\hline CHEMBL1572834 & 688161 & 4.7 & 4.8018 & TRN \\
\hline CHEMBL508112 & 688161 & 5.7 & 4.9948 & TRN \\
\hline CHEMBL1525442 & 688161 & 5.3 & 4.9003 & TST \\
\hline CHEMBL1602230 & 688161 & 5.9 & 4.9651 & TRN \\
\hline CHEMBL1337685 & 688161 & 4.8 & 4.9532 & TRN \\
\hline CHEMBL301100 & 688161 & 4.6 & 5.0078 & TRN \\
\hline CHEMBL1536497 & 688161 & 4.6 & 4.8854 & TRN \\
\hline CHEMBL1507162 & 688161 & 5.4 & 5.2847 & TRN \\
\hline CHEMBL1336155 & 688161 & 5.4 & 5.1678 & TST \\
\hline CHEMBL1561864 & 688161 & 4.4 & 4.9108 & TRN \\
\hline CHEMBL1548618 & 688161 & 4.5 & 5.0524 & TST \\
\hline CHEMBL1558834 & 688161 & 4.7 & 4.9306 & TRN \\
\hline
\end{tabular}




\begin{tabular}{|c|c|c|c|c|}
\hline \multicolumn{5}{|c|}{ Supplemental Table S2.txt } \\
\hline CHEMBL1370737 & 688161 & 4.5 & 4.9501 & TRN \\
\hline CHEMBL1537779 & 688161 & 4.4 & 4.8243 & TRN \\
\hline CHEMBL6597 & 688161 & 4.6 & 4.931 & TST \\
\hline CHEMBL1329551 & 688161 & 6.2 & 4.9866 & TRN \\
\hline CHEMBL1403350 & 688161 & 4.9 & 4.947 & TRN \\
\hline CHEMBL1327772 & 688161 & 5.1 & 4.8768 & TRN \\
\hline CHEMBL1375780 & 688161 & 4.9 & 4.816 & TST \\
\hline CHEMBL1383147 & 688161 & 5.7 & 4.8881 & TRN \\
\hline CHEMBL1558361 & 688161 & 5.4 & 4.8754 & TRN \\
\hline CHEMBL1594720 & 688161 & 5.9 & 4.8899 & TRN \\
\hline CHEMBL1548335 & 688161 & 4.4 & 4.936 & TRN \\
\hline CHEMBL1428977 & 688161 & 7.5003 & 4.8956 & TRN \\
\hline CHEMBL1537094 & 688161 & 6.0 & 5.0047 & TRN \\
\hline CHEMBL1356623 & 688161 & 4.8 & 4.9552 & TRN \\
\hline CHEMBL1325392 & 688161 & 5.0 & 4.81 & TRN \\
\hline CHEMBL1462735 & 688161 & 4.6 & 4.9528 & TRN \\
\hline CHEMBL1431969 & 688161 & 4.6 & 5.0174 & TRN \\
\hline CHEMBL1300534 & 688161 & 4.6 & 4.9659 & TRN \\
\hline CHEMBL1451835 & 688161 & 4.8 & 4.9416 & TRN \\
\hline CHEMBL1365541 & 688161 & 4.5 & 4.9029 & TRN \\
\hline CHEMBL1479543 & 688161 & 5.1 & 4.8964 & TRN \\
\hline CHEMBL1407862 & 688161 & 5.0 & 5.0861 & TRN \\
\hline CHEMBL 26320 & 688161 & 6.0 & 4.8066 & TRN \\
\hline CHEMBL1608043 & 688161 & 4.8 & 4.8448 & TRN \\
\hline CHEMBL1350547 & 688161 & 4.6 & 4.7971 & TRN \\
\hline CHEMBL1573722 & 688161 & 4.6 & 4.8854 & TRN \\
\hline CHEMBL1603878 & 688161 & 5.7 & 4.8599 & TRN \\
\hline CHEMBL1426762 & 688161 & 5.8 & 4.9494 & TRN \\
\hline CHEMBL 3212537 & 688161 & 4.5 & 4.9002 & TRN \\
\hline CHEMBL1350028 & 688161 & 4.5 & 4.8447 & TRN \\
\hline CHEMBL1386201 & 688161 & 5.0 & 4.9182 & TRN \\
\hline CHEMBL1362935 & 688161 & 4.9 & 5.0854 & TRN \\
\hline CHEMBL342375 & 688161 & 5.7 & 5.0101 & TST \\
\hline CHEMBL1567295 & 688161 & 4.6 & 4.8481 & TRN \\
\hline CHEMBL1371927 & 688161 & 4.8 & 4.8909 & TRN \\
\hline CHEMBL1407035 & 688161 & 4.6 & 4.8683 & TRN \\
\hline CHEMBL1423050 & 688161 & 4.8 & 4.8918 & TRN \\
\hline CHEMBL1608709 & 688161 & 4.8 & 4.8351 & TRN \\
\hline CHEMBL473107 & 688161 & 4.7 & 4.8556 & TST \\
\hline CHEMBL1597738 & 688161 & 4.4 & 4.9459 & TST \\
\hline CHEMBL1566780 & 688161 & 5.0 & 5.0403 & TRN \\
\hline CHEMBL170408 & 688161 & 4.5 & 4.7954 & TRN \\
\hline CHEMBL1362247 & 688161 & 4.5 & 4.8958 & TRN \\
\hline CHEMBL1402026 & 688161 & 4.6 & 4.8843 & TRN \\
\hline CHEMBL1572336 & 688161 & 4.4 & 4.8652 & TST \\
\hline CHEMBL1387667 & 688161 & 4.6 & 4.8328 & TRN \\
\hline CHEMBL1601910 & 688161 & 4.9 & 4.794 & TRN \\
\hline CHEMBL1471901 & 688161 & 4.6 & 4.9688 & TRN \\
\hline
\end{tabular}




\begin{tabular}{|c|c|c|c|c|c|}
\hline \multicolumn{6}{|c|}{ Supplemental Table S2.txt } \\
\hline CHEMBL366603 & 688161 & 4.6 & 4.9516 & TST & \\
\hline CHEMBL1558189 & 688161 & 5.6 & 5.0071 & TRN & \\
\hline CHEMBL1373177 & 688161 & 5.4 & 5.2799 & TST & \\
\hline CHEMBL1304385 & 688161 & 5.2 & 4.7688 & TRN & \\
\hline CHEMBL1500116 & 688161 & 4.8 & 4.7869 & TRN & \\
\hline CHEMBL1369878 & 688161 & 6.4 & 4.8704 & TRN & \\
\hline CHEMBL43383 & 688161 & 4.5 & 4.9053 & TST & \\
\hline CHEMBL1389239 & 688161 & 4.5 & 4.8652 & TRN & \\
\hline CHEMBL1469093 & 688161 & 4.8 & 4.8352 & TRN & \\
\hline CHEMBL1256625 & 688161 & 4.9 & 4.9501 & TST & \\
\hline CHEMBL1434747 & 688161 & 4.5 & 4.9299 & TRN & \\
\hline CHEMBL1454917 & 688161 & 6.6 & 4.9068 & TRN & \\
\hline CHEMBL1428236 & 688161 & 5.0 & 4.8885 & TRN & \\
\hline CHEMBL1499344 & 688161 & 4.5 & 4.8085 & TST & \\
\hline CHEMBL1543224 & 688161 & 5.0 & 4.9317 & TRN & \\
\hline CHEMBL1483348 & 688161 & 5.0 & 4.93199 & 99999999995 & TRN \\
\hline CHEMBL409695 & 688161 & 4.5 & 4.9832 & TST & \\
\hline CHEMBL1609319 & 688161 & 5.9 & 4.9771 & TRN & \\
\hline CHEMBL1530493 & 688161 & 6.1 & 4.9189 & TRN & \\
\hline CHEMBL1516054 & 688161 & 4.5 & 4.7985 & TRN & \\
\hline CHEMBL1396230 & 688161 & 5.0 & 4.8017 & TRN & \\
\hline CHEMBL1612850 & 688161 & 4.6 & 4.8793 & TRN & \\
\hline CHEMBL1506076 & 688161 & 5.6 & 4.9459 & TRN & \\
\hline CHEMBL1581818 & 688161 & 4.6 & 4.9318 & TRN & \\
\hline CHEMBL1368759 & 688161 & 7.8996 & 4.9428 & TRN & \\
\hline CHEMBL1349037 & 688161 & 4.5 & 4.8209 & TRN & \\
\hline CHEMBL1539307 & 688161 & 5.7 & 4.9539 & TRN & \\
\hline CHEMBL1532633 & 688161 & 5.5 & 5.1273 & TRN & \\
\hline CHEMBL1477081 & 688161 & 4.8 & 5.1068 & TST & \\
\hline CHEMBL1519533 & 688161 & 4.4 & 5.0049 & TRN & \\
\hline CHEMBL1533620 & 688161 & 5.1 & 4.8139 & TRN & \\
\hline CHEMBL1445582 & 688161 & 4.6 & 4.7718 & TRN & \\
\hline CHEMBL1323800 & 688161 & 5.5 & 4.9745 & TRN & \\
\hline CHEMBL1516613 & 688161 & 4.9 & 4.916 & TRN & \\
\hline CHEMBL1378049 & 688161 & 4.6 & 4.8998 & TRN & \\
\hline CHEMBL1991885 & 688161 & 4.6 & 4.9647 & TRN & \\
\hline CHEMBL1200717 & 688161 & 7.0 & 5.0291 & TST & \\
\hline CHEMBL1548010 & 688161 & 4.8 & 4.9528 & TRN & \\
\hline CHEMBL1338358 & 688161 & 4.4 & 4.9003 & TRN & \\
\hline CHEMBL1438401 & 688161 & 4.8 & 4.87 & TRN & \\
\hline CHEMBL1486235 & 688161 & 4.8 & 4.915 & TRN & \\
\hline CHEMBL1449478 & 688161 & 4.9 & 4.988 & TRN & \\
\hline CHEMBL1558101 & 688161 & 5.0 & 4.9911 & TRN & \\
\hline CHEMBL1608276 & 688161 & 5.0 & 5.0209 & TRN & \\
\hline CHEMBL1382425 & 688161 & 4.8 & 5.0224 & TRN & \\
\hline CHEMBL1566068 & 688161 & 5.5 & 5.0438 & TRN & \\
\hline CHEMBL1581518 & 688161 & 6.5 & 5.3926 & TRN & \\
\hline CHEMBL1550517 & 688161 & 4.5 & 5.0177 & TRN & \\
\hline
\end{tabular}




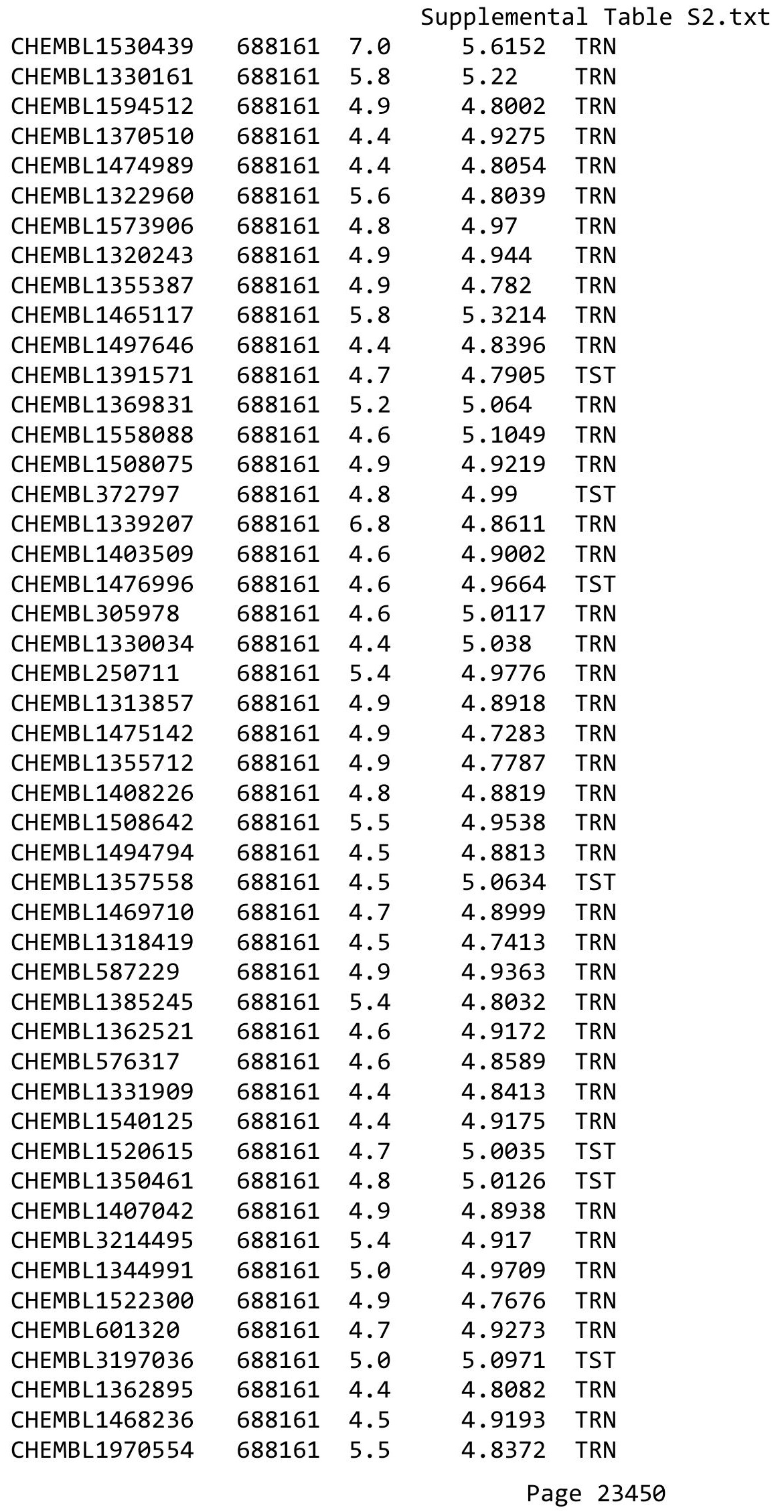




\begin{tabular}{|c|c|c|c|c|}
\hline \multicolumn{5}{|c|}{ Supplemental Table S2.txt } \\
\hline CHEMBL1538505 & 688161 & 5.2 & 4.8743 & TRN \\
\hline CHEMBL1559211 & 688161 & 5.5 & 4.9852 & TRN \\
\hline CHEMBL1531039 & 688161 & 5.2 & 4.9638 & TRN \\
\hline CHEMBL1489223 & 688161 & 4.6 & 4.9663 & TRN \\
\hline CHEMBL 8260 & 688161 & 5.7 & 5.2678 & TRN \\
\hline CHEMBL1331045 & 688161 & 4.8 & 5.0706 & TST \\
\hline CHEMBL1546161 & 688161 & 4.8 & 4.8715 & TRN \\
\hline CHEMBL1501188 & 688161 & 7.0 & 5.0191 & TRN \\
\hline CHEMBL1544324 & 688161 & 5.2 & 4.9344 & TRN \\
\hline CHEMBL1483132 & 688161 & 4.5 & 4.7698 & TRN \\
\hline CHEMBL1325735 & 688161 & 4.6 & 4.782 & TRN \\
\hline CHEMBL353971 & 688161 & 4.5 & 4.9748 & TRN \\
\hline CHEMBL1503922 & 688161 & 4.6 & 4.8849 & TRN \\
\hline CHEMBL1428812 & 688161 & 4.5 & 5.1076 & TRN \\
\hline CHEMBL1586156 & 688161 & 5.4 & 4.8481 & TRN \\
\hline CHEMBL1491959 & 688161 & 4.9 & 4.8303 & TRN \\
\hline CHEMBL1453648 & 688161 & 5.0 & 5.0161 & TST \\
\hline CHEMBL1358959 & 688161 & 4.7 & 4.9935 & TRN \\
\hline CHEMBL507900 & 688161 & 4.6 & 5.0381 & TST \\
\hline CHEMBL1608788 & 688161 & 4.8 & 4.8742 & TRN \\
\hline CHEMBL1492583 & 688161 & 4.6 & 4.937 & TRN \\
\hline CHEMBL242171 & 688161 & 6.3 & 5.5548 & TRN \\
\hline CHEMBL1489184 & 688161 & 4.9 & 4.8322 & TRN \\
\hline CHEMBL1558796 & 688161 & 5.5 & 5.0227 & TRN \\
\hline CHEMBL1315207 & 688161 & 4.7 & 5.032 & TST \\
\hline CHEMBL1381306 & 688161 & 4.5 & 5.2053 & TRN \\
\hline CHEMBL1362399 & 688161 & 5.0 & 4.8773 & TRN \\
\hline CHEMBL1333734 & 688161 & 4.9 & 4.8486 & TRN \\
\hline CHEMBL152557 & 688161 & 4.6 & 4.9686 & TST \\
\hline CHEMBL1302993 & 688161 & 4.5 & 4.9269 & TRN \\
\hline CHEMBL1535173 & 688161 & 6.0 & 4.8409 & TRN \\
\hline CHEMBL1402956 & 688161 & 4.6 & 4.9255 & TRN \\
\hline CHEMBL1613371 & 688161 & 4.4 & 4.9278 & TRN \\
\hline CHEMBL1451172 & 688161 & 4.7 & 4.9586 & TRN \\
\hline CHEMBL1526319 & 688161 & 5.0 & 5.1672 & TRN \\
\hline CHEMBL1419675 & 688161 & 5.5 & 4.8522 & TRN \\
\hline CHEMBL572994 & 688161 & 6.1 & 5.4957 & TST \\
\hline CHEMBL1474686 & 688161 & 4.8 & 4.8952 & TRN \\
\hline CHEMBL1526171 & 688161 & 5.3 & 5.0465 & TRN \\
\hline CHEMBL1322206 & 688161 & 4.6 & 4.8786 & TRN \\
\hline CHEMBL1459617 & 688161 & 4.5 & 4.8342 & TRN \\
\hline CHEMBL1560366 & 688161 & 5.2 & 4.9863 & TRN \\
\hline CHEMBL1522073 & 688161 & 5.5 & 4.9393 & TRN \\
\hline CHEMBL1449105 & 688161 & 6.1 & 4.8821 & TRN \\
\hline CHEMBL260316 & 688161 & 4.4 & 4.9844 & TST \\
\hline CHEMBL1596922 & 688161 & 4.6 & 4.828 & TRN \\
\hline CHEMBL1972346 & 688161 & 6.1 & 5.3329 & TRN \\
\hline CHEMBL1307795 & 688161 & 5.1 & 4.9582 & TRN \\
\hline
\end{tabular}




\begin{tabular}{|c|c|c|c|c|}
\hline & & & oplement & al $\mathrm{T}$ \\
\hline CHEMBL1601646 & 688161 & 4.6 & 4.9148 & TRN \\
\hline CHEMBL1516857 & 688161 & 5.0 & 4.9576 & TRN \\
\hline CHEMBL1562926 & 688161 & 5.5 & 4.8357 & TRN \\
\hline CHEMBL1497287 & 688161 & 4.9 & 5.0171 & TRN \\
\hline CHEMBL1312686 & 688161 & 4.7 & 4.8614 & TRN \\
\hline CHEMBL1400926 & 688161 & 4.7 & 4.8958 & TRN \\
\hline CHEMBL3191101 & 688161 & 4.5 & 5.0514 & TST \\
\hline CHEMBL1414263 & 688161 & 5.5 & 5.3843 & TRN \\
\hline CHEMBL1595098 & 688161 & 4.7 & 4.9194 & TRN \\
\hline CHEMBL144530 & 688161 & 4.9 & 5.0023 & TST \\
\hline CHEMBL1573220 & 688161 & 4.6 & 4.9053 & TRN \\
\hline CHEMBL1256910 & 688161 & 4.6 & 4.9674 & TRN \\
\hline CHEMBL1529812 & 688161 & 4.5 & 4.8146 & TRN \\
\hline CHEMBL1470579 & 688161 & 4.5 & 4.9477 & TRN \\
\hline CHEMBL1597877 & 688161 & 4.5 & 4.8737 & TRN \\
\hline CHEMBL1368728 & 688161 & 4.7 & 4.8899 & TRN \\
\hline CHEMBL1582379 & 688161 & 4.4 & 5.0406 & TRN \\
\hline CHEMBL1427447 & 688161 & 5.6 & 5.4362 & TRN \\
\hline CHEMBL1481517 & 688161 & 4.6 & 4.9338 & TST \\
\hline CHEMBL1330194 & 688161 & 4.5 & 4.989 & TST \\
\hline CHEMBL1376993 & 688161 & 5.3 & 4.8913 & TRN \\
\hline CHEMBL1376206 & 688161 & 4.5 & 4.8675 & TRN \\
\hline CHEMBL 297453 & 688161 & 5.7 & 5.1525 & TST \\
\hline CHEMBL1548834 & 688161 & 4.9 & 4.8603 & TRN \\
\hline CHEMBL1200765 & 688161 & 4.7 & 5.0036 & TST \\
\hline CHEMBL1316156 & 688161 & 4.8 & 4.9888 & TRN \\
\hline CHEMBL56393 & 688161 & 5.4 & 5.2488 & TRN \\
\hline CHEMBL3193792 & 688161 & 5.1 & 4.768 & TRN \\
\hline CHEMBL1390422 & 688161 & 4.5 & 5.0398 & TRN \\
\hline CHEMBL1484713 & 688161 & 4.8 & 4.89 & TST \\
\hline CHEMBL1503863 & 688161 & 7.4001 & 4.9831 & TRN \\
\hline CHEMBL3195336 & 688161 & 4.7 & 4.7986 & TST \\
\hline CHEMBL1569782 & 688161 & 4.5 & 4.9497 & TRN \\
\hline CHEMBL1533632 & 688161 & 4.8 & 4.9066 & TRN \\
\hline CHEMBL1542639 & 688161 & 5.6 & 4.8784 & TRN \\
\hline CHEMBL1448041 & 688161 & 4.9 & 5.1327 & TRN \\
\hline CHEMBL1394520 & 688161 & 4.4 & 4.8794 & TRN \\
\hline CHEMBL1380975 & 688161 & 6.2 & 4.9075 & TRN \\
\hline CHEMBL1380958 & 688161 & 4.6 & 5.4462 & TRN \\
\hline CHEMBL1373997 & 688161 & 4.9 & 4.8963 & TRN \\
\hline CHEMBL1424316 & 688161 & 4.7 & 4.8894 & TRN \\
\hline CHEMBL1576658 & 688161 & 5.5 & 4.9886 & TRN \\
\hline CHEMBL1570633 & 688161 & 4.7 & 4.8106 & TRN \\
\hline CHEMBL1611130 & 688161 & 4.7 & 4.7912 & TRN \\
\hline CHEMBL1549079 & 688161 & 4.9 & 4.8096 & TRN \\
\hline CHEMBL1413869 & 688161 & 4.4 & 4.9145 & TRN \\
\hline CHEMBL1342039 & 688161 & 4.5 & 4.7448 & TRN \\
\hline CHEMBL1602775 & 688161 & 5.0 & 5.1242 & TRN \\
\hline
\end{tabular}




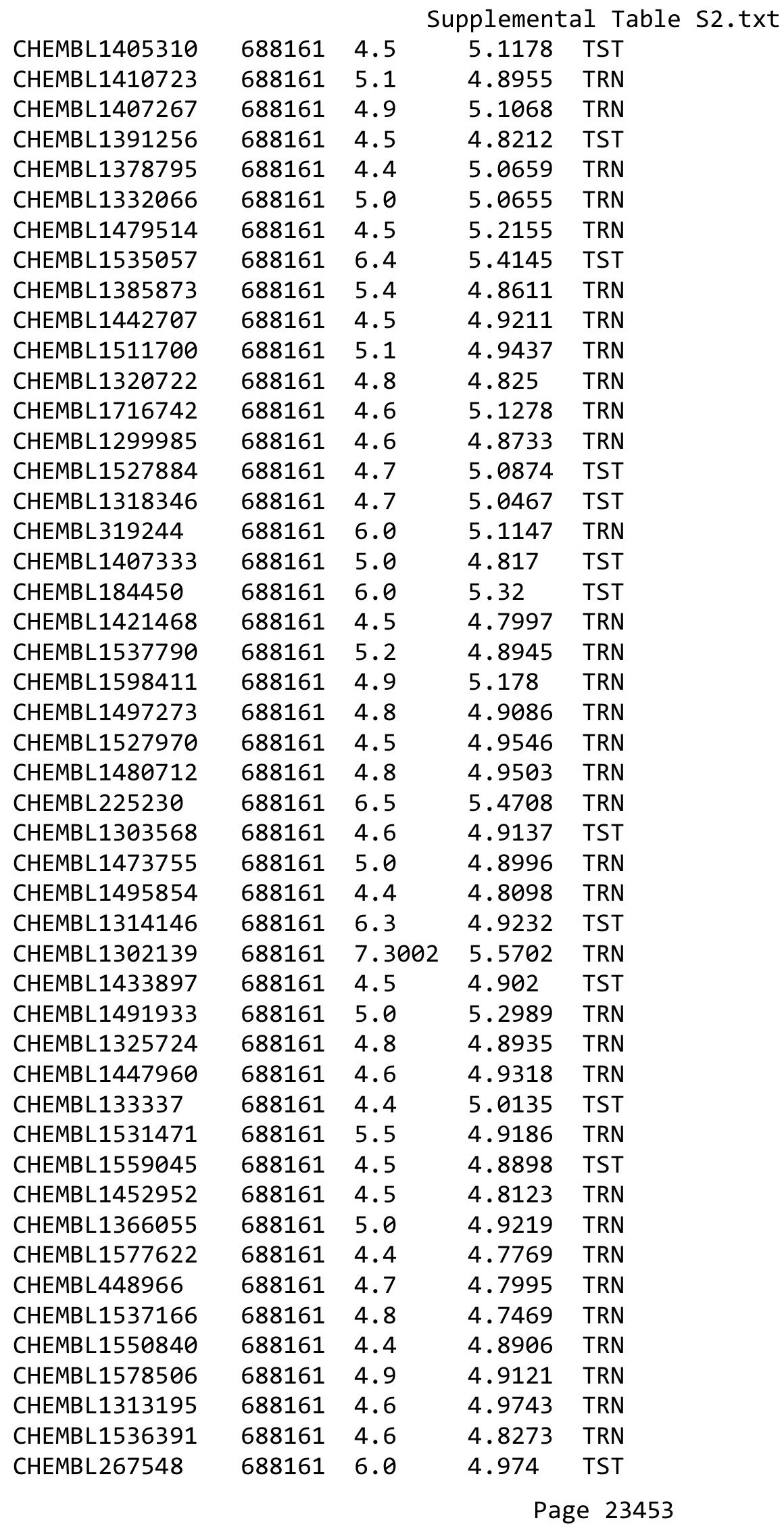




\begin{tabular}{|c|c|c|c|c|c|}
\hline \multicolumn{6}{|c|}{ Supplemental Table S2.txt } \\
\hline CHEMBL1424486 & 688161 & 4.7 & 4.963 & TRN & \\
\hline CHEMBL1509735 & 688161 & 4.5 & 4.8837 & TRN & \\
\hline CHEMBL1592468 & 688161 & 8.1024 & 5.0197 & TRN & \\
\hline CHEMBL476672 & 688161 & 5.4 & 5.008 & TRN & \\
\hline CHEMBL1379045 & 688161 & 4.4 & 4.8475 & TRN & \\
\hline CHEMBL1415406 & 688161 & 4.9 & 4.8245 & TRN & \\
\hline CHEMBL1534028 & 688161 & 5.1 & 4.9265 & TRN & \\
\hline CHEMBL1464208 & 688161 & 4.8 & 4.9962 & TRN & \\
\hline CHEMBL1324487 & 688161 & 4.6 & 4.8153 & TRN & \\
\hline CHEMBL1388901 & 688161 & 4.8 & 4.8999 & TRN & \\
\hline CHEMBL1491276 & 688161 & 4.5 & 4.9041 & TRN & \\
\hline CHEMBL1599037 & 688161 & 4.9 & 4.8665 & TRN & \\
\hline CHEMBL1492631 & 688161 & 5.4 & 5.3398 & TRN & \\
\hline CHEMBL1445598 & 688161 & 4.4 & 4.8632 & TRN & \\
\hline CHEMBL1377988 & 688161 & 4.9 & 4.9214 & TRN & \\
\hline CHEMBL 188 & 688161 & 4.6 & 4.9839 & TST & \\
\hline CHEMBL1576363 & 688161 & 5.4 & 5.0271 & TRN & \\
\hline CHEMBL1608425 & 688161 & 4.8 & 4.9626 & TRN & \\
\hline CHEMBL1407762 & 688161 & 4.5 & 5.0115 & TRN & \\
\hline CHEMBL1341981 & 688161 & 4.7 & 5.2465 & TST & \\
\hline CHEMBL1368927 & 688161 & 4.7 & 4.9051 & TST & \\
\hline CHEMBL3197660 & 688161 & 4.5 & 4.919 & TRN & \\
\hline CHEMBL1356824 & 688161 & 4.5 & 4.9038 & TRN & \\
\hline CHEMBL1547055 & 688161 & 4.4 & 4.7987 & TRN & \\
\hline CHEMBL1391863 & 688161 & 5.1 & 4.9704 & TRN & \\
\hline CHEMBL1380868 & 688161 & 5.6 & 5.2832 & TRN & \\
\hline CHEMBL1566731 & 688161 & 4.9 & 4.7601 & TRN & \\
\hline CHEMBL1586610 & 688161 & 5.2 & 4.7542 & TRN & \\
\hline CHEMBL1435916 & 688161 & 4.6 & 4.8013 & TRN & \\
\hline CHEMBL504791 & 688161 & 5.4 & 5.1293 & TRN & \\
\hline CHEMBL1339536 & 688161 & 4.4 & 4.9159 & TRN & \\
\hline CHEMBL1412272 & 688161 & 4.6 & 4.7857 & TRN & \\
\hline CHEMBL1405461 & 688161 & 4.7 & 4.8189 & TRN & \\
\hline CHEMBL1405178 & 688161 & 4.6 & 4.9228 & TRN & \\
\hline CHEMBL1482184 & 688161 & 4.4 & 5.0171 & TST & \\
\hline CHEMBL1550860 & 688161 & 4.6 & 4.9788 & TRN & \\
\hline CHEMBL1581560 & 688161 & 4.9 & 4.8412 & TRN & \\
\hline CHEMBL1465370 & 688161 & 5.6 & 4.8911 & TRN & \\
\hline CHEMBL34241 & 688161 & 4.4 & 5.2758 & TST & \\
\hline CHEMBL1487601 & 688161 & 4.4 & 4.8905 & TRN & \\
\hline CHEMBL1395162 & 688161 & 4.8 & 4.8958 & TRN & \\
\hline CHEMBL1525800 & 688161 & 5.5 & 4.87 & TRN & \\
\hline CHEMBL1450025 & 688161 & 4.4 & 4.7776 & TRN & \\
\hline CHEMBL3209093 & 688161 & 5.3 & $4.9510 €$ & 00000000005 & TST \\
\hline CHEMBL1309205 & 688161 & 4.9 & 4.9507 & TRN & \\
\hline CHEMBL1574864 & 688161 & 5.3 & 4.8575 & TRN & \\
\hline CHEMBL1446460 & 688161 & 4.7 & 4.8628 & TRN & \\
\hline CHEMBL1337629 & 688161 & 5.4 & 5.1511 & TRN & \\
\hline
\end{tabular}




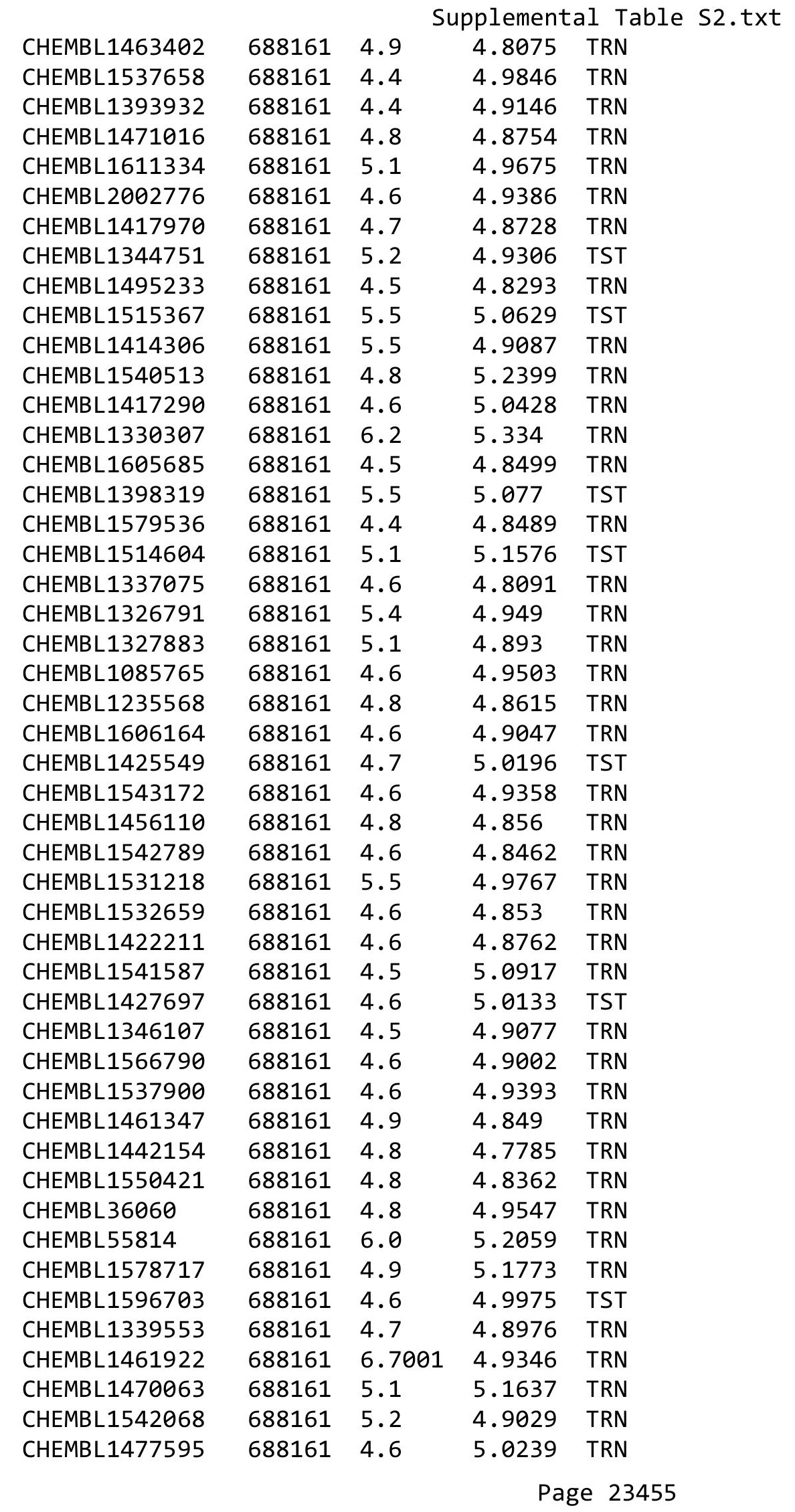




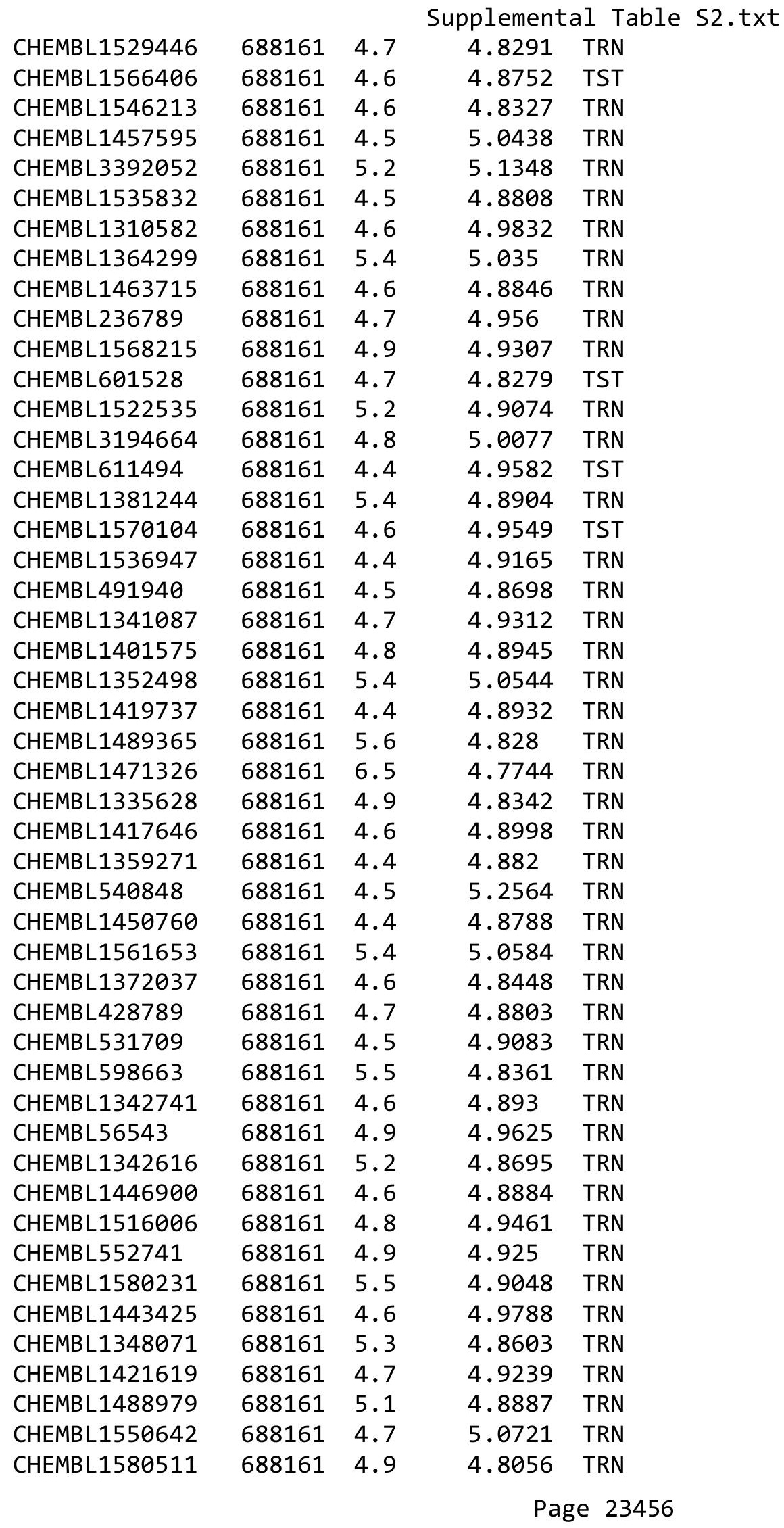




\begin{tabular}{|c|c|c|c|c|}
\hline \multicolumn{5}{|c|}{ Supplemental Table S2.txt } \\
\hline CHEMBL1496880 & 688161 & 5.2 & 4.8502 & TRN \\
\hline CHEMBL1468900 & 688161 & 4.8 & 4.8974 & TRN \\
\hline CHEMBL1579903 & 688161 & 4.7 & 4.923 & TRN \\
\hline CHEMBL1583101 & 688161 & 4.9 & 4.9094 & TRN \\
\hline CHEMBL1310234 & 688161 & 5.1 & 4.985 & TRN \\
\hline CHEMBL1477057 & 688161 & 4.4 & 4.812 & TRN \\
\hline CHEMBL1576787 & 688161 & 4.4 & 4.9249 & TRN \\
\hline CHEMBL1563213 & 688161 & 4.4 & 4.9736 & TRN \\
\hline CHEMBL1506716 & 688161 & 4.6 & 4.8047 & TST \\
\hline CHEMBL1498363 & 688161 & 4.7 & 4.8502 & TRN \\
\hline CHEMBL1405678 & 688161 & 4.5 & 5.1882 & TRN \\
\hline CHEMBL1522486 & 688161 & 5.2 & 4.8626 & TRN \\
\hline CHEMBL1580304 & 688161 & 4.6 & 4.8525 & TRN \\
\hline CHEMBL1519576 & 688161 & 4.6 & 4.7909 & TRN \\
\hline CHEMBL1548014 & 688161 & 5.0 & 4.8999 & TRN \\
\hline CHEMBL1417268 & 688161 & 6.0 & 4.9807 & TST \\
\hline CHEMBL1373994 & 688161 & 4.7 & 4.8335 & TRN \\
\hline CHEMBL393136 & 688161 & 6.0 & 5.2008 & TRN \\
\hline CHEMBL1322233 & 688161 & 4.9 & 4.8959 & TRN \\
\hline CHEMBL1529809 & 688161 & 4.9 & 5.2586 & TRN \\
\hline CHEMBL1489430 & 688161 & 4.7 & 4.8654 & TST \\
\hline CHEMBL3392040 & 688161 & 4.8 & 5.3757 & TRN \\
\hline CHEMBL1309478 & 688161 & 5.2 & 5.0484 & TRN \\
\hline CHEMBL54909 & 688161 & 4.9 & 5.3024 & TRN \\
\hline CHEMBL1356115 & 688161 & 4.9 & 5.0483 & TST \\
\hline CHEMBL1559347 & 688161 & 7.0 & 4.751 & TRN \\
\hline CHEMBL1300967 & 688161 & 4.8 & 4.8753 & TRN \\
\hline CHEMBL567130 & 688161 & 5.0 & 4.8302 & TRN \\
\hline CHEMBL1324935 & 688161 & 5.5 & 5.3716 & TRN \\
\hline CHEMBL1532645 & 688161 & 5.0 & 4.8462 & TRN \\
\hline CHEMBL1348663 & 688161 & 4.8 & 4.947 & TRN \\
\hline CHEMBL1326152 & 688161 & 4.9 & 4.8543 & TRN \\
\hline CHEMBL1525273 & 688161 & 5.1 & 5.6644 & TRN \\
\hline CHEMBL1433596 & 688161 & 5.3 & 4.7618 & TRN \\
\hline CHEMBL1392167 & 688161 & 4.6 & 5.1484 & TRN \\
\hline CHEMBL1408981 & 688161 & 4.6 & 4.8451 & TRN \\
\hline CHEMBL1448615 & 688161 & 5.0 & 4.8403 & TRN \\
\hline CHEMBL1398683 & 688161 & 4.8 & 4.9336 & TST \\
\hline CHEMBL1358628 & 688161 & 4.8 & 4.9471 & TST \\
\hline CHEMBL1534227 & 688161 & 4.9 & 4.8958 & TRN \\
\hline CHEMBL1602312 & 688161 & 7.4001 & 4.905 & TRN \\
\hline CHEMBL1479267 & 688161 & 4.4 & 4.9546 & TRN \\
\hline CHEMBL1356808 & 688161 & 4.8 & 4.8277 & TRN \\
\hline CHEMBL454173 & 688161 & 4.5 & 5.2675 & TST \\
\hline CHEMBL1333007 & 688161 & 5.0 & 4.8993 & TRN \\
\hline CHEMBL1496131 & 688161 & 5.0 & 5.1714 & TST \\
\hline CHEMBL1379164 & 688161 & 4.9 & 4.9724 & TST \\
\hline CHEMBL1374536 & 688161 & 5.3 & 4.9774 & TRN \\
\hline
\end{tabular}




\begin{tabular}{|c|c|c|c|c|c|}
\hline \multicolumn{6}{|c|}{ Supplemental Table S2.txt } \\
\hline CHEMBL1429988 & 688161 & 4.9 & 4.8006 & TRN & \\
\hline CHEMBL1333895 & 688161 & 5.5 & 4.9852 & TRN & \\
\hline CHEMBL405386 & 688161 & 4.5 & 4.8096 & TRN & \\
\hline CHEMBL1327492 & 688161 & 4.6 & 4.9675 & TST & \\
\hline CHEMBL1564932 & 688161 & 4.4 & 4.8645 & TST & \\
\hline CHEMBL1493117 & 688161 & 4.8 & 4.8801 & TST & \\
\hline CHEMBL1420005 & 688161 & 5.2 & 4.9111 & TRN & \\
\hline CHEMBL1579377 & 688161 & 4.6 & 4.9008 & TRN & \\
\hline CHEMBL1446608 & 688161 & 4.6 & 4.8922 & TRN & \\
\hline CHEMBL 258767 & 688161 & 6.0 & 5.3244 & TRN & \\
\hline CHEMBL1091971 & 688161 & 5.5 & 5.045 & TST & \\
\hline CHEMBL1539013 & 688161 & 4.6 & 4.8968 & TRN & \\
\hline CHEMBL1438452 & 688161 & 5.2 & 5.19799 & 99999999995 & TRN \\
\hline CHEMBL1487823 & 688161 & 4.6 & 5.0148 & TRN & \\
\hline CHEMBL1533853 & 688161 & 5.6 & 4.8113 & TRN & \\
\hline CHEMBL1415728 & 688161 & 4.6 & 4.8662 & TRN & \\
\hline CHEMBL1460466 & 688161 & 5.4 & 5.1626 & TRN & \\
\hline CHEMBL1589754 & 688161 & 4.6 & 4.9289 & TRN & \\
\hline CHEMBL1337575 & 688161 & 4.8 & 4.8909 & TRN & \\
\hline CHEMBL1550891 & 688161 & 4.4 & 4.8584 & TRN & \\
\hline CHEMBL1348978 & 688161 & 4.5 & 5.0905 & TRN & \\
\hline CHEMBL1381098 & 688161 & 4.5 & 4.8516 & TST & \\
\hline CHEMBL1340066 & 688161 & 5.0 & 4.9338 & TRN & \\
\hline CHEMBL1605394 & 688161 & 4.7 & 4.8369 & TRN & \\
\hline CHEMBL404923 & 688161 & 5.0 & 5.0132 & TST & \\
\hline CHEMBL1373793 & 688161 & 4.6 & 4.8866 & TST & \\
\hline CHEMBL131091 & 688161 & 5.0 & 5.0983 & TST & \\
\hline CHEMBL1417597 & 688161 & 4.8 & 4.9657 & TRN & \\
\hline CHEMBL1309141 & 688161 & 4.7 & 4.9455 & TRN & \\
\hline CHEMBL1464468 & 688161 & 5.2 & 4.8281 & TRN & \\
\hline CHEMBL1324871 & 688161 & 5.5 & 5.1022 & TST & \\
\hline CHEMBL 1577318 & 688161 & 4.4 & 4.9466 & TST & \\
\hline CHEMBL1372555 & 688161 & 4.8 & 4.7692 & TRN & \\
\hline CHEMBL1481974 & 688161 & 5.5 & 5.4392 & TRN & \\
\hline CHEMBL1360170 & 688161 & 4.8 & 4.7793 & TRN & \\
\hline CHEMBL1384321 & 688161 & 5.5 & 4.923 & TRN & \\
\hline CHEMBL1564425 & 688161 & 4.6 & 4.8387 & TRN & \\
\hline CHEMBL1256360 & 688161 & 8.2007 & 5.4062 & TRN & \\
\hline CHEMBL475908 & 688161 & 4.4 & 5.1993 & TRN & \\
\hline CHEMBL1550267 & 688161 & 4.6 & 4.8885 & TRN & \\
\hline CHEMBL1463242 & 688161 & 8.2007 & 4.9169 & TST & \\
\hline CHEMBL 1388452 & 688161 & 4.6 & 4.8932 & TRN & \\
\hline CHEMBL1365833 & 688161 & 4.9 & 4.8257 & TRN & \\
\hline CHEMBL1438442 & 688161 & 4.8 & 4.9138 & TRN & \\
\hline CHEMBL1322374 & 688161 & 5.0 & 4.9401 & TRN & \\
\hline CHEMBL1458627 & 688161 & 4.9 & 5.0119 & TST & \\
\hline CHEMBL1482751 & 688161 & 4.6 & 4.749 & TRN & \\
\hline CHEMBL1419855 & 688161 & 4.5 & 4.8738 & TRN & \\
\hline
\end{tabular}




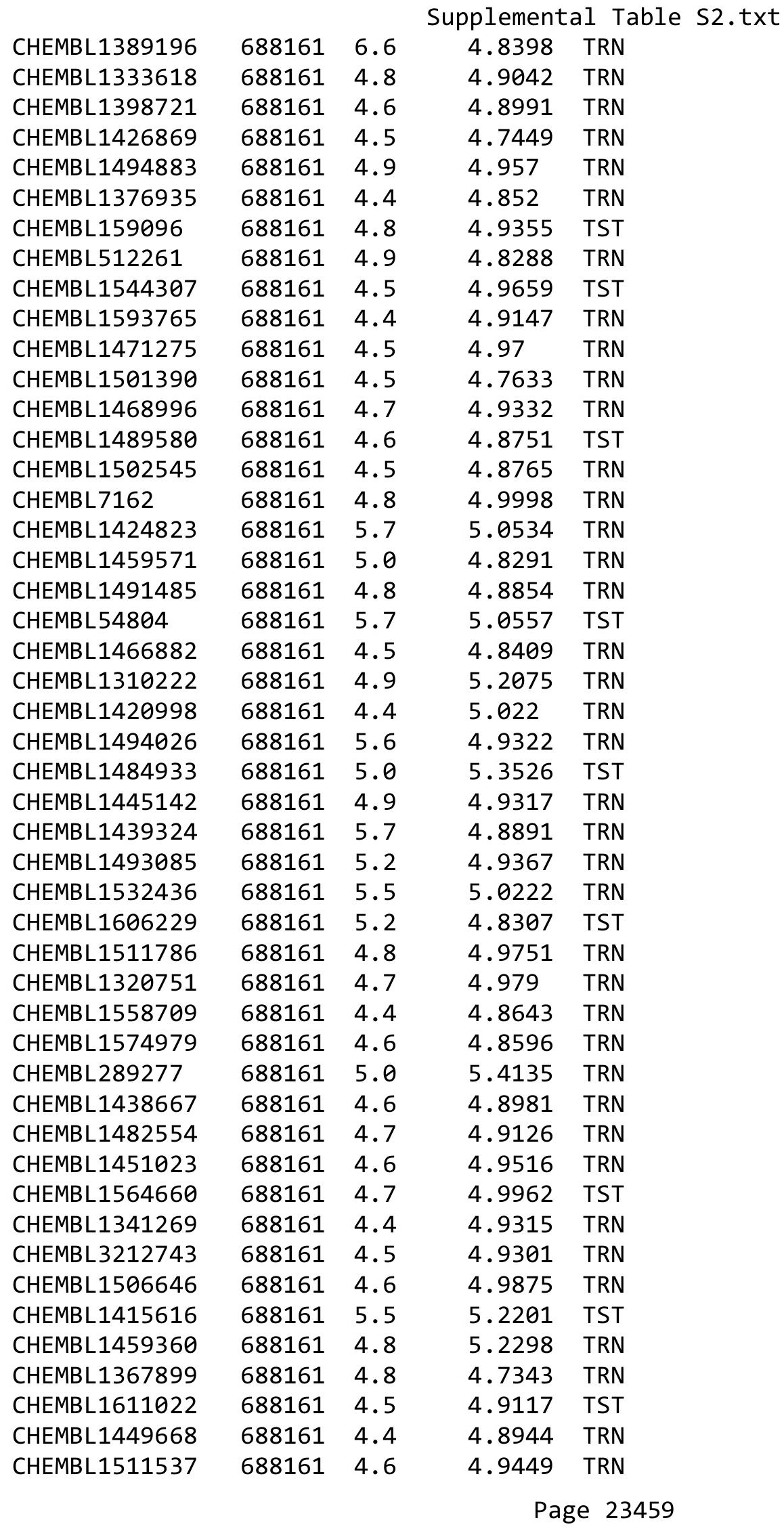




\begin{tabular}{|c|c|c|c|c|}
\hline \multicolumn{5}{|c|}{ Supplemental Table S2.txt } \\
\hline CHEMBL 3182828 & 688161 & 5.0 & 5.0364 & TRN \\
\hline CHEMBL1545156 & 688161 & 4.8 & 4.9859 & TRN \\
\hline CHEMBL1397636 & 688161 & 4.6 & 4.7652 & TRN \\
\hline CHEMBL1324680 & 688161 & 5.0 & 5.1459 & TRN \\
\hline CHEMBL 1441782 & 688161 & 4.7 & 4.8936 & TRN \\
\hline CHEMBL1439866 & 688161 & 6.0 & 5.0724 & TST \\
\hline CHEMBL596674 & 688161 & 4.9 & 5.2963 & TRN \\
\hline CHEMBL1570012 & 688161 & 4.6 & 4.899 & TST \\
\hline CHEMBL1975289 & 688161 & 5.4 & 5.3175 & TRN \\
\hline CHEMBL1372272 & 688161 & 4.8 & 4.904 & TRN \\
\hline CHEMBL1556792 & 688161 & 4.7 & 4.9777 & TRN \\
\hline CHEMBL244743 & 688161 & 5.0 & 5.0119 & TRN \\
\hline CHEMBL1388744 & 688161 & 5.0 & 4.9756 & TRN \\
\hline CHEMBL543767 & 688161 & 7.6003 & 4.9889 & TRN \\
\hline CHEMBL1455260 & 688161 & 4.6 & 5.1848 & TRN \\
\hline CHEMBL1305270 & 688161 & 4.7 & 4.9148 & TRN \\
\hline CHEMBL1418145 & 688161 & 4.6 & 4.8216 & TRN \\
\hline CHEMBL1568261 & 688161 & 4.7 & 4.9033 & TRN \\
\hline CHEMBL1585929 & 688161 & 5.5 & 4.9804 & TRN \\
\hline CHEMBL1325324 & 688161 & 4.8 & 4.95 & TRN \\
\hline CHEMBL1318117 & 688161 & 5.3 & 5.0914 & TST \\
\hline CHEMBL1496732 & 688161 & 5.5 & 4.9174 & TRN \\
\hline CHEMBL1470176 & 688161 & 4.4 & 4.9322 & TRN \\
\hline CHEMBL1565425 & 688161 & 6.8 & 4.9187 & TST \\
\hline CHEMBL1256623 & 688161 & 4.8 & 5.3083 & TRN \\
\hline CHEMBL437450 & 688161 & 4.9 & 4.9276 & TST \\
\hline CHEMBL1407095 & 688161 & 4.7 & 4.8099 & TRN \\
\hline CHEMBL1407509 & 688161 & 4.9 & 4.9043 & TRN \\
\hline CHEMBL1305149 & 688161 & 4.4 & 5.0125 & TRN \\
\hline CHEMBL1449005 & 688161 & 4.6 & 4.942 & TRN \\
\hline CHEMBL1474114 & 688161 & 5.0 & 4.8496 & TRN \\
\hline CHEMBL1577584 & 688161 & 4.4 & 4.8615 & TRN \\
\hline CHEMBL1314279 & 688161 & 4.7 & 4.7381 & TRN \\
\hline CHEMBL1478244 & 688161 & 4.6 & 4.9208 & TRN \\
\hline CHEMBL1570207 & 688161 & 5.4 & 4.8693 & TST \\
\hline CHEMBL1385448 & 688161 & 4.6 & 5.0445 & TRN \\
\hline CHEMBL399491 & 688161 & 5.8 & 5.2901 & TRN \\
\hline CHEMBL1529361 & 688161 & 4.4 & 4.9182 & TRN \\
\hline CHEMBL1503644 & 688161 & 8.0 & 4.9955 & TRN \\
\hline CHEMBL1556008 & 688161 & 4.5 & 4.9057 & TRN \\
\hline CHEMBL1506893 & 688161 & 4.4 & 4.878 & TRN \\
\hline CHEMBL1256678 & 688161 & 4.9 & 4.9387 & TST \\
\hline CHEMBL1349012 & 688161 & 4.6 & 4.8448 & TRN \\
\hline CHEMBL69086 & 688161 & 4.8 & 5.0839 & TRN \\
\hline CHEMBL1553825 & 688161 & 4.4 & 5.1225 & TRN \\
\hline CHEMBL1362496 & 688161 & 4.6 & 4.7782 & TRN \\
\hline CHEMBL1488714 & 688161 & 4.4 & 4.9901 & TRN \\
\hline CHEMBL1612493 & 688161 & 5.5 & 4.8298 & TRN \\
\hline
\end{tabular}




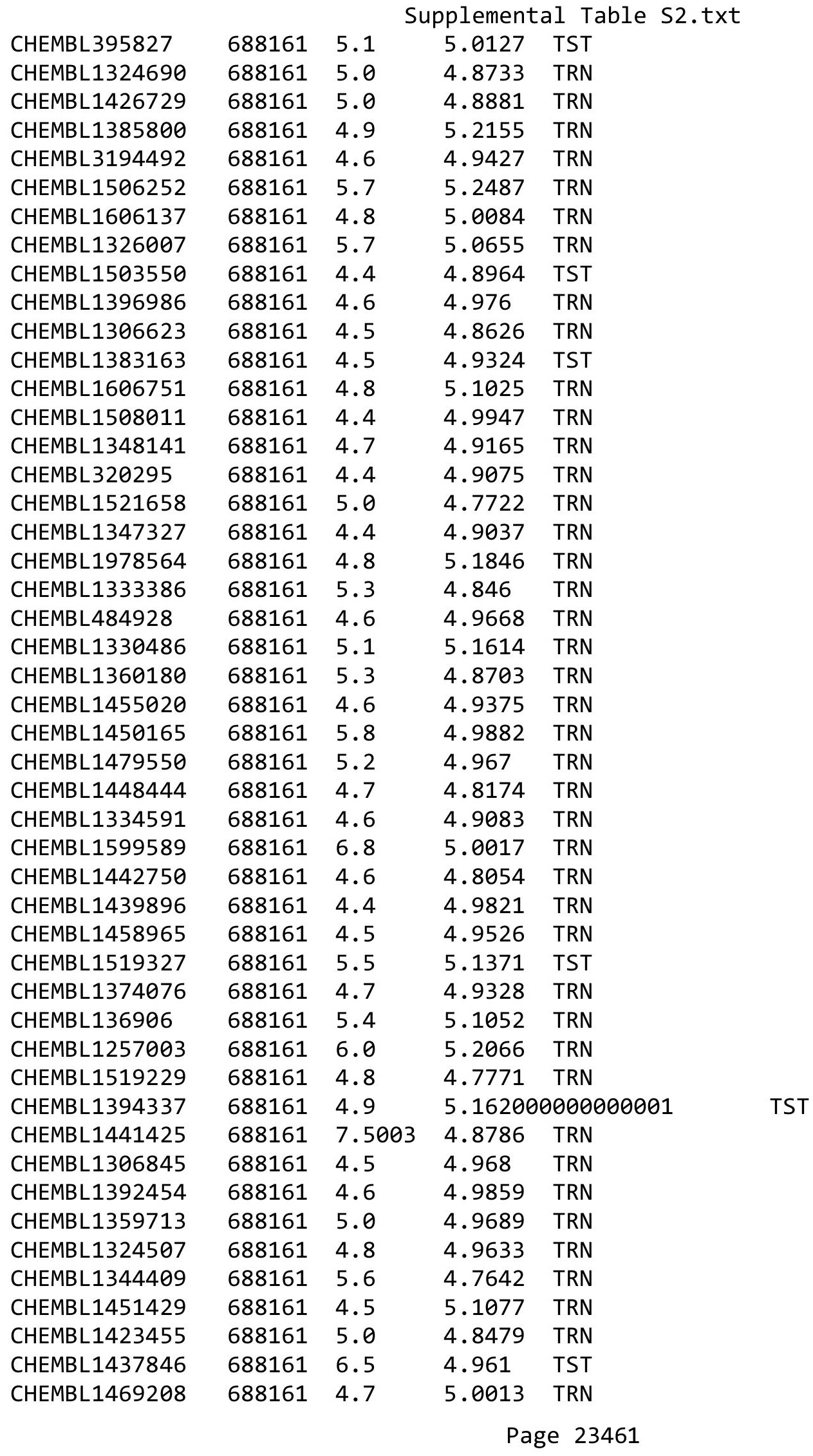




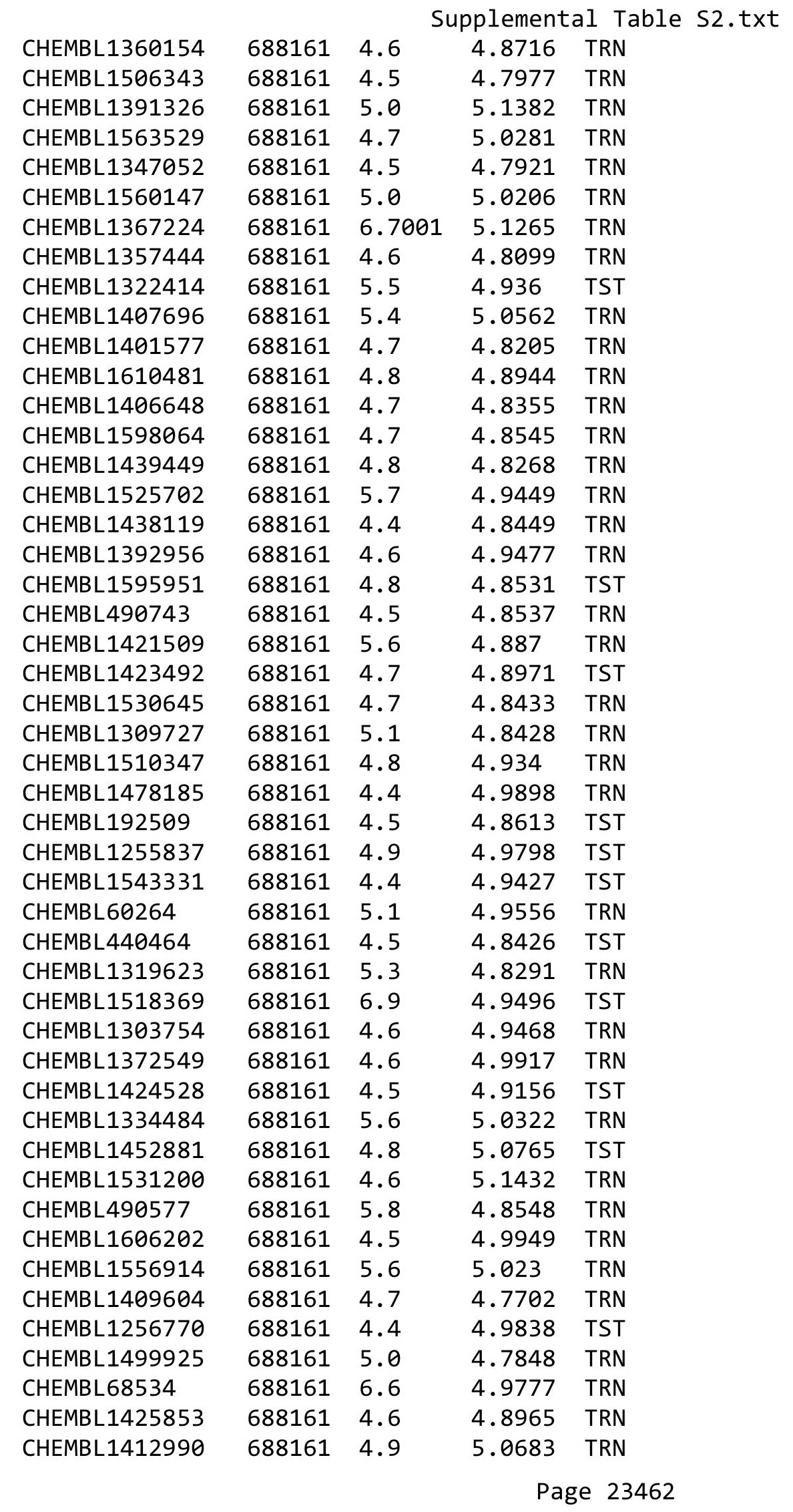




\begin{tabular}{|c|c|c|c|c|c|}
\hline \multirow{2}{*}{ CHEMBL1597805 } & \multirow{2}{*}{688161} & \multirow[b]{2}{*}{4.8} & \\
\hline & & & 4.9742 & TRN & \\
\hline CHEMBL1388976 & 688161 & 4.8 & 4.8473 & TRN & \\
\hline CHEMBL1488393 & 688161 & 5.5 & 5.0672 & TRN & \\
\hline CHEMBL1514634 & 688161 & 4.5 & 4.9528 & TST & \\
\hline CHEMBL1555208 & 688161 & 4.5 & \multicolumn{2}{|c|}{4.9639999999999995} & TST \\
\hline CHEMBL1530653 & 688161 & 5.5 & \multicolumn{2}{|c|}{5.242000000000001} & TRN \\
\hline CHEMBL1501898 & 688161 & 5.1 & 4.9679 & TST & \\
\hline CHEMBL1429149 & 688161 & 4.7 & 5.1288 & TRN & \\
\hline CHEMBL1544315 & 688161 & 4.5 & 4.9064 & TRN & \\
\hline CHEMBL1312261 & 688161 & 4.4 & 4.8751 & TRN & \\
\hline CHEMBL608699 & 688161 & 4.7 & 5.391 & TRN & \\
\hline CHEMBL1485132 & 688161 & 4.8 & 4.9835 & TRN & \\
\hline CHEMBL1519843 & 688161 & 4.8 & 4.8724 & TRN & \\
\hline CHEMBL1527366 & 688161 & 4.8 & 5.0011 & TRN & \\
\hline CHEMBL1380558 & 688161 & 4.4 & 4.8722 & TRN & \\
\hline CHEMBL1517350 & 688161 & 6.2 & 5.3737 & TRN & \\
\hline CHEMBL1482791 & 688161 & 5.4 & 4.9951 & TRN & \\
\hline CHEMBL1604063 & 688161 & 6.0 & 5.4329 & TST & \\
\hline CHEMBL1518566 & 688161 & 4.5 & 4.855 & TRN & \\
\hline CHEMBL1517255 & 688161 & 4.6 & 4.9544 & TRN & \\
\hline CHEMBL1429841 & 688161 & 5.5 & 4.8775 & TRN & \\
\hline CHEMBL1423299 & 688161 & 4.8 & 4.933 & TRN & \\
\hline CHEMBL1420286 & 688161 & 4.5 & 4.8975 & TRN & \\
\hline CHEMBL1411424 & 688161 & 4.5 & \multicolumn{2}{|c|}{4.888999999999999} & TRN \\
\hline CHEMBL1520216 & 688161 & 4.7 & 4.8151 & TRN & \\
\hline CHEMBL1410385 & 688161 & 4.9 & 4.7729 & TRN & \\
\hline CHEMBL1308627 & 688161 & 5.1 & 5.0797 & TST & \\
\hline CHEMBL1549179 & 688161 & 4.4 & 4.867 & TRN & \\
\hline CHEMBL1605478 & 688161 & 4.6 & 4.9257 & TRN & \\
\hline CHEMBL1362096 & 688161 & 4.8 & 4.8681 & TRN & \\
\hline CHEMBL1399447 & 688161 & 5.4 & 4.8485 & TRN & \\
\hline CHEMBL1323553 & 688161 & 5.7 & 4.9109 & TRN & \\
\hline CHEMBL1516700 & 688161 & 4.6 & 4.8885 & TRN & \\
\hline CHEMBL1604540 & 688161 & 6.0 & 4.8829 & TRN & \\
\hline CHEMBL1448862 & 688161 & 4.4 & 4.8524 & TRN & \\
\hline CHEMBL1556438 & 688161 & 4.4 & 4.9435 & TRN & \\
\hline CHEMBL1559341 & 688161 & 4.5 & 5.2601 & TST & \\
\hline CHEMBL1594218 & 688161 & 4.7 & 4.9572 & TRN & \\
\hline CHEMBL1548720 & 688161 & 5.0 & 4.8959 & TRN & \\
\hline CHEMBL1594312 & 688161 & 4.6 & 4.9537 & TRN & \\
\hline CHEMBL1346930 & 688161 & 4.4 & 4.8672 & TRN & \\
\hline CHEMBL310798 & 688161 & 5.1 & 5.186 & TRN & \\
\hline CHEMBL 3214002 & 688161 & 4.8 & 4.8509 & TRN & \\
\hline CHEMBL1540520 & 688161 & 4.4 & 4.8568 & TRN & \\
\hline CHEMBL1472377 & 688161 & 4.9 & 4.8257 & TRN & \\
\hline CHEMBL1338959 & 688161 & 5.4 & 4.9384 & TST & \\
\hline CHEMBL1270217 & 688161 & 5.7 & 4.8383 & TRN & \\
\hline \multirow[t]{2}{*}{ CHEMBL1425342 } & 688161 & 5.5 & 5.0074 & TRN & \\
\hline & & \multicolumn{4}{|c|}{ Page 23463} \\
\hline
\end{tabular}




\begin{tabular}{|c|c|c|c|c|c|}
\hline \multicolumn{6}{|c|}{ Supplemental Table S2.txt } \\
\hline CHEMBL1523819 & 688161 & 4.5 & 4.8726 & TST & \\
\hline CHEMBL1546369 & 688161 & 4.9 & 4.9071 & TRN & \\
\hline CHEMBL1505947 & 688161 & 4.7 & 5.2299 & TRN & \\
\hline CHEMBL1476049 & 688161 & 4.9 & 4.8202 & TRN & \\
\hline CHEMBL1484731 & 688161 & 6.4 & 5.2288 & TRN & \\
\hline CHEMBL1329027 & 688161 & 4.9 & 4.85 & TRN & \\
\hline CHEMBL1565346 & 688161 & 5.5 & 4.9045 & TRN & \\
\hline CHEMBL1485782 & 688161 & 4.6 & 4.9548 & TRN & \\
\hline CHEMBL1317124 & 688161 & 4.5 & 4.9797 & TST & \\
\hline CHEMBL1342311 & 688161 & 4.5 & 4.8587 & TRN & \\
\hline CHEMBL 30432 & 688161 & 4.6 & 4.8571 & TRN & \\
\hline CHEMBL1525602 & 688161 & 4.6 & 4.7848 & TRN & \\
\hline CHEMBL1547000 & 688161 & 5.0 & 4.8908 & TRN & \\
\hline CHEMBL1498962 & 688161 & 5.6 & 4.9228 & TRN & \\
\hline CHEMBL1417018 & 688161 & 5.1 & 4.9857 & TRN & \\
\hline CHEMBL1399362 & 688161 & 4.6 & 4.8792 & TRN & \\
\hline CHEMBL1448000 & 688161 & 4.7 & 4.8467 & TRN & \\
\hline CHEMBL1426421 & 688161 & 5.1 & 4.8364 & TRN & \\
\hline CHEMBL1343705 & 688161 & 5.0 & 4.9341 & TRN & \\
\hline CHEMBL1514953 & 688161 & 4.7 & 4.8529 & TRN & \\
\hline CHEMBL1492950 & 688161 & 4.6 & 4.8764 & TRN & \\
\hline CHEMBL1579811 & 688161 & 4.5 & 5.2161 & TRN & \\
\hline CHEMBL51085 & 688161 & 6.0 & 5.2398 & TST & \\
\hline CHEMBL1611450 & 688161 & 4.6 & 4.9172 & TRN & \\
\hline CHEMBL1367933 & 688161 & 5.4 & 4.9769 & TRN & \\
\hline CHEMBL1449065 & 688161 & 4.4 & 4.8643 & TRN & \\
\hline CHEMBL1429038 & 688161 & 4.9 & 4.9728 & TRN & \\
\hline CHEMBL1454601 & 688161 & 4.5 & 4.896 & TRN & \\
\hline CHEMBL1391491 & 688161 & 5.3 & 4.9854 & TRN & \\
\hline CHEMBL1453539 & 688161 & 4.4 & 4.9015 & TRN & \\
\hline CHEMBL1394464 & 688161 & 5.0 & 4.8748 & TST & \\
\hline CHEMBL1587552 & 688161 & 4.9 & 5.0035 & TST & \\
\hline CHEMBL1509860 & 688161 & 4.7 & 4.8136 & TRN & \\
\hline CHEMBL301707 & 688161 & 5.3 & 4.8857 & TRN & \\
\hline CHEMBL1564891 & 688161 & 4.4 & 4.9127 & TST & \\
\hline CHEMBL1537744 & 688161 & 4.6 & 4.8633 & TRN & \\
\hline CHEMBL 243652 & 688161 & 4.9 & 4.9716 & TST & \\
\hline CHEMBL1410318 & 688161 & 5.7 & 4.8987 & TRN & \\
\hline CHEMBL277127 & 688161 & 5.4 & 5.7658 & TRN & \\
\hline CHEMBL1321006 & 688161 & 5.5 & 4.9438 & TRN & \\
\hline CHEMBL1428244 & 688161 & 4.7 & 4.90600 & 0000000001 & TRN \\
\hline CHEMBL1352386 & 688161 & 4.6 & 4.9205 & TRN & \\
\hline CHEMBL1381551 & 688161 & 4.6 & 4.9722 & TRN & \\
\hline CHEMBL1445275 & 688161 & 4.9 & 4.9163 & TRN & \\
\hline CHEMBL1521872 & 688161 & 4.8 & 4.9272 & TRN & \\
\hline CHEMBL1338461 & 688161 & 5.0 & 4.9771 & TRN & \\
\hline CHEMBL1387313 & 688161 & 4.9 & 4.8851 & TRN & \\
\hline CHEMBL1486647 & 688161 & 6.2 & 4.9771 & TRN & \\
\hline
\end{tabular}




\begin{tabular}{|c|c|c|c|c|}
\hline & & & & \\
\hline CHEMBL1363568 & 688161 & 6.4 & 5.0813 & TRN \\
\hline CHEMBL1319499 & 688161 & 4.6 & 4.8285 & TRN \\
\hline CHEMBL1594718 & 688161 & 4.6 & 5.0252 & TRN \\
\hline CHEMBL1510870 & 688161 & 4.5 & 4.7654 & TRN \\
\hline CHEMBL1394002 & 688161 & 5.5 & 4.7981 & TRN \\
\hline CHEMBL1383267 & 688161 & 5.8 & 4.9302 & TRN \\
\hline CHEMBL1527833 & 688161 & 5.0 & 4.9049 & TRN \\
\hline CHEMBL3190679 & 688161 & 4.6 & 4.8826 & TST \\
\hline CHEMBL1441802 & 688161 & 4.9 & 4.8044 & TRN \\
\hline CHEMBL1479902 & 688161 & 4.6 & 4.8808 & TRN \\
\hline CHEMBL1581071 & 688161 & 4.8 & 4.873 & TRN \\
\hline CHEMBL428064 & 688161 & 6.2 & 4.9476 & TRN \\
\hline CHEMBL1402435 & 688161 & 5.2 & 4.927 & TRN \\
\hline CHEMBL1429310 & 688161 & 4.7 & 4.7821 & TRN \\
\hline CHEMBL1442603 & 688161 & 5.1 & 5.1429 & TST \\
\hline CHEMBL1502546 & 688161 & 4.6 & 4.9617 & TRN \\
\hline CHEMBL1447034 & 688161 & 4.8 & 4.9806 & TST \\
\hline CHEMBL1536303 & 688161 & 4.7 & 4.9148 & TRN \\
\hline CHEMBL1321846 & 688161 & 4.7 & 4.7798 & TRN \\
\hline CHEMBL1361294 & 688161 & 4.7 & 4.8719 & TRN \\
\hline CHEMBL563294 & 688161 & 4.5 & 4.9898 & TRN \\
\hline CHEMBL1386232 & 688161 & 5.0 & 4.9231 & TRN \\
\hline CHEMBL1326266 & 688161 & 4.8 & 4.9287 & TRN \\
\hline CHEMBL445177 & 688161 & 5.8 & 4.9191 & TRN \\
\hline CHEMBL1361119 & 688161 & 4.7 & 5.0045 & TRN \\
\hline CHEMBL1571968 & 688161 & 5.7 & 4.7988 & TRN \\
\hline CHEMBL1464777 & 688161 & 4.9 & 4.9064 & TRN \\
\hline CHEMBL1554194 & 688161 & 4.5 & 4.8036 & TRN \\
\hline CHEMBL491976 & 688161 & 4.7 & 4.8755 & TRN \\
\hline CHEMBL1428011 & 688161 & 4.8 & 4.9396 & TRN \\
\hline CHEMBL1525923 & 688161 & 4.6 & 4.8877 & TRN \\
\hline CHEMBL1463027 & 688161 & 4.7 & 4.87 & TRN \\
\hline CHEMBL1495072 & 688161 & 5.3 & 4.9592 & TRN \\
\hline CHEMBL1361552 & 688161 & 4.7 & 4.8816 & TRN \\
\hline CHEMBL1369918 & 688161 & 4.8 & 4.9071 & TRN \\
\hline CHEMBL1484261 & 688161 & 4.6 & 4.8595 & TRN \\
\hline CHEMBL26655 & 688161 & 6.2 & 4.9505 & TRN \\
\hline CHEMBL1501302 & 688161 & 4.5 & 4.9477 & TRN \\
\hline CHEMBL1360037 & 688161 & 5.5 & 5.0315 & TRN \\
\hline CHEMBL1365011 & 688161 & 5.9 & 4.8432 & TRN \\
\hline CHEMBL235672 & 688161 & 4.6 & 5.0107 & TST \\
\hline CHEMBL1527520 & 688161 & 5.8 & 4.9682 & TST \\
\hline CHEMBL1505320 & 688161 & 5.7 & 4.80399 & 9999999999 \\
\hline CHEMBL1373183 & 688161 & 4.6 & 4.8512 & TRN \\
\hline CHEMBL1344285 & 688161 & 4.9 & 4.7646 & TRN \\
\hline CHEMBL1383517 & 688161 & 5.0 & 4.784 & TRN \\
\hline CHEMBL1337448 & 688161 & 5.2 & 5.1556 & TST \\
\hline CHEMBL1352062 & 688161 & 4.6 & 4.8592 & TRN \\
\hline & & & & 23465 \\
\hline
\end{tabular}

TRN 


\begin{tabular}{|c|c|c|c|c|c|}
\hline \multicolumn{6}{|c|}{ Supplemental Table S2.txt } \\
\hline CHEMBL1386959 & 688161 & 4.6 & 4.9319 & TRN & \\
\hline CHEMBL1457597 & 688161 & 5.2 & 4.8927 & TRN & \\
\hline CHEMBL1488031 & 688161 & 4.7 & 4.8302 & TST & \\
\hline CHEMBL1526413 & 688161 & 4.9 & 4.9394 & TRN & \\
\hline CHEMBL1556909 & 688161 & 5.0 & 4.9032 & TRN & \\
\hline CHEMBL1454397 & 688161 & 4.9 & 5.105 & TRN & \\
\hline CHEMBL1561870 & 688161 & 4.4 & 4.8979 & TRN & \\
\hline CHEMBL1608013 & 688161 & 5.0 & 4.9428 & TST & \\
\hline CHEMBL1486923 & 688161 & 4.6 & 4.9439 & TRN & \\
\hline CHEMBL1192187 & 688161 & 4.7 & 4.9824 & TST & \\
\hline CHEMBL1564873 & 688161 & 4.6 & 4.92399 & 99999999995 & TRN \\
\hline CHEMBL444711 & 688161 & 4.9 & 5.01699 & 99999999995 & TRN \\
\hline CHEMBL81753 & 688161 & 5.4 & 5.3702 & TST & \\
\hline CHEMBL1483679 & 688161 & 4.6 & 4.8303 & TRN & \\
\hline CHEMBL1434460 & 688161 & 4.6 & 4.7494 & TRN & \\
\hline CHEMBL1484258 & 688161 & 4.7 & 4.931 & TRN & \\
\hline CHEMBL1563607 & 688161 & 5.0 & 4.9032 & TRN & \\
\hline CHEMBL1467411 & 688161 & 4.6 & 4.8613 & TST & \\
\hline CHEMBL266084 & 688161 & 7.1002 & 4.9294 & TRN & \\
\hline CHEMBL1587654 & 688161 & 4.5 & 4.752 & TRN & \\
\hline CHEMBL1877767 & 688161 & 6.7001 & 5.0326 & TRN & \\
\hline CHEMBL1364180 & 688161 & 4.4 & 5.0544 & TRN & \\
\hline CHEMBL1371060 & 688161 & 5.5 & 4.9794 & TRN & \\
\hline CHEMBL1545915 & 688161 & 4.8 & 4.9027 & TST & \\
\hline CHEMBL602213 & 688161 & 5.6 & 5.1285 & TRN & \\
\hline CHEMBL1523614 & 688161 & 4.9 & 4.797 & TRN & \\
\hline CHEMBL1339860 & 688161 & 4.8 & 5.0706 & TRN & \\
\hline CHEMBL1535202 & 688161 & 4.9 & 4.9057 & TRN & \\
\hline CHEMBL1411473 & 688161 & 5.4 & 4.8521 & TRN & \\
\hline CHEMBL1522146 & 688161 & 5.1 & 4.8852 & TRN & \\
\hline CHEMBL1304639 & 688161 & 4.7 & 4.8685 & TRN & \\
\hline CHEMBL1469885 & 688161 & 4.7 & 4.8904 & TRN & \\
\hline CHEMBL1566928 & 688161 & 4.8 & 4.8852 & TRN & \\
\hline CHEMBL1707911 & 688161 & 5.3 & 4.907 & TRN & \\
\hline CHEMBL1387072 & 688161 & 4.7 & 4.8331 & TRN & \\
\hline CHEMBL1344239 & 688161 & 8.0 & 4.8991 & TRN & \\
\hline CHEMBL1356794 & 688161 & 4.9 & 4.8171 & TRN & \\
\hline CHEMBL1490905 & 688161 & 4.6 & 4.8294 & TRN & \\
\hline CHEMBL1353809 & 688161 & 4.4 & 4.7852 & TRN & \\
\hline CHEMBL1357796 & 688161 & 4.6 & 4.8871 & TRN & \\
\hline CHEMBL1422481 & 688161 & 5.7 & 5.0952 & TRN & \\
\hline CHEMBL 371523 & 688161 & 5.0 & 4.9036 & TRN & \\
\hline CHEMBL1416364 & 688161 & 5.1 & 4.8343 & TRN & \\
\hline CHEMBL1496315 & 688161 & 5.4 & 4.8734 & TRN & \\
\hline CHEMBL 243677 & 688161 & 6.4 & 4.9306 & TRN & \\
\hline CHEMBL1583096 & 688161 & 4.5 & 5.0181 & TRN & \\
\hline CHEMBL1461319 & 688161 & 5.9 & 4.8588 & TRN & \\
\hline CHEMBL1311994 & 688161 & 5.2 & 4.9421 & TRN & \\
\hline
\end{tabular}




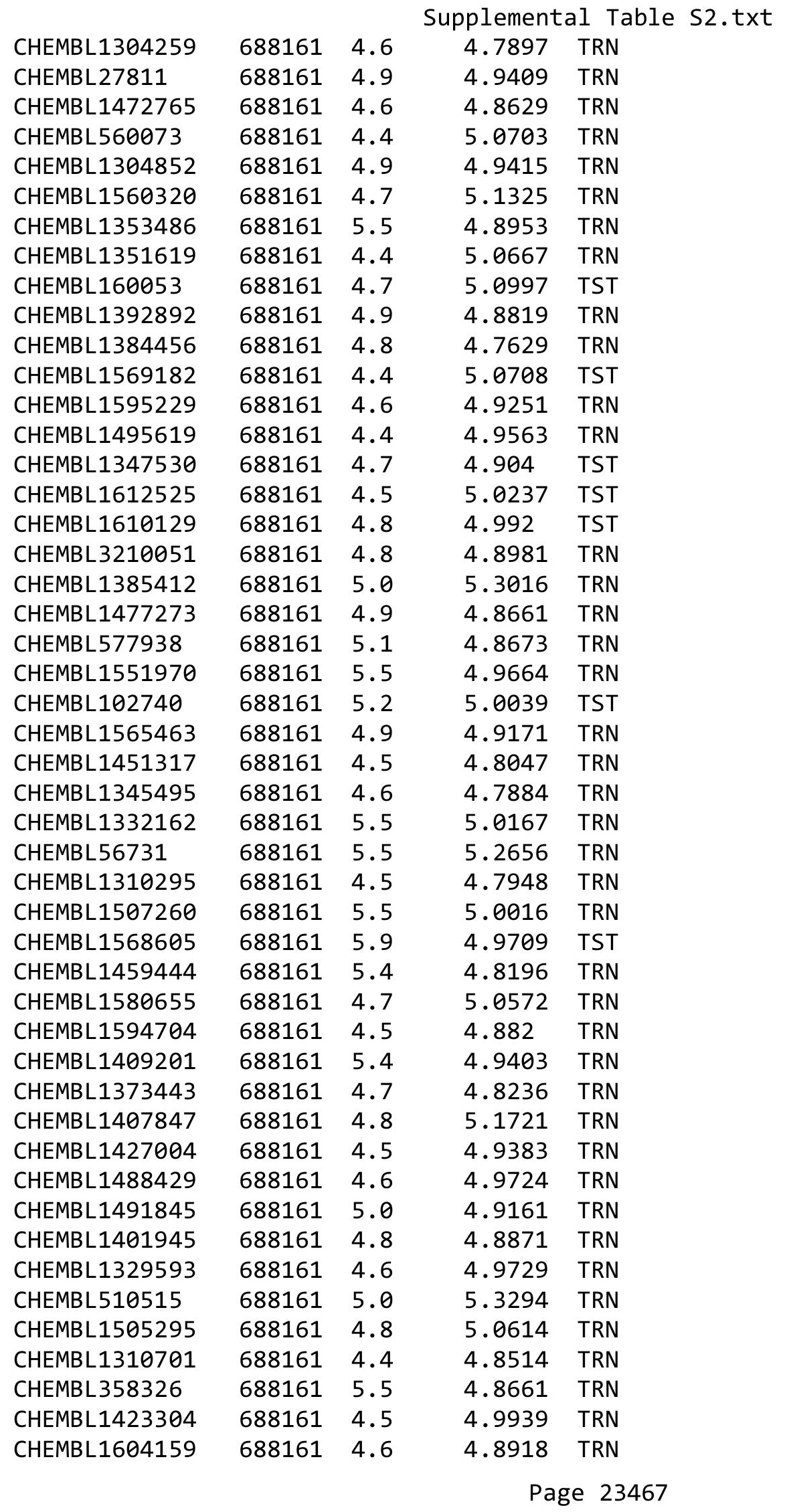




\begin{tabular}{|c|c|c|c|c|}
\hline & & & Supplement & al \\
\hline CHEMBL224720 & 688161 & 4.4 & 4.8991 & TST \\
\hline CHEMBL1375121 & 688161 & 5.2 & 4.9727 & TRN \\
\hline CHEMBL1469096 & 688161 & 4.4 & 4.7814 & TRN \\
\hline CHEMBL1419709 & 688161 & 5.8 & 5.2743 & TRN \\
\hline CHEMBL1378735 & 688161 & 4.7 & 4.7692 & TRN \\
\hline CHEMBL1575015 & 688161 & 4.7 & 4.9732 & TRN \\
\hline CHEMBL261782 & 688161 & 4.6 & 4.9684 & TST \\
\hline CHEMBL1421390 & 688161 & 5.0 & 4.9352 & TRN \\
\hline CHEMBL1557987 & 688161 & 4.6 & 4.9753 & TRN \\
\hline CHEMBL1389445 & 688161 & 4.6 & 4.872 & TRN \\
\hline CHEMBL1313193 & 688161 & 5.3 & 4.895 & TRN \\
\hline CHEMBL1303063 & 688161 & 5.0 & 5.0106 & TRN \\
\hline CHEMBL1565848 & 688161 & 4.6 & 4.9039 & TRN \\
\hline CHEMBL1380684 & 688161 & 6.0 & 5.4003 & TRN \\
\hline CHEMBL1572777 & 688161 & 5.3 & 5.0592 & TRN \\
\hline CHEMBL1524448 & 688161 & 6.2 & 4.8854 & TRN \\
\hline CHEMBL75267 & 688161 & 5.3 & 5.2862 & TRN \\
\hline CHEMBL 1142 & 688161 & 4.6 & 5.0918 & TRN \\
\hline CHEMBL173521 & 688161 & 4.6 & 4.8855 & TRN \\
\hline CHEMBL1338297 & 688161 & 5.1 & 4.9367 & TST \\
\hline CHEMBL1559731 & 688161 & 4.6 & 4.9098 & TRN \\
\hline CHEMBL1462631 & 688161 & 4.4 & 4.9436 & TRN \\
\hline CHEMBL1353205 & 688161 & 4.6 & 4.7984 & TRN \\
\hline CHEMBL1422438 & 688161 & 4.6 & 4.769 & TRN \\
\hline CHEMBL1349014 & 688161 & 4.8 & 4.8846 & TRN \\
\hline CHEMBL1538345 & 688161 & 4.7 & 4.9148 & TRN \\
\hline CHEMBL1463808 & 688161 & 5.4 & 4.809 & TRN \\
\hline CHEMBL1300327 & 688161 & 4.9 & 4.8699 & TST \\
\hline CHEMBL1580712 & 688161 & 4.7 & 4.9678 & TST \\
\hline CHEMBL1596014 & 688161 & 4.6 & 4.7999 & TRN \\
\hline CHEMBL1585485 & 688161 & 4.8 & 4.9184 & TRN \\
\hline CHEMBL1438621 & 688161 & 4.4 & 4.93 & TRN \\
\hline CHEMBL122701 & 688161 & 5.7 & 5.5996 & TRN \\
\hline CHEMBL1378800 & 688161 & 5.4 & 5.0396 & TST \\
\hline CHEMBL1558784 & 688161 & 4.8 & 4.9523 & TRN \\
\hline CHEMBL1558761 & 688161 & 4.6 & 4.8837 & TRN \\
\hline CHEMBL1405133 & 688161 & 4.6 & 4.8319 & TRN \\
\hline CHEMBL1350152 & 688161 & 4.7 & 4.9857 & TRN \\
\hline CHEMBL3145149 & 688161 & 5.4 & 4.9323 & TRN \\
\hline CHEMBL1525129 & 688161 & 4.5 & 4.9092 & TRN \\
\hline CHEMBL1359529 & 688161 & 5.3 & 5.0184 & TRN \\
\hline CHEMBL1388223 & 688161 & 5.3 & 4.926 & TRN \\
\hline CHEMBL1432038 & 688161 & 5.4 & 4.9332 & TRN \\
\hline CHEMBL1440383 & 688161 & 4.4 & 4.8705 & TRN \\
\hline CHEMBL1306731 & 688161 & 5.1 & 5.1149 & TRN \\
\hline CHEMBL198759 & 688161 & 4.8 & 4.9153 & TST \\
\hline CHEMBL1507981 & 688161 & 5.4 & 4.879 & TRN \\
\hline CHEMBL1365057 & 688161 & 5.2 & 4.9313 & TRN \\
\hline
\end{tabular}




\begin{tabular}{|c|c|c|c|c|}
\hline \multicolumn{5}{|c|}{ Supplemental Table S2.txt } \\
\hline CHEMBL1329033 & 688161 & 6.2 & 4.9994 & TRN \\
\hline CHEMBL1370517 & 688161 & 7.4001 & 4.9319 & TRN \\
\hline CHEMBL1495909 & 688161 & 4.8 & 4.8775 & TRN \\
\hline CHEMBL1583046 & 688161 & 5.5 & 4.876 & TRN \\
\hline CHEMBL1373821 & 688161 & 5.9 & 4.9228 & TRN \\
\hline CHEMBL1603505 & 688161 & 4.8 & 4.9202 & TRN \\
\hline CHEMBL1345363 & 688161 & 4.8 & 4.9922 & TRN \\
\hline CHEMBL1587680 & 688161 & 5.5 & 4.7528 & TRN \\
\hline CHEMBL1308910 & 688161 & 4.6 & 5.1111 & TRN \\
\hline CHEMBL1412821 & 688161 & 4.8 & 5.1533 & TST \\
\hline CHEMBL1412288 & 688161 & 4.8 & 4.8935 & TRN \\
\hline CHEMBL 276618 & 688161 & 5.0 & 5.2146 & TRN \\
\hline CHEMBL1492111 & 688161 & 4.5 & 5.2819 & TRN \\
\hline CHEMBL1590493 & 688161 & 5.4 & 4.765 & TRN \\
\hline CHEMBL1336006 & 688161 & 4.9 & 4.9081 & TRN \\
\hline CHEMBL1452291 & 688161 & 4.8 & 4.9662 & TRN \\
\hline CHEMBL1399489 & 688161 & 4.5 & 4.8801 & TRN \\
\hline CHEMBL 238188 & 688161 & 4.8 & 5.0782 & TRN \\
\hline CHEMBL531269 & 688161 & 7.0 & 4.8212 & TRN \\
\hline CHEMBL1302338 & 688161 & 4.4 & 5.0263 & TST \\
\hline CHEMBL37081 & 688161 & 6.4 & 4.9936 & TRN \\
\hline CHEMBL1402797 & 688161 & 4.6 & 4.8336 & TRN \\
\hline CHEMBL1521671 & 688161 & 5.2 & 4.8483 & TRN \\
\hline CHEMBL3198838 & 688161 & 4.7 & 4.9382 & TRN \\
\hline CHEMBL1381657 & 688161 & 4.6 & 4.9571 & TRN \\
\hline CHEMBL1552286 & 688161 & 4.6 & 4.7365 & TRN \\
\hline CHEMBL1331823 & 688161 & 4.6 & 5.1817 & TST \\
\hline CHEMBL1418209 & 688161 & 4.8 & 4.9381 & TRN \\
\hline CHEMBL1468247 & 688161 & 4.7 & 4.8941 & TRN \\
\hline CHEMBL1428474 & 688161 & 4.7 & 4.8777 & TRN \\
\hline CHEMBL1581337 & 688161 & 4.5 & 4.9072 & TRN \\
\hline CHEMBL1328649 & 688161 & 7.699 & 4.8961 & TRN \\
\hline CHEMBL1555348 & 688161 & 5.0 & 4.7859 & TRN \\
\hline CHEMBL1404408 & 688161 & 4.4 & 4.8934 & TRN \\
\hline CHEMBL1456967 & 688161 & 4.6 & 5.0884 & TRN \\
\hline CHEMBL1579564 & 688161 & 6.5 & 5.38899 & 9999999999 \\
\hline CHEMBL1316314 & 688161 & 4.4 & 4.9723 & TST \\
\hline CHEMBL1329440 & 688161 & 6.0 & 4.974 & TST \\
\hline CHEMBL435392 & 688161 & 4.5 & 4.9314 & TRN \\
\hline CHEMBL1605218 & 688161 & 5.4 & 4.879 & TRN \\
\hline CHEMBL1542538 & 688161 & 5.4 & 4.7954 & TRN \\
\hline CHEMBL1505105 & 688161 & 4.5 & 4.9288 & TRN \\
\hline CHEMBL366861 & 688161 & 4.6 & 5.0921 & TST \\
\hline CHEMBL1568735 & 688161 & 4.6 & 4.7768 & TRN \\
\hline CHEMBL1457918 & 688161 & 4.7 & 4.8051 & TRN \\
\hline CHEMBL1403384 & 688161 & 4.9 & 4.8782 & TRN \\
\hline CHEMBL1548533 & 688161 & 4.9 & 4.9105 & TRN \\
\hline CHEMBL1479449 & 688161 & 4.6 & 4.9286 & TRN \\
\hline
\end{tabular}




\begin{tabular}{|c|c|c|c|c|c|}
\hline \multicolumn{6}{|c|}{ Supplemental Table S2.txt } \\
\hline CHEMBL1522253 & 688161 & 5.6 & 4.7766 & TRN & \\
\hline CHEMBL1499120 & 688161 & 5.0 & 4.9371 & TRN & \\
\hline CHEMBL1332397 & 688161 & 5.0 & 4.9031 & TRN & \\
\hline CHEMBL1308965 & 688161 & 5.3 & 5.1442 & TRN & \\
\hline CHEMBL1469540 & 688161 & 4.5 & 4.8768 & TRN & \\
\hline CHEMBL1334439 & 688161 & 4.8 & 4.8777 & TRN & \\
\hline CHEMBL1584299 & 688161 & 4.4 & 4.8085 & TRN & \\
\hline CHEMBL1533246 & 688161 & 4.6 & 4.8089 & TRN & \\
\hline CHEMBL1373194 & 688161 & 4.9 & 4.9195 & TRN & \\
\hline CHEMBL1487114 & 688161 & 4.5 & 4.908 & TRN & \\
\hline CHEMBL1369599 & 688161 & 7.6003 & 5.0168 & TRN & \\
\hline CHEMBL1462450 & 688161 & 4.6 & 4.8039 & TRN & \\
\hline CHEMBL1448047 & 688161 & 4.5 & 4.9205 & TRN & \\
\hline CHEMBL1334768 & 688161 & 4.9 & 4.8944 & TRN & \\
\hline CHEMBL1391857 & 688161 & 4.8 & 4.8877 & TRN & \\
\hline CHEMBL1564461 & 688161 & 5.0 & 4.8725 & TRN & \\
\hline CHEMBL1421221 & 688161 & 6.8 & 4.7658 & TRN & \\
\hline CHEMBL1446180 & 688161 & 4.5 & 4.9615 & TST & \\
\hline CHEMBL13888 & 688161 & 5.8 & 5.0204 & TRN & \\
\hline CHEMBL1362206 & 688161 & 4.7 & 4.8121 & TRN & \\
\hline CHEMBL1370320 & 688161 & 4.8 & 5.0503 & TRN & \\
\hline CHEMBL1535402 & 688161 & 4.6 & 5.0822 & TST & \\
\hline CHEMBL1452716 & 688161 & 6.0 & $4.9910 e$ & 00000000005 & TRN \\
\hline CHEMBL66953 & 688161 & 5.4 & 5.0324 & TRN & \\
\hline CHEMBL1471583 & 688161 & 4.9 & 4.84 & TST & \\
\hline CHEMBL492719 & 688161 & 5.4 & 4.9044 & TRN & \\
\hline CHEMBL1540596 & 688161 & 4.8 & 4.8797 & TRN & \\
\hline CHEMBL1574261 & 688161 & 5.4 & 5.0127 & TRN & \\
\hline CHEMBL1305414 & 688161 & 4.9 & 4.8762 & TRN & \\
\hline CHEMBL1574687 & 688161 & 5.5 & 4.8747 & TRN & \\
\hline CHEMBL1335123 & 688161 & 5.0 & 4.8247 & TRN & \\
\hline CHEMBL1530229 & 688161 & 5.5 & 5.1013 & TRN & \\
\hline CHEMBL1543293 & 688161 & 4.8 & 4.87 & TRN & \\
\hline CHEMBL1571705 & 688161 & 4.6 & 4.9823 & TRN & \\
\hline CHEMBL 3191002 & 688161 & 4.9 & 4.8912 & TRN & \\
\hline CHEMBL1567815 & 688161 & 5.4 & 4.91 & TRN & \\
\hline CHEMBL1505545 & 688161 & 5.3 & 4.8299 & TRN & \\
\hline CHEMBL1561325 & 688161 & 4.5 & 4.9228 & TRN & \\
\hline CHEMBL151 & 688161 & 6.0 & 5.2869 & TRN & \\
\hline CHEMBL1319476 & 688161 & 5.1 & 5.4688 & TRN & \\
\hline CHEMBL51773 & 688161 & 4.4 & 4.8547 & TRN & \\
\hline CHEMBL1442411 & 688161 & 5.5 & 4.8973 & TRN & \\
\hline CHEMBL1403538 & 688161 & 4.7 & 4.8811 & TRN & \\
\hline CHEMBL602353 & 688161 & 5.0 & 4.902 & TRN & \\
\hline CHEMBL1441874 & 688161 & 4.8 & 5.3534 & TRN & \\
\hline CHEMBL1574878 & 688161 & 5.4 & 4.8477 & TRN & \\
\hline CHEMBL1582406 & 688161 & 5.0 & 4.9069 & TRN & \\
\hline CHEMBL430893 & 688161 & 6.0 & 4.9715 & TST & \\
\hline
\end{tabular}




\begin{tabular}{|c|c|c|c|c|c|}
\hline \multicolumn{6}{|c|}{ Supplemental Table S2.txt } \\
\hline CHEMBL1463132 & 688161 & 5.1 & 5.269 & TRN & \\
\hline CHEMBL238624 & 688161 & 5.4 & 5.055 & TST & \\
\hline CHEMBL1418057 & 688161 & 4.4 & 5.1488 & TST & \\
\hline CHEMBL1256191 & 688161 & 6.6 & 5.5198 & TST & \\
\hline CHEMBL1368138 & 688161 & 4.8 & 5.0714 & TRN & \\
\hline CHEMBL1576312 & 688161 & 4.7 & 4.7781 & TRN & \\
\hline CHEMBL1584930 & 688161 & 5.4 & 4.8916 & TRN & \\
\hline CHEMBL1545634 & 688161 & 4.5 & 5.2681 & TRN & \\
\hline CHEMBL1584452 & 688161 & 5.0 & 4.8183 & TST & \\
\hline CHEMBL1483700 & 688161 & 4.6 & 4.7784 & TRN & \\
\hline CHEMBL1478602 & 688161 & 4.4 & 4.8934 & TRN & \\
\hline CHEMBL3198719 & 688161 & 4.8 & 4.8767 & TST & \\
\hline CHEMBL 2373648 & 688161 & 5.5 & 5.1253 & TST & \\
\hline CHEMBL1526736 & 688161 & 4.5 & 4.9441 & TRN & \\
\hline CHEMBL1388486 & 688161 & 4.8 & 4.9103 & TRN & \\
\hline CHEMBL1466820 & 688161 & 4.5 & 4.9993 & TRN & \\
\hline CHEMBL1613567 & 688161 & 4.8 & 4.8546 & TRN & \\
\hline CHEMBL1368366 & 688161 & 4.6 & 4.9551 & TST & \\
\hline CHEMBL58343 & 688161 & 4.9 & 5.0682 & TST & \\
\hline CHEMBL1361000 & 688161 & 5.5 & 5.3494 & TRN & \\
\hline CHEMBL1365455 & 688161 & 5.0 & 5.0403 & TST & \\
\hline CHEMBL1340697 & 688161 & 4.5 & 4.9033 & TRN & \\
\hline CHEMBL1496825 & 688161 & 5.2 & 4.938 & TRN & \\
\hline CHEMBL1531788 & 688161 & 4.5 & 4.8328 & TRN & \\
\hline CHEMBL1328519 & 688161 & 5.6 & 5.3222 & TRN & \\
\hline CHEMBL1374415 & 688161 & 4.5 & 4.961 & TRN & \\
\hline CHEMBL1331749 & 688161 & 4.5 & 4.7798 & TRN & \\
\hline CHEMBL1569852 & 688161 & 5.2 & 4.9206 & TRN & \\
\hline CHEMBL1530697 & 688161 & 4.8 & 5.194 & TRN & \\
\hline CHEMBL1462481 & 688161 & 4.5 & 4.8968 & TRN & \\
\hline CHEMBL1513115 & 688161 & 5.2 & 4.9715 & TRN & \\
\hline CHEMBL1599971 & 688161 & 4.5 & 4.8852 & TRN & \\
\hline CHEMBL1483329 & 688161 & 4.5 & 4.8797 & TRN & \\
\hline CHEMBL492193 & 688161 & 5.1 & 4.967 & TST & \\
\hline CHEMBL1488522 & 688161 & 5.4 & 4.9484 & TRN & \\
\hline CHEMBL1539070 & 688161 & 4.9 & 4.8522 & TRN & \\
\hline CHEMBL1555899 & 688161 & 4.5 & $4.8660 e$ & 00000000005 & TRN \\
\hline CHEMBL1596334 & 688161 & 4.4 & 4.8598 & TRN & \\
\hline CHEMBL1300266 & 688161 & 5.4 & 5.3146 & TRN & \\
\hline CHEMBL489737 & 688161 & 4.7 & 4.8149 & TRN & \\
\hline CHEMBL1605101 & 688161 & 5.5 & 5.0673 & TRN & \\
\hline CHEMBL509256 & 688161 & 4.9 & 5.0386 & TRN & \\
\hline CHEMBL487187 & 688161 & 4.9 & 5.1947 & TRN & \\
\hline CHEMBL1590123 & 688161 & 4.7 & 4.7393 & TRN & \\
\hline CHEMBL1419102 & 688161 & 5.3 & 4.8941 & TRN & \\
\hline CHEMBL1532337 & 688161 & 6.5 & 4.8741 & TRN & \\
\hline CHEMBL456881 & 688161 & 5.5 & 4.7926 & TRN & \\
\hline CHEMBL1365172 & 688161 & 5.1 & 4.9913 & TRN & \\
\hline
\end{tabular}




\begin{tabular}{|c|c|c|c|c|c|}
\hline \multicolumn{6}{|c|}{ Supplemental Table S2.txt } \\
\hline CHEMBL3213560 & 688161 & 4.6 & 4.9299 & TRN & \\
\hline CHEMBL1466140 & 688161 & 5.3 & 5.0194 & TRN & \\
\hline CHEMBL1595775 & 688161 & 4.4 & 4.8999 & TRN & \\
\hline CHEMBL1345047 & 688161 & 4.9 & 4.9896 & TST & \\
\hline CHEMBL1565329 & 688161 & 5.5 & 5.3857 & TRN & \\
\hline CHEMBL1581436 & 688161 & 5.8 & 5.0256 & TRN & \\
\hline CHEMBL1232474 & 688161 & 5.3 & 5.05699 & 99999999995 & TRN \\
\hline CHEMBL1517045 & 688161 & 5.5 & 4.8129 & TRN & \\
\hline CHEMBL1340593 & 688161 & 4.6 & 4.8035 & TRN & \\
\hline CHEMBL1456417 & 688161 & 4.8 & 4.9223 & TRN & \\
\hline CHEMBL1303765 & 688161 & 4.7 & 5.0564 & TRN & \\
\hline CHEMBL1367484 & 688161 & 5.4 & 5.2082 & TRN & \\
\hline CHEMBL1607407 & 688161 & 5.1 & 4.9186 & TRN & \\
\hline CHEMBL1405419 & 688161 & 4.9 & 4.8158 & TRN & \\
\hline CHEMBL 266540 & 688161 & 4.4 & 4.9113 & TST & \\
\hline CHEMBL1481933 & 688161 & 4.7 & 4.8871 & TRN & \\
\hline CHEMBL1327315 & 688161 & 7.5003 & 4.9086 & TST & \\
\hline CHEMBL1431928 & 688161 & 5.4 & 4.8871 & TRN & \\
\hline CHEMBL1431342 & 688161 & 4.8 & 4.9239 & TRN & \\
\hline CHEMBL1341869 & 688161 & 4.8 & 5.0169 & TRN & \\
\hline CHEMBL1454868 & 688161 & 4.6 & 4.8881 & TRN & \\
\hline CHEMBL282731 & 688161 & 4.4 & 5.5089 & TRN & \\
\hline CHEMBL1501061 & 688161 & 5.0 & 4.9392 & TRN & \\
\hline CHEMBL1365882 & 688161 & 5.9 & 4.9807 & TST & \\
\hline CHEMBL1385074 & 688161 & 4.8 & 5.0677 & TRN & \\
\hline CHEMBL1581158 & 688161 & 4.6 & 4.8676 & TST & \\
\hline CHEMBL1562928 & 688161 & 4.6 & 4.9134 & TRN & \\
\hline CHEMBL1427643 & 688161 & 4.4 & 4.9288 & TRN & \\
\hline CHEMBL1550243 & 688161 & 4.5 & 4.982 & TRN & \\
\hline CHEMBL1493956 & 688161 & 4.8 & 4.9197 & TRN & \\
\hline CHEMBL1426798 & 688161 & 4.6 & 4.8416 & TRN & \\
\hline CHEMBL1393021 & 688161 & 5.3 & 5.2258 & TST & \\
\hline CHEMBL1469299 & 688161 & 5.1 & 4.912 & TRN & \\
\hline CHEMBL453797 & 688161 & 5.0 & 4.99100 & 00000000005 & TST \\
\hline CHEMBL1350117 & 688161 & 4.4 & 4.9176 & TRN & \\
\hline CHEMBL1499112 & 688161 & 4.7 & 5.1161 & TRN & \\
\hline CHEMBL1554411 & 688161 & 5.5 & 5.1597 & TRN & \\
\hline CHEMBL1438780 & 688161 & 4.6 & 4.8725 & TRN & \\
\hline CHEMBL1526405 & 688161 & 4.9 & 4.8552 & TST & \\
\hline CHEMBL1420487 & 688161 & 5.0 & 4.8834 & TRN & \\
\hline CHEMBL1566452 & 688161 & 4.4 & 4.925 & TRN & \\
\hline CHEMBL1464939 & 688161 & 6.1 & 4.9463 & TRN & \\
\hline CHEMBL1311338 & 688161 & 5.2 & 4.8241 & TRN & \\
\hline CHEMBL1369961 & 688161 & 5.5 & 4.8914 & TRN & \\
\hline CHEMBL1316949 & 688161 & 4.7 & 5.0532 & TST & \\
\hline CHEMBL1483095 & 688161 & 5.0 & 5.0425 & TRN & \\
\hline CHEMBL1454689 & 688161 & 4.6 & 4.8738 & TRN & \\
\hline CHEMBL1434081 & 688161 & 5.1 & 5.0186 & TST & \\
\hline
\end{tabular}




\begin{tabular}{|c|c|c|c|c|c|}
\hline \multicolumn{6}{|c|}{ Supplemental Table S2.txt } \\
\hline CHEMBL1574931 & 688161 & 4.9 & 4.9379 & TRN & \\
\hline CHEMBL1393484 & 688161 & 4.5 & 4.9031 & TRN & \\
\hline CHEMBL1495849 & 688161 & 4.8 & 4.8364 & TRN & \\
\hline CHEMBL1352628 & 688161 & 4.6 & 4.9174 & TRN & \\
\hline CHEMBL1442492 & 688161 & 5.3 & 4.9018 & TRN & \\
\hline CHEMBL1566938 & 688161 & 4.5 & 4.7721 & TRN & \\
\hline CHEMBL1466662 & 688161 & 4.6 & 4.8387 & TRN & \\
\hline CHEMBL1409056 & 688161 & 4.6 & $4.8210 e$ & 0000000001 & TRN \\
\hline CHEMBL269362 & 688161 & 8.0 & 4.9187 & TST & \\
\hline CHEMBL1399397 & 688161 & 5.1 & 4.9201 & TRN & \\
\hline CHEMBL1377307 & 688161 & 5.5 & 4.8671 & TRN & \\
\hline CHEMBL1530651 & 688161 & 4.4 & 4.9229 & TRN & \\
\hline CHEMBL1309774 & 688161 & 5.1 & 4.9077 & TRN & \\
\hline CHEMBL1322301 & 688161 & 4.4 & 4.9668 & TRN & \\
\hline CHEMBL1438439 & 688161 & 5.0 & 5.166 & TRN & \\
\hline CHEMBL1565594 & 688161 & 7.4001 & 4.925 & TRN & \\
\hline CHEMBL1514547 & 688161 & 6.3 & 5.5366 & TRN & \\
\hline CHEMBL1438567 & 688161 & 5.5 & 4.9504 & TRN & \\
\hline CHEMBL1441934 & 688161 & 4.5 & $4.8660 e$ & 00000000005 & TRN \\
\hline CHEMBL1311514 & 688161 & 4.4 & 4.8867 & TRN & \\
\hline CHEMBL1388271 & 688161 & 4.4 & 4.7549 & TRN & \\
\hline CHEMBL1321932 & 688161 & 4.7 & 4.9157 & TRN & \\
\hline CHEMBL1408865 & 688161 & 4.6 & 4.9021 & TRN & \\
\hline CHEMBL1498604 & 688161 & 5.0 & 4.8188 & TRN & \\
\hline CHEMBL1592754 & 688161 & 4.5 & 4.9239 & TRN & \\
\hline CHEMBL1543940 & 688161 & 4.6 & 4.8724 & TRN & \\
\hline CHEMBL1315690 & 688161 & 4.9 & 4.8341 & TRN & \\
\hline CHEMBL1494313 & 688161 & 4.7 & 4.9199 & TRN & \\
\hline CHEMBL1426886 & 688161 & 4.6 & 4.9563 & TRN & \\
\hline CHEMBL1596204 & 688161 & 5.1 & 4.8406 & TRN & \\
\hline CHEMBL1330311 & 688161 & 4.8 & 4.9165 & TRN & \\
\hline CHEMBL1342666 & 688161 & 4.9 & 4.8915 & TRN & \\
\hline CHEMBL1311975 & 688161 & 4.8 & 4.7883 & TRN & \\
\hline CHEMBL1397443 & 688161 & 6.3 & 4.9922 & TST & \\
\hline CHEMBL475375 & 688161 & 4.5 & 4.8482 & TRN & \\
\hline CHEMBL315268 & 688161 & 5.4 & 4.9768 & TST & \\
\hline CHEMBL3209422 & 688161 & 4.9 & 4.8697 & TST & \\
\hline CHEMBL1531716 & 688161 & 5.4 & 5.2196 & TRN & \\
\hline CHEMBL1422976 & 688161 & 4.5 & 4.8362 & TRN & \\
\hline CHEMBL1582353 & 688161 & 4.9 & 4.8477 & TRN & \\
\hline CHEMBL34117 & 688161 & 4.7 & 4.9846 & TRN & \\
\hline CHEMBL1542098 & 688161 & 4.6 & 5.0352 & TST & \\
\hline CHEMBL1584441 & 688161 & 4.4 & 4.8541 & TST & \\
\hline CHEMBL1476362 & 688161 & 5.0 & 5.1914 & TST & \\
\hline CHEMBL1563397 & 688161 & 4.7 & 4.7631 & TRN & \\
\hline CHEMBL1448578 & 688161 & 4.5 & 4.8914 & TRN & \\
\hline CHEMBL1334332 & 688161 & 4.6 & 4.8829 & TRN & \\
\hline CHEMBL1511191 & 688161 & 4.8 & 5.2557 & TRN & \\
\hline
\end{tabular}




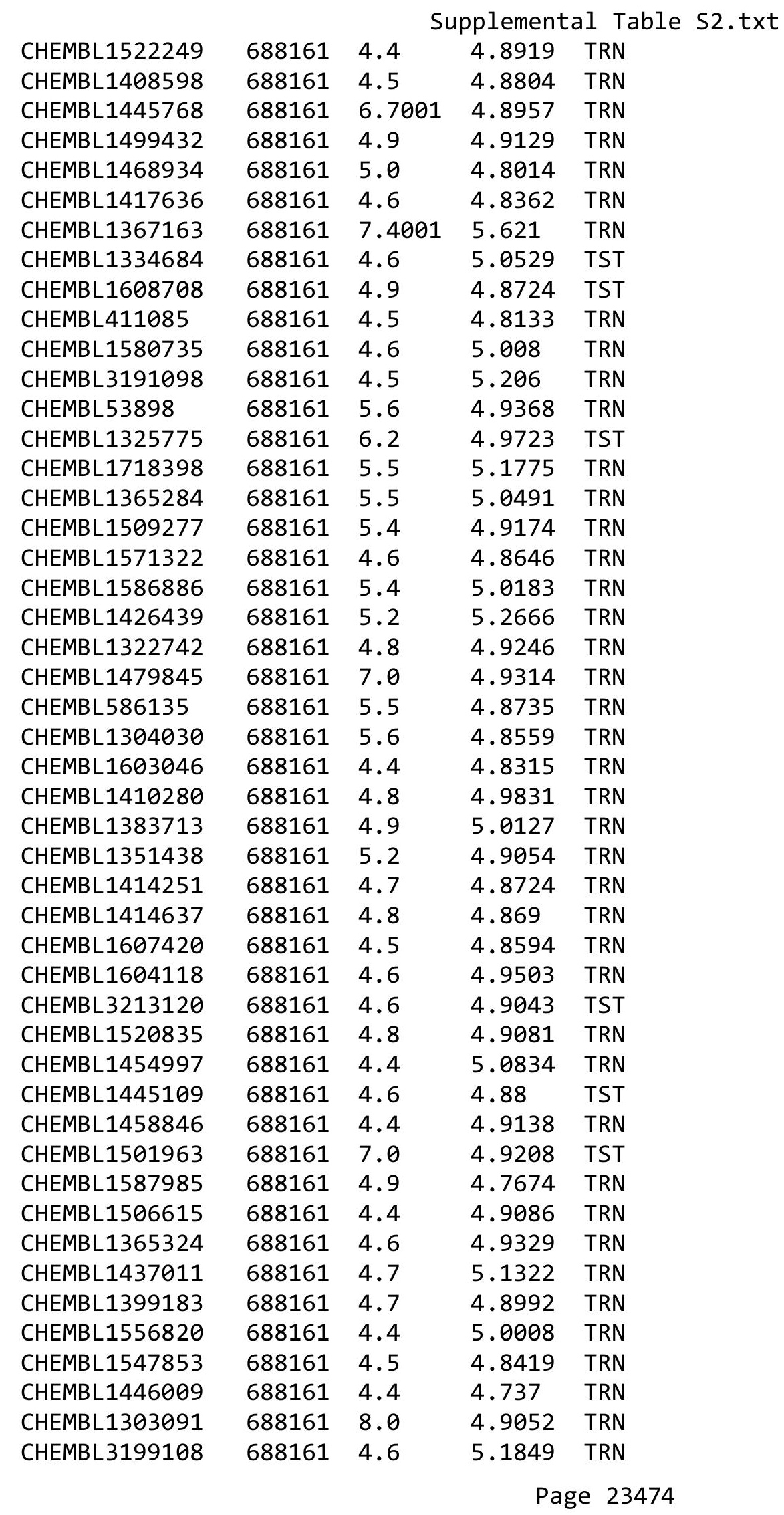




\begin{tabular}{|c|c|c|c|c|}
\hline \multicolumn{5}{|c|}{ Supplemental Table S2.txt } \\
\hline CHEMBL1502851 & 688161 & 5.3 & 5.1402 & TRN \\
\hline CHEMBL1550252 & 688161 & 4.7 & 4.937 & TRN \\
\hline CHEMBL1523920 & 688161 & 4.6 & 4.8998 & TRN \\
\hline CHEMBL1562605 & 688161 & 5.3 & 5.1485 & TRN \\
\hline CHEMBL1486645 & 688161 & 4.4 & 4.8569 & TRN \\
\hline CHEMBL1442487 & 688161 & 4.6 & 4.9331 & TRN \\
\hline CHEMBL1340197 & 688161 & 4.5 & 4.8841 & TRN \\
\hline CHEMBL1316285 & 688161 & 4.9 & 4.8111 & TRN \\
\hline CHEMBL1376616 & 688161 & 4.9 & 4.8612 & TRN \\
\hline CHEMBL1545617 & 688161 & 4.8 & 4.901 & TRN \\
\hline CHEMBL1541620 & 688161 & 4.9 & 4.9242 & TST \\
\hline CHEMBL1593511 & 688161 & 4.6 & 4.8882 & TRN \\
\hline CHEMBL1378282 & 688161 & 4.9 & 4.8718 & TRN \\
\hline CHEMBL1538757 & 688161 & 4.5 & 4.8272 & TRN \\
\hline CHEMBL1397308 & 688161 & 5.3 & 4.8451 & TRN \\
\hline CHEMBL1370284 & 688161 & 4.6 & 5.0368 & TST \\
\hline CHEMBL1356135 & 688161 & 4.4 & 4.8604 & TRN \\
\hline CHEMBL1526434 & 688161 & 4.9 & 4.9988 & TRN \\
\hline CHEMBL1390880 & 688161 & 4.7 & 4.8982 & TRN \\
\hline CHEMBL1299291 & 688161 & 4.5 & 4.85 & TRN \\
\hline CHEMBL1432130 & 688161 & 4.5 & 4.8053 & TRN \\
\hline CHEMBL1550339 & 688161 & 4.6 & 4.9005 & TRN \\
\hline CHEMBL1582888 & 688161 & 6.3 & 4.7775 & TST \\
\hline CHEMBL1555857 & 688161 & 4.8 & 4.7916 & TRN \\
\hline CHEMBL1573454 & 688161 & 4.5 & 4.787 & TRN \\
\hline CHEMBL1363710 & 688161 & 4.8 & 4.8885 & TRN \\
\hline CHEMBL1361777 & 688161 & 7.3002 & 4.846 & TRN \\
\hline CHEMBL1190214 & 688161 & 5.5 & 5.0414 & TST \\
\hline CHEMBL1582538 & 688161 & 4.4 & 4.7914 & TRN \\
\hline CHEMBL1374507 & 688161 & 5.0 & 4.9266 & TRN \\
\hline CHEMBL1451847 & 688161 & 4.6 & 4.9026 & TRN \\
\hline CHEMBL1708832 & 688161 & 5.2 & 5.3081 & TRN \\
\hline CHEMBL1562791 & 688161 & 4.8 & 4.7626 & TRN \\
\hline CHEMBL1609946 & 688161 & 4.9 & 4.8836 & TRN \\
\hline CHEMBL1445998 & 688161 & 4.4 & 4.9631 & TRN \\
\hline CHEMBL1596567 & 688161 & 4.6 & 4.9025 & TRN \\
\hline CHEMBL1409381 & 688161 & 4.6 & 5.2206 & TRN \\
\hline CHEMBL19612 & 688161 & 4.9 & 5.0176 & TST \\
\hline CHEMBL1400643 & 688161 & 4.8 & 4.8442 & TRN \\
\hline CHEMBL1452316 & 688161 & 5.2 & 4.9958 & TST \\
\hline CHEMBL1347978 & 688161 & 4.7 & 4.8646 & TRN \\
\hline CHEMBL1406016 & 688161 & 8.301 & 5.0456 & TRN \\
\hline CHEMBL1380940 & 688161 & 5.0 & 5.1445 & TRN \\
\hline CHEMBL1361615 & 688161 & 5.2 & 4.8246 & TRN \\
\hline CHEMBL3192682 & 688161 & 4.9 & 5.0926 & TRN \\
\hline CHEMBL1399958 & 688161 & 5.8 & 5.2679 & TRN \\
\hline CHEMBL 1302560 & 688161 & 8.2007 & 4.974 & TST \\
\hline CHEMBL1595831 & 688161 & 4.8 & 5.1787 & TRN \\
\hline
\end{tabular}




\begin{tabular}{|c|c|c|c|c|c|}
\hline \multicolumn{6}{|c|}{ Supplemental Table S2.txt } \\
\hline CHEMBL1410792 & 688161 & 4.6 & 4.9929 & TRN & \\
\hline CHEMBL1608205 & 688161 & 4.4 & 4.8658 & TRN & \\
\hline CHEMBL1595576 & 688161 & 5.4 & 4.7708 & TRN & \\
\hline CHEMBL1327954 & 688161 & 4.4 & 4.7911 & TRN & \\
\hline CHEMBL1419264 & 688161 & 4.5 & 4.9454 & TRN & \\
\hline CHEMBL1364887 & 688161 & 4.9 & 4.8725 & TRN & \\
\hline CHEMBL1364432 & 688161 & 4.5 & 4.8497 & TRN & \\
\hline CHEMBL1607363 & 688161 & 5.2 & 4.8298 & TRN & \\
\hline CHEMBL1491818 & 688161 & 5.0 & 4.8598 & TRN & \\
\hline CHEMBL1595820 & 688161 & 5.5 & 4.8684 & TRN & \\
\hline CHEMBL1531750 & 688161 & 4.9 & 4.8461 & TST & \\
\hline CHEMBL1385165 & 688161 & 4.4 & 4.84 & TRN & \\
\hline CHEMBL1332550 & 688161 & 4.5 & 4.812 & TRN & \\
\hline CHEMBL1541343 & 688161 & 4.8 & 4.8776 & TRN & \\
\hline CHEMBL252909 & 688161 & 4.8 & 4.9255 & TST & \\
\hline CHEMBL1363197 & 688161 & 4.4 & 4.9545 & TST & \\
\hline CHEMBL1421754 & 688161 & 4.9 & 4.7863 & TRN & \\
\hline CHEMBL1331245 & 688161 & 6.8 & 5.263 & TRN & \\
\hline CHEMBL 3214108 & 688161 & 4.4 & 4.8377 & TRN & \\
\hline CHEMBL1300962 & 688161 & 5.1 & 5.0339 & TRN & \\
\hline CHEMBL3194428 & 688161 & 8.2007 & 5.0532 & TST & \\
\hline CHEMBL1346978 & 688161 & 4.8 & 4.8391 & TRN & \\
\hline CHEMBL1403514 & 688161 & 4.6 & 4.8816 & TRN & \\
\hline CHEMBL1512919 & 688161 & 4.6 & 4.8068 & TRN & \\
\hline CHEMBL1379132 & 688161 & 4.4 & 4.8489 & TRN & \\
\hline CHEMBL1382835 & 688161 & 4.8 & 4.8614 & TRN & \\
\hline CHEMBL1344668 & 688161 & 5.5 & 4.851 & TST & \\
\hline CHEMBL1256996 & 688161 & 4.4 & 5.04 & TST & \\
\hline CHEMBL1459161 & 688161 & 4.5 & 4.9331 & TRN & \\
\hline CHEMBL1311210 & 688161 & 4.4 & 4.9009 & TRN & \\
\hline CHEMBL1613188 & 688161 & 4.7 & 4.7776 & TRN & \\
\hline CHEMBL1596176 & 688161 & 4.7 & 4.8738 & TRN & \\
\hline CHEMBL1539091 & 688161 & 6.1 & 4.8761 & TRN & \\
\hline CHEMBL1416615 & 688161 & 4.6 & 4.9361 & TRN & \\
\hline CHEMBL1481396 & 688161 & 4.4 & 4.8868 & TRN & \\
\hline CHEMBL1387029 & 688161 & 5.5 & 5.2469 & TRN & \\
\hline CHEMBL1520314 & 688161 & 4.6 & 4.9925 & TST & \\
\hline CHEMBL1560118 & 688161 & 5.4 & 4.9036 & TRN & \\
\hline CHEMBL1525813 & 688161 & 5.5 & 5.0906 & TRN & \\
\hline CHEMBL510539 & 688161 & 6.3 & 5.65600 & 0000000001 & TRN \\
\hline CHEMBL1416417 & 688161 & 4.7 & 5.1469 & TST & \\
\hline CHEMBL1336671 & 688161 & 6.9 & 4.9904 & TRN & \\
\hline CHEMBL1573627 & 688161 & 4.5 & 4.9044 & TRN & \\
\hline CHEMBL1318259 & 688161 & 4.4 & 4.7905 & TRN & \\
\hline CHEMBL1489064 & 688161 & 5.7 & 5.6957 & TST & \\
\hline CHEMBL1490504 & 688161 & 4.5 & 4.8665 & TRN & \\
\hline CHEMBL1600128 & 688161 & 4.6 & 4.9797 & TRN & \\
\hline CHEMBL1471112 & 688161 & 5.1 & 5.0254 & TST & \\
\hline
\end{tabular}




\begin{tabular}{|c|c|c|c|c|}
\hline & & & CIIC & al Ta \\
\hline CHEMBL1458840 & 688161 & 4.6 & 4.9904 & TRN \\
\hline CHEMBL1574042 & 688161 & 4.6 & 4.9456 & TRN \\
\hline CHEMBL1536237 & 688161 & 5.0 & 4.9288 & TRN \\
\hline CHEMBL1395497 & 688161 & 4.8 & 4.9285 & TRN \\
\hline CHEMBL1557841 & 688161 & 4.4 & 4.8726 & TRN \\
\hline CHEMBL1457899 & 688161 & 5.5 & 5.1644 & TST \\
\hline CHEMBL1407488 & 688161 & 4.8 & 4.8413 & TRN \\
\hline CHEMBL1565369 & 688161 & 4.8 & 4.9385 & TRN \\
\hline CHEMBL1495094 & 688161 & 5.0 & 4.9414 & TRN \\
\hline CHEMBL1452142 & 688161 & 5.2 & 4.9952 & TRN \\
\hline CHEMBL1501170 & 688161 & 5.0 & 4.886 & TRN \\
\hline CHEMBL604119 & 688161 & 4.9 & 4.9558 & TST \\
\hline CHEMBL1598592 & 688161 & 4.7 & 4.9362 & TST \\
\hline CHEMBL1458422 & 688161 & 4.6 & 4.9409 & TRN \\
\hline CHEMBL1530630 & 688161 & 4.7 & 4.8248 & TST \\
\hline CHEMBL1320534 & 688161 & 5.2 & 4.827 & TRN \\
\hline CHEMBL1485018 & 688161 & 4.8 & 4.9316 & TRN \\
\hline CHEMBL1591425 & 688161 & 4.9 & 5.0415 & TST \\
\hline CHEMBL1530572 & 688161 & 4.6 & 4.8475 & TRN \\
\hline CHEMBL1467595 & 688161 & 5.5 & 4.8935 & TRN \\
\hline CHEMBL1394113 & 688161 & 4.6 & 4.8365 & TRN \\
\hline CHEMBL1516673 & 688161 & 4.5 & 4.852 & TRN \\
\hline CHEMBL1597970 & 688161 & 4.9 & 4.9855 & TRN \\
\hline CHEMBL1489098 & 688161 & 4.5 & 4.8211 & TRN \\
\hline CHEMBL1547161 & 688161 & 4.9 & 4.9321 & TRN \\
\hline CHEMBL1609198 & 688161 & 5.4 & 4.9306 & TRN \\
\hline CHEMBL1304205 & 688161 & 4.7 & 4.7788 & TRN \\
\hline CHEMBL1460966 & 688161 & 4.6 & 4.9577 & TRN \\
\hline CHEMBL1299659 & 688161 & 4.4 & 4.992 & TRN \\
\hline CHEMBL1498173 & 688161 & 4.4 & 4.8035 & TRN \\
\hline CHEMBL520107 & 688161 & 4.8 & 4.8079 & TST \\
\hline CHEMBL1467802 & 688161 & 4.8 & 4.95 & TST \\
\hline CHEMBL428496 & 688161 & 4.8 & 5.2727 & TST \\
\hline CHEMBL1503433 & 688161 & 5.4 & 4.9404 & TRN \\
\hline CHEMBL1322801 & 688161 & 4.6 & 4.9888 & TRN \\
\hline CHEMBL1329135 & 688161 & 4.8 & 4.9145 & TRN \\
\hline CHEMBL1360310 & 688161 & 4.4 & 4.8127 & TRN \\
\hline CHEMBL1578769 & 688161 & 4.5 & 4.8293 & TRN \\
\hline CHEMBL1611088 & 688161 & 4.9 & 4.8655 & TRN \\
\hline CHEMBL1385011 & 688161 & 4.5 & 4.915 & TRN \\
\hline CHEMBL1606199 & 688161 & 4.4 & 4.8276 & TRN \\
\hline CHEMBL1459528 & 688161 & 4.6 & 4.9775 & TRN \\
\hline CHEMBL578136 & 688161 & 4.5 & 4.9278 & TRN \\
\hline CHEMBL1453752 & 688161 & 4.6 & 4.9125 & TST \\
\hline CHEMBL1208858 & 688161 & 4.7 & 5.5618 & TRN \\
\hline CHEMBL1404315 & 688161 & 5.9 & 5.0191 & TST \\
\hline CHEMBL1556511 & 688161 & 4.7 & 4.7856 & TRN \\
\hline CHEMBL1603870 & 688161 & 4.4 & 4.9934 & TRN \\
\hline
\end{tabular}




\begin{tabular}{|c|c|c|c|c|c|}
\hline \multicolumn{6}{|c|}{ Supplemental Table S2.txt } \\
\hline CHEMBL1342846 & 688161 & 4.6 & 5.0136 & TRN & \\
\hline CHEMBL1613292 & 688161 & 6.1 & 5.0233 & TRN & \\
\hline CHEMBL1332518 & 688161 & 4.4 & 4.9012 & TST & \\
\hline CHEMBL1538886 & 688161 & 5.3 & 5.0089 & TRN & \\
\hline CHEMBL1981464 & 688161 & 5.0 & 5.1849 & TRN & \\
\hline CHEMBL1374204 & 688161 & 4.7 & 4.9629 & TRN & \\
\hline CHEMBL1413592 & 688161 & 4.6 & 4.7908 & TRN & \\
\hline CHEMBL3190223 & 688161 & 4.5 & 4.9282 & TRN & \\
\hline CHEMBL1531365 & 688161 & 4.5 & 4.79 & TRN & \\
\hline CHEMBL1504507 & 688161 & 7.6003 & 4.9973 & TRN & \\
\hline CHEMBL1415374 & 688161 & 4.5 & 4.8962 & TRN & \\
\hline CHEMBL1585051 & 688161 & 4.6 & 5.232 & TRN & \\
\hline CHEMBL1401515 & 688161 & 4.6 & 4.9321 & TRN & \\
\hline CHEMBL1576369 & 688161 & 4.5 & 4.8551 & TRN & \\
\hline CHEMBL1386455 & 688161 & 5.5 & 5.06806 & 00000000005 & TRN \\
\hline CHEMBL1516418 & 688161 & 4.7 & 4.8891 & TRN & \\
\hline CHEMBL1550630 & 688161 & 4.5 & 4.9999 & TRN & \\
\hline CHEMBL1566795 & 688161 & 4.6 & 4.8959 & TRN & \\
\hline CHEMBL1595002 & 688161 & 4.6 & 4.852 & TRN & \\
\hline CHEMBL1413178 & 688161 & 4.6 & 4.8083 & TST & \\
\hline CHEMBL1996902 & 688161 & 4.9 & 4.9265 & TRN & \\
\hline CHEMBL1611574 & 688161 & 4.7 & 5.1963 & TRN & \\
\hline CHEMBL1398321 & 688161 & 4.9 & 4.9856 & TST & \\
\hline CHEMBL1392987 & 688161 & 4.7 & 4.8234 & TRN & \\
\hline CHEMBL165491 & 688161 & 4.5 & 4.9275 & TST & \\
\hline CHEMBL1302503 & 688161 & 4.5 & 4.9201 & TRN & \\
\hline CHEMBL1372535 & 688161 & 4.6 & 4.7753 & TRN & \\
\hline CHEMBL1504444 & 688161 & 4.6 & 4.8421 & TRN & \\
\hline CHEMBL1490740 & 688161 & 4.9 & 4.8121 & TRN & \\
\hline CHEMBL1591896 & 688161 & 4.4 & 4.7997 & TRN & \\
\hline CHEMBL1406070 & 688161 & 4.9 & 4.9334 & TRN & \\
\hline CHEMBL1372115 & 688161 & 4.6 & 4.7468 & TRN & \\
\hline CHEMBL3209302 & 688161 & 4.4 & 4.9531 & TST & \\
\hline CHEMBL1325779 & 688161 & 4.9 & 4.8716 & TRN & \\
\hline CHEMBL1364021 & 688161 & 4.6 & 4.8606 & TRN & \\
\hline CHEMBL1373572 & 688161 & 5.8 & 4.8258 & TRN & \\
\hline CHEMBL1357293 & 688161 & 4.6 & 4.7521 & TRN & \\
\hline CHEMBL1471212 & 688161 & 4.8 & 4.9893 & TRN & \\
\hline CHEMBL618 & 688161 & 4.4 & 4.8983 & TRN & \\
\hline CHEMBL1511785 & 688161 & 5.5 & 4.8887 & TRN & \\
\hline CHEMBL1596675 & 688161 & 6.5 & 5.5269 & TST & \\
\hline CHEMBL1330520 & 688161 & 4.6 & 5.416 & TRN & \\
\hline CHEMBL1343465 & 688161 & 4.4 & 4.9169 & TRN & \\
\hline CHEMBL1451258 & 688161 & 4.5 & 4.9119 & TRN & \\
\hline CHEMBL1468497 & 688161 & 4.5 & 4.9758 & TRN & \\
\hline CHEMBL1599408 & 688161 & 4.6 & 4.7682 & TRN & \\
\hline CHEMBL1536692 & 688161 & 4.7 & 4.8816 & TRN & \\
\hline CHEMBL1451878 & 688161 & 4.5 & 4.9679 & TST & \\
\hline
\end{tabular}




\begin{tabular}{|c|c|c|c|c|c|}
\hline \multicolumn{6}{|c|}{ Supplemental Table s2.txt } \\
\hline CHEMBL1305452 & 688161 & 4.9 & 4.9091 & TRN & \\
\hline CHEMBL1324524 & 688161 & 4.8 & 4.7659 & TRN & \\
\hline CHEMBL1473430 & 688161 & 4.4 & 4.7488 & TRN & \\
\hline CHEMBL1528757 & 688161 & 4.8 & 5.1421 & TST & \\
\hline CHEMBL602575 & 688161 & 4.7 & 4.9759 & TST & \\
\hline CHEMBL1492364 & 688161 & 4.9 & 4.8445 & TRN & \\
\hline CHEMBL1564346 & 688161 & 4.9 & 4.8654 & TRN & \\
\hline CHEMBL1303992 & 688161 & 4.9 & 5.2407 & TRN & \\
\hline CHEMBL393296 & 688161 & 4.8 & 4.8931 & TRN & \\
\hline CHEMBL1474475 & 688161 & 4.4 & 4.8657 & TRN & \\
\hline CHEMBL1565818 & 688161 & 5.5 & 5.0105 & TST & \\
\hline CHEMBL1425497 & 688161 & 5.3 & 5.3336 & TRN & \\
\hline CHEMBL1570245 & 688161 & 4.5 & 4.8722 & TRN & \\
\hline CHEMBL1401788 & 688161 & 6.0 & 4.9354 & TRN & \\
\hline CHEMBL1601294 & 688161 & 5.5 & 4.8791 & TRN & \\
\hline CHEMBL1572403 & 688161 & 4.9 & 4.8161 & TRN & \\
\hline CHEMBL1560313 & 688161 & 5.0 & 5.016 & TRN & \\
\hline CHEMBL1300779 & 688161 & 7.4001 & 4.7916 & TRN & \\
\hline CHEMBL1496523 & 688161 & 4.9 & 4.8125 & TRN & \\
\hline CHEMBL1364156 & 688161 & 4.8 & 4.8775 & TRN & \\
\hline CHEMBL1501836 & 688161 & 4.7 & 4.8419 & TRN & \\
\hline CHEMBL1531163 & 688161 & 7.4001 & 4.9738 & TST & \\
\hline CHEMBL1528142 & 688161 & 4.4 & 4.9008 & TRN & \\
\hline CHEMBL1347892 & 688161 & 5.8 & 4.8494 & TRN & \\
\hline CHEMBL1302713 & 688161 & 4.6 & 4.8915 & TRN & \\
\hline CHEMBL1486592 & 688161 & 5.4 & 4.8609 & TRN & \\
\hline CHEMBL1533635 & 688161 & 4.5 & 4.8564 & TRN & \\
\hline CHEMBL1357429 & 688161 & 4.4 & 4.8249 & TRN & \\
\hline CHEMBL1463575 & 688161 & 4.8 & 4.8685 & TRN & \\
\hline CHEMBL1387022 & 688161 & 4.7 & 4.8209 & TRN & \\
\hline CHEMBL1213834 & 688161 & 5.2 & 4.8059 & TRN & \\
\hline CHEMBL1302980 & 688161 & 5.1 & $5.2810 e$ & 0000000001 & TRN \\
\hline CHEMBL1418225 & 688161 & 5.2 & 4.879 & TRN & \\
\hline CHEMBL1605029 & 688161 & 4.5 & 4.9456 & TRN & \\
\hline CHEMBL1434266 & 688161 & 4.5 & 4.9412 & TRN & \\
\hline CHEMBL1471289 & 688161 & 6.4 & 5.1768 & TST & \\
\hline CHEMBL1609875 & 688161 & 4.4 & $5.1320 e$ & 0000000001 & TST \\
\hline CHEMBL2374367 & 688161 & 5.2 & 5.0236 & TST & \\
\hline CHEMBL1486880 & 688161 & 4.4 & 5.0232 & TRN & \\
\hline CHEMBL 3208364 & 688161 & 4.6 & 4.9223 & TRN & \\
\hline CHEMBL1567983 & 688161 & 4.8 & 4.8504 & TRN & \\
\hline CHEMBL1308536 & 688161 & 6.8 & 4.9541 & TST & \\
\hline CHEMBL1542903 & 688161 & 5.0 & 4.8624 & TRN & \\
\hline CHEMBL1452645 & 688161 & 5.5 & 5.0034 & TRN & \\
\hline CHEMBL1586416 & 688161 & 5.4 & 4.8024 & TRN & \\
\hline CHEMBL1396203 & 688161 & 4.7 & 4.9281 & TRN & \\
\hline CHEMBL1404141 & 688161 & 4.4 & 4.8937 & TRN & \\
\hline CHEMBL1446935 & 688161 & 5.3 & 5.0015 & TRN & \\
\hline
\end{tabular}




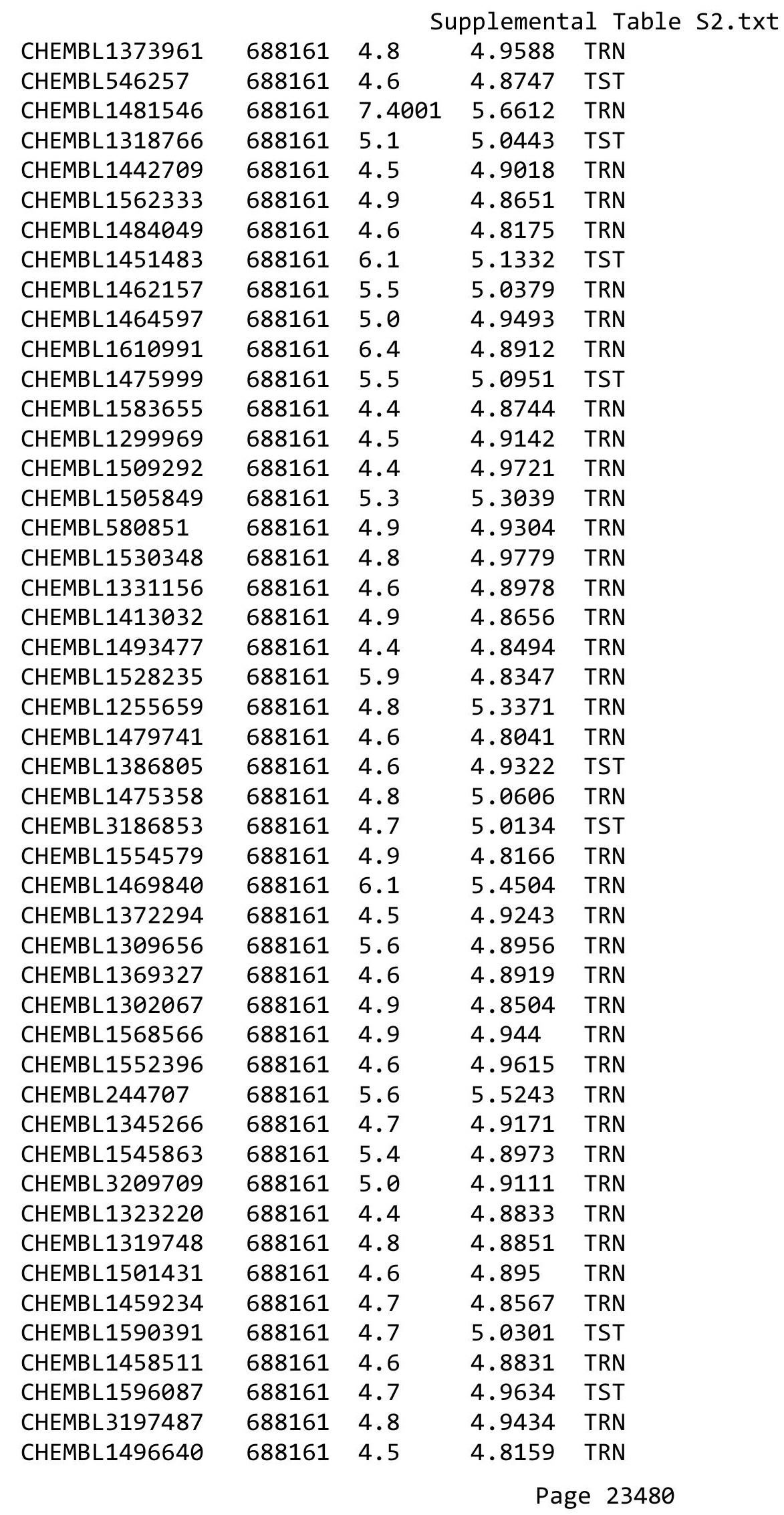




\begin{tabular}{|c|c|c|c|c|c|}
\hline \multicolumn{6}{|c|}{ Supplemental Table S2.txt } \\
\hline CHEMBL269550 & 688161 & 5.6 & 4.8304 & TRN & \\
\hline CHEMBL1512740 & 688161 & 4.7 & 4.9025 & TRN & \\
\hline CHEMBL1479386 & 688161 & 4.6 & 5.3144 & TRN & \\
\hline CHEMBL1413557 & 688161 & 5.4 & 4.8307 & TRN & \\
\hline CHEMBL1438893 & 688161 & 4.6 & 4.9115 & TRN & \\
\hline CHEMBL1385108 & 688161 & 4.8 & 4.8834 & TRN & \\
\hline CHEMBL1581308 & 688161 & 4.6 & 4.8505 & TRN & \\
\hline CHEMBL1300301 & 688161 & 5.1 & 4.9248 & TRN & \\
\hline CHEMBL530115 & 688161 & 4.9 & 5.0363 & TRN & \\
\hline CHEMBL1612246 & 688161 & 4.7 & 5.0814 & TRN & \\
\hline CHEMBL1338712 & 688161 & 4.5 & 4.8451 & TRN & \\
\hline CHEMBL1988679 & 688161 & 4.4 & 4.8796 & TRN & \\
\hline CHEMBL1565635 & 688161 & 5.1 & 4.9505 & TST & \\
\hline CHEMBL1386257 & 688161 & 4.7 & 4.8875 & TST & \\
\hline CHEMBL1256186 & 688161 & 5.0 & 4.9957 & TST & \\
\hline CHEMBL1446243 & 688161 & 4.8 & 4.9062 & TRN & \\
\hline CHEMBL1470527 & 688161 & 6.7001 & 4.9187 & TRN & \\
\hline CHEMBL1313979 & 688161 & 4.8 & 4.8695 & TRN & \\
\hline CHEMBL574583 & 688161 & 5.1 & 5.0071 & TRN & \\
\hline CHEMBL1466940 & 688161 & 4.4 & 4.8993 & TST & \\
\hline CHEMBL1594540 & 688161 & 5.2 & 4.8896 & TRN & \\
\hline CHEMBL1527008 & 688161 & 5.5 & 5.0731 & TRN & \\
\hline CHEMBL22304 & 688161 & 6.9 & 5.1363 & TST & \\
\hline CHEMBL1522777 & 688161 & 5.4 & 4.8899 & TRN & \\
\hline CHEMBL1405259 & 688161 & 4.5 & 5.1003 & TRN & \\
\hline CHEMBL1330946 & 688161 & 5.3 & 5.03606 & $\partial 0000000005$ & TRN \\
\hline CHEMBL1508597 & 688161 & 5.2 & 4.8836 & TRN & \\
\hline CHEMBL23194 & 688161 & 5.1 & 5.0094 & TST & \\
\hline CHEMBL1369911 & 688161 & 4.5 & 4.7809 & TRN & \\
\hline CHEMBL1495018 & 688161 & 4.5 & 4.8899 & TRN & \\
\hline CHEMBL567531 & 688161 & 4.6 & 4.9188 & TRN & \\
\hline CHEMBL57376 & 688161 & 4.8 & 4.9334 & TRN & \\
\hline CHEMBL1319230 & 688161 & 4.5 & 4.9504 & TRN & \\
\hline CHEMBL1365553 & 688161 & 4.9 & 5.2903 & TST & \\
\hline CHEMBL 295316 & 688161 & 5.5 & 5.0182 & TRN & \\
\hline CHEMBL1592220 & 688161 & 4.6 & 4.9433 & TRN & \\
\hline CHEMBL1426679 & 688161 & 4.6 & 4.8865 & TRN & \\
\hline CHEMBL1498959 & 688161 & 4.9 & 4.8944 & TRN & \\
\hline CHEMBL1460155 & 688161 & 5.4 & 5.149 & TRN & \\
\hline CHEMBL1550509 & 688161 & 6.1 & 5.1754 & TRN & \\
\hline CHEMBL1384374 & 688161 & 4.6 & 4.9557 & TRN & \\
\hline CHEMBL1542061 & 688161 & 5.6 & 5.4296 & TRN & \\
\hline CHEMBL1440883 & 688161 & 4.9 & 4.9512 & TRN & \\
\hline CHEMBL1371633 & 688161 & 4.4 & 4.8851 & TRN & \\
\hline CHEMBL1312972 & 688161 & 4.5 & 4.8495 & TRN & \\
\hline CHEMBL182653 & 688161 & 4.7 & 4.958 & TRN & \\
\hline CHEMBL1471728 & 688161 & 4.6 & 4.931 & TRN & \\
\hline CHEMBL611207 & 688161 & 5.8 & 5.1187 & TST & \\
\hline
\end{tabular}




\begin{tabular}{|c|c|c|c|c|c|}
\hline \multirow[b]{2}{*}{ CHEMBL1576673 } & \multicolumn{5}{|c|}{ a Iable š. } \\
\hline & 688161 & 4.4 & 4.8922 & TST & \\
\hline CHEMBL1301630 & 688161 & 4.7 & 4.80699 & 99999999995 & TRN \\
\hline CHEMBL1501334 & 688161 & 4.4 & 4.9972 & TRN & \\
\hline CHEMBL1981008 & 688161 & 4.9 & 5.1331 & TRN & \\
\hline CHEMBL1607194 & 688161 & 4.5 & 4.9655 & TRN & \\
\hline CHEMBL1345810 & 688161 & 4.7 & 4.8803 & TRN & \\
\hline CHEMBL1488368 & 688161 & 5.2 & 4.9447 & TRN & \\
\hline CHEMBL1588642 & 688161 & 4.7 & 5.0075 & TRN & \\
\hline CHEMBL1453231 & 688161 & 4.6 & 4.7858 & TRN & \\
\hline CHEMBL1514719 & 688161 & 4.4 & 4.8205 & TRN & \\
\hline CHEMBL1425091 & 688161 & 7.3002 & 4.8217 & TRN & \\
\hline CHEMBL1336664 & 688161 & 4.6 & 4.9269 & TRN & \\
\hline CHEMBL1505916 & 688161 & 4.7 & 4.8936 & TRN & \\
\hline CHEMBL1340473 & 688161 & 4.8 & 4.9687 & TRN & \\
\hline CHEMBL1531300 & 688161 & 4.8 & 5.1204 & TRN & \\
\hline CHEMBL1388598 & 688161 & 4.9 & 4.976 & TRN & \\
\hline CHEMBL1371348 & 688161 & 5.5 & 4.9508 & TRN & \\
\hline CHEMBL1439066 & 688161 & 4.9 & 4.8591 & TRN & \\
\hline CHEMBL1479729 & 688161 & 4.9 & 4.9412 & TRN & \\
\hline CHEMBL1610402 & 688161 & 4.6 & 4.8808 & TRN & \\
\hline CHEMBL1550793 & 688161 & 5.2 & 5.1636 & TRN & \\
\hline CHEMBL1338425 & 688161 & 4.7 & 5.0091 & TRN & \\
\hline CHEMBL1409273 & 688161 & 4.7 & 4.9881 & TRN & \\
\hline CHEMBL1478522 & 688161 & 4.4 & 4.9946 & TST & \\
\hline CHEMBL1492811 & 688161 & 5.4 & 4.7952 & TRN & \\
\hline CHEMBL1348356 & 688161 & 4.7 & 4.8578 & TRN & \\
\hline CHEMBL1427913 & 688161 & 4.5 & 4.9585 & TRN & \\
\hline CHEMBL1536840 & 688161 & 4.5 & 4.8662 & TRN & \\
\hline CHEMBL1516868 & 688161 & 4.4 & 4.9586 & TRN & \\
\hline CHEMBL1351078 & 688161 & 4.6 & 4.88399 & 99999999995 & TRN \\
\hline CHEMBL72365 & 688161 & 4.9 & 4.9585 & TST & \\
\hline CHEMBL1446905 & 688161 & 4.7 & 4.8763 & TRN & \\
\hline CHEMBL48310 & 688161 & 4.4 & 5.0361 & TRN & \\
\hline CHEMBL34704 & 688161 & 4.9 & 5.3088 & TRN & \\
\hline CHEMBL391877 & 688161 & 4.4 & 4.9441 & TRN & \\
\hline CHEMBL1367159 & 688161 & 4.9 & 5.2991 & TST & \\
\hline CHEMBL1469736 & 688161 & 4.5 & 4.8849 & TRN & \\
\hline CHEMBL1571106 & 688161 & 4.8 & 4.7927 & TST & \\
\hline CHEMBL1371413 & 688161 & 4.9 & 4.8979 & TRN & \\
\hline CHEMBL1300645 & 688161 & 4.5 & 4.9705 & TRN & \\
\hline CHEMBL1566950 & 688161 & 4.7 & 4.8751 & TRN & \\
\hline CHEMBL1323114 & 688161 & 4.7 & 4.9271 & TRN & \\
\hline CHEMBL1471335 & 688161 & 4.6 & 4.8603 & TRN & \\
\hline CHEMBL1581481 & 688161 & 4.4 & 4.9054 & TST & \\
\hline CHEMBL1307081 & 688161 & 5.1 & 4.8854 & TRN & \\
\hline CHEMBL15712 & 688161 & 5.9 & 4.8904 & TRN & \\
\hline CHEMBL1547498 & 688161 & 4.8 & 4.9329 & TRN & \\
\hline CHEMBL1490220 & 688161 & 5.8 & 4.995 & TRN & \\
\hline & & & & 348 & \\
\hline
\end{tabular}




\begin{tabular}{|c|c|c|c|c|c|}
\hline \multicolumn{6}{|c|}{ Supplemental Table S2.txt } \\
\hline CHEMBL1302534 & 688161 & 4.4 & 4.7814 & TRN & \\
\hline CHEMBL1377112 & 688161 & 4.8 & 4.8362 & TRN & \\
\hline CHEMBL1574719 & 688161 & 5.3 & 4.8271 & TRN & \\
\hline CHEMBL1493660 & 688161 & 4.4 & 4.9169 & TRN & \\
\hline CHEMBL1353105 & 688161 & 4.6 & 4.89199 & 99999999995 & TRN \\
\hline CHEMBL1318718 & 688161 & 4.7 & 5.1499 & TRN & \\
\hline CHEMBL1586577 & 688161 & 8.0 & 4.8208 & TST & \\
\hline CHEMBL500430 & 688161 & 5.1 & 5.277 & TRN & \\
\hline CHEMBL1490602 & 688161 & 5.3 & 4.8311 & TRN & \\
\hline CHEMBL1303585 & 688161 & 4.9 & 4.8744 & TRN & \\
\hline CHEMBL1364282 & 688161 & 5.3 & 4.9219 & TRN & \\
\hline CHEMBL606166 & 688161 & 4.6 & 4.8437 & TST & \\
\hline CHEMBL1371567 & 688161 & 4.9 & 4.8068 & TRN & \\
\hline CHEMBL1590261 & 688161 & 4.6 & 4.8949 & TRN & \\
\hline CHEMBL1313696 & 688161 & 4.5 & 4.9374 & TRN & \\
\hline CHEMBL1436715 & 688161 & 5.3 & 4.7765 & TRN & \\
\hline CHEMBL 259388 & 688161 & 4.8 & 4.7979 & TST & \\
\hline CHEMBL1507083 & 688161 & 4.4 & 4.8016 & TRN & \\
\hline CHEMBL1304351 & 688161 & 5.4 & 5.4431 & TRN & \\
\hline CHEMBL1522440 & 688161 & 5.1 & 5.1906 & TRN & \\
\hline CHEMBL1444133 & 688161 & 4.6 & 4.881 & TRN & \\
\hline CHEMBL1557417 & 688161 & 4.6 & 4.7673 & TST & \\
\hline CHEMBL3194496 & 688161 & 4.7 & 4.9691 & TRN & \\
\hline CHEMBL1378090 & 688161 & 8.1024 & 4.8395 & TST & \\
\hline CHEMBL1346072 & 688161 & 4.8 & 4.9844 & TRN & \\
\hline CHEMBL109037 & 688161 & 5.6 & 5.2927 & TRN & \\
\hline CHEMBL1427765 & 688161 & 4.5 & 4.9077 & TRN & \\
\hline CHEMBL1500413 & 688161 & 5.5 & 4.8893 & TRN & \\
\hline CHEMBL1486180 & 688161 & 4.5 & 4.9113 & TRN & \\
\hline CHEMBL1406978 & 688161 & 5.1 & 5.0119 & TRN & \\
\hline CHEMBL1491697 & 688161 & 4.7 & 4.9337 & TRN & \\
\hline CHEMBL1557048 & 688161 & 4.6 & 4.8913 & TST & \\
\hline CHEMBL338115 & 688161 & 5.2 & 4.8673 & TST & \\
\hline CHEMBL1540491 & 688161 & 4.4 & 4.9632 & TST & \\
\hline CHEMBL1491288 & 688161 & 5.8 & 5.2657 & TST & \\
\hline CHEMBL440687 & 688161 & 4.5 & 4.8919 & TST & \\
\hline CHEMBL1493610 & 688161 & 6.0 & 4.9573 & TST & \\
\hline CHEMBL1455325 & 688161 & 5.1 & 5.0604 & TST & \\
\hline CHEMBL1399466 & 688161 & 5.6 & 4.9159 & TST & \\
\hline CHEMBL1590550 & 688161 & 6.1 & 4.8123 & TST & \\
\hline CHEMBL1440119 & 688161 & 4.8 & 4.9339 & TST & \\
\hline CHEMBL1332328 & 688161 & 4.5 & 4.935 & TST & \\
\hline CHEMBL1527485 & 688161 & 4.5 & 4.8897 & TST & \\
\hline CHEMBL1440943 & 688161 & 4.6 & 4.7652 & TST & \\
\hline CHEMBL510698 & 688161 & 4.4 & 4.8798 & TST & \\
\hline CHEMBL1419647 & 688161 & 8.2007 & 4.9833 & TST & \\
\hline CHEMBL1359354 & 688161 & 4.8 & 4.8437 & TST & \\
\hline CHEMBL1551503 & 688161 & 4.4 & 4.7766 & TST & \\
\hline
\end{tabular}




\begin{tabular}{|c|c|c|c|c|}
\hline \multicolumn{5}{|c|}{ Supplemental Table S2.txt } \\
\hline CHEMBL1345018 & 688161 & 4.9 & 4.886 & TST \\
\hline CHEMBL1306140 & 688161 & 5.1 & 4.9016 & TST \\
\hline CHEMBL1464142 & 688161 & 5.0 & 4.8523 & TST \\
\hline CHEMBL1562945 & 688161 & 4.8 & 4.8282 & TST \\
\hline CHEMBL1596996 & 688161 & 4.8 & 4.9577 & TST \\
\hline CHEMBL1339315 & 688161 & 4.8 & 5.1179 & TST \\
\hline CHEMBL1526048 & 688161 & 4.5 & 4.9089 & TST \\
\hline CHEMBL1392248 & 688161 & 4.9 & 4.865 & TST \\
\hline CHEMBL1521509 & 688161 & 4.6 & 5.1135 & TST \\
\hline CHEMBL1311974 & 688161 & 5.3 & 5.0956 & TST \\
\hline CHEMBL1593827 & 688161 & 4.9 & 4.7935 & TST \\
\hline CHEMBL1487893 & 688161 & 4.4 & 4.8679 & TST \\
\hline CHEMBL1461818 & 688161 & 6.7001 & 4.8627 & TST \\
\hline CHEMBL1576399 & 688161 & 4.8 & 5.0471 & TST \\
\hline CHEMBL1378451 & 688161 & 4.9 & 4.9162 & TST \\
\hline CHEMBL1429994 & 688161 & 4.4 & 4.9032 & TST \\
\hline CHEMBL1333773 & 688161 & 5.0 & 5.0065 & TST \\
\hline CHEMBL1602710 & 688161 & 4.8 & 4.9419 & TST \\
\hline CHEMBL1381437 & 688161 & 4.4 & 4.8139 & TST \\
\hline CHEMBL566706 & 688161 & 5.0 & 4.8041 & TST \\
\hline CHEMBL1524581 & 688161 & 8.2007 & 4.9333 & TST \\
\hline CHEMBL323542 & 688161 & 4.4 & 4.9667 & TST \\
\hline CHEMBL1586877 & 688161 & 4.4 & 5.0608 & TST \\
\hline CHEMBL1369346 & 688161 & 4.6 & 4.8963 & TST \\
\hline CHEMBL1313467 & 688161 & 6.5 & 4.825 & TST \\
\hline CHEMBL1378817 & 688161 & 4.7 & 4.9289 & TST \\
\hline CHEMBL1542915 & 688161 & 4.7 & 4.9085 & TST \\
\hline CHEMBL530149 & 688161 & 4.9 & 4.7616 & TST \\
\hline CHEMBL1323110 & 688161 & 5.8 & 4.9161 & TST \\
\hline CHEMBL1609614 & 688161 & 4.9 & 4.9167 & TST \\
\hline CHEMBL1212984 & 688161 & 5.0 & 4.8219 & TST \\
\hline CHEMBL1331234 & 688161 & 4.9 & 5.141 & TST \\
\hline CHEMBL1318307 & 688161 & 4.9 & 4.9671 & TST \\
\hline CHEMBL1412919 & 688161 & 6.0 & 4.9087 & TST \\
\hline CHEMBL1200766 & 688161 & 5.6 & 5.1943 & TST \\
\hline CHEMBL1403748 & 688161 & 4.6 & 4.8833 & TST \\
\hline CHEMBL1556606 & 688161 & 4.8 & 4.8833 & TST \\
\hline CHEMBL1565435 & 688161 & 4.5 & 4.9462 & TST \\
\hline CHEMBL1487660 & 688161 & 5.6 & 4.9472 & TST \\
\hline CHEMBL1491633 & 688161 & 6.3 & 4.9977 & TST \\
\hline CHEMBL1318989 & 688161 & 4.5 & 4.8415 & TST \\
\hline CHEMBL1496815 & 688161 & 4.4 & 4.8047 & TST \\
\hline CHEMBL1326158 & 688161 & 5.8 & 4.9244 & TST \\
\hline CHEMBL1332828 & 688161 & 5.5 & 4.9137 & TST \\
\hline CHEMBL1438226 & 688161 & 4.8 & 4.9011 & TST \\
\hline CHEMBL1436726 & 688161 & 5.0 & 4.9181 & TST \\
\hline CHEMBL1538398 & 688161 & 4.8 & 5.0866 & TST \\
\hline CHEMBL1596944 & 688161 & 4.4 & 4.8849 & TST \\
\hline
\end{tabular}




\begin{tabular}{|c|c|c|c|c|}
\hline \multicolumn{5}{|c|}{ Supplemental Table s2.txt } \\
\hline CHEMBL1336875 & 688161 & 4.7 & 5.1882 & TST \\
\hline CHEMBL1596186 & 688161 & 6.5 & 4.9854 & TST \\
\hline CHEMBL1399922 & 688161 & 4.8 & 4.9268 & TST \\
\hline CHEMBL476833 & 688161 & 4.7 & 4.9572 & TST \\
\hline CHEMBL462314 & 688161 & 5.6 & 4.9361 & TST \\
\hline CHEMBL1468593 & 688161 & 5.7 & 4.8573 & TST \\
\hline CHEMBL1530531 & 688161 & 4.7 & 5.2602 & TST \\
\hline CHEMBL1318943 & 688161 & 5.5 & 4.9677 & TST \\
\hline CHEMBL1608455 & 688161 & 5.1 & 4.75 & TST \\
\hline CHEMBL1543055 & 688161 & 4.5 & 4.9299 & TST \\
\hline CHEMBL1563767 & 688161 & 4.9 & 5.0444 & TST \\
\hline CHEMBL1334129 & 688161 & 4.8 & 4.8661 & TST \\
\hline CHEMBL1349744 & 688161 & 4.9 & 4.8714 & TST \\
\hline CHEMBL1578533 & 688161 & 4.5 & 4.8448 & TST \\
\hline CHEMBL1593335 & 688161 & 4.5 & 4.7428 & TST \\
\hline CHEMBL1372821 & 688161 & 5.0 & 4.8874 & TST \\
\hline CHEMBL1608407 & 688161 & 5.1 & 4.8633 & TST \\
\hline CHEMBL1404860 & 688161 & 4.7 & 4.9178 & TST \\
\hline CHEMBL1331856 & 688161 & 5.0 & 4.8746 & TST \\
\hline CHEMBL1306490 & 688161 & 5.2 & 4.919 & TST \\
\hline CHEMBL1394499 & 688161 & 4.9 & 4.7379 & TST \\
\hline CHEMBL1567527 & 688161 & 4.6 & 4.9437 & TST \\
\hline CHEMBL1345354 & 688161 & 4.8 & 4.8564 & TST \\
\hline CHEMBL1355139 & 688161 & 4.4 & 4.817 & TST \\
\hline CHEMBL1482010 & 688161 & 6.1 & 4.9559 & TST \\
\hline CHEMBL3213500 & 688161 & 4.7 & 4.9218 & TST \\
\hline CHEMBL1419438 & 688161 & 4.6 & 4.9403 & TST \\
\hline CHEMBL1501436 & 688161 & 4.9 & 4.8512 & TST \\
\hline CHEMBL 222418 & 688161 & 4.8 & 5.0203 & TST \\
\hline CHEMBL1358885 & 688161 & 7.0 & 5.376 & TST \\
\hline CHEMBL1412731 & 688161 & 6.7001 & 5.5068 & TST \\
\hline CHEMBL1406702 & 688161 & 5.3 & 4.8737 & TST \\
\hline CHEMBL1526514 & 688161 & 4.9 & 4.9586 & TST \\
\hline CHEMBL1469055 & 688161 & 4.4 & 4.8659 & TST \\
\hline CHEMBL1430204 & 688161 & 4.8 & 5.0307 & TST \\
\hline CHEMBL3198782 & 688161 & 5.0 & 4.9165 & TST \\
\hline CHEMBL1552028 & 688161 & 4.4 & 4.9574 & TST \\
\hline CHEMBL1462633 & 688161 & 7.699 & 4.8988 & TST \\
\hline CHEMBL1305080 & 688161 & 4.6 & 5.0992 & TST \\
\hline CHEMBL1333890 & 688161 & 5.2 & 4.8387 & TST \\
\hline CHEMBL1412538 & 688161 & 4.6 & 4.9099 & TST \\
\hline CHEMBL595227 & 688161 & 7.0 & 5.2924 & TST \\
\hline CHEMBL1542576 & 688161 & 5.5 & 4.8372 & TST \\
\hline CHEMBL1526062 & 688161 & 4.9 & 4.8292 & TST \\
\hline CHEMBL1610867 & 688161 & 5.0 & 4.8971 & TST \\
\hline CHEMBL1489281 & 688161 & 4.7 & 4.8808 & TST \\
\hline CHEMBL1485984 & 688161 & 6.0 & 5.1714 & TST \\
\hline CHEMBL1329458 & 688161 & 4.8 & 4.97 & TST \\
\hline
\end{tabular}




\begin{tabular}{|c|c|c|c|c|c|}
\hline \multicolumn{6}{|c|}{ Supplemental Table S2.txt } \\
\hline CHEMBL1333900 & 688161 & 4.6 & 4.8632 & TST & \\
\hline CHEMBL 1440540 & 688161 & 4.4 & 4.7866 & TST & \\
\hline CHEMBL1463203 & 688161 & 4.7 & 5.0843 & TST & \\
\hline CHEMBL1380494 & 688161 & 4.6 & 4.8175 & TST & \\
\hline CHEMBL1431603 & 688161 & 4.5 & 4.9989 & TST & \\
\hline CHEMBL1319055 & 688161 & 4.4 & 4.8545 & TST & \\
\hline CHEMBL1514740 & 688161 & 5.0 & 4.8948 & TST & \\
\hline CHEMBL41680 & 688161 & 4.9 & 4.9567 & TST & \\
\hline CHEMBL1609159 & 688161 & 4.6 & 4.9466 & TST & \\
\hline CHEMBL1540610 & 688161 & 4.8 & 5.1477 & TST & \\
\hline CHEMBL1568791 & 688161 & 4.7 & 4.8431 & TST & \\
\hline CHEMBL1543689 & 688161 & 4.8 & 4.9068 & TST & \\
\hline CHEMBL1327611 & 688161 & 4.6 & 5.003 & TST & \\
\hline CHEMBL1441938 & 688161 & 4.7 & 5.336 & TST & \\
\hline CHEMBL1410260 & 688161 & 4.6 & 5.1236 & TST & \\
\hline CHEMBL1527022 & 688161 & 5.5 & 5.0445 & TST & \\
\hline CHEMBL1472971 & 688161 & 4.6 & 4.83899 & 99999999995 & TST \\
\hline CHEMBL1448017 & 688161 & 4.6 & 4.8631 & TST & \\
\hline CHEMBL1460410 & 688161 & 4.5 & 4.8782 & TST & \\
\hline CHEMBL1425067 & 688161 & 4.8 & 4.9184 & TST & \\
\hline CHEMBL1326705 & 688161 & 5.2 & 5.0881 & TST & \\
\hline CHEMBL529138 & 688161 & 4.6 & 4.8891 & TST & \\
\hline CHEMBL1578549 & 688161 & 6.7001 & 4.8642 & TST & \\
\hline CHEMBL1446151 & 688161 & 5.3 & 4.8951 & TST & \\
\hline CHEMBL1469341 & 688161 & 4.6 & 4.8141 & TST & \\
\hline CHEMBL1370120 & 688161 & 5.1 & 4.9082 & TST & \\
\hline CHEMBL1463698 & 688161 & 4.7 & 4.8144 & TST & \\
\hline CHEMBL3145187 & 688161 & 5.1 & 5.0301 & TST & \\
\hline CHEMBL1458900 & 688161 & 4.6 & 4.9878 & TST & \\
\hline CHEMBL1562116 & 688161 & 4.4 & 4.8457 & TST & \\
\hline CHEMBL1370636 & 688161 & 4.6 & 4.9383 & TST & \\
\hline CHEMBL1601200 & 688161 & 5.3 & 5.0095 & TST & \\
\hline CHEMBL1492918 & 688161 & 4.8 & 4.8961 & TST & \\
\hline CHEMBL10347 & 688161 & 6.0 & 4.8759 & TST & \\
\hline CHEMBL1428840 & 688161 & 4.5 & 4.8436 & TST & \\
\hline CHEMBL1521414 & 688161 & 4.9 & 4.7556 & TST & \\
\hline CHEMBL3213131 & 688161 & 5.4 & 4.9416 & TST & \\
\hline CHEMBL1409586 & 688161 & 5.4 & 5.3926 & TST & \\
\hline CHEMBL1454468 & 688161 & 4.5 & 4.9017 & TST & \\
\hline CHEMBL1428859 & 688161 & 5.6 & 4.9058 & TST & \\
\hline CHEMBL1395792 & 688161 & 4.6 & 4.8291 & TST & \\
\hline CHEMBL1407493 & 688161 & 8.0 & 5.0842 & TST & \\
\hline CHEMBL1592803 & 688161 & 4.4 & 4.752 & TST & \\
\hline CHEMBL1507284 & 688161 & 5.5 & 4.8654 & TST & \\
\hline CHEMBL1492087 & 688161 & 4.5 & 4.9226 & TST & \\
\hline CHEMBL1594964 & 688161 & 4.9 & 4.9371 & TST & \\
\hline CHEMBL16300 & 688161 & 4.5 & 4.8216 & TST & \\
\hline CHEMBL1459342 & 688161 & 4.8 & 4.9186 & TST & \\
\hline
\end{tabular}




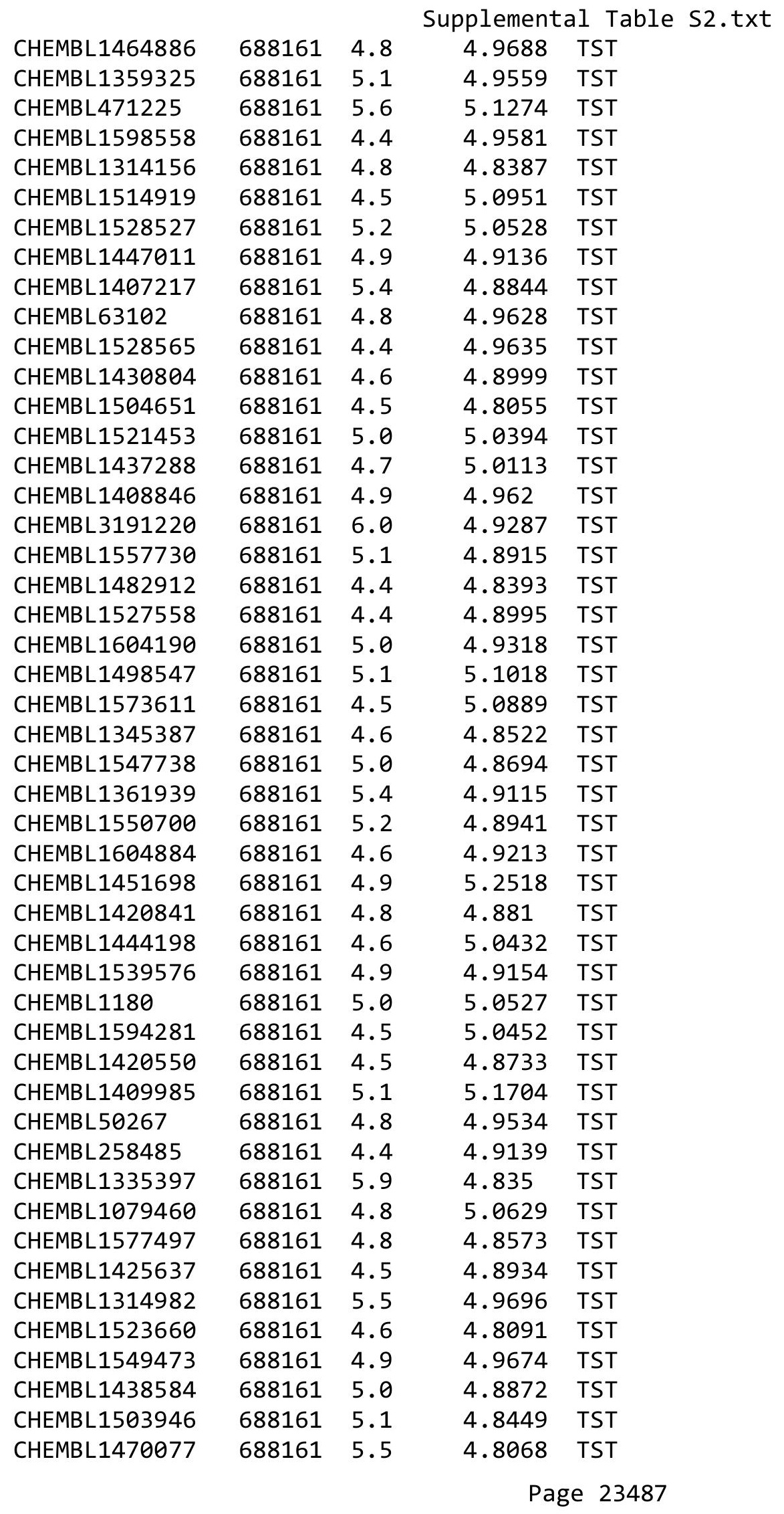




\begin{tabular}{|c|c|c|c|c|}
\hline & & & ipplement & al $\mathrm{T}$ \\
\hline CHEMBL1423234 & 688161 & 4.4 & 4.9374 & TST \\
\hline CHEMBL1411756 & 688161 & 4.5 & 4.974 & TST \\
\hline CHEMBL1441683 & 688161 & 4.7 & 4.8172 & TST \\
\hline CHEMBL1564327 & 688161 & 4.4 & 4.9516 & TST \\
\hline CHEMBL1394939 & 688161 & 4.5 & 4.7622 & TST \\
\hline CHEMBL1329225 & 688161 & 4.4 & 4.8725 & TST \\
\hline CHEMBL1376723 & 688161 & 4.9 & 5.5032 & TST \\
\hline CHEMBL1504376 & 688161 & 4.4 & 4.9981 & TST \\
\hline CHEMBL1408872 & 688161 & 5.3 & 5.2038 & TST \\
\hline CHEMBL1530090 & 688161 & 5.5 & 5.2718 & TST \\
\hline CHEMBL1433930 & 688161 & 4.8 & 5.0278 & TST \\
\hline CHEMBL 2261512 & 688161 & 4.7 & 4.9486 & TST \\
\hline CHEMBL1329707 & 688161 & 4.6 & 4.8798 & TST \\
\hline CHEMBL1559719 & 688161 & 5.0 & 5.1178 & TST \\
\hline CHEMBL1393325 & 688161 & 4.6 & 5.0816 & TST \\
\hline CHEMBL 1465860 & 688161 & 6.9 & 4.8875 & TST \\
\hline CHEMBL1373974 & 688161 & 4.5 & 4.8441 & TST \\
\hline CHEMBL1489069 & 688161 & 5.2 & 4.9107 & TST \\
\hline CHEMBL1574543 & 688161 & 5.8 & 5.0065 & TST \\
\hline CHEMBL1332463 & 688161 & 4.4 & 4.7763 & TST \\
\hline CHEMBL3191891 & 688161 & 4.6 & 5.0139 & TST \\
\hline CHEMBL1567185 & 688161 & 4.8 & 4.8866 & TST \\
\hline CHEMBL556024 & 688161 & 4.8 & 5.5736 & TST \\
\hline CHEMBL1603700 & 688161 & 4.4 & 4.8337 & TST \\
\hline CHEMBL1488723 & 688161 & 4.8 & 4.9385 & TST \\
\hline CHEMBL1565360 & 688161 & 4.7 & 4.8047 & TST \\
\hline CHEMBL1586442 & 688161 & 4.9 & 5.2478 & TST \\
\hline CHEMBL1342330 & 688161 & 4.4 & 4.9081 & TST \\
\hline CHEMBL1583717 & 688161 & 4.5 & 4.9417 & TST \\
\hline CHEMBL1485168 & 688161 & 5.7 & 4.9358 & TST \\
\hline CHEMBL3195791 & 688161 & 4.5 & 4.9784 & TST \\
\hline CHEMBL1352896 & 688161 & 4.9 & 5.0812 & TST \\
\hline CHEMBL1597951 & 688161 & 4.8 & 4.9625 & TST \\
\hline CHEMBL1606431 & 688161 & 4.5 & 4.8046 & TST \\
\hline CHEMBL1471435 & 688161 & 4.8 & 4.7939 & TST \\
\hline CHEMBL1354424 & 688161 & 4.8 & 5.086 & TST \\
\hline CHEMBL1589942 & 688161 & 5.7 & 5.1012 & TST \\
\hline CHEMBL1368116 & 688161 & 5.5 & 4.9382 & TST \\
\hline CHEMBL 282433 & 688161 & 4.9 & 4.8466 & TST \\
\hline CHEMBL1571456 & 688161 & 6.0 & 5.0447 & TST \\
\hline CHEMBL1578082 & 688161 & 4.5 & 4.9597 & TST \\
\hline CHEMBL1596499 & 688161 & 4.8 & 4.8216 & TST \\
\hline CHEMBL1374573 & 688161 & 4.8 & 4.845 & TST \\
\hline CHEMBL1437486 & 688161 & 5.6 & 5.2095 & TST \\
\hline CHEMBL542493 & 688161 & 5.7 & 5.5456 & TST \\
\hline CHEMBL1545764 & 688161 & 4.9 & 4.8275 & TST \\
\hline CHEMBL 1437226 & 688161 & 4.6 & 4.7755 & TST \\
\hline CHEMBL1462047 & 688161 & 5.5 & 4.9761 & TST \\
\hline
\end{tabular}




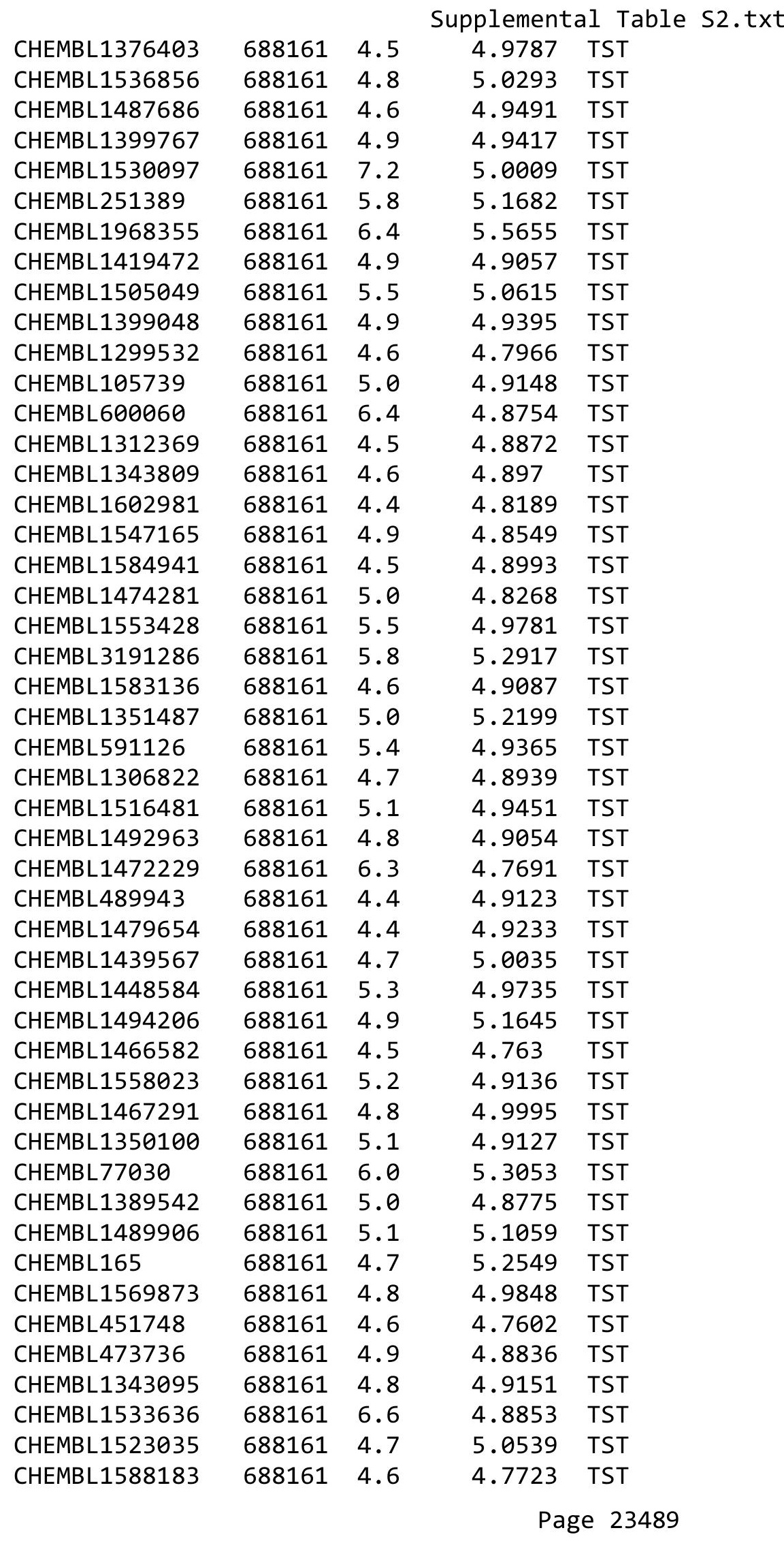




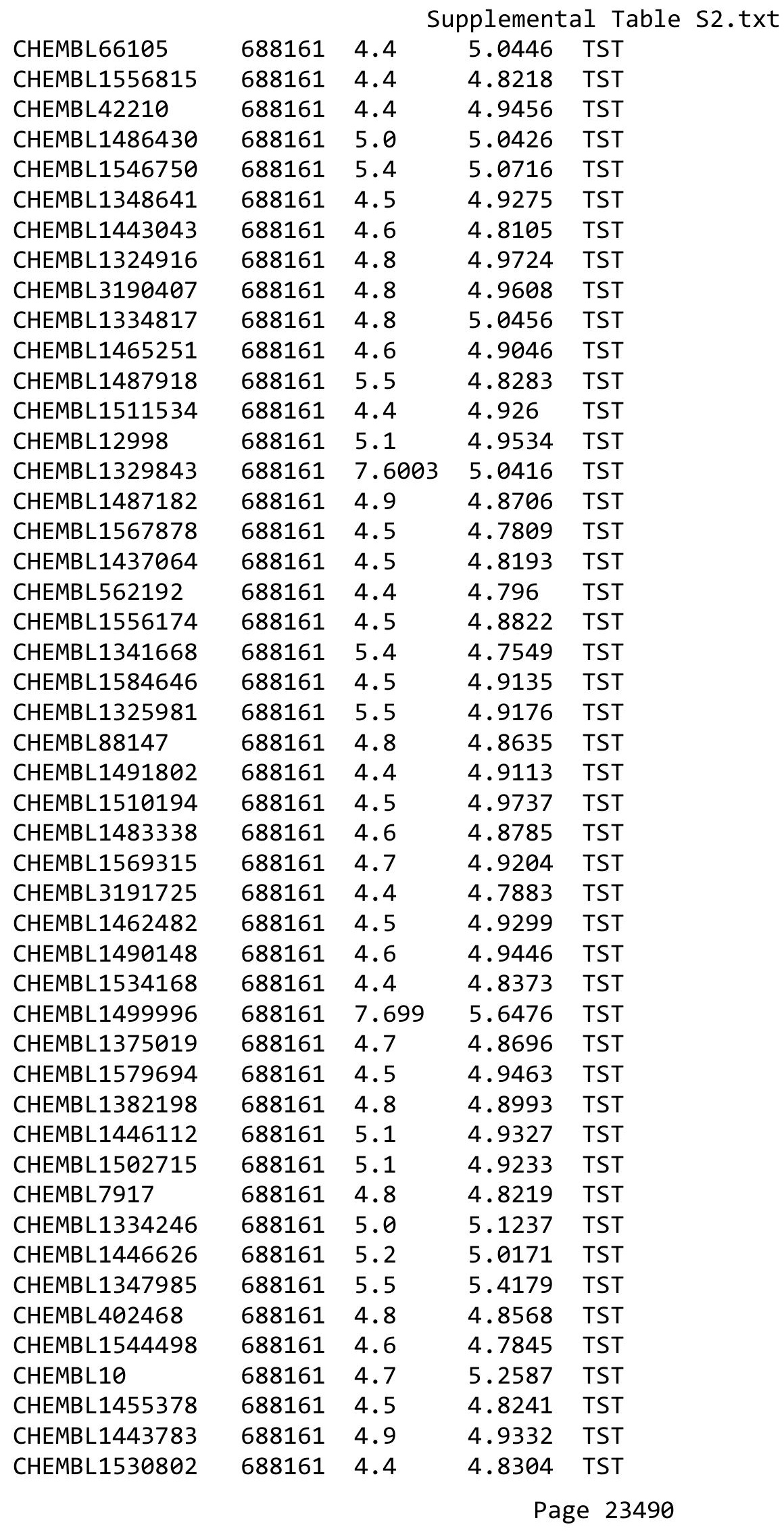




\begin{tabular}{|c|c|c|c|c|c|}
\hline & & & & & \\
\hline CHEMBL1599850 & 688161 & 4.7 & 4.9243 & TST & \\
\hline CHEMBL1371386 & 688161 & 4.5 & 4.815 & TST & \\
\hline CHEMBL1209369 & 688161 & 4.4 & 5.0885 & TST & \\
\hline CHEMBL1423096 & 688161 & 4.6 & 4.9216 & TST & \\
\hline CHEMBL1555396 & 688161 & 4.6 & 4.8446 & TST & \\
\hline CHEMBL1445333 & 688161 & 7.2 & 5.0139 & TST & \\
\hline CHEMBL1438371 & 688161 & 4.9 & 4.8658 & TST & \\
\hline CHEMBL1535525 & 688161 & 4.9 & 4.8513 & TST & \\
\hline CHEMBL1514153 & 688161 & 5.5 & 4.8869 & TST & \\
\hline CHEMBL1418898 & 688161 & 4.5 & $4.9060 e$ & 0000000001 & TST \\
\hline CHEMBL1554745 & 688161 & 4.5 & 4.7674 & TST & \\
\hline CHEMBL1497967 & 688161 & 4.9 & 4.9274 & TST & \\
\hline CHEMBL1568200 & 688161 & 4.6 & 4.9207 & TST & \\
\hline CHEMBL1339113 & 688161 & 4.5 & 4.9098 & TST & \\
\hline CHEMBL3197060 & 688161 & 4.8 & 5.1224 & TST & \\
\hline CHEMBL1368572 & 688161 & 5.6 & 5.303 & TST & \\
\hline CHEMBL1355840 & 688161 & 4.7 & 4.8645 & TST & \\
\hline CHEMBL1375487 & 688161 & 6.5 & 4.9086 & TST & \\
\hline CHEMBL1432345 & 688161 & 5.0 & 4.9144 & TST & \\
\hline CHEMBL1450573 & 688161 & 5.1 & 4.9803 & TST & \\
\hline CHEMBL1499775 & 688161 & 4.4 & 4.8963 & TST & \\
\hline CHEMBL1559033 & 688161 & 4.6 & 4.9162 & TST & \\
\hline CHEMBL1606325 & 688161 & 4.4 & 4.8898 & TST & \\
\hline CHEMBL1545971 & 688161 & 4.6 & 4.9932 & TST & \\
\hline CHEMBL1391390 & 688161 & 5.1 & 4.8687 & TST & \\
\hline CHEMBL1357130 & 688161 & 5.2 & 4.9571 & TST & \\
\hline CHEMBL1417556 & 688161 & 5.5 & 5.4025 & TST & \\
\hline CHEMBL1525989 & 688161 & 5.9 & 5.1448 & TST & \\
\hline CHEMBL1377864 & 688161 & 4.5 & 4.8435 & TST & \\
\hline CHEMBL1363056 & 688161 & 4.6 & 5.3312 & TST & \\
\hline CHEMBL1457696 & 688161 & 5.6 & 4.8603 & TST & \\
\hline CHEMBL42115 & 688161 & 4.9 & 5.0147 & TST & \\
\hline CHEMBL1464163 & 688161 & 4.7 & 4.9353 & TST & \\
\hline CHEMBL 32590 & 688161 & 4.6 & 5.0071 & TST & \\
\hline CHEMBL 260342 & 688161 & 5.4 & 4.8585 & TST & \\
\hline CHEMBL1383158 & 688161 & 4.8 & 5.0506 & TST & \\
\hline CHEMBL1592211 & 688161 & 4.6 & 4.76399 & 9999999999 & TST \\
\hline CHEMBL1319316 & 688161 & 5.5 & 4.9904 & TST & \\
\hline CHEMBL1491676 & 688161 & 5.2 & 4.9139 & TST & \\
\hline CHEMBL1610196 & 688161 & 4.9 & 4.9092 & TST & \\
\hline CHEMBL1496932 & 688161 & 4.8 & 4.81 & TST & \\
\hline CHEMBL1546783 & 688161 & 4.7 & 4.9764 & TST & \\
\hline CHEMBL1606108 & 688161 & 4.7 & 4.9135 & TST & \\
\hline CHEMBL 73711 & 688161 & 4.8 & 4.8919 & TST & \\
\hline CHEMBL1411292 & 688161 & 5.5 & $4.8660 e$ & 00000000005 & TST \\
\hline CHEMBL1448381 & 688161 & 5.5 & 5.3269 & TST & \\
\hline CHEMBL 264945 & 688161 & 4.7 & 4.9068 & TST & \\
\hline CHEMBL1408488 & 688161 & 5.4 & 4.9091 & TST & \\
\hline & & & & 23491 & \\
\hline
\end{tabular}




\begin{tabular}{|c|c|c|c|c|c|}
\hline \multirow{2}{*}{\multicolumn{6}{|c|}{ CHFMRI 1472193}} \\
\hline CHEMBL1472193 & 688161 & 4.4 & 4.9616 & & \\
\hline CHEMBL1506836 & 688161 & 4.7 & 4.9927 & TST & \\
\hline CHEMBL1315920 & 688161 & 4.8 & 4.8842 & TST & \\
\hline CHEMBL1604100 & 688161 & 4.9 & 5.0252 & TST & \\
\hline CHEMBL1583911 & 688161 & 4.9 & 4.9283 & TST & \\
\hline CHEMBL1438876 & 688161 & 4.4 & 4.8341 & TST & \\
\hline CHEMBL1594961 & 688161 & 4.9 & 4.882 & TST & \\
\hline CHEMBL1588811 & 688161 & 5.1 & 4.8458 & TST & \\
\hline CHEMBL1607161 & 688161 & 5.4 & 4.9684 & TST & \\
\hline CHEMBL1455422 & 688161 & 4.4 & 4.96399 & 99999999995 & TST \\
\hline CHEMBL1401376 & 688161 & 4.5 & 4.9487 & TST & \\
\hline CHEMBL35482 & 688161 & 4.8 & 4.9527 & TST & \\
\hline CHEMBL1533029 & 688161 & 4.5 & 4.9029 & TST & \\
\hline CHEMBL3190492 & 688161 & 5.5 & 5.008 & TST & \\
\hline CHEMBL1511173 & 688161 & 4.4 & 4.9764 & TST & \\
\hline CHEMBL1402614 & 688161 & 4.6 & 4.7769 & TST & \\
\hline CHEMBL1358826 & 688161 & 5.7 & 4.8858 & TST & \\
\hline CHEMBL1345135 & 688161 & 4.8 & 4.8498 & TST & \\
\hline CHEMBL1345297 & 688161 & 5.5 & 4.9249 & TST & \\
\hline CHEMBL1447852 & 688161 & 4.6 & 5.0701 & TST & \\
\hline CHEMBL1452139 & 688161 & 4.7 & 4.9106 & TST & \\
\hline CHEMBL1463801 & 688161 & 5.5 & 4.8696 & TST & \\
\hline CHEMBL3189194 & 688161 & 4.6 & 4.8355 & TST & \\
\hline CHEMBL1415169 & 688161 & 5.1 & 4.9137 & TST & \\
\hline CHEMBL1409473 & 688161 & 4.8 & 5.0987 & TST & \\
\hline CHEMBL1325756 & 688161 & 4.6 & 5.2062 & TST & \\
\hline CHEMBL1360011 & 688161 & 5.1 & 4.9055 & TST & \\
\hline CHEMBL1355665 & 688161 & 4.4 & 4.9192 & TST & \\
\hline CHEMBL477139 & 688161 & 4.5 & 4.7979 & TST & \\
\hline CHEMBL1331282 & 688161 & 4.4 & 4.8453 & TST & \\
\hline CHEMBL1528513 & 688161 & 4.6 & 4.942 & TST & \\
\hline CHEMBL1452448 & 688161 & 5.9 & 4.9372 & TST & \\
\hline CHEMBL1582906 & 688161 & 4.8 & 4.8985 & TST & \\
\hline CHEMBL478324 & 688161 & 5.4 & 4.9735 & TST & \\
\hline CHEMBL1567441 & 688161 & 4.5 & 4.9367 & TST & \\
\hline CHEMBL1560702 & 688161 & 4.6 & 4.8868 & TST & \\
\hline CHEMBL1375883 & 688161 & 5.0 & 5.1359 & TST & \\
\hline CHEMBL1551336 & 688161 & 4.5 & 4.9603 & TST & \\
\hline CHEMBL1401094 & 688161 & 5.9 & 4.9408 & TST & \\
\hline CHEMBL1420830 & 688161 & 4.9 & 4.905 & TST & \\
\hline CHEMBL1457985 & 688161 & 4.6 & 4.8647 & TST & \\
\hline CHEMBL1437987 & 688161 & 4.5 & 4.86 & TST & \\
\hline CHEMBL1512208 & 688161 & 4.4 & 4.7478 & TST & \\
\hline CHEMBL1477436 & 688161 & 5.4 & 4.9072 & TST & \\
\hline CHEMBL1380976 & 688161 & 4.4 & $4.9110 e$ & 30000000005 & TST \\
\hline CHEMBL1318285 & 688161 & 5.4 & 4.9285 & TST & \\
\hline CHEMBL1555058 & 688161 & 5.2 & 5.092 & TST & \\
\hline CHEMBL1500317 & 688161 & 4.6 & 4.8251 & TST & \\
\hline
\end{tabular}




\begin{tabular}{|c|c|c|c|c|c|}
\hline \multicolumn{6}{|c|}{ Supplemental Table s2.txt } \\
\hline CHEMBL19980 & 688161 & 4.8 & 5.0336 & TST & \\
\hline CHEMBL1299280 & 688161 & 4.4 & 4.8965 & TST & \\
\hline CHEMBL1386213 & 688161 & 7.8013 & 4.9044 & TST & \\
\hline CHEMBL1449890 & 688161 & 4.7 & 4.834 & TST & \\
\hline CHEMBL1568835 & 688161 & 4.5 & 4.797 & TST & \\
\hline CHEMBL1523881 & 688161 & 4.6 & 4.776 & TST & \\
\hline CHEMBL1390854 & 688161 & 4.5 & 4.9482 & TST & \\
\hline CHEMBL467706 & 688161 & 4.8 & 4.942 & TST & \\
\hline CHEMBL1506798 & 688161 & 4.7 & 4.8169 & TST & \\
\hline CHEMBL3189821 & 688161 & 4.8 & 4.8865 & TST & \\
\hline CHEMBL1434308 & 688161 & 4.6 & 4.8142 & TST & \\
\hline CHEMBL1531452 & 688161 & 4.8 & 4.8365 & TST & \\
\hline CHEMBL1390871 & 688161 & 4.8 & 4.8499 & TST & \\
\hline CHEMBL1577232 & 688161 & 4.4 & 4.8757 & TST & \\
\hline CHEMBL1604474 & 688161 & 4.5 & 4.8499 & TST & \\
\hline CHEMBL1589228 & 688161 & 4.6 & 4.8554 & TST & \\
\hline CHEMBL3191913 & 688161 & 4.8 & 4.8573 & TST & \\
\hline CHEMBL1454533 & 688161 & 4.7 & 4.9763 & TST & \\
\hline CHEMBL1337016 & 688161 & 4.8 & 4.762 & TST & \\
\hline CHEMBL1415927 & 688161 & 4.7 & 5.2705 & TST & \\
\hline CHEMBL1582644 & 688161 & 5.4 & 4.9057 & TST & \\
\hline CHEMBL1508109 & 688161 & 4.6 & 4.8535 & TST & \\
\hline CHEMBL3190626 & 688161 & 5.1 & 4.8882 & TST & \\
\hline CHEMBL1495846 & 688161 & 4.6 & 5.0686 & TST & \\
\hline CHEMBL1518723 & 688161 & 4.5 & 5.1355 & TST & \\
\hline CHEMBL3194157 & 688161 & 5.1 & 5.1062 & TST & \\
\hline CHEMBL1588672 & 688161 & 6.3 & 4.8431 & TST & \\
\hline CHEMBL556398 & 688161 & 5.5 & 4.92399 & 99999999995 & TST \\
\hline CHEMBL1303344 & 688161 & 4.7 & 5.0185 & TST & \\
\hline CHEMBL1581345 & 688161 & 4.5 & 4.7828 & TST & \\
\hline CHEMBL1528749 & 688161 & 5.0 & 4.9578 & TST & \\
\hline CHEMBL573524 & 688161 & 4.8 & 5.0068 & TST & \\
\hline CHEMBL1455971 & 688161 & 5.1 & 5.2266 & TST & \\
\hline CHEMBL1425498 & 688161 & 5.3 & 4.75899 & 99999999995 & TST \\
\hline CHEMBL3194220 & 688161 & 5.4 & 5.0811 & TST & \\
\hline CHEMBL1332450 & 688161 & 5.5 & 4.922 & TST & \\
\hline CHEMBL1604062 & 688161 & 4.6 & 4.7991 & TST & \\
\hline CHEMBL1462333 & 688161 & 4.5 & 4.9792 & TST & \\
\hline CHEMBL1411492 & 688161 & 4.6 & 4.7807 & TST & \\
\hline CHEMBL1390456 & 688161 & 4.4 & 4.9604 & TST & \\
\hline CHEMBL1372207 & 688161 & 4.6 & 4.8693 & TST & \\
\hline CHEMBL1405397 & 688161 & 4.8 & 4.8988 & TST & \\
\hline CHEMBL1577485 & 688161 & 4.8 & 5.2218 & TST & \\
\hline CHEMBL1551567 & 688161 & 4.8 & 4.8366 & TST & \\
\hline CHEMBL1544104 & 688161 & 4.9 & 4.8535 & TST & \\
\hline CHEMBL1404076 & 688161 & 6.4 & 4.8888 & TST & \\
\hline CHEMBL1361477 & 688161 & 5.5 & 4.9595 & TST & \\
\hline CHEMBL1578827 & 688161 & 4.7 & 4.971 & TST & \\
\hline
\end{tabular}




\begin{tabular}{|c|c|c|c|c|c|c|}
\hline \multicolumn{7}{|c|}{ Supplemental Table S2.txt } \\
\hline CHEMBL1563212 & 688161 & 5.0 & 4.7882 & TST & & \\
\hline CHEMBL 1358342 & 688161 & 4.9 & 4.7899 & TST & & \\
\hline CHEMBL1447909 & 688161 & 4.6 & 4.795 & TST & & \\
\hline CHEMBL1613269 & 688161 & 4.8 & 4.9115 & TST & & \\
\hline CHEMBL1432692 & 688161 & 4.9 & 4.9321 & TST & & \\
\hline CHEMBL1373107 & 688161 & 4.8 & 4.9947 & TST & & \\
\hline CHEMBL1598228 & 688161 & 6.9 & 5.0376 & TST & & \\
\hline CHEMBL1367025 & 688161 & 4.4 & 4.8736 & TST & & \\
\hline CHEMBL1370884 & 688161 & 4.5 & 5.3896 & TST & & \\
\hline CHEMBL1491136 & 688161 & 5.2 & 4.8421 & TST & & \\
\hline CHEMBL1316408 & 688161 & 4.4 & 4.8089 & TST & & \\
\hline CHEMBL 258844 & 954599 & 4.8494 & 4.738 & TRN & & \\
\hline CHEMBL483847 & 954599 & 4.5972 & 4.5515 & TRN & & \\
\hline CHEMBL 2363137 & 954599 & 5.305 & 5.3602 & TRN & & \\
\hline CHEMBL399530 & 954599 & 3.47899 & 99999999 & 996 & 3.7778 & TRN \\
\hline CHEMBL1190711 & 954599 & 5.9296 & 6.0279 & TRN & & \\
\hline CHEMBL3199475 & 954599 & 4.2238 & 4.3976 & TRN & & \\
\hline CHEMBL 209148 & 954599 & 4.6327 & 4.7276 & TRN & & \\
\hline CHEMBL1788116 & 954599 & 5.8787 & 5.9004 & TRN & & \\
\hline CHEMBL373751 & 954599 & 3.4254 & 3.5778 & TRN & & \\
\hline CHEMBL 2144069 & 954599 & 7.0156 & 6.8726 & TRN & & \\
\hline CHEMBL 300389 & 954599 & 7.5751 & 7.6917 & TRN & & \\
\hline CHEMBL514499 & 954599 & 7.5567 & 7.5106 & TRN & & \\
\hline CHEMBL 202721 & 954599 & 4.2733 & 4.4911 & TRN & & \\
\hline CHEMBL 379300 & 954599 & 6.5928 & 6.4958 & TRN & & \\
\hline CHEMBL392695 & 954599 & 6.0999 & 5.8625 & TRN & & \\
\hline CHEMBL 2005886 & 954599 & 5.7032 & 5.7726 & TRN & & \\
\hline CHEMBL393929 & 954599 & 3.6437 & 3.4658 & TRN & & \\
\hline CHEMBL379975 & 954599 & 4.5204 & 4.2337 & TRN & & \\
\hline CHEMBL512504 & 954599 & 3.9502 & 4.1011 & TRN & & \\
\hline CHEMBL1230020 & 954599 & 3.4668 & 3.3575 & TRN & & \\
\hline CHEMBL 255342 & 954599 & 3.3623 & 3.1861 & TRN & & \\
\hline CHEMBL 2134202 & 954599 & 3.998 & 3.7606 & TRN & & \\
\hline CHEMBL65 & 954599 & 7.6169 & 7.5179 & TRN & & \\
\hline CHEMBL585951 & 954599 & 6.2685 & 6.4236 & TRN & & \\
\hline CHEMBL217354 & 954599 & 7.2299 & 6.8821 & TRN & & \\
\hline CHEMBL1643959 & 954599 & 3.3127 & 3.4461 & TRN & & \\
\hline CHEMBL188678 & 954599 & 3.7552 & 3.7641 & TRN & & \\
\hline CHEMBL180127 & 954599 & 3.6928 & 4.1232 & TRN & & \\
\hline CHEMBL1404918 & 954599 & 3.1829 & 3.1124 & TRN & & \\
\hline CHEMBL 2137530 & 954599 & 4.488 & 4.8626 & TRN & & \\
\hline CHEMBL1516890 & 954599 & 3.736 & 3.6871 & TRN & & \\
\hline CHEMBL1357247 & 954599 & 3.6115 & 3.6855 & TRN & & \\
\hline CHEMBL9470 & 954599 & 6.4348 & 6.487 & TST & & \\
\hline CHEMBL515416 & 954599 & 4.4914 & 4.5845 & TRN & & \\
\hline CHEMBL1256459 & 954599 & 7.6484 & 7.941 & TRN & & \\
\hline CHEMBL1590308 & 954599 & 3.0639 & 3.0383 & TST & & \\
\hline CHEMBL449158 & 954599 & 6.5689 & 6.7568 & TST & & \\
\hline
\end{tabular}


Supplemental Table S2.txt

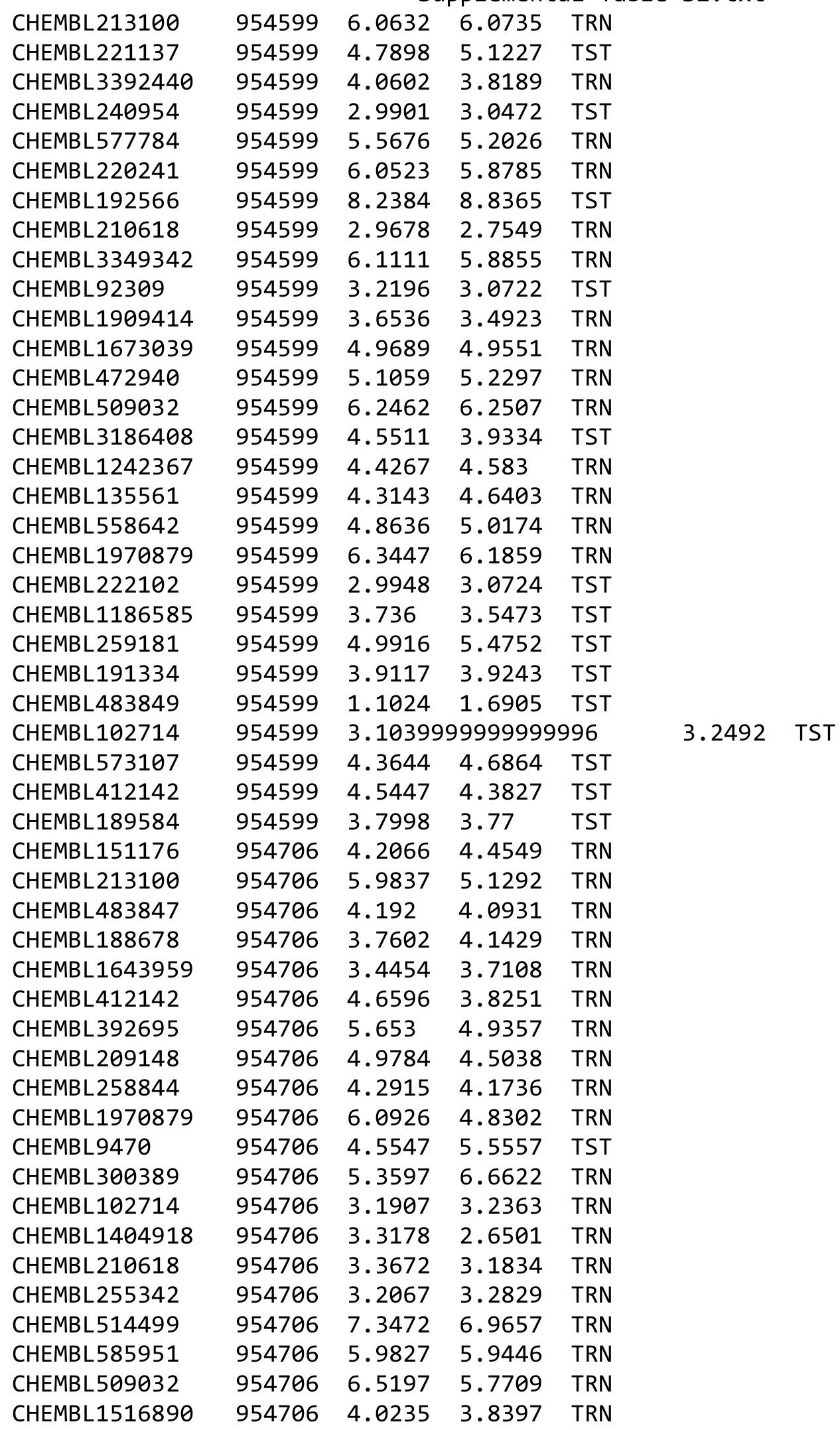

Page 23495 


\begin{tabular}{|c|c|c|c|c|c|}
\hline \multirow[b]{2}{*}{ CHEMBL1230020 } & \multicolumn{5}{|c|}{ Supplemental Table S2.txt } \\
\hline & 954706 & 3.1416 & 3.7874 & TRN & \\
\hline CHEMBL399530 & 954706 & 4.6062 & 4.3294 & TRN & \\
\hline CHEMBL221137 & 954706 & 4.5773 & 4.4207 & TST & \\
\hline CHEMBL1190711 & 954706 & 3.1871 & 4.8551 & TRN & \\
\hline CHEMBL 1788116 & 954706 & 4.4582 & 4.224 & TRN & \\
\hline CHEMBL 2134202 & 954706 & 3.1304 & 4.1156 & TRN & \\
\hline CHEMBL92309 & 954706 & 1.4401 & 2.7058 & TST & \\
\hline CHEMBL3392440 & 954706 & 4.0446 & 3.7567 & TRN & \\
\hline CHEMBL189584 & 954706 & 4.9557 & 4.4667 & TRN & \\
\hline CHEMBL 2137530 & 954706 & 4.9746 & 4.503 & TRN & \\
\hline CHEMBL259181 & 954706 & 2.9113 & 4.3022 & TRN & \\
\hline CHEMBL222102 & 954706 & 3.3374 & 3.5175 & TRN & \\
\hline CHEMBL1186585 & 954706 & 4.123 & 4.1707 & TRN & \\
\hline CHEMBL1256459 & 954706 & 7.2366 & 7.0698 & TRN & \\
\hline CHEMBL3349342 & 954706 & 4.3341 & 4.9676 & TRN & \\
\hline CHEMBL3199475 & 954706 & 4.5784 & 4.1696 & TRN & \\
\hline CHEMBL1909414 & 954706 & 3.5273 & 3.7183 & TST & \\
\hline CHEMBL217354 & 954706 & 6.6449 & 5.8853 & TRN & \\
\hline CHEMBL577784 & 954706 & 4.8165 & 5.1011 & TRN & \\
\hline CHEMBL515416 & 954706 & 4.4005 & 4.3755 & TRN & \\
\hline CHEMBL472940 & 954706 & 2.3922 & 3.3086 & TRN & \\
\hline CHEMBL 379300 & 954706 & 6.0913 & 6.3413 & TRN & \\
\hline CHEMBL483849 & 954706 & 3.1334 & 2.0375 & TST & \\
\hline CHEMBL379975 & 954706 & 3.8747 & 4.6895 & TRN & \\
\hline CHEMBL558642 & 954706 & 3.657 & 3.9985 & TRN & \\
\hline CHEMBL1242367 & 954706 & 4.8244 & 4.1236 & TRN & \\
\hline CHEMBL 2005886 & 954706 & 6.5611 & 5.4916 & TRN & \\
\hline CHEMBL 240954 & 954706 & 3.0174 & 3.4961 & TST & \\
\hline CHEMBL191334 & 954706 & 3.5511 & 4.0387 & TRN & \\
\hline CHEMBL65 & 954706 & 7.2699 & 7.75700 & 2000000001 & TRN \\
\hline CHEMBL512504 & 954706 & 4.3893 & 4.5136 & TST & \\
\hline CHEMBL135561 & 954706 & 4.1336 & 4.2916 & TST & \\
\hline CHEMBL1357247 & 954706 & 2.804 & 2.91600 & 00000000004 & TST \\
\hline CHEMBL393929 & 954706 & 4.1593 & 3.6905 & TST & \\
\hline CHEMBL192566 & 954706 & 9.6938 & 7.8966 & TST & \\
\hline CHEMBL573107 & 954706 & 3.9055 & 4.9575 & TST & \\
\hline CHEMBL449158 & 954706 & 5.9616 & 6.7095 & TST & \\
\hline CHEMBL202721 & 954706 & 4.0405 & 4.8151 & TST & \\
\hline CHEMBL 2363137 & 954706 & 5.2839 & 4.5446 & TST & \\
\hline CHEMBL 3260454 & 1351394 & 5.8861 & 5.9321 & TRN & \\
\hline CHEMBL3260457 & 1351394 & 8.8861 & 9.0213 & TRN & \\
\hline CHEMBL3260431 & 1351394 & 7.0969 & 7.1018 & TRN & \\
\hline CHEMBL3260451 & 1351394 & 4.0 & 3.9971 & TRN & \\
\hline CHEMBL1628698 & 1351394 & 8.5229 & 8.5613 & TRN & \\
\hline CHEMBL3260758 & 1351394 & 8.5229 & 8.5168 & TRN & \\
\hline CHEMBL3260445 & 1351394 & 5.8239 & 5.8473 & TRN & \\
\hline CHEMBL3260460 & 1351394 & 6.6615 & 6.6234 & TRN & \\
\hline CHEMBL3260766 & 1351394 & 8.699 & 8.7066 & TRN & \\
\hline
\end{tabular}


Supplemental Table S2.txt

\begin{tabular}{|c|c|c|}
\hline 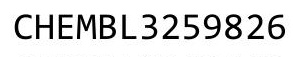 & & \\
\hline AEMBL 3260463 & 351394 & 8 \\
\hline AEMBL3260432 & 51394 & 420 \\
\hline 42 & 351394 & 519 \\
\hline IEMBL 3260763 & 351394 & 323 \\
\hline AEMBL3260462 & 351394 & 958 \\
\hline AEMBL3260760 & 351394 & 7.070 \\
\hline AEMBL3260435 & 351394 & \\
\hline EMBL3260771 & 351394 & 8.522 \\
\hline IEMBL3260459 & L351394 & \\
\hline AEMBL3260461 & 351394 & 8.301 \\
\hline AEMBL3260458 & 351394 & 557 \\
\hline AEMBL3260453 & L351394 & \\
\hline IEMBL32 & L351394 & 22 \\
\hline AEMBL32 & L351394 & 308 \\
\hline AEMBL3260759 & 351394 & 7.6778 \\
\hline AEMBL3260450 & 351394 & \\
\hline IEMBL3260 & 394 & 959 \\
\hline IEMB & 394 & \\
\hline AEMBL & 394 & \\
\hline AEMBL3260770 & 394 & 19 \\
\hline AEMBL3260429 & 394 & 861 \\
\hline HEMBL3260 & 394 & 9. \\
\hline HEMBL & 394 & 229 \\
\hline AEME & 394 & 218 \\
\hline AEMBL3260 & 394 & 3861 \\
\hline IEMBL 3260448 & 394 & \\
\hline AEMBL32604 & 394 & \\
\hline AEMBL & 394 & \\
\hline HEMBL 3266 & 394 & 8.1549 \\
\hline HEMBL3260 & 394 & 6. \\
\hline AEMBL3260433 & 394 & 3.522 \\
\hline LT & 394 & \\
\hline 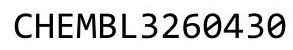 & 394 & 96 \\
\hline HEMBL 3260447 & 394 & 4. \\
\hline HEMBL3260764 & 394 & 5.9208 \\
\hline AEMBL3260437 & 394 & $7.045 \varepsilon$ \\
\hline & 94 & 539 \\
\hline M & 94 & 539 \\
\hline HEMBL3260440 & 394 & 5.5528 \\
\hline AEMBL3260446 & L351394 & 6.8239 \\
\hline HEMBL 3260757 & 394 & 8.4437 \\
\hline HEMBL 3260 & 394 & 6.3768 \\
\hline CHEMBL3260762 & 1351394 & 6.9393 \\
\hline HEMBL3260456 & 1351394 & 8.301 \\
\hline AEMBL3260455 & 1351394 & 7.6021 \\
\hline MBL 32 & 135 & 5.5229 \\
\hline & & \\
\hline
\end{tabular}
4.0353 TRN

8.9209 TRN

5.4214 TRN

5.6078 TRN

7.8133 TRN

7.9296 TRN

7.0449 TRN

5.0144 TRN

8.5029 TRN

7.6728 TRN

8.3101 TRN

7.5897 TRN

4.0258 TRN

9.5245 TRN

6.1259 TRN

7.6226 TRN

5.285 TST

5.8042 TRN

7.6124 TRN

3.9655 TRN

7.6848 TRN

5.5823 TST

9.1588 TRN

5.5247 TRN

6.2386 TRN

7.8645 TRN

3.9684 TRN

4.0194 TRN

4.555 TST

6.7741 TST

5.9739 TRN

5.934 TST

7.0535 TRN

7.0858 TRN

4.0042 TRN

5.9133 TRN

7.0781 TRN

5.8605 TST

7.8551 TRN

6.1293 TST

5.7749 TST

7.6365 TST

5.7143 TST

7.9587 TST

8.7313 TST

7.1994 TST

4.9985 TST

CHEMBL543431 $142572 \quad 6.6904$

6.492000000000001

TRN

Page 23497 


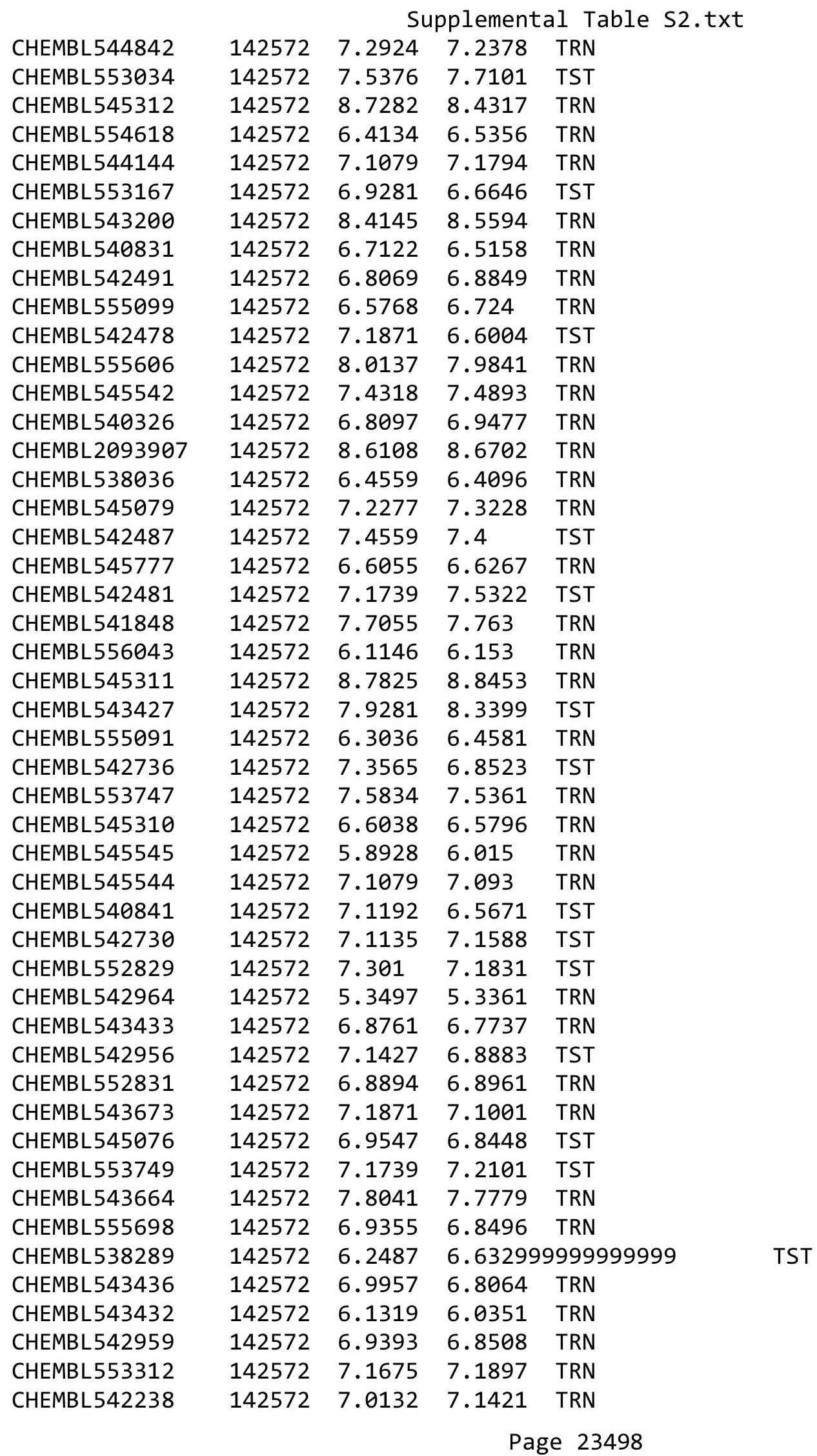




\begin{tabular}{|c|c|c|c|c|c|}
\hline \multicolumn{6}{|c|}{ Supplemental Table S2.txt } \\
\hline CHEMBL545537 & 142572 & 8.3696 & 8.5044 & TRN & \\
\hline CHEMBL554868 & 142572 & 7.341 & 7.5738 & TRN & \\
\hline CHEMBL552605 & 142572 & 7.9101 & 8.0046 & TRN & \\
\hline CHEMBL539549 & 142572 & 5.4765 & 5.5365 & TRN & \\
\hline CHEMBL542957 & 142572 & 6.9957 & 6.8293 & TRN & \\
\hline CHEMBL543192 & 142572 & 7.8861 & 7.6955 & TRN & \\
\hline CHEMBL543428 & 142572 & 7.3872 & 7.3591 & TRN & \\
\hline CHEMBL542486 & 142572 & 7.5686 & 7.2705 & TST & \\
\hline CHEMBL543199 & 142572 & 8.1612 & 8.0499 & TRN & \\
\hline CHEMBL538052 & 142572 & 8.2924 & 8.2859 & TRN & \\
\hline CHEMBL 78777 & 142572 & 6.1355 & 6.4722 & TRN & \\
\hline CHEMBL540838 & 142572 & 8.4067 & 8.4228 & TRN & \\
\hline CHEMBL545769 & 142572 & 8.1938 & 7.1043 & TST & \\
\hline CHEMBL91628 & 142572 & 6.7852 & 6.07299 & 99999999995 & TST \\
\hline CHEMBL538283 & 142572 & 7.0915 & 6.7891 & TST & \\
\hline CHEMBL554355 & 142572 & 6.9508 & 6.9204 & TRN & \\
\hline CHEMBL539299 & 142572 & 6.8539 & 6.9335 & TRN & \\
\hline CHEMBL541860 & 142572 & 6.6383 & 6.597 & TRN & \\
\hline CHEMBL544142 & 142572 & 6.3893 & 6.2465 & TRN & \\
\hline CHEMBL543196 & 142572 & 8.3841 & 8.2167 & TRN & \\
\hline CHEMBL1271854 & 674828 & 4.0 & 3.6318 & TST & \\
\hline CHEMBL1272131 & 674828 & 5.7423 & 5.4056 & TRN & \\
\hline CHEMBL1271581 & 674828 & 4.0 & 4.2856 & TRN & \\
\hline CHEMBL1271969 & 674828 & 6.6162 & 6.8644 & TRN & \\
\hline CHEMBL1272130 & 674828 & 7.1367 & 6.977 & TRN & \\
\hline CHEMBL1271857 & 674828 & 4.0 & 4.1348 & TRN & \\
\hline CHEMBL1271800 & 674828 & 7.1487 & 7.2871 & TRN & \\
\hline CHEMBL1272129 & 674828 & 6.7747 & 7.2131 & TRN & \\
\hline CHEMBL1271526 & 674828 & 5.6198 & 5.5411 & TRN & \\
\hline CHEMBL1269043 & 674828 & 5.3757 & 5.1374 & TRN & \\
\hline CHEMBL1272026 & 674828 & 5.699 & 5.6682 & TRN & \\
\hline CHEMBL1271968 & 674828 & 7.2007 & 7.1098 & TRN & \\
\hline CHEMBL1271798 & 674828 & 4.0 & 4.0643 & TRN & \\
\hline CHEMBL1271856 & 674828 & 4.0 & 3.9034 & TRN & \\
\hline CHEMBL1271911 & 674828 & 4.0 & 3.6052 & TST & \\
\hline CHEMBL1271473 & 674828 & 4.0 & 4.1499 & TRN & \\
\hline CHEMBL1272184 & 674828 & 6.8894 & 6.4792 & TRN & \\
\hline CHEMBL1272082 & 674828 & 6.9586 & 7.0006 & TRN & \\
\hline CHEMBL1271633 & 674828 & 4.0 & 3.9075 & TRN & \\
\hline CHEMBL 1271580 & 674828 & 6.3298 & 6.2244 & TRN & \\
\hline CHEMBL1271912 & 674828 & 6.4949 & 6.7122 & TRN & \\
\hline CHEMBL1269064 & 674828 & 4.0 & 3.8501 & TRN & \\
\hline CHEMBL1271474 & 674828 & 5.0 & 5.1657 & TRN & \\
\hline CHEMBL1271970 & 674828 & 6.0132 & 5.9898 & TRN & \\
\hline CHEMBL1272080 & 674828 & 4.0 & 3.6825 & TRN & \\
\hline CHEMBL1271855 & 674828 & 4.0 & 3.8367 & TST & \\
\hline CHEMBL1271684 & 674828 & 4.0 & 3.7731 & TRN & \\
\hline CHEMBL1271525 & 674828 & 6.9318 & 6.7954 & TRN & \\
\hline
\end{tabular}




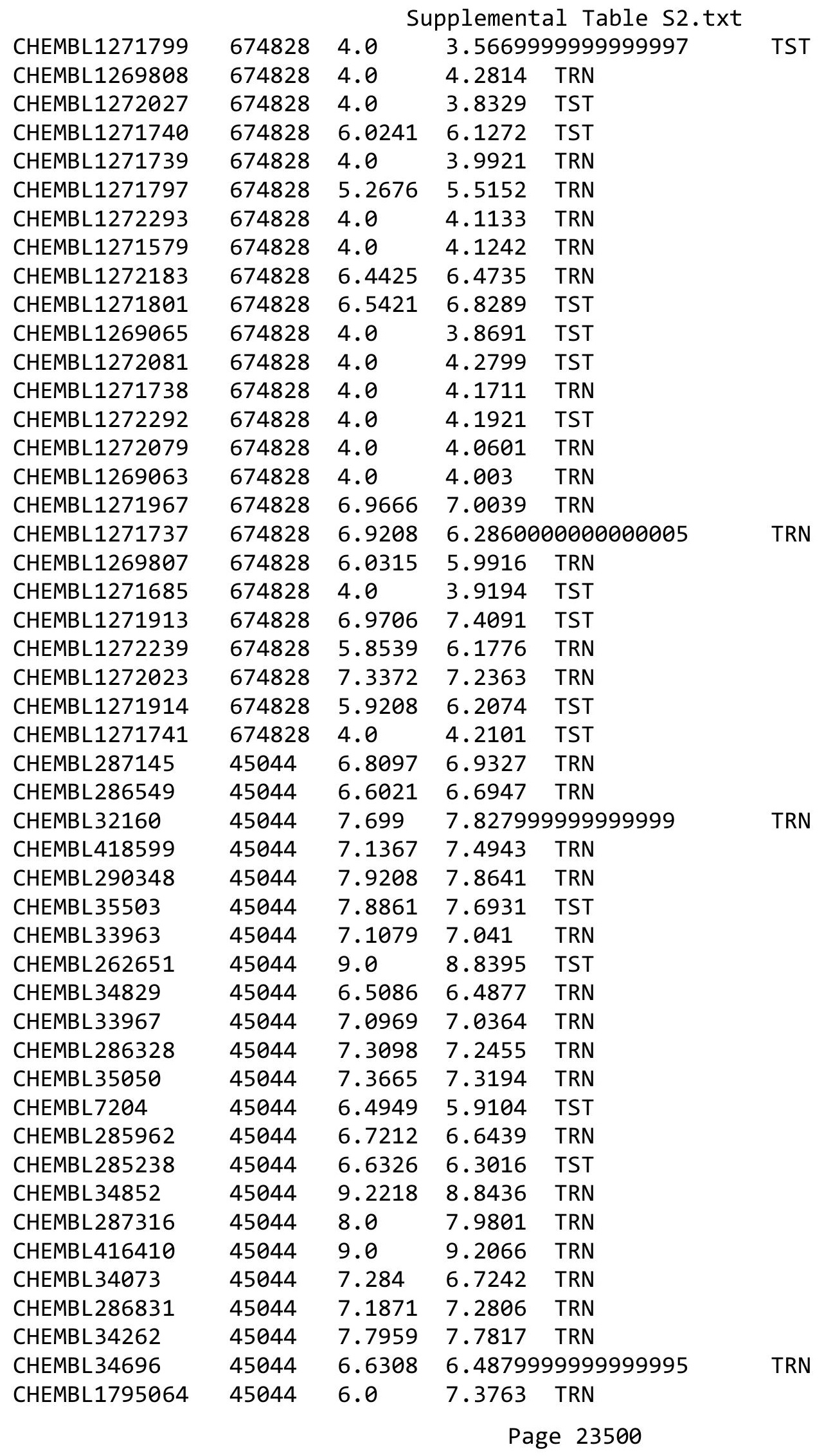




\begin{tabular}{|c|c|c|c|c|c|}
\hline \multirow[b]{2}{*}{ CHEMBL7092 } & & \multicolumn{4}{|c|}{ Supplemental Table S2.txt } \\
\hline & 45044 & 6.9586 & 6.7229 & TST & \\
\hline CHEMBL408857 & 45044 & 7.3665 & 7.25700 & 0000000001 & TRN \\
\hline CHEMBL286587 & 45044 & 7.0132 & 6.841 & TST & \\
\hline CHEMBL34809 & 45044 & 6.0 & 6.7547 & TRN & \\
\hline CHEMBL35746 & 45044 & 7.284 & 7.3918 & TRN & \\
\hline CHEMBL32735 & 45044 & 7.0458 & 6.9834 & TST & \\
\hline CHEMBL35227 & 45044 & 9.0 & 9.0556 & TRN & \\
\hline CHEMBL34488 & 45044 & 8.8239 & 8.5308 & TRN & \\
\hline CHEMBL33088 & 45044 & 7.6198 & 7.4623 & TST & \\
\hline CHEMBL32308 & 45044 & 8.5229 & 8.5385 & TRN & \\
\hline CHEMBL32848 & 45044 & 9.301 & 9.2127 & TRN & \\
\hline CHEMBL32982 & 45044 & 7.7959 & 7.9311 & TRN & \\
\hline CHEMBL34012 & 45044 & 7.0862 & 7.1388 & TRN & \\
\hline CHEMBL289401 & 45044 & 8.301 & 8.6947 & TRN & \\
\hline CHEMBL 36525 & 45044 & 6.7447 & 6.9327 & TRN & \\
\hline CHEMBL32198 & 45044 & 6.9957 & 6.819 & TRN & \\
\hline CHEMBL34471 & 45044 & 6.9031 & 6.8905 & TST & \\
\hline CHEMBL33914 & 45044 & 8.0 & 7.8545 & TRN & \\
\hline CHEMBL 30168 & 45044 & 8.0458 & 7.9311 & TRN & \\
\hline CHEMBL 7087 & 45044 & 6.7959 & 6.0678 & TST & \\
\hline CHEMBL35710 & 45044 & 8.0458 & 7.4362 & TST & \\
\hline CHEMBL 34473 & 45044 & 6.8386 & 6.8083 & TRN & \\
\hline CHEMBL286338 & 45044 & 7.6021 & 7.6403 & TRN & \\
\hline CHEMBL34582 & 45044 & 7.2147 & 7.0203 & TRN & \\
\hline CHEMBL 36334 & 45044 & 8.301 & 8.2322 & TRN & \\
\hline CHEMBL34147 & 45044 & 6.5768 & 6.539 & TRN & \\
\hline CHEMBL286669 & 45044 & 7.4202 & 7.2641 & TRN & \\
\hline CHEMBL32165 & 45044 & 7.5086 & 7.3918 & TRN & \\
\hline CHEMBL284500 & 45044 & 9.0458 & 9.1305 & TRN & \\
\hline CHEMBL35498 & 45044 & 8.301 & 8.2709 & TRN & \\
\hline CHEMBL36452 & 45044 & 7.1079 & 7.0102 & TRN & \\
\hline CHEMBL35747 & 45044 & 7.3279 & 7.2634 & TRN & \\
\hline CHEMBL35194 & 45044 & 7.0269 & 7.1251 & TRN & \\
\hline CHEMBL 284354 & 45044 & 9.301 & 9.0556 & TRN & \\
\hline CHEMBL287117 & 45044 & 8.1549 & 8.317 & TST & \\
\hline CHEMBL35496 & 45044 & 7.3279 & 7.276 & TRN & \\
\hline CHEMBL6753 & 45044 & 7.7212 & 7.2851 & TST & \\
\hline CHEMBL284831 & 45044 & 7.9586 & 7.8641 & TRN & \\
\hline CHEMBL33478 & 45044 & 9.2218 & 9.1305 & TRN & \\
\hline CHEMBL34016 & 45044 & 6.0 & 6.607 & TRN & \\
\hline CHEMBL34867 & 45044 & 8.699 & 8.9624 & TRN & \\
\hline CHEMBL34253 & 45044 & 8.699 & 8.6809 & TRN & \\
\hline CHEMBL285189 & 45044 & 8.2218 & 8.2791 & TRN & \\
\hline CHEMBL286666 & 45044 & 6.71 & 6.8083 & TRN & \\
\hline CHEMBL289647 & 45044 & 7.699 & 7.6768 & TRN & \\
\hline CHEMBL37730 & 45044 & 8.2218 & 8.4763 & TRN & \\
\hline CHEMBL265674 & 45044 & 7.2218 & 7.1968 & TST & \\
\hline CHEMBL34899 & 45044 & 8.0 & 8.0805 & TRN & \\
\hline
\end{tabular}




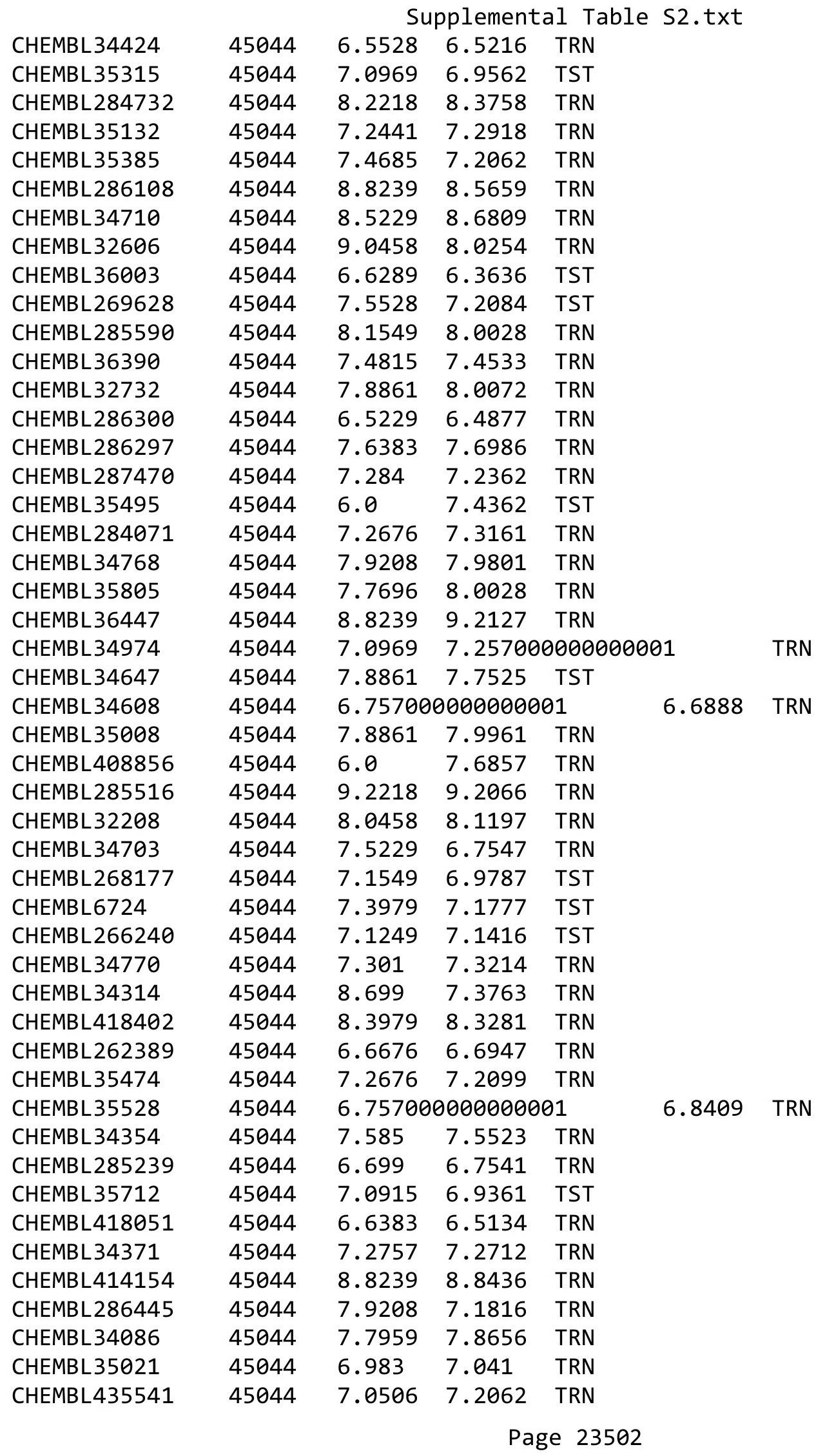




\begin{tabular}{|c|c|c|c|c|c|}
\hline \multicolumn{6}{|c|}{ Supplemental Table S2.txt } \\
\hline CHEMBL1795051 & 45044 & 6.0 & 6.9613 & TRN & \\
\hline CHEMBL1795065 & 45044 & 6.0 & 7.7231 & TST & \\
\hline CHEMBL35698 & 45044 & 6.6778 & 6.539 & TRN & \\
\hline CHEMBL6919 & 45044 & 6.9031 & 6.46899 & 9999999999 & TST \\
\hline CHEMBL32157 & 45044 & 8.1549 & 8.3647 & TRN & \\
\hline CHEMBL432282 & 45044 & 6.5436 & 6.3495 & TST & \\
\hline CHEMBL36567 & 45044 & 6.9747 & 6.8181 & TST & \\
\hline CHEMBL35338 & 45044 & 8.1549 & 8.0072 & TRN & \\
\hline CHEMBL36451 & 45044 & 7.6198 & 7.4396 & TST & \\
\hline CHEMBL284617 & 45044 & 8.0 & 8.1197 & TRN & \\
\hline CHEMBL6784 & 45044 & 6.9586 & 6.4904 & TST & \\
\hline CHEMBL35593 & 45044 & 9.0 & 8.8436 & TRN & \\
\hline CHEMBL416774 & 45044 & 7.2518 & 7.4533 & TRN & \\
\hline CHEMBL35327 & 45044 & 6.699 & 6.5864 & TST & \\
\hline CHEMBL35695 & 45044 & 6.9066 & 6.607 & TRN & \\
\hline CHEMBL284711 & 45044 & 7.4685 & 7.4441 & TRN & \\
\hline CHEMBL35907 & 45044 & 7.5086 & 7.6768 & TRN & \\
\hline CHEMBL35043 & 45044 & 7.2147 & 7.2062 & TRN & \\
\hline CHEMBL284398 & 45044 & 7.8239 & 7.82799 & 9999999999 & TRN \\
\hline CHEMBL6853 & 45044 & 7.2218 & 6.9706 & TST & \\
\hline CHEMBL35595 & 45044 & 6.5528 & 6.3556 & TST & \\
\hline CHEMBL286999 & 45044 & 7.0223 & 6.8108 & TST & \\
\hline CHEMBL36017 & 45044 & 6.5045 & 6.3869 & TST & \\
\hline CHEMBL417321 & 45044 & 6.5086 & 6.4703 & TRN & \\
\hline CHEMBL34546 & 45044 & 6.0 & 7.1816 & TRN & \\
\hline CHEMBL35420 & 45044 & 6.6778 & 6.6134 & TRN & \\
\hline CHEMBL 286586 & 45044 & 9.301 & 8.8704 & TRN & \\
\hline CHEMBL35061 & 45044 & 8.5229 & 8.2559 & TST & \\
\hline CHEMBL264608 & 45044 & 6.0 & 6.7154 & TRN & \\
\hline CHEMBL442265 & 45044 & 7.1805 & 7.3363 & TRN & \\
\hline CHEMBL 2112275 & 45044 & 7.7959 & 7.7245 & TRN & \\
\hline CHEMBL36322 & 45044 & 8.0969 & 7.9961 & TRN & \\
\hline CHEMBL34520 & 45044 & 7.2596 & 7.2619 & TRN & \\
\hline CHEMBL 284061 & 45044 & 8.699 & 8.5308 & TRN & \\
\hline CHEMBL35118 & 45044 & 8.0458 & 8.1195 & TST & \\
\hline CHEMBL33904 & 45044 & 7.0555 & 6.9483 & TRN & \\
\hline CHEMBL431112 & 45044 & 9.0 & 8.9624 & TST & \\
\hline CHEMBL 2112276 & 45044 & 8.0458 & 8.27 & TRN & \\
\hline CHEMBL 285408 & 45044 & 6.9872 & 7.0499 & TRN & \\
\hline CHEMBL35817 & 45044 & 7.1739 & 7.1537 & TRN & \\
\hline CHEMBL416221 & 45044 & 7.6198 & 7.4943 & TRN & \\
\hline CHEMBL 286602 & 45044 & 6.7959 & 6.7541 & TRN & \\
\hline CHEMBL6705 & 45044 & 6.5302 & 6.568 & TST & \\
\hline CHEMBL 35484 & 45044 & 7.0269 & 6.9947 & TRN & \\
\hline CHEMBL 2112274 & 45044 & 9.301 & 8.8808 & TST & \\
\hline CHEMBL32096 & 45044 & 7.8239 & 7.6541 & TRN & \\
\hline CHEMBL 285688 & 45044 & 7.6383 & 7.5358 & TRN & \\
\hline CHEMBL36253 & 45044 & 7.4437 & 7.4939 & TRN & \\
\hline
\end{tabular}


Supplemental Table S2.txt

\begin{tabular}{|c|c|c|c|c|}
\hline CHEMBL34711 & 45044 & 7.1675 & 7.2962 & TST \\
\hline CHEMBL284610 & 45044 & 7.9208 & 7.8895 & TST \\
\hline CHEMBL32836 & 45044 & 7.1249 & 7.1339 & TRN \\
\hline CHEMBL418047 & 45044 & 8.2218 & 8.3362 & TRN \\
\hline CHEMBL284118 & 45044 & 7.1612 & 7.0524 & TRN \\
\hline CHEMBL34998 & 45044 & 7.7212 & 7.6678 & TRN \\
\hline CHEMBL285435 & 45044 & 7.9208 & 8.0805 & TRN \\
\hline CHEMBL35262 & 45044 & 7.7447 & 6.9613 & TRN \\
\hline CHEMBL 35240 & 45044 & 7.8239 & 7.6403 & TRN \\
\hline CHEMBL285788 & 45044 & 7.6383 & 7.3788 & TRN \\
\hline CHEMBL34782 & 45044 & 8.3979 & 8.3316 & TRN \\
\hline CHEMBL35186 & 45044 & 9.2218 & 9.1631 & TRN \\
\hline CHEMBL34646 & 45044 & 7.8539 & 7.7204 & TST \\
\hline CHEMBL286561 & 45044 & 6.9586 & 6.9585 & TRN \\
\hline CHEMBL284694 & 45044 & 7.1938 & 7.1339 & TRN \\
\hline CHEMBL35410 & 45044 & 6.6289 & 6.5652 & TRN \\
\hline CHEMBL6685 & 45044 & 8.0969 & 8.1294 & TST \\
\hline CHEMBL35653 & 45044 & 7.4559 & 7.4967 & TRN \\
\hline CHEMBL35594 & 45044 & 6.6696 & 6.5414 & TST \\
\hline CHEMBL285170 & 45044 & 6.4976 & 6.4552 & TRN \\
\hline CHEMBL154106 & 45044 & 6.0 & 7.61600 & 00000000005 \\
\hline CHEMBL36283 & 45044 & 7.1024 & 6.7154 & TRN \\
\hline CHEMBL285531 & 45044 & 7.1612 & 7.2954 & TST \\
\hline CHEMBL286131 & 45044 & 9.0969 & 9.1631 & TRN \\
\hline CHEMBL 35532 & 45044 & 7.4202 & 7.4865 & TRN \\
\hline CHEMBL35189 & 45044 & 6.9586 & 6.8611 & TST \\
\hline CHEMBL284165 & 45044 & 7.8861 & 7.6678 & TRN \\
\hline CHEMBL289888 & 45044 & 8.699 & 7.61600 & 00000000005 \\
\hline CHEMBL417497 & 45044 & 7.301 & 7.2051 & TRN \\
\hline CHEMBL284481 & 45044 & 6.5017 & 6.3471 & TST \\
\hline CHEMBL33648 & 45044 & 8.699 & 8.5901 & TST \\
\hline CHEMBL286449 & 45044 & 7.7212 & 7.6986 & TRN \\
\hline CHEMBL32949 & 45044 & 6.5528 & 6.5134 & TRN \\
\hline CHEMBL432669 & 45044 & 7.9208 & 7.8545 & TRN \\
\hline CHEMBL6852 & 45044 & 6.6198 & 6.2942 & TST \\
\hline CHEMBL289672 & 45044 & 6.6778 & 6.8409 & TRN \\
\hline CHEMBL34317 & 45044 & 9.0969 & 7.6857 & TRN \\
\hline CHEMBL285266 & 45044 & 7.1487 & 7.2062 & TRN \\
\hline CHEMBL37958 & 45044 & 8.1549 & 8.5782 & TRN \\
\hline CHEMBL 36252 & 45044 & 8.699 & 7.7231 & TST \\
\hline CHEMBL34969 & 45044 & 6.5528 & 6.4725 & TRN \\
\hline CHEMBL262650 & 45044 & 7.8861 & 7.7817 & TRN \\
\hline CHEMBL1795055 & 45044 & 6.0 & 6.7242 & TRN \\
\hline CHEMBL34013 & 45044 & 6.6383 & 6.6439 & TRN \\
\hline CHEMBL35113 & 45044 & 7.2757 & 7.4982 & TST \\
\hline CHEMBL 35421 & 45044 & 8.699 & 8.5979 & TST \\
\hline CHEMBL35265 & 45044 & 7.1427 & 7.2641 & TRN \\
\hline CHEMBL35551 & 45044 & 8.0458 & 7.8656 & TRN \\
\hline
\end{tabular}

Page 23504 


\begin{tabular}{|c|c|c|c|c|c|c|}
\hline & & \multicolumn{5}{|c|}{ Supplemental Table S2.txt } \\
\hline CHEMBL34319 & 45044 & 7.4437 & 7.5358 & TRN & & \\
\hline CHEMBL13646 & 45044 & 8.5229 & 7.4848 & TST & & \\
\hline CHEMBL415466 & 45044 & 9.0969 & 8.8704 & TRN & & \\
\hline CHEMBL 2137530 & 954634 & 4.5658 & 4.8044 & TRN & & \\
\hline CHEMBL191334 & 954634 & 4.2823 & 4.2157 & TRN & & \\
\hline CHEMBL1357247 & 954634 & 3.8959 & 3.1664 & TRN & & \\
\hline CHEMBL 255342 & 954634 & 4.5448 & 3.6171 & TRN & & \\
\hline CHEMBL577784 & 954634 & 4.6749 & 5.2377 & TRN & & \\
\hline CHEMBL1256459 & 954634 & 7.1616 & 7.2981 & TRN & & \\
\hline CHEMBL 2144069 & 954634 & 5.1739 & 5.0241 & TRN & & \\
\hline CHEMBL585951 & 954634 & \multicolumn{3}{|c|}{5.712000000000001} & 6.1599 & TRN \\
\hline CHEMBL514499 & 954634 & 7.8173 & 7.1814 & TRN & & \\
\hline CHEMBL393929 & 954634 & 4.5237 & 3.9246 & TRN & & \\
\hline CHEMBL 2134202 & 954634 & 4.251 & 4.3462 & TRN & & \\
\hline CHEMBL399530 & 954634 & 4.6006 & 4.5768 & TRN & & \\
\hline CHEMBL65 & 954634 & 7.9948 & 8.0014 & TRN & & \\
\hline CHEMBL483849 & 954634 & 2.5793 & 2.2595 & TST & & \\
\hline CHEMBL1404918 & 954634 & 2.6892 & 2.9061 & TRN & & \\
\hline CHEMBL1788116 & 954634 & 3.3646 & 4.4223 & TRN & & \\
\hline CHEMBL1190711 & 954634 & 5.2252 & 5.0866 & TRN & & \\
\hline CHEMBL221137 & 954634 & 5.1737 & 4.7387 & TST & & \\
\hline CHEMBL1230020 & 954634 & 3.677 & 4.0135 & TRN & & \\
\hline CHEMBL373751 & 954634 & 3.752 & 3.7875 & TRN & & \\
\hline CHEMBL392695 & 954634 & 6.2073 & 5.2919 & TRN & & \\
\hline CHEMBL515416 & 954634 & 5.6595 & 4.6079 & TRN & & \\
\hline CHEMBL1186585 & 954634 & 3.3073 & 4.375 & TRN & & \\
\hline CHEMBL9470 & 954634 & 6.0622 & 5.8337 & TST & & \\
\hline CHEMBL379975 & 954634 & 4.2883 & 4.9612 & TRN & & \\
\hline CHEMBL509032 & 954634 & 5.5285 & 5.7063 & TRN & & \\
\hline CHEMBL1970879 & 954634 & 5.3624 & 4.8532 & TRN & & \\
\hline CHEMBL483847 & 954634 & 4.5763 & 4.2809 & TRN & & \\
\hline CHEMBL192566 & 954634 & 8.8576 & 8.1927 & TST & & \\
\hline CHEMBL188678 & 954634 & 3.6073 & 4.3754 & TRN & & \\
\hline CHEMBL92309 & 954634 & 2.6099 & 3.0161 & TST & & \\
\hline CHEMBL189584 & 954634 & 3.8539 & 4.6044 & TRN & & \\
\hline CHEMBL3349342 & 954634 & 5.0855 & 5.1517 & TRN & & \\
\hline CHEMBL449158 & 954634 & 6.5781 & 6.8313 & TST & & \\
\hline CHEMBL202721 & 954634 & 5.4559 & 4.9933 & TRN & & \\
\hline CHEMBL222102 & 954634 & 3.6895 & 3.761 & TRN & & \\
\hline CHEMBL 379300 & 954634 & 7.074 & 6.5271 & TRN & & \\
\hline CHEMBL209148 & 954634 & 3.9899 & 4.6472 & TRN & & \\
\hline CHEMBL 2005886 & 954634 & 5.0121 & 5.5327 & TRN & & \\
\hline CHEMBL1673039 & 954634 & 5.1824 & 4.8842 & TRN & & \\
\hline CHEMBL3199475 & 954634 & 3.9031 & 4.4148 & TRN & & \\
\hline CHEMBL 213100 & 954634 & 4.8334 & 5.0948 & TRN & & \\
\hline CHEMBL1909414 & 954634 & 4.3842 & 3.9563 & TRN & & \\
\hline CHEMBL573107 & 954634 & 4.9252 & 5.1288 & TRN & & \\
\hline CHEMBL1590308 & 954634 & 4.3707 & 3.4575 & TST & & \\
\hline
\end{tabular}


Supplemental Table S2.txt

\begin{tabular}{|c|c|c|c|c|}
\hline CHEMBL1516890 & 4 & 3.9112 & 13 & TRN \\
\hline CHEMBL102714 & 954634 & 3.4016 & 3.51 & \\
\hline HEMBL412142 & 4634 & 3.5058 & 25 & \\
\hline AEMBL 217354 & 54634 & .7766 & 0834 & \\
\hline HEMBL1643959 & 54634 & .1302 & 3.8172 & \\
\hline HEMBL 259181 & 54634 & .2845 & 5614 & \\
\hline AEMBL 2 & 54634 & .3067 & & \\
\hline HEMBL 220241 & 54634 & 4.2068 & & \\
\hline HEMBL 258844 & 54634 & .0638 & 4.3882 & \\
\hline HEMBL512504 & 954634 & 4.3755 & 877 & \\
\hline HEMBL135561 & 54634 & 4.4482 & 348 & \\
\hline HEMBL & & 7.3211 & & ST \\
\hline 86408 & 954634 & 4.3732 & & \\
\hline HEMBL1242367 & 954634 & 4.5331 & 208 & \\
\hline HEMBL 240954 & 954634 & 3.3006 & 98 & ומנו \\
\hline 92440 & 34 & 3.8818 & & \\
\hline HEMBL & & 5.1192 & & \\
\hline HEMBL & 954634 & 3.1048 & & \\
\hline HEMBL $\angle$ & 954634 & 3.2865 & & \\
\hline HEMBL180127 & 954634 & 3.9894 & 05 & I \\
\hline HEMBL & 45 & .6778 & & RI \\
\hline HEMBL & & .5058 & & \\
\hline HEMBL & 45 & 7.3979 & & נח \\
\hline IEMBL: & 45 & 5.8533 & & \\
\hline HEMBL 363633 & 45 & 6.4647 & 55 & RIV \\
\hline HEMBL: & 15 & .6289 & & $\mathrm{R}$ \\
\hline AEMBL & 5 & 6.6383 & & \\
\hline AEMBL & & 6.9031 & & \\
\hline AEMBL & & 7.0757 & & ГRN \\
\hline JEMBL 363634 & 306 & 7.585 & 32 & TRN \\
\hline AEMBL & 15 & 6.9355 & & \\
\hline |EMB| & & 79 & & \\
\hline AEMBL & & 5.5781 & & RN \\
\hline HEMBL & & 6.4034 & & ГST \\
\hline AEMBL & 306 & 6.9706 & & RN \\
\hline AEMBL & 45 & 6.9788 & & \\
\hline HEMBL & & 366 & & 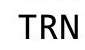 \\
\hline HEMBL: & & 6.5498 & & RI \\
\hline HEMBLI & 306245 & 7.1367 & & TRI \\
\hline AEMBL: & 45 & 7.4559 & & $\mathrm{~K}$ \\
\hline CHEMBL & 306245 & 6.6364 & & \\
\hline CHEMBL364092 & 306245 & 7.041 & 382 & RN \\
\hline CHEMBL194936 & 306245 & 6.5751 & 116 & RN \\
\hline CHEMBL191716 & 06245 & 7.0362 & 94 & $\mathrm{R}$ \\
\hline CHEMBL & 5 & 6.3546 & & 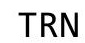 \\
\hline CHEMBL192621 & 306245 & 7.9872 & 8.0288 & \\
\hline CHEMBL192000 & 306245 & 7.0177 & 6.9165 & \\
\hline CHEMBL195290 & 306245 & 6.5952 & 6.456 & \\
\hline
\end{tabular}

Page 23506 


\begin{tabular}{|c|c|c|c|c|c|}
\hline \multicolumn{6}{|c|}{ 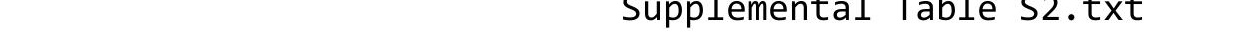 } \\
\hline CHEMBL195311 & 306245 & 8.0 & 8.0189 & TRN & \\
\hline CHEMBL362966 & 306245 & 6.8827 & 6.7757 & TRN & \\
\hline CHEMBL195807 & 306245 & 6.9626 & 7.0166 & TRN & \\
\hline CHEMBL195878 & 306245 & 7.6198 & 7.8085 & TRN & \\
\hline CHEMBL195208 & 306245 & 6.9469 & 6.8447 & TRN & \\
\hline CHEMBL195058 & 306245 & 4.301 & 4.5389 & TRN & \\
\hline CHEMBL191808 & 306245 & 6.8447 & 6.8244 & TRN & \\
\hline CHEMBL192876 & 306245 & 7.3665 & 7.1754 & TRN & \\
\hline CHEMBL371564 & 306245 & 6.057 & 5.7176 & TST & \\
\hline CHEMBL191238 & 306245 & 6.5243 & 6.4756 & TRN & \\
\hline CHEMBL193726 & 306245 & 7.6576 & 6.5742 & TST & \\
\hline CHEMBL192901 & 306245 & 7.1367 & 7.0256 & TRN & \\
\hline CHEMBL191710 & 306245 & 7.4437 & 7.265 & TRN & \\
\hline CHEMBL371126 & 306245 & 6.3915 & 6.2761 & TST & \\
\hline CHEMBL195154 & 306245 & 6.2612 & 6.278 & TRN & \\
\hline CHEMBL194772 & 306245 & 6.1952 & 6.0693 & TRN & \\
\hline CHEMBL426085 & 306245 & 6.4486 & 6.3825 & TRN & \\
\hline CHEMBL191300 & 306245 & 7.3979 & 7.1794 & TRN & \\
\hline CHEMBL193010 & 306245 & 5.83799 & 99999999 & 5.7333 & TST \\
\hline CHEMBL192390 & 306245 & 7.2596 & 6.4373 & TST & \\
\hline CHEMBL 363367 & 306245 & 7.5229 & 7.6098 & TRN & \\
\hline CHEMBL192068 & 306245 & 6.2848 & 6.3907 & TRN & \\
\hline CHEMBL193727 & 306245 & 7.0362 & 7.1719 & TRN & \\
\hline CHEMBL191974 & 306245 & 6.6757 & 6.7297 & TRN & \\
\hline CHEMBL195786 & 306245 & 6.0535 & 6.02 & TRN & \\
\hline CHEMBL192386 & 306245 & 7.6576 & 7.6686 & TRN & \\
\hline CHEMBL363177 & 306245 & 6.9281 & 6.8153 & TRN & \\
\hline CHEMBL195788 & 306245 & 6.1494 & 5.3354 & TST & \\
\hline CHEMBL363425 & 306245 & 7.6778 & 7.2359 & TRN & \\
\hline CHEMBL192016 & 306245 & 6.6073 & 6.6729 & TRN & \\
\hline CHEMBL192218 & 306245 & 7.0088 & 6.6338 & TST & \\
\hline CHEMBL192102 & 306245 & 5.9097 & 5.4149 & TST & \\
\hline CHEMBL191714 & 306245 & 5.8713 & 5.8391 & TRN & \\
\hline CHEMBL195289 & 306245 & 7.5686 & 7.4966 & TRN & \\
\hline CHEMBL427180 & 306245 & 6.7595 & 7.0026 & TST & \\
\hline CHEMBL192849 & 306245 & 6.7447 & 6.65 & TST & \\
\hline CHEMBL191648 & 306245 & 6.2782 & 6.5326 & TST & \\
\hline CHEMBL195389 & 306245 & 7.3979 & 7.5379 & TST & \\
\hline CHEMBL192782 & 306245 & 7.1135 & 6.7195 & TST & \\
\hline CHEMBL426641 & 306245 & 7.3468 & 7.52 & TST & \\
\hline CHEMBL194326 & 306245 & 6.7305 & 6.741006 & 00000000005 & TST \\
\hline CHEMBL211660 & 367910 & 5.2757 & 5.2031 & TST & \\
\hline CHEMBL210342 & 367910 & 5.7212 & 5.4671 & TRN & \\
\hline CHEMBL212733 & 367910 & 4.0088 & 4.5353 & TRN & \\
\hline CHEMBL212461 & 367910 & 5.0555 & 5.2382 & TRN & \\
\hline CHEMBL211271 & 367910 & 6.4089 & 6.3296 & TRN & \\
\hline CHEMBL210499 & 367910 & 5.9208 & 5.7162 & TRN & \\
\hline CHEMBL211435 & 367910 & 5.3372 & 5.7089 & TRN & \\
\hline
\end{tabular}


Supplemental Table S2.txt

\begin{tabular}{|c|c|c|c|c|}
\hline CHEMBL 211548 & 367910 & 6.3979 & 6.3503 & TRN \\
\hline CHEMBL211859 & 367910 & 5.2441 & 5.5011 & TRN \\
\hline CHEMBL209012 & 367910 & 5.6383 & 5.6061 & TRN \\
\hline CHEMBL211233 & 367910 & 5.2291 & 5.2953 & TRN \\
\hline CHEMBL211070 & 367910 & 5.9208 & 5.7131 & TRN \\
\hline CHEMBL1162930 & 367910 & 5.585 & 5.8012 & TRN \\
\hline CHEMBL 211148 & 367910 & 6.4202 & 6.4851 & TRN \\
\hline CHEMBL209722 & 367910 & 5.2924 & 4.9702 & TRN \\
\hline CHEMBL380194 & 367910 & 5.0315 & 5.4954 & TST \\
\hline CHEMBL377854 & 367910 & 5.5528 & 5.631 & TRN \\
\hline CHEMBL378631 & 367910 & 5.5686 & 5.7181 & TST \\
\hline CHEMBL 209368 & 367910 & 4.0862 & 4.1866 & TRN \\
\hline CHEMBL387176 & 367910 & 5.4949 & 5.4621 & TST \\
\hline CHEMBL212745 & 367910 & 6.3665 & 5.8814 & TST \\
\hline CHEMBL211607 & 367910 & 5.4685 & 5.4533 & TRN \\
\hline CHEMBL 209330 & 367910 & 5.9208 & 5.5037 & TST \\
\hline CHEMBL209942 & 367910 & 5.699 & 5.1287 & TRN \\
\hline CHEMBL379841 & 367910 & 4.0655 & 4.9768 & TST \\
\hline CHEMBL 209264 & 367910 & 5.5086 & 5.3576 & TRN \\
\hline CHEMBL211763 & 367910 & 4.8861 & 5.1622 & TRN \\
\hline CHEMBL377445 & 367910 & 3.0 & 2.9116 & TRN \\
\hline CHEMBL1162929 & 367910 & 6.7447 & 6.6421 & TRN \\
\hline CHEMBL 211155 & 367910 & 4.0706 & 4.6528 & TRN \\
\hline CHEMBL379782 & 367910 & 6.699 & 5.9876 & TST \\
\hline CHEMBL210500 & 367910 & 5.5528 & 5.5566 & TRN \\
\hline CHEMBL 211121 & 367910 & 6.2218 & 6.2419 & TST \\
\hline CHEMBL 209053 & 367910 & 5.6198 & 5.7081 & TRN \\
\hline CHEMBL378982 & 367910 & 6.4437 & 6.6261 & TRN \\
\hline CHEMBL376940 & 367910 & 6.2366 & 6.3526 & TRN \\
\hline CHEMBL 211080 & 367910 & 5.7696 & 5.6395 & TRN \\
\hline CHEMBL377424 & 367910 & 5.6778 & 6.2895 & TST \\
\hline CHEMBL 211019 & 367910 & 6.4318 & 5.9848 & TRN \\
\hline CHEMBL 212407 & 367910 & 5.1192 & 4.9236 & TST \\
\hline CHEMBL211788 & 367910 & 4.585 & 4.4028 & TRN \\
\hline CHEMBL1184942 & 367910 & 5.7212 & 5.6617 & TRN \\
\hline CHEMBL377811 & 367910 & 5.2924 & 5.2543 & TST \\
\hline CHEMBL209721 & 367910 & 5.301 & 5.2644 & TRN \\
\hline CHEMBL 209686 & 367910 & 5.9586 & 6.0199 & TRN \\
\hline CHEMBL 380218 & 367910 & 5.8539 & 5.4872 & TRN \\
\hline CHEMBL378993 & 367910 & 5.9586 & 6.1334 & TRN \\
\hline CHEMBL 210610 & 367910 & 6.4437 & 6.3941 & TRN \\
\hline CHEMBL209207 & 367910 & 5.585 & 5.49299 & 9999999999 \\
\hline CHEMBL377409 & 367910 & 5.7447 & 5.479 & TRN \\
\hline CHEMBL 208608 & 367910 & 5.1079 & 5.2661 & TRN \\
\hline CHEMBL209619 & 367910 & 5.2007 & 5.195 & TRN \\
\hline CHEMBL377128 & 367910 & 6.0 & 5.4658 & TRN \\
\hline CHEMBL377912 & 367910 & 5.7959 & 6.0142 & TRN \\
\hline CHEMBL 378561 & 367910 & 5.0605 & 5.103 & TST \\
\hline
\end{tabular}


Supplemental Table S2.txt

\begin{tabular}{|c|c|c|c|c|}
\hline CHEMBL380394 & 367910 & 4.0506 & 4.5249 & TST \\
\hline CHEMBL377526 & 367910 & 5.3565 & 5.6403 & TRN \\
\hline CHEMBL378724 & 367910 & 5.0969 & 5.5636 & TST \\
\hline CHEMBL379518 & 367910 & 5.4089 & 5.3541 & TRN \\
\hline CHEMBL 210557 & 367910 & 5.6778 & 5.289 & TST \\
\hline CHEMBL426324 & 367910 & 4.9747 & 5.3646 & TRN \\
\hline CHEMBL210085 & 367910 & 6.2757 & 6.2291 & TRN \\
\hline CHEMBL212362 & 367910 & 5.5376 & 5.4946 & TRN \\
\hline CHEMBL380267 & 367910 & 5.7696 & 5.6409 & TRN \\
\hline CHEMBL211687 & 367910 & 4.8239 & 5.2513 & TRN \\
\hline CHEMBL210559 & 367910 & 5.6198 & 5.6079 & TRN \\
\hline CHEMBL 212380 & 367910 & 3.0 & 2.7888 & TRN \\
\hline CHEMBL209277 & 367910 & 5.1487 & 5.4921 & TST \\
\hline CHEMBL212257 & 367910 & 5.6576 & 5.6262 & TRN \\
\hline CHEMBL211277 & 367910 & 5.6576 & 5.4202 & TRN \\
\hline CHEMBL378927 & 367910 & 3.0 & 3.3996 & TST \\
\hline CHEMBL211544 & 367910 & 5.6576 & 5.8194 & TRN \\
\hline CHEMBL208547 & 367910 & 7.2518 & 7.0595 & TRN \\
\hline CHEMBL438433 & 367910 & 6.4089 & 6.3209 & TST \\
\hline CHEMBL 209211 & 367910 & 5.1079 & 5.0395 & TRN \\
\hline CHEMBL377965 & 367910 & 5.5086 & 5.6049 & TRN \\
\hline CHEMBL209371 & 367910 & 5.5086 & 5.6949 & TRN \\
\hline CHEMBL 377555 & 367910 & 6.4559 & 6.3233 & TST \\
\hline CHEMBL1086730 & 619934 & 4.6021 & 4.7984 & TRN \\
\hline CHEMBL1076437 & 619934 & 7.7959 & 7.59200 & 30000000005 \\
\hline CHEMBL1087513 & 619934 & 4.6021 & 4.4785 & TRN \\
\hline CHEMBL1076471 & 619934 & 7.3098 & 7.3912 & TRN \\
\hline CHEMBL1088027 & 619934 & 4.6021 & 4.4107 & TRN \\
\hline CHEMBL1076201 & 619934 & 6.585 & 6.865 & TRN \\
\hline CHEMBL1087524 & 619934 & 4.6021 & 5.1785 & TRN \\
\hline CHEMBL1076202 & 619934 & 4.6021 & 4.4651 & TRN \\
\hline CHEMBL1076194 & 619934 & 4.6021 & 5.2102 & TRN \\
\hline CHEMBL1076472 & 619934 & 6.0942 & 6.2049 & TRN \\
\hline CHEMBL1076533 & 619934 & 4.6021 & 4.7179 & TRN \\
\hline CHEMBL1076198 & 619934 & 7.2518 & 6.5879 & TRN \\
\hline CHEMBL1076203 & 619934 & 7.2676 & 7.4385 & TRN \\
\hline CHEMBL1081090 & 619934 & 4.6021 & 4.6409 & TRN \\
\hline CHEMBL1087649 & 619934 & 4.6021 & 4.7164 & TRN \\
\hline CHEMBL1076199 & 619934 & 6.3233 & 6.6499 & TRN \\
\hline CHEMBL1088028 & 619934 & 4.6021 & 4.4492 & TRN \\
\hline CHEMBL1079424 & 619934 & 4.6021 & 4.6849 & TRN \\
\hline CHEMBL1087128 & 619934 & 6.857 & 6.8516 & TRN \\
\hline CHEMBL1086731 & 619934 & 7.0757 & 8.2332 & TST \\
\hline CHEMBL1076193 & 619934 & 6.0438 & 6.1042 & TRN \\
\hline CHEMBL1076196 & 619934 & 4.6021 & 4.8496 & TRN \\
\hline CHEMBL1076480 & 619934 & 6.3925 & 6.5708 & TRN \\
\hline CHEMBL1080930 & 619934 & 4.6021 & 4.4557 & TRN \\
\hline CHEMBL1076433 & 619934 & 8.0458 & 6.8551 & TST \\
\hline
\end{tabular}




\begin{tabular}{|c|c|c|c|c|c|}
\hline & & & & & \\
\hline CHEMBL1086860 & 619934 & 6.3507 & 6.0894 & TST & \\
\hline CHEMBL1075628 & 619934 & 7.9586 & 7.254 & TST & \\
\hline CHEMBL1087636 & 619934 & 4.6021 & 4.8425 & TRN & \\
\hline CHEMBL1076475 & 619934 & 6.0376 & 6.0814 & TRN & \\
\hline CHEMBL1076436 & 619934 & 7.699 & 7.7448 & TRN & \\
\hline CHEMBL1088153 & 619934 & 6.0737 & 7.1151 & TST & \\
\hline CHEMBL1087638 & 619934 & 6.7167 & 6.6728 & TRN & \\
\hline CHEMBL1081436 & 619934 & 4.6021 & 4.2653 & TST & \\
\hline CHEMBL1087002 & 619934 & 4.6021 & 4.3575 & TRN & \\
\hline CHEMBL1076465 & 619934 & 5.7077 & 5.6489 & TRN & \\
\hline CHEMBL1076469 & 619934 & 7.1871 & 7.3929 & TRN & \\
\hline CHEMBL1079945 & 619934 & 7.3665 & 7.1515 & TRN & \\
\hline CHEMBL1076432 & 619934 & 7.5686 & 7.4691 & TRN & \\
\hline CHEMBL1076200 & 619934 & 6.8861 & 6.30200 & 00000000005 & TRN \\
\hline CHEMBL1076476 & 619934 & 4.6021 & 4.4665 & TRN & \\
\hline CHEMBL1076478 & 619934 & 7.5086 & 7.6623 & TRN & \\
\hline CHEMBL1076197 & 619934 & 5.727 & 5.4457 & TRN & \\
\hline CHEMBL1076466 & 619934 & 6.4622 & 6.015 & TRN & \\
\hline CHEMBL1076474 & 619934 & 4.6021 & 4.8021 & TRN & \\
\hline CHEMBL1080299 & 619934 & 6.6108 & 6.5393 & TRN & \\
\hline CHEMBL1087127 & 619934 & $6.8210 e$ & 30000000 & 6.9062 & TRN \\
\hline CHEMBL1088429 & 619934 & 5.4173 & 5.4054 & TRN & \\
\hline CHEMBL1076195 & 619934 & 5.7423 & 5.397 & TRN & \\
\hline CHEMBL1079946 & 619934 & 6.9172 & 5.4279 & TST & \\
\hline CHEMBL1080294 & 619934 & 4.6021 & 3.7695 & TST & \\
\hline CHEMBL1080475 & 619934 & 7.3372 & 6.8963 & TST & \\
\hline CHEMBL1076470 & 619934 & 6.3665 & 7.5876 & TST & \\
\hline CHEMBL1076473 & 619934 & 6.3468 & 4.6021 & TST & \\
\hline CHEMBL1076468 & 619934 & 6.4225 & 6.5112 & TST & \\
\hline CHEMBL1079422 & 619934 & 6.3233 & 6.4387 & TST & \\
\hline CHEMBL1076477 & 619934 & 7.1612 & 7.0978 & TST & \\
\hline CHEMBL3234347 & 1337520 & 5.6778 & 4.7509 & TRN & \\
\hline CHEMBL3234364 & 1337520 & 6.585 & 6.3272 & TRN & \\
\hline CHEMBL3234359 & 1337520 & 3.5719 & 3.9172 & TRN & \\
\hline CHEMBL3234348 & 1337520 & 6.0915 & 4.5964 & TRN & \\
\hline CHEMBL3234371 & 1337520 & 7.0 & 6.5518 & TRN & \\
\hline CHEMBL3234349 & 1337520 & 2.0 & 4.3019 & TRN & \\
\hline CHEMBL3234369 & 1337520 & 5.4202 & 4.5077 & TST & \\
\hline CHEMBL 3234346 & 1337520 & 2.0 & 1.0901 & TRN & \\
\hline CHEMBL3234374 & 1337520 & 2.0 & 5.6806 & TST & \\
\hline CHEMBL3234377 & 1337520 & 3.8539 & 2.5574 & TRN & \\
\hline CHEMBL3234383 & 1337520 & 4.6198 & 4.3649 & TRN & \\
\hline CHEMBL3234360 & 1337520 & 2.0 & 3.3712 & TRN & \\
\hline CHEMBL 3234344 & 1337520 & 3.0 & 3.4402 & TRN & \\
\hline CHEMBL3234363 & 1337520 & 3.8962 & 4.8331 & TRN & \\
\hline CHEMBL 3234381 & 1337520 & 5.1675 & 4.1583 & TRN & \\
\hline CHEMBL3234382 & 1337520 & 4.9914 & 4.4273 & TRN & \\
\hline CHEMBL3234354 & 1337520 & 6.3098 & 6.034 & TST & \\
\hline
\end{tabular}




\begin{tabular}{|c|c|c|c|c|c|}
\hline \multicolumn{6}{|c|}{ Supplemental Table S2.txt } \\
\hline CHEMBL3234379 & 1337520 & 2.0 & 1.9563 & TRN & \\
\hline CHEMBL3234343 & 1337520 & 4.0 & 3.8252 & TRN & \\
\hline CHEMBL3233026 & 1337520 & 2.0 & 2.6528 & TRN & \\
\hline CHEMBL3234356 & 1337520 & 5.5686 & 5.2905 & TRN & \\
\hline CHEMBL 3234384 & 1337520 & 7.0458 & 7.309 & TRN & \\
\hline CHEMBL3234353 & 1337520 & 3.0 & 6.1844 & TST & \\
\hline CHEMBL3234361 & 1337520 & 3.0 & 3.4735 & TRN & \\
\hline CHEMBL 3234365 & 1337520 & 5.9208 & 5.8685 & TRN & \\
\hline CHEMBL 3234368 & 1337520 & 3.3382 & 5.0473 & TST & \\
\hline CHEMBL3234373 & 1337520 & 6.2757 & 6.4132 & TRN & \\
\hline CHEMBL 3234358 & 1337520 & 5.8539 & 5.0663 & TRN & \\
\hline CHEMBL3234345 & 1337520 & 2.0 & 2.1635 & TRN & \\
\hline CHEMBL3234350 & 1337520 & 2.0 & 2.0476 & TRN & \\
\hline CHEMBL3234389 & 1337520 & 4.0605 & 3.1851 & TRN & \\
\hline CHEMBL3234367 & 1337520 & 3.4647 & 3.5522 & TRN & \\
\hline CHEMBL1234674 & 1337520 & 5.1739 & 5.5194 & TRN & \\
\hline CHEMBL3234351 & 1337520 & 2.0 & 1.8723 & TRN & \\
\hline CHEMBL3234352 & 1337520 & 6.2147 & 6.1423 & TRN & \\
\hline CHEMBL3234366 & 1337520 & 2.0 & 2.7571 & TRN & \\
\hline CHEMBL3234357 & 1337520 & 5.2441 & 5.0652 & TRN & \\
\hline CHEMBL3234390 & 1337520 & 3.9318 & 4.1218 & TRN & \\
\hline CHEMBL3234388 & 1337520 & 2.0 & 1.9372 & TRN & \\
\hline CHEMBL 3234375 & 1337520 & 2.0 & 3.9379 & TRN & \\
\hline CHEMBL 3234387 & 1337520 & 5.5528 & 5.9952 & TRN & \\
\hline CHEMBL 3234342 & 1337520 & 5.4815 & 3.9701 & TRN & \\
\hline CHEMBL3234355 & 1337520 & 2.0 & 2.4337 & TRN & \\
\hline CHEMBL3234370 & 1337520 & 5.7696 & 5.4544 & TST & \\
\hline CHEMBL 3234372 & 1337520 & 6.284 & 6.25299 & 9999999999 & TST \\
\hline CHEMBL3234386 & 1337520 & 5.5086 & 5.9583 & TST & \\
\hline CHEMBL 3234376 & 1337520 & 3.4112 & 4.1744 & TST & \\
\hline CHEMBL 3234378 & 1337520 & 3.9245 & 4.4499 & TST & \\
\hline CHEMBL 3234385 & 1337520 & 5.1427 & 6.6784 & TST & \\
\hline CHEMBL3234362 & 1337520 & 2.0 & 3.8141 & TST & \\
\hline CHEMBL 3234380 & 1337520 & 3.0 & 2.513 & TST & \\
\hline CHEMBL513844 & 532295 & 5.0605 & 5.0997 & TRN & \\
\hline CHEMBL468957 & 532295 & 4.4461 & 5.4462 & TST & \\
\hline CHEMBL444762 & 532295 & 5.3872 & 5.343 & TRN & \\
\hline CHEMBL495682 & 532295 & 5.4559 & 5.1572 & TST & \\
\hline CHEMBL467784 & 532295 & 5.0315 & 5.0637 & TRN & \\
\hline CHEMBL467801 & 532295 & 4.4789 & 4.2721 & TRN & \\
\hline CHEMBL401138 & 532295 & 5.1192 & 5.36 & TRN & \\
\hline CHEMBL497551 & 532295 & 5.3098 & 5.3076 & TST & \\
\hline CHEMBL467800 & 532295 & 4.6003 & 4.8125 & TRN & \\
\hline CHEMBL249829 & 532295 & 4.857 & 4.8811 & TRN & \\
\hline CHEMBL498777 & 532295 & 4.2041 & 4.227 & TRN & \\
\hline CHEMBL506055 & 532295 & 4.71 & 4.6312 & TRN & \\
\hline CHEMBL467950 & 532295 & 5.7959 & 5.6281 & TRN & \\
\hline CHEMBL250654 & 532295 & 5.0223 & 4.9093 & TRN & \\
\hline
\end{tabular}

Page 23511 


\begin{tabular}{|c|c|c|c|c|c|}
\hline \multicolumn{6}{|c|}{ Supplemental Table s2.txt } \\
\hline CHEMBL525561 & 532295 & 4.5638 & 4.7374 & TRN & \\
\hline CHEMBL498776 & 532295 & 4.6968 & 4.6162 & TRN & \\
\hline CHEMBL468023 & 532295 & 4.8386 & 4.9084 & TRN & \\
\hline CHEMBL 249828 & 532295 & 4.6968 & 4.8096 & TRN & \\
\hline CHEMBL451176 & 532295 & 4.4425 & 4.4563 & TRN & \\
\hline CHEMBL467778 & 532295 & 4.4935 & 4.3689 & TRN & \\
\hline CHEMBL467764 & 532295 & 4.5406 & 3.8806 & TST & \\
\hline CHEMBL512115 & 532295 & 5.4685 & 4.3912 & TST & \\
\hline CHEMBL468152 & 532295 & 4.9469 & 4.8413 & TRN & \\
\hline CHEMBL430020 & 532295 & 5.0809 & 4.8855 & TRN & \\
\hline CHEMBL452104 & 532295 & 3.0 & 3.7784 & TST & \\
\hline CHEMBL467785 & 532295 & 4.7773 & 4.8132 & TRN & \\
\hline CHEMBL468814 & 532295 & 4.9872 & 4.8408 & TRN & \\
\hline CHEMBL468148 & 532295 & 4.6615 & 4.9341 & TRN & \\
\hline CHEMBL467777 & 532295 & 3.0 & 2.647 & TRN & \\
\hline CHEMBL498997 & 532295 & 5.5376 & 5.5661 & TST & \\
\hline CHEMBL469156 & 532295 & 5.6576 & 5.6556 & TRN & \\
\hline CHEMBL513337 & 532295 & 4.9586 & 4.8157 & TRN & \\
\hline CHEMBL467783 & 532295 & 6.0 & 6.12 & TRN & \\
\hline CHEMBL468771 & 532295 & 4.5272 & 4.4373 & TRN & \\
\hline CHEMBL399844 & 532295 & 3.0 & 3.7509 & TRN & \\
\hline CHEMBL513825 & 532295 & 5.9586 & 6.0331 & TRN & \\
\hline CHEMBL447195 & 532295 & 4.9547 & 4.3642 & TST & \\
\hline CHEMBL468153 & 532295 & 5.1079 & 5.0158 & TRN & \\
\hline CHEMBL468813 & 532295 & 5.4685 & 5.2853 & TST & \\
\hline CHEMBL468956 & 532295 & 4.118 & 4.1805 & TRN & \\
\hline CHEMBL 250469 & 532295 & 5.6383 & 5.4479 & TRN & \\
\hline CHEMBL467955 & 532295 & 4.4353 & 3.2403 & TST & \\
\hline CHEMBL513179 & 532295 & 4.2976 & 4.226 & TRN & \\
\hline CHEMBL399683 & 532295 & 4.3335 & 4.1368 & TRN & \\
\hline CHEMBL468770 & 532295 & 4.4908 & 4.3209 & TRN & \\
\hline CHEMBL 250467 & 532295 & 4.7986 & 4.8104 & TRN & \\
\hline CHEMBL468996 & 532295 & 6.0 & 5.4602 & TST & \\
\hline CHEMBL467956 & 532295 & 5.0701 & 3.9425 & TST & \\
\hline CHEMBL466355 & 532295 & 3.0 & 3.27100 & 00000000004 & TRN \\
\hline CHEMBL468147 & 532295 & 5.9208 & 5.8085 & TRN & \\
\hline CHEMBL 250468 & 532295 & 4.9355 & 5.0788 & TRN & \\
\hline CHEMBL498361 & 532295 & 5.0969 & 5.1374 & TST & \\
\hline CHEMBL 2179747 & 876706 & 3.699 & 4.6664 & TRN & \\
\hline CHEMBL2179769 & 876706 & 3.699 & 3.2875 & TRN & \\
\hline CHEMBL 2179735 & 876706 & 6.8356 & 6.777 & TRN & \\
\hline CHEMBL 2179753 & 876706 & 6.6925 & 6.54899 & 99999999995 & TRN \\
\hline CHEMBL2179755 & 876706 & 6.2255 & 5.6894 & TST & \\
\hline CHEMBL2179725 & 876706 & 5.2454 & 5.3764 & TST & \\
\hline CHEMBL 2179775 & 876706 & 4.9626 & 4.4301 & TRN & \\
\hline CHEMBL 2179749 & 876706 & 3.699 & 5.4422 & TST & \\
\hline CHEMBL 2179774 & 876706 & 4.8972 & 4.3849 & TRN & \\
\hline CHEMBL 2179773 & 876706 & 4.4519 & 4.7474 & TRN & \\
\hline
\end{tabular}




\begin{tabular}{|c|c|c|c|c|c|}
\hline & & \multicolumn{4}{|c|}{ Supplemental Table s2.txt } \\
\hline CHEMBL 2179771 & 876706 & 7.1938 & 6.8877 & TRN & \\
\hline CHEMBL 2179744 & 876706 & 3.699 & 3.2119 & TRN & \\
\hline CHEMBL2179757 & 876706 & 4.9646 & 5.1469 & TRN & \\
\hline CHEMBL2179729 & 876706 & 4.4441 & 6.4051 & TST & \\
\hline CHEMBL2179732 & 876706 & 5.4494 & 5.6335 & TRN & \\
\hline CHEMBL 2179743 & 876706 & 3.699 & 3.9975 & TRN & \\
\hline CHEMBL 2179766 & 876706 & 6.5045 & 6.3673 & TRN & \\
\hline CHEMBL2179738 & 876706 & 6.5086 & 6.1177 & TRN & \\
\hline CHEMBL 2179728 & 876706 & 6.7773 & 6.5171 & TST & \\
\hline CHEMBL 2179768 & 876706 & 6.2248 & 4.8887 & TRN & \\
\hline CHEMBL 2179764 & 876706 & 6.1062 & 6.148 & TRN & \\
\hline CHEMBL 2179726 & 876706 & 6.1624 & 6.1564 & TRN & \\
\hline CHEMBL 2179737 & 876706 & 6.3354 & 5.9382 & TRN & \\
\hline CHEMBL 2179745 & 876706 & 3.699 & 4.981 & TRN & \\
\hline CHEMBL 2179739 & 876706 & 6.8013 & 6.1388 & TRN & \\
\hline CHEMBL 2179730 & 876706 & 4.7399 & 6.5839 & TST & \\
\hline CHEMBL 2179727 & 876706 & 6.6716 & 6.8518 & TRN & \\
\hline CHEMBL 2179761 & 876706 & 5.6525 & 5.5094 & TRN & \\
\hline CHEMBL 2179772 & 876706 & 5.0031 & 5.3046 & TRN & \\
\hline CHEMBL 2179767 & 876706 & 4.9289 & 5.7118 & TRN & \\
\hline CHEMBL 2179754 & 876706 & 7.1487 & 5.6857 & TST & \\
\hline CHEMBL 2179751 & 876706 & 7.6576 & 7.1459 & TRN & \\
\hline CHEMBL 2179758 & 876706 & 3.699 & 4.471 & TRN & \\
\hline CHEMBL 2179742 & 876706 & 3.699 & 4.3448 & TRN & \\
\hline CHEMBL 2179746 & 876706 & 3.699 & 4.423 & TRN & \\
\hline CHEMBL 2179756 & 876706 & 3.699 & 5.79899 & 99999999995 & TRN \\
\hline CHEMBL381689 & 876706 & 8.6778 & 5.5834 & TST & \\
\hline CHEMBL 2179759 & 876706 & 6.8125 & 5.5941 & TRN & \\
\hline CHEMBL2179776 & 876706 & 6.1096 & 6.6246 & TRN & \\
\hline CHEMBL 2179741 & 876706 & 3.699 & 3.3882 & TRN & \\
\hline CHEMBL 2179760 & 876706 & 5.5113 & 6.3186 & TRN & \\
\hline CHEMBL 2179770 & 876706 & 4.9014 & 5.2983 & TRN & \\
\hline CHEMBL 2179733 & 876706 & 6.7399 & 6.4988 & TRN & \\
\hline CHEMBL 2179750 & 876706 & 5.0306 & 5.4777 & TST & \\
\hline CHEMBL2179731 & 876706 & 5.5791 & 6.0295 & TRN & \\
\hline CHEMBL 2179762 & 876706 & 6.3063 & 5.9215 & TRN & \\
\hline CHEMBL 2179740 & 876706 & 6.9957 & 4.981 & TRN & \\
\hline CHEMBL 2179763 & 876706 & 7.0706 & 6.3482 & TRN & \\
\hline CHEMBL 2179734 & 876706 & 7.6021 & 6.7427 & TST & \\
\hline CHEMBL 2179765 & 876706 & 5.8239 & 6.2708 & TST & \\
\hline CHEMBL 2179752 & 876706 & 6.6556 & 7.3517 & TST & \\
\hline CHEMBL 2179748 & 876706 & 3.699 & 4.0166 & TST & \\
\hline CHEMBL2179736 & 876706 & 6.7959 & 6.777 & TST & \\
\hline CHEMBL3113096 & 1290681 & 3.301 & 3.2932 & TRN & \\
\hline CHEMBL3113099 & 1290681 & 4.5817 & 4.572 & TRN & \\
\hline CHEMBL3113292 & 1290681 & 4.4763 & 4.4835 & TRN & \\
\hline CHEMBL558129 & 1290681 & 3.301 & 3.6671 & TST & \\
\hline CHEMBL3113318 & 1290681 & 4.4401 & 4.4282 & TRN & \\
\hline
\end{tabular}

Page 23513 
Supplemental Table S2.txt

\begin{tabular}{|c|c|c|c|c|c|c|}
\hline CHEMBL3113327 & 1290681 & 3.301 & 3.3001 & TRN & & \\
\hline CHEMBL3113303 & 1290681 & 4.327 & 4.3375 & TRN & & \\
\hline CHEMBL3113307 & 1290681 & 4.9469 & 4.9571 & TRN & & \\
\hline CHEMBL3113316 & 1290681 & 4.5421 & 4.5519 & TRN & & \\
\hline CHEMBL3113311 & 1290681 & 5.0915 & 5.0988 & TRN & & \\
\hline CHEMBL3113101 & 1290681 & 4.7932 & 4.7766 & TRN & & \\
\hline CHEMBL3113317 & 1290681 & 4.5017 & 4.5046 & TRN & & \\
\hline CHEMBL3113300 & 1290681 & 4.5361 & 4.4941 & TRN & & \\
\hline CHEMBL 3113331 & 1290681 & 3.301 & 3.2991 & TRN & & \\
\hline CHEMBL3113325 & 1290681 & 3.301 & 3.2981 & TRN & & \\
\hline CHEMBL3113336 & 1290681 & 3.301 & 3.293 & TRN & & \\
\hline CHEMBL3113304 & 1290681 & 4.3696 & 4.3626 & TRN & & \\
\hline CHEMBL3113293 & 1290681 & 4.9872 & 4.9917 & TRN & & \\
\hline CHEMBL 3113308 & 1290681 & 5.0506 & 5.0499 & TRN & & \\
\hline CHEMBL3113326 & 1290681 & 3.301 & 3.7056 & TST & & \\
\hline CHEMBL3113313 & 1290681 & 4.4401 & 4.4323 & TRN & & \\
\hline CHEMBL 226142 & 1290681 & 3.301 & 3.3028 & TRN & & \\
\hline CHEMBL3113298 & 1290681 & 4.4855 & 4.4543 & TRN & & \\
\hline CHEMBL3113295 & 1290681 & 4.5287 & 4.5239 & TRN & & \\
\hline CHEMBL3113328 & 1290681 & 3.301 & 3.4729 & TST & & \\
\hline CHEMBL3113329 & 1290681 & 3.301 & 3.2953 & TRN & & \\
\hline CHEMBL3113332 & 1290681 & 3.301 & 3.4311 & TST & & \\
\hline CHEMBL3113294 & 1290681 & 4.4067 & 4.4011 & TRN & & \\
\hline CHEMBL564467 & 1290681 & 3.301 & 3.4034 & TST & & \\
\hline CHEMBL3113323 & 1290681 & 3.301 & 3.4445 & TST & & \\
\hline CHEMBL3113314 & 1290681 & 4.6144 & 4.6152 & TRN & & \\
\hline CHEMBL3113330 & 1290681 & 3.301 & 3.3501 & TST & & \\
\hline CHEMBL3113324 & 1290681 & 3.301 & 3.3837 & TST & & \\
\hline CHEMBL3113296 & 1290681 & 4.7352 & 4.7564 & TRN & & \\
\hline CHEMBL3113306 & 1290681 & 4.4179 & 4.422 & TRN & & \\
\hline CHEMBL3113305 & 1290681 & 4.5622 & 4.5635 & TRN & & \\
\hline CHEMBL3113097 & 1290681 & 3.301 & 3.1424 & TST & & \\
\hline CHEMBL3113321 & 1290681 & 4.9547 & 4.9528 & TRN & & \\
\hline CHEMBL3113334 & 1290681 & 3.301 & 3.4047 & TST & & \\
\hline CHEMBL3113333 & 1290681 & 3.301 & 3.2874 & TRN & & \\
\hline CHEMBL3113297 & 1290681 & 4.71899 & 999999999 & 99 & 4.6911 & TRN \\
\hline CHEMBL3113335 & 1290681 & 3.301 & 3.3061 & TRN & & \\
\hline CHEMBL3113301 & 1290681 & 4.4473 & 4.4864 & TRN & & \\
\hline CHEMBL550866 & 1290681 & 3.301 & 3.3054 & TRN & & \\
\hline CHEMBL 3113320 & 1290681 & 4.8539 & 4.8601 & TRN & & \\
\hline CHEMBL3113310 & 1290681 & 4.5143 & 4.5151 & TRN & & \\
\hline CHEMBL3113322 & 1290681 & 3.301 & 3.39 & TST & & \\
\hline CHEMBL3113098 & 1290681 & 4.4202 & 4.4333 & TRN & & \\
\hline CHEMBL 3113302 & 1290681 & 4.3947 & 4.3847 & TRN & & \\
\hline CHEMBL 226093 & 1290681 & 3.301 & 3.3447 & TRN & & \\
\hline CHEMBL3113315 & 1290681 & 4.4123 & 4.4006 & TRN & & \\
\hline CHEMBL3113309 & 1290681 & 4.71 & 4.7091 & TRN & & \\
\hline CHEMBL3113319 & 1290681 & 4.6536 & 4.6632 & TRN & & \\
\hline
\end{tabular}

Page 23514 
Supplemental Table S2.txt

\begin{tabular}{|c|c|c|c|c|}
\hline CHEMBL 3113291 & 1290681 & 4.7447 & 4.7546 & r. \\
\hline CHEMBL554939 & 1290681 & 3.301 & 3.7828 & \\
\hline CHEMBL3113312 & 290681 & 4.4597 & 4.4765 & \\
\hline IEMBL3113100 & 1290681 & 4.5544 & 5588 & \\
\hline HEMBL3113299 & 290681 & 4.8962 & 4.955 & \\
\hline CHEMBL3113337 & 1290681 & 3.301 & 509 & \\
\hline CHEMBL168720 & 210578 & 4.699 & 5.6353 & \\
\hline CHEMBL352882 & 210578 & 3.8239 & & \\
\hline CHEMBL170611 & 210578 & 5.8239 & 5.7797 & \\
\hline CHEMBL355883 & 10578 & 5.4559 & 5.8673 & \\
\hline CHEMBL351371 & 210578 & 6.301 & 99 & \\
\hline HEMBL: & 210578 & 6.0 & 589 & \\
\hline CHEMBL & 210578 & & 968 & \\
\hline HEMBL 262275 & 210578 & 6.0 & 569 & \\
\hline CHEMBL354563 & 210578 & 4.0 & 85 & \\
\hline CHEMBL & 210578 & 6.5229 & 6. & \\
\hline CHEMBL & 210578 & 99 & & \\
\hline AEMBL. & 210578 & 218 & & \\
\hline AEMBL1C & 210578 & 5.2596 & 643 & \\
\hline CHEMBL & 10578 & 6.5229 & & \\
\hline CHEMBL & 210578 & 5.699 & 06 & \\
\hline CHEMB & 210578 & 7. & & \\
\hline CHEMBL & 210578 & 3.301 & 31 & \\
\hline CHEMBL168879 & 210578 & 6.0 & & \\
\hline CHEMBL & 10578 & 4. & & \\
\hline CHEMBL: & 210578 & 5.1871 & & \\
\hline CHEMB & 210578 & 7.0 & 32 & \\
\hline CHFMB & 210578 & 5.6778 & 57 & \\
\hline CHEMBL & 210578 & 3.8861 & & $\pi$ \\
\hline CHEMBL1 & 210578 & 5.1549 & & \\
\hline CHEMBL 1 & 210578 & 5.1549 & & \\
\hline $\mathrm{CHE}$ & 10578 & 6.0 & 6. & \\
\hline 94 & 210578 & 4. & 3 . & \\
\hline CHEMBL & 210578 & 4.3979 & & TR \\
\hline CHEMBL354511 & 210578 & & 05 & \\
\hline & 210578 & & & $1 \mathrm{~T}$ \\
\hline $\mathrm{CHE}$ & 10578 & 29 & 6. & \\
\hline CHEMBL & 210578 & 5.3979 & 5.8534 & $\mathrm{TR}$ \\
\hline CHEMBL166585 & 210578 & 2.9586 & 3.662 & TR \\
\hline CHEMBL 3 & 210578 & 6. & 989 & T] \\
\hline CHEMBL $\angle$ & 210578 & 6.5229 & & n \\
\hline CHEMBL3 & 210578 & 5.0 & 5.2792 & \\
\hline CHEMBLI & 210578 & 5.3979 & 5.4179 & TR \\
\hline CHEMBL354801 & 210578 & 5.699 & 6.1046 & $\mathrm{TR}$ \\
\hline CHEMBL1 & 210578 & 6.0 & 6.1199 & 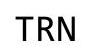 \\
\hline CHEMBL3 & 210578 & 6.2218 & 6.0298 & \\
\hline CHEMBL169419 & 210578 & 4.6021 & 5.4154 & \\
\hline CHEMBL167228 & 210578 & 4.2218 & 4.091 & \\
\hline
\end{tabular}

Page 23515 


\begin{tabular}{|c|c|c|c|c|c|}
\hline \multirow[b]{2}{*}{ CHEMBL168547 } & & \multicolumn{4}{|c|}{ Supplemental Table S2.txt } \\
\hline & 210578 & 6.1739 & 5.82799 & 9999999999 & TRN \\
\hline CHEMBL169106 & 210578 & 5.301 & 5.2769 & TRN & \\
\hline CHEMBL349991 & 210578 & 5.699 & 6.3592 & TRN & \\
\hline CHEMBL167028 & 210578 & 4.699 & 3.8198 & TST & \\
\hline CHEMBL169050 & 210578 & 6.3979 & 6.1253 & TRN & \\
\hline CHEMBL167349 & 210578 & 6.0 & 5.9859 & TRN & \\
\hline CHEMBL168677 & 210578 & 5.0969 & 5.1078 & TRN & \\
\hline CHEMBL168918 & 210578 & 6.8239 & 6.4458 & TRN & \\
\hline CHEMBL352359 & 210578 & 7.0 & 5.8984 & TRN & \\
\hline CHEMBL168727 & 210578 & 4.699 & 5.6392 & TST & \\
\hline CHEMBL168401 & 210578 & 7.0 & 6.1672 & TRN & \\
\hline CHEMBL355110 & 210578 & 3.0 & 4.8847 & TRN & \\
\hline CHEMBL352631 & 210578 & 5.3979 & 5.6815 & TRN & \\
\hline CHEMBL435463 & 210578 & 5.699 & 6.0066 & TRN & \\
\hline CHEMBL167100 & 210578 & 4.3979 & 4.3736 & TST & \\
\hline CHEMBL166882 & 210578 & 5.0 & 3.9321 & TST & \\
\hline CHEMBL354800 & 210578 & 6.301 & 5.806 & TST & \\
\hline CHEMBL354355 & 210578 & 4.0 & 5.1904 & TRN & \\
\hline CHEMBL165597 & 210578 & 3.301 & 3.9719 & TST & \\
\hline CHEMBL169627 & 210578 & 5.301 & 4.2694 & TST & \\
\hline CHEMBL166914 & 210578 & 4.3979 & 3.9192 & TST & \\
\hline CHEMBL167162 & 210578 & 5.0 & 5.7234 & TRN & \\
\hline CHEMBL354577 & 210578 & 4.8239 & 4.1484 & TST & \\
\hline CHEMBL350285 & 210578 & 5.1871 & 5.4757 & TRN & \\
\hline CHEMBL353154 & 210578 & 5.301 & 4.2588 & TST & \\
\hline CHEMBL168772 & 210578 & 4.301 & 4.6819 & TST & \\
\hline CHEMBL166451 & 210578 & 5.2218 & 5.4001 & TRN & \\
\hline CHEMBL352883 & 210578 & 5.3979 & 3.9701 & TST & \\
\hline CHEMBL169775 & 210578 & 4.7696 & 5.5856 & TRN & \\
\hline CHEMBL422205 & 210578 & 4.301 & 3.5388 & TST & \\
\hline CHEMBL167653 & 210578 & 5.699 & 5.8887 & TRN & \\
\hline CHEMBL355260 & 210578 & 5.2218 & 5.6474 & TRN & \\
\hline CHEMBL354977 & 210578 & 5.0 & 5.2519 & TRN & \\
\hline CHEMBL166858 & 210578 & 6.0 & 5.8751 & TRN & \\
\hline CHEMBL353933 & 210578 & 5.699 & 5.8327 & TRN & \\
\hline CHEMBL167279 & 210578 & 6.0969 & 6.23 & TRN & \\
\hline CHEMBL169433 & 210578 & 4.2596 & 4.7407 & TST & \\
\hline CHEMBL166785 & 210578 & 6.0458 & 6.0706 & TRN & \\
\hline CHEMBL352546 & 210578 & 3.301 & 4.7975 & TST & \\
\hline CHEMBL354135 & 210578 & 6.3979 & 5.8321 & TRN & \\
\hline CHEMBL352789 & 210578 & 4.0 & 4.5274 & TST & \\
\hline CHEMBL170488 & 210578 & 6.0 & 6.0706 & TRN & \\
\hline CHEMBL353809 & 210578 & 6.8239 & 5.928 & TRN & \\
\hline CHEMBL168763 & 210578 & 7.1249 & 6.6875 & TRN & \\
\hline CHEMBL169747 & 210578 & 5.3468 & 5.7916 & TRN & \\
\hline CHEMBL168977 & 210578 & 4.699 & 5.2735 & TST & \\
\hline CHEMBL433916 & 210578 & 6.0 & 5.6039 & TST & \\
\hline CHEMBL352851 & 210578 & 6.0 & 5.7126 & TRN & \\
\hline
\end{tabular}




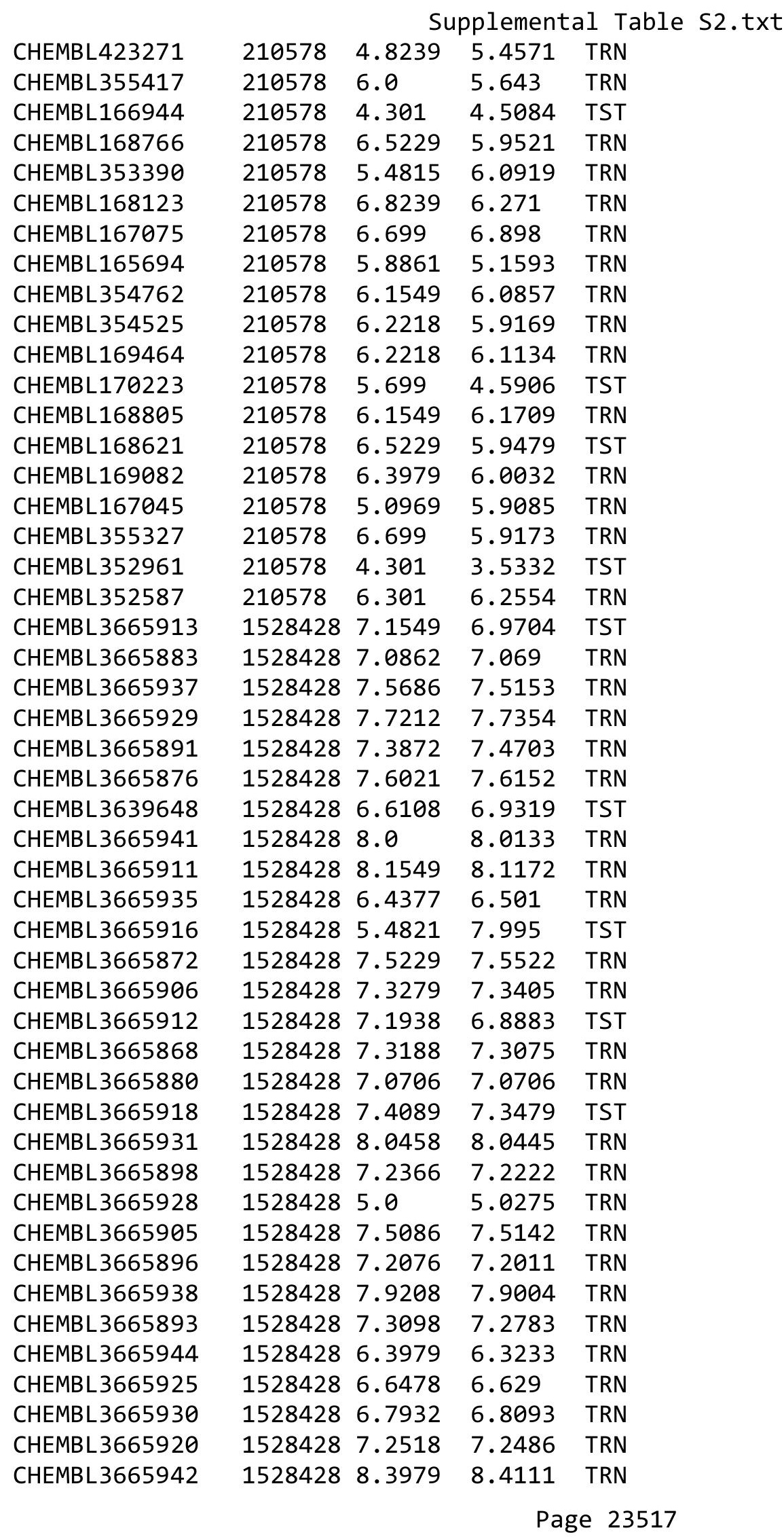


Supplemental Table S2.txt

\begin{tabular}{|c|c|c|c|c|c|}
\hline CHEMBL3665939 & 1528428 & 7.4202 & 7.4581 & TRN & \\
\hline CHEMBL3665873 & 1528428 & 7.3279 & 7.3185 & TRN & \\
\hline CHEMBL3665933 & 1528428 & 6.8962 & 7.1634 & TST & \\
\hline CHEMBL3665889 & 1528428 & 7.1739 & 7.1898 & TRN & \\
\hline CHEMBL3665885 & 1528428 & 7.3665 & 7.3583 & TRN & \\
\hline CHEMBL3665881 & 1528428 & 7.1079 & 7.1075 & TRN & \\
\hline CHEMBL3665892 & 1528428 & 7.4089 & 7.504 & TRN & \\
\hline CHEMBL3665943 & 1528428 & 7.9208 & 7.9001 & TRN & \\
\hline CHEMBL3665914 & 1528428 & 5.105 & 8.0821 & TST & \\
\hline CHEMBL3665877 & 1528428 & 7.7696 & 7.6838 & TRN & \\
\hline CHEMBL3665900 & 1528428 & 7.0915 & 7.0982 & TRN & \\
\hline CHEMBL3665882 & 1528428 & 6.4067 & 6.4452 & TRN & \\
\hline CHEMBL3665907 & 1528428 & 7.699 & 7.662999 & & TRN \\
\hline CHEMBL3665927 & 1528428 & 6.6536 & 6.642 & TRN & \\
\hline CHEMBL 3665870 & 1528428 & 7.284 & 7.2499 & TRN & \\
\hline CHEMBL3665902 & 1528428 & 7.5229 & 7.5364 & TRN & \\
\hline CHEMBL3665879 & 1528428 & 7.1938 & 7.1707 & TRN & \\
\hline CHEMBL3665934 & 1528428 & 8.5229 & 8.5256 & TRN & \\
\hline CHEMBL3665901 & 1528428 & 7.9208 & 7.9099 & TRN & \\
\hline CHEMBL3665917 & 1528428 & 7.7959 & 7.8035 & TRN & \\
\hline CHEMBL3665890 & 1528428 & 7.4437 & 7.4219 & TRN & \\
\hline CHEMBL3665919 & 1528428 & 7.8239 & 7.7902 & TRN & \\
\hline CHEMBL3665915 & 1528428 & 5.5151 & 8.3752 & TST & \\
\hline CHEMBL3665895 & 1528428 & 6.6234 & 6.6166 & TRN & \\
\hline CHEMBL3665921 & 1528428 & 7.1308 & 6.9514 & TST & \\
\hline CHEMBL3665904 & 1528428 & 8.0969 & 8.1193 & TRN & \\
\hline CHEMBL3665940 & 1528428 & 8.2218 & 8.2294 & TRN & \\
\hline CHEMBL3665926 & 1528428 & 7.2147 & 7.2 & TRN & \\
\hline CHEMBL 3665874 & 1528428 & 7.1938 & 7.1809 & TRN & \\
\hline CHEMBL 3665869 & 1528428 & 7.9586 & 8.015 & TRN & \\
\hline CHEMBL3665923 & 1528428 & 7.4437 & 7.419 & TRN & \\
\hline CHEMBL3665894 & 1528428 & 7.4437 & 7.377006 & 0000000001 & TRN \\
\hline CHEMBL3665910 & 1528428 & 8.2218 & 8.2842 & TRN & \\
\hline CHEMBL3665909 & 1528428 & 6.8239 & 6.8985 & TRN & \\
\hline CHEMBL3665924 & 1528428 & 7.3979 & 7.4389 & TRN & \\
\hline CHEMBL3665908 & 1528428 & 7.1612 & 7.0898 & TRN & \\
\hline CHEMBL 3665884 & 1528428 & 6.9431 & 6.9626 & TRN & \\
\hline CHEMBL3665903 & 1528428 & 7.5229 & 7.4737 & TRN & \\
\hline CHEMBL3665897 & 1528428 & 7.1871 & 7.2266 & TRN & \\
\hline CHEMBL3665867 & 1528428 & 7.0044 & 6.9386 & TST & \\
\hline CHEMBL3665922 & 1528428 & 6.983 & 7.1284 & TST & \\
\hline CHEMBL 3665886 & 1528428 & 7.7212 & 7.3022 & TST & \\
\hline CHEMBL3665936 & 1528428 & 8.0 & 7.9037 & TST & \\
\hline CHEMBL3665888 & 1528428 & 7.1308 & 7.3045 & TST & \\
\hline CHEMBL3665899 & 1528428 & 6.857 & 6.9421 & TST & \\
\hline CHEMBL3665866 & 1528428 & 7.0555 & 7.0657 & TST & \\
\hline CHEMBL3665932 & 1528428 & 6.3979 & 7.9298 & TST & \\
\hline CHEMBL 3665871 & 1528428 & 6.3979 & 7.3278 & TST & \\
\hline
\end{tabular}


Supplemental Table S2.txt

\begin{tabular}{|c|c|c|c|c|}
\hline CHEMBL3665875 & 1528428 & 8.0969 & 7.8338 & TST \\
\hline CHEMBL3665878 & 1528428 & 7.0506 & 7.4405 & TST \\
\hline CHEMBL2179548 & 1528657 & 7.1024 & 7.5614 & TRN \\
\hline CHEMBL3676960 & 1528657 & 6.8539 & 6.7603 & TRN \\
\hline CHEMBL3676974 & 1528657 & 8.0223 & 7.7463 & TRN \\
\hline CHEMBL3676978 & 1528657 & 8.2007 & 7.8946 & TRN \\
\hline CHEMBL3676957 & 1528657 & 6.4949 & 6.4051 & TRN \\
\hline CHEMBL 2179534 & 1528657 & 8.8239 & 8.4184 & TRN \\
\hline CHEMBL3676980 & 1528657 & 8.3979 & 8.0902 & TRN \\
\hline CHEMBL3676963 & 1528657 & 7.6021 & 7.6888 & TRN \\
\hline CHEMBL3676961 & 1528657 & 7.3665 & 6.9535 & TST \\
\hline CHEMBL3676964 & 1528657 & 7.0506 & 7.13299 & 9999999999 \\
\hline CHEMBL3676954 & 1528657 & 7.2757 & 7.2862 & TRN \\
\hline CHEMBL3676973 & 1528657 & 7.699 & 7.3748 & TST \\
\hline CHEMBL3676959 & 1528657 & 7.699 & 7.8116 & TRN \\
\hline CHEMBL3676985 & 1528657 & 6.6576 & 6.8825 & TRN \\
\hline CHEMBL 2179544 & 1528657 & 7.8861 & 7.8885 & TRN \\
\hline CHEMBL 2179545 & 1528657 & 7.0177 & 7.1579 & TST \\
\hline CHEMBL 3676944 & 1528657 & 6.6383 & 6.671 & TRN \\
\hline CHEMBL 2179541 & 1528657 & 7.5528 & 7.5462 & TRN \\
\hline CHEMBL3676946 & 1528657 & 6.8539 & 7.7886 & TST \\
\hline CHEMBL3094096 & 1528657 & 7.5086 & 7.6651 & TRN \\
\hline CHEMBL3676956 & 1528657 & 6.0 & 6.5329 & TST \\
\hline CHEMBL 2179543 & 1528657 & 7.8239 & 7.8851 & TRN \\
\hline CHEMBL 2179530 & 1528657 & 7.6778 & 7.6208 & TRN \\
\hline CHEMBL3676949 & 1528657 & 6.9586 & 7.3788 & TRN \\
\hline CHEMBL3676979 & 1528657 & 7.9208 & 7.6069 & TRN \\
\hline CHEMBL 2179526 & 1528657 & 8.0809 & 8.0792 & TRN \\
\hline CHEMBL3676955 & 1528657 & 6.4522 & 7.5827 & TST \\
\hline CHEMBL 3676986 & 1528657 & 7.4559 & 7.3319 & TRN \\
\hline CHEMBL3676981 & 1528657 & 7.1135 & 7.0587 & TRN \\
\hline CHEMBL 2179540 & 1528657 & 8.1938 & 8.3337 & TRN \\
\hline CHEMBL3676989 & 1528657 & 7.5686 & 7.5704 & TRN \\
\hline CHEMBL3676982 & 1528657 & 8.1249 & 7.8857 & TRN \\
\hline CHEMBL 3676943 & 1528657 & 7.7212 & 7.5208 & TRN \\
\hline CHEMBL2179966 & 1528657 & 7.699 & 7.6249 & TRN \\
\hline CHEMBL 2179532 & 1528657 & 7.2676 & 7.1778 & TRN \\
\hline CHEMBL3676966 & 1528657 & 7.301 & 7.2265 & TRN \\
\hline CHEMBL3676950 & 1528657 & 6.8239 & 7.0909 & TRN \\
\hline CHEMBL 2179538 & 1528657 & 6.8861 & 6.8735 & TRN \\
\hline CHEMBL3676953 & 1528657 & 7.2147 & 7.351 & TST \\
\hline CHEMBL 2179516 & 1528657 & 7.8239 & 7.6421 & TST \\
\hline CHEMBL3676970 & 1528657 & 8.2291 & 8.1871 & TRN \\
\hline CHEMBL3676945 & 1528657 & 7.7696 & 7.9182 & TRN \\
\hline CHEMBL3676975 & 1528657 & 7.5376 & 7.511 & TRN \\
\hline CHEMBL2179528 & 1528657 & 7.4559 & 7.6043 & TST \\
\hline CHEMBL3676968 & 1528657 & 7.2924 & 7.3824 & TST \\
\hline CHEMBL 3676987 & 1528657 & 6.301 & 7.1187 & TST \\
\hline
\end{tabular}


Supplemental Table S2.txt

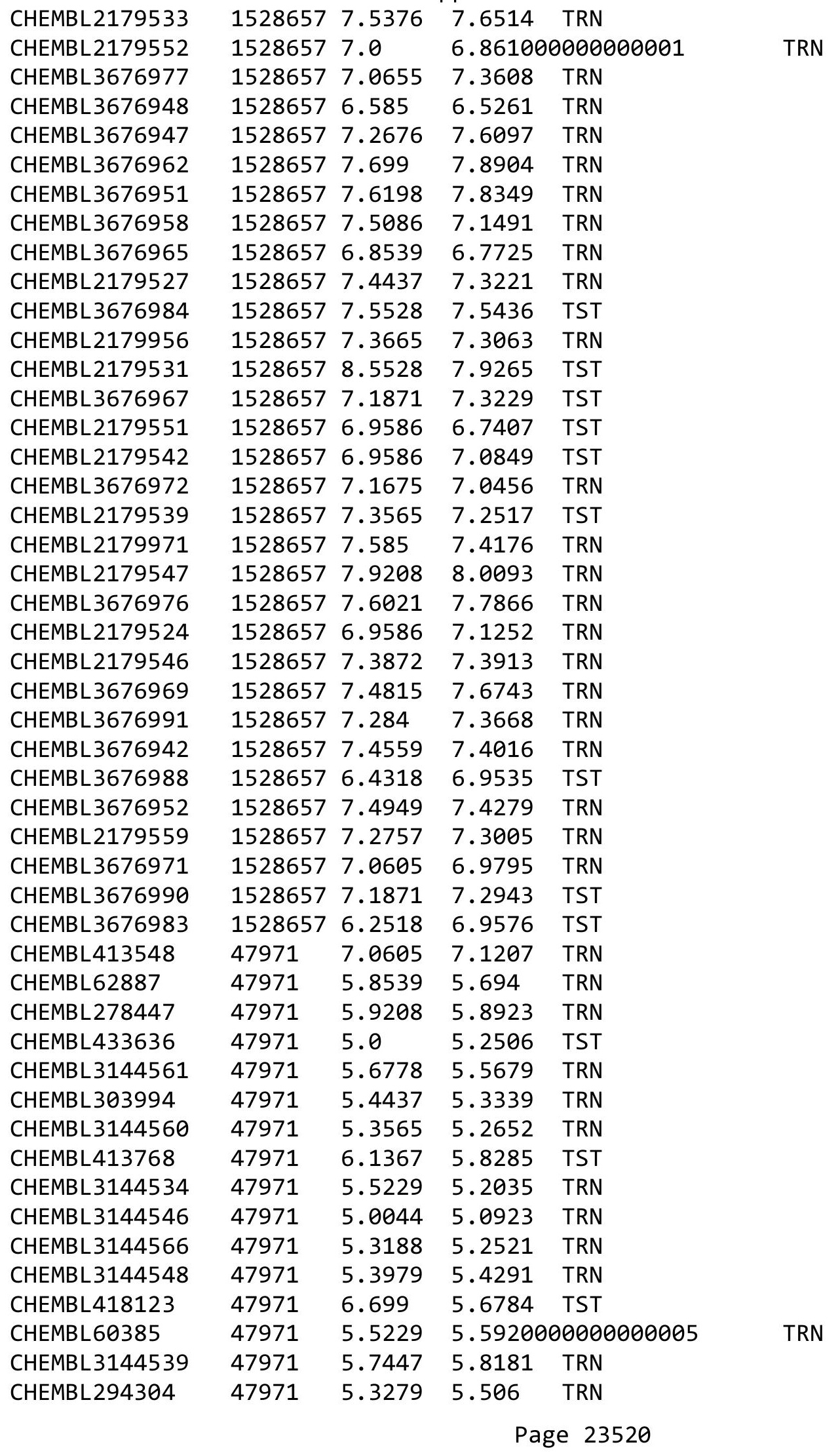




\begin{tabular}{|c|c|c|c|c|c|}
\hline & & \multicolumn{4}{|c|}{ Supplemental Table S2.txt } \\
\hline CHEMBL292298 & 47971 & 6.1739 & 6.1928 & TST & \\
\hline CHEMBL294542 & 47971 & 6.2441 & 5.6609 & TST & \\
\hline CHEMBL292490 & 47971 & 6.0757 & 6.03299 & 99999999995 & TRN \\
\hline CHEMBL3144563 & 47971 & 5.8239 & 5.8876 & TRN & \\
\hline CHEMBL62345 & 47971 & 6.5229 & 5.8819 & TST & \\
\hline CHEMBL3144535 & 47971 & 5.0 & 5.1143 & TRN & \\
\hline CHEMBL3144550 & 47971 & 5.301 & 5.2795 & TRN & \\
\hline CHEMBL3144545 & 47971 & 4.7212 & 4.6277 & TRN & \\
\hline CHEMBL3144542 & 47971 & 5.5229 & 5.5381 & TRN & \\
\hline CHEMBL 3144537 & 47971 & 6.0132 & 6.1725 & TRN & \\
\hline CHEMBL3144543 & 47971 & 5.3565 & 5.4536 & TRN & \\
\hline CHEMBL3144553 & 47971 & 5.7696 & 5.91299 & 9999999999 & TRN \\
\hline CHEMBL3144567 & 47971 & 5.2147 & 5.4445 & TRN & \\
\hline CHEMBL59404 & 47971 & 5.3665 & 5.9234 & TST & \\
\hline CHEMBL3144536 & 47971 & 6.1367 & 6.211 & TRN & \\
\hline CHEMBL3144544 & 47971 & 5.0 & 5.0377 & TRN & \\
\hline CHEMBL3144533 & 47971 & 5.1549 & 4.9614 & TRN & \\
\hline CHEMBL 3144549 & 47971 & 5.301 & 5.4063 & TRN & \\
\hline CHEMBL156559 & 47971 & 5.3468 & 5.6606 & TST & \\
\hline CHEMBL3144538 & 47971 & 6.6778 & 6.5318 & TRN & \\
\hline CHEMBL3144552 & 47971 & 5.2757 & 5.3847 & TRN & \\
\hline CHEMBL59759 & 47971 & 4.0 & 4.2299 & TRN & \\
\hline CHEMBL293026 & 47971 & 6.0809 & 6.1655 & TST & \\
\hline CHEMBL3144562 & 47971 & 5.2924 & 5.2748 & TRN & \\
\hline CHEMBL292071 & 47971 & 6.9208 & 7.0133 & TRN & \\
\hline CHEMBL3144551 & 47971 & 6.1249 & 6.1302 & TRN & \\
\hline CHEMBL 292519 & 47971 & 5.5686 & 5.3579 & TST & \\
\hline CHEMBL302911 & 47971 & 5.5229 & 5.4181 & TST & \\
\hline CHEMBL 3144564 & 47971 & 6.3279 & 6.1506 & TRN & \\
\hline CHEMBL292471 & 47971 & 5.6778 & 5.4059 & TST & \\
\hline CHEMBL3144565 & 47971 & 6.6234 & 6.3378 & TRN & \\
\hline CHEMBL3144531 & 47971 & 5.2291 & 4.7182 & TRN & \\
\hline CHEMBL 3144540 & 47971 & 4.0 & 4.4443 & TRN & \\
\hline CHEMBL3144555 & 47971 & 5.5376 & 5.6971 & TRN & \\
\hline CHEMBL64605 & 47971 & 7.6021 & 5.7464 & TST & \\
\hline CHEMBL387073 & 47971 & 6.0 & 6.1064 & TRN & \\
\hline CHEMBL433640 & 47971 & 6.1487 & 6.1059 & TRN & \\
\hline CHEMBL3144541 & 47971 & 6.3188 & 6.4307 & TRN & \\
\hline CHEMBL418500 & 47971 & 5.284 & 5.4733 & TST & \\
\hline CHEMBL 3144554 & 47971 & 5.7696 & 5.3878 & TRN & \\
\hline CHEMBL90319 & 87173 & 6.3979 & 5.9742 & TST & \\
\hline CHEMBL313641 & 87173 & 4.752 & 3.9441 & TRN & \\
\hline CHEMBL92000 & 87173 & 3.6198 & 3.9082 & TRN & \\
\hline CHEMBL 330090 & 87173 & 5.6778 & 5.8973 & TRN & \\
\hline CHEMBL92149 & 87173 & 6.699 & 5.5749 & TRN & \\
\hline CHEMBL93643 & 87173 & 5.9208 & 6.0083 & TST & \\
\hline CHEMBL420252 & 87173 & 5.2366 & 5.0778 & TRN & \\
\hline CHEMBL328808 & 87173 & 5.2924 & 5.5524 & TRN & \\
\hline
\end{tabular}




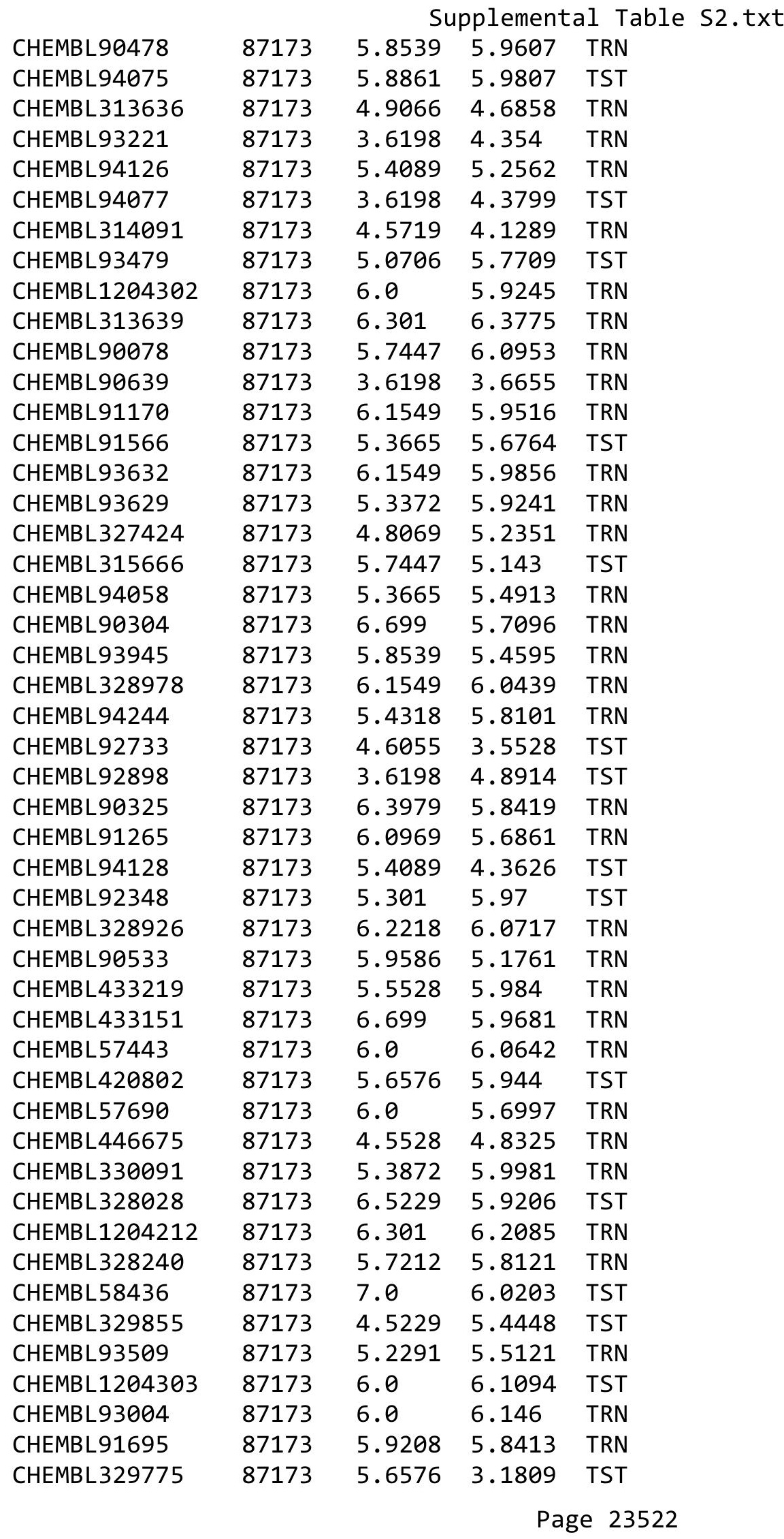




\begin{tabular}{|c|c|c|c|c|c|}
\hline \multicolumn{6}{|c|}{ Supplemental Table S2.txt } \\
\hline CHEMBL93831 & 87173 & 5.2441 & 5.715 & TRN & \\
\hline CHEMBL90800 & 87173 & 4.2218 & 4.694 & TRN & \\
\hline CHEMBL327237 & 87173 & 4.4949 & 5.6516 & TRN & \\
\hline CHEMBL93811 & 87173 & 6.699 & 5.8806 & TRN & \\
\hline CHEMBL90944 & 87173 & 5.7447 & 5.9415 & TST & \\
\hline CHEMBL91386 & 87173 & 6.699 & 6.3748 & TRN & \\
\hline CHEMBL314746 & 87173 & 6.301 & 5.876 & TRN & \\
\hline CHEMBL89925 & 87173 & 5.3372 & 5.6421 & TRN & \\
\hline CHEMBL327907 & 87173 & 5.8239 & 6.0056 & TRN & \\
\hline CHEMBL329461 & 87173 & 5.4318 & 5.9365 & TRN & \\
\hline CHEMBL91408 & 87173 & 5.7447 & 5.5528 & TRN & \\
\hline CHEMBL327897 & 87173 & 5.6778 & 5.9801 & TRN & \\
\hline CHEMBL 291963 & 87173 & 6.699 & 6.2257 & TST & \\
\hline CHEMBL328263 & 87173 & 5.8239 & 5.3631 & TRN & \\
\hline CHEMBL94285 & 87173 & 5.4815 & 5.9409 & TRN & \\
\hline CHEMBL90583 & 87173 & 5.8239 & 5.7372 & TRN & \\
\hline CHEMBL327686 & 87173 & 5.0809 & 5.5634 & TRN & \\
\hline CHEMBL93950 & 87173 & 6.3979 & 5.9229 & TST & \\
\hline CHEMBL93541 & 87173 & 5.3872 & 5.1855 & TRN & \\
\hline CHEMBL327397 & 87173 & 3.6198 & 4.3281 & TRN & \\
\hline CHEMBL93898 & 87173 & 5.4437 & 5.76 & TRN & \\
\hline CHEMBL92658 & 87173 & 6.2218 & 5.8305 & TST & \\
\hline CHEMBL93508 & 87173 & 7.0 & 5.8457 & TRN & \\
\hline CHEMBL419695 & 87173 & 4.5229 & 5.6341 & TRN & \\
\hline CHEMBL93563 & 87173 & 5.1192 & 5.8331 & TST & \\
\hline CHEMBL90357 & 87173 & 5.5229 & 4.9797 & TRN & \\
\hline CHEMBL90117 & 87173 & 6.2218 & 5.7451 & TRN & \\
\hline CHEMBL1202887 & 87173 & 4.857 & 3.9598 & TST & \\
\hline CHEMBL1202889 & 87173 & 5.5528 & 6.1035 & TRN & \\
\hline CHEMBL 94020 & 87173 & 3.6198 & 3.8513 & TRN & \\
\hline CHEMBL328286 & 87173 & 5.8861 & 5.6161 & TRN & \\
\hline CHEMBL 327173 & 87173 & 4.6778 & 5.4589 & TST & \\
\hline CHEMBL94291 & 87173 & 6.301 & 6.2248 & TRN & \\
\hline CHEMBL93786 & 87173 & 5.5229 & 5.3122 & TST & \\
\hline CHEMBL91294 & 87173 & 5.0088 & 4.6611 & TRN & \\
\hline CHEMBL90607 & 87173 & 6.5229 & 5.9981 & TRN & \\
\hline CHEMBL93114 & 87173 & 5.699 & 4.8932 & TRN & \\
\hline CHEMBL90892 & 87173 & 6.5229 & 5.2684 & TST & \\
\hline CHEMBL 328013 & 87173 & 6.0 & 5.4144 & TRN & \\
\hline CHEMBL329204 & 87173 & 6.699 & 5.9206 & TST & \\
\hline CHEMBL 329374 & 87173 & 6.3979 & 5.6594 & TST & \\
\hline CHEMBL93627 & 87173 & 5.6383 & 5.4952 & TRN & \\
\hline CHEMBL 327170 & 87173 & 5.6778 & 5.2683 & TRN & \\
\hline CHEMBL 93337 & 87173 & 6.0969 & 5.8206 & TRN & \\
\hline CHEMBL91292 & 87173 & 3.6198 & 5.09399 & 9999999999 & TRN \\
\hline CHEMBL93224 & 87173 & 5.0555 & 5.8414 & TRN & \\
\hline CHEMBL94010 & 87173 & 5.8539 & 5.8732 & TRN & \\
\hline CHEMBL 328053 & 87173 & 6.5229 & 6.2506 & TRN & \\
\hline
\end{tabular}

Page 23523 


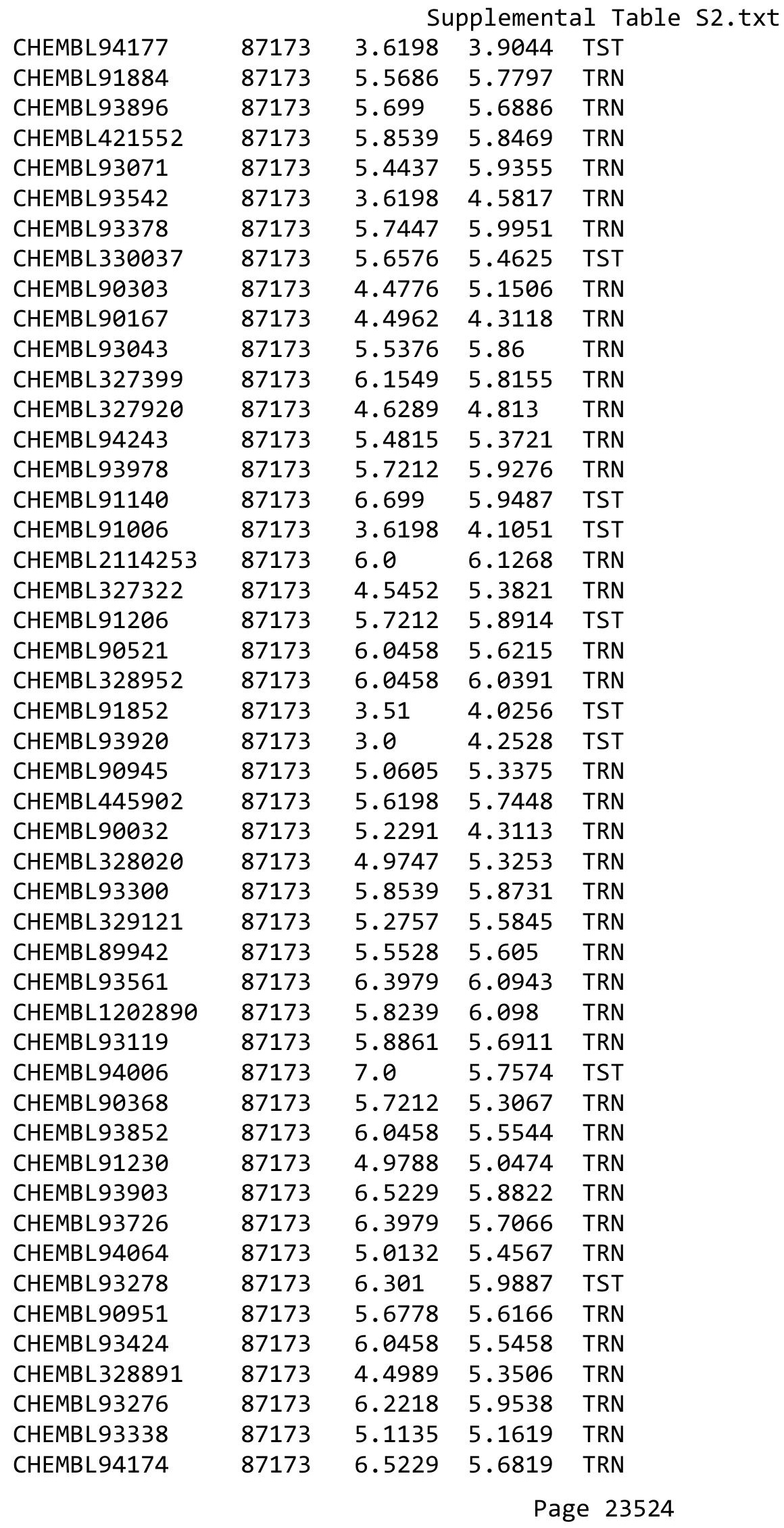




\begin{tabular}{|c|c|c|c|c|c|}
\hline \multirow[b]{2}{*}{ CHEMBL92382 } & \multicolumn{5}{|c|}{ Supplemental Table S2.txt } \\
\hline & 87173 & 6.0969 & 6.1587 & TST & \\
\hline CHEMBL300817 & 87173 & 5.8239 & 6.1398 & TRN & \\
\hline CHEMBL93778 & 87173 & 4.7167 & 4.55399 & 9999999999 & TRN \\
\hline CHEMBL328954 & 87173 & 5.3768 & 5.4063 & TRN & \\
\hline CHEMBL90724 & 87173 & 5.4559 & 5.7144 & TST & \\
\hline CHEMBL90535 & 87173 & 4.4413 & 4.8319 & TST & \\
\hline CHEMBL 330500 & 87173 & 5.3979 & 4.8267 & TST & \\
\hline CHEMBL421359 & 87173 & 5.2924 & 5.7997 & TRN & \\
\hline CHEMBL 94008 & 87173 & 5.4202 & 5.6687 & TRN & \\
\hline CHEMBL330027 & 87173 & 5.3098 & 5.1548 & TRN & \\
\hline CHEMBL93176 & 87173 & 5.7696 & 5.6176 & TRN & \\
\hline CHEMBL 3718368 & 1536983 & 6.8239 & 6.1302 & TST & \\
\hline CHEMBL3718636 & 1536983 & 6.3468 & 6.3796 & TRN & \\
\hline CHEMBL 3717532 & 1536983 & 7.2007 & 7.1941 & TRN & \\
\hline CHEMBL3716403 & 1536983 & 4.9208 & 4.9968 & TRN & \\
\hline CHEMBL3717190 & 1536983 & 4.699 & 2.7663 & TST & \\
\hline CHEMBL3715121 & 1536983 & 7.4685 & 7.4099 & TRN & \\
\hline CHEMBL3716936 & 1536983 & 5.3872 & 5.3803 & TRN & \\
\hline CHEMBL3718019 & 1536983 & 4.6383 & 4.6 & TRN & \\
\hline CHEMBL3715388 & 1536983 & 7.6198 & 8.2523 & TST & \\
\hline CHEMBL3716727 & 1536983 & 6.1308 & 6.1074 & TRN & \\
\hline CHEMBL 3714773 & 1536983 & 5.9208 & 5.9976 & TRN & \\
\hline CHEMBL 3717030 & 1536983 & 6.0 & 6.00200 & 0000000001 & TRN \\
\hline CHEMBL 3715494 & 1536983 & 7.4437 & 7.4459 & TRN & \\
\hline CHEMBL3718039 & 1536983 & 6.0 & 6.2501 & TRN & \\
\hline CHEMBL3715412 & 1536983 & 6.5229 & 6.6293 & TRN & \\
\hline CHEMBL 3717368 & 1536983 & 6.0 & 5.9084 & TRN & \\
\hline CHEMBL3718783 & 1536983 & 6.4685 & 6.4845 & TRN & \\
\hline CHEMBL3715553 & 1536983 & 5.6021 & 5.5562 & TRN & \\
\hline CHEMBL3718407 & 1536983 & 6.3372 & 6.2935 & TRN & \\
\hline CHEMBL3715259 & 1536983 & 6.4685 & 6.4497 & TRN & \\
\hline CHEMBL3716396 & 1536983 & 6.0 & 6.1002 & TRN & \\
\hline CHEMBL3716598 & 1536983 & 5.7447 & 5.4609 & TST & \\
\hline CHEMBL3716839 & 1536983 & 5.1487 & 5.1859 & TRN & \\
\hline CHEMBL 3715533 & 1536983 & 6.2007 & 6.17200 & 0000000001 & TRN \\
\hline CHEMBL 3716044 & 1536983 & 6.0 & 5.9631 & TRN & \\
\hline CHEMBL 3714893 & 1536983 & 5.8239 & 5.9735 & TRN & \\
\hline CHEMBL3718575 & 1536983 & 6.3098 & 6.26 & TRN & \\
\hline CHEMBL 3717063 & 1536983 & 6.8539 & 6.5901 & TRN & \\
\hline CHEMBL3718105 & 1536983 & 7.4685 & 7.2843 & TRN & \\
\hline CHEMBL3715939 & 1536983 & 5.0809 & 4.9031 & TRN & \\
\hline CHEMBL 3716415 & 1536983 & 4.7959 & 4.7278 & TRN & \\
\hline CHEMBL3715871 & 1536983 & 5.3979 & 5.3482 & TRN & \\
\hline CHEMBL 3716544 & 1536983 & 8.2757 & 8.9644 & TST & \\
\hline CHEMBL3716143 & 1536983 & 6.3372 & 6.2384 & TST & \\
\hline CHEMBL 3716900 & 1536983 & 5.4815 & 0.9755 & TST & \\
\hline CHEMBL3717200 & 1536983 & 6.5376 & 6.3059 & TRN & \\
\hline CHEMBL3718956 & 1536983 & 6.6576 & 6.6149 & TRN & \\
\hline
\end{tabular}




\begin{tabular}{|c|c|c|c|c|c|c|}
\hline \multicolumn{7}{|c|}{ Supplemental Table S2.txt } \\
\hline CHEMBL 3717470 & 1536983 & 6.0 & 6.0432 & TRN & & \\
\hline CHEMBL3716048 & 1536983 & 5.3098 & 5.5315 & TRN & & \\
\hline CHEMBL3715032 & 1536983 & 7.1427 & 7.1198 & TRN & & \\
\hline CHEMBL 3719067 & 1536983 & 6.9586 & 7.0315 & TRN & & \\
\hline CHEMBL3715360 & 1536983 & 8.283999 & 99999999 & 99 & 8.3626 & TRN \\
\hline CHEMBL3718268 & 1536983 & 7.2007 & 7.2286 & TRN & & \\
\hline CHEMBL3717191 & 1536983 & 5.0555 & 4.8014 & TRN & & \\
\hline CHEMBL 3718730 & 1536983 & 7.2596 & 7.6382 & TRN & & \\
\hline CHEMBL 3719157 & 1536983 & 4.699 & 4.7511 & TRN & & \\
\hline CHEMBL3716635 & 1536983 & 7.4815 & 7.3499 & TRN & & \\
\hline CHEMBL 3717295 & 1536983 & 5.4437 & 5.4915 & TRN & & \\
\hline CHEMBL 3717823 & 1536983 & 4.4318 & 4.6506 & TRN & & \\
\hline CHEMBL 3719148 & 1536983 & 6.0 & 5.9151 & TRN & & \\
\hline CHEMBL 3717234 & 1536983 & 4.9586 & 5.1229 & TRN & & \\
\hline CHEMBL 3719268 & 1536983 & 4.7959 & 2.9966 & TST & & \\
\hline CHEMBL 3716274 & 1536983 & 4.6576 & 4.7219 & TRN & & \\
\hline CHEMBL3717059 & 1536983 & 7.2291 & 7.285 & TRN & & \\
\hline CHEMBL 3715825 & 1536983 & 7.0044 & 6.7188 & TRN & & \\
\hline CHEMBL3718661 & 1536983 & 6.3872 & 6.3584 & TRN & & \\
\hline CHEMBL 3719302 & 1536983 & 5.1308 & 6.7523 & TST & & \\
\hline CHEMBL3715919 & 1536983 & 5.3188 & 7.3267 & TST & & \\
\hline CHEMBL3716309 & 1536983 & 6.1549 & 5.9198 & TST & & \\
\hline CHEMBL 3718405 & 1536983 & 4.0177 & 6.6777 & TST & & \\
\hline CHEMBL3718439 & 1536983 & 7.4559 & 7.2918 & TST & & \\
\hline CHEMBL 3717174 & 1536983 & 6.4815 & 7.3316 & TST & & \\
\hline CHEMBL 3718855 & 1536983 & 4.1135 & 4.0267 & TST & & \\
\hline CHEMBL3718776 & 1536983 & 5.3768 & 5.309 & TST & & \\
\hline CHEMBL 3609048 & 1513934 & 10.4202 & 9.4818 & TRN & & \\
\hline CHEMBL 3609051 & 1513934 & 8.8268 & 9.0302 & TST & & \\
\hline CHEMBL 3609034 & 1513934 & 9.6162 & 9.0607 & TRN & & \\
\hline CHEMBL 3609269 & 1513934 & 8.301 & 8.4029 & TRN & & \\
\hline CHEMBL 3609266 & 1513934 & 10.5086 & 10.1457 & TRN & & \\
\hline CHEMBL 3609044 & 1513934 & 9.4001 & 9.4818 & TRN & & \\
\hline CHEMBL 3609037 & 1513934 & 10.0605 & 10.3243 & TRN & & \\
\hline CHEMBL 3609262 & 1513934 & 9.3575 & 9.6135 & TST & & \\
\hline CHEMBL 3609257 & 1513934 & 9.4473 & 8.7701 & TRN & & \\
\hline CHEMBL 3609085 & 1513934 & 9.8601 & 9.9273 & TRN & & \\
\hline CHEMBL 3609084 & 1513934 & 10.1739 & 9.9879 & TRN & & \\
\hline CHEMBL 3609220 & 1513934 & 9.055 & 9.4818 & TRN & & \\
\hline CHEMBL 3609242 & 1513934 & 9.0655 & 9.2344 & TRN & & \\
\hline CHEMBL 3609045 & 1513934 & 9.6882 & 10.0583 & TRN & & \\
\hline CHEMBL3609095 & 1513934 & 10.5086 & 10.3405 & TST & & \\
\hline CHEMBL 3609273 & 1513934 & 8.8794 & 9.0607 & TRN & & \\
\hline CHEMBL3609236 & 1513934 & 10.2596 & 9.4818 & TRN & & \\
\hline CHEMBL 3609226 & 1513934 & 9.6003 & 9.4818 & TRN & & \\
\hline CHEMBL 3609054 & 1513934 & 10.0044 & 10.3013 & TRN & & \\
\hline CHEMBL 3609258 & 1513934 & 8.9706 & 8.7701 & TRN & & \\
\hline CHEMBL 3609271 & 1513934 & 10.4318 & 9.0607 & TRN & & \\
\hline
\end{tabular}

Page 23526 
Supplemental Table S2.txt

$\begin{array}{lllll}\text { CHEMBL3609243 } & 1513934 & 7.9355 & 8.0112 & \text { TRN } \\ \text { CHEMBL3609052 } & 1513934 & 6.0 & 9.4818 & \text { TRN } \\ \text { CHEMBL3609072 } & 1513934 & 9.3325 & 9.898 & \text { TST } \\ \text { CHEMBL3608318 } & 1513934 & 9.6536 & 9.7577 & \text { TST } \\ \text { CHEMBL3609042 } & 1513934 & 10.1192 & 9.4818 & \text { TRN } \\ \text { CHEMBL3609253 } & 1513934 & 8.1811 & 8.6445 & \text { TRN } \\ \text { CHEMBL3609267 } & 1513934 & 7.7721 & 7.0381 & \text { TRN } \\ \text { CHEMBL3609091 } & 1513934 & 9.0846 & 9.0924 & \text { TST } \\ \text { CHEMBL3609023 } & 1513934 & 9.6946 & 9.7254 & \text { TST } \\ \text { CHEMBL3608995 } & 1513934 & 10.2518 & 9.4818 & \text { TRN } \\ \text { CHEMBL3609057 } & 1513934 & 7.8861 & 9.4818 & \text { TRN } \\ \text { CHEMBL3609070 } & 1513934 & 9.5901 & 9.4818 & \text { TRN } \\ \text { CHEMBL3609060 } & 1513934 & 10.0506 & 10.0695 & \text { TST } \\ \text { CHEMBL3609224 } & 1513934 & 10.4949 & 9.4818 & \text { TRN } \\ \text { CHEMBL3609058 } & 1513934 & 10.3979 & 9.4818 & \text { TRN } \\ \text { CHEMBL3609063 } & 1513934 & 10.6383 & 10.3739 & \text { TRN } \\ \text { CHEMBL3609075 } & 1513934 & 9.9666 & 9.4818 & \text { TRN } \\ \text { CHEMBL3608996 } & 1513934 & 9.1261 & 9.0727 & \text { TRN } \\ \text { CHEMBL3609277 } & 1513934 & 9.5058 & 9.7254 & \text { TST } \\ \text { CHEMBL3609050 } & 1513934 & 7.5969 & 9.4818 & \text { TRN } \\ \text { CHEMBL3609248 } & 1513934 & 10.0506 & 10.0583 & \text { TRN } \\ \text { CHEMBL3609079 } & 1513934 & 9.5638 & 9.4818 & \text { TRN } \\ \text { CHEMBL3609046 } & 1513934 & 9.8447 & 9.898 & \text { TST } \\ \text { CHEMBL3609081 } & 1513934 & 10.3872 & 9.4818 & \text { TRN } \\ \text { CHEMBL3609230 } & 1513934 & 10.3468 & 9.4818 & \text { TRN } \\ \text { CHEMBL3609028 } & 1513934 & 8.9547 & 9.0607 & \text { TRN } \\ \text { CHEMBL3609027 } & 1513934 & 7.0 & 6.6764 & \text { TRN } \\ \text { CHEMBL3609039 } & 1513934 & 7.3925 & 6.8415 & \text { TRN } \\ \text { CHEMBL3609086 } & 1513934 & 10.0655 & 9.929 & \text { TRN } \\ \text { CHEMBL3609237 } & 1513934 & 10.2291 & 10.0695 & \text { TST } \\ \text { CHEMBL3609069 } & 1513934 & 10.0223 & 9.4818 & \text { TRN } \\ \text { CHEMBL3609235 } & 1513934 & 9.7305 & 9.4818 & \text { TRN } \\ \text { CHEMBL3609264 } & 1513934 & 9.6696 & 9.8459 & \text { TRN } \\ \text { CHEMBL3609080 } & 1513934 & 8.4572 & 9.4818 & \text { TRN } \\ \text { CHEMB } 3609033 & 1513934 & 10.699000000000002 \\ \text { CHEMBEM }\end{array}$

Page 23527 
Supplemental Table S2.txt

\begin{tabular}{|c|c|c|c|c|c|}
\hline CHEMBL3609077 & 1513934 & 10.3468 & 9.4818 & TRN & \\
\hline CHEMBL3609270 & 1513934 & 10.1427 & 9.843 & TST & \\
\hline CHEMBL3609227 & 1513934 & 9.4855 & 9.0302 & TST & \\
\hline CHEMBL3609068 & 1513934 & 10.284 & 9.4818 & TRN & \\
\hline CHEMBL3609088 & 1513934 & 9.8601 & 9.7363 & TST & \\
\hline CHEMBL3609090 & 1513934 & 9.6038 & 8.8484 & TST & \\
\hline CHEMBL3609274 & 1513934 & 9.1051 & 9.0607 & TRN & \\
\hline CHEMBL3609067 & 1513934 & 9.8125 & 9.8093 & TST & \\
\hline CHEMBL3609040 & 1513934 & 9.6676 & 9.9175 & TRN & \\
\hline CHEMBL3609076 & 1513934 & 8.4449 & 9.0302 & TST & \\
\hline CHEMBL3609231 & 1513934 & 9.7011 & 9.9347 & TRN & \\
\hline CHEMBL 3609241 & 1513934 & 7.1524 & 7.4016 & TRN & \\
\hline CHEMBL3609093 & 1513934 & 10.4318 & 9.4818 & TRN & \\
\hline CHEMBL 3609223 & 1513934 & 10.2676 & 9.929 & TRN & \\
\hline CHEMBL 3609260 & 1513934 & 10.0862 & 8.7701 & TRN & \\
\hline CHEMBL3608998 & 1513934 & 10.3468 & 9.4818 & TRN & \\
\hline CHEMBL3609074 & 1513934 & 10.3872 & 9.898 & TST & \\
\hline CHEMBL3609026 & 1513934 & 7.0 & 9.0607 & TRN & \\
\hline CHEMBL 3608994 & 1513934 & 10.6383 & 10.3739 & TRN & \\
\hline CHEMBL3609049 & 1513934 & 9.9431 & 9.898 & TST & \\
\hline CHEMBL3609228 & 1513934 & 8.7122 & 9.4818 & TRN & \\
\hline CHEMBL3609232 & 1513934 & 10.1871 & 9.4818 & TRN & \\
\hline CHEMBL3609024 & 1513934 & 7.0362 & 9.0607 & TRN & \\
\hline CHEMBL 3609254 & 1513934 & 6.0 & 8.7701 & TRN & \\
\hline CHEMBL 3609083 & 1513934 & 9.6615 & 10.0695 & TST & \\
\hline CHEMBL3609056 & 1513934 & 9.8013 & 9.4818 & TRN & \\
\hline CHEMBL3609245 & 1513934 & 9.6882 & 8.7701 & TRN & \\
\hline CHEMBL3609082 & 1513934 & 8.22299 & 99999999 & 99 & 9.4818 \\
\hline CHEMBL3609259 & 1513934 & 8.3261 & 8.7701 & TRN & \\
\hline CHEMBL3609239 & 1513934 & 9.6517 & 9.7437 & TST & \\
\hline CHEMBL3609071 & 1513934 & 10.1249 & 10.0583 & TRN & \\
\hline CHEMBL3609055 & 1513934 & 9.8633 & 9.9347 & TRN & \\
\hline CHEMBL3609087 & 1513934 & 9.6517 & 9.7033 & TST & \\
\hline CHEMBL3609065 & 1513934 & 9.9318 & 9.9175 & TRN & \\
\hline CHEMBL 3609038 & 1513934 & 10.0088 & 10.3739 & TRN & \\
\hline CHEMBL3609066 & 1513934 & 8.3307 & 8.4438 & TRN & \\
\hline CHEMBL3609251 & 1513934 & 9.8153 & 9.8655 & TST & \\
\hline CHEMBL3609043 & 1513934 & 10.1427 & 9.4818 & TRN & \\
\hline CHEMBL 3609035 & 1513934 & 10.2596 & 10.13 & TST & \\
\hline CHEMBL 3609047 & 1513934 & 9.4295 & 9.929 & TRN & \\
\hline CHEMBL3609031 & 1513934 & 8.0883 & 9.0607 & TRN & \\
\hline CHEMBL 3609250 & 1513934 & 7.5391 & 8.4896 & TRN & \\
\hline CHEMBL3609073 & 1513934 & 9.9666 & 9.929 & TRN & \\
\hline CHEMBL3608992 & 1513934 & 10.2147 & 10.0932 & TST & \\
\hline CHEMBL 3609025 & 1513934 & 7.7328 & 8.0359 & TST & \\
\hline CHEMBL3609041 & 1513934 & 9.5969 & 9.8093 & TST & \\
\hline CHEMBL3609061 & 1513934 & 9.4473 & 9.9879 & TRN & \\
\hline CHEMBL 3609244 & 1513934 & 9.4342 & 8.7701 & TRN & \\
\hline
\end{tabular}

Page 23528 
Supplemental Table S2.txt

\begin{tabular}{|c|c|c|c|c|}
\hline HEMBL 3609222 & 513934 & 10.3872 & 9.4818 & TRN \\
\hline HEMBL3608999 & 513934 & 9.0851 & 9.4818 & \\
\hline HEMBL3 & 513934 & 7.9547 & 9.4818 & \\
\hline HEMBL3608991 & 513934 & 9.3778 & 8.7701 & RN \\
\hline HEMBL3609249 & 513934 & 9.7352 & 8655 & ST \\
\hline HEMBL3609247 & 513934 & 8.4486 & 8.7701 & \\
\hline HEMBL3609022 & 513934 & 10.4437 & 9871 & \\
\hline HEMBL3609053 & 513934 & 6.0 & 7.3867 & RN \\
\hline HEMBL3608997 & 513934 & 10.4685 & 9.8093 & \\
\hline HEMBL3609229 & 513934 & 8.51 & 7.3867 & \\
\hline HEMBL3609089 & 513934 & 9.8153 & 9.7059 & \\
\hline HEMBL3609256 & 513934 & 10.2147 & 9.8754 & \\
\hline HEMBL3609092 & 513934 & 9.5157 & 544 & ST \\
\hline HEMBL3608317 & 513 & 8.1831 & 8.4438 & RN \\
\hline HEMBL3609268 & 513 & 10.1308 & 9.8848 & \\
\hline AEMBL3609265 & 513 & 10.5376 & 10.3639 & NIV \\
\hline HEMBL3609064 & 34 & 6.0 & 15 & KIV \\
\hline HEMBL3609032 & 34 & 9.1367 & 07 & \\
\hline HEMBL3609234 & 34 & 8.5406 & 9.4818 & $\mathrm{RN}$ \\
\hline HEMBL3609078 & 34 & 9.6459 & 347 & TRN \\
\hline HEMBL3609 & 4 & 8. & 01 & ונ \\
\hline HEMBL360 & 4 & 9.4078 & 18 & RN \\
\hline HEMBL360 & 34 & 9.3063 & 84 & RN \\
\hline HEMBL3609240 & 34 & 9.5622 & 5962 & TST \\
\hline HEMBL 3609 & 34 & 9.6946 & 07 & TRN \\
\hline HEMBL3609 & 4 & 10.2757 & 10.2295 & TRN \\
\hline HEMBL5 5 & 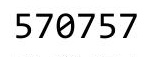 & 6.0 & 45 & RN \\
\hline HEMBL56 & 57 & 5.3 & 34 & RN \\
\hline HEMBL570545 & & 5.3 & 504 & IRN \\
\hline HEMBL418805 & 7 & 5.7 & 5 . & TRN \\
\hline HEMBL552230 & 7 & 4 . & 201 & RN \\
\hline HEMBL1€ & 7 & 7. & 7 & RN \\
\hline HEMBL 565 & 57 & 6.6 & 09 & TRN \\
\hline HEMBL 561413 & 57 & 7.2 & 93 & IRN \\
\hline HEMBL30294 & 70757 & 4 . & 5.1992 & TST \\
\hline HEMBL552433 & 57 & 6 & 48 & RN \\
\hline CHEMBL53 & 57 & 5 & 58 & RN \\
\hline LHEMBL182372 & 70757 & 5.9 & 5.5996 & TRN \\
\hline HEMBL184848 & 70757 & 5 & 5.9861 & TRN \\
\hline HEMBL1115 & 7 & 7. & 931 & TRN \\
\hline CHEMBL565181 & 57 & 5 & 3735 & RN \\
\hline CHEMBL549396 & 570757 & 6.9 & 7.2212 & RIN \\
\hline CHEMBL561490 & 70757 & 5.4 & 4.8598 & TST \\
\hline HEMBL108447 & 70757 & 8.2 & 7.7057 & $R$ \\
\hline HEMBL540173 & 70 & 6 & 5.8475 & Tार \\
\hline CHEMBL538181 & 70757 & 5.8 & 5.7943 & RN \\
\hline CHEMBL539738 & 70757 & 5.0 & 6.2799 & ST \\
\hline CHEMBL105171 & 570757 & 5.2 & 5.7932 & RN \\
\hline
\end{tabular}

Page 23529 


\begin{tabular}{|c|c|c|c|c|c|}
\hline \\
\hline CHEMBL104937 & 570757 & 6.2 & 6.483 & TRN & \\
\hline CHEMBL324168 & 570757 & 7.4 & 7.4882 & TRN & \\
\hline CHEMBL552030 & 570757 & 6.5 & 5.7138 & TST & \\
\hline CHEMBL556663 & 570757 & 6.2 & 6.3793 & TRN & \\
\hline CHEMBL60088 & 570757 & 7.1 & 6.7804 & TRN & \\
\hline CHEMBL560493 & 570757 & 7.3 & 7.6432 & TRN & \\
\hline CHEMBL105395 & 570757 & 7.0 & 7.4296 & TRN & \\
\hline CHEMBL560416 & 570757 & 7.5 & 7.6432 & TRN & \\
\hline CHEMBL 321944 & 570757 & 6.2 & 6.0019 & TRN & \\
\hline CHEMBL550342 & 570757 & 5.0 & 4.6624 & TRN & \\
\hline CHEMBL550138 & 570757 & 6.4 & 6.4724 & TRN & \\
\hline CHEMBL111471 & 570757 & 7.2 & 6.6475 & TRN & \\
\hline CHEMBL559897 & 570757 & 5.7 & 5.8702 & TRN & \\
\hline CHEMBL551628 & 570757 & 6.4 & 6.0901 & TRN & \\
\hline CHEMBL111567 & 570757 & 7.8 & 7.3155 & TRN & \\
\hline CHEMBL570081 & 570757 & 6.6 & 6.5148 & TRN & \\
\hline CHEMBL550275 & 570757 & 5.3 & 5.4071 & TRN & \\
\hline CHEMBL538931 & 570757 & 4.0 & 3.8942 & TRN & \\
\hline CHEMBL559895 & 570757 & 6.1 & 5.7292 & TRN & \\
\hline CHEMBL551228 & 570757 & 5.0 & 4.7699 & TRN & \\
\hline CHEMBL551227 & 570757 & 6.1 & 5.9958 & TRN & \\
\hline CHEMBL549732 & 570757 & 4.5 & 4.899 & TST & \\
\hline CHEMBL179941 & 570757 & 6.9 & 6.8365 & TRN & \\
\hline CHEMBL541262 & 570757 & 6.2 & 6.4525 & TRN & \\
\hline CHEMBL117368 & 570757 & 5.6 & 5.2618 & TRN & \\
\hline CHEMBL559698 & 570757 & 5.2 & 5.4923 & TRN & \\
\hline CHEMBL559504 & 570757 & 5.2 & 6.0797 & TRN & \\
\hline CHEMBL555129 & 570757 & 5.4 & 5.2332 & TRN & \\
\hline CHEMBL104166 & 570757 & 9.2 & 8.5349 & TRN & \\
\hline CHEMBL550621 & 570757 & 6.9 & 6.8373 & TRN & \\
\hline CHEMBL539405 & 570757 & 4.3 & 5.1393 & TST & \\
\hline CHEMBL549664 & 570757 & 5.5 & 5.5878 & TRN & \\
\hline CHEMBL550620 & 570757 & 5.9 & 5.6376 & TRN & \\
\hline CHEMBL426433 & 570757 & 5.9 & 6.3435 & TRN & \\
\hline CHEMBL442201 & 570757 & 7.6 & 7.4453 & TRN & \\
\hline CHEMBL549463 & 570757 & 5.0 & 4.9604 & TRN & \\
\hline CHEMBL 319264 & 570757 & 6.3 & 6.3382 & TRN & \\
\hline CHEMBL62083 & 570757 & 4.3 & 4.8154 & TST & \\
\hline CHEMBL563776 & 570757 & 6.2 & 6.2628 & TRN & \\
\hline CHEMBL 559562 & 570757 & 6.4 & $6.7520 e$ & 2000000001 & TRN \\
\hline CHEMBL182959 & 570757 & 8.3 & 7.3812 & TST & \\
\hline CHEMBL562412 & 570757 & 8.8 & 7.9837 & TST & \\
\hline CHEMBL555026 & 570757 & 7.4 & 6.5485 & TST & \\
\hline CHEMBL109367 & 570757 & 7.3 & 6.94 & TST & \\
\hline CHEMBL558669 & 570757 & 6.9 & 7.0709 & TST & \\
\hline CHEMBL562212 & 570757 & 5.8 & 6.0271 & TST & \\
\hline CHEMBL554141 & 570757 & 6.8 & 6.5497 & TST & \\
\hline CHEMBL185515 & 570757 & 7.3 & 7.0092 & TST & \\
\hline
\end{tabular}




\begin{tabular}{|c|c|c|c|c|c|}
\hline \multicolumn{6}{|c|}{ Supplemental Table S2.txt } \\
\hline CHEMBL572345 & 570757 & 6.4 & 6.4918 & TST & \\
\hline CHEMBL551755 & 570757 & 4.3 & 4.9649 & TST & \\
\hline CHEMBL551754 & 570757 & 4.4 & 4.8323 & TST & \\
\hline CHEMBL549807 & 570757 & 7.0 & 6.9436 & TST & \\
\hline CHEMBL87820 & 221308 & 4.5086 & 4.5158 & TRN & \\
\hline CHEMBL86694 & 221308 & 5.7235 & 5.7242 & TRN & \\
\hline CHEMBL86386 & 221308 & 7.699 & 7.7155 & TRN & \\
\hline CHEMBL313912 & 221308 & 8.0458 & 8.052 & TRN & \\
\hline CHEMBL86392 & 221308 & 8.0969 & 8.1008 & TRN & \\
\hline CHEMBL423312 & 221308 & 8.0 & 7.9839 & TRN & \\
\hline CHEMBL88009 & 221308 & 8.699 & 8.6932 & TRN & \\
\hline CHEMBL314838 & 221308 & 6.8601 & 6.86799 & 9999999999 & TRN \\
\hline CHEMBL87102 & 221308 & 8.2218 & 8.2247 & TRN & \\
\hline CHEMBL87486 & 221308 & 7.1427 & 7.1368 & TRN & \\
\hline CHEMBL86939 & 221308 & 9.0 & 8.9655 & TRN & \\
\hline CHEMBL314053 & 221308 & 7.8239 & 7.7149 & TRN & \\
\hline CHEMBL67237 & 221308 & 8.3979 & 7.4892 & TST & \\
\hline CHEMBL313384 & 221308 & 8.699 & 8.6977 & TRN & \\
\hline CHEMBL87582 & 221308 & 4.5086 & 4.4986 & TRN & \\
\hline CHEMBL315156 & 221308 & 6.7447 & 6.7436 & TRN & \\
\hline CHEMBL 86738 & 221308 & 7.8861 & 7.8363 & TRN & \\
\hline CHEMBL86908 & 221308 & 7.1135 & 7.1056 & TRN & \\
\hline CHEMBL85295 & 221308 & 7.7696 & 7.7952 & TRN & \\
\hline CHEMBL316223 & 221308 & 5.7595 & 5.744 & TRN & \\
\hline CHEMBL89562 & 221308 & 8.0969 & 8.0624 & TRN & \\
\hline CHEMBL86690 & 221308 & 8.699 & 8.6796 & TRN & \\
\hline CHEMBL87917 & 221308 & 8.0458 & 8.0616 & TRN & \\
\hline CHEMBL312888 & 221308 & 4.5086 & 5.6284 & TST & \\
\hline CHEMBL408849 & 221308 & 7.5686 & 7.6257 & TRN & \\
\hline CHEMBL313115 & 221308 & 8.301 & 8.2784 & TRN & \\
\hline CHEMBL431986 & 221308 & 8.5229 & 8.5044 & TRN & \\
\hline CHEMBL315778 & 221308 & 8.1549 & 8.1543 & TRN & \\
\hline CHEMBL87604 & 221308 & 8.0 & 8.0057 & TRN & \\
\hline CHEMBL315643 & 221308 & 9.0 & 8.9996 & TRN & \\
\hline CHEMBL 315279 & 221308 & 7.3872 & 7.4695 & TST & \\
\hline CHEMBL90002 & 221308 & 8.699 & 8.7506 & TRN & \\
\hline CHEMBL87933 & 221308 & 4.5086 & 4.5125 & TRN & \\
\hline CHEMBL314265 & 221308 & 6.3947 & 6.3356 & TRN & \\
\hline CHEMBL89592 & 221308 & 6.6289 & 6.7439 & TRN & \\
\hline CHEMBL 86742 & 221308 & 7.8861 & 7.8833 & TRN & \\
\hline CHEMBL 84846 & 221308 & 8.2218 & 8.2607 & TRN & \\
\hline CHEMBL87875 & 221308 & 6.4855 & 6.4699 & TRN & \\
\hline CHEMBL87894 & 221308 & 4.5086 & 4.5227 & TRN & \\
\hline CHEMBL86841 & 221308 & 7.5086 & 7.5125 & TRN & \\
\hline CHEMBL411893 & 221308 & 7.2757 & 7.3335 & TRN & \\
\hline CHEMBL87918 & 221308 & 6.3947 & 6.3932 & TRN & \\
\hline CHEMBL89194 & 221308 & 8.2218 & 8.2364 & TRN & \\
\hline CHEMBL86683 & 221308 & 7.4559 & 7.45 & TRN & \\
\hline
\end{tabular}




\begin{tabular}{|c|c|c|c|c|c|}
\hline \multirow[b]{2}{*}{ CHEMBL441998 } & \multicolumn{5}{|c|}{ Supplemental Table S2.txt } \\
\hline & 221308 & 4.5086 & 6.3662 & TST & \\
\hline CHEMBL87004 & 221308 & 7.699 & 7.807 & TRN & \\
\hline CHEMBL86592 & 221308 & 7.4949 & 7.3612 & TRN & \\
\hline CHEMBL 87727 & 221308 & 8.2218 & 8.2497 & TRN & \\
\hline CHEMBL316246 & 221308 & 7.699 & 7.6859 & TRN & \\
\hline CHEMBL316023 & 221308 & 4.5086 & 5.8063 & TST & \\
\hline CHEMBL 87518 & 221308 & 4.5086 & 4.5081 & TRN & \\
\hline CHEMBL419852 & 221308 & 4.5086 & 6.1387 & TST & \\
\hline CHEMBL87818 & 221308 & 4.5086 & 5.6295 & TST & \\
\hline CHEMBL89072 & 221308 & 7.6778 & 7.9629 & TST & \\
\hline CHEMBL89247 & 221308 & 8.0969 & 8.8542 & TST & \\
\hline CHEMBL 84624 & 221308 & 7.699 & 8.2008 & TST & \\
\hline CHEMBL312933 & 221308 & 9.301 & 9.2496 & TST & \\
\hline CHEMBL432189 & 221308 & 9.0 & 8.8452 & TST & \\
\hline CHEMBL313948 & 221308 & 5.7986 & 7.3541 & TST & \\
\hline CHEMBL66971 & 221308 & 4.8219 & 5.6657 & TST & \\
\hline CHEMBL86338 & 221308 & 8.301 & 8.1667 & TST & \\
\hline CHEMBL 85406 & 221308 & 7.0757 & 7.8294 & TST & \\
\hline CHEMBL1966087 & 809191 & 4.2 & 4.3015 & TRN & \\
\hline CHEMBL1964692 & 809191 & 6.6 & 6.1487 & TRN & \\
\hline CHEMBL1996931 & 809191 & 6.2 & 4.2629 & TRN & \\
\hline CHEMBL1973483 & 809191 & 4.2 & 4.2347 & TRN & \\
\hline CHEMBL1970735 & 809191 & 4.2 & 4.2049 & TRN & \\
\hline CHEMBL1997340 & 809191 & 7.7 & 4.2323 & TRN & \\
\hline CHEMBL 2004365 & 809191 & 5.5 & 5.0034 & TST & \\
\hline CHEMBL1522508 & 809191 & 4.2 & 4.2023 & TRN & \\
\hline CHEMBL1989474 & 809191 & 4.2 & 4.2551 & TRN & \\
\hline CHEMBL1090360 & 809191 & 4.2 & 4.2394 & TRN & \\
\hline CHEMBL 210887 & 809191 & 6.1 & 5.7509 & TRN & \\
\hline CHEMBL458997 & 809191 & 4.2 & 4.8405 & TRN & \\
\hline CHEMBL227271 & 809191 & 6.6 & 6.7607 & TRN & \\
\hline CHEMBL1971021 & 809191 & 4.2 & 4.268 & TRN & \\
\hline CHEMBL583144 & 809191 & 4.2 & 4.6396 & TRN & \\
\hline CHEMBL1974310 & 809191 & 6.1 & 5.8636 & TST & \\
\hline CHEMBL1982660 & 809191 & 4.2 & 4.434 & TRN & \\
\hline CHEMBL1994693 & 809191 & 5.7 & 5.1839 & TRN & \\
\hline CHEMBL1982957 & 809191 & 5.4 & 5.05399 & 9999999999 & TRN \\
\hline CHEMBL1725279 & 809191 & 4.2 & 5.3314 & TST & \\
\hline CHEMBL1975138 & 809191 & 4.2 & 5.2924 & TST & \\
\hline CHEMBL424872 & 809191 & 4.2 & 4.19600 & 0000000001 & TRN \\
\hline CHEMBL 2006836 & 809191 & 4.2 & 4.4182 & TST & \\
\hline CHEMBL412142 & 809191 & 5.5 & 4.4833 & TST & \\
\hline CHEMBL1980704 & 809191 & 4.2 & 4.4756 & TST & \\
\hline CHEMBL 2003271 & 809191 & 7.7 & 4.5032 & TRN & \\
\hline CHEMBL1966808 & 809191 & 4.2 & 4.7062 & TST & \\
\hline CHEMBL 2004447 & 809191 & 4.2 & 4.2636 & TST & \\
\hline CHEMBL1983111 & 809191 & 5.4 & 5.77 & TST & \\
\hline CHEMBL1973860 & 809191 & 4.2 & 4.2383 & TRN & \\
\hline
\end{tabular}




\begin{tabular}{|c|c|c|c|c|c|}
\hline \multicolumn{6}{|c|}{ Supplemental Table S2.txt } \\
\hline CHEMBL260135 & 809191 & 4.2 & 4.3416 & TRN & \\
\hline CHEMBL220241 & 809191 & 4.2 & 4.6262 & TRN & \\
\hline CHEMBL 2004544 & 809191 & 4.2 & 5.1574 & TST & \\
\hline CHEMBL1982610 & 809191 & 4.2 & 4.3884 & TRN & \\
\hline CHEMBL1999496 & 809191 & 4.2 & 4.379 & TRN & \\
\hline CHEMBL1988300 & 809191 & 5.8 & 5.4094 & TRN & \\
\hline CHEMBL1991078 & 809191 & 7.6 & 7.9716 & TRN & \\
\hline CHEMBL1987359 & 809191 & 4.2 & 4.2671 & TST & \\
\hline CHEMBL1989265 & 809191 & 4.2 & 4.3737 & TST & \\
\hline CHEMBL1965660 & 809191 & 7.6 & 7.2957 & TRN & \\
\hline CHEMBL1969502 & 809191 & 4.2 & 4.4128 & TRN & \\
\hline CHEMBL1682553 & 809191 & 4.2 & 5.6344 & TRN & \\
\hline CHEMBL1971430 & 809191 & 4.2 & 4.2645 & TRN & \\
\hline CHEMBL1997764 & 809191 & 6.2 & 4.3785 & TRN & \\
\hline CHEMBL1983963 & 809191 & 6.1 & 5.5186 & TRN & \\
\hline CHEMBL1985092 & 809191 & 5.6 & 5.2282 & TRN & \\
\hline CHEMBL 2004692 & 809191 & 4.2 & 4.2305 & TST & \\
\hline CHEMBL1981410 & 809191 & 4.2 & 4.5126 & TRN & \\
\hline CHEMBL1996234 & 809191 & 4.2 & 4.422 & TRN & \\
\hline CHEMBL1991434 & 809191 & 4.2 & 4.4294 & TRN & \\
\hline CHEMBL1967544 & 809191 & 4.2 & 4.5041 & TRN & \\
\hline CHEMBL340384 & 809191 & 6.2 & 5.7903 & TST & \\
\hline CHEMBL1996587 & 809191 & 4.2 & 4.1772 & TRN & \\
\hline CHEMBL1964804 & 809191 & 4.2 & 4.4643 & TRN & \\
\hline CHEMBL443962 & 809191 & 5.9 & 5.3845 & TST & \\
\hline CHEMBL1975815 & 809191 & 5.4 & 4.5902 & TRN & \\
\hline CHEMBL 2000354 & 809191 & 5.6 & 6.3571 & TRN & \\
\hline CHEMBL1965507 & 809191 & 4.2 & 4.9231 & TRN & \\
\hline CHEMBL1967564 & 809191 & 4.2 & 4.1774 & TRN & \\
\hline CHEMBL592030 & 809191 & 5.6 & 5.7607 & TST & \\
\hline CHEMBL 2000071 & 809191 & 4.2 & 4.4029 & TRN & \\
\hline CHEMBL1979176 & 809191 & 4.2 & 4.3669 & TRN & \\
\hline CHEMBL 2000408 & 809191 & 5.6 & 5.113 & TRN & \\
\hline CHEMBL1978014 & 809191 & 6.5 & 6.04299 & 7999999999 & TRN \\
\hline CHEMBL1994538 & 809191 & 4.2 & 4.2417 & TRN & \\
\hline CHEMBL1983195 & 809191 & 5.5 & 5.0558 & TST & \\
\hline CHEMBL1975490 & 809191 & 4.2 & 5.3243 & TRN & \\
\hline CHEMBL1964444 & 809191 & 4.2 & 4.4164 & TRN & \\
\hline CHEMBL1986139 & 809191 & 7.7 & 4.2782 & TRN & \\
\hline CHEMBL1980540 & 809191 & 4.2 & 4.2097 & TRN & \\
\hline CHEMBL1979883 & 809191 & 5.6 & 5.3026 & TRN & \\
\hline CHEMBL549730 & 809191 & 6.4 & 5.6466 & TRN & \\
\hline CHEMBL1970189 & 809191 & 4.2 & 4.1799 & TST & \\
\hline CHEMBL371206 & 809191 & 8.4 & 5.5277 & TRN & \\
\hline CHEMBL1996791 & 809191 & 4.2 & 5.1801 & TRN & \\
\hline CHEMBL1974664 & 809191 & 4.2 & 4.3465 & TRN & \\
\hline CHEMBL1970104 & 809191 & 5.8 & 5.8375 & TRN & \\
\hline CHEMBL1974288 & 809191 & 4.2 & 4.2143 & TRN & \\
\hline
\end{tabular}




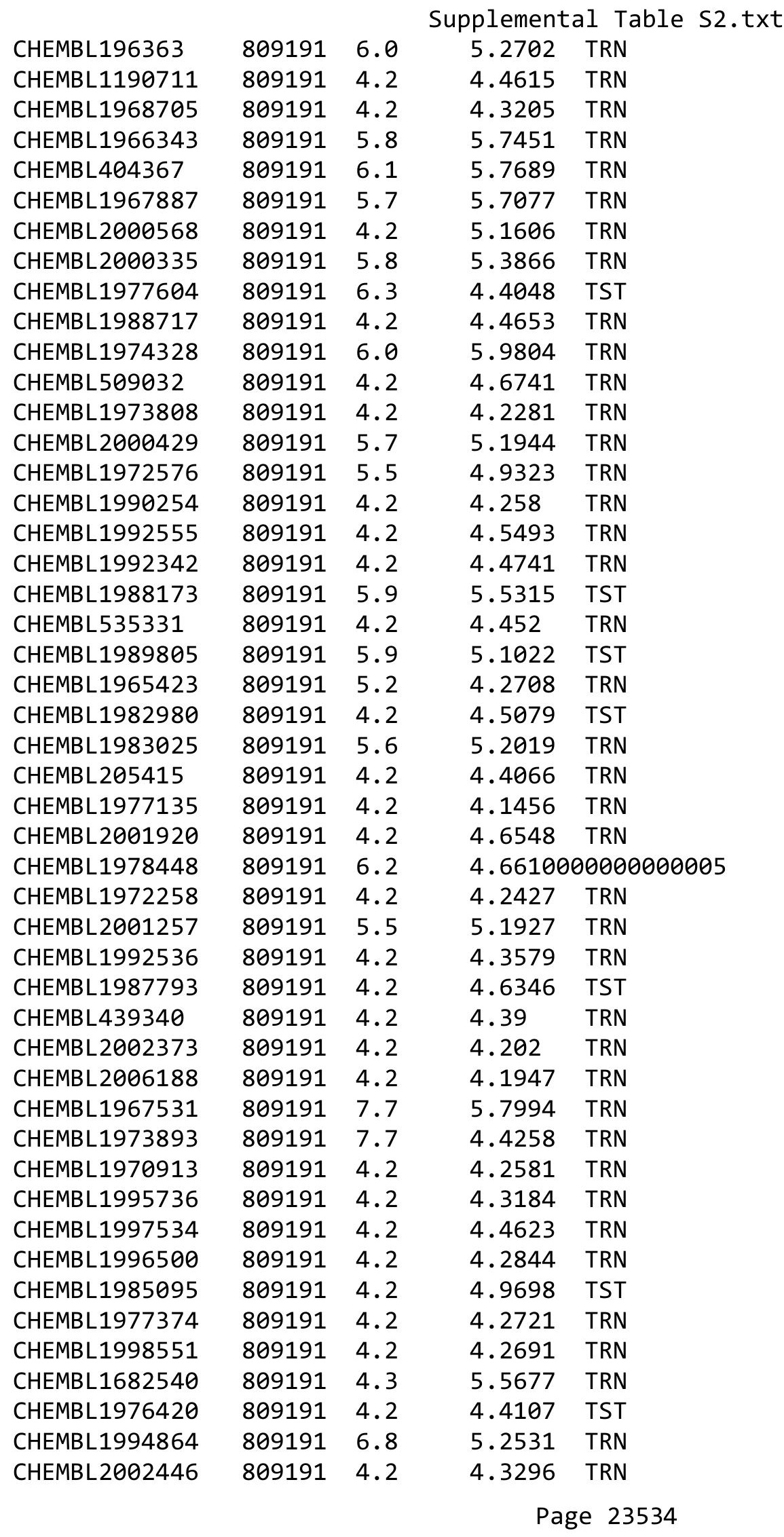




\begin{tabular}{|c|c|c|c|c|c|}
\hline & & & Supplementa & Table S2 & \\
\hline CHEMBL497151 & 809191 & 6.0 & 6.2003 & TST & \\
\hline CHEMBL 246970 & 809191 & 5.6 & 4.6591 & TST & \\
\hline CHEMBL340921 & 809191 & 5.5 & 5.3832 & TST & \\
\hline CHEMBL1999718 & 809191 & 4.2 & 4.3236 & TRN & \\
\hline CHEMBL1276446 & 809191 & 5.6 & 5.7401 & TST & \\
\hline CHEMBL1977346 & 809191 & 4.2 & 4.4008 & TRN & \\
\hline CHEMBL1971649 & 809191 & 5.6 & 5.2067 & TRN & \\
\hline CHEMBL1998435 & 809191 & 4.2 & 4.2023 & TRN & \\
\hline CHEMBL 2006439 & 809191 & 6.9 & 7.0259 & TRN & \\
\hline CHEMBL 2006156 & 809191 & 5.3 & 4.664 & TST & \\
\hline CHEMBL1969190 & 809191 & 4.2 & 4.3734 & TRN & \\
\hline CHEMBL1973937 & 809191 & 5.6 & 5.2087 & TRN & \\
\hline CHEMBL1991674 & 809191 & 5.5 & 5.8266 & TRN & \\
\hline CHEMBL1982711 & 809191 & 4.2 & 5.5027 & TRN & \\
\hline CHEMBL1998829 & 809191 & 4.2 & 4.2804 & TRN & \\
\hline CHEMBL50894 & 809191 & 5.7 & 5.105 & TST & \\
\hline CHEMBL1988838 & 809191 & 5.5 & 5.8282 & TRN & \\
\hline CHEMBL1981725 & 809191 & 4.2 & 4.7543 & TRN & \\
\hline CHEMBL1982866 & 809191 & 4.2 & 4.2786 & TRN & \\
\hline CHEMBL1968926 & 809191 & 4.2 & 4.3747 & TRN & \\
\hline CHEMBL462120 & 809191 & 4.2 & 4.2658 & TRN & \\
\hline CHEMBL1965570 & 809191 & 5.4 & 5.3123 & TRN & \\
\hline CHEMBL 2007592 & 809191 & 4.2 & 4.4646 & TST & \\
\hline CHEMBL210963 & 809191 & 4.2 & 4.1636 & TRN & \\
\hline CHEMBL1614705 & 809191 & 4.2 & 4.3436 & TRN & \\
\hline CHEMBL1984633 & 809191 & 5.3 & 4.208 & TRN & \\
\hline CHEMBL 2007372 & 809191 & 4.2 & 4.5325 & TRN & \\
\hline CHEMBL1965845 & 809191 & 4.2 & 4.6083 & TRN & \\
\hline CHEMBL 2006715 & 809191 & 4.2 & 4.3719 & TRN & \\
\hline CHEMBL1986597 & 809191 & 4.2 & 4.354 & TRN & \\
\hline CHEMBL1990482 & 809191 & 4.2 & 4.1806 & TRN & \\
\hline CHEMBL1990904 & 809191 & 4.3 & 5.4329 & TRN & \\
\hline CHEMBL1975121 & 809191 & 4.2 & 4.1088 & TRN & \\
\hline CHEMBL2005475 & 809191 & 5.8 & 5.7842 & TRN & \\
\hline CHEMBL402846 & 809191 & 6.0 & 5.6853 & TRN & \\
\hline CHEMBL183844 & 809191 & 4.2 & 4.2428 & TRN & \\
\hline CHEMBL1997349 & 809191 & 5.3 & 4.9661 & TST & \\
\hline CHEMBL220057 & 809191 & 4.2 & 5.1564 & TRN & \\
\hline CHEMBL1682545 & 809191 & 4.2 & 4.3483 & TRN & \\
\hline CHEMBL 383541 & 809191 & 5.5 & 5.0413 & TRN & \\
\hline CHEMBL 2001224 & 809191 & 4.2 & 4.338999 & 99999999995 & TRN \\
\hline CHEMBL10 & 809191 & 4.2 & 4.2023 & TRN & \\
\hline CHEMBL1976732 & 809191 & 4.2 & 4.2345 & TRN & \\
\hline CHEMBL1964937 & 809191 & 4.2 & 4.5599 & TRN & \\
\hline CHEMBL1969506 & 809191 & 4.3 & 4.5098 & TRN & \\
\hline CHEMBL1980163 & 809191 & 4.2 & 4.2427 & TRN & \\
\hline CHEMBL 2005899 & 809191 & 6.1 & 5.5284 & TRN & \\
\hline CHEMBL1682552 & 809191 & 5.7 & 5.8504 & TRN & \\
\hline
\end{tabular}




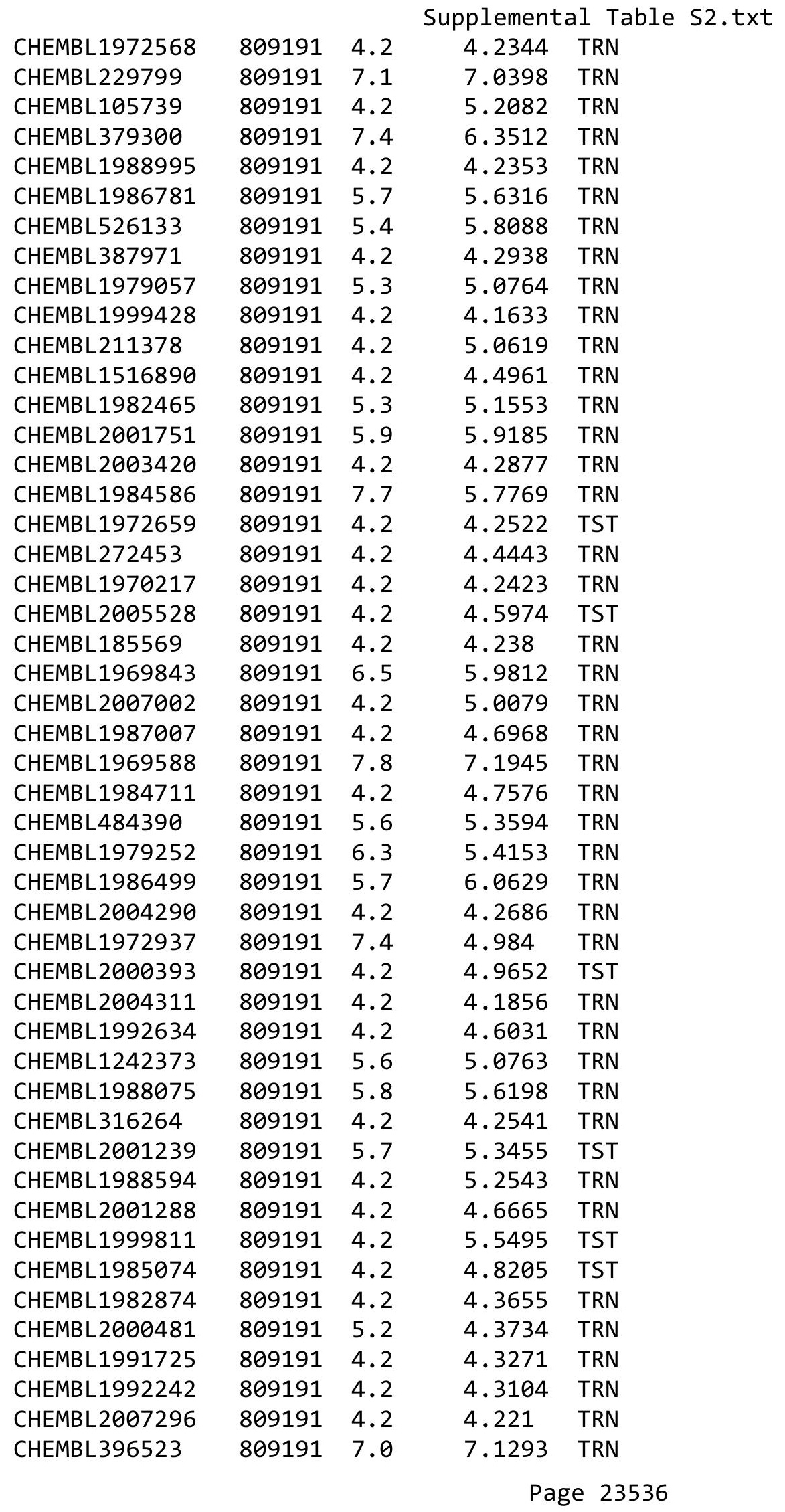




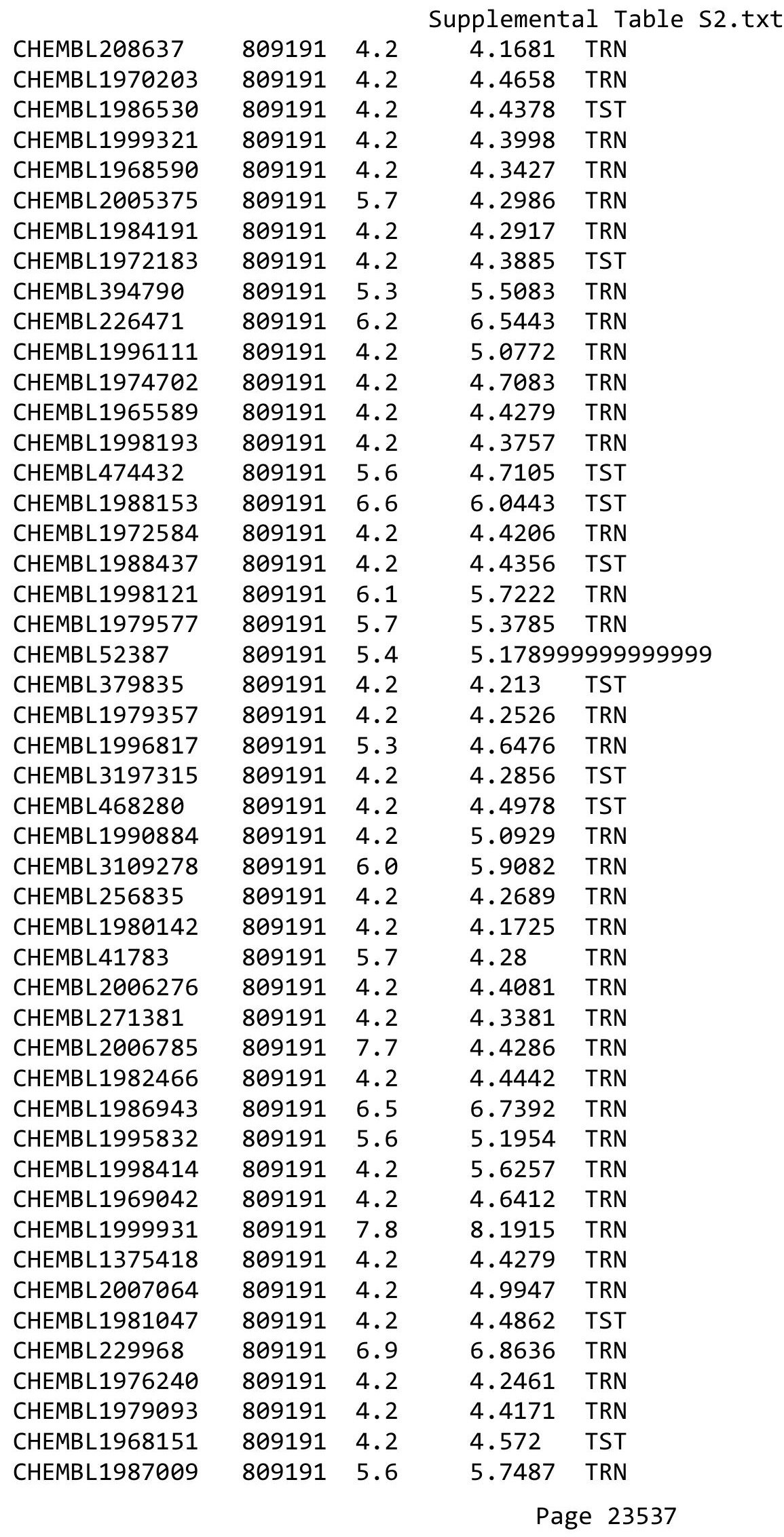




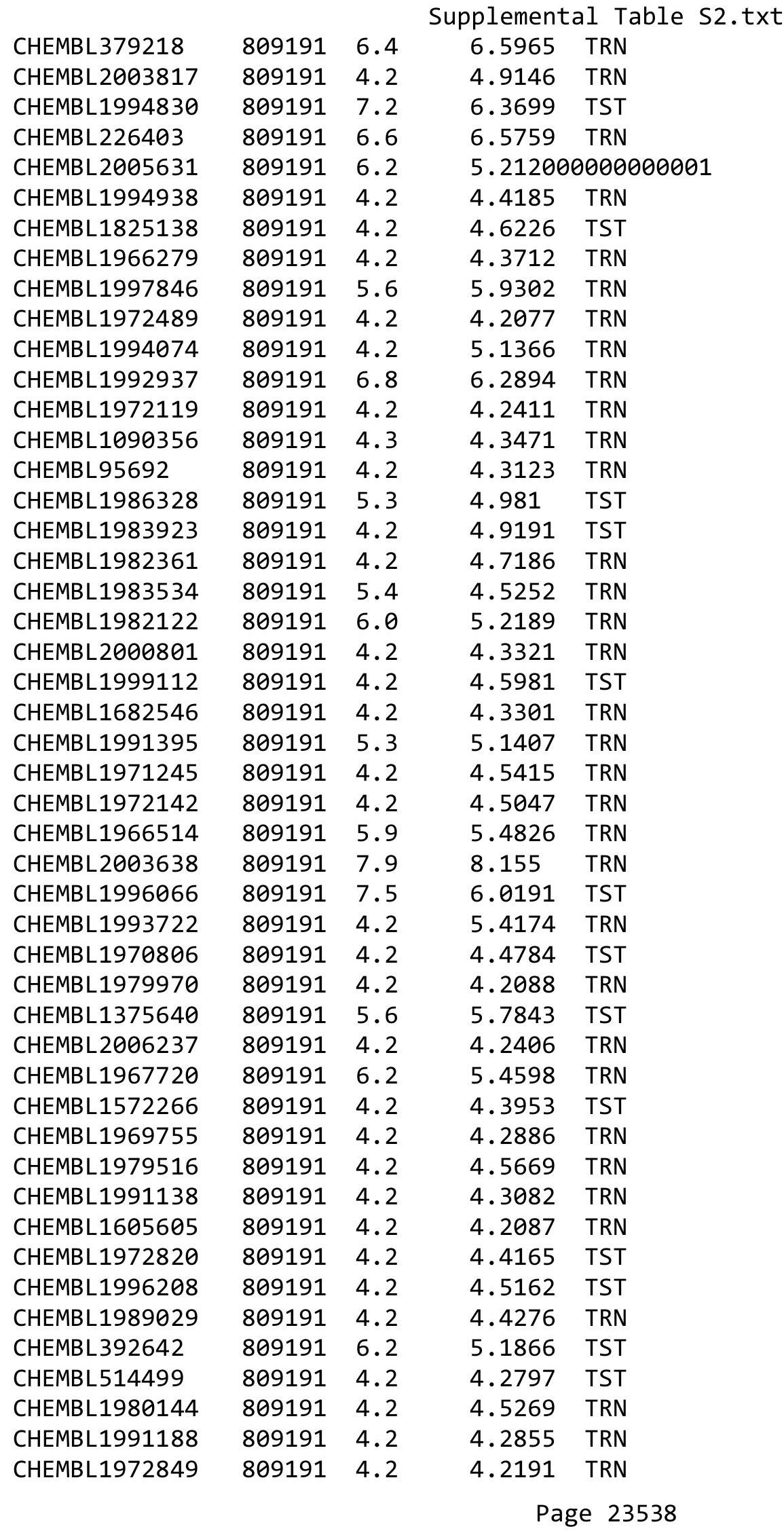

TRN 


\begin{tabular}{|c|c|c|c|c|c|}
\hline \multicolumn{6}{|c|}{ Supplemental Table S2.txt } \\
\hline CHEMBL231209 & 809191 & 5.4 & 5.4791 & TRN & \\
\hline CHEMBL1976220 & 809191 & 5.3 & 5.5018 & TRN & \\
\hline CHEMBL1997617 & 809191 & 4.2 & 4.3076 & TRN & \\
\hline CHEMBL259922 & 809191 & 4.2 & 4.3915 & TST & \\
\hline CHEMBL1982383 & 809191 & 6.1 & 5.346 & TRN & \\
\hline CHEMBL1969301 & 809191 & 5.9 & 5.5416 & TRN & \\
\hline CHEMBL17370 & 809191 & 4.2 & 4.7262 & TRN & \\
\hline CHEMBL1987910 & 809191 & 4.2 & 5.3026 & TRN & \\
\hline CHEMBL1983932 & 809191 & 4.2 & 4.5327 & TRN & \\
\hline CHEMBL1997822 & 809191 & 4.2 & 5.1836 & TRN & \\
\hline CHEMBL1991285 & 809191 & 4.2 & 4.419 & TRN & \\
\hline CHEMBL1984038 & 809191 & 4.2 & 4.3392 & TRN & \\
\hline CHEMBL243088 & 809191 & 6.8 & 6.8802 & TRN & \\
\hline CHEMBL1993661 & 809191 & 4.2 & 4.6326 & TRN & \\
\hline CHEMBL1974416 & 809191 & 4.2 & 4.3692 & TRN & \\
\hline CHEMBL 2004615 & 809191 & 4.2 & 4.4863 & TST & \\
\hline CHEMBL1984039 & 809191 & 4.2 & 4.484 & TST & \\
\hline CHEMBL1997872 & 809191 & 4.2 & 4.8686 & TRN & \\
\hline CHEMBL1964290 & 809191 & 7.1 & 7.0486 & TRN & \\
\hline CHEMBL 2003768 & 809191 & 4.2 & 4.5375 & TRN & \\
\hline CHEMBL213505 & 809191 & 5.7 & 5.3969 & TRN & \\
\hline CHEMBL1987034 & 809191 & 6.2 & 6.4315 & TRN & \\
\hline CHEMBL1993941 & 809191 & 4.2 & 4.5796 & TRN & \\
\hline CHEMBL377383 & 809191 & 4.2 & 4.2509 & TRN & \\
\hline CHEMBL 2005886 & 809191 & 4.2 & 4.6691 & TRN & \\
\hline CHEMBL481491 & 809191 & 4.2 & 4.2468 & TST & \\
\hline CHEMBL1973142 & 809191 & 4.2 & 4.4837 & TRN & \\
\hline CHEMBL1973145 & 809191 & 4.2 & 4.6009 & TRN & \\
\hline CHEMBL1982924 & 809191 & 6.0 & 4.849 & TRN & \\
\hline CHEMBL2005936 & 809191 & 5.9 & 5.8661 & TRN & \\
\hline CHEMBL1807515 & 809191 & 7.0 & 6.9012 & TRN & \\
\hline CHEMBL1971141 & 809191 & 4.2 & 4.3169 & TRN & \\
\hline CHEMBL1995813 & 809191 & 6.5 & 6.6864 & TRN & \\
\hline CHEMBL244378 & 809191 & 6.5 & 7.08899 & 99999999995 & TRN \\
\hline CHEMBL 2001957 & 809191 & 5.4 & 5.1864 & TRN & \\
\hline CHEMBL1969372 & 809191 & 4.2 & 5.0681 & TRN & \\
\hline CHEMBL 2006263 & 809191 & 4.3 & 4.3606 & TRN & \\
\hline CHEMBL1993584 & 809191 & 4.2 & 4.2912 & TRN & \\
\hline CHEMBL1986263 & 809191 & 6.5 & 6.428 & TRN & \\
\hline CHEMBL 2000114 & 809191 & 4.2 & 4.2745 & TRN & \\
\hline CHEMBL210618 & 809191 & 4.2 & 4.2006 & TRN & \\
\hline CHEMBL1975647 & 809191 & 4.2 & 4.3558 & TRN & \\
\hline CHEMBL1968380 & 809191 & 5.6 & 4.4749 & TRN & \\
\hline CHEMBL1964644 & 809191 & 4.2 & 4.3109 & TRN & \\
\hline CHEMBL1981782 & 809191 & 6.3 & 4.8396 & TRN & \\
\hline CHEMBL1977681 & 809191 & 5.9 & 5.95799 & 9999999999 & TRN \\
\hline CHEMBL1970142 & 809191 & 4.2 & 4.2782 & TRN & \\
\hline CHEMBL1990912 & 809191 & 4.2 & 4.3256 & TRN & \\
\hline
\end{tabular}




\begin{tabular}{|c|c|c|c|c|c|}
\hline \multicolumn{6}{|c|}{ Supplemental Table S2.txt } \\
\hline CHEMBL1988163 & 809191 & 5.9 & 6.1846 & TRN & \\
\hline CHEMBL 2006493 & 809191 & 4.2 & 4.3707 & TST & \\
\hline CHEMBL1996923 & 809191 & 4.2 & 4.2995 & TST & \\
\hline CHEMBL1983449 & 809191 & 4.2 & 4.5977 & TRN & \\
\hline CHEMBL1992323 & 809191 & 4.2 & 4.2565 & TRN & \\
\hline CHEMBL1969735 & 809191 & 4.2 & 4.9828 & TRN & \\
\hline CHEMBL 2002649 & 809191 & 4.2 & 4.6301 & TRN & \\
\hline CHEMBL1995172 & 809191 & 4.2 & 4.1832 & TST & \\
\hline CHEMBL1994321 & 809191 & 4.2 & 5.0087 & TRN & \\
\hline CHEMBL1984788 & 809191 & 4.2 & 4.5232 & TRN & \\
\hline CHEMBL 2000508 & 809191 & 5.7 & 5.12700 & 0000000001 & TRN \\
\hline CHEMBL1971694 & 809191 & 4.2 & 4.4709 & TST & \\
\hline CHEMBL 2001547 & 809191 & 4.2 & 4.3203 & TRN & \\
\hline CHEMBL 210928 & 809191 & 4.2 & 4.2246 & TRN & \\
\hline CHEMBL1986603 & 809191 & 4.2 & 4.3712 & TST & \\
\hline CHEMBL1977148 & 809191 & 4.2 & 4.2185 & TRN & \\
\hline CHEMBL1992306 & 809191 & 4.2 & 4.4824 & TRN & \\
\hline CHEMBL 2002165 & 809191 & 5.9 & 5.1078 & TRN & \\
\hline CHEMBL 2001668 & 809191 & 4.2 & 4.3612 & TRN & \\
\hline CHEMBL1979318 & 809191 & 4.2 & 4.1846 & TST & \\
\hline CHEMBL206382 & 809191 & 4.2 & 4.2768 & TRN & \\
\hline CHEMBL1998585 & 809191 & 5.5 & 5.6529 & TRN & \\
\hline CHEMBL127898 & 809191 & 4.2 & 4.4919 & TST & \\
\hline CHEMBL519697 & 809191 & 6.1 & 5.1621 & TRN & \\
\hline CHEMBL 2004934 & 809191 & 4.2 & 4.2339 & TRN & \\
\hline CHEMBL 2001485 & 809191 & 4.2 & 4.2806 & TRN & \\
\hline CHEMBL1966425 & 809191 & 4.2 & 4.5623 & TRN & \\
\hline CHEMBL1984363 & 809191 & 4.2 & 5.0032 & TRN & \\
\hline CHEMBL1978099 & 809191 & 4.2 & 5.5215 & TRN & \\
\hline CHEMBL1988608 & 809191 & 4.2 & 4.4014 & TRN & \\
\hline CHEMBL1984367 & 809191 & 4.2 & 5.5906 & TRN & \\
\hline CHEMBL178737 & 809191 & 4.2 & 4.3828 & TST & \\
\hline CHEMBL226898 & 809191 & 7.2 & 6.6096 & TRN & \\
\hline CHEMBL1982563 & 809191 & 5.5 & 5.1257 & TRN & \\
\hline CHEMBL539474 & 809191 & 5.4 & 4.6396 & TST & \\
\hline CHEMBL575824 & 809191 & 4.2 & 4.5816 & TRN & \\
\hline CHEMBL1988387 & 809191 & 4.2 & 4.4852 & TRN & \\
\hline CHEMBL1974803 & 809191 & 4.2 & 4.5372 & TRN & \\
\hline CHEMBL1970074 & 809191 & 4.2 & 5.1426 & TRN & \\
\hline CHEMBL1986970 & 809191 & 4.2 & 4.9999 & TRN & \\
\hline CHEMBL 2005112 & 809191 & 4.2 & 4.6364 & TST & \\
\hline CHEMBL1958401 & 809191 & 5.4 & 5.4191 & TRN & \\
\hline CHEMBL1984044 & 809191 & 4.2 & 4.3706 & TRN & \\
\hline CHEMBL 2003456 & 809191 & 4.2 & 4.8482 & TRN & \\
\hline CHEMBL1966816 & 809191 & 4.2 & 4.38399 & 99999999995 & TRN \\
\hline CHEMBL560813 & 809191 & 4.2 & 4.8612 & TRN & \\
\hline CHEMBL1968791 & 809191 & 4.2 & 4.3277 & TRN & \\
\hline CHEMBL 2002682 & 809191 & 4.2 & 4.6548 & TST & \\
\hline
\end{tabular}




\begin{tabular}{|c|c|c|c|c|}
\hline & & & Supplement & \\
\hline CHEMBL1971186 & 809191 & 6.1 & 5.5714 & TRN \\
\hline CHEMBL 2003482 & 809191 & 4.2 & 4.441 & TRN \\
\hline CHEMBL1973211 & 809191 & 6.0 & 5.5277 & TRN \\
\hline CHEMBL1984700 & 809191 & 4.2 & 5.0315 & TRN \\
\hline CHEMBL1972125 & 809191 & 4.3 & 4.3376 & TRN \\
\hline CHEMBL1461728 & 809191 & 4.2 & 4.3211 & TRN \\
\hline CHEMBL1976134 & 809191 & 4.2 & 5.2801 & TRN \\
\hline CHEMBL1965131 & 809191 & 4.2 & 4.5 & TRN \\
\hline CHEMBL1972158 & 809191 & 6.0 & 6.1955 & TRN \\
\hline CHEMBL 2006580 & 809191 & 4.2 & 4.3254 & TRN \\
\hline CHEMBL2006481 & 809191 & 4.2 & 4.2779 & TRN \\
\hline CHEMBL1979855 & 809191 & 4.2 & 4.3177 & TRN \\
\hline CHEMBL1970340 & 809191 & 4.2 & 4.1838 & TRN \\
\hline CHEMBL2005186 & 809191 & 4.2 & 4.5057 & TRN \\
\hline CHEMBL1995927 & 809191 & 4.2 & 4.2952 & TST \\
\hline CHEMBL1975534 & 809191 & 4.2 & 5.0476 & TRN \\
\hline CHEMBL1993424 & 809191 & 5.4 & 5.4791 & TRN \\
\hline CHEMBL1966703 & 809191 & 4.2 & 4.3607 & TST \\
\hline CHEMBL1997023 & 809191 & 4.2 & 4.5231 & TST \\
\hline CHEMBL1964687 & 809191 & 5.5 & 5.1313 & TRN \\
\hline CHEMBL1971943 & 809191 & 4.2 & 5.306 & TRN \\
\hline CHEMBL1974254 & 809191 & 4.2 & 4.3801 & TRN \\
\hline CHEMBL1988537 & 809191 & 4.2 & 4.3606 & TST \\
\hline CHEMBL1969049 & 809191 & 4.2 & 4.1716 & TRN \\
\hline CHEMBL 2005828 & 809191 & 7.7 & 5.8481 & TRN \\
\hline CHEMBL 2002240 & 809191 & 4.2 & 4.2289 & TRN \\
\hline CHEMBL1991143 & 809191 & 4.2 & 4.2623 & TST \\
\hline CHEMBL1998611 & 809191 & 4.3 & 4.5049 & TRN \\
\hline CHEMBL1975900 & 809191 & 6.8 & 5.6034 & TRN \\
\hline CHEMBL 255822 & 809191 & 7.7 & 6.2151 & TRN \\
\hline CHEMBL1972221 & 809191 & 5.6 & 4.4332 & TRN \\
\hline CHEMBL 2006778 & 809191 & 4.2 & 4.8868 & TRN \\
\hline CHEMBL378627 & 809191 & 4.2 & 4.1936 & TRN \\
\hline CHEMBL1996979 & 809191 & 5.3 & 4.9237 & TRN \\
\hline CHEMBL1997025 & 809191 & 4.2 & 4.3824 & TRN \\
\hline CHEMBL1968406 & 809191 & 5.6 & 5.1294 & TRN \\
\hline CHEMBL1984274 & 809191 & 4.2 & 4.4001 & TST \\
\hline CHEMBL1998545 & 809191 & 4.2 & 4.2353 & TRN \\
\hline CHEMBL1986869 & 809191 & 4.2 & 4.2642 & TRN \\
\hline CHEMBL 2006010 & 809191 & 4.2 & 4.1995 & TRN \\
\hline CHEMBL1682558 & 809191 & 4.2 & 4.3511 & TRN \\
\hline CHEMBL1990496 & 809191 & 4.2 & 4.1926 & TRN \\
\hline CHEMBL2002479 & 809191 & 6.3 & 5.904 & TRN \\
\hline CHEMBL1967094 & 809191 & 4.3 & 5.5127 & TRN \\
\hline CHEMBL1966035 & 809191 & 4.2 & 5.2774 & TRN \\
\hline CHEMBL2003341 & 809191 & 4.2 & 4.2044 & TRN \\
\hline CHEMBL1982992 & 809191 & 4.2 & 4.3948 & TRN \\
\hline CHEMBL1999590 & 809191 & 4.2 & 4.3321 & TST \\
\hline
\end{tabular}




\begin{tabular}{|c|c|c|c|c|}
\hline & & & & aI $\mid a b \perp$ \\
\hline CHEMBL1981079 & 809191 & 7.3 & 7.1346 & TRN \\
\hline CHEMBL1972276 & 809191 & 4.2 & 4.2769 & TRN \\
\hline CHEMBL1980489 & 809191 & 6.5 & 5.5489 & TRN \\
\hline CHEMBL1967116 & 809191 & 5.8 & 5.1363 & TRN \\
\hline CHEMBL2000832 & 809191 & 5.7 & 5.1924 & TRN \\
\hline CHEMBL513846 & 809191 & 4.2 & 4.5635 & TRN \\
\hline CHEMBL1970709 & 809191 & 4.2 & 4.3451 & TRN \\
\hline CHEMBL1998112 & 809191 & 4.2 & 4.3034 & TRN \\
\hline CHEMBL1969126 & 809191 & 4.2 & 4.8565 & TRN \\
\hline CHEMBL1980896 & 809191 & 5.4 & 5.1681 & TRN \\
\hline CHEMBL1991429 & 809191 & 4.2 & 4.29 & TRN \\
\hline CHEMBL1964777 & 809191 & 6.0 & 5.9768 & TST \\
\hline CHEMBL1999714 & 809191 & 7.4 & 4.2386 & TRN \\
\hline CHEMBL1971149 & 809191 & 4.2 & 4.3894 & TRN \\
\hline CHEMBL1987533 & 809191 & 4.2 & 4.2879 & TRN \\
\hline CHEMBL1994040 & 809191 & 4.2 & 4.9397 & TRN \\
\hline CHEMBL579246 & 809191 & 4.2 & 4.4465 & TRN \\
\hline CHEMBL398951 & 809191 & 4.2 & 4.1507 & TRN \\
\hline CHEMBL1982506 & 809191 & 4.2 & 4.2618 & TST \\
\hline CHEMBL2004716 & 809191 & 5.9 & 5.4872 & TRN \\
\hline CHEMBL1968127 & 809191 & 5.6 & 5.0814 & TST \\
\hline CHEMBL1975233 & 809191 & 4.2 & 4.7766 & TST \\
\hline CHEMBL1985406 & 809191 & 4.2 & 4.5279 & TST \\
\hline CHEMBL 207400 & 809191 & 4.2 & 4.2191 & TST \\
\hline CHEMBL2000894 & 809191 & 4.2 & 4.6124 & TST \\
\hline CHEMBL1982135 & 809191 & 5.6 & 5.1211 & TST \\
\hline CHEMBL1976090 & 809191 & 5.8 & 5.6786 & TST \\
\hline CHEMBL1993243 & 809191 & 4.2 & 4.3685 & TST \\
\hline CHEMBL1992922 & 809191 & 4.2 & 4.4119 & TST \\
\hline CHEMBL 2004771 & 809191 & 4.2 & 4.5064 & TST \\
\hline CHEMBL1997597 & 809191 & 4.2 & 4.458 & TST \\
\hline CHEMBL1969537 & 809191 & 4.2 & 4.8624 & TST \\
\hline CHEMBL1976093 & 809191 & 4.2 & 4.4988 & TST \\
\hline CHEMBL 210032 & 809191 & 4.2 & 4.19 & TST \\
\hline CHEMBL1975256 & 809191 & 4.2 & 4.2397 & TST \\
\hline CHEMBL508928 & 809191 & 4.2 & 4.53100 & 0000000001 \\
\hline CHEMBL1991356 & 809191 & 4.2 & 4.284 & TST \\
\hline CHEMBL1983309 & 809191 & 4.2 & 4.5143 & TST \\
\hline CHEMBL 2004892 & 809191 & 4.2 & 4.548 & TST \\
\hline CHEMBL1999126 & 809191 & 4.2 & 4.5674 & TST \\
\hline CHEMBL1997503 & 809191 & 4.2 & 4.3941 & TST \\
\hline CHEMBL116070 & 809191 & 6.4 & 6.0542 & TST \\
\hline CHEMBL1990821 & 809191 & 4.2 & 4.4633 & TST \\
\hline CHEMBL1970314 & 809191 & 4.2 & 4.4164 & TST \\
\hline CHEMBL 2004871 & 809191 & 4.2 & 4.248 & TST \\
\hline CHEMBL 2004872 & 809191 & 4.2 & 4.1916 & TST \\
\hline CHEMBL1727312 & 809191 & 4.2 & 4.2126 & TST \\
\hline CHEMBL1969879 & 809191 & 4.2 & 4.255 & TST \\
\hline
\end{tabular}




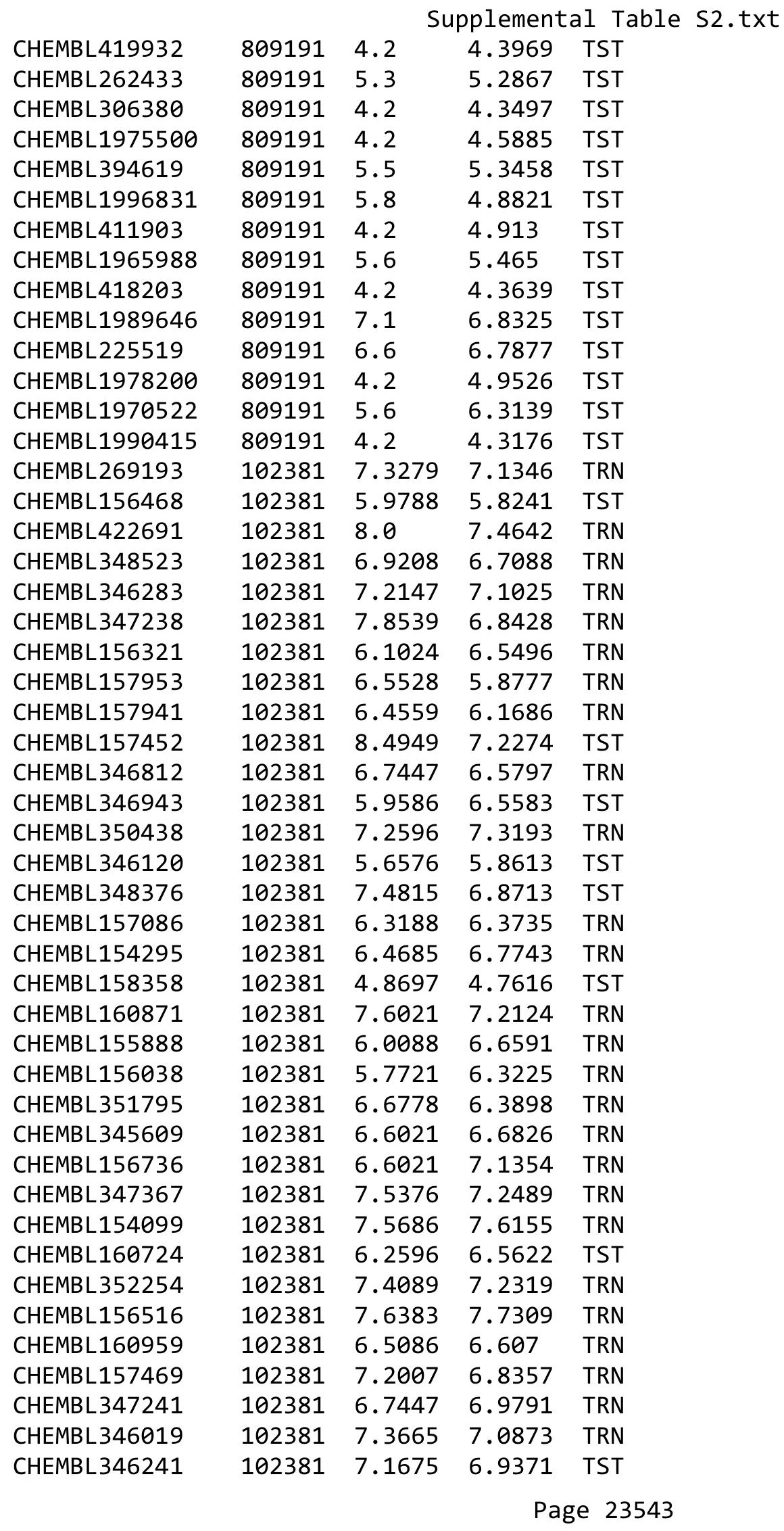


Supplemental Table S2.txt

\begin{tabular}{|c|c|c|c|c|}
\hline CHEMBL156572 & 102381 & 7.0132 & 6.8466 & TRN \\
\hline CHEMBL346593 & 102381 & 5.6778 & 5.8842 & TRN \\
\hline CHEMBL351763 & 102381 & 6.4318 & 6.5392 & TRN \\
\hline CHEMBL347683 & 102381 & 6.1675 & 6.0184 & TRN \\
\hline CHEMBL156873 & 102381 & 7.4089 & 7.3881 & TRN \\
\hline CHEMBL156739 & 102381 & 6.0706 & 6.1833 & TRN \\
\hline CHEMBL154831 & 102381 & 6.0 & 5.8155 & TRN \\
\hline CHEMBL347565 & 102381 & 8.0458 & 7.3392 & TST \\
\hline CHEMBL347802 & 102381 & 5.699 & \multicolumn{2}{|c|}{6.332999999999999} \\
\hline CHEMBL155171 & 102381 & 6.1135 & 5.9526 & TRN \\
\hline CHEMBL346944 & 102381 & 7.1739 & 6.7422 & TRN \\
\hline CHEMBL158118 & 102381 & 6.4318 & 6.468 & TST \\
\hline CHEMBL351797 & 102381 & 7.7696 & 7.3163 & TRN \\
\hline CHEMBL157484 & 102381 & 7.0 & 7.0085 & TRN \\
\hline CHEMBL154182 & 102381 & 7.699 & 7.5265 & TST \\
\hline CHEMBL156132 & 102381 & 7.3098 & 7.2796 & TRN \\
\hline CHEMBL156388 & 102381 & 6.7959 & 6.8874 & TRN \\
\hline CHEMBL154582 & 102381 & 6.585 & 6.4541 & TRN \\
\hline CHEMBL442772 & 102381 & 6.2596 & 5.9346 & TRN \\
\hline CHEMBL345428 & 102381 & 5.8416 & 6.0998 & TRN \\
\hline CHEMBL346648 & 102381 & 7.3279 & 7.1387 & TST \\
\hline CHEMBL350031 & 102381 & 6.1308 & 6.4418 & TST \\
\hline CHEMBL156192 & 102381 & 7.1192 & 7.3693 & TRN \\
\hline CHEMBL157899 & 102381 & 6.585 & 6.7009 & TRN \\
\hline CHEMBL160383 & 102381 & 6.2218 & 6.255 & TRN \\
\hline CHEMBL352252 & 102381 & 7.1487 & 7.1249 & TRN \\
\hline CHEMBL155995 & 102381 & 6.8539 & 6.6955 & TRN \\
\hline CHEMBL160922 & 102381 & 7.0 & 7.0471 & TRN \\
\hline CHEMBL349116 & 102381 & 7.0706 & 6.5645 & TST \\
\hline CHEMBL157849 & 102381 & 7.0458 & 6.8662 & TST \\
\hline CHEMBL155365 & 102381 & 6.0862 & 6.2609 & TRN \\
\hline CHEMBL155727 & 102381 & 7.4815 & 6.7042 & TST \\
\hline CHEMBL349346 & 102381 & 6.1805 & 6.3933 & TRN \\
\hline CHEMBL348358 & 102381 & 7.4089 & 7.4501 & TRN \\
\hline CHEMBL434663 & 102381 & 6.8539 & 7.1783 & TRN \\
\hline CHEMBL155636 & 102381 & 5.9208 & 5.968 & TRN \\
\hline CHEMBL158149 & 102381 & 7.7212 & 7.4186 & TRN \\
\hline CHEMBL345691 & 102381 & 7.0605 & 6.8404 & TRN \\
\hline CHEMBL347882 & 102381 & 6.6021 & 6.3866 & TRN \\
\hline CHEMBL156122 & 102381 & 7.0915 & 7.0356 & TST \\
\hline CHEMBL347363 & 102381 & 6.6576 & 6.6625 & TRN \\
\hline CHEMBL346942 & 102381 & 6.8539 & 6.9787 & TST \\
\hline CHEMBL158357 & 102381 & 6.7959 & 6.7997 & TRN \\
\hline CHEMBL346785 & 102381 & 7.4089 & 7.3084 & TRN \\
\hline CHEMBL351767 & 102381 & 7.0506 & 7.0848 & TRN \\
\hline CHEMBL345121 & 102381 & 6.699 & 6.6779 & TRN \\
\hline CHEMBL346571 & 102381 & 7.2924 & 7.4437 & TRN \\
\hline CHEMBL155795 & 102381 & 7.6021 & 6.8537 & TST \\
\hline
\end{tabular}


Supplemental Table S2.txt

\begin{tabular}{|c|c|c|c|c|}
\hline CHEMBL157666 & 102381 & 7.2676 & 7.2592 & TRN \\
\hline CHEMBL155170 & 102381 & 6.4685 & 6.2877 & TRN \\
\hline CHEMBL160862 & 102381 & 6.3872 & \multicolumn{2}{|c|}{6.3870000000000005} \\
\hline CHEMBL 347868 & 102381 & 7.041 & 6.5898 & TST \\
\hline CHEMBL 348102 & 102381 & 6.8861 & 6.7129 & TRN \\
\hline CHEMBL156860 & 102381 & 7.3098 & 7.5299 & TRN \\
\hline CHEMBL 346572 & 102381 & 7.2757 & 6.8123 & TRN \\
\hline CHEMBL157673 & 102381 & 5.5376 & 5.5865 & TRN \\
\hline CHEMBL 345151 & 102381 & 7.1135 & 6.9495 & TRN \\
\hline CHEMBL156022 & 102381 & 6.2596 & 5.9699 & TRN \\
\hline CHEMBL154262 & 102381 & 6.9586 & 7.1103 & TRN \\
\hline CHEMBL158005 & 102381 & 7.1192 & 6.7998 & TRN \\
\hline CHEMBL154771 & 102381 & 6.5528 & 6.3888 & TRN \\
\hline CHEMBL154261 & 102381 & 6.699 & 6.731 & TRN \\
\hline CHEMBL 278728 & 102381 & 8.0 & 8.1486 & TRN \\
\hline CHEMBL 349287 & 102381 & 6.8239 & 6.6504 & TRN \\
\hline CHEMBL157022 & 102381 & 6.6576 & 7.1724 & TST \\
\hline CHEMBL434506 & 102381 & 5.0155 & 5.1317 & TRN \\
\hline CHEMBL155241 & 102381 & 7.1675 & 7.2054 & TRN \\
\hline CHEMBL351145 & 102381 & 5.8239 & 6.3219 & TRN \\
\hline CHEMBL348103 & 102381 & 7.4815 & 6.5159 & TST \\
\hline CHEMBL155796 & 102381 & 7.0969 & 6.4872 & TST \\
\hline CHEMBL435239 & 102381 & 7.0506 & 6.3593 & TRN \\
\hline CHEMBL160863 & 102381 & 7.2441 & 7.1396 & TRN \\
\hline CHEMBL422170 & 102381 & 7.1938 & 7.0195 & TRN \\
\hline CHEMBL157834 & 102381 & 7.7212 & 7.6004 & TRN \\
\hline CHEMBL 345386 & 102381 & 7.1192 & 6.8695 & TST \\
\hline CHEMBL 264708 & 102381 & 7.1249 & 6.7104 & TRN \\
\hline CHEMBL 348271 & 102381 & 7.3768 & 7.2605 & TST \\
\hline CHEMBL 345604 & 102381 & 5.8697 & 6.822 & TRN \\
\hline CHEMBL155940 & 102381 & 5.9586 & 5.9574 & TRN \\
\hline CHEMBL160358 & 102381 & 7.0362 & 7.0726 & TRN \\
\hline CHEMBL 346922 & 102381 & 6.9586 & 6.6868 & TST \\
\hline CHEMBL157745 & 102381 & 7.1487 & 7.1671 & TRN \\
\hline CHEMBL155726 & 102381 & 7.2147 & 7.0779 & TST \\
\hline CHEMBL 345162 & 102381 & 7.2924 & 7.3426 & TRN \\
\hline CHEMBL 348571 & 102381 & 7.0757 & 7.1931 & TST \\
\hline CHEMBL 347266 & 102381 & 6.3098 & 6.78600 & 00000000005 \\
\hline CHEMBL 345806 & 102381 & 6.7447 & 6.2339 & TST \\
\hline CHEMBL349805 & 102381 & 7.3188 & 6.5528 & TST \\
\hline CHEMBL349812 & 102381 & 6.5376 & 6.5244 & TRN \\
\hline CHEMBL436030 & 102381 & 6.9208 & 6.7513 & TRN \\
\hline CHEMBL 345673 & 102381 & 6.3468 & 6.3395 & TRN \\
\hline CHEMBL 348147 & 102381 & 5.5654 & 5.428 & TRN \\
\hline CHEMBL 351798 & 102381 & 7.0 & 7.7719 & TRN \\
\hline CHEMBL 348560 & 102381 & 7.1871 & 7.1636 & TRN \\
\hline CHEMBL160132 & 102381 & 7.9586 & 7.7649 & TRN \\
\hline CHEMBL156305 & 102381 & 7.1192 & 7.1955 & TRN \\
\hline
\end{tabular}

Page 23545 
Supplemental Table S2.txt

\begin{tabular}{|c|c|c|c|c|c|}
\hline CHEMBL347484 & 102381 & 6.6576 & 6.561 & TRN & \\
\hline CHEMBL346939 & 102381 & 6.5376 & 7.0334 & TRN & \\
\hline CHEMBL348591 & 102381 & 6.6576 & 6.8498 & TST & \\
\hline CHEMBL157037 & 102381 & 7.9208 & 7.0846 & TST & \\
\hline CHEMBL157042 & 102381 & 6.9586 & 6.9954 & TRN & \\
\hline CHEMBL156224 & 102381 & 6.2007 & 6.5836 & TRN & \\
\hline CHEMBL156798 & 102381 & 6.4318 & 6.8429 & TRN & \\
\hline CHEMBL346018 & 102381 & 6.6778 & 6.7482 & TRN & \\
\hline CHEMBL348570 & 102381 & 6.7447 & 6.7804 & TRN & \\
\hline CHEMBL156483 & 102381 & 6.5229 & 6.4167 & TRN & \\
\hline CHEMBL264441 & 102381 & 5.9957 & 6.1796 & TST & \\
\hline CHEMBL352020 & 102381 & 6.2676 & 6.8418 & TST & \\
\hline CHEMBL415020 & 102381 & 6.5686 & 6.517 & TRN & \\
\hline CHEMBL155588 & 102381 & 4.8539 & 5.4666 & TRN & \\
\hline CHEMBL155457 & 102381 & 6.7447 & 6.98600 & 0000000001 & TRN \\
\hline CHEMBL434664 & 102381 & 8.301 & 7.8946 & TRN & \\
\hline CHEMBL155139 & 102381 & 7.1675 & 7.1946 & TRN & \\
\hline CHEMBL349813 & 102381 & 7.5376 & 7.4485 & TRN & \\
\hline CHEMBL345676 & 102381 & 7.2291 & 7.1908 & TRN & \\
\hline CHEMBL158126 & 102381 & 6.8861 & 6.8057 & TST & \\
\hline CHEMBL156363 & 102381 & 7.3768 & 7.5235 & TRN & \\
\hline CHEMBL346214 & 102381 & 7.3372 & 7.4964 & TRN & \\
\hline CHEMBL157247 & 102381 & 7.0 & 6.5358 & TST & \\
\hline CHEMBL155757 & 102381 & 6.6383 & 6.1643 & TST & \\
\hline CHEMBL348381 & 102381 & 7.1367 & 7.3009 & TST & \\
\hline CHEMBL351773 & 102381 & 6.7212 & 6.7484 & TRN & \\
\hline CHEMBL345399 & 102381 & 4.8539 & 6.2206 & TRN & \\
\hline CHEMBL357706 & 102381 & 4.7471 & 5.1606 & TST & \\
\hline CHEMBL156320 & 102381 & 5.1192 & 4.8559 & TRN & \\
\hline CHEMBL345142 & 102381 & 6.1612 & 6.49799 & 9999999999 & TRN \\
\hline CHEMBL346592 & 102381 & 6.7447 & 6.5525 & TRN & \\
\hline CHEMBL160636 & 102381 & 6.284 & 6.1673 & TST & \\
\hline CHEMBL423594 & 102381 & 6.4815 & 6.4012 & TRN & \\
\hline CHEMBL346709 & 102381 & 7.8861 & 7.3849 & TST & \\
\hline CHEMBL156646 & 102381 & 6.6383 & 6.8814 & TRN & \\
\hline CHEMBL157170 & 102381 & 6.5376 & 6.272 & TST & \\
\hline CHEMBL155643 & 102381 & 6.5376 & 6.6915 & TRN & \\
\hline CHEMBL156272 & 102381 & 7.7447 & 7.1895 & TST & \\
\hline CHEMBL346763 & 102381 & 6.2366 & 6.5131 & TRN & \\
\hline CHEMBL352021 & 102381 & 6.585 & 6.9072 & TRN & \\
\hline CHEMBL347368 & 102381 & 7.0 & 6.7748 & TRN & \\
\hline CHEMBL348592 & 102381 & 7.7447 & 7.6675 & TRN & \\
\hline CHEMBL265748 & 102381 & 7.0 & 6.8833 & TRN & \\
\hline CHEMBL347824 & 102381 & 5.699 & 5.6641 & TRN & \\
\hline CHEMBL154361 & 102381 & 6.4815 & 6.3372 & TRN & \\
\hline CHEMBL155583 & 102381 & 7.0177 & 7.0086 & TRN & \\
\hline CHEMBL155889 & 102381 & 6.0915 & 6.2007 & TRN & \\
\hline CHEMBL1818581 & 762863 & 5.1308 & 4.3838 & TRN & \\
\hline
\end{tabular}

Page 23546 


\begin{tabular}{|c|c|c|c|c|c|}
\hline & & & & & \\
\hline CHEMBL1818582 & 762863 & 4.4112 & 5.0343 & TRN & \\
\hline CHEMBL1818559 & 762863 & 5.5686 & 5.3328 & TRN & \\
\hline CHEMBL1818678 & 762863 & 5.0605 & 4.5038 & TRN & \\
\hline CHEMBL1818568 & 762863 & 3.3979 & 4.5013 & TRN & \\
\hline CHEMBL565269 & 762863 & 5.6778 & 4.8549 & TRN & \\
\hline CHEMBL1818584 & 762863 & 3.3979 & 4.4608 & TRN & \\
\hline CHEMBL1818570 & 762863 & 4.8928 & 4.7122 & TRN & \\
\hline CHEMBL1818557 & 762863 & 4.71 & 5.1628 & TRN & \\
\hline CHEMBL1428181 & 762863 & 5.0223 & 4.9973 & TST & \\
\hline CHEMBL1818564 & 762863 & 3.3979 & 5.1309 & TST & \\
\hline CHEMBL1818679 & 762863 & 5.5229 & 4.9834 & TRN & \\
\hline CHEMBL1818551 & 762863 & 5.9586 & 5.8697 & TRN & \\
\hline CHEMBL1818554 & 762863 & 5.585 & 5.84200 & 30000000005 & TRN \\
\hline CHEMBL1818684 & 762863 & 4.9393 & 5.0219 & TRN & \\
\hline CHEMBL1818572 & 762863 & 5.7959 & 5.2772 & TRN & \\
\hline CHEMBL1818552 & 762863 & 5.2007 & 6.2049 & TRN & \\
\hline CHEMBL1818561 & 762863 & 4.433 & 4.7867 & TRN & \\
\hline CHEMBL1818567 & 762863 & 4.8928 & 5.0699 & TRN & \\
\hline CHEMBL1818687 & 762863 & 5.2218 & 5.36600 & 00000000005 & TRN \\
\hline CHEMBL1818574 & 762863 & 3.3979 & 4.2662 & TRN & \\
\hline CHEMBL1818576 & 762863 & 4.5421 & 4.9311 & TST & \\
\hline CHEMBL 1818578 & 762863 & 3.3979 & 4.2374 & TST & \\
\hline CHEMBL1818583 & 762863 & 4.5391 & 4.9136 & TRN & \\
\hline CHEMBL 1818580 & 762863 & 5.0706 & 4.7999 & TRN & \\
\hline CHEMBL1818577 & 762863 & 3.3979 & 4.3464 & TST & \\
\hline CHEMBL1818680 & 762863 & 6.3188 & 5.1265 & TRN & \\
\hline CHEMBL 573226 & 762863 & 5.1549 & 4.2984 & TRN & \\
\hline CHEMBL1818553 & 762863 & 6.2441 & 5.83899 & 99999999995 & TRN \\
\hline CHEMBL1818571 & 762863 & 5.3979 & 5.5683 & TRN & \\
\hline CHEMBL1818681 & 762863 & 5.284 & 5.2326 & TRN & \\
\hline CHEMBL1818566 & 762863 & 4.8601 & 4.9707 & TRN & \\
\hline CHEMBL 1818555 & 762863 & 3.3979 & 4.4957 & TRN & \\
\hline CHEMBL1818565 & 762863 & 4.9355 & 4.9405 & TRN & \\
\hline CHEMBL1818682 & 762863 & 5.6576 & 4.9159 & TRN & \\
\hline CHEMBL1818585 & 762863 & 4.5784 & 4.9469 & TRN & \\
\hline CHEMBL1818683 & 762863 & 5.6778 & 5.0842 & TRN & \\
\hline CHEMBL 1818556 & 762863 & 5.585 & 5.3205 & TRN & \\
\hline CHEMBL1818573 & 762863 & 3.3979 & 4.3464 & TST & \\
\hline CHEMBL1818586 & 762863 & 5.5086 & 5.397 & TRN & \\
\hline CHEMBL1818575 & 762863 & 4.6055 & 4.4229 & TRN & \\
\hline CHEMBL1818562 & 762863 & 4.9101 & 5.1003 & TRN & \\
\hline CHEMBL 1818686 & 762863 & 5.1549 & 5.209 & TRN & \\
\hline CHEMBL1818550 & 762863 & 5.3468 & 5.2065 & TRN & \\
\hline CHEMBL1818558 & 762863 & 6.4949 & 5.7627 & TST & \\
\hline CHEMBL1818579 & 762863 & 4.6364 & 4.8336 & TST & \\
\hline CHEMBL93224 & 762863 & 5.1871 & 5.0696 & TST & \\
\hline CHEMBL 1818560 & 762863 & 4.71899 & 9999999 & 4.904 & 1 \\
\hline CHEMBL1818569 & 762863 & 5.3872 & 5.5521 & TST & \\
\hline
\end{tabular}


Supplemental Table S2.txt

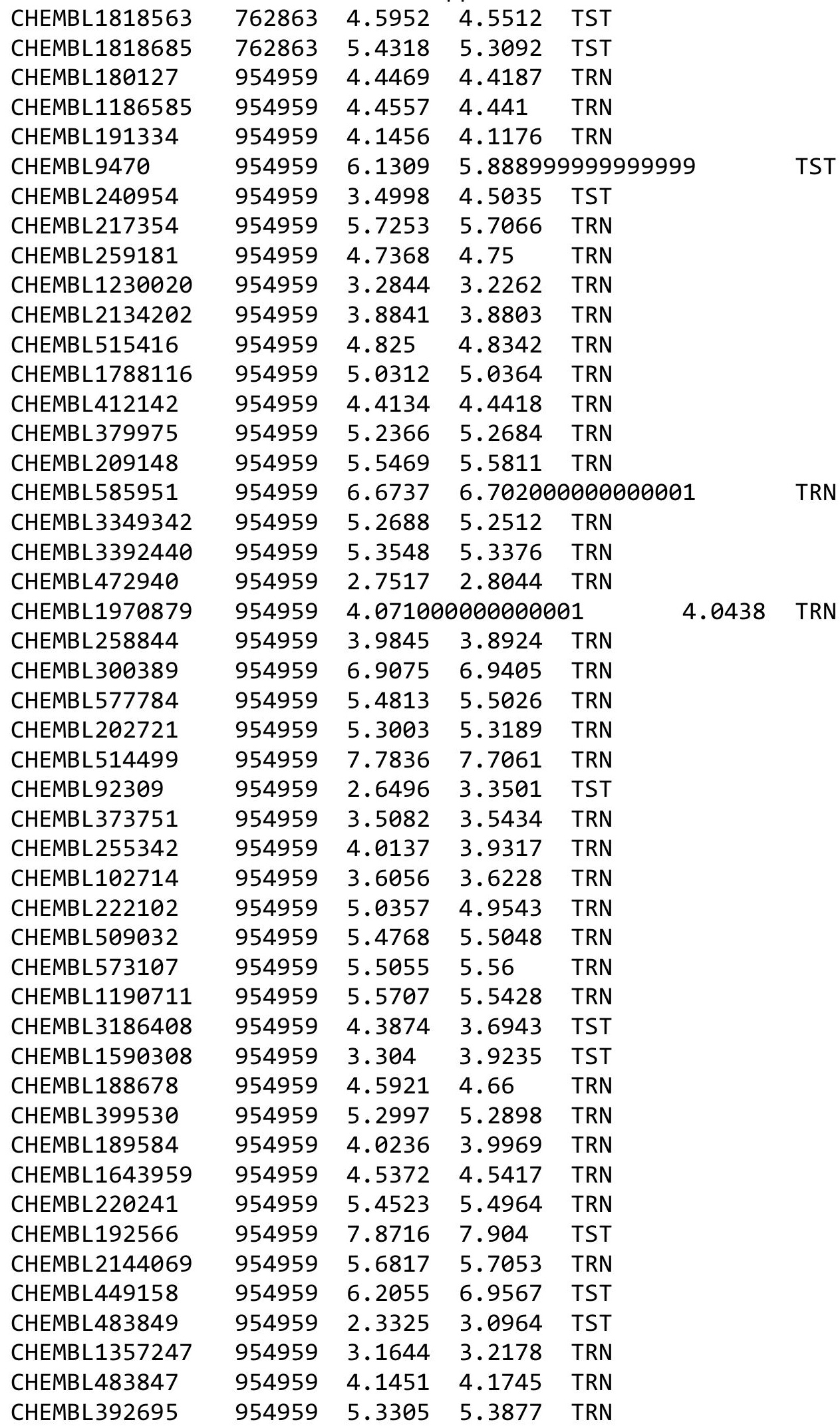

Page 23548 
Supplemental Table S2.txt

\begin{tabular}{|c|c|c|c|c|}
\hline CHEMBL135561 & 954959 & 5.0462 & 5.0023 & TRN \\
\hline CHEMBL1404918 & 954959 & 3.5035 & 3.4809 & TRN \\
\hline CHEMBL213100 & 954959 & 3.4039 & 3.4087 & TRN \\
\hline CHEMBL 221137 & 954959 & 4.8702 & 4.2177 & TST \\
\hline CHEMBL1242367 & 954959 & 3.6203 & 3.5602 & TRN \\
\hline CHEMBL1516890 & 954959 & 5.7128 & 5.6736 & TRN \\
\hline CHEMBL512504 & 954959 & 7.4931 & 7.4952 & TRN \\
\hline CHEMBL1909414 & 954959 & 3.8587 & 3.8904 & TRN \\
\hline CHEMBL393929 & 954959 & 3.6445 & 3.6755 & TRN \\
\hline CHEMBL65 & 954959 & 7.125 & 7.1113 & TRN \\
\hline CHEMBL210618 & 954959 & 3.4517 & 3.4815 & TRN \\
\hline CHEMBL 2363137 & 954959 & 5.2223 & 4.4555 & TST \\
\hline CHEMBL558642 & 954959 & 6.0702 & 4.7251 & TST \\
\hline CHEMBL 379300 & 954959 & 6.8511 & 6.2214 & TST \\
\hline CHEMBL 2005886 & 954959 & 7.5461 & 6.2487 & TST \\
\hline CHEMBL1256459 & 954959 & 7.1169 & 6.6847 & TST \\
\hline CHEMBL 2137530 & 954959 & 4.6246 & 4.2447 & TST \\
\hline CHEMBL 3199475 & 954959 & 4.6604 & 4.5731 & TST \\
\hline CHEMBL1673039 & 954959 & 5.0117 & 4.8048 & TST \\
\hline CHEMBL 310491 & 52650 & 5.7447 & 5.9033 & TRN \\
\hline CHEMBL 268368 & 52650 & 6.0472 & 6.3328 & TST \\
\hline CHEMBL75984 & 52650 & 5.9706 & 5.75 & TRN \\
\hline CHEMBL 73772 & 52650 & 5.8761 & 5.7699 & TRN \\
\hline CHEMBL311851 & 52650 & 6.0448 & 6.144 & TRN \\
\hline CHEMBL 73832 & 52650 & 8.0458 & 7.3373 & TRN \\
\hline CHEMBL75952 & 52650 & 6.0259 & 6.04899 & 99999999995 \\
\hline CHEMBL 73794 & 52650 & 5.7773 & 5.7202 & TRN \\
\hline CHEMBL308979 & 52650 & 6.1643 & 5.7378 & TRN \\
\hline CHEMBL307150 & 52650 & 7.1549 & 7.4515 & TRN \\
\hline CHEMBL 73343 & 52650 & 6.9469 & 6.4975 & TRN \\
\hline CHEMBL 75368 & 52650 & 6.0097 & 6.0205 & TRN \\
\hline CHEMBL 73742 & 52650 & 6.3979 & 5.6829 & TRN \\
\hline CHEMBL430606 & 52650 & 5.6925 & 5.9727 & TRN \\
\hline CHEMBL73781 & 52650 & 6.3645 & 6.4273 & TRN \\
\hline CHEMBL 307152 & 52650 & 5.9872 & 5.8215 & TRN \\
\hline CHEMBL73499 & 52650 & 4.699 & 5.4816 & TRN \\
\hline CHEMBL 75610 & 52650 & 6.0325 & 5.9326 & TRN \\
\hline CHEMBL 72754 & 52650 & 7.1739 & 5.9283 & TST \\
\hline CHEMBL308594 & 52650 & 6.6778 & 5.8497 & TRN \\
\hline CHEMBL 74637 & 52650 & 8.2218 & 6.9066 & TST \\
\hline CHEMBL 306527 & 52650 & 4.699 & 5.7167 & TRN \\
\hline CHEMBL 73413 & 52650 & 6.2534 & \multicolumn{2}{|c|}{5.877999999999999} \\
\hline CHEMBL308116 & 52650 & 7.1249 & 6.546 & TRN \\
\hline CHEMBL73080 & 52650 & 5.5436 & 5.5093 & TRN \\
\hline CHEMBL 74883 & 52650 & 7.1739 & 7.1183 & TRN \\
\hline CHEMBL 306856 & 52650 & 8.3979 & 6.4201 & TST \\
\hline CHEMBL 73764 & 52650 & 6.3468 & \multicolumn{2}{|c|}{6.031000000000001} \\
\hline CHEMBL76499 & 52650 & 6.6478 & 6.2552 & TRN \\
\hline
\end{tabular}

Page 23549 


\begin{tabular}{|c|c|c|c|c|c|}
\hline \multicolumn{6}{|c|}{ Supplemental Table S2.txt } \\
\hline CHEMBL308994 & 52650 & 5.699 & 6.6168 & TRN & \\
\hline CHEMBL 308252 & 52650 & 6.9031 & 6.6088 & TST & \\
\hline CHEMBL76390 & 52650 & 8.0 & 7.4192 & TRN & \\
\hline CHEMBL72076 & 52650 & 5.8239 & 5.8029 & TRN & \\
\hline CHEMBL308479 & 52650 & 7.6576 & 6.7751 & TRN & \\
\hline CHEMBL76326 & 52650 & 6.5768 & 6.2709 & TRN & \\
\hline CHEMBL 307630 & 52650 & 5.9747 & 5.8207 & TRN & \\
\hline CHEMBL73718 & 52650 & 7.0506 & 6.5013 & TST & \\
\hline CHEMBL72607 & 52650 & 7.0655 & 7.169 & TRN & \\
\hline CHEMBL306034 & 52650 & 5.8996 & 6.1181 & TST & \\
\hline CHEMBL306367 & 52650 & 6.5735 & \multicolumn{2}{|c|}{6.428999999999999} & TST \\
\hline CHEMBL 74289 & 52650 & 7.1249 & 7.5396 & TRN & \\
\hline CHEMBL76337 & 52650 & 6.2464 & 6.0998 & TRN & \\
\hline CHEMBL 306611 & 52650 & 6.9508 & 7.0217 & TRN & \\
\hline CHEMBL75953 & 52650 & 6.4841 & 6.6514 & TRN & \\
\hline CHEMBL308541 & 52650 & 7.6383 & 7.6582 & TRN & \\
\hline CHEMBL431181 & 52650 & 4.699 & 5.1764 & TRN & \\
\hline CHEMBL306501 & 52650 & 6.0 & 6.2598 & TST & \\
\hline CHEMBL76332 & 52650 & 4.699 & 6.3963 & TRN & \\
\hline CHEMBL76464 & 52650 & 5.9101 & 6.1606 & TST & \\
\hline CHEMBL306114 & 52650 & 6.4949 & 6.8722 & TRN & \\
\hline CHEMBL 307219 & 52650 & 4.699 & 5.9903 & TST & \\
\hline CHEMBL72808 & 52650 & 6.0123 & 5.9692 & TRN & \\
\hline CHEMBL 306748 & 52650 & 8.0969 & 6.2521 & TST & \\
\hline CHEMBL72077 & 52650 & 6.1451 & 6.1992 & TST & \\
\hline CHEMBL 310260 & 52650 & 6.9957 & 6.4288 & TST & \\
\hline CHEMBL312292 & 52650 & 6.0991 & 6.1229 & TRN & \\
\hline CHEMBL73751 & 52650 & 7.1938 & 6.4049 & TST & \\
\hline CHEMBL73485 & 52650 & 7.2441 & 7.3284 & TRN & \\
\hline CHEMBL306047 & 52650 & 5.8928 & 5.9296 & TRN & \\
\hline CHEMBL441258 & 52650 & 6.4895 & 7.0304 & TRN & \\
\hline CHEMBL3735233 & 1537998 & 3.0 & 4.1138 & TRN & \\
\hline CHEMBL3735788 & 1537998 & 3.0 & 3.3983 & TRN & \\
\hline CHEMBL3734762 & 1537998 & 3.0 & 2.6673 & TRN & \\
\hline CHEMBL3736258 & 1537998 & 3.0 & 4.1528 & TRN & \\
\hline CHEMBL3734848 & 1537998 & 4.6021 & 4.8556 & TRN & \\
\hline CHEMBL1515627 & 1537998 & 3.0 & 3.0347 & TRN & \\
\hline CHEMBL564201 & 1537998 & 5.9208 & 3.4499 & TST & \\
\hline CHEMBL3735786 & 1537998 & 5.0969 & 3.5744 & TST & \\
\hline CHEMBL3736497 & 1537998 & 3.0 & 3.4877 & TST & \\
\hline CHEMBL98778 & 1537998 & 3.0 & 3.324 & TST & \\
\hline CHEMBL 3735768 & 1537998 & 3.0 & 3.3116 & TRN & \\
\hline CHEMBL3735313 & 1537998 & 3.0 & 2.8254 & TRN & \\
\hline CHEMBL3735551 & 1537998 & 3.0 & 2.6426 & TRN & \\
\hline CHEMBL 3734841 & 1537998 & 5.0 & 5.1037 & TRN & \\
\hline CHEMBL3735011 & 1537998 & 3.0 & 3.6482 & TRN & \\
\hline CHEMBL3736492 & 1537998 & 3.0 & 2.87600 & 00000000003 & TRN \\
\hline CHEMBL3734996 & 1537998 & 3.0 & 3.1335 & TRN & \\
\hline
\end{tabular}


Supplemental Table S2.txt

\begin{tabular}{|c|c|c|c|c|}
\hline CHEMBL3736362 & 1537998 & 4.6576 & 4.188 & TRN \\
\hline CHEMBL 3736284 & 1537998 & 4.8239 & 4.387 & TRN \\
\hline CHEMBL3735182 & 1537998 & 3.0 & 2.952 & TRN \\
\hline CHEMBL3736219 & 1537998 & 3.0 & 3.0574 & TRN \\
\hline CHEMBL3736259 & 1537998 & 4.699 & 4.0351 & TRN \\
\hline CHEMBL3735443 & 1537998 & 3.0 & 2.7989 & TRN \\
\hline CHEMBL3735595 & 1537998 & 3.0 & 3.1585 & TRN \\
\hline CHEMBL3734874 & 1537998 & 3.0 & 3.6457 & TRN \\
\hline CHEMBL3735377 & 1537998 & 3.0 & 3.2902 & TRN \\
\hline CHEMBL3735729 & 1537998 & 3.0 & 2.9835 & TRN \\
\hline CHEMBL3735937 & 1537998 & 3.0 & 2.7803 & TST \\
\hline CHEMBL3735991 & 1537998 & 4.9208 & 5.181 & TRN \\
\hline CHEMBL3735685 & 1537998 & 3.0 & 3.3813 & TRN \\
\hline CHEMBL3735262 & 1537998 & 3.0 & 2.9516 & TRN \\
\hline CHEMBL 3736487 & 1537998 & 3.0 & 3.263 & TRN \\
\hline CHEMBL3736249 & 1537998 & 5.0969 & 5.0702 & TRN \\
\hline CHEMBL3734808 & 1537998 & 5.301 & 4.2078 & TRN \\
\hline CHEMBL3736102 & 1537998 & 4.0969 & 4.1 & TRN \\
\hline CHEMBL3736357 & 1537998 & 3.0 & 3.3815 & TRN \\
\hline CHEMBL 3735922 & 1537998 & 5.699 & 4.8984 & TRN \\
\hline CHEMBL 3735292 & 1537998 & 4.6021 & 4.3888 & TRN \\
\hline CHEMBL3735636 & 1537998 & 3.0 & 2.8916 & TRN \\
\hline CHEMBL3735946 & 1537998 & 3.0 & 2.8042 & TRN \\
\hline CHEMBL3734945 & 1537998 & 3.0 & 2.9452 & TRN \\
\hline CHEMBL3735328 & 1537998 & 3.0 & 2.9557 & TRN \\
\hline CHEMBL 3735807 & 1537998 & 3.0 & 2.7522 & TRN \\
\hline CHEMBL3735430 & 1537998 & 3.0 & 2.7859 & TRN \\
\hline CHEMBL418899 & 1537998 & 3.0 & 3.6109 & TST \\
\hline CHEMBL3735248 & 1537998 & 4.0458 & 3.5847 & TST \\
\hline CHEMBL3735742 & 1537998 & 3.0 & 2.6834 & TST \\
\hline CHEMBL3735442 & 1537998 & 3.0 & 3.574 & TST \\
\hline CHEMBL3736087 & 1537998 & 4.3979 & 4.3753 & TRN \\
\hline CHEMBL3734886 & 1537998 & 4.9586 & 4.3296 & TRN \\
\hline CHEMBL3736351 & 1537998 & 3.0 & 2.6688 & TST \\
\hline CHEMBL3735111 & 1537998 & 3.0 & 2.9324 & TRN \\
\hline CHEMBL3734766 & 1537998 & 3.0 & 2.7858 & TST \\
\hline CHEMBL 3735747 & 1537998 & 3.0 & 2.5055 & TST \\
\hline CHEMBL3735084 & 1537998 & 3.0 & 2.7132 & TST \\
\hline CHEMBL3735615 & 1537998 & 3.0 & 2.8566 & TST \\
\hline CHEMBL1904905 & 965915 & 6.6778 & 6.4777 & TRN \\
\hline CHEMBL 2392360 & 965915 & 5.9355 & 5.6455 & TRN \\
\hline CHEMBL1898197 & 965915 & 6.7959 & 6.6407 & TRN \\
\hline CHEMBL 2392392 & 965915 & 4.585 & 4.5144 & TRN \\
\hline CHEMBL 2392223 & 965915 & 4.6345 & 4.8231 & TRN \\
\hline CHEMBL 2392367 & 965915 & 5.7852 & 5.5235 & TST \\
\hline CHEMBL 2392225 & 965915 & 4.8356 & 4.7828 & TRN \\
\hline CHEMBL 2392230 & 965915 & 4.8847 & 4.7438 & TST \\
\hline CHEMBL 2392224 & 965915 & 4.8861 & 4.9979 & TRN \\
\hline
\end{tabular}

Page 23551 


\begin{tabular}{|c|c|c|c|c|c|}
\hline \multicolumn{6}{|c|}{ Supplemental Table S2.txt } \\
\hline CHEMBL2392227 & 965915 & 4.684 & 4.8444 & TRN & \\
\hline CHEMBL1892019 & 965915 & 6.4815 & 6.0487 & TST & \\
\hline CHEMBL2392242 & 965915 & 4.585 & 4.4539 & TRN & \\
\hline CHEMBL2392388 & 965915 & 4.5346 & 4.5682 & TRN & \\
\hline CHEMBL2392235 & 965915 & 4.6345 & 4.6947 & TRN & \\
\hline CHEMBL1436125 & 965915 & 4.585 & 4.7884 & TRN & \\
\hline CHEMBL1885536 & 965915 & 6.8861 & 6.8031 & TRN & \\
\hline CHEMBL1902528 & 965915 & 6.8239 & 6.6232 & TST & \\
\hline CHEMBL 2392246 & 965915 & 4.4841 & 4.4815 & TRN & \\
\hline CHEMBL2392237 & 965915 & 4.585 & 4.60800 & 00000000005 & TRN \\
\hline CHEMBL2392239 & 965915 & 4.5346 & 4.3977 & TRN & \\
\hline CHEMBL1868723 & 965915 & 7.1549 & 7.0243 & TRN & \\
\hline CHEMBL1331525 & 965915 & 4.5847 & 5.169 & TST & \\
\hline CHEMBL 2392226 & 965915 & 5.1871 & 4.8567 & TRN & \\
\hline CHEMBL2392228 & 965915 & 5.3851 & 5.1049 & TST & \\
\hline CHEMBL1877990 & 965915 & 7.3979 & 7.0239 & TRN & \\
\hline CHEMBL1872011 & 965915 & 5.684 & 5.2469 & TST & \\
\hline CHEMBL 2392375 & 965915 & 4.3851 & 4.4946 & TRN & \\
\hline CHEMBL 2392385 & 965915 & 4.684 & 4.3743 & TRN & \\
\hline CHEMBL1885748 & 965915 & 5.585 & 5.5041 & TST & \\
\hline CHEMBL1898211 & 965915 & 5.3344 & 4.9079 & TST & \\
\hline CHEMBL2392236 & 965915 & 4.585 & 4.4957 & TRN & \\
\hline CHEMBL 2392231 & 965915 & 5.4841 & 5.1145 & TST & \\
\hline CHEMBL1899640 & 965915 & 6.284 & 6.5727 & TRN & \\
\hline CHEMBL2392391 & 965915 & 4.7852 & 4.8842 & TRN & \\
\hline CHEMBL 2392234 & 965915 & 4.585 & 4.4857 & TRN & \\
\hline CHEMBL1884711 & 965915 & 6.1871 & 5.3756 & TST & \\
\hline CHEMBL2392361 & 965915 & 5.1349 & 5.5368 & TRN & \\
\hline CHEMBL2392379 & 965915 & 4.1844 & 4.1997 & TRN & \\
\hline CHEMBL 2392232 & 965915 & 4.4841 & 4.4947 & TRN & \\
\hline CHEMBL2392366 & 965915 & 4.5847 & 4.4341 & TRN & \\
\hline CHEMBL1894742 & 965915 & 6.6778 & 6.4738 & TST & \\
\hline CHEMBL2392363 & 965915 & 6.585 & 6.7398 & TRN & \\
\hline CHEMBL 2392222 & 965915 & 4.8356 & 4.6198 & TRN & \\
\hline CHEMBL 2392378 & 965915 & 4.3851 & 4.59399 & 9999999999 & TRN \\
\hline CHEMBL1357429 & 965915 & 4.7846 & 4.9439 & TRN & \\
\hline CHEMBL 2392390 & 965915 & 4.3344 & 4.5307 & TRN & \\
\hline CHEMBL2392238 & 965915 & 4.5346 & 4.3319 & TRN & \\
\hline CHEMBL1882945 & 965915 & 4.5847 & 4.9992 & TST & \\
\hline CHEMBL1899256 & 965915 & 6.0862 & 6.6404 & TRN & \\
\hline CHEMBL2392368 & 965915 & 6.284 & 6.6487 & TRN & \\
\hline CHEMBL 2392365 & 965915 & 7.1549 & 6.9369 & TRN & \\
\hline CHEMBL2392362 & 965915 & 5.2351 & 5.3905 & TRN & \\
\hline CHEMBL 2392240 & 965915 & 4.4841 & 4.6531 & TRN & \\
\hline CHEMBL 2392233 & 965915 & 4.5346 & 4.3765 & TRN & \\
\hline CHEMBL2392359 & 965915 & 5.684 & 5.8306 & TRN & \\
\hline CHEMBL2392355 & 965915 & 4.585 & 4.5215 & TST & \\
\hline CHEMBL2392229 & 965915 & 5.0348 & 4.9397 & TST & \\
\hline
\end{tabular}

Page 23552 


\begin{tabular}{|c|c|c|c|c|c|}
\hline & & \multicolumn{4}{|c|}{ Supplemental Table S2.txt } \\
\hline CHEMBL2392364 & 965915 & 7.301 & 6.8937 & TRN & \\
\hline CHEMBL 2392241 & 965915 & 4.585 & 4.5783 & TRN & \\
\hline CHEMBL259346 & 472940 & 3.0 & 3.27100 & 20000000004 & TRN \\
\hline CHEMBL409287 & 472940 & 4.6021 & 4.1968 & TRN & \\
\hline CHEMBL564201 & 472940 & 6.0 & 3.3343 & TST & \\
\hline CHEMBL265458 & 472940 & 3.0 & 3.7665 & TRN & \\
\hline CHEMBL407149 & 472940 & 3.0 & 3.5766 & TRN & \\
\hline CHEMBL258692 & 472940 & 3.0 & 2.8329 & TRN & \\
\hline CHEMBL259586 & 472940 & 3.0 & 3.5737 & TRN & \\
\hline CHEMBL259110 & 472940 & 6.0 & 3.8956 & TRN & \\
\hline CHEMBL407036 & 472940 & 3.0 & 2.9504 & TRN & \\
\hline CHEMBL265201 & 472940 & 3.0 & 3.5945 & TRN & \\
\hline CHEMBL258971 & 472940 & 3.0 & 3.6277 & TST & \\
\hline CHEMBL 258833 & 472940 & 3.0 & 3.6772 & TST & \\
\hline CHEMBL408837 & 472940 & 3.0 & 3.0279 & TRN & \\
\hline CHEMBL261889 & 472940 & 3.0 & 2.6858 & TRN & \\
\hline CHEMBL410698 & 472940 & 3.0 & 4.0579 & TRN & \\
\hline CHEMBL261411 & 472940 & 4.9586 & 4.0145 & TRN & \\
\hline CHEMBL 259903 & 472940 & 3.0 & 4.1315 & TRN & \\
\hline CHEMBL259369 & 472940 & 3.5229 & 4.0918 & TRN & \\
\hline CHEMBL259932 & 472940 & 3.0969 & 3.5949 & TRN & \\
\hline CHEMBL406413 & 472940 & 3.0 & 4.0631 & TRN & \\
\hline CHEMBL 259318 & 472940 & 3.0 & 3.094 & TRN & \\
\hline CHEMBL411929 & 472940 & 3.0 & 2.7928 & TRN & \\
\hline CHEMBL260182 & 472940 & 3.0 & 3.3966 & TRN & \\
\hline CHEMBL 259904 & 472940 & 4.7447 & 3.7429 & TRN & \\
\hline CHEMBL408223 & 472940 & 4.0458 & 3.784 & TRN & \\
\hline CHEMBL409307 & 472940 & 5.301 & 4.2667 & TRN & \\
\hline CHEMBL407721 & 472940 & 3.0 & 3.8682 & TST & \\
\hline CHEMBL406452 & 472940 & 3.0 & 3.0448 & TRN & \\
\hline CHEMBL259495 & 472940 & 3.0362 & 3.818 & TST & \\
\hline CHEMBL 259531 & 472940 & 5.1549 & 4.4655 & TRN & \\
\hline CHEMBL261666 & 472940 & 3.6021 & 3.4195 & TRN & \\
\hline CHEMBL 259348 & 472940 & 3.0 & 2.8778 & TRN & \\
\hline CHEMBL259606 & 472940 & 5.301 & 4.3031 & TRN & \\
\hline CHEMBL405461 & 472940 & 3.0 & 2.9065 & TRN & \\
\hline CHEMBL259915 & 472940 & 3.0 & 3.2718 & TST & \\
\hline CHEMBL 260181 & 472940 & 3.0 & 3.2529 & TRN & \\
\hline CHEMBL261448 & 472940 & 3.0 & 3.8468 & TST & \\
\hline CHEMBL408910 & 472940 & 3.2676 & 3.7112 & TST & \\
\hline CHEMBL260894 & 472940 & 3.0 & 3.0189 & TRN & \\
\hline CHEMBL428256 & 472940 & 3.0 & 4.0228 & TST & \\
\hline CHEMBL409923 & 472940 & 3.0 & 3.7537 & TST & \\
\hline CHEMBL 259391 & 472940 & 3.0 & 3.5181 & TRN & \\
\hline CHEMBL 258488 & 472940 & 4.585 & 3.7082 & TST & \\
\hline CHEMBL406970 & 472940 & 3.0 & 3.4337 & TST & \\
\hline CHEMBL407081 & 472940 & 3.0 & 2.6892 & TRN & \\
\hline CHEMBL410669 & 472940 & 4.699 & 4.3309 & TRN & \\
\hline
\end{tabular}




\begin{tabular}{|c|c|c|c|c|c|}
\hline \multicolumn{6}{|c|}{ Supplemental Table S2.txt } \\
\hline CHEMBL193416 & 472940 & 3.0 & 2.8379 & TRN & \\
\hline CHEMBL 258847 & 472940 & 3.0315 & 3.2534 & TRN & \\
\hline CHEMBL 258835 & 472940 & 3.6021 & 4.3585 & TRN & \\
\hline CHEMBL407805 & 472940 & 3.0 & 2.9246 & TRN & \\
\hline CHEMBL428087 & 472940 & 3.0 & 3.3066 & TRN & \\
\hline CHEMBL 261888 & 472940 & 3.0 & 3.0649 & TRN & \\
\hline CHEMBL407150 & 472940 & 3.0 & 2.8761 & TRN & \\
\hline CHEMBL259497 & 472940 & 4.3468 & 3.583 & TST & \\
\hline CHEMBL261414 & 472940 & 3.0 & 2.7042 & TRN & \\
\hline CHEMBL429856 & 472940 & 3.8861 & 3.9538 & TRN & \\
\hline CHEMBL261446 & 472940 & 4.6021 & 3.678 & TST & \\
\hline CHEMBL259109 & 472940 & 4.3979 & 3.8004 & TRN & \\
\hline CHEMBL261412 & 472940 & 3.0 & 3.1457 & TRN & \\
\hline CHEMBL260484 & 472940 & 3.0 & 3.8807 & TRN & \\
\hline CHEMBL418899 & 472940 & 3.0 & 3.3809 & TST & \\
\hline CHEMBL258864 & 472940 & 3.0 & 3.6939 & TST & \\
\hline CHEMBL265457 & 472940 & 4.2218 & 3.7714 & TST & \\
\hline CHEMBL409924 & 472940 & 4.0706 & 3.8562 & TRN & \\
\hline CHEMBL382756 & 472940 & 3.0 & 2.8243 & TRN & \\
\hline CHEMBL401040 & 453897 & 7.1938 & 7.2708 & TRN & \\
\hline CHEMBL238940 & 453897 & 4.0 & 4.0645 & TRN & \\
\hline CHEMBL241084 & 453897 & 7.041 & 6.9067 & TRN & \\
\hline CHEMBL392944 & 453897 & 4.0 & 3.9869 & TRN & \\
\hline CHEMBL394020 & 453897 & 7.0555 & 7.07600 & 20000000005 & TRN \\
\hline CHEMBL 393779 & 453897 & 7.1938 & 7.2058 & TRN & \\
\hline CHEMBL238508 & 453897 & 4.0 & 3.3487 & TRN & \\
\hline CHEMBL240406 & 453897 & 5.45100 & 00000000 & 6.6691 & TST \\
\hline CHEMBL392789 & 453897 & 5.9031 & 7.4152 & TST & \\
\hline CHEMBL238735 & 453897 & 6.7696 & 6.9617 & TRN & \\
\hline CHEMBL241265 & 453897 & 7.1024 & 6.9778 & TRN & \\
\hline CHEMBL238529 & 453897 & 7.2441 & 7.0823 & TRN & \\
\hline CHEMBL241075 & 453897 & 4.0 & 3.9192 & TRN & \\
\hline CHEMBL238938 & 453897 & 4.0 & 3.763 & TRN & \\
\hline CHEMBL391671 & 453897 & 4.0 & 4.2087 & TRN & \\
\hline CHEMBL 241465 & 453897 & 4.0 & 4.9641 & TST & \\
\hline CHEMBL429455 & 453897 & 6.041 & 5.9728 & TRN & \\
\hline CHEMBL238523 & 453897 & 4.0 & 3.7614 & TRN & \\
\hline CHEMBL 241466 & 453897 & 4.0 & 5.3559 & TST & \\
\hline CHEMBL392985 & 453897 & 4.0 & 4.2243 & TRN & \\
\hline CHEMBL 238525 & 453897 & 4.0 & 3.8638 & TRN & \\
\hline CHEMBL240606 & 453897 & 4.0 & 4.091 & TRN & \\
\hline CHEMBL 238528 & 453897 & 7.0177 & 6.8118 & TRN & \\
\hline CHEMBL392986 & 453897 & 4.0 & 3.9683 & TRN & \\
\hline CHEMBL393924 & 453897 & 5.9431 & 7.3292 & TST & \\
\hline CHEMBL 241669 & 453897 & 6.4559 & 6.5025 & TRN & \\
\hline CHEMBL238530 & 453897 & 6.9586 & 7.0289 & TRN & \\
\hline CHEMBL 202011 & 453897 & 7.301 & 8.1187 & TST & \\
\hline CHEMBL393418 & 453897 & 6.1308 & 7.0508 & TST & \\
\hline
\end{tabular}




\begin{tabular}{|c|c|c|c|c|c|}
\hline \multicolumn{6}{|c|}{ Supplemental Table s2.txt } \\
\hline CHEMBL240644 & 453897 & 4.0 & 4.0211 & TRN & \\
\hline CHEMBL391127 & 453897 & 7.0862 & 6.9928 & TRN & \\
\hline CHEMBL 238734 & 453897 & 4.0 & 4.1775 & TRN & \\
\hline CHEMBL429643 & 453897 & 6.9586 & 6.9912 & TRN & \\
\hline CHEMBL428028 & 453897 & 4.0 & 4.4137 & TRN & \\
\hline CHEMBL393964 & 453897 & 4.0 & 3.8199 & TRN & \\
\hline CHEMBL 238522 & 453897 & 7.1249 & 7.3036 & TRN & \\
\hline CHEMBL 240209 & 453897 & 6.8861 & 6.9598 & TRN & \\
\hline CHEMBL241492 & 453897 & 5.644 & 5.8525 & TRN & \\
\hline CHEMBL153843 & 453897 & 7.0458 & 7.1824 & TST & \\
\hline CHEMBL 241667 & 453897 & 6.2596 & 6.062 & TRN & \\
\hline CHEMBL 240455 & 453897 & 6.8861 & 6.7876 & TRN & \\
\hline CHEMBL 394203 & 453897 & 6.8239 & 6.70100 & 00000000005 & TRN \\
\hline CHEMBL 240608 & 453897 & 4.0 & 4.2756 & TRN & \\
\hline CHEMBL 238939 & 453897 & 4.0 & 2.8838 & TST & \\
\hline CHEMBL392513 & 453897 & 6.7447 & 6.5488 & TRN & \\
\hline CHEMBL 241668 & 453897 & 5.0177 & 5.2378 & TRN & \\
\hline CHEMBL400216 & 453897 & 6.9914 & 6.9017 & TRN & \\
\hline CHEMBL238719 & 453897 & 6.6778 & 6.6805 & TRN & \\
\hline CHEMBL392964 & 453897 & 4.0 & 3.4378 & TST & \\
\hline CHEMBL394204 & 453897 & 7.0506 & 7.0063 & TRN & \\
\hline CHEMBL 238526 & 453897 & 6.0362 & 7.5393 & TST & \\
\hline CHEMBL393963 & 453897 & 6.4949 & 5.8241 & TST & \\
\hline CHEMBL392987 & 453897 & 6.9586 & 6.8707 & TRN & \\
\hline CHEMBL 240642 & 453897 & 6.0 & 6.1181 & TRN & \\
\hline CHEMBL240456 & 453897 & 6.3279 & 6.3217 & TRN & \\
\hline CHEMBL 241314 & 453897 & 7.1612 & 7.0406 & TRN & \\
\hline CHEMBL393409 & 453897 & 4.0 & 3.94199 & 99999999997 & TRN \\
\hline CHEMBL 396144 & 453897 & 4.0 & 4.3885 & TRN & \\
\hline CHEMBL 240643 & 453897 & 7.0555 & 7.2518 & TRN & \\
\hline CHEMBL240607 & 453897 & 6.0315 & 5.8565 & TST & \\
\hline CHEMBL 240405 & 453897 & 4.0 & 4.4265 & TST & \\
\hline CHEMBL 241313 & 453897 & 6.6778 & 6.7658 & TRN & \\
\hline CHEMBL392767 & 453897 & 4.0 & 4.3732 & TST & \\
\hline CHEMBL401041 & 453897 & 7.3468 & 7.3615 & TRN & \\
\hline CHEMBL238737 & 453897 & 7.1938 & 7.1685 & TRN & \\
\hline CHEMBL 238531 & 453897 & 5.8729 & 5.80200 & 30000000005 & TRN \\
\hline CHEMBL 240818 & 453897 & 6.2291 & 5.9517 & TST & \\
\hline CHEMBL438142 & 453897 & 4.0 & 5.9927 & TST & \\
\hline CHEMBL 241073 & 453897 & 4.0 & 3.9557 & TRN & \\
\hline CHEMBL238521 & 453897 & 5.7825 & 5.6707 & TRN & \\
\hline CHEMBL 238720 & 453897 & 6.4559 & 6.4923 & TST & \\
\hline CHEMBL394436 & 453897 & 4.0 & 4.2142 & TRN & \\
\hline CHEMBL1459601 & 688653 & 5.033 & 5.3021 & TST & \\
\hline CHEMBL1389157 & 688653 & 4.73300 & 0000000 & 5.1939 & TRN \\
\hline CHEMBL1574206 & 688653 & 6.4829 & 5.2517 & TST & \\
\hline CHEMBL1491570 & 688653 & 4.833 & 5.2736 & TST & \\
\hline CHEMBL1458840 & 688653 & 4.633 & 4.6084 & TST & \\
\hline
\end{tabular}




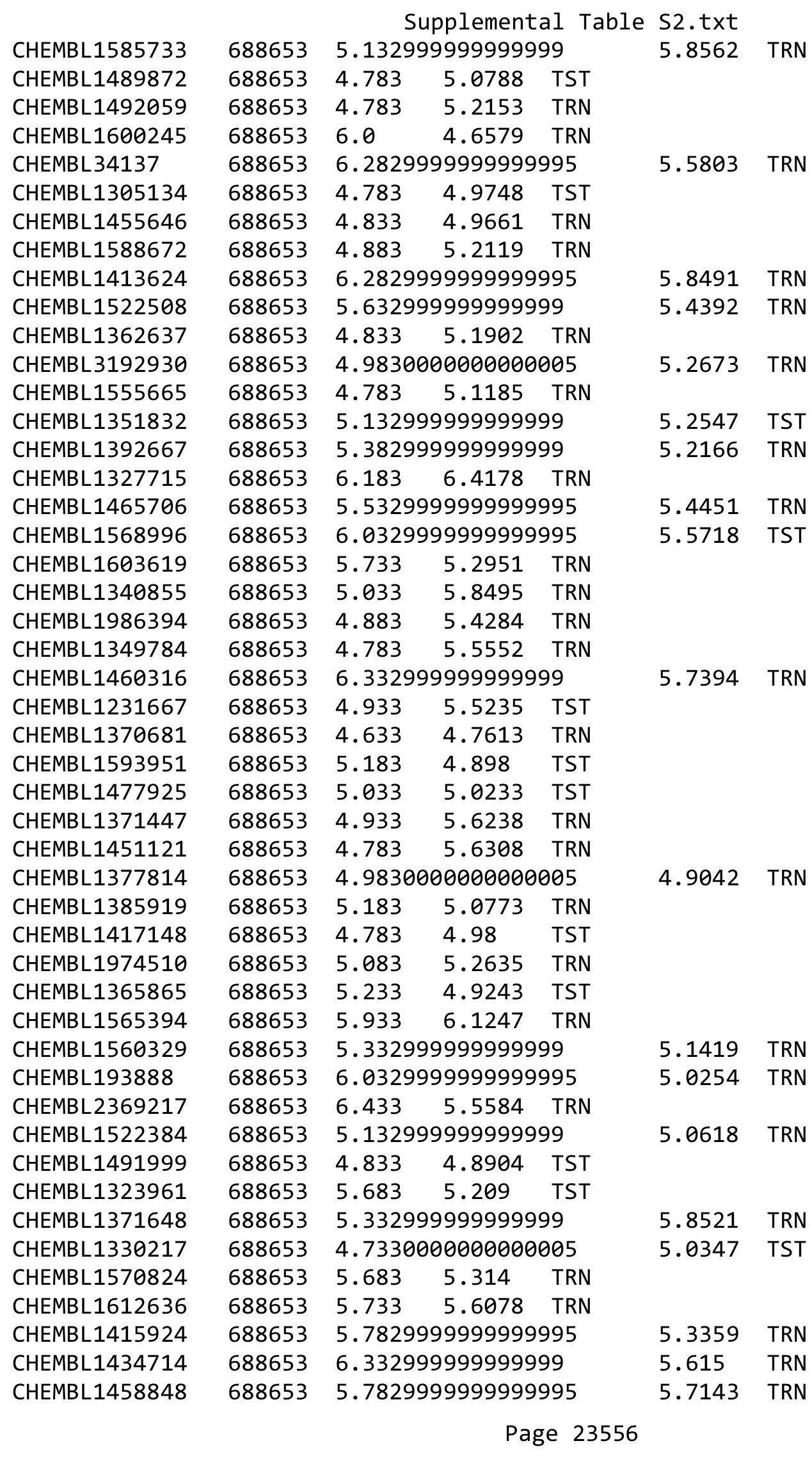




\begin{tabular}{|c|c|c|c|c|c|c|c|}
\hline \multirow[b]{2}{*}{ CHEMBL1383281 } & \multicolumn{6}{|c|}{ Supplemental Table S2.txt } & \\
\hline & 688653 & 4.883 & 5.9264 & TRN & & & \\
\hline CHEMBL1465298 & 688653 & 5.683 & 5.3762 & TRN & & & \\
\hline CHEMBL1508918 & 688653 & 6.13299 & 99999999 & & $5.4920 €$ & 0000000001 & TRN \\
\hline CHEMBL1343509 & 688653 & 5.33299 & 99999999 & & 5.4874 & TRN & \\
\hline CHEMBL1327601 & 688653 & 4.683 & 5.4066 & TRN & & & \\
\hline CHEMBL1525488 & 688653 & 5.28299 & 99999999 & 995 & 5.7731 & TRN & \\
\hline CHEMBL1398298 & 688653 & 5.233 & 5.1763 & TRN & & & \\
\hline CHEMBL585267 & 688653 & 4.833 & 5.2049 & TST & & & \\
\hline CHEMBL1423628 & 688653 & 4.933 & 5.1993 & TRN & & & \\
\hline CHEMBL1368552 & 688653 & 5.13299 & 99999999 & & 5.5934 & TRN & \\
\hline CHEMBL1481261 & 688653 & 4.833 & 5.4545 & TRN & & & \\
\hline CHEMBL1371213 & 688653 & 4.73300 & 00000000 & 005 & 5.3339 & TRN & \\
\hline CHEMBL1392742 & 688653 & 5.38299 & 99999999 & & 4.9169 & TRN & \\
\hline CHEMBL1549361 & 688653 & 5.683 & 5.4195 & TRN & & & \\
\hline CHEMBL1333957 & 688653 & 4.633 & 4.9967 & TRN & & & \\
\hline CHEMBL1411778 & 688653 & 5.183 & 4.9644 & TRN & & & \\
\hline CHEMBL 3194985 & 688653 & 5.88299 & 99999999 & & 5.2576 & TRN & \\
\hline CHEMBL1986214 & 688653 & 7.08299 & 99999999 & & 5.9034 & TRN & \\
\hline CHEMBL1410362 & 688653 & 5.38299 & 99999999 & & 5.2965 & TRN & \\
\hline CHEMBL1365259 & 688653 & 5.483 & 5.4453 & TST & & & \\
\hline CHEMBL1452128 & 688653 & 5.75 & 5.5869 & TRN & & & \\
\hline CHEMBL1528119 & 688653 & 6.33299 & 99999999 & & $5.4460 e$ & 0000000001 & TRN \\
\hline CHEMBL1311754 & 688653 & 5.83299 & 99999999 & & 5.6694 & TRN & \\
\hline CHEMBL1449997 & 688653 & 4.933 & 5.1919 & TRN & & & \\
\hline CHEMBL1377696 & 688653 & 6.38299 & 99999999 & & 5.3438 & TRN & \\
\hline CHEMBL1533991 & 688653 & 5.683 & 5.1227 & TRN & & & \\
\hline CHEMBL1300977 & 688653 & 5.53299 & 99999999 & 995 & 5.1818 & TRN & \\
\hline CHEMBL1306258 & 688653 & 5.33299 & 99999999 & & 5.3342 & TRN & \\
\hline CHEMBL1467952 & 688653 & 5.13299 & 99999999 & & 5.0404 & TST & \\
\hline CHEMBL1527081 & 688653 & 4.98300 & 00000000 & 005 & 5.1871 & TST & \\
\hline CHEMBL1513918 & 688653 & 5.733 & 5.1157 & TRN & & & \\
\hline CHEMBL1328504 & 688653 & 5.53299 & 99999999 & 995 & 5.8209 & TRN & \\
\hline CHEMBL1574120 & 688653 & 5.83299 & 99999999 & & 5.4269 & TRN & \\
\hline CHEMBL1516958 & 688653 & 4.633 & 5.1734 & TST & & & \\
\hline CHEMBL1427219 & 688653 & 5.033 & 5.205 & TRN & & & \\
\hline CHEMBL1565575 & 688653 & 5.1 & 5.0911 & TST & & & \\
\hline CHEMBL1537137 & 688653 & 5.683 & 5.7912 & TST & & & \\
\hline CHEMBL1610782 & 688653 & 4.783 & 5.0091 & TRN & & & \\
\hline CHEMBL1371774 & 688653 & 4.633 & 4.7236 & TRN & & & \\
\hline CHEMBL1571984 & 688653 & 6.0 & 5.6509 & TRN & & & \\
\hline CHEMBL1348675 & 688653 & 7.2328 & 5.9353 & TRN & & & \\
\hline CHEMBL1427152 & 688653 & 4.73300 & 00000000 & 005 & 4.893 & TRN & \\
\hline CHEMBL1990825 & 688653 & 5.33299 & 99999999 & & 5.7651 & TRN & \\
\hline CHEMBL165 & 688653 & 5.38299 & 99999999 & & 5.6862 & TST & \\
\hline CHEMBL1424531 & 688653 & 5.63299 & 99999999 & & 5.0628 & TRN & \\
\hline CHEMBL 3212343 & 688653 & 5.233 & 5.2045 & TRN & & & \\
\hline CHEMBL3195525 & 688653 & 5.05 & 5.2505 & TRN & & & \\
\hline CHEMBL1545000 & 688653 & 5.13299 & 99999999 & & 5.1676 & TST & \\
\hline
\end{tabular}




\begin{tabular}{|c|c|c|c|c|c|c|}
\hline & & \multicolumn{5}{|c|}{ Supplemental Table S2.txt } \\
\hline CHEMBL1405210 & 688653 & 5.183 & 5.0433 & TRN & & \\
\hline CHEMBL1413958 & 688653 & 4.98300 & 30000000 & 005 & 5.1907 & $\mathrm{~T}$ \\
\hline CHEMBL1984639 & 688653 & 6.38299 & 99999999 & & 5.6728 & \\
\hline CHEMBL1341029 & 688653 & 5.33299 & 99999999 & & 5.3216 & \\
\hline CHEMBL1400683 & 688653 & 5.53299 & 99999999 & 995 & 5.0828 & \\
\hline CHEMBL1402956 & 688653 & 5.33299 & 99999999 & & 5.3995 & \\
\hline CHEMBL1399134 & 688653 & 6.683 & 5.3053 & TRN & & \\
\hline CHEMBL1390121 & 88653 & 5.033 & 5.3255 & TST & & \\
\hline CHEMBL1462948 & 688653 & 5.78299 & 99999999 & 995 & 5.6105 & I \\
\hline CHEMBL1412539 & 688653 & 5.83299 & 99999999 & & 5.6065 & \\
\hline CHEMBL1346454 & 688653 & 4.73300 & 000000006 & 005 & 5.5314 & \\
\hline CHEMBL1483332 & 688653 & 4.833 & 4.9855 & TRN & & \\
\hline CHEMBL1491581 & 688653 & 5.033 & 5.0007 & TRN & & \\
\hline CHEMBL1452995 & 688653 & 4.783 & 5.3098 & TRN & & \\
\hline CHEMBL1503361 & 688653 & 4.73300 & $00000000 t$ & 005 & 5.3094 & TST \\
\hline CHEMBL1576816 & 688653 & 5.83299 & 99999999 & & 5.3341 & \\
\hline CHEMBL1409118 & 688653 & 4.833 & 5.3304 & TRN & & \\
\hline CHEMBL1334891 & 688653 & 4.933 & 5.3062 & TST & & \\
\hline CHEMBL 3145064 & 688653 & 5.63299 & 99999999 & & 5.5549 & \\
\hline CHEMBL1528631 & 688653 & 5.033 & 4.841 & TRN & & \\
\hline CHEMBL1549233 & 688653 & 4.933 & 5.1626 & TRN & & \\
\hline CHEMBL1342873 & 688653 & 5.38299 & 99999999 & & 5.4481 & \\
\hline CHEMBL1600828 & 688653 & 5.033 & 5.4228 & TRN & & \\
\hline CHEMBL1309882 & 688653 & 4.933 & 5.1294 & TRN & & \\
\hline CHEMBL1342544 & 688653 & 4.98300 & 00000000 & 005 & 5.6335 & $\mathrm{TH}$ \\
\hline CHEMBL1607844 & 688653 & 6.38299 & 99999999 & & & \\
\hline CHEMBL14 & 688653 & 4.933 & 5.2856 & TRN & & \\
\hline CHEMBL1312914 & 688653 & 5.233 & 5.1705 & TST & & \\
\hline CHEMBL1322332 & 688653 & 4.833 & 5.1407 & TRN & & \\
\hline CHEMBL1504323 & 688653 & 4.883 & 5.22 & TST & & \\
\hline CHEMBL1310810 & 688653 & 4.73300 & 00000000 & 005 & 5.3827 & \\
\hline CHEMBL15 & 688 & 4.633 & 4.5821 & TST & & \\
\hline CHEMBL14 & 688653 & 6.683 & 5.33799 & 99999 & 99 & TR \\
\hline CHEMBL1459542 & 688653 & 4.73300 & 00000000 & 005 & 4.9611 & \\
\hline CHEMBL1565056 & 688653 & 4.633 & 5.1035 & TRN & & \\
\hline CHEMBL1573500 & 688653 & 4.73300 & 00000000 & 005 & & $\mathrm{TH}$ \\
\hline CHEMBL15 & 688653 & 4.73300 & 00000000 & 005 & & \\
\hline CHEMBL13 & 688653 & 5.033 & 5.077 & TRN & & \\
\hline CHEMBL1424887 & 688653 & 5.53299 & 99999999 & 995 & 5.3503 & $\mathrm{TR}$ \\
\hline CHEMBL1351437 & 688653 & 4.783 & 5.6582 & TRN & & \\
\hline CHEMBL1490498 & 688653 & 6.38299 & 99999999 & & 508 & 1 \\
\hline CHEMBL1332882 & 688653 & 5.13299 & 99999999 & & 5.2739 & ונכו \\
\hline CHEMBL1523069 & 688653 & 5.33299 & 99999999 & & 5.4117 & TRN \\
\hline CHEMBL1475922 & 688653 & 5.733 & 5.6346 & TRN & & \\
\hline CHEMBL3212258 & 688653 & 4.98300 & 00000000 & 005 & 5.175 & m \\
\hline CHEMBL1302894 & 688653 & 4.933 & 5.0194 & TST & & \\
\hline CHEMBL1417863 & 688653 & 4.7330 & 00000000 & 005 & .1882 & TRN \\
\hline CHEMBL1315049 & 688653 & 4.633 & 5.3309 & TRN & & \\
\hline
\end{tabular}




\begin{tabular}{|c|c|c|c|c|c|c|}
\hline \multirow[b]{2}{*}{ CHEMBL1324273 } & & \multicolumn{5}{|c|}{ Supplemental Table S2.txt } \\
\hline & 688653 & 5.483 & 5.4213 & TRN & & \\
\hline CHEMBL1969543 & 688653 & \multicolumn{3}{|c|}{4.9830000000000005} & 4.8991 & TRN \\
\hline CHEMBL1314857 & 688653 & 5.183 & 5.1428 & TRN & & \\
\hline CHEMBL1469916 & 688653 & \multicolumn{3}{|c|}{4.7330000000000005} & 5.1913 & TRN \\
\hline CHEMBL1424574 & 688653 & \multicolumn{3}{|c|}{4.9830000000000005} & 4.6456 & TRN \\
\hline CHEMBL1467025 & 688653 & \multicolumn{3}{|c|}{5.832999999999999} & 5.5711 & TRN \\
\hline CHEMBL3210193 & 688653 & 4.783 & 5.45 & TST & & \\
\hline CHEMBL1429887 & 688653 & \multicolumn{3}{|c|}{5.132999999999999} & 5.4681 & TRN \\
\hline CHEMBL1531805 & 688653 & 5.483 & 4.9824 & TRN & & \\
\hline CHEMBL1376416 & 688653 & 4.883 & 5.0994 & TRN & & \\
\hline CHEMBL1507474 & 688653 & 6.183 & 5.3655 & TRN & & \\
\hline CHEMBL1465040 & 688653 & \multicolumn{3}{|c|}{5.382999999999999} & 5.6282 & TRN \\
\hline CHEMBL1528962 & 688653 & 5.733 & 5.3253 & TRN & & \\
\hline CHEMBL1428170 & 688653 & \multicolumn{3}{|c|}{5.332999999999999} & 5.4173 & TRN \\
\hline CHEMBL2269362 & 688653 & 4.633 & 5.3435 & TST & & \\
\hline CHEMBL1970272 & 688653 & \multicolumn{3}{|c|}{4.7330000000000005} & 5.2542 & TST \\
\hline CHEMBL1547873 & 688653 & 5.083 & 5.0304 & TRN & & \\
\hline CHEMBL1342970 & 688653 & 4.833 & 5.3082 & TRN & & \\
\hline CHEMBL1365482 & 688653 & 4.883 & 6.1376 & TRN & & \\
\hline CHEMBL1584691 & 688653 & 5.433 & 5.2913 & TRN & & \\
\hline CHEMBL1412315 & 688653 & 4.783 & 5.2269 & TRN & & \\
\hline CHEMBL1351525 & 688653 & \multicolumn{3}{|c|}{5.132999999999999} & 5.6779 & TRN \\
\hline CHEMBL 1605885 & 688653 & \multicolumn{3}{|c|}{5.132999999999999} & 5.4115 & TRN \\
\hline CHEMBL1395046 & 688653 & \multicolumn{3}{|c|}{5.382999999999999} & 5.1275 & TRN \\
\hline CHEMBL1540114 & 688653 & \multicolumn{3}{|c|}{5.5329999999999995} & 5.2145 & TRN \\
\hline CHEMBL1344875 & 688653 & \multicolumn{3}{|c|}{5.132999999999999} & 4.9033 & TRN \\
\hline CHEMBL1562465 & 688653 & 4.933 & 5.5457 & TRN & & \\
\hline CHEMBL3192928 & 688653 & 5.233 & 6.2152 & TRN & & \\
\hline CHEMBL1465049 & 688653 & 6.0 & 4.8306 & TST & & \\
\hline CHEMBL1337752 & 688653 & 7.0329 & 5.5047 & TRN & & \\
\hline CHEMBL1347192 & 688653 & \multicolumn{3}{|c|}{4.7330000000000005} & 5.1608 & TST \\
\hline CHEMBL1560201 & 688653 & 4.783 & 4.8766 & TRN & & \\
\hline CHEMBL1554886 & 688653 & 5.683 & 5.5997 & TRN & & \\
\hline CHEMBL1586649 & 688653 & 5.933 & 5.0545 & TRN & & \\
\hline CHEMBL1573618 & 688653 & \multicolumn{3}{|c|}{4.7330000000000005} & 5.0339 & TRN \\
\hline CHEMBL3213991 & 688653 & 5.733 & 5.2998 & TRN & & \\
\hline CHEMBL1580340 & 688653 & 5.233 & 5.9108 & TRN & & \\
\hline CHEMBL1464312 & 688653 & 4.683 & 4.7407 & TST & & \\
\hline CHEMBL1536258 & 688653 & 5.683 & 5.7604 & TST & & \\
\hline CHEMBL1450119 & 688653 & 7.0329 & 6.0122 & TRN & & \\
\hline CHEMBL3195647 & 688653 & 5.483 & 5.5015 & TRN & & \\
\hline CHEMBL1308878 & 688653 & 5.683 & 5.2359 & TRN & & \\
\hline CHEMBL1548164 & 688653 & 5.183 & 5.3002 & TRN & & \\
\hline CHEMBL1483362 & 688653 & 5.083 & 5.1112 & TST & & \\
\hline CHEMBL1602144 & 688653 & 4.633 & 5.1684 & TRN & & \\
\hline CHEMBL1305452 & 688653 & 4.783 & 5.8918 & TST & & \\
\hline CHEMBL1452108 & 688653 & 6.0 & 5.0774 & TRN & & \\
\hline CHEMBL 2369157 & 688653 & \multicolumn{3}{|c|}{4.9830000000000005} & 5.4616 & TRN \\
\hline
\end{tabular}




\begin{tabular}{|c|c|c|c|c|c|c|}
\hline \multicolumn{7}{|c|}{ Supplemental Table S2.txt } \\
\hline CHEMBL1441980 & 688653 & \multicolumn{3}{|c|}{5.132999999999999} & 5.14 & TRN \\
\hline CHEMBL1435418 & 688653 & 4.783 & 5.1058 & TRN & & \\
\hline CHEMBL3189629 & 688653 & \multicolumn{3}{|c|}{5.832999999999999} & 5.7189 & TRN \\
\hline CHEMBL1576665 & 688653 & 4.683 & 5.2294 & TRN & & \\
\hline CHEMBL1465202 & 688653 & 5.683 & 5.5721 & TRN & & \\
\hline CHEMBL1461741 & 688653 & 5.683 & 5.4557 & TRN & & \\
\hline CHEMBL1313788 & 688653 & 5.433 & 5.84 & TRN & & \\
\hline CHEMBL1512759 & 688653 & 4.583 & 5.2573 & TRN & & \\
\hline CHEMBL1377481 & 688653 & \multicolumn{3}{|c|}{4.7330000000000005} & 5.2753 & TRN \\
\hline CHEMBL 309848 & 688653 & \multicolumn{3}{|c|}{5.132999999999999} & 5.1531 & TRN \\
\hline CHEMBL1342946 & 688653 & \multicolumn{3}{|c|}{4.7330000000000005} & 5.2119 & TST \\
\hline CHEMBL1426328 & 688653 & \multicolumn{3}{|c|}{5.332999999999999} & 5.0793 & TRN \\
\hline CHEMBL1485578 & 688653 & \multicolumn{3}{|c|}{4.9830000000000005} & 5.0284 & TST \\
\hline CHEMBL1554164 & 688653 & \multicolumn{3}{|c|}{6.082999999999999} & 5.5958 & TRN \\
\hline CHEMBL1503342 & 688653 & \multicolumn{3}{|c|}{6.132999999999999} & 4.8182 & TST \\
\hline CHEMBL1328353 & 688653 & \multicolumn{3}{|c|}{5.132999999999999} & 4.8627 & TST \\
\hline CHEMBL1478843 & 688653 & 4.583 & 5.2964 & TST & & \\
\hline CHEMBL1303892 & 688653 & 6.433 & 5.5174 & TRN & & \\
\hline CHEMBL1517741 & 688653 & 5.433 & 5.4999 & TRN & & \\
\hline CHEMBL1387154 & 688653 & 4.883 & 5.3996 & TRN & & \\
\hline CHEMBL 1482750 & 688653 & 5.233 & 4.9741 & TST & & \\
\hline CHEMBL1518450 & 688653 & 5.683 & 5.5253 & TRN & & \\
\hline CHEMBL1999069 & 688653 & \multicolumn{3}{|c|}{4.7330000000000005} & 6.2695 & TRN \\
\hline CHEMBL373909 & 688653 & 5.733 & 5.1251 & TRN & & \\
\hline CHEMBL1608285 & 688653 & 4.883 & 5.1932 & TRN & & \\
\hline CHEMBL1324867 & 688653 & \multicolumn{3}{|c|}{5.2829999999999995} & 5.1722 & TST \\
\hline CHEMBL1336180 & 688653 & 5.683 & 5.5253 & TRN & & \\
\hline CHEMBL1516956 & 688653 & \multicolumn{3}{|c|}{4.7330000000000005} & 5.5238 & TRN \\
\hline CHEMBL1360346 & 688653 & 5.933 & 5.4252 & TRN & & \\
\hline CHEMBL1302481 & 688653 & \multicolumn{3}{|c|}{4.7330000000000005} & 5.1331 & TRN \\
\hline CHEMBL1599433 & 688653 & \multicolumn{3}{|c|}{5.332999999999999} & 5.4719 & TRN \\
\hline CHEMBL1609970 & 688653 & \multicolumn{3}{|c|}{6.382999999999999} & 5.5723 & TRN \\
\hline CHEMBL1570497 & 688653 & \multicolumn{3}{|c|}{4.7330000000000005} & 4.9934 & TST \\
\hline CHEMBL1602304 & 688653 & 5.233 & 5.2057 & TRN & & \\
\hline CHEMBL1992834 & 688653 & \multicolumn{3}{|c|}{5.132999999999999} & 5.23799 & 99999999995 \\
\hline CHEMBL1452467 & 688653 & \multicolumn{3}{|c|}{5.5329999999999995} & 5.5196 & TRN \\
\hline CHEMBL1994973 & 688653 & \multicolumn{3}{|c|}{4.7330000000000005} & 4.9324 & TRN \\
\hline CHEMBL1519521 & 688653 & 4.933 & 5.3007 & TRN & & \\
\hline CHEMBL1313340 & 688653 & 4.833 & 5.346 & TRN & & \\
\hline CHEMBL1383277 & 688653 & 4.7330 & 00000000 & 005 & 5.5458 & TRN \\
\hline CHEMBL1542330 & 688653 & 5.233 & 5.8606 & TRN & & \\
\hline CHEMBL1525458 & 688653 & 4.783 & 5.5272 & TRN & & \\
\hline CHEMBL1384000 & 688653 & 4.7330 & 00000000 & 005 & 4.9956 & TST \\
\hline CHEMBL1477139 & 688653 & 4.883 & 5.3272 & TRN & & \\
\hline CHEMBL1587615 & 688653 & 4.783 & 5.1558 & TST & & \\
\hline CHEMBL 272945 & 688653 & 5.183 & 5.1014 & TRN & & \\
\hline CHEMBL1510805 & 688653 & 5.183 & 5.1649 & TRN & & \\
\hline CHEMBL1591656 & 688653 & 5.433 & 5.6922 & TRN & & \\
\hline
\end{tabular}




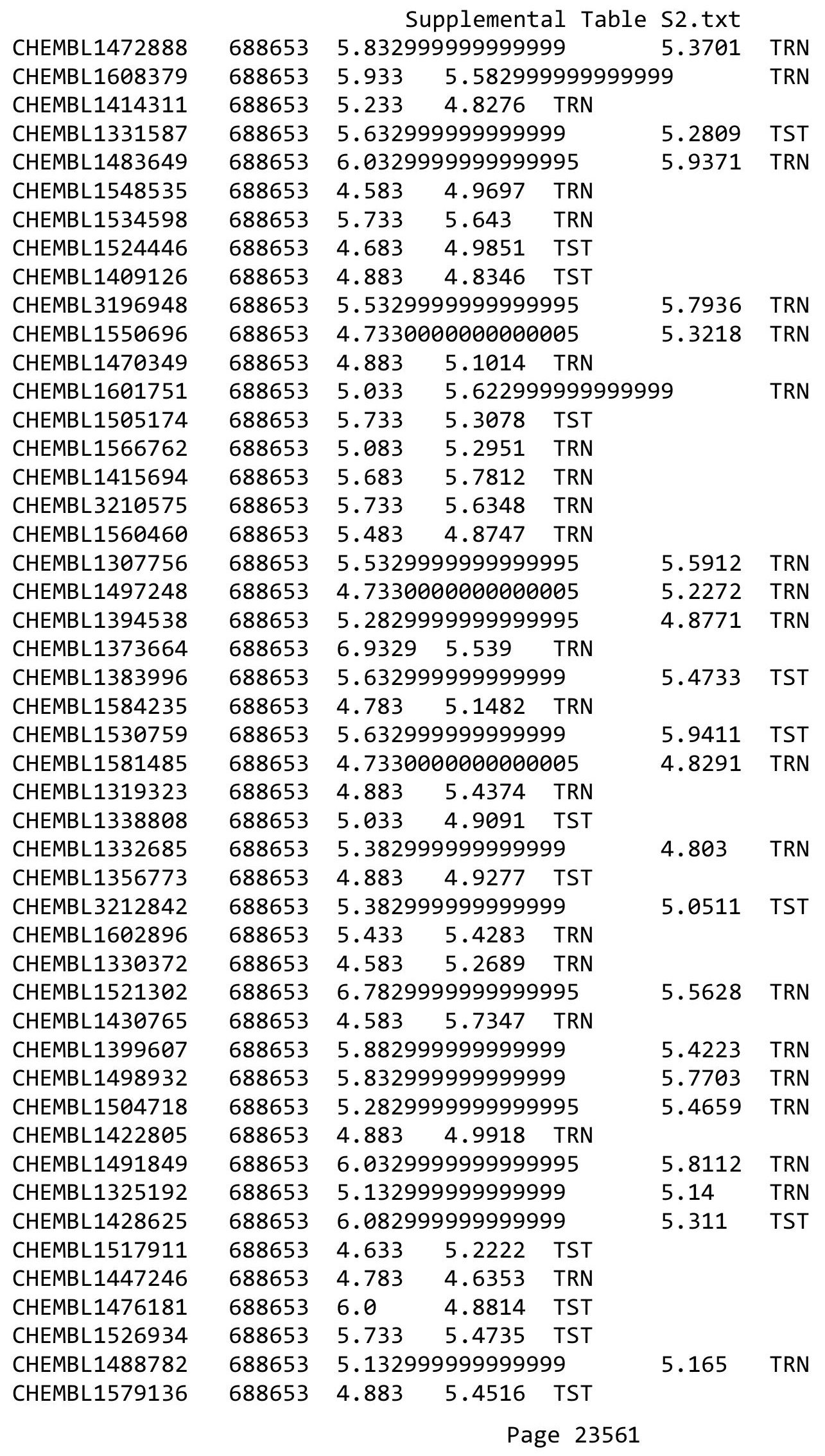




\begin{tabular}{|c|c|c|c|c|c|c|}
\hline & & \multicolumn{4}{|c|}{ Supplemental Table s2.txt } & \\
\hline CHEMBL1469108 & 688653 & \multicolumn{3}{|c|}{4.7330000000000005} & 5.3491 & TRN \\
\hline CHEMBL1497286 & 688653 & \multicolumn{3}{|c|}{4.7330000000000005} & 4.8567 & TST \\
\hline CHEMBL1333049 & 688653 & \multicolumn{3}{|c|}{6.832999999999999} & 5.4331 & TRN \\
\hline CHEMBL3189671 & 688653 & 6.183 & 5.5779 & TST & & \\
\hline CHEMBL1406753 & 688653 & \multicolumn{3}{|c|}{6.0329999999999995} & 5.7643 & TRN \\
\hline CHEMBL1324717 & 688653 & 5.083 & 5.1257 & TRN & & \\
\hline CHEMBL1327227 & 688653 & 5.083 & 4.9957 & TST & & \\
\hline CHEMBL1308062 & 688653 & \multicolumn{3}{|c|}{5.832999999999999} & 5.6348 & TRN \\
\hline CHEMBL1355541 & 688653 & 4.583 & 5.8038 & TST & & \\
\hline CHEMBL3195005 & 688653 & \multicolumn{3}{|c|}{4.7330000000000005} & 4.837 & TST \\
\hline CHEMBL1313883 & 688653 & 4.933 & 4.9167 & TRN & & \\
\hline CHEMBL1452048 & 688653 & \multicolumn{3}{|c|}{5.132999999999999} & 5.3931 & TRN \\
\hline CHEMBL1340694 & 688653 & 4.633 & 4.7449 & TRN & & \\
\hline CHEMBL3191589 & 688653 & \multicolumn{3}{|c|}{4.7330000000000005} & 5.3803 & TRN \\
\hline CHEMBL1550455 & 688653 & 4.683 & 5.4668 & TST & & \\
\hline CHEMBL1515322 & 688653 & \multicolumn{3}{|c|}{5.7829999999999995} & 5.1518 & TRN \\
\hline CHEMBL1442636 & 688653 & \multicolumn{3}{|c|}{4.7330000000000005} & 5.1293 & TRN \\
\hline CHEMBL1440713 & 688653 & 5.183 & 5.4012 & TRN & & \\
\hline CHEMBL1529295 & 688653 & 4.583 & 5.3695 & TRN & & \\
\hline CHEMBL1502070 & 688653 & 4.883 & 5.5377 & TRN & & \\
\hline CHEMBL442925 & 688653 & 5.183 & 5.9448 & TRN & & \\
\hline CHEMBL1338117 & 688653 & 5.033 & 5.9029 & TRN & & \\
\hline CHEMBL1472841 & 688653 & \multicolumn{3}{|c|}{4.9830000000000005} & 4.9188 & TRN \\
\hline CHEMBL1327983 & 688653 & \multicolumn{3}{|c|}{4.9830000000000005} & 5.3724 & TST \\
\hline CHEMBL1582817 & 688653 & \multicolumn{3}{|c|}{5.382999999999999} & 5.0256 & TST \\
\hline CHEMBL1464670 & 688653 & 4.883 & 5.2305 & TRN & & \\
\hline CHEMBL1448265 & 688653 & \multicolumn{3}{|c|}{4.7330000000000005} & 5.2275 & TST \\
\hline CHEMBL3212018 & 688653 & \multicolumn{3}{|c|}{4.7330000000000005} & 4.5559 & TST \\
\hline CHEMBL1979383 & 688653 & \multicolumn{3}{|c|}{6.332999999999999} & 6.0286 & TRN \\
\hline CHEMBL1609667 & 688653 & 4.633 & 5.1422 & TRN & & \\
\hline CHEMBL1360465 & 688653 & 4.883 & 5.5855 & TRN & & \\
\hline CHEMBL1492519 & 688653 & \multicolumn{3}{|c|}{4.7330000000000005} & 5.1397 & TST \\
\hline CHEMBL3189485 & 688653 & & 5.359 & TRN \\
\hline CHEMBL1320446 & 688653 & \multicolumn{3}{|c|}{$\begin{array}{lr}5.7829999999999995 \\
4.633 & 5.6739999999\end{array}$} & 995 & TRN \\
\hline CHEMBL1381673 & 688653 & 4.633 & 4.9275 & TRN & & \\
\hline CHEMBL1467921 & 688653 & \multicolumn{3}{|c|}{5.832999999999999} & 5.5462 & TST \\
\hline CHEMBL1392186 & 688653 & 5.083 & 5.1703 & TST & & \\
\hline CHEMBL1561897 & 688653 & 4.933 & 5.0919 & TRN & & \\
\hline CHEMBL1302146 & 688653 & 6.53299 & 99999999 & 995 & 6.2571 & TRN \\
\hline CHEMBL1520970 & 688653 & 4.583 & 5.2925 & TRN & & \\
\hline CHEMBL1580279 & 688653 & 5.083 & 5.1197 & TRN & & \\
\hline CHEMBL1332913 & 688653 & 4.73300 & 30000000 & 005 & 5.0134 & TRN \\
\hline CHEMBL1585116 & 688653 & 4.783 & 5.2 & TST & & \\
\hline CHEMBL1601263 & 688653 & 5.78299 & 99999999 & 995 & 5.3226 & TST \\
\hline CHEMBL1333686 & 688653 & 4.933 & 5.2687 & TRN & & \\
\hline CHEMBL1532797 & 688653 & 4.833 & 5.4843 & TRN & & \\
\hline CHEMBL1545169 & 688653 & 6.8831 & 5.4079 & TST & & \\
\hline CHEMBL1321343 & 688653 & 4.783 & 5.0746 & TST & & \\
\hline
\end{tabular}




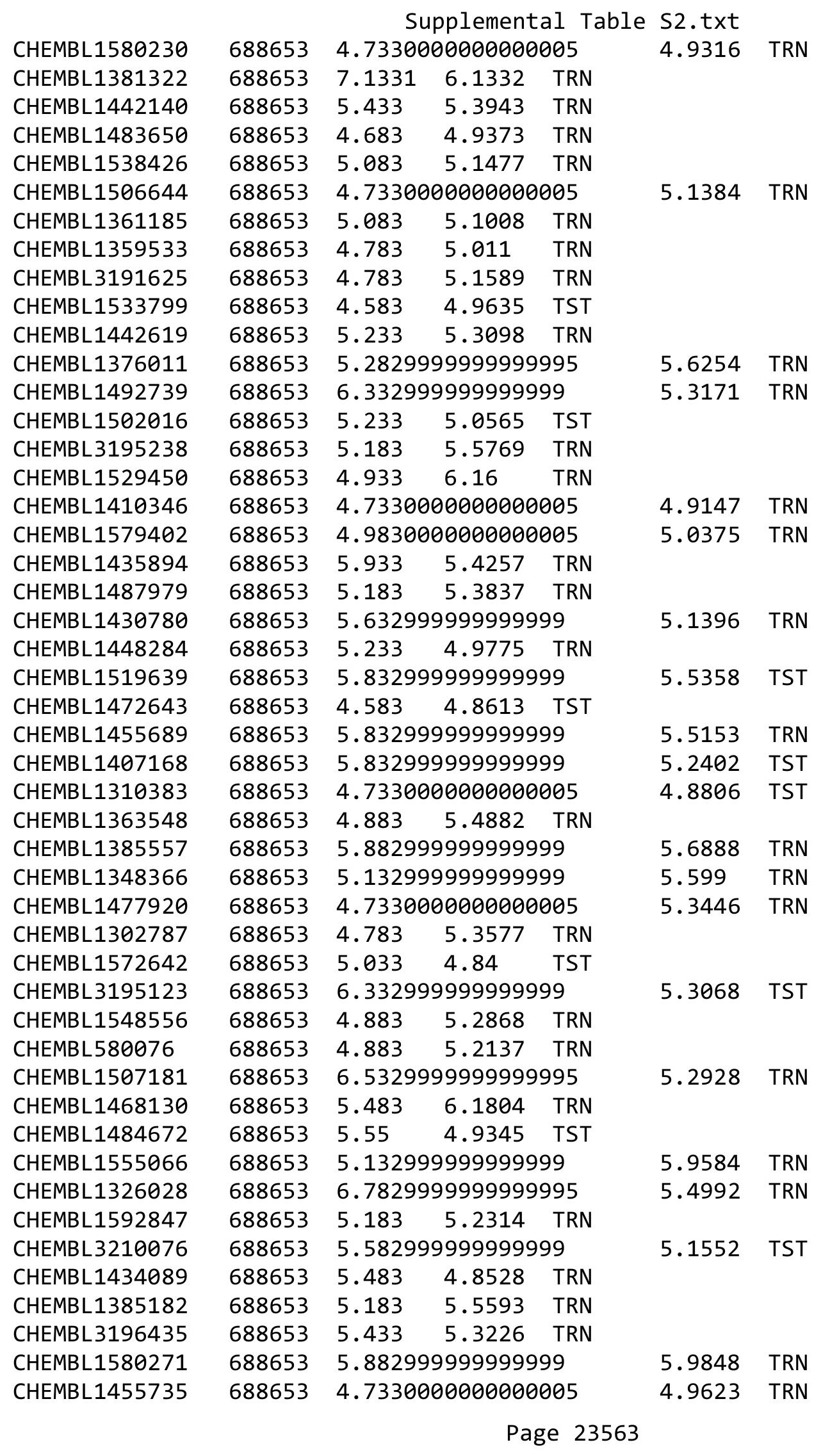




\begin{tabular}{|c|c|c|c|c|c|c|}
\hline \multirow{3}{*}{$\begin{array}{l}\text { CHEMBL1437001 } \\
\text { CHEMBL1596085 }\end{array}$} & & \multicolumn{5}{|c|}{ Supplemental Table s2.txt } \\
\hline & 688653 & \multicolumn{3}{|c|}{5.5329999999999995} & 4.6734 & $\mathrm{~T}$ \\
\hline & 688653 & 4.633 & 5.1004 & TST & & \\
\hline CHEMBL1606340 & 688653 & \multicolumn{3}{|c|}{4.7330000000000005} & 5.1023 & \\
\hline CHEMBL1571116 & 688653 & 5.033 & 5.3668 & TRN & & \\
\hline CHEMBL1524515 & 688653 & 4.683 & 5.2777 & TRN & & \\
\hline CHEMBL1473678 & 688653 & 4.633 & 5.2235 & TRN & & \\
\hline CHEMBL1305131 & 688653 & 5.683 & 4.7686 & TST & & \\
\hline CHEMBL1478531 & 688653 & 6.433 & 5.8525 & TRN & & \\
\hline CHEMBL1525127 & 688653 & 5.0 & 5.2487 & TRN & & \\
\hline CHEMBL1569626 & 688653 & \multicolumn{3}{|c|}{4.7330000000000005} & 5.5253 & \\
\hline CHEMBL1494628 & 688653 & 4.633 & 5.4102 & TST & & \\
\hline CHEMBL1552586 & 688653 & 4.783 & 5.4917 & TST & & \\
\hline CHEMBL1477350 & 688653 & 4.883 & 5.3435 & TRN & & \\
\hline CHEMBL1512137 & 688653 & 4.633 & 4.9224 & TRN & & \\
\hline CHEMBL84472 & 688653 & 5.183 & 5.1887 & TST & & \\
\hline CHEMBL1967031 & 688653 & 7.1831 & 5.6477 & TRN & & \\
\hline CHEMBL1393107 & 688653 & \multicolumn{3}{|c|}{4.7330000000000005} & 0926 & \\
\hline CHEMBL1437454 & 688653 & 4.833 & 4.9506 & TRN & & \\
\hline CHEMBL1480744 & 688653 & \multicolumn{3}{|c|}{5.5329999999999995} & 5.5453 & \\
\hline CHEMBL1607924 & 688653 & 4.833 & 5.4222 & TRN & & \\
\hline CHEMBL1609339 & 688653 & 4.883 & 5.4022 & TRN & & \\
\hline CHEMBL1 & 688653 & \multicolumn{3}{|c|}{4.9830000000000005} & 3.4100 & \\
\hline CHEMBL1472661 & 688653 & 4.883 & 4.9801 & TRN & & \\
\hline CHEMBL 1490123 & 688653 & \multicolumn{3}{|c|}{5.2829999999999995} & 5.4117 & \\
\hline CHEMBL1516043 & 688653 & 4.833 & 4.7869 & TST & & \\
\hline CHEMBL1575397 & 688653 & \multicolumn{3}{|c|}{4.9830000000000005} & 5.2927 & \\
\hline CHEMBL1 & 688653 & \multicolumn{3}{|c|}{5.2829999999999995} & 4.9874 & \\
\hline CHEMBL1 & 688653 & 4.883 & 5.2085 & TST & & \\
\hline CHEMBL1438124 & 688653 & 4.633 & 4.845 & TRN & & \\
\hline CHEMBL1491170 & 688653 & 4.933 & 5.2086 & TRN & & \\
\hline CHEMBL 3197445 & 688653 & 4.833 & 5.001 & TRN & & \\
\hline CHEME & 688653 & 5.183 & 5.2997 & TST & & \\
\hline CHEMBL1424822 & 688653 & \multicolumn{3}{|c|}{5.832999999999999} & 5.3668 & \\
\hline CHEMBL1541901 & 688653 & 4.633 & 4.9418 & TST & & \\
\hline CHEMBL1301159 & 688653 & \multicolumn{3}{|c|}{5.5329999999999995} & 4.9066 & \\
\hline CHEMBL1459113 & 688653 & \multicolumn{3}{|c|}{4.7330000000000005} & 4.9642 & \\
\hline CHEMBL1 & 688653 & \multicolumn{3}{|c|}{5.7829999999999995} & 5.6154 & $\mathrm{TI}$ \\
\hline CHEMBL1544377 & 688653 & \multicolumn{3}{|c|}{6.332999999999999} & 5.4415 & \\
\hline CHEMBL1501189 & 688653 & 4.783 & 5.2065 & TRN & & \\
\hline CHEMBL1582052 & 688653 & \multirow{2}{*}{\multicolumn{3}{|c|}{$\begin{array}{lrr}5.433 & 5.0561 & \text { TST } \\
6.5329999999999995\end{array}$}} & & \\
\hline CHEMBL1996068 & 688653 & & & & 6.3245 & \\
\hline CHEMBL1405922 & 688653 & 4.633 & 4.846 & TST & & \\
\hline CHEMBL1401550 & 688653 & 5.233 & 5.1645 & TRN & & \\
\hline CHEMBL1563081 & 688653 & 5.7829 & 99999999 & 995 & 5.0858 & \\
\hline CHEMBL1330201 & 688653 & 6.3329 & 99999999 & & 5.4697 & \\
\hline CHEMBL 3193752 & 688653 & 4.833 & 5.2185 & TST & & \\
\hline CHEMBL1425940 & 688653 & 4.883 & 5.1726 & TRN & & \\
\hline CHEMBL1612392 & 688653 & \multicolumn{3}{|c|}{5.7829999999999995} & 6.3333 & \\
\hline
\end{tabular}




\begin{tabular}{|c|c|c|c|c|c|c|c|}
\hline \multirow[b]{2}{*}{ CHEMBL1362680 } & & \\
\hline & 688653 & 5.083 & 5.6529 & TST & & & \\
\hline CHEMBL1507127 & 688653 & 5.33299 & 999999995 & & 5.3352 & TRN & \\
\hline CHEMBL1299715 & 688653 & 6.08299 & 99999999 & & 5.7181 & TRN & \\
\hline CHEMBL1357093 & 688653 & 5.483 & 5.327006 & 000000000 & & TST & \\
\hline CHEMBL1422034 & 688653 & 4.783 & 5.2908 & TRN & & & \\
\hline CHEMBL421088 & 688653 & 6.683 & 5.607 & TRN & & & \\
\hline CHEMBL1446609 & 688653 & 4.73300 & 000000006 & 005 & 5.2667 & TRN & \\
\hline CHEMBL1597829 & 688653 & 5.433 & 5.0066 & TST & & & \\
\hline CHEMBL1488285 & 688653 & 5.233 & 4.7807 & TRN & & & \\
\hline CHEMBL1608696 & 688653 & 4.583 & 5.0459 & TRN & & & \\
\hline CHEMBL1549214 & 688653 & 4.883 & 4.948 & TRN & & & \\
\hline CHEMBL1565349 & 688653 & 5.28299 & 999999995 & 995 & 5.044 & TRN & \\
\hline CHEMBL3189334 & 688653 & 4.583 & 5.1664 & TRN & & & \\
\hline CHEMBL1609096 & 688653 & 6.08299 & 999999995 & & 5.0798 & TST & \\
\hline CHEMBL1479657 & 688653 & 6.7331 & 5.6994 & TRN & & & \\
\hline CHEMBL1313467 & 688653 & 4.833 & 5.224 & TRN & & & \\
\hline CHEMBL1398242 & 688653 & 5.38299 & 999999995 & & 5.233 & TRN & \\
\hline CHEMBL1569436 & 688653 & 5.28299 & 999999999 & 995 & 5.4397 & TRN & \\
\hline CHEMBL1341848 & 688653 & 5.233 & 5.2976 & TRN & & & \\
\hline CHEMBL1445765 & 688653 & 4.883 & 5.5669 & TRN & & & \\
\hline CHEMBL1470195 & 688653 & 5.53299 & 999999995 & 995 & 5.2533 & TRN & \\
\hline CHEMBL1519019 & 688653 & 6.58299 & 999999995 & & 5.6039 & TRN & \\
\hline CHEMBL3195830 & 688653 & 4.73300 & 000000006 & 005 & 5.0412 & TST & \\
\hline CHEMBL1571541 & 688653 & 5.33299 & 99999999؛ & & 5.6213 & TRN & \\
\hline CHEMBL3211716 & 688653 & 5.683 & 5.2412 & TRN & & & \\
\hline CHEMBL1366346 & 688653 & 5.033 & 5.4129 & TRN & & & \\
\hline CHEMBL1532502 & 688653 & 4.883 & 5.59 & TRN & & & \\
\hline CHEMBL1542099 & 688653 & 7.0329 & 6.3151 & TRN & & & \\
\hline CHEMBL1599868 & 688653 & 4.73300 & 000000000 & 005 & 5.2446 & TST & \\
\hline CHEMBL69631 & 688653 & 4.73300 & 000000000 & 005 & 5.252999 & 9999999999 & TRN \\
\hline CHEMBL1472363 & 688653 & 6.38299 & 999999999 & & 5.6766 & TRN & \\
\hline CHEMBL1459826 & 688653 & 4.783 & 5.4307 & TST & & & \\
\hline CHEMBL3209900 & 688653 & 5.13299 & 999999999 & & 5.0555 & TRN & \\
\hline CHEMBL1592999 & 688653 & 6.433 & 5.6245 & TRN & & & \\
\hline CHEMBL1459701 & 688653 & 5.13299 & 999999999 & & 5.0818 & TRN & \\
\hline CHEMBL1600970 & 688653 & 4.633 & 5.3183 & TRN & & & \\
\hline CHEMBL1464490 & 688653 & 5.733 & 5.1862 & TST & & & \\
\hline CHEMBL3208380 & 688653 & 4.883 & 5.2482 & TRN & & & \\
\hline CHEMBL1582955 & 688653 & 5.13299 & 999999999 & & 5.2334 & TRN & \\
\hline CHEMBL1382564 & 688653 & 4.833 & 5.5526 & TRN & & & \\
\hline CHEMBL1594789 & 688653 & 4.783 & 4.8907 & TST & & & \\
\hline CHEMBL1344245 & 688653 & 4.833 & 4.9674 & TRN & & & \\
\hline CHEMBL3190217 & 688653 & 5.183 & 5.2915 & TRN & & & \\
\hline CHEMBL1389742 & 688653 & 4.73300 & 000000000 & 205 & 5.3832 & TRN & \\
\hline CHEMBL 3213267 & 688653 & 5.58299 & 999999999 & & $5.12200 e$ & 2000000001 & TRN \\
\hline CHEMBL1562079 & 688653 & 5.183 & 6.045 & TRN & & & \\
\hline CHEMBL1319698 & 688653 & 4.783 & 5.542999 & 999999999 & & TRN & \\
\hline CHEMBL1499615 & 688653 & 4.883 & 5.1456 & TRN & & & \\
\hline
\end{tabular}




\begin{tabular}{|c|c|c|c|c|c|c|c|}
\hline & & & pplement & al Table & s2.txt & & \\
\hline CHEMBL3197153 & 688653 & 4.98300 & 00000000 & 005 & 5.1393 & TRN & \\
\hline CHEMBL1978607 & 688653 & 5.58299 & 999999995 & & 5.63200 & 0000000001 & TST \\
\hline CHEMBL1544979 & 688653 & 4.883 & 4.9267 & TRN & & & \\
\hline CHEMBL1562411 & 688653 & 5.78299 & 99999999 & 995 & 5.6579 & TRN & \\
\hline CHEMBL1734063 & 688653 & 4.633 & 4.7324 & TRN & & & \\
\hline CHEMBL 3197200 & 688653 & 7.08299 & 99999999 & & 5.568 & TRN & \\
\hline CHEMBL1444711 & 688653 & 4.783 & 4.8646 & TRN & & & \\
\hline CHEMBL1386418 & 688653 & 4.98300 & 000000006 & 005 & 4.9246 & TRN & \\
\hline CHEMBL1546623 & 688653 & 5.733 & 5.8198 & TRN & & & \\
\hline CHEMBL1516217 & 688653 & 5.83299 & 99999999 & & 5.5998 & TRN & \\
\hline CHEMBL1361786 & 688653 & 5.33299 & 99999999 & & 4.9912 & TRN & \\
\hline CHEMBL1411527 & 688653 & 5.53299 & 99999999 & 995 & 5.4648 & TRN & \\
\hline CHEMBL1382300 & 688653 & 5.38299 & 99999999 & & 5.5796 & TRN & \\
\hline CHEMBL1434258 & 688653 & 5.88299 & 99999999 & & 5.8241 & TRN & \\
\hline CHEMBL1425330 & 688653 & 4.783 & 5.3306 & TRN & & & \\
\hline CHEMBL1589173 & 688653 & 5.483 & 4.9556 & TRN & & & \\
\hline CHEMBL1380805 & 688653 & 5.78299 & 99999999 & 995 & 6.0477 & TRN & \\
\hline CHEMBL1514242 & 688653 & 4.633 & 5.0998 & TRN & & & \\
\hline CHEMBL3198941 & 688653 & 5.733 & 5.2888 & TRN & & & \\
\hline CHEMBL1345046 & 688653 & 6.03299 & 99999999 & 995 & 5.6962 & TRN & \\
\hline CHEMBL 3192223 & 688653 & 5.683 & 5.5073 & TST & & & \\
\hline CHEMBL1427856 & 688653 & 4.883 & 5.3109 & TST & & & \\
\hline CHEMBL1443204 & 688653 & 4.583 & 5.447 & TST & & & \\
\hline CHEMBL1351651 & 688653 & 5.683 & 5.482 & TRN & & & \\
\hline CHEMBL1513064 & 688653 & 5.483 & 5.0535 & TST & & & \\
\hline CHEMBL1375921 & 688653 & 4.933 & 5.1343 & TRN & & & \\
\hline CHEMBL 3192838 & 688653 & 5.78299 & 99999999 & 995 & 5.2202 & TRN & \\
\hline CHEMBL3194104 & 688653 & 5.083 & 5.3033 & TRN & & & \\
\hline CHEMBL1363390 & 688653 & 5.683 & 5.4705 & TRN & & & \\
\hline CHEMBL1564911 & 688653 & 4.933 & 5.0495 & TRN & & & \\
\hline CHEMBL1415501 & 688653 & 5.183 & 5.0379 & TST & & & \\
\hline CHEMBL 3208395 & 688653 & 4.783 & 5.0765 & TRN & & & \\
\hline CHEMBL1490022 & 688653 & 4.933 & 5.296 & TST & & & \\
\hline CHEMBL1398582 & 688653 & 4.583 & 5.61 & TRN & & & \\
\hline CHEMBL1334219 & 688653 & 4.583 & 5.1982 & TST & & & \\
\hline CHEMBL1349033 & 688653 & 4.783 & 4.9369 & TRN & & & \\
\hline CHEMBL1371291 & 688653 & 4.883 & 5.1896 & TRN & & & \\
\hline CHEMBL1576393 & 688653 & 5.78299 & 99999999 & 995 & 5.7527 & TRN & \\
\hline CHEMBL1361116 & 688653 & 6.0 & $5.86600 t$ & 000000000 & 205 & TRN & \\
\hline CHEMBL1351577 & 688653 & 5.083 & 5.4992 & TRN & & & \\
\hline CHEMBL 3214372 & 688653 & 4.883 & $5.41200 t$ & 000000000 & & TST & \\
\hline CHEMBL1450164 & 688653 & 4.683 & 5.4114 & TRN & & & \\
\hline CHEMBL1501872 & 688653 & 6.13299 & 99999999 & & 5.6815 & TRN & \\
\hline CHEMBL1436291 & 688653 & 5.63299 & 999999995 & & 5.5879 & TRN & \\
\hline CHEMBL1456395 & 688653 & 4.933 & 5.2449 & TRN & & & \\
\hline CHEMBL1333541 & 688653 & 5.83299 & 99999999 & & 5.3719 & TRN & \\
\hline CHEMBL1563176 & 688653 & 4.583 & 4.9141 & TRN & & & \\
\hline CHEMBL1967184 & 688653 & 5.28299 & 99999999 & 995 & 5.0561 & TST & \\
\hline
\end{tabular}




\begin{tabular}{|c|c|c|c|c|c|c|}
\hline \multirow{3}{*}{$\begin{array}{l}\text { CHEMBL1305281 } \\
\text { CHEMBL1392151 }\end{array}$} & \multirow{3}{*}{$\begin{array}{l}688653 \\
688653\end{array}$} & \multicolumn{4}{|c|}{ Supplemental Table s2.txt } & \multirow{3}{*}{ TRN } \\
\hline & & \multicolumn{3}{|c|}{5.2829999999999995} & \multirow[t]{4}{*}{4.9403} & \\
\hline & & 4.883 & 5.2089 & TST & & \\
\hline CHEMBL3208298 & 688653 & 4.833 & 5.2725 & TRN & & \\
\hline CHEMBL1325231 & 588653 & 4.783 & 5.3386 & TRN & & \\
\hline CHEMBL226187 & 688653 & \multicolumn{3}{|c|}{5.832999999999999} & 5.6144 & 1 \\
\hline CHEMBL1303584 & 688653 & 4.683 & 5.1389 & TRN & & \\
\hline CHEMBL1335365 & 688653 & \multicolumn{3}{|c|}{5.2829999999999995} & 4.7858 & $\mathrm{~T}$ \\
\hline CHEMBL1316329 & 688653 & 4.583 & 5.0693 & TRN & & \\
\hline CHEMBL1504415 & 588653 & 5.233 & 5.113 & TRN & & \\
\hline CHEMBL1304864 & 688653 & \multicolumn{3}{|c|}{4.7330000000000005} & 5.0797 & TST \\
\hline CHEMBL1426791 & 688653 & \multicolumn{3}{|c|}{5.2829999999999995} & 5.062 & \\
\hline CHEMBL1526855 & 688653 & 4.833 & 4.9222 & TST & & \\
\hline CHEMBL3191447 & 688653 & 4.833 & 5.1234 & TRN & & \\
\hline CHEMBL1347101 & 688653 & \multicolumn{3}{|c|}{6.2829999999999995} & 5.1432 & \\
\hline CHEMBL1384957 & 688653 & 4.933 & 4.8473 & TRN & & \\
\hline CHEMBL1522 & 688 & \multicolumn{3}{|c|}{5.7829999999999995} & 17 & \\
\hline CHEMBL142 & 688 & 4.633 & 4.8041 & TST & & \\
\hline CHEMBL1476006 & 688653 & 4.633 & 4.9935 & TST & & \\
\hline CHEMBL1355134 & 688653 & 4.833 & 5.0623 & TRN & & \\
\hline CHEMBL1570977 & 688653 & \multicolumn{3}{|c|}{5.5329999999999995} & 5.2808 & \\
\hline CHEMBL & 688 & 4.833 & 4.7212 & TST & & \\
\hline CHEMBL 1 & 688 & \multicolumn{3}{|c|}{4.7330000000000005} & 4.7672 & 1. \\
\hline CHEMBL1445784 & 688653 & 5.083 & 5.1826 & TRN & & \\
\hline CHEMBL1491632 & 6886 & 4.783 & 4.7382 & TST & & \\
\hline CHEMBL1402704 & 688653 & \multicolumn{3}{|c|}{4.7330000000000005} & 5.7113 & \\
\hline CHEMBL & 688 & 4.833 & 5.0806 & TRN & & \\
\hline CHEMBL1372305 & 688 & 5.233 & 5.0994 & TRN & & \\
\hline CHEMBL1489123 & 688653 & \multicolumn{3}{|c|}{4.7330000000000005} & 5 . & TR \\
\hline CHEMBL1560210 & 688653 & \multicolumn{3}{|c|}{4.9830000000000005} & & 11 \\
\hline CHEMBL1499864 & 688 & \multicolumn{3}{|c|}{5.132999999999999} & 5.7768 & \\
\hline CHEMBL1 & $68 \varepsilon$ & 4.633 & 4.8714 & TRN & & \\
\hline CHEMBL1977173 & 688 & 4 . & 5.2606 & TRN & & \\
\hline CHEMBL3190480 & 688653 & 4. & 4.9917 & TRN & & \\
\hline CHEMBL3209083 & 688 & 5.183 & 5.1316 & TRN & & \\
\hline CHEMBL149 & $68 \varepsilon$ & \multicolumn{3}{|c|}{6.0329999999999995} & 5.6735 & $1 \mathrm{KI}$ \\
\hline CHEMBL148 & 688 & 4.883 & 5.4389 & TRN & & \\
\hline CHEMBL1357388 & 688653 & 4.933 & 5.6315 & TRN & & \\
\hline CHEMBL1528305 & 688653 & 4.883 & 5.6295 & TRN & & \\
\hline CHEMBL3209742 & 688653 & \multicolumn{3}{|c|}{4.7330000000000005} & & \\
\hline CHEMBL132 & 688 & \multicolumn{3}{|c|}{5.382999999999999} & 5.4505 & \\
\hline CHEMBL1374512 & 688653 & 5.183 & 5.2993 & TRN & & \\
\hline CHEMBL1373280 & 688653 & 4.7336 & 00000000 & 005 & 5.0522 & TRN \\
\hline CHEMBL1573688 & 688653 & 5.2829 & 99999999 & 995 & 4.9433 & \\
\hline CHEMBL1401828 & 688653 & 5.8329 & 99999999 & & 5.4274 & - \\
\hline CHEMBL1599444 & 688653 & 4.683 & 4.9614 & TST & & \\
\hline CHEMBL1318422 & 688653 & 6.0325 & 99999999 & 995 & 5.7574 & ונדו \\
\hline CHEMBL2171381 & 688653 & 5.7829 & 99999999 & 995 & 5.5002 & TRN \\
\hline CHEMBL1352934 & 688653 & 4.9836 & 00000000 & 005 & 5.2643 & \\
\hline
\end{tabular}




\begin{tabular}{|c|c|c|c|c|c|c|c|}
\hline \multirow[b]{2}{*}{ CHEMBL581346 } & \multicolumn{6}{|c|}{ Supplemental Table S2.txt } & \\
\hline & 688653 & 4.883 & 5.2634 & TRN & & & \\
\hline CHEMBL1517361 & 688653 & 5.13299 & 99999999 & & 5.53606 & 00000000005 & TRN \\
\hline CHEMBL1367602 & 688653 & 6.13299 & 99999999 & & 5.5692 & TST & \\
\hline CHEMBL1416655 & 688653 & 6.433 & 5.7427 & TRN & & & \\
\hline CHEMBL1404648 & 688653 & 5.33299 & 99999999 & & 5.5995 & TRN & \\
\hline CHEMBL1606338 & 688653 & 4.833 & 5.2327 & TRN & & & \\
\hline CHEMBL1371638 & 688653 & 4.833 & 5.1136 & TRN & & & \\
\hline CHEMBL1342328 & 688653 & 4.833 & 5.2899 & TST & & & \\
\hline CHEMBL1350040 & 688653 & 4.683 & 5.3845 & TRN & & & \\
\hline CHEMBL1352257 & 688653 & 5.483 & 5.5211 & TRN & & & \\
\hline CHEMBL1376588 & 688653 & 4.783 & 5.1418 & TST & & & \\
\hline CHEMBL1503339 & 688653 & 5.88299 & 99999999 & & 5.3424 & TRN & \\
\hline CHEMBL1526423 & 688653 & 4.73306 & 00000000 & 005 & 4.9343 & TRN & \\
\hline CHEMBL1563212 & 688653 & 5.78299 & 99999999 & 995 & 5.1522 & TRN & \\
\hline CHEMBL1533194 & 688653 & 5.33299 & 99999999 & & 5.1519 & TST & \\
\hline CHEMBL1442908 & 688653 & 4.583 & 4.7487 & TST & & & \\
\hline CHEMBL1602119 & 688653 & 5.183 & 5.0508 & TRN & & & \\
\hline CHEMBL1560119 & 688653 & 4.783 & 5.069 & TRN & & & \\
\hline CHEMBL3212830 & 688653 & 6.0 & 5.7027 & TRN & & & \\
\hline CHEMBL1480410 & 688653 & 4.833 & 5.0994 & TRN & & & \\
\hline CHEMBL1448029 & 688653 & 5.983 & 5.3512 & TRN & & & \\
\hline CHEMBL1600346 & 688653 & 4.783 & 5.159 & TRN & & & \\
\hline CHEMBL1388152 & 688653 & 4.583 & 5.1065 & TST & & & \\
\hline CHEMBL1317653 & 688653 & 4.633 & 4.8682 & TRN & & & \\
\hline CHEMBL1506967 & 688653 & 5.53299 & 99999999 & 995 & 4.7663 & TST & \\
\hline CHEMBL1381881 & 688653 & $4.9830 €$ & 00000000 & 005 & 4.9655 & TRN & \\
\hline CHEMBL1550859 & 688653 & 4.73306 & 00000000 & 005 & 5.0091 & TRN & \\
\hline CHEMBL1388738 & 688653 & 6.683 & 5.8042 & TRN & & & \\
\hline CHEMBL1465550 & 688653 & 4.73306 & 00000000 & 005 & 5.3644 & TRN & \\
\hline CHEMBL1306323 & 688653 & 7.3325 & 5.9168 & TRN & & & \\
\hline CHEMBL1397236 & 688653 & 4.683 & 4.8648 & TRN & & & \\
\hline CHEMBL1311351 & 688653 & 6.08299 & 99999999 & & 5.4564 & TST & \\
\hline CHEMBL1381395 & 688653 & $5.5329 c$ & 99999999 & 995 & 5.254 & TRN & \\
\hline CHEMBL1299786 & 688653 & 5.933 & 5.3332 & TST & & & \\
\hline CHEMBL1606956 & 688653 & 5.983 & 5.4298 & TRN & & & \\
\hline CHEMBL1580204 & 688653 & 5.183 & 5.5987 & TRN & & & \\
\hline CHEMBL1593752 & 688653 & 4.783 & 5.2407 & TRN & & & \\
\hline CHEMBL1480238 & 688653 & 5.2829 & 99999999 & 995 & 6.1451 & TRN & \\
\hline CHEMBL1440520 & 688653 & 5.63299 & 99999999 & & 5.915 & TRN & \\
\hline CHEMBL1376059 & 688653 & 4.883 & 5.295 & TST & & & \\
\hline CHEMBL1399757 & 688653 & 4.783 & 5.1859 & TST & & & \\
\hline CHEMBL1613733 & 688653 & 5.083 & 4.768 & TST & & & \\
\hline CHEMBL3196102 & 688653 & 5.78299 & 99999999 & 995 & 5.8466 & TRN & \\
\hline CHEMBL1453362 & 688653 & 5.13299 & 99999999 & & 5.5531 & TST & \\
\hline CHEMBL1349341 & 688653 & 5.0 & 5.2227 & TST & & & \\
\hline CHEMBL1481374 & 688653 & 4.833 & 4.9498 & TRN & & & \\
\hline CHEMBL1537857 & 688653 & 6.13299 & 99999999 & & 5.3336 & TRN & \\
\hline CHEMBL2311905 & 688653 & 5.1329 & 99999999 & & 5.1274 & TRN & \\
\hline
\end{tabular}




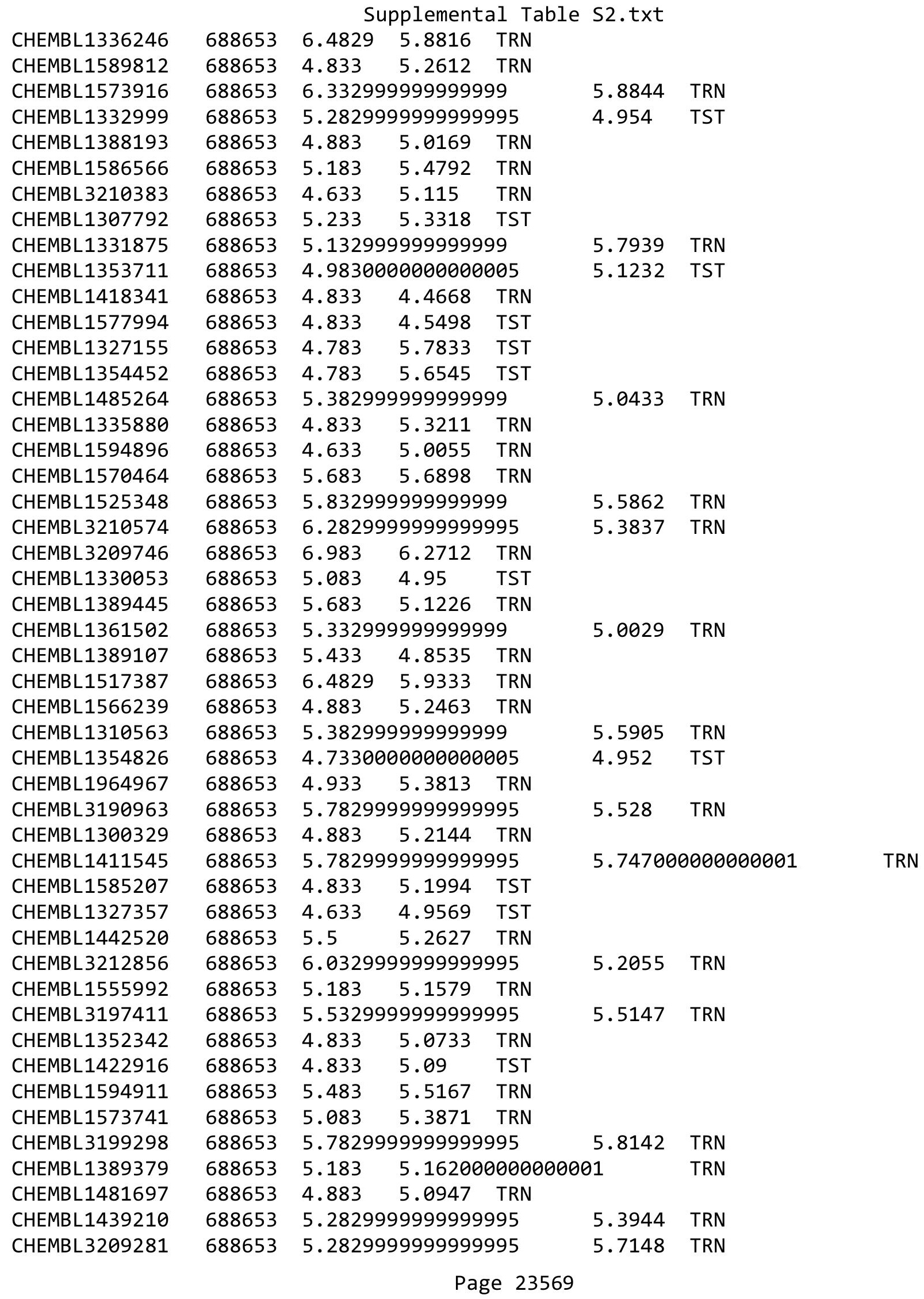




\begin{tabular}{|c|c|c|c|c|c|c|c|}
\hline \multicolumn{7}{|c|}{ Supplemental Table S2.txt } & \\
\hline CHEMBL1551080 & 688653 & \multicolumn{3}{|c|}{4.7330000000000005} & 4.7245 & TRN & \\
\hline CHEMBL1546121 & 688653 & 5.233 & 5.1984 & TRN & & & \\
\hline CHEMBL1424424 & 688653 & 4.833 & 5.1405 & TRN & & & \\
\hline CHEMBL1365398 & 688653 & 5.233 & 4.8206 & TRN & & & \\
\hline CHEMBL1993565 & 688653 & \multicolumn{3}{|c|}{5.2829999999999995} & 4.7948 & TRN & \\
\hline CHEMBL1560579 & 688653 & 5.033 & 4.7576 & TRN & & & \\
\hline CHEMBL1558102 & 688653 & 6.433 & 5.6761 & TRN & & & \\
\hline CHEMBL1568762 & 688653 & 4.783 & 5.6621 & TRN & & & \\
\hline CHEMBL1527299 & 688653 & 4.883 & \multicolumn{3}{|c|}{5.332000000000001} & TRN & \\
\hline CHEMBL297304 & 688653 & \multicolumn{3}{|c|}{4.7330000000000005} & 5.5766 & TST & \\
\hline CHEMBL1547851 & 688653 & 5.433 & 5.3617 & TRN & & & \\
\hline CHEMBL3193990 & 688653 & 4.933 & 5.08 & TST & & & \\
\hline CHEMBL1542947 & 688653 & 4.883 & 5.0525 & TRN & & & \\
\hline CHEMBL 1406680 & 688653 & \multicolumn{3}{|c|}{4.7330000000000005} & 5.0855 & TRN & \\
\hline CHEMBL1330019 & 688653 & 6.233 & 5.9635 & TRN & & & \\
\hline CHEMBL1566808 & 688653 & 4.883 & 4.6674 & TRN & & & \\
\hline CHEMBL1531419 & 688653 & \multicolumn{3}{|c|}{4.7330000000000005} & 5.1707 & TRN & \\
\hline CHEMBL1353285 & 688653 & 4.783 & 4.9445 & TST & & & \\
\hline CHEMBL1331362 & 688653 & \multicolumn{3}{|c|}{5.5329999999999995} & \multicolumn{2}{|c|}{5.178999999999999} & TRN \\
\hline CHEMBL1600446 & 688653 & 4.883 & 4.9483 & TST & & & \\
\hline CHEMBL 3194158 & 688653 & 5.483 & 5.6061 & TRN & & & \\
\hline CHEMBL1373792 & 688653 & \multicolumn{3}{|c|}{6.0329999999999995} & 5.4034 & TRN & \\
\hline CHEMBL1425260 & 688653 & 4.783 & 5.2873 & TRN & & & \\
\hline CHEMBL1329750 & 688653 & 6.183 & 5.8943 & TRN & & & \\
\hline CHEMBL1447067 & 688653 & \multicolumn{3}{|c|}{5.632999999999999} & 5.6268 & TRN & \\
\hline CHEMBL1545509 & 688653 & 5.183 & 5.3155 & TRN & & & \\
\hline CHEMBL1372009 & 688653 & 5.233 & 5.2291 & TRN & & & \\
\hline CHEMBL1487273 & 688653 & \multicolumn{3}{|c|}{4.7330000000000005} & 5.7046 & TRN & \\
\hline CHEMBL 3196563 & 688653 & 5.183 & 5.371 & TRN & & & \\
\hline CHEMBL 3194870 & 688653 & 4.933 & 6.1123 & TRN & & & \\
\hline CHEMBL1609175 & 688653 & \multicolumn{3}{|c|}{5.132999999999999} & 5.21899 & 9999999999 & TST \\
\hline CHEMBL 3194960 & 688653 & 4.933 & 4.9095 & TST & & & \\
\hline CHEMBL 1572244 & 688653 & 4.933 & 5.112 & TRN & & & \\
\hline CHEMBL1417871 & 688653 & 4.783 & 5.3299 & TRN & & & \\
\hline CHEMBL1585557 & 688653 & \multicolumn{3}{|c|}{5.132999999999999} & 5.7875 & TRN & \\
\hline CHEMBL1531927 & 688653 & 5.683 & 5.4145 & TRN & & & \\
\hline CHEMBL1327162 & 688653 & 5.933 & 5.1014 & TRN & & & \\
\hline CHEMBL1401174 & 688653 & \multicolumn{3}{|c|}{4.9830000000000005} & 4.9924 & TRN & \\
\hline CHEMBL1596590 & 688653 & \multicolumn{3}{|c|}{5.7829999999999995} & 5.5347 & TRN & \\
\hline CHEMBL1462346 & 688653 & \multicolumn{3}{|c|}{4.7330000000000005} & 5.4944 & TST & \\
\hline CHEMBL1434766 & 688653 & \multicolumn{3}{|c|}{5.2829999999999995} & 4.742 & TST & \\
\hline CHEMBL1526732 & 688653 & 4.883 & 5.1042 & TRN & & & \\
\hline CHEMBL1334565 & 688653 & 4.883 & 5.1541 & TST & & & \\
\hline CHEMBL1512249 & 688653 & 4.633 & 4.9522 & TST & & & \\
\hline CHEMBL1305668 & 688653 & 4.783 & 5.1271 & TST & & & \\
\hline CHEMBL 3189986 & 688653 & 4.833 & 5.2193 & TST & & & \\
\hline CHEMBL1535094 & 688653 & 5.433 & 5.3303 & TST & & & \\
\hline CHEMBL1491264 & 688653 & 5.983 & 5.6129 & TRN & & & \\
\hline
\end{tabular}




\begin{tabular}{|c|c|c|c|c|c|c|}
\hline & \multicolumn{5}{|c|}{ oplemental Ta } \\
\hline CHEMBL1339589 & 688653 & 4.833 & 5.4779 & TRN & & \\
\hline CHEMBL1501521 & 688653 & 5.28299 & 99999999 & 995 & 5.9059 & TRN \\
\hline CHEMBL1579428 & 688653 & 4.833 & 5.0936 & TRN & & \\
\hline CHEMBL1602608 & 688653 & 5.53299 & 99999999 & 995 & 5.7598 & TRN \\
\hline CHEMBL1496933 & 688653 & 6.08299 & 99999999 & 99 & 5.6116 & $\pi 0$ \\
\hline CHEMBL1347506 & 688653 & 5.083 & 5.2316 & TRN & & \\
\hline CHEMBL1573259 & 688653 & 5.733 & 5.1081 & TRN & & \\
\hline CHEMBL1450275 & 688653 & 4.883 & 5.1883 & TST & & \\
\hline CHEMBL1573333 & 688653 & 5.033 & 5.5778 & TRN & & \\
\hline CHEMBL1307312 & 688653 & 5.78299 & 99999999 & 995 & 4.9384 & TRN \\
\hline CHEMBL1436697 & 688653 & 5.78299 & 99999999 & 995 & 5.4563 & \\
\hline CHEMBL1384491 & 688653 & 5.933 & 5.9469 & TRN & & \\
\hline CHEMBL1341870 & 688653 & 6.0 & 5.0826 & TRN & & \\
\hline CHEMBL 2094456 & 688653 & 5.53299 & 99999999 & 995 & 7 & \\
\hline CHEMBL 3193940 & 688653 & 4.833 & 5.3273 & TRN & & \\
\hline CHEMBL1576626 & 688653 & 4.783 & 5.3833 & TRN & & \\
\hline CHEMBL1425218 & 688653 & 4.833 & 4.4822 & TST & & \\
\hline CHEMBL1349392 & 688653 & 5.933 & 5.2303 & TRN & & \\
\hline CHEMBL1436502 & 688653 & 4.783 & 5.0162 & TRN & & \\
\hline CHEMBL1558065 & 688653 & 5.683 & 5.6848 & TRN & & \\
\hline CHEMBL1470782 & 688653 & 4.883 & 4.9999 & TRN & & \\
\hline CHEMBL1345047 & 688653 & 4.73300 & 00000000 & 005 & 5.392 & SI \\
\hline CHEMBL1561286 & 688653 & 5.83299 & 99999999 & & 5.7788 & TST \\
\hline CHEMBL14 & 688653 & 4.933 & 5.29700 & 0000 & $\partial 1$ & \\
\hline CHEMBL1368413 & 688653 & 5.33299 & 99999999 & & 5.1478 & TRN \\
\hline CHEMBL1456614 & 688653 & 4.783 & 5.6067 & TRN & & \\
\hline CHEMBL1550863 & 688653 & 5.28299 & 99999999 & 995 & 5.3203 & TRN \\
\hline CHEMBL1444136 & 688653 & 5.63299 & 99999999 & & 5.4527 & \\
\hline CHEMBL1385323 & 688653 & 4.883 & 4.6134 & TST & & \\
\hline CHEMBL1479133 & 688653 & 5.433 & 5.4561 & TRN & & \\
\hline CHEMBL1495590 & 688653 & 6.33299 & 99999999 & & 5.4533 & TRN \\
\hline CHEMBL1407825 & 688653 & 5.13299 & 99999999 & & 4.9532 & TS \\
\hline CHEMBL1325846 & 688653 & 4.933 & 5.5112 & TRN & & \\
\hline CHEMBL1552590 & 688653 & 4.833 & 5.643 & TST & & \\
\hline CHEMBL1611150 & 688653 & 5.733 & 5.3075 & TRN & & \\
\hline CHEMBL1438381 & 688653 & 4.883 & $5.02800 t$ & 0000 & 205 & TST \\
\hline CHEMBL372629 & 688653 & 5.78299 & 99999999 & 995 & 5.2896 & TST \\
\hline CHEMBL1597978 & 688653 & 4.833 & 5.1572 & TST & & \\
\hline CHEMBL1569635 & 688653 & 7.1831 & 5.5483 & TRN & & \\
\hline CHEMBL1331469 & 688653 & 4.85 & 5.5827 & TRN & & \\
\hline CHEMBL1460805 & 688653 & 4.73300 & 00000000 & 005 & 5.1526 & TST \\
\hline CHEMBL1320935 & 688653 & 4.583 & 5.1874 & TRN & & \\
\hline CHEMBL1586285 & 688653 & 4.583 & 5.1141 & TRN & & \\
\hline CHEMBL1427232 & 688653 & 5.28299 & 99999999 & 995 & 4.9208 & \\
\hline CHEMBL 3193441 & 688653 & 5.433 & 4.8953 & TRN & & \\
\hline CHEMBL1515192 & 688653 & 5.28299 & 99999999 & 995 & 5.1923 & TRN \\
\hline CHEMBL1431291 & 688653 & 4.833 & 4.9214 & TST & & \\
\hline CHEMBL1337716 & 688653 & 4.633 & 4.9107 & TST & & \\
\hline
\end{tabular}




\begin{tabular}{|c|c|c|c|c|c|c|}
\hline \multirow[b]{2}{*}{ CHEMBL1388090 } & \multirow[b]{2}{*}{688653} & \multicolumn{5}{|c|}{ Supplemental Table S2.txt } \\
\hline & & 4.583 & 4.8718 & TST & & \\
\hline CHEMBL1328660 & 688653 & \multicolumn{3}{|c|}{5.882999999999999} & 5.0914 & TRN \\
\hline CHEMBL1430215 & 688653 & 4.883 & 5.1917 & TRN & & \\
\hline CHEMBL1587905 & 688653 & 4.833 & 4.9225 & TRN & & \\
\hline CHEMBL3213317 & 688653 & \multicolumn{3}{|c|}{5.7829999999999995} & 5.2032 & TRN \\
\hline CHEMBL1404397 & 688653 & \multicolumn{3}{|c|}{6.082999999999999} & 5.8424 & TRN \\
\hline CHEMBL1546102 & 688653 & \multicolumn{3}{|c|}{4.7330000000000005} & 5.5391 & TRN \\
\hline CHEMBL1424062 & 688653 & 5.433 & 5.2084 & TRN & & \\
\hline CHEMBL3196781 & 688653 & 5.733 & 5.2845 & TRN & & \\
\hline CHEMBL1468847 & 688653 & 4.883 & 4.975 & TRN & & \\
\hline CHEMBL1467561 & 688653 & 4.783 & 4.9656 & TST & & \\
\hline CHEMBL1438970 & 688653 & 4.833 & \multicolumn{3}{|c|}{5.297000000000001} & TRN \\
\hline CHEMBL1362403 & 688653 & \multicolumn{3}{|c|}{5.132999999999999} & 5.3955 & TRN \\
\hline CHEMBL1312462 & 688653 & 5.433 & 5.5585 & TRN & & \\
\hline CHEMBL3198812 & 688653 & 4.633 & 4.8185 & TRN & & \\
\hline CHEMBL 2004657 & 688653 & \multicolumn{3}{|c|}{4.7330000000000005} & 5.303 & TRN \\
\hline CHEMBL1549213 & 688653 & \multicolumn{3}{|c|}{5.582999999999999} & 5.4936 & TRN \\
\hline CHEMBL1359093 & 688653 & 5.083 & 5.2026 & TST & & \\
\hline CHEMBL1315971 & 688653 & 5.033 & 4.8675 & TRN & & \\
\hline CHEMBL1465762 & 688653 & \multicolumn{3}{|c|}{5.132999999999999} & 5.1129 & TRN \\
\hline CHEMBL1319158 & 688653 & \multicolumn{3}{|c|}{ 7.082999999999999 } & 5.6106 & TRN \\
\hline CHEMBL3198850 & 688653 & \multicolumn{3}{|c|}{4.7330000000000005} & 4.8984 & TST \\
\hline CHEMBL1526126 & 688653 & 5.233 & 5.1809 & TRN & & \\
\hline CHEMBL1604322 & 688653 & 6.233 & 6.0876 & TRN & & \\
\hline CHEMBL1604245 & 688653 & 5.233 & 6.185 & TRN & & \\
\hline CHEMBL1516624 & 688653 & 5.733 & 5.3417 & TRN & & \\
\hline CHEMBL1516887 & 688653 & 5.483 & 5.2906 & TRN & & \\
\hline CHEMBL1417994 & 688653 & 5.983 & 5.3933 & TRN & & \\
\hline CHEMBL1548086 & 688653 & 4.633 & 4.9028 & TST & & \\
\hline CHEMBL1539118 & 688653 & 4.683 & 5.6494 & TST & & \\
\hline CHEMBL1502470 & 688653 & 4.833 & 4.7835 & TST & & \\
\hline CHEMBL3208072 & 688653 & 4.833 & 5.2606 & TST & & \\
\hline CHEMBL1593290 & 688653 & 5.3820 & 99999999 & & 5.3794 & TRN \\
\hline CHEMBL1338053 & 688653 & 4.933 & 5.2858 & TRN & & \\
\hline CHEMBL1586887 & 688653 & 4.7336 & 0000000 & 005 & 5.0852 & TRN \\
\hline CHEMBL1604316 & 688653 & 5.083 & 4.9032 & TRN & & \\
\hline CHEMBL1363732 & 688653 & 4.933 & 5.2472 & TST & & \\
\hline CHEMBL354039 & 688653 & 5.3329 & 99999999 & & 5.2985 & TRN \\
\hline CHEMBL1541644 & 688653 & 4.7336 & 0000000 & 005 & 4.8912 & TST \\
\hline CHEMBL1420864 & 688653 & 5.233 & 5.2275 & TRN & & \\
\hline CHEMBL1608088 & 688653 & 4.783 & 5.1209 & TRN & & \\
\hline CHEMBL1322287 & 688653 & 5.3329 & 99999999 & 99 & 5.3212 & TRN \\
\hline CHEMBL1575159 & 688653 & 4.783 & 4.8811 & TRN & & \\
\hline CHEMBL1518205 & 688653 & 5.8329 & 99999999 & & 5.7847 & TRN \\
\hline CHEMBL3196733 & 688653 & 4.833 & 5.3073 & TRN & & \\
\hline CHEMBL1492357 & 688653 & 6.3825 & 99999999 & 99 & 5.0171 & TRN \\
\hline CHEMBL1520538 & 688653 & 4.883 & 4.9488 & TRN & & \\
\hline CHEMBL1461147 & 688653 & 4.683 & 4.8515 & TRN & & \\
\hline
\end{tabular}




\begin{tabular}{|c|c|c|c|c|c|c|c|}
\hline \multicolumn{7}{|c|}{ Supplemental Table S2.txt } & \\
\hline CHEMBL1486815 & 688653 & 4.633 & 5.0242 & TST & & & \\
\hline CHEMBL1588411 & 688653 & \multicolumn{3}{|c|}{4.7330000000000005} & 4.8862 & TRN & \\
\hline CHEMBL1341119 & 688653 & 6.15 & 5.6977 & TRN & & & \\
\hline CHEMBL1366578 & 688653 & \multicolumn{3}{|c|}{5.2829999999999995} & 5.3773 & TRN & \\
\hline CHEMBL1564350 & 688653 & 4.683 & 4.8545 & TRN & & & \\
\hline CHEMBL1471162 & 688653 & 5.183 & 5.1251 & TRN & & & \\
\hline CHEMBL1453880 & 688653 & 4.883 & 4.9994 & TRN & & & \\
\hline CHEMBL1348379 & 688653 & \multicolumn{3}{|c|}{5.7829999999999995} & 5.6797 & TRN & \\
\hline CHEMBL1515448 & 688653 & 4.783 & 4.6781 & TRN & & & \\
\hline CHEMBL1552351 & 688653 & \multicolumn{3}{|c|}{6.382999999999999} & 5.3564 & TRN & \\
\hline CHEMBL1483475 & 688653 & 4.633 & 5.3042 & TST & & & \\
\hline CHEMBL1337378 & 688653 & \multicolumn{3}{|c|}{5.382999999999999} & 5.5084 & TRN & \\
\hline CHEMBL1300711 & 688653 & \multicolumn{3}{|c|}{5.882999999999999} & 5.0955 & TST & \\
\hline CHEMBL1596801 & 688653 & 5.033 & 5.4504 & TRN & & & \\
\hline CHEMBL1441816 & 688653 & \multicolumn{3}{|c|}{5.7829999999999995} & 5.2046 & TRN & \\
\hline CHEMBL1317485 & 688653 & 4.883 & 5.2693 & TST & & & \\
\hline CHEMBL1592002 & 688653 & 5.083 & 5.7631 & TRN & & & \\
\hline CHEMBL1595847 & 688653 & \multicolumn{3}{|c|}{5.132999999999999} & 5.1944 & TRN & \\
\hline CHEMBL1364467 & 688653 & 4.883 & 5.4947 & TRN & & & \\
\hline CHEMBL1601182 & 688653 & 4.833 & 5.1143 & TRN & & & \\
\hline CHEMBL1462769 & 688653 & 5.483 & 5.3286 & TRN & & & \\
\hline CHEMBL1566940 & 688653 & 5.033 & 5.0504 & TST & & & \\
\hline CHEMBL1600151 & 688653 & 4.583 & 5.1671 & TRN & & & \\
\hline CHEMBL3210743 & 688653 & 5.183 & 5.7328 & TRN & & & \\
\hline CHEMBL 3211325 & 688653 & \multicolumn{3}{|c|}{5.632999999999999} & 5.3657 & TRN & \\
\hline CHEMBL602776 & 688653 & 4.883 & 5.1681 & TRN & & & \\
\hline CHEMBL1500344 & 688653 & \multicolumn{3}{|c|}{4.7330000000000005} & 5.1807 & TRN & \\
\hline CHEMBL1453439 & 688653 & \multicolumn{3}{|c|}{5.382999999999999} & 5.2115 & TRN & \\
\hline CHEMBL1385314 & 688653 & \multicolumn{3}{|c|}{6.332999999999999} & 6.1708 & TRN & \\
\hline CHEMBL1518900 & 688653 & 4.783 & 5.3805 & TRN & & & \\
\hline CHEMBL580324 & 688653 & \multicolumn{3}{|c|}{5.632999999999999} & 5.7327 & TST & \\
\hline CHEMBL1336056 & 688653 & \multicolumn{3}{|c|}{5.2829999999999995} & 4.9427 & TST & \\
\hline CHEMBL1436312 & 688653 & 4.833 & 5.1847 & TRN & & & \\
\hline CHEMBL1348357 & 688653 & \multicolumn{3}{|c|}{5.382999999999999} & \multicolumn{2}{|c|}{4.906000000000001} & TRN \\
\hline CHEMBL1335557 & 688653 & 6.433 & 5.2588 & TRN & & & \\
\hline CHEMBL1495242 & 688653 & 4.833 & 5.4316 & TST & & & \\
\hline CHEMBL1581725 & 688653 & 4.933 & 4.9557 & TST & & & \\
\hline CHEMBL1564201 & 688653 & 4.833 & 4.8572 & TST & & & \\
\hline CHEMBL1545127 & 688653 & 4.883 & 5.4248 & TRN & & & \\
\hline CHEMBL1557988 & 688653 & 5.483 & 5.5236 & TRN & & & \\
\hline CHEMBL3193417 & 688653 & 5.083 & 5.5122 & TRN & & & \\
\hline CHEMBL1325105 & 688653 & \multicolumn{3}{|c|}{5.332999999999999} & 5.8493 & TRN & \\
\hline CHEMBL1398224 & 688653 & 4.583 & 5.0264 & TST & & & \\
\hline CHEMBL1576674 & 688653 & 4.783 & 5.2643 & TRN & & & \\
\hline CHEMBL1469035 & 688653 & 5.233 & 5.2879 & TRN & & & \\
\hline CHEMBL1338745 & 688653 & \multicolumn{3}{|c|}{5.132999999999999} & 5.2804 & TST & \\
\hline CHEMBL1517971 & 688653 & 4.933 & 5.2662 & TRN & & & \\
\hline CHEMBL1539758 & 688653 & 4.73300 & 00000000 & 005 & 5.1855 & TRN & \\
\hline
\end{tabular}




\begin{tabular}{|c|c|c|c|c|c|c|}
\hline & & \multicolumn{5}{|c|}{ Supplemental Table S2.txt } \\
\hline CHEMBL1386744 & 688653 & 5.183 & 4.9052 & TRN & & \\
\hline CHEMBL1485905 & 688653 & 5.183 & 5.2278 & TST & & \\
\hline CHEMBL1562797 & 688653 & 5.033 & 5.4315 & TRN & & \\
\hline CHEMBL1322602 & 688653 & 6.433 & 5.7444 & TRN & & \\
\hline CHEMBL1477456 & 688653 & 4.633 & 4.8438 & TST & & \\
\hline CHEMBL1569337 & 688653 & \multicolumn{3}{|c|}{4.7330000000000005} & 5.3867 & TRN \\
\hline CHEMBL1499133 & 688653 & 4.783 & 5.3074 & TST & & \\
\hline CHEMBL1313769 & 688653 & 6.233 & 5.2158 & TRN & & \\
\hline CHEMBL1533662 & 688653 & 4.583 & 5.0733 & TRN & & \\
\hline CHEMBL1323015 & 688653 & \multicolumn{3}{|c|}{6.0329999999999995} & 5.6163 & I \\
\hline CHEMBL1453117 & 688653 & 5.683 & 5.6461 & TRN & & \\
\hline CHEMBL1378259 & 688653 & 5.033 & 5.4654 & TRN & & \\
\hline CHEMBL1432480 & 688653 & 4.833 & 4.7261 & TRN & & \\
\hline CHEMBL1573823 & 688653 & 5.033 & 5.4554 & TRN & & \\
\hline CHEMBL42288 & 688653 & 4.883 & 5.4665 & TRN & & \\
\hline CHEMBL1579003 & 688653 & \multicolumn{3}{|c|}{4.7330000000000005} & 5 & IRIN \\
\hline CHEMBL1532162 & 688653 & \multicolumn{3}{|c|}{6.632999999999999} & & \\
\hline CHEMBL1408662 & 688653 & 5.483 & 5.7973 & TRN & & \\
\hline CHEMBL1610870 & 688653 & 5.483 & 4.9641 & TRN & & \\
\hline CHEMBL1329472 & 688653 & 4.833 & 4.8944 & TRN & & \\
\hline CHEMBL1343689 & 688653 & 6.4829 & 6.1595 & TRN & & \\
\hline CHEMBL1429254 & 688653 & 4.783 & 5.2386 & TRN & & \\
\hline CHEMBL 3198090 & 688653 & \multicolumn{3}{|c|}{5.2829999999999995} & 5.3073 & TRN \\
\hline CHEMBL1476803 & 688653 & \multicolumn{3}{|c|}{4.7330000000000005} & 4.9045 & \\
\hline CHEMBL1326967 & 688653 & 7.1331 & 6.4436 & TRN & & \\
\hline CHEMBL1352130 & 688653 & 5.683 & \multicolumn{3}{|c|}{5.792000000000001} & \\
\hline CHEMBL1336903 & 688653 & 5.033 & 5.1174 & TST & & \\
\hline CHEMBL1343611 & 688653 & 4.833 & 5.4392 & TST & & \\
\hline CHEMBL1589457 & 688653 & 5.033 & 5.0588 & TRN & & \\
\hline CHEMBL1393407 & 688653 & 4.783 & 4.8401 & TRN & & \\
\hline CHEMBL1378884 & 688653 & \multicolumn{3}{|c|}{5.2829999999999995} & 4.9456 & \\
\hline CHEMBL1523775 & 688653 & 4.883 & 5.7779 & TST & & \\
\hline CHEMBL3196353 & 688653 & \multicolumn{3}{|c|}{4.7330000000000005} & 4.7139 & TR \\
\hline CHEMBL1501761 & 688653 & 4.583 & 5.4464 & TRN & & \\
\hline CHEMBL1414516 & 688653 & 5.433 & 5.7094 & TRN & & \\
\hline CHEMBL3199713 & 688653 & 4.883 & \multicolumn{3}{|c|}{5.8870000000000005} & $1 \mathrm{KN}$ \\
\hline CHEMBL1454714 & 688653 & 5.033 & 5.0508 & TRN & & \\
\hline CHEMBL1573350 & 688653 & \multicolumn{3}{|c|}{6.0329999999999995} & 5.2747 & TRN \\
\hline CHEMBL1553370 & 688653 & \multicolumn{3}{|c|}{5.7829999999999995} & 5.3181 & TRN \\
\hline CHEMBL1405828 & 688653 & 4.683 & 5.0198 & TST & & \\
\hline CHEMBL1412094 & 688653 & 5.9 & 5.3075 & TRN & & \\
\hline CHEMBL3190032 & 688653 & \multicolumn{3}{|c|}{4.7330000000000005} & 5.4046 & TST \\
\hline CHEMBL1493127 & 688653 & 4.883 & 5.0159 & TRN & & \\
\hline CHEMBL1490825 & 688653 & \multicolumn{3}{|c|}{5.132999999999999} & 5.1466 & I RIV \\
\hline CHEMBL1353153 & 688653 & \multicolumn{3}{|c|}{4.9830000000000005} & 4.9851 & TS \\
\hline CHEMBL1580234 & 688653 & 4.883 & 5.4064 & TRN & & \\
\hline CHEMBL1538677 & 688653 & 6.683 & 5.7798 & TRN & & \\
\hline CHEMBL1395800 & 688653 & 5.683 & 4.9698 & TRN & & \\
\hline
\end{tabular}




\begin{tabular}{|c|c|c|c|c|c|c|}
\hline & & \multicolumn{5}{|c|}{ Supplemental Table s2.txt } \\
\hline CHEMBL1361138 & 688653 & 4.933 & 5.0713 & TRN & & \\
\hline CHEMBL1605218 & 688653 & 4.883 & 5.1658 & TRN & & \\
\hline CHEMBL1608536 & 688653 & 4.633 & 5.0865 & TST & & \\
\hline CHEMBL1525953 & 688653 & 5.433 & 5.7833 & TRN & & \\
\hline CHEMBL1505703 & 688653 & \multicolumn{3}{|c|}{5.7829999999999995} & 5.5061 & TRN \\
\hline CHEMBL 2141886 & 688653 & \multicolumn{3}{|c|}{5.882999999999999} & 5.2821 & TST \\
\hline CHEMBL1299756 & 688653 & 5.733 & 5.4732 & TRN & & \\
\hline CHEMBL1397116 & 688653 & 4.633 & 4.9895 & TRN & & \\
\hline CHEMBL1522934 & 688653 & 5.233 & 5.5781 & TRN & & \\
\hline CHEMBL2369158 & 688653 & 5.233 & 5.3582 & TRN & & \\
\hline CHEMBL1424065 & 688653 & \multicolumn{3}{|c|}{7.082999999999999} & 6.483 & TRN \\
\hline CHEMBL1565626 & 688653 & 4.683 & 5.2757 & TRN & & \\
\hline CHEMBL1340381 & 688653 & 4.833 & 4.5429 & TRN & & \\
\hline CHEMBL3208465 & 688653 & 4.883 & 5.4883 & TRN & & \\
\hline CHEMBL1466675 & 688653 & 5.683 & 5.1196 & TRN & & \\
\hline CHEMBL1600668 & 688653 & \multicolumn{3}{|c|}{6.382999999999999} & 5.9843 & TRN \\
\hline CHEMBL1443755 & 688653 & 5.183 & 5.28100 & 000000000 & & TRN \\
\hline CHEMBL1495025 & 688653 & \multicolumn{3}{|c|}{6.2829999999999995} & 5.5904 & TST \\
\hline CHEMBL1433999 & 688653 & 4.833 & 5.2816 & TRN & & \\
\hline CHEMBL1369533 & 688653 & \multicolumn{3}{|c|}{5.132999999999999} & 5.2194 & TRN \\
\hline CHEMBL1408757 & 688653 & \multicolumn{3}{|c|}{4.7330000000000005} & 5.1348 & TRN \\
\hline CHEMBL1454165 & 688653 & 4.933 & 5.0148 & TST & & \\
\hline CHEMBL1344936 & 688653 & 4.833 & 5.0018 & TRN & & \\
\hline CHEMBL1416863 & 688653 & \multicolumn{3}{|c|}{4.7330000000000005} & 4.7981 & TST \\
\hline CHEMBL1326968 & 688653 & 5.683 & 5.1674 & TRN & & \\
\hline CHEMBL1435758 & 688653 & 4.583 & 5.3237 & TST & & \\
\hline CHEMBL1325658 & 688653 & 6.9329 & 5.8873 & TRN & & \\
\hline CHEMBL1592962 & 688653 & 4.583 & 5.0219 & TRN & & \\
\hline CHEMBL1343242 & 688653 & 5.683 & 5.4685 & TST & & \\
\hline CHEMBL1390361 & 688653 & \multicolumn{3}{|c|}{5.132999999999999} & 5.2118 & TRN \\
\hline CHEMBL1449954 & 688653 & \multicolumn{3}{|c|}{5.7829999999999995} & 5.4512 & TRN \\
\hline CHEMBL1554227 & 688653 & \multicolumn{4}{|c|}{7.18315 .611000000000001} & TRN \\
\hline CHEMBL1387668 & 688653 & \multicolumn{3}{|c|}{4.7330000000000005} & 4.9394 & TRN \\
\hline CHEMBL1301332 & 688653 & 5.083 & 5.182 & TRN & & \\
\hline CHEMBL1421568 & 688653 & \multicolumn{3}{|c|}{5.882999999999999} & 5.5481 & TRN \\
\hline CHEMBL1316696 & 688653 & 4.833 & 5.3652 & TRN & & \\
\hline CHEMBL1302406 & 688653 & 4.833 & 4.7777 & TST & & \\
\hline CHEMBL3195841 & 688653 & 7.1831 & 5.3308 & TRN & & \\
\hline CHEMBL1374333 & 688653 & 4.783 & 5.2496 & TRN & & \\
\hline CHEMBL1439181 & 688653 & \multicolumn{3}{|c|}{5.382999999999999} & 5.0379 & TST \\
\hline CHEMBL1524471 & 688653 & 4.883 & 4.9107 & TRN & & \\
\hline CHEMBL1490328 & 688653 & \multicolumn{3}{|c|}{5.832999999999999} & 5.6518 & TRN \\
\hline CHEMBL1515065 & 688653 & 6.433 & 5.5091 & TRN & & \\
\hline CHEMBL1549158 & 688653 & 4.883 & 4.8968 & TRN & & \\
\hline CHEMBL1610377 & 688653 & \multicolumn{3}{|c|}{5.382999999999999} & 5.3587 & TRN \\
\hline CHEMBL1409423 & 688653 & 4.883 & 4.9256 & TRN & & \\
\hline CHEMBL1308839 & 688653 & 4.783 & 5.1272 & TRN & & \\
\hline \multirow[t]{2}{*}{ CHEMBL1380341 } & 688653 & 5.483 & \multicolumn{3}{|c|}{5.486000000000001} & TRN \\
\hline & & & & 23575 & & \\
\hline
\end{tabular}




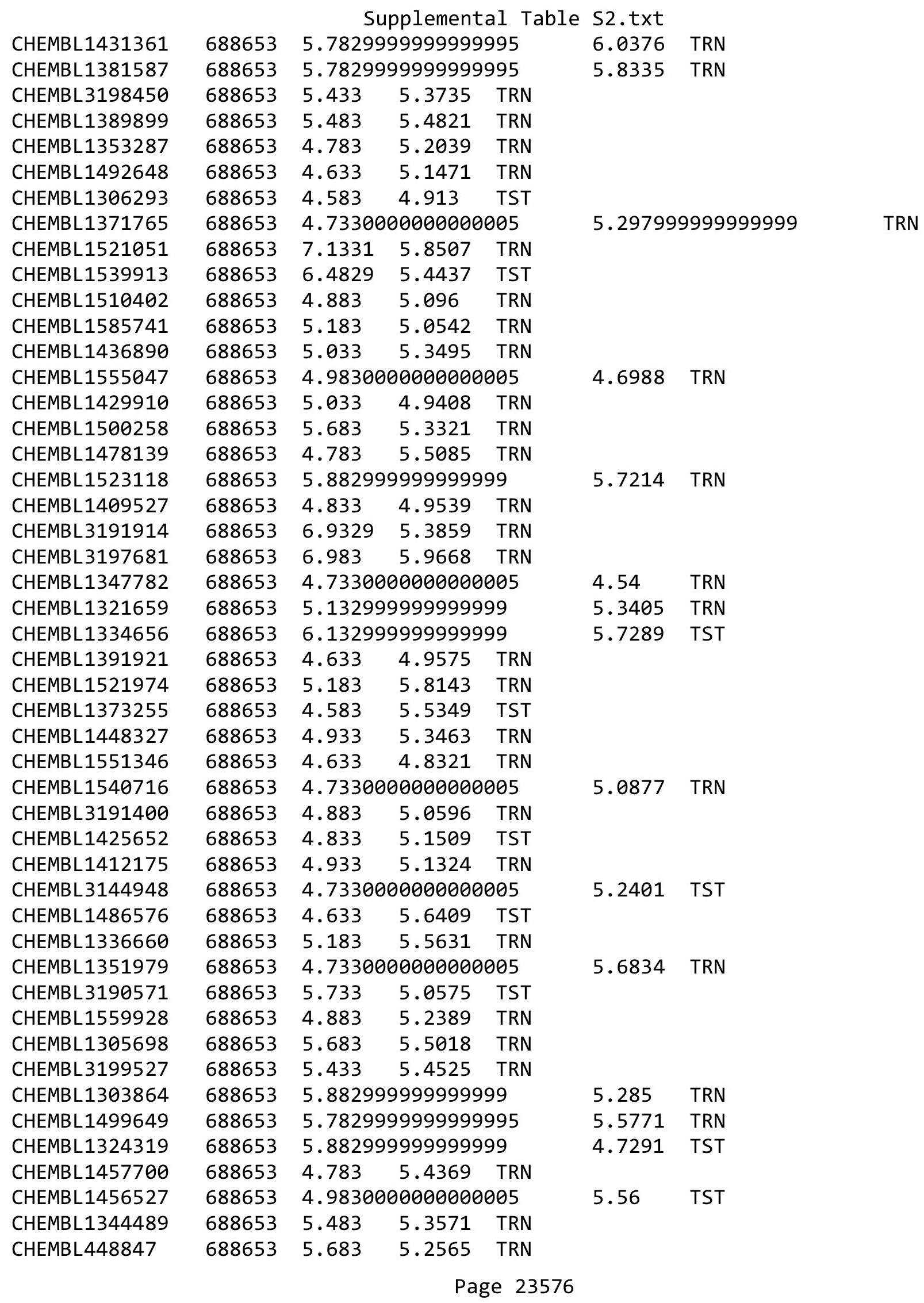




\begin{tabular}{|c|c|c|c|c|c|c|c|}
\hline \multicolumn{8}{|c|}{ Supplemental Table S2.txt } \\
\hline CHEMBL1486156 & 688653 & 5.483 & 5.2544 & TRN & & & \\
\hline CHEMBL1337279 & 688653 & 5.1329 & 99999999 & & 5.1298 & TRN & \\
\hline CHEMBL1445115 & 688653 & 4.683 & 5.0522 & TRN & & & \\
\hline CHEMBL1605940 & 688653 & 5.5329 & 99999995 & 995 & 5.70100 & 00000000005 & TRN \\
\hline CHEMBL1327277 & 688653 & 4.933 & 5.3425 & TRN & & & \\
\hline CHEMBL1534927 & 688653 & 4.7330 & 0000000 & 005 & 5.3882 & TST & \\
\hline CHEMBL1324600 & 688653 & 5.8329 & 99999999 & & 5.8676 & TRN & \\
\hline CHEMBL1433523 & 688653 & 6.2829 & 9999999 & 995 & 5.4205 & TRN & \\
\hline CHEMBL1439315 & 688653 & 4.883 & 5.4933 & TRN & & & \\
\hline CHEMBL1329585 & 688653 & 4.883 & 5.1418 & TRN & & & \\
\hline CHEMBL1581669 & 688653 & 4.7330 & 00000006 & 005 & 5.4667 & TRN & \\
\hline CHEMBL1612935 & 688653 & 5.683 & 5.6943 & TRN & & & \\
\hline CHEMBL1423263 & 688653 & 5.033 & 5.1451 & TRN & & & \\
\hline CHEMBL563919 & 688653 & 6.433 & 5.8474 & TRN & & & \\
\hline CHEMBL 1424752 & 688653 & 4.7330 & 00000006 & 005 & 5.5831 & TST & \\
\hline CHEMBL600315 & 688653 & 5.5329 & 9999999s & 995 & 5.2158 & TST & \\
\hline CHEMBL1558535 & 688653 & 5.3329 & 9999999 & & 5.0701 & TRN & \\
\hline CHEMBL1520459 & 688653 & 4.883 & 5.261 & TST & & & \\
\hline CHEMBL1483025 & 688653 & 5.5829 & 99999990 & & 5.2689 & TRN & \\
\hline CHEMBL1354016 & 688653 & 5.3329 & 99999995 & & 5.6563 & TRN & \\
\hline CHEMBL3197189 & 688653 & 5.733 & 4.9008 & TST & & & \\
\hline CHEMBL1504500 & 688653 & 4.683 & 5.1875 & TST & & & \\
\hline CHEMBL1361922 & 688653 & 6.683 & 6.4467 & TRN & & & \\
\hline CHEMBL 1578546 & 688653 & 4.883 & 5.29299 & 999999999 & & TRN & \\
\hline CHEMBL 1447606 & 688653 & 4.833 & 5.1813 & TST & & & \\
\hline CHEMBL1389304 & 688653 & 5.5329 & 9999999s & 995 & 5.7704 & TRN & \\
\hline CHEMBL1588516 & 688653 & 5.1329 & 99999995 & & 5.2193 & TRN & \\
\hline CHEMBL1559414 & 688653 & 6.433 & 6.1 & TRN & & & \\
\hline CHEMBL1592696 & 688653 & 5.233 & 5.245 & TST & & & \\
\hline CHEMBL1584953 & 688653 & 5.433 & 5.4607 & TRN & & & \\
\hline CHEMBL1310458 & 688653 & 6.0329 & 9999999 & 995 & 5.1369 & TRN & \\
\hline CHEMBL1369478 & 688653 & 4.883 & 5.0047 & TST & & & \\
\hline CHEMBL1397791 & 688653 & 4.783 & 4.9335 & TRN & & & \\
\hline CHEMBL1484078 & 688653 & 4.7330 & 00000006 & 005 & 5.0348 & TST & \\
\hline CHEMBL 1458533 & 688653 & 4.7330 & 00000006 & 005 & 5.2874 & TRN & \\
\hline CHEMBL1314457 & 688653 & 4.783 & 5.3223 & TRN & & & \\
\hline CHEMBL1613002 & 688653 & 4.883 & 4.8608 & TST & & & \\
\hline CHEMBL1417143 & 688653 & 5.1329 & 99999999 & & 5.0053 & TRN & \\
\hline CHEMBL1299297 & 688653 & 5.3829 & 99999995 & & 5.2936 & TST & \\
\hline CHEMBL1320318 & 688653 & 5.7829 & 99999999 & 995 & 5.9506 & TRN & \\
\hline CHEMBL1484658 & 688653 & 4.9830 & 0000000 & 005 & 5.335 & TRN & \\
\hline CHEMBL1494086 & 688653 & 5.2829 & 99999995 & 995 & 5.6754 & TRN & \\
\hline CHEMBL1567582 & 688653 & 4.783 & 4.8633 & TST & & & \\
\hline CHEMBL1494263 & 688653 & 5.183 & 5.5953 & TRN & & & \\
\hline CHEMBL1540700 & 688653 & 4.783 & 5.3609 & TRN & & & \\
\hline CHEMBL1358366 & 688653 & 5.083 & 5.3066 & TRN & & & \\
\hline CHEMBL1421232 & 688653 & 6.1329 & 99999999 & & 5.8832 & TRN & \\
\hline CHEMBL1415945 & 688653 & 4.933 & 5.2521 & TRN & & & \\
\hline
\end{tabular}




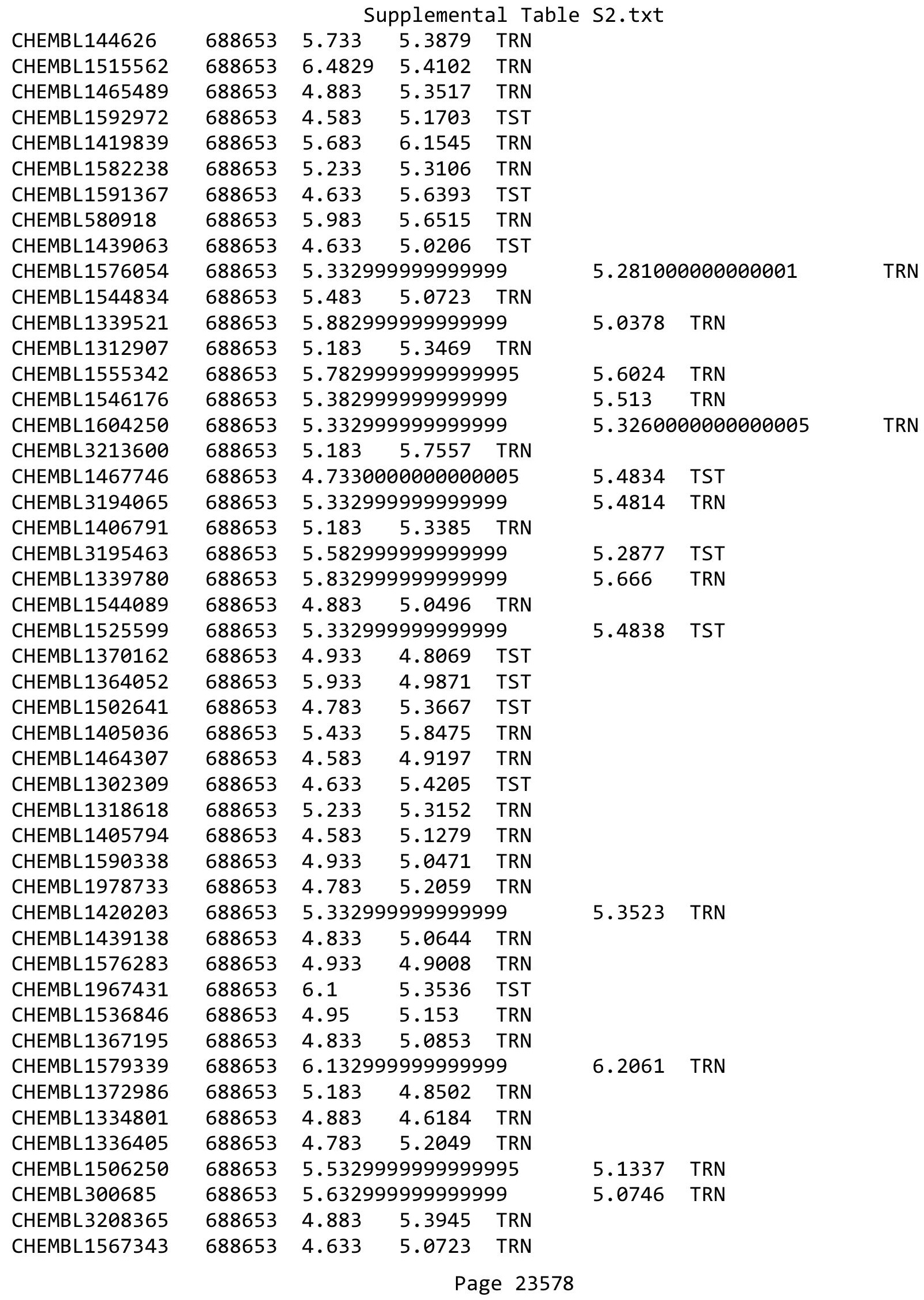




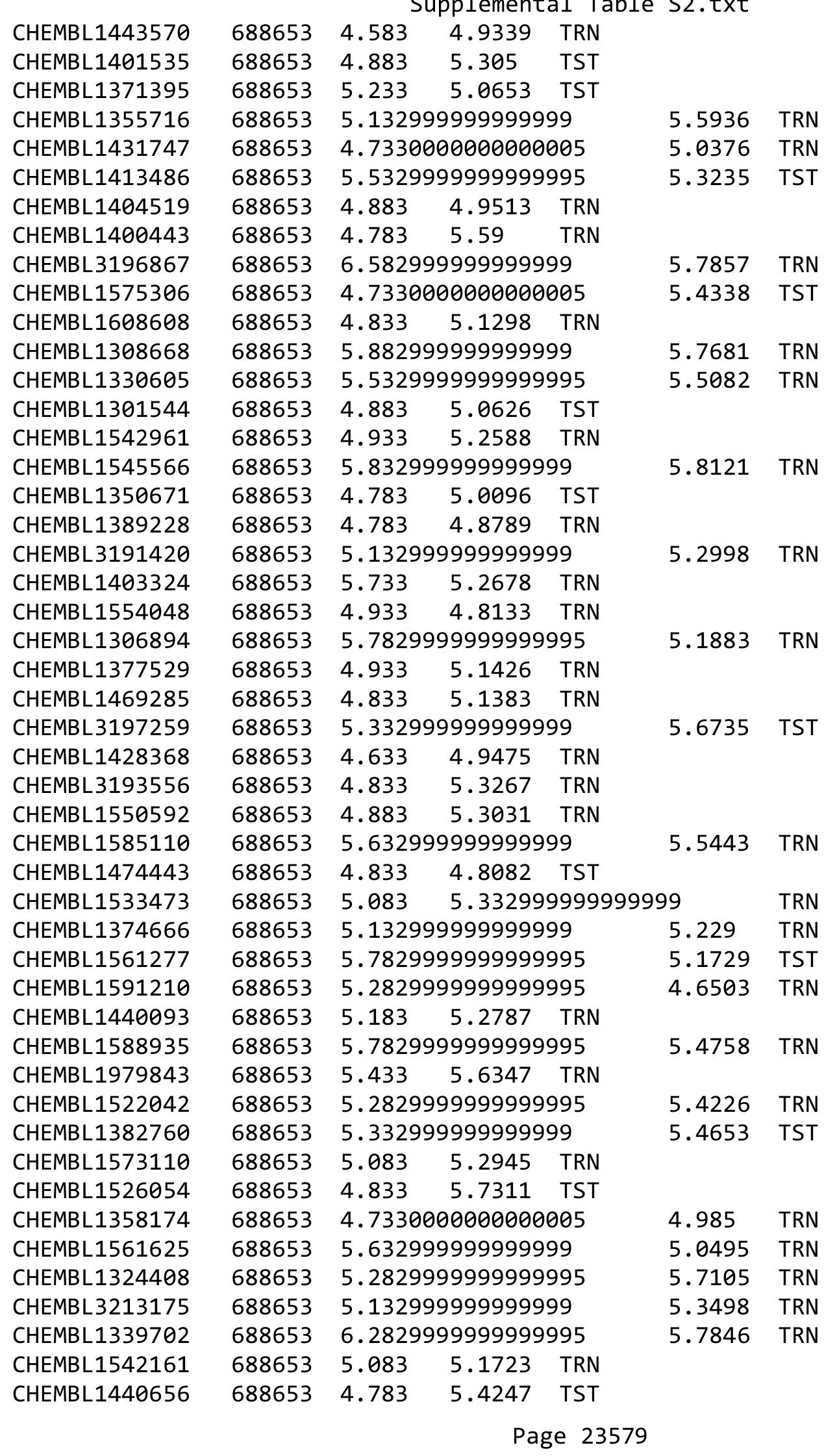




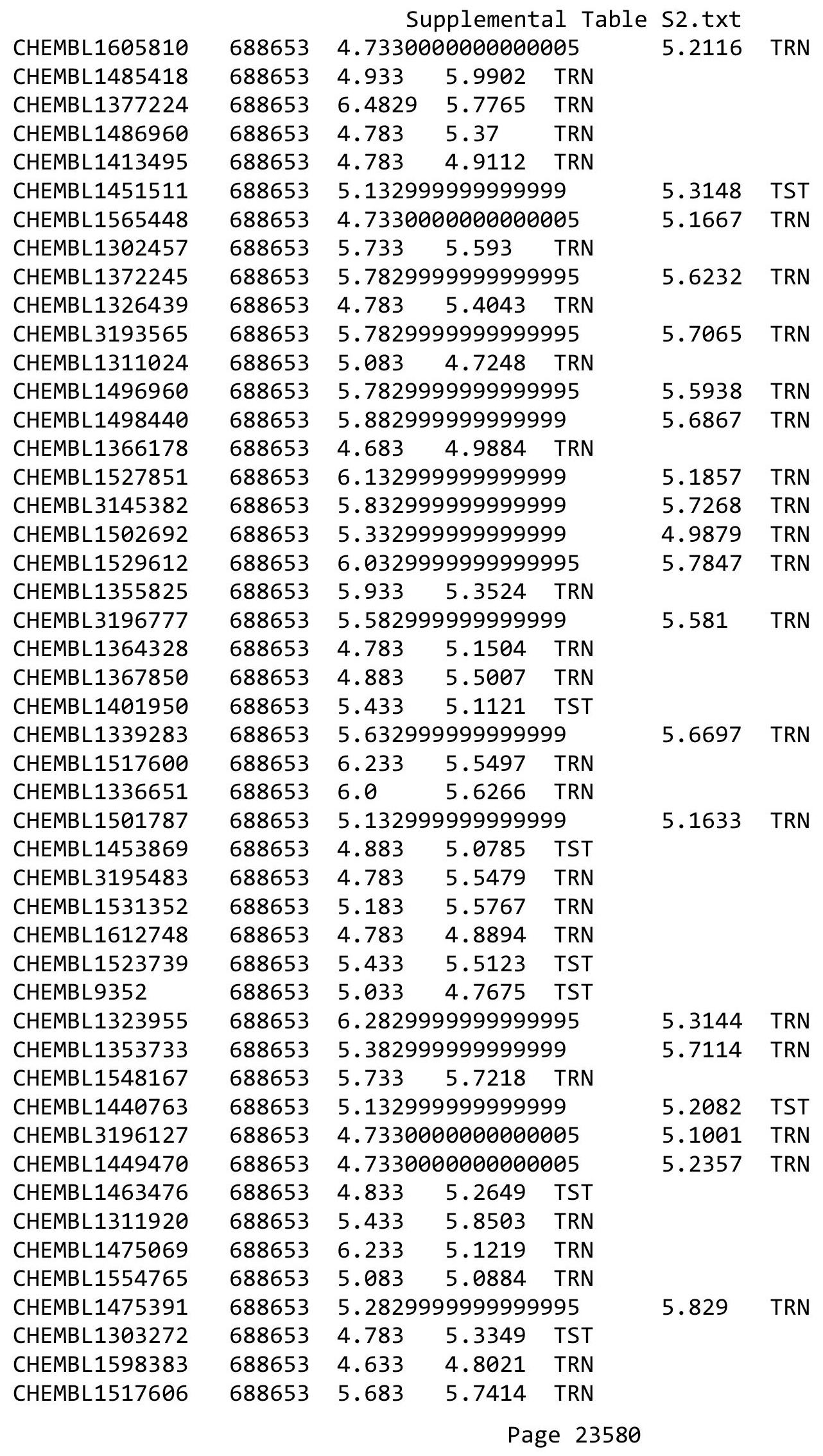




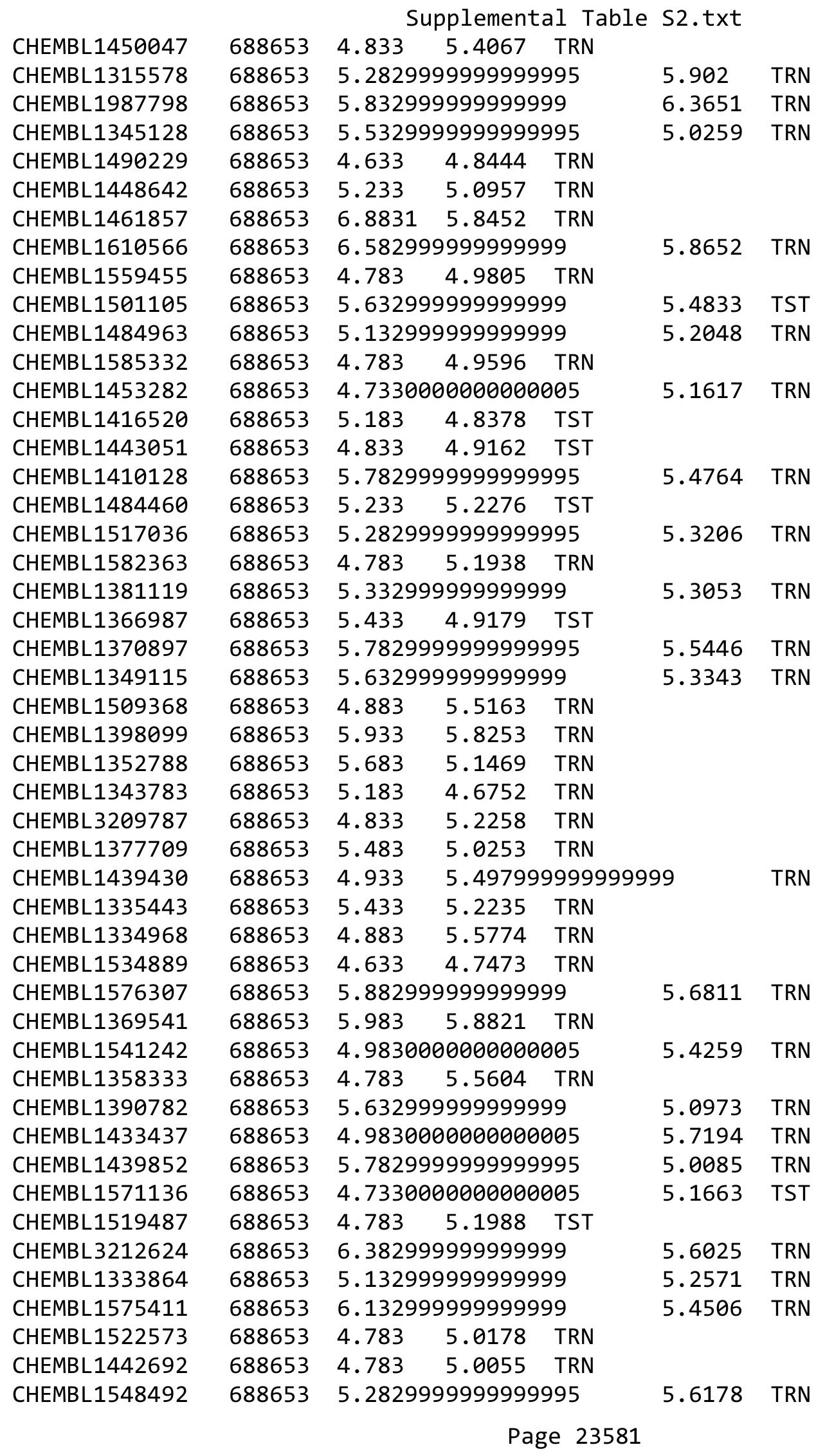




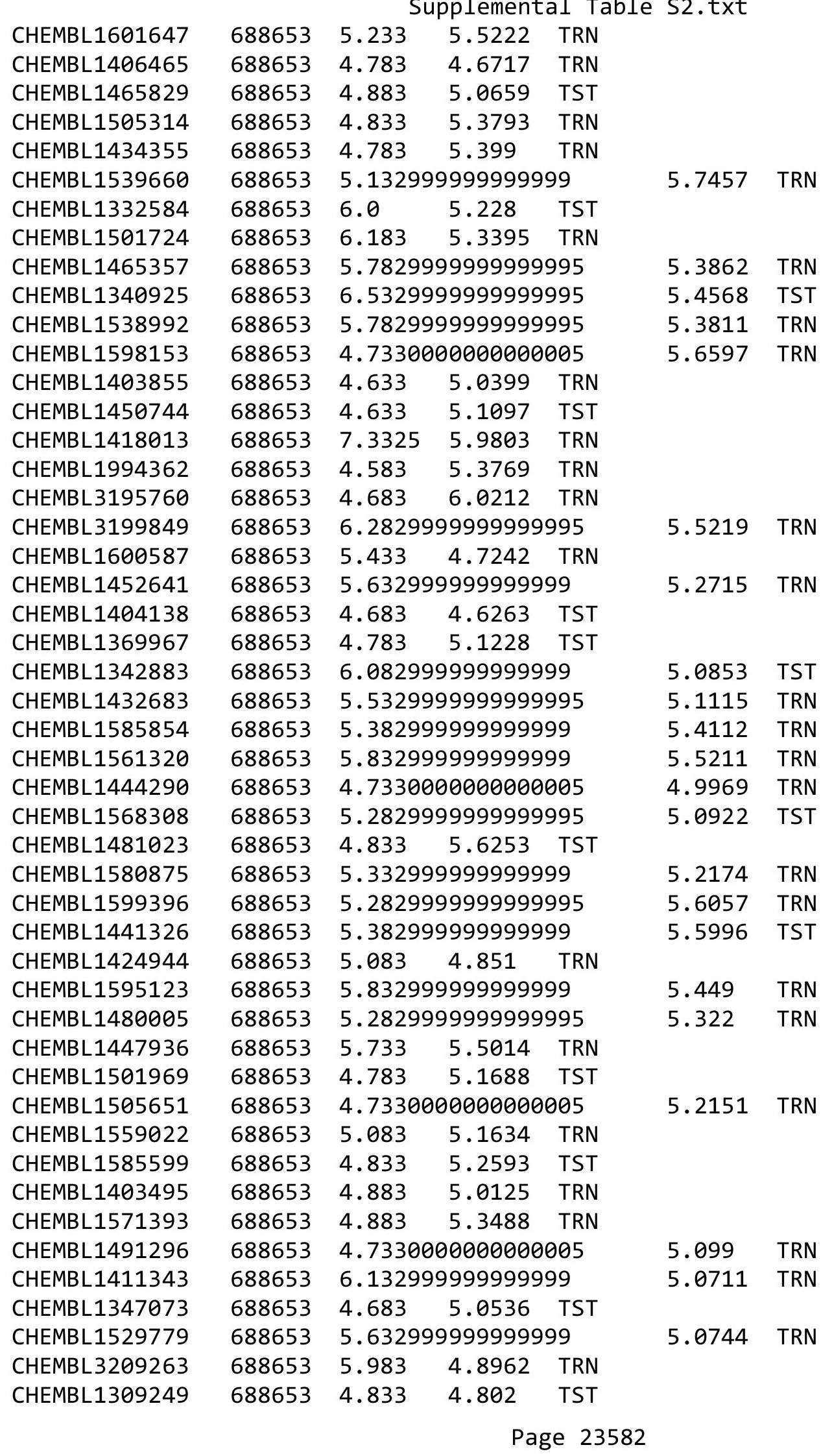




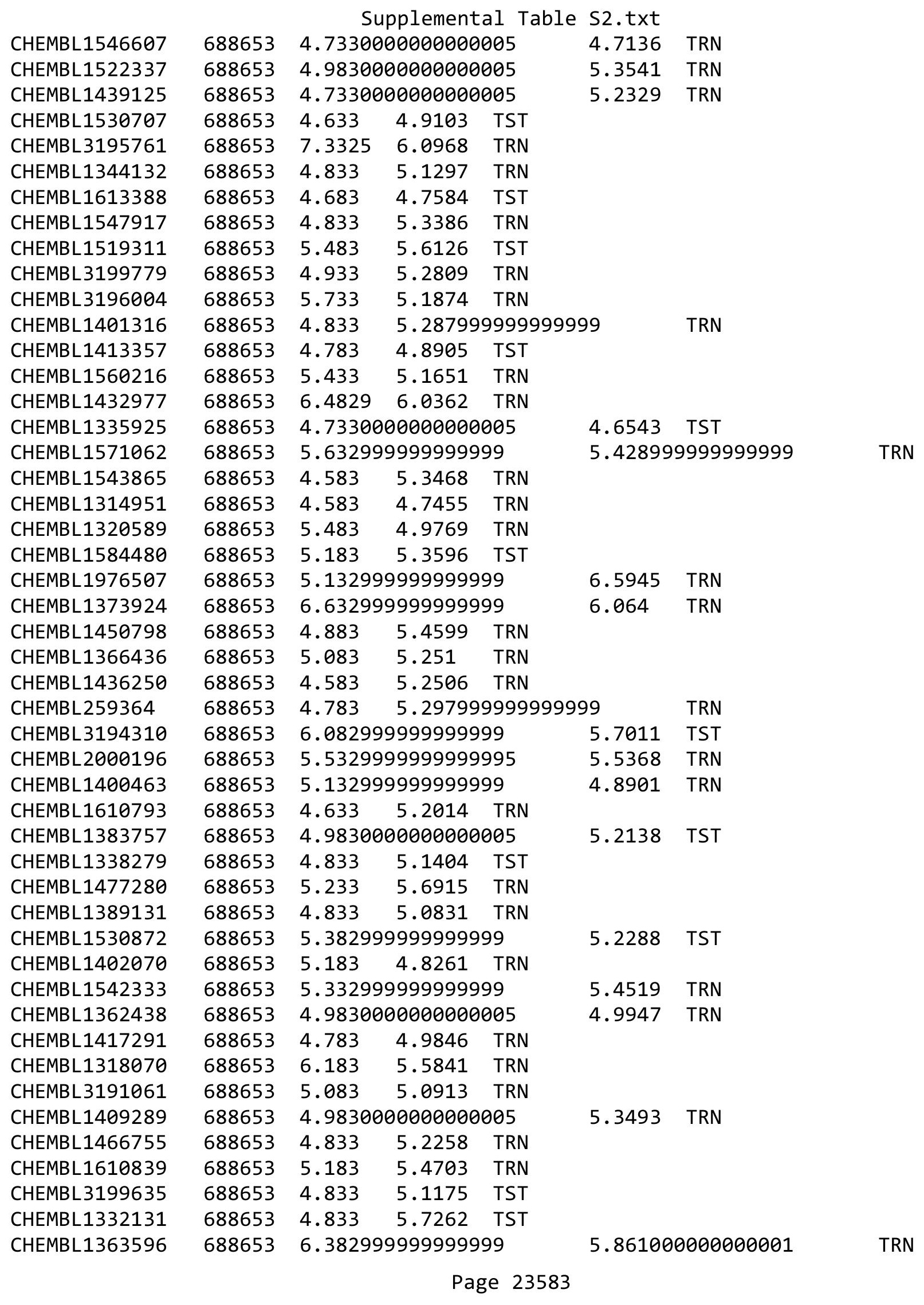




\begin{tabular}{|c|c|c|c|c|c|c|}
\hline & & \multicolumn{5}{|c|}{ Supplemental Table S2.txt } \\
\hline CHEMBL1447374 & 688653 & 5.983 & 5.3003 & TRN & & \\
\hline CHEMBL2369211 & 688653 & 6.233 & 5.5024 & TRN & & \\
\hline CHEMBL1340292 & 688653 & 4.783 & 5.0107 & TRN & & \\
\hline CHEMBL1379254 & 688653 & 4.933 & 5.6141 & TRN & & \\
\hline CHEMBL1467311 & 688653 & \multicolumn{3}{|c|}{4.7330000000000005} & 5.0674 & TRN \\
\hline CHEMBL1371190 & 688653 & \multicolumn{3}{|c|}{4.9830000000000005} & 5.4987 & TST \\
\hline CHEMBL1525869 & 688653 & \multicolumn{3}{|c|}{4.9830000000000005} & 631 & TST \\
\hline CHEMBL1389360 & 688653 & 4.783 & 5.7026 & TRN & & \\
\hline CHEMBL 3190008 & 688653 & 5.183 & 5.0767 & TST & & \\
\hline CHEMBL1530379 & 688653 & \multicolumn{3}{|c|}{6.7829999999999995} & 6.267 & TRN \\
\hline CHEMBL1479449 & 688653 & \multicolumn{3}{|c|}{5.832999999999999} & 5.4343 & TRN \\
\hline CHEMBL1348239 & 688653 & 5.483 & 5.5292 & TRN & & \\
\hline CHEMBL1390721 & 688653 & 4.883 & 5.2272 & TRN & & \\
\hline CHEMBL1534436 & 688653 & 6.183 & 5.2818 & TRN & & \\
\hline CHEMBL1611888 & 688653 & 5.183 & 5.4055 & TRN & & \\
\hline CHEMBL1403754 & 688653 & 4.833 & 5.5962 & TRN & & \\
\hline CHEMBL1326357 & 688653 & \multicolumn{3}{|c|}{6.0329999999999995} & 184 & \\
\hline CHEMBL1332454 & 688653 & 6.0 & 5.2839 & TRN & & \\
\hline CHEMBL1583808 & 688653 & 5.183 & 5.6082 & TRN & & \\
\hline CHEMBL14 & 688653 & 4.633 & 5.3466 & TST & & \\
\hline CHEMBL1559885 & 688653 & \multicolumn{3}{|c|}{5.2829999999999995} & 279 & TST \\
\hline CHEMBL1567272 & 688653 & \multicolumn{3}{|c|}{4.9830000000000005} & 103 & TST \\
\hline CHEMBL1483423 & 688653 & \multicolumn{3}{|c|}{5.132999999999999} & 271 & TRN \\
\hline CHEMBL1467219 & 688653 & \multicolumn{3}{|c|}{4.9830000000000005} & 5.4992 & TRN \\
\hline CHEMBL 1496360 & 688653 & 5.933 & 5.6807 & TRN & & \\
\hline CHEMBL1535601 & 688653 & \multicolumn{3}{|c|}{4.7330000000000005} & 422 & \\
\hline CHEMBL15 & 688653 & 7.1831 & 5.5364 & TRN & & \\
\hline CHEMBL1 & 688653 & 4.783 & 4.8428 & TRN & & \\
\hline CHEMBL1 & 688653 & 5.733 & 5.2368 & TST & & \\
\hline CHEMBL1394119 & 688653 & \multicolumn{3}{|c|}{6.2829999999999995} & 5.5868 & $\mathrm{TR}$ \\
\hline CHEMBL1439755 & 688653 & 5.933 & 6.104 & TRN & & \\
\hline CHEMBL3 & 688653 & 4.883 & \multicolumn{3}{|c|}{5.702999999999999} & וכנו \\
\hline CHEMBL1481543 & 688653 & \multicolumn{3}{|c|}{5.632999999999999} & 6.0577 & TRN \\
\hline CHEMBL1383228 & 688653 & 4.633 & 4.7183 & TST & & \\
\hline CHEMBL1613168 & 688653 & \multicolumn{3}{|c|}{5.132999999999999} & & TRN \\
\hline CHEMBL1550429 & 688653 & \multicolumn{3}{|c|}{5.832999999999999} & 5.7035 & $\mathrm{TH}$ \\
\hline CHEMBL1429292 & 688653 & \multicolumn{3}{|c|}{5.832999999999999} & 5.3324 & I \\
\hline CHEMBL1569716 & 688653 & 4.783 & 5.3684 & TRN & & \\
\hline CHEMBL1577720 & 688653 & 6.9329 & 5.3162 & TRN & & \\
\hline CHEMBL 3189460 & 688653 & 4.883 & 5.3856 & TRN & & \\
\hline CHEMBL1411151 & 688653 & 4.783 & 5.5429 & TRN & & \\
\hline CHEMBL1503172 & 688653 & 6.183 & 6.1579 & TRN & & \\
\hline CHEMBL1459446 & 688653 & 4.833 & 4.898 & TRN & & \\
\hline CHEMBL1304861 & 688653 & \multicolumn{3}{|c|}{6.5329999999999995} & 5.7671 & TRI \\
\hline CHEMBL1432339 & 688653 & 4.683 & 5.0578 & TRN & & \\
\hline CHEMBL1354129 & 688653 & \multicolumn{3}{|c|}{4.7330000000000005} & 54 & TST \\
\hline CHEMBL1612125 & 688653 & \multicolumn{3}{|c|}{6.132999999999999} & 5.8846 & RN \\
\hline CHEMBL3211553 & 688653 & 5.483 & 5.3051 & TRN & & \\
\hline
\end{tabular}




\begin{tabular}{|c|c|c|c|c|c|c|c|}
\hline \multicolumn{7}{|c|}{ Supplemental Table S2.txt } & \\
\hline CHEMBL1547916 & 688653 & 4.833 & 5.3022 & TST & & & \\
\hline CHEMBL1571647 & 688653 & 5.13299 & 99999999 & 99 & 5.9252 & TRN & \\
\hline CHEMBL1329586 & 688653 & 5.233 & 5.0977 & TRN & & & \\
\hline CHEMBL1463302 & 688653 & 4.833 & 4.9748 & TRN & & & \\
\hline CHEMBL1394695 & 688653 & 4.633 & 4.7722 & TRN & & & \\
\hline CHEMBL1369612 & 688653 & 5.183 & 5.5292 & TRN & & & \\
\hline CHEMBL1454811 & 688653 & 4.883 & 4.8618 & TST & & & \\
\hline CHEMBL1322624 & 688653 & 5.683 & 5.5318 & TRN & & & \\
\hline CHEMBL1468717 & 688653 & 4.783 & 5.3051 & TRN & & & \\
\hline CHEMBL1481849 & 688653 & 4.633 & 4.7377 & TRN & & & \\
\hline CHEMBL1451256 & 688653 & \multicolumn{3}{|c|}{6.0329999999999995} & 5.8078 & TRN & \\
\hline CHEMBL1504933 & 688653 & 4.783 & 5.4745 & TRN & & & \\
\hline CHEMBL1415143 & 688653 & 4.833 & 5.1176 & TRN & & & \\
\hline CHEMBL1512130 & 688653 & 4.583 & 5.0397 & TRN & & & \\
\hline CHEMBL1347531 & 688653 & \multicolumn{3}{|c|}{6.332999999999999} & 5.0508 & TST & \\
\hline CHEMBL1333191 & 688653 & 4.833 & 5.0873 & TRN & & & \\
\hline CHEMBL1580024 & 688653 & 5.183 & 5.2501 & TRN & & & \\
\hline CHEMBL1358676 & 688653 & 4.633 & 4.8464 & TST & & & \\
\hline CHEMBL1393708 & 688653 & 4.883 & 5.0223 & TRN & & & \\
\hline CHEMBL1367394 & 688653 & 6.0 & 4.9731 & TRN & & & \\
\hline CHEMBL1517983 & 688653 & 5.433 & 5.0472 & TRN & & & \\
\hline CHEMBL1316770 & 688653 & 4.783 & 6.029 & TRN & & & \\
\hline CHEMBL1591417 & 688653 & 5.983 & 4.9479 & TST & & & \\
\hline CHEMBL3210938 & 688653 & \multicolumn{3}{|c|}{5.132999999999999} & 5.3428 & TRN & \\
\hline CHEMBL 3192044 & 688653 & 4.683 & 5.1201 & TRN & & & \\
\hline CHEMBL1609529 & 688653 & \multicolumn{3}{|c|}{5.332999999999999} & 5.1678 & TRN & \\
\hline CHEMBL1533117 & 688653 & \multicolumn{3}{|c|}{5.382999999999999} & 5.3383 & TRN & \\
\hline CHEMBL1386002 & 688653 & \multicolumn{3}{|c|}{5.632999999999999} & 4.9687 & TST & \\
\hline CHEMBL1491243 & 688653 & 4.683 & 4.7205 & TST & & & \\
\hline CHEMBL1539001 & 688653 & 4.783 & 5.5776 & TRN & & & \\
\hline CHEMBL1490252 & 688653 & 5.733 & 5.5489 & TRN & & & \\
\hline CHEMBL 3209085 & 688653 & \multicolumn{3}{|c|}{4.7330000000000005} & 4.8735 & TST & \\
\hline CHEMBL1610470 & 688653 & 4.833 & 4.9359 & TST & & & \\
\hline CHEMBL1559632 & 688653 & 5.433 & 5.8313 & TRN & & & \\
\hline CHEMBL1324490 & 688653 & 4.883 & 5.9613 & TST & & & \\
\hline CHEMBL1536326 & 688653 & 4.933 & 5.2012 & TRN & & & \\
\hline CHEMBL1517169 & 688653 & 4.783 & 5.5448 & TRN & & & \\
\hline CHEMBL1402884 & 688653 & \multicolumn{3}{|c|}{5.332999999999999} & 5.2272 & TRN & \\
\hline CHEMBL1440824 & 688653 & 5.733 & 5.6363 & TST & & & \\
\hline CHEMBL1373635 & 688653 & 4.783 & 5.3545 & TRN & & & \\
\hline CHEMBL1490060 & 688653 & \multicolumn{3}{|c|}{6.082999999999999} & 5.7678 & TRN & \\
\hline CHEMBL1581997 & 688653 & 5.183 & 5.2423 & TRN & & & \\
\hline CHEMBL1606430 & 688653 & 4.933 & 4.9121 & TST & & & \\
\hline CHEMBL1993627 & 688653 & 7.1831 & 5.6726 & TRN & & & \\
\hline CHEMBL3193099 & 688653 & \multicolumn{3}{|c|}{4.7330000000000005} & 5.1389 & 9999999999 & TST \\
\hline CHEMBL1311825 & 688653 & 6.0 & 4.8918 & TRN & & & \\
\hline CHEMBL1449173 & 688653 & \multicolumn{3}{|c|}{6.0329999999999995} & 5.7582 & TST & \\
\hline CHEMBL3199322 & 688653 & 4.783 & 5.271 & TRN & & & \\
\hline
\end{tabular}




\begin{tabular}{|c|c|c|c|c|c|c|}
\hline \multirow[b]{2}{*}{ CHEMBL1349551 } & \multirow[b]{2}{*}{688653} & \multicolumn{5}{|c|}{ Supplemental Table S2.txt } \\
\hline & & \multicolumn{3}{|c|}{5.3792 TRN } & & \\
\hline CHEMBL1506637 & 688653 & \multicolumn{3}{|c|}{4.7330000000000005} & 4.9862 & TRN \\
\hline CHEMBL1347533 & 688653 & \multicolumn{3}{|c|}{6.0329999999999995} & 5.2943 & \\
\hline CHEMBL1463088 & 688653 & \multicolumn{3}{|c|}{6.582999999999999} & 5.9133 & \\
\hline CHEMBL1369635 & 588653 & \multicolumn{3}{|c|}{5.132999999999999} & 5.1436 & \\
\hline CHEMBL1501680 & 688653 & \multicolumn{3}{|c|}{4.7330000000000005} & 4.968 & \\
\hline CHEMBL1548439 & 688653 & 4.633 & 5.0222 & TRN & & \\
\hline CHEMBL1401778 & 688653 & 4.933 & 5.3442 & TST & & \\
\hline CHEMBL1603408 & 688653 & 4.883 & 5.3643 & TRN & & \\
\hline CHEMBL1325327 & 688653 & 5.35 & 5.2362 & TRN & & \\
\hline CHEMBL489 & 688653 & 4.833 & 4.8628 & TST & & \\
\hline CHEMBL1600194 & 688653 & 5.183 & 5.585 & TRN & & \\
\hline CHEMBL13 & 688653 & \multicolumn{3}{|c|}{5.582999999999999} & 5.0108 & \\
\hline CHEMBL1551293 & 688653 & \multicolumn{3}{|c|}{6.132999999999999} & 5.7234 & \\
\hline CHEMBL1558183 & 688653 & \multicolumn{3}{|c|}{4.9830000000000005} & 5.3992 & \\
\hline CHEMBL1463239 & 688653 & \multicolumn{3}{|c|}{5.632999999999999} & 5.5102 & \\
\hline CHEMBL1 & 688653 & 4.883 & 5.0343 & TRN & & \\
\hline CHEMBL1 14 & 688653 & \multicolumn{3}{|c|}{5.332999999999999} & 4.9388 & \\
\hline CHEMBL1392702 & 688653 & \multicolumn{3}{|c|}{$4.833 \quad 5.3242 \quad$ TRN } & & \\
\hline CHEMBL1498251 & 688653 & 5.233 & 5.3096 & TRN & & \\
\hline CHEMBL143 & 688653 & \multicolumn{3}{|c|}{$4.933 \quad 5.5778 \quad$ TRN } & & \\
\hline CHEMBL1 & 688653 & & 28 & \\
\hline CHEMBL1 & 688653 & \multicolumn{3}{|c|}{$\begin{array}{lll}4.833 & 5.1287 & \text { TRN }\end{array}$} & & \\
\hline CHEMBL135 & 688653 & 4.783 & 5.058 & TRN & & \\
\hline CHEMBL1518056 & 688653 & \multicolumn{3}{|c|}{5.132999999999999} & 5 . & $\mathrm{TI}$ \\
\hline CHEMBL15 & 688653 & \multicolumn{3}{|c|}{5.332999999999999} & 851 & \\
\hline CHEMB & 688653 & 4.833 & 5.1231 & TRN & & \\
\hline CHEMB & 688653 & \multicolumn{3}{|c|}{5.5329999999999995} & 5.3787 & $\mathrm{TS}$ \\
\hline CHEMBL1 & 688653 & 4.633 & 5.7439 & TST & & \\
\hline CHEMBL1559135 & 688653 & 5.5329 & 99999999 & 995 & 5.1773 & \\
\hline CHEMBL: & 688 & 4.583 & 4.758 & TRN & & \\
\hline CHEMB & 688653 & 4.833 & 5.0057 & TST & & \\
\hline CHEMBL1595849 & 688653 & 6.6329 & 99999999 & & 5.5891 & TP \\
\hline CHEMBL1364137 & 688653 & 4.833 & 5.5089 & TST & & \\
\hline CHEMBL1492780 & 688653 & 5.3329 & 99999999 & & 5.3265 & 10 \\
\hline CHEME & 688653 & 5 . & 5.1 & TRN & & \\
\hline CHEMBL 1 & 688653 & 4.783 & 4.8197 & TRN & & \\
\hline CHEMBL1429485 & 688653 & 4.7336 & 00000000 & 005 & 5.3567 & TST \\
\hline CHEMBL1409629 & 688653 & 6.1329 & 99999999 & & 5.1975 & TRN \\
\hline CHEMBL1420875 & 688653 & 4.7336 & 00000000 & 005 & 491 & $T$ \\
\hline CHEMBL1596379 & 688653 & 4.7336 & 00000000 & 005 & 971 & \\
\hline CHEMBL1456099 & 688653 & 5.033 & 5.5823 & TRN & & \\
\hline CHEMBL1971532 & 688653 & 5.3829 & 99999999 & & 5.2557 & TRI \\
\hline CHEMBL1431241 & 688653 & 5.433 & 5.2001 & TST & & \\
\hline CHEMBL1521797 & 688653 & 6.6329 & 99999999 & & 5.4844 & $\mathrm{TR}$ \\
\hline CHEMBL1463023 & 688653 & 4.783 & 5.044 & TRN & & \\
\hline CHEMBL1491053 & 688653 & 4.9836 & 00000000 & 005 & 5.3527 & TRN \\
\hline CHEMBL1333318 & 688653 & 5.7829 & 99999999 & 995 & 5.3117 & TS \\
\hline
\end{tabular}




\begin{tabular}{|c|c|c|c|c|c|c|}
\hline \multirow[b]{2}{*}{ CHEMBL1578012 } & \multicolumn{6}{|c|}{ Supplemental Table S2.txt } \\
\hline & 688653 & 6.183 & 5.8421 & TRN & & \\
\hline CHEMBL 3191012 & 688653 & 5.8329 & 99999999 & & 5.3442 & $\mathrm{~T}$ \\
\hline CHEMBL1612190 & 688653 & 5.1329 & 99999999 & & 5.1551 & \\
\hline CHEMBL1574604 & 688653 & 5.2829 & 99999999 & 995 & 5.8427 & \\
\hline CHEMBL3193641 & 688653 & 5.5329 & 99999999 & 995 & 5.25 & \\
\hline CHEMBL1434462 & 688653 & 5.3329 & 99999999 & & 5.5865 & \\
\hline CHEMBL3212706 & 688653 & 5.683 & 5.4204 & TRN & & \\
\hline CHEMBL67212 & 688653 & 5.3829 & 99999999 & & 5.1672 & \\
\hline CHEMBL1972090 & 688653 & 6.6329 & 99999999 & & 5.6976 & \\
\hline CHEMBL1540031 & 688653 & 4.683 & 5.5664 & TRN & & \\
\hline CHEMBL1585614 & 688653 & 5.233 & 5.166 & TST & & \\
\hline CHEMBL1609169 & 688653 & 5.1329 & 99999999 & & 5.3012 & \\
\hline CHEMBL1560655 & 688653 & 5.7829 & 99999999 & 995 & & \\
\hline CHEMBL1569489 & 688653 & 5.183 & 5.2917 & TRN & & \\
\hline CHEMBL1508155 & 688653 & 4.7330 & 00000000 & 005 & 5.0946 & \\
\hline CHEMBL1347563 & 688653 & 5.733 & 5.2511 & TRN & & \\
\hline CHEMBL1571682 & 688653 & 4.883 & 4.9762 & TRN & & \\
\hline CHEMBL1889837 & 688653 & 4.583 & 5.266 & TRN & & \\
\hline CHEMBL1336871 & 688653 & 5.2829 & 99999999 & 995 & 5.0363 & TRN \\
\hline CHEMBL1443659 & 688653 & 5.8329 & 99999999 & & 5.5274 & \\
\hline CHEMBL1571319 & 688653 & 5.933 & 5.4735 & TRN & & \\
\hline CHEMBL1425560 & 688653 & 5.1329 & 99999999 & & 5.9059 & \\
\hline CHEMBL3189899 & 688653 & 5.083 & 5.2304 & TRN & & \\
\hline CHEMBL1442927 & 688653 & 6.2829 & 99999999 & 995 & 5.4386 & TRN \\
\hline CHEMBL1431135 & 688653 & 4.9830 & 00000000 & 005 & 283 & \\
\hline CHEMBL1437135 & 688653 & 4.633 & 5.2617 & TRN & & \\
\hline CHEMBL1376777 & 688653 & 4.783 & 5.5196 & TRN & & \\
\hline CHEMBL1429164 & 688653 & 5.3329 & 99999999 & & 5.1741 & 11 \\
\hline CHEMBL1493074 & 688653 & 4.833 & 5.3671 & TST & & \\
\hline CHEMBL3197824 & 688653 & 5.183 & 5.7316 & TRN & & \\
\hline CHEMBL1493144 & 688653 & 4.933 & 5.0934 & TRN & & \\
\hline CHEMBL1450072 & 688653 & 6.3329 & 99999999 & & $3 \cdot$ & 1 \\
\hline CHEMBL3192901 & 688653 & 6.0 & 5.6018 & TRN & & \\
\hline CHEMBL1978279 & 688653 & 7.1831 & 5.6725 & TRN & & \\
\hline CHEMBL1336309 & 688653 & 5.1329 & 99999999 & & 5.0696 & TRN \\
\hline CHEMBL1551035 & 688653 & 5.8329 & 99999999 & & & TCT \\
\hline CHEMBL3197410 & 688653 & 5.5329 & 99999999 & 995 & 5.4519 & \\
\hline CHEMBL1444417 & 688653 & 4.933 & 5.4169 & TRN & & \\
\hline CHEMBL1499053 & 688653 & 4.7330 & 00000000 & 005 & 5.6419 & TRN \\
\hline CHEMBL1560672 & 688653 & 4.7330 & 00000000 & 005 & 5.0407 & \\
\hline CHEMBL1333859 & 688653 & 6.233 & 5.6707 & TRN & & \\
\hline CHEMBL1412825 & 688653 & 6.3329 & 99999999 & 99 & 5.3077 & \\
\hline CHEMBL1503935 & 688653 & 4.633 & 5.121 & TST & & \\
\hline CHEMBL1438118 & 688653 & 5.1329 & 99999999 & & 5.3952 & ובנו \\
\hline CHEMBL3199539 & 688653 & 5.5829 & 99999999 & & 5.4582 & TRN \\
\hline CHEMBL1382917 & 688653 & 5.8329 & 99999999 & & 6.3115 & \\
\hline CHEMBL1527724 & 688653 & 4.783 & 5.0879 & TRN & & \\
\hline CHEMBL1522726 & 688653 & 5.433 & 5.8403 & TRN & & \\
\hline
\end{tabular}




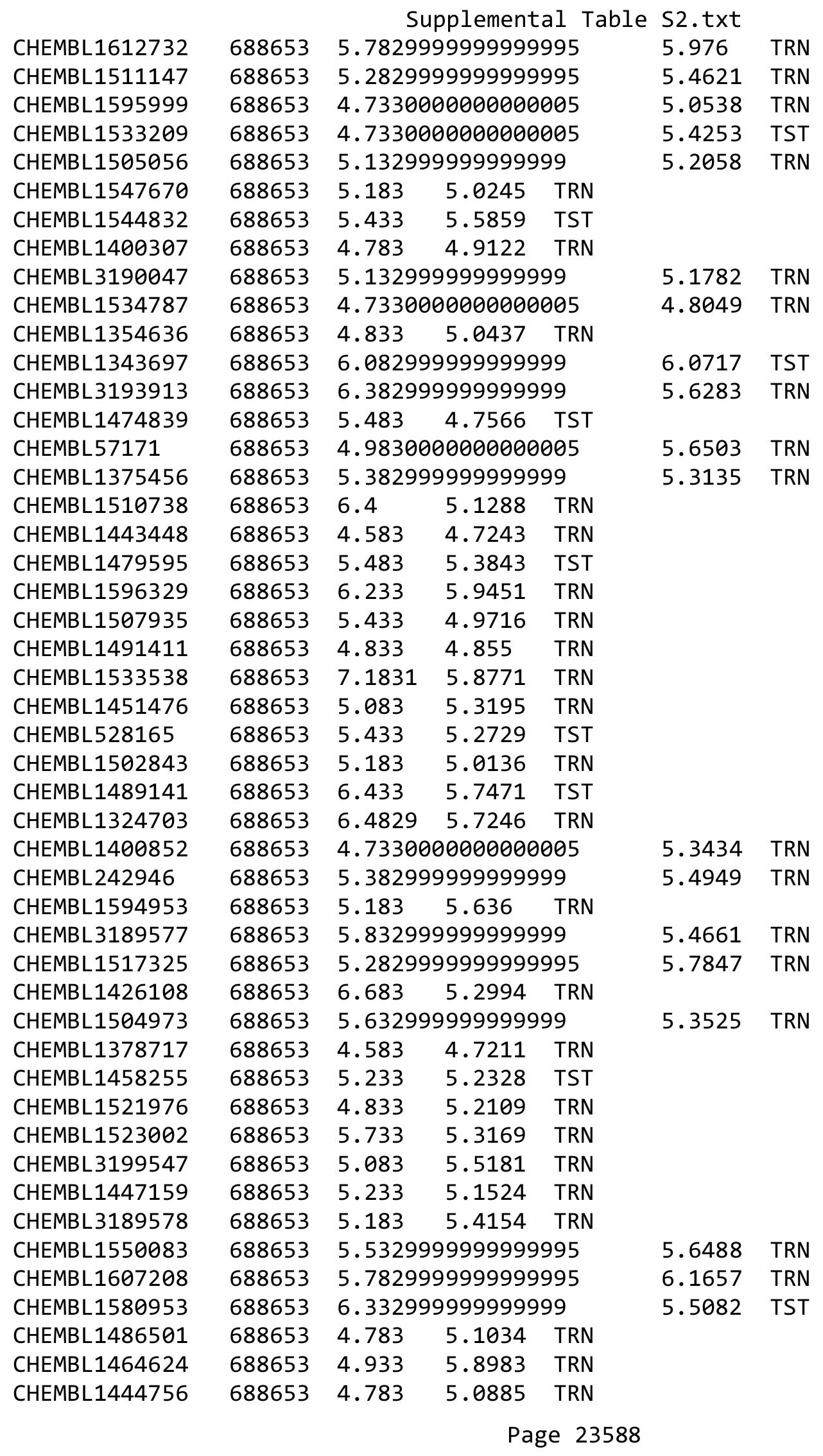




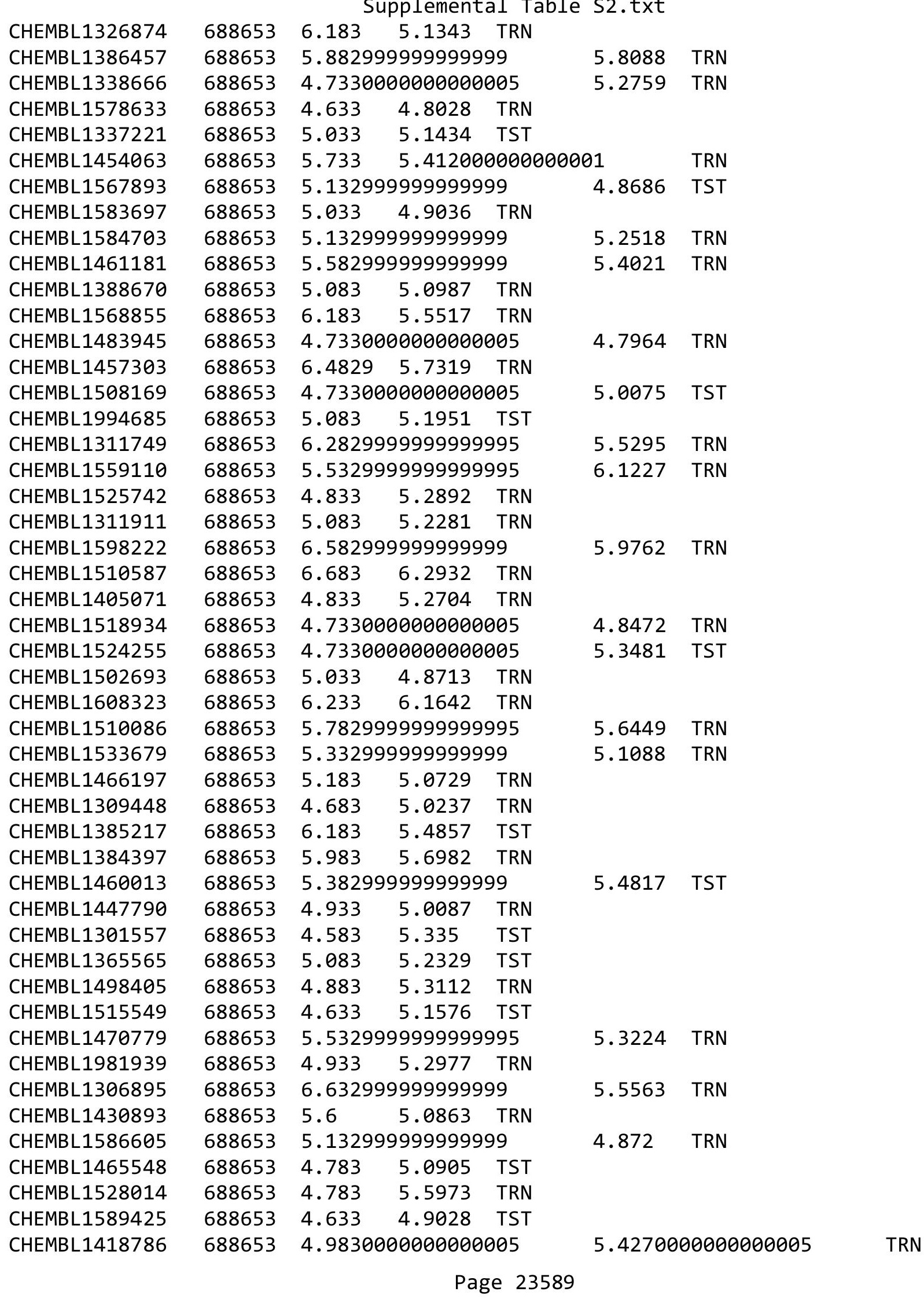




\begin{tabular}{|c|c|c|c|c|c|c|}
\hline CHEMBL1604345 & 688653 & 4.683 & 4.7554 & TST & & \\
\hline CHEMBL1323408 & 688653 & \multicolumn{3}{|c|}{6.082999999999999} & 5.2293 & $\mathrm{TP}$ \\
\hline CHEMBL1474710 & 688653 & 5.433 & 5.6765 & TRN & & \\
\hline CHEMBL1330326 & 88653 & 4.783 & 4.6642 & TRN & & \\
\hline CHEMBL1420703 & 688653 & \multicolumn{3}{|c|}{5.132999999999999} & 5.4194 & \\
\hline CHEMBL 2297342 & 688653 & 4.683 & 5.2062 & TRN & & \\
\hline CHEMBL1389668 & 688653 & \multicolumn{3}{|c|}{5.882999999999999} & 5.4414 & \\
\hline CHEMBL1450943 & 688653 & 5.733 & 5.8181 & TRN & & \\
\hline CHEMBL1391065 & 688653 & \multicolumn{3}{|c|}{6.332999999999999} & 6.1576 & \\
\hline CHEMBL1599341 & 688653 & 4.783 & 4.835 & TRN & & \\
\hline CHEMBL1371891 & 688653 & 4.883 & 5.0743 & TRN & & \\
\hline CHEMBL1604123 & 688653 & \multicolumn{3}{|c|}{5.882999999999999} & 5.3833 & TR \\
\hline HEMBL3191685 & 88653 & \multicolumn{3}{|c|}{5.132999999999999} & 5.4134 & \\
\hline CHEMBL 1474350 & 688653 & \multicolumn{3}{|c|}{4.7330000000000005} & 5.4665 & \\
\hline CHEMBL1419732 & 688653 & 5.0 & 4.9383 & TRN & & \\
\hline CHEMBL1466936 & 688653 & \multicolumn{3}{|c|}{5.382999999999999} & 5 . & \\
\hline CHEMBL1966499 & 688653 & 5.233 & 5.1647 & TST & & \\
\hline CHEMBL 3195175 & 688653 & \multicolumn{3}{|c|}{6.5329999999999995} & 997 & \\
\hline CHEMBL1399168 & 688653 & 5.083 & 5.2221 & TST & & \\
\hline CHEMBL1467838 & 688653 & \multicolumn{3}{|c|}{5.2829999999999995} & 3 & \\
\hline CHEMBL146€ & 688653 & 5.183 & 5.3475 & TRN & & \\
\hline CHEMBL1411494 & 688653 & \multicolumn{3}{|c|}{6.382999999999999} & $\partial 84$ & 15 \\
\hline CHEMBL1412250 & 688653 & \multicolumn{3}{|c|}{5.832999999999999} & 5 . & \\
\hline CHEMBL1406632 & 688653 & 4.783 & 5.3478 & TST & & \\
\hline CHEMBL1531521 & 688653 & \multicolumn{3}{|c|}{4.7330000000000005} & & \\
\hline CHEMBL1310721 & 688653 & \multicolumn{3}{|c|}{5.7829999999999995} & 75 & \\
\hline CHEMBL1385516 & 688653 & \multicolumn{3}{|c|}{5.132999999999999} & 5 . & \\
\hline CHEMBL1319272 & 688653 & \multicolumn{3}{|c|}{5.5329999999999995} & 4.8 & \\
\hline CHEMBL1608503 & 688653 & \multicolumn{3}{|c|}{5.7829999999999995} & & 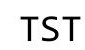 \\
\hline CHEMBL13 & 688653 & \multicolumn{3}{|c|}{5.832999999999999} & 5. & \\
\hline CHEMBL13 & 688653 & 4.933 & 4.8477 & TRN & & \\
\hline CHEMBL1357098 & 688653 & \multicolumn{3}{|c|}{6.382999999999999} & & \\
\hline CHEMBL1320874 & 688653 & \multicolumn{3}{|c|}{6.7829999999999995} & 5.5855 & \\
\hline CHEMBL336718 & 688653 & 6.183 & 5.6323 & TRN & & \\
\hline CHEMBL1337152 & 688653 & \multicolumn{3}{|c|}{5.2829999999999995} & & $1 \mathrm{k}$ \\
\hline CHEMBL1493773 & 688653 & \multicolumn{3}{|c|}{4.7330000000000005} & & \\
\hline CHEMBL1543482 & 688653 & 5.083 & 5.3515 & TST & & \\
\hline CHEMBL1603485 & 688653 & 5.733 & 5.2522 & TRN & & \\
\hline CHEMBL1572936 & 688653 & 4.833 & 4.8431 & TRN & & \\
\hline CHEMBL1597429 & 688653 & 4.73300 & 000000000 & 005 & 5.4725 & \\
\hline CHEMBL1529848 & 688653 & 4.633 & 5.1493 & TRN & & \\
\hline CHEMBL1458102 & 688653 & 5.13299 & 999999999 & & 3.001 & \\
\hline CHEMBL1446331 & 688653 & 5.13299 & 999999999 & & 5.77 & \\
\hline CHEMBL1580044 & 688653 & 6.38299 & 999999999 & & 4.7706 & \\
\hline CHEMBL502774 & 688653 & 6.28299 & 999999999 & 995 & 6.0774 & \\
\hline CHEMBL 3194711 & 688653 & 4.933 & 5.5736 & TST & & \\
\hline CHEMBL1541313 & 688653 & 5.13299 & 999999999 & & 4.87 & \\
\hline CHEMBL1450768 & 688653 & 6.08299 & 999999999 & 99 & 4.9136 & \\
\hline
\end{tabular}




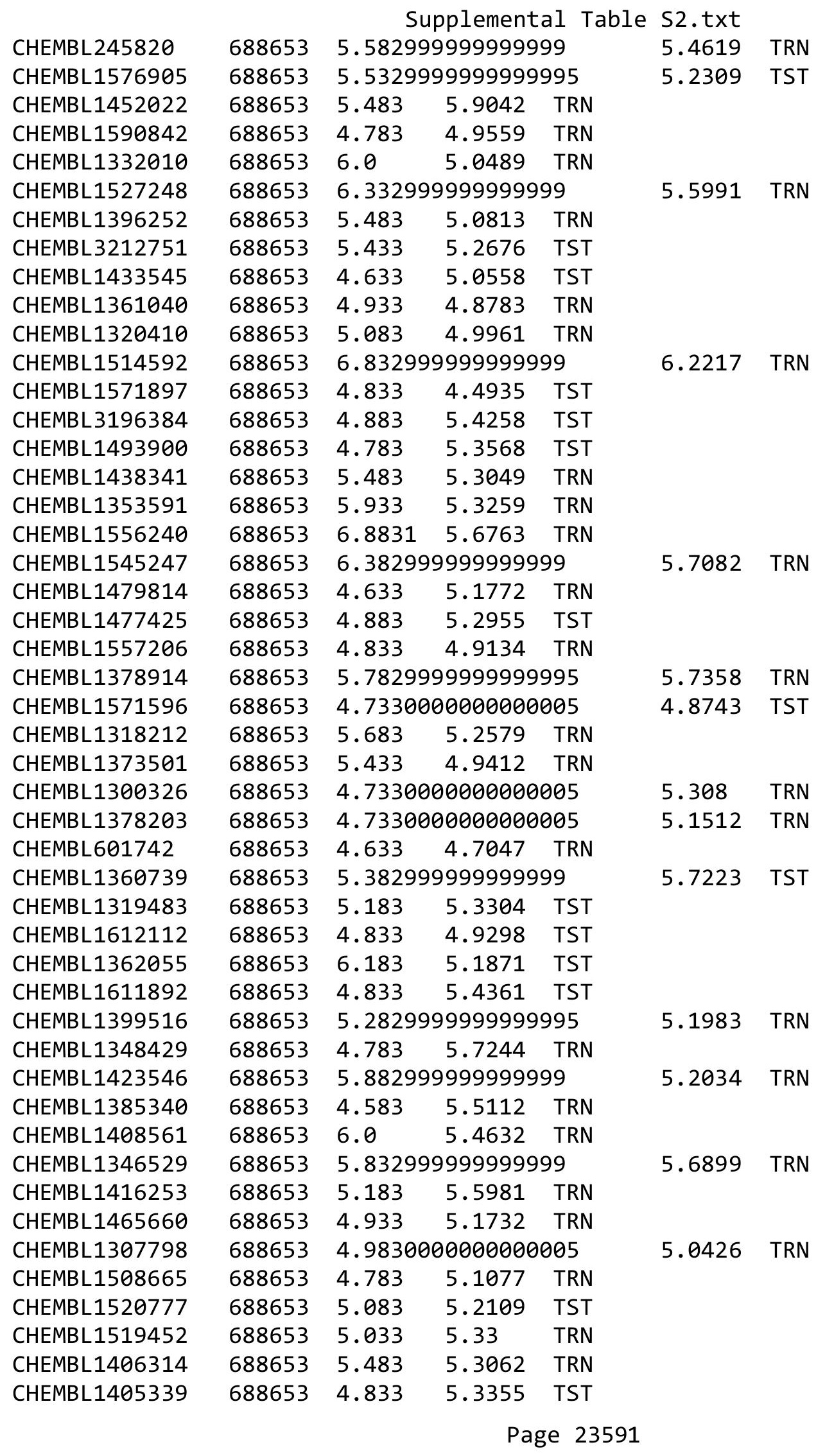




\begin{tabular}{|c|c|c|c|c|c|c|}
\hline \multirow[b]{2}{*}{ CHEMBL1526539 } & \multirow[b]{2}{*}{688653} & \multicolumn{5}{|c|}{ Supplemental Table S2.txt } \\
\hline & & \multicolumn{3}{|c|}{34.8607 TST } & & \\
\hline CHEMBL1350262 & 688653 & \multicolumn{3}{|c|}{4.7330000000000005} & 5.3501 & TST \\
\hline CHEMBL1542428 & 688653 & 5.483 & 5.2125 & TRN & & \\
\hline CHEMBL1312341 & 688653 & 5.083 & 5.1678 & TRN & & \\
\hline CHEMBL1348874 & 688653 & 4.633 & 4.9216 & TRN & & \\
\hline CHEMBL1435486 & 688653 & \multicolumn{3}{|c|}{5.632999999999999} & 5.5773 & TST \\
\hline CHEMBL1447445 & 688653 & \multicolumn{3}{|c|}{6.582999999999999} & 5.8323 & TRN \\
\hline CHEMBL1322112 & 688653 & 4.583 & 4.8385 & TRN & & \\
\hline CHEMBL1600144 & 688653 & 4.783 & 5.1934 & TRN & & \\
\hline CHEMBL1341482 & 688653 & 4.95 & 5.1093 & TRN & & \\
\hline CHEMBL1368351 & 688653 & \multicolumn{3}{|c|}{6.332999999999999} & 5.3633 & TRA \\
\hline CHEMBL1428528 & 688653 & 5.433 & 5.004 & TRN & & \\
\hline CHEMBL1585921 & 688653 & \multicolumn{3}{|c|}{4.9830000000000005} & 4.7092 & TST \\
\hline CHEMBL3189761 & 688653 & 5.233 & 5.3518 & TRN & & \\
\hline CHEMBL1557496 & 688653 & 4.883 & 4.8377 & TRN & & \\
\hline CHEMBL1510948 & 688653 & 5.683 & 5.03 & TST & & \\
\hline CHEMBL1566434 & 688653 & 6.7331 & 6.0089 & TRN & & \\
\hline CHEMBL1487152 & 688653 & 4.783 & 5.7014 & TRN & & \\
\hline CHEMBL1461532 & 688653 & \multicolumn{3}{|c|}{5.382999999999999} & 5.3737 & TRN \\
\hline CHEMBL1458874 & 688653 & \multicolumn{3}{|c|}{4.7330000000000005} & 5.2562 & TRN \\
\hline CHEMBL1593469 & 688653 & 4.633 & 4.7327 & TRN & & \\
\hline CHEMBL1345622 & 688653 & \multicolumn{3}{|c|}{6.082999999999999} & 5.7182 & TST \\
\hline CHEMBL1490617 & 688653 & \multicolumn{3}{|c|}{5.582999999999999} & 5.6522 & TRN \\
\hline CHEMBL1352800 & 688653 & \multicolumn{3}{|c|}{4.7330000000000005} & 5.1222 & TRN \\
\hline CHEMBL1547166 & 688653 & \multicolumn{3}{|c|}{5.132999999999999} & 5.2086 & TRA \\
\hline CHEMBL1301832 & 688653 & \multicolumn{3}{|c|}{4.9830000000000005} & 4.957 & TRA \\
\hline CHEMBL1434091 & 688653 & 4.833 & 5.148 & TRN & & \\
\hline CHEMBL1389422 & 688653 & 4.833 & 5.3392 & TST & & \\
\hline CHEMBL1329700 & 688653 & 5.033 & 5.1984 & TRN & & \\
\hline CHEMBL1418245 & 688653 & 5.183 & 4.888 & TST & & \\
\hline CHEMBL1492949 & 688653 & 4.783 & 5.2115 & TST & & \\
\hline CHEMBL1450060 & 688653 & 4.583 & 5.204 & TRN & & \\
\hline CHEMBL3198666 & 688653 & \multicolumn{3}{|c|}{5.582999999999999} & 5.7331 & TRN \\
\hline CHEMBL112610 & 688653 & 5.183 & 5.9448 & TRN & & \\
\hline CHEMBL1595277 & 688653 & 4.883 & 4.9481 & TRN & & \\
\hline CHEMBL2007276 & 688653 & 5.433 & 5.7521 & TRN & & \\
\hline CHEMBL1543701 & 688653 & 5.683 & 5.0137 & TRN & & \\
\hline CHEMBL1513894 & 688653 & 6.233 & 5.3366 & TRN & & \\
\hline CHEMBL1459908 & 688653 & 5.933 & 5.6855 & TRN & & \\
\hline CHEMBL1393761 & 688653 & 4.783 & 5.0828 & TRN & & \\
\hline CHEMBL1587495 & 688653 & 5.483 & 5.2329 & TRN & & \\
\hline CHEMBL1480615 & 688653 & \multicolumn{3}{|c|}{5.332999999999999} & 5.1287 & TRN \\
\hline CHEMBL1581770 & 688653 & 5.083 & 5.0864 & TRN & & \\
\hline CHEMBL 3212728 & 688653 & 4.783 & 5.1868 & TRN & & \\
\hline CHEMBL1490067 & 688653 & 4.783 & 5.1859 & TRN & & \\
\hline CHEMBL1544826 & 688653 & 4.883 & 5.5936 & TST & & \\
\hline CHEMBL1367397 & 688653 & \multicolumn{3}{|c|}{4.9830000000000005} & 5.4292 & TST \\
\hline CHEMBL1514379 & 688653 & 5.483 & 5.1213 & TRN & & \\
\hline
\end{tabular}




\begin{tabular}{|c|c|c|c|c|c|c|}
\hline & & \multicolumn{4}{|c|}{ Supplemental Table S2.txt } & \\
\hline CHEMBL1574059 & 688653 & \multicolumn{3}{|c|}{5.332999999999999} & 5.7086 & TRN \\
\hline CHEMBL1527175 & 688653 & \multicolumn{3}{|c|}{5.832999999999999} & 5.8975 & TRN \\
\hline CHEMBL1367487 & 688653 & \multicolumn{3}{|c|}{6.082999999999999} & 5.1882 & TRN \\
\hline CHEMBL1597758 & 688653 & 5.033 & 5.5941 & TST & & \\
\hline CHEMBL1318943 & 688653 & 4.583 & 4.9714 & TST & & \\
\hline CHEMBL1523095 & 688653 & 4.933 & 5.1465 & TRN & & \\
\hline CHEMBL1510792 & 688653 & \multicolumn{3}{|c|}{6.2829999999999995} & 5.7566 & TRN \\
\hline CHEMBL1565124 & 688653 & \multicolumn{3}{|c|}{4.7330000000000005} & 5.0407 & TRN \\
\hline CHEMBL1485857 & 688653 & 5.083 & 4.9967 & TST & & \\
\hline CHEMBL1371175 & 688653 & 5.733 & \multicolumn{3}{|c|}{5.3260000000000005} & TRN \\
\hline CHEMBL1466730 & 688653 & 5.183 & 5.3385 & TST & & \\
\hline CHEMBL3197304 & 688653 & \multicolumn{3}{|c|}{6.332999999999999} & 5.5533 & TST \\
\hline CHEMBL3192380 & 688653 & 4.933 & 5.4145 & TRN & & \\
\hline CHEMBL3208555 & 688653 & 4.883 & 5.6092 & TRN & & \\
\hline CHEMBL1456411 & 688653 & 4.783 & 5.3456 & TRN & & \\
\hline CHEMBL1448013 & 688653 & 4.783 & 5.1789 & TRN & & \\
\hline CHEMBL1469874 & 688653 & 4.833 & 4.8819 & TRN & & \\
\hline CHEMBL1575514 & 688653 & 4.933 & 5.3734 & TRN & & \\
\hline CHEMBL1393397 & 688653 & \multicolumn{3}{|c|}{4.9830000000000005} & 5.2763 & TRN \\
\hline CHEMBL1470472 & 688653 & 4.933 & 5.136 & TST & & \\
\hline CHEMBL1329228 & 688653 & 5.433 & 5.5767 & TRN & & \\
\hline CHEMBL1507209 & 688653 & \multicolumn{3}{|c|}{5.832999999999999} & 5.5554 & TRN \\
\hline CHEMBL1487799 & 688653 & \multicolumn{3}{|c|}{5.832999999999999} & 5.324 & TRN \\
\hline CHEMBL1368873 & 688653 & 4.933 & 5.0545 & TRN & & \\
\hline CHEMBL1581567 & 688653 & 4.833 & 5.0527 & TRN & & \\
\hline CHEMBL1980982 & 688653 & 4.933 & 5.2238 & TST & & \\
\hline CHEMBL1368336 & 688653 & 4.783 & 5.0971 & TST & & \\
\hline CHEMBL1299349 & 688653 & 5.033 & 5.2636 & TRN & & \\
\hline CHEMBL1389956 & 688653 & 6.4829 & 5.5982 & TRN & & \\
\hline CHEMBL1332642 & 688653 & 5.083 & 5.3911 & TRN & & \\
\hline CHEMBL1569085 & 688653 & 5.233 & 5.4141 & TRN & & \\
\hline CHEMBL1339806 & 688653 & 5.483 & 5.4537 & TRN & & \\
\hline CHEMBL1356739 & 688653 & 7.1831 & 5.8225 & TRN & & \\
\hline CHEMBL1514096 & 688653 & \multicolumn{3}{|c|}{5.5329999999999995} & 5.2298 & TST \\
\hline CHEMBL1415600 & 688653 & 5.183 & \multicolumn{3}{|c|}{5.3389999999999995} & TRN \\
\hline CHEMBL3195626 & 688653 & 4.783 & 5.2702 & TST & & \\
\hline CHEMBL1575066 & 688653 & \multicolumn{3}{|c|}{5.382999999999999} & 5.1803 & TRN \\
\hline CHEMBL1433539 & 688653 & 5.233 & 5.851 & TRN & & \\
\hline CHEMBL1561989 & 688653 & \multicolumn{3}{|c|}{6.2829999999999995} & 5.7014 & TRN \\
\hline CHEMBL1575028 & 688653 & \multicolumn{3}{|c|}{5.632999999999999} & 5.2734 & TRN \\
\hline CHEMBL1343705 & 688653 & \multicolumn{3}{|c|}{5.132999999999999} & 5.1206 & TST \\
\hline CHEMBL1523248 & 688653 & 5.483 & 5.6966 & TRN & & \\
\hline CHEMBL1423533 & 688653 & 4.783 & 5.2677 & TST & & \\
\hline CHEMBL1342357 & 688653 & 4.633 & 5.3035 & TST & & \\
\hline CHEMBL560073 & 688653 & 4.933 & 4.9165 & TRN & & \\
\hline CHEMBL1471230 & 688653 & \multicolumn{3}{|c|}{5.132999999999999} & 4.9264 & TRN \\
\hline CHEMBL3210133 & 688653 & 4.833 & 5.5356 & TRN & & \\
\hline \multirow[t]{2}{*}{ CHEMBL1311831 } & 688653 & 6.0 & 4.6453 & TRN & & \\
\hline & & \multicolumn{5}{|c|}{ Page 23593} \\
\hline
\end{tabular}




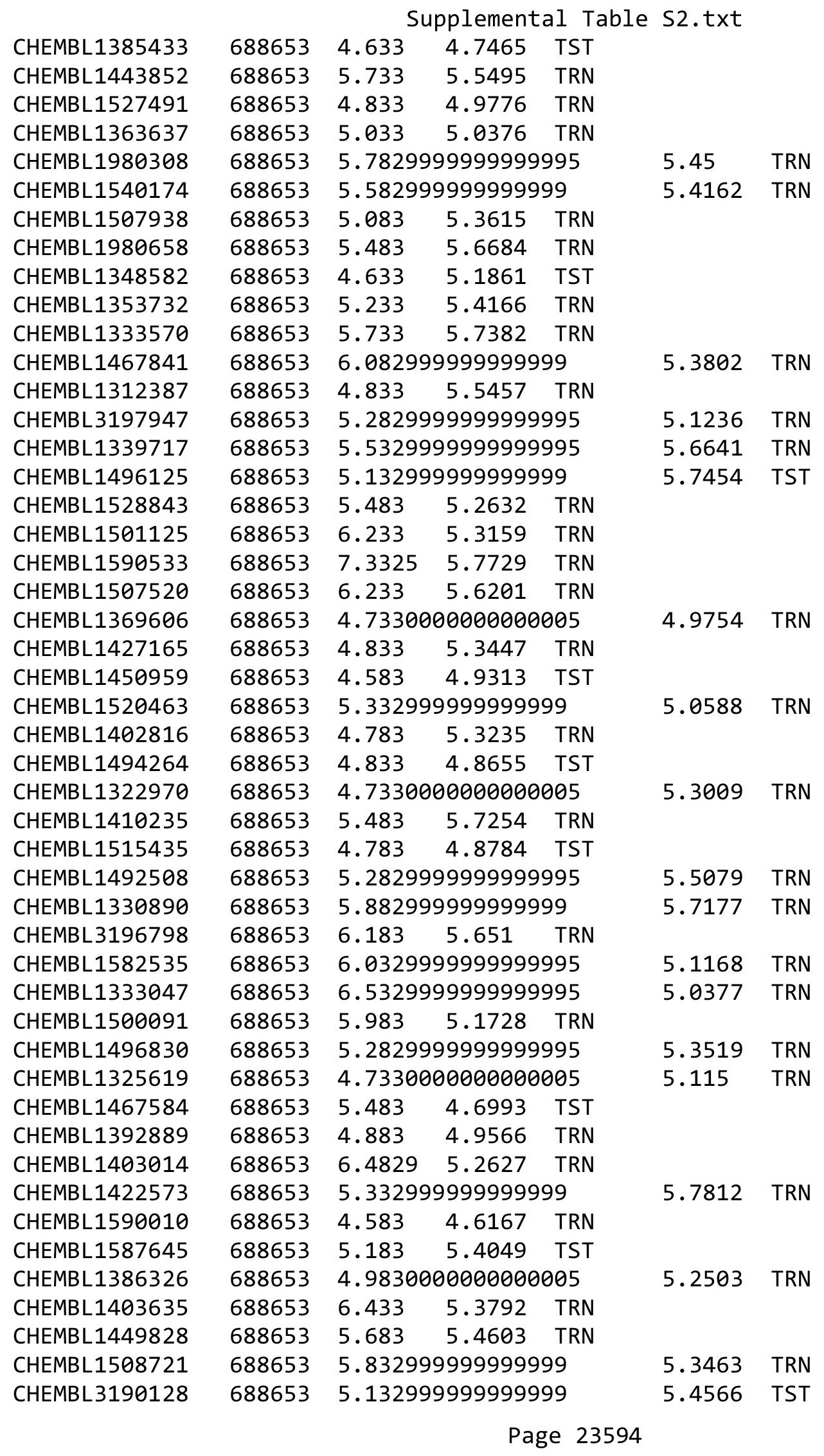




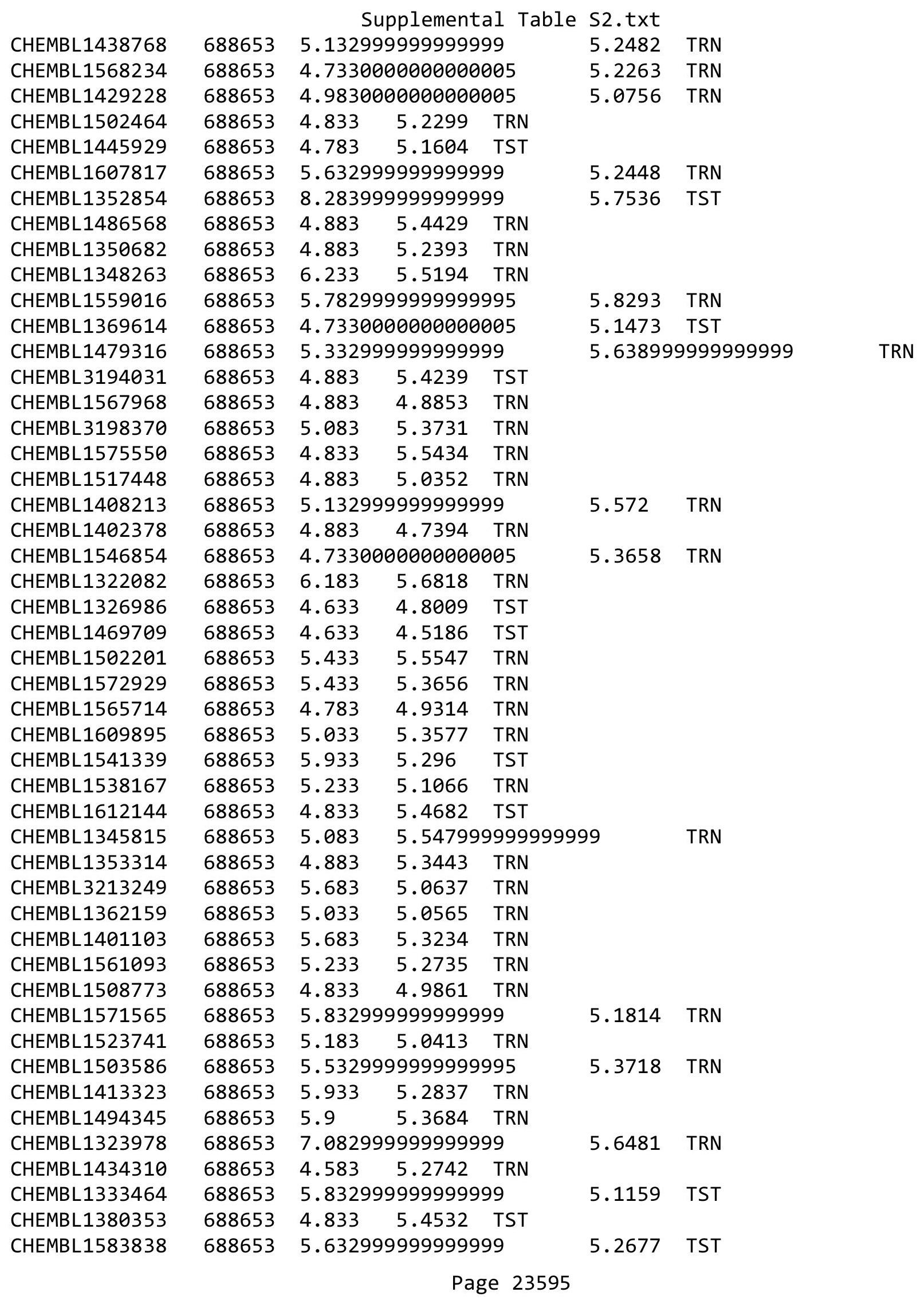




\begin{tabular}{|c|c|c|c|c|c|c|}
\hline \multirow[b]{2}{*}{ CHEMBL1422098 } & \multirow[b]{2}{*}{688653} & \multicolumn{5}{|c|}{ Supplemental Table S2.txt } \\
\hline & & \multicolumn{3}{|c|}{$3 \quad 5.0435$ TRN } & & \\
\hline CHEMBL1456572 & 688653 & 5.233 & 4.8894 & TRN & & \\
\hline CHEMBL3191343 & 688653 & \multicolumn{3}{|c|}{4.9830000000000005} & 5.3465 & TRA \\
\hline CHEMBL1467062 & 688653 & 4.833 & 5.2882 & TRN & & \\
\hline CHEMBL1613313 & 688653 & \multicolumn{3}{|c|}{5.632999999999999} & 5.3381 & TRN \\
\hline CHEMBL1325806 & 688653 & 5.233 & 5.2628 & TST & & \\
\hline CHEMBL1343364 & 688653 & \multicolumn{3}{|c|}{5.832999999999999} & 5.4453 & TRN \\
\hline CHEMBL1450402 & 688653 & 4.883 & 5.2526 & TRN & & \\
\hline CHEMBL1370483 & 688653 & \multicolumn{3}{|c|}{5.2829999999999995} & 5.1037 & TRA \\
\hline CHEMBL1464188 & 688653 & \multicolumn{3}{|c|}{4.9830000000000005} & 5.7378 & TST \\
\hline CHEMBL1439178 & 688653 & 4.883 & 5.5919 & TRN & & \\
\hline CHEMBL 1479057 & 688653 & \multicolumn{3}{|c|}{4.9830000000000005} & 5.0782 & TRN \\
\hline CHEMBL1385411 & 688653 & 5.233 & 5.8651 & TRN & & \\
\hline CHEMBL1576096 & 688653 & 4.883 & 5.4288 & TST & & \\
\hline CHEMBL1406162 & 688653 & 4.933 & 5.2826 & TST & & \\
\hline CHEMBL1340976 & 688653 & 4.883 & 4.9981 & TRN & & \\
\hline CHEMBL3198412 & 688653 & 6.683 & 5.7274 & TST & & \\
\hline CHEMBL1475259 & 688653 & \multicolumn{3}{|c|}{6.2829999999999995} & 5.7758 & TRN \\
\hline CHEMBL 1607720 & 688653 & 4.783 & 5.2421 & TRN & & \\
\hline CHEMBL1604695 & 688653 & 4.683 & 5.2693 & TST & & \\
\hline CHEMBL1528828 & 688653 & \multicolumn{3}{|c|}{5.5329999999999995} & 5.2462 & TRA \\
\hline CHEMBL1581030 & 688653 & \multicolumn{3}{|c|}{5.882999999999999} & 5.4624 & TRN \\
\hline CHEMBL1403902 & 688653 & \multicolumn{3}{|c|}{5.382999999999999} & 5.0124 & TST \\
\hline CHEMBL1454055 & 688653 & 4.933 & 5.2052 & TRN & & \\
\hline CHEMBL1421407 & 688653 & 4.633 & 5.0971 & TST & & \\
\hline CHEMBL1429218 & 688653 & 6.683 & 5.9348 & TRN & & \\
\hline CHEMBL1532879 & 688653 & 4.833 & 5.0634 & TRN & & \\
\hline CHEMBL1561548 & 688653 & \multicolumn{3}{|c|}{5.832999999999999} & 5.2886 & TST \\
\hline CHEMBL1423675 & 688653 & 4.783 & 4.8239 & TST & & \\
\hline CHEMBL1524829 & 688653 & 5.083 & 5.2663 & TRN & & \\
\hline CHEMBL1473864 & 688653 & 5.183 & 5.3078 & TRN & & \\
\hline CHEMBL1328840 & 688653 & \multicolumn{3}{|c|}{6.7829999999999995} & 6.0136 & TRN \\
\hline CHEMBL1214404 & 688653 & 4.883 & 5.6126 & TRN & & \\
\hline CHEMBL1380062 & 688653 & 5.233 & 5.4054 & TRN & & \\
\hline CHEMBL1597792 & 688653 & 4.883 & 5.1646 & TRN & & \\
\hline CHEMBL1306262 & 688653 & 5.933 & 4.9669 & TRN & & \\
\hline CHEMBL3196052 & 688653 & 4.833 & 5.3254 & TRN & & \\
\hline CHEMBL1380384 & 688653 & 5.183 & 5.0714 & TST & & \\
\hline CHEMBL1572456 & 688653 & 5.433 & 5.3458 & TRN & & \\
\hline CHEMBL1402312 & 688653 & \multicolumn{3}{|c|}{6.0329999999999995} & 5.5933 & TRA \\
\hline CHEMBL 1480100 & 688653 & 4.833 & 4.9468 & TST & & \\
\hline CHEMBL1445203 & 688653 & \multicolumn{3}{|c|}{6.382999999999999} & 5.3142 & TRN \\
\hline CHEMBL1438487 & 688653 & \multicolumn{3}{|c|}{4.7330000000000005} & 5.0262 & TST \\
\hline CHEMBL 1490730 & 688653 & 6.0 & 5.7592 & TRN & & \\
\hline CHEMBL1431318 & 688653 & 5.433 & 5.3178 & TRN & & \\
\hline CHEMBL1441505 & 688653 & \multicolumn{3}{|c|}{5.7829999999999995} & 5.3204 & TRA \\
\hline CHEMBL1584271 & 688653 & 5.183 & 5.6611 & TRN & & \\
\hline CHEMBL1379973 & 688653 & 6.183 & 5.3625 & TST & & \\
\hline
\end{tabular}




\begin{tabular}{|c|c|c|c|c|c|c|}
\hline \multirow[b]{2}{*}{ CHEMBL1321922 } & & \multicolumn{5}{|c|}{ Supplemental Table s2.txt } \\
\hline & 688653 & 4.833 & 4.9079 & TST & & \\
\hline CHEMBL1439220 & 688653 & 4.783 & \multicolumn{3}{|c|}{4.9510000000000005} & TRN \\
\hline CHEMBL1307449 & 688653 & \multicolumn{3}{|c|}{5.332999999999999} & 5.476 & TST \\
\hline CHEMBL1397813 & 688653 & 4.583 & 5.3585 & TST & & \\
\hline CHEMBL1386330 & 688653 & \multicolumn{3}{|c|}{5.382999999999999} & 5.1413 & TRN \\
\hline CHEMBL1299820 & 688653 & \multicolumn{3}{|c|}{4.9830000000000005} & 5.349 & TRN \\
\hline CHEMBL1351956 & 688653 & 4.833 & \multicolumn{3}{|c|}{5.2170000000000005} & TRN \\
\hline CHEMBL1601318 & 688653 & 5.483 & 5.4229 & TRN & & \\
\hline CHEMBL1440528 & 688653 & 6.8831 & 5.5451 & TST & & \\
\hline CHEMBL1602424 & 688653 & \multicolumn{3}{|c|}{5.132999999999999} & 5.2315 & TRN \\
\hline CHEMBL1586616 & 688653 & \multicolumn{3}{|c|}{4.7330000000000005} & 4.8817 & TST \\
\hline CHEMBL1570417 & 688653 & \multicolumn{3}{|c|}{6.082999999999999} & 5.1895 & TRN \\
\hline CHEMBL1470577 & 688653 & 4.933 & 5.6385 & TST & & \\
\hline CHEMBL3190603 & 688653 & \multicolumn{3}{|c|}{4.7330000000000005} & 5.3464 & TST \\
\hline CHEMBL1497776 & 688653 & \multicolumn{3}{|c|}{5.132999999999999} & 5.091 & TRN \\
\hline CHEMBL1320926 & 688653 & 5.683 & 5.7495 & TST & & \\
\hline CHEMBL1328268 & 688653 & 4.783 & 5.0508 & TRN & & \\
\hline CHEMBL1299787 & 688653 & 4.883 & 5.0751 & TRN & & \\
\hline CHEMBL1374845 & 688653 & 5.683 & 5.2454 & TRN & & \\
\hline CHEMBL1389881 & 688653 & 4.783 & 5.3279 & TST & & \\
\hline CHEMBL1488607 & 688653 & 4.833 & 5.5746 & TRN & & \\
\hline CHEMBL1592036 & 688653 & 5.683 & 5.0493 & TRN & & \\
\hline CHEMBL1401735 & 688653 & 4.783 & 5.6302 & TRN & & \\
\hline CHEMBL1309798 & 688653 & \multicolumn{3}{|c|}{5.332999999999999} & 5.5828 & TRN \\
\hline CHEMBL571228 & 688653 & \multicolumn{3}{|c|}{5.5329999999999995} & 5.9403 & TRN \\
\hline CHEMBL1578238 & 688653 & 4.883 & 5.6689 & TST & & \\
\hline CHEMBL1366652 & 688653 & 4.933 & 5.2357 & TRN & & \\
\hline CHEMBL117966 & 688653 & 5.433 & 5.6158 & TRN & & \\
\hline CHEMBL1444921 & 688653 & \multicolumn{3}{|c|}{5.2829999999999995} & 5.2629 & TRN \\
\hline CHEMBL1457509 & 688653 & 4.933 & 4.8452 & TST & & \\
\hline CHEMBL1421200 & 688653 & 4.933 & 4.9194 & TRN & & \\
\hline CHEMBL1556714 & 688653 & \multicolumn{3}{|c|}{4.7330000000000005} & 5.1969 & TST \\
\hline CHEMBL1582886 & 688653 & 4.833 & 5.2486 & TRN & & \\
\hline CHEMBL1519243 & 688653 & 4.883 & 5.0218 & TST & & \\
\hline CHEMBL1325279 & 688653 & 6.4829 & 5.4997 & TRN & & \\
\hline CHEMBL 3209370 & 688653 & 4.783 & 4.996 & TRN & & \\
\hline CHEMBL1556970 & 688653 & 5.733 & 5.3859 & TRN & & \\
\hline CHEMBL3211915 & 688653 & 4.783 & 5.4868 & TRN & & \\
\hline CHEMBL1463171 & 688653 & 6.433 & 5.9105 & TRN & & \\
\hline CHEMBL1570540 & 688653 & 4.833 & \multicolumn{3}{|c|}{5.031000000000001} & TRN \\
\hline CHEMBL1485806 & 688653 & \multicolumn{3}{|c|}{5.5329999999999995} & 6.0445 & TRN \\
\hline CHEMBL1363346 & 688653 & \multicolumn{3}{|c|}{5.132999999999999} & 5.6185 & TST \\
\hline CHEMBL3191670 & 688653 & \multicolumn{3}{|c|}{4.7330000000000005} & 5.3894 & TRN \\
\hline CHEMBL1543606 & 688653 & 4.883 & 5.4186 & TRN & & \\
\hline CHEMBL1995726 & 688653 & 5.033 & \multicolumn{3}{|c|}{5.156000000000001} & TST \\
\hline CHEMBL1402054 & 688653 & 4.883 & 5.4186 & TRN & & \\
\hline CHEMBL1362970 & 688653 & 4.783 & 5.4792 & TRN & & \\
\hline CHEMBL1568411 & 688653 & 5.233 & 5.7454 & TRN & & \\
\hline
\end{tabular}




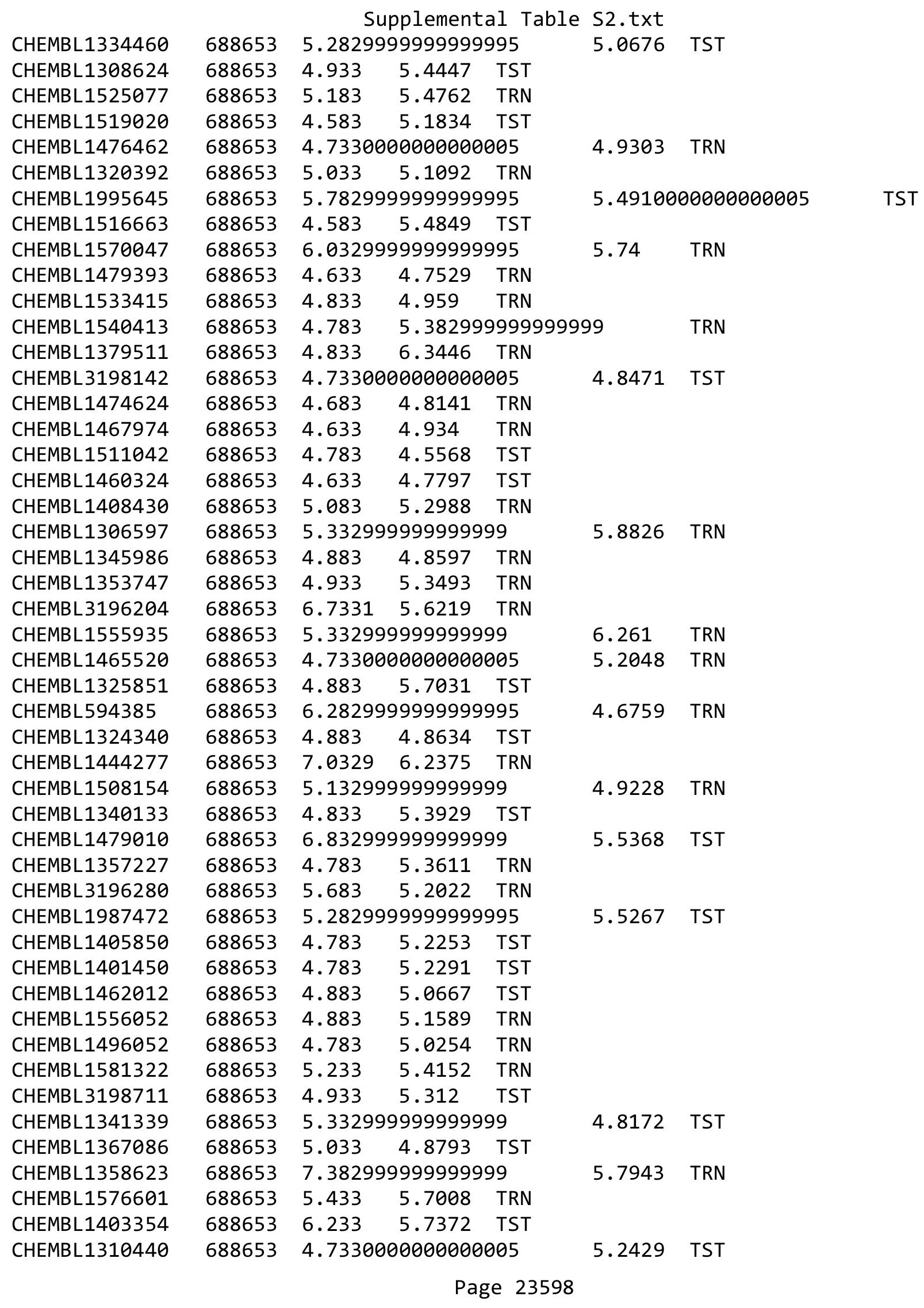




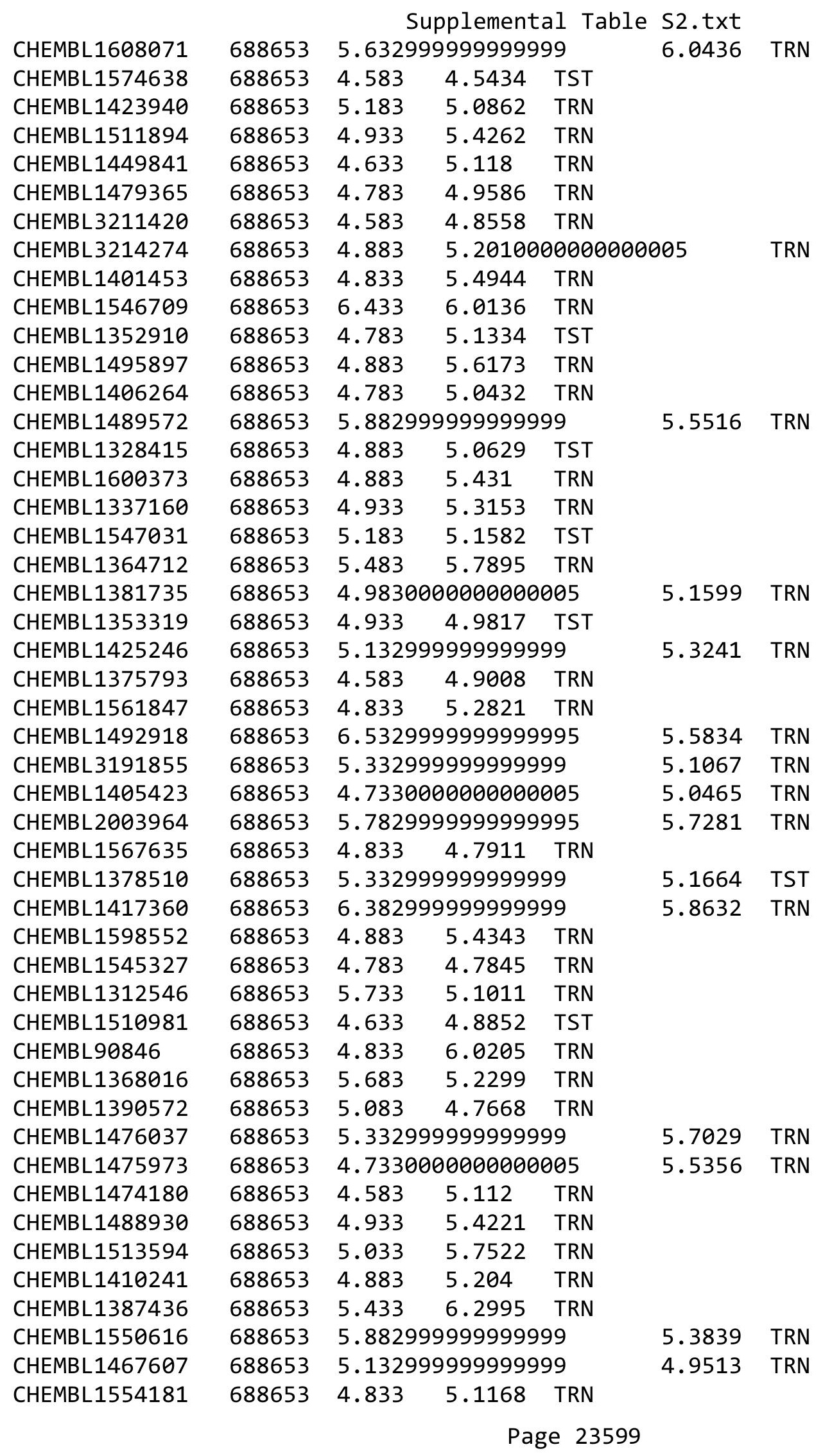




\begin{tabular}{|c|c|c|c|c|c|c|c|}
\hline \multicolumn{7}{|c|}{ Supplemental Table S2.txt } & \\
\hline CHEMBL3208389 & 688653 & \multicolumn{3}{|c|}{5.2829999999999995} & 5.6345 & TRN & \\
\hline CHEMBL1403806 & 688653 & 4.783 & 5.3024 & TRN & & & \\
\hline CHEMBL1428862 & 688653 & 4.633 & 5.2801 & TRN & & & \\
\hline CHEMBL 3191874 & 688653 & 4.583 & 5.8105 & TRN & & & \\
\hline CHEMBL1427951 & 688653 & 4.883 & 5.1274 & TRN & & & \\
\hline CHEMBL1463544 & 688653 & 4.833 & 5.3316 & TRN & & & \\
\hline CHEMBL1559858 & 688653 & 5.733 & 6.0183 & TRN & & & \\
\hline CHEMBL1371877 & 688653 & 5.483 & 5.3213 & TST & & & \\
\hline CHEMBL1403668 & 688653 & 5.033 & 5.5309 & TST & & & \\
\hline CHEMBL1418410 & 688653 & \multicolumn{3}{|c|}{5.2829999999999995} & 5.487 & TRN & \\
\hline CHEMBL1580912 & 688653 & \multicolumn{3}{|c|}{4.7330000000000005} & 5.0892 & TRN & \\
\hline CHEMBL1567608 & 688653 & 4.933 & 5.2221 & TRN & & & \\
\hline CHEMBL1521827 & 688653 & 5.433 & 4.9984 & TST & & & \\
\hline CHEMBL3193524 & 688653 & 5.233 & 5.1914 & TST & & & \\
\hline CHEMBL1493946 & 688653 & 4.833 & 5.1403 & TRN & & & \\
\hline CHEMBL1458511 & 688653 & 4.833 & 5.5862 & TRN & & & \\
\hline CHEMBL1490427 & 688653 & \multicolumn{3}{|c|}{7.082999999999999} & 6.0625 & TRN & \\
\hline CHEMBL1346935 & 688653 & 5.083 & 5.2559 & TRN & & & \\
\hline CHEMBL512387 & 688653 & 5.183 & 5.2934 & TRN & & & \\
\hline CHEMBL1299470 & 688653 & 4.633 & 5.1349 & TRN & & & \\
\hline CHEMBL 2021431 & 688653 & 4.883 & 5.2251 & TST & & & \\
\hline CHEMBL1596270 & 688653 & \multicolumn{3}{|c|}{5.882999999999999} & \multicolumn{2}{|c|}{5.7010000000000005} & TRN \\
\hline CHEMBL1512069 & 688653 & 4.833 & 4.9978 & TRN & & & \\
\hline CHEMBL1430994 & 688653 & 5.083 & 5.4229 & TRN & & & \\
\hline CHEMBL1590926 & 688653 & 4.583 & 4.8544 & TRN & & & \\
\hline CHEMBL1537480 & 688653 & \multicolumn{3}{|c|}{5.332999999999999} & 5.2873 & TST & \\
\hline CHEMBL1460407 & 688653 & \multicolumn{3}{|c|}{4.7330000000000005} & 5.6074 & TRN & \\
\hline CHEMBL1349636 & 688653 & \multicolumn{3}{|c|}{5.382999999999999} & 5.2445 & TST & \\
\hline CHEMBL1540761 & 688653 & \multicolumn{3}{|c|}{5.7829999999999995} & 5.8383 & TRN & \\
\hline CHEMBL1607877 & 688653 & 4.583 & 4.9697 & TRN & & & \\
\hline CHEMBL 3193782 & 688653 & \multicolumn{3}{|c|}{5.382999999999999} & 5.4205 & TST & \\
\hline CHEMBL1418846 & 688653 & 4.783 & \multicolumn{3}{|c|}{5.872999999999999} & TRN & \\
\hline CHEMBL1572753 & 688653 & \multicolumn{3}{|c|}{5.332999999999999} & 5.4888 & TRN & \\
\hline CHEMBL1546452 & 688653 & \multicolumn{3}{|c|}{5.582999999999999} & 5.0384 & TRN & \\
\hline CHEMBL1397745 & 688653 & \multicolumn{3}{|c|}{5.832999999999999} & 5.2168 & TRN & \\
\hline CHEMBL1312792 & 688653 & 5.083 & 5.2414 & TRN & & & \\
\hline CHEMBL1416490 & 688653 & 4.783 & 5.3051 & TRN & & & \\
\hline CHEMBL 3213785 & 688653 & 4.583 & 5.1961 & TRN & & & \\
\hline CHEMBL1454243 & 688653 & 4.833 & 5.1383 & TRN & & & \\
\hline CHEMBL1449472 & 688653 & \multicolumn{3}{|c|}{4.7330000000000005} & 4.9719 & TST & \\
\hline CHEMBL1970812 & 688653 & 5.933 & 5.4407 & TRN & & & \\
\hline CHEMBL1323477 & 688653 & 4.833 & 5.356 & TST & & & \\
\hline CHEMBL1481558 & 688653 & 5.733 & 5.4494 & TRN & & & \\
\hline CHEMBL1414166 & 688653 & \multicolumn{3}{|c|}{5.632999999999999} & 5.5423 & TST & \\
\hline CHEMBL1389196 & 688653 & 4.833 & 4.9706 & TRN & & & \\
\hline CHEMBL1994635 & 688653 & 5.683 & 5.4982 & TST & & & \\
\hline CHEMBL1300975 & 688653 & 4.783 & 5.1797 & TST & & & \\
\hline CHEMBL1400927 & 688653 & \multicolumn{3}{|c|}{5.132999999999999} & 5.1787 & TRN & \\
\hline
\end{tabular}




\begin{tabular}{|c|c|c|c|c|c|c|}
\hline \multirow[b]{2}{*}{ CHEMBL1570237 } & \multirow[b]{2}{*}{688653} & \multicolumn{5}{|c|}{ Supplemental Table S2.txt } \\
\hline & & \multicolumn{3}{|c|}{$\begin{array}{lll}4.883 & 5.2301 & \text { TST }\end{array}$} & & \\
\hline CHEMBL1443553 & 688653 & 4.933 & 5.1547 & TRN & \multirow{5}{*}{5.5662} & \\
\hline CHEMBL1494792 & 688653 & \multicolumn{3}{|c|}{5.632999999999999} & & \multirow[t]{4}{*}{ TRI } \\
\hline CHEMBL1363376 & 688653 & 5.983 & 6.4326 & TRN & & \\
\hline CHEMBL1553922 & 688653 & 4.583 & 5.1205 & TST & & \\
\hline CHEMBL3196203 & 688653 & 4.833 & 5.4209 & TRN & & \\
\hline CHEMBL1561136 & 688653 & \multicolumn{3}{|c|}{5.332999999999999} & \multirow[t]{3}{*}{4.7925} & \multirow[t]{3}{*}{ TRN } \\
\hline CHEMBL1368971 & 688653 & 4.833 & 5.3785 & TRN & & \\
\hline CHEMBL1429108 & 688653 & 4.583 & 4.8972 & TRN & & \\
\hline CHEMBL1325354 & 688653 & \multicolumn{3}{|c|}{5.632999999999999} & \multirow[t]{8}{*}{5.4027} & \multirow[t]{8}{*}{ TRA } \\
\hline CHEMBL1340733 & 688653 & 5.183 & 5.2701 & TRN & & \\
\hline CHEMBL1329307 & 688653 & 4.783 & 5.455 & TRN & & \\
\hline CHEMBL1545403 & 688653 & 4.883 & 5.3448 & TST & & \\
\hline CHEMBL3195663 & 688653 & 4.633 & 5.5749 & TST & & \\
\hline CHEMBL1472481 & 688653 & 4.933 & 5.1378 & TST & & \\
\hline CHEMBL1381088 & 688653 & 4.783 & 4.9919 & TRN & & \\
\hline CHEMBL1318614 & 688653 & 4.933 & 5.3295 & TRN & & \\
\hline CHEMBL1364260 & 688653 & \multicolumn{3}{|c|}{5.582999999999999} & 5.2518 & TRN \\
\hline CHEMBL1378433 & 688653 & \multicolumn{3}{|c|}{5.132999999999999} & 5.5295 & TRN \\
\hline CHEMBL1583446 & 688653 & 4.833 & 5.1566 & TST & & \\
\hline CHEMBL1988541 & 688653 & 4.583 & 5.015 & TRN & & \\
\hline CHEMBL1590929 & 688653 & 4.583 & 5.3064 & TST & & \\
\hline CHEMBL1392652 & 688653 & 4.783 & 5.3988 & TRN & & \\
\hline CHEMBL1460832 & 688653 & \multicolumn{3}{|c|}{5.882999999999999} & 5.3974 & TST \\
\hline CHEMBL1516527 & 688653 & 6.183 & 5.0457 & TRN & & \\
\hline CHEMBL1526966 & 688653 & 4.783 & 4.9412 & TST & & \\
\hline CHEMBL1402496 & 688653 & 4.783 & 5.2136 & TST & & \\
\hline CHEMBL1409189 & 688653 & \multicolumn{3}{|c|}{6.0329999999999995} & 5.9003 & TST \\
\hline CHEMBL1356126 & 688653 & 4.883 & 5.3855 & TST & & \\
\hline CHEMBL1568559 & 688653 & 4.833 & 5.023 & TRN & & \\
\hline CHEMBL1418518 & 688653 & 6.8831 & 5.7142 & TRN & & \\
\hline CHEMBL3196350 & 688653 & 4.783 & 5.1847 & TST & & \\
\hline CHEMBL1492569 & 688653 & \multicolumn{3}{|c|}{5.132999999999999} & 4.6598 & TRN \\
\hline CHEMBL1322420 & 688653 & \multicolumn{3}{|c|}{5.132999999999999} & 5.3456 & TRN \\
\hline CHEMBL1353940 & 688653 & 4.833 & 5.3437 & TST & & \\
\hline CHEMBL1358205 & 688653 & 5.183 & 5.1186 & TRN & & \\
\hline CHEMBL3214626 & 688653 & \multicolumn{3}{|c|}{5.132999999999999} & 5.256 & TRN \\
\hline CHEMBL3212126 & 688653 & 4.783 & 5.1013 & TRN & & \\
\hline CHEMBL1569634 & 688653 & 5.033 & 5.1319 & TST & & \\
\hline CHEMBL1576466 & 688653 & 5.033 & 5.1529 & TST & & \\
\hline CHEMBL1481417 & 688653 & 4.833 & 5.6019 & TST & & \\
\hline CHEMBL1522280 & 688653 & \multicolumn{3}{|c|}{5.7829999999999995} & 5.5337 & TRN \\
\hline CHEMBL1338768 & 688653 & 4.7330 & 0000000 & 005 & 5.0605 & TRA \\
\hline CHEMBL1410151 & 688653 & 4.783 & 5.3188 & TST & & \\
\hline CHEMBL1434134 & 688653 & 4.7330 & 00000006 & 005 & 5.0413 & TST \\
\hline CHEMBL1541860 & 688653 & 4.883 & 5.069 & TST & & \\
\hline CHEMBL1308329 & 688653 & 4.783 & 4.8684 & TST & & \\
\hline CHEMBL1521350 & 688653 & 4.783 & 5.3335 & TRN & & \\
\hline
\end{tabular}




\begin{tabular}{|c|c|c|c|c|c|c|}
\hline & \multicolumn{5}{|c|}{ oplemental Table } \\
\hline CHEMBL1525220 & 688653 & 5.433 & 5.3442 & TRN & & \\
\hline CHEMBL1501374 & 688653 & \multicolumn{3}{|c|}{6.832999999999999} & 5.8059 & $\mathrm{TR}$ \\
\hline CHEMBL1524645 & 688653 & 4.783 & 5.1845 & TRN & & \\
\hline CHEMBL1376710 & 688653 & \multicolumn{3}{|c|}{5.132999999999999} & 5.1388 & \\
\hline CHEMBL1328500 & 688653 & 4.883 & 4.9832 & TRN & & \\
\hline CHEMBL 3208916 & 688653 & 5.083 & 5.348 & TRN & & \\
\hline CHEMBL1330991 & 688653 & 6.183 & 5.307 & TRN & & \\
\hline CHEMBL1520225 & 688653 & 4.933 & 5.3524 & TRN & & \\
\hline CHEMBL1421422 & 688653 & \multicolumn{3}{|c|}{4.9830000000000005} & 5.2942 & \\
\hline CHEMBL1579235 & 688653 & 5.083 & 5.62 & TRN & & \\
\hline CHEMBL1451053 & 688653 & 5.233 & 5.3687 & TRN & & \\
\hline CHEMBL1310629 & 688653 & 4.633 & 4.9212 & TRN & & \\
\hline CHEMBL1503365 & 688653 & 5.733 & 5.3028 & TST & & \\
\hline CHEMBL1512097 & 688653 & 4.683 & 4.7903 & TST & & \\
\hline CHEMBL 3197268 & 688653 & \multicolumn{3}{|c|}{5.882999999999999} & 5.2671 & \\
\hline CHEMBL1429509 & 688653 & \multicolumn{3}{|c|}{6.332999999999999} & 5.6927 & \\
\hline CHEMBL1318502 & 688653 & 5.733 & 4.8465 & TRN & & \\
\hline CHEMBL1439995 & 688653 & \multicolumn{3}{|c|}{4.9830000000000005} & 5986 & \\
\hline CHEMBL1502462 & 688653 & \multicolumn{3}{|c|}{5.132999999999999} & & \\
\hline CHEMBL1569008 & 688653 & 4.783 & 4.9986 & TRN & & \\
\hline CHEMBL1414486 & 688653 & 5.983 & 5.4505 & TRN & & \\
\hline CHEMBL1521335 & 688653 & 4.783 & 5.1074 & TRN & & \\
\hline CHEMBL1538620 & 688653 & 5.083 & 5.4907 & TRN & & \\
\hline CHEMBL1331428 & 688 & 4.783 & 4.9239 & TRN & & \\
\hline CHEMBL1603011 & 688653 & \multicolumn{3}{|c|}{4.7330000000000005} & 5.468 & \\
\hline CHEMBL1452106 & 688653 & \multicolumn{3}{|c|}{5.382999999999999} & 5.2627 & \\
\hline CHEMBL1504873 & 688653 & \multicolumn{3}{|c|}{5.832999999999999} & 5.4259 & \\
\hline CHEMBL1307730 & 688653 & \multicolumn{3}{|c|}{5.632999999999999} & 5.0741 & \\
\hline CHEMBL1355537 & 688653 & 4.883 & 6.2985 & TST & & \\
\hline CHEMBL1459552 & 688653 & & & TST & & \\
\hline CHEMBL1456522 & 688653 & \multicolumn{3}{|c|}{4.9830000000000005} & 4.8642 & $\mathrm{~T}$ \\
\hline CHEMBL1432432 & 688653 & 4.633 & 5.1088 & TST & & \\
\hline CHEMBL1322715 & 688653 & \multicolumn{3}{|c|}{5.632999999999999} & 5.7467 & \\
\hline CHEMBL14 & 688653 & 5.683 & 5.1444 & TST & & \\
\hline CHEMBL1601472 & 688653 & 4.883 & 5.5773 & TRN & & \\
\hline CHEMBL1370985 & 688653 & 4.833 & 5.0689 & TRN & & \\
\hline CHEMBL1361740 & 688653 & \multicolumn{3}{|c|}{5.332999999999999} & 5.1984 & \\
\hline CHEMBL1487952 & 688653 & 4.783 & 5.0898 & TRN & & \\
\hline CHEMBL1300144 & 688653 & 4.633 & 4.8889 & TST & & \\
\hline CHEMBL1427103 & 688653 & \multicolumn{3}{|c|}{5.832999999999999} & 5.8514 & $\mathrm{TP}$ \\
\hline CHEMBL1381495 & 688653 & 4.783 & 5.397 & TST & & \\
\hline CHEMBL1585149 & 688653 & \multicolumn{3}{|c|}{6.082999999999999} & 5.3625 & Th \\
\hline CHEMBL1451037 & 688653 & 6.433 & 5.5466 & TRN & & \\
\hline CHEMBL1344923 & 688653 & 4.883 & 5.7866 & TRN & & \\
\hline CHEMBL1403657 & 688653 & \multicolumn{3}{|c|}{5.632999999999999} & 5.3373 & TRN \\
\hline CHEMBL1363490 & 688653 & 5.183 & 5.1007 & TRN & & \\
\hline CHEMBL1302365 & 688653 & \multicolumn{3}{|c|}{5.5329999999999995} & 5.2129 & 15 \\
\hline CHEMBL1609293 & 688653 & 4.783 & 4.993 & TRN & & \\
\hline
\end{tabular}




\begin{tabular}{|c|c|c|c|c|c|c|c|}
\hline \multicolumn{8}{|c|}{ pplemental Iable s2.txt } \\
\hline CHEMBL1414551 & 688653 & 4.883 & 5.072 & TRN & & & \\
\hline CHEMBL1301809 & 688653 & \multicolumn{3}{|c|}{4.7330000000000005} & 4.5649 & TRN & \\
\hline CHEMBL1610326 & 688653 & \multicolumn{3}{|c|}{5.882999999999999} & 5.7893 & TRN & \\
\hline CHEMBL1173570 & 688653 & 4.583 & 4.9843 & TRN & & & \\
\hline CHEMBL1371609 & 688653 & 4.783 & 4.7453 & TST & & & \\
\hline CHEMBL1398581 & 688653 & \multicolumn{3}{|c|}{4.7330000000000005} & 5.0922 & TRN & \\
\hline CHEMBL1487784 & 688653 & \multicolumn{3}{|c|}{5.832999999999999} & 5.7195 & TRN & \\
\hline CHEMBL1965086 & 688653 & 4.883 & 5.3435 & TRN & & & \\
\hline CHEMBL1424942 & 688653 & 5.083 & 5.7956 & TRN & & & \\
\hline CHEMBL1319241 & 688653 & 5.083 & 5.3763 & TST & & & \\
\hline CHEMBL1549805 & 688653 & 4.883 & 4.9016 & TRN & & & \\
\hline CHEMBL1324484 & 688653 & 5.083 & 6.0188 & TRN & & & \\
\hline CHEMBL1561294 & 688653 & \multicolumn{3}{|c|}{6.382999999999999} & 5.5655 & TRN & \\
\hline CHEMBL1348498 & 688653 & 5.483 & \multicolumn{3}{|c|}{5.3389999999999995} & TRN & \\
\hline CHEMBL1353188 & 688653 & \multicolumn{3}{|c|}{5.632999999999999} & 5.467006 & 00000000005 & TRN \\
\hline CHEMBL1309526 & 688653 & \multicolumn{3}{|c|}{5.382999999999999} & 5.4028 & TST & \\
\hline CHEMBL1539407 & 688653 & 5.433 & 4.7232 & TRN & & & \\
\hline CHEMBL1557155 & 688653 & \multicolumn{3}{|c|}{4.9830000000000005} & 5.1959 & TRN & \\
\hline CHEMBL1485551 & 688653 & 4.683 & 4.4079 & TRN & & & \\
\hline CHEMBL3194491 & 688653 & 4.933 & 5.1351 & TRN & & & \\
\hline CHEMBL1383183 & 688653 & 4.583 & 5.3664 & TST & & & \\
\hline CHEMBL1315554 & 688653 & \multicolumn{3}{|c|}{4.7330000000000005} & 5.4408 & TRN & \\
\hline CHEMBL1410682 & 688653 & 4.883 & 5.2911 & TRN & & & \\
\hline CHEMBL1600209 & 688653 & 4.633 & 4.9361 & TST & & & \\
\hline CHEMBL1445987 & 688653 & \multicolumn{3}{|c|}{4.9830000000000005} & 5.1142 & TST & \\
\hline CHEMBL1457518 & 688653 & \multicolumn{3}{|c|}{5.382999999999999} & 4.9889 & TRN & \\
\hline CHEMBL3211285 & 688653 & \multicolumn{3}{|c|}{5.7829999999999995} & 5.0835 & TST & \\
\hline CHEMBL1600602 & 688653 & 5.683 & 5.0113 & TRN & & & \\
\hline CHEMBL1599230 & 688653 & 4.833 & 5.4509 & TRN & & & \\
\hline CHEMBL1463624 & 688653 & 6.433 & 5.1549 & TRN & & & \\
\hline CHEMBL1536621 & 688653 & \multicolumn{3}{|c|}{5.2829999999999995} & 5.3327 & TRN & \\
\hline CHEMBL1939691 & 688653 & \multicolumn{3}{|c|}{5.132999999999999} & 5.2928 & TRN & \\
\hline CHEMBL1573365 & 688653 & \multicolumn{3}{|c|}{4.7330000000000005} & 5.3374 & TST & \\
\hline CHEMBL1506173 & 688653 & 4.833 & 5.2291 & TRN & & & \\
\hline CHEMBL1355265 & 688653 & 4.633 & 5.0531 & TST & & & \\
\hline CHEMBL1463115 & 688653 & 5.083 & 4.9867 & TRN & & & \\
\hline CHEMBL1568465 & 688653 & 5.933 & 5.5912 & TRN & & & \\
\hline CHEMBL1580743 & 688653 & 4.833 & 5.1299 & TRN & & & \\
\hline CHEMBL1602665 & 688653 & 4.883 & 5.2843 & TST & & & \\
\hline CHEMBL1375407 & 688653 & \multicolumn{3}{|c|}{5.132999999999999} & 4.8366 & TST & \\
\hline CHEMBL1562006 & 688653 & 5.7 & 5.1781 & TRN & & & \\
\hline CHEMBL1464666 & 688653 & 5.683 & 5.4585 & TRN & & & \\
\hline CHEMBL1336872 & 688653 & \multicolumn{3}{|c|}{5.132999999999999} & 4.8759 & TRN & \\
\hline CHEMBL1592400 & 688653 & 4.833 & 5.0876 & TRN & & & \\
\hline CHEMBL1389843 & 688653 & 4.833 & 5.4724 & TST & & & \\
\hline CHEMBL1571110 & 688653 & \multicolumn{3}{|c|}{6.0329999999999995} & 5.7557 & TST & \\
\hline CHEMBL1432261 & 688653 & \multicolumn{3}{|c|}{4.9830000000000005} & 5.2114 & TST & \\
\hline CHEMBL1317227 & 688653 & 4.783 & 5.2715 & TST & & & \\
\hline
\end{tabular}




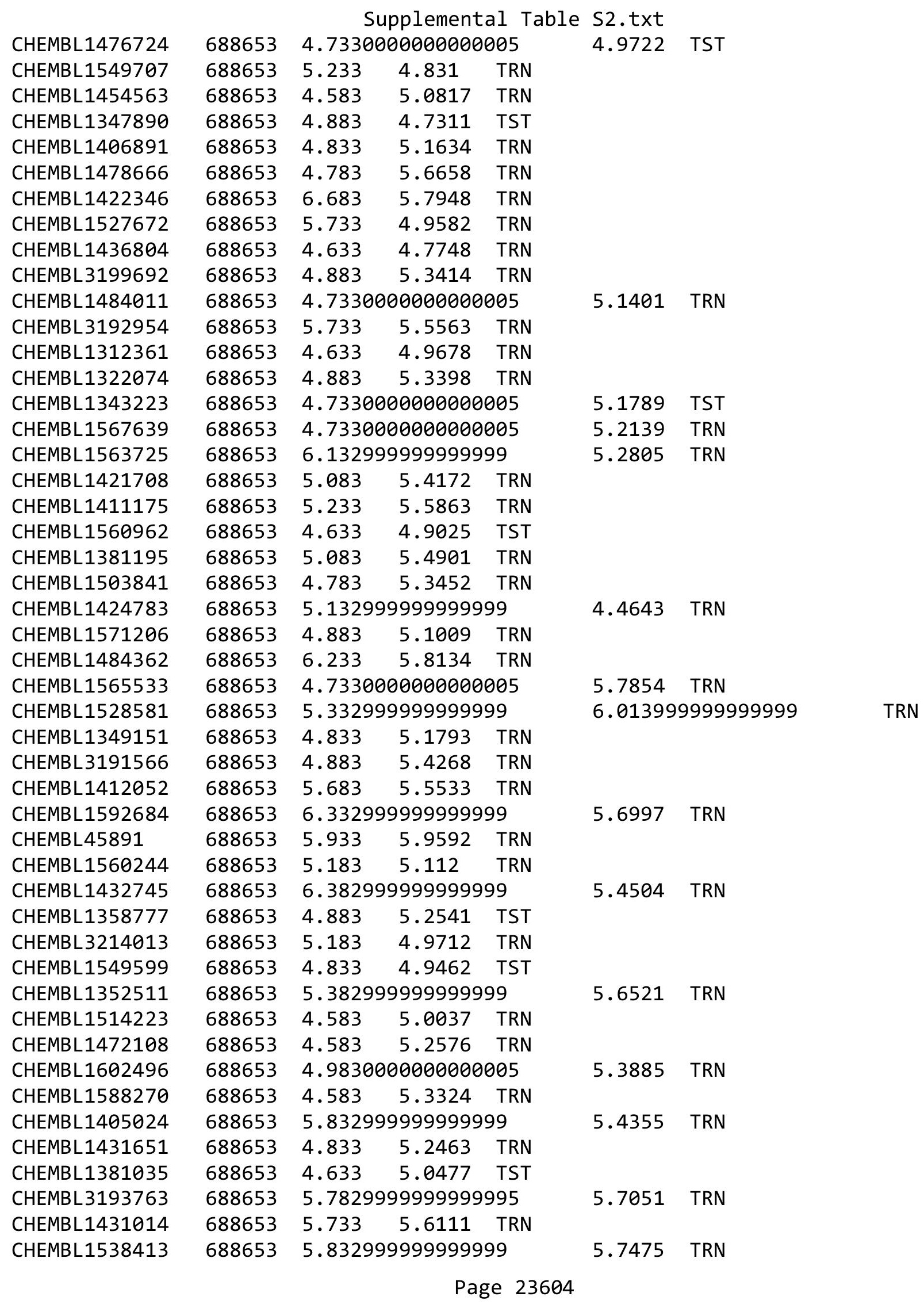




\begin{tabular}{|c|c|c|c|c|c|c|}
\hline \multirow{3}{*}{$\begin{array}{l}\text { CHEMBL1571459 } \\
\text { CHEMBL1589050 }\end{array}$} & \multirow{3}{*}{$\begin{array}{l}688653 \\
688653\end{array}$} & \multicolumn{4}{|c|}{ Supplemental Table S2.txt } & \multirow[b]{2}{*}{ TRN } \\
\hline & & \multicolumn{3}{|c|}{6.0329999999999995} & 5.3279 & \\
\hline & & 4.833 & 4.6715 & TST & & \\
\hline CHEMBL1438725 & 688653 & 5.733 & 5.6558 & TRN & & \\
\hline CHEMBL1500941 & 688653 & 5.233 & 5.3436 & TRN & & \\
\hline CHEMBL1608603 & 688653 & 4.783 & 5.4474 & TRN & & \\
\hline CHEMBL1426992 & 688653 & 5.433 & 5.4518 & TRN & & \\
\hline CHEMBL1386361 & 688653 & 4.783 & 4.9954 & TST & & \\
\hline CHEMBL1977007 & 688653 & \multicolumn{3}{|c|}{6.332999999999999} & 5.3613 & TRN \\
\hline CHEMBL1417192 & 688653 & \multicolumn{3}{|c|}{6.0329999999999995} & 5.749 & TRN \\
\hline CHEMBL1549360 & 688653 & 4.783 & 5.0393 & TRN & & \\
\hline CHEMBL 3214581 & 688653 & 4.833 & 5.0018 & TRN & & \\
\hline CHEMBL1512331 & 688653 & \multicolumn{3}{|c|}{6.382999999999999} & 5.6333 & TRN \\
\hline CHEMBL1374673 & 688653 & 5.0 & 5.2605 & TST & & \\
\hline CHEMBL3195918 & 688653 & \multicolumn{3}{|c|}{5.382999999999999} & 5.3547 & TRN \\
\hline CHEMBL1420494 & 688653 & 4.783 & 5.0128 & TRN & & \\
\hline CHEMBL 3145060 & 688653 & \multicolumn{3}{|c|}{5.582999999999999} & 5.3725 & TRN \\
\hline CHEMBL1581066 & 688653 & 6.433 & 5.5493 & TRN & & \\
\hline CHEMBL1340364 & 688653 & \multicolumn{3}{|c|}{4.7330000000000005} & 5.0441 & TRN \\
\hline CHEMBL1512920 & 688653 & \multicolumn{3}{|c|}{4.9830000000000005} & 5.2187 & TST \\
\hline CHEMBL1539487 & 688653 & \multicolumn{3}{|c|}{5.2829999999999995} & 4.9209 & TST \\
\hline CHEMBL1566320 & 688653 & \multicolumn{3}{|c|}{4.7330000000000005} & 5.0898 & TRN \\
\hline CHEMBL1304092 & 688653 & 4.783 & 4.8298 & TRN & & \\
\hline CHEMBL1333369 & 688653 & 5.683 & 4.9731 & TRN & & \\
\hline CHEMBL1483381 & 688653 & 4.783 & 4.9891 & TST & & \\
\hline CHEMBL1446690 & 688653 & 4.933 & 5.8174 & TRN & & \\
\hline CHEMBL1447208 & 688653 & 5.433 & 5.2865 & TRN & & \\
\hline CHEMBL1481317 & 688653 & 4.583 & 4.6775 & TST & & \\
\hline CHEMBL1410703 & 688653 & 5.233 & 5.0901 & TRN & & \\
\hline CHEMBL1378574 & 688653 & 4.883 & 5.2558 & TRN & & \\
\hline CHEMBL1512324 & 688653 & \multicolumn{3}{|c|}{5.132999999999999} & 5.4026 & TRN \\
\hline CHEMBL1383180 & 688653 & 4.833 & 4.9353 & TRN & & \\
\hline CHEMBL1500540 & 688653 & 5.183 & 5.1641 & TRN & & \\
\hline CHEMBL1501528 & 688653 & \multicolumn{3}{|c|}{5.7829999999999995} & 5.471 & TRN \\
\hline CHEMBL1516666 & 688653 & \multicolumn{3}{|c|}{6.082999999999999} & 5.3189 & TRN \\
\hline CHEMBL1532273 & 688653 & \multicolumn{3}{|c|}{5.132999999999999} & 5.5995 & TST \\
\hline CHEMBL1346084 & 688653 & 5.233 & 4.7292 & TST & & \\
\hline CHEMBL1306854 & 688653 & \multirow{2}{*}{\multicolumn{3}{|c|}{$\begin{array}{lr}4.633 & 5.0145 \\
5.5329999999999995\end{array}$}} & & \\
\hline CHEMBL1483668 & 688653 & & & & 5.4004 & TRN \\
\hline CHEMBL1411983 & 688653 & 5.483 & 5.126 & TST & & \\
\hline CHEMBL1558607 & 688653 & \multicolumn{3}{|c|}{5.332999999999999} & 5.4372 & TRN \\
\hline CHEMBL1383409 & 688653 & 4.933 & 5.4644 & TRN & & \\
\hline CHEMBL1977188 & 688653 & 4.683 & 5.1944 & TRN & & \\
\hline CHEMBL1605565 & 688653 & \multicolumn{3}{|c|}{5.5329999999999995} & 5.5954 & TRN \\
\hline CHEMBL1462960 & 688653 & 4.7330 & 00000000 & 005 & 4.8089 & TRN \\
\hline CHEMBL1321535 & 688653 & 4.783 & 5.20200 & 00006 & 01 & TRN \\
\hline CHEMBL3192430 & 688653 & 4.933 & 5.6784 & TST & & \\
\hline CHEMBL1414202 & 688653 & 4.883 & 5.147 & TRN & & \\
\hline CHEMBL1469727 & 688653 & 6.7331 & 6.1409 & TRN & & \\
\hline
\end{tabular}




\begin{tabular}{|c|c|c|c|c|c|c|c|}
\hline \multicolumn{8}{|c|}{ oplemental lable s2.txt } \\
\hline CHEMBL1971946 & 688653 & 4.933 & 5.4133 & TRN & & & \\
\hline CHEMBL1982203 & 688653 & \multicolumn{3}{|c|}{5.332999999999999} & \multicolumn{3}{|c|}{5.2699 TRN } \\
\hline CHEMBL1340551 & 688653 & 5.3329 & 99999999 & & 5.41100 & 00000000005 & TST \\
\hline CHEMBL1518730 & 688653 & 4.933 & \multicolumn{3}{|c|}{5.611000000000001} & TRN & \\
\hline CHEMBL1488193 & 688653 & 4.783 & 4.9449 & TRN & & & \\
\hline CHEMBL1541656 & 688653 & 4.683 & 4.9073 & TST & & & \\
\hline CHEMBL1537245 & 688653 & 4.783 & 5.1555 & TRN & & & \\
\hline CHEMBL1412529 & 688653 & 5.483 & 5.3169 & TRN & & & \\
\hline CHEMBL1590160 & 688653 & 5.033 & 5.4875 & TRN & & & \\
\hline CHEMBL1444292 & 688653 & \multicolumn{3}{|c|}{4.7330000000000005} & 5.0913 & TRN & \\
\hline CHEMBL1565376 & 688653 & 4.933 & 5.4626 & TRN & & & \\
\hline CHEMBL1988883 & 688653 & 6.683 & 5.4521 & TRN & & & \\
\hline CHEMBL1543647 & 688653 & 4.583 & 5.4069 & TST & & & \\
\hline CHEMBL1373709 & 688653 & 4.883 & 5.5546 & TST & & & \\
\hline CHEMBL1422646 & 688653 & \multicolumn{3}{|c|}{4.7330000000000005} & 5.17 & TRN & \\
\hline CHEMBL1412182 & 688653 & \multicolumn{3}{|c|}{5.382999999999999} & 5.5936 & TRN & \\
\hline CHEMBL1354555 & 688653 & 5.183 & 5.5435 & TRN & & & \\
\hline CHEMBL1478726 & 688653 & 5.233 & 5.0292 & TRN & & & \\
\hline CHEMBL1300188 & 688653 & 4.683 & 4.8323 & TRN & & & \\
\hline CHEMBL1585556 & 688653 & 4.933 & 4.8283 & TST & & & \\
\hline CHEMBL1329281 & 688653 & 4.883 & 5.1858 & TRN & & & \\
\hline CHEMBL1425131 & 688653 & \multicolumn{3}{|c|}{6.5329999999999995} & 5.7968 & TRN & \\
\hline CHEMBL1547710 & 688653 & 4.783 & 5.2509 & TRN & & & \\
\hline CHEMBL1319630 & 688653 & \multicolumn{3}{|c|}{5.5329999999999995} & 5.1439 & TRN & \\
\hline CHEMBL1315611 & 688653 & 4.783 & 4.9202 & TRN & & & \\
\hline CHEMBL1585399 & 688653 & 4.883 & 5.0992 & TST & & & \\
\hline CHEMBL1359067 & 688653 & \multicolumn{3}{|c|}{5.7829999999999995} & 5.1913 & TRN & \\
\hline CHEMBL1078244 & 688653 & 5.183 & 4.9693 & TST & & & \\
\hline CHEMBL1476592 & 688653 & \multicolumn{3}{|c|}{5.632999999999999} & 5.1835 & TRN & \\
\hline CHEMBL1304548 & 688653 & \multicolumn{3}{|c|}{5.132999999999999} & 5.1973 & TRN & \\
\hline CHEMBL1575708 & 688653 & \multicolumn{3}{|c|}{6.632999999999999} & 6.0941 & TRN & \\
\hline CHEMBL1327494 & 688653 & 5.083 & 5.46 & TRN & & & \\
\hline CHEMBL1314125 & 688653 & 4.833 & 5.1088 & TST & & & \\
\hline CHEMBL1420344 & 688653 & 4.933 & 5.2164 & TST & & & \\
\hline CHEMBL3194594 & 688653 & 5.083 & 4.9238 & TRN & & & \\
\hline CHEMBL1567973 & 688653 & 4.683 & 5.0951 & TST & & & \\
\hline CHEMBL1522816 & 688653 & \multicolumn{3}{|c|}{4.7330000000000005} & 5.5026 & TRN & \\
\hline CHEMBL1301453 & 688653 & \multicolumn{3}{|c|}{4.7330000000000005} & 4.8239 & TST & \\
\hline CHEMBL1516149 & 688653 & 4.683 & 5.6176 & TRN & & & \\
\hline CHEMBL1476361 & 688653 & \multicolumn{3}{|c|}{5.5329999999999995} & \multicolumn{2}{|c|}{5.422000000000001} & TRN \\
\hline CHEMBL1490787 & 688653 & 5.483 & 5.4656 & TRN & & & \\
\hline CHEMBL1479517 & 688653 & \multicolumn{3}{|c|}{4.7330000000000005} & 5.2941 & TST & \\
\hline CHEMBL1300133 & 688653 & \multicolumn{3}{|c|}{4.7330000000000005} & 5.1017 & TRN & \\
\hline CHEMBL1484975 & 688653 & 4.883 & 5.4993 & TRN & & & \\
\hline CHEMBL1502502 & 688653 & 5.733 & 5.1332 & TST & & & \\
\hline CHEMBL1313521 & 688653 & \multicolumn{3}{|c|}{4.7330000000000005} & 4.849 & TRN & \\
\hline CHEMBL1342400 & 688653 & 5.183 & 5.0403 & TRN & & & \\
\hline CHEMBL1489337 & 688653 & 5.683 & 5.6285 & TRN & & & \\
\hline
\end{tabular}




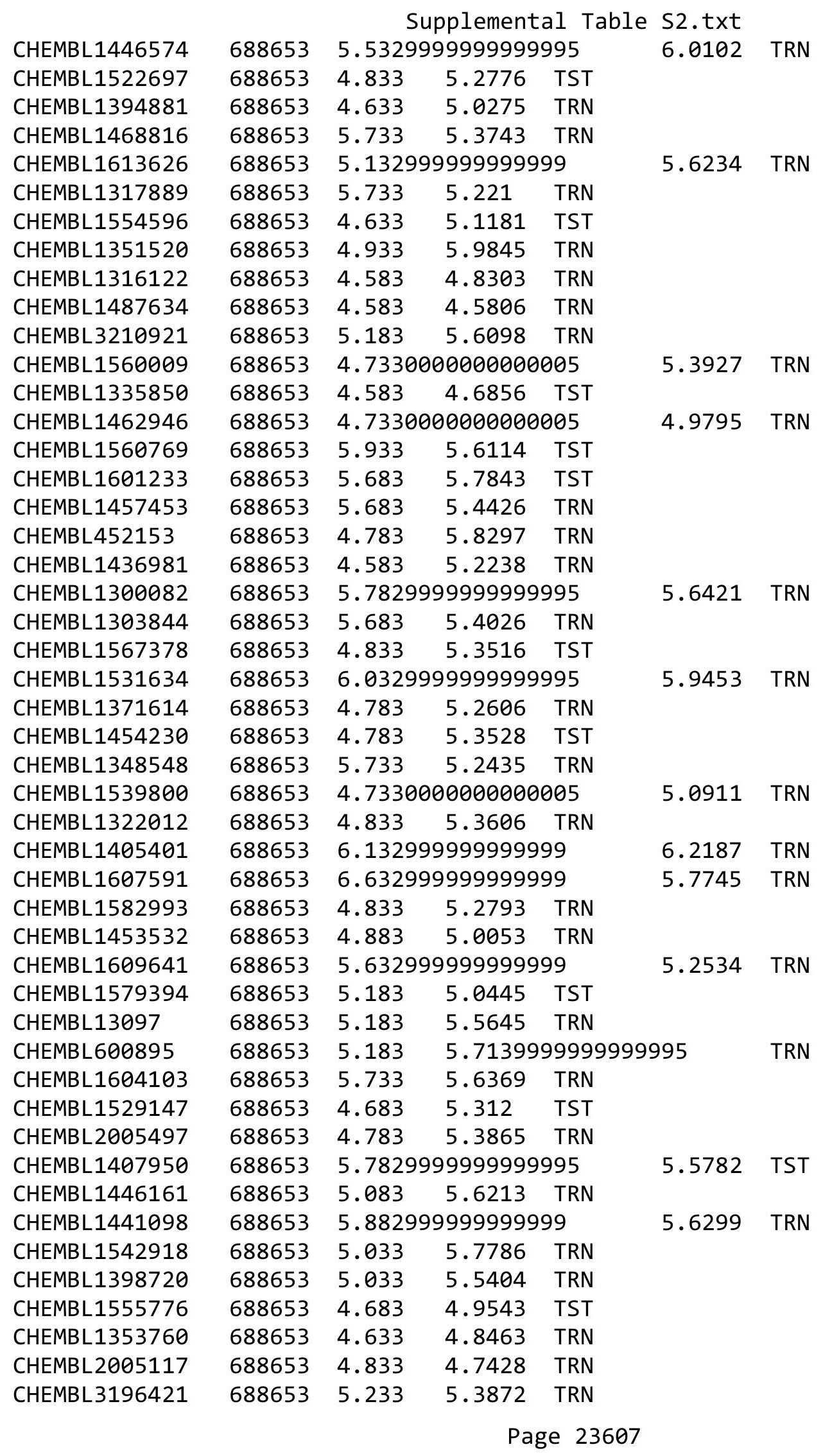




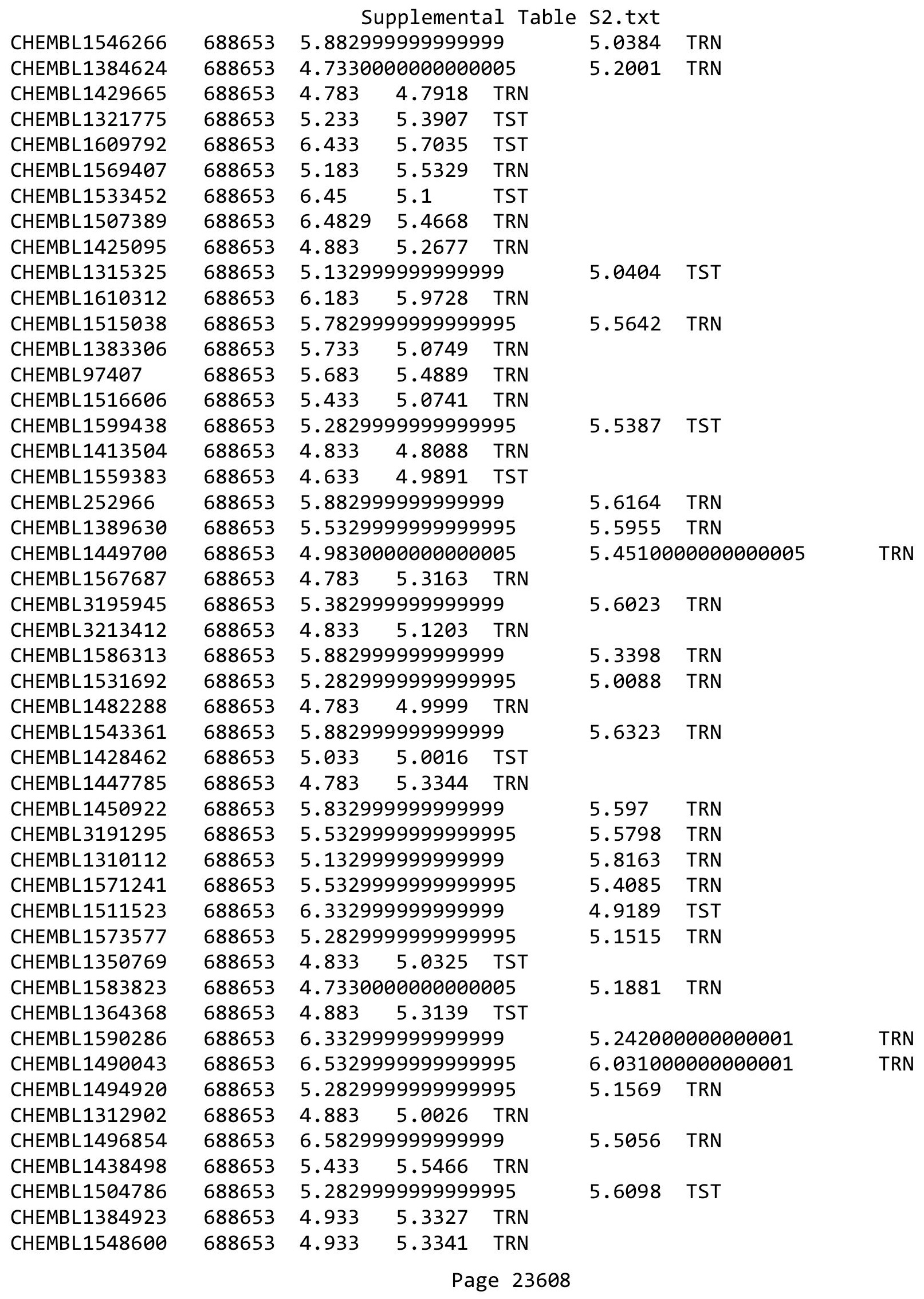




\begin{tabular}{|c|c|c|c|c|c|c|c|}
\hline \multirow[b]{2}{*}{ CHEMBL3198964 } & \multicolumn{6}{|c|}{ Supplemental Table S2.txt } & \\
\hline & 688653 & 7.1331 & 5.3776 & TRN & & & \\
\hline CHEMBL1564202 & 688653 & 5.233 & 4.9849 & TST & & & \\
\hline CHEMBL1402386 & 688653 & 6.332999 & 99999999 & 99 & 6.0292 & TRN & \\
\hline CHEMBL1454798 & 688653 & 4.933 & 5.2169 & TRN & & & \\
\hline CHEMBL1395072 & 688653 & 4.633 & 4.9833 & TRN & & & \\
\hline CHEMBL1585681 & 688653 & 5.782999 & 99999999 & 995 & 5.8659 & TRN & \\
\hline CHEMBL1504019 & 688653 & 6.032999 & 99999999 & 995 & 5.7771 & TRN & \\
\hline CHEMBL1516768 & 688653 & 4.833 & 5.1917 & TRN & & & \\
\hline CHEMBL3190816 & 688653 & 6.532999 & 99999999 & 995 & 5.29799 & 9999999999 & TRN \\
\hline CHEMBL1479679 & 688653 & 5.733 & 5.4013 & TRN & & & \\
\hline CHEMBL1394500 & 688653 & 4.833 & 5.1493 & TRN & & & \\
\hline CHEMBL 256202 & 688653 & 4.783 & 5.0875 & TST & & & \\
\hline CHEMBL531401 & 688653 & 5.683 & 5.8366 & TST & & & \\
\hline CHEMBL1327342 & 688653 & 5.183 & 5.1422 & TRN & & & \\
\hline CHEMBL1449886 & 688653 & 5.532999 & 99999999 & 995 & 5.2592 & TRN & \\
\hline CHEMBL1545996 & 688653 & 4.883 & 4.9874 & TRN & & & \\
\hline CHEMBL 2007297 & 688653 & 4.883 & 5.5453 & TRN & & & \\
\hline CHEMBL1594331 & 688653 & 4.783 & 5.2105 & TRN & & & \\
\hline CHEMBL1467069 & 688653 & 5.183 & 5.2041 & TRN & & & \\
\hline CHEMBL1977734 & 688653 & 4.983006 & 00000000 & 005 & 5.3861 & TRN & \\
\hline CHEMBL1535901 & 688653 & $4.73300 e$ & j0000000 & 005 & 5.0749 & TRN & \\
\hline CHEMBL1507744 & 688653 & 6.082999 & 99999999 & & 5.2856 & TRN & \\
\hline CHEMBL1482271 & 688653 & 6.183 & 5.8408 & TRN & & & \\
\hline CHEMBL1342393 & 688653 & $4.73300 e$ & 20000000 & 005 & 4.9049 & TST & \\
\hline CHEMBL1463993 & 688653 & 5.282999 & 99999999 & 995 & 5.685 & TST & \\
\hline CHEMBL1492231 & 688653 & 4.883 & 5.066 & TRN & & & \\
\hline CHEMBL1435570 & 688653 & 4.783 & 5.7169 & TST & & & \\
\hline CHEMBL1610364 & 688653 & 5.233 & 5.3391 & TRN & & & \\
\hline CHEMBL1335650 & 688653 & 4.583 & 5.1297 & TST & & & \\
\hline CHEMBL1523638 & 688653 & 5.282999 & 99999999 & 995 & 5.3446 & TRN & \\
\hline CHEMBL1554769 & 688653 & 4.833 & 5.7109 & TRN & & & \\
\hline CHEMBL1311977 & 688653 & 5.882999 & 99999999 & & 5.5589 & TRN & \\
\hline CHEMBL3196907 & 688653 & 5.832999 & 99999999 & & 5.1797 & TRN & \\
\hline CHEMBL1332994 & 688653 & 5.483 & 5.3461 & TRN & & & \\
\hline CHEMBL1569574 & 688653 & 5.233 & 5.7069 & TRN & & & \\
\hline CHEMBL1326083 & 688653 & 5.233 & 5.1706 & TRN & & & \\
\hline CHEMBL1312613 & 688653 & 6.132999 & 99999999 & & 6.0598 & TRN & \\
\hline CHEMBL1544083 & 688653 & 5.733 & 5.2698 & TRN & & & \\
\hline CHEMBL3198443 & 688653 & 4.933 & 5.4062 & TRN & & & \\
\hline CHEMBL1366626 & 688653 & 4.983006 & 00000000 & 005 & 5.3055 & TST & \\
\hline CHEMBL1431684 & 688653 & 4.583 & 4.9779 & TRN & & & \\
\hline CHEMBL1324794 & 688653 & 4.833 & 5.2448 & TRN & & & \\
\hline CHEMBL1396774 & 688653 & 4.833 & 4.8567 & TRN & & & \\
\hline CHEMBL1477014 & 688653 & 5.332999 & 99999999 & & 5.1252 & TRN & \\
\hline CHEMBL1495567 & 688653 & 5.13299 & 99999999 & & 5.19 & TST & \\
\hline CHEMBL1413516 & 688653 & 4.783 & 5.2914 & TRN & & & \\
\hline CHEMBL 3213708 & 688653 & 4.783 & 5.1877 & TRN & & & \\
\hline CHEMBL1432643 & 688653 & 5.382999 & 99999999 & & 5.6072 & TRN & \\
\hline
\end{tabular}




\begin{tabular}{|c|c|c|c|c|c|c|}
\hline \multirow[b]{2}{*}{ CHEMBL1507345 } & & \multicolumn{5}{|c|}{ Supplemental Table S2.txt } \\
\hline & 688653 & 4.583 & 4.5667 & TST & & \\
\hline CHEMBL3191410 & 688653 & \multicolumn{3}{|c|}{6.132999999999999} & 5.5168 & TRN \\
\hline CHEMBL1300101 & 688653 & \multicolumn{3}{|c|}{4.7330000000000005} & 5.4403 & \\
\hline CHEMBL1301112 & 688653 & 4.883 & 5.2179 & TRN & & \\
\hline CHEMBL1599537 & 688653 & 4.833 & 5.4268 & TST & & \\
\hline CHEMBL1554496 & 688653 & 5.433 & 5.3173 & TST & & \\
\hline CHEMBL475754 & 688653 & \multicolumn{3}{|c|}{5.832999999999999} & 5.5168 & \\
\hline CHEMBL1505303 & 688653 & 6.183 & 5.8016 & TRN & & \\
\hline CHEMBL3196602 & 688653 & 4.783 & 5.1622 & TRN & & \\
\hline CHEMBL1426968 & 688653 & 4.933 & 5.0424 & TRN & & \\
\hline CHEMBL1352269 & 688653 & \multicolumn{3}{|c|}{5.5329999999999995} & 5.4744 & \\
\hline CHEMBL3198902 & 688653 & 5.183 & 4.9122 & TRN & & \\
\hline CHEMBL1378442 & 688653 & \multicolumn{3}{|c|}{6.5329999999999995} & 5.9467 & \\
\hline CHEMBL7747 & 688653 & 4.933 & 5.5949 & TRN & & \\
\hline CHEMBL1344967 & 688653 & 4.833 & 5.42 & TRN & & \\
\hline CHEMBL 3189288 & 688653 & 5.183 & 5.0472 & TRN & & \\
\hline CHEMBL15£ & 688653 & 5.233 & 5.4314 & TRN & & \\
\hline CHEMBL3213162 & 688653 & 4.783 & 5.0279 & TRN & & \\
\hline CHEMBL1359902 & 688653 & \multicolumn{3}{|c|}{4.7330000000000005} & 5.1415 & \\
\hline CHEMBL1506065 & 688653 & 5.683 & 5.9075 & TRN & & \\
\hline CHEMBL1388370 & 688653 & 4.883 & 5.5323 & TST & & \\
\hline CHEMBL144 & 688653 & 4.633 & 5.0207 & TRN & & \\
\hline CHEMBL1334744 & 688653 & 4.883 & 5.5716 & TRN & & \\
\hline CHEMBL1405281 & 688653 & 4.633 & 4.9316 & TRN & & \\
\hline CHEMBL1480811 & 688653 & \multicolumn{3}{|c|}{4.9830000000000005} & 5.1212 & \\
\hline CHEMBL1403994 & 688653 & \multicolumn{3}{|c|}{5.2829999999999995} & 4.9332 & \\
\hline CHEMBL1603779 & 688653 & \multicolumn{3}{|c|}{5.7829999999999995} & 5.8048 & \\
\hline CHEMBL591178 & 688653 & 5.433 & 5.5363 & TRN & & \\
\hline CHEMBL1359055 & 688653 & 4.783 & 5.1664 & TST & & \\
\hline CHEMBL1383199 & 688653 & 4.783 & 4.9423 & TRN & & \\
\hline CHEMBL365257 & 688653 & 4.933 & 5.0603 & TRN & & \\
\hline CHEMBL 3211678 & 688 & 4.783 & 5.1919 & TST & & \\
\hline CHEMBL1606973 & 688653 & \multicolumn{3}{|c|}{5.382999999999999} & 5.2908 & \\
\hline CHEMBL1545060 & 688653 & \multicolumn{3}{|c|}{5.7829999999999995} & 5.4929 & \\
\hline CHEMBL1529631 & 688653 & \multicolumn{3}{|c|}{5.632999999999999} & 6.0388 & \\
\hline CHEMBL1525990 & 688653 & \multicolumn{3}{|c|}{5.132999999999999} & 5.1399 & \\
\hline CHEMBL1586511 & 688653 & 5.183 & 4.9658 & TRN & & \\
\hline CHEMBL1524706 & 688653 & \multicolumn{3}{|c|}{4.9830000000000005} & 4.9514 & \\
\hline CHEMBL225903 & 688653 & 5.233 & 6.3275 & TRN & & \\
\hline CHEMBL1374727 & 688653 & \multicolumn{3}{|c|}{5.882999999999999} & 5.7055 & \\
\hline CHEMBL1384326 & 688653 & \multicolumn{3}{|c|}{5.382999999999999} & 5.2291 & \\
\hline CHEMBL1490824 & 688653 & 5.033 & 5.4685 & TRN & & \\
\hline CHEMBL1440395 & 688653 & 5.483 & 5.9377 & TRN & & \\
\hline CHEMBL1349626 & 688653 & 5.433 & 4.9573 & TRN & & \\
\hline CHEMBL1299767 & 688653 & 4.883 & 5.1323 & TRN & & \\
\hline CHEMBL1376511 & 688653 & \multicolumn{3}{|c|}{5.332999999999999} & 5.2087 & \\
\hline CHEMBL475541 & 688653 & 4.933 & 5.0539 & TRN & & \\
\hline CHEMBL1581089 & 688653 & \multicolumn{3}{|c|}{5.7829999999999995} & 6.0428 & \\
\hline
\end{tabular}




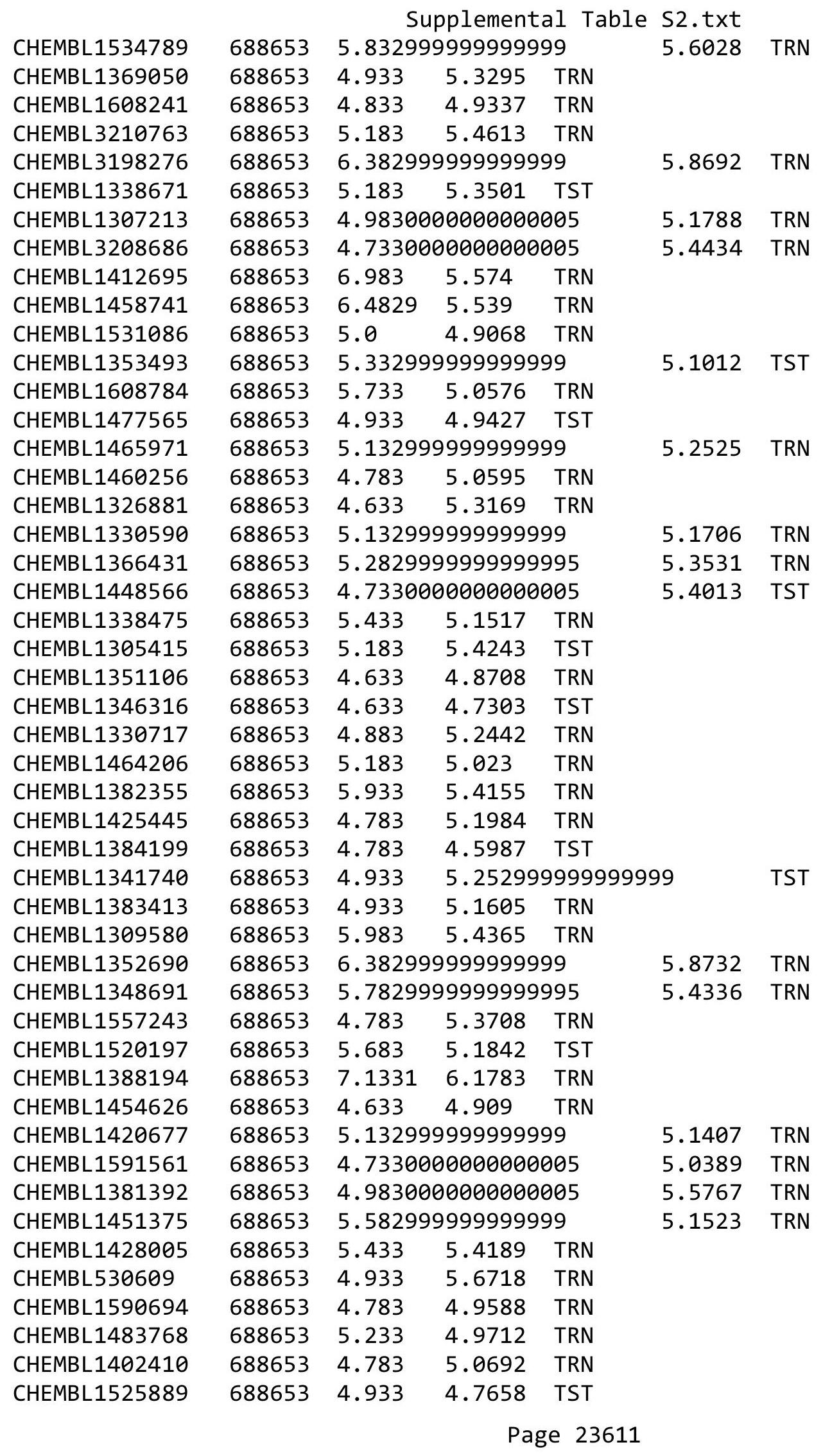




\begin{tabular}{|c|c|c|c|c|c|c|}
\hline \multirow[b]{2}{*}{ CHEMBL 3199780} & \multirow[b]{2}{*}{688653} & \multicolumn{5}{|c|}{ Supplemental Table S2.txt } \\
\hline & & 5.433 & 5.6689 & TRN & & \\
\hline CHEMBL1449493 & 688653 & \multicolumn{3}{|c|}{5.832999999999999} & 5.7678 & TRN \\
\hline CHEMBL1330314 & 688653 & \multicolumn{3}{|c|}{5.2829999999999995} & 5.6988 & TRN \\
\hline CHEMBL1444991 & 688653 & 5.733 & 5.0704 & TRN & & \\
\hline CHEMBL1612931 & 688653 & 6.183 & 5.4938 & TRN & & \\
\hline CHEMBL1451362 & 688653 & 5.933 & 5.5792 & TRN & & \\
\hline CHEMBL1483312 & 688653 & \multicolumn{3}{|c|}{4.7330000000000005} & 5.0317 & TRN \\
\hline CHEMBL1609009 & 688653 & 4.933 & 4.9717 & TST & & \\
\hline CHEMBL3189622 & 688653 & 4.883 & 4.945 & TRN & & \\
\hline CHEMBL1433739 & 688653 & 4.783 & 4.7918 & TRN & & \\
\hline CHEMBL1378837 & 688653 & 4.9 & 4.7316 & TRN & & \\
\hline CHEMBL1320263 & 688653 & 5.683 & 5.2969 & TRN & & \\
\hline CHEMBL1378013 & 688653 & \multicolumn{3}{|c|}{5.332999999999999} & 5.8032 & TRN \\
\hline CHEMBL1552385 & 688653 & 5.433 & 5.4582 & TST & & \\
\hline CHEMBL 3208587 & 688653 & 5.983 & 5.3289 & TRN & & \\
\hline CHEMBL1454216 & 688653 & 7.1831 & 5.215 & TRN & & \\
\hline CHEMBL1522192 & 688653 & 4.883 & 5.2831 & TRN & & \\
\hline CHEMBL1481066 & 688653 & 4.783 & 4.9284 & TRN & & \\
\hline CHEMBL1458023 & 688653 & 6.233 & 5.8276 & TRN & & \\
\hline CHEMBL1379457 & 688653 & 5.683 & 5.6516 & TRN & & \\
\hline CHEMBL1338975 & 688653 & 4.783 & 5.3003 & TST & & \\
\hline CHEMBL1543167 & 688653 & \multicolumn{3}{|c|}{6.2829999999999995} & 5.6577 & TRN \\
\hline CHEMBL1557119 & 688653 & \multicolumn{3}{|c|}{5.5329999999999995} & 4.9678 & TRN \\
\hline CHEMBL1411259 & 688653 & \multicolumn{3}{|c|}{4.7330000000000005} & 5.0413 & TST \\
\hline CHEMBL1371384 & 688653 & \multicolumn{3}{|c|}{6.632999999999999} & 5.6015 & TRN \\
\hline CHEMBL1338548 & 688653 & \multicolumn{3}{|c|}{5.332999999999999} & 5.4133 & TRN \\
\hline CHEMBL1385511 & 688653 & 4.883 & 5.4272 & TST & & \\
\hline CHEMBL1356139 & 688653 & 4.633 & 4.7378 & TRN & & \\
\hline CHEMBL1610987 & 688653 & 4.783 & 4.6735 & TST & & \\
\hline CHEMBL1425439 & 688653 & 4.783 & 5.008 & TRN & & \\
\hline CHEMBL1584111 & 688653 & \multicolumn{3}{|c|}{5.7829999999999995} & 5.2628 & TRN \\
\hline CHEMBL3194970 & 688653 & 5.183 & 5.4801 & TRN & & \\
\hline CHEMBL1463691 & 688653 & & 5.7567 & TST & & \\
\hline CHEMBL1475786 & 688653 & \multicolumn{3}{|c|}{5.882999999999999} & 5.5239 & TRN \\
\hline CHEMBL1454489 & 688653 & 4.933 & 5.1959 & TRN & & \\
\hline CHEMBL3212771 & 688653 & 5.733 & 5.2945 & TRN & & \\
\hline CHEMBL1569682 & 688653 & 4.933 & 5.0856 & TRN & & \\
\hline CHEMBL1547904 & 688653 & 4.783 & 5.3294 & TST & & \\
\hline CHEMBL1354700 & 688653 & 4.683 & 5.3788 & TRN & & \\
\hline CHEMBL1558563 & 688653 & 5.483 & 5.5092 & TST & & \\
\hline CHEMBL1568897 & 688653 & 6.0 & 5.1649 & TRN & & \\
\hline CHEMBL1442027 & 688653 & 5.033 & 5.2443 & TST & & \\
\hline CHEMBL1519024 & 688653 & \multicolumn{3}{|c|}{5.2829999999999995} & 5.3707 & TRN \\
\hline CHEMBL1607327 & 688653 & 4.933 & 4.8305 & TRN & & \\
\hline CHEMBL 3197324 & 688653 & \multicolumn{3}{|c|}{5.382999999999999} & 5.2272 & TRN \\
\hline CHEMBL1335952 & 688653 & 5.65 & 5.1213 & TRN & & \\
\hline CHEMBL1449697 & 688653 & \multicolumn{3}{|c|}{4.7330000000000005} & 5.1256 & TRN \\
\hline \multirow[t]{2}{*}{ CHEMBL1335835 } & 688653 & 4.833 & 5.1629 & TRN & & \\
\hline & & \multicolumn{5}{|c|}{ Page 236} \\
\hline
\end{tabular}




\begin{tabular}{|c|c|c|c|c|c|c|}
\hline \multirow[b]{2}{*}{ CHEMBL1309733 } & \multirow[b]{2}{*}{688653} & \multicolumn{5}{|c|}{ Supplemental Table S2.txt } \\
\hline & & \multicolumn{3}{|c|}{34.5472 TST } & & \\
\hline CHEMBL233119 & 688653 & 6.433 & 5.7836 & \multicolumn{2}{|l|}{ TRN } & \\
\hline CHEMBL1416310 & 688653 & 4.833 & \multicolumn{3}{|c|}{5.297000000000001} & $\mathrm{~T}$ \\
\hline CHEMBL1305938 & 688653 & 4.833 & 5.3074 & TST & & \\
\hline CHEMBL1590089 & 688653 & \multicolumn{3}{|c|}{5.2829999999999995} & 4.8037 & TS \\
\hline CHEMBL1384373 & 688653 & 4.633 & 5.2382 & TST & & \\
\hline CHEMBL1572615 & 688653 & 5.733 & 5.4587 & TRN & & \\
\hline CHEMBL3199762 & 688653 & \multicolumn{3}{|c|}{4.7330000000000005} & 5.0006 & \\
\hline CHEMBL1387514 & 688653 & 5.733 & 5.2808 & TST & & \\
\hline CHEMBL1344910 & 688653 & 4.833 & 5.0109 & TRN & & \\
\hline CHEMBL1576634 & 688653 & \multicolumn{3}{|c|}{5.132999999999999} & 5.3398 & In \\
\hline CHEMBL1494683 & 688653 & \multicolumn{3}{|c|}{4.7330000000000005} & & \\
\hline CHEMBL1479996 & 688653 & 4.933 & 5.6201 & TRN & & \\
\hline CHEMBL1487410 & 688653 & 5.033 & 5.7809 & TRN & & \\
\hline CHEMBL1305998 & 688653 & 5.183 & 5.0866 & TST & & \\
\hline CHEMBL1360446 & 688653 & \multicolumn{3}{|c|}{5.2829999999999995} & 997 & \\
\hline CHEMBL1502217 & 688653 & 4.633 & 5.0884 & TST & & \\
\hline CHEMBL1440263 & 688653 & 4.883 & 5.0848 & TRN & & \\
\hline CHEMBL1470371 & 688653 & 4.783 & 5.2396 & TRN & & \\
\hline CHEMBL1600515 & 688653 & 5.233 & 4.742 & TRN & & \\
\hline CHEMBL1498825 & 688653 & 5.083 & 5.0522 & TST & & \\
\hline CHEMBL1537701 & 688653 & \multicolumn{3}{|c|}{4.9830000000000005} & 5.1217 & \\
\hline CHEMBL1497584 & 688653 & 4.833 & 5.0248 & TRN & & \\
\hline CHEMBL1361911 & 688653 & 5 . & 5.4532 & TRN & & \\
\hline CHEMBL1403300 & 688653 & 4.7 & 4.8633 & TRN & & \\
\hline CHEMBL1359275 & 688653 & 4.883 & 5.2056 & TST & & \\
\hline CHEMBL1370865 & 688653 & 4.883 & 5.0818 & TRN & & \\
\hline CHEMBL1510137 & 688653 & 4.783 & 5.1666 & TRN & & \\
\hline CHEMBL1548608 & 688653 & 4.633 & 5.2306 & TST & & \\
\hline CHEMBL1561507 & 688653 & 5.683 & 5.5457 & TRN & & \\
\hline CHEMBL1303062 & 688653 & 5.083 & 5.1661 & TRN & & \\
\hline CHEMBL1449 & 68 & & 5.5385 & TRN & & \\
\hline CHEMBL1308206 & 688 & 5.083 & 5.0727 & TRN & & \\
\hline CHEMBL1519616 & 688653 & \multicolumn{3}{|c|}{4.7330000000000005} & 5.3938 & TRN \\
\hline CHEMBL1596465 & 688653 & \multicolumn{3}{|c|}{4.7330000000000005} & 5.2269 & TST \\
\hline CHEMBL1563149 & 688653 & \multicolumn{3}{|c|}{6.5329999999999995} & 282 & TST \\
\hline CHEMBL1396446 & 688653 & \multicolumn{3}{|c|}{5.7829999999999995} & 5.6286 & \\
\hline CHEMBL1439909 & 688653 & 6.8831 & 6.1856 & TRN & & \\
\hline CHEMBL2369311 & 688653 & \multirow{2}{*}{\multicolumn{3}{|c|}{$\begin{array}{lrl}5.983 & 5.6749 & \text { TRN } \\
5.132999999999999\end{array}$}} & & \\
\hline CHEMBL1449261 & 688653 & & & & 5.1744 & 13 \\
\hline CHEMBL1319384 & 688653 & 5.983 & 5.4199 & TRN & & \\
\hline CHEMBL1413843 & 688653 & \multicolumn{3}{|c|}{5.2829999999999995} & 5.7964 & (1) \\
\hline CHEMBL1430288 & 688653 & \multicolumn{3}{|c|}{6.332999999999999} & 5.2319 & TDN \\
\hline CHEMBL1536480 & 688653 & 4.833 & 5.1221 & TRN & & \\
\hline CHEMBL1303275 & 688653 & \multicolumn{3}{|c|}{4.7330000000000005} & 5.1605 & ונדו \\
\hline CHEMBL1381236 & 688653 & \multicolumn{3}{|c|}{4.7330000000000005} & 5.386 & $\pi \sigma^{-1}$ \\
\hline CHEMBL1443115 & 688653 & 5.7829 & 99999999 & & 4.7917 & $\mid$ \\
\hline CHEMBL1997990 & 688653 & 4.783 & 5.17200 & 0006 & & TRI \\
\hline & & & & & & \\
\hline
\end{tabular}




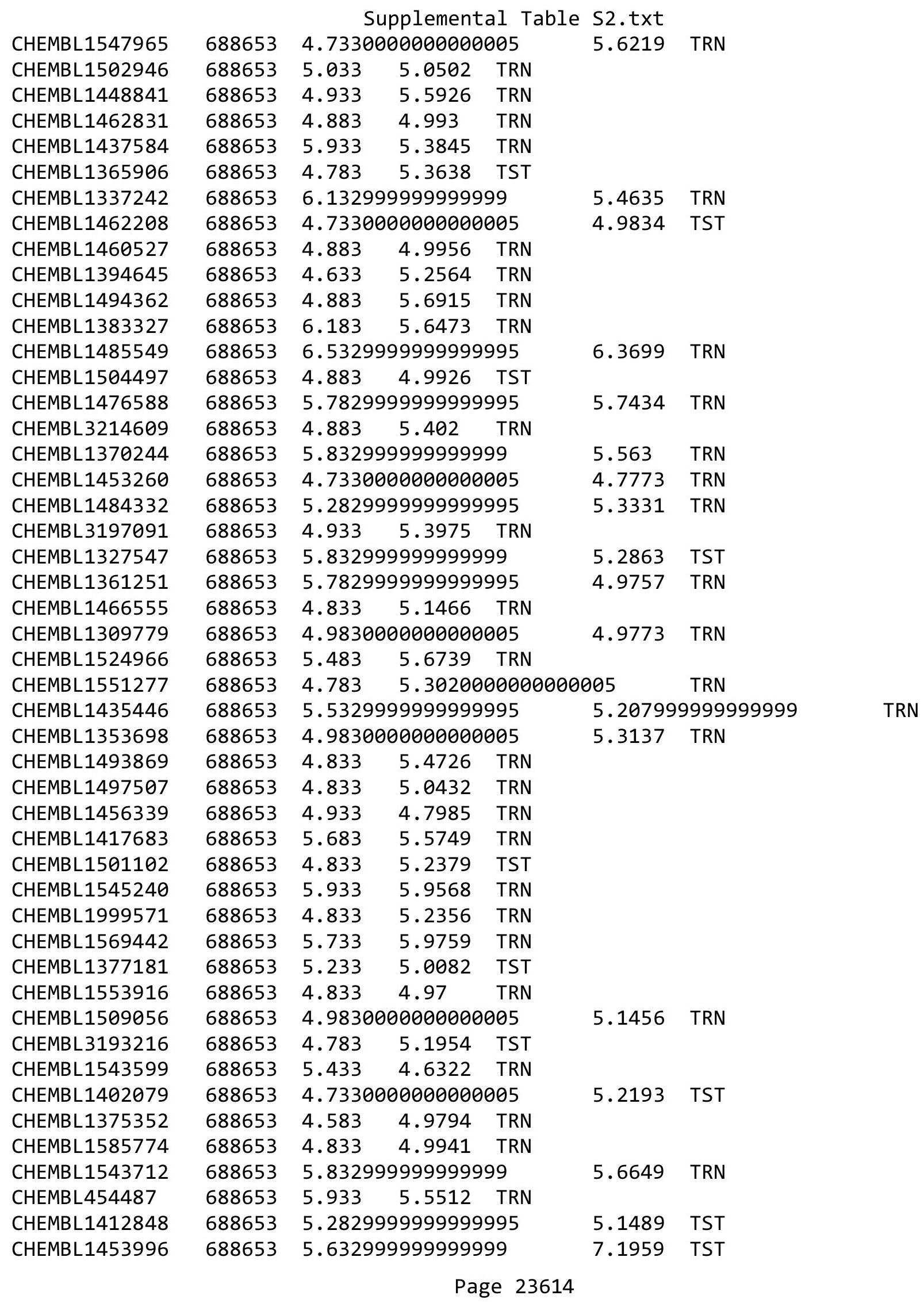




\begin{tabular}{|c|c|c|c|c|c|c|}
\hline \multirow[b]{2}{*}{ CHEMBL1589962 } & & \multicolumn{5}{|c|}{ Supplemental Table S2.txt } \\
\hline & 688653 & 5.183 & 5.4796 & TRN & & \\
\hline CHEMBL1451126 & 688653 & \multicolumn{3}{|c|}{4.7330000000000005} & 5.2359 & $\mathrm{~T}$ \\
\hline CHEMBL1353799 & 688653 & 4.783 & 5.4825 & TRN & & \\
\hline CHEMBL1470658 & 688653 & \multicolumn{3}{|c|}{5.132999999999999} & 5.2399 & TRN \\
\hline CHEMBL1532556 & 588653 & \multicolumn{3}{|c|}{6.382999999999999} & 5.6637 & \\
\hline CHEMBL1559014 & 688653 & 5.083 & 5.5165 & TRN & & \\
\hline CHEMBL1396028 & 688653 & 4.783 & 5.4906 & TRN & & \\
\hline CHEMBL1371239 & 688653 & 4.583 & 5.101 & TRN & & \\
\hline CHEMBL1361268 & 688653 & \multicolumn{3}{|c|}{6.2829999999999995} & 5.5285 & \\
\hline CHEMBL1613127 & 688653 & 4.883 & 5.5869 & TRN & & \\
\hline CHEMBL1326897 & 688653 & \multirow{2}{*}{\multicolumn{3}{|c|}{4.7330000000000005}} & & \\
\hline CHEMBL1451023 & 688653 & & & & 5.1026 & \\
\hline CHEMBL1611695 & 688653 & 4.583 & 4.7707 & TST & & \\
\hline CHEMBL1402255 & 688653 & \multicolumn{3}{|c|}{4.9830000000000005} & 5.1587 & 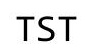 \\
\hline CHEMBL1412194 & 688653 & 4.783 & 5.3443 & TST & & \\
\hline CHEMBL1545104 & 688653 & 5.683 & & TRN & & \\
\hline CHEMBL1 & 688653 & \multicolumn{3}{|c|}{5.132999999999999} & 219 & \\
\hline CHEMBL & 688653 & 4.783 & 4.5384 & TST & & \\
\hline CHEMBL1 & 688653 & 4.833 & 5.1513 & TRN & & \\
\hline CHEMBL1434115 & 688653 & 4.883 & 5.0677 & TRN & & \\
\hline CHEMBL1423257 & 688653 & \multicolumn{3}{|c|}{6.5329999999999995} & 5.9023 & \\
\hline CHEMBL: & 688 & 4.683 & 4.8448 & TST & & \\
\hline CHEMBL & 688653 & & & TRN & & \\
\hline CHEMBL3192856 & 688653 & \multicolumn{3}{|c|}{5.5329999999999995} & 5.9434 & TR \\
\hline CHEMBL1518665 & 688653 & 4.783 & 5.5043 & TST & & \\
\hline CHEMBL1316936 & 688653 & \multicolumn{3}{|c|}{5.832999999999999} & כסשנ. & \\
\hline CHEMBL & 688 & 4.583 & 4.8596 & TST & & \\
\hline CHEMBL: & 688653 & \multicolumn{3}{|c|}{5.132999999999999} & 5.553 & TP \\
\hline CHEMBL 1 & 688653 & 4.833 & 4.9892 & TST & & \\
\hline CHEMBL1340295 & 688653 & \multicolumn{3}{|c|}{6.0329999999999995} & & TRN \\
\hline CHEMBL1429019 & 688653 & \multicolumn{3}{|c|}{5.332999999999999} & 5.2876 & \\
\hline CHEMBL: & 688 & 5.433 & 5.4652 & TRN & & \\
\hline CHEMBL & 688653 & 5.483 & \multicolumn{3}{|c|}{5.1979999999999995} & TS \\
\hline CHEMBL1507570 & 688653 & 4.833 & 5.3556 & TST & & \\
\hline CHEMBL1360872 & 688653 & \multicolumn{3}{|c|}{5.132999999999999} & צכשו.כ & 11 \\
\hline $\mathrm{CHE}$ & & 4.883 & 5.1803 & TST & & \\
\hline CHEMBL1 & 688 & \multicolumn{3}{|c|}{5.332999999999999} & 5.3215 & TRN \\
\hline CHEMBL1 & 688653 & \multicolumn{3}{|c|}{6.2829999999999995} & 5.233 & TRN \\
\hline CHEMBL1305810 & 688653 & \multicolumn{3}{|c|}{5.2829999999999995} & 5.3015 & TST \\
\hline CHEMBL1529404 & 688653 & 7.3325 & 5.8554 & TRN & & \\
\hline CHEMBL1471607 & 688653 & 4.883 & 5.3492 & TRN & & \\
\hline CHEMBL1511488 & 688653 & 4.883 & 5.2422 & TST & & \\
\hline CHEMBL1603283 & 688653 & 6.183 & 5.9657 & TRN & & \\
\hline CHEMBL66854 & 688653 & 4.783 & 5.3351 & TST & & \\
\hline CHEMBL375673 & 688653 & 4.7330 & 00000000 & 005 & 5.3052 & TS \\
\hline CHEMBL1969300 & 688653 & 4.633 & 5.5469 & TST & & \\
\hline CHEMBL1613659 & 688653 & 4.883 & 5.2159 & TRN & & \\
\hline CHEMBL3209681 & 688653 & 6.3829 & 99999999 & & 5.0363 & $\mathrm{InI}$ \\
\hline
\end{tabular}




\begin{tabular}{|c|c|c|c|c|c|c|c|}
\hline \multirow[b]{2}{*}{ CHEMBL1501579 } & \multicolumn{6}{|c|}{ oplemental Ta } & \\
\hline & 688653 & 4.883 & 5.1097 & TRN & & & \\
\hline CHEMBL1531958 & 688653 & 5.6329 & 999999999 & & 5.7185 & TST & \\
\hline CHEMBL1351850 & 688653 & 4.633 & 5.1411 & TRN & & & \\
\hline CHEMBL1347220 & 688653 & 4.7330 & 000000000 & 005 & 4.9746 & TRN & \\
\hline CHEMBL1362330 & 688653 & 4.9830 & 000000000 & 305 & 5.5417 & TRN & \\
\hline CHEMBL1304029 & 688653 & 5.8329 & 999999999 & & 5.44600 & 0000000001 & TRN \\
\hline CHEMBL 270605 & 688653 & 4.783 & 5.1119 & TRN & & & \\
\hline CHEMBL1316452 & 688653 & 4.9830 & 000000000 & 305 & 5.3603 & TRN & \\
\hline CHEMBL1527433 & 688653 & 6.983 & 5.9429 & TRN & & & \\
\hline CHEMBL1610025 & 688653 & 4.783 & 4.6045 & TRN & & & \\
\hline CHEMBL1488749 & 688653 & 5.733 & 5.6451 & TRN & & & \\
\hline CHEMBL1443898 & 688653 & 4.783 & 4.7676 & TST & & & \\
\hline CHEMBL1987820 & 688653 & 6.233 & 5.6376 & TRN & & & \\
\hline CHEMBL1540512 & 688653 & 4.7330 & 000000000 & 205 & 5.2652 & TRN & \\
\hline CHEMBL1985575 & 688653 & 6.8329 & 999999999 & & 5.9184 & TRN & \\
\hline CHEMBL1414853 & 688653 & 5.3829 & 999999999 & & 5.0936 & TRN & \\
\hline CHEMBL1389174 & 688653 & 4.633 & 5.1197 & TRN & & & \\
\hline CHEMBL1500800 & 688653 & 5.933 & 4.9177 & TRN & & & \\
\hline CHEMBL1557660 & 688653 & 6.183 & 5.3067 & TST & & & \\
\hline CHEMBL3213101 & 688653 & 6.233 & 5.6196 & TRN & & & \\
\hline CHEMBL1566633 & 688653 & 6.233 & 5.3637 & TRN & & & \\
\hline CHEMBL3192669 & 688653 & 4.833 & 4.9564 & TRN & & & \\
\hline CHEMBL1555580 & 688653 & 4.833 & 5.3477 & TRN & & & \\
\hline CHEMBL1459112 & 688653 & 5.1329 & 999999999 & & 5.6606 & TST & \\
\hline CHEMBL1301995 & 688653 & 4.683 & 5.3553 & TRN & & & \\
\hline CHEMBL1348808 & 688653 & 6.7331 & 5.3612 & TRN & & & \\
\hline CHEMBL1458171 & 688653 & 4.7330 & 000000000 & 305 & 5.5767 & TRN & \\
\hline CHEMBL1453809 & 688653 & 4.7330 & 000000000 & 005 & 4.8969 & TST & \\
\hline CHEMBL1386565 & 688653 & 5.083 & 5.6868 & TRN & & & \\
\hline CHEMBL1522324 & 688653 & 4.7330 & 000000000 & 305 & 5.4747 & TRN & \\
\hline CHEMBL1496187 & 688653 & 4.583 & 5.4398 & TRN & & & \\
\hline CHEMBL1480021 & 688653 & 4.783 & 5.5432 & TRN & & & \\
\hline CHEMBL1386706 & 688653 & 5.88299 & 999999999 & & 5.5092 & TRN & \\
\hline CHEMBL1463268 & 688653 & 5.6329 & 999999999 & & 5.6814 & TRN & \\
\hline CHEMBL3196623 & 688653 & 5.5329 & 999999999 & 995 & 5.2818 & TRN & \\
\hline CHEMBL1380524 & 688653 & 4.783 & 4.9802 & TRN & & & \\
\hline CHEMBL1525915 & 688653 & 5.8829 & 999999999 & & 5.722 & TRN & \\
\hline CHEMBL1303816 & 688653 & 4.73306 & 000000000 & 305 & 5.3634 & TRN & \\
\hline CHEMBL1517460 & 688653 & 5.683 & 5.3573 & TRN & & & \\
\hline CHEMBL1395480 & 688653 & 5.183 & 5.3353 & TRN & & & \\
\hline CHEMBL1430300 & 688653 & 4.833 & 4.7641 & TST & & & \\
\hline CHEMBL1412356 & 688653 & $4.7330 €$ & 000000000 & 305 & 5.3016 & TRN & \\
\hline CHEMBL1299450 & 688653 & 5.8329 & 999999999 & & 5.006 & TRN & \\
\hline CHEMBL1597433 & 688653 & $5.5829 \mathrm{c}$ & 999999999 & & 5.1067 & TRN & \\
\hline CHEMBL 3191840 & 688653 & 4.7330 & 000000000 & 305 & 5.273 & TRN & \\
\hline CHEMBL1572993 & 688653 & 6.433 & 5.4006 & TRN & & & \\
\hline CHEMBL1606043 & 688653 & 5.1329 & 999999999 & & 5.2485 & TST & \\
\hline CHEMBL1533287 & 688653 & 4.883 & 4.9651 & TRN & & & \\
\hline
\end{tabular}




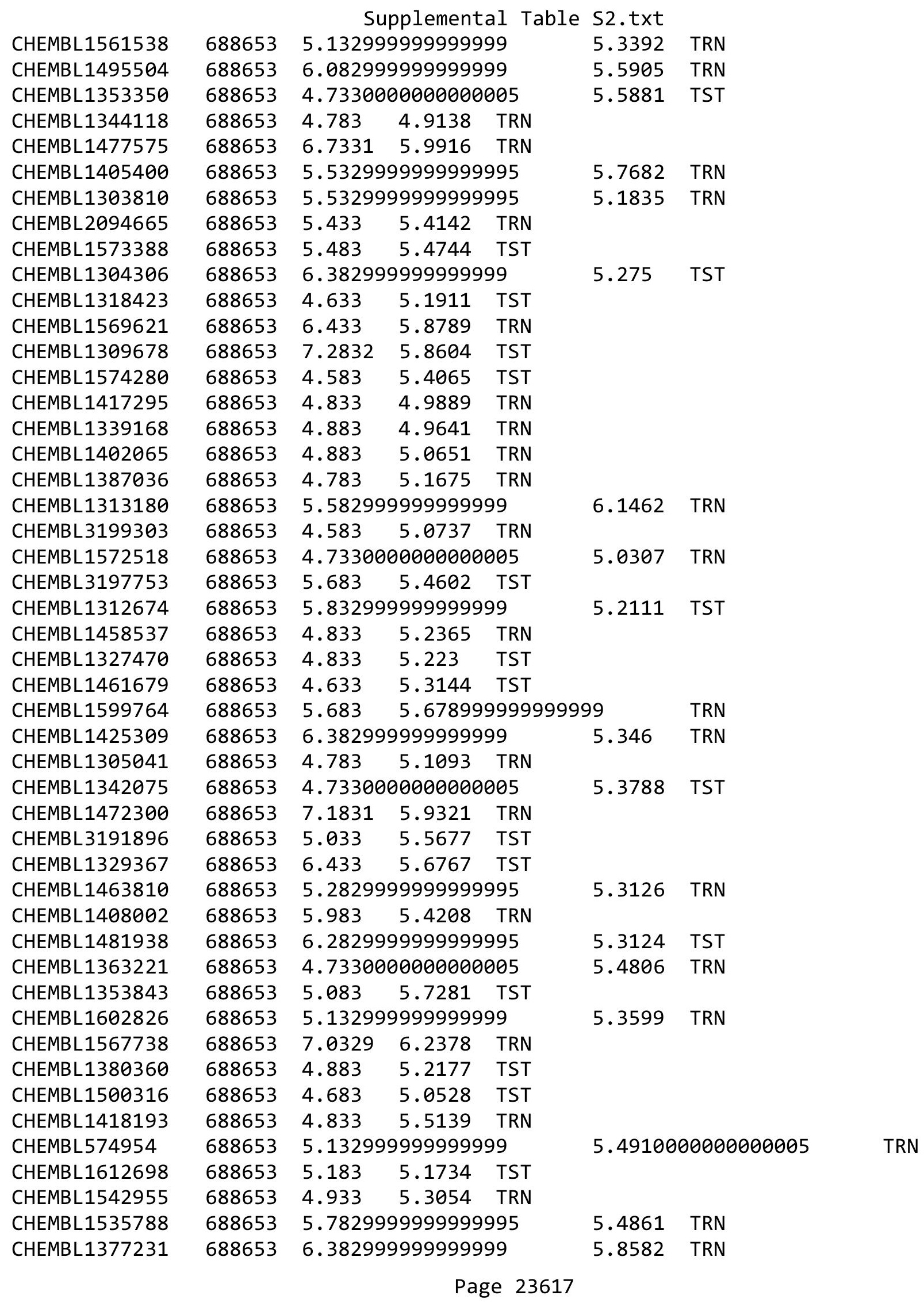




\begin{tabular}{|c|c|c|c|c|c|c|}
\hline \multirow[b]{2}{*}{ CHEMBL1343476 } & \multirow[b]{2}{*}{688653} & \multicolumn{5}{|c|}{ Supplemental Table S2.txt } \\
\hline & & \multirow{2}{*}{\multicolumn{3}{|c|}{$\begin{array}{lc}5.483 & 5.5883 \\
4.7330000000000005\end{array}$}} & & \\
\hline CHEMBL1319580 & 688653 & & & & 5.2024 & TST \\
\hline CHEMBL1405013 & 688653 & 4.883 & 5.0113 & TST & & \\
\hline CHEMBL1565635 & 688653 & \multicolumn{3}{|c|}{5.582999999999999} & 5.3321 & TST \\
\hline CHEMBL1378542 & 688653 & 6.7331 & 5.4146 & TRN & & \\
\hline CHEMBL1304131 & 688653 & 4.933 & 5.0543 & TST & & \\
\hline CHEMBL3191571 & 688653 & 6.433 & 5.8714 & TRN & & \\
\hline CHEMBL1598240 & 688653 & 5.733 & 5.3439 & TRN & & \\
\hline CHEMBL1536513 & 688653 & 5.683 & 5.085 & TRN & & \\
\hline CHEMBL3189510 & 688653 & \multicolumn{3}{|c|}{5.5329999999999995} & 5.325 & TRN \\
\hline CHEMBL1478303 & 688653 & 4.633 & 4.7514 & TST & & \\
\hline CHEMBL1302642 & 688653 & \multicolumn{3}{|c|}{4.7330000000000005} & 5.0173 & TST \\
\hline CHEMBL1454470 & 688653 & 4.783 & 5.3804 & TRN & & \\
\hline CHEMBL1592678 & 688653 & 4.633 & 5.1575 & TRN & & \\
\hline CHEMBL1572191 & 688653 & 4.583 & 4.7467 & TRN & & \\
\hline CHEMBL1526551 & 688653 & 5.183 & 5.3745 & TST & & \\
\hline CHEMBL1598419 & 688653 & 6.45 & 5.3166 & TST & & \\
\hline CHEMBL1411288 & 688653 & 5.733 & 5.1916 & TRN & & \\
\hline CHEMBL577752 & 688653 & 4.833 & 5.2078 & TRN & & \\
\hline CHEMBL1495905 & 688653 & \multicolumn{3}{|c|}{5.832999999999999} & 6.1214 & TRN \\
\hline CHEMBL1348641 & 688653 & 5.183 & 5.2117 & TST & & \\
\hline CHEMBL1466715 & 688653 & \multicolumn{3}{|c|}{5.132999999999999} & 5.2281 & TRN \\
\hline CHEMBL1559988 & 688653 & 5.033 & 5.4721 & TRN & & \\
\hline CHEMBL1485107 & 688653 & 4.833 & 5.1342 & TRN & & \\
\hline CHEMBL1362588 & 688653 & 4.883 & 4.7879 & TRN & & \\
\hline CHEMBL1327828 & 688653 & 5.183 & 5.7869 & TRN & & \\
\hline CHEMBL1529039 & 688653 & 4.833 & 5.2773 & TRN & & \\
\hline CHEMBL1599055 & 688653 & \multicolumn{3}{|c|}{5.882999999999999} & 5.3337 & TRN \\
\hline CHEMBL1609937 & 688653 & 4.633 & 4.7705 & TRN & & \\
\hline CHEMBL1448321 & 688653 & 4.833 & 4.6399 & TRN & & \\
\hline CHEMBL1610477 & 688653 & 4.883 & 5.2064 & TST & & \\
\hline CHEMBL1552723 & 688653 & 7.1331 & 5.5472 & TRN & & \\
\hline CHEMBL1482335 & 688653 & \multicolumn{3}{|c|}{4.7330000000000005} & 5.021 & TRN \\
\hline CHEMBL1473692 & 688653 & \multicolumn{3}{|c|}{5.832999999999999} & 5.1952 & TRN \\
\hline CHEMBL1534447 & 688653 & 5.083 & 5.2002 & TRN & & \\
\hline CHEMBL1493792 & 688653 & 4.783 & 5.1565 & TST & & \\
\hline CHEMBL148072 & 688653 & \multicolumn{3}{|c|}{4.9830000000000005} & 5.1745 & TST \\
\hline CHEMBL1566030 & 688653 & \multicolumn{3}{|c|}{4.9830000000000005} & 4.8524 & TRN \\
\hline CHEMBL1476179 & 688653 & 5.433 & 5.6444 & TRN & & \\
\hline CHEMBL1587270 & 688653 & \multicolumn{3}{|c|}{5.5329999999999995} & 5.5366 & TRN \\
\hline CHEMBL1433189 & 688653 & 6.683 & \multicolumn{3}{|c|}{5.757999999999999} & TRN \\
\hline CHEMBL1391343 & 688653 & 4.883 & 4.9089 & TRN & & \\
\hline CHEMBL1601275 & 688653 & \multicolumn{3}{|c|}{6.132999999999999} & 5.273 & TRN \\
\hline CHEMBL3196749 & 688653 & \multicolumn{3}{|c|}{6.332999999999999} & 5.2687 & TST \\
\hline CHEMBL1437979 & 688653 & 4.883 & 5.0551 & TRN & & \\
\hline CHEMBL1986805 & 688653 & \multicolumn{3}{|c|}{6.132999999999999} & 5.6693 & TRN \\
\hline CHEMBL1536689 & 688653 & 4.883 & 5.407 & TRN & & \\
\hline CHEMBL1336860 & 688653 & \multicolumn{3}{|c|}{5.832999999999999} & 5.4768 & TRN \\
\hline & & \multicolumn{5}{|c|}{ Page 23618} \\
\hline
\end{tabular}




\begin{tabular}{|c|c|c|c|c|c|c|}
\hline & \multicolumn{5}{|c|}{ oplemen } \\
\hline CHEMBL1579886 & 688653 & 4.783 & 5.1105 & TRN & & \\
\hline CHEMBL1461506 & 688653 & 6.2829 & 99999999 & 995 & 6.2404 & TRN \\
\hline CHEMBL1401359 & 688653 & 5.2829 & 9999999 & 995 & 5.4765 & TRN \\
\hline CHEMBL1310435 & 688653 & 6.4829 & 5.5886 & TST & & \\
\hline CHEMBL1392463 & 688653 & 4.7330 & 2000000e & 005 & 4.783 & TST \\
\hline CHEMBL1593799 & 688653 & 4.7330 & 00000006 & 005 & 4.6757 & TRN \\
\hline CHEMBL1325248 & 688653 & 5.3329 & 99999999 & 99 & 5.6364 & \\
\hline CHEMBL1489582 & 688653 & 4.933 & 5.1347 & TST & & \\
\hline CHEMBL1611187 & 688653 & 5.033 & 5.2733 & TRN & & \\
\hline CHEMBL1540089 & 688653 & 6.5829 & 99999999 & & 5.835 & TST \\
\hline CHEMBL1432707 & 688653 & 5.1329 & 99999999 & & 4.6698 & TST \\
\hline CHEMBL1463150 & 688653 & 5.433 & 5.3459 & TRN & & \\
\hline CHEMBL1326560 & 688653 & 4.883 & 4.8522 & TRN & & \\
\hline CHEMBL1421941 & 688653 & 5.1329 & 99999999 & & 6.0028 & TRN \\
\hline CHEMBL1391189 & 688653 & 6.3829 & 99999999 & & 5.2974 & \\
\hline CHEMBL1529885 & 688653 & 4.783 & 5.098 & TST & & \\
\hline CHEMBL1562707 & 688653 & 5.5829 & 99999999 & & 5.1698 & TRN \\
\hline CHEMBL1570935 & 688653 & 5.3829 & 9999999 & & 5.4154 & TRN \\
\hline CHEMBL1609660 & 688653 & 4.7330 & 2000000e & 005 & 5.1374 & \\
\hline CHEMBL1395692 & 688653 & 4.633 & 4.9763 & TST & & \\
\hline CHEMBL1510724 & 688653 & 4.633 & 5.1283 & TST & & \\
\hline CHEMBL1597225 & 688653 & 4.783 & 5.0892 & TRN & & \\
\hline CHEMBL1439864 & 688653 & 4.7330 & 2000000e & 005 & 5.0783 & TS \\
\hline CHEMBL1373037 & 688653 & 5.683 & 5.6045 & TRN & & \\
\hline CHEMBL1482499 & 688653 & 4.833 & 5.6707 & TRN & & \\
\hline CHEMBL1396701 & 688653 & 4.933 & 4.8083 & TRN & & \\
\hline CHEMBL1348114 & 688653 & 4.833 & 5.1401 & TRN & & \\
\hline CHEMBL1477459 & 688653 & 4.683 & 5.4346 & TRN & & \\
\hline CHEMBL1406429 & 688653 & 5.683 & 5.2946 & TRN & & \\
\hline CHEMBL1460748 & 688653 & 4.7330 & 2000000e & 005 & 4.6719 & TS \\
\hline CHEMBL1320175 & 688653 & 5.083 & 5.4487 & TRN & & \\
\hline CHEMBL1422720 & 688653 & 4.633 & 4.7376 & TST & & \\
\hline CHEMBL1540120 & 688653 & 5.8829 & 99999999 & & 5.5196 & Therv \\
\hline CHEMBL1326637 & 688653 & 6.3829 & 99999999 & & 5.4956 & TRN \\
\hline CHEMBL 3191813 & 688653 & 4.7330 & 00000006 & 005 & 4.8356 & TRN \\
\hline CHEMBL1530705 & 688653 & 5.233 & 5.9522 & TRN & & \\
\hline CHEMBL1571307 & 688653 & 5.733 & 5.4574 & TRN & & \\
\hline CHEMBL1576346 & 688653 & 4.9830 & 20000000 & 005 & 91 & TRIV \\
\hline CHEMBL1610863 & 688653 & 5.7829 & 99999999 & 995 & & ח \\
\hline CHEMBL1314609 & 688653 & 4.833 & 4.7787 & TRN & & \\
\hline CHEMBL1611408 & 688653 & 4.683 & 4.9872 & TRN & & \\
\hline CHEMBL1595549 & 688653 & 5.683 & 5.0624 & TST & & \\
\hline CHEMBL1342609 & 688653 & 5.7829 & 99999999 & 995 & 5.3259 & NIV \\
\hline CHEMBL1586379 & 688653 & 5.3829 & 99999999 & & 4.9434 & \\
\hline CHEMBL1423903 & 688653 & 4.783 & 5.0048 & TRN & & \\
\hline CHEMBL1501634 & 688653 & 5.033 & 4.8256 & TRN & & \\
\hline CHEMBL1319763 & 688653 & 4.833 & 5.4631 & TRN & & \\
\hline CHEMBL1555091 & 688653 & 4.583 & 4.7057 & TRN & & \\
\hline
\end{tabular}




\begin{tabular}{|c|c|c|c|c|c|c|}
\hline \multirow[b]{2}{*}{ CHEMBL1484561 } & \multirow[b]{2}{*}{688653} & \multicolumn{5}{|c|}{ Supplemental Table S2.txt } \\
\hline & & \multirow{2}{*}{\multicolumn{3}{|c|}{$\begin{array}{lrr}5.733 & 5.4267 & \text { TST } \\
4.7330000000000005\end{array}$}} & \multirow{2}{*}{5.0246} & \multirow[b]{2}{*}{ TRN } \\
\hline CHEMBL1395970 & 688653 & & & & & \\
\hline CHEMBL1473071 & 688653 & 4.783 & 5.0317 & TRN & & \\
\hline CHEMBL1474248 & 688653 & 5.683 & 5.9749 & TRN & & \\
\hline CHEMBL1388646 & 688653 & 5.183 & 5.1793 & TRN & & \\
\hline CHEMBL1968327 & 688653 & 5.933 & 5.414 & TRN & & \\
\hline CHEMBL1425768 & 688653 & 4.883 & 4.9015 & TST & & \\
\hline CHEMBL1555009 & 688653 & \multicolumn{3}{|c|}{5.132999999999999} & 5.444 & TRN \\
\hline CHEMBL1308460 & 688653 & \multicolumn{3}{|c|}{5.7829999999999995} & 5.5485 & TRN \\
\hline CHEMBL1531615 & 688653 & \multicolumn{3}{|c|}{4.7330000000000005} & 5.3417 & TST \\
\hline CHEMBL1421117 & 688653 & \multicolumn{3}{|c|}{6.7829999999999995} & 5.9337 & TRN \\
\hline CHEMBL516040 & 688653 & \multicolumn{3}{|c|}{6.0329999999999995} & 6.1006 & TRN \\
\hline CHEMBL1599256 & 688653 & 6.183 & 5.7293 & TRN & & \\
\hline CHEMBL1429927 & 688653 & \multirow{2}{*}{\multicolumn{3}{|c|}{$\begin{array}{lcc}4.883 & 5.279 & \text { TRN } \\
4.7330000000000005\end{array}$}} & & \\
\hline CHEMBL1380030 & 688653 & & & & 5.1084 & TRN \\
\hline CHEMBL1603315 & 688653 & \multicolumn{3}{|c|}{$\begin{array}{lll}5.083 & 5.4005 & \text { TST }\end{array}$} & & \\
\hline CHEMBL1543899 & 688653 & 4.633 & 5.0489 & TST & & \\
\hline CHEMBL1503692 & 688653 & \multirow{2}{*}{\multicolumn{3}{|c|}{$\begin{array}{l}2.083 \text { 2.1000 TKIV } \\
5.332999999999999\end{array}$}} & & \\
\hline CHEMBL 224844 & 688653 & & & & 6.0535 & TRN \\
\hline CHEMBL1426510 & 688653 & 5.233 & 5.401 & TRN & & \\
\hline CHEMBL1537477 & 688653 & 6.05 & 5.4927 & TRN & & \\
\hline CHEMBL1456282 & 688653 & 5.083 & 5.0904 & TRN & & \\
\hline CHEMBL1385503 & 688653 & \multicolumn{3}{|c|}{5.632999999999999} & 5.7755 & TRN \\
\hline CHEMBL1512678 & 688653 & 4.833 & 5.1989 & TRN & & \\
\hline CHEMBL1338984 & 688653 & 4.833 & 5.421 & TST & & \\
\hline CHEMBL1592723 & 688653 & 4.633 & 4.6032 & TRN & & \\
\hline CHEMBL1484478 & 688653 & \multicolumn{3}{|c|}{5.332999999999999} & 5.1344 & TRN \\
\hline CHEMBL1407794 & 688653 & \multicolumn{3}{|c|}{6.382999999999999} & 5.4573 & TRN \\
\hline CHEMBL1518865 & 688653 & \multicolumn{3}{|c|}{5.7829999999999995} & 5.3733 & TRN \\
\hline CHEMBL1508842 & 688653 & 5.083 & 5.5452 & TRN & & \\
\hline CHEMBL1325006 & 688653 & 4.833 & 5.5201 & TRN & & \\
\hline CHEMBL1596487 & 688653 & 4.783 & 5.1234 & TST & & \\
\hline CHEMBL1448769 & 688653 & \multicolumn{3}{|c|}{5.332999999999999} & 5.1289 & TRN \\
\hline CHEMBL1406356 & 688653 & \multicolumn{3}{|c|}{5.5329999999999995} & 5.5853 & TRN \\
\hline CHEMBL1360927 & 688653 & \multicolumn{3}{|c|}{4.7330000000000005} & 5.0119 & TST \\
\hline CHEMBL1431068 & 688653 & 6.0829 & 99999999 & & 5.6876 & TRN \\
\hline CHEMBL1577306 & 688653 & 5.5329 & 99999999 & 995 & 5.1924 & TRN \\
\hline CHEMBL1600932 & 688653 & 4.833 & 5.109 & TRN & & \\
\hline CHEMBL1508822 & 688653 & 5.5329 & 99999999 & 995 & 5.3647 & TRN \\
\hline CHEMBL1422751 & 688653 & 4.933 & 5.2815 & TRN & & \\
\hline CHEMBL19980 & 688653 & 6.0 & 6.07100 & 00006 & & TST \\
\hline CHEMBL1579102 & 688653 & 5.183 & 5.5081 & TRN & & \\
\hline CHEMBL1447507 & 688653 & 6.0829 & 99999999 & 99 & 5.2202 & TRN \\
\hline CHEMBL1402959 & 688653 & 4.633 & 6.0756 & TRN & & \\
\hline CHEMBL1428274 & 688653 & 4.633 & 5.2355 & TST & & \\
\hline CHEMBL3199264 & 688653 & 5.2829 & 99999999 & 995 & 5.1104 & TRN \\
\hline CHEMBL1364386 & 688653 & 5.083 & 5.4856 & TST & & \\
\hline CHEMBL3195343 & 688653 & 4.883 & 5.4007 & TST & & \\
\hline
\end{tabular}




\begin{tabular}{|c|c|c|c|c|c|c|}
\hline & & \multicolumn{5}{|c|}{ Supplemental Table S2.txt } \\
\hline CHEMBL1353549 & 688653 & 4.783 & 5.3095 & TRN & & \\
\hline CHEMBL1303798 & 688653 & 7.1331 & 5.9633 & TST & & \\
\hline CHEMBL1607392 & 688653 & 4.633 & 4.9843 & TRN & & \\
\hline CHEMBL1431440 & 688653 & \multicolumn{3}{|c|}{4.9830000000000005} & 5.6358 & $\mathrm{TH}$ \\
\hline CHEMBL1419524 & 688653 & 5.733 & 5.2533 & TRN & & \\
\hline CHEMBL1317520 & 688653 & \multicolumn{3}{|c|}{6.2829999999999995} & 5.527 & \\
\hline CHEMBL1358264 & 688653 & 4.583 & 4.8872 & TRN & & \\
\hline CHEMBL1343392 & 688653 & \multicolumn{3}{|c|}{5.5329999999999995} & 4.8324 & $\mathrm{TH}$ \\
\hline CHEMBL1477342 & 688653 & 4.833 & \multicolumn{3}{|c|}{5.542999999999999} & \\
\hline CHEMBL1606193 & 688653 & 5.733 & 5.2816 & TST & & \\
\hline CHEMBL1381882 & 688653 & 6.7331 & 5.8212 & TRN & & \\
\hline CHEMBL1571793 & 688653 & 4.833 & 5.0092 & TRN & & \\
\hline CHEMBL1 & 688653 & \multicolumn{3}{|c|}{4.7330000000000005} & 5.0963 & $\mathrm{TH}$ \\
\hline CHEMBL1 14 & 688653 & 4.883 & \multicolumn{3}{|c|}{5.372000000000001} & \\
\hline CHEMBL1530818 & 688653 & 4.883 & \multicolumn{3}{|c|}{5.178999999999999} & \\
\hline CHEMBL1507404 & 688653 & 4.633 & 5.4618 & TST & & \\
\hline CHEMBL486817 & 688653 & 4.883 & \multicolumn{3}{|c|}{5.2860000000000005} & \\
\hline CHEMBL1 & 688653 & 5.483 & 5.0212 & TRN & & \\
\hline CHEMBL1 & 688653 & 4.883 & 5.3142 & TRN & & \\
\hline CHEMBL1 & 688653 & 4.833 & 5.1841 & TST & & \\
\hline CHEMBL1311849 & 688653 & 5.483 & 5.2224 & TRN & & \\
\hline CHEMBL 1 & 6886 & 5.683 & 5.1153 & TRN & & \\
\hline CHEME & 688653 & 5.033 & 5.1666 & TRN & & \\
\hline CHEME & 688 & 4.933 & 5.3104 & TRN & & \\
\hline CHEMB & 688653 & 4.783 & 4.97 & TST & & \\
\hline CHEMBL1 & 688653 & \multicolumn{3}{|c|}{4.7330000000000005} & & \\
\hline CHEMBL1 & 688 & 4.833 & 5.3088 & TST & & \\
\hline CHEME & 688 & 4.683 & 4.8523 & TRN & & \\
\hline CHEMB & 688653 & \multicolumn{3}{|c|}{5.2829999999999995} & 4.8847 & \\
\hline CHEMBL1302762 & 688653 & 5.683 & 5.4116 & TRN & & \\
\hline CHEMBL1558198 & 688653 & \multicolumn{3}{|c|}{5.5329999999999995} & 58 & \\
\hline CHEME & 688 & 4.783 & \multicolumn{3}{|c|}{5.196000000000001} & \\
\hline CHEME & 688653 & 4.833 & 5.5267 & TRN & & \\
\hline CHEMBL1 & 688653 & 4.833 & 5.1999 & TRN & & \\
\hline CHEMBL1326851 & 688653 & 4.783 & 4.8689 & TST & & \\
\hline CHEMBL14€ & 688653 & \multicolumn{3}{|c|}{5.132999999999999} & 5.4734 & \\
\hline CHEME & $68 \varepsilon$ & 4.783 & 5.3253 & TST & & \\
\hline CHEMBL: & 688 & \multicolumn{3}{|c|}{5.882999999999999} & 5.397 & TRN \\
\hline CHEMBL1604444 & 688653 & \multicolumn{3}{|c|}{6.082999999999999} & 5.4961 & TR \\
\hline CHEMBL1338265 & 688653 & 4.883 & 4.8181 & TRN & & \\
\hline CHEMBL3211587 & 688653 & 4.833 & 5.1108 & TST & & \\
\hline CHEMBL137 & 688653 & \multicolumn{3}{|c|}{5.5329999999999995} & 4.6475 & TRN \\
\hline CHEMBL3209494 & 688653 & 5.033 & 5.0912 & TRN & & \\
\hline CHEMBL1495010 & 688653 & 4.633 & 4.965 & TST & & \\
\hline CHEMBL284742 & 688653 & 4.783 & 5.56 & TRN & & \\
\hline CHEMBL1608625 & 688653 & \multicolumn{3}{|c|}{5.7829999999999995} & 4.944 & TST \\
\hline CHEMBL3189638 & 688653 & 5.033 & 5.1937 & TRN & & \\
\hline CHEMBL1996150 & 688653 & \multicolumn{3}{|c|}{6.2829999999999995} & 5.8823 & \\
\hline
\end{tabular}




\begin{tabular}{|c|c|c|c|c|c|c|c|}
\hline \multicolumn{7}{|c|}{ Supplemental Table S2.txt } & \\
\hline CHEMBL1328688 & 688653 & \multicolumn{3}{|c|}{5.132999999999999} & 4.9452 & TRN & \\
\hline CHEMBL1417487 & 688653 & 4.933 & 4.7916 & TRN & & & \\
\hline CHEMBL1568925 & 688653 & 4.583 & 4.657 & TRN & & & \\
\hline CHEMBL1525878 & 688653 & 4.883 & 5.2586 & TRN & & & \\
\hline CHEMBL3196546 & 688653 & 5.683 & 5.353 & TRN & & & \\
\hline CHEMBL1436048 & 688653 & 4.633 & 4.8997 & TST & & & \\
\hline CHEMBL1491893 & 688653 & 5.033 & 5.0221 & TRN & & & \\
\hline CHEMBL1403349 & 688653 & 4.783 & 5.3295 & TRN & & & \\
\hline CHEMBL1485604 & 688653 & 4.583 & 5.0004 & TST & & & \\
\hline CHEMBL1383138 & 688653 & \multicolumn{3}{|c|}{5.132999999999999} & 5.4748 & TRN & \\
\hline CHEMBL1556012 & 688653 & 4.933 & 5.0231 & TRN & & & \\
\hline CHEMBL 3191564 & 688653 & \multicolumn{3}{|c|}{6.332999999999999} & 5.6478 & TRN & \\
\hline CHEMBL1439047 & 688653 & 4.883 & 4.9375 & TRN & & & \\
\hline CHEMBL1326444 & 688653 & 5.933 & 5.3006 & TRN & & & \\
\hline CHEMBL 3208285 & 688653 & \multicolumn{3}{|c|}{5.7829999999999995} & 5.17 & TRN & \\
\hline CHEMBL1605142 & 688653 & 4.883 & 5.2641 & TRN & & & \\
\hline CHEMBL1339789 & 688653 & 5.083 & 5.5456 & TRN & & & \\
\hline CHEMBL1513934 & 688653 & 6.433 & 5.3875 & TRN & & & \\
\hline CHEMBL3191937 & 688653 & 4.833 & 5.1164 & TRN & & & \\
\hline CHEMBL1304486 & 688653 & \multicolumn{3}{|c|}{5.132999999999999} & 4.7998 & TRN & \\
\hline CHEMBL1967241 & 688653 & 5.683 & 6.0679 & TRN & & & \\
\hline CHEMBL1584746 & 688653 & 5.433 & 5.0648 & TRN & & & \\
\hline CHEMBL1449853 & 688653 & \multicolumn{3}{|c|}{6.0329999999999995} & 5.0992 & TRN & \\
\hline CHEMBL1332672 & 688653 & \multicolumn{3}{|c|}{5.2829999999999995} & 5.1227 & TRN & \\
\hline CHEMBL1524134 & 688653 & \multicolumn{3}{|c|}{6.0329999999999995} & 5.08899 & 99999999995 & TRN \\
\hline CHEMBL1414535 & 688653 & 4.933 & 5.1618 & TRN & & & \\
\hline CHEMBL1585912 & 688653 & \multicolumn{3}{|c|}{5.332999999999999} & 5.2526 & TRN & \\
\hline CHEMBL1579902 & 688653 & \multicolumn{3}{|c|}{6.632999999999999} & 5.5613 & TRN & \\
\hline CHEMBL1534942 & 688653 & 5.933 & 5.1402 & TRN & & & \\
\hline CHEMBL1370471 & 688653 & 4.833 & 5.1639 & TST & & & \\
\hline CHEMBL1357326 & 688653 & \multicolumn{3}{|c|}{6.632999999999999} & 5.865 & TRN & \\
\hline CHEMBL1555079 & 688653 & 4.883 & 5.1801 & TRN & & & \\
\hline CHEMBL1478478 & 688653 & 5.183 & 5.2757 & TRN & & & \\
\hline CHEMBL1303198 & 688653 & 4.883 & 5.5227 & TRN & & & \\
\hline CHEMBL1348402 & 688653 & 4.933 & 5.6343 & TST & & & \\
\hline CHEMBL1563983 & 688653 & 4.933 & 5.1354 & TRN & & & \\
\hline CHEMBL1514885 & 688653 & \multicolumn{3}{|c|}{5.382999999999999} & 4.8558 & TRN & \\
\hline CHEMBL1308950 & 688653 & 5.483 & 5.1473 & TRN & & & \\
\hline CHEMBL1532099 & 688653 & 4.683 & 5.3065 & TRN & & & \\
\hline CHEMBL1605698 & 688653 & 4.633 & 5.221 & TRN & & & \\
\hline CHEMBL1340259 & 688653 & 5.483 & 5.0251 & TRN & & & \\
\hline CHEMBL1563784 & 688653 & 4.783 & 5.4675 & TRN & & & \\
\hline CHEMBL1350706 & 688653 & \multicolumn{3}{|c|}{6.0329999999999995} & 5.9979 & TRN & \\
\hline CHEMBL1421698 & 688653 & 4.883 & 5.2373 & TRN & & & \\
\hline CHEMBL1368138 & 688653 & \multicolumn{3}{|c|}{5.632999999999999} & 5.2624 & TRN & \\
\hline CHEMBL1595151 & 688653 & 4.783 & 5.2835 & TRN & & & \\
\hline CHEMBL1381358 & 688653 & \multicolumn{3}{|c|}{5.832999999999999} & 6.2046 & TRN & \\
\hline CHEMBL1525587 & 688653 & \multicolumn{3}{|c|}{ 7.082999999999999 } & 5.7477 & TST & \\
\hline
\end{tabular}




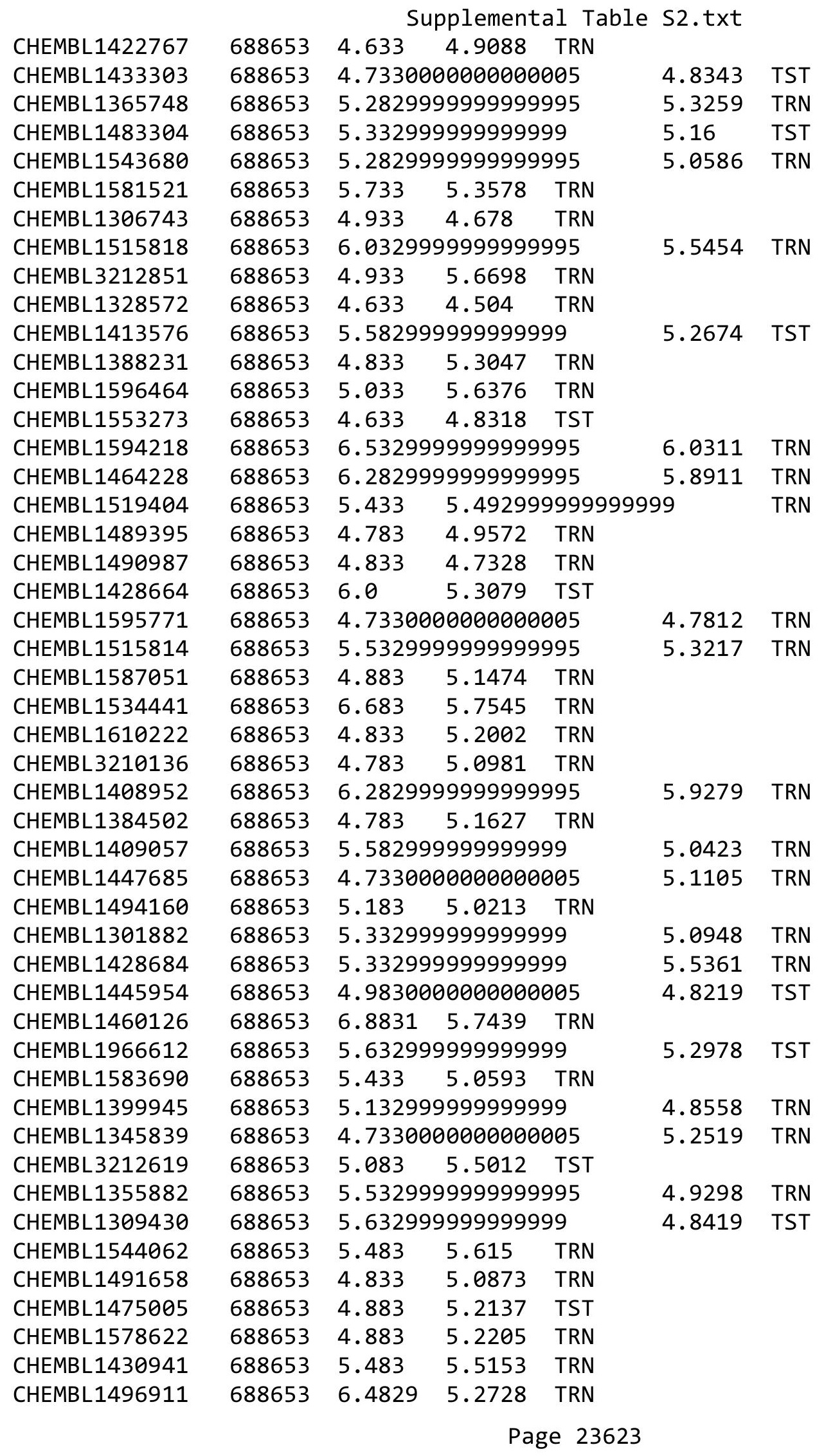




\begin{tabular}{|c|c|c|c|c|c|c|}
\hline \multirow{3}{*}{$\begin{array}{l}\text { CHEMBL1337299 } \\
\text { CHEMBL1547800 }\end{array}$} & \multicolumn{6}{|c|}{ Supplemental Table S2.txt } \\
\hline & 688653 & \multicolumn{3}{|c|}{4.7330000000000005} & 5.1352 & TRN \\
\hline & 688653 & \multicolumn{3}{|c|}{5.832999999999999} & 5.2654 & TRN \\
\hline CHEMBL578523 & 688653 & 4.633 & 5.3603 & TST & & \\
\hline CHEMBL1519341 & 688653 & 4.583 & 4.7919 & TRN & & \\
\hline CHEMBL1375958 & 688653 & 5.433 & 5.1255 & TRN & & \\
\hline CHEMBL1338462 & 688653 & 5.083 & 5.1328 & TST & & \\
\hline CHEMBL1514491 & 688653 & 4.783 & 5.1996 & TRN & & \\
\hline CHEMBL1310565 & 688653 & 5.233 & 5.0746 & TRN & & \\
\hline CHEMBL1412627 & 688653 & 5.733 & 5.6108 & TRN & & \\
\hline CHEMBL1537300 & 688653 & 4.933 & 5.2287 & TRN & & \\
\hline CHEMBL1603509 & 688653 & 6.5501 & 5.9248 & TRN & & \\
\hline CHEMBL1536902 & 688653 & 5.033 & 5.1829 & TRN & & \\
\hline CHEMBL1537364 & 688653 & 5.233 & 5.1784 & TRN & & \\
\hline CHEMBL1457817 & 688653 & \multicolumn{3}{|c|}{5.332999999999999} & 5.27 & TRN \\
\hline CHEMBL3191265 & 688653 & 7.1331 & 5.4789 & TRN & & \\
\hline CHEMBL1328322 & 688653 & \multicolumn{3}{|c|}{4.7330000000000005} & 5.5099 & TRN \\
\hline CHEMBL1520852 & 688653 & 4.833 & 4.6145 & TRN & & \\
\hline CHEMBL1401008 & 688653 & \multicolumn{3}{|c|}{5.132999999999999} & 5.2414 & TRN \\
\hline CHEMBL597874 & 688653 & \multicolumn{3}{|c|}{5.2829999999999995} & 5.0474 & TRN \\
\hline CHEMBL1420618 & 688653 & 5.083 & 5.306 & TRN & & \\
\hline CHEMBL1472496 & 688653 & \multicolumn{3}{|c|}{4.7330000000000005} & 5.5262 & TRN \\
\hline CHEMBL 2003149 & 688653 & \multicolumn{3}{|c|}{6.332999999999999} & 5.2492 & TST \\
\hline CHEMBL1608841 & 688653 & 4.883 & 5.3822 & TRN & & \\
\hline CHEMBL1595161 & 688653 & 4.633 & 4.8834 & TST & & \\
\hline CHEMBL1571416 & 688653 & 4.783 & 5.5148 & TRN & & \\
\hline CHEMBL1390335 & 688653 & 5.183 & 5.6529 & TST & & \\
\hline CHEMBL1551288 & 688653 & \multicolumn{3}{|c|}{5.7829999999999995} & 5.0639 & TST \\
\hline CHEMBL 3214154 & 688653 & \multicolumn{3}{|c|}{5.7829999999999995} & 5.4508 & TRN \\
\hline CHEMBL1488398 & 688653 & 4.883 & 5.1552 & TRN & & \\
\hline CHEMBL1326481 & 688653 & 5.733 & 5.3786 & TRN & & \\
\hline CHEMBL1564722 & 688653 & 4.783 & 5.1838 & TRN & & \\
\hline CHEMBL1316523 & 688653 & 5.033 & 5.9005 & TST & & \\
\hline CHEMBL1300552 & 688653 & \multicolumn{3}{|c|}{4.9830000000000005} & 5.0411 & TRN \\
\hline CHEMBL1478222 & 688653 & 4.583 & 4.8969 & TST & & \\
\hline CHEMBL3196599 & 688653 & 5.233 & 5.2142 & TRN & & \\
\hline CHEMBL1601695 & 688653 & 4.633 & 4.9027 & TRN & & \\
\hline CHEMBL1478812 & 688653 & \multicolumn{3}{|c|}{5.832999999999999} & 4.7853 & TRN \\
\hline CHEMBL1448199 & 688653 & \multicolumn{3}{|c|}{4.7330000000000005} & 4.955 & TRN \\
\hline CHEMBL1320886 & 688653 & 4.783 & 5.1271 & TST & & \\
\hline CHEMBL1385339 & 688653 & \multicolumn{3}{|c|}{4.7330000000000005} & 4.6089 & TST \\
\hline CHEMBL1481451 & 688653 & 5.683 & 5.3325 & TST & & \\
\hline CHEMBL1504361 & 688653 & \multicolumn{3}{|c|}{4.9830000000000005} & 4.9324 & TRN \\
\hline CHEMBL1526647 & 688653 & \multicolumn{3}{|c|}{5.382999999999999} & 5.3682 & TRN \\
\hline CHEMBL1533591 & 688653 & \multicolumn{3}{|c|}{5.832999999999999} & 4.926 & TRN \\
\hline CHEMBL1311094 & 688653 & \multicolumn{3}{|c|}{5.632999999999999} & 6.2701 & TRN \\
\hline CHEMBL1576669 & 688653 & 4.833 & 4.9221 & TST & & \\
\hline CHEMBL1516413 & 688653 & 4.783 & 5.5696 & TRN & & \\
\hline CHEMBL1463042 & 688653 & 5.7829 & 99999999 & 995 & 5.4916 & TRN \\
\hline
\end{tabular}




\begin{tabular}{|c|c|c|c|c|c|c|c|}
\hline \multicolumn{8}{|c|}{ supplemental lable s2.txt } \\
\hline CHEMBL1401584 & 688653 & 4.883 & 5.2317 & TST & & & \\
\hline CHEMBL1581943 & 688653 & 6.03299 & 999999999 & 995 & 5.357 & TRN & \\
\hline CHEMBL1487212 & 688653 & 5.233 & 5.0272 & TRN & & & \\
\hline CHEMBL1470161 & 688653 & 4.883 & 5.1809 & TRN & & & \\
\hline CHEMBL1451878 & 688653 & 4.633 & 5.1711 & TST & & & \\
\hline CHEMBL3190559 & 688653 & 4.883 & 5.2864 & TRN & & & \\
\hline CHEMBL1532268 & 688653 & 5.53299 & 999999999 & 995 & 4.99 & TRN & \\
\hline CHEMBL1368256 & 688653 & 5.033 & 5.4504 & TRN & & & \\
\hline CHEMBL1598805 & 688653 & 5.83299 & 999999995 & & 5.385 & TRN & \\
\hline CHEMBL379350 & 688653 & 4.73300 & 00000000 & 005 & 5.7885 & TRN & \\
\hline CHEMBL1309463 & 688653 & 4.833 & 4.6468 & TRN & & & \\
\hline CHEMBL1416804 & 688653 & 4.883 & 5.0253 & TST & & & \\
\hline CHEMBL1383978 & 688653 & 4.9 & 5.4179 & TRN & & & \\
\hline CHEMBL1543522 & 688653 & 4.783 & 5.1858 & TRN & & & \\
\hline CHEMBL1438032 & 688653 & 4.783 & 5.092 & TRN & & & \\
\hline CHEMBL1357996 & 688653 & 5.83299 & 999999995 & & 5.5909 & TRN & \\
\hline CHEMBL1552652 & 688653 & 5.83299 & 999999999 & & 4.8201 & TRN & \\
\hline CHEMBL1401676 & 688653 & 7.2832 & 5.8698 & TRN & & & \\
\hline CHEMBL1438588 & 688653 & 4.883 & 5.3172 & TRN & & & \\
\hline CHEMBL1422690 & 688653 & 5.28299 & 999999995 & 995 & 5.0745 & TST & \\
\hline CHEMBL1469745 & 688653 & 4.783 & 5.2547 & TRN & & & \\
\hline CHEMBL1599217 & 688653 & 4.933 & 5.324 & TRN & & & \\
\hline CHEMBL1611247 & 688653 & 5.33299 & 999999995 & & 5.3032 & TRN & \\
\hline CHEMBL1387718 & 688653 & 4.783 & 5.3941 & TRN & & & \\
\hline CHEMBL 3190484 & 688653 & 5.13299 & 999999995 & & 5.3186 & TST & \\
\hline CHEMBL1527217 & 688653 & 5.683 & 5.4928 & TRN & & & \\
\hline CHEMBL3212478 & 688653 & 5.733 & 5.6342 & TRN & & & \\
\hline CHEMBL3209045 & 688653 & 5.033 & 5.4181 & TRN & & & \\
\hline CHEMBL1410778 & 688653 & 5.28299 & 999999999 & 995 & 4.7774 & TST & \\
\hline CHEMBL1335169 & 688653 & 5.13299 & 999999995 & & 5.45100 & 00000000005 & TRN \\
\hline CHEMBL1434983 & 688653 & 4.633 & 5.0258 & TST & & & \\
\hline CHEMBL1386558 & 688653 & 5.683 & 5.0441 & TRN & & & \\
\hline CHEMBL1424691 & 688653 & 4.98300 & 000000006 & 005 & 4.3561 & TRN & \\
\hline CHEMBL1304996 & 688653 & 4.933 & 6.2235 & TRN & & & \\
\hline CHEMBL1613411 & 688653 & 5.433 & 5.8965 & TRN & & & \\
\hline CHEMBL1511487 & 688653 & 5.483 & 5.3135 & TRN & & & \\
\hline CHEMBL1439094 & 688653 & 4.883 & 5.3131 & TRN & & & \\
\hline CHEMBL1502933 & 688653 & 5.53299 & 999999995 & 995 & 5.4715 & TRN & \\
\hline CHEMBL1517233 & 688653 & 5.933 & 5.3497 & TRN & & & \\
\hline CHEMBL1367866 & 688653 & 4.783 & 4.6802 & TST & & & \\
\hline CHEMBL1501354 & 688653 & 4.73300 & 000000006 & 005 & 5.4819 & TST & \\
\hline CHEMBL1519969 & 688653 & 4.833 & 5.4794 & TRN & & & \\
\hline CHEMBL1304595 & 688653 & 5.233 & 5.1756 & TST & & & \\
\hline CHEMBL1597963 & 688653 & 5.183 & 5.0441 & TRN & & & \\
\hline CHEMBL1569967 & 688653 & 6.38299 & 999999999 & & 6.0656 & TRN & \\
\hline CHEMBL1597459 & 688653 & 4.833 & 5.0626 & TST & & & \\
\hline CHEMBL1491697 & 688653 & 4.73300 & 00000000 & 005 & 4.3178 & TRN & \\
\hline CHEMBL1450530 & 688653 & 4.933 & 5.3041 & TRN & & & \\
\hline
\end{tabular}




\begin{tabular}{|c|c|c|c|c|c|c|}
\hline & & \multicolumn{5}{|c|}{ Supplemental Table s2.txt } \\
\hline CHEMBL1402598 & 688653 & 5.483 & 5.3662 & TST & & \\
\hline CHEMBL1350503 & 688653 & 4.633 & 5.0 & TRN & & \\
\hline CHEMBL1336198 & 688653 & 6.0 & 5.6565 & TRN & & \\
\hline CHEMBL1311653 & 688653 & 5.083 & 4.8367 & TRN & & \\
\hline CHEMBL1495100 & 688653 & \multicolumn{3}{|c|}{4.7330000000000005} & 5.7005 & TRN \\
\hline CHEMBL1389438 & 688653 & 6.183 & 5.4198 & TRN & & \\
\hline CHEMBL1322449 & 688653 & \multicolumn{3}{|c|}{4.7330000000000005} & 5.1361 & TST \\
\hline CHEMBL1472798 & 688653 & \multicolumn{3}{|c|}{5.832999999999999} & 5.9427 & TRN \\
\hline CHEMBL1458062 & 688653 & 4.583 & 4.9846 & TST & & \\
\hline CHEMBL600908 & 688653 & 4.833 & 5.1048 & TRN & & \\
\hline CHEMBL1325267 & 688653 & 5.433 & 5.5019 & TRN & & \\
\hline CHEMBL1517542 & 688653 & \multicolumn{3}{|c|}{6.632999999999999} & 5.7722 & TRN \\
\hline CHEMBL1482382 & 688653 & 4.883 & 5.4918 & TRN & & \\
\hline CHEMBL1549574 & 688653 & 4.683 & 5.0245 & TST & & \\
\hline CHEMBL1331050 & 688653 & 4.683 & 4.8956 & TST & & \\
\hline CHEMBL1606816 & 688653 & \multicolumn{3}{|c|}{4.7330000000000005} & 5.0248 & TRN \\
\hline CHEMBL3194151 & 688653 & 5.183 & 5.2966 & TRN & & \\
\hline CHEMBL1502000 & 688653 & 4.633 & 5.1881 & TRN & & \\
\hline CHEMBL1607516 & 688653 & 4.833 & 5.1662 & TRN & & \\
\hline CHEMBL1534947 & 688653 & 4.783 & \multicolumn{3}{|c|}{5.138999999999999} & TST \\
\hline CHEMBL1500014 & 688653 & 4.683 & 4.8936 & TRN & & \\
\hline CHEMBL1488402 & 688653 & 4.783 & 5.3578 & TST & & \\
\hline CHEMBL1305530 & 688653 & 4.883 & 4.9816 & TST & & \\
\hline CHEMBL1300613 & 688653 & 6.183 & 5.6869 & TRN & & \\
\hline CHEMBL1495348 & 688653 & 5.233 & 5.3588 & TRN & & \\
\hline CHEMBL1577743 & 688653 & 4.833 & 5.2788 & TST & & \\
\hline CHEMBL1552686 & 688653 & \multicolumn{3}{|c|}{4.7330000000000005} & 5.5278 & TRN \\
\hline CHEMBL1300601 & 688653 & 4.883 & 4.8298 & TST & & \\
\hline CHEMBL1465675 & 688653 & 4.783 & 5.6521 & TRN & & \\
\hline CHEMBL1489271 & 688653 & 5.933 & 5.8665 & TRN & & \\
\hline CHEMBL1396458 & 688653 & 4.833 & 4.9519 & TST & & \\
\hline CHEMBL1328373 & 688653 & 4.833 & 5.7243 & TST & & \\
\hline CHEMBL1538854 & 688653 & \multicolumn{3}{|c|}{6.2829999999999995} & 6.1421 & TRN \\
\hline CHEMBL1407798 & 688653 & 4.583 & 4.9859 & TST & & \\
\hline CHEMBL1547194 & 688653 & \multicolumn{3}{|c|}{4.7330000000000005} & 5.2956 & TRN \\
\hline CHEMBL1592342 & 688653 & \multicolumn{3}{|c|}{6.632999999999999} & 5.9871 & TRN \\
\hline CHEMBL1577140 & 688653 & 5.683 & 5.5115 & TRN & & \\
\hline CHEMBL1611515 & 688653 & & 5.2095 & TRN & & \\
\hline CHEMBL 3213741 & 688653 & \multicolumn{3}{|c|}{6.332999999999999} & 5.8331 & TRN \\
\hline CHEMBL1377385 & 688653 & 6.4829 & 5.3504 & TRN & & \\
\hline CHEMBL1311602 & 688653 & \multicolumn{3}{|c|}{5.332999999999999} & 4.8971 & TRN \\
\hline CHEMBL1537737 & 688653 & 5.683 & 5.4658 & TRN & & \\
\hline CHEMBL460518 & 688653 & \multicolumn{3}{|c|}{6.0329999999999995} & 5.8124 & TRN \\
\hline CHEMBL1375970 & 688653 & 4.583 & 4.5512 & TRN & & \\
\hline CHEMBL1547363 & 688653 & 4.833 & 5.2995 & TRN & & \\
\hline CHEMBL1609636 & 688653 & 4.933 & 5.0902 & TRN & & \\
\hline CHEMBL1541001 & 688653 & 5.45 & 4.9551 & TRN & & \\
\hline CHEMBL1379020 & 688653 & 5.183 & 4.8943 & TST & & \\
\hline
\end{tabular}




\begin{tabular}{|c|c|c|c|c|c|c|c|}
\hline \multicolumn{8}{|c|}{ Supplemental Ta } \\
\hline CHEMBL1570697 & 688653 & 4.783 & 5.3724 & TRN & & & \\
\hline CHEMBL1331787 & 688653 & 6.0 & 5.8959 & TRN & & & \\
\hline CHEMBL1433692 & 688653 & 6.983 & 5.8032 & TRN & & & \\
\hline CHEMBL1974521 & 688653 & 5.433 & 5.2617 & TRN & & & \\
\hline CHEMBL1453126 & 688653 & \multicolumn{3}{|c|}{5.382999999999999} & 5.0667 & TRN & \\
\hline CHEMBL1589875 & 688653 & 4.633 & 4.9931 & TRN & & & \\
\hline CHEMBL1360416 & 688653 & \multicolumn{3}{|c|}{5.882999999999999} & 5.8643 & TRN & \\
\hline CHEMBL1613723 & 688653 & 4.583 & 5.0132 & TST & & & \\
\hline CHEMBL3190600 & 688653 & \multicolumn{3}{|c|}{5.5329999999999995} & \multicolumn{2}{|c|}{5.122000000000001} & TRN \\
\hline CHEMBL600554 & 688653 & 5.733 & 5.8217 & TRN & & & \\
\hline CHEMBL1537243 & 688653 & 5.033 & 5.2743 & TRN & & & \\
\hline CHEMBL1386546 & 688653 & 4.933 & 5.5878 & TST & & & \\
\hline CHEMBL1585928 & 688653 & 5.183 & 4.9293 & TST & & & \\
\hline CHEMBL1594065 & 688653 & 4.633 & 5.5349 & TST & & & \\
\hline CHEMBL1477538 & 688653 & 4.783 & 4.9397 & TRN & & & \\
\hline CHEMBL1392132 & 688653 & 6.233 & 5.9189 & TRN & & & \\
\hline CHEMBL1404208 & 688653 & 6.683 & 5.5719 & TRN & & & \\
\hline CHEMBL1562575 & 688653 & 6.4829 & 6.5196 & TRN & & & \\
\hline CHEMBL1600037 & 688653 & \multicolumn{3}{|c|}{4.9830000000000005} & 5.1187 & TRN & \\
\hline CHEMBL1500420 & 688653 & \multicolumn{3}{|c|}{5.5329999999999995} & 5.2777 & TST & \\
\hline CHEMBL1348807 & 688653 & \multicolumn{3}{|c|}{5.7829999999999995} & 5.4247 & TST & \\
\hline CHEMBL1463491 & 688653 & 4.583 & 4.9459 & TST & & & \\
\hline CHEMBL1392776 & 688653 & 6.4829 & 5.4787 & TRN & & & \\
\hline CHEMBL1309032 & 688653 & 4.583 & 5.2145 & TRN & & & \\
\hline CHEMBL1486018 & 688653 & \multicolumn{3}{|c|}{4.9830000000000005} & 5.6239 & TRN & \\
\hline CHEMBL1550553 & 688653 & 4.783 & 5.2415 & TST & & & \\
\hline CHEMBL1417851 & 688653 & \multicolumn{3}{|c|}{ 7. 382999999999999} & 6.2209 & TRN & \\
\hline CHEMBL1511686 & 688653 & \multicolumn{3}{|c|}{6.0329999999999995} & 5.7192 & TRN & \\
\hline CHEMBL1471069 & 688653 & \multicolumn{3}{|c|}{5.882999999999999} & 5.6852 & TRN & \\
\hline CHEMBL1442404 & 688653 & \multicolumn{3}{|c|}{5.832999999999999} & 5.1969 & TRN & \\
\hline CHEMBL1548026 & 688653 & 4.583 & 4.6176 & TRN & & & \\
\hline CHEMBL1503205 & 688653 & 4.933 & 5.1059 & TRN & & & \\
\hline CHEMBL1366800 & 688653 & \multicolumn{3}{|c|}{5.7829999999999995} & 5.2216 & TST & \\
\hline CHEMBL1463875 & 688653 & 4.683 & 6.0194 & TRN & & & \\
\hline CHEMBL1303103 & 688653 & \multicolumn{3}{|c|}{5.832999999999999} & 5.3999 & TRN & \\
\hline CHEMBL3191591 & 688653 & 5.433 & 5.2964 & TST & & & \\
\hline CHEMBL1544159 & 688653 & \multicolumn{3}{|c|}{6.582999999999999} & \multicolumn{2}{|c|}{5.593999999999999} & TRN \\
\hline CHEMBL1501461 & 688653 & 5.183 & 5.3616 & TRN & & & \\
\hline CHEMBL1321769 & 688653 & 4.933 & 5.2433 & TRN & & & \\
\hline CHEMBL1344180 & 688653 & \multicolumn{3}{|c|}{5.132999999999999} & 4.787 & TRN & \\
\hline CHEMBL1376578 & 688653 & \multicolumn{3}{|c|}{5.132999999999999} & 4.9198 & TST & \\
\hline CHEMBL1613456 & 688653 & \multicolumn{3}{|c|}{4.7330000000000005} & 5.3979 & TRN & \\
\hline CHEMBL602561 & 688653 & \multicolumn{3}{|c|}{5.832999999999999} & 5.0973 & TRN & \\
\hline CHEMBL1611697 & 688653 & 5.733 & 5.5299 & TRN & & & \\
\hline CHEMBL1488733 & 688653 & 6.4829 & 5.6789 & TRN & & & \\
\hline CHEMBL1434338 & 688653 & 5.78299 & 99999999 & 995 & 5.6272 & TRN & \\
\hline CHEMBL1345931 & 688653 & 4.933 & 5.1401 & TRN & & & \\
\hline CHEMBL1610789 & 688653 & 5.58299 & 99999999 & & 5.5433 & TRN & \\
\hline
\end{tabular}




\begin{tabular}{|c|c|c|c|c|c|c|c|}
\hline \multirow[b]{2}{*}{ CHEMBL1361322 } & \multicolumn{6}{|c|}{ 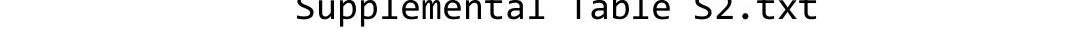 } & \\
\hline & 688653 & 4.583 & 5.3678 & TST & & & \\
\hline CHEMBL1530600 & 688653 & 4.883 & 4.79 & TRN & & & \\
\hline CHEMBL1562727 & 688653 & 4.833 & 5.1811 & TRN & & & \\
\hline CHEMBL3211025 & 688653 & 5.1329 & 99999999 & & 5.21299 & 9999999999 & TRN \\
\hline CHEMBL1523369 & 688653 & 6.433 & 5.3415 & TST & & & \\
\hline CHEMBL1421036 & 688653 & 5.233 & 5.0738 & TRN & & & \\
\hline CHEMBL1578155 & 688653 & 5.8329 & 9999999s & & 5.0627 & TRN & \\
\hline CHEMBL1342746 & 688653 & 4.7330 & 00000006 & 005 & 4.9737 & TST & \\
\hline CHEMBL1600253 & 688653 & 6.233 & 5.9683 & TRN & & & \\
\hline CHEMBL1610601 & 688653 & 5.7829 & 99999995 & 995 & 5.4637 & TRN & \\
\hline CHEMBL1581582 & 688653 & 4.633 & 5.0956 & TST & & & \\
\hline CHEMBL1538639 & 688653 & 5.033 & 5.186 & TST & & & \\
\hline CHEMBL1440416 & 688653 & 6.0 & 5.5982 & TRN & & & \\
\hline CHEMBL1559011 & 688653 & 4.833 & 5.7824 & TRN & & & \\
\hline CHEMBL1355543 & 688653 & 4.583 & 4.6611 & TRN & & & \\
\hline CHEMBL1381328 & 688653 & 5.683 & 5.6491 & TST & & & \\
\hline CHEMBL1571160 & 688653 & 6.3829 & 99999999 & & 5.1219 & TRN & \\
\hline CHEMBL1413743 & 688653 & 4.933 & 5.1932 & TRN & & & \\
\hline CHEMBL1396185 & 688653 & 4.833 & 5.1811 & TRN & & & \\
\hline CHEMBL1391836 & 688653 & 4.9830 & 00000006 & 005 & 5.1715 & TST & \\
\hline CHEMBL1499121 & 688653 & 6.183 & 5.6859 & TRN & & & \\
\hline CHEMBL1598190 & 688653 & 4.883 & 4.94606 & 000000000 & & TST & \\
\hline CHEMBL1602800 & 688653 & 5.183 & 4.7399 & TRN & & & \\
\hline CHEMBL1543685 & 688653 & 5.933 & 5.5992 & TST & & & \\
\hline CHEMBL1593990 & 688653 & 5.3329 & 99999999 & & 5.2879 & TRN & \\
\hline CHEMBL1545826 & 688653 & 5.733 & 4.9192 & TRN & & & \\
\hline CHEMBL1566285 & 688653 & 4.783 & 5.1133 & TST & & & \\
\hline CHEMBL3209635 & 688653 & 6.0829 & 99999999 & & 5.7816 & TRN & \\
\hline CHEMBL1442690 & 688653 & 4.883 & 4.9536 & TRN & & & \\
\hline CHEMBL3191570 & 688653 & 7.0829 & 99999999 & & 5.8754 & TRN & \\
\hline CHEMBL1584875 & 688653 & 6.8831 & 5.83290 & 999999999 & & TRN & \\
\hline CHEMBL3195267 & 688653 & 4.783 & 5.2734 & TRN & & & \\
\hline CHEMBL1528861 & 688653 & 5.1329 & 9999999s & & 5.0114 & TST & \\
\hline CHEMBL1393509 & 688653 & 5.183 & 5.3872 & TRN & & & \\
\hline CHEMBL 2004056 & 688653 & 4.633 & 4.9746 & TST & & & \\
\hline CHEMBL1397641 & 688653 & 4.633 & 5.2431 & TRN & & & \\
\hline CHEMBL1559957 & 688653 & 6.1329 & 99999999 & & 5.20100 & 00000000005 & TST \\
\hline CHEMBL1498996 & 688653 & 5.1329 & 9999999 & & 4.9235 & TRN & \\
\hline CHEMBL1453149 & 688653 & 4.633 & 4.6608 & TRN & & & \\
\hline CHEMBL1516294 & 688653 & 4.633 & 4.8793 & TRN & & & \\
\hline CHEMBL1353362 & 688653 & 6.1329 & 99999995 & & 5.5303 & TRN & \\
\hline CHEMBL1577923 & 688653 & 4.783 & 5.3327 & TRN & & & \\
\hline CHEMBL1594975 & 688653 & 4.883 & 4.7857 & TRN & & & \\
\hline CHEMBL1453319 & 688653 & 5.183 & 5.3706 & TRN & & & \\
\hline CHEMBL1350339 & 688653 & 6.5829 & 99999995 & & 5.1752 & TRN & \\
\hline CHEMBL3199238 & 688653 & 5.1329 & 99999995 & & 5.1457 & TST & \\
\hline CHEMBL1485831 & 688653 & 4.7330 & 00000006 & 005 & 4.8183 & TRN & \\
\hline CHEMBL1549860 & 688653 & 4.633 & 4.7496 & TRN & & & \\
\hline
\end{tabular}




\begin{tabular}{|c|c|c|c|c|c|c|}
\hline & \\
\hline CHEMBL1599778 & 688653 & 6.4829 & & TRN & & \\
\hline CHEMBL 3195811 & 688653 & \multicolumn{3}{|c|}{5.132999999999999} & 5.5701 & \\
\hline CHEMBL 3193124 & 688653 & \multicolumn{3}{|c|}{5.132999999999999} & 5.3735 & \\
\hline CHEMBL1324755 & 688653 & \multicolumn{3}{|c|}{5.2829999999999995} & 5.4071 & \\
\hline CHEMBL1425684 & 588653 & \multicolumn{3}{|c|}{5.2829999999999995} & 5.0926 & \\
\hline CHEMBL 2003831 & 688653 & \multicolumn{3}{|c|}{5.2829999999999995} & 5.3798 & \\
\hline CHEMBL1560582 & 688653 & \multicolumn{3}{|c|}{5.632999999999999} & 5.272 & \\
\hline CHEMBL1463626 & 688653 & \multicolumn{3}{|c|}{5.7829999999999995} & 5.1614 & \\
\hline CHEMBL1541291 & 688653 & \multicolumn{3}{|c|}{5.632999999999999} & 5.3987 & \\
\hline CHEMBL1558986 & 688653 & \multicolumn{3}{|c|}{5.882999999999999} & 468 & \\
\hline CHEMBL1571885 & 688653 & \multicolumn{3}{|c|}{5.332999999999999} & 4.8834 & \\
\hline CHEMBL1433741 & 688653 & 4.633 & 5.0409 & TST & & \\
\hline CHEMBL1467704 & 688653 & \multicolumn{3}{|c|}{5.7829999999999995} & 569 & \\
\hline CHEMBL1521145 & 688653 & \multicolumn{3}{|c|}{5.382999999999999} & 951 & \\
\hline CHEMBL1378708 & 688653 & 4.883 & 5.1313 & TRN & & \\
\hline CHEMBL14 & 688653 & \multicolumn{3}{|c|}{4.9830000000000005} & 5 & \\
\hline CHEMBL136 & 688653 & 4.583 & 4.7369 & TRN & & \\
\hline CHEMBL1456462 & 688653 & 4.883 & 5.3472 & TRN & & \\
\hline CHEMBL 3210160 & 688653 & 5.733 & 5.3477 & TRN & & \\
\hline CHEMBL1553124 & 688653 & 4.583 & 5.1042 & TRN & & \\
\hline CHEMBL1 & 688653 & \multicolumn{3}{|c|}{4.7330000000000005} & 5.4 & \\
\hline CHEMBL1470647 & 688653 & \multicolumn{3}{|c|}{6.332999999999999} & 5.6 & \\
\hline CHEMBL1537008 & 688653 & \multicolumn{3}{|c|}{6.832999999999999} & 5.6329 & \\
\hline CHEMBL1307350 & 688653 & \multicolumn{3}{|c|}{5.582999999999999} & & \\
\hline CHEMBL1368234 & 688653 & & 5.1636 & TRN & & \\
\hline CHEMBL1 & 688653 & 4.833 & 5.0766 & TRN & & \\
\hline CHEMBL1319820 & 688653 & 4.933 & 5.2844 & TRN & & \\
\hline CHEMBL1430035 & 688653 & 5.1329 & 99999999 & & 225 & \\
\hline CHEMBL1501871 & 688653 & 4.783 & $5.1220 €$ & 00000 & & \\
\hline CHEMBL1320211 & 688653 & 5.433 & 5.5464 & TRN & & \\
\hline CHEMBL1: & 688653 & 4.833 & 4.9243 & TRN & & \\
\hline CHEMBL 1520345 & 688653 & 5.7829 & 99999999 & 995 & 5.2496 & \\
\hline CHEMBL1511483 & 688653 & 4.7330 & 20000006 & 005 & 5.365 & \\
\hline CHEMBL1433112 & 688653 & 4.783 & 5.0634 & TRN & & \\
\hline CHEMBL1365266 & 688653 & 5.183 & 5.4046 & TRN & & \\
\hline CHEMBL1 & 688653 & 5.233 & 4.854 & TST & & \\
\hline CHEMBL 1517703 & 688653 & 6.5329 & 99999999 & 995 & 5.9194 & \\
\hline CHEMBL1526253 & 688653 & 4.783 & 5.1833 & TRN & & \\
\hline CHEMBL1609358 & 688653 & 4.933 & 5.5441 & TRN & & \\
\hline CHEMBL1593814 & 688653 & 4.583 & 4.76699 & 99999 & 995 & \\
\hline CHEMBL1604090 & 688653 & 4.633 & 4.414 & TST & & \\
\hline CHEMBL1334791 & 688653 & 6.0329 & 99999999 & 995 & 5.5248 & \\
\hline CHEMBL 1575830 & 688653 & 4.9830 & $2000000 €$ & 005 & 5.371 & 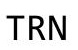 \\
\hline CHEMBL1552505 & 688653 & 6.9329 & 5.609 & TRN & & \\
\hline CHEMBL1462882 & 688653 & 5.733 & 6.0583 & TRN & & \\
\hline CHEMBL1578145 & 688653 & 5.6329 & 99999999 & & 5.2809 & \\
\hline CHEMBL1336325 & 688653 & 4.883 & 4.6764 & TST & & \\
\hline CHEMBL1337084 & 688653 & 5.5829 & 9999999 & & 5.3556 & RN \\
\hline
\end{tabular}




\begin{tabular}{|c|c|c|c|c|c|c|}
\hline \multicolumn{7}{|c|}{ Supplemental Table S2.txt } \\
\hline CHEMBL1336550 & 688653 & 5.433 & 5.3806 & TRN & & \\
\hline CHEMBL1484783 & 688653 & \multicolumn{3}{|c|}{4.9830000000000005} & 5.2881 & TST \\
\hline CHEMBL1579918 & 688653 & 5.733 & 5.2368 & TRN & & \\
\hline CHEMBL1323863 & 688653 & 5.433 & 5.1307 & TRN & & \\
\hline CHEMBL1445924 & 688653 & \multicolumn{3}{|c|}{4.7330000000000005} & 5.023 & TST \\
\hline CHEMBL1302492 & 688653 & 4.833 & 5.1731 & TST & & \\
\hline CHEMBL1790002 & 688653 & 4.883 & 5.1559 & TST & & \\
\hline CHEMBL1414634 & 688653 & 4.883 & 5.086 & TST & & \\
\hline CHEMBL1995078 & 688653 & 5.433 & 5.2346 & TRN & & \\
\hline CHEMBL1341951 & 688653 & 4.933 & 5.1135 & TRN & & \\
\hline CHEMBL1414992 & 688653 & 4.783 & 4.939 & TRN & & \\
\hline CHEMBL1608887 & 688653 & 5.183 & 5.2531 & TRN & & \\
\hline CHEMBL1450961 & 688653 & 4.883 & 5.4095 & TST & & \\
\hline CHEMBL1408482 & 688653 & 4.783 & 5.2985 & TRN & & \\
\hline CHEMBL1492852 & 688653 & 4.783 & 4.837 & TRN & & \\
\hline CHEMBL1351765 & 688653 & \multicolumn{3}{|c|}{4.9830000000000005} & 4.7533 & TRN \\
\hline CHEMBL1443306 & 688653 & 4.833 & 5.3244 & TRN & & \\
\hline CHEMBL1412669 & 688653 & 5.183 & 5.5139 & TRN & & \\
\hline CHEMBL1354694 & 688653 & 6.183 & 5.5675 & TRN & & \\
\hline CHEMBL1344539 & 688653 & 5.683 & 5.3367 & TRN & & \\
\hline CHEMBL1407281 & 688653 & \multicolumn{3}{|c|}{5.332999999999999} & 4.7338 & TRN \\
\hline CHEMBL1519919 & 688653 & \multicolumn{3}{|c|}{5.882999999999999} & 5.8737 & TRN \\
\hline CHEMBL1398770 & 688653 & 5.733 & \multicolumn{3}{|c|}{5.577000000000001} & TRN \\
\hline CHEMBL1521367 & 688653 & 5.183 & \multicolumn{3}{|c|}{5.138999999999999} & TRN \\
\hline CHEMBL1511026 & 688653 & \multicolumn{3}{|c|}{4.7330000000000005} & 5.0387 & TRN \\
\hline CHEMBL1611200 & 688653 & 5.483 & 5.2015 & TST & & \\
\hline CHEMBL1321076 & 688653 & 5.933 & 5.4037 & TRN & & \\
\hline CHEMBL1516125 & 688653 & 4.833 & 5.0928 & TRN & & \\
\hline CHEMBL1495625 & 688653 & \multicolumn{3}{|c|}{5.132999999999999} & 5.1742 & TRN \\
\hline CHEMBL1357788 & 688653 & \multicolumn{3}{|c|}{5.882999999999999} & 5.5522 & TRN \\
\hline CHEMBL1361487 & 688653 & 5.933 & 5.4546 & TST & & \\
\hline CHEMBL1325748 & 688653 & 4.833 & 5.3042 & TRN & & \\
\hline CHEMBL1501030 & 688653 & \multicolumn{3}{|c|}{4.7330000000000005} & 5.6966 & TST \\
\hline CHEMBL1322134 & 688653 & 5.033 & 5.113 & TRN & & \\
\hline CHEMBL1605598 & 688653 & 4.833 & 4.9115 & TRN & & \\
\hline CHEMBL1436805 & 688653 & \multicolumn{3}{|c|}{4.7330000000000005} & 4.9549 & TST \\
\hline CHEMBL1548075 & 688653 & 7.0329 & 6.1434 & TRN & & \\
\hline CHEMBL1456437 & 688653 & \multicolumn{3}{|c|}{6.832999999999999} & 6.1199 & TRN \\
\hline CHEMBL3196620 & 688653 & \multicolumn{3}{|c|}{6.332999999999999} & 5.4221 & TRN \\
\hline CHEMBL1430683 & 688653 & \multicolumn{3}{|c|}{4.7330000000000005} & 5.2641 & TST \\
\hline CHEMBL1488205 & 688653 & \multicolumn{3}{|c|}{6.082999999999999} & 5.1359 & TST \\
\hline CHEMBL1309608 & 688653 & 4.633 & 4.8539 & TRN & & \\
\hline CHEMBL1514790 & 688653 & 4.633 & 4.7181 & TRN & & \\
\hline CHEMBL1541655 & 688653 & 4.783 & 5.1553 & TRN & & \\
\hline CHEMBL1439781 & 688653 & \multicolumn{3}{|c|}{5.382999999999999} & 5.3513 & TRN \\
\hline CHEMBL1604642 & 688653 & 5.233 & 5.046 & TRN & & \\
\hline CHEMBL1577197 & 688653 & 4.783 & 5.2951 & TRN & & \\
\hline CHEMBL1601122 & 688653 & \multicolumn{3}{|c|}{6.632999999999999} & 5.99200 & 0000000001 \\
\hline
\end{tabular}




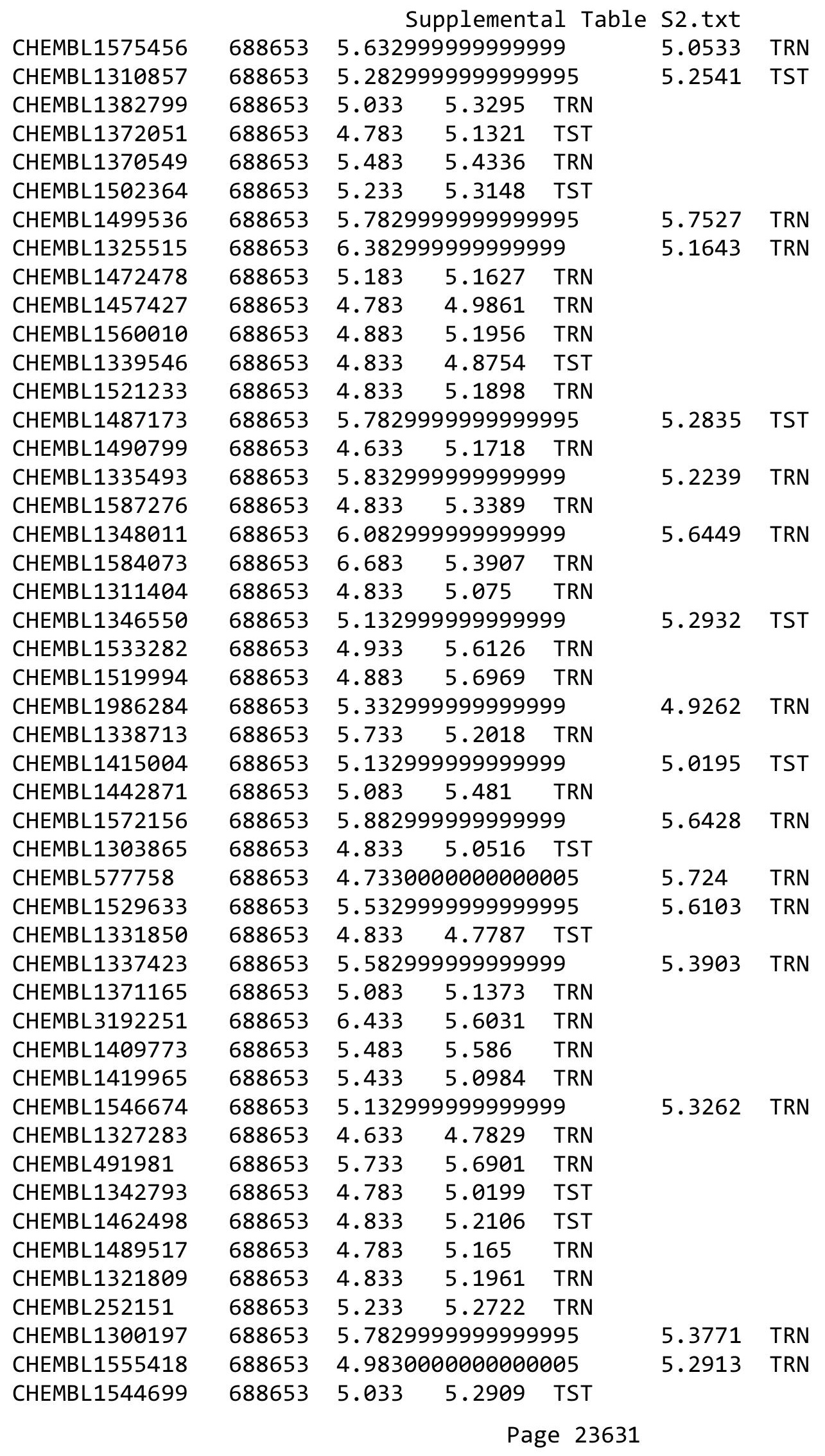




\begin{tabular}{|c|c|c|c|c|c|c|}
\hline & & \multicolumn{5}{|c|}{ Supplemental Table S2.txt } \\
\hline CHEMBL1461275 & 688653 & \multicolumn{3}{|c|}{6.0329999999999995} & 5.2583 & TRN \\
\hline CHEMBL1474411 & 688653 & \multicolumn{3}{|c|}{4.7330000000000005} & 5.4385 & TST \\
\hline CHEMBL1418311 & 688653 & 4.583 & 4.4887 & TST & & \\
\hline CHEMBL1399893 & 688653 & 4.783 & 5.3059 & TRN & & \\
\hline CHEMBL1311146 & 688653 & 4.833 & 5.1996 & TRN & & \\
\hline CHEMBL1571426 & 688653 & 5.983 & 5.6761 & TRN & & \\
\hline CHEMBL1351399 & 688653 & 6.433 & 5.6351 & TRN & & \\
\hline CHEMBL3192253 & 688653 & \multicolumn{3}{|c|}{5.332999999999999} & 5.8012 & TRN \\
\hline CHEMBL1402846 & 688653 & \multicolumn{3}{|c|}{6.2829999999999995} & 6.0362 & TRN \\
\hline CHEMBL1465091 & 688653 & 5.433 & 5.2871 & TRN & & \\
\hline CHEMBL1563671 & 688653 & \multicolumn{3}{|c|}{6.082999999999999} & 5.9494 & TRN \\
\hline CHEMBL1478082 & 688653 & 5.933 & \multicolumn{3}{|c|}{5.412000000000001} & TRN \\
\hline CHEMBL1465138 & 688653 & 5.483 & 5.6825 & TRN & & \\
\hline CHEMBL1434090 & 688653 & 4.633 & 4.9336 & TRN & & \\
\hline CHEMBL1416951 & 688653 & 5.733 & 5.6029 & TRN & & \\
\hline CHEMBL1499823 & 688653 & \multicolumn{3}{|c|}{5.882999999999999} & 5.5557 & TRN \\
\hline CHEMBL1387968 & 688653 & 4.833 & 5.6117 & TRN & & \\
\hline CHEMBL1519620 & 688653 & 4.883 & 5.0269 & TST & & \\
\hline CHEMBL1487501 & 688653 & \multicolumn{3}{|c|}{5.632999999999999} & 5.5122 & TRN \\
\hline CHEMBL1579138 & 688653 & 5.183 & 4.8555 & TST & & \\
\hline CHEMBL1303994 & 688653 & 5.233 & 5.0006 & TST & & \\
\hline CHEMBL1523356 & 688653 & 6.8831 & 5.6897 & TRN & & \\
\hline CHEMBL1315177 & 688653 & 5.683 & 5.2564 & TRN & & \\
\hline CHEMBL1532203 & 688653 & 5.683 & 6.0383 & TRN & & \\
\hline CHEMBL1545767 & 688653 & \multicolumn{3}{|c|}{5.132999999999999} & 6.0415 & TRN \\
\hline CHEMBL1517530 & 688653 & 5.183 & 5.4479 & TRN & & \\
\hline CHEMBL1567347 & 688653 & \multicolumn{3}{|c|}{5.2829999999999995} & 5.0905 & TRN \\
\hline CHEMBL3212989 & 688653 & 5.033 & 5.0958 & TRN & & \\
\hline CHEMBL1306267 & 688653 & \multicolumn{3}{|c|}{5.5329999999999995} & 5.9028 & TRN \\
\hline CHEMBL1362146 & 688653 & 4.833 & 5.505 & TRN & & \\
\hline CHEMBL1455387 & 688653 & 5.183 & 5.6496 & TRN & & \\
\hline CHEMBL1463349 & 688653 & 5.733 & 5.9653 & TRN & & \\
\hline CHEMBL3191246 & 688653 & \multicolumn{3}{|c|}{4.7330000000000005} & 5.1274 & TRN \\
\hline CHEMBL1329114 & 688653 & \multicolumn{3}{|c|}{5.5329999999999995} & 5.7904 & TRN \\
\hline CHEMBL1541549 & 688653 & \multicolumn{3}{|c|}{5.832999999999999} & 5.1839 & TRN \\
\hline CHEMBL1484108 & 688653 & \multicolumn{3}{|c|}{5.832999999999999} & 5.5588 & TRN \\
\hline CHEMBL1210920 & 688653 & 5.033 & 5.0862 & TRN & & \\
\hline CHEMBL1534390 & 688653 & \multicolumn{3}{|c|}{4.7330000000000005} & 5.2711 & TRN \\
\hline CHEMBL1412105 & 688653 & 5.683 & 5.5266 & TRN & & \\
\hline CHEMBL1499335 & 688653 & \multicolumn{3}{|c|}{6.332999999999999} & 5.6012 & TRN \\
\hline CHEMBL1582770 & 688653 & 5.233 & 5.2383 & TRN & & \\
\hline CHEMBL1485664 & 688653 & \multicolumn{3}{|c|}{5.132999999999999} & 5.2174 & TRN \\
\hline CHEMBL1413633 & 688653 & 5.083 & 5.2669 & TRN & & \\
\hline CHEMBL1419219 & 688653 & \multicolumn{3}{|c|}{6.382999999999999} & 6.0091 & TRN \\
\hline CHEMBL1586181 & 688653 & 4.783 & 5.5439 & TRN & & \\
\hline CHEMBL1530261 & 688653 & 5.083 & 5.1434 & TRN & & \\
\hline CHEMBL1485945 & 688653 & 4.833 & 5.0355 & TST & & \\
\hline CHEMBL1599947 & 688653 & 4.633 & 5.2105 & TST & & \\
\hline
\end{tabular}




\begin{tabular}{|c|c|c|c|c|c|c|}
\hline \multirow[b]{2}{*}{ CHEMBL1520210 } & \multicolumn{6}{|c|}{ Supplemental Table S2.txt } \\
\hline & 688653 & 5.233 & 4.9364 & TST & & \\
\hline CHEMBL1543658 & 688653 & 4.933 & 5.0299 & TRN & & \\
\hline CHEMBL1510646 & 88653 & 7.3325 & 6.05 & TRN & & \\
\hline CHEMBL1592612 & 688653 & \multicolumn{3}{|c|}{5.2829999999999995} & 5.0811 & $\mathrm{Ts}$ \\
\hline CHEMBL1513145 & 688653 & 4.633 & 4.9783 & TRN & & \\
\hline CHEMBL3190958 & 588653 & 6.4829 & 5.945 & TRN & & \\
\hline CHEMBL1560076 & 588653 & 5.683 & 5.5656 & TRN & & \\
\hline CHEMBL1457311 & 688653 & 5.183 & 5.7773 & TRN & & \\
\hline CHEMBL1427062 & 688653 & \multicolumn{3}{|c|}{5.882999999999999} & 5.705 & TRN \\
\hline CHEMBL1418955 & 688653 & \multicolumn{3}{|c|}{5.882999999999999} & 5.6371 & TRN \\
\hline CHEMBL1389410 & 688653 & \multicolumn{3}{|c|}{5.132999999999999} & 5.3432 & \\
\hline CHEMBL1412101 & 688653 & 5.183 & 5.4544 & TRN & & \\
\hline CHEMBL1440598 & 688653 & 4.583 & \multicolumn{3}{|c|}{5.627000000000001} & r \\
\hline CHEMBL1601059 & 688653 & 4.683 & 5.2739 & TRN & & \\
\hline CHEMBL1985797 & 688653 & \multicolumn{3}{|c|}{5.132999999999999} & 5.1563 & 17 \\
\hline CHEMBL1512253 & 688653 & 4.933 & 4.8697 & TST & & \\
\hline CHEMBL1384106 & 688653 & 5.033 & 5.1606 & TST & & \\
\hline CHEMBL1419997 & 688653 & \multicolumn{3}{|c|}{5.882999999999999} & 5.4339 & \\
\hline CHEMBL1315059 & 688653 & 5.683 & 5.4945 & TRN & & \\
\hline CHEMBL1353481 & 688653 & 4.583 & 5.2562 & TST & & \\
\hline CHEMBL1611356 & 688653 & 4.833 & 5.3109 & TST & & \\
\hline CHEMBL1358705 & 688653 & \multicolumn{3}{|c|}{5.632999999999999} & 5.3398 & \\
\hline CHEMBL1422740 & 688653 & \multicolumn{3}{|c|}{5.382999999999999} & 5.5225 & \\
\hline CHEMBL1311943 & 688653 & 4.933 & 5.4139 & TST & & \\
\hline CHEMBL1360809 & 688653 & \multirow{2}{*}{\multicolumn{3}{|c|}{$\begin{array}{lll}4.583 & 5.2475 & \text { TRN } \\
6.632999999999999\end{array}$}} & & \\
\hline CHEMBL1389366 & 688653 & & & & 5.9248 & \\
\hline CHEMBL1339172 & 6886 & \multicolumn{3}{|c|}{$5.683 \quad 5.3972$ TRN } & & \\
\hline CHEMBL14 & 688653 & \multicolumn{3}{|c|}{6.332999999999999} & 5.4321 & $\mathrm{TK}^{\mathrm{K}}$ \\
\hline CHEMBL1311868 & 688653 & 4.883 & 5.129 & TST & & \\
\hline CHEMBL1415227 & 688653 & \multicolumn{3}{|c|}{5.332999999999999} & 5.125 & TS \\
\hline CHEMBL1438369 & 688653 & 4.783 & 5.5299 & TRN & & \\
\hline CHEMBL1 & 688 & & 4.7066 & TST & & \\
\hline CHEMBL1 & 688653 & 5.183 & 5.0276 & TST & & \\
\hline CHEMBL 1 & 688653 & 4.833 & 5.6092 & TRN & & \\
\hline CHEMBL1610894 & 688653 & 6.4829 & 5.9665 & TRN & & \\
\hline CHEMBL1472885 & 688653 & 4.833 & 5.7345 & TRN & & \\
\hline CHEMBL13 & 688653 & \multicolumn{3}{|c|}{5.2829999999999995} & 5.118 & TRN \\
\hline CHEMBL13. & 688653 & 5.683 & 5.2766 & TRN & & \\
\hline CHEMBL1530506 & 688653 & \multicolumn{3}{|c|}{4.9830000000000005} & 4.9262 & TRN \\
\hline CHEMBL1446408 & 688653 & \multicolumn{3}{|c|}{5.632999999999999} & 5.1495 & TRN \\
\hline CHEMBL1523981 & 688653 & 4.933 & 5.0563 & TST & & \\
\hline CHEMBL1467036 & 688653 & 5.183 & 5.2994 & TRN & & \\
\hline CHEMBL408850 & 688653 & 6.8831 & 6.1455 & TRN & & \\
\hline CHEMBL1427959 & 688653 & 7.1331 & 6.1259 & TRN & & \\
\hline CHEMBL1536140 & 688653 & \multicolumn{3}{|c|}{4.7330000000000005} & 5.1434 & TS \\
\hline CHEMBL1409224 & 688653 & 4.783 & 4.9525 & TRN & & \\
\hline CHEMBL1416516 & 688653 & \multicolumn{3}{|c|}{5.132999999999999} & 5.1411 & 相 \\
\hline CHEMBL1324234 & 688653 & \multicolumn{3}{|c|}{5.2829999999999995} & 5.6882 & \\
\hline
\end{tabular}




\begin{tabular}{|c|c|c|c|c|c|c|}
\hline \multirow[b]{2}{*}{ CHEMBL1462933 } & \multirow[b]{2}{*}{688653} & \multicolumn{5}{|c|}{ Supplemental Table S2.txt } \\
\hline & & \multicolumn{2}{|c|}{34.7778} & TST & & \\
\hline CHEMBL1356222 & 688653 & 4.633 & 5.1439 & TST & & \\
\hline CHEMBL1321135 & 688653 & \multicolumn{3}{|c|}{4.7330000000000005} & 5.0977 & TST \\
\hline CHEMBL3196069 & 688653 & \multicolumn{3}{|c|}{5.832999999999999} & 5.4666 & TRN \\
\hline CHEMBL1397140 & 688653 & 4.633 & 5.5351 & TST & & \\
\hline CHEMBL3198969 & 688653 & 4.883 & 5.0163 & TRN & & \\
\hline CHEMBL1606025 & 688653 & 4.833 & 5.4628 & TRN & & \\
\hline CHEMBL1469904 & 688653 & \multicolumn{3}{|c|}{5.7829999999999995} & 5.0563 & TRN \\
\hline CHEMBL1544948 & 688653 & \multicolumn{3}{|c|}{4.7330000000000005} & 5.0404 & TRN \\
\hline CHEMBL1320971 & 688653 & 5.433 & 5.7656 & TRN & & \\
\hline CHEMBL3199411 & 688653 & \multicolumn{3}{|c|}{5.7829999999999995} & 5.6988 & TRN \\
\hline CHEMBL1563717 & 688653 & 4.833 & 5.2932 & TRN & & \\
\hline CHEMBL1351135 & 688653 & \multirow{2}{*}{\multicolumn{3}{|c|}{$\begin{array}{lll}4.933 & 5.3139 & \text { TST } \\
5.2829999999999995\end{array}$}} & & \\
\hline CHEMBL1472038 & 688653 & & & & 5.2817 & TST \\
\hline CHEMBL1549201 & 688653 & \multicolumn{3}{|c|}{$6.233 \quad 5.3414$ TST } & & \\
\hline CHEMBL3195637 & 688653 & 5.083 & 5.1174 & TRN & & \\
\hline CHEMBL1538275 & 688653 & \multicolumn{3}{|c|}{4.7330000000000005} & 4.7609 & TRN \\
\hline CHEMBL1560778 & 688653 & 5.683 & 5.7524 & TRN & & \\
\hline CHEMBL3209413 & 688653 & \multirow{2}{*}{\multicolumn{3}{|c|}{$\begin{array}{lcc}5.033 & 5.2205 & \text { TRN } \\
4.7330000000000005\end{array}$}} & & \\
\hline CHEMBL1307623 & 688653 & & & & 4.999 & TST \\
\hline CHEMBL1512687 & 688653 & \multicolumn{3}{|c|}{$\begin{array}{lll}4.633 & 4.8347 & \text { TRN }\end{array}$} & & \\
\hline CHEMBL1526628 & 688653 & 6.9329 & 5.5058 & TRN & & \\
\hline CHEMBL582507 & 688653 & \multicolumn{3}{|c|}{$5.733 \quad 5.9403$} & & \\
\hline CHEMBL1612551 & 688653 & \multicolumn{3}{|c|}{5.332999999999999} & 5.393 & TST \\
\hline CHEMBL1305556 & 688653 & 4.833 & 5.0595 & TRN & & \\
\hline CHEMBL1410986 & 688653 & \multirow{2}{*}{\multicolumn{3}{|c|}{$\begin{array}{lc}5.183 & 5.9025 \\
5.832999999999999\end{array}$}} & & \\
\hline CHEMBL3191056 & 688653 & & & & 5.693 & TRN \\
\hline CHEMBL1513301 & 688653 & \multicolumn{3}{|c|}{$4.833 \quad 5.4125$ TRN } & & \\
\hline CHEMBL1303617 & 688653 & 4.833 & 5.0874 & TST & & \\
\hline CHEMBL1585799 & 688653 & \multicolumn{3}{|c|}{$\begin{array}{lll}5.683 & 5.4575 & \text { TRN }\end{array}$} & & \\
\hline CHEMBL1423806 & 688653 & \multicolumn{3}{|c|}{4.9830000000000005} & 5.4786 & TST \\
\hline CHEMBL1476167 & 688653 & 5.033 & 5.5981 & TRN & & \\
\hline CHEMBL3212558 & 688653 & 4.833 & 5.222 & TST & & \\
\hline CHEMBL1490200 & 688653 & 4.783 & 4.9583 & TRN & & \\
\hline CHEMBL117813 & 688653 & 4.833 & 5.0242 & TRN & & \\
\hline CHEMBL3193039 & 688653 & 4.933 & 4.7607 & TRN & & \\
\hline CHEMBL1560735 & 688653 & 4.783 & 5.1251 & TRN & & \\
\hline CHEMBL3198203 & 688653 & 6.183 & 5.4167 & TRN & & \\
\hline CHEMBL1449490 & 688653 & 4.583 & 5.1665 & TST & & \\
\hline CHEMBL1407552 & 688653 & 6.5829 & 99999999 & & 5.813 & TRN \\
\hline CHEMBL1357896 & 688653 & 4.633 & 5.1643 & TST & & \\
\hline CHEMBL1603001 & 688653 & 5.083 & 5.4115 & TRN & & \\
\hline CHEMBL1391594 & 688653 & 4.7330 & 00000000 & 005 & 5.309 & TRN \\
\hline CHEMBL3192666 & 688653 & 5.8829 & 99999999 & & 5.4865 & TRN \\
\hline CHEMBL1357748 & 688653 & 4.633 & 5.0196 & TRN & & \\
\hline CHEMBL1356314 & 688653 & 4.883 & 4.9023 & TST & & \\
\hline CHEMBL1326403 & 688653 & 4.583 & 4.4692 & TRN & & \\
\hline CHEMBL1489483 & 688653 & 4.7330 & 30000000 & 005 & 5.4161 & TRN \\
\hline & & & & & & \\
\hline
\end{tabular}




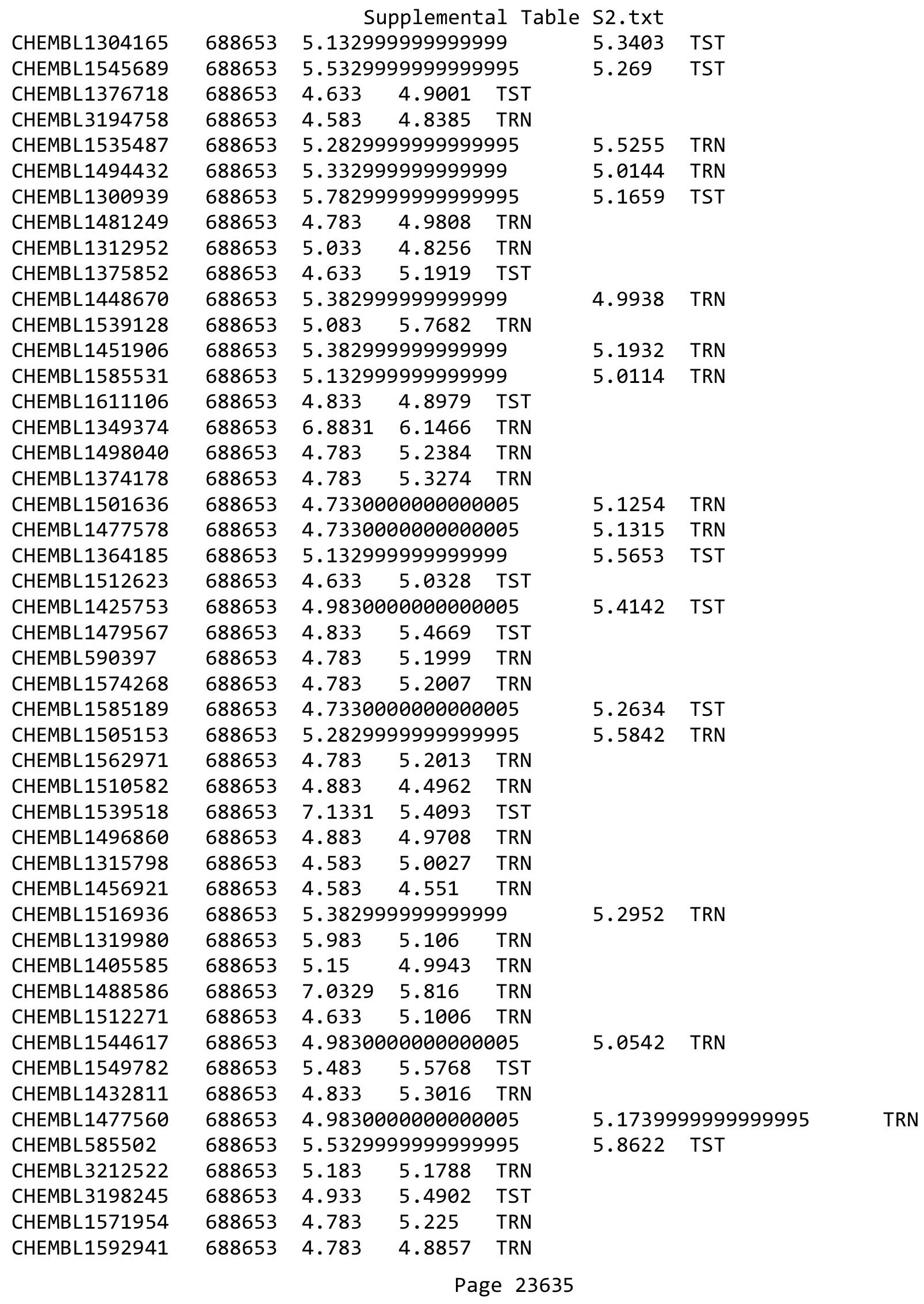




\begin{tabular}{|c|c|c|c|c|c|c|c|}
\hline \multicolumn{8}{|c|}{ Supplemental Table S2.txt } \\
\hline CHEMBL1733605 & 688653 & 4.833 & 5.3049 & TRN & & & \\
\hline CHEMBL1321104 & 688653 & \multicolumn{3}{|c|}{5.832999999999999} & 5.5377 & TRN & \\
\hline CHEMBL1325934 & 688653 & 4.883 & 5.1011 & TST & & & \\
\hline CHEMBL1443316 & 688653 & 4.833 & 5.4955 & TRN & & & \\
\hline CHEMBL1507384 & 688653 & 4.833 & 5.5087 & TRN & & & \\
\hline CHEMBL1556868 & 688653 & 4.583 & 4.9627 & TRN & & & \\
\hline CHEMBL1461583 & 688653 & 4.883 & 5.45100 & 00000000 & 205 & TRN & \\
\hline CHEMBL1372026 & 688653 & 4.633 & 5.2371 & TRN & & & \\
\hline CHEMBL1449556 & 688653 & 4.833 & 5.0542 & TST & & & \\
\hline CHEMBL1348205 & 688653 & 4.783 & 4.7748 & TRN & & & \\
\hline CHEMBL1576060 & 688653 & 5.733 & 5.3944 & TRN & & & \\
\hline CHEMBL3210737 & 688653 & 4.783 & 5.0382 & TRN & & & \\
\hline CHEMBL1317147 & 688653 & 5.683 & 5.4083 & TRN & & & \\
\hline CHEMBL1377477 & 688653 & 6.183 & 5.393 & TRN & & & \\
\hline CHEMBL1548933 & 688653 & \multicolumn{3}{|c|}{5.632999999999999} & 5.4036 & TRN & \\
\hline CHEMBL1501848 & 688653 & \multicolumn{3}{|c|}{5.132999999999999} & 5.8975 & TRN & \\
\hline CHEMBL 1477120 & 688653 & \multicolumn{3}{|c|}{5.132999999999999} & 5.4746 & TRN & \\
\hline CHEMBL1604622 & 688653 & 5.233 & 5.2516 & TRN & & & \\
\hline CHEMBL1572597 & 688653 & 6.233 & 5.8155 & TST & & & \\
\hline CHEMBL1583977 & 688653 & 4.833 & 5.1171 & TRN & & & \\
\hline CHEMBL1541756 & 688653 & \multicolumn{3}{|c|}{5.2829999999999995} & 5.1218 & TST & \\
\hline CHEMBL1356854 & 688653 & \multicolumn{3}{|c|}{5.882999999999999} & 5.739 & TRN & \\
\hline CHEMBL1407643 & 688653 & \multicolumn{3}{|c|}{5.582999999999999} & 5.6462 & TST & \\
\hline CHEMBL1481547 & 688653 & \multicolumn{3}{|c|}{5.332999999999999} & 4.8683 & TRN & \\
\hline CHEMBL1430053 & 688653 & \multicolumn{3}{|c|}{6.582999999999999} & 5.4932 & TRN & \\
\hline CHEMBL1306949 & 688653 & 5.733 & 5.3968 & TRN & & & \\
\hline CHEMBL 3193828 & 688653 & 5.683 & 5.5727 & TRN & & & \\
\hline CHEMBL1491238 & 688653 & 4.683 & 4.7358 & TRN & & & \\
\hline CHEMBL1398208 & 688653 & \multicolumn{3}{|c|}{5.332999999999999} & 5.1198 & TRN & \\
\hline CHEMBL1332895 & 688653 & 4.633 & 4.5922 & TRN & & & \\
\hline CHEMBL1551829 & 688653 & 5.083 & 4.9014 & TRN & & & \\
\hline CHEMBL1370667 & 688653 & \multicolumn{3}{|c|}{5.832999999999999} & 5.2128 & TRN & \\
\hline CHEMBL 3211273 & 688653 & \multicolumn{3}{|c|}{5.7829999999999995} & 5.3043 & TRN & \\
\hline CHEMBL1453237 & 688653 & 4.9 & 5.6367 & TST & & & \\
\hline CHEMBL1365324 & 688653 & 4.783 & 5.2368 & TRN & & & \\
\hline CHEMBL1462037 & 688653 & 6.7331 & 5.1882 & TRN & & & \\
\hline CHEMBL1333579 & 688653 & 5.733 & 5.3826 & TRN & & & \\
\hline CHEMBL1513046 & 688653 & 7.2328 & 6.0501 & TRN & & & \\
\hline CHEMBL1456349 & 688653 & 4.833 & 5.2076 & TST & & & \\
\hline CHEMBL1472809 & 688653 & 4.833 & 5.2104 & TST & & & \\
\hline CHEMBL1474926 & 688653 & 4.633 & 5.2791 & TRN & & & \\
\hline CHEMBL1549029 & 688653 & \multicolumn{3}{|c|}{5.582999999999999} & 5.3087 & TRN & \\
\hline CHEMBL1561614 & 688653 & 4.833 & 4.9123 & TRN & & & \\
\hline CHEMBL1602525 & 688653 & 4.783 & 4.9461 & TRN & & & \\
\hline CHEMBL1329532 & 688653 & \multicolumn{3}{|c|}{5.582999999999999} & $5.5760 e$ & 00000000005 & TST \\
\hline CHEMBL1363769 & 688653 & \multicolumn{3}{|c|}{5.5329999999999995} & 5.0531 & TRN & \\
\hline CHEMBL601119 & 688653 & \multicolumn{3}{|c|}{5.7829999999999995} & 5.3935 & TRN & \\
\hline CHEMBL1572168 & 688653 & 4.783 & 5.3539 & TST & & & \\
\hline
\end{tabular}




\begin{tabular}{|c|c|c|c|c|c|c|c|}
\hline & & & pplement & al Table & s2.txt & & \\
\hline CHEMBL 3198718 & 688653 & 4.73300 & 00000000 & 005 & 5.5414 & TRN & \\
\hline CHEMBL1411813 & 688653 & 4.833 & 5.2031 & TRN & & & \\
\hline CHEMBL1360064 & 688653 & 5.733 & 5.4482 & TST & & & \\
\hline CHEMBL1570735 & 688653 & 5.38299 & 99999999 & & 5.3277 & TRN & \\
\hline CHEMBL1561718 & 688653 & 6.83299 & 99999999 & & 5.7749 & TST & \\
\hline CHEMBL 243089 & 688653 & 4.73300 & 00000000 & 005 & $5.20200 €$ & 0000000001 & TRN \\
\hline CHEMBL1439000 & 688653 & 6.433 & 5.5999 & TRN & & & \\
\hline CHEMBL1984052 & 688653 & 5.83299 & 99999999ऽ & & 5.6852 & TRN & \\
\hline CHEMBL1390236 & 688653 & 4.933 & 5.0994 & TST & & & \\
\hline CHEMBL1549522 & 688653 & 4.833 & 5.0112 & TST & & & \\
\hline CHEMBL1370905 & 688653 & 5.13299 & 99999999 & & 5.3819 & TRN & \\
\hline CHEMBL1612447 & 688653 & 4.883 & 5.2448 & TRN & & & \\
\hline CHEMBL1313977 & 688653 & 5.13299 & 99999999 & & 4.8269 & TRN & \\
\hline CHEMBL1345787 & 688653 & 6.03299 & 99999999 & 995 & 5.7795 & TRN & \\
\hline CHEMBL3210249 & 688653 & 4.73300 & 00000000 & 005 & 5.1115 & TRN & \\
\hline CHEMBL1539416 & 688653 & 6.4829 & 5.4518 & TRN & & & \\
\hline CHEMBL1534523 & 688653 & 4.883 & 4.8951 & TRN & & & \\
\hline CHEMBL1574585 & 688653 & 4.683 & 5.1052 & TST & & & \\
\hline CHEMBL1584523 & 688653 & 5.933 & 5.5122 & TRN & & & \\
\hline CHEMBL1375672 & 688653 & 6.4829 & 5.9394 & TRN & & & \\
\hline CHEMBL1299997 & 688653 & 4.783 & 5.4845 & TST & & & \\
\hline CHEMBL1523928 & 688653 & 4.783 & 5.0168 & TRN & & & \\
\hline CHEMBL1505520 & 688653 & 4.783 & 5.2309 & TST & & & \\
\hline CHEMBL1325601 & 688653 & 5.53299 & 99999999 & 995 & 5.2339 & TRN & \\
\hline CHEMBL1503313 & 688653 & 5.58299 & 99999999 & & 5.5019 & TRN & \\
\hline CHEMBL 3193879 & 688653 & 6.233 & 5.4032 & TRN & & & \\
\hline CHEMBL1340716 & 688653 & 5.78299 & 99999999 & 995 & 5.6579 & TRN & \\
\hline CHEMBL1428655 & 688653 & 5.78299 & 99999999 & 995 & 5.7618 & TRN & \\
\hline CHEMBL3209305 & 688653 & 4.883 & 5.4323 & TRN & & & \\
\hline CHEMBL1342556 & 688653 & 5.78299 & 99999999 & 995 & 5.6391 & TST & \\
\hline CHEMBL1365319 & 688653 & 5.033 & 5.5804 & TRN & & & \\
\hline CHEMBL 3199458 & 688653 & 5.083 & 5.2975 & TRN & & & \\
\hline CHEMBL1387034 & 688653 & 4.833 & 5.1361 & TST & & & \\
\hline CHEMBL1352023 & 688653 & 6.233 & 5.6679 & TRN & & & \\
\hline CHEMBL1304389 & 688653 & 6.433 & 5.7832 & TRN & & & \\
\hline CHEMBL1543734 & 688653 & 5.78299 & 99999999 & 995 & 5.6275 & TRN & \\
\hline CHEMBL1442681 & 688653 & 5.88299 & 99999999 & & 5.9224 & TRN & \\
\hline CHEMBL1419794 & 688653 & 6.3 & 5.858 & TRN & & & \\
\hline CHEMBL1433251 & 688653 & 4.883 & 5.1337 & TST & & & \\
\hline CHEMBL1589508 & 688653 & 4.98300 & 00000000 & 005 & 5.1808 & TRN & \\
\hline CHEMBL1395100 & 688653 & 5.033 & 5.2426 & TRN & & & \\
\hline CHEMBL1558840 & 688653 & 4.73300 & 000000006 & 005 & 5.767 & TRN & \\
\hline CHEMBL1410792 & 688653 & 6.4829 & 5.9974 & TRN & & & \\
\hline CHEMBL1570569 & 688653 & 4.933 & 5.4829 & TRN & & & \\
\hline CHEMBL1502196 & 688653 & 4.833 & 5.51 & TST & & & \\
\hline CHEMBL1460356 & 688653 & 5.83299 & 99999999 & & 5.138 & TRN & \\
\hline CHEMBL1575576 & 688653 & 5.78299 & 99999999 & 995 & 5.2573 & TRN & \\
\hline CHEMBL1510806 & 688653 & 5.983 & 5.5414 & TRN & & & \\
\hline
\end{tabular}




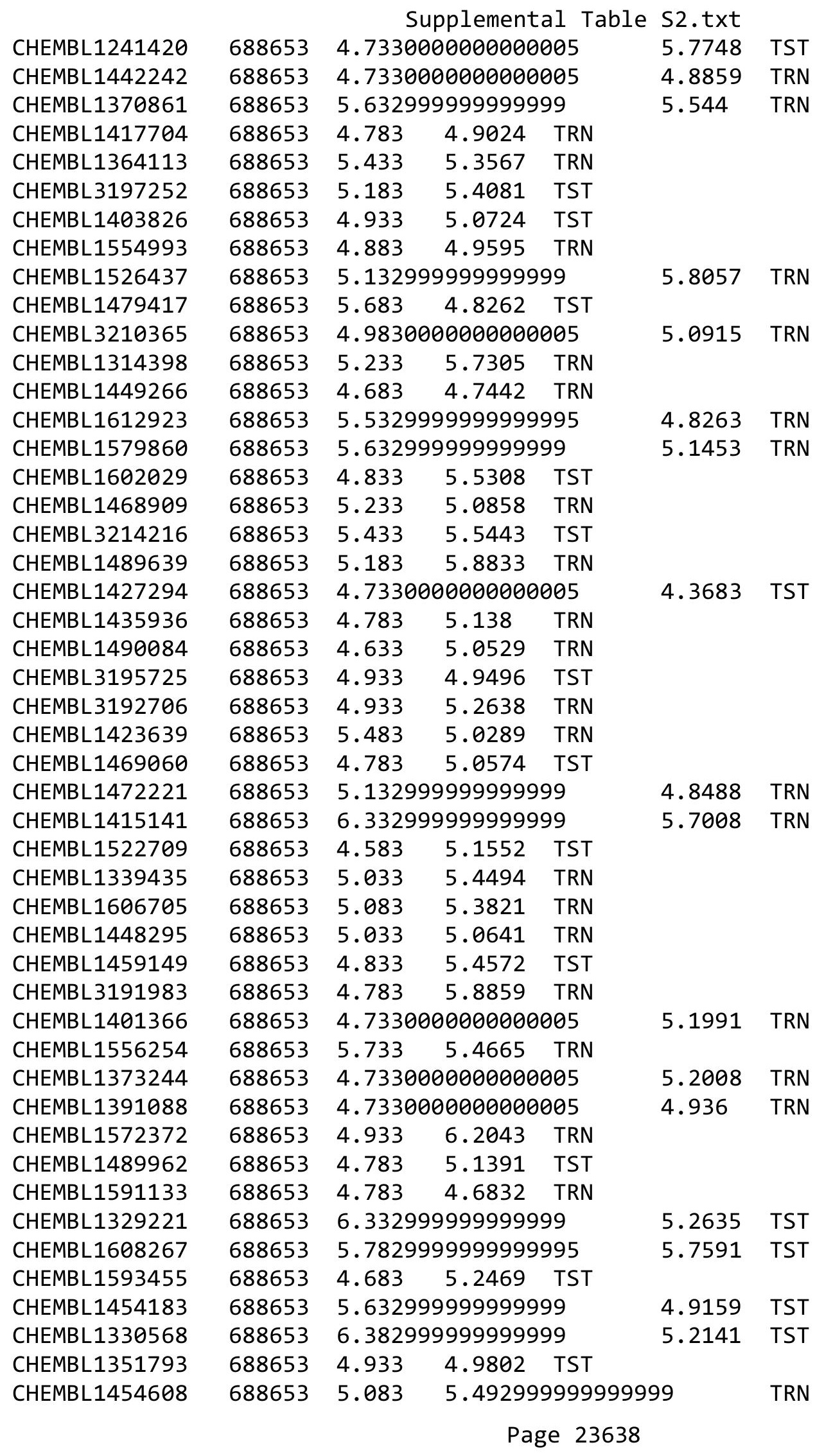




\begin{tabular}{|c|c|c|c|c|c|c|}
\hline \multirow[b]{2}{*}{ CHEMBL1513563 } & \multicolumn{6}{|c|}{ Supplemental Table S2.txt } \\
\hline & 688653 & 4.783 & 5.0055 & TRN & & \\
\hline CHEMBL1495312 & 688653 & 5.683 & 5.1562 & TRN & & \\
\hline CHEMBL1323776 & 688653 & 4.883 & 5.1584 & TRN & & \\
\hline CHEMBL1391281 & 688653 & \multicolumn{3}{|c|}{4.9830000000000005} & 5.3173 & $\mathrm{TP}$ \\
\hline CHEMBL1402589 & 688653 & 5.433 & 5.275 & TRN & & \\
\hline CHEMBL1398744 & 688653 & 4.783 & 4.8358 & TRN & & \\
\hline CHEMBL1608086 & 688653 & 5.483 & 5.362 & TRN & & \\
\hline CHEMBL1455675 & 688653 & \multicolumn{3}{|c|}{4.7330000000000005} & 5.4111 & \\
\hline CHEMBL1510080 & 688653 & \multicolumn{3}{|c|}{6.332999999999999} & 5.6405 & \\
\hline CHEMBL1436067 & 688653 & 4.783 & 5.0029 & TRN & & \\
\hline CHEMBL1607302 & 688653 & 5.433 & 5.2482 & TST & & \\
\hline CHEMBL 3198075 & 688653 & 4.583 & 5.1776 & TST & & \\
\hline CHEMBL1547825 & 688653 & 7.1831 & 5.5993 & TRN & & \\
\hline CHEMBL1484497 & 688653 & \multicolumn{3}{|c|}{5.2829999999999995} & 5.0498 & \\
\hline CHEMBL3209206 & 688653 & 5.733 & 5.3745 & TST & & \\
\hline CHEMBL1443693 & 688653 & 5.233 & 4.8243 & TRN & & \\
\hline CHEMBL136 & 688653 & 4.633 & 5.2082 & TST & & \\
\hline CHEMBL1429082 & 688653 & \multicolumn{3}{|c|}{5.132999999999999} & 5.4559 & \\
\hline CHEMBL1493102 & 688653 & \multicolumn{3}{|c|}{4.7330000000000005} & 5.0705 & \\
\hline CHEMBL1599486 & 688653 & \multicolumn{3}{|c|}{5.332999999999999} & 5.8363 & \\
\hline CHEMBL1502956 & 688653 & \multicolumn{3}{|c|}{5.632999999999999} & 5.4655 & \\
\hline CHEMBL13 & 688653 & 4.933 & 5.5216 & TRN & & \\
\hline CHEMBL1331097 & 688653 & 6.183 & 5.3894 & TRN & & \\
\hline CHEMBL1327597 & 688653 & 5.033 & 5.1217 & TRN & & \\
\hline CHEMBL1365262 & 688653 & 4.833 & 5.0376 & TRN & & \\
\hline CHEMBL1402812 & 688653 & \multicolumn{3}{|c|}{6.332999999999999} & 5.3834 & \\
\hline CHEMBL14 & 688653 & \multicolumn{3}{|c|}{5.382999999999999} & 5.3 & \\
\hline CHEMBL3190684 & 688653 & 4.583 & 5.5637 & TRN & & \\
\hline CHEMBL3197662 & 688653 & 4.833 & 4.8972 & TRN & & \\
\hline CHEMBL1356788 & 688653 & 4.633 & 4.6922 & TRN & & \\
\hline CHEMBL1541515 & 688653 & \multicolumn{3}{|c|}{5.7829999999999995} & 328 & \\
\hline CHEMBL1 & 688653 & \multicolumn{3}{|c|}{5.632999999999999} & 5.693 & \\
\hline CHEMBL1509072 & 688653 & 4.833 & 4.9423 & TRN & & \\
\hline CHEMBL1597288 & 688653 & 4.833 & 4.9605 & TRN & & \\
\hline CHEMBL1431996 & 688653 & 5.083 & \multicolumn{3}{|c|}{5.281000000000001} & \\
\hline CHEMBL48 & & 4.883 & 5.4449 & TST & & \\
\hline CHEMBL16 & 688653 & 5.183 & 5.1852 & TST & & \\
\hline CHEMBL 3190525 & 688653 & 4.683 & 5.4645 & TRN & & \\
\hline CHEMBL1379005 & 688653 & 5.083 & 5.063 & TST & & \\
\hline CHEMBL1309912 & 688653 & \multicolumn{3}{|c|}{4.9830000000000005} & 5.0468 & $1 \pi$ \\
\hline CHEMBL1332808 & 688653 & 4.683 & 5.0025 & TST & & \\
\hline CHEMBL1597753 & 688653 & 4.933 & 4.9971 & TST & & \\
\hline CHEMBL1311769 & 688653 & 4.833 & 5.1229 & TST & & \\
\hline CHEMBL1538360 & 688653 & \multicolumn{3}{|c|}{5.5329999999999995} & 5.2328 & N \\
\hline CHEMBL1320084 & 688653 & 5.483 & 5.3905 & TRN & & \\
\hline CHEMBL1604690 & 688653 & \multicolumn{3}{|c|}{4.7330000000000005} & 5.2665 & (1) \\
\hline CHEMBL1512514 & 688653 & \multicolumn{3}{|c|}{4.7330000000000005} & 5.7391 & TRN \\
\hline CHEMBL1388390 & 688653 & \multicolumn{3}{|c|}{5.832999999999999} & 5.5557 & - \\
\hline
\end{tabular}




\begin{tabular}{|c|c|c|c|c|c|c|}
\hline \multirow[b]{2}{*}{ CHEMBL1391318 } & & \multicolumn{5}{|c|}{ Supplemental Table S2.txt } \\
\hline & 688653 & 5.983 & 5.7372 & TST & & \\
\hline CHEMBL1428735 & 688653 & \multicolumn{3}{|c|}{5.832999999999999} & 5.496 & TRI \\
\hline CHEMBL1502802 & 688653 & 4.833 & 4.9318 & TRN & & \\
\hline CHEMBL1446099 & 688653 & 4.833 & 5.3897 & TRN & & \\
\hline CHEMBL1402324 & 588653 & 5.033 & 5.0777 & TRN & & \\
\hline CHEMBL3190150 & 688653 & \multicolumn{3}{|c|}{5.132999999999999} & 5.3064 & \\
\hline CHEMBL1582153 & 688653 & 5.033 & 5.1533 & TRN & & \\
\hline CHEMBL1407587 & 688653 & \multicolumn{3}{|c|}{5.882999999999999} & 5.0708 & TP \\
\hline CHEMBL1544695 & 688653 & \multicolumn{3}{|c|}{6.082999999999999} & 5.5179 & \\
\hline CHEMBL1594582 & 688653 & 4.633 & 4.9024 & TST & & \\
\hline CHEMBL1450023 & 688653 & 4.633 & 4.8456 & TRN & & \\
\hline CHEMBL1327694 & 688653 & 8.5376 & 5.4821 & TST & & \\
\hline CHEMBL13 & 688653 & 4.783 & 5.1488 & TRN & & \\
\hline CHEMBL1535555 & 688653 & \multicolumn{3}{|c|}{4.9830000000000005} & 4.9512 & 11 \\
\hline CHEMBL1463504 & 688653 & 4.883 & 4.9432 & TRN & & \\
\hline CHEMBL1426367 & 688653 & 4.783 & 4.8002 & TST & & \\
\hline CHEMBL1989426 & 688653 & 5.683 & 5.4917 & TST & & \\
\hline CHEMBL15 & 688653 & \multicolumn{3}{|c|}{5.5329999999999995} & 6.0333 & 11 \\
\hline CHEMBL1414667 & 688653 & 4.883 & 5.0806 & TST & & \\
\hline CHEMBL1432533 & 688653 & \multicolumn{3}{|c|}{6.082999999999999} & 5.6501 & \\
\hline CHEMBL1608480 & 688653 & 4.783 & 5.6371 & TRN & & \\
\hline CHEMBL1580164 & 688653 & \multicolumn{3}{|c|}{5.5329999999999995} & 4 & \\
\hline CHEMBL1 & 688653 & 5.233 & 5.3638 & TST & & \\
\hline CHEMBL1354290 & 688653 & \multicolumn{3}{|c|}{5.882999999999999} & 5.4896 & $\mathrm{TI}$ \\
\hline CHEMBL1405685 & 688653 & 5.733 & 4.7223 & TRN & & \\
\hline CHEMBL1489007 & 688653 & 5.083 & 4.927 & TST & & \\
\hline CHEMBL1601447 & 688 & 4.883 & 5.2567 & TST & & \\
\hline CHEMBL1 & 688653 & \multicolumn{3}{|c|}{6.0329999999999995} & 5.9309 & $\mathrm{TI}$ \\
\hline CHEMBL1300843 & 688653 & 4.833 & 5.1045 & TRN & & \\
\hline CHEMBL1470060 & 688653 & \multicolumn{3}{|c|}{4.7330000000000005} & 5.2993 & TRN \\
\hline CHEMBL1429893 & 688653 & \multicolumn{3}{|c|}{5.632999999999999} & 5.083 & \\
\hline CHEMBL1370936 & 688 & \multicolumn{3}{|c|}{4.7330000000000005} & 869 & (1) \\
\hline CHEMBL1417091 & 688653 & \multicolumn{3}{|c|}{4.7330000000000005} & 5.2231 & TRN \\
\hline CHEMBL1396099 & 688653 & \multicolumn{3}{|c|}{5.332999999999999} & 4.9311 & \\
\hline CHEMBL1512260 & 688653 & 4.783 & 4.8695 & TST & & \\
\hline CHEMBL1493022 & 688653 & 4.833 & 5.5025 & TRN & & \\
\hline CHEMBL1 & 688 & 4.633 & 5.3228 & TST & & \\
\hline CHEMBL1545363 & 688653 & \multicolumn{3}{|c|}{5.5329999999999995} & 5.3734 & $T$ \\
\hline CHEMBL1427944 & 688653 & 5.033 & 5.3361 & TRN & & \\
\hline CHEMBL1447683 & 688653 & 5.683 & 5.4239 & TRN & & \\
\hline CHEMBL1540848 & 688653 & 6.433 & 5.3816 & TRN & & \\
\hline CHEMBL1370081 & 688653 & 4.883 & 5.1427 & TRN & & \\
\hline CHEMBL1458041 & 688653 & \multicolumn{3}{|c|}{5.132999999999999} & 5.3334 & $T$ \\
\hline CHEMBL1345096 & 688653 & 4.783 & 5.2397 & TRN & & \\
\hline CHEMBL1590993 & 688653 & \multicolumn{3}{|c|}{5.382999999999999} & 5.0908 & 15 \\
\hline CHEMBL1332063 & 688653 & \multicolumn{3}{|c|}{4.9830000000000005} & 5.5995 & \\
\hline CHEMBL1517410 & 688653 & 4.683 & 4.9408 & TST & & \\
\hline CHEMBL1470598 & 688653 & 6.08299 & 99999999 & & 5.581 & n \\
\hline
\end{tabular}




\begin{tabular}{|c|c|c|c|c|c|c|}
\hline \multirow[b]{2}{*}{ CHEMBL1530042 } & \multirow[b]{2}{*}{688653} & \multicolumn{5}{|c|}{ Supplemental Table S2.txt } \\
\hline & & \multicolumn{3}{|c|}{34.9195 TRN } & & \\
\hline CHEMBL 2002332 & 688653 & 5.683 & 5.4011 & TRN & & \\
\hline CHEMBL1362392 & 688653 & 5.933 & 5.1116 & TST & & \\
\hline CHEMBL 3194360 & 688653 & \multicolumn{3}{|c|}{5.7829999999999995} & 5.6998 & TRN \\
\hline CHEMBL1593285 & 688653 & 4.783 & 4.7359 & TRN & & \\
\hline CHEMBL1386813 & 688653 & 4.783 & 5.266 & TRN & & \\
\hline CHEMBL1332674 & 688653 & 4.783 & 5.0732 & TRN & & \\
\hline CHEMBL1524866 & 688653 & \multicolumn{3}{|c|}{6.132999999999999} & 5.3999 & TST \\
\hline CHEMBL1391312 & 688653 & 4.883 & 5.2882 & TRN & & \\
\hline CHEMBL1539521 & 688653 & 4.883 & 5.3967 & TRN & & \\
\hline CHEMBL1409053 & 688653 & 6.233 & 5.2814 & TRN & & \\
\hline CHEMBL1408090 & 688653 & \multicolumn{3}{|c|}{4.9830000000000005} & 5.5325 & TST \\
\hline CHEMBL1597933 & 688653 & 5.933 & 5.3769 & TRN & & \\
\hline CHEMBL1388470 & 688653 & 5.083 & 5.3072 & TST & & \\
\hline CHEMBL1367691 & 688653 & 4.583 & 4.9119 & TST & & \\
\hline CHEMBL1539464 & 688653 & 4.933 & 5.3328 & TRN & & \\
\hline CHEMBL1434810 & 688653 & \multicolumn{3}{|c|}{5.332999999999999} & 4.9443 & TRN \\
\hline CHEMBL1466452 & 688653 & \multicolumn{3}{|c|}{4.7330000000000005} & 5.3926 & TST \\
\hline CHEMBL1418565 & 688653 & \multicolumn{3}{|c|}{4.9830000000000005} & 5.3309 & TRN \\
\hline CHEMBL136008 & 688653 & 4.833 & 5.4318 & TRN & & \\
\hline CHEMBL1315497 & 688653 & 4.783 & 5.2113 & TRN & & \\
\hline CHEMBL1435240 & 688653 & 5.183 & 5.1434 & TST & & \\
\hline CHEMBL1553773 & 688653 & \multicolumn{3}{|c|}{5.882999999999999} & 5.6928 & TRN \\
\hline CHEMBL 3193547 & 688653 & 5.733 & 5.8137 & TRN & & \\
\hline CHEMBL1348721 & 688653 & \multicolumn{3}{|c|}{6.382999999999999} & 5.2711 & TST \\
\hline CHEMBL1459140 & 688653 & 6.0 & 4.9063 & TRN & & \\
\hline CHEMBL1588641 & 688653 & \multicolumn{3}{|c|}{5.832999999999999} & 5.1746 & TRN \\
\hline CHEMBL1312115 & 688653 & 5.183 & 5.0386 & TST & & \\
\hline CHEMBL1342948 & 688653 & \multicolumn{3}{|c|}{5.2829999999999995} & 4.9585 & TRN \\
\hline CHEMBL1500106 & 688653 & \multicolumn{3}{|c|}{6.332999999999999} & 5.7891 & TRN \\
\hline CHEMBL3210309 & 688653 & 4.783 & 5.2647 & TRN & & \\
\hline CHEMBL1497967 & 688653 & 5.083 & 4.9953 & TST & & \\
\hline CHEMBL1588100 & 688653 & 4.933 & 5.416 & TRN & & \\
\hline CHEMBL1461457 & 688653 & 4.933 & 5.3286 & TRN & & \\
\hline CHEMBL1507620 & 688653 & 6.183 & \multicolumn{3}{|c|}{5.507999999999999} & TRN \\
\hline CHEMBL 3214022 & 688653 & 4.933 & 5.2134 & TRN & & \\
\hline CHEMBL1482588 & 688653 & 5.733 & 5.3412 & TRN & & \\
\hline CHEMBL3195946 & 688653 & 5.983 & 5.7602 & TRN & & \\
\hline CHEMBL567422 & 688653 & 5.233 & 5.01 & TST & & \\
\hline CHEMBL 3210147 & 688653 & \multicolumn{3}{|c|}{5.2829999999999995} & 5.1525 & TST \\
\hline CHEMBL1404179 & 688653 & \multicolumn{3}{|c|}{5.132999999999999} & 5.8205 & TRN \\
\hline CHEMBL1317906 & 688653 & 5.083 & 5.7008 & TRN & & \\
\hline CHEMBL1581700 & 688653 & 5.183 & 4.7175 & TRN & & \\
\hline CHEMBL1377656 & 688653 & 4.833 & 4.9788 & TST & & \\
\hline CHEMBL1431355 & 688653 & 4.833 & 5.3729 & TRN & & \\
\hline CHEMBL1456466 & 688653 & \multicolumn{3}{|c|}{5.582999999999999} & 5.0354 & TRN \\
\hline CHEMBL1365633 & 688653 & 5.233 & 5.4164 & TRN & & \\
\hline CHEMBL1594786 & 688653 & 5.983 & 5.409 & TRN & & \\
\hline
\end{tabular}




\begin{tabular}{|c|c|c|c|c|c|c|}
\hline & & \multicolumn{5}{|c|}{ Supplemental Table S2.txt } \\
\hline CHEMBL1385171 & 688653 & 5.033 & 5.4563 & TST & & \\
\hline CHEMBL1588852 & 688653 & 6.233 & 5.4755 & TRN & & \\
\hline CHEMBL1322766 & 688653 & 4.633 & 4.9341 & TRN & & \\
\hline CHEMBL1590419 & 688653 & 4.883 & 5.0771 & TRN & & \\
\hline CHEMBL1493258 & 688653 & 5.183 & 5.0901 & TST & & \\
\hline CHEMBL1595724 & 688653 & 4.633 & 4.9944 & TST & & \\
\hline CHEMBL1591111 & 688653 & \multicolumn{3}{|c|}{4.7330000000000005} & 4.8197 & TRN \\
\hline CHEMBL1561103 & 688653 & \multicolumn{3}{|c|}{5.832999999999999} & 5.3816 & TRA \\
\hline CHEMBL1385765 & 688653 & 4.883 & 4.993 & TST & & \\
\hline CHEMBL1456278 & 688653 & 4.783 & 4.9123 & TRN & & \\
\hline CHEMBL1541721 & 688653 & 5.183 & 5.4228 & TRN & & \\
\hline CHEMBL1610124 & 688653 & 6.233 & 5.6647 & TRN & & \\
\hline CHEMBL2094573 & 688653 & 5.483 & 5.2995 & TRN & & \\
\hline CHEMBL1392228 & 688653 & \multicolumn{3}{|c|}{5.632999999999999} & 6.6401 & TRN \\
\hline CHEMBL1419938 & 688653 & \multicolumn{3}{|c|}{6.382999999999999} & 5.1061 & TRN \\
\hline CHEMBL1540897 & 688653 & 4.783 & 4.9222 & TRN & & \\
\hline CHEMBL1462330 & 688653 & 4.783 & 5.0093 & TRN & & \\
\hline CHEMBL1560848 & 688653 & 5.433 & 5.346 & TRN & & \\
\hline CHEMBL1974563 & 688653 & \multicolumn{3}{|c|}{6.132999999999999} & 6.3689 & TRN \\
\hline CHEMBL1364018 & 688653 & 4.833 & 4.9892 & TST & & \\
\hline CHEMBL1399904 & 688653 & 4.633 & 4.9078 & TRN & & \\
\hline CHEMBL1306531 & 688653 & \multicolumn{3}{|c|}{6.2829999999999995} & 5.7465 & TRN \\
\hline CHEMBL1383515 & 688653 & 4.833 & 5.1461 & TRN & & \\
\hline CHEMBL1310104 & 688653 & 5.083 & 4.8443 & TST & & \\
\hline CHEMBL1993662 & 688653 & \multicolumn{3}{|c|}{6.382999999999999} & 5.7257 & TRN \\
\hline CHEMBL1569287 & 688653 & 5.433 & 5.2811 & TRN & & \\
\hline CHEMBL1989110 & 688653 & 5.183 & 4.7812 & TST & & \\
\hline CHEMBL1559611 & 688653 & \multicolumn{3}{|c|}{6.382999999999999} & 5.3033 & TRN \\
\hline CHEMBL1389983 & 688653 & 4.833 & 5.322 & TRN & & \\
\hline CHEMBL1472778 & 688653 & \multicolumn{3}{|c|}{6.332999999999999} & 5.2692 & TRN \\
\hline CHEMBL1453959 & 688653 & 5.433 & 5.6798 & TRN & & \\
\hline CHEMBL1969001 & 688653 & 4.783 & 5.1964 & TST & & \\
\hline CHEMBL1411203 & 688653 & 5.033 & 4.8975 & TRN & & \\
\hline CHEMBL1585747 & 688653 & 5.733 & 5.2952 & TRN & & \\
\hline CHEMBL1472799 & 688653 & 5.683 & 5.4107 & TRN & & \\
\hline CHEMBL1546619 & 688653 & \multicolumn{3}{|c|}{5.132999999999999} & 4.9966 & TRN \\
\hline CHEMBL1373327 & 688653 & 5.083 & 5.2745 & TRN & & \\
\hline CHEMBL1374184 & 688653 & 5.033 & 5.3301 & TRN & & \\
\hline CHEMBL1594032 & 688653 & \multicolumn{3}{|c|}{5.332999999999999} & 5.1228 & TRA \\
\hline CHEMBL1439324 & 688653 & \multicolumn{3}{|c|}{6.2829999999999995} & 4.9828 & TRA \\
\hline CHEMBL1466932 & 688653 & 4.833 & 4.9844 & TST & & \\
\hline CHEMBL1428437 & 688653 & \multicolumn{3}{|c|}{5.132999999999999} & 4.8338 & TRA \\
\hline CHEMBL1512526 & 688653 & \multicolumn{3}{|c|}{4.7330000000000005} & 5.0207 & TRN \\
\hline CHEMBL1522903 & 688653 & 5.483 & 5.3409 & TRN & & \\
\hline CHEMBL389723 & 688653 & 4.883 & 5.3932 & TRN & & \\
\hline CHEMBL3199007 & 688653 & \multicolumn{3}{|c|}{5.2829999999999995} & 5.2838 & TRN \\
\hline CHEMBL1346944 & 688653 & 4.883 & 4.9902 & TRN & & \\
\hline CHEMBL1327596 & 688653 & 4.583 & 5.3291 & TRN & & \\
\hline
\end{tabular}




\begin{tabular}{|c|c|c|c|c|c|c|}
\hline \multirow[b]{2}{*}{ CHEMBL1563383 } & & \\
\hline & 688653 & 6.9329 & 6.1908 & TRN & & \\
\hline CHEMBL1311630 & 688653 & \multicolumn{3}{|c|}{5.132999999999999} & 4.9513 & TRN \\
\hline CHEMBL1499514 & 688653 & \multicolumn{3}{|c|}{5.382999999999999} & 5.5138 & TRN \\
\hline CHEMBL1255733 & 688653 & 5.933 & 5.8604 & TST & & \\
\hline CHEMBL1480916 & 688653 & \multicolumn{3}{|c|}{5.7829999999999995} & 5.445 & 11 \\
\hline CHEMBL1482802 & 688653 & 5.683 & 5.0204 & TRN & & \\
\hline CHEMBL1498927 & 688653 & 4.833 & 5.225 & TST & & \\
\hline CHEMBL1407861 & 688653 & 4.833 & 4.8915 & TRN & & \\
\hline CHEMBL1431377 & 688653 & \multicolumn{3}{|c|}{6.2829999999999995} & 6.0624 & TST \\
\hline CHEMBL1508384 & 688653 & 5.183 & 5.3293 & TST & & \\
\hline CHEMBL1466141 & 688653 & 5.233 & 5.1889 & TRN & & \\
\hline CHEMBL1487041 & 688653 & 5.683 & 5.6101 & TRN & & \\
\hline CHEMBL1485574 & 688653 & 5.683 & 5.1668 & TRN & & \\
\hline CHEMBL1508180 & 688653 & \multicolumn{3}{|c|}{5.5329999999999995} & 5.4826 & TRN \\
\hline CHEMBL1491869 & 688653 & \multicolumn{3}{|c|}{5.882999999999999} & 5.5268 & \\
\hline CHEMBL1362855 & 688653 & 4.633 & 4.9158 & TRN & & \\
\hline CHEMBL1502501 & 688653 & 5.033 & 5.395 & TRN & & \\
\hline CHEMBL 1497463 & 688653 & 4.883 & 5.5924 & TRN & & \\
\hline CHEMBL1309857 & 688653 & \multicolumn{3}{|c|}{5.882999999999999} & 5.2591 & TRN \\
\hline CHEMBL1558523 & 688653 & 6.4829 & 5.8365 & TRN & & \\
\hline CHEMBL1501204 & 688653 & \multicolumn{3}{|c|}{4.7330000000000005} & 5.356 & \\
\hline CHEMBL1311573 & 688653 & \multicolumn{3}{|c|}{4.7330000000000005} & 5.3738 & \\
\hline CHEMBL1599803 & 688653 & \multicolumn{3}{|c|}{5.7829999999999995} & 5.3206 & \\
\hline CHEMBL1450536 & 688653 & \multicolumn{3}{|c|}{5.7829999999999995} & 5.9079 & TR \\
\hline CHEMBL1315947 & 688653 & 4.883 & 4.9108 & TST & & \\
\hline CHEMBL1369655 & 688653 & \multirow{2}{*}{\multicolumn{3}{|c|}{$\begin{array}{ll}5.483 & 5.5649 \\
4.7330000000000005\end{array}$}} & & \\
\hline CHEMBL1476553 & 688653 & & & & 5.3262 & $1 \pi$ \\
\hline CHEMBL1413941 & 688653 & 5.683 & 5.5982 & TRN & & \\
\hline CHEMBL1321335 & 688653 & 6.4829 & 5.5869 & TRN & & \\
\hline CHEMBL1491651 & 688653 & 6.4829 & 5.9207 & TRN & & \\
\hline CHEMBL1599515 & 688653 & 4.833 & 4.9181 & TRN & & \\
\hline CHEMBL1506407 & 688653 & 5.683 & 5.9155 & TRN & & \\
\hline CHEMBL1299739 & 688653 & 4.583 & 4.9366 & TST & & \\
\hline CHEMBL1352287 & 688653 & 4.783 & 4.8665 & TST & & \\
\hline CHEMBL1533104 & 688653 & 5.933 & 5.2286 & TRN & & \\
\hline CHEMBL 2000517 & 688653 & \multicolumn{3}{|c|}{5.2829999999999995} & 5.4845 & $\mathrm{TP}$ \\
\hline CHEMBL1451470 & 688653 & 5.183 & 4.5806 & TRN & & \\
\hline CHEMBL1595853 & 688653 & 5.233 & 5.1134 & TRN & & \\
\hline CHEMBL1591989 & 688653 & \multicolumn{3}{|c|}{4.9830000000000005} & 5.2574 & TR \\
\hline CHEMBL1545411 & 688653 & \multicolumn{3}{|c|}{4.9830000000000005} & 5.1623 & TS \\
\hline CHEMBL1392355 & 688653 & 5.733 & 5.2602 & TST & & \\
\hline CHEMBL1552204 & 688653 & 4.633 & 5.6379 & TRN & & \\
\hline CHEMBL1480691 & 688653 & 4.833 & 5.2753 & TRN & & \\
\hline CHEMBL1523463 & 688653 & \multicolumn{3}{|c|}{4.7330000000000005} & 5.7348 & I RIV \\
\hline CHEMBL1556122 & 688653 & \multicolumn{3}{|c|}{4.7330000000000005} & 5.5303 & $\cdots$ \\
\hline CHEMBL1489087 & 688653 & \multicolumn{3}{|c|}{6.5329999999999995} & 5.5665 & TRN \\
\hline CHEMBL1547952 & 688653 & 5.3329 & 99999999 & & 5.4166 & TST \\
\hline CHEMBL1471889 & 688653 & 4.833 & 5.1863 & TST & & \\
\hline
\end{tabular}




\begin{tabular}{|c|c|c|c|c|c|c|c|}
\hline \multicolumn{7}{|c|}{ Supplemental Table S2.txt } & \\
\hline CHEMBL1563561 & 688653 & \multicolumn{3}{|c|}{4.7330000000000005} & 5.0627 & TST & \\
\hline CHEMBL3211480 & 688653 & 4.833 & 5.40177 & TRN & & & \\
\hline CHEMBL1381255 & 688653 & 4.833 & 5.43457 & TRN & & & \\
\hline CHEMBL1427464 & 688653 & 4.783 & 5.25147 & TRN & & & \\
\hline CHEMBL428789 & 688653 & \multicolumn{3}{|c|}{6.582999999999999} & 5.939 & TRN & \\
\hline CHEMBL1432066 & 688653 & 4.833 & 5.2325 & TRN & & & \\
\hline CHEMBL1988339 & 688653 & \multicolumn{3}{|c|}{5.382999999999999} & 5.2995 & TRN & \\
\hline CHEMBL1417189 & 688653 & 4.933 & 4.90367 & TRN & & & \\
\hline CHEMBL1346630 & 688653 & \multicolumn{3}{|c|}{5.2829999999999995} & 5.2975 & TST & \\
\hline CHEMBL1456521 & 688653 & 7.1331 & 5.8031 & TRN & & & \\
\hline CHEMBL1482497 & 688653 & 4.783 & 4.97247 & TRN & & & \\
\hline CHEMBL1332013 & 688653 & 6.0 & 5.55627 & TRN & & & \\
\hline CHEMBL3189799 & 688653 & 4.933 & 5.32867 & TST & & & \\
\hline CHEMBL1549568 & 688653 & \multicolumn{3}{|c|}{6.382999999999999} & 5.5872 & TST & \\
\hline CHEMBL1561928 & 688653 & \multicolumn{3}{|c|}{6.632999999999999} & 5.94 & TRN & \\
\hline CHEMBL1407918 & 688653 & 5.683 & 5.7528 & TRN & & & \\
\hline CHEMBL1525209 & 688653 & 4.783 & 5.76447 & TRN & & & \\
\hline CHEMBL578915 & 688653 & \multicolumn{3}{|c|}{4.7330000000000005} & 5.0388 & TST & \\
\hline CHEMBL1316024 & 688653 & 4.883 & 5.1327 & TRN & & & \\
\hline CHEMBL1492709 & 688653 & \multicolumn{3}{|c|}{5.132999999999999} & 5.1318 & TRN & \\
\hline CHEMBL1362461 & 688653 & 4.833 & 5.0234 & TST & & & \\
\hline CHEMBL1483431 & 688653 & \multicolumn{3}{|c|}{4.7330000000000005} & \multicolumn{3}{|c|}{5.0680000000000005} \\
\hline CHEMBL2369223 & 688653 & \multicolumn{3}{|c|}{5.7829999999999995} & 5.3038 & TRN & \\
\hline CHEMBL1529701 & 688653 & 4.933 & 4.91537 & TRN & & & \\
\hline CHEMBL1450223 & 688653 & 4.883 & 5.232 & TST & & & \\
\hline CHEMBL1319104 & 688653 & 5.033 & 5.35137 & TRN & & & \\
\hline CHEMBL1334562 & 688653 & 5.033 & 5.216 & TRN & & & \\
\hline CHEMBL1304449 & 688653 & \multicolumn{3}{|c|}{5.7829999999999995} & 5.7495 & TRN & \\
\hline CHEMBL1305712 & 688653 & \multicolumn{3}{|c|}{5.382999999999999} & 4.7922 & TRN & \\
\hline CHEMBL1412708 & 688653 & 4.833 & 4.98837 & TRN & & & \\
\hline CHEMBL1455179 & 688653 & \multicolumn{3}{|c|}{4.7330000000000005} & 5.3667 & TST & \\
\hline CHEMBL1440254 & 688653 & 4.833 & 5.337999 & 999999999 & & TRN & \\
\hline CHEMBL 3210447 & 688653 & \multicolumn{3}{|c|}{5.332999999999999} & \multicolumn{2}{|c|}{5.0489999999999995} & TST \\
\hline CHEMBL1374723 & 688653 & 5.933 & 6.2422 & TRN & & & \\
\hline CHEMBL1540387 & 688653 & 4.783 & 5.0413 & TRN & & & \\
\hline CHEMBL1591136 & 688653 & 4.783 & 5.46027 & TRN & & & \\
\hline CHEMBL1410928 & 688653 & 4.933 & 5.421 & TRN & & & \\
\hline CHEMBL1497859 & 688653 & 5.033 & 5.44 & TRN & & & \\
\hline CHEMBL592123 & 688653 & 6.183 & 5.5559 & TRN & & & \\
\hline CHEMBL1478464 & 688653 & 4.883 & 5.0959 & TRN & & & \\
\hline CHEMBL1455643 & 688653 & \multicolumn{3}{|c|}{5.132999999999999} & 5.5469 & TRN & \\
\hline CHEMBL1586635 & 688653 & 4.833 & 5.25167 & TRN & & & \\
\hline CHEMBL1309441 & 688653 & 4.683 & 5.2187 & TRN & & & \\
\hline CHEMBL1560359 & 688653 & \multicolumn{3}{|c|}{5.2829999999999995} & 5.4569 & TRN & \\
\hline CHEMBL1410121 & 688653 & 4.933 & 5.09627 & TRN & & & \\
\hline CHEMBL 3195248 & 688653 & \multicolumn{3}{|c|}{5.832999999999999} & 5.3882 & TRN & \\
\hline CHEMBL1558021 & 688653 & 5.233 & 4.69 & TRN & & & \\
\hline CHEMBL1447076 & 688653 & 4.683 & 5.11497 & TST & & & \\
\hline
\end{tabular}




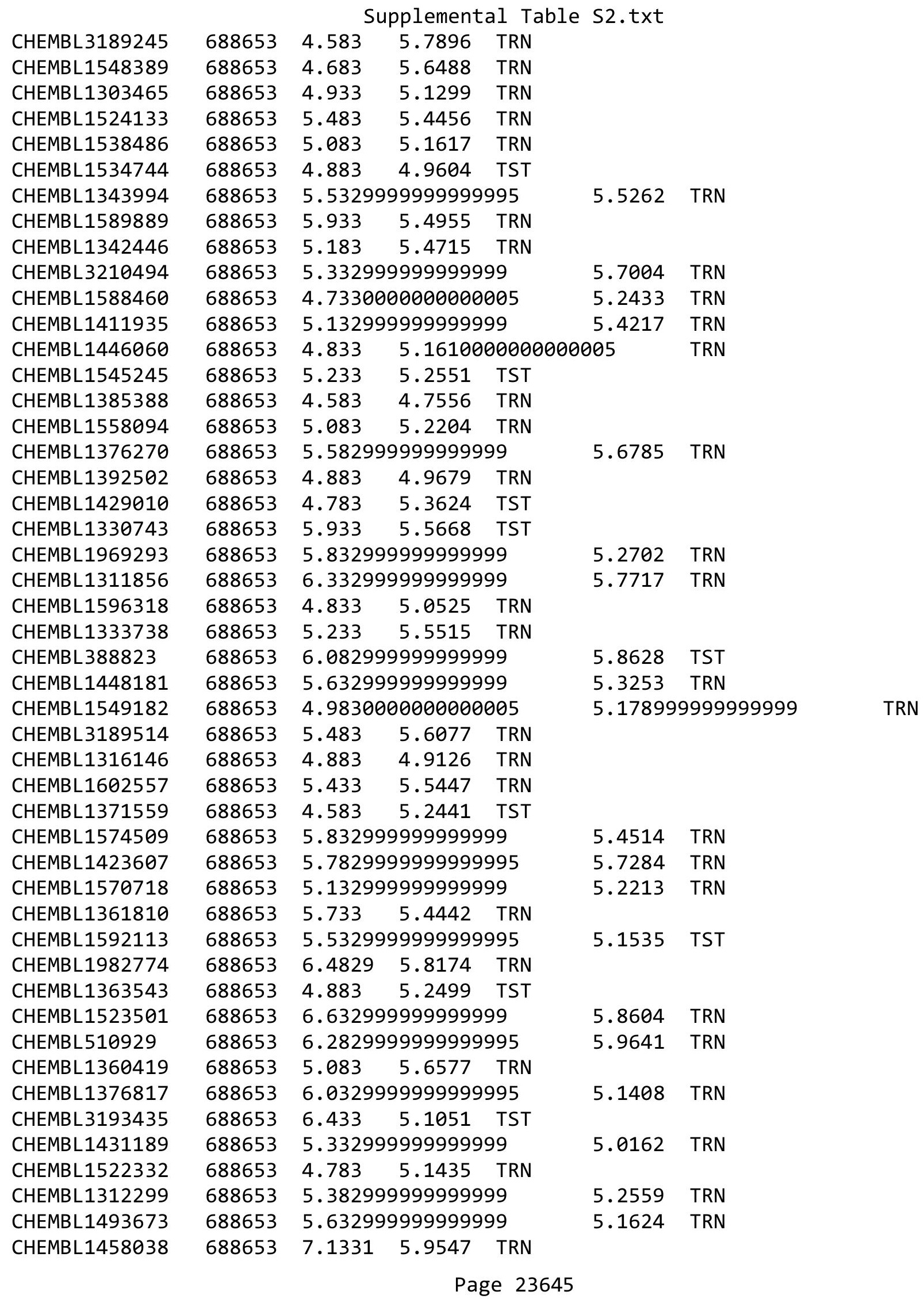




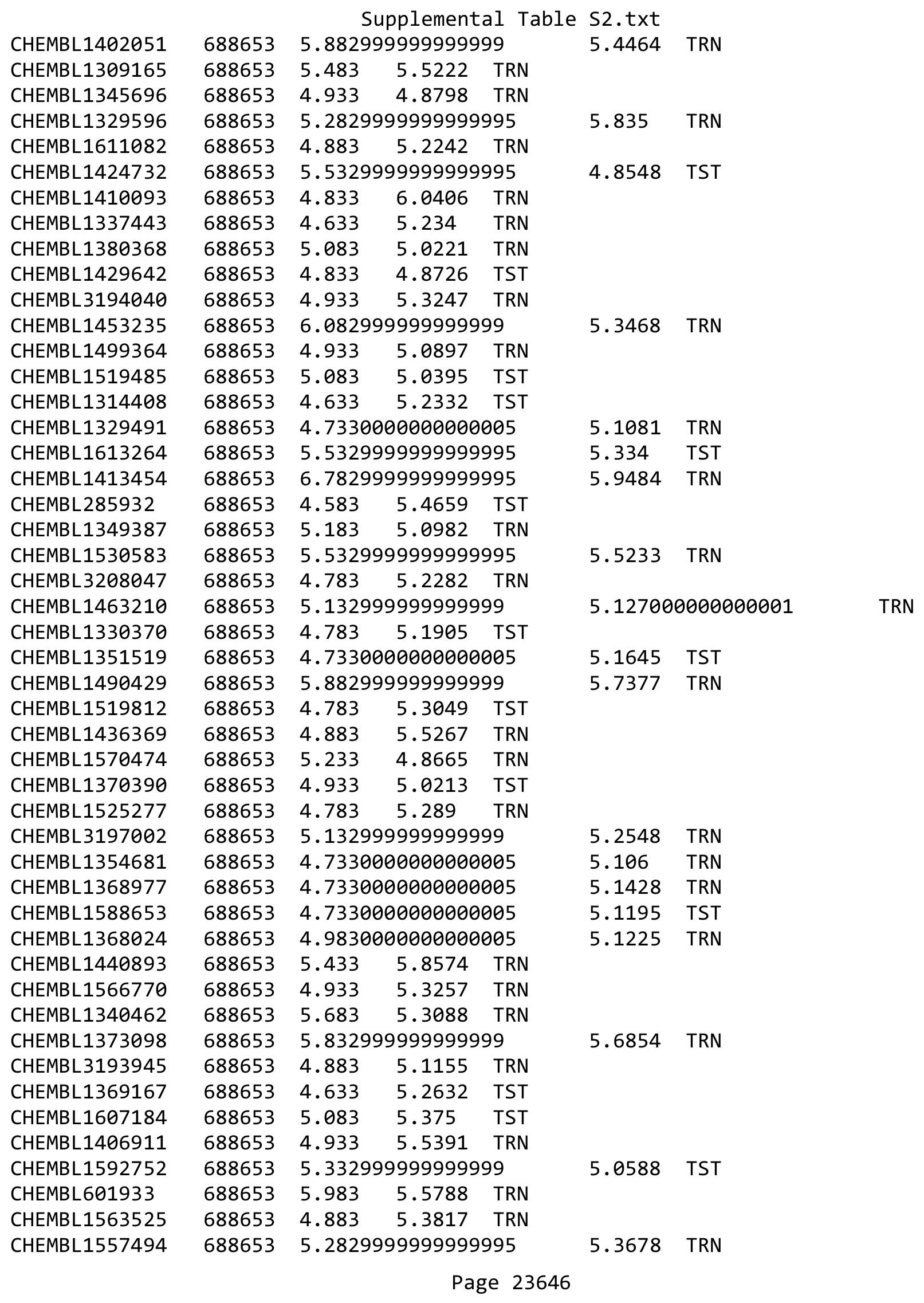




\begin{tabular}{|c|c|c|c|c|c|c|}
\hline \multirow[b]{2}{*}{ CHEMBL1389268 } & & \multicolumn{5}{|c|}{ Supplemental Table S2.txt } \\
\hline & 688653 & 5.033 & 5.3999 & TRN & & \\
\hline CHEMBL1444696 & 688653 & \multicolumn{3}{|c|}{5.332999999999999} & 4.8347 & 1 \\
\hline CHEMBL1440156 & 688653 & \multicolumn{3}{|c|}{6.132999999999999} & 5.4347 & \\
\hline CHEMBL1313722 & 688653 & 6.0 & 4.5828 & TRN & & \\
\hline CHEMBL1525447 & 688653 & \multicolumn{3}{|c|}{6.582999999999999} & 6.0445 & \\
\hline CHEMBL3199833 & 688653 & 4.783 & 5.0082 & TRN & & \\
\hline CHEMBL1594160 & 688653 & 4.633 & 4.9222 & TRN & & \\
\hline CHEMBL1598996 & 688653 & \multicolumn{3}{|c|}{4.7330000000000005} & 5.1577 & \\
\hline CHEMBL1513133 & 688653 & 4.783 & 5.6379 & TRN & & \\
\hline CHEMBL1570835 & 688653 & 4.833 & 5.4649 & TRN & & \\
\hline CHEMBL1523375 & 688653 & \multicolumn{3}{|c|}{6.2829999999999995} & 5.4737 & \\
\hline CHEMBL1310182 & 688653 & 5.733 & 5.8185 & TRN & & \\
\hline CHEMBL1385535 & 688653 & \multicolumn{3}{|c|}{4.7330000000000005} & 5.2527 & \\
\hline CHEMBL1345724 & 688653 & \multicolumn{3}{|c|}{6.2829999999999995} & 5.5452 & \\
\hline CHEMBL1535236 & 688653 & \multicolumn{3}{|c|}{4.9830000000000005} & 5.052 & \\
\hline CHEMBL1595786 & 688653 & 4.633 & 4.7751 & TST & & \\
\hline CHEMBL1428338 & 688653 & 5.083 & 5.3409 & TRN & & \\
\hline CHEMBL1341735 & 688653 & 5.683 & 5.6438 & TRN & & \\
\hline CHEMBL1438621 & 688653 & \multicolumn{3}{|c|}{5.832999999999999} & 5.62 & \\
\hline CHEMBL1305047 & 688653 & 5.183 & 5.1682 & TRN & & \\
\hline CHEMBL1429065 & 688653 & \multicolumn{3}{|c|}{5.5329999999999995} & 2 & \\
\hline CHEMBL1545556 & 688653 & 5.733 & 6.0409 & TRN & & \\
\hline CHEMBL1412828 & 688653 & \multirow{2}{*}{\multicolumn{3}{|c|}{$\begin{array}{l}0.6 \text { 2.1935 IRIV } \\
6.582999999999999\end{array}$}} & & \\
\hline CHEMBL1504840 & 688653 & & & & 6.0777 & \\
\hline CHEMBL1369047 & 688653 & 5.033 & 5.3188 & TRN & & \\
\hline CHEMBL3193974 & 688653 & \multicolumn{3}{|c|}{5.632999999999999} & .4871 & \\
\hline CHEMBL1373344 & 688653 & \multicolumn{3}{|c|}{5.5329999999999995} & 5.1326 & \\
\hline CHEMBL3210629 & 688653 & 4.783 & 5.2536 & TRN & & \\
\hline CHEMBL1299332 & 688653 & \multicolumn{3}{|c|}{4.9830000000000005} & 5.2882 & TST \\
\hline CHEMBL1573296 & 688653 & \multicolumn{3}{|c|}{4.7330000000000005} & 5.0958 & \\
\hline CHEMBL3190526 & 688653 & 4.883 & 5.2965 & TST & & \\
\hline CHEMBL1496294 & 688 & 4.883 & 5.188 & TRN & & \\
\hline CHEMBL1537279 & 688653 & 5.35 & 5.1133 & TST & & \\
\hline CHEMBL355496 & 688653 & \multicolumn{3}{|c|}{6.332999999999999} & 5.2025 & \\
\hline CHEMBL1538600 & 688653 & 4.833 & 4.9077 & TST & & \\
\hline CHEMBL1379313 & 688653 & 5.933 & 5.1884 & TRN & & \\
\hline CHEMBL1974432 & 688653 & \multicolumn{3}{|c|}{6.332999999999999} & 6.0298 & 10 \\
\hline CHEMBL1401302 & 688653 & \multicolumn{3}{|c|}{6.832999999999999} & 5.6243 & \\
\hline CHEMBL1409076 & 688653 & 4.783 & 4.9941 & TRN & & \\
\hline CHEMBL3192188 & 688653 & 4.933 & 5.0931 & TRN & & \\
\hline CHEMBL1592643 & 688653 & \multicolumn{3}{|c|}{8.283999999999999} & 229 & TR \\
\hline CHEMBL1424754 & 688653 & 5.6329 & 99999999 & & 5.5037 & \\
\hline CHEMBL1550634 & 688653 & 4.833 & 5.2385 & TRN & & \\
\hline CHEMBL1389083 & 688653 & 4.783 & 5.6448 & TRN & & \\
\hline CHEMBL1300911 & 688653 & 4.833 & 4.9432 & TST & & \\
\hline CHEMBL1446972 & 688653 & 4.833 & 4.9881 & TRN & & \\
\hline CHEMBL1477875 & 688653 & 4.783 & 5.7098 & TRN & & \\
\hline CHEMBL3210532 & 688653 & 5.183 & 5.153 & TRN & & \\
\hline
\end{tabular}




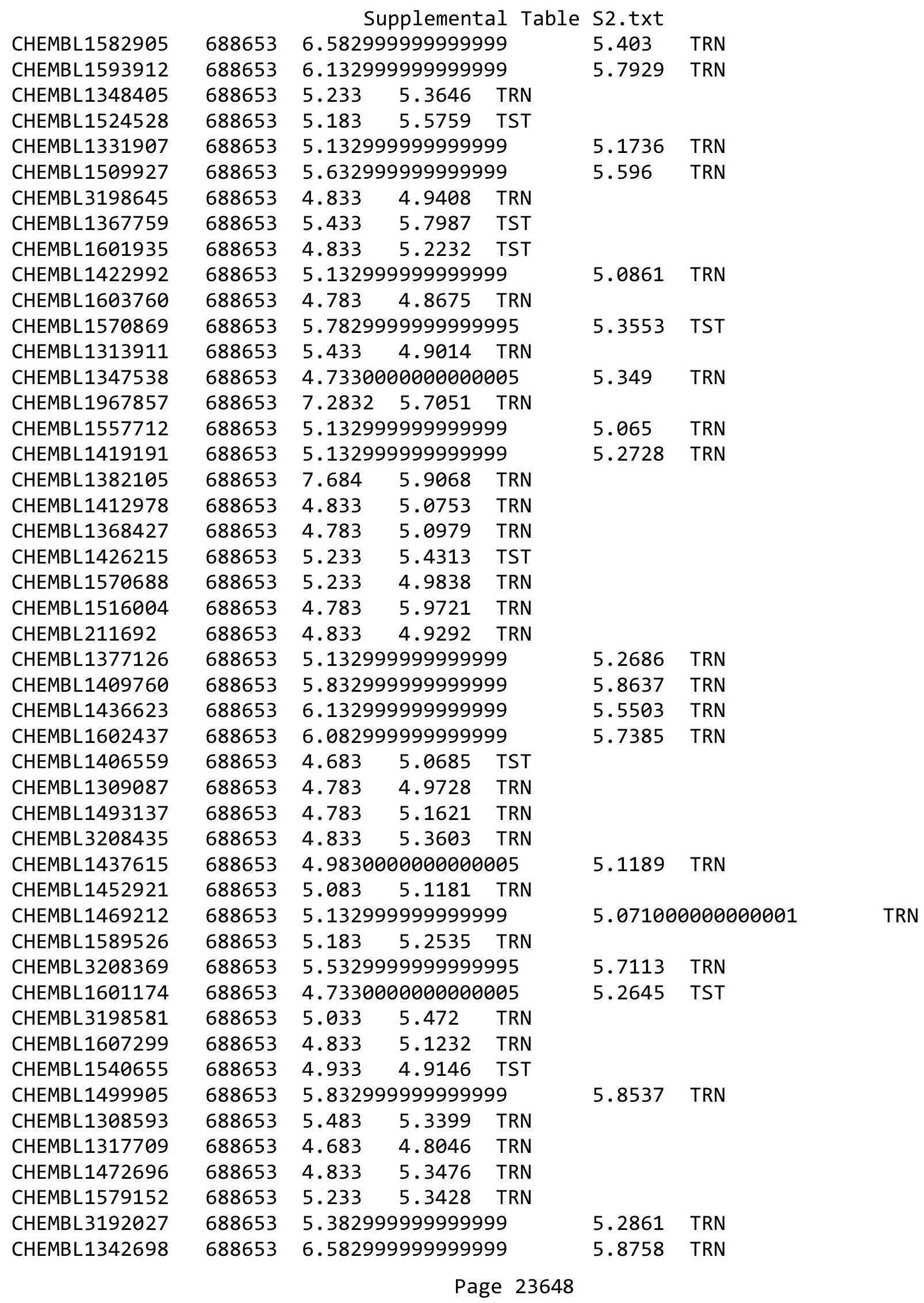




\begin{tabular}{|c|c|c|c|c|c|c|}
\hline & & \multicolumn{4}{|c|}{ Supplemental Table s2.txt } & \\
\hline CHEMBL1331702 & 688653 & \multicolumn{3}{|c|}{5.2829999999999995} & 5.3596 & TRN \\
\hline CHEMBL1322983 & 688653 & 4.583 & 5.355 & TRN & & \\
\hline CHEMBL1500986 & 688653 & \multicolumn{3}{|c|}{7.082999999999999} & 5.4842 & TST \\
\hline CHEMBL1443873 & 688653 & \multicolumn{3}{|c|}{5.632999999999999} & 5.6359 & TRN \\
\hline CHEMBL1568268 & 688653 & 4.883 & 5.1985 & TRN & & \\
\hline CHEMBL1416275 & 688653 & 5.933 & 5.0428 & TRN & & \\
\hline CHEMBL1592241 & 688653 & 5.083 & 5.2699 & TRN & & \\
\hline CHEMBL1472143 & 688653 & 4.783 & 5.4492 & TRN & & \\
\hline CHEMBL1383774 & 688653 & 4.633 & 4.8022 & TRN & & \\
\hline CHEMBL1406565 & 688653 & 4.583 & 5.3132 & TST & & \\
\hline CHEMBL1508503 & 688653 & \multicolumn{3}{|c|}{5.832999999999999} & 5.4245 & TRN \\
\hline CHEMBL1482003 & 688653 & 4.783 & 5.1342 & TRN & & \\
\hline CHEMBL1380478 & 688653 & 5.083 & 5.2717 & TST & & \\
\hline CHEMBL1567587 & 688653 & \multicolumn{3}{|c|}{5.7829999999999995} & 5.1321 & TRN \\
\hline CHEMBL1494495 & 688653 & \multicolumn{3}{|c|}{6.382999999999999} & 5.6069 & TRN \\
\hline CHEMBL1492702 & 688653 & 5.683 & 5.2111 & TST & & \\
\hline CHEMBL1488473 & 688653 & 5.683 & 5.235 & TRN & & \\
\hline CHEMBL1533657 & 688653 & 6.4829 & 5.6289 & TRN & & \\
\hline CHEMBL1553475 & 688653 & 4.633 & 5.1835 & TRN & & \\
\hline CHEMBL1410042 & 688653 & 6.8831 & 5.9865 & TRN & & \\
\hline CHEMBL1328865 & 688653 & 5.733 & 5.6057 & TRN & & \\
\hline CHEMBL1459239 & 688653 & 4.783 & 5.435 & TST & & \\
\hline CHEMBL 3210082 & 688653 & \multicolumn{3}{|c|}{5.132999999999999} & 5.9059 & TRN \\
\hline CHEMBL1423238 & 688653 & 5.683 & 4.9499 & TST & & \\
\hline CHEMBL1585146 & 688653 & \multicolumn{3}{|c|}{4.7330000000000005} & 5.3199 & TRN \\
\hline CHEMBL504598 & 688653 & 6.683 & 5.7133 & TRN & & \\
\hline CHEMBL1435750 & 688653 & 4.783 & 5.11 & TRN & & \\
\hline CHEMBL1547175 & 688653 & 4.833 & 5.2619 & TST & & \\
\hline CHEMBL1565932 & 688653 & 4.833 & 5.1209 & TRN & & \\
\hline CHEMBL1582707 & 688653 & \multicolumn{3}{|c|}{5.632999999999999} & 5.5784 & TRN \\
\hline CHEMBL1308879 & 688653 & 4.833 & 4.8106 & TRN & & \\
\hline CHEMBL 2000039 & 688653 & 4.783 & 5.4184 & TRN & & \\
\hline CHEMBL1591038 & 688653 & \multicolumn{3}{|c|}{6.082999999999999} & 5.8214 & TRN \\
\hline CHEMBL1486667 & 688653 & 4.783 & 5.3903 & TRN & & \\
\hline CHEMBL1543779 & 688653 & 4.883 & 5.0628 & TRN & & \\
\hline CHEMBL1520005 & 688653 & \multicolumn{3}{|c|}{6.632999999999999} & 5.5657 & TRN \\
\hline CHEMBL1521587 & 688653 & 4.583 & 4.885 & TST & & \\
\hline CHEMBL1495910 & 688653 & \multicolumn{3}{|c|}{5.132999999999999} & 5.3807 & TRN \\
\hline CHEMBL1550237 & 688653 & \multicolumn{3}{|c|}{5.132999999999999} & 5.2944 & TRN \\
\hline CHEMBL1321751 & 688653 & 5.233 & 5.6687 & TRN & & \\
\hline CHEMBL1521909 & 688653 & \multicolumn{3}{|c|}{4.9830000000000005} & 5.2656 & TRN \\
\hline CHEMBL1516177 & 688653 & 7.1331 & 5.6096 & TRN & & \\
\hline CHEMBL3213759 & 688653 & 5.483 & 5.3351 & TST & & \\
\hline CHEMBL3210789 & 688653 & 4.783 & 5.1415 & TST & & \\
\hline CHEMBL1354320 & 688653 & 5.233 & 5.2767 & TST & & \\
\hline CHEMBL1538019 & 688653 & 5.183 & 5.0694 & TST & & \\
\hline CHEMBL1348679 & 688653 & 4.933 & 5.0135 & TST & & \\
\hline CHEMBL1504438 & 688653 & 6.983 & 5.535 & TRN & & \\
\hline
\end{tabular}




\begin{tabular}{|c|c|c|c|c|c|c|}
\hline \multirow{3}{*}{$\begin{array}{l}\text { CHEMBL1556930 } \\
\text { CHEMBL1386822 }\end{array}$} & \multirow{3}{*}{$\begin{array}{l}688653 \\
688653\end{array}$} & \multicolumn{5}{|c|}{ Supplemental Table S2.txt } \\
\hline & & \multicolumn{3}{|c|}{5.2829999999999995} & \multirow{4}{*}{5.0416} & \multirow[t]{4}{*}{ TRN } \\
\hline & & 5.683 & 6.1066 & TRN & & \\
\hline CHEMBL1421668 & 688653 & 4.933 & 5.1387 & TRN & & \\
\hline CHEMBL3212087 & 688653 & 4.833 & 5.0343 & TST & & \\
\hline CHEMBL1550486 & 688653 & \multicolumn{3}{|c|}{6.582999999999999} & 6.0129 & TRN \\
\hline CHEMBL1560825 & 688653 & 4.883 & 5.3218 & TST & & \\
\hline CHEMBL1515266 & 688653 & \multicolumn{3}{|c|}{4.7330000000000005} & 4.863 & TRN \\
\hline CHEMBL1309008 & 688653 & 5.183 & 5.2432 & TRN & & \\
\hline CHEMBL1490478 & 688653 & 6.7331 & 6.0282 & TRN & & \\
\hline CHEMBL1544663 & 688653 & \multicolumn{3}{|c|}{7.082999999999999} & 5.5799 & TRN \\
\hline CHEMBL1413055 & 688653 & 4.85 & 5.4603 & TRN & & \\
\hline CHEMBL1385643 & 688653 & \multicolumn{3}{|c|}{4.7330000000000005} & 5.1226 & TRN \\
\hline CHEMBL1501845 & 688653 & \multicolumn{3}{|c|}{5.2829999999999995} & 5.2303 & TRN \\
\hline CHEMBL1353771 & 688653 & 5.683 & 5.3475 & TRN & & \\
\hline CHEMBL1574990 & 688653 & 5.683 & 5.2791 & TRN & & \\
\hline CHEMBL1432801 & 688653 & 5.733 & 5.3763 & TRN & & \\
\hline CHEMBL1346338 & 688653 & 6.0 & 5.9674 & TRN & & \\
\hline CHEMBL1576095 & 688653 & \multicolumn{3}{|c|}{5.832999999999999} & 5.3229 & TRN \\
\hline CHEMBL1573961 & 688653 & \multicolumn{3}{|c|}{5.5329999999999995} & 5.4227 & TRN \\
\hline CHEMBL1384238 & 688653 & 4.783 & 5.0707 & TRN & & \\
\hline CHEMBL1424355 & 688653 & 5.733 & 5.7872 & TRN & & \\
\hline CHEMBL1485582 & 688653 & 6.233 & 4.9938 & TRN & & \\
\hline CHEMBL1429762 & 688653 & 5.033 & 5.3816 & TST & & \\
\hline CHEMBL1423926 & 688653 & \multicolumn{3}{|c|}{5.632999999999999} & 5.4228 & TRN \\
\hline CHEMBL1405497 & 688653 & 4.933 & 5.2059 & TRN & & \\
\hline CHEMBL1451503 & 688653 & 4.883 & 5.822 & TRN & & \\
\hline CHEMBL1604192 & 688653 & 5.683 & 5.6299 & TST & & \\
\hline CHEMBL1312371 & 688653 & 4.783 & 4.5558 & TST & & \\
\hline CHEMBL1463470 & 688653 & 5.683 & 5.1948 & TRN & & \\
\hline CHEMBL3199856 & 688653 & \multicolumn{3}{|c|}{4.9830000000000005} & 5.5145 & TRN \\
\hline CHEMBL1408752 & 688653 & \multicolumn{3}{|c|}{5.832999999999999} & 6.0761 & TRN \\
\hline CHEMBL 3190078 & 688653 & & 5.425 & TRN \\
\hline CHEMBL1399900 & 688653 & \multicolumn{3}{|c|}{5.382999999999999} & 005 & TRN \\
\hline CHEMBL1441548 & 688653 & 5.733 & 5.3739 & TRN & & \\
\hline CHEMBL1606679 & 688653 & 4.783 & 5.9182 & TRN & & \\
\hline CHEMBL1367175 & 688653 & 4.9830 & j000000 & 005 & 5.1058 & TST \\
\hline CHEMBL1391219 & 688653 & 5.1329 & 9999999 & & 5.2565 & TRN \\
\hline CHEMBL1326654 & 688653 & 5.7829 & 9999999 & 995 & 5.8072 & TRN \\
\hline CHEMBL89671 & 688653 & 5.483 & 6.1089 & TRN & & \\
\hline CHEMBL 123 & 688653 & 5.183 & 5.3412 & TST & & \\
\hline CHEMBL1450420 & 688653 & 5.5329 & 9999999 & 995 & 5.3617 & TRN \\
\hline CHEMBL1555311 & 688653 & 4.7330 & 3000000 & 005 & 5.1237 & TRN \\
\hline CHEMBL1467985 & 688653 & 5.183 & 5.2711 & TRN & & \\
\hline CHEMBL1368004 & 688653 & 5.933 & 5.2576 & TRN & & \\
\hline CHEMBL1560526 & 688653 & 4.9830 & 3000000 & 005 & 5.1802 & TRN \\
\hline CHEMBL1994935 & 688653 & 4.583 & 5.1778 & TRN & & \\
\hline CHEMBL3191931 & 688653 & 4.7330 & 3000000 & 005 & 5.0338 & TRN \\
\hline CHEMBL1473497 & 688653 & 5.733 & 5.535 & TRN & & \\
\hline
\end{tabular}




\begin{tabular}{|c|c|c|c|c|c|c|c|}
\hline \multicolumn{7}{|c|}{ Supplemental Table S2.txt } & \\
\hline CHEMBL1309011 & 688653 & \multicolumn{3}{|c|}{6.082999999999999} & 5.8693 & TRN & \\
\hline CHEMBL1356752 & 688653 & 4.833 & 5.1751 & TRN & & & \\
\hline CHEMBL1568689 & 688653 & 5.083 & 5.016 & TRN & & & \\
\hline CHEMBL1592530 & 688653 & 4.583 & 5.0587 & TRN & & & \\
\hline CHEMBL1431070 & 688653 & 5.183 & 5.4629 & TRN & & & \\
\hline CHEMBL128427 & 688653 & 5.733 & 5.6685 & TRN & & & \\
\hline CHEMBL1342757 & 688653 & 5.183 & 5.3547 & TRN & & & \\
\hline CHEMBL1967273 & 688653 & 5.683 & 5.5745 & TRN & & & \\
\hline CHEMBL1447700 & 688653 & 4.833 & 5.0597 & TST & & & \\
\hline CHEMBL1309445 & 688653 & 4.933 & 5.2289 & TRN & & & \\
\hline CHEMBL1347888 & 688653 & \multicolumn{3}{|c|}{5.582999999999999} & 4.7998 & TRN & \\
\hline CHEMBL1568412 & 688653 & \multicolumn{3}{|c|}{6.632999999999999} & 5.1479 & TST & \\
\hline CHEMBL72683 & 688653 & \multicolumn{3}{|c|}{6.082999999999999} & 5.9784 & TRN & \\
\hline CHEMBL135701 & 688653 & 4.783 & 5.3499 & TRN & & & \\
\hline CHEMBL1505197 & 688653 & 4.583 & 5.1384 & TST & & & \\
\hline CHEMBL1351159 & 688653 & 4.833 & 4.9784 & TST & & & \\
\hline CHEMBL1501003 & 688653 & 4.783 & 5.1727 & TRN & & & \\
\hline CHEMBL1572158 & 688653 & \multicolumn{3}{|c|}{4.9830000000000005} & 4.8271 & TRN & \\
\hline CHEMBL 1557948 & 688653 & 6.183 & 5.5953 & TRN & & & \\
\hline CHEMBL1402483 & 688653 & 4.783 & 4.6992 & TRN & & & \\
\hline CHEMBL1397664 & 688653 & \multicolumn{3}{|c|}{5.2829999999999995} & 5.2505 & TST & \\
\hline CHEMBL1313115 & 688653 & \multicolumn{3}{|c|}{4.7330000000000005} & 5.3494 & TST & \\
\hline CHEMBL1613005 & 688653 & 4.933 & 4.9947 & TST & & & \\
\hline CHEMBL1331790 & 688653 & 4.783 & 5.2113 & TST & & & \\
\hline CHEMBL1323696 & 688653 & 5.733 & 5.4992 & TRN & & & \\
\hline CHEMBL1448102 & 688653 & 4.783 & 5.1134 & TRN & & & \\
\hline CHEMBL1306137 & 688653 & 5.033 & 5.7865 & TRN & & & \\
\hline CHEMBL1325121 & 688653 & \multicolumn{3}{|c|}{4.7330000000000005} & 5.3278 & TST & \\
\hline CHEMBL1423728 & 688653 & \multicolumn{3}{|c|}{4.7330000000000005} & 5.0049 & TRN & \\
\hline CHEMBL1411441 & 688653 & \multicolumn{3}{|c|}{4.7330000000000005} & 5.0912 & TRN & \\
\hline CHEMBL589207 & 688653 & 5.083 & 5.3154 & TRN & & & \\
\hline CHEMBL1510327 & 688653 & 6.8831 & 6.1457 & TRN & & & \\
\hline CHEMBL1428284 & 688653 & 4.833 & 5.4018 & TRN & & & \\
\hline CHEMBL1601278 & 688653 & 5.233 & 5.5943 & TST & & & \\
\hline CHEMBL1313849 & 688653 & \multicolumn{3}{|c|}{5.132999999999999} & 5.0632 & TST & \\
\hline CHEMBL1326997 & 688653 & 4.783 & 5.4028 & TRN & & & \\
\hline CHEMBL1371347 & 688653 & 5.183 & 4.9665 & TST & & & \\
\hline CHEMBL 1450513 & 688653 & \multicolumn{3}{|c|}{5.7829999999999995} & 5.4948 & TRN & \\
\hline CHEMBL1458884 & 688653 & 5.483 & 5.1005 & TRN & & & \\
\hline CHEMBL1335003 & 688653 & 4.633 & 4.8656 & TST & & & \\
\hline CHEMBL1536630 & 688653 & \multicolumn{3}{|c|}{6.0329999999999995} & 5.6599 & TRN & \\
\hline CHEMBL1364829 & 688653 & \multicolumn{3}{|c|}{5.2829999999999995} & 5.2129 & 9999999999 & TRN \\
\hline CHEMBL1514089 & 688653 & \multicolumn{3}{|c|}{5.132999999999999} & 5.1548 & TRN & \\
\hline CHEMBL1984804 & 688653 & \multicolumn{3}{|c|}{5.632999999999999} & 5.4679 & TST & \\
\hline CHEMBL1582405 & 688653 & \multicolumn{3}{|c|}{5.2829999999999995} & 5.2452 & TST & \\
\hline CHEMBL1493070 & 688653 & 4.783 & 5.0261 & TRN & & & \\
\hline CHEMBL1442886 & 688653 & \multicolumn{3}{|c|}{4.7330000000000005} & 5.6592 & TRN & \\
\hline CHEMBL1335088 & 688653 & 5.233 & 5.3898 & TRN & & & \\
\hline
\end{tabular}




\begin{tabular}{|c|c|c|c|c|c|c|}
\hline & & & pplement & al & s2.txt & \\
\hline CHEMBL3208247 & 688653 & 5.3329 & 99999999 & & 5.5979 & TST \\
\hline CHEMBL1371386 & 688653 & 5.5829 & 99999999 & & 5.5399 & TRN \\
\hline CHEMBL1364036 & 688653 & 4.783 & 5.1757 & TRN & & \\
\hline CHEMBL1586930 & 688653 & 5.733 & 5.0058 & TRN & & \\
\hline CHEMBL1366470 & 688653 & 6.0 & 5.6799 & TRN & & \\
\hline CHEMBL1459714 & 688653 & 5.5329 & 99999999 & 995 & 5.4465 & TST \\
\hline CHEMBL178531 & 688653 & 6.0329 & 99999999 & 995 & 4.9535 & TRN \\
\hline CHEMBL1613064 & 688653 & 4.683 & 4.9687 & TST & & \\
\hline CHEMBL1550123 & 688653 & 5.983 & 5.5685 & TRN & & \\
\hline CHEMBL1396824 & 688653 & 5.3329 & 99999999 & & 4.9454 & TST \\
\hline CHEMBL1370995 & 688653 & 4.833 & 5.2423 & TST & & \\
\hline CHEMBL1593441 & 688653 & 4.633 & 5.1768 & TRN & & \\
\hline CHEMBL1358845 & 688653 & 4.883 & 4.7131 & TRN & & \\
\hline CHEMBL1486728 & 688653 & 6.0829 & 99999999 & & 5.6832 & TRA \\
\hline CHEMBL1463220 & 688653 & 4.783 & 4.9022 & TRN & & \\
\hline CHEMBL1596226 & 688653 & 4.683 & 5.0362 & TST & & \\
\hline CHEMBL1409108 & 688653 & 4.833 & 5.0511 & TRN & & \\
\hline CHEMBL1380779 & 688653 & 4.783 & 5.2446 & TRN & & \\
\hline CHEMBL1382071 & 688653 & 5.6329 & 99999999 & & 5.3259 & TRN \\
\hline CHEMBL1325445 & 688653 & 4.7330 & 00000000 & 005 & 5.1048 & TRN \\
\hline CHEMBL1410165 & 688653 & 4.7330 & 00000000 & 005 & 5.0632 & TRA \\
\hline CHEMBL1453819 & 688653 & 4.7330 & 00000000 & 005 & 5.4 & TST \\
\hline CHEMBL1569357 & 688653 & 5.55 & 5.4292 & TRN & & \\
\hline CHEMBL1323898 & 688653 & 5.483 & 5.0471 & TRN & & \\
\hline CHEMBL1551155 & 688653 & 4.633 & 5.13700 & 00000 & 005 & TRN \\
\hline CHEMBL1390221 & 688653 & 6.0 & 5.266 & TRN & & \\
\hline CHEMBL1446828 & 688653 & 6.0829 & 99999999 & & 5.425 & TST \\
\hline CHEMBL1481264 & 688653 & 4.7330 & 00000000 & 005 & 5.1367 & TST \\
\hline CHEMBL3190427 & 688653 & 4.7330 & 00000000 & 005 & 5.2597 & TRA \\
\hline CHEMBL1436950 & 688653 & 4.833 & 5.5584 & TRN & & \\
\hline CHEMBL1534200 & 688653 & 5.3829 & 99999999 & & 5.7339 & TRA \\
\hline CHEMBL1403424 & 688653 & 5.2829 & 99999999 & 995 & 5.3668 & TST \\
\hline CHEMBL1381251 & 688653 & 5.8829 & 99999999 & & 5.6002 & TST \\
\hline CHEMBL1541673 & 688653 & 4.883 & 5.3436 & TRN & & \\
\hline CHEMBL3193229 & 688653 & 6.9329 & 5.4857 & TRN & & \\
\hline CHEMBL1388147 & 688653 & 4.933 & 5.0454 & TST & & \\
\hline CHEMBL1503275 & 688653 & 5.5329 & 99999999 & 995 & 4.8813 & TRN \\
\hline CHEMBL1529444 & 688653 & 5.483 & 5.3474 & TRN & & \\
\hline CHEMBL1578302 & 688653 & 5.933 & 5.7479 & TRN & & \\
\hline CHEMBL1326884 & 688653 & 4.783 & 5.3383 & TST & & \\
\hline CHEMBL1506750 & 688653 & 6.0 & 5.0943 & TRN & & \\
\hline CHEMBL1559308 & 688653 & 5.3829 & 99999999 & & 5.3738 & TRN \\
\hline CHEMBL1441491 & 688653 & 6.1329 & 99999999 & & 5.4659 & TST \\
\hline CHEMBL1390581 & 688653 & 4.783 & 5.0373 & TST & & \\
\hline CHEMBL1523528 & 688653 & 4.783 & 5.256 & TST & & \\
\hline CHEMBL1558285 & 688653 & 6.1329 & 99999999 & & 5.5734 & TST \\
\hline CHEMBL3199205 & 688653 & 5.183 & 5.0771 & TRN & & \\
\hline CHEMBL1492268 & 688653 & 6.0 & 5.0003 & TRN & & \\
\hline
\end{tabular}




\begin{tabular}{|c|c|c|c|c|c|c|c|}
\hline \multicolumn{8}{|c|}{ Supplemental Table s2.txt } \\
\hline CHEMBL1609978 & 688653 & 5.983 & 5.5959 & TRN & & & \\
\hline CHEMBL1553776 & 688653 & 4.933 & 5.3723 & TST & & & \\
\hline CHEMBL3189304 & 688653 & 4.683 & 4.8465 & TST & & & \\
\hline CHEMBL1372396 & 688653 & \multicolumn{3}{|c|}{6.0329999999999995} & 5.2941 & TST & \\
\hline CHEMBL1313327 & 688653 & 4.783 & 5.6529 & TRN & & & \\
\hline CHEMBL1314841 & 688653 & 7.1831 & 6.0234 & TRN & & & \\
\hline CHEMBL1503406 & 688653 & 4.883 & 4.6056 & TRN & & & \\
\hline CHEMBL1469403 & 688653 & \multicolumn{3}{|c|}{5.832999999999999} & 6.1486 & TRN & \\
\hline CHEMBL 3212483 & 688653 & \multicolumn{3}{|c|}{5.132999999999999} & 4.7068 & TST & \\
\hline CHEMBL1381396 & 688653 & \multicolumn{3}{|c|}{5.882999999999999} & 5.4955 & TRN & \\
\hline CHEMBL1570037 & 688653 & 4.783 & 5.307 & TRN & & & \\
\hline CHEMBL1304754 & 688653 & \multicolumn{3}{|c|}{4.9830000000000005} & 4.9834 & TST & \\
\hline CHEMBL1473832 & 688653 & \multicolumn{3}{|c|}{5.832999999999999} & 5.4234 & TRN & \\
\hline CHEMBL1565909 & 688653 & \multicolumn{3}{|c|}{6.382999999999999} & 5.646 & TRN & \\
\hline CHEMBL1567962 & 688653 & 4.833 & 5.4649 & TRN & & & \\
\hline CHEMBL1349976 & 688653 & 4.783 & 4.7874 & TRN & & & \\
\hline CHEMBL1395211 & 688653 & 4.833 & 5.1391 & TRN & & & \\
\hline CHEMBL1369269 & 688653 & 4.833 & 5.2067 & TST & & & \\
\hline CHEMBL1312667 & 688653 & \multicolumn{3}{|c|}{5.132999999999999} & 5.2096 & TRN & \\
\hline CHEMBL3211797 & 688653 & 5.183 & 4.9315 & TRN & & & \\
\hline CHEMBL1448649 & 688653 & 4.833 & 5.1899 & TRN & & & \\
\hline CHEMBL1378375 & 688653 & 5.483 & 5.5144 & TST & & & \\
\hline CHEMBL1511679 & 688653 & \multicolumn{3}{|c|}{5.632999999999999} & \multicolumn{2}{|c|}{5.593999999999999} & TRN \\
\hline CHEMBL1464497 & 688653 & 5.85 & 5.3007 & TRN & & & \\
\hline CHEMBL1392651 & 688653 & 4.633 & 4.751 & TST & & & \\
\hline CHEMBL3211864 & 688653 & 4.783 & 4.9882 & TRN & & & \\
\hline CHEMBL1334340 & 688653 & \multicolumn{3}{|c|}{5.582999999999999} & 5.5004 & TRN & \\
\hline CHEMBL1533255 & 688653 & \multicolumn{3}{|c|}{5.832999999999999} & 5.2025 & TST & \\
\hline CHEMBL 3192804 & 688653 & 4.583 & 5.178 & TRN & & & \\
\hline CHEMBL1327388 & 688653 & \multicolumn{3}{|c|}{6.132999999999999} & 5.9584 & TST & \\
\hline CHEMBL1448810 & 688653 & \multicolumn{3}{|c|}{4.7330000000000005} & 5.0384 & TRN & \\
\hline CHEMBL1506542 & 688653 & \multicolumn{3}{|c|}{5.5329999999999995} & 5.5003 & TRN & \\
\hline CHEMBL1339437 & 688653 & 4.833 & 5.1071 & TST & & & \\
\hline CHEMBL1486831 & 688653 & \multicolumn{3}{|c|}{6.0329999999999995} & 5.7056 & TST & \\
\hline CHEMBL1434786 & 688653 & \multicolumn{3}{|c|}{6.332999999999999} & 5.9395 & TRN & \\
\hline CHEMBL1595695 & 688653 & 4.833 & 5.2417 & TRN & & & \\
\hline CHEMBL1503383 & 688653 & 4.833 & 5.106 & TRN & & & \\
\hline CHEMBL1607640 & 688653 & 4.583 & 4.5428 & TST & & & \\
\hline CHEMBL1407228 & 688653 & 4.633 & 5.1386 & TST & & & \\
\hline CHEMBL1467491 & 688653 & 5.033 & 4.9895 & TST & & & \\
\hline CHEMBL3207312 & 688653 & 4.883 & 5.1881 & TRN & & & \\
\hline CHEMBL1526193 & 688653 & 4.833 & 5.4323 & TRN & & & \\
\hline CHEMBL1425832 & 688653 & 4.73300 & 00000000 & 005 & 5.0449 & TST & \\
\hline CHEMBL1224757 & 688653 & 5.38299 & 99999999 & & 5.1958 & TRN & \\
\hline CHEMBL1439523 & 688653 & 4.98300 & 00000000 & 005 & 5.0781 & TRN & \\
\hline CHEMBL1513105 & 688653 & 6.683 & 5.4768 & TRN & & & \\
\hline CHEMBL1402332 & 688653 & 6.0 & 4.7191 & TRN & & & \\
\hline CHEMBL1374043 & 688653 & 5.63299 & 99999999 & & 5.3214 & TRN & \\
\hline
\end{tabular}




\begin{tabular}{|c|c|c|c|c|c|c|}
\hline \multirow[b]{2}{*}{ CHEMBL1431324 } & \multirow[b]{2}{*}{688653} & \multicolumn{5}{|c|}{ Supplemental Table S2.txt } \\
\hline & & \multirow{2}{*}{\multicolumn{3}{|c|}{$\begin{array}{lrr}5.483 & 5.3262 & \text { TST } \\
5.7829999999999995\end{array}$}} & & \\
\hline CHEMBL1432357 & 688653 & & & & 5.2989 & TST \\
\hline CHEMBL1350778 & 688653 & \multicolumn{3}{|c|}{4.7330000000000005} & 4.7065 & TRN \\
\hline CHEMBL1543258 & 688653 & \multicolumn{3}{|c|}{5.832999999999999} & 5.1276 & TRN \\
\hline CHEMBL1536087 & 688653 & 6.233 & 5.3868 & TRN & & \\
\hline CHEMBL1338809 & 688653 & 5.733 & 5.3688 & TRN & & \\
\hline CHEMBL1512059 & 688653 & 4.783 & 5.2933 & TRN & & \\
\hline CHEMBL1505015 & 688653 & 4.783 & 4.9176 & TRN & & \\
\hline CHEMBL1214407 & 688653 & \multicolumn{3}{|c|}{5.832999999999999} & 5.5512 & TRN \\
\hline CHEMBL1500367 & 688653 & 4.883 & 5.2884 & TRN & & \\
\hline CHEMBL1560925 & 688653 & 4.583 & 4.8942 & TST & & \\
\hline CHEMBL1557592 & 688653 & 5.433 & 5.3378 & TRN & & \\
\hline CHEMBL3195897 & 688653 & \multicolumn{3}{|c|}{5.832999999999999} & 4.9792 & TRN \\
\hline CHEMBL1471619 & 688653 & 4.883 & 5.8536 & TRN & & \\
\hline CHEMBL1483842 & 688653 & \multicolumn{3}{|c|}{4.7330000000000005} & 5.3553 & TRN \\
\hline CHEMBL1984793 & 688653 & 4.883 & 5.1005 & TRN & & \\
\hline CHEMBL1980208 & 688653 & 4.883 & 5.2258 & TRN & & \\
\hline CHEMBL1306686 & 688653 & 4.883 & 5.2322 & TRN & & \\
\hline CHEMBL1417456 & 688653 & 4.783 & 4.7648 & TRN & & \\
\hline CHEMBL1526482 & 688653 & 5.483 & 5.199 & TRN & & \\
\hline CHEMBL1323451 & 688653 & 4.783 & 5.0799 & TRN & & \\
\hline CHEMBL1435667 & 688653 & 4.583 & 5.4294 & TST & & \\
\hline CHEMBL1449789 & 688653 & \multicolumn{3}{|c|}{5.5329999999999995} & 5.2405 & TRN \\
\hline CHEMBL1601049 & 688653 & 4.883 & 5.3382 & TRN & & \\
\hline CHEMBL1437695 & 688653 & 5.083 & 5.5505 & TRN & & \\
\hline CHEMBL1514727 & 688653 & 4.783 & 5.2272 & TST & & \\
\hline CHEMBL1537338 & 688653 & \multicolumn{3}{|c|}{5.382999999999999} & 5.1984 & TRN \\
\hline CHEMBL1491234 & 688653 & 4.783 & 5.4655 & TRN & & \\
\hline CHEMBL1378286 & 688653 & 4.883 & 4.9408 & TRN & & \\
\hline CHEMBL1586297 & 688653 & 5.083 & 5.0766 & TST & & \\
\hline CHEMBL1347663 & 688653 & 5.733 & 5.7502 & TRN & & \\
\hline CHEMBL1532699 & 688653 & \multicolumn{3}{|c|}{4.7330000000000005} & 4.9941 & TRN \\
\hline CHEMBL1511729 & 688653 & \multicolumn{3}{|c|}{5.582999999999999} & 5.4996 & TRN \\
\hline CHEMBL1542524 & 688653 & 4.783 & 5.0079 & TRN & & \\
\hline CHEMBL1537604 & 688653 & \multicolumn{3}{|c|}{4.7330000000000005} & 5.1865 & TRN \\
\hline CHEMBL125970 & 688653 & \multicolumn{3}{|c|}{6.582999999999999} & 5.7792 & TRN \\
\hline CHEMBL1332178 & 688653 & 4.683 & 4.8541 & TST & & \\
\hline CHEMBL1355230 & 688653 & \multirow{2}{*}{\multicolumn{3}{|c|}{$\begin{array}{l}5.9334 .9166 \\
5.132999999999999\end{array}$}} & & \\
\hline CHEMBL1480309 & 688653 & & & & 5.1578 & TRN \\
\hline CHEMBL1308687 & 688653 & 4.583 & 5.1049 & TRN & & \\
\hline CHEMBL1379377 & 688653 & 5.433 & 5.8607 & TST & & \\
\hline CHEMBL1561187 & 688653 & 4.583 & 4.8665 & TRN & & \\
\hline CHEMBL1604930 & 688653 & 4.633 & 5.3727 & TRN & & \\
\hline CHEMBL1406952 & 688653 & \multicolumn{3}{|c|}{6.2829999999999995} & 5.7937 & TRN \\
\hline CHEMBL1592201 & 688653 & 5.733 & 5.7462 & TRN & & \\
\hline CHEMBL1402580 & 688653 & 4.933 & 4.9044 & TST & & \\
\hline CHEMBL3194330 & 688653 & 4.783 & 5.0549 & TST & & \\
\hline CHEMBL1587181 & 688653 & 4.883 & 4.7355 & TST & & \\
\hline
\end{tabular}




\begin{tabular}{|c|c|c|c|c|c|c|}
\hline \multirow{3}{*}{$\begin{array}{l}\text { CHEMBL1437633 } \\
\text { CHEMBL1422619 }\end{array}$} & \multirow{3}{*}{$\begin{array}{l}688653 \\
688653\end{array}$} & \multicolumn{4}{|c|}{ Supplemental Table S2.txt } & \multirow{2}{*}{ TRN } \\
\hline & & \multicolumn{3}{|c|}{4.7330000000000005} & 4.7315 & \\
\hline & & 5.683 & 5.1326 & TRN & & \\
\hline CHEMBL1612227 & 688653 & 4.783 & 5.0883 & TST & & \\
\hline CHEMBL1528460 & 688653 & \multicolumn{3}{|c|}{5.882999999999999} & 5.2298 & TRN \\
\hline CHEMBL1375315 & 688653 & \multicolumn{3}{|c|}{5.332999999999999} & 5.5289 & TRN \\
\hline CHEMBL1457225 & 688653 & 4.783 & 5.3603 & TRN & & \\
\hline CHEMBL1392431 & 688653 & \multicolumn{3}{|c|}{4.7330000000000005} & 5.3394 & TRN \\
\hline CHEMBL1540107 & 688653 & 5.683 & 5.7024 & TRN & & \\
\hline CHEMBL3189395 & 688653 & \multicolumn{3}{|c|}{4.7330000000000005} & 4.8829 & TRN \\
\hline CHEMBL1542701 & 688653 & \multicolumn{3}{|c|}{4.7330000000000005} & 4.9051 & TRN \\
\hline CHEMBL1559992 & 688653 & \multicolumn{3}{|c|}{4.7330000000000005} & 4.8821 & TST \\
\hline CHEMBL1394918 & 688653 & \multicolumn{3}{|c|}{6.332999999999999} & 5.6252 & TRN \\
\hline CHEMBL1589769 & 688653 & \multicolumn{3}{|c|}{5.832999999999999} & 5.6596 & TRN \\
\hline CHEMBL1519429 & 688653 & 5.033 & 5.76 & TRN & & \\
\hline CHEMBL1397993 & 688653 & \multicolumn{3}{|c|}{5.2829999999999995} & 5.176 & TRN \\
\hline CHEMBL1576279 & 688653 & 4.833 & 5.4151 & TRN & & \\
\hline CHEMBL1610953 & 688653 & 5.733 & 5.4207 & TRN & & \\
\hline CHEMBL 3195387 & 688653 & 4.883 & 5.2587 & TRN & & \\
\hline CHEMBL1383007 & 688653 & \multicolumn{3}{|c|}{5.5329999999999995} & 5.4054 & TRN \\
\hline CHEMBL1439341 & 688653 & 4.683 & 5.2181 & TRN & & \\
\hline CHEMBL3213665 & 688653 & 5.233 & 5.6281 & TRN & & \\
\hline CHEMBL1401004 & 688653 & 4.883 & 4.9648 & TRN & & \\
\hline CHEMBL1431091 & 688653 & 5.083 & 5.4284 & TRN & & \\
\hline CHEMBL1484048 & 688653 & 4.783 & 5.1883 & TST & & \\
\hline CHEMBL1381579 & 688653 & \multicolumn{3}{|c|}{4.7330000000000005} & 5.0222 & TRN \\
\hline CHEMBL3190714 & 688653 & \multicolumn{3}{|c|}{5.382999999999999} & 5.2302 & TST \\
\hline CHEMBL1507533 & 688653 & 4.833 & 5.2007 & TRN & & \\
\hline CHEMBL1396937 & 688653 & 5.733 & 4.9388 & TRN & & \\
\hline CHEMBL3196859 & 688653 & 4.933 & 4.7842 & TRN & & \\
\hline CHEMBL1478997 & 688653 & \multicolumn{3}{|c|}{5.882999999999999} & & TRN \\
\hline CHEMBL1545203 & 688653 & 5.033 & 6.0416 & TRN & & \\
\hline CHEMBL1463053 & 688653 & 4.933 & 5.0261 & TRN & & \\
\hline CHEMBL1415519 & 688653 & 5.083 & 5.306 & TST & & \\
\hline CHEMBL3198173 & 688653 & 4.783 & 4.7237 & TRN & & \\
\hline CHEMBL1330432 & 688653 & \multicolumn{3}{|c|}{5.632999999999999} & 4.8828 & TRN \\
\hline CHEMBL1483480 & 688653 & \multicolumn{3}{|c|}{4.9830000000000005} & 5.5567 & TST \\
\hline CHEMBL1441181 & 688653 & 4.883 & 4.7678 & TRN & & \\
\hline CHEMBL1600616 & 688653 & 4.583 & 5.0043 & TRN & & \\
\hline CHEMBL1314926 & 688653 & 5.983 & 5.2771 & TRN & & \\
\hline CHEMBL1519844 & 688653 & \multicolumn{3}{|c|}{5.882999999999999} & 5.8116 & TRN \\
\hline CHEMBL3197463 & 688653 & 5.183 & 4.6717 & TRN & & \\
\hline CHEMBL1368839 & 688653 & 4.933 & 5.3002 & TRN & & \\
\hline CHEMBL1553168 & 688653 & 5.433 & 5.0614 & TRN & & \\
\hline CHEMBL1590803 & 688653 & 5.933 & 5.3657 & TRN & & \\
\hline CHEMBL1334612 & 688653 & 5.433 & 5.8161 & TRN & & \\
\hline CHEMBL1313936 & 688653 & 6.632 & 99999995 & & 5.9674 & TRN \\
\hline CHEMBL1514829 & 688653 & 4.683 & 5.1623 & TRN & & \\
\hline CHEMBL1465214 & 688653 & 4.9836 & 0000000 & 005 & 5.0368 & TRN \\
\hline
\end{tabular}




\begin{tabular}{|c|c|c|c|c|c|c|c|}
\hline \multirow[b]{2}{*}{ CHEMBL1464920 } & \multicolumn{6}{|c|}{ Supplemental Table S2.txt } & \\
\hline & 688653 & 4.783 & 5.5371 & TRN & & & \\
\hline CHEMBL1412463 & 688653 & $4.7330 e$ & 00000000 & 005 & 5.4141 & TRN & \\
\hline CHEMBL1361514 & 688653 & 5.8329 & 99999999 & 99 & 5.69799 & 99999999995 & TRN \\
\hline CHEMBL1519769 & 688653 & 5.733 & 5.1005 & TRN & & & \\
\hline CHEMBL1487764 & 688653 & 5.183 & 5.1708 & TRN & & & \\
\hline CHEMBL1594678 & 688653 & 5.6329 & 99999999 & & 5.0734 & TRN & \\
\hline CHEMBL1541975 & 688653 & 4.833 & 5.3467 & TST & & & \\
\hline CHEMBL1564636 & 688653 & 4.73306 & 00000000 & 005 & 5.3294 & TST & \\
\hline CHEMBL1334017 & 688653 & 4.683 & 5.4302 & TRN & & & \\
\hline CHEMBL1485788 & 688653 & 5.933 & 5.5617 & TRN & & & \\
\hline CHEMBL1313217 & 688653 & 4.833 & 5.5008 & TRN & & & \\
\hline CHEMBL1584666 & 688653 & 5.2829 & 99999999 & 995 & 5.6659 & TRN & \\
\hline CHEMBL1548065 & 688653 & 5.6329 & 99999999 & & 5.1457 & TST & \\
\hline CHEMBL1364494 & 688653 & 5.8329 & 99999999 & & 5.3396 & TRN & \\
\hline CHEMBL1980031 & 688653 & 5.483 & 5.3307 & TRN & & & \\
\hline CHEMBL1545890 & 688653 & 4.833 & 5.0328 & TST & & & \\
\hline CHEMBL1561545 & 688653 & 5.233 & 5.4976 & TRN & & & \\
\hline CHEMBL1509413 & 688653 & 4.883 & 4.9684 & TST & & & \\
\hline CHEMBL1555725 & 688653 & 5.483 & 5.5659 & TRN & & & \\
\hline CHEMBL1312888 & 688653 & 5.433 & 5.3484 & TRN & & & \\
\hline CHEMBL3199520 & 688653 & 6.1329 & 99999999 & & 5.7857 & TRN & \\
\hline CHEMBL1468087 & 688653 & 4.7330 & 00000000 & 005 & 5.2362 & TST & \\
\hline CHEMBL3198006 & 688653 & 4.933 & 5.5951 & TRN & & & \\
\hline CHEMBL586602 & 688653 & 6.0829 & 99999999 & & 5.6515 & TRN & \\
\hline CHEMBL 3192440 & 688653 & 4.783 & 5.2123 & TRN & & & \\
\hline CHEMBL1518824 & 688653 & 4.633 & 4.5614 & TRN & & & \\
\hline CHEMBL1587691 & 688653 & 4.883 & 4.8833 & TRN & & & \\
\hline CHEMBL3197251 & 688653 & 6.7331 & 5.8612 & TRN & & & \\
\hline CHEMBL1400587 & 688653 & 5.733 & 5.0754 & TRN & & & \\
\hline CHEMBL1453794 & 688653 & 5.183 & 5.1945 & TRN & & & \\
\hline CHEMBL1599079 & 688653 & 4.833 & 5.3644 & TRN & & & \\
\hline CHEMBL1459878 & 688653 & 5.033 & 5.433 & TRN & & & \\
\hline CHEMBL3191563 & 688653 & 5.933 & 5.5182 & TRN & & & \\
\hline CHEMBL1612538 & 688653 & $6.5829 \mathrm{c}$ & 99999999 & & 5.106 & TRN & \\
\hline CHEMBL3198372 & 688653 & $4.7330 e$ & 00000000 & 005 & 5.2494 & TRN & \\
\hline CHEMBL1564852 & 688653 & 5.033 & 5.3461 & TRN & & & \\
\hline CHEMBL1564792 & 688653 & 6.3329 & 99999999 & & 5.9328 & TRN & \\
\hline CHEMBL1542492 & 688653 & 4.783 & 5.263 & TST & & & \\
\hline CHEMBL1443381 & 688653 & 4.73306 & 00000000 & 205 & 5.1913 & TRN & \\
\hline CHEMBL1563894 & 688653 & 6.983 & 6.1757 & TRN & & & \\
\hline CHEMBL1394461 & 688653 & 4.883 & 5.3768 & TRN & & & \\
\hline CHEMBL1435212 & 688653 & 5.683 & 5.1863 & TRN & & & \\
\hline CHEMBL1440061 & 688653 & 6.683 & 6.3174 & TRN & & & \\
\hline CHEMBL1430260 & 688653 & 4.883 & 5.3823 & TRN & & & \\
\hline CHEMBL3199471 & 688653 & 4.883 & 5.31 & TRN & & & \\
\hline CHEMBL1429536 & 688653 & 4.683 & 5.2541 & TRN & & & \\
\hline CHEMBL 1514558 & 688653 & 5.7829 & 99999999 & 995 & 5.1792 & TRN & \\
\hline CHEMBL1366238 & 688653 & 4.73306 & 00000000 & $\partial 05$ & 5.2461 & TST & \\
\hline
\end{tabular}




\begin{tabular}{|c|c|c|c|c|c|c|}
\hline \multirow[b]{2}{*}{ CHEMBL3192941 } & & \multicolumn{5}{|c|}{ Supplemental Table S2.txt } \\
\hline & 688653 & 5.183 & 6.2167 & TRN & & \\
\hline CHEMBL1549301 & 688653 & 5.233 & 5.7798 & TRN & & \\
\hline CHEMBL3198860 & 688653 & \multicolumn{3}{|c|}{6.332999999999999} & 5.3128 & TRN \\
\hline CHEMBL1574751 & 688653 & \multicolumn{3}{|c|}{5.832999999999999} & 5.4407 & TRN \\
\hline CHEMBL3198582 & 688653 & 5.683 & 5.3952 & TST & & \\
\hline CHEMBL1588968 & 688653 & \multicolumn{3}{|c|}{6.582999999999999} & 5.8925 & TRN \\
\hline CHEMBL1571946 & 688653 & \multicolumn{3}{|c|}{5.5329999999999995} & 5.2974 & TRN \\
\hline CHEMBL1596302 & 688653 & \multicolumn{3}{|c|}{5.332999999999999} & 5.5472 & TRN \\
\hline CHEMBL3199785 & 688653 & \multicolumn{3}{|c|}{4.7330000000000005} & 5.1994 & TRN \\
\hline CHEMBL3191671 & 688653 & 5.083 & 5.3144 & TRN & & \\
\hline CHEMBL3209462 & 688653 & 5.683 & 5.2234 & TRN & & \\
\hline CHEMBL1419688 & 688653 & 6.183 & 5.3967 & TST & & \\
\hline CHEMBL1318039 & 688653 & 4.633 & 4.9305 & TRN & & \\
\hline CHEMBL1437652 & 688653 & 4.633 & 4.8909 & TST & & \\
\hline CHEMBL1392056 & 688653 & 5.683 & 4.7241 & TST & & \\
\hline CHEMBL1401945 & 688653 & \multicolumn{3}{|c|}{6.382999999999999} & 5.4985 & TST \\
\hline CHEMBL445696 & 688653 & 4.783 & 5.1588 & TST & & \\
\hline CHEMBL3208892 & 688653 & & 5.1852 & TRN & & \\
\hline CHEMBL1439085 & 688653 & \multicolumn{3}{|c|}{5.132999999999999} & 5.3043 & TRN \\
\hline CHEMBL1521130 & 688653 & 5.233 & 5.2588 & TRN & & \\
\hline CHEMBL3190794 & 688653 & \multicolumn{3}{|c|}{4.9830000000000005} & 5.3731 & TRN \\
\hline CHEMBL380979 & 688653 & \multicolumn{3}{|c|}{6.132999999999999} & 5.7828 & TRN \\
\hline CHEMBL1537402 & 688653 & \multicolumn{3}{|c|}{4.9830000000000005} & 5.187 & TRN \\
\hline CHEMBL1546458 & 688653 & \multicolumn{3}{|c|}{6.2829999999999995} & 5.3231 & TST \\
\hline CHEMBL1299417 & 688653 & 4.883 & 5.6157 & TRN & & \\
\hline CHEMBL3198308 & 688653 & 4.633 & 5.2842 & TRN & & \\
\hline CHEMBL1476071 & 688653 & 5.183 & 5.2268 & TRN & & \\
\hline CHEMBL 3190800 & 688653 & 4.833 & 5.2973 & TRN & & \\
\hline CHEMBL1368402 & 688653 & 4.833 & 5.3117 & TRN & & \\
\hline CHEMBL1361424 & 688653 & 5.233 & 5.7948 & TRN & & \\
\hline CHEMBL1523542 & 688653 & \multicolumn{3}{|c|}{4.9830000000000005} & 5.5077 & TST \\
\hline CHEMBL1427920 & 688653 & 4.933 & 4.9298 & TST & & \\
\hline CHEMBL1536629 & 688653 & \multirow{2}{*}{\multicolumn{3}{|c|}{$\begin{array}{lr}4.783 & 4.7678 \\
5.132999999999999\end{array}$}} & & \\
\hline CHEMBL1404713 & 688653 & & & & 5.2842 & TRN \\
\hline CHEMBL1330440 & 688653 & \multicolumn{3}{|c|}{$\begin{array}{lll}4.883 & 5.0236 & \text { TST }\end{array}$} & & \\
\hline CHEMBL1538726 & 688653 & 5.083 & 5.0919 & TRN & & \\
\hline CHEMBL1545723 & 688653 & \multirow{2}{*}{\multicolumn{3}{|c|}{$\begin{array}{lcc}4.833 & 4.7261 & \text { TRN } \\
5.832999999999999\end{array}$}} & & \\
\hline CHEMBL1381874 & 688653 & & & & 5.1866 & TST \\
\hline CHEMBL1531035 & 688653 & \multicolumn{3}{|c|}{$\begin{array}{lll}5.083 & 4.711 & \text { TRN }\end{array}$} & & \\
\hline CHEMBL1342090 & 688653 & 5.033 & 5.1692 & TRN & & \\
\hline CHEMBL1989922 & 688653 & \multicolumn{3}{|c|}{5.882999999999999} & 5.7248 & TRN \\
\hline CHEMBL1491220 & 688653 & 5.683 & 5.5283 & TRN & & \\
\hline CHEMBL1487893 & 688653 & 5.433 & 5.5614 & TRN & & \\
\hline CHEMBL1479529 & 688653 & \multicolumn{3}{|c|}{4.7330000000000005} & 5.2087 & TRN \\
\hline CHEMBL1610690 & 688653 & 4.9830 & 30000000 & 005 & 5.2847 & TRN \\
\hline CHEMBL1399521 & 688653 & 5.6329 & 99999999 & & 5.1011 & TRN \\
\hline CHEMBL1594327 & 688653 & 5.1329 & 79999999 & & 4.7582 & TRN \\
\hline CHEMBL1316795 & 688653 & 4.783 & 5.4147 & TRN & & \\
\hline
\end{tabular}




\begin{tabular}{|c|c|c|c|c|c|c|c|}
\hline \multicolumn{8}{|c|}{ 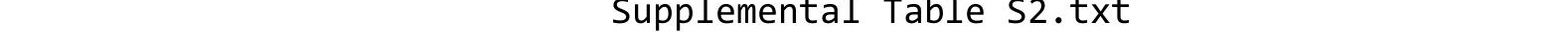 } \\
\hline CHEMBL1980959 & 688653 & 4.833 & 5.1352 & TRN & & & \\
\hline CHEMBL1454894 & 688653 & 6.433 & 5.4871 & TRN & & & \\
\hline CHEMBL1595029 & 688653 & 5.183 & 5.4672 & TRN & & & \\
\hline CHEMBL1403829 & 688653 & 4.583 & 4.9638 & TRN & & & \\
\hline CHEMBL1596955 & 688653 & 5.38299 & 99999999 & & 5.2545 & TRN & \\
\hline CHEMBL1404400 & 688653 & 4.833 & 5.1862 & TRN & & & \\
\hline CHEMBL1511238 & 688653 & 4.98300 & 00000000 & 005 & 5.4729 & TST & \\
\hline CHEMBL1552308 & 688653 & 4.833 & 4.9374 & TST & & & \\
\hline CHEMBL1482427 & 688653 & 4.683 & 4.9004 & TRN & & & \\
\hline CHEMBL1583461 & 688653 & 4.633 & 5.145 & TRN & & & \\
\hline CHEMBL1499479 & 688653 & 5.28299 & 99999999 & 995 & 5.3028 & TRN & \\
\hline CHEMBL1536914 & 688653 & 5.183 & 5.37799 & 999999999 & & TRN & \\
\hline CHEMBL1575293 & 688653 & 4.883 & 4.9716 & TRN & & & \\
\hline CHEMBL1355892 & 688653 & 5.13299 & 99999999 & & 4.8706 & TRN & \\
\hline CHEMBL1477204 & 688653 & 4.833 & 5.1621 & TRN & & & \\
\hline CHEMBL1419624 & 688653 & 5.53299 & 99999999 & 995 & 5.25299 & 9999999999 & TST \\
\hline CHEMBL1423144 & 688653 & 5.483 & 5.6546 & TRN & & & \\
\hline CHEMBL1382054 & 688653 & 6.28299 & 99999999 & 995 & 5.4056 & TRN & \\
\hline CHEMBL1477333 & 688653 & 5.63299 & 99999999 & & 5.0887 & TST & \\
\hline CHEMBL3212994 & 688653 & 4.73300 & 00000000 & 005 & 5.0603 & TRN & \\
\hline CHEMBL399632 & 688653 & 4.683 & 5.2707 & TST & & & \\
\hline CHEMBL1611994 & 688653 & 5.733 & 5.1254 & TST & & & \\
\hline CHEMBL1510645 & 688653 & 4.633 & 5.274 & TST & & & \\
\hline CHEMBL452241 & 688653 & 4.783 & 5.2887 & TRN & & & \\
\hline CHEMBL1322078 & 688653 & 5.58299 & 99999999 & & 5.2776 & TRN & \\
\hline CHEMBL1403148 & 688653 & 5.083 & 4.7893 & TRN & & & \\
\hline CHEMBL1560217 & 688653 & 4.73300 & 00000000 & 005 & 4.8508 & TRN & \\
\hline CHEMBL1333193 & 688653 & 4.73300 & 00000000 & 005 & 5.0929 & TRN & \\
\hline CHEMBL1527214 & 688653 & 5.483 & 6.1567 & TRN & & & \\
\hline CHEMBL1607518 & 688653 & 4.833 & 4.91 & TRN & & & \\
\hline CHEMBL1542979 & 688653 & 6.8831 & 6.0152 & TRN & & & \\
\hline CHEMBL1560106 & 688653 & 6.38299 & 99999999 & & 5.12200 & 3000000001 & TRN \\
\hline CHEMBL1358621 & 688653 & 5.78299 & 99999999 & 995 & 5.4366 & TRN & \\
\hline CHEMBL1543237 & 688653 & 4.98300 & 00000000 & 005 & 5.6436 & TST & \\
\hline CHEMBL1382599 & 688653 & 5.483 & 5.0002 & TST & & & \\
\hline CHEMBL1333377 & 688653 & 4.933 & 5.4175 & TRN & & & \\
\hline CHEMBL1545504 & 688653 & 4.783 & 5.0909 & TST & & & \\
\hline CHEMBL1387787 & 688653 & 4.98300 & 00000000 & 005 & 5.1495 & TRN & \\
\hline CHEMBL1569018 & 688653 & 5.733 & 5.3063 & TST & & & \\
\hline CHEMBL1441056 & 688653 & 4.683 & 4.9185 & TST & & & \\
\hline CHEMBL3198108 & 688653 & 5.433 & 5.2781 & TST & & & \\
\hline CHEMBL1593722 & 688653 & 5.83299 & 99999999 & & 5.5703 & TRN & \\
\hline CHEMBL1535050 & 688653 & 6.78299 & 99999999 & 995 & 5.8813 & TRN & \\
\hline CHEMBL1542928 & 688653 & 6.53299 & 99999999 & 995 & 5.4712 & TRN & \\
\hline CHEMBL3193377 & 688653 & 6.433 & 5.7343 & TRN & & & \\
\hline CHEMBL3189998 & 688653 & 5.13299 & 99999999 & & 5.1915 & TRN & \\
\hline CHEMBL1405412 & 688653 & 4.883 & 5.1595 & TRN & & & \\
\hline CHEMBL1474810 & 688653 & 5.933 & 5.5268 & TRN & & & \\
\hline
\end{tabular}




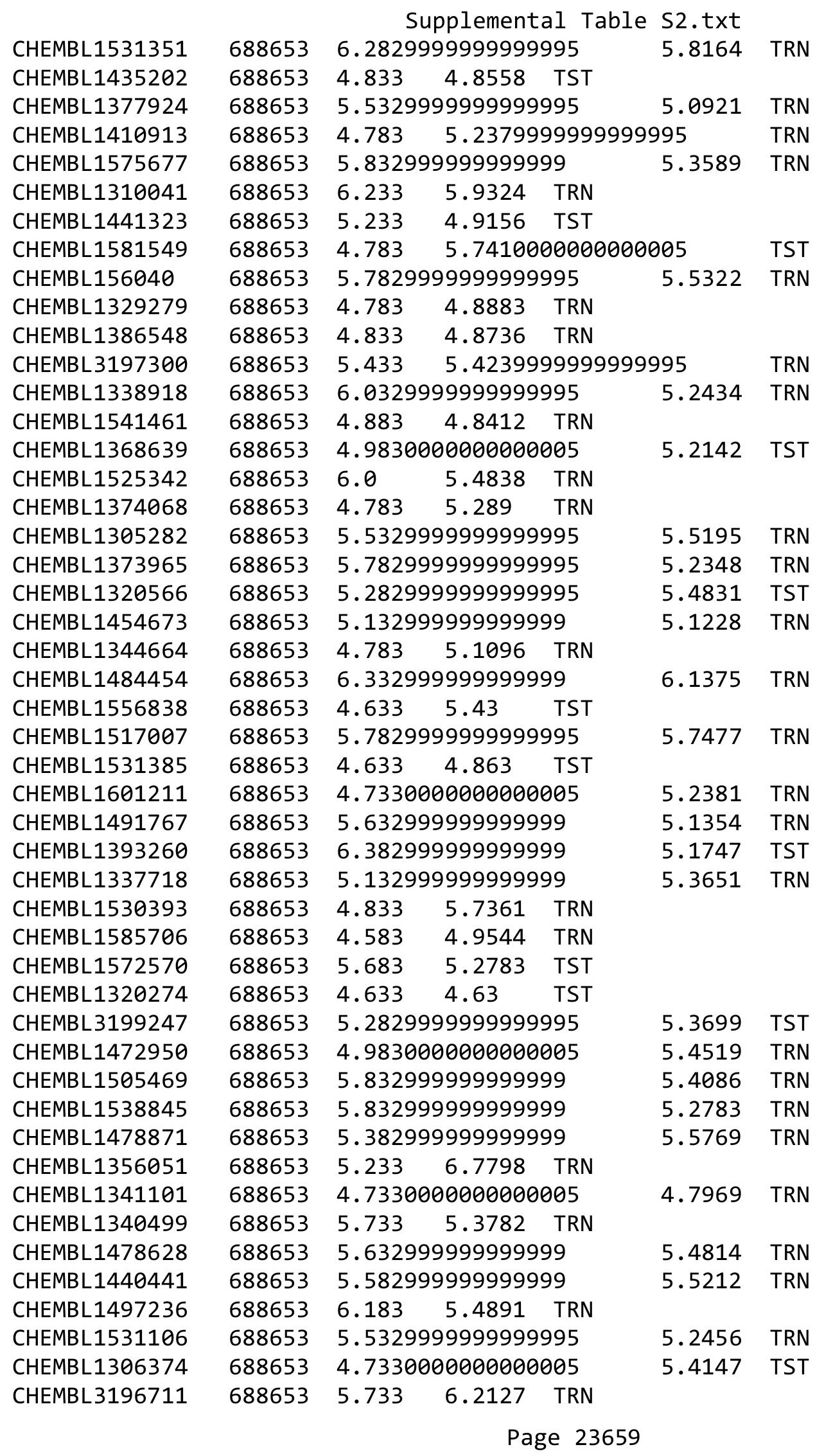




\begin{tabular}{|c|c|c|c|c|c|c|}
\hline \multirow{3}{*}{$\begin{array}{l}\text { CHEMBL1532227 } \\
\text { CHEMBL1333515 }\end{array}$} & \multirow{3}{*}{$\begin{array}{l}688653 \\
688653\end{array}$} & \multicolumn{4}{|c|}{ Supplemental Table S2.txt } & \multirow{2}{*}{ TRN } \\
\hline & & \multicolumn{3}{|c|}{5.7829999999999995} & 5.9207 & \\
\hline & & 6.4829 & 5.6602 & TRN & & \\
\hline CHEMBL1452114 & 688653 & 4.783 & 5.1351 & TRN & & \\
\hline CHEMBL1571051 & 688653 & 5.183 & 4.865 & TRN & & \\
\hline CHEMBL1517400 & 688653 & 5.083 & 5.0316 & TRN & & \\
\hline CHEMBL1313706 & 688653 & 5.733 & 5.5156 & TST & & \\
\hline CHEMBL1336288 & 688653 & 4.783 & 5.2695 & TRN & & \\
\hline CHEMBL1510925 & 688653 & \multicolumn{3}{|c|}{5.632999999999999} & 5.6612 & TRN \\
\hline CHEMBL1553021 & 688653 & 5.733 & 5.1973 & TRN & & \\
\hline CHEMBL1461592 & 688653 & 4.933 & 5.2981 & TST & & \\
\hline CHEMBL 260311 & 688653 & 6.0 & 5.612 & TRN & & \\
\hline CHEMBL3199673 & 688653 & 5.233 & 6.6795 & TRN & & \\
\hline CHEMBL1422337 & 688653 & 5.683 & 4.8508 & TST & & \\
\hline CHEMBL1534380 & 688653 & 4.583 & 5.0016 & TRN & & \\
\hline CHEMBL1469931 & 688653 & 4.783 & 5.2271 & TST & & \\
\hline CHEMBL1567019 & 688653 & 5.683 & 5.4724 & TRN & & \\
\hline CHEMBL1464753 & 688653 & \multicolumn{3}{|c|}{5.7829999999999995} & 4.979 & TRN \\
\hline CHEMBL1545059 & 688653 & 5.083 & 5.2671 & TRN & & \\
\hline CHEMBL581152 & 688653 & 4.633 & 5.1603 & TST & & \\
\hline CHEMBL1538973 & 688653 & 6.0 & 5.9298 & TRN & & \\
\hline CHEMBL1507410 & 688653 & 4.783 & 5.5857 & TRN & & \\
\hline CHEMBL1535087 & 688653 & 5.733 & 5.9022 & TRN & & \\
\hline CHEMBL1418943 & 688653 & 5.433 & 5.0254 & TST & & \\
\hline CHEMBL1407688 & 688653 & 4.833 & 5.0459 & TRN & & \\
\hline CHEMBL1556389 & 688653 & \multicolumn{3}{|c|}{4.7330000000000005} & 4.7186 & TRN \\
\hline CHEMBL1560861 & 688653 & 4.883 & 5.1074 & TRN & & \\
\hline CHEMBL1578100 & 688653 & 5.033 & 5.1238 & TRN & & \\
\hline CHEMBL3190106 & 688653 & 5.233 & 5.2771 & TRN & & \\
\hline CHEMBL1332688 & 688653 & \multicolumn{3}{|c|}{6.582999999999999} & 5.6826 & TRN \\
\hline CHEMBL3191418 & 688653 & \multicolumn{3}{|c|}{5.132999999999999} & 5.0596 & TRN \\
\hline CHEMBL1446172 & 688653 & 4.633 & 5.2647 & TRN & & \\
\hline CHEMBL1579388 & 688653 & \multirow{2}{*}{\multicolumn{3}{|c|}{$\begin{array}{l}4.933 \quad 5.6716 \text { TRN } \\
4.7330000000000005\end{array}$}} & & \\
\hline CHEMBL1446947 & 688653 & & & & 5.6169 & TRN \\
\hline CHEMBL1470841 & 688653 & 4.783 & 5.0583 & TRN & & \\
\hline CHEMBL1599542 & 688653 & 5.233 & 5.3981 & TRN & & \\
\hline CHEMBL1600749 & 688653 & \multicolumn{3}{|c|}{5.882999999999999} & 6.2002 & TRN \\
\hline CHEMBL1601492 & 688653 & \multicolumn{3}{|c|}{5.832999999999999} & 5.1397 & TRN \\
\hline CHEMBL1540484 & 688653 & 5.183 & 5.1018 & TST & & \\
\hline CHEMBL162783 & 688653 & 5.183 & 4.9443 & TST & & \\
\hline CHEMBL1328024 & 688653 & \multicolumn{3}{|c|}{5.5329999999999995} & 5.1526 & TRN \\
\hline CHEMBL1500819 & 688653 & \multicolumn{3}{|c|}{6.0329999999999995} & 5.2518 & TRN \\
\hline CHEMBL1489588 & 688653 & 6.433 & 6.0365 & TRN & & \\
\hline CHEMBL1590482 & 688653 & \multicolumn{3}{|c|}{5.582999999999999} & 5.2699 & TRN \\
\hline CHEMBL1387868 & 688653 & 5.083 & 5.5065 & TRN & & \\
\hline CHEMBL1587945 & 688653 & \multicolumn{3}{|c|}{5.332999999999999} & 5.1212 & TRN \\
\hline CHEMBL 261777 & 688653 & \multicolumn{3}{|c|}{6.382999999999999} & 5.761 & TRN \\
\hline CHEMBL1410690 & 688653 & \multicolumn{3}{|c|}{7.082999999999999} & 5.6673 & TRN \\
\hline CHEMBL1319258 & 688653 & 4.633 & 5.2757 & TRN & & \\
\hline
\end{tabular}




\begin{tabular}{|c|c|c|c|c|c|c|c|}
\hline \multicolumn{7}{|c|}{ Supplemental Table S2.txt } & \\
\hline CHEMBL1370087 & 688653 & \multicolumn{3}{|c|}{6.2829999999999995} & 5.8821 & TRN & \\
\hline CHEMBL1335863 & 688653 & \multicolumn{3}{|c|}{6.632999999999999} & 5.5306 & TRN & \\
\hline CHEMBL1446909 & 688653 & 5.483 & 5.4179 & TRN & & & \\
\hline CHEMBL1452159 & 688653 & 4.933 & 5.4804 & TRN & & & \\
\hline CHEMBL1602453 & 688653 & 4.783 & 5.1566 & TRN & & & \\
\hline CHEMBL1420641 & 688653 & 5.083 & 5.4661 & TRN & & & \\
\hline CHEMBL1331322 & 688653 & 4.633 & 5.1989 & TRN & & & \\
\hline CHEMBL588028 & 688653 & \multicolumn{3}{|c|}{5.132999999999999} & 5.2537 & TRN & \\
\hline CHEMBL1448741 & 688653 & \multicolumn{3}{|c|}{5.382999999999999} & 5.0983 & TRN & \\
\hline CHEMBL1301278 & 688653 & 4.583 & 4.6131 & TST & & & \\
\hline CHEMBL1378838 & 688653 & 4.833 & 5.0199 & TRN & & & \\
\hline CHEMBL1968628 & 688653 & \multicolumn{3}{|c|}{5.882999999999999} & 5.8705 & TRN & \\
\hline CHEMBL1299268 & 688653 & 5.483 & 5.555 & TRN & & & \\
\hline CHEMBL1566113 & 688653 & \multicolumn{3}{|c|}{4.9830000000000005} & 5.1108 & TST & \\
\hline CHEMBL1520468 & 688653 & \multicolumn{3}{|c|}{4.7330000000000005} & 5.66700 & 0000000001 & TST \\
\hline CHEMBL1380561 & 688653 & \multicolumn{3}{|c|}{5.332999999999999} & 5.22 & TRN & \\
\hline CHEMBL142652 & 688653 & \multicolumn{3}{|c|}{5.332999999999999} & 5.1716 & TST & \\
\hline CHEMBL1322534 & 688653 & 4.833 & 5.2304 & TRN & & & \\
\hline CHEMBL84010 & 688653 & 6.183 & 5.7722 & TRN & & & \\
\hline CHEMBL1524656 & 688653 & \multicolumn{3}{|c|}{4.7330000000000005} & 5.2667 & TST & \\
\hline CHEMBL1558539 & 688653 & \multicolumn{3}{|c|}{5.832999999999999} & 5.1942 & TRN & \\
\hline CHEMBL1421811 & 688653 & \multicolumn{3}{|c|}{5.7829999999999995} & 5.8024 & TRN & \\
\hline CHEMBL1549290 & 688653 & 5.183 & 5.1582 & TRN & & & \\
\hline CHEMBL1390832 & 688653 & \multicolumn{3}{|c|}{4.7330000000000005} & 4.9047 & TST & \\
\hline CHEMBL1602694 & 688653 & \multicolumn{3}{|c|}{5.5329999999999995} & 5.2329 & TRN & \\
\hline CHEMBL 3199348 & 688653 & 4.783 & 5.5246 & TRN & & & \\
\hline CHEMBL1376997 & 688653 & 4.883 & 5.1637 & TRN & & & \\
\hline CHEMBL1352987 & 688653 & 5.983 & 5.5468 & TRN & & & \\
\hline CHEMBL1568160 & 688653 & 5.233 & 4.9963 & TRN & & & \\
\hline CHEMBL1464195 & 688653 & 5.433 & 5.9775 & TRN & & & \\
\hline CHEMBL599307 & 688653 & 4.833 & 4.8926 & TST & & & \\
\hline CHEMBL1497198 & 688653 & \multicolumn{3}{|c|}{5.132999999999999} & 5.0959 & TRN & \\
\hline CHEMBL1443354 & 688653 & \multicolumn{3}{|c|}{5.882999999999999} & 5.4009 & TST & \\
\hline CHEMBL1486503 & 688653 & 4.783 & 5.0864 & TRN & & & \\
\hline CHEMBL1369125 & 688653 & 4.783 & 4.7423 & TRN & & & \\
\hline CHEMBL1323670 & 688653 & 4.783 & 5.4125 & TST & & & \\
\hline CHEMBL1597750 & 688653 & 6.7331 & 5.8757 & TRN & & & \\
\hline CHEMBL1603553 & 688653 & \multicolumn{3}{|c|}{6.132999999999999} & 5.7742 & TRN & \\
\hline CHEMBL1302281 & 688653 & 4.833 & 5.0969 & TRN & & & \\
\hline CHEMBL1499190 & 688653 & \multicolumn{3}{|c|}{5.382999999999999} & 5.2434 & TRN & \\
\hline CHEMBL1456371 & 688653 & 4.833 & 5.0083 & TST & & & \\
\hline CHEMBL1534215 & 688653 & 4.783 & \multicolumn{3}{|c|}{4.7860000000000005} & TRN & \\
\hline CHEMBL3195305 & 688653 & 4.883 & 5.1836 & TST & & & \\
\hline CHEMBL 3192470 & 688653 & \multicolumn{3}{|c|}{4.7330000000000005} & 5.2525 & TRN & \\
\hline CHEMBL1364200 & 688653 & 5.3329 & 99999999 & & 5.138 & TRN & \\
\hline CHEMBL1489433 & 688653 & 4.833 & 5.2115 & TRN & & & \\
\hline CHEMBL1417451 & 688653 & 4.9 & 5.3642 & TST & & & \\
\hline CHEMBL1418750 & 688653 & 4.583 & 5.0889 & TRN & & & \\
\hline
\end{tabular}




\begin{tabular}{|c|c|c|c|c|c|c|}
\hline \multirow{3}{*}{$\begin{array}{l}\text { CHEMBL } 3211451 \\
\text { CHEMBL1423729 }\end{array}$} & \multirow{3}{*}{$\begin{array}{l}688653 \\
688653\end{array}$} & \multicolumn{5}{|c|}{ Supplemental Table S2.txt } \\
\hline & & \multicolumn{3}{|c|}{5.132999999999999} & \multirow[t]{3}{*}{4.7621} & \multirow[t]{3}{*}{ TRN } \\
\hline & & 5.083 & 5.9409 & TRN & & \\
\hline CHEMBL1598287 & 688653 & 5.733 & 5.4297 & TRN & & \\
\hline CHEMBL1523967 & 688653 & \multicolumn{3}{|c|}{5.7829999999999995} & 5.0591 & TST \\
\hline CHEMBL1996922 & 688653 & 5.983 & 5.6432 & TRN & & \\
\hline CHEMBL1512145 & 688653 & 4.933 & 5.2033 & TRN & & \\
\hline CHEMBL3191644 & 688653 & \multicolumn{3}{|c|}{6.0329999999999995} & 5.5258 & TRN \\
\hline CHEMBL1495180 & 688653 & \multicolumn{3}{|c|}{5.332999999999999} & 5.4714 & TRN \\
\hline CHEMBL1594388 & 688653 & 4.883 & 4.8281 & TST & & \\
\hline CHEMBL1515797 & 688653 & 5.183 & 4.9661 & TRN & & \\
\hline CHEMBL3194959 & 688653 & 4.833 & 5.0511 & TRN & & \\
\hline CHEMBL1392259 & 688653 & \multicolumn{3}{|c|}{5.132999999999999} & 5.5545 & TRN \\
\hline CHEMBL1546895 & 688653 & 5.483 & 5.263 & TRN & & \\
\hline CHEMBL1386821 & 688653 & 4.833 & 5.1148 & TRN & & \\
\hline CHEMBL1486726 & 688653 & 6.983 & 6.1908 & TRN & & \\
\hline CHEMBL1513762 & 688653 & \multicolumn{3}{|c|}{6.382999999999999} & 5.4672 & TRN \\
\hline CHEMBL1549407 & 688653 & \multicolumn{3}{|c|}{5.7829999999999995} & 5.0585 & TRN \\
\hline CHEMBL1499828 & 688653 & \multicolumn{3}{|c|}{4.7330000000000005} & 4.9908 & TRN \\
\hline CHEMBL1564625 & 688653 & 4.8 & 5.6555 & TRN & & \\
\hline CHEMBL1484663 & 688653 & 4.683 & 5.5765 & TRN & & \\
\hline CHEMBL1611896 & 688653 & 6.4829 & 6.0013 & TRN & & \\
\hline CHEMBL1507129 & 688653 & \multicolumn{3}{|c|}{6.082999999999999} & 5.7104 & TRN \\
\hline CHEMBL1336236 & 688653 & \multicolumn{3}{|c|}{5.2829999999999995} & 4.8368 & TRN \\
\hline CHEMBL1403977 & 688653 & 4.783 & 5.2597 & TRN & & \\
\hline CHEMBL1389570 & 688653 & 4.883 & 5.2935 & TST & & \\
\hline CHEMBL1325754 & 688653 & \multicolumn{3}{|c|}{4.7330000000000005} & 5.2197 & TRN \\
\hline CHEMBL1452173 & 688653 & 4.633 & 4.7504 & TRN & & \\
\hline CHEMBL1573534 & 688653 & 4.633 & 5.2888 & TRN & & \\
\hline CHEMBL1331100 & 688653 & \multicolumn{3}{|c|}{5.632999999999999} & 5.3736 & TRN \\
\hline CHEMBL1554159 & 688653 & \multicolumn{3}{|c|}{5.7829999999999995} & 5.7317 & TRN \\
\hline CHEMBL1510676 & 688653 & \multicolumn{3}{|c|}{4.7330000000000005} & 5.2273 & TST \\
\hline CHEMBL1418320 & 688653 & 5.083 & 5.2966 & TRN & & \\
\hline CHEMBL3209601 & 688653 & 4.833 & 5.0693 & TRN & & \\
\hline CHEMBL1306640 & 688653 & 5.233 & 5.0945 & TST & & \\
\hline CHEMBL1534262 & 688653 & \multicolumn{3}{|c|}{5.2829999999999995} & 5.3218 & TRN \\
\hline CHEMBL1501846 & 688653 & 4.833 & 5.2749 & TRN & & \\
\hline CHEMBL1411348 & 688653 & 4.883 & 5.5424 & TRN & & \\
\hline CHEMBL1333360 & 688653 & 4.783 & 5.2741 & TRN & & \\
\hline CHEMBL1408581 & 688653 & \multicolumn{3}{|c|}{6.0329999999999995} & 5.7447 & TRN \\
\hline CHEMBL1412359 & 688653 & 4.833 & 4.7972 & TRN & & \\
\hline CHEMBL1610581 & 688653 & 5.2829 & 9999999 & 995 & 5.3753 & TRN \\
\hline CHEMBL1380884 & 688653 & 5.183 & 5.2294 & TRN & & \\
\hline CHEMBL1508269 & 688653 & 5.8329 & 9999999 & & 5.7383 & TRN \\
\hline CHEMBL1317201 & 688653 & 5.483 & 4.994 & TRN & & \\
\hline CHEMBL1453873 & 688653 & 4.7330 & 0000000 & 005 & 5.1079 & TRN \\
\hline CHEMBL 3208543 & 688653 & 4.783 & 5.3337 & TST & & \\
\hline CHEMBL1310407 & 688653 & 4.883 & 5.4435 & TST & & \\
\hline CHEMBL1532568 & 688653 & 6.183 & 5.6916 & TRN & & \\
\hline
\end{tabular}





\begin{tabular}{|c|c|c|c|c|c|c|c|}
\hline \multicolumn{8}{|c|}{ Supplemental Table S2.txt } \\
\hline CHEMBL3199254 & 688653 & 4.833 & 5.3089 & TRN & & & \\
\hline CHEMBL1407248 & 688653 & \multicolumn{3}{|c|}{5.332999999999999} & 5.3679 & TRN & \\
\hline CHEMBL1504269 & 688653 & 5.033 & 5.2408 & TRN & & & \\
\hline CHEMBL1317158 & 688653 & 4.783 & 4.9945 & TRN & & & \\
\hline CHEMBL1539807 & 688653 & 4.833 & 5.5525 & TRN & & & \\
\hline CHEMBL 235036 & 688653 & 4.883 & 4.8903 & TRN & & & \\
\hline CHEMBL1600656 & 688653 & 4.883 & 5.0377 & TRN & & & \\
\hline CHEMBL1302824 & 688653 & 4.633 & 4.933 & TRN & & & \\
\hline CHEMBL1345341 & 688653 & 5.433 & 6.0009 & TRN & & & \\
\hline CHEMBL1599035 & 688653 & 4.933 & 5.0465 & TST & & & \\
\hline CHEMBL 3145201 & 688653 & 4.833 & 5.5218 & TRN & & & \\
\hline CHEMBL3190653 & 688653 & 6.983 & 6.2578 & TRN & & & \\
\hline CHEMBL1302101 & 688653 & 4.833 & 5.0281 & TRN & & & \\
\hline CHEMBL1514409 & 688653 & \multicolumn{3}{|c|}{6.632999999999999} & 5.3466 & TRN & \\
\hline CHEMBL1459759 & 688653 & 4.883 & 5.2017 & TRN & & & \\
\hline CHEMBL1482624 & 688653 & 5.983 & 5.5322 & TRN & & & \\
\hline CHEMBL3195853 & 688653 & 4.883 & 5.1575 & TST & & & \\
\hline CHEMBL1337616 & 688653 & 4.883 & 5.309 & TRN & & & \\
\hline CHEMBL3195933 & 688653 & 4.883 & 5.1658 & TST & & & \\
\hline CHEMBL 3210770 & 688653 & 5.933 & 5.3811 & TRN & & & \\
\hline CHEMBL1321449 & 688653 & 4.783 & \multicolumn{3}{|c|}{5.1160000000000005} & TST & \\
\hline CHEMBL546649 & 688653 & 5.183 & 5.3991 & TRN & & & \\
\hline CHEMBL1312057 & 688653 & \multicolumn{3}{|c|}{6.0329999999999995} & 5.6447 & TRN & \\
\hline CHEMBL1526738 & 688653 & \multicolumn{3}{|c|}{6.2829999999999995} & 5.9899 & TRN & \\
\hline CHEMBL1300459 & 688653 & 4.683 & 5.1553 & TRN & & & \\
\hline CHEMBL1518624 & 688653 & \multicolumn{3}{|c|}{6.2829999999999995} & 5.3004 & TRN & \\
\hline CHEMBL1366523 & 688653 & 5.733 & 5.6361 & TRN & & & \\
\hline CHEMBL1522468 & 688653 & 5.183 & 5.4529 & TRN & & & \\
\hline CHEMBL1597850 & 688653 & 5.433 & 5.2134 & TRN & & & \\
\hline CHEMBL3211390 & 688653 & 4.783 & 5.1058 & TRN & & & \\
\hline CHEMBL1473619 & 688653 & 5.033 & 4.9232 & TST & & & \\
\hline CHEMBL1559067 & 688653 & 5.683 & 5.0547 & TRN & & & \\
\hline CHEMBL3194445 & 688653 & 4.783 & 4.92 & TST & & & \\
\hline CHEMBL1574671 & 688653 & 5.683 & 5.7908 & TST & & & \\
\hline CHEMBL1376656 & 688653 & \multicolumn{3}{|c|}{6.2829999999999995} & 5.4023 & TRN & \\
\hline CHEMBL 1574553 & 688653 & \multicolumn{3}{|c|}{6.7829999999999995} & \multicolumn{2}{|c|}{6.787000000000001} & TST \\
\hline CHEMBL1579826 & 688653 & 4.883 & 4.8468 & TST & & & \\
\hline CHEMBL1578936 & 688653 & 4.783 & 5.3049 & TST & & & \\
\hline CHEMBL1386466 & 688653 & \multicolumn{3}{|c|}{6.832999999999999} & \multicolumn{2}{|c|}{5.577000000000001} & TRN \\
\hline CHEMBL1472773 & 688653 & 5.983 & \multicolumn{2}{|c|}{5.321000000000001} & & TST & \\
\hline CHEMBL1347759 & 688653 & 5.033 & 5.2503 & TRN & & & \\
\hline CHEMBL1582368 & 688653 & 5.683 & 5.9258 & TRN & & & \\
\hline CHEMBL1482373 & 688653 & 4.683 & 5.0455 & TRN & & & \\
\hline CHEMBL1387775 & 688653 & 4.933 & 6.3435 & TRN & & & \\
\hline CHEMBL1440725 & 688653 & \multicolumn{3}{|c|}{5.2829999999999995} & 5.26 & TRN & \\
\hline CHEMBL1369671 & 688653 & 4.633 & 4.7498 & TRN & & & \\
\hline CHEMBL1386291 & 688653 & 5.233 & 5.0393 & TST & & & \\
\hline CHEMBL1558765 & 688653 & \multicolumn{3}{|c|}{5.132999999999999} & 4.9314 & TRN & \\
\hline
\end{tabular}




\begin{tabular}{|c|c|c|c|c|c|c|c|}
\hline \multicolumn{7}{|c|}{ Supplemental Table S2.txt } & \\
\hline CHEMBL1548329 & 688653 & \multicolumn{3}{|c|}{5.632999999999999} & \multirow[t]{3}{*}{5.1076} & \multirow[t]{3}{*}{ TST } & \\
\hline CHEMBL1459739 & 688653 & 4.783 & 4.9794 & TRN & & & \\
\hline CHEMBL1525719 & 688653 & 4.633 & 4.9665 & TRN & & & \\
\hline CHEMBL1541539 & 688653 & \multicolumn{3}{|c|}{6.2829999999999995} & 5.4765 & TRN & \\
\hline CHEMBL1581706 & 688653 & 4.783 & 4.9704 & TST & & & \\
\hline CHEMBL1544272 & 688653 & 5.733 & 5.2275 & TRN & & & \\
\hline CHEMBL1503081 & 688653 & \multicolumn{3}{|c|}{5.632999999999999} & 5.1417 & TRN & \\
\hline CHEMBL1339694 & 688653 & \multicolumn{3}{|c|}{5.332999999999999} & \multicolumn{2}{|c|}{5.297999999999999} & TRN \\
\hline CHEMBL1595855 & 688653 & 4.783 & 5.3272 & TRN & & & \\
\hline CHEMBL1508982 & 688653 & 5.233 & 5.8786 & TRN & & & \\
\hline CHEMBL1472103 & 688653 & 4.783 & 5.0849 & TST & & & \\
\hline CHEMBL1379858 & 688653 & 5.183 & 5.1055 & TRN & & & \\
\hline CHEMBL1383541 & 688653 & 5.683 & 5.9972 & TRN & & & \\
\hline CHEMBL1501113 & 688653 & \multicolumn{3}{|c|}{5.632999999999999} & 4.7188 & TRN & \\
\hline CHEMBL1523568 & 688653 & 4.633 & 4.9373 & TRN & & & \\
\hline CHEMBL1306164 & 688653 & 4.833 & 4.9731 & TRN & & & \\
\hline CHEMBL1410167 & 688653 & 4.633 & 4.9511 & TRN & & & \\
\hline CHEMBL1556399 & 688653 & 5.683 & 4.9586 & TRN & & & \\
\hline CHEMBL1501729 & 688653 & \multicolumn{3}{|c|}{5.132999999999999} & 4.9763 & TRN & \\
\hline CHEMBL1490962 & 688653 & 4.783 & 5.524 & TRN & & & \\
\hline CHEMBL1417661 & 688653 & 4.883 & 5.8205 & TRN & & & \\
\hline CHEMBL1326394 & 688653 & 4.783 & 5.3921 & TRN & & & \\
\hline CHEMBL1362973 & 688653 & 4.833 & 5.0564 & TRN & & & \\
\hline CHEMBL1483831 & 688653 & \multicolumn{3}{|c|}{5.382999999999999} & 5.2025 & TRN & \\
\hline CHEMBL1341232 & 688653 & \multicolumn{3}{|c|}{5.7829999999999995} & 5.8055 & TRN & \\
\hline CHEMBL599359 & 688653 & 4.783 & 5.1817 & TRN & & & \\
\hline CHEMBL1329375 & 688653 & \multicolumn{3}{|c|}{5.5329999999999995} & 5.6733 & TRN & \\
\hline CHEMBL1510669 & 688653 & \multicolumn{3}{|c|}{6.332999999999999} & 5.3174 & TRN & \\
\hline CHEMBL1582111 & 688653 & 5.433 & \multicolumn{3}{|c|}{5.531000000000001} & TST & \\
\hline CHEMBL601335 & 688653 & 4.783 & 5.7534 & TRN & & & \\
\hline CHEMBL1540903 & 688653 & \multicolumn{3}{|c|}{4.9830000000000005} & 5.2516 & TST & \\
\hline CHEMBL 3196328 & 688653 & \multicolumn{3}{|c|}{5.132999999999999} & 5.9432 & TRN & \\
\hline CHEMBL1542737 & 688653 & 5.033 & 5.1574 & TRN & & & \\
\hline CHEMBL358546 & 688653 & 4.783 & 5.0736 & TST & & & \\
\hline CHEMBL1323028 & 688653 & 6.4829 & 5.4136 & TRN & & & \\
\hline CHEMBL1478081 & 688653 & 5.183 & 5.0051 & TRN & & & \\
\hline CHEMBL1475334 & 688653 & 4.783 & 5.3096 & TST & & & \\
\hline CHEMBL1473898 & 688653 & 4.783 & 5.4928 & TRN & & & \\
\hline CHEMBL 3194393 & 688653 & \multicolumn{3}{|c|}{5.132999999999999} & 4.8032 & TRN & \\
\hline CHEMBL585439 & 688653 & \multicolumn{3}{|c|}{4.7330000000000005} & 4.8095 & TRN & \\
\hline CHEMBL1425794 & 688653 & \multicolumn{3}{|c|}{6.332999999999999} & 5.4801 & TRN & \\
\hline CHEMBL1591519 & 688653 & 4.633 & 4.9143 & TST & & & \\
\hline CHEMBL1594589 & 688653 & \multicolumn{3}{|c|}{4.7330000000000005} & 4.7736 & TRN & \\
\hline CHEMBL1324329 & 688653 & 4.683 & 4.5986 & TRN & & & \\
\hline CHEMBL1582213 & 688653 & 4.98300 & 00000000 & 005 & 4.6643 & TST & \\
\hline CHEMBL85826 & 688653 & 7.1331 & 5.9414 & TST & & & \\
\hline CHEMBL1420960 & 688653 & 4.833 & 5.1247 & TRN & & & \\
\hline CHEMBL1326817 & 688653 & 5.33299 & 99999999 & & 5.2916 & TRN & \\
\hline
\end{tabular}




\begin{tabular}{|c|c|c|c|c|c|c|}
\hline \multirow[b]{2}{*}{ CHEMBL1331773 } & \multirow[b]{2}{*}{688653} & \multicolumn{5}{|c|}{ Supplemental Table S2.txt } \\
\hline & & 4.633 & 5.1057 & TST & & \\
\hline CHEMBL1331514 & 688653 & \multicolumn{3}{|c|}{5.632999999999999} & 5.9706 & TRN \\
\hline CHEMBL1579260 & 688653 & 5.033 & 5.3559 & TRN & & \\
\hline CHEMBL1334674 & 688653 & 7.1331 & 5.7611 & TRN & & \\
\hline CHEMBL1388817 & 688653 & \multicolumn{3}{|c|}{5.5329999999999995} & 5.6737 & TRN \\
\hline CHEMBL1350364 & 688653 & \multicolumn{3}{|c|}{4.7330000000000005} & 5.153 & TRN \\
\hline CHEMBL1343256 & 688653 & \multicolumn{3}{|c|}{4.7330000000000005} & 5.3074 & TRN \\
\hline CHEMBL1377193 & 688653 & \multicolumn{3}{|c|}{5.832999999999999} & 5.2309 & TRN \\
\hline CHEMBL1459751 & 688653 & 4.933 & 5.2415 & TRN & & \\
\hline CHEMBL1311387 & 688653 & 4.783 & 5.3537 & TST & & \\
\hline CHEMBL1608495 & 688653 & 4.783 & 5.4609 & TRN & & \\
\hline CHEMBL3211368 & 688653 & \multicolumn{3}{|c|}{5.332999999999999} & 5.5363 & TRN \\
\hline CHEMBL1390703 & 688653 & 5.683 & 5.8292 & TRN & & \\
\hline CHEMBL1531935 & 688653 & \multicolumn{3}{|c|}{5.832999999999999} & 5.2175 & TRN \\
\hline CHEMBL1349435 & 688653 & 5.083 & 5.1086 & TST & & \\
\hline CHEMBL1542502 & 688653 & 4.783 & 5.3059 & TRN & & \\
\hline CHEMBL1453871 & 688653 & 4.933 & 4.7727 & TRN & & \\
\hline CHEMBL1380651 & 688653 & 5.233 & 5.3201 & TRN & & \\
\hline CHEMBL1309336 & 688653 & \multicolumn{3}{|c|}{5.7829999999999995} & 5.2833 & TRN \\
\hline CHEMBL1568022 & 688653 & 4.583 & 4.8721 & TRN & & \\
\hline CHEMBL1387701 & 688653 & \multicolumn{3}{|c|}{5.132999999999999} & 4.8657 & TRN \\
\hline CHEMBL1592616 & 688653 & 4.583 & 4.8071 & TRN & & \\
\hline CHEMBL1571239 & 688653 & 6.4 & 5.7558 & TRN & & \\
\hline CHEMBL1523828 & 688653 & 5.183 & 5.699 & TRN & & \\
\hline CHEMBL1548377 & 688653 & \multicolumn{3}{|c|}{4.7330000000000005} & 5.4781 & TST \\
\hline CHEMBL1414596 & 688653 & 7.0329 & 5.3536 & TRN & & \\
\hline CHEMBL510132 & 688653 & \multicolumn{3}{|c|}{4.7330000000000005} & 5.1602 & TRN \\
\hline CHEMBL1590015 & 688653 & 5.183 & 5.1469 & TRN & & \\
\hline CHEMBL1303929 & 688653 & 5.683 & 5.1833 & TRN & & \\
\hline CHEMBL1363469 & 688653 & 5.933 & 5.7035 & TRN & & \\
\hline CHEMBL1407983 & 688653 & 4.683 & 4.8845 & TRN & & \\
\hline CHEMBL1544460 & 688653 & \multicolumn{3}{|c|}{5.582999999999999} & 5.2785 & TRN \\
\hline CHEMBL1393333 & 688653 & \multicolumn{3}{|c|}{4.9830000000000005} & 4.5891 & TRN \\
\hline CHEMBL1613479 & 688653 & \multicolumn{3}{|c|}{6.582999999999999} & 6.0863 & TRN \\
\hline CHEMBL1370495 & 688653 & 4.883 & 5.1277 & TST & & \\
\hline CHEMBL1535188 & 688653 & 5.183 & 5.0463 & TST & & \\
\hline CHEMBL1405293 & 688653 & \multicolumn{3}{|c|}{4.9830000000000005} & 5.273 & TRN \\
\hline CHEMBL1567235 & 688653 & \multicolumn{3}{|c|}{4.9830000000000005} & 5.2976 & TRN \\
\hline CHEMBL1319467 & 688653 & \multicolumn{3}{|c|}{5.582999999999999} & 5.4567 & TST \\
\hline CHEMBL1490260 & 688653 & 4.783 & 5.4607 & TST & & \\
\hline CHEMBL3212243 & 688653 & \multirow{2}{*}{\multicolumn{3}{|c|}{$\begin{array}{lcc}4.783 & 5.1128 & \text { TRN } \\
4.7330000000000005\end{array}$}} & & \\
\hline CHEMBL1975620 & 688653 & & & & 5.1518 & TRN \\
\hline CHEMBL1517045 & 688653 & 5.183 & 5.5918 & TST & & \\
\hline CHEMBL1478996 & 688653 & 6.53299 & 99999999 & 995 & 5.7069 & TRN \\
\hline CHEMBL1578487 & 688653 & 5.183 & 4.6729 & TRN & & \\
\hline CHEMBL1548996 & 688653 & 4.783 & 5.3163 & TST & & \\
\hline CHEMBL1553121 & 688653 & 5.733 & 5.4157 & TST & & \\
\hline CHEMBL536008 & 688653 & 4.683 & 5.0173 & TST & & \\
\hline
\end{tabular}




\begin{tabular}{|c|c|c|c|c|c|c|}
\hline & & & pplemen & 1 & s2.txt & \\
\hline CHEMBL1321703 & 688653 & 5.1329 & 9999999 & & 5.6886 & TRA \\
\hline CHEMBL1394916 & 688653 & 5.733 & 5.4456 & TRN & & \\
\hline CHEMBL1313683 & 688653 & 6.433 & 5.5321 & TRN & & \\
\hline CHEMBL1612691 & 688653 & 5.683 & 5.1218 & TST & & \\
\hline CHEMBL1341926 & 688653 & 6.5829 & 9999999 & & 6.1063 & TRN \\
\hline CHEMBL1789993 & 688653 & 5.3829 & 9999999 & & 5.1659 & TST \\
\hline CHEMBL1534312 & 688653 & 5.183 & 5.1577 & TRN & & \\
\hline CHEMBL1523140 & 688653 & 5.683 & 5.6658 & TRN & & \\
\hline CHEMBL1496470 & 688653 & 4.883 & 4.9591 & TRN & & \\
\hline CHEMBL1401001 & 688653 & 5.1325 & 9999999 & & 5.5436 & TRN \\
\hline CHEMBL1341312 & 688653 & 5.3829 & 9999999 & & 5.0353 & TRA \\
\hline CHEMBL1310290 & 688653 & 5.1329 & 9999999 & & 5.0927 & TRN \\
\hline CHEMBL1515343 & 688653 & 5.183 & 5.3716 & TRN & & \\
\hline CHEMBL1327684 & 688653 & 5.033 & 5.3012 & TRN & & \\
\hline CHEMBL1322995 & 688653 & 6.0 & 4.824 & TRN & & \\
\hline CHEMBL1312665 & 688653 & 5.983 & 5.5918 & TST & & \\
\hline CHEMBL1337753 & 688653 & 5.083 & 5.016 & TRN & & \\
\hline CHEMBL1473964 & 688653 & 4.7336 & 0000000 & 005 & 5.0208 & TRN \\
\hline CHEMBL1422958 & 688653 & 5.5329 & 9999999 & 995 & 5.3389 & TRN \\
\hline CHEMBL1582340 & 688653 & 4.783 & 5.192 & TRN & & \\
\hline CHEMBL1557468 & 688653 & 5.733 & 5.4284 & TRN & & \\
\hline CHEMBL1383299 & 688653 & 4.9836 & 0000000 & 005 & 5.4588 & TRN \\
\hline CHEMBL1366494 & 688653 & 4.933 & 5.2929 & TST & & \\
\hline CHEMBL1330734 & 688653 & 4.883 & 5.0555 & TRN & & \\
\hline CHEMBL3194699 & 688653 & 5.033 & 4.7986 & TST & & \\
\hline CHEMBL1369876 & 688653 & 5.7829 & 9999999 & 995 & 5.1533 & TRA \\
\hline CHEMBL1483199 & 688653 & 4.783 & 5.3451 & TST & & \\
\hline CHEMBL1464689 & 688653 & 6.183 & 5.1591 & TRN & & \\
\hline CHEMBL1508377 & 688653 & 6.3329 & 9999999 & & 5.8757 & TRA \\
\hline CHEMBL1433046 & 688653 & 5.183 & 5.8323 & TRN & & \\
\hline CHEMBL1503459 & 688653 & 4.7336 & 0000000 & 005 & 5.5633 & TST \\
\hline CHEMBL1570979 & 688653 & 4.7336 & 0000000 & 005 & 5.5952 & TRN \\
\hline CHEMBL1436964 & 688653 & 5.2829 & 9999999 & 995 & 4.6026 & TRN \\
\hline CHEMBL1417858 & 688653 & 5.1329 & 9999999 & & 5.1793 & TRA \\
\hline CHEMBL1540795 & 688653 & 4.633 & 4.7667 & TST & & \\
\hline CHEMBL1469897 & 688653 & 5.1329 & 9999999 & & 5.1471 & TRA \\
\hline CHEMBL1597334 & 688653 & 5.2829 & 9999999 & 995 & 5.4784 & TRN \\
\hline CHEMBL1329230 & 688653 & 4.833 & 5.2774 & TRN & & \\
\hline CHEMBL1603512 & 688653 & 5.5329 & 9999999 & 995 & 5.3879 & TST \\
\hline CHEMBL1579233 & 688653 & 4.7336 & 0000000 & 005 & 5.4698 & TRA \\
\hline CHEMBL1397396 & 688653 & 4.633 & 4.7758 & TRN & & \\
\hline CHEMBL1571742 & 688653 & 5.1320 & 9999999 & & 5.7572 & TRN \\
\hline CHEMBL1356864 & 688653 & 4.7336 & 0000000 & 005 & 4.9485 & TRN \\
\hline CHEMBL1493761 & 688653 & 5.8329 & 9999999 & & 5.3621 & TRN \\
\hline CHEMBL1418923 & 688653 & 6.3820 & 9999999 & & 5.2294 & TRN \\
\hline CHEMBL603020 & 688653 & 4.883 & 4.857 & TRN & & \\
\hline CHEMBL1397770 & 688653 & 4.833 & 5.5628 & TRN & & \\
\hline CHEMBL1611055 & 688653 & 4.833 & 5.3664 & TRN & & \\
\hline
\end{tabular}




\begin{tabular}{|c|c|c|c|c|c|c|c|}
\hline \multicolumn{7}{|c|}{ Supplemental Table s2.txt } & \\
\hline CHEMBL1456003 & 688653 & 6.233 & 5.5686 & TRN & & & \\
\hline CHEMBL1512957 & 688653 & 4.783 & 5.4434 & TRN & & & \\
\hline CHEMBL1319679 & 688653 & 6.7331 & 5.7178 & TRN & & & \\
\hline CHEMBL1353187 & 688653 & 4.833 & 5.3469 & TRN & & & \\
\hline CHEMBL1557668 & 688653 & 5.933 & 5.2648 & TRN & & & \\
\hline CHEMBL1500304 & 688653 & 4.783 & 5.0681 & TRN & & & \\
\hline CHEMBL1482740 & 688653 & 5.78299 & 999999999 & 995 & 5.2701 & TST & \\
\hline CHEMBL1336321 & 688653 & 4.783 & 5.0394 & TRN & & & \\
\hline CHEMBL1558549 & 688653 & 5.733 & 5.5762 & TRN & & & \\
\hline CHEMBL1412057 & 688653 & 5.683 & 5.1697 & TRN & & & \\
\hline CHEMBL1511065 & 688653 & 6.28299 & 999999999 & 995 & 5.0803 & TRN & \\
\hline CHEMBL1490128 & 688653 & 4.833 & 5.2081 & TRN & & & \\
\hline CHEMBL3197789 & 688653 & 5.933 & 5.2877 & TRN & & & \\
\hline CHEMBL1364908 & 688653 & 5.183 & 5.0802 & TST & & & \\
\hline CHEMBL1448207 & 688653 & 4.933 & 5.4315 & TRN & & & \\
\hline CHEMBL1550040 & 688653 & 5.33299 & 999999999 & & 5.296 & TST & \\
\hline CHEMBL1451648 & 688653 & 5.63299 & 999999999 & & 5.4907 & TRN & \\
\hline CHEMBL1491894 & 688653 & 5.733 & 5.7298 & TST & & & \\
\hline CHEMBL1410603 & 688653 & 4.73300 & 000000000 & 005 & 4.8735 & TRN & \\
\hline CHEMBL 1453870 & 688653 & 4.933 & 5.3914 & TRN & & & \\
\hline CHEMBL1548740 & 688653 & 4.783 & 5.1703 & TRN & & & \\
\hline CHEMBL1361333 & 688653 & 5.183 & 5.2297 & TRN & & & \\
\hline CHEMBL1385413 & 688653 & 4.633 & 5.2773 & TRN & & & \\
\hline CHEMBL1476717 & 688653 & 4.933 & 5.3074 & TRN & & & \\
\hline CHEMBL1461168 & 688653 & 5.83299 & 999999999 & & 5.215 & TRN & \\
\hline CHEMBL1355038 & 688653 & 4.633 & 5.0661 & TRN & & & \\
\hline CHEMBL1368465 & 688653 & 6.0 & 5.3946 & TRN & & & \\
\hline CHEMBL1405619 & 688653 & 5.483 & 5.2333 & TRN & & & \\
\hline CHEMBL1580054 & 688653 & 4.73300 & 000000000 & 005 & 5.1654 & TRN & \\
\hline CHEMBL1404457 & 688653 & 4.98300 & 000000000 & 005 & 5.9607 & TRN & \\
\hline CHEMBL1452763 & 688653 & 5.13299 & 999999999 & & 5.1482 & TST & \\
\hline CHEMBL1419498 & 688653 & 4.783 & 4.9419 & TRN & & & \\
\hline CHEMBL1599777 & 688653 & 4.783 & 4.8984 & TST & & & \\
\hline CHEMBL1548695 & 688653 & 4.73300 & 000000000 & 005 & 4.9547 & TRN & \\
\hline CHEMBL1556952 & 688653 & 5.683 & 5.2725 & TST & & & \\
\hline CHEMBL1390330 & 688653 & 5.083 & 5.6169 & TRN & & & \\
\hline CHEMBL1489467 & 688653 & 4.783 & 5.1346 & TRN & & & \\
\hline CHEMBL3198241 & 688653 & 4.98300 & 000000000 & 005 & 5.1945 & TRN & \\
\hline CHEMBL1332930 & 688653 & 5.0 & 5.4161 & TST & & & \\
\hline CHEMBL1376879 & 688653 & 5.683 & 5.1267 & TRN & & & \\
\hline CHEMBL1600136 & 688653 & 5.483 & 5.1941 & TST & & & \\
\hline CHEMBL1611905 & 688653 & 8.3872 & 5.1322 & TRN & & & \\
\hline CHEMBL1490874 & 688653 & 4.783 & 5.285 & TRN & & & \\
\hline CHEMBL1353341 & 688653 & 4.883 & 4.8373 & TST & & & \\
\hline CHEMBL590691 & 688653 & 4.683 & 5.1731 & TRN & & & \\
\hline CHEMBL1393834 & 688653 & 5.83299 & 999999999 & & 5.3039 & 9999999999 & TRN \\
\hline CHEMBL1506670 & 688653 & 5.233 & 5.5606 & TRN & & & \\
\hline CHEMBL1372556 & 688653 & 5.83299 & 999999999 & & 5.1767 & TRN & \\
\hline
\end{tabular}




\begin{tabular}{|c|c|c|c|c|c|c|c|}
\hline \multicolumn{8}{|c|}{ Supplemental Table S2.txt } \\
\hline CHEMBL1460303 & 688653 & 5.683 & 5.3164 & TRN & & & \\
\hline CHEMBL1586754 & 688653 & 4.883 & 4.8779 & TRN & & & \\
\hline CHEMBL1416196 & 688653 & 4.833 & 5.115 & TRN & & & \\
\hline CHEMBL1548913 & 688653 & \multicolumn{3}{|c|}{4.7330000000000005} & 5.4059 & TRN & \\
\hline CHEMBL1498118 & 688653 & \multicolumn{3}{|c|}{5.7829999999999995} & 5.398 & TRN & \\
\hline CHEMBL1593664 & 688653 & 4.933 & 5.6462 & TRN & & & \\
\hline CHEMBL1340458 & 688653 & 5.033 & 5.4691 & TRN & & & \\
\hline CHEMBL1434953 & 688653 & \multicolumn{3}{|c|}{5.5329999999999995} & 5.1289 & TST & \\
\hline CHEMBL1491467 & 688653 & \multicolumn{3}{|c|}{5.5329999999999995} & 5.1839 & TRN & \\
\hline CHEMBL1413193 & 688653 & 5.033 & 4.9926 & TRN & & & \\
\hline CHEMBL1317516 & 688653 & 5.483 & 4.8253 & TRN & & & \\
\hline CHEMBL1539395 & 688653 & 4.633 & 4.7179 & TRN & & & \\
\hline CHEMBL1535335 & 688653 & 4.933 & 5.0751 & TRN & & & \\
\hline CHEMBL118009 & 688653 & \multicolumn{3}{|c|}{6.582999999999999} & \multicolumn{2}{|c|}{5.622999999999999} & TRN \\
\hline CHEMBL1598401 & 688653 & 4.833 & 5.2478 & TRN & & & \\
\hline CHEMBL1368683 & 688653 & 5.983 & 5.1886 & TRN & & & \\
\hline CHEMBL1467984 & 688653 & \multicolumn{3}{|c|}{5.332999999999999} & 5.5955 & TRN & \\
\hline CHEMBL1586767 & 688653 & \multicolumn{3}{|c|}{4.7330000000000005} & 5.8425 & TRN & \\
\hline CHEMBL1607391 & 688653 & 5.033 & 4.9973 & TRN & & & \\
\hline CHEMBL1483788 & 688653 & \multicolumn{3}{|c|}{4.7330000000000005} & \multicolumn{2}{|c|}{4.821000000000001} & TST \\
\hline CHEMBL1596661 & 688653 & 4.783 & 5.3194 & TRN & & & \\
\hline CHEMBL1337415 & 688653 & 4.933 & 5.0976 & TST & & & \\
\hline CHEMBL1430278 & 688653 & 5.083 & 5.4579 & TRN & & & \\
\hline CHEMBL1341399 & 688653 & 5.233 & 5.3756 & TST & & & \\
\hline CHEMBL3190666 & 688653 & 5.483 & 5.3562 & TRN & & & \\
\hline CHEMBL1532993 & 688653 & \multicolumn{3}{|c|}{6.582999999999999} & 5.7109 & TRN & \\
\hline CHEMBL1336191 & 688653 & 4.883 & 5.3882 & TRN & & & \\
\hline CHEMBL1327265 & 688653 & \multicolumn{3}{|c|}{4.9830000000000005} & 5.2649 & TRN & \\
\hline CHEMBL1387927 & 688653 & \multicolumn{3}{|c|}{5.582999999999999} & 5.5832 & TRN & \\
\hline CHEMBL1407268 & 688653 & 4.883 & 5.9011 & TRN & & & \\
\hline CHEMBL1333069 & 688653 & \multicolumn{3}{|c|}{5.132999999999999} & 5.3593 & TST & \\
\hline CHEMBL1456669 & 688653 & 5.933 & 5.1484 & TRN & & & \\
\hline CHEMBL1331409 & 688653 & 6.0 & 5.1736 & TST & & & \\
\hline CHEMBL1366891 & 688653 & 4.783 & 5.3003 & TST & & & \\
\hline CHEMBL1584363 & 688653 & \multicolumn{3}{|c|}{6.082999999999999} & 5.7855 & TRN & \\
\hline CHEMBL1423422 & 688653 & 4.783 & 5.6324 & TRN & & & \\
\hline CHEMBL1591915 & 688653 & 5.733 & 5.7138 & TRN & & & \\
\hline CHEMBL1555347 & 688653 & 4.583 & 5.2211 & TRN & & & \\
\hline CHEMBL3191488 & 688653 & \multicolumn{3}{|c|}{5.882999999999999} & 5.4691 & TRN & \\
\hline CHEMBL3191336 & 688653 & \multicolumn{3}{|c|}{5.332999999999999} & 5.1259 & TRN & \\
\hline CHEMBL1394378 & 688653 & 5.933 & 4.97 & TRN & & & \\
\hline CHEMBL 1457150 & 688653 & \multicolumn{3}{|c|}{5.332999999999999} & 5.7391 & TRN & \\
\hline CHEMBL1601598 & 688653 & 5.183 & 5.1448 & TRN & & & \\
\hline CHEMBL1532801 & 688653 & 5.683 & 5.4115 & TRN & & & \\
\hline CHEMBL1610393 & 688653 & 4.883 & 5.2408 & TRN & & & \\
\hline CHEMBL3197533 & 688653 & 6.983 & 5.4508 & TRN & & & \\
\hline CHEMBL1516989 & 688653 & 4.833 & 5.3547 & TST & & & \\
\hline CHEMBL1487157 & 688653 & 5.7829 & 9999999 & 95 & 5.4373 & TST & \\
\hline
\end{tabular}




\begin{tabular}{|c|c|c|c|c|c|c|}
\hline & & \multicolumn{5}{|c|}{ Supplemental Table S2.txt } \\
\hline CHEMBL1553727 & 688653 & 5.733 & 5.3296 & TST & & \\
\hline CHEMBL3209515 & 688653 & 4.933 & 5.0761 & TST & & \\
\hline CHEMBL1332610 & 688653 & \multicolumn{3}{|c|}{5.632999999999999} & 5.5396 & \\
\hline CHEMBL1528475 & 688653 & 5.183 & 5.0432 & TRN & & \\
\hline CHEMBL1544764 & 588653 & 4.883 & 5.4476 & TST & & \\
\hline CHEMBL1582450 & 588653 & \multicolumn{3}{|c|}{5.332999999999999} & 5.4682 & \\
\hline CHEMBL1600598 & 688653 & \multicolumn{3}{|c|}{5.632999999999999} & 5.5959 & \\
\hline CHEMBL1479647 & 688653 & 4.633 & 4.8611 & TRN & & \\
\hline CHEMBL1339028 & 688653 & 4.783 & 5.1846 & TST & & \\
\hline HEMBL3194041 & 588653 & 4.783 & 5.2014 & TRN & & \\
\hline CHEMBL1371080 & 688653 & 7.2328 & 5.644 & TRN & & \\
\hline CHEMBL1525161 & 688653 & 6.183 & 5.3294 & TRN & & \\
\hline CHEMBL3 & 688653 & 4.583 & 5.7832 & TST & & \\
\hline CHEMBL3199891 & 688653 & 5.033 & 4.9747 & TRN & & \\
\hline CHEMBL151 & 588653 & 5.483 & 5.9945 & TRN & & \\
\hline CHEMBL1 & 688653 & \multicolumn{3}{|c|}{4.9830000000000005} & 8 & \\
\hline CHEMBL1559554 & 688653 & 4.783 & 5.2599 & TRN & & \\
\hline CHEMBL1 & 688653 & 6.7331 & 5.79299 & 999999 & 99 & \\
\hline CHEMBL3209422 & 688653 & 5.233 & 4.9225 & TST & & \\
\hline CHEMBL1525966 & 688653 & 4.883 & 5.1753 & TRN & & \\
\hline CHEMBL1413968 & 688653 & \multicolumn{3}{|c|}{4.7330000000000005} & 7 & \\
\hline CHEMBL1442740 & 688653 & 4.583 & 5.2173 & TST & & \\
\hline CHEMBL1 & 688653 & 5.183 & 5.0442 & TRN & & \\
\hline CHEMBL: & 688 & 5.983 & 5.8802 & TRN & & \\
\hline CHEMBL1 & 688653 & 4.583 & 5.3309 & TRN & & \\
\hline CHEMBL1 & 688653 & 5.183 & 5.2248 & TRN & & \\
\hline CHEMBL1 & 688653 & 5.483 & 5.32799 & 9999999 & & \\
\hline CHEMBL 1 & 688653 & 4.633 & 4.8467 & TRN & & \\
\hline CHEMBL1576399 & 688653 & \multicolumn{3}{|c|}{5.882999999999999} & 5.3516 & $\mathrm{TI}$ \\
\hline CHEMBL1586425 & 688653 & 5.433 & 4.8537 & TRN & & \\
\hline CHEMBL1434127 & 688653 & \multicolumn{3}{|c|}{4.7330000000000005} & & \\
\hline CHEMBL1 & 688653 & \multicolumn{3}{|c|}{4.7330000000000005} & 5.1576 & \\
\hline CHEMBL3 & 688653 & \multicolumn{3}{|c|}{4.7330000000000005} & 5.1543 & 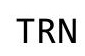 \\
\hline CHEMBL 1 & 688653 & 4.883 & 4.905 & TRN & & \\
\hline CHEMBL1561089 & 688653 & \multicolumn{3}{|c|}{4.7330000000000005} & 5.2412 & \\
\hline CHEMBL1535899 & 688653 & 5.683 & 5.2445 & TRN & & \\
\hline CHEMBL13 & 688653 & \multicolumn{3}{|c|}{5.2829999999999995} & 5.0304 & \\
\hline CHEMBL14€ & 688653 & 5.183 & 5.1797 & TRN & & \\
\hline CHEMBL1463027 & 688653 & \multicolumn{3}{|c|}{4.9830000000000005} & 5.1698 & TRN \\
\hline CHEMBL1968732 & 688653 & \multicolumn{3}{|c|}{5.2829999999999995} & 5.2435 & 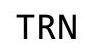 \\
\hline CHEMBL1308210 & 688653 & \multicolumn{3}{|c|}{5.7829999999999995} & 6.1243 & \\
\hline CHEMBL3193372 & 688653 & \multicolumn{3}{|c|}{4.7330000000000005} & 5.1676 & נו \\
\hline CHEMBL1989298 & 688653 & \multicolumn{3}{|c|}{5.832999999999999} & 5.4115 & TRN \\
\hline CHEMBL1594488 & 688653 & \multicolumn{3}{|c|}{5.132999999999999} & 5.4687 & $-\pi$ \\
\hline CHEMBL1388491 & 688653 & 5.483 & 5.3926 & TRN & & \\
\hline CHEMBL1597368 & 688653 & 4.583 & 4.9338 & TRN & & \\
\hline CHEMBL1325520 & 688653 & \multicolumn{3}{|c|}{5.332999999999999} & 5.2555 & \\
\hline CHEMBL1493663 & 688653 & \multicolumn{3}{|c|}{4.7330000000000005} & 5.3951 & \\
\hline
\end{tabular}




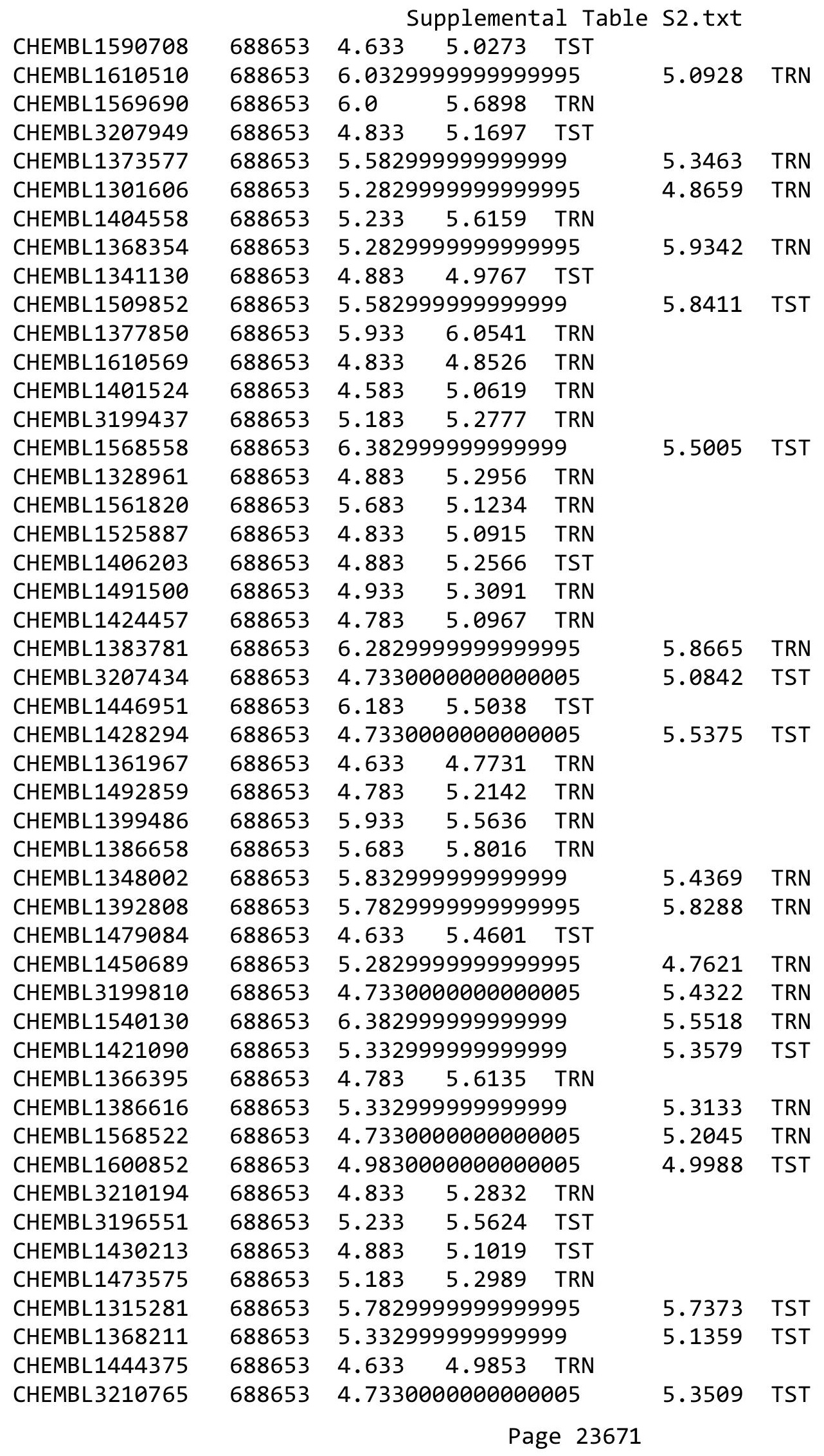




\begin{tabular}{|c|c|c|c|c|c|c|}
\hline \multirow{3}{*}{$\begin{array}{l}\text { CHEMBL1432234 } \\
\text { CHEMBL3193280 }\end{array}$} & \multirow{3}{*}{$\begin{array}{l}688653 \\
688653\end{array}$} & \multicolumn{4}{|c|}{ Supplemental Table S2.txt } & \multirow{2}{*}{ TRN } \\
\hline & & \multicolumn{3}{|c|}{4.7330000000000005} & 5.2783 & \\
\hline & & 5.483 & 5.6982 & TRN & & \\
\hline CHEMBL1472505 & 688653 & 4.833 & 4.9971 & TRN & & \\
\hline CHEMBL1327068 & 688653 & 5.483 & 5.2386 & TST & & \\
\hline CHEMBL1349318 & 688653 & 4.633 & 5.2098 & TST & & \\
\hline CHEMBL1564834 & 688653 & 7.3325 & 5.7098 & TRN & & \\
\hline CHEMBL1323000 & 688653 & 4.633 & 4.9892 & TRN & & \\
\hline CHEMBL1528792 & 688653 & 4.933 & 5.0059 & TRN & & \\
\hline CHEMBL1372760 & 688653 & 6.4829 & 5.7984 & TRN & & \\
\hline CHEMBL1371460 & 688653 & 5.483 & 5.6805 & TRN & & \\
\hline CHEMBL1589244 & 688653 & 5.433 & 5.6466 & TRN & & \\
\hline CHEMBL1429813 & 688653 & \multicolumn{3}{|c|}{5.132999999999999} & 5.1429 & TST \\
\hline CHEMBL1400597 & 688653 & \multicolumn{3}{|c|}{5.382999999999999} & 5.013 & TRN \\
\hline CHEMBL1327531 & 688653 & 4.633 & 5.3157 & TST & & \\
\hline CHEMBL1519603 & 688653 & 4.833 & 5.5346 & TST & & \\
\hline CHEMBL1554096 & 688653 & 4.783 & 5.2087 & TRN & & \\
\hline CHEMBL1534503 & 688653 & 4.583 & 4.5039 & TRN & & \\
\hline CHEMBL1383189 & 688653 & 5.683 & 5.2911 & TRN & & \\
\hline CHEMBL1303553 & 688653 & \multicolumn{3}{|c|}{6.2829999999999995} & 5.2948 & TST \\
\hline CHEMBL3196523 & 688653 & \multicolumn{3}{|c|}{5.632999999999999} & 5.3903 & TRN \\
\hline CHEMBL1517536 & 688653 & 6.233 & 5.7913 & TRN & & \\
\hline CHEMBL1398181 & 688653 & 4.633 & 4.8541 & TST & & \\
\hline CHEMBL1517525 & 688653 & \multicolumn{3}{|c|}{5.382999999999999} & 5.2712 & TRN \\
\hline CHEMBL1352636 & 688653 & \multicolumn{3}{|c|}{5.382999999999999} & 5.6344 & TRN \\
\hline CHEMBL1599634 & 688653 & 4.633 & 5.0942 & TRN & & \\
\hline CHEMBL1546780 & 688653 & \multicolumn{3}{|c|}{4.7330000000000005} & 5.2017 & TRN \\
\hline CHEMBL1408491 & 688653 & 5.033 & 5.3293 & TST & & \\
\hline CHEMBL1891843 & 688653 & 4.783 & 5.2911 & TST & & \\
\hline CHEMBL1463029 & 688653 & 5.483 & 5.456 & TRN & & \\
\hline CHEMBL1428703 & 688653 & 5.083 & 5.4044 & TRN & & \\
\hline CHEMBL1506175 & 688653 & 6.4829 & 5.5421 & TRN & & \\
\hline CHEMBL1970135 & 688653 & 7.1331 & 6.3511 & TRN & & \\
\hline CHEMBL3195906 & 688653 & 5.933 & 6.0249 & TRN & & \\
\hline CHEMBL1425443 & 688653 & 6.4829 & 5.2131 & TST & & \\
\hline CHEMBL1482277 & 688653 & \multicolumn{3}{|c|}{5.832999999999999} & 5.4055 & TRN \\
\hline CHEMBL1423138 & 688653 & 4.783 & 5.2125 & TRN & & \\
\hline CHEMBL1547884 & 688653 & 5.083 & 5.1348 & TRN & & \\
\hline CHEMBL1386276 & 688653 & 5.083 & 5.3154 & TRN & & \\
\hline CHEMBL1397668 & 688653 & 4.883 & 5.0081 & TRN & & \\
\hline CHEMBL1560198 & 688653 & \multicolumn{3}{|c|}{4.9830000000000005} & 5.1155 & TRN \\
\hline CHEMBL 1443350 & 688653 & \multicolumn{3}{|c|}{6.0329999999999995} & 5.5449 & TRN \\
\hline CHEMBL1486245 & 688653 & 6.233 & 5.4357 & TRN & & \\
\hline CHEMBL1522895 & 688653 & \multicolumn{3}{|c|}{5.332999999999999} & 5.4185 & TRN \\
\hline CHEMBL1304261 & 688653 & \multicolumn{3}{|c|}{4.9830000000000005} & 5.2266 & TRN \\
\hline CHEMBL1597076 & 688653 & \multicolumn{3}{|c|}{6.332999999999999} & 5.7714 & TRN \\
\hline CHEMBL1571456 & 688653 & 5.233 & 5.1534 & TRN & & \\
\hline CHEMBL 3213405 & 688653 & 4.833 & 5.0858 & TST & & \\
\hline \multirow[t]{2}{*}{ CHEMBL1391722 } & 688653 & 4.933 & 5.3743 & TRN & & \\
\hline & & \multicolumn{5}{|c|}{ Page 23672} \\
\hline
\end{tabular}




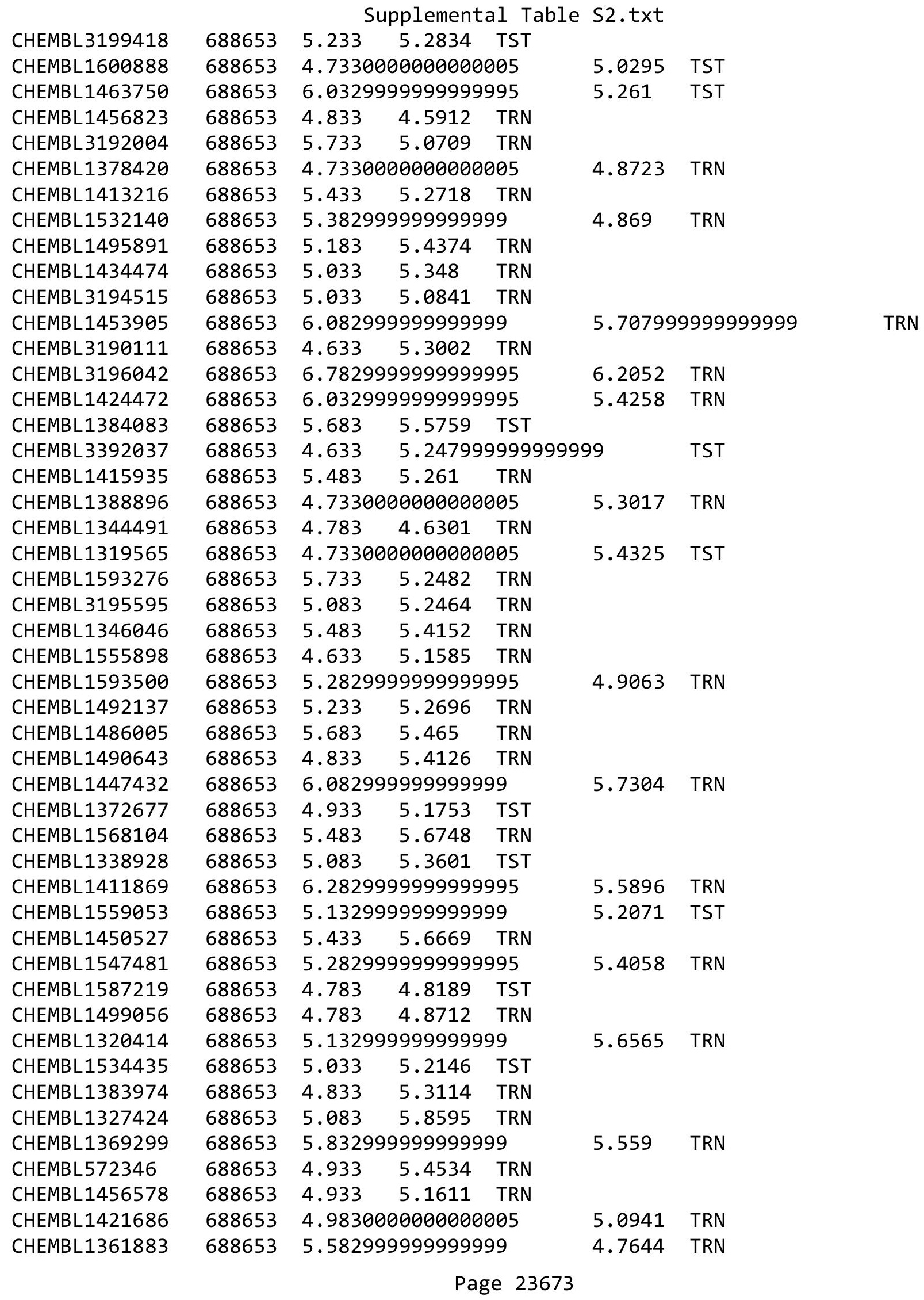




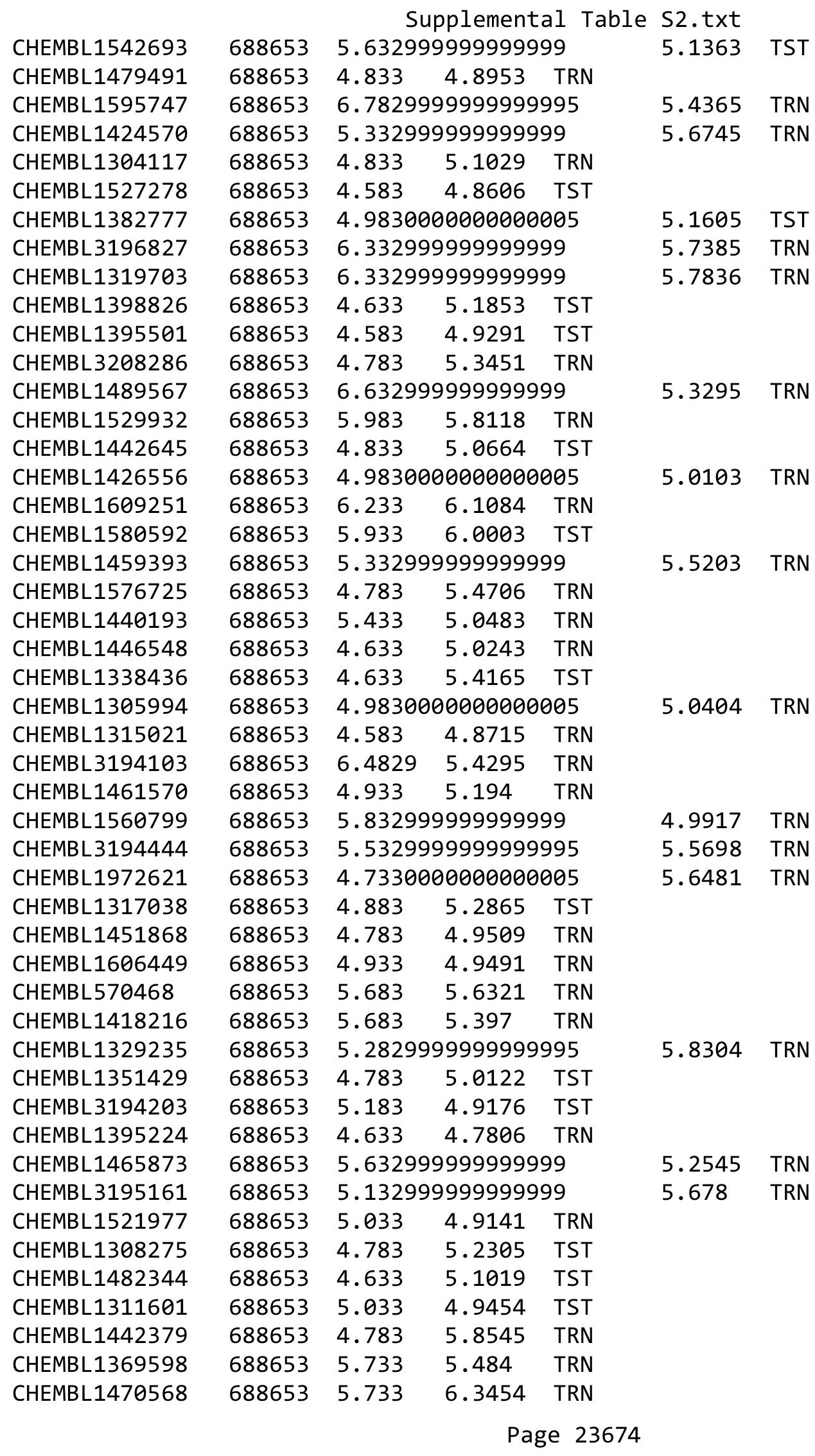




\begin{tabular}{|c|c|c|c|c|c|c|c|}
\hline \multicolumn{7}{|c|}{ Supplemental Table S2.txt } & \\
\hline CHEMBL1573578 & 688653 & 5.433 & 5.5559 & TRN & & & \\
\hline CHEMBL1481372 & 688653 & 4.833 & 5.1713 & TRN & & & \\
\hline CHEMBL1337996 & 688653 & 4.98300 & 20000000 & 005 & 5.1791 & TRN & \\
\hline CHEMBL1572530 & 688653 & 4.883 & 4.8726 & TRN & & & \\
\hline CHEMBL1567097 & 688653 & 7.2328 & 5.8248 & TST & & & \\
\hline CHEMBL1414845 & 688653 & 4.583 & 4.835 & TRN & & & \\
\hline CHEMBL1334986 & 688653 & 4.73300 & 00000000 & 005 & 5.2705 & TRN & \\
\hline CHEMBL1353653 & 688653 & 4.833 & 4.7669 & TRN & & & \\
\hline CHEMBL1371117 & 688653 & 4.783 & 4.8945 & TST & & & \\
\hline CHEMBL1349389 & 688653 & 5.83299 & 99999999 & 99 & 5.09699 & 99999999995 & TRN \\
\hline CHEMBL1601636 & 688653 & 5.13299 & 99999999 & & 5.3017 & TRN & \\
\hline CHEMBL1555213 & 688653 & 4.833 & 4.9488 & TRN & & & \\
\hline CHEMBL1582333 & 688653 & 5.483 & 5.829 & TRN & & & \\
\hline CHEMBL1350239 & 688653 & 4.933 & 5.0803 & TRN & & & \\
\hline CHEMBL1384904 & 688653 & 5.53299 & 99999999 & 995 & 5.3516 & TST & \\
\hline CHEMBL1372905 & 688653 & 5.183 & 5.7128 & TRN & & & \\
\hline CHEMBL1551118 & 688653 & 4.783 & 5.0719 & TST & & & \\
\hline CHEMBL1492507 & 688653 & 5.733 & 5.0969 & TRN & & & \\
\hline CHEMBL1403365 & 688653 & 4.883 & 5.0635 & TST & & & \\
\hline CHEMBL1511301 & 688653 & 4.783 & 5.1171 & TRN & & & \\
\hline CHEMBL1608402 & 688653 & 5.033 & 5.0583 & TST & & & \\
\hline CHEMBL1594799 & 688653 & 4.883 & 5.1033 & TRN & & & \\
\hline CHEMBL1573375 & 688653 & 4.883 & 5.4346 & TST & & & \\
\hline CHEMBL1364725 & 688653 & 4.98300 & 00000000 & 005 & 5.2781 & TST & \\
\hline CHEMBL1465409 & 688653 & 4.633 & 5.0324 & TRN & & & \\
\hline CHEMBL3208128 & 688653 & 4.883 & 5.6493 & TRN & & & \\
\hline CHEMBL1547643 & 688653 & 4.633 & 5.0403 & TST & & & \\
\hline CHEMBL1536961 & 688653 & 6.38299 & 99999999 & & 5.3536 & TRN & \\
\hline CHEMBL1604027 & 688653 & 4.833 & 5.1333 & TRN & & & \\
\hline CHEMBL380370 & 688653 & 5.88299 & 99999999 & & 5.9161 & TRN & \\
\hline CHEMBL1585145 & 688653 & 6.28299 & 99999999 & 995 & 5.4187 & TST & \\
\hline CHEMBL1447844 & 688653 & 5.28299 & 99999999 & 995 & 5.4584 & TRN & \\
\hline CHEMBL1442243 & 688653 & 5.33299 & 99999999 & & 5.1405 & TRN & \\
\hline CHEMBL1323575 & 688653 & 6.433 & 5.4206 & TST & & & \\
\hline CHEMBL1465861 & 688653 & 5.983 & 5.434 & TRN & & & \\
\hline CHEMBL1475756 & 688653 & 4.73300 & 20000000 & 005 & 5.0475 & TRN & \\
\hline CHEMBL1485354 & 688653 & 6.0 & 5.5957 & TRN & & & \\
\hline CHEMBL1363674 & 688653 & 4.783 & 5.0446 & TRN & & & \\
\hline CHEMBL1375143 & 688653 & 4.73300 & 00000000 & 005 & 5.3084 & TRN & \\
\hline CHEMBL1583300 & 688653 & 4.73300 & 00000000 & 005 & 5.1205 & TRN & \\
\hline CHEMBL1529010 & 688653 & 4.883 & 5.3007 & TRN & & & \\
\hline CHEMBL1461800 & 688653 & 5.33299 & 99999999 & & 5.1464 & TRN & \\
\hline CHEMBL1481190 & 688653 & 5.183 & 4.9317 & TRN & & & \\
\hline CHEMBL1454378 & 688653 & 5.683 & 5.3089 & TRN & & & \\
\hline CHEMBL1562618 & 688653 & 4.73300 & 30000000 & 005 & 4.7636 & TRN & \\
\hline CHEMBL1456768 & 688653 & 4.833 & 5.0217 & TRN & & & \\
\hline CHEMBL1392563 & 688653 & 4.783 & 5.468 & TST & & & \\
\hline CHEMBL1509922 & 688653 & 4.98300 & 0000000 & 005 & 5.0817 & TRN & \\
\hline
\end{tabular}




\begin{tabular}{|c|c|c|c|c|c|c|}
\hline \multirow{3}{*}{$\begin{array}{l}\text { CHEMBL1437602 } \\
\text { CHEMBL1439234 }\end{array}$} & \multicolumn{6}{|c|}{ Supplemental Table S2.txt } \\
\hline & 688653 & \multicolumn{4}{|c|}{$6.582999999999999 \quad 5.5506$} & \multirow{2}{*}{ TRA } \\
\hline & 688653 & 6.433 & 5.7293 & TRN & & \\
\hline CHEMBL1582841 & 688653 & \multicolumn{3}{|c|}{5.332999999999999} & 5.0417 & TRN \\
\hline CHEMBL1547068 & 688653 & \multicolumn{3}{|c|}{4.7330000000000005} & 4.7955 & TST \\
\hline CHEMBL1423967 & 688653 & \multicolumn{3}{|c|}{4.7330000000000005} & 5.1783 & TRN \\
\hline CHEMBL3196737 & 688653 & 5.483 & \multicolumn{3}{|c|}{5.327000000000001} & TST \\
\hline CHEMBL1573025 & 688653 & \multicolumn{3}{|c|}{4.7330000000000005} & 5.1456 & TST \\
\hline CHEMBL1611067 & 688653 & \multicolumn{3}{|c|}{5.832999999999999} & 5.4857 & TRN \\
\hline CHEMBL3197539 & 688653 & 5.233 & 4.6633 & TRN & & \\
\hline CHEMBL1534496 & 688653 & 6.9329 & 5.5674 & TRN & & \\
\hline CHEMBL1608727 & 688653 & \multicolumn{3}{|c|}{5.882999999999999} & 5.1481 & TST \\
\hline CHEMBL1517141 & 688653 & 5.433 & 5.1272 & TRN & & \\
\hline CHEMBL1338979 & 688653 & 4.883 & \multicolumn{3}{|c|}{4.9510000000000005} & TRN \\
\hline CHEMBL1517035 & 688653 & \multicolumn{3}{|c|}{4.7330000000000005} & 4.9336 & TRA \\
\hline CHEMBL1508105 & 688653 & 4.833 & 5.4558 & TRN & & \\
\hline CHEMBL3427333 & 688653 & 4.883 & 5.1357 & TRN & & \\
\hline CHEMBL1413092 & 688653 & 5.433 & 5.4384 & TRN & & \\
\hline CHEMBL1489782 & 688653 & \multicolumn{3}{|c|}{5.832999999999999} & 5.6864 & TRN \\
\hline CHEMBL1405405 & 688653 & \multicolumn{3}{|c|}{5.2829999999999995} & 5.1804 & TRA \\
\hline CHEMBL1313592 & 688653 & 4.583 & 4.8811 & TRN & & \\
\hline CHEMBL1522803 & 688653 & 5.683 & 5.2412 & TST & & \\
\hline CHEMBL1310704 & 688653 & \multicolumn{3}{|c|}{4.9830000000000005} & 3 & TRN \\
\hline CHEMBL 388978 & 688653 & 6.9329 & 5.9042 & TST & & \\
\hline CHEMBL1304658 & 688653 & 5.183 & 4.958 & TRN & & \\
\hline CHEMBL 3195471 & 688653 & \multicolumn{3}{|c|}{5.632999999999999} & 5.7181 & TRN \\
\hline CHEMBL1393221 & 688653 & 5.983 & 5.6133 & TRN & & \\
\hline CHEMBL1522250 & 688653 & 4.833 & 5.4015 & TST & & \\
\hline CHEMBL1473734 & 688653 & \multicolumn{3}{|c|}{4.7330000000000005} & 5.0221 & TRA \\
\hline CHEMBL1526362 & 688653 & 5.183 & 5.3877 & TRN & & \\
\hline CHEMBL1444828 & 688653 & 4.833 & 5.4362 & TRN & & \\
\hline CHEMBL1526825 & 688653 & 5.983 & \multicolumn{3}{|c|}{5.5520000000000005} & TRN \\
\hline CHEMBL1489719 & 688653 & 4.883 & 5.2809 & TRN & & \\
\hline CHEMBL1392394 & 688653 & \multicolumn{3}{|c|}{5.332999999999999} & 4.9902 & TRN \\
\hline CHEMBL1583847 & 688653 & \multicolumn{3}{|c|}{6.582999999999999} & 5.1009 & TRN \\
\hline CHEMBL1473887 & 688653 & 4.9830 & 00000000 & 005 & 5.2867 & TRN \\
\hline CHEMBL1445355 & 688653 & 5.1329 & 99999999 & & 4.9946 & TRA \\
\hline CHEMBL3198842 & 688653 & 4.9830 & 00000000 & 005 & 5.4942 & TRN \\
\hline CHEMBL3193843 & 688653 & 5.8329 & 99999999 & & 5.0689 & TRN \\
\hline CHEMBL1508682 & 688653 & 5.1329 & 99999999 & & 5.0845 & TST \\
\hline CHEMBL1309602 & 688653 & 4.9830 & 00000000 & 005 & 5.0283 & TRN \\
\hline CHEMBL1453937 & 688653 & 5.433 & 5.1395 & TRN & & \\
\hline CHEMBL1340089 & 688653 & 5.233 & 5.3294 & TRN & & \\
\hline CHEMBL1442024 & 688653 & 5.5329 & 99999999 & 995 & 5.1873 & TRN \\
\hline CHEMBL1580192 & 688653 & 5.3329 & 99999999 & & 4.9201 & TST \\
\hline CHEMBL3197896 & 688653 & 5.083 & 5.28299 & 99995 & 995 & TRN \\
\hline CHEMBL1600438 & 688653 & 5.8829 & 99999999 & & 5.4474 & TRN \\
\hline CHEMBL1528452 & 688653 & 4.633 & 5.1089 & TRN & & \\
\hline CHEMBL1977983 & 688653 & 4.883 & 5.2604 & TRN & & \\
\hline
\end{tabular}




\begin{tabular}{|c|c|c|c|c|c|c|c|}
\hline \multicolumn{7}{|c|}{ Supplemental Table S2.txt } & \\
\hline CHEMBL1593396 & 688653 & 4.883 & 5.019 & TRN & & & \\
\hline CHEMBL1425956 & 688653 & 4.9 & 5.0779 & TRN & & & \\
\hline CHEMBL1372356 & 688653 & 4.833 & 5.0602 & TST & & & \\
\hline CHEMBL1564313 & 688653 & \multicolumn{3}{|c|}{5.832999999999999} & 5.9793 & TRN & \\
\hline CHEMBL1438635 & 688653 & \multicolumn{3}{|c|}{4.7330000000000005} & 5.2167 & TRN & \\
\hline CHEMBL1359984 & 688653 & \multicolumn{3}{|c|}{4.9830000000000005} & 5.4155 & TST & \\
\hline CHEMBL1494192 & 688653 & 4.833 & 5.3181 & TRN & & & \\
\hline CHEMBL1544997 & 688653 & 4.683 & 5.2547 & TST & & & \\
\hline CHEMBL1453129 & 688653 & 4.833 & 5.3689 & TRN & & & \\
\hline CHEMBL1476749 & 688653 & 4.683 & 4.7792 & TRN & & & \\
\hline CHEMBL1606307 & 688653 & \multicolumn{3}{|c|}{5.7829999999999995} & \multicolumn{2}{|c|}{5.5760000000000005} & TRN \\
\hline CHEMBL1600162 & 688653 & 4.833 & 4.919 & TRN & & & \\
\hline CHEMBL1516274 & 688653 & 4.583 & 4.7467 & TRN & & & \\
\hline CHEMBL1968462 & 688653 & 4.633 & 4.8254 & TRN & & & \\
\hline CHEMBL1605873 & 688653 & 4.833 & 5.1341 & TRN & & & \\
\hline CHEMBL1495602 & 688653 & 4.633 & 5.0119 & TST & & & \\
\hline CHEMBL1340397 & 688653 & \multicolumn{3}{|c|}{5.132999999999999} & 5.4465 & TRN & \\
\hline CHEMBL133576 & 688653 & 4.633 & 4.8923 & TST & & & \\
\hline CHEMBL1573176 & 688653 & \multicolumn{3}{|c|}{4.9830000000000005} & 4.8272 & TRN & \\
\hline CHEMBL1337185 & 688653 & \multicolumn{3}{|c|}{4.7330000000000005} & 5.1658 & TST & \\
\hline CHEMBL1507477 & 688653 & \multicolumn{3}{|c|}{5.582999999999999} & 5.4153 & TRN & \\
\hline CHEMBL1576127 & 688653 & \multicolumn{3}{|c|}{4.7330000000000005} & 4.9271 & TRN & \\
\hline CHEMBL1453211 & 688653 & \multicolumn{3}{|c|}{6.332999999999999} & 5.728 & TRN & \\
\hline CHEMBL 2170108 & 688653 & 4.833 & 5.0372 & TRN & & & \\
\hline CHEMBL1559251 & 688653 & \multicolumn{3}{|c|}{5.5329999999999995} & 6.3253 & TRN & \\
\hline CHEMBL1482681 & 688653 & 4.633 & 5.2074 & TST & & & \\
\hline CHEMBL1449967 & 688653 & 5.033 & 5.18 & TST & & & \\
\hline CHEMBL1531764 & 688653 & 5.733 & 5.6182 & TST & & & \\
\hline CHEMBL1344179 & 688653 & 5.183 & 4.9924 & TRN & & & \\
\hline CHEMBL1598518 & 688653 & 4.633 & 5.0059 & TRN & & & \\
\hline CHEMBL1542264 & 688653 & \multicolumn{3}{|c|}{5.132999999999999} & 5.5901 & TRN & \\
\hline CHEMBL1425773 & 688653 & \multicolumn{3}{|c|}{5.882999999999999} & 5.767 & TRN & \\
\hline CHEMBL1490465 & 688653 & 6.233 & 5.5435 & TRN & & & \\
\hline CHEMBL1307285 & 688653 & \multicolumn{3}{|c|}{5.632999999999999} & 5.5963 & TRN & \\
\hline CHEMBL1561385 & 688653 & \multicolumn{3}{|c|}{5.5329999999999995} & 5.9696 & TST & \\
\hline CHEMBL1500013 & 688653 & 4.833 & 5.8067 & TRN & & & \\
\hline CHEMBL1383319 & 688653 & \multicolumn{3}{|c|}{5.132999999999999} & 5.5066 & TRN & \\
\hline CHEMBL1501168 & 688653 & \multicolumn{3}{|c|}{5.7829999999999995} & 5.7781 & TRN & \\
\hline CHEMBL1366740 & 688653 & \multicolumn{3}{|c|}{4.9830000000000005} & 5.1301 & TRN & \\
\hline CHEMBL1307605 & 688653 & 4.883 & 5.1842 & TST & & & \\
\hline CHEMBL1568243 & 688653 & 4.633 & 5.1198 & TST & & & \\
\hline CHEMBL1415206 & 688653 & 4.683 & 5.0429 & TRN & & & \\
\hline CHEMBL1350079 & 688653 & 5.733 & 5.6595 & TRN & & & \\
\hline CHEMBL1606047 & 688653 & 5.683 & 5.3962 & TRN & & & \\
\hline CHEMBL1527616 & 688653 & 4.883 & 4.9625 & TST & & & \\
\hline CHEMBL1399711 & 688653 & 4.9830 & 00000000 & 005 & 5.6977 & TRN & \\
\hline CHEMBL1445439 & 688653 & 4.633 & 5.0803 & TST & & & \\
\hline CHEMBL1563174 & 688653 & 4.783 & 5.15799 & 9999 & & TRN & \\
\hline
\end{tabular}




\begin{tabular}{|c|c|c|c|c|c|c|c|}
\hline \multirow[b]{2}{*}{ CHEMBL1327546 } & & \\
\hline & 688653 & 4.783 & 5.077 & TST & & & \\
\hline CHEMBL1346179 & 688653 & 4.633 & 4.6194 & TST & & & \\
\hline CHEMBL1482352 & 688653 & 4.833 & 5.0933 & TST & & & \\
\hline CHEMBL1400761 & 688653 & \multicolumn{3}{|c|}{5.382999999999999} & 5.2918 & TRN & \\
\hline CHEMBL1319354 & 688653 & 4.833 & 5.4109 & TRN & & & \\
\hline CHEMBL3194277 & 688653 & 5.483 & 5.4814 & TRN & & & \\
\hline CHEMBL1472780 & 688653 & \multicolumn{3}{|c|}{5.7829999999999995} & 5.6704 & TRN & \\
\hline CHEMBL1314830 & 688653 & 5.183 & 5.0929 & TST & & & \\
\hline CHEMBL1317768 & 688653 & 4.783 & 4.9372 & TRN & & & \\
\hline CHEMBL1400260 & 688653 & 4.933 & 4.6183 & TRN & & & \\
\hline CHEMBL3209574 & 688653 & \multicolumn{3}{|c|}{5.5329999999999995} & 5.3401 & TST & \\
\hline CHEMBL1442500 & 688653 & \multicolumn{3}{|c|}{5.382999999999999} & 5.6967 & TRN & \\
\hline CHEMBL1481567 & 688653 & 4.583 & 4.8722 & TRN & & & \\
\hline CHEMBL1604637 & 688653 & 4.883 & 5.5722 & TRN & & & \\
\hline CHEMBL1486956 & 688653 & \multicolumn{3}{|c|}{5.582999999999999} & 5.7328 & TRN & \\
\hline CHEMBL1359379 & 688653 & \multicolumn{3}{|c|}{6.2829999999999995} & 5.5113 & TRN & \\
\hline CHEMBL1460372 & 688653 & 4.783 & 5.0666 & TST & & & \\
\hline CHEMBL1554865 & 688653 & \multicolumn{3}{|c|}{4.9830000000000005} & 5.2749 & TRN & \\
\hline CHEMBL1606976 & 688653 & \multicolumn{3}{|c|}{5.382999999999999} & 5.1537 & TRN & \\
\hline CHEMBL1313845 & 688653 & 5.733 & 5.2239 & TRN & & & \\
\hline CHEMBL1530866 & 688653 & 4.633 & 5.0584 & TST & & & \\
\hline CHEMBL 337821 & 688653 & 4.583 & \multicolumn{3}{|c|}{5.412000000000001} & TRN & \\
\hline CHEMBL1421236 & 688653 & 4.683 & 5.2659 & TRN & & & \\
\hline CHEMBL1335487 & 688653 & 5.683 & 4.9133 & TST & & & \\
\hline CHEMBL1595216 & 688653 & 4.933 & 5.2096 & TST & & & \\
\hline CHEMBL1365140 & 688653 & \multicolumn{3}{|c|}{5.132999999999999} & 4.9435 & TST & \\
\hline CHEMBL1381066 & 688653 & 4.783 & 5.0638 & TST & & & \\
\hline CHEMBL1602192 & 688653 & 5.083 & 5.4041 & TRN & & & \\
\hline CHEMBL1425889 & 688653 & \multicolumn{3}{|c|}{6.132999999999999} & 5.1685 & TRN & \\
\hline CHEMBL1330018 & 688653 & \multicolumn{3}{|c|}{5.132999999999999} & 5.6398 & TRN & \\
\hline CHEMBL1563202 & 688653 & 4.833 & 4.962 & TRN & & & \\
\hline CHEMBL 3190383 & 688653 & \multicolumn{3}{|c|}{4.9830000000000005} & 4.9187 & TRN & \\
\hline CHEMBL1443814 & 688653 & 5.033 & 5.1483 & TRN & & & \\
\hline CHEMBL1412761 & 688653 & \multicolumn{3}{|c|}{6.0329999999999995} & 4.954 & TRN & \\
\hline CHEMBL1409420 & 688653 & \multicolumn{3}{|c|}{5.882999999999999} & 5.4984 & TRN & \\
\hline CHEMBL1341308 & 688653 & \multicolumn{3}{|c|}{5.582999999999999} & 5.1083 & TST & \\
\hline CHEMBL1416641 & 688653 & 4.933 & 4.9374 & TRN & & & \\
\hline CHEMBL1977678 & 688653 & 5.483 & 5.4718 & TRN & & & \\
\hline CHEMBL3190822 & 688653 & 4.833 & 5.2011 & TST & & & \\
\hline CHEMBL3190299 & 688653 & 5.683 & 5.0339 & TST & & & \\
\hline CHEMBL1441499 & 688653 & \multicolumn{3}{|c|}{5.832999999999999} & \multicolumn{2}{|c|}{5.627000000000001} & TRN \\
\hline CHEMBL1438978 & 688653 & 5.1329 & 99999999 & & 5.0932 & TST & \\
\hline CHEMBL1415755 & 688653 & 6.433 & 5.9182 & TRN & & & \\
\hline CHEMBL1612673 & 688653 & 5.8829 & 99999999 & & 5.5024 & TRN & \\
\hline CHEMBL1379799 & 688653 & 5.8329 & 99999999 & & 5.3818 & TRN & \\
\hline CHEMBL1362509 & 688653 & 4.7330 & 00000000 & 005 & 5.2096 & TRN & \\
\hline CHEMBL1444626 & 688653 & 5.433 & 5.5773 & TRN & & & \\
\hline CHEMBL1574948 & 688653 & 6.3829 & 99999999 & & 5.2346 & TRN & \\
\hline
\end{tabular}




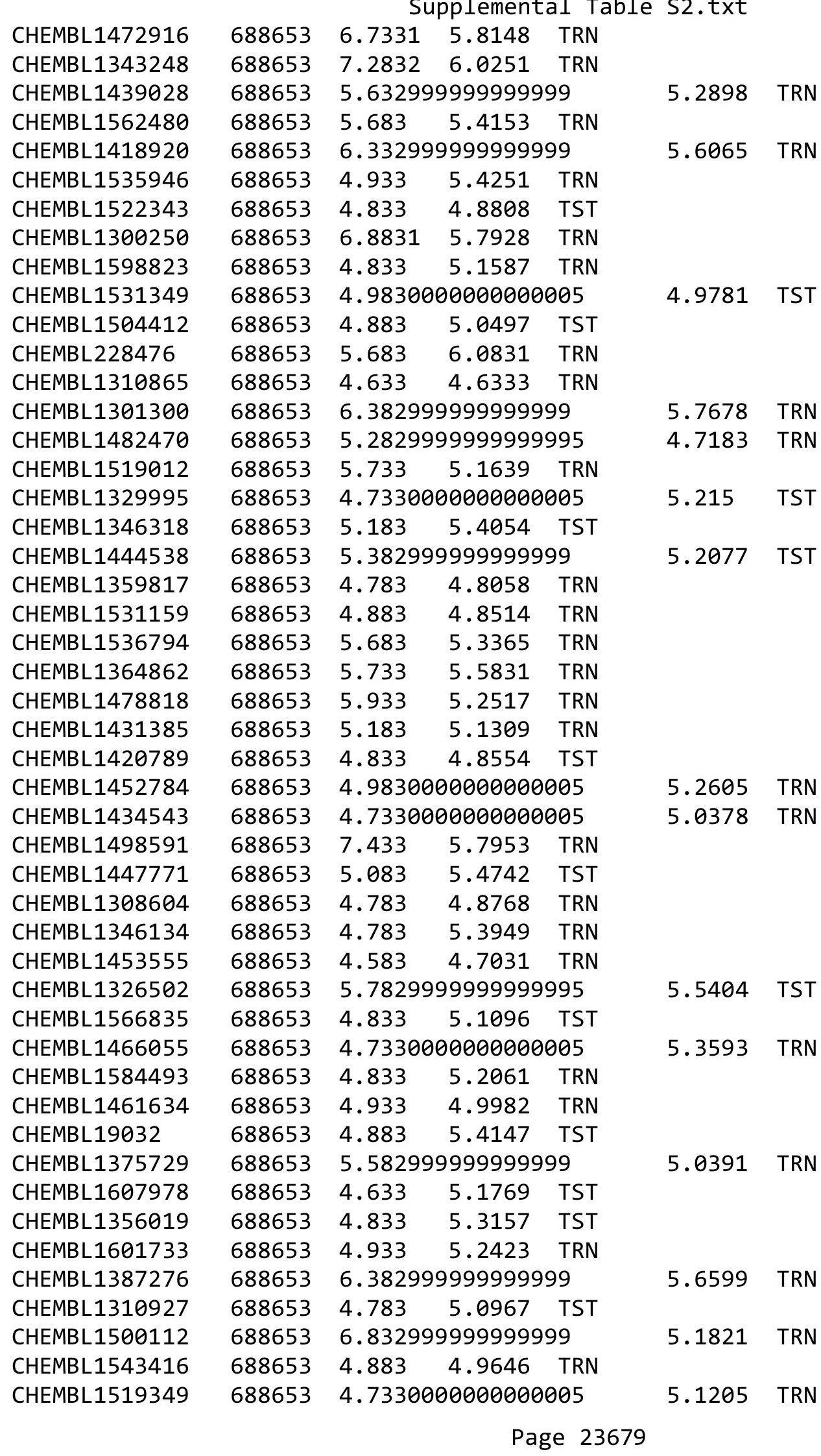




\begin{tabular}{|c|c|c|c|c|c|c|}
\hline & & \multicolumn{5}{|c|}{ Supplemental Table S2.txt } \\
\hline CHEMBL1337931 & 688653 & 5.483 & 5.647 & TRN & & \\
\hline CHEMBL1337337 & 688653 & \multicolumn{3}{|c|}{5.382999999999999} & 5.2672 & TRN \\
\hline CHEMBL1514150 & 688653 & \multicolumn{3}{|c|}{5.882999999999999} & 5.0491 & TRN \\
\hline CHEMBL1426079 & 688653 & \multicolumn{3}{|c|}{5.2829999999999995} & 5.1131 & TST \\
\hline CHEMBL1355558 & 688653 & \multicolumn{3}{|c|}{5.332999999999999} & 5.1108 & TRN \\
\hline CHEMBL1414703 & 688653 & \multicolumn{3}{|c|}{6.5329999999999995} & 5.2724 & TRN \\
\hline CHEMBL1536095 & 688653 & \multicolumn{3}{|c|}{4.7330000000000005} & 5.2766 & TST \\
\hline CHEMBL1494620 & 688653 & \multicolumn{3}{|c|}{4.7330000000000005} & 5.5541 & TST \\
\hline CHEMBL1463447 & 688653 & \multicolumn{3}{|c|}{5.882999999999999} & 5.8953 & TRN \\
\hline CHEMBL1378090 & 688653 & \multicolumn{3}{|c|}{5.632999999999999} & 5.401 & TST \\
\hline CHEMBL588683 & 688653 & \multicolumn{3}{|c|}{6.382999999999999} & 5.4328 & TRN \\
\hline CHEMBL1439137 & 688653 & \multicolumn{3}{|c|}{5.882999999999999} & 5.4037 & TST \\
\hline CHEMBL1577977 & 688653 & & 5.2233 & TRN \\
\hline CHEMBL1500537 & 688653 & \multicolumn{3}{|c|}{$\begin{array}{l}6.382999999999999 \\
5.483 \quad 5.6643 \quad \text { TRN }\end{array}$} & & \\
\hline CHEMBL1354625 & 688653 & 4.633 & 4.815 & TRN & & \\
\hline CHEMBL1338689 & 688653 & 5.233 & 5.1562 & TRN & & \\
\hline CHEMBL1408478 & 688653 & 5.033 & 5.7486 & TRN & & \\
\hline CHEMBL1569927 & 688653 & 4.683 & 5.35 & TRN & & \\
\hline CHEMBL3193266 & 688653 & 4.883 & 5.5712 & TRN & & \\
\hline CHEMBL1489803 & 688653 & 6.233 & 5.3563 & TRN & & \\
\hline CHEMBL1512661 & 688653 & 4.833 & 5.1766 & TRN & & \\
\hline CHEMBL1992359 & 688653 & 5.183 & 5.3286 & TRN & & \\
\hline CHEMBL1549591 & 688653 & 4.783 & 5.2838 & TRN & & \\
\hline CHEMBL1376582 & 688653 & 4.783 & 5.0341 & TRN & & \\
\hline CHEMBL1408287 & 688653 & 6.433 & 5.9068 & TRN & & \\
\hline CHEMBL1360613 & 688653 & 5.6329 & 99999999 & & 5.4571 & TRN \\
\hline CHEMBL1314856 & 688653 & 6.683 & 5.1853 & TRN & & \\
\hline CHEMBL1579255 & 688653 & 4.933 & 5.8581 & TRN & & \\
\hline CHEMBL1583897 & 688653 & 5.183 & 5.2705 & TRN & & \\
\hline CHEMBL1474791 & 688653 & 5.683 & 5.6951 & TST & & \\
\hline CHEMBL1466023 & 688653 & 5.183 & 5.4209 & TST & & \\
\hline CHEMBL1531619 & 688653 & 5.433 & 5.3084 & TRN & & \\
\hline CHEMBL1398695 & 688653 & 4.7336 & 00000000 & 205 & 4.7545 & TST \\
\hline CHEMBL1460129 & 688653 & 4.933 & 5.2177 & TRN & & \\
\hline CHEMBL1365162 & 688653 & 6.3829 & 99999999 & & 5.4743 & TRN \\
\hline CHEMBL3193976 & 688653 & 4.7336 & j000000e & 005 & 5.7259 & TRN \\
\hline CHEMBL1547102 & 688653 & 4.883 & 5.5483 & TRN & & \\
\hline CHEMBL1309110 & 688653 & 4.883 & 5.2246 & TRN & & \\
\hline CHEMBL1583944 & 688653 & 4.833 & 4.8751 & TST & & \\
\hline CHEMBL1491847 & 688653 & 4.833 & 5.0458 & TRN & & \\
\hline CHEMBL1578377 & 688653 & 4.783 & 4.9534 & TST & & \\
\hline CHEMBL1340393 & 688653 & 4.833 & 5.2405 & TRN & & \\
\hline CHEMBL1432252 & 688653 & 6.183 & 5.4753 & TRN & & \\
\hline CHEMBL1542162 & 688653 & 5.433 & 5.7186 & TST & & \\
\hline CHEMBL1984688 & 688653 & 5.483 & 5.7311 & TRN & & \\
\hline CHEMBL1598901 & 688653 & 4.633 & 5.0586 & TST & & \\
\hline CHEMBL1502738 & 688653 & 4.683 & 4.9928 & TST & & \\
\hline CHEMBL1607021 & 688653 & $5.132 \mathrm{c}$ & 99999999 & & 5.0773 & TRN \\
\hline & & & & & & \\
\hline
\end{tabular}




\begin{tabular}{|c|c|c|c|c|c|c|c|}
\hline \multicolumn{8}{|c|}{ Supplemental Table s2.txt } \\
\hline CHEMBL1569304 & 688653 & 5.183 & 5.9821 & TRN & & & \\
\hline CHEMBL1599640 & 688653 & 4.833 & 5.0198 & TRN & & & \\
\hline CHEMBL1557083 & 688653 & 6.4829 & 5.3807 & TRN & & & \\
\hline CHEMBL1601787 & 688653 & 4.833 & 4.9824 & TRN & & & \\
\hline CHEMBL1501014 & 688653 & 7.1331 & 5.4471 & TRN & & & \\
\hline CHEMBL1576270 & 688653 & 4.833 & 5.5828 & TRN & & & \\
\hline CHEMBL1440207 & 688653 & 5.233 & 5.4018 & TST & & & \\
\hline CHEMBL1510369 & 688653 & 6.233 & 4.8653 & TRN & & & \\
\hline CHEMBL1599964 & 688653 & 4.633 & 5.3962 & TRN & & & \\
\hline CHEMBL1598397 & 688653 & \multicolumn{3}{|c|}{6.2829999999999995} & 5.5232 & TRN & \\
\hline CHEMBL1348943 & 688653 & \multicolumn{3}{|c|}{5.7829999999999995} & 5.7711 & TRN & \\
\hline CHEMBL1358391 & 688653 & \multicolumn{3}{|c|}{5.582999999999999} & 5.5489 & TST & \\
\hline CHEMBL1444565 & 688653 & \multicolumn{3}{|c|}{5.5329999999999995} & 5.2814 & TRN & \\
\hline CHEMBL1506503 & 688653 & 7.0329 & 6.3969 & TRN & & & \\
\hline CHEMBL1393019 & 688653 & \multicolumn{3}{|c|}{4.7330000000000005} & 5.1641 & TRN & \\
\hline CHEMBL1429821 & 688653 & 6.983 & 6.1374 & TRN & & & \\
\hline CHEMBL1356913 & 688653 & 4.683 & 5.3776 & TRN & & & \\
\hline CHEMBL1343627 & 688653 & \multicolumn{3}{|c|}{6.382999999999999} & 5.7291 & TRN & \\
\hline CHEMBL1302102 & 688653 & 4.633 & 5.4165 & TRN & & & \\
\hline CHEMBL1408078 & 688653 & 4.833 & 5.1752 & TRN & & & \\
\hline CHEMBL1370034 & 688653 & \multicolumn{3}{|c|}{5.7829999999999995} & 6.0289 & TRN & \\
\hline CHEMBL1401409 & 688653 & \multicolumn{3}{|c|}{5.832999999999999} & 5.2298 & TRN & \\
\hline CHEMBL1352702 & 688653 & 4.783 & 5.1805 & TRN & & & \\
\hline CHEMBL1427421 & 688653 & 5.033 & 5.3822 & TRN & & & \\
\hline CHEMBL1582477 & 688653 & 5.983 & 5.2725 & TRN & & & \\
\hline CHEMBL1430944 & 688653 & 5.083 & 5.7245 & TRN & & & \\
\hline CHEMBL1449748 & 688653 & 4.633 & 5.0529 & TRN & & & \\
\hline CHEMBL1442028 & 688653 & 4.833 & 5.2655 & TST & & & \\
\hline CHEMBL 3190528 & 688653 & 5.033 & 5.2248 & TRN & & & \\
\hline CHEMBL1574443 & 688653 & \multicolumn{3}{|c|}{5.582999999999999} & 5.224 & TRN & \\
\hline CHEMBL1516160 & 688653 & 4.783 & 4.8567 & TRN & & & \\
\hline CHEMBL1386869 & 688653 & 5.083 & 5.0542 & TST & & & \\
\hline CHEMBL1606091 & 688653 & \multicolumn{3}{|c|}{5.2829999999999995} & 5.1006 & TRN & \\
\hline CHEMBL1526702 & 688653 & 6.0 & 5.0685 & TRN & & & \\
\hline CHEMBL1378212 & 688653 & \multicolumn{3}{|c|}{5.7829999999999995} & 5.5767 & TRN & \\
\hline CHEMBL1611573 & 688653 & 4.683 & 5.5115 & TRN & & & \\
\hline CHEMBL1551325 & 688653 & \multicolumn{3}{|c|}{5.132999999999999} & \multicolumn{2}{|c|}{5.3260000000000005} & TST \\
\hline CHEMBL1966080 & 688653 & 5.083 & 5.5709 & TRN & & & \\
\hline CHEMBL1451273 & 688653 & 4.833 & 5.2537 & TST & & & \\
\hline CHEMBL1512706 & 688653 & 4.933 & 5.9431 & TRN & & & \\
\hline CHEMBL1596997 & 688653 & 4.583 & 5.1666 & TST & & & \\
\hline CHEMBL1486467 & 688653 & 6.0 & 5.0306 & TRN & & & \\
\hline CHEMBL1611026 & 688653 & 4.633 & 4.7151 & TST & & & \\
\hline CHEMBL1551874 & 688653 & \multicolumn{3}{|c|}{6.082999999999999} & 5.4166 & TRN & \\
\hline CHEMBL1548972 & 688653 & \multicolumn{3}{|c|}{5.632999999999999} & 5.2428 & TRN & \\
\hline CHEMBL1595640 & 688653 & 4.883 & 5.3683 & TST & & & \\
\hline CHEMBL1499747 & 688653 & 4.683 & 5.2327 & TST & & & \\
\hline CHEMBL1472609 & 688653 & 4.633 & 4.8719 & TST & & & \\
\hline
\end{tabular}




\begin{tabular}{|c|c|c|c|c|c|c|}
\hline \multirow[b]{2}{*}{ CHEMBL1439562 } & \multirow[b]{2}{*}{688653} & \multicolumn{5}{|c|}{ Supplemental Table S2.txt } \\
\hline & & \multicolumn{3}{|c|}{$3 \quad 5.8753$ TRN } & & \\
\hline CHEMBL1528196 & 688653 & 4.783 & 5.2526 & TST & & \\
\hline CHEMBL1420325 & 688653 & \multicolumn{3}{|c|}{5.332999999999999} & 5.1094 & TST \\
\hline CHEMBL1350361 & 688653 & 5.033 & 5.0517 & TRN & & \\
\hline CHEMBL1529406 & 688653 & 5.483 & 5.3583 & TRN & & \\
\hline CHEMBL1965444 & 688653 & 4.833 & 5.4105 & TRN & & \\
\hline CHEMBL1337808 & 688653 & 5.433 & 5.2708 & TRN & & \\
\hline CHEMBL473162 & 688653 & \multicolumn{3}{|c|}{5.882999999999999} & 6.1413 & TRN \\
\hline CHEMBL1495448 & 688653 & 5.183 & 5.0917 & TRN & & \\
\hline CHEMBL1563798 & 688653 & \multicolumn{3}{|c|}{5.882999999999999} & 5.1286 & ThN \\
\hline CHEMBL1350120 & 688653 & 6.4829 & 6.0268 & TRN & & \\
\hline CHEMBL1301055 & 688653 & 5.733 & 5.7874 & TRN & & \\
\hline CHEMBL1322289 & 688653 & 5.433 & 4.9091 & TRN & & \\
\hline CHEMBL1315403 & 688653 & 5.483 & 5.4657 & TST & & \\
\hline CHEMBL1380068 & 688653 & 6.0 & 5.4727 & TRN & & \\
\hline CHEMBL1573043 & 688653 & \multicolumn{3}{|c|}{6.7829999999999995} & 6.0034 & \\
\hline CHEMBL1532349 & 688653 & 5.233 & 5.2184 & TST & & \\
\hline CHEMBL1365019 & 688653 & \multicolumn{3}{|c|}{5.7829999999999995} & 5.6562 & TRN \\
\hline CHEMBL1451172 & 688653 & 4.783 & 4.8769 & TRN & & \\
\hline CHEMBL1965122 & 688653 & 4.833 & 5.4979 & TRN & & \\
\hline CHEMBL1438577 & 688653 & 4.933 & 5.0532 & TRN & & \\
\hline CHEMBL1413765 & 688653 & \multicolumn{3}{|c|}{4.7330000000000005} & 5.3597 & TRN \\
\hline CHEMBL1596738 & 688653 & 5.083 & 5.1941 & TRN & & \\
\hline CHEMBL1332052 & 688653 & \multicolumn{3}{|c|}{5.132999999999999} & 5.4167 & TRN \\
\hline CHEMBL3195723 & 688653 & \multicolumn{3}{|c|}{5.132999999999999} & 5.5053 & \\
\hline CHEMBL1581738 & 688653 & 5.083 & 4.8949 & TRN & & \\
\hline CHEMBL1511680 & 688653 & \multirow{2}{*}{\multicolumn{3}{|c|}{4.9830000000000005}} & & \\
\hline CHEMBL1455034 & 688653 & & & & 4.9555 & TST \\
\hline CHEMBL1513601 & 688653 & 5.033 & 5.1521 & TRN & & \\
\hline CHEMBL1448375 & 688653 & 4.833 & 5.6939 & TRN & & \\
\hline CHEMBL1487644 & 688653 & 5.483 & 5.3089 & TRN & & \\
\hline CHEMBL1496615 & 688653 & \multicolumn{3}{|c|}{5.132999999999999} & 5.1256 & TRN \\
\hline CHEMBL1502403 & 688653 & \multicolumn{3}{|c|}{5.332999999999999} & 5.5892 & TRN \\
\hline CHEMBL1496862 & 688653 & 4.833 & 5.1191 & TRN & & \\
\hline CHEMBL1543465 & 688653 & 4.833 & 4.9575 & TRN & & \\
\hline CHEMBL1584340 & 688653 & 5.083 & 4.9704 & TRN & & \\
\hline CHEMBL1402834 & 688653 & 5.933 & 5.0714 & TRN & & \\
\hline CHEMBL1576502 & 688653 & 5.483 & 4.9448 & TRN & & \\
\hline CHEMBL1316778 & 688653 & 4.633 & 5.2025 & TST & & \\
\hline CHEMBL1572378 & 688653 & 5.683 & 5.0685 & TRN & & \\
\hline CHEMBL1612172 & 688653 & 5.233 & 5.222 & TRN & & \\
\hline CHEMBL3195345 & 688653 & 4.883 & 5.2836 & TRN & & \\
\hline CHEMBL1566242 & 688653 & 4.833 & 5.1125 & TRN & & \\
\hline CHEMBL1480918 & 688653 & 4.833 & 5.115 & TRN & & \\
\hline CHEMBL3195747 & 688653 & 6.5829 & 99999999 & & 5.8605 & TKIV \\
\hline CHEMBL1411199 & 688653 & 4.7330 & 00000000 & 005 & 5.0393 & TRN \\
\hline CHEMBL1478356 & 688653 & 5.5829 & 99999999 & & 5.8978 & TRN \\
\hline CHEMBL1345325 & 688653 & 4.7330 & 00000000 & 005 & 5.0506 & TRN \\
\hline
\end{tabular}




\begin{tabular}{|c|c|c|c|c|c|c|c|}
\hline \multirow[b]{2}{*}{ CHEMBL1560181 } & \multicolumn{6}{|c|}{ Supplemental Table S2.txt } & \\
\hline & 688653 & 4.833 & 5.4569 & TST & & & \\
\hline CHEMBL1427051 & 688653 & 5.28299 & 999999999 & 995 & 5.4559 & TRN & \\
\hline CHEMBL1497932 & 688653 & 6.433 & 5.68 & TRN & & & \\
\hline CHEMBL1587710 & 688653 & 4.73300 & 000000000 & 005 & 5.142 & TRN & \\
\hline CHEMBL3194392 & 688653 & 4.833 & 5.193 & TRN & & & \\
\hline CHEMBL1426490 & 688653 & 6.0 & 5.1932 & TRN & & & \\
\hline CHEMBL1366293 & 688653 & 6.08299 & 999999999 & & 5.5079 & TRN & \\
\hline CHEMBL 3211782 & 688653 & 4.933 & 5.0558 & TRN & & & \\
\hline CHEMBL1361016 & 688653 & 6.58299 & 999999999 & & 5.561 & TRN & \\
\hline CHEMBL1551808 & 688653 & 5.58299 & 999999999 & & 5.1813 & TRN & \\
\hline CHEMBL1535599 & 688653 & 4.98300 & 000000000 & 005 & 4.947 & TST & \\
\hline CHEMBL1519862 & 688653 & 5.28299 & 999999999 & 995 & 5.2917 & TRN & \\
\hline CHEMBL1552724 & 688653 & 4.883 & 5.047 & TST & & & \\
\hline CHEMBL1307810 & 688653 & 4.583 & 4.9801 & TST & & & \\
\hline CHEMBL1303429 & 688653 & 5.933 & 5.7381 & TST & & & \\
\hline CHEMBL1440308 & 688653 & 5.083 & 4.9652 & TRN & & & \\
\hline CHEMBL1331007 & 688653 & 6.13299 & 999999999 & & 5.3239 & TRN & \\
\hline CHEMBL1411473 & 688653 & 4.73300 & 000000000 & 005 & 5.1635 & TRN & \\
\hline CHEMBL1588685 & 688653 & 5.33299 & 999999999 & & 5.2115 & TRN & \\
\hline CHEMBL1407138 & 688653 & 6.13299 & 999999999 & & 5.8018 & TRN & \\
\hline CHEMBL1971185 & 688653 & 5.13299 & 999999999 & & 5.1993 & TRN & \\
\hline CHEMBL1557764 & 688653 & 4.73300 & 000000000 & 005 & 5.58299 & 9999999999 & TRN \\
\hline CHEMBL1399949 & 688653 & 4.583 & 5.0657 & TST & & & \\
\hline CHEMBL3194929 & 688653 & 4.883 & 5.3797 & TRN & & & \\
\hline CHEMBL1485516 & 688653 & 5.28299 & 999999999 & 995 & 5.49700 & 0000000001 & TRN \\
\hline CHEMBL1488131 & 688653 & 4.683 & 5.081 & TST & & & \\
\hline CHEMBL1531113 & 688653 & 5.683 & 5.4603 & TRN & & & \\
\hline CHEMBL1445652 & 688653 & 5.233 & 5.544 & TRN & & & \\
\hline CHEMBL1328159 & 688653 & 6.233 & 5.6382 & TRN & & & \\
\hline CHEMBL3191149 & 688653 & 4.783 & 5.0507 & TRN & & & \\
\hline CHEMBL1486939 & 688653 & 5.88299 & 999999999 & & 5.8243 & TRN & \\
\hline CHEMBL1427724 & 688653 & 4.783 & 5.2121 & TRN & & & \\
\hline CHEMBL1420361 & 688653 & 5.33299 & 999999999 & & 5.1615 & TRN & \\
\hline CHEMBL1416472 & 688653 & 4.73300 & 000000000 & 005 & 5.49299 & 9999999999 & TRN \\
\hline CHEMBL1588213 & 688653 & 5.88299 & 999999999 & & 5.3354 & TRN & \\
\hline CHEMBL1564100 & 688653 & 5.13299 & 999999999 & & 5.3654 & TRN & \\
\hline CHEMBL1469912 & 688653 & 5.733 & 4.9526 & TRN & & & \\
\hline CHEMBL1540694 & 688653 & 5.13299 & 999999999 & & 5.3692 & TST & \\
\hline CHEMBL1546823 & 688653 & 4.73300 & 000000000 & 005 & 4.7536 & TST & \\
\hline CHEMBL1304209 & 688653 & 4.783 & 5.4408 & TST & & & \\
\hline CHEMBL3195227 & 688653 & 4.833 & 5.0429 & TRN & & & \\
\hline CHEMBL1557635 & 688653 & 4.683 & 5.3332 & TRN & & & \\
\hline CHEMBL1572844 & 688653 & 6.08299 & 999999999 & & 5.4652 & TRN & \\
\hline CHEMBL490324 & 688653 & 4.633 & 5.1483 & TRN & & & \\
\hline CHEMBL3197181 & 688653 & 5.13299 & 999999999 & 99 & 5.3842 & TRN & \\
\hline CHEMBL1582665 & 688653 & 7.2328 & 6.2194 & TRN & & & \\
\hline CHEMBL1418683 & 688653 & 4.933 & 4.8682 & TST & & & \\
\hline CHEMBL1427044 & 688653 & 5.78299 & 999999999 & 995 & 5.4138 & TRN & \\
\hline
\end{tabular}




\begin{tabular}{|c|c|c|c|c|c|c|}
\hline \multirow[b]{2}{*}{ CHEMBL1430116 } & \multicolumn{6}{|c|}{ oplemental T } \\
\hline & 688653 & 4.933 & 5.2052 & TRN & & \\
\hline CHEMBL1609921 & 688653 & 4.7330 & 00000000 & 005 & 5.5784 & TRN \\
\hline CHEMBL1512956 & 688653 & 5.683 & 5.4528 & TRN & & \\
\hline CHEMBL1594696 & 688653 & 5.3329 & 99999999 & 99 & 5.2936 & I KIV \\
\hline CHEMBL445420 & 688653 & 5.8829 & 99999999 & 99 & 5.6885 & \\
\hline CHEMBL1373385 & 688653 & 4.633 & 5.1186 & TST & & \\
\hline CHEMBL1600395 & 688653 & 5.2829 & 99999999 & 995 & 5.2421 & \\
\hline CHEMBL1429007 & 688653 & 5.733 & 5.5594 & TRN & & \\
\hline CHEMBL1587460 & 688653 & 5.1329 & 99999999 & 99 & 5.3538 & \\
\hline CHEMBL1448655 & 688653 & 4.833 & 4.8247 & TST & & \\
\hline CHEMBL1480653 & 688653 & 5.433 & 5.6211 & TST & & \\
\hline CHEMBL1387395 & 688653 & 5.733 & 5.8532 & TRN & & \\
\hline CHEMBL1552195 & 688653 & 5.5329 & 99999999 & 995 & 5.2441 & \\
\hline CHEMBL1548007 & 688653 & 5.083 & 5.4464 & TRN & & \\
\hline CHEMBL1541522 & 688653 & 4.9830 & 00000000 & 005 & 5.5316 & \\
\hline CHEMBL1396758 & 688653 & 5.5829 & 99999999 & 99 & 5.5818 & \\
\hline CHEMBL1420103 & 688653 & 5.733 & 5.4905 & TRN & & \\
\hline CHEMBL 3208173 & 688653 & 4.7330 & 00000000 & 005 & 7858 & \\
\hline CHEMBL1520035 & 688653 & 5.683 & 5.6787 & TRN & & \\
\hline CHEMBL1491373 & 688653 & 5.083 & 5.1628 & TRN & & \\
\hline CHEMBL1308380 & 688653 & 5.1329 & 99999999 & & 5.0499 & $\mathrm{~T}$ \\
\hline CHEMBL1442412 & 688653 & 4.683 & 5.1922 & TST & & \\
\hline CHEMBL1545674 & 688653 & 5.1329 & 99999999 & & .4328 & \\
\hline CHEMBL1307129 & 688653 & 5.033 & 4.8446 & TST & & \\
\hline CHEMBL1371794 & 688653 & 5.2829 & 99999999 & 995 & 4.9423 & $1 \pi$ \\
\hline CHEMBL 3197775 & 688653 & 5.733 & 5.2322 & TRN & & \\
\hline CHEMBL1577226 & 688653 & 4.833 & 5.0082 & TRN & & \\
\hline CHEMBL1565151 & 688653 & 4.783 & 5.20299 & 99999 & 99 & \\
\hline CHEMBL1300674 & 688653 & 4.933 & 5.3072 & TRN & & \\
\hline CHEMBL1343506 & 688653 & 4.783 & 5.0361 & TST & & \\
\hline CHEMBL1351406 & 688653 & 4.833 & 5.494 & TRN & & \\
\hline CHEMBL1573746 & 688653 & 4.783 & 5.1591 & TRN & & \\
\hline CHEMBL 3189908 & 688653 & 4.833 & 5.2953 & TRN & & \\
\hline CHEMBL1428565 & 688653 & 6.3329 & 99999999 & & 5.3595 & \\
\hline CHEMBL1493296 & 688653 & 5.1329 & 99999999 & & 5.2631 & TRN \\
\hline CHEMBL1584460 & 688653 & 5.75 & 5.4828 & TRN & & \\
\hline CHEMBL1545526 & 688653 & 5.983 & 5.689 & TRN & & \\
\hline CHEMBL1452746 & 688653 & 4.833 & 5.0072 & TRN & & \\
\hline CHEMBL1569012 & 688653 & 5.983 & 5.5471 & TRN & & \\
\hline CHEMBL1606486 & 688653 & 5.233 & 5.5549 & TRN & & \\
\hline CHEMBL1546231 & 688653 & 5.3329 & 99999999 & & 5.2305 & I TIV \\
\hline CHEMBL1528161 & 688653 & 4.7330 & 00000000 & 005 & 5.0034 & TST \\
\hline CHEMBL1392479 & 688653 & 4.9830 & 00000000 & 005 & 4.8122 & \\
\hline CHEMBL1327041 & 688653 & 4.7330 & 00000000 & 005 & 4.8434 & TRN \\
\hline CHEMBL 3192332 & 688653 & 5.2829 & 99999999 & 995 & 5.274 & TST \\
\hline CHEMBL1375478 & 688653 & 5.1329 & 99999999 & & 4.8997 & TRN \\
\hline CHEMBL 3198709 & 688653 & 5.1329 & 99999999 & & 5.7887 & \\
\hline CHEMBL3193855 & 688653 & 5.6329 & 99999999 & & 5.4299 & \\
\hline
\end{tabular}




\begin{tabular}{|c|c|c|c|c|c|c|c|}
\hline \multicolumn{8}{|c|}{ 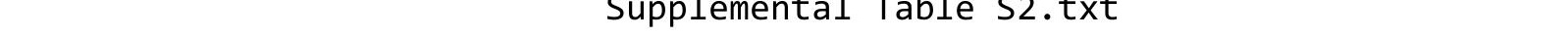 } \\
\hline CHEMBL1513338 & 688653 & 4.833 & 4.9983 & TRN & & & \\
\hline CHEMBL1469111 & 688653 & 5.183 & 5.6275 & TRN & & & \\
\hline CHEMBL1448292 & 688653 & \multicolumn{3}{|c|}{4.7330000000000005} & 5.0909 & TRN & \\
\hline CHEMBL3212798 & 688653 & 4.833 & 5.0492 & TRN & & & \\
\hline CHEMBL1324123 & 688653 & 6.433 & 5.9847 & TRN & & & \\
\hline CHEMBL1540365 & 688653 & \multicolumn{3}{|c|}{5.132999999999999} & 5.6466 & TRN & \\
\hline CHEMBL1461464 & 688653 & \multicolumn{3}{|c|}{4.7330000000000005} & 5.0906 & TRN & \\
\hline CHEMBL1382773 & 688653 & \multicolumn{3}{|c|}{5.2829999999999995} & 4.7856 & TST & \\
\hline CHEMBL1345595 & 688653 & 4.783 & 4.784 & TRN & & & \\
\hline CHEMBL1490876 & 688653 & \multicolumn{3}{|c|}{5.2829999999999995} & 5.3029 & TST & \\
\hline CHEMBL1368561 & 688653 & 6.7331 & 6.1347 & TRN & & & \\
\hline CHEMBL1603314 & 688653 & \multicolumn{3}{|c|}{5.882999999999999} & 5.4667 & TRN & \\
\hline CHEMBL1509380 & 688653 & 4.583 & 5.0063 & TRN & & & \\
\hline CHEMBL1386240 & 688653 & \multicolumn{3}{|c|}{4.7330000000000005} & 4.9952 & TST & \\
\hline CHEMBL1537091 & 688653 & \multicolumn{3}{|c|}{5.132999999999999} & 5.4555 & TRN & \\
\hline CHEMBL1391054 & 688653 & \multicolumn{3}{|c|}{4.7330000000000005} & 5.2784 & TRN & \\
\hline CHEMBL1386322 & 688653 & \multicolumn{3}{|c|}{6.832999999999999} & 5.8124 & TRN & \\
\hline CHEMBL1522986 & 688653 & 4.833 & 5.2798 & TST & & & \\
\hline CHEMBL1609470 & 688653 & \multicolumn{3}{|c|}{4.7330000000000005} & 5.4243 & TST & \\
\hline CHEMBL1333489 & 688653 & 4.883 & 5.141 & TRN & & & \\
\hline CHEMBL 2004764 & 688653 & \multicolumn{3}{|c|}{6.132999999999999} & 5.4601 & TRN & \\
\hline CHEMBL1347186 & 688653 & \multicolumn{3}{|c|}{6.132999999999999} & 5.7342 & TST & \\
\hline CHEMBL1584008 & 688653 & 4.883 & 5.6317 & TST & & & \\
\hline CHEMBL1333230 & 688653 & 4.933 & 4.9215 & TST & & & \\
\hline CHEMBL1593022 & 688653 & \multicolumn{3}{|c|}{5.132999999999999} & 5.6884 & TRN & \\
\hline CHEMBL1489999 & 688653 & \multicolumn{3}{|c|}{5.132999999999999} & 5.1668 & TST & \\
\hline CHEMBL 1475270 & 688653 & \multicolumn{3}{|c|}{6.382999999999999} & 5.5518 & TRN & \\
\hline CHEMBL1362720 & 688653 & 4.683 & 4.7918 & TRN & & & \\
\hline CHEMBL1490077 & 688653 & \multicolumn{3}{|c|}{4.9830000000000005} & \multirow{2}{*}{\multicolumn{2}{|c|}{5.617000000000001}} & TRN \\
\hline CHEMBL3198439 & 688653 & 5.483 & 5.7315 & TRN & & & \\
\hline CHEMBL1531266 & 688653 & 4.783 & 5.225 & TRN & & & \\
\hline CHEMBL1533907 & 688653 & 4.783 & 5.6042 & TRN & & & \\
\hline CHEMBL1363094 & 688653 & \multicolumn{3}{|c|}{4.9830000000000005} & 5.1374 & TRN & \\
\hline CHEMBL1341742 & 688653 & \multicolumn{3}{|c|}{5.832999999999999} & 5.3907 & TRN & \\
\hline CHEMBL 1494270 & 688653 & 4.633 & 4.9544 & TRN & & & \\
\hline CHEMBL1359381 & 688653 & 5.033 & 4.7585 & TST & & & \\
\hline CHEMBL1407945 & 688653 & 5.733 & 5.4077 & TRN & & & \\
\hline CHEMBL1551585 & 688653 & 4.633 & 5.1699 & TRN & & & \\
\hline CHEMBL1357550 & 688653 & 5.58299 & 99999999 & & 4.9566 & TST & \\
\hline CHEMBL1510398 & 688653 & 4.783 & 4.9657 & TRN & & & \\
\hline CHEMBL1372889 & 688653 & 5.933 & 7.0213 & TRN & & & \\
\hline CHEMBL1420428 & 688653 & 6.33299 & 99999999 & & 5.3969 & TRN & \\
\hline CHEMBL1468133 & 688653 & 5.033 & 5.0985 & TRN & & & \\
\hline CHEMBL3210154 & 688653 & 5.53299 & 99999999 & 995 & 5.0175 & TRN & \\
\hline CHEMBL1609819 & 688653 & 4.633 & 4.9453 & TRN & & & \\
\hline CHEMBL1606467 & 688653 & 4.783 & 5.1509 & TRN & & & \\
\hline CHEMBL1331356 & 688653 & 5.033 & 4.9885 & TRN & & & \\
\hline CHEMBL1324779 & 688653 & 6.183 & 5.6396 & TRN & & & \\
\hline
\end{tabular}




\begin{tabular}{|c|c|c|c|c|c|c|c|}
\hline \multicolumn{8}{|c|}{ Supplemental Table s2.txt } \\
\hline CHEMBL1316188 & 688653 & 4.833 & 4.8789 & TRN & & & \\
\hline CHEMBL1567070 & 688653 & 5.233 & 5.3397 & TRN & & & \\
\hline CHEMBL1314740 & 688653 & 4.883 & 4.8382 & TRN & & & \\
\hline CHEMBL1394226 & 688653 & 4.633 & 5.0068 & TST & & & \\
\hline CHEMBL1302998 & 688653 & \multicolumn{3}{|c|}{5.132999999999999} & 5.3995 & TST & \\
\hline CHEMBL1344291 & 688653 & 4.833 & 5.2675 & TRN & & & \\
\hline CHEMBL1546072 & 688653 & \multicolumn{3}{|c|}{4.7330000000000005} & 4.9597 & TST & \\
\hline CHEMBL1596719 & 688653 & \multicolumn{3}{|c|}{6.832999999999999} & 6.2349 & TRN & \\
\hline CHEMBL1449229 & 688653 & 4.883 & 5.6435 & TRN & & & \\
\hline CHEMBL1429791 & 688653 & \multicolumn{3}{|c|}{4.7330000000000005} & 4.6929 & TST & \\
\hline CHEMBL1998302 & 688653 & 4.833 & 5.4043 & TRN & & & \\
\hline CHEMBL1409282 & 688653 & \multicolumn{3}{|c|}{4.7330000000000005} & 5.7478 & TRN & \\
\hline CHEMBL 381518 & 688653 & \multicolumn{3}{|c|}{5.7829999999999995} & 5.7625 & TRN & \\
\hline CHEMBL1352651 & 688653 & \multicolumn{3}{|c|}{5.632999999999999} & 4.9836 & TST & \\
\hline CHEMBL1319684 & 688653 & \multicolumn{3}{|c|}{4.7330000000000005} & 5.3151 & TST & \\
\hline CHEMBL1475991 & 688653 & 4.783 & 5.1209 & TST & & & \\
\hline CHEMBL1450251 & 688653 & 5.933 & 5.4801 & TST & & & \\
\hline CHEMBL261123 & 688653 & 7.1831 & 6.4001 & TRN & & & \\
\hline CHEMBL1449555 & 688653 & 4.883 & 5.1302 & TST & & & \\
\hline CHEMBL1528791 & 688653 & 6.7331 & 5.7927 & TRN & & & \\
\hline CHEMBL1405602 & 688653 & 4.883 & \multicolumn{3}{|c|}{5.236000000000001} & TRN & \\
\hline CHEMBL1486073 & 688653 & \multicolumn{3}{|c|}{4.7330000000000005} & 4.9798 & TRN & \\
\hline CHEMBL1535200 & 688653 & 6.4829 & 4.8825 & TRN & & & \\
\hline CHEMBL1453459 & 688653 & 5.483 & 5.1839 & TST & & & \\
\hline CHEMBL1444077 & 688653 & \multicolumn{3}{|c|}{6.2829999999999995} & 5.728 & TRN & \\
\hline CHEMBL1532318 & 688653 & \multicolumn{3}{|c|}{5.132999999999999} & 5.5578 & TRN & \\
\hline CHEMBL1418889 & 688653 & 4.633 & 5.1338 & TRN & & & \\
\hline CHEMBL3212664 & 688653 & \multicolumn{3}{|c|}{5.132999999999999} & 5.5876 & TRN & \\
\hline CHEMBL1347657 & 688653 & \multicolumn{3}{|c|}{4.9830000000000005} & 4.7809 & TRN & \\
\hline CHEMBL1568694 & 688653 & 4.933 & 5.2377 & TST & & & \\
\hline CHEMBL1586443 & 688653 & 4.933 & 5.5361 & TST & & & \\
\hline CHEMBL1318974 & 688653 & \multicolumn{3}{|c|}{5.2829999999999995} & 5.2092 & TRN & \\
\hline CHEMBL1482928 & 688653 & 4.783 & 5.1379 & TST & & & \\
\hline CHEMBL1314454 & 688653 & 5.233 & 5.9198 & TRN & & & \\
\hline CHEMBL1469415 & 688653 & \multicolumn{3}{|c|}{5.5329999999999995} & 5.0767 & TST & \\
\hline CHEMBL1401959 & 688653 & \multicolumn{3}{|c|}{5.5329999999999995} & \multicolumn{2}{|c|}{5.531000000000001} & TRN \\
\hline CHEMBL1375138 & 688653 & 4.783 & 5.3058 & TRN & & & \\
\hline CHEMBL1309731 & 688653 & 5.733 & 5.7542 & TRN & & & \\
\hline CHEMBL1350621 & 688653 & \multicolumn{3}{|c|}{5.5329999999999995} & 5.4019 & TRN & \\
\hline CHEMBL1367082 & 688653 & 5.033 & \multicolumn{3}{|c|}{5.1160000000000005} & TST & \\
\hline CHEMBL1582302 & 688653 & 4.833 & 5.0911 & TRN & & & \\
\hline CHEMBL1372568 & 688653 & 5.88299 & 99999999 & & 5.2561 & TRN & \\
\hline CHEMBL1392700 & 688653 & 5.083 & 5.1949 & TST & & & \\
\hline CHEMBL1351881 & 688653 & 5.183 & 5.3049 & TRN & & & \\
\hline CHEMBL1501255 & 688653 & 5.78299 & 99999999 & 995 & 5.7796 & TRN & \\
\hline CHEMBL1301904 & 688653 & 4.73300 & 00000000 & 005 & 4.945 & TRN & \\
\hline CHEMBL1397831 & 688653 & 5.183 & 4.8036 & TST & & & \\
\hline CHEMBL1607199 & 688653 & 4.73300 & 00000000 & 005 & 4.9376 & TRN & \\
\hline
\end{tabular}




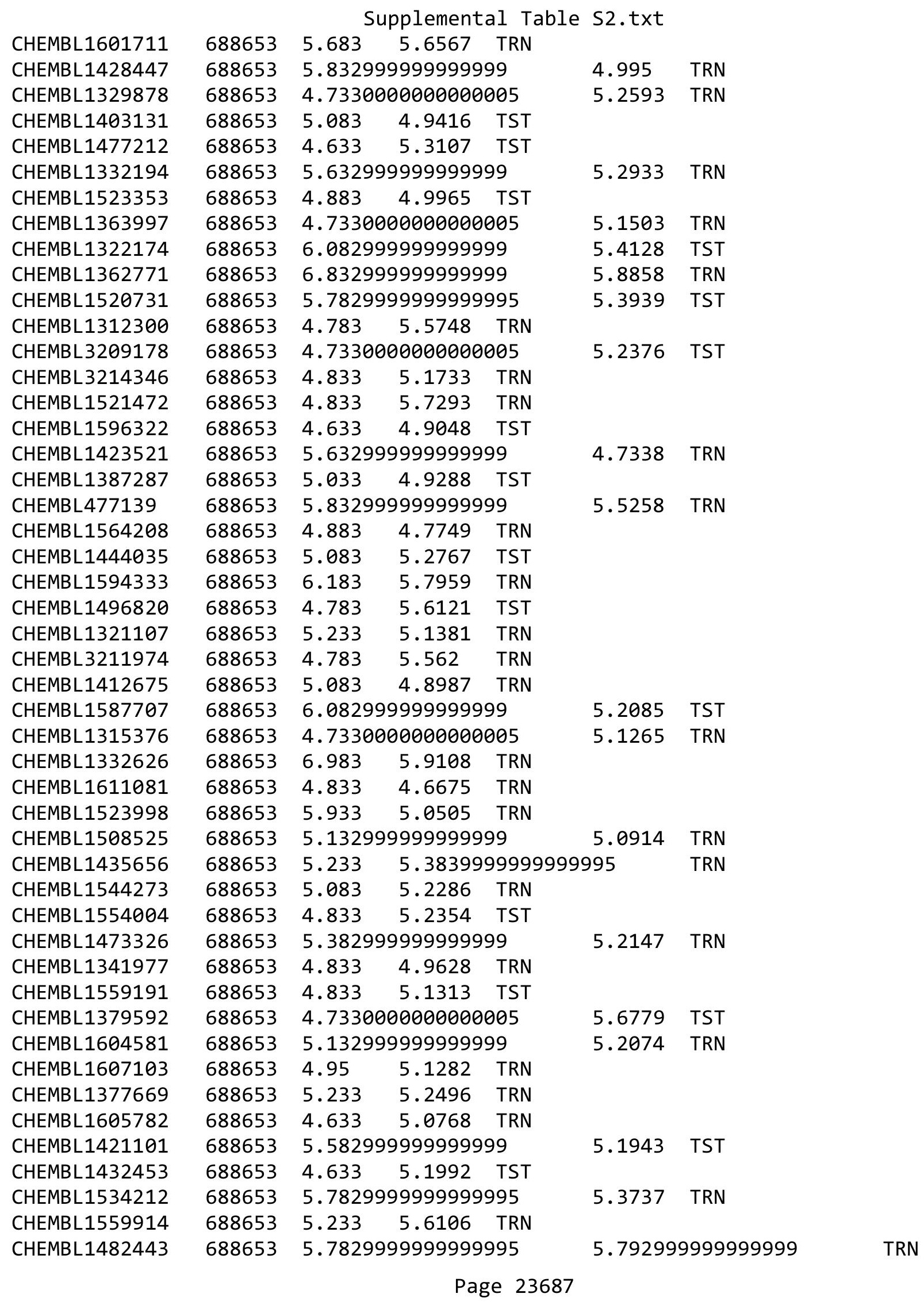




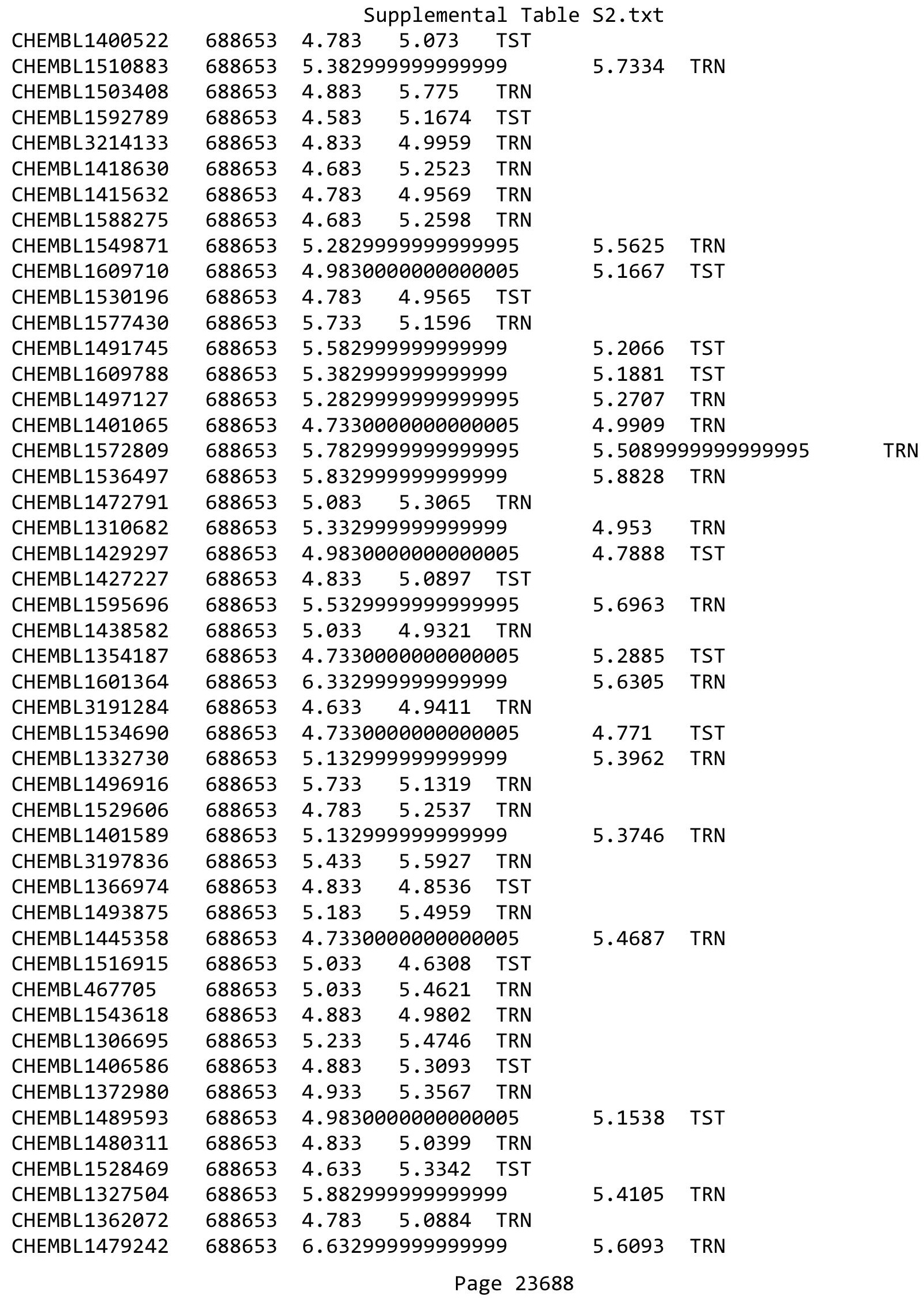




\begin{tabular}{|c|c|c|c|c|c|c|c|}
\hline \multirow{2}{*}{ CHEMBL3211717 } & \multicolumn{5}{|c|}{ Supplemental Table S2.txt } & \multirow{2}{*}{\multicolumn{2}{|c|}{ 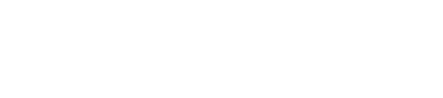 }} \\
\hline & 688653 & 4.883 & 5.0672 & TRN & & & \\
\hline CHEMBL1449208 & 688653 & 5.78299 & 99999999 & 995 & 5.2242 & TRN & \\
\hline CHEMBL1560252 & 688653 & 5.083 & 5.0566 & TRN & & & \\
\hline CHEMBL1457931 & 688653 & 4.98300 & 00000000 & 005 & 5.4759 & TRN & \\
\hline CHEMBL1365610 & 688653 & 5.033 & 5.5895 & TRN & & & \\
\hline CHEMBL1388949 & 688653 & 4.73300 & 00000000 & 005 & 4.8776 & TRN & \\
\hline CHEMBL1550062 & 688653 & 5.033 & 5.3513 & TST & & & \\
\hline CHEMBL1491625 & 688653 & 4.583 & 4.8784 & TRN & & & \\
\hline CHEMBL1508470 & 688653 & 5.033 & 5.4234 & TRN & & & \\
\hline CHEMBL1313747 & 688653 & 5.78299 & 99999999 & 995 & 5.3601 & TRN & \\
\hline CHEMBL1469032 & 688653 & 5.483 & 5.9071 & TRN & & & \\
\hline CHEMBL1570135 & 688653 & 4.583 & 4.8038 & TRN & & & \\
\hline CHEMBL3194782 & 688653 & 4.883 & 5.5206 & TST & & & \\
\hline CHEMBL1323838 & 688653 & 5.083 & 5.307 & TRN & & & \\
\hline CHEMBL1488010 & 688653 & 4.73300 & 00000000 & 005 & 5.4722 & TST & \\
\hline CHEMBL1346269 & 688653 & 5.33299 & 99999999 & & 5.334 & TRN & \\
\hline CHEMBL582070 & 688653 & 4.933 & 4.9791 & TRN & & & \\
\hline CHEMBL1312337 & 688653 & 4.833 & 5.0095 & TRN & & & \\
\hline CHEMBL1475826 & 688653 & 5.13299 & 99999999 & & 5.8952 & TRN & \\
\hline CHEMBL1400530 & 688653 & 4.683 & 5.1432 & TRN & & & \\
\hline CHEMBL1448867 & 688653 & 6.233 & 5.6254 & TRN & & & \\
\hline CHEMBL1340302 & 688653 & 4.633 & 4.8431 & TRN & & & \\
\hline CHEMBL1343817 & 688653 & 6.33299 & 99999999 & & 6.0544 & TRN & \\
\hline CHEMBL1605674 & 688653 & 6.38299 & 99999999 & & 5.4789 & TST & \\
\hline CHEMBL1510664 & 688653 & 4.833 & 5.1085 & TST & & & \\
\hline CHEMBL1578411 & 688653 & 5.483 & 5.1738 & TRN & & & \\
\hline CHEMBL1472821 & 688653 & 4.583 & 4.9837 & TST & & & \\
\hline CHEMBL3208165 & 688653 & 4.73300 & 00000000 & 005 & 5.0735 & TRN & \\
\hline CHEMBL1470281 & 688653 & 5.183 & 5.0455 & TST & & & \\
\hline CHEMBL1390654 & 688653 & 4.633 & 4.9504 & TST & & & \\
\hline CHEMBL1375660 & 688653 & 5.683 & 5.329 & TRN & & & \\
\hline CHEMBL1373521 & 688653 & 5.83299 & 99999999 & & 5.2223 & TRN & \\
\hline CHEMBL1533634 & 688653 & 5.933 & 5.6109 & TRN & & & \\
\hline CHEMBL1360023 & 688653 & 5.13299 & 99999999 & & 5.3982 & TRN & \\
\hline CHEMBL3196072 & 688653 & 5.78299 & 99999999 & 995 & 5.17200 & 0000000001 & TRN \\
\hline CHEMBL1970537 & 688653 & 4.73300 & 00000000 & 005 & 5.4022 & TST & \\
\hline CHEMBL1441600 & 688653 & 5.233 & 4.9745 & TST & & & \\
\hline CHEMBL1318128 & 688653 & 6.683 & 5.7739 & TRN & & & \\
\hline CHEMBL1477689 & 688653 & 5.88299 & 99999999 & 99 & 5.2025 & TRN & \\
\hline CHEMBL1320920 & 688653 & 5.683 & 5.4359 & TRN & & & \\
\hline CHEMBL1560399 & 688653 & 5.083 & 5.3352 & TRN & & & \\
\hline CHEMBL1434710 & 688653 & 5.083 & 5.3602 & TRN & & & \\
\hline CHEMBL1350122 & 688653 & 4.783 & 4.9702 & TST & & & \\
\hline CHEMBL1471741 & 688653 & 5.63299 & 99999999 & 99 & 5.4515 & TRN & \\
\hline CHEMBL1357663 & 688653 & 5.683 & 4.9483 & TST & & & \\
\hline CHEMBL1565290 & 688653 & 4.73300 & 00000000 & 005 & 5.1596 & TST & \\
\hline CHEMBL1331509 & 688653 & 6.58299 & 99999999 & & 5.8111 & TRN & \\
\hline CHEMBL1424475 & 688653 & 5.183 & 5.2703 & TST & & & \\
\hline
\end{tabular}




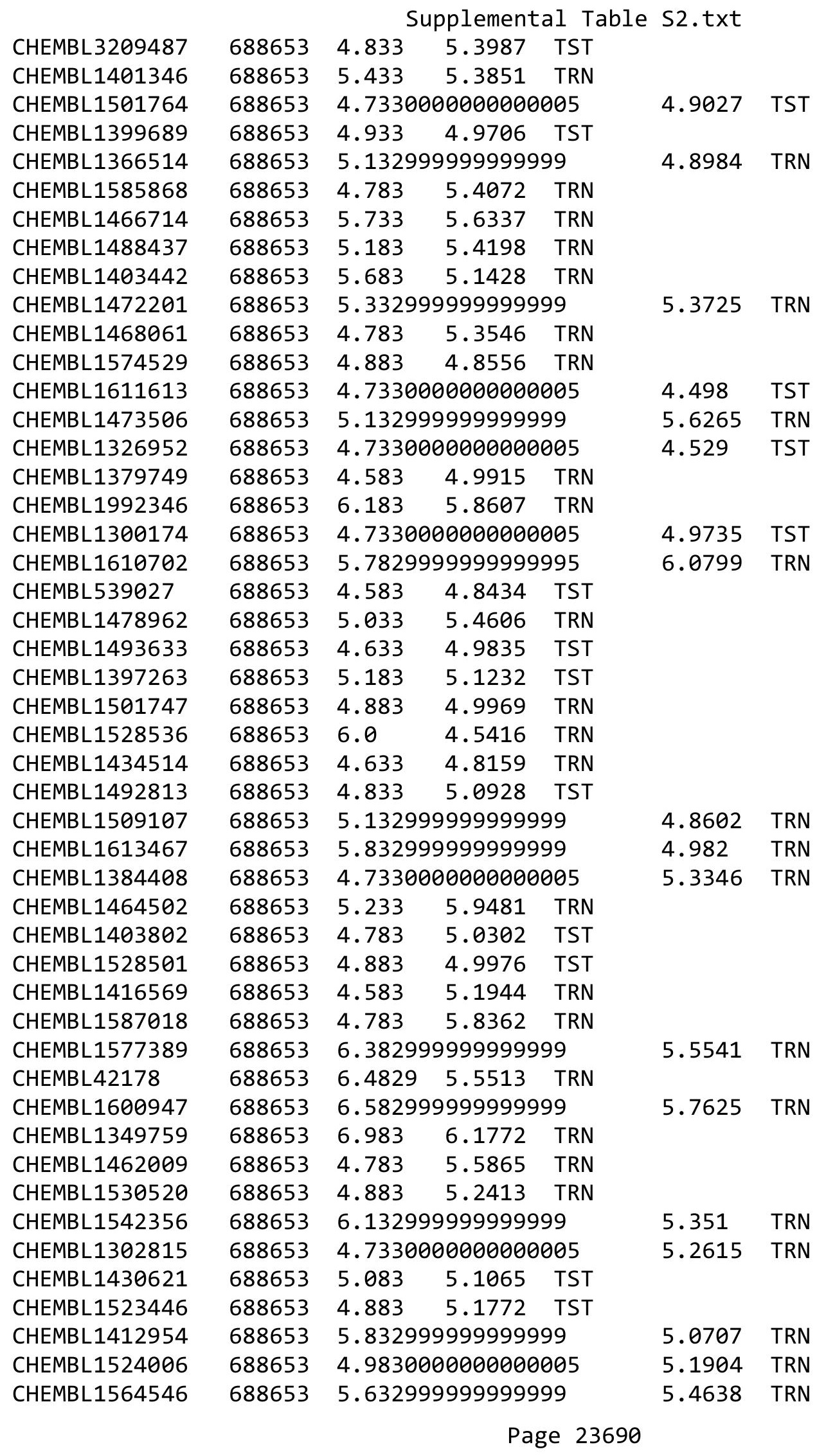




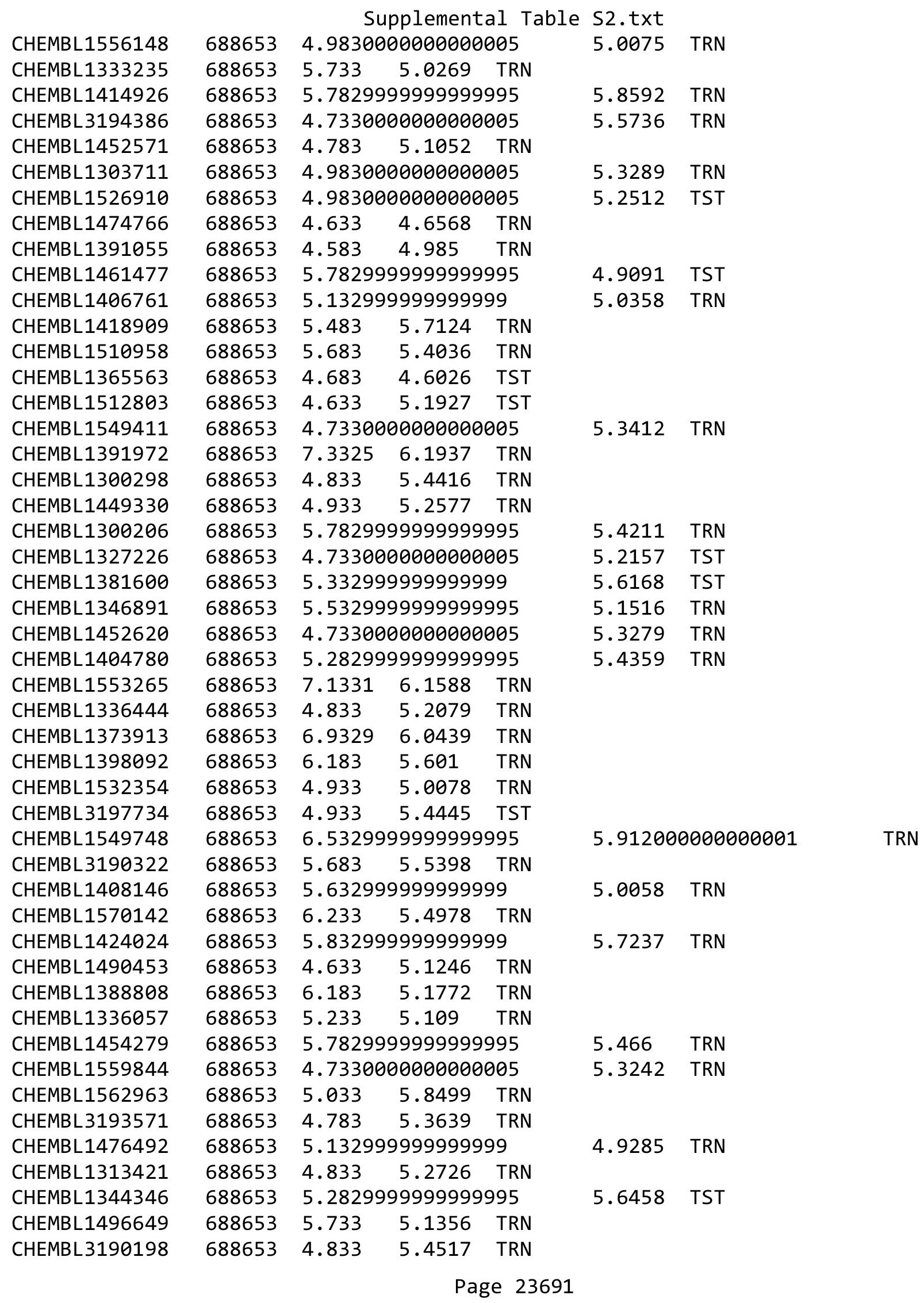




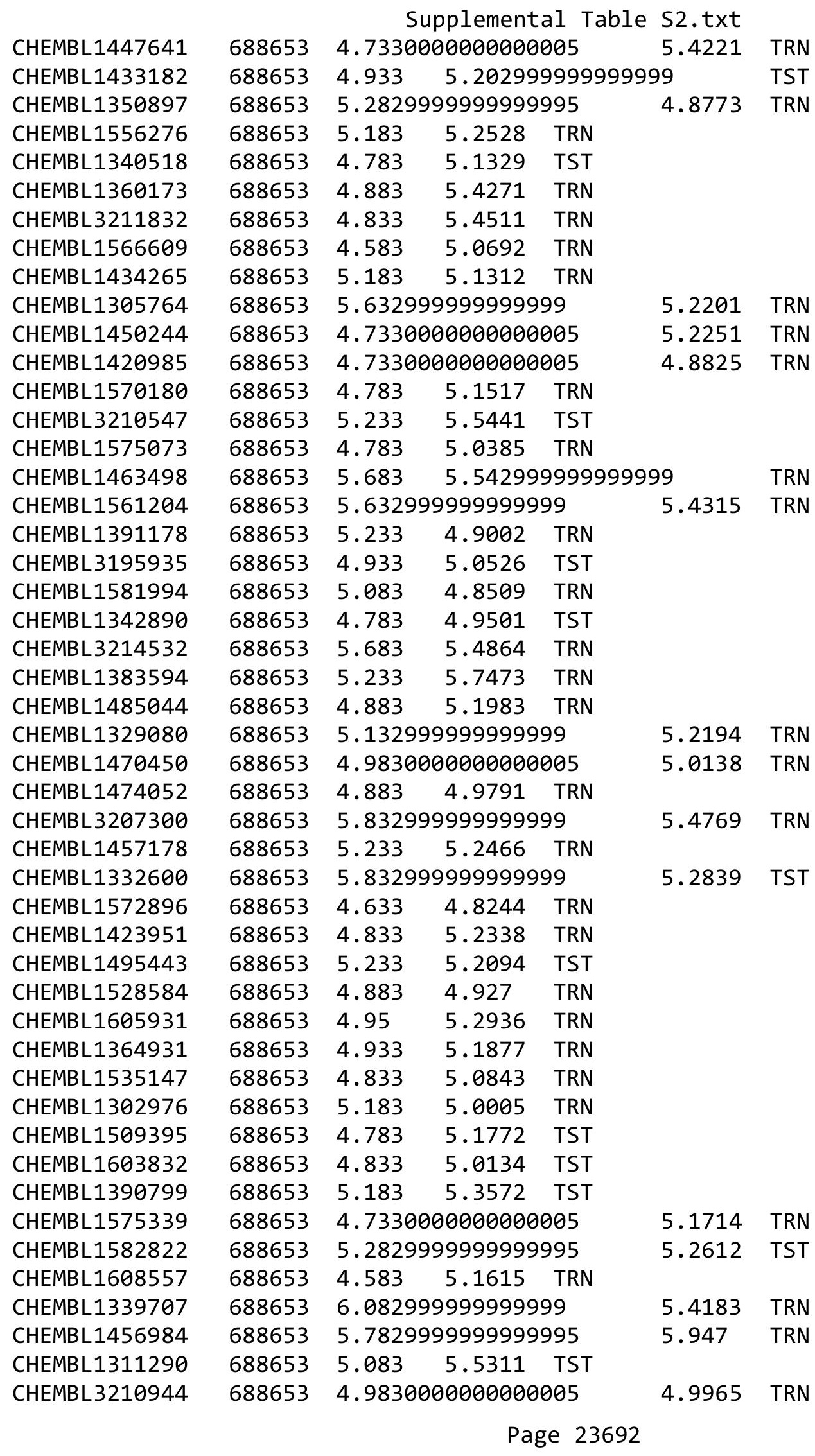




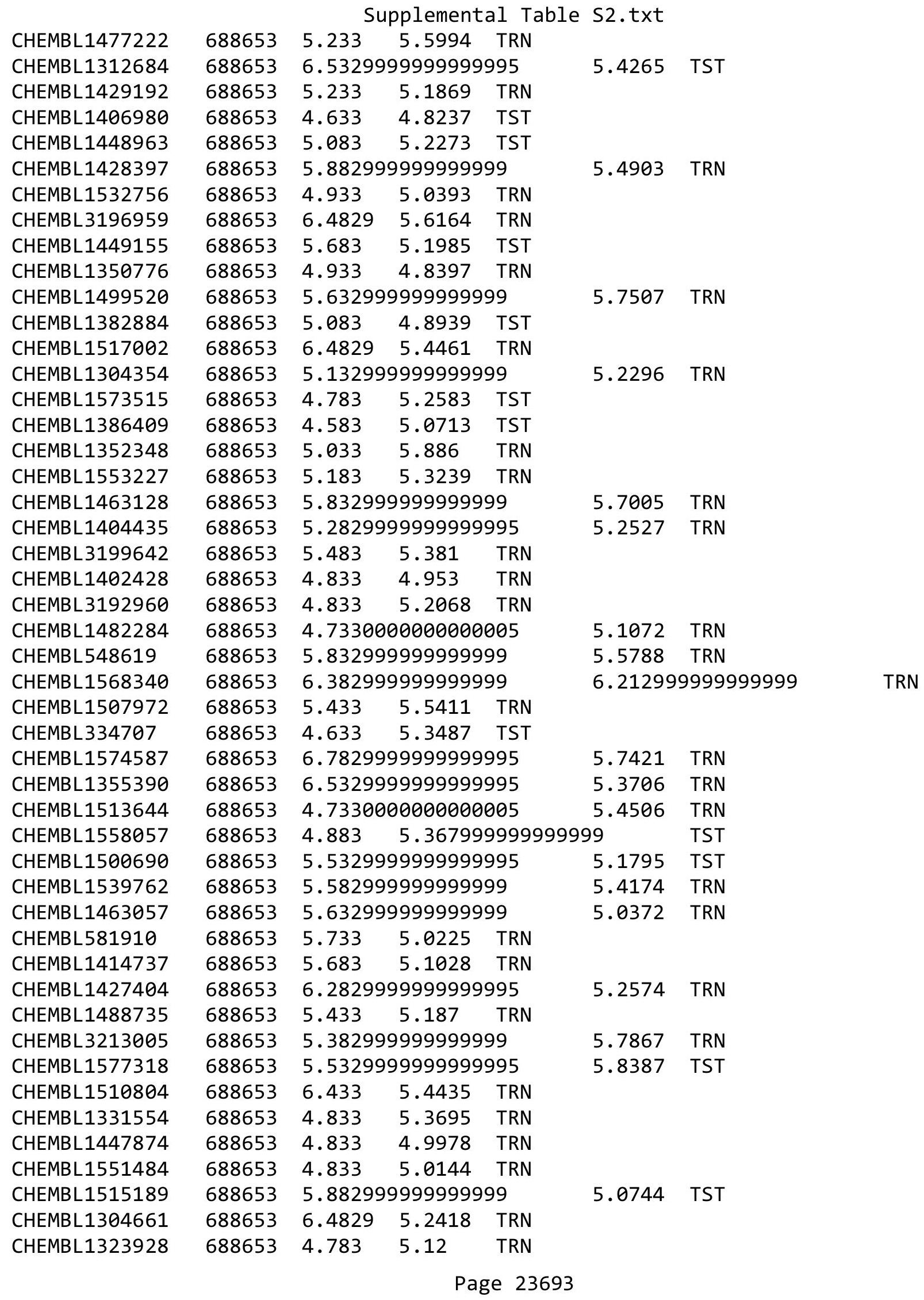




\begin{tabular}{|c|c|c|c|c|c|c|c|}
\hline \multicolumn{7}{|c|}{ Supplemental Table s2.txt } & \\
\hline CHEMBL1403383 & 688653 & \multicolumn{3}{|c|}{5.5329999999999995} & 5.1939 & TST & \\
\hline CHEMBL1320867 & 688653 & 5.233 & 5.5886 & TST & & & \\
\hline CHEMBL1543930 & 688653 & 4.783 & 5.3532 & TRN & & & \\
\hline CHEMBL1342028 & 688653 & \multicolumn{3}{|c|}{4.7330000000000005} & 5.7285 & TRN & \\
\hline CHEMBL1447451 & 688653 & 5.183 & 5.2646 & TRN & & & \\
\hline CHEMBL1241371 & 688653 & 5.433 & 5.6462 & TRN & & & \\
\hline CHEMBL1516772 & 688653 & 4.783 & 4.8872 & TRN & & & \\
\hline CHEMBL1335814 & 688653 & 5.683 & 5.2914 & TRN & & & \\
\hline CHEMBL1338749 & 688653 & 4.583 & 5.0462 & TRN & & & \\
\hline CHEMBL1511172 & 688653 & 5.483 & \multicolumn{3}{|c|}{5.236000000000001} & TRN & \\
\hline CHEMBL1518684 & 688653 & \multicolumn{3}{|c|}{5.332999999999999} & 5.5255 & TRN & \\
\hline CHEMBL1500583 & 688653 & \multicolumn{3}{|c|}{5.132999999999999} & 5.3103 & TST & \\
\hline CHEMBL3194311 & 688653 & \multicolumn{3}{|c|}{5.132999999999999} & 5.3734 & TRN & \\
\hline CHEMBL1407407 & 688653 & \multicolumn{3}{|c|}{5.332999999999999} & 5.1121 & TST & \\
\hline CHEMBL1586263 & 688653 & \multicolumn{3}{|c|}{4.7330000000000005} & 4.7253 & TRN & \\
\hline CHEMBL3209609 & 688653 & 4.883 & 5.2948 & TRN & & & \\
\hline CHEMBL1598993 & 688653 & 4.633 & 5.2749 & TST & & & \\
\hline CHEMBL1599576 & 688653 & \multicolumn{3}{|c|}{6.0329999999999995} & 5.4378 & TST & \\
\hline CHEMBL1342479 & 688653 & 5.733 & 5.2822 & TRN & & & \\
\hline CHEMBL1369594 & 688653 & \multicolumn{3}{|c|}{5.132999999999999} & 5.5016 & TRN & \\
\hline CHEMBL1558556 & 688653 & \multicolumn{3}{|c|}{5.132999999999999} & 5.7298 & TRN & \\
\hline CHEMBL1509768 & 688653 & 4.883 & 5.1429 & TST & & & \\
\hline CHEMBL1602133 & 688653 & 4.633 & 4.8382 & TRN & & & \\
\hline CHEMBL1502558 & 688653 & 4.783 & 5.6854 & TRN & & & \\
\hline CHEMBL1510355 & 688653 & 5.083 & 5.2283 & TRN & & & \\
\hline CHEMBL1523756 & 688653 & 5.433 & 5.6176 & TRN & & & \\
\hline CHEMBL1353062 & 688653 & \multicolumn{3}{|c|}{6.832999999999999} & 5.9544 & TRN & \\
\hline CHEMBL1412369 & 688653 & 4.633 & 5.0549 & TST & & & \\
\hline CHEMBL1398960 & 688653 & \multicolumn{3}{|c|}{5.382999999999999} & 4.9319 & TRN & \\
\hline CHEMBL1352627 & 688653 & \multicolumn{3}{|c|}{4.7330000000000005} & 5.0707 & TRN & \\
\hline CHEMBL1590410 & 688653 & 5.233 & 5.2682 & TST & & & \\
\hline CHEMBL1333664 & 688653 & 5.233 & 5.1552 & TST & & & \\
\hline CHEMBL1450967 & 688653 & 5.483 & 5.083 & TRN & & & \\
\hline CHEMBL1331221 & 688653 & 4.933 & 4.5165 & TRN & & & \\
\hline CHEMBL1367354 & 688653 & \multicolumn{3}{|c|}{5.332999999999999} & 5.22 & TRN & \\
\hline CHEMBL1578021 & 688653 & \multicolumn{3}{|c|}{4.7330000000000005} & 5.2921 & TRN & \\
\hline CHEMBL1312265 & 688653 & 5.683 & 5.5338 & TRN & & & \\
\hline CHEMBL1585624 & 688653 & \multicolumn{3}{|c|}{5.5329999999999995} & 5.3654 & TRN & \\
\hline CHEMBL1439318 & 688653 & 4.833 & 5.2045 & TRN & & & \\
\hline CHEMBL1396837 & 688653 & 6.183 & 5.2877 & TST & & & \\
\hline CHEMBL1325873 & 688653 & 5.683 & 5.5569 & TRN & & & \\
\hline CHEMBL1322336 & 688653 & 5.433 & 5.1768 & TRN & & & \\
\hline CHEMBL3210095 & 688653 & \multicolumn{3}{|c|}{6.0329999999999995} & 5.3498 & TST & \\
\hline CHEMBL1442316 & 688653 & \multicolumn{3}{|c|}{5.582999999999999} & 5.9910 & 00000000005 & TRN \\
\hline CHEMBL1391963 & 688653 & 4.833 & 5.0874 & TST & & & \\
\hline CHEMBL 3212560 & 688653 & \multicolumn{3}{|c|}{5.832999999999999} & 5.4196 & TRN & \\
\hline CHEMBL1321943 & 688653 & 5.382 & 79999999 & & 5.5208 & TRN & \\
\hline CHEMBL1443817 & 688653 & 4.783 & 5.1742 & TRN & & & \\
\hline
\end{tabular}




\begin{tabular}{|c|c|c|c|c|c|c|c|}
\hline \multicolumn{8}{|c|}{ Supplemental Table S2.txt } \\
\hline CHEMBL303846 & 688653 & 4.883 & 5.4437 & TST & & & \\
\hline CHEMBL3192617 & 688653 & 4.833 & 5.2754 & TRN & & & \\
\hline CHEMBL1558342 & 688653 & 5.53299 & 99999999 & 995 & 5.7345 & TRN & \\
\hline CHEMBL1315886 & 688653 & 5.683 & 5.1543 & TRN & & & \\
\hline CHEMBL1358256 & 688653 & 5.13299 & 99999999 & & 5.2936 & TRN & \\
\hline CHEMBL1466389 & 688653 & 6.183 & 5.2339 & TRN & & & \\
\hline CHEMBL1306775 & 688653 & 5.183 & 5.6619 & TRN & & & \\
\hline CHEMBL1454739 & 688653 & 5.183 & 5.5545 & TRN & & & \\
\hline CHEMBL1394287 & 688653 & 5.433 & 6.0146 & TRN & & & \\
\hline CHEMBL1522846 & 688653 & 4.883 & 5.1243 & TST & & & \\
\hline CHEMBL1468030 & 688653 & 5.78299 & 99999999 & 995 & 5.5155 & TRN & \\
\hline CHEMBL1578918 & 688653 & 4.833 & 4.9863 & TST & & & \\
\hline CHEMBL1375955 & 688653 & 4.833 & 4.9268 & TRN & & & \\
\hline CHEMBL1558327 & 688653 & 4.833 & 5.8909 & TRN & & & \\
\hline CHEMBL1558092 & 688653 & 7.08299 & 99999999 & & 5.8062 & TRN & \\
\hline CHEMBL1391417 & 688653 & 4.633 & 4.9022 & TST & & & \\
\hline CHEMBL1321672 & 688653 & 4.833 & 5.0269 & TRN & & & \\
\hline CHEMBL1451763 & 688653 & 4.933 & 5.4329 & TST & & & \\
\hline CHEMBL1573627 & 688653 & 4.73300 & 00000000 & 005 & 5.3906 & TST & \\
\hline CHEMBL1613055 & 688653 & 4.73300 & 00000000 & 005 & 5.1429 & TST & \\
\hline CHEMBL1347925 & 688653 & 4.883 & 5.2787 & TRN & & & \\
\hline CHEMBL1355018 & 688653 & 5.13299 & 99999999 & & 5.8136 & TRN & \\
\hline CHEMBL1490955 & 688653 & 5.53299 & 99999999 & 995 & 5.45700 & 0000000001 & TRN \\
\hline CHEMBL1386299 & 688653 & 5.58299 & 99999999 & & 5.1458 & TRN & \\
\hline CHEMBL1306573 & 688653 & 4.883 & 5.1343 & TST & & & \\
\hline CHEMBL1404024 & 688653 & 4.783 & 5.1617 & TRN & & & \\
\hline CHEMBL1336632 & 688653 & 4.833 & 5.341 & TRN & & & \\
\hline CHEMBL1445427 & 688653 & 6.08299 & 99999999 & & 5.4594 & TST & \\
\hline CHEMBL3191715 & 688653 & 6.53299 & 99999999 & 995 & 6.3718 & TRN & \\
\hline CHEMBL1450778 & 688653 & 6.08299 & 99999999 & & 5.8311 & TRN & \\
\hline CHEMBL1423463 & 688653 & 5.28299 & 99999999 & 995 & 4.9402 & TRN & \\
\hline CHEMBL1589657 & 688653 & 4.883 & 5.0915 & TST & & & \\
\hline CHEMBL1327089 & 688653 & 5.683 & 5.4281 & TRN & & & \\
\hline CHEMBL1334265 & 688653 & 4.833 & 4.9093 & TRN & & & \\
\hline CHEMBL1574589 & 688653 & 4.783 & 5.0922 & TRN & & & \\
\hline CHEMBL1406454 & 688653 & 4.783 & 5.53700 & 000000000 & & TST & \\
\hline CHEMBL3214536 & 688653 & 4.73300 & 00000000 & 005 & 5.4963 & TST & \\
\hline CHEMBL1447669 & 688653 & 6.0 & 5.6443 & TRN & & & \\
\hline CHEMBL1574031 & 688653 & 4.633 & 5.4269 & TST & & & \\
\hline CHEMBL1441555 & 688653 & 4.633 & 5.2024 & TRN & & & \\
\hline CHEMBL1998566 & 688653 & 4.583 & 5.2075 & TRN & & & \\
\hline CHEMBL1389289 & 688653 & 5.28299 & 99999999 & 995 & 5.7602 & TRN & \\
\hline CHEMBL1417736 & 688653 & 4.73300 & 00000000 & 005 & 4.9852 & TRN & \\
\hline CHEMBL1605987 & 688653 & 5.183 & 5.1559 & TST & & & \\
\hline CHEMBL1435533 & 688653 & 6.53299 & 99999999 & 995 & 5.7165 & TRN & \\
\hline CHEMBL1466658 & 688653 & 4.833 & 5.2569 & TRN & & & \\
\hline CHEMBL1389467 & 688653 & 4.883 & 5.279 & TRN & & & \\
\hline CHEMBL1405249 & 688653 & 4.933 & 4.904 & TST & & & \\
\hline
\end{tabular}




\begin{tabular}{|c|c|c|c|c|c|c|}
\hline \multirow[b]{2}{*}{ CHEMBL1448258 } & & \multicolumn{5}{|c|}{ Supplemental Table S2.txt } \\
\hline & 688653 & 5.083 & 5.2041 & TRN & & \\
\hline CHEMBL1311157 & 688653 & 4.833 & 5.0573 & TRN & & \\
\hline CHEMBL1444204 & 688653 & 4.783 & 5.0451 & TRN & & \\
\hline CHEMBL1577912 & 688653 & \multicolumn{3}{|c|}{6.132999999999999} & 5.5646 & TRN \\
\hline CHEMBL1417043 & 688653 & \multicolumn{3}{|c|}{5.632999999999999} & 5.2355 & TRN \\
\hline CHEMBL1537583 & 688653 & \multicolumn{3}{|c|}{5.132999999999999} & 5.3757 & TRN \\
\hline CHEMBL3194312 & 688653 & 4.783 & 5.1743 & TRN & & \\
\hline CHEMBL1376212 & 688653 & 5.433 & 5.4212 & TRN & & \\
\hline CHEMBL1450032 & 688653 & 4.683 & 5.7645 & TRN & & \\
\hline CHEMBL1476038 & 688653 & \multicolumn{3}{|c|}{6.332999999999999} & 4.9472 & TST \\
\hline CHEMBL3199543 & 688653 & 5.483 & 5.2141 & TRN & & \\
\hline CHEMBL1480798 & 688653 & 5.083 & 5.8717 & TRN & & \\
\hline CHEMBL1430923 & 688653 & 6.183 & 5.2003 & TRN & & \\
\hline CHEMBL 3197576 & 688653 & \multicolumn{3}{|c|}{5.5329999999999995} & 5.2521 & TRN \\
\hline CHEMBL1484934 & 688653 & 4.633 & 4.8092 & TRN & & \\
\hline CHEMBL3209987 & 688653 & 4.833 & 5.811 & TST & & \\
\hline CHEMBL3190606 & 688653 & \multicolumn{3}{|c|}{5.7829999999999995} & 5.6179 & TRN \\
\hline CHEMBL3199085 & 688653 & 5.233 & 5.4092 & TRN & & \\
\hline CHEMBL1542925 & 688653 & 4.833 & 5.3515 & TRN & & \\
\hline CHEMBL1455211 & 688653 & \multicolumn{3}{|c|}{5.5329999999999995} & 5.8056 & TRN \\
\hline CHEMBL1518385 & 688653 & \multicolumn{3}{|c|}{5.2829999999999995} & 5.1613 & TST \\
\hline CHEMBL1410491 & 688653 & 4.833 & 5.3633 & TST & & \\
\hline CHEMBL3193947 & 688653 & 5.083 & 4.9419 & TRN & & \\
\hline CHEMBL1517191 & 688653 & 5.083 & 5.2834 & TRN & & \\
\hline CHEMBL1544911 & 688653 & \multicolumn{3}{|c|}{4.7330000000000005} & 5.2526 & TST \\
\hline CHEMBL1498393 & 688653 & 5.033 & 5.0072 & TRN & & \\
\hline CHEMBL1424599 & 688653 & \multirow{2}{*}{\multicolumn{3}{|c|}{6.082999999999999}} & & \\
\hline CHEMBL1331513 & 688653 & & & & 5.5033 & TRN \\
\hline CHEMBL1610032 & 688653 & 5.483 & 5.755 & TRN & & \\
\hline CHEMBL1331206 & 688653 & 4.633 & 5.1318 & TST & & \\
\hline CHEMBL1443946 & 688653 & 4.883 & 5.2198 & TRN & & \\
\hline CHEMBL1469609 & 688653 & \multicolumn{3}{|c|}{5.382999999999999} & 5.1088 & TRA \\
\hline CHEMBL1590795 & 688653 & 4.783 & 4.9229 & TRN & & \\
\hline CHEMBL490592 & 688653 & \multicolumn{3}{|c|}{6.382999999999999} & 5.6261 & TRA \\
\hline CHEMBL1448047 & 688653 & 5.483 & 5.1227 & TRN & & \\
\hline CHEMBL1409576 & 688653 & 4.633 & 5.1523 & TRN & & \\
\hline CHEMBL1566578 & 688653 & 4.783 & 4.8641 & TRN & & \\
\hline CHEMBL1512970 & 688653 & 4.633 & 4.7315 & TRN & & \\
\hline CHEMBL3198530 & 688653 & 5.183 & 5.5362 & TST & & \\
\hline CHEMBL3198460 & 688653 & \multicolumn{3}{|c|}{6.5329999999999995} & 5.5286 & TRA \\
\hline CHEMBL1338721 & 688653 & 5.933 & 5.3446 & TRN & & \\
\hline CHEMBL1396127 & 688653 & \multicolumn{3}{|c|}{4.7330000000000005} & 4.9486 & TST \\
\hline CHEMBL1535510 & 688653 & 4.583 & 4.9972 & TRN & & \\
\hline CHEMBL 2007021 & 688653 & \multicolumn{3}{|c|}{5.632999999999999} & 5.468 & TRA \\
\hline CHEMBL3214515 & 688653 & 6.0 & 5.7871 & TRN & & \\
\hline CHEMBL1393056 & 688653 & 5.483 & 5.5581 & TRN & & \\
\hline CHEMBL1339737 & 688653 & \multicolumn{3}{|c|}{4.7330000000000005} & 5.5788 & TRA \\
\hline CHEMBL1312292 & 688653 & 5.933 & 6.0558 & TRN & & \\
\hline
\end{tabular}




\begin{tabular}{|c|c|c|c|c|c|c|}
\hline \multirow[b]{2}{*}{ CHEMBL1603807 } & \multirow[b]{2}{*}{688653} & \multicolumn{5}{|c|}{ Supplemental Table S2.txt } \\
\hline & & \multirow{2}{*}{\multicolumn{3}{|c|}{$\begin{array}{lcc}4.883 & 5.1445 & \text { TRN } \\
4.9830000000000005\end{array}$}} & \multirow{3}{*}{5.1055} & \multirow{3}{*}{ TST } \\
\hline CHEMBL1504792 & 688653 & & & & & \\
\hline CHEMBL1341787 & 688653 & 4.783 & 4.873 & TRN & & \\
\hline CHEMBL1471529 & 688653 & \multicolumn{3}{|c|}{5.5329999999999995} & 5.2662 & TRN \\
\hline CHEMBL1500169 & 688653 & 4.633 & 4.9698 & TRN & & \\
\hline CHEMBL1436522 & 688653 & 5.033 & 4.9648 & TRN & & \\
\hline CHEMBL3198019 & 688653 & 5.483 & 5.0968 & TRN & & \\
\hline CHEMBL1554040 & 688653 & 4.583 & 5.2509 & TRN & & \\
\hline CHEMBL1427004 & 688653 & 4.833 & 4.9409 & TRN & & \\
\hline CHEMBL1566929 & 688653 & 4.883 & 4.9585 & TRN & & \\
\hline CHEMBL1305421 & 688653 & 4.783 & 5.2158 & TST & & \\
\hline CHEMBL1359912 & 688653 & 4.883 & 4.7283 & TRN & & \\
\hline CHEMBL1446163 & 688653 & 4.833 & 5.5614 & TRN & & \\
\hline CHEMBL1352911 & 688653 & 5.733 & 5.4083 & TST & & \\
\hline CHEMBL1361702 & 688653 & 4.783 & 5.7222 & TRN & & \\
\hline CHEMBL1310637 & 688653 & \multicolumn{3}{|c|}{5.382999999999999} & 5.646 & TRN \\
\hline CHEMBL1485364 & 688653 & 4.833 & 4.7974 & TRN & & \\
\hline CHEMBL1338450 & 688653 & 4.783 & 4.9619 & TRN & & \\
\hline CHEMBL1312919 & 688653 & 4.883 & 5.0974 & TRN & & \\
\hline CHEMBL1344082 & 688653 & \multicolumn{3}{|c|}{4.7330000000000005} & 5.2421 & TRN \\
\hline CHEMBL1492825 & 688653 & 4.933 & 5.2053 & TRN & & \\
\hline CHEMBL1363219 & 688653 & 4.633 & 5.0274 & TST & & \\
\hline CHEMBL1520838 & 688653 & \multicolumn{3}{|c|}{4.7330000000000005} & 5.024 & TST \\
\hline CHEMBL1305322 & 688653 & 4.833 & 5.1275 & TST & & \\
\hline CHEMBL1479597 & 688653 & 4.583 & 5.2234 & TRN & & \\
\hline CHEMBL1466824 & 688653 & 5.433 & 5.29 & TRN & & \\
\hline CHEMBL3210802 & 688653 & 4.783 & 5.1326 & TST & & \\
\hline CHEMBL1505141 & 688653 & 4.833 & 5.2287 & TST & & \\
\hline CHEMBL1771411 & 688653 & 5.233 & 5.5423 & TRN & & \\
\hline CHEMBL1582978 & 688653 & 5.183 & 5.0164 & TRN & & \\
\hline CHEMBL3197616 & 688653 & \multicolumn{3}{|c|}{4.7330000000000005} & 5.0249 & TST \\
\hline CHEMBL1442033 & 688653 & 4.833 & 4.8149 & TRN & & \\
\hline CHEMBL 1423760 & 688653 & 4.883 & 5.3187 & TRN & & \\
\hline CHEMBL3195090 & 688653 & 4.933 & 5.2965 & TRN & & \\
\hline CHEMBL1509216 & 688653 & \multicolumn{3}{|c|}{4.9830000000000005} & 5.3594 & TST \\
\hline CHEMBL1527223 & 688653 & 5.083 & 5.2977 & TST & & \\
\hline CHEMBL1351385 & 688653 & 4.633 & 4.4841 & TRN & & \\
\hline CHEMBL1465437 & 688653 & \multicolumn{3}{|c|}{5.132999999999999} & 5.7118 & TRN \\
\hline CHEMBL1965873 & 688653 & 4.783 & 5.2936 & TRN & & \\
\hline CHEMBL3213994 & 688653 & \multicolumn{3}{|c|}{4.7330000000000005} & 5.1851 & TRN \\
\hline CHEMBL1604459 & 688653 & \multicolumn{3}{|c|}{4.7330000000000005} & 4.8672 & TRN \\
\hline CHEMBL1539237 & 688653 & 4.633 & 4.7375 & TRN & & \\
\hline CHEMBL3198707 & 688653 & 5.733 & 5.2524 & TST & & \\
\hline CHEMBL1418432 & 688653 & 5.483 & 5.3799 & TST & & \\
\hline CHEMBL1476765 & 688653 & 5.083 & 5.722 & TRN & & \\
\hline CHEMBL1454767 & 688653 & 5.083 & 4.9688 & TRN & & \\
\hline CHEMBL1468810 & 688653 & 5.033 & 5.0783 & TRN & & \\
\hline CHEMBL1976161 & 688653 & \multicolumn{3}{|c|}{5.832999999999999} & 5.4423 & TRN \\
\hline
\end{tabular}




\begin{tabular}{|c|c|c|c|c|c|c|c|}
\hline \multicolumn{7}{|c|}{ Supplemental Table S2.txt } & \\
\hline CHEMBL1593012 & 688653 & \multicolumn{3}{|c|}{5.132999999999999} & 5.0527 & TST & \\
\hline CHEMBL1476415 & 688653 & 5.483 & 5.6999 & TST & & & \\
\hline CHEMBL1454900 & 688653 & \multicolumn{3}{|c|}{5.2829999999999995} & 4.859 & TRN & \\
\hline CHEMBL1301051 & 688653 & 5.433 & 5.1081 & TRN & & & \\
\hline CHEMBL1403030 & 688653 & 5.983 & 4.8837 & TRN & & & \\
\hline CHEMBL1575624 & 688653 & 5.233 & 5.2374 & TRN & & & \\
\hline CHEMBL1484400 & 688653 & \multicolumn{3}{|c|}{4.7330000000000005} & 5.2117 & TST & \\
\hline CHEMBL1605613 & 688653 & \multicolumn{3}{|c|}{6.2829999999999995} & 5.7431 & TRN & \\
\hline CHEMBL1550899 & 688653 & 4.633 & 4.3932 & TRN & & & \\
\hline CHEMBL1503305 & 688653 & 4.783 & 5.5114 & TRN & & & \\
\hline CHEMBL1509359 & 688653 & \multicolumn{3}{|c|}{4.7330000000000005} & 5.5638 & TRN & \\
\hline CHEMBL1413345 & 688653 & 4.583 & 5.0148 & TST & & & \\
\hline CHEMBL1589567 & 688653 & \multicolumn{3}{|c|}{5.882999999999999} & 5.7468 & TRN & \\
\hline CHEMBL1549354 & 688653 & 4.883 & 5.3411 & TRN & & & \\
\hline CHEMBL1324518 & 688653 & 4.883 & 4.885 & TRN & & & \\
\hline CHEMBL1408276 & 688653 & \multicolumn{3}{|c|}{5.582999999999999} & 6.0124 & TRN & \\
\hline CHEMBL1381487 & 688653 & \multicolumn{3}{|c|}{4.7330000000000005} & 5.0323 & TRN & \\
\hline CHEMBL1534404 & 688653 & 5.733 & 5.4269 & TRN & & & \\
\hline CHEMBL1574311 & 688653 & 4.833 & 5.386 & TRN & & & \\
\hline CHEMBL1459709 & 688653 & 5.933 & 5.8867 & TRN & & & \\
\hline CHEMBL1389591 & 688653 & 4.583 & 5.0546 & TRN & & & \\
\hline CHEMBL473106 & 688653 & 6.4829 & 5.083 & TST & & & \\
\hline CHEMBL1496970 & 688653 & 5.083 & 5.3666 & TRN & & & \\
\hline CHEMBL1450011 & 688653 & \multicolumn{3}{|c|}{4.9830000000000005} & 5.0315 & TRN & \\
\hline CHEMBL1316927 & 688653 & 5.033 & 5.4087 & TST & & & \\
\hline CHEMBL1451402 & 688653 & \multicolumn{3}{|c|}{5.7829999999999995} & 5.294 & TRN & \\
\hline CHEMBL1556354 & 688653 & 4.833 & 4.8516 & TRN & & & \\
\hline CHEMBL407817 & 688653 & \multicolumn{3}{|c|}{5.882999999999999} & 5.6741 & TRN & \\
\hline CHEMBL1306338 & 688653 & 4.883 & 5.1681 & TRN & & & \\
\hline CHEMBL1485127 & 688653 & 4.833 & 5.3208 & TRN & & & \\
\hline CHEMBL1309061 & 688653 & \multicolumn{3}{|c|}{4.7330000000000005} & 5.0534 & TRN & \\
\hline CHEMBL 3194829 & 688653 & 4.783 & 5.3055 & TRN & & & \\
\hline CHEMBL 3145369 & 688653 & 4.833 & 5.8004 & TRN & & & \\
\hline CHEMBL1450448 & 688653 & 5.933 & 5.4804 & TRN & & & \\
\hline CHEMBL1542790 & 688653 & \multicolumn{3}{|c|}{4.7330000000000005} & 5.1292 & TRN & \\
\hline CHEMBL 3189217 & 688653 & 5.083 & 4.8965 & TRN & & & \\
\hline CHEMBL1487587 & 688653 & 5.083 & 4.9508 & TRN & & & \\
\hline CHEMBL1519387 & 688653 & \multicolumn{3}{|c|}{5.632999999999999} & \multirow{2}{*}{\multicolumn{2}{|c|}{5.867999999999999}} & TRN \\
\hline CHEMBL1320907 & 688653 & 4.783 & 5.199 & TRN & & & \\
\hline CHEMBL1603300 & 688653 & \multicolumn{3}{|c|}{6.132999999999999} & 5.468 & TRN & \\
\hline CHEMBL1537098 & 688653 & \multicolumn{3}{|c|}{6.582999999999999} & 6.0264 & TRN & \\
\hline CHEMBL1510353 & 688653 & 4.883 & \multicolumn{3}{|c|}{5.0169999999999995} & TRN & \\
\hline CHEMBL1390139 & 688653 & 4.783 & 4.8077 & TRN & & & \\
\hline CHEMBL1481523 & 688653 & 5.033 & 4.9547 & TRN & & & \\
\hline CHEMBL1545088 & 688653 & \multicolumn{3}{|c|}{5.832999999999999} & 5.54799 & 9999999999 & TRN \\
\hline CHEMBL 3189752 & 688653 & 4.833 & 5.1422 & TST & & & \\
\hline CHEMBL1433404 & 688653 & 4.783 & 5.1627 & TRN & & & \\
\hline CHEMBL1354427 & 688653 & 4.883 & 5.4122 & TST & & & \\
\hline
\end{tabular}




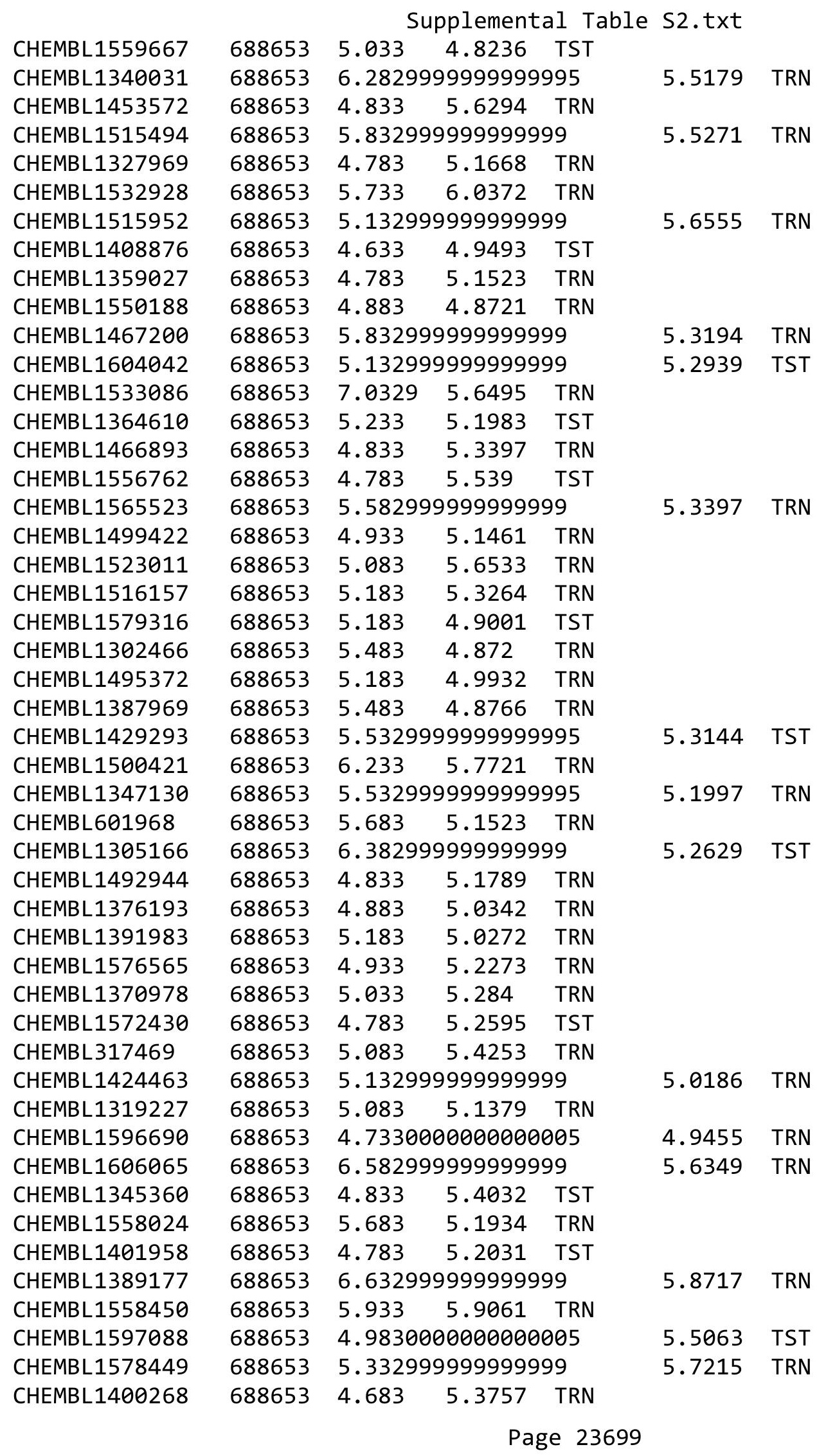




\begin{tabular}{|c|c|c|c|c|c|c|c|}
\hline \multicolumn{8}{|c|}{ Supplemental Table S2.txt } \\
\hline CHEMBL1378909 & 688653 & 5.233 & 5.0535 & TRN & & & \\
\hline CHEMBL1346564 & 688653 & 5.58299 & 99999999 & & 5.625 & TRN & \\
\hline CHEMBL1518800 & 688653 & 5.83299 & 99999999 & & 5.2194 & TRN & \\
\hline CHEMBL1424477 & 688653 & 4.73300 & 00000000 & 005 & 5.6813 & TST & \\
\hline CHEMBL1589029 & 688653 & 5.58299 & 99999999 & & 5.6177 & TRN & \\
\hline CHEMBL1563714 & 688653 & 4.833 & 5.3949 & TST & & & \\
\hline CHEMBL1324875 & 688653 & 4.683 & 5.4936 & TST & & & \\
\hline CHEMBL1446073 & 688653 & 5.33299 & 99999999 & & 5.3989 & TRN & \\
\hline CHEMBL1329389 & 688653 & 5.683 & 5.6459 & TRN & & & \\
\hline CHEMBL1424038 & 688653 & 4.73300 & 00000000 & 005 & 5.53299 & 99999999995 & TRN \\
\hline CHEMBL1444505 & 688653 & 4.783 & 4.981 & TST & & & \\
\hline CHEMBL1393074 & 688653 & 4.73300 & 00000000 & 005 & 5.2414 & TRN & \\
\hline CHEMBL1604677 & 688653 & 5.63299 & 99999999 & & 5.4546 & TST & \\
\hline CHEMBL3191989 & 688653 & 4.73300 & 00000000 & 005 & 5.1592 & TST & \\
\hline CHEMBL1438407 & 688653 & 4.933 & 5.1776 & TRN & & & \\
\hline CHEMBL1385368 & 688653 & 5.433 & 5.2285 & TRN & & & \\
\hline CHEMBL1377418 & 688653 & 4.73300 & 00000000 & 005 & 4.9095 & TRN & \\
\hline CHEMBL1563230 & 688653 & 5.38299 & 99999999 & & 5.38299 & 9999999999 & TRN \\
\hline CHEMBL1314881 & 688653 & 5.183 & 4.9451 & TRN & & & \\
\hline CHEMBL1512628 & 688653 & 5.083 & 5.3736 & TRN & & & \\
\hline CHEMBL3189242 & 688653 & 7.08299 & 99999999 & & 6.1738 & TRN & \\
\hline CHEMBL1384567 & 688653 & 4.783 & 5.1307 & TST & & & \\
\hline CHEMBL1502389 & 688653 & 4.73300 & 00000000 & 005 & 5.1202 & TST & \\
\hline CHEMBL1339775 & 688653 & 5.733 & 5.4386 & TRN & & & \\
\hline CHEMBL3195432 & 688653 & 5.83299 & 99999999 & & 5.9107 & TRN & \\
\hline CHEMBL592068 & 688653 & 5.38299 & 99999999 & & 5.4184 & TRN & \\
\hline CHEMBL1366478 & 688653 & 5.933 & 5.69799 & 999999999 & 995 & TRN & \\
\hline CHEMBL1365411 & 688653 & 5.33299 & 99999999 & & 5.352 & TRN & \\
\hline CHEMBL1440681 & 688653 & 4.883 & 5.1852 & TRN & & & \\
\hline CHEMBL1512973 & 688653 & 4.73300 & 00000000 & 005 & 5.1325 & TRN & \\
\hline CHEMBL1471872 & 688653 & 4.833 & 5.3928 & TRN & & & \\
\hline CHEMBL1395789 & 688653 & 4.783 & 5.2778 & TST & & & \\
\hline CHEMBL1378896 & 688653 & 5.53299 & 99999999 & 995 & 5.3536 & TRN & \\
\hline CHEMBL1517047 & 688653 & 4.783 & 5.3118 & TST & & & \\
\hline CHEMBL1582771 & 688653 & 4.73300 & 00000000 & 005 & 5.5168 & TST & \\
\hline CHEMBL1605780 & 688653 & 5.13299 & 99999999 & & 5.0195 & TST & \\
\hline CHEMBL1468202 & 688653 & 5.433 & 5.2886 & TRN & & & \\
\hline CHEMBL1308093 & 688653 & 4.933 & 4.8386 & TRN & & & \\
\hline CHEMBL1517054 & 688653 & 4.833 & 4.9318 & TRN & & & \\
\hline CHEMBL1327703 & 688653 & 6.0 & 5.1613 & TRN & & & \\
\hline CHEMBL1471516 & 688653 & 5.033 & 5.1636 & TST & & & \\
\hline CHEMBL1375448 & 688653 & 4.933 & 4.9599 & TRN & & & \\
\hline CHEMBL3198702 & 688653 & 4.883 & 5.21399 & 999999999 & 995 & TRN & \\
\hline CHEMBL1323007 & 688653 & 4.933 & 4.8125 & TST & & & \\
\hline CHEMBL1495918 & 688653 & 5.83299 & 99999999 & 99 & 5.4977 & TRN & \\
\hline CHEMBL1602947 & 688653 & 5.083 & 5.2192 & TRN & & & \\
\hline CHEMBL1606825 & 688653 & 5.83299 & 99999999 & 99 & 5.2023 & TST & \\
\hline CHEMBL1443863 & 688653 & 4.833 & 5.2302 & TRN & & & \\
\hline
\end{tabular}




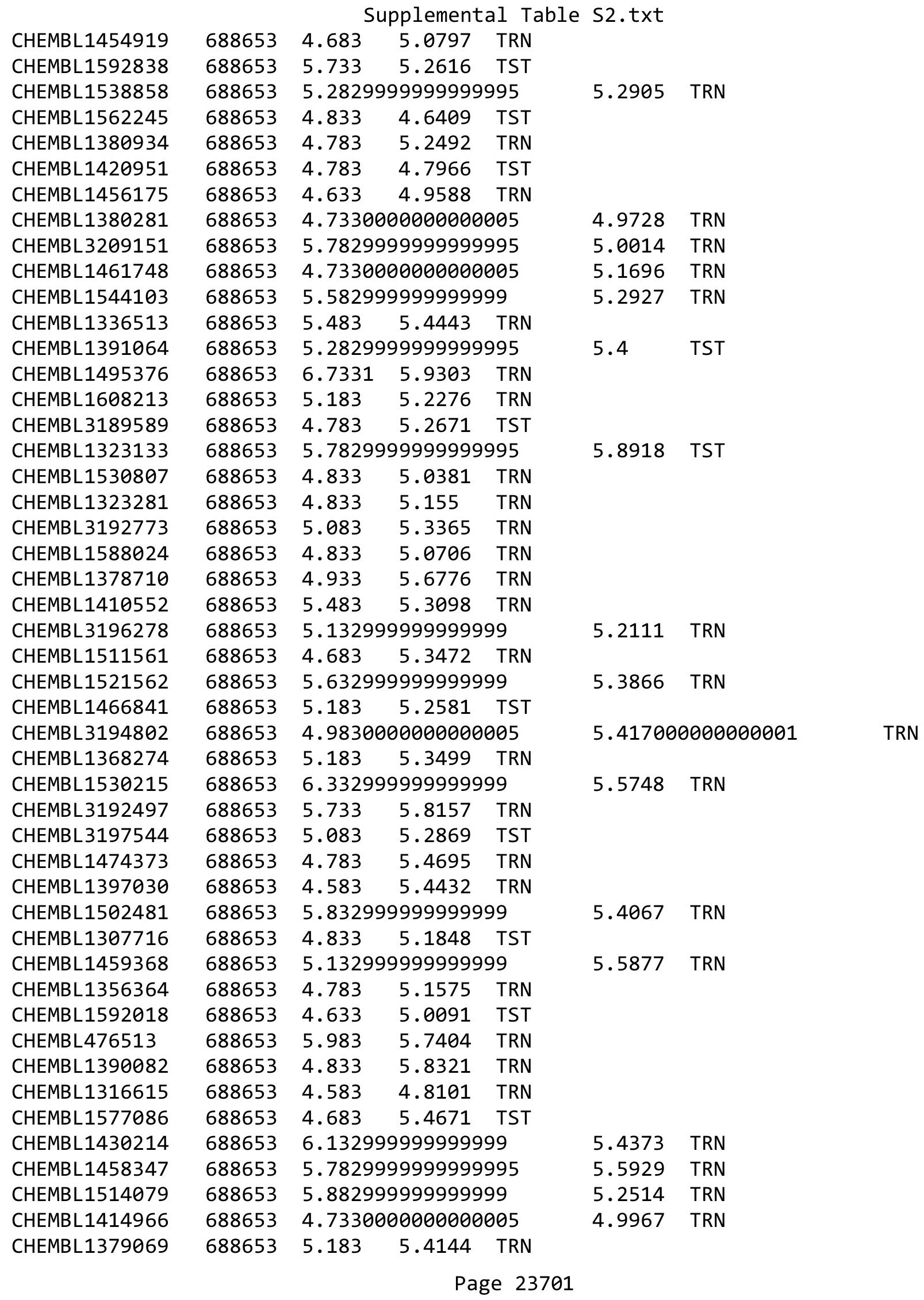




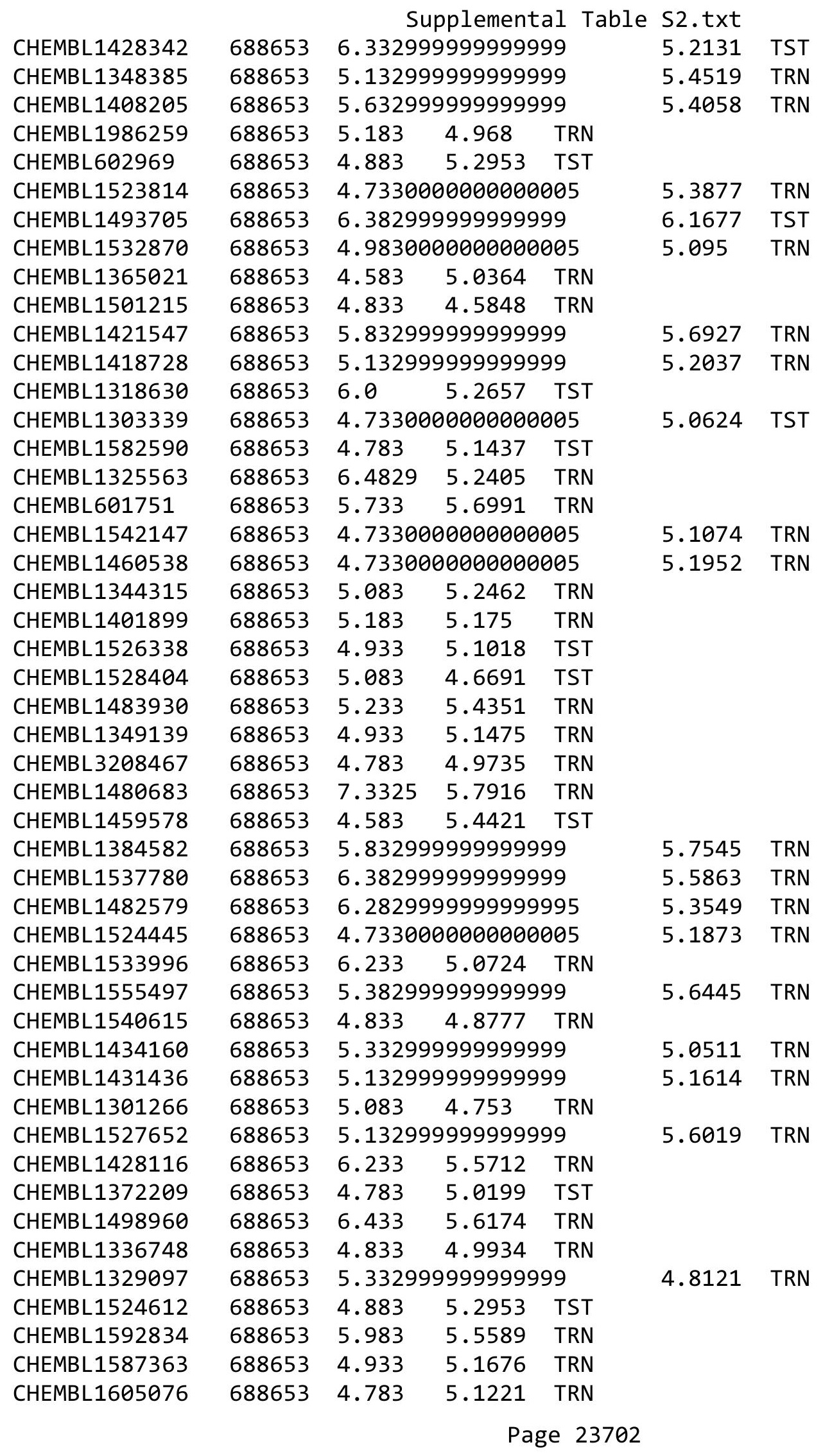




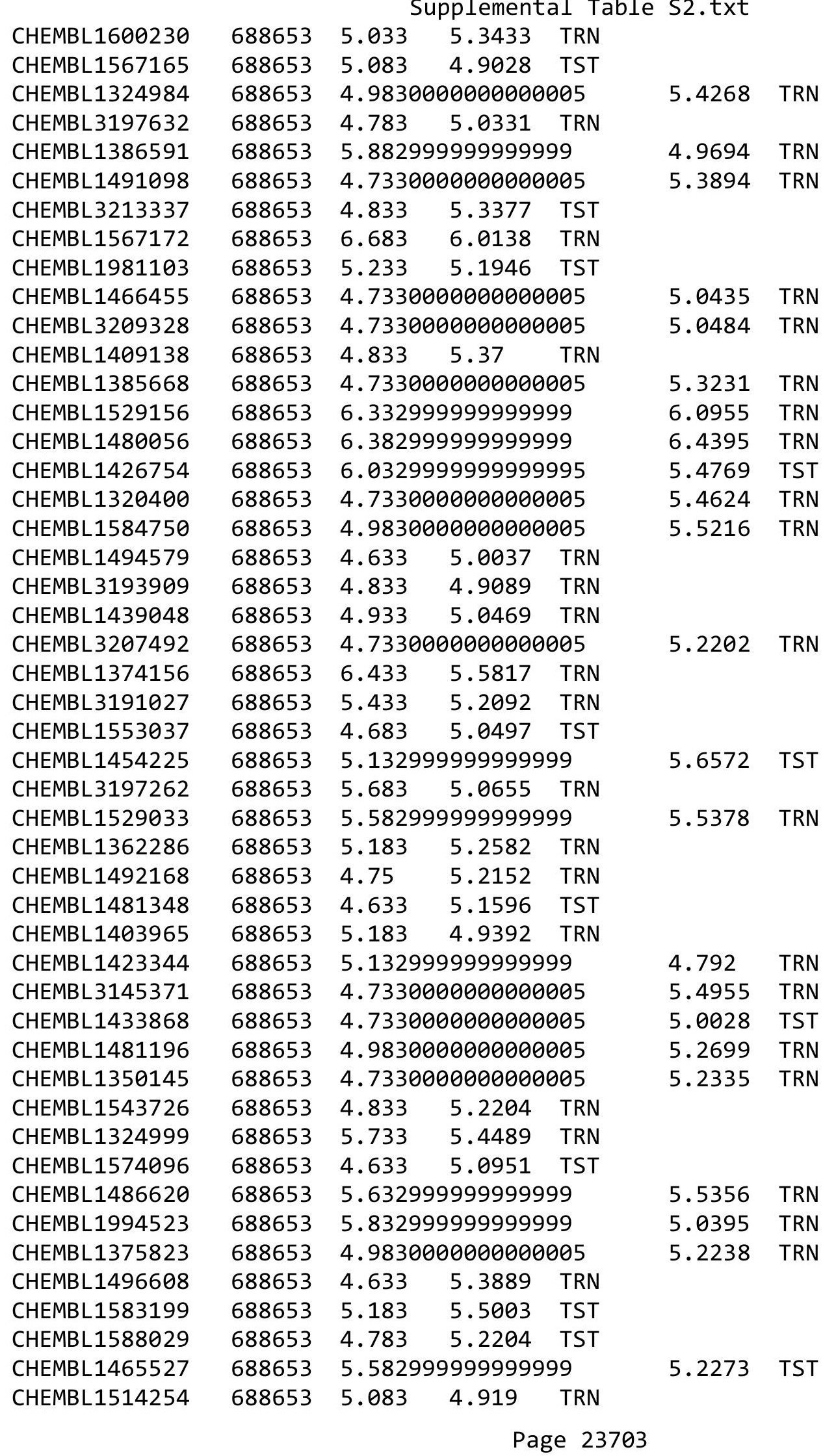




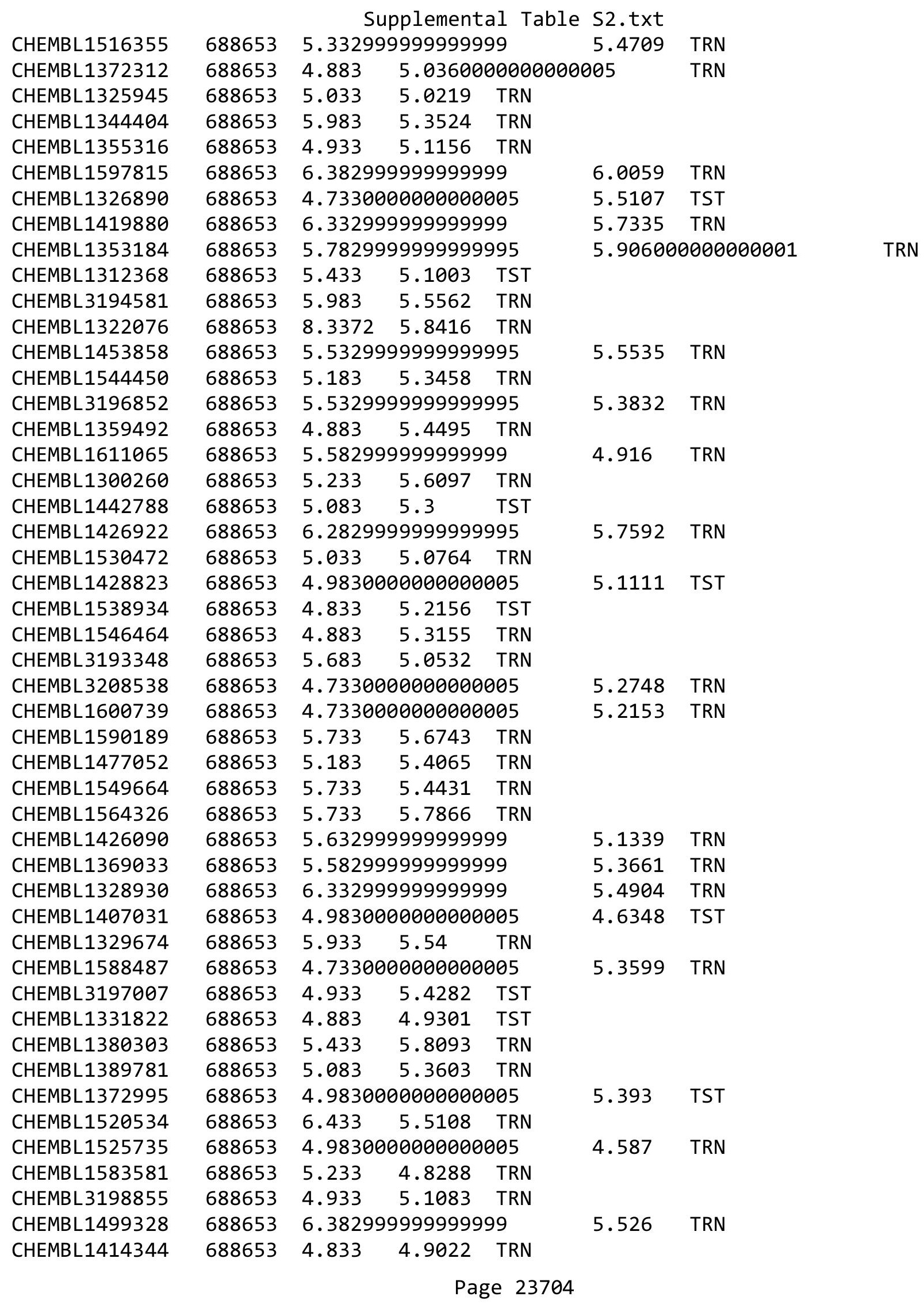




\begin{tabular}{|c|c|c|c|c|c|c|}
\hline & & \multicolumn{5}{|c|}{ Supplemental Table S2.txt } \\
\hline CHEMBL1339170 & 688653 & \multicolumn{3}{|c|}{4.7330000000000005} & 5.235 & TRN \\
\hline CHEMBL1359029 & 688653 & \multicolumn{3}{|c|}{6.632999999999999} & 5.599 & TRN \\
\hline CHEMBL1378618 & 688653 & 4.783 & 5.1692 & TRN & & \\
\hline CHEMBL1557656 & 688653 & \multicolumn{3}{|c|}{6.382999999999999} & 5.443 & TRN \\
\hline CHEMBL1309113 & 688653 & 4.833 & 5.2348 & TRN & & \\
\hline CHEMBL1430851 & 688653 & 5.183 & 5.1892 & TST & & \\
\hline CHEMBL1364763 & 688653 & \multicolumn{3}{|c|}{6.2829999999999995} & 5.3923 & TRN \\
\hline CHEMBL1484441 & 688653 & \multicolumn{3}{|c|}{4.9830000000000005} & 4.9675 & TRN \\
\hline CHEMBL1418201 & 688653 & \multicolumn{3}{|c|}{5.832999999999999} & 6.0499 & TRN \\
\hline CHEMBL3197673 & 688653 & \multicolumn{3}{|c|}{5.5329999999999995} & 4.8303 & TRN \\
\hline CHEMBL1498679 & 688653 & 5.733 & 5.0309 & TRN & & \\
\hline CHEMBL1382137 & 688653 & 4.883 & 5.37 & TRN & & \\
\hline CHEMBL1595178 & 688653 & \multicolumn{3}{|c|}{5.5329999999999995} & 5.6881 & TRN \\
\hline CHEMBL1586371 & 688653 & \multicolumn{3}{|c|}{5.882999999999999} & 4.7165 & TST \\
\hline CHEMBL3194357 & 688653 & 6.9329 & 6.5974 & TRN & & \\
\hline CHEMBL1303390 & 688653 & 5.683 & 5.2412 & TRN & & \\
\hline CHEMBL1376145 & 688653 & 4.933 & 5.0768 & TRN & & \\
\hline CHEMBL1485793 & 688653 & 5.233 & 5.0528 & TST & & \\
\hline CHEMBL1376244 & 688653 & \multicolumn{3}{|c|}{6.582999999999999} & 5.8214 & TRN \\
\hline CHEMBL1495505 & 688653 & \multicolumn{3}{|c|}{5.2829999999999995} & 5.9534 & TRN \\
\hline CHEMBL1327079 & 688653 & 6.183 & 5.0713 & TST & & \\
\hline CHEMBL3193543 & 688653 & \multicolumn{3}{|c|}{5.132999999999999} & 5.4013 & TRN \\
\hline CHEMBL1472832 & 688653 & 4.583 & \multicolumn{3}{|c|}{5.412999999999999} & TRN \\
\hline CHEMBL1431364 & 688653 & 6.4829 & 5.8236 & TRN & & \\
\hline CHEMBL1415900 & 688653 & 4.783 & 5.2515 & TRN & & \\
\hline CHEMBL 3210260 & 688653 & 4.783 & 5.4227 & TRN & & \\
\hline CHEMBL1548670 & 688653 & 5.083 & 5.6535 & TRN & & \\
\hline CHEMBL1306432 & 688653 & 5.433 & 5.0896 & TRN & & \\
\hline CHEMBL1314497 & 688653 & \multicolumn{3}{|c|}{5.2829999999999995} & 5.6521 & TRN \\
\hline CHEMBL1539847 & 688653 & 4.833 & 4.9643 & TRN & & \\
\hline CHEMBL1609724 & 688653 & 4.583 & 4.9313 & TST & & \\
\hline CHEMBL1466445 & 688653 & \multicolumn{3}{|c|}{5.132999999999999} & 4.8127 & TST \\
\hline CHEMBL1335805 & 688653 & 4.883 & 4.9404 & TST & & \\
\hline CHEMBL3196145 & 688653 & 6.433 & 5.0687 & TRN & & \\
\hline CHEMBL1392774 & 688653 & 4.833 & 5.0371 & TRN & & \\
\hline CHEMBL1551968 & 688653 & 4.783 & 5.487 & TRN & & \\
\hline CHEMBL1353731 & 688653 & 6.233 & 5.6718 & TRN & & \\
\hline CHEMBL1321638 & 688653 & 6.233 & 5.9961 & TRN & & \\
\hline CHEMBL1461757 & 688653 & 5.483 & 5.4105 & TRN & & \\
\hline CHEMBL1436318 & 688653 & \multicolumn{3}{|c|}{5.2829999999999995} & 5.8461 & TRN \\
\hline CHEMBL1461972 & 688653 & 7.0329 & 5.7537 & TRN & & \\
\hline CHEMBL1428456 & 688653 & \multicolumn{3}{|c|}{5.882999999999999} & 5.7527 & TRN \\
\hline CHEMBL36920 & 688653 & 4.583 & 5.0811 & TRN & & \\
\hline CHEMBL586031 & 688653 & 5.483 & 5.1831 & TRN & & \\
\hline CHEMBL1433116 & 688653 & \multicolumn{3}{|c|}{5.7829999999999995} & 5.2771 & TRN \\
\hline CHEMBL1596217 & 688653 & 4.683 & 5.4463 & TST & & \\
\hline CHEMBL1979558 & 688653 & 5.233 & 5.4048 & TST & & \\
\hline \multirow[t]{2}{*}{ CHEMBL3198883 } & 688653 & 4.933 & 5.3091 & TRN & & \\
\hline & & \multicolumn{4}{|c|}{ Page 23705} & \\
\hline
\end{tabular}




\begin{tabular}{|c|c|c|c|c|c|c|}
\hline \multirow{3}{*}{$\begin{array}{l}\text { CHEMBL1450952 } \\
\text { CHEMBL1366883 }\end{array}$} & \multirow{3}{*}{$\begin{array}{l}688653 \\
688653\end{array}$} & \multicolumn{4}{|c|}{ Supplemental Table S2.txt } & \multirow[b]{2}{*}{ TRN } \\
\hline & & \multicolumn{3}{|c|}{5.2829999999999995} & 5.1393 & \\
\hline & & 6.233 & 5.9651 & TRN & & \\
\hline CHEMBL546344 & 688653 & 7.1331 & 5.8275 & TRN & & \\
\hline CHEMBL1346308 & 688653 & 5.183 & 4.959 & TST & & \\
\hline CHEMBL1391557 & 688653 & 4.783 & 4.9662 & TRN & & \\
\hline CHEMBL3198258 & 688653 & 5.233 & 5.3777 & TRN & & \\
\hline CHEMBL1543757 & 688653 & 4.683 & 5.1279 & TST & & \\
\hline CHEMBL1535551 & 688653 & \multicolumn{3}{|c|}{5.132999999999999} & 5.1233 & TST \\
\hline CHEMBL1605420 & 688653 & 5.083 & 5.3018 & TST & & \\
\hline CHEMBL1497162 & 688653 & 6.0 & 5.5168 & TRN & & \\
\hline CHEMBL1299646 & 688653 & 5.033 & 5.2627 & TRN & & \\
\hline CHEMBL1465453 & 688653 & \multicolumn{3}{|c|}{5.632999999999999} & 5.6392 & TRN \\
\hline CHEMBL1433040 & 688653 & 5.433 & 5.6866 & TRN & & \\
\hline CHEMBL1369858 & 688653 & 4.833 & 5.5379 & TRN & & \\
\hline CHEMBL1459473 & 688653 & \multicolumn{3}{|c|}{4.7330000000000005} & 5.0191 & TRN \\
\hline CHEMBL3191677 & 688653 & 4.883 & 5.4856 & TST & & \\
\hline CHEMBL1442112 & 688653 & 4.883 & 5.2695 & TRN & & \\
\hline CHEMBL1545002 & 688653 & \multicolumn{3}{|c|}{5.7829999999999995} & 5.4639 & TRN \\
\hline CHEMBL1371318 & 688653 & 7.2832 & 5.8712 & TRN & & \\
\hline CHEMBL3199125 & 688653 & 5.683 & 5.3664 & TRN & & \\
\hline CHEMBL1311007 & 688653 & \multicolumn{3}{|c|}{5.7829999999999995} & 5.1433 & TST \\
\hline CHEMBL1379247 & 688653 & 4.933 & 5.2914 & TRN & & \\
\hline CHEMBL1575731 & 688653 & \multicolumn{3}{|c|}{4.7330000000000005} & 5.3172 & TST \\
\hline CHEMBL1576415 & 688653 & \multicolumn{3}{|c|}{4.7330000000000005} & 5.138 & TRN \\
\hline CHEMBL1539522 & 688653 & 4.883 & 4.9615 & TRN & & \\
\hline CHEMBL1527254 & 688653 & 4.883 & 5.5038 & TRN & & \\
\hline CHEMBL1353158 & 688653 & 4.883 & 5.0854 & TST & & \\
\hline CHEMBL1429695 & 688653 & 4.833 & 5.1866 & TRN & & \\
\hline CHEMBL1575565 & 688653 & 4.833 & 5.1256 & TRN & & \\
\hline CHEMBL1365350 & 688653 & 4.883 & 4.9421 & TRN & & \\
\hline CHEMBL1337235 & 688653 & 4.633 & 5.3485 & TRN & & \\
\hline CHEMBL1589623 & 688653 & 4.833 & 5.607 & TRN & & \\
\hline CHEMBL1567041 & 688653 & \multicolumn{3}{|c|}{5.332999999999999} & 5.0689 & TRN \\
\hline CHEMBL2369298 & 688653 & \multicolumn{3}{|c|}{5.832999999999999} & 5.397 & TRA \\
\hline CHEMBL1448592 & 688653 & \multicolumn{3}{|c|}{5.5329999999999995} & 5.3048 & TRN \\
\hline CHEMBL1386310 & 688653 & 5.933 & 5.9178 & TRN & & \\
\hline CHEMBL1344667 & 688653 & 5.083 & 5.2889 & TST & & \\
\hline CHEMBL1299633 & 688653 & 4.833 & 5.5489 & TST & & \\
\hline CHEMBL1437965 & 688653 & \multicolumn{3}{|c|}{5.632999999999999} & 5.5282 & TRN \\
\hline CHEMBL1349884 & 688653 & 4.783 & 5.4513 & TRN & & \\
\hline CHEMBL1442508 & 688653 & 5.733 & 4.6598 & TRN & & \\
\hline CHEMBL1546760 & 688653 & 6.8831 & 5.7167 & TRN & & \\
\hline CHEMBL1495292 & 688653 & 4.833 & 5.0577 & TRN & & \\
\hline CHEMBL1589345 & 688653 & \multicolumn{3}{|c|}{5.2829999999999995} & 4.9627 & TRN \\
\hline CHEMBL1369383 & 688653 & 4.783 & 5.0936 & TRN & & \\
\hline CHEMBL1379600 & 688653 & & & TRN & & \\
\hline CHEMBL1477540 & 688653 & \multicolumn{3}{|c|}{5.332999999999999} & 5.2076 & TRN \\
\hline CHEMBL1483948 & 688653 & 4.933 & 5.1103 & TRN & & \\
\hline
\end{tabular}




\begin{tabular}{|c|c|c|c|c|c|c|}
\hline \multirow[b]{2}{*}{ CHEMBL1608041 } & \multirow[b]{2}{*}{688653} & \multicolumn{5}{|c|}{ Supplemental Table S2.txt } \\
\hline & & 4.633 & 5.4357 & TST & & \\
\hline CHEMBL1527518 & 688653 & 4.98300 & 000000006 & 005 & 5.7049 & TRN \\
\hline CHEMBL1368672 & 688653 & 5.483 & 5.0957 & TST & & \\
\hline CHEMBL1347057 & 688653 & 6.08299 & 99999999 & & 5.5213 & TRN \\
\hline CHEMBL1400143 & 688653 & 6.433 & 6.1109 & TRN & & \\
\hline CHEMBL1476816 & 688653 & 5.63299 & 99999999 & & 5.7341 & TRN \\
\hline CHEMBL1464088 & 688653 & 5.733 & 5.1953 & TRN & & \\
\hline CHEMBL1508667 & 688653 & 5.58299 & 99999999 & 99 & 5.4783 & TRN \\
\hline CHEMBL1385132 & 688653 & 5.033 & 5.4794 & TRN & & \\
\hline CHEMBL1585195 & 688653 & 4.73300 & $00000000 t$ & 005 & 5.4516 & TST \\
\hline CHEMBL1393575 & 688653 & 6.08299 & 99999999 & & 5.546 & TRN \\
\hline CHEMBL1456353 & 688653 & 5.88299 & 99999999 & & 5.9347 & TRN \\
\hline CHEMBL1303155 & 688653 & 5.233 & 5.403 & TRN & & \\
\hline CHEMBL 3214032 & 688653 & 4.933 & 5.2152 & TRN & & \\
\hline CHEMBL1443559 & 688653 & 5.78299 & 99999999 & 995 & 5.1331 & TRN \\
\hline CHEMBL1370476 & 688653 & 4.783 & 5.3736 & TRN & & \\
\hline CHEMBL1381634 & 688653 & 5.28299 & 99999999 & 995 & 5.4083 & TRN \\
\hline CHEMBL1518377 & 688653 & 5.33299 & 99999999 & 99 & 5.6645 & TST \\
\hline CHEMBL3213011 & 688653 & 4.833 & 5.0271 & TRN & & \\
\hline CHEMBL1472104 & 688653 & 5.38299 & 99999999 & 99 & 5.2441 & TST \\
\hline CHEMBL1381378 & 688653 & 4.783 & 5.0411 & TRN & & \\
\hline CHEMBL1606925 & 688653 & 5.683 & 5.5751 & TRN & & \\
\hline CHEMBL1591598 & 688653 & 5.083 & 5.4493 & TRN & & \\
\hline CHEMBL1512279 & 688653 & 6.08299 & 99999999 & & 6.2102 & TRN \\
\hline CHEMBL1378316 & 688653 & 5.683 & 5.7724 & TRN & & \\
\hline CHEMBL1324113 & 688653 & 6.183 & 5.5639 & TRN & & \\
\hline CHEMBL1494135 & 688653 & 4.73300 & 00000000 & 005 & 5.0454 & TST \\
\hline CHEMBL1373785 & 688653 & 5.28299 & 99999999 & 995 & 5.3382 & TRN \\
\hline CHEMBL1473398 & 688653 & 4.783 & 4.9848 & TRN & & \\
\hline CHEMBL1377826 & 688653 & 5.13299 & 99999999 & & 5.4389 & TRN \\
\hline CHEMBL1390106 & 688653 & 5.28299 & 99999999 & 995 & 5.1308 & TRN \\
\hline CHEMBL1506662 & 688653 & 4.633 & 4.4416 & TRN & & \\
\hline CHEMBL1599320 & 688653 & 4.73300 & 00000000 & 005 & 4.9631 & TST \\
\hline CHEMBL3195363 & 688653 & 5.033 & 5.1437 & TRN & & \\
\hline CHEMBL1303501 & 688653 & 6.13299 & 99999999 & 99 & 6.0616 & TRN \\
\hline CHEMBL1528917 & 688653 & 4.933 & 5.2013 & TST & & \\
\hline CHEMBL1414465 & 688653 & 5.433 & 5.2337 & TST & & \\
\hline CHEMBL1514237 & 688653 & 4.633 & 4.8712 & TRN & & \\
\hline CHEMBL3211078 & 688653 & 5.233 & 5.216 & TST & & \\
\hline CHEMBL1458448 & 688653 & 4.783 & 5.2814 & TST & & \\
\hline CHEMBL1491360 & 688653 & 5.433 & 4.9652 & TRN & & \\
\hline CHEMBL1338695 & 688653 & 6.433 & 5.7136 & TRN & & \\
\hline CHEMBL1541129 & 688653 & 4.783 & 4.9815 & TRN & & \\
\hline CHEMBL1400439 & 688653 & 4.73300 & 00000000 & 005 & 5.4456 & TST \\
\hline CHEMBL1536460 & 688653 & 5.58299 & 99999999 & & 5.0259 & TRN \\
\hline CHEMBL1536674 & 688653 & 5.53299 & 99999999 & 995 & 5.3739 & TST \\
\hline CHEMBL1313410 & 688653 & 4.633 & 5.4203 & TST & & \\
\hline CHEMBL1360135 & 688653 & 4.683 & 5.0796 & TST & & \\
\hline
\end{tabular}




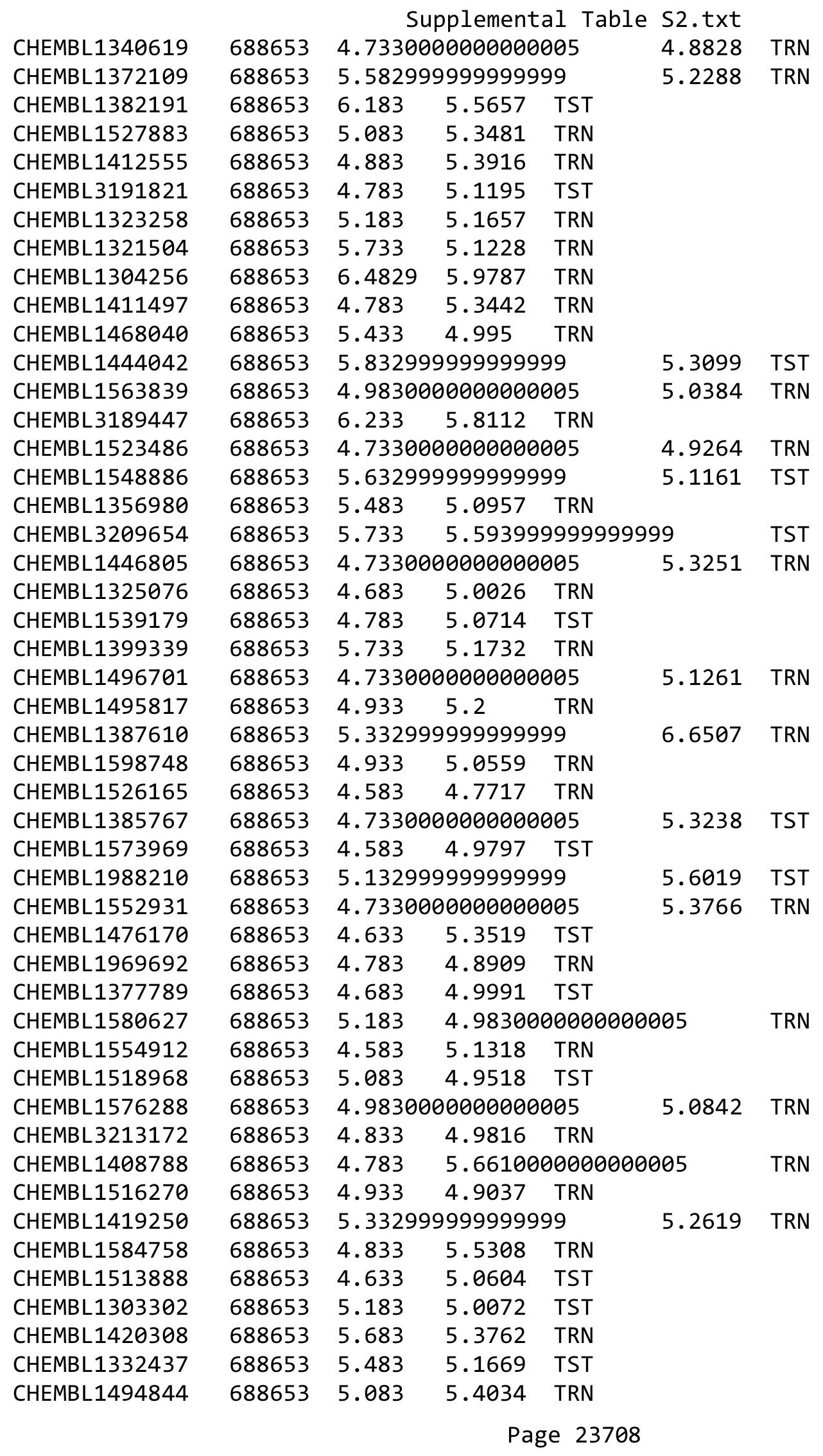




\begin{tabular}{|c|c|c|c|c|c|c|}
\hline \multirow{3}{*}{$\begin{array}{l}\text { CHEMBL1472274 } \\
\text { CHEMBL1332880 }\end{array}$} & \multirow{3}{*}{$\begin{array}{l}688653 \\
688653\end{array}$} & \multicolumn{4}{|c|}{ Supplemental Table S2.txt } & \multirow{2}{*}{ TRN } \\
\hline & & \multicolumn{3}{|c|}{5.332999999999999} & 5.0517 & \\
\hline & & 6.0 & 5.803 & TRN & & \\
\hline CHEMBL1359181 & 688653 & 4.633 & 5.3092 & TST & & \\
\hline CHEMBL1401678 & 688653 & 4.583 & 4.7895 & TRN & & \\
\hline CHEMBL1372179 & 688653 & 4.783 & 4.6268 & TST & & \\
\hline CHEMBL1232179 & 688653 & \multicolumn{3}{|c|}{5.132999999999999} & 4.9593 & TRN \\
\hline CHEMBL1443160 & 688653 & 4.933 & 5.2101 & TRN & & \\
\hline CHEMBL1370888 & 688653 & \multicolumn{3}{|c|}{4.7330000000000005} & 4.9618 & TST \\
\hline CHEMBL1452264 & 688653 & 5.733 & 5.1415 & TRN & & \\
\hline CHEMBL1586441 & 688653 & \multicolumn{3}{|c|}{5.5329999999999995} & 5.2817 & TST \\
\hline CHEMBL1596181 & 688653 & 5.483 & 5.1793 & TST & & \\
\hline CHEMBL1414226 & 688653 & 4.833 & 4.9163 & TRN & & \\
\hline CHEMBL1413108 & 688653 & 5.033 & 5.1965 & TRN & & \\
\hline CHEMBL1319768 & 688653 & 5.083 & 5.8508 & TRN & & \\
\hline CHEMBL1591023 & 688653 & 6.683 & 5.1308 & TRN & & \\
\hline CHEMBL3211423 & 688653 & 4.883 & 5.3908 & TST & & \\
\hline CHEMBL1570797 & 688653 & \multicolumn{3}{|c|}{4.7330000000000005} & 4.4219 & TRN \\
\hline CHEMBL1569685 & 688653 & 5.083 & 5.4175 & TRN & & \\
\hline CHEMBL 2005198 & 688653 & 4.833 & 5.2716 & TRN & & \\
\hline CHEMBL1543240 & 688653 & 5.3 & 5.1873 & TRN & & \\
\hline CHEMBL1990767 & 688653 & \multicolumn{3}{|c|}{5.132999999999999} & 5.2883 & TRN \\
\hline CHEMBL1442781 & 688653 & 4.95 & 5.2356 & TRN & & \\
\hline CHEMBL1500025 & 688653 & 4.933 & 4.9958 & TRN & & \\
\hline CHEMBL3195773 & 688653 & 4.783 & 5.312 & TRN & & \\
\hline CHEMBL1241452 & 688653 & \multicolumn{3}{|c|}{5.132999999999999} & 5.5549 & TST \\
\hline CHEMBL1569404 & 688653 & 4.933 & 5.0723 & TRN & & \\
\hline CHEMBL1414645 & 688653 & 5.733 & 5.8068 & TST & & \\
\hline CHEMBL1558385 & 688653 & 4.883 & 5.2146 & TST & & \\
\hline CHEMBL1568223 & 688653 & \multicolumn{3}{|c|}{6.382999999999999} & 5.5365 & TRN \\
\hline CHEMBL1487935 & 688653 & \multicolumn{3}{|c|}{4.7330000000000005} & 5.2886 & TRN \\
\hline CHEMBL1468473 & 688653 & 4.633 & 4.8955 & TRN & & \\
\hline CHEMBL1439384 & 688653 & 4.883 & 4.706 & TRN & & \\
\hline CHEMBL1378287 & 688653 & 4.633 & 5.0972 & TST & & \\
\hline CHEMBL1557125 & 688653 & 4.783 & 5.0919 & TRN & & \\
\hline CHEMBL1422320 & 688653 & 5.933 & 5.4206 & TRN & & \\
\hline CHEMBL31840 & 688653 & \multicolumn{3}{|c|}{5.5329999999999995} & 5.2482 & TST \\
\hline CHEMBL1345015 & 688653 & \multicolumn{3}{|c|}{5.132999999999999} & 5.4196 & TRN \\
\hline CHEMBL2369190 & 688653 & 5.483 & 5.2748 & TST & & \\
\hline CHEMBL1497464 & 688653 & \multicolumn{3}{|c|}{4.9830000000000005} & 5.0369 & TST \\
\hline CHEMBL1558553 & 688653 & \multicolumn{3}{|c|}{5.632999999999999} & 5.2779 & TRN \\
\hline CHEMBL1394182 & 688653 & 4.883 & 5.0175 & TST & & \\
\hline CHEMBL1565660 & 688653 & 4.933 & 5.4156 & TST & & \\
\hline CHEMBL1305496 & 688653 & 4.933 & 5.1724 & TRN & & \\
\hline CHEMBL1531943 & 688653 & 4.95 & 5.722 & TRN & & \\
\hline CHEMBL1585980 & 688653 & 6.4825 & 5.5931 & TRN & & \\
\hline CHEMBL1411012 & 688653 & \multicolumn{3}{|c|}{5.132999999999999} & 5.2498 & TST \\
\hline CHEMBL1402896 & 688653 & 4.833 & 5.3585 & TRN & & \\
\hline CHEMBL1608676 & 688653 & 4.783 & 4.938 & TRN & & \\
\hline
\end{tabular}




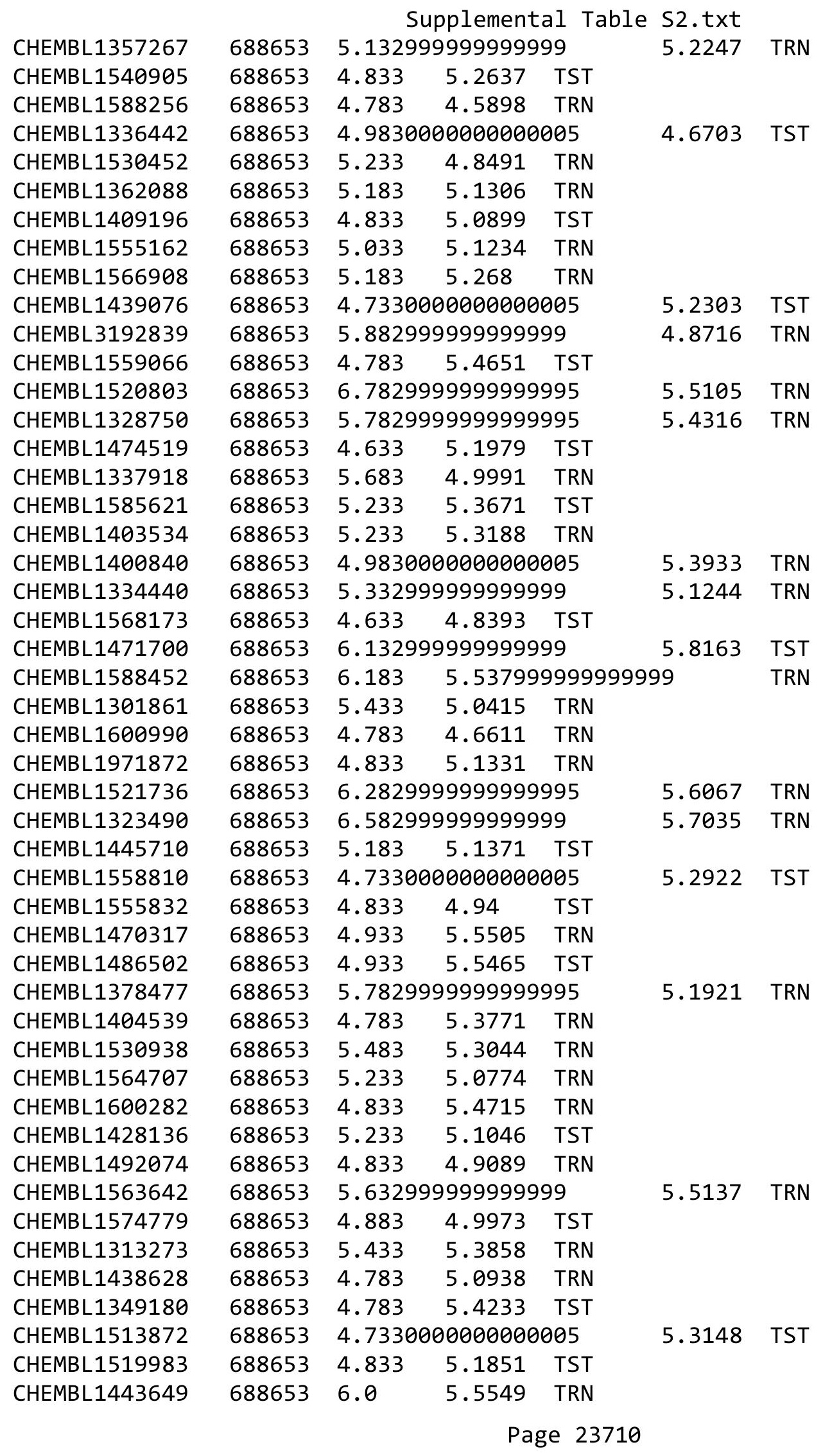




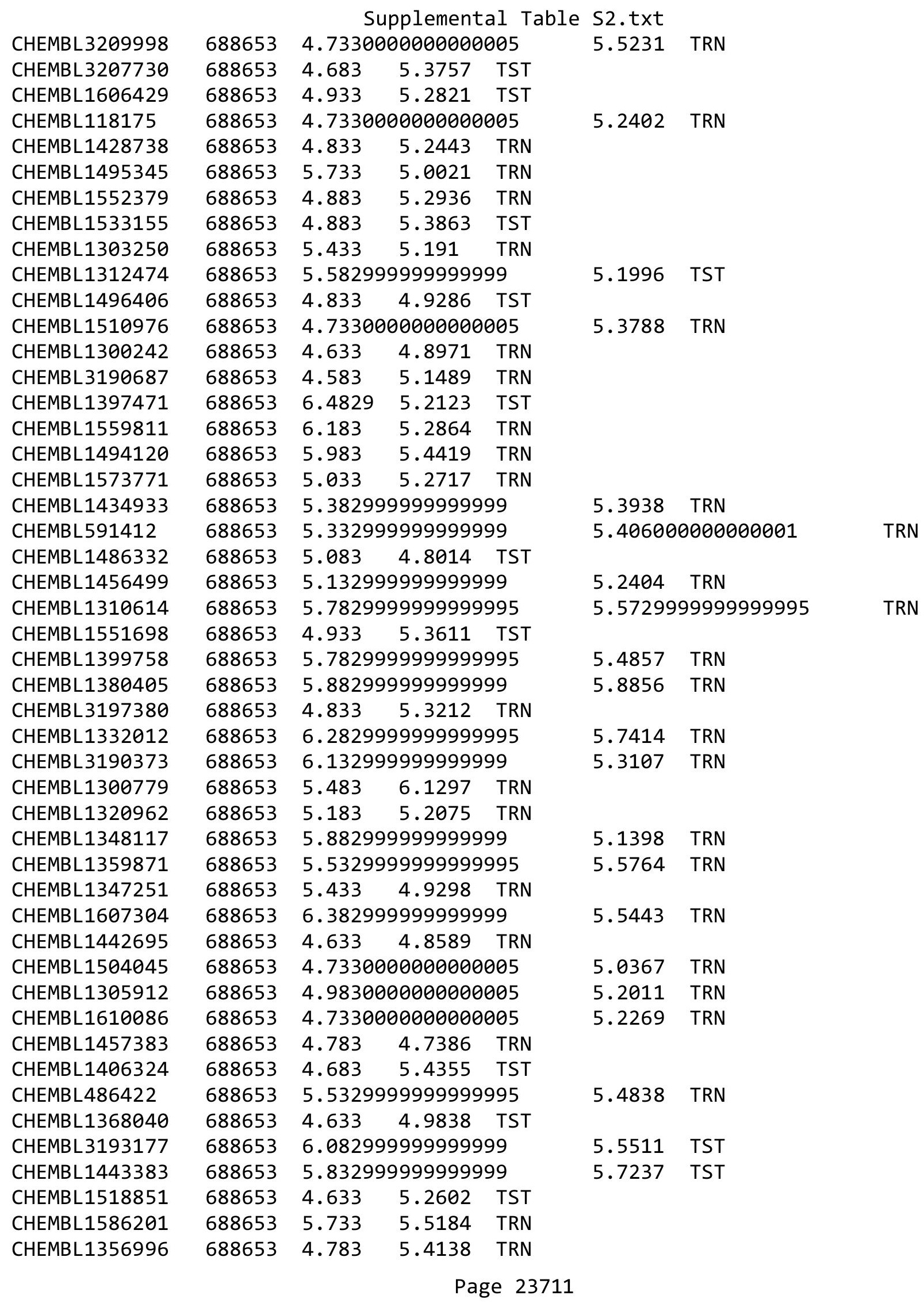




\begin{tabular}{|c|c|c|c|c|c|c|}
\hline & \multicolumn{5}{|c|}{$\mathrm{b} \perp \mathrm{e}$ s2.t } \\
\hline CHEMBL1344395 & 688653 & 4.783 & 5.2129 & TRN & & \\
\hline CHEMBL1568140 & 688653 & \multicolumn{3}{|c|}{6.582999999999999} & 5.3835 & TST \\
\hline CHEMBL1448363 & 688653 & 5.233 & 5.0247 & TST & & \\
\hline CHEMBL1380757 & 688653 & 4.783 & 5.2353 & TRN & & \\
\hline CHEMBL1382006 & 688653 & 4.683 & 5.2102 & TRN & & \\
\hline CHEMBL1481939 & 688653 & 5.233 & 5.3429 & TRN & & \\
\hline CHEMBL1601707 & 688653 & 4.783 & 5.61 & TRN & & \\
\hline CHEMBL3192697 & 688653 & 4.783 & 5.5549 & TRN & & \\
\hline CHEMBL1475818 & 688653 & \multicolumn{3}{|c|}{7.082999999999999} & 5.7921 & TRN \\
\hline CHEMBL3191697 & 688653 & 5.033 & 5.3652 & TRN & & \\
\hline CHEMBL3212307 & 688653 & 5.183 & 5.3228 & TST & & \\
\hline CHEMBL1606790 & 688653 & \multicolumn{3}{|c|}{5.7829999999999995} & 5.7167 & TRN \\
\hline CHEMBL1345489 & 688653 & \multicolumn{3}{|c|}{6.132999999999999} & 5.6098 & TRN \\
\hline CHEMBL1407319 & 688653 & 4.933 & 5.2668 & TRN & & \\
\hline CHEMBL1541456 & 688653 & 4.933 & 4.9782 & TRN & & \\
\hline CHEMBL1423762 & 688653 & 4.933 & 5.7144 & TRN & & \\
\hline CHEMBL1525901 & 688653 & \multicolumn{3}{|c|}{5.832999999999999} & 6.2516 & TST \\
\hline CHEMBL1368059 & 688653 & 5.933 & 5.808 & TRN & & \\
\hline CHEMBL1599319 & 688653 & 5.483 & 5.2034 & TRN & & \\
\hline CHEMBL3192707 & 688653 & \multicolumn{3}{|c|}{4.7330000000000005} & 5.3324 & TST \\
\hline CHEMBL3195910 & 688653 & 5.083 & 5.1589 & TRN & & \\
\hline CHEMBL1446678 & 688653 & 4.633 & 4.9275 & TST & & \\
\hline CHEMBL1545387 & 688653 & \multicolumn{3}{|c|}{5.332999999999999} & 5.2909 & TST \\
\hline CHEMBL1370428 & 688653 & 5.183 & 5.29 & TST & & \\
\hline CHEMBL1518174 & 688653 & \multicolumn{3}{|c|}{4.7330000000000005} & 5.1546 & TRN \\
\hline CHEMBL1536349 & 688653 & \multicolumn{3}{|c|}{5.832999999999999} & 5.5412 & TRN \\
\hline CHEMBL3197188 & 688653 & 5.033 & 5.1387 & TRN & & \\
\hline CHEMBL1468733 & 688653 & \multicolumn{3}{|c|}{6.382999999999999} & 5.7995 & TRN \\
\hline CHEMBL1549398 & 688653 & 5.733 & 5.9432 & TRN & & \\
\hline CHEMBL1471399 & 688653 & \multicolumn{3}{|c|}{5.332999999999999} & 5.244 & TRN \\
\hline CHEMBL1363806 & 688653 & \multicolumn{3}{|c|}{5.2829999999999995} & 5.2312 & TST \\
\hline CHEMBL1491028 & 688653 & \multicolumn{3}{|c|}{4.9830000000000005} & 5.2053 & TRN \\
\hline CHEMBL1590521 & 688653 & 4.583 & 5.0607 & TRN & & \\
\hline CHEMBL1524562 & 688653 & 4.833 & 5.3432 & TST & & \\
\hline CHEMBL1389220 & 688653 & \multicolumn{3}{|c|}{6.332999999999999} & 5.2413 & TST \\
\hline CHEMBL1444147 & 688653 & 4.933 & 5.1765 & TRN & & \\
\hline CHEMBL1487314 & 688653 & 4.783 & 5.4507 & TRN & & \\
\hline CHEMBL1487374 & 688653 & \multicolumn{3}{|c|}{5.7829999999999995} & 5.5334 & TRN \\
\hline CHEMBL1539956 & 688653 & \multicolumn{3}{|c|}{4.7330000000000005} & 4.9749 & TRN \\
\hline CHEMBL1417809 & 688653 & 4.783 & 5.5395 & TRN & & \\
\hline CHEMBL1580040 & 688653 & \multicolumn{3}{|c|}{6.082999999999999} & 5.5532 & TRN \\
\hline CHEMBL1372127 & 688653 & \multicolumn{3}{|c|}{5.132999999999999} & 5.4641 & TRN \\
\hline CHEMBL1352758 & 688653 & \multicolumn{3}{|c|}{5.832999999999999} & 5.7797 & TRN \\
\hline CHEMBL1369728 & 688653 & 5.3829 & 99999999 & & 5.5288 & TST \\
\hline CHEMBL1564822 & 688653 & 5.183 & 5.0549 & TST & & \\
\hline CHEMBL1222386 & 688653 & 5.5329 & 99999999 & 995 & 5.4266 & TRN \\
\hline CHEMBL 3209078 & 688653 & 5.733 & 5.1522 & TRN & & \\
\hline CHEMBL1461688 & 688653 & 4.883 & 5.0598 & TST & & \\
\hline
\end{tabular}




\begin{tabular}{|c|c|c|c|c|c|c|}
\hline \multirow[b]{2}{*}{ CHEMBL1596598 } & & \multicolumn{5}{|c|}{ Supplemental Table S2.txt } \\
\hline & 688653 & 5.183 & 5.4611 & TRN & & \\
\hline CHEMBL1481531 & 688653 & \multicolumn{3}{|c|}{4.9830000000000005} & 5.3194 & TRN \\
\hline CHEMBL1482621 & 688653 & \multicolumn{3}{|c|}{5.132999999999999} & 5.5423 & TRN \\
\hline CHEMBL1349921 & 688653 & \multicolumn{3}{|c|}{5.332999999999999} & 5.2835 & TRN \\
\hline CHEMBL1597292 & 688653 & 4.783 & 4.9343 & TST & & \\
\hline CHEMBL1455759 & 688653 & \multicolumn{3}{|c|}{4.7330000000000005} & 4.86 & TRN \\
\hline CHEMBL1319970 & 688653 & \multicolumn{3}{|c|}{4.7330000000000005} & 4.9663 & TRN \\
\hline CHEMBL1563428 & 688653 & 4.833 & 5.6513 & TRN & & \\
\hline CHEMBL1504556 & 688653 & 4.783 & 5.0458 & TRN & & \\
\hline CHEMBL1526372 & 688653 & 4.833 & 5.4246 & TRN & & \\
\hline CHEMBL3195805 & 688653 & \multicolumn{3}{|c|}{5.132999999999999} & 5.6915 & TST \\
\hline CHEMBL1546450 & 688653 & \multicolumn{3}{|c|}{5.332999999999999} & 5.1131 & TRN \\
\hline CHEMBL45152 & 688653 & 4.883 & 5.3805 & TST & & \\
\hline CHEMBL1560215 & 688653 & 6.45 & 5.4011 & TRN & & \\
\hline CHEMBL3212972 & 688653 & 4.783 & 5.2953 & TRN & & \\
\hline CHEMBL1526537 & 688653 & 4.583 & 4.8727 & TRN & & \\
\hline CHEMBL1427423 & 688653 & 5.483 & 5.4882 & TRN & & \\
\hline CHEMBL 3213733 & 688653 & 5.933 & 5.6776 & TRN & & \\
\hline CHEMBL1516315 & 688653 & 4.933 & 5.081 & TRN & & \\
\hline CHEMBL1529507 & 688653 & \multicolumn{3}{|c|}{6.0329999999999995} & 5.4991 & TRN \\
\hline CHEMBL1353073 & 688653 & \multicolumn{3}{|c|}{4.7330000000000005} & 5.1779 & TRN \\
\hline CHEMBL1548743 & 688653 & \multicolumn{3}{|c|}{5.2829999999999995} & 5.1258 & TRN \\
\hline CHEMBL1500309 & 688653 & 6.183 & 5.9567 & TRN & & \\
\hline CHEMBL1457689 & 688653 & \multicolumn{3}{|c|}{4.7330000000000005} & 5.3068 & TRN \\
\hline CHEMBL1448922 & 688653 & \multicolumn{3}{|c|}{5.332999999999999} & 5.4435 & TST \\
\hline CHEMBL1412963 & 688653 & \multicolumn{3}{|c|}{6.382999999999999} & 5.9539 & TRN \\
\hline CHEMBL1447830 & 688653 & \multicolumn{3}{|c|}{6.332999999999999} & 5.8642 & TRN \\
\hline CHEMBL10050 & 688653 & 5.733 & 5.5524 & TRN & & \\
\hline CHEMBL362941 & 688653 & 4.783 & 4.9044 & TRN & & \\
\hline CHEMBL1598445 & 688653 & 6.233 & 6.1579 & TRN & & \\
\hline CHEMBL590672 & 688653 & \multicolumn{3}{|c|}{4.7330000000000005} & 5.4086 & TST \\
\hline CHEMBL3212046 & 688653 & \multicolumn{3}{|c|}{5.382999999999999} & 5.4154 & TST \\
\hline CHEMBL1504625 & 688653 & \multicolumn{3}{|c|}{4.9830000000000005} & 5.0732 & TRN \\
\hline CHEMBL1524742 & 688653 & 4.783 & 5.2991 & TRN & & \\
\hline CHEMBL1456045 & 688653 & 4.783 & 5.5339 & TRN & & \\
\hline CHEMBL1327939 & 688653 & 4.933 & 4.9752 & TRN & & \\
\hline CHEMBL1496375 & 688653 & 4.933 & 5.4649 & TRN & & \\
\hline CHEMBL1485405 & 688653 & 4.783 & 4.9456 & TRN & & \\
\hline CHEMBL2003485 & 688653 & 4.933 & 5.0333 & TRN & & \\
\hline CHEMBL3209853 & 688653 & 5.733 & 5.2987 & TRN & & \\
\hline CHEMBL1509392 & 688653 & 5.233 & 5.0981 & TST & & \\
\hline CHEMBL1397639 & 688653 & \multicolumn{3}{|c|}{4.7330000000000005} & 5.0957 & TRN \\
\hline CHEMBL1600589 & 688653 & 4.833 & 5.1492 & TRN & & \\
\hline CHEMBL1477262 & 688653 & 5.233 & 5.0304 & TST & & \\
\hline CHEMBL1322587 & 688653 & 5.033 & 5.0439 & TRN & & \\
\hline CHEMBL3212613 & 688653 & 4.7336 & 3000000 & 005 & 5.4129 & TRN \\
\hline CHEMBL1470123 & 688653 & 5.933 & 5.6022 & TST & & \\
\hline CHEMBL1517662 & 688653 & 4.783 & 4.919 & TST & & \\
\hline
\end{tabular}




\begin{tabular}{|c|c|c|c|c|c|c|c|}
\hline \multicolumn{7}{|c|}{ Supplemental Table S2.txt } & \\
\hline CHEMBL1304655 & 688653 & \multicolumn{3}{|c|}{4.7330000000000005} & 5.267 & TST & \\
\hline CHEMBL1612693 & 688653 & 5.083 & 5.0455 & TST & & & \\
\hline CHEMBL1506417 & 688653 & 4.783 & 5.4056 & TRN & & & \\
\hline CHEMBL1498039 & 688653 & 4.883 & 5.0448 & TRN & & & \\
\hline CHEMBL1320542 & 688653 & 4.783 & 5.1472 & TRN & & & \\
\hline CHEMBL1580497 & 688653 & \multicolumn{3}{|c|}{6.332999999999999} & 5.6452 & TRN & \\
\hline CHEMBL1561370 & 688653 & 5.433 & 5.4431 & TST & & & \\
\hline CHEMBL3197828 & 688653 & 5.933 & 5.235 & TRN & & & \\
\hline CHEMBL1390650 & 688653 & \multicolumn{3}{|c|}{6.7829999999999995} & 5.9284 & TRN & \\
\hline CHEMBL1536079 & 688653 & 5.033 & 5.0375 & TRN & & & \\
\hline CHEMBL1326918 & 688653 & \multicolumn{3}{|c|}{5.2829999999999995} & 5.4785 & TRN & \\
\hline CHEMBL1531356 & 688653 & \multicolumn{3}{|c|}{4.7330000000000005} & 4.9106 & TST & \\
\hline CHEMBL1613412 & 688653 & \multicolumn{3}{|c|}{6.132999999999999} & 5.7318 & TRN & \\
\hline CHEMBL1485503 & 688653 & 4.833 & 5.18 & TST & & & \\
\hline CHEMBL3211972 & 688653 & \multicolumn{3}{|c|}{4.7330000000000005} & 5.4011 & TRN & \\
\hline CHEMBL1573487 & 688653 & \multicolumn{3}{|c|}{4.7330000000000005} & 5.1399 & TRN & \\
\hline CHEMBL1403377 & 688653 & 4.783 & 4.9288 & TRN & & & \\
\hline CHEMBL1555689 & 688653 & \multicolumn{3}{|c|}{5.7829999999999995} & 5.5539 & TRN & \\
\hline CHEMBL1495154 & 688653 & 6.4829 & 5.6557 & TRN & & & \\
\hline CHEMBL1426158 & 688653 & \multicolumn{3}{|c|}{5.632999999999999} & 5.1958 & TRN & \\
\hline CHEMBL1548253 & 688653 & 4.883 & 5.0098 & TST & & & \\
\hline CHEMBL1602317 & 688653 & 4.833 & 5.6671 & TRN & & & \\
\hline CHEMBL1482824 & 688653 & 4.883 & 5.1196 & TST & & & \\
\hline CHEMBL1454515 & 688653 & \multicolumn{3}{|c|}{5.882999999999999} & 5.4623 & TRN & \\
\hline CHEMBL1491496 & 688653 & \multicolumn{3}{|c|}{6.132999999999999} & 5.73799 & 99999999995 & TRN \\
\hline CHEMBL1555387 & 688653 & \multicolumn{3}{|c|}{5.132999999999999} & 5.4967 & TRN & \\
\hline CHEMBL1381239 & 688653 & 5.483 & 5.3142 & TRN & & & \\
\hline CHEMBL1312088 & 688653 & 5.433 & 5.3532 & TRN & & & \\
\hline CHEMBL1447080 & 688653 & 4.783 & 5.615 & TST & & & \\
\hline CHEMBL1304130 & 688653 & \multicolumn{3}{|c|}{4.7330000000000005} & 5.3081 & TRN & \\
\hline CHEMBL1525280 & 688653 & 4.833 & 5.229 & TRN & & & \\
\hline CHEMBL1327134 & 688653 & 6.683 & 5.8766 & TRN & & & \\
\hline CHEMBL1973226 & 688653 & \multicolumn{3}{|c|}{6.5329999999999995} & 5.6295 & TRN & \\
\hline CHEMBL1508710 & 688653 & 4.933 & 5.0711 & TRN & & & \\
\hline CHEMBL1381586 & 688653 & 4.833 & 5.1415 & TST & & & \\
\hline CHEMBL1396284 & 688653 & \multicolumn{3}{|c|}{5.5329999999999995} & 6.3584 & TRN & \\
\hline CHEMBL3198953 & 688653 & 4.833 & 4.9827 & TRN & & & \\
\hline CHEMBL1486599 & 688653 & 5.083 & 5.3025 & TST & & & \\
\hline CHEMBL1472212 & 688653 & \multicolumn{3}{|c|}{6.632999999999999} & 5.9256 & TRN & \\
\hline CHEMBL1524763 & 688653 & 6.4829 & 6.3185 & TRN & & & \\
\hline CHEMBL1419271 & 688653 & 4.833 & 5.1603 & TRN & & & \\
\hline CHEMBL1433891 & 688653 & 4.883 & 4.9758 & TRN & & & \\
\hline CHEMBL1517390 & 688653 & 4.933 & 5.5036 & TRN & & & \\
\hline CHEMBL1454606 & 688653 & 4.833 & 5.4364 & TST & & & \\
\hline CHEMBL1547932 & 688653 & \multicolumn{3}{|c|}{5.382999999999999} & 5.2236 & TRN & \\
\hline CHEMBL1321788 & 688653 & \multicolumn{3}{|c|}{4.7330000000000005} & 5.1176 & TRN & \\
\hline CHEMBL1329479 & 688653 & \multicolumn{3}{|c|}{5.332999999999999} & 5.03100 & 0000000001 & TST \\
\hline CHEMBL1436159 & 688653 & 5.3829 & 99999999 & & 5.6933 & TRN & \\
\hline
\end{tabular}




\begin{tabular}{|c|c|c|c|c|c|c|c|}
\hline \multicolumn{7}{|c|}{ Supplemental Table S2.txt } & \\
\hline CHEMBL1450252 & 688653 & \multicolumn{3}{|c|}{4.7330000000000005} & 4.9694 & TRN & \\
\hline CHEMBL1490272 & 688653 & 5.083 & 4.8971 & TRN & & & \\
\hline CHEMBL1491688 & 688653 & \multicolumn{3}{|c|}{4.7330000000000005} & 5.2844 & TRN & \\
\hline CHEMBL1609494 & 688653 & 5.233 & 5.3267 & TRN & & & \\
\hline CHEMBL1528733 & 688653 & \multicolumn{3}{|c|}{5.132999999999999} & 5.1519 & TRN & \\
\hline CHEMBL1602145 & 688653 & 4.633 & 5.2197 & TST & & & \\
\hline CHEMBL1364280 & 688653 & \multicolumn{3}{|c|}{4.7330000000000005} & \multicolumn{2}{|c|}{5.218999999999999} & TRN \\
\hline CHEMBL1426676 & 688653 & 4.783 & 4.9048 & TRN & & & \\
\hline CHEMBL3191669 & 688653 & 5.483 & 5.5243 & TRN & & & \\
\hline CHEMBL1371571 & 688653 & 5.733 & 5.2821 & TST & & & \\
\hline CHEMBL1535083 & 688653 & \multicolumn{3}{|c|}{5.7829999999999995} & 5.482 & TST & \\
\hline CHEMBL1349067 & 688653 & 6.233 & 6.0638 & TRN & & & \\
\hline CHEMBL1533234 & 688653 & 4.933 & 5.2868 & TST & & & \\
\hline CHEMBL1391533 & 688653 & \multicolumn{3}{|c|}{5.832999999999999} & 5.6016 & TRN & \\
\hline CHEMBL1307069 & 688653 & \multicolumn{3}{|c|}{5.632999999999999} & 5.4647 & TRN & \\
\hline CHEMBL1347555 & 688653 & 5.483 & 5.2456 & TRN & & & \\
\hline CHEMBL1606305 & 688653 & \multicolumn{3}{|c|}{5.132999999999999} & 5.2237 & TRN & \\
\hline CHEMBL1595100 & 688653 & \multicolumn{3}{|c|}{6.2829999999999995} & 5.4227 & TRN & \\
\hline CHEMBL 241858 & 688653 & 5.183 & 4.7667 & TRN & & & \\
\hline CHEMBL1525404 & 688653 & \multicolumn{3}{|c|}{4.7330000000000005} & 4.8733 & TRN & \\
\hline CHEMBL1522330 & 688653 & 6.8831 & 5.5126 & TRN & & & \\
\hline CHEMBL1352372 & 688653 & \multicolumn{3}{|c|}{5.132999999999999} & \multicolumn{2}{|c|}{5.422000000000001} & TST \\
\hline CHEMBL1384068 & 688653 & 4.933 & 4.9954 & TRN & & & \\
\hline CHEMBL1398836 & 688653 & \multicolumn{3}{|c|}{5.7829999999999995} & 6.2628 & TRN & \\
\hline CHEMBL1554400 & 688653 & \multicolumn{3}{|c|}{5.582999999999999} & 6.3061 & TRN & \\
\hline CHEMBL1491556 & 688653 & 4.783 & 5.3376 & TRN & & & \\
\hline CHEMBL1514269 & 688653 & 4.883 & 4.9638 & TRN & & & \\
\hline CHEMBL1365276 & 688653 & 6.4829 & 5.7969 & TRN & & & \\
\hline CHEMBL1306274 & 688653 & 5.433 & 5.1707 & TRN & & & \\
\hline CHEMBL1518767 & 688653 & 4.883 & 5.4343 & TRN & & & \\
\hline CHEMBL 1600380 & 688653 & 4.783 & 5.4948 & TRN & & & \\
\hline CHEMBL1453946 & 688653 & \multicolumn{3}{|c|}{4.7330000000000005} & 4.8851 & TRN & \\
\hline CHEMBL3198106 & 688653 & 4.783 & 5.0277 & TST & & & \\
\hline CHEMBL1434165 & 688653 & 4.633 & 4.9469 & TRN & & & \\
\hline CHEMBL1407928 & 688653 & 5.033 & 5.2011 & TRN & & & \\
\hline CHEMBL1514189 & 688653 & \multicolumn{3}{|c|}{5.582999999999999} & 5.0751 & TRN & \\
\hline CHEMBL1412137 & 688653 & \multicolumn{3}{|c|}{6.5329999999999995} & 6.1505 & TRN & \\
\hline CHEMBL1605248 & 688653 & \multicolumn{3}{|c|}{5.5329999999999995} & 5.2617 & TRN & \\
\hline CHEMBL1492483 & 688653 & \multicolumn{3}{|c|}{5.2829999999999995} & 5.5802 & TRN & \\
\hline CHEMBL1421103 & 688653 & 4.783 & 5.0489 & TST & & & \\
\hline CHEMBL1429594 & 688653 & 4.833 & 5.9738 & TRN & & & \\
\hline CHEMBL1343028 & 688653 & 4.883 & 5.3455 & TST & & & \\
\hline CHEMBL1348803 & 688653 & 5.28299 & 99999999 & 995 & 5.4106 & TST & \\
\hline CHEMBL1527527 & 688653 & 4.883 & 5.53 & TRN & & & \\
\hline CHEMBL1435313 & 688653 & 7.3325 & 5.404 & TST & & & \\
\hline CHEMBL1589734 & 688653 & 4.583 & 4.9746 & TRN & & & \\
\hline CHEMBL1452232 & 688653 & 5.183 & 5.2696 & TRN & & & \\
\hline CHEMBL1354241 & 688653 & 4.73300 & 00000000 & 005 & 5.3511 & TST & \\
\hline
\end{tabular}




\begin{tabular}{|c|c|c|c|c|c|c|}
\hline \multirow{3}{*}{$\begin{array}{l}\text { CHEMBL1304397 } \\
\text { CHEMBL1566906 }\end{array}$} & \multicolumn{6}{|c|}{ Supplemental Table S2.txt } \\
\hline & 688653 & \multicolumn{3}{|c|}{5.7829999999999995} & \multirow[t]{4}{*}{5.4347} & \multirow[t]{4}{*}{ TRN } \\
\hline & 688653 & 4.883 & 5.5897 & TRN & & \\
\hline CHEMBL1313298 & 688653 & 5.233 & 5.3412 & TRN & & \\
\hline CHEMBL1548869 & 88653 & 4.633 & 5.7325 & TRN & & \\
\hline CHEMBL1320734 & 688653 & \multicolumn{3}{|c|}{4.7330000000000005} & 5.3975 & $\mathrm{~T}$ \\
\hline CHEMBL1410316 & 688653 & \multicolumn{3}{|c|}{4.7330000000000005} & 5.3996 & \\
\hline CHEMBL1384559 & 688653 & \multicolumn{3}{|c|}{4.7330000000000005} & 5.0735 & \\
\hline CHEMBL1524513 & 688653 & \multicolumn{3}{|c|}{5.2829999999999995} & 4.9347 & \\
\hline CHEMBL1447607 & 688653 & 4.833 & 5.0966 & TRN & & \\
\hline CHEMBL1388233 & 688653 & 6.233 & 5.7175 & TRN & & \\
\hline CHEMBL1577695 & 688653 & \multicolumn{3}{|c|}{6.382999999999999} & 5.5478 & \\
\hline CHEMBL1434948 & 688653 & 4.633 & 4.8219 & TRN & & \\
\hline CHEMBL1308497 & 688653 & \multicolumn{3}{|c|}{5.332999999999999} & 5.0528 & TP \\
\hline CHEMBL1554140 & 688653 & 4.783 & 4.8345 & TRN & & \\
\hline CHEMBL1365260 & 688653 & \multicolumn{3}{|c|}{5.132999999999999} & 5639 & \\
\hline CHEMBL130 & 688 & 4.633 & 4.891 & TST & & \\
\hline CHEMBL1 & $68 \varepsilon$ & 5 . & 4.9461 & TRN & & \\
\hline CHEMBL1490032 & 688653 & 4.633 & 4.9408 & TST & & \\
\hline CHEMBL3196880 & 688653 & \multicolumn{3}{|c|}{5.582999999999999} & 998 & TRN \\
\hline CHEMBL1341132 & 688653 & \multicolumn{3}{|c|}{4.9830000000000005} & 5.6025 & TST \\
\hline CHEMBL14 & 688 & \multicolumn{3}{|c|}{6.5329999999999995} & 83 & \\
\hline CHEMBL1 & 688 & 5.083 & 4.9122 & TRN & & \\
\hline CHEMBL1473819 & 688653 & 7.1831 & 5.6923 & TRN & & \\
\hline CHEMBL1306966 & 688653 & \multicolumn{3}{|c|}{6.2829999999999995} & 504 & TRN \\
\hline CHEMBL1591388 & 688653 & \multicolumn{3}{|c|}{4.7330000000000005} & 4.9765 & \\
\hline CHEMBL1 & 688 & 4.633 & 5.0658 & TRN & & \\
\hline CHEMBL 1 & $68 \varepsilon$ & 5.433 & 6.0 & TRN & & \\
\hline CHEMBL1348144 & 688653 & 6.683 & \multicolumn{3}{|c|}{5.7829999999999995} & $\mathrm{TI}$ \\
\hline CHEMBL1319502 & 688653 & \multicolumn{3}{|c|}{5.132999999999999} & 5.2082 & \\
\hline CHEMBL1326751 & 688653 & 5.683 & 5.4155 & TRN & & \\
\hline CHEMBL: & $6 \varepsilon$ & \multicolumn{3}{|c|}{5.332999999999999} & & TRN \\
\hline CHEMBL & $68 \varepsilon$ & \multicolumn{3}{|c|}{5.132999999999999} & 5.1574 & \\
\hline CHEMBL505670 & 688653 & 5.5829 & 99999999 & & 5.2192 & TST \\
\hline CHEMBL1386801 & 688653 & 5.5829 & 99999999 & & 6.023 & TRN \\
\hline CHEMBL1419580 & 688653 & 4. & 5.1946 & TRN & & \\
\hline CHEMBL & $68 \varepsilon$ & 4. & 5.5 & TST & & \\
\hline CHEMBL & 688653 & 4.633 & 5.0495 & TRN & & \\
\hline CHEMBL1551790 & 688653 & 4.633 & 5.0373 & TST & & \\
\hline CHEMBL1378644 & 688653 & 4.783 & 5.3892 & TRN & & \\
\hline CHEMBL3 & 688653 & 5.3829 & 99999999 & & & TST \\
\hline CHEMBL1461591 & 688653 & 4.7336 & 00000000 & 005 & a & $T$ \\
\hline CHEMBL1551433 & 688653 & 4.633 & 5.1622 & TRN & & \\
\hline CHEMBL3207928 & 688653 & 4.933 & 5.0221 & TRN & & \\
\hline CHEMBL1404585 & 688653 & 5.5829 & 99999999 & & 5. & 11 \\
\hline CHEMBL1517940 & 688653 & $5.582 \mathrm{c}$ & 99999999 & & 5.1782 & \\
\hline CHEMBL1338313 & 688653 & 4.883 & 5.2173 & TRN & & \\
\hline CHEMBL259805 & 688653 & 5.1329 & 99999999 & & 6.3599 & TIN \\
\hline CHEMBL1557501 & 688653 & 5.683 & 5.3485 & TRN & & \\
\hline
\end{tabular}




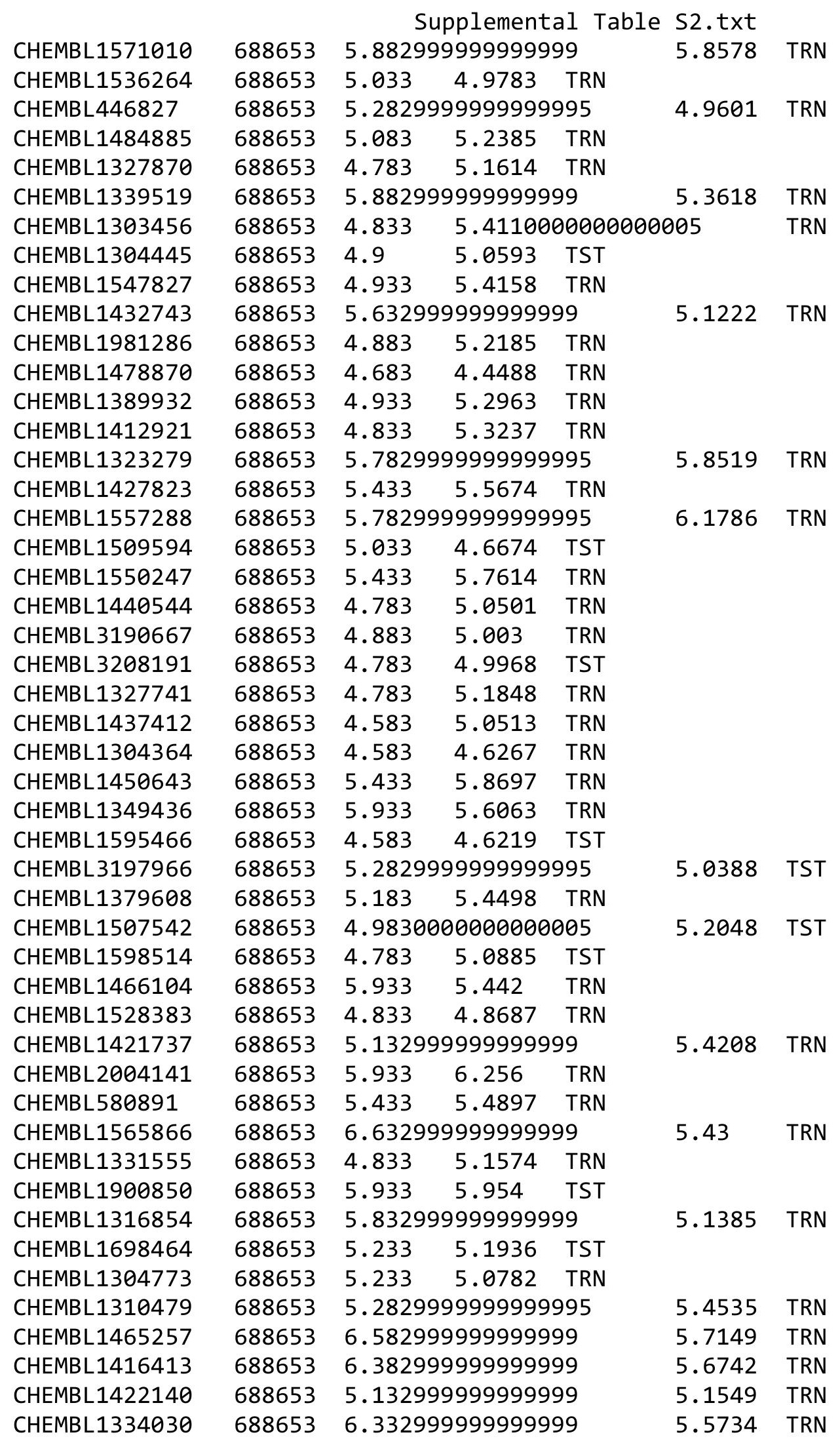




\begin{tabular}{|c|c|c|c|c|c|c|}
\hline \multirow[b]{2}{*}{ CHEMBL1494461 } & \multirow[b]{2}{*}{688653} & \multicolumn{5}{|c|}{ Supplemental Table S2.txt } \\
\hline & & \multirow{2}{*}{\multicolumn{2}{|c|}{$\begin{array}{lc}5.483 & 4.8539 \\
5.1329999999999\end{array}$}} & TRN & \multirow[b]{2}{*}{4.9055} & \multirow[b]{2}{*}{ TRN } \\
\hline CHEMBL1585320 & 688653 & & & & & \\
\hline CHEMBL1733957 & 688653 & 4.783 & 4.7686 & TST & & \\
\hline CHEMBL1510156 & 688653 & 4.783 & 4.9377 & TRN & & \\
\hline CHEMBL1498428 & 688653 & 4.883 & 5.101 & TST & & \\
\hline CHEMBL1474183 & 688653 & \multicolumn{3}{|c|}{5.382999999999999} & 5.3056 & TRN \\
\hline CHEMBL1365239 & 688653 & 6.183 & 5.9655 & TRN & & \\
\hline CHEMBL1584036 & 688653 & \multicolumn{3}{|c|}{5.332999999999999} & 4.9734 & TST \\
\hline CHEMBL1561038 & 688653 & 4.783 & 4.7354 & TST & & \\
\hline CHEMBL1452139 & 688653 & 6.9329 & 5.2496 & TST & & \\
\hline CHEMBL1325198 & 688653 & 4.633 & 4.8195 & TRN & & \\
\hline CHEMBL1311906 & 688653 & \multicolumn{3}{|c|}{5.132999999999999} & 4.8438 & TST \\
\hline CHEMBL1530137 & 688653 & \multicolumn{3}{|c|}{5.332999999999999} & 5.0263 & TRN \\
\hline CHEMBL1497808 & 688653 & 5.733 & 5.3331 & TRN & & \\
\hline CHEMBL1600525 & 688653 & 4.633 & 5.3425 & TRN & & \\
\hline CHEMBL1563861 & 688653 & \multicolumn{3}{|c|}{5.332999999999999} & 5.8067 & TRN \\
\hline CHEMBL1601779 & 688653 & \multicolumn{3}{|c|}{6.132999999999999} & 5.5087 & TST \\
\hline CHEMBL3189660 & 688653 & 4.583 & 5.4179 & TRN & & \\
\hline CHEMBL1452616 & 688653 & 4.933 & 5.1236 & TRN & & \\
\hline CHEMBL 3197608 & 688653 & 4.783 & 5.6789 & TRN & & \\
\hline CHEMBL 1443936 & 688653 & 5.433 & 6.1313 & TRN & & \\
\hline CHEMBL1558889 & 688653 & \multicolumn{3}{|c|}{5.332999999999999} & 5.4447 & TRN \\
\hline CHEMBL3208079 & 688653 & 4.833 & 5.1096 & TRN & & \\
\hline CHEMBL1358089 & 688653 & 5.433 & 5.4777 & TRN & & \\
\hline CHEMBL1458275 & 688653 & \multicolumn{3}{|c|}{4.9830000000000005} & 5.13 & TST \\
\hline CHEMBL1369993 & 688653 & 4.933 & \multicolumn{3}{|c|}{5.2139999999999995} & TRN \\
\hline CHEMBL1341053 & 688653 & 5.483 & \multicolumn{3}{|c|}{5.462999999999999} & TRN \\
\hline CHEMBL1586840 & 688653 & 4.883 & 5.0026 & TRN & & \\
\hline CHEMBL265686 & 688653 & \multicolumn{3}{|c|}{5.632999999999999} & 6.8795 & TRN \\
\hline CHEMBL1461798 & 688653 & 4.883 & 5.3948 & TRN & & \\
\hline CHEMBL1416229 & 688653 & 5.683 & 5.17 & TST & & \\
\hline CHEMBL1410134 & 688653 & 5.233 & 4.9459 & TST & & \\
\hline CHEMBL1551537 & 688653 & \multicolumn{3}{|c|}{5.7829999999999995} & 5.0975 & TST \\
\hline CHEMBL1314742 & 688653 & 4.883 & 5.0903 & TRN & & \\
\hline CHEMBL1464620 & 688653 & 6.683 & 5.4807 & TRN & & \\
\hline CHEMBL1423466 & 688653 & \multicolumn{3}{|c|}{6.082999999999999} & 5.7951 & TRN \\
\hline CHEMBL1333599 & 688653 & 4.833 & 5.029 & TRN & & \\
\hline CHEMBL1322033 & 688653 & 4.833 & 5.0593 & TRN & & \\
\hline CHEMBL3207987 & 688653 & 5.183 & 5.3203 & TST & & \\
\hline CHEMBL1510087 & 688653 & \multicolumn{3}{|c|}{4.7330000000000005} & 5.026 & TRN \\
\hline CHEMBL1327018 & 688653 & 5.183 & 5.1867 & TRN & & \\
\hline CHEMBL1587561 & 688653 & 5.183 & 5.1691 & TRN & & \\
\hline CHEMBL1531933 & 688653 & 5.033 & 5.3362 & TRN & & \\
\hline CHEMBL1483875 & 688653 & 5.433 & 5.1674 & TRN & & \\
\hline CHEMBL1414180 & 688653 & 4.883 & 5.131 & TST & & \\
\hline CHEMBL1436850 & 688653 & 5.233 & 5.4058 & TST & & \\
\hline CHEMBL1405155 & 688653 & 4.633 & 4.8621 & TST & & \\
\hline CHEMBL1506677 & 688653 & 5.13299 & 99999999 & & 5.1645 & TRN \\
\hline
\end{tabular}




\begin{tabular}{|c|c|c|c|c|c|c|}
\hline \multirow[b]{2}{*}{ CHEMBL1349757 } & & \multicolumn{5}{|c|}{ Supplemental Table S2.txt } \\
\hline & 688653 & 4.933 & 5.4908 & TRN & & \\
\hline CHEMBL1509197 & 688653 & \multicolumn{3}{|c|}{4.7330000000000005} & 5.2647 & TRN \\
\hline CHEMBL576607 & 688653 & 6.0 & 5.8055 & TRN & & \\
\hline CHEMBL1988056 & 688653 & 4.833 & 5.3879 & TST & & \\
\hline CHEMBL1372094 & 688653 & \multicolumn{3}{|c|}{5.7829999999999995} & 6.0145 & TRN \\
\hline CHEMBL1400965 & 688653 & 5.983 & 5.5732 & TRN & & \\
\hline CHEMBL1396103 & 688653 & 5.733 & 5.5608 & TRN & & \\
\hline CHEMBL1484564 & 688653 & 5.733 & 5.6533 & TRN & & \\
\hline CHEMBL1364171 & 688653 & 4.883 & 5.3465 & TST & & \\
\hline CHEMBL1555729 & 688653 & 6.183 & 5.7765 & TRN & & \\
\hline CHEMBL1343460 & 688653 & 4.833 & 5.3476 & TST & & \\
\hline CHEMBL494326 & 688653 & 5.183 & 5.0794 & TRN & & \\
\hline CHEMBL1326488 & 688653 & \multicolumn{3}{|c|}{4.9830000000000005} & 5.2567 & TST \\
\hline CHEMBL3193230 & 688653 & 5.183 & 5.9886 & TRN & & \\
\hline CHEMBL1392771 & 688653 & 5.183 & 5.6446 & TST & & \\
\hline CHEMBL1377013 & 688653 & 4.833 & 5.0977 & TRN & & \\
\hline CHEMBL1362964 & 688653 & 6.683 & 5.9248 & TRN & & \\
\hline CHEMBL1583945 & 688653 & 4.683 & 5.1465 & TST & & \\
\hline CHEMBL1349863 & 688653 & 5.033 & 6.1097 & TRN & & \\
\hline CHEMBL1473239 & 688653 & 4.783 & 5.2824 & TRN & & \\
\hline CHEMBL246447 & 688653 & 5.183 & 5.9162 & TST & & \\
\hline CHEMBL1368187 & 688653 & 4.833 & 5.1383 & TRN & & \\
\hline CHEMBL1583326 & 688653 & 4.833 & 5.2773 & TRN & & \\
\hline CHEMBL1305680 & 688653 & \multicolumn{3}{|c|}{5.132999999999999} & 5.2821 & TRN \\
\hline CHEMBL1535610 & 688653 & \multicolumn{3}{|c|}{5.632999999999999} & 5.5498 & TRN \\
\hline CHEMBL1367347 & 688653 & 4.633 & 5.3502 & TRN & & \\
\hline CHEMBL3191198 & 688653 & 5.183 & 5.2636 & TRN & & \\
\hline CHEMBL3196317 & 688653 & 5.033 & 5.0896 & TRN & & \\
\hline CHEMBL1512807 & 688653 & \multicolumn{3}{|c|}{5.7829999999999995} & 5.2775 & TRN \\
\hline CHEMBL1360618 & 688653 & 7.0329 & 6.0962 & TRN & & \\
\hline CHEMBL1531311 & 688653 & 7.0329 & 5.5881 & TRN & & \\
\hline CHEMBL1366374 & 688653 & \multicolumn{3}{|c|}{5.582999999999999} & 5.1045 & TST \\
\hline CHEMBL1589914 & 688653 & \multicolumn{3}{|c|}{5.382999999999999} & 5.5173 & TST \\
\hline CHEMBL478825 & 688653 & \multicolumn{3}{|c|}{5.332999999999999} & 5.4746 & TRN \\
\hline CHEMBL1353266 & 688653 & \multicolumn{3}{|c|}{5.7829999999999995} & 5.3988 & TRN \\
\hline CHEMBL3198532 & 688653 & 4.783 & 4.9089 & TST & & \\
\hline CHEMBL1313121 & 688653 & 4.633 & 4.7502 & TRN & & \\
\hline CHEMBL1595942 & 688653 & \multicolumn{3}{|c|}{6.632999999999999} & 6.1688 & TST \\
\hline CHEMBL1570756 & 688653 & \multicolumn{3}{|c|}{5.132999999999999} & 5.3043 & TRN \\
\hline CHEMBL3197012 & 688653 & 6.433 & 5.6353 & TRN & & \\
\hline CHEMBL1511037 & 688653 & 5.683 & 5.3532 & TRN & & \\
\hline CHEMBL1605973 & 688653 & 4.833 & 5.0129 & TST & & \\
\hline CHEMBL1590179 & 688653 & 4.783 & 5.2534 & TST & & \\
\hline CHEMBL1306816 & 688653 & 5.083 & 4.775 & TST & & \\
\hline CHEMBL1442502 & 688653 & \multicolumn{3}{|c|}{6.332999999999999} & 5.6917 & TRN \\
\hline CHEMBL1522796 & 688653 & \multicolumn{3}{|c|}{6.082999999999999} & 6.062 & TRN \\
\hline CHEMBL1564496 & 688653 & \multicolumn{3}{|c|}{4.7330000000000005} & 5.107 & TRN \\
\hline CHEMBL1377034 & 688653 & 5.233 & 5.4474 & TRN & & \\
\hline
\end{tabular}




\begin{tabular}{|c|c|c|c|c|c|c|}
\hline \multirow[b]{2}{*}{ CHEMBL1370166 } & & \multicolumn{5}{|c|}{ Supplemental Table S2.txt } \\
\hline & 688653 & 6.433 & 5.6992 & TRN & & \\
\hline CHEMBL1613042 & 688653 & 5.483 & 5.2875 & TST & & \\
\hline CHEMBL1307691 & 688653 & 5.183 & 4.9786 & TRN & & \\
\hline CHEMBL1432275 & 688653 & \multicolumn{3}{|c|}{5.132999999999999} & 4.7851 & TRN \\
\hline CHEMBL1341942 & 688653 & \multicolumn{3}{|c|}{5.132999999999999} & 5.6221 & \\
\hline CHEMBL1349505 & 688653 & 4.883 & 5.1265 & TST & & \\
\hline CHEMBL1320256 & 688653 & 5.083 & 5.1869 & TRN & & \\
\hline CHEMBL1596022 & 688653 & 4.633 & 5.1298 & TRN & & \\
\hline CHEMBL1613054 & 688653 & \multicolumn{3}{|c|}{5.7829999999999995} & 5.294 & $\mathrm{~T}$ \\
\hline CHEMBL1514320 & 688653 & 6.4829 & 5.7436 & TRN & & \\
\hline CHEMBL1400055 & 688653 & 4.883 & 5.3325 & TRN & & \\
\hline CHEMBL1439787 & 688653 & 6.683 & 5.5022 & TRN & & \\
\hline CHEMBL1576995 & 688653 & 4.783 & 4.9987 & TRN & & \\
\hline CHEMBL3192116 & 688653 & 5.033 & 5.4417 & TRN & & \\
\hline CHEMBL1427218 & 688653 & \multicolumn{3}{|c|}{6.382999999999999} & 5.8868 & \\
\hline CHEMBL1403094 & 688653 & 4.783 & 5.3054 & TRN & & \\
\hline CHEMBL1569546 & 688653 & 5.733 & 5.4485 & TRN & & \\
\hline CHEMBL3189978 & 688653 & \multicolumn{3}{|c|}{4.7330000000000005} & 5.1104 & \\
\hline CHEMBL1421603 & 688653 & 6.433 & 5.6305 & TST & & \\
\hline CHEMBL1431339 & 688653 & \multicolumn{3}{|c|}{4.7330000000000005} & 5.0568 & \\
\hline CHEMBL1405288 & 688653 & 5.183 & 5.3761 & TST & & \\
\hline CHEMBL300389 & 688653 & 6.683 & 6.0818 & TST & & \\
\hline CHEMBL1336806 & 688653 & \multicolumn{3}{|c|}{5.132999999999999} & 5.3984 & \\
\hline CHEMBL1444642 & 688653 & 5.433 & 5.5026 & TRN & & \\
\hline CHEMBL1517192 & 688653 & \multicolumn{3}{|c|}{5.382999999999999} & 5.0758 & \\
\hline CHEMBL1421720 & 688653 & 5.683 & 5.2367 & TRN & & \\
\hline CHEMBL1584108 & 688653 & 4.883 & 5.1434 & TRN & & \\
\hline CHEMBL13 & 688653 & \multicolumn{3}{|c|}{5.382999999999999} & 5.405 & TRT \\
\hline CHEMBL1538021 & 688653 & \multicolumn{3}{|c|}{6.332999999999999} & 5.9283 & \\
\hline CHEMBL1603158 & 688653 & \multicolumn{3}{|c|}{4.7330000000000005} & 4.9502 & TP \\
\hline CHEMBL1404107 & 688653 & \multicolumn{3}{|c|}{6.082999999999999} & 5.4453 & \\
\hline CHEMBL1606613 & 688653 & 4.633 & 4.7084 & TRN & & \\
\hline CHEMBL1308391 & 688653 & \multicolumn{3}{|c|}{5.132999999999999} & 5.4694 & TRN \\
\hline CHEMBL1481499 & 688653 & \multicolumn{3}{|c|}{5.5329999999999995} & 5.3698 & \\
\hline CHEMBL1341886 & 688653 & 4.783 & 5.1628 & TRN & & \\
\hline CHEMBL1571696 & 688653 & 5.033 & 5.0165 & TRN & & \\
\hline CHEMBL1359216 & 688653 & 6.233 & 5.4625 & TST & & \\
\hline CHEMBL1369307 & 688653 & 4.833 & 4.9495 & TRN & & \\
\hline CHEMBL1470519 & 688653 & 6.233 & 5.3738 & TRN & & \\
\hline CHEMBL1370219 & 688653 & 5.683 & 5.4648 & TRN & & \\
\hline CHEMBL1450458 & 688653 & 5.1329 & 99999999 & & 4.9477 & 17 \\
\hline CHEMBL141110 & 688653 & 4.9830 & 00000000 & 005 & 4.9555 & \\
\hline CHEMBL1606217 & 688653 & 4.833 & 5.2518 & TST & & \\
\hline CHEMBL1349758 & 688653 & 5.083 & 4.9804 & TRN & & \\
\hline CHEMBL1373447 & 688653 & 5.5329 & 99999999 & 995 & 5.7525 & N \\
\hline CHEMBL1401434 & 688653 & 4.783 & 5.0865 & TST & & \\
\hline CHEMBL3195086 & 688653 & 5.7829 & 99999999 & 995 & 5.5231 & I RIV \\
\hline CHEMBL1425808 & 688653 & 4.7330 & 00000000 & 005 & 5.0326 & \\
\hline
\end{tabular}




\begin{tabular}{|c|c|c|c|c|c|c|}
\hline & & \multicolumn{5}{|c|}{ Supplemental Table s2.txt } \\
\hline CHEMBL3191175 & 688653 & 4.883 & 5.1159 & TRN & & \\
\hline CHEMBL1426951 & 688653 & 5.733 & 5.2753 & TST & & \\
\hline CHEMBL1544961 & 688653 & 5.683 & 5.6563 & TRN & & \\
\hline CHEMBL1583188 & 688653 & \multicolumn{3}{|c|}{4.9830000000000005} & 4.971 & TST \\
\hline CHEMBL1339788 & 688653 & \multicolumn{3}{|c|}{4.7330000000000005} & 5.2306 & \\
\hline CHEMBL1490104 & 688653 & 6.233 & 5.9553 & TRN & & \\
\hline CHEMBL1482096 & 688653 & 5.183 & 5.265 & TRN & & \\
\hline CHEMBL1313771 & 688653 & 4.883 & 5.1318 & TRN & & \\
\hline CHEMBL1363037 & 688653 & 4.933 & 5.1144 & TRN & & \\
\hline CHEMBL1596046 & 688653 & \multicolumn{3}{|c|}{6.382999999999999} & 6.3359 & TRN \\
\hline CHEMBL1449009 & 688653 & \multicolumn{3}{|c|}{5.632999999999999} & 5.3372 & \\
\hline CHEMBL1369425 & 688653 & 4.833 & 4.6684 & TRN & & \\
\hline CHEMBL1360273 & 688653 & \multicolumn{3}{|c|}{5.7829999999999995} & 5.4475 & (10 \\
\hline CHEMBL1329457 & 688653 & \multicolumn{3}{|c|}{6.2829999999999995} & 5.5833 & \\
\hline CHEMBL1413478 & 688653 & 5.483 & 4.9618 & TRN & & \\
\hline CHEMBL1492794 & 688653 & 5.933 & 5.6373 & TRN & & \\
\hline CHEMBL1424236 & 688653 & 5.083 & 5.6297 & TRN & & \\
\hline CHEMBL1506264 & 688653 & 5.683 & 5.4017 & TRN & & \\
\hline CHEMBL1537629 & 688653 & 4.833 & 5.2257 & TRN & & \\
\hline CHEMBL3199219 & 688653 & \multicolumn{3}{|c|}{5.2829999999999995} & 5.3971 & TRN \\
\hline CHEMBL1383030 & 688653 & \multicolumn{3}{|c|}{5.5329999999999995} & 5.8897 & \\
\hline CHEMBL1389385 & 688653 & 4.783 & 5.0043 & TST & & \\
\hline CHEMBL1321475 & 688653 & \multirow{2}{*}{\multicolumn{3}{|c|}{$\begin{array}{l}5.033 \text { S. } \\
5.132999999999999\end{array}$}} & & \\
\hline CHEMBL1540306 & 688653 & & & & 5.6648 & $\mathrm{TP}$ \\
\hline CHEMBL1336531 & 688653 & 5.733 & 5.9529 & TRN & & \\
\hline CHEMBL1406209 & 688653 & 4.883 & 4.9454 & TRN & & \\
\hline CHEMBL1303338 & 688653 & 4.783 & 5.5917 & TRN & & \\
\hline CHEMBL1419822 & 688653 & 4.933 & 5.1921 & TRN & & \\
\hline CHEMBL1424655 & 688653 & 4.683 & 5.4354 & TST & & \\
\hline CHEMBL3190990 & 688653 & 5.683 & 5.3255 & TRN & & \\
\hline CHEMBL1610041 & 688653 & 4.783 & 4.9554 & TRN & & \\
\hline CHEMBL15 & 688 & 4.833 & 5.3093 & TRN & & \\
\hline CHEMBL1552079 & 688653 & 5.083 & 5.1606 & TRN & & \\
\hline CHEMBL3189974 & 688653 & \multicolumn{3}{|c|}{5.132999999999999} & 5.2458 & TRN \\
\hline CHEMBL1477057 & 688653 & \multicolumn{3}{|c|}{6.382999999999999} & 5.831 & TRN \\
\hline CHEMBL1553696 & 688653 & 4.883 & 5.5893 & TRN & & \\
\hline CHEMBL1526686 & 688653 & 4.883 & 5.7549 & TRN & & \\
\hline CHEMBL1610255 & 688653 & 5.033 & 5.0633 & TRN & & \\
\hline CHEMBL77285 & 688653 & 4.633 & 5.0201 & TRN & & \\
\hline CHEMBL1299726 & 688653 & 4.783 & 5.1767 & TRN & & \\
\hline CHEMBL1413615 & 688653 & \multicolumn{3}{|c|}{5.5329999999999995} & 5.2572 & TP \\
\hline CHEMBL229907 & 688653 & 4.833 & 5.598 & TRN & & \\
\hline CHEMBL1464259 & 688653 & \multicolumn{3}{|c|}{5.5329999999999995} & 5.0712 & TR \\
\hline CHEMBL1495028 & 688653 & 6.233 & 5.4061 & TRN & & \\
\hline CHEMBL3196314 & 688653 & \multicolumn{3}{|c|}{4.9830000000000005} & 5.2683 & TRN \\
\hline CHEMBL1555279 & 688653 & \multicolumn{3}{|c|}{5.882999999999999} & 5.1863 & TP \\
\hline CHEMBL1409896 & 688653 & 4.783 & 4.8784 & TRN & & \\
\hline CHEMBL1304079 & 688653 & \multicolumn{3}{|c|}{5.2829999999999995} & 5.4309 & 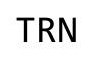 \\
\hline
\end{tabular}




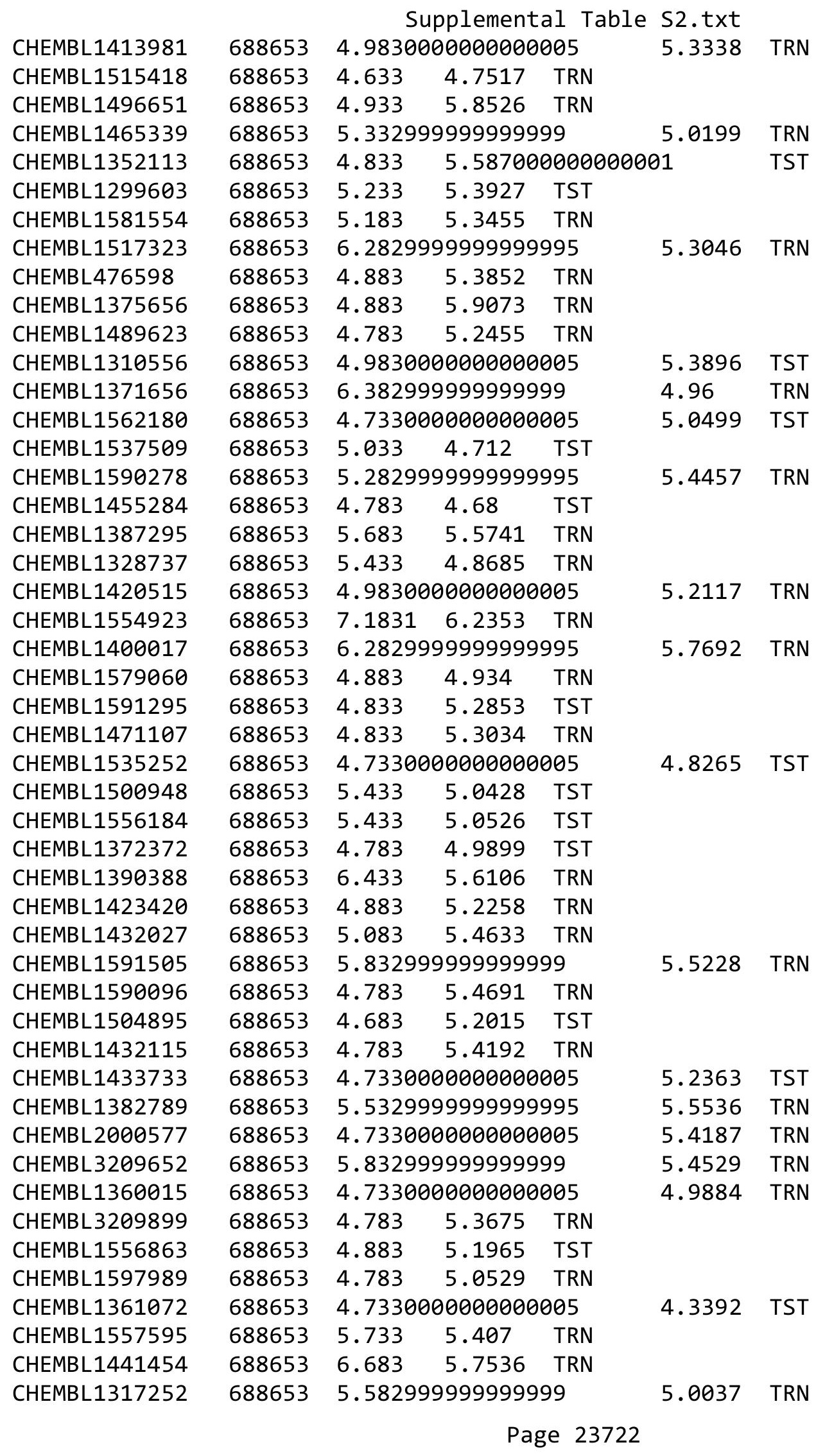




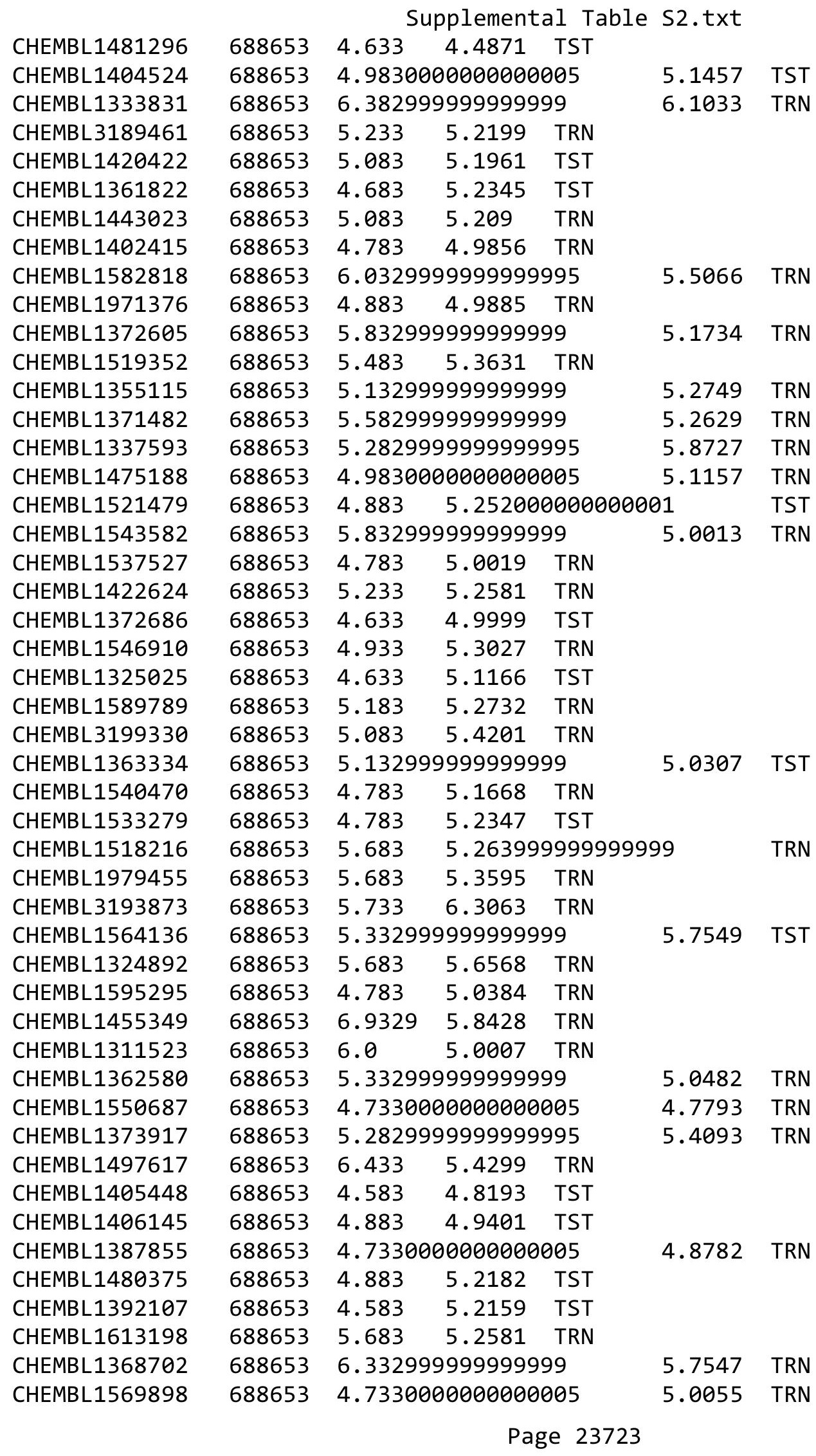




\begin{tabular}{|c|c|c|c|c|c|c|}
\hline \multirow{3}{*}{$\begin{array}{l}\text { CHEMBL1333088 } \\
\text { CHEMBL1586234 }\end{array}$} & \multirow{3}{*}{$\begin{array}{l}688653 \\
688653\end{array}$} & \multicolumn{4}{|c|}{ Supplemental Table S2.txt } & \multirow[b]{2}{*}{ TST } \\
\hline & & \multicolumn{3}{|c|}{5.2829999999999995} & 4.8128 & \\
\hline & & 5.733 & 5.7336 & TRN & & \\
\hline CHEMBL1366811 & 688653 & 4.833 & 5.2306 & TRN & & \\
\hline CHEMBL1328894 & 688653 & 5.983 & 5.6557 & TST & & \\
\hline CHEMBL1362188 & 688653 & \multicolumn{3}{|c|}{6.332999999999999} & 5.2666 & TRN \\
\hline CHEMBL1593701 & 688653 & \multicolumn{3}{|c|}{4.7330000000000005} & 5.0985 & TST \\
\hline CHEMBL1473486 & 688653 & 4.583 & 5.2071 & TST & & \\
\hline CHEMBL1370297 & 688653 & 6.4829 & 5.3699 & TRN & & \\
\hline CHEMBL1322828 & 688653 & 6.4829 & 5.885 & TRN & & \\
\hline CHEMBL1363322 & 688653 & \multicolumn{3}{|c|}{5.582999999999999} & 5.3613 & TRN \\
\hline CHEMBL1524967 & 688653 & \multicolumn{3}{|c|}{5.7829999999999995} & 5.204 & TRN \\
\hline CHEMBL1597276 & 688653 & 6.9329 & 5.6856 & TRN & & \\
\hline CHEMBL1515175 & 688653 & 5.233 & 5.1352 & TRN & & \\
\hline CHEMBL1404335 & 688653 & 5.083 & 5.2505 & TST & & \\
\hline CHEMBL1356710 & 688653 & 4.933 & 5.1156 & TRN & & \\
\hline CHEMBL1396804 & 688653 & 4.883 & 4.7871 & TRN & & \\
\hline CHEMBL1434816 & 688653 & \multicolumn{3}{|c|}{5.5329999999999995} & 5.3059 & TRN \\
\hline CHEMBL1568330 & 688653 & 6.433 & 5.4842 & TRN & & \\
\hline CHEMBL1504686 & 688653 & 4.933 & 5.2671 & TRN & & \\
\hline CHEMBL1382550 & 688653 & \multicolumn{3}{|c|}{5.632999999999999} & 5.5237 & TRN \\
\hline CHEMBL1410156 & 688653 & 4.883 & 5.1357 & TRN & & \\
\hline CHEMBL1461403 & 688653 & \multicolumn{3}{|c|}{5.2829999999999995} & 5.3104 & TST \\
\hline CHEMBL1535021 & 688653 & 7.1331 & 5.8386 & TST & & \\
\hline CHEMBL1358429 & 688653 & 4.783 & 5.0352 & TRN & & \\
\hline CHEMBL1381872 & 688653 & \multicolumn{3}{|c|}{5.5329999999999995} & 5.7121 & TST \\
\hline CHEMBL1523803 & 688653 & \multicolumn{3}{|c|}{6.082999999999999} & 6.0526 & TRN \\
\hline CHEMBL1437888 & 688653 & 4.633 & 5.1304 & TRN & & \\
\hline CHEMBL1397496 & 688653 & 4.933 & 4.8591 & TRN & & \\
\hline CHEMBL1303960 & 688653 & 5.683 & 5.2242 & TRN & & \\
\hline CHEMBL1336013 & 688653 & 5.183 & 4.9929 & TRN & & \\
\hline CHEMBL1362564 & 688653 & 4.633 & 4.8772 & TRN & & \\
\hline CHEMBL1525701 & 688653 & 4.783 & 5.3174 & TST & & \\
\hline CHEMBL1320977 & 688653 & \multicolumn{3}{|c|}{6.132999999999999} & 5.3526 & TRN \\
\hline CHEMBL1451834 & 688653 & 6.683 & 5.809 & TRN & & \\
\hline CHEMBL1304458 & 688653 & 4.683 & 5.4278 & TST & & \\
\hline CHEMBL1361154 & 688653 & 5.033 & 5.2893 & TRN & & \\
\hline CHEMBL1389396 & 688653 & 4.783 & 5.1722 & TRN & & \\
\hline CHEMBL1321519 & 688653 & \multicolumn{3}{|c|}{5.2829999999999995} & 5.7088 & TRN \\
\hline CHEMBL1439723 & 688653 & \multicolumn{3}{|c|}{4.7330000000000005} & 5.1361 & TRN \\
\hline CHEMBL1541933 & 688653 & 6.233 & 5.2278 & TRN & & \\
\hline CHEMBL1369378 & 688653 & \multicolumn{3}{|c|}{4.9830000000000005} & 5.3548 & TRN \\
\hline CHEMBL1430056 & 688653 & 5.233 & 5.2896 & TRN & & \\
\hline CHEMBL1414427 & 688653 & 4.783 & 4.9738 & TRN & & \\
\hline CHEMBL1469802 & 688653 & \multicolumn{3}{|c|}{5.132999999999999} & 5.0605 & TRN \\
\hline CHEMBL1455819 & 688653 & 5.083 & 5.6195 & TRN & & \\
\hline CHEMBL1509607 & 688653 & 4.833 & 5.2745 & TRN & & \\
\hline CHEMBL1588561 & 688653 & 5.183 & 5.5852 & TST & & \\
\hline CHEMBL3191502 & 688653 & 4.833 & 5.29 & TST & & \\
\hline
\end{tabular}




\begin{tabular}{|c|c|c|c|c|c|c|c|}
\hline \multirow{2}{*}{ CHEMBL1335843 } & \multicolumn{6}{|c|}{ Supplemental Table S2.txt } & \\
\hline & 688653 & 6.0 & 5.9937 & TRN & & & \\
\hline CHEMBL3214545 & 688653 & 5.13299 & 99999999 & & 5.4104 & TRN & \\
\hline CHEMBL587892 & 688653 & 6.8831 & 5.7128 & TRN & & & \\
\hline CHEMBL1596033 & 688653 & 4.98300 & 00000000 & 005 & 5.0921 & TRN & \\
\hline CHEMBL1361796 & 688653 & 4.833 & 5.2191 & TRN & & & \\
\hline CHEMBL1334319 & 688653 & 4.783 & 5.6325 & TRN & & & \\
\hline CHEMBL1453331 & 688653 & 4.783 & 5.1035 & TRN & & & \\
\hline CHEMBL1556360 & 688653 & 5.083 & 5.1924 & TST & & & \\
\hline CHEMBL1591325 & 688653 & 5.13299 & 99999999 & & 5.1661 & TRN & \\
\hline CHEMBL1333149 & 688653 & 5.38299 & 99999999 & & 5.58799 & 9999999999 & TRN \\
\hline CHEMBL1543776 & 688653 & 4.633 & 5.3892 & TRN & & & \\
\hline CHEMBL1464482 & 688653 & 6.58299 & 99999999 & & 5.5175 & TST & \\
\hline CHEMBL1572722 & 688653 & 5.733 & 5.291 & TST & & & \\
\hline CHEMBL1361217 & 688653 & 4.883 & 4.9399 & TST & & & \\
\hline CHEMBL1454593 & 688653 & 5.13299 & 99999999 & & 4.9987 & TRN & \\
\hline CHEMBL1309863 & 688653 & 4.833 & 4.9883 & TRN & & & \\
\hline CHEMBL1490654 & 688653 & 5.33299 & 99999999 & & 5.3359 & TST & \\
\hline CHEMBL1411970 & 688653 & 4.583 & 4.9604 & TRN & & & \\
\hline CHEMBL1460456 & 688653 & 4.683 & 5.3192 & TRN & & & \\
\hline CHEMBL1566179 & 688653 & 4.583 & 5.2474 & TST & & & \\
\hline CHEMBL1498966 & 688653 & 6.03299 & 99999999 & 995 & 5.4034 & TST & \\
\hline CHEMBL1568589 & 688653 & 5.13299 & 99999999 & & 4.8713 & TST & \\
\hline CHEMBL1356970 & 688653 & 6.28299 & 999999995 & 995 & 5.5796 & TST & \\
\hline CHEMBL1450964 & 688653 & 4.583 & 4.7705 & TRN & & & \\
\hline CHEMBL1507394 & 688653 & 6.08299 & 99999999 & & 4.9917 & TST & \\
\hline CHEMBL567337 & 688653 & 4.783 & 5.319 & TRN & & & \\
\hline CHEMBL1564980 & 688653 & 6.03299 & 99999999 & 995 & 5.7598 & TRN & \\
\hline CHEMBL1389646 & 688653 & 5.933 & 5.8186 & TRN & & & \\
\hline CHEMBL3194264 & 688653 & 5.38299 & 99999999 & & 5.1556 & TRN & \\
\hline CHEMBL 1455352 & 688653 & 4.833 & 4.8611 & TRN & & & \\
\hline CHEMBL3194568 & 688653 & 6.78299 & 99999999 & 995 & 5.7539 & TRN & \\
\hline CHEMBL1309675 & 688653 & 5.13299 & 99999999 & & 4.9613 & TRN & \\
\hline CHEMBL1391266 & 688653 & 5.88299 & 999999995 & & 5.2915 & TRN & \\
\hline CHEMBL1311979 & 688653 & 4.783 & 5.4854 & TST & & & \\
\hline CHEMBL572531 & 688653 & 4.633 & 5.0875 & TRN & & & \\
\hline CHEMBL1482409 & 688653 & 5.233 & 5.1237 & TRN & & & \\
\hline CHEMBL1306610 & 688653 & 5.683 & 4.8568 & TST & & & \\
\hline CHEMBL1394209 & 688653 & 5.13299 & 999999999 & & 4.8131 & TRN & \\
\hline CHEMBL1964439 & 688653 & 5.78299 & 999999999 & 995 & 5.3025 & TST & \\
\hline CHEMBL1390868 & 688653 & 7.0329 & 5.9081 & TST & & & \\
\hline CHEMBL1356689 & 688653 & 5.88299 & 999999999 & & 5.6265 & TRN & \\
\hline CHEMBL1462650 & 688653 & 4.683 & 5.4342 & TRN & & & \\
\hline CHEMBL 1444274 & 688653 & 5.33299 & 999999999 & & 5.5484 & TRN & \\
\hline CHEMBL1346494 & 688653 & 5.58299 & 999999999 & & 5.0474 & TRN & \\
\hline CHEMBL1580053 & 688653 & 4.933 & 4.9252 & TRN & & & \\
\hline CHEMBL1316590 & 688653 & 4.783 & 5.0647 & TST & & & \\
\hline CHEMBL1471957 & 688653 & 5.13299 & 999999999 & & 5.4356 & TRN & \\
\hline CHEMBL547924 & 688653 & 6.58299 & 999999999 & & 5.7953 & TRN & \\
\hline
\end{tabular}




\begin{tabular}{|c|c|c|c|c|c|c|}
\hline \multirow[b]{2}{*}{ CHEMBL1328124 } & \multirow[b]{2}{*}{688653} & \multicolumn{5}{|c|}{ Supplemental Table S2.txt } \\
\hline & & \multirow{2}{*}{\multicolumn{3}{|c|}{$\begin{array}{ll}4.633 & 4.4093 \\
5.832999999999999\end{array}$}} & & \\
\hline CHEMBL1482872 & 688653 & & & & 5.8656 & TRN \\
\hline CHEMBL1511516 & 688653 & \multicolumn{3}{|c|}{4.7330000000000005} & 5.2517 & \\
\hline CHEMBL 3208784 & 688653 & \multicolumn{3}{|c|}{5.882999999999999} & 5.6049 & \\
\hline CHEMBL1580603 & 688653 & 4.683 & 5.2544 & TRN & & \\
\hline CHEMBL1382257 & 688653 & 4.883 & 5.2889 & TRN & & \\
\hline CHEMBL1336282 & 688653 & \multicolumn{3}{|c|}{4.9830000000000005} & 4.9242 & \\
\hline CHEMBL3195256 & 688653 & 4.933 & 4.8206 & TRN & & \\
\hline CHEMBL1408767 & 688653 & \multicolumn{3}{|c|}{5.7829999999999995} & 5.8115 & \\
\hline CHEMBL1570658 & 688653 & 5.233 & 5.6448 & TRN & & \\
\hline CHEMBL1583314 & 688653 & 5.233 & 5.2083 & TRN & & \\
\hline CHEMBL1345550 & 688653 & 4.883 & 5.1403 & TRN & & \\
\hline CHEMBL3193166 & 688653 & \multicolumn{3}{|c|}{5.2829999999999995} & 5.7761 & \\
\hline CHEMBL1332934 & 688653 & \multicolumn{3}{|c|}{5.5329999999999995} & 5.0659 & \\
\hline CHEMBL1363130 & 688653 & 5.933 & 5.0767 & TRN & & \\
\hline CHEMBL1483575 & 688653 & 4.783 & 5.144 & TST & & \\
\hline CHEMBL1431160 & 688653 & 4.883 & 5.394 & TRN & & \\
\hline CHEMBL1315161 & 688653 & 4.783 & 5.1991 & TRN & & \\
\hline CHEMBL1411712 & 688653 & 5.683 & 5.5154 & TRN & & \\
\hline CHEMBL 3214007 & 688653 & \multicolumn{3}{|c|}{5.632999999999999} & 571 & \\
\hline CHEMBL1544669 & 688653 & 5.733 & 5.1756 & TRN & & \\
\hline CHEMBL3197935 & 688653 & 4.883 & 4.9991 & TST & & \\
\hline CHEMBL1450211 & 688653 & \multicolumn{3}{|c|}{5.132999999999999} & 5.6119 & \\
\hline CHEMBL1585609 & 688653 & \multicolumn{3}{|c|}{5.332999999999999} & 4.9092 & TS \\
\hline CHEMBL1479386 & 688653 & 5.933 & 5.0865 & TRN & & \\
\hline CHEMBL1402664 & 688653 & 5.983 & 5.8167 & TRN & & \\
\hline CHEMBL1581310 & 688653 & 6.233 & 5.6881 & TRN & & \\
\hline CHEMBL1352430 & 688653 & \multicolumn{3}{|c|}{4.7330000000000005} & 5.5238 & $\mathrm{TI}$ \\
\hline CHEMBL1496625 & 688653 & \multicolumn{3}{|c|}{5.7829999999999995} & 5.1986 & $\mathrm{TR}$ \\
\hline CHEMBL1554107 & 688653 & 5.683 & 5.5814 & TRN & & \\
\hline CHEMBL1344934 & 688653 & 5.233 & 5.1464 & TST & & \\
\hline CHEMBL1543054 & 688653 & \multicolumn{3}{|c|}{5.632999999999999} & 5.7289 & TRN \\
\hline CHEMBL1353013 & 688653 & \multicolumn{3}{|c|}{5.332999999999999} & 5.025 & TRN \\
\hline CHEMBL1346165 & 688653 & \multicolumn{3}{|c|}{6.332999999999999} & 5.3846 & TST \\
\hline CHEMBL1382410 & 688653 & \multicolumn{3}{|c|}{5.2829999999999995} & 5.7341 & TR \\
\hline CHEMBL1559500 & 688653 & 6.433 & 5.8742 & TRN & & \\
\hline CHEMBL1608818 & 688653 & 4.883 & 5.5637 & TRN & & \\
\hline CHEMBL3193174 & 688653 & 4.833 & 5.4947 & TRN & & \\
\hline CHEMBL3198453 & 688653 & 5.483 & 5.439 & TRN & & \\
\hline CHEMBL1543317 & 688653 & 5.733 & 4.9621 & TRN & & \\
\hline CHEMBL1400308 & 688653 & 4.883 & 5.18 & TRN & & \\
\hline CHEMBL 2003973 & 688653 & 4.583 & 4.8511 & TST & & \\
\hline CHEMBL1559638 & 688653 & 5.033 & 4.9362 & TRN & & \\
\hline CHEMBL1520399 & 688653 & 4.833 & 5.8489 & TRN & & \\
\hline CHEMBL1598631 & 688653 & 5.233 & 5.2718 & TST & & \\
\hline CHEMBL1429863 & 688653 & 4.933 & 5.171 & TRN & & \\
\hline CHEMBL1591135 & 688653 & 5.683 & 5.2143 & TRN & & \\
\hline CHEMBL1491223 & 688653 & 4.783 & 4.9933 & TRN & & \\
\hline
\end{tabular}




\begin{tabular}{|c|c|c|c|c|c|c|c|}
\hline & & & pplement & al & s2.txt & & \\
\hline CHEMBL1555930 & 688653 & 6.3829 & 99999999 & & 5.9953 & TRN & \\
\hline CHEMBL1566701 & 688653 & 4.7330 & 00000000 & 005 & 5.0864 & TST & \\
\hline CHEMBL1570250 & 688653 & 5.233 & 5.4424 & TRN & & & \\
\hline CHEMBL1317812 & 688653 & 4.583 & 4.8155 & TRN & & & \\
\hline CHEMBL1547444 & 688653 & 4.7330 & 00000000 & 005 & 5.4815 & TST & \\
\hline CHEMBL 3197056 & 688653 & 5.1329 & 99999999 & & 5.3569 & TRN & \\
\hline CHEMBL1515495 & 688653 & 6.2829 & 99999999 & 995 & 5.55200 & 00000000005 & TRN \\
\hline CHEMBL1448194 & 688653 & 4.7330 & 00000000 & 005 & 5.0336 & TRN & \\
\hline CHEMBL1595736 & 688653 & 4.583 & 5.0363 & TRN & & & \\
\hline CHEMBL1490111 & 688653 & 4.833 & 5.3276 & TRN & & & \\
\hline CHEMBL1467016 & 688653 & 5.683 & 5.433 & TRN & & & \\
\hline CHEMBL 3209857 & 688653 & 5.983 & 5.8395 & TRN & & & \\
\hline CHEMBL1486500 & 688653 & 4.583 & 5.0579 & TRN & & & \\
\hline CHEMBL1523621 & 688653 & 4.9830 & 00000000 & 005 & 4.8655 & TST & \\
\hline CHEMBL1373692 & 688653 & 5.3329 & 99999999 & & 5.1718 & TST & \\
\hline CHEMBL1381982 & 688653 & 5.433 & 5.1336 & TST & & & \\
\hline CHEMBL1512760 & 688653 & 4.633 & 5.5289 & TRN & & & \\
\hline CHEMBL3196986 & 688653 & 4.833 & 5.018 & TRN & & & \\
\hline CHEMBL1499317 & 688653 & 4.833 & 4.8492 & TRN & & & \\
\hline CHEMBL1545349 & 688653 & 5.3829 & 99999999 & & 5.0273 & TRN & \\
\hline CHEMBL1376258 & 688653 & 6.0 & 5.5597 & TRN & & & \\
\hline CHEMBL1348349 & 688653 & 4.883 & 5.15600 & 00000 & 01 & TST & \\
\hline CHEMBL 3195774 & 688653 & 5.8829 & 999999995 & & 5.481 & TST & \\
\hline CHEMBL1327254 & 688653 & 6.2829 & 99999999 & 995 & 5.6735 & TRN & \\
\hline CHEMBL1483803 & 688653 & 4.633 & 5.2788 & TST & & & \\
\hline CHEMBL1583236 & 688653 & 5.033 & 5.7579 & TRN & & & \\
\hline CHEMBL 3193797 & 688653 & 5.033 & 5.4155 & TRN & & & \\
\hline CHEMBL1326723 & 688653 & 5.5829 & 999999995 & & 5.1473 & TST & \\
\hline CHEMBL1383777 & 688653 & 5.483 & 5.2936 & TRN & & & \\
\hline CHEMBL1372267 & 688653 & 5.8329 & 99999999 & & 5.4022 & TRN & \\
\hline CHEMBL1337846 & 688653 & 6.433 & 5.3308 & TST & & & \\
\hline CHEMBL1506451 & 688653 & 4.583 & 4.8699 & TST & & & \\
\hline CHEMBL1368508 & 688653 & $4.9830 t$ & 00000000 & 005 & 5.0901 & TRN & \\
\hline CHEMBL1527634 & 688653 & 5.2829 & 99999999 & 995 & 5.1035 & TRN & \\
\hline CHEMBL1482883 & 688653 & 4.7330 & 00000000 & 005 & 5.2155 & TRN & \\
\hline CHEMBL1359308 & 688653 & 5.683 & 5.6401 & TRN & & & \\
\hline CHEMBL 3212718 & 688653 & 6.7331 & 5.026 & TST & & & \\
\hline CHEMBL1535546 & 688653 & 4.833 & 5.3449 & TRN & & & \\
\hline CHEMBL1462099 & 688653 & 4.883 & 5.4287 & TRN & & & \\
\hline CHEMBL1325079 & 688653 & 5.933 & 5.2976 & TRN & & & \\
\hline CHEMBL1591376 & 688653 & 5.7829 & 99999999 & 995 & 5.6822 & TRN & \\
\hline CHEMBL1354343 & 688653 & 4.783 & 5.0715 & TST & & & \\
\hline CHEMBL1528976 & 688653 & 4.783 & 5.1791 & TRN & & & \\
\hline CHEMBL1351166 & 688653 & 4.783 & 5.0995 & TRN & & & \\
\hline CHEMBL1397620 & 688653 & 5.2829 & 99999999 & 995 & 4.8905 & TRN & \\
\hline CHEMBL1495788 & 688653 & 4.883 & 5.5339 & TRN & & & \\
\hline CHEMBL1456393 & 688653 & 6.433 & 5.8224 & TRN & & & \\
\hline CHEMBL1577459 & 688653 & 5.8829 & 99999999 & & 5.0031 & TRN & \\
\hline
\end{tabular}




\begin{tabular}{|c|c|c|c|c|c|c|}
\hline & & \multicolumn{5}{|c|}{ Supplemental Table S2.txt } \\
\hline CHEMBL1416558 & 688653 & 4.883 & 5.1028 & TRN & & \\
\hline CHEMBL1432797 & 688653 & 5.683 & 5.4384 & TRN & & \\
\hline CHEMBL1572373 & 688653 & \multicolumn{3}{|c|}{4.7330000000000005} & 5.2117 & TP \\
\hline CHEMBL1505121 & 688653 & 4.833 & 5.1657 & TST & & \\
\hline CHEMBL1553464 & 688653 & 4.583 & 5.2436 & TRN & & \\
\hline CHEMBL104916 & 588653 & 4.933 & 5.2958 & TRN & & \\
\hline CHEMBL1565809 & 688653 & \multicolumn{3}{|c|}{5.882999999999999} & 5.1043 & \\
\hline CHEMBL1508216 & 688653 & 5.983 & 5.4203 & TRN & & \\
\hline CHEMBL1506330 & 688653 & \multicolumn{3}{|c|}{6.082999999999999} & 5.6554 & 1 \\
\hline CHEMBL1339720 & 688653 & 5.183 & 5.5317 & TRN & & \\
\hline CHEMBL1418885 & 688653 & 4.883 & 5.0468 & TRN & & \\
\hline CHEMBL1531595 & 688653 & \multicolumn{3}{|c|}{5.132999999999999} & 5.5433 & TRIV \\
\hline CHEMBL1519211 & 688653 & \multicolumn{3}{|c|}{5.882999999999999} & & \\
\hline CHEMBL1505964 & 688653 & 4.633 & 4.7002 & TST & & \\
\hline CHEMBL1501202 & 688653 & 4.833 & 5.2602 & TRN & & \\
\hline CHEMBL1328973 & 688653 & \multicolumn{3}{|c|}{4.7330000000000005} & 5.2724 & TRN \\
\hline CHEMBL1422087 & 688653 & \multicolumn{3}{|c|}{5.832999999999999} & 5.2295 & \\
\hline CHEMBL1321101 & 688653 & \multicolumn{3}{|c|}{5.7829999999999995} & 5.6134 & \\
\hline CHEMBL1560408 & 688653 & 4.783 & 5.1087 & TRN & & \\
\hline CHEMBL1548037 & 688653 & 5.483 & 5.3998 & TRN & & \\
\hline CHEMBL1992651 & 688653 & 5.033 & 5.494 & TRN & & \\
\hline CHEMBL 3212143 & 688653 & \multicolumn{3}{|c|}{5.7829999999999995} & & \\
\hline CHEMBL15 & 688653 & \multicolumn{3}{|c|}{4.7330000000000005} & 5.7217 & TRN \\
\hline CHEMBL1493497 & 688653 & \multicolumn{3}{|c|}{6.832999999999999} & 5.7983 & TRN \\
\hline CHEMBL1379173 & 688653 & \multicolumn{3}{|c|}{5.132999999999999} & 5.5869 & TRN \\
\hline CHEMBL1522607 & 688653 & \multicolumn{3}{|c|}{5.132999999999999} & 5.4315 & \\
\hline CHEMBL15£ & 688653 & 5.683 & 5.7402 & TRN & & \\
\hline CHEMBL1 & 688653 & 5.483 & 5.5016 & TRN & & \\
\hline CHEMBL 1407128 & 688 & 4.783 & 4.8614 & TRN & & \\
\hline CHEMBL1483847 & 688653 & \multicolumn{3}{|c|}{5.832999999999999} & 5.9819 & \\
\hline CHEMBL1530857 & 688653 & 4.833 & 5.0714 & TST & & \\
\hline CHEMBL15 & 688653 & \multicolumn{3}{|c|}{5.132999999999999} & 5.3035 & 11 \\
\hline CHEMBL15 & 688653 & 4.833 & 5.1423 & TST & & \\
\hline CHEMBL1368019 & 688653 & \multicolumn{3}{|c|}{5.2829999999999995} & 5.0878 & TS \\
\hline CHEMBL1387910 & 688653 & 5.183 & 5.42 & TRN & & \\
\hline CHEMBL1425096 & 688653 & 4.8 & 5.17 & TRN & & \\
\hline CHEMBL14 & 688 & & 5.3719 & TST & & \\
\hline CHEMBL15 & 688653 & 5.733 & 5.0952 & TRN & & \\
\hline CHEMBL1421119 & 688653 & 5.733 & 5.3276 & TST & & \\
\hline CHEMBL1410509 & 688653 & \multicolumn{3}{|c|}{4.9830000000000005} & & TRN \\
\hline CHEMBL1478542 & 688653 & \multicolumn{3}{|c|}{4.7330000000000005} & 202 & \\
\hline CHEMBL1413246 & 688653 & \multicolumn{3}{|c|}{5.7829999999999995} & 4.9674 & IRIV \\
\hline CHEMBL1469317 & 688653 & \multicolumn{3}{|c|}{4.7330000000000005} & 5.3649 & 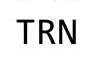 \\
\hline CHEMBL3208028 & 688653 & 5.433 & 5.2911 & TST & & \\
\hline CHEMBL316796 & 688653 & 4.9836 & 00000000 & 005 & 5.4634 & IRIN \\
\hline CHEMBL1524482 & 688653 & 6.6325 & 99999999 & & 6.1776 & \\
\hline CHEMBL1380397 & 688653 & 5.1325 & 99999999 & & 4.9141 & TRN \\
\hline CHEMBL1970753 & 688653 & 5.683 & 5.7852 & $\mathrm{TR}$ & & \\
\hline
\end{tabular}




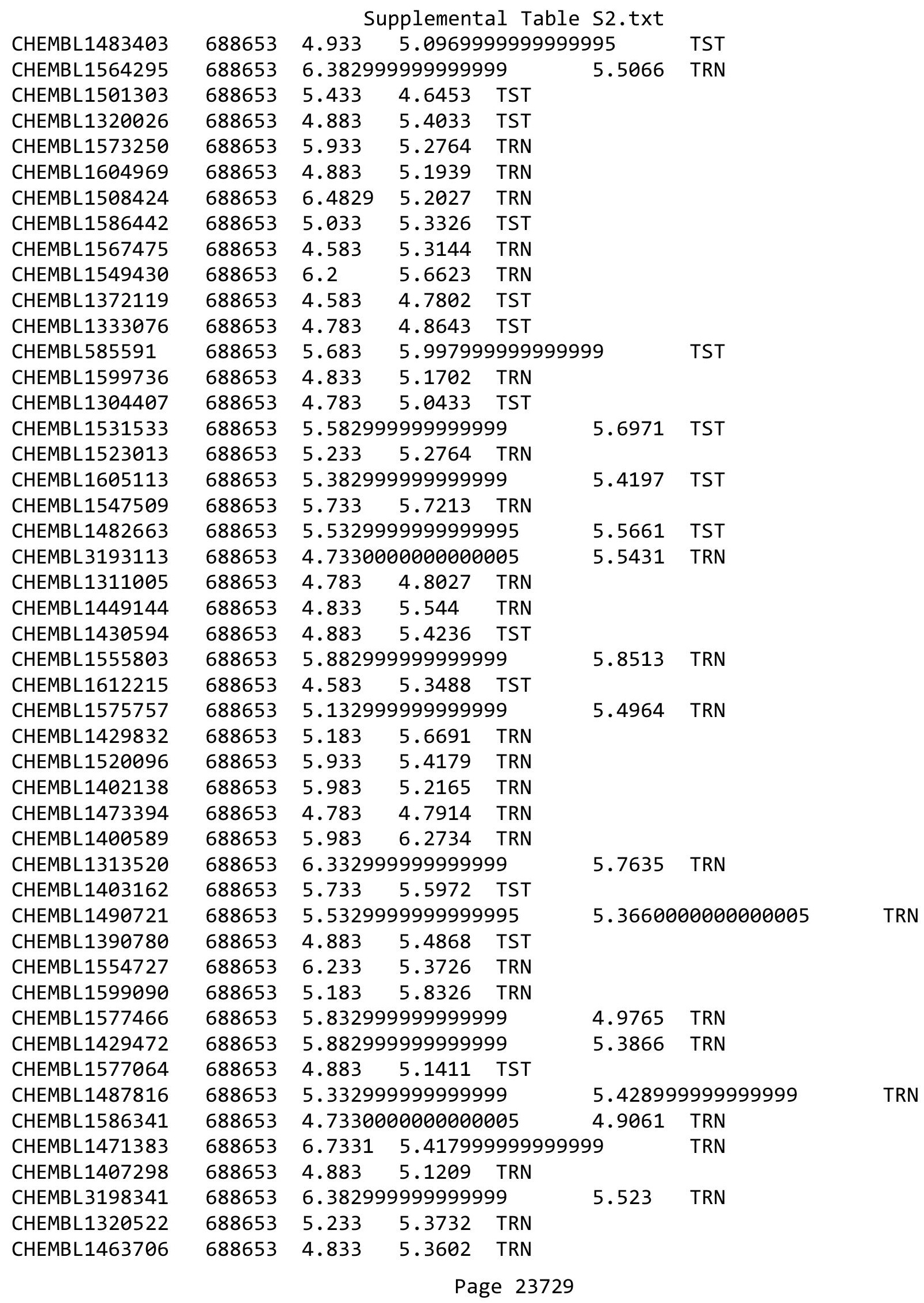




\begin{tabular}{|c|c|c|c|c|c|c|}
\hline \multirow[b]{2}{*}{ CHEMBL1403468 } & \multirow[b]{2}{*}{688653} & \multicolumn{5}{|c|}{ Supplemental Table S2.txt } \\
\hline & & \multicolumn{5}{|c|}{$3 \quad 5.2532$ TST } \\
\hline CHEMBL3210669 & 688653 & \multicolumn{3}{|c|}{6.2829999999999995} & 5.4518 & 11 \\
\hline CHEMBL1305388 & 688653 & 5.233 & 5.7107 & TRN & & \\
\hline CHEMBL1344216 & 688653 & \multicolumn{3}{|c|}{5.832999999999999} & 5.5791 & $\mathrm{TI}$ \\
\hline CHEMBL1565757 & 688653 & 5.483 & 5.7556 & TST & & \\
\hline CHEMBL1554066 & 688653 & 4.933 & 5.1453 & TRN & & \\
\hline CHEMBL 260028 & 688653 & \multicolumn{3}{|c|}{6.832999999999999} & 6.4966 & \\
\hline CHEMBL1352142 & 688653 & \multicolumn{3}{|c|}{5.2829999999999995} & 5.4575 & \\
\hline CHEMBL1408059 & 688653 & 4.833 & 5.1716 & TRN & & \\
\hline CHEMBL1328036 & 688653 & \multicolumn{3}{|c|}{6.5329999999999995} & 6.0504 & TItr \\
\hline CHEMBL1543956 & 688653 & \multicolumn{3}{|c|}{5.632999999999999} & 5.0463 & TST \\
\hline CHEMBL1472141 & 688653 & \multicolumn{3}{|c|}{5.132999999999999} & 5.2763 & \\
\hline CHEMBL1354925 & 688653 & 5.983 & 5.2926 & TRN & & \\
\hline CHEMBL1509262 & 688653 & 4.833 & 5.0354 & TRN & & \\
\hline CHEMBL3193110 & 688653 & 4.833 & 5.1448 & TRN & & \\
\hline CHEMBL1570640 & 688653 & \multicolumn{3}{|c|}{4.7330000000000005} & 5.2226 & \\
\hline CHEMBL3192159 & 688653 & 5.183 & 4.9683 & TRN & & \\
\hline CHEMBL 3191837 & 688653 & \multirow{2}{*}{\multicolumn{3}{|c|}{4.7330000000000005}} & & \\
\hline CHEMBL1507374 & 688653 & & & & 5.3956 & TST \\
\hline CHEMBL1388509 & 688653 & 4.833 & 5.6337 & TST & & \\
\hline CHEMBL1424068 & 688653 & \multicolumn{3}{|c|}{4.7330000000000005} & 471 & TRN \\
\hline CHEMBL1354045 & 688653 & \multicolumn{3}{|c|}{6.132999999999999} & & \\
\hline CHEMBL1449485 & 688653 & 4.933 & 5.2936 & TRN & & \\
\hline CHEMBL1343604 & 688653 & 4.883 & 5.0017 & TRN & & \\
\hline CHEMBL1325466 & 688653 & 4.933 & 4.7692 & TRN & & \\
\hline CHEMBL1415363 & 688653 & 5.933 & 5.7709 & TRN & & \\
\hline CHEMBL1344214 & 688653 & 4.833 & 5.0449 & TRN & & \\
\hline CHEMBL1522700 & 688653 & 4.833 & 5.6358 & TRN & & \\
\hline CHEMBL1365850 & 688653 & 6.4 & 5.7077 & TRN & & \\
\hline CHEMBL1501734 & 688653 & \multicolumn{3}{|c|}{5.632999999999999} & 3 & \\
\hline CHEMBL1303177 & 688653 & 5.683 & 5.4093 & TST & & \\
\hline CHEMBL1425391 & 688653 & \multicolumn{3}{|c|}{5.582999999999999} & 5.4831 & 11 \\
\hline CHEMBL1539959 & 688653 & 4.933 & 5.4843 & TRN & & \\
\hline CHEMBL1541455 & 688653 & 4.883 & 4.9703 & TRN & & \\
\hline CHEMBL1373092 & 688653 & 4.683 & 4.7726 & TRN & & \\
\hline CHEMBL229887 & 688653 & 4.833 & 5.5411 & TRN & & \\
\hline CHEMBL1977683 & 688653 & 5 . & 4.8826 & TST & & \\
\hline CHEMBL1439745 & 688653 & 4.883 & 4.9919 & TRN & & \\
\hline CHEMBL1404854 & 688653 & 4.833 & 5.0553 & TRN & & \\
\hline CHEMBL1588926 & 688653 & \multicolumn{3}{|c|}{5.7829999999999995} & 5.8378 & TP \\
\hline CHEMBL3211378 & 688653 & 5.483 & 5.4383 & TRN & & \\
\hline CHEMBL1559323 & 688653 & \multicolumn{3}{|c|}{4.7330000000000005} & 5.2298 & IRIV \\
\hline CHEMBL1379171 & 688653 & \multicolumn{3}{|c|}{5.832999999999999} & 5.8441 & TDN \\
\hline CHEMBL1452424 & 688653 & 5.233 & 5.3324 & TRN & & \\
\hline CHEMBL1405504 & 688653 & \multicolumn{3}{|c|}{5.2829999999999995} & 5.385 & INIV \\
\hline CHEMBL1324885 & 688653 & 6.03299 & 99999999 & 995 & 5.0974 & \\
\hline CHEMBL1371653 & 688653 & 4.98300 & $\partial 0000000$ & 005 & 5.1753 & TRN \\
\hline CHEMBL1405830 & 688653 & 5.433 & 5.4991 & TRN & & \\
\hline
\end{tabular}




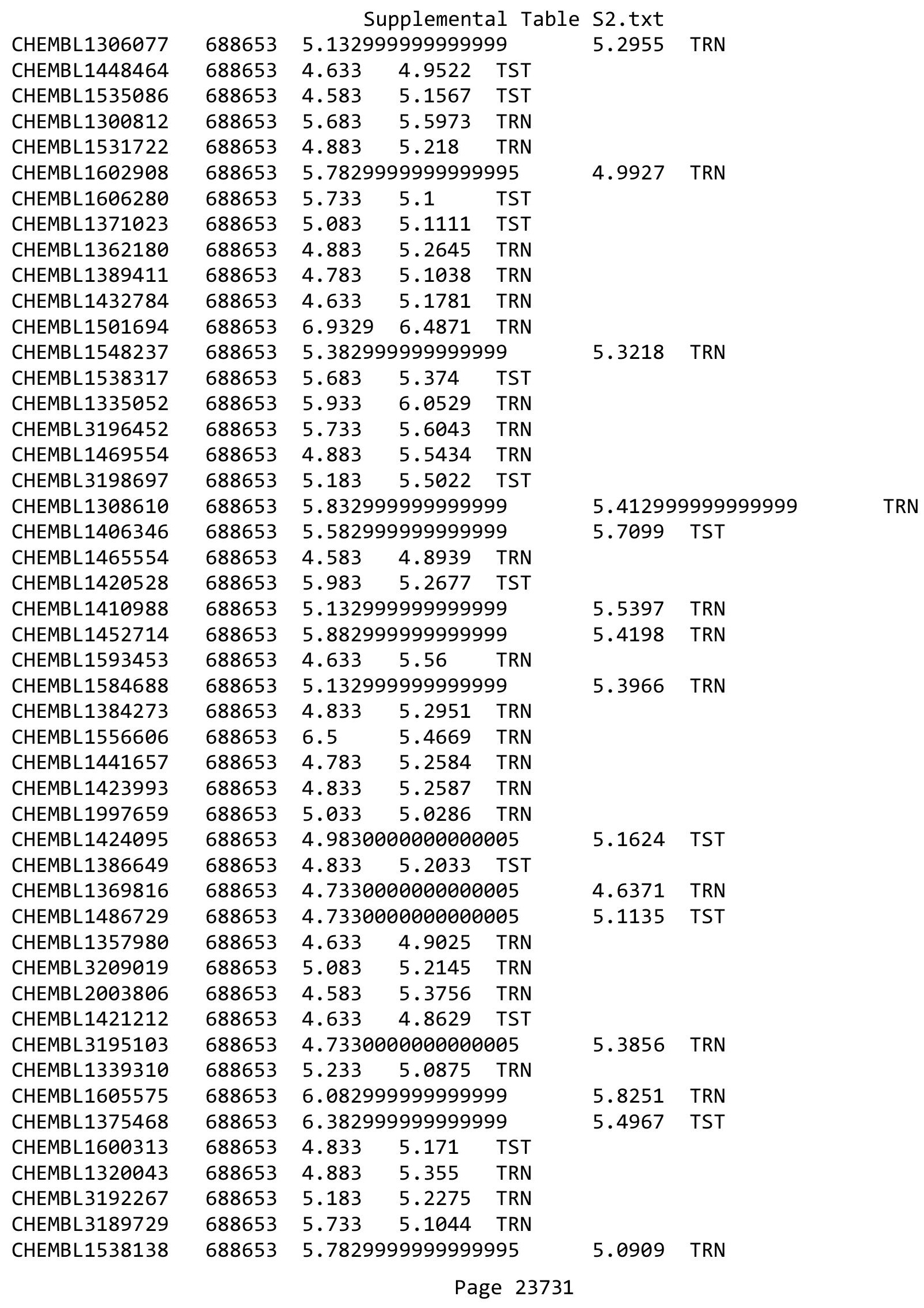




\begin{tabular}{|c|c|c|c|c|c|c|}
\hline \multirow[b]{2}{*}{ CHEMBL1414603 } & \multirow[b]{2}{*}{688653} & \multicolumn{5}{|c|}{ Supplemental Table S2.txt } \\
\hline & & 4.633 & 5.0137 & TRN & & \\
\hline CHEMBL1397872 & 688653 & 4.633 & 5.0882 & TRN & & \\
\hline CHEMBL1374367 & 688653 & 7.2328 & 6.0742 & TRN & & \\
\hline CHEMBL1361456 & 688653 & \multicolumn{3}{|c|}{5.382999999999999} & 5.3889 & TST \\
\hline CHEMBL1488081 & 688653 & 5.683 & \multicolumn{3}{|c|}{5.542999999999999} & TRN \\
\hline CHEMBL1368559 & 688653 & \multicolumn{3}{|c|}{4.9830000000000005} & 5.0734 & TRN \\
\hline CHEMBL1437508 & 688653 & \multicolumn{3}{|c|}{4.9830000000000005} & 5.3541 & TRN \\
\hline CHEMBL1500243 & 688653 & 4.933 & 5.1981 & TRN & & \\
\hline CHEMBL3198423 & 688653 & \multicolumn{3}{|c|}{5.132999999999999} & 5.0254 & TST \\
\hline CHEMBL3198174 & 688653 & 4.633 & 5.211 & TRN & & \\
\hline CHEMBL1529335 & 688653 & 5.433 & 4.7991 & TRN & & \\
\hline CHEMBL3194630 & 688653 & \multicolumn{3}{|c|}{5.132999999999999} & 5.6269 & TRN \\
\hline CHEMBL1568981 & 688653 & 5.8 & 5.4797 & TRN & & \\
\hline CHEMBL1334888 & 688653 & \multicolumn{3}{|c|}{5.132999999999999} & 5.0205 & TRN \\
\hline CHEMBL1570798 & 688653 & \multicolumn{3}{|c|}{5.2829999999999995} & 4.78 & TST \\
\hline CHEMBL3192729 & 688653 & 4.933 & 5.4549 & TRN & & \\
\hline CHEMBL1464734 & 688653 & 5.483 & 5.3418 & TRN & & \\
\hline CHEMBL1450510 & 688653 & \multicolumn{3}{|c|}{4.7330000000000005} & 5.3061 & TRN \\
\hline CHEMBL1375292 & 688653 & \multicolumn{3}{|c|}{5.2829999999999995} & 5.5289 & TRN \\
\hline CHEMBL1365960 & 688653 & 4.883 & 4.9949 & TRN & & \\
\hline CHEMBL1477760 & 688653 & 5.433 & 5.3103 & TST & & \\
\hline CHEMBL1422597 & 688653 & 5.183 & 5.4688 & TRN & & \\
\hline CHEMBL1613238 & 688653 & \multicolumn{3}{|c|}{6.082999999999999} & 5.9423 & TRN \\
\hline CHEMBL1328189 & 688653 & 4.583 & 5.3272 & TRN & & \\
\hline CHEMBL1361525 & 688653 & \multicolumn{3}{|c|}{6.0329999999999995} & 5.2941 & TRN \\
\hline CHEMBL1320643 & 688653 & 6.4829 & 5.5799 & TRN & & \\
\hline CHEMBL1390551 & 688653 & \multicolumn{3}{|c|}{6.5329999999999995} & 5.8673 & TRN \\
\hline CHEMBL1346677 & 688653 & 4.883 & 5.7223 & TRN & & \\
\hline CHEMBL1462764 & 688653 & 4.783 & 5.1914 & TST & & \\
\hline CHEMBL1555952 & 688653 & 5.933 & 5.3101 & TRN & & \\
\hline CHEMBL1435458 & 688653 & 5.483 & 5.0477 & TRN & & \\
\hline CHEMBL1967586 & 688653 & 5.683 & 5.3745 & TST & & \\
\hline CHEMBL1448343 & 688653 & 4.633 & 5.2319 & TST & & \\
\hline CHEMBL1321172 & 688653 & 4.783 & 5.1474 & TRN & & \\
\hline CHEMBL1387166 & 688653 & 4.933 & 5.0548 & TRN & & \\
\hline CHEMBL1410006 & 688653 & 7.1331 & 5.9005 & TRN & & \\
\hline CHEMBL1613710 & 688653 & 4.783 & 5.072 & TRN & & \\
\hline CHEMBL1588590 & 688653 & 4.783 & 5.2391 & TRN & & \\
\hline CHEMBL1438555 & 688653 & \multicolumn{3}{|c|}{5.132999999999999} & 5.7208 & TRN \\
\hline CHEMBL1529530 & 688653 & 6.0 & 5.4279 & TRN & & \\
\hline CHEMBL1416902 & 688653 & \multicolumn{3}{|c|}{5.132999999999999} & 5.317 & TRN \\
\hline CHEMBL1382089 & 688653 & 4.833 & 5.6687 & TRN & & \\
\hline CHEMBL1301513 & 688653 & 4.883 & 5.2375 & TST & & \\
\hline CHEMBL1455054 & 688653 & 4.783 & 5.2474 & TRN & & \\
\hline CHEMBL1488267 & 688653 & \multicolumn{3}{|c|}{5.832999999999999} & 5.4748 & TRN \\
\hline CHEMBL1590348 & 688653 & 4.833 & 5.1147 & TRN & & \\
\hline CHEMBL1559842 & 688653 & 4.783 & 5.3586 & TRN & & \\
\hline \multirow[t]{2}{*}{ CHEMBL3191626 } & 688653 & 5.083 & 4.9138 & TRN & & \\
\hline & & \multicolumn{5}{|c|}{ Page 23732} \\
\hline
\end{tabular}




\begin{tabular}{|c|c|c|c|c|c|c|c|}
\hline \multirow[b]{2}{*}{ CHEMBL1566120 } & \multicolumn{6}{|c|}{ 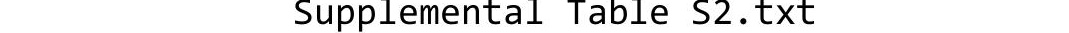 } & \\
\hline & 688653 & 4.883 & 5.4986 & TST & & & \\
\hline CHEMBL1449499 & 688653 & 4.9830 & 00000000 & 005 & 4.4921 & TRN & \\
\hline CHEMBL1439363 & 688653 & 5.3829 & 99999999 & 99 & 5.1813 & TRN & \\
\hline CHEMBL 3211161 & 688653 & 4.883 & 4.9019 & TRN & & & \\
\hline CHEMBL1602151 & 688653 & 5.5829 & 99999999 & 99 & 5.2837 & TRN & \\
\hline CHEMBL1318730 & 688653 & 5.1329 & 199999999 & 99 & 5.4911 & TRN & \\
\hline CHEMBL1455316 & 688653 & 5.8829 & 99999999 & 99 & 5.6641 & TRN & \\
\hline CHEMBL1468158 & 688653 & 5.2829 & 99999999 & 995 & 4.8255 & TST & \\
\hline CHEMBL1419093 & 688653 & 4.783 & 4.9335 & TST & & & \\
\hline CHEMBL1472058 & 688653 & 4.933 & 5.2929 & TRN & & & \\
\hline CHEMBL1390212 & 688653 & 4.783 & 5.2213 & TST & & & \\
\hline CHEMBL1364818 & 688653 & 5.033 & 5.3167 & TST & & & \\
\hline CHEMBL1373048 & 688653 & 5.083 & 5.269 & TST & & & \\
\hline CHEMBL3190842 & 688653 & 4.7330 & 00000000 & 005 & 5.2337 & TRN & \\
\hline CHEMBL1343742 & 688653 & 4.883 & 5.2403 & TRN & & & \\
\hline CHEMBL1623028 & 688653 & 6.1329 & 99999999 & & 5.7954 & TRN & \\
\hline CHEMBL1564250 & 688653 & 5.233 & 5.4628 & TST & & & \\
\hline CHEMBL 2369304 & 688653 & 5.7829 & 99999999 & 995 & 5.2668 & TRN & \\
\hline CHEMBL1453089 & 688653 & 4.833 & 5.1339 & TRN & & & \\
\hline CHEMBL1428091 & 688653 & 4.683 & 4.9865 & TRN & & & \\
\hline CHEMBL1555002 & 688653 & 5.183 & 5.6263 & TRN & & & \\
\hline CHEMBL1508045 & 688653 & 5.083 & 5.0299 & TRN & & & \\
\hline CHEMBL1513560 & 688653 & 5.483 & 5.1685 & TRN & & & \\
\hline CHEMBL1517879 & 688653 & 5.3329 & 99999999 & 99 & 5.2944 & TST & \\
\hline CHEMBL1434194 & 688653 & 4.7330 & 00000000 & 005 & 5.3285 & TRN & \\
\hline CHEMBL3196673 & 688653 & 4.9830 & 00000000 & 005 & 5.2596 & TRN & \\
\hline CHEMBL3210664 & 688653 & 4.783 & 5.2632 & TRN & & & \\
\hline CHEMBL1593418 & 688653 & 4.9830 & 00000000 & 005 & 4.8521 & TRN & \\
\hline CHEMBL1583118 & 688653 & 4.9830 & 00000000 & 005 & 5.4735 & TST & \\
\hline CHEMBL1309232 & 688653 & 5.3829 & 99999999 & & 5.4119 & TRN & \\
\hline CHEMBL1325892 & 688653 & 4.7330 & 100000000 & 005 & 5.6160 & 00000000005 & TRN \\
\hline CHEMBL1607872 & 688653 & 4.883 & 4.7615 & TST & & & \\
\hline CHEMBL1484888 & 688653 & 4.783 & 5.03100 & 00000 & & TRN & \\
\hline CHEMBL1503951 & 688653 & 4.833 & 4.9739 & TST & & & \\
\hline CHEMBL1483585 & 688653 & 5.183 & 5.34399 & 99999 & & TRN & \\
\hline CHEMBL1501273 & 688653 & 4.683 & 5.2082 & TST & & & \\
\hline CHEMBL1447047 & 688653 & 4.833 & 5.3164 & TST & & & \\
\hline CHEMBL1562409 & 688653 & 4.7330 & 00000000 & 005 & 5.0588 & TST & \\
\hline CHEMBL1603839 & 688653 & 4.9830 & 00000000 & 005 & 5.2267 & TRN & \\
\hline CHEMBL1439383 & 688653 & 4.9830 & 00000000 & 005 & 5.0375 & TRN & \\
\hline CHEMBL1405969 & 688653 & 6.45 & 5.401 & TST & & & \\
\hline CHEMBL1417719 & 688653 & 6.5829 & 99999999 & 99 & 5.5584 & TRN & \\
\hline CHEMBL1553420 & 688653 & 4.933 & 5.3064 & TRN & & & \\
\hline CHEMBL3211361 & 688653 & 5.433 & 5.318 & TST & & & \\
\hline CHEMBL3196241 & 688653 & 5.8829 & 99999999 & & 5.2954 & TST & \\
\hline CHEMBL3211251 & 688653 & 4.7330 & 00000000 & 005 & 5.4786 & TRN & \\
\hline CHEMBL1494158 & 688653 & 4.683 & 5.345 & TST & & & \\
\hline CHEMBL1415148 & 688653 & 5.6329 & 99999999 & 99 & 5.2326 & TST & \\
\hline
\end{tabular}




\begin{tabular}{|c|c|c|c|c|c|c|}
\hline \multirow[b]{2}{*}{ CHEMBL1468783 } & & \multicolumn{5}{|c|}{ Demion } \\
\hline & 688653 & 6.4829 & 5.5168 & TRN & & \\
\hline CHEMBL1606513 & 688653 & \multicolumn{3}{|c|}{6.2829999999999995} & \multirow{2}{*}{5.7471} & \multirow[t]{2}{*}{ TRN } \\
\hline CHEMBL1369469 & 688653 & 4.883 & 4.8741 & TRN & & \\
\hline CHEMBL1370454 & 688653 & 5.433 & 5.9448 & TRN & & \\
\hline CHEMBL1326938 & 688653 & \multicolumn{3}{|c|}{5.2829999999999995} & 5.0587 & \\
\hline CHEMBL1448946 & 688653 & 4.633 & 4.8285 & TRN & & \\
\hline CHEMBL1333995 & 688653 & 7.2328 & 5.8863 & TRN & & \\
\hline CHEMBL1302598 & 688653 & \multicolumn{3}{|c|}{5.882999999999999} & 5.4637 & ונכו \\
\hline CHEMBL1548093 & 688653 & \multicolumn{3}{|c|}{6.5329999999999995} & 6.0456 & \\
\hline CHEMBL1373729 & 688653 & 4.933 & 4.9122 & TRN & & \\
\hline CHEMBL1581682 & 688653 & 4.633 & 5.3075 & TRN & & \\
\hline CHEMBL1332088 & 688653 & 4.883 & 4.8766 & TRN & & \\
\hline CHEMBL1522504 & 688653 & 4.933 & 5.5698 & TRN & & \\
\hline CHEMBL1524385 & 688653 & 4.933 & 5.5477 & TRN & & \\
\hline CHEMBL1360261 & 688653 & \multicolumn{3}{|c|}{4.7330000000000005} & 6 & \\
\hline CHEMBL1093507 & 688653 & 5.483 & 5.1965 & TRN & & \\
\hline CHEMBL 3189237 & 688653 & 4.683 & 4.961 & TRN & & \\
\hline CHEMBL 3199386 & 688653 & 4.933 & 5.0995 & TST & & \\
\hline CHEMBL 1478578 & 688653 & 4.883 & 5.1218 & TRN & & \\
\hline CHEMBL1406674 & 688653 & 5.083 & \multicolumn{3}{|c|}{5.337999999999999} & \\
\hline CHEMBL1520048 & 688653 & 5.033 & \multicolumn{3}{|c|}{5.071000000000001} & \\
\hline CHEMBL1580492 & 688653 & 4.783 & 5.1118 & TRN & & \\
\hline CHEMBL1593226 & 688653 & 4.633 & 5.0925 & TRN & & \\
\hline CHEMBL1442049 & 688653 & 4.783 & 5.1666 & TRN & & \\
\hline CHEMBL1364512 & 688653 & \multicolumn{3}{|c|}{5.5329999999999995} & 5.2274 & \\
\hline CHEMBL599100 & 688653 & \multicolumn{3}{|c|}{5.7829999999999995} & 5.7217 & \\
\hline CHEMBL1585273 & 688653 & \multicolumn{3}{|c|}{6.082999999999999} & 5.6882 & \\
\hline CHEMBL1567888 & 688653 & 4.783 & 4.7866 & TST & & \\
\hline CHEMBL1583570 & 688653 & 4.783 & 5.0182 & TRN & & \\
\hline CHEMBL13 & 688653 & 5.083 & 5.037 & TRN & & \\
\hline CHEMBL1311867 & 688653 & 4.883 & 5.1591 & TRN & & \\
\hline CHEMBL1487593 & 688653 & 4.583 & 4.7161 & TRN & & \\
\hline CHEMBL104728 & 688653 & \multicolumn{3}{|c|}{5.5329999999999995} & 5.5439 & \\
\hline CHEMBL1567301 & 688653 & 4.783 & 5.0167 & TST & & \\
\hline CHEMBL 31 & 688653 & \multicolumn{3}{|c|}{4.7330000000000005} & 5.2473 & \\
\hline CHEMBL1302493 & 688653 & \multicolumn{3}{|c|}{5.332999999999999} & 4.7891 & \\
\hline CHEMBL1315645 & 688653 & \multicolumn{3}{|c|}{5.2829999999999995} & 5.082 & \\
\hline CHEMBL1444098 & 688653 & 4.683 & 5.3517 & TST & & \\
\hline CHEMBL 3214548 & 688653 & 4.783 & 5.553 & TRN & & \\
\hline CHEMBL1605209 & 688653 & 4.933 & 5.5355 & TRN & & \\
\hline CHEMBL1994877 & 688653 & \multicolumn{3}{|c|}{5.5329999999999995} & 4.923 & \\
\hline CHEMBL1594679 & 688653 & \multicolumn{3}{|c|}{4.7330000000000005} & 5.2292 & \\
\hline CHEMBL1368699 & 688653 & 4.883 & 5.17 & TST & & \\
\hline CHEMBL1502431 & 688653 & \multicolumn{3}{|c|}{4.7330000000000005} & 5.0753 & \\
\hline CHEMBL 3213465 & 688653 & 4.933 & 5.0436 & TRN & & \\
\hline CHEMBL 3191597 & 688653 & 5.433 & 5.2033 & TRN & & \\
\hline CHEMBL1540211 & 688653 & 4.73300 & $\partial 0000000$ & 005 & 5.0399 & \\
\hline CHEMBL1450725 & 688653 & 5.433 & 5.4774 & TRN & & \\
\hline
\end{tabular}




\begin{tabular}{|c|c|c|c|c|c|c|}
\hline \multicolumn{7}{|c|}{ pplemental Ta } \\
\hline CHEMBL3198025 & 688653 & 5.933 & 5.3303 & TST & & \\
\hline CHEMBL1421466 & 688653 & 4.833 & 4.6063 & TRN & & \\
\hline CHEMBL1357215 & 688653 & 5.683 & 5.0256 & TRN & & \\
\hline CHEMBL1577737 & 688653 & 5.983 & 5.4739 & TRN & & \\
\hline CHEMBL1401381 & 688653 & \multicolumn{3}{|c|}{4.9830000000000005} & 5.0115 & $\mathrm{Tr}$ \\
\hline CHEMBL1380937 & 688653 & \multicolumn{3}{|c|}{5.5329999999999995} & 5.1594 & \\
\hline CHEMBL1325808 & 688653 & \multicolumn{3}{|c|}{6.2829999999999995} & 5.318 & \\
\hline CHEMBL1332140 & 688653 & \multicolumn{3}{|c|}{5.832999999999999} & 5.8451 & \\
\hline CHEMBL 3190751 & 688653 & 6.233 & 5.5129 & TRN & & \\
\hline CHEMBL1539969 & 688653 & 5.233 & 5.1853 & TRN & & \\
\hline CHEMBL1348070 & 688653 & 5.983 & 5.6279 & TRN & & \\
\hline CHEMBL1333225 & 688653 & 5.683 & 5.6777 & TRN & & \\
\hline CHEMBL1427299 & 688653 & 5.183 & 5.4441 & TST & & \\
\hline CHEMBL 3189841 & 688653 & \multicolumn{3}{|c|}{5.7829999999999995} & 5.4826 & \\
\hline CHEMBL3189652 & 688653 & \multicolumn{3}{|c|}{4.9830000000000005} & & \\
\hline CHEMBL1476988 & 688653 & 4.783 & 5.2201 & TRN & & \\
\hline CHEMBL1557380 & 688653 & 4.933 & 5.0611 & TRN & & \\
\hline CHEMBL1312353 & 688653 & \multicolumn{3}{|c|}{4.7330000000000005} & 5.1991 & \\
\hline CHEMBL1405661 & 688653 & \multicolumn{3}{|c|}{5.2829999999999995} & 5.1884 & \\
\hline CHEMBL51 & 688653 & \multicolumn{3}{|c|}{5.132999999999999} & 6.1369 & \\
\hline CHEMBL1336041 & 688653 & 4.783 & 5.4864 & TRN & & \\
\hline CHEMBL1372203 & 688653 & 5.183 & 5.303 & TRN & & \\
\hline CHEMBL1431130 & 688653 & 5.733 & 5.3821 & TRN & & \\
\hline CHEMBL144 & 688 & 5.683 & 5.4094 & TRN & & \\
\hline CHEMBL1356030 & 688653 & 5.733 & 5.7211 & TRN & & \\
\hline CHEMBL1595663 & 688653 & \multicolumn{3}{|c|}{5.632999999999999} & 3676 & \\
\hline CHEMBL 3191375 & 688653 & \multicolumn{3}{|c|}{5.5329999999999995} & 5.1681 & \\
\hline CHEMBL1420728 & 688653 & \multicolumn{3}{|c|}{4.7330000000000005} & 5.0109 & \\
\hline CHEMBL1613709 & 688653 & 5.033 & 5.1735 & TRN & & \\
\hline CHEMBL 3191134 & 688653 & \multicolumn{3}{|c|}{5.132999999999999} & 5.4098 & \\
\hline CHEMBL1376908 & 688653 & \multicolumn{3}{|c|}{4.7330000000000005} & & $\mathrm{~T}$ \\
\hline CHEMBL 3190177 & 688653 & 5.083 & 4.9695 & TRN & & \\
\hline CHEMBL1403044 & 688653 & 4.933 & 5.5366 & TRN & & \\
\hline CHEMBL1543276 & 688653 & 6.8831 & \multicolumn{3}{|c|}{5.872000000000001} & I KIV \\
\hline CHEMBL1608407 & 688653 & \multicolumn{3}{|c|}{5.7829999999999995} & 5.1572 & \\
\hline CHEMBL1305478 & 688653 & 4.633 & 5.347 & TST & & \\
\hline CHEMBL 3210804 & 688653 & \multicolumn{3}{|c|}{5.2829999999999995} & 5.1909 & \\
\hline CHEMBL1319802 & 688653 & 4.883 & 5.334 & TST & & \\
\hline CHEMBL1436728 & 688653 & \multirow{2}{*}{\multicolumn{3}{|c|}{$\begin{array}{lr}5.733 & 5.5139 \\
5.132999999999999\end{array}$}} & & \\
\hline CHEMBL1525597 & 688653 & & & & 5.1806 & 11 \\
\hline CHEMBL 3208740 & 688653 & \multicolumn{3}{|c|}{4.9334 .7655 TRN } & & \\
\hline CHEMBL1426852 & 688653 & 6.4829 & 5.2165 & TRN & & \\
\hline CHEMBL1302460 & 688653 & \multicolumn{3}{|c|}{4.9830000000000005} & 5.6472 & - \\
\hline CHEMBL1476023 & 688653 & 5.233 & 5.0889 & TRN & & \\
\hline CHEMBL1328293 & 688653 & 4.783 & 4.9692 & TST & & \\
\hline CHEMBL 2002262 & 688653 & 4.583 & 5.4084 & TST & & \\
\hline CHEMBL1560184 & 688653 & 4.833 & 4.8418 & TST & & \\
\hline CHEMBL3208254 & 688653 & 4.9830 & 2000000e & & 5.326 & \\
\hline
\end{tabular}




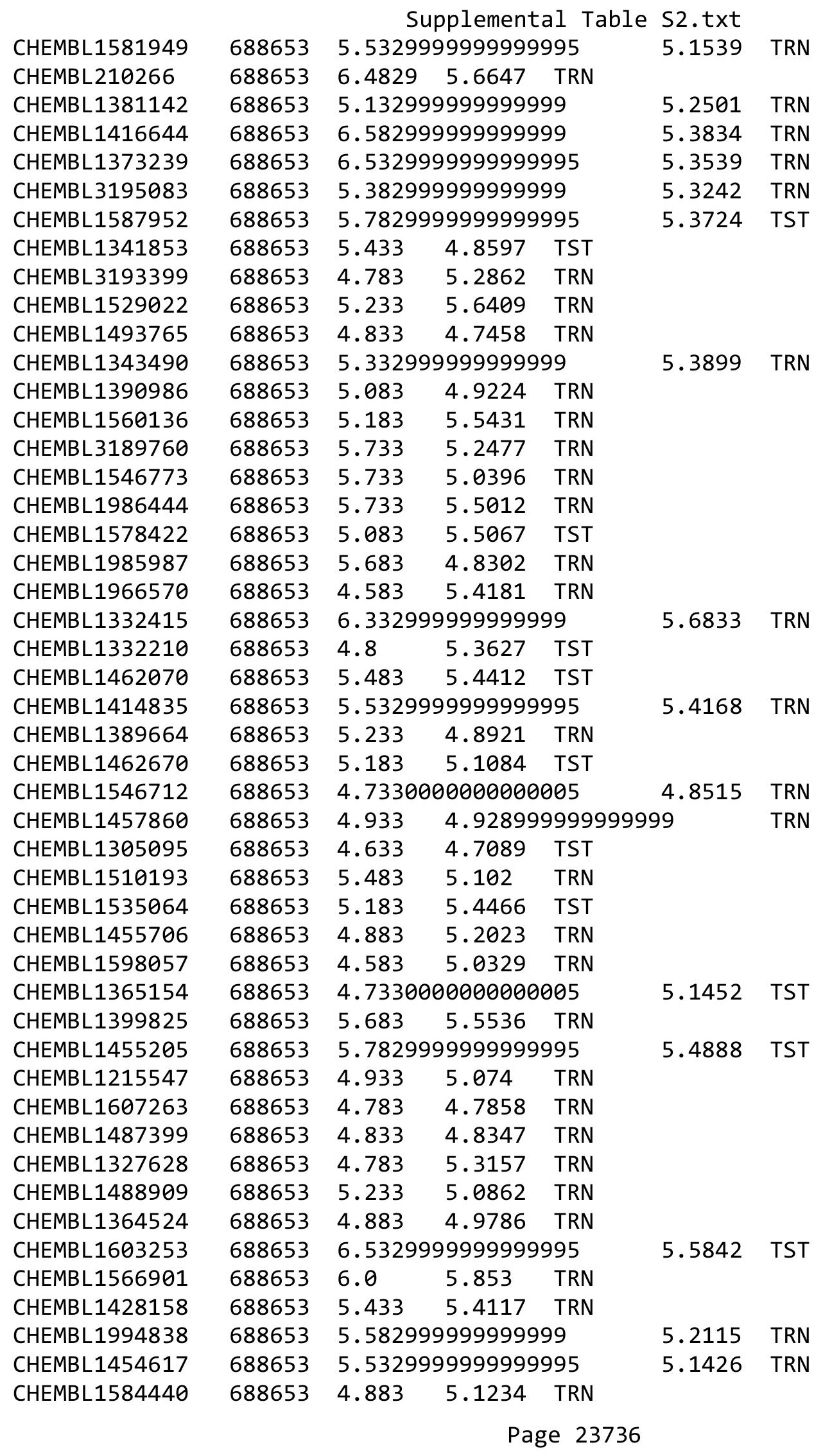




\begin{tabular}{|c|c|c|c|c|c|c|}
\hline \multirow[b]{2}{*}{ CHEMBL1355310 } & & \multicolumn{5}{|c|}{ Supplemental Table S2.txt } \\
\hline & 688653 & 4.933 & 5.3027 & TRN & & \\
\hline CHEMBL1302832 & 688653 & 4.633 & 5.5151 & TRN & & \\
\hline CHEMBL3189716 & 688653 & 4.583 & 5.0584 & TRN & & \\
\hline CHEMBL 1422450 & 688653 & 5.433 & 5.2854 & TRN & & \\
\hline CHEMBL1516364 & 688653 & 4.883 & 5.1711 & TRN & & \\
\hline CHEMBL1425932 & 688653 & 5.483 & 5.3978 & TRN & & \\
\hline CHEMBL1490176 & 688653 & 5.183 & 4.9567 & TRN & & \\
\hline CHEMBL1311341 & 688653 & 5.033 & 5.1148 & TRN & & \\
\hline CHEMBL1559775 & 688653 & \multicolumn{3}{|c|}{4.9830000000000005} & 4.9006 & II \\
\hline CHEMBL1410494 & 688653 & 4.633 & 5.4614 & TRN & & \\
\hline CHEMBL1496907 & 688653 & 4.783 & 5.0203 & TRN & & \\
\hline CHEMBL 2001024 & 688653 & \multicolumn{3}{|c|}{5.2829999999999995} & 5.1422 & $\mathrm{TS}$ \\
\hline CHEMBL1432894 & 688653 & 4.783 & 5.0541 & TST & & \\
\hline CHEMBL1575201 & 688653 & 5.183 & \multicolumn{3}{|c|}{5.617999999999999} & \\
\hline CHEMBL1428935 & 688653 & \multicolumn{3}{|c|}{5.332999999999999} & 5.3203 & \\
\hline CHEMBL1571982 & 688653 & 4.583 & 5.0322 & TRN & & \\
\hline CHEMBL3208066 & 688653 & \multicolumn{3}{|c|}{5.382999999999999} & 5.2385 & 11 \\
\hline CHEMBL1452933 & 688653 & 5.483 & 5.9013 & TRN & & \\
\hline CHEMBL1419035 & 688653 & 5.983 & 5.6166 & TRN & & \\
\hline CHEMBL1397296 & 688653 & \multicolumn{3}{|c|}{4.9830000000000005} & 5.3877 & \\
\hline CHEMBL1609518 & 688653 & \multicolumn{3}{|c|}{5.7829999999999995} & 5.558 & \\
\hline CHEMBL1429204 & 688653 & \multicolumn{3}{|c|}{4.7330000000000005} & 5.3037 & \\
\hline CHEMBL1321310 & 688653 & \multicolumn{3}{|c|}{6.382999999999999} & 5.7175 & TRN \\
\hline CHEMBL1550895 & 688653 & 6.433 & 6.1793 & TRN & & \\
\hline CHEMBL1436423 & 688653 & 4.633 & 5.2324 & TRN & & \\
\hline CHEMBL1608341 & 688653 & 5.083 & 4.8052 & TST & & \\
\hline CHEMBL1363834 & 688653 & 5.933 & 5.2628 & TRN & & \\
\hline CHEMBL1398908 & 688653 & 4.833 & 4.9727 & TRN & & \\
\hline CHEMBL1427257 & 688653 & \multicolumn{3}{|c|}{4.7330000000000005} & 4.952 & \\
\hline CHEMBL 1474590 & 688653 & 4.633 & 4.8095 & TRN & & \\
\hline CHEMBL1533461 & 688653 & 5.033 & 5.0451 & TRN & & \\
\hline CHEMBL1423735 & 688653 & 4.783 & 5.0989 & TRN & & \\
\hline CHEMBL1453476 & 688653 & 5.483 & 5.4644 & TRN & & \\
\hline CHEMBL1592422 & 688653 & 5.733 & 5.7848 & TRN & & \\
\hline CHEMBL1359587 & 688653 & \multicolumn{3}{|c|}{5.382999999999999} & 5.6967 & $1 \mathrm{n}$ \\
\hline CHEMBL1562638 & 688653 & 5.083 & 5.4441 & TRN & & \\
\hline CHEMBL1329829 & 688653 & & & TRN & & \\
\hline CHEMBL1577750 & 688653 & \multicolumn{3}{|c|}{4.7330000000000005} & 4.8164 & $\mathrm{TR}$ \\
\hline CHEMBL1572095 & 688653 & 4.783 & 5.3326 & TST & & \\
\hline CHEMBL1341981 & 688653 & & 5.0531 & TRN & & \\
\hline CHEMBL1499773 & 688653 & 4.783 & 5.1274 & TRN & & \\
\hline CHEMBL1329962 & 688653 & 4.633 & 5.157 & TST & & \\
\hline CHEMBL1469756 & 688653 & 4.883 & 5.015 & TRN & & \\
\hline CHEMBL68613 & 688653 & 5.083 & 5.6696 & TRN & & \\
\hline CHEMBL1546509 & 688653 & 5.033 & 5.0773 & TRN & & \\
\hline CHEMBL 3197234 & 688653 & \multicolumn{3}{|c|}{6.2829999999999995} & 5.9166 & TRN \\
\hline CHEMBL1508938 & 688653 & 5.483 & 5.3756 & TRN & & \\
\hline CHEMBL1316013 & 688653 & 6.5329 & 99999999 & 95 & 5.3677 & \\
\hline
\end{tabular}




\begin{tabular}{|c|c|c|c|c|c|c|}
\hline \multirow[b]{2}{*}{ CHEMBL1504131 } & \multirow[b]{2}{*}{688653} & \multicolumn{5}{|c|}{ Supplemental Table S2.txt } \\
\hline & & 5.733 & 5.1266 & TST & & \\
\hline CHEMBL1343826 & 688653 & 4.783 & 4.7935 & TST & & \\
\hline CHEMBL1303391 & 688653 & 5.083 & 5.1634 & TRN & & \\
\hline CHEMBL1309328 & 688653 & \multicolumn{3}{|c|}{4.7330000000000005} & 5.1191 & TST \\
\hline CHEMBL 1448774 & 688653 & 7.0329 & 5.8557 & TRN & & \\
\hline CHEMBL1486003 & 688653 & \multicolumn{3}{|c|}{5.132999999999999} & 5.2022 & TRN \\
\hline CHEMBL1356586 & 688653 & 4.633 & 4.7978 & TRN & & \\
\hline CHEMBL1449466 & 688653 & \multicolumn{3}{|c|}{5.5329999999999995} & 5.2584 & TRN \\
\hline CHEMBL1447542 & 688653 & 5.05 & 5.3715 & TRN & & \\
\hline CHEMBL1465153 & 688653 & \multicolumn{3}{|c|}{5.582999999999999} & 5.4591 & TRN \\
\hline CHEMBL1379985 & 688653 & 4.833 & 5.2611 & TST & & \\
\hline CHEMBL1377341 & 688653 & \multicolumn{3}{|c|}{6.332999999999999} & 5.0134 & TRN \\
\hline CHEMBL3199355 & 688653 & \multicolumn{3}{|c|}{6.132999999999999} & 5.7606 & TRN \\
\hline CHEMBL1312743 & 688653 & 6.433 & 6.1121 & TRN & & \\
\hline CHEMBL1501864 & 688653 & \multicolumn{3}{|c|}{5.2829999999999995} & 5.2515 & TST \\
\hline CHEMBL1426196 & 688653 & 4.783 & 4.7644 & TRN & & \\
\hline CHEMBL1384228 & 688653 & \multicolumn{3}{|c|}{6.332999999999999} & 5.5869 & TST \\
\hline CHEMBL3194218 & 688653 & \multicolumn{3}{|c|}{4.9830000000000005} & 5.2734 & TRN \\
\hline CHEMBL1317532 & 688653 & 5.083 & 5.0975 & TRN & & \\
\hline CHEMBL1970453 & 688653 & 4.883 & 5.2236 & TRN & & \\
\hline CHEMBL1445871 & 688653 & 6.4829 & 6.0329 & TRN & & \\
\hline CHEMBL1320096 & 688653 & 4.833 & 5.2829 & TST & & \\
\hline CHEMBL1520374 & 688653 & 5.933 & 5.4571 & TRN & & \\
\hline CHEMBL1364988 & 688653 & 5.683 & 5.6744 & TRN & & \\
\hline CHEMBL1454778 & 688653 & 4.833 & 4.9633 & TRN & & \\
\hline CHEMBL 2003564 & 688653 & \multicolumn{3}{|c|}{6.832999999999999} & 6.0393 & TRN \\
\hline CHEMBL1427617 & 688653 & 5.733 & 5.3068 & TST & & \\
\hline CHEMBL1439717 & 688653 & \multicolumn{3}{|c|}{5.832999999999999} & 5.4567 & TRN \\
\hline CHEMBL1578232 & 688653 & 6.4829 & 5.6313 & TRN & & \\
\hline CHEMBL1587229 & 688653 & \multicolumn{3}{|c|}{5.132999999999999} & 4.8675 & TST \\
\hline CHEMBL1495706 & 688653 & \multicolumn{3}{|c|}{5.7829999999999995} & 5.0563 & TRN \\
\hline CHEMBL1564212 & 688653 & 5.683 & 5.3142 & TRN & & \\
\hline CHEMBL1460200 & 688653 & \multicolumn{3}{|c|}{5.2829999999999995} & 4.9976 & TRN \\
\hline CHEMBL399249 & 688653 & 4.783 & 4.7853 & TRN & & \\
\hline CHEMBL1606511 & 688653 & 4.633 & 5.2857 & TST & & \\
\hline CHEMBL1405458 & 688653 & 5.233 & 5.4371 & TRN & & \\
\hline CHEMBL1376845 & 688653 & \multicolumn{3}{|c|}{5.5329999999999995} & 5.3518 & TRN \\
\hline CHEMBL1388824 & 688653 & \multicolumn{3}{|c|}{4.9830000000000005} & 5.2447 & TST \\
\hline CHEMBL1501135 & 688653 & 4.583 & 5.1613 & TST & & \\
\hline CHEMBL1419190 & 688653 & 5.033 & 5.2624 & TST & & \\
\hline CHEMBL1317989 & 688653 & 4.633 & 5.3262 & TRN & & \\
\hline CHEMBL1519809 & 688653 & 5.433 & 5.1246 & TRN & & \\
\hline CHEMBL1522008 & 688653 & 5.233 & 5.2649 & TRN & & \\
\hline CHEMBL1420568 & 688653 & \multicolumn{3}{|c|}{6.082999999999999} & 5.2024 & TST \\
\hline CHEMBL3192260 & 688653 & 5.233 & 5.1816 & TRN & & \\
\hline CHEMBL1612555 & 688653 & 5.183 & 5.2076 & TST & & \\
\hline CHEMBL1605193 & 688653 & 5.733 & 5.8373 & TRN & & \\
\hline CHEMBL1612288 & 688653 & 4.833 & 5.2937 & TRN & & \\
\hline
\end{tabular}




\begin{tabular}{|c|c|c|c|c|c|c|}
\hline CHEMBL1552464 & 688653 & 4.633 & 4.7288 & TRN & & \\
\hline CHEMBL1492524 & 688653 & \multicolumn{3}{|c|}{6.7829999999999995} & 5.9186 & $\mathrm{TP}$ \\
\hline CHEMBL1585720 & 688653 & \multicolumn{3}{|c|}{6.582999999999999} & 5.5748 & \\
\hline CHEMBL1484137 & 688653 & 4.783 & 5.2126 & TRN & & \\
\hline CHEMBL1556733 & 588653 & \multicolumn{3}{|c|}{5.632999999999999} & 5.3 & \\
\hline CHEMBL1367503 & 588653 & 4.833 & 5.9713 & TRN & & \\
\hline CHEMBL1383401 & 588653 & 5.733 & 6.1209 & TRN & & \\
\hline CHEMBL1337594 & 688653 & \multicolumn{3}{|c|}{5.132999999999999} & 5.2836 & \\
\hline CHEMBL1358598 & 588653 & \multicolumn{3}{|c|}{5.132999999999999} & & \\
\hline CHEMBL1553793 & 688653 & 4.783 & 5.0209 & TRN & & \\
\hline CHEMBL1364050 & 688653 & 5.183 & 5.5225 & TST & & \\
\hline CHEMBL1311218 & 688653 & 4.833 & 4.9184 & TRN & & \\
\hline CHEMBL1532707 & 688653 & \multicolumn{3}{|c|}{6.0329999999999995} & 5.4346 & \\
\hline HEMBL1613274 & 688653 & 4.833 & 5.1279 & TRN & & \\
\hline HEMBL1341005 & 688653 & 4.883 & 5.1687 & TRN & & \\
\hline CHEMBL1327335 & 688653 & \multicolumn{3}{|c|}{5.132999999999999} & & \\
\hline CHEMBL1493206 & 688653 & \multicolumn{3}{|c|}{6.082999999999999} & & \\
\hline CHEMBL1586300 & 688653 & \multicolumn{3}{|c|}{4.9830000000000005} & 4 . & \\
\hline CHEMBL1369337 & 688653 & \multicolumn{3}{|c|}{4.7330000000000005} & 49 & \\
\hline CHEMBL1481030 & 688653 & 4.783 & 5.2015 & TST & & \\
\hline CHEMBL1337142 & 688653 & \multicolumn{3}{|c|}{4.7330000000000005} & & \\
\hline CHEMBL1407579 & 688653 & \multicolumn{3}{|c|}{5.582999999999999} & & \\
\hline CHEMBL1553829 & 688653 & \multicolumn{3}{|c|}{5.332999999999999} & & \\
\hline HEMBL 3211218 & 688653 & 5.683 & 5.2303 & TRN & & \\
\hline CHEMBL 3198058 & 688653 & \multirow{2}{*}{\multicolumn{3}{|c|}{$\begin{array}{lrr}5.483 & 5.3818 & \text { TRN } \\
5.2829999999999995\end{array}$}} & & \\
\hline CHEMBL1601249 & 688653 & & & & 5.1683 & \\
\hline CHEMBL1409400 & 688653 & 6.4829 & 5.6582 & TRN & & \\
\hline CHEMBL & 688653 & \multicolumn{3}{|c|}{5.132999999999999} & & \\
\hline CHEMBL1450561 & 688653 & \multicolumn{3}{|c|}{5.332999999999999} & & \\
\hline CHEMBL 3197982 & 688653 & 7.0329 & 5.8954 & TRN & & \\
\hline CHEMBL1376721 & 688653 & 4.933 & 4.9867 & TST & & \\
\hline CHEMBL & 688653 & \multicolumn{3}{|c|}{5.2829999999999995} & 392 & \\
\hline CHEMBL1390366 & 688653 & \multicolumn{3}{|c|}{5.2829999999999995} & 5.7826 & \\
\hline CHEMBL1444739 & 688653 & 4.783 & 4.9786 & TRN & & \\
\hline CHEMBL1391591 & 688653 & \multicolumn{3}{|c|}{5.132999999999999} & & \\
\hline CHEMBL1 & 688653 & \multicolumn{3}{|c|}{5.382999999999999} & & \\
\hline CHEMBL1415155 & 688653 & \multicolumn{3}{|c|}{5.7829999999999995} & 11 & \\
\hline CHEMBL 1411645 & 688653 & 5.033 & 5.064 & TRN & & \\
\hline CHEMBL1507644 & 688653 & 4.933 & 4.8717 & TRN & & \\
\hline CHEMBL1562664 & 688653 & 5.983 & 5.5788 & TRN & & \\
\hline CHEMBL1553965 & 688653 & 5.33299 & 999999999 & & 406 & \\
\hline CHEMBL1363889 & 688653 & 5.13299 & 999999999 & & 5.2908 & \\
\hline CHEMBL1565207 & 688653 & 4.783 & 5.1925 & TRN & & \\
\hline CHEMBL1609032 & 688653 & 4.73300 & 000000000 & 205 & & \\
\hline CHEMBL 1487947 & 688653 & 4.98300 & 000000000 & 205 & 4.8649 & \\
\hline CHEMBL1378699 & 688653 & 5.483 & 5.0979 & TRN & & \\
\hline CHEMBL1972519 & 688653 & 5.433 & 5.8596 & TRN & & \\
\hline CHEMBL1479973 & 688653 & 6.53299 & 999999999 & & 5.6609 & \\
\hline
\end{tabular}




\begin{tabular}{|c|c|c|c|c|c|c|}
\hline \multirow[b]{2}{*}{ CHEMBL1568612 } & \multirow[b]{2}{*}{688653} & \multicolumn{5}{|c|}{ Supplemental Table S2.txt } \\
\hline & & \multicolumn{3}{|c|}{$\begin{array}{lll}4.833 & 5.1377 & \text { TRN }\end{array}$} & & \\
\hline CHEMBL1461981 & 688653 & 5.983 & 5.7045 & \multicolumn{2}{|l|}{ TRN } & \\
\hline CHEMBL1471040 & 688653 & 6.433 & \multicolumn{3}{|c|}{5.742000000000001} & TRN \\
\hline CHEMBL1388497 & 688653 & \multicolumn{3}{|c|}{5.882999999999999} & 5.2964 & TRN \\
\hline CHEMBL1308936 & 688653 & 5.033 & 4.6414 & TST & & \\
\hline CHEMBL1496925 & 688653 & 5.683 & 5.2639 & TST & & \\
\hline CHEMBL1447151 & 688653 & 4.783 & 5.1076 & TST & & \\
\hline CHEMBL1421807 & 688653 & \multicolumn{3}{|c|}{5.5329999999999995} & 5.5999 & TRN \\
\hline CHEMBL1546000 & 688653 & 4.833 & 5.4054 & TRN & & \\
\hline CHEMBL1538422 & 688653 & \multicolumn{3}{|c|}{5.132999999999999} & 5.1117 & TRN \\
\hline CHEMBL1420181 & 688653 & \multicolumn{3}{|c|}{5.632999999999999} & 5.7508 & TRN \\
\hline CHEMBL1328147 & 688653 & \multicolumn{3}{|c|}{5.132999999999999} & 5.3328 & TRN \\
\hline CHEMBL1360654 & 688653 & 6.433 & 5.8115 & TRN & & \\
\hline CHEMBL1523331 & 688653 & 4.783 & 4.8535 & TRN & & \\
\hline CHEMBL1519164 & 688653 & 5.433 & 5.6274 & TRN & & \\
\hline CHEMBL1554002 & 688653 & 4.633 & 5.4921 & TRN & & \\
\hline CHEMBL1470295 & 688653 & 5.933 & 5.4357 & TRN & & \\
\hline CHEMBL1409275 & 688653 & 5.033 & \multicolumn{3}{|c|}{5.3389999999999995} & TRN \\
\hline CHEMBL1487360 & 688653 & \multicolumn{3}{|c|}{5.132999999999999} & 5.2167 & TRN \\
\hline CHEMBL1323278 & 688653 & \multicolumn{3}{|c|}{4.7330000000000005} & 4.9518 & TRN \\
\hline CHEMBL1603125 & 688653 & 5.183 & 5.1217 & TRN & & \\
\hline CHEMBL1484995 & 688653 & 8.7959 & 5.4288 & TST & & \\
\hline CHEMBL1531222 & 688653 & 5.233 & 5.7767 & TST & & \\
\hline CHEMBL1562946 & 688653 & 4.883 & 5.048 & TRN & & \\
\hline CHEMBL1547619 & 688653 & \multicolumn{3}{|c|}{5.2829999999999995} & 4.7117 & TRN \\
\hline CHEMBL1536874 & 688653 & 5.033 & 5.1325 & TRN & & \\
\hline CHEMBL1587385 & 688653 & 5.033 & 5.2445 & TRN & & \\
\hline CHEMBL1401696 & 688653 & 5.483 & 5.2506 & TST & & \\
\hline CHEMBL193747 & 688653 & 5.033 & 5.0895 & TRN & & \\
\hline CHEMBL1468514 & 688653 & 5.033 & 5.9351 & TST & & \\
\hline CHEMBL1461139 & 688653 & 4.833 & 5.2351 & TRN & & \\
\hline CHEMBL1517953 & 688653 & \multicolumn{3}{|c|}{5.132999999999999} & 5.067 & TRN \\
\hline CHEMBL3197126 & 688653 & \multicolumn{3}{|c|}{5.5329999999999995} & 5.3042 & TRN \\
\hline CHEMBL3193157 & 688653 & 4.933 & 5.2985 & TST & & \\
\hline CHEMBL1440751 & 688653 & 5.183 & 4.9588 & TRN & & \\
\hline CHEMBL1479601 & 688653 & 4.883 & 5.0943 & TST & & \\
\hline CHEMBL1489383 & 688653 & \multicolumn{3}{|c|}{5.332999999999999} & 5.0268 & TST \\
\hline CHEMBL1599839 & 688653 & 4.833 & 5.1237 & TRN & & \\
\hline CHEMBL1443368 & 688653 & \multirow{2}{*}{\multicolumn{3}{|c|}{$\begin{array}{ll}4.833 & 5.0721 \\
4.7330000000000005\end{array}$}} & & \\
\hline CHEMBL1394433 & 688653 & & & & 5.5124 & TRN \\
\hline CHEMBL1572707 & 688653 & 5.683 & 5.9577 & TRN & & \\
\hline CHEMBL1485323 & 688653 & \multirow{2}{*}{\multicolumn{3}{|c|}{$\begin{array}{ll}4.883 & 5.5684 \\
5.582999999999999\end{array}$}} & & \\
\hline CHEMBL1496583 & 688653 & & & & 5.5442 & TRN \\
\hline CHEMBL1450794 & 688653 & 4.883 & 5.2692 & TRN & & \\
\hline CHEMBL1429327 & 688653 & \multicolumn{3}{|c|}{5.132999999999999} & 5.4827 & TRN \\
\hline CHEMBL1439109 & 688653 & 4.633 & 4.8546 & TRN & & \\
\hline CHEMBL1340593 & 688653 & 4.783 & 5.4199 & TST & & \\
\hline CHEMBL138007 & 688653 & 5.483 & 5.24299 & 99999 & & TRN \\
\hline & & & & & & \\
\hline
\end{tabular}




\begin{tabular}{|c|c|c|c|c|c|c|}
\hline \multicolumn{7}{|c|}{ Supplemental Table S2.txt } \\
\hline CHEMBL1370787 & 688653 & 5.25 & 5.626 & TRN & & \\
\hline CHEMBL1388137 & 688653 & 5.033 & 4.8998 & TRN & & \\
\hline CHEMBL1518005 & 688653 & 6.983 & 5.5245 & TRN & & \\
\hline CHEMBL1426047 & 688653 & \multicolumn{3}{|c|}{5.2829999999999995} & 5.2523 & $\mathrm{Tr}$ \\
\hline CHEMBL1474024 & 688653 & 4.633 & \multicolumn{3}{|c|}{5.2139999999999995} & \\
\hline CHEMBL 3191593 & 688653 & 4.833 & 4.9611 & TST & & \\
\hline CHEMBL1457475 & 688653 & 5.433 & 5.2763 & TRN & & \\
\hline CHEMBL1371477 & 688653 & \multicolumn{3}{|c|}{5.132999999999999} & 5.0875 & \\
\hline CHEMBL1437881 & 688653 & 4.933 & 5.6023 & TRN & & \\
\hline CHEMBL 3193204 & 688653 & 4.633 & 5.0483 & TST & & \\
\hline CHEMBL1372641 & 688653 & 4.883 & 5.3392 & TRN & & \\
\hline CHEMBL1490066 & 688653 & 4.933 & 5.1725 & TRN & & \\
\hline CHEMBL1493743 & 688653 & 4.783 & 5.4417 & TRN & & \\
\hline CHEMBL1349337 & 688653 & \multicolumn{3}{|c|}{4.7330000000000005} & 5.1268 & \\
\hline CHEMBL1518386 & 688653 & 5.65 & \multicolumn{3}{|c|}{5.212000000000001} & \\
\hline CHEMBL1340513 & 688653 & \multicolumn{3}{|c|}{5.832999999999999} & 5.1622 & \\
\hline CHEMBL1405539 & 688653 & \multicolumn{3}{|c|}{4.7330000000000005} & & \\
\hline CHEMBL1319122 & 688653 & 4.683 & 5.556 & TRN & & \\
\hline CHEMBL1402668 & 688653 & 4.633 & 5.2433 & TRN & & \\
\hline CHEMBL1448646 & 688653 & \multicolumn{3}{|c|}{4.7330000000000005} & 5.0819 & \\
\hline CHEMBL1471361 & 688653 & 5.083 & 5.1454 & TST & & \\
\hline CHEMBL1560105 & 688653 & 4.833 & 5.3693 & TRN & & \\
\hline CHEMBL1537028 & 688653 & 4.783 & 5.2213 & TRN & & \\
\hline CHEMBL1428282 & 688653 & 4.833 & 5.4574 & TRN & & \\
\hline CHEMBL1598150 & 688653 & \multicolumn{3}{|c|}{5.7829999999999995} & 5.7837 & $\mathrm{Tr}$ \\
\hline CHEMBL1508121 & 688653 & \multicolumn{3}{|c|}{4.7330000000000005} & 5.1822 & TS \\
\hline CHEMBL 3195889 & 688653 & \multicolumn{3}{|c|}{6.332999999999999} & 5.4856 & \\
\hline CHEMBL1459374 & 688653 & 4.783 & 4.9 & TST & & \\
\hline CHEMBL1538458 & 688653 & 4.833 & 5.1194 & TRN & & \\
\hline CHEMBL1529810 & 688653 & 5.083 & 5.4173 & TRN & & \\
\hline CHEMBL1580910 & 688653 & \multicolumn{3}{|c|}{4.7330000000000005} & 4.7902 & \\
\hline CHEMBL1531243 & 688653 & 4.783 & 4.8204 & TST & & \\
\hline CHEMBL1538919 & 688653 & 4.833 & 4.9512 & TST & & \\
\hline CHEMBL1552954 & 688653 & 5.183 & 5.3104 & TST & & \\
\hline CHEMBL1413316 & 688653 & 5.483 & 5.3425 & TRN & & \\
\hline CHEMBL1387293 & 688653 & 4.583 & 5.0341 & TST & & \\
\hline CHEMBL14 & 688653 & 4.683 & 5.2403 & TRN & & \\
\hline CHEMBL1990174 & 688653 & \multicolumn{3}{|c|}{5.7829999999999995} & 6.2052 & $\mathrm{TH}$ \\
\hline CHEMBL1355470 & 688653 & 4.883 & 4.8007 & TST & & \\
\hline CHEMBL1388065 & 688653 & 4.833 & 5.2844 & TRN & & \\
\hline CHEMBL1497725 & 688653 & \multicolumn{3}{|c|}{5.832999999999999} & 5.0811 & TR \\
\hline CHEMBL1389324 & 688653 & \multicolumn{3}{|c|}{6.332999999999999} & 5.7698 & \\
\hline CHEMBL1443086 & 688653 & 6.0 & 5.35917 & TRN & & \\
\hline CHEMBL587849 & 688653 & 4.783 & 5.3692 & TST & & \\
\hline CHEMBL1346972 & 688653 & 4.883 & 4.8717 & TRN & & \\
\hline CHEMBL1556453 & 688653 & \multicolumn{3}{|c|}{ 5.382999999999999 } & 4.9361 & TST \\
\hline CHEMBL1486199 & 688653 & 4.883 & 5.33157 & TRN & & \\
\hline CHEMBL1342441 & 688653 & \multicolumn{3}{|c|}{5.832999999999999} & 5.3544 & \\
\hline
\end{tabular}




\begin{tabular}{|c|c|c|c|c|c|c|}
\hline \multirow[b]{2}{*}{ CHEMBL1598442 } & \multirow[b]{2}{*}{688653} & \multicolumn{5}{|c|}{ Supplemental Table S2.txt } \\
\hline & & 4.583 & 5.3456 & TRN & & \\
\hline CHEMBL1508637 & 688653 & \multicolumn{3}{|c|}{5.832999999999999} & 5.3989 & TRN \\
\hline CHEMBL1389695 & 688653 & 5.733 & 5.6304 & TRN & & \\
\hline CHEMBL1545424 & 688653 & \multicolumn{3}{|c|}{4.7330000000000005} & 5.8808 & TRN \\
\hline CHEMBL3213555 & 688653 & 4.633 & 5.1497 & TST & & \\
\hline CHEMBL1449758 & 688653 & \multicolumn{3}{|c|}{4.7330000000000005} & 5.2309 & TRN \\
\hline CHEMBL1599938 & 688653 & 4.783 & 5.2203 & TRN & & \\
\hline CHEMBL1491031 & 688653 & \multicolumn{3}{|c|}{5.582999999999999} & 5.4048 & TRN \\
\hline CHEMBL1385149 & 688653 & 4.833 & 5.3732 & TST & & \\
\hline CHEMBL1526257 & 688653 & \multicolumn{3}{|c|}{5.582999999999999} & 5.6133 & TRN \\
\hline CHEMBL1342525 & 688653 & 4.933 & 4.8162 & TRN & & \\
\hline CHEMBL1408968 & 688653 & 4.783 & 5.4778 & TRN & & \\
\hline CHEMBL1302420 & 688653 & 5.083 & 4.9567 & TRN & & \\
\hline CHEMBL1524395 & 688653 & 5.033 & 5.1292 & TST & & \\
\hline CHEMBL1256364 & 688653 & 5.683 & 5.683 & TRN & & \\
\hline CHEMBL1505324 & 688653 & 5.483 & 5.4425 & TRN & & \\
\hline CHEMBL47875 & 688653 & 6.433 & 6.0616 & TRN & & \\
\hline CHEMBL1546886 & 688653 & 5.183 & 5.1655 & TRN & & \\
\hline CHEMBL1433782 & 688653 & 5.733 & 5.2192 & TRN & & \\
\hline CHEMBL1462840 & 688653 & \multicolumn{3}{|c|}{5.832999999999999} & 5.3952 & TRN \\
\hline CHEMBL1340407 & 688653 & 5.933 & 5.5774 & TRN & & \\
\hline CHEMBL1333876 & 688653 & \multicolumn{3}{|c|}{6.332999999999999} & 5.6937 & TRN \\
\hline CHEMBL1487958 & 688653 & \multicolumn{3}{|c|}{6.132999999999999} & 5.1085 & TRN \\
\hline CHEMBL1406021 & 688653 & \multicolumn{3}{|c|}{5.7829999999999995} & 5.8469 & TRN \\
\hline CHEMBL1505044 & 688653 & 4.583 & 5.204 & TST & & \\
\hline CHEMBL1384370 & 688653 & \multicolumn{3}{|c|}{5.2829999999999995} & 5.3596 & TRN \\
\hline CHEMBL1473738 & 688653 & 4.833 & 4.9239 & TRN & & \\
\hline CHEMBL1534410 & 688653 & \multicolumn{3}{|c|}{5.132999999999999} & 5.0912 & TRN \\
\hline CHEMBL548540 & 688653 & 5.733 & 5.4085 & TRN & & \\
\hline CHEMBL3196345 & 688653 & 5.733 & 5.6056 & TRN & & \\
\hline CHEMBL1585372 & 688653 & \multicolumn{3}{|c|}{5.7829999999999995} & 5.5007 & TRN \\
\hline CHEMBL1606826 & 688653 & \multicolumn{3}{|c|}{4.7330000000000005} & 5.1381 & TRN \\
\hline CHEMBL1404912 & 688653 & \multicolumn{3}{|c|}{6.382999999999999} & 6.0468 & TST \\
\hline CHEMBL1599656 & 688653 & 5.083 & 4.771 & TST & & \\
\hline CHEMBL1477639 & 688653 & \multicolumn{3}{|c|}{5.632999999999999} & 5.3526 & TRN \\
\hline CHEMBL1496441 & 688653 & 5.983 & 5.9245 & TRN & & \\
\hline CHEMBL1441026 & 688653 & 6.4829 & 5.7744 & TRN & & \\
\hline CHEMBL1463659 & 688653 & 5.083 & 5.438 & TRN & & \\
\hline CHEMBL1495829 & 688653 & 5.483 & 5.8606 & TRN & & \\
\hline CHEMBL1402459 & 688653 & 5.183 & 5.5691 & TRN & & \\
\hline CHEMBL1584467 & 688653 & \multicolumn{3}{|c|}{5.582999999999999} & 5.3715 & TRN \\
\hline CHEMBL1308690 & 688653 & 5.433 & 4.6233 & TRN & & \\
\hline CHEMBL1449236 & 688653 & 4.833 & 4.9523 & TRN & & \\
\hline CHEMBL1445137 & 688653 & \multicolumn{3}{|c|}{5.132999999999999} & 5.3926 & TRN \\
\hline CHEMBL1547557 & 688653 & 5.983 & 5.3496 & TRN & & \\
\hline CHEMBL1354268 & 688653 & 6.183 & 5.3682 & TRN & & \\
\hline CHEMBL1409890 & 688653 & \multicolumn{3}{|c|}{6.082999999999999} & 5.2092 & TR \\
\hline CHEMBL1524212 & 688653 & 5.683 & 5.0948 & TRN & & \\
\hline & & & & & & \\
\hline
\end{tabular}




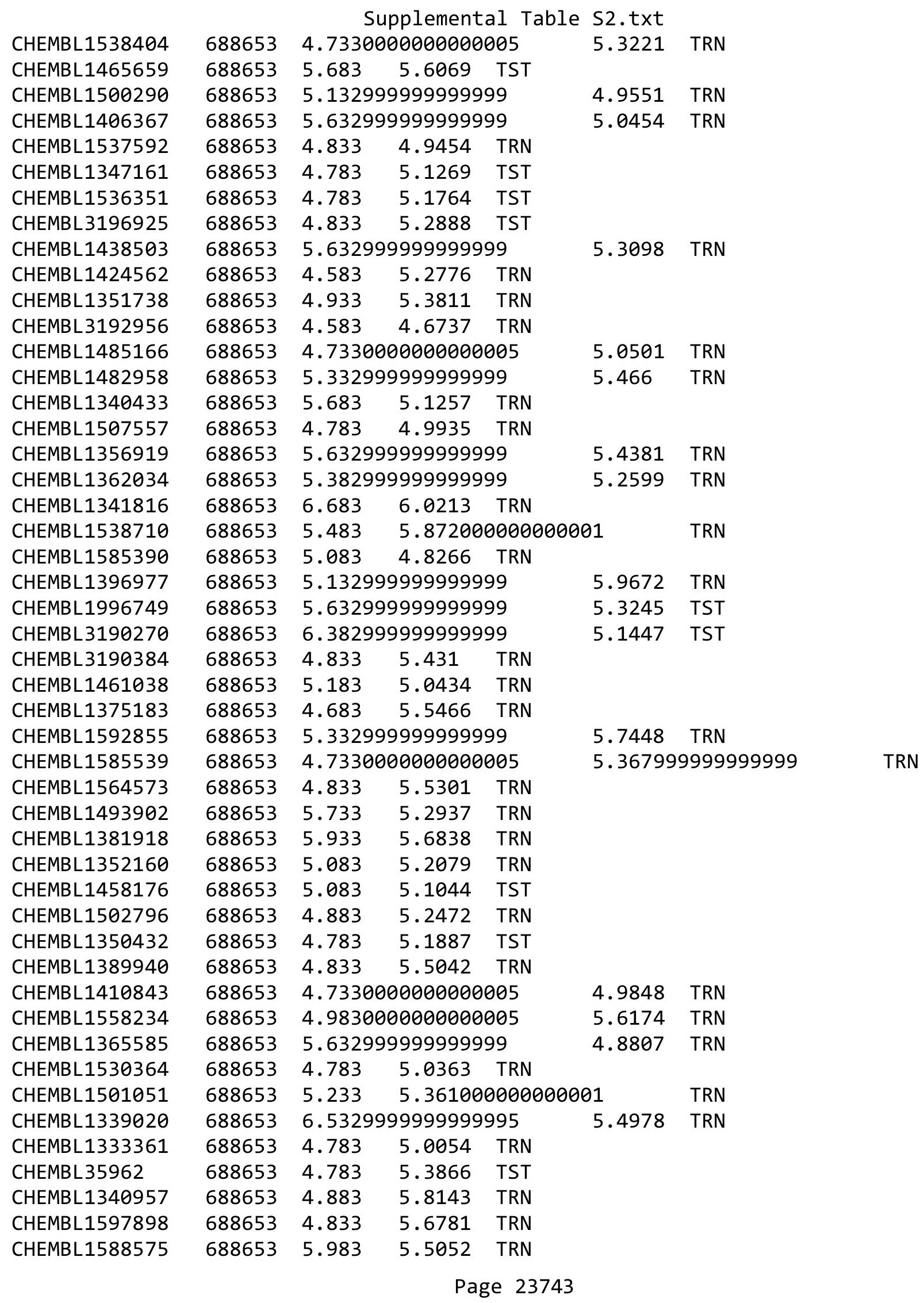




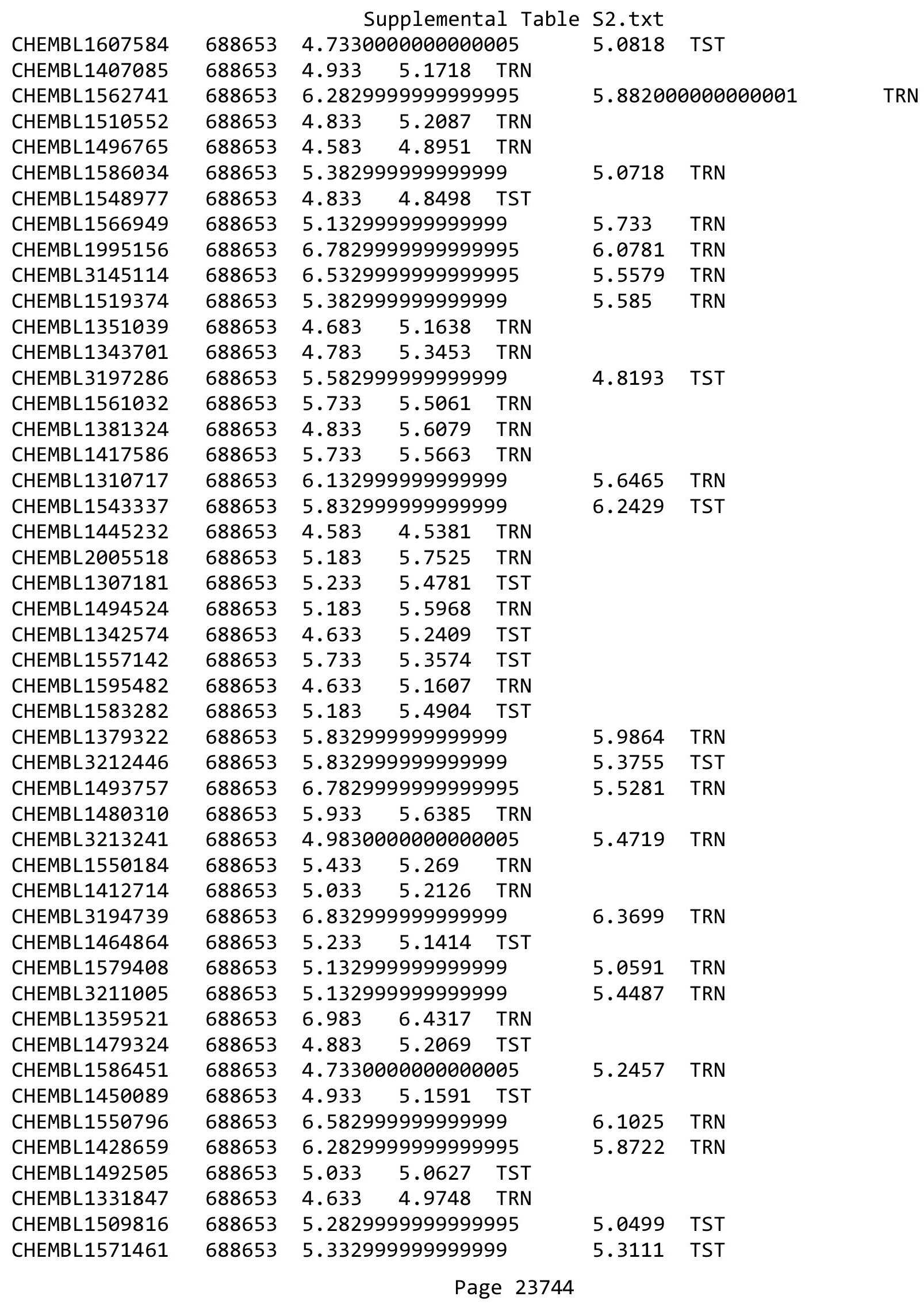




\begin{tabular}{|c|c|c|c|c|c|c|}
\hline \multirow[b]{2}{*}{ CHEMBL1568007 } & \multirow[b]{2}{*}{688653} & \multicolumn{5}{|c|}{ Supplemental Table S2.txt } \\
\hline & & \multirow{2}{*}{\multicolumn{3}{|c|}{$\begin{array}{lcc}4.633 & 4.9735 & \text { TRN } \\
4.7330000000000005\end{array}$}} & \multirow[b]{2}{*}{5.0009} & \multirow[b]{2}{*}{ TST } \\
\hline CHEMBL1559953 & 688653 & & & & & \\
\hline CHEMBL593254 & 688653 & 4.683 & 5.0251 & TRN & & \\
\hline CHEMBL1450586 & 688653 & \multicolumn{3}{|c|}{5.382999999999999} & 5.1108 & TST \\
\hline CHEMBL1305477 & 688653 & \multicolumn{3}{|c|}{5.7829999999999995} & 5.09 & TRN \\
\hline CHEMBL1392992 & 688653 & \multicolumn{3}{|c|}{5.832999999999999} & 5.6163 & TRN \\
\hline CHEMBL1364058 & 688653 & \multicolumn{3}{|c|}{5.332999999999999} & 5.6739 & TRN \\
\hline CHEMBL3189406 & 688653 & \multicolumn{3}{|c|}{5.5329999999999995} & 4.9638 & TRN \\
\hline CHEMBL1529460 & 688653 & \multicolumn{3}{|c|}{5.132999999999999} & 5.0439 & TST \\
\hline CHEMBL1609713 & 688653 & \multicolumn{3}{|c|}{4.7330000000000005} & 5.0361 & TRN \\
\hline CHEMBL 3210557 & 688653 & \multicolumn{3}{|c|}{4.7330000000000005} & 5.2896 & TRN \\
\hline CHEMBL1558672 & 688653 & 4.833 & 5.2487 & TRN & & \\
\hline CHEMBL1609987 & 688653 & 5.183 & 5.3646 & TRN & & \\
\hline CHEMBL1510989 & 688653 & 5.183 & 4.9855 & TRN & & \\
\hline CHEMBL1456618 & 688653 & 4.833 & 5.6885 & TRN & & \\
\hline CHEMBL603728 & 688653 & \multicolumn{3}{|c|}{5.132999999999999} & 5.7932 & TRN \\
\hline CHEMBL1349635 & 688653 & 5.733 & 6.1147 & TRN & & \\
\hline CHEMBL1365214 & 688653 & 4.783 & 5.3612 & TRN & & \\
\hline CHEMBL1480039 & 688653 & 5.433 & 5.3865 & TRN & & \\
\hline CHEMBL1431566 & 688653 & \multicolumn{3}{|c|}{5.882999999999999} & 6.0836 & TRN \\
\hline CHEMBL1316700 & 688653 & 4.833 & 5.4003 & TRN & & \\
\hline CHEMBL1544907 & 688653 & \multicolumn{3}{|c|}{6.082999999999999} & 5.7806 & TRN \\
\hline CHEMBL1581537 & 688653 & 4.633 & 5.1019 & TST & & \\
\hline CHEMBL1309467 & 688653 & \multicolumn{3}{|c|}{5.582999999999999} & 5.3826 & TST \\
\hline CHEMBL1466684 & 688653 & 4.883 & 5.606 & TST & & \\
\hline CHEMBL1343475 & 688653 & 4.783 & 5.2413 & TRN & & \\
\hline CHEMBL1531697 & 688653 & 5.933 & 5.1671 & TRN & & \\
\hline CHEMBL1452645 & 688653 & \multicolumn{3}{|c|}{6.5329999999999995} & 5.5772 & TRN \\
\hline CHEMBL1524709 & 688653 & \multicolumn{3}{|c|}{4.7330000000000005} & 5.2087 & TRN \\
\hline CHEMBL1439446 & 688653 & 4.833 & 5.5742 & TRN & & \\
\hline CHEMBL1449118 & 688653 & 5.683 & 5.4994 & TRN & & \\
\hline CHEMBL1460137 & 688653 & 4.883 & 5.3639 & TRN & & \\
\hline CHEMBL1973062 & 688653 & 4.883 & 5.0876 & TRN & & \\
\hline CHEMBL1350251 & 688653 & \multicolumn{3}{|c|}{6.0329999999999995} & 5.5359 & TST \\
\hline CHEMBL1560791 & 688653 & 5.483 & 5.294 & TRN & & \\
\hline CHEMBL1350919 & 688653 & & & TRN & & \\
\hline CHEMBL1445297 & 688653 & 6.8329 & 99999999 & & 5.5532 & TST \\
\hline CHEMBL1459360 & 688653 & 4.883 & 5.1304 & TST & & \\
\hline CHEMBL1528061 & 688653 & 4.783 & 5.0289 & TST & & \\
\hline CHEMBL1527990 & 688653 & 4.833 & 5.3104 & TST & & \\
\hline CHEMBL1389553 & 688653 & 4.783 & 5.38399 & 99999 & 995 & TRN \\
\hline CHEMBL1429512 & 688653 & 4.833 & 5.4251 & TRN & & \\
\hline CHEMBL3207633 & 688653 & 4.7330 & 00000000 & 005 & 5.2659 & TRN \\
\hline CHEMBL3193181 & 688653 & 5.2829 & 99999999 & 995 & 5.2183 & TST \\
\hline CHEMBL1419834 & 688653 & 4.783 & 5.4166 & TRN & & \\
\hline CHEMBL3209468 & 688653 & 5.1329 & 99999999 & & 5.23 & TST \\
\hline CHEMBL1301155 & 688653 & 5.7829 & 99999999 & 995 & 5.6705 & TRN \\
\hline CHEMBL1305752 & 688653 & 4.883 & 5.0596 & TRN & & \\
\hline
\end{tabular}




\begin{tabular}{|c|c|c|c|c|c|c|}
\hline \\
\hline CHEMBL1428811 & 688653 & 5.233 & 4.9049 & TRN & & \\
\hline CHEMBL1396563 & 688653 & 4.783 & 5.0306 & TRN & & \\
\hline CHEMBL1471515 & 688653 & 6.08299 & 99999999 & & 5.2979 & TRN \\
\hline CHEMBL1337527 & 688653 & 6.63299 & 99999999 & & 5.683 & TRN \\
\hline CHEMBL1407500 & 688653 & 4.783 & 5.2629 & TRN & & \\
\hline CHEMBL1414355 & 688653 & 5.13299 & 99999999 & & 5.4311 & TRN \\
\hline CHEMBL1552807 & 688653 & 5.58299 & 99999999 & & 5.8393 & TST \\
\hline CHEMBL476668 & 688653 & 5.38299 & 99999999 & & 5.1578 & TRN \\
\hline CHEMBL1467159 & 688653 & 4.98300 & 00000000 & 005 & 5.0789 & TRN \\
\hline CHEMBL1587832 & 688653 & 5.33299 & 99999999 & & 5.6521 & \\
\hline CHEMBL1568958 & 688653 & 6.4829 & 5.9845 & TRN & & \\
\hline CHEMBL1466707 & 688653 & 6.4829 & 5.2423 & TRN & & \\
\hline CHEMBL1470809 & 688653 & 4.633 & 5.3148 & TRN & & \\
\hline CHEMBL1489104 & 688653 & 5.63299 & 99999999 & & 5.0265 & \\
\hline CHEMBL1547370 & 688653 & 5.183 & 5.3336 & TRN & & \\
\hline CHEMBL1518747 & 688653 & 4.73300 & 00000000 & 005 & 5.2054 & $1 \mathrm{NIV}$ \\
\hline CHEMBL1442507 & 688653 & 5.83299 & 99999999 & & 5.6576 & \\
\hline CHEMBL1462938 & 688653 & 6.83299 & 99999999 & & 5.5397 & \\
\hline CHEMBL1544611 & 688653 & 5.233 & 5.1455 & TRN & & \\
\hline CHEMBL1314527 & 688653 & 4.683 & 4.8245 & TRN & & \\
\hline CHEMBL1354830 & 688653 & 4.583 & 5.0396 & TST & & \\
\hline CHEMBL1596978 & 688653 & 4.98300 & 00000000 & 005 & 5.0219 & $\mathrm{TP}$ \\
\hline CHEMBL 3213483 & 688653 & 5.78299 & 99999999 & 995 & 5.4939 & \\
\hline CHEMBL1304498 & 688653 & 4.683 & 5.0847 & TRN & & \\
\hline CHEMBL1598510 & 688653 & 6.63299 & 99999999 & & 5.8759 & $1 \pi$ \\
\hline CHEMBL1563309 & 688653 & 5.483 & 5.2936 & TRN & & \\
\hline CHEMBL1376944 & 688653 & 4.783 & 5.11100 & 000000 & & \\
\hline CHEMBL1440181 & 688653 & 5.683 & 5.1806 & TST & & \\
\hline CHEMBL1498973 & 688653 & 5.233 & 5.0091 & TRN & & \\
\hline CHEMBL1299745 & 688653 & 4.933 & 5.4068 & TRN & & \\
\hline CHEMBL1359442 & 688653 & 5.733 & 5.6486 & TRN & & \\
\hline CHEMBL1558421 & 688653 & 5.28299 & 99999999 & 995 & 4.7109 & TR \\
\hline CHEMBL1598692 & 688653 & 4.683 & 5.1587 & TST & & \\
\hline CHEMBL 3194197 & 688653 & 4.73300 & 00000000 & 005 & 5.7634 & TRN \\
\hline CHEMBL1482901 & 688653 & 6.58299 & 99999999 & & 5.2536 & TRN \\
\hline CHEMBL1480539 & 688653 & 5.083 & 6.025 & TRN & & \\
\hline CHEMBL1577498 & 688653 & 6.03299 & 99999999 & 995 & 5.4287 & \\
\hline CHEMBL1548099 & 688653 & 4.98300 & 00000000 & 005 & 4.8954 & \\
\hline CHEMBL1470436 & 688653 & 5.63299 & 99999999 & & 5.3746 & TRN \\
\hline CHEMBL 3209015 & 688653 & 4.73300 & 00000000 & 005 & 4.6346 & TST \\
\hline CHEMBL1369867 & 688653 & 5.63299 & 99999999 & & 5.5494 & TST \\
\hline CHEMBL3194239 & 688653 & 5.58299 & 99999999 & & 5.2179 & - \\
\hline CHEMBL1445758 & & 4.583 & 5.3122 & TRN & & \\
\hline CHEMBL1529296 & 688653 & 5.083 & 5.5297 & TRN & & \\
\hline CHEMBL1366300 & 688653 & 5.433 & 5.0949 & TRN & & \\
\hline CHEMBL1425629 & 688653 & 5.53299 & 99999999 & 995 & 5.1321 & I \\
\hline CHEMBL1475346 & 688653 & 5.733 & 5.2244 & TST & & \\
\hline CHEMBL3209353 & 688653 & 4.833 & 5.3037 & TRN & & \\
\hline
\end{tabular}




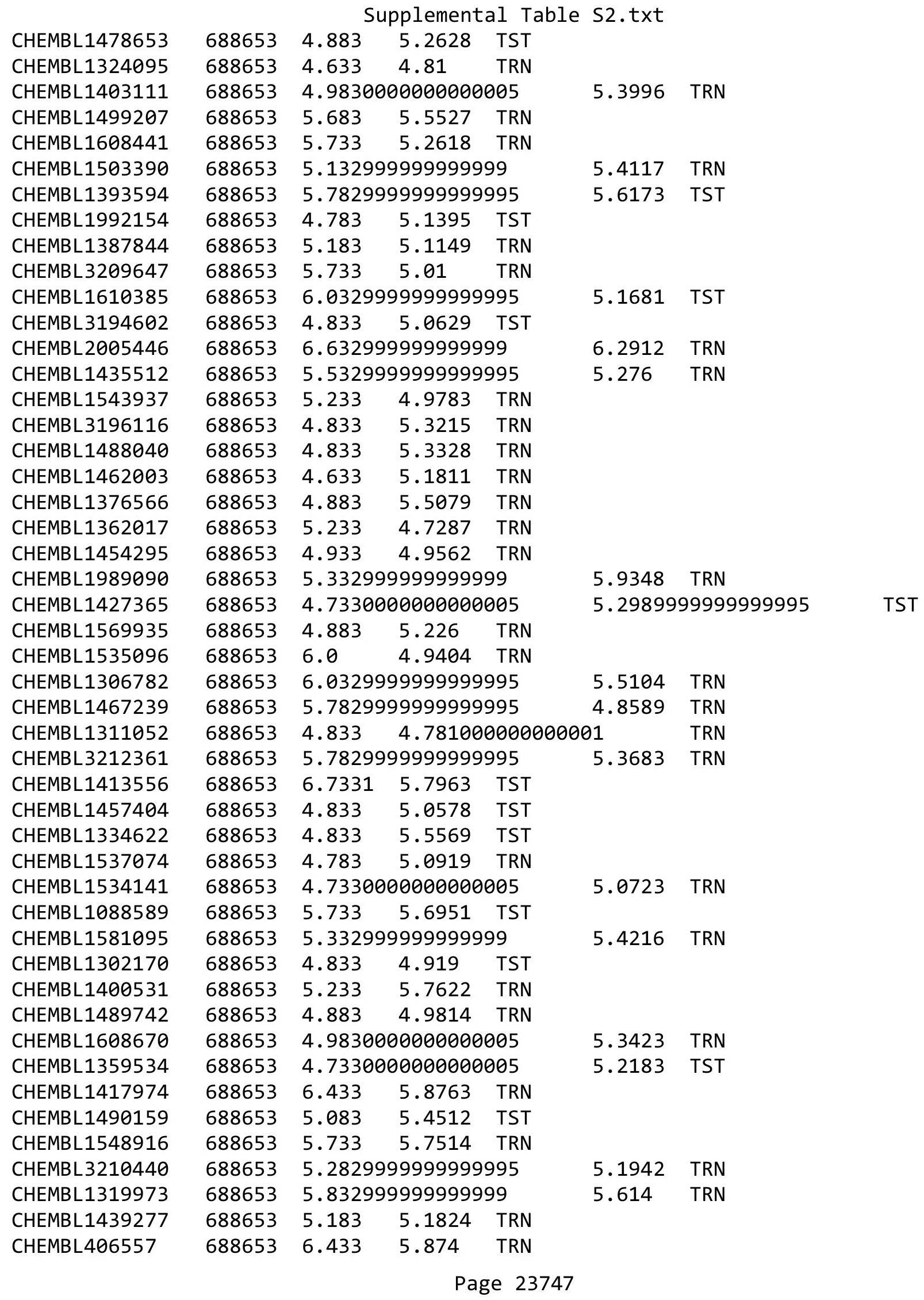




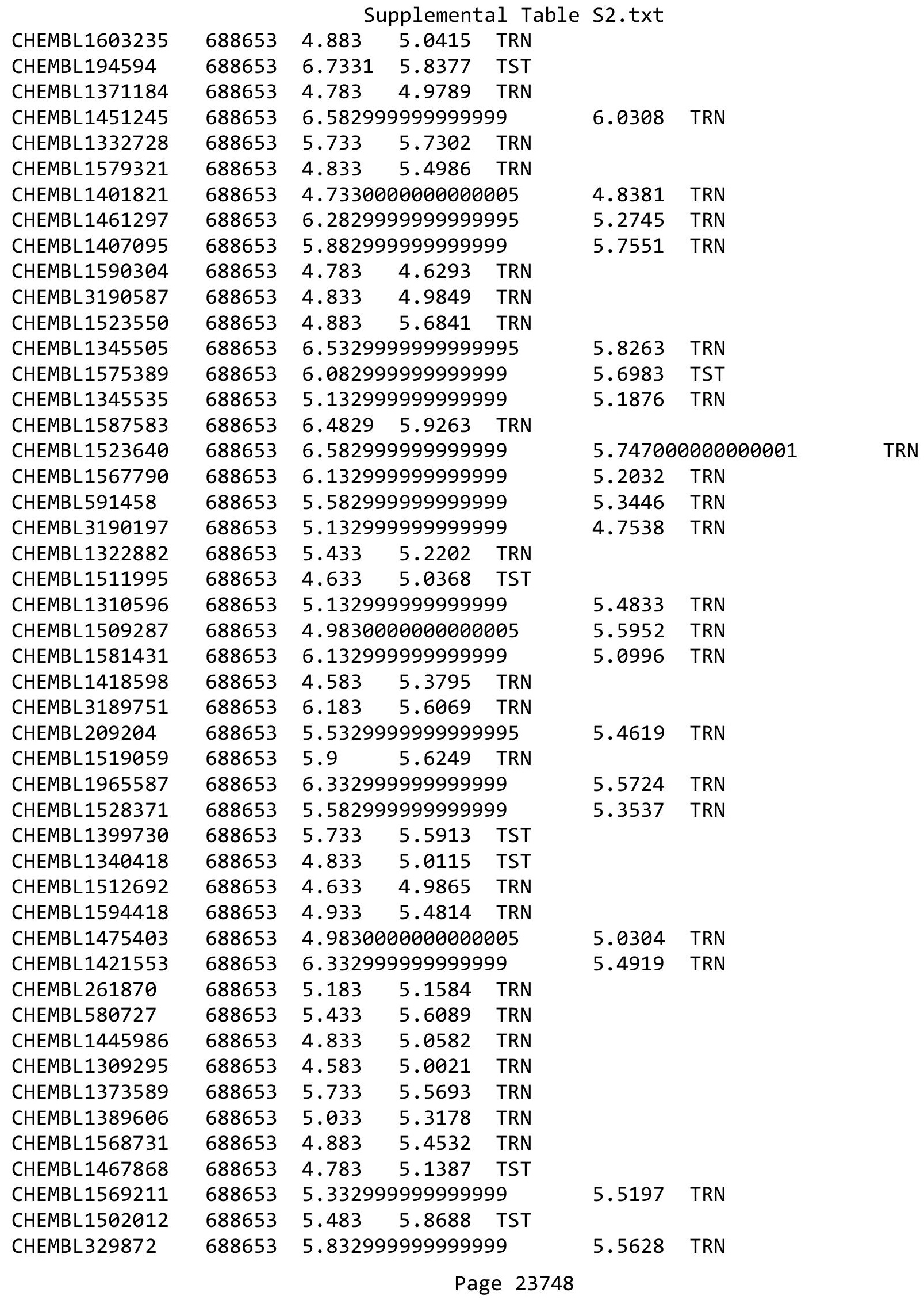




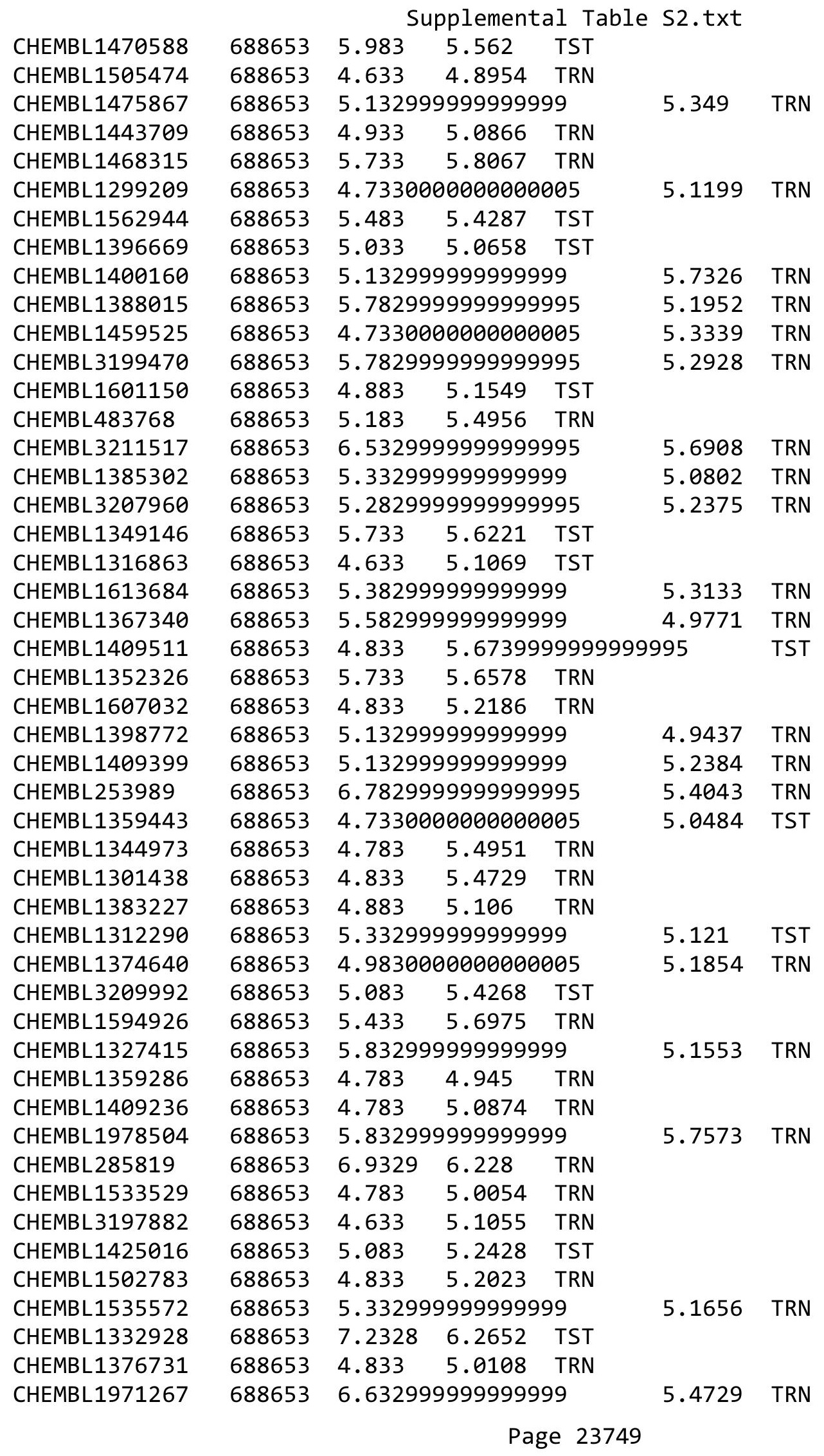




\begin{tabular}{|c|c|c|c|c|c|c|}
\hline \multirow[b]{2}{*}{ CHEMBL1561329 } & \multicolumn{6}{|c|}{ 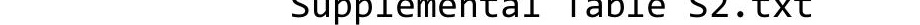 } \\
\hline & 688653 & 4.783 & 5.2395 & TRN & & \\
\hline CHEMBL1344119 & 688653 & \multicolumn{3}{|c|}{5.2829999999999995} & 5.2723 & TST \\
\hline CHEMBL1559040 & 688653 & \multicolumn{3}{|c|}{5.832999999999999} & 5.4517 & TRN \\
\hline CHEMBL1510845 & 688653 & \multicolumn{3}{|c|}{4.7330000000000005} & 5.146 & TST \\
\hline CHEMBL1327790 & 688653 & \multicolumn{3}{|c|}{6.632999999999999} & 5.979 & TRN \\
\hline CHEMBL1486356 & 688653 & \multicolumn{3}{|c|}{4.7330000000000005} & 5.1466 & TRN \\
\hline CHEMBL 1335770 & 688653 & 4.833 & 5.3116 & TST & & \\
\hline CHEMBL1172405 & 688653 & \multicolumn{3}{|c|}{5.382999999999999} & 5.2616 & TRN \\
\hline CHEMBL1996724 & 688653 & \multicolumn{3}{|c|}{5.2829999999999995} & 5.6446 & TRN \\
\hline CHEMBL1353885 & 688653 & 4.883 & 5.4664 & TRN & & \\
\hline CHEMBL1306163 & 688653 & 4.883 & 5.1457 & TRN & & \\
\hline CHEMBL1435821 & 688653 & \multicolumn{3}{|c|}{4.9830000000000005} & 5.1653 & TRN \\
\hline CHEMBL1604484 & 688653 & 5.733 & 5.2117 & TST & & \\
\hline CHEMBL1300423 & 688653 & 4.783 & 5.3026 & TRN & & \\
\hline CHEMBL1324398 & 688653 & 5.183 & 5.416 & TRN & & \\
\hline CHEMBL1486546 & 688653 & 5.183 & 5.0921 & TRN & & \\
\hline CHEMBL1502716 & 688653 & \multicolumn{3}{|c|}{5.882999999999999} & 5.3214 & TRN \\
\hline CHEMBL1463997 & 688653 & 5.183 & 5.7331 & TST & & \\
\hline CHEMBL1339084 & 688653 & \multicolumn{3}{|c|}{5.132999999999999} & 4552 & TRN \\
\hline CHEMBL1602082 & 688653 & 4.783 & 5.0044 & TRN & & \\
\hline CHEMBL1343988 & 688653 & 4.683 & 5.4977 & TRN & & \\
\hline CHEMBL1534937 & 688653 & 4.833 & 5.244 & TRN & & \\
\hline CHEMBL94512 & 688653 & \multicolumn{3}{|c|}{4.9830000000000005} & 5.6302 & TRN \\
\hline CHEMBL1347021 & 688653 & \multicolumn{3}{|c|}{4.7330000000000005} & 5.6264 & TST \\
\hline CHEMBL1593766 & 688653 & 4.583 & 4.6987 & TRN & & \\
\hline CHEMBL1337578 & 688653 & 6.4829 & 5.4507 & TRN & & \\
\hline CHEMBL1525519 & 688653 & 5.433 & 5.5407 & TRN & & \\
\hline CHEMBL1539406 & 688653 & 4.933 & 5.4753 & TRN & & \\
\hline CHEMBL1606409 & 688653 & 4.833 & \multicolumn{3}{|c|}{5.1339999999999995} & TRN \\
\hline CHEMBL1581808 & 688653 & 4.883 & 4.4338 & TRN & & \\
\hline CHEMBL1492738 & 688653 & 6.7331 & 5.6429 & TRN & & \\
\hline CHEMBL3197848 & 688653 & 4.883 & 4.9254 & TRN & & \\
\hline CHEMBL1412734 & 688653 & \multicolumn{3}{|c|}{5.5329999999999995} & 5.4841 & TST \\
\hline CHEMBL1337332 & 688653 & 4.683 & 4.9176 & TRN & & \\
\hline CHEMBL1567431 & 688653 & \multicolumn{3}{|c|}{4.7330000000000005} & 5.4659 & TST \\
\hline CHEMBL1364157 & 688653 & \multicolumn{3}{|c|}{6.2829999999999995} & 5.2474 & TRN \\
\hline CHEMBL1461432 & 688653 & \multicolumn{3}{|c|}{4.7330000000000005} & 5.4574 & TST \\
\hline CHEMBL1431048 & 688653 & 4.933 & 5.5002 & TST & & \\
\hline CHEMBL1501950 & 688653 & \multicolumn{3}{|c|}{4.7330000000000005} & 5.3415 & TRN \\
\hline CHEMBL3199546 & 688653 & 4.933 & 5.153 & TST & & \\
\hline CHEMBL1313356 & 688653 & 4.633 & 4.7968 & TRN & & \\
\hline CHEMBL1596751 & 688653 & 4.783 & 5.1624 & TRN & & \\
\hline CHEMBL1531407 & 688653 & 5.483 & 5.0595 & TRN & & \\
\hline CHEMBL1519655 & 688653 & 4.633 & 4.9805 & TRN & & \\
\hline CHEMBL1303800 & 688653 & \multicolumn{3}{|c|}{4.7330000000000005} & 4.9956 & TRN \\
\hline CHEMBL1322694 & 688653 & 4.73300 & 00000000 & 005 & 4.9257 & TRN \\
\hline CHEMBL1394609 & 688653 & 4.883 & 5.0583 & TRN & & \\
\hline CHEMBL3212136 & 688653 & 6.183 & 5.2686 & TRN & & \\
\hline
\end{tabular}




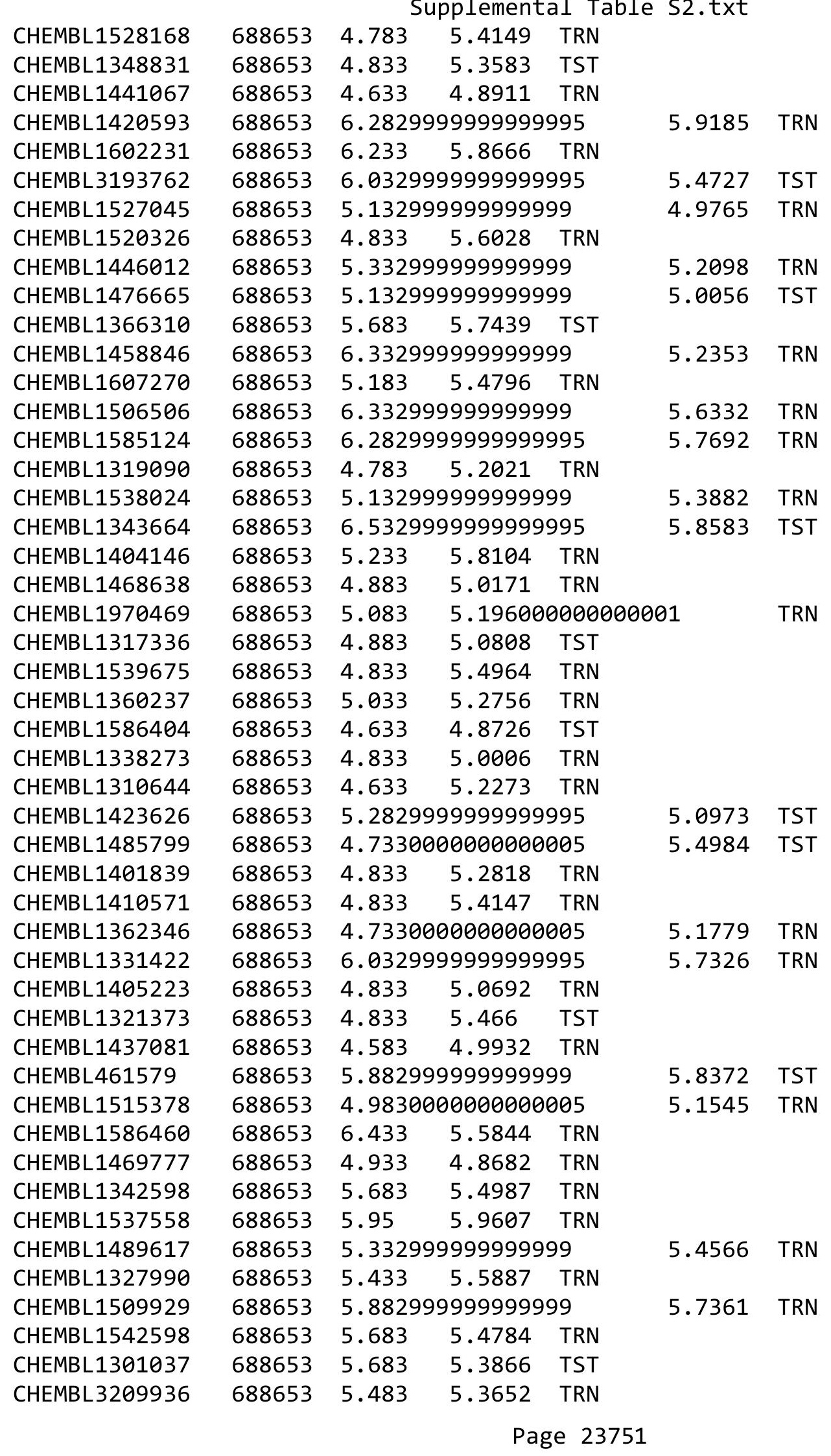




\begin{tabular}{|c|c|c|c|c|c|c|}
\hline CHEMBL1396001 & 688653 & 4.883 & 5.1926 & TRN & & \\
\hline CHEMBL1496045 & 688653 & \multicolumn{3}{|c|}{4.7330000000000005} & 5.3207 & TR \\
\hline CHEMBL 3210608 & 688653 & \multicolumn{3}{|c|}{6.332999999999999} & & \\
\hline HEMBL1339289 & 588653 & 6.183 & 5.6232 & TST & & \\
\hline CHEMBL1995997 & 88653 & \multicolumn{3}{|c|}{4.7330000000000005} & 5.5117 & \\
\hline CHEMBL1550078 & 588653 & \multicolumn{3}{|c|}{5.382999999999999} & 5.8905 & \\
\hline CHEMBL1303595 & 688653 & 4.683 & 5.4119 & TST & & \\
\hline CHEMBL585222 & 588653 & 5.233 & 5.3603 & TRN & & \\
\hline HEMBL1579629 & 88653 & \multicolumn{3}{|c|}{5.5329999999999995} & 5.6773 & \\
\hline CHEMBL1443770 & 588653 & 5.733 & 5.5548 & TRN & & \\
\hline CHEMBL1448453 & 688653 & \multicolumn{3}{|c|}{6.382999999999999} & 5.3343 & \\
\hline HEMBL1885024 & 688653 & 4.583 & 5.3798 & TRN & & \\
\hline HEMBL1403138 & 688653 & 4.783 & \multicolumn{3}{|c|}{4.8389999999999995} & \\
\hline HEMBL1426909 & 688653 & 4.583 & 5.48 & TRN & & \\
\hline HEMBL1583545 & 688653 & 4.683 & 4.797 & TRN & & \\
\hline CHEMBL1471090 & 688653 & 5.033 & 5.263 & TRN & & \\
\hline 68458 & 88653 & 6.0 & 5.4424 & TRN & & \\
\hline HEMBL1556196 & 688653 & 4.833 & \multicolumn{3}{|c|}{5.031000000000001} & \\
\hline HEMBL1593426 & 688653 & \multicolumn{3}{|c|}{5.5329999999999995} & 5.8482 & \\
\hline CHEMBL 3189468 & 688653 & \multicolumn{3}{|c|}{5.132999999999999} & & \\
\hline CHEMBL1560967 & 688653 & 5.183 & 5.3308 & TRN & & \\
\hline HEMBL: & 88653 & 5.983 & 5.9902 & TRN & & \\
\hline HEMBL3 & 688653 & 5.083 & 5.0765 & TRN & & \\
\hline HEMBL1 & 688653 & \multicolumn{3}{|c|}{5.332999999999999} & 41 & \\
\hline CHEMBL1549419 & 688653 & 4.633 & 5.2812 & TST & & \\
\hline CHEMBL1325217 & 688653 & 5.683 & 5.0153 & TRN & & \\
\hline CHEMBL & 688653 & \multicolumn{3}{|c|}{5.5329999999999995} & 5.2513 & \\
\hline HEMBL: & 688653 & 4.833 & 5.0069 & TST & & \\
\hline CHEMBL1301929 & 688653 & \multicolumn{3}{|c|}{5.132999999999999} & 46 & \\
\hline HEMBL1323085 & 688653 & 4.883 & 5.5742 & TRN & & \\
\hline CHEMBL1 & 688653 & \multicolumn{3}{|c|}{5.7829999999999995} & 3 . & \\
\hline CHEMBL & 688653 & 5.683 & 5.2871 & TRN & & \\
\hline CHEMBL: & 688653 & 6.233 & 5.4593 & TRN & & \\
\hline HEMBL1404649 & 688653 & 5.083 & 5.0605 & TRN & & \\
\hline CHEMBL1403065 & 688653 & \multicolumn{3}{|c|}{5.632999999999999} & 5.9573 & \\
\hline CHEMBL & 688653 & 4.783 & 5.3821 & TRN & & \\
\hline CHEMBL: & 688653 & 4.583 & 4.435 & TST & & \\
\hline CHEMBL1 & 688653 & 6.4829 & 5.8129 & TST & & \\
\hline CHEMBL 3194426 & 688653 & 4.783 & 5.4989 & TRN & & \\
\hline CHEMBL 1578310 & 688653 & 4.683 & 5.3522 & TRN & & \\
\hline CHEMBL1401284 & 688653 & 5.683 & 5.5335 & TRN & & \\
\hline CHEMBL1595162 & 688653 & \multicolumn{3}{|c|}{5.832999999999999} & 4.871 & \\
\hline CHEMBL3195986 & 688653 & 4.883 & 5.6003 & TST & & \\
\hline CHEMBL1519558 & 688653 & \multicolumn{3}{|c|}{5.332999999999999} & 5.3338 & \\
\hline CHEMBL1305429 & 688653 & 5.733 & 5.4238 & TRN & & \\
\hline CHEMBL1469733 & 688653 & 6.433 & 6.1428 & TRN & & \\
\hline CHEMBL 3190829 & 688653 & \multicolumn{3}{|c|}{6.632999999999999} & 3.0140 & \\
\hline CHEMBL 3212365 & 688653 & \multicolumn{3}{|c|}{5.2829999999999995} & 5.1491 & \\
\hline
\end{tabular}




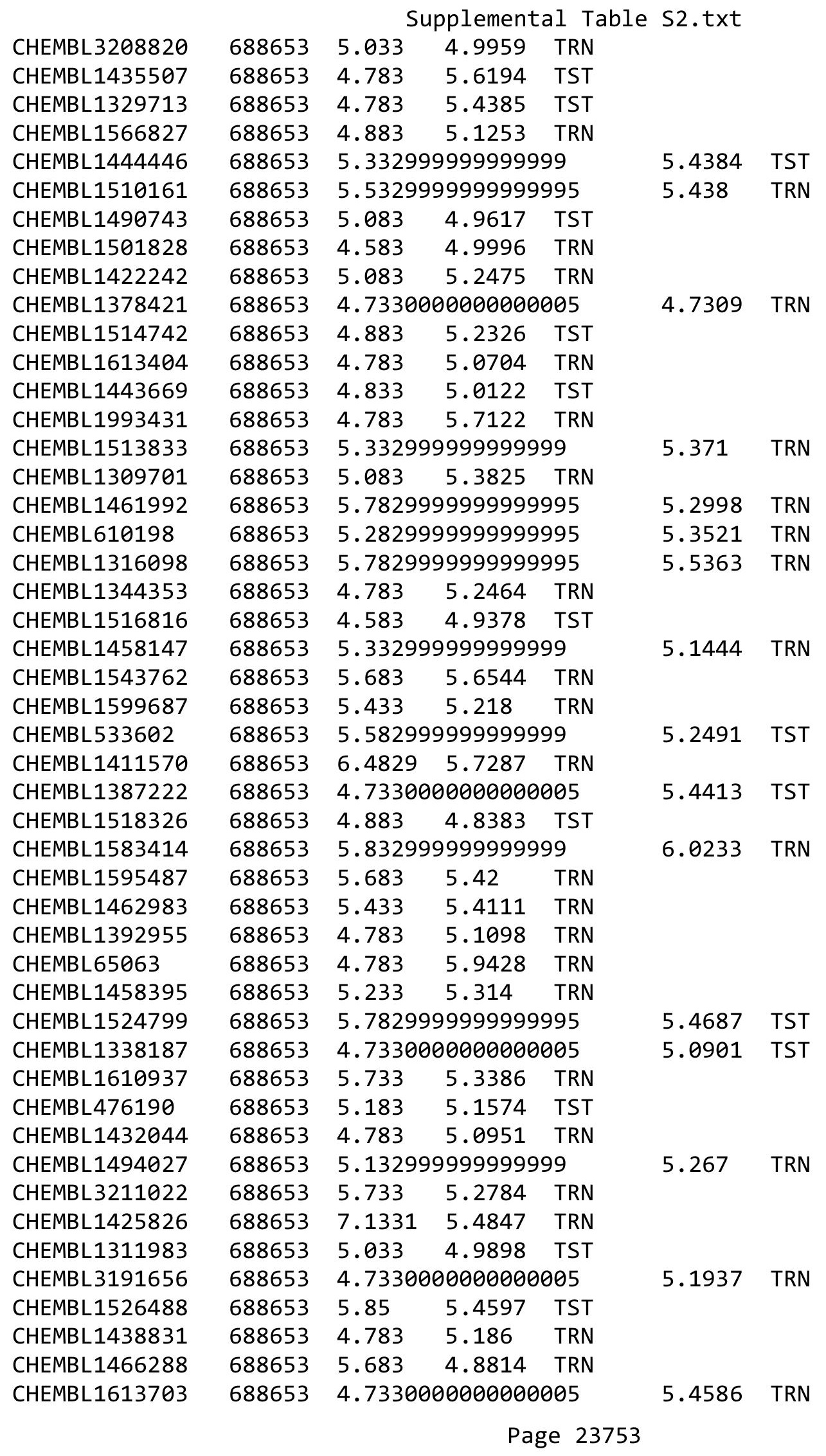




\begin{tabular}{|c|c|c|c|c|c|c|}
\hline \multirow[b]{2}{*}{ CHEMBL1313907 } & \multirow[b]{2}{*}{688653} & \multicolumn{5}{|c|}{ Supplemental Table S2.txt } \\
\hline & & \multirow{2}{*}{\multicolumn{3}{|c|}{$\begin{array}{ll}5.033 & 6.0132 \\
6.582999999999999\end{array}$}} & & \\
\hline CHEMBL3209766 & 688653 & & & & 5.8206 & TRN \\
\hline CHEMBL1605158 & 688653 & \multicolumn{3}{|c|}{5.5329999999999995} & 6.0632 & TRN \\
\hline CHEMBL1523461 & 688653 & 5.933 & 5.5474 & \multicolumn{2}{|l|}{ TRN } & \\
\hline CHEMBL1478953 & 688653 & 4.633 & 4.894 & \multicolumn{2}{|l|}{ TRN } & \\
\hline CHEMBL1598285 & 688653 & 5.683 & 5.3221 & \multicolumn{2}{|l|}{ TRN } & \\
\hline CHEMBL1548899 & 688653 & \multicolumn{3}{|c|}{6.2829999999999995} & \multirow[t]{3}{*}{5.3094} & \multirow[t]{3}{*}{ TST } \\
\hline CHEMBL3189518 & 688653 & 5.733 & 5.4069 & TRN & & \\
\hline CHEMBL1595137 & 688653 & 4.583 & 5.016 & TRN & & \\
\hline CHEMBL1302868 & 688653 & \multicolumn{3}{|c|}{6.2829999999999995} & \multirow[t]{3}{*}{5.7229} & \multirow[t]{3}{*}{ TRN } \\
\hline CHEMBL1352280 & 688653 & 4.933 & 5.1301 & TRN & & \\
\hline CHEMBL1525999 & 688653 & 4.783 & 5.0695 & TRN & & \\
\hline CHEMBL1309801 & 688653 & \multicolumn{3}{|c|}{4.7330000000000005} & \multirow[t]{3}{*}{5.0758} & \multirow[t]{3}{*}{ TST } \\
\hline CHEMBL1471492 & 688653 & 4.583 & 5.5767 & TST & & \\
\hline CHEMBL1490308 & 688653 & 4.783 & 5.0866 & TST & & \\
\hline CHEMBL1459699 & 688653 & \multicolumn{3}{|c|}{5.132999999999999} & \multirow[t]{4}{*}{5.2687} & TST \\
\hline CHEMBL1587328 & 688653 & 5.183 & 5.0069 & TST & & \\
\hline CHEMBL1318170 & 688653 & 5.183 & 5.1323 & TRN & & \\
\hline CHEMBL1343670 & 688653 & 4.783 & 4.8854 & TRN & & \\
\hline CHEMBL1604705 & 688653 & 4.683 & 4.98300 & 00000 & 005 & TRN \\
\hline CHEMBL 3190347 & 688653 & 4.833 & 5.1482 & TST & & \\
\hline CHEMBL1312802 & 688653 & 5.3329 & 79999999 & & 5.2875 & TRN \\
\hline CHEMBL1486661 & 688653 & 5.683 & 5.6499 & TRN & & \\
\hline CHEMBL1540556 & 688653 & 4.883 & 5.4377 & TST & & \\
\hline CHEMBL1390860 & 688653 & 5.433 & 5.322 & TRN & & \\
\hline CHEMBL1482541 & 688653 & 5.733 & 5.6162 & TST & & \\
\hline CHEMBL1388894 & 688653 & 4.833 & 5.6005 & TRN & & \\
\hline CHEMBL1301921 & 688653 & 5.1329 & 99999999 & & 5.1246 & TRN \\
\hline CHEMBL1455317 & 688653 & 4.7330 & 00000000 & 005 & 5.1676 & TST \\
\hline CHEMBL1470289 & 688653 & 4.833 & 5.1737 & TRN & & \\
\hline CHEMBL1422281 & 688653 & 4.783 & 5.1058 & TRN & & \\
\hline CHEMBL1365055 & 688653 & 4.833 & 5.2234 & TRN & & \\
\hline CHEMBL3211298 & 688653 & 5.5829 & 79999999 & & 5.5283 & TRN \\
\hline CHEMBL1610646 & 688653 & 5.233 & 5.084 & TRN & & \\
\hline CHEMBL1375894 & 688653 & 4.933 & 4.9203 & TRN & & \\
\hline CHEMBL1343916 & 688653 & 5.3329 & 99999999 & & 5.2269 & TRN \\
\hline CHEMBL1390258 & 688653 & 4.7330 & 30000000 & 005 & 5.1761 & TRN \\
\hline CHEMBL1365638 & 688653 & 5.733 & 5.3468 & TRN & & \\
\hline CHEMBL1439295 & 688653 & 6.233 & 5.4682 & TRN & & \\
\hline CHEMBL1461102 & 688653 & 4.833 & 4.998 & TRN & & \\
\hline CHEMBL1572695 & 688653 & 6.683 & 4.9736 & TST & & \\
\hline CHEMBL1442002 & 688653 & 4.683 & 4.9917 & TRN & & \\
\hline CHEMBL1406032 & 688653 & 5.683 & 5.4218 & TRN & & \\
\hline CHEMBL1331087 & 688653 & 4.783 & 5.1864 & TRN & & \\
\hline CHEMBL1461176 & 688653 & 5.033 & 4.8328 & TST & & \\
\hline CHEMBL3195053 & 688653 & 4.833 & 5.3965 & TRN & & \\
\hline CHEMBL1558205 & 688653 & 4.9830 & 30000000 & 005 & 4.9481 & TRN \\
\hline CHEMBL1340573 & 688653 & 4.7330 & 30000000 & 005 & 4.8444 & TST \\
\hline & & & & & & \\
\hline
\end{tabular}




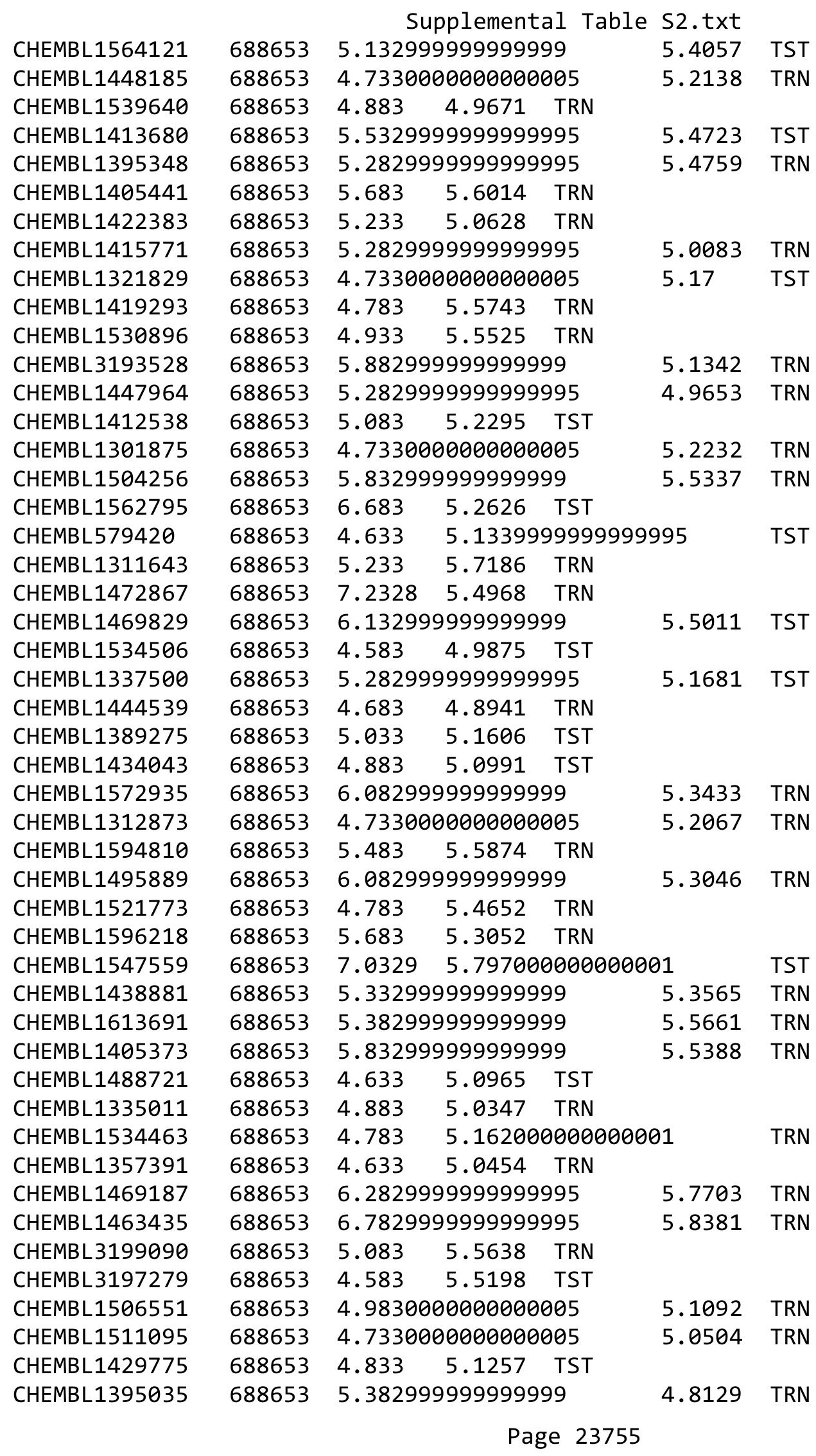




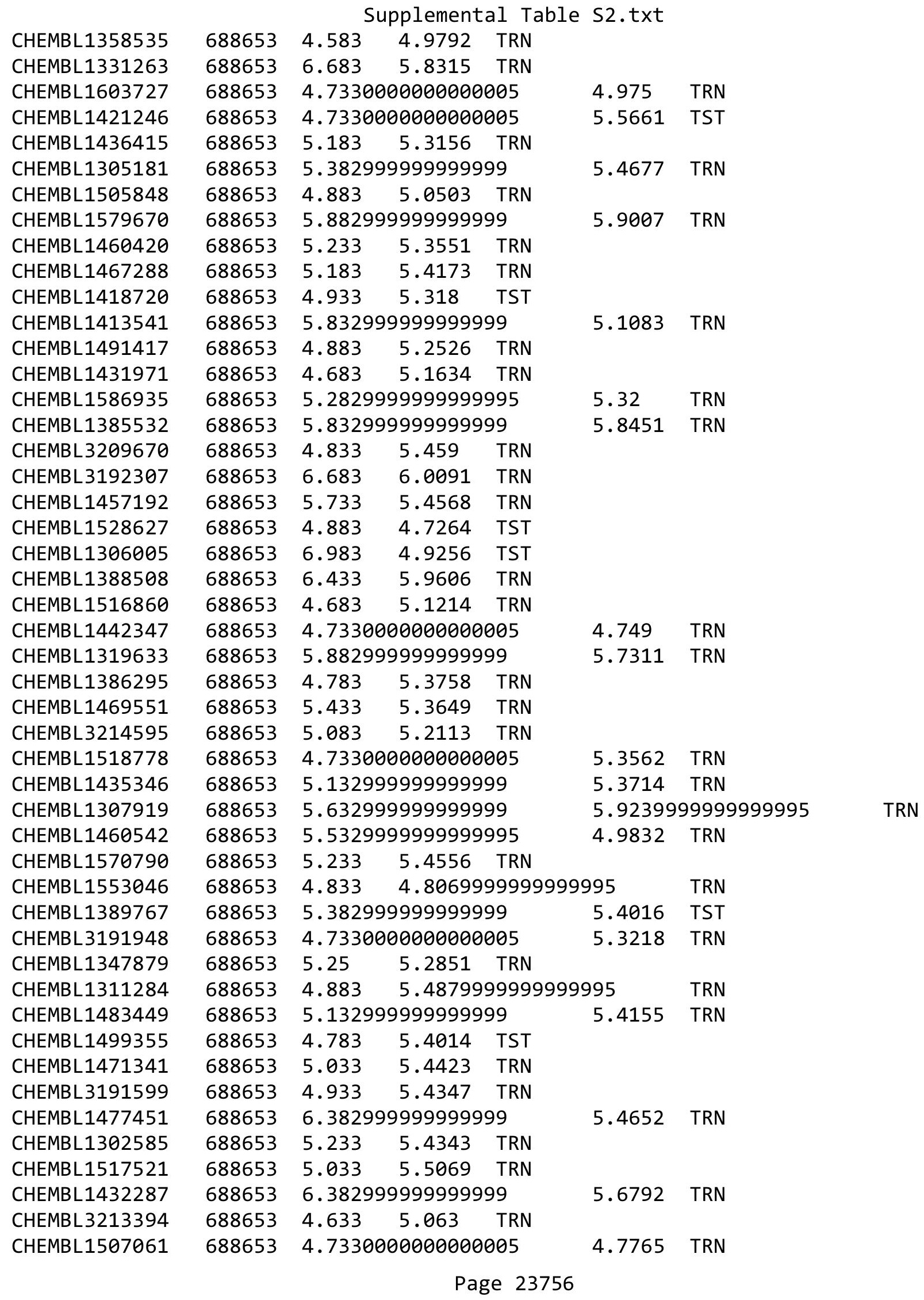




\begin{tabular}{|c|c|c|c|c|c|c|}
\hline & \multicolumn{5}{|c|}{ plemental } \\
\hline CHEMBL1413003 & 688653 & 5.233 & 4.7578 & TRN & & \\
\hline CHEMBL1417654 & 688653 & \multicolumn{3}{|c|}{5.7829999999999995} & 5.1497 & TRI \\
\hline CHEMBL1476467 & 688653 & 4.933 & 5.4879 & TRN & & \\
\hline CHEMBL1526462 & 688653 & \multicolumn{3}{|c|}{4.7330000000000005} & 4.9371 & ונכו \\
\hline CHEMBL1502379 & 688653 & \multicolumn{3}{|c|}{4.7330000000000005} & 5.3458 & \\
\hline CHEMBL1365688 & 688653 & 4.883 & 5.8125 & TRN & & \\
\hline CHEMBL1409606 & 688653 & 5.083 & 4.9577 & TST & & \\
\hline CHEMBL1602652 & 688653 & 6.4829 & 6.0295 & TRN & & \\
\hline CHEMBL1486935 & 688653 & \multicolumn{3}{|c|}{5.2829999999999995} & 5.4272 & \\
\hline CHEMBL1449597 & 688653 & 6.233 & 5.6792 & TRN & & \\
\hline CHEMBL 3193627 & 688653 & \multicolumn{3}{|c|}{6.832999999999999} & 6.1008 & Tr \\
\hline CHEMBL1353642 & 688653 & 5.033 & 4.836 & TRN & & \\
\hline CHEMBL1604852 & 688653 & 4.683 & 4.9671 & TST & & \\
\hline CHEMBL1370759 & 688653 & 5.033 & 5.6592 & TRN & & \\
\hline CHEMBL1371682 & 688653 & \multicolumn{3}{|c|}{4.7330000000000005} & 5.0324 & TS \\
\hline CHEMBL1419974 & 688653 & \multicolumn{3}{|c|}{4.7330000000000005} & 4.7708 & \\
\hline CHEMBL1359446 & 688653 & \multicolumn{3}{|c|}{6.132999999999999} & 5.3459 & \\
\hline CHEMBL1349897 & 688653 & 4.783 & 5.2523 & TST & & \\
\hline CHEMBL1564448 & 688653 & \multirow{2}{*}{\multicolumn{3}{|c|}{$\begin{array}{l}4.833 \quad 5.1754 \quad \text { TRN } \\
6.5329999999999995\end{array}$}} & & \\
\hline CHEMBL1213831 & 688653 & & & & 5.7312 & IT \\
\hline CHEMBL1545171 & 688653 & 4.833 & 5.0106 & TRN & & \\
\hline CHEMBL1436229 & 688653 & 4.883 & 4.7688 & TST & & \\
\hline CHEMBL1540575 & 688653 & 5.733 & 4.9679 & TRN & & \\
\hline CHEMBL 3199837 & 53 & 4.783 & 5.0733 & TRN & & \\
\hline CHEMBL1310184 & 688653 & 5.183 & \multicolumn{3}{|c|}{5.638999999999999} & \\
\hline CHEMBL1573217 & 688653 & \multicolumn{3}{|c|}{4.7330000000000005} & 5.185 & \\
\hline CHEMBL1395943 & 688653 & \multicolumn{3}{|c|}{5.832999999999999} & 5.5394 & \\
\hline CHEMBL145781 & 688653 & \multicolumn{3}{|c|}{5.132999999999999} & 5.4904 & \\
\hline CHEMBL1315048 & 688653 & 5.183 & 5.7625 & TRN & & \\
\hline CHEMBL1505940 & 688653 & \multicolumn{3}{|c|}{5.7829999999999995} & 5.204 & $\mathrm{TP}$ \\
\hline CHEMBL1350257 & 688653 & 5.183 & 5.0236 & TRN & & \\
\hline CHEMBL1433353 & 688653 & 4.833 & 5.3725 & TST & & \\
\hline CHEMBL1475002 & 688653 & 4.933 & 5.5254 & TRN & & \\
\hline CHEMBL1556686 & 688653 & 4.933 & 5.907 & TRN & & \\
\hline CHEMBL1373725 & 688653 & 4.783 & 5.4166 & TRN & & \\
\hline CHEMBL1401156 & 688653 & 5.683 & 5.2804 & TST & & \\
\hline CHEMBL1609228 & 688653 & 4.883 & 5.0544 & TRN & & \\
\hline CHEMBL1589679 & 688653 & \multicolumn{3}{|c|}{5.832999999999999} & של & Tin \\
\hline CHEMBL1409782 & 688653 & \multicolumn{3}{|c|}{5.132999999999999} & 5.5776 & IT \\
\hline CHEMBL1608084 & 688653 & \multicolumn{3}{|c|}{4.7330000000000005} & 5.0252 & \\
\hline CHEMBL1309573 & 688653 & 6.983 & 6.3574 & TRN & & \\
\hline CHEMBL1459638 & 688653 & 5.033 & 5.2351 & TRN & & \\
\hline CHEMBL1516913 & 688653 & 5.733 & 5.4422 & TRN & & \\
\hline CHEMBL1446218 & 688653 & 5.28299 & 99999999 & 995 & 5.0513 & - \\
\hline CHEMBL1602506 & 688653 & 5.83299 & 99999999 & & 5.6872 & TRN \\
\hline CHEMBL1300639 & 688653 & 4.73300 & 00000000 & 005 & 5.1436 & 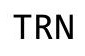 \\
\hline CHEMBL1585055 & 688653 & 5.983 & 6.0284 & TRN & & \\
\hline CHEMBL1371987 & 688653 & 4.98300 & 00000000 & 005 & 5.4591 & \\
\hline
\end{tabular}




\begin{tabular}{|c|c|c|c|c|c|c|}
\hline & & & pplement & al & s2.txt & \\
\hline CHEMBL1080213 & 688653 & 5.3329 & 99999999 & & 5.5463 & TRN \\
\hline CHEMBL1404128 & 688653 & 4.9830 & 00000000 & 005 & 5.4039 & TST \\
\hline CHEMBL1478645 & 688653 & 5.8829 & 99999999 & & 5.6401 & TRN \\
\hline CHEMBL1514806 & 688653 & 4.683 & 5.0378 & TRN & & \\
\hline CHEMBL1566677 & 688653 & 4.933 & 5.0065 & TRN & & \\
\hline CHEMBL1458403 & 688653 & 4.783 & 4.7041 & TST & & \\
\hline CHEMBL1575019 & 688653 & 4.783 & 4.9007 & TRN & & \\
\hline CHEMBL1307081 & 688653 & 5.183 & 5.4189 & TRN & & \\
\hline CHEMBL1384906 & 688653 & 5.183 & 4.9659 & TRN & & \\
\hline CHEMBL1390498 & 688653 & 4.783 & 5.2182 & TRN & & \\
\hline CHEMBL1304556 & 688653 & 5.1329 & 99999999 & & 5.6819 & TRN \\
\hline CHEMBL1588075 & 688653 & 4.7330 & 20000000 & 005 & 4.8687 & TRN \\
\hline CHEMBL1565753 & 688653 & 5.083 & 5.2999 & TST & & \\
\hline CHEMBL1422405 & 688653 & 5.6329 & 99999999 & & 5.2408 & TRN \\
\hline CHEMBL 3198304 & 688653 & 5.933 & 5.4401 & TRN & & \\
\hline CHEMBL1404345 & 688653 & 6.1329 & 99999999 & & 5.1771 & TRN \\
\hline CHEMBL1424398 & 688653 & 4.633 & 5.0207 & TRN & & \\
\hline CHEMBL1331465 & 688653 & 4.883 & 5.4768 & TRN & & \\
\hline CHEMBL1428578 & 688653 & 4.633 & 5.1327 & TRN & & \\
\hline CHEMBL1300300 & 688653 & 4.7330 & 00000000 & 005 & 5.0843 & TRN \\
\hline CHEMBL1349450 & 688653 & 5.683 & 6.0671 & TRN & & \\
\hline CHEMBL1438534 & 688653 & 4.7330 & 20000000 & 005 & 4.9242 & TST \\
\hline CHEMBL1392924 & 688653 & 4.7330 & 20000000 & 005 & 5.0427 & TST \\
\hline CHEMBL1424351 & 688653 & 4.683 & 5.0775 & TRN & & \\
\hline CHEMBL1600873 & 688653 & 4.783 & 5.5001 & TRN & & \\
\hline CHEMBL1330155 & 688653 & 4.783 & 5.3684 & TRN & & \\
\hline CHEMBL1304631 & 688653 & 5.8829 & 99999999 & & 5.4542 & TRN \\
\hline CHEMBL3191393 & 688653 & 4.783 & 5.1818 & TST & & \\
\hline CHEMBL1553519 & 688653 & 5.5329 & 99999999 & 995 & 5.3196 & TRN \\
\hline CHEMBL1564007 & 688653 & 4.7330 & 00000000 & 005 & 5.0032 & TRN \\
\hline CHEMBL1487098 & 688653 & 5.8329 & 99999999 & & 5.0476 & TST \\
\hline CHEMBL1594707 & 688653 & 4.783 & 5.1816 & TST & & \\
\hline CHEMBL1396107 & 688653 & 4.933 & 5.3219 & TRN & & \\
\hline CHEMBL1403877 & 688653 & 5.3829 & 99999999 & & 5.805 & TRN \\
\hline CHEMBL1540081 & 688653 & 5.1329 & 99999999 & & 5.2063 & TRN \\
\hline CHEMBL1407955 & 688653 & 5.3329 & 99999999 & & 4.9741 & TRN \\
\hline CHEMBL1502879 & 688653 & 4.783 & 5.0606 & TRN & & \\
\hline CHEMBL1980829 & 688653 & 4.7330 & 00000000 & 005 & 5.1199 & TRN \\
\hline CHEMBL1536647 & 688653 & 5.8329 & 99999999 & & 5.6082 & TRN \\
\hline CHEMBL1381841 & 688653 & 4.933 & 4.8735 & TRN & & \\
\hline CHEMBL1567944 & 688653 & 7.4828 & 6.3973 & TST & & \\
\hline CHEMBL1308947 & 688653 & 5.733 & 6.0771 & TRN & & \\
\hline CHEMBL1335133 & 688653 & 5.6329 & 99999999 & 99 & 5.4661 & TRN \\
\hline CHEMBL1493626 & 688653 & 4.633 & 4.9084 & TRN & & \\
\hline CHEMBL1569990 & 688653 & 5.5329 & 99999999 & 995 & 5.9785 & TRN \\
\hline CHEMBL1306090 & 688653 & 5.683 & 5.4236 & TST & & \\
\hline CHEMBL1306401 & 688653 & 5.083 & 5.2615 & TRN & & \\
\hline CHEMBL1562851 & 688653 & 4.783 & 5.0913 & TRN & & \\
\hline
\end{tabular}




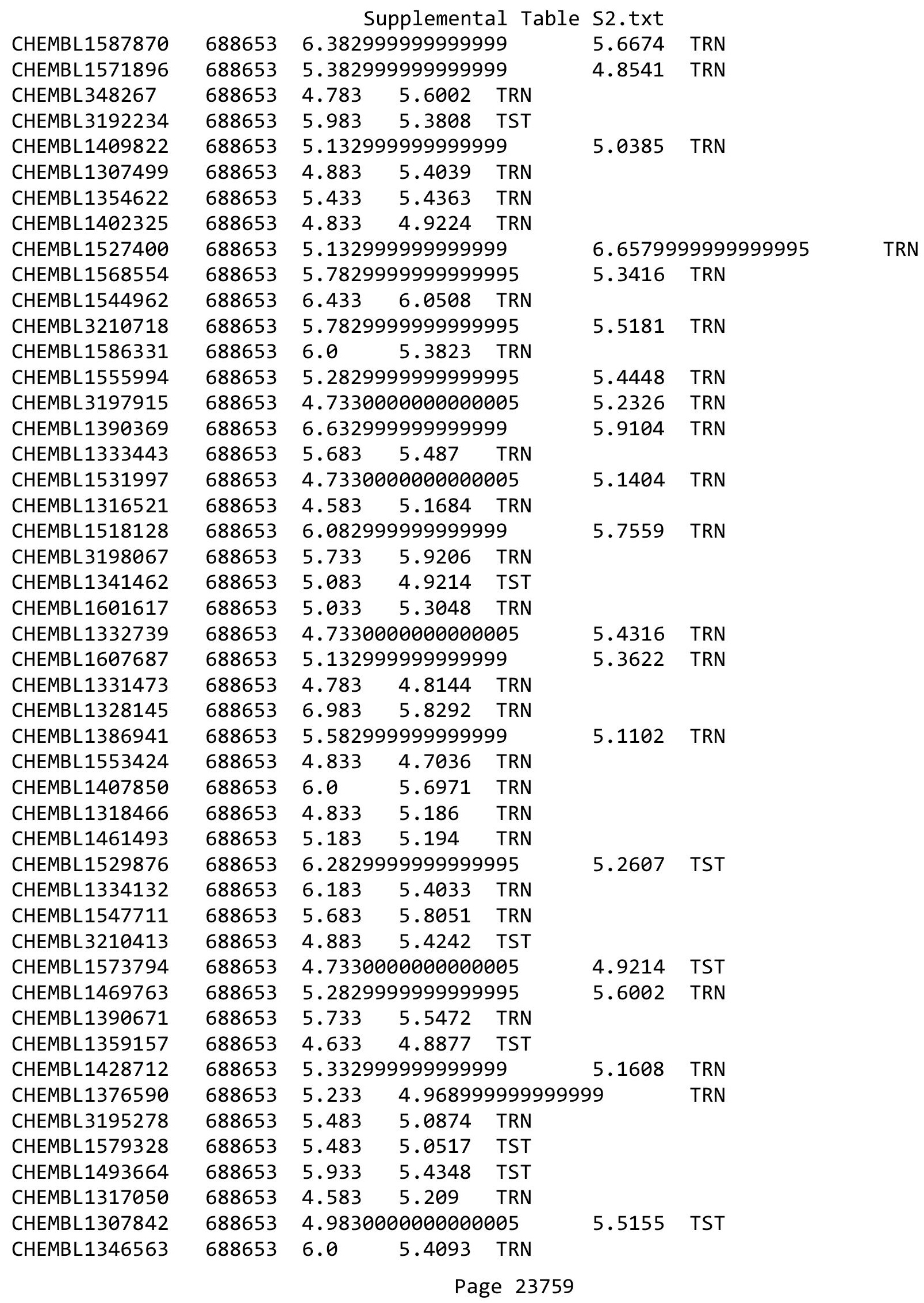




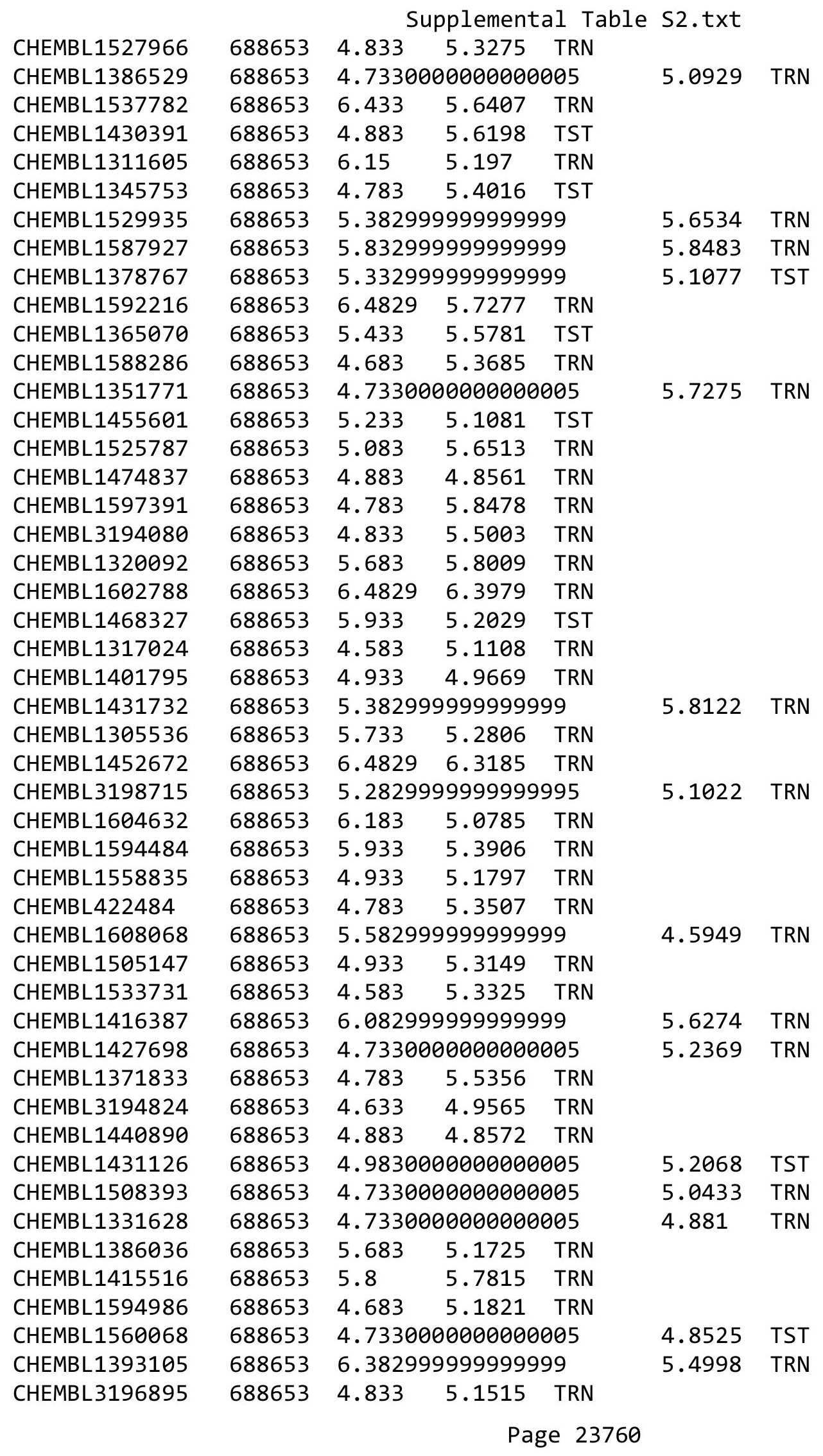




\begin{tabular}{|c|c|c|c|c|c|c|}
\hline \multirow{3}{*}{$\begin{array}{l}\text { CHEMBL1540719 } \\
\text { CHEMBL1386245 }\end{array}$} & \multirow{3}{*}{$\begin{array}{l}688653 \\
688653\end{array}$} & \multicolumn{5}{|c|}{ Supplemental Table S2.txt } \\
\hline & & \multicolumn{3}{|c|}{5.332999999999999} & \multirow{5}{*}{6.1666} & \multirow[t]{5}{*}{ TRN } \\
\hline & & 4.683 & 5.1454 & TRN & & \\
\hline CHEMBL1540638 & 688653 & 5.183 & 5.4126 & TRN & & \\
\hline CHEMBL1476852 & 688653 & 6.433 & 5.6745 & TRN & & \\
\hline CHEMBL1416494 & 688653 & 4.833 & 5.147 & TST & & \\
\hline CHEMBL1607973 & 688653 & \multicolumn{3}{|c|}{4.9830000000000005} & \multirow[t]{2}{*}{5.6144} & \multirow[t]{2}{*}{ TRA } \\
\hline CHEMBL1539075 & 688653 & 4.633 & 5.4997 & TST & & \\
\hline CHEMBL1556284 & 688653 & 5.85 & \multicolumn{3}{|c|}{5.5889999999999995} & \multirow[t]{2}{*}{ TRA } \\
\hline CHEMBL1358515 & 688653 & 4.583 & 5.1765 & TRN & & \\
\hline CHEMBL1415838 & 688653 & \multicolumn{3}{|c|}{6.632999999999999} & \multirow[t]{3}{*}{6.2556} & \multirow[t]{3}{*}{ TRN } \\
\hline CHEMBL1385348 & 688653 & 5.183 & 5.5037 & TRN & & \\
\hline CHEMBL1476946 & 688653 & 6.233 & 5.3765 & TST & & \\
\hline CHEMBL1344226 & 688653 & \multicolumn{3}{|c|}{5.382999999999999} & \multirow[t]{3}{*}{4.9731} & \multirow[t]{3}{*}{ TRA } \\
\hline CHEMBL1514596 & 688653 & 4.583 & 5.1729 & TRN & & \\
\hline CHEMBL1413946 & 688653 & 4.933 & 5.3543 & TRN & & \\
\hline CHEMBL1525533 & 688653 & \multicolumn{3}{|c|}{5.632999999999999} & \multirow[t]{7}{*}{5.2584} & \multirow[t]{7}{*}{ TRN } \\
\hline CHEMBL1436729 & 688653 & 5.083 & 4.6535 & TST & & \\
\hline CHEMBL1585578 & 688653 & 4.783 & 5.3839 & TST & & \\
\hline CHEMBL1523058 & 688653 & 4.783 & 4.9544 & TRN & & \\
\hline CHEMBL1486782 & 688653 & 4.833 & 4.9827 & TRN & & \\
\hline CHEMBL1562712 & 688653 & 6.8831 & 5.9353 & TRN & & \\
\hline CHEMBL1447306 & 688653 & 4.833 & 5.231 & TST & & \\
\hline CHEMBL1411498 & 688653 & \multicolumn{3}{|c|}{4.7330000000000005} & 5.2211 & TST \\
\hline CHEMBL1583837 & 688653 & 6.5829 & 99999995 & & 5.8962 & TST \\
\hline CHEMBL1421868 & 688653 & 4.633 & 5.2470 & 000000000 & & TRN \\
\hline CHEMBL3189331 & 688653 & 5.183 & 5.3656 & TRN & & \\
\hline CHEMBL3197522 & 688653 & 5.5829 & 9999999 & & 4.9919 & TRN \\
\hline CHEMBL1580114 & 688653 & 4.583 & 5.3334 & TRN & & \\
\hline CHEMBL1444540 & 688653 & 4.833 & 5.0932 & TRN & & \\
\hline CHEMBL1425269 & 688653 & 5.683 & 5.1503 & TST & & \\
\hline CHEMBL1519966 & 688653 & 4.833 & 5.0782 & TRN & & \\
\hline CHEMBL1385784 & 688653 & 5.033 & 4.941 & TRN & & \\
\hline CHEMBL1309946 & 688653 & 6.683 & 5.6789 & TRN & & \\
\hline CHEMBL1316226 & 688653 & 6.1329 & 99999995 & & 5.6122 & TRN \\
\hline CHEMBL1513630 & 688653 & 5.3329 & 99999995 & & 5.6529 & TRN \\
\hline CHEMBL1440341 & 688653 & 5.8829 & 9999999 & & 5.5986 & TRN \\
\hline CHEMBL1492968 & 688653 & 5.1329 & 9999999 & & 4.9799 & TST \\
\hline CHEMBL1518701 & 688653 & 4.883 & 5.2242 & TST & & \\
\hline CHEMBL1421664 & 688653 & 5.483 & 5.8267 & TRN & & \\
\hline CHEMBL1496177 & 688653 & 5.183 & 5.1907 & TST & & \\
\hline CHEMBL1373898 & 688653 & 5.933 & 5.3005 & TRN & & \\
\hline CHEMBL1484368 & 688653 & 5.1329 & 9999999 & & 5.2888 & TRN \\
\hline CHEMBL1393222 & 688653 & 5.083 & 5.041 & TST & & \\
\hline CHEMBL192984 & 688653 & 7.1831 & 6.04 & TRN & & \\
\hline CHEMBL1483639 & 688653 & 4.7330 & 0000000 & 005 & 5.0527 & TRN \\
\hline CHEMBL1409542 & 688653 & 4.7330 & 00000006 & 005 & 5.2282 & TRN \\
\hline CHEMBL1609950 & 688653 & 5.733 & 5.5932 & TRN & & \\
\hline CHEMBL1400986 & 688653 & 4.7330 & 0000000 & 005 & 4.9155 & TRN \\
\hline
\end{tabular}




\begin{tabular}{|c|c|c|c|c|c|c|}
\hline & & \multicolumn{5}{|c|}{ Supplemental Table S2.txt } \\
\hline CHEMBL1464721 & 688653 & 4.633 & 5.7629 & TRN & & \\
\hline CHEMBL3209146 & 688653 & 6.233 & 4.797 & TRN & & \\
\hline CHEMBL1369283 & 688653 & 4.783 & 5.0438 & TST & & \\
\hline CHEMBL1531688 & 688653 & 5.983 & 5.4772 & TRN & & \\
\hline CHEMBL1332711 & 688653 & \multicolumn{3}{|c|}{4.7330000000000005} & 5.7989 & TRN \\
\hline CHEMBL3193628 & 688653 & 6.9329 & 5.5338 & TRN & & \\
\hline CHEMBL1493993 & 688653 & 6.433 & 6.2418 & TRN & & \\
\hline CHEMBL1383992 & 688653 & 4.933 & 5.5991 & TST & & \\
\hline CHEMBL1483966 & 688653 & 4.883 & 5.4328 & TRN & & \\
\hline CHEMBL1501859 & 688653 & \multicolumn{3}{|c|}{5.2829999999999995} & 5.4858 & ThN \\
\hline CHEMBL1552488 & 688653 & 5.983 & 5.3698 & TRN & & \\
\hline CHEMBL3199152 & 688653 & 5.433 & 5.3471 & TST & & \\
\hline CHEMBL1483215 & 688653 & 4.883 & 5.3372 & TRN & & \\
\hline CHEMBL1476215 & 688653 & 6.9329 & 5.4215 & TRN & & \\
\hline CHEMBL1493796 & 688653 & 5.033 & 5.0895 & TRN & & \\
\hline CHEMBL1525778 & 688653 & 4.783 & 5.0902 & TRN & & \\
\hline CHEMBL1494324 & 688653 & 5.983 & 5.2759 & TRN & & \\
\hline CHEMBL1489726 & 688653 & 5.683 & 5.0385 & TST & & \\
\hline CHEMBL579143 & 688653 & 4.933 & 4.6507 & TRN & & \\
\hline CHEMBL1602538 & 688653 & 6.433 & 5.8607 & TRN & & \\
\hline CHEMBL1323629 & 688653 & 4.883 & 5.0234 & TST & & \\
\hline CHEMBL1364287 & 688653 & \multicolumn{3}{|c|}{5.2829999999999995} & 5 . & \\
\hline CHEMBL1367757 & 688653 & 4.783 & 5.1045 & TRN & & \\
\hline CHEMBL1558529 & 688653 & 4.833 & 5.29 & TRN & & \\
\hline CHEMBL1348871 & 688653 & 4.933 & 5.2744 & TRN & & \\
\hline CHEMBL1453005 & 688653 & \multicolumn{3}{|c|}{5.132999999999999} & 5.3111 & \\
\hline CHEMBL1415017 & 688653 & \multicolumn{3}{|c|}{5.132999999999999} & 5.1206 & \\
\hline CHEMBL1583578 & 688653 & 4.933 & 5.1052 & TRN & & \\
\hline CHEMBL1600694 & 688653 & 4.933 & 5.1188 & TST & & \\
\hline CHEMBL1322058 & 688653 & \multicolumn{3}{|c|}{5.332999999999999} & 5.4143 & TRN \\
\hline CHEMBL1425532 & 688653 & \multicolumn{3}{|c|}{5.132999999999999} & 4.9887 & TST \\
\hline CHEMBL1573657 & 688653 & 5.733 & 5.2803 & TRN & & \\
\hline CHEMBL1325207 & 688653 & \multicolumn{3}{|c|}{5.2829999999999995} & 5.2285 & TRN \\
\hline CHEMBL1576751 & 688653 & 4.833 & 5.4384 & TRN & & \\
\hline CHEMBL1361020 & 688653 & 4.833 & 5.456 & TST & & \\
\hline CHEMBL1509763 & 688653 & 4.783 & 5.166 & TRN & & \\
\hline CHEMBL1569394 & 688653 & 5.183 & 5.6083 & TRN & & \\
\hline CHEMBL1335018 & 688653 & 5.083 & 5.3972 & TRN & & \\
\hline CHEMBL1609787 & 688653 & 5.933 & 5.4795 & TRN & & \\
\hline CHEMBL1528010 & 688653 & \multicolumn{3}{|c|}{5.332999999999999} & 5.4939 & $1 \mathrm{~K}$ \\
\hline CHEMBL1384671 & 688653 & 5.483 & 5.2787 & TST & & \\
\hline CHEMBL1326358 & 688653 & \multicolumn{3}{|c|}{5.7829999999999995} & 5.4668 & TRN \\
\hline CHEMBL1453218 & 688653 & \multicolumn{3}{|c|}{4.7330000000000005} & 5.7476 & TRN \\
\hline CHEMBL3193464 & 688653 & \multicolumn{3}{|c|}{4.7330000000000005} & 5.1042 & TRN \\
\hline CHEMBL1353400 & 688653 & 5.083 & 5.0847 & TRN & & \\
\hline CHEMBL1444807 & 688653 & 4.833 & 5.1687 & TRN & & \\
\hline CHEMBL1406726 & 688653 & \multicolumn{3}{|c|}{6.2829999999999995} & 5.5474 & TRN \\
\hline CHEMBL1398590 & 688653 & 4.883 & 5.5825 & TRN & & \\
\hline
\end{tabular}




\begin{tabular}{|c|c|c|c|c|c|c|c|}
\hline & & & 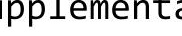 & & . txt & & \\
\hline CHEMBL1462106 & 688653 & 4.783 & 4.9375 & TRN & & & \\
\hline CHEMBL1497989 & 688653 & 5.433 & 5.0424 & TRN & & & \\
\hline CHEMBL1362260 & 688653 & 5.63299 & 99999999 & 99 & 5.745 & TST & \\
\hline CHEMBL 3198254 & 688653 & 4.833 & 5.2468 & TRN & & & \\
\hline CHEMBL1359806 & 688653 & 5.53299 & 99999999 & 995 & 5.3712 & TRN & \\
\hline CHEMBL3197555 & 688653 & 5.433 & 5.1343 & TRN & & & \\
\hline CHEMBL1323581 & 688653 & 5.683 & 5.0393 & TST & & & \\
\hline CHEMBL 297548 & 688653 & 4.633 & 5.2896 & TRN & & & \\
\hline CHEMBL1501419 & 688653 & 4.883 & 5.315 & TST & & & \\
\hline CHEMBL1411739 & 688653 & 5.53299 & 99999999 & 995 & 4.8689 & TST & \\
\hline CHEMBL1429922 & 688653 & 5.83299 & 99999999 & & 5.58 & TRN & \\
\hline CHEMBL1607979 & 688653 & 5.63299 & 99999999 & & 5.365 & TST & \\
\hline CHEMBL1370183 & 688653 & 4.583 & 4.8656 & TRN & & & \\
\hline CHEMBL1545431 & 688653 & 4.833 & 5.13200 & 000000000 & & TST & \\
\hline CHEMBL1437506 & 688653 & 5.483 & 5.1348 & TRN & & & \\
\hline CHEMBL1390471 & 688653 & 4.583 & 4.4331 & TRN & & & \\
\hline CHEMBL1355755 & 688653 & 6.433 & 6.0736 & TRN & & & \\
\hline CHEMBL1567381 & 688653 & 5.38299 & 99999999 & & 5.0129 & TRN & \\
\hline CHEMBL1370267 & 688653 & 4.883 & 5.3313 & TRN & & & \\
\hline CHEMBL1416181 & 688653 & 4.783 & 5.5039 & TRN & & & \\
\hline CHEMBL1471008 & 688653 & 4.933 & 5.113 & TRN & & & \\
\hline CHEMBL1393161 & 688653 & 5.78299 & 99999999 & 995 & 5.2391 & TRN & \\
\hline CHEMBL1583473 & 688653 & 5.83299 & 99999999 & & 5.2828 & TRN & \\
\hline CHEMBL1351751 & 688653 & 4.933 & 5.1409 & TRN & & & \\
\hline CHEMBL3208515 & 688653 & 4.883 & 5.2154 & TRN & & & \\
\hline CHEMBL1603568 & 688653 & 5.13299 & 99999999 & & 5.28299 & 99999999995 & TRN \\
\hline CHEMBL1588367 & 688653 & 4.783 & 5.4466 & TRN & & & \\
\hline CHEMBL1417969 & 688653 & 5.38299 & 99999999 & & 5.3487 & TST & \\
\hline CHEMBL1301023 & 688653 & 4.73300 & 00000000 & 005 & 5.0412 & TRN & \\
\hline CHEMBL1537363 & 688653 & 4.633 & 5.2667 & TRN & & & \\
\hline CHEMBL1515577 & 688653 & 5.88299 & 99999999 & & 5.5973 & TRN & \\
\hline CHEMBL1323036 & 688653 & 4.883 & 4.9701 & TST & & & \\
\hline CHEMBL1449204 & 688653 & 4.583 & 4.8606 & TRN & & & \\
\hline CHEMBL1612786 & 688653 & 4.98300 & 00000000 & 005 & 5.0691 & TST & \\
\hline CHEMBL1513613 & 688653 & 5.733 & 5.003 & TRN & & & \\
\hline CHEMBL1426110 & 688653 & 4.883 & 5.6893 & TRN & & & \\
\hline CHEMBL1467277 & 688653 & 4.783 & 5.251 & TRN & & & \\
\hline CHEMBL1531885 & 688653 & 4.73300 & 00000000 & 005 & 5.0485 & TRN & \\
\hline CHEMBL1533549 & 688653 & 4.883 & 5.4307 & TRN & & & \\
\hline CHEMBL1367069 & 688653 & 4.73300 & 00000000 & 005 & 5.4963 & TRN & \\
\hline CHEMBL1452568 & 688653 & 4.833 & 4.7601 & TRN & & & \\
\hline CHEMBL1496528 & 688653 & 5.933 & 5.7315 & TRN & & & \\
\hline CHEMBL1463218 & 688653 & 5.63299 & 99999999 & & 5.008 & TRN & \\
\hline CHEMBL1451206 & 688653 & 5.183 & 5.15799 & 999999999 & & TRN & \\
\hline CHEMBL1588715 & 688653 & 4.883 & 5.2993 & TRN & & & \\
\hline CHEMBL1400527 & 688653 & 5.033 & 5.0604 & TRN & & & \\
\hline CHEMBL1409161 & 688653 & 4.683 & 5.1897 & TRN & & & \\
\hline CHEMBL1390376 & 688653 & 5.13299 & 99999999 & & 4.8937 & TST & \\
\hline
\end{tabular}




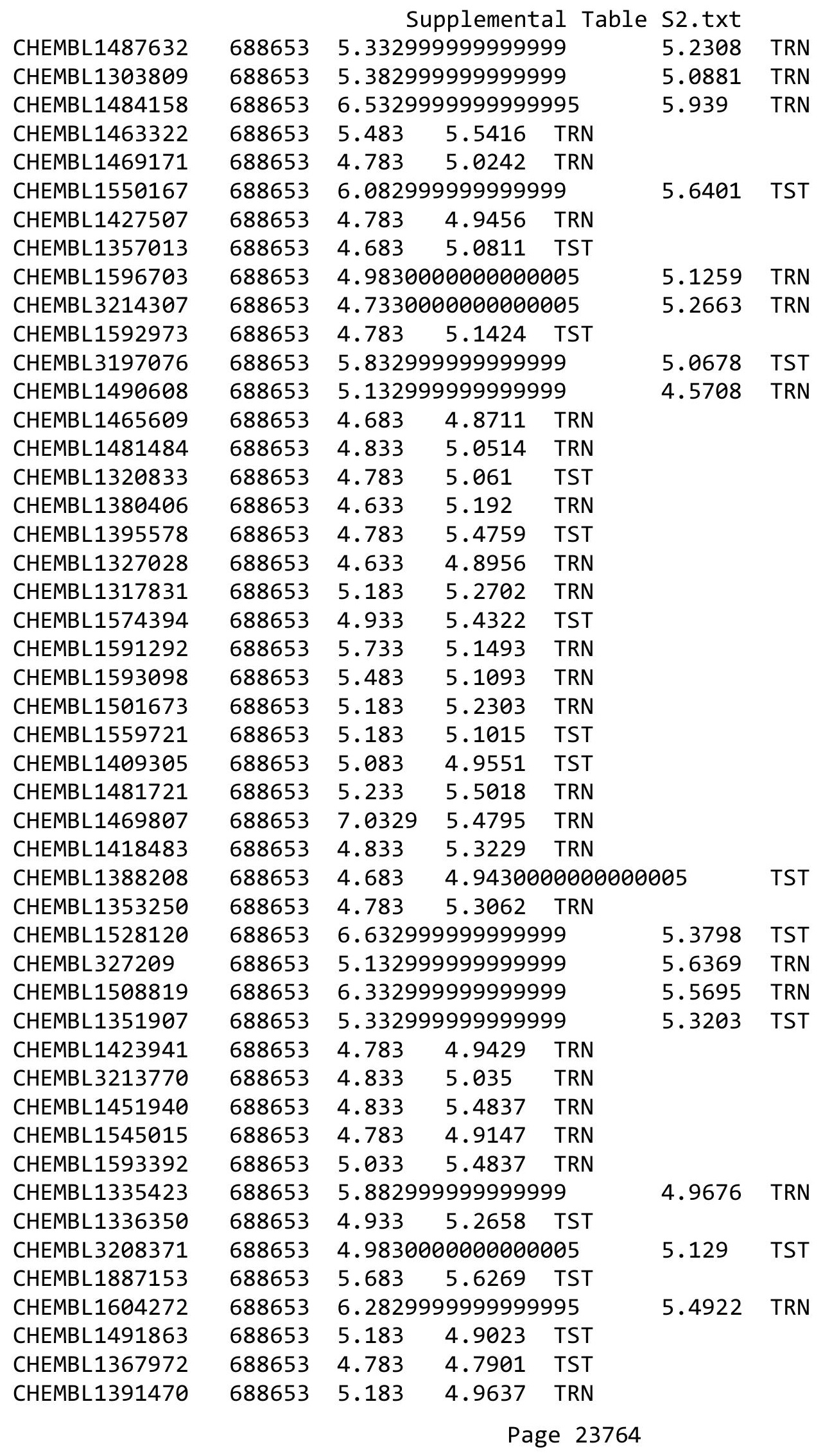




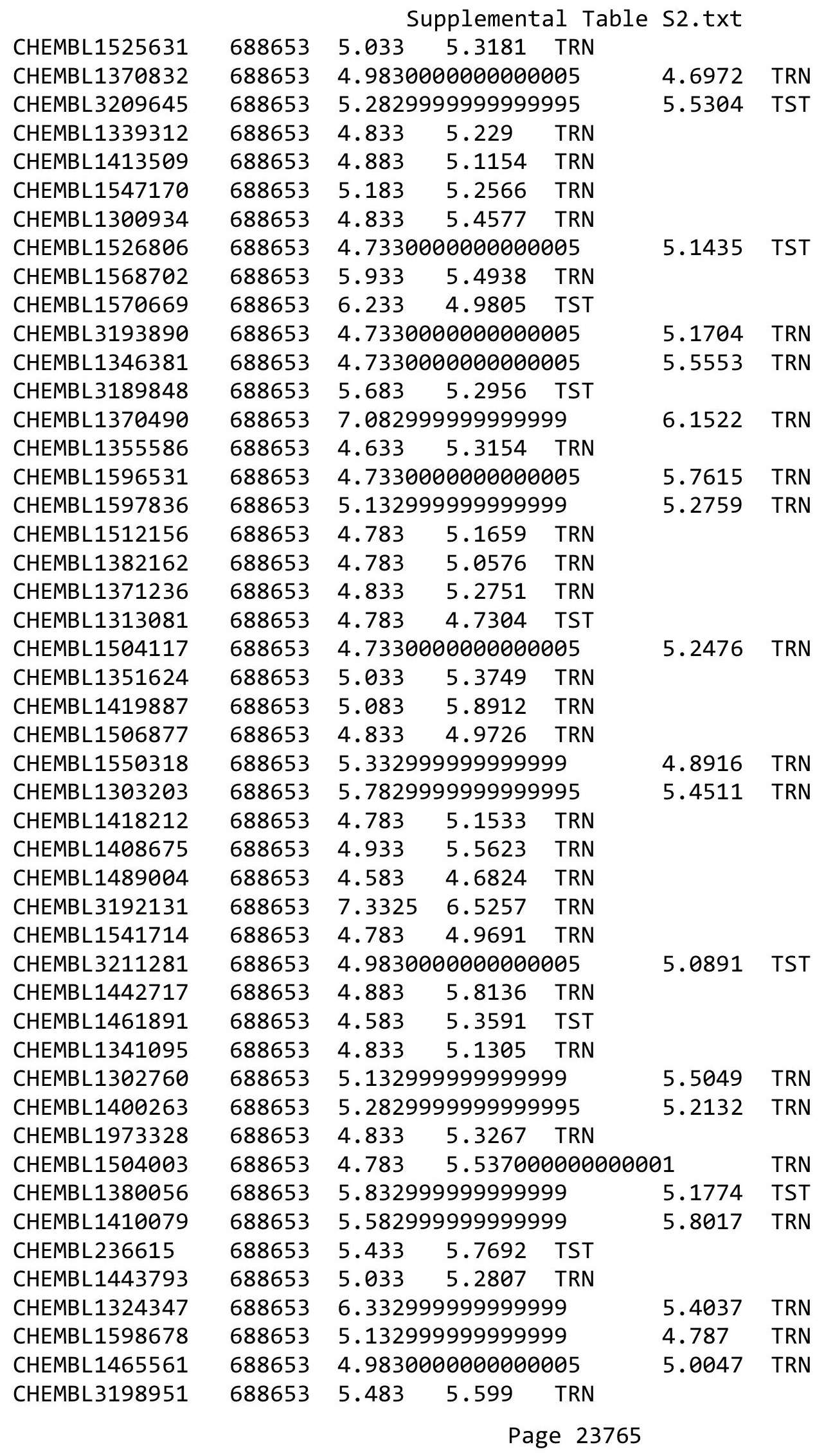




\begin{tabular}{|c|c|c|c|c|c|c|}
\hline \multirow[b]{2}{*}{ CHEMBL1497574 } & \multirow[b]{2}{*}{688653} & \multicolumn{5}{|c|}{ Supplemental Table S2.txt } \\
\hline & & \multicolumn{3}{|c|}{15.9014 TRN } & & \\
\hline CHEMBL1545578 & 688653 & 5.733 & 5.4492 & \multicolumn{3}{|l|}{ TRN } \\
\hline CHEMBL1422674 & 688653 & 4.833 & 5.1412 & \multicolumn{3}{|l|}{ TRN } \\
\hline CHEMBL1317672 & 688653 & \multicolumn{3}{|c|}{5.5329999999999995} & \multirow[t]{3}{*}{5.6044} & \multirow[t]{3}{*}{ TRN } \\
\hline CHEMBL1576893 & 688653 & 5.483 & 5.3105 & TRN & & \\
\hline CHEMBL1384969 & 588653 & 4.833 & 5.2882 & TRN & & \\
\hline CHEMBL1488893 & 688653 & \multicolumn{3}{|c|}{5.882999999999999} & 5.6125 & \\
\hline CHEMBL1497129 & 688653 & \multicolumn{3}{|c|}{4.7330000000000005} & 5.2215 & \\
\hline CHEMBL1444012 & 688653 & 4.833 & 5.5127 & TRN & & \\
\hline CHEMBL1445402 & 688653 & \multicolumn{3}{|c|}{4.9830000000000005} & 5.0188 & \\
\hline CHEMBL1422014 & 688653 & \multicolumn{3}{|c|}{5.5329999999999995} & 5.3681 & \\
\hline CHEMBL1372913 & 688653 & 4.883 & 4.7252 & TRN & & \\
\hline CHEMBL1573380 & 688653 & 6.9329 & 5.6559 & TRN & & \\
\hline CHEMBL1589539 & 688653 & 5.233 & 5.8664 & TST & & \\
\hline CHEMBL1326590 & 688653 & 4.833 & 5.1057 & TRN & & \\
\hline CHEMBL1578993 & 688653 & 5.683 & 4.8526 & TRN & & \\
\hline CHEMBL1460115 & 688653 & \multicolumn{3}{|c|}{4.9830000000000005} & .6165 & \\
\hline CHEMBL1602923 & 688653 & 6.4829 & 6.0327 & TRN & & \\
\hline CHEMBL1366388 & 688653 & \multicolumn{3}{|c|}{4.7330000000000005} & 5.0058 & \\
\hline CHEMBL1452399 & 688653 & 5.483 & 5.3602 & TRN & & \\
\hline CHEMBL1486491 & 688653 & 5.033 & 4.9974 & TRN & & \\
\hline CHEMBL161 & 688653 & 4.883 & 5.2939 & TRN & & \\
\hline CHEMBL13 & 688653 & 5.233 & 5.5423 & TST & & \\
\hline CHEMBL1603078 & 688653 & 4.783 & 4.684 & TRN & & \\
\hline CHEMBL1429620 & 688653 & 5.233 & 5.4055 & TRN & & \\
\hline CHEMBL1386911 & 688653 & 5.183 & 5.1699 & TRN & & \\
\hline CHEMBL1440937 & 688653 & \multicolumn{3}{|c|}{4.9830000000000005} & 5.2414 & \\
\hline CHEMBL14ع & 688653 & \multicolumn{3}{|c|}{5.832999999999999} & 5.0146 & \\
\hline CHEMBL 3189442 & 688653 & \multicolumn{3}{|c|}{6.7829999999999995} & 5.8478 & \\
\hline CHEMBL1547025 & 688653 & 4.633 & 4.7529 & TRN & & \\
\hline CHEMBL1329440 & 688653 & \multicolumn{3}{|c|}{4.7330000000000005} & 4.921 & \\
\hline CHEMBL1 & 688653 & 5.033 & 5.0286 & TRN & & \\
\hline CHEMBL13 & 688653 & \multicolumn{3}{|c|}{5.582999999999999} & 4.8663 & $\mathrm{~T}$ \\
\hline CHEMBL1401680 & 688653 & 5.183 & 5.1766 & TRN & & \\
\hline CHEMBL1536489 & 688653 & 4.933 & 5.07600 & 00006 & 005 & \\
\hline CHEMBL1586553 & 688653 & 5.683 & 5.9101 & TRN & & \\
\hline CHEMBL135 & 688653 & 4.73300 & 00000000 & 005 & 4.9009 & IRIV \\
\hline CHEMBL1339531 & 688653 & 4.98300 & 00000000 & 005 & 5.118 & TPN \\
\hline CHEMBL1491943 & 688653 & 5.083 & 5.2243 & TRN & & \\
\hline CHEMBL3191763 & 688653 & 6.4829 & 5.5713 & TRN & & \\
\hline CHEMBL455284 & 688653 & 7.5834 & 6.2464 & TST & & \\
\hline CHEMBL1321815 & 688653 & 5.58299 & 99999999 & & 5.8008 & TRN \\
\hline CHEMBL1526993 & 688653 & 4.98300 & 00000000 & 005 & 5.1107 & TRN \\
\hline CHEMBL83527 & 688653 & 5.53299 & 99999999 & 995 & 5.3142 & TRN \\
\hline CHEMBL1503102 & 688653 & 4.933 & 5.4543 & TRN & & \\
\hline CHEMBL1462848 & 688653 & 7.2328 & 5.9198 & TRN & & \\
\hline CHEMBL405317 & 688653 & 5.83299 & 99999999 & & 6.9708 & IRIV \\
\hline CHEMBL1532051 & 688653 & 4.73300 & 00000000 & & 5.1759 & \\
\hline
\end{tabular}




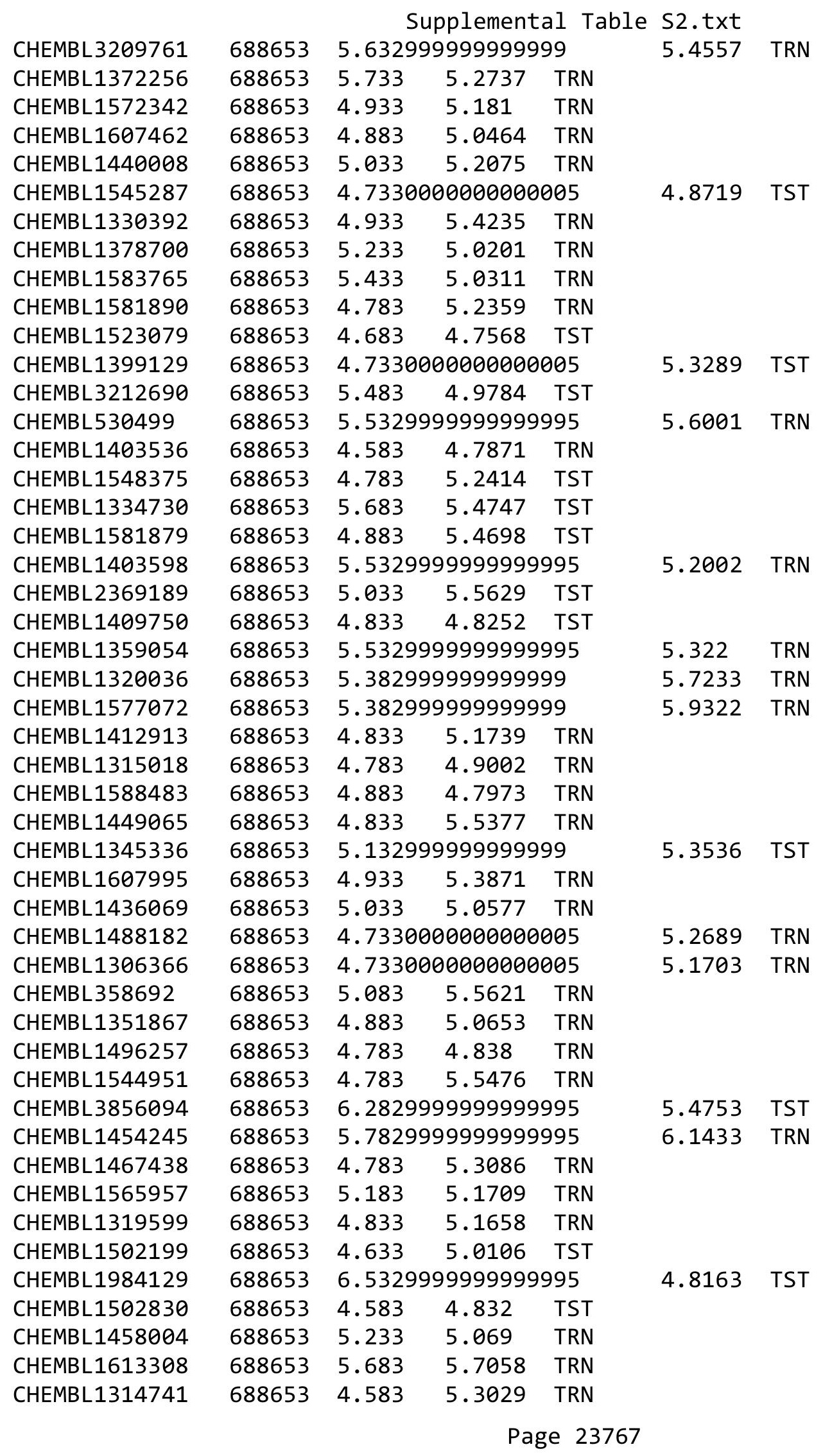




\begin{tabular}{|c|c|c|c|c|c|c|}
\hline \multirow[b]{2}{*}{ CHEMBL3191307 } & \multirow[b]{2}{*}{688653} & \multicolumn{5}{|c|}{ Supplemental Table S2.txt } \\
\hline & & 7.1831 & 5.5298 & TRN & & \\
\hline CHEMBL1448153 & 688653 & 6.433 & 5.8099 & TRN & & \\
\hline CHEMBL1440691 & 688653 & 4.783 & 4.9224 & TST & & \\
\hline CHEMBL1321882 & 688653 & 5.033 & 5.2224 & TST & & \\
\hline CHEMBL1375000 & 688653 & 4.833 & 5.4286 & TRN & & \\
\hline CHEMBL1372857 & 688653 & \multicolumn{3}{|c|}{5.832999999999999} & 4.9167 & TRN \\
\hline CHEMBL1442755 & 688653 & 5.083 & 5.3809 & TRN & & \\
\hline CHEMBL1444476 & 688653 & \multicolumn{3}{|c|}{6.582999999999999} & 5.6703 & TRN \\
\hline CHEMBL1463365 & 688653 & 5.083 & 4.8937 & TRN & & \\
\hline CHEMBL1529837 & 688653 & 5.433 & 5.5343 & TRN & & \\
\hline CHEMBL1364646 & 688653 & \multicolumn{3}{|c|}{6.0329999999999995} & 5.4306 & TST \\
\hline CHEMBL606167 & 688653 & 4.633 & 5.1196 & TST & & \\
\hline CHEMBL1561929 & 688653 & 4.833 & 5.0642 & TRN & & \\
\hline CHEMBL1391942 & 688653 & 4.933 & 5.2332 & TRN & & \\
\hline CHEMBL1326053 & 688653 & 4.633 & 4.9891 & TST & & \\
\hline CHEMBL1607673 & 688653 & \multicolumn{3}{|c|}{4.7330000000000005} & 5.2957 & TRN \\
\hline CHEMBL340701 & 688653 & \multicolumn{3}{|c|}{6.632999999999999} & 5.8137 & TST \\
\hline CHEMBL1352181 & 688653 & 4.783 & 5.3919 & TRN & & \\
\hline CHEMBL1416783 & 688653 & 4.933 & 5.4529 & TRN & & \\
\hline CHEMBL1356308 & 688653 & \multicolumn{3}{|c|}{5.332999999999999} & 4.9702 & TRN \\
\hline CHEMBL1569432 & 688653 & 5.183 & 4.9358 & TST & & \\
\hline CHEMBL581225 & 688653 & \multicolumn{3}{|c|}{5.132999999999999} & 5.2642 & TST \\
\hline CHEMBL1557130 & 688653 & 4.783 & 5.2607 & TRN & & \\
\hline CHEMBL1600513 & 688653 & 4.633 & 4.981 & TRN & & \\
\hline CHEMBL1300792 & 688653 & \multicolumn{3}{|c|}{5.582999999999999} & 5.5845 & TRN \\
\hline CHEMBL1324122 & 688653 & \multicolumn{3}{|c|}{5.632999999999999} & 5.1391 & TRN \\
\hline CHEMBL1570587 & 688653 & 5.033 & 5.6123 & TRN & & \\
\hline CHEMBL1541000 & 688653 & \multicolumn{3}{|c|}{6.382999999999999} & 5.8295 & TRN \\
\hline CHEMBL1344799 & 688653 & \multicolumn{3}{|c|}{5.132999999999999} & 5.2401 & TRN \\
\hline CHEMBL1371689 & 688653 & 4.783 & 5.3596 & TRN & & \\
\hline CHEMBL1600299 & 688653 & 4.783 & 5.3204 & TRN & & \\
\hline CHEMBL1426481 & 688653 & 5.233 & 5.5595 & TRN & & \\
\hline CHEMBL3212409 & 688653 & \multicolumn{3}{|c|}{5.632999999999999} & 5.0054 & TRN \\
\hline CHEMBL1412795 & 688653 & 6.7331 & 5.8298 & TRN & & \\
\hline CHEMBL1342977 & 688653 & 4.833 & 5.3008 & TRN & & \\
\hline CHEMBL1549310 & 688653 & 7.3325 & 5.9942 & TRN & & \\
\hline CHEMBL1500546 & 688653 & 4.883 & 5.5691 & TRN & & \\
\hline CHEMBL1466810 & 688653 & 5.033 & 4.8529 & TRN & & \\
\hline CHEMBL1325528 & 688653 & \multicolumn{3}{|c|}{4.7330000000000005} & 5.0038 & TRN \\
\hline CHEMBL1542862 & 688653 & \multicolumn{3}{|c|}{5.382999999999999} & 4.894 & TRN \\
\hline CHEMBL1495888 & 688653 & 5.733 & 5.4361 & TST & & \\
\hline CHEMBL1492830 & 688653 & 4.933 & 5.3407 & TRN & & \\
\hline CHEMBL1580713 & 688653 & 4.783 & 5.3057 & TST & & \\
\hline CHEMBL1476355 & 688653 & \multicolumn{3}{|c|}{4.7330000000000005} & 5.2147 & TRN \\
\hline CHEMBL1509087 & 688653 & 4.833 & 5.0779 & TST & & \\
\hline CHEMBL3191378 & 688653 & \multicolumn{3}{|c|}{5.7829999999999995} & 5.1142 & TST \\
\hline CHEMBL1313649 & 688653 & 4.833 & 5.1828 & TRN & & \\
\hline CHEMBL1307498 & 688653 & 4.783 & 5.3645 & TRN & & \\
\hline
\end{tabular}




\begin{tabular}{|c|c|c|c|c|c|c|}
\hline CHEMBL1350392 & 688653 & 6.433 & 5.517 & TRN & & \\
\hline CHEMBL1585826 & 688653 & \multicolumn{3}{|c|}{4.7330000000000005} & 4.9983 & TST \\
\hline CHEMBL1434124 & 688653 & 5.733 & 5.5136 & TRN & & \\
\hline CHEMBL 3196413 & 688653 & \multicolumn{3}{|c|}{4.9830000000000005} & 5.3314 & TRN \\
\hline CHEMBL1558952 & 688653 & 5.183 & 4.8076 & TST & & \\
\hline CHEMBL1352298 & 688653 & 4.833 & 5.6218 & TRN & & \\
\hline CHEMBL1301175 & 688653 & 5.983 & 5.5107 & TRN & & \\
\hline CHEMBL1434157 & 688653 & \multicolumn{3}{|c|}{5.632999999999999} & 4.9265 & TST \\
\hline CHEMBL1456847 & 688653 & 4.783 & 5.023 & TRN & & \\
\hline CHEMBL1320798 & 688653 & 4.883 & 4.9469 & TRN & & \\
\hline CHEMBL1397743 & 688653 & 5.733 & 5.3631 & TST & & \\
\hline CHEMBL1405521 & 688653 & 5.233 & 5.3374 & TRN & & \\
\hline CHEMBL1499694 & 688653 & \multicolumn{3}{|c|}{4.7330000000000005} & 5.0733 & TST \\
\hline CHEMBL1355094 & 688653 & 5.433 & 5.4327 & TST & & \\
\hline CHEMBL1318021 & 688653 & 5.083 & 4.8822 & TRN & & \\
\hline CHEMBL1350376 & 688653 & 4.883 & 5.5082 & TST & & \\
\hline CHEMBL1580686 & 688653 & 5.033 & \multicolumn{3}{|c|}{5.281000000000001} & TRN \\
\hline CHEMBL 3194760 & 688653 & 5.683 & 5.2514 & TST & & \\
\hline CHEMBL1495434 & 688653 & 4.633 & 5.0078 & TST & & \\
\hline CHEMBL1491636 & 688653 & \multicolumn{3}{|c|}{6.132999999999999} & 5.197 & TRN \\
\hline CHEMBL1332887 & 688653 & \multicolumn{3}{|c|}{5.632999999999999} & 5.1852 & TRN \\
\hline CHEMBL1365174 & 688653 & \multicolumn{3}{|c|}{4.7330000000000005} & 4.9601 & TRN \\
\hline CHEMBL1517198 & 688653 & \multicolumn{3}{|c|}{5.882999999999999} & 5.4079 & TRN \\
\hline CHEMBL1456251 & 688653 & 5.983 & 5.6864 & TRN & & \\
\hline CHEMBL1576542 & 688653 & \multicolumn{3}{|c|}{4.7330000000000005} & 5.5524 & TST \\
\hline CHEMBL1606031 & 688653 & 5.233 & 6.0633 & TRN & & \\
\hline CHEMBL1574539 & 688653 & 5.983 & 5.869 & TRN & & \\
\hline CHEMBL1406040 & 688653 & \multicolumn{3}{|c|}{5.5329999999999995} & 5.5486 & TRN \\
\hline CHEMBL1506896 & 688653 & \multicolumn{3}{|c|}{4.9830000000000005} & 5.0522 & TRN \\
\hline CHEMBL1354324 & 688653 & \multicolumn{3}{|c|}{ 5.382999999999999 } & 4.9537 & TRN \\
\hline CHEMBL1594537 & 688653 & 5.483 & 5.047 & TRN & & \\
\hline CHEMBL 3213314 & 688653 & \multicolumn{3}{|c|}{6.0329999999999995} & 5.7224 & TRN \\
\hline CHEMBL1429241 & 688653 & \multicolumn{3}{|c|}{5.832999999999999} & 5.7419 & TST \\
\hline CHEMBL1548814 & 688653 & \multicolumn{3}{|c|}{5.882999999999999} & 5.7339 & TRN \\
\hline CHEMBL1586427 & 688653 & \multicolumn{3}{|c|}{5.7829999999999995} & 5.557 & TST \\
\hline CHEMBL1455171 & 688653 & 5.083 & 5.5606 & TRN & & \\
\hline CHEMBL3197353 & 688653 & 4.783 & \multicolumn{3}{|c|}{5.382000000000001} & TRN \\
\hline CHEMBL1564875 & 688653 & 4.933 & 5.1424 & TRN & & \\
\hline CHEMBL1409107 & 688653 & \multicolumn{3}{|c|}{4.7330000000000005} & 5.4362 & TST \\
\hline CHEMBL1417266 & 688653 & 4.833 & 5.4607 & TST & & \\
\hline CHEMBL1336113 & 688653 & 5.683 & 5.1665 & TST & & \\
\hline CHEMBL1499926 & 688653 & 5.933 & 5.8974 & TRN & & \\
\hline CHEMBL1492412 & 688653 & \multicolumn{3}{|c|}{5.7829999999999995} & 5.754 & TRN \\
\hline CHEMBL1505118 & 688653 & 4.783 & 4.9735 & TST & & \\
\hline CHEMBL 3199870 & 688653 & \multicolumn{3}{|c|}{5.632999999999999} & 5.5627 & TRN \\
\hline CHEMBL1319960 & 688653 & 4.883 & \multicolumn{3}{|c|}{5.372999999999999} & TRN \\
\hline CHEMBL1419015 & 688653 & 4.7330 & 00000000 & 005 & 5.0353 & TRN \\
\hline CHEMBL1388559 & 688653 & 6.2829 & 99999999 & 995 & 5.0309 & TRN \\
\hline
\end{tabular}

Page 23769 


\begin{tabular}{|c|c|c|c|c|c|c|}
\hline \multicolumn{7}{|c|}{ Supplemental Table S2.txt } \\
\hline CHEMBL1446849 & 688653 & \multicolumn{3}{|c|}{5.7829999999999995} & 5.1299 & TRN \\
\hline CHEMBL1590402 & 688653 & \multicolumn{3}{|c|}{4.7330000000000005} & 4.9308 & TRN \\
\hline CHEMBL164103 & 688653 & 4.783 & 5.8031 & TST & & \\
\hline CHEMBL1333162 & 688653 & \multicolumn{3}{|c|}{5.832999999999999} & 5.4643 & TRN \\
\hline CHEMBL1342754 & 688653 & 4.883 & 5.4062 & TRN & & \\
\hline CHEMBL1546185 & 688653 & 5.733 & 5.5082 & TST & & \\
\hline CHEMBL1573533 & 688653 & \multicolumn{3}{|c|}{4.9830000000000005} & 5.0788 & TRN \\
\hline CHEMBL1594072 & 688653 & 4.633 & 4.9323 & TRN & & \\
\hline CHEMBL 3190911 & 688653 & 5.233 & 5.2828 & TST & & \\
\hline CHEMBL3213784 & 688653 & \multicolumn{3}{|c|}{5.882999999999999} & 5.2701 & TST \\
\hline CHEMBL1399704 & 688653 & 4.833 & 5.4241 & TST & & \\
\hline CHEMBL1470256 & 688653 & \multicolumn{3}{|c|}{5.582999999999999} & 5.4449 & TRN \\
\hline CHEMBL1496413 & 688653 & 6.433 & \multicolumn{3}{|c|}{5.542000000000001} & TRN \\
\hline CHEMBL1412033 & 688653 & 5.083 & 5.0774 & TRN & & \\
\hline CHEMBL1565008 & 688653 & 4.933 & 5.0624 & TRN & & \\
\hline CHEMBL1564558 & 688653 & \multicolumn{3}{|c|}{5.2829999999999995} & 5.5523 & TRN \\
\hline CHEMBL1567689 & 688653 & 4.883 & 5.1059 & TRN & & \\
\hline CHEMBL 1404056 & 688653 & \multicolumn{3}{|c|}{4.7330000000000005} & 5.2308 & TRN \\
\hline CHEMBL1301234 & 688653 & 4.883 & \multicolumn{3}{|c|}{5.0969999999999995} & TRN \\
\hline CHEMBL1329756 & 688653 & \multicolumn{3}{|c|}{4.9830000000000005} & 4.956 & TRN \\
\hline CHEMBL1403949 & 688653 & \multicolumn{3}{|c|}{4.7330000000000005} & 5.0967 & TRN \\
\hline CHEMBL1580545 & 688653 & \multicolumn{3}{|c|}{5.132999999999999} & 4.9879 & TRN \\
\hline CHEMBL1444023 & 688653 & \multicolumn{3}{|c|}{5.582999999999999} & 5.5226 & TRN \\
\hline CHEMBL1612398 & 688653 & 4.783 & 5.2622 & TST & & \\
\hline CHEMBL1353386 & 688653 & 4.583 & 5.0204 & TRN & & \\
\hline CHEMBL1214345 & 688653 & 5.683 & 5.6357 & TRN & & \\
\hline CHEMBL 3192246 & 688653 & 5.183 & 5.3655 & TRN & & \\
\hline CHEMBL1539454 & 688653 & \multicolumn{3}{|c|}{5.632999999999999} & 5.5044 & TRN \\
\hline CHEMBL1328132 & 688653 & \multicolumn{3}{|c|}{5.132999999999999} & 4.8656 & TRN \\
\hline CHEMBL3193507 & 688653 & 5.233 & 5.237 & TRN & & \\
\hline CHEMBL1333410 & 688653 & \multicolumn{3}{|c|}{6.5329999999999995} & 5.1375 & TRN \\
\hline CHEMBL1558727 & 688653 & 6.9329 & 5.6999 & TRN & & \\
\hline CHEMBL1336467 & 688653 & 5.083 & 4.9185 & TST & & \\
\hline CHEMBL1610481 & 688653 & 4.583 & 5.0941 & TST & & \\
\hline CHEMBL3210997 & 688653 & 5.733 & \multicolumn{3}{|c|}{5.2860000000000005} & TRN \\
\hline CHEMBL1373816 & 688653 & 5.083 & 5.2487 & TRN & & \\
\hline CHEMBL1583889 & 688653 & \multicolumn{3}{|c|}{5.5329999999999995} & 5.069 & TRN \\
\hline CHEMBL1569588 & 688653 & 4.783 & 5.3717 & TRN & & \\
\hline CHEMBL1581370 & 688653 & 5.233 & 5.3035 & TRN & & \\
\hline CHEMBL1600675 & 688653 & 5.083 & 5.2483 & TRN & & \\
\hline CHEMBL1325794 & 688653 & 4.833 & 5.4771 & TRN & & \\
\hline CHEMBL1504527 & 688653 & 5.033 & 5.1748 & TRN & & \\
\hline CHEMBL1568928 & 688653 & 4.783 & 5.2682 & TRN & & \\
\hline CHEMBL1582269 & 688653 & 5.683 & 5.2797 & TRN & & \\
\hline CHEMBL1380186 & 688653 & 5.933 & 5.0973 & TRN & & \\
\hline CHEMBL1514744 & 688653 & 5.433 & 4.8354 & TST & & \\
\hline CHEMBL1577648 & 688653 & 4.883 & 5.1803 & TRN & & \\
\hline CHEMBL1466749 & 688653 & 5.28299 & 99999999 & 995 & 5.21399 & 99999999995 \\
\hline
\end{tabular}




\begin{tabular}{|c|c|c|c|c|c|c|c|}
\hline \multicolumn{8}{|c|}{ Supplemental Table s2.txt } \\
\hline CHEMBL1347069 & 688653 & 5.033 & 5.2216 & TRN & & & \\
\hline CHEMBL1445251 & 688653 & 5.483 & 5.5343 & TRN & & & \\
\hline CHEMBL1522556 & 688653 & 4.98300 & 00000000 & 005 & 5.234 & TRN & \\
\hline CHEMBL3192368 & 688653 & 5.733 & 5.2243 & TST & & & \\
\hline CHEMBL1555145 & 688653 & 6.08299 & 99999999 & & 5.5425 & TRN & \\
\hline CHEMBL1355643 & 688653 & 5.88299 & 99999999 & & 5.2849 & TRN & \\
\hline CHEMBL1561737 & 688653 & 5.683 & 5.2704 & TRN & & & \\
\hline CHEMBL1592987 & 688653 & 4.73300 & 00000000 & 005 & 5.0282 & TRN & \\
\hline CHEMBL1524233 & 688653 & 4.583 & 4.7837 & TRN & & & \\
\hline CHEMBL1371379 & 688653 & 4.883 & 5.3317 & TST & & & \\
\hline CHEMBL1388983 & 688653 & 4.883 & 5.5938 & TRN & & & \\
\hline CHEMBL1439709 & 688653 & 4.933 & 5.0393 & TST & & & \\
\hline CHEMBL1593820 & 688653 & 4.73300 & 00000000 & 005 & 5.28100 & 0000000001 & TRN \\
\hline CHEMBL1452626 & 688653 & 5.63299 & 99999999 & & 5.7238 & TRN & \\
\hline CHEMBL1461593 & 688653 & 5.38299 & 99999999 & & 5.9172 & TRN & \\
\hline CHEMBL1449120 & 688653 & 4.783 & 5.4686 & TST & & & \\
\hline CHEMBL1473136 & 688653 & 4.73300 & 00000000 & 005 & 4.8493 & TRN & \\
\hline CHEMBL1366369 & 688653 & 5.733 & 5.9281 & TRN & & & \\
\hline CHEMBL1408742 & 688653 & 6.08299 & 99999999 & & 6.1116 & TRN & \\
\hline CHEMBL1431719 & 688653 & 4.98300 & 00000000 & 005 & 4.9664 & TST & \\
\hline CHEMBL578420 & 688653 & 5.683 & 5.6589 & TRN & & & \\
\hline CHEMBL3193967 & 688653 & 5.433 & 5.5712 & TRN & & & \\
\hline CHEMBL1553419 & 688653 & 5.683 & 5.6612 & TRN & & & \\
\hline CHEMBL1338307 & 688653 & 5.88299 & 99999999 & & 5.1831 & TST & \\
\hline CHEMBL1605926 & 688653 & 5.38299 & 99999999 & & 5.3102 & TRN & \\
\hline CHEMBL1382278 & 688653 & 5.483 & 5.7357 & TRN & & & \\
\hline CHEMBL1567567 & 688653 & 4.73300 & 00000000 & 005 & 5.4423 & TRN & \\
\hline CHEMBL1460004 & 688653 & 5.53299 & 99999999 & 995 & 5.1071 & TRN & \\
\hline CHEMBL1303164 & 688653 & 4.73300 & 00000000 & 005 & 5.17299 & 9999999999 & TRN \\
\hline CHEMBL1433153 & 688653 & 5.63299 & 99999999 & & 5.2594 & TRN & \\
\hline CHEMBL1508896 & 688653 & 4.833 & 5.0654 & TST & & & \\
\hline CHEMBL1429121 & 688653 & 4.783 & 5.3687 & TRN & & & \\
\hline CHEMBL1359125 & 688653 & 5.433 & 5.3687 & TRN & & & \\
\hline CHEMBL1336470 & 688653 & 5.983 & 5.8495 & TRN & & & \\
\hline CHEMBL1379666 & 688653 & 5.83299 & 99999999 & 99 & 5.4335 & TRN & \\
\hline CHEMBL1466745 & 688653 & 4.933 & 5.4806 & TRN & & & \\
\hline CHEMBL1500876 & 688653 & 4.633 & 5.75700 & 000000000 & & TRN & \\
\hline CHEMBL1320313 & 688653 & 4.783 & 5.0294 & TRN & & & \\
\hline CHEMBL1449675 & 688653 & 4.833 & 5.7953 & TRN & & & \\
\hline CHEMBL1487298 & 688653 & 4.783 & 5.1067 & TST & & & \\
\hline CHEMBL1507872 & 688653 & 5.483 & 5.2215 & TST & & & \\
\hline CHEMBL1501550 & 688653 & 5.033 & 5.4896 & TRN & & & \\
\hline CHEMBL1537398 & 688653 & 5.0 & 5.2256 & TST & & & \\
\hline CHEMBL507237 & 688653 & 5.183 & 5.4188 & TST & & & \\
\hline CHEMBL1382538 & 688653 & 6.83299 & 99999999 & 99 & 5.7653 & TST & \\
\hline CHEMBL3196009 & 688653 & 5.433 & 5.0304 & TRN & & & \\
\hline CHEMBL1420410 & 688653 & 4.833 & 4.869 & TRN & & & \\
\hline CHEMBL1462272 & 688653 & 4.833 & 5.4397 & TRN & & & \\
\hline
\end{tabular}




\begin{tabular}{|c|c|c|c|c|c|c|}
\hline \multirow[b]{2}{*}{ CHEMBL1435462 } & \multirow[b]{2}{*}{688653} & \multicolumn{5}{|c|}{ Supplemental Table S2.txt } \\
\hline & & 4.633 & 5.1607 & TST & & \\
\hline CHEMBL1311348 & 688653 & 5.83299 & 999999999 & & 5.6165 & TST \\
\hline CHEMBL1469660 & 688653 & 5.033 & 5.6012 & TRN & & \\
\hline CHEMBL1523081 & 688653 & 5.733 & 5.1334 & TRN & & \\
\hline CHEMBL1406433 & 688653 & 5.183 & 5.0187 & TRN & & \\
\hline CHEMBL1598180 & 688653 & 5.933 & 5.8109 & TRN & & \\
\hline CHEMBL1393714 & 688653 & 5.933 & 5.7438 & TRN & & \\
\hline CHEMBL1564080 & 688653 & 6.53299 & 999999999 & 995 & 5.4892 & TRN \\
\hline CHEMBL1569547 & 688653 & 5.9718 & 5.4575 & TST & & \\
\hline CHEMBL1402755 & 688653 & 4.73300 & 000000000 & 005 & 5.3398 & TST \\
\hline CHEMBL1374870 & 688653 & 5.83299 & 999999999 & & 5.7105 & TRN \\
\hline CHEMBL1385691 & 688653 & 4.783 & 5.0119 & TRN & & \\
\hline CHEMBL1599851 & 688653 & 5.033 & 4.959 & TRN & & \\
\hline CHEMBL1303449 & 688653 & 6.233 & 5.1396 & TRN & & \\
\hline CHEMBL1497694 & 688653 & 5.683 & 5.1272 & TRN & & \\
\hline CHEMBL1442805 & 688653 & 4.833 & 4.9956 & TST & & \\
\hline CHEMBL1598418 & 688653 & 6.433 & 5.4619 & TRN & & \\
\hline CHEMBL583378 & 688653 & 5.78299 & 999999999 & 995 & 5.874 & TRN \\
\hline CHEMBL1540570 & 688653 & 5.983 & 5.1305 & TST & & \\
\hline CHEMBL1401137 & 688653 & 5.933 & 5.7298 & TRN & & \\
\hline CHEMBL1990057 & 688653 & 5.58299 & 999999999 & & 5.3756 & TRN \\
\hline CHEMBL1596442 & 688653 & 4.783 & 4.713 & TRN & & \\
\hline CHEMBL3213329 & 688653 & 5.83299 & 999999999 & & 5.1473 & TST \\
\hline CHEMBL 210658 & 688653 & 5.983 & 5.9993 & TRN & & \\
\hline CHEMBL1327912 & 688653 & 4.73300 & 000000000 & 005 & 5.1129 & TRN \\
\hline CHEMBL1449522 & 688653 & 4.883 & 5.1193 & TRN & & \\
\hline CHEMBL1462541 & 688653 & 4.98300 & 000000000 & 005 & 5.596 & TST \\
\hline CHEMBL1485101 & 688653 & 6.78299 & 999999999 & 995 & 5.8953 & TRA \\
\hline CHEMBL1299628 & 688653 & 5.683 & 5.0691 & TST & & \\
\hline CHEMBL1336269 & 688653 & 5.683 & 5.3813 & TRN & & \\
\hline CHEMBL 3193541 & 688653 & 5.183 & 5.3615 & TRN & & \\
\hline CHEMBL1404018 & 688653 & 4.883 & 5.4187 & TRN & & \\
\hline CHEMBL1330768 & 688653 & 5.483 & 5.1322 & TRN & & \\
\hline CHEMBL1356438 & 688653 & 5.88299 & 999999999 & & 5.7913 & TRN \\
\hline CHEMBL1465899 & 688653 & 4.583 & 4.6039 & TRN & & \\
\hline CHEMBL1575543 & 688653 & 5.28299 & 999999999 & 995 & 5.1965 & TRN \\
\hline CHEMBL3198324 & 688653 & 4.883 & 5.3791 & TRN & & \\
\hline CHEMBL1377335 & 688653 & 5.38299 & 999999999 & & 5.0496 & TRN \\
\hline CHEMBL1335610 & 688653 & 4.633 & 4.6162 & TRN & & \\
\hline CHEMBL1451985 & 688653 & 5.58299 & 999999999 & 99 & 5.3472 & TRN \\
\hline CHEMBL1369039 & 688653 & 4.883 & 4.9594 & TRN & & \\
\hline CHEMBL3196573 & 688653 & 5.53299 & 999999999 & 995 & 5.2719 & TRN \\
\hline CHEMBL1433269 & 688653 & 4.683 & 4.737 & TST & & \\
\hline CHEMBL1392200 & 688653 & 5.733 & 6.1382 & TRN & & \\
\hline CHEMBL1321914 & 688653 & 4.933 & 4.8816 & TRN & & \\
\hline CHEMBL1414254 & 688653 & 5.83299 & 999999999 & 99 & 5.5757 & TST \\
\hline CHEMBL1450675 & 688653 & 5.083 & 5.4065 & TRN & & \\
\hline CHEMBL1416184 & 688653 & 4.633 & 4.8076 & TRN & & \\
\hline
\end{tabular}




\begin{tabular}{|c|c|c|c|c|c|c|}
\hline \multirow[b]{2}{*}{ CHEMBL1491181 } & \multirow[b]{2}{*}{688653} & \multicolumn{5}{|c|}{ Supplemental Table S2.txt } \\
\hline & & \multirow{2}{*}{\multicolumn{3}{|c|}{$\begin{array}{lc}5.183 & 5.0838 \\
5.382999999999999\end{array}$}} & \multirow[b]{2}{*}{5.3532} & \multirow[b]{2}{*}{ TRA } \\
\hline CHEMBL1407442 & 688653 & & & & & \\
\hline CHEMBL394287 & 688653 & 4.883 & 5.3043 & TST & & \\
\hline CHEMBL1524743 & 688653 & 4.883 & 4.9807 & TST & & \\
\hline CHEMBL1368414 & 688653 & 4.783 & 4.9679 & TRN & & \\
\hline CHEMBL1453903 & 688653 & 5.433 & 4.8983 & TRN & & \\
\hline CHEMBL3198408 & 688653 & 5.083 & 5.1727 & TRN & & \\
\hline CHEMBL1534284 & 688653 & 4.783 & 5.5282 & TRN & & \\
\hline CHEMBL1372799 & 688653 & \multicolumn{3}{|c|}{5.5329999999999995} & 5.1739 & TRN \\
\hline CHEMBL1457070 & 688653 & \multicolumn{3}{|c|}{5.7829999999999995} & 5.3045 & TRN \\
\hline CHEMBL1600504 & 688653 & \multicolumn{3}{|c|}{4.7330000000000005} & 4.7204 & TST \\
\hline CHEMBL1339609 & 688653 & 5.733 & 5.2 & TRN & & \\
\hline CHEMBL1597766 & 688653 & \multicolumn{3}{|c|}{4.9830000000000005} & 5.1292 & TST \\
\hline CHEMBL1457356 & 688653 & 6.433 & 5.1859 & TRN & & \\
\hline CHEMBL1572411 & 688653 & \multicolumn{3}{|c|}{5.882999999999999} & 5.7562 & TRN \\
\hline CHEMBL1300882 & 688653 & \multicolumn{3}{|c|}{5.132999999999999} & 5.4284 & TRN \\
\hline CHEMBL1396285 & 688653 & 4.583 & 4.9808 & TST & & \\
\hline CHEMBL1521187 & 688653 & 6.983 & 5.9208 & TRN & & \\
\hline CHEMBL1334244 & 688653 & 6.183 & 5.376 & TRN & & \\
\hline CHEMBL1525755 & 688653 & 4.883 & 5.3156 & TST & & \\
\hline CHEMBL1564239 & 688653 & 4.833 & 4.6428 & TRN & & \\
\hline CHEMBL3192618 & 688653 & \multicolumn{3}{|c|}{5.5329999999999995} & 5.3086 & TRN \\
\hline CHEMBL1347628 & 688653 & 4.633 & 5.4501 & TRN & & \\
\hline CHEMBL1391348 & 688653 & 4.883 & 5.0335 & TRN & & \\
\hline CHEMBL1567438 & 688653 & 4.833 & 4.9659 & TRN & & \\
\hline CHEMBL1308482 & 688653 & \multicolumn{3}{|c|}{5.5329999999999995} & 5.7017 & TRN \\
\hline CHEMBL260148 & 688653 & 4.633 & 5.1503 & TRN & & \\
\hline CHEMBL1554406 & 688653 & & 4.8817 & TRN & & \\
\hline CHEMBL1453314 & 688653 & \multicolumn{3}{|c|}{6.082999999999999} & 4.7661 & TST \\
\hline CHEMBL1613402 & 688653 & 5.033 & 5.2784 & TST & & \\
\hline CHEMBL1508110 & 688653 & 5.183 & 5.6635 & TRN & & \\
\hline CHEMBL1345081 & 688653 & 6.983 & 5.865 & TRN & & \\
\hline CHEMBL1514917 & 688653 & 4.683 & 5.2236 & TST & & \\
\hline CHEMBL1518412 & 688653 & \multicolumn{3}{|c|}{6.582999999999999} & 5.8 & TRN \\
\hline CHEMBL1347541 & 688653 & 4.683 & 5.1732 & TST & & \\
\hline CHEMBL1314507 & 688653 & 4.833 & 5.0809 & TST & & \\
\hline CHEMBL1601556 & 688653 & 4.783 & 4.9926 & TST & & \\
\hline CHEMBL3211498 & 688653 & \multicolumn{3}{|c|}{4.9830000000000005} & 5.269 & TST \\
\hline CHEMBL1342644 & 688653 & 5.483 & 5.4408 & TRN & & \\
\hline CHEMBL1384253 & 688653 & \multicolumn{3}{|c|}{5.5329999999999995} & 5.5772 & TRN \\
\hline CHEMBL1447465 & 688653 & \multicolumn{3}{|c|}{5.132999999999999} & 5.3976 & TRN \\
\hline CHEMBL1394510 & 688653 & 4.583 & 4.8839 & TRN & & \\
\hline CHEMBL1571522 & 688653 & \multirow{2}{*}{\multicolumn{3}{|c|}{$\begin{array}{lr}4.683 & 5.2815 \\
6.0329999999999995\end{array}$}} & & \\
\hline CHEMBL1598005 & 688653 & & & & 5.7877 & TRN \\
\hline CHEMBL1542481 & 688653 & 5.433 & 5.0485 & TRN & & \\
\hline CHEMBL3198766 & 688653 & 4.933 & 5.1996 & TST & & \\
\hline CHEMBL1591534 & 688653 & 4.633 & 5.0097 & TRN & & \\
\hline CHEMBL1415025 & 688653 & 5.183 & 5.3137 & TRN & & \\
\hline
\end{tabular}




\begin{tabular}{|c|c|c|c|c|c|c|}
\hline \multirow{3}{*}{$\begin{array}{l}\text { CHEMBL1502183 } \\
\text { CHEMBL3210655 }\end{array}$} & \multirow{3}{*}{$\begin{array}{l}688653 \\
688653\end{array}$} & \multicolumn{4}{|c|}{ Supplemental Table S2.txt } & \multirow[b]{2}{*}{ TRN } \\
\hline & & \multicolumn{3}{|c|}{6.582999999999999} & 5.8065 & \\
\hline & & 4.833 & 5.3518 & TRN & & \\
\hline CHEMBL1604376 & 688653 & \multicolumn{3}{|c|}{6.2829999999999995} & 5.9105 & TRN \\
\hline CHEMBL1299537 & 688653 & 4.883 & 5.145 & TST & & \\
\hline CHEMBL3191239 & 688653 & \multicolumn{3}{|c|}{6.582999999999999} & 5.9325 & TRN \\
\hline CHEMBL1511243 & 688653 & \multicolumn{3}{|c|}{5.5329999999999995} & 5.2974 & TRN \\
\hline CHEMBL1545729 & 688653 & \multicolumn{3}{|c|}{6.2829999999999995} & 5.1589 & TRN \\
\hline CHEMBL1547438 & 688653 & \multicolumn{3}{|c|}{5.7829999999999995} & 5.5799 & TRN \\
\hline CHEMBL1387283 & 688653 & \multicolumn{3}{|c|}{5.132999999999999} & 5.4628 & TRA \\
\hline CHEMBL3198492 & 688653 & 6.183 & 5.2886 & TRN & & \\
\hline CHEMBL1498359 & 688653 & \multicolumn{3}{|c|}{6.2829999999999995} & 5.2299 & TRN \\
\hline CHEMBL1476692 & 688653 & 5.483 & 5.0809 & TRN & & \\
\hline CHEMBL1483638 & 688653 & \multicolumn{3}{|c|}{5.582999999999999} & 5.317 & TRN \\
\hline CHEMBL1333785 & 688653 & \multicolumn{3}{|c|}{5.382999999999999} & 5.1294 & TRA \\
\hline CHEMBL1463581 & 688653 & 4.833 & 4.9121 & TRN & & \\
\hline CHEMBL1386793 & 688653 & 4.933 & 5.3174 & TRN & & \\
\hline CHEMBL1362990 & 688653 & 4.783 & 4.7709 & TRN & & \\
\hline CHEMBL1571971 & 688653 & 6.0 & 5.5586 & TRN & & \\
\hline CHEMBL1579114 & 688653 & \multicolumn{3}{|c|}{5.2829999999999995} & 5.2099 & TRN \\
\hline CHEMBL1393224 & 688653 & \multicolumn{3}{|c|}{4.7330000000000005} & 4.9898 & TRN \\
\hline CHEMBL1368493 & 688653 & 4.783 & 4.8425 & TRN & & \\
\hline CHEMBL1386689 & 688653 & 7.2832 & 5.403 & TRN & & \\
\hline CHEMBL1404269 & 688653 & 5.083 & 5.1865 & TST & & \\
\hline CHEMBL1570881 & 688653 & 4.933 & 5.2745 & TRN & & \\
\hline CHEMBL1526782 & 688653 & 4.883 & 5.2408 & TST & & \\
\hline CHEMBL 3194073 & 688653 & \multicolumn{3}{|c|}{5.132999999999999} & 5.2844 & TRN \\
\hline CHEMBL1575652 & 688653 & 4.833 & 5.2711 & TST & & \\
\hline CHEMBL1522587 & 688653 & \multicolumn{3}{|c|}{6.5329999999999995} & 4.8126 & TST \\
\hline CHEMBL1388229 & 688653 & \multicolumn{3}{|c|}{5.132999999999999} & 4.9649 & TRN \\
\hline CHEMBL1362763 & 688653 & \multicolumn{3}{|c|}{4.7330000000000005} & 5.3665 & TST \\
\hline CHEMBL 3192572 & 688653 & 4.933 & 5.0452 & TRN & & \\
\hline CHEMBL1484987 & 688653 & \multicolumn{3}{|c|}{4.7330000000000005} & 5.0595 & TST \\
\hline CHEMBL1377737 & 688653 & 5.983 & 5.4521 & TRN & & \\
\hline CHEMBL3193566 & 688653 & 5.83299 & 99999999 & & 5.6317 & TRN \\
\hline CHEMBL1371392 & 688653 & 4.73300 & 00000000 & 005 & 4.8634 & TST \\
\hline CHEMBL1319810 & 688653 & 5.13299 & 99999999 & & 5.7272 & TRA \\
\hline CHEMBL3190952 & 688653 & 5.78299 & 99999999 & 995 & 5.4195 & TRN \\
\hline CHEMBL1400851 & 688653 & 5.33299 & 99999999 & & 5.355 & TRN \\
\hline CHEMBL1483191 & 688653 & 5.683 & 5.575 & TRN & & \\
\hline CHEMBL3190592 & 688653 & 5.683 & 5.3308 & TRN & & \\
\hline CHEMBL1359879 & 688653 & 5.983 & 5.6544 & TRN & & \\
\hline CHEMBL1326567 & 688653 & 4.833 & 5.0827 & TRN & & \\
\hline CHEMBL1510242 & 688653 & 5.33299 & 99999999 & & 5.0909 & TRN \\
\hline CHEMBL1329152 & 688653 & 5.1 & 5.2031 & TRN & & \\
\hline CHEMBL1497010 & 688653 & 4.73300 & 00000000 & 005 & 5.1966 & TRN \\
\hline CHEMBL 3209300 & 688653 & 5.33299 & 99999999 & & 5.6115 & TRN \\
\hline CHEMBL1375414 & 688653 & 5.58299 & 99999999 & 99 & 5.0097 & TST \\
\hline CHEMBL1421460 & 688653 & 5.733 & 5.4123 & TRN & & \\
\hline
\end{tabular}




\begin{tabular}{|c|c|c|c|c|c|c|}
\hline & & \multicolumn{5}{|c|}{ Supplemental Table S2.txt } \\
\hline CHEMBL544584 & 688653 & 5.083 & 5.0682 & TRN & & \\
\hline CHEMBL1602792 & 688653 & 4.683 & 4.9575 & TST & & \\
\hline CHEMBL1502567 & 688653 & \multicolumn{3}{|c|}{4.7330000000000005} & 5.5546 & 151 \\
\hline CHEMBL1549577 & 688653 & \multicolumn{3}{|c|}{6.2829999999999995} & 5.7305 & \\
\hline CHEMBL1587299 & 688653 & 5.033 & 5.4297 & TRN & & \\
\hline CHEMBL1385608 & 688653 & 4.633 & 5.3832 & TST & & \\
\hline CHEMBL1565794 & 688653 & 4.883 & 5.2545 & TRN & & \\
\hline CHEMBL1533774 & 688653 & \multicolumn{3}{|c|}{4.7330000000000005} & 4.8594 & TRN \\
\hline CHEMBL1513430 & 688653 & \multicolumn{3}{|c|}{5.7829999999999995} & 5.1933 & \\
\hline CHEMBL1501197 & 688653 & \multicolumn{3}{|c|}{6.582999999999999} & 6.1761 & \\
\hline CHEMBL1384160 & 688653 & 5.733 & 5.3868 & TRN & & \\
\hline CHEMBL1303988 & 688653 & 5.933 & 5.4595 & TRN & & \\
\hline CHEMBL13 & 688653 & 4.833 & 5.481 & TRN & & \\
\hline CHEMBL1328408 & 688653 & \multicolumn{3}{|c|}{7.082999999999999} & 6.1822 & \\
\hline CHEMBL1561715 & 688653 & 5.433 & 5.211 & TST & & \\
\hline CHEMBL1392073 & 688653 & \multicolumn{3}{|c|}{5.5329999999999995} & 2181 & \\
\hline CHEMBL1339547 & 688653 & \multicolumn{3}{|c|}{4.9830000000000005} & 5.3528 & \\
\hline CHEMBL1311809 & 688653 & 5.233 & 5.1973 & TST & & \\
\hline CHEMBL1552547 & 688653 & 7.1331 & 5.5202 & TST & & \\
\hline CHEMBL1548929 & 688653 & 5.483 & 5.664 & TRN & & \\
\hline CHEMBL1395126 & 688653 & 5.433 & 5.5628 & TST & & \\
\hline CHEMBL1333655 & 688653 & 4.783 & 5.3338 & TST & & \\
\hline CHEMBL1534021 & 688653 & \multicolumn{3}{|c|}{5.132999999999999} & 5.4334 & \\
\hline CHEMBL1445698 & 688653 & \multicolumn{3}{|c|}{5.7829999999999995} & 5.5065 & \\
\hline CHEMBL1313212 & 688653 & \multicolumn{3}{|c|}{4.9830000000000005} & 4.9606 & \\
\hline CHEMBL 3190220 & 688653 & 4.783 & 5.0127 & TST & & \\
\hline CHEMBL1974308 & 688653 & \multicolumn{3}{|c|}{5.632999999999999} & 5.5732 & \\
\hline CHEMBL 32 & 688653 & 5.183 & 5.2397 & TRN & & \\
\hline CHEMBL 1 & 688653 & 4.883 & 4.9871 & TRN & & \\
\hline CHEMBL1493060 & 688653 & 4.783 & 4.8219 & TRN & & \\
\hline CHEMBL1368818 & 688653 & 6.183 & 5.7455 & TRN & & \\
\hline CHEMBL3189699 & 688653 & \multicolumn{3}{|c|}{4.9830000000000005} & & $1=$ \\
\hline CHEMBL1407668 & 688653 & \multicolumn{3}{|c|}{4.7330000000000005} & 5.9035 & \\
\hline CHEMBL1532358 & 688653 & 4.783 & 4.8047 & TRN & & \\
\hline CHEMBL1443819 & 688653 & 6.433 & 5.8738 & TRN & & \\
\hline CHEMBL1458972 & 688653 & 5.1 & 5.7077 & TRN & & \\
\hline CHEMBL3209330 & 688653 & 4.933 & 5.0167 & TRN & & \\
\hline CHEMBL1410534 & 688653 & \multicolumn{3}{|c|}{5.882999999999999} & 5.0347 & $T$ \\
\hline CHEMBL1977078 & 688653 & 5.183 & 5.3307 & TST & & \\
\hline CHEMBL1304270 & 688653 & \multicolumn{3}{|c|}{4.7330000000000005} & 5.3041 & In \\
\hline CHEMBL1547108 & 688653 & \multicolumn{3}{|c|}{5.2829999999999995} & 4.9041 & \\
\hline CHEMBL1492286 & 688653 & 4.783 & 4.7753 & TST & & \\
\hline CHEMBL1330902 & 688653 & 4.783 & 4.7681 & TST & & \\
\hline CHEMBL1503287 & 688653 & 5.033 & 5.1517 & TST & & \\
\hline CHEMBL1460819 & 688653 & 5.683 & 5.4114 & TRN & & \\
\hline CHEMBL1373256 & 688653 & \multicolumn{3}{|c|}{6.382999999999999} & 5.7018 & IRN \\
\hline CHEMBL1601250 & 688653 & 5.183 & 5.4414 & TRN & & \\
\hline CHEMBL3213545 & 688653 & \multicolumn{3}{|c|}{4.7330000000000005} & 5.0907 & \\
\hline
\end{tabular}




\begin{tabular}{|c|c|c|c|c|c|c|c|}
\hline \multicolumn{8}{|c|}{ Supplemental Table S2.txt } \\
\hline CHEMBL1399101 & 688653 & 5.033 & 5.1019 & TRN & & & \\
\hline CHEMBL1559982 & 688653 & 5.683 & 5.5728 & TST & & & \\
\hline CHEMBL1495733 & 688653 & 5.183 & 4.925 & TRN & & & \\
\hline CHEMBL1380914 & 688653 & 4.883 & 5.0046 & TRN & & & \\
\hline CHEMBL1477502 & 688653 & 4.833 & 4.9839 & TRN & & & \\
\hline CHEMBL1326934 & 688653 & 4.783 & 4.9259 & TRN & & & \\
\hline CHEMBL1388776 & 688653 & 4.933 & 5.1811 & TRN & & & \\
\hline CHEMBL1371289 & 688653 & \multicolumn{3}{|c|}{6.5329999999999995} & 5.7719 & TRN & \\
\hline CHEMBL3195779 & 688653 & 7.2328 & 6.5426 & TRN & & & \\
\hline CHEMBL1300219 & 688653 & \multicolumn{3}{|c|}{4.9830000000000005} & 5.4059 & TRN & \\
\hline CHEMBL1429874 & 688653 & \multicolumn{3}{|c|}{5.332999999999999} & 5.2142 & TST & \\
\hline CHEMBL1584379 & 688653 & 6.4829 & 5.9188 & TRN & & & \\
\hline CHEMBL1471710 & 688653 & 6.683 & 5.5882 & TRN & & & \\
\hline CHEMBL1341073 & 688653 & 4.633 & 5.4932 & TST & & & \\
\hline CHEMBL3195498 & 688653 & 5.933 & 5.2388 & TRN & & & \\
\hline CHEMBL1976000 & 688653 & 4.833 & 4.9377 & TRN & & & \\
\hline CHEMBL1579535 & 688653 & 5.033 & 5.113 & TRN & & & \\
\hline CHEMBL3196864 & 688653 & 4.883 & 5.5208 & TRN & & & \\
\hline CHEMBL1338852 & 688653 & 4.633 & 5.0869 & TRN & & & \\
\hline CHEMBL3196008 & 688653 & 6.183 & 5.5738 & TRN & & & \\
\hline CHEMBL3211413 & 688653 & \multicolumn{3}{|c|}{5.7829999999999995} & 5.1217 & TRN & \\
\hline CHEMBL1468110 & 688653 & \multicolumn{3}{|c|}{7.082999999999999} & 5.2168 & TRN & \\
\hline CHEMBL1522836 & 688653 & \multicolumn{3}{|c|}{5.382999999999999} & 5.2343 & TST & \\
\hline CHEMBL1582180 & 688653 & 4.833 & 5.0915 & TRN & & & \\
\hline CHEMBL1498470 & 688653 & 6.183 & 5.7155 & TRN & & & \\
\hline CHEMBL1495759 & 688653 & \multicolumn{3}{|c|}{5.7829999999999995} & 5.1112 & TST & \\
\hline CHEMBL1323152 & 688653 & \multicolumn{3}{|c|}{5.632999999999999} & 5.1223 & TRN & \\
\hline CHEMBL1580491 & 688653 & 5.183 & 4.8877 & TRN & & & \\
\hline CHEMBL1596813 & 688653 & \multicolumn{3}{|c|}{5.832999999999999} & 5.5214 & TRN & \\
\hline CHEMBL1413507 & 688653 & 4.9 & 5.565 & TST & & & \\
\hline CHEMBL1461129 & 688653 & 5.683 & 5.4739 & TRN & & & \\
\hline CHEMBL1480814 & 688653 & 6.4829 & 5.9311 & TRN & & & \\
\hline CHEMBL1469485 & 688653 & 4.783 & 5.1592 & TRN & & & \\
\hline CHEMBL1388639 & 688653 & 4.633 & 5.0336 & TRN & & & \\
\hline CHEMBL1558877 & 688653 & 4.583 & 4.9233 & TRN & & & \\
\hline CHEMBL1574074 & 688653 & \multicolumn{3}{|c|}{5.2829999999999995} & 4.963 & TRN & \\
\hline CHEMBL1522922 & 688653 & 5.483 & 5.6504 & TRN & & & \\
\hline CHEMBL1364562 & 688653 & 4.833 & 5.1511 & TST & & & \\
\hline CHEMBL1417180 & 688653 & \multicolumn{3}{|c|}{4.7330000000000005} & \multicolumn{2}{|c|}{5.2010000000000005} & TST \\
\hline CHEMBL1405075 & 688653 & 4.883 & 5.4123 & TST & & & \\
\hline CHEMBL1548098 & 688653 & \multicolumn{3}{|c|}{5.132999999999999} & 5.3507 & TRN & \\
\hline CHEMBL 3192844 & 688653 & 5.233 & 5.2175 & TRN & & & \\
\hline CHEMBL1380978 & 688653 & \multicolumn{3}{|c|}{5.5329999999999995} & 5.5904 & TRN & \\
\hline CHEMBL1399037 & 688653 & \multicolumn{3}{|c|}{4.7330000000000005} & 4.8586 & TRN & \\
\hline CHEMBL3208106 & 688653 & 4.833 & 5.1017 & TRN & & & \\
\hline CHEMBL1525271 & 688653 & 5.433 & 5.691 & TRN & & & \\
\hline CHEMBL 3207340 & 688653 & 5.483 & 5.0531 & TRN & & & \\
\hline CHEMBL1345002 & 688653 & 5.13299 & 99999999 & & 5.3732 & TRN & \\
\hline
\end{tabular}




\begin{tabular}{|c|c|c|c|c|c|c|}
\hline \multirow[b]{2}{*}{ CHEMBL1484953 } & & \multicolumn{5}{|c|}{ Supplemental Table S2.txt } \\
\hline & 688653 & 5.183 & 4.8459 & TRN & & \\
\hline CHEMBL 3189604 & 688653 & 4.883 & 5.2973 & TRN & & \\
\hline CHEMBL1395851 & 688653 & 4.783 & 5.5642 & TST & & \\
\hline CHEMBL1483747 & 688653 & \multicolumn{3}{|c|}{4.7330000000000005} & 4.981 & $\mathrm{TI}$ \\
\hline CHEMBL1445242 & 688653 & 5.733 & 5.1571 & TRN & & \\
\hline CHEMBL1491864 & 688653 & \multicolumn{3}{|c|}{4.9830000000000005} & 5.6598 & 1 \\
\hline CHEMBL578061 & 688653 & \multicolumn{3}{|c|}{6.132999999999999} & 5.4408 & \\
\hline CHEMBL1546586 & 688653 & 4.883 & 4.8949 & TRN & & \\
\hline CHEMBL1562878 & 688653 & 4.883 & 5.3743 & TRN & & \\
\hline CHEMBL1418004 & 688653 & 4.933 & 5.2094 & TRN & & \\
\hline CHEMBL1510618 & 688653 & 4.783 & 5.0835 & TRN & & \\
\hline CHEMBL1339676 & 688653 & 4.833 & 4.8793 & TST & & \\
\hline CHEMBL1394373 & 688653 & 5.233 & 5.2073 & TST & & \\
\hline CHEMBL1602172 & 688653 & \multicolumn{3}{|c|}{6.382999999999999} & 5.6656 & \\
\hline CHEMBL1314406 & 688653 & 5.433 & 5.3332 & TRN & & \\
\hline CHEMBL1420122 & 688653 & 4.833 & \multicolumn{3}{|c|}{5.638999999999999} & \\
\hline CHEMBL1559671 & 688653 & \multicolumn{3}{|c|}{5.2829999999999995} & 5.5601 & \\
\hline CHEMBL1363025 & 688653 & 4.833 & 5.4701 & TRN & & \\
\hline CHEMBL1536912 & 688653 & 4.783 & 5.2993 & TST & & \\
\hline CHEMBL1562796 & 688653 & \multicolumn{3}{|c|}{4.7330000000000005} & 298 & \\
\hline CHEMBL1440956 & 688653 & 5.683 & 5.0233 & TRN & & \\
\hline CHEMBL 2 & 688653 & \multicolumn{3}{|c|}{4.9830000000000005} & 154 & In \\
\hline CHEMBL1415793 & 688653 & \multicolumn{3}{|c|}{5.332999999999999} & 5.8618 & \\
\hline CHEMBL1569643 & 688653 & 6.433 & 5.7858 & TRN & & \\
\hline CHEMBL1327474 & 688653 & 6.183 & 5.8708 & TRN & & \\
\hline CHEMBL1345420 & 688653 & 4.783 & 5.0565 & TRN & & \\
\hline CHEMBL1 & 688653 & \multicolumn{3}{|c|}{4.7330000000000005} & 4.9565 & \\
\hline CHEMBL1 & 688653 & 5.233 & 4.8384 & TRN & & \\
\hline CHEMBL1502980 & 688653 & 4.633 & 4.8207 & TST & & \\
\hline CHEMBL1597594 & 688653 & \multicolumn{3}{|c|}{5.832999999999999} & & $\mathrm{TI}$ \\
\hline CHEMBL1536432 & 688653 & \multicolumn{3}{|c|}{5.132999999999999} & 5.4139 & \\
\hline CHEMBL: & 688653 & 5.183 & 5.2338 & TST & & \\
\hline CHEMBL15e & 688653 & \multirow{2}{*}{\multicolumn{3}{|c|}{$\begin{array}{l}5.483 \quad 5.6032 \text { ISI } \\
6.832999999999999\end{array}$}} & & \\
\hline CHEMBL1451735 & 688653 & & & & 5.4405 & $T$ \\
\hline CHEMBL1391415 & 688653 & 4.833 & 5.1023 & TRN & & \\
\hline CHEMBL15尺 & 688653 & \multicolumn{3}{|c|}{5.2829999999999995} & 5.4892 & 15 \\
\hline CHEMBL1 & 688653 & 4.633 & 5.1917 & TST & & \\
\hline CHEMBL1541067 & 688653 & 5.733 & 5.565 & TRN & & \\
\hline CHEMBL1375571 & 688653 & 6.433 & 6.0754 & TRN & & \\
\hline CHEMBL1471266 & 688653 & \multicolumn{3}{|c|}{5.132999999999999} & 5.3475 & It \\
\hline CHEMBL1337906 & 688653 & 6.233 & 5.56 & TST & & \\
\hline CHEMBL1452572 & 688653 & \multirow{2}{*}{\multicolumn{3}{|c|}{$\begin{array}{l}4.883 \\
6.382999999999999\end{array}$}} & & \\
\hline CHEMBL1345379 & 688653 & & & & 5.5759 & TR \\
\hline CHEMBL1465980 & 688653 & 6.983 & 5.9246 & TRN & & \\
\hline CHEMBL1369101 & 688653 & \multicolumn{3}{|c|}{4.7330000000000005} & 5.0964 & $r=8$ \\
\hline CHEMBL1407912 & 688653 & 5.733 & 5.5491 & TRN & & \\
\hline CHEMBL 233194 & 688653 & \multicolumn{3}{|c|}{6.132999999999999} & 0.412 & TRN \\
\hline CHEMBL1333029 & 688653 & 4.583 & 4.9847 & TST & & \\
\hline
\end{tabular}




\begin{tabular}{|c|c|c|c|c|c|c|}
\hline & & & oplemen & al & s2.txt & \\
\hline CHEMBL1490118 & 688653 & 4.7330 & 0000000 & 005 & 5.2072 & TRN \\
\hline CHEMBL1506466 & 688653 & 4.833 & 5.2898 & TRN & & \\
\hline CHEMBL1425388 & 688653 & 4.833 & 5.1767 & TST & & \\
\hline CHEMBL1560024 & 688653 & 5.3829 & 7999999 & & 5.4779 & TRN \\
\hline CHEMBL1353805 & 688653 & 6.6329 & 7999999 & & 5.7835 & TRN \\
\hline CHEMBL1386302 & 688653 & 6.183 & 5.0918 & TRN & & \\
\hline CHEMBL1466240 & 688653 & 5.033 & 5.4177 & TRN & & \\
\hline CHEMBL1314667 & 688653 & 4.9830 & 3000000 & 005 & 5.0936 & TRN \\
\hline CHEMBL1588969 & 688653 & 6.0829 & 7999999 & & 5.0586 & TST \\
\hline CHEMBL3191348 & 688653 & 5.683 & 4.9354 & TRN & & \\
\hline CHEMBL1572967 & 688653 & 5.483 & 4.7534 & TRN & & \\
\hline CHEMBL1488922 & 688653 & 6.3829 & 9999999 & & 5.7049 & TRN \\
\hline CHEMBL1491843 & 688653 & 7.1331 & 5.7381 & TRN & & \\
\hline CHEMBL1515468 & 688653 & 6.8831 & 6.0186 & TRN & & \\
\hline CHEMBL1593674 & 688653 & 4.633 & 4.52 & TRN & & \\
\hline CHEMBL1607548 & 688653 & 4.633 & 4.8192 & TST & & \\
\hline CHEMBL1393502 & 688653 & 5.7829 & 7999999 & 995 & 5.7566 & TRN \\
\hline CHEMBL 3191854 & 688653 & 4.783 & 5.3327 & TRN & & \\
\hline CHEMBL1414869 & 688653 & 4.883 & 4.7827 & TRN & & \\
\hline CHEMBL3199263 & 688653 & 5.733 & 4.9956 & TST & & \\
\hline CHEMBL1457955 & 688653 & 4.833 & 5.1313 & TRN & & \\
\hline CHEMBL3211002 & 688653 & 4.933 & 5.1139 & TRN & & \\
\hline CHEMBL1356999 & 688653 & 4.783 & 5.0318 & TRN & & \\
\hline CHEMBL 3198334 & 688653 & 5.2829 & 7999999 & 995 & 5.3688 & TRN \\
\hline CHEMBL1598017 & 688653 & 5.1329 & 9999999 & & 5.184 & TRN \\
\hline CHEMBL1586732 & 688653 & 6.9329 & 5.7633 & TRN & & \\
\hline CHEMBL3194052 & 688653 & 6.5829 & ج999999 & & 5.5858 & TRN \\
\hline CHEMBL1347716 & 688653 & 4.783 & 4.949 & TST & & \\
\hline CHEMBL1497400 & 688653 & 4.883 & 5.3324 & TRN & & \\
\hline CHEMBL1971760 & 688653 & 5.483 & 6.5822 & TST & & \\
\hline CHEMBL1396485 & 688653 & 5.6329 & 7999999 & & 5.8586 & TRN \\
\hline CHEMBL1429021 & 688653 & 5.683 & 5.42 & TRN & & \\
\hline CHEMBL1350809 & 688653 & 5.483 & 5.4577 & TRN & & \\
\hline CHEMBL1595194 & 688653 & 5.5829 & 7999999 & 99 & 5.3435 & TRN \\
\hline CHEMBL1567662 & 688653 & 4.833 & 4.8424 & TRN & & \\
\hline CHEMBL1527438 & 688653 & 5.083 & 5.2729 & TRN & & \\
\hline CHEMBL1589478 & 688653 & 5.183 & 5.4268 & TRN & & \\
\hline CHEMBL2369215 & 688653 & 4.783 & 5.0896 & TST & & \\
\hline CHEMBL1470485 & 688653 & 4.883 & 5.6964 & TST & & \\
\hline CHEMBL 3193573 & 688653 & 4.583 & 5.0141 & TST & & \\
\hline CHEMBL1422806 & 688653 & 5.233 & 5.1335 & TST & & \\
\hline CHEMBL 3212802 & 688653 & 6.0329 & 7999999 & 995 & 5.5885 & TRN \\
\hline CHEMBL1408452 & 688653 & 5.8329 & 9999999 & & 5.8162 & TRN \\
\hline CHEMBL1399108 & 688653 & 4.883 & 5.3743 & TRN & & \\
\hline CHEMBL1358788 & 688653 & 6.183 & 5.1579 & TST & & \\
\hline CHEMBL1599704 & 688653 & 5.6329 & 7999999 & 99 & 5.5094 & TRN \\
\hline CHEMBL1540736 & 688653 & 5.083 & 5.4504 & TRN & & \\
\hline CHEMBL1356109 & 688653 & 4.633 & 5.1055 & TRN & & \\
\hline
\end{tabular}




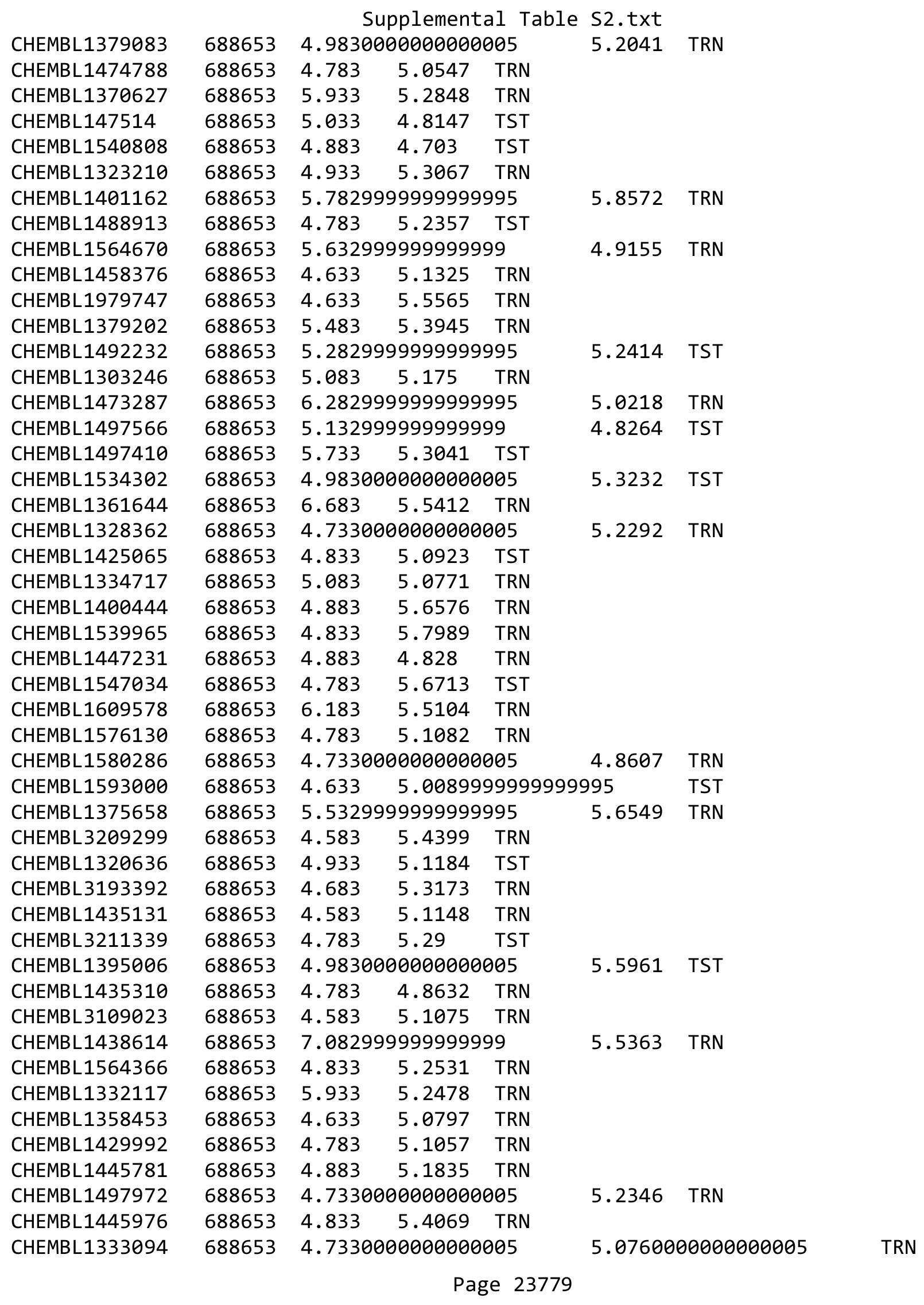




\begin{tabular}{|c|c|c|c|c|c|c|}
\hline & & \multicolumn{5}{|c|}{ Supplemental Table s2.txt } \\
\hline CHEMBL1431765 & 688653 & 4.933 & 5.0742 & TRN & & \\
\hline CHEMBL1558433 & 688653 & 6.233 & 5.6302 & TRN & & \\
\hline CHEMBL1312928 & 688653 & 6.0 & 5.345 & TRN & & \\
\hline CHEMBL1602303 & 688653 & 4.883 & 4.9661 & TRN & & \\
\hline CHEMBL3213039 & 688653 & \multicolumn{3}{|c|}{5.132999999999999} & 5.3952 & TRN \\
\hline CHEMBL1997585 & 688653 & 4.633 & 5.1919 & TST & & \\
\hline CHEMBL1405202 & 688653 & 4.783 & 5.2242 & TRN & & \\
\hline CHEMBL538430 & 688653 & 5.483 & 5.1063 & TRN & & \\
\hline CHEMBL1336370 & 688653 & 4.583 & 5.0681 & TRN & & \\
\hline CHEMBL1411617 & 688653 & \multicolumn{3}{|c|}{5.2829999999999995} & 5.8008 & TRN \\
\hline CHEMBL1993173 & 688653 & \multicolumn{3}{|c|}{4.7330000000000005} & 5.6202 & \\
\hline CHEMBL3209816 & 688653 & 5.983 & 5.8229 & TRN & & \\
\hline CHEMBL3207839 & 688653 & 5.733 & 5.3401 & TRN & & \\
\hline CHEMBL1355715 & 688653 & \multicolumn{3}{|c|}{4.9830000000000005} & 5.4866 & ובנו \\
\hline CHEMBL1361689 & 688653 & 4.583 & 5.4477 & TST & & \\
\hline CHEMBL1502812 & 688653 & 4.683 & 5.1232 & TRN & & \\
\hline CHEMBL1553596 & 688653 & 4.783 & 5.1015 & TRN & & \\
\hline CHEMBL1498531 & 688653 & 4.683 & \multicolumn{3}{|c|}{5.207999999999999} & (1.1. \\
\hline CHEMBL3191120 & 688653 & \multicolumn{3}{|c|}{4.9830000000000005} & 4.8302 & TRN \\
\hline CHEMBL1354245 & 688653 & \multicolumn{3}{|c|}{5.2829999999999995} & 5.311 & TRN \\
\hline CHEMBL1471462 & 688653 & 4.783 & 5.3727 & TRN & & \\
\hline CHEMBL1475322 & 688653 & \multicolumn{3}{|c|}{5.332999999999999} & 5.038 & \\
\hline CHEMBL1306564 & 688653 & 4.633 & 4.9183 & TRN & & \\
\hline CHEMBL1468862 & 688653 & 4.833 & 5.1082 & TRN & & \\
\hline CHEMBL1518557 & 688653 & 4.633 & 4.794 & TST & & \\
\hline CHEMBL1477473 & 688653 & 5.983 & 5.8256 & TRN & & \\
\hline CHEMBL1530173 & 688653 & 4.633 & 5.2339 & TRN & & \\
\hline CHEMBL1445067 & 688653 & 6.183 & 5.7317 & TRN & & \\
\hline CHEMBL1390214 & 688653 & 4.933 & 4.89 & TRN & & \\
\hline CHEMBL1562447 & 688653 & 4.783 & 4.8306 & TRN & & \\
\hline CHEMBL1548851 & 688653 & 5.433 & 5.2691 & TST & & \\
\hline CHEMBL1603392 & 688653 & 4.833 & 5.2636 & TRN & & \\
\hline CHEMBL1604341 & 688653 & \multicolumn{3}{|c|}{6.0329999999999995} & 5.605 & TRN \\
\hline CHEMBL1425720 & 688653 & \multicolumn{3}{|c|}{5.5329999999999995} & 5.5222 & \\
\hline CHEMBL1360566 & 688653 & 5.733 & 5.4521 & TRN & & \\
\hline CHEMBL1498562 & 688653 & \multicolumn{3}{|c|}{5.632999999999999} & 5.7836 & \\
\hline CHEMBL1387804 & 688653 & 4.783 & 5.5183 & TRN & & \\
\hline CHEMBL1529007 & 688653 & \multicolumn{3}{|c|}{6.132999999999999} & 5.3107 & $\mathrm{TR}$ \\
\hline CHEMBL1410426 & 688653 & 5.0 & 5.0185 & TRN & & \\
\hline CHEMBL1558691 & 688653 & 6.183 & 5.1879 & TRN & & \\
\hline CHEMBL1329210 & 688653 & 4.883 & 5.2843 & TRN & & \\
\hline CHEMBL1445195 & 688653 & 5.233 & 5.2392 & TST & & \\
\hline CHEMBL1389332 & 688653 & \multicolumn{3}{|c|}{5.132999999999999} & 5.8041 & TR \\
\hline CHEMBL1413596 & 688653 & 5.683 & 5.285 & TRN & & \\
\hline CHEMBL1335515 & 688653 & 5.433 & 5.2826 & TRN & & \\
\hline CHEMBL1320297 & 688653 & 4.783 & 4.9761 & TRN & & \\
\hline CHEMBL1408512 & 688653 & \multicolumn{3}{|c|}{4.7330000000000005} & 5.0733 & IRIV \\
\hline CHEMBL1368212 & 688653 & \multicolumn{3}{|c|}{6.332999999999999} & 5.6612 & \\
\hline
\end{tabular}




\begin{tabular}{|c|c|c|c|c|c|c|}
\hline \multirow{3}{*}{$\begin{array}{l}\text { CHEMBL1400720 } \\
\text { CHEMBL1568201 }\end{array}$} & \multirow{3}{*}{$\begin{array}{l}688653 \\
688653\end{array}$} & \multicolumn{4}{|c|}{ Supplemental Table S2.txt } & \multirow{2}{*}{ TRN } \\
\hline & & \multicolumn{3}{|c|}{5.882999999999999} & 5.6968 & \\
\hline & & 5.433 & 6.193 & TRN & & \\
\hline CHEMBL1526724 & 688653 & 6.433 & 5.9059 & TRN & & \\
\hline CHEMBL1488408 & 688653 & 4.883 & 5.0436 & TST & & \\
\hline CHEMBL1502279 & 688653 & 5.083 & 5.7366 & TRN & & \\
\hline CHEMBL1593442 & 688653 & \multicolumn{3}{|c|}{5.5329999999999995} & 5.449 & TRN \\
\hline CHEMBL1481612 & 688653 & \multicolumn{3}{|c|}{5.5329999999999995} & 5.335 & TRN \\
\hline CHEMBL1504424 & 688653 & 6.433 & 5.7463 & TRN & & \\
\hline CHEMBL1495008 & 688653 & \multicolumn{3}{|c|}{4.9830000000000005} & 5.3232 & TRN \\
\hline CHEMBL1566838 & 688653 & \multicolumn{3}{|c|}{6.5329999999999995} & 5.7751 & TRN \\
\hline CHEMBL1987082 & 688653 & 5.983 & 5.6942 & TRN & & \\
\hline CHEMBL1381584 & 688653 & \multicolumn{3}{|c|}{6.082999999999999} & 5.6627 & TST \\
\hline CHEMBL1521681 & 688653 & \multicolumn{3}{|c|}{6.632999999999999} & 5.3631 & TST \\
\hline CHEMBL3195869 & 688653 & \multicolumn{3}{|c|}{6.2829999999999995} & 5.2694 & TST \\
\hline CHEMBL1448638 & 688653 & \multicolumn{3}{|c|}{4.7330000000000005} & 5.0628 & TRN \\
\hline CHEMBL1556239 & 688653 & 4.933 & 4.9704 & TST & & \\
\hline CHEMBL1425521 & 688653 & 5.033 & 4.7568 & TST & & \\
\hline CHEMBL1327356 & 688653 & 4.883 & 4.9588 & TRN & & \\
\hline CHEMBL1360480 & 688653 & \multicolumn{3}{|c|}{4.9830000000000005} & 5.2164 & TST \\
\hline CHEMBL1323584 & 688653 & 6.183 & 5.772 & TRN & & \\
\hline CHEMBL1608474 & 688653 & \multicolumn{3}{|c|}{5.132999999999999} & 5.091 & TRN \\
\hline CHEMBL1414133 & 688653 & 4.883 & 4.737 & TST & & \\
\hline CHEMBL1581897 & 688653 & & 4.7634 & TRN & & \\
\hline CHEMBL1361801 & 688653 & \multicolumn{3}{|c|}{5.132999999999999} & 5.1386 & TST \\
\hline CHEMBL1576347 & 688653 & 4.833 & 5.2353 & TRN & & \\
\hline CHEMBL1600176 & 688653 & 5.083 & 5.4367 & TRN & & \\
\hline CHEMBL3194947 & 688653 & \multicolumn{3}{|c|}{5.2829999999999995} & 5.5069 & TRN \\
\hline CHEMBL576353 & 688653 & 4.783 & 5.7447 & TRN & & \\
\hline CHEMBL1538296 & 688653 & 5.183 & 5.3312 & TRN & & \\
\hline CHEMBL1414624 & 688653 & 6.4829 & 5.8214 & TRN & & \\
\hline CHEMBL1595375 & 688653 & 5.033 & 5.1108 & TRN & & \\
\hline CHEMBL1370175 & 688653 & 4.783 & 5.6277 & TRN & & \\
\hline CHEMBL1602798 & 688653 & 4.833 & 5.3912 & TRN & & \\
\hline CHEMBL1543948 & 688653 & \multicolumn{3}{|c|}{6.132999999999999} & 5.2714 & TRN \\
\hline CHEMBL1525316 & 688653 & 5.033 & 5.1757 & TRN & & \\
\hline CHEMBL1416153 & 688653 & 4.883 & 5.0445 & TRN & & \\
\hline CHEMBL1563623 & 688653 & 4.883 & 5.2711 & TST & & \\
\hline CHEMBL1604076 & 688653 & 4.783 & 5.2818 & TRN & & \\
\hline CHEMBL 2005721 & 688653 & 4.633 & 5.1239 & TST & & \\
\hline CHEMBL1444667 & 688653 & \multicolumn{3}{|c|}{4.7330000000000005} & 5.0943 & TST \\
\hline CHEMBL1417743 & 688653 & \multicolumn{3}{|c|}{4.9830000000000005} & 5.0987 & TRN \\
\hline CHEMBL1374416 & 688653 & \multicolumn{3}{|c|}{4.7330000000000005} & 4.8582 & TRN \\
\hline CHEMBL1329862 & 688653 & 4.833 & 4.9147 & TST & & \\
\hline CHEMBL1313436 & 688653 & 6.433 & 5.8074 & TRN & & \\
\hline CHEMBL1408596 & 688653 & 4.833 & 4.5761 & TRN & & \\
\hline CHEMBL1310832 & 688653 & 5.683 & 4.9286 & TST & & \\
\hline CHEMBL1556429 & 688653 & 4.883 & 5.5333 & TRN & & \\
\hline CHEMBL1406948 & 688653 & 6.6329 & 79999999 & & 5.3612 & TST \\
\hline & & & & 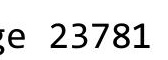 & & \\
\hline
\end{tabular}




\begin{tabular}{|c|c|c|c|c|c|c|}
\hline \multirow[b]{2}{*}{ CHEMBL1607316 } & \multicolumn{6}{|c|}{ pplemental Ta } \\
\hline & 688653 & 4.85 & 5.1287 & TRN & & \\
\hline CHEMBL 1480003 & 688653 & 6.183 & 5.6125 & TRN & & \\
\hline CHEMBL1384734 & 688653 & 6.1329 & 9999999 & 99 & 5.5845 & TRN \\
\hline CHEMBL1528258 & 688653 & 4.633 & 5.0732 & TRN & & \\
\hline CHEMBL1585489 & 688653 & 4.683 & 4.6868 & TRN & & \\
\hline CHEMBL1335433 & 688653 & 4.833 & 5.1687 & TRN & & \\
\hline CHEMBL1383480 & 688653 & 4.783 & 4.7852 & TST & & \\
\hline CHEMBL1491431 & 688653 & 5.483 & 5.0296 & TRN & & \\
\hline CHEMBL1346839 & 688653 & 4.583 & 5.40799 & 9999 & 995 & TRN \\
\hline CHEMBL1322267 & 688653 & 4.7330 & $0000000 €$ & 005 & 5.1879 & \\
\hline CHEMBL1479106 & 688653 & 4.7330 & $0000000 €$ & 005 & 5.1685 & \\
\hline CHEMBL1311534 & 688653 & 6.25 & 5.0862 & TRN & & \\
\hline CHEMBL1441990 & 688653 & 4.933 & 5.2478 & TRN & & \\
\hline CHEMBL1397479 & 688653 & 4.883 & 4.9536 & TRN & & \\
\hline CHEMBL1340331 & 688653 & 5.733 & 5.5169 & TRN & & \\
\hline CHEMBL1559204 & 688653 & 4.933 & 4.8666 & TRN & & \\
\hline CHEMBL1349063 & 688653 & 5.483 & 5.6824 & TRN & & \\
\hline CHEMBL 3194804 & 688653 & 4.7330 & 00000000 & 005 & 5.4806 & \\
\hline CHEMBL1498051 & 688653 & 5.483 & 5.385 & TST & & \\
\hline CHEMBL171596 & 688653 & 5.033 & $5.1670 €$ & 0000 & & Tror \\
\hline CHEMBL1611463 & 688653 & 4.7330 & $0000000 €$ & 005 & 4.9016 & TST \\
\hline CHEMBL1988780 & 688653 & 5.8329 & 99999999 & & 5.3283 & TRN \\
\hline CHEMBL1422250 & 688653 & 5.183 & 5.5249 & TRN & & \\
\hline CHEMBL597251 & 688653 & 4.633 & 4.6877 & TST & & \\
\hline CHEMBL1388369 & 688653 & 4.7330 & 00000006 & 005 & 5.2013 & TRN \\
\hline CHEMBL1389436 & 688653 & 4.833 & 5.4151 & TST & & \\
\hline CHEMBL1402097 & 688653 & 5.8329 & 99999999 & & 5.4342 & TR \\
\hline CHEMBL1459270 & 688653 & 5.933 & 5.1821 & TRN & & \\
\hline CHEMBL1366672 & 688653 & 4.9830 & 2000000e & 005 & 4.9641 & וצנו \\
\hline CHEMBL1537234 & 688653 & 5.2829 & 99999999 & 995 & 5.3701 & TRN \\
\hline CHEMBL1421199 & 688653 & 6.7331 & 5.2923 & TST & & \\
\hline CHEMBL1431742 & 688653 & 5.8829 & 99999999 & & & TRN \\
\hline CHEMBL1984523 & 688653 & 5.2829 & 99999999 & 995 & 5.0477 & TST \\
\hline CHEMBL1334778 & 688653 & 5.8829 & 99999999 & & 5.3712 & TST \\
\hline CHEMBL1340682 & 688653 & 5.8329 & 99999999 & & 5.817 & TRN \\
\hline CHEMBL1412319 & 688653 & 6.1 & 5.8297 & TRN & & \\
\hline CHEMBL1427221 & 688653 & 5.483 & 5.2964 & TRN & & \\
\hline CHEMBL 3193260 & 688653 & 4.7330 & 20000000 & 005 & 5.4046 & NIV \\
\hline CHEMBL1347743 & 688653 & 6.2829 & 99999999 & 995 & 5.1728 & TRN \\
\hline CHEMBL1309929 & 688653 & 4.7330 & 2000000e & 005 & 5.2459 & TRN \\
\hline CHEMBL1574148 & 688653 & 5.2829 & 99999999 & 995 & 5.2694 & TRN \\
\hline CHEMBL1376882 & 688653 & 6.433 & 5.3201 & TRN & & \\
\hline CHEMBL1313646 & 688653 & 5.683 & 5.3613 & TST & & \\
\hline CHEMBL1376620 & 688653 & 4.783 & 5.3722 & TRN & & \\
\hline CHEMBL1540692 & 688653 & 5.2829 & 99999999 & 995 & 4.709 & I KIV \\
\hline CHEMBL1308882 & 688653 & 4.7330 & 2000000e & 005 & 5.0316 & TRN \\
\hline CHEMBL 3195652 & 688653 & 4.583 & 5.0481 & TRN & & \\
\hline CHEMBL 3195184 & 688653 & 5.933 & 5.5492 & TRN & & \\
\hline
\end{tabular}




\begin{tabular}{|c|c|c|c|c|c|c|}
\hline & & \multicolumn{5}{|c|}{ Supplemental Table S2.txt } \\
\hline CHEMBL1383520 & 688653 & 4.833 & 5.3312 & TRN & & \\
\hline CHEMBL1359959 & 688653 & 4.883 & 5.5372 & TRN & & \\
\hline CHEMBL1330858 & 688653 & 5.233 & 5.3034 & TST & & \\
\hline CHEMBL3192335 & 688653 & \multicolumn{3}{|c|}{6.382999999999999} & 5.8044 & TRN \\
\hline CHEMBL1574136 & 688653 & \multicolumn{3}{|c|}{4.9830000000000005} & 5.1449 & TRN \\
\hline CHEMBL1458521 & 688653 & \multicolumn{3}{|c|}{4.7330000000000005} & 5.4487 & TRN \\
\hline CHEMBL1447004 & 688653 & 5.15 & 4.9424 & TRN & & \\
\hline CHEMBL1395250 & 688653 & 5.183 & 5.4046 & TRN & & \\
\hline CHEMBL1604097 & 688653 & \multicolumn{3}{|c|}{4.9830000000000005} & 5.2801 & TRN \\
\hline CHEMBL1445493 & 688653 & 5.733 & 5.6514 & TRN & & \\
\hline CHEMBL3214466 & 688653 & \multicolumn{3}{|c|}{5.832999999999999} & 5.3185 & TRN \\
\hline CHEMBL1494105 & 688653 & \multicolumn{3}{|c|}{5.5329999999999995} & 5.1571 & TRN \\
\hline CHEMBL1313978 & 688653 & 4.833 & 4.6956 & TRN & & \\
\hline CHEMBL1595038 & 688653 & 4.633 & 4.935 & TRN & & \\
\hline CHEMBL1418382 & 688653 & 4.633 & 5.0204 & TRN & & \\
\hline CHEMBL1425389 & 688653 & 4.883 & 4.9562 & TRN & & \\
\hline CHEMBL1395969 & 688653 & 4.633 & 4.9826 & TRN & & \\
\hline CHEMBL1380683 & 688653 & 6.433 & 5.6229 & TRN & & \\
\hline CHEMBL1351332 & 688653 & 4.883 & 5.0898 & TRN & & \\
\hline CHEMBL1300445 & 688653 & 5.233 & 5.0783 & TRN & & \\
\hline CHEMBL1593357 & 688653 & \multicolumn{3}{|c|}{5.7829999999999995} & 5.0137 & TRN \\
\hline CHEMBL1506659 & 688653 & 4.833 & 5.1424 & TRN & & \\
\hline CHEMBL1400358 & 688653 & 4.833 & 5.0716 & TRN & & \\
\hline CHEMBL1349660 & 688653 & \multicolumn{3}{|c|}{4.7330000000000005} & 5.3752 & TRN \\
\hline CHEMBL1390049 & 688653 & \multicolumn{3}{|c|}{5.582999999999999} & 5.6929 & TST \\
\hline CHEMBL588525 & 688653 & 5.483 & 5.3167 & TRN & & \\
\hline CHEMBL1403316 & 688653 & 4.833 & 5.4403 & TST & & \\
\hline CHEMBL1374445 & 688653 & 4.583 & 5.1943 & TRN & & \\
\hline CHEMBL1609723 & 688653 & 4.633 & 5.443 & TRN & & \\
\hline CHEMBL1569984 & 688653 & \multicolumn{3}{|c|}{7.082999999999999} & 5.996 & TRN \\
\hline CHEMBL1465186 & 688653 & 4.583 & 5.0597 & TST & & \\
\hline CHEMBL1327867 & 688653 & 4.833 & 5.3769 & TRN & & \\
\hline CHEMBL1489461 & 688653 & 5.483 & 5.5479 & TRN & & \\
\hline CHEMBL3189418 & 688653 & 4.833 & 5.2582 & TRN & & \\
\hline CHEMBL1493071 & 688653 & \multicolumn{3}{|c|}{4.7330000000000005} & 5.2797 & TRN \\
\hline CHEMBL1364743 & 688653 & \multicolumn{3}{|c|}{5.2829999999999995} & 5.6019 & TRN \\
\hline CHEMBL1988042 & 688653 & 5.683 & 5.3391 & TST & & \\
\hline CHEMBL1528803 & 688653 & \multicolumn{3}{|c|}{5.832999999999999} & 5.1904 & TRN \\
\hline CHEMBL1346145 & 688653 & 5.183 & 5.1367 & TRN & & \\
\hline CHEMBL1536786 & 688653 & \multicolumn{3}{|c|}{5.632999999999999} & 5.6953 & TRN \\
\hline CHEMBL1455846 & 688653 & \multicolumn{3}{|c|}{5.332999999999999} & 5.7159 & TRN \\
\hline CHEMBL1555726 & 688653 & \multicolumn{3}{|c|}{4.9830000000000005} & 5.2456 & TRN \\
\hline CHEMBL1473991 & 688653 & 4.833 & 5.2047 & TRN & & \\
\hline CHEMBL1415459 & 688653 & \multirow{2}{*}{\multicolumn{3}{|c|}{$\begin{array}{lcc}4.583 & 4.8147 & \text { TST } \\
4.7330000000000005\end{array}$}} & & \\
\hline CHEMBL1538410 & 688653 & & & & 5.2857 & TRN \\
\hline CHEMBL1463270 & 688653 & \multicolumn{3}{|c|}{$\begin{array}{l}4.7330000000000005 \\
4.833 \quad 5.1344 \quad \text { TRN }\end{array}$} & & \\
\hline CHEMBL1444483 & 688653 & 5.183 & 5.2515 & TRN & & \\
\hline CHEMBL1365356 & 688653 & 4.883 & 5.4034 & TRN & & \\
\hline
\end{tabular}




\begin{tabular}{|c|c|c|c|c|c|c|}
\hline \multicolumn{7}{|c|}{ Supplemental Table s2.txt } \\
\hline CHEMBL1560607 & 688653 & \multicolumn{3}{|c|}{5.882999999999999} & 5.1842 & TRN \\
\hline CHEMBL1336277 & 688653 & 5.433 & 6.2653 & TST & & \\
\hline CHEMBL1430506 & 688653 & \multicolumn{3}{|c|}{5.882999999999999} & 5.3646 & TRN \\
\hline CHEMBL1559071 & 688653 & 5.233 & 5.2763 & TRN & & \\
\hline CHEMBL1389725 & 688653 & 4.783 & 5.1056 & TRN & & \\
\hline CHEMBL1399361 & 688653 & \multicolumn{3}{|c|}{5.832999999999999} & 5.7005 & TRN \\
\hline CHEMBL1454686 & 688653 & \multicolumn{3}{|c|}{4.7330000000000005} & 5.3511 & TST \\
\hline CHEMBL1476778 & 688653 & \multicolumn{3}{|c|}{4.7330000000000005} & 5.318 & TST \\
\hline CHEMBL1497245 & 688653 & 5.683 & 5.5712 & TRN & & \\
\hline CHEMBL3190938 & 688653 & \multicolumn{3}{|c|}{4.7330000000000005} & 5.4267 & TRN \\
\hline CHEMBL1362945 & 688653 & \multicolumn{3}{|c|}{5.7829999999999995} & 5.371 & TRN \\
\hline CHEMBL 3196526 & 688653 & \multicolumn{3}{|c|}{5.882999999999999} & 5.4908 & TRN \\
\hline CHEMBL1320210 & 688653 & \multicolumn{3}{|c|}{5.5329999999999995} & 5.2924 & TRN \\
\hline CHEMBL1397418 & 688653 & \multicolumn{3}{|c|}{5.882999999999999} & 4.9919 & TRN \\
\hline CHEMBL1308481 & 688653 & 4.833 & 4.9067 & TST & & \\
\hline CHEMBL1385747 & 688653 & \multicolumn{3}{|c|}{5.882999999999999} & 5.3914 & TRN \\
\hline CHEMBL3210634 & 688653 & \multicolumn{3}{|c|}{6.082999999999999} & \multicolumn{2}{|c|}{5.3660000000000005} \\
\hline CHEMBL1323332 & 688653 & 5.933 & 5.3166 & TRN & & \\
\hline CHEMBL1404312 & 688653 & 4.683 & 5.1655 & TST & & \\
\hline CHEMBL1099177 & 688653 & 6.183 & 5.8025 & TRN & & \\
\hline CHEMBL1528034 & 688653 & \multicolumn{3}{|c|}{4.7330000000000005} & 5.2923 & TRN \\
\hline CHEMBL1375470 & 688653 & \multicolumn{3}{|c|}{5.132999999999999} & 4.942 & TRN \\
\hline CHEMBL1423409 & 688653 & 6.433 & 6.001 & TRN & & \\
\hline CHEMBL1375822 & 688653 & 4.833 & 6.1196 & TRN & & \\
\hline CHEMBL1521849 & 688653 & \multicolumn{3}{|c|}{6.582999999999999} & 5.5519 & TRN \\
\hline CHEMBL1581410 & 688653 & \multicolumn{3}{|c|}{4.7330000000000005} & 5.3695 & TRN \\
\hline CHEMBL 3195501 & 688653 & 5.183 & 5.1815 & TST & & \\
\hline CHEMBL1495198 & 688653 & \multicolumn{3}{|c|}{$\begin{array}{lll}5.683 & 5.1491 & \text { TST }\end{array}$} & & \\
\hline CHEMBL1524339 & 688653 & \multicolumn{3}{|c|}{6.382999999999999} & 5.8022 & TRN \\
\hline CHEMBL1968290 & 688653 & \multicolumn{3}{|c|}{6.2829999999999995} & 5.3131 & TST \\
\hline CHEMBL1550406 & 688653 & 5.3829 & 99999999 & & 4.7845 & TST \\
\hline CHEMBL1550646 & 688653 & 4.783 & 5.2159 & TST & & \\
\hline CHEMBL1530621 & 688653 & 5.183 & 5.1981 & TRN & & \\
\hline CHEMBL1553157 & 688653 & 5.483 & 5.5593 & TRN & & \\
\hline CHEMBL1453460 & 688653 & 6.3829 & 99999999 & & 5.8931 & TST \\
\hline CHEMBL1495283 & 688653 & 4.783 & 5.3249 & TRN & & \\
\hline CHEMBL1427851 & 688653 & 4.783 & 4.9918 & TRN & & \\
\hline CHEMBL 1556026 & 688653 & 5.6329 & 99999999 & & 5.4235 & TRN \\
\hline CHEMBL1516456 & 688653 & 4.7330 & 00000000 & 005 & 5.2726 & TST \\
\hline CHEMBL1583665 & 688653 & 4.583 & 5.1557 & TRN & & \\
\hline CHEMBL 3192704 & 688653 & 5.033 & 4.8936 & TRN & & \\
\hline CHEMBL1506498 & 688653 & 5.3329 & 99999999 & & 5.1206 & TST \\
\hline CHEMBL1547005 & 688653 & 5.3829 & 99999999 & & 4.9884 & TRN \\
\hline CHEMBL1484528 & 688653 & 6.433 & 5.6377 & TRN & & \\
\hline CHEMBL1604825 & 688653 & 4.833 & 5.1482 & TRN & & \\
\hline CHEMBL1503523 & 688653 & 4.783 & 4.7837 & TST & & \\
\hline CHEMBL1315959 & 688653 & 5.233 & 6.0341 & TRN & & \\
\hline CHEMBL1490289 & 688653 & 5.933 & 5.8198 & TST & & \\
\hline
\end{tabular}




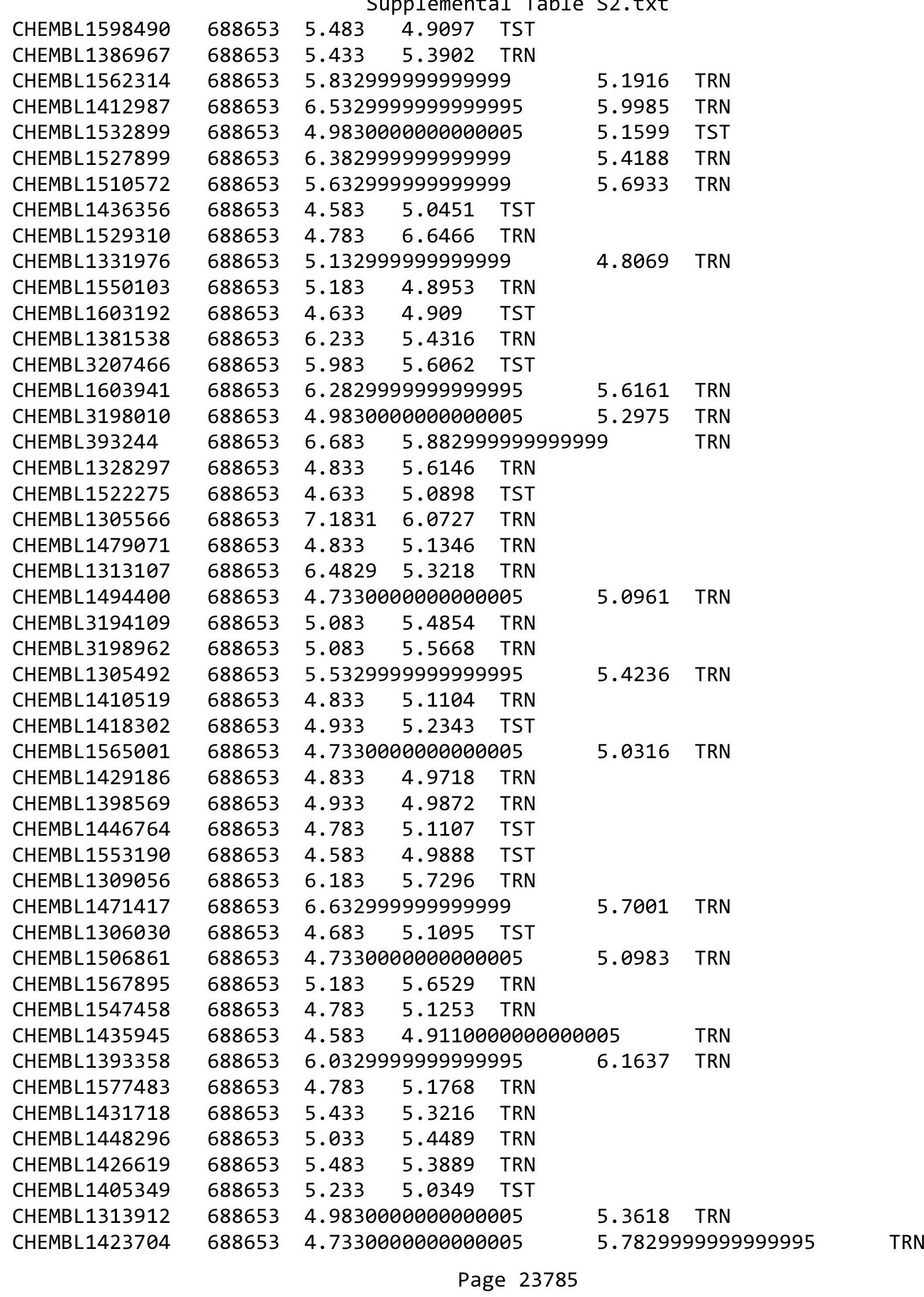




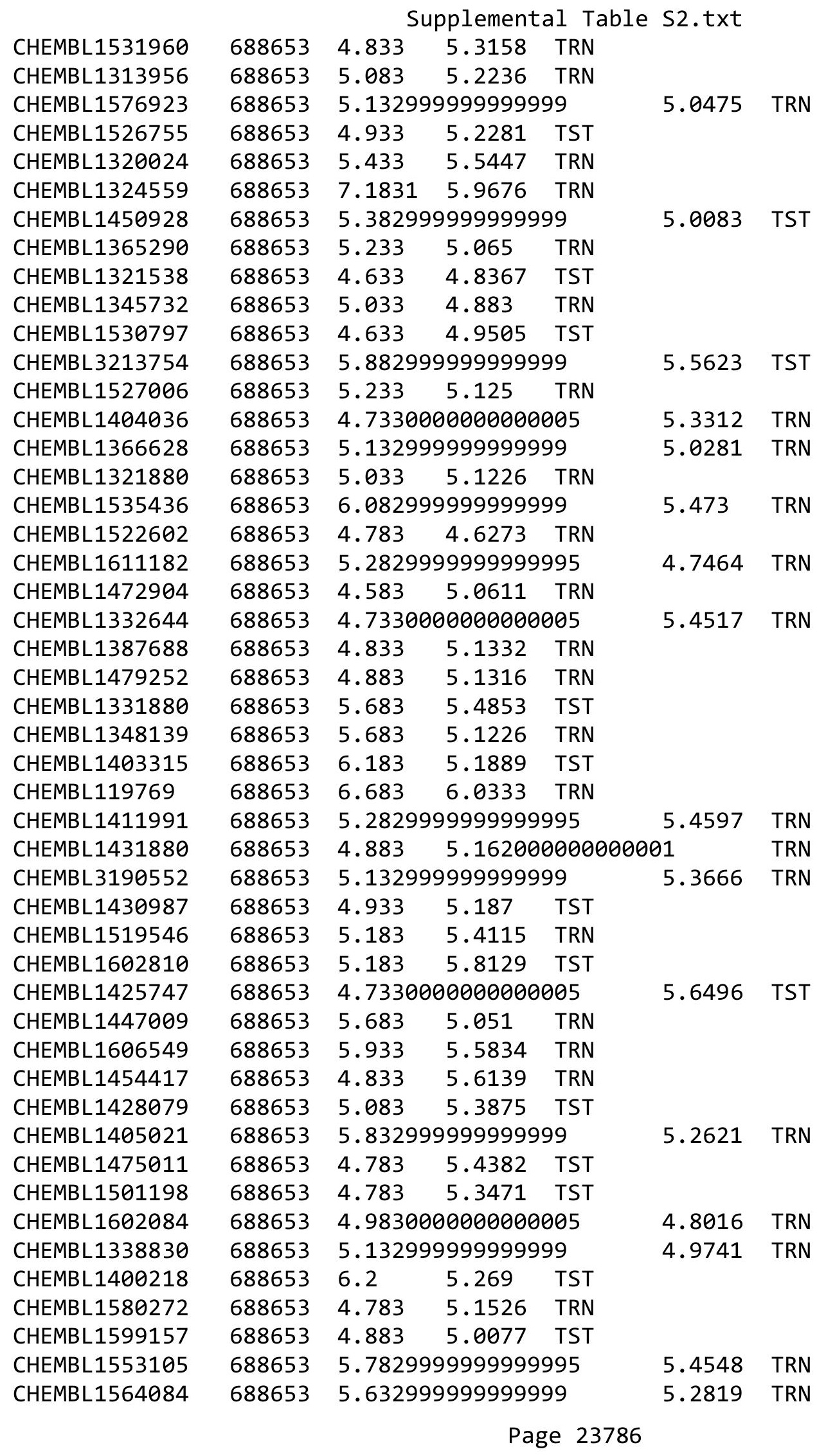




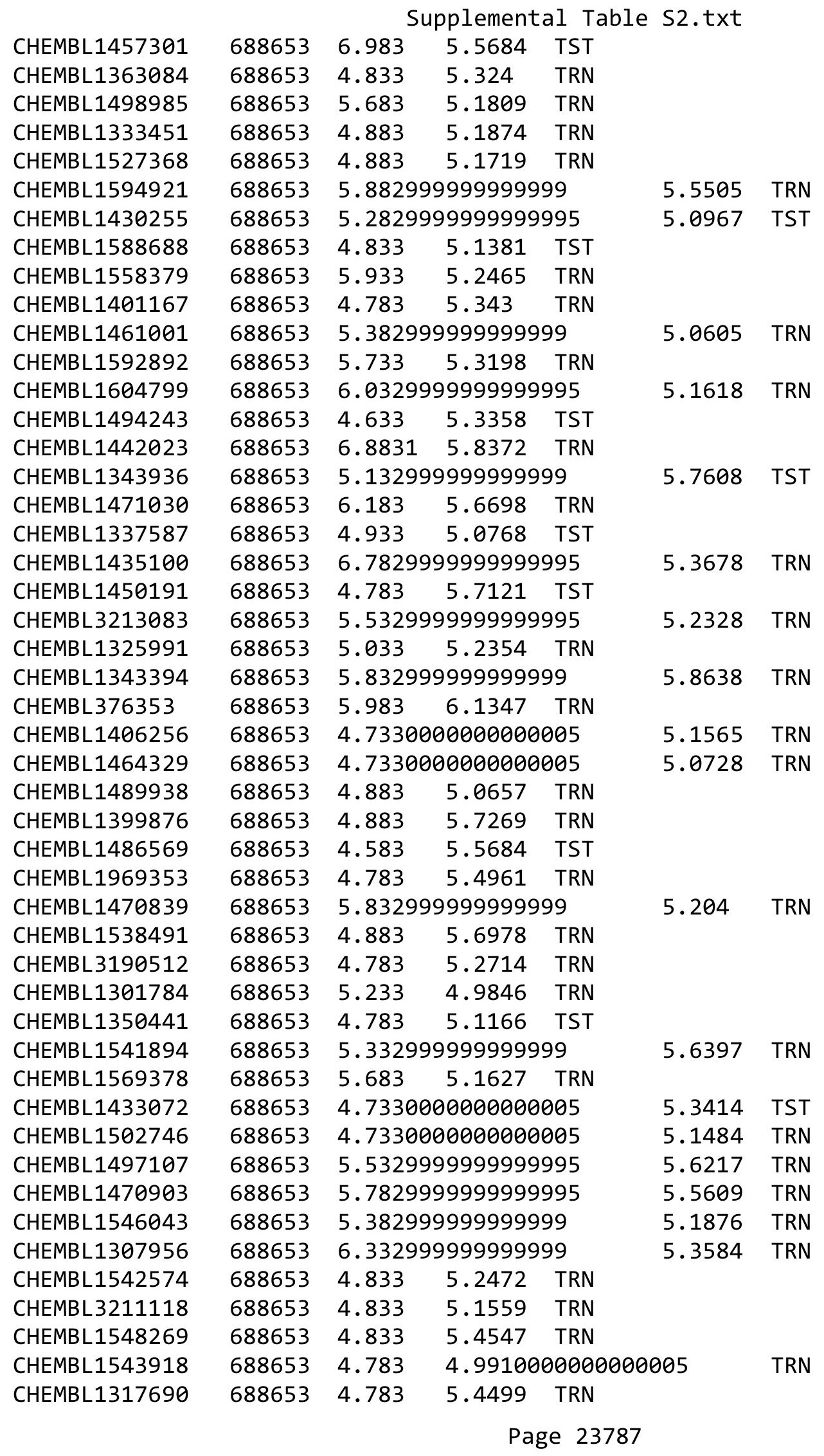




\begin{tabular}{|c|c|c|c|c|c|c|}
\hline \multirow[b]{2}{*}{ CHEMBL1570010 } & \multicolumn{6}{|c|}{ splemental T } \\
\hline & 688653 & 4.783 & 4.8047 & TRN & & \\
\hline CHEMBL1555525 & 688653 & 5.3329 & 99999999 & & 5.205 & TST \\
\hline CHEMBL1337589 & 688653 & 4.7330 & 00000000 & 005 & 5.4855 & \\
\hline CHEMBL1454011 & 688653 & 4.833 & 5.3555 & TST & & \\
\hline CHEMBL1549537 & 688653 & 4.7330 & 00000000 & 005 & 5.484 & \\
\hline CHEMBL1604974 & 688653 & 5.7829 & 99999999 & 995 & 5.9003 & \\
\hline CHEMBL1581235 & 688653 & 4.883 & 5.008 & TST & & \\
\hline CHEMBL1441257 & 688653 & 4.7330 & 00000000 & 005 & 4.8456 & \\
\hline CHEMBL1535261 & 688653 & 5.233 & 4.7717 & TST & & \\
\hline CHEMBL1389751 & 688653 & 5.083 & 5.0896 & TRN & & \\
\hline CHEMBL1343740 & 688653 & 5.433 & 4.9757 & TRN & & \\
\hline CHEMBL1431536 & 688653 & 5.183 & 5.5138 & TRN & & \\
\hline CHEMBL1463718 & 688653 & 5.1329 & 99999999 & & 4.9277 & \\
\hline CHEMBL 38739 & 688653 & 4.783 & 5.3788 & TST & & \\
\hline CHEMBL1562470 & 688653 & 4.783 & 5.1806 & TRN & & \\
\hline CHEMBL1459123 & 688653 & 5.483 & 5.1311 & TRN & & \\
\hline CHEMBL1392956 & 688653 & 4.7330 & 00000000 & 005 & 5.2272 & \\
\hline CHEMBL1588338 & 688653 & 4.933 & 5.3425 & TRN & & \\
\hline CHEMBL1304798 & 688653 & 5.683 & 5.1492 & TRN & & \\
\hline CHEMBL1333087 & 688653 & 6.0 & 5.1665 & TRN & & \\
\hline CHEMBL1611432 & 688653 & 5.483 & 5.169 & TRN & & \\
\hline CHEMBL1508240 & 688653 & 5.8829 & 99999999 & & 5.606 & \\
\hline CHEMBL1986151 & 688653 & 5.233 & 5.4907 & TRN & & \\
\hline CHEMBL1584663 & 688653 & 6.3329 & 99999999 & & 5.9211 & \\
\hline CHEMBL1595271 & 688653 & 5.083 & 5.1694 & TRN & & \\
\hline CHEMBL1565232 & 688653 & 4.833 & 5.3494 & TRN & & \\
\hline CHEMBL1571775 & 688653 & 5.8329 & 99999999 & & 5.5592 & \\
\hline CHEMBL1479114 & 688653 & 5.233 & 5.5406 & TST & & \\
\hline CHEMBL 3194075 & 688653 & 5.6329 & 99999999 & & 5.3311 & \\
\hline CHEMBL1326180 & 688653 & 4.633 & 5.0352 & TST & & \\
\hline CHEMBL1479974 & 688653 & 6.5329 & 99999999 & 995 & 5.6611 & $\mathrm{TH}$ \\
\hline CHEMBL1472101 & 688653 & 5.733 & 5.6635 & TRN & & \\
\hline CHEMBL1393041 & 688653 & 4.9830 & 00000000 & 005 & 5.5157 & 11 \\
\hline CHEMBL1549111 & 688653 & 4.7330 & 00000000 & 005 & 5.4177 & 1. \\
\hline CHEMBL1442565 & 688653 & 4.7330 & 00000000 & 005 & 5.6222 & \\
\hline CHEMBL 3194500 & 688653 & 5.983 & 5.6567 & TRN & & \\
\hline CHEMBL1569183 & 688653 & 5.5329 & 99999999 & 995 & 5.6078 & \\
\hline CHEMBL1558187 & 688653 & 5.483 & 5.1278 & TRN & & \\
\hline CHEMBL1385607 & 688653 & 4.9830 & 00000000 & 205 & 5.1006 & TRN \\
\hline CHEMBL1363679 & 688653 & 4.783 & 4.8597 & TRN & & \\
\hline CHEMBL1540883 & 688653 & 4.933 & 4.9458 & TST & & \\
\hline CHEMBL1347687 & 688653 & 7.2328 & 5.8243 & TRN & & \\
\hline CHEMBL1323486 & 688653 & 5.7829 & 99999999 & 995 & 5.8563 & . \\
\hline CHEMBL 3214285 & 688653 & 4.933 & 5.5916 & TST & & \\
\hline CHEMBL1566734 & 688653 & 5.233 & 4.8742 & TRN & & \\
\hline CHEMBL1595911 & 688653 & 4.633 & 4.8503 & TRN & & \\
\hline CHEMBL1514165 & 688653 & 5.233 & 5.5878 & TRN & & \\
\hline CHEMBL1315170 & 688653 & 4.9830 & 0000000 & 205 & 4.761 & \\
\hline
\end{tabular}




\begin{tabular}{|c|c|c|c|c|c|c|c|}
\hline \multirow{4}{*}{$\begin{array}{l}\text { CHEMBL } 3197545 \\
\text { CHEMBL1468838 } \\
\text { CHFMBI } 1534724\end{array}$} & \multicolumn{4}{|c|}{ Supplemental Table } & \multicolumn{2}{|l|}{ s2.txt } & \multirow{2}{*}{ TRN } \\
\hline & 688653 & \multicolumn{3}{|c|}{6.0329999999999995} & \multicolumn{2}{|c|}{5.327999999999999} & \\
\hline & 688653 & \multicolumn{3}{|c|}{4.7330000000000005} & \multirow[t]{2}{*}{5.2114} & \multirow[t]{2}{*}{ TRN } & \\
\hline & 688653 & 5.483 & 5.0696 & TRN & & & \\
\hline CHEMBL1439020 & 688653 & \multicolumn{3}{|c|}{5.582999999999999} & 5.1395 & TRN & \\
\hline CHEMBL1568106 & 688653 & 4.783 & 5.6701 & TST & & & \\
\hline CHEMBL1332123 & 688653 & 4.783 & 5.0494 & TRN & & & \\
\hline CHEMBL1612653 & 688653 & 5.683 & 5.2527 & TRN & & & \\
\hline CHEMBL1585607 & 688653 & 5.433 & 5.1721 & TST & & & \\
\hline CHEMBL1385904 & 688653 & \multicolumn{3}{|c|}{6.2829999999999995} & 5.6014 & TST & \\
\hline CHEMBL1544572 & 688653 & 4.883 & 5.3818 & TRN & & & \\
\hline CHEMBL1557805 & 688653 & 5.983 & 5.2345 & TST & & & \\
\hline CHEMBL1568237 & 688653 & 5.683 & 5.5397 & TRN & & & \\
\hline CHEMBL1323722 & 688653 & 5.683 & 5.2573 & TRN & & & \\
\hline CHEMBL1541632 & 688653 & 5.033 & 5.6021 & TST & & & \\
\hline CHEMBL3211375 & 688653 & 5.083 & 5.2606 & TST & & & \\
\hline CHEMBL1092508 & 688653 & 5.683 & 5.0893 & TRN & & & \\
\hline CHEMBL1488813 & 688653 & \multicolumn{3}{|c|}{5.2829999999999995} & 5.2757 & TST & \\
\hline CHEMBL1384292 & 688653 & 5.933 & 6.2156 & TRN & & & \\
\hline CHEMBL1478089 & 688653 & \multicolumn{3}{|c|}{5.132999999999999} & 5.4826 & TRN & \\
\hline CHEMBL1583133 & 688653 & \multicolumn{3}{|c|}{5.132999999999999} & 5.3332 & TRN & \\
\hline CHEMBL1313428 & 688653 & \multicolumn{3}{|c|}{5.132999999999999} & 6.2339 & TRN & \\
\hline CHEMBL1351040 & 688653 & 5.683 & 5.4255 & TRN & & & \\
\hline CHEMBL3194642 & 688653 & 4.783 & 5.403 & TST & & & \\
\hline CHEMBL1469698 & 688653 & 4.633 & 4.9406 & TRN & & & \\
\hline CHEMBL1502512 & 688653 & 4.833 & 5.2315 & TST & & & \\
\hline CHEMBL 3196297 & 688653 & \multicolumn{3}{|c|}{4.7330000000000005} & 5.3358 & TRN & \\
\hline CHEMBL1487401 & 688653 & 4.633 & 5.5667 & TRN & & & \\
\hline CHEMBL1310082 & 688653 & 4.783 & 4.8909 & TRN & & & \\
\hline CHEMBL 3195943 & 688653 & 4.783 & 4.6396 & TRN & & & \\
\hline CHEMBL3191170 & 688653 & 5.433 & 6.1271 & TRN & & & \\
\hline CHEMBL1545806 & 688653 & \multicolumn{3}{|c|}{5.5329999999999995} & 4.9164 & TST & \\
\hline CHEMBL1306850 & 688653 & \multicolumn{3}{|c|}{5.882999999999999} & 5.6938 & TRN & \\
\hline CHEMBL1422078 & 688653 & 4.833 & 6.146 & TRN & & & \\
\hline CHEMBL1306034 & 688653 & \multicolumn{3}{|c|}{5.382999999999999} & 5.0672 & TRN & \\
\hline CHEMBL1452286 & 688653 & 4.583 & 4.8918 & TRN & & & \\
\hline CHEMBL1497930 & 688653 & \multicolumn{3}{|c|}{5.132999999999999} & 5.3797 & TRN & \\
\hline CHEMBL1321954 & 688653 & 4.95 & 5.5285 & TRN & & & \\
\hline CHEMBL1556325 & 688653 & 4.833 & 5.1798 & TRN & & & \\
\hline CHEMBL1397179 & 688653 & \multicolumn{3}{|c|}{5.7829999999999995} & 5.2554 & TRN & \\
\hline CHEMBL1550249 & 688653 & 5.083 & 4.8627 & TRN & & & \\
\hline CHEMBL1345973 & 688653 & 4.9830 & 00000000 & 005 & 5.2387 & TRN & \\
\hline CHEMBL1392554 & 688653 & 5.033 & 4.9388 & TST & & & \\
\hline CHEMBL1484036 & 688653 & 4.7330 & 00000000 & 005 & 5.5916 & TST & \\
\hline CHEMBL1493772 & 688653 & 4.933 & 4.9634 & TRN & & & \\
\hline CHEMBL1562506 & 688653 & 5.5329 & 99999999 & 995 & 4.6425 & TRN & \\
\hline CHEMBL1580889 & 688653 & 4.783 & 4.8755 & TRN & & & \\
\hline CHEMBL1499494 & 688653 & 4.883 & 4.835 & TST & & & \\
\hline CHEMBL1524360 & 688653 & 5.8329 & 99999999 & & 5.7006 & TRN & \\
\hline
\end{tabular}




\begin{tabular}{|c|c|c|c|c|c|c|}
\hline \multirow[b]{2}{*}{ CHEMBL1493886 } & & \multicolumn{5}{|c|}{ Supplemental Table S2.txt } \\
\hline & 688653 & 6.233 & 6.0816 & TRN & & \\
\hline CHEMBL 3207295 & 688653 & 4.783 & 5.1456 & TST & & \\
\hline CHEMBL1399793 & 688653 & 4.583 & 5.3509 & TST & & \\
\hline CHEMBL 3199262 & 688653 & \multicolumn{3}{|c|}{6.332999999999999} & 5.7593 & TST \\
\hline CHEMBL1582683 & 688653 & 4.833 & 5.4244 & TRN & & \\
\hline CHEMBL1544685 & 688653 & 5.033 & 6.5027 & TRN & & \\
\hline CHEMBL1496274 & 688653 & 4.783 & 5.5082 & TRN & & \\
\hline CHEMBL1530994 & 688653 & 5.233 & 5.1539 & TRN & & \\
\hline CHEMBL1375522 & 688653 & 4.783 & 5.2605 & TRN & & \\
\hline CHEMBL1414067 & 688653 & \multicolumn{3}{|c|}{5.382999999999999} & 5.6377 & TRN \\
\hline CHEMBL1448732 & 688653 & 4.833 & 5.0457 & TST & & \\
\hline CHEMBL1414472 & 688653 & 5.233 & 5.3356 & TRN & & \\
\hline CHEMBL1583201 & 688653 & 5.433 & 4.852 & TRN & & \\
\hline CHEMBL1488948 & 688653 & 5.183 & 5.0653 & TRN & & \\
\hline CHEMBL1499023 & 688653 & 4.933 & 5.1338 & TST & & \\
\hline CHEMBL1503659 & 688653 & \multicolumn{3}{|c|}{5.332999999999999} & 6.2384 & TRN \\
\hline CHEMBL1320000 & 688653 & \multicolumn{3}{|c|}{5.832999999999999} & & \\
\hline CHEMBL1303984 & 688653 & 5.083 & 4.9725 & TRN & & \\
\hline CHEMBL1305255 & 688653 & 4.933 & 5.2296 & TRN & & \\
\hline CHEMBL1510259 & 688653 & 4.783 & 4.9559 & TST & & \\
\hline CHEMBL1545961 & 688653 & 5.233 & 5.1738 & TRN & & \\
\hline CHEMBL1571162 & 688653 & 4.833 & 5.2267 & TRN & & \\
\hline CHEMBL1363022 & 688653 & 4.883 & 5.2937 & TRN & & \\
\hline CHEMBL1605916 & 688653 & 4.833 & 5.4258 & TST & & \\
\hline CHEMBL1533198 & 688653 & \multicolumn{3}{|c|}{6.0329999999999995} & 5.0636 & $\mathrm{Tl}$ \\
\hline CHEMBL1387117 & 688653 & 4.783 & 5.0269 & TRN & & \\
\hline CHEMBL1594945 & 688653 & \multicolumn{3}{|c|}{4.9830000000000005} & 5.1445 & m \\
\hline CHEMBL1474887 & 688653 & 4.633 & 5.1252 & TRN & & \\
\hline CHEMBL1417725 & 688653 & 4.883 & 4.9343 & TRN & & \\
\hline CHEMBL1467015 & 688653 & 5.033 & 5.0122 & TRN & & \\
\hline CHEMBL1523699 & 688653 & 4.833 & 5.0102 & TRN & & \\
\hline CHEMBL1396853 & 688653 & 4.633 & 5.2819 & TST & & \\
\hline CHEMBL1479900 & 688653 & \multicolumn{3}{|c|}{ 5.382999999999999 } & 5.0053 & TRN \\
\hline CHEMBL1391864 & 688653 & \multicolumn{3}{|c|}{5.132999999999999} & 5.5875 & $\mathrm{TR}$ \\
\hline CHEMBL1465969 & 688653 & 5.433 & 5.5137 & TRN & & \\
\hline CHEMBL1300800 & 688653 & 4.883 & 5.113 & TRN & & \\
\hline CHEMBL1594371 & 688653 & 4.933 & 5.0953 & TRN & & \\
\hline CHEMBL1333801 & 688653 & \multicolumn{3}{|c|}{5.2829999999999995} & 5.0616 & $\mathrm{TP}$ \\
\hline CHEMBL191750 & 688653 & 5.033 & 5.1436 & TRN & & \\
\hline CHEMBL1505212 & 688653 & \multicolumn{3}{|c|}{5.7829999999999995} & 5.4214 & TRN \\
\hline CHEMBL1603691 & 688653 & \multicolumn{3}{|c|}{6.5329999999999995} & 5.3077 & TR \\
\hline CHEMBL1389625 & 688653 & 4.883 & 5.2534 & TRN & & \\
\hline CHEMBL1492235 & 688653 & 5.233 & 5.3423 & TRN & & \\
\hline CHEMBL1353922 & 688653 & \multicolumn{3}{|c|}{5.7829999999999995} & 5.517 & I KIV \\
\hline CHEMBL1491135 & 688653 & \multicolumn{3}{|c|}{5.2829999999999995} & 5.6729 & TRN \\
\hline CHEMBL1395894 & 688653 & \multicolumn{3}{|c|}{5.832999999999999} & 5.3044 & $\pi \theta^{-1}$ \\
\hline CHEMBL1545737 & 688653 & \multicolumn{3}{|c|}{4.7330000000000005} & 5.0021 & TRN \\
\hline CHEMBL 3192148 & 688653 & \multicolumn{3}{|c|}{5.582999999999999} & 5.1134 & TRN \\
\hline
\end{tabular}




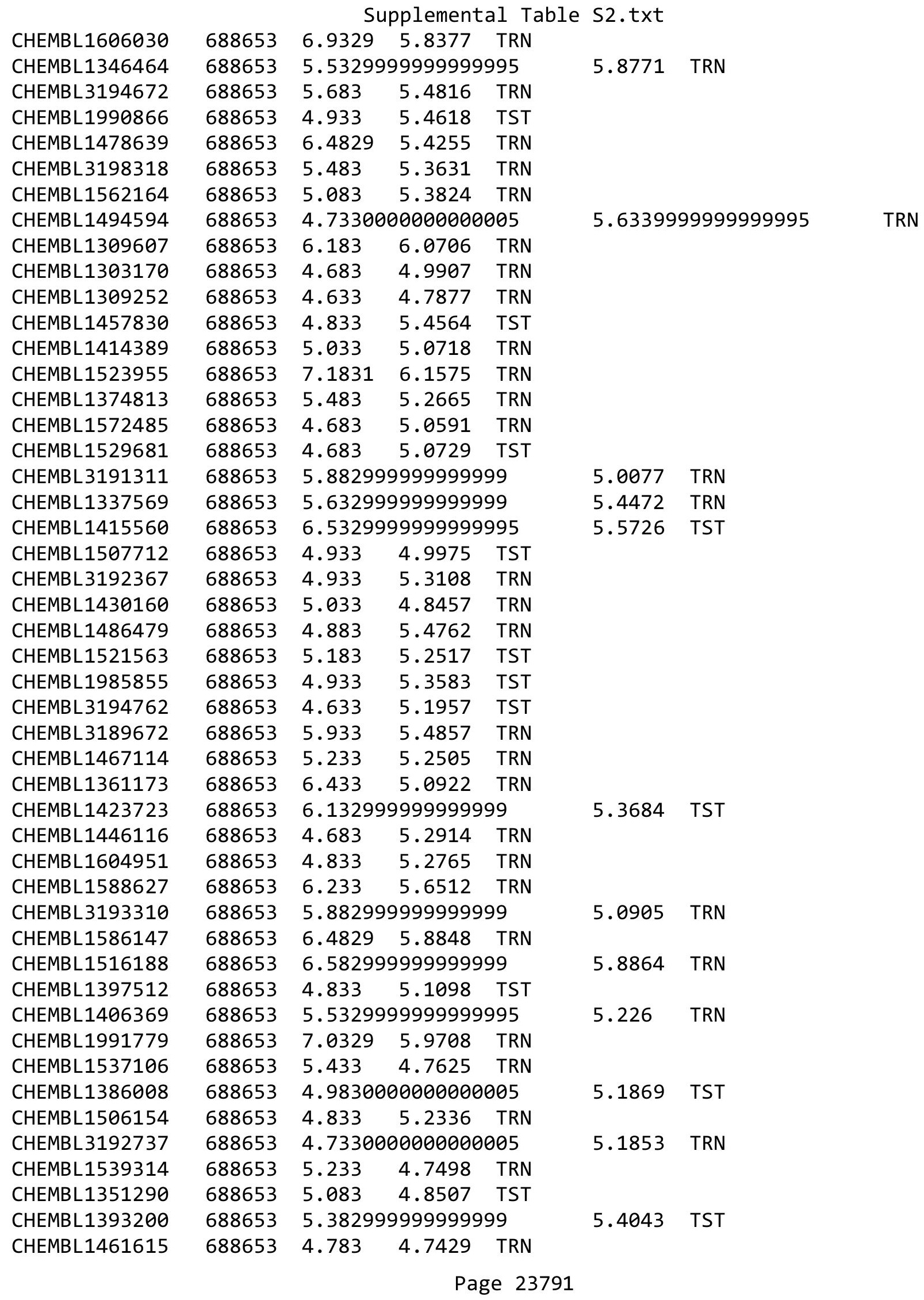




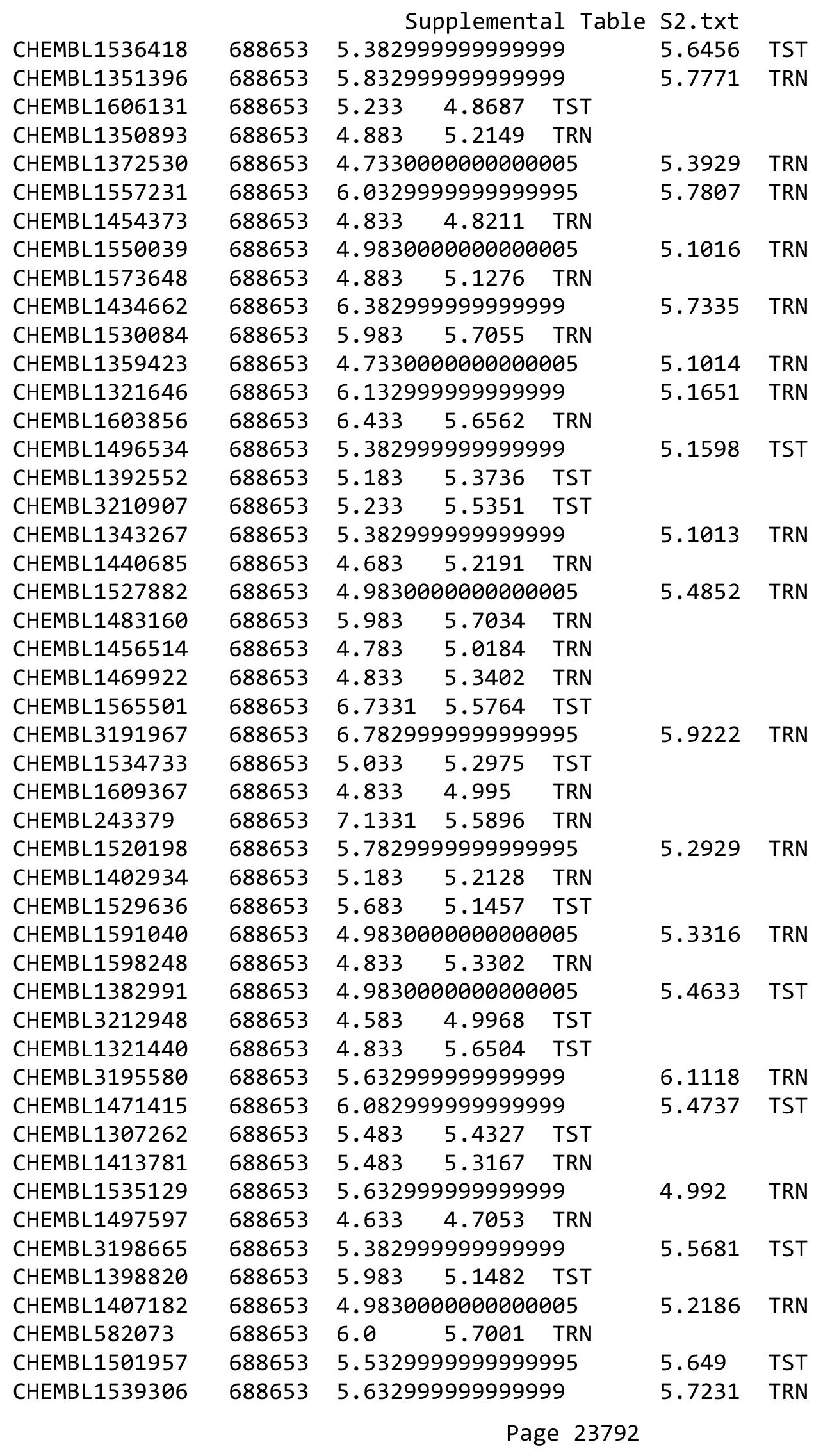




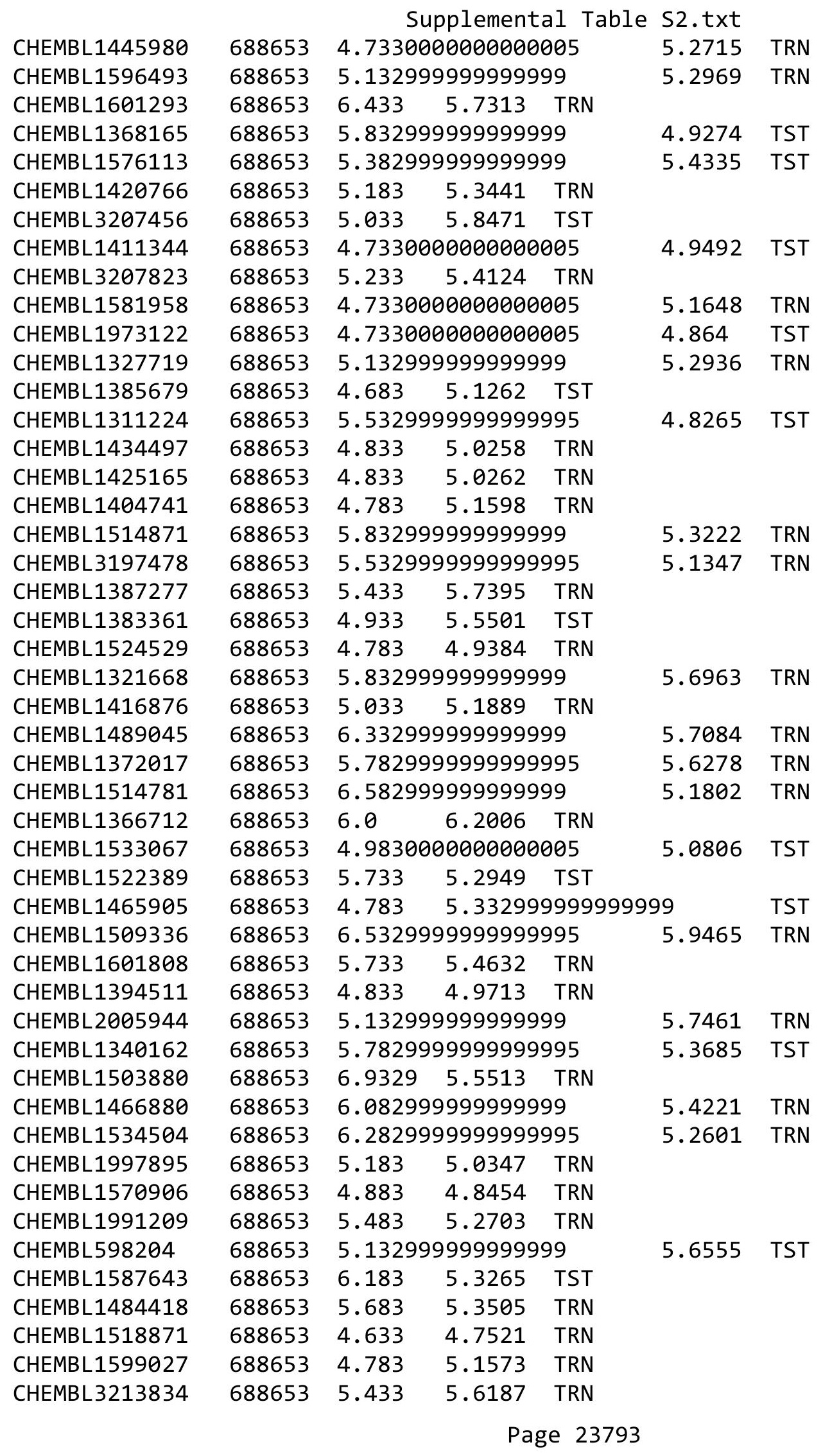




\begin{tabular}{|c|c|c|c|c|c|c|}
\hline & & & & & \\
\hline CHEMBL1398003 & 688653 & 4.883 & 5.0981 & TRN & & \\
\hline CHEMBL1603399 & 688653 & 5.483 & 5.5876 & TRN & & \\
\hline CHEMBL1436358 & 688653 & 4.833 & 5.4492 & TRN & & \\
\hline CHEMBL1322104 & 688653 & \multicolumn{3}{|c|}{5.832999999999999} & 5.5206 & TRN \\
\hline CHEMBL1417191 & 688653 & \multicolumn{3}{|c|}{5.132999999999999} & 4.9967 & TRN \\
\hline CHEMBL1349399 & 688653 & \multicolumn{3}{|c|}{5.7829999999999995} & 5.5445 & TRN \\
\hline CHEMBL1301718 & 688653 & 5.733 & 5.3433 & TRN & & \\
\hline CHEMBL1325689 & 688653 & 4.633 & 4.9365 & TRN & & \\
\hline CHEMBL 1477437 & 688653 & \multicolumn{3}{|c|}{4.9830000000000005} & 4.9762 & TRN \\
\hline CHEMBL1484569 & 688653 & 4.583 & 4.7834 & TRN & & \\
\hline CHEMBL1573636 & 688653 & 5.683 & 5.8791 & TRN & & \\
\hline CHEMBL1362507 & 688653 & 6.0 & 6.3787 & TST & & \\
\hline CHEMBL1556848 & 688653 & 6.183 & 5.3978 & TRN & & \\
\hline CHEMBL1553528 & 688653 & \multicolumn{3}{|c|}{6.132999999999999} & 5.3246 & TRN \\
\hline CHEMBL1310824 & 688653 & 4.883 & 5.2836 & TRN & & \\
\hline CHEMBL 3212885 & 688653 & \multicolumn{3}{|c|}{4.7330000000000005} & 5.3094 & TRN \\
\hline CHEMBL1302780 & 688653 & \multicolumn{3}{|c|}{5.2829999999999995} & 4.9879 & TRN \\
\hline CHEMBL1369641 & 688653 & 4.933 & 5.8931 & TRN & & \\
\hline CHEMBL1567111 & 688653 & 4.933 & 5.6152 & TST & & \\
\hline CHEMBL1550809 & 688653 & 6.15 & 5.3186 & TRN & & \\
\hline CHEMBL1444305 & 688653 & \multicolumn{3}{|c|}{4.7330000000000005} & 5.072 & TRN \\
\hline CHEMBL1339222 & 688653 & 5.233 & 5.7725 & TST & & \\
\hline CHEMBL1187074 & 688653 & 5.683 & 5.5779 & TRN & & \\
\hline CHEMBL1310405 & 688653 & 4.783 & 5.1745 & TST & & \\
\hline CHEMBL1463739 & 688653 & 4.783 & 5.3458 & TRN & & \\
\hline CHEMBL1449627 & 688653 & \multicolumn{3}{|c|}{5.882999999999999} & 5.9608 & TRN \\
\hline CHEMBL1435262 & 688653 & 4.633 & 4.7705 & TRN & & \\
\hline CHEMBL1579212 & 688653 & 4.883 & 5.2005 & TST & & \\
\hline CHEMBL380184 & 688653 & 5.683 & 5.5264 & TRN & & \\
\hline CHEMBL1410840 & 688653 & 4.783 & 5.0857 & TRN & & \\
\hline CHEMBL1515073 & 688653 & 4.883 & 5.2817 & TST & & \\
\hline CHEMBL1422352 & 688653 & 5.233 & 5.4358 & TRN & & \\
\hline CHEMBL1465006 & 688653 & 6.433 & 5.6475 & TRN & & \\
\hline CHEMBL1447796 & 688653 & 4.783 & 5.1261 & TST & & \\
\hline CHEMBL1507170 & 688653 & 4.783 & \multicolumn{3}{|c|}{5.236000000000001} & TRN \\
\hline CHEMBL1506034 & 688653 & \multicolumn{3}{|c|}{5.332999999999999} & 5.2171 & TRN \\
\hline CHEMBL1442344 & 688653 & 5.983 & 5.4218 & TRN & & \\
\hline CHEMBL1408981 & 688653 & 4.783 & 5.4782 & TRN & & \\
\hline CHEMBL1500770 & 688653 & \multicolumn{3}{|c|}{4.7330000000000005} & 5.4339 & TRN \\
\hline CHEMBL1562970 & 688653 & 4.833 & 5.0166 & TRN & & \\
\hline CHEMBL1549097 & 688653 & 6.0 & 5.4631 & TRN & & \\
\hline CHEMBL1571017 & 688653 & 5.733 & 5.5593 & TRN & & \\
\hline CHEMBL1312173 & 688653 & 5.183 & 5.2605 & TRN & & \\
\hline CHEMBL1491862 & 688653 & 4.783 & 5.1661 & TRN & & \\
\hline CHEMBL 3198980 & 688653 & \multicolumn{3}{|c|}{5.382999999999999} & 5.0097 & TRN \\
\hline CHEMBL1600023 & 688653 & \multicolumn{3}{|c|}{5.5329999999999995} & 5.1862 & TRN \\
\hline CHEMBL1606349 & 688653 & \multicolumn{3}{|c|}{5.632999999999999} & 5.0835 & TRN \\
\hline CHEMBL1412874 & 688653 & \multicolumn{3}{|c|}{5.2829999999999995} & 4.8439 & TRN \\
\hline
\end{tabular}




\begin{tabular}{|c|c|c|c|c|c|c|}
\hline & & \multicolumn{5}{|c|}{ Supplemental Table S2.txt } \\
\hline CHEMBL1384696 & 688653 & 4.583 & 4.8021 & TST & & \\
\hline CHEMBL1422335 & 688653 & 6.433 & 6.1906 & TRN & & \\
\hline CHEMBL1594558 & 588653 & 5.983 & 5.3813 & TRN & & \\
\hline CHEMBL1460751 & 688653 & \multicolumn{3}{|c|}{6.0329999999999995} & 5.5684 & $\mathrm{TI}$ \\
\hline CHEMBL1408442 & 688653 & \multicolumn{3}{|c|}{5.382999999999999} & 4.5301 & \\
\hline CHEMBL 3197024 & 688653 & \multicolumn{3}{|c|}{5.5329999999999995} & 5.398 & \\
\hline CHEMBL1352189 & 688653 & \multicolumn{3}{|c|}{4.7330000000000005} & 5.0346 & \\
\hline CHEMBL1362846 & 688653 & 5.033 & 5.0693 & TRN & & \\
\hline CHEMBL1545364 & 688653 & \multicolumn{3}{|c|}{5.382999999999999} & 4.9768 & \\
\hline CHEMBL1329399 & 688653 & 4.833 & 5.0169 & TRN & & \\
\hline CHEMBL1352240 & 688653 & \multicolumn{3}{|c|}{5.2829999999999995} & 5.1487 & \\
\hline CHEMBL1391705 & 688653 & 4.933 & 4.8541 & TST & & \\
\hline CHEMBL1530434 & 688653 & \multicolumn{3}{|c|}{6.5329999999999995} & 036 & \\
\hline CHEMBL6665 & 688653 & 4.783 & 5.5073 & TRN & & \\
\hline HEMBL14 & 688653 & 4.883 & 5.1448 & TRN & & \\
\hline CHEMBL1477958 & 688653 & 5.933 & \multicolumn{3}{|c|}{5.9670000000000005} & \\
\hline CHEMBL1398943 & 688653 & 5.083 & 5.1323 & TRN & & \\
\hline CHEMBL15 & 688653 & 4.933 & 4.7483 & TRN & & \\
\hline CHEMBL1 & 688653 & 5.183 & 4.766 & TRN & & \\
\hline CHEMBL1571649 & 688653 & 4.833 & 5.0243 & TST & & \\
\hline CHEMBL1451365 & 688653 & 4.883 & 5.124 & TRN & & \\
\hline CHEMBL3 & 688653 & 5.683 & 5.6058 & TRN & & \\
\hline CHEMBL1 & 688653 & \multicolumn{3}{|c|}{6.382999999999999} & 818 & \\
\hline CHEMBL16: & 688653 & 4.783 & 5.2397 & TST & & \\
\hline CHEMBL1 & 688653 & \multicolumn{3}{|c|}{6.2829999999999995} & 5.0915 & TRN \\
\hline CHEMBL158 & 688653 & \multicolumn{3}{|c|}{4.7330000000000005} & & \\
\hline CHEMBL1 & 688653 & 6.183 & 5.504 & TRN & & \\
\hline CHEMBL1 & 688653 & \multicolumn{3}{|c|}{5.5329999999999995} & 5.2515 & \\
\hline CHEMBL1 & 688653 & 4.783 & 5.2047 & TRN & & \\
\hline CHEMBL1524960 & 688653 & 4.833 & 4.8987 & TRN & & \\
\hline CHEMBL3195034 & 688653 & 4.833 & 5.4274 & TRN & & \\
\hline CHEMBL: & 688 & 5.183 & 5.4142 & TST & & \\
\hline CHEMBL1 & 688653 & \multicolumn{3}{|c|}{5.832999999999999} & 5.1721 & TR \\
\hline CHEMBL1577985 & 688653 & 4.783 & 5.2186 & TST & & \\
\hline CHEMBL1531778 & 688653 & \multicolumn{3}{|c|}{5.832999999999999} & & TRN \\
\hline CHEMBL1599601 & 688653 & \multicolumn{3}{|c|}{5.882999999999999} & 5.5546 & \\
\hline CHEMBL132 & 688653 & 7.0329 & 5.9027 & TRN & & \\
\hline CHEMBL146 & 688653 & 4.833 & 4.9743 & TRN & & \\
\hline CHEMBL1500992 & 688653 & 4.783 & 5.0015 & TRN & & \\
\hline CHEMBL1486711 & 688653 & \multicolumn{3}{|c|}{6.2829999999999995} & 5.5061 & \\
\hline CHEMBL1502791 & 688653 & \multicolumn{3}{|c|}{4.7330000000000005} & 5.1145 & \\
\hline CHEMBL1876078 & 688653 & 6.233 & 5.0363 & TRN & & \\
\hline CHEMBL1497537 & 688653 & \multicolumn{3}{|c|}{5.2829999999999995} & 5.0492 & TRN \\
\hline CHEMBL1515201 & 688653 & 5.983 & 5.4971 & TRN & & \\
\hline CHEMBL1415598 & 688653 & \multicolumn{3}{|c|}{6.332999999999999} & 5.599 & דו \\
\hline CHEMBL1526731 & 688653 & \multicolumn{3}{|c|}{5.5329999999999995} & 5.0047 & \\
\hline CHEMBL1619418 & 688653 & 4.73300 & 00000000 & 005 & 5.091 & \\
\hline CHEMBL1401545 & 688653 & 6.183 & 5.8121 & TRN & & \\
\hline
\end{tabular}




\begin{tabular}{|c|c|c|c|c|c|c|}
\hline \multirow[b]{2}{*}{ CHEMBL1445626 } & \multicolumn{6}{|c|}{ ellent } \\
\hline & 688653 & 4.783 & 5.8103 & TRN & & \\
\hline CHEMBL1498695 & 688653 & \multicolumn{3}{|c|}{5.382999999999999} & 5.8977 & TR \\
\hline CHEMBL1500925 & 688653 & 5.183 & 5.1564 & TST & & \\
\hline CHEMBL1474073 & 688653 & 5.233 & 5.1063 & TST & & \\
\hline CHEMBL1376292 & 88653 & 5.033 & 5.2457 & TRN & & \\
\hline CHEMBL1598264 & 688653 & \multicolumn{3}{|c|}{6.2829999999999995} & 5.5461 & \\
\hline CHEMBL1466874 & 688653 & \multicolumn{3}{|c|}{6.132999999999999} & 5.5695 & \\
\hline CHEMBL1303012 & 688653 & 4.783 & 5.3122 & TRN & & \\
\hline CHEMBL1375627 & 688653 & 4.783 & 5.1502 & TST & & \\
\hline CHEMBL1474059 & 688653 & 6.433 & 6.1038 & TRN & & \\
\hline CHEMBL1541459 & 688653 & 5.683 & 5.3824 & TRN & & \\
\hline CHEMBL1536547 & 688653 & 4.833 & 5.3912 & TRN & & \\
\hline CHEMBL1403523 & 688653 & 4.633 & 4.8058 & TST & & \\
\hline CHEMBL1513868 & 688653 & \multicolumn{3}{|c|}{4.7330000000000005} & & \\
\hline CHEMBL1 & 688653 & 5.983 & 5.5499 & TRN & & \\
\hline CHEMBL15 & 688653 & \multicolumn{3}{|c|}{6.332999999999999} & 5.6534 & \\
\hline CHEMBL1573814 & 688653 & \multicolumn{3}{|c|}{5.582999999999999} & 5.2616 & \\
\hline CHEMBL1550330 & 688653 & \multicolumn{3}{|c|}{5.382999999999999} & & \\
\hline CHEMBL 1 & 688 & 5.683 & 5.2099 & TRN & & \\
\hline CHEMB & $68 \varepsilon$ & \multirow{2}{*}{\multicolumn{3}{|c|}{4.9830000000000005}} & & \\
\hline CHEMBL1 & 688653 & & & & 5.3094 & \\
\hline CHEMBL1609565 & 688653 & \multicolumn{3}{|c|}{$\begin{array}{l}4.9830000000000005 \\
5.033 \quad 4.97199999\end{array}$} & 995 & \\
\hline CHEMBL1392142 & 688653 & \multicolumn{3}{|c|}{5.332999999999999} & 6.3689 & \\
\hline CHEMBL13 & 688 & \multicolumn{3}{|c|}{4.9830000000000005} & & \\
\hline CHEMBL1 & 688653 & \multicolumn{3}{|c|}{6.132999999999999} & & \\
\hline CHEMBL1372201 & 688653 & 5.233 & 5.0998 & TRN & & \\
\hline CHEMBL 4 & 688 & \multirow{2}{*}{\multicolumn{3}{|c|}{$\begin{array}{lrr}5.933 & 5.3978 \text { TST } \\
4.9830000000000005\end{array}$}} & & \\
\hline CHEMBL15 & 688653 & & & & 5.0236 & \\
\hline CHEMBL: & 688 & \multicolumn{3}{|c|}{$6.4829 \quad 5.7693$ TRN } & & \\
\hline CHEMBL1 & 688 & 5.233 & 5.2923 & TST & & \\
\hline CHEMBL1445748 & 688653 & \multicolumn{3}{|c|}{5.882999999999999} & 5.2687 & TRN \\
\hline CHEMBL1335017 & 688653 & \multicolumn{3}{|c|}{4.7330000000000005} & & \\
\hline CHEMBL1465465 & 688653 & 5.183 & 5.2637 & TRN & & \\
\hline CHEMBL & 688 & \multicolumn{3}{|c|}{4.7330000000000005} & 4.965 & 11 \\
\hline CHEMBL1 & 688653 & 7.0329 & 6.1198 & TRN & & \\
\hline CHEMBL1510543 & 688653 & 4.633 & 4.9829 & TST & & \\
\hline CHEMBL1520273 & 688653 & 5.733 & 6.1058 & TRN & & \\
\hline CHEMBL1498373 & 688653 & 4.833 & \multicolumn{3}{|c|}{5.6579999999999995} & \\
\hline CHEMBL1355245 & 688653 & 5.433 & 5.4648 & TST & & \\
\hline CHEMBL1517473 & 688653 & \multicolumn{3}{|c|}{5.132999999999999} & 5.3827 & TRN \\
\hline CHEMBL1387529 & 688653 & 6.5329 & 99999999 & 995 & 6.2559 & $\mathrm{TR}$ \\
\hline CHEMBL1488052 & 688653 & 4.833 & 4.9927 & TRN & & \\
\hline CHEMBL1536507 & 688653 & 5.5829 & 99999999 & & 6.1167 & $\mathrm{IRN}$ \\
\hline CHEMBL1578642 & 688653 & 4.833 & 5.4399 & TST & & \\
\hline CHEMBL1451926 & 688653 & 5.7829 & 99999999 & 995 & 5.8664 & TRN \\
\hline CHEMBL1532037 & 688653 & 6.1329 & 99999999 & & 5.6742 & $\pi 0$ \\
\hline CHEMBL1586641 & 688653 & 4.683 & 5.5497 & TRN & & \\
\hline CHEMBL1506416 & 688653 & 5.3829 & 9999999 & & 4.9531 & TRN \\
\hline
\end{tabular}




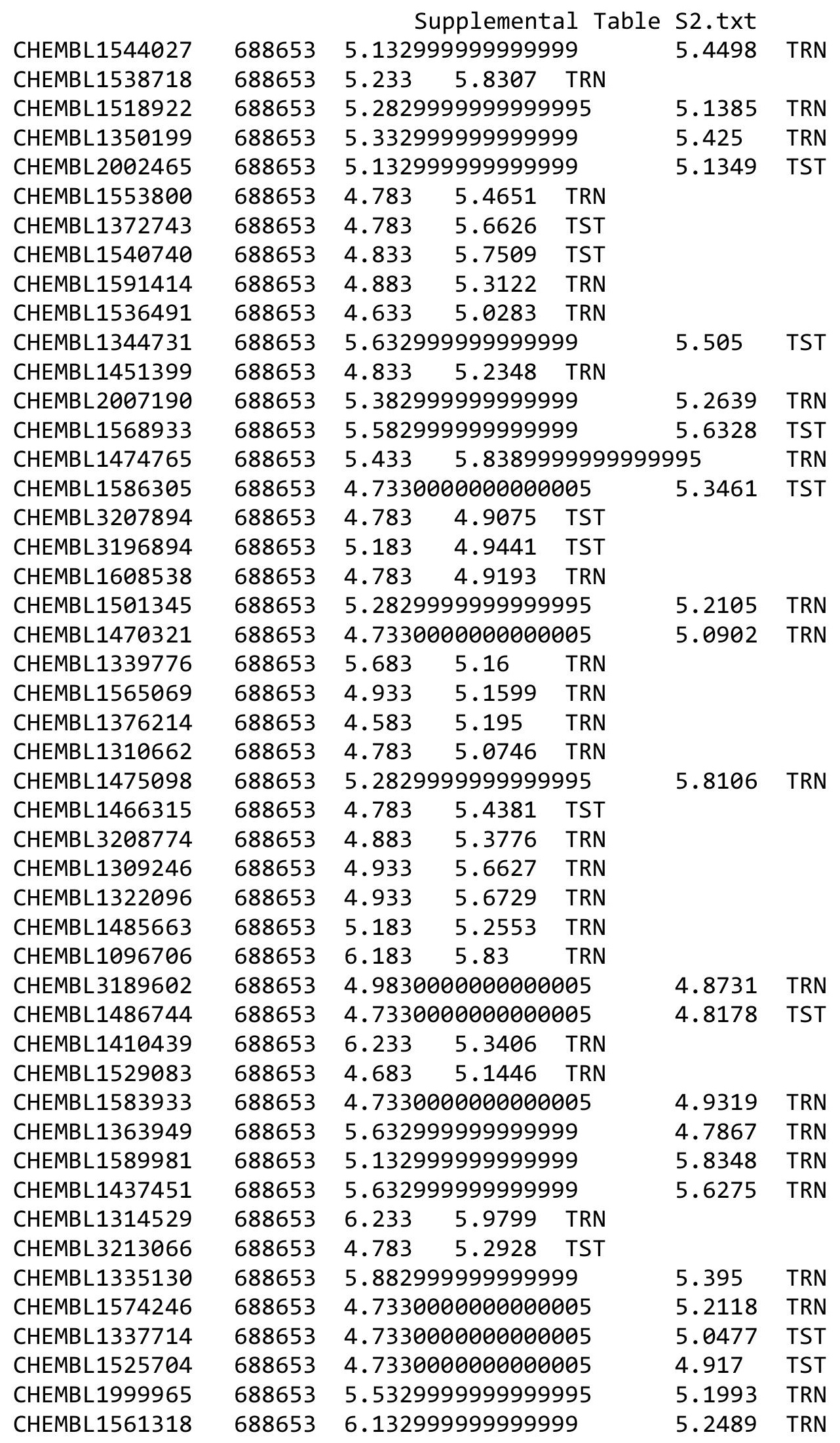




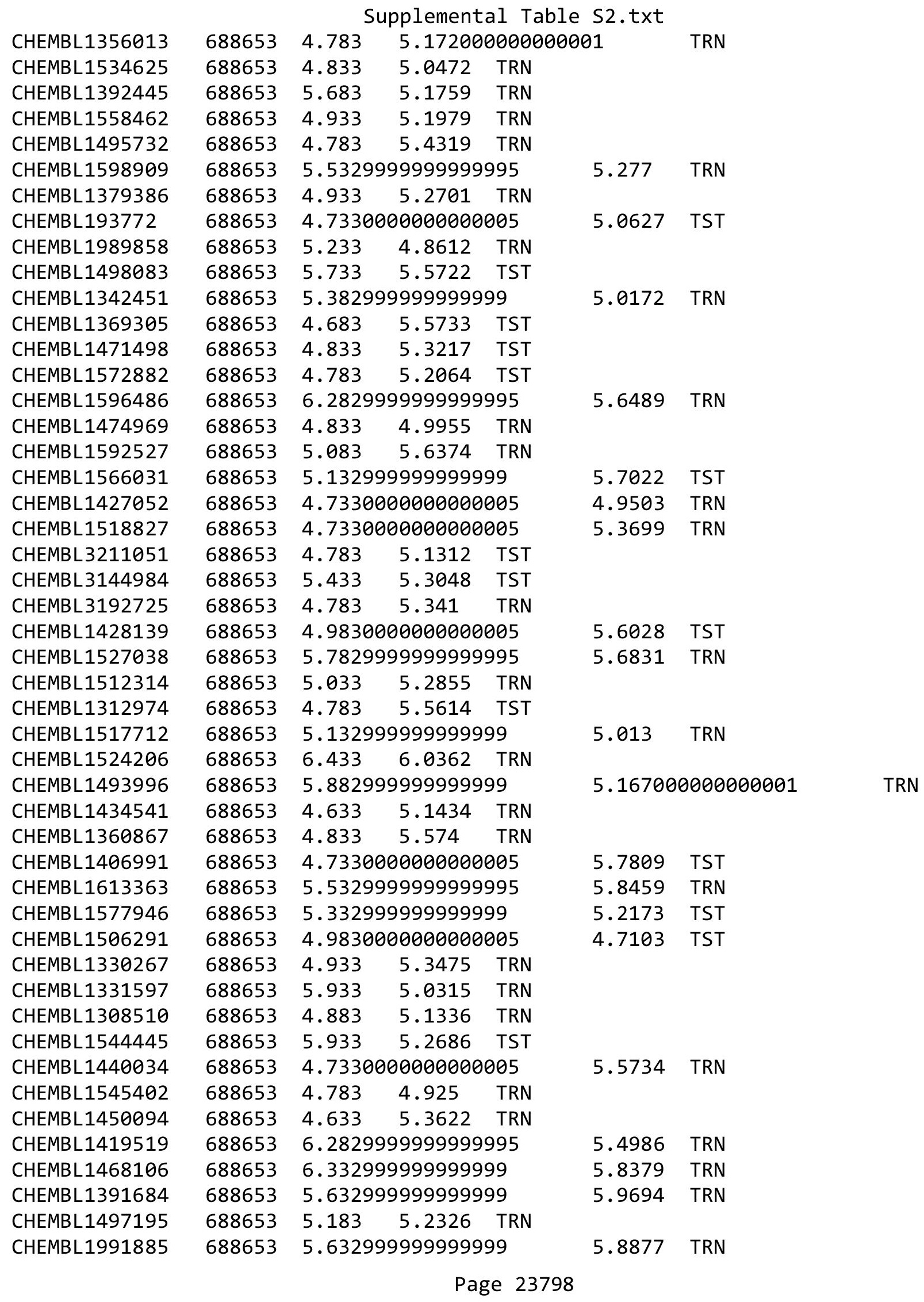




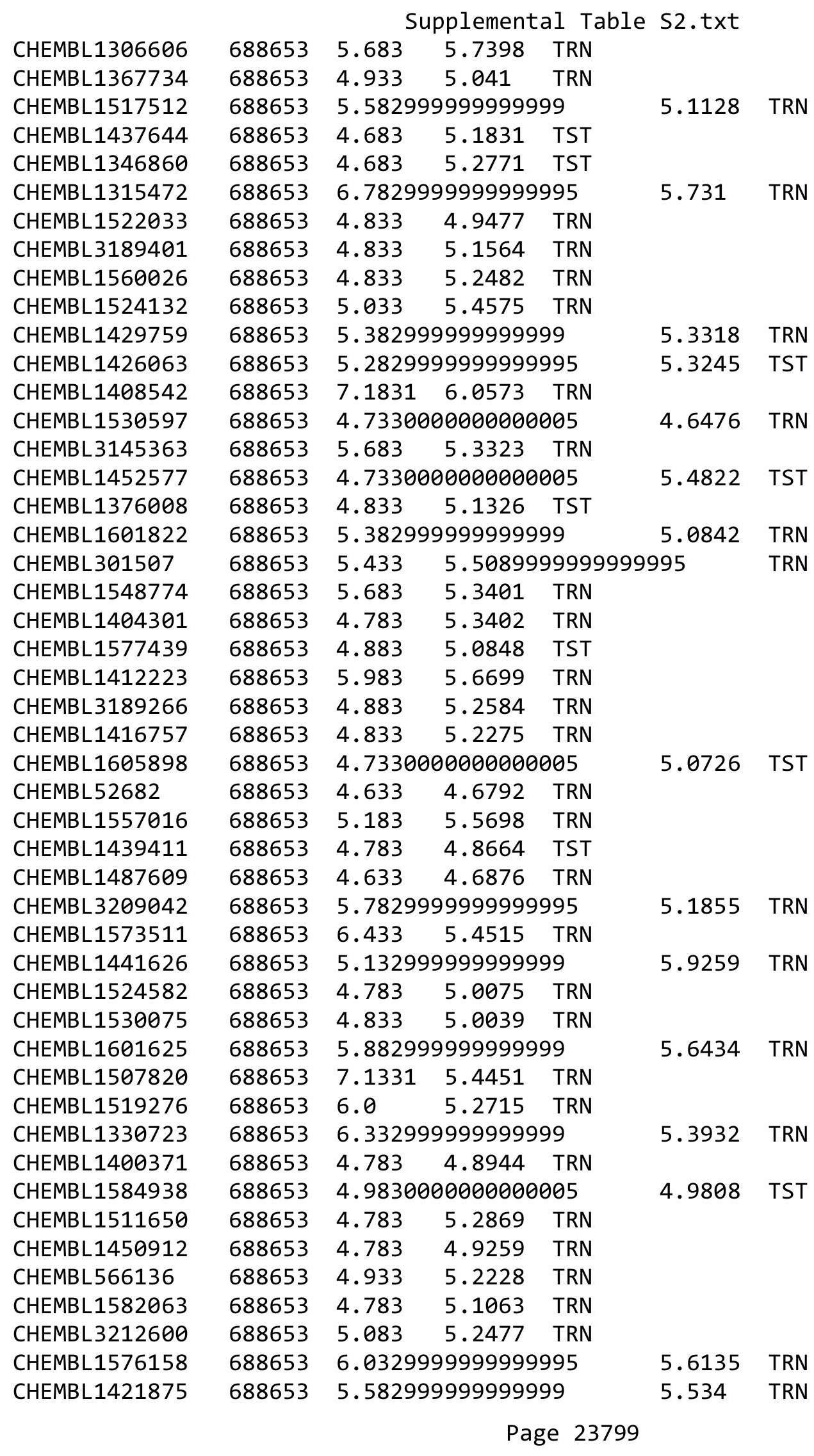




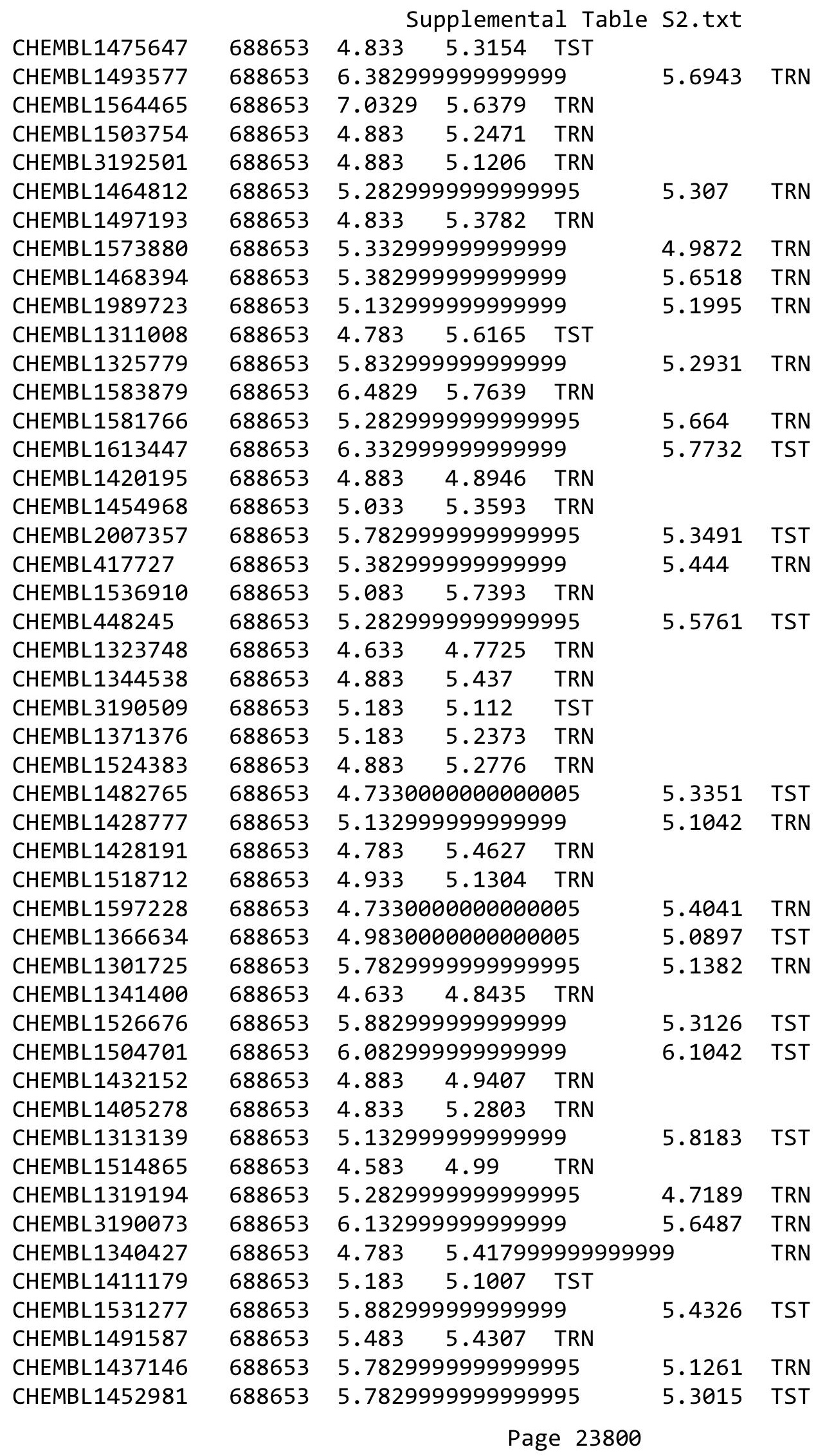




\begin{tabular}{|c|c|c|c|c|c|c|}
\hline \multirow{3}{*}{$\begin{array}{l}\text { CHEMBL1359770 } \\
\text { CHEMBL1583496 }\end{array}$} & & \multicolumn{5}{|c|}{ Supplemental Table S2.txt } \\
\hline & 688653 & \multicolumn{3}{|c|}{5.2829999999999995} & 5.4571 & TRN \\
\hline & 688653 & 6.233 & 5.5426 & TRN & & \\
\hline CHEMBL1604005 & 688653 & 4.783 & 5.1712 & TRN & & \\
\hline CHEMBL1483479 & 688653 & 4.883 & 4.823 & TRN & & \\
\hline CHEMBL1536188 & 688653 & \multicolumn{3}{|c|}{4.7330000000000005} & 5.2965 & TRN \\
\hline CHEMBL1322010 & 688653 & \multicolumn{3}{|c|}{5.832999999999999} & 5.8848 & TRN \\
\hline CHEMBL1419771 & 688653 & \multicolumn{3}{|c|}{5.2829999999999995} & 5.2411 & TRN \\
\hline CHEMBL1471198 & 688653 & 5.033 & 5.5057 & TRN & & \\
\hline CHEMBL1445676 & 688653 & \multicolumn{3}{|c|}{6.2829999999999995} & 5.6805 & TRN \\
\hline CHEMBL3213501 & 688653 & \multicolumn{3}{|c|}{6.332999999999999} & 6.2857 & TRN \\
\hline CHEMBL1533132 & 688653 & 4.633 & 5.3899 & TRN & & \\
\hline CHEMBL1551648 & 688653 & 4.583 & 5.0074 & TST & & \\
\hline CHEMBL1596341 & 688653 & 4.883 & 5.1244 & TRN & & \\
\hline CHEMBL1558806 & 688653 & 5.233 & 5.376 & TRN & & \\
\hline CHEMBL1551519 & 688653 & 5.683 & 4.8788 & TRN & & \\
\hline CHEMBL1390926 & 688653 & 4.783 & 5.2003 & TST & & \\
\hline CHEMBL1370884 & 688653 & \multicolumn{3}{|c|}{5.632999999999999} & 5.2831 & TST \\
\hline CHEMBL1307877 & 688653 & 4.833 & 5.256 & TRN & & \\
\hline CHEMBL1458831 & 688653 & 5.183 & 5.1367 & TRN & & \\
\hline CHEMBL1545125 & 688653 & 4.833 & 5.32100 & 00000 & 01 & TRN \\
\hline CHEMBL1314758 & 688653 & 4.633 & 4.8706 & TST & & \\
\hline CHEMBL1358016 & 688653 & 4.633 & 5.4439 & TRN & & \\
\hline CHEMBL1434307 & 688653 & \multicolumn{3}{|c|}{4.7330000000000005} & 4.8386 & TRN \\
\hline CHEMBL1547437 & 688653 & \multicolumn{3}{|c|}{5.2829999999999995} & 5.0629 & TRN \\
\hline CHEMBL1563106 & 688653 & 5.483 & 5.4165 & TST & & \\
\hline CHEMBL1327888 & 688653 & \multicolumn{3}{|c|}{5.132999999999999} & 5.1579 & TRN \\
\hline CHEMBL1306245 & 688653 & 5.233 & 5.2241 & TRN & & \\
\hline CHEMBL1984447 & 688653 & \multirow{2}{*}{\multicolumn{3}{|c|}{$\begin{array}{ll}4 . / 83 & 3.2218 \\
6.2829999999999995\end{array}$}} & & \\
\hline CHEMBL1488499 & 688653 & & & & 5.6317 & TRN \\
\hline CHEMBL1331735 & 688653 & 4.933 & 5.0828 & TRN & & \\
\hline CHEMBL1475415 & 688653 & 4.883 & 5.2187 & TRN & & \\
\hline CHEMBL1446802 & 688653 & \multicolumn{3}{|c|}{4.7330000000000005} & 5.0478 & TST \\
\hline CHEMBL1469417 & 688653 & \multicolumn{3}{|c|}{5.582999999999999} & 5.4522 & TRN \\
\hline CHEMBL1524326 & 688653 & 4.783 & 5.2162 & TRN & & \\
\hline CHEMBL1380676 & 688653 & \multicolumn{3}{|c|}{6.382999999999999} & 5.624 & TRN \\
\hline CHEMBL1578901 & 688653 & \multicolumn{3}{|c|}{4.7330000000000005} & 4.8179 & TRN \\
\hline CHEMBL1499026 & 688653 & 6.8831 & 5.4109 & TST & & \\
\hline CHEMBL1516547 & 688653 & 4.683 & 5.3562 & TRN & & \\
\hline CHEMBL1608401 & 688653 & 5.033 & 4.7428 & TRN & & \\
\hline CHEMBL1332943 & 688653 & \multicolumn{3}{|c|}{4.7330000000000005} & 4.9765 & TST \\
\hline CHEMBL1572805 & 688653 & 4.633 & 5.4112 & TRN & & \\
\hline CHEMBL1342055 & 688653 & 5.233 & 5.3933 & TRN & & \\
\hline CHEMBL1395322 & 688653 & \multicolumn{3}{|c|}{5.5329999999999995} & 5.4235 & TRN \\
\hline CHEMBL1522837 & 688653 & \multicolumn{3}{|c|}{6.2829999999999995} & 5.2552 & TRN \\
\hline CHEMBL1418528 & 688653 & 5.683 & 5.5019 & TST & & \\
\hline CHEMBL1302422 & 688653 & 5.033 & 4.9086 & TRN & & \\
\hline CHEMBL1318797 & 688653 & 4.583 & 4.9714 & TST & & \\
\hline CHEMBL1538800 & 688653 & 4.783 & 5.2274 & TRN & & \\
\hline
\end{tabular}




\begin{tabular}{|c|c|c|c|c|c|c|}
\hline \multirow{3}{*}{$\begin{array}{l}\text { CHEMBL1322054 } \\
\text { CHEMBL1518285 }\end{array}$} & \multicolumn{6}{|c|}{ Supplemental Table S2.txt } \\
\hline & 688653 & \multicolumn{3}{|c|}{5.332999999999999} & \multirow[t]{3}{*}{5.6716} & \multirow[t]{2}{*}{ TRA } \\
\hline & 688653 & 5.033 & 5.0545 & TRN & & \\
\hline CHEMBL1551541 & 688653 & 4.883 & 5.2737 & TST & & \\
\hline CHEMBL1339320 & 688653 & \multicolumn{3}{|c|}{5.132999999999999} & 5.5494 & TST \\
\hline CHEMBL1503834 & 688653 & 4.583 & 5.4716 & TST & & \\
\hline CHEMBL530049 & 588653 & 5.2 & 5.5478 & TST & & \\
\hline CHEMBL1599927 & 688653 & 5.083 & 5.5542 & TRN & & \\
\hline CHEMBL1598863 & 688653 & \multicolumn{3}{|c|}{4.9830000000000005} & 5.3324 & $\mathrm{TI}$ \\
\hline CHEMBL1391187 & 588653 & 4.883 & 5.12299 & 999999999 & 99 & \\
\hline CHEMBL1322285 & 688653 & \multicolumn{3}{|c|}{4.9830000000000005} & 5.4571 & \\
\hline CHEMBL1431211 & 688653 & 6.233 & 4.7924 & TRN & & \\
\hline CHEMBL3197115 & 688653 & \multicolumn{3}{|c|}{5.832999999999999} & 5.5733 & TS \\
\hline CHEMBL1345171 & 688653 & 4.833 & 5.2974 & TRN & & \\
\hline CHEMBL1410758 & 688653 & 5.233 & 5.1952 & TRN & & \\
\hline CHEMBL1468229 & 688653 & 4.933 & 5.3127 & TRN & & \\
\hline HEMBL1 & 53 & 4.783 & 5.0122 & TRN & & \\
\hline CHEMBL 1 & 53 & 6.4829 & 5.8842 & TRN & & \\
\hline CHEMBL1490334 & 688653 & \multicolumn{3}{|c|}{6.132999999999999} & 6.061 & \\
\hline CHEMBL1452634 & 688653 & 5.233 & 5.9735 & TRN & & \\
\hline CHEMBL14 & 688 & 4.633 & 4.9198 & TRN & & \\
\hline HEMBL: & 53 & 83 & 5.1274 & TST & & \\
\hline CHEMBL 1 & $68 \varepsilon$ & 4.783 & \multicolumn{3}{|c|}{5.172999999999999} & 11 \\
\hline CHEMBL1538749 & 688653 & 7.0329 & 6.0064 & TRN & & \\
\hline CHEMBL1408294 & 688653 & 4.783 & 4.7493 & TST & & \\
\hline CHEMBL15 & 688 & \multicolumn{3}{|c|}{5.382999999999999} & 6971 & \\
\hline CHEMBL1 & 53 & \multicolumn{3}{|c|}{5.632999999999999} & 37 & \\
\hline CHEMBL1475149 & 688 & \multicolumn{3}{|c|}{5.132999999999999} & 724 & \\
\hline CHEMBL1547262 & 688653 & 4.833 & 5.0986 & TST & & \\
\hline CHEMBL1381714 & 688653 & 4.833 & 5.199 & TST & & \\
\hline CHEMBL156 & 3 & & 5.2 & TRN & & \\
\hline CHEMBL & 53 & 5.033 & 5.4357 & TRN & & \\
\hline CHEMBL1413999 & $68 \varepsilon$ & \multicolumn{3}{|c|}{6.0329999999999995} & 5.4162 & TP \\
\hline CHEMBL1534282 & 688653 & \multicolumn{3}{|c|}{5.332999999999999} & & $\mathrm{RN}$ \\
\hline CHEMBL1461897 & 688653 & \multicolumn{3}{|c|}{5.832999999999999} & 5.3464 & TR \\
\hline CHEMBL: & 688 & \multicolumn{3}{|c|}{5.5329999999999995} & 5.2971 & \\
\hline CHEMBL & 688 & 4.883 & 4.9051 & TRN & & \\
\hline CHEMBL1444294 & 688653 & 4.633 & 5.2014 & TST & & \\
\hline CHEMBL1547064 & 688653 & \multicolumn{3}{|c|}{5.332999999999999} & 5.6443 & $T$ \\
\hline CHEMBL1481470 & 688653 & 4.933 & 5.4975 & TRN & & \\
\hline CHEMBL1 & $68 \varepsilon$ & & 4.7 & TRN & & \\
\hline CHEMBL15 & $68 \varepsilon$ & 4.833 & 5.2311 & TRN & & \\
\hline CHEMBL1501774 & 688653 & \multicolumn{3}{|c|}{4.7330000000000005} & 5.6882 & TRN \\
\hline CHEMBL1424489 & 688653 & \multicolumn{3}{|c|}{4.9830000000000005} & 4.6124 & \\
\hline CHEMBL1389716 & 688653 & 4.783 & 5.0631 & TRN & & \\
\hline CHEMBL1495566 & 688653 & 5.433 & 5.3946 & TRN & & \\
\hline CHEMBL3191933 & 688653 & 5.8329 & 9999999 & & 5.6775 & Tाז \\
\hline CHEMBL1343143 & 688653 & 5.5829 & 9999999 & & 5.159 & TR \\
\hline CHEMBL1408473 & 688653 & 5.2829 & 9999999 & 95 & 4.8838 & \\
\hline
\end{tabular}




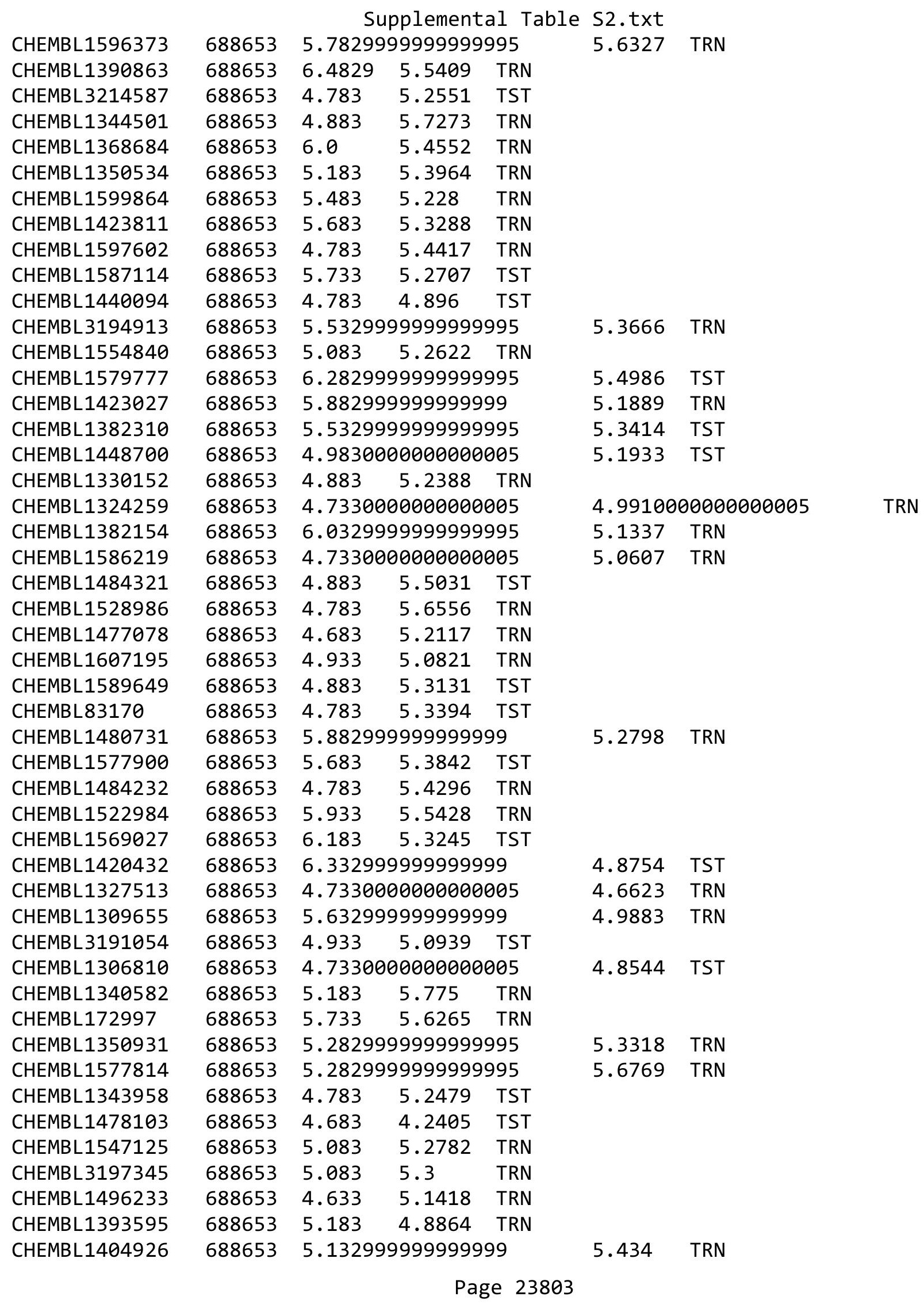




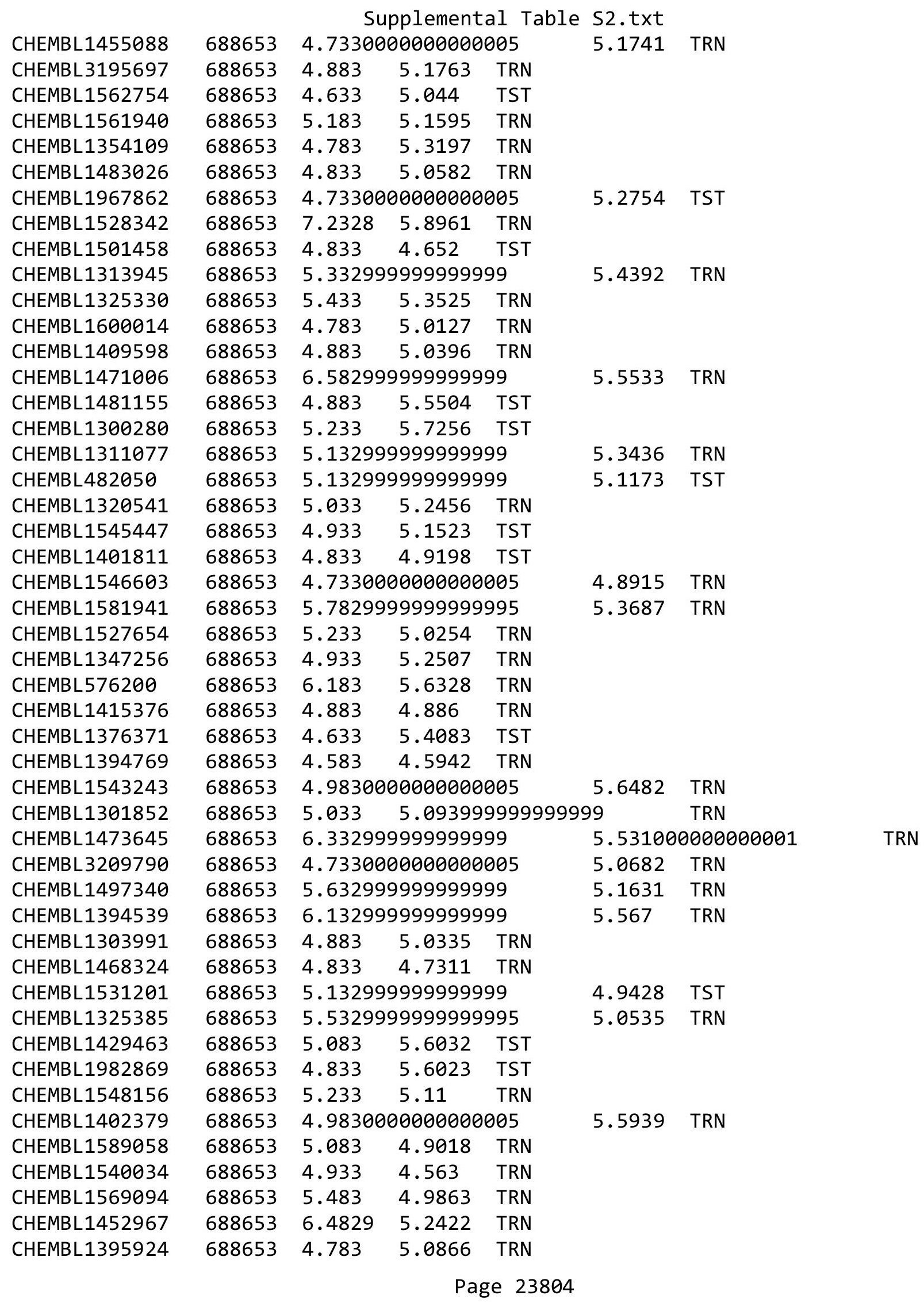




\begin{tabular}{|c|c|c|c|c|c|c|c|}
\hline \multicolumn{7}{|c|}{ Supplemental Table S2.txt } & \\
\hline CHEMBL1525646 & 688653 & \multicolumn{3}{|c|}{4.9830000000000005} & 5.1712 & TST & \\
\hline CHEMBL1373181 & 688653 & 4.833 & 4.8114 & TST & & & \\
\hline CHEMBL1535329 & 688653 & \multicolumn{3}{|c|}{4.7330000000000005} & 5.1699 & TRN & \\
\hline CHEMBL1383050 & 688653 & \multicolumn{3}{|c|}{5.332999999999999} & 5.1624 & TRN & \\
\hline CHEMBL3189742 & 688653 & \multicolumn{3}{|c|}{5.7829999999999995} & 5.6795 & TST & \\
\hline CHEMBL1578434 & 688653 & \multicolumn{3}{|c|}{4.7330000000000005} & 5.1934 & TRN & \\
\hline CHEMBL1445436 & 688653 & 5.683 & 6.0486 & TRN & & & \\
\hline CHEMBL585769 & 688653 & \multicolumn{3}{|c|}{6.0329999999999995} & 5.4462 & TRN & \\
\hline CHEMBL 2004226 & 688653 & \multicolumn{3}{|c|}{4.7330000000000005} & 5.8087 & TST & \\
\hline CHEMBL1381834 & 688653 & 5.483 & 5.1518 & TRN & & & \\
\hline CHEMBL1502964 & 688653 & 5.183 & 5.3387 & TRN & & & \\
\hline CHEMBL 3214002 & 688653 & 4.9 & 5.7261 & TST & & & \\
\hline CHEMBL1332684 & 688653 & 5.483 & 5.3066 & TST & & & \\
\hline CHEMBL1404668 & 688653 & \multicolumn{3}{|c|}{5.2829999999999995} & 5.5067 & TRN & \\
\hline CHEMBL1495579 & 688653 & \multicolumn{3}{|c|}{4.7330000000000005} & 5.2699 & TST & \\
\hline CHEMBL1463161 & 688653 & 5.733 & 5.4434 & TRN & & & \\
\hline CHEMBL1531041 & 688653 & 5.683 & 5.7395 & TRN & & & \\
\hline CHEMBL1462391 & 688653 & 5.433 & 5.3686 & TST & & & \\
\hline CHEMBL1386503 & 688653 & 4.833 & 5.4102 & TST & & & \\
\hline CHEMBL1378059 & 688653 & \multicolumn{3}{|c|}{4.7330000000000005} & 5.3183 & TRN & \\
\hline CHEMBL1544831 & 688653 & \multicolumn{3}{|c|}{6.382999999999999} & 6.0669 & TRN & \\
\hline CHEMBL1334136 & 688653 & 6.233 & \multicolumn{3}{|c|}{6.117000000000001} & TRN & \\
\hline CHEMBL1398812 & 688653 & \multicolumn{3}{|c|}{4.7330000000000005} & 5.1343 & TST & \\
\hline CHEMBL1590384 & 688653 & 5.483 & 5.289 & TRN & & & \\
\hline CHEMBL1169929 & 688653 & 4.833 & \multicolumn{3}{|c|}{5.172000000000001} & TRN & \\
\hline CHEMBL1575720 & 688653 & \multicolumn{3}{|c|}{6.632999999999999} & 5.5619 & TRN & \\
\hline CHEMBL 3208758 & 688653 & 4.783 & 4.9233 & TRN & & & \\
\hline CHEMBL1450911 & 688653 & \multicolumn{3}{|c|}{6.582999999999999} & 5.6106 & TRN & \\
\hline CHEMBL3209218 & 688653 & \multicolumn{3}{|c|}{5.382999999999999} & 5.0804 & TST & \\
\hline CHEMBL1594366 & 688653 & \multicolumn{3}{|c|}{4.7330000000000005} & 5.1985 & TRN & \\
\hline CHEMBL1370435 & 688653 & \multicolumn{3}{|c|}{5.7829999999999995} & 5.5557 & TRN & \\
\hline CHEMBL1520223 & 688653 & 5.083 & 5.2009 & TRN & & & \\
\hline CHEMBL1371956 & 688653 & 4.933 & 5.4142 & TRN & & & \\
\hline CHEMBL1423101 & 688653 & 5.233 & 5.4784 & TRN & & & \\
\hline CHEMBL1371873 & 688653 & 4.633 & 4.9976 & TST & & & \\
\hline CHEMBL1532347 & 688653 & 5.083 & 5.155 & TRN & & & \\
\hline CHEMBL1440471 & 688653 & 5.983 & 5.6116 & TRN & & & \\
\hline CHEMBL1569729 & 688653 & \multicolumn{3}{|c|}{4.7330000000000005} & 4.9902 & TRN & \\
\hline CHEMBL1536782 & 688653 & 5.3329 & 99999999 & & 5.5499 & TRN & \\
\hline CHEMBL1588307 & 688653 & 4.9830 & 00000000 & 005 & 5.211 & TST & \\
\hline CHEMBL1389819 & 688653 & 5.2829 & 99999999 & 995 & 5.4717 & TRN & \\
\hline CHEMBL1499061 & 688653 & 4.7330 & 00000000 & 005 & 5.32799 & 9999999999 & TST \\
\hline CHEMBL1410538 & 688653 & 4.833 & 4.9671 & TRN & & & \\
\hline CHEMBL1383855 & 688653 & 4.883 & 5.1178 & TRN & & & \\
\hline CHEMBL3212122 & 688653 & 5.183 & 5.1484 & TRN & & & \\
\hline CHEMBL1431316 & 688653 & 4.9830 & 00000000 & 005 & 5.0297 & TRN & \\
\hline CHEMBL3195514 & 688653 & 5.083 & 4.9793 & TRN & & & \\
\hline CHEMBL1304589 & 688653 & 5.1329 & 99999999 & & 5.1032 & TRN & \\
\hline
\end{tabular}




\begin{tabular}{|c|c|c|c|c|c|c|}
\hline \multirow[b]{2}{*}{ CHEMBL1372247 } & & \multicolumn{5}{|c|}{ Supplemental Table s2.txt } \\
\hline & 688653 & 5.483 & 5.5055 & TRN & & \\
\hline CHEMBL492468 & 688653 & 5.083 & 5.1835 & TRN & & \\
\hline CHEMBL1322261 & 688653 & \multicolumn{3}{|c|}{5.132999999999999} & 5.4575 & TRN \\
\hline CHEMBL1312714 & 688653 & \multicolumn{3}{|c|}{4.7330000000000005} & 5.2963 & TST \\
\hline CHEMBL1397276 & 688653 & 5.683 & 5.6909 & TRN & & \\
\hline CHEMBL1349269 & 688653 & 5.233 & 5.1774 & TST & & \\
\hline CHEMBL1563323 & 688653 & \multicolumn{3}{|c|}{4.9830000000000005} & 5.1348 & TRN \\
\hline CHEMBL1502010 & 688653 & 4.633 & 5.4297 & TST & & \\
\hline CHEMBL1442991 & 688653 & 4.783 & 5.1906 & TRN & & \\
\hline CHEMBL1503105 & 688653 & \multicolumn{3}{|c|}{5.332999999999999} & 5.7233 & TRN \\
\hline CHEMBL1977867 & 688653 & \multicolumn{3}{|c|}{5.632999999999999} & 4.9069 & TRN \\
\hline CHEMBL1469911 & 688653 & 4.783 & 5.1263 & TRN & & \\
\hline CHEMBL1388044 & 688653 & 4.783 & 5.0244 & TST & & \\
\hline CHEMBL1580321 & 688653 & 5.083 & 5.779 & TRN & & \\
\hline CHEMBL1485358 & 688653 & 6.8831 & 5.6056 & TRN & & \\
\hline CHEMBL1576791 & 688653 & \multicolumn{3}{|c|}{5.2829999999999995} & 5.0002 & TRN \\
\hline CHEMBL1323970 & 688653 & 4.833 & 5.0627 & TRN & & \\
\hline CHEMBL1375712 & 688653 & \multicolumn{3}{|c|}{5.132999999999999} & 5.4159 & TRN \\
\hline CHEMBL1409766 & 688653 & \multicolumn{3}{|c|}{5.132999999999999} & 5.2257 & TRN \\
\hline CHEMBL1581665 & 688653 & \multicolumn{3}{|c|}{5.132999999999999} & 5.0219 & TRN \\
\hline CHEMBL1300476 & 688653 & \multicolumn{3}{|c|}{5.382999999999999} & 6.0775 & TRN \\
\hline CHEMBL1575152 & 688653 & \multicolumn{3}{|c|}{5.5329999999999995} & 5.3001 & TRN \\
\hline CHEMBL1552316 & 688653 & 4.833 & 5.1285 & TRN & & \\
\hline CHEMBL1452601 & 688653 & 4.633 & 4.9474 & TRN & & \\
\hline CHEMBL1594046 & 688653 & 6.9329 & 5.5604 & TRN & & \\
\hline CHEMBL 293776 & 688653 & \multicolumn{3}{|c|}{5.632999999999999} & 5.5728 & TRN \\
\hline CHEMBL1588110 & 688653 & 5.433 & 5.4939 & TRN & & \\
\hline CHEMBL1489221 & 688653 & \multicolumn{3}{|c|}{5.382999999999999} & 5.5805 & TRN \\
\hline CHEMBL1371282 & 688653 & \multicolumn{3}{|c|}{5.832999999999999} & 5.3493 & TRN \\
\hline CHEMBL1405776 & 688653 & 4.833 & 5.1909 & TST & & \\
\hline CHEMBL1337663 & 688653 & 5.183 & 5.2777 & TRN & & \\
\hline CHEMBL1565717 & 688653 & 5.933 & 5.5893 & TRN & & \\
\hline CHEMBL1386094 & 688653 & \multicolumn{3}{|c|}{5.382999999999999} & 5.0629 & TST \\
\hline CHEMBL1480962 & 688653 & 4.933 & 5.081 & TRN & & \\
\hline CHEMBL1476225 & 688653 & \multicolumn{3}{|c|}{5.132999999999999} & 5.2059 & TRN \\
\hline CHEMBL1464037 & 688653 & \multicolumn{3}{|c|}{5.5329999999999995} & 5.2591 & TRN \\
\hline CHEMBL1525157 & 688653 & 6.0 & 4.8903 & TRN & & \\
\hline CHEMBL1424316 & 688653 & 4.783 & 5.1821 & TST & & \\
\hline CHEMBL1370292 & 688653 & 5.683 & 5.1998 & TRN & & \\
\hline CHEMBL3191890 & 688653 & \multicolumn{3}{|c|}{5.5329999999999995} & 5.8413 & TRN \\
\hline CHEMBL1497255 & 688653 & 4.883 & 4.9795 & TRN & & \\
\hline CHEMBL1527580 & 688653 & \multicolumn{3}{|c|}{5.5329999999999995} & 5.4786 & TRN \\
\hline CHEMBL1312444 & 688653 & 4.683 & 5.5321 & TRN & & \\
\hline CHEMBL1521251 & 688653 & 4.833 & 4.8406 & TRN & & \\
\hline CHEMBL1344530 & 688653 & 4.783 & 4.8915 & TRN & & \\
\hline CHEMBL1428095 & 688653 & 4.783 & 5.2996 & TRN & & \\
\hline CHEMBL1485910 & 688653 & 5.83299 & 99999999 & 99 & 5.4989 & TST \\
\hline CHEMBL1533825 & 688653 & 4.833 & 5.0521 & TRN & & \\
\hline
\end{tabular}




\begin{tabular}{|c|c|c|c|c|c|c|}
\hline & \\
\hline CHEMBL1375082 & 688653 & 4.933 & 4.9901 & TRN & & \\
\hline CHEMBL1355379 & 688653 & \multicolumn{3}{|c|}{6.2829999999999995} & 5.5378 & \\
\hline CHEMBL1608982 & 688653 & 4.633 & 5.0588 & TST & & \\
\hline CHEMBL1441721 & 688653 & 4.833 & 5.7381 & TRN & & \\
\hline CHEMBL1455962 & 688653 & 5.183 & 5.0065 & TRN & & \\
\hline CHEMBL1547095 & 688653 & 4.833 & 5.419 & TRN & & \\
\hline CHEMBL1539288 & 688653 & 5.083 & 5.1779 & TRN & & \\
\hline CHEMBL1461987 & 688653 & 4.933 & 5.40606 & 0000 & & \\
\hline CHEMBL1545641 & 688653 & 4.883 & 5.0919 & TRN & & \\
\hline CHEMBL1173141 & 688653 & 4.783 & 5.3895 & TRN & & \\
\hline CHEMBL 3211684 & 688653 & \multicolumn{3}{|c|}{4.7330000000000005} & 5.4671 & \\
\hline CHEMBL1722566 & 688653 & 5.483 & 4.827 & TST & & \\
\hline CHEMBL1466554 & 688653 & 5.983 & 5.2688 & TST & & \\
\hline CHEMBL1397330 & 688653 & 4.683 & 5.2189 & TST & & \\
\hline CHEMBL1451931 & 688653 & \multicolumn{3}{|c|}{4.7330000000000005} & 4.9585 & \\
\hline CHEMBL1590733 & 688653 & 4.933 & 5.2283 & TRN & & \\
\hline CHEMBL1489335 & 688653 & \multicolumn{3}{|c|}{6.582999999999999} & 5.7864 & \\
\hline CHEMBL1436282 & 688653 & \multicolumn{3}{|c|}{4.7330000000000005} & 5.3302 & \\
\hline CHEMBL1549657 & 688653 & 4.833 & 4.9528 & TRN & & \\
\hline CHEMBL1489047 & 688653 & \multicolumn{3}{|c|}{6.2829999999999995} & 5.7336 & \\
\hline CHEMBL1473234 & 688653 & 4.633 & 4.9618 & TST & & \\
\hline CHEMBL1393283 & 688653 & 4.633 & 4.887 & TST & & \\
\hline CHEMBL1574431 & 688653 & 6.433 & 5.7504 & TRN & & \\
\hline CHEMBL1581632 & 688653 & 5.033 & \multicolumn{3}{|c|}{5.3420000000000005} & \\
\hline CHEMBL1305892 & 688653 & 4.883 & 5.0657 & TRN & & \\
\hline CHEMBL1347452 & 688653 & \multicolumn{3}{|c|}{4.7330000000000005} & 5.0243 & \\
\hline CHEMBL1495531 & 688653 & \multicolumn{3}{|c|}{5.5329999999999995} & 5.4309 & \\
\hline CHEMBL1488187 & 688653 & \multicolumn{3}{|c|}{4.9830000000000005} & 4.935 & TRN \\
\hline CHEMBL1377690 & 688653 & \multicolumn{3}{|c|}{5.2829999999999995} & 5.0845 & TST \\
\hline CHEMBL1964776 & 688653 & \multicolumn{3}{|c|}{5.5329999999999995} & 5.2736 & TRN \\
\hline CHEMBL1546016 & 688653 & \multicolumn{3}{|c|}{5.2829999999999995} & 5.1479 & TRN \\
\hline CHEMBL1529258 & 688653 & 5.483 & 5.5919 & TST & & \\
\hline CHEMBL1513820 & 688653 & \multirow{2}{*}{\multicolumn{3}{|c|}{$\begin{array}{ll}4.933 & 5.5621 \\
4.9830000000000005\end{array}$}} & & \\
\hline CHEMBL1561290 & 688653 & & & & 5.3256 & \\
\hline CHEMBL1464431 & 688653 & \multicolumn{3}{|c|}{$\begin{array}{lll}4.833 & 5.1038 & \text { TRN }\end{array}$} & & \\
\hline CHEMBL1611624 & 688653 & \multicolumn{3}{|c|}{4.9830000000000005} & 5.6503 & $\mathrm{Tr}$ \\
\hline CHEMBL1453868 & 688653 & 4.883 & 5.1052 & TRN & & \\
\hline CHEMBL1372639 & 688653 & \multicolumn{3}{|c|}{5.2829999999999995} & 5.2154 & $\mathrm{~T}$ \\
\hline CHEMBL1487883 & 688653 & 6.233 & 5.9299 & TRN & & \\
\hline CHEMBL1611003 & 688653 & \multicolumn{3}{|c|}{5.332999999999999} & 5.6132 & TRN \\
\hline CHEMBL1497673 & 688653 & 5.45 & 5.0132 & TRN & & \\
\hline CHEMBL1444631 & 688653 & 4.833 & 5.2397 & TRN & & \\
\hline CHEMBL1354512 & 688653 & 4.633 & 5.0722 & TRN & & \\
\hline CHEMBL1411776 & 688653 & \multicolumn{3}{|c|}{4.7330000000000005} & 5.0642 & $1 /$ \\
\hline CHEMBL1556435 & 688653 & 4.883 & 4.9883 & TRN & & \\
\hline CHEMBL1428614 & 688653 & 5.132 & 99999999 & & 5.2377 & TR \\
\hline CHEMBL1557674 & 688653 & 5.782 & 99999999 & 995 & 5.4313 & TR \\
\hline CHEMBL1531898 & 688653 & 5.083 & 5.4827 & TRN & & \\
\hline
\end{tabular}




\begin{tabular}{|c|c|c|c|c|c|c|}
\hline & & \multicolumn{5}{|c|}{ Supplemental Table s2.txt } \\
\hline CHEMBL1521425 & 688653 & 4.683 & 5.013 & TRN & & \\
\hline CHEMBL1604194 & 688653 & 4.783 & 5.4276 & TRN & & \\
\hline CHEMBL1573665 & 688653 & 5.033 & 5.1376 & TRN & & \\
\hline CHEMBL1310043 & 688653 & 4.783 & 4.9272 & TRN & & \\
\hline CHEMBL1525949 & 688653 & 4.783 & 5.04 & TRN & & \\
\hline CHEMBL1402437 & 688653 & \multicolumn{3}{|c|}{5.332999999999999} & 5.7756 & 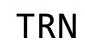 \\
\hline CHEMBL1495092 & 688653 & 5.183 & 5.5098 & TRN & & \\
\hline CHEMBL1447513 & 688653 & 6.433 & 5.5865 & TRN & & \\
\hline CHEMBL1610434 & 688653 & 4.783 & 5.3085 & TST & & \\
\hline CHEMBL1589415 & 688653 & \multicolumn{3}{|c|}{5.882999999999999} & 5.3404 & \\
\hline CHEMBL1347084 & 688653 & \multicolumn{3}{|c|}{4.9830000000000005} & 5.3667 & \\
\hline CHEMBL1329631 & 688653 & 4.833 & 4.58 & TRN & & \\
\hline CHEMBL3196361 & 688653 & \multicolumn{3}{|c|}{532999999999} & 5.8724 & \\
\hline CHEMBL3195772 & 688653 & 5.033 & \multicolumn{3}{|c|}{4.968999999999999} & \\
\hline CHEMBL1529021 & 688653 & 4.833 & 5.2344 & TST & & \\
\hline CHEMBL584015 & 688653 & 4.883 & 4.734 & TST & & \\
\hline CHEMBL1602859 & 688653 & \multicolumn{3}{|c|}{5.7829999999999995} & 176 & \\
\hline CHEMBL1383338 & 688653 & 4.783 & 5.0086 & TRN & & \\
\hline CHEMBL1545802 & 688653 & 5.433 & 5.2232 & TRN & & \\
\hline CHEMBL1488229 & 688653 & \multicolumn{3}{|c|}{6.0329999999999995} & 5.4178 & \\
\hline CHEMBL1320453 & 688653 & 5.433 & 6.1389 & TRN & & \\
\hline CHEMBL3192017 & 688653 & 4.833 & 5.2306 & TRN & & \\
\hline CHEMBL14 & 688653 & 4.783 & 5.1527 & TRN & & \\
\hline CHEMBL1469154 & 688653 & 4.883 & 5.2135 & TRN & & \\
\hline CHEMBL1387123 & 688653 & 4.783 & 5.7475 & TRN & & \\
\hline CHEMBL1472660 & 688653 & \multicolumn{3}{|c|}{5.2829999999999995} & 5.2877 & \\
\hline CHEMBL1521125 & 688653 & 4.783 & 4.8788 & TST & & \\
\hline CHEMBL132 & 688653 & \multicolumn{3}{|c|}{5.132999999999999} & 5.2352 & TRN \\
\hline CHEMBL1449892 & 688653 & \multicolumn{3}{|c|}{4.9830000000000005} & 5.4072 & TRN \\
\hline CHEMBL1455606 & 688653 & \multicolumn{3}{|c|}{4.7330000000000005} & 5.3397 & $\mathrm{~T}$ \\
\hline CHEMBL3194660 & 688653 & 4.883 & 5.1584 & TST & & \\
\hline CHEMBL1 & 688 & 5.483 & 5.0855 & TRN & & \\
\hline CHEMBL1164403 & 688653 & \multicolumn{3}{|c|}{6.382999999999999} & 5.6932 & TRN \\
\hline CHEMBL1419590 & 688653 & 6.0 & \multicolumn{3}{|c|}{5.492999999999999} & TRN \\
\hline CHEMBL1492352 & 688653 & 5.183 & 5.0702 & TRN & & \\
\hline CHEMBL1344547 & 688653 & \multicolumn{3}{|c|}{4.7330000000000005} & 4.9273 & 11 \\
\hline CHEMBL158 & 688653 & & 5.0644 & TRN & & \\
\hline CHEMBL1408725 & 688653 & 4.683 & 4.8739 & TST & & \\
\hline CHEMBL1584326 & 688653 & 4.833 & 5.2579 & TRN & & \\
\hline CHEMBL1497362 & 688653 & 4.833 & 5.1036 & TRN & & \\
\hline CHEMBL1347635 & 688653 & \multicolumn{3}{|c|}{6.382999999999999} & 248 & TRN \\
\hline CHEMBL1451600 & 688653 & \multicolumn{3}{|c|}{5.382999999999999} & 4.9231 & \\
\hline CHEMBL1416928 & 688653 & 4.883 & 5.0449 & TST & & \\
\hline CHEMBL1479295 & 688653 & 5.733 & 5.4318 & TRN & & \\
\hline CHEMBL472839 & 688653 & 5.433 & 5.6853 & TRN & & \\
\hline CHEMBL1567428 & 688653 & \multicolumn{3}{|c|}{6.132999999999999} & 5.6275 & TRN \\
\hline CHEMBL22062 & 688653 & 5.183 & 5.2488 & TRN & & \\
\hline CHEMBL1384526 & 688653 & \multicolumn{3}{|c|}{6.0329999999999995} & 5.329 & 筮 \\
\hline
\end{tabular}




\begin{tabular}{|c|c|c|c|c|c|c|}
\hline \multirow[b]{2}{*}{ CHEMBL1574958 } & & \multicolumn{5}{|c|}{ Supplemental Table S2.txt } \\
\hline & 688653 & 5.683 & 5.0138 & TST & & \\
\hline CHEMBL1414932 & 688653 & \multicolumn{3}{|c|}{6.082999999999999} & 5.6727 & $\mathrm{TR}$ \\
\hline CHEMBL1436487 & 688653 & 4.883 & 5.3541 & TRN & & \\
\hline CHEMBL1533244 & 688653 & \multicolumn{3}{|c|}{5.2829999999999995} & 5.7998 & TRN \\
\hline CHEMBL1379745 & 688653 & \multicolumn{3}{|c|}{6.582999999999999} & 5.5074 & \\
\hline CHEMBL1398990 & 688653 & 4.933 & 4.9301 & TST & & \\
\hline CHEMBL1600941 & 688653 & 4.933 & 5.0533 & TRN & & \\
\hline CHEMBL1424344 & 688653 & 5.183 & 5.2629 & TRN & & \\
\hline CHEMBL1571574 & 688653 & \multicolumn{3}{|c|}{6.332999999999999} & 5.7704 & TRN \\
\hline CHEMBL1315194 & 688653 & \multicolumn{3}{|c|}{4.7330000000000005} & 4.8542 & TST \\
\hline CHEMBL1509308 & 688653 & \multicolumn{3}{|c|}{4.9830000000000005} & 5.445 & \\
\hline CHEMBL1458059 & 688653 & 4.783 & 5.2501 & TRN & & \\
\hline CHEMBL1 & 688653 & & 5.1714 & TST & & \\
\hline CHEMBL 2004185 & 688653 & \multicolumn{3}{|c|}{4.7330000000000005} & 5.4806 & TRN \\
\hline CHEMBL1365435 & 688653 & \multicolumn{3}{|c|}{5.2829999999999995} & 4.7348 & \\
\hline CHEMBL1475952 & 688653 & 4.633 & 5.0435 & TRN & & \\
\hline CHEMBL1446 & 688653 & 5.433 & 5.3813 & TRN & & \\
\hline CHEMBL2 & 688653 & 7.2328 & 6.1625 & TRN & & \\
\hline CHEMBL14 & 688653 & 5.733 & 5.1165 & TRN & & \\
\hline CHEMBL1467905 & 688653 & 4.883 & 4.8466 & TRN & & \\
\hline CHEMBL1523036 & 688653 & & 5.6848 & TRN & & \\
\hline CHEMBL1 & 688 & 4.883 & 5.1512 & TRN & & \\
\hline CHEMBL3 & 688653 & \multicolumn{3}{|c|}{5.632999999999999} & 5.3932 & In \\
\hline CHEMBL1305599 & 688653 & 4.783 & 5.0615 & TRN & & \\
\hline CHEMBL1522237 & 688653 & & 5.2419 & TRN & & \\
\hline CHEMBL1313116 & 688653 & \multicolumn{3}{|c|}{5.582999999999999} & 列 & \\
\hline CHEMBL1411125 & 688653 & 4.883 & 4.9718 & TRN & & \\
\hline CHEMBL1 & 688 & 4.583 & 4.9426 & TST & & \\
\hline CHEMBL1483811 & 688653 & \multicolumn{3}{|c|}{4.7330000000000005} & 5.1262 & TRN \\
\hline CHEMBL1316086 & 688653 & \multicolumn{3}{|c|}{4.7330000000000005} & 5.0844 & TRN \\
\hline CHEMBL1522988 & 688653 & \multicolumn{3}{|c|}{5.632999999999999} & 4.8584 & \\
\hline CHEMBL1 & 688 & 4.883 & 4.869 & TRN & & \\
\hline CHEMBL1 & 688653 & \multicolumn{3}{|c|}{4.7330000000000005} & 4.9332 & $\mathrm{TR}$ \\
\hline CHEMBL1489209 & 688653 & 5.733 & 5.6337 & TRN & & \\
\hline CHEMBL1610123 & 688653 & 5.233 & 5.2786 & TRN & & \\
\hline CHEMBL1461495 & 688653 & 4.783 & 5.0908 & TRN & & \\
\hline CHEMBL & 688 & & 4.8982 & TRN & & \\
\hline CHEMBL15 & 688 & 6.433 & 5.9284 & TRN & & \\
\hline CHEMBL1470792 & 688653 & \multicolumn{3}{|c|}{5.332999999999999} & 5.2416 & TRN \\
\hline CHEMBL1582709 & 688653 & \multicolumn{3}{|c|}{4.9830000000000005} & 5.2568 & TRN \\
\hline CHEMBL1453831 & 688653 & \multicolumn{3}{|c|}{5.332999999999999} & 5.1602 & TST \\
\hline CHEMBL3196921 & 688653 & \multicolumn{3}{|c|}{5.632999999999999} & 5.2462 & IRIV \\
\hline CHEMBL1373245 & 688653 & \multicolumn{3}{|c|}{4.7330000000000005} & 5.0852 & TRM \\
\hline CHEMBL1606179 & 688653 & 4.783 & 5.3877 & TRN & & \\
\hline CHEMBL1420295 & 688653 & 5.53299 & 99999999 & 995 & 5.0709 & IRIN \\
\hline CHEMBL3189391 & 688653 & 5.28299 & 99999999 & 995 & 5.2542 & \\
\hline CHEMBL1394961 & 688653 & 6.4829 & 5.7415 & TRN & & \\
\hline CHEMBL1361815 & 688653 & 4.73300 & 00000000 & & 4.9293 & \\
\hline
\end{tabular}




\begin{tabular}{|c|c|c|c|c|c|c|}
\hline \multicolumn{7}{|c|}{ Supplemental Table S2.txt } \\
\hline CHEMBL1380493 & 688653 & 5.433 & 5.42 & TRN & & \\
\hline CHEMBL1575435 & 688653 & 5.483 & 5.2783 & TRN & & \\
\hline CHEMBL1541596 & 688653 & 4.833 & 4.917 & TST & & \\
\hline CHEMBL1472806 & 688653 & 4.583 & 5.1453 & TST & & \\
\hline CHEMBL1494073 & 688653 & \multicolumn{3}{|c|}{5.832999999999999} & 5.3036 & $\mathrm{TP}$ \\
\hline CHEMBL1387192 & 688653 & 5.083 & 5.6868 & TST & & \\
\hline CHEMBL1526122 & 688653 & 4.883 & 4.8942 & TRN & & \\
\hline CHEMBL1427511 & 688653 & \multicolumn{3}{|c|}{6.0329999999999995} & 5.3443 & . \\
\hline CHEMBL1498691 & 688653 & \multicolumn{3}{|c|}{4.7330000000000005} & 5.2603 & \\
\hline CHEMBL1476042 & 688653 & 4.783 & 4.9577 & TRN & & \\
\hline CHEMBL1371533 & 688653 & 4.783 & 5.2172 & TRN & & \\
\hline CHEMBL 3199729 & 688653 & 5.183 & 5.4575 & TST & & \\
\hline CHEMBL1428357 & 688653 & 4.883 & 4.8939 & TRN & & \\
\hline CHEMBL1510489 & 688653 & 4.883 & 4.8352 & TRN & & \\
\hline CHEMBL1590611 & 688653 & \multicolumn{3}{|c|}{4.9830000000000005} & 4.9501 & \\
\hline CHEMBL 3211065 & 688653 & \multicolumn{3}{|c|}{5.132999999999999} & 5.1984 & \\
\hline CHEMBL3194186 & 688653 & \multicolumn{3}{|c|}{5.582999999999999} & & \\
\hline CHEMBL1452185 & 688653 & 4.833 & 5.4783 & TRN & & \\
\hline CHEMBL1376633 & 688653 & 4.833 & 5.2665 & TST & & \\
\hline CHEMBL1990214 & 688653 & \multicolumn{3}{|c|}{6.332999999999999} & 5.8075 & \\
\hline CHEMBL1421793 & 688653 & \multicolumn{3}{|c|}{5.132999999999999} & 81 & \\
\hline CHEMBL1582367 & 688653 & 4.833 & 5.3778 & TRN & & \\
\hline CHEMBL 3190139 & 688653 & 4.833 & 5.0466 & TRN & & \\
\hline CHEMBL1409825 & 688653 & 5.083 & 5.2338 & TST & & \\
\hline CHEMBL1584661 & 688653 & \multicolumn{3}{|c|}{6.082999999999999} & 5.1768 & $\mathrm{TP}$ \\
\hline CHEMBL1541973 & 688653 & \multicolumn{3}{|c|}{4.7330000000000005} & & \\
\hline CHEMBL1474305 & 688653 & 4.833 & 4.9457 & TRN & & \\
\hline CHEMBL1386788 & 688653 & \multicolumn{3}{|c|}{5.132999999999999} & 5.4321 & \\
\hline CHEMBL1556297 & 688653 & 4.583 & 5.3608 & TRN & & \\
\hline CHEMBL1441525 & 688653 & \multicolumn{3}{|c|}{5.132999999999999} & 5.6446 & TR \\
\hline CHEMBL1584098 & 688653 & \multicolumn{3}{|c|}{4.9830000000000005} & 5.1091 & \\
\hline CHEMBL1562064 & 688653 & 4.833 & 5.3548 & TST & & \\
\hline CHEMBL1491957 & 688653 & 6.683 & 5.4936 & TRN & & \\
\hline CHEMBL1496402 & 688653 & 4.633 & 4.9073 & TRN & & \\
\hline CHEMBL1461906 & 688653 & \multicolumn{3}{|c|}{5.832999999999999} & 6.0211 & \\
\hline CHEMBL1485736 & 688653 & \multicolumn{3}{|c|}{5.132999999999999} & 5.0273 & \\
\hline CHEMBL1327926 & 688653 & \multicolumn{3}{|c|}{6.582999999999999} & 75 & \\
\hline CHEMBL1541305 & 688653 & 4.683 & 5.093999 & 999999999 & 99 & TRN \\
\hline CHEMBL1374828 & 688653 & \multicolumn{3}{|c|}{5.832999999999999} & 5.5782 & TR \\
\hline CHEMBL1374155 & 688653 & 4.583 & 4.98 & TRN & & \\
\hline CHEMBL1612465 & 688653 & \multicolumn{3}{|c|}{5.7829999999999995} & 5.5887 & 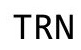 \\
\hline CHEMBL1360114 & 688653 & 4.933 & 5.0007 & TRN & & \\
\hline CHEMBL1538435 & 688653 & \multicolumn{3}{|c|}{5.332999999999999} & 5.9463 & TRI \\
\hline CHEMBL1587607 & 688653 & 4.833 & 5.4663 & TRN & & \\
\hline CHEMBL1303530 & 688653 & 5.683 & 5.5644 & TRN & & \\
\hline CHEMBL1519688 & 688653 & 4.933 & 5.0315 & TRN & & \\
\hline CHEMBL1523960 & 688653 & \multicolumn{3}{|c|}{5.132999999999999} & .2756 & TRN \\
\hline CHEMBL1325869 & 688653 & 6.7331 & 5.6935 & TRN & & \\
\hline
\end{tabular}




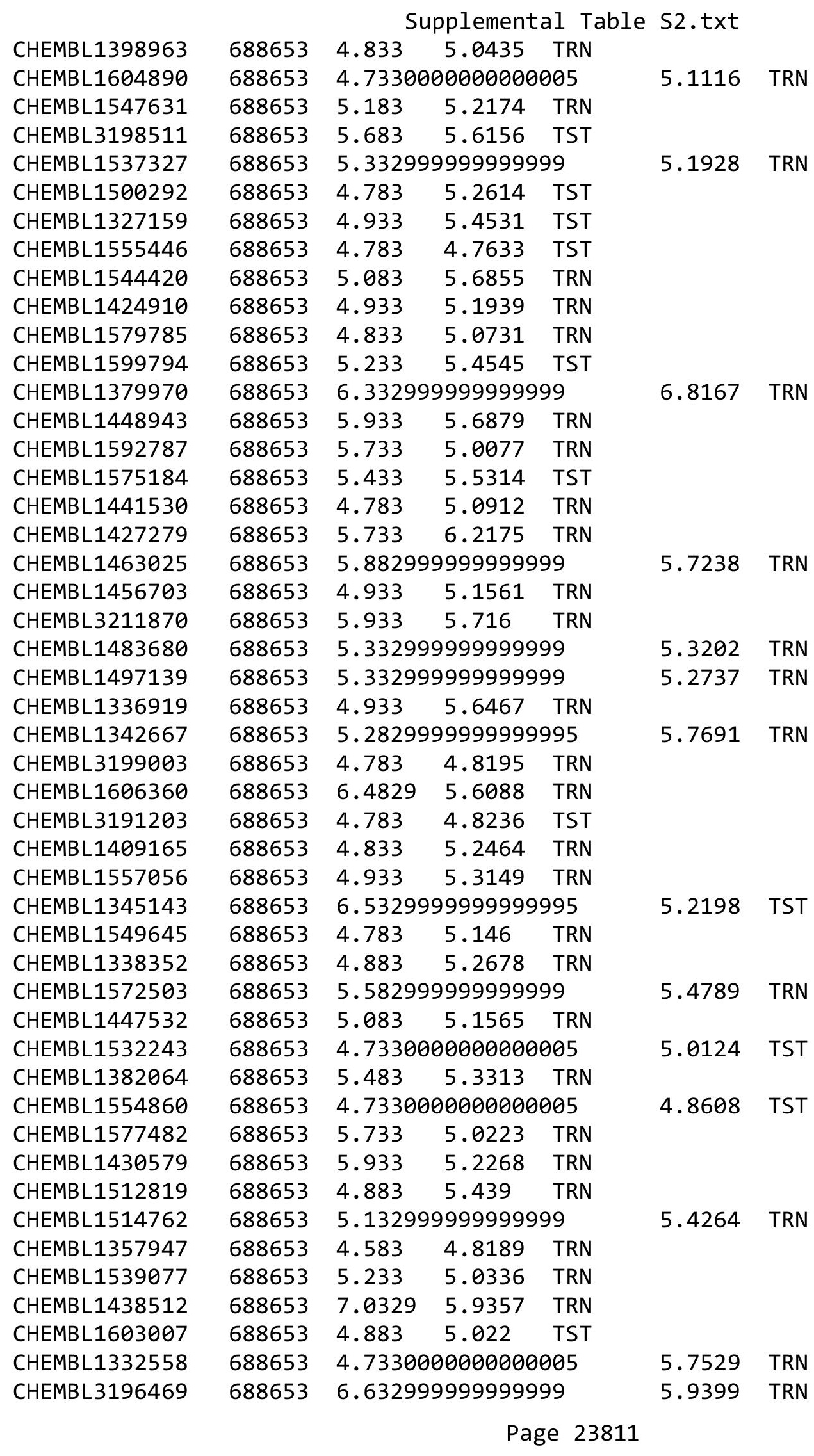




\begin{tabular}{|c|c|c|c|c|c|c|}
\hline \multirow{3}{*}{$\begin{array}{l}\text { CHEMBL } 1427730 \\
\text { CHEMBL1359760 }\end{array}$} & \multirow{3}{*}{$\begin{array}{l}688653 \\
688653\end{array}$} & \multicolumn{5}{|c|}{ Supplemental Table S2.txt } \\
\hline & & \multicolumn{3}{|c|}{5.832999999999999} & 5.5229 & TRN \\
\hline & & 6.4829 & 5.3356 & TRN & & \\
\hline CHEMBL1610388 & 688653 & 6.683 & 5.5489 & TRN & & \\
\hline CHEMBL1403706 & 688653 & 5.033 & 5.1967 & TST & & \\
\hline CHEMBL1532242 & 688653 & \multicolumn{3}{|c|}{5.132999999999999} & 4.9134 & TRN \\
\hline CHEMBL1351479 & 688653 & \multicolumn{3}{|c|}{4.7330000000000005} & 5.5503 & TST \\
\hline CHEMBL1535245 & 688653 & \multicolumn{3}{|c|}{5.882999999999999} & 5.4706 & TRN \\
\hline CHEMBL1362691 & 688653 & 4.783 & 5.215 & TRN & & \\
\hline CHEMBL1449313 & 688653 & \multicolumn{3}{|c|}{4.7330000000000005} & 4.9539 & TST \\
\hline CHEMBL1500961 & 688653 & \multicolumn{3}{|c|}{5.382999999999999} & 5.2633 & TRN \\
\hline CHEMBL1338404 & 688653 & 4.783 & 5.2309 & TRN & & \\
\hline CHEMBL3199337 & 688653 & \multicolumn{3}{|c|}{5.2829999999999995} & 5.3966 & TRN \\
\hline CHEMBL1407779 & 688653 & 6.9329 & 5.6052 & TRN & & \\
\hline CHEMBL1455196 & 688653 & \multirow{2}{*}{\multicolumn{3}{|c|}{$\begin{array}{lll}4.933 & 4.9134 & \text { TST } \\
5.632999999999999\end{array}$}} & & \\
\hline CHEMBL1526874 & 688653 & & & & 5.4149 & TRN \\
\hline CHEMBL1383892 & 688653 & 6.4829 & 5.3161 & TRN & & \\
\hline CHEMBL1522334 & 688653 & \multirow{2}{*}{\multicolumn{3}{|c|}{$\begin{array}{lll}5.183 & 5.5716 & \text { TRN } \\
5.882999999999999\end{array}$}} & & \\
\hline CHEMBL1486451 & 688653 & & & & 5.2803 & TRN \\
\hline CHEMBL1418869 & 688653 & \multirow{2}{*}{\multicolumn{3}{|c|}{$\begin{array}{lcc}4.783 & 4.9054 & \text { TRN } \\
5.5329999999999995\end{array}$}} & & \\
\hline CHEMBL1563519 & 688653 & & & & 5.5864 & TRN \\
\hline CHEMBL1483048 & 688653 & \multicolumn{3}{|c|}{$\begin{array}{lll}5.683 & 5.0566 & \text { TST }\end{array}$} & & \\
\hline CHEMBL1317272 & 688653 & \multicolumn{3}{|c|}{5.132999999999999} & 8 & TRN \\
\hline CHEMBL1416304 & 688653 & 4.783 & 5.4163 & TRN & & \\
\hline CHEMBL1507251 & 688653 & 4.633 & 5.8393 & TRN & & \\
\hline CHEMBL1325180 & 688653 & \multicolumn{3}{|c|}{4.7330000000000005} & 5.3674 & TST \\
\hline CHEMBL1498903 & 688653 & \multicolumn{3}{|c|}{5.2829999999999995} & 5.7619 & TRN \\
\hline CHEMBL1474831 & 688653 & \multicolumn{3}{|c|}{4.7330000000000005} & 5.1877 & TRN \\
\hline CHEMBL1608424 & 688653 & 4.833 & 5.3708 & TST & & \\
\hline CHEMBL1460408 & 688653 & 5.683 & 5.5179 & TRN & & \\
\hline CHEMBL1332174 & 688653 & 4.833 & \multicolumn{3}{|c|}{5.172000000000001} & TRN \\
\hline CHEMBL1359482 & 688653 & \multicolumn{3}{|c|}{5.7829999999999995} & 5.7733 & TRN \\
\hline CHEMBL1509086 & 688653 & \multicolumn{3}{|c|}{5.582999999999999} & 5.426 & TRN \\
\hline CHEMBL1402422 & 688653 & 5.033 & 5.1477 & TST & & \\
\hline CHEMBL3193256 & 688653 & 4.883 & 5.3449 & TRN & & \\
\hline CHEMBL492091 & 688653 & 5.733 & 5.5875 & TRN & & \\
\hline CHEMBL1508797 & 688653 & 4.783 & 4.9571 & TRN & & \\
\hline CHEMBL1577049 & 688653 & 4.883 & 5.2223 & TRN & & \\
\hline CHEMBL1418596 & 688653 & 5.683 & 5.1315 & TST & & \\
\hline CHEMBL1450497 & 688653 & 8.3872 & 6.532999 & 99999 & 995 & TRN \\
\hline CHEMBL1335489 & 688653 & 6.9329 & 5.9534 & TRN & & \\
\hline CHEMBL1582476 & 688653 & 5.33299 & 999999999 & & 5.2494 & TRN \\
\hline CHEMBL1400731 & 688653 & 4.73300 & 000000000 & 005 & 5.043 & TRN \\
\hline CHEMBL1383801 & 688653 & 5.683 & 5.2811 & TRN & & \\
\hline CHEMBL1524310 & 688653 & 5.83299 & 999999999 & & 5.2452 & TST \\
\hline CHEMBL 3196845 & 688653 & 4.833 & 5.6826 & TRN & & \\
\hline CHEMBL1577117 & 688653 & 5.33299 & 999999999 & 99 & 5.5601 & TRN \\
\hline CHEMBL1371255 & 688653 & 4.783 & 5.2765 & TRN & & \\
\hline CHEMBL1308937 & 688653 & 4.833 & 4.6472 & TRN & & \\
\hline
\end{tabular}




\begin{tabular}{|c|c|c|c|c|c|c|}
\hline \multirow[b]{2}{*}{ CHEMBL1585216 } & \multirow[b]{2}{*}{688653} & \multicolumn{5}{|c|}{ Supplemental Table s2.txt } \\
\hline & & \multirow{2}{*}{\multicolumn{3}{|c|}{$\begin{array}{lcc}5.733 & 5.5776 & \text { TRN } \\
5.632999999999999\end{array}$}} & & \\
\hline CHEMBL1504601 & 688653 & & & & 5.1828 & TRN \\
\hline CHEMBL1508320 & 688653 & \multicolumn{3}{|c|}{6.582999999999999} & 5.3605 & TST \\
\hline CHEMBL1430790 & 688653 & 4.633 & 5.0127 & TST & & \\
\hline CHEMBL1338418 & 688653 & 5.433 & 5.0856 & TRN & & \\
\hline CHEMBL1589137 & 688653 & 5.683 & 5.1924 & TST & & \\
\hline CHEMBL1491495 & 688653 & \multicolumn{3}{|c|}{4.7330000000000005} & 5.4133 & TRN \\
\hline CHEMBL1364213 & 688653 & \multicolumn{3}{|c|}{5.132999999999999} & 5.3581 & TRN \\
\hline CHEMBL1588191 & 688653 & 4.783 & 4.9855 & TRN & & \\
\hline CHEMBL1380684 & 688653 & 6.0 & 5.5187 & TST & & \\
\hline CHEMBL1436190 & 688653 & 5.733 & 5.3018 & TRN & & \\
\hline CHEMBL1474085 & 688653 & 4.633 & 5.4314 & TST & & \\
\hline CHEMBL527677 & 688653 & 4.833 & 5.35 & TRN & & \\
\hline CHEMBL1373061 & 688653 & 5.433 & 5.2005 & TRN & & \\
\hline CHEMBL3211930 & 688653 & 5.683 & 5.4235 & TRN & & \\
\hline CHEMBL1466040 & 688653 & 4.883 & 5.2128 & TRN & & \\
\hline CHEMBL1401323 & 688653 & \multicolumn{3}{|c|}{4.7330000000000005} & 5.1621 & TRN \\
\hline CHEMBL1456762 & 688653 & 5.483 & 5.4674 & TRN & & \\
\hline CHEMBL1381427 & 688653 & 4.783 & 5.0092 & TRN & & \\
\hline CHEMBL1578017 & 688653 & 5.733 & 5.3395 & TRN & & \\
\hline CHEMBL1454871 & 688653 & \multicolumn{3}{|c|}{4.7330000000000005} & 5.1844 & TRN \\
\hline CHEMBL1553996 & 688653 & \multicolumn{3}{|c|}{5.2829999999999995} & 5.1626 & TST \\
\hline CHEMBL3209203 & 688653 & 5.483 & 4.9065 & TRN & & \\
\hline CHEMBL1490671 & 688653 & 6.4829 & 5.9218 & TST & & \\
\hline CHEMBL1370316 & 688653 & 4.933 & 6.1679 & TRN & & \\
\hline CHEMBL1527913 & 688653 & \multicolumn{3}{|c|}{6.082999999999999} & 5.4439 & TRN \\
\hline CHEMBL3194656 & 688653 & 4.633 & 5.53 & TRN & & \\
\hline CHEMBL1374129 & 688653 & 4.783 & 5.2931 & TRN & & \\
\hline CHEMBL1465060 & 688653 & 6.233 & 5.1571 & TRN & & \\
\hline CHEMBL1376504 & 688653 & 4.833 & 5.2522 & TST & & \\
\hline CHEMBL1488030 & 688653 & 5.933 & 5.5496 & TRN & & \\
\hline CHEMBL1506780 & 688653 & \multicolumn{3}{|c|}{6.382999999999999} & 5.5705 & TRN \\
\hline CHEMBL1336237 & 688653 & 6.433 & 5.5357 & TRN & & \\
\hline CHEMBL1455115 & 688653 & \multicolumn{3}{|c|}{5.132999999999999} & 5.3443 & TRN \\
\hline CHEMBL1381976 & 688653 & \multicolumn{3}{|c|}{6.0329999999999995} & 5.322 & TRN \\
\hline CHEMBL1584144 & 688653 & \multicolumn{3}{|c|}{5.332999999999999} & 5.6506 & TRN \\
\hline CHEMBL1609223 & 688653 & 4.783 & 5.2465 & TRN & & \\
\hline CHEMBL1474482 & 688653 & \multicolumn{3}{|c|}{5.882999999999999} & 5.0546 & TRN \\
\hline CHEMBL1612818 & 688653 & 4.833 & 5.1832 & TRN & & \\
\hline CHEMBL1457777 & 688653 & \multicolumn{3}{|c|}{4.7330000000000005} & 5.0753 & TRN \\
\hline CHEMBL 222021 & 688653 & 4.883 & 5.2176 & TRN & & \\
\hline CHEMBL1323906 & 688653 & 4.883 & 5.1678 & TRN & & \\
\hline CHEMBL1562040 & 688653 & 4.783 & 4.7603 & TRN & & \\
\hline CHEMBL1502306 & 688653 & \multicolumn{3}{|c|}{ 5.332999999999999 } & 5.5468 & TRN \\
\hline CHEMBL1554305 & 688653 & \multicolumn{3}{|c|}{5.132999999999999} & 5.3248 & TRN \\
\hline CHEMBL1421415 & 688653 & 4.833 & 5.2165 & TST & & \\
\hline CHEMBL1410232 & 688653 & 5.733 & 5.6181 & TRN & & \\
\hline CHEMBL1467414 & 688653 & 4.633 & 5.2235 & TST & & \\
\hline
\end{tabular}




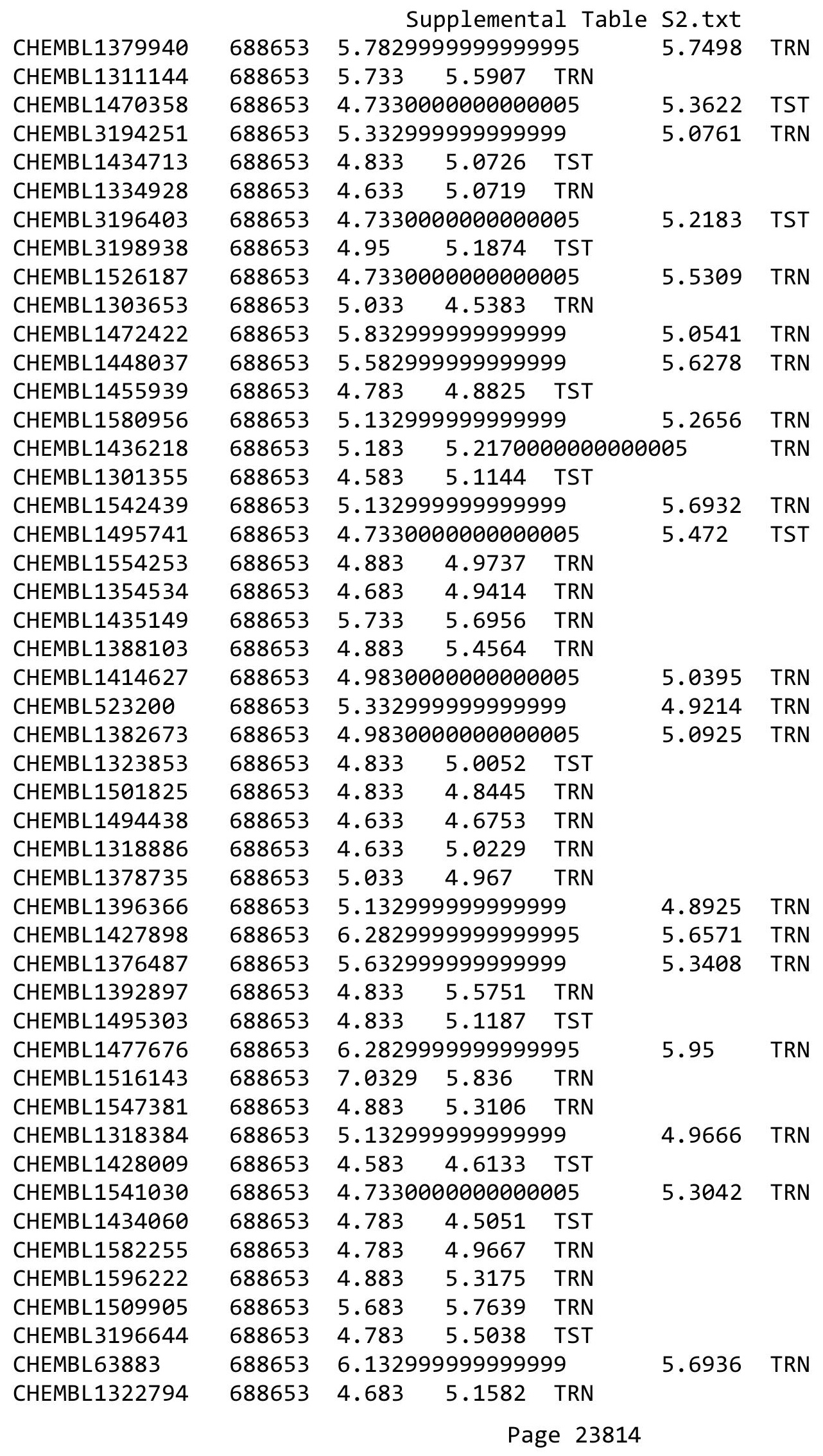




\begin{tabular}{|c|c|c|c|c|c|c|}
\hline CHEMBL1457402 & 688653 & 5.483 & 5.933 & TRN & & \\
\hline CHEMBL1522276 & 688653 & 4.583 & 5.1654 & TRN & & \\
\hline CHEMBL1303687 & 688653 & \multicolumn{3}{|c|}{5.7829999999999995} & 5.4022 & TR \\
\hline CHEMBL1438752 & 688653 & 4.933 & 5.3326 & TRN & & \\
\hline CHEMBL1500037 & 88653 & 4.683 & \multicolumn{3}{|c|}{5.111000000000001} & TR \\
\hline CHEMBL1537258 & 88653 & 5.183 & 5.6491 & TRN & & \\
\hline CHEMBL1395688 & 588653 & 4.783 & 4.9946 & TRN & & \\
\hline CHEMBL1504338 & 688653 & 4.883 & 5.1508 & TRN & & \\
\hline HEMBL1479468 & 88653 & 5.483 & 5.6128 & TRN & & \\
\hline HEMBL1495561 & 88653 & \multicolumn{3}{|c|}{5.7829999999999995} & 5.9926 & ThIV \\
\hline CHEMBL1368365 & 588653 & \multicolumn{3}{|c|}{4.7330000000000005} & 5.1326 & IST \\
\hline HEMBL1300493 & 688653 & \multicolumn{3}{|c|}{6.582999999999999} & 6.1197 & \\
\hline HEMBL1469517 & 688653 & \multicolumn{3}{|c|}{6.2829999999999995} & 5.1679 & \\
\hline HEMBL1305092 & 588653 & \multicolumn{3}{|c|}{5.132999999999999} & 5.0628 & \\
\hline CHEMBL602069 & 588653 & \multicolumn{3}{|c|}{ 5.382999999999999 } & 5.1362 & \\
\hline CHEMBL1401402 & 688653 & \multicolumn{3}{|c|}{5.582999999999999} & 5.1375 & \\
\hline HEMBL3189714 & 688653 & \multicolumn{3}{|c|}{5.2829999999999995} & & \\
\hline HEMBL1340266 & 688653 & 5.733 & 5.7392 & TST & & \\
\hline HEMBL1609231 & 688653 & 5.233 & \multicolumn{3}{|c|}{5.1080000000000005} & \\
\hline CHEMBL 3210546 & 688653 & 4.783 & 5.3957 & TST & & \\
\hline CHEMBL1555814 & 688653 & 5.183 & 5.3722 & TRN & & \\
\hline HEMBL1 & 88653 & 4.633 & 4.8863 & TRN & & \\
\hline HEMBL1585989 & 688653 & 5.033 & 5.0679 & TRN & & \\
\hline HEMBL1411257 & 688653 & 6.95 & 5.8662 & TRN & & \\
\hline CHEMBL 254530 & 688653 & \multicolumn{3}{|c|}{4.7330000000000005} & 4. & \\
\hline CHEMBL 3197532 & 688653 & 4.633 & 4.8079 & TRN & & \\
\hline CHEMBL & 688653 & 5.233 & 5.2745 & TRN & & \\
\hline CHEMBL: & 688653 & \multicolumn{3}{|c|}{5.832999999999999} & 5.1941 & $T R$ \\
\hline CHEMBL1337227 & 688653 & 4.683 & 4.9725 & TRN & & \\
\hline CHEMBL1390015 & 688653 & 5.033 & 5.1316 & TST & & \\
\hline CHEMBL 3190323 & 688653 & 4.783 & 5.3024 & TRN & & \\
\hline CHEMBL: & 688653 & 4.683 & 5.1387 & TRN & & \\
\hline CHEMBL: & 688653 & 5.483 & 5.4289 & TRN & & \\
\hline CHEMBL578512 & 688653 & 5.233 & 5.5428 & TRN & & \\
\hline CHEMBL1510094 & 688653 & 6.183 & 5.4499 & TRN & & \\
\hline CHEMBL: & 38653 & 5.083 & 5.1272 & TRN & & \\
\hline CHEMBL & 653 & 4.783 & 5.4519 & TST & & \\
\hline CHEMBL1991303 & 688653 & \multicolumn{3}{|c|}{4.7330000000000005} & 5.5 & \\
\hline CHEMBL1492846 & 688653 & \multicolumn{3}{|c|}{5.132999999999999} & 5.0579 & \\
\hline CHEMBL1416089 & 688653 & 6.0 & 5.3673 & TRN & & \\
\hline CHEMBL1346522 & 688653 & 6.233 & 5.8226 & TRN & & \\
\hline CHEMBL 3193287 & 688653 & 5.233 & 5.3014 & TRN & & \\
\hline CHEMBL1586531 & 688653 & 5.083 & 5.0338 & TST & & \\
\hline CHEMBL1607129 & 688653 & \multicolumn{3}{|c|}{6.132999999999999} & 5.4743 & $r$ \\
\hline CHEMBL1413850 & 688653 & 4.933 & 5.7558 & TRN & & \\
\hline CHEMBL1307935 & 688653 & 5.033 & 4.8716 & TRN & & \\
\hline CHEMBL1454503 & 688653 & \multicolumn{3}{|c|}{4.7330000000000005} & 5.5496 & \\
\hline CHEMBL1389540 & 688653 & \multicolumn{3}{|c|}{5.832999999999999} & 6.0335 & \\
\hline
\end{tabular}




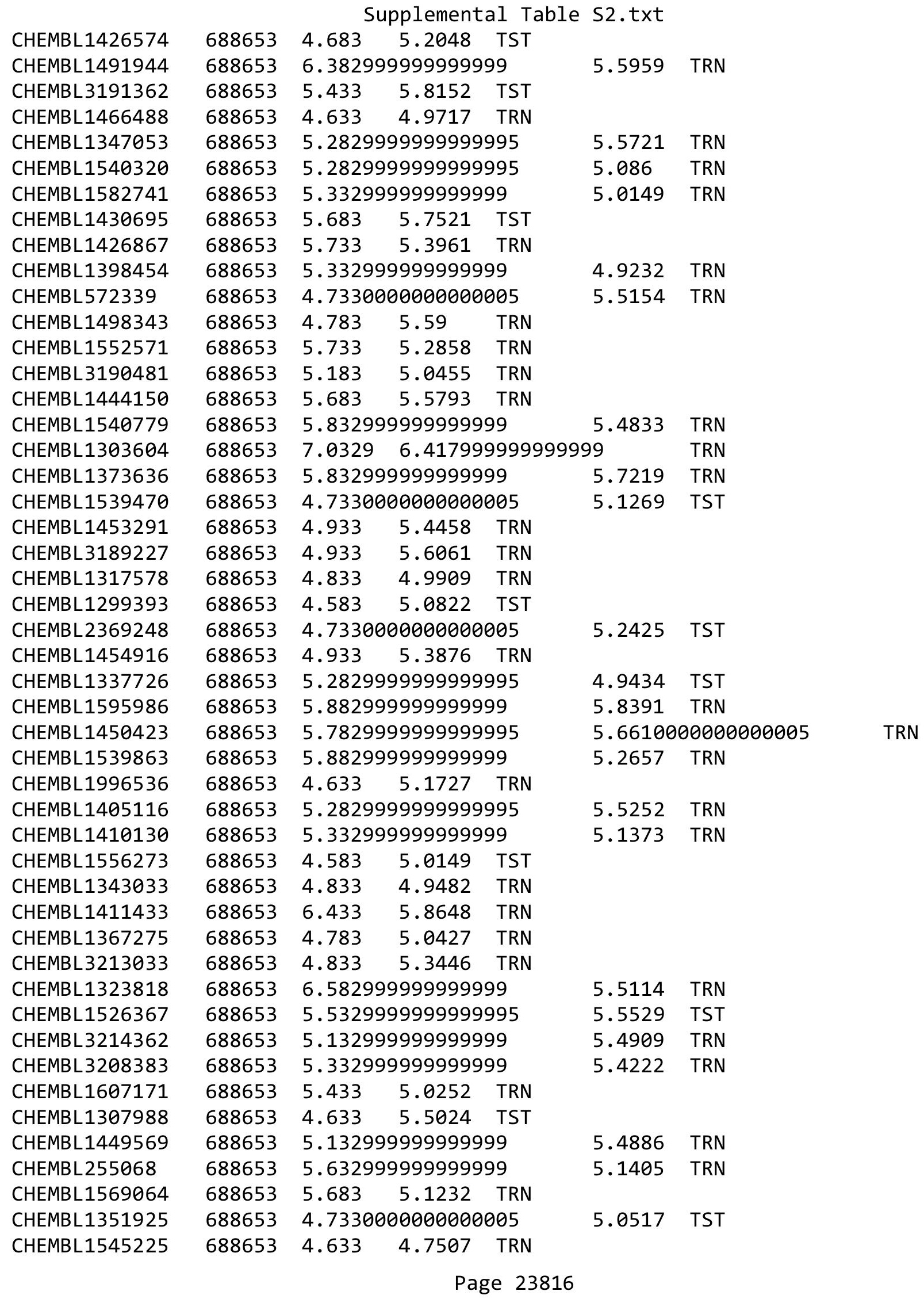




\begin{tabular}{|c|c|c|c|c|c|c|c|}
\hline \multirow{3}{*}{$\begin{array}{l}\text { CHEMBL1562485 } \\
\text { CHEMBL1330583 }\end{array}$} & \multicolumn{6}{|c|}{ Supplemental Table S2.txt } & \multirow[b]{2}{*}{ TRN } \\
\hline & 688653 & \multicolumn{3}{|c|}{5.2829999999999995} & \multicolumn{2}{|c|}{5.242000000000001} & \\
\hline & 688653 & \multicolumn{3}{|c|}{7.082999999999999} & 6.2122 & TRN & \\
\hline CHEMBL1343768 & 688653 & \multicolumn{3}{|c|}{5.632999999999999} & 5.309 & TRN & \\
\hline CHEMBL1447209 & 688653 & 4.95 & 5.0853 & TRN & & & \\
\hline CHEMBL1470634 & 688653 & 5.083 & \multicolumn{3}{|c|}{5.093999999999999} & TRN & \\
\hline CHEMBL1368120 & 688653 & \multicolumn{3}{|c|}{5.832999999999999} & 5.8543 & TRN & \\
\hline CHEMBL1430895 & 688653 & 4.633 & 4.8684 & TRN & & & \\
\hline CHEMBL1361124 & 688653 & 5.483 & 5.0599 & TRN & & & \\
\hline CHEMBL1420037 & 688653 & \multicolumn{3}{|c|}{5.882999999999999} & 5.2081 & TRN & \\
\hline CHEMBL1997059 & 688653 & \multicolumn{3}{|c|}{5.7829999999999995} & 5.5336 & TST & \\
\hline CHEMBL1301295 & 688653 & 4.883 & 4.8992 & TST & & & \\
\hline CHEMBL1576166 & 688653 & 7.1331 & 6.4362 & TRN & & & \\
\hline CHEMBL1571004 & 688653 & 5.433 & 5.2067 & TRN & & & \\
\hline CHEMBL1422572 & 688653 & 5.183 & 4.9842 & TRN & & & \\
\hline CHEMBL1577902 & 688653 & 6.433 & 5.6372 & TRN & & & \\
\hline CHEMBL1314100 & 688653 & \multicolumn{3}{|c|}{4.7330000000000005} & 5.438 & TST & \\
\hline CHEMBL3207994 & 688653 & 4.883 & 5.0966 & TRN & & & \\
\hline CHEMBL1387274 & 688653 & \multicolumn{3}{|c|}{5.7829999999999995} & 4.961 & TRN & \\
\hline CHEMBL1460593 & 688653 & 5.083 & 5.3549 & TRN & & & \\
\hline CHEMBL1530341 & 688653 & 5.483 & 5.8145 & TRN & & & \\
\hline CHEMBL1438681 & 688653 & \multicolumn{3}{|c|}{4.7330000000000005} & 5.1483 & TST & \\
\hline CHEMBL1549154 & 688653 & 4.783 & 4.9962 & TRN & & & \\
\hline CHEMBL1337017 & 688653 & \multicolumn{3}{|c|}{4.7330000000000005} & 4.9448 & TST & \\
\hline CHEMBL 1385169 & 688653 & \multicolumn{3}{|c|}{5.832999999999999} & 5.5204 & TST & \\
\hline CHEMBL 3189508 & 688653 & \multicolumn{3}{|c|}{5.2829999999999995} & 5.3432 & TST & \\
\hline CHEMBL1305223 & 688653 & \multicolumn{3}{|c|}{5.132999999999999} & 5.3157 & TRN & \\
\hline CHEMBL1347188 & 688653 & \multicolumn{3}{|c|}{5.332999999999999} & 5.5703 & TST & \\
\hline CHEMBL1524779 & 688653 & 5.083 & 5.0729 & TST & & & \\
\hline CHEMBL1313979 & 688653 & \multicolumn{3}{|c|}{6.632999999999999} & \multicolumn{2}{|c|}{5.571000000000001} & TRN \\
\hline CHEMBL1468684 & 688653 & 4.633 & 5.6219 & TRN & & & \\
\hline CHEMBL1605334 & 688653 & 4.833 & 5.2138 & TRN & & & \\
\hline CHEMBL1334915 & 688653 & 4.833 & 5.0934 & TST & & & \\
\hline CHEMBL1552221 & 688653 & 5.88299 & 99999999 & & 5.1924 & TST & \\
\hline CHEMBL1398684 & 688653 & 4.783 & 5.3495 & TRN & & & \\
\hline CHEMBL1493559 & 688653 & 4.883 & 5.2532 & TRN & & & \\
\hline CHEMBL1333382 & 688653 & 4.833 & 5.1788 & TRN & & & \\
\hline CHEMBL1522518 & 688653 & 5.13299 & 99999999 & & 4.9307 & TRN & \\
\hline CHEMBL1451110 & 688653 & 5.33299 & 99999999 & & 5.6239 & TRN & \\
\hline CHEMBL1411831 & 688653 & 4.883 & 5.5388 & TRN & & & \\
\hline CHEMBL1370387 & 688653 & 5.683 & 5.5646 & TRN & & & \\
\hline CHEMBL1400478 & 688653 & 5.033 & 5.4449 & TRN & & & \\
\hline CHEMBL 1558562 & 688653 & 4.883 & 4.9739 & TST & & & \\
\hline CHEMBL1548674 & 688653 & 4.783 & 5.2249 & TRN & & & \\
\hline CHEMBL1611013 & 688653 & 4.633 & 4.7758 & TST & & & \\
\hline CHEMBL1369972 & 688653 & 4.933 & 5.1881 & TRN & & & \\
\hline CHEMBL1512953 & 688653 & 4.583 & 4.6912 & TRN & & & \\
\hline CHEMBL1531841 & 688653 & 4.633 & 4.2638 & TST & & & \\
\hline CHEMBL1505997 & 688653 & 5.88299 & 99999999 & & 5.5358 & TRN & \\
\hline
\end{tabular}




\begin{tabular}{|c|c|c|c|c|c|c|}
\hline \multirow[b]{2}{*}{ CHEMBL1496439 } & \multicolumn{6}{|c|}{ plemental Table S2. } \\
\hline & 688653 & 5.483 & \multirow{2}{*}{\multicolumn{2}{|c|}{1548 TRN }} & & \\
\hline CHEMBL1303887 & 688653 & 5.78299 & & 995 & 5.3206 & TST \\
\hline CHEMBL1496380 & 688653 & 5.183 & \multicolumn{3}{|c|}{5.412999999999999} & \\
\hline CHEMBL1521164 & 688653 & \multicolumn{3}{|c|}{5.582999999999999} & 5.2077 & \\
\hline CHEMBL1435214 & 688653 & \multicolumn{3}{|c|}{4.9830000000000005} & 5.5583 & \\
\hline CHEMBL1370159 & 688653 & \multicolumn{3}{|c|}{4.7330000000000005} & 5.3032 & \\
\hline CHEMBL1347685 & 688653 & 4.933 & 5.2498 & TRN & & \\
\hline CHEMBL1345312 & 688653 & 4.783 & 5.8477 & TST & & \\
\hline CHEMBL1405542 & 688653 & \multicolumn{3}{|c|}{4.9830000000000005} & 5.1534 & \\
\hline CHEMBL1488300 & 688653 & \multicolumn{3}{|c|}{5.132999999999999} & 5.2861 & \\
\hline CHEMBL1569402 & 688653 & \multicolumn{3}{|c|}{4.9830000000000005} & 4.7483 & \\
\hline CHEMBL3211295 & 688653 & 4.683 & 4.7562 & TRN & & \\
\hline CHEMBL156692 & 688653 & \multicolumn{3}{|c|}{4.7330000000000005} & 5.4591 & \\
\hline CHEMBL1403178 & 688653 & \multicolumn{3}{|c|}{4.7330000000000005} & 5.1668 & \\
\hline CHEMBL1434938 & 688653 & 4.783 & \multicolumn{3}{|c|}{4.843999999999999} & \\
\hline CHEMBL1340287 & 688653 & 5.033 & 4.9732 & TRN & & \\
\hline CHEMBL1522007 & 688653 & 5.233 & 5.3683 & TST & & \\
\hline CHEMBL3210380 & 688653 & 4.833 & 5.5293 & TRN & & \\
\hline CHEMBL1S & 688653 & 4.9 & 5.7535 & TRN & & \\
\hline CHEMBL1S & 688653 & 5.733 & 5.7092 & TRN & & \\
\hline CHEMBL1349165 & 688653 & 4.933 & 5.2882 & TRN & & \\
\hline CHEMBL1480878 & 688653 & 4.633 & 4.9301 & TRN & & \\
\hline CHEMBL1467843 & 688653 & 6.233 & 5.7781 & TRN & & \\
\hline CHEMBL1 & 688653 & \multicolumn{3}{|c|}{4.7330000000000005} & 4 & \\
\hline CHEMBL1553712 & 688653 & 4.783 & 4.5736 & TRN & & \\
\hline CHEMBL3207305 & 688653 & 4.783 & 5.0386 & TST & & \\
\hline CHEMBL1324130 & 688653 & \multicolumn{3}{|c|}{5.5329999999999995} & 5.5743 & \\
\hline CHEMBL1506301 & 688653 & 5.183 & 5.4347 & TRN & & \\
\hline CHEMBL5 & 3 & 5.033 & 6.0464 & TRN & & \\
\hline CHEMBL15 & 688653 & \multicolumn{3}{|c|}{4.9830000000000005} & 4.5509 & \\
\hline CHEMBL1316998 & 688653 & \multicolumn{3}{|c|}{4.7330000000000005} & 5.4077 & \\
\hline CHEMBL3190648 & 688653 & \multicolumn{3}{|c|}{5.7829999999999995} & 5.296 & \\
\hline CHEMBL1484597 & 688653 & 4.633 & 4.8116 & TST & & \\
\hline CHEMBL1 & 688 & 4.883 & 5.5383 & TRN & & \\
\hline CHEMBL1580740 & 688653 & \multicolumn{3}{|c|}{4.7330000000000005} & 5.1715 & \\
\hline CHEMBL1456696 & 688653 & \multicolumn{3}{|c|}{5.5329999999999995} & 5.671 & \\
\hline CHEMBL1359315 & 688653 & 4.783 & 5.2425 & TRN & & \\
\hline CHEMBL13 & 688653 & \multicolumn{3}{|c|}{4.9830000000000005} & 599 & \\
\hline CHEMBL13 & 688653 & 4.73300 & 00000000 & 005 & 322 & \\
\hline CHEMBL1438948 & 688653 & 4.783 & 5.184 & TRN & & \\
\hline CHEMBL1380712 & 688653 & 4.98300 & 0000000 & 005 & 5.1341 & \\
\hline CHEMBL1414005 & 688653 & 5.983 & 5.381 & TRN & & \\
\hline CHEMBL1335591 & & 5.033 & 5.0611 & TRN & & \\
\hline CHEMBL 3194258 & 688653 & 4.73300 & 00000000 & 005 & 4.7077 & $\mathrm{TR}$ \\
\hline CHEMBL1397579 & 688653 & 4.73300 & 00000000 & 005 & 4.9501 & 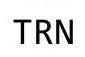 \\
\hline CHEMBL1457498 & 688653 & 4.883 & 4.9422 & TRN & & \\
\hline CHEMBL3214616 & 688653 & 5.33299 & 99999999 & & 5.4344 & 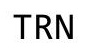 \\
\hline CHEMBL1548454 & 688653 & 4.933 & 5.1897 & TRN & & \\
\hline
\end{tabular}




\begin{tabular}{|c|c|c|c|c|c|c|}
\hline \multirow[b]{2}{*}{ CHEMBL1302785 } & & \multicolumn{5}{|c|}{ Supplemental Table S2.txt } \\
\hline & 688653 & 5.233 & 4.9848 & TST & & \\
\hline CHEMBL1585026 & 688653 & 5.733 & 5.0633 & TST & & \\
\hline CHEMBL1438861 & 688653 & 4.883 & 5.0143 & TRN & & \\
\hline CHEMBL1566730 & 688653 & \multicolumn{3}{|c|}{6.332999999999999} & 5.526 & TRN \\
\hline CHEMBL1556786 & 688653 & 7.1331 & 5.9414 & TRN & & \\
\hline CHEMBL1333433 & 688653 & 4.683 & 4.9343 & TRN & & \\
\hline CHEMBL1469857 & 688653 & 5.433 & 5.2341 & TST & & \\
\hline CHEMBL1513226 & 688653 & \multicolumn{3}{|c|}{4.9830000000000005} & 4.7767 & TRN \\
\hline CHEMBL1390612 & 688653 & 4.583 & 5.3447 & TST & & \\
\hline CHEMBL1534661 & 688653 & 4.883 & 5.1588 & TRN & & \\
\hline CHEMBL1538636 & 688653 & \multicolumn{3}{|c|}{5.132999999999999} & 4.9767 & TST \\
\hline CHEMBL 3189188 & 688653 & 5.183 & 5.1791 & TRN & & \\
\hline CHEMBL1485714 & 688653 & 4.833 & 4.7647 & TST & & \\
\hline CHEMBL3199163 & 688653 & \multicolumn{3}{|c|}{6.5329999999999995} & 5.2455 & TRN \\
\hline CHEMBL1367180 & 688653 & 5.083 & 5.5634 & TRN & & \\
\hline CHEMBL1306237 & 688653 & 5.183 & 5.7954 & TRN & & \\
\hline CHEMBL1368342 & 688653 & 4.933 & 5.0558 & TRN & & \\
\hline CHEMBL1599425 & 688653 & \multicolumn{3}{|c|}{5.632999999999999} & 5.2161 & TRN \\
\hline CHEMBL1500499 & 688653 & 4.833 & 5.4221 & TST & & \\
\hline CHEMBL1461605 & 688653 & 5.183 & 5.0772 & TRN & & \\
\hline CHEMBL1301396 & 688653 & 4.883 & 4.731 & TRN & & \\
\hline CHEMBL1419173 & 688653 & 4.633 & 4.8508 & TST & & \\
\hline CHEMBL 3196788 & 688653 & 4.833 & 5.2138 & TRN & & \\
\hline CHEMBL1510215 & 688653 & 5.233 & 4.8982 & TRN & & \\
\hline CHEMBL1448038 & 688653 & \multicolumn{3}{|c|}{5.132999999999999} & 5.5803 & TRN \\
\hline CHEMBL3209656 & 688653 & 4.783 & 5.3779 & TRN & & \\
\hline CHEMBL1572651 & 688653 & 5.683 & 5.0502 & TST & & \\
\hline CHEMBL1391744 & 688653 & 5.233 & 5.2669 & TRN & & \\
\hline CHEMBL1371252 & 688653 & 4.883 & 5.4883 & TST & & \\
\hline CHEMBL1549852 & 688653 & \multicolumn{3}{|c|}{6.082999999999999} & 5.2364 & TRN \\
\hline CHEMBL1541071 & 688653 & 4.883 & 5.4301 & TRN & & \\
\hline CHEMBL2004511 & 688653 & 4.833 & 4.9313 & TRN & & \\
\hline CHEMBL1331338 & 688653 & 5.483 & 5.1149 & TRN & & \\
\hline CHEMBL1420365 & 688653 & \multicolumn{3}{|c|}{5.7829999999999995} & 5.9312 & TRN \\
\hline CHEMBL1510448 & 688653 & 4.783 & 5.4277 & TST & & \\
\hline CHEMBL1525062 & 688653 & \multicolumn{3}{|c|}{5.332999999999999} & 5.2994 & TRN \\
\hline CHEMBL3192198 & 688653 & 4.633 & 4.9023 & TRN & & \\
\hline CHEMBL1521031 & 688653 & 4.883 & 5.3238 & TST & & \\
\hline CHEMBL3193223 & 688653 & 4.833 & 4.9385 & TRN & & \\
\hline CHEMBL1994683 & 688653 & \multicolumn{3}{|c|}{5.882999999999999} & 5.9614 & TRN \\
\hline CHEMBL1325342 & 688653 & \multicolumn{3}{|c|}{6.132999999999999} & 5.5968 & TRN \\
\hline CHEMBL1518736 & 688653 & 5.233 & 5.2495 & TRN & & \\
\hline CHEMBL1492459 & 688653 & 5.933 & 5.8188 & TRN & & \\
\hline CHEMBL1611957 & 688653 & 4.633 & 4.6347 & TRN & & \\
\hline CHEMBL1409856 & 688653 & 4.783 & 5.1781 & TRN & & \\
\hline CHEMBL1420628 & 688653 & \multicolumn{3}{|c|}{5.7829999999999995} & 5.7394 & TRN \\
\hline CHEMBL1332949 & 688653 & 4.783 & 4.9376 & TRN & & \\
\hline CHEMBL1549700 & 688653 & 6.0 & 5.1507 & TST & & \\
\hline
\end{tabular}




\begin{tabular}{|c|c|c|c|c|c|c|c|}
\hline \multicolumn{8}{|c|}{ Supplemental Ta } \\
\hline CHEMBL1398008 & 688653 & 5.933 & 5.4448 & TRN & & & \\
\hline CHEMBL1546328 & 688653 & 4.883 & 5.0086 & TST & & & \\
\hline CHEMBL3194415 & 688653 & 5.033 & 5.1604 & TST & & & \\
\hline CHEMBL1602290 & 688653 & 4.633 & 4.8409 & TRN & & & \\
\hline CHEMBL1464928 & 688653 & 5.233 & 5.3583 & TST & & & \\
\hline CHEMBL1527947 & 688653 & 4.783 & 5.2543 & TST & & & \\
\hline CHEMBL1448415 & 688653 & 4.583 & 5.4861 & TRN & & & \\
\hline CHEMBL1524725 & 688653 & 4.783 & 5.0591 & TRN & & & \\
\hline CHEMBL1407489 & 688653 & \multicolumn{3}{|c|}{6.5329999999999995} & 5.2881 & TST & \\
\hline CHEMBL1379230 & 688653 & 4.583 & 4.7223 & TRN & & & \\
\hline CHEMBL1317713 & 688653 & \multicolumn{3}{|c|}{6.082999999999999} & 5.6101 & TRN & \\
\hline CHEMBL1472013 & 688653 & 4.583 & 5.2787 & TST & & & \\
\hline CHEMBL1424243 & 688653 & \multicolumn{3}{|c|}{5.7829999999999995} & 5.4219 & TRN & \\
\hline CHEMBL1536437 & 688653 & 5.483 & 5.4582 & TRN & & & \\
\hline CHEMBL1351116 & 688653 & 4.833 & 5.2429 & TST & & & \\
\hline CHEMBL1573261 & 688653 & 7.2832 & 6.0637 & TRN & & & \\
\hline CHEMBL1400807 & 688653 & \multicolumn{3}{|c|}{5.132999999999999} & 5.1415 & TRN & \\
\hline CHEMBL1391486 & 688653 & 5.033 & 5.7241 & TRN & & & \\
\hline CHEMBL1464609 & 688653 & 6.683 & 5.6019 & TRN & & & \\
\hline CHEMBL899 & 688653 & \multicolumn{3}{|c|}{5.632999999999999} & 5.095 & TRN & \\
\hline CHEMBL1443965 & 688653 & 6.233 & 5.5877 & TRN & & & \\
\hline CHEMBL1300470 & 688653 & \multicolumn{3}{|c|}{4.7330000000000005} & 5.2474 & TRN & \\
\hline CHEMBL1373752 & 688653 & 5.483 & 5.4348 & TRN & & & \\
\hline CHEMBL1598598 & 688653 & \multicolumn{3}{|c|}{5.832999999999999} & 5.5408 & TRN & \\
\hline CHEMBL1574642 & 688653 & \multicolumn{3}{|c|}{5.2829999999999995} & 4.8141 & TRN & \\
\hline CHEMBL1348057 & 688653 & 4.883 & 4.4994 & TRN & & & \\
\hline CHEMBL1541214 & 688653 & 5.033 & 5.3105 & TST & & & \\
\hline CHEMBL1465063 & 688653 & \multicolumn{3}{|c|}{5.832999999999999} & \multicolumn{2}{|c|}{5.672999999999999} & TRN \\
\hline CHEMBL1357447 & 688653 & 4.883 & 4.7614 & TRN & & & \\
\hline CHEMBL1324802 & 688653 & \multicolumn{3}{|c|}{4.9830000000000005} & 5.1518 & TRN & \\
\hline CHEMBL1531480 & 688653 & \multicolumn{3}{|c|}{4.7330000000000005} & 5.3778 & TST & \\
\hline CHEMBL1429089 & 688653 & 4.833 & 5.0963 & TRN & & & \\
\hline CHEMBL1542068 & 688653 & \multicolumn{3}{|c|}{6.332999999999999} & 5.6848 & TRN & \\
\hline CHEMBL1455337 & 688653 & 4.633 & 5.2197 & TRN & & & \\
\hline CHEMBL1389810 & 688653 & \multicolumn{3}{|c|}{5.882999999999999} & 5.3778 & TRN & \\
\hline CHEMBL1556998 & 688653 & 5.983 & 5.4246 & TRN & & & \\
\hline CHEMBL1399851 & 688653 & \multicolumn{3}{|c|}{4.7330000000000005} & 4.9626 & TST & \\
\hline CHEMBL1324632 & 688653 & 4.583 & 5.1073 & TRN & & & \\
\hline CHEMBL1330725 & 688653 & 5.233 & 4.8252 & TRN & & & \\
\hline CHEMBL3194193 & 688653 & 4.833 & 5.1938 & TRN & & & \\
\hline CHEMBL1431577 & 688653 & 6.0 & 5.9669 & TRN & & & \\
\hline CHEMBL1524929 & 688653 & 6.433 & 6.2658 & TRN & & & \\
\hline CHEMBL531710 & 688653 & 6.8831 & 5.8178 & TRN & & & \\
\hline CHEMBL1451492 & 688653 & \multicolumn{3}{|c|}{6.2829999999999995} & 5.4422 & TRN & \\
\hline CHEMBL1562027 & 688653 & 4.833 & 5.3754 & TRN & & & \\
\hline CHEMBL1450281 & 688653 & \multicolumn{3}{|c|}{4.7330000000000005} & 5.5336 & TRN & \\
\hline CHEMBL1467157 & 688653 & 6.433 & 5.4386 & TRN & & & \\
\hline CHEMBL1304638 & 688653 & \multicolumn{3}{|c|}{4.7330000000000005} & 4.9454 & TST & \\
\hline
\end{tabular}




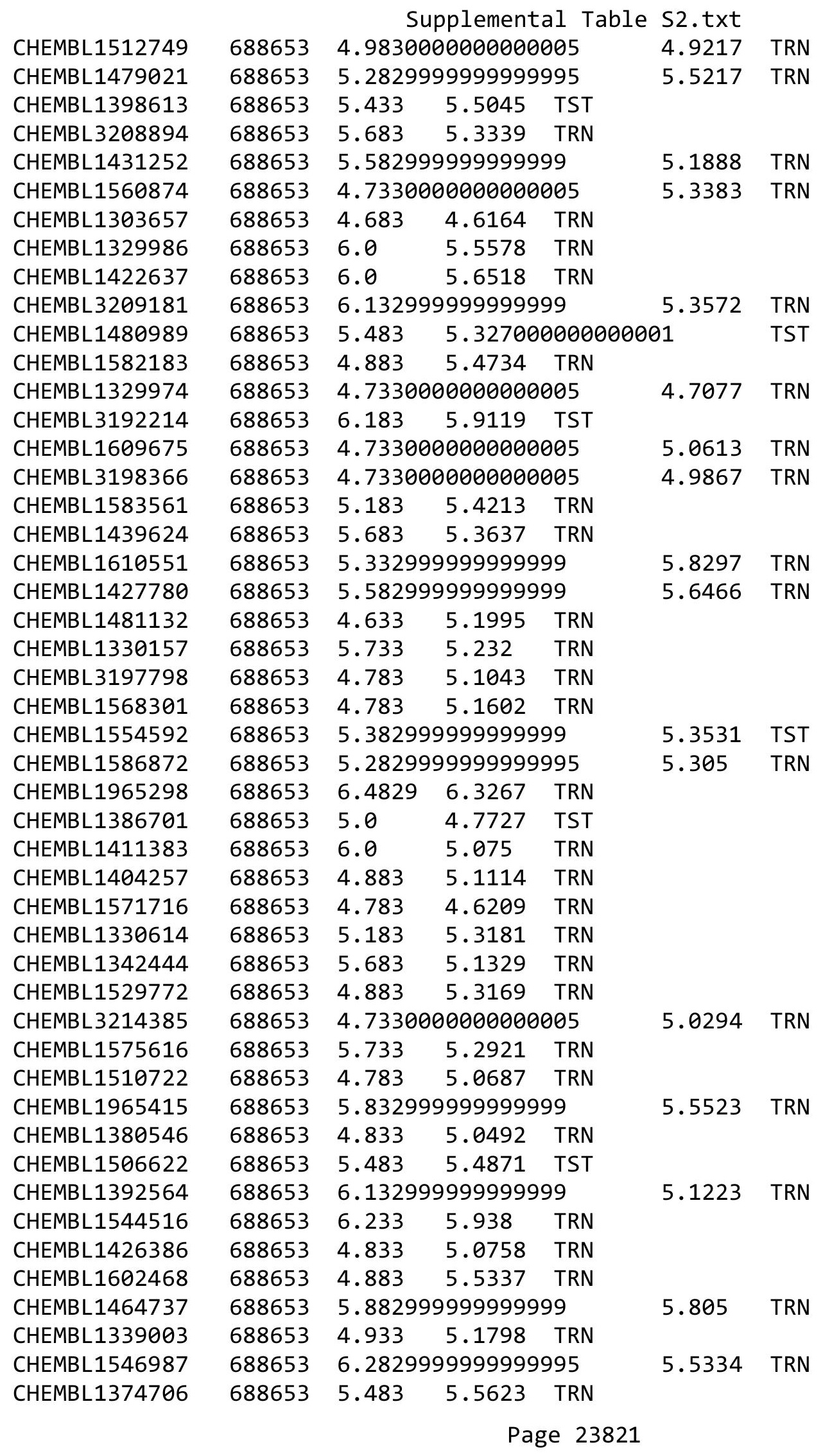




\begin{tabular}{|c|c|c|c|c|c|c|}
\hline \multirow[b]{2}{*}{ CHEMBL1492164 } & & \multicolumn{5}{|c|}{ Supplemental Table s2.txt } \\
\hline & 688653 & 4.833 & 4.8681 & TRN & & \\
\hline CHEMBL1407885 & 688653 & 4.683 & 4.9903 & TRN & & \\
\hline CHEMBL1444103 & 688653 & 5.233 & 5.6102 & TST & & \\
\hline CHEMBL1352489 & 688653 & \multicolumn{3}{|c|}{6.382999999999999} & 5.6449 & TST \\
\hline CHEMBL1338209 & 688653 & 4.883 & 5.1514 & TRN & & \\
\hline CHEMBL1517447 & 688653 & 5.183 & 4.8447 & TRN & & \\
\hline CHEMBL1548897 & 688653 & 4.783 & 4.877 & TRN & & \\
\hline CHEMBL1357651 & 688653 & \multicolumn{3}{|c|}{4.7330000000000005} & 5.1875 & TST \\
\hline CHEMBL1310650 & 688653 & 5.033 & 4.8573 & TRN & & \\
\hline CHEMBL1552445 & 688653 & 4.783 & 4.9531 & TRN & & \\
\hline CHEMBL1469710 & 688653 & 4.633 & 4.8285 & TRN & & \\
\hline CHEMBL3194385 & 688653 & 4.833 & 5.1222 & TRN & & \\
\hline CHEMBL1455781 & 688653 & 4.633 & 5.1882 & TRN & & \\
\hline CHEMBL1451100 & 688653 & 5.083 & 5.3592 & TRN & & \\
\hline CHEMBL1386908 & 688653 & 5.483 & 5.0698 & TRN & & \\
\hline CHEMBL1433075 & 688653 & 4.883 & 5.2281 & TST & & \\
\hline CHEMBL1348787 & 688653 & 4.833 & 5.2413 & TRN & & \\
\hline CHEMBL1492021 & 688653 & 4.583 & 4.7849 & TRN & & \\
\hline CHEMBL1995550 & 688653 & 4.633 & 5.5058 & TST & & \\
\hline CHEMBL1325877 & 688653 & \multicolumn{3}{|c|}{4.7330000000000005} & 4.8354 & TST \\
\hline CHEMBL1579279 & 688653 & 4.783 & 5.2122 & TRN & & \\
\hline CHEMBL1491795 & 688653 & 5.233 & 5.3177 & TRN & & \\
\hline CHEMBL1537329 & 688653 & \multicolumn{3}{|c|}{5.832999999999999} & 5.4739 & TRN \\
\hline CHEMBL1324718 & 688653 & 4.883 & 5.2761 & TRN & & \\
\hline CHEMBL1540631 & 688653 & 5.433 & 5.1793 & TST & & \\
\hline CHEMBL1344587 & 688653 & 4.883 & 5.1765 & TRN & & \\
\hline CHEMBL1299208 & 688653 & \multicolumn{3}{|c|}{5.2829999999999995} & 5.9378 & TRN \\
\hline CHEMBL1303102 & 688653 & 5.483 & 5.3032 & TRN & & \\
\hline CHEMBL1507436 & 688653 & 4.933 & 5.7463 & TRN & & \\
\hline CHEMBL1347436 & 688653 & \multicolumn{3}{|c|}{6.2829999999999995} & 4.9346 & TRN \\
\hline CHEMBL1387251 & 688653 & \multicolumn{3}{|c|}{5.632999999999999} & 5.6609 & TRN \\
\hline CHEMBL1408818 & 688653 & 4.783 & 5.2977 & TRN & & \\
\hline CHEMBL1536228 & 688653 & 5.233 & 5.5686 & TRN & & \\
\hline CHEMBL1535516 & 688653 & 5.183 & 5.5259 & TRN & & \\
\hline CHEMBL1361135 & 688653 & \multicolumn{3}{|c|}{5.2829999999999995} & 4.655 & TRN \\
\hline CHEMBL1468420 & 688653 & \multicolumn{3}{|c|}{5.882999999999999} & 5.7886 & TRN \\
\hline CHEMBL1610659 & 688653 & 6.433 & 5.5816 & TRN & & \\
\hline CHEMBL3190995 & 688653 & \multicolumn{3}{|c|}{5.7829999999999995} & 5.3861 & TST \\
\hline CHEMBL1607026 & 688653 & 4.783 & 5.3848 & TRN & & \\
\hline CHEMBL1549827 & 688653 & 4.583 & 5.409 & TST & & \\
\hline CHEMBL1315721 & 688653 & 7.8827 & \multicolumn{3}{|c|}{6.127000000000001} & TRN \\
\hline CHEMBL1367567 & 688653 & \multicolumn{3}{|c|}{4.9830000000000005} & 5.1521 & TRN \\
\hline CHEMBL1593016 & 688653 & 5.683 & 5.2471 & TRN & & \\
\hline CHEMBL1581417 & 688653 & 5.083 & 5.5295 & TRN & & \\
\hline CHEMBL1359062 & 688653 & 4.783 & 4.9686 & TST & & \\
\hline CHEMBL1361148 & 688653 & 5.033 & 5.16 & TRN & & \\
\hline CHEMBL1388469 & 688653 & 4.883 & 4.7277 & TRN & & \\
\hline CHEMBL1495450 & 688653 & 4.783 & 5.1477 & TST & & \\
\hline
\end{tabular}




\begin{tabular}{|c|c|c|c|c|c|c|c|}
\hline \multicolumn{8}{|c|}{ premicticas } \\
\hline CHEMBL1314210 & 688653 & 5.033 & 5.1744 & TST & & & \\
\hline CHEMBL1388490 & 688653 & 4.783 & 5.103 & TST & & & \\
\hline CHEMBL1432548 & 688653 & 4.633 & 5.1544 & TRN & & & \\
\hline CHEMBL1428685 & 688653 & 5.1329 & 99999999 & 99 & 5.39 & TRN & \\
\hline CHEMBL1521960 & 688653 & 6.2829 & 9999999 & 995 & 5.541 & TST & \\
\hline CHEMBL1509431 & 688653 & 5.683 & 5.267 & TRN & & & \\
\hline CHEMBL1597655 & 688653 & 5.5329 & 99999999 & 995 & 5.2336 & TRN & \\
\hline CHEMBL1300831 & 688653 & 4.7330 & 00000006 & 005 & 5.193 & TRN & \\
\hline CHEMBL1517865 & 688653 & 5.983 & 5.4798 & TRN & & & \\
\hline CHEMBL1533321 & 688653 & 5.5329 & 9999999 & 995 & 5.0115 & TST & \\
\hline CHEMBL1971142 & 688653 & 5.6329 & 99999999 & 99 & 6.6413 & TRN & \\
\hline CHEMBL3212638 & 688653 & 4.883 & $5.3660 e$ & 0000 & 005 & TRN & \\
\hline CHEMBL1394681 & 688653 & 5.3329 & 99999999 & 99 & 5.8329 & TRN & \\
\hline CHEMBL1476950 & 688653 & 4.7330 & $\partial 0000000$ & 005 & 5.0214 & TRN & \\
\hline CHEMBL1339073 & 688653 & 4.783 & 5.7807 & TRN & & & \\
\hline CHEMBL1313364 & 688653 & 4.933 & 5.1418 & TST & & & \\
\hline CHEMBL1368806 & 688653 & 6.5829 & 99999999 & 99 & 5.2416 & TRN & \\
\hline CHEMBL1364984 & 688653 & 4.833 & 5.2695 & TRN & & & \\
\hline CHEMBL1341731 & 688653 & 4.833 & 5.3913 & TRN & & & \\
\hline CHEMBL1587054 & 688653 & 4.933 & 5.5324 & TRN & & & \\
\hline CHEMBL1464768 & 688653 & 4.883 & 5.0258 & TRN & & & \\
\hline CHEMBL1581532 & 688653 & 4.933 & 5.3166 & TRN & & & \\
\hline CHEMBL1420490 & 688653 & 5.183 & 5.7648 & TRN & & & \\
\hline CHEMBL1486507 & 688653 & 5.8829 & 99999999 & 99 & 5.2186 & TRN & \\
\hline CHEMBL1471693 & 688653 & 5.183 & 5.4845 & TST & & & \\
\hline CHEMBL1449707 & 688653 & 5.8329 & 99999999 & 99 & 5.2801 & TRN & \\
\hline CHEMBL1484487 & 688653 & 5.2829 & 99999999 & 995 & 5.03100 & 0000000001 & TST \\
\hline CHEMBL3191921 & 688653 & 7.0329 & 5.5005 & TRN & & & \\
\hline CHEMBL1501310 & 688653 & 4.7330 & 2000000e & 005 & 4.8968 & TRN & \\
\hline CHEMBL1585187 & 688653 & 5.8829 & 99999999 & & 5.6136 & TRN & \\
\hline CHEMBL1523417 & 688653 & 4.883 & 4.6194 & TST & & & \\
\hline CHEMBL1365635 & 688653 & 6.3829 & 99999999 & 99 & 5.3328 & TRN & \\
\hline CHEMBL1600508 & 688653 & 4.7330 & 2000000e & 005 & 5.0638 & TRN & \\
\hline CHEMBL1540770 & 688653 & 5.7829 & 99999999 & 995 & 5.4623 & TRN & \\
\hline CHEMBL1966114 & 688653 & 4.7330 & 20000000 & 005 & 5.129 & TST & \\
\hline CHEMBL454549 & 688653 & 5.733 & 5.7207 & TRN & & & \\
\hline CHEMBL1517288 & 688653 & 4.933 & 5.4931 & TST & & & \\
\hline CHEMBL1569598 & 688653 & 4.883 & 5.0675 & TRN & & & \\
\hline CHEMBL1560101 & 688653 & 5.7829 & 99999999 & 995 & 5.9906 & TRN & \\
\hline CHEMBL1506646 & 688653 & 4.883 & 5.5495 & TRN & & & \\
\hline CHEMBL1543177 & 688653 & 5.183 & 4.8638 & TRN & & & \\
\hline CHEMBL1372624 & 688653 & 4.883 & 5.2112 & TRN & & & \\
\hline CHEMBL1611002 & 688653 & 5.233 & 5.9752 & TRN & & & \\
\hline CHEMBL1595637 & 688653 & 4.9830 & $\partial 000000 \epsilon$ & 005 & 5.2204 & TRN & \\
\hline CHEMBL1971324 & 688653 & 6.3829 & 99999999 & 99 & 5.9964 & TRN & \\
\hline CHEMBL1423617 & 688653 & 5.3829 & 99999999 & 99 & 5.5846 & TRN & \\
\hline CHEMBL1307738 & 688653 & 4.783 & 5.2194 & TRN & & & \\
\hline CHEMBL1527291 & 688653 & 5.683 & 4.9335 & TST & & & \\
\hline
\end{tabular}




\begin{tabular}{|c|c|c|c|c|c|c|c|}
\hline \multicolumn{8}{|c|}{ Supplemental Table S2.txt } \\
\hline CHEMBL1412393 & 688653 & 5.233 & 5.1732 & TRN & & & \\
\hline CHEMBL1585738 & 688653 & 5.13299 & 99999999 & & 5.2145 & TRN & \\
\hline CHEMBL1441328 & 688653 & 5.183 & 5.407 & TST & & & \\
\hline CHEMBL1516735 & 688653 & 4.98300 & 00000000 & 005 & 5.2832 & TRN & \\
\hline CHEMBL1532008 & 688653 & 4.833 & 4.6941 & TRN & & & \\
\hline CHEMBL1384446 & 688653 & 5.33299 & 99999999 & & 5.2258 & TRN & \\
\hline CHEMBL1360735 & 688653 & 4.583 & 5.0886 & TRN & & & \\
\hline CHEMBL1548220 & 688653 & 5.13299 & 99999999 & & 5.1944 & TRN & \\
\hline CHEMBL3191889 & 688653 & 5.63299 & 99999999 & & 5.33200 & 0000000001 & TRN \\
\hline CHEMBL1517625 & 688653 & 4.98300 & 00000000 & 005 & 4.6503 & TRN & \\
\hline CHEMBL1340122 & 688653 & 4.633 & 4.9017 & TST & & & \\
\hline CHEMBL 3207526 & 688653 & 5.78299 & 99999999 & 995 & 5.4815 & TRN & \\
\hline CHEMBL1372085 & 688653 & 5.28299 & 99999999 & 995 & 5.5914 & TST & \\
\hline CHEMBL600034 & 688653 & 5.78299 & 99999999 & 995 & 5.6002 & TRN & \\
\hline CHEMBL1334971 & 688653 & 4.833 & 5.1796 & TRN & & & \\
\hline CHEMBL1506327 & 688653 & 4.933 & 4.9344 & TRN & & & \\
\hline CHEMBL1451966 & 688653 & 6.38299 & 99999999 & & 5.1703 & TST & \\
\hline CHEMBL1329109 & 688653 & 4.783 & 5.2968 & TST & & & \\
\hline CHEMBL1359489 & 688653 & 4.783 & 5.1162 & TRN & & & \\
\hline CHEMBL1568945 & 688653 & 4.783 & 5.0725 & TRN & & & \\
\hline CHEMBL1437112 & 688653 & 4.783 & 4.7729 & TRN & & & \\
\hline CHEMBL154762 & 688653 & 4.833 & 5.5063 & TRN & & & \\
\hline CHEMBL1493656 & 688653 & 5.33299 & 99999999 & & 5.2002 & TRN & \\
\hline CHEMBL1406139 & 688653 & 4.73300 & 00000000 & 005 & 4.9261 & TRN & \\
\hline CHEMBL3195270 & 688653 & 5.13299 & 99999999 & & 5.1789 & TRN & \\
\hline CHEMBL1566877 & 688653 & 6.13299 & 99999999 & & 6.4778 & TRN & \\
\hline CHEMBL1505064 & 688653 & 5.683 & 5.0678 & TRN & & & \\
\hline CHEMBL1332277 & 688653 & 5.683 & 4.9206 & TRN & & & \\
\hline CHEMBL3210181 & 688653 & 5.13299 & 99999999 & & 5.2626 & TST & \\
\hline CHEMBL1481542 & 688653 & 4.783 & 5.0077 & TRN & & & \\
\hline CHEMBL1966192 & 688653 & 4.833 & 5.032 & TST & & & \\
\hline CHEMBL3207541 & 688653 & 5.53299 & 99999999 & 995 & 5.5341 & TST & \\
\hline CHEMBL1585571 & 688653 & 5.483 & 5.7206 & TRN & & & \\
\hline CHEMBL1511388 & 688653 & 4.98300 & 00000000 & 005 & 5.2741 & TST & \\
\hline CHEMBL596839 & 688653 & 5.933 & 5.6924 & TRN & & & \\
\hline CHEMBL1323899 & 688653 & 6.0 & 5.2513 & TST & & & \\
\hline CHEMBL1556248 & 688653 & 5.53299 & 99999999 & 995 & 5.064 & TRN & \\
\hline CHEMBL1488963 & 688653 & 5.78299 & 99999999 & 995 & 5.49299 & 9999999999 & TRN \\
\hline CHEMBL1565047 & 688653 & 6.38299 & 99999999 & & 6.0181 & TRN & \\
\hline CHEMBL1422621 & 688653 & 5.58299 & 99999999 & & 5.1671 & TST & \\
\hline CHEMBL1565161 & 688653 & 4.73300 & 20000000 & 005 & 5.0338 & TST & \\
\hline CHEMBL1573748 & 688653 & 4.833 & 5.2391 & TRN & & & \\
\hline CHEMBL1530612 & 688653 & 4.783 & 5.115 & TRN & & & \\
\hline CHEMBL1596785 & 688653 & 4.783 & 5.1286 & TST & & & \\
\hline CHEMBL1336148 & 688653 & 5.83299 & 99999999 & & 5.8745 & TRN & \\
\hline CHEMBL588038 & 688653 & 5.28299 & 99999999 & 995 & 5.0882 & TST & \\
\hline CHEMBL1600114 & 688653 & 5.63299 & 99999999 & & 5.5421 & TST & \\
\hline CHEMBL3189873 & 688653 & 4.783 & 4.8503 & TST & & & \\
\hline
\end{tabular}




\begin{tabular}{|c|c|c|c|c|c|c|c|}
\hline \multicolumn{7}{|c|}{ Supplemental Table S2.txt } & \\
\hline CHEMBL1477988 & 688653 & \multicolumn{3}{|c|}{5.332999999999999} & 5.0694 & TRN & \\
\hline CHEMBL1300766 & 688653 & 5.733 & 5.5679 & TST & & & \\
\hline CHEMBL1452680 & 688653 & \multicolumn{3}{|c|}{5.382999999999999} & 5.0642 & TRN & \\
\hline CHEMBL1514367 & 688653 & 4.633 & 5.0283 & TRN & & & \\
\hline CHEMBL1608875 & 688653 & 5.183 & 5.3895 & TRN & & & \\
\hline CHEMBL1488250 & 688653 & \multicolumn{3}{|c|}{6.382999999999999} & 5.9053 & TRN & \\
\hline CHEMBL1472115 & 688653 & \multicolumn{3}{|c|}{5.132999999999999} & 5.3438 & TRN & \\
\hline CHEMBL1416270 & 688653 & 5.983 & 5.2738 & TRN & & & \\
\hline CHEMBL1498893 & 688653 & 4.833 & 5.2886 & TRN & & & \\
\hline CHEMBL3198974 & 688653 & 5.233 & 5.5011 & TRN & & & \\
\hline CHEMBL 3208451 & 688653 & 5.033 & 5.605 & TST & & & \\
\hline CHEMBL1470207 & 688653 & 4.683 & 5.0423 & TRN & & & \\
\hline CHEMBL1421759 & 688653 & 4.833 & 5.0671 & TST & & & \\
\hline CHEMBL 1571450 & 688653 & 4.783 & 5.0726 & TRN & & & \\
\hline CHEMBL1593924 & 688653 & \multicolumn{3}{|c|}{6.332999999999999} & 5.4476 & TRN & \\
\hline CHEMBL1417354 & 688653 & 6.4829 & 6.0238 & TRN & & & \\
\hline CHEMBL1420142 & 688653 & \multicolumn{3}{|c|}{5.5329999999999995} & 5.2452 & TST & \\
\hline CHEMBL1313077 & 688653 & \multicolumn{3}{|c|}{5.582999999999999} & 5.175 & TRN & \\
\hline CHEMBL1504089 & 688653 & 6.183 & 5.69 & TRN & & & \\
\hline CHEMBL1318388 & 688653 & 5.083 & 5.3464 & TST & & & \\
\hline CHEMBL1513267 & 688653 & 4.683 & 4.9244 & TST & & & \\
\hline CHEMBL1333484 & 688653 & \multicolumn{3}{|c|}{6.082999999999999} & 5.4767 & TRN & \\
\hline CHEMBL474749 & 688653 & 4.833 & 5.7287 & TRN & & & \\
\hline CHEMBL1490073 & 688653 & \multicolumn{3}{|c|}{5.2829999999999995} & 5.20299 & 9999999999 & TRN \\
\hline CHEMBL1353281 & 688653 & \multicolumn{3}{|c|}{5.132999999999999} & 5.0968 & TRN & \\
\hline CHEMBL1429248 & 688653 & 4.833 & 5.256 & TST & & & \\
\hline CHEMBL1442186 & 688653 & 4.833 & 4.7917 & TST & & & \\
\hline CHEMBL1407292 & 688653 & \multicolumn{3}{|c|}{5.132999999999999} & 5.4441 & TRN & \\
\hline CHEMBL1338853 & 688653 & 5.7 & 5.9831 & TRN & & & \\
\hline CHEMBL1353741 & 688653 & 4.583 & 5.2079 & TST & & & \\
\hline CHEMBL 3190092 & 688653 & 5.033 & 4.9122 & TST & & & \\
\hline CHEMBL1335888 & 688653 & \multicolumn{3}{|c|}{5.382999999999999} & 4.9998 & TST & \\
\hline CHEMBL1449964 & 688653 & 5.683 & 5.22 & TRN & & & \\
\hline CHEMBL3196670 & 688653 & 5.683 & 5.4669 & TRN & & & \\
\hline CHEMBL1479424 & 688653 & 4.933 & 5.30399 & 999999999 & 99 & TST & \\
\hline CHEMBL1532811 & 688653 & \multicolumn{3}{|c|}{5.132999999999999} & 5.8215 & TRN & \\
\hline CHEMBL1536556 & 688653 & 5.183 & 5.3366 & TST & & & \\
\hline CHEMBL1608194 & 688653 & 4.783 & 5.9672 & TRN & & & \\
\hline CHEMBL1543912 & 688653 & 5.683 & 4.8957 & TRN & & & \\
\hline CHEMBL1567077 & 688653 & \multicolumn{3}{|c|}{5.2829999999999995} & 5.1566 & TST & \\
\hline CHEMBL1574288 & 688653 & 6.183 & 5.7009 & TRN & & & \\
\hline CHEMBL1438294 & 688653 & \multicolumn{3}{|c|}{5.832999999999999} & 5.9876 & TRN & \\
\hline CHEMBL1476141 & 688653 & 5.233 & 5.1019 & TRN & & & \\
\hline CHEMBL1609325 & 688653 & 4.933 & 5.0061 & TRN & & & \\
\hline CHEMBL3191521 & 688653 & 5.083 & 5.1374 & TRN & & & \\
\hline CHEMBL112597 & 688653 & 6.0 & 5.9883 & TRN & & & \\
\hline CHEMBL 3211521 & 688653 & 4.783 & 5.3382 & TRN & & & \\
\hline CHEMBL1596742 & 688653 & 5.733 & 5.4717 & TRN & & & \\
\hline
\end{tabular}




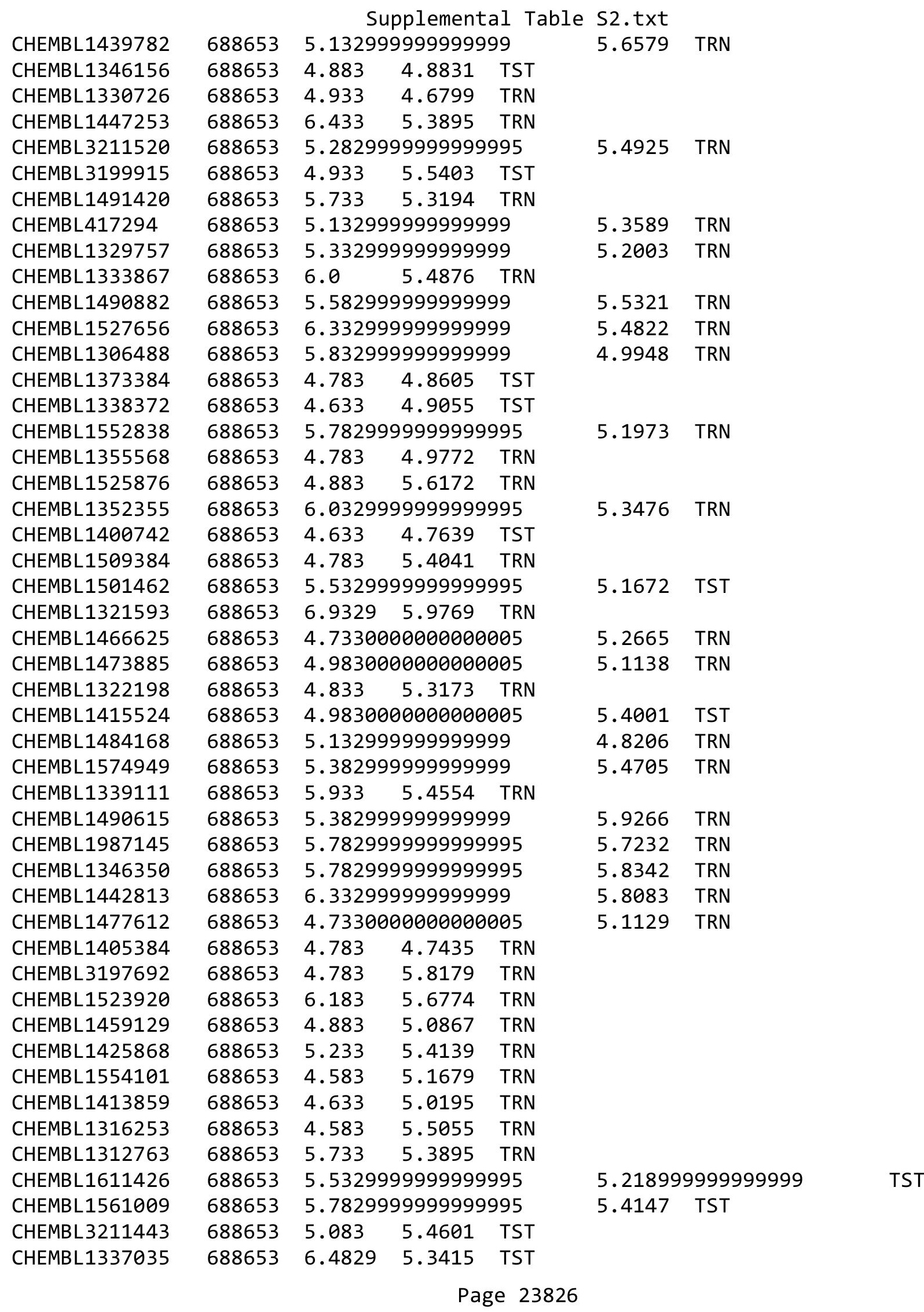




\begin{tabular}{|c|c|c|c|c|c|c|}
\hline & \multicolumn{5}{|c|}{ oplemental Table } \\
\hline CHEMBL1409488 & 688653 & 6.233 & 5.7261 & TRN & & \\
\hline CHEMBL1426980 & 688653 & 4.73300 & 000000006 & 005 & 5.2361 & $\mathrm{~T}$ \\
\hline CHEMBL1309091 & 688653 & 5.733 & 5.4818 & TRN & & \\
\hline CHEMBL1456019 & 688653 & 4.73300 & 000000006 & 005 & 5.0553 & \\
\hline CHEMBL1499842 & 688653 & 4.683 & 5.1699 & TRN & & \\
\hline CHEMBL1426615 & 688653 & 4.783 & 5.1204 & TRN & & \\
\hline CHEMBL1339785 & 688653 & 5.53299 & 999999999 & 995 & 5.1936 & \\
\hline CHEMBL1483519 & 688653 & 4.883 & 5.1847 & TST & & \\
\hline CHEMBL1304997 & 688653 & 4.73300 & 000000006 & 005 & 5.3752 & \\
\hline CHEMBL1344937 & 688653 & 5.53299 & 999999999 & 995 & & \\
\hline CHEMBL1612772 & 688653 & 4.933 & 4.9703 & TRN & & \\
\hline CHEMBL1409525 & 688653 & 6.28299 & 999999999 & 995 & 5.8962 & \\
\hline CHEMBL 3190918 & 688653 & 5.28299 & 999999999 & 995 & 4.7976 & \\
\hline CHEMBL1315956 & 688653 & 4.783 & 5.0338 & TRN & & \\
\hline CHEMBL 3194611 & 688653 & 4.583 & 5.3181 & TRN & & \\
\hline CHEMBL1385839 & 688653 & 4.883 & 4.9449 & TRN & & \\
\hline CHEMBL406845 & 688653 & 5.88299 & 999999999 & & 5.7769 & \\
\hline CHEMBL1531755 & 688653 & 5.78299 & 999999999 & 995 & 5.965 & \\
\hline CHEMBL1523053 & 688653 & 5.683 & 5.605 & TRN & & \\
\hline CHEMBL14C & 688653 & 5.683 & 5.7684 & TRN & & \\
\hline CHEMBL1428929 & 688653 & 4.833 & 5.2432 & TRN & & \\
\hline CHEMBL1447279 & 688653 & 5.83299 & 999999999 & & 5.5378 & \\
\hline CHEMBL 3214164 & 688653 & 6.58299 & 999999999 & & 5.3615 & \\
\hline CHEMBL1446583 & 688653 & 5.433 & 5.2465 & TRN & & \\
\hline CHEMBL1495849 & 688653 & 6.15 & 5.9304 & TRN & & \\
\hline CHEMBL1387096 & 688653 & 4.73300 & 000000000 & 005 & 2906 & \\
\hline CHEMBL1364045 & 688653 & 4.883 & 5.4831 & TRN & & \\
\hline CHEMBL1455610 & 688653 & 5.33299 & 999999999 & & (נ. & \\
\hline CHEMBL1367872 & 688653 & 5.683 & 5.239 & TST & & \\
\hline CHEMBL592869 & 688653 & 4.73300 & 000000000 & 005 & 4.9669 & \\
\hline CHEMBL1590824 & 688653 & 5.433 & 4.9622 & TRN & & \\
\hline CHEMBL1352983 & 688653 & 5.78299 & 999999999 & 995 & 5.2658 & \\
\hline CHEMBL1430208 & 688653 & 5.183 & 5.2669 & TST & & \\
\hline CHEMBL1393727 & 688653 & 6.38299 & 999999999 & & 5.8068 & TR \\
\hline CHEMBL1434537 & 688653 & 4.633 & 4.8976 & TST & & \\
\hline CHEMBL3192530 & 688653 & 4.98300 & 000000000 & 005 & 4.9445 & TR \\
\hline CHEMBL1557436 & 688653 & 4.783 & 5.2241 & TST & & \\
\hline CHEMBL1331109 & 688653 & 6.53299 & 999999999 & 995 & 5.7407 & \\
\hline CHEMBL1418374 & 688653 & 4.883 & 5.5924 & TRN & & \\
\hline CHEMBL1439989 & 688653 & 5.433 & 5.1496 & TRN & & \\
\hline CHEMBL1380502 & 688653 & 4.783 & 5.1695 & TRN & & \\
\hline CHEMBL1386646 & 688653 & 5.233 & 5.4692 & TRN & & \\
\hline CHEMBL1397459 & 688653 & 5.88299 & 999999999 & & 5.6004 & \\
\hline CHEMBL1381354 & 688653 & 6.13299 & 999999999 & & 5.9117 & (2010 \\
\hline CHEMBL1446069 & 688653 & 4.98300 & 000000000 & 005 & 5.0241 & TRN \\
\hline CHEMBL1561202 & 688653 & 5.28299 & 999999999 & 995 & 4.7262 & 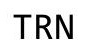 \\
\hline CHEMBL1527795 & 688653 & 4.833 & 5.4567 & TRN & & \\
\hline CHEMBL3194245 & 688653 & 4.883 & 5.4056 & TRN & & \\
\hline
\end{tabular}




\begin{tabular}{|c|c|c|c|c|c|c|}
\hline \multirow[b]{2}{*}{ CHEMBL1407379 } & \multicolumn{6}{|c|}{ Supplemental Table S2.txt } \\
\hline & 688653 & 4.783 & 5.3838 & TST & & \\
\hline CHEMBL1587630 & 688653 & 5.483 & 5.1093 & TRN & & \\
\hline CHEMBL1602953 & 688653 & 4.833 & 5.0098 & TRN & & \\
\hline CHEMBL1407036 & 688653 & \multicolumn{3}{|c|}{5.382999999999999} & 5.4301 & TR \\
\hline CHEMBL472760 & 688653 & 4.883 & 5.0616 & TRN & & \\
\hline CHEMBL1567560 & 688653 & 5.683 & 5.3671 & TRN & & \\
\hline CHEMBL1396536 & 688653 & 4.633 & \multicolumn{3}{|c|}{4.968999999999999} & \\
\hline CHEMBL1477550 & 688653 & \multicolumn{3}{|c|}{6.582999999999999} & 5.8805 & \\
\hline CHEMBL1517622 & 688653 & 5.033 & 5.0155 & TRN & & \\
\hline CHEMBL1397747 & 688653 & \multicolumn{3}{|c|}{5.132999999999999} & 5.4126 & 10 \\
\hline CHEMBL1349101 & 688653 & 5.483 & 5.147 & TST & & \\
\hline CHEMBL1496754 & 688653 & 4.783 & 5.586 & TRN & & \\
\hline CHEMBL1352801 & 688653 & 7.2832 & 5.7725 & TRN & & \\
\hline CHEMBL1992088 & 688653 & \multicolumn{3}{|c|}{4.7330000000000005} & 5.2066 & TRN \\
\hline CHEMBL1455144 & 688653 & \multicolumn{3}{|c|}{5.582999999999999} & 5.0033 & \\
\hline CHEMBL1345334 & 688653 & \multicolumn{3}{|c|}{5.7829999999999995} & 5.3051 & \\
\hline CHEMBL1505809 & 688653 & 6.683 & 5.4676 & TRN & & \\
\hline CHEMBL1327350 & 688653 & \multirow{2}{*}{\multicolumn{3}{|c|}{ ال }} & & \\
\hline CHEMBL1544340 & 688653 & & & & 5.3041 & TRN \\
\hline CHEMBL120089 & 688653 & 5.033 & 5.3629 & TRN & & \\
\hline CHEMBL1552543 & 688653 & \multicolumn{3}{|c|}{5.332999999999999} & 397 & \\
\hline CHEMBL3196367 & 688653 & 7.0329 & 5.4582 & TST & & \\
\hline CHEMBL1608045 & 688653 & 4.883 & 5.228 & TRN & & \\
\hline CHEMBL14 & 688653 & 5.683 & 5.7335 & TST & & \\
\hline CHEMBL1315007 & 688653 & 5.083 & 5.6393 & TRN & & \\
\hline CHEMBL1307376 & 688653 & 4.783 & 5.1003 & TST & & \\
\hline CHEMBL 2000525 & 688653 & \multicolumn{3}{|c|}{5.332999999999999} & 5.8806 & \\
\hline CHEMBL1352339 & 688653 & \multicolumn{3}{|c|}{5.832999999999999} & 5.5785 & \\
\hline CHEMBL1488548 & 688653 & \multicolumn{3}{|c|}{5.132999999999999} & 5.379 & \\
\hline CHEMBL1353298 & 688653 & \multicolumn{3}{|c|}{5.132999999999999} & 5.5823 & $\mathrm{TH}$ \\
\hline CHEMBL 3192730 & 688653 & 5.083 & 5.1811 & TRN & & \\
\hline CHEMBL1497825 & 688653 & \multicolumn{3}{|c|}{6.332999999999999} & 5.9166 & \\
\hline CHEMBL1407401 & 688653 & 4.583 & 4.9978 & TRN & & \\
\hline CHEMBL66279 & 688653 & \multirow{2}{*}{\multicolumn{3}{|c|}{$\begin{array}{l}5.233 \quad 5.204 / \\
4.7330000000000005\end{array}$}} & & \\
\hline CHEMBL1390537 & 688653 & & & & 5.6208 & \\
\hline CHEMBL1393610 & 688653 & 5.233 & 5.1789 & TRN & & \\
\hline CHEMBL13 & 688653 & \multicolumn{3}{|c|}{4.9830000000000005} & 4.996 & 10 \\
\hline CHEMBL1336032 & 688653 & 4.583 & 5.0834 & TRN & & \\
\hline CHEMBL1389904 & 688653 & 5.083 & 5.1816 & TRN & & \\
\hline CHEMBL1499306 & 688653 & 5.433 & 5.2251 & TRN & & \\
\hline CHEMBL1336070 & 688653 & 5.733 & 5.3564 & TST & & \\
\hline CHEMBL1548000 & 688653 & \multicolumn{3}{|c|}{5.332999999999999} & 5.5213 & TRN \\
\hline CHEMBL 3193831 & 688653 & 5.733 & 5.2407 & TRN & & \\
\hline CHEMBL1324831 & 688653 & 4.583 & 5.2576 & TRN & & \\
\hline CHEMBL1489356 & 688653 & 4.783 & 5.2644 & TRN & & \\
\hline CHEMBL1457388 & 688653 & 6.0 & 5.0619 & TRN & & \\
\hline CHEMBL1335844 & 688653 & \multicolumn{3}{|c|}{5.332999999999999} & 5.1002 & \\
\hline CHEMBL1345159 & 688653 & 5.5829 & 999999999 & & 5.4429 & \\
\hline
\end{tabular}




\begin{tabular}{|c|c|c|c|c|c|c|}
\hline & & & oplemen & al Table $s$ & S2.txt & \\
\hline CHEMBL1452351 & 688653 & 5.8329 & 79999999 & & 5.0707 & TRN \\
\hline CHEMBL1519891 & 688653 & 4.583 & 5.0275 & TRN & & \\
\hline CHEMBL1416018 & 688653 & 5.2829 & 79999999 & 995 & 4.8808 & TRN \\
\hline CHEMBL1577730 & 688653 & 5.033 & 5.4153 & TST & & \\
\hline CHEMBL1487436 & 688653 & 5.083 & 5.0797 & TRN & & \\
\hline CHEMBL1444763 & 688653 & 5.6329 & 79999999 & & 5.4649 & TRN \\
\hline CHEMBL3190662 & 688653 & 5.1329 & 99999999 & & 5.0932 & TST \\
\hline CHEMBL1997098 & 688653 & 4.7330 & 30000000 & 005 & 5.4596 & TRN \\
\hline CHEMBL1581009 & 688653 & 4.883 & 6.3271 & TRN & & \\
\hline CHEMBL1423219 & 688653 & 4.783 & 5.1587 & TST & & \\
\hline CHEMBL1303263 & 688653 & 5.033 & 4.737 & TRN & & \\
\hline CHEMBL1581760 & 688653 & 5.183 & 5.2578 & TST & & \\
\hline CHEMBL1536318 & 688653 & 5.733 & 5.3699 & TRN & & \\
\hline CHEMBL1565613 & 688653 & 4.833 & 4.8773 & TRN & & \\
\hline CHEMBL1388311 & 688653 & 4.783 & 5.2685 & TST & & \\
\hline CHEMBL1580587 & 688653 & 6.3829 & 79999999 & & 5.2903 & TRN \\
\hline CHEMBL1516729 & 688653 & 4.933 & 5.6757 & TRN & & \\
\hline CHEMBL1605021 & 688653 & 5.5329 & 99999999 & 995 & 6.3778 & TST \\
\hline CHEMBL1419772 & 688653 & 4.833 & 4.92399 & 9999999999 & 95 & TST \\
\hline CHEMBL1529148 & 688653 & 5.733 & 6.0662 & TRN & & \\
\hline CHEMBL1319262 & 688653 & 4.783 & 5.3483 & TRN & & \\
\hline CHEMBL582286 & 688653 & 4.633 & 5.3799 & TRN & & \\
\hline CHEMBL1378200 & 688653 & 4.933 & 5.1023 & TRN & & \\
\hline CHEMBL1302028 & 688653 & 4.933 & 4.5426 & TRN & & \\
\hline CHEMBL1373923 & 688653 & 4.883 & 5.1707 & TST & & \\
\hline CHEMBL1350057 & 688653 & 5.433 & 5.3152 & TRN & & \\
\hline CHEMBL1423156 & 688653 & 5.083 & 5.112 & TRN & & \\
\hline CHEMBL1377568 & 688653 & 6.2829 & 99999999 & 995 & 5.54 & TST \\
\hline CHEMBL1337171 & 688653 & 5.2829 & 99999999 & 995 & 5.1867 & TRN \\
\hline CHEMBL1451684 & 688653 & 5.7829 & 99999999 & 995 & 5.5833 & TRN \\
\hline CHEMBL1514160 & 688653 & 4.583 & 4.7162 & TRN & & \\
\hline CHEMBL1587805 & 688653 & 5.8329 & 99999999 & & 5.4236 & TST \\
\hline CHEMBL3207736 & 688653 & 5.2829 & 99999999 & 995 & 5.0482 & TRN \\
\hline CHEMBL1496428 & 688653 & 4.833 & 4.7241 & TRN & & \\
\hline CHEMBL1440501 & 688653 & 5.183 & 5.4416 & TRN & & \\
\hline CHEMBL1420175 & 688653 & 4.883 & 5.0405 & TST & & \\
\hline CHEMBL1368179 & 688653 & 4.933 & 5.2634 & TRN & & \\
\hline CHEMBL1511843 & 688653 & 5.3829 & 99999999 & & 5.3345 & TRN \\
\hline CHEMBL1428644 & 688653 & 6.433 & 5.9193 & TRN & & \\
\hline CHEMBL1564416 & 688653 & 6.2829 & 99999999 & 995 & 5.4852 & TST \\
\hline CHEMBL1570450 & 688653 & 7.1331 & 5.5085 & TRN & & \\
\hline CHEMBL1308373 & 688653 & 4.783 & 5.5181 & TRN & & \\
\hline CHEMBL1505608 & 688653 & 4.9830 & 00000000 & 005 & 5.2641 & TRN \\
\hline CHEMBL1342493 & 688653 & 5.3329 & 99999999 & & 5.2172 & TRN \\
\hline CHEMBL1336019 & 688653 & 4.683 & 5.63299 & 9999999999 & & TRN \\
\hline CHEMBL1519418 & 688653 & 5.733 & 5.5797 & TST & & \\
\hline CHEMBL1527359 & 688653 & 4.783 & 5.1022 & TRN & & \\
\hline CHEMBL1303789 & 688653 & 4.7330 & 20000000 & 005 & 5.1885 & TST \\
\hline
\end{tabular}




\begin{tabular}{|c|c|c|c|c|c|c|}
\hline \multirow[b]{2}{*}{ CHEMBL1423346 } & \multicolumn{6}{|c|}{ Supplemental Table S2 } \\
\hline & 688653 & 6.9329 & 6.0503 & TRN & & \\
\hline CHEMBL1980667 & 688653 & 6.38299 & $\begin{array}{l}6.0503 \\
999999999\end{array}$ & & 5.8856 & TRN \\
\hline CHEMBL1594747 & 688653 & 4.883 & \multicolumn{3}{|c|}{5.707999999999999} & \\
\hline CHEMBL1608666 & 688653 & 4.883 & 5.0521 & TST & & \\
\hline CHEMBL1394912 & 688653 & 5.083 & 5.404 & TRN & & \\
\hline CHEMBL1539789 & 688653 & \multicolumn{3}{|c|}{6.2829999999999995} & 5.9566 & \\
\hline CHEMBL1338998 & 688653 & 5.683 & 5.943 & TRN & & \\
\hline CHEMBL1488502 & 688653 & 5.933 & 4.9441 & TRN & & \\
\hline CHEMBL1412478 & 688653 & \multicolumn{3}{|c|}{5.632999999999999} & 5.9026 & \\
\hline CHEMBL1575124 & 688653 & 7.2832 & 6.397 & TRN & & \\
\hline CHEMBL1516506 & 688653 & 4.583 & 5.1661 & TRN & & \\
\hline CHEMBL1476963 & 688653 & 4.933 & 5.0625 & TRN & & \\
\hline CHEMBL1496313 & 688653 & 4.833 & 4.9603 & TST & & \\
\hline CHEMBL1349632 & 688653 & 5.683 & 5.0025 & TRN & & \\
\hline CHEMBL1344041 & 688653 & 6.433 & 5.8569 & TRN & & \\
\hline CHEMBL1365009 & 688653 & \multicolumn{3}{|c|}{5.582999999999999} & 5.1063 & \\
\hline CHEMBL1333059 & 688653 & \multicolumn{3}{|c|}{4.7330000000000005} & 5.1932 & \\
\hline CHEMBL1578527 & 688653 & \multicolumn{3}{|c|}{6.0329999999999995} & 5.6259 & \\
\hline CHEMBL 3211393 & 688653 & 4.833 & 5.2016 & TST & & \\
\hline CHEMBL1583720 & 688653 & \multicolumn{3}{|c|}{5.332999999999999} & 5.596 & \\
\hline CHEMBL1485463 & 688653 & 4.583 & 5.1248 & TRN & & \\
\hline CHEMBL1535469 & 688653 & 4.933 & 4.8694 & TRN & & \\
\hline CHEMBL1532020 & 688653 & 4.633 & 4.8127 & TRN & & \\
\hline CHEMBL1526509 & 688653 & 4.883 & 5.2427 & TRN & & \\
\hline CHEMBL1562579 & 688653 & 4.933 & 5.237 & TST & & \\
\hline CHEMBL1485566 & 688653 & \multicolumn{3}{|c|}{5.132999999999999} & 5.1218 & \\
\hline CHEMBL1459865 & 688653 & \multicolumn{3}{|c|}{4.7330000000000005} & 5.3556 & \\
\hline CHEMBL1603384 & 688653 & \multicolumn{3}{|c|}{5.5329999999999995} & 5.8657 & \\
\hline CHEMBL1417692 & 688653 & 4.783 & 5.0175 & TRN & & \\
\hline CHEMBL1539723 & 688653 & 4.833 & 5.0153 & TRN & & \\
\hline CHEMBL 252744 & 688653 & 4.633 & 5.1285 & TST & & \\
\hline CHEMBL 3198026 & 688653 & 4.833 & 5.2884 & TRN & & \\
\hline CHEMBL1992286 & 688653 & 5.083 & 5.7168 & TRN & & \\
\hline CHEMBL1346027 & 688653 & \multicolumn{3}{|c|}{5.2829999999999995} & 5.1679 & \\
\hline CHEMBL 3190625 & 688653 & 4.933 & 5.2223 & TST & & \\
\hline CHEMBL 3196745 & 688653 & 5.033 & 5.5499 & TRN & & \\
\hline CHEMBL 2002444 & 688653 & 4.933 & 5.3943 & TST & & \\
\hline CHEMBL1541239 & 688653 & \multicolumn{3}{|c|}{6.0329999999999995} & 5.3057 & \\
\hline CHEMBL1594506 & 688653 & 4.783 & 4.9727 & TST & & \\
\hline CHEMBL1415528 & 688653 & \multicolumn{3}{|c|}{4.9830000000000005} & 5.4056 & Tt \\
\hline CHEMBL1473000 & 688653 & 4.883 & 5.5214 & TST & & \\
\hline CHEMBL1342141 & 688653 & 4.633 & 5.3784 & TST & & \\
\hline CHEMBL1611765 & 688653 & \multicolumn{3}{|c|}{5.132999999999999} & 5.6334 & RN \\
\hline CHEMBL1561191 & 688653 & \multicolumn{3}{|c|}{4.7330000000000005} & 5.5144 & \\
\hline CHEMBL1342771 & 688653 & 4.783 & 5.2021 & TST & & \\
\hline CHEMBL1453722 & 688653 & \multicolumn{3}{|c|}{5.832999999999999} & 5.3753 & TRN \\
\hline CHEMBL1330474 & 688653 & 4.883 & 4.9751 & TRN & & \\
\hline CHEMBL1475225 & 688653 & 4.783 & 4.7252 & TRN & & \\
\hline
\end{tabular}




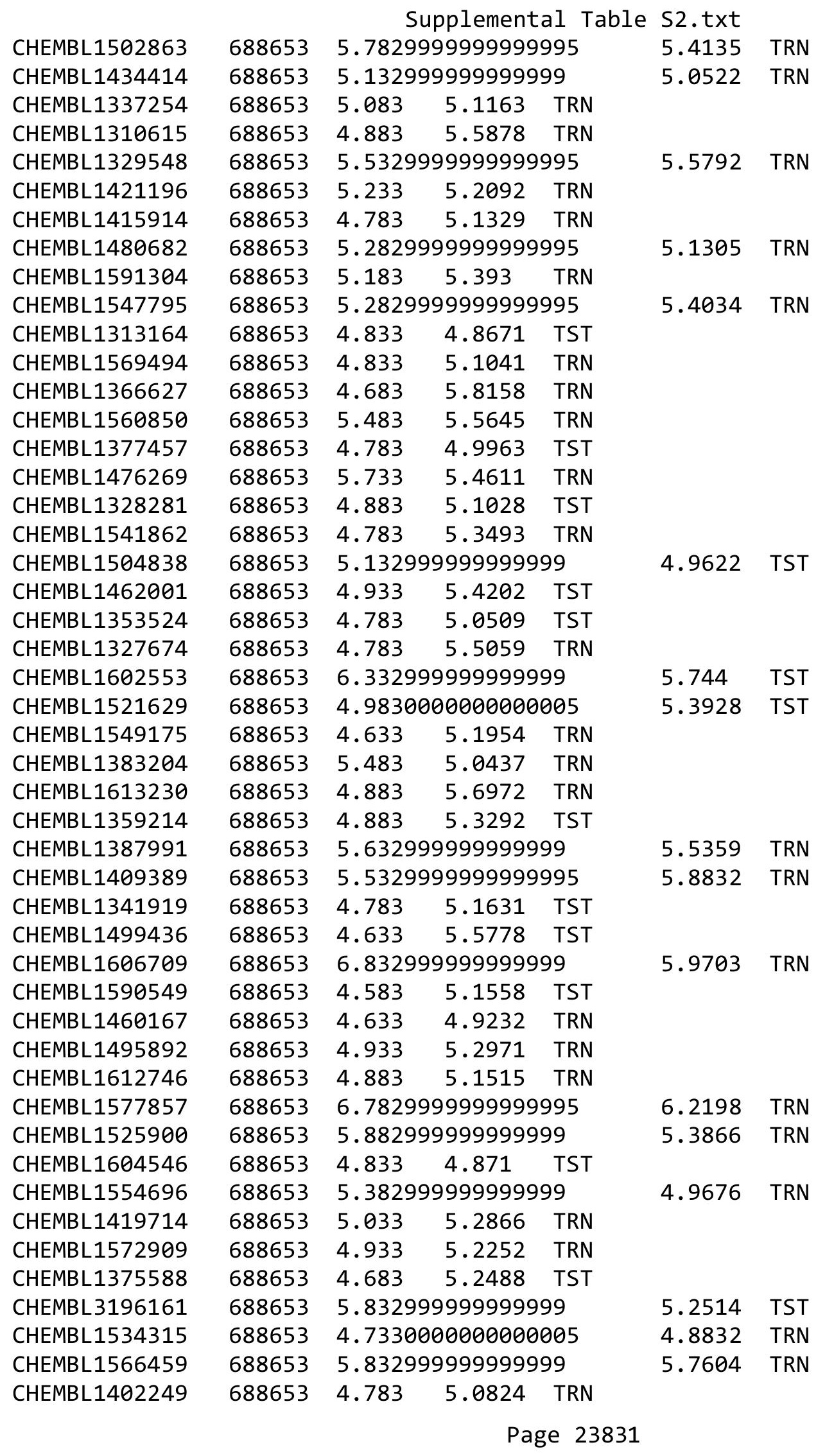




\begin{tabular}{|c|c|c|c|c|c|c|}
\hline \multirow[b]{2}{*}{ CHEMBL1494500 } & \multirow[b]{2}{*}{688653} & \multicolumn{5}{|c|}{ Supplemental Table S2.txt } \\
\hline & & 4.883 & 5.0702 & TRN & & \\
\hline CHEMBL1525436 & 688653 & \multicolumn{3}{|c|}{5.832999999999999} & 5.2479 & TRN \\
\hline CHEMBL1353522 & 688653 & \multicolumn{3}{|c|}{4.7330000000000005} & 4.9126 & TST \\
\hline CHEMBL1458796 & 688653 & 5.183 & 4.9449 & TRN & & \\
\hline CHEMBL1469732 & 688653 & \multicolumn{3}{|c|}{5.132999999999999} & 5.4965 & TIN \\
\hline CHEMBL1356931 & 688653 & 4.633 & 4.9518 & TRN & & \\
\hline CHEMBL1336834 & 688653 & \multicolumn{3}{|c|}{5.132999999999999} & 5.2559 & TST \\
\hline CHEMBL1498481 & 688653 & 5.683 & 5.2734 & TRN & & \\
\hline CHEMBL1497536 & 688653 & 4.833 & 5.6309 & TST & & \\
\hline CHEMBL1595492 & 688653 & 5.483 & 5.7725 & TRN & & \\
\hline CHEMBL1361980 & 688653 & 4.783 & 5.4965 & TST & & \\
\hline CHEMBL1352208 & 688653 & 4.833 & 5.0114 & TRN & & \\
\hline CHEMBL1572494 & 688653 & 5.433 & 5.4391 & TRN & & \\
\hline CHEMBL1498284 & 688653 & 4.883 & 5.4312 & TST & & \\
\hline CHEMBL1467635 & 688653 & 5.083 & 5.334 & TRN & & \\
\hline CHEMBL1535631 & 688653 & \multicolumn{3}{|c|}{5.832999999999999} & 6 & \\
\hline CHEMBL13 & 688653 & 5.083 & 5.0819 & TRN & & \\
\hline CHEMBL35 & 688653 & 4.683 & 4.8796 & TRN & & \\
\hline CHEMBL14] & 688653 & 5.683 & 5.2709 & TRN & & \\
\hline CHEMBL1480147 & 688653 & 5.733 & 5.9708 & TRN & & \\
\hline CHEMBL1472164 & 688653 & \multicolumn{3}{|c|}{6.582999999999999} & 789 & $\mathrm{~T}$ \\
\hline CHEMBL13 & 688653 & \multicolumn{3}{|c|}{5.332999999999999} & & \\
\hline CHEMBL1 & 688653 & 5.233 & 5.435 & TRN & & \\
\hline CHEMBL1551505 & 688653 & \multicolumn{3}{|c|}{4.7330000000000005} & 219 & TST \\
\hline CHEMBL1322698 & 688653 & \multicolumn{3}{|c|}{5.132999999999999} & & \\
\hline CHEMBL 3210623 & 688653 & 4.833 & 5.077 & TRN & & \\
\hline CHEMBL & 688 & \multicolumn{3}{|c|}{6.5329999999999995} & 986 & TRN \\
\hline CHEMBL1 & 688653 & \multicolumn{3}{|c|}{4.7330000000000005} & 4.9081 & TRN \\
\hline CHEMBL1373823 & 688653 & \multicolumn{3}{|c|}{5.2829999999999995} & 971 & TRN \\
\hline CHEMBL1413470 & 688653 & 5.233 & 5.5303 & TRN & & \\
\hline CHEMBL1360200 & 688653 & & 4.7871 & TRN & & \\
\hline CHEMBL & 688653 & 33 & 4.8 & TRN & & \\
\hline CHEMBL: & 688653 & 5 . & 5.6157 & TST & & \\
\hline CHEMBL1362327 & 688653 & 6.233 & 5.6317 & TRN & & \\
\hline CHEMBL1429127 & 688653 & 4.783 & 5.4342 & TST & & \\
\hline CHEMBL14 & 688 & & 5. & TRN & & \\
\hline CHEMBL1 & 688653 & 4.783 & 5.1144 & TRN & & \\
\hline CHEMBL1366534 & 688653 & \multicolumn{3}{|c|}{4.7330000000000005} & 5.1039 & $\mathrm{TI}$ \\
\hline CHEMBL1609562 & 688653 & 5.683 & 5.4422 & TRN & & \\
\hline CHEMBL1535703 & 688653 & \multicolumn{3}{|c|}{6.082999999999999} & 5.6976 & It \\
\hline CHEMBL1542118 & 688653 & 4.783 & 5.6439 & TRN & & \\
\hline CHEMBL1528847 & 688653 & \multicolumn{3}{|c|}{5.7829999999999995} & 5.5981 & $T$ \\
\hline CHEMBL1300383 & 688653 & 6.4829 & 5.8742 & TST & & \\
\hline CHEMBL1400093 & 688653 & \multicolumn{3}{|c|}{5.832999999999999} & 5.0866 & 11 \\
\hline CHEMBL1501282 & 688653 & 5.733 & 5.4443 & TRN & & \\
\hline CHEMBL1598916 & 688653 & 4.883 & 5.0136 & TRN & & \\
\hline CHEMBL1353510 & 688653 & \multicolumn{3}{|c|}{5.7829999999999995} & 5.789 & TाTा \\
\hline \multirow[t]{2}{*}{ CHEMBL268559 } & 688653 & 4.783 & $5.41200 e$ & 000000 & & TRN \\
\hline & & & & & & \\
\hline
\end{tabular}




\begin{tabular}{|c|c|c|c|c|c|c|c|}
\hline \multicolumn{7}{|c|}{ Supplemental Table s2.txt } & \\
\hline CHEMBL1210791 & 688653 & \multicolumn{3}{|c|}{5.332999999999999} & 5.0309 & TRN & \\
\hline CHEMBL1525000 & 688653 & 4.783 & 5.3596 & TRN & & & \\
\hline CHEMBL1311403 & 688653 & 5.3 & 4.8339 & TRN & & & \\
\hline CHEMBL1471168 & 688653 & 4.783 & 5.4907 & TRN & & & \\
\hline CHEMBL1520597 & 688653 & 4.933 & 5.0872 & TST & & & \\
\hline CHEMBL1389669 & 688653 & 6.7331 & 6.0046 & TRN & & & \\
\hline CHEMBL1332970 & 688653 & \multicolumn{3}{|c|}{6.382999999999999} & 5.8759 & TRN & \\
\hline CHEMBL1386704 & 688653 & 5.483 & 5.5381 & TRN & & & \\
\hline CHEMBL582980 & 688653 & \multicolumn{3}{|c|}{4.7330000000000005} & 5.3232 & TRN & \\
\hline CHEMBL1468789 & 688653 & \multicolumn{3}{|c|}{4.7330000000000005} & \multicolumn{2}{|c|}{5.0760000000000005} & TRN \\
\hline CHEMBL398765 & 688653 & 5.183 & 5.3969 & TRN & & & \\
\hline CHEMBL1351384 & 688653 & 5.483 & 5.266 & TRN & & & \\
\hline CHEMBL1507606 & 688653 & 5.233 & 5.4097 & TRN & & & \\
\hline CHEMBL1603149 & 688653 & 4.783 & 4.9489 & TST & & & \\
\hline CHEMBL1327364 & 688653 & 4.883 & 5.5193 & TRN & & & \\
\hline CHEMBL1451617 & 688653 & \multicolumn{3}{|c|}{6.382999999999999} & 5.9112 & TRN & \\
\hline CHEMBL1532607 & 688653 & 4.833 & 5.6012 & TRN & & & \\
\hline CHEMBL1607515 & 688653 & \multicolumn{3}{|c|}{6.382999999999999} & 6.2321 & TRN & \\
\hline CHEMBL1455485 & 688653 & 4.833 & 6.034 & TST & & & \\
\hline CHEMBL1409944 & 688653 & 5.183 & 5.0625 & TRN & & & \\
\hline CHEMBL 3192865 & 688653 & \multicolumn{3}{|c|}{4.9830000000000005} & 5.3629 & TRN & \\
\hline CHEMBL1527585 & 688653 & 4.933 & 5.4249 & TST & & & \\
\hline CHEMBL1611902 & 688653 & 4.583 & 5.2494 & TST & & & \\
\hline CHEMBL1520465 & 688653 & 4.633 & 4.9111 & TST & & & \\
\hline CHEMBL1386556 & 688653 & 4.883 & 4.7304 & TRN & & & \\
\hline CHEMBL 3210543 & 688653 & 5.033 & 5.3309 & TRN & & & \\
\hline CHEMBL1387312 & 688653 & 4.783 & 5.6528 & TRN & & & \\
\hline CHEMBL1429236 & 688653 & 5.983 & 5.6746 & TRN & & & \\
\hline CHEMBL1567593 & 688653 & 8.4318 & 5.598 & TRN & & & \\
\hline CHEMBL1591813 & 688653 & \multicolumn{3}{|c|}{5.2829999999999995} & 5.3763 & TRN & \\
\hline CHEMBL1553318 & 688653 & 5.183 & 5.438 & TRN & & & \\
\hline CHEMBL1511652 & 688653 & \multicolumn{3}{|c|}{4.7330000000000005} & 5.0721 & TST & \\
\hline CHEMBL1510147 & 688653 & 4.883 & 4.9578 & TRN & & & \\
\hline CHEMBL1589249 & 688653 & \multicolumn{3}{|c|}{4.7330000000000005} & 5.1934 & TST & \\
\hline CHEMBL1425542 & 688653 & \multicolumn{3}{|c|}{5.882999999999999} & 5.5106 & TRN & \\
\hline CHEMBL1332863 & 688653 & \multicolumn{3}{|c|}{5.132999999999999} & 5.247999 & 9999999999 & TRN \\
\hline CHEMBL1372813 & 688653 & 4.85 & 5.0368 & TRN & & & \\
\hline CHEMBL1609790 & 688653 & 4.833 & 5.3088 & TRN & & & \\
\hline CHEMBL1557761 & 688653 & 5.183 & 5.2821 & TRN & & & \\
\hline CHEMBL1302239 & 688653 & 5.733 & 5.6359 & TRN & & & \\
\hline CHEMBL1386012 & 688653 & 5.433 & 5.4041 & TRN & & & \\
\hline CHEMBL1488228 & 688653 & \multicolumn{3}{|c|}{5.5329999999999995} & 5.2297 & TRN & \\
\hline CHEMBL3194494 & 688653 & 5.683 & 4.8442 & TST & & & \\
\hline CHEMBL1329803 & 688653 & 6.983 & 5.3619 & TST & & & \\
\hline CHEMBL1519535 & 688653 & 4.783 & 4.9181 & TST & & & \\
\hline CHEMBL1470381 & 688653 & \multicolumn{3}{|c|}{6.632999999999999} & 5.9521 & TRN & \\
\hline CHEMBL1458200 & 688653 & 4.833 & 5.8384 & TRN & & & \\
\hline CHEMBL1432768 & 688653 & 4.933 & 5.3089 & TRN & & & \\
\hline
\end{tabular}




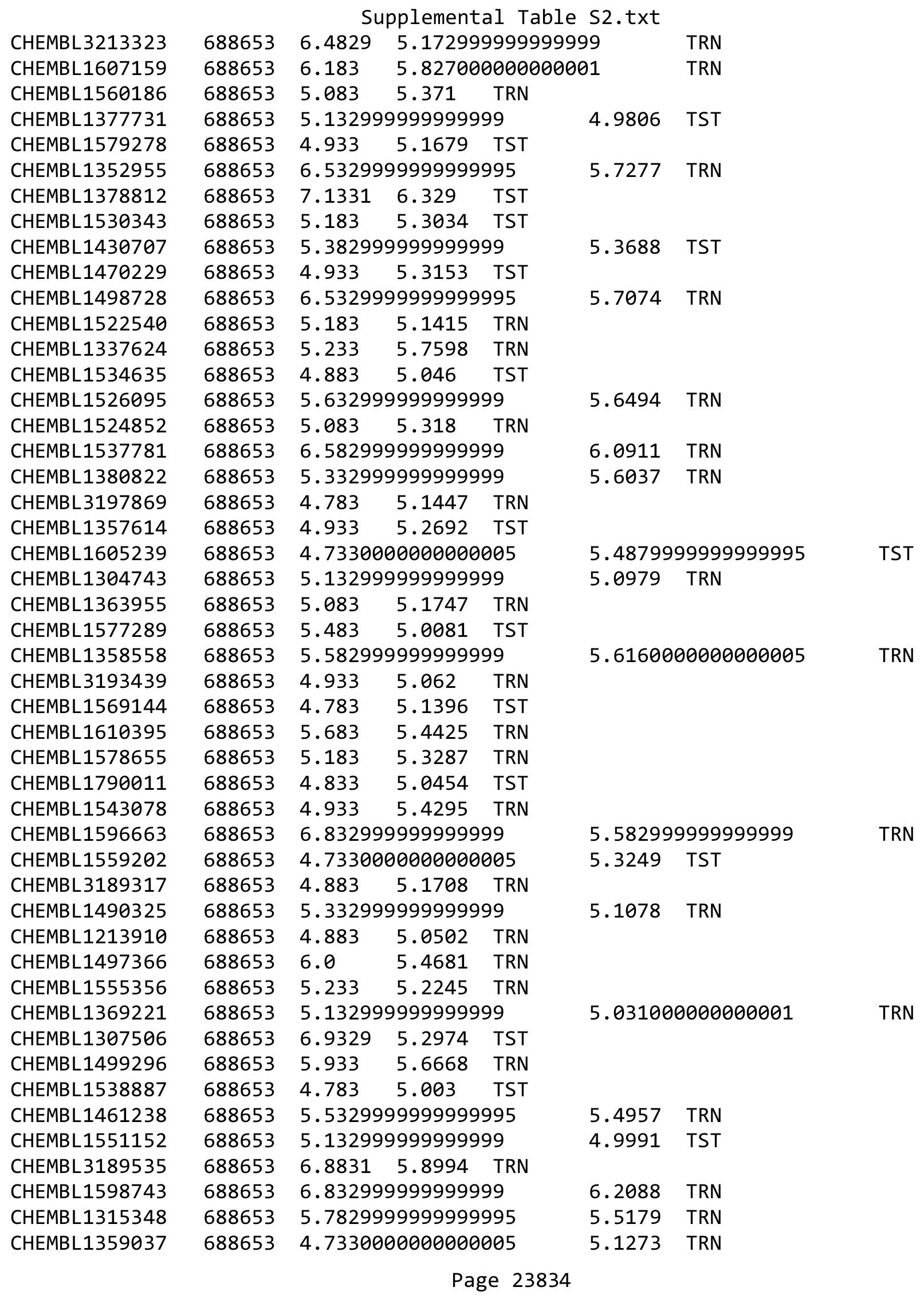




\begin{tabular}{|c|c|c|c|c|c|c|c|}
\hline \multicolumn{7}{|c|}{ Supplemental Table S2.txt } & \\
\hline CHEMBL1562077 & 688653 & \multicolumn{3}{|c|}{4.9830000000000005} & 5.2794 & TRN & \\
\hline CHEMBL1591887 & 688653 & \multicolumn{3}{|c|}{5.2829999999999995} & \multicolumn{2}{|c|}{5.202999999999999} & TST \\
\hline CHEMBL1343407 & 688653 & \multicolumn{3}{|c|}{5.132999999999999} & 5.534 & TRN & \\
\hline CHEMBL1513442 & 688653 & 4.583 & 4.7159 & TRN & & & \\
\hline CHEMBL1546781 & 688653 & \multicolumn{3}{|c|}{6.0329999999999995} & 5.5852 & TRN & \\
\hline CHEMBL1378733 & 688653 & \multicolumn{3}{|c|}{5.832999999999999} & 5.5385 & TRN & \\
\hline CHEMBL1372863 & 688653 & 6.8831 & 5.7112 & TRN & & & \\
\hline CHEMBL1444690 & 688653 & \multicolumn{3}{|c|}{5.2829999999999995} & 4.9672 & TST & \\
\hline CHEMBL1512730 & 688653 & 4.833 & 5.1738 & TRN & & & \\
\hline CHEMBL1400312 & 688653 & \multicolumn{3}{|c|}{5.5329999999999995} & 5.3692 & TST & \\
\hline CHEMBL1490738 & 688653 & \multicolumn{3}{|c|}{5.7829999999999995} & 5.3077 & TRN & \\
\hline CHEMBL3198306 & 688653 & \multicolumn{3}{|c|}{5.5329999999999995} & 5.8292 & TST & \\
\hline CHEMBL1498043 & 688653 & 4.633 & \multicolumn{3}{|c|}{4.9110000000000005} & TRN & \\
\hline CHEMBL1392498 & 688653 & \multicolumn{3}{|c|}{5.132999999999999} & 5.143 & TST & \\
\hline CHEMBL1326225 & 688653 & \multicolumn{3}{|c|}{4.9830000000000005} & 5.4054 & TRN & \\
\hline CHEMBL1353601 & 688653 & \multicolumn{3}{|c|}{4.9830000000000005} & 5.3825 & TST & \\
\hline CHEMBL1419995 & 688653 & 5.733 & 5.1982 & TRN & & & \\
\hline CHEMBL1347071 & 688653 & \multicolumn{3}{|c|}{5.882999999999999} & 5.5732 & TRN & \\
\hline CHEMBL1487635 & 688653 & 4.783 & 5.1345 & TRN & & & \\
\hline CHEMBL1398356 & 688653 & 4.583 & 5.0905 & TST & & & \\
\hline CHEMBL1592795 & 688653 & 5.033 & 5.0177 & TRN & & & \\
\hline CHEMBL1598108 & 688653 & 5.183 & 5.1683 & TRN & & & \\
\hline CHEMBL1534577 & 688653 & 6.183 & 5.7407 & TRN & & & \\
\hline CHEMBL 3208320 & 688653 & 4.933 & 5.0429 & TST & & & \\
\hline CHEMBL1337435 & 688653 & 4.883 & 5.0753 & TRN & & & \\
\hline CHEMBL1341393 & 688653 & \multicolumn{3}{|c|}{5.132999999999999} & 5.5844 & TRN & \\
\hline CHEMBL1423825 & 688653 & \multicolumn{3}{|c|}{4.7330000000000005} & 5.1723 & TRN & \\
\hline CHEMBL1602449 & 688653 & 6.433 & 5.5513 & TRN & & & \\
\hline CHEMBL1357497 & 688653 & 5.183 & 5.5418 & TRN & & & \\
\hline CHEMBL1610763 & 688653 & 5.033 & 5.3 & TRN & & & \\
\hline CHEMBL1339194 & 688653 & 4.783 & 4.6867 & TRN & & & \\
\hline CHEMBL1308212 & 688653 & 4.933 & 5.0222 & TST & & & \\
\hline CHEMBL 2369271 & 688653 & \multicolumn{3}{|c|}{5.132999999999999} & 5.3856 & TRN & \\
\hline CHEMBL1429574 & 688653 & \multicolumn{3}{|c|}{6.332999999999999} & 5.7623 & TST & \\
\hline CHEMBL1554119 & 688653 & 4.783 & 4.8971 & TRN & & & \\
\hline CHEMBL1457165 & 688653 & \multicolumn{3}{|c|}{6.2829999999999995} & 5.3425 & TST & \\
\hline CHEMBL1549660 & 688653 & 4.783 & 4.8508 & TRN & & & \\
\hline CHEMBL1486934 & 688653 & 4.833 & 4.913 & TRN & & & \\
\hline CHEMBL1528880 & 688653 & 4.633 & 5.1506 & TST & & & \\
\hline CHEMBL3191230 & 688653 & 4.933 & 5.6916 & TRN & & & \\
\hline CHEMBL1317320 & 688653 & 4.683 & 4.8576 & TST & & & \\
\hline CHEMBL1428129 & 688653 & 5.083 & 5.0646 & TST & & & \\
\hline CHEMBL1565696 & 688653 & 6.983 & 5.1975 & TRN & & & \\
\hline CHEMBL1390470 & 688653 & 4.833 & 5.1102 & TST & & & \\
\hline CHEMBL1458111 & 688653 & 4.583 & 5.9439 & TST & & & \\
\hline CHEMBL1325704 & 688653 & 4.833 & 4.8291 & TRN & & & \\
\hline CHEMBL1426792 & 688653 & 5.233 & 5.2023 & TRN & & & \\
\hline CHEMBL1511377 & 688653 & 4.783 & 5.331 & TRN & & & \\
\hline
\end{tabular}




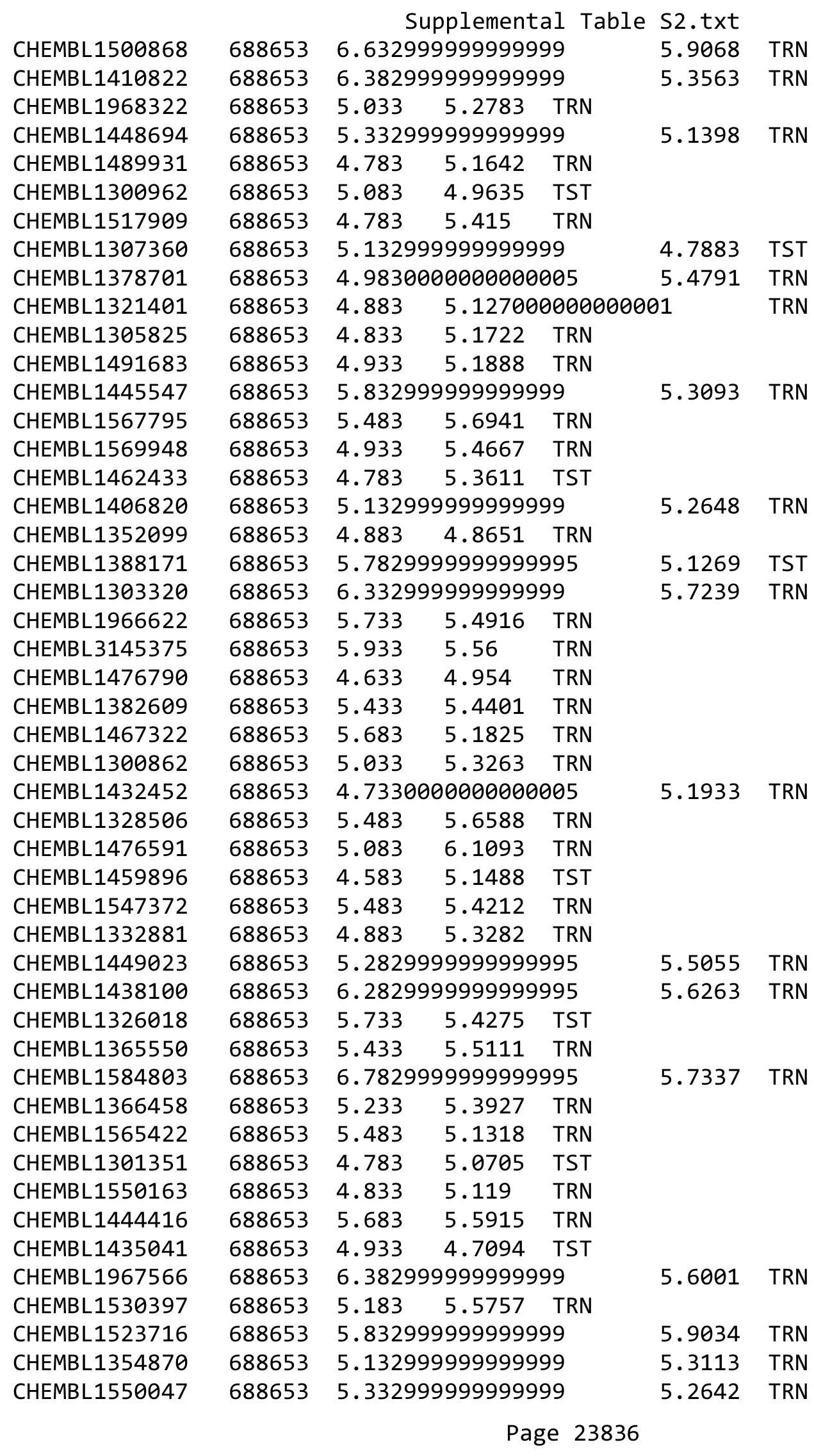




\begin{tabular}{|c|c|c|c|c|c|c|}
\hline \multirow{3}{*}{$\begin{array}{l}\text { CHEMBL1382536 } \\
\text { CHEMBL1300633 }\end{array}$} & \multirow{3}{*}{$\begin{array}{l}688653 \\
688653\end{array}$} & \multicolumn{5}{|c|}{ Supplemental Table S2.txt } \\
\hline & & 4.783 & \multicolumn{3}{|c|}{5.196000000000001} & \multirow[t]{3}{*}{ TRN } \\
\hline & & 4.833 & 5.4147 & TRN & & \\
\hline CHEMBL1440238 & 688653 & 5.95 & 5.4516 & TRN & & \\
\hline CHEMBL1581382 & 688653 & \multicolumn{3}{|c|}{5.2829999999999995} & 4.7256 & $\mathrm{TI}$ \\
\hline CHEMBL1457146 & 688653 & \multicolumn{3}{|c|}{5.832999999999999} & 5.2092 & \\
\hline CHEMBL1570466 & 688653 & 5.933 & 4.9766 & TST & & \\
\hline CHEMBL1387325 & 688653 & 5.483 & 5.5601 & TRN & & \\
\hline CHEMBL114249 & 688653 & \multicolumn{3}{|c|}{5.832999999999999} & 6.2446 & $\mathrm{~T}$ \\
\hline CHEMBL1546746 & 688653 & 4.783 & 5.0983 & TRN & & \\
\hline CHEMBL1544192 & 688653 & 5.183 & 4.7788 & TRN & & \\
\hline CHEMBL1301700 & 688653 & 4.933 & 4.7918 & TST & & \\
\hline CHEMBL1526016 & 688653 & 5.083 & 5.4099 & TRN & & \\
\hline CHEMBL1304356 & 688653 & \multicolumn{3}{|c|}{4.9830000000000005} & 5.8356 & TRN \\
\hline CHEMBL1600779 & 688653 & \multicolumn{3}{|c|}{4.9830000000000005} & 5.2374 & \\
\hline CHEMBL1604833 & 688653 & 5.983 & 5.7369 & TRN & & \\
\hline CHEMBL1530426 & 688653 & \multicolumn{3}{|c|}{5.5329999999999995} & 5.7239 & TRN \\
\hline CHEMBL1471189 & 688653 & \multicolumn{3}{|c|}{4.9830000000000005} & & \\
\hline CHEMBL1562462 & 688653 & 4.883 & 4.8621 & TST & & \\
\hline CHEMBL1315269 & 688653 & \multicolumn{3}{|c|}{5.332999999999999} & 5.0053 & TRN \\
\hline CHEMBL 3194196 & 688653 & \multicolumn{3}{|c|}{5.382999999999999} & & \\
\hline CHEMBL1345699 & 688653 & 4.783 & 5.1034 & TRN & & \\
\hline CHEMBL1410285 & 688653 & 5.083 & 6.0188 & TRN & & \\
\hline CHEMBL156 & 688653 & 6.433 & 5.6447 & TRN & & \\
\hline CHEMBL1360592 & 688653 & 4.883 & 5.3337 & TRN & & \\
\hline CHEMBL510349 & 688653 & 4.7 & 5.8234 & TRN & & \\
\hline CHEMBL1444328 & 688653 & 4.883 & 5.2115 & TST & & \\
\hline CHEMBL1 & 688 & 4.5 & 5.2 & TST & & \\
\hline CHEMBL1 & 688 & 4.633 & 4.4559 & TRN & & \\
\hline CHEMBL1372449 & 688653 & \multicolumn{3}{|c|}{5.882999999999999} & 5.318 & $\mathrm{TI}$ \\
\hline CHEMBL1449945 & 688653 & 5.233 & 5.9377 & TRN & & \\
\hline CHEMBL3193953 & 688653 & \multicolumn{3}{|c|}{4.7330000000000005} & 4.9628 & \\
\hline CHEMBL: & 688 & 4.883 & 5.5033 & TST & & \\
\hline CHEMBL1462109 & 688653 & \multicolumn{3}{|c|}{5.7829999999999995} & 5.6824 & TST \\
\hline CHEMBL1452502 & 688653 & \multicolumn{3}{|c|}{6.332999999999999} & & $\mathrm{~T}$ \\
\hline CHEMBL1413491 & 688653 & 4.633 & 4.9053 & TRN & & \\
\hline CHEMBL3191806 & 688653 & \multicolumn{3}{|c|}{5.882999999999999} & 5.2842 & TR \\
\hline CHEMBL1 & 6886 & 4.883 & 5.2412 & TRN & & \\
\hline CHEMBL1 & 688653 & \multicolumn{3}{|c|}{4.7330000000000005} & 5.2217 & TRN \\
\hline CHEMBL1524554 & 688653 & \multicolumn{3}{|c|}{5.382999999999999} & 5.1594 & TR \\
\hline CHEMBL1594536 & 688653 & 4.783 & 4.9016 & TRN & & \\
\hline CHEMBL1317412 & 688653 & 4.933 & 5.2217 & TRN & & \\
\hline CHEMBL1431766 & 688653 & 5.6329 & 99999999 & & 5.5594 & TRN \\
\hline CHEMBL1411044 & 688653 & 5.6329 & 99999999 & & 5.279 & TRN \\
\hline CHEMBL1375858 & 688653 & 5.683 & 5.1079 & TRN & & \\
\hline CHEMBL3198502 & 688653 & 5.933 & 5.5557 & TRN & & \\
\hline CHEMBL3191094 & 688653 & 5.733 & 5.5372 & TRN & & \\
\hline CHEMBL 3199294 & 688653 & 6.0329 & 99999999 & 995 & 5.54 & 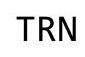 \\
\hline CHEMBL 3145373 & 688653 & 5.7829 & 99999999 & 995 & 5.5708 & \\
\hline & & & & & & \\
\hline
\end{tabular}




\begin{tabular}{|c|c|c|c|c|c|c|}
\hline \multirow{3}{*}{$\begin{array}{l}\text { CHEMBL1579606 } \\
\text { CHEMBL1572921 }\end{array}$} & & \multicolumn{5}{|c|}{ Supplemental Table S2.txt } \\
\hline & 688653 & \multicolumn{3}{|c|}{5.2829999999999995} & 5.0801 & TRN \\
\hline & 688653 & 5.033 & 5.5524 & TST & & \\
\hline CHEMBL1341336 & 688653 & \multicolumn{3}{|c|}{5.132999999999999} & 5.1539 & TST \\
\hline CHEMBL1581634 & 688653 & \multicolumn{3}{|c|}{4.9830000000000005} & 5.3879 & TRN \\
\hline CHEMBL1582417 & 688653 & 4.933 & 5.4539 & TRN & & \\
\hline CHEMBL1541019 & 688653 & 4.883 & 5.6816 & TRN & & \\
\hline CHEMBL1481793 & 688653 & \multicolumn{3}{|c|}{5.632999999999999} & 5.9246 & TRN \\
\hline CHEMBL1451080 & 688653 & \multicolumn{3}{|c|}{6.0329999999999995} & 5.6896 & TRN \\
\hline CHEMBL1612792 & 688653 & \multicolumn{3}{|c|}{4.9830000000000005} & 5.3385 & TRN \\
\hline CHEMBL1459864 & 688653 & 5.083 & 5.2161 & TRN & & \\
\hline CHEMBL1554240 & 688653 & 6.683 & 5.4378 & TRN & & \\
\hline CHEMBL1514827 & 688653 & 4.833 & 5.0173 & TRN & & \\
\hline CHEMBL355280 & 688653 & 5.933 & 5.4094 & TRN & & \\
\hline CHEMBL1486387 & 688653 & 4.633 & 5.2229 & TRN & & \\
\hline CHEMBL1346118 & 688653 & 6.7331 & 5.7084 & TRN & & \\
\hline CHEMBL1492177 & 688653 & \multicolumn{3}{|c|}{4.7330000000000005} & 4.7803 & TST \\
\hline CHEMBL1601470 & 688653 & 5.733 & 5.1789 & TST & & \\
\hline CHEMBL1457961 & 688653 & \multicolumn{3}{|c|}{6.5329999999999995} & 5.3742 & TST \\
\hline CHEMBL1383991 & 688653 & 5.233 & 5.8926 & TRN & & \\
\hline CHEMBL1306157 & 688653 & \multicolumn{3}{|c|}{4.9830000000000005} & 5.2065 & TRN \\
\hline CHEMBL1357025 & 688653 & 4.783 & 5.0448 & TRN & & \\
\hline CHEMBL 3214630 & 688653 & \multirow{2}{*}{\multicolumn{3}{|c|}{4.7330000000000005}} & & \\
\hline CHEMBL1387294 & 688653 & & & & 5.1584 & TST \\
\hline CHEMBL1526866 & 688653 & 4.783 & 5.5386 & TRN & & \\
\hline CHEMBL1411330 & 688653 & 6.233 & 5.9974 & TRN & & \\
\hline CHEMBL1213834 & 688653 & 6.233 & 5.8084 & TRN & & \\
\hline CHEMBL1335957 & 688653 & 5.083 & 5.2228 & TRN & & \\
\hline CHEMBL1300888 & 688653 & \multicolumn{3}{|c|}{4.7330000000000005} & 4.9892 & TST \\
\hline CHEMBL1588832 & 688653 & 4.783 & 5.1605 & TRN & & \\
\hline CHEMBL1440011 & 688653 & 6.45 & 5.2747 & TRN & & \\
\hline CHEMBL1414080 & 688653 & 4.883 & 5.4644 & TST & & \\
\hline CHEMBL1444341 & 688653 & 4.883 & 5.2966 & TST & & \\
\hline CHEMBL1581831 & 688653 & 4.883 & 5.0784 & TRN & & \\
\hline CHEMBL1588361 & 688653 & 4.783 & 5.2094 & TRN & & \\
\hline CHEMBL1461390 & 688653 & 4.783 & 5.5178 & TRN & & \\
\hline CHEMBL3213808 & 688653 & \multicolumn{3}{|c|}{5.5329999999999995} & 5.0627 & TRN \\
\hline CHEMBL1546392 & 688653 & 4.833 & 5.4264 & TRN & & \\
\hline CHEMBL1388102 & 688653 & \multicolumn{3}{|c|}{5.332999999999999} & 5.5388 & TRN \\
\hline CHEMBL1544256 & 688653 & \multicolumn{3}{|c|}{5.132999999999999} & 4.9297 & TRN \\
\hline CHEMBL1334993 & 688653 & \multicolumn{3}{|c|}{5.382999999999999} & 5.7779 & TRN \\
\hline CHEMBL 1602472 & 688653 & 4.833 & 5.3601 & TRN & & \\
\hline CHEMBL1300952 & 688653 & \multicolumn{3}{|c|}{5.832999999999999} & 5.0659 & TRN \\
\hline CHEMBL1550182 & 688653 & 5.183 & 5.2706 & TRN & & \\
\hline CHEMBL1564120 & 688653 & 5.033 & 5.6781 & TRN & & \\
\hline CHEMBL1588130 & 688653 & 4.933 & 4.685 & TRN & & \\
\hline CHEMBL1450406 & 688653 & 4.883 & 5.37700 & 00006 & & TRN \\
\hline CHEMBL1354671 & 688653 & 4.583 & 5.0143 & TST & & \\
\hline \multirow[t]{2}{*}{ CHEMBL1311793 } & 688653 & 5.183 & 5.4189 & TRN & & \\
\hline & & \multicolumn{4}{|c|}{ Page 238} & \\
\hline
\end{tabular}




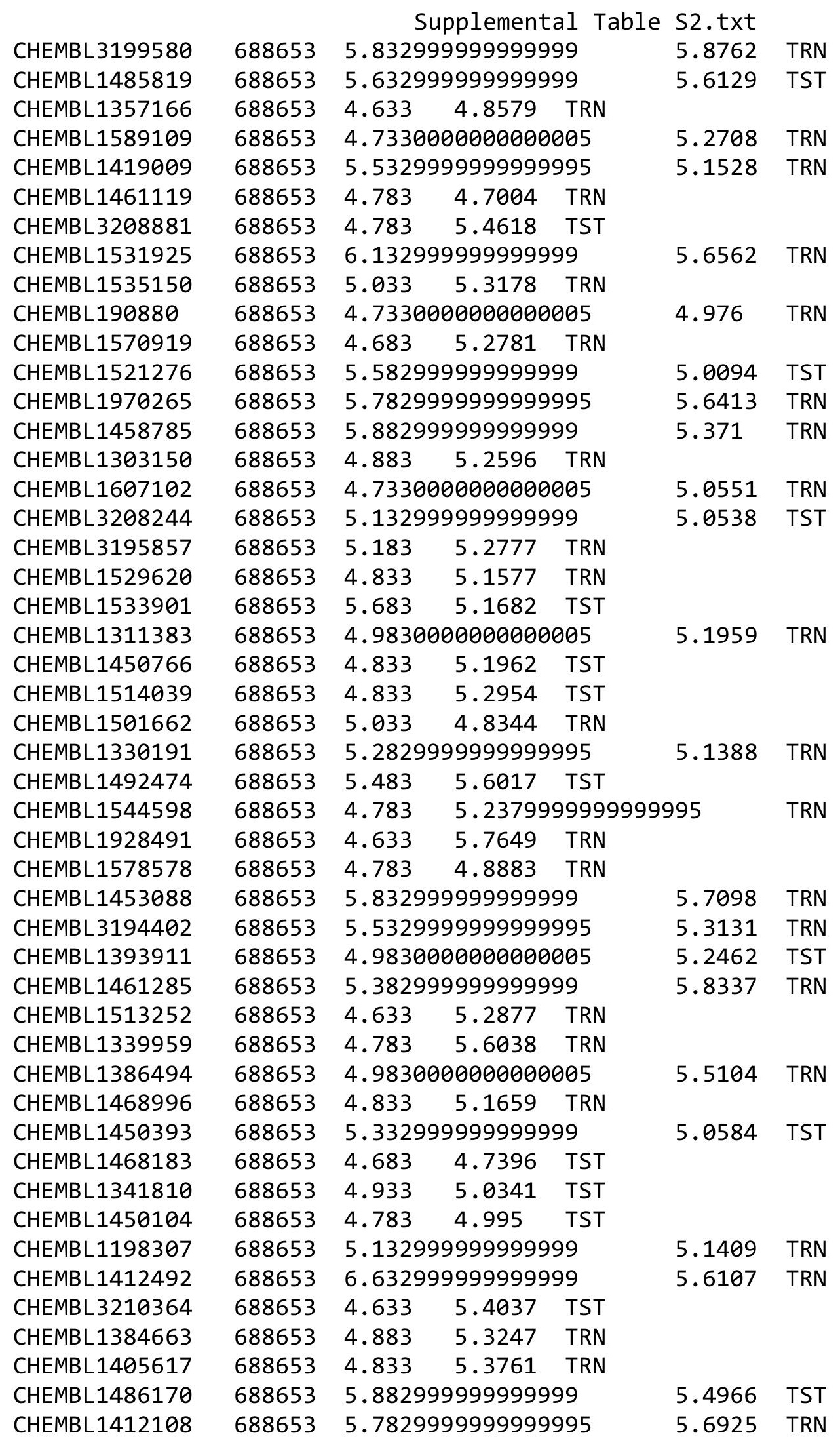




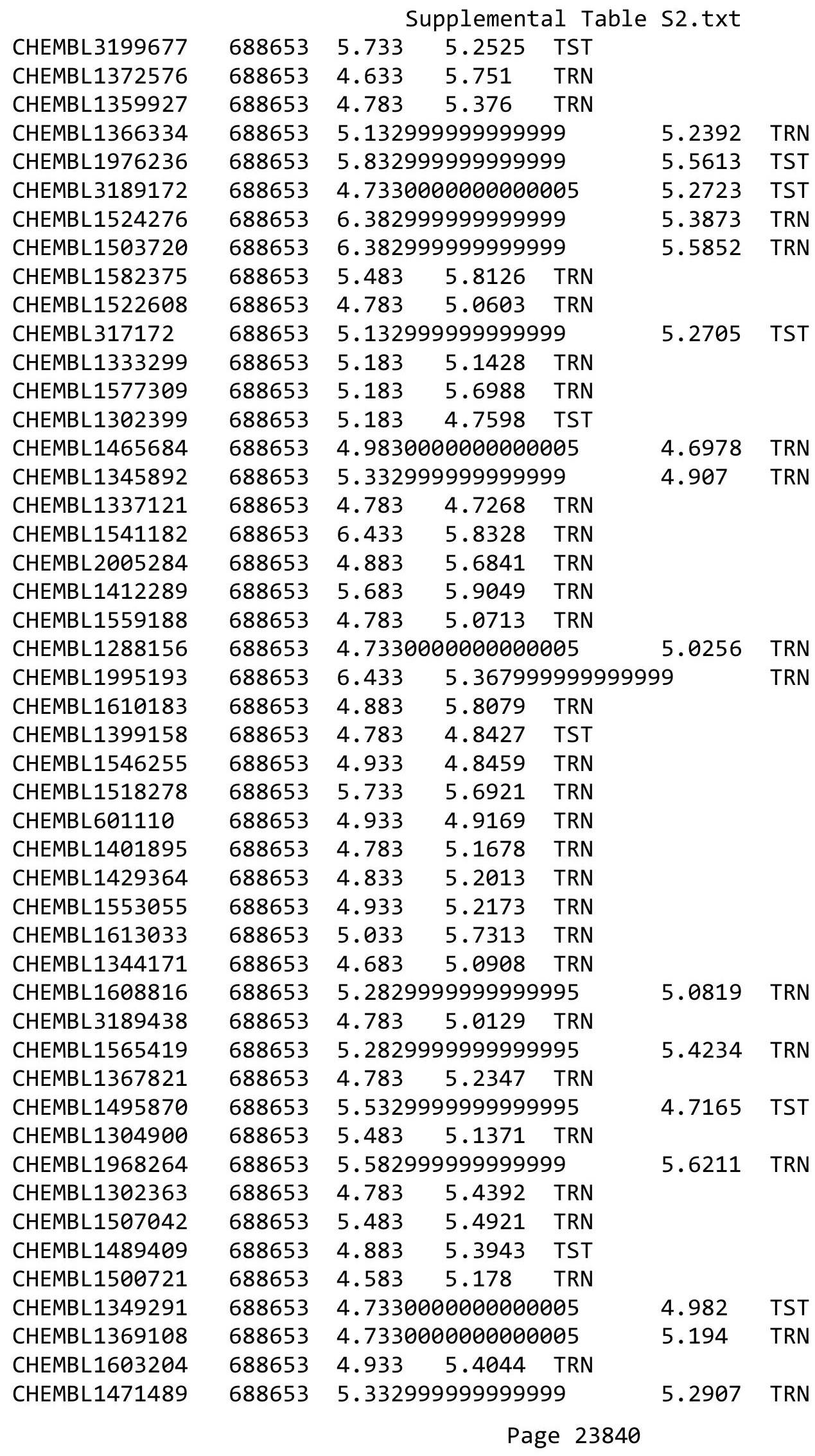




\begin{tabular}{|c|c|c|c|c|c|c|c|}
\hline \multicolumn{8}{|c|}{ Supplemental Table S2.txt } \\
\hline CHEMBL1526549 & 688653 & 5.733 & 5.6249 & TRN & & & \\
\hline CHEMBL1477375 & 688653 & \multicolumn{3}{|c|}{5.332999999999999} & 6.0857 & TST & \\
\hline CHEMBL1385361 & 688653 & \multicolumn{3}{|c|}{5.332999999999999} & 5.5968 & TRN & \\
\hline CHEMBL1436508 & 688653 & \multicolumn{3}{|c|}{6.132999999999999} & \multicolumn{2}{|c|}{5.1610000000000005} & TRN \\
\hline CHEMBL1392424 & 688653 & \multicolumn{3}{|c|}{5.382999999999999} & 5.0887 & TRN & \\
\hline CHEMBL 244857 & 688653 & 4.883 & 5.4711 & TRN & & & \\
\hline CHEMBL1537692 & 688653 & 4.883 & 5.0404 & TRN & & & \\
\hline CHEMBL1358134 & 688653 & \multicolumn{3}{|c|}{4.9830000000000005} & 5.1883 & TST & \\
\hline CHEMBL3191391 & 688653 & \multicolumn{3}{|c|}{5.5329999999999995} & 5.3565 & TRN & \\
\hline CHEMBL1534411 & 688653 & 5.683 & 5.4816 & TRN & & & \\
\hline CHEMBL1365670 & 688653 & 6.683 & 5.6585 & TRN & & & \\
\hline CHEMBL1522764 & 688653 & 4.883 & 5.3301 & TST & & & \\
\hline CHEMBL1567025 & 688653 & 4.633 & 4.8689 & TST & & & \\
\hline CHEMBL1401953 & 688653 & 6.183 & 6.1117 & TRN & & & \\
\hline CHEMBL1372585 & 688653 & 5.083 & 4.9026 & TRN & & & \\
\hline CHEMBL1350132 & 688653 & \multicolumn{3}{|c|}{4.9830000000000005} & 4.9448 & TST & \\
\hline CHEMBL1382920 & 688653 & 5.733 & 5.4923 & TRN & & & \\
\hline CHEMBL3195927 & 688653 & 4.633 & 5.1369 & TRN & & & \\
\hline CHEMBL1604837 & 688653 & \multicolumn{3}{|c|}{5.332999999999999} & 5.3557 & TRN & \\
\hline CHEMBL1375425 & 688653 & 5.433 & 5.3064 & TRN & & & \\
\hline CHEMBL1333893 & 688653 & 5.033 & 5.17 & TRN & & & \\
\hline CHEMBL1309516 & 688653 & 4.883 & 5.15 & TRN & & & \\
\hline CHEMBL1338502 & 688653 & 5.683 & 6.1075 & TRN & & & \\
\hline CHEMBL1423794 & 688653 & 4.783 & 5.2424 & TRN & & & \\
\hline CHEMBL1339614 & 688653 & 5.233 & 5.3674 & TRN & & & \\
\hline CHEMBL1444003 & 688653 & \multicolumn{3}{|c|}{5.332999999999999} & 5.2253 & TRN & \\
\hline CHEMBL1333000 & 688653 & \multicolumn{3}{|c|}{4.7330000000000005} & 5.125 & TST & \\
\hline CHEMBL1447762 & 688653 & 4.633 & 4.8227 & TST & & & \\
\hline CHEMBL1403350 & 688653 & \multicolumn{3}{|c|}{4.7330000000000005} & 5.381 & TRN & \\
\hline CHEMBL1549738 & 688653 & \multicolumn{3}{|c|}{5.2829999999999995} & 5.2987 & TST & \\
\hline CHEMBL1558144 & 688653 & 4.683 & 4.7684 & TST & & & \\
\hline CHEMBL1330131 & 688653 & 5.683 & 5.5134 & TST & & & \\
\hline CHEMBL1505683 & 688653 & 5.033 & 5.157 & TRN & & & \\
\hline CHEMBL 2006274 & 688653 & \multicolumn{3}{|c|}{5.632999999999999} & 5.2425 & TRN & \\
\hline CHEMBL3212959 & 688653 & \multicolumn{3}{|c|}{5.582999999999999} & 5.17899 & 9999999999 & TRN \\
\hline CHEMBL1596560 & 688653 & \multicolumn{3}{|c|}{6.632999999999999} & 5.403 & TRN & \\
\hline CHEMBL1484902 & 688653 & \multicolumn{3}{|c|}{5.7829999999999995} & 5.6787 & TRN & \\
\hline CHEMBL1355273 & 688653 & 5.083 & 5.9299 & TRN & & & \\
\hline CHEMBL1455189 & 688653 & \multirow{2}{*}{\multicolumn{3}{|c|}{$\begin{array}{ll}5.683 \\
4.9830000000000005\end{array}$}} & & & \\
\hline CHEMBL1312941 & 688653 & & & & 5.1122 & TRN & \\
\hline CHEMBL1398976 & 688653 & 4.633 & 5.4535 & TRN & & & \\
\hline CHEMBL1434768 & 688653 & 6.7331 & 5.7644 & TRN & & & \\
\hline CHEMBL3212566 & 688653 & 5.083 & 5.1758 & TRN & & & \\
\hline CHEMBL1415614 & 688653 & 5.983 & 5.6883 & TRN & & & \\
\hline CHEMBL1527046 & 688653 & 4.933 & 5.041 & TRN & & & \\
\hline CHEMBL1591644 & 688653 & 5.83299 & 99999999 & & 5.5058 & TRN & \\
\hline CHEMBL1444768 & 688653 & 5.78299 & 99999999 & 995 & 5.3607 & TRN & \\
\hline CHEMBL1350245 & 688653 & 6.0 & 5.2363 & TRN & & & \\
\hline
\end{tabular}




\begin{tabular}{|c|c|c|c|c|c|c|}
\hline & & \multicolumn{5}{|c|}{ Supplemental Table s2.txt } \\
\hline CHEMBL1584133 & 688653 & 5.033 & 5.4678 & TRN & & \\
\hline CHEMBL1346277 & 688653 & 5.183 & 5.1042 & TRN & & \\
\hline CHEMBL1405033 & 688653 & 5.683 & 5.5188 & TRN & & \\
\hline CHEMBL 3197801 & 688653 & 6.233 & 5.2845 & TRN & & \\
\hline CHEMBL3208232 & 688653 & 4.883 & 5.0968 & TRN & & \\
\hline CHEMBL1431605 & 688653 & 4.883 & 4.9568 & TRN & & \\
\hline CHEMBL1435403 & 688653 & 4.633 & 4.9614 & TST & & \\
\hline CHEMBL1474935 & 688653 & 5.483 & 5.1317 & TRN & & \\
\hline CHEMBL1532295 & 688653 & 4.633 & 5.1247 & TRN & & \\
\hline CHEMBL1300575 & 688653 & 6.9329 & 5.6068 & TRN & & \\
\hline CHEMBL1553369 & 688653 & \multicolumn{3}{|c|}{5.2829999999999995} & 5.0333 & TST \\
\hline CHEMBL2369161 & 688653 & 5.683 & 5.2668 & TRN & & \\
\hline CHEMBL1546317 & 688653 & 5.683 & 5.0911 & TRN & & \\
\hline CHEMBL1350679 & 688653 & \multicolumn{3}{|c|}{4.7330000000000005} & 5.1636 & TRN \\
\hline CHEMBL1536135 & 688653 & 6.433 & 5.4166 & TRN & & \\
\hline CHEMBL1385485 & 688653 & \multicolumn{3}{|c|}{5.5329999999999995} & 5.0446 & TST \\
\hline CHEMBL1492204 & 688653 & 4.783 & 4.8754 & TRN & & \\
\hline CHEMBL1484314 & 688653 & \multicolumn{3}{|c|}{4.7330000000000005} & 5.3581 & TST \\
\hline CHEMBL1588833 & 688653 & 6.4829 & 5.3744 & TRN & & \\
\hline CHEMBL1478212 & 688653 & 5.983 & 5.481 & TRN & & \\
\hline CHEMBL3191185 & 688653 & \multicolumn{3}{|c|}{ 5.382999999999999 } & 5.2056 & TRN \\
\hline CHEMBL1447684 & 688653 & \multicolumn{3}{|c|}{4.7330000000000005} & 5.6067 & TRN \\
\hline CHEMBL1547862 & 688653 & 4.583 & 5.1553 & TST & & \\
\hline CHEMBL1438927 & 688653 & \multicolumn{3}{|c|}{5.632999999999999} & 5.2331 & TRN \\
\hline CHEMBL1435324 & 688653 & \multicolumn{3}{|c|}{5.5329999999999995} & 4.9256 & TRN \\
\hline CHEMBL1386779 & 688653 & \multicolumn{3}{|c|}{6.132999999999999} & 5.7255 & TRN \\
\hline CHEMBL1577599 & 688653 & \multicolumn{3}{|c|}{5.132999999999999} & 5.5201 & TRN \\
\hline CHEMBL1344619 & 688653 & 5.933 & 5.1596 & TRN & & \\
\hline CHEMBL1587031 & 688653 & & 4.9906 & TST & & \\
\hline CHEMBL 3145000 & 688653 & \multicolumn{3}{|c|}{5.332999999999999} & 5.0851 & TRN \\
\hline CHEMBL1402597 & 688653 & 5.183 & 5.2726 & TRN & & \\
\hline CHEMBL1305918 & 688653 & 6.433 & 5.7374 & TRN & & \\
\hline CHEMBL1572894 & 688653 & 5.083 & \multicolumn{3}{|c|}{5.422000000000001} & TRN \\
\hline CHEMBL1586474 & 688653 & 5.183 & 5.4988 & TRN & & \\
\hline CHEMBL1575970 & 688653 & \multicolumn{3}{|c|}{7.082999999999999} & 6.1309 & TRN \\
\hline CHEMBL1372159 & 688653 & \multicolumn{3}{|c|}{5.832999999999999} & 5.0376 & TST \\
\hline CHEMBL1491110 & 688653 & \multicolumn{3}{|c|}{5.832999999999999} & 5.5704 & TRN \\
\hline CHEMBL1387412 & 688653 & \multicolumn{3}{|c|}{5.5329999999999995} & 5.5056 & TRN \\
\hline CHEMBL1428254 & 688653 & \multicolumn{3}{|c|}{5.132999999999999} & 5.0177 & TST \\
\hline CHEMBL1365620 & 688653 & 5.183 & 5.4323 & TRN & & \\
\hline CHEMBL1584517 & 688653 & 4.833 & 5.3698 & TRN & & \\
\hline CHEMBL1483193 & 688653 & 6.7331 & 5.7161 & TRN & & \\
\hline CHEMBL1328499 & 688653 & 4.633 & 4.9637 & TST & & \\
\hline CHEMBL1531336 & 688653 & \multicolumn{3}{|c|}{5.332999999999999} & 5.0688 & TRN \\
\hline CHEMBL3197248 & 688653 & 4.933 & 5.3255 & TST & & \\
\hline CHEMBL1389853 & 688653 & \multicolumn{3}{|c|}{6.132999999999999} & 5.2525 & TRN \\
\hline CHEMBL1352019 & 688653 & 5.083 & 5.2904 & TRN & & \\
\hline CHEMBL1533260 & 688653 & 4.883 & 5.2144 & TRN & & \\
\hline
\end{tabular}




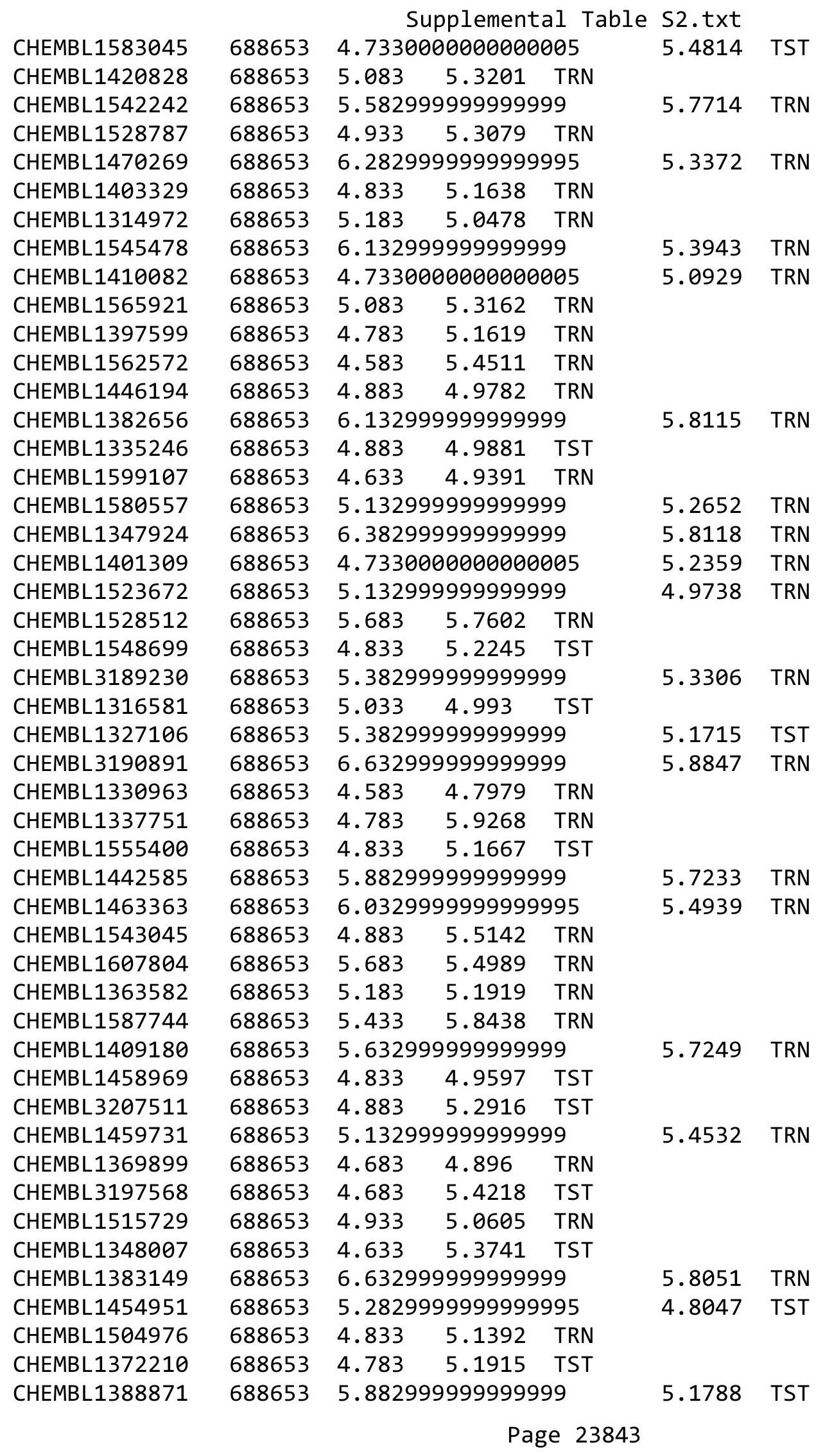




\begin{tabular}{|c|c|c|c|c|c|c|c|}
\hline \multicolumn{7}{|c|}{ Supplemental Table S2.txt } & \\
\hline CHEMBL1569170 & 688653 & \multicolumn{3}{|c|}{6.332999999999999} & 5.9196 & TRN & \\
\hline CHEMBL1330591 & 688653 & \multicolumn{3}{|c|}{5.132999999999999} & 5.187 & TRN & \\
\hline CHEMBL1598545 & 688653 & 4.883 & 5.2068 & TRN & & & \\
\hline CHEMBL1563101 & 688653 & 4.783 & 4.8926 & TRN & & & \\
\hline CHEMBL1377584 & 688653 & 5.433 & 5.1502 & TST & & & \\
\hline CHEMBL1351283 & 688653 & \multicolumn{3}{|c|}{5.332999999999999} & \multicolumn{2}{|c|}{5.292999999999999} & TRN \\
\hline CHEMBL1475047 & 688653 & \multicolumn{3}{|c|}{5.7829999999999995} & 5.3118 & TRN & \\
\hline CHEMBL1471369 & 688653 & 4.783 & 5.5391 & TRN & & & \\
\hline CHEMBL1571629 & 688653 & 4.883 & 4.8276 & TRN & & & \\
\hline CHEMBL1524240 & 688653 & \multicolumn{3}{|c|}{5.5329999999999995} & 5.1042 & TRN & \\
\hline CHEMBL1393497 & 688653 & 4.633 & 5.0418 & TRN & & & \\
\hline CHEMBL3208161 & 688653 & 5.933 & 5.1828 & TRN & & & \\
\hline CHEMBL1467230 & 688653 & 4.833 & 5.0004 & TRN & & & \\
\hline CHEMBL1432434 & 688653 & \multicolumn{3}{|c|}{6.2829999999999995} & 5.6076 & TST & \\
\hline CHEMBL578257 & 688653 & \multicolumn{3}{|c|}{5.2829999999999995} & 5.4755 & TRN & \\
\hline CHEMBL1330655 & 688653 & \multicolumn{3}{|c|}{5.832999999999999} & 5.6241 & TRN & \\
\hline CHEMBL1344961 & 688653 & 5.083 & 5.0721 & TRN & & & \\
\hline CHEMBL1328215 & 688653 & 4.583 & 5.0526 & TST & & & \\
\hline CHEMBL1309923 & 688653 & \multicolumn{3}{|c|}{5.5329999999999995} & 5.2166 & TRN & \\
\hline CHEMBL1399281 & 688653 & 5.933 & 5.6272 & TST & & & \\
\hline CHEMBL1418503 & 688653 & 6.433 & 5.7609 & TRN & & & \\
\hline CHEMBL 3192747 & 688653 & 4.783 & 5.0313 & TST & & & \\
\hline CHEMBL1511384 & 688653 & \multicolumn{3}{|c|}{4.7330000000000005} & 5.1078 & TRN & \\
\hline CHEMBL1334832 & 688653 & \multicolumn{3}{|c|}{5.332999999999999} & 5.1926 & TRN & \\
\hline CHEMBL1397041 & 688653 & 4.783 & 5.6241 & TST & & & \\
\hline CHEMBL452409 & 688653 & \multicolumn{3}{|c|}{6.382999999999999} & 5.8295 & TRN & \\
\hline CHEMBL 3189361 & 688653 & \multicolumn{3}{|c|}{6.332999999999999} & 6.0985 & TRN & \\
\hline CHEMBL1481301 & 688653 & 4.783 & 5.5703 & TRN & & & \\
\hline CHEMBL1421436 & 688653 & 5.183 & 5.565 & TST & & & \\
\hline CHEMBL1375539 & 688653 & 4.633 & 4.6439 & TST & & & \\
\hline CHEMBL1420711 & 688653 & 5.083 & 5.2029 & TRN & & & \\
\hline CHEMBL1466964 & 688653 & \multicolumn{3}{|c|}{5.7829999999999995} & 5.2328 & TST & \\
\hline CHEMBL1386172 & 688653 & 5.483 & 5.3014 & TRN & & & \\
\hline CHEMBL1486297 & 688653 & \multicolumn{3}{|c|}{5.882999999999999} & 5.5903 & TRN & \\
\hline CHEMBL1541557 & 688653 & \multicolumn{3}{|c|}{5.132999999999999} & 5.1135 & TRN & \\
\hline CHEMBL1432104 & 688653 & 5.483 & 5.4454 & TRN & & & \\
\hline CHEMBL1331548 & 688653 & & & TST & & & \\
\hline CHEMBL1462220 & 688653 & \multicolumn{3}{|c|}{5.7829999999999995} & 5.0287 & TRN & \\
\hline CHEMBL1566451 & 688653 & 5.733 & 5.4087 & TST & & & \\
\hline CHEMBL1605614 & 688653 & 4.783 & \multicolumn{3}{|c|}{5.172999999999999} & TRN & \\
\hline CHEMBL1340811 & 688653 & 4.783 & 5.3901 & TRN & & & \\
\hline CHEMBL1597412 & 688653 & 4.883 & 5.3358 & TST & & & \\
\hline CHEMBL3189976 & 688653 & 4.833 & 5.1769 & TRN & & & \\
\hline CHEMBL1308010 & 688653 & 5.683 & 5.005 & TRN & & & \\
\hline CHEMBL1389243 & 688653 & 5.033 & 5.081 & TST & & & \\
\hline CHEMBL1552326 & 688653 & \multicolumn{3}{|c|}{4.9830000000000005} & 5.6483 & TST & \\
\hline CHEMBL1541727 & 688653 & 5.083 & 5.1309 & TRN & & & \\
\hline CHEMBL1537298 & 688653 & 4.783 & 4.9288 & TST & & & \\
\hline
\end{tabular}




\begin{tabular}{|c|c|c|c|c|c|c|}
\hline & & \multicolumn{4}{|c|}{ Supplemental Table S2.txt } & \\
\hline CHEMBL1355328 & 688653 & \multicolumn{3}{|c|}{5.132999999999999} & 5.5516 & TRN \\
\hline CHEMBL3209036 & 688653 & \multicolumn{3}{|c|}{6.332999999999999} & 5.6884 & TRN \\
\hline CHEMBL1311425 & 688653 & 4.833 & 5.2374 & TST & & \\
\hline CHEMBL1599959 & 688653 & 4.583 & 4.9345 & TST & & \\
\hline CHEMBL1428858 & 688653 & 4.833 & 5.4161 & TST & & \\
\hline CHEMBL1503070 & 688653 & 4.933 & 4.5691 & TRN & & \\
\hline CHEMBL1538034 & 688653 & 4.783 & 5.0433 & TRN & & \\
\hline CHEMBL1975447 & 688653 & 6.683 & 5.845 & TRN & & \\
\hline CHEMBL1558842 & 688653 & 4.833 & 5.311 & TST & & \\
\hline CHEMBL3198383 & 688653 & 4.783 & 5.1611 & TRN & & \\
\hline CHEMBL1441858 & 688653 & \multicolumn{3}{|c|}{5.832999999999999} & 5.6567 & TRN \\
\hline CHEMBL1382364 & 688653 & 4.833 & 5.3109 & TRN & & \\
\hline CHEMBL1597789 & 688653 & 5.183 & 5.1003 & TRN & & \\
\hline CHEMBL1438073 & 688653 & \multicolumn{3}{|c|}{5.382999999999999} & 5.2137 & TRN \\
\hline CHEMBL1387669 & 688653 & \multicolumn{3}{|c|}{4.7330000000000005} & 5.3491 & TRN \\
\hline CHEMBL1554259 & 688653 & 4.633 & 5.2704 & TRN & & \\
\hline CHEMBL1575756 & 688653 & 5.683 & 5.1558 & TRN & & \\
\hline CHEMBL1579718 & 688653 & 5.733 & 5.0468 & TST & & \\
\hline CHEMBL1583455 & 688653 & 6.0 & 5.4304 & TST & & \\
\hline CHEMBL1536425 & 688653 & \multicolumn{3}{|c|}{6.132999999999999} & 5.0081 & TRN \\
\hline CHEMBL1401901 & 688653 & 5.083 & 5.1686 & TRN & & \\
\hline CHEMBL1348350 & 688653 & 5.233 & 5.4037 & TRN & & \\
\hline CHEMBL3198351 & 688653 & 4.783 & 5.3075 & TRN & & \\
\hline CHEMBL1582071 & 688653 & 4.833 & 5.3451 & TRN & & \\
\hline CHEMBL1497626 & 688653 & 4.783 & 5.3604 & TST & & \\
\hline CHEMBL1564062 & 688653 & \multicolumn{3}{|c|}{5.882999999999999} & 5.7938 & TRN \\
\hline CHEMBL1308887 & 688653 & 4.833 & 5.3868 & TST & & \\
\hline CHEMBL1366350 & 688653 & \multicolumn{3}{|c|}{5.2829999999999995} & 5.6003 & TRN \\
\hline CHEMBL1336701 & 688653 & 5.683 & 5.1624 & TST & & \\
\hline CHEMBL1341898 & 688653 & 5.683 & 5.3331 & TRN & & \\
\hline CHEMBL1587764 & 688653 & \multicolumn{3}{|c|}{4.7330000000000005} & 5.3944 & TST \\
\hline CHEMBL1300307 & 688653 & 5.983 & 5.6489 & TRN & & \\
\hline CHEMBL1480202 & 688653 & \multicolumn{3}{|c|}{5.332999999999999} & 5.5811 & TRN \\
\hline CHEMBL1571703 & 688653 & 5.733 & 4.9758 & TRN & & \\
\hline CHEMBL1458184 & 688653 & 4.833 & 5.2572 & TST & & \\
\hline CHEMBL1601870 & 688653 & 5.183 & 5.0207 & TRN & & \\
\hline CHEMBL1412074 & 688653 & 5.183 & 5.2154 & TRN & & \\
\hline CHEMBL1339405 & 688653 & 4.633 & 4.8833 & TST & & \\
\hline CHEMBL1446437 & 688653 & 4.933 & 4.9417 & TST & & \\
\hline CHEMBL1456038 & 688653 & 4.833 & 5.2984 & TRN & & \\
\hline CHEMBL1969515 & 688653 & \multicolumn{3}{|c|}{4.9830000000000005} & 5.2104 & TRN \\
\hline CHEMBL1319967 & 688653 & 4.833 & 4.8183 & TRN & & \\
\hline CHEMBL1439772 & 688653 & \multicolumn{3}{|c|}{5.132999999999999} & 5.7579 & TRN \\
\hline CHEMBL1413922 & 688653 & 4.783 & 5.151 & TRN & & \\
\hline CHEMBL1423002 & 688653 & 4.783 & 5.4948 & TRN & & \\
\hline CHEMBL1420843 & 688653 & \multicolumn{3}{|c|}{5.382999999999999} & 5.5737 & TRN \\
\hline CHEMBL1451376 & 688653 & \multicolumn{3}{|c|}{5.132999999999999} & 5.3341 & TST \\
\hline CHEMBL1384135 & 688653 & 4.783 & 5.1771 & TRN & & \\
\hline
\end{tabular}




\begin{tabular}{|c|c|c|c|c|c|c|}
\hline \multirow{3}{*}{$\begin{array}{l}\text { CHEMBL1368333 } \\
\text { CHEMBL1328947 }\end{array}$} & \multicolumn{6}{|c|}{ Supplemental Table S2.txt } \\
\hline & 688653 & \multicolumn{3}{|c|}{5.2829999999999995} & 5.3344 & TRA \\
\hline & 688653 & 5.083 & 5.3101 & TRN & & \\
\hline CHEMBL1500301 & 688653 & 4.833 & 4.8824 & TRN & & \\
\hline CHEMBL1574955 & 688653 & \multicolumn{3}{|c|}{5.582999999999999} & 5.0758 & TRN \\
\hline CHEMBL241987 & 688653 & \multicolumn{3}{|c|}{5.332999999999999} & 5.2007 & \\
\hline CHEMBL1585773 & 688653 & \multicolumn{3}{|c|}{6.5329999999999995} & 5.3864 & \\
\hline CHEMBL399121 & 688653 & 4.783 & 4.6676 & TST & & \\
\hline CHEMBL1319106 & 688653 & 4.783 & 4.7433 & TRN & & \\
\hline CHEMBL1326785 & 688653 & 6.433 & 6.0578 & TRN & & \\
\hline CHEMBL1424168 & 688653 & 4.883 & 5.4219 & TRN & & \\
\hline CHEMBL1367421 & 688653 & \multicolumn{3}{|c|}{5.7829999999999995} & 5.0293 & TST \\
\hline CHEMBL1303116 & 688653 & \multicolumn{3}{|c|}{4.9830000000000005} & 5.24 & \\
\hline CHEMBL1402526 & 688653 & \multicolumn{3}{|c|}{5.632999999999999} & 5.2455 & \\
\hline CHEMBL1360291 & 688653 & \multicolumn{3}{|c|}{4.7330000000000005} & 5.2042 & \\
\hline CHEMBL2006221 & 688653 & 4.633 & 4.9684 & TST & & \\
\hline CHEMBL145 & 688653 & 6.433 & 6.2272 & TRN & & \\
\hline CHEMBL15 & 688653 & 4.583 & 4.7735 & TRN & & \\
\hline CHEMBL1565884 & 688653 & 4.883 & 5.0774 & TRN & & \\
\hline CHEMBL1323426 & 688653 & 4.883 & 5.646 & TST & & \\
\hline CHEMBL1560379 & 688653 & 4.883 & 5.2403 & TST & & \\
\hline CHEMBL15 & 688653 & \multicolumn{3}{|c|}{5.832999999999999} & .3101 & \\
\hline CHEMBL14 & 688653 & 4.683 & 5.3115 & TRN & & \\
\hline CHEMBL1446154 & 688653 & 5.033 & 5.1902 & TST & & \\
\hline CHEMBL1352897 & 688653 & 6.433 & 5.7548 & TRN & & \\
\hline CHEMBL1493983 & 688653 & \multicolumn{3}{|c|}{5.132999999999999} & 5.1095 & \\
\hline CHEMBL1451144 & 688 & 4.783 & 5.6755 & TRN & & \\
\hline CHEMBL 3194884 & 688653 & 4.783 & 5.1106 & TRN & & \\
\hline CHEMBL1489706 & 688653 & 4.783 & 5.056 & TST & & \\
\hline CHEMBL171699 & 688653 & \multicolumn{3}{|c|}{6.382999999999999} & 5.8596 & \\
\hline CHEMBL1437755 & 688 & 5.233 & 5.9432 & TRN & & \\
\hline CHEMBL14 & 688 & \multicolumn{3}{|c|}{5.632999999999999} & 5.6755 & TRN \\
\hline CHEMBL1563659 & 688653 & \multicolumn{3}{|c|}{4.7330000000000005} & 5.465 & TRN \\
\hline CHEMBL1492432 & 688653 & 5.683 & 5.5532 & TRN & & \\
\hline CHEMBL1488133 & 688653 & 6.4829 & 5.4955 & TST & & \\
\hline CHEMBL15 & $68 \varepsilon$ & & 5.0 & TST & & \\
\hline CHEMBL14 & 688 & 5.083 & 5.0633 & TRN & & \\
\hline CHEMBL1394798 & 688653 & 4.683 & 5.0133 & TRN & & \\
\hline CHEMBL3197885 & 688653 & \multicolumn{3}{|c|}{6.632999999999999} & 5.5401 & $\mathrm{TR}$ \\
\hline CHEMBL1450449 & 688653 & 4.833 & 5.2638 & TRN & & \\
\hline CHEMBL1339573 & 688653 & \multicolumn{3}{|c|}{5.632999999999999} & & 151 \\
\hline CHEMBL1558243 & 688653 & \multicolumn{3}{|c|}{5.7829999999999995} & 5.4819 & TRN \\
\hline CHEMBL1492932 & 688653 & \multicolumn{3}{|c|}{5.5329999999999995} & 5.4842 & TRN \\
\hline CHEMBL3192520 & 688653 & 4.783 & 5.2422 & TRN & & \\
\hline CHEMBL1485879 & 688653 & 4.783 & 5.0721 & TST & & \\
\hline CHEMBL3212956 & 688653 & \multicolumn{3}{|c|}{5.382999999999999} & 5.1318 & TST \\
\hline CHEMBL1721986 & 688653 & 5.3329 & 99999995 & & 5.2767 & TRN \\
\hline CHEMBL1384809 & 688653 & 4.7330 & 0000000 & 005 & 5.3555 & TRN \\
\hline CHEMBL1366491 & 688653 & 4.9830 & 0000000 & 005 & 4.9861 & $\mathrm{TR}$ \\
\hline
\end{tabular}




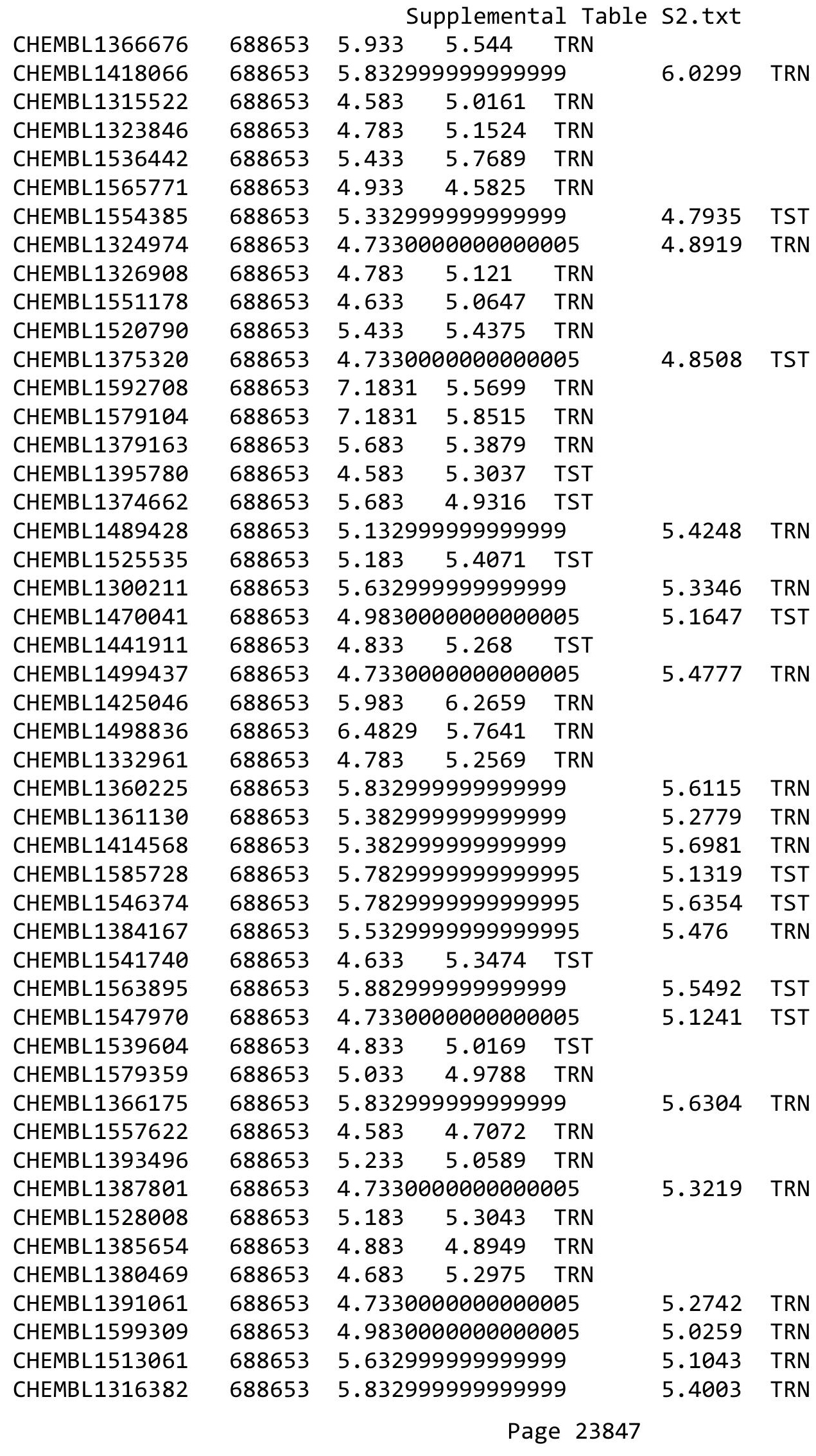




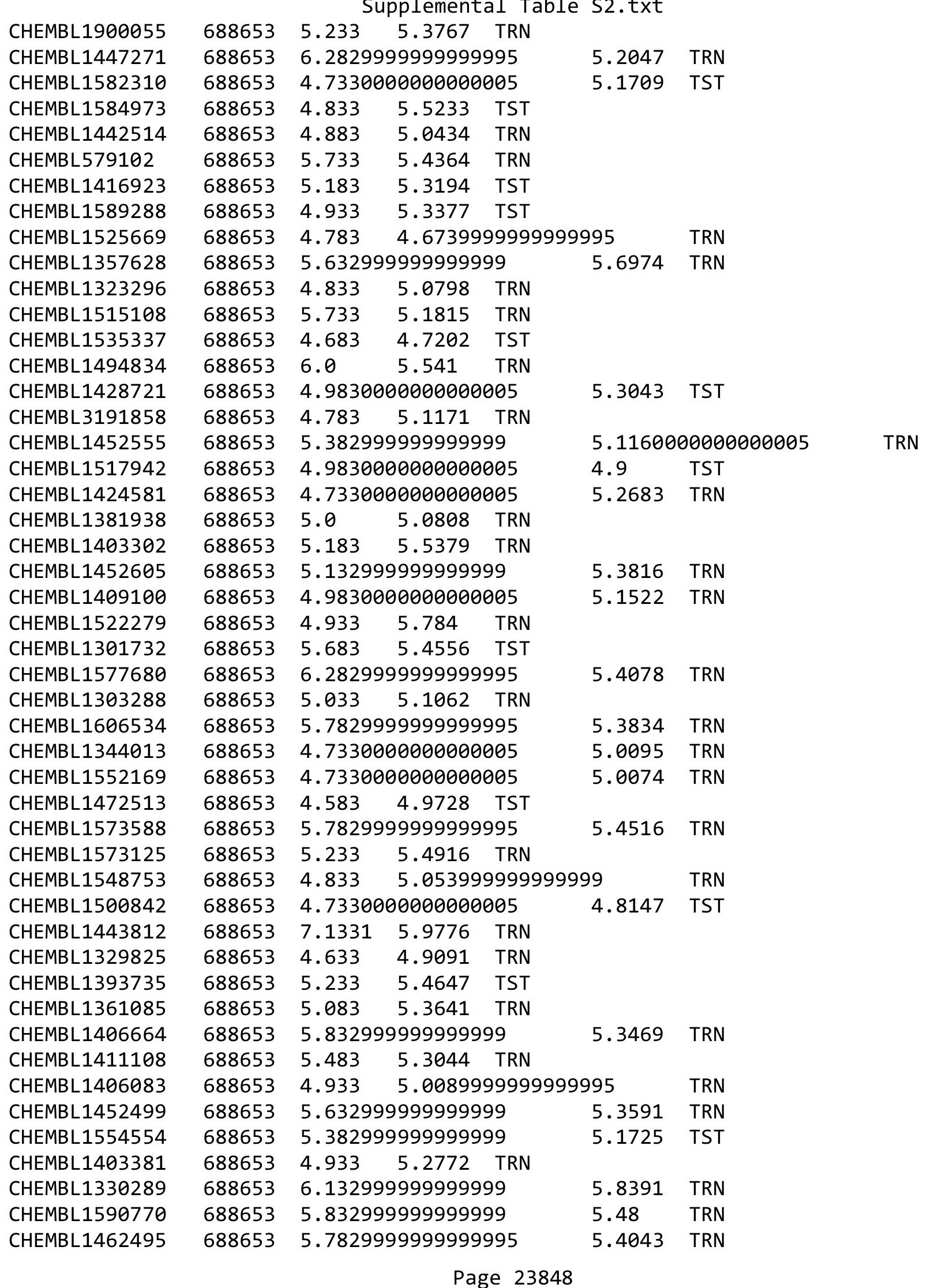




\begin{tabular}{|c|c|c|c|c|c|c|}
\hline \multirow{3}{*}{$\begin{array}{l}\text { CHEMBL } 1356838 \\
\text { CHFMRI } 1497779\end{array}$} & \multicolumn{6}{|c|}{ Supplemental Table S2.txt } \\
\hline & 688653 & \multicolumn{3}{|c|}{5.7829999999999995} & 5.5472 & TRN \\
\hline & 688653 & \multicolumn{3}{|c|}{4.7330000000000005} & 5.5633 & TRN \\
\hline CHEMBL1370581 & 688653 & 4.933 & 5.0489 & TRN & & \\
\hline CHEMBL466933 & 688653 & 4.9 & 5.3891 & TRN & & \\
\hline CHEMBL1441225 & 688653 & \multicolumn{3}{|c|}{5.632999999999999} & 5.4422 & TST \\
\hline CHEMBL1381126 & 688653 & \multicolumn{3}{|c|}{6.332999999999999} & 5.6381 & TRN \\
\hline CHEMBL1547326 & 688653 & 4.833 & 5.0514 & TRN & & \\
\hline CHEMBL1374674 & 688653 & 4.633 & 4.8999 & TRN & & \\
\hline CHEMBL1350077 & 688653 & \multicolumn{3}{|c|}{5.132999999999999} & 5.2543 & TST \\
\hline CHEMBL1464798 & 688653 & 4.833 & 4.718 & TRN & & \\
\hline CHEMBL1302906 & 688653 & \multicolumn{3}{|c|}{6.132999999999999} & 5.0094 & TRN \\
\hline CHEMBL1576493 & 688653 & \multicolumn{3}{|c|}{5.2829999999999995} & 5.7798 & TRN \\
\hline CHEMBL1449554 & 688653 & 4.933 & 5.3638 & TRN & & \\
\hline CHEMBL 2002223 & 688653 & \multicolumn{3}{|c|}{6.0329999999999995} & 5.7761 & TRN \\
\hline CHEMBL1565701 & 688653 & 4.883 & 4.9937 & TRN & & \\
\hline CHEMBL1373549 & 688653 & 6.183 & 5.8317 & TRN & & \\
\hline CHEMBL1533419 & 688653 & 4.783 & 5.3549 & TRN & & \\
\hline CHEMBL1470120 & 688653 & 5.483 & 5.7644 & TRN & & \\
\hline CHEMBL1446253 & 688653 & 4.833 & 5.3134 & TRN & & \\
\hline CHEMBL3209112 & 688653 & \multicolumn{3}{|c|}{6.5329999999999995} & 5.1788 & TRN \\
\hline CHEMBL 1307715 & 688653 & \multicolumn{3}{|c|}{4.9830000000000005} & 5.0002 & TST \\
\hline CHEMBL1601972 & 688653 & 4.833 & 4.7343 & TRN & & \\
\hline CHEMBL1584207 & 688653 & \multicolumn{3}{|c|}{5.582999999999999} & 5.1161 & TRN \\
\hline CHEMBL1372397 & 688653 & 5.033 & 5.003 & TRN & & \\
\hline CHEMBL 3198180 & 688653 & 5.033 & 4.8125 & TRN & & \\
\hline CHEMBL1519021 & 688653 & 5.183 & 5.4248 & TRN & & \\
\hline CHEMBL1489071 & 688653 & \multicolumn{3}{|c|}{5.5329999999999995} & 5.4937 & TRN \\
\hline CHEMBL1314853 & 688653 & 4.633 & 4.9923 & TRN & & \\
\hline CHEMBL1476353 & 688653 & 4.783 & 4.6482 & TRN & & \\
\hline CHEMBL1411342 & 688653 & 4.833 & 5.188 & TST & & \\
\hline CHEMBL1577623 & 688653 & 5.083 & 5.6393 & TST & & \\
\hline CHEMBL1332804 & 688653 & \multicolumn{3}{|c|}{6.382999999999999} & 5.9157 & TRN \\
\hline CHEMBL1574888 & 688653 & 5.683 & 5.5312 & TRN & & \\
\hline CHEMBL1377154 & 688653 & 4.95 & 5.2586 & TRN & & \\
\hline CHEMBL1534174 & 688653 & \multicolumn{3}{|c|}{5.882999999999999} & 6.0229 & TRN \\
\hline CHEMBL1310343 & 688653 & \multicolumn{3}{|c|}{5.332999999999999} & 5.5526 & TST \\
\hline CHEMBL236899 & 688653 & \multicolumn{3}{|c|}{5.2829999999999995} & 5.6067 & TRN \\
\hline CHEMBL1552486 & 688653 & \multicolumn{3}{|c|}{5.882999999999999} & 4.872 & TST \\
\hline CHEMBL1400889 & 688653 & 6.183 & 5.2572 & TRN & & \\
\hline CHEMBL 260342 & 688653 & \multicolumn{3}{|c|}{6.832999999999999} & 6.1408 & TRN \\
\hline CHEMBL602174 & 688653 & 4.783 & 5.1683 & TST & & \\
\hline CHEMBL1606607 & 688653 & \multicolumn{3}{|c|}{6.632999999999999} & 5.1182 & TRN \\
\hline CHEMBL1710 & 688653 & 4.633 & 4.8508 & TST & & \\
\hline CHEMBL1609927 & 688653 & 4.833 & 5.2959 & TRN & & \\
\hline CHEMBL1343769 & 688653 & 5.882 & 9999999؟ & & 5.1281 & TST \\
\hline CHEMBL1509462 & 688653 & 5.132 & 99999995 & & 5.9959 & TRN \\
\hline CHEMBL1370818 & 688653 & 5.983 & 5.3889 & 9999 & 99 & TRN \\
\hline CHEMBL1578576 & 688653 & 4.933 & 5.3595 & TRN & & \\
\hline
\end{tabular}




\begin{tabular}{|c|c|c|c|c|c|c|}
\hline & & \multicolumn{5}{|c|}{ Supplemental Table S2.txt } \\
\hline CHEMBL1466243 & 688653 & 5.083 & 5.027 & TRN & & \\
\hline CHEMBL1551969 & 688653 & 4.683 & 5.1828 & TST & & \\
\hline CHEMBL1319307 & 688653 & 4.783 & 4.9967 & TST & & \\
\hline CHEMBL1363275 & 688653 & 4.883 & 5.1795 & TRN & & \\
\hline CHEMBL1965976 & 688653 & \multicolumn{3}{|c|}{5.132999999999999} & 5.8883 & TRN \\
\hline CHEMBL1391837 & 688653 & \multicolumn{3}{|c|}{5.132999999999999} & 4.981 & TRN \\
\hline CHEMBL1303620 & 688653 & 5.733 & 6.1075 & TRN & & \\
\hline CHEMBL1445373 & 688653 & \multicolumn{3}{|c|}{5.132999999999999} & 5.0709 & TRN \\
\hline CHEMBL1350332 & 688653 & \multicolumn{3}{|c|}{6.132999999999999} & 5.7027 & TRN \\
\hline CHEMBL1429140 & 688653 & 5.683 & 4.9278 & TRN & & \\
\hline CHEMBL1599104 & 688653 & \multicolumn{3}{|c|}{5.7829999999999995} & 5.251 & TRN \\
\hline CHEMBL1519607 & 688653 & \multicolumn{3}{|c|}{4.7330000000000005} & 5.3542 & TRN \\
\hline CHEMBL1372558 & 688653 & 4.833 & 5.3613 & TRN & & \\
\hline CHEMBL1454397 & 688653 & 5.683 & 4.9985 & TRN & & \\
\hline CHEMBL1520839 & 688653 & \multicolumn{3}{|c|}{4.9830000000000005} & 5.1268 & TRN \\
\hline CHEMBL1544818 & 688653 & 6.183 & 5.3383 & TST & & \\
\hline CHEMBL1385387 & 688653 & 4.583 & 5.3362 & TST & & \\
\hline CHEMBL1582518 & 688653 & 4.783 & 5.3369 & TST & & \\
\hline CHEMBL1535455 & 688653 & 4.783 & 4.9256 & TRN & & \\
\hline CHEMBL591519 & 688653 & 4.883 & 5.25 & TRN & & \\
\hline CHEMBL1427832 & 688653 & 5.933 & 5.7546 & TRN & & \\
\hline CHEMBL3209474 & 688653 & 5.733 & 5.4399 & TST & & \\
\hline CHEMBL1510319 & 688653 & 5.033 & 5.0774 & TRN & & \\
\hline CHEMBL1467992 & 688653 & 5.183 & 5.0459 & TRN & & \\
\hline CHEMBL1399587 & 688653 & 4.883 & 5.0565 & TRN & & \\
\hline CHEMBL1375009 & 688653 & 4.883 & 5.2677 & TST & & \\
\hline CHEMBL1553394 & 688653 & 5.233 & 4.9738 & TRN & & \\
\hline CHEMBL1394726 & 688653 & \multicolumn{3}{|c|}{5.132999999999999} & 5.1923 & TRN \\
\hline CHEMBL1362849 & 688653 & \multicolumn{3}{|c|}{5.2829999999999995} & 5.2979 & TRN \\
\hline CHEMBL1608766 & 688653 & 5.433 & 5.2991 & TRN & & \\
\hline CHEMBL1401034 & 688653 & 5.233 & 5.3263 & TST & & \\
\hline CHEMBL1537902 & 688653 & \multicolumn{3}{|c|}{4.7330000000000005} & 5.1957 & TST \\
\hline CHEMBL1601832 & 688653 & 4.883 & 4.945 & TRN & & \\
\hline CHEMBL3209378 & 688653 & \multicolumn{3}{|c|}{5.832999999999999} & 5.274 & TRN \\
\hline CHEMBL3208453 & 688653 & 4.833 & 5.5371 & TST & & \\
\hline CHEMBL1605025 & 688653 & 6.183 & 5.7414 & TST & & \\
\hline CHEMBL282234 & 688653 & \multicolumn{3}{|c|}{5.882999999999999} & 5.4759 & TRN \\
\hline CHEMBL3207939 & 688653 & 5.233 & 5.3711 & TRN & & \\
\hline CHEMBL1337614 & 688653 & 5.083 & 5.2172 & TRN & & \\
\hline CHEMBL1532418 & 688653 & 4.583 & 5.4845 & TRN & & \\
\hline CHEMBL1454211 & 688653 & \multicolumn{3}{|c|}{5.332999999999999} & 5.0202 & TRN \\
\hline CHEMBL1575448 & 688653 & 5.083 & 5.3663 & TRN & & \\
\hline CHEMBL1411450 & 688653 & \multicolumn{3}{|c|}{5.632999999999999} & 5.3296 & TRN \\
\hline CHEMBL1610938 & 688653 & \multicolumn{3}{|c|}{5.332999999999999} & 5.9027 & TRN \\
\hline CHEMBL1306726 & 688653 & 4.883 & 5.1919 & TRN & & \\
\hline CHEMBL1379729 & 688653 & \multicolumn{3}{|c|}{5.882999999999999} & 5.5202 & TRN \\
\hline CHEMBL1378507 & 688653 & 4.883 & 5.2036 & TST & & \\
\hline CHEMBL1309315 & 688653 & 4.883 & 5.9289 & TST & & \\
\hline
\end{tabular}




\begin{tabular}{|c|c|c|c|c|c|c|c|}
\hline \multicolumn{8}{|c|}{ Supplemental Table S2.txt } \\
\hline CHEMBL1374788 & 688653 & 4.933 & 4.6603 & TST & & & \\
\hline CHEMBL1541324 & 688653 & 4.833 & 5.1056 & TRN & & & \\
\hline CHEMBL1362236 & 688653 & \multicolumn{3}{|c|}{4.7330000000000005} & 5.6106 & TRN & \\
\hline CHEMBL3212023 & 688653 & \multicolumn{3}{|c|}{4.9830000000000005} & \multicolumn{2}{|c|}{5.093999999999999} & TST \\
\hline CHEMBL1359848 & 688653 & \multicolumn{3}{|c|}{4.7330000000000005} & 5.3967 & TRN & \\
\hline CHEMBL1572538 & 688653 & 6.0 & 5.5563 & TRN & & & \\
\hline CHEMBL1466092 & 688653 & 4.833 & 4.8625 & TRN & & & \\
\hline CHEMBL1556289 & 688653 & 5.683 & 5.4233 & TRN & & & \\
\hline CHEMBL1562012 & 688653 & 6.433 & 5.9601 & TRN & & & \\
\hline CHEMBL1498988 & 688653 & 4.783 & 4.5842 & TST & & & \\
\hline CHEMBL1338640 & 688653 & \multicolumn{3}{|c|}{4.9830000000000005} & 5.6528 & TRN & \\
\hline CHEMBL1464372 & 688653 & 4.783 & 5.142 & TRN & & & \\
\hline CHEMBL1439347 & 688653 & \multicolumn{3}{|c|}{6.0329999999999995} & 5.2186 & TRN & \\
\hline CHEMBL1471762 & 688653 & 5.683 & 5.0883 & TRN & & & \\
\hline CHEMBL1410070 & 688653 & 4.883 & \multicolumn{3}{|c|}{5.257999999999999} & TRN & \\
\hline CHEMBL1600540 & 688653 & \multicolumn{3}{|c|}{5.332999999999999} & 5.2316 & TRN & \\
\hline CHEMBL1300722 & 688653 & \multicolumn{3}{|c|}{5.7829999999999995} & 5.0419 & TRN & \\
\hline CHEMBL1503703 & 688653 & 5.483 & 5.0439 & TST & & & \\
\hline CHEMBL1542140 & 688653 & 5.683 & 5.7271 & TRN & & & \\
\hline CHEMBL1314570 & 688653 & 5.483 & 5.5284 & TRN & & & \\
\hline CHEMBL1518905 & 688653 & \multicolumn{3}{|c|}{6.582999999999999} & 5.8764 & TST & \\
\hline CHEMBL1521136 & 688653 & \multicolumn{3}{|c|}{6.332999999999999} & \multicolumn{2}{|c|}{6.037000000000001} & TRN \\
\hline CHEMBL1589095 & 688653 & 5.183 & 5.1531 & TRN & & & \\
\hline CHEMBL1610709 & 688653 & 4.883 & 4.9492 & TRN & & & \\
\hline CHEMBL1528795 & 688653 & \multicolumn{3}{|c|}{4.7330000000000005} & 5.073 & TST & \\
\hline CHEMBL1483218 & 688653 & \multicolumn{3}{|c|}{5.882999999999999} & 5.5091 & TRN & \\
\hline CHEMBL2004776 & 688653 & 4.633 & 4.9973 & TST & & & \\
\hline CHEMBL3194767 & 688653 & 5.983 & 5.4488 & TRN & & & \\
\hline CHEMBL1428107 & 688653 & \multicolumn{3}{|c|}{5.332999999999999} & 5.3323 & TRN & \\
\hline CHEMBL1356546 & 688653 & 4.833 & 5.1648 & TRN & & & \\
\hline CHEMBL1424241 & 688653 & 5.183 & 5.2911 & TRN & & & \\
\hline CHEMBL 3207880 & 688653 & 4.833 & 5.648 & TRN & & & \\
\hline CHEMBL 3211735 & 688653 & 4.833 & 5.1724 & TRN & & & \\
\hline CHEMBL1426427 & 688653 & 5.483 & 5.2272 & TST & & & \\
\hline CHEMBL3191977 & 688653 & 5.683 & 5.6353 & TRN & & & \\
\hline CHEMBL1323128 & 688653 & 4.683 & 4.8058 & TRN & & & \\
\hline CHEMBL1421682 & 688653 & 5.483 & 5.2359 & TRN & & & \\
\hline CHEMBL1578173 & 688653 & \multicolumn{3}{|c|}{5.132999999999999} & 5.3102 & TST & \\
\hline CHEMBL1964833 & 688653 & 5.483 & 4.9821 & TRN & & & \\
\hline CHEMBL1301785 & 688653 & 4.783 & 5.2524 & TRN & & & \\
\hline CHEMBL1363936 & 688653 & \multicolumn{3}{|c|}{5.2829999999999995} & 4.9731 & TRN & \\
\hline CHEMBL1603967 & 688653 & \multicolumn{3}{|c|}{5.582999999999999} & 5.1762 & TRN & \\
\hline CHEMBL1497927 & 688653 & 5.933 & 5.5211 & TRN & & & \\
\hline CHEMBL1422237 & 688653 & \multicolumn{3}{|c|}{ 4.783 5.4315 TRN } & & & \\
\hline CHEMBL1396899 & 688653 & \multicolumn{3}{|c|}{4.7330000000000005} & 4.9194 & TRN & \\
\hline CHEMBL586465 & 688653 & 5.733 & 5.4383 & TRN & & & \\
\hline CHEMBL1567836 & 688653 & 5.2829 & 99999999 & 995 & 5.5314 & TRN & \\
\hline CHEMBL1507868 & 688653 & 5.3329 & 99999999 & & 5.3462 & TRN & \\
\hline
\end{tabular}




\begin{tabular}{|c|c|c|c|c|c|c|}
\hline \multirow{3}{*}{$\begin{array}{l}\text { CHEMBL1511727 } \\
\text { CHEMBL1317724 }\end{array}$} & \multirow{3}{*}{$\begin{array}{l}688653 \\
688653\end{array}$} & \multicolumn{5}{|c|}{ Supplemental Table S2.txt } \\
\hline & & \multicolumn{3}{|c|}{5.832999999999999} & 5.8128 & $\mathrm{~T}$ \\
\hline & & 4.583 & 5.477 & TST & & \\
\hline CHEMBL1588219 & 688653 & 6.183 & 5.4509 & TRN & & \\
\hline CHEMBL1569891 & 688653 & 5.183 & 5.584 & TRN & & \\
\hline CHEMBL1386815 & 688653 & \multicolumn{3}{|c|}{4.7330000000000005} & 5.5236 & \\
\hline CHEMBL3194013 & 688653 & 7.3325 & 5.88 & TRN & & \\
\hline CHEMBL1325319 & 688653 & \multicolumn{3}{|c|}{5.2829999999999995} & 5.3167 & \\
\hline CHEMBL1337801 & 688653 & \multicolumn{3}{|c|}{5.832999999999999} & 5.5397 & \\
\hline CHEMBL1387933 & 688653 & \multicolumn{3}{|c|}{5.2829999999999995} & 5.4034 & \\
\hline CHEMBL1396750 & 688653 & 4.883 & 5.0433 & TRN & & \\
\hline CHEMBL1539834 & 688653 & \multicolumn{3}{|c|}{5.2829999999999995} & 5.6832 & \\
\hline CHEMBL1561182 & 688653 & \multicolumn{3}{|c|}{4.7330000000000005} & 4.7009 & \\
\hline CHEMBL1570217 & 688653 & \multicolumn{3}{|c|}{6.2829999999999995} & 6.0968 & \\
\hline CHEMBL1360086 & 688653 & \multicolumn{3}{|c|}{5.832999999999999} & 6.079 & \\
\hline CHEMBL1562167 & 688653 & \multicolumn{3}{|c|}{5.382999999999999} & 4.6709 & \\
\hline CHEMBL1411680 & 688653 & 5.683 & 5.2706 & TRN & & \\
\hline CHEMBL1431019 & 688653 & 4.633 & 5.4787 & TRN & & \\
\hline CHEMBL 3192847 & 688653 & 5.083 & 5.1732 & TRN & & \\
\hline CHEMBL 3214388 & 688653 & \multicolumn{3}{|c|}{5.382999999999999} & 5.025 & \\
\hline CHEMBL1553867 & 688653 & 4.633 & 5.1553 & TST & & \\
\hline CHEMBL1527377 & 688653 & 5.683 & 5.4016 & TRN & & \\
\hline CHEMBL & 688 & 4.583 & 5.1 & TST & & \\
\hline CHEMBL 1 & 688653 & 4.833 & 5.0 & TRN & & \\
\hline CHEMBL1349634 & 688653 & 4.833 & 4.6096 & TRN & & \\
\hline CHEMBL1362914 & 688653 & 4.933 & 4.768 & TST & & \\
\hline CHEMBL1333349 & 688653 & 6.0 & 5.6531 & TRN & & \\
\hline CHEMB & 688 & \multicolumn{3}{|c|}{6.2829999999999995} & 5.093 & \\
\hline CHEMBL1: & 688653 & \multicolumn{3}{|c|}{6.0329999999999995} & 5.2124 & \\
\hline CHEMBL1550565 & 688653 & \multicolumn{3}{|c|}{6.332999999999999} & 5.3315 & TP \\
\hline CHEMBL1379238 & 688653 & \multicolumn{3}{|c|}{5.332999999999999} & 5.2473 & \\
\hline CHEMBL1564383 & 688653 & 6.4829 & 5.8574 & TRN & & \\
\hline CHEMB & 688653 & \multicolumn{3}{|c|}{5.2829999999999995} & 5.3259 & \\
\hline CHEMBL & 688653 & 4.933 & 5.6229 & TST & & \\
\hline CHEMBL1325640 & 688653 & 4.783 & 5.2452 & TST & & \\
\hline CHEMBL1398282 & 688653 & \multicolumn{3}{|c|}{6.082999999999999} & 5.3403 & \\
\hline CHEMBL3197571 & 688653 & \multicolumn{3}{|c|}{5.332999999999999} & 5.1253 & \\
\hline CHEMB & 688653 & 4.933 & 4.9617 & TST & & \\
\hline CHEMBL1 & 688653 & 4.633 & 4.7943 & TRN & & \\
\hline CHEMBL 3212574 & 688653 & 4.833 & 4.9797 & TRN & & \\
\hline CHEMBL1418818 & 688653 & 5.183 & 5.5785 & TRN & & \\
\hline CHEMBL1417238 & 688653 & 6.233 & 5.7491 & TRN & & \\
\hline CHEMBL 3198507 & 688653 & 5.683 & 5.7169 & TRN & & \\
\hline CHEMBL1416347 & 688653 & 5.2829 & 99999999 & 995 & 5.8534 & \\
\hline CHEMBL1582806 & 688653 & 4.9830 & 00000000 & 005 & 5.3913 & \\
\hline CHEMBL1410343 & 688653 & 4.9830 & 00000000 & 005 & 4.9615 & \\
\hline CHEMBL1551653 & 688653 & 4.7330 & 00000000 & 005 & 5.3546 & \\
\hline CHEMBL1517153 & 688653 & 5.483 & 5.065 & TRN & & \\
\hline CHEMBL 3197758 & 688653 & 4.9830 & 00000000 & 005 & 5.0317 & $\mathrm{n}$ \\
\hline
\end{tabular}




\begin{tabular}{|c|c|c|c|c|c|c|}
\hline \multirow[b]{2}{*}{ CHEMBL1464170 } & \multirow[b]{2}{*}{688653} & \multicolumn{5}{|c|}{ Supplemental Table S2.txt } \\
\hline & & 5.683 & 4.8414 & TRN & & \\
\hline CHEMBL1977570 & 688653 & \multicolumn{3}{|c|}{5.632999999999999} & 5.7927 & TRN \\
\hline CHEMBL3196927 & 688653 & 4.883 & 5.1457 & TRN & & \\
\hline CHEMBL1381754 & 688653 & 5.033 & 5.48 & TST & & \\
\hline CHEMBL1402936 & 688653 & \multicolumn{3}{|c|}{5.7829999999999995} & 5.7403 & TRA \\
\hline CHEMBL 3213637 & 688653 & \multicolumn{3}{|c|}{6.382999999999999} & 5.2746 & TRN \\
\hline CHEMBL1509992 & 688653 & \multicolumn{3}{|c|}{5.832999999999999} & 5.3879 & TRN \\
\hline CHEMBL1308359 & 688653 & 4.933 & 5.315 & TRN & & \\
\hline CHEMBL1345298 & 688653 & 4.833 & 4.7203 & TST & & \\
\hline CHEMBL1417929 & 688653 & 5.183 & 5.2789 & TST & & \\
\hline CHEMBL1566772 & 688653 & 4.833 & 5.3671 & TST & & \\
\hline CHEMBL3189607 & 688653 & \multicolumn{3}{|c|}{5.882999999999999} & 5.7245 & TRA \\
\hline CHEMBL1532997 & 688653 & 4.833 & 5.4566 & TST & & \\
\hline CHEMBL1438123 & 688653 & 4.783 & 4.7556 & TRN & & \\
\hline CHEMBL1401601 & 688653 & 4.933 & 5.0882 & TST & & \\
\hline CHEMBL1342524 & 688653 & 6.7331 & 5.396 & TRN & & \\
\hline CHEMBL1554881 & 688653 & 6.0 & 5.8259 & TRN & & \\
\hline CHEMBL1352129 & 688653 & 5.233 & 5.0475 & TST & & \\
\hline CHEMBL1580176 & 688653 & \multicolumn{3}{|c|}{4.9830000000000005} & 5.0882 & TRN \\
\hline CHEMBL1342896 & 688653 & \multicolumn{3}{|c|}{6.7829999999999995} & 5.7596 & TRN \\
\hline CHEMBL1384550 & 688653 & 4.583 & 4.9732 & TST & & \\
\hline CHEMBL1539502 & 688653 & \multicolumn{3}{|c|}{7.082999999999999} & 6.1112 & TRA \\
\hline CHEMBL1420243 & 688653 & \multicolumn{3}{|c|}{6.7829999999999995} & 5.8902 & TRN \\
\hline CHEMBL1398391 & 688653 & 4.633 & 5.0225 & TRN & & \\
\hline CHEMBL1449685 & 688653 & \multicolumn{3}{|c|}{5.2829999999999995} & 5.3749 & TST \\
\hline CHEMBL1383514 & 688653 & 4.833 & 5.5317 & TST & & \\
\hline CHEMBL1465434 & 688653 & \multicolumn{3}{|c|}{6.082999999999999} & 5.6329 & TRN \\
\hline CHEMBL1303489 & 688653 & 4.633 & 4.4071 & TRN & & \\
\hline CHEMBL1388694 & 688653 & 5.233 & 5.6876 & TRN & & \\
\hline CHEMBL1330065 & 688653 & 4.85 & 5.1643 & TRN & & \\
\hline CHEMBL1439115 & 688653 & \multicolumn{3}{|c|}{5.382999999999999} & 5.3917 & TRN \\
\hline CHEMBL1570624 & 688653 & 7.2832 & 5.8986 & TST & & \\
\hline CHEMBL1328862 & 688653 & \multicolumn{3}{|c|}{5.132999999999999} & 5.5569 & TRN \\
\hline CHEMBL 2000499 & 688653 & 5.183 & 5.4926 & TRN & & \\
\hline CHEMBL1428108 & 688653 & \multicolumn{3}{|c|}{6.382999999999999} & 5.8324 & TRN \\
\hline CHEMBL1495688 & 688653 & 6.8831 & 5.5359 & TRN & & \\
\hline CHEMBL1309842 & 688653 & \multicolumn{3}{|c|}{4.7330000000000005} & 5.3632 & TRN \\
\hline CHEMBL1600867 & 688653 & 6.9329 & 5.2203 & TRN & & \\
\hline CHEMBL1390956 & 688653 & 5.033 & 5.2528 & TST & & \\
\hline CHEMBL1506708 & 688653 & \multicolumn{3}{|c|}{5.832999999999999} & 5.3386 & TST \\
\hline CHEMBL1551641 & 688653 & 4.583 & 5.1969 & TST & & \\
\hline CHEMBL1321820 & 688653 & 5.033 & 5.0594 & TRN & & \\
\hline CHEMBL1401951 & 688653 & 4.683 & 5.1191 & TST & & \\
\hline CHEMBL1525468 & 688653 & 5.933 & 5.6098 & TRN & & \\
\hline CHEMBL1460071 & 688653 & 4.783 & 5.1993 & TRN & & \\
\hline CHEMBL1429517 & 688653 & \multicolumn{3}{|c|}{5.132999999999999} & 5.5198 & TRN \\
\hline CHEMBL1489834 & 688653 & \multicolumn{3}{|c|}{4.9830000000000005} & 5.0688 & TRN \\
\hline CHEMBL1412300 & 688653 & 4.883 & 5.2884 & TST & & \\
\hline
\end{tabular}




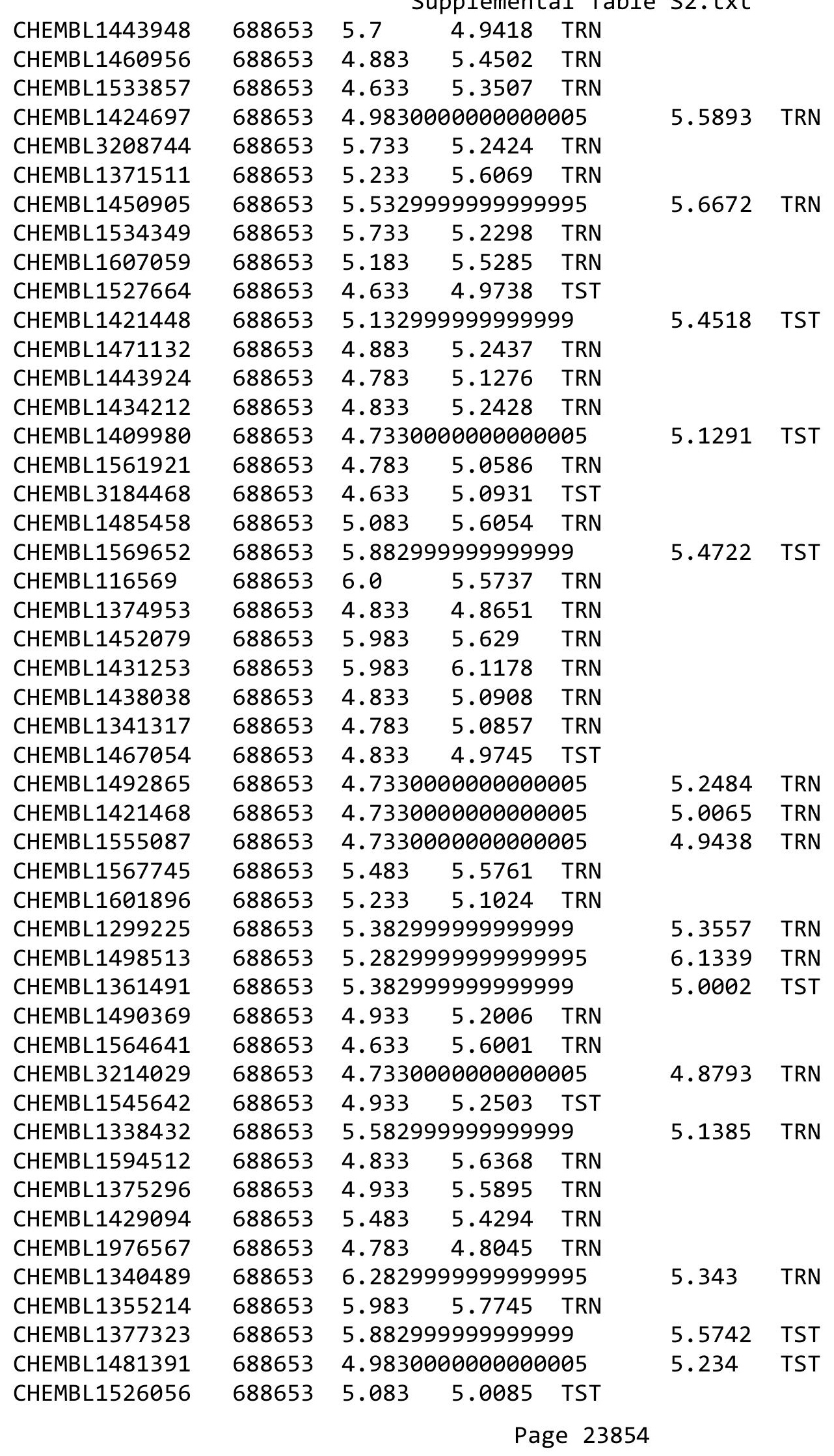




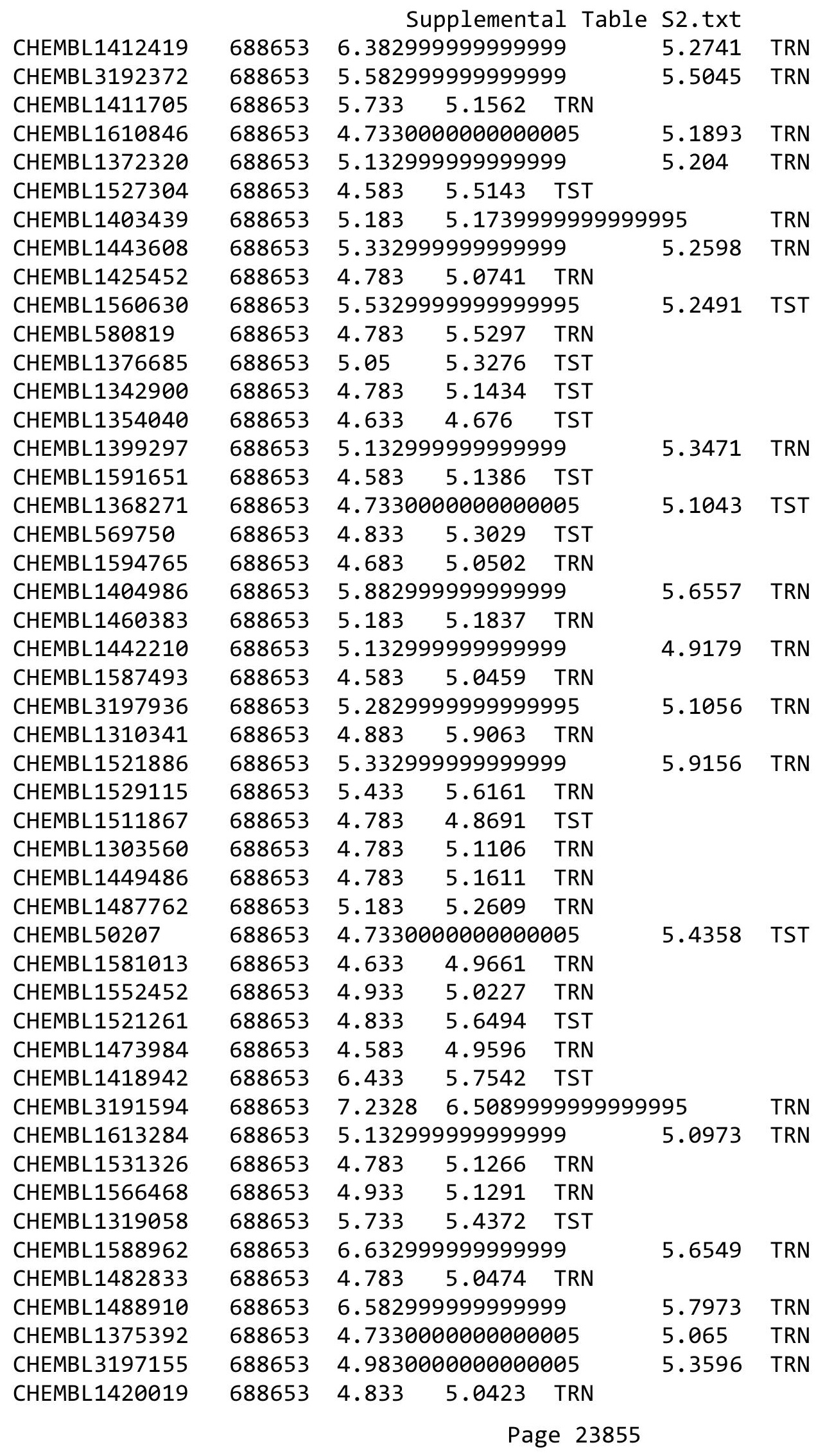




\begin{tabular}{|c|c|c|c|c|c|c|}
\hline \multirow{3}{*}{$\begin{array}{l}\text { CHEMBL } 1494925 \\
\text { CHEMBL1537520 }\end{array}$} & \multicolumn{6}{|c|}{ Supplemental Table S2.txt } \\
\hline & 688653 & \multicolumn{4}{|c|}{4.7330000000000005} & \\
\hline & 688653 & \multicolumn{3}{|c|}{4.7330000000000005} & 4.9599 & \\
\hline CHEMBL1387418 & 688653 & 4.833 & 4.9933 & TRN & & \\
\hline CHEMBL1528245 & 688653 & 5.033 & 5.2886 & TRN & & \\
\hline CHEMBL1356896 & 688653 & \multicolumn{3}{|c|}{5.132999999999999} & 5.1879 & \\
\hline CHEMBL1334323 & 688653 & \multicolumn{3}{|c|}{4.7330000000000005} & 5.2705 & \\
\hline CHEMBL1537417 & 688653 & 5.233 & 5.0089 & TST & & \\
\hline CHEMBL1517690 & 688653 & \multicolumn{3}{|c|}{4.7330000000000005} & 4.8731 & \\
\hline CHEMBL1488253 & 688653 & 5.983 & 5.3376 & TRN & & \\
\hline CHEMBL201221 & 688653 & 5.183 & 5.6483 & TRN & & \\
\hline CHEMBL1356867 & 688653 & 5.683 & 5.6152 & TRN & & \\
\hline CHEMBL138 & 688653 & 5.083 & 6.024 & TRN & & \\
\hline CHEMBL1508091 & 688653 & \multicolumn{3}{|c|}{6.382999999999999} & 5.9948 & \\
\hline CHEMBL1362848 & 688653 & 4.833 & 5.5416 & TRN & & \\
\hline CHEMBL1457974 & 688653 & 4.783 & 4.8127 & TST & & \\
\hline CHEMBL132 & 688 & 4.933 & 5.16 & TRN & & \\
\hline CHEMBL14 & $68 \varepsilon$ & 5.233 & 5.3611 & TRN & & \\
\hline CHEMBL1401652 & 688653 & \multicolumn{3}{|c|}{5.832999999999999} & 6.3653 & \\
\hline CHEMBL3213515 & 688653 & \multicolumn{3}{|c|}{5.882999999999999} & 5.4702 & \\
\hline CHEMBL1525554 & 688653 & \multicolumn{3}{|c|}{5.2829999999999995} & 1579 & \\
\hline CHEMBL1 & 688 & 4.783 & 5.2915 & TRN & & \\
\hline CHEMBL1 & 688 & 4.883 & 4.9585 & TRN & & \\
\hline CHEMBL1476322 & 688653 & 5.033 & 5.2678 & TST & & \\
\hline CHEMBL1563629 & 688653 & 4.633 & 4.8662 & TRN & & \\
\hline CHEMBL1990383 & 688653 & \multicolumn{3}{|c|}{5.632999999999999} & 5.1092 & \\
\hline CHEMBL1 & 688 & 5.683 & 5.6611 & TRN & & \\
\hline CHEMBL1411878 & 688 & 5.733 & 5.6978 & TRN & & \\
\hline CHEMBL1373648 & 688653 & 4.883 & 5.6082 & TRN & & \\
\hline CHEMBL1312720 & 688653 & 6.4829 & 5.3633 & TRN & & \\
\hline CHEMBL1453731 & 688653 & \multicolumn{3}{|c|}{5.7829999999999995} & 5.6301 & \\
\hline CHEMBL1 & 688 & \multicolumn{3}{|c|}{6.632999999999999} & 5.4984 & \\
\hline CHEMBL14ع & 688653 & 4.683 & 5.8885 & TRN & & \\
\hline CHEMBL1368519 & 688653 & \multicolumn{3}{|c|}{6.582999999999999} & 6.2662 & \\
\hline CHEMBL1396715 & 688653 & 6.9329 & 6.2017 & TRN & & \\
\hline CHEMBL1327873 & 688653 & \multicolumn{3}{|c|}{4.9830000000000005} & 5.3604 & \\
\hline CHEMBL1 & 688653 & 4.933 & 5.0301 & TST & & \\
\hline CHEMBL3 & 688653 & 4.883 & 5.349 & TST & & \\
\hline CHEMBL1440908 & 688653 & 4.833 & 5.2337 & TRN & & \\
\hline CHEMBL1517823 & 688653 & 4.833 & 5.3175 & TST & & \\
\hline CHEMBL16 & 688653 & \multicolumn{3}{|c|}{4.7330000000000005} & 4.9913 & \\
\hline CHEMBL 31 & 688653 & 5.733 & \multicolumn{3}{|c|}{5.531000000000001} & \\
\hline CHEMBL1470676 & 688653 & 7.2832 & 6.0705 & TRN & & \\
\hline CHEMBL1564034 & 688653 & 5.033 & 5.115 & TRN & & \\
\hline CHEMBL1382069 & 688653 & 4.883 & 5.2537 & TST & & \\
\hline CHEMBL1343711 & 688653 & 5.083 & 4.9145 & TST & & \\
\hline CHEMBL3198613 & 688653 & 5.733 & 5.3205 & TRN & & \\
\hline CHEMBL1562906 & 688653 & \multicolumn{3}{|c|}{4.7330000000000005} & 4.8924 & \\
\hline CHEMBL1421315 & 688653 & \multicolumn{3}{|c|}{5.832999999999999} & 5.9534 & \\
\hline
\end{tabular}




\begin{tabular}{|c|c|c|c|c|c|c|c|}
\hline \multicolumn{8}{|c|}{ Supplemental Table S2.txt } \\
\hline CHEMBL1577299 & 688653 & 4.833 & 5.1251 & TRN & & & \\
\hline CHEMBL1377625 & 688653 & 4.683 & 4.9797 & TRN & & & \\
\hline CHEMBL1583827 & 688653 & 4.73300 & 00000000 & 005 & 5.2206 & TRN & \\
\hline CHEMBL1382030 & 688653 & 6.13299 & 99999999 & & 5.0495 & TRN & \\
\hline CHEMBL1595763 & 688653 & 4.583 & 5.4558 & TST & & & \\
\hline CHEMBL1575202 & 688653 & 4.783 & 5.3481 & TST & & & \\
\hline CHEMBL1613595 & 688653 & 5.483 & 5.0891 & TRN & & & \\
\hline CHEMBL1475634 & 688653 & 4.583 & 4.7225 & TRN & & & \\
\hline CHEMBL1319041 & 688653 & 4.833 & 5.0627 & TST & & & \\
\hline CHEMBL1422015 & 688653 & 5.53299 & 99999999 & 995 & 5.3476 & TRN & \\
\hline CHEMBL1419469 & 688653 & 4.633 & 5.04899 & 999999 & 995 & TST & \\
\hline CHEMBL3199917 & 688653 & 6.38299 & 99999999 & & 5.6329 & TST & \\
\hline CHEMBL1496095 & 688653 & 4.583 & 4.7693 & TST & & & \\
\hline CHEMBL1487676 & 688653 & 4.98300 & 00000000 & 005 & 5.1675 & TST & \\
\hline CHEMBL3191271 & 688653 & 5.683 & 4.9613 & TRN & & & \\
\hline CHEMBL1428400 & 688653 & 4.933 & 5.30200 & 000000 & 005 & TRN & \\
\hline CHEMBL1572391 & 688653 & 5.13299 & 99999999 & & 5.2096 & TRN & \\
\hline CHEMBL1552341 & 688653 & 4.73300 & 00000000 & 005 & 4.8978 & TST & \\
\hline CHEMBL1344516 & 688653 & 4.783 & 5.4031 & TRN & & & \\
\hline CHEMBL1481699 & 688653 & 4.833 & 5.237 & TRN & & & \\
\hline CHEMBL1403028 & 688653 & 4.783 & 5.0837 & TRN & & & \\
\hline CHEMBL1310663 & 688653 & 5.53299 & 99999999 & 995 & 5.3787 & TST & \\
\hline CHEMBL1429711 & 688653 & 5.78299 & 99999999 & 995 & 5.5443 & TST & \\
\hline CHEMBL1302849 & 688653 & 4.833 & 5.1199 & TRN & & & \\
\hline CHEMBL1463545 & 688653 & 4.73300 & 00000000 & 005 & 5.1734 & TRN & \\
\hline CHEMBL1496258 & 688653 & 4.683 & 5.2802 & TRN & & & \\
\hline CHEMBL1442418 & 688653 & 4.73300 & 00000000 & 005 & 4.8597 & TST & \\
\hline CHEMBL1361577 & 688653 & 6.8831 & 5.6761 & TRN & & & \\
\hline CHEMBL1304531 & 688653 & 4.783 & 5.2242 & TRN & & & \\
\hline CHEMBL1502945 & 688653 & 4.683 & 5.1173 & TRN & & & \\
\hline CHEMBL1422647 & 688653 & 5.233 & 5.4551 & TST & & & \\
\hline CHEMBL1359746 & 688653 & 4.633 & 5.131 & TRN & & & \\
\hline CHEMBL1508357 & 688653 & 6.183 & 5.24 & TST & & & \\
\hline CHEMBL1406144 & 688653 & 5.483 & 4.9373 & TRN & & & \\
\hline CHEMBL1440489 & 688653 & 5.58299 & 99999999 & & 5.16299 & 9999999999 & TRN \\
\hline CHEMBL1601903 & 688653 & 5.25 & 5.0255 & TST & & & \\
\hline CHEMBL1505300 & 688653 & 6.33299 & 99999999 & & 5.4103 & TRN & \\
\hline CHEMBL1320281 & 688653 & 6.433 & 5.3535 & TST & & & \\
\hline CHEMBL1333784 & 688653 & 5.78299 & 99999999 & 995 & 5.4665 & TRN & \\
\hline CHEMBL3189663 & 688653 & 5.683 & 5.2006 & TRN & & & \\
\hline CHEMBL1300074 & 688653 & 5.683 & 5.6121 & TRN & & & \\
\hline CHEMBL1525940 & 688653 & 5.233 & 5.4008 & TRN & & & \\
\hline CHEMBL1335855 & 688653 & 4.933 & 5.8395 & TRN & & & \\
\hline CHEMBL1374234 & 688653 & 4.98300 & 00000000 & 005 & 5.1607 & TRN & \\
\hline CHEMBL1507104 & 688653 & 4.73300 & 00000000 & 005 & 4.9853 & TRN & \\
\hline CHEMBL1424485 & 688653 & 5.033 & 5.2894 & TRN & & & \\
\hline CHEMBL1438256 & 688653 & 5.53299 & 99999999 & 995 & 5.5644 & TRN & \\
\hline CHEMBL1455078 & 688653 & 4.783 & 4.8221 & TST & & & \\
\hline
\end{tabular}




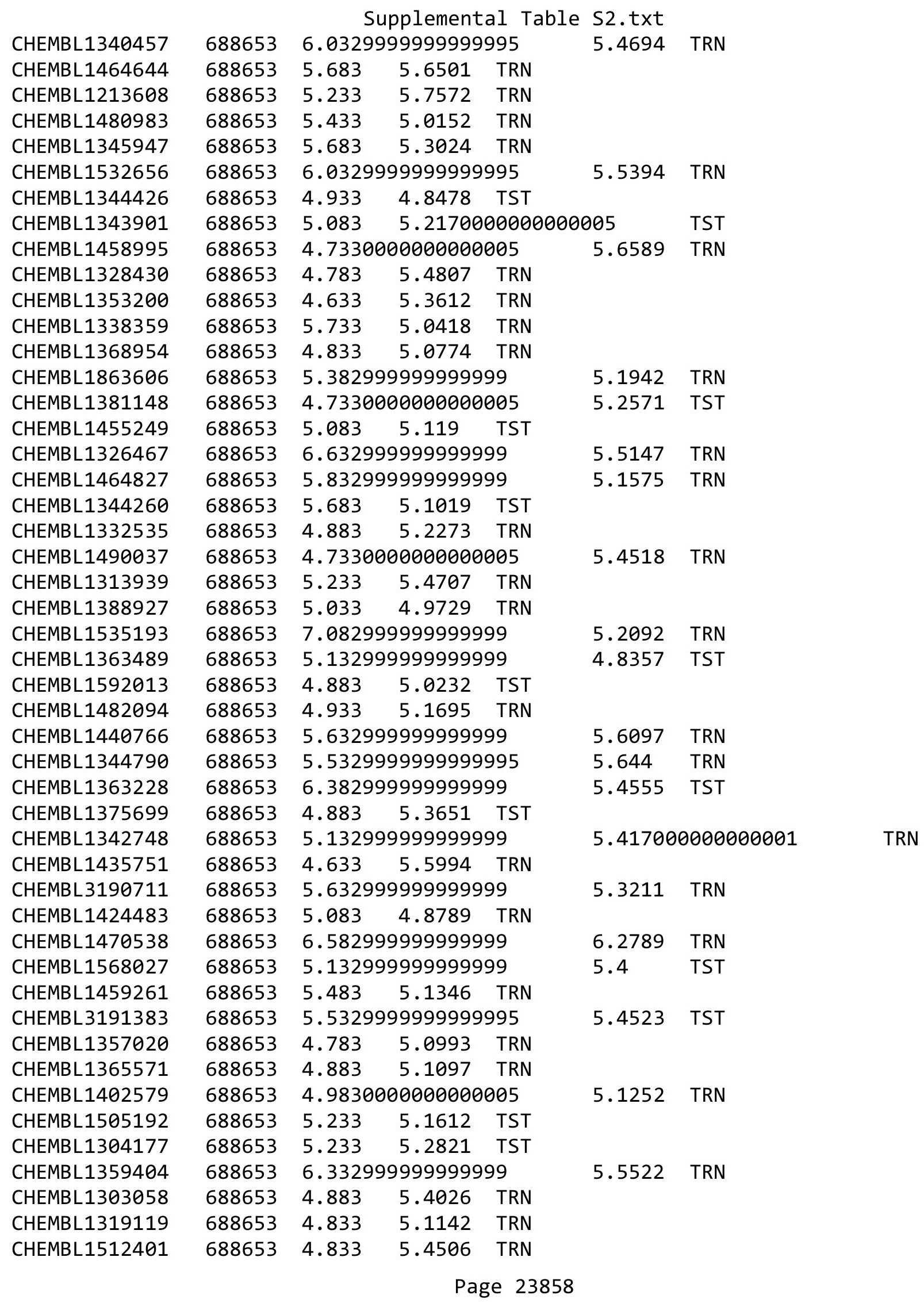




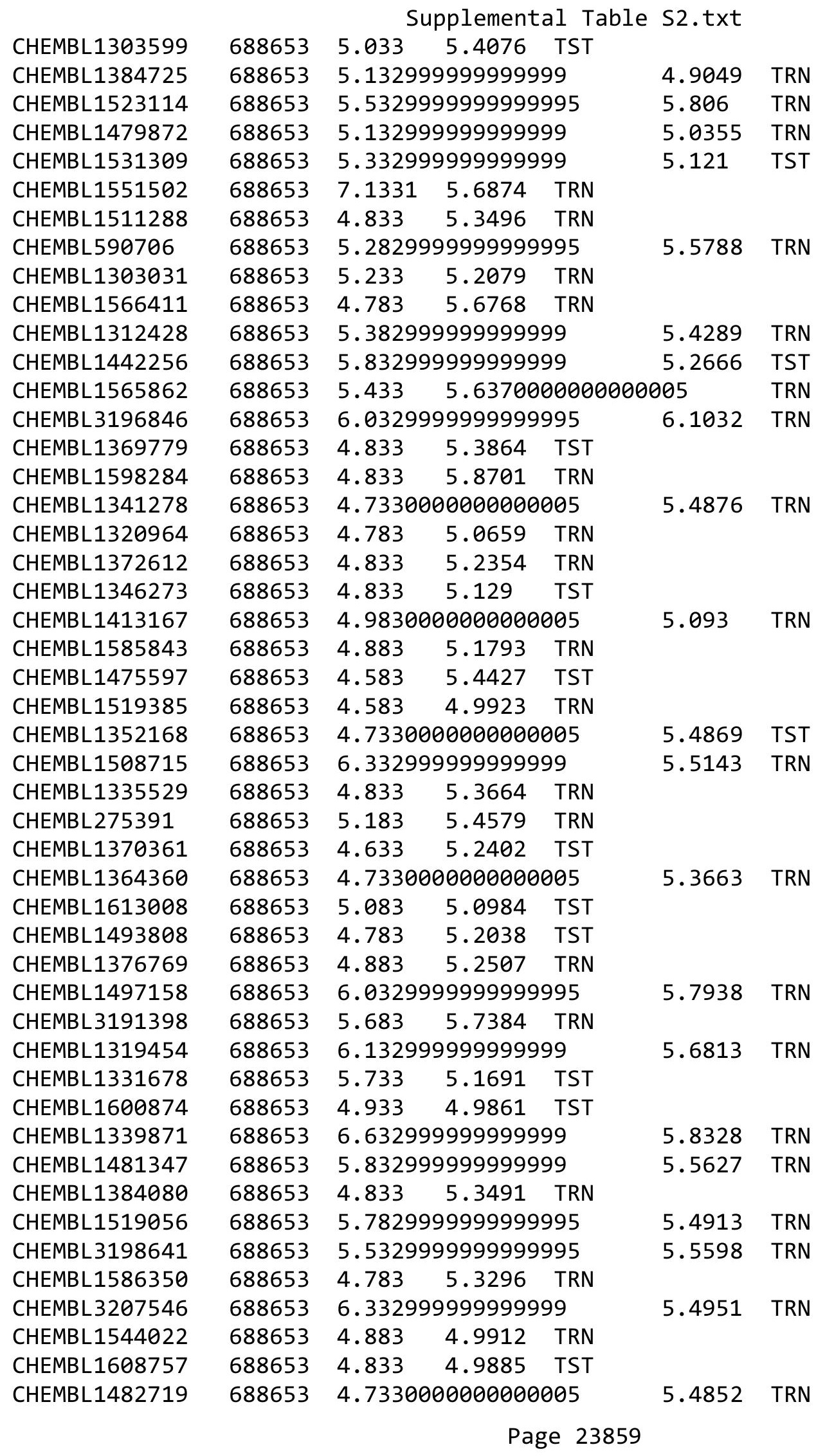




\begin{tabular}{|c|c|c|c|c|c|c|}
\hline & & & pplemer & al & s2.txt & \\
\hline CHEMBL1537712 & 688653 & 4.7336 & 0000000 & 205 & 5.1599 & TST \\
\hline CHEMBL1592703 & 688653 & 5.2829 & 99999995 & 995 & 5.774 & TST \\
\hline CHEMBL1387649 & 688653 & 4.783 & 5.1592 & TRN & & \\
\hline CHEMBL1387307 & 688653 & 4.783 & 4.9732 & TRN & & \\
\hline CHEMBL276139 & 688653 & 4.583 & 5.1993 & TST & & \\
\hline CHEMBL3196800 & 688653 & 5.433 & 5.7943 & TRN & & \\
\hline CHEMBL1444822 & 688653 & 6.3829 & 9999999 & & 6.2677 & TRN \\
\hline CHEMBL1440488 & 688653 & 5.183 & 5.2153 & TRN & & \\
\hline CHEMBL1512003 & 688653 & 4.9836 & $\partial 000000 t$ & 205 & 5.2286 & TST \\
\hline CHEMBL1471225 & 688653 & 6.5325 & 9999999 & 995 & 5.9623 & TRN \\
\hline CHEMBL1488848 & 688653 & 4.833 & 5.3694 & TST & & \\
\hline CHEMBL511995 & 688653 & 4.833 & 5.0724 & TST & & \\
\hline CHEMBL1463686 & 688653 & 5.733 & 6.0081 & TRN & & \\
\hline CHEMBL1571248 & 688653 & 5.3329 & 9999999 & & 5.1209 & TRN \\
\hline CHEMBL1604466 & 688653 & 4.583 & 5.1686 & TST & & \\
\hline CHEMBL3207828 & 688653 & 5.3829 & 9999999 & & 5.3408 & TRN \\
\hline CHEMBL1379544 & 688653 & 4.7336 & $\partial 000000$ & 205 & 5.5232 & TRN \\
\hline CHEMBL1975473 & 688653 & 5.3329 & 9999999 & & 5.435 & TST \\
\hline CHEMBL1511456 & 688653 & 5.8829 & 9999999 & & 5.5607 & TRN \\
\hline CHEMBL1525849 & 688653 & 5.183 & 5.6025 & TRN & & \\
\hline CHEMBL1570359 & 688653 & 5.2829 & 9999999 & 995 & 4.9693 & TRN \\
\hline CHEMBL1418018 & 688653 & 6.5329 & 9999999 & 995 & 6.1621 & TRN \\
\hline CHEMBL3199016 & 688653 & 6.0325 & 9999999 & 995 & 6.0552 & TRN \\
\hline CHEMBL107218 & 688653 & 4.833 & 5.1670 & 0000 & $\partial 1$ & TRN \\
\hline CHEMBL1342833 & 688653 & 4.9836 & 00000006 & 205 & 4.7092 & TST \\
\hline CHEMBL1591597 & 688653 & 4.683 & 5.0385 & TRN & & \\
\hline CHEMBL1559645 & 688653 & 4.783 & 4.9142 & TRN & & \\
\hline CHEMBL1439663 & 688653 & 5.2829 & 9999999 & 995 & 5.4308 & TRN \\
\hline CHEMBL1590677 & 688653 & 4.833 & 4.9359 & TST & & \\
\hline CHEMBL1353081 & 688653 & 5.183 & 5.0949 & TRN & & \\
\hline CHEMBL3195472 & 688653 & 4.933 & 5.2433 & TST & & \\
\hline CHEMBL1429527 & 688653 & 5.033 & 5.1584 & TRN & & \\
\hline CHEMBL1451743 & 688653 & 4.683 & 5.0958 & TRN & & \\
\hline CHEMBL1530306 & 688653 & 4.9836 & 0000000 & 205 & 5.3388 & TRN \\
\hline CHEMBL1497472 & 688653 & 5.5320 & 9999999 & 995 & 4.8572 & TRN \\
\hline CHEMBL1610118 & 688653 & 6.183 & 5.1074 & TRN & & \\
\hline CHEMBL1400989 & 688653 & 6.183 & 5.1858 & TRN & & \\
\hline CHEMBL1450242 & 688653 & 4.783 & 5.171 & TRN & & \\
\hline CHEMBL1549208 & 688653 & 6.8329 & 9999999 & & 6.2984 & TRN \\
\hline CHEMBL1348895 & 688653 & 5.6320 & 9999999 & & 5.1712 & TRN \\
\hline CHEMBL1579474 & 688653 & 5.2829 & 9999999 & 995 & 5.1486 & TST \\
\hline CHEMBL1302928 & 688653 & 5.033 & 4.827 & TRN & & \\
\hline CHEMBL1455676 & 688653 & 5.433 & 5.1124 & TRN & & \\
\hline CHEMBL1584860 & 688653 & 4.833 & 5.8551 & TRN & & \\
\hline CHEMBL1351997 & 688653 & 5.3820 & 9999999 & & 5.0925 & TRN \\
\hline CHEMBL1381193 & 688653 & 5.7829 & 9999999 & 995 & 5.5149 & TRN \\
\hline CHEMBL1563224 & 688653 & 5.683 & 5.1985 & TRN & & \\
\hline CHEMBL1330075 & 688653 & 4.883 & 4.9086 & TST & & \\
\hline
\end{tabular}




\begin{tabular}{|c|c|c|c|c|c|c|c|}
\hline \\
\hline CHEMBL1477613 & 688653 & 4.883 & 5.1849 & TRN & & & \\
\hline CHEMBL1591261 & 688653 & 4.633 & 5.021 & TST & & & \\
\hline CHEMBL1393813 & 688653 & 5.433 & 5.4233 & TRN & & & \\
\hline CHEMBL 3212747 & 688653 & 5.13299 & 999999999 & & 4.966 & TRN & \\
\hline CHEMBL1503145 & 688653 & 5.38299 & 999999999 & & 5.57 & TRN & \\
\hline CHEMBL1465179 & 688653 & 6.433 & 5.036000 & 000000000 & 305 & TRN & \\
\hline CHEMBL 1467180 & 688653 & 5.13299 & 999999999 & & 5.0437 & TRN & \\
\hline CHEMBL1492611 & 688653 & 5.78299 & 999999999 & 995 & 5.4292 & TRN & \\
\hline CHEMBL3209352 & 688653 & 5.083 & 5.1413 & TRN & & & \\
\hline CHEMBL1519940 & 688653 & 5.13299 & 999999999 & & 4.8353 & TST & \\
\hline CHEMBL1481513 & 688653 & 4.73300 & 000000000 & 005 & 5.3248 & TRN & \\
\hline CHEMBL1436431 & 688653 & 4.883 & 5.0954 & TRN & & & \\
\hline CHEMBL1523355 & 688653 & 6.33299 & 999999999 & & 6.0232 & TRN & \\
\hline CHEMBL1327845 & 688653 & 4.633 & 4.8096 & TST & & & \\
\hline CHEMBL1531481 & 688653 & 5.28299 & 999999999 & 995 & 5.0898 & TST & \\
\hline CHEMBL1357723 & 688653 & 4.98300 & 000000000 & 005 & 5.051 & TRN & \\
\hline CHEMBL1563532 & 688653 & 5.38299 & 999999999 & & 5.3728 & TST & \\
\hline CHEMBL1502220 & 688653 & 5.683 & 5.7982 & TRN & & & \\
\hline CHEMBL1324790 & 688653 & 4.583 & 5.0476 & TRN & & & \\
\hline CHEMBL3192849 & 688653 & 4.73300 & 000000000 & 005 & 5.1894 & TRN & \\
\hline CHEMBL1499016 & 688653 & 4.73300 & 000000000 & 005 & 5.4498 & TST & \\
\hline CHEMBL1358972 & 688653 & 5.933 & 5.3804 & TRN & & & \\
\hline CHEMBL1387385 & 688653 & 4.73300 & 000000000 & 005 & 5.0272 & TRN & \\
\hline CHEMBL1301226 & 688653 & 4.883 & 4.9654 & TRN & & & \\
\hline CHEMBL1496401 & 688653 & 6.6499 & 6.1583 & TRN & & & \\
\hline CHEMBL 3210571 & 688653 & 4.833 & 5.3657 & TRN & & & \\
\hline CHEMBL 1420003 & 688653 & 4.73300 & 000000000 & 005 & 5.2505 & TRN & \\
\hline CHEMBL1372137 & 688653 & 5.733 & 5.2964 & TRN & & & \\
\hline CHEMBL1511197 & 688653 & 6.03299 & 999999999 & 995 & 5.6384 & TRN & \\
\hline CHEMBL1300339 & 688653 & 5.233 & 5.1491 & TRN & & & \\
\hline CHEMBL1347732 & 688653 & 4.98300 & 000000000 & 005 & 5.018 & TRN & \\
\hline CHEMBL1525093 & 688653 & 5.53299 & 999999999 & 995 & 5.4797 & TST & \\
\hline CHEMBL1519630 & 688653 & 4.833 & 5.2441 & TST & & & \\
\hline CHEMBL460517 & 688653 & 5.983 & 6.1308 & TRN & & & \\
\hline CHEMBL1542660 & 688653 & 5.683 & 5.1832 & TRN & & & \\
\hline CHEMBL1509067 & 688653 & 4.783 & 5.6213 & TRN & & & \\
\hline CHEMBL424581 & 688653 & 5.78299 & 999999999 & 995 & 5.421 & TRN & \\
\hline CHEMBL1460464 & 688653 & 5.183 & 5.153 & TST & & & \\
\hline CHEMBL1486093 & 688653 & 5.233 & 5.8111 & TRN & & & \\
\hline CHEMBL1383315 & 688653 & 5.13299 & 999999999 & & 4.9739 & TST & \\
\hline CHEMBL1409285 & 688653 & 4.783 & 4.8067 & TST & & & \\
\hline CHEMBL1498938 & 688653 & 4.833 & 5.0188 & TST & & & \\
\hline CHEMBL 3209627 & 688653 & 4.783 & 5.2236 & TRN & & & \\
\hline CHEMBL1494916 & 688653 & 5.083 & 5.1748 & TRN & & & \\
\hline CHEMBL 1462962 & 688653 & 4.683 & 5.0963 & TST & & & \\
\hline CHEMBL1518692 & 688653 & 6.33299 & 999999999 & & 5.6549 & TRN & \\
\hline CHEMBL1601947 & 688653 & 5.63299 & 999999999 & & 5.42899 & 9999999999 & TRN \\
\hline CHEMBL1408208 & 688653 & 4.883 & 4.6282 & TST & & & \\
\hline
\end{tabular}




\begin{tabular}{|c|c|c|c|c|c|c|}
\hline \multirow[b]{2}{*}{ CHEMBL1409580 } & \multicolumn{6}{|c|}{ Supplemental Ta } \\
\hline & 688653 & 4.683 & 4.6542 & TRN & & \\
\hline CHEMBL1444064 & 688653 & 5.28299 & 999999999 & 995 & 5.1374 & TRN \\
\hline CHEMBL1337756 & 688653 & 5.28299 & 999999999 & 995 & 5.3844 & \\
\hline CHEMBL1973785 & 688653 & 4.883 & 5.351 & TST & & \\
\hline CHEMBL1381599 & 688653 & 4.883 & 4.8847 & TRN & & \\
\hline CHEMBL1528419 & 688653 & 4.73300 & 000000006 & 005 & 5.1112 & \\
\hline CHEMBL1413937 & 688653 & 4.73300 & 000000006 & 005 & 5.3654 & \\
\hline CHEMBL 2006757 & 688653 & 5.933 & 5.9078 & TRN & & \\
\hline CHEMBL1587596 & 688653 & 5.28299 & 999999999 & 995 & 5.3271 & \\
\hline CHEMBL1584401 & 688653 & 5.63299 & 999999999 & & 5.4013 & \\
\hline CHEMBL1547823 & 688653 & 5.83299 & 999999999 & & 5.808 & \\
\hline CHEMBL 3196814 & 688653 & 4.73300 & 000000006 & 005 & 5.51 & \\
\hline CHEMBL1338138 & 688653 & 5.38299 & 999999999 & & 5.2009 & \\
\hline CHEMBL601135 & 688653 & 4.633 & 4.8934 & TRN & & \\
\hline CHEMBL1965791 & 688653 & 6.183 & 5.1758 & TRN & & \\
\hline CHEMBL1564873 & 688653 & 4.933 & 5.4065 & TRN & & \\
\hline CHEMBL1320094 & 688653 & 5.53299 & 999999999 & 995 & 5.4195 & \\
\hline CHEMBL1548843 & 688653 & 4.73300 & 000000000 & 005 & 5.3062 & \\
\hline CHEMBL1601222 & 688653 & 4.73300 & 000000000 & 005 & 5.067 & \\
\hline CHEMBL1500180 & 688653 & 4.933 & 4.8629 & TRN & & \\
\hline CHEMBL1534173 & 688653 & 6.13299 & 999999999 & & 5.4295 & \\
\hline CHEMBL1592404 & 688653 & 5.183 & 5.3226 & TST & & \\
\hline CHEMBL1536545 & 688653 & 6.53299 & 999999999 & 995 & 7 & \\
\hline CHEMBL1589382 & 688653 & 4.833 & 4.9003 & TRN & & \\
\hline CHEMBL1438075 & 688653 & 5.433 & 5.2201 & TST & & \\
\hline CHEMBL1492358 & 688653 & 4.883 & 5.301 & TRN & & \\
\hline CHEMBL1312712 & 688653 & 5.983 & 5.8269 & TRN & & \\
\hline CHEMBL 3199694 & 688653 & 5.53299 & 999999999 & 995 & 5.4077 & \\
\hline CHEMBL1460248 & 688653 & 5.58299 & 999999999 & & 5.6843 & \\
\hline CHEMBL1567722 & 688653 & 5.13299 & 999999999 & & 5.4407 & \\
\hline CHEMBL1355548 & 688653 & 4.633 & 5.0948 & TRN & & \\
\hline CHEMBL1558603 & 688653 & 6.03299 & 999999999 & 995 & 5.6243 & \\
\hline CHEMBL1397613 & 688653 & 4.833 & 5.2147 & TRN & & \\
\hline CHEMBL1530113 & 688653 & 5.63299 & 999999999 & & 5.4558 & \\
\hline CHEMBL1471540 & 688653 & 6.03299 & 999999999 & 995 & 5.2825 & TRN \\
\hline CHEMBL1599131 & 688653 & 4.883 & 5.2651 & TRN & & \\
\hline CHEMBL1304136 & 688653 & 4.833 & 5.1742 & TRN & & \\
\hline CHEMBL1483474 & 688653 & 5.33299 & 999999999 & & 5.4981 & \\
\hline CHEMBL 3189745 & 688653 & 4.833 & 5.1889 & TRN & & \\
\hline CHEMBL1463860 & 688653 & 5.83299 & 999999999 & & 5.1244 & 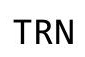 \\
\hline CHEMBL 3210142 & 688653 & 5.483 & 5.0558 & TST & & \\
\hline CHEMBL1494823 & 688653 & 4.783 & 5.0794 & TRN & & \\
\hline CHEMBL3209333 & 688653 & 4.833 & 5.3327 & TST & & \\
\hline CHEMBL1333767 & 688653 & 4.633 & 4.7972 & TRN & & \\
\hline CHEMBL1567528 & 688653 & 4.73300 & 000000000 & 205 & 5.45 & TI \\
\hline CHEMBL1474743 & 688653 & 5.78299 & 999999999 & 995 & 5.2018 & 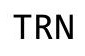 \\
\hline CHEMBL1517405 & 688653 & 5.183 & 5.606 & TRN & & \\
\hline CHEMBL1504426 & 688653 & 6.7331 & 5.8507 & TRN & & \\
\hline
\end{tabular}




\begin{tabular}{|c|c|c|c|c|c|c|}
\hline & & & pplement & al & s2.txt & \\
\hline CHEMBL1442085 & 688653 & 5.3829 & 99999999 & & 5.2533 & TRN \\
\hline CHEMBL1489649 & 688653 & 4.7336 & $\partial 0000000$ & 005 & 5.0194 & TRN \\
\hline CHEMBL1530139 & 688653 & 5.233 & 5.119 & TRN & & \\
\hline CHEMBL1359387 & 688653 & 5.9 & 5.20700 & 00000 & & TRN \\
\hline CHEMBL1399377 & 688653 & 4.933 & 4.8504 & TRN & & \\
\hline CHEMBL3193709 & 688653 & 5.183 & 5.1705 & TST & & \\
\hline CHEMBL1995910 & 688653 & 4.883 & 5.2115 & TST & & \\
\hline CHEMBL1385051 & 688653 & 4.833 & 5.0596 & TRN & & \\
\hline CHEMBL1496195 & 688653 & 5.7829 & 99999999 & 995 & 6.1197 & TRN \\
\hline CHEMBL1511267 & 688653 & 4.7336 & 00000000 & 005 & 5.2429 & TST \\
\hline CHEMBL1329937 & 688653 & 5.2829 & 99999999 & 995 & 4.9763 & TRN \\
\hline CHEMBL1408857 & 688653 & 5.433 & 5.0017 & TST & & \\
\hline CHEMBL1406781 & 688653 & 4.833 & 5.2824 & TST & & \\
\hline CHEMBL1433155 & 688653 & 6.5329 & 99999999 & 995 & 5.7735 & TRN \\
\hline CHEMBL1304586 & 688653 & 4.85 & 4.7751 & TST & & \\
\hline CHEMBL1465897 & 688653 & 5.083 & 5.2488 & TST & & \\
\hline CHEMBL1486602 & 688653 & 4.783 & 5.0762 & TST & & \\
\hline CHEMBL1322834 & 688653 & 6.1329 & 99999999 & & 5.9165 & TRN \\
\hline CHEMBL1535519 & 688653 & 5.233 & 5.8593 & TRN & & \\
\hline CHEMBL1509230 & 688653 & 5.7829 & 99999999 & 995 & 5.7369 & TRN \\
\hline CHEMBL1598569 & 688653 & 5.683 & 5.7485 & TRN & & \\
\hline CHEMBL1583094 & 688653 & 4.7336 & 00000000 & 005 & 5.2321 & TRN \\
\hline CHEMBL1370437 & 688653 & 6.3829 & 99999999 & & 5.6806 & TRN \\
\hline CHEMBL1532402 & 688653 & 4.7336 & 00000000 & 005 & 4.9392 & TRN \\
\hline CHEMBL1557075 & 688653 & 4.833 & 5.3305 & TRN & & \\
\hline CHEMBL1347065 & 688653 & 4.7336 & 00000000 & 005 & 5.1277 & TRN \\
\hline CHEMBL3198998 & 688653 & 5.433 & 5.5341 & TRN & & \\
\hline CHEMBL1588170 & 688653 & 5.8329 & 99999999 & 99 & 5.118 & TRN \\
\hline CHEMBL1584502 & 688653 & 5.233 & 4.3001 & TST & & \\
\hline CHEMBL3193751 & 688653 & 5.183 & 5.3004 & TST & & \\
\hline CHEMBL1470660 & 688653 & 4.883 & 5.2405 & TRN & & \\
\hline CHEMBL1307854 & 688653 & 4.683 & 5.5365 & TST & & \\
\hline CHEMBL1387774 & 688653 & 4.833 & 5.2395 & TST & & \\
\hline CHEMBL1437993 & 688653 & 4.7336 & 0000000 & 005 & 5.2861 & TST \\
\hline CHEMBL1458725 & 688653 & 5.033 & 4.7889 & TST & & \\
\hline CHEMBL1320706 & 688653 & 5.1329 & 99999999 & & 5.4155 & TRN \\
\hline CHEMBL1437701 & 688653 & 5.183 & 5.0902 & TRN & & \\
\hline CHEMBL1524253 & 688653 & 5.683 & 5.2826 & TRN & & \\
\hline CHEMBL1540086 & 688653 & 4.7336 & 0000000 & 005 & 5.4556 & TRN \\
\hline CHEMBL1419663 & 688653 & 4.7336 & 00000000 & 005 & 5.3856 & TST \\
\hline CHEMBL1383500 & 688653 & 5.083 & 4.9002 & TRN & & \\
\hline CHEMBL1300302 & 688653 & 5.183 & 4.783 & TRN & & \\
\hline CHEMBL1585527 & 688653 & 5.5829 & 99999999 & 99 & 5.3812 & TRN \\
\hline CHEMBL1380787 & 688653 & 5.183 & 5.0252 & TRN & & \\
\hline CHEMBL 3193883 & 688653 & 5.183 & 5.3357 & TST & & \\
\hline CHEMBL1454953 & 688653 & 6.983 & 5.4384 & TST & & \\
\hline CHEMBL1412392 & 688653 & 5.683 & 5.4064 & TST & & \\
\hline CHEMBL1578300 & 688653 & 5.083 & 5.6571 & TST & & \\
\hline
\end{tabular}




\begin{tabular}{|c|c|c|c|c|c|c|}
\hline \multirow[b]{2}{*}{ CHEMBL1486039 } & \multicolumn{6}{|c|}{ Supplemental Table S2.txt } \\
\hline & 688653 & 4.883 & 5.6317 & TRN & & \\
\hline CHEMBL1417197 & 688653 & \multicolumn{3}{|c|}{5.132999999999999} & 4.8862 & TRN \\
\hline CHEMBL1386999 & 688653 & 5.733 & 5.1353 & TRN & & \\
\hline CHEMBL1371865 & 688653 & 6.183 & \multicolumn{3}{|c|}{5.6739999999999995} & \\
\hline CHEMBL1601433 & 688653 & \multicolumn{3}{|c|}{5.332999999999999} & 5.3119 & \\
\hline CHEMBL1325867 & 688653 & 4.633 & 5.3152 & TRN & & \\
\hline CHEMBL1222382 & 688653 & \multicolumn{3}{|c|}{5.632999999999999} & 5.4124 & \\
\hline CHEMBL1401242 & 688653 & 6.683 & 6.2054 & TRN & & \\
\hline CHEMBL1328844 & 688653 & \multicolumn{3}{|c|}{5.582999999999999} & 5.4645 & \\
\hline CHEMBL1579046 & 688653 & \multicolumn{3}{|c|}{5.2829999999999995} & 5.6187 & \\
\hline CHEMBL1465999 & 688653 & 5.183 & 5.341 & TRN & & \\
\hline CHEMBL1430227 & 688653 & 5.033 & 5.1359 & TRN & & \\
\hline CHEMBL1336616 & 688653 & 5.083 & 5.3591 & TRN & & \\
\hline CHEMBL1461600 & 688653 & 5.733 & 5.5142 & TST & & \\
\hline CHEMBL1345975 & 688653 & 4.833 & 5.517 & TRN & & \\
\hline CHEMBL1485306 & 688653 & 4.933 & 5.1457 & TRN & & \\
\hline CHEMBL1588983 & 688653 & 5.183 & 5.2385 & TST & & \\
\hline CHEMBL1600268 & 688653 & 4.833 & 5.0193 & TST & & \\
\hline CHEMBL14: & 688653 & 4.783 & 5.2042 & TRN & & \\
\hline CHEMBL1348430 & 688653 & 5.933 & 5.265 & TRN & & \\
\hline CHEMBL1313719 & 688653 & \multicolumn{3}{|c|}{5.632999999999999} & 241 & \\
\hline CHEMBL1323470 & 688653 & 4.833 & 5.2287 & TST & & \\
\hline CHEMBL13 & 688653 & \multirow{2}{*}{\multicolumn{3}{|c|}{$\begin{array}{l}5.683 \quad 5.4156 \quad I R I N \\
5.5329999999999995\end{array}$}} & & \\
\hline CHEMBL1413793 & 688653 & & & & 5.5519 & \\
\hline CHEMBL1486672 & 688653 & 4.833 & 5.2416 & TST & & \\
\hline CHEMBL1358939 & 688653 & 5.183 & 5.0951 & TRN & & \\
\hline CHEMBL1465736 & 688653 & \multicolumn{3}{|c|}{5.882999999999999} & 5.6874 & \\
\hline CHEMBL19 & 688653 & 5.433 & 5.2676 & TST & & \\
\hline CHEMBL1486342 & 688653 & \multicolumn{3}{|c|}{4.7330000000000005} & 4.9411 & \\
\hline CHEMBL1596898 & 688653 & 4.883 & 5.461 & TST & & \\
\hline CHEMBL1447313 & 688653 & 4.783 & 5.2765 & TRN & & \\
\hline CHEMBL1480613 & 688653 & \multicolumn{3}{|c|}{6.2829999999999995} & 6.0001 & \\
\hline CHEMBL1536569 & 688653 & 4.583 & 5.2162 & TRN & & \\
\hline CHEMBL 3189624 & 688653 & 4.683 & 4.8321 & TST & & \\
\hline CHEMBL1589781 & 688653 & \multicolumn{3}{|c|}{5.582999999999999} & 5.6113 & \\
\hline CHEMBL1388529 & 688653 & 7.2328 & 5.5523 & TRN & & \\
\hline CHEMBL1455963 & 688653 & 5.433 & 5.2067 & TRN & & \\
\hline CHEMBL1390460 & 688653 & 5.483 & 5.1339 & TRN & & \\
\hline CHEMBL 3195108 & 688653 & 5.733 & 5.6566 & TRN & & \\
\hline CHEMBL1318736 & 688653 & 5.483 & 6.0108 & TRN & & \\
\hline CHEMBL1323634 & 688653 & \multicolumn{3}{|c|}{6.082999999999999} & 5.4494 & \\
\hline CHEMBL1320653 & 688653 & \multicolumn{3}{|c|}{4.9830000000000005} & 5.2732 & \\
\hline CHEMBL1561349 & 688653 & \multicolumn{3}{|c|}{4.7330000000000005} & 4.6389 & \\
\hline CHEMBL1548132 & 688653 & \multicolumn{3}{|c|}{6.0329999999999995} & 5.6908 & 7 \\
\hline CHEMBL3209382 & 688653 & 5.483 & 5.8637 & TRN & & \\
\hline CHEMBL1607713 & 688653 & 6.433 & 5.5819 & TRN & & \\
\hline CHEMBL1393476 & 688653 & 5.033 & 4.9879 & TST & & \\
\hline CHEMBL1429368 & 688653 & \multicolumn{3}{|c|}{4.7330000000000005} & 5.3829 & \\
\hline
\end{tabular}




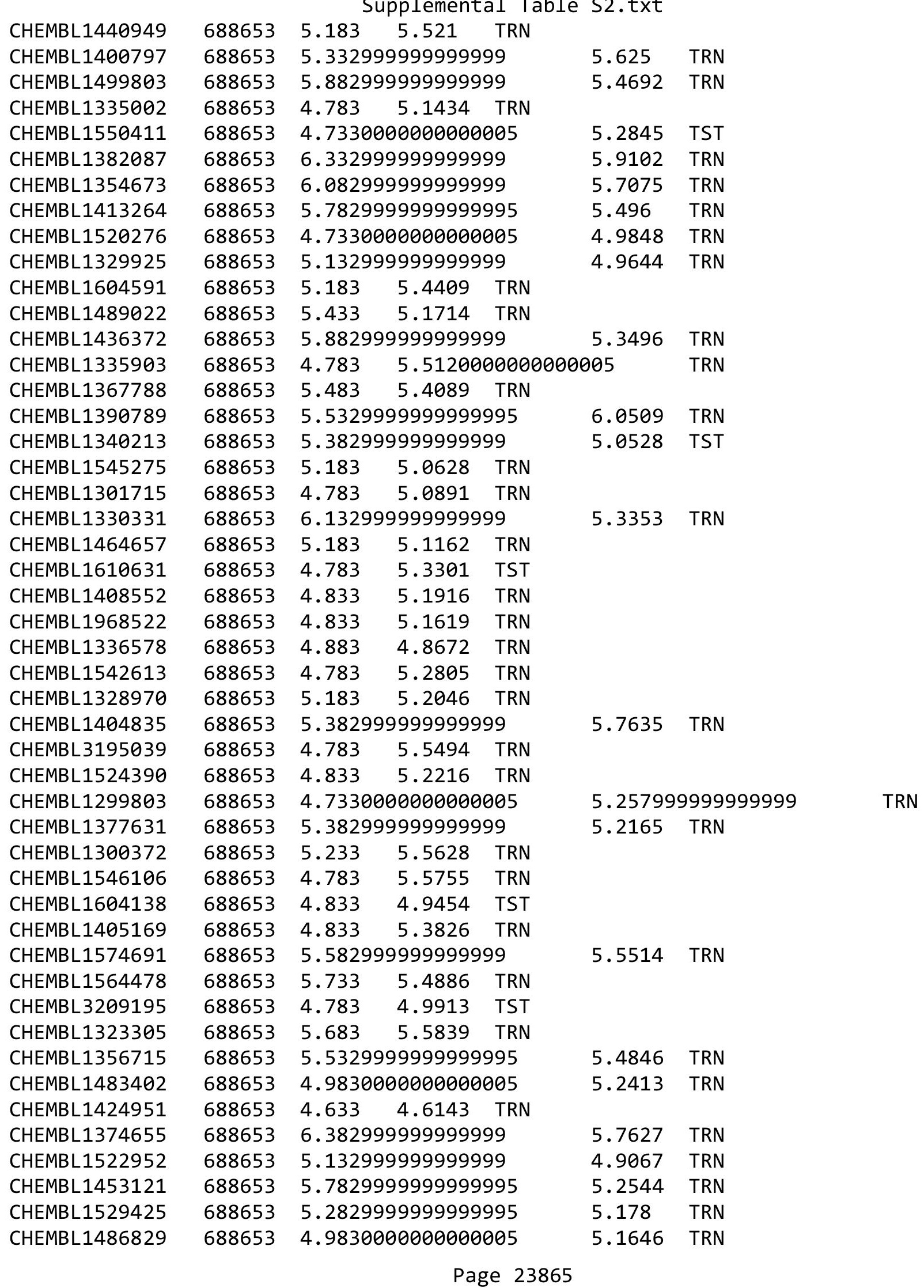




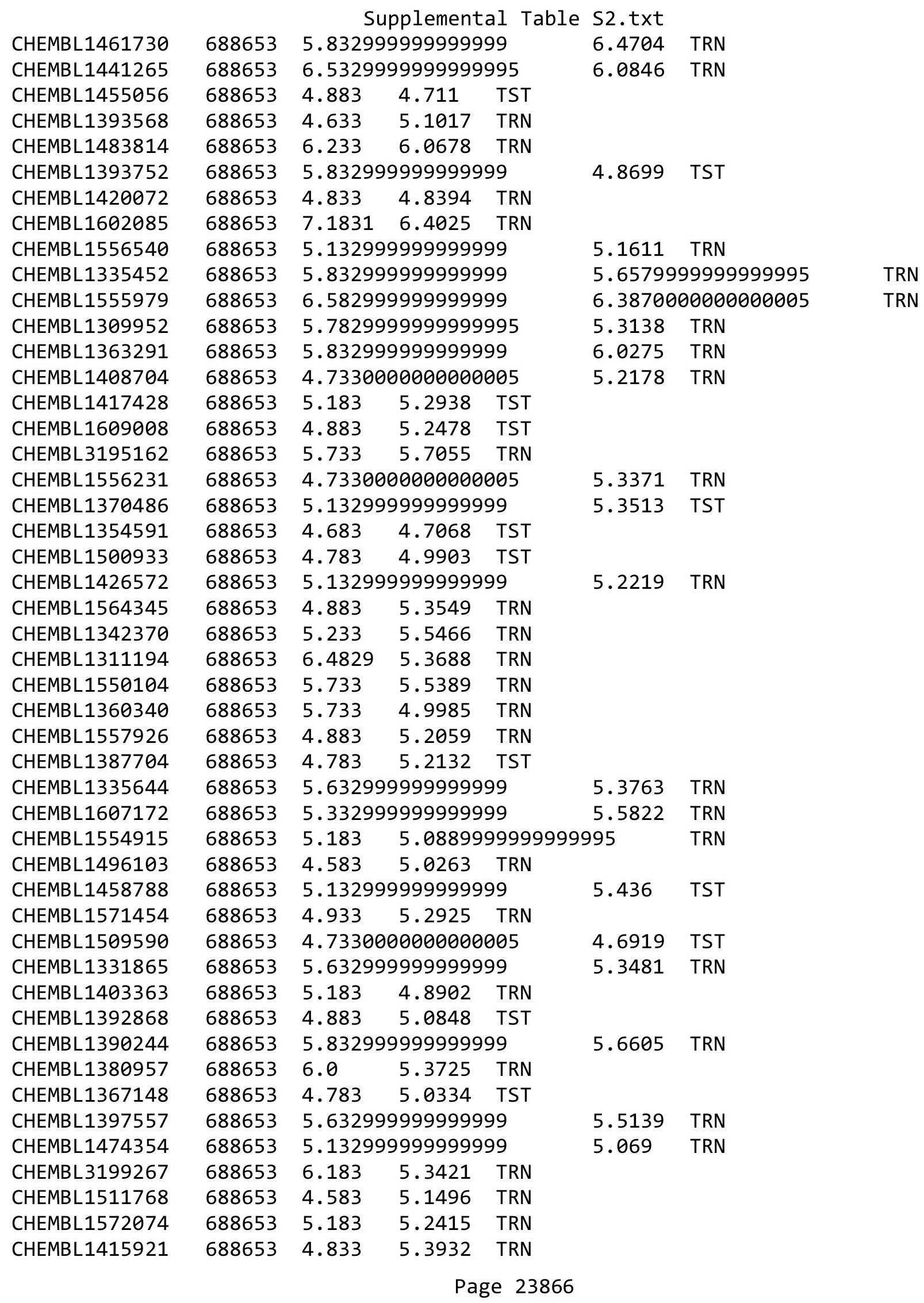




\begin{tabular}{|c|c|c|c|c|c|c|c|}
\hline \multicolumn{8}{|c|}{ Supplemental Table S2.txt } \\
\hline CHEMBL1384428 & 688653 & 5.033 & 4.9894 & TRN & & & \\
\hline CHEMBL1390691 & 688653 & 5.083 & 5.0763 & TRN & & & \\
\hline CHEMBL1524727 & 688653 & 4.833 & 5.0817 & TRN & & & \\
\hline CHEMBL1399248 & 688653 & 4.7330 & 00000000 & 005 & 4.98606 & 0000000001 & TRN \\
\hline CHEMBL1399252 & 688653 & 5.6329 & 99999999 & & 5.2175 & TST & \\
\hline CHEMBL1447872 & 688653 & 4.9830 & 00000000 & 005 & 4.4945 & TRN & \\
\hline CHEMBL1539277 & 688653 & 5.683 & 5.3924 & TRN & & & \\
\hline CHEMBL1329446 & 688653 & 6.5329 & 99999999 & 995 & 5.8842 & TRN & \\
\hline CHEMBL1544703 & 688653 & 5.6329 & 99999999 & & 5.4096 & TRN & \\
\hline CHEMBL1365768 & 688653 & 6.5329 & 99999999 & 995 & 5.9149 & TRN & \\
\hline CHEMBL472931 & 688653 & 5.3829 & 99999999 & & 5.3992 & TRN & \\
\hline CHEMBL1465283 & 688653 & 6.3829 & 99999999 & & 5.6458 & TRN & \\
\hline CHEMBL1410532 & 688653 & 5.6329 & 99999999 & & 5.7667 & TRN & \\
\hline CHEMBL1378111 & 688653 & 5.033 & 5.008 & TST & & & \\
\hline CHEMBL1399794 & 688653 & 5.483 & 5.3906 & TRN & & & \\
\hline CHEMBL1350761 & 688653 & 5.3829 & 99999999 & & 4.9227 & TST & \\
\hline CHEMBL1488160 & 688653 & 6.233 & 5.3935 & TRN & & & \\
\hline CHEMBL1303748 & 688653 & 5.5329 & 99999999 & 995 & 5.0939 & TRN & \\
\hline CHEMBL1583698 & 688653 & 5.033 & 4.8243 & TST & & & \\
\hline CHEMBL1573195 & 688653 & 5.933 & 4.9243 & TRN & & & \\
\hline CHEMBL3193795 & 688653 & 6.9329 & 6.5231 & TRN & & & \\
\hline CHEMBL1535576 & 688653 & 5.233 & 4.872 & TRN & & & \\
\hline CHEMBL1374755 & 688653 & 5.1329 & 99999999 & & 5.4797 & TRN & \\
\hline CHEMBL1388751 & 688653 & 5.433 & 5.3685 & TRN & & & \\
\hline CHEMBL 1424878 & 688653 & 4.833 & 5.0608 & TRN & & & \\
\hline CHEMBL1301527 & 688653 & 4.833 & 5.0039 & TRN & & & \\
\hline CHEMBL1602164 & 688653 & 5.183 & 4.7344 & TST & & & \\
\hline CHEMBL1333504 & 688653 & 5.683 & 5.4454 & TST & & & \\
\hline CHEMBL1336396 & 688653 & 4.883 & 5.1349 & TST & & & \\
\hline CHEMBL1326141 & 688653 & 5.483 & 5.8455 & TRN & & & \\
\hline CHEMBL1464718 & 688653 & 4.683 & 4.8236 & TST & & & \\
\hline CHEMBL1397822 & 688653 & 4.583 & 4.8217 & TRN & & & \\
\hline CHEMBL1464710 & 688653 & 4.583 & 5.2142 & TRN & & & \\
\hline CHEMBL1382264 & 688653 & 5.2829 & 99999999 & 995 & 5.5047 & TRN & \\
\hline CHEMBL1335851 & 688653 & 6.3329 & 99999999 & & 5.6007 & TRN & \\
\hline CHEMBL1504462 & 688653 & 6.433 & 5.1163 & TST & & & \\
\hline CHEMBL1416100 & 688653 & 4.883 & 5.2122 & TRN & & & \\
\hline CHEMBL1440699 & 688653 & 6.3829 & 99999999 & & 5.0474 & TST & \\
\hline CHEMBL1461656 & 688653 & 4.883 & 4.9211 & TST & & & \\
\hline CHEMBL1343686 & 688653 & 4.933 & 4.994 & TRN & & & \\
\hline CHEMBL1480999 & 688653 & 4.783 & 5.0833 & TRN & & & \\
\hline CHEMBL1314555 & 688653 & 4.583 & 5.0267 & TRN & & & \\
\hline CHEMBL1520039 & 688653 & 4.783 & 5.0694 & TRN & & & \\
\hline CHEMBL1586127 & 688653 & 4.933 & 5.2125 & TRN & & & \\
\hline CHEMBL1378324 & 688653 & 6.3829 & 99999999 & & 5.3954 & TRN & \\
\hline CHEMBL1530260 & 688653 & 4.7330 & 00000000 & 005 & 4.7157 & TST & \\
\hline CHEMBL1448220 & 688653 & 5.083 & 5.1738 & TST & & & \\
\hline CHEMBL1411369 & 688653 & 5.483 & 5.7376 & TRN & & & \\
\hline
\end{tabular}




\begin{tabular}{|c|c|c|c|c|c|c|}
\hline \multirow[b]{2}{*}{ CHEMBL1326164 } & \multirow[b]{2}{*}{688653} & \multicolumn{5}{|c|}{ Supplemental Table S2.txt } \\
\hline & & 5.983 & 5.6353 & TST & & \\
\hline CHEMBL1478826 & 688653 & \multicolumn{3}{|c|}{5.382999999999999} & \multirow[t]{3}{*}{5.425} & \multirow[t]{3}{*}{ TRN } \\
\hline CHEMBL1604413 & 688653 & 5.433 & 5.1995 & TRN & & \\
\hline CHEMBL1441292 & 688653 & 5.433 & 5.1018 & TRN & & \\
\hline CHEMBL1600092 & 688653 & \multicolumn{3}{|c|}{4.7330000000000005} & 5.0618 & TST \\
\hline CHEMBL1570080 & 688653 & 6.0 & 5.1522 & TRN & & \\
\hline CHEMBL1377053 & 688653 & \multicolumn{3}{|c|}{4.7330000000000005} & 5.2564 & TST \\
\hline CHEMBL1514773 & 688653 & 4.933 & 5.4244 & TRN & & \\
\hline CHEMBL1308660 & 688653 & \multicolumn{3}{|c|}{5.7829999999999995} & 5.1853 & TRN \\
\hline CHEMBL1533566 & 688653 & 4.633 & 5.3092 & TRN & & \\
\hline CHEMBL1394513 & 688653 & 4.583 & 4.7165 & TST & & \\
\hline CHEMBL1989225 & 688653 & 7.2832 & 5.7884 & TRN & & \\
\hline CHEMBL3213442 & 688653 & 4.833 & 5.3339 & TRN & & \\
\hline CHEMBL1320212 & 688653 & 4.783 & 5.1396 & TRN & & \\
\hline CHEMBL1389929 & 688653 & 5.233 & 5.6173 & TRN & & \\
\hline CHEMBL3198073 & 688653 & \multicolumn{3}{|c|}{5.332999999999999} & 5.5233 & TRN \\
\hline CHEMBL1387902 & 688653 & 4.883 & 5.7577 & TRN & & \\
\hline CHEMBL3190375 & 688653 & 4.883 & 5.3629 & TST & & \\
\hline CHEMBL1311663 & 688653 & 4.883 & 5.1586 & TST & & \\
\hline CHEMBL1539633 & 688653 & 4.633 & 5.0773 & TRN & & \\
\hline CHEMBL1364999 & 688653 & 5.233 & 5.3733 & TST & & \\
\hline CHEMBL1300899 & 688653 & 5.733 & 5.2401 & TST & & \\
\hline CHEMBL1404569 & 688653 & \multicolumn{3}{|c|}{5.832999999999999} & 5.2813 & TRN \\
\hline CHEMBL1460857 & 688653 & 6.0 & 4.7843 & TRN & & \\
\hline CHEMBL1398398 & 688653 & 4.783 & 5.1231 & TRN & & \\
\hline CHEMBL1567017 & 688653 & \multicolumn{3}{|c|}{5.7829999999999995} & 5.2524 & TRN \\
\hline CHEMBL1421546 & 688653 & 5.083 & 5.1875 & TRN & & \\
\hline CHEMBL1414716 & 688653 & 5.083 & \multicolumn{3}{|c|}{5.2860000000000005} & TRN \\
\hline CHEMBL1478232 & 688653 & 5.983 & 5.4637 & TRN & & \\
\hline CHEMBL1320670 & 688653 & 4.783 & 5.1946 & TST & & \\
\hline CHEMBL1440197 & 688653 & 5.983 & 5.3797 & TRN & & \\
\hline CHEMBL1350195 & 688653 & \multicolumn{3}{|c|}{5.382999999999999} & 5.5015 & TST \\
\hline CHEMBL3211502 & 688653 & \multicolumn{3}{|c|}{5.582999999999999} & 5.4379 & TRN \\
\hline CHEMBL1592590 & 688653 & \multicolumn{3}{|c|}{4.7330000000000005} & 5.0048 & TRN \\
\hline CHEMBL1375185 & 688653 & \multicolumn{3}{|c|}{4.7330000000000005} & 5.0739 & TRN \\
\hline CHEMBL1579736 & 688653 & 4.683 & 4.9736 & TRN & & \\
\hline CHEMBL1456238 & 688653 & \multicolumn{3}{|c|}{5.132999999999999} & 4.6554 & TST \\
\hline CHEMBL1499414 & 688653 & \multicolumn{3}{|c|}{5.382999999999999} & 5.0674 & TST \\
\hline CHEMBL1502514 & 688653 & 5.183 & 5.1637 & TST & & \\
\hline CHEMBL1374664 & 688653 & \multicolumn{3}{|c|}{6.382999999999999} & 5.8321 & TRN \\
\hline CHEMBL1523736 & 688653 & \multicolumn{3}{|c|}{4.7330000000000005} & 5.4252 & TRN \\
\hline CHEMBL1562819 & 688653 & 4.633 & 5.2536 & TRN & & \\
\hline CHEMBL1399783 & 688653 & 4.95 & 5.0247 & TRN & & \\
\hline CHEMBL1972435 & 688653 & 4.833 & 4.7906 & TRN & & \\
\hline CHEMBL1453896 & 688653 & 5.083 & 5.0599 & TRN & & \\
\hline CHEMBL1569383 & 688653 & 4.73300 & 00000000 & 005 & 5.4123 & TST \\
\hline CHEMBL1499003 & 688653 & 4.783 & 4.8762 & TST & & \\
\hline CHEMBL1310570 & 688653 & 4.783 & 4.9801 & TRN & & \\
\hline
\end{tabular}




\begin{tabular}{|c|c|c|c|c|c|c|}
\hline & & \multicolumn{4}{|c|}{ Supplemental Table S2.txt } & \\
\hline CHEMBL1320593 & 688653 & \multicolumn{3}{|c|}{6.832999999999999} & 5.2431 & $\mathrm{~T}$ \\
\hline CHEMBL1377059 & 688653 & 4.833 & 4.8364 & TRN & & \\
\hline CHEMBL1395271 & 688653 & 4.583 & 4.887 & TST & & \\
\hline CHEMBL1352538 & 588653 & 5.733 & 5.3804 & TRN & & \\
\hline CHEMBL1531846 & 588653 & 5.033 & 5.7894 & TST & & \\
\hline CHEMBL1994211 & 688653 & \multicolumn{3}{|c|}{5.7829999999999995} & 5.3776 & \\
\hline CHEMBL3210073 & 688653 & 4.933 & 4.6697 & TRN & & \\
\hline CHEMBL1377488 & 688653 & \multicolumn{3}{|c|}{5.2829999999999995} & 5.7578 & TRN \\
\hline CHEMBL1530523 & 688653 & \multicolumn{3}{|c|}{6.0329999999999995} & 5.6481 & \\
\hline CHEMBL1585185 & 688653 & 4.583 & 4.5213 & TRN & & \\
\hline CHEMBL1450753 & 688653 & 6.683 & 6.1134 & TRN & & \\
\hline CHEMBL3211666 & 688653 & 5.733 & 4.9942 & TRN & & \\
\hline CHEMBL1319867 & 688653 & \multicolumn{3}{|c|}{4.7330000000000005} & 4.9578 & TI \\
\hline CHEMBL1309785 & 688653 & 4.833 & 5.392 & TRN & & \\
\hline CHEMBL1330164 & 688653 & 4.883 & \multicolumn{3}{|c|}{5.702000000000001} & \\
\hline CHEMBL127066 & 688653 & 4.783 & 5.5439 & TRN & & \\
\hline CHEMBL1 & 688653 & \multicolumn{3}{|c|}{5.2829999999999995} & 5.3846 & \\
\hline CHEMBL1356920 & 688653 & 4.833 & 4.8708 & TRN & & \\
\hline CHEMBL1525545 & 688653 & 5.183 & 5.5771 & TST & & \\
\hline CHEMBL1374097 & 688653 & \multicolumn{3}{|c|}{6.7829999999999995} & 5.7002 & TRN \\
\hline CHEMBL1565736 & 688653 & \multicolumn{3}{|c|}{5.832999999999999} & 208 & \\
\hline CHEMBL1 & 688653 & 4.783 & 5.3694 & TRN & & \\
\hline CHEMBL3193019 & 688653 & 4.783 & 4.9707 & TRN & & \\
\hline CHEMBL1349604 & 688653 & 5.933 & 5.4787 & TRN & & \\
\hline CHEMBL1436438 & 688653 & \multicolumn{3}{|c|}{6.382999999999999} & 5.9226 & TRN \\
\hline CHEMBL13 & 688653 & \multicolumn{3}{|c|}{5.132999999999999} & 325 & \\
\hline CHEMBL1 & 688653 & 4.883 & 5.6993 & TRN & & \\
\hline CHEMBL1403741 & 688653 & \multicolumn{3}{|c|}{5.832999999999999} & 5.6559 & TRN \\
\hline CHEMBL1468863 & 688653 & \multicolumn{3}{|c|}{6.2829999999999995} & & TRN \\
\hline CHEMBL1373412 & 688653 & 6.683 & 5.2135 & TST & & \\
\hline CHEMBL1592716 & 688653 & 4.5 & 5.0931 & TST & & \\
\hline CHEMB & 688 & 4.933 & 5.1967 & TRN & & \\
\hline CHEMBL1408969 & 688653 & \multicolumn{3}{|c|}{6.382999999999999} & 5.8043 & TP \\
\hline CHEMBL1590442 & 688653 & 6.183 & 5.607 & TRN & & \\
\hline CHEMBL1526365 & 688653 & 4.783 & 5.3142 & TST & & \\
\hline CHEMBL1403123 & 688653 & \multicolumn{3}{|c|}{5.7829999999999995} & 5.6393 & $\mathrm{~T}$ \\
\hline CHEMBL14 & 688653 & 4.883 & 5.0154 & TRN & & \\
\hline CHEMBL1456163 & 688653 & 5.233 & 5.4632 & TRN & & \\
\hline CHEMBL1572605 & 688653 & \multicolumn{3}{|c|}{6.632999999999999} & 5.4495 & TST \\
\hline CHEMBL304069 & 688653 & \multicolumn{3}{|c|}{6.132999999999999} & 5.2661 & \\
\hline CHEMBL1539111 & 688653 & \multicolumn{3}{|c|}{5.132999999999999} & 5.0607 & TाN \\
\hline CHEMBL1510089 & 688653 & \multicolumn{3}{|c|}{5.632999999999999} & 5.4838 & TRN \\
\hline CHEMBL1460302 & 688653 & \multicolumn{3}{|c|}{6.632999999999999} & 5.5944 & TST \\
\hline CHEMBL1476044 & 688653 & 5.2829 & 99999999 & 995 & 5.0299 & TRN \\
\hline CHEMBL1305968 & 688653 & $5.882 \mathrm{C}$ & 99999999 & & 5.3717 & \\
\hline CHEMBL1438919 & 688653 & 5.033 & 5.2696 & TRN & & \\
\hline CHEMBL1377970 & 688653 & 5.183 & 5.5139 & TRN & & \\
\hline CHEMBL1587893 & 688653 & 4.783 & 4.8573 & TRN & & \\
\hline
\end{tabular}




\begin{tabular}{|c|c|c|c|c|c|c|}
\hline \multirow[b]{2}{*}{ CHEMBL1386032 } & \multirow[b]{2}{*}{688653} & \multicolumn{5}{|c|}{ Supplemental Table S2.txt } \\
\hline & & 4.783 & 5.5465 & TST & & \\
\hline CHEMBL1431272 & 688653 & 5.33299 & 99999999 & & 4.9981 & TRN \\
\hline CHEMBL1341992 & 688653 & 5.033 & 5.5156 & TST & & \\
\hline CHEMBL1612177 & 688653 & 5.13299 & 99999999 & 99 & 5.0697 & TRN \\
\hline CHEMBL1386636 & 688653 & 7.0329 & 5.7969 & TRN & & \\
\hline CHEMBL1327408 & 688653 & 5.53299 & 99999999 & 995 & 5.4339 & TRN \\
\hline CHEMBL1331727 & 688653 & 4.833 & 5.3026 & TRN & & \\
\hline CHEMBL1405698 & 688653 & 4.933 & 5.3012 & TRN & & \\
\hline CHEMBL1595361 & 688653 & 4.833 & 5.223 & TRN & & \\
\hline CHEMBL1584225 & 688653 & 4.783 & 5.3524 & TRN & & \\
\hline CHEMBL1310482 & 688653 & 4.833 & 5.3597 & TST & & \\
\hline CHEMBL3212666 & 688653 & 5.78299 & 99999999 & 995 & 5.0264 & TRN \\
\hline CHEMBL1307475 & 688653 & 5.483 & 5.5434 & TRN & & \\
\hline CHEMBL1338178 & 688653 & 4.833 & 5.5429 & TRN & & \\
\hline CHEMBL1356290 & 688653 & 5.28299 & 99999999 & 995 & 5.0367 & TST \\
\hline CHEMBL1324233 & 688653 & 4.783 & 5.4918 & TST & & \\
\hline CHEMBL1306534 & 688653 & 6.4829 & 5.5754 & TRN & & \\
\hline CHEMBL1453953 & 688653 & 6.28299 & 99999999 & 995 & 5.6155 & TRN \\
\hline CHEMBL1516916 & 688653 & 4.933 & 5.5833 & TRN & & \\
\hline CHEMBL1575640 & 688653 & 4.783 & 5.1304 & TRN & & \\
\hline CHEMBL1375689 & 688653 & 4.73300 & 00000000 & 005 & 5.2634 & TST \\
\hline CHEMBL1436234 & 688653 & 6.53299 & 99999999 & 995 & 5.9864 & TRN \\
\hline CHEMBL1492209 & 688653 & 6.33299 & 99999999 & & 4.9856 & TRN \\
\hline CHEMBL1605635 & 688653 & 4.55 & 5.3402 & TRN & & \\
\hline CHEMBL1498639 & 688653 & 6.8831 & 6.0039 & TRN & & \\
\hline CHEMBL1583900 & 688653 & 4.73300 & 20000000 & 005 & 5.0187 & TRN \\
\hline CHEMBL1500060 & 688653 & 6.33299 & 99999999 & & 5.8608 & TRN \\
\hline CHEMBL1300465 & 688653 & 4.883 & 5.3343 & TRN & & \\
\hline CHEMBL1510301 & 688653 & 6.03299 & 99999999 & 995 & 5.5513 & TRN \\
\hline CHEMBL1534666 & 688653 & 4.583 & 5.765 & TRN & & \\
\hline CHEMBL1489077 & 688653 & 5.033 & 5.3973 & TST & & \\
\hline CHEMBL463175 & 688653 & 5.183 & 5.0325 & TST & & \\
\hline CHEMBL1504598 & 688653 & 5.28299 & 99999999 & 995 & 5.4091 & TRN \\
\hline CHEMBL1538096 & 688653 & 4.633 & 4.9827 & TRN & & \\
\hline CHEMBL1383265 & 688653 & 5.233 & 5.1721 & TRN & & \\
\hline CHEMBL1415059 & 688653 & 4.98300 & 00000000 & 005 & 5.0846 & TRN \\
\hline CHEMBL1533360 & 688653 & 4.833 & 5.2268 & TRN & & \\
\hline CHEMBL1387280 & 688653 & 5.483 & 5.4533 & TRN & & \\
\hline CHEMBL1600930 & 688653 & 5.78299 & 99999999 & 995 & 5.4614 & TRN \\
\hline CHEMBL1304087 & 688653 & 5.28299 & 99999999 & 995 & 5.6773 & TRN \\
\hline CHEMBL1320437 & 688653 & 4.883 & 5.1073 & TST & & \\
\hline CHEMBL1445650 & 688653 & 4.833 & 5.3059 & TRN & & \\
\hline CHEMBL1315225 & 688653 & 4.933 & 5.171 & TRN & & \\
\hline CHEMBL 2005895 & 688653 & 6.233 & 5.9002 & TRN & & \\
\hline CHEMBL1560147 & 688653 & 5.683 & 5.8486 & TRN & & \\
\hline CHEMBL1524630 & 688653 & 5.53299 & 99999999 & 995 & 5.3151 & TRN \\
\hline CHEMBL1375415 & 688653 & 5.183 & 5.1112 & TRN & & \\
\hline CHEMBL1398915 & 688653 & 4.883 & 5.2776 & TRN & & \\
\hline
\end{tabular}




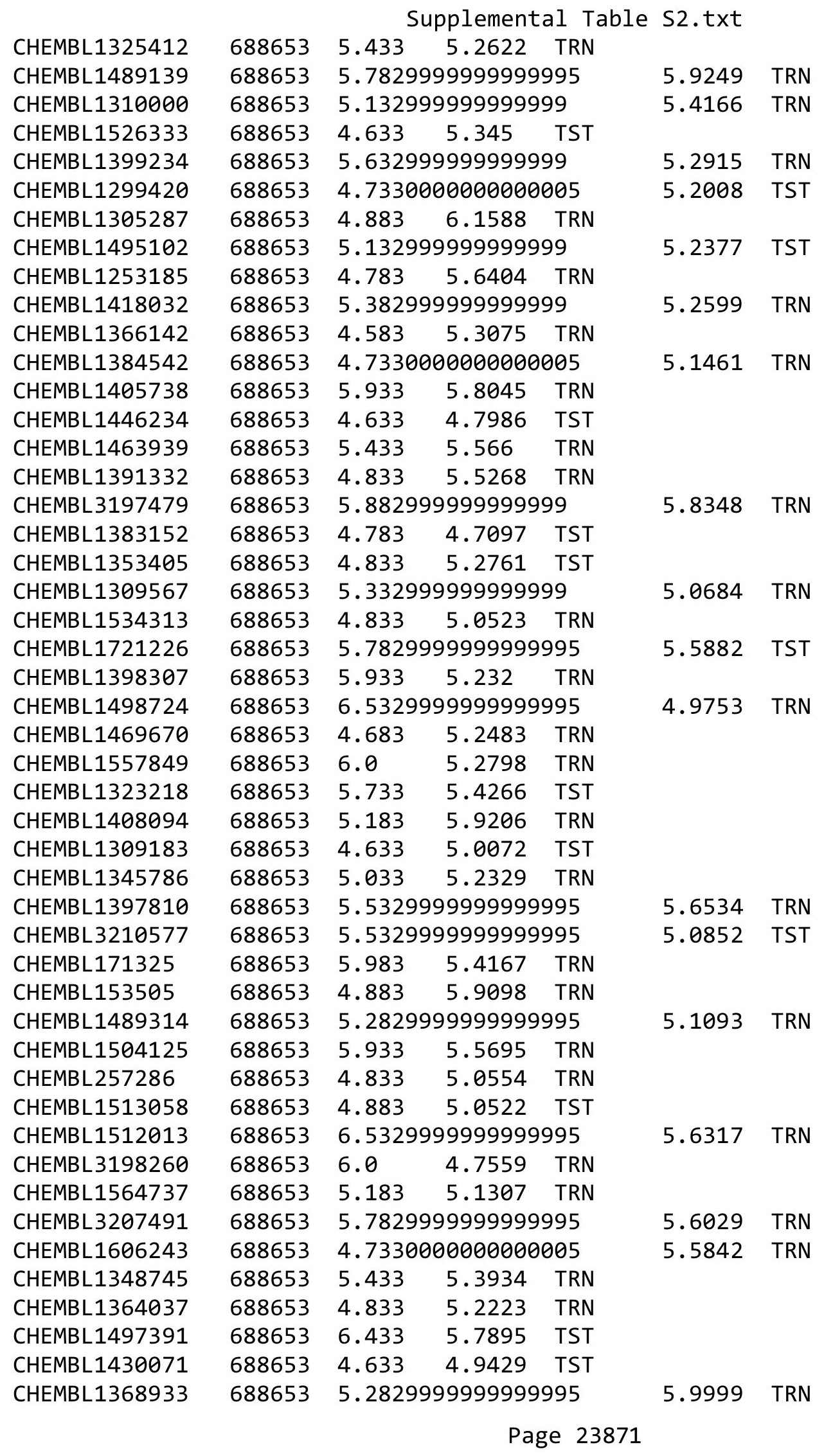




\begin{tabular}{|c|c|c|c|c|c|c|}
\hline & & \multicolumn{5}{|c|}{ Supplemental Table S2.txt } \\
\hline CHEMBL1491120 & 688653 & 6.8831 & 5.7825 & TRN & & \\
\hline CHEMBL1525050 & 688653 & 4.783 & 5.0568 & TST & & \\
\hline CHEMBL1553321 & 688653 & 4.633 & 5.2331 & TRN & & \\
\hline CHEMBL1523413 & 688653 & 4.883 & 4.8661 & TRN & & \\
\hline CHEMBL1444884 & 688653 & \multicolumn{3}{|c|}{6.082999999999999} & 5.8738 & $\mathrm{TH}$ \\
\hline CHEMBL1340115 & 688653 & 4.783 & 4.9956 & TRN & & \\
\hline CHEMBL1554987 & 688653 & 4.633 & 4.7374 & TRN & & \\
\hline CHEMBL1606246 & 688653 & 4.883 & 4.8762 & TRN & & \\
\hline CHEMBL1543979 & 688653 & 4.783 & 5.6263 & TST & & \\
\hline CHEMBL1540336 & 688653 & 5.083 & 5.1124 & TST & & \\
\hline CHEMBL1314762 & 688653 & \multicolumn{3}{|c|}{6.332999999999999} & 5.1138 & II \\
\hline CHEMBL1301567 & 688653 & 4.833 & 5.4765 & TST & & \\
\hline CHEMBL1342148 & 688653 & 5.483 & 5.3141 & TRN & & \\
\hline CHEMBL1527452 & 688653 & 4.783 & 4.9427 & TRN & & \\
\hline CHEMBL1585318 & 688653 & 4.783 & 5.3028 & TST & & \\
\hline CHEMBL1532428 & 688653 & \multicolumn{3}{|c|}{4.7330000000000005} & 4.8607 & TRN \\
\hline CHEMBL1472583 & 688653 & \multicolumn{3}{|c|}{5.2829999999999995} & 5.1931 & \\
\hline CHEMBL1399631 & 688653 & 6.233 & 5.395 & TRN & & \\
\hline CHEMBL31 & 688653 & 4.933 & 5.3242 & TRN & & \\
\hline CHEMBL1497197 & 688653 & 7.1331 & 6.1242 & TST & & \\
\hline CHEMBL1556881 & 688653 & \multicolumn{3}{|c|}{4.7330000000000005} & 4.8627 & \\
\hline CHEMBL1604104 & 688653 & 4.783 & 5.1049 & TST & & \\
\hline CHEMBL1603682 & 688653 & \multicolumn{3}{|c|}{4.9830000000000005} & 5.1422 & TRN \\
\hline CHEMBL1569469 & 688653 & \multicolumn{3}{|c|}{5.582999999999999} & 5.2965 & \\
\hline CHEMBL3210519 & 688653 & 4.783 & 5.3265 & TRN & & \\
\hline CHEMBL1538954 & 688653 & 5.733 & 5.7667 & TRN & & \\
\hline CHEMBL1414808 & 688653 & \multicolumn{3}{|c|}{4.7330000000000005} & 4.6961 & \\
\hline CHEMBL1 & 688653 & 5.183 & 5.4337 & TRN & & \\
\hline CHEMBL1315551 & 688653 & \multicolumn{3}{|c|}{5.332999999999999} & 5.3137 & TRN \\
\hline CHEMBL584668 & 688653 & \multicolumn{3}{|c|}{6.082999999999999} & 5.6273 & TRN \\
\hline CHEMBL3194845 & 688653 & 4.933 & 5.5354 & TST & & \\
\hline CHEMBL1486028 & 688653 & \multicolumn{3}{|c|}{5.632999999999999} & 5.4613 & $1 \mathrm{nI}$ \\
\hline CHEMBL1303173 & 688653 & 4.933 & 5.9022 & TRN & & \\
\hline CHEMBL1535538 & 688653 & & 4.7484 & TST & & \\
\hline CHEMBL1586085 & 688653 & \multicolumn{3}{|c|}{5.332999999999999} & 5.4985 & TP \\
\hline CHEMBL1379136 & 688653 & 4.583 & 5.5569 & TRN & & \\
\hline CHEMBL1547188 & 688653 & 5.083 & 5.3341 & TRN & & \\
\hline CHEMBL1337341 & 688653 & \multicolumn{3}{|c|}{5.132999999999999} & 5.1708 & $\mathrm{TH}$ \\
\hline CHEMBL1331285 & 688653 & 4.883 & 5.3956 & TRN & & \\
\hline CHEMBL1422074 & 688653 & \multicolumn{3}{|c|}{4.7330000000000005} & 5.4396 & $\mathrm{TR}$ \\
\hline CHEMBL3198735 & 688653 & 4.783 & 5.4656 & TRN & & \\
\hline CHEMBL1992104 & 688653 & 5.483 & 5.8111 & TRN & & \\
\hline CHEMBL1582488 & 688653 & \multicolumn{3}{|c|}{5.382999999999999} & 5.3403 & $T$ \\
\hline CHEMBL600100 & 688653 & 5.233 & 5.6026 & TRN & & \\
\hline CHEMBL3197971 & 688653 & \multicolumn{3}{|c|}{5.582999999999999} & 5.2582 & S1 \\
\hline CHEMBL3195060 & 688653 & 5.433 & 5.3102 & TRN & & \\
\hline CHEMBL1525425 & 688653 & \multicolumn{3}{|c|}{5.132999999999999} & 3101 & TRN \\
\hline CHEMBL1332275 & 688653 & 4.933 & 5.206 & TRN & & \\
\hline
\end{tabular}




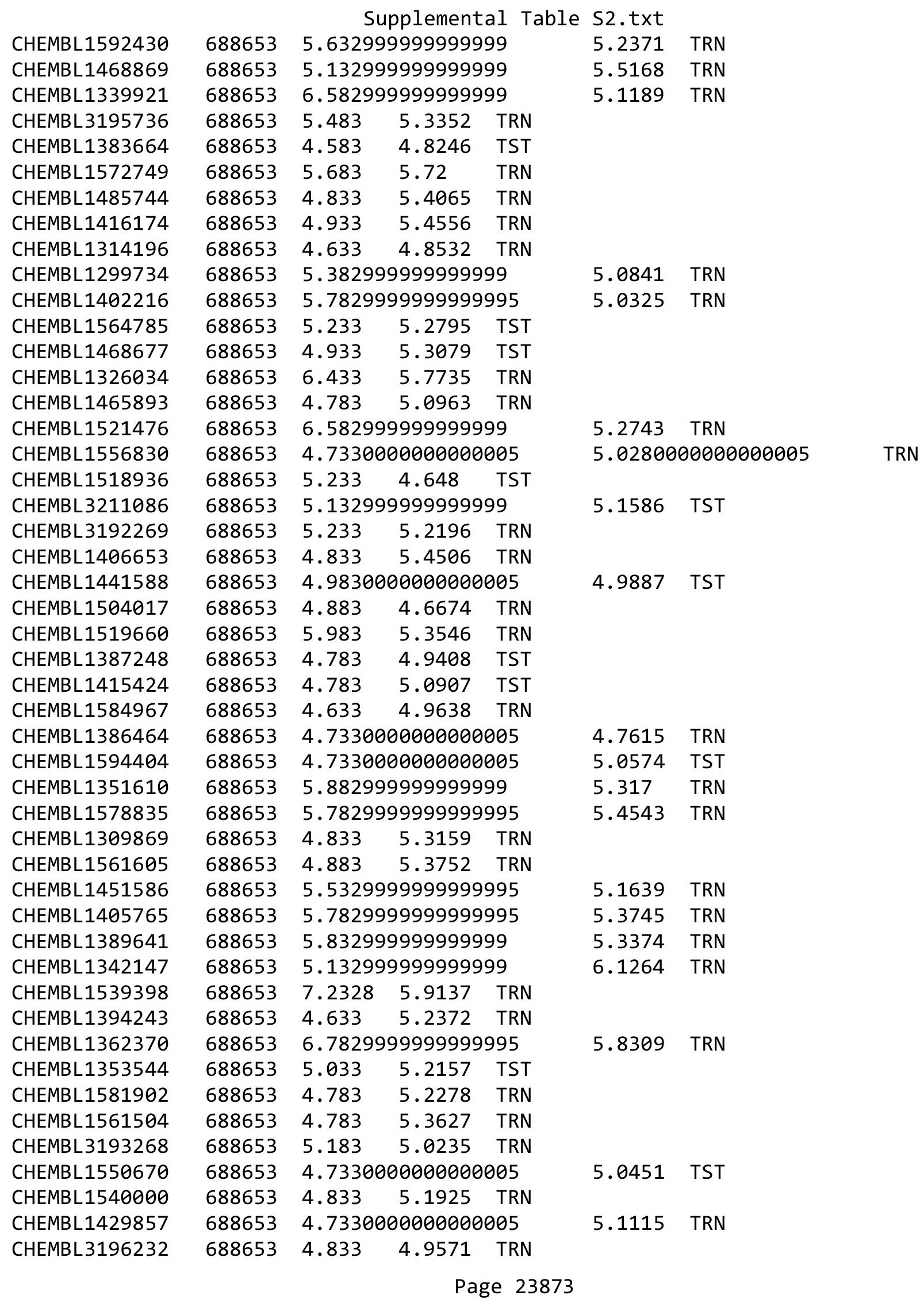




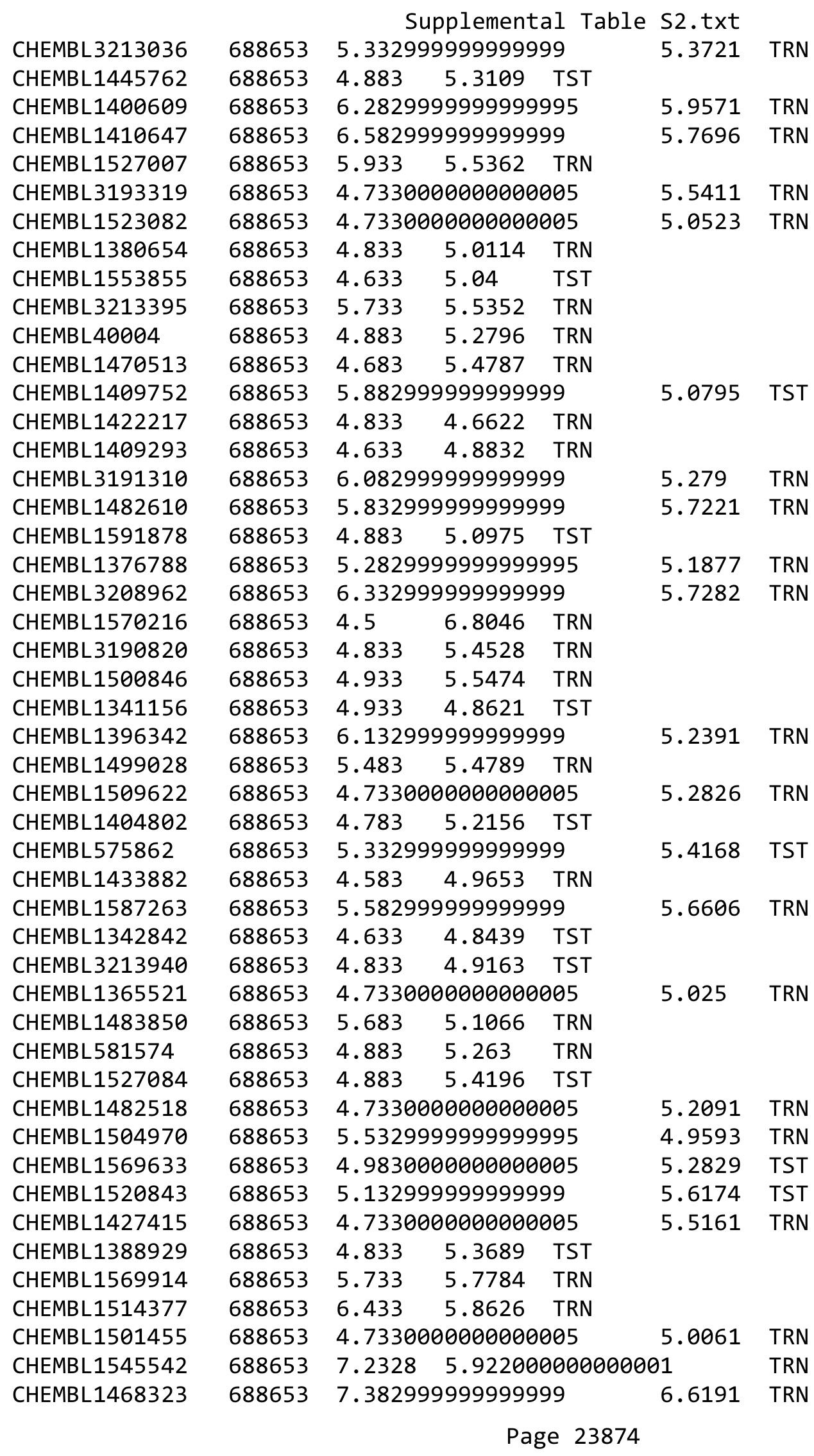




\begin{tabular}{|c|c|c|c|c|c|c|c|}
\hline \multicolumn{7}{|c|}{ Supplemental Table S2.txt } & \\
\hline CHEMBL1443206 & 688653 & 4.933 & 4.9751 & TRN & & & \\
\hline CHEMBL1309059 & 688653 & 5.233 & 5.4049 & TST & & & \\
\hline CHEMBL1449007 & 688653 & 5.083 & 5.5032 & TST & & & \\
\hline CHEMBL1344718 & 688653 & 5.38299 & 999999999 & & 5.1409 & TRN & \\
\hline CHEMBL1473661 & 688653 & 4.883 & 4.8021 & TST & & & \\
\hline CHEMBL3193327 & 688653 & 4.683 & 5.2388 & TRN & & & \\
\hline CHEMBL1556692 & 688653 & 5.53299 & 999999999 & 995 & 5.5823 & TST & \\
\hline CHEMBL546170 & 688653 & 4.583 & 5.8107 & TST & & & \\
\hline CHEMBL 2369289 & 688653 & 4.73300 & 000000000 & 005 & 5.3847 & TST & \\
\hline CHEMBL1524192 & 688653 & 6.4829 & 5.3642 & TRN & & & \\
\hline CHEMBL1441178 & 688653 & 4.633 & 4.6588 & TRN & & & \\
\hline CHEMBL1385056 & 688653 & 5.33299 & 999999999 & & 5.7037 & TRN & \\
\hline CHEMBL1404287 & 688653 & 5.183 & 5.2345 & TST & & & \\
\hline CHEMBL 3197270 & 688653 & 6.28299 & 999999999 & 995 & 5.9805 & TRN & \\
\hline CHEMBL3211529 & 688653 & 4.583 & 4.5708 & TRN & & & \\
\hline CHEMBL1594952 & 688653 & 5.433 & 5.4594 & TRN & & & \\
\hline CHEMBL1612368 & 688653 & 5.733 & 5.5331 & TRN & & & \\
\hline CHEMBL1472437 & 688653 & 5.78299 & 999999999 & 995 & 5.3971 & TRN & \\
\hline CHEMBL1436105 & 688653 & 6.03299 & 999999999 & 995 & 5.28299 & 99999999995 & TRN \\
\hline CHEMBL1536260 & 688653 & 5.033 & 5.0475 & TRN & & & \\
\hline CHEMBL1538850 & 688653 & 4.633 & 5.0995 & TRN & & & \\
\hline CHEMBL1422097 & 688653 & 5.683 & 5.7755 & TRN & & & \\
\hline CHEMBL1577925 & 688653 & 4.98300 & 000000000 & 005 & 5.1474 & TRN & \\
\hline CHEMBL1539755 & 688653 & 4.73300 & 000000000 & 005 & 5.1628 & TST & \\
\hline CHEMBL589245 & 688653 & 4.583 & 4.7375 & TST & & & \\
\hline CHEMBL1419935 & 688653 & 6.03299 & 999999999 & 995 & 5.2153 & TRN & \\
\hline CHEMBL1312727 & 688653 & 5.233 & 5.5778 & TRN & & & \\
\hline CHEMBL1494316 & 688653 & 4.883 & 5.595 & TRN & & & \\
\hline CHEMBL1992547 & 688653 & 4.833 & 5.356 & TRN & & & \\
\hline CHEMBL1522960 & 688653 & 5.033 & 5.0577 & TRN & & & \\
\hline CHEMBL3198801 & 688653 & 4.833 & 4.8619 & TRN & & & \\
\hline CHEMBL1349693 & 688653 & 5.083 & 5.0924 & TST & & & \\
\hline CHEMBL1404137 & 688653 & 6.4829 & 5.4423 & TRN & & & \\
\hline CHEMBL1340027 & 688653 & 4.783 & 5.5559 & TST & & & \\
\hline CHEMBL1563193 & 688653 & 5.233 & 5.6346 & TRN & & & \\
\hline CHEMBL1340076 & 688653 & 5.13299 & 999999999 & & 4.7405 & TST & \\
\hline CHEMBL1471769 & 688653 & 4.883 & 5.172000 & 000000000 & & TRN & \\
\hline CHEMBL1565774 & 688653 & 6.28299 & 999999999 & 995 & 5.5241 & TRN & \\
\hline CHEMBL1327098 & 688653 & 5.683 & 5.2312 & TRN & & & \\
\hline CHEMBL1335597 & 688653 & 6.233 & 6.1107 & TRN & & & \\
\hline CHEMBL1473461 & 688653 & 5.733 & 5.5591 & TRN & & & \\
\hline CHEMBL1357330 & 688653 & 5.233 & 5.1171 & TST & & & \\
\hline CHEMBL1299995 & 688653 & 4.583 & 4.9256 & TST & & & \\
\hline CHEMBL1508749 & 688653 & 4.883 & 5.6205 & TST & & & \\
\hline CHEMBL1361506 & 688653 & 5.233 & 5.3587 & TRN & & & \\
\hline CHEMBL 3198294 & 688653 & 6.08299 & 999999999 & & 5.6005 & TRN & \\
\hline CHEMBL3211542 & 688653 & 4.883 & 5.1306 & TRN & & & \\
\hline CHEMBL1572293 & 688653 & 4.98300 & 000000000 & 005 & 5.0929 & TRN & \\
\hline
\end{tabular}




\begin{tabular}{|c|c|c|c|c|c|c|}
\hline \multirow{3}{*}{$\begin{array}{l}\text { CHEMBL1573883 } \\
\text { CHEMBL3214260 }\end{array}$} & \multirow{3}{*}{$\begin{array}{l}688653 \\
688653\end{array}$} & \multicolumn{4}{|c|}{ Supplemental Table S2.txt } & \multirow{2}{*}{ TRN } \\
\hline & & 5.28299 & 99999999 & 995 & 6.0102 & \\
\hline & & 4.933 & \multicolumn{3}{|c|}{5.287999999999999} & TRN \\
\hline CHEMBL1443346 & 688653 & 4.783 & 5.0922 & TST & & \\
\hline CHEMBL1442115 & 688653 & 6.7331 & 5.4559 & TRN & & \\
\hline CHEMBL1307766 & 688653 & 5.83299 & 99999999 & & 5.4562 & TRN \\
\hline CHEMBL1507729 & 688653 & 4.783 & 4.6618 & TRN & & \\
\hline CHEMBL1593516 & 688653 & 4.633 & 4.8973 & TST & & \\
\hline CHEMBL240333 & 688653 & 5.233 & 5.7743 & TRN & & \\
\hline CHEMBL1505546 & 688653 & \multicolumn{3}{|c|}{4.7330000000000005} & 5.1221 & TRN \\
\hline CHEMBL1362119 & 688653 & \multicolumn{3}{|c|}{4.9830000000000005} & 4.9193 & TRN \\
\hline CHEMBL1424048 & 688653 & \multicolumn{3}{|c|}{5.882999999999999} & 5.6003 & TRN \\
\hline CHEMBL3197302 & 688653 & 5.183 & 5.4985 & TST & & \\
\hline CHEMBL1545910 & 688653 & 4.783 & 4.9816 & TRN & & \\
\hline CHEMBL1437722 & 688653 & 4.683 & 4.6701 & TRN & & \\
\hline CHEMBL1477957 & 688653 & 5.083 & 5.7539 & TRN & & \\
\hline CHEMBL1458187 & 688653 & \multicolumn{3}{|c|}{5.882999999999999} & 4.5881 & TST \\
\hline CHEMBL1521680 & 688653 & 5.983 & 5.6916 & TRN & & \\
\hline CHEMBL1371383 & 688653 & 5.4 & 5.4461 & TRN & & \\
\hline CHEMBL1564230 & 688653 & 5.083 & 4.8399 & TRN & & \\
\hline CHEMBL1336000 & 688653 & \multicolumn{3}{|c|}{4.7330000000000005} & 5.3356 & TRN \\
\hline CHEMBL3213602 & 688653 & 4.683 & 5.3361 & TRN & & \\
\hline CHEMBL1492665 & 688653 & 5.433 & 5.7547 & TRN & & \\
\hline CHEMBL1529158 & 688653 & 4.883 & 4.8018 & TST & & \\
\hline CHEMBL1334545 & 688653 & 4.833 & 4.9962 & TST & & \\
\hline CHEMBL1368235 & 688653 & \multicolumn{3}{|c|}{5.7829999999999995} & 5.3671 & TRN \\
\hline CHEMBL1594316 & 688653 & \multicolumn{3}{|c|}{6.5329999999999995} & 6.4042 & TRN \\
\hline CHEMBL1997130 & 688653 & \multicolumn{3}{|c|}{5.2829999999999995} & 5.3405 & TRN \\
\hline CHEMBL1309808 & 688653 & \multicolumn{3}{|c|}{4.7330000000000005} & 4.9278 & TRN \\
\hline CHEMBL1488223 & 688653 & \multicolumn{3}{|c|}{5.7829999999999995} & 5.0227 & TRN \\
\hline CHEMBL1490409 & 688653 & 4.633 & 5.2972 & TST & & \\
\hline CHEMBL1369196 & 688653 & 5.683 & 5.7528 & TRN & & \\
\hline CHEMBL 3211541 & 688653 & 4.783 & 5.4415 & TRN & & \\
\hline CHEMBL1601421 & 688653 & 5.033 & 5.0723 & TRN & & \\
\hline CHEMBL1462588 & 688653 & 5.933 & 5.3677 & TRN & & \\
\hline CHEMBL1466712 & 688653 & \multicolumn{3}{|c|}{5.382999999999999} & 5.1834 & TRN \\
\hline CHEMBL1519864 & 688653 & \multicolumn{3}{|c|}{6.382999999999999} & 5.4903 & TRN \\
\hline CHEMBL1425259 & 688653 & 4.883 & 4.9274 & TST & & \\
\hline CHEMBL1609865 & 688653 & 4.783 & 5.3697 & TST & & \\
\hline CHEMBL1330852 & 688653 & 4.783 & 5.7079 & TRN & & \\
\hline CHEMBL1532931 & 688653 & 6.8831 & 5.8072 & TRN & & \\
\hline CHEMBL1573994 & 688653 & \multicolumn{3}{|c|}{5.332999999999999} & 6.6438 & TRN \\
\hline CHEMBL1575744 & 688653 & \multicolumn{3}{|c|}{5.582999999999999} & 5.3631 & TRN \\
\hline CHEMBL601146 & 688653 & 6.0 & 5.3423 & TRN & & \\
\hline CHEMBL1324089 & 688653 & \multicolumn{3}{|c|}{6.0329999999999995} & 5.1778 & TST \\
\hline CHEMBL1474843 & 688653 & \multicolumn{3}{|c|}{5.332999999999999} & 5.8664 & TRN \\
\hline CHEMBL1424935 & 688653 & 4.683 & 5.3807 & TRN & & \\
\hline CHEMBL1530937 & 688653 & 5.483 & 5.1314 & TRN & & \\
\hline CHEMBL1603047 & 688653 & 6.83299 & 99999999 & & 6.1502 & TRN \\
\hline
\end{tabular}




\begin{tabular}{|c|c|c|c|c|c|c|}
\hline CHEMBL1429411 & 688653 & \multicolumn{3}{|c|}{ Supplemental Table } & $\begin{array}{l}\text { S2.txt } \\
5.279\end{array}$ & TRN \\
\hline CHEMBL1352093 & 688653 & 4.783 & 5.2025 & TRN & & \\
\hline CHEMBL1367720 & 688653 & \multicolumn{3}{|c|}{4.7330000000000005} & 4.9432 & TRN \\
\hline CHEMBL1410609 & 688653 & 5.083 & 5.664 & TRN & & \\
\hline CHEMBL3193584 & 688653 & 4.783 & 5.106 & TST & & \\
\hline CHEMBL1540645 & 688653 & 4.833 & 4.8501 & TRN & & \\
\hline CHEMBL1542889 & 688653 & 6.433 & 5.8547 & TRN & & \\
\hline CHEMBL1451193 & 688653 & 5.083 & 5.0979 & TRN & & \\
\hline CHEMBL1603038 & 688653 & 6.183 & 5.8514 & TRN & & \\
\hline CHEMBL1382906 & 688653 & \multicolumn{3}{|c|}{4.7330000000000005} & 5.1308 & TST \\
\hline CHEMBL1558218 & 688653 & 5.733 & 4.7198 & TRN & & \\
\hline CHEMBL1447186 & 688653 & \multicolumn{3}{|c|}{6.2829999999999995} & 5.8982 & TRN \\
\hline CHEMBL1536850 & 688653 & 4.883 & 4.8917 & TST & & \\
\hline CHEMBL1514691 & 688653 & \multicolumn{3}{|c|}{4.9830000000000005} & 6.0815 & TST \\
\hline CHEMBL1345979 & 688653 & \multicolumn{3}{|c|}{5.2829999999999995} & 5.4168 & TST \\
\hline CHEMBL1606867 & 688653 & 4.583 & 4.6611 & TRN & & \\
\hline CHEMBL1326282 & 688653 & 4.783 & 5.0776 & TRN & & \\
\hline CHEMBL1301075 & 688653 & 5.233 & 5.3589 & TST & & \\
\hline CHEMBL1460982 & 688653 & 4.783 & 5.1125 & TRN & & \\
\hline CHEMBL1360487 & 688653 & 4.833 & 4.6068 & TST & & \\
\hline CHEMBL1546726 & 688653 & 5.233 & 5.1414 & TRN & & \\
\hline CHEMBL1301307 & 688653 & \multicolumn{3}{|c|}{5.582999999999999} & 5.5118 & TRN \\
\hline CHEMBL1415785 & 688653 & 4.633 & 4.8594 & TRN & & \\
\hline CHEMBL1440071 & 688653 & \multicolumn{3}{|c|}{4.9830000000000005} & 5.1422 & TRN \\
\hline CHEMBL1310929 & 688653 & 4.683 & 5.1896 & TST & & \\
\hline CHEMBL1403048 & 688653 & 6.4829 & 5.7654 & TRN & & \\
\hline CHEMBL1499032 & 688653 & \multicolumn{3}{|c|}{4.7330000000000005} & 4.9575 & TRN \\
\hline CHEMBL 3190880 & 688653 & 4.583 & 5.4433 & TRN & & \\
\hline CHEMBL1330934 & 688653 & 4.683 & 4.7445 & TRN & & \\
\hline CHEMBL1483684 & 688653 & \multicolumn{3}{|c|}{5.2829999999999995} & 5.3878 & TST \\
\hline CHEMBL1440603 & 688653 & 4.833 & 4.7677 & TRN & & \\
\hline CHEMBL1572857 & 688653 & 5.033 & 5.1638 & TRN & & \\
\hline CHEMBL1575487 & 688653 & 4.633 & 5.2635 & TST & & \\
\hline CHEMBL3212879 & 688653 & \multicolumn{3}{|c|}{6.382999999999999} & 5.4896 & TRN \\
\hline CHEMBL1516784 & 688653 & 4.783 & 5.063 & TST & & \\
\hline CHEMBL1452783 & 688653 & \multicolumn{3}{|c|}{5.132999999999999} & 5.0694 & TRN \\
\hline CHEMBL1325574 & 688653 & \multicolumn{3}{|c|}{4.9830000000000005} & 5.1843 & TRN \\
\hline CHEMBL1308917 & 688653 & 4.833 & 5.2247 & TST & & \\
\hline CHEMBL1331376 & 688653 & \multicolumn{3}{|c|}{5.5329999999999995} & 5.1879 & TRN \\
\hline CHEMBL1454300 & 688653 & \multicolumn{3}{|c|}{7.082999999999999} & 6.0535 & TRN \\
\hline CHEMBL1531731 & 688653 & \multicolumn{3}{|c|}{5.632999999999999} & 5.2507 & TRN \\
\hline CHEMBL1348506 & 688653 & \multicolumn{3}{|c|}{5.2829999999999995} & 5.2285 & TRN \\
\hline CHEMBL1305924 & 688653 & 5.033 & 5.8944 & TST & & \\
\hline CHEMBL1613374 & 688653 & 5.683 & 5.8529 & TRN & & \\
\hline CHEMBL1310110 & 688653 & 4.783 & 4.9292 & TRN & & \\
\hline CHEMBL1446259 & 688653 & 5.0 & 5.1695 & TRN & & \\
\hline CHEMBL1467649 & 688653 & 5.083 & 5.4288 & TRN & & \\
\hline CHEMBL1529438 & 688653 & 4.783 & 5.3882 & TST & & \\
\hline
\end{tabular}




\begin{tabular}{|c|c|c|c|c|c|c|}
\hline \multirow[b]{2}{*}{ CHEMBL1299977 } & & \multicolumn{5}{|c|}{ Supplemental Table S2.txt } \\
\hline & 688653 & 5.983 & 5.8967 & TRN & & \\
\hline CHEMBL1505711 & 688653 & \multicolumn{3}{|c|}{5.132999999999999} & 4.9181 & TRN \\
\hline CHEMBL1593151 & 688653 & 5.183 & 4.8688 & TRN & & \\
\hline CHEMBL1426366 & 688653 & 5.033 & 5.9921 & TRN & & \\
\hline CHEMBL1495409 & 688653 & 5.933 & 5.3045 & TST & & \\
\hline CHEMBL1493877 & 688653 & \multicolumn{3}{|c|}{5.132999999999999} & 4.7874 & TST \\
\hline CHEMBL1331887 & 688653 & 5.083 & 5.426 & TRN & & \\
\hline CHEMBL1438254 & 688653 & \multicolumn{3}{|c|}{4.9830000000000005} & 5.2739 & TRN \\
\hline CHEMBL1483099 & 688653 & 4.783 & 5.7753 & TST & & \\
\hline CHEMBL1378124 & 688653 & 4.833 & 4.9523 & TRN & & \\
\hline CHEMBL1389427 & 688653 & \multicolumn{3}{|c|}{5.832999999999999} & 5.3394 & TRN \\
\hline CHEMBL1313647 & 688653 & \multicolumn{3}{|c|}{5.5329999999999995} & 5.3234 & TRN \\
\hline CHEMBL1609931 & 688653 & \multicolumn{3}{|c|}{4.7330000000000005} & 5.1836 & TRN \\
\hline CHEMBL1348941 & 688653 & 5.683 & 5.5501 & TRN & & \\
\hline CHEMBL3213428 & 688653 & \multicolumn{3}{|c|}{4.9830000000000005} & 5.6199 & TST \\
\hline CHEMBL590184 & 688653 & \multicolumn{3}{|c|}{5.382999999999999} & 5.6811 & TRN \\
\hline CHEMBL1299682 & 688653 & 5.033 & 5.3361 & TRN & & \\
\hline CHEMBL1384739 & 688653 & 5.183 & 5.5635 & TRN & & \\
\hline CHEMBL1610168 & 688653 & \multicolumn{3}{|c|}{5.132999999999999} & 4.7475 & TST \\
\hline CHEMBL1395832 & 688653 & 4.633 & 5.0949 & TST & & \\
\hline CHEMBL1553674 & 688653 & 4.933 & 5.0369 & TRN & & \\
\hline CHEMBL1430981 & 688653 & 4.583 & 5.2678 & TRN & & \\
\hline CHEMBL573226 & 688653 & 4.683 & 5.3965 & TRN & & \\
\hline CHEMBL1570804 & 688653 & 5.983 & 5.2482 & TST & & \\
\hline CHEMBL1581580 & 688653 & 5.033 & 5.5549 & TRN & & \\
\hline CHEMBL3213307 & 688653 & \multicolumn{3}{|c|}{4.7330000000000005} & 4.8667 & TST \\
\hline CHEMBL1349088 & 688653 & \multicolumn{3}{|c|}{4.7330000000000005} & 5.5312 & TRN \\
\hline CHEMBL1390971 & 688653 & 5.183 & 5.45100 & 000000000 & 005 & TST \\
\hline CHEMBL1382797 & 688653 & \multicolumn{3}{|c|}{6.0329999999999995} & 5.5649 & TRN \\
\hline CHEMBL1508457 & 688653 & 6.9329 & 5.5586 & TRN & & \\
\hline CHEMBL1423711 & 688653 & 5.083 & 4.8227 & TRN & & \\
\hline CHEMBL1600311 & 688653 & 5.933 & 5.3956 & TRN & & \\
\hline CHEMBL3190063 & 688653 & 4.833 & 5.371 & TST & & \\
\hline CHEMBL1566141 & 688653 & 5.933 & 6.0929 & TRN & & \\
\hline CHEMBL1457670 & 688653 & 5.983 & 5.1162 & TST & & \\
\hline CHEMBL1496958 & 688653 & 5.083 & 5.1827 & TRN & & \\
\hline CHEMBL 234583 & 688653 & 6.433 & 5.9283 & TRN & & \\
\hline CHEMBL608673 & 688653 & \multicolumn{3}{|c|}{4.7330000000000005} & 5.0915 & TRN \\
\hline CHEMBL1369226 & 688653 & 5.483 & 5.2684 & TRN & & \\
\hline CHEMBL1476320 & 688653 & \multicolumn{3}{|c|}{4.7330000000000005} & 5.2434 & TRN \\
\hline CHEMBL1604797 & 688653 & 4.683 & 4.9348 & TST & & \\
\hline CHEMBL1516572 & 688653 & 5.233 & 5.2034 & TRN & & \\
\hline CHEMBL1532472 & 688653 & \multicolumn{3}{|c|}{5.832999999999999} & 5.8524 & TRN \\
\hline CHEMBL1473922 & 688653 & 5.683 & 5.7647 & TRN & & \\
\hline CHEMBL1601652 & 688653 & 6.7331 & 5.3766 & TRN & & \\
\hline CHEMBL3207376 & 688653 & 5.083 & 5.1975 & TRN & & \\
\hline CHEMBL1428466 & 688653 & 5.083 & 5.0264 & TRN & & \\
\hline CHEMBL1509479 & 688653 & 4.833 & 4.9166 & TRN & & \\
\hline
\end{tabular}




\begin{tabular}{|c|c|c|c|c|c|c|}
\hline \multicolumn{7}{|c|}{ Supplemental Table S2.txt } \\
\hline CHEMBL1504728 & 688653 & \multicolumn{3}{|c|}{5.332999999999999} & 5.221 & TRN \\
\hline CHEMBL52347 & 688653 & \multicolumn{3}{|c|}{4.9830000000000005} & 5.4591 & TST \\
\hline CHEMBL1440068 & 688653 & 6.4829 & 6.0486 & TRN & & \\
\hline CHEMBL590408 & 688653 & 4.583 & 4.7467 & TST & & \\
\hline CHEMBL1991311 & 688653 & 5.433 & 5.3641 & TRN & & \\
\hline CHEMBL1567005 & 688653 & \multicolumn{3}{|c|}{5.132999999999999} & 5.3303 & TRN \\
\hline CHEMBL1575525 & 688653 & 5.183 & 5.6032 & TRN & & \\
\hline CHEMBL1531028 & 688653 & 4.833 & 4.6689 & TRN & & \\
\hline CHEMBL1310496 & 688653 & 6.4829 & 6.0414 & TRN & & \\
\hline CHEMBL1602717 & 688653 & \multicolumn{3}{|c|}{7.082999999999999} & 5.9289 & TRN \\
\hline CHEMBL1391272 & 688653 & 4.633 & 5.0431 & TRN & & \\
\hline CHEMBL1575926 & 688653 & 6.433 & 6.3684 & TRN & & \\
\hline CHEMBL1310409 & 688653 & 5.683 & 5.2935 & TRN & & \\
\hline CHEMBL1494877 & 688653 & 4.683 & 5.4909 & TST & & \\
\hline CHEMBL1445725 & 688653 & 5.983 & 5.9767 & TRN & & \\
\hline CHEMBL1608486 & 688653 & 6.183 & 5.6343 & TRN & & \\
\hline CHEMBL1459476 & 688653 & \multicolumn{3}{|c|}{4.7330000000000005} & 4.8509 & TST \\
\hline CHEMBL1521092 & 688653 & \multicolumn{3}{|c|}{6.2829999999999995} & 5.7178 & TRN \\
\hline CHEMBL1350254 & 688653 & 4.933 & 5.3296 & TRN & & \\
\hline CHEMBL1363803 & 688653 & \multicolumn{3}{|c|}{5.132999999999999} & 5.4595 & TRN \\
\hline CHEMBL1339679 & 688653 & 4.783 & 5.4264 & TRN & & \\
\hline CHEMBL1361228 & 688653 & 5.083 & 5.145 & TRN & & \\
\hline CHEMBL1365615 & 688653 & 6.433 & 5.9712 & TRN & & \\
\hline CHEMBL1479418 & 688653 & \multicolumn{3}{|c|}{4.9830000000000005} & 5.2818 & TRN \\
\hline CHEMBL1538571 & 688653 & \multicolumn{3}{|c|}{5.382999999999999} & 5.6145 & TST \\
\hline CHEMBL1371119 & 688653 & 4.883 & 5.0289 & TST & & \\
\hline CHEMBL 3195230 & 688653 & \multicolumn{3}{|c|}{4.7330000000000005} & \multicolumn{2}{|c|}{5.3260000000000005} \\
\hline CHEMBL1353244 & 688653 & 5.683 & 5.6382 & TRN & & \\
\hline CHEMBL1567827 & 688653 & 4.633 & 5.3313 & TRN & & \\
\hline CHEMBL1598684 & 688653 & 4.783 & 5.5148 & TRN & & \\
\hline CHEMBL1465510 & 688653 & 5.083 & 5.0557 & TST & & \\
\hline CHEMBL1376360 & 688653 & 6.433 & 5.6066 & TRN & & \\
\hline CHEMBL1598123 & 688653 & 4.833 & 4.9865 & TST & & \\
\hline CHEMBL1499277 & 688653 & \multicolumn{3}{|c|}{5.7829999999999995} & 5.2641 & TRN \\
\hline CHEMBL1572136 & 688653 & 4.883 & 5.2693 & TRN & & \\
\hline CHEMBL1299494 & 688653 & 4.833 & 5.1195 & TST & & \\
\hline CHEMBL1503017 & 688653 & 4.783 & 5.313 & TST & & \\
\hline CHEMBL1544297 & 688653 & 4.833 & 5.0117 & TRN & & \\
\hline CHEMBL1548867 & 688653 & 5.4 & 5.5644 & TRN & & \\
\hline CHEMBL1572145 & 688653 & \multicolumn{3}{|c|}{6.382999999999999} & 5.8348 & TRN \\
\hline CHEMBL 3195188 & 688653 & 4.883 & 5.69600 & 000000000 & & TRN \\
\hline CHEMBL160012 & 688653 & \multicolumn{3}{|c|}{4.7330000000000005} & 5.5324 & TRN \\
\hline CHEMBL1585298 & 688653 & 4.783 & 5.0476 & TRN & & \\
\hline CHEMBL1511029 & 688653 & 5.233 & 5.4923 & TRN & & \\
\hline CHEMBL1331213 & 688653 & 5.683 & 5.2647 & TRN & & \\
\hline CHEMBL1496529 & 688653 & 5.183 & 5.1353 & TRN & & \\
\hline CHEMBL454746 & 688653 & 4.883 & 5.4839 & TRN & & \\
\hline CHEMBL1606064 & 688653 & \multicolumn{3}{|c|}{4.7330000000000005} & 4.7426 & TRN \\
\hline
\end{tabular}




\begin{tabular}{|c|c|c|c|c|c|c|}
\hline \multirow[b]{2}{*}{ CHEMBL1414261 } & & \multicolumn{5}{|c|}{ Supplemental Table S2.txt } \\
\hline & 688653 & 4.833 & 5.4206 & TRN & & \\
\hline CHEMBL1604782 & 688653 & 5.683 & \multicolumn{3}{|c|}{5.712999999999999} & TRN \\
\hline CHEMBL1402035 & 688653 & \multicolumn{3}{|c|}{4.7330000000000005} & 5.2971 & TRN \\
\hline CHEMBL1301780 & 688653 & \multicolumn{3}{|c|}{5.632999999999999} & 5.1097 & TRN \\
\hline CHEMBL1400275 & 688653 & 4.933 & 5.0333 & TST & & \\
\hline CHEMBL1543804 & 688653 & 6.4829 & 5.9547 & TRN & & \\
\hline CHEMBL1522808 & 688653 & 5.183 & 5.5605 & TRN & & \\
\hline CHEMBL1315978 & 688653 & \multicolumn{3}{|c|}{5.332999999999999} & 5.7239 & TRN \\
\hline CHEMBL 3192082 & 688653 & \multicolumn{3}{|c|}{5.132999999999999} & 5.2053 & TST \\
\hline CHEMBL3194539 & 688653 & 4.883 & 5.3355 & TRN & & \\
\hline CHEMBL1448914 & 688653 & \multicolumn{3}{|c|}{4.7330000000000005} & 5.3682 & TRN \\
\hline CHEMBL1430573 & 688653 & \multicolumn{3}{|c|}{6.2829999999999995} & 5.4806 & TRN \\
\hline CHEMBL1606113 & 688653 & \multicolumn{3}{|c|}{5.582999999999999} & 5.771 & TRN \\
\hline CHEMBL1425287 & 688653 & \multicolumn{3}{|c|}{6.382999999999999} & 5.4562 & TRN \\
\hline CHEMBL1406396 & 688653 & \multicolumn{3}{|c|}{5.132999999999999} & 5.0765 & TST \\
\hline CHEMBL1321490 & 688653 & 4.833 & 4.9323 & TRN & & \\
\hline CHEMBL1523189 & 688653 & 4.633 & 5.2017 & TST & & \\
\hline CHEMBL528791 & 688653 & 5.233 & 4.7501 & TST & & \\
\hline CHEMBL1454091 & 688653 & 4.783 & 5.1111 & TRN & & \\
\hline CHEMBL1488667 & 688653 & \multicolumn{3}{|c|}{5.5329999999999995} & 5.6171 & TRN \\
\hline CHEMBL1403320 & 688653 & 6.0 & 4.8097 & TRN & & \\
\hline CHEMBL1421735 & 688653 & 5.683 & 5.3371 & TST & & \\
\hline CHEMBL1427626 & 688653 & 5.233 & 5.0998 & TST & & \\
\hline CHEMBL1527271 & 688653 & 4.933 & 4.9564 & TRN & & \\
\hline CHEMBL1604964 & 688653 & 5.083 & 5.2208 & TRN & & \\
\hline CHEMBL1349194 & 688653 & 4.783 & 4.9565 & TST & & \\
\hline CHEMBL1608989 & 688653 & 5.983 & 6.141 & TRN & & \\
\hline CHEMBL1416076 & 688653 & 4.583 & 5.6967 & TRN & & \\
\hline CHEMBL1378934 & 688653 & 4.933 & 5.4252 & TST & & \\
\hline CHEMBL1330199 & 688653 & \multicolumn{3}{|c|}{4.7330000000000005} & 5.3305 & TRN \\
\hline CHEMBL1595519 & 688653 & \multicolumn{3}{|c|}{5.332999999999999} & 5.7916 & TRN \\
\hline CHEMBL1530257 & 688653 & 5.183 & 5.2973 & TRN & & \\
\hline CHEMBL1511858 & 688653 & 5.933 & 5.2416 & TRN & & \\
\hline CHEMBL1386604 & 688653 & 5.733 & 5.23 & TRN & & \\
\hline CHEMBL365939 & 688653 & 5.183 & 5.3811 & TRN & & \\
\hline CHEMBL1346909 & 688653 & 4.783 & 5.3086 & TST & & \\
\hline CHEMBL1580432 & 688653 & \multicolumn{3}{|c|}{4.9830000000000005} & 4.7079 & TRN \\
\hline CHEMBL1415573 & 688653 & 4.783 & 5.3996 & TST & & \\
\hline CHEMBL1442118 & 688653 & 5.033 & 5.1068 & TST & & \\
\hline CHEMBL1527842 & 688653 & 4.883 & 5.4154 & TST & & \\
\hline CHEMBL1429373 & 688653 & 4.783 & 5.3699 & TRN & & \\
\hline CHEMBL3194597 & 688653 & \multicolumn{3}{|c|}{5.132999999999999} & 5.0315 & TRN \\
\hline CHEMBL1491122 & 688653 & \multicolumn{3}{|c|}{5.2829999999999995} & 5.3953 & TRN \\
\hline CHEMBL1385137 & 688653 & \multicolumn{3}{|c|}{5.132999999999999} & 5.1425 & TRN \\
\hline CHEMBL1591348 & 688653 & \multicolumn{3}{|c|}{4.7330000000000005} & 5.2197 & TRN \\
\hline CHEMBL1427640 & 688653 & 5.983 & 5.3056 & TRN & & \\
\hline CHEMBL1548142 & 688653 & \multicolumn{3}{|c|}{5.832999999999999} & 5.2668 & TST \\
\hline CHEMBL3191481 & 688653 & 5.083 & 5.3299 & TRN & & \\
\hline
\end{tabular}




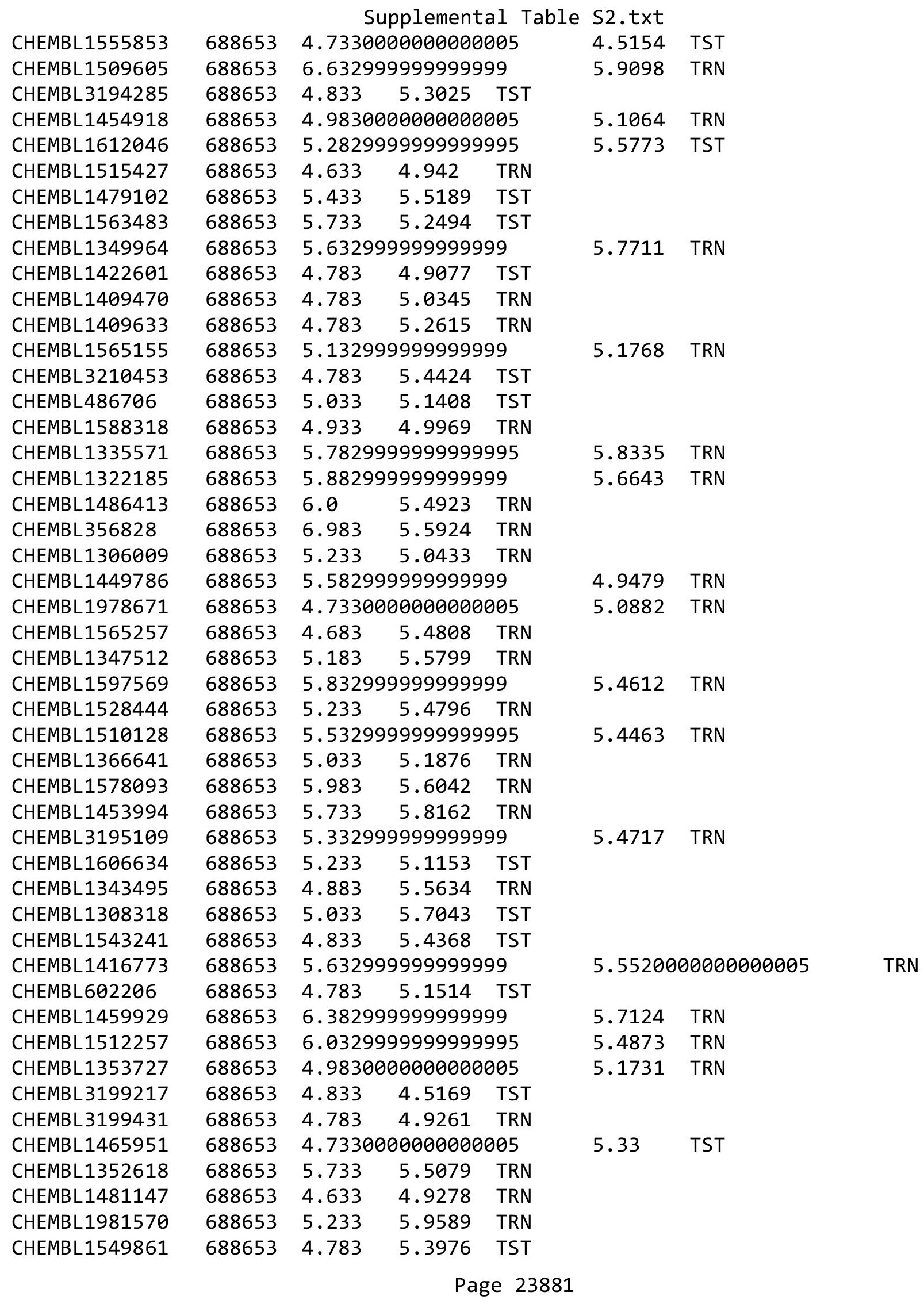




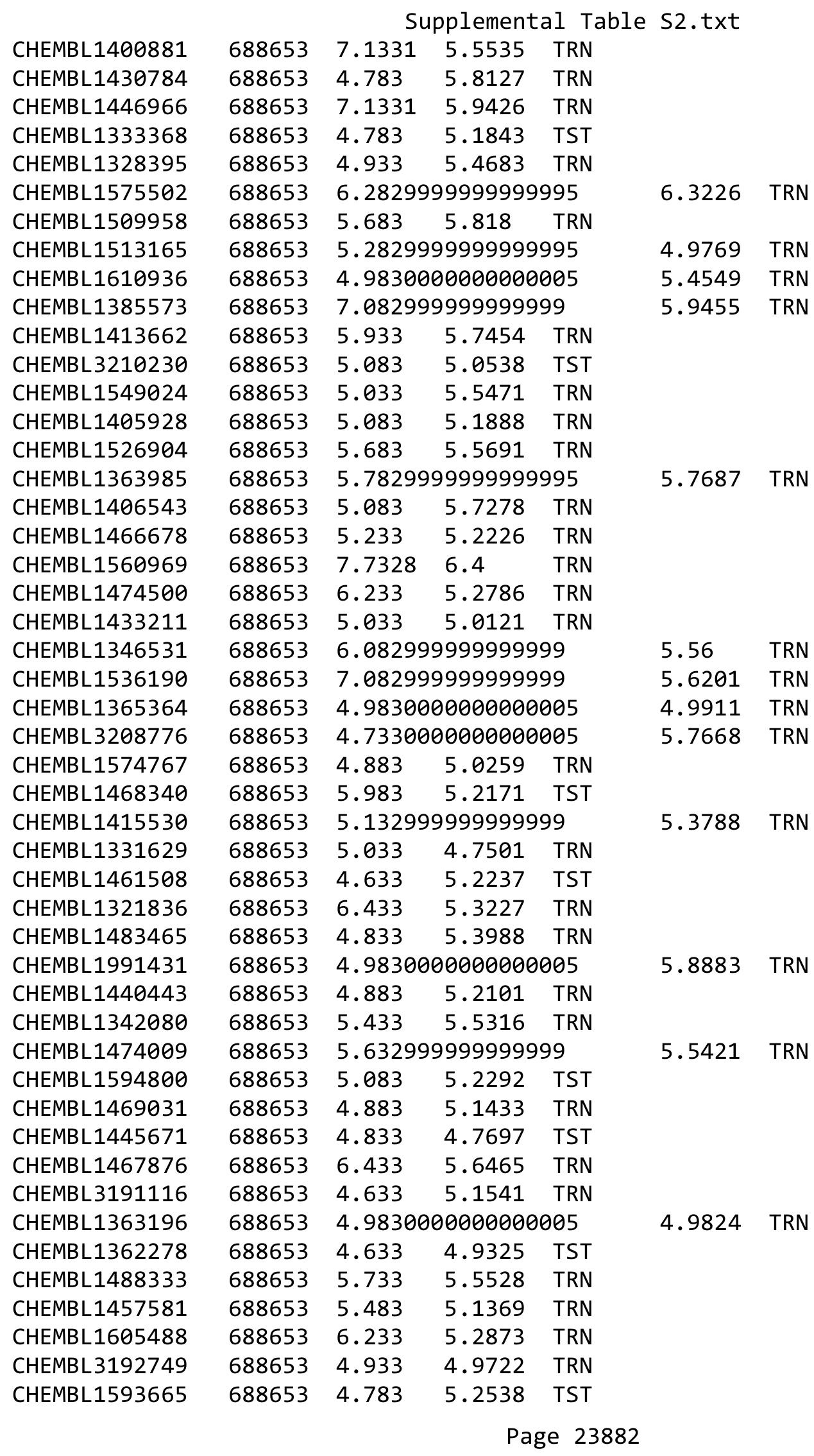




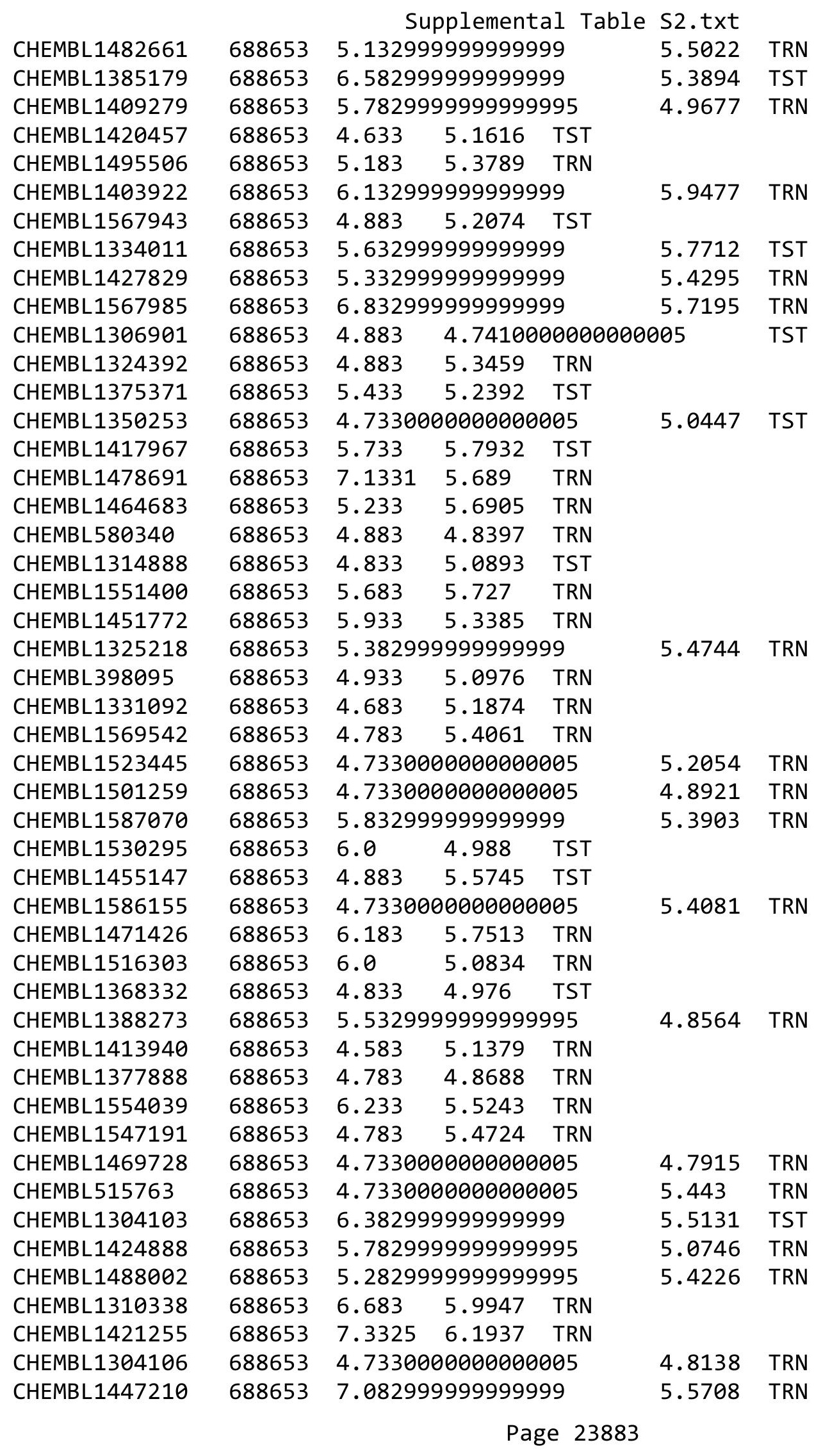




\begin{tabular}{|c|c|c|c|c|c|c|}
\hline & \multicolumn{5}{|c|}{ oplemental Ta } \\
\hline CHEMBL1456328 & 688653 & 6.183 & 5.5397 & TRN & & \\
\hline CHEMBL1356215 & 688653 & 5.28299 & 999999999 & 995 & 5.2516 & TRN \\
\hline CHEMBL1451105 & 688653 & 6.53299 & 999999999 & 995 & 5.5119 & \\
\hline CHEMBL1387637 & 688653 & 4.73300 & 000000006 & 005 & 5.893 & \\
\hline CHEMBL1487113 & 688653 & 5.58299 & 999999999 & & 4.7991 & \\
\hline CHEMBL1334555 & 688653 & 4.73300 & 000000006 & 005 & 5.3929 & \\
\hline CHEMBL1595499 & 688653 & 5.683 & 5.6596 & TST & & \\
\hline CHEMBL 3190259 & 688653 & 5.78299 & 999999999 & 995 & 5.2262 & \\
\hline CHEMBL1386853 & 688653 & 4.833 & 5.2098 & TRN & & \\
\hline CHEMBL1462015 & 688653 & 5.88299 & 999999999 & & 5.459 & \\
\hline CHEMBL1360475 & 688653 & 5.733 & 5.1613 & TRN & & \\
\hline CHEMBL1360031 & 688653 & 4.833 & 5.8079 & TST & & \\
\hline CHEMBL1326428 & 688653 & 5.38299 & 999999999 & & 4832 & \\
\hline CHEMBL1344521 & 688653 & 4.833 & 5.0879 & TST & & \\
\hline CHEMBL1370293 & 688653 & 6.58299 & 999999999 & & 5.7146 & \\
\hline CHEMBL1422397 & 688653 & 4.98300 & 000000006 & 005 & 5.2019 & \\
\hline CHEMBL1976433 & 688653 & 4.833 & 5.2707 & TRN & & \\
\hline CHEMBL1593036 & 688653 & 4.933 & 5.6747 & TRN & & \\
\hline CHEMBL1536462 & 688653 & 4.783 & 5.2593 & TST & & \\
\hline CHEMBL1429268 & 688653 & 5.733 & 5.3291 & TRN & & \\
\hline CHEMBL1479643 & 688653 & 4.73300 & 000000000 & 005 & 9139 & \\
\hline CHEMBL1532112 & 688653 & 4.633 & 5.3032 & TST & & \\
\hline CHEMBL 252901 & 688653 & 5.53299 & 999999999 & 995 & 845 & \\
\hline CHEMBL1493134 & 688653 & 4.98300 & 000000006 & 005 & 6 & \\
\hline CHEMBL1360947 & 688653 & 5.233 & 5.4376 & TRN & & \\
\hline CHEMBL1577491 & 688653 & 5.83299 & 999999999 & & 849 & $\mathrm{TH}$ \\
\hline CHEMBL1487938 & 688653 & 5.033 & 4.7121 & TST & & \\
\hline CHEMBL1578077 & 688653 & 5.13299 & 999999999 & & 5.3043 & \\
\hline CHEMBL1485273 & 688653 & 4.883 & 5.112 & TST & & \\
\hline CHEMBL1548852 & 688653 & 4.73300 & 000000000 & 005 & 5.3295 & TRN \\
\hline CHEMBL1401099 & 688653 & 5.88299 & 999999999 & & 5.4561 & TST \\
\hline CHEMBL 3192205 & 688653 & 5.38299 & 999999999 & & 5.2386 & TRN \\
\hline CHEMBL1413172 & 688653 & 4.633 & 4.9569 & TST & & \\
\hline CHEMBL551004 & 688653 & 5.78299 & 999999999 & 995 & 5.3948 & TRN \\
\hline CHEMBL1608522 & 688653 & 4.783 & 5.4603 & TRN & & \\
\hline CHEMBL1499155 & 688653 & 4.73300 & 000000000 & 005 & 4.9202 & TRN \\
\hline CHEMBL1403707 & 688653 & 6.28299 & 999999999 & 995 & 5.4029 & TST \\
\hline CHEMBL1592332 & 688653 & 4.633 & 5.132999 & 99999 & 99 & - \\
\hline CHEMBL 3207708 & 688653 & 4.933 & 4.9395 & TST & & \\
\hline CHEMBL1452465 & 688653 & 5.78299 & 999999999 & 995 & 5.6796 & TRN \\
\hline CHEMBL 3190869 & 688653 & 4.783 & 5.7121 & TRN & & \\
\hline CHEMBL1400068 & 688653 & 4.933 & 5.1434 & TRN & & \\
\hline CHEMBL1321884 & 688653 & 4.783 & 5.0816 & TRN & & \\
\hline CHEMBL1371242 & 688653 & 6.33299 & 999999999 & & 5.4621 & TRN \\
\hline CHEMBL1401268 & 688653 & 5.78299 & 999999999 & 995 & 5.2925 & TRN \\
\hline CHEMBL1969298 & 688653 & 5.733 & 5.6215 & TRN & & \\
\hline CHEMBL1432011 & 688653 & 5.033 & 5.4666 & TRN & & \\
\hline CHEMBL1609944 & 688653 & 4.783 & 5.4059 & TST & & \\
\hline
\end{tabular}




\begin{tabular}{|c|c|c|c|c|c|c|}
\hline \multicolumn{7}{|c|}{ Supplemental Table S2.txt } \\
\hline CHEMBL1502209 & 688653 & 6.233 & 5.115 & TRN & & \\
\hline CHEMBL1310628 & 688653 & 4.833 & 5.2872 & TST & & \\
\hline CHEMBL 3190636 & 688653 & 6.53299 & 999999999 & 995 & 5.4967 & TRN \\
\hline CHEMBL1597538 & 688653 & 4.833 & 5.1504 & TST & & \\
\hline CHEMBL1591480 & 688653 & 4.73300 & 000000000 & 005 & 4.8354 & TRN \\
\hline CHEMBL1448932 & 688653 & 5.63299 & 999999999 & 99 & 5.3083 & \\
\hline CHEMBL1577150 & 688653 & 4.883 & 5.0795 & TRN & & \\
\hline CHEMBL 3198516 & 688653 & 4.73300 & 000000006 & 005 & 5.2244 & ותנו \\
\hline CHEMBL1569594 & 688653 & 4.833 & 5.0028 & TRN & & \\
\hline CHEMBL1300747 & 688653 & 4.833 & 5.0066 & TRN & & \\
\hline CHEMBL1545900 & 688653 & 4.633 & 4.8561 & TST & & \\
\hline CHEMBL1557047 & 688653 & 4.833 & 4.8858 & TRN & & \\
\hline CHEMBL1299353 & 688653 & 4.833 & 5.2293 & TST & & \\
\hline CHEMBL1572324 & 688653 & 5.78299 & 999999999 & 995 & 6.1151 & \\
\hline CHEMBL1554919 & 688653 & 4.633 & 5.0921 & TRN & & \\
\hline CHEMBL1420730 & 688653 & 4.833 & 5.3025 & TRN & & \\
\hline CHEMBL1489794 & 688653 & 5.233 & 5.587999 & 999999999 & & \\
\hline CHEMBL1447743 & 688653 & 4.783 & 5.155 & TST & & \\
\hline CHEMBL1555812 & 688653 & 4.783 & 4.8338 & TRN & & \\
\hline CHEMBL 2369280 & 688653 & 5.433 & 5.37 & TST & & \\
\hline CHEMBL1540038 & 688653 & 4.683 & 5.5664 & TST & & \\
\hline CHEMBL1520311 & 688653 & 4.783 & 5.3954 & TRN & & \\
\hline CHEMBL1441311 & 688653 & 4.833 & 4.9718 & TRN & & \\
\hline CHEMBL 3196809 & 688653 & 6.8831 & 5.8366 & TRN & & \\
\hline CHEMBL 3210931 & 688653 & 5.233 & 5.2398 & TRN & & \\
\hline CHEMBL1468284 & 688653 & 4.883 & 5.2678 & TST & & \\
\hline CHEMBL1380559 & 688653 & 4.883 & 5.1531 & TRN & & \\
\hline CHEMBL 3192210 & 688653 & 5.933 & 6.3014 & TRN & & \\
\hline CHEMBL1522953 & 688653 & 4.783 & 4.7141 & TRN & & \\
\hline CHEMBL1594867 & 688653 & 6.78299 & 999999999 & 995 & 6.1745 & TRN \\
\hline CHEMBL1320796 & 688653 & 4.633 & 5.008999 & 999999999 & 995 & TR \\
\hline CHEMBL1428779 & 688653 & 4.783 & 5.1842 & TST & & \\
\hline CHEMBL1469483 & 688653 & 4.933 & 5.1698 & TST & & \\
\hline CHEMBL1526913 & 688653 & 4.933 & 5.0671 & TRN & & \\
\hline CHEMBL1322304 & 688653 & 4.583 & 5.1246 & TST & & \\
\hline CHEMBL1369420 & 688653 & 5.63299 & 999999999 & & 5.5411 & TC \\
\hline CHEMBL1570954 & 688653 & 4.633 & 4.9105 & TRN & & \\
\hline CHEMBL1490423 & 688653 & 6.08299 & 999999999 & & 5.4387 & TIV \\
\hline CHEMBL 3197629 & 688653 & 4.73300 & 000000000 & 005 & 5.0464 & - \\
\hline CHEMBL1462064 & 688653 & 5.28299 & 999999999 & 995 & 5.3918 & $\pi$ \\
\hline CHEMBL1564049 & 688653 & 4.783 & 5.1301 & TRN & & \\
\hline CHEMBL1419183 & 688653 & 4.783 & 5.3257 & TST & & \\
\hline CHEMBL1380687 & 688653 & 5.53299 & 999999999 & 995 & 5.2166 & IRN \\
\hline CHEMBL 2000340 & 688653 & 4.73300 & 000000000 & 005 & 5.2449 & \\
\hline CHEMBL1560830 & 688653 & 4.783 & 4.7232 & TRN & & \\
\hline CHEMBL1534571 & 688653 & 4.933 & 5.1686 & TST & & \\
\hline CHEMBL1376242 & 688653 & 5.4 & 5.1771 & TRN & & \\
\hline CHEMBL1501745 & 688653 & 4.933 & 5.2013 & TRN & & \\
\hline
\end{tabular}




\begin{tabular}{|c|c|c|c|c|c|c|}
\hline \multirow[b]{2}{*}{ CHEMBL1418939 } & & \multicolumn{5}{|c|}{ Supplemental Table S2.txt } \\
\hline & 688653 & 5.233 & 5.2227 & TRN & & \\
\hline CHEMBL1501697 & 688653 & 5.083 & 5.3394 & TRN & & \\
\hline CHEMBL1608986 & 688653 & \multicolumn{3}{|c|}{4.7330000000000005} & 5.1573 & TRN \\
\hline CHEMBL 3210474 & 688653 & \multicolumn{3}{|c|}{5.382999999999999} & 5.1954 & TRN \\
\hline CHEMBL278779 & 688653 & 4.783 & 5.335 & TRN & & \\
\hline CHEMBL1409770 & 688653 & 5.233 & 5.2274 & TRN & & \\
\hline CHEMBL1382405 & 688653 & 5.033 & 5.3538 & TST & & \\
\hline CHEMBL1523974 & 688653 & 5.933 & 5.5298 & TRN & & \\
\hline CHEMBL1461303 & 688653 & \multicolumn{3}{|c|}{4.7330000000000005} & 5.0739 & $\mathrm{~T}$ \\
\hline CHEMBL1460869 & 688653 & 7.0329 & 5.8319 & TRN & & \\
\hline CHEMBL1333804 & 688653 & 4.633 & 5.1795 & TRN & & \\
\hline CHEMBL1519953 & 688653 & \multicolumn{3}{|c|}{4.7330000000000005} & 4.6626 & \\
\hline CHEMBL1578340 & 688653 & 4.783 & 5.0266 & TRN & & \\
\hline CHEMBL1433713 & 688653 & & & TRN & & \\
\hline CHEMBL 3214280 & 688653 & \multicolumn{3}{|c|}{6.0329999999999995} & 5.5791 & 1 \\
\hline CHEMBL1590956 & 688653 & 5.483 & 5.22 & TRN & & \\
\hline CHEMBL1459373 & 688653 & 4.883 & 5.0272 & TRN & & \\
\hline CHEMBL1541828 & 688653 & 4.633 & 5.2296 & TRN & & \\
\hline CHEMBL1605104 & 688653 & \multicolumn{3}{|c|}{5.5329999999999995} & 5.6349 & \\
\hline CHEMBL1303281 & 688653 & 4.583 & 4.8685 & TRN & & \\
\hline CHEMBL1327810 & 688653 & 4.633 & 5.5143 & TRN & & \\
\hline CHEMBL1547542 & 688653 & 4.833 & 5.2324 & TST & & \\
\hline CHEMBL1343377 & 688653 & 4.933 & 5.6111 & TST & & \\
\hline CHEMBL1504289 & 688653 & 6.4829 & 5.1941 & TST & & \\
\hline CHEMBL1527091 & 688653 & \multicolumn{3}{|c|}{5.632999999999999} & 5.3824 & $\mathrm{TH}$ \\
\hline CHEMBL1358028 & 688653 & 5.433 & 5.3484 & TRN & & \\
\hline CHEMBL1448691 & 688653 & \multicolumn{3}{|c|}{5.132999999999999} & 5.1881 & \\
\hline CHEMBL1334252 & 688653 & 5.183 & 5.2634 & TRN & & \\
\hline CHEMBL1503864 & 688653 & 4.933 & 5.4128 & TST & & \\
\hline CHEMBL1414871 & 688653 & \multicolumn{3}{|c|}{5.2829999999999995} & 4.9986 & TR \\
\hline CHEMBL1546387 & 688653 & 4.783 & 5.1508 & TRN & & \\
\hline CHEMBL 3208980 & 688653 & 4.883 & 4.9462 & TST & & \\
\hline CHEMBL1599344 & 688653 & 6.683 & 5.7089 & TRN & & \\
\hline CHEMBL1497379 & 688653 & 5.233 & 5.3438 & TRN & & \\
\hline CHEMBL1606870 & 688653 & \multicolumn{3}{|c|}{5.632999999999999} & 5.7151 & TRN \\
\hline CHEMBL1586224 & 688653 & \multicolumn{3}{|c|}{5.832999999999999} & 5.599 & \\
\hline CHEMBL1413826 & 688653 & \multicolumn{3}{|c|}{4.7330000000000005} & 4.9981 & \\
\hline CHEMBL1395520 & 688653 & 4.933 & 5.3874 & TRN & & \\
\hline CHEMBL1542854 & 688653 & \multicolumn{3}{|c|}{5.5329999999999995} & 5.6015 & TRN \\
\hline CHEMBL510773 & 688653 & \multicolumn{3}{|c|}{5.2829999999999995} & 5.4122 & TRN \\
\hline CHEMBL1448142 & 688653 & 4.783 & 5.0673 & TRN & & \\
\hline CHEMBL1313423 & 688653 & 5.933 & 5.6992 & TRN & & \\
\hline CHEMBL1436429 & 688653 & 4.583 & 5.0067 & TRN & & \\
\hline CHEMBL1494587 & 688653 & \multicolumn{3}{|c|}{5.7829999999999995} & 5.2983 & Tा \\
\hline CHEMBL1388947 & 688653 & 4.633 & 5.2303 & TST & & \\
\hline CHEMBL1564109 & 688653 & \multicolumn{3}{|c|}{5.832999999999999} & 5.5186 & T \\
\hline CHEMBL1361161 & 688653 & 4.783 & 5.2216 & TRN & & \\
\hline CHEMBL1426502 & 688653 & 4.933 & 5.3448 & TST & & \\
\hline
\end{tabular}




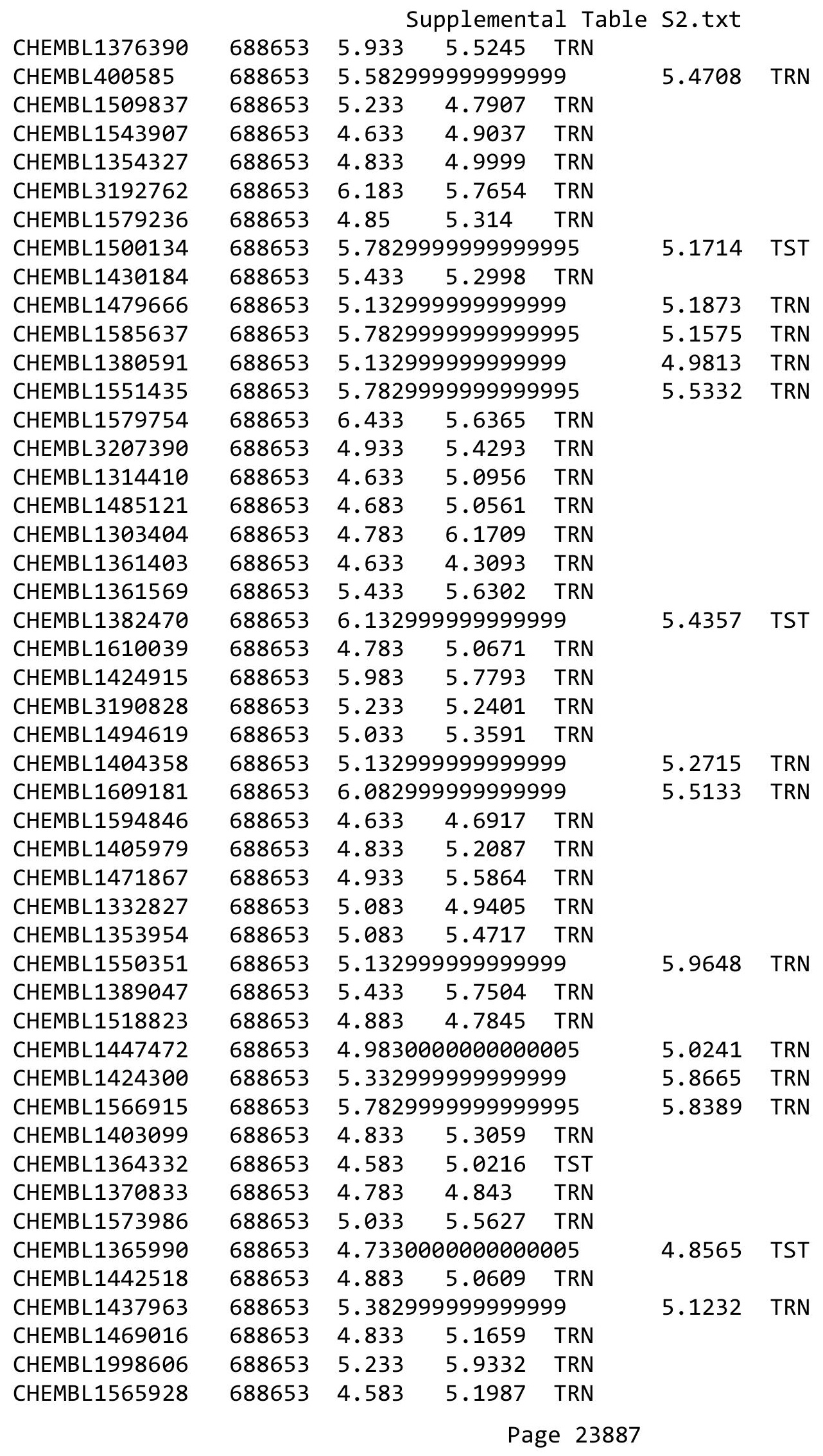




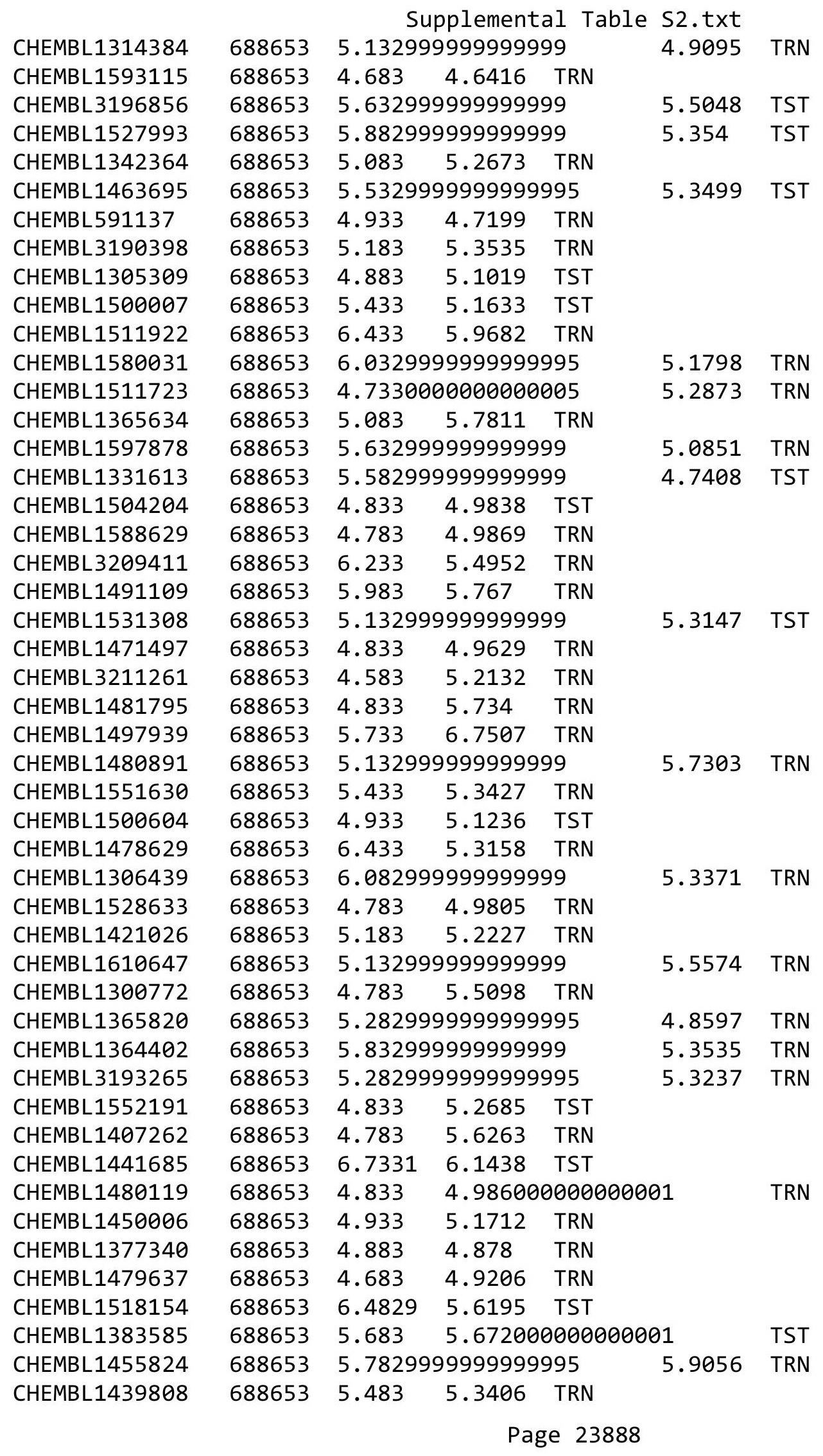




\begin{tabular}{|c|c|c|c|c|c|c|}
\hline \multirow[b]{2}{*}{ CHEMBL1473209 } & \multirow[b]{2}{*}{688653} & \multicolumn{5}{|c|}{ Supplemental Table S2.txt } \\
\hline & & \multirow{2}{*}{\multicolumn{3}{|c|}{$\begin{array}{lcc}5.733 & 4.9693 & \text { TRN } \\
4.9830000000000005\end{array}$}} & \multirow{2}{*}{5.7558} & \multirow{2}{*}{ TRA } \\
\hline CHEMBL1356927 & 688653 & & & & & \\
\hline CHEMBL1323422 & 688653 & 6.0 & 5.7193 & TRN & & \\
\hline CHEMBL1533100 & 688653 & 4.783 & 5.4331 & TRN & & \\
\hline CHEMBL1441246 & 688653 & 5.083 & 5.3066 & TRN & & \\
\hline CHEMBL1411531 & 688653 & 4.583 & 4.7016 & TST & & \\
\hline CHEMBL1608597 & 688653 & 4.933 & 5.4099 & TRN & & \\
\hline CHEMBL1492451 & 688653 & \multicolumn{3}{|c|}{4.7330000000000005} & 5.3293 & TST \\
\hline CHEMBL1444606 & 688653 & 4.933 & 5.3911 & TST & & \\
\hline CHEMBL1308120 & 688653 & 4.883 & 5.3141 & TST & & \\
\hline CHEMBL 3190291 & 688653 & 4.833 & 5.1629 & TRN & & \\
\hline CHEMBL1589383 & 688653 & 4.783 & 5.5738 & TST & & \\
\hline CHEMBL1395133 & 688653 & \multicolumn{3}{|c|}{5.7829999999999995} & 5.6126 & TRN \\
\hline CHEMBL1463856 & 688653 & \multicolumn{3}{|c|}{4.9830000000000005} & 5.4836 & TST \\
\hline CHEMBL1443188 & 688653 & 4.633 & 4.6004 & TST & & \\
\hline CHEMBL1592605 & 688653 & 4.583 & 5.0449 & TRN & & \\
\hline CHEMBL1585126 & 688653 & \multicolumn{3}{|c|}{4.7330000000000005} & 4.9282 & TRN \\
\hline CHEMBL1604451 & 688653 & \multicolumn{3}{|c|}{5.332999999999999} & 5.362 & TRN \\
\hline CHEMBL1535241 & 688653 & \multicolumn{3}{|c|}{6.082999999999999} & 5.2582 & TST \\
\hline CHEMBL1496465 & 688653 & 4.783 & 5.2777 & TST & & \\
\hline CHEMBL1383800 & 688653 & 4.933 & 4.9624 & TRN & & \\
\hline CHEMBL1558792 & 688653 & 5.933 & 5.5188 & TRN & & \\
\hline CHEMBL1242180 & 688653 & 5.683 & 6.2248 & TRN & & \\
\hline CHEMBL1532476 & 688653 & \multicolumn{3}{|c|}{4.7330000000000005} & 5.4893 & TRN \\
\hline CHEMBL1988329 & 688653 & 5.733 & 5.4505 & TRN & & \\
\hline CHEMBL1303349 & 688653 & 4.783 & 5.4299 & TRN & & \\
\hline CHEMBL1488279 & 688653 & 4.833 & 5.1063 & TRN & & \\
\hline CHEMBL 3190035 & 688653 & 5.733 & 5.0805 & TST & & \\
\hline CHEMBL1435790 & 688653 & 5.233 & 5.2803 & TRN & & \\
\hline CHEMBL1335792 & 688653 & 5.033 & 5.4429 & TRN & & \\
\hline CHEMBL1321345 & 688653 & 4.883 & 5.051 & TRN & & \\
\hline CHEMBL1502747 & 688653 & 5.683 & 5.6325 & TST & & \\
\hline CHEMBL1539867 & 688653 & \multicolumn{3}{|c|}{5.132999999999999} & 5.3839 & TRN \\
\hline CHEMBL1425380 & 688653 & 5.233 & 5.2249 & TRN & & \\
\hline CHEMBL1419233 & 688653 & \multicolumn{3}{|c|}{5.882999999999999} & 5.9921 & TRN \\
\hline CHEMBL1533343 & 688653 & \multicolumn{3}{|c|}{6.582999999999999} & 5.895 & TRN \\
\hline CHEMBL1374897 & 688653 & 4.783 & 5.1817 & TRN & & \\
\hline CHEMBL1380117 & 688653 & 5.233 & 4.9795 & TST & & \\
\hline CHEMBL1521327 & 688653 & 5.933 & 5.3738 & TRN & & \\
\hline CHEMBL3199093 & 688653 & \multicolumn{3}{|c|}{6.132999999999999} & 5.9606 & TRN \\
\hline CHEMBL1442487 & 688653 & 4.833 & 5.2666 & TST & & \\
\hline CHEMBL1486214 & 688653 & \multicolumn{3}{|c|}{5.582999999999999} & 4.7442 & TST \\
\hline CHEMBL1588233 & 688653 & 4.783 & 5.2966 & TST & & \\
\hline CHEMBL1583685 & 688653 & 4.783 & 5.4607 & TST & & \\
\hline CHEMBL1342739 & 688653 & 7.2328 & 5.9962 & TRN & & \\
\hline CHEMBL1602564 & 688653 & \multicolumn{3}{|c|}{5.382999999999999} & 5.2043 & TRN \\
\hline CHEMBL1412672 & 688653 & 4.583 & 4.6975 & TRN & & \\
\hline CHEMBL1378608 & 688653 & \multicolumn{3}{|c|}{5.382999999999999} & 5.5392 & TRN \\
\hline
\end{tabular}




\begin{tabular}{|c|c|c|c|c|c|c|}
\hline \multirow[b]{2}{*}{ CHEMBL579045 } & \multirow[b]{2}{*}{688653} & \multicolumn{5}{|c|}{ Supplemental Table S2.txt } \\
\hline & & 4.883 & 5.4977 & TRN & & \\
\hline CHEMBL1494685 & 688653 & 6.03299 & 99999999 & 995 & 5.6064 & TRN \\
\hline CHEMBL1410388 & 688653 & 5.83299 & 99999999 & 99 & 5.2826 & TRN \\
\hline CHEMBL1582636 & 688653 & 4.883 & 5.0955 & TRN & & \\
\hline CHEMBL1313643 & 688653 & 4.73300 & 00000000 & 005 & 4.9906 & TRN \\
\hline CHEMBL1478779 & 688653 & 4.883 & 5.1761 & TST & & \\
\hline CHEMBL1424269 & 688653 & 5.83299 & 99999999 & & 5.2027 & TST \\
\hline CHEMBL1496447 & 688653 & 4.98300 & 00000000 & 005 & 5.0877 & TRN \\
\hline CHEMBL1371225 & 688653 & 5.483 & 5.6722 & TRN & & \\
\hline CHEMBL1532793 & 688653 & 5.13299 & 99999999 & & 5.1372 & TRN \\
\hline CHEMBL1481224 & 688653 & 4.633 & 5.0968 & TRN & & \\
\hline CHEMBL1563957 & 688653 & 5.33299 & 99999999 & & 5.3334 & TRN \\
\hline CHEMBL1505245 & 688653 & 4.783 & 5.647 & TRN & & \\
\hline CHEMBL1445254 & 688653 & 6.58299 & 99999999 & & 5.8862 & TRN \\
\hline CHEMBL1362510 & 688653 & 6.433 & 5.4843 & TRN & & \\
\hline CHEMBL602987 & 688653 & 4.783 & 5.2909 & TST & & \\
\hline CHEMBL1556484 & 688653 & 5.183 & 5.4445 & TRN & & \\
\hline CHEMBL1542972 & 688653 & 5.58299 & 99999999 & & 5.1009 & TRN \\
\hline CHEMBL3211733 & 688653 & 4.73300 & 00000000 & 005 & 5.3222 & TST \\
\hline CHEMBL3190251 & 688653 & 5.58299 & 99999999 & & 5.9111 & TRN \\
\hline CHEMBL1461869 & 688653 & 4.933 & 5.0532 & TST & & \\
\hline CHEMBL1507978 & 688653 & 4.833 & 5.2896 & TRN & & \\
\hline CHEMBL488140 & 688653 & 6.03299 & 99999999 & 995 & 5.6338 & TRN \\
\hline CHEMBL1396428 & 688653 & 4.783 & 5.1481 & TST & & \\
\hline CHEMBL1467839 & 688653 & 5.733 & 5.2144 & TRN & & \\
\hline CHEMBL1478676 & 688653 & 4.883 & 5.3942 & TST & & \\
\hline CHEMBL1454480 & 688653 & 5.78299 & 99999999 & 995 & 5.1765 & TRN \\
\hline CHEMBL1299540 & 688653 & 6.183 & 5.3125 & TRN & & \\
\hline CHEMBL1516337 & 688653 & 5.233 & 5.6435 & TST & & \\
\hline CHEMBL1511502 & 688653 & 6.33299 & 99999999 & & 5.9896 & TRN \\
\hline CHEMBL1605203 & 688653 & 4.833 & 4.9493 & TRN & & \\
\hline CHEMBL1557254 & 688653 & 4.833 & 5.1428 & TRN & & \\
\hline CHEMBL1576722 & 688653 & 5.13299 & 99999999 & & 4.716 & TST \\
\hline CHEMBL1608009 & 688653 & 6.45 & 5.2047 & TRN & & \\
\hline CHEMBL1411158 & 688653 & 5.033 & 4.8116 & TST & & \\
\hline CHEMBL1536942 & 688653 & 4.583 & 4.5723 & TRN & & \\
\hline CHEMBL 1435875 & 688653 & 4.883 & 5.2961 & TRN & & \\
\hline CHEMBL1330874 & 688653 & 5.483 & 6.0478 & TRN & & \\
\hline CHEMBL1491887 & 688653 & 4.583 & 4.945 & TRN & & \\
\hline CHEMBL1612605 & 688653 & 5.183 & 5.2372 & TST & & \\
\hline CHEMBL1550740 & 688653 & 6.8831 & 5.6042 & TRN & & \\
\hline CHEMBL1504881 & 688653 & 4.73300 & 00000000 & 005 & 5.6334 & TRN \\
\hline CHEMBL578504 & 688653 & 5.28299 & 99999999 & 995 & 5.7273 & TRN \\
\hline CHEMBL1334212 & 688653 & 4.73300 & 00000000 & 005 & 5.4965 & TRN \\
\hline CHEMBL1357910 & 688653 & 5.83299 & 99999999 & & 5.1943 & TRN \\
\hline CHEMBL1597642 & 688653 & 5.233 & 4.9473 & TST & & \\
\hline CHEMBL1492509 & 688653 & 5.033 & 5.5423 & TRN & & \\
\hline CHEMBL1604521 & 688653 & 4.783 & 5.6651 & TRN & & \\
\hline
\end{tabular}




\begin{tabular}{|c|c|c|c|c|c|c|}
\hline & & \multicolumn{5}{|c|}{ Supplemental Table s2.txt } \\
\hline CHEMBL1539865 & 688653 & 5.083 & 4.8888 & TRN & & \\
\hline CHEMBL591135 & 688653 & 5.183 & 5.186 & TRN & & \\
\hline CHEMBL1331516 & 688653 & .783 & 5.3534 & TST & & \\
\hline CHEMBL 3190212 & 688653 & \multicolumn{3}{|c|}{6.082999999999999} & 5.3585 & $\mathrm{~T}$ \\
\hline CHEMBL1574463 & 688653 & 5.183 & 4.9185 & TST & & \\
\hline CHEMBL1449308 & 688653 & \multicolumn{3}{|c|}{4.7330000000000005} & 5.4925 & \\
\hline CHEMBL1571316 & 688653 & 4.883 & 5.5577 & TST & & \\
\hline CHEMBL1587504 & 688653 & 5.733 & 5.5002 & TRN & & \\
\hline CHEMBL1315071 & 688653 & 5.433 & 5.2819 & TST & & \\
\hline CHEMBL1498627 & 688653 & \multicolumn{3}{|c|}{4.7330000000000005} & 5.432 & \\
\hline CHEMBL1349408 & 688653 & \multicolumn{3}{|c|}{5.582999999999999} & 5.3961 & \\
\hline CHEMBL1541661 & 688653 & 4.883 & 5.4278 & TRN & & \\
\hline CHEMBL1477130 & 688653 & \multicolumn{3}{|c|}{4.9830000000000005} & 5.0655 & \\
\hline CHEMBL1300982 & 688653 & 4.883 & 5.3734 & TRN & & \\
\hline CHEMBL1417112 & 688653 & \multicolumn{3}{|c|}{6.632999999999999} & 6.2674 & 11 \\
\hline CHEMBL1520528 & 688653 & 4.933 & 5.2726 & TRN & & \\
\hline CHEMBL1457342 & 688653 & 5.083 & 5.1666 & TRN & & \\
\hline CHEMBL1450782 & 688653 & \multicolumn{3}{|c|}{4.7330000000000005} & 4.8693 & \\
\hline CHEMBL1414405 & 688653 & 5.183 & 5.9928 & TRN & & \\
\hline CHEMBL1344912 & 688653 & 4.633 & 4.8575 & TRN & & \\
\hline CHEMBL1429925 & 688653 & 5.183 & 4.9432 & TRN & & \\
\hline CHEMBL1584280 & 688653 & 4.833 & 4.9034 & TRN & & \\
\hline CHEMBL 3189853 & 688653 & 5.733 & 5.2472 & TRN & & \\
\hline CHEMBL1566123 & 688653 & \multicolumn{3}{|c|}{6.5329999999999995} & 4.8654 & TST \\
\hline CHEMBL1429633 & 688653 & \multicolumn{3}{|c|}{5.7829999999999995} & & \\
\hline CHEMBL1445776 & 688653 & 5.083 & 5.3417 & TRN & & \\
\hline CHEMBL1992801 & 688653 & \multicolumn{3}{|c|}{5.5329999999999995} & 5.7475 & \\
\hline CHEMBL1518094 & 688653 & 4.683 & 5.1313 & TRN & & \\
\hline CHEMBL1401344 & 688653 & \multicolumn{3}{|c|}{6.082999999999999} & 6.1634 & TP \\
\hline CHEMBL1471013 & 688653 & 4.833 & 5.0796 & TRN & & \\
\hline CHEMBL1977978 & 688653 & 5.483 & 5.7604 & TRN & & \\
\hline CHEMBL1498144 & 688653 & \multicolumn{3}{|c|}{5.382999999999999} & 5.0463 & TI \\
\hline CHEMBL1390196 & 688653 & 5.683 & 4.9506 & TST & & \\
\hline CHEMBL1572885 & 688653 & 5.083 & 5.439 & TRN & & \\
\hline CHEMBL1515537 & 688653 & 5.733 & 5.6445 & TRN & & \\
\hline CHEMBL1402669 & 688653 & 4.783 & 5.0951 & TRN & & \\
\hline CHEMBL1423097 & 688653 & \multicolumn{3}{|c|}{4.7330000000000005} & 5.3313 & 1 \\
\hline CHEMBL1585797 & 688653 & 4.783 & 5.0001 & TRN & & \\
\hline CHEMBL1573623 & 688653 & \multicolumn{3}{|c|}{5.132999999999999} & 5.155 & 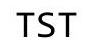 \\
\hline CHEMBL1366454 & 688653 & 4.783 & 5.3171 & TRN & & \\
\hline CHEMBL1544709 & 688653 & \multicolumn{3}{|c|}{4.7330000000000005} & 5.4 & TR \\
\hline CHEMBL1553089 & 688653 & \multicolumn{3}{|c|}{5.832999999999999} & 5.0351 & \\
\hline CHEMBL1304898 & 688653 & 4.783 & 5.8303 & TST & & \\
\hline CHEMBL1438333 & 688653 & \multirow{2}{*}{\multicolumn{3}{|c|}{$\begin{array}{ll}5.933 & 5.0194 \\
5.2829999999999995\end{array}$}} & & \\
\hline CHEMBL41864 & 688653 & & & & 5.4734 & $1 K$ \\
\hline CHEMBL1392377 & 688653 & 4.633 & 5.4221 & TRN & & \\
\hline CHEMBL1527840 & 688653 & 5.083 & 5.0039 & TRN & & \\
\hline CHEMBL1495375 & 688653 & \multicolumn{3}{|c|}{5.882999999999999} & 5.5091 & 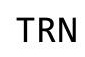 \\
\hline
\end{tabular}




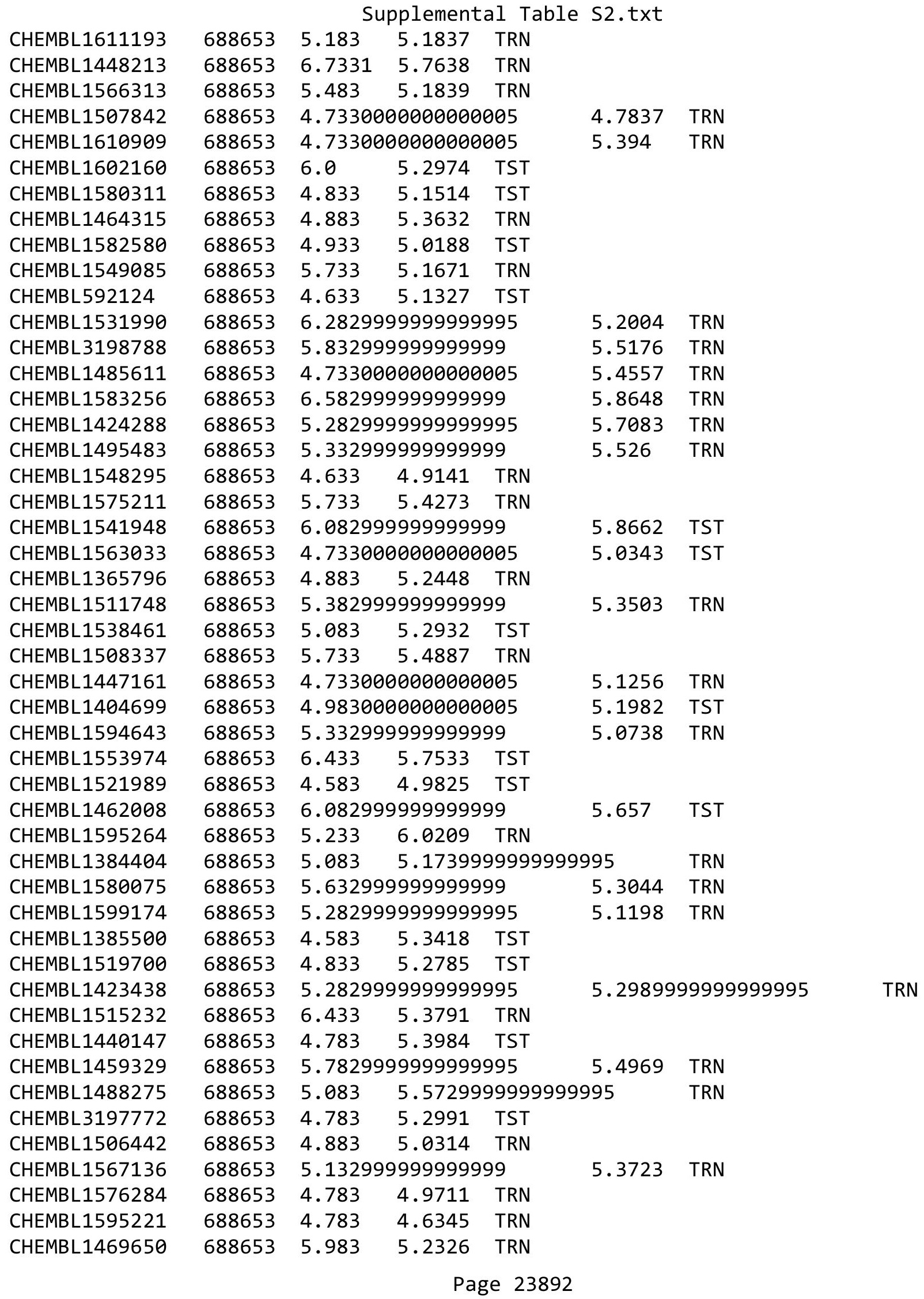




\begin{tabular}{|c|c|c|c|c|c|c|}
\hline & & \multicolumn{5}{|c|}{ Supplemental Table S2.txt } \\
\hline CHEMBL1517697 & 688653 & 4.833 & 5.0417 & TRN & & \\
\hline CHEMBL1556327 & 688653 & 5.683 & 5.7683 & TRN & & \\
\hline CHEMBL1512284 & 688653 & 4.583 & 5.2718 & TST & & \\
\hline CHEMBL1329715 & 688653 & 5.683 & 5.3473 & TRN & & \\
\hline CHEMBL1307100 & 688653 & 4.683 & 5.0566 & TRN & & \\
\hline CHEMBL1409623 & 688653 & \multicolumn{3}{|c|}{4.7330000000000005} & 5.1397 & TST \\
\hline CHEMBL1536102 & 688653 & 4.833 & 5.1889 & TRN & & \\
\hline CHEMBL1585755 & 688653 & \multicolumn{3}{|c|}{4.7330000000000005} & 5.0149 & TRN \\
\hline CHEMBL1612899 & 688653 & 5.683 & 5.4232 & TRN & & \\
\hline CHEMBL1584690 & 688653 & \multicolumn{3}{|c|}{6.632999999999999} & 5.8525 & TST \\
\hline CHEMBL1478262 & 688653 & \multicolumn{3}{|c|}{5.7829999999999995} & 5.2155 & TRN \\
\hline CHEMBL3211569 & 688653 & 5.483 & 5.2265 & TRN & & \\
\hline CHEMBL1538109 & 688653 & \multicolumn{3}{|c|}{5.632999999999999} & 6.0424 & TRN \\
\hline CHEMBL1475164 & 688653 & \multicolumn{3}{|c|}{5.2829999999999995} & 5.2931 & TRN \\
\hline CHEMBL1547246 & 688653 & \multicolumn{3}{|c|}{5.332999999999999} & 5.0887 & TST \\
\hline CHEMBL1554151 & 688653 & 5.683 & 5.4766 & TRN & & \\
\hline CHEMBL1468931 & 688653 & 5.483 & 5.4499 & TRN & & \\
\hline CHEMBL1612466 & 688653 & \multicolumn{3}{|c|}{5.132999999999999} & 5.0071 & TRN \\
\hline CHEMBL1323625 & 688653 & 4.833 & 4.599 & TST & & \\
\hline CHEMBL1395045 & 688653 & 4.783 & 5.6827 & TST & & \\
\hline CHEMBL1496033 & 688653 & 4.783 & 5.1627 & TRN & & \\
\hline CHEMBL3214033 & 688653 & 5.233 & 5.3107 & TST & & \\
\hline CHEMBL1302081 & 688653 & 5.733 & 5.2235 & TRN & & \\
\hline CHEMBL1538246 & 688653 & 5.083 & 5.3875 & TST & & \\
\hline CHEMBL1471808 & 688653 & 5.033 & 4.9571 & TRN & & \\
\hline CHEMBL1556051 & 688653 & 4.883 & 5.4923 & TRN & & \\
\hline CHEMBL1418908 & 688653 & 5.433 & 5.584 & TST & & \\
\hline CHEMBL1469748 & 688653 & 5.683 & 5.4554 & TRN & & \\
\hline CHEMBL3199686 & 688653 & \multicolumn{3}{|c|}{4.7330000000000005} & 5.0125 & TRN \\
\hline CHEMBL3214527 & 688653 & \multicolumn{3}{|c|}{4.9830000000000005} & 5.3208 & TST \\
\hline CHEMBL1524930 & 688653 & 5.233 & 5.4164 & TRN & & \\
\hline CHEMBL1531984 & 688653 & 4.833 & 5.706 & TST & & \\
\hline CHEMBL1412413 & 688653 & 4.933 & 5.4275 & TST & & \\
\hline CHEMBL1992138 & 688653 & 5.233 & 5.3564 & TRN & & \\
\hline CHEMBL1447147 & 688653 & 4.833 & 5.2469 & TST & & \\
\hline CHEMBL1575729 & 688653 & 5.233 & 4.9915 & TRN & & \\
\hline CHEMBL1349007 & 688653 & \multicolumn{3}{|c|}{6.2829999999999995} & 5.4461 & TRN \\
\hline CHEMBL 2002046 & 688653 & 5.033 & 5.0157 & TST & & \\
\hline CHEMBL1302809 & 688653 & 4.933 & 5.476 & TST & & \\
\hline CHEMBL1531640 & 688653 & 5.083 & 5.6592 & TRN & & \\
\hline CHEMBL3195344 & 688653 & 4.633 & 5.1454 & TRN & & \\
\hline CHEMBL1423601 & 688653 & \multicolumn{3}{|c|}{5.2829999999999995} & 5.2728 & TRN \\
\hline CHEMBL1487567 & 688653 & 4.583 & 4.9104 & TRN & & \\
\hline CHEMBL1343113 & 688653 & \multicolumn{3}{|c|}{4.7330000000000005} & 5.2163 & TRN \\
\hline CHEMBL1509000 & 688653 & \multicolumn{3}{|c|}{5.882999999999999} & 5.4744 & TRN \\
\hline CHEMBL1490120 & 688653 & 4.783 & 5.0256 & TST & & \\
\hline CHEMBL585071 & 688653 & 5.733 & 4.746 & TRN & & \\
\hline CHEMBL1318984 & 688653 & 4.833 & 5.0838 & TRN & & \\
\hline
\end{tabular}




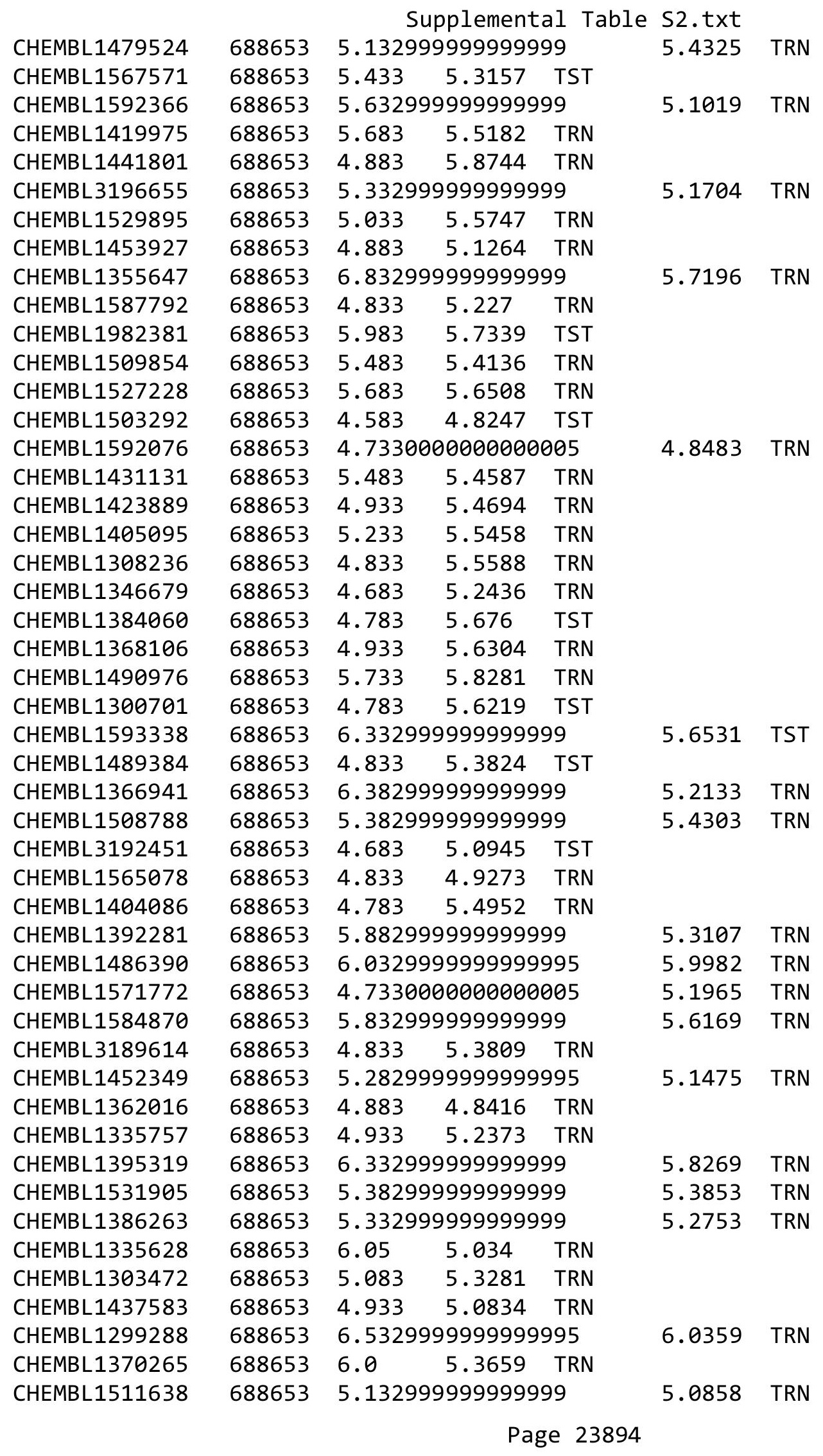




\begin{tabular}{|c|c|c|c|c|c|c|}
\hline \multirow{3}{*}{$\begin{array}{l}\text { CHEMBL1596076 } \\
\text { CHEMBL3197499 }\end{array}$} & \multirow{3}{*}{$\begin{array}{l}688653 \\
688653\end{array}$} & \multicolumn{5}{|c|}{ Supplemental Table S2.txt } \\
\hline & & \multicolumn{3}{|c|}{5.2829999999999995} & \multirow{5}{*}{5.2264} & \multirow[t]{5}{*}{ TRN } \\
\hline & & 4.883 & 5.1 & TRN & & \\
\hline CHEMBL1512787 & 688653 & 4.633 & 5.1229 & TRN & & \\
\hline CHEMBL1583479 & 688653 & 4.583 & 4.8891 & TST & & \\
\hline CHEMBL1356905 & 688653 & 4.833 & 4.9976 & TRN & & \\
\hline CHEMBL1583913 & 688653 & \multicolumn{3}{|c|}{5.832999999999999} & 5.115 & TRN \\
\hline CHEMBL1324890 & 688653 & 4.783 & 5.0272 & TST & & \\
\hline CHEMBL1304425 & 688653 & 4.833 & 5.2408 & TRN & & \\
\hline CHEMBL1539483 & 688653 & 4.583 & 4.8987 & TRN & & \\
\hline CHEMBL1529920 & 688653 & 4.683 & 4.8992 & TST & & \\
\hline CHEMBL1599332 & 688653 & \multicolumn{3}{|c|}{4.7330000000000005} & 5.2217 & TRN \\
\hline CHEMBL3193141 & 688653 & 5.233 & 5.2933 & TRN & & \\
\hline CHEMBL1502635 & 688653 & 6.233 & 5.4208 & TRN & & \\
\hline CHEMBL1445548 & 688653 & 5.683 & 5.4099 & TRN & & \\
\hline CHEMBL1562717 & 688653 & 5.483 & 5.2703 & TRN & & \\
\hline CHEMBL1373867 & 688653 & \multicolumn{3}{|c|}{6.082999999999999} & 5.6795 & TRN \\
\hline CHEMBL1322844 & 688653 & 5.483 & 5.3467 & TRN & & \\
\hline CHEMBL1563340 & 688653 & 5.233 & 5.41 & TRN & & \\
\hline CHEMBL1417665 & 688653 & 4.783 & 5.2572 & TRN & & \\
\hline CHEMBL1537556 & 688653 & 4.883 & 5.4048 & TST & & \\
\hline CHEMBL1531738 & 688653 & 4.633 & 5.3491 & TST & & \\
\hline CHEMBL1547207 & 688653 & 4.583 & 5.1598 & TRN & & \\
\hline CHEMBL1335034 & 688653 & 4.833 & 5.1978 & TRN & & \\
\hline CHEMBL1300405 & 688653 & 4.833 & 4.9635 & TST & & \\
\hline CHEMBL1483544 & 688653 & 4.783 & 5.195 & TST & & \\
\hline CHEMBL1538035 & 688653 & 4.633 & 4.7629 & TRN & & \\
\hline CHEMBL1498292 & 688653 & \multicolumn{3}{|c|}{6.5329999999999995} & 6.1934 & TRN \\
\hline CHEMBL1348215 & 688653 & 4.833 & 4.8319 & TST & & \\
\hline CHEMBL3191888 & 688653 & 5.983 & 5.1292 & TRN & & \\
\hline CHEMBL1520312 & 688653 & \multicolumn{3}{|c|}{5.5329999999999995} & 5.4255 & TRN \\
\hline CHEMBL1546683 & 688653 & 4.883 & 5.2088 & TST & & \\
\hline CHEMBL1416497 & 688653 & 4.683 & 4.7941 & TRN & & \\
\hline CHEMBL1385176 & 688653 & \multicolumn{3}{|c|}{6.632999999999999} & 5.7734 & TRN \\
\hline CHEMBL1605100 & 688653 & \multicolumn{3}{|c|}{5.5329999999999995} & 4.9743 & TRN \\
\hline CHEMBL1521301 & 688653 & \multicolumn{3}{|c|}{6.0329999999999995} & 5.4645 & TRN \\
\hline CHEMBL1451162 & 688653 & 4.583 & 4.7087 & TRN & & \\
\hline CHEMBL1572715 & 688653 & & & TRN & & \\
\hline CHEMBL1464706 & 688653 & \multicolumn{3}{|c|}{4.7330000000000005} & 4.9944 & TRN \\
\hline CHEMBL1580724 & 688653 & 5.733 & 5.0744 & TRN & & \\
\hline CHEMBL3199417 & 688653 & 5.433 & 5.0398 & TST & & \\
\hline CHEMBL1527075 & 688653 & 4.933 & 5.3813 & TRN & & \\
\hline CHEMBL1353561 & 688653 & \multicolumn{3}{|c|}{6.382999999999999} & 6.0088 & TRN \\
\hline CHEMBL1524020 & 688653 & \multicolumn{3}{|c|}{6.2829999999999995} & 5.9764 & TRN \\
\hline CHEMBL1425038 & 688653 & 4.833 & 5.1484 & TRN & & \\
\hline CHEMBL1603926 & 688653 & 4.933 & 5.4092 & TRN & & \\
\hline CHEMBL1472921 & 688653 & 4.833 & 4.9157 & TRN & & \\
\hline CHEMBL1546379 & 688653 & 4.783 & 5.421 & TRN & & \\
\hline CHEMBL1325381 & 688653 & \multicolumn{3}{|c|}{6.632999999999999} & 5.8764 & TRN \\
\hline
\end{tabular}




\begin{tabular}{|c|c|c|c|c|c|c|}
\hline \multirow{3}{*}{$\begin{array}{l}\text { CHEMBL1379635 } \\
\text { CHEMBL3208375 }\end{array}$} & \multirow{3}{*}{$\begin{array}{l}688653 \\
688653\end{array}$} & \multicolumn{4}{|c|}{ Supplemental Table S2.txt } & \multirow[b]{2}{*}{ TRN } \\
\hline & & \multicolumn{3}{|c|}{5.632999999999999} & 5.4107 & \\
\hline & & 5.483 & 5.1227 & TST & & \\
\hline CHEMBL1494703 & 688653 & 4.783 & 5.5682 & TRN & & \\
\hline CHEMBL1597093 & 688653 & 5.083 & 5.0752 & TRN & & \\
\hline CHEMBL1339024 & 688653 & 4.783 & 5.2688 & TRN & & \\
\hline CHEMBL1381205 & 688653 & \multicolumn{3}{|c|}{6.2829999999999995} & 5.7239 & TRN \\
\hline CHEMBL1311937 & 688653 & 4.833 & 5.1102 & TST & & \\
\hline CHEMBL1327154 & 688653 & 4.883 & 5.2295 & TST & & \\
\hline CHEMBL1580737 & 688653 & 4.683 & 4.9573 & TST & & \\
\hline CHEMBL1438315 & 688653 & \multicolumn{3}{|c|}{4.7330000000000005} & 5.2508 & TRN \\
\hline CHEMBL1484462 & 688653 & \multicolumn{3}{|c|}{5.2829999999999995} & 4.8587 & TST \\
\hline CHEMBL1423174 & 688653 & 5.233 & 5.1971 & TRN & & \\
\hline CHEMBL1379831 & 688653 & \multicolumn{3}{|c|}{4.9830000000000005} & 5.0247 & TRN \\
\hline CHEMBL602234 & 688653 & 4.833 & 4.6852 & TRN & & \\
\hline CHEMBL1465552 & 688653 & 5.183 & 5.8461 & TRN & & \\
\hline CHEMBL1598792 & 688653 & \multicolumn{3}{|c|}{4.7330000000000005} & 5.4815 & TRN \\
\hline CHEMBL1478972 & 688653 & 5.483 & 4.9337 & TST & & \\
\hline CHEMBL1526729 & 688653 & 4.883 & 5.3546 & TST & & \\
\hline CHEMBL1433460 & 688653 & 5.933 & 5.2095 & TRN & & \\
\hline CHEMBL1330740 & 688653 & 6.0 & 5.0972 & TST & & \\
\hline CHEMBL3209095 & 688653 & 5.433 & 5.7081 & TRN & & \\
\hline CHEMBL1406441 & 688653 & 5.983 & 5.63 & TRN & & \\
\hline CHEMBL1547314 & 688653 & 5.083 & 5.6652 & TRN & & \\
\hline CHEMBL1408661 & 688653 & 5.483 & 5.4405 & TRN & & \\
\hline CHEMBL1504776 & 688653 & 4.633 & 5.2557 & TRN & & \\
\hline CHEMBL1466206 & 688653 & \multicolumn{3}{|c|}{6.382999999999999} & 6.3719 & TRN \\
\hline CHEMBL1489817 & 688653 & 5.933 & 5.3737 & TRN & & \\
\hline CHEMBL1351568 & 688653 & 5.683 & 5.1259 & TRN & & \\
\hline CHEMBL1466905 & 688653 & 4.833 & 5.4507 & TST & & \\
\hline CHEMBL1529834 & 688653 & 4.783 & 5.1665 & TRN & & \\
\hline CHEMBL1421878 & 688653 & \multicolumn{3}{|c|}{6.082999999999999} & 5.9737 & I KIV \\
\hline CHEMBL1361452 & 688653 & 6.433 & \multicolumn{3}{|c|}{5.7010000000000005} & TRN \\
\hline CHEMBL1525678 & 688653 & 6.183 & 6.0312 & TRN & & \\
\hline CHEMBL1500981 & 688653 & 4.633 & 4.7281 & TST & & \\
\hline CHEMBL1517864 & 688653 & 4.783 & 4.7727 & TST & & \\
\hline CHEMBL1362619 & 688653 & \multicolumn{3}{|c|}{4.7330000000000005} & 4.9087 & TST \\
\hline CHEMBL1438308 & 688653 & \multicolumn{3}{|c|}{5.2829999999999995} & 5.1133 & TST \\
\hline CHEMBL1591817 & 688653 & 4.783 & 4.9673 & TRN & & \\
\hline CHEMBL1612277 & 688653 & 5.733 & 5.4548 & TRN & & \\
\hline CHEMBL1536196 & 688653 & 4.633 & 4.8439 & TST & & \\
\hline CHEMBL1388017 & 688653 & 4.783 & 5.1701 & TRN & & \\
\hline CHEMBL1545471 & 688653 & 5.983 & 4.9461 & TRN & & \\
\hline CHEMBL1310006 & 688653 & 6.433 & 5.8381 & TRN & & \\
\hline CHEMBL1538113 & 688653 & \multicolumn{3}{|c|}{6.7829999999999995} & 5.2474 & TRN \\
\hline CHEMBL1387181 & 688653 & \multicolumn{3}{|c|}{5.132999999999999} & 5.3208 & TRN \\
\hline CHEMBL1386149 & 688653 & \multicolumn{3}{|c|}{5.632999999999999} & 5.8195 & TRN \\
\hline CHEMBL1427865 & 688653 & 5.733 & 4.9232 & TRN & & \\
\hline CHEMBL1536292 & 688653 & \multicolumn{3}{|c|}{5.5329999999999995} & 5.2624 & TST \\
\hline
\end{tabular}




\begin{tabular}{|c|c|c|c|c|c|c|}
\hline & & \multicolumn{5}{|c|}{ Supplemental Table S2.txt } \\
\hline CHEMBL 3193701 & 688653 & 4.883 & 5.3074 & TRN & & \\
\hline CHEMBL379099 & 688653 & 4.583 & 5.3208 & TRN & & \\
\hline CHEMBL1541328 & 688653 & \multicolumn{3}{|c|}{5.832999999999999} & 5.6468 & I KN \\
\hline CHEMBL1518745 & 688653 & 5.033 & 5.5905 & TRN & & \\
\hline CHEMBL 2005947 & 688653 & 6.233 & 5.4993 & TST & & \\
\hline CHEMBL1451548 & 688653 & \multicolumn{3}{|c|}{4.9830000000000005} & 5.1211 & $\mathrm{TR}$ \\
\hline CHEMBL1527929 & 688653 & 4.833 & 4.9246 & TRN & & \\
\hline CHEMBL1484167 & 688653 & 5.433 & 5.3542 & TST & & \\
\hline CHEMBL1583917 & 688653 & \multicolumn{3}{|c|}{5.7829999999999995} & 5.8035 & TRN \\
\hline CHEMBL1408929 & 688653 & \multicolumn{3}{|c|}{6.082999999999999} & 5.407 & \\
\hline CHEMBL1400523 & 688653 & 4.633 & 5.0669 & TST & & \\
\hline CHEMBL1374141 & 688653 & 4.783 & 4.8755 & TST & & \\
\hline CHEMBL1509032 & 688653 & \multicolumn{3}{|c|}{5.5329999999999995} & 5.3831 & \\
\hline CHEMBL1601294 & 688653 & 4.883 & 5.3632 & TRN & & \\
\hline CHEMBL1371568 & 688653 & \multicolumn{3}{|c|}{5.832999999999999} & 5.5808 & Th \\
\hline CHEMBL1314425 & 688653 & 5.033 & 5.5491 & TRN & & \\
\hline CHEMBL1612955 & 688653 & 5.083 & 5.2538 & TST & & \\
\hline CHEMBL1552496 & 688653 & 4.783 & 5.0288 & TRN & & \\
\hline CHEMBL1482168 & 688653 & 4.583 & 5.5232 & TRN & & \\
\hline CHEMBL1374954 & 688653 & 4.583 & 5.2946 & TRN & & \\
\hline CHEMBL1532581 & 688653 & 4.833 & 5.2928 & TRN & & \\
\hline CHEMBL1584484 & 688653 & \multicolumn{3}{|c|}{5.2829999999999995} & 4 & \\
\hline CHEMBL13: & 688 & 5.933 & 4.8488 & TRN & & \\
\hline CHEMBL13: & 688653 & 4.683 & 5.3323 & TST & & \\
\hline CHEMBL1414223 & 688653 & \multicolumn{3}{|c|}{4.7330000000000005} & 4.9484 & $\mathrm{TP}$ \\
\hline CHEMBL1314167 & 688653 & 4.833 & 5.0489 & TST & & \\
\hline CHEMBL1386117 & 688653 & 4.833 & 5.112 & TST & & \\
\hline CHEMBL1377336 & 53 & 4.633 & 5.3384 & TRN & & \\
\hline CHEMBL585374 & 688653 & 4.783 & 5.2836 & TRN & & \\
\hline CHEMBL1407390 & 688653 & \multicolumn{3}{|c|}{5.632999999999999} & 5.9641 & TRN \\
\hline CHEMBL1321911 & 688653 & \multicolumn{3}{|c|}{5.132999999999999} & 5.0151 & TRN \\
\hline CHEMBL1492208 & 688653 & \multicolumn{3}{|c|}{5.332999999999999} & 5.7784 & TST \\
\hline CHEMBL1315655 & 688653 & \multicolumn{3}{|c|}{4.7330000000000005} & 4.7205 & \\
\hline CHEMBL1613331 & 688653 & 4.783 & 5.6155 & TRN & & \\
\hline CHEMBL1966298 & 688653 & \multicolumn{3}{|c|}{4.9830000000000005} & 5.4986 & TST \\
\hline CHEMBL1562836 & 688653 & 4.833 & 5.2433 & TRN & & \\
\hline CHEMBL 3197130 & 688653 & 5.683 & 5.5994 & TRN & & \\
\hline CHEMBL1565081 & 688653 & 5.683 & 5.5097 & TRN & & \\
\hline CHEMBL1528067 & 688653 & 7.3325 & 6.0105 & TRN & & \\
\hline CHEMBL1391154 & 688653 & 4.833 & 5.2216 & TRN & & \\
\hline CHEMBL1551135 & 688653 & 4.933 & 5.4101 & TRN & & \\
\hline CHEMBL1363756 & 688653 & 4.583 & 4.9803 & TRN & & \\
\hline CHEMBL1332925 & 688653 & 5.683 & 5.4112 & TST & & \\
\hline CHEMBL1382431 & 688653 & \multicolumn{3}{|c|}{4.7330000000000005} & 5.0074 & Tho \\
\hline CHEMBL1542533 & 688653 & \multicolumn{3}{|c|}{5.832999999999999} & 6.0211 & TS \\
\hline CHEMBL1447950 & 688653 & 4.933 & 4.9112 & TRN & & \\
\hline CHEMBL1448119 & 688653 & \multicolumn{3}{|c|}{4.9830000000000005} & 5.3378 & \\
\hline CHEMBL1485007 & 688653 & 6.683 & 6.0706 & TRN & & \\
\hline
\end{tabular}




\begin{tabular}{|c|c|c|c|c|c|c|c|}
\hline \multicolumn{7}{|c|}{ Supplemental Table S2.txt } & \\
\hline CHEMBL1352295 & 688653 & 5.683 & 5.1156 & TRN & & & \\
\hline CHEMBL1416809 & 688653 & 6.08299 & 99999999 & & 5.6924 & TRN & \\
\hline CHEMBL1431659 & 688653 & 5.683 & 5.6383 & TRN & & & \\
\hline CHEMBL1337274 & 688653 & 6.13290 & 99999999 & & 5.4396 & TRN & \\
\hline CHEMBL1421305 & 688653 & 4.783 & 4.9219 & TRN & & & \\
\hline CHEMBL1511008 & 688653 & 5.8829 & 99999999 & & 5.9388 & TRN & \\
\hline CHEMBL1611046 & 688653 & 6.13299 & 99999999 & & 5.7453 & TRN & \\
\hline CHEMBL1466147 & 688653 & 5.733 & 5.8938 & TST & & & \\
\hline CHEMBL1338787 & 688653 & 4.883 & 5.0433 & TRN & & & \\
\hline CHEMBL1516388 & 688653 & 5.483 & 5.6075 & TST & & & \\
\hline CHEMBL1457336 & 688653 & 5.58299 & 999999995 & & 5.6947 & TRN & \\
\hline CHEMBL1602865 & 688653 & 5.083 & 5.5409 & TRN & & & \\
\hline CHEMBL1493273 & 688653 & 5.433 & 5.3425 & TRN & & & \\
\hline CHEMBL1422482 & 688653 & 5.38299 & 99999999 & & 5.6045 & TRN & \\
\hline CHEMBL1508753 & 688653 & $4.7330 e$ & 00000000 & 005 & 5.5155 & TRN & \\
\hline CHEMBL1306522 & 688653 & 6.38299 & 99999999s & & 5.8932 & TRN & \\
\hline CHEMBL1494473 & 688653 & 5.83299 & 99999999 & & 5.4456 & TRN & \\
\hline CHEMBL1546928 & 688653 & 5.33290 & 99999999 & & 5.11 & TRN & \\
\hline CHEMBL3208410 & 688653 & 4.833 & 5.25 & TRN & & & \\
\hline CHEMBL1443251 & 688653 & 5.083 & 5.42399 & 999999999 & 995 & TRN & \\
\hline CHEMBL1337903 & 688653 & 5.8829 & 99999999s & & 5.4822 & TRN & \\
\hline CHEMBL1340962 & 688653 & 4.633 & 4.9363 & TRN & & & \\
\hline CHEMBL1430335 & 688653 & 5.53290 & 99999999 & 995 & 5.4686 & TRN & \\
\hline CHEMBL1326423 & 688653 & 5.733 & 6.0892 & TRN & & & \\
\hline CHEMBL1321432 & 688653 & 4.933 & 5.579 & TRN & & & \\
\hline CHEMBL1532220 & 688653 & 5.78299 & 99999999 & 995 & 5.3452 & TRN & \\
\hline CHEMBL1423291 & 688653 & 4.98306 & 00000000 & 005 & 5.4574 & TRN & \\
\hline CHEMBL3198539 & 688653 & 5.683 & 5.3533 & TRN & & & \\
\hline CHEMBL 1458800 & 688653 & 4.833 & 5.0774 & TRN & & & \\
\hline CHEMBL1544953 & 688653 & 5.233 & 5.3036 & TRN & & & \\
\hline CHEMBL1411488 & 688653 & 5.433 & 4.9619 & TRN & & & \\
\hline CHEMBL1606520 & 688653 & 6.3829 & 99999999 & & 5.2023 & TRN & \\
\hline CHEMBL1599558 & 688653 & 4.783 & 5.4154 & TRN & & & \\
\hline CHEMBL1397129 & 688653 & 4.883 & 5.2156 & TST & & & \\
\hline CHEMBL1364683 & 688653 & 5.733 & 5.0045 & TRN & & & \\
\hline CHEMBL3196485 & 688653 & 4.783 & 5.5583 & TRN & & & \\
\hline CHEMBL1570942 & 688653 & 4.98306 & 00000000 & 005 & 5.1446 & TST & \\
\hline CHEMBL1407513 & 688653 & 6.5829 & 99999999 & & 5.9338 & TST & \\
\hline CHEMBL1466855 & 688653 & 5.733 & 5.2158 & TRN & & & \\
\hline CHEMBL1547092 & 688653 & 4.73306 & 00000000 & 005 & 5.0891 & TST & \\
\hline CHEMBL1326791 & 688653 & 4.73306 & 00000000 & 005 & 4.9493 & TST & \\
\hline CHEMBL1410975 & 688653 & 5.83299 & 999999995 & & 5.62799 & 9999999999 & TRN \\
\hline CHEMBL1517391 & 688653 & 4.883 & 5.5731 & TRN & & & \\
\hline CHEMBL1416030 & 688653 & 4.883 & 5.0545 & TRN & & & \\
\hline CHEMBL1481387 & 688653 & 4.783 & 5.1767 & TRN & & & \\
\hline CHEMBL1560698 & 688653 & 4.833 & 5.0269 & TRN & & & \\
\hline CHEMBL1447731 & 688653 & 5.033 & 5.3399 & TRN & & & \\
\hline CHEMBL1337724 & 688653 & 5.733 & 5.7065 & TRN & & & \\
\hline
\end{tabular}




\begin{tabular}{|c|c|c|c|c|c|c|}
\hline \multirow{3}{*}{$\begin{array}{l}\text { CHEMBL1343376 } \\
\text { CHEMBL1358751 }\end{array}$} & \multirow{3}{*}{$\begin{array}{l}688653 \\
688653\end{array}$} & \multicolumn{5}{|c|}{ Supplemental Table S2.txt } \\
\hline & & \multicolumn{3}{|c|}{5.132999999999999} & 5.3501 & TR \\
\hline & & 5.083 & 5.4665 & TRN & & \\
\hline CHEMBL1439391 & 688653 & 4.933 & 5.5377 & TRN & & \\
\hline CHEMBL1346456 & 688653 & 4.633 & 5.4428 & TST & & \\
\hline CHEMBL1392555 & 688653 & 4.933 & 5.5782 & TRN & & \\
\hline CHEMBL1451916 & 688653 & 5.483 & 5.1954 & TRN & & \\
\hline CHEMBL1470721 & 688653 & 4.883 & 5.3757 & TST & & \\
\hline CHEMBL1608078 & 688653 & 4.633 & 5.0628 & TST & & \\
\hline CHEMBL1421583 & 688653 & 4.783 & 5.9505 & TRN & & \\
\hline CHEMBL1437275 & 688653 & 5.183 & 5.3451 & TRN & & \\
\hline CHEMBL1513866 & 688653 & 4.633 & 5.1798 & TRN & & \\
\hline CHEMBL1454850 & 688653 & \multicolumn{3}{|c|}{5.632999999999999} & 5.086 & \\
\hline CHEMBL1430384 & 688653 & 4.833 & 5.2758 & TRN & & \\
\hline CHEMBL1487528 & 688653 & 5.933 & 5.6359 & TRN & & \\
\hline CHEMBL1427426 & 688653 & 5.983 & 5.7498 & TRN & & \\
\hline CHEMBL1376200 & 688653 & \multicolumn{3}{|c|}{4.7330000000000005} & 5.4503 & TST \\
\hline CHEMBL1565837 & 688653 & \multicolumn{3}{|c|}{5.132999999999999} & 5.5071 & \\
\hline CHEMBL1538470 & 688653 & 5.083 & 5.4427 & TRN & & \\
\hline CHEMBL1341390 & 688653 & \multicolumn{3}{|c|}{5.882999999999999} & 5.7125 & TRN \\
\hline CHEMBL1578170 & 688653 & 5.733 & 5.1787 & TRN & & \\
\hline CHEMBL1303189 & 688653 & \multirow{2}{*}{\multicolumn{3}{|c|}{4.7330000000000005}} & & \\
\hline CHEMBL1501552 & 688653 & & & & 5.4455 & \\
\hline CHEMBL1575715 & 688653 & 4.783 & 4.9299 & TRN & & \\
\hline CHEMBL1352452 & 688653 & 4.833 & 5.1173 & TRN & & \\
\hline CHEMBL1928483 & 688653 & 5.033 & 5.5643 & TRN & & \\
\hline CHEMBL1569904 & 688653 & \multicolumn{3}{|c|}{4.7330000000000005} & 2.600 & \\
\hline CHEMBL1599571 & 688653 & 5.683 & 5.379 & TRN & & \\
\hline CHEMBL1306731 & 688653 & 4.933 & 5.2636 & TST & & \\
\hline CHEMBL1591345 & 688653 & 5.983 & 5.2355 & TRN & & \\
\hline CHEMBL1408238 & 688653 & 6.983 & 5.776 & TRN & & \\
\hline CHEMBL1352829 & 688653 & 4.783 & 5.4722 & TRN & & \\
\hline CHEMBL1365310 & 688653 & 4.933 & 5.0765 & TST & & \\
\hline CHEMBL1399550 & 688653 & \multicolumn{3}{|c|}{5.7829999999999995} & 5.3584 & TRN \\
\hline CHEMBL3199104 & 688653 & \multicolumn{3}{|c|}{5.632999999999999} & 5.6595 & $\mathrm{TH}$ \\
\hline CHEMBL1582152 & 688653 & 5.683 & 5.3737 & TST & & \\
\hline CHEMBL1487415 & 688653 & 5.9 & 6.2234 & TRN & & \\
\hline CHEMBL1364620 & 688653 & 5.733 & 5.9314 & TRN & & \\
\hline CHEMBL3210407 & 688653 & 4.833 & 5.3999 & TRN & & \\
\hline CHEMBL1531227 & 688653 & 4.833 & 5.1457 & TST & & \\
\hline CHEMBL1432857 & 688653 & 4.883 & 4.9696 & TRN & & \\
\hline CHEMBL1530714 & 688653 & 5.033 & 5.06 & TST & & \\
\hline CHEMBL3195817 & 688653 & 4.783 & 5.1928 & TRN & & \\
\hline CHEMBL1482351 & 688653 & 4.933 & 4.6886 & TRN & & \\
\hline CHEMBL1608208 & 688653 & 6.2829 & 9999999 & 995 & 5.6556 & TRN \\
\hline CHEMBL493153 & 688653 & 5.8829 & 9999999 & & 5.2095 & \\
\hline CHEMBL1383407 & 688653 & 5.1329 & 9999999 & & 5.1292 & \\
\hline CHEMBL1441811 & 688653 & 5.433 & 5.5615 & TRN & & \\
\hline CHEMBL1372874 & 688653 & 4.9836 & $\partial 000000$ & 005 & 5.5429 & I NIV \\
\hline
\end{tabular}




\begin{tabular}{|c|c|c|c|c|c|c|}
\hline \multirow[b]{2}{*}{ CHEMBL1354557 } & \multirow[b]{2}{*}{688653} & \multicolumn{5}{|c|}{ Supplemental Table S2.txt } \\
\hline & & \multicolumn{3}{|c|}{35.4928 TRN } & & \\
\hline CHEMBL1592953 & 688653 & 4.833 & 5.0431 & TRN & & \\
\hline CHEMBL1487591 & 688653 & \multicolumn{3}{|c|}{5.132999999999999} & 5.3959 & TRN \\
\hline CHEMBL1554981 & 688653 & 4.633 & 5.1431 & TST & & \\
\hline CHEMBL1470997 & 688653 & \multicolumn{3}{|c|}{5.7829999999999995} & 5.7733 & TRN \\
\hline CHEMBL1328624 & 688653 & \multicolumn{3}{|c|}{6.332999999999999} & 5.4096 & TRN \\
\hline CHEMBL1323633 & 688653 & \multicolumn{3}{|c|}{6.382999999999999} & 6.1269 & TST \\
\hline CHEMBL1380158 & 688653 & 5.433 & 5.5645 & TRN & & \\
\hline CHEMBL1324064 & 688653 & 5.033 & 5.0013 & TRN & & \\
\hline CHEMBL1423803 & 688653 & 4.783 & 4.7841 & TST & & \\
\hline CHEMBL3193236 & 688653 & 4.683 & 5.2134 & TST & & \\
\hline CHEMBL1325019 & 688653 & 4.783 & 5.2687 & TST & & \\
\hline CHEMBL1598581 & 688653 & \multicolumn{3}{|c|}{6.632999999999999} & 5.9179 & TRN \\
\hline CHEMBL1516899 & 688653 & 4.933 & 4.6684 & TRN & & \\
\hline CHEMBL1374722 & 688653 & 4.783 & 5.7043 & TST & & \\
\hline CHEMBL1563660 & 688653 & 4.833 & 5.1748 & TST & & \\
\hline CHEMBL1387640 & 688653 & 4.783 & 5.2031 & TRN & & \\
\hline CHEMBL1510796 & 688653 & 5.733 & 5.0227 & TRN & & \\
\hline CHEMBL1515160 & 688653 & 4.583 & 5.1842 & TRN & & \\
\hline CHEMBL536166 & 688653 & 5.433 & 5.6515 & TRN & & \\
\hline CHEMBL1353573 & 688653 & 5.033 & 4.9569 & TRN & & \\
\hline CHEMBL1348406 & 688653 & \multicolumn{3}{|c|}{5.7829999999999995} & 5.5542 & TST \\
\hline CHEMBL1498676 & 688653 & \multicolumn{3}{|c|}{4.9830000000000005} & 5.1192 & TRN \\
\hline CHEMBL1343224 & 688653 & \multicolumn{3}{|c|}{6.332999999999999} & 5.9206 & TRN \\
\hline CHEMBL3210412 & 688653 & 4.683 & 5.4788 & TRN & & \\
\hline CHEMBL1458471 & 688653 & 5.183 & 4.9704 & TRN & & \\
\hline CHEMBL1347339 & 688653 & 4.833 & 5.3479 & TST & & \\
\hline CHEMBL1402055 & 688653 & 4.633 & 5.1777 & TST & & \\
\hline CHEMBL1491196 & 688653 & 4.833 & 4.9381 & TRN & & \\
\hline CHEMBL1588668 & 688653 & 4.883 & 5.1266 & TRN & & \\
\hline CHEMBL1362715 & 688653 & \multicolumn{3}{|c|}{4.9830000000000005} & 4.9652 & TRN \\
\hline CHEMBL1570079 & 688653 & 5.033 & 5.4811 & TRN & & \\
\hline CHEMBL1533959 & 688653 & \multirow{2}{*}{\multicolumn{3}{|c|}{$\begin{array}{l}4.633 \text { 4. } 6409 \\
6.582999999999999\end{array}$}} & & \\
\hline CHEMBL1593141 & 688653 & & & & 5.6981 & TRN \\
\hline CHEMBL1580699 & 688653 & 5.033 & 5.3381 & TST & & \\
\hline CHEMBL1564710 & 688653 & \multicolumn{3}{|c|}{4.7330000000000005} & 5.2974 & TRN \\
\hline CHEMBL1317174 & 688653 & 4.633 & 5.0432 & TST & & \\
\hline CHEMBL1437449 & 688653 & 4.933 & 5.1747 & TST & & \\
\hline CHEMBL1438250 & 688653 & 4.683 & 5.0121 & TRN & & \\
\hline CHEMBL1354026 & 688653 & \multicolumn{3}{|c|}{4.7330000000000005} & 5.1525 & TST \\
\hline CHEMBL1412996 & 688653 & \multicolumn{3}{|c|}{5.832999999999999} & 5.4728 & TRN \\
\hline CHEMBL1518707 & 688653 & 7.0329 & 5.2418 & TRN & & \\
\hline CHEMBL1485220 & 688653 & 4.833 & 5.2728 & TST & & \\
\hline CHEMBL1610332 & 688653 & 4.933 & 5.6127 & TRN & & \\
\hline CHEMBL1484968 & 688653 & \multicolumn{3}{|c|}{6.7829999999999995} & 5.5649 & TRN \\
\hline CHEMBL1409802 & 688653 & \multicolumn{3}{|c|}{6.7829999999999995} & 5.9524 & TST \\
\hline CHEMBL1389851 & 688653 & \multicolumn{3}{|c|}{5.132999999999999} & 5.2306 & TST \\
\hline CHEMBL1537984 & 688653 & 4.883 & 5.3718 & TST & & \\
\hline
\end{tabular}




\begin{tabular}{|c|c|c|c|c|c|c|}
\hline \multirow[b]{2}{*}{ CHEMBL1364627 } & \multicolumn{6}{|c|}{ splemental } \\
\hline & 688653 & 4.783 & 4.8404 & TST & & \\
\hline CHEMBL1451272 & 688653 & 5.683 & 5.3591 & TRN & & \\
\hline CHEMBL1488034 & 688653 & 5.3829 & 99999999 & & 5.3644 & TRN \\
\hline CHEMBL1478590 & 688653 & 4.833 & 5.1626 & TRN & & \\
\hline CHEMBL1455137 & 688653 & 5.2829 & 99999999 & 995 & 5.291 & TRN \\
\hline CHEMBL1415958 & 688653 & 5.3829 & 999999995 & & 6.0071 & TST \\
\hline CHEMBL3188020 & 688653 & 5.1329 & 99999999 & & 5.1593 & TRN \\
\hline CHEMBL3198218 & 688653 & 5.1329 & 99999999 & & 5.2672 & TR \\
\hline CHEMBL1355020 & 688653 & 4.783 & 5.5081 & TRN & & \\
\hline CHEMBL1499966 & 688653 & 5.233 & 5.4709 & TRN & & \\
\hline CHEMBL1499671 & 688653 & 5.8329 & 999999995 & & 5.3654 & $T$ \\
\hline CHEMBL1333754 & 688653 & 4.7330 & 00000000 & 005 & 5.061 & \\
\hline CHEMBL1495192 & 688653 & 4.633 & 5.1318 & TRN & & \\
\hline CHEMBL1488354 & 688653 & 4.7330 & 00000000 & 005 & 5.0497 & \\
\hline CHEMBL1567422 & 688653 & 5.5829 & 99999999 & & 5.1967 & \\
\hline CHEMBL1544530 & 688653 & 5.1329 & 99999999 & & 5.528 & TRN \\
\hline CHEMBL460508 & 688653 & 5.7829 & 99999999 & 995 & 6.3961 & \\
\hline CHEMBL1343732 & 688653 & 4.783 & 5.0798 & TST & & \\
\hline CHEMBL3197333 & 688653 & 4.783 & 5.1944 & TRN & & \\
\hline CHEMBL1564728 & 688653 & 4.933 & 5.2193 & TRN & & \\
\hline CHEMBL1505655 & 688653 & 4.7330 & 00000000 & 005 & 5.0089 & TRN \\
\hline CHEMBL1542250 & 688653 & 4.7330 & 00000000 & 005 & 5.5216 & \\
\hline CHEMBL1349328 & 688653 & 4.833 & 5.1647 & TRN & & \\
\hline CHEMBL1523703 & 688 & 4.9830 & 00000000 & 005 & 5.398 & \\
\hline CHEMBL1346297 & 688653 & 5.1329 & 99999999 & & 4.9394 & \\
\hline CHEMBL1484105 & 688653 & 5.1329 & 99999999 & & 5.41299 & 999 \\
\hline CHEMBL1576600 & 688653 & 6.3329 & 99999999 & & 5.9471 & $\mathrm{TI}$ \\
\hline CHEMBL1542279 & 688653 & 5.3329 & 99999999 & & 5.0653 & \\
\hline CHEMBL3213769 & 688653 & 5.083 & 5.4978 & TRN & & \\
\hline CHEMBL1443174 & 688653 & 6.1329 & 99999999 & & 6.0349 & \\
\hline CHEMBL 3194261 & 688653 & 5.733 & 5.4525 & TRN & & \\
\hline CHEMBL1509661 & 688653 & 5.183 & 4.7523 & TST & & \\
\hline CHEMBL1369506 & 688653 & 6.3829 & 99999999 & & 5.6005 & \\
\hline CHEMBL1393380 & 688653 & 4.883 & 5.3044 & TRN & & \\
\hline CHEMBL1465328 & 688653 & 4.883 & 5.2673 & TRN & & \\
\hline CHEMBL1370223 & 688653 & 5.083 & 5.1682 & TRN & & \\
\hline CHEMBL1319999 & 688653 & 5.733 & 4.7231 & TST & & \\
\hline CHEMBL1451630 & 688653 & 4.933 & 4.988 & TRN & & \\
\hline CHEMBL1978564 & 688653 & 5.733 & 5.5823 & TRN & & \\
\hline CHEMBL1497166 & 688653 & 5.033 & 5.0137 & TRN & & \\
\hline CHEMBL1311455 & 688653 & 5.3829 & 99999999 & & 5.5643 & \\
\hline CHEMBL1392944 & 688653 & 5.433 & 5.7626 & TST & & \\
\hline CHEMBL1313488 & 688653 & 5.233 & 5.4942 & TRN & & \\
\hline CHEMBL1471502 & 688653 & 5.5329 & 99999999 & 995 & 5.1291 & \\
\hline CHEMBL1575421 & 688653 & 4.683 & 5.3301 & TST & & \\
\hline CHEMBL1321017 & 688653 & 5.2829 & 99999999 & 995 & 5.7018 & $\Pi$ \\
\hline CHEMBL1489315 & 688653 & 4.7330 & 00000000 & 005 & 5.5418 & \\
\hline CHEMBL1451312 & 688653 & 5.6329 & 99999999 & & 5.5263 & \\
\hline
\end{tabular}




\begin{tabular}{|c|c|c|c|c|c|c|c|}
\hline \multicolumn{8}{|c|}{ Supplemental Table s2.txt } \\
\hline CHEMBL1389832 & 688653 & 5.183 & 4.8829 & TST & & & \\
\hline CHEMBL1320709 & 688653 & 5.183 & 5.3951 & TRN & & & \\
\hline CHEMBL1384293 & 688653 & \multicolumn{3}{|c|}{6.082999999999999} & 5.0576 & TRN & \\
\hline CHEMBL1351668 & 688653 & 4.633 & 4.5927 & TRN & & & \\
\hline CHEMBL1331093 & 688653 & 5.683 & 5.5544 & TRN & & & \\
\hline CHEMBL1449106 & 688653 & 4.833 & 5.0342 & TRN & & & \\
\hline CHEMBL1394675 & 688653 & 4.583 & 4.8983 & TRN & & & \\
\hline CHEMBL1552056 & 688653 & \multicolumn{3}{|c|}{4.7330000000000005} & 4.9336 & TRN & \\
\hline CHEMBL1547213 & 688653 & \multicolumn{3}{|c|}{5.7829999999999995} & 5.7193 & TRN & \\
\hline CHEMBL1601036 & 688653 & \multicolumn{3}{|c|}{5.2829999999999995} & \multicolumn{2}{|c|}{5.3389999999999995} & TRN \\
\hline CHEMBL1430768 & 688653 & 4.883 & 5.002 & TST & & & \\
\hline CHEMBL1561441 & 688653 & 4.933 & 5.4455 & TRN & & & \\
\hline CHEMBL1338049 & 688653 & 4.933 & 5.1791 & TRN & & & \\
\hline CHEMBL1610203 & 688653 & \multicolumn{3}{|c|}{5.632999999999999} & 5.6657 & TRN & \\
\hline CHEMBL1611658 & 688653 & 4.833 & 4.7947 & TST & & & \\
\hline CHEMBL1429258 & 688653 & 4.883 & 4.9886 & TRN & & & \\
\hline CHEMBL1487727 & 688653 & 4.883 & 5.3575 & TST & & & \\
\hline CHEMBL1436262 & 688653 & 5.433 & 4.9693 & TRN & & & \\
\hline CHEMBL1500910 & 688653 & \multicolumn{3}{|c|}{4.7330000000000005} & 5.1753 & TRN & \\
\hline CHEMBL3197106 & 688653 & \multicolumn{3}{|c|}{5.132999999999999} & 5.3063 & TRN & \\
\hline CHEMBL3212188 & 688653 & 5.483 & 5.789 & TRN & & & \\
\hline CHEMBL1338658 & 688653 & \multicolumn{3}{|c|}{6.0329999999999995} & \multicolumn{2}{|c|}{5.428999999999999} & TRN \\
\hline CHEMBL1367060 & 688653 & \multicolumn{3}{|c|}{5.832999999999999} & 5.4908 & TRN & \\
\hline CHEMBL1364954 & 688653 & \multicolumn{3}{|c|}{4.7330000000000005} & 5.2408 & TRN & \\
\hline CHEMBL1411637 & 688653 & \multicolumn{3}{|c|}{6.2829999999999995} & 5.2949 & TST & \\
\hline CHEMBL1586323 & 688653 & \multicolumn{3}{|c|}{5.132999999999999} & 5.0046 & TRN & \\
\hline CHEMBL1376933 & 688653 & \multicolumn{3}{|c|}{5.882999999999999} & 5.3922 & TRN & \\
\hline CHEMBL3189474 & 688653 & 4.883 & 5.4203 & TRN & & & \\
\hline CHEMBL1563830 & 688653 & \multicolumn{3}{|c|}{5.2829999999999995} & 5.4939 & TRN & \\
\hline CHEMBL1584476 & 688653 & \multicolumn{3}{|c|}{5.7829999999999995} & 5.61 & TRN & \\
\hline CHEMBL1299411 & 688653 & 5.733 & 5.7954 & TRN & & & \\
\hline CHEMBL1534814 & 688653 & 4.783 & 5.0065 & TRN & & & \\
\hline CHEMBL1394393 & 688653 & 5.083 & 4.974 & TRN & & & \\
\hline CHEMBL1424727 & 688653 & \multicolumn{3}{|c|}{4.7330000000000005} & 5.2027 & TRN & \\
\hline CHEMBL1539910 & 688653 & 5.683 & 5.2446 & TRN & & & \\
\hline CHEMBL1340992 & 688653 & 5.083 & 5.4899 & TST & & & \\
\hline CHEMBL1450797 & 688653 & 5.433 & 6.0126 & TRN & & & \\
\hline CHEMBL1412155 & 688653 & \multicolumn{3}{|c|}{4.7330000000000005} & 5.0119 & TST & \\
\hline CHEMBL1467031 & 688653 & 5.683 & 5.063 & TRN & & & \\
\hline CHEMBL1526346 & 688653 & 4.933 & 4.9784 & TST & & & \\
\hline CHEMBL1550291 & 688653 & 4.783 & 5.2182 & TRN & & & \\
\hline CHEMBL1464024 & 688653 & \multicolumn{3}{|c|}{5.382999999999999} & 5.1437 & TRN & \\
\hline CHEMBL1562713 & 688653 & 6.0329 & 99999999 & 995 & 5.3621 & TRN & \\
\hline CHEMBL1456134 & 688653 & 4.783 & 5.2007 & TRN & & & \\
\hline CHEMBL3208851 & 688653 & 6.433 & 5.4956 & TRN & & & \\
\hline CHEMBL1546932 & 688653 & 4.683 & 5.2847 & TRN & & & \\
\hline CHEMBL1398957 & 688653 & 5.683 & 5.4033 & TRN & & & \\
\hline CHEMBL1400481 & 688653 & 4.633 & 4.9126 & TST & & & \\
\hline
\end{tabular}




\begin{tabular}{|c|c|c|c|c|c|c|}
\hline \multirow{3}{*}{$\begin{array}{l}\text { CHEMBL1564720 } \\
\text { CHEMBL1411306 }\end{array}$} & \multirow{3}{*}{$\begin{array}{l}688653 \\
688653\end{array}$} & \multicolumn{5}{|c|}{ Supplemental Table S2.txt } \\
\hline & & \multicolumn{3}{|c|}{5.132999999999999} & \multirow[t]{2}{*}{4.9705} & \multirow[t]{2}{*}{ TRN } \\
\hline & & 6.233 & 5.7679 & TRN & & \\
\hline CHEMBL1441467 & 688653 & \multicolumn{3}{|c|}{5.7829999999999995} & 5.9666 & TRN \\
\hline CHEMBL3195002 & 688653 & 6.433 & 5.1893 & TRN & & \\
\hline CHEMBL1612016 & 688653 & 4.583 & 5.022 & TST & & \\
\hline CHEMBL1305605 & 688653 & \multicolumn{3}{|c|}{6.382999999999999} & 6.0066 & TRN \\
\hline CHEMBL1409528 & 688653 & 5.933 & 5.6669 & TRN & & \\
\hline CHEMBL1461773 & 688653 & 5.083 & 5.3362 & TRN & & \\
\hline CHEMBL1437484 & 688653 & \multicolumn{3}{|c|}{5.832999999999999} & 5.0095 & TRN \\
\hline CHEMBL1596248 & 688653 & 5.933 & 5.8186 & TRN & & \\
\hline CHEMBL1356253 & 688653 & 4.883 & 4.9543 & TRN & & \\
\hline CHEMBL1577200 & 688653 & 6.183 & 5.3504 & TST & & \\
\hline CHEMBL1305213 & 688653 & \multicolumn{3}{|c|}{5.332999999999999} & 5.1988 & TRN \\
\hline CHEMBL1391048 & 688653 & \multicolumn{3}{|c|}{5.5329999999999995} & 5.2977 & TST \\
\hline CHEMBL1599388 & 688653 & 4.883 & 5.0852 & TST & & \\
\hline CHEMBL1489601 & 688653 & 5.683 & 5.6956 & TRN & & \\
\hline CHEMBL3196616 & 688653 & \multicolumn{3}{|c|}{5.832999999999999} & 5.5946 & TRN \\
\hline CHEMBL1303718 & 688653 & 4.833 & 5.1667 & TRN & & \\
\hline CHEMBL1347798 & 688653 & \multicolumn{3}{|c|}{5.382999999999999} & 5.3662 & TRN \\
\hline CHEMBL1471344 & 688653 & 4.933 & 5.1816 & TRN & & \\
\hline CHEMBL1340511 & 688653 & 5.083 & 5.0408 & TRN & & \\
\hline CHEMBL1598619 & 688653 & \multicolumn{3}{|c|}{6.332999999999999} & 3455 & TRN \\
\hline CHEMBL1568597 & 688653 & 5.183 & 5.659 & TRN & & \\
\hline CHEMBL1560756 & 688653 & 4.633 & 5.0923 & TST & & \\
\hline CHEMBL169272 & 688653 & 4.783 & 4.8885 & TST & & \\
\hline CHEMBL1609965 & 688653 & 5.183 & 5.0957 & TST & & \\
\hline CHEMBL1570720 & 688653 & 5.183 & 5.5726 & TRN & & \\
\hline CHEMBL1378551 & 688653 & 5.033 & 5.1958 & TRN & & \\
\hline CHEMBL1593308 & 688653 & 4.933 & 5.4792 & TST & & \\
\hline CHEMBL1608996 & 688653 & 4.783 & 5.1724 & TST & & \\
\hline CHEMBL1383603 & 688653 & 4.683 & 5.2222 & TRN & & \\
\hline CHEMBL3199170 & 688653 & \multicolumn{3}{|c|}{5.832999999999999} & 5.6622 & TRN \\
\hline CHEMBL1346290 & 688653 & 4.833 & 5.2809 & TST & & \\
\hline CHEMBL1394657 & 688653 & 4.783 & 5.3897 & TST & & \\
\hline CHEMBL1583785 & 688653 & \multicolumn{3}{|c|}{6.132999999999999} & 5.2225 & TRN \\
\hline CHEMBL1362869 & 688653 & \multicolumn{3}{|c|}{5.882999999999999} & 5.6291 & TRN \\
\hline CHEMBL1515301 & 688653 & 4.583 & 4.613 & TST & & \\
\hline CHEMBL1563822 & 688653 & 4.833 & 5.1241 & TRN & & \\
\hline CHEMBL1479458 & 688653 & 4.783 & 4.9861 & TRN & & \\
\hline CHEMBL1557315 & 688653 & \multicolumn{3}{|c|}{5.632999999999999} & 5.7274 & TRN \\
\hline CHEMBL1464002 & 688653 & 4.783 & 5.0941 & TST & & \\
\hline CHEMBL1319446 & 688653 & 4.783 & 5.1445 & TRN & & \\
\hline CHEMBL1464294 & 688653 & 5.183 & 5.4391 & TRN & & \\
\hline CHEMBL1338662 & 688653 & \multicolumn{3}{|c|}{5.382999999999999} & 5.2713 & TRN \\
\hline CHEMBL1471064 & 688653 & \multicolumn{3}{|c|}{4.7330000000000005} & 5.0356 & TST \\
\hline CHEMBL1526722 & 688653 & \multicolumn{3}{|c|}{5.7829999999999995} & 5.6435 & TRN \\
\hline CHEMBL1502698 & 688653 & 4.833 & 5.3531 & TRN & & \\
\hline CHEMBL1462776 & 688653 & 5.933 & 6.0554 & TRN & & \\
\hline
\end{tabular}




\begin{tabular}{|c|c|c|c|c|c|c|}
\hline \multirow[b]{2}{*}{ CHEMBL1306633 } & \multirow[b]{2}{*}{688653} & \multicolumn{5}{|c|}{ Supplemental Table S2.txt } \\
\hline & & \multirow{2}{*}{\multicolumn{3}{|c|}{$\begin{array}{lcc}5.433 & 5.1686 & \text { TRN } \\
4.7330000000000005\end{array}$}} & \multirow{3}{*}{5.1398} & \multirow{3}{*}{ TRN } \\
\hline CHEMBL1310277 & 688653 & & & & & \\
\hline CHEMBL1519307 & 688653 & 4.683 & 5.5068 & TST & & \\
\hline CHEMBL3212392 & 688653 & \multicolumn{3}{|c|}{5.132999999999999} & 5.2007 & TRN \\
\hline CHEMBL1395259 & 688653 & 6.433 & 5.4963 & TRN & & \\
\hline CHEMBL1372194 & 688653 & 4.783 & 5.4022 & TST & & \\
\hline CHEMBL1340977 & 688653 & \multicolumn{3}{|c|}{4.7330000000000005} & 5.1554 & TRN \\
\hline CHEMBL1970554 & 688653 & 4.883 & 5.0528 & TST & & \\
\hline CHEMBL1359483 & 688653 & 5.683 & 4.9533 & TRN & & \\
\hline CHEMBL1330541 & 688653 & 4.833 & 4.9754 & TST & & \\
\hline CHEMBL1483297 & 688653 & 4.683 & 5.4099 & TRN & & \\
\hline CHEMBL1324080 & 688653 & \multicolumn{3}{|c|}{4.7330000000000005} & 5.2821 & TRN \\
\hline CHEMBL1590627 & 688653 & \multicolumn{3}{|c|}{4.7330000000000005} & 5.1051 & TRN \\
\hline CHEMBL1355560 & 688653 & 7.1831 & 5.6879 & TRN & & \\
\hline CHEMBL1982477 & 688653 & 5.733 & 5.7843 & TST & & \\
\hline CHEMBL1418762 & 688653 & 5.083 & 5.2614 & TRN & & \\
\hline CHEMBL1339070 & 688653 & 4.783 & \multicolumn{3}{|c|}{5.132999999999999} & TRN \\
\hline CHEMBL1608872 & 688653 & \multicolumn{3}{|c|}{4.7330000000000005} & 5.6061 & TRN \\
\hline CHEMBL 3214294 & 688653 & 4.783 & 4.9897 & TST & & \\
\hline CHEMBL1566802 & 688653 & \multicolumn{3}{|c|}{6.632999999999999} & 4.9617 & TST \\
\hline CHEMBL1431307 & 688653 & \multicolumn{3}{|c|}{5.332999999999999} & 4.7511 & TST \\
\hline CHEMBL3194626 & 688653 & \multicolumn{3}{|c|}{5.832999999999999} & 5.3061 & TST \\
\hline CHEMBL1387571 & 688653 & \multicolumn{3}{|c|}{5.5329999999999995} & 5.4187 & TRN \\
\hline CHEMBL1424561 & 688653 & 4.883 & 4.9595 & TRN & & \\
\hline CHEMBL1546348 & 688653 & 4.783 & 5.1298 & TRN & & \\
\hline CHEMBL1455166 & 688653 & 5.033 & 5.1593 & TST & & \\
\hline CHEMBL1328527 & 688653 & 6.9329 & 5.8423 & TRN & & \\
\hline CHEMBL1966283 & 688653 & 4.883 & 5.1421 & TST & & \\
\hline CHEMBL1400744 & 688653 & \multicolumn{3}{|c|}{5.132999999999999} & 5.2225 & TRN \\
\hline CHEMBL3192475 & 688653 & 4.633 & 5.2627 & TST & & \\
\hline CHEMBL1582740 & 688653 & 5.183 & 5.7036 & TRN & & \\
\hline CHEMBL1551941 & 688653 & \multicolumn{3}{|c|}{4.7330000000000005} & 4.8425 & TRN \\
\hline CHEMBL1448626 & 688653 & 4.883 & 5.052 & TRN & & \\
\hline CHEMBL1472327 & 688653 & 4.833 & 4.9443 & TST & & \\
\hline CHEMBL1426583 & 688653 & 4.883 & 5.3103 & TRN & & \\
\hline CHEMBL1374040 & 688653 & 4.933 & 5.1136 & TRN & & \\
\hline CHEMBL1382479 & 688653 & 6.0 & 5.348 & TST & & \\
\hline CHEMBL3193502 & 688653 & \multicolumn{3}{|c|}{4.7330000000000005} & 5.4328 & TST \\
\hline CHEMBL1527565 & 688653 & 4.633 & 5.2057 & TST & & \\
\hline CHEMBL1564952 & 688653 & \multicolumn{3}{|c|}{5.632999999999999} & 5.1063 & TRN \\
\hline CHEMBL1461131 & 688653 & \multicolumn{3}{|c|}{5.5329999999999995} & 5.2948 & TRN \\
\hline CHEMBL1446987 & 688653 & 5.83290 & 99999999 & & 4.9913 & TRN \\
\hline CHEMBL1403095 & 688653 & 5.683 & 5.0989 & TRN & & \\
\hline CHEMBL1524438 & 688653 & 5.233 & 4.7975 & TRN & & \\
\hline CHEMBL 3214571 & 688653 & 5.683 & 5.70200 & 00006 & & TRN \\
\hline CHEMBL1415218 & 688653 & 5.183 & 5.1925 & TRN & & \\
\hline CHEMBL1445569 & 688653 & 4.883 & 5.1939 & TRN & & \\
\hline CHEMBL1567904 & 688653 & 4.833 & 4.8146 & TRN & & \\
\hline
\end{tabular}




\begin{tabular}{|c|c|c|c|c|c|c|}
\hline & & \multicolumn{5}{|c|}{ Supplemental Table S2.txt } \\
\hline CHEMBL1440781 & 688653 & \multicolumn{3}{|c|}{6.832999999999999} & 5.5848 & TST \\
\hline CHEMBL1366942 & 688653 & \multicolumn{3}{|c|}{5.632999999999999} & 5.8542 & \\
\hline CHEMBL1535665 & 688653 & 5.233 & 4.8639 & TST & & \\
\hline CHEMBL1363474 & 688653 & 4.933 & \multicolumn{3}{|c|}{5.4239999999999995} & \\
\hline CHEMBL1536809 & 688653 & 4.883 & 5.1702 & TST & & \\
\hline CHEMBL1422182 & 688653 & 5.033 & 4.9461 & TRN & & \\
\hline CHEMBL1418531 & 688653 & 4.883 & 5.5576 & TRN & & \\
\hline CHEMBL1498158 & 688653 & \multicolumn{3}{|c|}{4.7330000000000005} & 5.3438 & \\
\hline CHEMBL1578775 & 688653 & 4.783 & 5.0422 & TRN & & \\
\hline CHEMBL3211452 & 688653 & 7.0329 & 5.8604 & TST & & \\
\hline CHEMBL1341995 & 688653 & 5.183 & 5.1162 & TRN & & \\
\hline CHEMBL1450679 & 688653 & 4.783 & 4.7396 & TST & & \\
\hline CHEMBL1337367 & 688653 & 6.4829 & 5.7647 & TRN & & \\
\hline CHEMBL 3210972 & 688653 & \multicolumn{3}{|c|}{5.832999999999999} & 5.155 & \\
\hline CHEMBL1366838 & 688653 & \multicolumn{3}{|c|}{5.332999999999999} & 5.1688 & \\
\hline CHEMBL1585050 & 688653 & \multicolumn{3}{|c|}{5.582999999999999} & 5.5607 & \\
\hline CHEMBL1520146 & 688653 & 4.883 & 5.0468 & TST & & \\
\hline CHEMBL13 & 688653 & 6.683 & 5.4724 & TRN & & \\
\hline CHEMBL1601456 & 688653 & 7.2832 & 5.7998 & TRN & & \\
\hline CHEMBL1335944 & 688653 & 5.033 & 4.7924 & TRN & & \\
\hline CHEMBL1533107 & 688653 & \multicolumn{3}{|c|}{5.832999999999999} & 5 & \\
\hline CHEMBL15 & 688653 & 5.433 & 5.2409 & TRN & & \\
\hline CHEMBL44 & 688653 & 5.683 & 5.6648 & TRN & & \\
\hline CHEMBL3197335 & 688653 & 5.233 & 5.3751 & TRN & & \\
\hline CHEMBL1501998 & 688653 & 4.783 & 5.2456 & TRN & & \\
\hline CHEMBL1572491 & 688653 & 4.783 & 4.9716 & TST & & \\
\hline CHEMBL3 & 688653 & \multicolumn{3}{|c|}{6.332999999999999} & 5.631 & \\
\hline CHEMBL1 & 688653 & 4.883 & 5.3333 & TST & & \\
\hline CHEMBL1444899 & 688653 & \multicolumn{3}{|c|}{4.9830000000000005} & 4.8975 & $\mathrm{TH}$ \\
\hline CHEMBL193627 & 688653 & \multicolumn{3}{|c|}{5.7829999999999995} & 5.8512 & $\mathrm{TI}$ \\
\hline CHEMBL1578952 & 688653 & \multicolumn{3}{|c|}{5.832999999999999} & 5.8162 & TRN \\
\hline CHEMBL & 688653 & \multicolumn{3}{|c|}{6.582999999999999} & 6.075 & \\
\hline CHEMBL & 688653 & 4.783 & 4.9253 & TST & & \\
\hline CHEMBL1343389 & 688653 & 6.8831 & 6.0901 & TRN & & \\
\hline CHEMBL1496864 & 688653 & \multicolumn{3}{|c|}{5.5329999999999995} & 5.5497 & 11 \\
\hline CHEMBL136 & 688653 & 4.783 & 4.8465 & TRN & & \\
\hline CHEMB & 688653 & 5.733 & 5.3731 & TRN & & \\
\hline CHEMBL14 & 688653 & 4.883 & 5.7793 & TRN & & \\
\hline CHEMBL1422727 & 688653 & 6.9329 & 5.8369 & TRN & & \\
\hline CHEMBL1358695 & 688653 & 6.7331 & 5.7483 & TST & & \\
\hline CHEMBL1478551 & 688653 & 4.833 & 5.1826 & TRN & & \\
\hline CHEMBL1413159 & 688653 & \multicolumn{3}{|c|}{5.582999999999999} & 5.0073 & $\mathrm{Tt}$ \\
\hline CHEMBL1598791 & 688653 & 4.833 & 5.4129 & TST & & \\
\hline CHEMBL1973778 & 688653 & \multicolumn{3}{|c|}{5.5329999999999995} & 5.6464 & TP \\
\hline CHEMBL1531961 & 688653 & \multicolumn{3}{|c|}{4.7330000000000005} & 5.1398 & \\
\hline CHEMBL1335336 & 688653 & 5.083 & 5.7445 & TRN & & \\
\hline CHEMBL1326041 & 688653 & 5.683 & 5.0809 & TRN & & \\
\hline CHEMBL 3189415 & 688653 & \multicolumn{3}{|c|}{5.582999999999999} & 4.6885 & 3 \\
\hline
\end{tabular}




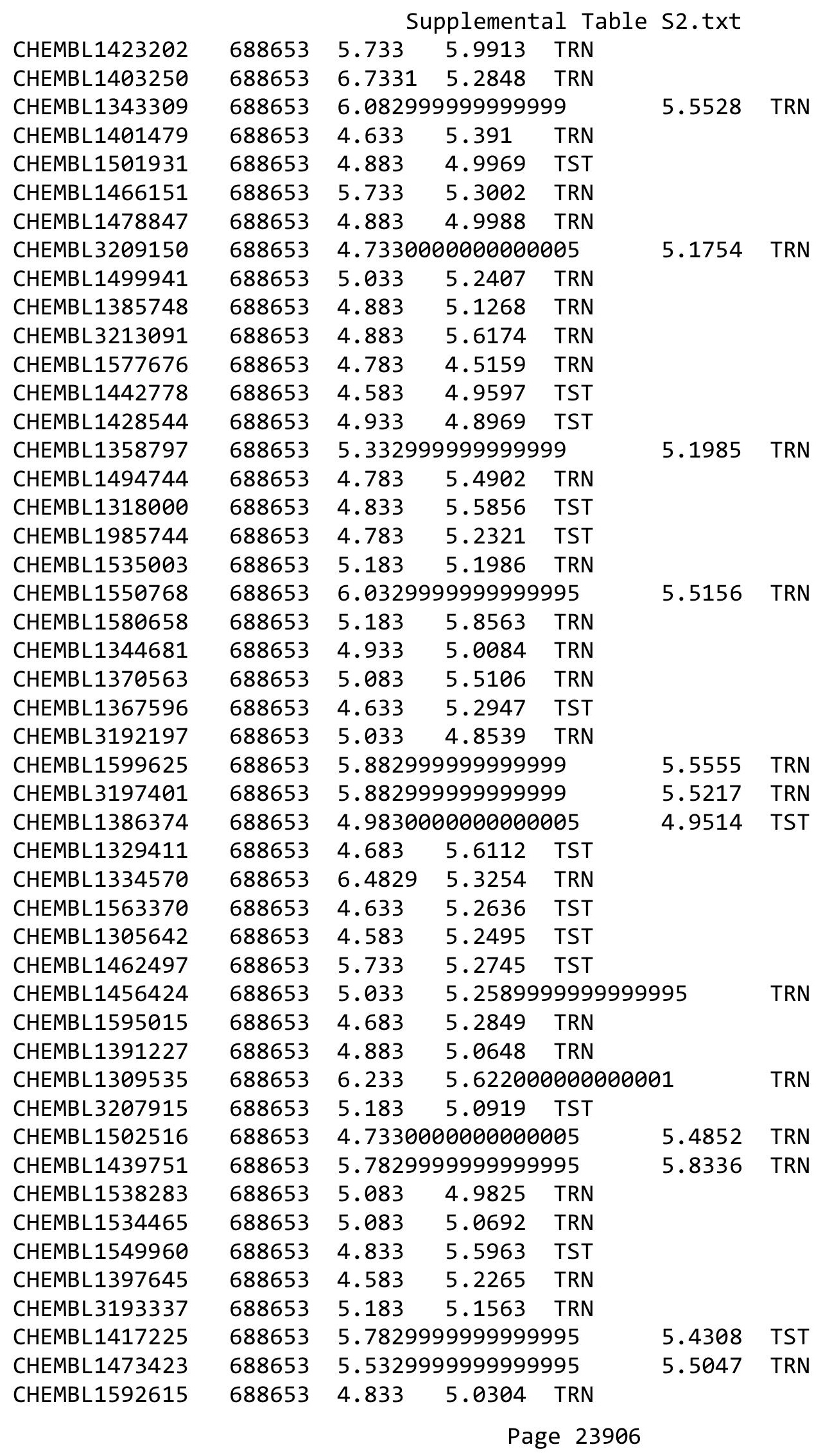




\begin{tabular}{|c|c|c|c|c|c|c|c|}
\hline \multicolumn{7}{|c|}{ Supplemental Table S2.txt } & \\
\hline CHEMBL1530133 & 688653 & \multicolumn{3}{|c|}{5.382999999999999} & 5.0674 & TRN & \\
\hline CHEMBL1573190 & 688653 & 5.483 & 4.9517 & TRN & & & \\
\hline CHEMBL1310270 & 688653 & 4.833 & 5.2788 & TRN & & & \\
\hline CHEMBL 1485588 & 688653 & \multicolumn{3}{|c|}{4.7330000000000005} & 5.0292 & TST & \\
\hline CHEMBL1318418 & 688653 & \multicolumn{3}{|c|}{4.7330000000000005} & 5.0526 & TST & \\
\hline CHEMBL1375563 & 688653 & 4.883 & 4.9315 & TST & & & \\
\hline CHEMBL1425447 & 688653 & 4.833 & 5.1469 & TRN & & & \\
\hline CHEMBL1549835 & 688653 & 4.583 & 4.9572 & TST & & & \\
\hline CHEMBL1543297 & 688653 & \multicolumn{3}{|c|}{4.7330000000000005} & 5.3669 & TRN & \\
\hline CHEMBL1423997 & 688653 & 4.85 & 4.9814 & TRN & & & \\
\hline CHEMBL1518440 & 688653 & \multicolumn{3}{|c|}{5.5329999999999995} & 5.6872 & TRN & \\
\hline CHEMBL3211626 & 688653 & 4.933 & 4.6416 & TST & & & \\
\hline CHEMBL1448066 & 688653 & \multicolumn{3}{|c|}{6.0329999999999995} & 5.4475 & TRN & \\
\hline CHEMBL1427943 & 688653 & \multicolumn{3}{|c|}{5.2829999999999995} & 5.4243 & TRN & \\
\hline CHEMBL1547464 & 688653 & 5.983 & 5.5631 & TRN & & & \\
\hline CHEMBL1300285 & 688653 & 4.783 & 5.4142 & TRN & & & \\
\hline CHEMBL1310201 & 688653 & \multicolumn{3}{|c|}{5.382999999999999} & 5.4166 & TRN & \\
\hline CHEMBL3199737 & 688653 & \multicolumn{3}{|c|}{5.582999999999999} & 5.2989 & TST & \\
\hline CHEMBL42355 & 688653 & \multicolumn{3}{|c|}{5.332999999999999} & 5.2797 & TRN & \\
\hline CHEMBL1489933 & 688653 & \multicolumn{3}{|c|}{5.382999999999999} & 5.191 & TST & \\
\hline CHEMBL 2000529 & 688653 & 6.183 & 5.7522 & TRN & & & \\
\hline CHEMBL1504964 & 688653 & 5.733 & 5.6826 & TRN & & & \\
\hline CHEMBL1554673 & 688653 & 5.433 & 5.2572 & TRN & & & \\
\hline CHEMBL1511784 & 688653 & \multicolumn{3}{|c|}{4.7330000000000005} & 5.2309 & TRN & \\
\hline CHEMBL1490048 & 688653 & 4.833 & 5.0352 & TRN & & & \\
\hline CHEMBL1604415 & 688653 & \multicolumn{3}{|c|}{4.7330000000000005} & 5.275 & TRN & \\
\hline CHEMBL1594294 & 688653 & 4.883 & 5.0703 & TRN & & & \\
\hline CHEMBL 1586575 & 688653 & \multicolumn{3}{|c|}{4.7330000000000005} & 5.0698 & TST & \\
\hline CHEMBL1574660 & 688653 & 4.783 & 5.03100 & 000000000 & & TST & \\
\hline CHEMBL1559605 & 688653 & \multicolumn{3}{|c|}{6.132999999999999} & 5.7953 & TRN & \\
\hline CHEMBL1404458 & 688653 & 5.733 & 6.0039 & TRN & & & \\
\hline CHEMBL 3190044 & 688653 & 4.583 & 5.0845 & TST & & & \\
\hline CHEMBL 1345170 & 688653 & 5.433 & \multicolumn{3}{|c|}{5.388999999999999} & TST & \\
\hline CHEMBL3198359 & 688653 & 5.083 & 5.0349 & TRN & & & \\
\hline CHEMBL1402604 & 688653 & \multicolumn{3}{|c|}{5.132999999999999} & 5.4394 & TRN & \\
\hline CHEMBL 3198374 & 688653 & 4.833 & 5.1059 & TRN & & & \\
\hline CHEMBL 3196341 & 688653 & \multicolumn{3}{|c|}{5.582999999999999} & \multicolumn{2}{|c|}{5.196000000000001} & TST \\
\hline CHEMBL1331661 & 688653 & 5.733 & 5.4121 & TRN & & & \\
\hline CHEMBL1352479 & 688653 & 4.833 & 5.2277 & TRN & & & \\
\hline CHEMBL3194813 & 688653 & 4.883 & 5.3392 & TRN & & & \\
\hline CHEMBL1363938 & 688653 & \multicolumn{3}{|c|}{5.7829999999999995} & 5.3372 & TRN & \\
\hline CHEMBL1460975 & 688653 & 5.083 & 5.2763 & TRN & & & \\
\hline CHEMBL1364704 & 688653 & 5.733 & 5.3992 & TRN & & & \\
\hline CHEMBL1439833 & 688653 & 5.033 & 5.6378 & TRN & & & \\
\hline CHEMBL1609270 & 688653 & 4.583 & 5.1147 & TRN & & & \\
\hline CHEMBL1481659 & 688653 & 5.3829 & 99999999 & & 5.0255 & TRN & \\
\hline CHEMBL1612916 & 688653 & 6.2829 & 99999999 & 995 & 4.9775 & TST & \\
\hline CHEMBL1391475 & 688653 & 4.7330 & 00000000 & 005 & 5.5448 & TST & \\
\hline
\end{tabular}




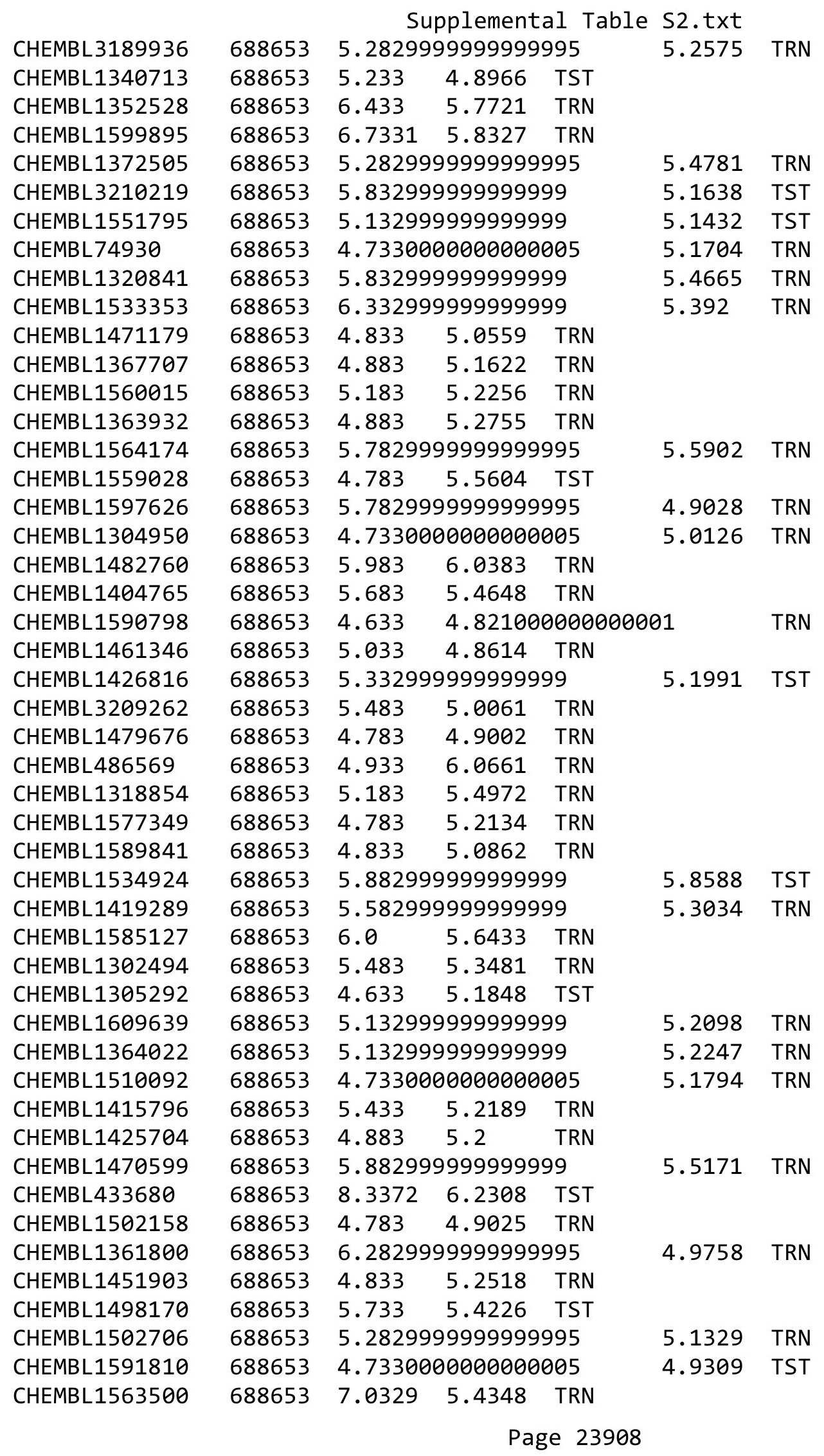




\begin{tabular}{|c|c|c|c|c|c|c|}
\hline \multirow[b]{2}{*}{ CHEMBL1598230 } & \multirow[b]{2}{*}{688653} & \multicolumn{5}{|c|}{ Supplemental Table s2.txt } \\
\hline & & \multirow{2}{*}{\multicolumn{3}{|c|}{$\begin{array}{lrr}4.583 & 5.8488 & \text { TRN } \\
5.5329999999999995\end{array}$}} & \multirow{2}{*}{5.7494} & \multirow[b]{2}{*}{ TRN } \\
\hline CHEMBL1323308 & 688653 & & & & & \\
\hline CHEMBL1407332 & 688653 & 4.883 & 5.2012 & TRN & & \\
\hline CHEMBL1607398 & 688653 & 4.833 & \multicolumn{2}{|c|}{5.571000000000001} & & TRN \\
\hline CHEMBL1529064 & 688653 & \multicolumn{3}{|c|}{5.382999999999999} & 5.7427 & TRN \\
\hline CHEMBL1542868 & 688653 & \multicolumn{3}{|c|}{5.2829999999999995} & 5.0241 & TST \\
\hline CHEMBL3210723 & 688653 & \multicolumn{3}{|c|}{5.7829999999999995} & 5.5382 & TRN \\
\hline CHEMBL1334514 & 688653 & 4.633 & 6.0101 & TRN & & \\
\hline CHEMBL1576160 & 688653 & 4.883 & 5.0117 & TRN & & \\
\hline CHEMBL1359797 & 688653 & 4.933 & 5.2648 & TST & & \\
\hline CHEMBL1489205 & 688653 & 4.833 & 5.3104 & TRN & & \\
\hline CHEMBL1434990 & 688653 & \multicolumn{3}{|c|}{5.5329999999999995} & 5.8835 & TRN \\
\hline CHEMBL1363415 & 688653 & \multicolumn{3}{|c|}{5.832999999999999} & 5.4846 & TRN \\
\hline CHEMBL1593403 & 688653 & 5.033 & 5.0422 & TRN & & \\
\hline CHEMBL1421092 & 688653 & 5.683 & 5.6005 & TRN & & \\
\hline CHEMBL1375227 & 688653 & \multicolumn{3}{|c|}{5.7829999999999995} & 5.9013 & TRN \\
\hline CHEMBL1967041 & 688653 & 4.783 & 4.9619 & TST & & \\
\hline CHEMBL1387193 & 688653 & 5.733 & 5.2717 & TST & & \\
\hline CHEMBL1348555 & 688653 & \multicolumn{3}{|c|}{5.582999999999999} & 5.2392 & TRN \\
\hline CHEMBL1469960 & 688653 & 4.783 & 4.9209 & TRN & & \\
\hline CHEMBL1349405 & 688653 & 4.583 & 4.7749 & TRN & & \\
\hline CHEMBL1540029 & 688653 & \multicolumn{3}{|c|}{5.132999999999999} & 5.6673 & TRN \\
\hline CHEMBL1410495 & 688653 & 4.933 & 5.1504 & TST & & \\
\hline CHEMBL1474627 & 688653 & 6.683 & 5.4049 & TST & & \\
\hline CHEMBL1364105 & 688653 & \multicolumn{3}{|c|}{4.7330000000000005} & 5.1167 & TRN \\
\hline CHEMBL1373432 & 688653 & \multicolumn{3}{|c|}{5.2829999999999995} & 4.9488 & TST \\
\hline CHEMBL1446788 & 688653 & \multicolumn{3}{|c|}{5.5329999999999995} & 5.4176 & TST \\
\hline CHEMBL1545972 & 688653 & \multicolumn{3}{|c|}{5.5329999999999995} & 5.7178 & TRN \\
\hline CHEMBL1415585 & 688653 & \multicolumn{3}{|c|}{6.0329999999999995} & 5.2459 & TST \\
\hline CHEMBL1516066 & 688653 & 7.2328 & 5.6165 & TRN & & \\
\hline CHEMBL1310905 & 688653 & 4.833 & 5.4357 & TST & & \\
\hline CHEMBL1563099 & 688653 & \multicolumn{3}{|c|}{6.382999999999999} & 5.3918 & TRN \\
\hline CHEMBL1597833 & 688653 & 4.98300 & 00000000 & 205 & 5.5637 & TRN \\
\hline CHEMBL1330492 & 688653 & 5.13299 & 99999999 & & 5.0237 & TRN \\
\hline CHEMBL1436947 & 688653 & 6.28299 & 99999999 & 995 & 5.1586 & TRN \\
\hline CHEMBL1480541 & 688653 & 4.883 & 5.4294 & TRN & & \\
\hline CHEMBL1477949 & 688653 & 5.183 & 4.8785 & TST & & \\
\hline CHEMBL1600710 & 688653 & 5.033 & 5.1946 & TRN & & \\
\hline CHEMBL1536478 & 688653 & 6.8831 & 5.855 & TRN & & \\
\hline CHEMBL1560988 & 688653 & 5.683 & 5.5523 & TRN & & \\
\hline CHEMBL1464966 & 688653 & 5.683 & 5.5316 & TST & & \\
\hline CHEMBL3192388 & 688653 & 4.73300 & $\partial 0000000$ & 205 & 5.5041 & TST \\
\hline CHEMBL1511557 & 688653 & 5.88299 & 99999999 & & 5.6739 & TRN \\
\hline CHEMBL1424373 & 688653 & 5.83299 & 99999999 & & 5.6549 & TRN \\
\hline CHEMBL1473454 & 688653 & 5.13299 & 99999999 & & 5.5322 & TRN \\
\hline CHEMBL1342256 & 688653 & 5.983 & 4.9811 & TST & & \\
\hline CHEMBL1505517 & 688653 & 4.783 & 5.5286 & TRN & & \\
\hline CHEMBL1372678 & 688653 & 4.933 & 4.9582 & TRN & & \\
\hline
\end{tabular}




\begin{tabular}{|c|c|c|c|c|c|c|c|}
\hline \multirow[b]{2}{*}{ CHEMBL1470875 } & & \\
\hline & 688653 & 5.683 & 5.104 & TST & & & \\
\hline CHEMBL3211478 & 688653 & 6.433 & 5.5738 & TST & & & \\
\hline CHEMBL1522706 & 688653 & 4.883 & 5.2269 & TRN & & & \\
\hline CHEMBL1596681 & 688653 & 5.933 & 5.5627 & TRN & & & \\
\hline CHEMBL1487322 & 688653 & \multicolumn{3}{|c|}{6.132999999999999} & 5.1812 & TRN & \\
\hline CHEMBL 3211648 & 688653 & 4.883 & 5.5107 & TRN & & & \\
\hline CHEMBL1542060 & 688653 & \multicolumn{3}{|c|}{5.132999999999999} & 5.3945 & TRN & \\
\hline CHEMBL1513003 & 688653 & 5.183 & 4.7986 & TST & & & \\
\hline CHEMBL1388703 & 688653 & \multicolumn{3}{|c|}{5.5329999999999995} & 5.447 & TRN & \\
\hline CHEMBL3213774 & 688653 & 4.883 & 5.1602 & TRN & & & \\
\hline CHEMBL3211142 & 688653 & 5.183 & 5.5933 & TRN & & & \\
\hline CHEMBL1361926 & 688653 & \multicolumn{3}{|c|}{5.5329999999999995} & 5.2828 & TRN & \\
\hline CHEMBL1532940 & 688653 & 5.083 & 4.9238 & TRN & & & \\
\hline CHEMBL1582938 & 688653 & 5.483 & 5.3835 & TRN & & & \\
\hline CHEMBL1534252 & 688653 & 4.833 & 5.8642 & TRN & & & \\
\hline CHEMBL1373454 & 688653 & \multicolumn{3}{|c|}{6.382999999999999} & 5.8547 & TRN & \\
\hline CHEMBL1462944 & 688653 & 7.0329 & 6.0424 & TRN & & & \\
\hline CHEMBL 3196276 & 688653 & 4.783 & 5.3009 & TRN & & & \\
\hline CHEMBL1410745 & 688653 & \multicolumn{3}{|c|}{5.382999999999999} & 5.2995 & TST & \\
\hline CHEMBL1595153 & 688653 & \multicolumn{3}{|c|}{5.382999999999999} & 5.7152 & TRN & \\
\hline CHEMBL1602331 & 688653 & 4.633 & 5.1001 & TRN & & & \\
\hline CHEMBL1457482 & 688653 & \multicolumn{3}{|c|}{4.7330000000000005} & \multicolumn{2}{|c|}{5.167000000000001} & TRN \\
\hline CHEMBL1472299 & 688653 & 4.85 & 5.545 & TRN & & & \\
\hline CHEMBL1571631 & 688653 & \multicolumn{3}{|c|}{6.0329999999999995} & 5.5905 & TRN & \\
\hline CHEMBL 1457634 & 688653 & \multicolumn{3}{|c|}{6.582999999999999} & 5.9134 & TRN & \\
\hline CHEMBL1407961 & 688653 & 5.183 & 5.1387 & TRN & & & \\
\hline CHEMBL1596533 & 688653 & 5.433 & 5.4492 & TRN & & & \\
\hline CHEMBL1319037 & 688653 & \multicolumn{3}{|c|}{6.582999999999999} & 5.7771 & TRN & \\
\hline CHEMBL1996752 & 688653 & \multicolumn{3}{|c|}{5.2829999999999995} & 6.0151 & TRN & \\
\hline CHEMBL 1503780 & 688653 & \multicolumn{3}{|c|}{6.582999999999999} & 6.3 & TRN & \\
\hline CHEMBL1593184 & 688653 & \multicolumn{3}{|c|}{6.132999999999999} & 5.7176 & TRN & \\
\hline CHEMBL1439732 & 688653 & \multicolumn{3}{|c|}{4.7330000000000005} & 5.0197 & TST & \\
\hline CHEMBL1410403 & 688653 & \multicolumn{3}{|c|}{4.7330000000000005} & 5.1141 & TRN & \\
\hline CHEMBL1334962 & 688653 & 5.483 & 5.3127 & TRN & & & \\
\hline CHEMBL1523027 & 688653 & 4.783 & 4.7861 & TRN & & & \\
\hline CHEMBL396323 & 688653 & 4.883 & 4.9125 & TRN & & & \\
\hline CHEMBL1588860 & 688653 & 5.733 & 6.0161 & TRN & & & \\
\hline CHEMBL1509778 & 688653 & 5.483 & 5.6894 & TRN & & & \\
\hline CHEMBL1350903 & 688653 & \multicolumn{3}{|c|}{4.9830000000000005} & 5.5512 & TST & \\
\hline CHEMBL1427981 & 688653 & 6.433 & 5.5184 & TRN & & & \\
\hline CHEMBL1465289 & 688653 & 4.833 & 5.5058 & TRN & & & \\
\hline CHEMBL1377687 & 688653 & 6.233 & 5.4762 & TRN & & & \\
\hline CHEMBL1304283 & 688653 & 5.183 & 5.3489 & TRN & & & \\
\hline CHEMBL1530594 & 688653 & 4.783 & 4.9025 & TRN & & & \\
\hline CHEMBL1586959 & 688653 & 5.033 & 4.8638 & TRN & & & \\
\hline CHEMBL1340837 & 688653 & 5.83299 & 99999999 & 99 & 5.6455 & TRN & \\
\hline CHEMBL1484818 & 688653 & 4.833 & 5.6092 & TRN & & & \\
\hline CHEMBL1367851 & 688653 & 4.583 & 5.2292 & TST & & & \\
\hline
\end{tabular}




\begin{tabular}{|c|c|c|c|c|c|c|}
\hline & & \multicolumn{5}{|c|}{ Supplemental Table S2.txt } \\
\hline CHEMBL1516425 & 688653 & 5.233 & 5.186 & TRN & & \\
\hline CHEMBL1350056 & 688653 & 4.833 & 5.0595 & TRN & & \\
\hline CHEMBL1500507 & 688653 & 4.833 & 5.2676 & TRN & & \\
\hline CHEMBL3196362 & 688653 & 4.883 & 5.8056 & TRN & & \\
\hline CHEMBL1501853 & 688653 & 4.683 & 4.9369 & TRN & & \\
\hline CHEMBL1374009 & 688653 & 7.2832 & 5.9926 & TRN & & \\
\hline CHEMBL1536582 & 688653 & 5.683 & 5.4977 & TRN & & \\
\hline CHEMBL1381134 & 688653 & 5.233 & 5.3562 & TST & & \\
\hline CHEMBL1454995 & 688653 & \multicolumn{3}{|c|}{4.9830000000000005} & 5.3683 & TST \\
\hline CHEMBL1459348 & 688653 & 4.833 & 5.2863 & TRN & & \\
\hline CHEMBL1501169 & 688653 & 5.483 & 5.5358 & TST & & \\
\hline CHEMBL3190315 & 688653 & \multicolumn{3}{|c|}{5.832999999999999} & 5.3366 & \\
\hline CHEMBL1476282 & 688653 & 4.833 & 5.6693 & TRN & & \\
\hline CHEMBL1356488 & 688653 & 4.833 & 4.9023 & TRN & & \\
\hline CHEMBL1383544 & 688653 & \multicolumn{3}{|c|}{4.9830000000000005} & 5.1785 & 11 \\
\hline CHEMBL1586354 & 688653 & 5.983 & 5.6051 & TRN & & \\
\hline CHEMBL1443597 & 688653 & 5.183 & 5.2546 & TRN & & \\
\hline CHEMBL1327941 & 688653 & 4.783 & 4.7564 & TRN & & \\
\hline CHEMBL1332324 & 688653 & 4.833 & 5.2965 & TRN & & \\
\hline CHEMBL3211353 & 688653 & 5.683 & 5.246 & TRN & & \\
\hline CHEMBL1386344 & 688653 & \multicolumn{3}{|c|}{5.332999999999999} & 4 & \\
\hline CHEMBL1450337 & 688653 & 4.883 & 5.3216 & TRN & & \\
\hline CHEMBL1376975 & 688653 & \multicolumn{3}{|c|}{4.9830000000000005} & 4.91 & \\
\hline CHEMBL1371349 & 688653 & 5.233 & 5.0706 & TST & & \\
\hline CHEMBL1409622 & 688653 & 5.683 & 5.154 & TRN & & \\
\hline CHEMBL1468936 & 688653 & 5.233 & 5.1427 & TRN & & \\
\hline CHEMBL1513162 & 688653 & \multicolumn{3}{|c|}{5.7829999999999995} & 5.3708 & \\
\hline CHEMBL1452623 & 688653 & 4.933 & 5.1473 & TRN & & \\
\hline CHEMBL1488418 & 688653 & \multicolumn{3}{|c|}{5.132999999999999} & 5.4494 & $\mathrm{TI}$ \\
\hline CHEMBL1535856 & 688653 & 4.633 & 4.9356 & TST & & \\
\hline CHEMBL1345391 & 688653 & 6.233 & 5.2965 & TRN & & \\
\hline CHEMBL1386296 & 688653 & \multicolumn{3}{|c|}{5.7829999999999995} & 589 & Tार \\
\hline CHEMBL1431773 & 688653 & \multicolumn{3}{|c|}{4.9830000000000005} & 5.0155 & TST \\
\hline CHEMBL1509675 & 688653 & 4.783 & 4.8589 & TST & & \\
\hline CHEMBL1442398 & 688653 & 4.883 & 5.215 & TRN & & \\
\hline CHEMBL1605309 & 688653 & 5.083 & 5.5348 & TRN & & \\
\hline CHEMBL1374692 & 688653 & \multicolumn{3}{|c|}{5.382999999999999} & 5.3291 & it \\
\hline CHEMBL1438636 & 688653 & 5.233 & 4.9368 & TRN & & \\
\hline CHEMBL1441880 & 688653 & 4.683 & 5.2623 & TRN & & \\
\hline CHEMBL1502544 & 688653 & \multicolumn{3}{|c|}{6.632999999999999} & 5.6484 & TRN \\
\hline CHEMBL1413239 & 688653 & \multicolumn{3}{|c|}{4.7330000000000005} & 4.8839 & 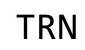 \\
\hline CHEMBL1387849 & 688653 & \multicolumn{3}{|c|}{5.382999999999999} & 5.3923 & IRN \\
\hline CHEMBL1438499 & 688653 & \multicolumn{3}{|c|}{4.9830000000000005} & 5.5324 & TST \\
\hline CHEMBL1485265 & 688653 & 6.433 & 5.5077 & TRN & & \\
\hline CHEMBL1970422 & 688653 & \multicolumn{3}{|c|}{6.082999999999999} & 5.7918 & $1 \mathrm{KN}$ \\
\hline CHEMBL1535762 & 688653 & 4.783 & 5.4889 & TRN & & \\
\hline CHEMBL1338933 & 688653 & 4.783 & \multicolumn{3}{|c|}{5.877000000000001} & rRN \\
\hline CHEMBL1587581 & 688653 & 4.883 & 5.2213 & TRN & & \\
\hline
\end{tabular}




\begin{tabular}{|c|c|c|c|c|c|c|}
\hline & & \multicolumn{5}{|c|}{ Supplemental Table S2.txt } \\
\hline CHEMBL1329107 & 688653 & \multicolumn{3}{|c|}{6.382999999999999} & 4.5766 & TST \\
\hline CHEMBL1406960 & 688653 & \multicolumn{3}{|c|}{6.082999999999999} & 5.475 & TRN \\
\hline CHEMBL1595014 & 688653 & 6.4829 & 5.9853 & TRN & & \\
\hline CHEMBL1563037 & 688653 & \multicolumn{3}{|c|}{4.7330000000000005} & 5.0746 & TST \\
\hline CHEMBL1407247 & 688653 & 4.783 & 4.9435 & TRN & & \\
\hline CHEMBL3190071 & 688653 & \multicolumn{3}{|c|}{5.882999999999999} & 5.0989 & TRN \\
\hline CHEMBL1513883 & 688653 & 4.583 & \multicolumn{3}{|c|}{4.888999999999999} & TRN \\
\hline CHEMBL3198647 & 688653 & \multicolumn{3}{|c|}{5.132999999999999} & 5.3981 & TRN \\
\hline CHEMBL1546933 & 688653 & 5.183 & 5.36 & TST & & \\
\hline CHEMBL1381292 & 688653 & 5.033 & 4.9909 & TRN & & \\
\hline CHEMBL1380276 & 688653 & 6.8831 & 5.6607 & TRN & & \\
\hline CHEMBL1502550 & 688653 & 4.633 & 5.2931 & TST & & \\
\hline CHEMBL1438994 & 688653 & \multicolumn{3}{|c|}{4.7330000000000005} & 5.0585 & TRN \\
\hline CHEMBL1529172 & 688653 & 5.183 & 5.0437 & TRN & & \\
\hline CHEMBL1358722 & 688653 & \multicolumn{3}{|c|}{6.632999999999999} & 5.3828 & TST \\
\hline CHEMBL1398047 & 688653 & \multicolumn{3}{|c|}{6.632999999999999} & 5.7597 & TRN \\
\hline CHEMBL1423164 & 688653 & \multicolumn{3}{|c|}{5.2829999999999995} & 5.5063 & TRN \\
\hline CHEMBL1375477 & 688653 & \multicolumn{3}{|c|}{5.2829999999999995} & 5.2732 & TST \\
\hline CHEMBL1349559 & 688653 & 6.233 & 5.1712 & TRN & & \\
\hline CHEMBL1339663 & 688653 & \multicolumn{3}{|c|}{4.7330000000000005} & 4.9472 & TST \\
\hline CHEMBL1577782 & 688653 & 5.033 & 5.0865 & TRN & & \\
\hline CHEMBL1380535 & 688653 & \multicolumn{3}{|c|}{6.332999999999999} & 6.1408 & TRN \\
\hline CHEMBL 3198867 & 688653 & 5.183 & 4.99 & TRN & & \\
\hline CHEMBL153208 & 688653 & 5.083 & 5.4972 & TRN & & \\
\hline CHEMBL3195212 & 688653 & \multicolumn{3}{|c|}{6.082999999999999} & 5.8782 & TST \\
\hline CHEMBL1543182 & 688653 & \multicolumn{3}{|c|}{6.332999999999999} & 5.5762 & TRN \\
\hline CHEMBL1488450 & 688653 & 5.733 & 4.9779 & TRN & & \\
\hline CHEMBL1439868 & 688653 & \multicolumn{3}{|c|}{5.382999999999999} & 5.3529 & TRN \\
\hline CHEMBL1355848 & 688653 & 4.583 & 4.5439 & TRN & & \\
\hline CHEMBL1336101 & 688653 & \multicolumn{3}{|c|}{4.7330000000000005} & 5.5718 & TST \\
\hline CHEMBL1299459 & 688653 & 4.883 & 5.4129 & TRN & & \\
\hline CHEMBL1409356 & 688653 & 6.9329 & 5.5984 & TRN & & \\
\hline CHEMBL1496969 & 688653 & 4.933 & 5.4128 & TST & & \\
\hline CHEMBL1305920 & 688653 & \multicolumn{3}{|c|}{4.7330000000000005} & 5.0194 & TST \\
\hline CHEMBL1439404 & 688653 & 4.583 & 4.7513 & TST & & \\
\hline CHEMBL1374848 & 688653 & 4.833 & 5.1957 & TRN & & \\
\hline CHEMBL1451423 & 688653 & 4.933 & 4.9091 & TRN & & \\
\hline CHEMBL1377376 & 688653 & 6.183 & 5.6419 & TST & & \\
\hline CHEMBL1530492 & 688653 & 4.833 & 5.0269 & TRN & & \\
\hline CHEMBL1387736 & 688653 & 4.833 & 5.1715 & TRN & & \\
\hline CHEMBL1444219 & 688653 & \multicolumn{3}{|c|}{5.2829999999999995} & 4.9295 & TST \\
\hline CHEMBL552178 & 688653 & 5.233 & 5.0502 & TRN & & \\
\hline CHEMBL1598561 & 688653 & \multicolumn{3}{|c|}{4.7330000000000005} & 4.7375 & TRN \\
\hline CHEMBL1490467 & 688653 & 4.783 & 5.0695 & TRN & & \\
\hline CHEMBL530291 & 688653 & 5.933 & 5.5627 & TRN & & \\
\hline CHEMBL3207658 & 688653 & 5.033 & 5.2652 & TRN & & \\
\hline CHEMBL1570169 & 688653 & 4.783 & 5.3929 & TRN & & \\
\hline CHEMBL1351022 & 688653 & 5.83299 & 99999999 & & 5.4418 & TRN \\
\hline
\end{tabular}




\begin{tabular}{|c|c|c|c|c|c|c|}
\hline & & \multicolumn{5}{|c|}{ Supplemental Table S2.txt } \\
\hline CHEMBL1342383 & 688653 & 5.233 & 5.6932 & TST & & \\
\hline CHEMBL1590006 & 688653 & 4.633 & 5.4468 & TST & & \\
\hline CHEMBL1329507 & 688653 & 5.183 & 5.4432 & TST & & \\
\hline CHEMBL1520356 & 688653 & 6.433 & 5.5031 & TST & & \\
\hline CHEMBL1340348 & 688653 & 5.483 & 5.4826 & TST & & \\
\hline CHEMBL1490744 & 688653 & 5.033 & 5.4487 & TRN & & \\
\hline CHEMBL1505083 & 688653 & 5.483 & 5.0333 & TRN & & \\
\hline CHEMBL1483310 & 688653 & 5.033 & 5.3025 & TRN & & \\
\hline CHEMBL1317145 & 688653 & \multicolumn{3}{|c|}{5.332999999999999} & 5.0138 & TP \\
\hline CHEMBL1447517 & 688653 & \multicolumn{3}{|c|}{5.132999999999999} & 5.6834 & TRN \\
\hline CHEMBL1485228 & 688653 & \multicolumn{3}{|c|}{5.882999999999999} & 5.2353 & \\
\hline CHEMBL1454141 & 688653 & \multicolumn{3}{|c|}{6.082999999999999} & 5.5263 & \\
\hline CHEMBL1604129 & 688653 & 4.833 & 5.0721 & TRN & & \\
\hline CHEMBL1337129 & 688653 & 4.833 & 4.9582 & TRN & & \\
\hline CHEMBL3192389 & 688653 & \multicolumn{3}{|c|}{6.382999999999999} & 5.7672 & 11 \\
\hline CHEMBL1597956 & 688653 & 4.883 & 5.7515 & TST & & \\
\hline CHEMBL1413588 & 688653 & \multicolumn{3}{|c|}{4.7330000000000005} & 5.176 & \\
\hline CHEMBL1349724 & 688653 & 5.183 & 4.8465 & TST & & \\
\hline CHEMBL1305673 & 688653 & 4.783 & 4.7394 & TRN & & \\
\hline CHEMBL1348693 & 688653 & \multicolumn{3}{|c|}{5.7829999999999995} & 5.0662 & TRN \\
\hline CHEMBL1374893 & 688653 & \multicolumn{3}{|c|}{5.882999999999999} & 5.2487 & \\
\hline CHEMBL1579301 & 688653 & 4.883 & 4.9968 & TRN & & \\
\hline CHEMBL1458514 & 688653 & \multicolumn{3}{|c|}{5.2829999999999995} & 5.3055 & Thiv \\
\hline CHEMBL1304009 & 688653 & \multicolumn{3}{|c|}{6.7829999999999995} & 5.7567 & TRN \\
\hline CHEMBL1587179 & 688653 & \multicolumn{3}{|c|}{4.7330000000000005} & 5.3749 & TRN \\
\hline CHEMBL1486128 & 688653 & \multicolumn{3}{|c|}{4.7330000000000005} & 5.1125 & \\
\hline CHEMBL1346286 & 688653 & 4.783 & 5.1939 & TRN & & \\
\hline CHEMBL1508764 & 688653 & 4.933 & 5.2115 & TST & & \\
\hline CHEMBL1606510 & 688653 & 5.083 & 5.1173 & TRN & & \\
\hline CHEMBL3208905 & 688653 & 5.183 & 5.3137 & TRN & & \\
\hline CHEMBL 3192028 & 688653 & 5.433 & 5.5416 & TRN & & \\
\hline CHEMBL1524702 & 688653 & & 5.1075 & TST & & \\
\hline CHEMBL1518539 & 688653 & 4.833 & 5.1694 & TRN & & \\
\hline CHEMBL1395876 & 688653 & 4.633 & 4.8233 & TRN & & \\
\hline CHEMBL 3194093 & 688653 & 5.033 & 5.5756 & TRN & & \\
\hline CHEMBL1392596 & 688653 & \multicolumn{3}{|c|}{5.5329999999999995} & 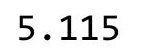 & $1 \mathrm{n}$ \\
\hline CHEMBL1570236 & 688653 & 5.183 & 5.3568 & TRN & & \\
\hline CHEMBL1394275 & 688653 & 5.183 & 5.3577 & TRN & & \\
\hline CHEMBL1529647 & 688653 & 6.183 & 5.4351 & TRN & & \\
\hline CHEMBL1462058 & 688653 & 4.883 & 5.2402 & TRN & & \\
\hline CHEMBL1510185 & 688653 & 5.433 & 5.1991 & TRN & & \\
\hline CHEMBL1437895 & 688653 & \multicolumn{3}{|c|}{5.132999999999999} & 5.3518 & TRN \\
\hline CHEMBL1302096 & 688653 & 4.833 & 5.2156 & TRN & & \\
\hline CHEMBL1481319 & 688653 & \multicolumn{3}{|c|}{5.882999999999999} & 5.359 & $\mathrm{TR}$ \\
\hline CHEMBL 3210908 & 688653 & 6.433 & \multicolumn{3}{|c|}{5.7410000000000005} & . \\
\hline CHEMBL1399401 & 688653 & 4.583 & 4.7195 & TRN & & \\
\hline CHEMBL1561214 & 688653 & \multicolumn{3}{|c|}{5.132999999999999} & 4.8944 & ST \\
\hline CHEMBL1461214 & 688653 & 5.733 & 5.45 & TRN & & \\
\hline
\end{tabular}




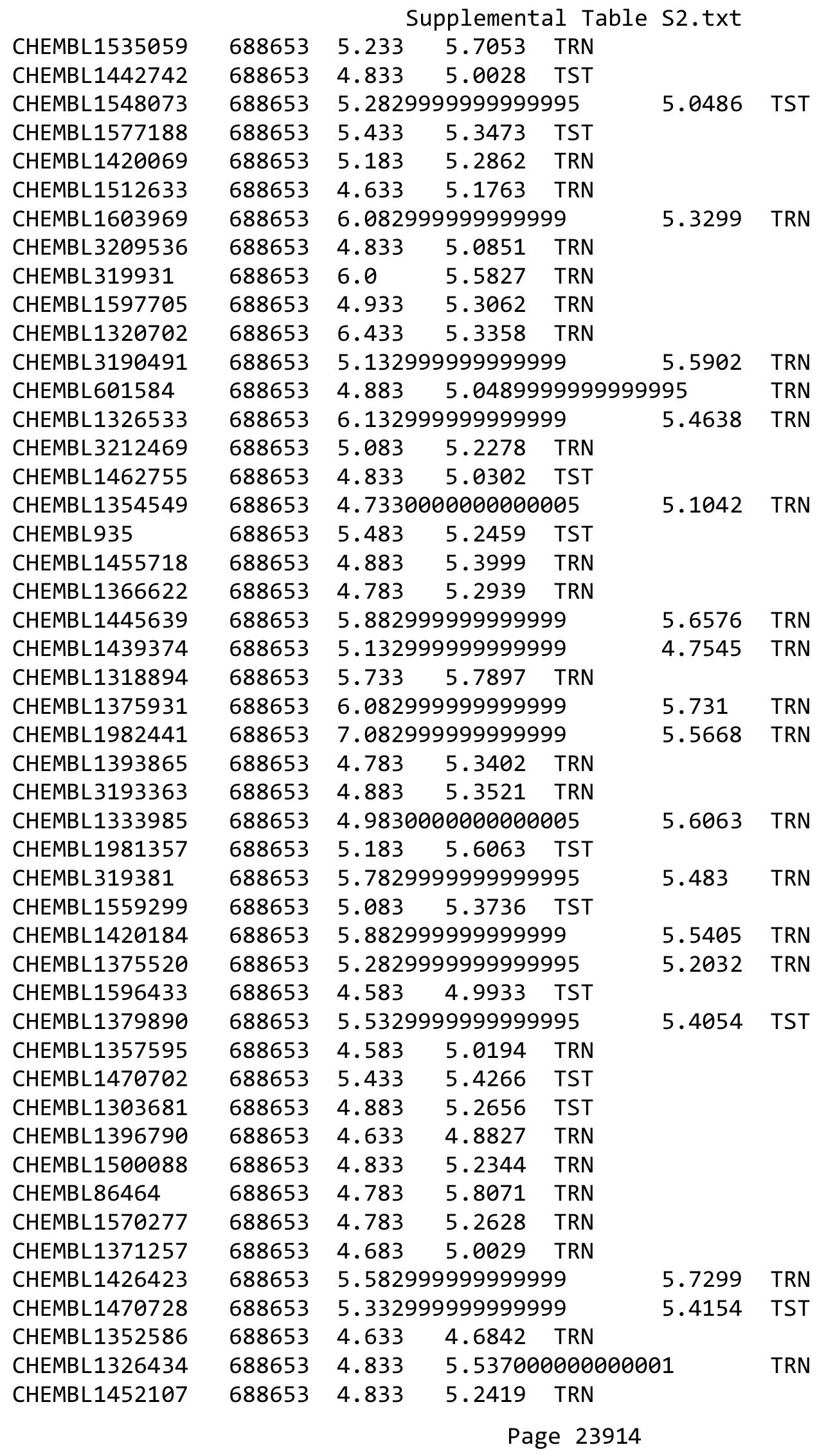




\begin{tabular}{|c|c|c|c|c|c|c|}
\hline \multirow{3}{*}{$\begin{array}{l}\text { CHEMBL1479422 } \\
\text { CHEMBL1358581 }\end{array}$} & \multirow{3}{*}{$\begin{array}{l}688653 \\
688653\end{array}$} & \multicolumn{4}{|c|}{ Supplemental Table S2.txt } & \multirow{2}{*}{ TRN } \\
\hline & & \multicolumn{3}{|c|}{5.132999999999999} & 5.5391 & \\
\hline & & 5.933 & 5.8297 & TRN & & \\
\hline CHEMBL1406359 & 688653 & 4.933 & 4.9521 & TST & & \\
\hline CHEMBL1450575 & 688653 & 4.833 & 4.7455 & TRN & & \\
\hline CHEMBL3199410 & 688653 & 5.233 & 5.2063 & TRN & & \\
\hline CHEMBL1332984 & 688653 & 4.633 & 5.6448 & TST & & \\
\hline CHEMBL1344655 & 688653 & \multicolumn{3}{|c|}{4.7330000000000005} & 5.1421 & TRN \\
\hline CHEMBL1567607 & 688653 & 5.683 & 5.8345 & TRN & & \\
\hline CHEMBL1345519 & 688653 & 5.433 & 5.5015 & TRN & & \\
\hline CHEMBL518575 & 688653 & 5.683 & 5.6134 & TST & & \\
\hline CHEMBL1461199 & 688653 & 5.183 & 4.9916 & TST & & \\
\hline CHEMBL3213937 & 688653 & 4.883 & 5.154 & TRN & & \\
\hline CHEMBL1356499 & 688653 & 5.083 & 5.3368 & TRN & & \\
\hline CHEMBL1964843 & 688653 & \multicolumn{3}{|c|}{5.582999999999999} & 5.7221 & TRN \\
\hline CHEMBL1339206 & 688653 & 4.883 & 4.9479 & TRN & & \\
\hline CHEMBL1597290 & 688653 & \multicolumn{3}{|c|}{6.382999999999999} & 5.6275 & TRN \\
\hline CHEMBL1582179 & 688653 & 5.983 & 5.6121 & TRN & & \\
\hline CHEMBL1361727 & 688653 & 4.783 & 5.2495 & TRN & & \\
\hline CHEMBL1353630 & 688653 & 6.433 & 5.9392 & TRN & & \\
\hline CHEMBL1392030 & 688653 & 5.033 & 4.9815 & TRN & & \\
\hline CHEMBL1368993 & 688653 & 5.083 & 5.6105 & TRN & & \\
\hline CHEMBL1540577 & 688653 & \multicolumn{3}{|c|}{6.332999999999999} & 5.8264 & TRN \\
\hline CHEMBL1419680 & 688653 & \multicolumn{3}{|c|}{5.382999999999999} & 5.8121 & TST \\
\hline CHEMBL1379840 & 688653 & 5.233 & 5.5379 & TRN & & \\
\hline CHEMBL1310825 & 688653 & 5.683 & 5.3676 & TST & & \\
\hline CHEMBL1505081 & 688653 & \multicolumn{3}{|c|}{4.7330000000000005} & 5.0864 & TRN \\
\hline CHEMBL1487786 & 688653 & 6.433 & 5.5518 & TRN & & \\
\hline CHEMBL3214291 & 688653 & \multicolumn{3}{|c|}{4.9830000000000005} & 5.3671 & TST \\
\hline CHEMBL1400579 & 688653 & 4.783 & 4.8252 & TRN & & \\
\hline CHEMBL1352200 & 688653 & 5.683 & 5.6387 & TRN & & \\
\hline CHEMBL3213422 & 688653 & 5.733 & 5.0326 & TRN & & \\
\hline CHEMBL1521159 & 688653 & 4.883 & 5.2068 & TRN & & \\
\hline CHEMBL1485970 & 688653 & \multicolumn{3}{|c|}{5.7829999999999995} & 5.5026 & TRN \\
\hline CHEMBL1340788 & 688653 & \multicolumn{3}{|c|}{4.9830000000000005} & 5.5701 & TRN \\
\hline CHEMBL1606256 & 688653 & \multicolumn{3}{|c|}{4.7330000000000005} & 5.1498 & TRN \\
\hline CHEMBL1572788 & 688653 & \multicolumn{3}{|c|}{6.332999999999999} & 5.9139 & TRN \\
\hline CHEMBL1472449 & 688653 & 4.783 & 5.1824 & TRN & & \\
\hline CHEMBL1316255 & 688653 & 7.2832 & 6.0554 & TRN & & \\
\hline CHEMBL1309290 & 688653 & 4.633 & 4.9935 & TST & & \\
\hline CHEMBL3209355 & 688653 & 4.833 & 5.1578 & TST & & \\
\hline CHEMBL 3191887 & 688653 & \multicolumn{3}{|c|}{5.332999999999999} & 4.8141 & TRN \\
\hline CHEMBL1566635 & 688653 & 5.733 & 5.6674 & TRN & & \\
\hline CHEMBL1346003 & 688653 & 4.633 & 4.8795 & TRN & & \\
\hline CHEMBL1440273 & 688653 & 4.933 & 4.9762 & TST & & \\
\hline CHEMBL1544212 & 688653 & 5.733 & 5.1802 & TST & & \\
\hline CHEMBL1443442 & 688653 & \multicolumn{3}{|c|}{5.582999999999999} & 5.4048 & TRN \\
\hline CHEMBL1602281 & 688653 & 4.783 & 4.9459 & TRN & & \\
\hline CHEMBL1364339 & 688653 & 5.033 & 5.5688 & TRN & & \\
\hline
\end{tabular}




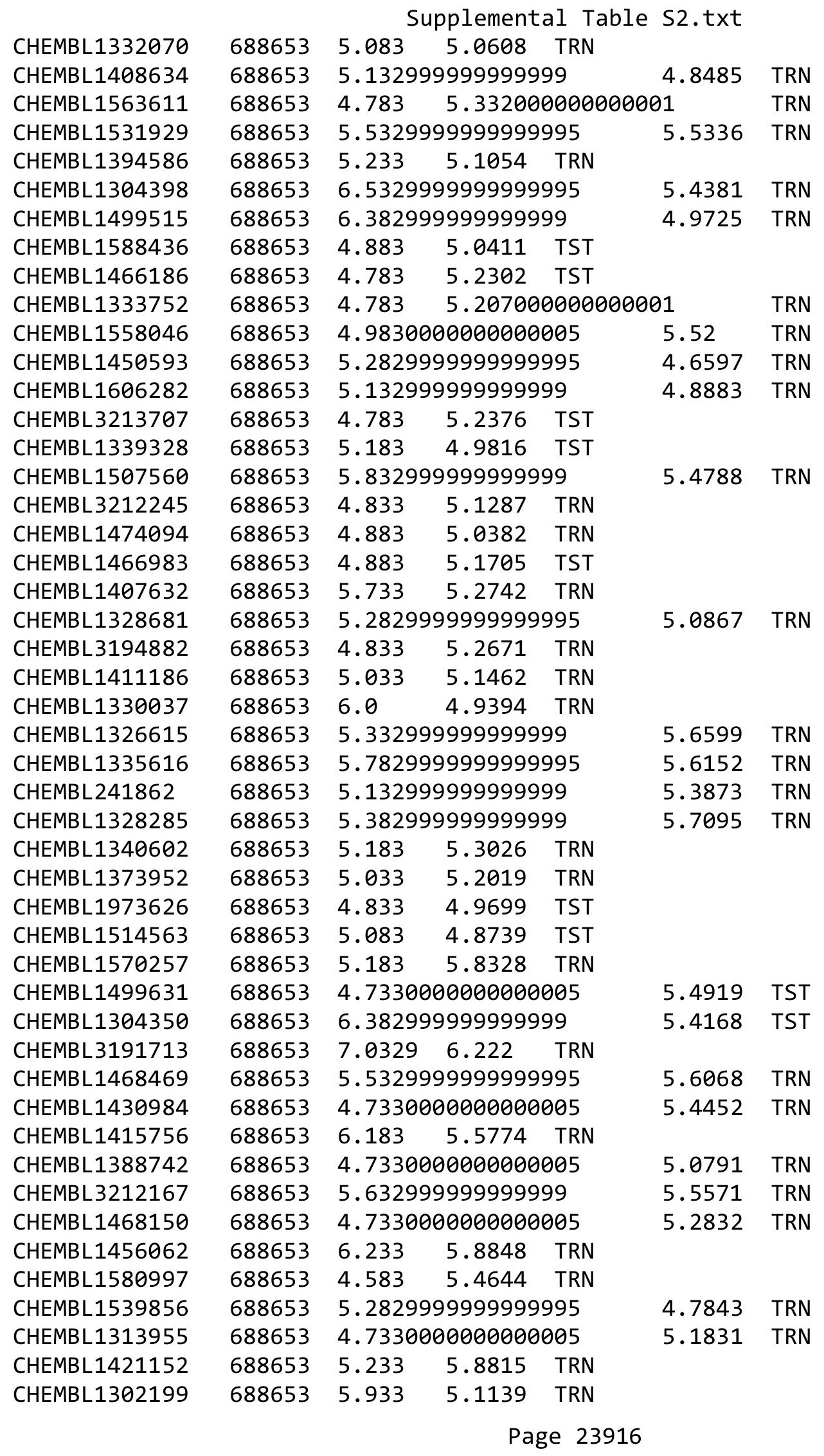




\begin{tabular}{|c|c|c|c|c|c|c|}
\hline & & \multicolumn{5}{|c|}{ Supplemental Table s2.txt } \\
\hline CHEMBL1509469 & 688653 & 4.833 & 5.2228 & TRN & & \\
\hline CHEMBL1449333 & 688653 & 5.733 & 5.6749 & TRN & & \\
\hline CHEMBL1435883 & 688653 & \multicolumn{3}{|c|}{5.582999999999999} & 4.9175 & TRN \\
\hline CHEMBL1427621 & 688653 & 6.433 & 5.9875 & TRN & & \\
\hline CHEMBL1389613 & 688653 & 5.683 & 5.0275 & TST & & \\
\hline CHEMBL1517624 & 688653 & 5.733 & 5.5244 & TRN & & \\
\hline CHEMBL1381793 & 688653 & 4.783 & 4.801 & TRN & & \\
\hline CHEMBL1336853 & 688653 & \multicolumn{3}{|c|}{4.9830000000000005} & 5.2832 & TST \\
\hline CHEMBL1492668 & 688653 & 5.233 & 5.2845 & TRN & & \\
\hline CHEMBL1410897 & 688653 & 4.633 & 5.1648 & TRN & & \\
\hline CHEMBL1466479 & 688653 & \multicolumn{3}{|c|}{5.132999999999999} & 5.0915 & TRN \\
\hline CHEMBL1436988 & 688653 & 4.783 & \multicolumn{3}{|c|}{4.8660000000000005} & TRN \\
\hline CHEMBL1368891 & 688653 & 4.883 & 5.1332 & TST & & \\
\hline CHEMBL1319214 & 688653 & \multicolumn{3}{|c|}{6.382999999999999} & 5.4422 & TST \\
\hline CHEMBL1337115 & 688653 & 4.833 & 5.2211 & TRN & & \\
\hline CHEMBL3191437 & 688653 & \multicolumn{3}{|c|}{6.632999999999999} & 5.4677 & TRN \\
\hline CHEMBL1488703 & 688653 & \multicolumn{3}{|c|}{5.132999999999999} & 5.5203 & TRN \\
\hline CHEMBL1408668 & 688653 & 5.933 & 5.5147 & TRN & & \\
\hline CHEMBL91609 & 688653 & \multicolumn{3}{|c|}{5.332999999999999} & 5.5557 & TST \\
\hline CHEMBL1606385 & 688653 & \multicolumn{3}{|c|}{6.0329999999999995} & 5.8623 & TRN \\
\hline CHEMBL1474792 & 688653 & 4.883 & 5.0153 & TST & & \\
\hline CHEMBL1503689 & 688653 & 4.833 & 5.12 & TRN & & \\
\hline CHEMBL1608743 & 688653 & \multicolumn{3}{|c|}{5.5329999999999995} & 5.2047 & TST \\
\hline CHEMBL3213469 & 688653 & 4.783 & 5.0533 & TRN & & \\
\hline CHEMBL1431321 & 688653 & \multicolumn{3}{|c|}{4.7330000000000005} & 5.0521 & TRN \\
\hline CHEMBL1369237 & 688653 & \multicolumn{3}{|c|}{6.382999999999999} & 5.4522 & TRN \\
\hline CHEMBL1535532 & 688653 & 4.833 & 5.0448 & TST & & \\
\hline CHEMBL1981539 & 688653 & & 4.9329 & TST & & \\
\hline CHEMBL1374956 & 688653 & \multicolumn{3}{|c|}{5.632999999999999} & 5.4842 & TRN \\
\hline CHEMBL1387710 & 688653 & 6.433 & 5.5628 & TST & & \\
\hline CHEMBL1393872 & 688653 & 5.733 & 5.4648 & TRN & & \\
\hline CHEMBL1549665 & 688653 & 5.483 & 5.7075 & TRN & & \\
\hline CHEMBL596028 & 688653 & 5.483 & 5.2806 & TRN & & \\
\hline CHEMBL1555531 & 688653 & \multicolumn{3}{|c|}{5.7829999999999995} & 5.1271 & TRN \\
\hline CHEMBL3194579 & 688653 & 4.833 & \multicolumn{3}{|c|}{5.632000000000001} & TST \\
\hline CHEMBL1349832 & 688653 & \multicolumn{3}{|c|}{4.9830000000000005} & 5.2503 & TRN \\
\hline CHEMBL1508306 & 688653 & \multicolumn{3}{|c|}{5.632999999999999} & 5.2323 & TRN \\
\hline CHEMBL1418109 & 688653 & 5.483 & 4.9678 & TRN & & \\
\hline CHEMBL1303881 & 688653 & \multicolumn{3}{|c|}{4.7330000000000005} & 5.1148 & TRN \\
\hline CHEMBL1342520 & 688653 & 4.883 & 5.0263 & TRN & & \\
\hline CHEMBL1326237 & 688653 & 4.783 & 4.926 & TRN & & \\
\hline CHEMBL1389153 & 688653 & 5.733 & 5.3056 & TRN & & \\
\hline CHEMBL1538354 & 688653 & 4.883 & 5.2128 & TST & & \\
\hline CHEMBL3211751 & 688653 & 5.683 & 4.8822 & TRN & & \\
\hline CHEMBL1465522 & 688653 & 6.7331 & 5.6916 & TST & & \\
\hline CHEMBL3196538 & 688653 & 6.183 & 5.6746 & TRN & & \\
\hline CHEMBL1428992 & 688653 & \multicolumn{3}{|c|}{5.632999999999999} & 5.104 & TST \\
\hline CHEMBL1491948 & 688653 & 4.783 & 5.2313 & TRN & & \\
\hline
\end{tabular}




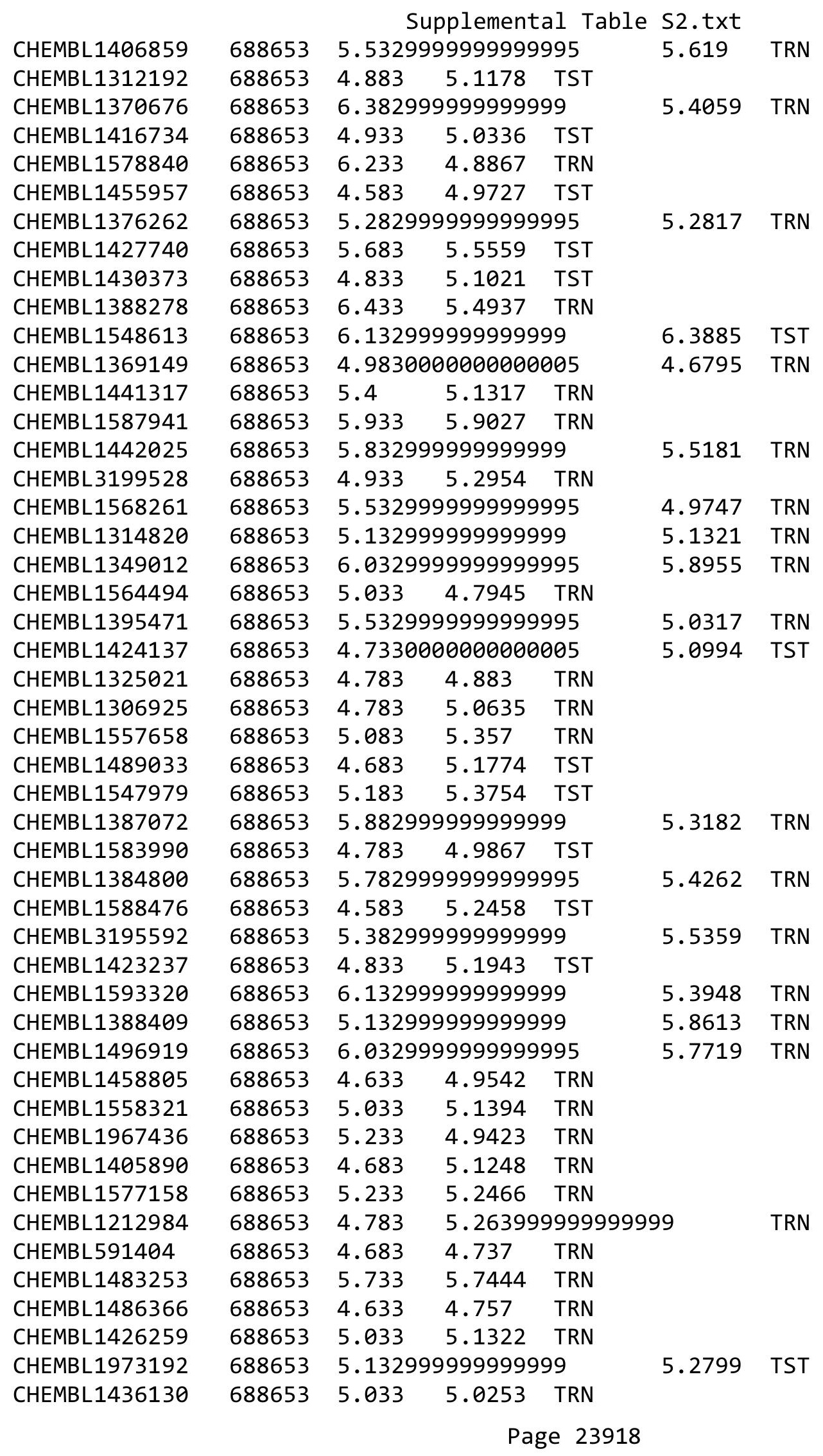




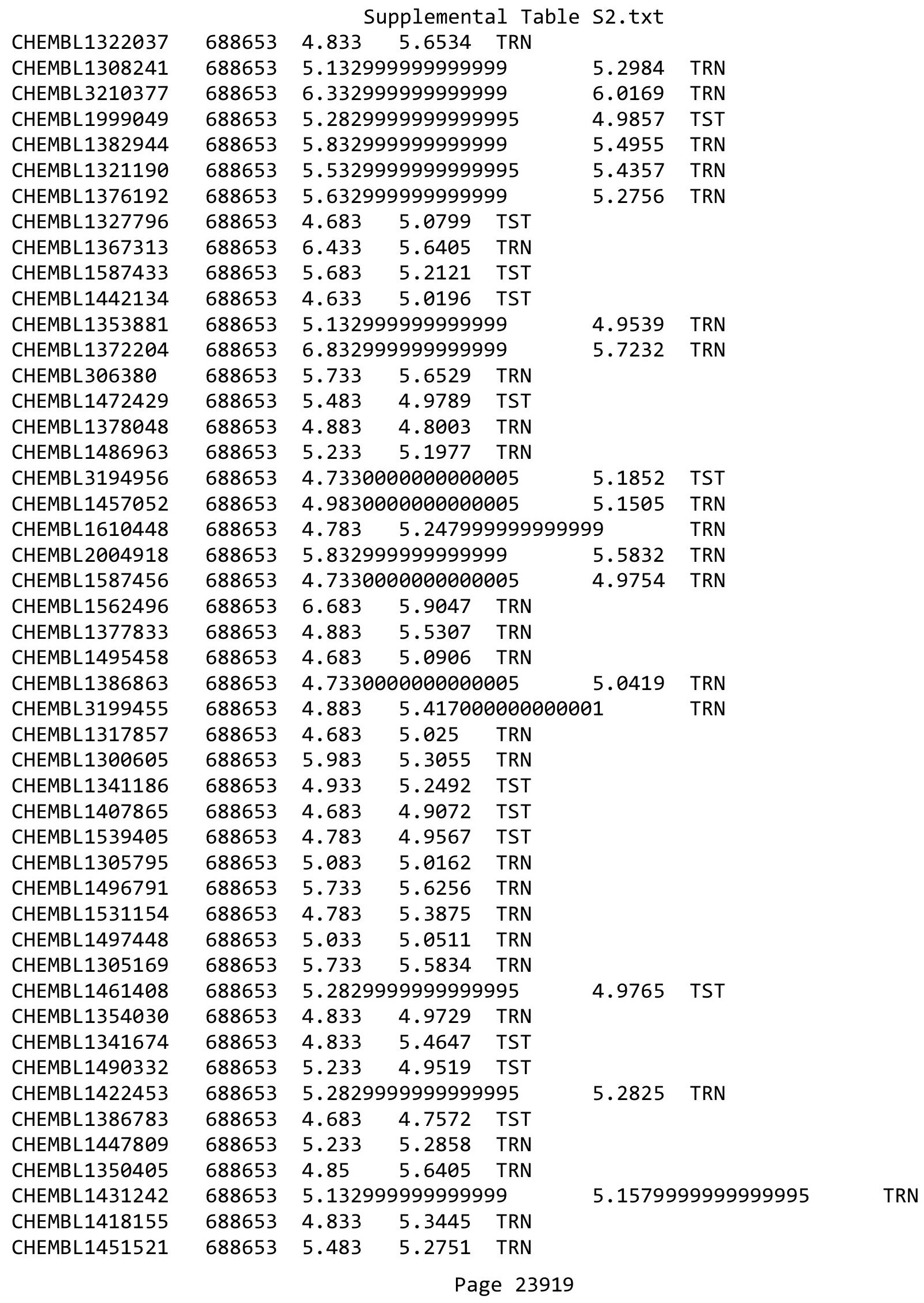




\begin{tabular}{|c|c|c|c|c|c|c|c|}
\hline \multicolumn{7}{|c|}{ Supplemental Table S2.txt } & \\
\hline CHEMBL1399398 & 688653 & \multicolumn{3}{|c|}{6.2829999999999995} & 5.4798 & TRN & \\
\hline CHEMBL1555982 & 688653 & 5.983 & 5.8518 & TRN & & & \\
\hline CHEMBL1485313 & 688653 & 4.933 & 5.0857 & TRN & & & \\
\hline CHEMBL1481234 & 688653 & 4.933 & 4.7535 & TST & & & \\
\hline CHEMBL1451592 & 688653 & 5.933 & 5.1997 & TRN & & & \\
\hline CHEMBL1369752 & 688653 & 4.883 & 5.0627 & TST & & & \\
\hline CHEMBL1491559 & 688653 & 5.183 & 5.3069 & TRN & & & \\
\hline CHEMBL1412124 & 688653 & \multicolumn{3}{|c|}{4.7330000000000005} & 5.1542 & TST & \\
\hline CHEMBL1511385 & 688653 & \multicolumn{3}{|c|}{5.7829999999999995} & 5.7088 & TRN & \\
\hline CHEMBL1373411 & 688653 & 4.783 & 5.3208 & TRN & & & \\
\hline CHEMBL1379991 & 688653 & 4.833 & 5.0893 & TST & & & \\
\hline CHEMBL3194854 & 688653 & 6.183 & 5.4267 & TRN & & & \\
\hline CHEMBL1302779 & 688653 & 6.683 & 6.053 & TRN & & & \\
\hline CHEMBL1326369 & 688653 & 4.633 & 5.0631 & TRN & & & \\
\hline CHEMBL1369841 & 688653 & \multicolumn{3}{|c|}{5.382999999999999} & 5.4074 & TRN & \\
\hline CHEMBL3194037 & 688653 & \multicolumn{3}{|c|}{4.7330000000000005} & 4.9305 & TST & \\
\hline CHEMBL1379917 & 688653 & 4.783 & \multicolumn{3}{|c|}{5.457000000000001} & TRN & \\
\hline CHEMBL3195167 & 688653 & \multicolumn{3}{|c|}{5.5329999999999995} & 5.3094 & TRN & \\
\hline CHEMBL1372926 & 688653 & 4.783 & 4.6775 & TST & & & \\
\hline CHEMBL1521083 & 688653 & \multicolumn{3}{|c|}{4.9830000000000005} & 4.9864 & TRN & \\
\hline CHEMBL1580736 & 688653 & \multicolumn{3}{|c|}{5.832999999999999} & 5.2611 & TRN & \\
\hline CHEMBL1562587 & 688653 & 4.783 & 5.3227 & TRN & & & \\
\hline CHEMBL1384642 & 688653 & 4.783 & 5.5078 & TRN & & & \\
\hline CHEMBL1355083 & 688653 & \multicolumn{3}{|c|}{4.9830000000000005} & 5.5533 & TRN & \\
\hline CHEMBL1430240 & 688653 & 5.933 & 5.3254 & TRN & & & \\
\hline CHEMBL1439118 & 688653 & 4.683 & 5.0921 & TRN & & & \\
\hline CHEMBL1477147 & 688653 & \multicolumn{3}{|c|}{4.7330000000000005} & \multicolumn{2}{|c|}{5.127000000000001} & TST \\
\hline CHEMBL1449759 & 688653 & 5.033 & 5.0642 & TRN & & & \\
\hline CHEMBL1439091 & 688653 & 5.183 & 5.5347 & TRN & & & \\
\hline CHEMBL1515825 & 688653 & 5.733 & 5.0618 & TRN & & & \\
\hline CHEMBL1461196 & 688653 & 5.683 & 5.974 & TRN & & & \\
\hline CHEMBL1376305 & 688653 & 5.683 & 5.5294 & TST & & & \\
\hline CHEMBL 1470326 & 688653 & 4.783 & 4.8701 & TRN & & & \\
\hline CHEMBL600485 & 688653 & 4.883 & 5.4357 & TST & & & \\
\hline CHEMBL1991055 & 688653 & \multicolumn{3}{|c|}{5.882999999999999} & 6.2161 & TRN & \\
\hline CHEMBL1367350 & 688653 & 5.233 & 5.181 & TRN & & & \\
\hline CHEMBL3191009 & 688653 & 5.233 & 5.1667 & TRN & & & \\
\hline CHEMBL1320891 & 688653 & 4.883 & 5.0219 & TRN & & & \\
\hline CHEMBL1571018 & 688653 & \multicolumn{3}{|c|}{6.582999999999999} & 6.0092 & TRN & \\
\hline CHEMBL 3198171 & 688653 & 4.783 & 5.55399 & 999999999 & & TRN & \\
\hline CHEMBL1585019 & 688653 & \multicolumn{3}{|c|}{6.632999999999999} & 6.5583 & TRN & \\
\hline CHEMBL1377233 & 688653 & 5.933 & 5.254 & TRN & & & \\
\hline CHEMBL1371882 & 688653 & 5.733 & 5.0085 & TRN & & & \\
\hline CHEMBL1602715 & 688653 & 5.483 & 5.584 & TRN & & & \\
\hline CHEMBL1423196 & 688653 & 4.883 & 5.1712 & TST & & & \\
\hline CHEMBL1378956 & 688653 & 4.833 & 4.9334 & TRN & & & \\
\hline CHEMBL1411211 & 688653 & 5.083 & 5.2038 & TRN & & & \\
\hline CHEMBL1531964 & 688653 & 4.633 & 4.8723 & TST & & & \\
\hline
\end{tabular}




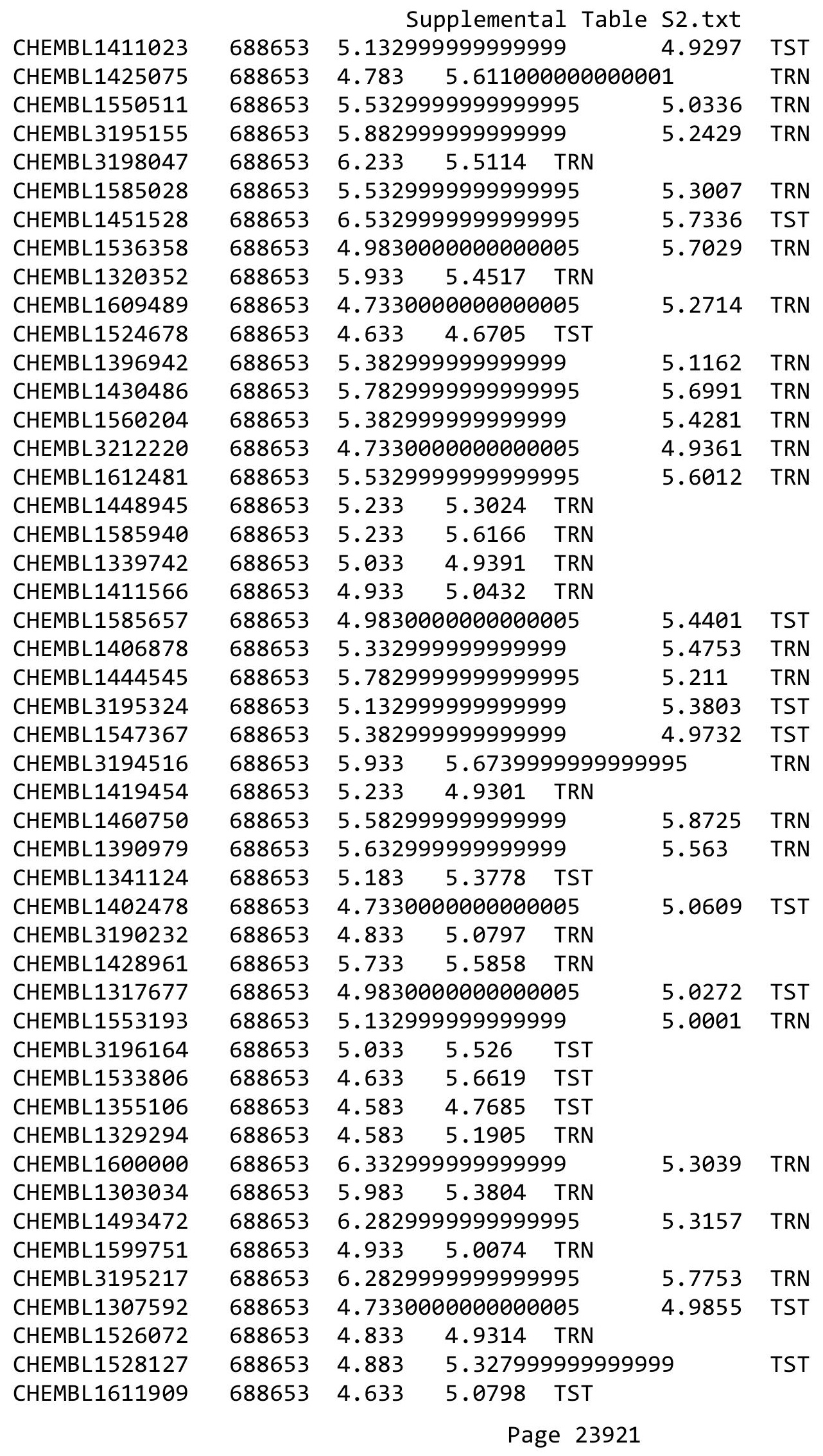




\begin{tabular}{|c|c|c|c|c|c|c|}
\hline & & & oplement & al Table $s$ & $x t$ & \\
\hline CHEMBL1513265 & 688653 & 4.73300 & 30000000 & 005 & 5.1605 & TST \\
\hline CHEMBL1552307 & 688653 & 4.883 & 5.0228 & TST & & \\
\hline CHEMBL1612197 & 688653 & 4.883 & 5.0887 & TST & & \\
\hline CHEMBL1603335 & 688653 & 4.633 & 5.0127 & TST & & \\
\hline CHEMBL1513687 & 688653 & 4.633 & 4.966 & TRN & & \\
\hline CHEMBL1473219 & 688653 & 4.683 & 4.6357 & TRN & & \\
\hline CHEMBL1490742 & 688653 & 4.883 & 5.1892 & TRN & & \\
\hline CHEMBL1509158 & 688653 & 4.833 & 5.31 & TST & & \\
\hline CHEMBL1568441 & 688653 & 5.233 & 5.5298 & TRN & & \\
\hline CHEMBL127579 & 688653 & 7.1331 & 6.175 & TRN & & \\
\hline CHEMBL1533159 & 688653 & 4.933 & 5.57600 & 0000000006 & 05 & TST \\
\hline CHEMBL1497677 & 688653 & 5.183 & 5.0828 & TRN & & \\
\hline CHEMBL1535908 & 688653 & 4.683 & 4.6646 & TRN & & \\
\hline CHEMBL1475593 & 688653 & 4.783 & 5.0591 & TRN & & \\
\hline CHEMBL1471768 & 688653 & 5.683 & 5.3726 & TRN & & \\
\hline CHEMBL1486138 & 688653 & 4.783 & 5.2641 & TRN & & \\
\hline CHEMBL1457953 & 688653 & 5.183 & 5.0898 & TRN & & \\
\hline CHEMBL1537101 & 688653 & 5.483 & 5.1751 & TST & & \\
\hline CHEMBL1440422 & 688653 & 5.63299 & 99999999 & & 6.3499 & TRN \\
\hline CHEMBL1356301 & 688653 & 4.833 & 5.2223 & TST & & \\
\hline CHEMBL1324509 & 688653 & 4.633 & 4.8784 & TST & & \\
\hline CHEMBL1411665 & 688653 & 6.683 & 5.6587 & TRN & & \\
\hline CHEMBL1579518 & 688653 & 5.483 & 5.0892 & TRN & & \\
\hline CHEMBL2000167 & 688653 & 5.683 & 5.1438 & TST & & \\
\hline CHEMBL1577682 & 688653 & 4.783 & 5.301 & TRN & & \\
\hline CHEMBL1389729 & 688653 & 4.833 & 5.0612 & TRN & & \\
\hline CHEMBL1429951 & 688653 & 4.633 & 5.186 & TST & & \\
\hline CHEMBL1397848 & 688653 & 4.73300 & 30000000 & 005 & 5.1224 & TRN \\
\hline CHEMBL1339592 & 688653 & 5.183 & 5.4694 & TRN & & \\
\hline CHEMBL1345313 & 688653 & 4.783 & 5.0828 & TRN & & \\
\hline CHEMBL1469662 & 688653 & 5.88299 & 79999999 & & 5.6811 & TST \\
\hline CHEMBL1522537 & 688653 & 4.883 & 4.9773 & TRN & & \\
\hline CHEMBL1450386 & 688653 & 7.08299 & 99999999 & & 6.3189 & TRN \\
\hline CHEMBL1535386 & 688653 & 5.78299 & 99999999 & 995 & 5.4714 & TST \\
\hline CHEMBL1398616 & 688653 & 5.683 & 5.6727 & TST & & \\
\hline CHEMBL1575654 & 688653 & 4.73300 & 30000000 & 005 & 5.093 & TRN \\
\hline CHEMBL1463198 & 688653 & 4.583 & 4.98300 & 0000000006 & 05 & TST \\
\hline CHEMBL1471601 & 688653 & 4.73300 & 30000000 & 005 & 5.0604 & TST \\
\hline CHEMBL595700 & 688653 & 4.633 & 5.0738 & TRN & & \\
\hline CHEMBL3212376 & 688653 & 5.183 & 5.5624 & TRN & & \\
\hline CHEMBL1480104 & 688653 & 5.38299 & 79999999 & 99 & 5.1087 & TRN \\
\hline CHEMBL1469404 & 688653 & 4.933 & 4.8794 & TRN & & \\
\hline CHEMBL1466106 & 688653 & 4.833 & 4.9966 & TRN & & \\
\hline CHEMBL1540632 & 688653 & 4.933 & 4.9771 & TRN & & \\
\hline CHEMBL414890 & 688653 & 5.233 & 5.4575 & TST & & \\
\hline CHEMBL3207648 & 688653 & 4.883 & 5.0424 & TST & & \\
\hline CHEMBL1342679 & 688653 & 5.733 & 5.3362 & TRN & & \\
\hline CHEMBL1460817 & 688653 & 4.683 & 4.8835 & TRN & & \\
\hline
\end{tabular}




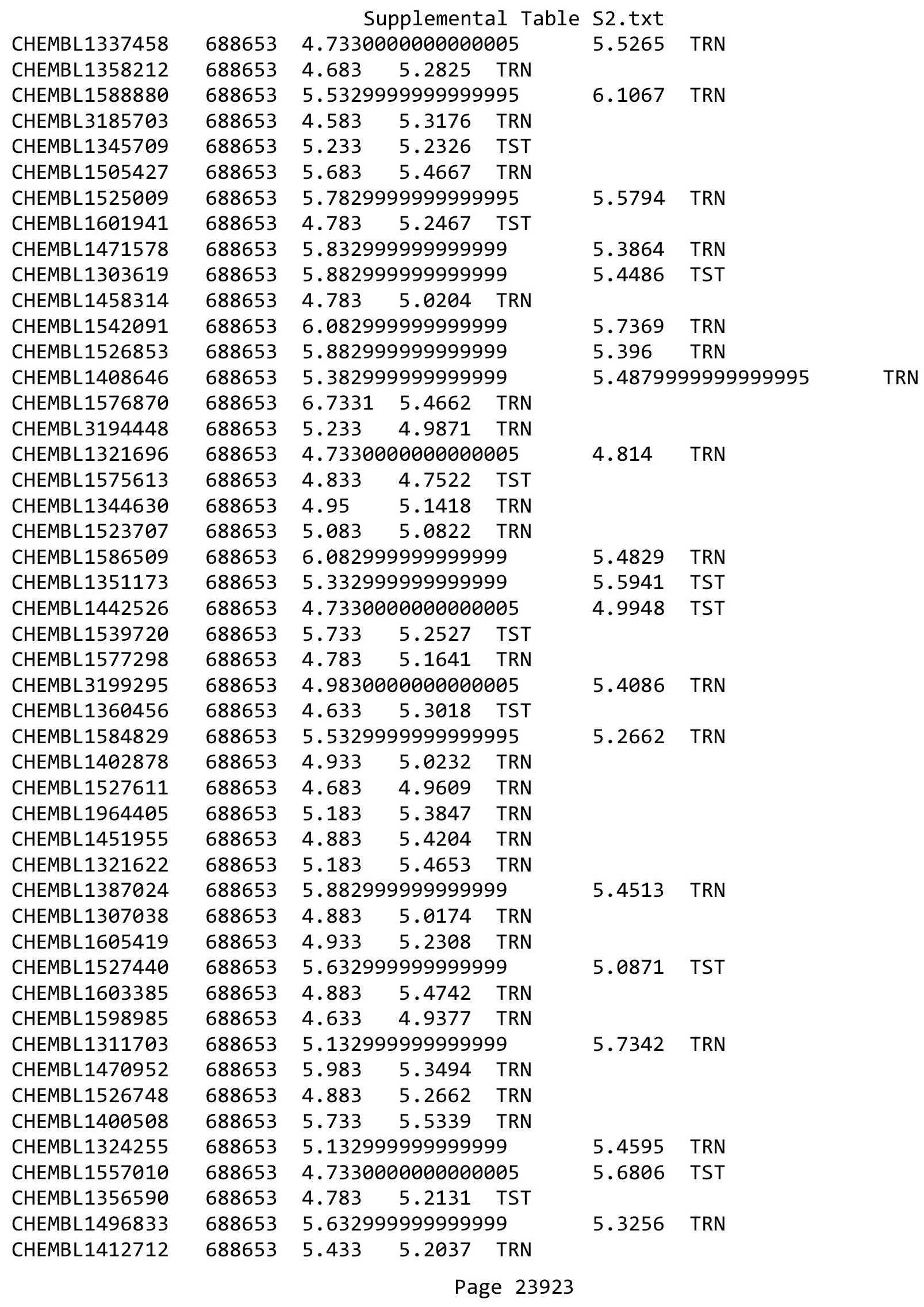




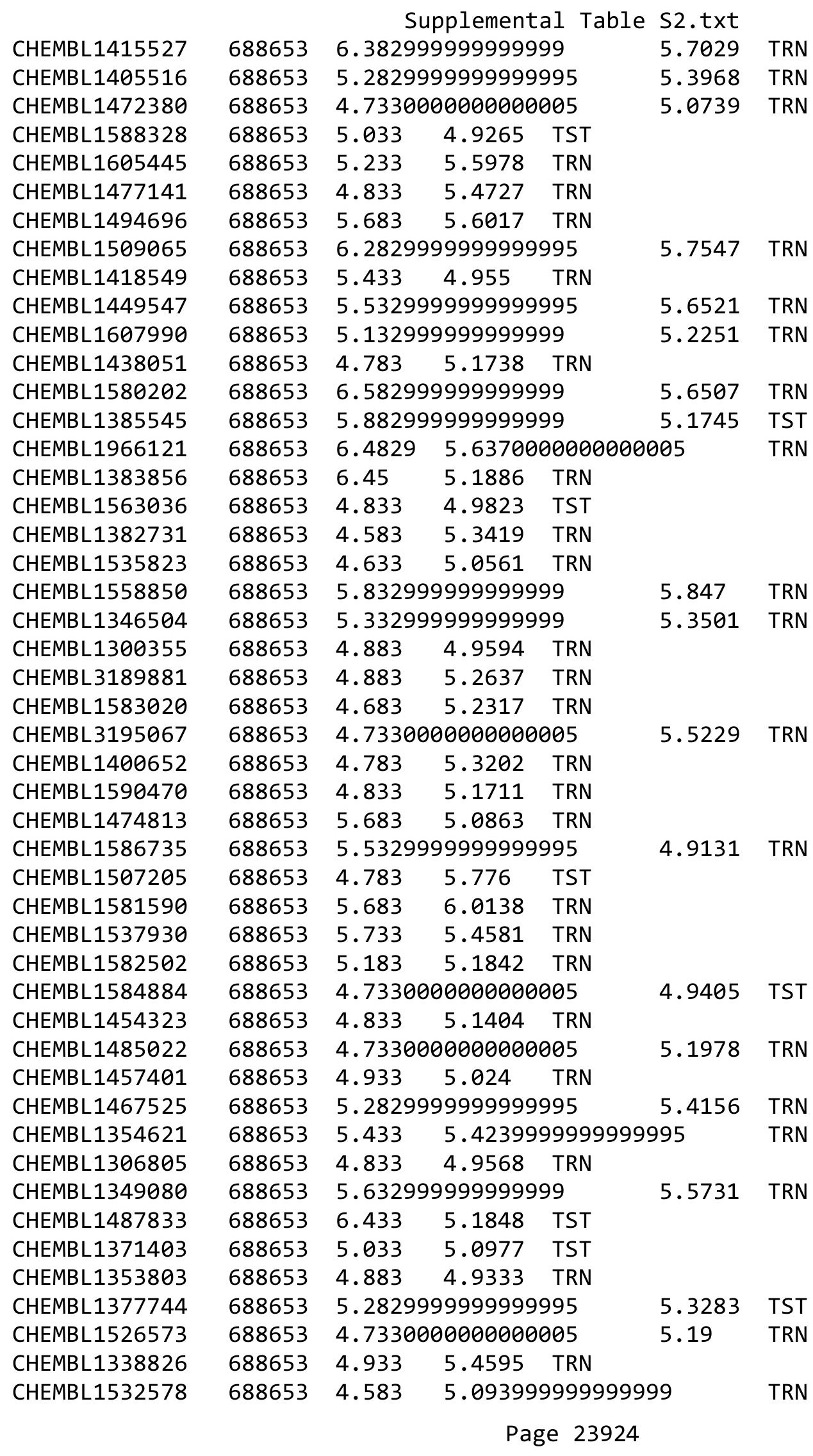




\begin{tabular}{|c|c|c|c|c|c|c|c|}
\hline \multicolumn{8}{|c|}{ oplemental á } \\
\hline CHEMBL1359478 & 688653 & 4.95 & 5.2473 & TST & & & \\
\hline CHEMBL1315140 & 688653 & 4.633 & 5.2909 & TRN & & & \\
\hline CHEMBL1435939 & 688653 & 5.083 & 5.1783 & TRN & & & \\
\hline CHEMBL1499955 & 688653 & 4.7330 & 00000000 & 005 & 4.9645 & TRN & \\
\hline CHEMBL1459203 & 688653 & 4.683 & 5.0811 & TST & & & \\
\hline CHEMBL1603921 & 688653 & 5.2829 & 99999999 & 995 & 5.2954 & TRN & \\
\hline CHEMBL1407635 & 688653 & 4.833 & 4.9479 & TRN & & & \\
\hline CHEMBL1448533 & 688653 & 4.633 & 5.0368 & TRN & & & \\
\hline CHEMBL1553208 & 688653 & 5.433 & 4.8775 & TRN & & & \\
\hline CHEMBL3199133 & 688653 & 4.883 & 5.0419 & TST & & & \\
\hline CHEMBL1404909 & 688653 & 4.633 & 4.9093 & TST & & & \\
\hline CHEMBL1444451 & 688653 & 4.833 & 5.2208 & TRN & & & \\
\hline CHEMBL1450116 & 688653 & 6.0829 & 99999999 & 99 & 5.0494 & TRN & \\
\hline CHEMBL1484190 & 688653 & 4.783 & 5.4066 & TRN & & & \\
\hline CHEMBL486078 & 688653 & 4.7330 & 00000000 & 005 & 5.0968 & TRN & \\
\hline CHEMBL1302889 & 688653 & 5.983 & 6.1236 & TRN & & & \\
\hline CHEMBL1404448 & 688653 & 4.883 & 4.8943 & TRN & & & \\
\hline CHEMBL3190686 & 688653 & 5.183 & 5.1016 & TRN & & & \\
\hline CHEMBL1997293 & 688653 & 5.8829 & 99999999 & 99 & 5.4741 & TRN & \\
\hline CHEMBL1339235 & 688653 & 4.933 & 5.3064 & TRN & & & \\
\hline CHEMBL1327858 & 688653 & 6.183 & 5.3036 & TRN & & & \\
\hline CHEMBL3190798 & 688653 & 4.933 & 5.2234 & TRN & & & \\
\hline CHEMBL3198239 & 688653 & 5.033 & 5.7044 & TRN & & & \\
\hline CHEMBL1421803 & 688653 & 4.933 & 4.9928 & TST & & & \\
\hline CHEMBL1457369 & 688653 & 4.933 & 5.1239 & TRN & & & \\
\hline CHEMBL1479026 & 688653 & 4.833 & 5.0719 & TRN & & & \\
\hline CHEMBL1449513 & 688653 & 5.7829 & 99999999 & 995 & 5.4193 & TRN & \\
\hline CHEMBL1466028 & 688653 & 6.3829 & 99999999 & & 5.61299 & 99999999995 & TRN \\
\hline CHEMBL3192579 & 688653 & 4.7330 & 00000000 & 005 & 5.1197 & TRN & \\
\hline CHEMBL1311572 & 688653 & 4.583 & 5.2631 & TST & & & \\
\hline CHEMBL1411325 & 688653 & 4.783 & 5.0423 & TRN & & & \\
\hline CHEMBL1599723 & 688653 & 4.583 & 5.4335 & TST & & & \\
\hline CHEMBL1361170 & 688653 & 5.183 & 5.6463 & TRN & & & \\
\hline CHEMBL1452191 & 688653 & 5.5329 & 99999999 & 995 & 5.312 & TST & \\
\hline CHEMBL1525394 & 688653 & 4.783 & 5.2547 & TST & & & \\
\hline CHEMBL1331718 & 688653 & 4.783 & 5.3559 & TRN & & & \\
\hline CHEMBL1302115 & 688653 & 4.7330 & 00000000 & 005 & 4.9627 & TRN & \\
\hline CHEMBL1407627 & 688653 & 4.633 & 4.7331 & TRN & & & \\
\hline CHEMBL1381862 & 688653 & 4.783 & 5.2813 & TRN & & & \\
\hline CHEMBL3195676 & 688653 & 5.8829 & 99999999 & & 5.3239 & TRN & \\
\hline CHEMBL1327916 & 688653 & 4.7330 & 00000000 & 005 & 5.1674 & TRN & \\
\hline CHEMBL1575863 & 688653 & 4.95 & 5.1334 & TRN & & & \\
\hline CHEMBL 3193178 & 688653 & 4.933 & 5.4289 & TRN & & & \\
\hline CHEMBL1310979 & 688653 & 4.883 & 5.6714 & TRN & & & \\
\hline CHEMBL1360460 & 688653 & 4.883 & 4.9773 & TRN & & & \\
\hline CHEMBL1312363 & 688653 & 5.3329 & 99999999 & & 5.4317 & TST & \\
\hline CHEMBL1561336 & 688653 & 5.5329 & 99999999 & 995 & 5.2916 & TRN & \\
\hline CHEMBL1497732 & 688653 & 5.5329 & 99999999 & 995 & 5.4777 & TRN & \\
\hline
\end{tabular}




\begin{tabular}{|c|c|c|c|c|c|c|c|}
\hline \multicolumn{7}{|c|}{ Supplemental Table S2.txt } & \\
\hline CHEMBL1485680 & 688653 & 5.083 & 5.4874 & TRN & & & \\
\hline CHEMBL1534854 & 688653 & 6.13299 & 99999999 & & 5.8177 & TRN & \\
\hline CHEMBL1490791 & 688653 & 5.183 & 5.1848 & TRN & & & \\
\hline CHEMBL1489024 & 688653 & 5.63299 & 99999999 & & 4.9605 & TST & \\
\hline CHEMBL1553242 & 688653 & 5.083 & 5.6322 & TRN & & & \\
\hline CHEMBL1536801 & 688653 & 4.833 & 5.3031 & TRN & & & \\
\hline CHEMBL1536001 & 688653 & 5.483 & 5.9072 & TRN & & & \\
\hline CHEMBL1499681 & 688653 & 4.783 & 5.7912 & TRN & & & \\
\hline CHEMBL1408962 & 688653 & 4.833 & 5.1688 & TST & & & \\
\hline CHEMBL1533618 & 688653 & 5.233 & 5.0524 & TRN & & & \\
\hline CHEMBL1545515 & 688653 & 5.78299 & 99999999 & 995 & 5.7999 & TRN & \\
\hline CHEMBL1567642 & 688653 & 4.883 & 5.3322 & TST & & & \\
\hline CHEMBL 3197842 & 688653 & 5.28299 & 99999999 & 995 & 5.1286 & TST & \\
\hline CHEMBL1489687 & 688653 & 6.0 & 5.7134 & TST & & & \\
\hline CHEMBL1385925 & 688653 & 4.683 & 5.5061 & TST & & & \\
\hline CHEMBL3197524 & 688653 & 5.13299 & 99999999 & 99 & 5.2178 & TST & \\
\hline CHEMBL1541290 & 688653 & 4.883 & 5.3251 & TST & & & \\
\hline CHEMBL1412271 & 688653 & 5.233 & 4.9915 & TRN & & & \\
\hline CHEMBL1324690 & 688653 & 4.683 & 5.0026 & TRN & & & \\
\hline CHEMBL1543952 & 688653 & 5.13299 & 99999999 & & 5.0887 & TRN & \\
\hline CHEMBL1603334 & 688653 & 6.13299 & 99999999 & & 5.6448 & TRN & \\
\hline CHEMBL1974529 & 688653 & 4.73300 & 00000000 & 005 & 5.0327 & TST & \\
\hline CHEMBL3212329 & 688653 & 4.633 & 5.5185 & TRN & & & \\
\hline CHEMBL1600964 & 688653 & 5.53299 & 99999999 & 995 & 5.32700 & 0000000001 & TST \\
\hline CHEMBL1418948 & 688653 & 4.783 & 5.0113 & TRN & & & \\
\hline CHEMBL1307910 & 688653 & 6.233 & 6.2478 & TRN & & & \\
\hline CHEMBL1395590 & 688653 & 5.683 & 5.7918 & TRN & & & \\
\hline CHEMBL1469231 & 688653 & 4.98300 & 00000000 & 005 & 5.3132 & TRN & \\
\hline CHEMBL1486954 & 688653 & 4.783 & 5.3854 & TST & & & \\
\hline CHEMBL1380874 & 688653 & 4.73300 & 00000000 & 005 & 5.1474 & TRN & \\
\hline CHEMBL1499814 & 688653 & 4.833 & 5.0693 & TST & & & \\
\hline CHEMBL1475937 & 688653 & 5.53299 & 99999999 & 995 & 4.9382 & TRN & \\
\hline CHEMBL1534915 & 688653 & 6.233 & 5.657 & TST & & & \\
\hline CHEMBL1507066 & 688653 & 4.833 & 5.3322 & TRN & & & \\
\hline CHEMBL1459472 & 688653 & 5.183 & 5.6677 & TRN & & & \\
\hline CHEMBL1353851 & 688653 & 5.13299 & 99999999 & & 5.5595 & TST & \\
\hline CHEMBL1307168 & 688653 & 5.58299 & 99999999 & & 4.9091 & TRN & \\
\hline CHEMBL1531495 & 688653 & 5.233 & 5.6635 & TRN & & & \\
\hline CHEMBL1572217 & 688653 & 4.73300 & 00000000 & 005 & 5.4529 & TST & \\
\hline CHEMBL1580838 & 688653 & 5.53299 & 99999999 & 995 & 5.4137 & TRN & \\
\hline CHEMBL1368631 & 688653 & 4.833 & 5.7255 & TRN & & & \\
\hline CHEMBL1315282 & 688653 & 4.833 & 5.12299 & 999999999 & & TST & \\
\hline CHEMBL1577941 & 688653 & 5.33299 & 99999999 & 99 & 5.2707 & TRN & \\
\hline CHEMBL 2003511 & 688653 & 4.933 & 4.9297 & TRN & & & \\
\hline CHEMBL3197781 & 688653 & 4.683 & 4.8925 & TRN & & & \\
\hline CHEMBL1468660 & 688653 & 4.883 & 5.3097 & TRN & & & \\
\hline CHEMBL1430867 & 688653 & 4.783 & 5.4098 & TRN & & & \\
\hline CHEMBL1450249 & 688653 & 6.233 & 5.8818 & TRN & & & \\
\hline
\end{tabular}




\begin{tabular}{|c|c|c|c|c|c|c|}
\hline & & \multicolumn{5}{|c|}{ Supplemental Table S2.txt } \\
\hline CHEMBL1342313 & 688653 & 5.183 & 5.1842 & TRN & & \\
\hline CHEMBL1451286 & 688653 & 4.833 & 5.2279 & TRN & & \\
\hline CHEMBL1565369 & 688653 & 4.833 & 5.5161 & TST & & \\
\hline CHEMBL1367311 & 688653 & 5.683 & 4.9286 & TRN & & \\
\hline CHEMBL1428415 & 688653 & 6.0 & 5.2825 & TRN & & \\
\hline CHEMBL1493383 & 688653 & \multicolumn{3}{|c|}{5.7829999999999995} & 5.1971 & TRN \\
\hline CHEMBL1362153 & 688653 & \multicolumn{3}{|c|}{6.632999999999999} & 5.6408 & \\
\hline CHEMBL1471524 & 688653 & \multicolumn{3}{|c|}{4.9830000000000005} & 5.4929 & \\
\hline CHEMBL1553189 & 688653 & \multicolumn{3}{|c|}{4.7330000000000005} & 5.0313 & \\
\hline CHEMBL1591299 & 688653 & 4.933 & 4.79437 & TRN & & \\
\hline CHEMBL1461971 & 688653 & 4.783 & 5.1409 & TRN & & \\
\hline CHEMBL1505840 & 688653 & 6.983 & 5.7759 & TST & & \\
\hline CHEMBL1301814 & 688653 & 4.833 & 5.7437 & TRN & & \\
\hline CHEMBL1592230 & 688653 & 5.483 & 5.074 & TST & & \\
\hline CHEMBL1451732 & 688653 & 5.233 & 5.3942 & TST & & \\
\hline CHEMBL1448008 & 688653 & 4.783 & 5.2368 & TST & & \\
\hline CHEMBL1533600 & 688653 & 4.783 & \multicolumn{3}{|c|}{5.218999999999999} & \\
\hline CHEMBL1608927 & 688653 & \multicolumn{3}{|c|}{4.7330000000000005} & 5.1 & \\
\hline CHEMBL1547237 & 688653 & 5.733 & 5.1702 & TRN & & \\
\hline CHEMBL1540682 & 688653 & \multicolumn{3}{|c|}{5.582999999999999} & 5.2522 & \\
\hline CHEMBL125044 & 688653 & 7.2832 & 6.00427 & TRN & & \\
\hline CHEMBL 32 & 688653 & 4.683 & 4.9865 & TST & & \\
\hline CHEMBL 1 & 688653 & 5.033 & 4.913 & TRN & & \\
\hline CHEMBL1 & 688653 & 5.433 & \multicolumn{3}{|c|}{5.513999999999999} & \\
\hline CHEMBL1445702 & 688653 & \multicolumn{3}{|c|}{5.832999999999999} & 5.5387 & \\
\hline CHEMBL1455411 & 688653 & 4.633 & 5.42587 & TRN & & \\
\hline CHEMBL1579988 & 688653 & \multicolumn{3}{|c|}{5.2829999999999995} & 5.1063 & \\
\hline CHEMBL1 & 688653 & 4.633 & 5.2328 & TRN & & \\
\hline CHEMBL: & 688653 & 4.883 & 5.3195 & TRN & & \\
\hline CHEMBL1599273 & 688653 & 4.683 & 5.0833 & TRN & & \\
\hline CHEMBL1596190 & 688653 & \multicolumn{3}{|c|}{6.632999999999999} & & \\
\hline CHEMBL19 & 688 & \multicolumn{3}{|c|}{5.382999999999999} & & \\
\hline CHEMBL1527862 & 688653 & \multicolumn{3}{|c|}{5.7829999999999995} & 831 & TRN \\
\hline CHEMBL1256737 & 688653 & \multicolumn{3}{|c|}{4.7330000000000005} & 4.933 & TST \\
\hline CHEMBL1537255 & 688653 & \multicolumn{3}{|c|}{4.7330000000000005} & 5.1151 & TST \\
\hline CHEMBL1550657 & 688653 & 5.683 & 5.529 & TST & & \\
\hline CHEMBL1369270 & 688653 & \multicolumn{3}{|c|}{5.7829999999999995} & & TRIV \\
\hline CHEMBL3193613 & 688653 & \multicolumn{3}{|c|}{5.832999999999999} & 5.8166 & TRN \\
\hline CHEMBL 3196226 & 688653 & 6.183 & 5.3438 & TRN & & \\
\hline CHEMBL1421266 & 688653 & 5.733 & 5.2675 & TRN & & \\
\hline CHEMBL1379646 & 688653 & \multicolumn{3}{|c|}{5.882999999999999} & 777 & $\mathrm{TI}$ \\
\hline CHEMBL1585400 & 688653 & \multicolumn{3}{|c|}{7.082999999999999} & 5.7758 & \\
\hline CHEMBL1586472 & 688653 & 4.883 & 5.6182 & TRN & & \\
\hline CHEMBL1452077 & 688653 & \multirow{2}{*}{\multicolumn{3}{|c|}{$\begin{array}{lcc}5.433 & 5.3784 \\
5.132999999999999\end{array}$}} & & \\
\hline CHEMBL1586396 & 688653 & & & & 5.1404 & אוד \\
\hline CHEMBL1327920 & 688653 & 4.883 & & TRN & & \\
\hline CHEMBL1431679 & 688653 & 6.3829 & 999999999 & 99 & 5.362 & \\
\hline CHEMBL1418548 & 688653 & 5.483 & 5.0696 & TRN & & \\
\hline
\end{tabular}




\begin{tabular}{|c|c|c|c|c|c|c|}
\hline \multirow{3}{*}{$\begin{array}{l}\text { CHEMBL1328587 } \\
\text { CHEMBL1489830 }\end{array}$} & \multirow{3}{*}{$\begin{array}{l}688653 \\
688653\end{array}$} & \multicolumn{5}{|c|}{ Supplemental Table S2.txt } \\
\hline & & \multicolumn{3}{|c|}{6.5329999999999995} & \multirow{2}{*}{5.7427} & \multirow{2}{*}{ TRA } \\
\hline & & 5.233 & 5.0749 & TRN & & \\
\hline CHEMBL1542512 & 688653 & 4.833 & \multicolumn{3}{|c|}{4.8660000000000005} & TST \\
\hline CHEMBL1500303 & 688653 & \multicolumn{3}{|c|}{6.382999999999999} & 5.7179 & TRA \\
\hline CHEMBL1447829 & 688653 & 4.633 & 5.1986 & TRN & & \\
\hline CHEMBL3208972 & 688653 & 4.783 & 5.2149 & TRN & & \\
\hline CHEMBL1444938 & 688653 & \multicolumn{3}{|c|}{5.2829999999999995} & 5.1133 & TRN \\
\hline CHEMBL1415237 & 688653 & 5.183 & 5.3732 & TRN & & \\
\hline CHEMBL1322094 & 688653 & 5.233 & 5.3147 & TRN & & \\
\hline CHEMBL1467789 & 688653 & \multicolumn{3}{|c|}{5.132999999999999} & 5.0331 & TRN \\
\hline CHEMBL1532364 & 688653 & \multicolumn{3}{|c|}{5.332999999999999} & 5.3327 & TRN \\
\hline CHEMBL1609036 & 688653 & 4.683 & 4.9058 & TST & & \\
\hline CHEMBL1423074 & 688653 & 4.783 & 5.0767 & TST & & \\
\hline CHEMBL1422611 & 688653 & 4.783 & 4.7328 & TST & & \\
\hline CHEMBL3208002 & 688653 & 4.883 & 5.3507 & TRN & & \\
\hline CHEMBL1372214 & 688653 & 5.683 & 5.4987 & TRN & & \\
\hline CHEMBL1530375 & 688653 & 5.433 & 5.7074 & TRN & & \\
\hline CHEMBL1374854 & 688653 & 5.733 & 5.4934 & TST & & \\
\hline CHEMBL1455402 & 688653 & \multicolumn{3}{|c|}{5.132999999999999} & 5.0806 & TRN \\
\hline CHEMBL1600901 & 688653 & \multicolumn{3}{|c|}{6.582999999999999} & 5.945 & TST \\
\hline CHEMBL1438026 & 688653 & \multicolumn{3}{|c|}{5.132999999999999} & 5.4321 & TRN \\
\hline CHEMBL1487026 & 688653 & \multicolumn{3}{|c|}{5.5329999999999995} & 5.6287 & TRN \\
\hline CHEMBL 3213387 & 688653 & 5.033 & 4.8563 & TST & & \\
\hline CHEMBL1315713 & 688653 & \multicolumn{3}{|c|}{5.382999999999999} & 5.2239 & TRN \\
\hline CHEMBL1355003 & 688653 & 4.883 & 4.9462 & TRN & & \\
\hline CHEMBL1343883 & 688653 & 4.583 & 4.8969 & TST & & \\
\hline CHEMBL1608535 & 688653 & 5.033 & 5.0133 & TST & & \\
\hline CHEMBL1587454 & 688653 & 4.783 & 5.0173 & TRN & & \\
\hline CHEMBL1603830 & 688653 & 4.583 & 5.1284 & TRN & & \\
\hline CHEMBL1462406 & 688653 & \multicolumn{3}{|c|}{5.132999999999999} & 4.9908 & TST \\
\hline CHEMBL1977424 & 688653 & 6.683 & 5.8023 & TRN & & \\
\hline CHEMBL1385068 & 688653 & 4.783 & 4.6727 & TST & & \\
\hline CHEMBL1290138 & 688653 & \multicolumn{3}{|c|}{5.132999999999999} & 4.7475 & TRN \\
\hline CHEMBL1526670 & 688653 & 4.883 & 4.9295 & TRN & & \\
\hline CHEMBL1557499 & 688653 & \multicolumn{3}{|c|}{4.7330000000000005} & 5.2811 & TST \\
\hline CHEMBL1511746 & 688653 & 5.183 & 4.9546 & TST & & \\
\hline CHEMBL3209435 & 688653 & \multirow{2}{*}{\multicolumn{3}{|c|}{$\begin{array}{l}4.833 \quad 4.9585 \text { ISI } \\
6.382999999999999\end{array}$}} & & \\
\hline CHEMBL1414729 & 688653 & & & & 5.1279 & TRN \\
\hline CHEMBL1299674 & 688653 & 5.233 & 5.9388 & TRN & & \\
\hline CHEMBL1559243 & 688653 & \multicolumn{3}{|c|}{4.7330000000000005} & 5.2695 & TRN \\
\hline CHEMBL1417316 & 688653 & 4.783 & 4.9986 & TRN & & \\
\hline CHEMBL3197151 & 688653 & 5.7829 & 99999999 & 995 & 5.3204 & TRN \\
\hline CHEMBL1413583 & 688653 & 4.833 & 5.7354 & TRN & & \\
\hline CHEMBL1330168 & 688653 & 4.883 & 5.2049 & TST & & \\
\hline CHEMBL1549229 & 688653 & 4.9830 & 00000000 & 005 & 5.5131 & TST \\
\hline CHEMBL1526249 & 688653 & 6.5829 & 99999999 & & 5.9349 & TRN \\
\hline CHEMBL1348049 & 688653 & 4.583 & 5.1023 & TST & & \\
\hline CHEMBL1340487 & 688653 & 4.583 & 5.1914 & TRN & & \\
\hline
\end{tabular}




\begin{tabular}{|c|c|c|c|c|c|c|}
\hline \multirow{3}{*}{$\begin{array}{l}\text { CHEMBL1517468 } \\
\text { CHEMBL1968064 }\end{array}$} & \multirow{3}{*}{$\begin{array}{l}688653 \\
688653\end{array}$} & \multicolumn{5}{|c|}{ Supplemental Table S2.txt } \\
\hline & & 4.833 & \multicolumn{3}{|c|}{5.132000000000001} & \multirow{2}{*}{$\begin{array}{l}\text { TRN } \\
\text { TRN }\end{array}$} \\
\hline & & \multicolumn{3}{|c|}{5.832999999999999} & \multirow{3}{*}{5.0988} & \\
\hline CHEMBL1436175 & 688653 & 5.083 & 5.2644 & TRN & & \\
\hline CHEMBL1560213 & 688653 & 5.233 & 5.1739 & TRN & & \multirow{4}{*}{ TRN } \\
\hline CHEMBL1526938 & 688653 & \multicolumn{3}{|c|}{5.5329999999999995} & \multirow[t]{3}{*}{5.2918} & \\
\hline CHEMBL1498693 & 688653 & 4.633 & 4.7724 & TST & & \\
\hline CHEMBL1480630 & 688653 & 4.633 & 5.0298 & TRN & & \\
\hline CHEMBL1594726 & 688653 & \multicolumn{3}{|c|}{5.132999999999999} & 5.5207 & TRN \\
\hline CHEMBL3191062 & 688653 & \multicolumn{3}{|c|}{6.5329999999999995} & 5.7129 & TRN \\
\hline CHEMBL1584902 & 688653 & 4.833 & 5.6249 & TRN & & \\
\hline CHEMBL1399980 & 688653 & \multicolumn{3}{|c|}{6.582999999999999} & 5.6192 & TRN \\
\hline CHEMBL1512398 & 688653 & \multicolumn{3}{|c|}{5.2829999999999995} & 5.761 & TRN \\
\hline CHEMBL1387605 & 688653 & \multicolumn{3}{|c|}{6.5329999999999995} & 5.9993 & TRN \\
\hline CHEMBL1470332 & 688653 & 4.683 & 5.0066 & TST & & \\
\hline CHEMBL1472817 & 688653 & \multicolumn{3}{|c|}{6.7829999999999995} & 5.8914 & TST \\
\hline CHEMBL3209143 & 688653 & \multicolumn{3}{|c|}{5.832999999999999} & 5.2423 & TRN \\
\hline CHEMBL1372032 & 688653 & \multicolumn{3}{|c|}{4.9830000000000005} & 5.1215 & TRN \\
\hline CHEMBL3197566 & 688653 & \multicolumn{3}{|c|}{5.132999999999999} & 4.9156 & TST \\
\hline CHEMBL1352649 & 688653 & 5.183 & 5.0761 & TST & & \\
\hline CHEMBL3193979 & 688653 & \multicolumn{3}{|c|}{5.832999999999999} & 5.2316 & TRN \\
\hline CHEMBL3211191 & 688653 & 5.083 & 5.4684 & TRN & & \\
\hline CHEMBL1570928 & 688653 & \multicolumn{3}{|c|}{5.132999999999999} & 395 & TRN \\
\hline CHEMBL1421980 & 688653 & 6.13299 & 99999999 & & 5.8066 & TRN \\
\hline CHEMBL1520098 & 688653 & 5.38299 & 99999999 & & 5.0759 & TST \\
\hline CHEMBL1472468 & 688653 & 4.833 & 5.5561 & TST & & \\
\hline CHEMBL1339121 & 688653 & 6.983 & 6.1366 & TRN & & \\
\hline CHEMBL1550649 & 688653 & 4.783 & 5.0782 & TRN & & \\
\hline CHEMBL1486803 & 688653 & 4.73300 & 00000000 & 005 & 5.4164 & TST \\
\hline CHEMBL3193135 & 688653 & 5.28299 & 99999999 & 995 & 5.3358 & TST \\
\hline CHEMBL1544489 & 688653 & 6.38299 & 99999999 & & 5.5364 & TST \\
\hline CHEMBL1611383 & 688653 & 5.63299 & 99999999 & & 5.5078 & TRN \\
\hline CHEMBL1516032 & 688653 & 5.183 & 5.0549 & TRN & & \\
\hline CHEMBL1504077 & 688653 & 5.433 & 5.1864 & TRN & & \\
\hline CHEMBL3209990 & 688653 & 4.933 & 5.789 & TRN & & \\
\hline CHEMBL1425741 & 688653 & 4.783 & 5.2962 & TST & & \\
\hline CHEMBL1561532 & 688653 & 4.833 & 4.8614 & TRN & & \\
\hline CHEMBL1542703 & 688653 & 4.783 & 5.131 & TRN & & \\
\hline CHEMBL1380189 & 688653 & 5.0 & 5.517 & TST & & \\
\hline CHEMBL1403645 & 688653 & 5.33299 & 99999999 & & 5.5081 & TST \\
\hline CHEMBL1379733 & 688653 & 4.683 & 5.0424 & TST & & \\
\hline CHEMBL1360431 & 688653 & 6.03299 & 99999999 & 995 & 5.5574 & TRN \\
\hline CHEMBL1394116 & 688653 & 4.833 & 5.0481 & TRN & & \\
\hline CHEMBL1351696 & 688653 & 5.83299 & 99999999 & & 5.3026 & TRN \\
\hline CHEMBL1313266 & 688653 & 4.883 & 5.1534 & TRN & & \\
\hline CHEMBL3191511 & 688653 & 4.73300 & 00000000 & 005 & 5.3433 & TRN \\
\hline CHEMBL1305277 & 688653 & 4.73300 & 00000000 & 005 & 5.1522 & TRN \\
\hline CHEMBL1587734 & 688653 & 5.58299 & 99999999 & & 5.2603 & TRN \\
\hline CHEMBL1461946 & 688653 & 5.78299 & 99999999 & 995 & 5.2116 & TRN \\
\hline
\end{tabular}




\begin{tabular}{|c|c|c|c|c|c|c|c|}
\hline \multicolumn{7}{|c|}{ Supplemental Table S2.txt } & \\
\hline CHEMBL1513416 & 688653 & 5.083 & 5.6329 & TRN & & & \\
\hline CHEMBL1513844 & 688653 & 4.98300 & 00000000 & 005 & 4.9644 & TST & \\
\hline CHEMBL1478389 & 688653 & 5.483 & 5.074 & TRN & & & \\
\hline CHEMBL1504147 & 688653 & 6.33299 & 99999999 & & 5.4992 & TRN & \\
\hline CHEMBL1397866 & 688653 & 4.73300 & 00000000 & 005 & 4.9455 & TRN & \\
\hline CHEMBL1336259 & 688653 & 5.38299 & 99999999 & & 5.3761 & TST & \\
\hline CHEMBL1359188 & 688653 & 4.583 & 5.0897 & TST & & & \\
\hline CHEMBL3210192 & 688653 & 5.483 & 4.8653 & TRN & & & \\
\hline CHEMBL227881 & 688653 & 5.83299 & 99999999 & & 5.5336 & TRN & \\
\hline CHEMBL1411072 & 688653 & 4.73300 & 00000000 & 005 & 5.5023 & TRN & \\
\hline CHEMBL1568167 & 688653 & 5.983 & 5.8468 & TRN & & & \\
\hline CHEMBL1529203 & 688653 & 4.583 & 5.0452 & TRN & & & \\
\hline CHEMBL3190871 & 688653 & 4.783 & 5.1501 & TRN & & & \\
\hline CHEMBL3192328 & 688653 & 5.733 & 5.5055 & TRN & & & \\
\hline CHEMBL1547767 & 688653 & 5.183 & 5.3138 & TRN & & & \\
\hline CHEMBL1545250 & 688653 & 6.8831 & 6.37299 & 999999999 & & TRN & \\
\hline CHEMBL1415716 & 688653 & 5.733 & 4.8506 & TST & & & \\
\hline CHEMBL1531848 & 688653 & 4.833 & 5.24 & TRN & & & \\
\hline CHEMBL1329383 & 688653 & 4.883 & 5.2216 & TST & & & \\
\hline CHEMBL1347211 & 688653 & 4.98300 & 00000000 & 005 & 4.9548 & TRN & \\
\hline CHEMBL1496717 & 688653 & 4.73300 & 00000000 & 005 & 5.3259 & TRN & \\
\hline CHEMBL1343438 & 688653 & 5.13299 & 99999999 & & 5.11100 & 0000000001 & TRN \\
\hline CHEMBL3196688 & 688653 & 5.38299 & 99999999 & & 4.5506 & TRN & \\
\hline CHEMBL1359648 & 688653 & 7.3325 & 5.8496 & TRN & & & \\
\hline CHEMBL1375465 & 688653 & 4.783 & 4.768 & TRN & & & \\
\hline CHEMBL1321263 & 688653 & 5.38299 & 99999999 & & 5.1382 & TRN & \\
\hline CHEMBL1324930 & 688653 & 4.73300 & 00000000 & 005 & 5.3518 & TRN & \\
\hline CHEMBL1483252 & 688653 & 5.483 & 5.1865 & TRN & & & \\
\hline CHEMBL 1450286 & 688653 & 5.483 & 5.1822 & TRN & & & \\
\hline CHEMBL1335825 & 688653 & 4.783 & 5.2299 & TST & & & \\
\hline CHEMBL1506350 & 688653 & 5.183 & 4.9699 & TRN & & & \\
\hline CHEMBL1605210 & 688653 & 5.933 & 5.48799 & 999999999 & 995 & TRN & \\
\hline CHEMBL1383783 & 688653 & 5.33299 & 99999999 & & 4.8904 & TRN & \\
\hline CHEMBL1517873 & 688653 & 4.583 & 4.8325 & TRN & & & \\
\hline CHEMBL3211386 & 688653 & 4.73300 & 00000000 & 005 & 5.1851 & TRN & \\
\hline CHEMBL1593678 & 688653 & 4.833 & 5.2121 & TRN & & & \\
\hline CHEMBL1603857 & 688653 & 5.483 & 6.2819 & TRN & & & \\
\hline CHEMBL 387618 & 688653 & 5.88299 & 99999999 & & 5.9681 & TRN & \\
\hline CHEMBL1473162 & 688653 & 5.183 & 4.7058 & TST & & & \\
\hline CHEMBL1373213 & 688653 & 5.683 & 5.2053 & TRN & & & \\
\hline CHEMBL1312636 & 688653 & 4.783 & 5.2265 & TRN & & & \\
\hline CHEMBL1329566 & 688653 & 4.633 & 4.9327 & TST & & & \\
\hline CHEMBL1387794 & 688653 & 4.783 & 5.3708 & TRN & & & \\
\hline CHEMBL1329009 & 688653 & 5.83299 & 99999999 & & 5.4961 & TST & \\
\hline CHEMBL1391286 & 688653 & 4.883 & 4.7979 & TRN & & & \\
\hline CHEMBL3189632 & 688653 & 4.98300 & 00000000 & 005 & 5.2191 & TRN & \\
\hline CHEMBL3207850 & 688653 & 4.73300 & 00000000 & 005 & 5.3189 & TRN & \\
\hline CHEMBL3195842 & 688653 & 5.78299 & 99999999 & 995 & 5.1014 & TST & \\
\hline
\end{tabular}




\begin{tabular}{|c|c|c|c|c|c|c|}
\hline \multirow[b]{2}{*}{ CHEMBL455571 } & & \multicolumn{5}{|c|}{ Supplemental Table S2.txt } \\
\hline & 688653 & 4.833 & 5.5046 & TRN & & \\
\hline CHEMBL3192257 & 688653 & 4.883 & 5.1544 & TST & & \\
\hline CHEMBL1562950 & 688653 & 4.783 & 4.925 & TRN & & \\
\hline CHEMBL1344763 & 688653 & 4.633 & 5.501 & TRN & & \\
\hline CHEMBL1557863 & 688653 & \multicolumn{3}{|c|}{5.632999999999999} & 5.607 & TP \\
\hline CHEMBL1422438 & 688653 & \multicolumn{3}{|c|}{5.132999999999999} & 5.0846 & TRN \\
\hline CHEMBL1542110 & 688653 & 5.183 & 5.6574 & TRN & & \\
\hline CHEMBL1452406 & 688653 & 6.183 & 5.2629 & TRN & & \\
\hline CHEMBL344344 & 588653 & 4.783 & 4.9882 & TRN & & \\
\hline CHEMBL1538118 & 688653 & \multicolumn{3}{|c|}{5.7829999999999995} & 5.4823 & TST \\
\hline CHEMBL1354689 & 688653 & \multicolumn{3}{|c|}{4.7330000000000005} & 5.4768 & \\
\hline CHEMBL1447723 & 688653 & 5.233 & 5.6637 & TRN & & \\
\hline CHEMBL1483340 & 688653 & 4.783 & 5.0716 & TST & & \\
\hline CHEMBL1538985 & 688653 & 4.833 & 5.0412 & TRN & & \\
\hline CHEMBL1398572 & 688653 & 5.733 & 5.8954 & TRN & & \\
\hline CHEMBL1447121 & 688653 & \multicolumn{3}{|c|}{4.9830000000000005} & 5.1135 & $T$ \\
\hline CHEMBL145 & 688653 & 4.833 & 5.3623 & TRN & & \\
\hline CHEMBL1398149 & 688653 & 6.7331 & 5.6032 & TRN & & \\
\hline CHEMBL1317083 & 688653 & \multicolumn{3}{|c|}{4.7330000000000005} & 3135 & \\
\hline CHEMBL3197228 & 688653 & 5.183 & 5.4693 & TRN & & \\
\hline CHEMBL14 & 688 & \multicolumn{3}{|c|}{5.2829999999999995} & 585 & 11 \\
\hline CHEMBL319 & 688653 & 4.933 & 5.4429 & TRN & & \\
\hline CHEMBL1390512 & 688653 & \multirow{2}{*}{\multicolumn{3}{|c|}{$\begin{array}{lcc}5.433 & 5.1448 & \text { TRN } \\
4.9830000000000005\end{array}$}} & & \\
\hline CHEMBL1571094 & 688653 & & & & 2 & $\mathrm{TI}$ \\
\hline CHEMBL1427394 & 688653 & 4.883 & 5.3354 & TRN & & \\
\hline CHEMBL1 & 688 & \multirow{2}{*}{\multicolumn{3}{|c|}{4.9830000000000005}} & & \\
\hline CHEMBL3190487 & 688653 & & & & 5.5422 & $\mathrm{TS}$ \\
\hline CHEMBL1480424 & 688653 & 4.783 & 4.9102 & TRN & & \\
\hline CHEMBL1529331 & 688653 & \multirow{2}{*}{\multicolumn{3}{|c|}{$\begin{array}{lll}4.833 & 5.0543 & \text { TST } \\
5.382999999999999\end{array}$}} & & \\
\hline CHEMBL1532403 & 688653 & & & & 6 & \\
\hline CHEMBL14 & 688 & 4.833 & 4.8542 & TRN & & \\
\hline CHEMBL1482777 & 688653 & \multirow{2}{*}{\multicolumn{2}{|c|}{$\begin{array}{lr}4.583 & 5.1351 \\
5.382999999999\end{array}$}} & TRN & & \\
\hline CHEMBL1525073 & 688653 & & & 5.382999999999999 & 4.8538 & $\mathrm{TR}$ \\
\hline CHEMBL1571635 & 688653 & 4.933 & 4.9852 & TRN & & \\
\hline CHEMBL14 & 688 & \multicolumn{3}{|c|}{4.7330000000000005} & 5.4717 & 12 \\
\hline CHEMBL1406571 & 688653 & 6.233 & 5.4122 & TRN & & \\
\hline CHEMBL1417750 & 688653 & 4.933 & 5.4184 & TRN & & \\
\hline CHEMBL1427233 & 688653 & 4.783 & 4.9652 & TST & & \\
\hline CHEMBL1472362 & 688653 & \multicolumn{3}{|c|}{5.632999999999999} & 5.29 & TST \\
\hline CHEMBL15 & & 4.833 & 5.3222 & TST & & \\
\hline CHEMBL3208919 & 688653 & \multicolumn{3}{|c|}{5.2829999999999995} & 4.9048 & Th \\
\hline CHEMBL1333339 & 688653 & 6.433 & 5.7987 & TRN & & \\
\hline CHEMBL1379389 & 688653 & 5.933 & 6.0163 & TRN & & \\
\hline CHEMBL175296 & 688653 & 4.833 & 5.3403 & TRN & & \\
\hline CHEMBL1611715 & 688653 & \multicolumn{3}{|c|}{4.9830000000000005} & .9063 & TST \\
\hline CHEMBL1322645 & 688653 & 6.0 & 4.7274 & TRN & & \\
\hline CHEMBL1557096 & 688653 & \multicolumn{3}{|c|}{5.132999999999999} & 4.8903 & IKIN \\
\hline CHEMBL1584315 & 688653 & \multicolumn{3}{|c|}{5.882999999999999} & 5.5598 & - \\
\hline
\end{tabular}




\begin{tabular}{|c|c|c|c|c|c|c|}
\hline \multirow[b]{2}{*}{ CHEMBL1347976 } & & \multicolumn{5}{|c|}{ Supplemental Table S2.txt } \\
\hline & 688653 & 4.883 & 5.331 & TST & & \\
\hline CHEMBL1256686 & 688653 & \multicolumn{3}{|c|}{5.132999999999999} & 5.5436 & $\mathrm{~T}$ \\
\hline CHEMBL1939687 & 688653 & 5.233 & 5.7846 & TRN & & \\
\hline CHEMBL1562493 & 688653 & 4.833 & 5.5489 & TRN & & \\
\hline CHEMBL1524524 & 688653 & \multicolumn{3}{|c|}{5.832999999999999} & 5.4942 & \\
\hline CHEMBL1534488 & 688653 & 5.733 & 5.6487 & TRN & & \\
\hline CHEMBL1389542 & 688653 & 4.633 & 5.3687 & TRN & & \\
\hline CHEMBL1423935 & 688653 & 5.433 & 5.2258 & TRN & & \\
\hline CHEMBL1545108 & 688653 & 5.183 & 4.6596 & TRN & & \\
\hline CHEMBL3208278 & 688653 & 4.783 & 5.1057 & TRN & & \\
\hline CHEMBL472929 & 688653 & 6.4829 & 5.8976 & TRN & & \\
\hline CHEMBL1477844 & 688653 & 5.183 & 4.9653 & TRN & & \\
\hline CHEMBL1348092 & 688653 & \multicolumn{3}{|c|}{6.332999999999999} & 5.0311 & \\
\hline CHEMBL1967952 & 688653 & 4.933 & 4.9335 & TST & & \\
\hline CHEMBL1609980 & 688653 & 4.633 & 5.3281 & TST & & \\
\hline CHEMBL1535921 & 688653 & \multicolumn{3}{|c|}{6.832999999999999} & 5.8729 & \\
\hline CHEMBL1568474 & 688653 & \multicolumn{3}{|c|}{5.5329999999999995} & 5.2935 & \\
\hline CHEMBL1525991 & 688653 & 4.783 & 5.0519 & TRN & & \\
\hline CHEMBL1592831 & 688653 & 4.833 & 5.3405 & TRN & & \\
\hline CHEMBL1502856 & 688653 & 4.583 & 5.8499 & TRN & & \\
\hline CHEMBL1599520 & 688653 & \multicolumn{3}{|c|}{4.7330000000000005} & 6 & \\
\hline CHEMBL1303426 & 688653 & 5.433 & 4.8935 & TRN & & \\
\hline CHEMBL1416946 & 688653 & \multicolumn{3}{|c|}{5.882999999999999} & 5.1901 & TP \\
\hline CHEMBL1582654 & 688653 & \multicolumn{3}{|c|}{6.632999999999999} & 6.2324 & \\
\hline CHEMBL1389506 & 688653 & 4.933 & 5.2904 & TRN & & \\
\hline CHEMBL1383945 & 688653 & 4.883 & 5.0945 & TST & & \\
\hline CHEMBL1301356 & 688653 & \multicolumn{3}{|c|}{5.132999999999999} & 4.7479 & \\
\hline CHEMBL1342380 & 688653 & 4.783 & 4.8468 & TRN & & \\
\hline CHEMBL1491932 & 688653 & 5.683 & 5.3606 & TRN & & \\
\hline CHEMBL1489055 & 688653 & \multicolumn{3}{|c|}{5.132999999999999} & 5.3185 & \\
\hline CHEMBL1312656 & 688653 & 6.0 & 5.8898 & TRN & & \\
\hline CHEMBL31S & 688653 & \multicolumn{3}{|c|}{5.332999999999999} & 5.3584 & II \\
\hline CHEMBL1309562 & 688653 & 4.833 & 5.3616 & TRN & & \\
\hline CHEMBL3207579 & 688653 & 5.183 & 5.1381 & TRN & & \\
\hline CHEMBL1477629 & 688653 & 4.683 & 4.7789 & TRN & & \\
\hline CHEMBL1549525 & 688653 & \multicolumn{3}{|c|}{5.332999999999999} & 5.4065 & \\
\hline CHEMBL1471418 & 688653 & 4.633 & 4.5025 & TRN & & \\
\hline CHEMBL1569289 & 688653 & 4.833 & 5.2571 & TRN & & \\
\hline CHEMBL1434829 & 688653 & 5.483 & 5.0453 & TRN & & \\
\hline CHEMBL1412906 & 688653 & 5.233 & 5.1519 & TST & & \\
\hline CHEMBL1588298 & 688653 & 4.783 & 5.3121 & TRN & & \\
\hline CHEMBL1317960 & 688653 & 5.183 & 5.2158 & TRN & & \\
\hline CHEMBL1402159 & 688653 & 5.483 & 5.4498 & TRN & & \\
\hline CHEMBL1376141 & 688653 & \multicolumn{3}{|c|}{5.7829999999999995} & 5.3748 & Tiv \\
\hline CHEMBL1529225 & 688653 & 4.783 & 4.8123 & TRN & & \\
\hline CHEMBL1499127 & 688653 & 4.883 & 4.8026 & TRN & & \\
\hline CHEMBL1519868 & 688653 & \multicolumn{3}{|c|}{6.132999999999999} & 5.4908 & Tार \\
\hline CHEMBL1591740 & 688653 & \multicolumn{3}{|c|}{5.5329999999999995} & 5.8381 & TRN \\
\hline
\end{tabular}




\begin{tabular}{|c|c|c|c|c|c|c|}
\hline & & \multicolumn{5}{|c|}{ Supplemental Table s2.txt } \\
\hline CHEMBL1353902 & 688653 & 5.733 & 5.4102 & TRN & & \\
\hline CHEMBL1464009 & 688653 & 4.833 & 5.5008 & TST & & \\
\hline CHEMBL1367439 & 688653 & 4.633 & 5.3328 & TST & & \\
\hline CHEMBL1602307 & 688653 & \multicolumn{3}{|c|}{5.632999999999999} & 5.5905 & TRN \\
\hline CHEMBL1325491 & 688653 & 5.183 & 4.857 & TRN & & \\
\hline CHEMBL1439396 & 688653 & \multicolumn{3}{|c|}{6.2829999999999995} & 5.9234 & TRN \\
\hline CHEMBL1503900 & 688653 & \multicolumn{3}{|c|}{6.382999999999999} & 5.4759 & TRN \\
\hline CHEMBL1393898 & 688653 & 4.833 & 5.0146 & TST & & \\
\hline CHEMBL1365439 & 688653 & 5.083 & 5.3282 & TRN & & \\
\hline CHEMBL1380153 & 688653 & 4.833 & 4.8557 & TRN & & \\
\hline CHEMBL1462215 & 688653 & \multicolumn{3}{|c|}{5.882999999999999} & 5.5346 & TST \\
\hline CHEMBL1482400 & 688653 & 4.883 & 5.3014 & TRN & & \\
\hline CHEMBL1422210 & 688653 & 4.9 & 5.6101 & TRN & & \\
\hline CHEMBL1437358 & 688653 & \multicolumn{3}{|c|}{4.9830000000000005} & 5.3549 & TST \\
\hline CHEMBL1391081 & 688653 & 4.833 & 5.1716 & TST & & \\
\hline CHEMBL1369668 & 688653 & 5.033 & 5.2016 & TRN & & \\
\hline CHEMBL1371961 & 688653 & 5.933 & 5.3783 & TRN & & \\
\hline CHEMBL1402985 & 688653 & \multicolumn{3}{|c|}{5.2829999999999995} & 5.4237 & TRN \\
\hline CHEMBL1472350 & 688653 & 4.833 & \multicolumn{3}{|c|}{5.167999999999999} & TRN \\
\hline CHEMBL1601812 & 688653 & \multicolumn{3}{|c|}{5.832999999999999} & 5.7367 & TRN \\
\hline CHEMBL3195410 & 688653 & 4.633 & 5.3541 & TRN & & \\
\hline CHEMBL1598973 & 688653 & 5.083 & 5.5311 & TRN & & \\
\hline CHEMBL1368428 & 688653 & 4.583 & 5.6289 & TRN & & \\
\hline CHEMBL1436741 & 688653 & \multicolumn{3}{|c|}{5.2829999999999995} & 5.0485 & TRN \\
\hline CHEMBL1353437 & 688653 & 5.233 & 5.3108 & TRN & & \\
\hline CHEMBL1464277 & 688653 & 4.833 & 4.9759 & TRN & & \\
\hline CHEMBL1337183 & 688653 & 6.0 & 5.1261 & TRN & & \\
\hline CHEMBL 2005079 & 688653 & 5.033 & 5.7652 & TST & & \\
\hline CHEMBL1493860 & 688653 & 4.933 & 5.3536 & TST & & \\
\hline CHEMBL1475049 & 688653 & \multicolumn{3}{|c|}{5.582999999999999} & 5.7381 & TRN \\
\hline CHEMBL153535 & 688653 & 5.983 & 6.0662 & TRN & & \\
\hline CHEMBL1582048 & 688653 & 6.433 & 5.6648 & TRN & & \\
\hline CHEMBL1588495 & 688653 & 6.4829 & 5.4785 & TRN & & \\
\hline CHEMBL3189847 & 688653 & 4.883 & 5.3627 & TRN & & \\
\hline CHEMBL1992517 & 688653 & 4.783 & 5.3576 & TRN & & \\
\hline CHEMBL1611344 & 688653 & 4.583 & 5.0322 & TST & & \\
\hline CHEMBL3207956 & 688653 & 5.433 & 5.3659 & TRN & & \\
\hline CHEMBL1557850 & 688653 & \multicolumn{3}{|c|}{5.882999999999999} & 5.4721 & TRN \\
\hline CHEMBL1488837 & 688653 & \multicolumn{3}{|c|}{4.7330000000000005} & 5.1131 & TRN \\
\hline CHEMBL1611713 & 688653 & 6.683 & \multicolumn{3}{|c|}{6.0120000000000005} & TRN \\
\hline CHEMBL1323984 & 688653 & \multicolumn{3}{|c|}{4.7330000000000005} & 4.8509 & TRN \\
\hline CHEMBL1896042 & 688653 & 4.833 & 5.4518 & TRN & & \\
\hline CHEMBL73451 & 688653 & 4.883 & 5.2474 & TST & & \\
\hline CHEMBL1486369 & 688653 & 4.783 & 5.1733 & TST & & \\
\hline CHEMBL3199945 & 688653 & 4.633 & 5.3797 & TRN & & \\
\hline CHEMBL 3193478 & 688653 & 4.833 & 4.8259 & TST & & \\
\hline CHEMBL1329290 & 688653 & 4.883 & 4.5405 & TRN & & \\
\hline CHEMBL1562873 & 688653 & 5.033 & 5.6349 & TRN & & \\
\hline
\end{tabular}




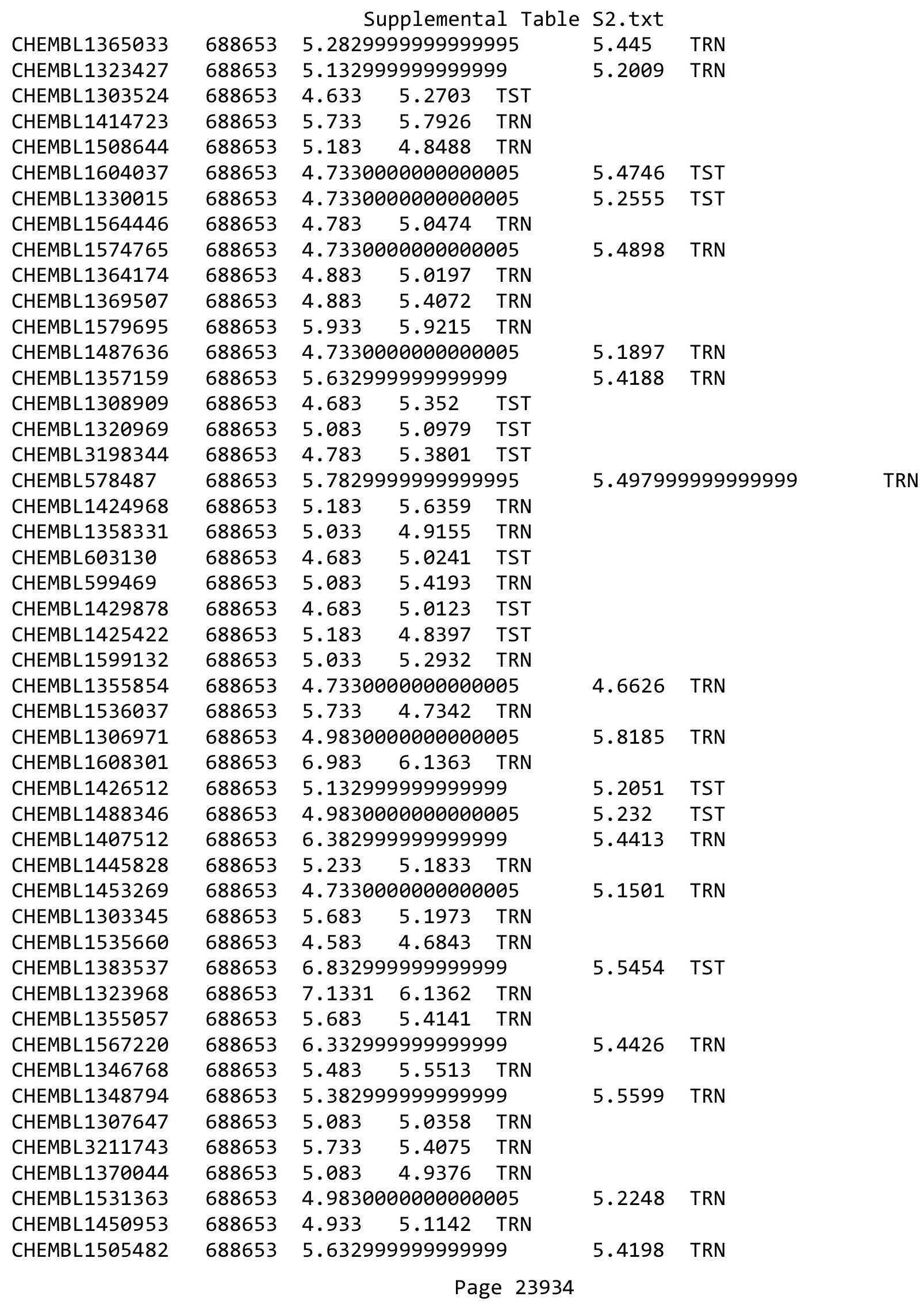




\begin{tabular}{|c|c|c|c|c|c|c|c|}
\hline \multicolumn{7}{|c|}{ Supplemental Table S2.txt } & \\
\hline CHEMBL1506601 & 688653 & \multicolumn{3}{|c|}{4.7330000000000005} & 5.5449 & TRN & \\
\hline CHEMBL 3208184 & 688653 & 4.783 & 5.2883 & TRN & & & \\
\hline CHEMBL1324098 & 688653 & 6.433 & 5.7825 & TRN & & & \\
\hline CHEMBL1326664 & 688653 & 5.05 & 4.9863 & TRN & & & \\
\hline CHEMBL1992745 & 688653 & 6.183 & 5.4415 & TRN & & & \\
\hline CHEMBL1364801 & 688653 & 4.883 & 5.3974 & TST & & & \\
\hline CHEMBL1582181 & 688653 & \multicolumn{3}{|c|}{5.882999999999999} & 5.5613 & TRN & \\
\hline CHEMBL1572758 & 688653 & 5.483 & 5.7905 & TRN & & & \\
\hline CHEMBL1504927 & 688653 & 4.883 & 5.0965 & TRN & & & \\
\hline CHEMBL3214023 & 688653 & 4.583 & 4.669 & TRN & & & \\
\hline CHEMBL1476760 & 688653 & 4.883 & 5.0721 & TRN & & & \\
\hline CHEMBL1366463 & 688653 & \multicolumn{3}{|c|}{4.9830000000000005} & 5.4101 & TRN & \\
\hline CHEMBL1588752 & 688653 & \multicolumn{3}{|c|}{4.9830000000000005} & 5.2019 & TST & \\
\hline CHEMBL3213826 & 688653 & \multicolumn{3}{|c|}{5.132999999999999} & 5.4491 & TRN & \\
\hline CHEMBL1456468 & 688653 & \multicolumn{3}{|c|}{5.632999999999999} & 5.2802 & TRN & \\
\hline CHEMBL1307101 & 688653 & 4.833 & 5.6489 & TRN & & & \\
\hline CHEMBL1378724 & 688653 & \multicolumn{3}{|c|}{5.7829999999999995} & 5.1851 & TRN & \\
\hline CHEMBL1529558 & 688653 & \multicolumn{3}{|c|}{5.132999999999999} & 5.4634 & TRN & \\
\hline CHEMBL1431047 & 688653 & 4.883 & 5.2388 & TST & & & \\
\hline CHEMBL1517894 & 688653 & 5.733 & 5.4266 & TRN & & & \\
\hline CHEMBL1450556 & 688653 & \multicolumn{3}{|c|}{5.132999999999999} & 5.3156 & TRN & \\
\hline CHEMBL1310385 & 688653 & 5.083 & 5.1272 & TRN & & & \\
\hline CHEMBL1458772 & 688653 & 5.483 & 5.2507 & TRN & & & \\
\hline CHEMBL3145367 & 688653 & 4.933 & 5.4403 & TRN & & & \\
\hline CHEMBL1523268 & 688653 & 6.433 & 5.5274 & TRN & & & \\
\hline CHEMBL1346635 & 688653 & \multicolumn{3}{|c|}{5.2829999999999995} & 5.1037 & TRN & \\
\hline CHEMBL1358869 & 688653 & 4.933 & 5.1925 & TRN & & & \\
\hline CHEMBL1416660 & 688653 & \multicolumn{3}{|c|}{5.382999999999999} & 5.5196 & TRN & \\
\hline CHEMBL1414503 & 688653 & 5.733 & 5.4175 & TRN & & & \\
\hline CHEMBL1560434 & 688653 & 4.883 & 5.7789 & TST & & & \\
\hline CHEMBL3210117 & 688653 & \multicolumn{3}{|c|}{5.382999999999999} & 5.3798 & TST & \\
\hline CHEMBL1590804 & 688653 & \multicolumn{3}{|c|}{6.382999999999999} & 5.6235 & TRN & \\
\hline CHEMBL1463478 & 688653 & \multicolumn{3}{|c|}{5.7829999999999995} & 5.3059 & TST & \\
\hline CHEMBL1600887 & 688653 & 4.933 & 5.3922 & TST & & & \\
\hline CHEMBL1593491 & 688653 & \multicolumn{3}{|c|}{5.132999999999999} & 5.1458 & TRN & \\
\hline CHEMBL3209306 & 688653 & \multicolumn{3}{|c|}{5.632999999999999} & 5.3681 & TRN & \\
\hline CHEMBL1486715 & 688653 & 5.733 & 5.5223 & TRN & & & \\
\hline CHEMBL1479892 & 688653 & 4.883 & 5.8924 & TRN & & & \\
\hline CHEMBL1314810 & 688653 & 5.233 & 5.1843 & TRN & & & \\
\hline CHEMBL1453002 & 688653 & 5.5329 & 99999999 & 995 & 5.3242 & TRN & \\
\hline CHEMBL2007318 & 688653 & 4.833 & 5.2222 & TRN & & & \\
\hline CHEMBL1534683 & 688653 & 6.3329 & 99999999 & & 5.4170 & 0000000001 & TRN \\
\hline CHEMBL1511860 & 688653 & 5.3329 & 99999999 & & 5.4946 & TRN & \\
\hline CHEMBL3197446 & 688653 & 6.0329 & 99999999 & 995 & 5.9773 & TRN & \\
\hline CHEMBL1422256 & 688653 & 4.833 & 5.1122 & TRN & & & \\
\hline CHEMBL1429551 & 688653 & 4.783 & 4.7882 & TRN & & & \\
\hline CHEMBL1319762 & 688653 & 4.783 & 5.3068 & TRN & & & \\
\hline CHEMBL1589529 & 688653 & 4.7330 & 00000000 & 005 & 5.358 & TST & \\
\hline
\end{tabular}




\begin{tabular}{|c|c|c|c|c|c|c|c|}
\hline \multicolumn{8}{|c|}{ plemen } \\
\hline CHEMBL1392887 & 688653 & 4.783 & 5.2826 & TRN & & & \\
\hline CHEMBL1555618 & 688653 & \multicolumn{3}{|c|}{5.582999999999999} & 4.7677 & TST & \\
\hline CHEMBL1488093 & 688653 & 5.683 & \multicolumn{3}{|c|}{5.787000000000001} & TRN & \\
\hline CHEMBL1429432 & 688653 & 6.9329 & 5.8614 & TST & & & \\
\hline CHEMBL1319729 & 688653 & \multicolumn{3}{|c|}{5.132999999999999} & 5.1633 & TRN & \\
\hline CHEMBL1434706 & 688653 & 5.183 & 5.303 & TRN & & & \\
\hline CHEMBL1382185 & 688653 & 4.833 & 5.244 & TRN & & & \\
\hline CHEMBL1347493 & 688653 & 5.733 & 5.4302 & TRN & & & \\
\hline CHEMBL1521023 & 688653 & \multicolumn{3}{|c|}{6.082999999999999} & 5.7651 & TRN & \\
\hline CHEMBL1524710 & 688653 & 4.633 & 5.1823 & TST & & & \\
\hline CHEMBL1594868 & 688653 & 5.683 & 5.7011 & TRN & & & \\
\hline CHEMBL1468962 & 688653 & 4.633 & 5.0093 & TRN & & & \\
\hline CHEMBL1447068 & 688653 & 5.933 & 4.9584 & TRN & & & \\
\hline CHEMBL1422255 & 688653 & 4.833 & 5.2277 & TRN & & & \\
\hline CHEMBL1469826 & 688653 & 5.683 & 5.356 & TRN & & & \\
\hline CHEMBL1308108 & 688653 & \multicolumn{3}{|c|}{4.7330000000000005} & 5.2264 & TRN & \\
\hline CHEMBL 2004942 & 688653 & 5.233 & 5.3016 & TRN & & & \\
\hline CHEMBL1313187 & 688653 & \multicolumn{3}{|c|}{6.5329999999999995} & 5.9173 & TRN & \\
\hline CHEMBL1386577 & 688653 & 4.583 & 4.9374 & TST & & & \\
\hline CHEMBL1464757 & 688653 & 5.683 & 4.7751 & TST & & & \\
\hline CHEMBL1367146 & 688653 & \multicolumn{3}{|c|}{4.7330000000000005} & 5.4152 & TST & \\
\hline CHEMBL1473362 & 688653 & 5.183 & 5.7684 & TRN & & & \\
\hline CHEMBL1514732 & 688653 & \multicolumn{3}{|c|}{5.582999999999999} & 5.5281 & TST & \\
\hline CHEMBL1511313 & 688653 & 4.883 & 5.1354 & TRN & & & \\
\hline CHEMBL1423071 & 688653 & 6.983 & 5.6534 & TRN & & & \\
\hline CHEMBL3198899 & 688653 & \multicolumn{3}{|c|}{6.332999999999999} & 5.2746 & TRN & \\
\hline CHEMBL1308188 & 688653 & \multicolumn{3}{|c|}{5.7829999999999995} & 5.4582 & TRN & \\
\hline CHEMBL1416585 & 688653 & 4.883 & 5.3991 & TRN & & & \\
\hline CHEMBL1337776 & 688653 & 5.183 & 5.6879 & TRN & & & \\
\hline CHEMBL1405252 & 688653 & 4.883 & 5.1341 & TRN & & & \\
\hline CHEMBL1332770 & 688653 & \multicolumn{3}{|c|}{5.132999999999999} & 5.6203 & TRN & \\
\hline CHEMBL1600468 & 688653 & 4.783 & 5.3732 & TRN & & & \\
\hline CHEMBL1415851 & 688653 & 4.783 & 5.4039 & TST & & & \\
\hline CHEMBL1312289 & 688653 & \multicolumn{3}{|c|}{5.832999999999999} & 5.483 & TRN & \\
\hline CHEMBL1464144 & 688653 & 6.183 & 5.6795 & TRN & & & \\
\hline CHEMBL1391623 & 688653 & \multicolumn{3}{|c|}{5.132999999999999} & 5.3993 & TRN & \\
\hline CHEMBL1512230 & 688653 & \multicolumn{3}{|c|}{4.7330000000000005} & 5.1272 & TRN & \\
\hline CHEMBL1505248 & 688653 & 5.033 & 4.5223 & TST & & & \\
\hline CHEMBL1394491 & 688653 & \multicolumn{3}{|c|}{5.2829999999999995} & 4.7552 & TRN & \\
\hline CHEMBL1439817 & 688653 & 4.833 & 5.3907 & TRN & & & \\
\hline CHEMBL1459630 & 688653 & 4.833 & 5.1157 & TRN & & & \\
\hline CHEMBL1409243 & 688653 & \multicolumn{3}{|c|}{5.7829999999999995} & 5.12700 & 0000000001 & TRN \\
\hline CHEMBL 274070 & 688653 & \multicolumn{3}{|c|}{5.882999999999999} & 5.9938 & TST & \\
\hline CHEMBL1324125 & 688653 & 5.683 & 5.4302 & TST & & & \\
\hline CHEMBL1467749 & 688653 & \multicolumn{3}{|c|}{6.2829999999999995} & 5.1812 & TST & \\
\hline CHEMBL1340591 & 688653 & 4.933 & 5.2965 & TRN & & & \\
\hline CHEMBL1571014 & 688653 & 4.833 & 5.2673 & TRN & & & \\
\hline CHEMBL1433343 & 688653 & 6.28299 & 999999999 & 995 & 5.9207 & TRN & \\
\hline
\end{tabular}




\begin{tabular}{|c|c|c|c|c|c|c|}
\hline & & & pplemen & I & s2.txt & \\
\hline CHEMBL1480069 & 688653 & 4.9830 & 0000000 & 205 & 5.3545 & TRN \\
\hline CHEMBL1339467 & 688653 & 5.033 & 5.381 & TRN & & \\
\hline CHEMBL1550862 & 688653 & 4.583 & 5.246 & TRN & & \\
\hline CHEMBL1505267 & 688653 & 5.2829 & 9999999 & 995 & 5.7911 & TRN \\
\hline CHEMBL1550339 & 688653 & 4.9830 & 0000000 & 205 & 5.1489 & TRN \\
\hline CHEMBL3196049 & 688653 & 4.933 & 4.8985 & TRN & & \\
\hline CHEMBL1560628 & 688653 & 5.233 & 5.5146 & TST & & \\
\hline CHEMBL1540231 & 688653 & 4.633 & 4.3583 & TST & & \\
\hline CHEMBL1504572 & 688653 & 4.7330 & 0000000 & 205 & 5.064 & TRN \\
\hline CHEMBL1453876 & 688653 & 4.883 & 4.9177 & TRN & & \\
\hline CHEMBL1364224 & 688653 & 5.733 & 5.8598 & TRN & & \\
\hline CHEMBL473074 & 688653 & 4.833 & 4.9883 & TST & & \\
\hline CHEMBL1359358 & 688653 & 5.5329 & 9999999 & 995 & 5.6523 & TRN \\
\hline CHEMBL3195881 & 688653 & 5.683 & 5.1734 & TST & & \\
\hline CHEMBL1497836 & 688653 & 4.883 & 5.4256 & TRN & & \\
\hline CHEMBL1440235 & 688653 & 4.633 & 5.5651 & TRN & & \\
\hline CHEMBL3192360 & 688653 & 5.1329 & 9999999 & & 5.0145 & TST \\
\hline CHEMBL1568436 & 688653 & 4.833 & 5.1278 & TRN & & \\
\hline CHEMBL3193315 & 688653 & 4.883 & 5.3848 & TRN & & \\
\hline CHEMBL1436458 & 688653 & 4.583 & 5.3119 & TRN & & \\
\hline CHEMBL1463574 & 688653 & 5.183 & 5.3404 & TST & & \\
\hline CHEMBL 3145048 & 688653 & 7.5834 & 5.5561 & TRN & & \\
\hline CHEMBL1595787 & 688653 & 5.1329 & 9999999 & & 5.3235 & TRN \\
\hline CHEMBL1516657 & 688653 & 5.983 & 5.1335 & TRN & & \\
\hline CHEMBL1463121 & 688653 & 4.883 & 5.056 & TST & & \\
\hline CHEMBL1359241 & 688653 & 4.7330 & 0000000 & 205 & 4.9811 & TRN \\
\hline CHEMBL1511132 & 688653 & 4.883 & 5.0668 & TRN & & \\
\hline CHEMBL1464103 & 688653 & 6.183 & 5.1776 & TST & & \\
\hline CHEMBL3195922 & 688653 & 4.9830 & 0000000 & 205 & 5.5002 & TRN \\
\hline CHEMBL1372087 & 688653 & 5.7829 & 9999999 & 995 & 5.4516 & TRN \\
\hline CHEMBL1355741 & 688653 & 4.683 & 5.2122 & TRN & & \\
\hline CHEMBL1491406 & 688653 & 4.883 & 5.4213 & TST & & \\
\hline CHEMBL1378459 & 688653 & 5.5329 & 9999999 & 995 & 5.7517 & TRN \\
\hline CHEMBL1406463 & 688653 & 4.7330 & 0000000 & 205 & 5.2171 & TRN \\
\hline CHEMBL112115 & 688653 & 6.433 & 5.9206 & TRN & & \\
\hline CHEMBL1453914 & 688653 & 5.733 & 5.4113 & TRN & & \\
\hline CHEMBL1408224 & 688653 & 6.0329 & 9999999 & 995 & 5.5431 & TRN \\
\hline CHEMBL1404430 & 688653 & 4.633 & 4.938 & TRN & & \\
\hline CHEMBL1379195 & 688653 & 4.783 & 5.439 & TST & & \\
\hline CHEMBL1551944 & 688653 & 4.583 & 4.7626 & TRN & & \\
\hline CHEMBL1380702 & 688653 & 5.6329 & 9999999 & & 5.4461 & TRN \\
\hline CHEMBL1379390 & 688653 & 4.933 & 5.9676 & TRN & & \\
\hline CHEMBL1563187 & 688653 & 6.0829 & 9999999 & & 5.6785 & TRN \\
\hline CHEMBL1404118 & 688653 & 6.3329 & 9999999 & & 4.9668 & TRN \\
\hline CHEMBL3197509 & 688653 & 4.783 & 5.0328 & TST & & \\
\hline CHEMBL1369926 & 688653 & 6.2829 & 9999999 & 995 & 5.7664 & TRN \\
\hline CHEMBL1365725 & 688653 & 4.9830 & 0000000 & 205 & 5.3784 & TST \\
\hline CHEMBL3209279 & 688653 & 5.7829 & 9999999 & 995 & 5.4384 & TRN \\
\hline
\end{tabular}




\begin{tabular}{|c|c|c|c|c|c|c|c|}
\hline \multicolumn{8}{|c|}{ Supplemental Table s2.txt } \\
\hline CHEMBL1344841 & 688653 & 5.683 & 5.4761 & TRN & & & \\
\hline CHEMBL1372414 & 688653 & 5.183 & 5.7534 & TRN & & & \\
\hline CHEMBL3196309 & 688653 & 6.433 & 5.9581 & TRN & & & \\
\hline CHEMBL1306377 & 688653 & 5.033 & 4.8101 & TRN & & & \\
\hline CHEMBL1577702 & 688653 & 4.833 & 4.9288 & TRN & & & \\
\hline CHEMBL1393435 & 688653 & 4.833 & 5.0277 & TST & & & \\
\hline CHEMBL1523337 & 688653 & \multicolumn{3}{|c|}{5.632999999999999} & 4.7815 & TRN & \\
\hline CHEMBL1519381 & 688653 & 4.933 & 5.7715 & TST & & & \\
\hline CHEMBL1331686 & 688653 & \multicolumn{3}{|c|}{6.332999999999999} & 5.7332 & TRN & \\
\hline CHEMBL1418940 & 688653 & 4.583 & 5.1315 & TST & & & \\
\hline CHEMBL1354315 & 688653 & \multicolumn{3}{|c|}{5.382999999999999} & 5.2744 & TST & \\
\hline CHEMBL1322922 & 688653 & 4.9 & 5.1692 & TRN & & & \\
\hline CHEMBL1450300 & 688653 & 4.883 & 4.7373 & TRN & & & \\
\hline CHEMBL1485802 & 688653 & 4.783 & 4.9356 & TRN & & & \\
\hline CHEMBL1342214 & 688653 & 5.183 & 4.9507 & TRN & & & \\
\hline CHEMBL1453960 & 688653 & \multicolumn{3}{|c|}{6.582999999999999} & 5.3712 & TRN & \\
\hline CHEMBL1583361 & 688653 & 5.183 & 5.0922 & TRN & & & \\
\hline CHEMBL1449551 & 688653 & \multicolumn{3}{|c|}{5.132999999999999} & 5.5668 & TRN & \\
\hline CHEMBL 3191477 & 688653 & 5.183 & 5.3328 & TST & & & \\
\hline CHEMBL1437216 & 688653 & 5.183 & 4.8703 & TST & & & \\
\hline CHEMBL1570559 & 688653 & \multicolumn{3}{|c|}{5.132999999999999} & 5.1187 & TRN & \\
\hline CHEMBL3195799 & 688653 & 4.783 & 5.3441 & TRN & & & \\
\hline CHEMBL1409268 & 688653 & 6.0 & 5.483 & TRN & & & \\
\hline CHEMBL1372672 & 688653 & \multicolumn{3}{|c|}{4.7330000000000005} & 5.4897 & TST & \\
\hline CHEMBL1339359 & 688653 & 4.883 & 5.1274 & TRN & & & \\
\hline CHEMBL1585812 & 688653 & \multicolumn{3}{|c|}{4.9830000000000005} & 5.2638 & TRN & \\
\hline CHEMBL1589970 & 688653 & 4.783 & 5.1684 & TST & & & \\
\hline CHEMBL3199633 & 688653 & 5.683 & 5.3667 & TRN & & & \\
\hline CHEMBL1492945 & 688653 & 4.783 & 5.0455 & TRN & & & \\
\hline CHEMBL1356550 & 688653 & 4.933 & 5.3529 & TRN & & & \\
\hline CHEMBL1597244 & 688653 & 4.833 & 5.0912 & TRN & & & \\
\hline CHEMBL1446875 & 688653 & 5.733 & 5.4942 & TRN & & & \\
\hline CHEMBL1455821 & 688653 & \multicolumn{3}{|c|}{5.882999999999999} & 5.3953 & TST & \\
\hline CHEMBL1307618 & 688653 & \multicolumn{3}{|c|}{5.582999999999999} & 5.5782 & TRN & \\
\hline CHEMBL1330933 & 688653 & \multicolumn{3}{|c|}{6.332999999999999} & 5.6608 & TRN & \\
\hline CHEMBL1428197 & 688653 & 4.833 & 5.1556 & TRN & & & \\
\hline CHEMBL1975525 & 688653 & 6.183 & 5.3533 & TRN & & & \\
\hline CHEMBL3211100 & 688653 & \multicolumn{3}{|c|}{5.2829999999999995} & 5.1025 & TRN & \\
\hline CHEMBL1450944 & 688653 & 5.083 & 5.0589 & TRN & & & \\
\hline CHEMBL1482333 & 688653 & 4.633 & 4.816 & TRN & & & \\
\hline CHEMBL1594396 & 688653 & \multicolumn{3}{|c|}{4.7330000000000005} & 5.2029 & 9999999999 & TST \\
\hline CHEMBL3198076 & 688653 & 4.833 & 5.244 & TRN & & & \\
\hline CHEMBL1357904 & 688653 & \multicolumn{3}{|c|}{5.582999999999999} & 4.8845 & TRN & \\
\hline CHEMBL1540036 & 688653 & 4.583 & 5.1725 & TST & & & \\
\hline CHEMBL1307065 & 688653 & \multicolumn{3}{|c|}{5.132999999999999} & 4.9614 & TST & \\
\hline CHEMBL3192121 & 688653 & 5.683 & 5.6955 & TRN & & & \\
\hline CHEMBL1383620 & 688653 & 4.833 & 5.171 & TRN & & & \\
\hline CHEMBL1391134 & 688653 & \multicolumn{3}{|c|}{5.7829999999999995} & 5.0152 & TRN & \\
\hline
\end{tabular}




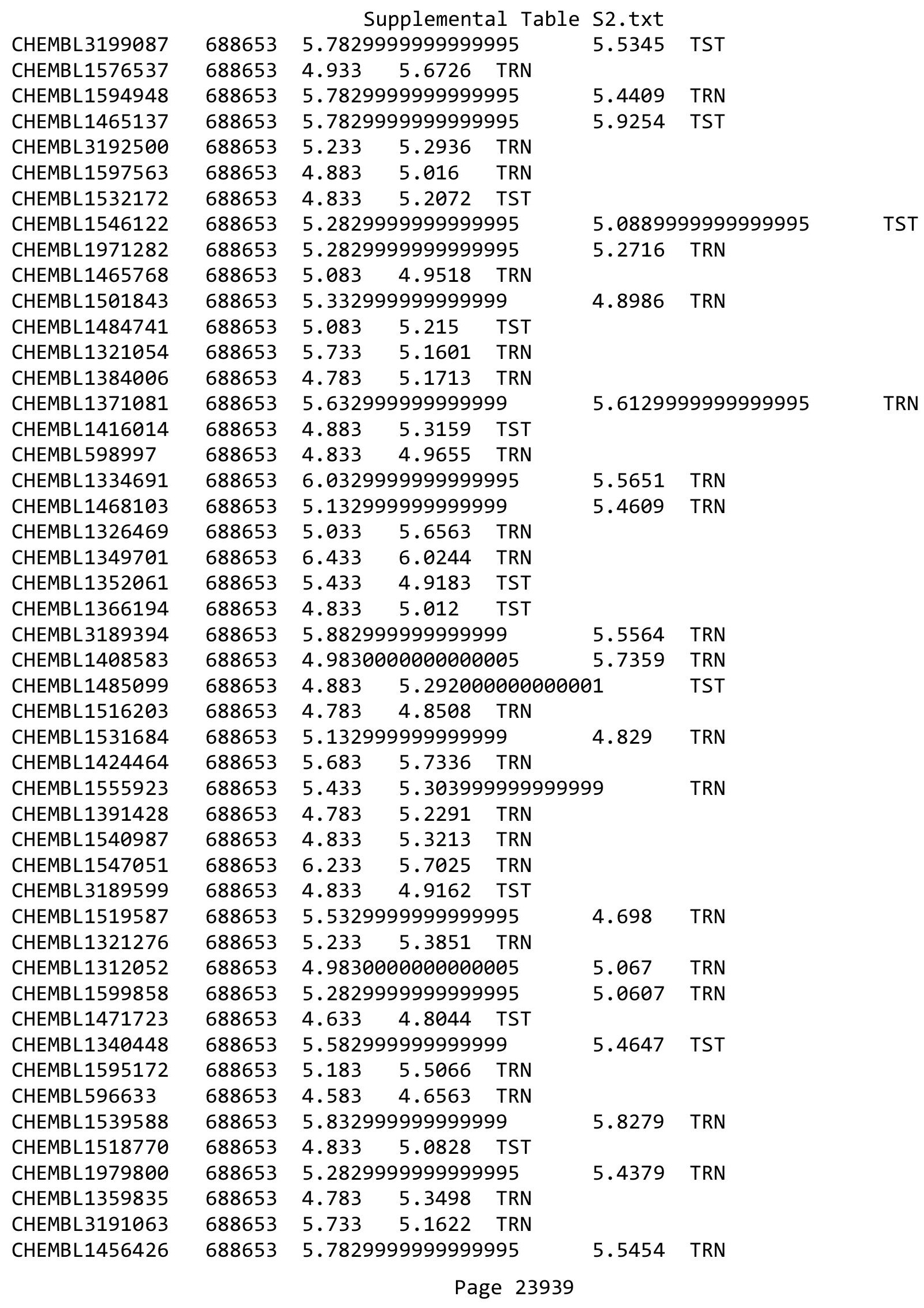




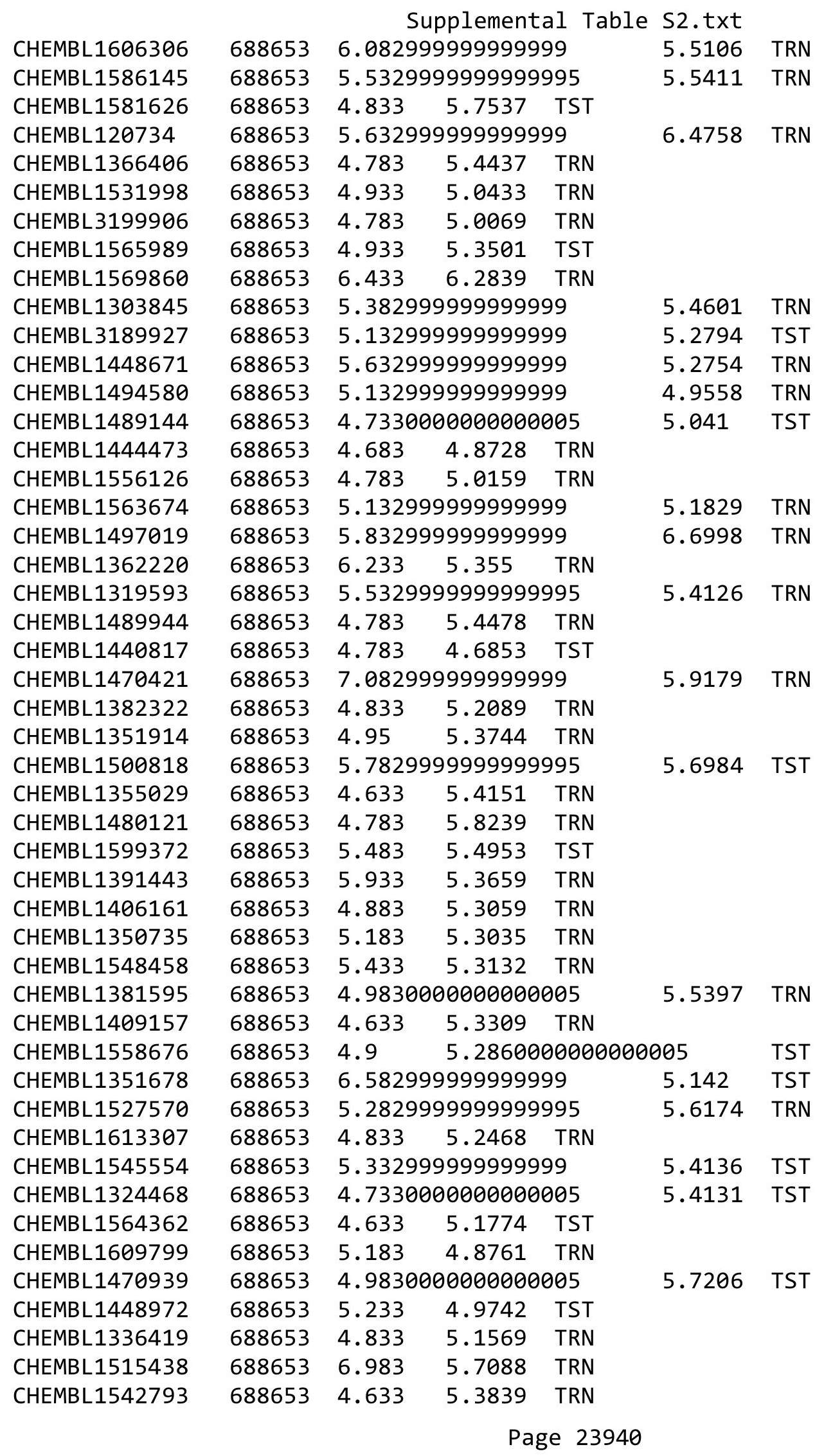




\begin{tabular}{|c|c|c|c|c|c|c|}
\hline \multirow{3}{*}{$\begin{array}{l}\text { CHEMBL1381270 } \\
\text { CHEMBL1323331 }\end{array}$} & \multirow{3}{*}{$\begin{array}{l}688653 \\
688653\end{array}$} & \multicolumn{4}{|c|}{ Supplemental Table S2.txt } & \multirow{2}{*}{ TRN } \\
\hline & & \multicolumn{3}{|c|}{5.382999999999999} & 5.4066 & \\
\hline & & 5.183 & 4.7969 & TRN & & \\
\hline CHEMBL1354471 & 688653 & 5.483 & 5.0351 & TRN & & \\
\hline CHEMBL3190638 & 688653 & 4.783 & 5.1726 & TST & & \\
\hline CHEMBL1530166 & 688653 & 4.833 & 4.9864 & TRN & & \\
\hline CHEMBL3195225 & 688653 & 5.033 & 5.7585 & TRN & & \\
\hline CHEMBL1395301 & 688653 & \multicolumn{3}{|c|}{6.0329999999999995} & 5.2511 & TRN \\
\hline CHEMBL1419626 & 688653 & 4.933 & 5.5446 & TRN & & \\
\hline CHEMBL1346887 & 688653 & 4.933 & 5.3164 & TRN & & \\
\hline CHEMBL1324384 & 688653 & \multicolumn{3}{|c|}{4.7330000000000005} & 5.1923 & TRN \\
\hline CHEMBL1571556 & 688653 & 4.583 & 4.9247 & TST & & \\
\hline CHEMBL1582854 & 688653 & \multicolumn{3}{|c|}{6.382999999999999} & 5.7236 & TST \\
\hline CHEMBL1365226 & 688653 & 4.783 & 5.0902 & TST & & \\
\hline CHEMBL1580032 & 688653 & 5.033 & 4.9964 & TRN & & \\
\hline CHEMBL1444917 & 688653 & \multicolumn{3}{|c|}{4.9830000000000005} & 5.4815 & TRN \\
\hline CHEMBL1497091 & 688653 & \multicolumn{3}{|c|}{5.382999999999999} & 5.1274 & TST \\
\hline CHEMBL1579597 & 688653 & 4.883 & 5.4047 & TST & & \\
\hline CHEMBL1420873 & 688653 & 5.183 & 5.309 & TST & & \\
\hline CHEMBL585221 & 688653 & 4.783 & 5.4448 & TST & & \\
\hline CHEMBL1411761 & 688653 & 4.933 & 5.7466 & TST & & \\
\hline CHEMBL1505395 & 688653 & 5.233 & 5.3039 & TRN & & \\
\hline CHEMBL3198091 & 688653 & 5.433 & 5.5392 & TST & & \\
\hline CHEMBL3199175 & 688653 & 4.883 & 5.5343 & TRN & & \\
\hline CHEMBL1519501 & 688653 & 4.833 & 5.8332 & TRN & & \\
\hline CHEMBL1435190 & 688653 & 5.033 & 5.6431 & TRN & & \\
\hline CHEMBL1605715 & 688653 & 4.583 & 4.8459 & TST & & \\
\hline CHEMBL1382429 & 688653 & \multicolumn{3}{|c|}{5.7829999999999995} & 5.2377 & TRN \\
\hline CHEMBL1517382 & 688653 & \multicolumn{3}{|c|}{6.582999999999999} & 4.9603 & TST \\
\hline CHEMBL1473689 & 688653 & 4.883 & \multicolumn{3}{|c|}{5.662000000000001} & TRN \\
\hline CHEMBL1563733 & 688653 & 4.883 & 5.226 & TRN & & \\
\hline CHEMBL1458728 & 688653 & \multicolumn{3}{|c|}{4.9830000000000005} & 5.1076 & TRN \\
\hline CHEMBL1399011 & 688653 & 5.683 & 5.0567 & TRN & & \\
\hline CHEMBL581929 & 688653 & \multicolumn{3}{|c|}{5.332999999999999} & 5.1051 & TRN \\
\hline CHEMBL1600434 & 688653 & 4.883 & 5.5757 & TRN & & \\
\hline CHEMBL1611142 & 688653 & \multicolumn{3}{|c|}{6.082999999999999} & 5.4256 & TRN \\
\hline CHEMBL1479779 & 688653 & 5.933 & 5.3036 & TST & & \\
\hline CHEMBL1407088 & 688653 & \multirow{2}{*}{\multicolumn{3}{|c|}{ 6.132999999999999 }} & & \\
\hline CHEMBL465980 & 688653 & & & & 5.695 & TRN \\
\hline CHEMBL1170069 & 688653 & 5.683 & 5.2097 & TRN & & \\
\hline CHEMBL1537475 & 688653 & 4.833 & 5.1787 & TRN & & \\
\hline CHEMBL1366037 & 688653 & \multicolumn{3}{|c|}{5.7829999999999995} & 5.4492 & TRN \\
\hline CHEMBL1528739 & 688653 & 4.583 & 5.1211 & TRN & & \\
\hline CHEMBL1439477 & 688653 & 5.933 & 5.8597 & TRN & & \\
\hline CHEMBL1347777 & 688653 & \multicolumn{3}{|c|}{5.132999999999999} & 5.5166 & TRN \\
\hline CHEMBL3197909 & 688653 & 5.083 & 5.1577 & TST & & \\
\hline CHEMBL1440203 & 688653 & 4.683 & 5.0773 & TRN & & \\
\hline CHEMBL1562170 & 688653 & 5.183 & 5.9761 & TRN & & \\
\hline CHEMBL1343037 & 688653 & \multicolumn{3}{|c|}{5.5329999999999995} & 5.4515 & TRN \\
\hline
\end{tabular}




\begin{tabular}{|c|c|c|c|c|c|c|c|}
\hline \multicolumn{7}{|c|}{ Supplemental Table S2.txt } & \\
\hline CHEMBL1504529 & 688653 & \multicolumn{3}{|c|}{5.382999999999999} & 4.8387 & TST & \\
\hline CHEMBL1503034 & 688653 & 4.583 & 5.4956 & TRN & & & \\
\hline CHEMBL1483161 & 688653 & 4.633 & 5.129 & TST & & & \\
\hline CHEMBL1306040 & 688653 & 4.833 & 5.2072 & TST & & & \\
\hline CHEMBL3195314 & 688653 & 5.233 & 5.3033 & TRN & & & \\
\hline CHEMBL1356887 & 688653 & \multicolumn{3}{|c|}{5.7829999999999995} & 5.4193 & TRN & \\
\hline CHEMBL1393548 & 688653 & \multicolumn{3}{|c|}{4.7330000000000005} & 4.9371 & TST & \\
\hline CHEMBL1382562 & 688653 & \multicolumn{3}{|c|}{5.5329999999999995} & 4.9819 & TST & \\
\hline CHEMBL1530363 & 688653 & 4.883 & 5.3365 & TST & & & \\
\hline CHEMBL1527187 & 688653 & \multicolumn{3}{|c|}{6.132999999999999} & 5.7869 & TRN & \\
\hline CHEMBL1604794 & 688653 & \multicolumn{3}{|c|}{6.582999999999999} & 5.6481 & TRN & \\
\hline CHEMBL1466948 & 688653 & 6.8831 & 6.3309 & TRN & & & \\
\hline CHEMBL3199275 & 688653 & 5.483 & 5.2113 & TRN & & & \\
\hline CHEMBL3192802 & 688653 & \multicolumn{3}{|c|}{5.332999999999999} & 4.9997 & TST & \\
\hline CHEMBL1319945 & 688653 & \multicolumn{3}{|c|}{4.9830000000000005} & 5.4872 & TST & \\
\hline CHEMBL1506203 & 688653 & \multicolumn{3}{|c|}{5.882999999999999} & 5.3278 & TST & \\
\hline CHEMBL1312422 & 688653 & 4.933 & 4.9402 & TST & & & \\
\hline CHEMBL1424379 & 688653 & 4.783 & 5.1781 & TRN & & & \\
\hline CHEMBL1480325 & 688653 & 4.783 & 4.9972 & TRN & & & \\
\hline CHEMBL1396329 & 688653 & 4.833 & 5.4345 & TRN & & & \\
\hline CHEMBL1378444 & 688653 & \multicolumn{3}{|c|}{5.2829999999999995} & 5.483 & TRN & \\
\hline CHEMBL3196123 & 688653 & \multicolumn{3}{|c|}{5.7829999999999995} & 5.5154 & TRN & \\
\hline CHEMBL1601807 & 688653 & \multicolumn{3}{|c|}{6.0329999999999995} & 5.4741 & TRN & \\
\hline CHEMBL1998521 & 688653 & 7.0329 & 6.0898 & TRN & & & \\
\hline CHEMBL1501924 & 688653 & \multicolumn{3}{|c|}{5.132999999999999} & 5.3239 & TRN & \\
\hline CHEMBL1528157 & 688653 & \multicolumn{3}{|c|}{5.632999999999999} & 5.6694 & TRN & \\
\hline CHEMBL1485287 & 688653 & 5.683 & 5.5018 & TRN & & & \\
\hline CHEMBL1416380 & 688653 & 5.233 & 5.2426 & TRN & & & \\
\hline CHEMBL1517000 & 688653 & 6.4829 & 6.0097 & TRN & & & \\
\hline CHEMBL1437363 & 688653 & \multicolumn{3}{|c|}{4.7330000000000005} & 5.3541 & TRN & \\
\hline CHEMBL1382331 & 688653 & 4.833 & 5.2237 & TST & & & \\
\hline CHEMBL3196868 & 688653 & \multicolumn{3}{|c|}{5.582999999999999} & 5.6674 & TST & \\
\hline CHEMBL1518000 & 688653 & 4.833 & 5.2778 & TST & & & \\
\hline CHEMBL1536020 & 688653 & \multirow{2}{*}{\multicolumn{3}{|c|}{$\begin{array}{lll}5.083 & 5.6318 & \text { TRN }\end{array}$}} & & & \\
\hline CHEMBL1501851 & 688653 & \multicolumn{2}{|c|}{5.832999999999999} & & 5.3775 & TST & \\
\hline CHEMBL1448627 & 688653 & 4.883 & 5.5311 & TST & & & \\
\hline CHEMBL1338965 & 688653 & 5.033 & 5.3288 & TRN & & & \\
\hline CHEMBL1312568 & 688653 & 5.033 & 6.1261 & TRN & & & \\
\hline CHEMBL1420007 & 688653 & 5.233 & 5.0798 & TRN & & & \\
\hline CHEMBL1404262 & 688653 & 5.033 & 5.0421 & TRN & & & \\
\hline CHEMBL1586994 & 688653 & \multicolumn{3}{|c|}{5.7829999999999995} & \multicolumn{2}{|c|}{5.281000000000001} & TRN \\
\hline CHEMBL1460414 & 688653 & 5.083 & 4.8677 & TRN & & & \\
\hline CHEMBL1372066 & 688653 & 5.6329 & 99999999 & & 5.6655 & TRN & \\
\hline CHEMBL1509747 & 688653 & 4.783 & 5.1067 & TRN & & & \\
\hline CHEMBL1353989 & 688653 & 5.2829 & 99999999 & 995 & 5.8272 & TRN & \\
\hline CHEMBL1611342 & 688653 & 4.7330 & 00000000 & 005 & 5.1166 & TRN & \\
\hline CHEMBL1612169 & 688653 & 4.833 & 5.0744 & TST & & & \\
\hline CHEMBL3190207 & 688653 & 5.3829 & 99999999 & & 5.6224 & TRN & \\
\hline
\end{tabular}




\begin{tabular}{|c|c|c|c|c|c|c|c|}
\hline \multicolumn{8}{|c|}{ Supplemental Ta } \\
\hline CHEMBL1410469 & 688653 & 5.433 & 5.2565 & TRN & & & \\
\hline CHEMBL3195378 & 688653 & $4.7330 e$ & 000000006 & 005 & 5.4083 & TST & \\
\hline CHEMBL1383378 & 688653 & 5.733 & 5.6977 & TRN & & & \\
\hline CHEMBL1420838 & 688653 & 6.28299 & 999999995 & 995 & 5.5568 & TRN & \\
\hline CHEMBL1540611 & 688653 & 4.883 & 5.117 & TRN & & & \\
\hline CHEMBL1441319 & 688653 & 5.983 & 5.5994 & TRN & & & \\
\hline CHEMBL3197456 & 688653 & 5.083 & 5.2671 & TRN & & & \\
\hline CHEMBL1376466 & 688653 & 4.833 & 5.1904 & TRN & & & \\
\hline CHEMBL1392322 & 688653 & 5.433 & 5.2568 & TRN & & & \\
\hline CHEMBL1372535 & 688653 & 6.83299 & 999999995 & & 5.7174 & TRN & \\
\hline CHEMBL1447489 & 688653 & 4.783 & 5.1487 & TRN & & & \\
\hline CHEMBL1380513 & 688653 & 6.63299 & 999999995 & & 5.5677 & TRN & \\
\hline CHEMBL3193092 & 688653 & 4.883 & 5.0002 & TST & & & \\
\hline CHEMBL1584247 & 688653 & $4.7330 e$ & 00000000 & 005 & 5.0966 & TRN & \\
\hline CHEMBL1559360 & 688653 & 5.38299 & 99999999 & & 5.3077 & TRN & \\
\hline CHEMBL1459195 & 688653 & 5.083 & 5.4489 & TST & & & \\
\hline CHEMBL1540986 & 688653 & 5.13299 & 999999999 & & 5.1222 & TRN & \\
\hline CHEMBL1470495 & 688653 & 6.58299 & 999999995 & & 5.88299 & 9999999999 & TRN \\
\hline CHEMBL1414877 & 688653 & 4.783 & 5.1227 & TRN & & & \\
\hline CHEMBL1340015 & 688653 & 5.183 & 5.8974 & TRN & & & \\
\hline CHEMBL1580368 & 688653 & 5.33299 & 999999999 & & 5.2314 & TRN & \\
\hline CHEMBL3213140 & 688653 & 4.883 & 5.4311 & TST & & & \\
\hline CHEMBL1405760 & 688653 & $4.7330 e$ & 000000006 & 005 & 4.9693 & TRN & \\
\hline CHEMBL1487834 & 688653 & 4.833 & 4.9871 & TRN & & & \\
\hline CHEMBL1484017 & 688653 & 4.783 & 5.221 & TRN & & & \\
\hline CHEMBL1459020 & 688653 & 5.83299 & 999999999 & & 5.2816 & TRN & \\
\hline CHEMBL1557044 & 688653 & 4.833 & 5.8301 & TRN & & & \\
\hline CHEMBL1499860 & 688653 & 4.833 & 4.9504 & TRN & & & \\
\hline CHEMBL1425795 & 688653 & 5.683 & 5.4803 & TRN & & & \\
\hline CHEMBL1573488 & 688653 & 5.733 & 5.3916 & TRN & & & \\
\hline CHEMBL3192108 & 688653 & 7.3325 & 6.7395 & TRN & & & \\
\hline CHEMBL1463989 & 688653 & 6.233 & 5.1484 & TRN & & & \\
\hline CHEMBL1504310 & 688653 & 5.483 & 5.2263 & TST & & & \\
\hline CHEMBL1562186 & 688653 & 4.933 & 5.2451 & TST & & & \\
\hline CHEMBL1376080 & 688653 & 5.183 & 5.1975 & TRN & & & \\
\hline CHEMBL1325776 & 688653 & 5.28299 & 999999995 & 995 & 5.1239 & TRN & \\
\hline CHEMBL1418430 & 688653 & 4.833 & 5.0754 & TRN & & & \\
\hline CHEMBL1470059 & 688653 & 4.933 & 5.0784 & TRN & & & \\
\hline CHEMBL1499934 & 688653 & 5.88299 & 999999995 & & 5.192 & TRN & \\
\hline CHEMBL3193180 & 688653 & 5.38299 & 999999995 & & 4.923 & TST & \\
\hline CHEMBL1319897 & 688653 & 4.73300 & 000000006 & 005 & 5.6864 & TRN & \\
\hline CHEMBL1354352 & 688653 & 5.483 & 4.9982 & TRN & & & \\
\hline CHEMBL1464603 & 688653 & 5.88299 & 999999995 & & 5.3696 & TRN & \\
\hline CHEMBL1507328 & 688653 & 5.683 & 5.6408 & TRN & & & \\
\hline CHEMBL1598707 & 688653 & 4.833 & 5.814 & TRN & & & \\
\hline CHEMBL1601487 & 688653 & 5.183 & 5.0398 & TRN & & & \\
\hline CHEMBL1453947 & 688653 & 5.88299 & 999999995 & & 5.1475 & TRN & \\
\hline CHEMBL1394526 & 688653 & 4.833 & 5.4665 & TST & & & \\
\hline
\end{tabular}




\begin{tabular}{|c|c|c|c|c|c|c|}
\hline \multirow{3}{*}{$\begin{array}{l}\text { CHEMBL1476556 } \\
\text { CHEMBL1395300 }\end{array}$} & \multirow{3}{*}{$\begin{array}{l}688653 \\
688653\end{array}$} & \multicolumn{5}{|c|}{ Supplemental Table S2.txt } \\
\hline & & \multicolumn{3}{|c|}{5.832999999999999} & \multirow[t]{3}{*}{5.2544} & \multirow[t]{3}{*}{ TST } \\
\hline & & 4.633 & 4.7504 & TST & & \\
\hline CHEMBL1507785 & 688653 & 5.733 & 5.4447 & TRN & & \\
\hline CHEMBL1385987 & 688653 & \multicolumn{3}{|c|}{5.632999999999999} & 5.2205 & TRN \\
\hline CHEMBL1425505 & 688653 & 4.833 & 5.1717 & TRN & & \\
\hline CHEMBL1363156 & 688653 & \multicolumn{3}{|c|}{5.132999999999999} & 5.4583 & TRN \\
\hline CHEMBL600313 & 688653 & 5.233 & 4.966 & TST & & \\
\hline CHEMBL1561557 & 688653 & \multicolumn{3}{|c|}{5.382999999999999} & 5.1339 & TRN \\
\hline CHEMBL3195397 & 688653 & \multicolumn{3}{|c|}{6.5329999999999995} & 5.3842 & TRN \\
\hline CHEMBL1455900 & 688653 & 4.583 & 4.9197 & TRN & & \\
\hline CHEMBL1393189 & 688653 & 6.433 & 5.343 & TST & & \\
\hline CHEMBL1494249 & 688653 & \multicolumn{3}{|c|}{5.632999999999999} & 5.7341 & TRN \\
\hline CHEMBL1482193 & 688653 & 4.683 & 4.4118 & TRN & & \\
\hline CHEMBL1609751 & 688653 & 5.683 & 5.197 & TRN & & \\
\hline CHEMBL1571290 & 688653 & 6.0 & 4.7742 & TRN & & \\
\hline CHEMBL1341698 & 688653 & 5.733 & 5.2192 & TRN & & \\
\hline CHEMBL1485202 & 688653 & \multicolumn{3}{|c|}{5.832999999999999} & 5.277 & TRN \\
\hline CHEMBL1466059 & 688653 & 4.933 & 5.2123 & TRN & & \\
\hline CHEMBL1437035 & 688653 & \multicolumn{3}{|c|}{5.132999999999999} & 4541 & TRN \\
\hline CHEMBL1474419 & 688653 & 5.083 & 5.1546 & TRN & & \\
\hline CHEMBL258549 & 688653 & \multicolumn{3}{|c|}{6.5329999999999995} & 5206 & TRN \\
\hline CHEMBL3198299 & 688653 & 5.733 & 5.8329 & TRN & & \\
\hline CHEMBL1550676 & 688653 & 4.833 & 4.8906 & TST & & \\
\hline CHEMBL3198269 & 688653 & 4.883 & 5.2723 & TRN & & \\
\hline CHEMBL1484327 & 688653 & \multicolumn{3}{|c|}{4.7330000000000005} & 5.6544 & TRN \\
\hline CHEMBL1409043 & 688653 & \multicolumn{3}{|c|}{6.582999999999999} & 5.7268 & TRN \\
\hline CHEMBL1480571 & 688653 & \multicolumn{3}{|c|}{4.7330000000000005} & 4.8799 & TRN \\
\hline CHEMBL1457057 & 688653 & 6.4829 & 5.8937 & TST & & \\
\hline CHEMBL1363516 & 688653 & 4.633 & 5.1947 & TRN & & \\
\hline CHEMBL1373057 & 688653 & 5.683 & 5.3928 & TST & & \\
\hline CHEMBL1588675 & 688653 & 4.783 & 5.0969 & TRN & & \\
\hline CHEMBL1582277 & 688653 & \multicolumn{3}{|c|}{6.5329999999999995} & 5.5567 & TRN \\
\hline CHEMBL1445489 & 688653 & 4.633 & 4.7067 & TRN & & \\
\hline CHEMBL1499327 & 688653 & \multicolumn{3}{|c|}{5.332999999999999} & 5.1478 & TRN \\
\hline CHEMBL1307583 & 688653 & 4.883 & 5.5569 & TRN & & \\
\hline CHEMBL1465311 & 688653 & \multicolumn{3}{|c|}{4.7330000000000005} & 5.2759 & TRN \\
\hline CHEMBL1602763 & 688653 & 4.833 & 5.3949 & TRN & & \\
\hline CHEMBL1592701 & 688653 & \multicolumn{3}{|c|}{4.7330000000000005} & 5.2788 & TST \\
\hline CHEMBL1557649 & 688653 & 5.7829 & 99999999 & 995 & 5.0876 & TST \\
\hline CHEMBL1333405 & 688653 & 4.783 & 4.8401 & TST & & \\
\hline CHEMBL1479175 & 688653 & 5.7829 & 99999999 & 995 & 5.4279 & TRN \\
\hline CHEMBL1573088 & 688653 & 5.483 & 5.2179 & TRN & & \\
\hline CHEMBL1583585 & 688653 & 5.683 & 5.7977 & TST & & \\
\hline CHEMBL1311136 & 688653 & 5.3829 & 99999999 & & 4.9153 & TRN \\
\hline CHEMBL1353336 & 688653 & 4.9836 & 00000000 & 005 & 5.0344 & TRN \\
\hline CHEMBL1374835 & 688653 & 4.683 & 5.3788 & TST & & \\
\hline CHEMBL1346294 & 688653 & 4.883 & 5.3575 & TRN & & \\
\hline CHEMBL1343568 & 688653 & 4.833 & 5.2582 & TST & & \\
\hline
\end{tabular}




\begin{tabular}{|c|c|c|c|c|c|c|}
\hline \multirow[b]{2}{*}{ CHEMBL1383636 } & \multirow[b]{2}{*}{688653} & \multicolumn{5}{|c|}{ Supplemental Table S2.txt } \\
\hline & & \multirow{2}{*}{\multicolumn{3}{|c|}{$\begin{array}{lcc}4.883 & 5.6734 & \text { TRN } \\
4.7330000000000005\end{array}$}} & & \\
\hline CHEMBL1449372 & 688653 & & & & 5.0902 & TRN \\
\hline CHEMBL1579332 & 688653 & \multicolumn{3}{|c|}{5.632999999999999} & 5.331 & TST \\
\hline CHEMBL1591647 & 688653 & \multicolumn{3}{|c|}{6.5329999999999995} & 6.0149 & TRN \\
\hline CHEMBL1303546 & 688653 & 4.833 & 5.2579 & TRN & & \\
\hline CHEMBL1499350 & 688653 & \multicolumn{3}{|c|}{5.2829999999999995} & 5.1948 & TST \\
\hline CHEMBL3189541 & 688653 & \multicolumn{3}{|c|}{7.082999999999999} & 6.0703 & TRN \\
\hline CHEMBL3199594 & 688653 & 4.883 & 4.8553 & TRN & & \\
\hline CHEMBL1330731 & 688653 & 6.0 & 5.4939 & TST & & \\
\hline CHEMBL1423419 & 688653 & 4.633 & 5.3489 & TST & & \\
\hline CHEMBL1970836 & 688653 & 4.833 & 5.386 & TST & & \\
\hline CHEMBL1356932 & 688653 & \multicolumn{3}{|c|}{5.132999999999999} & 5.6209 & TRN \\
\hline CHEMBL1528015 & 688653 & 5.733 & 5.7444 & TRN & & \\
\hline CHEMBL1560273 & 688653 & \multirow{2}{*}{\multicolumn{3}{|c|}{ 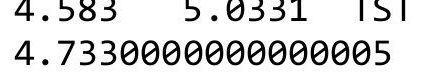 }} & & \\
\hline CHEMBL1456610 & 688653 & & & & 5.2575 & TRN \\
\hline CHEMBL1552826 & 688653 & 5.183 & 4.6531 & TRN & & \\
\hline CHEMBL1525496 & 688653 & 5.033 & 5.1105 & TRN & & \\
\hline CHEMBL1333732 & 688653 & \multicolumn{3}{|c|}{5.332999999999999} & 5.7977 & TRN \\
\hline CHEMBL1346166 & 688653 & \multicolumn{3}{|c|}{5.132999999999999} & 5.4027 & TRN \\
\hline CHEMBL1384511 & 688653 & \multicolumn{3}{|c|}{4.7330000000000005} & 5.3374 & TST \\
\hline CHEMBL1519234 & 688653 & 4.683 & 5.1681 & TST & & \\
\hline CHEMBL1458167 & 688653 & \multicolumn{3}{|c|}{5.132999999999999} & 5.1688 & TRN \\
\hline CHEMBL1589689 & 688653 & 4.883 & 5.233 & TST & & \\
\hline CHEMBL1362503 & 688653 & 4.833 & 4.9633 & TRN & & \\
\hline CHEMBL1318298 & 688653 & 4.583 & 5.0114 & TST & & \\
\hline CHEMBL3191945 & 688653 & 4.783 & 4.97 & TRN & & \\
\hline CHEMBL1390469 & 688653 & 4.933 & 4.8349 & TST & & \\
\hline CHEMBL1549880 & 688653 & 4.783 & \multicolumn{3}{|c|}{4.7989999999999995} & TRN \\
\hline CHEMBL1328232 & 688653 & \multicolumn{3}{|c|}{5.2829999999999995} & 5.1175 & TRN \\
\hline CHEMBL1408363 & 688653 & 4.933 & 4.9678 & TRN & & \\
\hline CHEMBL1418563 & 688653 & 5.35 & 5.0241 & TRN & & \\
\hline CHEMBL1560679 & 688653 & \multicolumn{3}{|c|}{6.0329999999999995} & 5.2877 & TST \\
\hline CHEMBL1524795 & 688653 & \multicolumn{3}{|c|}{4.7330000000000005} & 5.1847 & TRN \\
\hline CHEMBL1442407 & 688653 & \multicolumn{3}{|c|}{4.7330000000000005} & 5.0041 & TRN \\
\hline CHEMBL3190885 & 688653 & \multicolumn{3}{|c|}{5.382999999999999} & 5.5705 & TST \\
\hline CHEMBL3192262 & 688653 & 4.883 & 5.4643 & TRN & & \\
\hline CHEMBL1475159 & 688653 & \multicolumn{3}{|c|}{5.132999999999999} & 5.6466 & TRN \\
\hline CHEMBL1528904 & 688653 & 4.833 & 5.0575 & TRN & & \\
\hline CHEMBL1604715 & 688653 & 5.63299 & 99999999 & & 5.6962 & TRN \\
\hline CHEMBL1342416 & 688653 & 5.28299 & 99999999 & 995 & 5.5144 & TST \\
\hline CHEMBL1479234 & 688653 & 4.73300 & 00000000 & 005 & 5.0874 & TRN \\
\hline CHEMBL1317164 & 688653 & 4.833 & 4.9857 & TRN & & \\
\hline CHEMBL1382367 & 688653 & 4.933 & 5.0539 & TRN & & \\
\hline CHEMBL1984666 & 688653 & 5.433 & 5.7295 & TRN & & \\
\hline CHEMBL1352344 & 688653 & 5.483 & 5.5596 & TST & & \\
\hline CHEMBL1443347 & 688653 & 4.783 & 5.3067 & TRN & & \\
\hline CHEMBL1486922 & 688653 & 6.4829 & 5.4568 & TRN & & \\
\hline CHEMBL1553839 & 688653 & 4.583 & 5.125 & TST & & \\
\hline
\end{tabular}




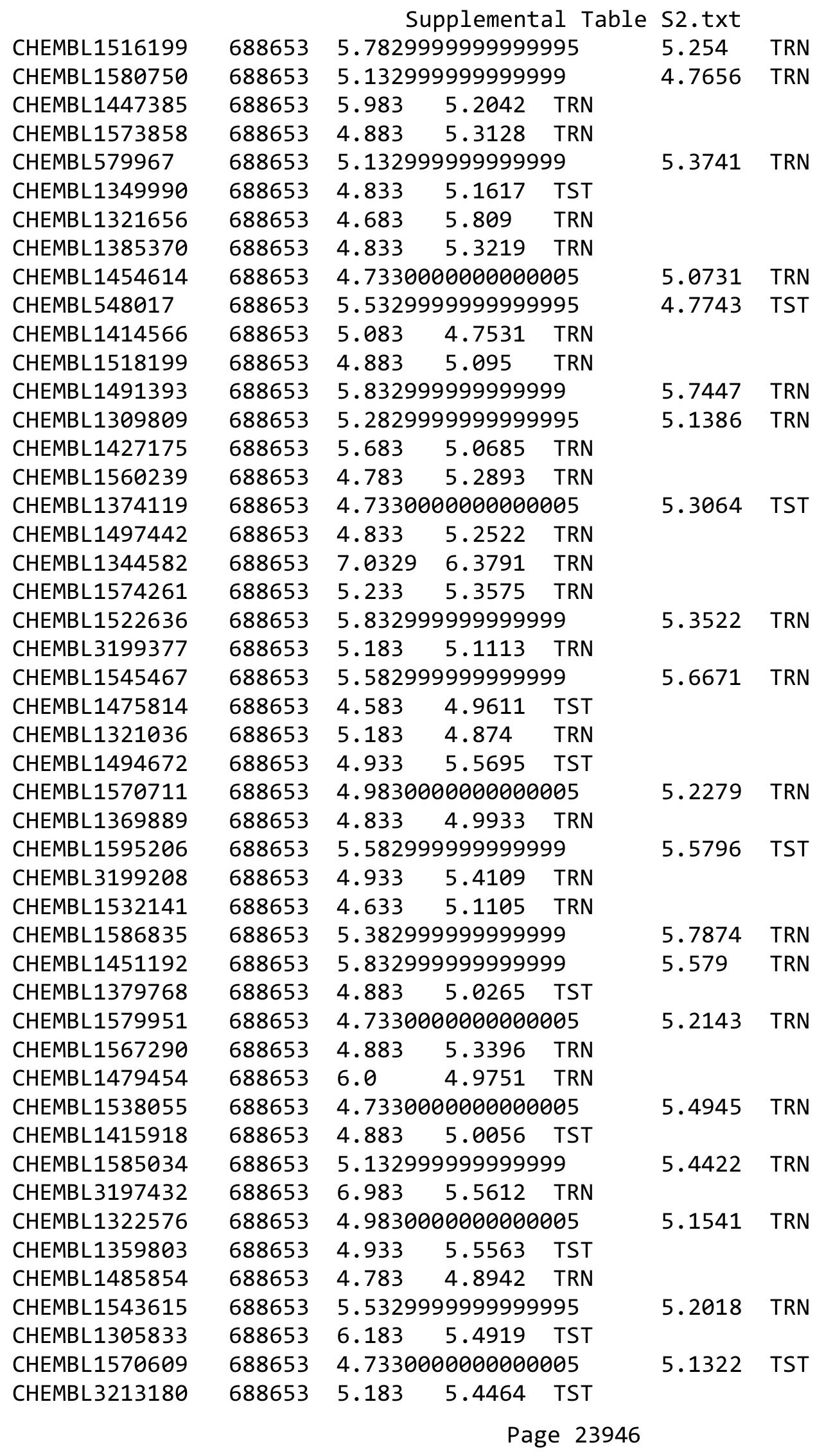




\begin{tabular}{|c|c|c|c|c|c|c|c|}
\hline \multicolumn{8}{|c|}{ Supplemental Table s2.txt } \\
\hline CHEMBL1501737 & 688653 & 4.783 & 5.0173 & TRN & & & \\
\hline CHEMBL1343422 & 688653 & 4.783 & 5.0126 & TRN & & & \\
\hline CHEMBL1598052 & 688653 & 4.883 & 4.7667 & TRN & & & \\
\hline CHEMBL1602306 & 688653 & \multicolumn{3}{|c|}{4.7330000000000005} & 4.967 & TRN & \\
\hline CHEMBL1311629 & 688653 & 4.683 & 5.0193 & TST & & & \\
\hline CHEMBL1558333 & 688653 & 4.933 & 5.3174 & TST & & & \\
\hline CHEMBL1562266 & 688653 & 4.783 & 4.9621 & TRN & & & \\
\hline CHEMBL1411426 & 688653 & 4.783 & 4.7734 & TRN & & & \\
\hline CHEMBL1573586 & 688653 & \multicolumn{3}{|c|}{5.2829999999999995} & 5.4189 & TST & \\
\hline CHEMBL1331282 & 688653 & 4.833 & 5.4187 & TST & & & \\
\hline CHEMBL1533229 & 688653 & 4.933 & 5.1646 & TRN & & & \\
\hline CHEMBL1423636 & 688653 & 4.833 & 4.8987 & TST & & & \\
\hline CHEMBL1309027 & 688653 & 5.683 & 5.6073 & TRN & & & \\
\hline CHEMBL1418312 & 688653 & 4.883 & 5.1817 & TRN & & & \\
\hline CHEMBL1325360 & 688653 & \multicolumn{3}{|c|}{5.2829999999999995} & 5.1922 & TRN & \\
\hline CHEMBL1529654 & 688653 & 5.733 & 5.4377 & TRN & & & \\
\hline CHEMBL1339768 & 688653 & 5.433 & 5.6077 & TRN & & & \\
\hline CHEMBL1489717 & 688653 & 4.783 & 5.5669 & TRN & & & \\
\hline CHEMBL 3195507 & 688653 & \multicolumn{3}{|c|}{4.9830000000000005} & 5.3177 & TST & \\
\hline CHEMBL3213109 & 688653 & \multicolumn{3}{|c|}{4.9830000000000005} & 5.2957 & TST & \\
\hline CHEMBL1506611 & 688653 & \multicolumn{3}{|c|}{4.9830000000000005} & 4.9739 & TRN & \\
\hline CHEMBL3199872 & 688653 & \multicolumn{3}{|c|}{5.132999999999999} & 5.1712 & TRN & \\
\hline CHEMBL1491542 & 688653 & \multicolumn{3}{|c|}{5.832999999999999} & 5.2527 & TST & \\
\hline CHEMBL1491374 & 688653 & 4.633 & 4.8841 & TRN & & & \\
\hline CHEMBL1530335 & 688653 & \multicolumn{3}{|c|}{4.7330000000000005} & 5.251 & TRN & \\
\hline CHEMBL1533359 & 688653 & 4.783 & 5.3508 & TRN & & & \\
\hline CHEMBL1428056 & 688653 & 4.783 & 5.0284 & TRN & & & \\
\hline CHEMBL1564261 & 688653 & \multicolumn{3}{|c|}{6.5329999999999995} & 5.4608 & TRN & \\
\hline CHEMBL1371834 & 688653 & \multicolumn{3}{|c|}{4.7330000000000005} & 4.9946 & TRN & \\
\hline CHEMBL1986681 & 688653 & 5.233 & 5.2711 & TRN & & & \\
\hline CHEMBL1365216 & 688653 & \multicolumn{3}{|c|}{6.332999999999999} & 5.695 & TRN & \\
\hline CHEMBL1299967 & 688653 & 4.583 & 5.0115 & TST & & & \\
\hline CHEMBL1422995 & 688653 & \multicolumn{3}{|c|}{4.9830000000000005} & 5.0235 & TRN & \\
\hline CHEMBL1333530 & 688653 & \multicolumn{3}{|c|}{5.5329999999999995} & 4.8826 & TST & \\
\hline CHEMBL1376554 & 688653 & \multicolumn{3}{|c|}{6.2829999999999995} & 5.6941 & TRN & \\
\hline CHEMBL1498773 & 688653 & 5.483 & 5.1571 & TST & & & \\
\hline CHEMBL1492624 & 688653 & 4.883 & 5.1723 & TST & & & \\
\hline CHEMBL1495013 & 688653 & 4.783 & 5.1216 & TST & & & \\
\hline CHEMBL1403985 & 688653 & \multicolumn{3}{|c|}{5.132999999999999} & 5.0494 & TRN & \\
\hline CHEMBL1517847 & 688653 & \multicolumn{3}{|c|}{6.0329999999999995} & 4.96899 & 9999999999 & TRN \\
\hline CHEMBL1320514 & 688653 & \multicolumn{3}{|c|}{6.382999999999999} & 5.6354 & TST & \\
\hline CHEMBL1380297 & 688653 & 4.783 & 5.3416 & TRN & & & \\
\hline CHEMBL1330701 & 688653 & \multirow{2}{*}{\multicolumn{3}{|c|}{ 5.382999999999999 }} & & & \\
\hline CHEMBL1575022 & 688653 & & & & 5.67399 & 99999999995 & TRN \\
\hline CHEMBL1365422 & 688653 & 4.833 & 5.1828 & TST & & & \\
\hline CHEMBL1393874 & 688653 & \multicolumn{3}{|c|}{6.582999999999999} & 5.9252 & TRN & \\
\hline CHEMBL1549777 & 688653 & 5.1329 & 99999999 & & 5.3136 & TRN & \\
\hline CHEMBL1332909 & 688653 & 5.683 & 5.6449 & TRN & & & \\
\hline
\end{tabular}




\begin{tabular}{|c|c|c|c|c|c|c|}
\hline & & \multicolumn{4}{|c|}{ Supplemental Table s2.txt } & \\
\hline CHEMBL1605528 & 688653 & \multicolumn{3}{|c|}{5.882999999999999} & 5.5211 & TRN \\
\hline CHEMBL1496868 & 688653 & \multicolumn{3}{|c|}{4.7330000000000005} & 5.5127 & TRN \\
\hline CHEMBL1375338 & 688653 & \multicolumn{3}{|c|}{4.7330000000000005} & 5.1113 & TRN \\
\hline CHEMBL1590986 & 688653 & 4.633 & 5.1018 & TST & & \\
\hline CHEMBL1359573 & 688653 & 5.683 & 5.4352 & TRN & & \\
\hline CHEMBL1534933 & 688653 & \multicolumn{3}{|c|}{5.132999999999999} & 4.9512 & TRN \\
\hline CHEMBL3193424 & 688653 & \multicolumn{3}{|c|}{6.5329999999999995} & 5.648 & TRN \\
\hline CHEMBL1395868 & 688653 & 4.633 & 5.0957 & TRN & & \\
\hline CHEMBL1502828 & 688653 & 4.833 & 5.349 & TST & & \\
\hline CHEMBL1363939 & 688653 & \multicolumn{3}{|c|}{4.9830000000000005} & 5.1547 & TST \\
\hline CHEMBL522140 & 688653 & 4.783 & 5.0816 & TRN & & \\
\hline CHEMBL3192514 & 688653 & 5.183 & 5.2751 & TST & & \\
\hline CHEMBL3190095 & 688653 & 4.833 & 5.4203 & TST & & \\
\hline CHEMBL1492007 & 688653 & 4.833 & 5.4699 & TRN & & \\
\hline CHEMBL1584598 & 688653 & \multicolumn{3}{|c|}{7.082999999999999} & 5.7607 & TRN \\
\hline CHEMBL1518817 & 688653 & 4.883 & 4.7332 & TRN & & \\
\hline CHEMBL1573955 & 688653 & \multicolumn{3}{|c|}{5.5329999999999995} & 5.4534 & TRN \\
\hline CHEMBL1506017 & 688653 & 5.033 & 5.3844 & TRN & & \\
\hline CHEMBL1464469 & 688653 & 5.683 & 4.954 & TST & & \\
\hline CHEMBL1598143 & 688653 & \multicolumn{3}{|c|}{5.2829999999999995} & 4.7617 & TRN \\
\hline CHEMBL3199914 & 688653 & \multicolumn{3}{|c|}{5.132999999999999} & 5.3303 & TRN \\
\hline CHEMBL1501573 & 688653 & 4.933 & 5.4713 & TST & & \\
\hline CHEMBL1538448 & 688653 & \multicolumn{3}{|c|}{5.832999999999999} & 5.4132 & TRN \\
\hline CHEMBL3191971 & 688653 & 4.933 & 4.9367 & TRN & & \\
\hline CHEMBL3198031 & 688653 & 5.733 & 5.4037 & TRN & & \\
\hline CHEMBL1490884 & 688653 & 4.783 & 5.1147 & TRN & & \\
\hline CHEMBL1493893 & 688653 & \multicolumn{3}{|c|}{5.2829999999999995} & 4.9374 & TRN \\
\hline CHEMBL1347514 & 688653 & 4.883 & 5.3721 & TST & & \\
\hline CHEMBL3194003 & 688653 & 5.433 & 5.2038 & TRN & & \\
\hline CHEMBL2369243 & 688653 & \multicolumn{3}{|c|}{5.332999999999999} & 5.4262 & TRN \\
\hline CHEMBL1214410 & 688653 & \multicolumn{3}{|c|}{5.832999999999999} & 5.36 & TRN \\
\hline CHEMBL1522980 & 688653 & \multicolumn{3}{|c|}{5.2829999999999995} & 4.6578 & TST \\
\hline CHEMBL3198145 & 688653 & 4.783 & 4.9456 & TRN & & \\
\hline CHEMBL1520589 & 688653 & 4.833 & 5.2788 & TST & & \\
\hline CHEMBL1547627 & 688653 & 5.683 & 5.4488 & TST & & \\
\hline CHEMBL1325324 & 688653 & 5.733 & 5.2747 & TST & & \\
\hline CHEMBL1990819 & 688653 & 5.483 & 5.2414 & TRN & & \\
\hline CHEMBL1382934 & 688653 & 5.033 & 5.1419 & TRN & & \\
\hline CHEMBL1407150 & 688653 & \multicolumn{3}{|c|}{5.5329999999999995} & 5.4825 & TRN \\
\hline CHEMBL1526629 & 688653 & \multicolumn{3}{|c|}{6.0329999999999995} & 5.9015 & TRN \\
\hline CHEMBL1310980 & 688653 & 5.983 & 5.5202 & TRN & & \\
\hline CHEMBL1359195 & 688653 & \multicolumn{3}{|c|}{5.132999999999999} & 5.3615 & TRN \\
\hline CHEMBL1467425 & 688653 & 5.233 & 5.0388 & TRN & & \\
\hline CHEMBL1398939 & 688653 & 5.233 & 5.1666 & TRN & & \\
\hline CHEMBL1970478 & 688653 & \multicolumn{3}{|c|}{5.632999999999999} & 6.0793 & TRN \\
\hline CHEMBL1501454 & 688653 & 5.083 & 5.0856 & TRN & & \\
\hline CHEMBL1360989 & 688653 & 4.583 & 4.9978 & TRN & & \\
\hline CHEMBL1346427 & 688653 & 4.833 & 5.4109 & TRN & & \\
\hline
\end{tabular}




\begin{tabular}{|c|c|c|c|c|c|c|}
\hline \multirow[b]{2}{*}{ CHEMBL1300733 } & & \multicolumn{5}{|c|}{ Supplemental Table S2.txt } \\
\hline & 688653 & 5.933 & 5.815 & TRN & & \\
\hline CHEMBL172350 & 688653 & 5.28299 & 99999999 & 995 & 5.7451 & TRN \\
\hline CHEMBL1333896 & 688653 & 4.783 & 5.1697 & TRN & & \\
\hline CHEMBL1378535 & 688653 & 5.78299 & 99999999 & 995 & 5.6278 & TST \\
\hline CHEMBL1596655 & 688653 & 4.833 & 5.1597 & TST & & \\
\hline CHEMBL3212894 & 688653 & 5.233 & 5.3734 & TST & & \\
\hline CHEMBL3207651 & 688653 & 4.833 & 5.2295 & TRN & & \\
\hline CHEMBL1493691 & 688653 & 4.633 & 5.0526 & TST & & \\
\hline CHEMBL1572176 & 688653 & 4.783 & 4.9566 & TST & & \\
\hline CHEMBL1522885 & 688653 & 5.88299 & 99999999 & 99 & 5.987 & TRN \\
\hline CHEMBL1390409 & 688653 & 4.883 & 5.5166 & TRN & & \\
\hline CHEMBL1402000 & 688653 & 5.7 & 5.144 & TRN & & \\
\hline CHEMBL1582327 & 688653 & 4.933 & 4.9809 & TRN & & \\
\hline CHEMBL1494639 & 688653 & 4.783 & 5.1303 & TST & & \\
\hline CHEMBL1441182 & 688653 & 5.183 & 5.2493 & TRN & & \\
\hline CHEMBL1487358 & 688653 & 4.833 & 4.9185 & TRN & & \\
\hline CHEMBL1564145 & 688653 & 4.833 & 5.3694 & TRN & & \\
\hline CHEMBL3213584 & 688653 & 5.733 & 5.2413 & TRN & & \\
\hline CHEMBL1481110 & 688653 & 4.933 & 5.226 & TRN & & \\
\hline CHEMBL1595566 & 688653 & 4.933 & 5.4969 & TRN & & \\
\hline CHEMBL1538189 & 688653 & 4.783 & 5.1023 & TRN & & \\
\hline CHEMBL1510541 & 688653 & 5.13299 & 99999999 & & 5.115 & TRN \\
\hline CHEMBL1561920 & 688653 & 4.883 & 5.0831 & TRN & & \\
\hline CHEMBL1535529 & 688653 & 4.98300 & 00000000 & 005 & 5.2415 & TST \\
\hline CHEMBL1549001 & 688653 & 5.63299 & 99999999 & 99 & 5.4102 & TST \\
\hline CHEMBL1397899 & 688653 & 4.683 & 5.3418 & TRN & & \\
\hline CHEMBL428064 & 688653 & 5.183 & 5.4522 & TST & & \\
\hline CHEMBL3191439 & 688653 & 4.783 & 5.2251 & TRN & & \\
\hline CHEMBL1327001 & 688653 & 5.53299 & 99999999 & 995 & 5.7675 & TRN \\
\hline CHEMBL1495216 & 688653 & 4.73300 & 20000000 & 005 & 4.7299 & TRN \\
\hline CHEMBL1587804 & 688653 & 5.38299 & 99999999 & & 4.8677 & TRN \\
\hline CHEMBL1967151 & 688653 & 5.683 & 5.8053 & TRN & & \\
\hline CHEMBL1464833 & 688653 & 5.433 & 5.5412 & TRN & & \\
\hline CHEMBL1594659 & 688653 & 4.98300 & 00000000 & 005 & 5.048 & TRN \\
\hline CHEMBL1367758 & 688653 & 5.033 & 5.36600 & 000000000 & 05 & TST \\
\hline CHEMBL1593293 & 688653 & 7.0329 & 5.7259 & TRN & & \\
\hline CHEMBL1554715 & 688653 & 4.583 & 5.1741 & TST & & \\
\hline CHEMBL1592154 & 688653 & 4.98300 & 20000000 & 005 & 5.4 & TRN \\
\hline CHEMBL486094 & 688653 & 4.883 & 5.05399 & 999999999 & & TRN \\
\hline CHEMBL1393258 & 688653 & 4.783 & 5.101 & TST & & \\
\hline CHEMBL1468379 & 688653 & 4.933 & 5.4017 & TST & & \\
\hline CHEMBL1603438 & 688653 & 4.883 & 5.4724 & TRN & & \\
\hline CHEMBL3199346 & 688653 & 5.083 & 5.289 & TRN & & \\
\hline CHEMBL1443077 & 688653 & 4.73300 & 00000000 & 005 & 4.9475 & TRN \\
\hline CHEMBL1356286 & 688653 & 5.483 & 5.1345 & TRN & & \\
\hline CHEMBL1367191 & 688653 & 6.233 & 5.7449 & TRN & & \\
\hline CHEMBL1412068 & 688653 & 5.483 & 5.7445 & TRN & & \\
\hline CHEMBL3209902 & 688653 & 5.033 & 5.2042 & TRN & & \\
\hline
\end{tabular}




\begin{tabular}{|c|c|c|c|c|c|c|}
\hline \multirow[b]{2}{*}{ CHEMBL1439399 } & & \multicolumn{5}{|c|}{ Supplemental Table S2.txt } \\
\hline & 688653 & 4.783 & 5.4017 & TRN & & \\
\hline CHEMBL1400128 & 688653 & 6.233 & 5.5825 & TRN & & \\
\hline CHEMBL1560901 & 688653 & 4.933 & 5.2024 & TRN & & \\
\hline CHEMBL1428629 & 688653 & \multicolumn{3}{|c|}{6.082999999999999} & 5.9331 & $\mathrm{Tr}$ \\
\hline CHEMBL1420346 & 688653 & 4.783 & 5.1189 & TRN & & \\
\hline CHEMBL 3195823 & 688653 & 5.033 & 5.3629 & TRN & & \\
\hline CHEMBL1420724 & 688653 & \multicolumn{3}{|c|}{5.632999999999999} & 5.2623 & \\
\hline CHEMBL 3207354 & 688653 & 4.883 & 4.9004 & TRN & & \\
\hline CHEMBL1341788 & 688653 & 5.433 & 5.5158 & TRN & & \\
\hline CHEMBL1517587 & 688653 & 4.833 & 5.4043 & TRN & & \\
\hline CHEMBL1420159 & 688653 & \multicolumn{3}{|c|}{5.132999999999999} & 5.3891 & \\
\hline CHEMBL1590263 & 688653 & \multicolumn{3}{|c|}{4.9830000000000005} & 5.4788 & \\
\hline CHEMBL1451336 & 688653 & 4.883 & 4.7863 & TST & & \\
\hline CHEMBL1369585 & 688653 & 4.633 & 4.7876 & TST & & \\
\hline CHEMBL1213905 & 688653 & 5.233 & 5.2667 & TRN & & \\
\hline CHEMBL1483870 & 688653 & \multicolumn{3}{|c|}{5.7829999999999995} & 5.0786 & \\
\hline CHEMBL1557124 & 688653 & 4.633 & 4.8957 & TST & & \\
\hline CHEMBL1376580 & 688653 & 4.633 & 5.3617 & TST & & \\
\hline CHEMBL 600090 & 688653 & 5.033 & 5.0738 & TRN & & \\
\hline CHEMBL1605061 & 688653 & \multicolumn{3}{|c|}{5.132999999999999} & 5.3411 & \\
\hline CHEMBL1419024 & 688653 & 4.783 & 5.5363 & TST & & \\
\hline CHEMBL1606991 & 688653 & \multicolumn{3}{|c|}{4.9830000000000005} & 5.4977 & \\
\hline CHEMBL1593692 & 688653 & 6.983 & 5.8269 & TRN & & \\
\hline CHEMBL1601781 & 688653 & \multirow{2}{*}{\multicolumn{3}{|c|}{$\begin{array}{l}4.883 \quad 4.7156 \quad \text { TRN } \\
5.832999999999999\end{array}$}} & & \\
\hline CHEMBL1394547 & 688653 & & & & 5.5663 & $\mathrm{Tr}$ \\
\hline CHEMBL1492017 & 688653 & 5.083 & 5.1158 & TST & & \\
\hline CHEMBL1532663 & 688653 & 5.683 & 5.2234 & TRN & & \\
\hline CHEMBL3. & 688653 & 6.183 & 5.8904 & TRN & & \\
\hline CHEMBL1492380 & 688653 & \multicolumn{3}{|c|}{4.7330000000000005} & 5.7275 & $\mathrm{Tr}$ \\
\hline CHEMBL1487451 & 688653 & 5.433 & 5.581 & TRN & & \\
\hline CHEMBL1596723 & 688653 & \multicolumn{3}{|c|}{5.632999999999999} & & TS \\
\hline CHEMBL1341894 & 688653 & \multicolumn{3}{|c|}{4.7330000000000005} & 5.0974 & \\
\hline CHEMBL1425061 & 688653 & 4.833 & 5.0961 & TRN & & \\
\hline CHEMBL 3210433 & 688653 & 4.833 & 5.2712 & TRN & & \\
\hline CHEMBL1563741 & 688653 & 5.033 & 5.1923 & TRN & & \\
\hline CHEMBL1382927 & 688653 & \multicolumn{3}{|c|}{6.332999999999999} & & \\
\hline CHEMBL14 & 688653 & \multicolumn{3}{|c|}{4.7330000000000005} & & \\
\hline CHEMBL1593252 & 688653 & 6.433 & 5.5322 & TRN & & \\
\hline CHEMBL1436025 & 688653 & \multicolumn{3}{|c|}{5.132999999999999} & 5.0693 & $T$ \\
\hline CHEMBL1507382 & 688653 & 5.483 & 4.6443 & TRN & & \\
\hline CHEMBL 3191975 & 688653 & \multicolumn{3}{|c|}{5.832999999999999} & 5.808 & 13 \\
\hline CHEMBL1332476 & 688653 & \multicolumn{3}{|c|}{5.132999999999999} & 5.14 & \\
\hline CHEMBL3196522 & 688653 & 4.933 & 5.0237 & TST & & \\
\hline CHEMBL1389555 & 688653 & \multicolumn{3}{|c|}{7.082999999999999} & 6.2485 & 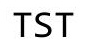 \\
\hline CHEMBL1467470 & 688653 & 4.933 & 4.9959 & TST & & \\
\hline CHEMBL162609 & 688653 & 6.233 & 5.9656 & TST & & \\
\hline CHEMBL1535693 & 688653 & 5.483 & 5.4246 & TRN & & \\
\hline CHEMBL1379886 & 688653 & \multicolumn{3}{|c|}{5.7829999999999995} & 5.419 & \\
\hline
\end{tabular}




\begin{tabular}{|c|c|c|c|c|c|c|c|}
\hline \multicolumn{7}{|c|}{ Supplemental Table S2.txt } & \\
\hline CHEMBL1419413 & 688653 & \multicolumn{3}{|c|}{4.7330000000000005} & 5.4815 & TRN & \\
\hline CHEMBL1436598 & 688653 & 4.633 & 4.77 & TRN & & & \\
\hline CHEMBL1509795 & 688653 & \multicolumn{3}{|c|}{6.332999999999999} & 4.947 & TRN & \\
\hline CHEMBL1304934 & 688653 & \multicolumn{3}{|c|}{5.332999999999999} & 6.0627 & TRN & \\
\hline CHEMBL1355932 & 688653 & \multicolumn{3}{|c|}{4.9830000000000005} & 5.6234 & TRN & \\
\hline CHEMBL1369873 & 688653 & \multicolumn{3}{|c|}{4.7330000000000005} & 5.1221 & TRN & \\
\hline CHEMBL1352371 & 688653 & \multicolumn{3}{|c|}{6.332999999999999} & 5.3279 & TRN & \\
\hline CHEMBL1311391 & 688653 & 5.083 & 5.006 & TRN & & & \\
\hline CHEMBL1390354 & 688653 & 5.433 & 5.8655 & TRN & & & \\
\hline CHEMBL1349851 & 688653 & 5.433 & 5.528 & TRN & & & \\
\hline CHEMBL1455746 & 688653 & 4.883 & 5.3291 & TRN & & & \\
\hline CHEMBL1590839 & 688653 & 4.633 & 4.7431 & TRN & & & \\
\hline CHEMBL1313386 & 688653 & 4.883 & 5.769 & TRN & & & \\
\hline CHEMBL1330129 & 688653 & \multicolumn{3}{|c|}{5.132999999999999} & 5.0202 & TRN & \\
\hline CHEMBL1542748 & 688653 & 5.983 & 6.0191 & TRN & & & \\
\hline CHEMBL1443305 & 688653 & \multicolumn{3}{|c|}{5.2829999999999995} & 5.4555 & TRN & \\
\hline CHEMBL 3198763 & 688653 & \multicolumn{3}{|c|}{5.132999999999999} & 5.6195 & TRN & \\
\hline CHEMBL 1487783 & 688653 & \multicolumn{3}{|c|}{5.132999999999999} & 5.5406 & TRN & \\
\hline CHEMBL 2002162 & 688653 & \multicolumn{3}{|c|}{5.2829999999999995} & 5.5316 & TST & \\
\hline CHEMBL1353069 & 688653 & 5.233 & 5.5319 & TRN & & & \\
\hline CHEMBL1446371 & 688653 & 5.733 & 5.5046 & TRN & & & \\
\hline CHEMBL1487795 & 688653 & 5.733 & \multicolumn{3}{|c|}{5.486000000000001} & TRN & \\
\hline CHEMBL1379892 & 688653 & 6.433 & 5.8626 & TRN & & & \\
\hline CHEMBL234978 & 688653 & \multicolumn{3}{|c|}{5.382999999999999} & 5.2413 & TRN & \\
\hline CHEMBL3209796 & 688653 & 6.7331 & 5.9057 & TRN & & & \\
\hline CHEMBL 3214441 & 688653 & 5.033 & 5.0069 & TRN & & & \\
\hline CHEMBL1435820 & 688653 & 4.583 & 4.7909 & TST & & & \\
\hline CHEMBL1342529 & 688653 & 4.8 & 4.9185 & TRN & & & \\
\hline CHEMBL1457909 & 688653 & \multicolumn{3}{|c|}{5.5329999999999995} & 5.3221 & TRN & \\
\hline CHEMBL1355466 & 688653 & 6.0 & 4.7858 & TST & & & \\
\hline CHEMBL1404130 & 688653 & 4.633 & 5.0923 & TST & & & \\
\hline CHEMBL1546597 & 688653 & \multicolumn{3}{|c|}{4.7330000000000005} & 5.2545 & TRN & \\
\hline CHEMBL1313240 & 688653 & 4.883 & 5.2108 & TRN & & & \\
\hline CHEMBL1997543 & 688653 & 5.733 & 5.0856 & TST & & & \\
\hline CHEMBL1591172 & 688653 & \multicolumn{3}{|c|}{4.9830000000000005} & 5.0271 & TST & \\
\hline CHEMBL1333222 & 688653 & 6.0 & 5.6155 & TRN & & & \\
\hline CHEMBL1493576 & 688653 & 4.783 & 5.4617 & TST & & & \\
\hline CHEMBL1409166 & 688653 & 5.933 & 6.047999 & 999999999 & 99 & TRN & \\
\hline CHEMBL1449696 & 688653 & 6.433 & 5.2455 & TRN & & & \\
\hline CHEMBL1313500 & 688653 & 4.933 & 5.1415 & TRN & & & \\
\hline CHEMBL 3191048 & 688653 & \multicolumn{3}{|c|}{5.882999999999999} & 5.70299 & 9999999999 & TRN \\
\hline CHEMBL1535477 & 688653 & 4.933 & 5.6864 & TST & & & \\
\hline CHEMBL1462768 & 688653 & 5.733 & 5.541 & TRN & & & \\
\hline CHEMBL1385477 & 688653 & 4.633 & 5.0431 & TRN & & & \\
\hline CHEMBL1376167 & 688653 & \multicolumn{3}{|c|}{5.832999999999999} & 5.7955 & TRN & \\
\hline CHEMBL1608890 & 688653 & 4.883 & 5.0503 & TST & & & \\
\hline CHEMBL1313595 & 688653 & \multicolumn{3}{|c|}{5.132999999999999} & 5.1316 & TST & \\
\hline CHEMBL1588660 & 688653 & 4.683 & 5.0845 & TRN & & & \\
\hline
\end{tabular}




\begin{tabular}{|c|c|c|c|c|c|c|}
\hline & & \multicolumn{5}{|c|}{ Supplemental Table s2.txt } \\
\hline CHEMBL1415032 & 688653 & 5.033 & 5.2486 & TST & & \\
\hline CHEMBL1405092 & 688653 & 4.633 & 5.2744 & TRN & & \\
\hline CHEMBL1520179 & 688653 & 4.783 & 5.1565 & TRN & & \\
\hline CHEMBL1401633 & 688653 & \multicolumn{3}{|c|}{5.382999999999999} & 5.1959 & TRN \\
\hline CHEMBL3192001 & 688653 & \multicolumn{3}{|c|}{5.2829999999999995} & 5.0592 & TRN \\
\hline CHEMBL1308594 & 688653 & 4.783 & 5.1137 & TRN & & \\
\hline CHEMBL1485537 & 688653 & \multicolumn{3}{|c|}{5.832999999999999} & 5.4154 & TST \\
\hline CHEMBL1575228 & 688653 & \multicolumn{3}{|c|}{6.2829999999999995} & 5.4884 & TRN \\
\hline CHEMBL1528467 & 688653 & 5.483 & 5.1477 & TRN & & \\
\hline CHEMBL1966867 & 688653 & \multicolumn{3}{|c|}{6.582999999999999} & 5.4647 & TST \\
\hline CHEMBL1416159 & 688653 & \multicolumn{3}{|c|}{5.832999999999999} & 6.0486 & TRN \\
\hline CHEMBL3144987 & 688653 & 4.833 & 5.3975 & TST & & \\
\hline CHEMBL1484054 & 688653 & 5.183 & 5.085 & TRN & & \\
\hline CHEMBL1473521 & 688653 & 4.833 & 5.3505 & TST & & \\
\hline CHEMBL1493750 & 688653 & \multicolumn{3}{|c|}{5.332999999999999} & 5.2282 & TRN \\
\hline CHEMBL1377500 & 688653 & \multicolumn{3}{|c|}{5.382999999999999} & 5.4311 & TRN \\
\hline CHEMBL1546270 & 688653 & 4.583 & 4.869 & TST & & \\
\hline CHEMBL1438324 & 688653 & \multicolumn{3}{|c|}{5.832999999999999} & 5.2344 & TRN \\
\hline CHEMBL1501463 & 688653 & 4.883 & 5.0727 & TRN & & \\
\hline CHEMBL1572780 & 688653 & \multicolumn{3}{|c|}{5.5329999999999995} & 5.4501 & TRN \\
\hline CHEMBL1530984 & 688653 & \multicolumn{3}{|c|}{5.5329999999999995} & 5.9236 & TRN \\
\hline CHEMBL1407839 & 688653 & \multicolumn{3}{|c|}{4.7330000000000005} & 4.9916 & TRN \\
\hline CHEMBL1464181 & 688653 & \multicolumn{3}{|c|}{5.2829999999999995} & 5.1747 & TRN \\
\hline CHEMBL1601738 & 688653 & \multicolumn{3}{|c|}{5.832999999999999} & 5.3526 & TRN \\
\hline CHEMBL1422468 & 688653 & \multicolumn{3}{|c|}{5.332999999999999} & 5.0871 & TRN \\
\hline CHEMBL1465725 & 688653 & 6.233 & 5.2045 & TRN & & \\
\hline CHEMBL1377303 & 688653 & 6.233 & 5.7409 & TRN & & \\
\hline CHEMBL1348714 & 688653 & 4.883 & 5.654 & TST & & \\
\hline CHEMBL1411011 & 688653 & 5.683 & 5.3489 & TRN & & \\
\hline CHEMBL1344339 & 688653 & 4.633 & 5.1837 & TST & & \\
\hline CHEMBL1483214 & 688653 & 4.883 & 5.0547 & TRN & & \\
\hline CHEMBL1516258 & 688653 & 4.783 & 5.1598 & TST & & \\
\hline CHEMBL1486981 & 688653 & 4.883 & 5.1324 & TRN & & \\
\hline CHEMBL1965973 & 688653 & 5.733 & 5.8078 & TST & & \\
\hline CHEMBL1344081 & 688653 & \multicolumn{3}{|c|}{4.7330000000000005} & 5.6432 & TRN \\
\hline CHEMBL1498258 & 688653 & 4.883 & 4.8406 & TRN & & \\
\hline CHEMBL1541312 & 688653 & \multicolumn{3}{|c|}{4.7330000000000005} & 5.2614 & TST \\
\hline CHEMBL1399878 & 688653 & 6.9329 & 5.8688 & TRN & & \\
\hline CHEMBL1527136 & 688653 & 4.783 & 5.2343 & TRN & & \\
\hline CHEMBL1565413 & 688653 & 6.183 & 5.9504 & TRN & & \\
\hline CHEMBL1460837 & 688653 & 5.483 & 5.4988 & TRN & & \\
\hline CHEMBL1443657 & 688653 & 4.633 & 4.7529 & TST & & \\
\hline CHEMBL3189961 & 688653 & 4.833 & 5.1139 & TST & & \\
\hline CHEMBL1353318 & 688653 & 5.433 & 5.1108 & TST & & \\
\hline CHEMBL3198481 & 688653 & 5.483 & 5.1315 & TST & & \\
\hline CHEMBL1444221 & 688653 & \multicolumn{3}{|c|}{5.632999999999999} & 5.2215 & TRN \\
\hline CHEMBL1557232 & 688653 & 5.083 & 5.443 & TRN & & \\
\hline CHEMBL1565391 & 688653 & 4.633 & 4.8268 & TST & & \\
\hline
\end{tabular}




\begin{tabular}{|c|c|c|c|c|c|c|c|}
\hline \multicolumn{7}{|c|}{ Supplemental Table S2.txt } & \\
\hline CHEMBL1306343 & 688653 & 5.033 & 5.3732 & TRN & & & \\
\hline CHEMBL1507421 & 688653 & 4.783 & 5.1539 & TRN & & & \\
\hline CHEMBL1309208 & 688653 & 5.733 & 5.8077 & TST & & & \\
\hline CHEMBL1488906 & 688653 & 5.183 & 5.2782 & TRN & & & \\
\hline CHEMBL3194761 & 688653 & 5.683 & 5.4267 & TRN & & & \\
\hline CHEMBL3193616 & 688653 & \multicolumn{3}{|c|}{5.382999999999999} & 5.4335 & TRN & \\
\hline CHEMBL1458733 & 688653 & 4.833 & 4.9941 & TRN & & & \\
\hline CHEMBL1484249 & 688653 & 5.083 & 5.8128 & TRN & & & \\
\hline CHEMBL1428157 & 688653 & 4.583 & 4.44300 & 00000000 & 005 & TRN & \\
\hline CHEMBL1605430 & 688653 & 6.433 & 5.4855 & TST & & & \\
\hline CHEMBL1530142 & 688653 & 4.833 & 5.0502 & TRN & & & \\
\hline CHEMBL1325062 & 688653 & 5.083 & 5.2441 & TRN & & & \\
\hline CHEMBL3213546 & 688653 & 5.683 & 5.5821 & TST & & & \\
\hline CHEMBL1349704 & 688653 & \multicolumn{3}{|c|}{6.382999999999999} & 5.5491 & TRN & \\
\hline CHEMBL1973571 & 688653 & \multicolumn{3}{|c|}{6.582999999999999} & 5.71 & TRN & \\
\hline CHEMBL3198668 & 688653 & \multicolumn{3}{|c|}{5.7829999999999995} & 5.4391 & TRN & \\
\hline CHEMBL1483007 & 688653 & 5.233 & 4.507 & TST & & & \\
\hline CHEMBL1439354 & 688653 & \multicolumn{3}{|c|}{5.632999999999999} & \multicolumn{2}{|c|}{5.1770000000000005} & TRN \\
\hline CHEMBL2369241 & 688653 & 5.483 & 5.4853 & TRN & & & \\
\hline CHEMBL1359406 & 688653 & 4.783 & 5.1425 & TRN & & & \\
\hline CHEMBL1413283 & 688653 & \multicolumn{3}{|c|}{5.2829999999999995} & 5.6374 & TST & \\
\hline CHEMBL1527869 & 688653 & 6.8831 & 5.4265 & TRN & & & \\
\hline CHEMBL1465824 & 688653 & 4.883 & 5.5051 & TRN & & & \\
\hline CHEMBL1396637 & 688653 & 4.933 & 5.6168 & TRN & & & \\
\hline CHEMBL1343814 & 688653 & 4.633 & 5.0333 & TRN & & & \\
\hline CHEMBL1557844 & 688653 & \multicolumn{3}{|c|}{5.132999999999999} & 4.9071 & TST & \\
\hline CHEMBL1375273 & 688653 & \multicolumn{3}{|c|}{6.582999999999999} & 6.2821 & TRN & \\
\hline CHEMBL1424490 & 688653 & 6.683 & 5.7654 & TRN & & & \\
\hline CHEMBL1560506 & 688653 & \multicolumn{3}{|c|}{4.7330000000000005} & 4.9128 & TST & \\
\hline CHEMBL1530854 & 688653 & 5.083 & 5.2545 & TRN & & & \\
\hline CHEMBL1465915 & 688653 & \multicolumn{3}{|c|}{5.882999999999999} & 5.9371 & TRN & \\
\hline CHEMBL1387899 & 688653 & 4.833 & 4.8874 & TRN & & & \\
\hline CHEMBL1537418 & 688653 & \multicolumn{3}{|c|}{5.832999999999999} & 5.6974 & TRN & \\
\hline CHEMBL1305986 & 688653 & \multicolumn{3}{|c|}{4.7330000000000005} & 5.5998 & TST & \\
\hline CHEMBL585656 & 688653 & 4.883 & 4.8328 & TST & & & \\
\hline CHEMBL1409552 & 688653 & 4.883 & 5.1749 & TRN & & & \\
\hline CHEMBL1577998 & 688653 & \multicolumn{3}{|c|}{5.832999999999999} & 5.3905 & TRN & \\
\hline CHEMBL3199038 & 688653 & \multicolumn{3}{|c|}{4.7330000000000005} & 5.4773 & TRN & \\
\hline CHEMBL1573646 & 688653 & \multicolumn{3}{|c|}{6.0329999999999995} & 5.5701 & TRN & \\
\hline CHEMBL1384936 & 688653 & \multicolumn{3}{|c|}{4.7330000000000005} & 4.9526 & TRN & \\
\hline CHEMBL1554324 & 688653 & \multicolumn{3}{|c|}{5.332999999999999} & 5.0603 & TRN & \\
\hline CHEMBL1524027 & 688653 & \multicolumn{3}{|c|}{4.7330000000000005} & 4.7946 & TST & \\
\hline CHEMBL3213942 & 688653 & 4.633 & 5.1088 & TRN & & & \\
\hline CHEMBL1458316 & 688653 & 4.883 & 4.9753 & TRN & & & \\
\hline CHEMBL1584229 & 688653 & 4.583 & 4.8561 & TST & & & \\
\hline CHEMBL1486465 & 688653 & 7.3325 & 6.1564 & TST & & & \\
\hline CHEMBL3190999 & 688653 & 4.783 & 5.0653 & TRN & & & \\
\hline CHEMBL1407542 & 688653 & 4.833 & 5.3916 & TRN & & & \\
\hline
\end{tabular}




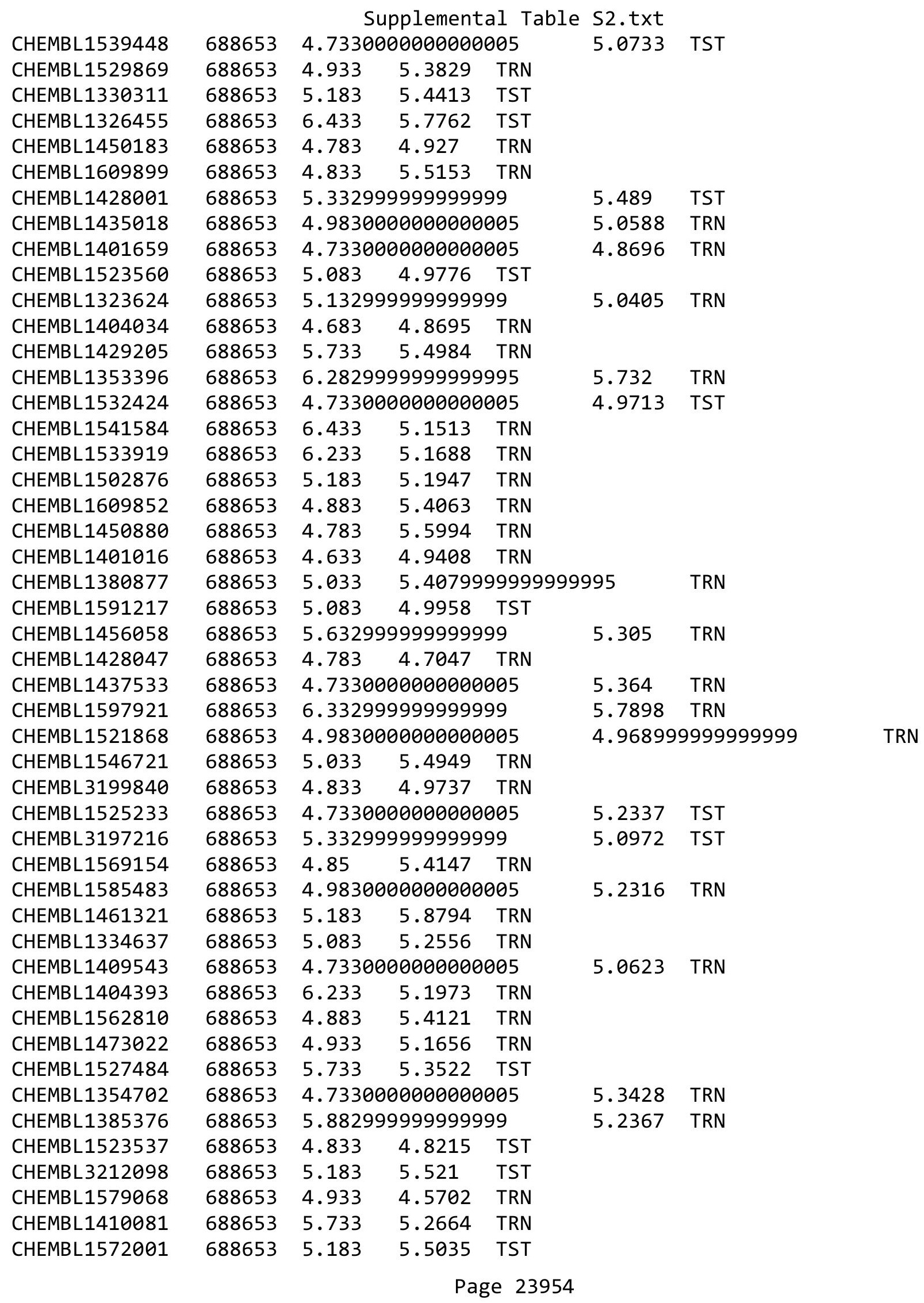




\begin{tabular}{|c|c|c|c|c|c|c|}
\hline CHEMBL1534012 & 688653 & $\begin{array}{r}\mathrm{S} \\
6.3829\end{array}$ & \multicolumn{2}{|c|}{ Supplemental Table S2.txt } & $\begin{array}{l}\text { S2.txt } \\
5.345\end{array}$ & TRN \\
\hline CHEMBL1346252 & 688653 & 5.033 & \multicolumn{3}{|c|}{5.207000000000001} & TRN \\
\hline CHEMBL1446150 & 688653 & 4.933 & 5.0788 & TRN & & \\
\hline CHEMBL1526386 & 688653 & \multicolumn{3}{|c|}{5.382999999999999} & 5.5158 & TRN \\
\hline CHEMBL1597665 & 688653 & 4.833 & 5.1189 & TRN & & \\
\hline CHEMBL1534058 & 688653 & 4.883 & 4.937 & TRN & & \\
\hline CHEMBL1370589 & 688653 & 4.883 & 5.0678 & TRN & & \\
\hline CHEMBL3210221 & 688653 & 4.883 & 5.3147 & TST & & \\
\hline CHEMBL1325485 & 688653 & \multicolumn{3}{|c|}{4.9830000000000005} & 5.3203 & TRN \\
\hline CHEMBL1518347 & 688653 & 4.783 & 4.9463 & TRN & & \\
\hline CHEMBL1481621 & 688653 & \multicolumn{3}{|c|}{5.2829999999999995} & 5.994 & TRN \\
\hline CHEMBL1555101 & 688653 & 5.233 & 5.3748 & TRN & & \\
\hline CHEMBL3211458 & 688653 & 4.833 & 4.9512 & TRN & & \\
\hline CHEMBL1403689 & 688653 & 4.583 & 5.0582 & TST & & \\
\hline CHEMBL233107 & 688653 & \multicolumn{3}{|c|}{5.132999999999999} & 5.4781 & TRN \\
\hline CHEMBL1414917 & 688653 & 4.883 & 5.5015 & TST & & \\
\hline CHEMBL3193340 & 688653 & 5.433 & 5.2235 & TST & & \\
\hline CHEMBL1581517 & 688653 & 4.633 & 5.0722 & TST & & \\
\hline CHEMBL1605026 & 688653 & \multicolumn{3}{|c|}{5.2829999999999995} & 5.2671 & TRN \\
\hline CHEMBL1447977 & 688653 & \multicolumn{3}{|c|}{5.132999999999999} & 5.2264 & TRN \\
\hline CHEMBL1607399 & 688653 & 4.933 & 5.5112 & TRN & & \\
\hline CHEMBL1468472 & 688653 & 4.833 & 5.5825 & TST & & \\
\hline CHEMBL1472112 & 688653 & \multicolumn{3}{|c|}{4.7330000000000005} & 5.1809 & TRN \\
\hline CHEMBL1444348 & 688653 & 5.183 & 5.4949 & TRN & & \\
\hline CHEMBL1331634 & 688653 & 4.783 & 5.0354 & TRN & & \\
\hline CHEMBL1605956 & 688653 & 4.883 & 4.7308 & TRN & & \\
\hline CHEMBL1445724 & 688653 & 5.033 & 5.6844 & TRN & & \\
\hline CHEMBL1315580 & 688653 & \multicolumn{3}{|c|}{5.7829999999999995} & 5.3181 & TRN \\
\hline CHEMBL1412192 & 688653 & \multicolumn{3}{|c|}{4.7330000000000005} & 5.001 & TST \\
\hline CHEMBL1587767 & 688653 & \multicolumn{3}{|c|}{5.132999999999999} & 5.4395 & TRN \\
\hline CHEMBL1409530 & 688653 & 4.883 & 5.2428 & TRN & & \\
\hline CHEMBL1302596 & 688653 & 5.183 & 5.3237 & TRN & & \\
\hline CHEMBL1405015 & 688653 & \multicolumn{3}{|c|}{5.132999999999999} & 5.635 & TST \\
\hline CHEMBL1446128 & 688653 & \multicolumn{3}{|c|}{5.882999999999999} & 5.5022 & TRN \\
\hline CHEMBL1577962 & 688653 & 6.433 & \multicolumn{3}{|c|}{6.2860000000000005} & TRN \\
\hline CHEMBL1559669 & 688653 & 5.733 & 5.4818 & TRN & & \\
\hline CHEMBL1589772 & 688653 & 4.783 & 5.2943 & TRN & & \\
\hline CHEMBL1478403 & 688653 & \multicolumn{3}{|c|}{5.7829999999999995} & 5.4518 & TRN \\
\hline CHEMBL1321290 & 688653 & \multicolumn{3}{|c|}{6.082999999999999} & 5.5076 & TRN \\
\hline CHEMBL1329594 & 688653 & 4.633 & 4.8838 & TRN & & \\
\hline CHEMBL244683 & 688653 & 4.783 & 5.7736 & TRN & & \\
\hline CHEMBL1396734 & 688653 & 5.083 & 5.5359 & TRN & & \\
\hline CHEMBL1306548 & 688653 & 6.183 & 5.8791 & TRN & & \\
\hline CHEMBL1455630 & 688653 & 4.633 & 5.5875 & TRN & & \\
\hline CHEMBL241608 & 688653 & \multicolumn{3}{|c|}{5.832999999999999} & 5.6519 & TRN \\
\hline CHEMBL441370 & 688653 & 4.883 & 4.8659 & TST & & \\
\hline CHEMBL1559862 & 688653 & 4.683 & 4.9118 & TST & & \\
\hline CHEMBL379376 & 688653 & \multicolumn{3}{|c|}{4.7330000000000005} & 5.6978 & TRN \\
\hline
\end{tabular}




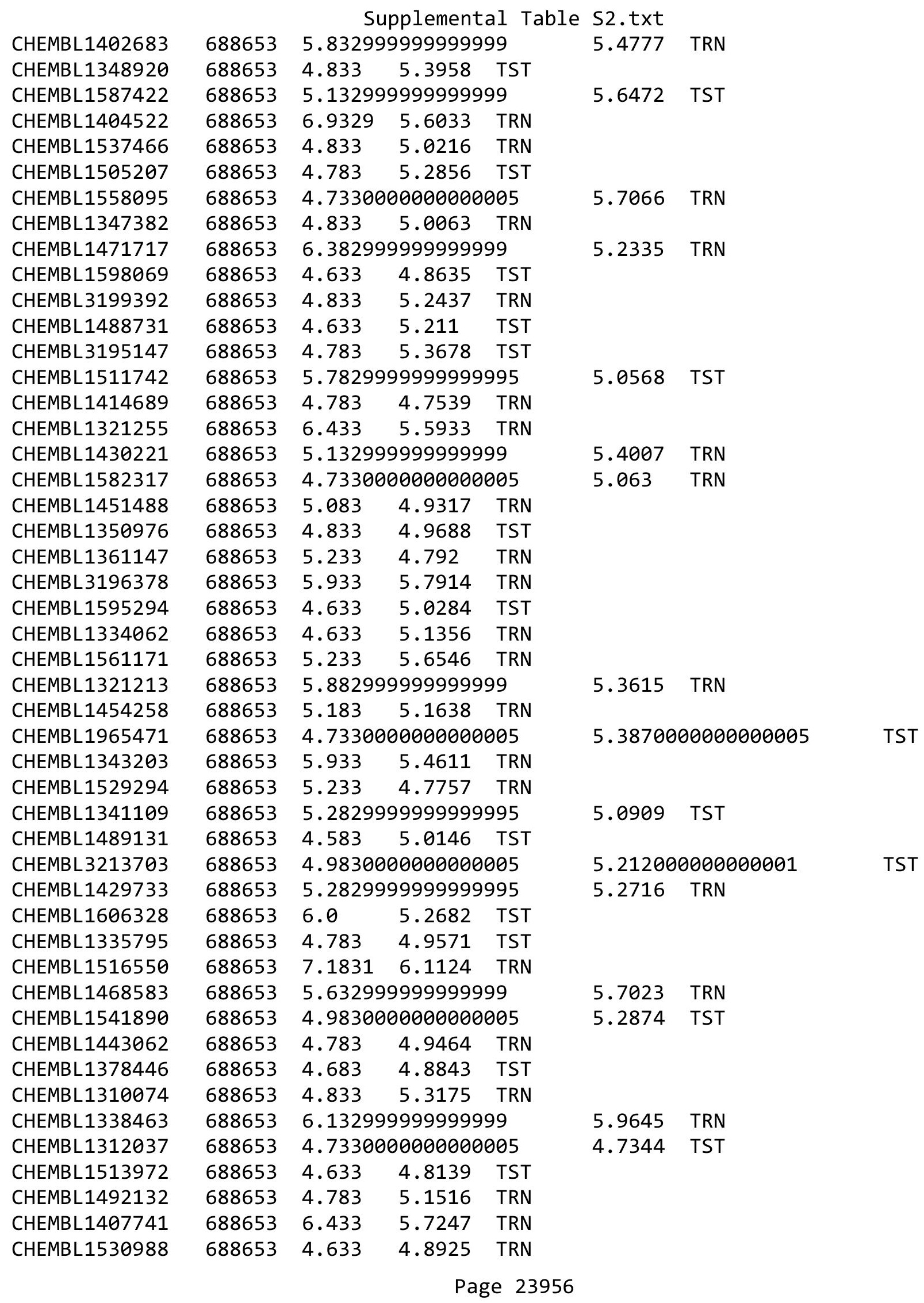




\begin{tabular}{|c|c|c|c|c|c|c|c|}
\hline \multicolumn{8}{|c|}{ Supplemental Table s2.txt } \\
\hline CHEMBL1541008 & 688653 & 4.883 & 5.7474 & TST & & & \\
\hline CHEMBL1500474 & 688653 & 5.933 & 5.1255 & TRN & & & \\
\hline CHEMBL1490748 & 688653 & 4.883 & 4.8814 & TST & & & \\
\hline CHEMBL 3199300 & 688653 & \multicolumn{3}{|c|}{6.382999999999999} & 5.7822 & TRN & \\
\hline CHEMBL1328084 & 688653 & \multicolumn{3}{|c|}{5.582999999999999} & \multicolumn{2}{|c|}{5.5120000000000005} & TRN \\
\hline CHEMBL1569136 & 688653 & \multicolumn{3}{|c|}{6.382999999999999} & 5.4151 & TRN & \\
\hline CHEMBL1597924 & 688653 & \multicolumn{3}{|c|}{5.332999999999999} & 5.5515 & TRN & \\
\hline CHEMBL1337224 & 688653 & 4.633 & 5.5701 & TRN & & & \\
\hline CHEMBL1564356 & 688653 & 5.683 & 5.3698 & TRN & & & \\
\hline CHEMBL1317524 & 688653 & \multicolumn{3}{|c|}{5.382999999999999} & 5.4212 & TRN & \\
\hline CHEMBL1515135 & 688653 & 4.633 & 4.9205 & TRN & & & \\
\hline CHEMBL1333863 & 688653 & 4.583 & 5.3294 & TST & & & \\
\hline CHEMBL1372696 & 688653 & 5.683 & 5.2352 & TRN & & & \\
\hline CHEMBL1980889 & 688653 & 5.233 & 5.4595 & TRN & & & \\
\hline CHEMBL1299379 & 688653 & 4.883 & 5.4504 & TRN & & & \\
\hline CHEMBL1540513 & 688653 & 4.783 & 5.7403 & TRN & & & \\
\hline CHEMBL1372490 & 688653 & \multicolumn{3}{|c|}{4.7330000000000005} & 5.0136 & TST & \\
\hline CHEMBL1477496 & 688653 & 4.833 & 5.1999 & TST & & & \\
\hline CHEMBL1392152 & 688653 & 4.883 & 4.8051 & TRN & & & \\
\hline CHEMBL1462710 & 688653 & \multicolumn{3}{|c|}{5.332999999999999} & 5.6756 & TST & \\
\hline CHEMBL1408807 & 688653 & 5.683 & 5.0924 & TRN & & & \\
\hline CHEMBL1563821 & 688653 & \multicolumn{3}{|c|}{6.0329999999999995} & 5.9869 & TRN & \\
\hline CHEMBL1998334 & 688653 & \multicolumn{3}{|c|}{5.132999999999999} & 5.3823 & TRN & \\
\hline CHEMBL1390294 & 688653 & \multicolumn{3}{|c|}{6.332999999999999} & 5.5568 & TRN & \\
\hline CHEMBL1409893 & 688653 & \multicolumn{3}{|c|}{4.7330000000000005} & 5.2618 & TST & \\
\hline CHEMBL1418096 & 688653 & \multicolumn{3}{|c|}{6.5329999999999995} & 5.8527 & TRN & \\
\hline CHEMBL1596101 & 688653 & \multicolumn{3}{|c|}{6.0329999999999995} & 5.9876 & TRN & \\
\hline CHEMBL1346493 & 688653 & 7.1831 & 5.3344 & TST & & & \\
\hline CHEMBL1476787 & 688653 & 6.4829 & 6.0037 & TRN & & & \\
\hline CHEMBL1502702 & 688653 & 5.683 & 5.4835 & TRN & & & \\
\hline CHEMBL1471750 & 688653 & 4.583 & 4.7322 & TST & & & \\
\hline CHEMBL1307014 & 688653 & 4.833 & 5.0336 & TRN & & & \\
\hline CHEMBL 3193058 & 688653 & 4.933 & 5.0547 & TST & & & \\
\hline CHEMBL1587552 & 688653 & 4.883 & 5.0766 & TST & & & \\
\hline CHEMBL1393669 & 688653 & \multicolumn{3}{|c|}{5.882999999999999} & 5.1246 & TRN & \\
\hline CHEMBL1467405 & 688653 & 7.3325 & 5.8565 & TRN & & & \\
\hline CHEMBL1994510 & 688653 & \multicolumn{3}{|c|}{5.7829999999999995} & 5.5425 & TRN & \\
\hline CHEMBL1332103 & 688653 & 4.883 & 4.9731 & TRN & & & \\
\hline CHEMBL1381081 & 688653 & \multirow{2}{*}{\multicolumn{3}{|c|}{$\begin{array}{lcc}4.833 & 4.9989 & \text { TST } \\
4.7330000000000005\end{array}$}} & & & \\
\hline CHEMBL1576070 & 688653 & & & & 5.0512 & TST & \\
\hline CHEMBL1613173 & 688653 & \multicolumn{3}{|c|}{$\begin{array}{lll}4.833 & 5.2813 & \text { TST }\end{array}$} & & & \\
\hline CHEMBL3194634 & 688653 & 4.883 & 5.2434 & TST & & & \\
\hline CHEMBL1330532 & 688653 & 4.783 & 4.817 & TRN & & & \\
\hline CHEMBL1586992 & 688653 & 4.833 & \multicolumn{3}{|c|}{5.2829999999999995} & TRN & \\
\hline CHEMBL1347770 & 688653 & \multicolumn{3}{|c|}{4.7330000000000005} & 4.7294 & TST & \\
\hline CHEMBL1410357 & 688653 & 5.683 & 5.7176 & TRN & & & \\
\hline CHEMBL1605871 & 688653 & 4.633 & 5.8332 & TRN & & & \\
\hline CHEMBL3198477 & 688653 & 4.783 & 4.9282 & TRN & & & \\
\hline
\end{tabular}




\begin{tabular}{|c|c|c|c|c|c|c|}
\hline & & & oplement & al & s2.txt & \\
\hline CHEMBL3208908 & 688653 & 5.1329 & 79999999 & & 5.3181 & TRN \\
\hline CHEMBL1502721 & 688653 & 5.5329 & 79999999 & 995 & 5.6532 & TRN \\
\hline CHEMBL3199662 & 688653 & 4.7336 & 00000000 & 205 & 5.0919 & TRN \\
\hline CHEMBL1444980 & 688653 & 4.783 & 5.6806 & TRN & & \\
\hline CHEMBL1592923 & 688653 & 4.633 & 5.011 & TRN & & \\
\hline CHEMBL1306017 & 688653 & 4.883 & 5.2847 & TRN & & \\
\hline CHEMBL1991234 & 688653 & 5.3829 & 99999999 & & 5.2802 & TST \\
\hline CHEMBL1478310 & 688653 & 5.433 & 5.5894 & TST & & \\
\hline CHEMBL1478604 & 688653 & 5.1329 & 99999999 & & 4.8881 & TST \\
\hline CHEMBL1383419 & 688653 & 5.033 & 5.5225 & TST & & \\
\hline CHEMBL1330322 & 688653 & 5.7829 & 79999999 & 995 & 5.1564 & TST \\
\hline CHEMBL1515551 & 688653 & 5.483 & 4.9986 & TRN & & \\
\hline CHEMBL1558960 & 688653 & 5.3329 & 99999999 & & 5.5941 & TRN \\
\hline CHEMBL1582143 & 688653 & 4.883 & 5.1818 & TRN & & \\
\hline CHEMBL1450087 & 688653 & 4.833 & 5.1977 & TRN & & \\
\hline CHEMBL1164527 & 688653 & 5.7829 & 79999999 & 995 & 5.098 & TRN \\
\hline CHEMBL1529509 & 688653 & 4.833 & 5.0427 & TRN & & \\
\hline CHEMBL1565801 & 688653 & 5.683 & 5.3568 & TRN & & \\
\hline CHEMBL1533835 & 688653 & 4.7336 & 00000000 & 205 & 5.7954 & TRN \\
\hline CHEMBL1437430 & 688653 & 4.633 & 4.7524 & TST & & \\
\hline CHEMBL1379777 & 688653 & 4.833 & 5.0445 & TRN & & \\
\hline CHEMBL1527764 & 688653 & 4.933 & 5.1891 & TRN & & \\
\hline CHEMBL1540371 & 688653 & 6.1329 & و9999999 & & 5.1954 & TST \\
\hline CHEMBL3197703 & 688653 & 5.983 & 5.1431 & TST & & \\
\hline CHEMBL1500438 & 688653 & 4.783 & 5.2117 & TRN & & \\
\hline CHEMBL1525320 & 688653 & 5.033 & 5.5548 & TRN & & \\
\hline CHEMBL1419330 & 688653 & 4.883 & 5.0125 & TST & & \\
\hline CHEMBL1303419 & 688653 & 4.9836 & 30000000 & 205 & 5.2515 & TST \\
\hline CHEMBL1310097 & 688653 & 4.883 & 5.3732 & TRN & & \\
\hline CHEMBL1402920 & 688653 & 4.633 & 4.9724 & TST & & \\
\hline CHEMBL3192114 & 688653 & 4.783 & 5.2025 & TST & & \\
\hline CHEMBL1411134 & 688653 & 5.7829 & 99999999 & 995 & 5.4675 & TRN \\
\hline CHEMBL3198012 & 688653 & 4.933 & 5.3384 & TRN & & \\
\hline CHEMBL3193118 & 688653 & 5.933 & 5.6082 & TRN & & \\
\hline CHEMBL1315572 & 688653 & 4.583 & 5.1066 & TRN & & \\
\hline CHEMBL3199860 & 688653 & 4.933 & 5.65 & TRN & & \\
\hline CHEMBL1388353 & 688653 & 5.683 & 5.226 & TRN & & \\
\hline CHEMBL1415109 & 688653 & 4.783 & 5.0603 & TRN & & \\
\hline CHEMBL1317784 & 688653 & 4.633 & 5.1321 & TST & & \\
\hline CHEMBL1411585 & 688653 & 4.783 & 5.2005 & TRN & & \\
\hline CHEMBL1469326 & 688653 & 5.983 & 5.8277 & TRN & & \\
\hline CHEMBL1609538 & 688653 & 5.3329 & 99999999 & & 5.4372 & TRN \\
\hline CHEMBL1978063 & 688653 & 5.933 & 6.3486 & TRN & & \\
\hline CHEMBL1306079 & 688653 & 4.633 & 4.785 & TST & & \\
\hline CHEMBL1308127 & 688653 & 4.783 & 5.3619 & TST & & \\
\hline CHEMBL1432218 & 688653 & 5.233 & 5.8373 & TRN & & \\
\hline CHEMBL1543874 & 688653 & 4.933 & 5.279 & TST & & \\
\hline CHEMBL608109 & 688653 & 4.683 & 5.4899 & TRN & & \\
\hline
\end{tabular}




\begin{tabular}{|c|c|c|c|c|c|c|}
\hline & & \multicolumn{5}{|c|}{ Supplemental Table s2.txt } \\
\hline CHEMBL581257 & 688653 & 5.183 & 5.1962 & TST & & \\
\hline CHEMBL1601546 & 688653 & 4.583 & 5.0615 & TRN & & \\
\hline CHEMBL1480234 & 688653 & 4.933 & 5.724 & TST & & \\
\hline CHEMBL1572474 & 688653 & 6.433 & 6.2413 & TRN & & \\
\hline CHEMBL1313856 & 688653 & 5.083 & 5.1883 & TST & & \\
\hline CHEMBL3190508 & 688653 & 4.833 & 5.0848 & TRN & & \\
\hline CHEMBL1327542 & 688653 & \multicolumn{3}{|c|}{4.7330000000000005} & 5.3244 & \\
\hline CHEMBL1574687 & 688653 & 4.933 & 5.0952 & TRN & & \\
\hline CHEMBL1518833 & 688653 & \multicolumn{3}{|c|}{5.382999999999999} & 5.4552 & TRN \\
\hline CHEMBL1449916 & 688653 & 6.433 & 5.9536 & TRN & & \\
\hline CHEMBL1426415 & 688653 & 5.183 & 5.004 & TST & & \\
\hline CHEMBL1512806 & 688653 & 4.933 & 5.3031 & TRN & & \\
\hline CHEMBL3193962 & 688653 & 4.883 & 5.3491 & TST & & \\
\hline CHEMBL1583762 & 688653 & 5.433 & 5.3465 & TST & & \\
\hline CHEMBL1589560 & 688653 & 5.233 & 5.2504 & TST & & \\
\hline CHEMBL1546321 & 688653 & 5.683 & 5.3923 & TRN & & \\
\hline CHEMBL3195657 & 688653 & 7.3325 & 6.851 & TRN & & \\
\hline CHEMBL1350246 & 688653 & 4.833 & 5.2979 & TRN & & \\
\hline CHEMBL3199619 & 688653 & \multicolumn{3}{|c|}{5.7829999999999995} & 4.9163 & 1. \\
\hline CHEMBL1439207 & 688653 & 4.933 & 5.2152 & TRN & & \\
\hline CHEMBL1591131 & 688653 & \multicolumn{3}{|c|}{5.382999999999999} & 5.3702 & \\
\hline CHEMBL1390183 & 688653 & 5.933 & 5.1538 & TRN & & \\
\hline CHEMBL1480389 & 688653 & \multicolumn{3}{|c|}{5.332999999999999} & 5.4755 & . \\
\hline CHEMBL1478925 & 688653 & \multicolumn{3}{|c|}{5.332999999999999} & 5.3192 & \\
\hline CHEMBL1588461 & 688653 & 4.633 & 4.9659 & TST & & \\
\hline CHEMBL1341540 & 688653 & 5.733 & 5.5874 & TRN & & \\
\hline CHEMBL1480605 & 688653 & \multicolumn{3}{|c|}{6.132999999999999} & 5.1976 & \\
\hline CHEMBL1442665 & 688653 & 4.883 & 5.3627 & TRN & & \\
\hline CHEMBL1462417 & 688653 & 5.733 & 5.5758 & TRN & & \\
\hline CHEMBL1555575 & 688653 & 4.833 & 5.2773 & TST & & \\
\hline CHEMBL1600760 & 688653 & 5.233 & 4.8814 & TST & & \\
\hline CHEMBL1457832 & 688653 & 4.883 & 5.343 & TRN & & \\
\hline CHEMBL1388901 & 688653 & \multicolumn{3}{|c|}{5.832999999999999} & 5.892 & $\mathrm{~T}$ \\
\hline CHEMBL1423867 & 688653 & 5.233 & 4.9861 & TRN & & \\
\hline CHEMBL1974800 & 688653 & \multicolumn{3}{|c|}{4.7330000000000005} & 5.2052 & \\
\hline CHEMBL1570908 & 688653 & \multicolumn{3}{|c|}{5.5329999999999995} & 5.3518 & \\
\hline CHEMBL1374157 & 688653 & 5.733 & 5.1826 & TRN & & \\
\hline CHEMBL1515169 & 688653 & 4.633 & 4.8319 & TRN & & \\
\hline CHEMBL1585997 & 688653 & 4.783 & 5.4393 & TRN & & \\
\hline CHEMBL582030 & 688653 & \multicolumn{3}{|c|}{5.382999999999999} & 5.1757 & \\
\hline CHEMBL1555166 & 688653 & 5.183 & 5.4143 & TRN & & \\
\hline CHEMBL3207538 & 688653 & 5.483 & 5.2446 & TRN & & \\
\hline CHEMBL1392570 & 688653 & \multicolumn{3}{|c|}{5.132999999999999} & 6.0927 & TRA \\
\hline CHEMBL1590903 & 688653 & 4.783 & 5.1032 & TRN & & \\
\hline CHEMBL1534545 & 688653 & 4.583 & 5.1462 & TST & & \\
\hline CHEMBL1491572 & 688653 & \multicolumn{3}{|c|}{5.132999999999999} & 5.4798 & \\
\hline CHEMBL1593062 & 688653 & 5.433 & 5.608 & TRN & & \\
\hline CHEMBL1448751 & 688653 & \multicolumn{3}{|c|}{4.9830000000000005} & 5.2675 & \\
\hline
\end{tabular}




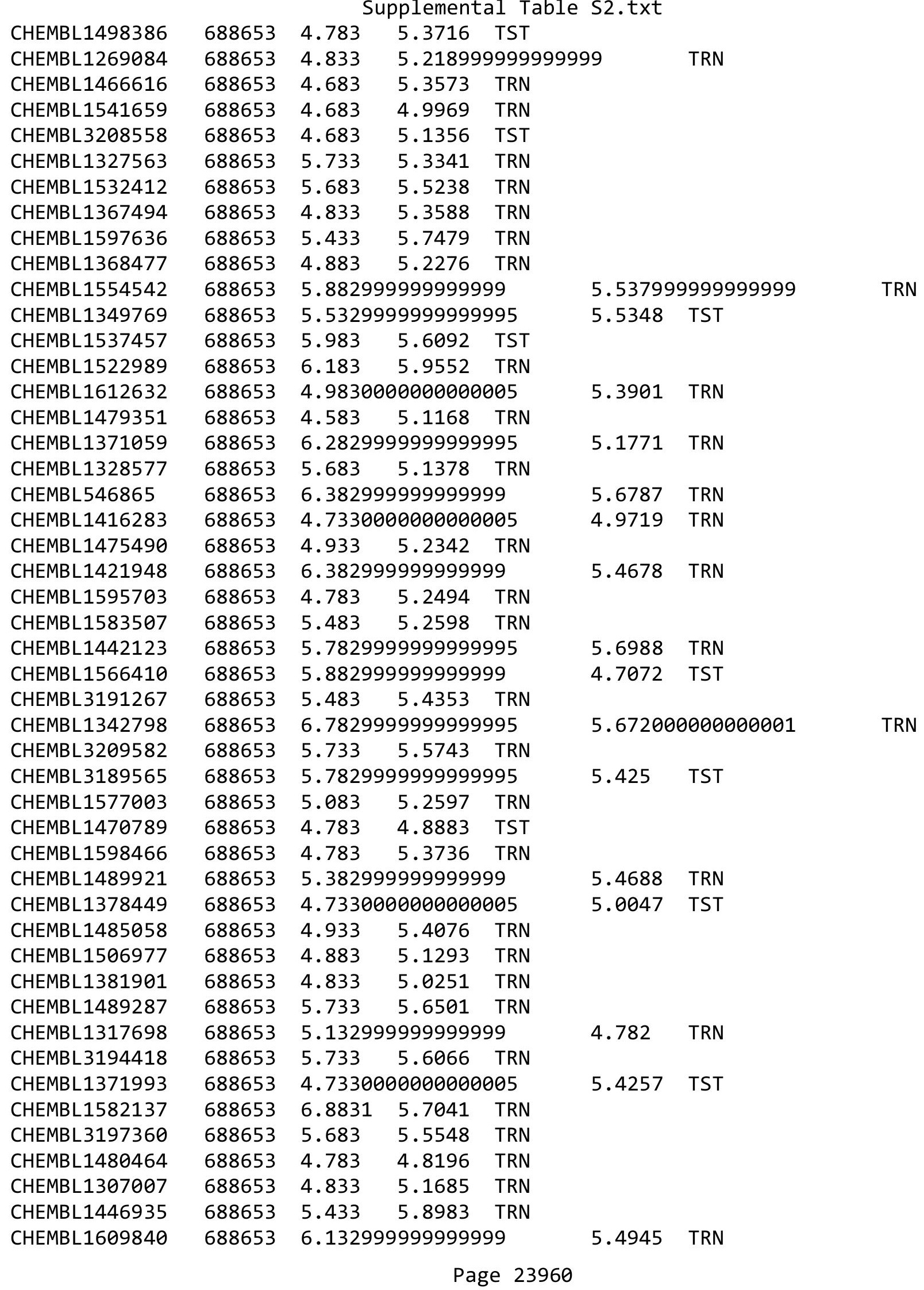




\begin{tabular}{|c|c|c|c|c|c|c|c|}
\hline \multicolumn{8}{|c|}{ Supplemental Table s2.txt } \\
\hline CHEMBL1439576 & 688653 & 5.433 & 5.3721 & TRN & & & \\
\hline CHEMBL1492864 & 688653 & 4.833 & 4.857 & TRN & & & \\
\hline CHEMBL1459958 & 688653 & 4.633 & 4.9717 & TST & & & \\
\hline CHEMBL1369182 & 688653 & \multicolumn{3}{|c|}{4.7330000000000005} & 5.5702 & TRN & \\
\hline CHEMBL1378017 & 688653 & 5.183 & 5.2825 & TRN & & & \\
\hline CHEMBL1394808 & 688653 & 5.683 & 5.6796 & TRN & & & \\
\hline CHEMBL1538056 & 688653 & 6.4829 & 5.8471 & TRN & & & \\
\hline CHEMBL1354798 & 688653 & 4.833 & 5.0743 & TRN & & & \\
\hline CHEMBL3193928 & 688653 & 4.783 & 5.0877 & TRN & & & \\
\hline CHEMBL1402024 & 688653 & 4.783 & 4.9443 & TST & & & \\
\hline CHEMBL 3213871 & 688653 & 5.083 & 5.3549 & TRN & & & \\
\hline CHEMBL1582176 & 688653 & \multicolumn{3}{|c|}{6.382999999999999} & 5.6964 & TRN & \\
\hline CHEMBL1316087 & 688653 & \multicolumn{3}{|c|}{5.132999999999999} & 4.9657 & TRN & \\
\hline CHEMBL1430641 & 688653 & \multicolumn{3}{|c|}{5.632999999999999} & 5.2917 & TRN & \\
\hline CHEMBL1311636 & 688653 & \multicolumn{3}{|c|}{4.7330000000000005} & 4.9908 & TST & \\
\hline CHEMBL1589149 & 688653 & 4.633 & 4.9943 & TRN & & & \\
\hline CHEMBL1581139 & 688653 & 5.983 & 5.3904 & TRN & & & \\
\hline CHEMBL1413384 & 688653 & \multicolumn{3}{|c|}{5.382999999999999} & 5.1134 & TST & \\
\hline CHEMBL1508512 & 688653 & \multicolumn{3}{|c|}{5.632999999999999} & 5.1008 & TRN & \\
\hline CHEMBL1318628 & 688653 & 4.933 & 5.2844 & TST & & & \\
\hline CHEMBL1389372 & 688653 & 5.233 & 5.6471 & TST & & & \\
\hline CHEMBL1371816 & 688653 & 4.783 & 5.8109 & TRN & & & \\
\hline CHEMBL1543752 & 688653 & 4.633 & 4.813 & TST & & & \\
\hline CHEMBL 3209070 & 688653 & \multicolumn{3}{|c|}{5.132999999999999} & 5.316 & TST & \\
\hline CHEMBL3192086 & 688653 & 4.783 & 5.0984 & TRN & & & \\
\hline CHEMBL1462462 & 688653 & 6.233 & 5.6325 & TRN & & & \\
\hline CHEMBL1457787 & 688653 & \multicolumn{3}{|c|}{5.332999999999999} & 5.3397 & TST & \\
\hline CHEMBL1487006 & 688653 & \multicolumn{3}{|c|}{5.332999999999999} & 5.675 & TRN & \\
\hline CHEMBL1488007 & 688653 & 4.833 & 4.7606 & TRN & & & \\
\hline CHEMBL1471962 & 688653 & 5.683 & 4.9889 & TRN & & & \\
\hline CHEMBL1464100 & 688653 & 6.183 & 5.9292 & TRN & & & \\
\hline CHEMBL1448776 & 688653 & 5.733 & 5.3682 & TRN & & & \\
\hline CHEMBL1420939 & 688653 & 5.53299 & 99999999 & 995 & 5.9046 & TST & \\
\hline CHEMBL1492240 & 688653 & 5.53299 & 99999999 & 995 & 5.5796 & TRN & \\
\hline CHEMBL1328435 & 688653 & 5.28299 & 99999999 & 995 & 4.9912 & TRN & \\
\hline CHEMBL1325967 & 688653 & 5.83299 & 99999999 & & 5.8124 & TRN & \\
\hline CHEMBL1308121 & 688653 & 4.783 & 5.4263 & TST & & & \\
\hline CHEMBL1609140 & 688653 & 7.08299 & 99999999 & & 5.6739 & 99999999995 & TRN \\
\hline CHEMBL1502173 & 688653 & 5.033 & 5.0714 & TST & & & \\
\hline CHEMBL1488001 & 688653 & 4.833 & 4.6738 & TST & & & \\
\hline CHEMBL1468250 & 688653 & 4.833 & 5.3729 & TRN & & & \\
\hline CHEMBL1558933 & 688653 & 5.88299 & 99999999 & & 5.2828 & TRN & \\
\hline CHEMBL1478741 & 688653 & 5.63299 & 99999999 & & 5.9411 & TRN & \\
\hline CHEMBL1467611 & 688653 & 4.98306 & 00000000 & 205 & 5.2501 & TRN & \\
\hline CHEMBL1467837 & 688653 & 5.38299 & 99999999 & & 5.2604 & TST & \\
\hline CHEMBL1495299 & 688653 & 4.633 & 5.0808 & TRN & & & \\
\hline CHEMBL1453492 & 688653 & 6.233 & 5.2621 & TRN & & & \\
\hline CHEMBL1337824 & 688653 & 4.633 & 5.0431 & TST & & & \\
\hline
\end{tabular}




\begin{tabular}{|c|c|c|c|c|c|c|c|}
\hline \multicolumn{7}{|c|}{ Supplemental Table s2.txt } & \\
\hline CHEMBL1452795 & 688653 & 5.683 & 5.7611 & TST & & & \\
\hline CHEMBL1519975 & 688653 & 5.28299 & 99999999 & 995 & 6.3061 & TRN & \\
\hline CHEMBL1594312 & 688653 & 5.233 & 5.0762 & TST & & & \\
\hline CHEMBL1419847 & 688653 & 5.683 & 5.8788 & TRN & & & \\
\hline CHEMBL1503324 & 688653 & 4.833 & 4.7848 & TST & & & \\
\hline CHEMBL1377552 & 688653 & 5.33299 & 99999999 & & 5.3626 & TRN & \\
\hline CHEMBL1548460 & 688653 & 4.783 & 5.3586 & TST & & & \\
\hline CHEMBL1407606 & 688653 & 5.78299 & 99999999 & 995 & 4.8148 & TRN & \\
\hline CHEMBL1980744 & 688653 & 6.433 & 5.0684 & TST & & & \\
\hline CHEMBL1351542 & 688653 & 5.483 & 4.9898 & TRN & & & \\
\hline CHEMBL1604350 & 688653 & 6.0 & 4.9857 & TRN & & & \\
\hline CHEMBL3190389 & 688653 & 4.883 & 5.1804 & TST & & & \\
\hline CHEMBL1322960 & 688653 & 5.233 & 5.2071 & TRN & & & \\
\hline CHEMBL 3214467 & 688653 & 5.38299 & 99999999 & & 5.0957 & TST & \\
\hline CHEMBL1571842 & 688653 & 4.783 & 5.4943 & TRN & & & \\
\hline CHEMBL1605583 & 688653 & 5.183 & 5.2311 & TRN & & & \\
\hline CHEMBL1351194 & 688653 & 4.783 & 5.1573 & TST & & & \\
\hline CHEMBL1307732 & 688653 & 5.63299 & 99999999 & & 5.0809 & TST & \\
\hline CHEMBL 3189570 & 688653 & 5.78299 & 99999999 & 995 & 5.3879 & TRN & \\
\hline CHEMBL1558324 & 688653 & 6.38299 & 99999999 & & 5.2811 & TRN & \\
\hline CHEMBL1438047 & 688653 & 5.63299 & 99999999 & & 5.4965 & TST & \\
\hline CHEMBL1993029 & 688653 & 6.63299 & 99999999 & & 5.8951 & TRN & \\
\hline CHEMBL1523761 & 688653 & 5.233 & 4.9833 & TST & & & \\
\hline CHEMBL1329616 & 688653 & 5.033 & 4.9631 & TRN & & & \\
\hline CHEMBL1584148 & 688653 & 4.933 & 5.0036 & TRN & & & \\
\hline CHEMBL3192204 & 688653 & 4.783 & 5.7352 & TRN & & & \\
\hline CHEMBL1442145 & 688653 & 4.933 & 5.4316 & TRN & & & \\
\hline CHEMBL1353470 & 688653 & 5.433 & 5.0482 & TRN & & & \\
\hline CHEMBL1320545 & 688653 & 5.183 & 5.38200 & 000000000 & & TRN & \\
\hline CHEMBL1425162 & 688653 & 4.883 & 5.1047 & TRN & & & \\
\hline CHEMBL1575588 & 688653 & 5.58299 & 99999999 & & 5.0861 & TST & \\
\hline CHEMBL1371479 & 688653 & 6.53299 & 99999999 & 995 & 6.1279 & TRN & \\
\hline CHEMBL1507274 & 688653 & 6.8831 & 5.8559 & TRN & & & \\
\hline CHEMBL3191244 & 688653 & 5.733 & 5.353 & TRN & & & \\
\hline CHEMBL3211775 & 688653 & 6.03299 & 99999999 & 995 & 5.4135 & TRN & \\
\hline CHEMBL1502170 & 688653 & 5.78299 & 99999999 & 995 & 5.9789 & TRN & \\
\hline CHEMBL1363614 & 688653 & 5.13299 & 99999999 & & 4.8298 & TST & \\
\hline CHEMBL1335000 & 688653 & 4.833 & 5.2761 & TST & & & \\
\hline CHEMBL1488730 & 688653 & 5.233 & 6.6038 & TRN & & & \\
\hline CHEMBL3191747 & 688653 & 4.833 & 5.0072 & TRN & & & \\
\hline CHEMBL1428180 & 688653 & 6.03299 & 99999999 & 995 & 5.7188 & TRN & \\
\hline CHEMBL1501506 & 688653 & 5.38299 & 99999999 & & 5.362999 & 99999999995 & TST \\
\hline CHEMBL1337484 & 688653 & 4.98300 & 00000000 & 005 & 5.4225 & TRN & \\
\hline CHEMBL1599860 & 688653 & 4.583 & 4.904 & TRN & & & \\
\hline CHEMBL1307556 & 688653 & 4.98300 & 00000000 & 005 & 5.7321 & TRN & \\
\hline CHEMBL1409202 & 688653 & 4.633 & 4.9181 & TST & & & \\
\hline CHEMBL1604144 & 688653 & 4.683 & 4.9075 & TST & & & \\
\hline CHEMBL1532352 & 688653 & 5.483 & 5.1718 & TRN & & & \\
\hline
\end{tabular}




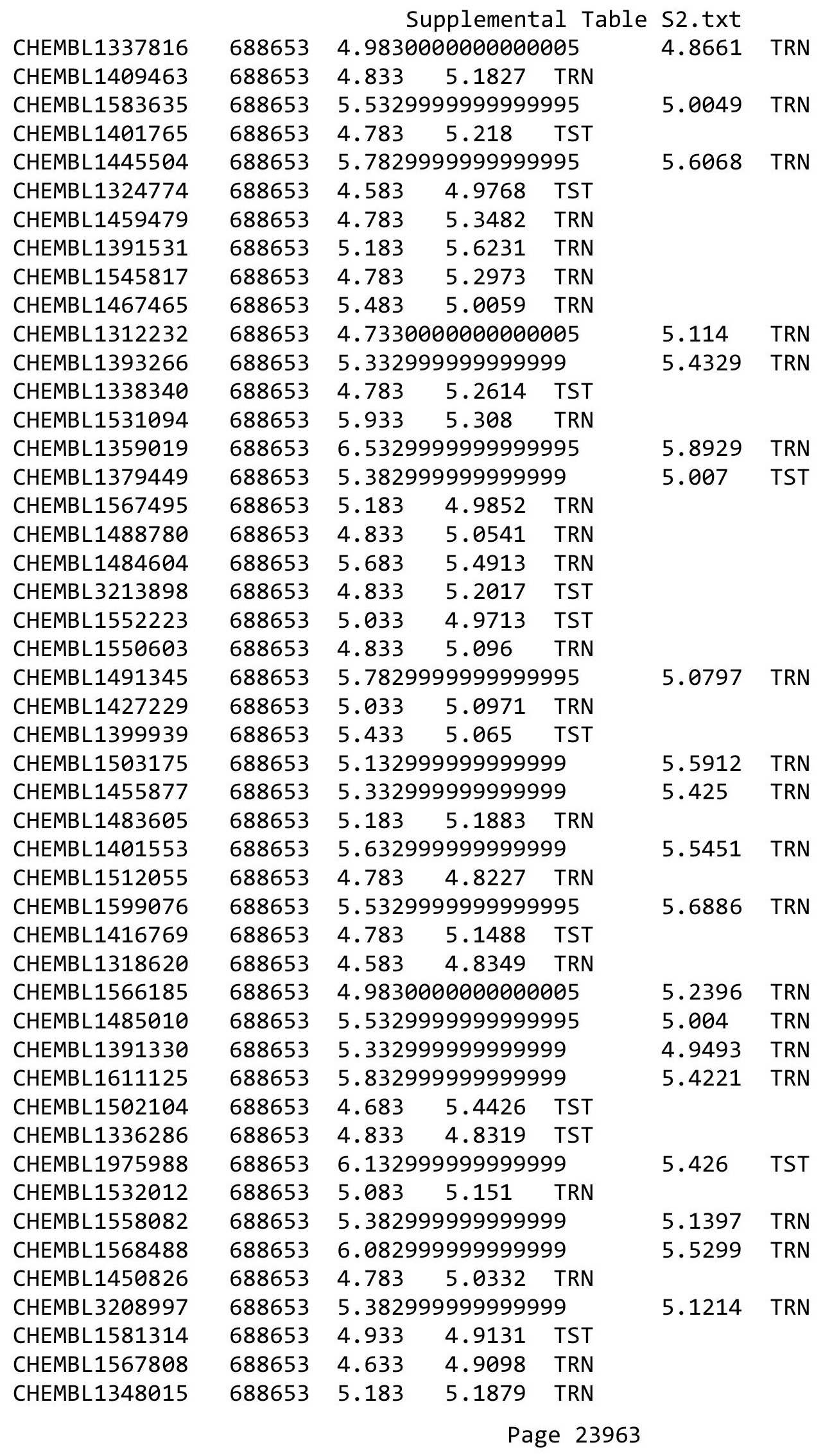




\begin{tabular}{|c|c|c|c|c|c|c|c|}
\hline & & & pplement & a] $\mathrm{T}$ & s2.txt & & \\
\hline CHEMBL1372920 & 688653 & 4.783 & 5.2889 & TST & & & \\
\hline CHEMBL1560430 & 688653 & 5.33299 & 99999999 & & 5.6772 & TRN & \\
\hline CHEMBL1587886 & 688653 & 4.883 & 5.3656 & TRN & & & \\
\hline CHEMBL1399085 & 688653 & 4.73300 & 00000000 & 005 & 5.3186 & TRN & \\
\hline CHEMBL1405452 & 688653 & 4.833 & 5.1624 & TRN & & & \\
\hline CHEMBL1480820 & 688653 & 5.63299 & 99999999 & & 5.0875 & TRN & \\
\hline CHEMBL1526203 & 688653 & 4.783 & 5.4199 & TRN & & & \\
\hline CHEMBL1541425 & 688653 & 5.13299 & 99999999 & & 5.1995 & TRN & \\
\hline CHEMBL1999648 & 688653 & 5.733 & 5.064 & TST & & & \\
\hline CHEMBL1563513 & 688653 & 6.03299 & 99999999 & 995 & 5.3252 & TRN & \\
\hline CHEMBL186368 & 688653 & 5.13299 & 99999999 & & 5.546 & TRN & \\
\hline CHEMBL1504879 & 688653 & 5.733 & 5.5355 & TRN & & & \\
\hline CHEMBL1308234 & 688653 & 5.38299 & 99999999 & & 4.8882 & TRN & \\
\hline CHEMBL1559722 & 688653 & 4.883 & 5.1853 & TRN & & & \\
\hline CHEMBL1299301 & 688653 & 6.38299 & 99999999 & & 5.5588 & TRN & \\
\hline CHEMBL1542819 & 688653 & 5.483 & 5.0062 & TRN & & & \\
\hline CHEMBL1481068 & 688653 & 4.833 & 5.2647 & TRN & & & \\
\hline CHEMBL1355153 & 688653 & $4.9830 e$ & 00000000 & 005 & 4.8908 & TRN & \\
\hline CHEMBL1453006 & 688653 & 5.78299 & 99999999 & 995 & 5.7021 & TRN & \\
\hline CHEMBL1597057 & 688653 & 4.783 & 5.0983 & TST & & & \\
\hline CHEMBL1551012 & 688653 & 5.733 & 5.8036 & TRN & & & \\
\hline CHEMBL1607986 & 688653 & 5.13299 & 99999999 & & 5.2991 & TRN & \\
\hline CHEMBL1299444 & 688653 & 6.58299 & 99999999 & & 5.9363 & TRN & \\
\hline CHEMBL1366101 & 688653 & 4.833 & 5.1642 & TRN & & & \\
\hline CHEMBL1528203 & 688653 & 5.733 & 4.963 & TRN & & & \\
\hline CHEMBL1439253 & 688653 & 5.53299 & 99999999 & 995 & 4.8938 & TRN & \\
\hline CHEMBL3209244 & 688653 & 6.53299 & 99999999 & 995 & 5.6326 & TRN & \\
\hline CHEMBL1606239 & 688653 & 4.633 & 5.5766 & TST & & & \\
\hline CHEMBL1412585 & 688653 & 5.78299 & 99999999 & 995 & 5.2266 & TRN & \\
\hline CHEMBL3189267 & 688653 & 5.58299 & 99999999 & & 5.9011 & TRN & \\
\hline CHEMBL1603136 & 688653 & 4.833 & 5.3337 & TRN & & & \\
\hline CHEMBL1469986 & 688653 & 6.13299 & 99999999 & & 6.0125 & TRN & \\
\hline CHEMBL1319969 & 688653 & 5.63299 & 99999999 & & 5.71899 & 9999999999 & TRN \\
\hline CHEMBL1412674 & 688653 & 5.83299 & 99999999 & & 5.0638 & TST & \\
\hline CHEMBL3210859 & 688653 & 5.233 & 5.0495 & TRN & & & \\
\hline CHEMBL1607366 & 688653 & 5.433 & 5.5098 & TRN & & & \\
\hline CHEMBL1314149 & 688653 & 4.833 & 5.6123 & TRN & & & \\
\hline CHEMBL1417341 & 688653 & 5.983 & 5.6236 & TST & & & \\
\hline CHEMBL1391710 & 688653 & 4.833 & 5.3638 & TRN & & & \\
\hline CHEMBL1336496 & 688653 & 6.33299 & 99999999 & & 5.9616 & TRN & \\
\hline CHEMBL1549042 & 688653 & 4.933 & 5.0576 & TRN & & & \\
\hline CHEMBL1588780 & 688653 & 6.433 & 5.9388 & TRN & & & \\
\hline CHEMBL1369100 & 688653 & 4.583 & 5.0043 & TRN & & & \\
\hline CHEMBL1519193 & 688653 & 6.58299 & 99999999 & & 5.3416 & TRN & \\
\hline CHEMBL1549081 & 688653 & 4.783 & 5.5316 & TRN & & & \\
\hline CHEMBL1313548 & 688653 & 6.38299 & 99999999 & & 5.7289 & TRN & \\
\hline CHEMBL1501191 & 688653 & 5.33299 & 99999999 & & 5.9281 & TRN & \\
\hline CHEMBL1470934 & 688653 & 6.4829 & 5.4451 & TRN & & & \\
\hline
\end{tabular}




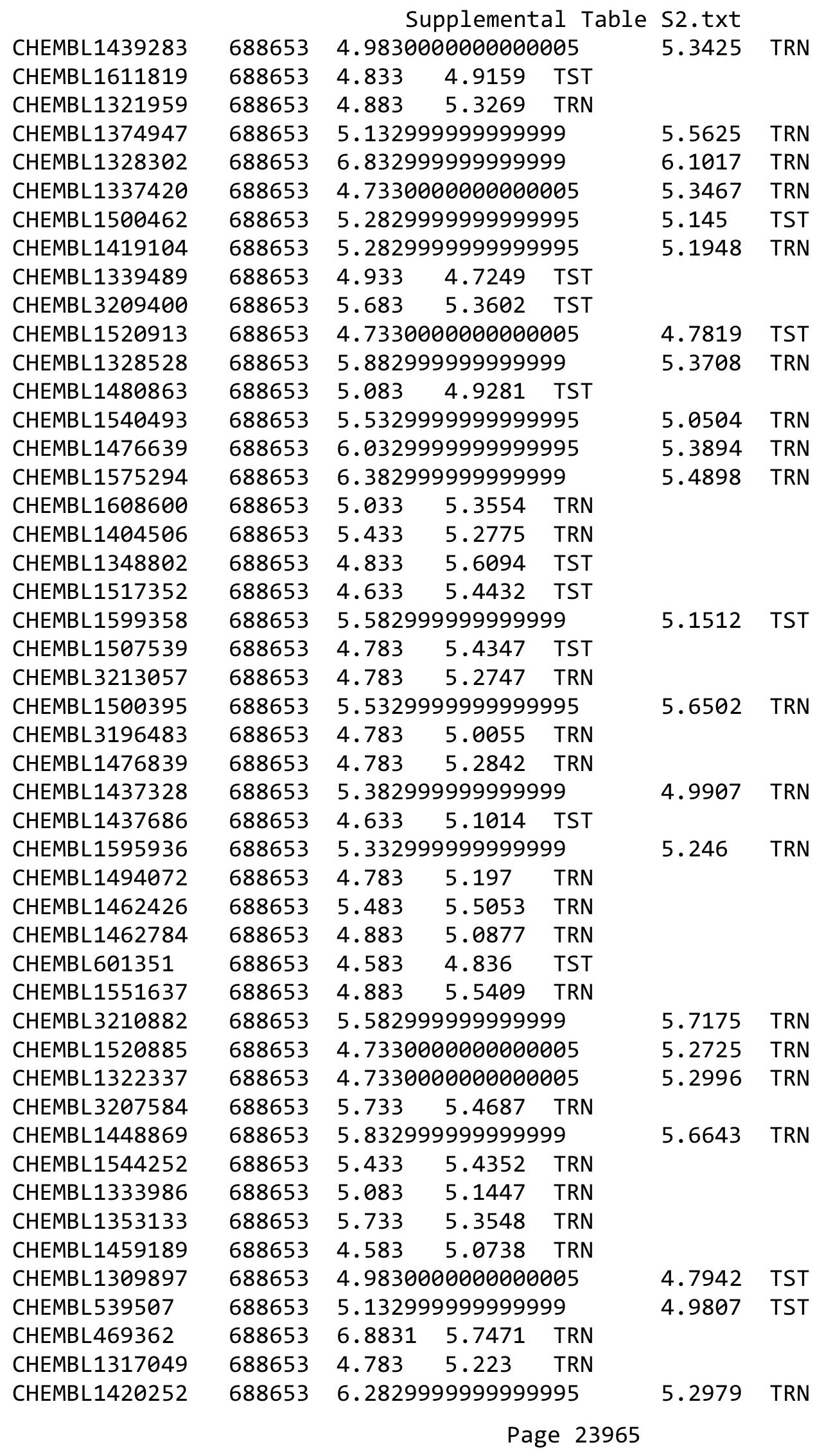




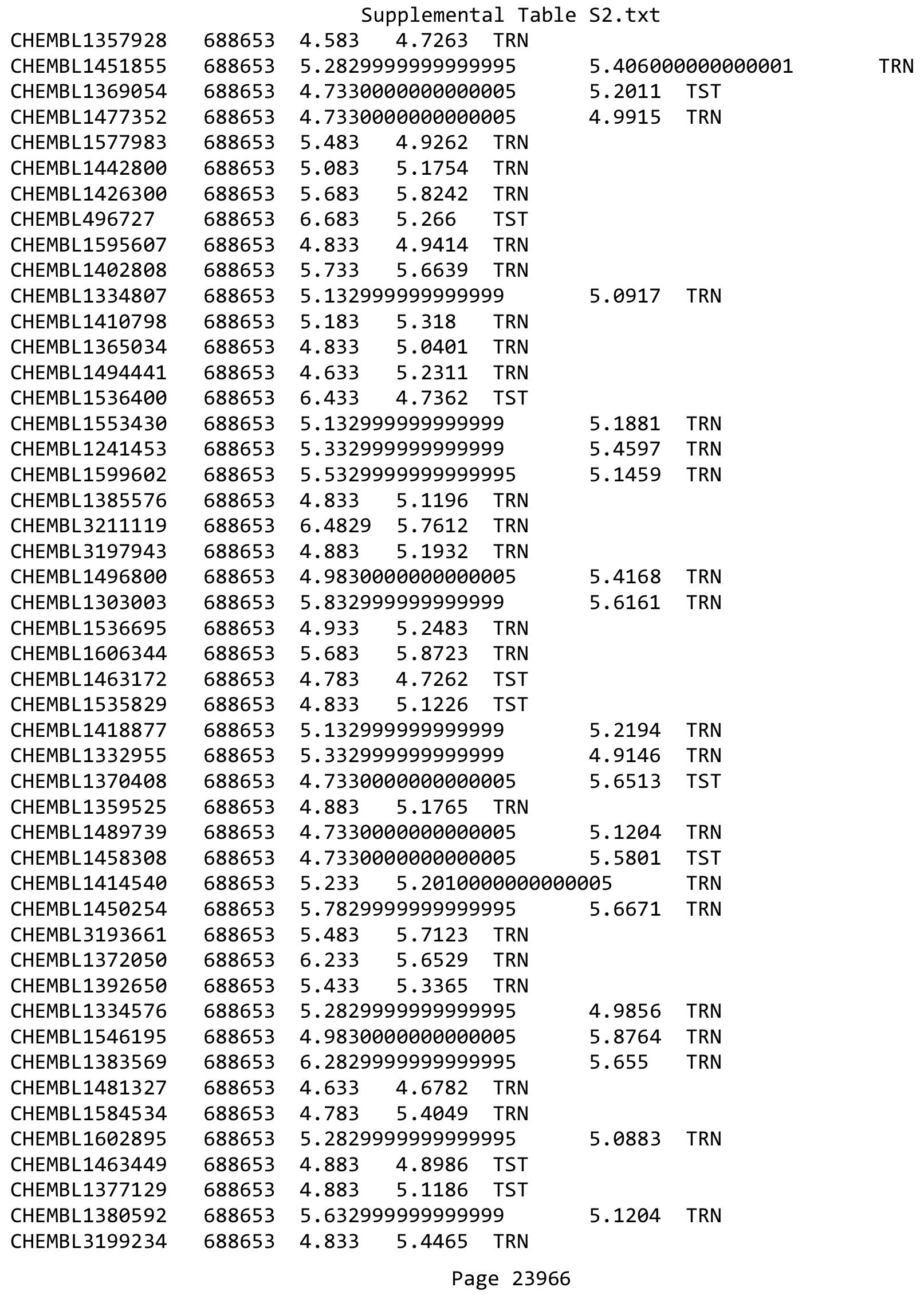




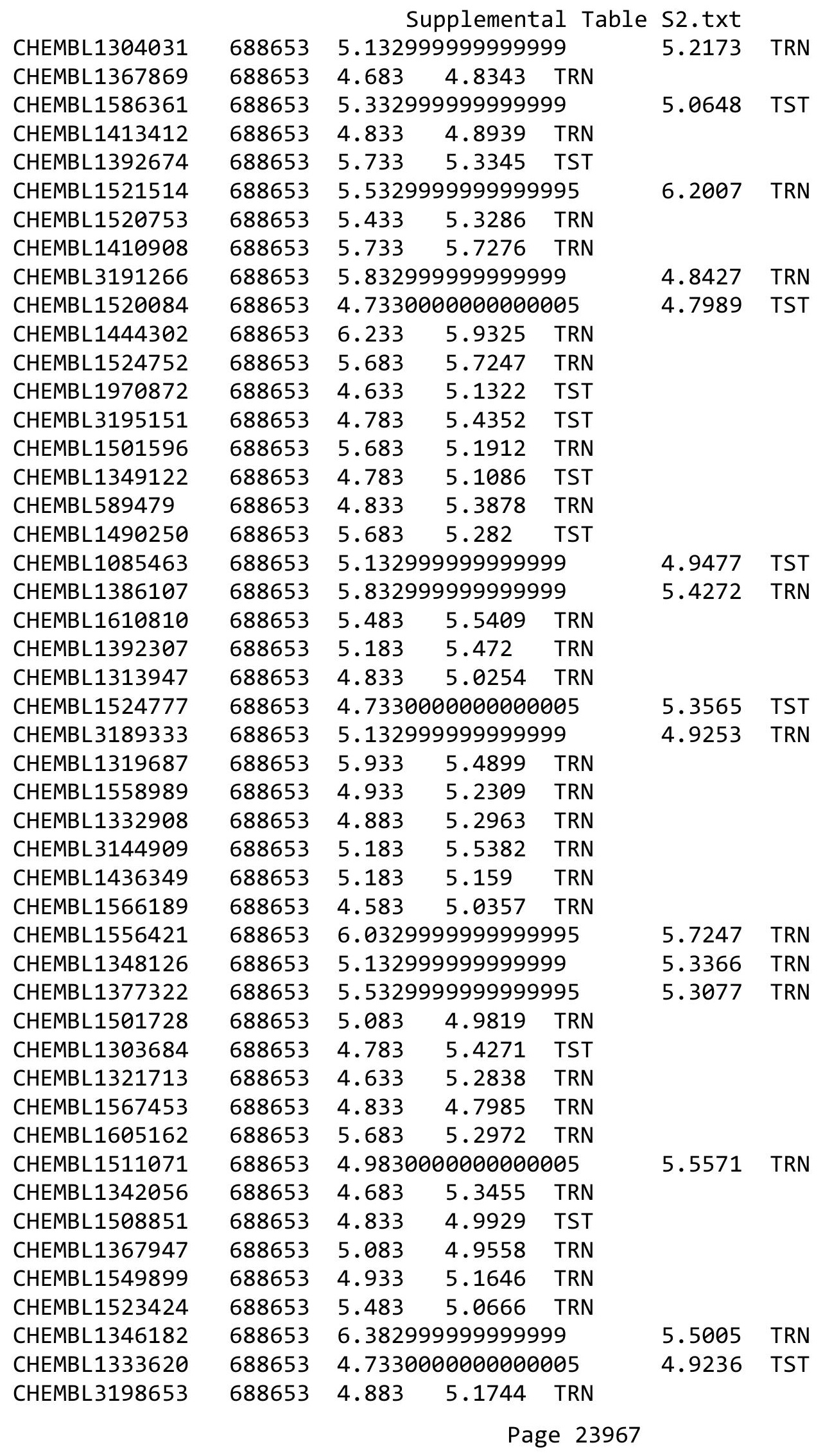




\begin{tabular}{|c|c|c|c|c|c|c|}
\hline & & \multicolumn{5}{|c|}{ Supplemental Table S2.txt } \\
\hline CHEMBL1359288 & 688653 & 4.883 & 5.1683 & TST & & \\
\hline CHEMBL3213419 & 688653 & 7.0329 & 5.2811 & TRN & & \\
\hline CHEMBL1329321 & 688653 & 5.683 & 5.1006 & TRN & & \\
\hline CHEMBL1338554 & 688653 & 4.783 & 5.6134 & TRN & & \\
\hline CHEMBL1441550 & 688653 & 5.183 & 5.0296 & TRN & & \\
\hline CHEMBL1598696 & 688653 & \multicolumn{3}{|c|}{6.582999999999999} & 6.1129 & TST \\
\hline CHEMBL1555030 & 688653 & 4.783 & 4.8097 & TRN & & \\
\hline CHEMBL1449015 & 688653 & 4.883 & 4.9705 & TRN & & \\
\hline CHEMBL1496794 & 688653 & 4.833 & 5.2882 & TRN & & \\
\hline CHEMBL1578471 & 688653 & \multicolumn{3}{|c|}{4.9830000000000005} & 5.3234 & TST \\
\hline CHEMBL1461059 & 688653 & 5.733 & 5.4532 & TRN & & \\
\hline CHEMBL3189191 & 688653 & 4.783 & 4.6935 & TST & & \\
\hline CHEMBL1581754 & 688653 & 5.183 & 5.0109 & TRN & & \\
\hline CHEMBL1332800 & 688653 & \multicolumn{3}{|c|}{5.582999999999999} & 5.3466 & TRN \\
\hline CHEMBL1410762 & 688653 & 5.733 & 4.9456 & TRN & & \\
\hline CHEMBL1603360 & 688653 & 5.233 & 5.3179 & TRN & & \\
\hline CHEMBL3193321 & 688653 & 4.883 & 5.1283 & TST & & \\
\hline CHEMBL1329016 & 688653 & 4.583 & 5.0236 & TRN & & \\
\hline CHEMBL1446759 & 688653 & 6.233 & 5.1593 & TRN & & \\
\hline CHEMBL1470633 & 688653 & \multicolumn{3}{|c|}{5.2829999999999995} & 5.1764 & TST \\
\hline CHEMBL1315300 & 688653 & \multicolumn{3}{|c|}{4.9830000000000005} & 5.3054 & TST \\
\hline CHEMBL1585361 & 688653 & \multicolumn{3}{|c|}{4.7330000000000005} & 4.7985 & TST \\
\hline CHEMBL 234378 & 688653 & \multicolumn{3}{|c|}{7.082999999999999} & 6.2271 & TRN \\
\hline CHEMBL1453609 & 688653 & \multicolumn{3}{|c|}{5.582999999999999} & 5.5534 & TRN \\
\hline CHEMBL1443082 & 688653 & 5.083 & 4.9511 & TST & & \\
\hline CHEMBL1329035 & 688653 & \multicolumn{3}{|c|}{6.082999999999999} & 5.6729 & TRN \\
\hline CHEMBL1483198 & 688653 & 4.783 & 4.9824 & TST & & \\
\hline CHEMBL1447831 & 688653 & 5.683 & 5.2198 & TRN & & \\
\hline CHEMBL1315928 & 688653 & 4.583 & 5.23 & TRN & & \\
\hline CHEMBL1315442 & 688653 & 4.633 & 4.5272 & TST & & \\
\hline CHEMBL1429812 & 688653 & 4.783 & 5.3293 & TRN & & \\
\hline CHEMBL2006762 & 688653 & \multicolumn{3}{|c|}{5.5329999999999995} & 5.4095 & TRN \\
\hline CHEMBL3193723 & 688653 & 5.033 & 5.2487 & TRN & & \\
\hline CHEMBL1502937 & 688653 & 4.583 & 5.0698 & TRN & & \\
\hline CHEMBL2369292 & 688653 & \multicolumn{3}{|c|}{5.132999999999999} & 5.2457 & TRN \\
\hline CHEMBL1579396 & 688653 & 5.433 & 5.7824 & TRN & & \\
\hline CHEMBL1599820 & 688653 & 5.233 & 5.0363 & TRN & & \\
\hline CHEMBL1323387 & 688653 & 5.683 & 5.2154 & TRN & & \\
\hline CHEMBL1419866 & 688653 & \multicolumn{3}{|c|}{6.382999999999999} & 5.414 & TRN \\
\hline CHEMBL1452771 & 688653 & \multicolumn{3}{|c|}{5.632999999999999} & 5.1854 & TST \\
\hline CHEMBL1573230 & 688653 & \multicolumn{3}{|c|}{4.7330000000000005} & 4.7817 & TST \\
\hline CHEMBL1395702 & 688653 & 4.633 & 5.0826 & TST & & \\
\hline CHEMBL1542043 & 688653 & 5.083 & 5.5838 & TRN & & \\
\hline CHEMBL1348026 & 688653 & 4.583 & 4.9132 & TRN & & \\
\hline CHEMBL1598426 & 688653 & \multicolumn{3}{|c|}{5.2829999999999995} & 5.5111 & TST \\
\hline CHEMBL1473009 & 688653 & 4.633 & 4.9324 & TRN & & \\
\hline CHEMBL1532583 & 688653 & 5.483 & 4.9098 & TST & & \\
\hline CHEMBL1387822 & 688653 & 5.433 & 5.2466 & TRN & & \\
\hline
\end{tabular}




\begin{tabular}{|c|c|c|c|c|c|c|}
\hline \multirow[b]{2}{*}{ CHEMBL1543589 } & \multicolumn{6}{|c|}{ } \\
\hline & 688653 & 4.783 & 5.2767 & TRN & & \\
\hline CHEMBL1573272 & 688653 & 5.733 & 5.2115 & TST & & \\
\hline CHEMBL68442 & 688653 & \multicolumn{3}{|c|}{5.632999999999999} & 4.9818 & TRN \\
\hline CHEMBL1413286 & 688653 & \multicolumn{3}{|c|}{5.582999999999999} & 5.5889 & TRN \\
\hline CHEMBL1353660 & 688653 & 4.783 & 5.3469 & TRN & & \\
\hline CHEMBL3194665 & 688653 & \multicolumn{3}{|c|}{6.0329999999999995} & 5.4338 & TST \\
\hline CHEMBL1528181 & 688653 & \multicolumn{3}{|c|}{6.332999999999999} & 5.6282 & TST \\
\hline CHEMBL3145136 & 688653 & 5.083 & 5.2837 & TRN & & \\
\hline CHEMBL1564134 & 688653 & 4.933 & 4.8912 & TRN & & \\
\hline CHEMBL1484825 & 688653 & 5.933 & 5.7354 & TRN & & \\
\hline CHEMBL1388951 & 688653 & 5.183 & 5.3739 & TST & & \\
\hline CHEMBL1377357 & 688653 & \multicolumn{3}{|c|}{4.7330000000000005} & 5.3921 & TRN \\
\hline CHEMBL1303642 & 688653 & 4.883 & 5.0299 & TST & & \\
\hline CHEMBL1420595 & 688653 & 4.833 & 5.2805 & TST & & \\
\hline CHEMBL1393855 & 688653 & \multicolumn{3}{|c|}{4.7330000000000005} & 5.0258 & TRN \\
\hline CHEMBL1519414 & 688653 & 5.033 & 5.7485 & TRN & & \\
\hline CHEMBL1483745 & 688653 & \multicolumn{3}{|c|}{5.382999999999999} & 6.0227 & TRN \\
\hline CHEMBL1332459 & 688653 & 4.783 & 5.2644 & TRN & & \\
\hline CHEMBL3192163 & 688653 & \multicolumn{3}{|c|}{5.882999999999999} & 5.277 & TRN \\
\hline CHEMBL1372333 & 688653 & \multicolumn{3}{|c|}{6.7829999999999995} & 5.965 & TRN \\
\hline CHEMBL1304328 & 688653 & \multicolumn{3}{|c|}{5.332999999999999} & 5.1815 & TRN \\
\hline CHEMBL3191809 & 688653 & 5.083 & 5.6283 & TRN & & \\
\hline CHEMBL1407708 & 688653 & 4.783 & 5.3773 & TST & & \\
\hline CHEMBL1372289 & 688653 & \multicolumn{3}{|c|}{5.132999999999999} & 5.3258 & TRN \\
\hline CHEMBL1313489 & 688653 & 4.783 & 5.2031 & TRN & & \\
\hline CHEMBL1577231 & 688653 & 5.683 & 5.7603 & TRN & & \\
\hline CHEMBL1442881 & 688653 & 4.933 & 5.1296 & TRN & & \\
\hline CHEMBL1421401 & 688653 & 5.933 & 6.0134 & TRN & & \\
\hline CHEMBL1549532 & 688653 & 4.783 & 5.0078 & TST & & \\
\hline CHEMBL1400981 & 688653 & \multicolumn{3}{|c|}{4.7330000000000005} & 4.9965 & TRN \\
\hline CHEMBL1567934 & 688653 & 5.483 & 5.1692 & TST & & \\
\hline CHEMBL1605478 & 688653 & 6.233 & 6.0919 & TRN & & \\
\hline CHEMBL1441583 & 688653 & 5.983 & 5.5864 & TRN & & \\
\hline CHEMBL3195129 & 688653 & 5.033 & 5.3916 & TRN & & \\
\hline CHEMBL 3212775 & 688653 & \multicolumn{3}{|c|}{5.132999999999999} & 4.9755 & TST \\
\hline CHEMBL1421503 & 688653 & 4.683 & 5.1143 & TST & & \\
\hline CHEMBL1307790 & 688653 & 5.033 & 5.0906 & TRN & & \\
\hline CHEMBL1301723 & 688653 & \multicolumn{3}{|c|}{5.332999999999999} & 5.3782 & TRN \\
\hline CHEMBL3145376 & 688653 & 5.733 & 5.2896 & TRN & & \\
\hline CHEMBL1458749 & 688653 & \multirow{2}{*}{\multicolumn{3}{|c|}{4.7330000000000005}} & & \\
\hline CHEMBL1304601 & 688653 & & & & 5.6113 & TRN \\
\hline CHEMBL3189876 & 688653 & 4.783 & 5.3636 & TRN & & \\
\hline CHEMBL1335779 & 688653 & 5.483 & 4.9075 & TST & & \\
\hline CHEMBL1384377 & 688653 & 5.033 & 5.192 & TRN & & \\
\hline CHEMBL1443834 & 688653 & \multicolumn{3}{|c|}{4.9830000000000005} & 5.2752 & TRN \\
\hline CHEMBL1384158 & 688653 & \multicolumn{3}{|c|}{5.382999999999999} & 5.3954 & TRN \\
\hline CHEMBL1553324 & 688653 & 4.883 & 4.8526 & TRN & & \\
\hline CHEMBL1596015 & 688653 & 4.783 & 5.0406 & TRN & & \\
\hline
\end{tabular}




\begin{tabular}{|c|c|c|c|c|c|c|c|}
\hline \multirow{3}{*}{$\begin{array}{l}\text { CHEMBL1576273 } \\
\text { CHEMBL1305480 }\end{array}$} & \multicolumn{6}{|c|}{ Supplemental Table S2.txt } & \\
\hline & 688653 & \multicolumn{3}{|c|}{6.082999999999999} & 5.9184 & TRN & \\
\hline & 688653 & 4.833 & 5.2614 & TST & & & \\
\hline CHEMBL1595509 & 688653 & \multicolumn{3}{|c|}{6.132999999999999} & \multicolumn{2}{|c|}{5.337000000000001} & TRN \\
\hline CHEMBL1303494 & 688653 & \multicolumn{3}{|c|}{5.7829999999999995} & 5.2732 & TRN & \\
\hline CHEMBL1542516 & 688653 & \multicolumn{3}{|c|}{5.7829999999999995} & 5.2904 & TRN & \\
\hline CHEMBL1353514 & 688653 & \multicolumn{3}{|c|}{4.7330000000000005} & 4.9684 & TRN & \\
\hline CHEMBL1436143 & 688653 & 7.1331 & 5.8506 & TRN & & & \\
\hline CHEMBL1532205 & 688653 & \multicolumn{3}{|c|}{5.832999999999999} & 5.7702 & TRN & \\
\hline CHEMBL1544408 & 688653 & \multicolumn{3}{|c|}{4.7330000000000005} & 5.2347 & TRN & \\
\hline CHEMBL3195199 & 688653 & \multicolumn{3}{|c|}{5.5329999999999995} & 5.4278 & TST & \\
\hline CHEMBL1539485 & 688653 & 5.683 & 5.7561 & TRN & & & \\
\hline CHEMBL1355065 & 688653 & & & TST & & & \\
\hline CHEMBL1569067 & 688653 & \multicolumn{3}{|c|}{5.332999999999999} & 5.4638 & TRN & \\
\hline CHEMBL1572719 & 688653 & \multicolumn{3}{|c|}{5.132999999999999} & 4.8231 & TRN & \\
\hline CHEMBL1302758 & 688653 & \multicolumn{3}{|c|}{6.2829999999999995} & 5.9736 & TRN & \\
\hline CHEMBL1310773 & 688653 & \multicolumn{3}{|c|}{4.7330000000000005} & 5.1249 & TRN & \\
\hline CHEMBL1480356 & 688653 & 4.783 & 5.2907 & TRN & & & \\
\hline CHEMBL1346995 & 688653 & 4.883 & 5.4544 & TRN & & & \\
\hline CHEMBL1568082 & 688653 & 4.883 & 5.3663 & TRN & & & \\
\hline CHEMBL1418614 & 688653 & 4.583 & 4.8985 & TRN & & & \\
\hline CHEMBL1565380 & 688653 & \multicolumn{3}{|c|}{5.382999999999999} & 4.9582 & TRN & \\
\hline CHEMBL1478880 & 688653 & \multicolumn{3}{|c|}{5.132999999999999} & 5.3168 & TRN & \\
\hline CHEMBL3190723 & 688653 & \multicolumn{3}{|c|}{5.332999999999999} & 5.0904 & TRN & \\
\hline CHEMBL1522020 & 688653 & 4.883 & 5.004 & TST & & & \\
\hline CHEMBL1372586 & 688653 & 5.183 & 5.2173 & TST & & & \\
\hline CHEMBL1361637 & 688653 & \multicolumn{3}{|c|}{5.2829999999999995} & 5.1355 & TST & \\
\hline CHEMBL1576245 & 688653 & \multicolumn{3}{|c|}{4.7330000000000005} & 5.0415 & TRN & \\
\hline CHEMBL1535104 & 688653 & 4.783 & 5.2017 & TRN & & & \\
\hline CHEMBL1544131 & 688653 & 5.183 & 5.7752 & TRN & & & \\
\hline CHEMBL1613323 & 688653 & 5.483 & 5.0843 & TRN & & & \\
\hline CHEMBL3193144 & 688653 & 4.833 & 5.4535 & TST & & & \\
\hline CHEMBL3190616 & 688653 & 4.783 & 5.6054 & TRN & & & \\
\hline CHEMBL1427736 & 688653 & 5.033 & 5.8281 & TRN & & & \\
\hline CHEMBL1552800 & 688653 & 5.1329 & 99999999 & & 4.791 & TRN & \\
\hline CHEMBL1577756 & 688653 & 5.8829 & 99999999 & & 5.892 & TRN & \\
\hline CHEMBL1402869 & 688653 & 4.633 & 4.838 & TRN & & & \\
\hline CHEMBL1535262 & 688653 & 4.883 & 4.833 & TST & & & \\
\hline CHEMBL1318311 & 688653 & 4.583 & 5.0509 & TRN & & & \\
\hline CHEMBL1565972 & 688653 & 5.683 & 5.0893 & TST & & & \\
\hline CHEMBL1593518 & 688653 & 4.783 & 4.7117 & TRN & & & \\
\hline CHEMBL1410309 & 688653 & 4.833 & 4.7887 & TRN & & & \\
\hline CHEMBL1452702 & 688653 & 5.5829 & 99999999 & & 5.0894 & TST & \\
\hline CHEMBL3208332 & 688653 & 5.5329 & 99999999 & 995 & 5.4482 & TRN & \\
\hline CHEMBL1346937 & 688653 & 5.3329 & 99999999 & & 5.1346 & TST & \\
\hline CHEMBL1388095 & 688653 & 4.9830 & 00000000 & 005 & 5.1746 & TRN & \\
\hline CHEMBL3198101 & 688653 & 5.683 & 5.5868 & TRN & & & \\
\hline CHEMBL1456878 & 688653 & 5.3329 & 99999999 & & 5.4198 & TRN & \\
\hline CHEMBL1408325 & 688653 & 6.1329 & 99999999 & & 5.6178 & TRN & \\
\hline
\end{tabular}




\begin{tabular}{|c|c|c|c|c|c|c|c|}
\hline \multicolumn{8}{|c|}{ Supplemental Table S2.txt } \\
\hline CHEMBL1981454 & 688653 & 5.183 & 5.5188 & TRN & & & \\
\hline CHEMBL1466598 & 688653 & \multicolumn{3}{|c|}{4.9830000000000005} & 4.8031 & TRN & \\
\hline CHEMBL1449188 & 688653 & 5.033 & 5.3881 & TRN & & & \\
\hline CHEMBL 3195868 & 688653 & 4.783 & 5.0775 & TRN & & & \\
\hline CHEMBL1502503 & 688653 & \multicolumn{3}{|c|}{5.7829999999999995} & 6.0589 & TRN & \\
\hline CHEMBL1387462 & 688653 & 4.783 & 4.5784 & TRN & & & \\
\hline CHEMBL1322183 & 688653 & \multicolumn{3}{|c|}{5.2829999999999995} & 5.1278 & TRN & \\
\hline CHEMBL1525930 & 688653 & \multicolumn{3}{|c|}{4.9830000000000005} & 5.0207 & TRN & \\
\hline CHEMBL1580996 & 688653 & 4.833 & 5.4292 & TRN & & & \\
\hline CHEMBL1514373 & 688653 & 4.883 & 5.6082 & TRN & & & \\
\hline CHEMBL 3207517 & 688653 & 4.933 & 5.14 & TRN & & & \\
\hline CHEMBL1329138 & 688653 & \multicolumn{3}{|c|}{5.382999999999999} & 5.6893 & TRN & \\
\hline CHEMBL1528905 & 688653 & \multicolumn{3}{|c|}{6.082999999999999} & 5.3984 & TRN & \\
\hline CHEMBL1590743 & 688653 & 4.833 & 5.1878 & TST & & & \\
\hline CHEMBL1472390 & 688653 & \multicolumn{3}{|c|}{4.7330000000000005} & \multicolumn{2}{|c|}{4.781000000000001} & TST \\
\hline CHEMBL 3193799 & 688653 & 4.783 & 5.3822 & TRN & & & \\
\hline CHEMBL1397197 & 688653 & 5.433 & 5.206 & TRN & & & \\
\hline CHEMBL1459746 & 688653 & \multicolumn{3}{|c|}{5.382999999999999} & 5.2621 & TRN & \\
\hline CHEMBL 3196400 & 688653 & 4.783 & 5.2359 & TRN & & & \\
\hline CHEMBL475627 & 688653 & 7.0329 & 5.9663 & TRN & & & \\
\hline CHEMBL1331423 & 688653 & 4.833 & 5.5985 & TRN & & & \\
\hline CHEMBL1558211 & 688653 & \multicolumn{3}{|c|}{5.882999999999999} & 5.6109 & TRN & \\
\hline CHEMBL1483183 & 688653 & \multicolumn{3}{|c|}{4.7330000000000005} & 5.0208 & TRN & \\
\hline CHEMBL1479172 & 688653 & \multicolumn{3}{|c|}{6.382999999999999} & 5.2152 & TST & \\
\hline CHEMBL1531555 & 688653 & \multicolumn{3}{|c|}{5.5329999999999995} & 5.5922 & TRN & \\
\hline CHEMBL1545410 & 688653 & 5.233 & 5.5915 & TST & & & \\
\hline CHEMBL 357170 & 688653 & \multicolumn{3}{|c|}{5.382999999999999} & 5.7583 & TRN & \\
\hline CHEMBL1365221 & 688653 & 4.783 & 5.1701 & TRN & & & \\
\hline CHEMBL1510116 & 688653 & 6.4829 & 5.6555 & TRN & & & \\
\hline CHEMBL1489856 & 688653 & \multicolumn{3}{|c|}{5.882999999999999} & 5.3954 & TST & \\
\hline CHEMBL1575517 & 688653 & \multicolumn{3}{|c|}{5.832999999999999} & 5.6111 & TRN & \\
\hline CHEMBL484663 & 688653 & 5.233 & 5.534 & TRN & & & \\
\hline CHEMBL1406200 & 688653 & 4.833 & 5.5574 & TRN & & & \\
\hline CHEMBL1561993 & 688653 & 5.483 & 5.6526 & TRN & & & \\
\hline CHEMBL1402230 & 688653 & 4.833 & 5.3487 & TST & & & \\
\hline CHEMBL1476297 & 688653 & \multicolumn{3}{|c|}{5.2829999999999995} & 5.1731 & TRN & \\
\hline CHEMBL1428196 & 688653 & 6.683 & 5.811 & TST & & & \\
\hline CHEMBL1418045 & 688653 & 5.683 & 5.4293 & TRN & & & \\
\hline CHEMBL3210323 & 688653 & 4.833 & 5.7698 & TRN & & & \\
\hline CHEMBL1598977 & 688653 & \multicolumn{3}{|c|}{5.132999999999999} & 5.6667 & TRN & \\
\hline CHEMBL1488240 & 688653 & 4.883 & 4.8882 & TRN & & & \\
\hline CHEMBL1523251 & 688653 & \multicolumn{3}{|c|}{5.5329999999999995} & 4.9912 & TST & \\
\hline CHEMBL1398304 & 688653 & 4.933 & 5.0504 & TRN & & & \\
\hline CHEMBL1308783 & 688653 & \multicolumn{3}{|c|}{$\begin{array}{lll}4.633 & 5.022 & \text { TST }\end{array}$} & & & \\
\hline CHEMBL3211215 & 688653 & 4.98300 & 00000000 & 005 & 4.93 & TST & \\
\hline CHEMBL1334240 & 688653 & 4.683 & 5.1329 & TRN & & & \\
\hline CHEMBL1339465 & 688653 & 4.73300 & 00000000 & 005 & 5.1682 & TRN & \\
\hline CHEMBL1563664 & 688653 & 5.683 & 5.4882 & TST & & & \\
\hline
\end{tabular}




\begin{tabular}{|c|c|c|c|c|c|c|c|}
\hline \multicolumn{8}{|c|}{ Supplemental Table S2.txt } \\
\hline CHEMBL1369081 & 688653 & 4.633 & 5.1851 & TST & & & \\
\hline CHEMBL1544548 & 688653 & 5.733 & 5.74 & TST & & & \\
\hline CHEMBL1508789 & 688653 & 5.733 & 5.1862 & TRN & & & \\
\hline CHEMBL1338466 & 688653 & 4.833 & 5.2215 & TST & & & \\
\hline CHEMBL1302862 & 688653 & 6.433 & 5.7191 & TRN & & & \\
\hline CHEMBL1542169 & 688653 & 6.7331 & 5.37299 & 999999999 & & TRN & \\
\hline CHEMBL1593138 & 688653 & 4.633 & 5.3747 & TRN & & & \\
\hline CHEMBL1607294 & 688653 & 4.833 & 5.0868 & TRN & & & \\
\hline CHEMBL3195455 & 688653 & 4.783 & 4.8855 & TST & & & \\
\hline CHEMBL1413341 & 688653 & 4.783 & 5.0914 & TRN & & & \\
\hline CHEMBL1549784 & 688653 & \multicolumn{3}{|c|}{5.332999999999999} & 4.9926 & TRN & \\
\hline CHEMBL565486 & 688653 & \multicolumn{3}{|c|}{5.832999999999999} & 5.4305 & TRN & \\
\hline CHEMBL3192486 & 688653 & 4.583 & 5.1217 & TRN & & & \\
\hline CHEMBL1977473 & 688653 & 4.783 & 5.093 & TST & & & \\
\hline CHEMBL 29542 & 688653 & 5.733 & 5.5158 & TRN & & & \\
\hline CHEMBL1510696 & 688653 & 4.583 & 5.3616 & TRN & & & \\
\hline CHEMBL1364962 & 688653 & 4.833 & 5.13899 & 999999999 & & TST & \\
\hline CHEMBL1552352 & 688653 & 4.933 & 5.6919 & TRN & & & \\
\hline CHEMBL1525751 & 688653 & 5.233 & 5.7002 & TRN & & & \\
\hline CHEMBL1401710 & 688653 & 5.183 & 5.1626 & TST & & & \\
\hline CHEMBL1369014 & 688653 & 4.633 & 5.3341 & TST & & & \\
\hline CHEMBL1524751 & 688653 & 4.833 & 5.1817 & TST & & & \\
\hline CHEMBL1349524 & 688653 & 4.933 & 5.0765 & TRN & & & \\
\hline CHEMBL1611180 & 688653 & \multicolumn{3}{|c|}{5.882999999999999} & 5.0166 & TRN & \\
\hline CHEMBL1568030 & 688653 & 5.033 & 5.7938 & TRN & & & \\
\hline CHEMBL1461287 & 688653 & 6.7331 & 5.7423 & TRN & & & \\
\hline CHEMBL1547349 & 688653 & \multicolumn{3}{|c|}{6.0329999999999995} & 5.9269 & TRN & \\
\hline CHEMBL1387597 & 688653 & 4.883 & 5.5391 & TRN & & & \\
\hline CHEMBL564201 & 688653 & \multicolumn{3}{|c|}{6.082999999999999} & \multicolumn{2}{|c|}{5.7860000000000005} & TST \\
\hline CHEMBL1534071 & 688653 & \multicolumn{3}{|c|}{5.332999999999999} & 5.1016 & TST & \\
\hline CHEMBL1461333 & 688653 & \multicolumn{3}{|c|}{4.7330000000000005} & 5.3924 & TRN & \\
\hline CHEMBL1452978 & 688653 & 4.933 & 5.3022 & TRN & & & \\
\hline CHEMBL1310319 & 688653 & \multicolumn{3}{|c|}{4.7330000000000005} & 5.3237 & TST & \\
\hline CHEMBL1362490 & 688653 & 5.483 & 5.2655 & TRN & & & \\
\hline CHEMBL1357846 & 688653 & \multicolumn{3}{|c|}{5.332999999999999} & 5.0937 & TRN & \\
\hline CHEMBL1595236 & 688653 & \multicolumn{3}{|c|}{5.132999999999999} & 5.4889 & TRN & \\
\hline CHEMBL1605143 & 688653 & \multicolumn{3}{|c|}{4.9830000000000005} & 5.1176 & TRN & \\
\hline CHEMBL1408438 & 688653 & 6.683 & 6.1003 & TRN & & & \\
\hline CHEMBL1361595 & 688653 & 4.633 & 4.8127 & TRN & & & \\
\hline CHEMBL1373045 & 688653 & 4.783 & 4.9528 & TST & & & \\
\hline CHEMBL1464317 & 688653 & \multicolumn{3}{|c|}{5.382999999999999} & 4.7472 & TST & \\
\hline CHEMBL1442317 & 688653 & \multicolumn{3}{|c|}{5.632999999999999} & 5.1142 & TST & \\
\hline CHEMBL1439533 & 688653 & 4.683 & 4.9471 & TRN & & & \\
\hline CHEMBL1463996 & 688653 & 4.783 & 4.8072 & TRN & & & \\
\hline CHEMBL1446106 & 688653 & 5.233 & 5.5 & TRN & & & \\
\hline CHEMBL1328440 & 688653 & \multicolumn{3}{|c|}{4.7330000000000005} & 5.6486 & TRN & \\
\hline CHEMBL1319086 & 688653 & \multicolumn{3}{|c|}{4.7330000000000005} & 5.0999 & TST & \\
\hline CHEMBL1327326 & 688653 & 5.083 & 5.3888 & TRN & & & \\
\hline
\end{tabular}




\begin{tabular}{|c|c|c|c|c|c|c|}
\hline \multirow[b]{2}{*}{ CHEMBL1529989 } & \multirow[b]{2}{*}{688653} & \multicolumn{5}{|c|}{ sen } \\
\hline & & 6.4829 & 5.5512 & TRN & & \\
\hline CHEMBL1490415 & 688653 & 4.783 & 4.9968 & TST & & \\
\hline CHEMBL1535526 & 688653 & \multicolumn{3}{|c|}{4.7330000000000005} & 5.4836 & TRA \\
\hline CHEMBL1371052 & 688653 & 5.083 & 5.1455 & TST & & \\
\hline CHEMBL1313318 & 688653 & \multicolumn{3}{|c|}{5.382999999999999} & 5.3889 & Trov \\
\hline CHEMBL1353113 & 688653 & 5.683 & 5.556 & TST & & \\
\hline CHEMBL1559996 & 688653 & \multicolumn{3}{|c|}{5.7829999999999995} & 5.5364 & TRN \\
\hline CHEMBL1416916 & 688653 & \multicolumn{3}{|c|}{4.7330000000000005} & 5.2876 & \\
\hline CHEMBL1613578 & 688653 & \multicolumn{3}{|c|}{5.2829999999999995} & 5.0081 & 13 \\
\hline CHEMBL2001211 & 688653 & 5.983 & 5.5663 & TST & & \\
\hline CHEMBL1491210 & 688653 & \multirow{2}{*}{\multicolumn{3}{|c|}{5.5329999999999995}} & & \\
\hline CHEMBL1341802 & 688653 & & & & 5.4255 & \\
\hline CHEMBL1397162 & 688653 & 4.833 & 5.3525 & TRN & & \\
\hline CHEMBL1335244 & 688653 & \multicolumn{3}{|c|}{4.7330000000000005} & 5.352 & \\
\hline CHEMBL1357087 & 688653 & 5.483 & 5.0227 & TRN & & \\
\hline CHEMBL 3194305 & 688653 & 5.983 & 5.4296 & TRN & & \\
\hline CHEMBL1341289 & 688653 & \multicolumn{3}{|c|}{5.332999999999999} & 5.8402 & \\
\hline CHEMBL1469668 & 688653 & \multicolumn{3}{|c|}{5.7829999999999995} & 5.5672 & \\
\hline CHEMBL1592561 & 688653 & 5.483 & 5.2423 & TRN & & \\
\hline CHEMBL1559750 & 688653 & \multicolumn{3}{|c|}{6.332999999999999} & 9 & \\
\hline CHEMBL1314968 & 688653 & 4.883 & 5.09 & TRN & & \\
\hline CHEMBL 3196677 & 688653 & \multicolumn{3}{|c|}{4.7330000000000005} & 5.1604 & $1 / \mathrm{K}$ \\
\hline CHEMBL1489396 & 688653 & 5.683 & 4.9749 & TRN & & \\
\hline CHEMBL1598377 & 688653 & 5.233 & 6.0241 & TRN & & \\
\hline CHEMBL14 & 688 & \multicolumn{3}{|c|}{6.5329999999999995} & 3.014 & ..... \\
\hline CHEMBL1410569 & 688653 & \multicolumn{3}{|c|}{5.5329999999999995} & 5.1093 & \\
\hline CHEMBL1437962 & 688653 & 4.883 & 5.4298 & TST & & \\
\hline CHEMBL1597435 & 688653 & 4.783 & 5.0695 & TRN & & \\
\hline CHEMBL1543259 & 688653 & 4.883 & \multicolumn{3}{|c|}{5.287999999999999} & \\
\hline CHEMBL1385520 & 688653 & \multicolumn{3}{|c|}{4.7330000000000005} & 5.7038 & \\
\hline CHEMBL 3191050 & 688653 & 4.783 & 5.2184 & TRN & & \\
\hline CHEMBL1498030 & 688653 & \multicolumn{3}{|c|}{4.7330000000000005} & 5.0333 & TRN \\
\hline CHEMBL3192181 & 688653 & \multicolumn{3}{|c|}{5.2829999999999995} & 5.6457 & \\
\hline CHEMBL1378739 & 688653 & 4.883 & 4.9241 & TRN & & \\
\hline CHEMBL14C & 688653 & 7.2328 & 5.7908 & TRN & & \\
\hline CHEMBL1572507 & 688653 & 5.933 & 5.4841 & TRN & & \\
\hline CHEMBL1369678 & 688653 & 4.883 & 5.175 & TRN & & \\
\hline CHEMBL1441032 & 688653 & 4.583 & 4.8722 & TST & & \\
\hline CHEMBL1307244 & 688653 & 5.983 & 6.1365 & TRN & & \\
\hline CHEMBL1424042 & 688653 & 4.98300 & 00000000 & 005 & 4.547 & \\
\hline CHEMBL1302089 & 688653 & 5.983 & 5.2477 & TRN & & \\
\hline CHEMBL1314330 & 688653 & 4.783 & 5.0572 & TRN & & \\
\hline CHEMBL1505902 & 688653 & 4.633 & 5.0396 & TST & & \\
\hline CHEMBL1457298 & 688653 & 5.033 & 4.8773 & TRN & & \\
\hline CHEMBL1426536 & 688653 & 5.733 & 5.8126 & TRN & & \\
\hline CHEMBL1465878 & 688653 & 4.683 & 5.0782 & TRN & & \\
\hline CHEMBL1346662 & 688653 & 4.783 & 5.24799 & 99999 & 99 & \\
\hline CHEMBL1546668 & 688653 & 5.38299 & 99999999 & & 5.4852 & \\
\hline
\end{tabular}




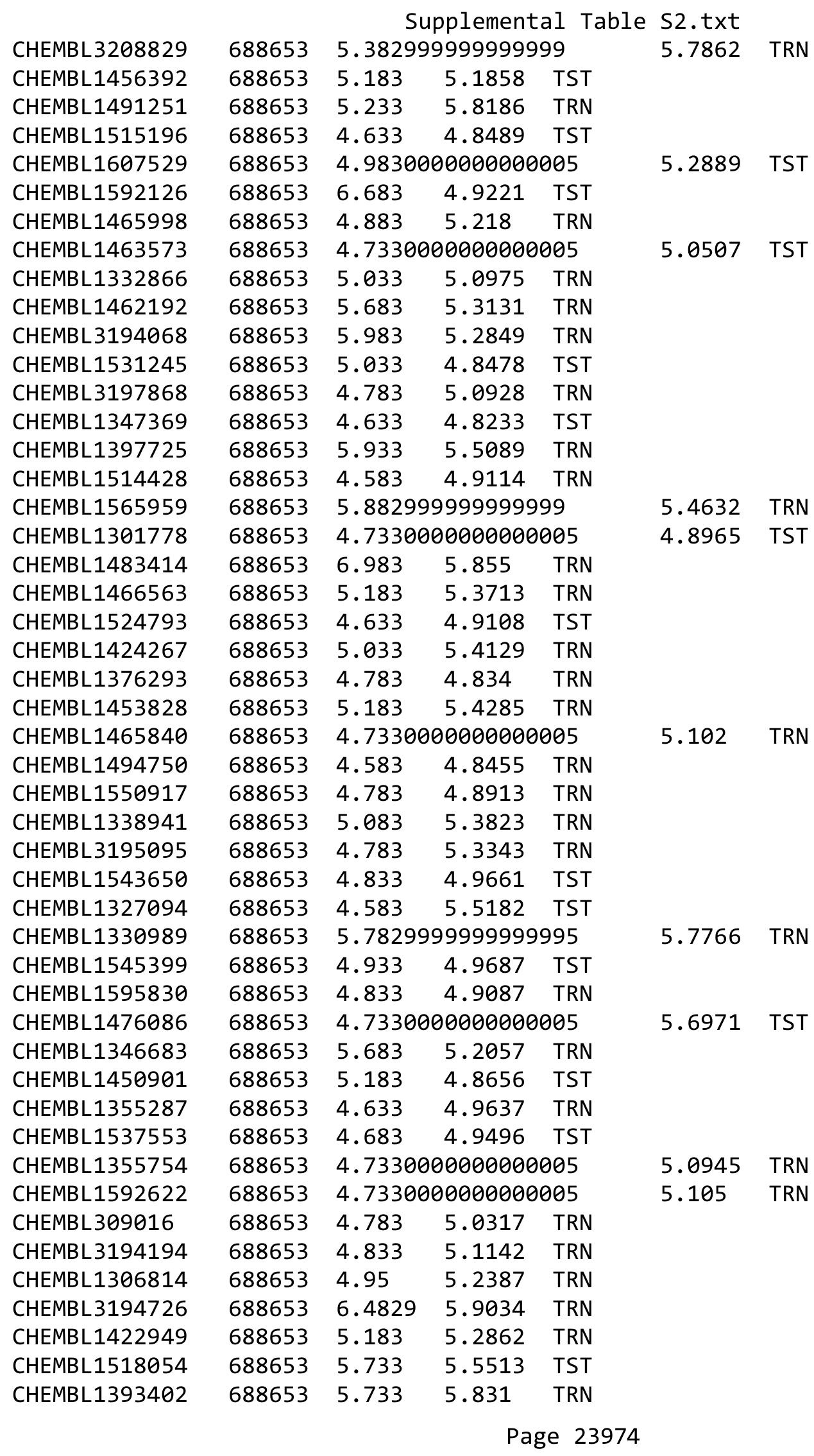




\begin{tabular}{|c|c|c|c|c|c|c|c|}
\hline \multicolumn{8}{|c|}{ Supplemental Table s2.txt } \\
\hline CHEMBL1371364 & 688653 & 4.833 & 5.5769 & TRN & & & \\
\hline CHEMBL1589858 & 688653 & 5.683 & 5.6138 & TRN & & & \\
\hline CHEMBL1326452 & 688653 & 4.633 & 5.0731 & TRN & & & \\
\hline CHEMBL1474958 & 688653 & 4.583 & 5.0728 & TST & & & \\
\hline CHEMBL1501469 & 688653 & \multicolumn{3}{|c|}{4.7330000000000005} & 4.9904 & TRN & \\
\hline CHEMBL1428808 & 688653 & 4.633 & 4.982 & TST & & & \\
\hline CHEMBL1517853 & 688653 & 5.033 & 5.0132 & TST & & & \\
\hline CHEMBL1323607 & 688653 & \multicolumn{3}{|c|}{4.9830000000000005} & 5.5962 & TRN & \\
\hline CHEMBL1400111 & 688653 & \multicolumn{3}{|c|}{4.7330000000000005} & 4.9946 & TST & \\
\hline CHEMBL1599498 & 688653 & 4.583 & 5.2932 & TRN & & & \\
\hline CHEMBL1382651 & 688653 & 5.233 & 5.5014 & TRN & & & \\
\hline CHEMBL3196997 & 688653 & 5.933 & 5.6391 & TRN & & & \\
\hline CHEMBL1341629 & 688653 & 4.583 & 5.5826 & TRN & & & \\
\hline CHEMBL1531206 & 688653 & \multicolumn{3}{|c|}{5.2829999999999995} & 5.3953 & TRN & \\
\hline CHEMBL1402339 & 688653 & \multicolumn{3}{|c|}{5.2829999999999995} & 5.0442 & TRN & \\
\hline CHEMBL1412199 & 688653 & \multicolumn{3}{|c|}{5.382999999999999} & 5.3142 & TRN & \\
\hline CHEMBL1329344 & 688653 & 5.183 & 5.2974 & TRN & & & \\
\hline CHEMBL1448830 & 688653 & 4.933 & \multicolumn{3}{|c|}{4.7589999999999995} & TRN & \\
\hline CHEMBL1370654 & 688653 & 4.783 & 5.0643 & TRN & & & \\
\hline CHEMBL1399193 & 688653 & \multicolumn{3}{|c|}{6.5329999999999995} & 5.8832 & TRN & \\
\hline CHEMBL1589285 & 688653 & 4.933 & 5.1007 & TRN & & & \\
\hline CHEMBL1597669 & 688653 & \multicolumn{3}{|c|}{6.5329999999999995} & 6.224 & TRN & \\
\hline CHEMBL1473105 & 688653 & 4.783 & 5.2844 & TST & & & \\
\hline CHEMBL1366778 & 688653 & 5.033 & 5.2243 & TRN & & & \\
\hline CHEMBL3191923 & 688653 & \multicolumn{3}{|c|}{4.7330000000000005} & 5.0491 & TRN & \\
\hline CHEMBL3208401 & 688653 & \multicolumn{3}{|c|}{5.832999999999999} & 5.4968 & TRN & \\
\hline CHEMBL1522743 & 688653 & \multicolumn{3}{|c|}{5.882999999999999} & 5.5258 & TRN & \\
\hline CHEMBL1465677 & 688653 & \multicolumn{3}{|c|}{4.7330000000000005} & 5.3308 & TRN & \\
\hline CHEMBL1309228 & 688653 & \multicolumn{3}{|c|}{4.7330000000000005} & 4.8327 & TRN & \\
\hline CHEMBL1450360 & 688653 & \multicolumn{3}{|c|}{5.632999999999999} & 5.1068 & TST & \\
\hline CHEMBL1393674 & 688653 & 5.733 & 5.3648 & TST & & & \\
\hline CHEMBL1469152 & 688653 & 5.983 & \multicolumn{3}{|c|}{5.138999999999999} & TRN & \\
\hline CHEMBL1315574 & 688653 & 5.233 & 6.023 & TRN & & & \\
\hline CHEMBL1455566 & 688653 & 4.783 & 5.2718 & TRN & & & \\
\hline CHEMBL1305758 & 688653 & 4.833 & 5.0402 & TRN & & & \\
\hline CHEMBL1593730 & 688653 & 4.883 & 4.8546 & TST & & & \\
\hline CHEMBL1511409 & 688653 & \multicolumn{3}{|c|}{4.7330000000000005} & 4.6871 & TRN & \\
\hline CHEMBL1602226 & 688653 & \multicolumn{3}{|c|}{5.332999999999999} & 4.96899 & 9999999999 & TRN \\
\hline CHEMBL1551472 & 688653 & 5.733 & 5.51 & TRN & & & \\
\hline CHEMBL1571722 & 688653 & 4.933 & 5.3157 & TRN & & & \\
\hline CHEMBL1541177 & 688653 & 4.783 & 5.0477 & TRN & & & \\
\hline CHEMBL1477524 & 688653 & 5.683 & 5.365 & TRN & & & \\
\hline CHEMBL1532845 & 688653 & 5.483 & 5.2098 & TRN & & & \\
\hline CHEMBL1983323 & 688653 & \multicolumn{3}{|c|}{6.332999999999999} & 5.6344 & TRN & \\
\hline CHEMBL1587485 & 688653 & \multicolumn{3}{|c|}{4.7330000000000005} & 5.2652 & TRN & \\
\hline CHEMBL1325298 & 688653 & 4.883 & 4.9464 & TST & & & \\
\hline CHEMBL1520703 & 688653 & 5.8329 & 99999999 & 99 & 5.6577 & TST & \\
\hline CHEMBL1528353 & 688653 & 4.783 & 5.1261 & TRN & & & \\
\hline
\end{tabular}




\begin{tabular}{|c|c|c|c|c|c|c|}
\hline \multirow[b]{2}{*}{ CHEMBL3189492 } & \multirow[b]{2}{*}{688653} & \multicolumn{5}{|c|}{ Supplemental Table s2.txt } \\
\hline & & 6.4829 & 5.8636 & TRN & & \\
\hline CHEMBL1402807 & 688653 & 5.083 & 5.3037 & TRN & & \\
\hline CHEMBL1351986 & 688653 & 4.883 & 5.199 & TRN & & \\
\hline CHEMBL1487320 & 688653 & \multicolumn{3}{|c|}{4.7330000000000005} & 5.1769 & TST \\
\hline CHEMBL1415691 & 688653 & 4.783 & 5.5965 & TRN & & \\
\hline CHEMBL1612489 & 688653 & 5.183 & 5.3209 & TRN & & \\
\hline CHEMBL1362372 & 688653 & \multicolumn{3}{|c|}{4.7330000000000005} & 5.2994 & TRN \\
\hline CHEMBL1510584 & 688653 & 5.033 & 5.1115 & TRN & & \\
\hline CHEMBL1412266 & 688653 & 5.933 & 5.8812 & TRN & & \\
\hline CHEMBL1445707 & 688653 & \multicolumn{3}{|c|}{6.0329999999999995} & 5.3682 & TST \\
\hline CHEMBL1370573 & 688653 & \multicolumn{3}{|c|}{5.832999999999999} & 5.1017 & TRN \\
\hline CHEMBL1300969 & 688653 & \multicolumn{3}{|c|}{6.382999999999999} & 5.7173 & TRN \\
\hline CHEMBL1476428 & 688653 & 4.783 & 5.2729 & TST & & \\
\hline CHEMBL1594538 & 688653 & 4.883 & 4.9604 & TRN & & \\
\hline CHEMBL1533989 & 688653 & 4.783 & 4.7857 & TRN & & \\
\hline CHEMBL1450777 & 688653 & 5.033 & 5.1314 & TRN & & \\
\hline CHEMBL3213402 & 688653 & \multicolumn{3}{|c|}{4.7330000000000005} & 5.3617 & TRN \\
\hline CHEMBL1579467 & 688653 & \multicolumn{3}{|c|}{4.7330000000000005} & 5.3557 & TRN \\
\hline CHEMBL1470760 & 688653 & \multicolumn{3}{|c|}{5.332999999999999} & 5.3144 & TRN \\
\hline CHEMBL1597278 & 688653 & 4.783 & 5.7671 & TRN & & \\
\hline CHEMBL1527620 & 688653 & 4.883 & 5.1632 & TRN & & \\
\hline CHEMBL1461026 & 688653 & 4.833 & 5.2887 & TST & & \\
\hline CHEMBL3192353 & 688653 & \multicolumn{3}{|c|}{4.7330000000000005} & 5.3521 & TRN \\
\hline CHEMBL1492936 & 688653 & 5.433 & 5.4981 & TRN & & \\
\hline CHEMBL1381494 & 688653 & \multicolumn{3}{|c|}{5.382999999999999} & 5.1839 & TRN \\
\hline CHEMBL1307112 & 688653 & 4.783 & 5.4534 & TST & & \\
\hline CHEMBL1558072 & 688653 & \multicolumn{3}{|c|}{4.7330000000000005} & 5.4876 & TRN \\
\hline CHEMBL1349622 & 688653 & 4.783 & 5.2583 & TST & & \\
\hline CHEMBL1410773 & 688653 & 5.183 & 5.2835 & TST & & \\
\hline CHEMBL1336308 & 688653 & 4.883 & 5.0116 & TST & & \\
\hline CHEMBL193872 & 688653 & \multicolumn{3}{|c|}{5.832999999999999} & 5.5546 & TRN \\
\hline CHEMBL1357752 & 688653 & \multicolumn{3}{|c|}{5.632999999999999} & 5.8339 & TRN \\
\hline CHEMBL1507839 & 688653 & \multicolumn{3}{|c|}{4.9830000000000005} & 5.2862 & TRN \\
\hline CHEMBL1426037 & 688653 & 4.683 & 4.961 & TST & & \\
\hline CHEMBL1403074 & 688653 & \multicolumn{3}{|c|}{5.132999999999999} & 5.5195 & TST \\
\hline CHEMBL1567229 & 688653 & \multicolumn{3}{|c|}{4.7330000000000005} & 5.2761 & TRN \\
\hline CHEMBL1592688 & 688653 & 5.183 & 4.6645 & TRN & & \\
\hline CHEMBL1382164 & 688653 & 4.883 & 4.905 & TRN & & \\
\hline CHEMBL1521225 & 688653 & 5.033 & 4.8964 & TRN & & \\
\hline CHEMBL3190855 & 688653 & \multicolumn{3}{|c|}{4.7330000000000005} & 5.2909 & TST \\
\hline CHEMBL1453948 & 688653 & 4.833 & 5.2554 & TRN & & \\
\hline CHEMBL1437262 & 688653 & 4.883 & 5.1962 & TRN & & \\
\hline CHEMBL1565949 & 688653 & 4.783 & 5.2141 & TRN & & \\
\hline CHEMBL1563048 & 688653 & 4.783 & 4.9838 & TST & & \\
\hline CHEMBL1346587 & 688653 & 4.633 & 4.8581 & TST & & \\
\hline CHEMBL1517442 & 688653 & 4.933 & 5.1598 & TRN & & \\
\hline CHEMBL1537047 & 688653 & 4.633 & 5.2395 & TST & & \\
\hline CHEMBL1398946 & 688653 & 5.433 & 5.3372 & TRN & & \\
\hline
\end{tabular}




\begin{tabular}{|c|c|c|c|c|c|c|}
\hline \multirow[b]{2}{*}{ CHEMBL1371093 } & & \multicolumn{5}{|c|}{ Supplemental Table S2.txt } \\
\hline & 688653 & 5.183 & 5.6648 & TRN & & \\
\hline CHEMBL1501971 & 688653 & 5.483 & 5.733 & TRN & & \\
\hline CHEMBL1394414 & 88653 & 5.683 & 5.075 & TRN & & \\
\hline CHEMBL1540417 & 688653 & \multicolumn{3}{|c|}{5.7829999999999995} & 5.8627 & TST \\
\hline CHEMBL1468876 & 688653 & \multicolumn{3}{|c|}{6.382999999999999} & 5.5068 & TRN \\
\hline CHEMBL1492532 & 688653 & 6.9329 & 5.8615 & TRN & & \\
\hline CHEMBL1589863 & 688653 & \multicolumn{3}{|c|}{4.7330000000000005} & 5.0588 & TST \\
\hline CHEMBL1510264 & 688653 & \multicolumn{3}{|c|}{5.332999999999999} & 5.1737 & \\
\hline CHEMBL1453437 & 688653 & 4.883 & 4.7888 & TST & & \\
\hline CHEMBL1302189 & 688653 & \multicolumn{3}{|c|}{5.832999999999999} & 4.9503 & TNT \\
\hline CHEMBL1533877 & 688653 & 4.933 & 5.2516 & TRN & & \\
\hline CHEMBL1580834 & 688653 & \multirow{2}{*}{\multicolumn{3}{|c|}{ 6.382999999999999 }} & & \\
\hline CHEMBL15 & 688653 & & & & 5.9174 & $\mathrm{TR}$ \\
\hline CHEMBL1416511 & 688653 & 4.833 & 5.3698 & TRN & & \\
\hline CHEMBL1505364 & 688653 & \multicolumn{3}{|c|}{4.7330000000000005} & 5.8115 & TRN \\
\hline CHEMBL1431006 & 688653 & \multicolumn{3}{|c|}{5.132999999999999} & 4.9197 & TRN \\
\hline CHEMBL1446271 & 688653 & \multicolumn{3}{|c|}{5.382999999999999} & & \\
\hline CHEMBL1409666 & 688653 & 4.833 & 4.9571 & TRN & & \\
\hline CHEMBL1 & 688653 & 5.083 & 5.271 & TRN & & \\
\hline CHEMBL1518622 & 688653 & \multicolumn{3}{|c|}{6.5329999999999995} & 5.6908 & TP \\
\hline CHEMBL1397890 & 688653 & 4.583 & 4.5743 & TRN & & \\
\hline CHEMBL1502977 & 688653 & \multicolumn{3}{|c|}{6.082999999999999} & & \\
\hline CHEMBL14 & 688653 & \multicolumn{3}{|c|}{6.382999999999999} & 884 & TRN \\
\hline CHEMBL1300290 & 688653 & \multicolumn{3}{|c|}{4.9830000000000005} & 3863 & TRN \\
\hline CHEMBL1417724 & 688653 & 4.583 & 4.9133 & TST & & \\
\hline CHEMBL3195978 & 688653 & \multicolumn{3}{|c|}{$5.183 \quad 5.4917$ TRN } & & \\
\hline CHEMBL1307915 & 688 & & 45 & TINo \\
\hline CHEMBL1 & 688653 & & & & 489 & TST \\
\hline CHEMBL1531413 & 688653 & \multicolumn{3}{|c|}{$\begin{array}{l}6.5329999999999995 \\
5.483 \quad 5.3768 \quad \text { TRN }\end{array}$} & & \\
\hline CHEMBL1460106 & 688653 & 4.833 & 5.1815 & TRN & & \\
\hline CHEMBL1569751 & 688653 & \multicolumn{3}{|c|}{5.7829999999999995} & 3.0407 & \\
\hline CHEMBL 1 & $68 \varepsilon$ & 4.833 & 5.3132 & TST & & \\
\hline CHEMB & 688 & \multirow{2}{*}{\multicolumn{3}{|c|}{$\begin{array}{lrr}5.033 & 5.2907 & \mathrm{~T} \\
5.332999999999999\end{array}$}} & & \\
\hline CHEMBL1572146 & 688653 & & & & 5.5036 & $\mathrm{TR}$ \\
\hline CHEMBL1380072 & 688653 & \multicolumn{3}{|c|}{$5.183 \quad 5.4493$ TRN } & & \\
\hline CHEMBL1378158 & 688653 & & 4.9228 & TRN & & \\
\hline CHEMBL & 688 & & 5.4176 & TRN & & \\
\hline CHEMBL: & 688 & 5.233 & 5.2714 & TST & & \\
\hline CHEMBL1367496 & 688653 & 4.883 & 5.2091 & TST & & \\
\hline CHEMBL252925 & 688653 & 4.7330 & 00000000 & 005 & & TRN \\
\hline CHEMBL1428054 & 688653 & 5.5329 & 99999999 & 995 & 6.1699 & TP \\
\hline CHEMBL1414694 & 688653 & 5.183 & 5.3303 & TRN & & \\
\hline CHEMBL1523697 & 688653 & 5.2829 & 99999999 & 995 & 5.9127 & TRN \\
\hline CHEMBL1368377 & 688653 & 5.2829 & 99999999 & 995 & 5.1401 & TRN \\
\hline CHEMBL1568095 & 688653 & 4.633 & 5.6359 & TRN & & \\
\hline CHEMBL1333810 & 688653 & 4.633 & 4.7394 & TST & & \\
\hline CHEMBL1344838 & 688653 & 5.3329 & 99999999 & & & a \\
\hline CHEMBL1410935 & 688653 & 4.7330 & 00000000 & & 4.9869 & \\
\hline
\end{tabular}




\begin{tabular}{|c|c|c|c|c|c|c|}
\hline \multirow[b]{2}{*}{ CHEMBL1546629 } & & \multicolumn{5}{|c|}{ Supplemental Table S2.txt } \\
\hline & 688653 & 4.833 & 5.1607 & TRN & & \\
\hline CHEMBL1571314 & 688653 & \multicolumn{3}{|c|}{5.582999999999999} & 5.5062 & TRN \\
\hline CHEMBL1528571 & 688653 & 4.933 & 5.29 & TRN & & \\
\hline CHEMBL1400688 & 688653 & 5.183 & 5.4722 & TST & & \\
\hline CHEMBL1364203 & 688653 & 5.233 & \multicolumn{3}{|c|}{5.4079999999999995} & TST \\
\hline CHEMBL1310031 & 688653 & \multicolumn{3}{|c|}{5.382999999999999} & 5.3546 & TST \\
\hline CHEMBL1352234 & 688653 & 4.783 & 5.2216 & TRN & & \\
\hline CHEMBL1490734 & 688653 & 5.683 & 5.8693 & TST & & \\
\hline CHEMBL1480179 & 688653 & 6.983 & 5.4893 & TST & & \\
\hline CHEMBL1387562 & 688653 & 4.633 & 5.1752 & TRN & & \\
\hline CHEMBL1564883 & 688653 & 5.483 & 5.5433 & TRN & & \\
\hline CHEMBL1501717 & 688653 & \multicolumn{3}{|c|}{5.7829999999999995} & 5.2047 & TRN \\
\hline CHEMBL3209454 & 688653 & 4.883 & 5.4559 & TRN & & \\
\hline CHEMBL1514232 & 688653 & \multicolumn{3}{|c|}{5.2829999999999995} & 5.0067 & TRN \\
\hline CHEMBL1570276 & 688653 & 5.183 & 5.5562 & TRN & & \\
\hline CHEMBL1505219 & 688653 & 5.733 & 5.2959 & TST & & \\
\hline CHEMBL1438925 & 688653 & 6.233 & 5.775 & TRN & & \\
\hline CHEMBL1982152 & 688653 & \multicolumn{3}{|c|}{5.382999999999999} & 5.6672 & TRN \\
\hline CHEMBL1306342 & 688653 & \multicolumn{3}{|c|}{4.7330000000000005} & 4.9518 & TST \\
\hline CHEMBL1401768 & 688653 & \multicolumn{3}{|c|}{5.2829999999999995} & 5.4022 & TRN \\
\hline CHEMBL1610213 & 688653 & 4.883 & 5.075 & TRN & & \\
\hline CHEMBL1423244 & 688653 & 4.783 & 5.4476 & TRN & & \\
\hline CHEMBL1312272 & 688653 & 4.833 & 5.3922 & TRN & & \\
\hline CHEMBL3190895 & 688653 & 5.083 & 5.284 & TRN & & \\
\hline CHEMBL1523200 & 688653 & 4.883 & 5.0777 & TRN & & \\
\hline CHEMBL1345632 & 688653 & 5.483 & 5.8127 & TST & & \\
\hline CHEMBL1527850 & 688653 & 5.683 & 5.301 & TRN & & \\
\hline CHEMBL1573451 & 688653 & \multicolumn{3}{|c|}{4.7330000000000005} & 4.6201 & TRN \\
\hline CHEMBL1342128 & 688653 & 4.9 & 5.2778 & TRN & & \\
\hline CHEMBL1351535 & 688653 & \multicolumn{3}{|c|}{6.382999999999999} & 5.7816 & TRN \\
\hline CHEMBL1550800 & 688653 & 7.1831 & 6.1101 & TRN & & \\
\hline CHEMBL1439493 & 688653 & 4.783 & 5.3597 & TST & & \\
\hline CHEMBL1435253 & 688653 & 5.483 & 5.461 & TRN & & \\
\hline CHEMBL1402080 & 688653 & \multicolumn{3}{|c|}{5.2829999999999995} & 4.9646 & TRN \\
\hline CHEMBL1302337 & 688653 & 5.983 & 6.1875 & TRN & & \\
\hline CHEMBL1546261 & 688653 & 4.883 & 5.2111 & TRN & & \\
\hline CHEMBL69151 & 688653 & 5.433 & 5.6654 & TRN & & \\
\hline CHEMBL1536129 & 688653 & 5.183 & 5.1967 & TRN & & \\
\hline CHEMBL3193035 & 688653 & \multicolumn{3}{|c|}{4.9830000000000005} & 5.5284 & TRN \\
\hline CHEMBL1586545 & 688653 & 4.833 & 5.425 & TST & & \\
\hline CHEMBL1423497 & 688653 & \multicolumn{3}{|c|}{4.9830000000000005} & 5.6167 & TRN \\
\hline CHEMBL1611028 & 688653 & 4.833 & 5.2392 & TST & & \\
\hline CHEMBL1476915 & 688653 & 4.583 & 5.0303 & TRN & & \\
\hline CHEMBL1505598 & 688653 & 4.833 & 5.0194 & TRN & & \\
\hline CHEMBL1544255 & 688653 & 4.833 & 4.9217 & TRN & & \\
\hline CHEMBL3191542 & 688653 & 4.833 & 5.8078 & TST & & \\
\hline CHEMBL3210630 & 688653 & 5.683 & 5.7055 & TRN & & \\
\hline CHEMBL1412891 & 688653 & 4.633 & 5.0497 & TRN & & \\
\hline
\end{tabular}




\begin{tabular}{|c|c|c|c|c|c|c|}
\hline \multirow[b]{2}{*}{ CHEMBL1319658 } & & \multicolumn{5}{|c|}{ Supplemental Table S2.txt } \\
\hline & 688653 & 5.233 & 5.1814 & TRN & & \multirow{3}{*}{ TST } \\
\hline CHEMBL1587150 & 688653 & 4.883 & \multicolumn{3}{|c|}{5.1160000000000005} & \\
\hline CHEMBL1566881 & 688653 & 5.483 & 5.722 & TRN & & \\
\hline CHEMBL1502027 & 688653 & 4.883 & 5.2986 & TRN & & \\
\hline CHEMBL1529274 & 688653 & 5.183 & 5.2515 & TRN & & \\
\hline CHEMBL1438775 & 688653 & \multicolumn{3}{|c|}{5.632999999999999} & 5.4053 & TRN \\
\hline CHEMBL1518721 & 688653 & 5.433 & \multicolumn{3}{|c|}{5.6160000000000005} & TRN \\
\hline CHEMBL1321138 & 688653 & 5.683 & 5.2663 & TRN & & \\
\hline CHEMBL1465096 & 688653 & 4.633 & 4.9427 & TRN & & \\
\hline CHEMBL1344871 & 688653 & \multicolumn{3}{|c|}{5.7829999999999995} & 5.1345 & TRN \\
\hline CHEMBL1433143 & 688653 & \multicolumn{3}{|c|}{5.5329999999999995} & 5.1001 & TST \\
\hline CHEMBL1537211 & 688653 & \multicolumn{3}{|c|}{6.332999999999999} & 5.9207 & TST \\
\hline CHEMBL259615 & 688653 & 4.833 & 5.6065 & TRN & & \\
\hline CHEMBL1520214 & 688653 & 4.833 & 4.664 & TRN & & \\
\hline CHEMBL1371859 & 688653 & 5.683 & 5.1366 & TST & & \\
\hline CHEMBL1440081 & 688653 & \multicolumn{3}{|c|}{6.332999999999999} & 5.6304 & TRN \\
\hline CHEMBL1505808 & 688653 & 5.183 & 5.0461 & TRN & & \\
\hline CHEMBL1301371 & 688653 & \multicolumn{3}{|c|}{4.9830000000000005} & 5.0255 & TRN \\
\hline CHEMBL1408099 & 688653 & 5.433 & 5.5425 & TRN & & \\
\hline CHEMBL1492980 & 688653 & 6.0 & 5.4642 & TRN & & \\
\hline CHEMBL1588663 & 688653 & 4.683 & 4.9214 & TST & & \\
\hline CHEMBL1335070 & 688653 & \multicolumn{3}{|c|}{5.2829999999999995} & 5.1832 & TRN \\
\hline CHEMBL1313894 & 688653 & 4.683 & 5.0173 & TRN & & \\
\hline CHEMBL1479901 & 688653 & 4.783 & 5.1972 & TST & & \\
\hline CHEMBL1602501 & 688653 & 4.883 & 4.9792 & TRN & & \\
\hline CHEMBL1445073 & 688653 & \multicolumn{3}{|c|}{5.5329999999999995} & 5.4622 & TRN \\
\hline CHEMBL1469652 & 688653 & \multicolumn{3}{|c|}{5.332999999999999} & 5.0903 & TRN \\
\hline CHEMBL1601205 & 688653 & 4.833 & 5.3666 & TST & & \\
\hline CHEMBL1462078 & 688653 & \multicolumn{3}{|c|}{5.382999999999999} & 5.0915 & TST \\
\hline CHEMBL1557179 & 688653 & 7.0329 & 6.0437 & TRN & & \\
\hline CHEMBL1486158 & 688653 & 5.683 & 5.4401 & TRN & & \\
\hline CHEMBL1427596 & 688653 & \multicolumn{3}{|c|}{4.7330000000000005} & 5.1598 & TRN \\
\hline CHEMBL1543281 & 688653 & \multicolumn{3}{|c|}{4.7330000000000005} & 4.8194 & TRN \\
\hline CHEMBL1314849 & 688653 & \multicolumn{3}{|c|}{5.882999999999999} & 5.1247 & TRN \\
\hline CHEMBL3190349 & 688653 & 4.783 & 5.0612 & TST & & \\
\hline CHEMBL1574153 & 688653 & 4.883 & 5.4389 & TRN & & \\
\hline CHEMBL1600062 & 688653 & 6.983 & \multicolumn{3}{|c|}{5.542000000000001} & TRN \\
\hline CHEMBL1583323 & 688653 & 5.683 & 5.5967 & TRN & & \\
\hline CHEMBL1436367 & 688653 & \multicolumn{3}{|c|}{5.132999999999999} & 5.5899 & TRN \\
\hline CHEMBL1330067 & 688653 & \multicolumn{3}{|c|}{6.382999999999999} & 5.4048 & TRN \\
\hline CHEMBL1389665 & 688653 & 4.833 & 5.2213 & TRN & & \\
\hline CHEMBL1358267 & 688653 & 5.933 & & TRN & & \\
\hline CHEMBL1966679 & 688653 & 4.7330 & 3000000 & 005 & 5.1419 & TRN \\
\hline CHEMBL1568747 & 688653 & 5.683 & 5.2782 & TST & & \\
\hline CHEMBL1326464 & 688653 & 5.933 & 5.6928 & TST & & \\
\hline CHEMBL1558220 & 688653 & 4.7330 & 3000000 & 005 & 5.3815 & TRN \\
\hline CHEMBL1503484 & 688653 & 4.933 & 5.182 & TRN & & \\
\hline CHEMBL1488108 & 688653 & 5.6329 & 7999999 & & 5.6337 & TST \\
\hline
\end{tabular}




\begin{tabular}{|c|c|c|c|c|c|c|c|}
\hline \multicolumn{7}{|c|}{ Supplemental Table S2.txt } & \\
\hline CHEMBL1542806 & 688653 & \multicolumn{3}{|c|}{4.7330000000000005} & 5.4959 & TST & \\
\hline CHEMBL1565981 & 688653 & \multicolumn{3}{|c|}{5.832999999999999} & 5.8344 & TRN & \\
\hline CHEMBL391351 & 688653 & 5.483 & 5.6019 & TRN & & & \\
\hline CHEMBL1430757 & 688653 & \multicolumn{3}{|c|}{5.132999999999999} & 5.1467 & TRN & \\
\hline CHEMBL1461376 & 688653 & 4.783 & 4.9317 & TRN & & & \\
\hline CHEMBL1389817 & 688653 & \multicolumn{3}{|c|}{5.382999999999999} & 5.9301 & TRN & \\
\hline CHEMBL1462286 & 688653 & \multicolumn{3}{|c|}{5.7829999999999995} & 5.0805 & TRN & \\
\hline CHEMBL 3208387 & 688653 & 6.233 & 5.2223 & TRN & & & \\
\hline CHEMBL1424249 & 688653 & 5.483 & 5.2389 & TRN & & & \\
\hline CHEMBL591522 & 688653 & \multicolumn{3}{|c|}{4.7330000000000005} & 5.6678 & TRN & \\
\hline CHEMBL1982433 & 688653 & 5.983 & 5.5975 & TRN & & & \\
\hline CHEMBL1368910 & 688653 & 5.683 & 6.2887 & TRN & & & \\
\hline CHEMBL1592948 & 688653 & 5.083 & 4.9633 & TRN & & & \\
\hline CHEMBL1965911 & 688653 & 4.833 & 5.0054 & TRN & & & \\
\hline CHEMBL1505080 & 688653 & 4.883 & 5.647 & TST & & & \\
\hline CHEMBL1589844 & 688653 & \multicolumn{3}{|c|}{4.7330000000000005} & 5.2432 & TRN & \\
\hline CHEMBL1384771 & 688653 & 5.483 & 5.2031 & TRN & & & \\
\hline CHEMBL1507220 & 688653 & \multicolumn{3}{|c|}{5.2829999999999995} & 5.0285 & TST & \\
\hline CHEMBL1474763 & 688653 & 4.783 & 5.2785 & TRN & & & \\
\hline CHEMBL1468275 & 688653 & \multicolumn{3}{|c|}{5.332999999999999} & 5.5327 & TRN & \\
\hline CHEMBL1526653 & 688653 & \multicolumn{3}{|c|}{6.582999999999999} & 5.8305 & TRN & \\
\hline CHEMBL1578423 & 688653 & \multicolumn{3}{|c|}{5.332999999999999} & \multicolumn{2}{|c|}{5.531000000000001} & TRN \\
\hline CHEMBL1522455 & 688653 & 4.833 & 5.0492 & TRN & & & \\
\hline CHEMBL1415565 & 688653 & 5.183 & 5.2212 & TRN & & & \\
\hline CHEMBL1604966 & 688653 & \multicolumn{3}{|c|}{5.5329999999999995} & 5.9582 & TRN & \\
\hline CHEMBL1361369 & 688653 & 4.783 & \multicolumn{3}{|c|}{5.2010000000000005} & TST & \\
\hline CHEMBL1556516 & 688653 & \multicolumn{3}{|c|}{5.632999999999999} & 5.4712 & TRN & \\
\hline CHEMBL1404071 & 688653 & 5.733 & 5.0493 & TST & & & \\
\hline CHEMBL 3208718 & 688653 & \multicolumn{3}{|c|}{5.132999999999999} & 5.3076 & TST & \\
\hline CHEMBL1509061 & 688653 & 4.583 & 5.3108 & TRN & & & \\
\hline CHEMBL 2007163 & 688653 & \multicolumn{3}{|c|}{4.9830000000000005} & 5.4203 & TRN & \\
\hline CHEMBL1409903 & 688653 & 5.083 & 5.0411 & TST & & & \\
\hline CHEMBL1302039 & 688653 & 4.783 & 5.1892 & TRN & & & \\
\hline CHEMBL 3191475 & 688653 & 5.033 & 5.6523 & TRN & & & \\
\hline CHEMBL1513086 & 688653 & 5.033 & 5.0183 & TRN & & & \\
\hline CHEMBL1365811 & 688653 & \multicolumn{3}{|c|}{5.882999999999999} & 4.9987 & TRN & \\
\hline CHEMBL1490146 & 688653 & 5.033 & 5.0654 & TRN & & & \\
\hline CHEMBL1437698 & 688653 & \multicolumn{3}{|c|}{4.7330000000000005} & 4.9913 & TST & \\
\hline CHEMBL1581362 & 688653 & \multicolumn{3}{|c|}{5.382999999999999} & 4.8384 & TRN & \\
\hline CHEMBL1380848 & 688653 & 4.883 & 5.2311 & TRN & & & \\
\hline CHEMBL1429418 & 688653 & 4.883 & 4.5652 & TRN & & & \\
\hline CHEMBL1556379 & 688653 & 4.783 & 5.3238 & TRN & & & \\
\hline CHEMBL1366185 & 688653 & 4.98300 & 000000000 & 005 & 4.9049 & TRN & \\
\hline CHEMBL1408762 & 688653 & 5.83299 & 999999999 & & 5.6937 & TST & \\
\hline CHEMBL1579513 & 688653 & 5.63299 & 999999999 & & 5.8879 & TST & \\
\hline CHEMBL1489757 & 688653 & 4.73300 & 000000000 & 005 & 4.6741 & TST & \\
\hline CHEMBL1426162 & 688653 & 4.833 & 5.3346 & TST & & & \\
\hline CHEMBL 3193610 & 688653 & 5.033 & 5.1298 & TST & & & \\
\hline
\end{tabular}




\begin{tabular}{|c|c|c|c|c|c|c|}
\hline \multicolumn{7}{|c|}{ Supplemental Table S2.txt } \\
\hline CHEMBL1594544 & 688653 & 5.933 & 5.479 & TRN & & \\
\hline CHEMBL1417277 & 688653 & 6.433 & 5.8138 & TRN & & \\
\hline CHEMBL1589238 & 688653 & 5.033 & 5.0722 & TRN & & \\
\hline CHEMBL1340829 & 688653 & 5.2829 & 999999999 & 995 & 4.7938 & TST \\
\hline CHEMBL1543836 & 688653 & 4.583 & 4.3625 & TST & & \\
\hline CHEMBL1362727 & 688653 & 4.833 & 5.1362 & TRN & & \\
\hline CHEMBL1445742 & 688653 & 4.783 & 4.8605 & TST & & \\
\hline CHEMBL1389325 & 688653 & 5.7829 & 999999999 & 995 & 5.0996 & \\
\hline CHEMBL1488035 & 688653 & 4.583 & 5.3226 & TRN & & \\
\hline CHEMBL1543872 & 688653 & 4.833 & 4.8068 & TRN & & \\
\hline CHEMBL 3190318 & 688653 & 6.5829 & 999999999 & & 5.7905 & \\
\hline CHEMBL1543036 & 688653 & 4.933 & 5.0352 & TRN & & \\
\hline CHEMBL1310355 & 688653 & 6.183 & 5.4668 & TST & & \\
\hline CHEMBL1531190 & 688653 & 5.233 & 5.1975 & TRN & & \\
\hline CHEMBL1384101 & 688653 & 4.933 & 5.1036 & TRN & & \\
\hline CHEMBL 3192790 & 688653 & 5.2829 & 999999999 & 995 & 5.1495 & \\
\hline CHEMBL1464799 & 688653 & 5.3829 & 999999999 & & 5.1213 & \\
\hline CHEMBL1592109 & 688653 & 4.583 & 5.0711 & TRN & & \\
\hline CHEMBL1503113 & 688653 & 5.083 & 5.0238 & TRN & & \\
\hline CHEMBL1449093 & 688653 & 5.3829 & 999999999 & & 5.0498 & \\
\hline CHEMBL1499893 & 688653 & 5.083 & 4.7352 & TRN & & \\
\hline CHEMBL 3197219 & 688653 & 5.8329 & 999999999 & & 5.5813 & \\
\hline CHEMBL1594855 & 688653 & 5.1329 & 999999999 & & 4.9239 & \\
\hline CHEMBL1409702 & 688653 & 5.683 & 5.3875 & TRN & & \\
\hline CHEMBL1342143 & 688653 & 5.183 & 5.3478 & TST & & \\
\hline CHEMBL1472031 & 688653 & 4.783 & 5.1084 & TST & & \\
\hline CHEMBL1321450 & 688653 & 6.7331 & 6.241000 & 000000000 & 305 & \\
\hline CHEMBL1468942 & 688653 & 5.683 & 5.5087 & TRN & & \\
\hline CHEMBL1530663 & 688653 & 4.933 & 5.5246 & TRN & & \\
\hline CHEMBL1383022 & 688653 & 6.3329 & 999999999 & & 5.5412 & \\
\hline CHEMBL1316947 & 688653 & 5.3329 & 999999999 & & 5.4617 & TST \\
\hline CHEMBL1363154 & 688653 & 4.7330 & 000000000 & 005 & 5.3455 & TS \\
\hline CHEMBL1362448 & 688653 & 4.883 & 5.524 & TST & & \\
\hline CHEMBL1485727 & 688653 & 5.1329 & 999999999 & & 5.0342 & וצנו \\
\hline CHEMBL1560088 & 688653 & 4.7330 & 000000000 & 005 & 5.6657 & TRN \\
\hline CHEMBL1516282 & 688653 & 4.9830 & 000000000 & 005 & 5.4215 & TR \\
\hline CHEMBL1565407 & 688653 & 5.183 & 5.2985 & TRN & & \\
\hline CHEMBL1501987 & 688653 & 4.7330 & 000000000 & 005 & 5.3575 & 151 \\
\hline CHEMBL1594301 & 688653 & 5.233 & 5.3784 & TRN & & \\
\hline CHEMBL1554985 & 688653 & 5.933 & 5.2228 & TRN & & \\
\hline CHEMBL1364051 & 688653 & 4.933 & 4.8863 & TRN & & \\
\hline CHEMBL1457665 & 688653 & 6.4829 & 5.2572 & TRN & & \\
\hline CHEMBL3196819 & 688653 & 4.783 & 5.266 & TRN & & \\
\hline CHEMBL1529521 & 688653 & 5.733 & 5.7664 & TRN & & \\
\hline CHEMBL1337412 & 688653 & 4.7330 & 000000000 & 005 & 4.9844 & TRN \\
\hline CHEMBL1370512 & 688653 & 4.833 & 5.0883 & TRN & & \\
\hline CHEMBL1598405 & 688653 & 6.3329 & 999999999 & 99 & 5.938 & TI \\
\hline CHEMBL1580543 & 688653 & 5.483 & 5.4113 & TRN & & \\
\hline
\end{tabular}




\begin{tabular}{|c|c|c|c|c|c|c|}
\hline \multicolumn{7}{|c|}{ Supplemental Table S2.txt } \\
\hline CHEMBL1429920 & 688653 & 5.733 & 5.3052 & TRN & & \\
\hline CHEMBL551604 & 688653 & 5.683 & 5.3406 & TRN & & \\
\hline CHEMBL1385459 & 688653 & 5.083 & 5.4704 & TST & & \\
\hline CHEMBL1442453 & 688653 & \multicolumn{3}{|c|}{4.9830000000000005} & 5.1488 & TRN \\
\hline CHEMBL 1449578 & 688653 & \multicolumn{3}{|c|}{4.9830000000000005} & 4.9982 & \\
\hline CHEMBL1429080 & 688653 & 5.033 & 5.0809 & TRN & & \\
\hline CHEMBL1503995 & 688653 & 4.633 & 5.1125 & TRN & & \\
\hline CHEMBL1498920 & 688653 & \multicolumn{3}{|c|}{4.7330000000000005} & 5.2104 & \\
\hline CHEMBL1429397 & 688653 & 5.733 & 5.37 & TRN & & \\
\hline CHEMBL1439902 & 688653 & 5.033 & 5.5182 & TST & & \\
\hline CHEMBL1584634 & 688653 & \multicolumn{3}{|c|}{5.832999999999999} & 5.5827 & \\
\hline CHEMBL84316 & 688653 & 4.883 & 5.2315 & TST & & \\
\hline CHEMBL1350521 & 688653 & \multicolumn{3}{|c|}{4.7330000000000005} & 4.971 & \\
\hline CHEMBL1345082 & 688653 & 5.733 & 5.3414 & TRN & & \\
\hline CHEMBL1485687 & 688653 & \multicolumn{3}{|c|}{4.7330000000000005} & 5.3121 & \\
\hline CHEMBL3195995 & 688653 & \multicolumn{3}{|c|}{5.632999999999999} & 5.4413 & \\
\hline CHEMBL1609323 & 688653 & 4.933 & 5.0528 & TRN & & \\
\hline CHEMBL1408717 & 688653 & 5.683 & \multicolumn{3}{|c|}{5.2410000000000005} & \\
\hline CHEMBL15 & 688653 & 4.683 & 4.8396 & TST & & \\
\hline CHEMBL1336920 & 688653 & 7.3325 & 6.1259 & TRN & & \\
\hline CHEMBL 3213717 & 688653 & 4.583 & 5.1743 & TRN & & \\
\hline CHEMBL1574625 & 688653 & 4.783 & 5.1179 & TST & & \\
\hline CHEMBL1998940 & 688 & \multicolumn{3}{|c|}{5.132999999999999} & 2 & \\
\hline CHEMBL1601638 & 688653 & 4.833 & \multicolumn{3}{|c|}{5.178999999999999} & \\
\hline CHEMBL1580335 & 688653 & 5.983 & 5.6223 & TRN & & \\
\hline CHEMBL1325549 & 688653 & \multicolumn{3}{|c|}{5.832999999999999} & 6.0582 & \\
\hline CHEMBL1596061 & 688653 & \multicolumn{3}{|c|}{6.082999999999999} & 5.4708 & \\
\hline CHEMBL & 53 & 5.733 & 5.0638 & TST & & \\
\hline CHEMBL1605081 & 688653 & \multicolumn{3}{|c|}{5.132999999999999} & 5.2278 & \\
\hline CHEMBL59026 & 688653 & 4.783 & 5.0126 & TRN & & \\
\hline CHEMBL1324351 & 688653 & 5.483 & 5.5107 & TRN & & \\
\hline CHEMBL1542047 & 688653 & \multicolumn{3}{|c|}{5.832999999999999} & 5.1002 & \\
\hline CHEMBL1346565 & 688 & 5.733 & 5.5266 & TRN & & \\
\hline CHEMBL1417436 & 553 & \multicolumn{3}{|c|}{5.332999999999999} & 5.3721 & \\
\hline CHEMBL1590174 & 688653 & \multicolumn{3}{|c|}{4.7330000000000005} & 4.7234 & TR \\
\hline CHEMBL1568346 & 688653 & \multicolumn{3}{|c|}{6.382999999999999} & 5.7941 & \\
\hline CHEMBL1971634 & 688653 & 4.633 & 5.5624 & TRN & & \\
\hline CHEMBL15 & 688653 & 4.85 & 5.1085 & TRN & & \\
\hline CHEMBL1604999 & 688653 & 5.933 & 5.3496 & TRN & & \\
\hline CHEMBL1545397 & 688653 & 4.783 & 5.2943 & TST & & \\
\hline CHEMBL1547222 & 688653 & \multicolumn{3}{|c|}{6.332999999999999} & 5.898 & \\
\hline CHEMBL 3208570 & 688653 & \multicolumn{3}{|c|}{5.832999999999999} & 5.8111 & \\
\hline CHEMBL1369124 & 688653 & \multicolumn{3}{|c|}{4.9830000000000005} & 5.0795 & \\
\hline CHEMBL1412940 & 688653 & 5.683 & 5.4589 & TRN & & \\
\hline CHEMBL 3198074 & 688653 & 5.183 & 4.9599 & TRN & & \\
\hline CHEMBL1532731 & 688653 & 4.783 & 5.5475 & TRN & & \\
\hline CHEMBL1426499 & 688653 & 4.933 & 4.9823 & TRN & & \\
\hline CHEMBL1374484 & 688653 & 4.783 & 5.0829 & TST & & \\
\hline
\end{tabular}




\begin{tabular}{|c|c|c|c|c|c|c|c|}
\hline \multirow{3}{*}{$\begin{array}{l}\text { CHEMBL1364845 } \\
\text { CHEMBL1450947 }\end{array}$} & \multicolumn{6}{|c|}{ Supplemental Table S2.txt } & \\
\hline & 688653 & \multicolumn{3}{|c|}{5.2829999999999995} & 5.5817 & TRN & \\
\hline & 688653 & 4.833 & 5.1291 & TST & & & \\
\hline CHEMBL1608805 & 688653 & 4.883 & 5.725 & TRN & & & \\
\hline CHEMBL1520360 & 688653 & 4.833 & 5.3751 & TRN & & & \\
\hline CHEMBL1493275 & 688653 & 4.883 & 5.3159 & TST & & & \\
\hline CHEMBL1490351 & 688653 & \multicolumn{3}{|c|}{7.082999999999999} & 5.1433 & TRN & \\
\hline CHEMBL1366593 & 688653 & \multicolumn{3}{|c|}{4.7330000000000005} & 5.0335 & TRN & \\
\hline CHEMBL1466507 & 688653 & 4.833 & 5.081 & TST & & & \\
\hline CHEMBL228527 & 688653 & 4.783 & 5.3806 & TRN & & & \\
\hline CHEMBL3199393 & 688653 & 5.733 & 5.5149 & TRN & & & \\
\hline CHEMBL1584740 & 688653 & 4.783 & 5.1711 & TST & & & \\
\hline CHEMBL1353750 & 688653 & 5.183 & 5.078 & TST & & & \\
\hline CHEMBL1531553 & 688653 & 4.833 & 5.1617 & TST & & & \\
\hline CHEMBL3193901 & 688653 & 4.783 & 5.306 & TRN & & & \\
\hline CHEMBL1486651 & 688653 & \multicolumn{3}{|c|}{5.582999999999999} & 5.4138 & TRN & \\
\hline CHEMBL1448379 & 688653 & \multicolumn{3}{|c|}{5.2829999999999995} & 5.5466 & TST & \\
\hline CHEMBL1458670 & 688653 & \multicolumn{3}{|c|}{5.7829999999999995} & 6.0569 & TRN & \\
\hline CHEMBL1529127 & 688653 & 4.633 & 4.9876 & TRN & & & \\
\hline CHEMBL1417538 & 688653 & 4.933 & 5.1515 & TST & & & \\
\hline CHEMBL1313086 & 688653 & \multicolumn{3}{|c|}{5.5329999999999995} & 5.4759 & TRN & \\
\hline CHEMBL1499500 & 688653 & \multicolumn{3}{|c|}{5.332999999999999} & 5.343 & TRN & \\
\hline CHEMBL1509671 & 688653 & \multicolumn{3}{|c|}{6.132999999999999} & 5.5934 & TST & \\
\hline CHEMBL1571012 & 688653 & \multicolumn{3}{|c|}{6.0329999999999995} & 5.57799 & 9999999999 & TRN \\
\hline CHEMBL1366790 & 688653 & 4.883 & 5.9598 & TRN & & & \\
\hline CHEMBL1319900 & 688653 & \multicolumn{3}{|c|}{5.882999999999999} & 5.7138 & TRN & \\
\hline CHEMBL1326458 & 688653 & 4.583 & 4.8848 & TRN & & & \\
\hline CHEMBL1313891 & 688653 & 5.683 & 6.1898 & TRN & & & \\
\hline CHEMBL1466558 & 688653 & 4.883 & 5.4448 & TRN & & & \\
\hline CHEMBL1472693 & 688653 & 4.883 & 5.3155 & TRN & & & \\
\hline CHEMBL3211877 & 688653 & 4.633 & 5.2587 & TRN & & & \\
\hline CHEMBL3210141 & 688653 & 5.483 & \multicolumn{3}{|c|}{5.5329999999999995} & TRN & \\
\hline CHEMBL1578593 & 688653 & 4.833 & 5.362 & TRN & & & \\
\hline CHEMBL1429188 & 688653 & 4.833 & 5.2797 & TRN & & & \\
\hline CHEMBL1564818 & 688653 & \multicolumn{3}{|c|}{4.7330000000000005} & 5.0225 & TRN & \\
\hline CHEMBL1435119 & 688653 & \multicolumn{3}{|c|}{6.632999999999999} & 6.0261 & TRN & \\
\hline CHEMBL1399879 & 688653 & 4.783 & 5.5181 & TRN & & & \\
\hline CHEMBL1514145 & 688653 & & & TST & & & \\
\hline CHEMBL1493646 & 688653 & \multicolumn{3}{|c|}{6.832999999999999} & 5.3834 & TRN & \\
\hline CHEMBL1440969 & 688653 & 5.083 & 5.4037 & TRN & & & \\
\hline CHEMBL1470566 & 688653 & \multicolumn{3}{|c|}{4.9830000000000005} & 5.3729 & TRN & \\
\hline CHEMBL1467238 & 688653 & \multicolumn{3}{|c|}{5.7829999999999995} & 5.4043 & TRN & \\
\hline CHEMBL1559385 & 688653 & \multicolumn{3}{|c|}{6.382999999999999} & 5.5159 & TRN & \\
\hline CHEMBL1551186 & 688653 & 6.9329 & 5.496 & TRN & & & \\
\hline CHEMBL1496367 & 688653 & 4.883 & 5.2983 & TST & & & \\
\hline CHEMBL202366 & 688653 & 6.233 & 5.8763 & TRN & & & \\
\hline CHEMBL1413671 & 688653 & 6.5829 & 9999999 & & 6.0789 & TRN & \\
\hline CHEMBL1507052 & 688653 & 6.0829 & 9999999 & & 5.4738 & TRN & \\
\hline CHEMBL1434035 & 688653 & 5.3829 & 9999999 & & 5.4699 & TRN & \\
\hline
\end{tabular}




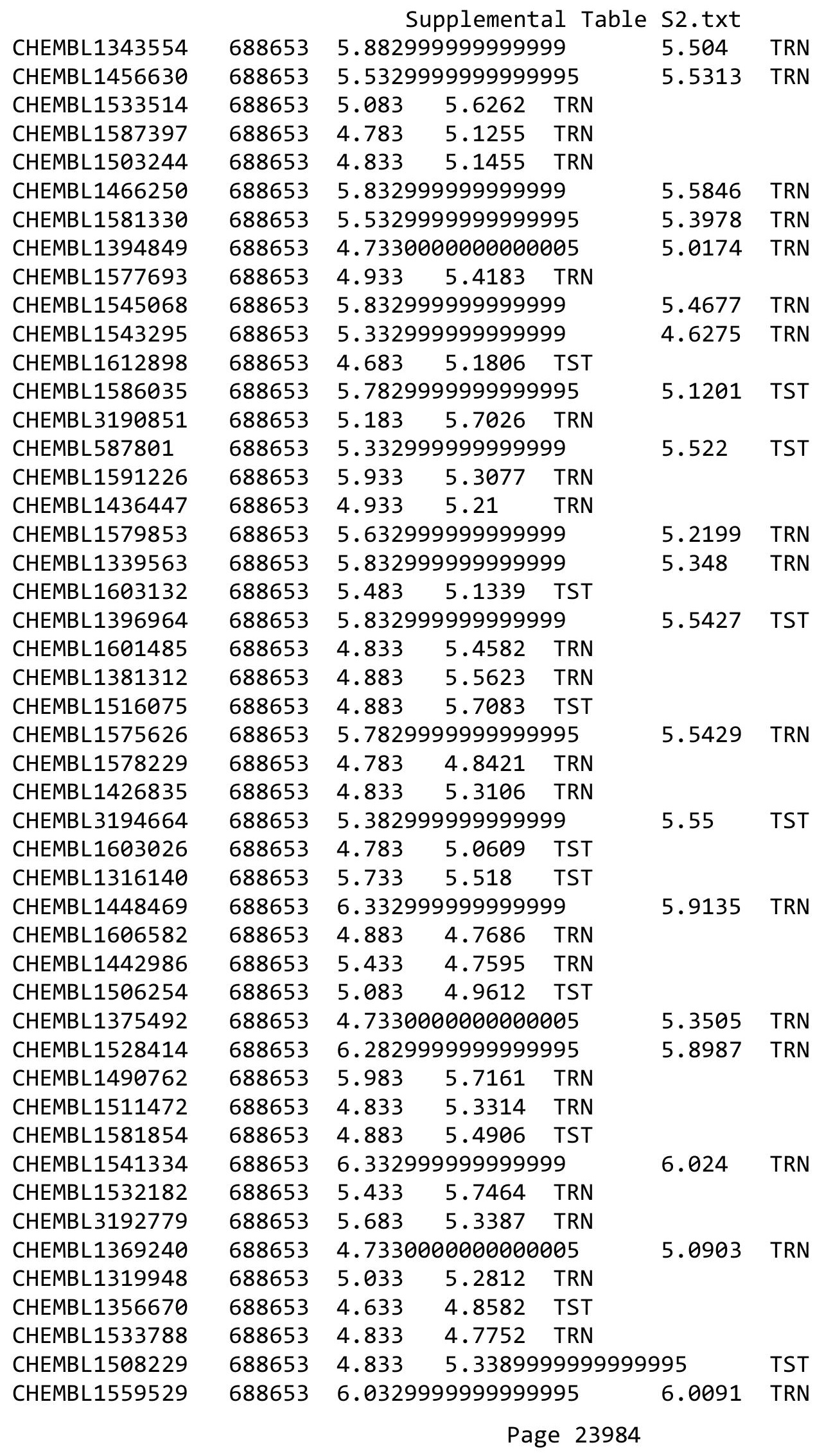




\begin{tabular}{|c|c|c|c|c|c|c|}
\hline \multirow{3}{*}{$\begin{array}{l}\text { CHEMBL1441706 } \\
\text { CHEMBL1328569 }\end{array}$} & \multirow{3}{*}{$\begin{array}{l}688653 \\
688653\end{array}$} & \multicolumn{5}{|c|}{ Supplemental Table S2.txt } \\
\hline & & \multicolumn{3}{|c|}{4.7330000000000005} & \multirow[t]{3}{*}{4.9326} & \multirow[t]{3}{*}{ TRN } \\
\hline & & 6.7331 & 5.8085 & TRN & & \\
\hline CHEMBL1343639 & 688653 & 4.783 & 4.9399 & TRN & & \\
\hline CHEMBL1518716 & 688653 & \multicolumn{3}{|c|}{5.7829999999999995} & \multirow{4}{*}{5.1805} & \multirow[t]{2}{*}{ TST } \\
\hline CHEMBL1471326 & 688653 & 6.4829 & 5.7535 & TRN & & \\
\hline CHEMBL1424411 & 688653 & 6.983 & 5.4435 & TRN & & \\
\hline CHEMBL1367078 & 688653 & 4.883 & 5.5004 & TRN & & \\
\hline CHEMBL1476095 & 688653 & \multicolumn{3}{|c|}{5.632999999999999} & \multirow[t]{7}{*}{5.3176} & \\
\hline CHEMBL1332362 & 688653 & 5.183 & 5.5561 & TRN & & \\
\hline CHEMBL1603170 & 688653 & 6.433 & 6.0519 & TRN & & \\
\hline CHEMBL1569537 & 688653 & 4.883 & 5.0962 & TRN & & \\
\hline CHEMBL1306725 & 688653 & 5.183 & 4.8468 & TRN & & \\
\hline CHEMBL1301035 & 688653 & 4.783 & 5.1972 & TST & & \\
\hline CHEMBL1484485 & 688653 & 4.883 & 5.2622 & TRN & & \\
\hline CHEMBL1358546 & 688653 & \multicolumn{3}{|c|}{5.5329999999999995} & \multirow[t]{4}{*}{5.131} & \\
\hline CHEMBL1385207 & 688653 & 4.783 & 5.4629 & TRN & & \\
\hline CHEMBL1483754 & 688653 & 5.733 & 5.2137 & TST & & \\
\hline CHEMBL1424158 & 688653 & 5.483 & 5.1513 & TST & & \\
\hline CHEMBL1517615 & 688653 & \multicolumn{3}{|c|}{4.7330000000000005} & 5.2266 & \\
\hline CHEMBL1452606 & 688653 & \multicolumn{3}{|c|}{5.5329999999999995} & 4.9478 & \\
\hline CHEMBL1328713 & 688653 & 6.4829 & 5.3999 & TRN & & \\
\hline CHEMBL14 & 688653 & 4.833 & 4.9412 & TRN & & \\
\hline CHEMBL1363849 & 688653 & 4.833 & 5.1258 & TST & & \\
\hline CHEMBL1530528 & 688653 & \multicolumn{3}{|c|}{5.632999999999999} & 5.3881 & \\
\hline CHEMBL1604558 & 688653 & 6.433 & 5.814 & TRN & & \\
\hline CHEMBL1569074 & 688653 & \multicolumn{3}{|c|}{6.582999999999999} & 5.7706 & \\
\hline CHEMBL1 & 688653 & 4.833 & 5.169 & TST & & \\
\hline CHEMBL1494693 & 688653 & 5.683 & 5.0014 & TRN & & \\
\hline CHEMBL1313188 & 688653 & 6.0 & 4.8597 & TRN & & \\
\hline CHEMBL1326849 & 688653 & \multicolumn{3}{|c|}{5.332999999999999} & 5.2064 & \\
\hline CHEMBL1301625 & 688653 & 5.683 & 5.8306 & TRN & & \\
\hline CHEMB & 688653 & 4.883 & 4.9543 & TRN & & \\
\hline CHEMBL1412005 & 688653 & 5.983 & 5.8247 & TRN & & \\
\hline CHEMBL3192599 & 688653 & 5.183 & 5.0904 & TRN & & \\
\hline CHEMBL1502192 & 688653 & 6.683 & 6.5135 & TRN & & \\
\hline CHEMBL1375130 & 688653 & \multicolumn{3}{|c|}{5.632999999999999} & 5.0125 & \\
\hline CHEMBL 3213078 & 688653 & 4.883 & 5.1723 & TST & & \\
\hline CHEMBL1538265 & 688653 & 4.883 & 4.9619 & TRN & & \\
\hline CHEMBL1585520 & 688653 & 4.783 & 5.5283 & TRN & & \\
\hline CHEMBL579640 & 688653 & 4.883 & 5.2895 & TST & & \\
\hline CHEMBL3213231 & 688653 & \multicolumn{3}{|c|}{4.9830000000000005} & 4.8468 & \\
\hline CHEMBL1539430 & 688653 & 5.183 & 5.1038 & TRN & & \\
\hline CHEMBL1593398 & 688653 & 4.833 & 5.1142 & TST & & \\
\hline CHEMBL1526841 & 688653 & \multicolumn{3}{|c|}{4.7330000000000005} & 5.2709 & \\
\hline CHEMBL1423661 & 688653 & 5.183 & 5.0868 & TST & & \\
\hline CHEMBL1493782 & 688653 & 5.13299 & 99999995 & & 4.9694 & \\
\hline CHEMBL 3191575 & 688653 & 4.833 & 5.6692 & TRN & & \\
\hline CHEMBL1384857 & 688653 & 5.88299 & 9999999 & & 4.9952 & $\mathrm{NI}$ \\
\hline
\end{tabular}




\begin{tabular}{|c|c|c|c|c|c|c|c|}
\hline \multicolumn{8}{|c|}{ Supplemental Table s2.txt } \\
\hline CHEMBL1341855 & 688653 & 4.833 & 4.9872 & TRN & & & \\
\hline CHEMBL1600646 & 688653 & 4.933 & 5.0939 & TRN & & & \\
\hline CHEMBL1456197 & 688653 & 4.9830 & 20000000 & 005 & 6.024 & TST & \\
\hline CHEMBL1393529 & 688653 & 4.9830 & 00000000 & 005 & 5.0014 & TRN & \\
\hline CHEMBL1493171 & 688653 & 4.9830 & 00000000 & 005 & 5.2279 & TST & \\
\hline CHEMBL1567832 & 688653 & 5.8829 & 99999999 & & 5.6799 & TRN & \\
\hline CHEMBL1426578 & 688653 & 5.083 & 5.3177 & TRN & & & \\
\hline CHEMBL 3208147 & 688653 & 4.783 & 5.2071 & TST & & & \\
\hline CHEMBL1600374 & 688653 & 5.933 & 5.13899 & 99999 & 99 & TRN & \\
\hline CHEMBL1469222 & 688653 & 6.1329 & 99999999 & & 5.5619 & TRN & \\
\hline CHEMBL1522037 & 688653 & 4.933 & 5.0361 & TRN & & & \\
\hline CHEMBL1431283 & 688653 & 6.183 & 5.2259 & TRN & & & \\
\hline CHEMBL3213798 & 688653 & 5.233 & 5.2377 & TST & & & \\
\hline CHEMBL1347686 & 688653 & 5.5829 & 99999999 & & 5.6969 & TRN & \\
\hline CHEMBL1358435 & 688653 & 5.6329 & 99999999 & & 5.0983 & TRN & \\
\hline CHEMBL1555873 & 688653 & 6.983 & 5.8459 & TRN & & & \\
\hline CHEMBL1370781 & 688653 & 4.883 & 4.8418 & TST & & & \\
\hline CHEMBL1480652 & 688653 & 5.6329 & 99999999 & & 5.1176 & TRN & \\
\hline CHEMBL1318796 & 688653 & 4.683 & 4.9984 & TRN & & & \\
\hline CHEMBL1424724 & 688653 & 4.683 & 5.0315 & TST & & & \\
\hline CHEMBL1431210 & 688653 & 5.6329 & 99999999 & & 5.7989 & 99999999995 & TRN \\
\hline CHEMBL1471402 & 688653 & 4.783 & 5.1239 & TST & & & \\
\hline CHEMBL1424299 & 688653 & 4.583 & 5.037 & TST & & & \\
\hline CHEMBL1393538 & 688653 & 4.7330 & 00000000 & 005 & 4.9257 & TRN & \\
\hline CHEMBL1310491 & 688653 & 5.1329 & 99999999 & & 5.195 & TRN & \\
\hline CHEMBL1414939 & 688653 & 5.183 & 5.2985 & TST & & & \\
\hline CHEMBL1342618 & 688653 & 5.8829 & 99999999 & & 5.2529 & 9999999999 & TST \\
\hline CHEMBL1556168 & 688653 & 5.083 & 4.7951 & TRN & & & \\
\hline CHEMBL1554870 & 688653 & 4.7330 & 30000000 & 005 & 5.065 & TRN & \\
\hline CHEMBL3197622 & 688653 & 5.3329 & 99999999 & & 5.3902 & TST & \\
\hline CHEMBL1433457 & 688653 & 5.433 & 5.2778 & TRN & & & \\
\hline CHEMBL1325930 & 688653 & 4.833 & 4.8928 & TST & & & \\
\hline CHEMBL1301074 & 688653 & 6.0329 & 99999999 & 995 & 5.7641 & TRN & \\
\hline CHEMBL3194247 & 688653 & 5.733 & 5.6853 & TRN & & & \\
\hline CHEMBL1455796 & 688653 & 5.683 & 5.9171 & TRN & & & \\
\hline CHEMBL1412540 & 688653 & 4.7330 & 20000000 & 005 & 5.1677 & TRN & \\
\hline CHEMBL1339427 & 688653 & 5.083 & 5.2452 & TRN & & & \\
\hline CHEMBL1543489 & 688653 & 5.183 & 5.1617 & TRN & & & \\
\hline CHEMBL1492957 & 688653 & 5.5829 & 99999999 & & 5.4179 & 9999999999 & TRN \\
\hline CHEMBL1426049 & 688653 & 4.933 & 5.0194 & TST & & & \\
\hline CHEMBL1324115 & 688653 & 4.583 & 4.9268 & TRN & & & \\
\hline CHEMBL1425605 & 688653 & 4.7330 & $\partial 0000000$ & 005 & 5.4343 & TRN & \\
\hline CHEMBL1526076 & 688653 & 5.5829 & 99999999 & & 5.1757 & TST & \\
\hline CHEMBL3195837 & 688653 & 5.233 & 5.3271 & TRN & & & \\
\hline CHEMBL1422880 & 688653 & 4.633 & 5.1379 & TRN & & & \\
\hline CHEMBL1571983 & 688653 & 4.883 & 4.8092 & TRN & & & \\
\hline CHEMBL1468673 & 688653 & 4.833 & 5.0464 & TRN & & & \\
\hline CHEMBL1358220 & 688653 & 4.683 & 5.0473 & TRN & & & \\
\hline
\end{tabular}




\begin{tabular}{|c|c|c|c|c|c|c|}
\hline \multirow[b]{2}{*}{ CHEMBL1364400 } & \multirow[b]{2}{*}{688653} & \multicolumn{5}{|c|}{ Supplemental Table S2.txt } \\
\hline & & 5.233 & 5.3665 & TRN & & \\
\hline CHEMBL1373107 & 688653 & \multicolumn{3}{|c|}{5.382999999999999} & 5.78 & TRN \\
\hline CHEMBL1516466 & 688653 & 5.033 & 4.8412 & TRN & & \\
\hline CHEMBL1322056 & 688653 & 4.783 & 4.9943 & TRN & & \\
\hline CHEMBL1535172 & 688653 & 5.233 & 5.7619 & TRN & & \\
\hline CHEMBL1515437 & 688653 & 4.783 & 4.9053 & TST & & \\
\hline CHEMBL1341756 & 688653 & 4.833 & 4.9094 & TRN & & \\
\hline CHEMBL1368727 & 688653 & 4.933 & 5.1404 & TRN & & \\
\hline CHEMBL1437051 & 688653 & \multicolumn{3}{|c|}{6.132999999999999} & 5.1917 & TRN \\
\hline CHEMBL1084955 & 688653 & \multicolumn{3}{|c|}{5.132999999999999} & 5.6693 & TRN \\
\hline CHEMBL1301753 & 688653 & \multicolumn{3}{|c|}{5.2829999999999995} & 5.4742 & TRN \\
\hline CHEMBL260624 & 688653 & 5.183 & 5.3591 & TRN & & \\
\hline CHEMBL1366277 & 688653 & \multicolumn{3}{|c|}{6.332999999999999} & 5.6208 & TRN \\
\hline CHEMBL456446 & 688653 & \multicolumn{3}{|c|}{5.632999999999999} & 5.2143 & TRN \\
\hline CHEMBL1518866 & 688653 & \multicolumn{3}{|c|}{6.5329999999999995} & 5.9817 & TRN \\
\hline CHEMBL1562877 & 688653 & 5.683 & 5.3668 & TRN & & \\
\hline CHEMBL1300331 & 688653 & 4.833 & 5.2956 & TRN & & \\
\hline CHEMBL1525579 & 688653 & 5.233 & 4.8174 & TRN & & \\
\hline CHEMBL1531220 & 688653 & 5.483 & 4.9785 & TRN & & \\
\hline CHEMBL1537522 & 688653 & 4.683 & 5.3842 & TRN & & \\
\hline CHEMBL1405318 & 688653 & 4.883 & 5.044 & TRN & & \\
\hline CHEMBL1478388 & 688653 & 5.733 & 5.6195 & TRN & & \\
\hline CHEMBL1404190 & 688653 & \multicolumn{3}{|c|}{5.832999999999999} & 5.4495 & TRN \\
\hline CHEMBL1532668 & 688653 & 4.883 & 5.1337 & TRN & & \\
\hline CHEMBL1492763 & 688653 & & 5.311 & TRN & & \\
\hline CHEMBL1569719 & 688653 & \multicolumn{3}{|c|}{5.132999999999999} & 5.1308 & TRN \\
\hline CHEMBL237253 & 688653 & 5.933 & 5.6118 & TRN & & \\
\hline CHEMBL1605970 & 688653 & \multicolumn{3}{|c|}{4.7330000000000005} & 4.7448 & TRN \\
\hline CHEMBL1306215 & 688653 & 4.633 & 5.349 & TST & & \\
\hline CHEMBL1432524 & 688653 & \multicolumn{3}{|c|}{5.882999999999999} & 5.4477 & TRN \\
\hline CHEMBL1495873 & 688653 & 5.183 & 5.6092 & TRN & & \\
\hline CHEMBL1317846 & 688653 & \multicolumn{3}{|c|}{5.2829999999999995} & 5.7919 & TRN \\
\hline CHEMBL1420901 & 688653 & 4.933 & 5.1611 & TRN & & \\
\hline CHEMBL1557226 & 688653 & \multicolumn{3}{|c|}{5.7829999999999995} & 5.22 & TRN \\
\hline CHEMBL1502712 & 688653 & \multicolumn{3}{|c|}{4.7330000000000005} & 4.6013 & TST \\
\hline CHEMBL1546083 & 688653 & 5.733 & 5.2492 & TRN & & \\
\hline CHEMBL1317276 & 688653 & 5.233 & 4.9257 & TST & & \\
\hline CHEMBL1596622 & 688653 & 5.683 & 5.8243 & TRN & & \\
\hline CHEMBL1367248 & 688653 & 4.783 & 5.5648 & TST & & \\
\hline CHEMBL1591179 & 688653 & 4.583 & 5.4636 & TST & & \\
\hline CHEMBL1390287 & 688653 & 4.783 & 5.0484 & TST & & \\
\hline CHEMBL1601745 & 688653 & 5.083 & 5.1732 & TRN & & \\
\hline CHEMBL1579932 & 688653 & 5.6329 & 99999999 & & 5.3242 & TRN \\
\hline CHEMBL1404733 & 688653 & 5.483 & 5.3843 & TRN & & \\
\hline CHEMBL1306736 & 688653 & 4.883 & 5.3148 & TST & & \\
\hline CHEMBL1567058 & 688653 & 4.7330 & 90000000 & 005 & 5.5205 & TRN \\
\hline CHEMBL1458019 & 688653 & 4.933 & 5.0877 & TST & & \\
\hline CHEMBL1600315 & 688653 & 4.9830 & 30000000 & & 5.1805 & TRN \\
\hline & & & & & & \\
\hline
\end{tabular}




\begin{tabular}{|c|c|c|c|c|c|c|c|}
\hline \multicolumn{7}{|c|}{ Supplemental Table S2.txt } & \\
\hline CHEMBL1596232 & 688653 & \multicolumn{3}{|c|}{4.7330000000000005} & 4.9045 & \multicolumn{2}{|l|}{ TRN } \\
\hline CHEMBL1579931 & 688653 & \multicolumn{3}{|c|}{4.9830000000000005} & \multicolumn{2}{|c|}{5.2410000000000005} & TRN \\
\hline CHEMBL1606422 & 688653 & 5.733 & 5.8702 & TRN & & & \\
\hline CHEMBL1540564 & 688653 & 4.833 & 4.9069 & TRN & & & \\
\hline CHEMBL1408733 & 688653 & 4.833 & 4.9146 & TRN & & & \\
\hline CHEMBL1300429 & 688653 & 4.833 & 5.0252 & TRN & & & \\
\hline CHEMBL1509916 & 688653 & 4.783 & 5.3391 & TRN & & & \\
\hline CHEMBL1345529 & 688653 & \multicolumn{3}{|c|}{4.7330000000000005} & 4.8804 & TST & \\
\hline CHEMBL1580852 & 688653 & 4.883 & 5.4582 & TRN & & & \\
\hline CHEMBL1497950 & 688653 & 4.633 & 5.05 & TRN & & & \\
\hline CHEMBL 3189400 & 688653 & \multicolumn{3}{|c|}{6.832999999999999} & 5.6162 & TRN & \\
\hline CHEMBL1369769 & 688653 & 4.883 & 5.2827 & TST & & & \\
\hline CHEMBL1377073 & 688653 & \multicolumn{3}{|c|}{4.9830000000000005} & 5.3071 & TRN & \\
\hline CHEMBL 3190334 & 688653 & 6.9329 & 5.8635 & TRN & & & \\
\hline CHEMBL1468444 & 688653 & 5.733 & 4.9323 & TRN & & & \\
\hline CHEMBL1601181 & 688653 & \multicolumn{3}{|c|}{5.832999999999999} & 6.2228 & TRN & \\
\hline CHEMBL1388073 & 688653 & \multicolumn{3}{|c|}{5.132999999999999} & 5.4732 & TRN & \\
\hline CHEMBL1606578 & 688653 & \multicolumn{3}{|c|}{5.132999999999999} & 5.3396 & TST & \\
\hline CHEMBL1532098 & 688653 & 5.233 & 5.0254 & TRN & & & \\
\hline CHEMBL1559820 & 688653 & 5.933 & 5.5925 & TRN & & & \\
\hline CHEMBL1412630 & 688653 & \multicolumn{3}{|c|}{5.632999999999999} & 5.0447 & TST & \\
\hline CHEMBL1482364 & 688653 & 5.033 & 5.2818 & TRN & & & \\
\hline CHEMBL1328073 & 688653 & \multicolumn{3}{|c|}{6.132999999999999} & 5.9883 & TRN & \\
\hline CHEMBL3198267 & 688653 & \multicolumn{3}{|c|}{5.382999999999999} & 5.268 & TRN & \\
\hline CHEMBL1347459 & 688653 & 5.733 & 5.312 & TRN & & & \\
\hline CHEMBL1611513 & 688653 & 4.633 & 4.8331 & TRN & & & \\
\hline CHEMBL1529638 & 688653 & \multicolumn{3}{|c|}{4.7330000000000005} & 5.1414 & TRN & \\
\hline CHEMBL1345545 & 688653 & \multicolumn{3}{|c|}{5.382999999999999} & 5.1096 & TRN & \\
\hline CHEMBL1527599 & 688653 & 5.683 & 5.5396 & TRN & & & \\
\hline CHEMBL1416282 & 688653 & \multicolumn{3}{|c|}{5.882999999999999} & 5.5011 & TRN & \\
\hline CHEMBL1597102 & 688653 & \multicolumn{3}{|c|}{5.382999999999999} & 5.021 & TST & \\
\hline CHEMBL1587430 & 688653 & 4.783 & 5.2884 & TRN & & & \\
\hline CHEMBL1323994 & 688653 & 5.483 & 5.3249 & TRN & & & \\
\hline CHEMBL1596411 & 688653 & \multicolumn{3}{|c|}{4.7330000000000005} & 4.802 & TRN & \\
\hline CHEMBL1490626 & 688653 & 6.983 & 5.6093 & TRN & & & \\
\hline CHEMBL1401432 & 688653 & 5.183 & 5.0706 & TRN & & & \\
\hline CHEMBL1559427 & 688653 & \multicolumn{3}{|c|}{4.9830000000000005} & 5.0035 & TST & \\
\hline CHEMBL 3212097 & 688653 & \multicolumn{3}{|c|}{4.9830000000000005} & 5.2094 & TRN & \\
\hline CHEMBL1565906 & 688653 & 5.433 & 5.5525 & TRN & & & \\
\hline CHEMBL1330039 & 688653 & 4.583 & 4.81 & TST & & & \\
\hline CHEMBL1503644 & 688653 & 5.483 & 6.0972 & TRN & & & \\
\hline CHEMBL1532083 & 688653 & 4.883 & 4.9252 & TST & & & \\
\hline CHEMBL1452938 & 688653 & 6.2829 & 99999999 & 995 & 5.1248 & TRN & \\
\hline CHEMBL1588982 & 688653 & 5.483 & 5.6758 & TRN & & & \\
\hline CHEMBL1460962 & 688653 & 5.5829 & 99999999 & & 4.9933 & TRN & \\
\hline CHEMBL1480762 & 688653 & 4.933 & 4.79899 & 999999999 & & TRN & \\
\hline CHEMBL1405432 & 688653 & 5.183 & 5.3949 & TST & & & \\
\hline CHEMBL1491729 & 688653 & 5.733 & 5.7783 & TRN & & & \\
\hline
\end{tabular}




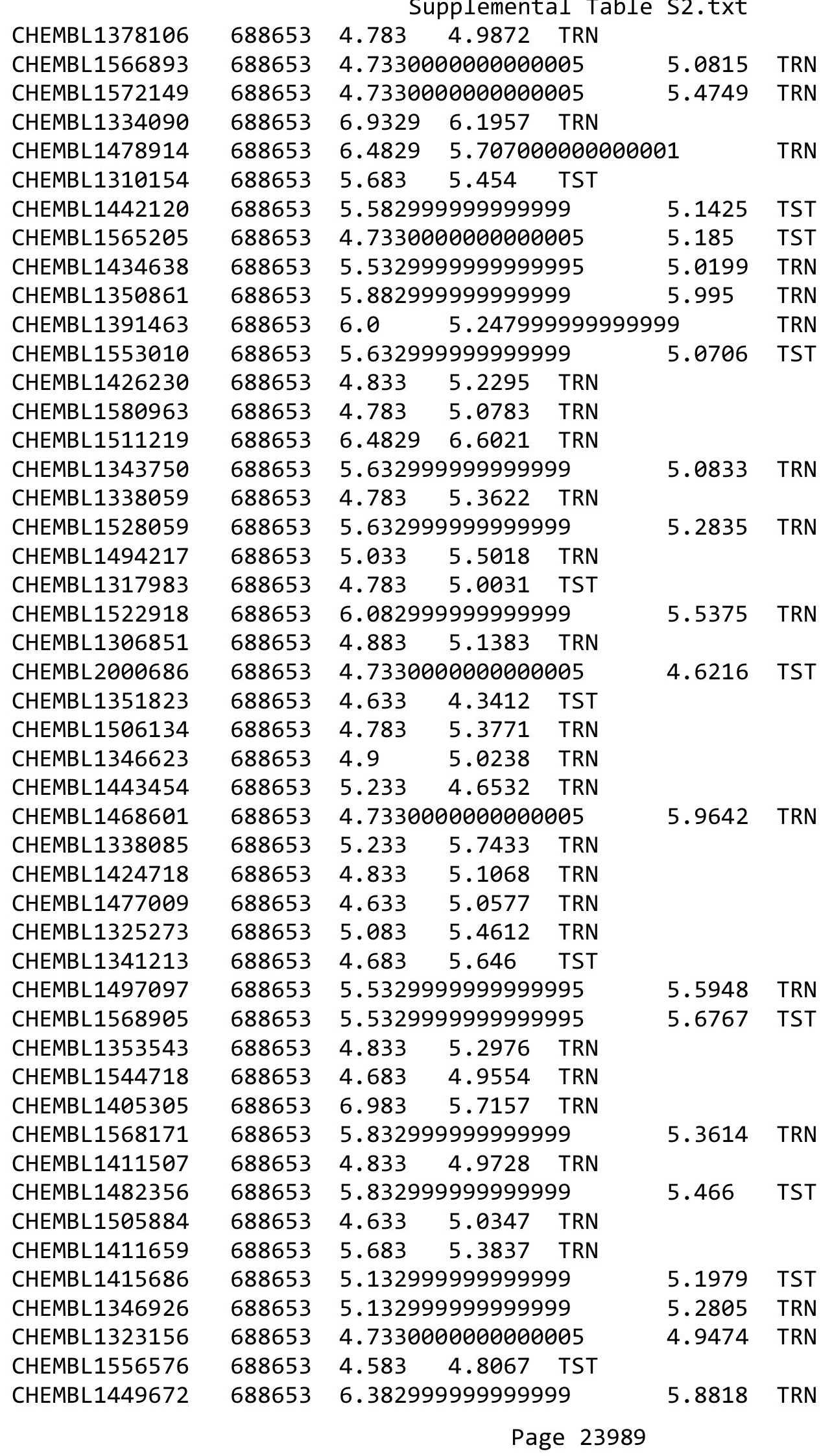




\begin{tabular}{|c|c|c|c|c|c|c|}
\hline \multirow{3}{*}{$\begin{array}{l}\text { CHEMBL1368611 } \\
\text { CHEMBL1502620 }\end{array}$} & \multicolumn{6}{|c|}{ Supplemental Table S2.txt } \\
\hline & 688653 & \multicolumn{4}{|c|}{5.2829999999999995} & $\mathrm{TI}$ \\
\hline & 688653 & 4.783 & 5.3193 & TRN & & \\
\hline CHEMBL3194192 & 688653 & 6.0 & 5.2218 & TST & & \\
\hline CHEMBL1471683 & 588653 & \multicolumn{3}{|c|}{6.2829999999999995} & 5.602 & TRN \\
\hline CHEMBL1336098 & 588653 & \multicolumn{3}{|c|}{6.0329999999999995} & 5.4594 & \\
\hline CHEMBL1390162 & 688653 & 5.183 & \multicolumn{3}{|c|}{5.122999999999999} & \\
\hline CHEMBL1345067 & 688653 & 5.183 & 5.385 & TRN & & \\
\hline CHEMBL1496182 & 688653 & 5.733 & \multicolumn{3}{|c|}{5.5920000000000005} & \\
\hline CHEMBL1567110 & 688653 & \multicolumn{3}{|c|}{5.5329999999999995} & 5.4448 & \\
\hline CHEMBL3191397 & 688653 & 5.083 & 5.3426 & TRN & & \\
\hline CHEMBL1300590 & 688653 & 4.833 & 5.2058 & TST & & \\
\hline CHEMBL1488141 & 688653 & \multicolumn{3}{|c|}{6.332999999999999} & 5.638 & $\mathrm{~T}$ \\
\hline CHEMBL1345630 & 688653 & \multicolumn{3}{|c|}{5.7829999999999995} & 5.0448 & \\
\hline CHEMBL1405435 & 688653 & 4.833 & 5.0747 & TRN & & \\
\hline CHEMBL1585349 & 688653 & 5.033 & 5.6646 & TRN & & \\
\hline CHEMBL1 & 3 & 7.2328 & 5.8639 & TRN & & \\
\hline CHEMBL & $68 \varepsilon$ & 5.483 & 5.24 & TRN & & \\
\hline CHEMBL1586660 & 688653 & 4.633 & 5.2193 & TRN & & \\
\hline CHEMBL1334550 & 688653 & 6.0 & 4.6438 & TRN & & \\
\hline CHEMBL147 & 688 & 5.033 & 4.8473 & TRN & & \\
\hline CHEMBL3 & 3 & .783 & 5.0501 & TST & & \\
\hline CHEMBL & $68 \varepsilon$ & 4.883 & 4.7398 & TRN & & \\
\hline CHEMBL1494784 & 688653 & 4.583 & 4.5297 & TST & & \\
\hline CHEMBL1526637 & 688 & 5.933 & 5.9571 & TRN & & \\
\hline CHEMBL134 & 688653 & 4.633 & 4.6024 & TRN & & \\
\hline CHEMBL1 & 688 & \multicolumn{3}{|c|}{4.7330000000000005} & 4.9109 & \\
\hline CHEMBL 1 & 688 & 5.483 & 5.0956 & TRN & & \\
\hline CHEMBL1379536 & 688 & 4.883 & 5.1589 & TRN & & \\
\hline CHEMBL 3197506 & 688653 & \multicolumn{3}{|c|}{5.132999999999999} & 5.3425 & \\
\hline CHEMBL1531173 & 688653 & 4.933 & 5.2441 & TRN & & \\
\hline CHEMBL: & 688 & \multicolumn{3}{|c|}{6.2829999999999995} & 5.1622 & \\
\hline CHEMBL & $68 \varepsilon$ & 4.783 & 5.2337 & TRN & & \\
\hline CHEMBL 3194248 & 688653 & 7.2832 & 6.2999 & TRN & & \\
\hline CHEMBL 3212450 & 688653 & \multicolumn{3}{|c|}{4.9830000000000005} & 5.2391 & \\
\hline CHEMBL1598049 & 688653 & 5.483 & 5.0974 & TRN & & \\
\hline CHEMBL & 688 & \multicolumn{3}{|c|}{6.082999999999999} & 5.5092 & $\mathrm{~T}$ \\
\hline CHEMBL 1 & 688653 & 4.833 & 4.9755 & TRN & & \\
\hline CHEMBL1345909 & 688653 & 4.833 & 5.0521 & TRN & & \\
\hline CHEMBL1384214 & 688653 & 4.833 & \multicolumn{3}{|c|}{5.877999999999999} & ובנו \\
\hline CHEMBL 1 & 688653 & \multicolumn{3}{|c|}{5.132999999999999} & 4.9188 & T \\
\hline CHEMBL146 & 688653 & \multicolumn{3}{|c|}{5.632999999999999} & 4.9693 & TST \\
\hline CHEMBL1490254 & 688653 & \multicolumn{3}{|c|}{5.5329999999999995} & 5.2874 & TRN \\
\hline CHEMBL3213996 & 688653 & 4.683 & 5.1802 & TST & & \\
\hline CHEMBL1530088 & 688653 & 5.733 & 5.9093 & TST & & \\
\hline CHEMBL1325114 & 688653 & \multicolumn{3}{|c|}{5.132999999999999} & 5.4824 & 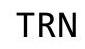 \\
\hline CHEMBL1550268 & 688653 & \multicolumn{3}{|c|}{5.5329999999999995} & 55217 & \\
\hline CHEMBL1564217 & 688653 & 4.783 & 4.9765 & TRN & & \\
\hline CHEMBL1446198 & 688653 & 5.38299 & 99999999 & & 5.5708 & $\cdots$ \\
\hline
\end{tabular}




\begin{tabular}{|c|c|c|c|c|c|c|}
\hline \multirow{3}{*}{$\begin{array}{l}\text { CHEMBL1528874 } \\
\text { CHEMBL1376118 }\end{array}$} & \multicolumn{6}{|c|}{ Supplemental Table S2.txt } \\
\hline & 688653 & \multicolumn{4}{|c|}{5.882999999999999} & TST \\
\hline & 688653 & 5.733 & 6.0578 & TRN & & \\
\hline CHEMBL1411646 & 688653 & \multicolumn{3}{|c|}{5.2829999999999995} & 5.0722 & \\
\hline CHEMBL203543 & 688653 & 5.033 & 5.4594 & TRN & & \\
\hline CHEMBL1577968 & 688653 & \multicolumn{3}{|c|}{4.9830000000000005} & 5.0666 & \\
\hline CHEMBL1392635 & 688653 & \multicolumn{3}{|c|}{5.382999999999999} & 5.2406 & \\
\hline CHEMBL1305626 & 688653 & 4.783 & 5.7816 & TRN & & \\
\hline CHEMBL1473110 & 688653 & \multicolumn{3}{|c|}{5.2829999999999995} & 5.8821 & \\
\hline CHEMBL1518241 & 688653 & 5.483 & 5.1372 & TRN & & \\
\hline CHEMBL2369265 & 688653 & \multicolumn{3}{|c|}{4.9830000000000005} & 5.4609 & \\
\hline CHEMBL1465221 & 688653 & \multicolumn{3}{|c|}{5.2829999999999995} & 5.5568 & \\
\hline CHEMBL1551312 & 688653 & 4.833 & 4.8968 & TRN & & \\
\hline CHEMBL1491213 & 688653 & \multicolumn{3}{|c|}{5.132999999999999} & 5.0983 & \\
\hline CHEMBL1359952 & 688653 & \multicolumn{3}{|c|}{5.132999999999999} & 5.8202 & \\
\hline CHEMBL1573242 & 688653 & 4.633 & 5.2859 & TRN & & \\
\hline CHEMBL1 & 688 & \multicolumn{3}{|c|}{4.7330000000000005} & 5.1352 & \\
\hline CHEMBL1 & 688 & 5.083 & 5.34 & TRN & & \\
\hline CHEMBL1370448 & 688653 & \multirow{2}{*}{\multicolumn{3}{|c|}{$\begin{array}{lr}5.233 & 5.5335 \\
4.7330000000000005\end{array}$}} & & \\
\hline CHEMBL1501095 & 688653 & & & & 5.2144 & \\
\hline CHEMBL1391313 & 688653 & 5.083 & 5.3919 & TRN & & \\
\hline CHEMBL1 & 3 & 5.433 & 5.147 & TST & & \\
\hline CHEMBL & 688 & 83 & 5.5393 & TRN & & \\
\hline CHEMBL84532 & 688653 & \multicolumn{3}{|c|}{5.7829999999999995} & 5.5208 & \\
\hline CHEMBL162347 & 688653 & \multicolumn{3}{|c|}{5.132999999999999} & 4.9629 & \\
\hline CHEMBL1582563 & 688653 & \multicolumn{3}{|c|}{5.132999999999999} & 5.6522 & $17 v$ \\
\hline CHEMBL1 & 688 & \multicolumn{3}{|c|}{5.7829999999999995} & 4.9845 & \\
\hline CHEMBL1 & 688 & 4.833 & 5.3727 & TRN & & \\
\hline CHEMBL1300736 & 688653 & \multicolumn{3}{|c|}{5.332999999999999} & 5.2261 & $T$ \\
\hline CHEMBL1392265 & 688653 & 4.783 & 5.4604 & TST & & \\
\hline CHEMBL1409658 & 688653 & 7.2328 & 6.184 & TRN & & \\
\hline CHEMBL: & 53 & 4.783 & 5.4458 & TRN & & \\
\hline CHEMBL & 688 & \multicolumn{3}{|c|}{5.132999999999999} & 4.9989 & $\mathrm{TI}$ \\
\hline CHEMBL1991441 & 688653 & 5.483 & 5.4649 & TST & & \\
\hline CHEMBL1346125 & 688653 & \multirow{2}{*}{\multicolumn{3}{|c|}{5.632999999999999}} & & \\
\hline CHEMBL1448605 & 688653 & & & & 5.5979 & TS \\
\hline CHEMBL: & $68 \varepsilon$ & 4.883 & 5.1719 & TRN & & \\
\hline CHEMBL 1 & 688653 & 4.98300 & 00000000 & 205 & 5.4013 & TP \\
\hline CHEMBL1577990 & 688653 & 4.73300 & 00000000 & 205 & 4.9293 & $T$ \\
\hline CHEMBL1517665 & 688653 & 5.483 & 5.3839 & TRN & & \\
\hline CHEMBL1345614 & 688653 & & 4.9105 & TRN & & \\
\hline CHEMBL1439887 & 688653 & 4.783 & 5.0265 & TST & & \\
\hline CHEMBL1338805 & 688653 & 5.083 & 4.9649 & TRN & & \\
\hline CHEMBL1459984 & 688653 & 4.783 & 5.1534 & TRN & & \\
\hline CHEMBL1528180 & 688653 & 5.13299 & 99999999 & & 4.9057 & 17 \\
\hline CHEMBL3210035 & 688653 & 4.783 & 5.1991 & TRN & & \\
\hline CHEMBL1424131 & 688653 & 5.683 & 5.0326 & TRN & & \\
\hline CHEMBL1546367 & 688653 & 5.183 & 5.1167 & TRN & & \\
\hline CHEMBL1479618 & 688653 & 5.33299 & 99999999 & & 5.6056 & נו \\
\hline
\end{tabular}




\begin{tabular}{|c|c|c|c|c|c|c|}
\hline \multirow{3}{*}{ CHEMBL1479675 } & \multirow{2}{*}{\multicolumn{5}{|c|}{$\begin{array}{l}\text { supplemental lable S2.txt } \\
5.127000000000001\end{array}$}} & \multirow{2}{*}{ TRN } \\
\hline & & & & & & \\
\hline & 688653 & 4.933 & 4.9219 & TRN & & \\
\hline CHEMBL1571636 & 688653 & \multicolumn{3}{|c|}{5.332999999999999} & 5.1394 & TST \\
\hline CHEMBL 3190181 & 688653 & \multicolumn{3}{|c|}{5.332999999999999} & 5.6713 & \\
\hline CHEMBL1421835 & 688653 & 5.033 & 5.3847 & TRN & & \\
\hline CHEMBL1360631 & 688653 & 5.033 & 5.4878 & TRN & & \\
\hline CHEMBL1448242 & 688653 & \multicolumn{3}{|c|}{5.7829999999999995} & 5.2199 & \\
\hline CHEMBL1502125 & 688653 & \multicolumn{3}{|c|}{4.9830000000000005} & 5.0237 & \\
\hline CHEMBL1501515 & 688653 & \multicolumn{3}{|c|}{6.2829999999999995} & 5.9405 & \\
\hline CHEMBL1309951 & 688653 & \multicolumn{3}{|c|}{5.5329999999999995} & 5.0927 & \\
\hline CHEMBL1346584 & 688653 & \multicolumn{3}{|c|}{5.882999999999999} & 5.1766 & \\
\hline CHEMBL1554426 & 688653 & 4.583 & 5.3529 & TRN & & \\
\hline CHEMBL1361195 & 688653 & \multicolumn{3}{|c|}{5.832999999999999} & 5.5431 & \\
\hline CHEMBL1385089 & 688653 & 5.433 & 5.3856 & TST & & \\
\hline CHEMBL1586775 & 688653 & 5.483 & 5.4389 & TST & & \\
\hline CHEMBL1440188 & 688653 & 6.4829 & 6.1236 & TRN & & \\
\hline CHEMBL1451802 & 688653 & 4.883 & 4.9458 & TRN & & \\
\hline CHEMBL1527492 & 688653 & \multicolumn{3}{|c|}{6.632999999999999} & 5.2613 & \\
\hline CHEMBL1445238 & 688653 & \multicolumn{3}{|c|}{4.9830000000000005} & & \\
\hline CHEMBL1518085 & 688653 & \multicolumn{3}{|c|}{5.332999999999999} & 905 & \\
\hline CHEMBL1388351 & 688653 & 6.433 & 5.4889 & TST & & \\
\hline CHEMBL 3194349 & 688653 & \multicolumn{3}{|c|}{4.7330000000000005} & 5.2317 & \\
\hline CHEMBL1487849 & 688653 & 5.233 & 5.2468 & TRN & & \\
\hline CHEMBL1398778 & 688653 & \multicolumn{3}{|c|}{4.7330000000000005} & 4352 & \\
\hline CHEMBL1426329 & 688653 & 5.183 & 5.3353 & TRN & & \\
\hline CHEMBL1435904 & 688653 & \multicolumn{3}{|c|}{5.832999999999999} & 5.4559 & \\
\hline CHEMBL1346780 & 688653 & 4.633 & 5.2647 & TRN & & \\
\hline CHEMBL1554691 & 688653 & 5.933 & 5.4081 & TRN & & \\
\hline CHEMBL1537620 & 688653 & 4.783 & 5.2139 & TST & & \\
\hline CHEMBL1459475 & 688653 & \multicolumn{3}{|c|}{4.7330000000000005} & 4.9593 & \\
\hline CHEMBL1404908 & 688653 & 4.833 & 5.1087 & TRN & & \\
\hline CHEMBL1448755 & 688653 & \multicolumn{3}{|c|}{4.9830000000000005} & 4.6263 & \\
\hline CHEMBL1334008 & 688653 & \multicolumn{3}{|c|}{5.7829999999999995} & 5.2463 & \\
\hline CHEMBL1357775 & 688653 & 4.883 & 5.0334 & TST & & \\
\hline CHEMBL13 & 688653 & 4.833 & 4. & TST & & \\
\hline CHEMBL1322110 & 688653 & 4.633 & 5.3205 & TST & & \\
\hline CHEMBL1462665 & 688653 & 4.933 & 5.44 & TRN & & \\
\hline CHEMBL1310999 & 688653 & \multicolumn{3}{|c|}{6.382999999999999} & 5.8864 & \\
\hline CHEMBL1522328 & 688653 & 5.33299 & 99999999 & & 5.1163 & \\
\hline CHEMBL1387365 & 688653 & 5.63299 & 99999999 & & 5.8311 & \\
\hline CHEMBL1545267 & 688653 & 5.13299 & 99999999 & & 5.0083 & \\
\hline CHEMBL1495014 & 688653 & 5.183 & 5.3128 & TRN & & \\
\hline CHEMBL1524838 & 688653 & 4.933 & 5.2737 & TRN & & \\
\hline CHEMBL1529595 & 688653 & 5.033 & 5.3224 & TRN & & \\
\hline CHEMBL1409229 & 688653 & 4.883 & 5.2291 & TRN & & \\
\hline CHEMBL1409318 & 688653 & 6.38299 & 99999999 & & 5.7383 & \\
\hline CHEMBL1540305 & 688653 & 5.983 & 5.3966 & TRN & & \\
\hline CHEMBL1423054 & 688653 & 5.033 & 4.9177 & TRN & & \\
\hline
\end{tabular}




\begin{tabular}{|c|c|c|c|c|c|c|}
\hline \multirow[b]{2}{*}{ CHEMBL1511552 } & \multirow[b]{2}{*}{688653} & \multicolumn{5}{|c|}{ Supplemental Table S2.txt } \\
\hline & & \multicolumn{5}{|c|}{$4.633 \quad 5.3939$ TST } \\
\hline CHEMBL1981797 & 688653 & \multicolumn{3}{|c|}{5.132999999999999} & 4.9911 & TRN \\
\hline CHEMBL1360670 & 688653 & 5.083 & 5.3877 & TRN & & \\
\hline CHEMBL1494785 & 688653 & 4.883 & 4.9933 & TST & & \\
\hline CHEMBL1609062 & 688653 & \multicolumn{3}{|c|}{5.832999999999999} & 5.8047 & TRN \\
\hline CHEMBL1327682 & 688653 & \multicolumn{3}{|c|}{7.082999999999999} & 5.6988 & TRN \\
\hline CHEMBL1523520 & 688653 & \multicolumn{3}{|c|}{6.082999999999999} & 5.2616 & TST \\
\hline CHEMBL3213125 & 688653 & \multicolumn{3}{|c|}{4.7330000000000005} & 5.3504 & TRN \\
\hline CHEMBL1507676 & 688653 & 6.233 & 6.0433 & TRN & & \\
\hline CHEMBL1330038 & 688653 & 5.033 & 4.8032 & TRN & & \\
\hline CHEMBL1591478 & 688653 & \multicolumn{3}{|c|}{5.132999999999999} & 5.0036 & TRN \\
\hline CHEMBL1565450 & 688653 & 5.083 & 5.2536 & TRN & & \\
\hline CHEMBL1587940 & 688653 & \multicolumn{3}{|c|}{4.7330000000000005} & 5.3424 & TRN \\
\hline CHEMBL1494344 & 688653 & 5.683 & 5.0307 & TRN & & \\
\hline CHEMBL1520849 & 688653 & 6.233 & 5.6599 & TRN & & \\
\hline CHEMBL1600748 & 688653 & 4.883 & \multicolumn{3}{|c|}{4.9830000000000005} & TST \\
\hline CHEMBL1605091 & 688653 & \multicolumn{3}{|c|}{4.7330000000000005} & 5.2068 & TRN \\
\hline CHEMBL1545284 & 688653 & \multicolumn{3}{|c|}{6.0329999999999995} & 5.5397 & TRN \\
\hline CHEMBL1498612 & 688653 & 5.033 & 5.0478 & TRN & & \\
\hline CHEMBL1993190 & 688653 & 5.733 & 6.0022 & TRN & & \\
\hline CHEMBL1591733 & 688653 & 5.033 & 5.1211 & TRN & & \\
\hline CHEMBL3207919 & 688653 & \multicolumn{3}{|c|}{5.382999999999999} & 5.5019 & TST \\
\hline CHEMBL1563401 & 688653 & \multicolumn{3}{|c|}{5.882999999999999} & 5.5421 & TRN \\
\hline CHEMBL1480124 & 688653 & 4.933 & 5.0058 & TST & & \\
\hline CHEMBL1345845 & 688653 & \multicolumn{3}{|c|}{6.132999999999999} & 5.4095 & TRN \\
\hline CHEMBL3197825 & 688653 & 4.933 & 5.1924 & TST & & \\
\hline CHEMBL3189861 & 688653 & \multicolumn{3}{|c|}{5.332999999999999} & 5.1779 & TST \\
\hline CHEMBL1361693 & 688653 & 5.683 & 5.6277 & TRN & & \\
\hline CHEMBL3208241 & 688653 & 4.583 & 5.4792 & TRN & & \\
\hline CHEMBL1331348 & 688653 & 4.883 & 4.9403 & TST & & \\
\hline CHEMBL1401261 & 688653 & 5.683 & 5.1195 & TST & & \\
\hline CHEMBL1479475 & 688653 & 4.933 & 4.7728 & TRN & & \\
\hline CHEMBL1529103 & 688653 & 4.783 & 5.1969 & TRN & & \\
\hline CHEMBL1302128 & 688653 & 4.9 & 4.9129 & TST & & \\
\hline CHEMBL16312 & 688653 & 5.233 & 5.7557 & TRN & & \\
\hline CHEMBL1612840 & 688653 & 5.083 & 5.0742 & TST & & \\
\hline CHEMBL1579773 & 688653 & 6.4829 & 5.568 & TRN & & \\
\hline CHEMBL1434392 & 688653 & 4.833 & 4.9542 & TRN & & \\
\hline CHEMBL1408947 & 688653 & \multicolumn{3}{|c|}{4.7330000000000005} & 5.1743 & TRN \\
\hline CHEMBL1417814 & 688653 & 5.083 & 5.1417 & TRN & & \\
\hline CHEMBL1354564 & 688653 & 4.583 & 5.0879 & TRN & & \\
\hline CHEMBL1607984 & 688653 & 5.183 & 5.2454 & TRN & & \\
\hline CHEMBL1541744 & 688653 & 6.683 & 5.7742 & TRN & & \\
\hline CHEMBL1455403 & 688653 & 4.633 & \multicolumn{3}{|c|}{5.257999999999999} & TST \\
\hline CHEMBL1482053 & 688653 & 5.233 & 5.0919 & TST & & \\
\hline CHEMBL1581447 & 688653 & 4.883 & 4.9762 & TRN & & \\
\hline CHEMBL1463134 & 688653 & 4.583 & 5.2003 & TST & & \\
\hline CHEMBL1558598 & 688653 & 4.883 & 5.3161 & TST & & \\
\hline
\end{tabular}




\begin{tabular}{|c|c|c|c|c|c|c|}
\hline & & \multicolumn{5}{|c|}{ Supplemental Table S2.txt } \\
\hline CHEMBL3191122 & 688653 & 4.933 & 5.6142 & TRN & & \\
\hline CHEMBL 3189898 & 688653 & 5.033 & 5.3785 & TRN & & \\
\hline CHEMBL1421441 & 688653 & 4.633 & 4.822 & TRN & & \\
\hline CHEMBL1381372 & 688653 & \multicolumn{3}{|c|}{5.2829999999999995} & 5.3413 & TRN \\
\hline CHEMBL1401721 & 688653 & \multicolumn{3}{|c|}{4.7330000000000005} & 5.0194 & \\
\hline CHEMBL1377820 & 688653 & 5.483 & 5.397 & TST & & \\
\hline CHEMBL1347404 & 688653 & \multicolumn{3}{|c|}{5.132999999999999} & 5.4134 & \\
\hline CHEMBL1451627 & 688653 & 4.933 & 4.9629 & TRN & & \\
\hline CHEMBL1576103 & 688653 & 4.883 & 5.314 & TST & & \\
\hline CHEMBL1440547 & 688653 & 4.633 & 5.4651 & TST & & \\
\hline CHEMBL1581560 & 688653 & \multicolumn{3}{|c|}{5.5329999999999995} & 5.1371 & \\
\hline CHEMBL1318705 & 688653 & 4.883 & 5.1454 & TST & & \\
\hline CHEMBL1362315 & 688653 & \multicolumn{3}{|c|}{5.132999999999999} & 5.7197 & \\
\hline CHEMBL1312690 & 688653 & 4.783 & 4.9557 & TST & & \\
\hline CHEMBL1534466 & 688653 & \multicolumn{3}{|c|}{5.7829999999999995} & 5.352 & \\
\hline CHEMBL1318038 & 688653 & 5.083 & 5.1201 & TRN & & \\
\hline CHEMBL1605165 & 688653 & \multicolumn{3}{|c|}{4.9830000000000005} & 5.8637 & \\
\hline CHEMBL1543780 & 688653 & \multicolumn{3}{|c|}{5.882999999999999} & & \\
\hline CHEMBL 1483180 & 688653 & 5.8 & 5.0783 & TRN & & \\
\hline CHEMBL3194008 & 688653 & 6.8831 & 5.4762 & TRN & & \\
\hline CHEMBL1434522 & 688653 & 5.233 & 4.643 & TRN & & \\
\hline CHEMBL1524371 & 688653 & \multicolumn{3}{|c|}{5.132999999999999} & 5.3426 & \\
\hline CHEMBL15: & 688653 & 4.633 & 4.8406 & TRN & & \\
\hline CHEMBL1543433 & 688653 & 33 & 5.3281 & TST & & \\
\hline CHEMBL1578479 & 688653 & 4.883 & 5.0134 & TRN & & \\
\hline CHEMBL1347556 & 688653 & \multicolumn{3}{|c|}{4.9830000000000005} & 5.2288 & \\
\hline CHEMBL1367886 & 688653 & 5.233 & 5.3786 & TST & & \\
\hline CHEMBL16 & 688653 & 5.183 & 4.9303 & TRN & & \\
\hline CHEMBL1426035 & 688 & 4.833 & 4.6803 & TST & & \\
\hline CHEMBL1547431 & 688653 & \multicolumn{3}{|c|}{5.582999999999999} & 5.3862 & TRN \\
\hline CHEMBL1369231 & 688653 & \multicolumn{3}{|c|}{5.882999999999999} & 5.695 & \\
\hline CHEMBL14€ & 688 & & 5.0734 & TRN & & \\
\hline CHEMBL15: & 688653 & 4. & 4.897 & TST & & \\
\hline CHEMBL1590107 & 688653 & 4.583 & 4.8409 & TRN & & \\
\hline CHEMBL1462713 & 688653 & \multicolumn{3}{|c|}{6.632999999999999} & 5.649 & \\
\hline CHEMBL1417353 & 688653 & 4.583 & 5.0931 & TRN & & \\
\hline CHEMBL143 & 688653 & \multicolumn{3}{|c|}{5.382999999999999} & 4.8432 & \\
\hline CHEMBL1368829 & 688653 & 5.183 & 5.1602 & TRN & & \\
\hline CHEMBL1354155 & 688653 & \multicolumn{3}{|c|}{5.5329999999999995} & 5.3752 & II \\
\hline CHEMBL1368562 & 688653 & 5.083 & 5.3308 & TRN & & \\
\hline CHEMBL1557205 & 688653 & 4.783 & 5.266 & TRN & & \\
\hline CHEMBL1413808 & 688653 & \multicolumn{3}{|c|}{5.832999999999999} & 5.2168 & II \\
\hline CHEMBL1986443 & 688653 & 5.683 & 5.541 & TRN & & \\
\hline CHEMBL1444463 & 688653 & \multicolumn{3}{|c|}{4.7330000000000005} & 5.5494 & TI \\
\hline CHEMBL1433837 & 688653 & 4.833 & 5.1168 & TST & & \\
\hline CHEMBL1500140 & 688653 & 5.233 & 5.3522 & TRN & & \\
\hline CHEMBL3213955 & 688653 & \multicolumn{3}{|c|}{4.7330000000000005} & .2757 & \\
\hline CHEMBL1603173 & 688653 & 4.583 & 4.9952 & TRN & & \\
\hline
\end{tabular}




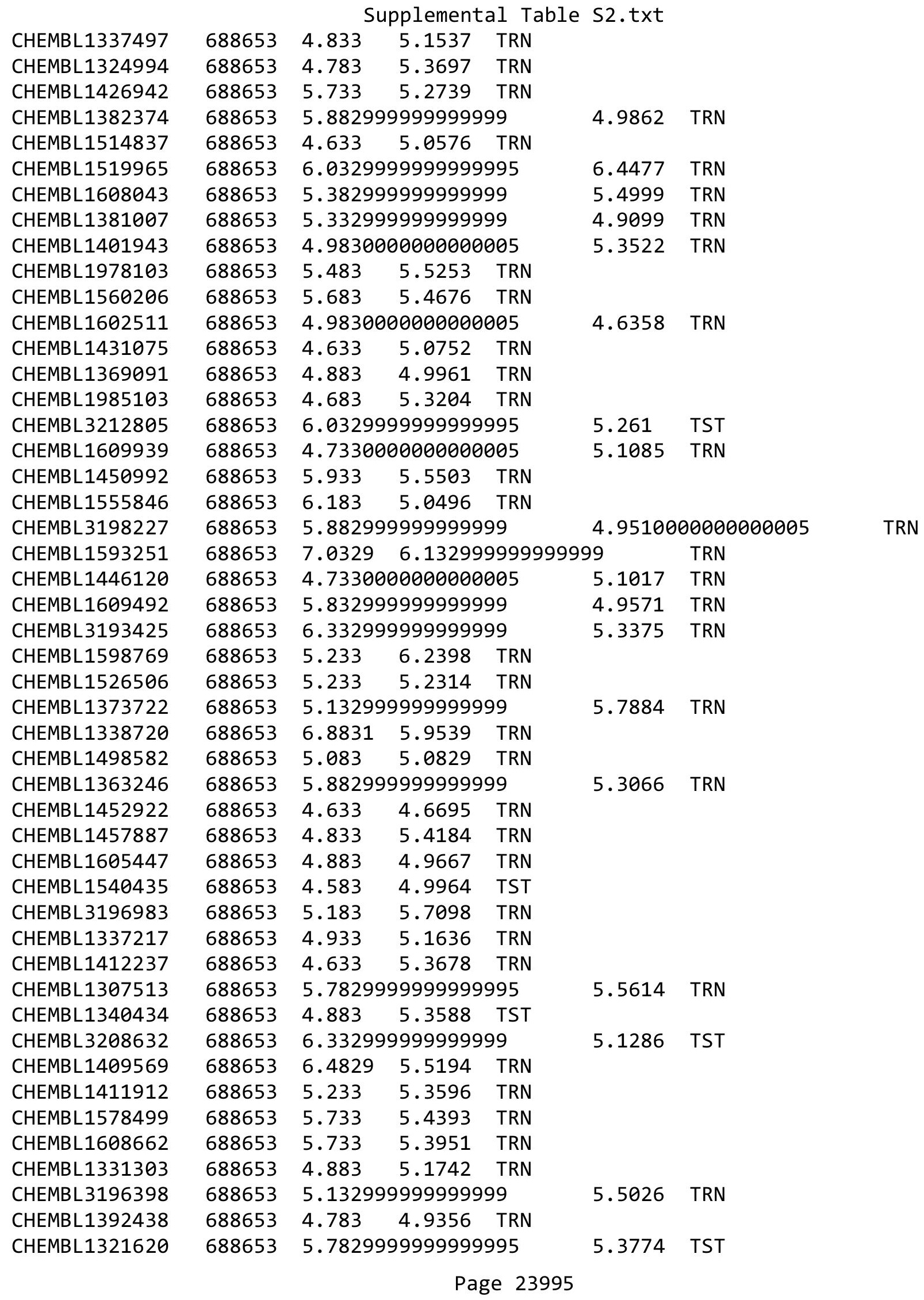




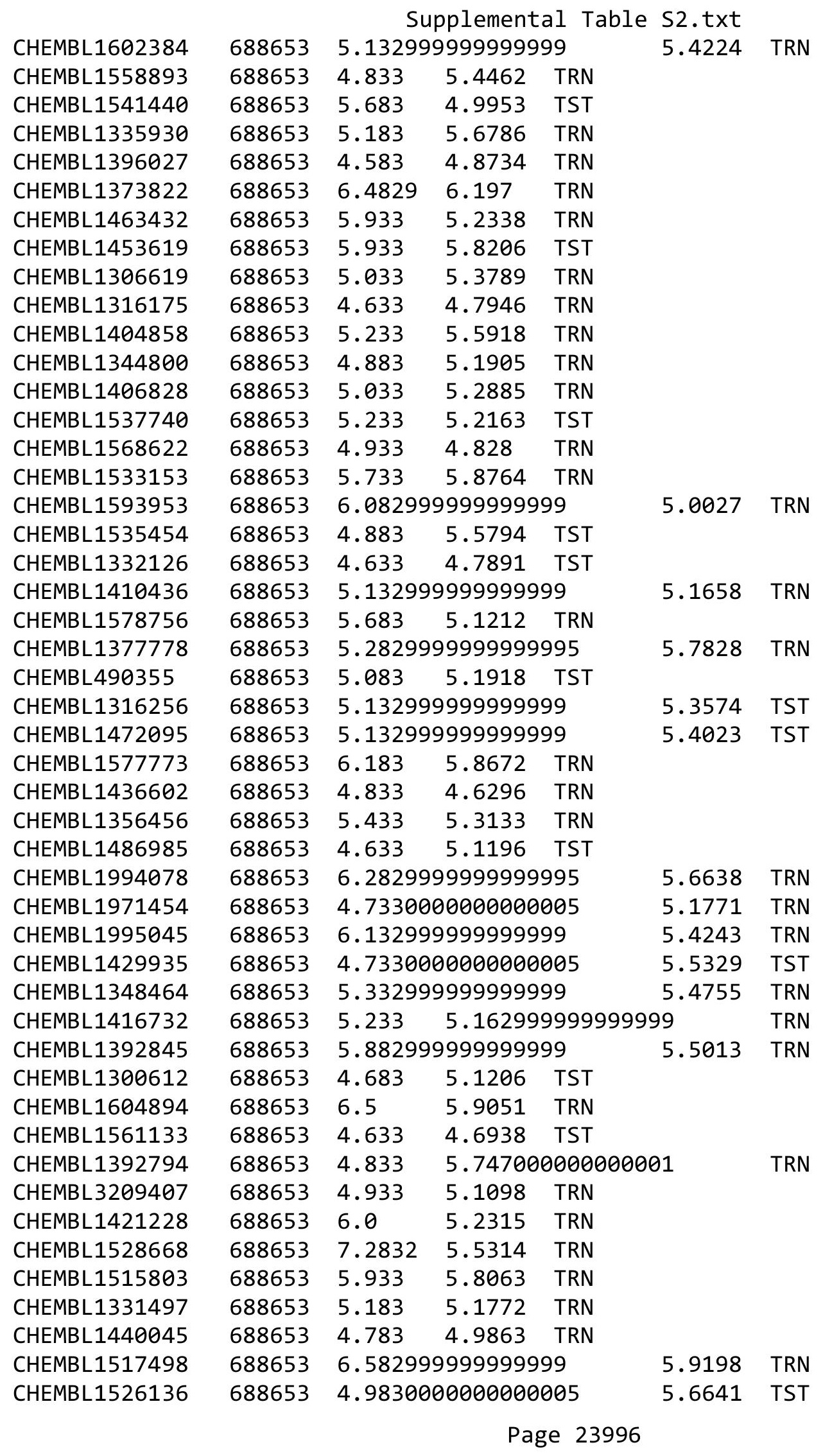




\begin{tabular}{|c|c|c|c|c|c|c|}
\hline \multirow[b]{2}{*}{ CHEMBL1429016 } & \multirow[b]{2}{*}{688653} & \multicolumn{5}{|c|}{ Supplemental Table S2.txt } \\
\hline & & \multirow{2}{*}{\multicolumn{3}{|c|}{$\begin{array}{lcc}4.833 & 4.913 & \text { TRN } \\
6.082999999999999\end{array}$}} & & \\
\hline CHEMBL1417614 & 688653 & & & & 5.8889 & TRN \\
\hline CHEMBL1516976 & 688653 & \multicolumn{3}{|c|}{6.2829999999999995} & 5.2745 & TST \\
\hline CHEMBL1581818 & 688653 & 5.083 & 5.4049 & TST & & \\
\hline CHEMBL1449601 & 688653 & 5.183 & 5.5108 & TRN & & \\
\hline CHEMBL1437252 & 688653 & \multicolumn{3}{|c|}{6.082999999999999} & 5.8539 & TRN \\
\hline CHEMBL1477474 & 688653 & 5.033 & 5.4433 & TRN & & \\
\hline CHEMBL1395858 & 688653 & 5.483 & 4.7635 & TST & & \\
\hline CHEMBL513436 & 688653 & \multicolumn{3}{|c|}{6.132999999999999} & 5.1084 & TRN \\
\hline CHEMBL1364824 & 688653 & 4.783 & 5.1065 & TRN & & \\
\hline CHEMBL1310534 & 688653 & \multicolumn{3}{|c|}{5.132999999999999} & 5.0645 & TRN \\
\hline CHEMBL1588946 & 688653 & \multicolumn{3}{|c|}{5.332999999999999} & 5.274 & TRN \\
\hline CHEMBL2095095 & 688653 & 4.633 & 5.6795 & TRN & & \\
\hline CHEMBL1423597 & 688653 & \multicolumn{3}{|c|}{4.9830000000000005} & 5.3721 & TST \\
\hline CHEMBL1487921 & 688653 & 4.783 & 5.1106 & TRN & & \\
\hline CHEMBL1466899 & 688653 & \multicolumn{3}{|c|}{6.332999999999999} & 5.8978 & TRN \\
\hline CHEMBL1574935 & 688653 & 6.233 & 5.6422 & TRN & & \\
\hline CHEMBL1414795 & 688653 & 4.783 & 4.852 & TST & & \\
\hline CHEMBL1412709 & 688653 & 4.933 & 5.4125 & TRN & & \\
\hline CHEMBL62044 & 688653 & 4.783 & 5.0438 & TRN & & \\
\hline CHEMBL1594042 & 688653 & 7.0329 & 5.7277 & TRN & & \\
\hline CHEMBL1547425 & 688653 & 5.683 & 5.1695 & TRN & & \\
\hline CHEMBL3193804 & 688653 & 5.033 & 5.4065 & TRN & & \\
\hline CHEMBL1504575 & 688653 & 6.8831 & 6.0158 & TRN & & \\
\hline CHEMBL1497717 & 688653 & 4.633 & 4.9719 & TRN & & \\
\hline CHEMBL2003086 & 688653 & \multicolumn{3}{|c|}{5.132999999999999} & 5.3531 & TRN \\
\hline CHEMBL1502261 & 688653 & 5.483 & 5.3495 & TRN & & \\
\hline CHEMBL1347609 & 688653 & \multicolumn{3}{|c|}{5.132999999999999} & 5.2852 & TRN \\
\hline CHEMBL1528931 & 688653 & 4.933 & 4.9209 & TRN & & \\
\hline CHEMBL1483678 & 688653 & \multicolumn{3}{|c|}{4.9830000000000005} & 5.516 & TRN \\
\hline CHEMBL1571909 & 688653 & \multicolumn{3}{|c|}{6.5329999999999995} & 5.1151 & TRN \\
\hline CHEMBL1575351 & 688653 & 5.183 & 5.2898 & TRN & & \\
\hline CHEMBL1490031 & 688653 & 5.083 & 5.023 & TRN & & \\
\hline CHEMBL1356728 & 688653 & 6.183 & 5.3278 & TRN & & \\
\hline CHEMBL1594910 & 688653 & 5.683 & 5.597 & TRN & & \\
\hline CHEMBL1599830 & 688653 & 4.583 & 4.8025 & TRN & & \\
\hline CHEMBL1335945 & 688653 & \multicolumn{3}{|c|}{5.882999999999999} & 5.4131 & TST \\
\hline CHEMBL1442915 & 688653 & \multicolumn{3}{|c|}{6.582999999999999} & 5.7248 & TRN \\
\hline CHEMBL1384350 & 688653 & \multicolumn{3}{|c|}{4.7330000000000005} & 5.0305 & TRN \\
\hline CHEMBL1530686 & 688653 & \multicolumn{3}{|c|}{4.9830000000000005} & 5.1302 & TRN \\
\hline CHEMBL1345300 & 688653 & 5.483 & 5.5394 & TRN & & \\
\hline CHEMBL1376412 & 688653 & 5.433 & 5.5031 & TRN & & \\
\hline CHEMBL1456023 & 688653 & 5.483 & 5.32 & TRN & & \\
\hline CHEMBL1559717 & 688653 & 6.0 & 5.1262 & TST & & \\
\hline CHEMBL1328740 & 688653 & 5.733 & 5.4134 & TST & & \\
\hline CHEMBL1475717 & 688653 & 5.233 & 5.7315 & TRN & & \\
\hline CHEMBL1511747 & 688653 & 5.433 & 5.2956 & TRN & & \\
\hline CHEMBL1416824 & 688653 & \multicolumn{3}{|c|}{5.632999999999999} & 5.6467 & TRN \\
\hline
\end{tabular}




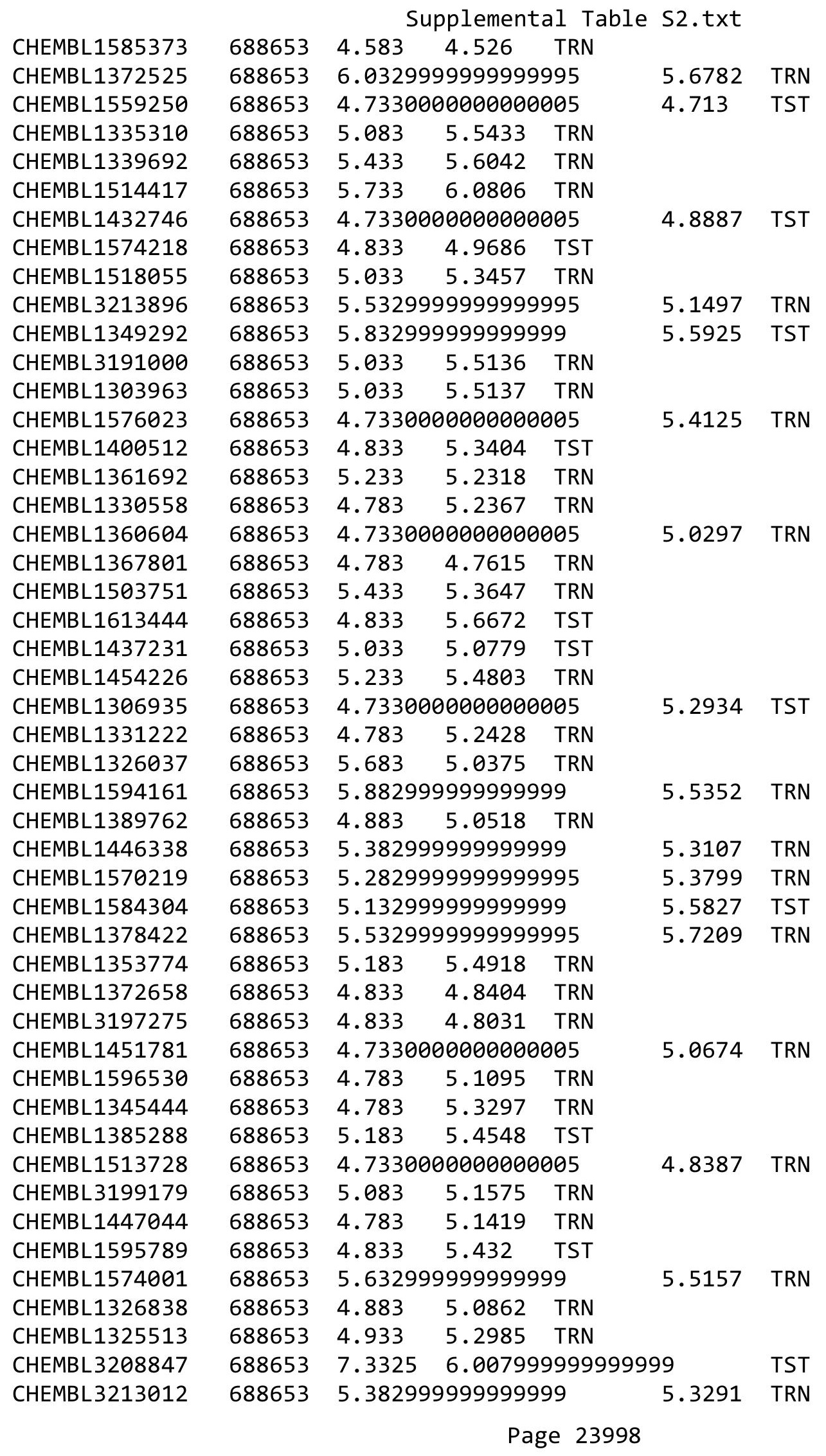




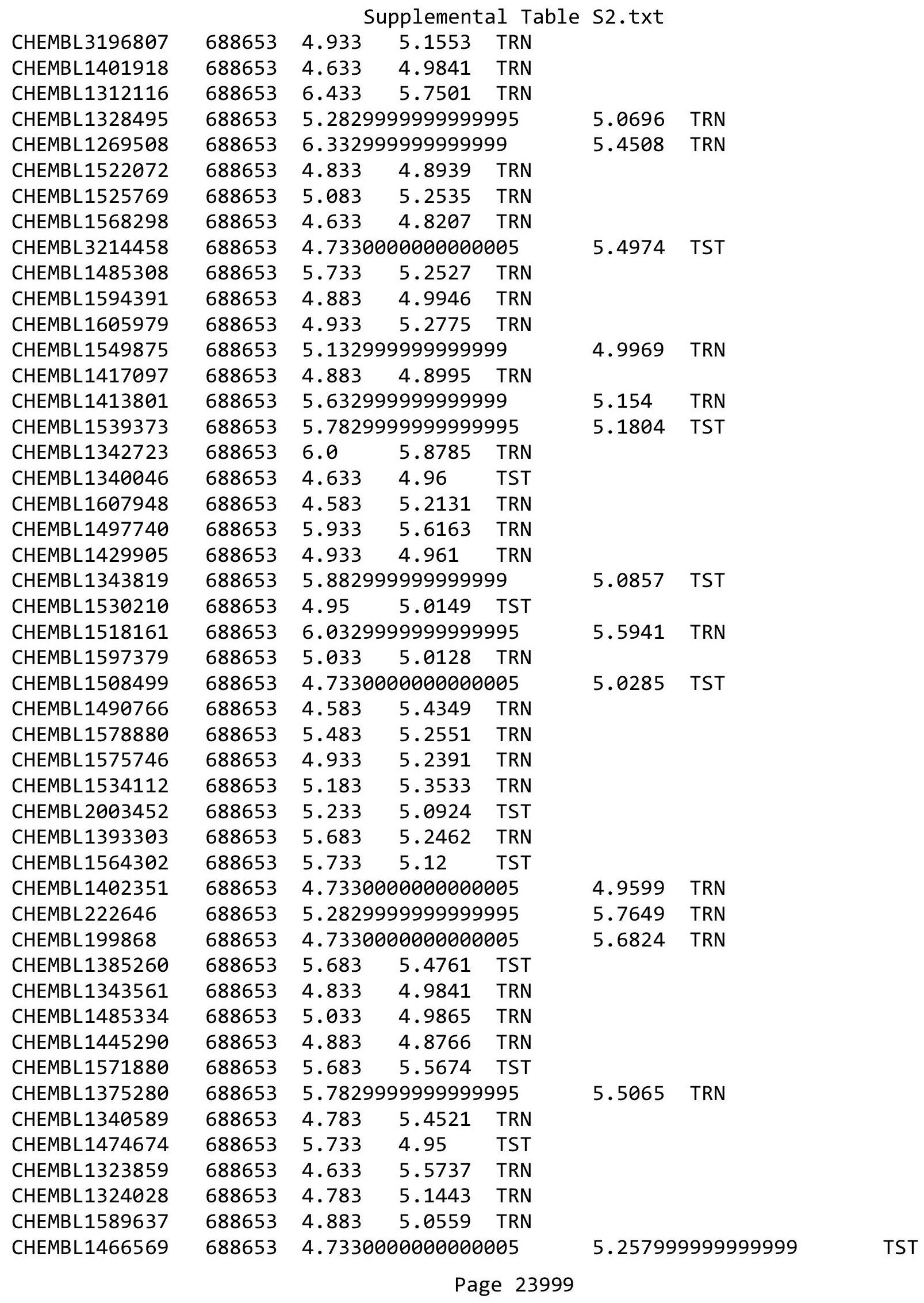




\begin{tabular}{|c|c|c|c|c|c|c|c|}
\hline \multicolumn{7}{|c|}{ Supplemental Table s2.txt } & \\
\hline CHEMBL1607514 & 688653 & 5.033 & 5.1468 & TST & & & \\
\hline CHEMBL1545876 & 688653 & 5.733 & 5.5365 & TRN & & & \\
\hline CHEMBL1410498 & 688653 & 4.583 & 5.045 & TST & & & \\
\hline CHEMBL1362464 & 688653 & 4.933 & 5.2134 & TRN & & & \\
\hline CHEMBL1566639 & 688653 & 5.38299 & 99999999 & & 5.4966 & TRN & \\
\hline CHEMBL1482930 & 688653 & 5.13299 & 99999999 & & 4.6301 & TRN & \\
\hline CHEMBL1493246 & 688653 & 4.933 & 4.845 & TRN & & & \\
\hline CHEMBL1519874 & 688653 & 5.233 & 5.2394 & TST & & & \\
\hline CHEMBL1432127 & 688653 & 5.483 & 5.0745 & TRN & & & \\
\hline CHEMBL1581508 & 688653 & 4.73300 & 00000000 & 005 & 5.7649 & TST & \\
\hline CHEMBL1611074 & 688653 & 5.233 & 5.3527 & TST & & & \\
\hline CHEMBL1388677 & 688653 & 4.73300 & 20000000 & 005 & 5.1463 & TRN & \\
\hline CHEMBL1471836 & 688653 & 5.78299 & 99999999 & 995 & 5.1373 & TRN & \\
\hline CHEMBL1326386 & 688653 & 4.833 & 4.9146 & TRN & & & \\
\hline CHEMBL1300928 & 688653 & 5.33299 & 99999999 & 99 & 5.5202 & TRN & \\
\hline CHEMBL1376594 & 688653 & 4.833 & 4.9472 & TRN & & & \\
\hline CHEMBL1339229 & 688653 & 4.583 & 5.3075 & TST & & & \\
\hline CHEMBL1318619 & 688653 & 4.98300 & $\partial 0000000$ & 005 & 5.0639 & TRN & \\
\hline CHEMBL1580344 & 688653 & 5.58299 & 99999999 & & 5.2353 & TRN & \\
\hline CHEMBL1345580 & 688653 & 5.183 & 5.1505 & TRN & & & \\
\hline CHEMBL1370675 & 688653 & 4.833 & 4.8049 & TST & & & \\
\hline CHEMBL1432063 & 688653 & 5.33299 & 99999999 & & 5.138 & TRN & \\
\hline CHEMBL1436762 & 688653 & 4.833 & 5.1738 & TRN & & & \\
\hline CHEMBL1323878 & 688653 & 5.733 & 5.4711 & TRN & & & \\
\hline CHEMBL1490856 & 688653 & 5.433 & 5.365 & TRN & & & \\
\hline CHEMBL1483624 & 688653 & 5.88299 & 99999999 & & 5.4286 & TRN & \\
\hline CHEMBL1326159 & 688653 & 5.53299 & 99999999 & 995 & 5.6527 & TRN & \\
\hline CHEMBL1428141 & 688653 & 5.083 & 5.3264 & TRN & & & \\
\hline CHEMBL1307905 & 688653 & 4.933 & 5.2297 & TRN & & & \\
\hline CHEMBL1366736 & 688653 & 5.38299 & 99999999 & 99 & 5.1399 & TRN & \\
\hline CHEMBL3189897 & 688653 & 5.983 & 5.3861 & TRN & & & \\
\hline CHEMBL1600919 & 688653 & 6.7331 & 6.0736 & TRN & & & \\
\hline CHEMBL1513354 & 688653 & 5.33299 & 99999999 & & 5.5439 & TRN & \\
\hline CHEMBL3208032 & 688653 & 5.63299 & 99999999 & & 5.4006 & TRN & \\
\hline CHEMBL1573328 & 688653 & 4.73300 & 00000000 & 005 & 5.0812 & TRN & \\
\hline CHEMBL1572986 & 688653 & 5.13299 & 99999999 & & 5.5134 & TRN & \\
\hline CHEMBL1347104 & 688653 & 4.833 & 4.8541 & TRN & & & \\
\hline CHEMBL1571648 & 688653 & 5.78299 & 99999999 & 995 & 6.1220 & 0000000001 & TST \\
\hline CHEMBL 3210573 & 688653 & 5.233 & 5.395 & TRN & & & \\
\hline CHEMBL1327292 & 688653 & 5.13299 & 99999999 & 99 & 4.8322 & TRN & \\
\hline CHEMBL1512544 & 688653 & 5.033 & 4.6734 & TRN & & & \\
\hline CHEMBL1527158 & 688653 & 5.433 & 5.7301 & TRN & & & \\
\hline CHEMBL1474683 & 688653 & 5.78299 & 99999999 & 995 & 5.5277 & TRN & \\
\hline CHEMBL1485800 & 688653 & 4.633 & 5.3812 & TRN & & & \\
\hline CHEMBL1391090 & 688653 & 4.883 & 5.1128 & TST & & & \\
\hline CHEMBL1358368 & 688653 & 4.783 & 4.9868 & TRN & & & \\
\hline CHEMBL1572968 & 688653 & 5.683 & 5.3507 & TRN & & & \\
\hline CHEMBL1461478 & 688653 & 4.883 & 5.5737 & TRN & & & \\
\hline
\end{tabular}




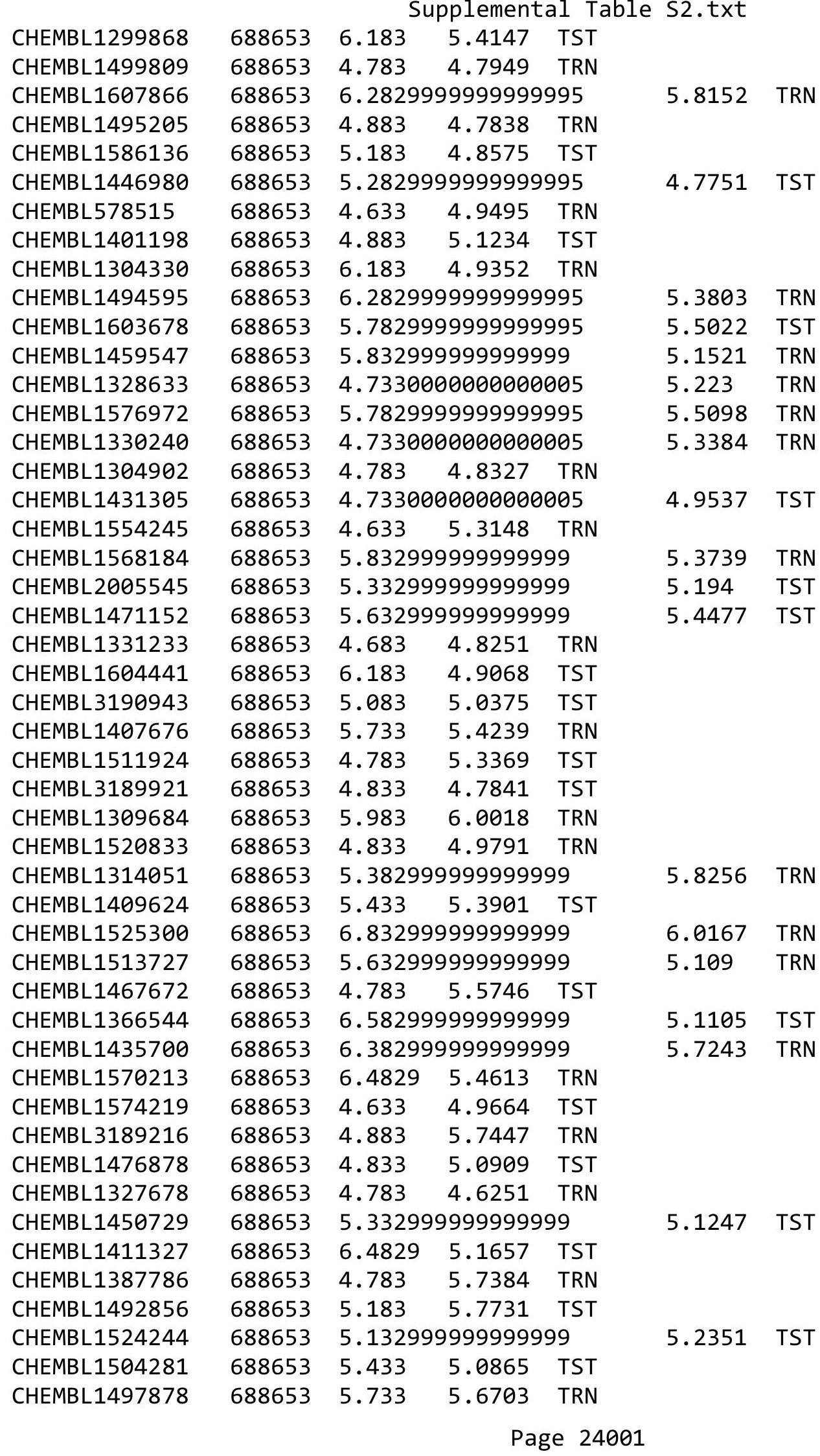




\begin{tabular}{|c|c|c|c|c|c|c|c|}
\hline \multicolumn{8}{|c|}{ Supplemental Table S2.txt } \\
\hline CHEMBL1352995 & 688653 & 4.583 & 5.2372 & TRN & & & \\
\hline CHEMBL1365022 & 688653 & 5.483 & 5.3823 & TRN & & & \\
\hline CHEMBL1990793 & 688653 & 5.33299 & 99999999 & 99 & 5.3423 & TRN & \\
\hline CHEMBL1312318 & 688653 & 7.3325 & 6.0737 & TRN & & & \\
\hline CHEMBL1307327 & 688653 & 5.483 & 5.4929 & TRN & & & \\
\hline CHEMBL1336439 & 688653 & 4.583 & 4.9548 & TST & & & \\
\hline CHEMBL1351016 & 688653 & 4.583 & 4.7702 & TST & & & \\
\hline CHEMBL1548590 & 688653 & 4.683 & 4.8139 & TST & & & \\
\hline CHEMBL1514650 & 688653 & 5.233 & 5.2788 & TRN & & & \\
\hline CHEMBL3198829 & 688653 & 4.833 & 5.0482 & TRN & & & \\
\hline CHEMBL1523124 & 688653 & 6.183 & 5.6974 & TRN & & & \\
\hline CHEMBL1563905 & 688653 & 4.783 & 5.0984 & TRN & & & \\
\hline CHEMBL1356910 & 688653 & 5.083 & 5.0034 & TRN & & & \\
\hline CHEMBL3192789 & 688653 & 5.433 & 5.5488 & TRN & & & \\
\hline CHEMBL1370349 & 688653 & 5.083 & 5.3084 & TRN & & & \\
\hline CHEMBL1321527 & 688653 & 4.683 & 5.3363 & TST & & & \\
\hline CHEMBL1565857 & 688653 & 4.883 & 5.6106 & TRN & & & \\
\hline CHEMBL1579926 & 688653 & 5.183 & 5.2893 & TRN & & & \\
\hline CHEMBL1441374 & 688653 & 5.33299 & 99999999 & & 5.4368 & TRN & \\
\hline CHEMBL1608143 & 688653 & 4.633 & 4.7825 & TST & & & \\
\hline CHEMBL1311185 & 688653 & 5.433 & 5.4591 & TST & & & \\
\hline CHEMBL1454747 & 688653 & 6.08299 & 99999999 & & 5.6406 & TRN & \\
\hline CHEMBL1456709 & 688653 & 7.1831 & 6.0939 & TRN & & & \\
\hline CHEMBL1604748 & 688653 & 6.13299 & 99999999 & & 5.9405 & TST & \\
\hline CHEMBL1388823 & 688653 & 6.38299 & 99999999 & & 5.0501 & TRN & \\
\hline CHEMBL1403196 & 688653 & 4.583 & 4.8277 & TRN & & & \\
\hline CHEMBL3199572 & 688653 & 5.183 & 5.2784 & TRN & & & \\
\hline CHEMBL1335592 & 688653 & 4.73300 & 30000000 & 005 & 5.0184 & TRN & \\
\hline CHEMBL1307787 & 688653 & 5.83299 & 99999999 & & 5.0373 & TRN & \\
\hline CHEMBL1520939 & 688653 & 5.78299 & 99999999 & 995 & 5.6389 & TRN & \\
\hline CHEMBL1364726 & 688653 & 4.933 & 5.1729 & TRN & & & \\
\hline CHEMBL1454247 & 688653 & 7.2328 & 5.6576 & TRN & & & \\
\hline CHEMBL1557587 & 688653 & 5.483 & 5.0282 & TRN & & & \\
\hline CHEMBL1532369 & 688653 & 4.883 & 4.4826 & TST & & & \\
\hline CHEMBL3207988 & 688653 & 5.88299 & 99999999 & 99 & 5.2139 & 99999999995 & TRN \\
\hline CHEMBL1571121 & 688653 & 4.783 & 5.1641 & TRN & & & \\
\hline CHEMBL1457573 & 688653 & 6.28299 & 99999999 & 995 & 5.4471 & TRN & \\
\hline CHEMBL1542742 & 688653 & 5.683 & 5.0788 & TRN & & & \\
\hline CHEMBL1528436 & 688653 & 6.183 & 5.8138 & TRN & & & \\
\hline CHEMBL1582553 & 688653 & 4.883 & 5.444 & TRN & & & \\
\hline CHEMBL1431795 & 688653 & 4.833 & 5.4282 & TRN & & & \\
\hline CHEMBL1349859 & 688653 & 5.5 & 5.4296 & TST & & & \\
\hline CHEMBL1560356 & 688653 & 5.78299 & 99999999 & 995 & 5.261 & TRN & \\
\hline CHEMBL1612515 & 688653 & 4.883 & 5.4465 & TRN & & & \\
\hline CHEMBL1314925 & 688653 & 4.883 & 4.8674 & TRN & & & \\
\hline CHEMBL1536821 & 688653 & 4.933 & 5.2641 & TRN & & & \\
\hline CHEMBL1307724 & 688653 & 5.033 & 5.1436 & TRN & & & \\
\hline CHEMBL1224755 & 688653 & 5.433 & 4.8418 & TST & & & \\
\hline
\end{tabular}




\begin{tabular}{|c|c|c|c|c|c|c|}
\hline & & \multicolumn{5}{|c|}{ Supplemental Table s2.txt } \\
\hline CHEMBL1463990 & 688653 & 4.833 & 5.4002 & TST & & \\
\hline CHEMBL1522206 & 688653 & 5.5329 & 99999999 & 995 & 5.8786 & TST \\
\hline CHEMBL1334245 & 688653 & 6.233 & 5.5424 & TST & & \\
\hline CHEMBL1429466 & 688653 & 4.933 & 5.6784 & TRN & & \\
\hline CHEMBL1498993 & 688653 & 4.7330 & 00000000 & 005 & 5.4474 & $\mathrm{TP}$ \\
\hline CHEMBL1610542 & 688653 & 4.833 & 4.9803 & TRN & & \\
\hline CHEMBL1466483 & 688653 & 5.433 & 4.5993 & TST & & \\
\hline CHEMBL1486418 & 688653 & 5.733 & 5.2384 & TST & & \\
\hline CHEMBL 3212323 & 688653 & 4.783 & 5.2297 & TRN & & \\
\hline CHEMBL1381755 & 688653 & 5.683 & 5.4866 & TRN & & \\
\hline CHEMBL1357048 & 688653 & 4.583 & 4.6254 & TST & & \\
\hline CHEMBL1365705 & 688653 & 5.8829 & 99999999 & & 5.8165 & \\
\hline CHEMBL1593028 & 688653 & 4.7330 & 00000000 & 005 & 5.1483 & \\
\hline CHEMBL51085 & 688653 & 4.833 & 5.58299 & 999999999 & 99 & \\
\hline CHEMBL3208475 & 688653 & 6.433 & 5.5691 & TRN & & \\
\hline CHEMBL1300506 & 688653 & 6.183 & 5.1279 & TST & & \\
\hline CHEMBL1603289 & 688653 & 4.833 & 5.4381 & TRN & & \\
\hline CHEMBL3197994 & 688653 & 4.883 & 4.6487 & TST & & \\
\hline CHEMBL1568968 & 688653 & 6.433 & 6.0526 & TRN & & \\
\hline CHEMBL1438117 & 688653 & 5.2829 & 99999999 & 995 & 5.4032 & \\
\hline CHEMBL1980306 & 688653 & 6.0829 & 99999999 & & 5.5114 & \\
\hline CHEMBL1599747 & 688653 & 4.933 & 5.052 & TRN & & \\
\hline CHEMBL1584059 & 688653 & 6.5829 & 99999999 & & 5.8999 & \\
\hline CHEMBL585628 & 688653 & 4.833 & 5.0534 & TST & & \\
\hline CHEMBL1343332 & 688653 & 4.783 & 5.3256 & TST & & \\
\hline CHEMBL1580362 & 688653 & 5.733 & 5.3658 & TRN & & \\
\hline CHEMBL1442632 & 688653 & 5.433 & 5.3437 & TRN & & \\
\hline CHEMBL1531992 & 688653 & 5.683 & 5.7434 & TRN & & \\
\hline CHEMBL1569063 & 688653 & 4.583 & 4.8037 & TST & & \\
\hline CHEMBL1564360 & 688653 & 5.5829 & 99999999 & & 5.2767 & \\
\hline CHEMBL1528761 & 688653 & 4.783 & $5.23600 t$ & 000000000 & 31 & \\
\hline CHEMBL1536391 & 688653 & 5.8829 & 99999999 & & 5.5818 & TRN \\
\hline CHEMBL3210499 & 688653 & 5.1329 & 99999999 & & 5.2654 & \\
\hline CHEMBL1457407 & 688653 & 6.4829 & 5.6884 & TRN & & \\
\hline CHEMBL1368243 & 688653 & 5.6329 & 99999999 & & 5.2889 & TRN \\
\hline CHEMBL3195654 & 688653 & 5.3329 & 99999999 & & 5.2979 & TST \\
\hline CHEMBL1378863 & 688653 & 7.3829 & 99999999 & & 5.3757 & TRN \\
\hline CHEMBL1420306 & 688653 & 6.3329 & 99999999 & & 5.1805 & 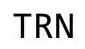 \\
\hline CHEMBL1462345 & 688653 & 4.833 & 5.0444 & TRN & & \\
\hline CHEMBL1451669 & 688653 & 4.833 & 5.1695 & TRN & & \\
\hline CHEMBL1447148 & 688653 & 4.633 & 4.8583 & TRN & & \\
\hline CHEMBL1333766 & 688653 & 6.3329 & 99999999 & 99 & 5.7637 & t \\
\hline CHEMBL1370414 & 688653 & 5.183 & 4.9371 & TRN & & \\
\hline CHEMBL1370262 & 688653 & 4.783 & 5.0625 & TRN & & \\
\hline CHEMBL1580142 & 688653 & 5.033 & 5.4428 & TRN & & \\
\hline CHEMBL1610587 & 688653 & 5.233 & 5.2922 & TST & & \\
\hline CHEMBL1526250 & 688653 & 4.883 & 5.2273 & TRN & & \\
\hline CHEMBL1590657 & 688653 & 4.783 & 4.7375 & TRN & & \\
\hline
\end{tabular}




\begin{tabular}{|c|c|c|c|c|c|c|}
\hline \multirow[b]{2}{*}{ CHEMBL1384621 } & \multirow[b]{2}{*}{688653} & \multicolumn{5}{|c|}{ Supplemental Table S2.txt } \\
\hline & & \multicolumn{3}{|c|}{5.2098 TRN } & \multirow{3}{*}{5.1058} & \multirow{3}{*}{ TRA } \\
\hline CHEMBL1549643 & 688653 & \multicolumn{3}{|c|}{5.132999999999999} & & \\
\hline CHEMBL1462585 & 688653 & 4.583 & 5.3172 & TST & & \\
\hline CHEMBL1329231 & 688653 & \multicolumn{3}{|c|}{4.7330000000000005} & 5.2785 & TRN \\
\hline CHEMBL1500825 & 688653 & 5.183 & 5.5212 & TRN & & \\
\hline CHEMBL1475864 & 688653 & 4.883 & 5.5302 & TRN & & \\
\hline CHEMBL1334701 & 688653 & \multicolumn{3}{|c|}{5.382999999999999} & 5.4771 & TRN \\
\hline CHEMBL1426098 & 688653 & \multicolumn{3}{|c|}{5.5329999999999995} & 5.565 & TRN \\
\hline CHEMBL1580980 & 688653 & 5.683 & 5.1911 & TRN & & \\
\hline CHEMBL1389745 & 688653 & 5.733 & 5.6969 & TRN & & \\
\hline CHEMBL1334123 & 688653 & 5.483 & 5.1583 & TRN & & \\
\hline CHEMBL1524091 & 688653 & \multicolumn{3}{|c|}{4.7330000000000005} & 4.8132 & TST \\
\hline CHEMBL1431608 & 688653 & 5.083 & 5.271 & TST & & \\
\hline CHEMBL 3192580 & 688653 & 4.833 & 4.9863 & TRN & & \\
\hline CHEMBL1451358 & 688653 & \multicolumn{3}{|c|}{5.382999999999999} & 5.1272 & TRN \\
\hline CHEMBL1547112 & 688653 & 5.733 & \multicolumn{3}{|c|}{5.122999999999999} & TST \\
\hline CHEMBL1375223 & 688653 & 4.833 & 5.0109 & TRN & & \\
\hline CHEMBL1392850 & 688653 & \multicolumn{3}{|c|}{6.132999999999999} & 4.8995 & TRN \\
\hline CHEMBL1367303 & 688653 & 4.883 & 5.0664 & TST & & \\
\hline CHEMBL1535900 & 688653 & 5.183 & 5.6874 & TST & & \\
\hline CHEMBL1491322 & 688653 & 4.633 & 4.8858 & TST & & \\
\hline CHEMBL1477562 & 688653 & \multicolumn{3}{|c|}{6.0329999999999995} & 5.7774 & TRN \\
\hline CHEMBL1457140 & 688653 & 5.183 & 5.2258 & TRN & & \\
\hline CHEMBL1433895 & 688653 & 6.233 & 5.6437 & TRN & & \\
\hline CHEMBL 3198249 & 688653 & 5.083 & 5.1357 & TRN & & \\
\hline CHEMBL1305316 & 688653 & \multicolumn{3}{|c|}{5.5329999999999995} & 4.8686 & TRN \\
\hline CHEMBL1510681 & 688653 & \multicolumn{3}{|c|}{5.5329999999999995} & 5.3681 & TRN \\
\hline CHEMBL1485882 & 688653 & \multicolumn{3}{|c|}{5.5329999999999995} & 5.0499 & TRN \\
\hline CHEMBL1421213 & 688653 & \multicolumn{3}{|c|}{5.382999999999999} & 4.9386 & TRN \\
\hline CHEMBL1404493 & 688653 & \multicolumn{3}{|c|}{5.832999999999999} & 6.1283 & TRN \\
\hline CHEMBL1483669 & 688653 & 4.583 & 5.0796 & TST & & \\
\hline CHEMBL1401986 & 688653 & 4.783 & 5.1445 & TST & & \\
\hline CHEMBL1534876 & 688653 & 5.433 & 5.4462 & TRN & & \\
\hline CHEMBL1969934 & 688653 & 5.183 & 4.9605 & TRN & & \\
\hline CHEMBL1408982 & 688653 & 5.733 & 5.3867 & TRN & & \\
\hline CHEMBL1390331 & 688653 & 4.633 & 5.0561 & TST & & \\
\hline CHEMBL1304128 & 688653 & \multicolumn{3}{|c|}{4.7330000000000005} & 5.1487 & TRN \\
\hline CHEMBL1487869 & 688653 & 5.733 & 5.8974 & TRN & & \\
\hline CHEMBL1446929 & 688653 & 4.833 & 5.184 & TST & & \\
\hline CHEMBL1427266 & 688653 & 5.733 & 5.7475 & TST & & \\
\hline CHEMBL1470920 & 688653 & 5.2829 & 99999999 & 995 & 5.4329 & TRN \\
\hline CHEMBL1412583 & 688653 & 4.883 & 5.1172 & TST & & \\
\hline CHEMBL1573954 & 688653 & 5.183 & 5.1715 & TRN & & \\
\hline CHEMBL1362331 & 688653 & 4.883 & 5.1343 & TST & & \\
\hline CHEMBL1557027 & 688653 & 5.683 & 4.8818 & TST & & \\
\hline CHEMBL1424280 & 688653 & 5.8329 & 99999999 & & 5.0385 & TST \\
\hline CHEMBL1500220 & 688653 & 5.483 & 5.2992 & TRN & & \\
\hline CHEMBL1339672 & 688653 & 5.3320 & 99999999 & & 5.4492 & TRN \\
\hline
\end{tabular}




\begin{tabular}{|c|c|c|c|c|c|c|}
\hline \multirow[b]{2}{*}{ CHEMBL1578193 } & & \multicolumn{5}{|c|}{ Supplemental Table S2.txt } \\
\hline & 688653 & 4.783 & \multicolumn{3}{|c|}{5.207000000000001} & \multirow[t]{2}{*}{ TRN } \\
\hline CHEMBL1539263 & 688653 & 4.933 & 5.2641 & TST & & \\
\hline CHEMBL3193394 & 688653 & \multicolumn{3}{|c|}{4.9830000000000005} & 5.2957 & TRN \\
\hline CHEMBL1432780 & 688653 & \multicolumn{3}{|c|}{5.7829999999999995} & 5.2374 & \\
\hline CHEMBL1510643 & 688653 & 4.633 & 4.8605 & TST & & \\
\hline CHEMBL1301313 & 688653 & 4.583 & 4.8723 & TST & & \\
\hline CHEMBL1445899 & 688653 & 4.933 & 4.3539 & TST & & \\
\hline CHEMBL1494376 & 588653 & 4.933 & 5.6094 & TRN & & \\
\hline CHEMBL370256 & 688653 & \multicolumn{3}{|c|}{5.332999999999999} & 5.2242 & TRN \\
\hline CHEMBL3190454 & 688653 & \multicolumn{3}{|c|}{6.082999999999999} & 5.6173 & \\
\hline CHEMBL1573981 & 688653 & 5.183 & 5.4087 & TRN & & \\
\hline CHEMBL1557663 & 688653 & \multicolumn{3}{|c|}{6.0329999999999995} & 6.1731 & Thiv \\
\hline CHEMBL1470219 & 688653 & \multicolumn{3}{|c|}{4.7330000000000005} & & \\
\hline CHEMBL1546262 & 688653 & 5.183 & 5.047 & TRN & & \\
\hline CHEMBL1415477 & 688653 & 5.683 & 5.053 & TST & & \\
\hline CHEMBL1397186 & 688653 & 5.733 & 5.5603 & TRN & & \\
\hline CHEMBL1553494 & 688653 & 5.083 & 5.0073 & TRN & & \\
\hline CHEMBL1568952 & 688653 & 5.433 & 5.3549 & TRN & & \\
\hline CHEMBL1529957 & 688653 & 5.483 & 5.3486 & TRN & & \\
\hline CHEMBL1988666 & 688653 & 5.083 & 5.6779 & TST & & \\
\hline CHEMBL1338157 & 688653 & 6.233 & 5.6354 & TRN & & \\
\hline CHEMBL1431286 & 688653 & 4.783 & 4.6955 & TST & & \\
\hline CHEMBL1558769 & 688653 & 4.883 & 5.4788 & TRN & & \\
\hline CHEMBL1468435 & 688653 & \multicolumn{3}{|c|}{5.5329999999999995} & 31 & TST \\
\hline CHEMBL1462522 & 688653 & \multicolumn{3}{|c|}{5.332999999999999} & & \\
\hline CHEMBL1973272 & 688653 & 5.433 & 5.5233 & TST & & \\
\hline CHEMBL1588511 & 688653 & \multicolumn{3}{|c|}{5.7829999999999995} & ובינו & \\
\hline CHEMBL1470762 & 688653 & 4.833 & 4.8339 & TRN & & \\
\hline CHEMBL1368496 & 688653 & \multicolumn{3}{|c|}{5.2829999999999995} & 5.5306 & TP \\
\hline CHEMBL1486968 & 688653 & 4.583 & 5.142 & TST & & \\
\hline CHEMBL1576829 & 688653 & \multicolumn{3}{|c|}{4.7330000000000005} & 5.3375 & \\
\hline CHEMBL1556732 & 688 & 5.433 & 5.5189 & TRN & & \\
\hline CHEMBL1590537 & 688653 & \multicolumn{3}{|c|}{5.632999999999999} & 4.8554 & $\mathrm{TR}$ \\
\hline CHEMBL1583619 & 688653 & 4.783 & 5.3877 & TRN & & \\
\hline CHEMBL1465797 & 688653 & \multicolumn{3}{|c|}{4.7330000000000005} & 4.7439 & $\mathrm{TR}$ \\
\hline CHEMBL2369168 & 688653 & 4.683 & 4.8507 & TRN & & \\
\hline CHEMBL1532190 & 688653 & 7. & 6.1986 & TRN & & \\
\hline CHEMBL1488743 & 688653 & 4.933 & 4.9994 & TRN & & \\
\hline CHEMBL1449618 & 688653 & 4.883 & 5.2674 & TRN & & \\
\hline CHEMBL1559434 & 688653 & 4.783 & 5.2645 & TRN & & \\
\hline CHEMBL3193623 & 688653 & \multicolumn{3}{|c|}{6.632999999999999} & 5.9955 & 15 \\
\hline CHEMBL1535706 & 688653 & 4.783 & 5.199 & TST & & \\
\hline CHEMBL3191772 & 688653 & \multicolumn{3}{|c|}{5.832999999999999} & 5.2075 & TST \\
\hline CHEMBL1520712 & 688653 & \multicolumn{3}{|c|}{4.9830000000000005} & 4.8961 & TRN \\
\hline CHEMBL1416956 & 688653 & 4.783 & 4.9848 & TRN & & \\
\hline CHEMBL1548136 & 688653 & \multicolumn{3}{|c|}{6.332999999999999} & 35 & TST \\
\hline CHEMBL1565058 & 688653 & 5.1329 & 9999999 & & 5.4096 & 西 \\
\hline CHEMBL1299725 & 688653 & 6.6329 & 9999999 & & 5.8693 & $\mathrm{TR}$ \\
\hline
\end{tabular}




\begin{tabular}{|c|c|c|c|c|c|c|}
\hline & & \multicolumn{5}{|c|}{ Supplemental Table S2.txt } \\
\hline CHEMBL1356155 & 688653 & 4.633 & 4.979 & TST & & \\
\hline CHEMBL1327627 & 688653 & 4.633 & 4.953 & TRN & & \\
\hline CHEMBL1507349 & 688653 & 5.183 & 5.3323 & TRN & & \\
\hline CHEMBL1554752 & 688653 & 4.883 & 5.2361 & TRN & & \\
\hline CHEMBL1576774 & 688653 & \multicolumn{3}{|c|}{6.132999999999999} & 5.8013 & TRN \\
\hline CHEMBL1468761 & 688653 & 5.933 & 5.2134 & TRN & & \\
\hline CHEMBL1584080 & 688653 & 4.783 & 4.9664 & TST & & \\
\hline CHEMBL1518550 & 688653 & \multicolumn{3}{|c|}{7.082999999999999} & 6.0597 & TRN \\
\hline CHEMBL1409288 & 688653 & 4.783 & 5.771 & TST & & \\
\hline CHEMBL1299834 & 688653 & 5.483 & 5.6153 & TRN & & \\
\hline CHEMBL1307243 & 688653 & \multicolumn{3}{|c|}{5.632999999999999} & 5.5976 & TRN \\
\hline CHEMBL1382801 & 688653 & 4.883 & 5.2034 & TRN & & \\
\hline CHEMBL1527435 & 688653 & 6.0 & 5.6214 & TRN & & \\
\hline CHEMBL1582928 & 688653 & 4.883 & 5.2537 & TRN & & \\
\hline CHEMBL1543923 & 688653 & \multicolumn{3}{|c|}{4.7330000000000005} & 5.1826 & TRN \\
\hline CHEMBL1427500 & 688653 & 4.783 & 5.2069 & TRN & & \\
\hline CHEMBL1363854 & 688653 & \multicolumn{3}{|c|}{4.9830000000000005} & 5.043 & TRN \\
\hline CHEMBL1437680 & 688653 & 4.633 & 4.8342 & TRN & & \\
\hline CHEMBL1448090 & 688653 & 4.833 & 5.4245 & TST & & \\
\hline CHEMBL1308048 & 688653 & \multicolumn{3}{|c|}{6.382999999999999} & 5.572 & TRN \\
\hline CHEMBL1414608 & 688653 & \multicolumn{3}{|c|}{4.9830000000000005} & 4.9457 & TST \\
\hline CHEMBL1469033 & 688653 & 5.433 & 5.8639 & TRN & & \\
\hline CHEMBL1470925 & 688653 & 4.833 & 5.5218 & TST & & \\
\hline CHEMBL1991908 & 688653 & 4.783 & 5.2737 & TST & & \\
\hline CHEMBL1589640 & 688653 & 6.0 & 5.4802 & TRN & & \\
\hline CHEMBL1337912 & 688653 & \multicolumn{3}{|c|}{5.832999999999999} & 5.6623 & TRN \\
\hline CHEMBL1414199 & 688653 & \multicolumn{3}{|c|}{5.882999999999999} & 5.1185 & TST \\
\hline CHEMBL1553346 & 688653 & 5.033 & 4.8226 & TRN & & \\
\hline CHEMBL1516333 & 688653 & 4.633 & 4.7679 & TRN & & \\
\hline CHEMBL1573553 & 688653 & 5.483 & 5.3222 & TRN & & \\
\hline CHEMBL1501432 & 688653 & 4.933 & 5.2404 & TRN & & \\
\hline CHEMBL1400195 & 688653 & 4.833 & 5.3346 & TST & & \\
\hline CHEMBL1508827 & 688653 & 4.833 & 5.0384 & TST & & \\
\hline CHEMBL1568555 & 688653 & \multicolumn{3}{|c|}{5.5329999999999995} & 5.4901 & TST \\
\hline CHEMBL374632 & 688653 & 8.4318 & 6.0854 & TRN & & \\
\hline CHEMBL1411567 & 688653 & \multicolumn{3}{|c|}{5.132999999999999} & 5.3713 & TRN \\
\hline CHEMBL1383468 & 688653 & 4.9 & 4.965 & TRN & & \\
\hline CHEMBL1578866 & 688653 & \multicolumn{3}{|c|}{5.132999999999999} & 5.2362 & TST \\
\hline CHEMBL1487914 & 688653 & \multicolumn{3}{|c|}{5.582999999999999} & 5.1481 & TRN \\
\hline CHEMBL3194408 & 688653 & \multicolumn{3}{|c|}{5.2829999999999995} & 4.8561 & TRN \\
\hline CHEMBL1492491 & 688653 & 5.183 & 5.3444 & TRN & & \\
\hline CHEMBL1559091 & 688653 & \multicolumn{3}{|c|}{4.7330000000000005} & 5.3562 & TST \\
\hline CHEMBL1577631 & 688653 & 4.633 & 5.1131 & TRN & & \\
\hline CHEMBL1321426 & 688653 & 4.833 & 5.1316 & TRN & & \\
\hline CHEMBL3189949 & 688653 & 4.783 & 5.3878 & TRN & & \\
\hline CHEMBL1372704 & 688653 & \multicolumn{3}{|c|}{5.5329999999999995} & 5.6085 & TST \\
\hline CHEMBL1387254 & 688653 & 4.933 & 5.553 & TRN & & \\
\hline CHEMBL1313232 & 688653 & 5.733 & 5.2011 & TRN & & \\
\hline
\end{tabular}




\begin{tabular}{|c|c|c|c|c|c|c|c|}
\hline \multirow[b]{2}{*}{ CHEMBL1507515 } & \multicolumn{6}{|c|}{ Supplemental T } & \\
\hline & 688653 & 6.233 & 5.6208 & TRN & & & \\
\hline CHEMBL1574688 & 688653 & 5.8829 & 99999999 & & 5.3819 & TRN & \\
\hline CHEMBL1303632 & 688653 & 4.833 & 5.2859 & TRN & & & \\
\hline CHEMBL1385588 & 688653 & 6.0829 & 99999999 & & 5.0531 & TRN & \\
\hline CHEMBL1541652 & 688653 & 5.733 & 5.1822 & TST & & & \\
\hline CHEMBL1585842 & 688653 & 5.083 & 5.5357 & TRN & & & \\
\hline CHEMBL1528478 & 688653 & 4.783 & 4.7595 & TST & & & \\
\hline CHEMBL1589310 & 688653 & 5.733 & 4.989 & TST & & & \\
\hline CHEMBL1327169 & 688653 & 6.183 & 5.8571 & TRN & & & \\
\hline CHEMBL1440474 & 688653 & 5.733 & 5.4421 & TRN & & & \\
\hline CHEMBL1317551 & 688653 & 4.633 & 4.9116 & TRN & & & \\
\hline CHEMBL1502346 & 688653 & 4.633 & 4.8114 & TST & & & \\
\hline CHEMBL1343260 & 688653 & 4.633 & 5.3097 & TST & & & \\
\hline CHEMBL1455992 & 688653 & 6.433 & 5.5721 & TRN & & & \\
\hline CHEMBL1465127 & 688653 & 5.5329 & 99999999 & 995 & 5.3861 & TRN & \\
\hline CHEMBL1601724 & 688653 & 5.7829 & 99999999 & 995 & 5.6713 & TRN & \\
\hline CHEMBL1577893 & 688653 & 5.5329 & 99999999 & 995 & 5.4152 & TST & \\
\hline CHEMBL1603331 & 688653 & 4.633 & 4.7667 & TST & & & \\
\hline CHEMBL1311267 & 688653 & 5.183 & 4.9366 & TRN & & & \\
\hline CHEMBL1393739 & 688653 & 6.0829 & 99999999 & & 5.5136 & TRN & \\
\hline CHEMBL1452993 & 688653 & 4.933 & 5.0865 & TRN & & & \\
\hline CHEMBL1470018 & 688653 & 5.7829 & 99999999 & 995 & 5.3342 & TRN & \\
\hline CHEMBL1367677 & 688653 & 4.933 & 4.9697 & TRN & & & \\
\hline CHEMBL1443896 & 688653 & 4.783 & 5.176 & TST & & & \\
\hline CHEMBL1577922 & 688653 & 5.6329 & 99999999 & & 5.4860 & 0000000001 & TRN \\
\hline CHEMBL1349723 & 688653 & 5.033 & 5.4173 & TST & & & \\
\hline CHEMBL1440152 & 688653 & 5.683 & 5.1993 & TST & & & \\
\hline CHEMBL1468774 & 688653 & 5.65 & 5.3799 & TST & & & \\
\hline CHEMBL1473363 & 688653 & 4.883 & 5.0052 & TRN & & & \\
\hline CHEMBL1392157 & 688653 & 4.9830 & 00000000 & 005 & 5.4687 & TRN & \\
\hline CHEMBL1541843 & 688653 & 5.2829 & 99999999 & 995 & 5.0642 & TRN & \\
\hline CHEMBL1576000 & 688653 & 5.5329 & 99999999 & 995 & 5.2861 & TRN & \\
\hline CHEMBL3198531 & 688653 & 5.1329 & 99999999 & & 5.6557 & TRN & \\
\hline CHEMBL1493178 & 688653 & 6.233 & 5.8558 & TRN & & & \\
\hline CHEMBL1367940 & 688653 & 5.2829 & 99999999 & 995 & 5.0825 & TST & \\
\hline CHEMBL1601721 & 688653 & 7.0829 & 99999999 & & 5.7166 & TRN & \\
\hline CHEMBL1383842 & 688653 & 6.183 & 5.4327 & TRN & & & \\
\hline CHEMBL1392905 & 688653 & 4.833 & 5.1233 & TST & & & \\
\hline CHEMBL1424196 & 688653 & 6.2829 & 99999999 & 995 & 4.9801 & TRN & \\
\hline CHEMBL1490225 & 688653 & 4.633 & 5.007 & TST & & & \\
\hline CHEMBL1332782 & 688653 & 6.0829 & 99999999 & & 5.7081 & TRN & \\
\hline CHEMBL1607286 & 688653 & 4.7330 & 00000000 & 005 & 5.3136 & TST & \\
\hline CHEMBL1609493 & 688653 & 4.7330 & 00000000 & 005 & 4.9871 & TRN & \\
\hline CHEMBL3208873 & 688653 & 4.883 & 5.2891 & TRN & & & \\
\hline CHEMBL1401761 & 688653 & 4.9830 & 00000000 & 005 & 5.0421 & TRN & \\
\hline CHEMBL1520301 & 688653 & 5.3329 & 99999999 & & 5.088 & TRN & \\
\hline CHEMBL3208479 & 688653 & 5.3829 & 99999999 & & 5.6469 & TRN & \\
\hline CHEMBL1527814 & 688653 & 5.2829 & 99999999 & 995 & 5.3394 & TRN & \\
\hline
\end{tabular}




\begin{tabular}{|c|c|c|c|c|c|c|c|}
\hline \multicolumn{7}{|c|}{ Supplemental Table S2.txt } & \\
\hline CHEMBL1331257 & 688653 & \multicolumn{4}{|c|}{5.132999999999999} & TRN & \\
\hline CHEMBL 3190837 & 688653 & \multicolumn{3}{|c|}{5.882999999999999} & 4.9813 & TST & \\
\hline CHEMBL1407683 & 688653 & \multicolumn{3}{|c|}{7.082999999999999} & \multicolumn{2}{|c|}{6.1339999999999995} & TRN \\
\hline CHEMBL604321 & 688653 & 5.183 & 5.0258 & TST & & & \\
\hline CHEMBL1446038 & 688653 & \multicolumn{3}{|c|}{5.132999999999999} & 5.5191 & TRN & \\
\hline CHEMBL1330686 & 688653 & 4.683 & 4.9019 & TRN & & & \\
\hline CHEMBL1348066 & 688653 & \multicolumn{3}{|c|}{6.382999999999999} & 6.2699 & TST & \\
\hline CHEMBL1370601 & 688653 & \multicolumn{3}{|c|}{5.132999999999999} & 5.1194 & TST & \\
\hline CHEMBL1300777 & 688653 & \multicolumn{3}{|c|}{5.332999999999999} & 5.7332 & TST & \\
\hline CHEMBL1482955 & 688653 & \multicolumn{3}{|c|}{5.382999999999999} & 5.5544 & TRN & \\
\hline CHEMBL1465223 & 688653 & 4.933 & 5.4592 & TRN & & & \\
\hline CHEMBL1336661 & 688653 & \multicolumn{3}{|c|}{5.132999999999999} & 5.2376 & TST & \\
\hline CHEMBL1538103 & 688653 & \multicolumn{3}{|c|}{5.582999999999999} & 5.6795 & TRN & \\
\hline CHEMBL1520989 & 688653 & 4.783 & 5.1768 & TRN & & & \\
\hline CHEMBL1589389 & 688653 & \multicolumn{3}{|c|}{5.882999999999999} & 4.7671 & TRN & \\
\hline CHEMBL1584684 & 688653 & \multicolumn{3}{|c|}{5.7829999999999995} & 6.1494 & TRN & \\
\hline CHEMBL1365313 & 688653 & \multicolumn{3}{|c|}{6.0329999999999995} & 6.0462 & TRN & \\
\hline CHEMBL1562224 & 688653 & \multicolumn{3}{|c|}{4.7330000000000005} & 5.2493 & TRN & \\
\hline CHEMBL1355630 & 688653 & \multicolumn{3}{|c|}{4.7330000000000005} & 4.9479 & TRN & \\
\hline CHEMBL1443217 & 688653 & \multicolumn{3}{|c|}{4.7330000000000005} & 5.3453 & TRN & \\
\hline CHEMBL1568803 & 688653 & \multicolumn{3}{|c|}{5.7829999999999995} & 5.3277 & TRN & \\
\hline CHEMBL1368307 & 688653 & 5.433 & 5.1655 & TRN & & & \\
\hline CHEMBL1319015 & 688653 & 4.633 & 4.9976 & TRN & & & \\
\hline CHEMBL 3208471 & 688653 & 4.933 & 5.4599 & TST & & & \\
\hline CHEMBL1353675 & 688653 & 4.883 & 5.1385 & TRN & & & \\
\hline CHEMBL1464608 & 688653 & 5.733 & 5.7995 & TRN & & & \\
\hline CHEMBL1337799 & 688653 & \multicolumn{3}{|c|}{4.7330000000000005} & 5.3026 & TRN & \\
\hline CHEMBL589238 & 688653 & 5.983 & 5.318 & TST & & & \\
\hline CHEMBL582717 & 688653 & \multirow{2}{*}{\multicolumn{3}{|c|}{$\begin{array}{lrl}5.433 & 5.0309 & \text { TST } \\
5.332999999999999\end{array}$}} & & & \\
\hline CHEMBL1399740 & 688653 & & & & 5.3152 & TRN & \\
\hline CHEMBL1551301 & 688653 & 4.633 & 5.5187 & TRN & & & \\
\hline CHEMBL1610697 & 688653 & 4.933 & 4.9236 & TRN & & & \\
\hline CHEMBL1347277 & 688653 & 5.083 & 4.6564 & TRN & & & \\
\hline CHEMBL1372828 & 688653 & 5.483 & 5.4584 & TRN & & & \\
\hline CHEMBL1550224 & 688653 & 4.583 & 5.2664 & TST & & & \\
\hline CHEMBL1329077 & 688653 & 4.883 & 5.2483 & TRN & & & \\
\hline CHEMBL1480189 & 688653 & 4.683 & 4.9579 & TRN & & & \\
\hline CHEMBL1347951 & 688653 & 4.73306 & 00000000 & 005 & 4.8935 & TST & \\
\hline CHEMBL1482689 & 688653 & 5.2829 & 99999999 & 995 & 4.8953 & TRN & \\
\hline CHEMBL1501465 & 688653 & 6.1329 & 99999999 & & 5.4082 & TRN & \\
\hline CHEMBL1545057 & 688653 & 5.6329 & 99999999 & & 5.9059 & TRN & \\
\hline CHEMBL1489491 & 688653 & 5.3329 & 99999999 & & 5.1595 & TRN & \\
\hline CHEMBL1335963 & 688653 & 4.883 & 5.2064 & TRN & & & \\
\hline CHEMBL1461433 & 688653 & 4.9830 & 00000000 & 005 & 5.1846 & TST & \\
\hline CHEMBL1452811 & 688653 & 6.2829 & 99999999 & 995 & 5.6869 & TRN & \\
\hline CHEMBL338474 & 688653 & 5.8829 & 99999999 & & 5.7515 & TRN & \\
\hline CHEMBL1301452 & 688653 & 4.933 & 5.1406 & TRN & & & \\
\hline CHEMBL1376513 & 688653 & 5.733 & 5.2592 & TRN & & & \\
\hline
\end{tabular}




\begin{tabular}{|c|c|c|c|c|c|c|c|}
\hline \multicolumn{8}{|c|}{ Supplemental Table S2.txt } \\
\hline CHEMBL1533942 & 688653 & 4.683 & 4.8769 & TRN & & & \\
\hline CHEMBL1319488 & 688653 & 5.233 & 5.0162 & TRN & & & \\
\hline CHEMBL1551240 & 688653 & 4.633 & 5.1403 & TRN & & & \\
\hline CHEMBL1538689 & 688653 & \multicolumn{3}{|c|}{6.332999999999999} & \multicolumn{2}{|c|}{5.5360000000000005} & TRN \\
\hline CHEMBL1345531 & 688653 & 5.433 & 5.3411 & TRN & & & \\
\hline CHEMBL1413749 & 688653 & 4.833 & 5.1118 & TST & & & \\
\hline CHEMBL1443895 & 688653 & 6.4829 & 5.5013 & TST & & & \\
\hline CHEMBL3193579 & 688653 & 4.583 & 5.4638 & TRN & & & \\
\hline CHEMBL3214321 & 688653 & 4.883 & 5.1427 & TST & & & \\
\hline CHEMBL1538764 & 688653 & 5.983 & 5.8788 & TRN & & & \\
\hline CHEMBL3194911 & 688653 & \multicolumn{3}{|c|}{4.7330000000000005} & 5.0669 & TRN & \\
\hline CHEMBL1600963 & 688653 & 4.783 & 4.637 & TRN & & & \\
\hline CHEMBL1585677 & 688653 & 4.933 & 5.3964 & TRN & & & \\
\hline CHEMBL1371588 & 688653 & 4.783 & 5.0806 & TST & & & \\
\hline CHEMBL1392025 & 688653 & 4.833 & 4.9137 & TRN & & & \\
\hline CHEMBL3192813 & 688653 & 5.033 & 5.1099 & TRN & & & \\
\hline CHEMBL3212647 & 688653 & \multicolumn{3}{|c|}{4.9830000000000005} & 5.1837 & TRN & \\
\hline CHEMBL1319667 & 688653 & \multicolumn{3}{|c|}{5.382999999999999} & 5.0841 & TRN & \\
\hline CHEMBL1431427 & 688653 & 4.883 & 5.1918 & TST & & & \\
\hline CHEMBL 3207847 & 688653 & 4.933 & 5.2425 & TRN & & & \\
\hline CHEMBL1332932 & 688653 & 4.933 & 5.2066 & TRN & & & \\
\hline CHEMBL1605586 & 688653 & 4.783 & 4.9504 & TRN & & & \\
\hline CHEMBL1318268 & 688653 & \multicolumn{3}{|c|}{4.7330000000000005} & 5.2798 & TRN & \\
\hline CHEMBL1483280 & 688653 & 5.183 & 4.6705 & TRN & & & \\
\hline CHEMBL1424980 & 688653 & 4.583 & 5.0917 & TRN & & & \\
\hline CHEMBL1545565 & 688653 & \multicolumn{3}{|c|}{5.132999999999999} & 5.3057 & TRN & \\
\hline CHEMBL1386286 & 688653 & 5.05 & 5.3036 & TRN & & & \\
\hline CHEMBL270635 & 688653 & 4.583 & 5.2344 & TRN & & & \\
\hline CHEMBL1489340 & 688653 & 4.633 & 4.9625 & TRN & & & \\
\hline CHEMBL1610004 & 688653 & 5.483 & 4.9398 & TRN & & & \\
\hline CHEMBL1516925 & 688653 & 5.933 & 5.528 & TRN & & & \\
\hline CHEMBL1607928 & 688653 & \multicolumn{3}{|c|}{6.332999999999999} & 5.8206 & TRN & \\
\hline CHEMBL1537419 & 688653 & 5.083 & 5.1177 & TRN & & & \\
\hline CHEMBL1402875 & 688653 & \multicolumn{3}{|c|}{5.2829999999999995} & 5.2999 & TRN & \\
\hline CHEMBL1401599 & 688653 & \multicolumn{3}{|c|}{4.9830000000000005} & 5.1478 & TRN & \\
\hline CHEMBL1594556 & 688653 & \multicolumn{3}{|c|}{5.332999999999999} & 5.2657 & TRN & \\
\hline CHEMBL1309749 & 688653 & 5.483 & 5.0734 & TRN & & & \\
\hline CHEMBL1601595 & 688653 & 4.833 & 5.0805 & TRN & & & \\
\hline CHEMBL1420450 & 688653 & \multicolumn{3}{|c|}{5.132999999999999} & 4.9859 & TRN & \\
\hline CHEMBL1307660 & 688653 & 5.483 & 5.2537 & TRN & & & \\
\hline CHEMBL1314212 & 688653 & \multicolumn{3}{|c|}{5.832999999999999} & 5.6817 & TRN & \\
\hline CHEMBL1325502 & 688653 & 5.083 & 4.93 & TRN & & & \\
\hline CHEMBL1459255 & 688653 & 5.183 & 4.9943 & TRN & & & \\
\hline CHEMBL1333719 & 688653 & 4.933 & 5.3774 & TRN & & & \\
\hline CHEMBL1314161 & 688653 & \multicolumn{3}{|c|}{5.132999999999999} & 5.5899 & TRN & \\
\hline CHEMBL1424478 & 688653 & \multicolumn{3}{|c|}{5.5329999999999995} & 5.2003 & TRN & \\
\hline CHEMBL1470446 & 688653 & 4.633 & 5.0007 & TST & & & \\
\hline CHEMBL1366158 & 688653 & \multicolumn{3}{|c|}{6.332999999999999} & 5.6482 & TRN & \\
\hline
\end{tabular}




\begin{tabular}{|c|c|c|c|c|c|c|}
\hline \multirow[b]{2}{*}{ CHEMBL1511445 } & \multirow[b]{2}{*}{688653} & \multicolumn{5}{|c|}{ Supplemental Table S2.txt } \\
\hline & & \multicolumn{3}{|c|}{34.965 TRN } & & \\
\hline CHEMBL1973383 & 688653 & 4.883 & 5.2583 & TRN & & \\
\hline CHEMBL1476144 & 688653 & 4.633 & 5.1236 & \multicolumn{3}{|l|}{ TRN } \\
\hline CHEMBL1420463 & 688653 & \multicolumn{3}{|c|}{4.9830000000000005} & \multirow[t]{4}{*}{5.5855} & \multirow[t]{4}{*}{ TRN } \\
\hline CHEMBL1322008 & 688653 & 4.633 & 4.7958 & TST & & \\
\hline CHEMBL1369135 & 688653 & 4.783 & 5.4829 & TST & & \\
\hline CHEMBL1510732 & 688653 & 4.783 & 5.4112 & TRN & & \\
\hline CHEMBL1990598 & 688653 & \multicolumn{3}{|c|}{5.832999999999999} & \multirow[t]{2}{*}{4.9884} & \multirow[t]{2}{*}{ TST } \\
\hline CHEMBL1370196 & 688653 & 5.183 & 5.0838 & TRN & & \\
\hline CHEMBL1584991 & 688653 & \multicolumn{3}{|c|}{5.832999999999999} & 5.2899 & TRN \\
\hline CHEMBL1550510 & 688653 & \multicolumn{3}{|c|}{5.132999999999999} & 5.46 & TST \\
\hline CHEMBL1570969 & 688653 & \multicolumn{3}{|c|}{6.632999999999999} & 5.6617 & TRN \\
\hline CHEMBL1543959 & 688653 & 4.783 & 5.4436 & TRN & & \\
\hline CHEMBL3191072 & 688653 & 4.783 & 5.4709 & TRN & & \\
\hline CHEMBL1584089 & 688653 & 4.833 & 5.2745 & TRN & & \\
\hline CHEMBL1512794 & 688653 & 4.583 & \multicolumn{3}{|c|}{4.8069999999999995} & TRN \\
\hline CHEMBL1500052 & 688653 & 4.883 & 4.9885 & TST & & \\
\hline CHEMBL1418839 & 688653 & \multicolumn{3}{|c|}{5.7829999999999995} & 5.2356 & TRN \\
\hline CHEMBL1428990 & 688653 & \multicolumn{3}{|c|}{5.7829999999999995} & 4.7535 & TRN \\
\hline CHEMBL1383967 & 688653 & 5.983 & 5.7764 & TRN & & \\
\hline CHEMBL1461141 & 688653 & \multicolumn{3}{|c|}{5.332999999999999} & 5.1473 & TRN \\
\hline CHEMBL1468400 & 688653 & \multicolumn{3}{|c|}{5.132999999999999} & 5.3412 & TRN \\
\hline CHEMBL1499852 & 688653 & \multicolumn{3}{|c|}{5.7829999999999995} & 5.0613 & TST \\
\hline CHEMBL1458548 & 688653 & 5.2829 & 99999999 & 995 & 4.9095 & TRN \\
\hline CHEMBL1310617 & 688653 & 5.8829 & 99999999 & & 5.7452 & TST \\
\hline CHEMBL1531084 & 688653 & 4.783 & 5.1721 & TRN & & \\
\hline CHEMBL1364205 & 688653 & 6.0329 & 99999999 & 995 & 5.7002 & TRN \\
\hline CHEMBL1469590 & 688653 & 5.8329 & 99999999 & & 5.675 & TRN \\
\hline CHEMBL3198303 & 688653 & 6.0329 & 99999999 & 995 & 5.7112 & TRN \\
\hline CHEMBL1500498 & 688653 & 4.833 & 5.1246 & TRN & & \\
\hline CHEMBL1414961 & 688653 & 4.933 & 4.8354 & TRN & & \\
\hline CHEMBL1494406 & 688653 & 4.933 & 5.0036 & TRN & & \\
\hline CHEMBL1420032 & 688653 & 5.433 & 5.2715 & TRN & & \\
\hline CHEMBL1370295 & 688653 & 5.6329 & 99999999 & & 5.0268 & TRN \\
\hline CHEMBL1534726 & 688653 & 4.7330 & 20000000 & 005 & 5.1413 & TST \\
\hline CHEMBL1610770 & 688653 & 5.3329 & 99999999 & & 5.1792 & TST \\
\hline CHEMBL1407931 & 688653 & 5.183 & 5.21399 & 99999 & 995 & TRN \\
\hline CHEMBL1454136 & 688653 & 5.0 & 5.1998 & TST & & \\
\hline CHEMBL1506222 & 688653 & 5.933 & 5.435 & TRN & & \\
\hline CHEMBL1529881 & 688653 & 4.833 & 5.3876 & TRN & & \\
\hline CHEMBL1552413 & 688653 & 4.783 & 4.9954 & TRN & & \\
\hline CHEMBL1329747 & 688653 & 5.3829 & 99999999 & & 5.2136 & TRN \\
\hline CHEMBL1577159 & 688653 & 4.783 & 5.5176 & TST & & \\
\hline CHEMBL1382022 & 688653 & 4.583 & 4.5132 & TRN & & \\
\hline CHEMBL1530943 & 688653 & 6.3829 & 99999999 & & 6.6043 & TRN \\
\hline CHEMBL1388060 & 688653 & 5.1329 & 99999999 & & 5.0505 & TRN \\
\hline CHEMBL1361670 & 688653 & 5.733 & 5.2978 & TRN & & \\
\hline CHEMBL 2005394 & 688653 & 5.433 & 5.7271 & TRN & & \\
\hline
\end{tabular}




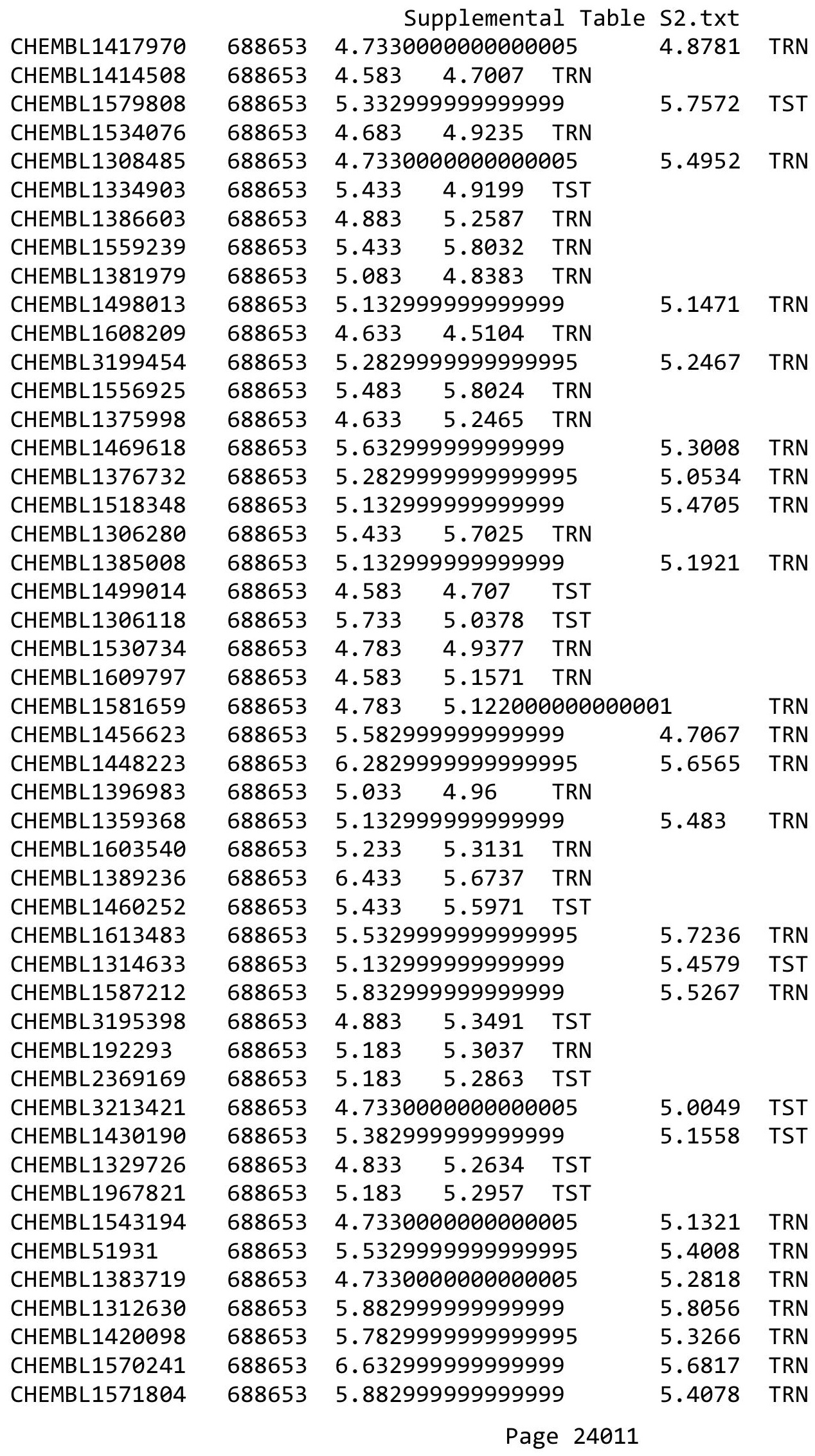




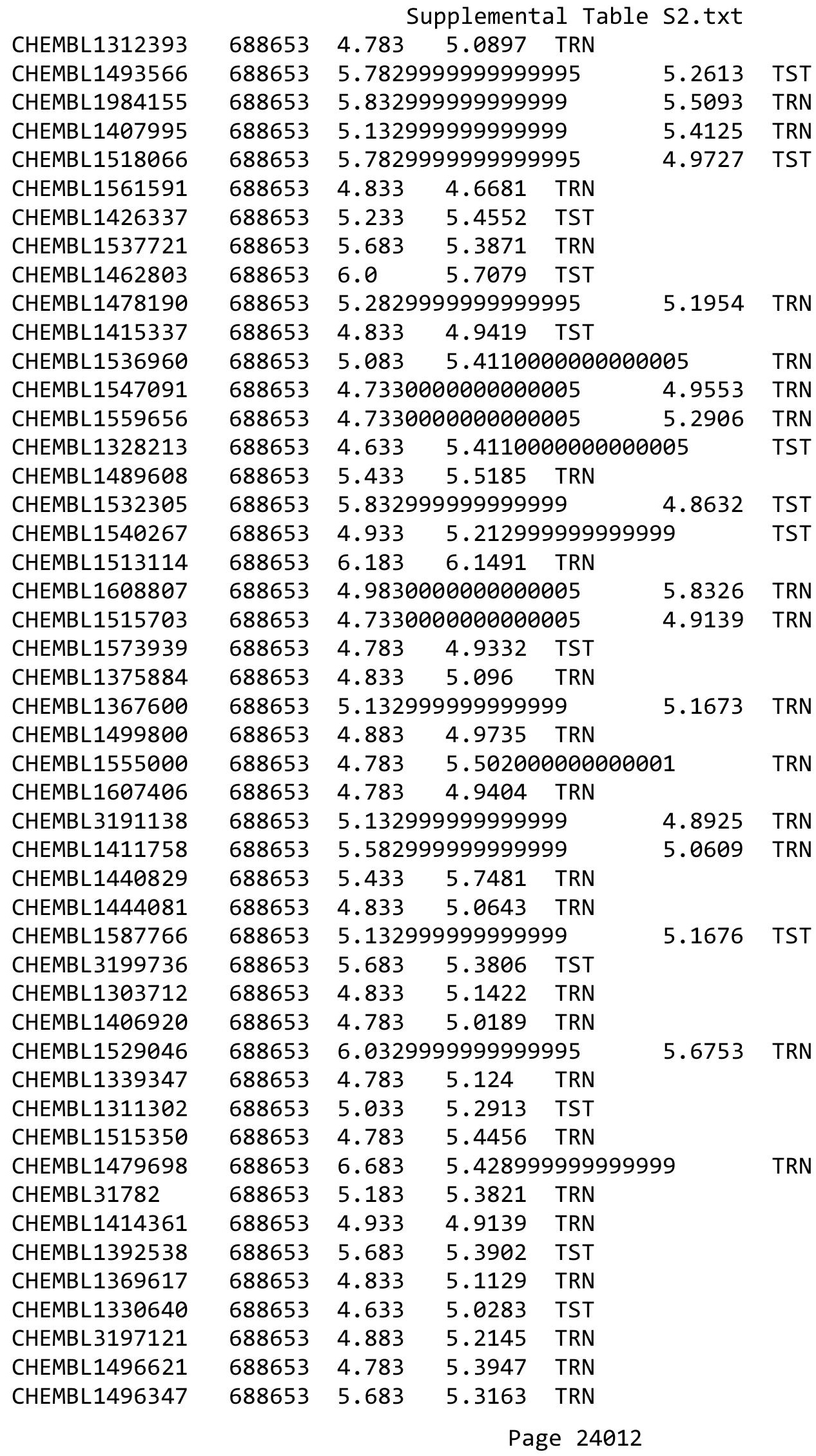




\begin{tabular}{|c|c|c|c|c|c|c|}
\hline \multirow[b]{2}{*}{ CHEMBL1507362 } & \multirow[b]{2}{*}{688653} & \multicolumn{5}{|c|}{ Supplemental Table S2.txt } \\
\hline & & \multicolumn{3}{|c|}{$\begin{array}{l}\text { Supplemental Ta } \\
3 \quad 5.0855 \text { TRN }\end{array}$} & & \\
\hline CHEMBL1593084 & 688653 & 4.583 & 5.1677 & TRN & & \\
\hline CHEMBL1597960 & 688653 & \multicolumn{3}{|c|}{5.2829999999999995} & 5.3881 & TR \\
\hline CHEMBL1446545 & 688653 & 4.783 & 5.5515 & TST & & \\
\hline CHEMBL1423796 & 688653 & \multicolumn{3}{|c|}{5.582999999999999} & 5.5496 & TR \\
\hline CHEMBL1498361 & 688653 & 5.083 & 5.35 & TRN & & \\
\hline CHEMBL1512098 & 688653 & 4.933 & 5.1868 & TRN & & \\
\hline CHEMBL1322399 & 688653 & 4.783 & 4.9399 & TST & & \\
\hline CHEMBL1411111 & 688653 & 4.833 & 5.4125 & TRN & & \\
\hline CHEMBL1474270 & 688653 & 4.683 & 5.0687 & TRN & & \\
\hline CHEMBL1313660 & 688653 & \multicolumn{3}{|c|}{5.582999999999999} & 5.6791 & \\
\hline CHEMBL1444019 & 688653 & 4.933 & 4.944 & TRN & & \\
\hline CHEMBL1387510 & 688653 & \multicolumn{3}{|c|}{5.132999999999999} & 5.2455 & \\
\hline CHEMBL1538737 & 688653 & 4.683 & 4.8564 & TST & & \\
\hline CHEMBL1358776 & 688653 & 5.433 & 5.5503 & TST & & \\
\hline CHEMBL1971727 & 688653 & 5.083 & 5.1252 & TRN & & \\
\hline CHEMBL1305637 & 688653 & \multicolumn{3}{|c|}{5.332999999999999} & 5.2287 & \\
\hline CHEMBL1521005 & 688653 & \multicolumn{3}{|c|}{6.082999999999999} & 5.2873 & \\
\hline CHEMBL1374258 & 688653 & 6.7331 & 5.7106 & TRN & & \\
\hline CHEMBL1546240 & 688653 & \multicolumn{3}{|c|}{5.632999999999999} & 5.6387 & \\
\hline CHEMBL1449168 & 688653 & 5.233 & 5.5173 & TST & & \\
\hline CHEMBL1409330 & 688653 & 5.483 & 5.3545 & TRN & & \\
\hline CHEMBL1332112 & 688653 & 4.833 & 5.0601 & TRN & & \\
\hline CHEMBL1577844 & 688653 & \multicolumn{3}{|c|}{5.132999999999999} & 5.6464 & \\
\hline CHEMBL1322854 & 688653 & \multicolumn{3}{|c|}{5.132999999999999} & 5.3724 & \\
\hline CHEMBL1531428 & 688653 & 4.833 & 5.2874 & TRN & & \\
\hline CHEMBL1556326 & 688653 & 4.833 & 5.2892 & TRN & & \\
\hline CHEMBL1313338 & 688653 & 5.033 & 4.9978 & TST & & \\
\hline CHEMBL1422830 & 688653 & 4.783 & 5.0508 & TRN & & \\
\hline CHEMBL1325243 & 688653 & 6.4829 & 5.7902 & TRN & & \\
\hline CHEMBL1339090 & 688653 & 4.783 & 4.9665 & TST & & \\
\hline CHEMBL1491946 & 688653 & \multicolumn{3}{|c|}{5.382999999999999} & 5.1523 & \\
\hline CHEMBL1543783 & 688653 & 4.833 & 5.3665 & TRN & & \\
\hline CHEMBL1378385 & 688653 & 4.883 & 5.0816 & TRN & & \\
\hline CHEMBL1609696 & 688653 & 4.683 & 4.5959 & TRN & & \\
\hline CHEMBL1429966 & 688653 & 5.483 & 4.9457 & TST & & \\
\hline CHEMBL1385440 & 688653 & \multicolumn{3}{|c|}{5.882999999999999} & 5.6292 & \\
\hline CHEMBL1580102 & 688653 & 4.783 & 5.1107 & TRN & & \\
\hline CHEMBL1345643 & 688653 & \multicolumn{3}{|c|}{5.632999999999999} & 5.6296 & TRN \\
\hline CHEMBL1548624 & 688653 & \multicolumn{3}{|c|}{4.7330000000000005} & 5.2723 & \\
\hline CHEMBL1521719 & 688653 & 4.633 & 4.9999 & TST & & \\
\hline CHEMBL1418764 & 688653 & \multicolumn{3}{|c|}{5.5329999999999995} & 5.6373 & \\
\hline CHEMBL 3213893 & 688653 & 5.683 & 5.6463 & TST & & \\
\hline CHEMBL1466731 & 688653 & \multicolumn{3}{|c|}{4.7330000000000005} & 4.936 & 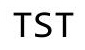 \\
\hline CHEMBL1534605 & 688653 & 4.883 & 5.1168 & TST & & \\
\hline CHEMBL1381377 & 688653 & 6.433 & 5.5236 & TRN & & \\
\hline CHEMBL1416329 & 688653 & 4.633 & 4.5869 & TRN & & \\
\hline CHEMBL1346595 & 688653 & 5.1329 & 999999999 & & 5.3284 & 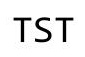 \\
\hline
\end{tabular}




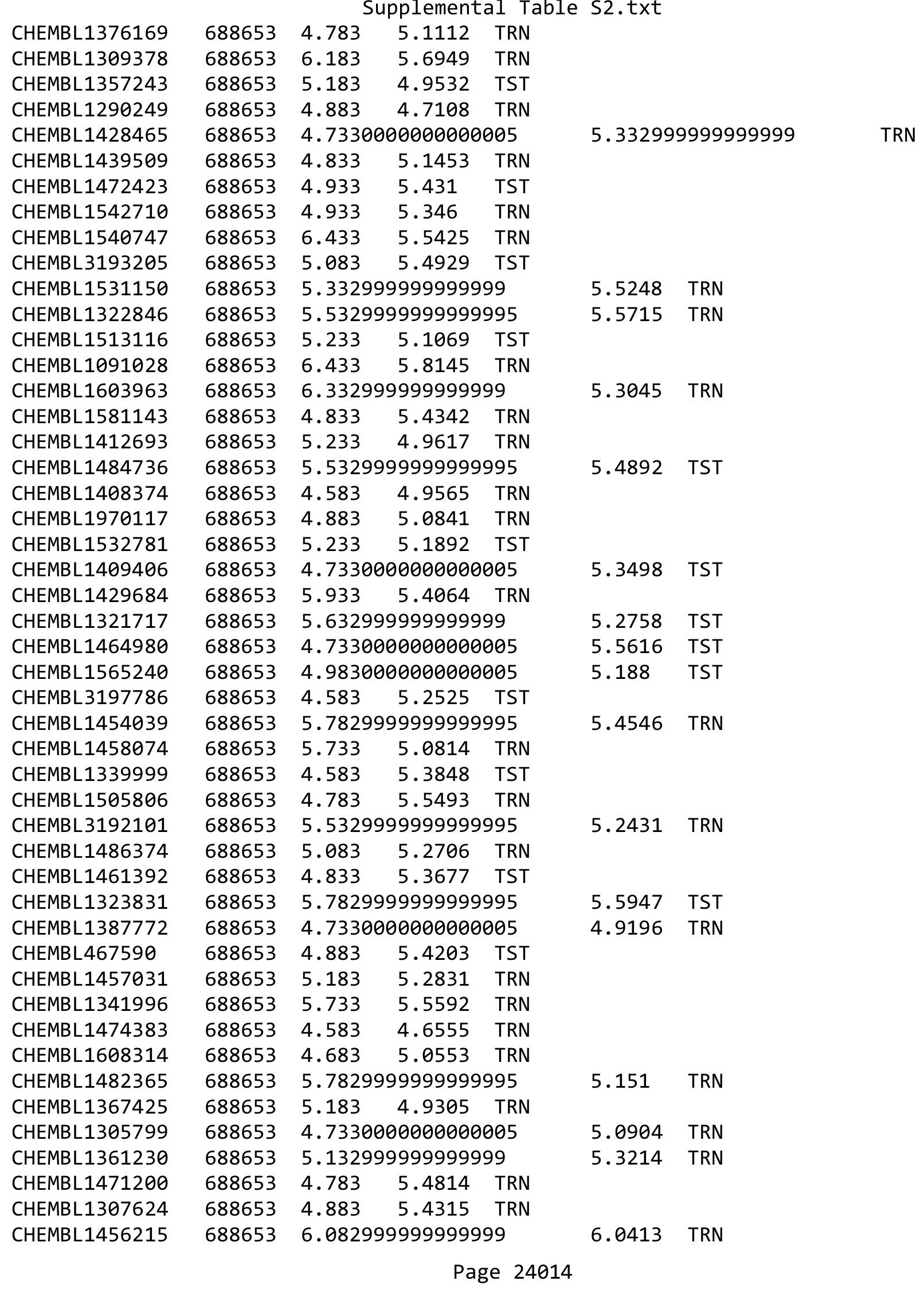




\begin{tabular}{|c|c|c|c|c|c|c|c|}
\hline \multicolumn{8}{|c|}{ pplemental Ta } \\
\hline CHEMBL1508402 & 688653 & 4.833 & 4.9892 & TST & & & \\
\hline CHEMBL1539655 & 688653 & 4.583 & 4.9618 & TRN & & & \\
\hline CHEMBL1390589 & 688653 & 4.833 & 5.4044 & TST & & & \\
\hline CHEMBL1301261 & 688653 & \multicolumn{3}{|c|}{5.132999999999999} & \multicolumn{2}{|c|}{5.632999999999999} & TRN \\
\hline CHEMBL1608358 & 688653 & \multicolumn{3}{|c|}{5.632999999999999} & 5.1888 & TST & \\
\hline CHEMBL1317703 & 688653 & 4.883 & 5.3439 & TRN & & & \\
\hline CHEMBL1364733 & 688653 & 6.233 & 5.3671 & TST & & & \\
\hline CHEMBL1497868 & 688653 & 5.183 & 5.0054 & TRN & & & \\
\hline CHEMBL1412736 & 688653 & 5.433 & 5.5131 & TRN & & & \\
\hline CHEMBL1490792 & 688653 & 5.683 & 5.524 & TST & & & \\
\hline CHEMBL1463407 & 688653 & 4.783 & 4.7871 & TRN & & & \\
\hline CHEMBL 3190622 & 688653 & 4.883 & 5.3554 & TRN & & & \\
\hline CHEMBL1392787 & 688653 & \multicolumn{3}{|c|}{5.5329999999999995} & 5.1749 & TRN & \\
\hline CHEMBL1501741 & 688653 & \multicolumn{3}{|c|}{6.082999999999999} & 5.0236 & TST & \\
\hline CHEMBL 3195831 & 688653 & \multicolumn{3}{|c|}{4.7330000000000005} & 5.0345 & TRN & \\
\hline CHEMBL1492000 & 688653 & \multicolumn{3}{|c|}{5.2829999999999995} & 5.5083 & TST & \\
\hline CHEMBL1526677 & 688653 & 4.783 & 5.235 & TRN & & & \\
\hline CHEMBL1390641 & 688653 & 6.7331 & 5.9679 & TRN & & & \\
\hline CHEMBL1404678 & 688653 & 5.733 & 5.2151 & TRN & & & \\
\hline CHEMBL1592350 & 688653 & 5.183 & 5.1127 & TRN & & & \\
\hline CHEMBL1343605 & 688653 & \multicolumn{3}{|c|}{5.7829999999999995} & 4.7384 & TRN & \\
\hline CHEMBL3196515 & 688653 & 5.083 & 5.1399 & TST & & & \\
\hline CHEMBL 1461170 & 688653 & 5.733 & 5.5025 & TRN & & & \\
\hline CHEMBL1442017 & 688653 & \multicolumn{3}{|c|}{4.9830000000000005} & 5.3525 & TST & \\
\hline CHEMBL1334307 & 688653 & \multicolumn{3}{|c|}{6.382999999999999} & 5.0025 & TST & \\
\hline CHEMBL1335085 & 688653 & \multicolumn{3}{|c|}{4.9830000000000005} & 5.4676 & TRN & \\
\hline CHEMBL1540822 & 688653 & 4.833 & 5.3124 & TRN & & & \\
\hline CHEMBL 1413640 & 688653 & 4.783 & 5.2721 & TRN & & & \\
\hline CHEMBL1318477 & 688653 & 4.633 & 5.2648 & TST & & & \\
\hline CHEMBL1384374 & 688653 & \multicolumn{3}{|c|}{5.632999999999999} & 5.3186 & TRN & \\
\hline CHEMBL3191951 & 688653 & 4.633 & 5.6415 & TRN & & & \\
\hline CHEMBL1301125 & 688653 & \multicolumn{3}{|c|}{5.382999999999999} & 5.5619 & TST & \\
\hline CHEMBL 2000122 & 688653 & \multicolumn{3}{|c|}{6.5329999999999995} & 5.7477 & TRN & \\
\hline CHEMBL1331809 & 688653 & 5.433 & 4.9778 & TST & & & \\
\hline CHEMBL1578342 & 688653 & 5.233 & 5.3917 & TRN & & & \\
\hline CHEMBL1308619 & 688653 & 4.783 & 5.1469 & TRN & & & \\
\hline CHEMBL1422220 & 688653 & \multicolumn{3}{|c|}{5.2829999999999995} & 5.1594 & TRN & \\
\hline CHEMBL1365153 & 688653 & 4.933 & 4.8908 & TST & & & \\
\hline CHEMBL1399456 & 688653 & \multicolumn{3}{|c|}{4.9830000000000005} & 5.2834 & TRN & \\
\hline CHEMBL1475743 & 688653 & 6.433 & 5.8447 & TRN & & & \\
\hline CHEMBL1546836 & 688653 & \multicolumn{3}{|c|}{5.832999999999999} & 5.5185 & TRN & \\
\hline CHEMBL1499976 & 688653 & 6.183 & 5.3372 & TST & & & \\
\hline CHEMBL1502572 & 688653 & 5.033 & 5.2394 & TRN & & & \\
\hline CHEMBL1496792 & 688653 & \multicolumn{3}{|c|}{4.7330000000000005} & 4.8187 & TRN & \\
\hline CHEMBL1446596 & 688653 & 5.733 & 5.1722 & TRN & & & \\
\hline CHEMBL1355404 & 688653 & 4.883 & 4.954 & TST & & & \\
\hline CHEMBL1373732 & 688653 & 5.233 & 4.8908 & TST & & & \\
\hline CHEMBL1575223 & 688653 & 4.933 & 5.4723 & TRN & & & \\
\hline
\end{tabular}




\begin{tabular}{|c|c|c|c|c|c|c|}
\hline \multirow[b]{2}{*}{ CHEMBL1547495 } & \multicolumn{6}{|c|}{ मетा } \\
\hline & 688653 & 4.783 & 5.289 & TRN & & \\
\hline CHEMBL1353316 & 688653 & 4.883 & 5.1137 & TST & & \\
\hline CHEMBL1578743 & 688653 & \multicolumn{3}{|c|}{5.332999999999999} & 5.465 & TST \\
\hline CHEMBL1377188 & 688653 & \multicolumn{3}{|c|}{5.5329999999999995} & 5.1219 & \\
\hline CHEMBL1376949 & 688653 & \multicolumn{3}{|c|}{6.332999999999999} & 5.8047 & \\
\hline CHEMBL1365927 & 688653 & 5.683 & 5.2121 & TRN & & \\
\hline CHEMBL1442840 & 688653 & \multicolumn{3}{|c|}{5.832999999999999} & 5.443 & TRN \\
\hline CHEMBL1370760 & 688653 & \multicolumn{3}{|c|}{4.7330000000000005} & 5.0785 & \\
\hline CHEMBL1465644 & 688653 & 4.833 & 5.121 & TST & & \\
\hline CHEMBL1301409 & 688653 & 4.783 & 5.3145 & TST & & \\
\hline CHEMBL1578663 & 688653 & \multicolumn{3}{|c|}{4.7330000000000005} & 5.1401 & $\mathrm{~T}$ \\
\hline CHEMBL1549607 & 688653 & 4.783 & 5.1096 & TST & & \\
\hline CHEMBL1348468 & 688653 & 4.833 & 5.1117 & TST & & \\
\hline CHEMBL1327783 & 688653 & 4.833 & 5.1755 & TRN & & \\
\hline CHEMBL1484711 & 688653 & \multicolumn{3}{|c|}{5.2829999999999995} & 5.231 & \\
\hline CHEMBL1607932 & 688653 & \multicolumn{3}{|c|}{5.2829999999999995} & 5.9217 & \\
\hline CHEMBL1421254 & 688653 & \multicolumn{3}{|c|}{5.382999999999999} & 5.0826 & TST \\
\hline CHEMBL1362237 & 688653 & 4.683 & 4.8819 & TST & & \\
\hline CHEMBL1592073 & 688653 & 4.633 & 5.0344 & TST & & \\
\hline CHEMBL1475099 & 688653 & 4.633 & 5.0932 & TST & & \\
\hline CHEMBL1428897 & 688653 & \multicolumn{3}{|c|}{5.7829999999999995} & 5.4114 & TRN \\
\hline CHEMBL1575750 & 688653 & \multicolumn{3}{|c|}{4.7330000000000005} & 5.2782 & TRN \\
\hline CHEMBL1505977 & 688653 & \multicolumn{3}{|c|}{5.132999999999999} & 5.2677 & TRN \\
\hline CHEMBL3197750 & 688653 & 5.433 & 5.5831 & TRN & & \\
\hline CHEMBL1443596 & 688653 & \multicolumn{3}{|c|}{5.332999999999999} & 5.1439 & TST \\
\hline CHEMBL1372729 & 688653 & 4.833 & 5.4195 & TST & & \\
\hline CHEMBL1327172 & 688653 & 4.633 & 5.2545 & TRN & & \\
\hline CHEMBL1997220 & 688653 & 5.233 & 5.8821 & TRN & & \\
\hline CHEMBL1489382 & 688653 & 4.783 & 5.2084 & TST & & \\
\hline CHEMBL1540119 & 688653 & 5.183 & 4.8446 & TRN & & \\
\hline CHEMBL1423879 & 688653 & \multicolumn{3}{|c|}{6.632999999999999} & 5.5313 & TRN \\
\hline CHEMBL1556764 & 688653 & \multicolumn{3}{|c|}{4.7330000000000005} & & TRN \\
\hline CHEMBL1968356 & 688653 & 6.4829 & 5.4617 & TST & & \\
\hline CHEMBL1604707 & 688653 & \multirow{2}{*}{\multicolumn{3}{|c|}{$\begin{array}{lcc}5.433 & 5.402 & \text { TRN } \\
5.832999999999999\end{array}$}} & & \\
\hline CHEMBL148 & 688653 & & & & 5.4369 & $\mathrm{TH}$ \\
\hline CHEMBL1483819 & 688653 & 4.833 & 5.2647 & TST & & \\
\hline CHEMBL1420629 & 688653 & \multicolumn{3}{|c|}{5.582999999999999} & 5.1963 & TS \\
\hline CHEMBL1457815 & 688653 & 5.033 & 5.294 & TRN & & \\
\hline CHEMBL 3190260 & 688653 & 5.683 & 5.8658 & TRN & & \\
\hline CHEMBL1595525 & 688653 & \multicolumn{3}{|c|}{4.7330000000000005} & 5.4914 & TRN \\
\hline CHEMBL579322 & 688653 & \multicolumn{3}{|c|}{5.382999999999999} & 5.6226 & TRN \\
\hline CHEMBL1540446 & 688653 & 4.633 & 4.8785 & TRN & & \\
\hline CHEMBL1455616 & 688653 & 5.3329 & 99999999 & & 5.2004 & TST \\
\hline CHEMBL1360584 & 688653 & 5.1329 & 99999999 & & 5.115 & TRN \\
\hline CHEMBL1349937 & 688653 & 5.733 & 5.5954 & TRN & & \\
\hline CHEMBL1518168 & 688653 & 5.183 & 4.7283 & TST & & \\
\hline CHEMBL3211892 & 688653 & 4.883 & 4.9273 & TST & & \\
\hline CHEMBL1556098 & 688653 & 4.833 & 5.3303 & TST & & \\
\hline
\end{tabular}




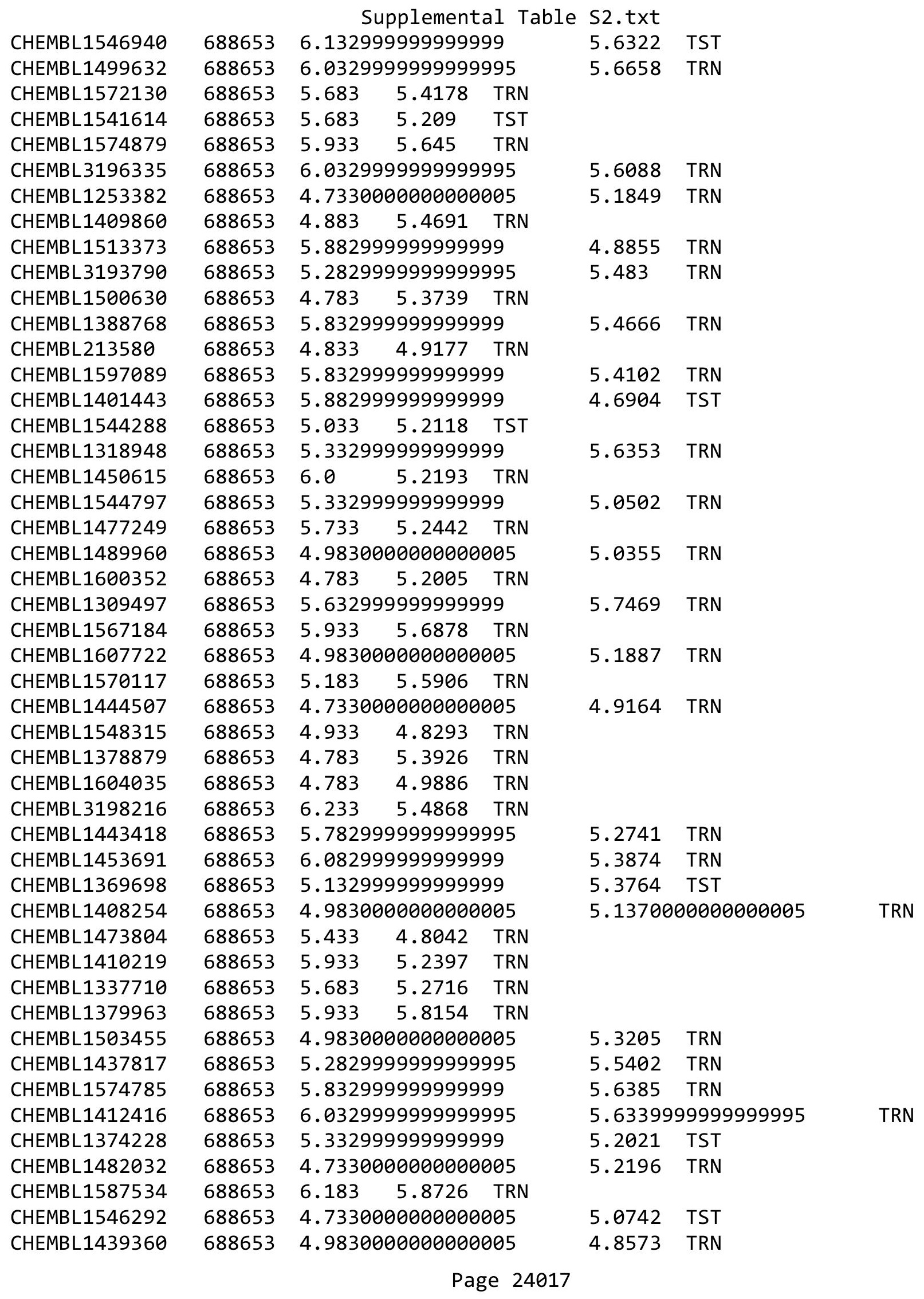




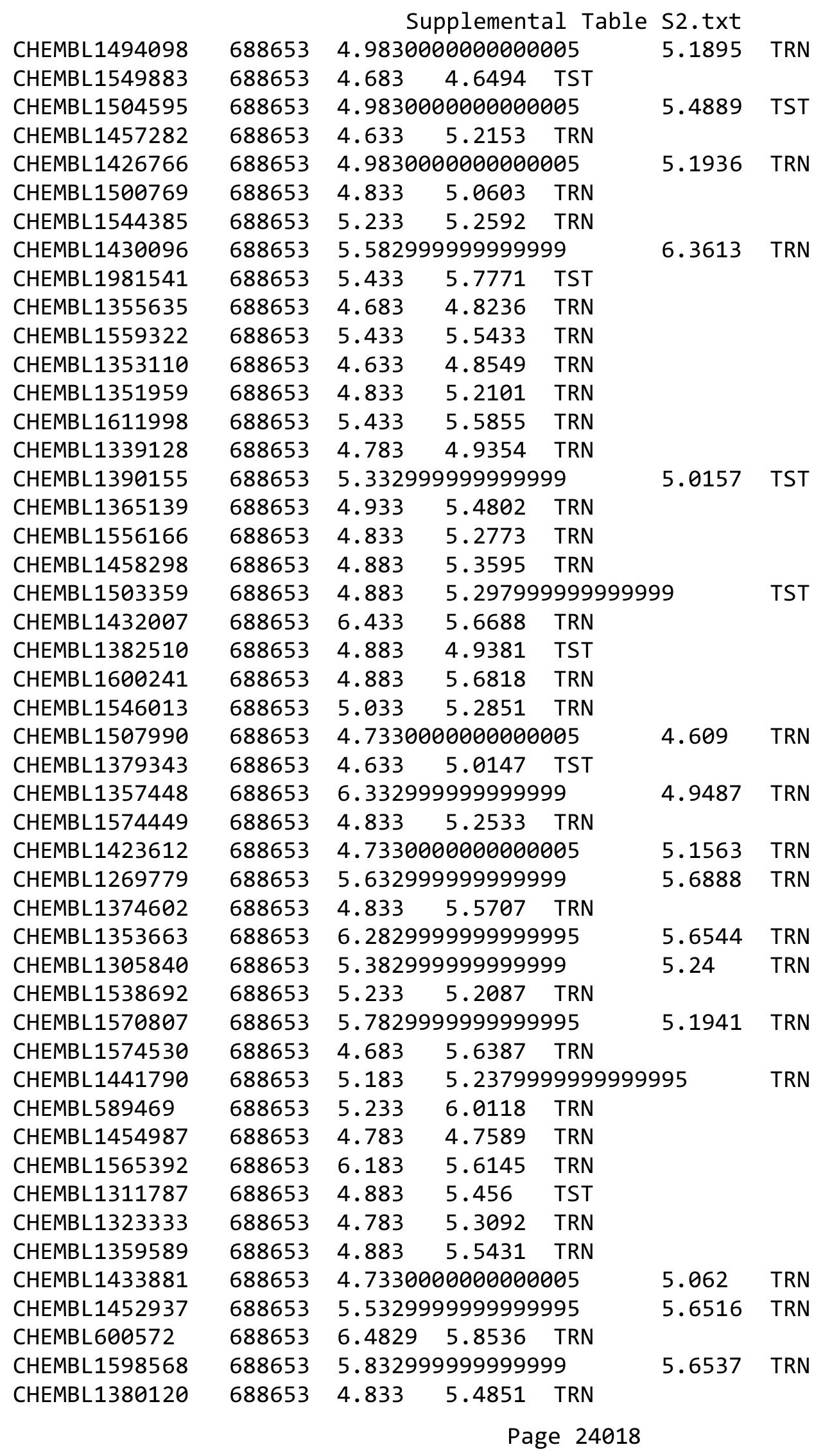




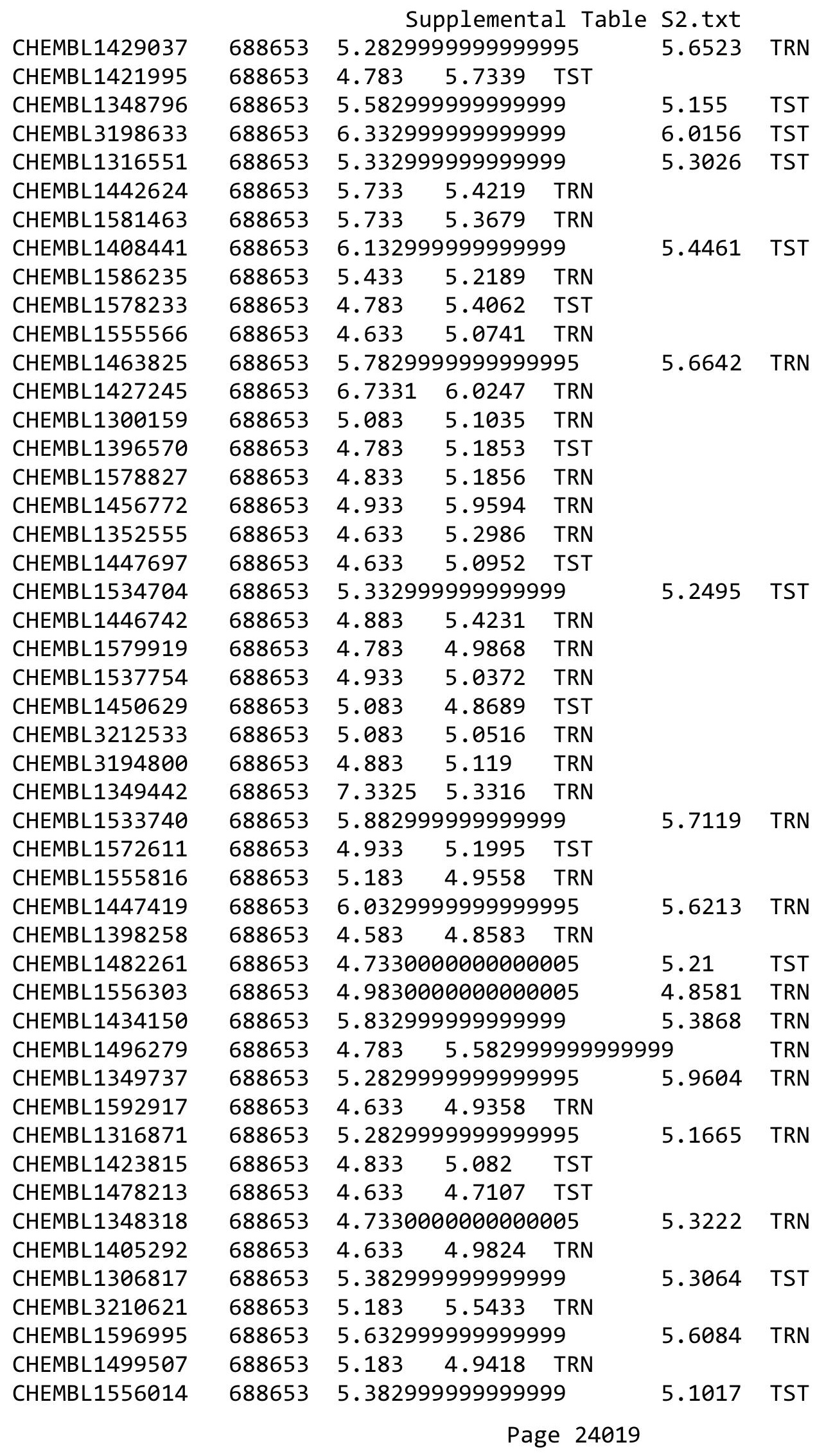





\begin{tabular}{|c|c|c|c|c|c|c|c|}
\hline \multicolumn{8}{|c|}{ Supplemental Table s2.txt } \\
\hline CHEMBL1419585 & 688653 & 4.933 & 4.7563 & TST & & & \\
\hline CHEMBL1996833 & 688653 & 5.733 & 5.5916 & TRN & & & \\
\hline CHEMBL1398662 & 688653 & 4.883 & 5.4151 & TRN & & & \\
\hline CHEMBL1549026 & 688653 & 4.883 & 5.0829 & TRN & & & \\
\hline CHEMBL1300942 & 688653 & \multicolumn{3}{|c|}{4.9830000000000005} & 5.2401 & TST & \\
\hline CHEMBL1514570 & 688653 & 4.783 & 4.9303 & TRN & & & \\
\hline CHEMBL1431767 & 688653 & 4.933 & 5.3697 & TRN & & & \\
\hline CHEMBL1421679 & 688653 & \multicolumn{3}{|c|}{6.0329999999999995} & 5.0704 & TRN & \\
\hline CHEMBL1348062 & 688653 & \multicolumn{3}{|c|}{4.9830000000000005} & \multicolumn{2}{|c|}{5.513999999999999} & TRN \\
\hline CHEMBL1602754 & 688653 & 5.733 & 5.8704 & TRN & & & \\
\hline CHEMBL1454641 & 688653 & 4.583 & 5.153 & TST & & & \\
\hline CHEMBL1328375 & 688653 & \multicolumn{3}{|c|}{5.5329999999999995} & 5.1906 & TRN & \\
\hline CHEMBL1410152 & 688653 & 5.733 & 5.1671 & TRN & & & \\
\hline CHEMBL1382847 & 688653 & 5.983 & 5.1123 & TST & & & \\
\hline CHEMBL1490774 & 688653 & 5.033 & 5.1891 & TST & & & \\
\hline CHEMBL1362574 & 688653 & 4.683 & 5.6036 & TRN & & & \\
\hline CHEMBL1525541 & 688653 & \multicolumn{3}{|c|}{5.832999999999999} & 5.5612 & TRN & \\
\hline CHEMBL1575869 & 688653 & 4.883 & 5.0885 & TST & & & \\
\hline CHEMBL1575747 & 688653 & 4.833 & 5.1674 & TRN & & & \\
\hline CHEMBL1464424 & 688653 & 7.2328 & 5.94 & TRN & & & \\
\hline CHEMBL1538690 & 688653 & 4.883 & 4.8046 & TST & & & \\
\hline CHEMBL1353759 & 688653 & \multicolumn{3}{|c|}{6.632999999999999} & 6.0857 & TRN & \\
\hline CHEMBL1527473 & 688653 & 6.4829 & 5.7442 & TRN & & & \\
\hline CHEMBL3197079 & 688653 & \multicolumn{3}{|c|}{5.7829999999999995} & 5.4276 & TRN & \\
\hline CHEMBL1410311 & 688653 & 4.883 & 5.4884 & TST & & & \\
\hline CHEMBL1550164 & 688653 & 4.783 & 4.9574 & TRN & & & \\
\hline CHEMBL1401668 & 688653 & 4.633 & 4.8202 & TST & & & \\
\hline CHEMBL1584686 & 688653 & \multicolumn{3}{|c|}{5.132999999999999} & 5.1334 & TST & \\
\hline CHEMBL1444655 & 688653 & 4.933 & 4.9755 & TRN & & & \\
\hline CHEMBL1313411 & 688653 & 5.733 & 5.3205 & TRN & & & \\
\hline CHEMBL1543201 & 688653 & 4.883 & 5.0453 & TRN & & & \\
\hline CHEMBL1321572 & 688653 & \multicolumn{3}{|c|}{4.7330000000000005} & 4.9457 & TST & \\
\hline CHEMBL1449495 & 688653 & \multicolumn{3}{|c|}{5.2829999999999995} & 5.9387 & TRN & \\
\hline CHEMBL3197917 & 688653 & 5.233 & 4.9597 & TST & & & \\
\hline CHEMBL1453421 & 688653 & 5.733 & 5.3243 & TRN & & & \\
\hline CHEMBL1973669 & 688653 & 4.683 & 5.7024 & TRN & & & \\
\hline CHEMBL3195992 & 688653 & \multicolumn{3}{|c|}{6.082999999999999} & 5.4702 & TRN & \\
\hline CHEMBL1312469 & 688653 & \multicolumn{3}{|c|}{4.9830000000000005} & 4.91100 & 00000000005 & TRN \\
\hline CHEMBL1499925 & 688653 & \multicolumn{3}{|c|}{5.632999999999999} & 5.8269 & TRN & \\
\hline CHEMBL1411818 & 688653 & 5.083 & 5.6824 & TRN & & & \\
\hline CHEMBL1431572 & 688653 & 4.933 & 4.9178 & TRN & & & \\
\hline CHEMBL1429585 & 688653 & 5.183 & 5.4134 & TRN & & & \\
\hline CHEMBL1310111 & 688653 & 4.783 & 5.3791 & TST & & & \\
\hline CHEMBL1362617 & 688653 & 4.933 & 5.0052 & TST & & & \\
\hline CHEMBL1529092 & 688653 & 6.33299 & 99999999 & & 5.5424 & TRN & \\
\hline CHEMBL1457810 & 688653 & 4.73300 & 00000000 & 005 & 5.2771 & TRN & \\
\hline CHEMBL1399633 & 688653 & 4.833 & 4.9298 & TRN & & & \\
\hline CHEMBL1568951 & 688653 & 5.38299 & 99999999 & & 5.5369 & TRN & \\
\hline
\end{tabular}




\begin{tabular}{|c|c|c|c|c|c|c|}
\hline & & \multicolumn{5}{|c|}{ Supplemental Table s2.txt } \\
\hline CHEMBL1606694 & 688653 & 4.783 & 5.0565 & TRN & & \\
\hline CHEMBL1477805 & 688653 & 4.633 & 5.2084 & TRN & & \\
\hline CHEMBL1510935 & 688653 & 5.183 & 5.4786 & TRN & & \\
\hline CHEMBL3193057 & 688653 & \multicolumn{3}{|c|}{5.132999999999999} & 5.1875 & $\mathrm{TS}$ \\
\hline CHEMBL1999538 & 688653 & 4.833 & 5.1182 & TST & & \\
\hline CHEMBL1612852 & 688653 & 5.183 & 5.0149 & TRN & & \\
\hline CHEMBL1435972 & 688653 & 4.883 & 5.5913 & TRN & & \\
\hline CHEMBL1530374 & 688653 & \multicolumn{3}{|c|}{5.5329999999999995} & 5.2298 & TRN \\
\hline CHEMBL1593154 & 688653 & \multicolumn{3}{|c|}{5.2829999999999995} & 5.5722 & \\
\hline CHEMBL1555900 & 688653 & \multicolumn{3}{|c|}{4.7330000000000005} & 4.573 & \\
\hline CHEMBL1307593 & 688653 & 4.783 & 5.1413 & TRN & & \\
\hline CHEMBL1339878 & 688653 & 4.933 & 5.2159 & TRN & & \\
\hline CHEMBL1527772 & 688653 & \multicolumn{3}{|c|}{4.9830000000000005} & 5.1732 & \\
\hline CHEMBL1412085 & 688653 & 4.883 & 5.2332 & TRN & & \\
\hline CHEMBL1423212 & 688653 & 4.833 & 5.2557 & TRN & & \\
\hline CHEMBL1310806 & 688653 & \multicolumn{3}{|c|}{4.7330000000000005} & 5.193 & \\
\hline CHEMBL1332598 & 688653 & 4.883 & 5.2151 & TRN & & \\
\hline CHEMBL1354238 & 688653 & 4.933 & 5.0619 & TRN & & \\
\hline CHEMBL1441476 & 688653 & 5.083 & 5.7229 & TRN & & \\
\hline CHEMBL1533469 & 688653 & 7.1831 & 5.6497 & TST & & \\
\hline CHEMBL3189735 & 688653 & \multicolumn{3}{|c|}{5.132999999999999} & 2 & \\
\hline CHEMBL1901606 & 688653 & 4.633 & 5.2084 & TRN & & \\
\hline CHEMBL1348618 & 688653 & \multicolumn{3}{|c|}{5.832999999999999} & 5.1661 & \\
\hline CHEMBL1578433 & 688653 & 4.783 & 5.1673 & TRN & & \\
\hline CHEMBL1355234 & 688653 & \multicolumn{3}{|c|}{5.5329999999999995} & 5.5204 & $\mathrm{TI}$ \\
\hline CHEMBL1517195 & 688653 & 4.783 & 5.2613 & TRN & & \\
\hline CHEMBL1578386 & 688653 & 4.633 & 4.5962 & TRN & & \\
\hline CHEMBL1610640 & 688653 & \multicolumn{3}{|c|}{5.832999999999999} & 5.7185 & TP \\
\hline CHEMBL1427517 & 688653 & 5.433 & 5.5018 & TST & & \\
\hline CHEMBL1543393 & 688653 & \multicolumn{3}{|c|}{5.5329999999999995} & 296 & TR \\
\hline CHEMBL3210013 & 688653 & 5.733 & 5.2558 & TRN & & \\
\hline CHEMBL1 & 688653 & \multicolumn{3}{|c|}{5.632999999999999} & & וכנו \\
\hline CHEMBL 23 & 688653 & \multicolumn{3}{|c|}{4.7330000000000005} & 5.0018 & TRN \\
\hline CHEMBL3196346 & 688653 & 4.833 & 4.7904 & TRN & & \\
\hline CHEMBL1365045 & 688653 & 4.833 & 4.8056 & TRN & & \\
\hline CHEMBL1563797 & 688653 & & 5.1559 & TRN & & \\
\hline CHEMBL1 & 688653 & & 5.056 & TRN & & \\
\hline CHEMBL15 & 688653 & 4.633 & 4.8063 & TRN & & \\
\hline CHEMBL1442460 & 688653 & \multicolumn{3}{|c|}{5.632999999999999} & 5.8225 & TST \\
\hline CHEMBL1313477 & 688653 & \multicolumn{3}{|c|}{5.2829999999999995} & 5.3854 & $T D M$ \\
\hline CHEMBL1494038 & 688653 & 5.183 & 5.0655 & TST & & \\
\hline CHEMBL1609033 & 688653 & \multicolumn{3}{|c|}{5.832999999999999} & 5.6587 & TRN \\
\hline CHEMBL1613237 & 688653 & 4.583 & 4.575 & TRN & & \\
\hline CHEMBL1332871 & 688653 & 5.183 & 5.445 & TRN & & \\
\hline CHEMBL1493353 & 688653 & 4.933 & 5.3765 & TST & & \\
\hline CHEMBL1607848 & 688653 & \multicolumn{3}{|c|}{4.7330000000000005} & 4.9001 & \\
\hline CHEMBL1305886 & 688653 & \multicolumn{3}{|c|}{5.5329999999999995} & 5.2882 & TRN \\
\hline CHEMBL1544147 & 688653 & 4.833 & 5.5511 & TRN & & \\
\hline
\end{tabular}




\begin{tabular}{|c|c|c|c|c|c|c|}
\hline \multirow[b]{2}{*}{ CHEMBL526776 } & \multirow[b]{2}{*}{688653} & \multicolumn{5}{|c|}{ Supplemental Table S2.txt } \\
\hline & & \multirow{2}{*}{\multicolumn{3}{|c|}{5.6948 TRN }} & & \\
\hline CHEMBL1535988 & 688653 & & & & 5.3626 & TRN \\
\hline CHEMBL1413042 & 688653 & \multicolumn{3}{|c|}{5.7829999999999995} & 5.2343 & TRN \\
\hline CHEMBL1493226 & 688653 & 5.433 & 5.3793 & TST & & \\
\hline CHEMBL3209559 & 688653 & \multicolumn{3}{|c|}{5.132999999999999} & 5.1892 & TRN \\
\hline CHEMBL1585906 & 688653 & 5.033 & 5.6799 & TRN & & \\
\hline CHEMBL1315549 & 688653 & 4.833 & 4.7386 & TRN & & \\
\hline CHEMBL1362195 & 688653 & \multicolumn{3}{|c|}{4.7330000000000005} & 4.8233 & TST \\
\hline CHEMBL1420649 & 688653 & 4.833 & 4.9484 & TST & & \\
\hline CHEMBL1505472 & 688653 & 5.683 & \multicolumn{3}{|c|}{5.2010000000000005} & TRN \\
\hline CHEMBL477396 & 688653 & \multicolumn{3}{|c|}{5.7829999999999995} & 5.8468 & TRN \\
\hline CHEMBL1463953 & 688653 & \multicolumn{3}{|c|}{4.7330000000000005} & 5.4889 & TRN \\
\hline CHEMBL1540982 & 688653 & \multicolumn{3}{|c|}{4.7330000000000005} & 5.4695 & TST \\
\hline CHEMBL1580449 & 688653 & 4.933 & 5.1002 & TST & & \\
\hline CHEMBL1551605 & 688653 & 5.433 & 5.1637 & TRN & & \\
\hline CHEMBL1569897 & 688653 & 4.783 & 5.033 & TRN & & \\
\hline CHEMBL1545553 & 688653 & \multicolumn{3}{|c|}{4.7330000000000005} & 5.2773 & TST \\
\hline CHEMBL1381275 & 688653 & 4.933 & 4.9767 & TRN & & \\
\hline CHEMBL1320504 & 688653 & \multicolumn{3}{|c|}{6.382999999999999} & 5.3058 & TRN \\
\hline CHEMBL1483840 & 688653 & 4.833 & 5.1686 & TST & & \\
\hline CHEMBL1493725 & 688653 & \multicolumn{3}{|c|}{6.132999999999999} & 5.8807 & TRN \\
\hline CHEMBL1401392 & 688653 & 4.783 & 5.6172 & TRN & & \\
\hline CHEMBL1606586 & 688653 & & & TRN & & \\
\hline CHEMBL1540432 & 688653 & \multicolumn{3}{|c|}{4.7330000000000005} & 5.2226 & TRN \\
\hline CHEMBL1331300 & 688653 & 7.0329 & 5.7985 & TRN & & \\
\hline CHEMBL1301273 & 688653 & 4.833 & 4.982 & TST & & \\
\hline CHEMBL1511183 & 688653 & \multicolumn{3}{|c|}{4.7330000000000005} & 5.3033 & TRN \\
\hline CHEMBL1502184 & 688653 & 5.933 & 5.5803 & TRN & & \\
\hline CHEMBL1318880 & 688653 & \multirow{2}{*}{\multicolumn{3}{|c|}{$\begin{array}{ll}4.833 & 5.2081 \\
5.132999999999999\end{array}$}} & & \\
\hline CHEMBL1580434 & 688653 & & & & 5.3792 & TST \\
\hline CHEMBL1300305 & 688653 & 4.783 & 5.0006 & TRN & & \\
\hline CHEMBL1390241 & 688653 & 5.083 & 5.0445 & TRN & & \\
\hline CHEMBL1325596 & 688653 & 5.433 & 5.3332 & TST & & \\
\hline CHEMBL1358044 & 688653 & \multicolumn{3}{|c|}{5.832999999999999} & 5.2543 & TST \\
\hline CHEMBL1353226 & 688653 & \multicolumn{3}{|c|}{5.5329999999999995} & 5.5542 & TST \\
\hline CHEMBL1312263 & 688653 & 5.183 & 5.526 & TRN & & \\
\hline CHEMBL1542228 & 688653 & 4.933 & 5.2925 & TRN & & \\
\hline CHEMBL1411900 & 688653 & \multicolumn{3}{|c|}{6.132999999999999} & 5.2707 & TRN \\
\hline CHEMBL1398171 & 688653 & \multicolumn{3}{|c|}{6.382999999999999} & 5.68 & TRN \\
\hline CHEMBL1328241 & 688653 & 4.783 & 5.4017 & TST & & \\
\hline CHEMBL1410730 & 688653 & 5.233 & 5.3431 & TST & & \\
\hline CHEMBL1530566 & 688653 & 5.183 & 5.3095 & TRN & & \\
\hline CHEMBL1480534 & 688653 & 5.83299 & 999999999 & & 5.6377 & TRN \\
\hline CHEMBL1542620 & 688653 & 4.833 & 4.9412 & TRN & & \\
\hline CHEMBL191015 & 688653 & 6.38299 & 999999999 & & 5.8561 & TRN \\
\hline CHEMBL1307050 & 688653 & 5.233 & 5.3895 & TRN & & \\
\hline CHEMBL1491836 & 688653 & 4.783 & 5.1126 & TRN & & \\
\hline CHEMBL3208987 & 688653 & 5.183 & 5.5289 & TRN & & \\
\hline
\end{tabular}




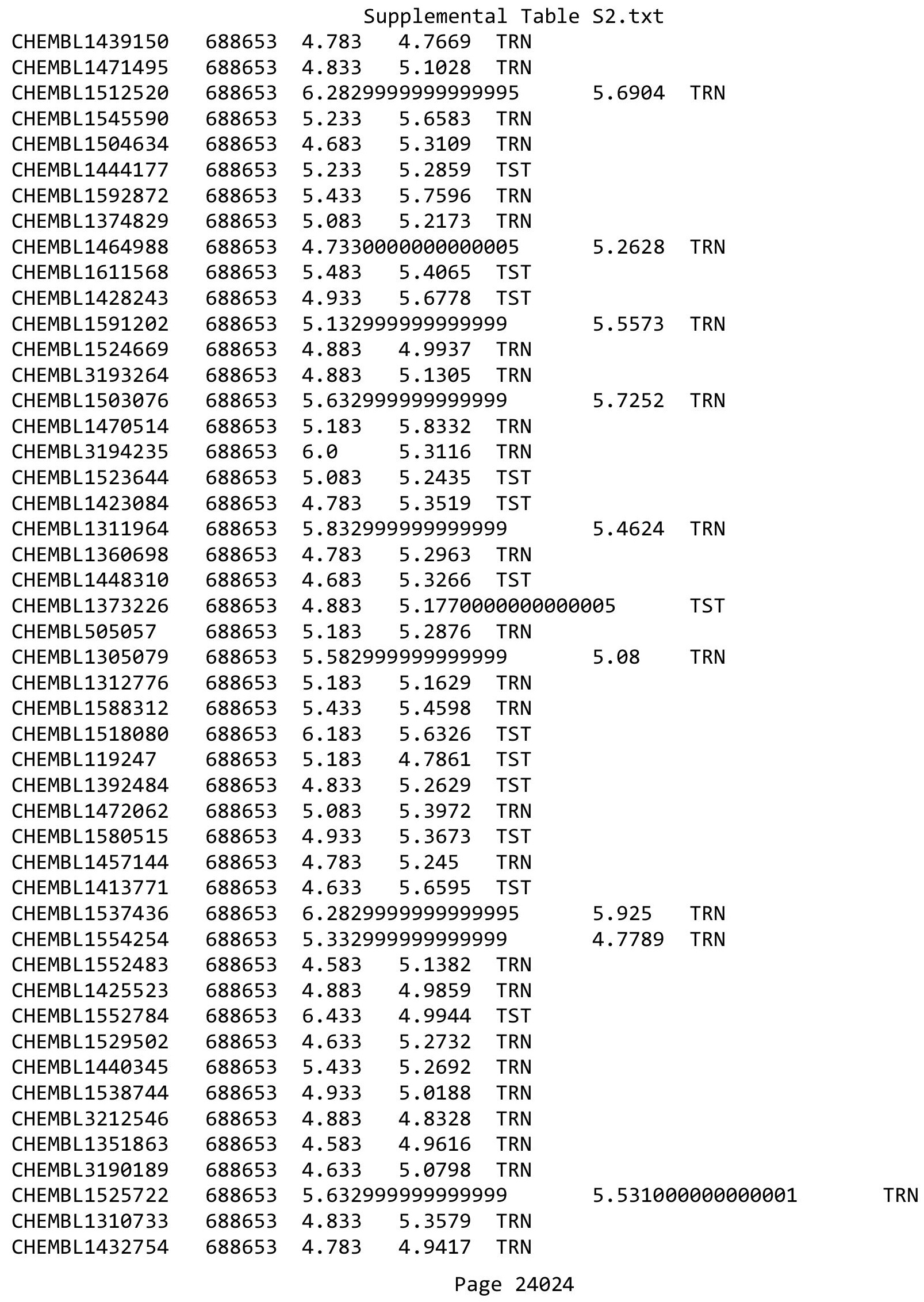




\begin{tabular}{|c|c|c|c|c|c|c|}
\hline & & \multicolumn{5}{|c|}{ Supplemental Table S2.txt } \\
\hline CHEMBL1341593 & 688653 & \multicolumn{4}{|c|}{4.7330000000000005} & TRN \\
\hline CHEMBL1385837 & 688653 & \multicolumn{3}{|c|}{4.9830000000000005} & 5.1727 & TRN \\
\hline CHEMBL1356974 & 688653 & 6.433 & 5.6055 & TRN & & \\
\hline CHEMBL1389975 & 688653 & \multicolumn{3}{|c|}{5.7829999999999995} & 5.9329 & TRN \\
\hline CHEMBL1596930 & 688653 & 4.583 & 4.9813 & TRN & & \\
\hline CHEMBL1507486 & 688653 & \multicolumn{3}{|c|}{4.7330000000000005} & 5.2854 & TST \\
\hline CHEMBL1550196 & 688653 & 4.833 & 5.2042 & TRN & & \\
\hline CHEMBL1566931 & 688653 & 5.733 & 5.6056 & TRN & & \\
\hline CHEMBL1548306 & 688653 & 4.683 & 5.2905 & TRN & & \\
\hline CHEMBL1422046 & 688653 & 5.433 & 5.8859 & TRN & & \\
\hline CHEMBL1397448 & 688653 & 5.183 & 5.2094 & TRN & & \\
\hline CHEMBL1360402 & 688653 & \multicolumn{3}{|c|}{4.7330000000000005} & 5.2023 & TRN \\
\hline CHEMBL1529860 & 688653 & 5.083 & 5.8179 & TRN & & \\
\hline CHEMBL1438406 & 688653 & \multicolumn{3}{|c|}{6.5329999999999995} & 5.686 & TRN \\
\hline CHEMBL1409468 & 688653 & \multicolumn{3}{|c|}{5.882999999999999} & 5.7114 & TRN \\
\hline CHEMBL1321743 & 688653 & \multicolumn{3}{|c|}{4.7330000000000005} & 5.2225 & TRN \\
\hline CHEMBL1425843 & 688653 & \multicolumn{3}{|c|}{5.632999999999999} & 5.7589 & TRN \\
\hline CHEMBL1445361 & 688653 & \multicolumn{3}{|c|}{5.332999999999999} & 5.1219 & TST \\
\hline CHEMBL1418237 & 688653 & 5.933 & 5.5185 & TRN & & \\
\hline CHEMBL1339208 & 688653 & 4.633 & 4.7836 & TRN & & \\
\hline CHEMBL1446039 & 688653 & \multicolumn{3}{|c|}{6.332999999999999} & 6.0693 & TRN \\
\hline CHEMBL1609596 & 688653 & 4.833 & 5.0105 & TRN & & \\
\hline CHEMBL1533450 & 688653 & & 4.7632 & TRN & & \\
\hline CHEMBL601140 & 688653 & \multicolumn{3}{|c|}{4.7330000000000005} & 5.1116 & TRN \\
\hline CHEMBL1610263 & 688653 & 5.483 & 5.8808 & TST & & \\
\hline CHEMBL1486395 & 688653 & 4.883 & 5.3217 & TRN & & \\
\hline CHEMBL1305239 & 688653 & 6.433 & 6.2707 & TRN & & \\
\hline CHEMBL1607080 & 688653 & \multicolumn{3}{|c|}{4.7330000000000005} & 5.2042 & TST \\
\hline CHEMBL1320387 & 688653 & 4.633 & 4.8834 & TRN & & \\
\hline CHEMBL1362599 & 688653 & 4.783 & 5.0977 & TRN & & \\
\hline CHEMBL1477528 & 688653 & 5.033 & 4.9207 & TRN & & \\
\hline CHEMBL1322034 & 688653 & 5.733 & 5.4555 & TRN & & \\
\hline CHEMBL1605052 & 688653 & 4.633 & 4.6902 & TRN & & \\
\hline CHEMBL1983034 & 688653 & 6.233 & 5.5057 & TST & & \\
\hline CHEMBL1387401 & 688653 & \multicolumn{3}{|c|}{5.132999999999999} & 5.0962 & TST \\
\hline CHEMBL1367306 & 688653 & \multicolumn{3}{|c|}{4.7330000000000005} & 5.5058 & TRN \\
\hline CHEMBL1544497 & 688653 & 5.733 & 5.8764 & TRN & & \\
\hline CHEMBL1519633 & 688653 & \multicolumn{3}{|c|}{5.7829999999999995} & 5.8884 & TST \\
\hline CHEMBL1598834 & 688653 & 4.833 & 4.8858 & TRN & & \\
\hline CHEMBL1413082 & 688653 & \multicolumn{3}{|c|}{5.632999999999999} & 5.539 & TRN \\
\hline CHEMBL3190953 & 688653 & 5.683 & 5.7354 & TRN & & \\
\hline CHEMBL1322004 & 688653 & 4.783 & 4.967 & TRN & & \\
\hline CHEMBL1357138 & 688653 & 5.483 & 4.8379 & TRN & & \\
\hline CHEMBL1562457 & 688653 & 4.783 & 5.6162 & TRN & & \\
\hline CHEMBL1561361 & 688653 & \multicolumn{3}{|c|}{5.132999999999999} & 5.0015 & TST \\
\hline CHEMBL1369691 & 688653 & \multicolumn{3}{|c|}{6.7829999999999995} & 5.4705 & TRN \\
\hline CHEMBL1563668 & 688653 & \multicolumn{3}{|c|}{5.632999999999999} & 5.3827 & TST \\
\hline CHEMBL1311378 & 688653 & 5.083 & 5.0456 & TRN & & \\
\hline
\end{tabular}




\begin{tabular}{|c|c|c|c|c|c|c|}
\hline \multirow[b]{2}{*}{ CHEMBL1328193 } & & \multicolumn{5}{|c|}{ Supplemental Table S2.txt } \\
\hline & 688653 & 4.633 & 5.0462 & TST & & \\
\hline CHEMBL1367139 & 688653 & 4.783 & 5.0146 & TRN & & \\
\hline CHEMBL1434205 & 688653 & 4.783 & 5.2018 & TRN & & \\
\hline CHEMBL1392770 & 688653 & 4.783 & 5.0416 & TRN & & \\
\hline CHEMBL3190791 & 688653 & 4.933 & 5.9466 & TRN & & \\
\hline CHEMBL1521723 & 688653 & \multicolumn{3}{|c|}{5.2829999999999995} & 5.077 & TRN \\
\hline CHEMBL1548989 & 688653 & \multicolumn{3}{|c|}{4.7330000000000005} & 5.6559 & TST \\
\hline CHEMBL1552139 & 688653 & \multicolumn{3}{|c|}{4.9830000000000005} & 5.1503 & TST \\
\hline CHEMBL1494676 & 688653 & \multicolumn{3}{|c|}{6.132999999999999} & 5.5511 & TRN \\
\hline CHEMBL1611997 & 688653 & 4.883 & 4.9561 & TRN & & \\
\hline CHEMBL1348597 & 688653 & 5.083 & 5.6904 & TRN & & \\
\hline CHEMBL1597249 & 688653 & 5.033 & 5.2631 & TRN & & \\
\hline CHEMBL1566519 & 688653 & \multicolumn{3}{|c|}{5.2829999999999995} & 4.9948 & \\
\hline CHEMBL3194460 & 688653 & 4.933 & 5.4901 & TST & & \\
\hline CHEMBL1537082 & 688653 & 4.783 & 5.5795 & TST & & \\
\hline CHEMBL1375246 & 688653 & 5.183 & 5.2647 & TST & & \\
\hline CHEMBL1500227 & 688 & 4.783 & 4.9274 & TRN & & \\
\hline CHEMBL13 & 688653 & \multicolumn{3}{|c|}{5.832999999999999} & 5.5947 & TP \\
\hline CHEMBL1547987 & 688653 & 4.783 & 5.6844 & TRN & & \\
\hline CHEMBL1372155 & 688653 & \multicolumn{3}{|c|}{5.5329999999999995} & 5.5038 & \\
\hline CHEMBL1558117 & 688653 & 4.783 & 5.0837 & TRN & & \\
\hline CHEMBL 32 & 688653 & \multicolumn{3}{|c|}{4.7330000000000005} & 525 & TST \\
\hline CHEMBL13 & 688653 & 4.883 & 5.1695 & TRN & & \\
\hline CHEMBL1344059 & 688653 & 4.633 & 4.8611 & TST & & \\
\hline CHEMBL1576941 & 688653 & 4.633 & 4.855 & TRN & & \\
\hline CHEMBL1561135 & 688653 & 5.233 & 5.3578 & TRN & & \\
\hline CHEMBL: & 688653 & 4.7 & 5.1448 & TRN & & \\
\hline CHEMBL1455814 & 688653 & 6.233 & 6.0208 & TRN & & \\
\hline CHEMBL1607281 & 688653 & \multicolumn{3}{|c|}{5.332999999999999} & 4.9447 & TP \\
\hline CHEMBL1547966 & 688653 & 4.833 & 5.2063 & TST & & \\
\hline CHEMBL1338304 & 688653 & 5.433 & 5.2376 & TRN & & \\
\hline CHEMBL: & 688653 & 4.883 & 4.853 & TST & & \\
\hline CHEMBL1301368 & 688653 & 4.633 & 5.2585 & TRN & & \\
\hline CHEMBL1352810 & 688653 & \multicolumn{3}{|c|}{5.832999999999999} & 5.4503 & TP \\
\hline CHEMBL1568413 & 688653 & 5.233 & 5.0612 & TRN & & \\
\hline CHEMBL1411420 & 688653 & \multicolumn{3}{|c|}{5.132999999999999} & 5.1654 & $1 \mathrm{~K}$ \\
\hline CHEMBL1496371 & 688653 & 4.883 & 5.2857 & TST & & \\
\hline CHEMBL1470388 & 688653 & \multirow{2}{*}{\multicolumn{3}{|c|}{$\begin{array}{lcc}5.183 & 5.1 & \text { TRN } \\
5.7829999999999995\end{array}$}} & & \\
\hline CHEMBL1516891 & 688653 & & & & 5.5908 & TRN \\
\hline CHEMBL1536024 & 688653 & \multicolumn{3}{|c|}{$\begin{array}{lll}4.783 & 4.9248 & \text { TRN }\end{array}$} & & \\
\hline CHEMBL1321291 & 688653 & \multicolumn{3}{|c|}{4.9830000000000005} & 5.2185 & $\mathrm{TR}$ \\
\hline CHEMBL1341325 & 688653 & 4.833 & 5.4305 & TRN & & \\
\hline CHEMBL3196227 & 688653 & \multicolumn{3}{|c|}{5.882999999999999} & 5.7699 & $\mathrm{TR}$ \\
\hline CHEMBL1497555 & 688653 & 5.733 & 5.4668 & TRN & & \\
\hline CHEMBL3207610 & 688653 & \multicolumn{3}{|c|}{5.7829999999999995} & 5.4778 & TRN \\
\hline CHEMBL1344238 & 688653 & \multicolumn{3}{|c|}{5.632999999999999} & 5.6202 & TRN \\
\hline CHEMBL3145119 & 688653 & \multicolumn{3}{|c|}{4.9830000000000005} & 4.9274 & TRN \\
\hline CHEMBL1520092 & 688653 & \multicolumn{3}{|c|}{5.7829999999999995} & 5.7883 & TRN \\
\hline & & & & & & \\
\hline
\end{tabular}




\begin{tabular}{|c|c|c|c|c|c|c|c|}
\hline \multicolumn{7}{|c|}{ Supplemental Table S2.txt } & \\
\hline CHEMBL1318818 & 688653 & 5.083 & 5.0685 & TRN & & & \\
\hline CHEMBL1540907 & 688653 & 6.83299 & 99999999 & & 5.907 & TRN & \\
\hline CHEMBL546257 & 688653 & 5.58299 & 99999999 & & 5.2882 & TST & \\
\hline CHEMBL1305960 & 688653 & 4.833 & 4.3817 & TRN & & & \\
\hline CHEMBL 3212227 & 688653 & 5.83299 & 999999995 & & 5.7671 & TRN & \\
\hline CHEMBL1546134 & 688653 & 4.633 & 5.1522 & TST & & & \\
\hline CHEMBL1575374 & 688653 & 6.78299 & 99999999 & 995 & 5.6326 & TRN & \\
\hline CHEMBL1580941 & 688653 & 5.63299 & 99999999ऽ & & 5.2863 & TRN & \\
\hline CHEMBL1343231 & 688653 & 4.833 & 5.0272 & TRN & & & \\
\hline CHEMBL1474098 & 688653 & 4.633 & 4.7271 & TRN & & & \\
\hline CHEMBL1395326 & 688653 & 5.683 & 5.6269 & TRN & & & \\
\hline CHEMBL 1415404 & 688653 & 5.0 & 5.367006 & 000000000 & & TRN & \\
\hline CHEMBL1503192 & 688653 & 5.433 & 5.0533 & TRN & & & \\
\hline CHEMBL1371974 & 688653 & 6.683 & 5.4649 & TRN & & & \\
\hline CHEMBL1374394 & 688653 & 5.033 & 5.4427 & TRN & & & \\
\hline CHEMBL1541379 & 688653 & 4.583 & 4.9213 & TRN & & & \\
\hline CHEMBL1610691 & 688653 & 7.3325 & 6.1842 & TRN & & & \\
\hline CHEMBL1316264 & 688653 & 4.933 & 4.9935 & TRN & & & \\
\hline CHEMBL1529024 & 688653 & 5.183 & 5.3659 & TRN & & & \\
\hline CHEMBL1473089 & 688653 & 4.633 & 5.1654 & TRN & & & \\
\hline CHEMBL1519174 & 688653 & 5.983 & 5.4847 & TRN & & & \\
\hline CHEMBL1566066 & 688653 & 4.783 & 5.109 & TST & & & \\
\hline CHEMBL1590942 & 688653 & 5.83299 & 99999999 & & 5.5071 & TRN & \\
\hline CHEMBL1582739 & 688653 & 4.783 & 4.8528 & TRN & & & \\
\hline CHEMBL1365344 & 688653 & 4.73300 & $00000000 t$ & 005 & 5.082 & TRN & \\
\hline CHEMBL1379530 & 688653 & 5.78299 & 99999999 & 995 & 5.66700 & 0000000001 & TRN \\
\hline CHEMBL1330251 & 688653 & 4.633 & 5.3529 & TST & & & \\
\hline CHEMBL1519962 & 688653 & 5.483 & 5.4732 & TRN & & & \\
\hline CHEMBL1386648 & 688653 & 4.633 & 5.3752 & TST & & & \\
\hline CHEMBL1314713 & 688653 & 5.28299 & 99999999 & 995 & 5.5843 & TRN & \\
\hline CHEMBL1522891 & 688653 & 5.083 & 5.3246 & TRN & & & \\
\hline CHEMBL3192051 & 688653 & 6.63299 & 99999999 & & 5.4428 & TRN & \\
\hline CHEMBL1389978 & 688653 & 4.933 & 5.3942 & TRN & & & \\
\hline CHEMBL1358967 & 688653 & 4.783 & 5.3202 & TRN & & & \\
\hline CHEMBL1354064 & 688653 & 5.733 & 5.8566 & TRN & & & \\
\hline CHEMBL1530023 & 688653 & 5.683 & 5.3942 & TST & & & \\
\hline CHEMBL1598564 & 688653 & 4.98300 & 00000000 & 005 & 4.9496 & TRN & \\
\hline CHEMBL1455756 & 688653 & 7.08299 & 99999999 & & 5.6062 & TRN & \\
\hline CHEMBL1420437 & 688653 & 4.833 & 5.0107 & TRN & & & \\
\hline CHEMBL1303720 & 688653 & 5.683 & 5.371 & TST & & & \\
\hline CHEMBL1330446 & 688653 & 5.63299 & 99999999 & & 5.6101 & TRN & \\
\hline CHEMBL1432416 & 688653 & 5.13299 & 99999999 & & 4.8225 & TRN & \\
\hline CHEMBL1541678 & 688653 & 5.933 & 5.3784 & TRN & & & \\
\hline CHEMBL3196396 & 688653 & 5.183 & 5.41 & TRN & & & \\
\hline CHEMBL1533920 & 688653 & 5.13299 & 99999999 & & 5.0704 & TST & \\
\hline CHEMBL1555223 & 688653 & 4.73300 & 00000000 & 005 & 4.9767 & TRN & \\
\hline CHEMBL1978424 & 688653 & 6.13299 & 99999999 & & 5.4953 & TRN & \\
\hline CHEMBL1331181 & 688653 & 7.1831 & 5.4822 & TRN & & & \\
\hline
\end{tabular}




\begin{tabular}{|c|c|c|c|c|c|c|}
\hline & & \multicolumn{5}{|c|}{ Supplemental Table s2.txt } \\
\hline CHEMBL1373336 & 688653 & 4.833 & 5.5509 & TRN & & \\
\hline CHEMBL1494059 & 688653 & 5.683 & 5.718 & TRN & & \\
\hline CHEMBL1490451 & 688653 & 4.933 & 5.3296 & TRN & & \\
\hline CHEMBL1418976 & 688653 & \multicolumn{3}{|c|}{5.332999999999999} & 5.3325 & TRN \\
\hline CHEMBL1552281 & 688653 & \multicolumn{3}{|c|}{6.0329999999999995} & 5.105 & TRN \\
\hline CHEMBL3198362 & 688653 & 7.0329 & 5.6183 & TRN & & \\
\hline CHEMBL1613425 & 688653 & \multicolumn{3}{|c|}{4.7330000000000005} & 5.0164 & TST \\
\hline CHEMBL1559226 & 688653 & 5.733 & 5.3574 & TRN & & \\
\hline CHEMBL1303663 & 688653 & \multicolumn{3}{|c|}{5.132999999999999} & 5.3739 & TRN \\
\hline CHEMBL1490034 & 688653 & 5.683 & 5.0442 & TRN & & \\
\hline CHEMBL1554073 & 688653 & 4.583 & 4.61 & TRN & & \\
\hline CHEMBL1522136 & 688653 & 4.833 & 5.067 & TRN & & \\
\hline CHEMBL1537615 & 688653 & 4.783 & 5.3214 & TST & & \\
\hline CHEMBL1559145 & 688653 & 4.683 & \multicolumn{3}{|c|}{5.2860000000000005} & TRN \\
\hline CHEMBL1529321 & 688653 & 5.683 & 5.4452 & TRN & & \\
\hline CHEMBL1603268 & 688653 & 5.483 & 5.7723 & TST & & \\
\hline CHEMBL1547039 & 688653 & 5.233 & 5.1456 & TRN & & \\
\hline CHEMBL1592516 & 688653 & 4.883 & 4.9766 & TRN & & \\
\hline CHEMBL1345289 & 688653 & 5.483 & 5.0401 & TRN & & \\
\hline CHEMBL1479078 & 688653 & 4.833 & 4.9044 & TRN & & \\
\hline CHEMBL1477199 & 688653 & 4.883 & 5.2079 & TST & & \\
\hline CHEMBL1557437 & 688653 & \multicolumn{3}{|c|}{6.0329999999999995} & 5.4667 & TST \\
\hline CHEMBL3195584 & 688653 & \multicolumn{3}{|c|}{5.832999999999999} & 5.5492 & TRN \\
\hline CHEMBL1364522 & 688653 & 4.833 & 4.6752 & TST & & \\
\hline CHEMBL1363870 & 688653 & 5.033 & 4.9925 & TST & & \\
\hline CHEMBL1339358 & 688653 & 4.833 & 5.4902 & TRN & & \\
\hline CHEMBL1520801 & 688653 & 5.233 & 5.1439 & TRN & & \\
\hline CHEMBL1579150 & 688653 & \multicolumn{3}{|c|}{5.132999999999999} & 4.8597 & TRN \\
\hline CHEMBL501358 & 688653 & \multicolumn{3}{|c|}{4.7330000000000005} & 5.2574 & TST \\
\hline CHEMBL1316850 & 688653 & 4.833 & 4.9762 & TRN & & \\
\hline CHEMBL1581188 & 688653 & \multicolumn{3}{|c|}{5.382999999999999} & 5.5781 & TST \\
\hline CHEMBL1518957 & 688653 & 5.733 & 5.5479 & TRN & & \\
\hline CHEMBL1308385 & 688653 & 6.233 & 5.0972 & TST & & \\
\hline CHEMBL1389578 & 688653 & 4.883 & 5.3671 & TRN & & \\
\hline CHEMBL1347876 & 688653 & \multicolumn{3}{|c|}{4.7330000000000005} & 5.0588 & TST \\
\hline CHEMBL1610019 & 688653 & 5.683 & 4.877 & TST & & \\
\hline CHEMBL1540145 & 688653 & 4.783 & 5.3995 & TST & & \\
\hline CHEMBL1553347 & 688653 & \multicolumn{3}{|c|}{5.132999999999999} & 5.7585 & TRN \\
\hline CHEMBL1376222 & 688653 & 4.633 & 4.7503 & TRN & & \\
\hline CHEMBL1310884 & 688653 & 5.733 & 5.3391 & TRN & & \\
\hline CHEMBL1540794 & 688653 & \multicolumn{3}{|c|}{6.582999999999999} & 5.5194 & TRN \\
\hline CHEMBL1334710 & 688653 & \multicolumn{3}{|c|}{4.7330000000000005} & 4.658 & TRN \\
\hline CHEMBL1376551 & 688653 & 5.433 & 5.0916 & TST & & \\
\hline CHEMBL1449156 & 688653 & \multicolumn{3}{|c|}{6.132999999999999} & 5.2998 & TRN \\
\hline CHEMBL1586985 & 688653 & 6.183 & 5.8669 & TRN & & \\
\hline CHEMBL1428795 & 688653 & 5.033 & 5.011 & TRN & & \\
\hline CHEMBL1546438 & 688653 & 5.233 & 4.7739 & TST & & \\
\hline CHEMBL1385148 & 688653 & 5.0 & 5.0891 & TRN & & \\
\hline
\end{tabular}




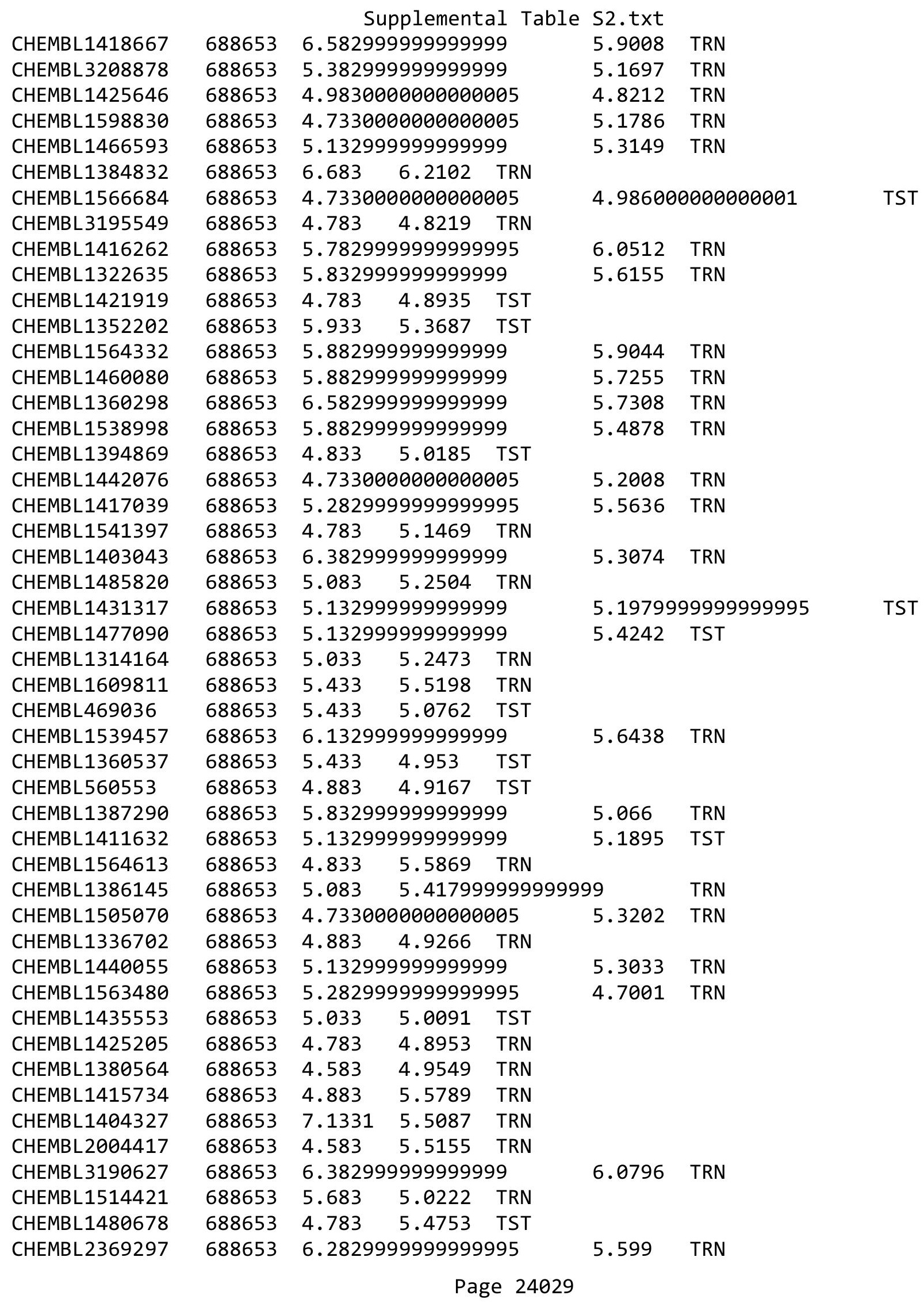




\begin{tabular}{|c|c|c|c|c|c|c|}
\hline \multirow[b]{2}{*}{ CHEMBL1484163 } & \multicolumn{6}{|c|}{ Supplemental T } \\
\hline & 688653 & 4.783 & 4.9279 & TRN & & \\
\hline CHEMBL 3194325 & 688653 & 5.78299 & 99999999 & 995 & 5.3603 & TRN \\
\hline CHEMBL1968361 & 688653 & 5.83299 & 99999999 & & 5.3611 & \\
\hline CHEMBL1459215 & 688653 & 5.53299 & 99999999 & 995 & 5.3973 & \\
\hline CHEMBL1417172 & 688653 & 6.63299 & 99999999 & & 5.6482 & \\
\hline CHEMBL1590888 & 688653 & 4.73300 & 00000000 & 005 & 5.3704 & \\
\hline CHEMBL1519284 & 688653 & 4.833 & 5.308 & TRN & & \\
\hline CHEMBL1414989 & 688653 & 5.88299 & 99999999 & & 5.756 & \\
\hline CHEMBL3191946 & 688653 & 6.233 & 6.4129 & TRN & & \\
\hline CHEMBL1564542 & 688653 & 4.633 & 4.6951 & TRN & & \\
\hline CHEMBL1460595 & 688653 & 7.3325 & 6.0071 & TRN & & \\
\hline CHEMBL1556219 & 688653 & 4.73300 & 00000000 & 005 & 4.8401 & \\
\hline CHEMBL1460321 & 688653 & 5.433 & 5.4282 & TRN & & \\
\hline CHEMBL1398633 & 688653 & 6.0 & 5.5531 & TRN & & \\
\hline CHEMBL1496231 & 688653 & 5.88299 & 99999999 & & 4.8164 & \\
\hline CHEMBL1588056 & 688653 & 5.33299 & 99999999 & & 5.5609 & \\
\hline CHEMBL1986898 & 688653 & 4.98300 & 00000000 & 005 & 5.445 & \\
\hline CHEMBL1550582 & 688653 & 5.983 & 5.4744 & TRN & & \\
\hline CHEMBL1349611 & 688653 & 5.28299 & 99999999 & 995 & 5.6708 & \\
\hline CHEMBL1534289 & 688653 & 5.13299 & 99999999 & & 5.3309 & \\
\hline CHEMBL1578888 & 688653 & 5.63299 & 99999999 & & 5.7018 & \\
\hline CHEMBL1556570 & 688653 & 4.633 & 5.0166 & TRN & & \\
\hline CHEMBL1339678 & 688653 & 5.733 & 6.7673 & TRN & & \\
\hline CHEMBL136 & 688653 & 4.633 & 4.7865 & TRN & & \\
\hline CHEMBL1421615 & 688653 & 5.58299 & 99999999 & & 5.2843 & \\
\hline CHEMBL 3211109 & 688653 & 4.883 & 5.2982 & TRN & & \\
\hline CHEMBL 3211414 & 688653 & 5.733 & 5.3267 & TRN & & \\
\hline CHEMBL1405284 & 688653 & 5.733 & 5.3362 & TST & & \\
\hline CHEMBL1527992 & 688653 & 6.53299 & 99999999 & 995 & 6.2192 & \\
\hline CHEMBL 3191679 & 688653 & 4.783 & 5.5055 & TRN & & \\
\hline CHEMBL1387331 & 688653 & 5.733 & 5.5493 & TRN & & \\
\hline CHEMBL1330204 & 688653 & 5.53299 & 99999999 & 995 & 5.7306 & $\mathrm{TP}$ \\
\hline CHEMBL1443205 & 688653 & 5.38299 & 99999999 & & 5.6394 & \\
\hline CHEMBL1582546 & 688653 & 4.933 & 4.9025 & TRN & & \\
\hline CHEMBL1550543 & 688653 & 4.933 & 5.3628 & TRN & & \\
\hline CHEMBL2004475 & 688653 & 4.633 & 5.4503 & TST & & \\
\hline CHEMBL1506697 & 688653 & 6.28299 & 99999999 & 995 & 5.7259 & \\
\hline CHEMBL1548495 & 688653 & 4.783 & 5.2788 & TRN & & \\
\hline CHEMBL1339058 & 688653 & 5.183 & 5.0265 & TST & & \\
\hline CHEMBL1366319 & 688653 & 5.33299 & 99999999 & & 5.5434 & TRN \\
\hline CHEMBL1512119 & 688653 & 5.38299 & 99999999 & & 5.4299 & TR \\
\hline CHEMBL1583715 & 688653 & 5.033 & 4.7286 & TRN & & \\
\hline CHEMBL1601827 & 688653 & 4.883 & 5.29200 & 00000 & & RN \\
\hline CHEMBL1503169 & 688653 & 4.683 & 5.0027 & TST & & \\
\hline CHEMBL1486457 & 688653 & 5.33299 & 99999999 & & 4.9997 & TINIV \\
\hline CHEMBL1378967 & 688653 & 5.83299 & 99999999 & & 5.4337 & $-\pi x^{-}$ \\
\hline CHEMBL1331512 & 688653 & 4.833 & 5.5368 & TRN & & \\
\hline CHEMBL1569176 & 688653 & 5.78299 & 99999999 & 995 & 5.2128 & \\
\hline
\end{tabular}




\begin{tabular}{|c|c|c|c|c|c|c|}
\hline \multirow[b]{2}{*}{ CHEMBL1437734 } & \multirow[b]{2}{*}{688653} & \multicolumn{5}{|c|}{ Supplemental Table S2.txt } \\
\hline & & \multicolumn{3}{|c|}{$\begin{array}{lll}5.183 & 4.8239 & \text { TRN }\end{array}$} & \\
\hline CHEMBL1412778 & 688653 & 5.733 & 5.6124 & \multicolumn{3}{|l|}{ TRN } \\
\hline CHEMBL1531859 & 688653 & 4.833 & 4.9546 & \multicolumn{3}{|l|}{ TRN } \\
\hline CHEMBL1970965 & 688653 & \multicolumn{3}{|c|}{5.632999999999999} & 5.2083 & TST \\
\hline CHEMBL1500521 & 688653 & 4.833 & 5.2397 & TRN & & \\
\hline CHEMBL1316250 & 688653 & \multicolumn{3}{|c|}{5.332999999999999} & 4.9682 & TST \\
\hline CHEMBL1382721 & 688653 & \multicolumn{3}{|c|}{4.7330000000000005} & 5.1116 & TRN \\
\hline CHEMBL1593484 & 688653 & \multicolumn{3}{|c|}{4.7330000000000005} & 5.33 & TRN \\
\hline CHEMBL1544409 & 688653 & \multicolumn{3}{|c|}{5.332999999999999} & 5.0914 & TRN \\
\hline CHEMBL1507070 & 688653 & 4.633 & 4.9397 & TST & & \\
\hline CHEMBL1080171 & 688653 & \multicolumn{3}{|c|}{5.382999999999999} & 5.3667 & TRN \\
\hline CHEMBL1343823 & 688653 & \multicolumn{3}{|c|}{5.882999999999999} & 5.7012 & TRN \\
\hline CHEMBL1561146 & 688653 & \multicolumn{3}{|c|}{5.882999999999999} & 4.7691 & TST \\
\hline CHEMBL1474675 & 688653 & \multicolumn{3}{|c|}{6.132999999999999} & 5.9608 & TRN \\
\hline CHEMBL1321669 & 688653 & 6.0 & 5.7919 & TRN & & \\
\hline CHEMBL1412106 & 688653 & \multicolumn{3}{|c|}{5.832999999999999} & 5.1711 & TST \\
\hline CHEMBL1310761 & 688653 & 5.183 & 5.2427 & TRN & & \\
\hline CHEMBL1309627 & 688653 & \multicolumn{3}{|c|}{4.7330000000000005} & 5.3798 & TRN \\
\hline CHEMBL1404544 & 688653 & 4.683 & 5.2198 & TST & & \\
\hline CHEMBL1382438 & 688653 & 5.733 & 5.2973 & \multicolumn{2}{|l|}{ TRN } & \\
\hline CHEMBL 2006856 & 688653 & 5.733 & \multirow{2}{*}{\multicolumn{3}{|c|}{5.1080000000000005}} & TRN \\
\hline CHEMBL1523885 & 688653 & 5.733 & & & & TST \\
\hline CHEMBL1463371 & 688653 & \multicolumn{3}{|c|}{6.082999999999999} & 5.8927 & TRN \\
\hline CHEMBL1467194 & 688653 & 4.633 & 5.1731 & TST & & \\
\hline CHEMBL1344507 & 688653 & 5.63299 & 99999999 & & 5.6651 & TRN \\
\hline CHEMBL1535938 & 688653 & 4.933 & 5.1088 & TST & & \\
\hline CHEMBL3195396 & 688653 & 5.33299 & 99999999 & & 5.2331 & TRN \\
\hline CHEMBL1493662 & 688653 & 4.883 & 4.7771 & TRN & & \\
\hline CHEMBL1385601 & 688653 & 4.73300 & 00000000 & 205 & 5.148 & TRN \\
\hline CHEMBL1429800 & 688653 & 5.183 & 4.9024 & TRN & & \\
\hline CHEMBL1441538 & 688653 & 5.683 & 5.1351 & TRN & & \\
\hline CHEMBL1324270 & 688653 & 4.683 & 4.9169 & TST & & \\
\hline CHEMBL1436966 & 688653 & 4.633 & 5.4151 & TRN & & \\
\hline CHEMBL1343733 & 688653 & 6.4829 & 5.3929 & TRN & & \\
\hline CHEMBL1368054 & 688653 & 4.933 & 5.2708 & TST & & \\
\hline CHEMBL1460791 & 688653 & 4.73300 & 00000000 & 205 & 5.4355 & TST \\
\hline CHEMBL1546980 & 688653 & 4.833 & 4.9837 & TRN & & \\
\hline CHEMBL1391340 & 688653 & 5.083 & 5.0221 & TST & & \\
\hline CHEMBL1551514 & 688653 & 4.73300 & 00000000 & 005 & 5.0765 & TRN \\
\hline CHEMBL1479255 & 688653 & 6.08299 & 99999999 & & 5.4468 & TRN \\
\hline CHEMBL1591668 & 688653 & 4.833 & 4.9298 & TRN & & \\
\hline CHEMBL1483900 & 688653 & 4.833 & 4.9699 & TRN & & \\
\hline CHEMBL1511318 & 688653 & 4.833 & 5.0589 & TRN & & \\
\hline CHEMBL3209641 & 688653 & 5.083 & 4.9278 & TST & & \\
\hline CHEMBL1306132 & 688653 & 4.98300 & 00000000 & 005 & 6.37 & TST \\
\hline CHEMBL1423461 & 688653 & 4.883 & 5.0345 & TRN & & \\
\hline CHEMBL1519652 & 688653 & 5.183 & 5.4594 & TRN & & \\
\hline CHEMBL1420576 & 688653 & 4.73300 & 00000000 & 005 & 5.8061 & TRN \\
\hline & & & & & & \\
\hline
\end{tabular}




\begin{tabular}{|c|c|c|c|c|c|c|}
\hline & & \multicolumn{5}{|c|}{ Supplemental Table S2.txt } \\
\hline CHEMBL1344397 & 688653 & 4.783 & 5.0162 & TRN & & \\
\hline CHEMBL1533372 & 688653 & 5.983 & 5.4142 & TRN & & \\
\hline CHEMBL1386989 & 688653 & 5.933 & 5.5118 & TRN & & \\
\hline CHEMBL1610206 & 688653 & 4.833 & 5.2497 & TST & & \\
\hline CHEMBL1563110 & 688653 & 4.583 & 5.3025 & TRN & & \\
\hline CHEMBL1389982 & 688653 & \multicolumn{3}{|c|}{5.2829999999999995} & 5.1663 & TST \\
\hline CHEMBL1367361 & 688653 & \multicolumn{3}{|c|}{4.7330000000000005} & 5.3541 & \\
\hline CHEMBL1511423 & 688653 & 5.183 & 5.1285 & TRN & & \\
\hline CHEMBL1546985 & 688653 & 4.783 & 5.2204 & TRN & & \\
\hline CHEMBL1374554 & 688653 & 4.883 & 4.9258 & TRN & & \\
\hline CHEMBL 3199050 & 688653 & 4.883 & 5.0403 & TRN & & \\
\hline CHEMBL1492469 & 688653 & 5.733 & 5.6101 & TRN & & \\
\hline CHEMBL1590686 & 688653 & 4.583 & 5.0994 & TRN & & \\
\hline CHEMBL1309514 & 688653 & 6.7331 & 5.2782 & TST & & \\
\hline CHEMBL1588463 & 688653 & 5.483 & 5.3934 & TRN & & \\
\hline CHEMBL1601900 & 688653 & 5.183 & 5.2063 & TRN & & \\
\hline CHEMBL1537954 & 688653 & 5.733 & 5.1715 & TST & & \\
\hline CHEMBL1469281 & 688653 & 4.633 & 4.5999 & TRN & & \\
\hline CHEMBL1607610 & 688653 & 4.683 & 5.1071 & TRN & & \\
\hline CHEMBL1386640 & 688653 & 5.233 & 5.7606 & TST & & \\
\hline CHEMBL1414843 & 688653 & 4.833 & 5.3799 & TRN & & \\
\hline CHEMBL1436656 & 688653 & 5.033 & 5.6903 & TRN & & \\
\hline CHEMBL1311241 & 688653 & 4.833 & 4.9329 & TRN & & \\
\hline CHEMBL1481398 & 688653 & 4.833 & 4.9554 & TRN & & \\
\hline CHEMBL1397962 & 688653 & 4.883 & 5.6482 & TRN & & \\
\hline CHEMBL1441085 & 688653 & 5.433 & 5.428 & TST & & \\
\hline CHEMBL1557639 & 688653 & 4.883 & 4.6868 & TST & & \\
\hline CHEMBL1597030 & 688653 & 4.783 & 5.1945 & TRN & & \\
\hline CHEMBL1373614 & 688653 & \multicolumn{3}{|c|}{4.7330000000000005} & 4.8595 & TST \\
\hline CHEMBL1516327 & 688653 & 4.583 & 5.1231 & TST & & \\
\hline CHEMBL1304647 & 688653 & \multicolumn{3}{|c|}{5.2829999999999995} & 5.4427 & TS \\
\hline CHEMBL1477878 & 688653 & 4.883 & 5.1923 & TRN & & \\
\hline CHEMBL1438983 & 688653 & 4.583 & 4.9568 & TST & & \\
\hline CHEMBL1416421 & 688653 & 4.933 & 4.8703 & TST & & \\
\hline CHEMBL3199855 & 688653 & 7.1331 & 6.2255 & TRN & & \\
\hline CHEMBL1412505 & 688653 & 5.433 & 5.0637 & TRN & & \\
\hline CHEMBL1371198 & 688653 & \multicolumn{3}{|c|}{5.7829999999999995} & 5.4267 & $\pi$ \\
\hline CHEMBL 3210025 & 688653 & 6.233 & 5.5424 & TRN & & \\
\hline CHEMBL1340915 & 688653 & \multicolumn{3}{|c|}{5.382999999999999} & 5.6012 & TRN \\
\hline CHEMBL1581488 & 688653 & \multicolumn{3}{|c|}{5.332999999999999} & 5.4983 & TRN \\
\hline CHEMBL1361227 & 688653 & 4.833 & 4.7717 & TST & & \\
\hline CHEMBL1544221 & 688653 & \multicolumn{3}{|c|}{5.832999999999999} & 5.1643 & TR \\
\hline CHEMBL1537123 & 688653 & 4.633 & 5.1109 & TST & & \\
\hline CHEMBL1303283 & 688653 & \multicolumn{3}{|c|}{6.5329999999999995} & 5.7967 & TRN \\
\hline CHEMBL1443777 & 688653 & \multicolumn{3}{|c|}{4.9830000000000005} & 5.4461 & TRN \\
\hline CHEMBL1351458 & 688653 & 4.783 & 4.648 & TRN & & \\
\hline CHEMBL1590573 & 688653 & \multicolumn{3}{|c|}{5.632999999999999} & 5.0253 & $\mathrm{RN}$ \\
\hline CHEMBL1467586 & 688653 & 4.633 & 5.3124 & TST & & \\
\hline
\end{tabular}




\begin{tabular}{|c|c|c|c|c|c|c|}
\hline \multirow[b]{2}{*}{ CHEMBL1312595 } & \multicolumn{6}{|c|}{ Supplemental Table S2.txt } \\
\hline & 688653 & 4.783 & 5.062 & TRN & & \\
\hline CHEMBL1567793 & 688653 & 5.433 & 5.9653 & TRN & & \\
\hline CHEMBL1486587 & 688653 & 5.983 & 5.6125 & TRN & & \\
\hline CHEMBL1509487 & 688653 & \multicolumn{3}{|c|}{6.2829999999999995} & 5.0396 & TRN \\
\hline CHEMBL1439355 & 688653 & 5.483 & 4.9961 & TRN & & \\
\hline CHEMBL1363917 & 688653 & \multicolumn{3}{|c|}{6.5329999999999995} & 5.5494 & TRN \\
\hline CHEMBL1500643 & 688653 & 4.883 & 5.5138 & TRN & & \\
\hline CHEMBL1359371 & 688653 & 4.833 & 5.4109 & TRN & & \\
\hline CHEMBL1610220 & 688653 & \multicolumn{3}{|c|}{5.132999999999999} & 5.3516 & TRN \\
\hline CHEMBL1516492 & 688653 & \multicolumn{3}{|c|}{6.0329999999999995} & 6.1206 & TRN \\
\hline CHEMBL1377081 & 688653 & 4.883 & 5.0952 & TRN & & \\
\hline CHEMBL514612 & 688653 & 5.933 & 5.7519 & TRN & & \\
\hline CHEMBL1450676 & 688653 & \multicolumn{3}{|c|}{6.632999999999999} & 5.5589 & TRN \\
\hline CHEMBL1604919 & 688653 & 4.583 & 4.856 & TRN & & \\
\hline CHEMBL578636 & 688653 & \multicolumn{3}{|c|}{5.382999999999999} & 5.3907 & TRN \\
\hline CHEMBL1488591 & 688653 & 4.583 & 5.1162 & TST & & \\
\hline CHEMBL1453607 & 688653 & \multicolumn{3}{|c|}{5.7829999999999995} & 5.5941 & TRN \\
\hline CHEMBL1384519 & 688653 & 5.183 & 5.3711 & TRN & & \\
\hline CHEMBL1458399 & 688653 & 6.4829 & 6.0463 & TRN & & \\
\hline CHEMBL1445381 & 688653 & 4.783 & 5.2579 & TRN & & \\
\hline CHEMBL1558056 & 688653 & 4.833 & 5.3691 & TRN & & \\
\hline CHEMBL1461826 & 688653 & 4.833 & 4.9823 & TST & & \\
\hline CHEMBL1255778 & 688653 & \multicolumn{3}{|c|}{5.2829999999999995} & 5.0385 & TST \\
\hline CHEMBL1320007 & 688653 & \multicolumn{3}{|c|}{6.0329999999999995} & 5.2989 & TRN \\
\hline CHEMBL1385158 & 688653 & \multicolumn{3}{|c|}{5.132999999999999} & 5.5362 & TRN \\
\hline CHEMBL1509760 & 688653 & 4.833 & 4.9804 & TRN & & \\
\hline CHEMBL1510307 & 688653 & 4.783 & 5.6706 & TRN & & \\
\hline CHEMBL1569862 & 688653 & 6.233 & 5.4659 & TRN & & \\
\hline CHEMBL1427061 & 688653 & 5.733 & 5.5677 & TST & & \\
\hline CHEMBL3195974 & 688653 & 5.683 & 5.4185 & TRN & & \\
\hline CHEMBL533082 & 688653 & 5.233 & 5.1931 & TST & & \\
\hline CHEMBL3213353 & 688653 & 5.033 & 5.2473 & TST & & \\
\hline CHEMBL1501923 & 688653 & \multicolumn{3}{|c|}{6.382999999999999} & 6.0349 & TRN \\
\hline CHEMBL3192075 & 688653 & 4.783 & 4.8492 & TRN & & \\
\hline CHEMBL1322920 & 688653 & 4.783 & 5.1495 & TRN & & \\
\hline CHEMBL3195200 & 688653 & \multicolumn{3}{|c|}{6.632999999999999} & 5.5361 & TRN \\
\hline CHEMBL1409644 & 688653 & \multicolumn{3}{|c|}{4.7330000000000005} & 5.0844 & TST \\
\hline CHEMBL1389204 & 688653 & \multicolumn{3}{|c|}{5.882999999999999} & 5.7298 & TRN \\
\hline CHEMBL1516076 & 688653 & 4.583 & 4.9954 & TRN & & \\
\hline CHEMBL1403844 & 688653 & 4.783 & 5.0025 & TRN & & \\
\hline CHEMBL1486827 & 688653 & 5.033 & 5.0748 & TRN & & \\
\hline CHEMBL1423028 & 688653 & 4.933 & 5.2368 & TST & & \\
\hline CHEMBL3197575 & 688653 & 5.28299 & 99999999 & 995 & 5.2723 & TRN \\
\hline CHEMBL1500810 & 688653 & 4.783 & 5.078 & TRN & & \\
\hline CHEMBL1577781 & 688653 & 4.73300 & 00000000 & 005 & 5.5669 & TRN \\
\hline CHEMBL1506272 & 688653 & 4.98300 & 00000000 & 005 & 5.76206 & 00000000005 \\
\hline CHEMBL1479181 & 688653 & 4.73300 & 00000000 & 005 & 4.942 & TST \\
\hline CHEMBL1477651 & 688653 & 5.28299 & 99999999 & 995 & 5.0876 & TRN \\
\hline
\end{tabular}




\begin{tabular}{|c|c|c|c|c|c|c|}
\hline & & \multicolumn{5}{|c|}{ Supplemental Table s2.txt } \\
\hline CHEMBL1561490 & 688653 & \multicolumn{3}{|c|}{4.7330000000000005} & 5.3921 & TRN \\
\hline CHEMBL1513353 & 688653 & \multicolumn{3}{|c|}{4.9830000000000005} & 5.2975 & TRN \\
\hline CHEMBL1389377 & 688653 & 4.783 & 5.1713 & TRN & & \\
\hline CHEMBL1352498 & 688653 & 5.683 & 5.6364 & TRN & & \\
\hline CHEMBL3193850 & 688653 & \multicolumn{3}{|c|}{5.832999999999999} & 5.3755 & TRN \\
\hline CHEMBL1405593 & 688653 & \multicolumn{3}{|c|}{5.832999999999999} & 5.6595 & TRN \\
\hline CHEMBL1443752 & 688653 & 5.1 & 5.4261 & TST & & \\
\hline CHEMBL1384933 & 688653 & 4.833 & 5.0444 & TRN & & \\
\hline CHEMBL1605120 & 688653 & 4.833 & 5.2013 & TST & & \\
\hline CHEMBL1471157 & 688653 & \multicolumn{3}{|c|}{6.2829999999999995} & 5.4529 & TRN \\
\hline CHEMBL600589 & 688653 & 4.933 & 5.1078 & TRN & & \\
\hline CHEMBL1482213 & 688653 & 4.933 & 4.8463 & TRN & & \\
\hline CHEMBL1583739 & 688653 & \multicolumn{3}{|c|}{4.7330000000000005} & 5.2441 & TRN \\
\hline CHEMBL1577944 & 688653 & \multicolumn{3}{|c|}{5.5329999999999995} & 5.1964 & TRN \\
\hline CHEMBL1509947 & 688653 & 4.583 & 5.3655 & TST & & \\
\hline CHEMBL1449615 & 688653 & 5.933 & 5.4116 & TST & & \\
\hline CHEMBL1326893 & 688653 & 4.833 & 5.2138 & TRN & & \\
\hline CHEMBL1345988 & 688653 & 4.883 & 5.8536 & TRN & & \\
\hline CHEMBL1328781 & 688653 & \multicolumn{3}{|c|}{4.7330000000000005} & 5.4629 & TRN \\
\hline CHEMBL 3214543 & 688653 & 4.783 & 5.3339 & TRN & & \\
\hline CHEMBL1329212 & 688653 & 4.933 & 5.0374 & TRN & & \\
\hline CHEMBL1435903 & 688653 & 4.633 & 4.8659 & TST & & \\
\hline CHEMBL1487204 & 688653 & 4.833 & 5.6094 & TST & & \\
\hline CHEMBL1501452 & 688653 & \multicolumn{3}{|c|}{5.132999999999999} & 5.3655 & TST \\
\hline CHEMBL1600914 & 688653 & 4.633 & \multicolumn{3}{|c|}{4.611000000000001} & TRN \\
\hline CHEMBL1502723 & 688653 & 4.783 & 5.1637 & TST & & \\
\hline CHEMBL1578728 & 688653 & 4.783 & 4.8964 & TST & & \\
\hline CHEMBL1411123 & 688653 & 5.433 & 5.6463 & TRN & & \\
\hline CHEMBL485690 & 688653 & 4.833 & 5.7272 & TST & & \\
\hline CHEMBL1424923 & 688653 & 4.783 & 5.3165 & TRN & & \\
\hline CHEMBL3189243 & 688653 & \multicolumn{3}{|c|}{4.7330000000000005} & 5.2931 & TRN \\
\hline CHEMBL1306419 & 688653 & \multicolumn{3}{|c|}{5.132999999999999} & 5.2752 & TRN \\
\hline CHEMBL1574899 & 688653 & \multicolumn{3}{|c|}{4.9830000000000005} & 5.0605 & TRN \\
\hline CHEMBL1593646 & 688653 & \multicolumn{3}{|c|}{5.132999999999999} & 5.657 & TRN \\
\hline CHEMBL1323146 & 688653 & \multicolumn{3}{|c|}{5.132999999999999} & 5.4515 & TRN \\
\hline CHEMBL1317596 & 688653 & \multicolumn{3}{|c|}{4.9830000000000005} & 4.755 & TRN \\
\hline CHEMBL1513175 & 688653 & 4.783 & 5.166 & TST & & \\
\hline CHEMBL1347285 & 688653 & 5.083 & 5.659 & TRN & & \\
\hline CHEMBL1449119 & 688653 & \multicolumn{3}{|c|}{5.332999999999999} & 5.2834 & TRN \\
\hline CHEMBL1369228 & 688653 & \multicolumn{3}{|c|}{5.2829999999999995} & 5.4853 & TRN \\
\hline CHEMBL 3211050 & 688653 & 5.483 & 5.2307 & TST & & \\
\hline CHEMBL 3195544 & 688653 & \multicolumn{3}{|c|}{5.132999999999999} & 5.6105 & TRN \\
\hline CHEMBL1416888 & 688653 & 4.633 & 4.963 & TST & & \\
\hline CHEMBL1505717 & 688653 & \multicolumn{3}{|c|}{5.882999999999999} & 5.4665 & TRN \\
\hline CHEMBL1578675 & 688653 & 5.183 & 5.3306 & TRN & & \\
\hline CHEMBL1368144 & 688653 & 5.683 & 5.671 & TRN & & \\
\hline CHEMBL1513122 & 688653 & 4.683 & 4.6887 & TST & & \\
\hline CHEMBL1378830 & 688653 & 6.5 & 5.697 & TST & & \\
\hline
\end{tabular}




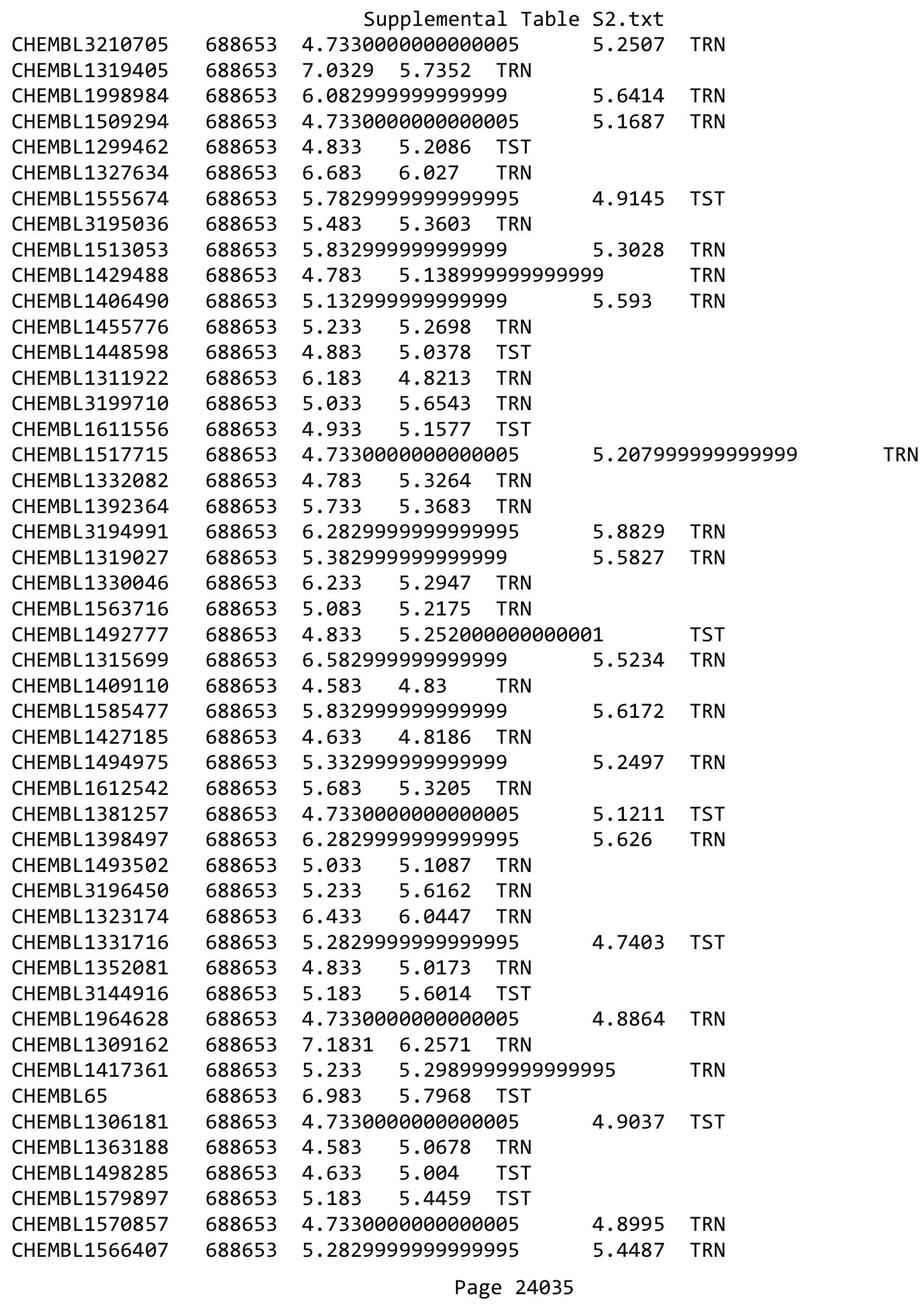




\begin{tabular}{|c|c|c|c|c|c|c|}
\hline \multirow[b]{2}{*}{ CHEMBL1336549 } & \multirow[b]{2}{*}{688653} & \multicolumn{5}{|c|}{ Supplemental Table S2.txt } \\
\hline & & 4.783 & 5.0252 & TRN & & \\
\hline CHEMBL1468256 & 688653 & 6.13299 & 99999999 & & 5.7608 & TRN \\
\hline CHEMBL1554527 & 688653 & 5.63299 & 99999999 & 99 & 5.2117 & TRN \\
\hline CHEMBL1611138 & 688653 & 4.933 & 5.2 & TRN & & \\
\hline CHEMBL1502975 & 688653 & 5.78299 & 99999999 & 995 & 4.9974 & TRN \\
\hline CHEMBL1360611 & 688653 & 4.583 & 4.6321 & TRN & & \\
\hline CHEMBL1502386 & 688653 & 5.083 & 5.5816 & TRN & & \\
\hline CHEMBL1383475 & 688653 & 5.88299 & 99999999 & 99 & 5.3923 & TST \\
\hline CHEMBL1489253 & 688653 & 4.683 & 5.1524 & TRN & & \\
\hline CHEMBL1599146 & 688653 & 5.58299 & 99999999 & 99 & 5.2576 & TRN \\
\hline CHEMBL1349371 & 688653 & 4.933 & 4.7976 & TST & & \\
\hline CHEMBL1416710 & 688653 & 4.783 & 5.4206 & TRN & & \\
\hline CHEMBL1484071 & 688653 & 4.583 & 5.1929 & TST & & \\
\hline CHEMBL1379916 & 688653 & 4.683 & 5.2042 & TST & & \\
\hline CHEMBL449690 & 688653 & 4.633 & 5.2279 & TST & & \\
\hline CHEMBL1525113 & 688653 & 5.083 & 5.1947 & TRN & & \\
\hline CHEMBL1454651 & 688653 & 5.83299 & 99999999 & & 5.353 & TRN \\
\hline CHEMBL1324188 & 688653 & 5.933 & 6.4 & TRN & & \\
\hline CHEMBL1450813 & 688653 & 4.98300 & 00000000 & 005 & 4.9934 & TRN \\
\hline CHEMBL1381855 & 688653 & 5.63299 & 99999999 & & 5.5549 & TRN \\
\hline CHEMBL1510373 & 688653 & 4.933 & 5.3861 & TST & & \\
\hline CHEMBL1472197 & 688653 & 5.88299 & 99999999 & & 5.3185 & TST \\
\hline CHEMBL1611716 & 688653 & 4.73300 & $\partial 0000000$ & 005 & 5.0668 & TRN \\
\hline CHEMBL1458688 & 688653 & 6.7331 & 5.95299 & 999999999 & & TRN \\
\hline CHEMBL1449415 & 688653 & 5.83299 & 99999999 & 99 & 5.6646 & TRN \\
\hline CHEMBL1343061 & 688653 & 5.033 & 5.4297 & TRN & & \\
\hline CHEMBL1561296 & 688653 & 5.53299 & 99999999 & 995 & 5.3439 & TRN \\
\hline CHEMBL1426910 & 688653 & 5.733 & 5.2851 & TRN & & \\
\hline CHEMBL1528938 & 688653 & 5.33299 & 99999999 & & 5.6402 & TST \\
\hline CHEMBL1396723 & 688653 & 4.783 & 5.0777 & TRN & & \\
\hline CHEMBL1488614 & 688653 & 6.433 & 5.3821 & TRN & & \\
\hline CHEMBL1341284 & 688653 & 6.28299 & 99999999 & 995 & 5.1028 & TRN \\
\hline CHEMBL1579694 & 688653 & 5.733 & 5.0914 & TST & & \\
\hline CHEMBL1441848 & 688653 & 5.083 & 5.5553 & TRN & & \\
\hline CHEMBL1500749 & 688653 & 5.733 & 4.9838 & TST & & \\
\hline CHEMBL1422644 & 688653 & 5.233 & 5.5208 & TRN & & \\
\hline CHEMBL1479557 & 688653 & 4.933 & 5.5223 & TRN & & \\
\hline CHEMBL1406961 & 688653 & 4.73300 & 20000000 & 005 & 5.3723 & TRN \\
\hline CHEMBL1509871 & 688653 & 4.73300 & 00000000 & 005 & 5.0038 & TST \\
\hline CHEMBL1372112 & 688653 & 4.73300 & 00000000 & 005 & 4.5104 & TRN \\
\hline CHEMBL1346274 & 688653 & 4.783 & 5.2712 & TST & & \\
\hline CHEMBL599102 & 688653 & 4.833 & 5.2124 & TST & & \\
\hline CHEMBL1378439 & 688653 & 4.933 & 5.1759 & TRN & & \\
\hline CHEMBL1414490 & 688653 & 6.0 & 5.1609 & TRN & & \\
\hline CHEMBL1605913 & 688653 & 5.83299 & 99999999 & & 5.5039 & TRN \\
\hline CHEMBL1303884 & 688653 & 5.13299 & 99999999 & & 5.231 & TRN \\
\hline CHEMBL1455362 & 688653 & 5.933 & 5.7181 & TRN & & \\
\hline CHEMBL1534030 & 688653 & 5.433 & 5.095 & TRN & & \\
\hline
\end{tabular}




\begin{tabular}{|c|c|c|c|c|c|c|}
\hline \multirow[b]{2}{*}{ CHEMBL1518735 } & \multicolumn{6}{|c|}{ Supplemental Table S2.txt } \\
\hline & 688653 & 4.633 & 4.9819 & TRN & & \\
\hline CHEMBL1351501 & 688653 & \multicolumn{3}{|c|}{4.7330000000000005} & 4.9686 & TRN \\
\hline CHEMBL1570709 & 688653 & 4.933 & \multicolumn{3}{|c|}{4.9719999999999995} & \\
\hline CHEMBL1606172 & 688653 & \multicolumn{3}{|c|}{5.2829999999999995} & 5.2513 & \\
\hline CHEMBL1393367 & 688653 & 5.183 & 5.7399 & TRN & & \\
\hline CHEMBL1372625 & 688653 & 4.883 & 5.3176 & TRN & & \\
\hline CHEMBL1328289 & 688653 & 6.9329 & 5.291 & TRN & & \\
\hline CHEMBL1304152 & 688653 & \multicolumn{3}{|c|}{5.832999999999999} & 5.3236 & \\
\hline CHEMBL1351929 & 688653 & \multicolumn{3}{|c|}{6.582999999999999} & 6.0325 & \\
\hline CHEMBL1560229 & 688653 & 4.833 & 4.9177 & TST & & \\
\hline CHEMBL1544923 & 688653 & 5.683 & 5.2403 & TST & & \\
\hline CHEMBL1303635 & 688653 & 4.633 & 4.8777 & TRN & & \\
\hline CHEMBL1522758 & 688653 & 4.833 & 5.2554 & TRN & & \\
\hline CHEMBL1475263 & 688653 & 5.033 & 5.4007 & TRN & & \\
\hline CHEMBL1507152 & 688653 & \multicolumn{3}{|c|}{5.832999999999999} & 714 & \\
\hline CHEMBL1392754 & 688 & 4.783 & 5.153 & TRN & & \\
\hline CHEMBL1 & 688 & 5.2 & 5.4916 & TST & & \\
\hline CHEMBL1361429 & 688653 & 4.883 & 5.3058 & TRN & & \\
\hline CHEMBL1302139 & 688653 & 4.633 & 5.3581 & TST & & \\
\hline CHEMBL1390836 & 688653 & \multicolumn{3}{|c|}{5.2829999999999995} & 5.2478 & \\
\hline CHEMBL14€ & 688 & \multicolumn{3}{|c|}{6.582999999999999} & 969 & \\
\hline CHEMBL1 & 688 & 5.233 & 5.5529 & TRN & & \\
\hline CHEMBL1320321 & 688653 & 5.183 & 5.0077 & TST & & \\
\hline CHEMBL3198798 & 688653 & \multicolumn{3}{|c|}{5.132999999999999} & 42 & \\
\hline CHEMBL15 & 688 & 4.583 & 5.3021 & TRN & & \\
\hline CHEMBL1 & 53 & 5.183 & 5.1797 & TRN & & \\
\hline CHEMBL1344531 & 688 & \multicolumn{3}{|c|}{5.332999999999999} & 5.1591 & \\
\hline CHEMBL1499772 & 688 & 4.783 & 5.3341 & TRN & & \\
\hline CHEMBL1484097 & 688653 & \multicolumn{3}{|c|}{5.7829999999999995} & 5.6102 & $\mathrm{TH}$ \\
\hline CHEMBL1343919 & 688 & 5.683 & 5.5648 & TRN & & \\
\hline CHEMBL & 53 & 5 . & 5.2673 & TRN & & \\
\hline CHEMBL: & $68 \varepsilon$ & 4. & 5.0661 & TRN & & \\
\hline CHEMBL1503414 & 688653 & 5 . & 5.2367 & TST & & \\
\hline CHEMBL1540337 & 688653 & 4.7 & 5.1372 & TRN & & \\
\hline CHEMBL1 & 3 & & 5.7052 & TRN & & \\
\hline CHEMBL: & 53 & 4.883 & 5.3353 & TST & & \\
\hline CHEMBL1411520 & 688653 & \multicolumn{3}{|c|}{4.7330000000000005} & 5.2596 & \\
\hline CHEMBL1475029 & 688653 & 6.233 & 5.7827 & TST & & \\
\hline CHEMBL1507595 & 688653 & 4.633 & 4.7786 & TST & & \\
\hline CHEMBL15 & 688 & \multicolumn{3}{|c|}{5.632999999999999} & 5.1352 & \\
\hline CHEMBL138 & 688653 & 4.883 & 5.0749 & TST & & \\
\hline CHEMBL1603503 & 688653 & \multicolumn{3}{|c|}{4.7330000000000005} & 5.1069 & 14 \\
\hline CHEMBL1503930 & 688653 & 6.433 & 5.9135 & TRN & & \\
\hline CHEMBL1393809 & 688653 & 5.183 & 5.4743 & TRN & & \\
\hline CHEMBL1578482 & 688653 & \multicolumn{3}{|c|}{5.132999999999999} & 5.2687 & TST \\
\hline CHEMBL1425166 & 688653 & 4.633 & 4.6254 & TST & & \\
\hline CHEMBL1484559 & 688653 & 4.933 & 5.0336 & TST & & \\
\hline CHEMBL1307028 & 688653 & \multicolumn{3}{|c|}{6.132999999999999} & 5.5871 & \\
\hline
\end{tabular}




\begin{tabular}{|c|c|c|c|c|c|c|}
\hline & & \multicolumn{4}{|c|}{ Supplemental Table S2.txt } & \\
\hline CHEMBL1492399 & 688653 & \multicolumn{3}{|c|}{5.632999999999999} & 6.1728 & $\mathrm{TR}$ \\
\hline CHEMBL 3198107 & 688653 & 4.883 & 4.4003 & TST & & \\
\hline CHEMBL1318302 & 688653 & 4.683 & 5.2971 & TRN & & \\
\hline CHEMBL1465908 & 688653 & 5.233 & 5.9731 & TRN & & \\
\hline CHEMBL1524632 & 688653 & 5.233 & 5.2575 & TST & & \\
\hline CHEMBL1531367 & 688653 & 5.233 & 5.3735 & TRN & & \\
\hline CHEMBL1403980 & 688653 & 4.833 & 4.6947 & TST & & \\
\hline CHEMBL1330762 & 688653 & \multicolumn{3}{|c|}{6.382999999999999} & 5.0413 & TST \\
\hline CHEMBL1568669 & 688653 & 4.833 & 5.4511 & TST & & \\
\hline CHEMBL1512727 & 688653 & 5.483 & 4.9855 & TRN & & \\
\hline CHEMBL1316782 & 688653 & 4.583 & 4.938 & TST & & \\
\hline CHEMBL1476987 & 688653 & 5.733 & 5.48 & TRN & & \\
\hline CHEMBL1347600 & 688653 & 5.733 & 5.4338 & TRN & & \\
\hline CHEMBL1409409 & 688653 & 4.783 & 4.8725 & TRN & & \\
\hline CHEMBL1462611 & 688653 & 5.15 & 4.9848 & TRN & & \\
\hline CHEMBL1385704 & 688 & 5.033 & 5.0649 & TRN & & \\
\hline CHEMBL1473836 & 688653 & \multicolumn{3}{|c|}{5.132999999999999} & 5.2464 & \\
\hline CHEMBL1416831 & 688653 & \multicolumn{3}{|c|}{4.7330000000000005} & 5.1467 & \\
\hline CHEMBL1503002 & 688653 & \multicolumn{3}{|c|}{6.2829999999999995} & 5.9879 & \\
\hline CHEMBL1509571 & 688653 & 4.833 & 5.3214 & TST & & \\
\hline CHEMBL149 & 688653 & \multicolumn{3}{|c|}{6.832999999999999} & 80 & \\
\hline CHEMBL1379976 & 688653 & 6.983 & 5.9999 & TRN & & \\
\hline CHEMBL 1424970 & 688653 & \multicolumn{3}{|c|}{5.382999999999999} & 5.0531 & TST \\
\hline CHEMBL1381099 & 688653 & \multicolumn{3}{|c|}{4.7330000000000005} & 5.4453 & TRN \\
\hline CHEMBL1554759 & 688653 & \multicolumn{3}{|c|}{5.382999999999999} & 5.5314 & TRN \\
\hline CHEMBL1453190 & 688653 & \multicolumn{3}{|c|}{6.382999999999999} & 5.5741 & \\
\hline CHEMBL1483645 & 688653 & 5.233 & 5.4708 & TRN & & \\
\hline CHEMBL1548992 & 688653 & \multirow{2}{*}{\multicolumn{3}{|c|}{$\begin{array}{lrr}5.683 & 5.2923 & \text { TRN } \\
5.2829999999999995\end{array}$}} & & \\
\hline CHEMBL1451237 & 688653 & & & & 5.2371 & TP \\
\hline CHEMBL1365874 & 688653 & \multicolumn{3}{|c|}{$4.683 \quad 5.2151$ TRN } & & \\
\hline CHEMBL3. & 688 & 4.883 & 5.3346 & TRN & & \\
\hline CHEMBL1361002 & 688653 & \multicolumn{3}{|c|}{5.2829999999999995} & 5.4909 & TST \\
\hline CHEMBL1354661 & 688653 & 4.833 & 5.1385 & TRN & & \\
\hline CHEMBL1575402 & 688653 & \multicolumn{3}{|c|}{5.632999999999999} & 5.8074 & TRN \\
\hline CHEMBL 3199576 & 688653 & \multicolumn{3}{|c|}{6.0329999999999995} & 5.1567 & TRN \\
\hline CHEMBL13 & 688653 & \multicolumn{3}{|c|}{5.332999999999999} & 4.9484 & TRN \\
\hline CHEMBL1490116 & 688653 & 5.183 & 5.0932 & TRN & & \\
\hline CHEMBL1345199 & 688653 & 4.783 & 5.526 & TRN & & \\
\hline CHEMBL1308989 & 688653 & 4.783 & 5.141 & TRN & & \\
\hline CHEMBL1552060 & 688653 & 4.7 & 5.0013 & TRN & & \\
\hline CHEMBL1332491 & 688653 & 5.983 & 5.5057 & TRN & & \\
\hline CHEMBL1457519 & 688653 & 5.7829 & 99999999 & 995 & 5.1057 & TRN \\
\hline CHEMBL1523301 & 688653 & 5.2829 & 99999999 & 995 & 5.4127 & TRN \\
\hline CHEMBL3211809 & 688653 & 6.2829 & 99999999 & 995 & 5.2878 & TR \\
\hline CHEMBL1361605 & 688653 & 4.783 & 5.5208 & TRN & & \\
\hline CHEMBL1423995 & 688653 & 5.1329 & 99999999 & & 5.2715 & TRN \\
\hline CHEMBL1530743 & 688653 & 5.6320 & 99999999 & & 5.7218 & TRN \\
\hline CHEMBL2006568 & 688653 & 4.883 & 5.3448 & TRN & & \\
\hline
\end{tabular}




\begin{tabular}{|c|c|c|c|c|c|c|c|}
\hline \multicolumn{7}{|c|}{ Supplemental Table S2.txt } & \\
\hline CHEMBL1423377 & 688653 & 7.3325 & 5.9936 & TRN & & & \\
\hline CHEMBL1529489 & 688653 & 4.933 & 5.3558 & TRN & & & \\
\hline CHEMBL1576748 & 688653 & 4.98300 & 00000000 & 005 & 5.2381 & TRN & \\
\hline CHEMBL1600862 & 688653 & 4.683 & 5.0529 & TRN & & & \\
\hline CHEMBL1318589 & 688653 & 4.833 & 5.2404 & TST & & & \\
\hline CHEMBL1579644 & 688653 & 5.233 & 4.7641 & TRN & & & \\
\hline CHEMBL1402587 & 688653 & 6.9329 & 5.6854 & TRN & & & \\
\hline CHEMBL1374916 & 688653 & 4.683 & 5.1248 & TRN & & & \\
\hline CHEMBL1496462 & 688653 & 6.183 & 5.1415 & TRN & & & \\
\hline CHEMBL1598734 & 688653 & 5.88299 & 99999999 & & 5.6329 & TRN & \\
\hline CHEMBL1095276 & 688653 & 6.28299 & 99999999 & 995 & 6.1088 & TRN & \\
\hline CHEMBL1544034 & 688653 & 5.083 & 5.1618 & TRN & & & \\
\hline CHEMBL1505222 & 688653 & 5.38299 & 99999999 & & 5.7782 & TST & \\
\hline CHEMBL1344603 & 688653 & 4.73300 & 00000000 & 005 & 5.8959 & TRN & \\
\hline CHEMBL1566477 & 688653 & 4.833 & 4.8974 & TST & & & \\
\hline CHEMBL1451460 & 688653 & 4.73300 & 00000000 & 005 & 5.0295 & TRN & \\
\hline CHEMBL1574726 & 688653 & 5.53299 & 99999999 & 995 & 5.1179 & TRN & \\
\hline CHEMBL1435434 & 688653 & 4.73300 & 00000000 & 005 & 5.1413 & TRN & \\
\hline CHEMBL1484285 & 688653 & 4.683 & 5.2347 & TST & & & \\
\hline CHEMBL1351105 & 688653 & 4.633 & 4.6678 & TST & & & \\
\hline CHEMBL601385 & 688653 & 5.33299 & 99999999 & 99 & $6.1560 e$ & 0000000001 & TST \\
\hline CHEMBL1399065 & 688653 & 5.083 & 5.0368 & TST & & & \\
\hline CHEMBL1325839 & 688653 & 6.233 & 5.3415 & TRN & & & \\
\hline CHEMBL1524791 & 688653 & 5.58299 & 99999999 & & 5.4839 & TRN & \\
\hline CHEMBL1402711 & 688653 & 5.183 & 5.7167 & TRN & & & \\
\hline CHEMBL3210482 & 688653 & 4.583 & 5.0506 & TRN & & & \\
\hline CHEMBL 2000592 & 688653 & 5.733 & 5.6305 & TST & & & \\
\hline CHEMBL 3214588 & 688653 & 4.883 & 5.5306 & TRN & & & \\
\hline CHEMBL1426505 & 688653 & 5.233 & 5.2283 & TST & & & \\
\hline CHEMBL1528357 & 688653 & 4.833 & 5.021 & TST & & & \\
\hline CHEMBL1448282 & 688653 & 5.13299 & 99999999 & & 5.5944 & TRN & \\
\hline CHEMBL1596726 & 688653 & 5.83299 & 99999999 & & 5.7349 & TRN & \\
\hline CHEMBL1352992 & 688653 & 5.63299 & 99999999 & & 5.0189 & TRN & \\
\hline CHEMBL1518525 & 688653 & 4.833 & 5.0978 & TRN & & & \\
\hline CHEMBL3212380 & 688653 & 5.33299 & 99999999 & & 4.7812 & TRN & \\
\hline CHEMBL1324157 & 688653 & 5.58299 & 99999999 & & 5.5841 & TRN & \\
\hline CHEMBL1383535 & 688653 & 4.833 & 5.0224 & TRN & & & \\
\hline CHEMBL1581319 & 688653 & 4.783 & 5.4229 & TRN & & & \\
\hline CHEMBL1323208 & 688653 & 5.183 & 5.5764 & TRN & & & \\
\hline CHEMBL1602807 & 688653 & 4.583 & 4.8611 & TRN & & & \\
\hline CHEMBL1524487 & 688653 & 4.883 & 5.2195 & TST & & & \\
\hline CHEMBL1476419 & 688653 & 5.183 & 5.1462 & TRN & & & \\
\hline CHEMBL1338501 & 688653 & 5.33299 & 99999999 & 99 & 5.4262 & TRN & \\
\hline CHEMBL1514543 & 688653 & 5.683 & 5.5499 & TRN & & & \\
\hline CHEMBL1331760 & 688653 & 4.783 & 5.3935 & TST & & & \\
\hline CHEMBL1483226 & 688653 & 6.08299 & 99999999 & 99 & 5.5253 & TRN & \\
\hline CHEMBL1584427 & 688653 & 5.183 & 5.4489 & TRN & & & \\
\hline CHEMBL1471088 & 688653 & 4.833 & 4.9768 & TRN & & & \\
\hline
\end{tabular}




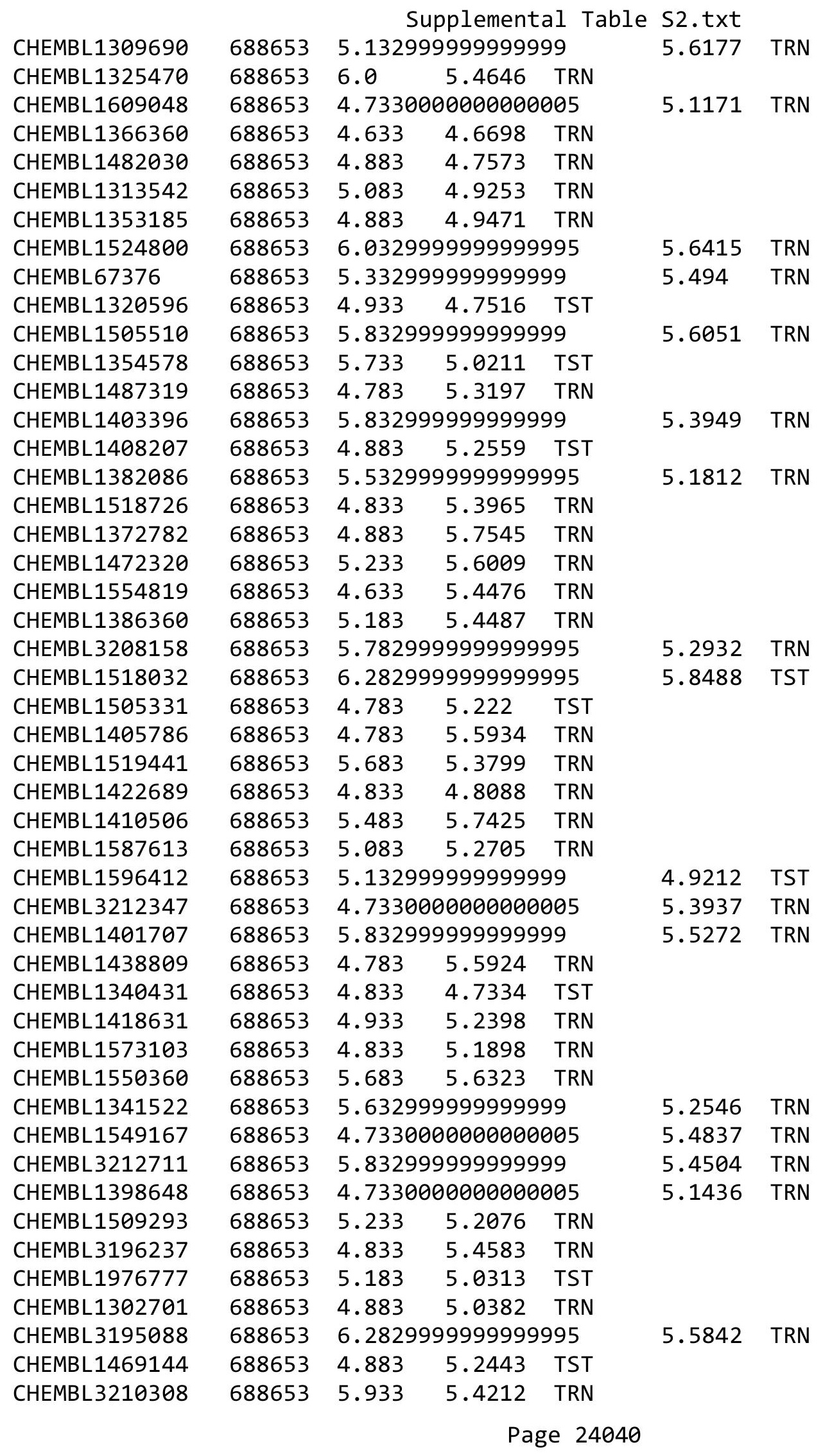




\begin{tabular}{|c|c|c|c|c|c|c|c|}
\hline \multicolumn{8}{|c|}{ Supplemental Table S2.txt } \\
\hline CHEMBL1485198 & 688653 & 4.583 & 5.3343 & TRN & & & \\
\hline CHEMBL1480646 & 688653 & 6.233 & 5.7032 & TRN & & & \\
\hline CHEMBL1384151 & 688653 & 5.183 & 5.204 & TRN & & & \\
\hline CHEMBL1968383 & 688653 & 5.683 & 6.1341 & TRN & & & \\
\hline CHEMBL1400921 & 688653 & 4.883 & 4.8652 & TRN & & & \\
\hline CHEMBL1386984 & 688653 & 4.783 & 5.2641 & TST & & & \\
\hline CHEMBL1505090 & 688653 & \multicolumn{3}{|c|}{5.582999999999999} & \multicolumn{2}{|c|}{5.457999999999999} & TRN \\
\hline CHEMBL528696 & 688653 & 4.883 & 5.2934 & TST & & & \\
\hline CHEMBL1389590 & 688653 & 4.783 & 5.1245 & TRN & & & \\
\hline CHEMBL1377067 & 688653 & \multicolumn{3}{|c|}{6.582999999999999} & 5.3942 & TRN & \\
\hline CHEMBL1520523 & 688653 & 5.983 & \multicolumn{3}{|c|}{5.122000000000001} & TRN & \\
\hline CHEMBL1395874 & 688653 & 6.4829 & 5.454 & TRN & & & \\
\hline CHEMBL1413886 & 688653 & \multicolumn{3}{|c|}{5.7829999999999995} & 5.0567 & TRN & \\
\hline CHEMBL1586007 & 688653 & \multicolumn{3}{|c|}{5.5329999999999995} & 5.5707 & TST & \\
\hline CHEMBL1464550 & 688653 & \multicolumn{3}{|c|}{6.082999999999999} & 5.3826 & TRN & \\
\hline CHEMBL1436610 & 688653 & \multicolumn{3}{|c|}{5.882999999999999} & 5.3279 & TRN & \\
\hline CHEMBL1596918 & 688653 & \multicolumn{3}{|c|}{6.382999999999999} & 5.6099 & TRN & \\
\hline CHEMBL568419 & 688653 & \multicolumn{3}{|c|}{5.332999999999999} & 5.9251 & TRN & \\
\hline CHEMBL1548890 & 688653 & 4.583 & 4.9987 & TRN & & & \\
\hline CHEMBL1462936 & 688653 & 5.933 & 5.3423 & TRN & & & \\
\hline CHEMBL3193212 & 688653 & \multicolumn{3}{|c|}{5.132999999999999} & 5.4421 & TRN & \\
\hline CHEMBL1380130 & 688653 & \multicolumn{3}{|c|}{4.7330000000000005} & 5.25700 & 0000000001 & TST \\
\hline CHEMBL1582825 & 688653 & \multicolumn{3}{|c|}{6.382999999999999} & 5.3788 & TRN & \\
\hline CHEMBL1534844 & 688653 & 4.633 & \multicolumn{3}{|c|}{4.8180000000000005} & TST & \\
\hline CHEMBL1520996 & 688653 & 5.483 & 4.7755 & TRN & & & \\
\hline CHEMBL235453 & 688653 & 4.833 & 5.1871 & TRN & & & \\
\hline CHEMBL1590120 & 688653 & 4.583 & 4.9463 & TST & & & \\
\hline CHEMBL1567082 & 688653 & 5.233 & 5.3206 & TRN & & & \\
\hline CHEMBL1602960 & 688653 & 4.883 & 4.9177 & TRN & & & \\
\hline CHEMBL1411079 & 688653 & 4.683 & 5.0106 & TRN & & & \\
\hline CHEMBL 3198542 & 688653 & 5.033 & 5.5213 & TRN & & & \\
\hline CHEMBL1333847 & 688653 & 6.0 & 5.66700 & 000000000 & & TST & \\
\hline CHEMBL1541270 & 688653 & 4.833 & 5.0346 & TRN & & & \\
\hline CHEMBL1518282 & 688653 & 6.183 & 5.2179 & TRN & & & \\
\hline CHEMBL1469995 & 688653 & 5.233 & 5.0351 & TST & & & \\
\hline CHEMBL1449172 & 688653 & 6.33299 & 99999999 & & 5.7019 & TRN & \\
\hline CHEMBL1379264 & 688653 & 4.73300 & 00000000 & 005 & 5.1883 & TRN & \\
\hline CHEMBL1310148 & 688653 & 5.38299 & 99999999 & & 5.0707 & TRN & \\
\hline CHEMBL1339226 & 688653 & 4.73300 & 30000000 & 005 & 4.8199 & TST & \\
\hline CHEMBL1392817 & 688653 & 5.78299 & 99999999 & 995 & 5.5846 & TRN & \\
\hline CHEMBL1531774 & 688653 & 5.033 & 5.4071 & TRN & & & \\
\hline CHEMBL1978594 & 688653 & 6.8831 & 5.5024 & TRN & & & \\
\hline CHEMBL1460972 & 688653 & 4.98300 & 00000000 & 005 & 5.3666 & TRN & \\
\hline CHEMBL1462691 & 688653 & 7.0329 & 5.9266 & TRN & & & \\
\hline CHEMBL1598732 & 688653 & 5.733 & 5.0797 & TST & & & \\
\hline CHEMBL1441941 & 688653 & 4.98300 & 00000000 & 005 & 5.2172 & TRN & \\
\hline CHEMBL1367089 & 688653 & 5.13299 & 99999999 & & 4.7834 & TST & \\
\hline CHEMBL1325178 & 688653 & 5.78299 & 99999999 & 995 & 5.4142 & TRN & \\
\hline
\end{tabular}




\begin{tabular}{|c|c|c|c|c|c|c|}
\hline \multirow[b]{2}{*}{ CHEMBL1584232 } & \multirow[b]{2}{*}{688653} & \multicolumn{5}{|c|}{ Supplemental Table S2.txt } \\
\hline & & \multicolumn{3}{|c|}{$6.233 \quad 5.4333$ TRN } & & \\
\hline CHEMBL1496705 & 688653 & 4.783 & 5.2749 & TST & & \\
\hline CHEMBL1607084 & 688653 & \multicolumn{3}{|c|}{4.7330000000000005} & 5.7157 & TRN \\
\hline CHEMBL1508793 & 688653 & 4.883 & 5.1524 & TST & & \\
\hline CHEMBL1544938 & 688653 & 4.933 & 5.1918 & TRN & & \\
\hline CHEMBL1373122 & 688653 & 4.833 & 5.3042 & TRN & & \\
\hline CHEMBL1341281 & 688653 & 4.883 & 5.0783 & TST & & \\
\hline CHEMBL1447423 & 688653 & 4.883 & 5.3179 & TRN & & \\
\hline CHEMBL1422976 & 688653 & \multicolumn{3}{|c|}{6.082999999999999} & 5.7285 & TRN \\
\hline CHEMBL1429406 & 688653 & 5.183 & 5.6155 & TRN & & \\
\hline CHEMBL10276 & 688653 & \multicolumn{3}{|c|}{5.132999999999999} & 5.6099 & TST \\
\hline CHEMBL1547111 & 688653 & \multicolumn{3}{|c|}{5.2829999999999995} & 5.3405 & TRN \\
\hline CHEMBL1480144 & 688653 & 4.633 & 5.2499 & TRN & & \\
\hline CHEMBL1971151 & 688653 & \multirow{2}{*}{\multicolumn{3}{|c|}{$\begin{array}{lcc}4.583 & 4.96 & \text { TRN } \\
5.2829999999999995\end{array}$}} & & \\
\hline CHEMBL3195684 & 688653 & & & & 4.9997 & TRN \\
\hline CHEMBL1539509 & 688653 & 4.683 & 5.0234 & TST & & \\
\hline CHEMBL1596406 & 688653 & 7.1831 & 6.1567 & TRN & & \\
\hline CHEMBL1417483 & 688653 & 4.833 & 5.0905 & TRN & & \\
\hline CHEMBL1332825 & 688653 & 5.033 & 5.2711 & TST & & \\
\hline CHEMBL3213155 & 688653 & \multicolumn{3}{|c|}{6.382999999999999} & 5.335 & TRN \\
\hline CHEMBL1519727 & 688653 & 5.683 & 5.4175 & TRN & & \\
\hline CHEMBL1598907 & 688653 & \multicolumn{3}{|c|}{5.382999999999999} & 5.3653 & TST \\
\hline CHEMBL1315519 & 688653 & 4.633 & 5.0283 & TRN & & \\
\hline CHEMBL1565863 & 688653 & \multicolumn{3}{|c|}{6.2829999999999995} & 5.5163 & TRN \\
\hline CHEMBL1484329 & 688653 & 4.783 & 5.1078 & TST & & \\
\hline CHEMBL1313355 & 688653 & \multicolumn{3}{|c|}{4.7330000000000005} & 4.9867 & TRN \\
\hline CHEMBL1590350 & 688653 & 4.633 & 4.9976 & TRN & & \\
\hline CHEMBL1492113 & 688653 & 4.783 & 5.4568 & TRN & & \\
\hline CHEMBL1309143 & 688653 & 4.783 & 5.1796 & TST & & \\
\hline CHEMBL1349908 & 688653 & \multicolumn{3}{|c|}{5.132999999999999} & 5.7265 & TRN \\
\hline CHEMBL1538197 & 688653 & 4.833 & 5.1445 & TRN & & \\
\hline CHEMBL1318060 & 688653 & 8.4318 & 6.0695 & TRN & & \\
\hline CHEMBL1565562 & 688653 & 5.233 & 5.4936 & TRN & & \\
\hline CHEMBL1448905 & 688653 & \multicolumn{3}{|c|}{5.332999999999999} & 5.3223 & TRN \\
\hline CHEMBL1488260 & 688653 & \multicolumn{3}{|c|}{5.132999999999999} & 5.4123 & TRN \\
\hline CHEMBL1338156 & 688653 & \multicolumn{3}{|c|}{5.632999999999999} & 5.282 & TST \\
\hline CHEMBL587836 & 688653 & 4.833 & 5.2916 & TRN & & \\
\hline CHEMBL3211012 & 688653 & 4.783 & 5.2572 & TRN & & \\
\hline CHEMBL1482306 & 688653 & 4.933 & 5.4625 & TST & & \\
\hline CHEMBL1612606 & 688653 & \multicolumn{3}{|c|}{ 7.082999999999999 } & 5.8529 & TRN \\
\hline CHEMBL1539653 & 688653 & 5.183 & 5.6428 & TST & & \\
\hline CHEMBL1480974 & 688653 & 4.783 & 5.6632 & TRN & & \\
\hline CHEMBL1431995 & 688653 & \multicolumn{3}{|c|}{6.582999999999999} & 5.7931 & TRN \\
\hline CHEMBL579324 & 688653 & \multicolumn{3}{|c|}{5.332999999999999} & 5.1987 & TST \\
\hline CHEMBL1593303 & 688653 & \multicolumn{3}{|c|}{4.7330000000000005} & 5.334 & TRN \\
\hline CHEMBL1598327 & 688653 & 5.683 & 5.6612 & TRN & & \\
\hline CHEMBL1597828 & 688653 & 5.483 & 4.939 & TRN & & \\
\hline CHEMBL1308224 & 688653 & 4.783 & 4.3676 & TST & & \\
\hline
\end{tabular}




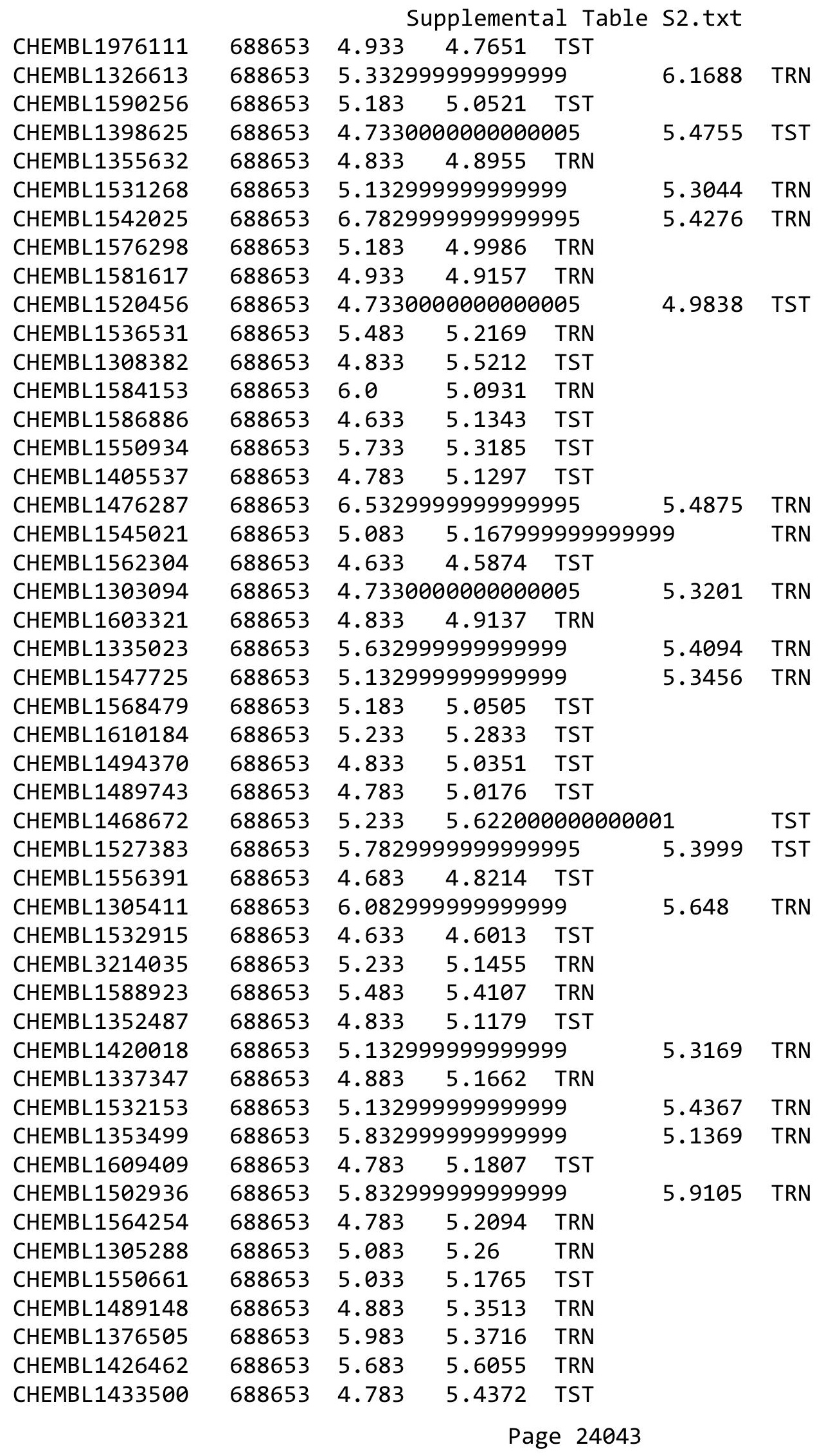




\begin{tabular}{|c|c|c|c|c|c|c|}
\hline & & \multicolumn{5}{|c|}{ Supplemental Table S2.txt } \\
\hline CHEMBL1420780 & 688653 & 4.933 & 5.0228 & TRN & & \\
\hline CHEMBL1588237 & 688653 & 4.933 & 5.3676 & TRN & & \\
\hline CHEMBL1509913 & 688653 & 4.783 & 5.159 & TST & & \\
\hline CHEMBL1481444 & 688653 & 4.783 & 4.855 & TST & & \\
\hline CHEMBL1213771 & 588653 & 4.933 & 5.2738 & TRN & & \\
\hline CHEMBL1498022 & 588653 & 4.883 & 5.2551 & TST & & \\
\hline CHEMBL1497784 & 688653 & 6.7331 & 5.6886 & TRN & & \\
\hline CHEMBL1492020 & 688653 & \multicolumn{3}{|c|}{5.632999999999999} & 5.3698 & $\mathrm{TR}$ \\
\hline CHEMBL1424060 & 688653 & \multicolumn{3}{|c|}{6.082999999999999} & 5.6754 & \\
\hline CHEMBL1585902 & 688653 & 6.4829 & 5.9891 & TRN & & \\
\hline CHEMBL1400514 & 688653 & \multicolumn{3}{|c|}{7.082999999999999} & 5.8108 & \\
\hline CHEMBL1524050 & 688653 & \multicolumn{3}{|c|}{4.7330000000000005} & 5.3893 & \\
\hline CHEMBL1494302 & 688653 & \multicolumn{3}{|c|}{4.9830000000000005} & 154 & \\
\hline CHEMBL3198939 & 688653 & \multicolumn{3}{|c|}{6.832999999999999} & 6.2863 & \\
\hline CHEMBL1461925 & 688653 & 4.933 & 5.3173 & TRN & & \\
\hline CHEMBL1605918 & 688653 & 4.883 & 5.0128 & TRN & & \\
\hline CHEMBL1510903 & 688653 & 4.933 & 5.1603 & TRN & & \\
\hline CHEMBL1458369 & 688653 & 4.783 & \multicolumn{3}{|c|}{5.672000000000001} & \\
\hline CHEMBL1486025 & 688653 & 5.25 & 5.3564 & TRN & & \\
\hline CHEMBL1397045 & 688653 & 6.683 & 5.7711 & TRN & & \\
\hline CHEMBL1530924 & 688653 & \multicolumn{3}{|c|}{5.882999999999999} & 99 & \\
\hline CHEMBL1568521 & 688653 & 4.783 & 5.2942 & TST & & \\
\hline CHEMBL 5 & 688653 & 5.683 & \multicolumn{3}{|c|}{5.702000000000001} & \\
\hline CHEMBL1312602 & 688653 & \multicolumn{3}{|c|}{4.9830000000000005} & 5.0554 & \\
\hline CHEMBL1565220 & 688653 & \multicolumn{3}{|c|}{5.5329999999999995} & 5.3285 & 1 \\
\hline CHEMBL1389857 & 688653 & \multicolumn{3}{|c|}{5.832999999999999} & 5.8717 & \\
\hline CHEMBL3216654 & 688653 & 5.433 & 5.0664 & TST & & \\
\hline CHEMBL1 & 688 & \multirow{2}{*}{\multicolumn{3}{|c|}{$\begin{array}{l}4.933 \quad 4.3889 \text { ISI } \\
6.332999999999999\end{array}$}} & & \\
\hline CHEMBL1367327 & 688653 & & & & 5.9604 & \\
\hline CHEMBL1595449 & 688653 & 4.783 & 5.1663 & TRN & & \\
\hline CHEMBL1368480 & 688653 & \multicolumn{3}{|c|}{4.7330000000000005} & 5.2854 & \\
\hline CHEMBL1 & 688653 & 5.233 & 5.1676 & TST & & \\
\hline CHEMBL1 & 688653 & 4.583 & 5.101 & TST & & \\
\hline CHEMBL1 & 688 & 5.683 & 5.0335 & TRN & & \\
\hline CHEMBL1403078 & 688653 & \multicolumn{3}{|c|}{6.0329999999999995} & 5.9191 & TS \\
\hline CHEMBL1370337 & 688653 & \multicolumn{3}{|c|}{5.132999999999999} & 4.8822 & \\
\hline CHEMBL1 & $68 \varepsilon$ & 5.683 & 5.2515 & TRN & & \\
\hline CHEMBL15 & 688 & \multirow{2}{*}{\multicolumn{3}{|c|}{$\begin{array}{l}5.483 \quad 5.404 \\
5.832999999999999\end{array}$}} & & \\
\hline CHEMBL1530662 & 688653 & & & & 5.6169 & \\
\hline CHEMBL1366145 & 688653 & 4.883 & 5.4788 & TRN & & \\
\hline CHEMBL1469798 & 688653 & \multirow{2}{*}{\multicolumn{3}{|c|}{$\begin{array}{lll}5.233 & 5.235 & \text { TRN } \\
5.582999999999999\end{array}$}} & & \\
\hline CHEMBL1461573 & 688653 & & & & 5.391 & \\
\hline CHEMBL1394544 & 688653 & 4.583 & 4.7652 & TRN & & \\
\hline CHEMBL1410727 & 688653 & \multirow{2}{*}{\multicolumn{3}{|c|}{$\begin{array}{lll}4.933 & 5.4539 & \text { TRN } \\
5.132999999999999\end{array}$}} & & \\
\hline CHEMBL1465044 & 688653 & & & & 5.5172 & \\
\hline CHEMBL1333792 & 688653 & 4.783 & 5.0595 & TST & & \\
\hline CHEMBL1304227 & 688653 & 4.833 & 5.7071 & TRN & & \\
\hline CHEMBL1310489 & 688653 & 4.7330 & 00000000 & & 5.2534 & \\
\hline
\end{tabular}




\begin{tabular}{|c|c|c|c|c|c|c|}
\hline \multirow[b]{2}{*}{ CHEMBL1533711 } & & \multicolumn{5}{|c|}{ Supplemental Table s2.txt } \\
\hline & 688653 & 6.8831 & 5.8836 & TRN & & \\
\hline CHEMBL1427115 & 688653 & 4.783 & 5.7077 & TRN & & \\
\hline CHEMBL1459184 & 688653 & 4.833 & 5.3443 & TRN & & \\
\hline CHEMBL1449317 & 688653 & 5.483 & 5.5102 & TRN & & \\
\hline CHEMBL1330258 & 688653 & \multicolumn{3}{|c|}{5.132999999999999} & 5.0194 & TST \\
\hline CHEMBL1494034 & 688653 & \multicolumn{3}{|c|}{4.7330000000000005} & 5.3634 & TST \\
\hline CHEMBL1419973 & 688653 & \multicolumn{3}{|c|}{6.2829999999999995} & 5.5123 & TRN \\
\hline CHEMBL1511655 & 688653 & 4.833 & 5.5281 & TRN & & \\
\hline CHEMBL1418366 & 688653 & 4.833 & 4.993 & TRN & & \\
\hline CHEMBL1396877 & 688653 & 4.583 & 4.5949 & TRN & & \\
\hline CHEMBL1965669 & 688653 & \multicolumn{3}{|c|}{5.7829999999999995} & 5.8648 & TRN \\
\hline CHEMBL1390579 & 688653 & 4.783 & 5.1018 & TST & & \\
\hline CHEMBL1337538 & 688653 & \multicolumn{3}{|c|}{5.132999999999999} & 4.6125 & TRN \\
\hline CHEMBL1432019 & 688653 & \multicolumn{3}{|c|}{4.7330000000000005} & 5.3791 & TST \\
\hline CHEMBL1402345 & 688653 & 4.783 & 5.1715 & TST & & \\
\hline CHEMBL1366146 & 688653 & 5.183 & 5.2348 & TRN & & \\
\hline CHEMBL1498161 & 688653 & 4.783 & 5.379 & TRN & & \\
\hline CHEMBL1338261 & 688653 & 4.783 & 5.0265 & TRN & & \\
\hline CHEMBL1310425 & 688653 & 4.783 & 5.3072 & TRN & & \\
\hline CHEMBL1346418 & 688653 & 6.4 & 5.7629 & TRN & & \\
\hline CHEMBL1368515 & 688653 & 5.483 & 5.1391 & TRN & & \\
\hline CHEMBL1518774 & 688653 & 6.4829 & 6.0106 & TRN & & \\
\hline CHEMBL1550443 & 688653 & \multicolumn{3}{|c|}{5.2829999999999995} & 5.4286 & TRN \\
\hline CHEMBL1387923 & 688653 & 4.833 & 5.4878 & TRN & & \\
\hline CHEMBL1410567 & 688653 & 5.683 & 5.7426 & TRN & & \\
\hline CHEMBL1353847 & 688653 & \multicolumn{3}{|c|}{6.0329999999999995} & 5.2712 & TRN \\
\hline CHEMBL1601571 & 688653 & 4.883 & 5.3083 & TRN & & \\
\hline CHEMBL1492947 & 688653 & 4.783 & 4.9464 & TST & & \\
\hline CHEMBL1407667 & 688653 & \multicolumn{3}{|c|}{5.832999999999999} & 5.5583 & TST \\
\hline CHEMBL1557156 & 688653 & \multicolumn{3}{|c|}{5.5329999999999995} & 5.721 & TRN \\
\hline CHEMBL1603412 & 688653 & 5.733 & 5.6829 & TRN & & \\
\hline CHEMBL1547946 & 688653 & 5.033 & 5.1152 & TST & & \\
\hline CHEMBL1557400 & 688653 & 4.783 & 5.1183 & TRN & & \\
\hline CHEMBL1364528 & 688653 & \multicolumn{3}{|c|}{5.382999999999999} & 5.9317 & TRN \\
\hline CHEMBL1322727 & 688653 & \multicolumn{3}{|c|}{5.132999999999999} & 5.2625 & TRN \\
\hline CHEMBL1576610 & 688653 & 4.833 & 5.0143 & TST & & \\
\hline CHEMBL1995922 & 688653 & \multirow{2}{*}{\multicolumn{3}{|c|}{4.7330000000000005}} & & \\
\hline CHEMBL1546139 & 688653 & & & & 4.5854 & TST \\
\hline CHEMBL1318074 & 688653 & 4.783 & 5.0841 & TRN & & \\
\hline CHEMBL1402801 & 688653 & 4.633 & 5.2854 & TRN & & \\
\hline CHEMBL1319419 & 688653 & 4.633 & 4.9001 & TRN & & \\
\hline CHEMBL1349571 & 688653 & 4.833 & \multicolumn{3}{|c|}{5.212999999999999} & TRN \\
\hline CHEMBL1489569 & 688653 & \multicolumn{3}{|c|}{6.132999999999999} & 5.2836 & TRN \\
\hline CHEMBL1495474 & 688653 & \multicolumn{3}{|c|}{5.632999999999999} & 5.3158 & TRN \\
\hline CHEMBL1405341 & 688653 & \multicolumn{3}{|c|}{5.882999999999999} & 5.5325 & TRN \\
\hline CHEMBL1444157 & 688653 & 5.683 & 5.3299 & TRN & & \\
\hline CHEMBL1435117 & 688653 & 4.883 & 4.9052 & TRN & & \\
\hline CHEMBL1441134 & 688653 & 4.633 & 4.7551 & TRN & & \\
\hline
\end{tabular}




\begin{tabular}{|c|c|c|c|c|c|c|}
\hline \multirow{3}{*}{$\begin{array}{l}\text { CHEMBL1445231 } \\
\text { CHEMBL1356554 }\end{array}$} & \multirow{3}{*}{$\begin{array}{l}688653 \\
688653\end{array}$} & \multicolumn{5}{|c|}{ Supplemental Table S2.txt } \\
\hline & & \multicolumn{4}{|c|}{$\begin{array}{ll}5.7829999999999995 & 5.357\end{array}$} & \multirow{2}{*}{ TRA } \\
\hline & & 7.0329 & 5.6351 & TRN & & \\
\hline CHEMBL1371920 & 688653 & \multicolumn{3}{|c|}{4.7330000000000005} & 4.9455 & TRN \\
\hline CHEMBL1530630 & 688653 & 4.783 & 5.6333 & TST & & \\
\hline CHEMBL1600868 & 688653 & \multicolumn{3}{|c|}{4.9830000000000005} & 5.7002 & TST \\
\hline CHEMBL1537066 & 688653 & 5.483 & \multicolumn{3}{|c|}{5.707000000000001} & TRN \\
\hline CHEMBL1383915 & 688653 & 6.8831 & \multicolumn{3}{|c|}{6.2170000000000005} & TRN \\
\hline CHEMBL1213769 & 688653 & 5.983 & 5.5853 & TRN & & \\
\hline CHEMBL365374 & 688653 & 4.633 & 5.225 & TRN & & \\
\hline CHEMBL1518138 & 688653 & 6.233 & 5.1938 & TRN & & \\
\hline CHEMBL1382661 & 688653 & 4.933 & 4.8957 & TRN & & \\
\hline CHEMBL1493736 & 688653 & 4.833 & 5.3867 & TST & & \\
\hline CHEMBL1369629 & 688653 & \multicolumn{3}{|c|}{4.9830000000000005} & 4.9496 & TST \\
\hline CHEMBL1539876 & 688653 & 6.233 & 5.4217 & TST & & \\
\hline CHEMBL1400179 & 688653 & 5.683 & 5.4934 & TRN & & \\
\hline CHEMBL1989260 & 688653 & \multicolumn{3}{|c|}{5.832999999999999} & 5.4703 & TRN \\
\hline CHEMBL1548657 & 688653 & 4.883 & 5.0645 & TST & & \\
\hline CHEMBL1331391 & 688653 & 5.433 & 5.5304 & TRN & & \\
\hline CHEMBL1564808 & 688653 & 5.733 & 5.5175 & TRN & & \\
\hline CHEMBL1445456 & 688653 & \multicolumn{3}{|c|}{5.382999999999999} & 5.2541 & TRN \\
\hline CHEMBL1418367 & 688653 & \multicolumn{3}{|c|}{5.5329999999999995} & 5.296 & TRN \\
\hline CHEMBL1336090 & 688653 & 5.733 & 5.1293 & TST & & \\
\hline CHEMBL1302118 & 688653 & 5.183 & 5.3128 & TRN & & \\
\hline CHEMBL1604679 & 688653 & \multicolumn{3}{|c|}{5.832999999999999} & 5.2964 & TRN \\
\hline CHEMBL1336722 & 688653 & 5.733 & 4.9767 & TRN & & \\
\hline CHEMBL 3212770 & 688653 & 5.033 & 5.3203 & TRN & & \\
\hline CHEMBL1316567 & 688653 & 4.833 & 5.0753 & TRN & & \\
\hline CHEMBL1397171 & 688653 & 5.183 & 5.7698 & TRN & & \\
\hline CHEMBL1605751 & 688653 & 4.833 & 5.1993 & TST & & \\
\hline CHEMBL1340845 & 688653 & \multicolumn{3}{|c|}{6.5329999999999995} & 5.7276 & TST \\
\hline CHEMBL1610061 & 688653 & 4.883 & 5.4098 & TRN & & \\
\hline CHEMBL1521676 & 688653 & 5.083 & 5.5438 & TRN & & \\
\hline CHEMBL1604685 & 688653 & 5.683 & 5.3301 & TRN & & \\
\hline CHEMBL1320261 & 688653 & 4.933 & 5.9311 & TRN & & \\
\hline CHEMBL1550612 & 688653 & 5.683 & 5.4334 & TRN & & \\
\hline CHEMBL1336848 & 688653 & 6.233 & 5.5829 & TST & & \\
\hline CHEMBL3189879 & 688653 & \multicolumn{3}{|c|}{4.7330000000000005} & 4.9443 & TST \\
\hline CHEMBL1358732 & 688653 & 4.933 & 4.945 & TST & & \\
\hline CHEMBL1440551 & 688653 & 5.233 & 5.5869 & TRN & & \\
\hline CHEMBL1588726 & 688653 & 5.933 & 5.2261 & TRN & & \\
\hline CHEMBL1564386 & 688653 & 5.933 & 5.1925 & TRN & & \\
\hline CHEMBL1567655 & 688653 & 5.483 & 5.0028 & TRN & & \\
\hline CHEMBL1494178 & 688653 & \multicolumn{3}{|c|}{5.7829999999999995} & 5.3887 & TRN \\
\hline CHEMBL1544656 & 688653 & \multicolumn{3}{|c|}{4.7330000000000005} & 6.0416 & TRN \\
\hline CHEMBL1570319 & 688653 & 4.633 & 4.9844 & TST & & \\
\hline CHEMBL1348055 & 688653 & 4.883 & 5.0649 & TST & & \\
\hline CHEMBL1521791 & 688653 & 5.433 & 5.0869 & TST & & \\
\hline CHEMBL1311497 & 688653 & \multicolumn{3}{|c|}{5.832999999999999} & 5.5764 & TRN \\
\hline
\end{tabular}




\begin{tabular}{|c|c|c|c|c|c|c|}
\hline \multirow[b]{2}{*}{ CHEMBL3196853 } & \multirow[b]{2}{*}{688653} & \multicolumn{5}{|c|}{ Supplemental Table S2.txt } \\
\hline & & 6.183 & 5.4267 & TRN & & \\
\hline CHEMBL1613234 & 688653 & 4.833 & 5.4075 & TRN & & \\
\hline CHEMBL1388922 & 688653 & \multicolumn{3}{|c|}{5.2829999999999995} & 5.6297 & TRN \\
\hline CHEMBL1390815 & 688653 & \multicolumn{3}{|c|}{5.332999999999999} & 5.4545 & TRN \\
\hline CHEMBL1350041 & 688653 & \multicolumn{3}{|c|}{5.832999999999999} & 5.7327 & TST \\
\hline CHEMBL1541474 & 688653 & 4.783 & 5.3238 & TST & & \\
\hline CHEMBL1417099 & 688653 & \multicolumn{3}{|c|}{6.0329999999999995} & 5.4193 & TST \\
\hline CHEMBL1299707 & 688653 & \multicolumn{3}{|c|}{4.7330000000000005} & 5.2387 & TST \\
\hline CHEMBL1471848 & 688653 & 4.883 & 5.1924 & TST & & \\
\hline CHEMBL1308313 & 688653 & 4.633 & 5.3789 & TST & & \\
\hline CHEMBL1529259 & 688653 & \multicolumn{3}{|c|}{5.2829999999999995} & 5.3094 & TRN \\
\hline CHEMBL1324787 & 688653 & \multicolumn{3}{|c|}{$\begin{array}{lll}7.1331 & 5.7544 & \text { TRN }\end{array}$} & & \\
\hline CHEMBL1334407 & 688653 & \multicolumn{3}{|c|}{4.7330000000000005} & 5.2802 & TRN \\
\hline CHEMBL1526651 & 688653 & 4.883 & 5.1633 & TRN & & \\
\hline CHEMBL1597322 & 688653 & \multicolumn{3}{|c|}{6.832999999999999} & 5.8055 & TRN \\
\hline CHEMBL1391277 & 688653 & 4.833 & 5.0773 & TRN & & \\
\hline CHEMBL1410893 & 688653 & 4.683 & 5.0619 & TST & & \\
\hline CHEMBL1577201 & 688653 & 5.733 & 5.2961 & TRN & & \\
\hline CHEMBL1417064 & 688653 & \multicolumn{3}{|c|}{6.582999999999999} & 6.0676 & TRN \\
\hline CHEMBL1579416 & 688653 & 5.183 & 5.4167 & TRN & & \\
\hline CHEMBL3207602 & 688653 & \multicolumn{3}{|c|}{4.7330000000000005} & 5.5839 & TRN \\
\hline CHEMBL1338706 & 688653 & 4.883 & 5.329 & TST & & \\
\hline CHEMBL3199086 & 688653 & \multicolumn{3}{|c|}{5.632999999999999} & 0092 & TRN \\
\hline CHEMBL3196622 & 688653 & 6.183 & 5.8536 & TRN & & \\
\hline CHEMBL1405295 & 688653 & \multicolumn{3}{|c|}{5.832999999999999} & 5.6965 & TST \\
\hline CHEMBL1609337 & 688653 & \multicolumn{3}{|c|}{4.7330000000000005} & 5.0122 & TST \\
\hline CHEMBL1510400 & 688653 & 6.183 & 5.331 & TST & & \\
\hline CHEMBL1348326 & 688653 & \multicolumn{3}{|c|}{5.632999999999999} & 5.5185 & TRN \\
\hline CHEMBL1597210 & 688653 & \multicolumn{3}{|c|}{5.332999999999999} & 5.1106 & TRN \\
\hline CHEMBL1330799 & 688653 & 4.883 & 5.8125 & TRN & & \\
\hline CHEMBL1553009 & 688653 & \multicolumn{3}{|c|}{5.7829999999999995} & 5.0861 & TRN \\
\hline CHEMBL1449104 & 688653 & \multicolumn{3}{|c|}{4.7330000000000005} & 5.1019 & TRN \\
\hline CHEMBL1520661 & 688653 & 4.9830 & 00000000 & 005 & 5.1642 & TST \\
\hline CHEMBL1447563 & 688653 & 5.1329 & 99999999 & & 5.3894 & TST \\
\hline CHEMBL1551671 & 688653 & 4.633 & 5.2085 & TRN & & \\
\hline CHEMBL1412216 & 688653 & 4.783 & 5.4323 & TRN & & \\
\hline CHEMBL1449921 & 688653 & 4.933 & 4.995 & TRN & & \\
\hline CHEMBL1602086 & 688653 & 5.8329 & 99999999 & & 6.8525 & TRN \\
\hline CHEMBL1498995 & 688653 & 4.933 & 5.5292 & TRN & & \\
\hline CHEMBL1610719 & 688653 & 6.5329 & 99999999 & 995 & 5.9416 & TRN \\
\hline CHEMBL1445570 & 688653 & 4.833 & 5.0732 & TRN & & \\
\hline CHEMBL1538546 & 688653 & 5.2829 & 99999999 & 995 & 5.4464 & TRN \\
\hline CHEMBL1478971 & 688653 & 4.833 & 5.1218 & TRN & & \\
\hline CHEMBL1435461 & 688653 & 4.633 & 4.8624 & TST & & \\
\hline CHEMBL1591415 & 688653 & 5.8829 & 99999999 & & 5.756 & TST \\
\hline CHEMBL1326724 & 688653 & 5.483 & 5.3965 & TRN & & \\
\hline CHEMBL1505784 & 688653 & 5.2829 & 99999999 & 995 & 5.5042 & TRN \\
\hline CHEMBL1545149 & 688653 & 5.2829 & 99999999 & 995 & 5.3043 & TRN \\
\hline
\end{tabular}




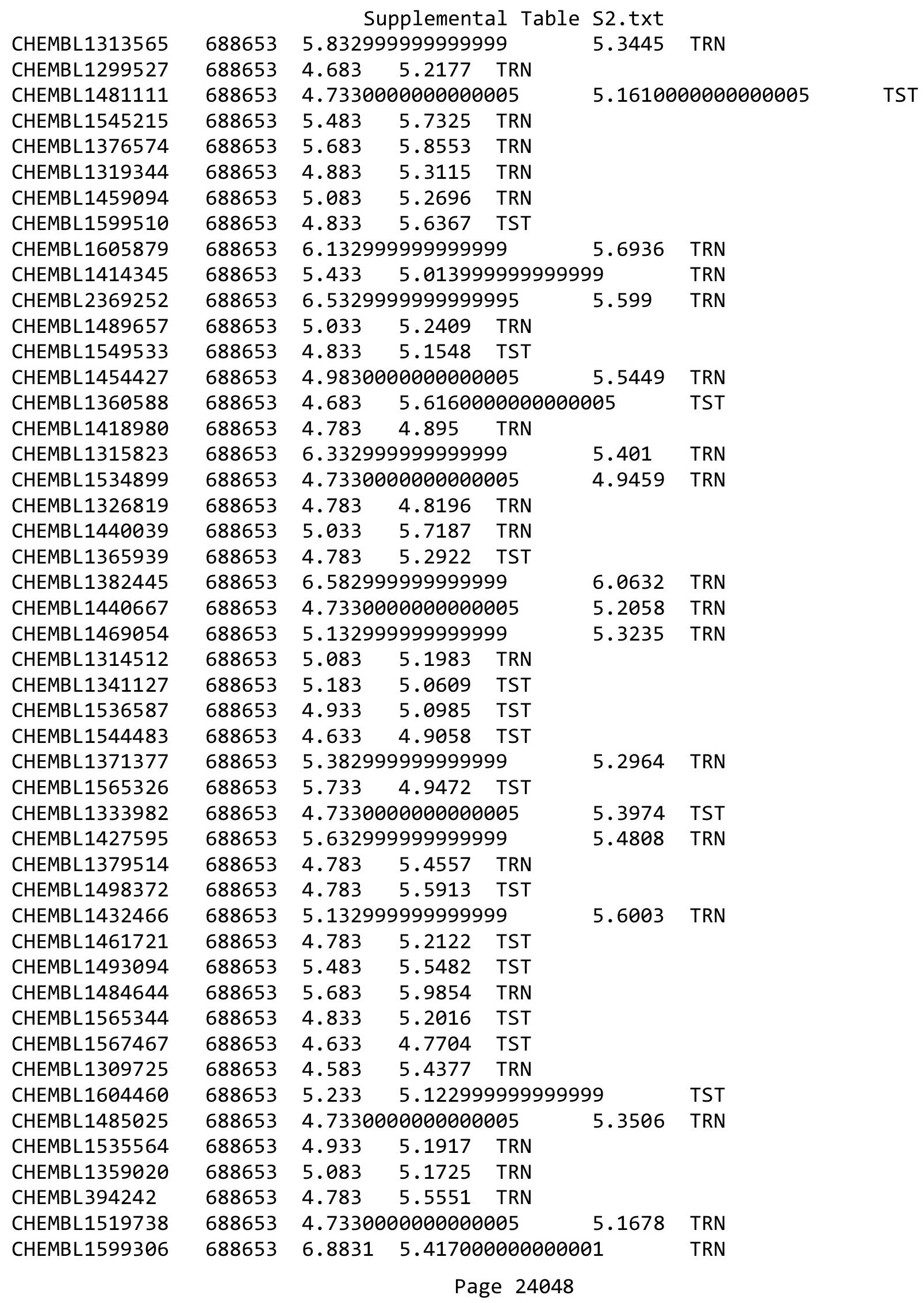




\begin{tabular}{|c|c|c|c|c|c|c|}
\hline & & \multicolumn{5}{|c|}{ Supplemental Table S2.txt } \\
\hline CHEMBL1571315 & 688653 & \multicolumn{3}{|c|}{6.5329999999999995} & 6.0923 & TRN \\
\hline CHEMBL114544 & 688653 & 6.0 & 5.8388 & TST & & \\
\hline CHEMBL1397089 & 688653 & 5.683 & 5.6444 & TST & & \\
\hline CHEMBL1366506 & 688653 & 5.033 & 5.2963 & TRN & & \\
\hline CHEMBL1596709 & 688653 & 5.933 & 5.3729 & TRN & & \\
\hline CHEMBL1535304 & 688653 & \multicolumn{3}{|c|}{5.332999999999999} & 5.5167 & TRN \\
\hline CHEMBL3191808 & 688653 & \multicolumn{3}{|c|}{5.582999999999999} & 5.2359 & TRN \\
\hline CHEMBL1381351 & 688653 & \multicolumn{3}{|c|}{4.7330000000000005} & 5.7142 & TRN \\
\hline CHEMBL1344929 & 688653 & 5.9 & 5.2751 & TRN & & \\
\hline CHEMBL1608312 & 688653 & 5.183 & 5.4394 & TRN & & \\
\hline CHEMBL1348219 & 688653 & 5.683 & 4.961 & TRN & & \\
\hline CHEMBL1426657 & 688653 & 5.483 & 5.1805 & TRN & & \\
\hline CHEMBL1428175 & 688653 & \multicolumn{3}{|c|}{4.9830000000000005} & 5.2473 & TST \\
\hline CHEMBL1553969 & 688653 & 4.833 & 5.2092 & TST & & \\
\hline CHEMBL1410615 & 688653 & 5.233 & 5.3269 & TST & & \\
\hline CHEMBL1301015 & 688653 & 4.883 & 5.4302 & TRN & & \\
\hline CHEMBL1385464 & 688653 & 4.883 & 5.7323 & TRN & & \\
\hline CHEMBL1378589 & 688653 & \multicolumn{3}{|c|}{5.2829999999999995} & 5.1913 & TRN \\
\hline CHEMBL1364392 & 688653 & \multicolumn{3}{|c|}{4.9830000000000005} & 5.7774 & TRN \\
\hline CHEMBL1579844 & 688653 & 5.433 & 5.5379 & TRN & & \\
\hline CHEMBL1539929 & 688653 & 4.883 & 5.3076 & TRN & & \\
\hline CHEMBL1489721 & 688653 & \multicolumn{3}{|c|}{5.382999999999999} & 5.1736 & TRN \\
\hline CHEMBL1511077 & 688653 & 4.783 & 5.4067 & TRN & & \\
\hline CHEMBL1478988 & 688653 & 4.883 & 4.9659 & TST & & \\
\hline CHEMBL1446330 & 688653 & 4.833 & 5.2353 & TRN & & \\
\hline CHEMBL1380443 & 688653 & 4.783 & 5.0544 & TRN & & \\
\hline CHEMBL1602701 & 688653 & 5.483 & 5.0615 & TRN & & \\
\hline CHEMBL1603763 & 688653 & 5.433 & 5.5624 & TST & & \\
\hline CHEMBL1504859 & 688653 & \multicolumn{3}{|c|}{5.632999999999999} & 5.559 & TRN \\
\hline CHEMBL1612979 & 688653 & 4.583 & 5.8252 & TST & & \\
\hline CHEMBL1438788 & 688653 & 4.683 & 4.9471 & TRN & & \\
\hline CHEMBL97542 & 688653 & 4.833 & 4.9865 & TRN & & \\
\hline CHEMBL1496952 & 688653 & 4.583 & 4.9458 & TRN & & \\
\hline CHEMBL1315812 & 688653 & 4.583 & 4.955 & TRN & & \\
\hline CHEMBL 3192054 & 688653 & \multicolumn{3}{|c|}{4.7330000000000005} & 4.8897 & TRN \\
\hline CHEMBL1486673 & 688653 & 5.083 & 5.002 & TST & & \\
\hline CHEMBL1404809 & 688653 & 4.933 & 5.5147 & TRN & & \\
\hline CHEMBL482116 & 688653 & 5.483 & 5.7723 & TRN & & \\
\hline CHEMBL1419108 & 688653 & 5.05 & 5.5443 & TRN & & \\
\hline CHEMBL1535159 & 688653 & 4.783 & 5.1634 & TRN & & \\
\hline CHEMBL1411391 & 688653 & 5.683 & 5.1173 & TRN & & \\
\hline CHEMBL1388039 & 688653 & 6.4829 & 5.2872 & TST & & \\
\hline CHEMBL1419099 & 688653 & \multicolumn{3}{|c|}{5.832999999999999} & 5.1499 & TRN \\
\hline CHEMBL1423851 & 688653 & 4.833 & 5.9507 & TRN & & \\
\hline CHEMBL1313157 & 688653 & \multicolumn{3}{|c|}{5.5329999999999995} & 5.1202 & TRN \\
\hline CHEMBL1507242 & 688653 & 4.833 & 5.3196 & TRN & & \\
\hline CHEMBL 259018 & 688653 & 4.783 & 4.728 & TRN & & \\
\hline CHEMBL1383581 & 688653 & 4.783 & 5.4778 & TRN & & \\
\hline
\end{tabular}




\begin{tabular}{|c|c|c|c|c|c|c|c|}
\hline \multirow[b]{2}{*}{ CHEMBL1309549 } & \multicolumn{6}{|c|}{ Supplemental Table S2.txt } & \\
\hline & 688653 & 4.833 & 5.2402 & TRN & & & \\
\hline CHEMBL1466923 & 688653 & 6.33299 & 99999999 & & $5.3610 \ell$ & 0000000001 & TRN \\
\hline CHEMBL1457410 & 688653 & 4.783 & 5.3754 & TRN & & & \\
\hline CHEMBL 3197870 & 688653 & 5.88299 & 99999999 & & 5.7033 & TRN & \\
\hline CHEMBL1475371 & 688653 & 4.883 & 5.379 & TRN & & & \\
\hline CHEMBL1502935 & 688653 & 5.88299 & 99999999 & & 5.3353 & TRN & \\
\hline CHEMBL1332160 & 688653 & 5.28299 & 99999999 & 995 & 5.2316 & TST & \\
\hline CHEMBL1503623 & 688653 & 5.78299 & 99999999 & 995 & 5.2976 & TST & \\
\hline CHEMBL 3190098 & 688653 & 4.73300 & 00000000 & 005 & 5.7446 & TRN & \\
\hline CHEMBL1458979 & 688653 & 5.38299 & 99999999 & 99 & 5.1157 & TRN & \\
\hline CHEMBL1478231 & 688653 & 4.73300 & 00000000 & 005 & 5.3849 & TST & \\
\hline CHEMBL1555331 & 688653 & 6.28299 & 99999999 & 995 & 5.2292 & TRN & \\
\hline CHEMBL1449678 & 688653 & 4.883 & 5.0927 & TRN & & & \\
\hline CHEMBL1499666 & 688653 & 4.783 & 4.783 & TRN & & & \\
\hline CHEMBL1327832 & 688653 & 4.833 & 5.345 & TRN & & & \\
\hline CHEMBL1420725 & 688653 & 5.083 & 5.1678 & TRN & & & \\
\hline CHEMBL1326979 & 688653 & 6.38299 & 99999999 & & 5.4819 & TRN & \\
\hline CHEMBL1613213 & 688653 & 5.88299 & 99999999 & & 5.3316 & TRN & \\
\hline CHEMBL1540210 & 688653 & 5.183 & 5.6706 & TRN & & & \\
\hline CHEMBL1451871 & 688653 & 5.38299 & 99999999 & & 5.1492 & TRN & \\
\hline CHEMBL1583703 & 688653 & 4.683 & 5.5466 & TRN & & & \\
\hline CHEMBL1340158 & 688653 & 4.73300 & 00000000 & 005 & 5.2189 & 9999999999 & TRN \\
\hline CHEMBL1359983 & 688653 & 4.73300 & 00000000 & 005 & 4.9289 & TRN & \\
\hline CHEMBL1454434 & 688653 & 4.783 & 5.2766 & TRN & & & \\
\hline CHEMBL1597344 & 688653 & 4.933 & 4.9605 & TRN & & & \\
\hline CHEMBL1592525 & 688653 & 5.033 & 5.2476 & TST & & & \\
\hline CHEMBL1360758 & 688653 & 5.28299 & 99999999 & 995 & 5.2523 & TRN & \\
\hline CHEMBL1527551 & 688653 & 4.833 & 5.5145 & TRN & & & \\
\hline CHEMBL1299957 & 688653 & 5.233 & 5.3068 & TST & & & \\
\hline CHEMBL1468329 & 688653 & 5.63299 & 99999999 & & $5.8270 e$ & 0000000001 & TRN \\
\hline CHEMBL1542645 & 688653 & 5.683 & 5.5651 & TRN & & & \\
\hline CHEMBL1457655 & 688653 & 5.033 & 5.1204 & TST & & & \\
\hline CHEMBL1422742 & 688653 & 5.683 & 5.7015 & TST & & & \\
\hline CHEMBL1562191 & 688653 & 4.883 & 5.2481 & TST & & & \\
\hline CHEMBL1431451 & 688653 & 4.883 & 5.7155 & TRN & & & \\
\hline CHEMBL1524033 & 688653 & 6.03299 & 99999999 & 995 & 5.926 & TRN & \\
\hline CHEMBL1556683 & 688653 & 4.833 & 4.5771 & TRN & & & \\
\hline CHEMBL1416739 & 688653 & 4.73300 & $\partial 0000000$ & 005 & 5.2045 & TST & \\
\hline CHEMBL1389833 & 688653 & 5.733 & 5.7123 & TRN & & & \\
\hline CHEMBL3196718 & 688653 & 5.433 & 5.6413 & TRN & & & \\
\hline CHEMBL1385421 & 688653 & 5.78299 & 99999999 & 995 & 5.5557 & TRN & \\
\hline CHEMBL1582132 & 688653 & 6.233 & 5.7137 & TRN & & & \\
\hline CHEMBL1490895 & 688653 & 4.783 & 5.309 & TRN & & & \\
\hline CHEMBL 2002818 & 688653 & 5.13299 & 99999999 & & 5.3182 & TRN & \\
\hline CHEMBL1482424 & 688653 & 4.783 & 5.186 & TRN & & & \\
\hline CHEMBL1456585 & 688653 & 4.633 & 5.0586 & TRN & & & \\
\hline CHEMBL1422678 & 688653 & 6.0 & 6.0747 & TRN & & & \\
\hline CHEMBL1573024 & 688653 & 5.33299 & 99999999 & & 5.0488 & TRN & \\
\hline
\end{tabular}




\begin{tabular}{|c|c|c|c|c|c|c|}
\hline \multirow{3}{*}{$\begin{array}{l}\text { CHEMBL1326315 } \\
\text { CHEMBL1373967 }\end{array}$} & \multirow{3}{*}{$\begin{array}{l}688653 \\
688653\end{array}$} & \multicolumn{4}{|c|}{ Supplemental Table S2.txt } & \multirow{2}{*}{ TST } \\
\hline & & \multicolumn{3}{|c|}{6.632999999999999} & 5.6834 & \\
\hline & & 4.833 & 5.0325 & TRN & & \\
\hline CHEMBL1499620 & 688653 & 4.933 & 4.8983 & TRN & & \\
\hline CHEMBL1435266 & 688653 & 4.883 & 4.8855 & TRN & & \\
\hline CHEMBL1342112 & 688653 & \multicolumn{3}{|c|}{4.7330000000000005} & 4.9709 & TRN \\
\hline CHEMBL1416349 & 688653 & \multicolumn{3}{|c|}{5.332999999999999} & 4.7747 & TST \\
\hline CHEMBL1595616 & 688653 & 5.033 & 5.1327 & TRN & & \\
\hline CHEMBL1473750 & 688653 & 4.883 & 5.2375 & TRN & & \\
\hline CHEMBL1470468 & 688653 & 5.033 & 5.3276 & TRN & & \\
\hline CHEMBL1500771 & 688653 & 4.883 & 5.5523 & TST & & \\
\hline CHEMBL1464256 & 688653 & 5.683 & 5.0028 & TRN & & \\
\hline CHEMBL1347466 & 688653 & \multicolumn{3}{|c|}{6.0329999999999995} & 5.4568 & TRN \\
\hline CHEMBL1548742 & 688653 & 4.883 & 5.0413 & TRN & & \\
\hline CHEMBL1305809 & 688653 & \multicolumn{3}{|c|}{5.332999999999999} & 5.1617 & TST \\
\hline CHEMBL1538099 & 688653 & 4.683 & 5.2056 & TST & & \\
\hline CHEMBL1408098 & 688653 & 4.833 & 5.4255 & TRN & & \\
\hline CHEMBL 3214284 & 688653 & 5.033 & 5.1412 & TRN & & \\
\hline CHEMBL1604911 & 688653 & 5.433 & 5.3857 & TRN & & \\
\hline CHEMBL3213800 & 688653 & 5.033 & 5.0949 & TRN & & \\
\hline CHEMBL1464056 & 688653 & 5.233 & 5.2308 & TRN & & \\
\hline CHEMBL1572594 & 688653 & 4.783 & 5.4011 & TST & & \\
\hline CHEMBL1428023 & 688653 & 4.933 & 4.9948 & TRN & & \\
\hline CHEMBL1354522 & 688653 & \multicolumn{3}{|c|}{5.132999999999999} & 5.3703 & TST \\
\hline CHEMBL1438476 & 688653 & \multicolumn{3}{|c|}{4.7330000000000005} & 5.8137 & TST \\
\hline CHEMBL1420408 & 688653 & \multicolumn{3}{|c|}{4.7330000000000005} & 5.0489 & TST \\
\hline CHEMBL1486982 & 688653 & \multicolumn{3}{|c|}{5.382999999999999} & 5.107 & TRN \\
\hline CHEMBL1557921 & 688653 & \multicolumn{3}{|c|}{4.7330000000000005} & 5.0136 & TRN \\
\hline CHEMBL1299906 & 688653 & 5.483 & 5.7353 & TRN & & \\
\hline CHEMBL1591942 & 688653 & 4.633 & 4.6083 & TST & & \\
\hline CHEMBL1565719 & 688653 & 4.883 & 4.9101 & TRN & & \\
\hline CHEMBL1325141 & 688653 & 4.583 & 4.7914 & TST & & \\
\hline CHEMBL1401234 & 688653 & \multicolumn{3}{|c|}{6.082999999999999} & 5.8529 & TRN \\
\hline CHEMBL1362823 & 688653 & \multicolumn{3}{|c|}{5.132999999999999} & 5.2173 & TRN \\
\hline CHEMBL1524288 & 688653 & 4.633 & 5.0394 & TRN & & \\
\hline CHEMBL1443113 & 688653 & 5.933 & 5.6167 & TRN & & \\
\hline CHEMBL1485375 & 688653 & \multicolumn{3}{|c|}{5.2829999999999995} & 5.4332 & TRN \\
\hline CHEMBL1309788 & 688653 & \multicolumn{3}{|c|}{5.832999999999999} & 5.9876 & TRN \\
\hline CHEMBL 1407340 & 688653 & 4.583 & 4.8812 & TRN & & \\
\hline CHEMBL1534210 & 688653 & \multicolumn{3}{|c|}{5.132999999999999} & 5.1482 & TRN \\
\hline CHEMBL1571395 & 688653 & \multicolumn{3}{|c|}{4.7330000000000005} & 5.0805 & TST \\
\hline CHEMBL3209077 & 688653 & 4.783 & 5.5617 & TRN & & \\
\hline CHEMBL3195091 & 688653 & \multicolumn{3}{|c|}{5.632999999999999} & 5.1463 & TST \\
\hline CHEMBL1418121 & 688653 & 5.6329 & 99999999 & & 5.3815 & TRN \\
\hline CHEMBL1361936 & 688653 & 7.1831 & 6.3602 & TRN & & \\
\hline CHEMBL 3195170 & 688653 & 4.783 & 5.059 & TST & & \\
\hline CHEMBL1569945 & 688653 & 5.1329 & 99999999 & & 5.8115 & TRN \\
\hline CHEMBL1478644 & 688653 & 6.433 & 6.1357 & TRN & & \\
\hline CHEMBL1556708 & 688653 & 4.833 & 5.4429 & TRN & & \\
\hline
\end{tabular}




\begin{tabular}{|c|c|c|c|c|c|c|}
\hline \multirow[b]{2}{*}{ CHEMBL1608383 } & \multirow[b]{2}{*}{688653} & \\
\hline & & 7.2832 & \multicolumn{2}{|c|}{5.8076 TRN } & \multicolumn{2}{|l|}{ S2.txt } \\
\hline CHEMBL1313750 & 688653 & 5.233 & 5.5295 & TST & & \\
\hline CHEMBL1377507 & 688653 & \multicolumn{3}{|c|}{7.382999999999999} & 5.1402 & $\mathrm{TS}^{-}$ \\
\hline CHEMBL1416617 & 688653 & 5.183 & 5.5275 & TRN & & \\
\hline CHEMBL1329031 & 688653 & 4.633 & 4.7723 & TRN & & \\
\hline CHEMBL1308321 & 688653 & 7.0329 & 6.1545 & TRN & & \\
\hline CHEMBL1366592 & 688653 & 5.483 & 5.5249 & TRN & & \\
\hline CHEMBL1586951 & 688653 & 5.183 & 5.6032 & TRN & & \\
\hline CHEMBL1531003 & 688653 & 4.633 & 5.2476 & TST & & \\
\hline CHEMBL1333417 & 688653 & \multicolumn{3}{|c|}{4.7330000000000005} & 5.3824 & \\
\hline CHEMBL1427465 & 688653 & 6.433 & 5.6823 & TRN & & \\
\hline CHEMBL1316483 & 688653 & 4.633 & 5.0605 & TRN & & \\
\hline CHEMBL1408101 & 688653 & 5.983 & 5.4166 & TRN & & \\
\hline CHEMBL1569446 & 688653 & \multicolumn{3}{|c|}{5.5329999999999995} & 5.3874 & \\
\hline CHEMBL1311991 & 688653 & \multicolumn{3}{|c|}{5.582999999999999} & 5.2152 & \\
\hline CHEMBL1481074 & 688653 & 5.033 & 5.0886 & TST & & \\
\hline CHEMBL1516537 & 688653 & \multicolumn{3}{|c|}{6.0329999999999995} & 5.3906 & \\
\hline CHEMBL467423 & 688653 & 5.933 & 5.5434 & TRN & & \\
\hline CHEMBL1419733 & 688653 & \multicolumn{3}{|c|}{5.5329999999999995} & 9 & \\
\hline CHEMBL1576523 & 688653 & 4.883 & 4.9594 & TRN & & \\
\hline CHEMBL1475198 & 688653 & \multicolumn{3}{|c|}{4.7330000000000005} & 5.1604 & $\mathrm{TS}$ \\
\hline CHEMBL1411783 & 688653 & 4.833 & 5.3865 & TST & & \\
\hline CHEMBL3190726 & 688653 & 5.233 & 5.6977 & TRN & & \\
\hline CHEMBL1320983 & 688653 & \multicolumn{3}{|c|}{6.0329999999999995} & 2 & \\
\hline CHEMBL3209135 & 688653 & \multicolumn{3}{|c|}{4.7330000000000005} & 5.17 & \\
\hline CHEMBL1564403 & 688653 & 4.833 & 5.1006 & TRN & & \\
\hline CHEMBL1516815 & 688653 & \multicolumn{3}{|c|}{5.632999999999999} & 5.5722 & TRN \\
\hline CHEMBL1505173 & 688653 & \multicolumn{3}{|c|}{5.2829999999999995} & 5.3221 & TRN \\
\hline CHEMBL1487543 & 688653 & \multicolumn{3}{|c|}{6.0329999999999995} & 5.6359 & \\
\hline CHEMBL1406411 & 688653 & 5.233 & 5.6621 & TRN & & \\
\hline CHEMBL1343918 & 688653 & \multirow{2}{*}{\multicolumn{3}{|c|}{$\begin{array}{lll}4.183 & 5.1 / / 1 \\
4.7330000000000005\end{array}$}} & & \\
\hline CHEMBL1490481 & 688653 & & & & 5.2089 & TRN \\
\hline CHEMBL3190435 & 688653 & 5.433 & 5.7661 & TRN & & \\
\hline CHEMBL1557307 & 688653 & 4.933 & 5.6089 & TST & & \\
\hline CHEMBL1524345 & 688653 & 4.683 & 5.5668 & TRN & & \\
\hline CHEMBL1397569 & 688653 & 4.633 & 4.9114 & TRN & & \\
\hline CHEMBL1392208 & 688653 & 5.45 & 5.5311 & TRN & & \\
\hline CHEMBL1488781 & 688653 & \multicolumn{3}{|c|}{5.132999999999999} & 5.5111 & TR \\
\hline CHEMBL1319385 & 688653 & 5.033 & 5.3046 & TST & & \\
\hline CHEMBL1971604 & 688653 & & 5.3381 & TRN & & \\
\hline CHEMBL1476813 & 688653 & \multicolumn{3}{|c|}{5.832999999999999} & 5.5978 & TRN \\
\hline CHEMBL1600381 & 688653 & \multicolumn{3}{|c|}{5.882999999999999} & 5.5744 & TRN \\
\hline CHEMBL1540667 & 688653 & 4.783 & 5.0802 & TST & & \\
\hline CHEMBL3192212 & 688653 & 5.83299 & 99999999 & & 5.3419 & TRN \\
\hline CHEMBL3196279 & 688653 & 5.33299 & 99999999 & & 5.2151 & TRN \\
\hline CHEMBL1400351 & 688653 & 6.7331 & 5.7094 & TRN & & \\
\hline CHEMBL1558119 & 688653 & 5.63299 & 99999999 & & 5.1116 & TRN \\
\hline CHEMBL1465258 & 688653 & 4.73300 & 0000000 & 005 & 4.8852 & TS \\
\hline
\end{tabular}




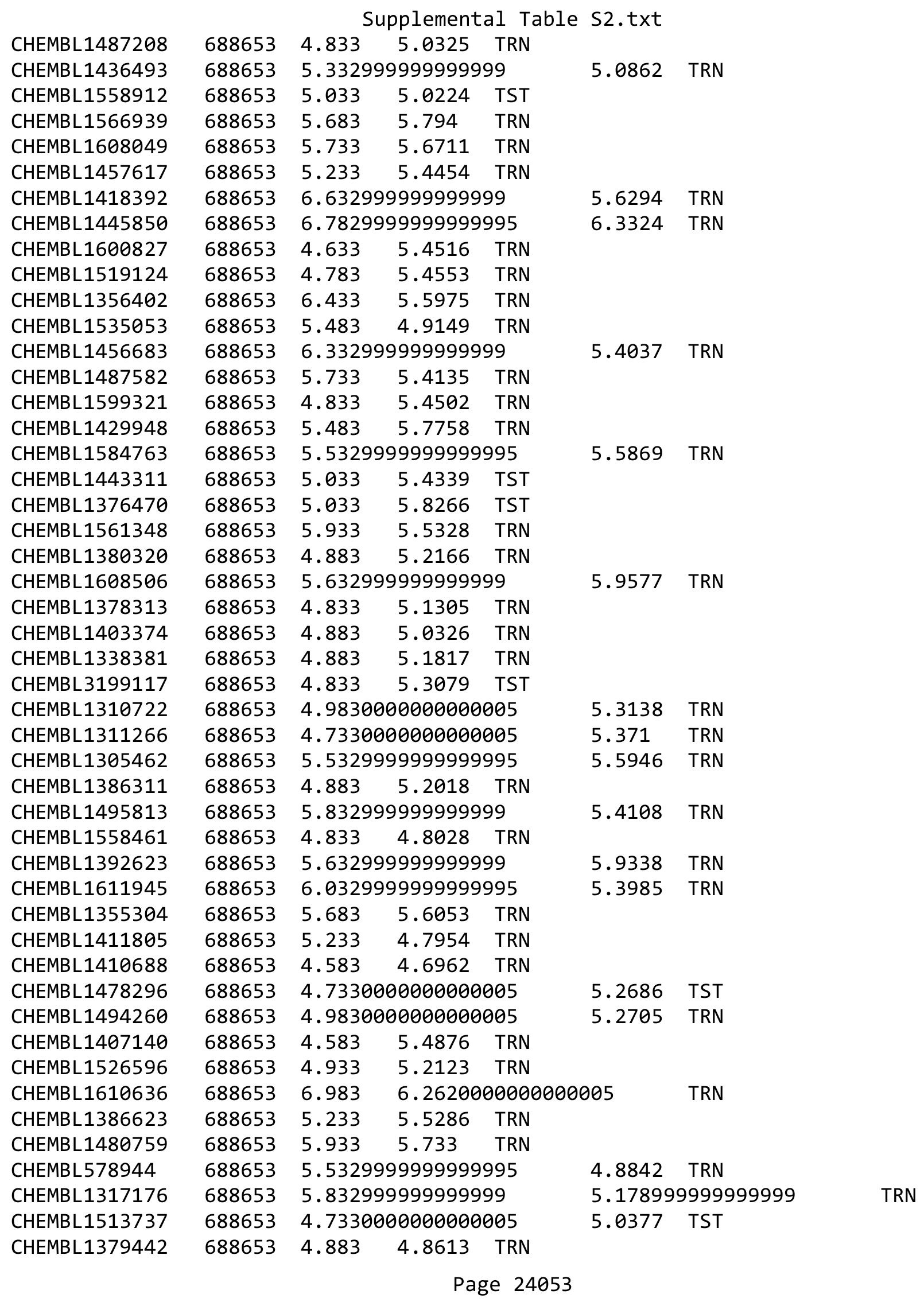




\begin{tabular}{|c|c|c|c|c|c|c|}
\hline \multirow{3}{*}{$\begin{array}{l}\text { CHEMBL1483846 } \\
\text { CHEMBL1361236 }\end{array}$} & \multirow{3}{*}{$\begin{array}{l}688653 \\
688653\end{array}$} & \multicolumn{5}{|c|}{ Supplemental Table S2.txt } \\
\hline & & \multicolumn{3}{|c|}{4.7330000000000005} & \multirow[t]{6}{*}{5.0442} & \multirow[t]{6}{*}{ TRN } \\
\hline & & 5.733 & 5.7237 & TRN & & \\
\hline CHEMBL1372681 & 688653 & 6.433 & 5.3157 & TST & & \\
\hline CHEMBL1418087 & 688653 & 5.183 & 5.727 & TRN & & \\
\hline CHEMBL1534684 & 88653 & 4.833 & 5.1003 & TRN & & \\
\hline CHEMBL1409797 & 588653 & 4.783 & 5.1039 & TRN & & \\
\hline CHEMBL1478058 & 688653 & \multicolumn{3}{|c|}{4.9830000000000005} & 5.5141 & \\
\hline CHEMBL1519597 & 688653 & 7.1331 & 5.7942 & TRN & & \\
\hline CHEMBL1451348 & 688653 & \multicolumn{3}{|c|}{5.132999999999999} & 4.9609 & \\
\hline CHEMBL3196087 & 688653 & 5.483 & 5.5737 & TRN & & \\
\hline CHEMBL1392719 & 688653 & \multicolumn{3}{|c|}{4.7330000000000005} & 4.9737 & $\mathrm{~T}$ \\
\hline CHEMBL1369567 & 688653 & \multicolumn{3}{|c|}{5.132999999999999} & 5.3059 & \\
\hline CHEMBL1372938 & 688653 & 4.883 & 5.5832 & TST & & \\
\hline CHEMBL1491655 & 688653 & 5.433 & 5.0816 & TST & & \\
\hline CHEMBL3198630 & 688653 & \multicolumn{3}{|c|}{5.832999999999999} & 5.2948 & TRN \\
\hline CHEMBL1442590 & 688653 & \multicolumn{3}{|c|}{5.5329999999999995} & 5.3479 & \\
\hline CHEMBL1 & 688653 & 5.933 & 5.7644 & TRN & & \\
\hline CHEMBL1 & 688653 & 4.633 & 4.9157 & TST & & \\
\hline CHEMBL1590615 & 688653 & 4.633 & 4.7932 & TST & & \\
\hline CHEMBL1980103 & 688653 & \multicolumn{3}{|c|}{6.5329999999999995} & 265 & \\
\hline CHEMBL1364753 & 688653 & 4.683 & 5.0085 & TRN & & \\
\hline CHEME & 688 & 5.033 & 5.3629 & TRN & & \\
\hline CHEMB & 688653 & 4.783 & 5.1024 & TRN & & \\
\hline CHEMBL1311838 & 688653 & \multicolumn{3}{|c|}{5.2829999999999995} & 5.3533 & $\mathrm{TH}$ \\
\hline CHEMBL1356025 & 688653 & 7.1831 & 5.8014 & TRN & & \\
\hline CHEMBL1553895 & 688653 & \multicolumn{3}{|c|}{4.9830000000000005} & 5.4429 & \\
\hline CHEME & 688 & 5.183 & 5.6522 & TRN & & \\
\hline CHEME & 688653 & 4.933 & 5.3147 & TST & & \\
\hline CHEMB & 688653 & 4.883 & 5.3675 & TST & & \\
\hline CHEMBL 2094652 & 688653 & \multicolumn{3}{|c|}{5.882999999999999} & 5.5896 & \\
\hline CHEMBL1330079 & 688653 & 5.083 & 5.2994 & TRN & & \\
\hline CHEMB & 688653 & \multicolumn{3}{|c|}{5.7829999999999995} & 5.3816 & \\
\hline CHEMB & 688653 & 4.633 & 4.6312 & TRN & & \\
\hline CHEMBL1304147 & 688653 & 4.783 & \multicolumn{3}{|c|}{5.0760000000000005} & TRN \\
\hline CHEMBL1302891 & 688653 & \multicolumn{3}{|c|}{5.882999999999999} & 6.0194 & $\mathrm{TI}$ \\
\hline CHEMBL1413841 & 688653 & \multicolumn{3}{|c|}{5.882999999999999} & 5.8818 & \\
\hline CHEMB & 688653 & 4.883 & 5.3217 & TRN & & \\
\hline CHEMBL: & 688653 & 5.033 & 5.3878 & TRN & & \\
\hline CHEMBL1468008 & 688653 & \multicolumn{3}{|c|}{4.9830000000000005} & 4.9372 & TRN \\
\hline CHEMBL 2005317 & 688653 & 5.6329 & 99999999 & & 5.3649 & \\
\hline CHEMBL1568028 & 688653 & 6.3825 & 99999999 & & 5.476 & TP \\
\hline CHEMBL1571328 & 688653 & 4.7336 & 00000000 & 005 & 5.4 & TST \\
\hline CHEMBL1611047 & 688653 & 5.8829 & 99999999 & & 5.1681 & TRN \\
\hline CHEMBL1444004 & 688653 & 5.6329 & 99999999 & & 5.6921 & $T$ \\
\hline CHEMBL1520927 & 688653 & 4.833 & 5.0562 & TRN & & \\
\hline CHEMBL1975547 & 688653 & 6.0325 & 99999999 & 995 & & \\
\hline CHEMBL1448357 & 688653 & 5.5820 & 99999999 & & 5.2547 & \\
\hline CHEMBL1521903 & 688653 & 5.233 & 5.1354 & TRN & & \\
\hline
\end{tabular}




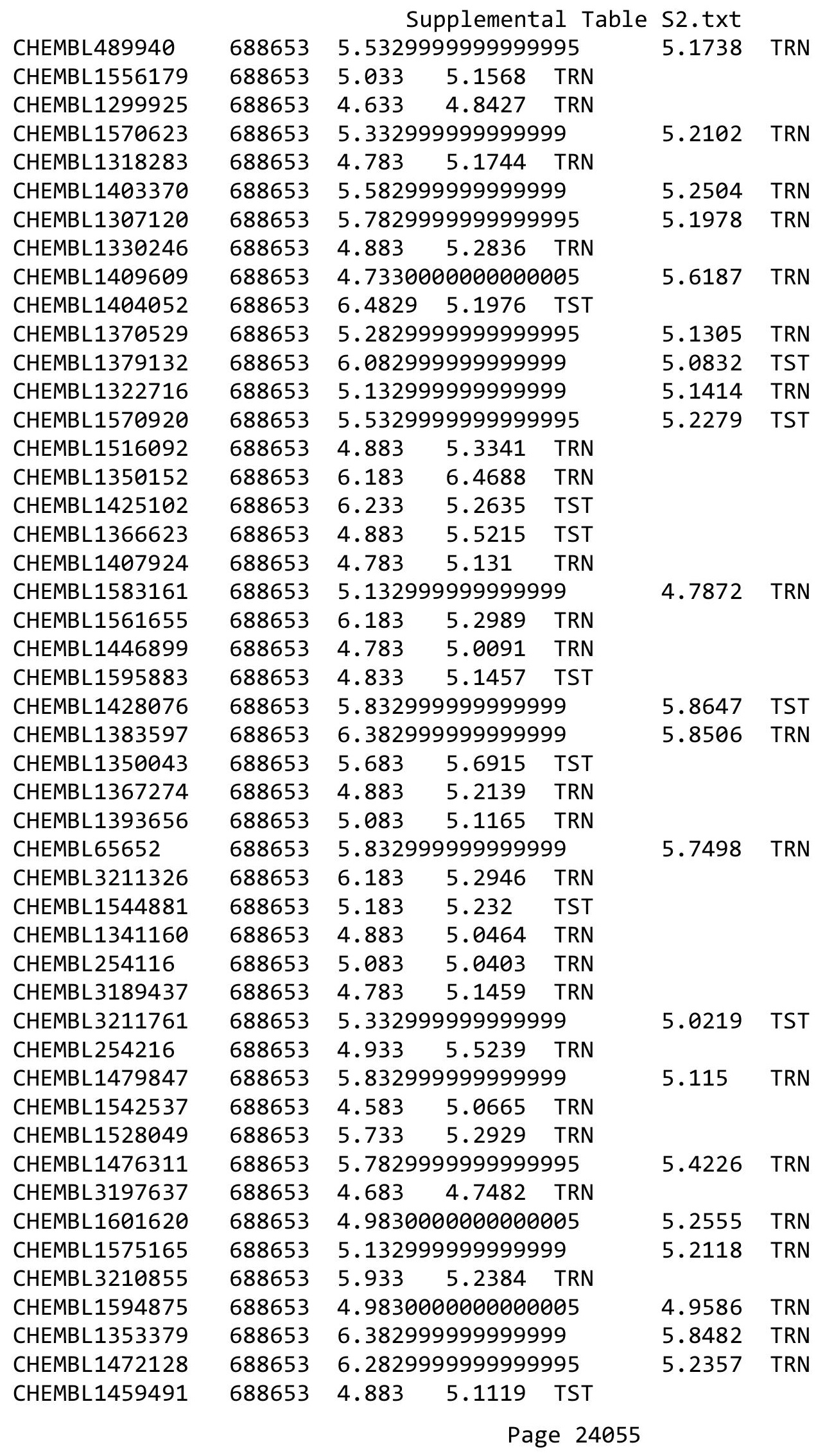




\begin{tabular}{|c|c|c|c|c|c|c|}
\hline \multirow[b]{2}{*}{ CHEMBL1338774 } & \multirow{3}{*}{$\begin{array}{l}688653 \\
688653\end{array}$} & \multicolumn{5}{|c|}{ Supplemental Table S2.txt } \\
\hline & & \multicolumn{4}{|c|}{35.486000000000001} & \multirow{2}{*}{ TST } \\
\hline CHEMBL1531233 & & 7.1331 & 5.8399 & TRN & & \\
\hline CHEMBL1345956 & 688653 & \multicolumn{3}{|c|}{4.7330000000000005} & 5.2156 & TST \\
\hline CHEMBL1593888 & 688653 & \multicolumn{3}{|c|}{5.332999999999999} & 5.273 & TRN \\
\hline CHEMBL1559283 & 688653 & 5.733 & 5.555 & TRN & & \\
\hline CHEMBL1589458 & 688653 & \multicolumn{3}{|c|}{5.132999999999999} & 4.9531 & TST \\
\hline CHEMBL1381736 & 688653 & 4.833 & 4.7173 & TRN & & \\
\hline CHEMBL1547086 & 688653 & 4.783 & 4.9872 & TRN & & \\
\hline CHEMBL375966 & 688653 & \multicolumn{3}{|c|}{5.7829999999999995} & 5.8232 & TRN \\
\hline CHEMBL1530839 & 688653 & 4.633 & 5.1271 & TRN & & \\
\hline CHEMBL1490887 & 688653 & 4.633 & 5.0106 & TST & & \\
\hline CHEMBL1508694 & 688653 & \multicolumn{3}{|c|}{6.382999999999999} & 6.0892 & TRN \\
\hline CHEMBL1375708 & 688653 & 4.583 & 4.9928 & TRN & & \\
\hline CHEMBL1550829 & 688653 & \multicolumn{3}{|c|}{5.132999999999999} & 4.935 & TRN \\
\hline CHEMBL1479700 & 688653 & 5.183 & 5.6301 & TRN & & \\
\hline CHEMBL1568828 & 688653 & 5.083 & 5.402 & TRN & & \\
\hline CHEMBL1527239 & 688653 & 5.483 & 5.5211 & TRN & & \\
\hline CHEMBL1360149 & 688653 & 4.783 & 5.21 & TRN & & \\
\hline CHEMBL1355447 & 688653 & 5.183 & 5.2043 & TRN & & \\
\hline CHEMBL1559430 & 688653 & 5.083 & 5.5124 & TRN & & \\
\hline CHEMBL1347736 & 688653 & 5.083 & 5.2028 & TRN & & \\
\hline CHEMBL1596331 & 688653 & \multicolumn{3}{|c|}{5.7829999999999995} & 5.4283 & TRN \\
\hline CHEMBL1360928 & 688653 & \multicolumn{3}{|c|}{5.332999999999999} & 5.899 & TRN \\
\hline CHEMBL1444767 & 688653 & 4.583 & 4.9025 & TST & & \\
\hline CHEMBL1358189 & 688653 & 4.633 & 5.2764 & TRN & & \\
\hline CHEMBL1388873 & 688653 & \multicolumn{3}{|c|}{4.7330000000000005} & 5.1006 & TRN \\
\hline CHEMBL573111 & 688653 & 6.233 & 5.6683 & TRN & & \\
\hline CHEMBL1496319 & 688653 & & 5.4655 & TRN & & \\
\hline CHEMBL1376804 & 688653 & \multicolumn{3}{|c|}{5.632999999999999} & 5.3321 & TRN \\
\hline CHEMBL586135 & 688653 & 4.783 & 5.6955 & TST & & \\
\hline CHEMBL3189439 & 688653 & 4.833 & 5.1753 & TST & & \\
\hline CHEMBL1488150 & 688653 & 4.633 & 4.7887 & TRN & & \\
\hline CHEMBL1579648 & 688653 & 4.833 & 5.0614 & TRN & & \\
\hline CHEMBL1393647 & 688653 & 4.783 & 5.2464 & TRN & & \\
\hline CHEMBL1482795 & 688653 & 4.933 & 5.8901 & TRN & & \\
\hline CHEMBL1530061 & 688653 & \multicolumn{3}{|c|}{5.332999999999999} & 5.8221 & TRN \\
\hline CHEMBL1417800 & 688653 & 5.733 & 4.9958 & TRN & & \\
\hline CHEMBL1595945 & 688653 & 5.433 & 5.4791 & TST & & \\
\hline CHEMBL1513025 & 688653 & 5.233 & 5.7141 & TRN & & \\
\hline CHEMBL1460296 & 688653 & 6.433 & 5.8647 & TRN & & \\
\hline CHEMBL1554125 & 688653 & 5.933 & 5.4188 & TRN & & \\
\hline CHEMBL1485651 & 688653 & \multicolumn{3}{|c|}{6.382999999999999} & 5.5402 & TRN \\
\hline CHEMBL1543986 & 688653 & 4.833 & 5.1887 & TST & & \\
\hline CHEMBL1977087 & 688653 & \multicolumn{3}{|c|}{4.9830000000000005} & 4.9877 & TST \\
\hline CHEMBL395808 & 688653 & 5.083 & 5.4779 & TRN & & \\
\hline CHEMBL 1417275 & 688653 & 4.883 & 5.07 & TRN & & \\
\hline CHEMBL1573706 & 688653 & 4.933 & 5.0633 & TRN & & \\
\hline CHEMBL1415760 & 688653 & 4.883 & 4.8614 & TRN & & \\
\hline
\end{tabular}




\begin{tabular}{|c|c|c|c|c|c|c|}
\hline \multirow[b]{2}{*}{ CHEMBL1399170 } & & \multicolumn{5}{|c|}{ LeIIL } \\
\hline & 688653 & 5.083 & 4.8007 & TRN & & \\
\hline CHEMBL1319858 & 688653 & 4.583 & 4.7896 & TST & & \\
\hline CHEMBL3192153 & 688653 & 5.733 & 4.7783 & TRN & & \\
\hline CHEMBL1524205 & 688653 & \multicolumn{3}{|c|}{5.332999999999999} & 5.4173 & \\
\hline CHEMBL1430531 & 688653 & 4.883 & 5.0145 & TRN & & \\
\hline CHEMBL1301470 & 688653 & \multicolumn{3}{|c|}{4.7330000000000005} & 5.1298 & TRN \\
\hline CHEMBL1347504 & 688653 & \multicolumn{3}{|c|}{5.882999999999999} & 5.9435 & \\
\hline CHEMBL1516985 & 688653 & \multicolumn{3}{|c|}{5.5329999999999995} & 5.4201 & \\
\hline CHEMBL1522113 & 688653 & 4.633 & 5.4466 & TST & & \\
\hline CHEMBL1371337 & 688653 & \multirow{2}{*}{\multicolumn{3}{|c|}{4.7330000000000005}} & & \\
\hline CHEMBL1559441 & 688653 & & & & 5.4351 & \\
\hline CHEMBL1503082 & 688653 & 5.433 & 5.6563 & TRN & & \\
\hline CHEMBL3195196 & 688653 & 5.683 & 5.3493 & TST & & \\
\hline CHEMBL1576324 & 688653 & \multicolumn{3}{|c|}{4.7330000000000005} & 5.1885 & \\
\hline CHEMBL3209097 & 688653 & \multicolumn{3}{|c|}{5.132999999999999} & 5.4298 & \\
\hline CHEMBL1384493 & 688653 & \multicolumn{3}{|c|}{5.832999999999999} & 5.1155 & \\
\hline CHEMBL1399621 & 688653 & 4.833 & 5.3008 & TRN & & \\
\hline CHEMBL1473238 & 688653 & 4.933 & 4.9487 & TRN & & \\
\hline CHEMBL15 & 688 & 4.783 & 5.4755 & TST & & \\
\hline CHEMBL1 & 688653 & \multicolumn{3}{|c|}{5.382999999999999} & 5 . & \\
\hline CHEMBL1330960 & 688653 & 5.733 & 5.5262 & TRN & & \\
\hline CHEMBL1511314 & 688653 & & 5.2597 & TRN & & \\
\hline CHEMBL1472308 & 688653 & \multicolumn{3}{|c|}{5.632999999999999} & 6 & \\
\hline CHEMBL15 & 688 & 4.633 & 4.5411 & TST & & \\
\hline CHEMBL137 & 688653 & \multicolumn{3}{|c|}{5.832999999999999} & 5.6391 & \\
\hline CHEMBL1349825 & 688653 & 5.683 & 5.7651 & TRN & & \\
\hline CHEMBL1510704 & 688653 & \multicolumn{3}{|c|}{5.382999999999999} & 5.4115 & \\
\hline CHEMBL1413987 & 688653 & \multicolumn{3}{|c|}{6.0329999999999995} & 5.642 & \\
\hline CHEMBL13 & 688 & 5.483 & 5.3843 & TST & & \\
\hline CHEMBL136 & 688653 & \multirow{2}{*}{\multicolumn{3}{|c|}{$\begin{array}{lcr}4.633 & 4.8484 & T \\
5.132999999999999\end{array}$}} & & \\
\hline CHEMBL1456412 & 688653 & & & & 5.1955 & \\
\hline CHEMBL1480031 & 688653 & 5.033 & 5.6272 & TRN & & \\
\hline CHEMBL1419798 & 688653 & \multicolumn{3}{|c|}{5.832999999999999} & כוש & \\
\hline CHEMBL147 & 688 & 5.083 & 4.9254 & TRN & & \\
\hline CHEMBL1426387 & 688653 & \multicolumn{3}{|c|}{5.5329999999999995} & 5.2954 & \\
\hline CHEMBL3209944 & 688653 & 5.233 & 5.2915 & TRN & & \\
\hline CHEMBL1549758 & 688653 & \multirow{2}{*}{\multicolumn{3}{|c|}{$\begin{array}{lc}4.833 & 5.1443 \\
5.132999999999999\end{array}$}} & & \\
\hline CHEMBL 1465386 & 688653 & & & & 5.7945 & \\
\hline CHEMBL584883 & 688653 & \multicolumn{3}{|c|}{$\begin{array}{lll}6.0 & 5.1157 & \text { TRN }\end{array}$} & & \\
\hline CHEMBL1464514 & 688653 & 5.683 & 5.1973 & TRN & & \\
\hline CHEMBL3197901 & 688653 & \multicolumn{3}{|c|}{5.2829999999999995} & 5.2416 & \\
\hline CHEMBL 3191640 & 688653 & 6.6329 & 99999995 & & 5.5748 & \\
\hline CHEMBL1991888 & 688653 & 4.633 & 4.9581 & TST & & \\
\hline CHEMBL601184 & 688653 & 4.583 & 5.285 & TRN & & \\
\hline CHEMBL1432495 & 688653 & 4.9830 & 0000000 & 005 & 5.7059 & \\
\hline CHEMBL1427272 & 688653 & 4.783 & 5.084 & TST & & \\
\hline CHEMBL1588078 & 688653 & 4.883 & 4.735 & TST & & \\
\hline CHEMBL1892270 & 688653 & 5.8829 & 9999999 & & 5.4503 & \\
\hline
\end{tabular}




\begin{tabular}{|c|c|c|c|c|c|c|}
\hline & & \multicolumn{5}{|c|}{ Supplemental Table s2.txt } \\
\hline CHEMBL1350624 & 688653 & 4.95 & 5.5963 & TST & & \\
\hline CHEMBL1494202 & 688653 & 4.883 & 4.9196 & TST & & \\
\hline CHEMBL1569541 & 688653 & 5.083 & 5.2939 & TST & & \\
\hline CHEMBL1604405 & 688653 & 5.083 & 4.988 & TRN & & \\
\hline CHEMBL1506732 & 688653 & 7.0329 & 5.4814 & TRN & & \\
\hline CHEMBL1567363 & 688653 & 5.233 & 5.4217 & TRN & & \\
\hline CHEMBL1380182 & 688653 & \multicolumn{3}{|c|}{5.2829999999999995} & 5.2124 & TST \\
\hline CHEMBL1360398 & 688653 & \multicolumn{3}{|c|}{6.332999999999999} & 5.2841 & TRN \\
\hline CHEMBL1399208 & 688653 & 5.733 & 5.9226 & TRN & & \\
\hline CHEMBL1577562 & 688653 & \multicolumn{3}{|c|}{5.5329999999999995} & 5.5237 & TRN \\
\hline CHEMBL1353240 & 688653 & 4.783 & 5.2261 & TST & & \\
\hline CHEMBL1429710 & 688653 & \multicolumn{3}{|c|}{6.632999999999999} & 5.4547 & TRN \\
\hline CHEMBL1446095 & 688653 & 4.683 & 4.8588 & TST & & \\
\hline CHEMBL1364072 & 688653 & 4.883 & 5.2282 & TST & & \\
\hline CHEMBL3191966 & 688653 & 5.733 & 5.2144 & TRN & & \\
\hline CHEMBL1583316 & 688653 & 5.083 & 5.5918 & TRN & & \\
\hline CHEMBL1506712 & 688653 & 5.083 & 5.4438 & TRN & & \\
\hline CHEMBL1496708 & 688653 & 4.783 & 4.6192 & TRN & & \\
\hline CHEMBL1610992 & 688653 & 6.433 & 5.4042 & TRN & & \\
\hline CHEMBL1337583 & 688653 & \multicolumn{3}{|c|}{6.582999999999999} & 5.4587 & TRN \\
\hline CHEMBL1311783 & 688653 & \multicolumn{3}{|c|}{6.082999999999999} & 5.8335 & TRN \\
\hline CHEMBL1611639 & 688653 & 4.833 & 5.11 & TST & & \\
\hline CHEMBL1553461 & 688653 & \multicolumn{3}{|c|}{5.832999999999999} & 5.6489 & TRN \\
\hline CHEMBL1331564 & 688653 & \multicolumn{3}{|c|}{5.582999999999999} & 5.7026 & TRN \\
\hline CHEMBL1602928 & 688653 & 5.233 & 5.5481 & TST & & \\
\hline CHEMBL1301576 & 688653 & 7.0329 & 5.6401 & TRN & & \\
\hline CHEMBL1970274 & 688653 & 4.783 & 5.2477 & TRN & & \\
\hline CHEMBL1379943 & 688653 & \multicolumn{3}{|c|}{6.5329999999999995} & 5.5979 & TRN \\
\hline CHEMBL1536808 & 688653 & \multicolumn{3}{|c|}{5.582999999999999} & 5.3276 & TST \\
\hline CHEMBL1500926 & 688653 & \multicolumn{3}{|c|}{5.132999999999999} & 5.1346 & TRN \\
\hline CHEMBL 223453 & 688653 & 4.833 & 5.2804 & TRN & & \\
\hline CHEMBL1384387 & 688653 & 4.633 & 4.9028 & TST & & \\
\hline CHEMBL1964407 & 688653 & 4.783 & 4.8939 & TST & & \\
\hline CHEMBL1563870 & 688653 & 5.033 & 5.0454 & TST & & \\
\hline CHEMBL3213367 & 688653 & \multicolumn{3}{|c|}{4.9830000000000005} & 5.2265 & TRN \\
\hline CHEMBL1489928 & 688653 & 4.883 & 5.0699 & TRN & & \\
\hline CHEMBL1482122 & 688653 & 5.183 & 5.0588 & TRN & & \\
\hline CHEMBL1514426 & 688653 & 5.483 & 5.6342 & TRN & & \\
\hline CHEMBL1364432 & 688653 & 6.233 & 5.4678 & TRN & & \\
\hline CHEMBL1333890 & 688653 & 4.783 & 5.1818 & TST & & \\
\hline CHEMBL1333761 & 688653 & \multicolumn{3}{|c|}{4.9830000000000005} & 5.3524 & TST \\
\hline CHEMBL1329099 & 688653 & 4.833 & 5.2247 & TST & & \\
\hline CHEMBL1431033 & 688653 & \multicolumn{3}{|c|}{4.7330000000000005} & 5.0458 & TRN \\
\hline CHEMBL1437043 & 688653 & \multicolumn{3}{|c|}{5.132999999999999} & 5.2547 & TST \\
\hline CHEMBL3144898 & 688653 & 5.483 & 5.7112 & TRN & & \\
\hline CHEMBL1561797 & 688653 & \multicolumn{3}{|c|}{6.632999999999999} & 5.7438 & TRN \\
\hline \multirow{2}{*}{ CHEMBL1967770 } & 688653 & 4.883 & 5.0359 & TRN & & \\
\hline & 688653 & 4.783 & 5.0322 & TST & & \\
\hline
\end{tabular}




\begin{tabular}{|c|c|c|c|c|c|c|}
\hline \multirow[b]{2}{*}{ CHEMBL1546066 } & \multirow[b]{2}{*}{688653} & \multicolumn{5}{|c|}{ Supplemental Table S2.txt } \\
\hline & & \multicolumn{5}{|c|}{5.6015 TRN } \\
\hline CHEMBL1340673 & 688653 & \multicolumn{3}{|c|}{5.882999999999999} & 5.2303 & TRA \\
\hline CHEMBL1385727 & 688653 & 4.833 & 5.5502 & TST & & \\
\hline CHEMBL1613210 & 688653 & \multicolumn{3}{|c|}{5.132999999999999} & 5.0345 & TRA \\
\hline CHEMBL1395912 & 688653 & \multicolumn{3}{|c|}{6.082999999999999} & 5.8059 & TRN \\
\hline CHEMBL1518147 & 688653 & \multicolumn{3}{|c|}{5.382999999999999} & 5.0314 & TST \\
\hline CHEMBL1535460 & 688653 & 5.233 & 5.2194 & TRN & & \\
\hline CHEMBL1366133 & 688653 & \multicolumn{3}{|c|}{5.132999999999999} & 5.3535 & TRN \\
\hline CHEMBL1465726 & 688653 & \multicolumn{3}{|c|}{4.9830000000000005} & 5.4058 & TRN \\
\hline CHEMBL1503152 & 688653 & 4.583 & 4.7231 & TRN & & \\
\hline CHEMBL1493046 & 688653 & 4.833 & 5.4872 & TRN & & \\
\hline CHEMBL1456833 & 688653 & 4.933 & 5.1474 & TRN & & \\
\hline CHEMBL3189421 & 688653 & 4.783 & 4.9602 & TRN & & \\
\hline CHEMBL1320992 & 688653 & \multicolumn{3}{|c|}{5.2829999999999995} & 4.673 & TST \\
\hline CHEMBL1338162 & 688653 & 4.933 & 4.8121 & TRN & & \\
\hline CHEMBL1536303 & 688653 & 4.833 & 4.9299 & TST & & \\
\hline CHEMBL1304613 & 688653 & \multicolumn{3}{|c|}{6.382999999999999} & 5.6598 & TRN \\
\hline CHEMBL1452421 & 688653 & 5.233 & 5.2238 & TRN & & \\
\hline CHEMBL1612044 & 688653 & 5.933 & 6.2386 & TRN & & \\
\hline CHEMBL1471305 & 688653 & \multicolumn{3}{|c|}{4.7330000000000005} & 5.1258 & TRN \\
\hline CHEMBL3145322 & 688653 & \multicolumn{3}{|c|}{6.2829999999999995} & 5.4419 & TRN \\
\hline CHEMBL1499489 & 688653 & \multicolumn{3}{|c|}{6.0329999999999995} & 5.5315 & TRN \\
\hline CHEMBL1330052 & 688653 & 5.083 & 5.1366 & TRN & & \\
\hline CHEMBL1431578 & 688653 & \multirow{2}{*}{\multicolumn{3}{|c|}{$\begin{array}{lll}4.683 & 5.3683 & \text { TST } \\
6.632999999999999\end{array}$}} & & \\
\hline CHEMBL3213690 & 688653 & & & & 5.8584 & TRN \\
\hline CHEMBL1302565 & 688653 & 4.883 & 4.8488 & TRN & & \\
\hline CHEMBL1385873 & 688653 & 5.683 & 6.2094 & TST & & \\
\hline CHEMBL1463306 & 688653 & 5.433 & 4.9778 & TRN & & \\
\hline CHEMBL1596931 & 688653 & 5.233 & 5.3101 & TST & & \\
\hline CHEMBL1361277 & 688653 & 4.883 & 5.375 & TRN & & \\
\hline CHEMBL1483444 & 688653 & 6.0 & 5.3906 & TRN & & \\
\hline CHEMBL3196687 & 688653 & 5.233 & 4.8947 & TST & & \\
\hline CHEMBL1443564 & 688653 & 5.433 & 5.1712 & TRN & & \\
\hline CHEMBL1394917 & 688653 & 4.783 & 5.5109 & TRN & & \\
\hline CHEMBL1589873 & 688653 & 4.883 & 4.7504 & TRN & & \\
\hline CHEMBL1306126 & 688653 & 5.483 & 5.4261 & TRN & & \\
\hline CHEMBL1575010 & 688653 & \multicolumn{3}{|c|}{4.7330000000000005} & 5.4983 & TST \\
\hline CHEMBL1611110 & 688653 & 5.733 & 5.0229 & TRN & & \\
\hline CHEMBL1356650 & 688653 & 5.233 & 5.5148 & TRN & & \\
\hline CHEMBL1582448 & 688653 & 5.233 & 5.8094 & TRN & & \\
\hline CHEMBL1441614 & 688653 & 5.933 & 5.0991 & TRN & & \\
\hline CHEMBL1412678 & 688653 & \multicolumn{3}{|c|}{5.332999999999999} & 5.1213 & TST \\
\hline CHEMBL1371751 & 688653 & 4.883 & 5.3551 & TST & & \\
\hline CHEMBL1414522 & 688653 & 5.5 & 4.9558 & TRN & & \\
\hline CHEMBL1997568 & 688653 & 5.983 & 5.8671 & TRN & & \\
\hline CHEMBL1321322 & 688653 & \multicolumn{3}{|c|}{5.132999999999999} & 5.033 & TRN \\
\hline CHEMBL1303948 & 688653 & 6.433 & 5.6002 & TRN & & \\
\hline CHEMBL1566510 & 688653 & 4.633 & 5.15 & TRN & & \\
\hline
\end{tabular}




\begin{tabular}{|c|c|c|c|c|c|c|}
\hline \multirow[b]{2}{*}{ CHEMBL1384581 } & \multirow[b]{2}{*}{688653} & \multicolumn{5}{|c|}{ Supplemental Table S2.txt } \\
\hline & & \multicolumn{2}{|c|}{$33 \quad 5.3628$} & TRN & & \\
\hline CHEMBL1605553 & 688653 & 5.733 & 4.8391 & TRN & & \\
\hline CHEMBL3189872 & 688653 & \multicolumn{3}{|c|}{6.2829999999999995} & 5.4348 & TRN \\
\hline CHEMBL1600758 & 688653 & 4.783 & 4.8928 & TRN & & \\
\hline CHEMBL1327005 & 688653 & 6.233 & 6.2424 & TRN & & \\
\hline CHEMBL1324036 & 688653 & 4.933 & 5.082 & TRN & & \\
\hline CHEMBL1999161 & 688653 & 5.233 & 5.465 & TST & & \\
\hline CHEMBL1466652 & 688653 & 5.983 & 5.4947 & TRN & & \\
\hline CHEMBL1368525 & 688653 & 5.083 & 5.3468 & TRN & & \\
\hline CHEMBL1998852 & 688653 & 5.183 & 5.5825 & TRN & & \\
\hline CHEMBL1338750 & 688653 & 5.983 & 6.0293 & TRN & & \\
\hline CHEMBL1494586 & 688653 & 4.633 & 4.6697 & TST & & \\
\hline CHEMBL1496184 & 688653 & 4.833 & 5.3908 & TRN & & \\
\hline CHEMBL1362096 & 688653 & 4.933 & 5.045 & TST & & \\
\hline CHEMBL1523728 & 688653 & 5.933 & 5.5421 & TRN & & \\
\hline CHEMBL1544991 & 688653 & 4.833 & 5.0947 & TRN & & \\
\hline CHEMBL1587121 & 688653 & 7.1831 & 5.2546 & TRN & & \\
\hline CHEMBL1460522 & 688653 & 4.933 & 5.2694 & TRN & & \\
\hline CHEMBL3208946 & 688653 & \multicolumn{3}{|c|}{5.5329999999999995} & 5.3177 & TRN \\
\hline CHEMBL1420765 & 688653 & \multicolumn{3}{|c|}{4.7330000000000005} & 5.6002 & TRN \\
\hline CHEMBL3191171 & 688653 & 6.983 & 5.6684 & TRN & & \\
\hline CHEMBL1455985 & 688653 & 5.183 & 5.1943 & TRN & & \\
\hline CHEMBL1334083 & 688653 & 6.183 & 5.0892 & TRN & & \\
\hline CHEMBL1523093 & 688653 & 6.683 & 5.8947 & TRN & & \\
\hline CHEMBL1444261 & 688653 & \multicolumn{3}{|c|}{5.132999999999999} & 5.2659 & TRN \\
\hline CHEMBL1520615 & 688653 & 4.783 & 5.1373 & TST & & \\
\hline CHEMBL1525877 & 688653 & 5.183 & 5.112 & TRN & & \\
\hline CHEMBL1344873 & 688653 & 4.933 & 5.0186 & TRN & & \\
\hline CHEMBL1448593 & 688653 & 4.583 & 5.0552 & TRN & & \\
\hline CHEMBL603967 & 688653 & 5.083 & 4.8215 & TRN & & \\
\hline CHEMBL1469715 & 688653 & 5.183 & 5.3935 & TST & & \\
\hline CHEMBL1372573 & 688653 & \multicolumn{3}{|c|}{5.7829999999999995} & 5.2681 & TRN \\
\hline CHEMBL3193022 & 688653 & \multicolumn{3}{|c|}{6.2829999999999995} & 5.5707 & TRN \\
\hline CHEMBL1323360 & 688653 & 5.183 & 5.2321 & TST & & \\
\hline CHEMBL1531392 & 688653 & \multicolumn{3}{|c|}{5.882999999999999} & 5.3549 & TST \\
\hline CHEMBL3208358 & 688653 & \multicolumn{3}{|c|}{5.7829999999999995} & 5.6685 & TRN \\
\hline CHEMBL1981667 & 688653 & 4.633 & 5.6213 & TRN & & \\
\hline CHEMBL1487614 & 688653 & 4.633 & 5.0902 & TST & & \\
\hline CHEMBL1502367 & 688653 & 5.233 & 5.3313 & TST & & \\
\hline CHEMBL1593804 & 688653 & 4.833 & 4.9831 & TRN & & \\
\hline CHEMBL1581133 & 688653 & 4.633 & 5.4119 & TRN & & \\
\hline CHEMBL1400183 & 688653 & 4.95 & 5.2066 & TRN & & \\
\hline CHEMBL1520549 & 688653 & \multicolumn{3}{|c|}{4.7330000000000005} & 5.3712 & TST \\
\hline CHEMBL1610579 & 688653 & 4.933 & 4.8949 & TST & & \\
\hline CHEMBL1539778 & 688653 & 4.633 & 4.9179 & TST & & \\
\hline CHEMBL1583928 & 688653 & \multicolumn{3}{|c|}{4.7330000000000005} & 5.3784 & TRN \\
\hline CHEMBL1568213 & 688653 & 7.2832 & 6.0808 & TRN & & \\
\hline CHEMBL1326231 & 688653 & 5.083 & 5.8705 & TRN & & \\
\hline
\end{tabular}




\begin{tabular}{|c|c|c|c|c|c|c|c|}
\hline \multicolumn{8}{|c|}{ pplemetrat } \\
\hline CHEMBL1524049 & 688653 & 4.783 & 5.4424 & TST & & & \\
\hline CHEMBL1354789 & 688653 & 4.833 & 5.0239 & TRN & & & \\
\hline CHEMBL1480352 & 688653 & \multicolumn{3}{|c|}{5.882999999999999} & 5.9346 & TRN & \\
\hline CHEMBL1388563 & 688653 & 4.783 & 4.9889 & TRN & & & \\
\hline CHEMBL1454103 & 688653 & 5.033 & 5.0598 & TST & & & \\
\hline CHEMBL1491094 & 688653 & 5.933 & 5.5706 & TRN & & & \\
\hline CHEMBL1365428 & 688653 & 4.883 & 5.0873 & TRN & & & \\
\hline CHEMBL1540690 & 688653 & 4.783 & 4.7928 & TST & & & \\
\hline CHEMBL1493929 & 688653 & \multicolumn{3}{|c|}{4.7330000000000005} & 5.1539 & TST & \\
\hline CHEMBL1426107 & 688653 & \multicolumn{3}{|c|}{6.7829999999999995} & 5.7452 & TRN & \\
\hline CHEMBL1375572 & 688653 & \multicolumn{3}{|c|}{4.9830000000000005} & \multicolumn{2}{|c|}{5.172000000000001} & TST \\
\hline CHEMBL1585931 & 688653 & 4.883 & 5.2226 & TRN & & & \\
\hline CHEMBL1591047 & 688653 & 5.183 & 4.9476 & TRN & & & \\
\hline CHEMBL1428568 & 688653 & 4.833 & 5.3125 & TRN & & & \\
\hline CHEMBL1318243 & 688653 & 4.633 & 5.2306 & TRN & & & \\
\hline CHEMBL1338834 & 688653 & \multicolumn{3}{|c|}{4.7330000000000005} & 5.1713 & TST & \\
\hline CHEMBL1538234 & 688653 & \multicolumn{3}{|c|}{5.2829999999999995} & 5.0745 & TRN & \\
\hline CHEMBL1598706 & 688653 & 6.183 & 5.3436 & TRN & & & \\
\hline CHEMBL1505415 & 688653 & 5.433 & \multicolumn{3}{|c|}{5.0760000000000005} & TRN & \\
\hline CHEMBL1518753 & 688653 & \multicolumn{3}{|c|}{5.882999999999999} & 5.2162 & TST & \\
\hline CHEMBL1597984 & 688653 & \multicolumn{3}{|c|}{5.132999999999999} & 5.1139 & TRN & \\
\hline CHEMBL1562298 & 688653 & \multicolumn{3}{|c|}{5.832999999999999} & 5.2629 & TRN & \\
\hline CHEMBL1342076 & 688653 & 5.933 & 5.0796 & TRN & & & \\
\hline CHEMBL1332004 & 688653 & 4.883 & 5.4277 & TRN & & & \\
\hline CHEMBL1576412 & 688653 & \multicolumn{3}{|c|}{4.7330000000000005} & 5.3019 & TRN & \\
\hline CHEMBL1495445 & 688653 & \multicolumn{3}{|c|}{4.9830000000000005} & 5.0098 & TRN & \\
\hline CHEMBL1506193 & 688653 & 4.633 & 5.1123 & TRN & & & \\
\hline CHEMBL493863 & 688653 & 5.233 & 5.1109 & TST & & & \\
\hline CHEMBL1510117 & 688653 & 5.083 & 5.6484 & TRN & & & \\
\hline CHEMBL1979295 & 688653 & 6.683 & 5.6573 & TRN & & & \\
\hline CHEMBL1541919 & 688653 & 5.433 & 5.4067 & TRN & & & \\
\hline CHEMBL1509574 & 688653 & 5.683 & 5.2536 & TRN & & & \\
\hline CHEMBL1586169 & 688653 & \multicolumn{3}{|c|}{4.9830000000000005} & 5.0554 & TRN & \\
\hline CHEMBL3190295 & 688653 & 6.183 & 5.4328 & TRN & & & \\
\hline CHEMBL3191275 & 688653 & 4.883 & 5.234 & TRN & & & \\
\hline CHEMBL1570262 & 688653 & 6.9329 & 5.9265 & TRN & & & \\
\hline CHEMBL1329884 & 688653 & 4.933 & 5.404 & TRN & & & \\
\hline CHEMBL1336136 & 688653 & \multicolumn{3}{|c|}{6.2829999999999995} & 5.0113 & TRN & \\
\hline CHEMBL 3195490 & 688653 & 4.683 & 4.8668 & TRN & & & \\
\hline CHEMBL 1486766 & 688653 & \multicolumn{3}{|c|}{6.082999999999999} & 5.92 & TRN & \\
\hline CHEMBL1527907 & 688653 & 4.633 & 5.1257 & TRN & & & \\
\hline CHEMBL1557161 & 688653 & \multicolumn{3}{|c|}{5.132999999999999} & 4.959 & TRN & \\
\hline CHEMBL1596571 & 688653 & \multicolumn{3}{|c|}{4.7330000000000005} & 5.2331 & TST & \\
\hline CHEMBL1373446 & 688653 & \multicolumn{3}{|c|}{6.082999999999999} & 5.5715 & TRN & \\
\hline CHEMBL1379918 & 688653 & \multicolumn{3}{|c|}{5.582999999999999} & 5.0862 & TRN & \\
\hline CHEMBL 3207836 & 688653 & 4.833 & 5.3177 & TRN & & & \\
\hline CHEMBL3213621 & 688653 & 5.033 & 5.1841 & TRN & & & \\
\hline CHEMBL1446305 & 688653 & 5.483 & 4.8605 & TRN & & & \\
\hline
\end{tabular}




\begin{tabular}{|c|c|c|c|c|c|c|c|}
\hline \multicolumn{8}{|c|}{ Supplemental Table s2.txt } \\
\hline CHEMBL1542584 & 688653 & 4.783 & 5.4779 & TRN & & & \\
\hline CHEMBL1404392 & 688653 & 5.433 & 5.8216 & TRN & & & \\
\hline CHEMBL1343306 & 688653 & 4.883 & 4.9935 & TRN & & & \\
\hline CHEMBL1480059 & 688653 & 4.883 & 5.1547 & TST & & & \\
\hline CHEMBL1587224 & 688653 & 5.183 & 5.6496 & TRN & & & \\
\hline CHEMBL1470958 & 688653 & 5.433 & 5.2617 & TRN & & & \\
\hline CHEMBL1367525 & 688653 & \multicolumn{3}{|c|}{4.7330000000000005} & 5.3999 & TRN & \\
\hline CHEMBL1518405 & 688653 & \multicolumn{3}{|c|}{6.382999999999999} & 5.6193 & TRN & \\
\hline CHEMBL1173146 & 688653 & \multicolumn{3}{|c|}{6.382999999999999} & 5.6259 & TRN & \\
\hline CHEMBL1525529 & 688653 & 5.983 & 5.6621 & TST & & & \\
\hline CHEMBL1326042 & 688653 & \multicolumn{3}{|c|}{6.332999999999999} & 5.1498 & TRN & \\
\hline CHEMBL1339268 & 688653 & \multicolumn{3}{|c|}{5.882999999999999} & 5.1851 & TRN & \\
\hline CHEMBL1424899 & 688653 & \multicolumn{3}{|c|}{5.882999999999999} & 4.9686 & TRN & \\
\hline CHEMBL1424408 & 688653 & 4.883 & 4.71 & TRN & & & \\
\hline CHEMBL1574649 & 688653 & 5.683 & 5.7492 & TRN & & & \\
\hline CHEMBL1381850 & 688653 & 5.233 & 5.5909 & TRN & & & \\
\hline CHEMBL1409801 & 688653 & 6.0 & 5.5397 & TST & & & \\
\hline CHEMBL1611170 & 688653 & 4.633 & 4.7801 & TRN & & & \\
\hline CHEMBL1610226 & 688653 & \multicolumn{3}{|c|}{5.882999999999999} & 5.239 & TRN & \\
\hline CHEMBL607553 & 688653 & \multicolumn{3}{|c|}{5.5329999999999995} & 5.2534 & TRN & \\
\hline CHEMBL1534368 & 688653 & 4.833 & 5.6738 & TRN & & & \\
\hline CHEMBL1448583 & 688653 & 4.883 & 5.4268 & TST & & & \\
\hline CHEMBL1483967 & 688653 & 4.633 & 5.2984 & TRN & & & \\
\hline CHEMBL1545164 & 688653 & 4.683 & 4.9504 & TRN & & & \\
\hline CHEMBL1438594 & 688653 & 5.683 & 5.6581 & TRN & & & \\
\hline CHEMBL1440736 & 688653 & \multicolumn{3}{|c|}{4.7330000000000005} & 4.9341 & TRN & \\
\hline CHEMBL1432488 & 688653 & 5.183 & 4.68 & TRN & & & \\
\hline CHEMBL1197556 & 688653 & \multicolumn{3}{|c|}{6.0329999999999995} & 5.8519 & TRN & \\
\hline CHEMBL1352356 & 688653 & 4.783 & 5.0846 & TST & & & \\
\hline CHEMBL1501587 & 688653 & 6.4829 & 5.6162 & TRN & & & \\
\hline CHEMBL583351 & 688653 & 5.033 & 5.6736 & TRN & & & \\
\hline CHEMBL1452214 & 688653 & 5.983 & 5.9 & TRN & & & \\
\hline CHEMBL1548988 & 688653 & 4.783 & 5.6297 & TRN & & & \\
\hline CHEMBL1322962 & 688653 & 4.783 & 5.0415 & TST & & & \\
\hline CHEMBL1516746 & 688653 & \multicolumn{3}{|c|}{5.2829999999999995} & \multicolumn{2}{|c|}{4.9319999999999995} & TR \\
\hline CHEMBL1489151 & 688653 & \multicolumn{3}{|c|}{6.0329999999999995} & 5.1201 & TRN & \\
\hline CHEMBL2004449 & 688653 & \multicolumn{3}{|c|}{6.7829999999999995} & 5.9246 & TRN & \\
\hline CHEMBL472930 & 688653 & \multicolumn{3}{|c|}{4.9830000000000005} & 5.449 & TRN & \\
\hline CHEMBL1493516 & 688653 & \multicolumn{3}{|c|}{5.332999999999999} & 5.0937 & TRN & \\
\hline CHEMBL1306023 & 688653 & \multicolumn{3}{|c|}{6.2829999999999995} & 5.9338 & TRN & \\
\hline CHEMBL1529872 & 688653 & 4.833 & 4.987 & TST & & & \\
\hline CHEMBL1599077 & 688653 & 4.783 & 5.1585 & TRN & & & \\
\hline CHEMBL1310125 & 688653 & 5.033 & 5.3402 & TRN & & & \\
\hline CHEMBL1453589 & 688653 & \multicolumn{3}{|c|}{4.7330000000000005} & 5.0419 & TRN & \\
\hline CHEMBL1582803 & 688653 & 5.183 & 5.2066 & TRN & & & \\
\hline CHEMBL3195785 & 688653 & 5.183 & 5.1729 & TRN & & & \\
\hline CHEMBL1370071 & 688653 & \multicolumn{3}{|c|}{6.2829999999999995} & 5.7907 & TRN & \\
\hline CHEMBL1404414 & 688653 & 6.183 & 5.8858 & TRN & & & \\
\hline
\end{tabular}




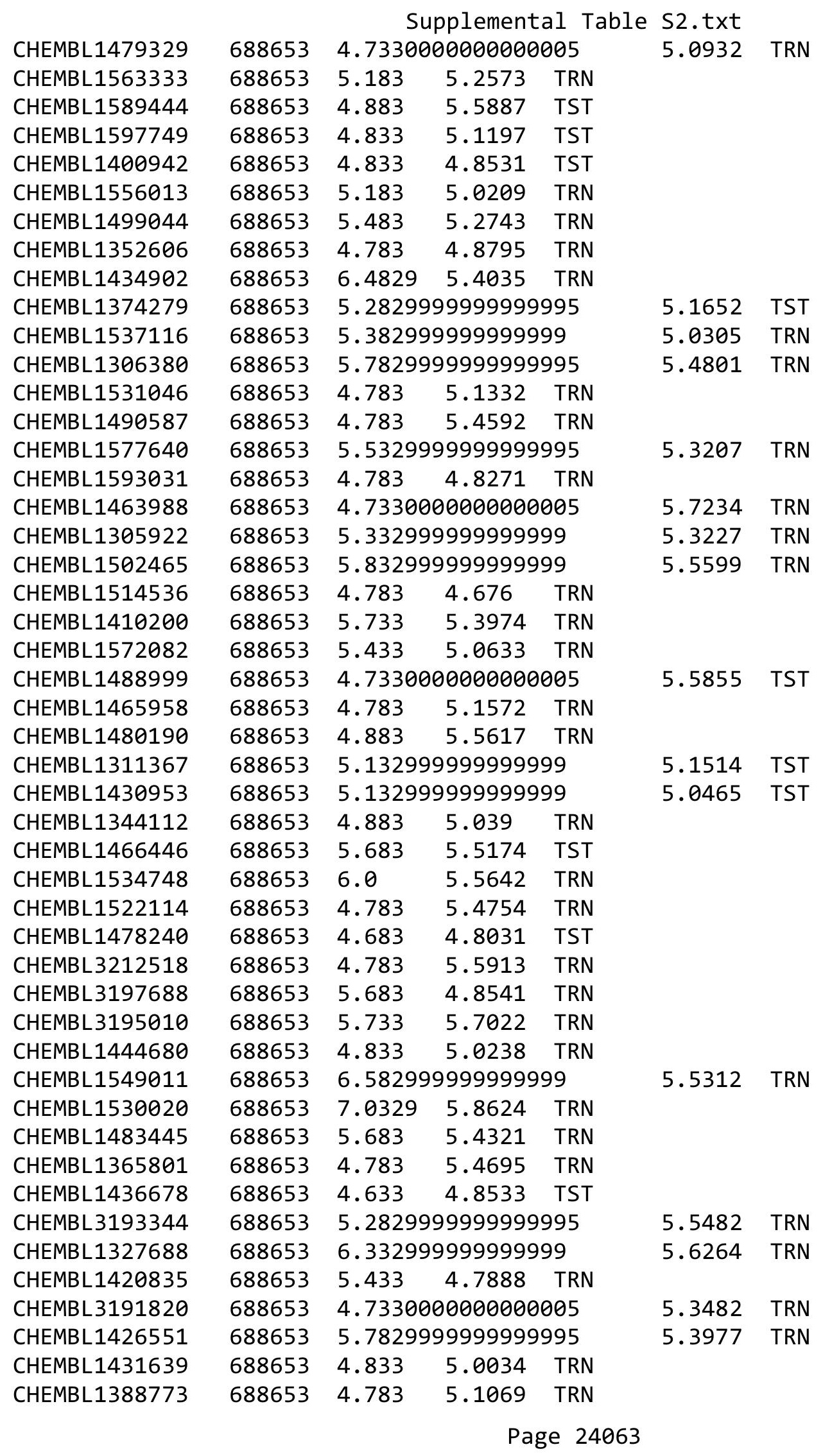




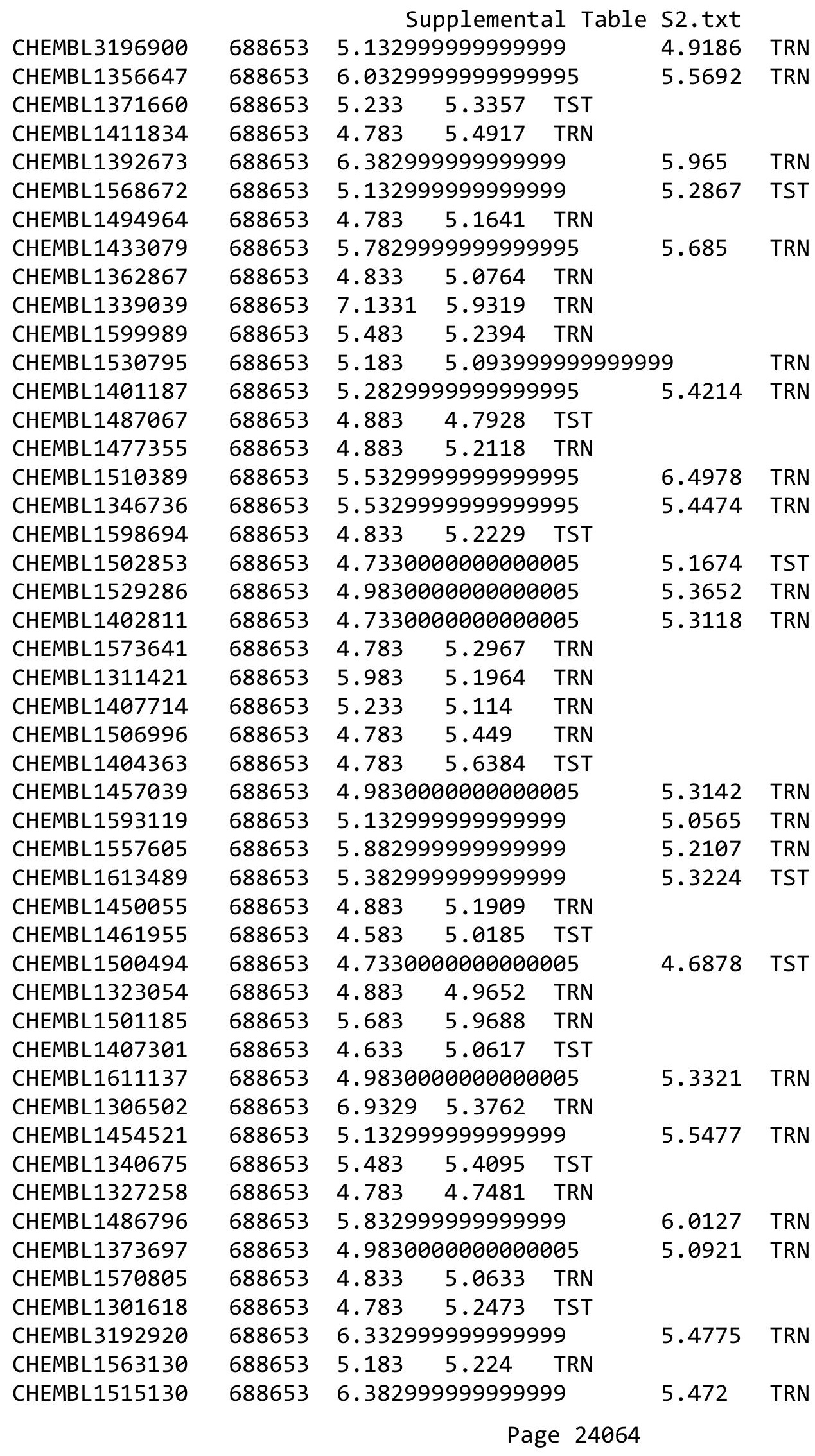




\begin{tabular}{|c|c|c|c|c|c|c|}
\hline & & & oplement & al Table & s2.txt & \\
\hline CHEMBL1420157 & 688653 & 4.98300 & 00000000 & 005 & 4.9312 & TST \\
\hline CHEMBL1564490 & 688653 & 6.4829 & 5.6563 & TRN & & \\
\hline CHEMBL3198985 & 688653 & 6.4829 & 5.5871 & TST & & \\
\hline CHEMBL1438177 & 688653 & 6.0 & 4.9087 & TRN & & \\
\hline CHEMBL1474507 & 688653 & 4.683 & 5.5581 & TRN & & \\
\hline CHEMBL581880 & 688653 & 5.233 & 4.9709 & TRN & & \\
\hline CHEMBL1599945 & 688653 & 4.833 & 4.9751 & TRN & & \\
\hline CHEMBL1403050 & 688653 & 4.783 & 5.0135 & TST & & \\
\hline CHEMBL1430297 & 688653 & 4.833 & 4.9734 & TST & & \\
\hline CHEMBL1475072 & 688653 & 5.033 & 5.4797 & TRN & & \\
\hline CHEMBL1300450 & 688653 & 4.833 & 5.1906 & TRN & & \\
\hline CHEMBL1483408 & 688653 & 4.783 & 5.0063 & TRN & & \\
\hline CHEMBL1427035 & 688653 & 5.233 & 5.1844 & TRN & & \\
\hline CHEMBL3190362 & 688653 & 5.483 & 5.3808 & TRN & & \\
\hline CHEMBL600734 & 688653 & 5.033 & 4.9053 & TST & & \\
\hline CHEMBL1301591 & 688653 & 4.833 & 5.6097 & TRN & & \\
\hline CHEMBL3199416 & 688653 & 5.683 & 5.7897 & TST & & \\
\hline CHEMBL1423162 & 688653 & 4.883 & 5.0333 & TRN & & \\
\hline CHEMBL1464486 & 688653 & 4.73300 & 00000000 & 005 & 4.7926 & TRN \\
\hline CHEMBL 2001582 & 688653 & 5.28299 & 99999999 & 995 & 5.2444 & TRN \\
\hline CHEMBL1982334 & 688653 & 5.933 & 5.7343 & TRN & & \\
\hline CHEMBL1383394 & 688653 & 5.433 & 5.2871 & TRN & & \\
\hline CHEMBL1303307 & 688653 & 5.683 & 5.3508 & TRN & & \\
\hline CHEMBL1567899 & 688653 & 4.583 & 5.4792 & TRN & & \\
\hline CHEMBL1458814 & 688653 & 5.183 & 5.1078 & TRN & & \\
\hline CHEMBL1375806 & 688653 & 4.783 & 4.989 & TRN & & \\
\hline CHEMBL1453741 & 688653 & 6.183 & 4.8812 & TRN & & \\
\hline CHEMBL1349317 & 688653 & 5.53299 & 99999999 & 995 & 5.313 & TRN \\
\hline CHEMBL1606557 & 688653 & 4.73300 & 00000000 & 005 & 4.7767 & TRN \\
\hline CHEMBL1526499 & 688653 & 6.58299 & 99999999 & & 6.3644 & TRN \\
\hline CHEMBL1451347 & 688653 & 5.83299 & 79999999 & & 4.9747 & TRN \\
\hline CHEMBL1550430 & 688653 & 4.883 & 5.3609 & TRN & & \\
\hline CHEMBL1546405 & 688653 & 6.63299 & 99999999 & & 5.6193 & TRN \\
\hline CHEMBL1578075 & 688653 & 5.183 & 5.0761 & TRN & & \\
\hline CHEMBL1493778 & 688653 & 6.683 & 5.5769 & TRN & & \\
\hline CHEMBL1492914 & 688653 & 4.783 & 5.0599 & TST & & \\
\hline CHEMBL1560004 & 688653 & 5.13299 & 99999999 & & 5.2957 & TRN \\
\hline CHEMBL1588153 & 688653 & 4.883 & 5.579 & TRN & & \\
\hline CHEMBL1506308 & 688653 & 4.883 & 5.2559 & TRN & & \\
\hline CHEMBL1427349 & 688653 & 5.78299 & 99999999 & 995 & 5.1453 & TRN \\
\hline CHEMBL1563898 & 688653 & 4.783 & 5.2213 & TST & & \\
\hline CHEMBL3197844 & 688653 & 7.1831 & 5.7937 & TRN & & \\
\hline CHEMBL1393877 & 688653 & 6.33299 & 99999999 & 99 & 5.2244 & TRN \\
\hline CHEMBL1575523 & 688653 & 4.783 & 5.0024 & TRN & & \\
\hline CHEMBL1392984 & 688653 & 4.783 & 5.289 & TRN & & \\
\hline CHEMBL1461991 & 688653 & 5.983 & 5.9601 & TRN & & \\
\hline CHEMBL1321903 & 688653 & 4.783 & 5.2819 & TRN & & \\
\hline CHEMBL1474284 & 688653 & 5.233 & 5.3026 & TST & & \\
\hline
\end{tabular}




\begin{tabular}{|c|c|c|c|c|c|c|c|}
\hline \multicolumn{8}{|c|}{ Supplemental Table s2.txt } \\
\hline CHEMBL1325709 & 688653 & 5.233 & 5.4389 & TRN & & & \\
\hline CHEMBL1468618 & 688653 & 5.683 & 5.2159 & TRN & & & \\
\hline CHEMBL1534193 & 688653 & 6.28299 & 99999999 & 995 & 5.5527 & TRN & \\
\hline CHEMBL1460688 & 688653 & 4.833 & 5.0799 & TRN & & & \\
\hline CHEMBL1499069 & 688653 & 5.88299 & 99999999 & & 5.6148 & TRN & \\
\hline CHEMBL1330653 & 688653 & 5.28299 & 99999999 & 995 & 4.8894 & TST & \\
\hline CHEMBL1343966 & 688653 & 4.833 & 4.9482 & TRN & & & \\
\hline CHEMBL1540917 & 688653 & 4.73300 & 000000006 & 005 & 5.2942 & TRN & \\
\hline CHEMBL1452256 & 688653 & 5.13299 & 99999999 & & 5.0169 & TRN & \\
\hline CHEMBL1476313 & 688653 & 5.033 & 4.8187 & TRN & & & \\
\hline CHEMBL3208459 & 688653 & 5.483 & 5.1911 & TST & & & \\
\hline CHEMBL1425297 & 688653 & 5.683 & 5.2164 & TRN & & & \\
\hline CHEMBL1467350 & 688653 & 5.88299 & 999999995 & & 5.9062 & TRN & \\
\hline CHEMBL1478650 & 688653 & 4.95 & 5.1105 & TRN & & & \\
\hline CHEMBL1405315 & 688653 & 5.183 & 5.1846 & TRN & & & \\
\hline CHEMBL1416917 & 688653 & 5.53299 & 99999999 & 995 & 5.5157 & TRN & \\
\hline CHEMBL1349615 & 688653 & 4.833 & 5.1437 & TRN & & & \\
\hline CHEMBL1347274 & 688653 & 5.13299 & 99999999 & & 5.1075 & TRN & \\
\hline CHEMBL1370991 & 688653 & 6.78299 & 99999999 & 995 & 5.9879 & 99999999995 & TRN \\
\hline CHEMBL1452842 & 688653 & 6.0 & 4.7202 & TRN & & & \\
\hline CHEMBL1578879 & 688653 & 6.53299 & 99999999 & 995 & 5.9511 & TRN & \\
\hline CHEMBL1432053 & 688653 & 5.183 & 5.518 & TST & & & \\
\hline CHEMBL1611874 & 688653 & 5.083 & 5.2135 & TRN & & & \\
\hline CHEMBL1453484 & 688653 & 5.483 & 5.5413 & TRN & & & \\
\hline CHEMBL1339052 & 688653 & 5.483 & 5.2445 & TST & & & \\
\hline CHEMBL1315948 & 688653 & 4.98300 & 00000000 & 005 & 5.1560 & 0000000001 & TRN \\
\hline CHEMBL1582550 & 688653 & 5.88299 & 99999999 & & 5.7810 & 0000000001 & TRN \\
\hline CHEMBL1553483 & 688653 & 5.53299 & 99999999 & 995 & 5.82 & TRN & \\
\hline CHEMBL3194638 & 688653 & 4.683 & 5.5834 & TST & & & \\
\hline CHEMBL1315463 & 688653 & 4.633 & 4.8633 & TRN & & & \\
\hline CHEMBL1321316 & 688653 & 4.833 & 5.1099 & TRN & & & \\
\hline CHEMBL1402346 & 688653 & 5.13299 & 99999999 & & 5.7749 & TRN & \\
\hline CHEMBL1478274 & 688653 & 4.933 & 5.0949 & TRN & & & \\
\hline CHEMBL1513318 & 688653 & 5.183 & 5.1166 & TST & & & \\
\hline CHEMBL1557623 & 688653 & 5.33299 & 99999999 & 99 & 5.477 & TRN & \\
\hline CHEMBL3198682 & 688653 & 4.833 & 5.2965 & TST & & & \\
\hline CHEMBL1575594 & 688653 & 5.38299 & 99999999 & & 5.3707 & TRN & \\
\hline CHEMBL1366269 & 688653 & 5.683 & 5.6781 & TRN & & & \\
\hline CHEMBL1336312 & 688653 & 4.683 & 5.4316 & TRN & & & \\
\hline CHEMBL1373467 & 688653 & 4.833 & 5.5276 & TST & & & \\
\hline CHEMBL3190036 & 688653 & 5.28299 & 99999999 & 995 & 4.7504 & TRN & \\
\hline CHEMBL1525786 & 688653 & 4.883 & 5.455 & TST & & & \\
\hline CHEMBL1588329 & 688653 & 6.08299 & 99999999 & & 5.2429 & 9999999999 & TRN \\
\hline CHEMBL1503790 & 688653 & 4.783 & 5.0594 & TRN & & & \\
\hline CHEMBL1326212 & 688653 & 6.58299 & 99999999 & & 6.0702 & TRN & \\
\hline CHEMBL1393724 & 688653 & 4.98300 & 00000000 & 005 & 5.1195 & TRN & \\
\hline CHEMBL1315150 & 688653 & 4.783 & 4.8795 & TRN & & & \\
\hline CHEMBL3190294 & 688653 & 4.73300 & 00000000 & 005 & 5.0165 & TRN & \\
\hline
\end{tabular}




\begin{tabular}{|c|c|c|c|c|c|c|}
\hline \multirow{3}{*}{$\begin{array}{l}\text { CHEMBL1490152 } \\
\text { CHEMBL1573581 }\end{array}$} & \multirow{3}{*}{$\begin{array}{l}688653 \\
688653\end{array}$} & \multicolumn{4}{|c|}{ Supplemental Table S2.txt } & \multirow[b]{2}{*}{ TRN } \\
\hline & & \multicolumn{3}{|c|}{5.5329999999999995} & \multirow[t]{4}{*}{5.397} & \\
\hline & & 6.983 & 6.0635 & TRN & & \\
\hline CHEMBL1575704 & 688653 & 5.233 & 5.2604 & TRN & & \\
\hline CHEMBL1321689 & 688653 & 4.883 & 5.2997 & TRN & & \\
\hline CHEMBL1515400 & 688653 & \multicolumn{3}{|c|}{6.332999999999999} & 5.621 & 1 \\
\hline CHEMBL1302727 & 688653 & 4.85 & 5.2927 & TRN & & \\
\hline CHEMBL1484856 & 688653 & \multicolumn{3}{|c|}{5.7829999999999995} & 5.4612 & $\mathrm{~T}$ \\
\hline CHEMBL1509691 & 688653 & 4.933 & 5.3007 & TRN & & \\
\hline CHEMBL1534402 & 688653 & \multicolumn{3}{|c|}{6.332999999999999} & 5.8903 & in \\
\hline CHEMBL1330332 & 688653 & 4.933 & 5.2387 & TRN & & \\
\hline CHEMBL1300301 & 688653 & \multicolumn{3}{|c|}{5.832999999999999} & 5.4183 & TRN \\
\hline CHEMBL1354574 & 688653 & \multicolumn{3}{|c|}{5.5329999999999995} & 5.2587 & TRN \\
\hline CHEMBL1431688 & 688653 & \multicolumn{3}{|c|}{6.132999999999999} & 5.9241 & \\
\hline CHEMBL1508905 & 688653 & 4.933 & 5.6368 & TRN & & \\
\hline CHEMBL3209916 & 688653 & 4.883 & 5.3452 & TST & & \\
\hline CHEMBL1358754 & 688 & 4.933 & 5.0536 & TRN & & \\
\hline CHEMBL1 & 688 & 4.833 & 5.1173 & TRN & & \\
\hline CHEMBL1423047 & 688653 & 5.183 & 5.773 & TRN & & \\
\hline CHEMBL1307051 & 688653 & 5.733 & 5.4771 & TRN & & \\
\hline CHEMBL1552178 & 688653 & 5.983 & 5.0601 & TRN & & \\
\hline CHEMBL1 & 688 & 4.833 & 5.0392 & TST & & \\
\hline CHEMBL1214519 & 688 & \multicolumn{3}{|c|}{6.382999999999999} & 5.6398 & $\mathrm{TI}$ \\
\hline CHEMBL1554476 & 688653 & \multicolumn{3}{|c|}{5.332999999999999} & 5.0464 & TRN \\
\hline CHEMBL1471095 & 688653 & \multicolumn{3}{|c|}{5.332999999999999} & 5.4434 & \\
\hline CHEMBL1579812 & 688653 & \multicolumn{3}{|c|}{5.882999999999999} & 5.5998 & \\
\hline CHEMBL1368098 & 688 & \multicolumn{3}{|c|}{6.332999999999999} & 5.8543 & \\
\hline CHEMBL1448355 & 688653 & 4.633 & 4.8566 & TRN & & \\
\hline CHEMBL1396168 & 688653 & \multicolumn{3}{|c|}{4.7330000000000005} & 4.9909 & TRN \\
\hline CHEMBL1410454 & 688653 & \multicolumn{3}{|c|}{6.382999999999999} & 5.3218 & \\
\hline CHEMBL1499398 & 688 & & 5.3183 & TRN & & \\
\hline CHEMBL & 688 & 4. & 5.3575 & TRN & & \\
\hline CHEMBL: & 688653 & 6.183 & 5.9147 & TRN & & \\
\hline CHEMBL1587515 & 688653 & 4.783 & 5.1729 & TST & & \\
\hline CHEMBL1344163 & 688653 & \multicolumn{3}{|c|}{5.2829999999999995} & 5.2971 & ThN \\
\hline CHEMBL3193416 & 688 & \multicolumn{3}{|c|}{5.882999999999999} & 5.3019 & וכנו \\
\hline CHEMBL1429408 & 688653 & 5.7829 & 99999999 & 995 & 5.1167 & TRN \\
\hline CHEMBL1965808 & 688653 & 5.733 & 5.5776 & TST & & \\
\hline CHEMBL1359801 & 688653 & 4.7336 & 00000000 & 005 & 5.2895 & TRN \\
\hline CHEMBL1358294 & 688653 & 5.78 & 99999999 & 995 & 5.7103 & \\
\hline CHEMBL1377726 & 688 & 5.083 & 4.989 & TRN & & \\
\hline CHEMBL1361242 & 688653 & 5.7829 & 99999999 & 995 & 5.6559 & Th \\
\hline CHEMBL1323198 & 688653 & 4.833 & 5.1876 & TRN & & \\
\hline CHEMBL1510310 & 688653 & 4.883 & 5.4227 & TST & & \\
\hline CHEMBL1528485 & 688653 & 4.833 & 5.1486 & TST & & \\
\hline CHEMBL1985350 & 688653 & 4.633 & 4.9295 & TST & & \\
\hline CHEMBL1480093 & 688653 & 4.9836 & 00000000 & 005 & 5.61 & Tाז \\
\hline CHEMBL3194259 & 688653 & 6.2829 & 99999999 & 995 & 5.5496 & TRN \\
\hline CHEMBL1475873 & 688653 & 5.1329 & 99999999 & & 5.1225 & $-\pi$ \\
\hline
\end{tabular}




\begin{tabular}{|c|c|c|c|c|c|c|}
\hline \multicolumn{7}{|c|}{ Supplemental Table S2.txt } \\
\hline CHEMBL1567240 & 688653 & 5.233 & 5.3958 & TRN & & \\
\hline CHEMBL1584414 & 688653 & 4.933 & 5.3749 & TRN & & \\
\hline CHEMBL1489184 & 688653 & \multicolumn{3}{|c|}{6.582999999999999} & 5.7069 & TRN \\
\hline CHEMBL1496831 & 688653 & 6.183 & 5.8507 & TRN & & \\
\hline CHEMBL1530391 & 688653 & 5.683 & \multicolumn{3}{|c|}{6.3020000000000005} & TRN \\
\hline CHEMBL1423345 & 688653 & 4.783 & 5.5892 & TRN & & \\
\hline CHEMBL1367860 & 688653 & \multicolumn{3}{|c|}{4.7330000000000005} & 5.2212 & TST \\
\hline CHEMBL3211092 & 688653 & \multicolumn{3}{|c|}{6.332999999999999} & 5.3612 & TST \\
\hline CHEMBL1406924 & 688653 & 5.433 & 5.4839 & TRN & & \\
\hline CHEMBL1419517 & 688653 & 4.933 & 5.3775 & TRN & & \\
\hline CHEMBL1612646 & 688653 & 5.033 & 5.038 & TRN & & \\
\hline CHEMBL1553117 & 688653 & 6.183 & 5.5882 & TRN & & \\
\hline CHEMBL1334223 & 688653 & \multicolumn{3}{|c|}{5.132999999999999} & 5.2787 & TRN \\
\hline CHEMBL1465010 & 688653 & \multicolumn{3}{|c|}{4.7330000000000005} & 5.6338 & TRN \\
\hline CHEMBL3197239 & 688653 & 5.183 & 5.3249 & TRN & & \\
\hline CHEMBL1449349 & 688653 & \multicolumn{3}{|c|}{4.9830000000000005} & 5.1255 & TRN \\
\hline CHEMBL1524357 & 688653 & 4.633 & 4.955 & TST & & \\
\hline CHEMBL1402439 & 688653 & 6.983 & 6.0584 & TRN & & \\
\hline CHEMBL1485206 & 688653 & 4.583 & 5.1578 & TRN & & \\
\hline CHEMBL1380762 & 688653 & 4.783 & 5.0344 & TRN & & \\
\hline CHEMBL1321474 & 688653 & 5.183 & 5.1141 & TRN & & \\
\hline CHEMBL1443740 & 688653 & 5.233 & 5.3047 & TRN & & \\
\hline CHEMBL1346236 & 688653 & \multicolumn{3}{|c|}{5.5329999999999995} & 5.6684 & TRN \\
\hline CHEMBL1468166 & 688653 & \multicolumn{3}{|c|}{5.832999999999999} & 5.5933 & TRN \\
\hline CHEMBL1380071 & 688653 & 4.683 & 5.2892 & TST & & \\
\hline CHEMBL1575279 & 688653 & 4.933 & 5.0764 & TRN & & \\
\hline CHEMBL1302377 & 688653 & 4.833 & 5.4944 & TRN & & \\
\hline CHEMBL1367683 & 688653 & 5.183 & 5.1722 & TST & & \\
\hline CHEMBL1352153 & 688653 & 5.033 & 5.0751 & TST & & \\
\hline CHEMBL 1424170 & 688653 & \multicolumn{3}{|c|}{5.882999999999999} & 5.7425 & TRN \\
\hline CHEMBL1578819 & 688653 & 6.433 & 5.435 & TST & & \\
\hline CHEMBL1564522 & 688653 & \multicolumn{3}{|c|}{5.332999999999999} & 5.098 & TRN \\
\hline CHEMBL1394010 & 688653 & 4.883 & 5.0662 & TST & & \\
\hline CHEMBL1337151 & 688653 & 4.883 & 4.8707 & TRN & & \\
\hline CHEMBL1401361 & 688653 & \multicolumn{3}{|c|}{5.832999999999999} & 6.0474 & TST \\
\hline CHEMBL1373164 & 688653 & 4.783 & 5.3946 & TRN & & \\
\hline CHEMBL1975216 & 688653 & 5.483 & 5.1182 & TRN & & \\
\hline CHEMBL1427212 & 688653 & 5.183 & 5.1287 & TST & & \\
\hline CHEMBL1323877 & 688653 & 4.633 & 4.9475 & TST & & \\
\hline CHEMBL1406731 & 688653 & 4.883 & 5.4978 & TRN & & \\
\hline CHEMBL1414655 & 688653 & \multicolumn{3}{|c|}{4.7330000000000005} & 5.609 & TRN \\
\hline CHEMBL1569800 & 688653 & 5.183 & 5.085 & TST & & \\
\hline CHEMBL1467605 & 688653 & \multicolumn{3}{|c|}{6.2829999999999995} & 5.5854 & TRN \\
\hline CHEMBL1606785 & 688653 & \multicolumn{3}{|c|}{4.9830000000000005} & 5.1549 & TRN \\
\hline CHEMBL1407154 & 688653 & \multicolumn{3}{|c|}{5.132999999999999} & 5.2323 & TRN \\
\hline CHEMBL1502841 & 688653 & \multicolumn{3}{|c|}{4.7330000000000005} & 4.8971 & TST \\
\hline CHEMBL1353387 & 688653 & \multicolumn{3}{|c|}{5.2829999999999995} & 5.4961 & TRN \\
\hline CHEMBL1406698 & 688653 & \multicolumn{3}{|c|}{5.7829999999999995} & 5.2420 & 0000000001 \\
\hline
\end{tabular}




\begin{tabular}{|c|c|c|c|c|c|c|c|}
\hline \multirow{3}{*}{$\begin{array}{l}\text { CHEMBL1531184 } \\
\text { CHEMBL1329024 }\end{array}$} & \multicolumn{6}{|c|}{ Supplemental Table S2.txt } & \multirow[b]{2}{*}{ TRN } \\
\hline & 688653 & \multicolumn{3}{|c|}{4.9830000000000005} & \multicolumn{2}{|c|}{5.6610000000000005} & \\
\hline & 688653 & \multicolumn{3}{|c|}{5.132999999999999} & 5.5595 & TRN & \\
\hline CHEMBL1580812 & 688653 & 5.433 & 5.7223 & TRN & & & \\
\hline CHEMBL1466545 & 688653 & \multicolumn{3}{|c|}{4.9830000000000005} & 4.7686 & TST & \\
\hline CHEMBL 3211551 & 688653 & 4.633 & 5.4657 & TST & & & \\
\hline CHEMBL1320374 & 688653 & 4.783 & 5.5653 & TST & & & \\
\hline CHEMBL1492608 & 688653 & 5.433 & 5.489 & TRN & & & \\
\hline CHEMBL1606690 & 688653 & \multicolumn{3}{|c|}{5.582999999999999} & 5.1777 & TST & \\
\hline CHEMBL1322617 & 688653 & \multicolumn{3}{|c|}{4.7330000000000005} & 5.1407 & TST & \\
\hline CHEMBL1504067 & 688653 & 5.733 & 5.6781 & TRN & & & \\
\hline CHEMBL1529079 & 688653 & \multicolumn{3}{|c|}{5.382999999999999} & 5.3817 & TRN & \\
\hline CHEMBL 1417390 & 688653 & \multicolumn{3}{|c|}{5.132999999999999} & 5.1645 & TST & \\
\hline CHEMBL1331788 & 688653 & 4.883 & 5.2964 & TRN & & & \\
\hline CHEMBL1372229 & 688653 & \multicolumn{3}{|c|}{5.382999999999999} & 5.6158 & TRN & \\
\hline CHEMBL1539980 & 688653 & \multicolumn{3}{|c|}{5.132999999999999} & 6.1184 & TRN & \\
\hline CHEMBL1606940 & 688653 & 5.183 & 5.1216 & TRN & & & \\
\hline CHEMBL1506396 & 688653 & 4.783 & 5.5647 & TRN & & & \\
\hline CHEMBL 2004950 & 688653 & \multicolumn{3}{|c|}{6.2829999999999995} & 5.4957 & TRN & \\
\hline CHEMBL1462343 & 688653 & 4.833 & 5.0686 & TRN & & & \\
\hline CHEMBL1321661 & 688653 & \multicolumn{3}{|c|}{4.7330000000000005} & 5.0486 & TST & \\
\hline CHEMBL1492696 & 688653 & 4.833 & 5.369 & TRN & & & \\
\hline CHEMBL1349786 & 688653 & \multicolumn{3}{|c|}{4.7330000000000005} & 5.2615 & TRN & \\
\hline CHEMBL1314346 & 688653 & 5.183 & 5.3014 & TRN & & & \\
\hline CHEMBL1984604 & 688653 & 4.783 & 5.1438 & TRN & & & \\
\hline CHEMBL 3145106 & 688653 & \multicolumn{3}{|c|}{5.382999999999999} & 5.4646 & TST & \\
\hline CHEMBL1368753 & 688653 & \multicolumn{3}{|c|}{6.382999999999999} & 5.0974 & TRN & \\
\hline CHEMBL1374746 & 688653 & 6.4829 & 5.8901 & TST & & & \\
\hline CHEMBL1525025 & 688653 & 4.833 & 4.8038 & TRN & & & \\
\hline CHEMBL1352850 & 688653 & 4.783 & 5.1476 & TST & & & \\
\hline CHEMBL1389690 & 688653 & \multicolumn{3}{|c|}{5.382999999999999} & 5.652 & TRN & \\
\hline CHEMBL1400375 & 688653 & 4.883 & 5.3349 & TST & & & \\
\hline CHEMBL1433255 & 688653 & \multicolumn{3}{|c|}{6.7829999999999995} & 5.7053 & TRN & \\
\hline CHEMBL206483 & 688653 & 4.583 & 5.2666 & TRN & & & \\
\hline CHEMBL1401528 & 688653 & \multicolumn{3}{|c|}{6.2829999999999995} & 5.0593 & TRN & \\
\hline CHEMBL1476045 & 688653 & 5.433 & 5.1734 & TRN & & & \\
\hline CHEMBL1397215 & 688653 & 4.583 & 5.2976 & TRN & & & \\
\hline CHEMBL1380514 & 688653 & 6.38299 & 999999995 & & 5.4841 & TRN & \\
\hline CHEMBL1410768 & 688653 & 4.633 & 5.3865 & TRN & & & \\
\hline CHEMBL1526216 & 688653 & 4.95 & 5.5478 & TRN & & & \\
\hline CHEMBL1490330 & 688653 & 4.783 & 4.9737 & TST & & & \\
\hline CHEMBL1312502 & 688653 & 4.833 & 5.5341 & TRN & & & \\
\hline CHEMBL1529041 & 688653 & 4.73300 & 00000000 & 005 & 5.3627 & TST & \\
\hline CHEMBL1328010 & 688653 & 4.783 & 5.6857 & TRN & & & \\
\hline CHEMBL1567293 & 688653 & 4.933 & 5.4559 & TRN & & & \\
\hline CHEMBL1324332 & 688653 & 5.433 & 5.1864 & TRN & & & \\
\hline CHEMBL1388107 & 688653 & 4.883 & 4.9624 & TRN & & & \\
\hline CHEMBL1407169 & 688653 & 4.98300 & 00000000 & 005 & 5.5976 & TST & \\
\hline CHEMBL1549477 & 688653 & 4.73300 & 00000000 & 005 & 5.3153 & TRN & \\
\hline
\end{tabular}




\begin{tabular}{|c|c|c|c|c|c|c|}
\hline \multirow[b]{2}{*}{ CHEMBL1331777 } & \multirow[b]{2}{*}{688653} & \multicolumn{5}{|c|}{ Supplemental Table S2.txt } \\
\hline & & \multicolumn{3}{|c|}{$\begin{array}{lll}4.583 & 4.8111 & \text { TRN }\end{array}$} & & \\
\hline CHEMBL1417001 & 688653 & & 5.1507 & TRN \\
\hline CHEMBL1399050 & 688653 & \multicolumn{3}{|c|}{4.9830000000000005} & 5.3889 & TRN \\
\hline CHEMBL1511833 & 688653 & 4.833 & 4.8408 & TRN & & \\
\hline CHEMBL1307461 & 688653 & 4.883 & 5.062 & TST & & \\
\hline CHEMBL1436848 & 688653 & 5.933 & 5.2023 & TRN & & \\
\hline CHEMBL1301502 & 688653 & 4.883 & 5.2109 & TRN & & \\
\hline CHEMBL1582474 & 688653 & 4.783 & 5.3949 & TRN & & \\
\hline CHEMBL1590535 & 688653 & 4.783 & 5.0569 & TST & & \\
\hline CHEMBL1305841 & 688653 & 4.783 & 5.3442 & TRN & & \\
\hline CHEMBL1367374 & 688653 & 4.833 & 5.0715 & TRN & & \\
\hline CHEMBL1431755 & 688653 & 4.783 & 4.8494 & TST & & \\
\hline CHEMBL1601580 & 688653 & 5.733 & 5.4787 & TRN & & \\
\hline CHEMBL1514817 & 688653 & \multicolumn{3}{|c|}{5.132999999999999} & 4.7762 & 131 \\
\hline CHEMBL1326031 & 688653 & 5.183 & 5.5387 & TST & & \\
\hline CHEMBL1598804 & 688653 & 4.833 & 5.0383 & TST & & \\
\hline CHEMBL201325 & 688653 & \multicolumn{3}{|c|}{6.632999999999999} & 6.2201 & TRN \\
\hline CHEMBL1530181 & 688653 & \multicolumn{3}{|c|}{5.332999999999999} & 5.0967 & TRN \\
\hline CHEMBL1576663 & 688653 & \multicolumn{3}{|c|}{5.332999999999999} & 5.2615 & TRN \\
\hline CHEMBL1468981 & 688653 & \multicolumn{3}{|c|}{4.7330000000000005} & 4.8667 & TRN \\
\hline CHEMBL1441577 & 688653 & 4.883 & 5.6097 & TRN & & \\
\hline CHEMBL1308343 & 688653 & 4.833 & 5.0106 & TRN & & \\
\hline CHEMBL1603053 & 688653 & 6.233 & 5.2534 & TRN & & \\
\hline CHEMBL1574741 & 688653 & \multicolumn{3}{|c|}{5.132999999999999} & 5.1928 & $\mathrm{TR}$ \\
\hline CHEMBL1376016 & 688653 & 4.783 & 4.8266 & TST & & \\
\hline CHEMBL1429995 & 688653 & \multicolumn{3}{|c|}{5.5329999999999995} & 5.3587 & $1 \mathrm{KI}$ \\
\hline CHEMBL1 & 688653 & 6.183 & 5.4881 & TRN & & \\
\hline CHEMBL1477650 & 688653 & 4.833 & 5.1502 & TRN & & \\
\hline CHEMBL1557633 & 688653 & 5.233 & 4.7506 & TST & & \\
\hline CHEMBL1309395 & 688653 & 6.183 & 5.5684 & TRN & & \\
\hline CHEMBL1559181 & 688653 & \multicolumn{3}{|c|}{5.632999999999999} & 703 & TKIV \\
\hline CHEMBL1426718 & 688653 & \multicolumn{3}{|c|}{5.632999999999999} & 455 & TST \\
\hline CHEMBL1332602 & 688653 & \multicolumn{3}{|c|}{6.632999999999999} & 5.9276 & TRN \\
\hline CHEMBL1401763 & 688653 & 5.033 & 5.3887 & TST & & \\
\hline CHEMBL1399771 & 688653 & 5.033 & 5.2378 & TRN & & \\
\hline CHEMBL1516748 & 688653 & 4.583 & 5.0413 & TST & & \\
\hline CHEMBL1481871 & 688653 & \multicolumn{3}{|c|}{4.7330000000000005} & 4.7387 & $\mathrm{TI}$ \\
\hline CHEMBL1376413 & 688653 & 5.733 & 5.2997 & TRN & & \\
\hline CHEMBL1452585 & 688653 & \multicolumn{3}{|c|}{4.9830000000000005} & 5.401 & TST \\
\hline CHEMBL1401622 & 688653 & 5.733 & 5.2678 & TRN & & \\
\hline CHEMBL1553692 & 688653 & \multirow{2}{*}{\multicolumn{3}{|c|}{$\begin{array}{lcc}4.633 & 5.1475 & \text { TRN } \\
4.7330000000000005\end{array}$}} & & \\
\hline CHEMBL1602059 & 688653 & & & & 5.0925 & $T$ \\
\hline CHEMBL1986111 & 688653 & 4.883 & 5.4877 & TST & & \\
\hline CHEMBL1343458 & 688653 & \multicolumn{3}{|c|}{6.332999999999999} & 6.5097 & $\mathrm{TR}$ \\
\hline CHEMBL1409187 & 688653 & 5.233 & 5.02 & TST & & \\
\hline CHEMBL1610831 & 688653 & 4.633 & 5.1199 & TST & & \\
\hline CHEMBL1560442 & 688653 & 4.933 & 5.0679 & TRN & & \\
\hline CHEMBL1385343 & 688653 & 4.9830 & 0000000 & 005 & 5.6083 & IJ \\
\hline
\end{tabular}




\begin{tabular}{|c|c|c|c|c|c|c|}
\hline & & & & & & \\
\hline CHEMBL1601031 & 688653 & 6.233 & 5.1233 & TST & & \\
\hline CHEMBL1303160 & 688653 & 4.833 & 5.6714 & TRN & & \\
\hline CHEMBL1452884 & 688653 & 4.7330 & 000000000 & 005 & 5.4494 & TRN \\
\hline CHEMBL 3194537 & 688653 & 4.9830 & 000000000 & 005 & 5.349 & TST \\
\hline CHEMBL1343345 & 688653 & 5.5829 & 999999999 & & 5.8769 & TRN \\
\hline CHEMBL1596626 & 688653 & 4.783 & 5.2167 & TRN & & \\
\hline CHEMBL1389756 & 688653 & 4.883 & 5.2487 & TRN & & \\
\hline CHEMBL1317643 & 688653 & 4.633 & 5.2817 & TRN & & \\
\hline CHEMBL1537321 & 688653 & 5.183 & 5.3007 & TRN & & \\
\hline CHEMBL1423902 & 688653 & 4.9830 & 000000000 & 005 & 5.5007 & SI \\
\hline CHEMBL1444863 & 688653 & 4.883 & 5.0186 & TRN & & \\
\hline CHEMBL1565238 & 688653 & 4.633 & 5.4625 & TRN & & \\
\hline CHEMBL1575621 & 688653 & 4.7330 & 000000000 & 005 & 5.5381 & TR \\
\hline CHEMBL1529662 & 688653 & 4.783 & 5.2067 & TRN & & \\
\hline CHEMBL1565401 & 688653 & 6.5829 & 999999999 & & 5.9995 & TST \\
\hline CHEMBL1604431 & 688653 & 6.3829 & 999999999 & & 5.6 & \\
\hline CHEMBL1341020 & 688653 & 5.683 & 5.4753 & TRN & & \\
\hline CHEMBL1486795 & 688653 & 4.833 & 5.309 & TRN & & \\
\hline CHEMBL 2001895 & 688653 & 6.3329 & 999999999 & & 596 & TR \\
\hline CHEMBL1529749 & 688653 & 6.183 & 5.5784 & TST & & \\
\hline CHEMBL1544838 & 688653 & 4.783 & 5.0796 & TST & & \\
\hline CHEMBL1333474 & 688653 & 5.6329 & 999999999 & & 5.3103 & 13 \\
\hline CHEMBL1487761 & 688653 & 5.483 & 5.6029 & TRN & & \\
\hline CHEMBL1551243 & 688653 & 4.583 & 4.968999 & 999999 & & TS \\
\hline CHEMBL1572363 & 688653 & 5.733 & 5.2438 & TRN & & \\
\hline CHEMBL1316877 & 688653 & 4.633 & 4.9301 & TST & & \\
\hline CHEMBL1508184 & 688653 & 4.833 & 5.2161 & TST & & \\
\hline CHEMBL1428789 & 688653 & 5.2829 & 999999999 & 995 & 4.9989 & TS \\
\hline CHEMBL1338443 & 688653 & 5.033 & 5.1464 & TRN & & \\
\hline CHEMBL 3211710 & 688653 & 4.783 & 5.1941 & TRN & & \\
\hline CHEMBL 3197569 & 688653 & 4.7330 & 000000000 & 005 & 5.1324 & TST \\
\hline CHEMBL 1406325 & 688653 & 4.7330 & 000000000 & 005 & 5.1108 & TST \\
\hline CHEMBL405844 & 688653 & 4.683 & 5.5961 & TRN & & \\
\hline CHEMBL1470965 & 688653 & 5.683 & 5.2524 & TST & & \\
\hline CHEMBL1548927 & 688653 & 4.7330 & 000000000 & 005 & 4.9014 & וS1 \\
\hline CHEMBL1365098 & 688653 & 4.633 & 4.9486 & TRN & & \\
\hline CHEMBL 1488059 & 688653 & 4.633 & 5.1738 & TST & & \\
\hline CHEMBL1557186 & 688653 & 5.683 & 5.167000 & 000000000 & & TRN \\
\hline CHEMBL602763 & 688653 & 5.5329 & 999999999 & 995 & 5.0698 & TRN \\
\hline CHEMBL1603303 & 688653 & 5.433 & 4.8542 & TRN & & \\
\hline CHEMBL 3194963 & 688653 & 4.7330 & 000000000 & 005 & 5.0902 & TRN \\
\hline CHEMBL 1550941 & 688653 & 4.883 & 5.467000 & 000000000 & 005 & TST \\
\hline CHEMBL323936 & 688653 & 5.3829 & 999999999 & & 5.5661 & TRN \\
\hline CHEMBL1352283 & 688653 & 4.783 & 5.147 & TST & & \\
\hline CHEMBL1411803 & 688653 & 5.983 & 5.555 & TRN & & \\
\hline CHEMBL 3192913 & 688653 & 6.0329 & 999999999 & 995 & 5.6604 & TRN \\
\hline CHEMBL 1463272 & 688653 & 5.7829 & 999999999 & 995 & 5.7106 & TRN \\
\hline CHEMBL1377972 & 688653 & 4.683 & 5.2383 & TRN & & \\
\hline
\end{tabular}




\begin{tabular}{|c|c|c|c|c|c|c|c|}
\hline \multirow{3}{*}{$\begin{array}{l}\text { CHEMBL1581581 } \\
\text { CHEMBL1362899 }\end{array}$} & \multicolumn{6}{|c|}{ Supplemental Table S2.txt } & \\
\hline & 688653 & \multicolumn{3}{|c|}{4.7330000000000005} & \multicolumn{2}{|c|}{5.1579999999999995} & TRN \\
\hline & 688653 & 4.883 & 5.1297 & TRN & & & \\
\hline CHEMBL1578495 & 688653 & 6.183 & 5.822 & TRN & & & \\
\hline CHEMBL1573538 & 688653 & 5.033 & 4.9514 & TRN & & & \\
\hline CHEMBL1546062 & 688653 & 4.883 & 5.1709 & TRN & & & \\
\hline CHEMBL1467411 & 688653 & 6.183 & 6.2062 & TRN & & & \\
\hline CHEMBL1483769 & 688653 & 4.833 & 5.3829 & TRN & & & \\
\hline CHEMBL1535011 & 688653 & 5.983 & 5.5725 & TRN & & & \\
\hline CHEMBL 1402360 & 688653 & 4.633 & 4.8416 & TRN & & & \\
\hline CHEMBL1426411 & 688653 & 4.633 & 5.0592 & TST & & & \\
\hline CHEMBL1326704 & 688653 & 4.783 & 5.1021 & TRN & & & \\
\hline CHEMBL1513092 & 688653 & \multicolumn{3}{|c|}{5.2829999999999995} & 5.5155 & TST & \\
\hline CHEMBL1493159 & 688653 & 4.883 & 5.6699 & TRN & & & \\
\hline CHEMBL1346516 & 688653 & 6.0329 & 99999999 & 995 & 5.2447 & TRN & \\
\hline CHEMBL1323644 & 688653 & 5.8829 & 99999999 & & 6.0223 & TRN & \\
\hline CHEMBL1546068 & 688653 & 4.633 & 5.0826 & TST & & & \\
\hline CHEMBL1444082 & 688653 & 4.783 & 5.541 & TRN & & & \\
\hline CHEMBL1426515 & 688653 & 4.883 & 5.7288 & TRN & & & \\
\hline CHEMBL1459083 & 688653 & 5.933 & 5.2525 & TST & & & \\
\hline CHEMBL1401582 & 688653 & \multicolumn{3}{|c|}{4.7330000000000005} & 4.6847 & TRN & \\
\hline CHEMBL1434332 & 688653 & \multicolumn{3}{|c|}{4.7330000000000005} & 5.1138 & TRN & \\
\hline CHEMBL1445134 & 688653 & 5.083 & 5.3482 & TRN & & & \\
\hline CHEMBL1986392 & 688653 & 5.483 & 5.3955 & TRN & & & \\
\hline CHEMBL1345568 & 688653 & 4.783 & 5.08 & TRN & & & \\
\hline CHEMBL1319786 & 688653 & 5.183 & 5.2967 & TRN & & & \\
\hline CHEMBL1404241 & 688653 & 5.733 & 5.3337 & TRN & & & \\
\hline CHEMBL1415834 & 688653 & \multicolumn{3}{|c|}{5.332999999999999} & 5.3201 & TRN & \\
\hline CHEMBL1301158 & 688653 & \multicolumn{3}{|c|}{6.5329999999999995} & 5.9667 & TST & \\
\hline CHEMBL1349167 & 688653 & 4.783 & 4.9657 & TRN & & & \\
\hline CHEMBL1325173 & 688653 & 6.7331 & 5.6809 & TRN & & & \\
\hline CHEMBL1553980 & 688653 & 4.883 & 5.1285 & TST & & & \\
\hline CHEMBL1514278 & 688653 & \multicolumn{3}{|c|}{5.5329999999999995} & 5.0636 & TRN & \\
\hline CHEMBL444376 & 688653 & 5.933 & 5.6974 & TRN & & & \\
\hline CHEMBL 3189610 & 688653 & 6.433 & 5.8393 & TRN & & & \\
\hline CHEMBL3193349 & 688653 & \multicolumn{3}{|c|}{5.882999999999999} & 5.6619 & TRN & \\
\hline CHEMBL1591021 & 688653 & 4.883 & 5.2043 & TRN & & & \\
\hline CHEMBL1583644 & 688653 & 5.083 & 5.1534 & TRN & & & \\
\hline CHEMBL1448851 & 688653 & 5.733 & 5.8568 & TRN & & & \\
\hline CHEMBL1467225 & 688653 & 4.633 & 4.9193 & TST & & & \\
\hline CHEMBL 2000380 & 688653 & \multicolumn{3}{|c|}{6.2829999999999995} & 5.8305 & TRN & \\
\hline CHEMBL1368578 & 688653 & \multicolumn{3}{|c|}{5.832999999999999} & 5.2415 & TRN & \\
\hline CHEMBL1479210 & 688653 & 4.883 & 5.4039 & TRN & & & \\
\hline CHEMBL1527622 & 688653 & 4.783 & 5.0165 & TST & & & \\
\hline CHEMBL3212041 & 688653 & \multicolumn{3}{|c|}{5.832999999999999} & 5.1831 & TST & \\
\hline CHEMBL1535680 & 688653 & 4.783 & 4.809 & TST & & & \\
\hline CHEMBL1578053 & 688653 & \multicolumn{3}{|c|}{6.5329999999999995} & 5.9943 & TRN & \\
\hline CHEMBL1503053 & 688653 & 6.433 & 5.9662 & TRN & & & \\
\hline CHEMBL1515851 & 688653 & 4.633 & 4.7831 & TRN & & & \\
\hline
\end{tabular}




\begin{tabular}{|c|c|c|c|c|c|c|}
\hline & & \multicolumn{5}{|c|}{ Supplemental Table S2.txt } \\
\hline CHEMBL1333561 & 688653 & 5.733 & 5.4913 & TRN & & \\
\hline CHEMBL1414770 & 688653 & 4.933 & 5.0683 & TRN & & \\
\hline CHEMBL1473320 & 688653 & 4.583 & 4.8683 & TRN & & \\
\hline CHEMBL 3195070 & 688653 & 4.783 & 5.4992 & TRN & & \\
\hline CHEMBL1468577 & 688653 & 5.983 & 5.5108 & TRN & & \\
\hline CHEMBL1530208 & 688653 & 4.783 & 5.3086 & TRN & & \\
\hline CHEMBL1533668 & 688653 & 5.233 & \multicolumn{3}{|c|}{5.257999999999999} & \\
\hline CHEMBL1324181 & 688653 & 6.0 & 4.902 & TST & & \\
\hline CHEMBL1412093 & 688653 & \multicolumn{3}{|c|}{5.132999999999999} & 5.4938 & TRN \\
\hline CHEMBL1478817 & 688653 & \multicolumn{3}{|c|}{5.882999999999999} & 5.3902 & \\
\hline CHEMBL1550386 & 688653 & 5.983 & 6.0496 & TRN & & \\
\hline CHEMBL1339433 & 688653 & 5.683 & 4.5647 & TRN & & \\
\hline CHEMBL1361821 & 688653 & 4.883 & 4.9599 & TRN & & \\
\hline CHEMBL1334169 & 688653 & 4.633 & 4.7595 & TRN & & \\
\hline CHEMBL1547209 & 688653 & 4.883 & 4.9934 & TRN & & \\
\hline CHEMBL1435501 & 688653 & \multicolumn{3}{|c|}{5.332999999999999} & 4.9072 & \\
\hline CHEMBL1562193 & 688653 & 5.683 & 5.3184 & TRN & & \\
\hline CHEMBL32 & 688653 & 5.183 & 5.0902 & TST & & \\
\hline CHEMBL1 & 688653 & 4.633 & 5.0874 & TRN & & \\
\hline CHEMBL1559298 & 688653 & 4.583 & 4.3764 & TRN & & \\
\hline CHEMBL1334210 & 688653 & \multicolumn{3}{|c|}{6.332999999999999} & 5 . & \\
\hline CHEMBL1325673 & 688653 & \multicolumn{3}{|c|}{6.2829999999999995} & & \\
\hline CHEMBL15 & 688653 & 4.883 & 5.2682 & TRN & & \\
\hline CHEMBL1491335 & 688653 & 4.933 & 5.1802 & TRN & & \\
\hline CHEMBL1336476 & 688653 & 4.883 & 5.0129 & TRN & & \\
\hline CHEMBL1573280 & 688653 & \multicolumn{3}{|c|}{4.9830000000000005} & 5.5014 & \\
\hline CHEMBL13 & 688653 & 5.483 & 4.8514 & TST & & \\
\hline CHEMBL1 & 688653 & 4.833 & 5.0462 & TRN & & \\
\hline CHEMBL1489196 & 688653 & \multicolumn{3}{|c|}{4.9830000000000005} & 5.1634 & $\mathrm{~T}$ \\
\hline CHEMBL1314202 & 688653 & 5.083 & 5.0616 & TRN & & \\
\hline CHEMBL1475398 & 688653 & 4.833 & 5.0401 & TRN & & \\
\hline CHEMBL13 & 688 & \multicolumn{3}{|c|}{5.5329999999999995} & 5.6927 & (1) \\
\hline CHEMBL1501110 & 688653 & \multicolumn{3}{|c|}{5.582999999999999} & 5.3868 & TRN \\
\hline CHEMBL3195228 & 688653 & \multicolumn{3}{|c|}{5.5329999999999995} & 5.541 & TRN \\
\hline CHEMBL1468770 & 688653 & 4.933 & 5.3367 & TRN & & \\
\hline CHEMBL1452559 & 688653 & \multicolumn{3}{|c|}{5.2829999999999995} & $1 / 4$ & \\
\hline CHEMBL1429330 & 688653 & \multicolumn{3}{|c|}{6.582999999999999} & & (1) \\
\hline CHEMBL1567961 & 688653 & \multirow{2}{*}{\multicolumn{3}{|c|}{$\begin{array}{ll}5.183 & 5.122000006 \\
4.7330000000000005\end{array}$}} & 01 & TRN \\
\hline CHEMBL1525466 & 688653 & & & & 5.0758 & TST \\
\hline CHEMBL3197437 & 688653 & 4.933 & 5.0466 & TRN & & \\
\hline CHEMBL3207581 & 688653 & 4.833 & 4.9036 & TRN & & \\
\hline CHEMBL1613561 & 688653 & \multicolumn{3}{|c|}{4.7330000000000005} & 4.9442 & TRN \\
\hline CHEMBL1501660 & 688653 & \multicolumn{3}{|c|}{5.132999999999999} & 5.1446 & TRN \\
\hline CHEMBL1559227 & 688653 & 4.933 & 4.8176 & TRN & & \\
\hline CHEMBL1465828 & 688653 & \multicolumn{3}{|c|}{5.132999999999999} & 5.3812 & $1 \mathrm{~K}$ \\
\hline CHEMBL1379470 & 688653 & 5.183 & 5.0919 & TRN & & \\
\hline CHEMBL1431887 & 688653 & 4.833 & 5.3831 & TST & & \\
\hline CHEMBL1413087 & 688653 & \multicolumn{3}{|c|}{5.382999999999999} & 5.3423 & 等 \\
\hline
\end{tabular}




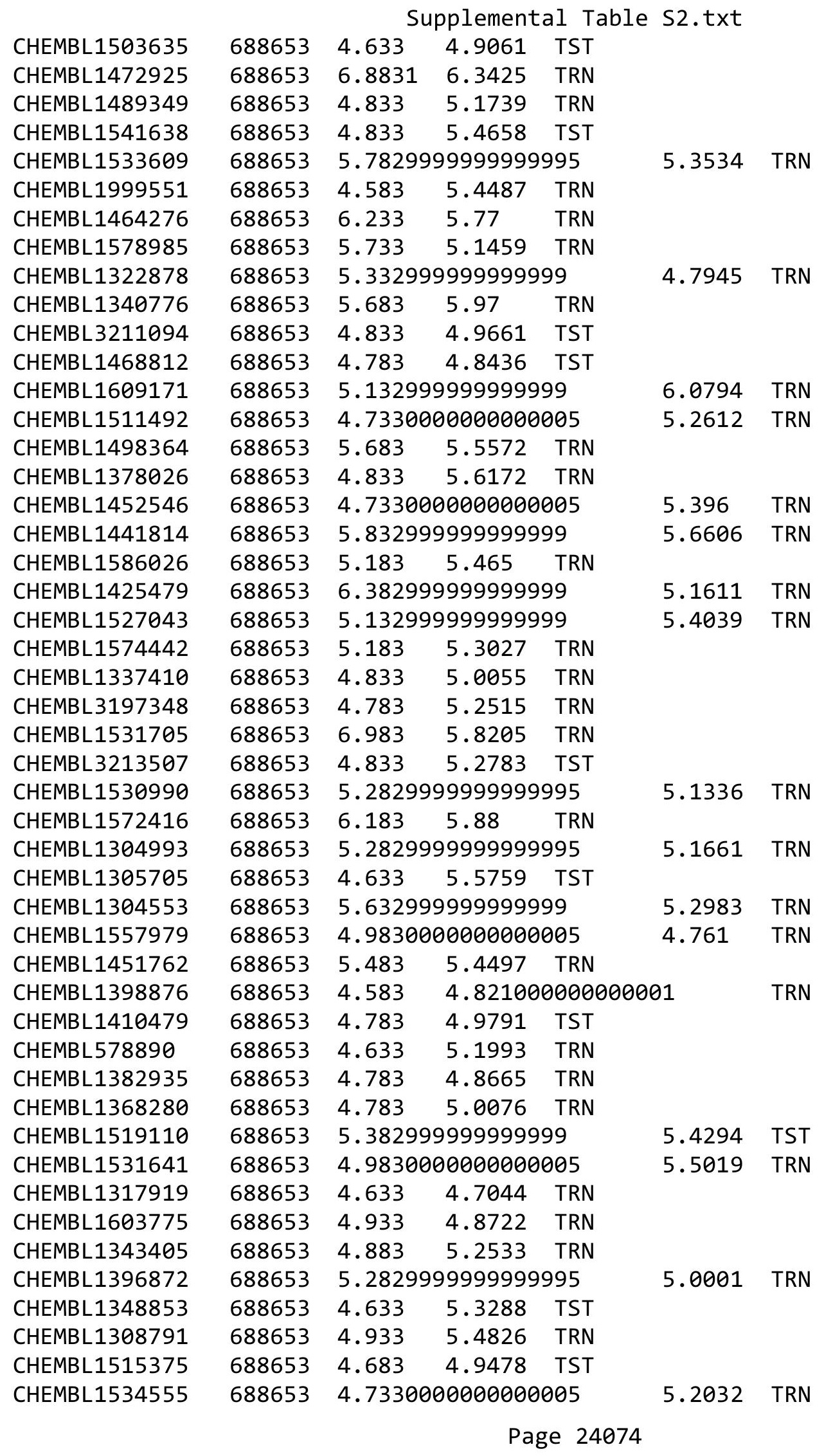




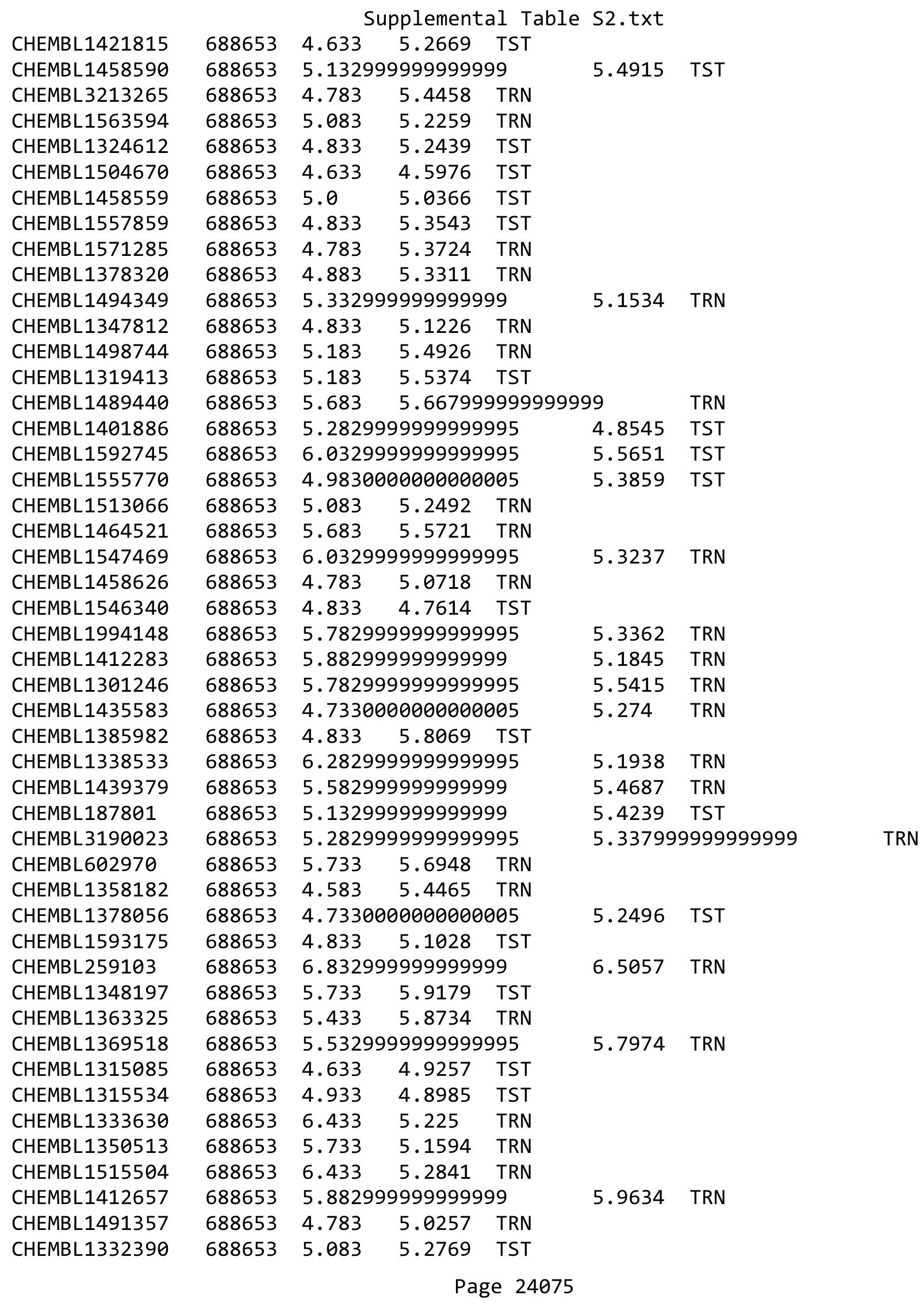




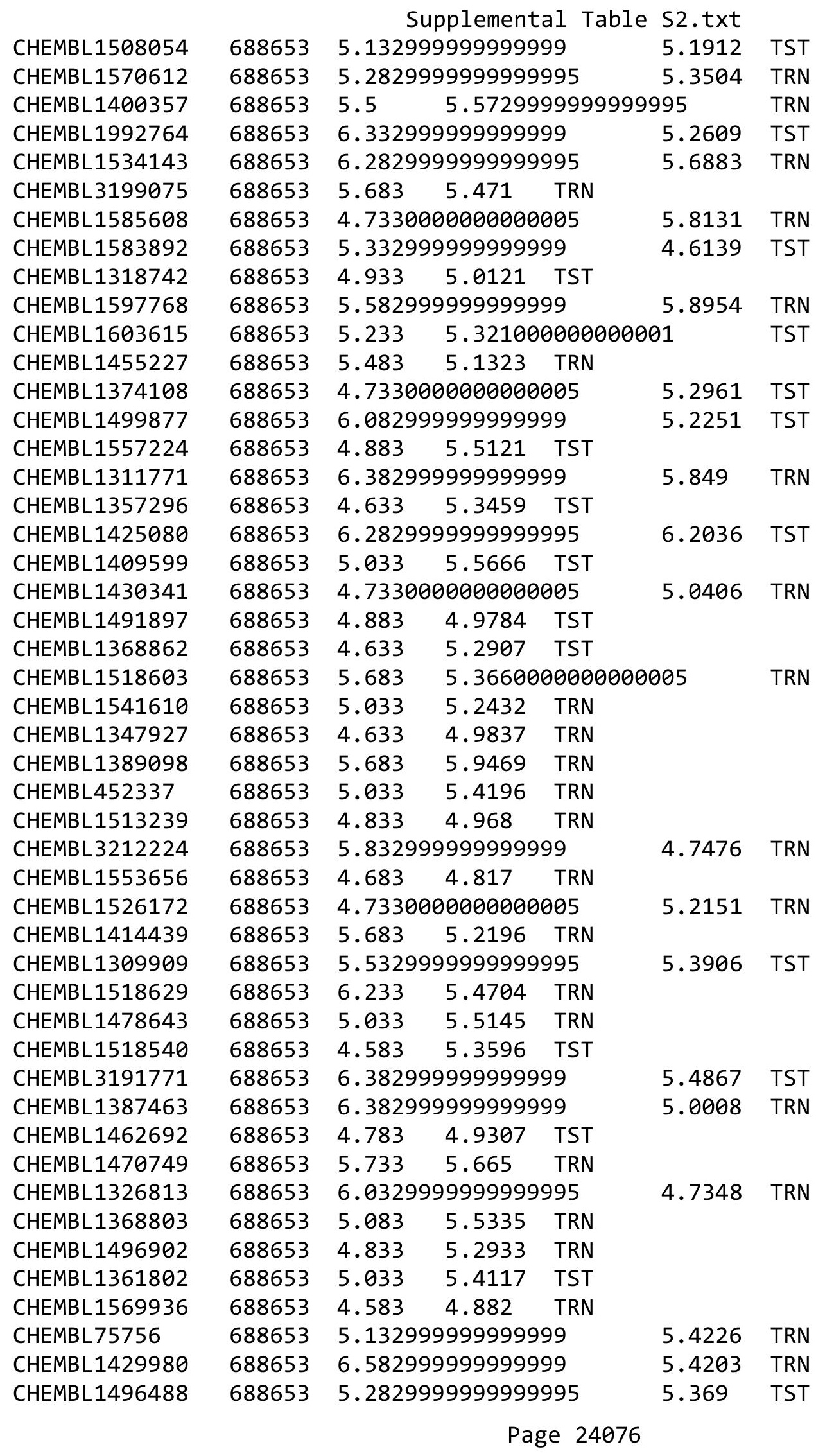




\begin{tabular}{|c|c|c|c|c|c|c|}
\hline \multirow[b]{2}{*}{ CHEMBL 3194331} & \multicolumn{6}{|c|}{ pplemental T } \\
\hline & 688653 & 4.933 & 5.0924 & TRN & & \\
\hline CHEMBL1370889 & 688653 & 4.883 & 4.7954 & TRN & & \\
\hline CHEMBL1351967 & 688653 & 5.433 & 5.5917 & TRN & & \\
\hline CHEMBL1312632 & 688653 & \multicolumn{3}{|c|}{4.7330000000000005} & 5.1774 & $\mathrm{TP}$ \\
\hline CHEMBL1370412 & 688653 & 6.183 & 6.2104 & TRN & & \\
\hline CHEMBL1496748 & 688653 & 5.933 & 5.8146 & TRN & & \\
\hline CHEMBL1419210 & 688653 & 5.733 & 5.6397 & TRN & & \\
\hline CHEMBL1460435 & 688653 & 5.733 & 5.2123 & TST & & \\
\hline CHEMBL1452136 & 688653 & 4.683 & 4.999 & TST & & \\
\hline CHEMBL1348198 & 688653 & \multicolumn{3}{|c|}{6.2829999999999995} & 5.3352 & \\
\hline CHEMBL1452032 & 688653 & 4.933 & 5.3992 & TRN & & \\
\hline CHEMBL1461853 & 688653 & 4.683 & 4.7791 & TST & & \\
\hline CHEMBL1499770 & 688653 & \multicolumn{3}{|c|}{6.582999999999999} & 5.5252 & TRN \\
\hline CHEMBL1309013 & 688653 & 4.683 & \multicolumn{3}{|c|}{5.372999999999999} & \\
\hline CHEMBL1366105 & 688653 & \multicolumn{3}{|c|}{4.9830000000000005} & 5.0946 & \\
\hline CHEMBL1569866 & 688653 & 4.933 & 4.756 & TRN & & \\
\hline CHEMBL1390067 & 688653 & \multicolumn{3}{|c|}{5.5329999999999995} & 5.6102 & 15 \\
\hline CHEMBL1437922 & 688653 & 4.783 & 5.0044 & TRN & & \\
\hline CHEMBL 3189244 & 688653 & \multicolumn{3}{|c|}{5.5329999999999995} & & זענו \\
\hline CHEMBL1300249 & 688653 & & 5.7 & \\
\hline CHEMBL1450526 & 688653 & $\begin{array}{l}6.582999999999999 \\
5.933 \\
5 \quad 372999999\end{array}$ & \multicolumn{3}{|c|}{5.372999999999999} & TRN \\
\hline CHEMBL1472999 & 688653 & & 5.0823 & TRN & & \\
\hline CHEMBL1537906 & 688653 & \multicolumn{3}{|c|}{5.882999999999999} & 5.0009 & TST \\
\hline CHEMBL 318 & 688 & \multicolumn{3}{|c|}{6.332999999999999} & 5.7632 & TRN \\
\hline CHEMBL1513172 & 688653 & \multicolumn{3}{|c|}{6.2829999999999995} & 5.7214 & \\
\hline CHEMBL1368970 & 688653 & \multicolumn{3}{|c|}{5.132999999999999} & 5.2919 & TST \\
\hline CHEMBL1476747 & 688653 & \multicolumn{3}{|c|}{4.7330000000000005} & 5.1419 & TST \\
\hline CHEMBL1422132 & 688653 & \multicolumn{3}{|c|}{5.7829999999999995} & 5.2488 & $\mathrm{TR}$ \\
\hline CHEMBL13 & 688653 & 4.783 & 5.3671 & TRN & & \\
\hline CHEMBL 3199142 & 688653 & 5.733 & 5.1857 & TRN & & \\
\hline CHEMBL108660 & 688653 & 5.733 & 5.5389 & TRN & & \\
\hline CHEMBL1520341 & 688653 & 4.783 & 5.0857 & TRN & & \\
\hline CHEMBL1406419 & 688653 & 4.583 & 5.3501 & TST & & \\
\hline CHEMBL1 & 53 & 4.85 & 5.5973 & TST & & \\
\hline CHEMBL1545709 & 688653 & 5.733 & 5.5103 & TRN & & \\
\hline CHEMBL1544811 & 688653 & \multicolumn{3}{|c|}{5.382999999999999} & 5.761 & $T$ \\
\hline CHEMBL1392663 & 688653 & 4.933 & 4.9333 & TST & & \\
\hline CHEMBL1563552 & 688653 & 4.583 & 5.1848 & TRN & & \\
\hline CHEMBL146 & 688653 & \multicolumn{3}{|c|}{5.5329999999999995} & 5.4609 & TR \\
\hline CHEMBL1502056 & 688653 & \multicolumn{3}{|c|}{4.7330000000000005} & 5.449 & $\pi$ \\
\hline CHEMBL1492541 & 688653 & 4.633 & 4.9608 & TST & & \\
\hline CHEMBL1560675 & 688653 & 4.783 & 5.0056 & TST & & \\
\hline CHEMBL1453812 & 688653 & 5.5329 & 99999999 & 995 & 5 & TRN \\
\hline CHEMBL 3212249 & 688653 & 4.7330 & 00000000 & 205 & 55021 & $\pi$ \\
\hline CHEMBL451208 & 688653 & 4.783 & 5.5351 & TRN & & \\
\hline CHEMBL1515461 & 688653 & 4.783 & 4.9823 & TRN & & \\
\hline CHEMBL1583285 & 688653 & 4.7330 & 00000000 & 205 & 5.1221 & m \\
\hline CHEMBL1333386 & 688653 & 5.983 & 5.5638 & TST & & \\
\hline
\end{tabular}




\begin{tabular}{|c|c|c|c|c|c|c|}
\hline & & \multicolumn{5}{|c|}{ Supplemental Table s2.txt } \\
\hline CHEMBL1498669 & 688653 & 5.733 & 5.6387 & TST & & \\
\hline CHEMBL1338563 & 688653 & 4.583 & 5.2549 & TRN & & \\
\hline CHEMBL1365006 & 688653 & 4.633 & 5.0085 & TRN & & \\
\hline CHEMBL1454662 & 688653 & 4.85 & 5.3402 & TST & & \\
\hline CHEMBL1413222 & 688653 & \multicolumn{3}{|c|}{5.2829999999999995} & 5.8592 & TRN \\
\hline CHEMBL1490937 & 688653 & \multicolumn{3}{|c|}{4.7330000000000005} & 4.6508 & TRN \\
\hline CHEMBL1371750 & 688653 & 4.833 & 5.1055 & TRN & & \\
\hline CHEMBL1329581 & 688653 & 4.833 & 5.1656 & TST & & \\
\hline CHEMBL1418573 & 688653 & \multicolumn{3}{|c|}{5.132999999999999} & 5.3226 & TRN \\
\hline CHEMBL1582697 & 688653 & 4.933 & 5.3358 & TST & & \\
\hline CHEMBL1352960 & 688653 & \multicolumn{3}{|c|}{6.082999999999999} & 5.4063 & TRN \\
\hline CHEMBL1534905 & 688653 & \multicolumn{3}{|c|}{4.9830000000000005} & 5.0488 & TRN \\
\hline CHEMBL1336536 & 688653 & 5.033 & 4.9438 & TRN & & \\
\hline CHEMBL1529588 & 688653 & 4.633 & 5.2552 & TRN & & \\
\hline CHEMBL1579477 & 688653 & 4.783 & 4.941 & TRN & & \\
\hline CHEMBL1422769 & 688653 & 4.883 & 5.1173 & TRN & & \\
\hline CHEMBL1425614 & 688653 & 6.0 & 5.5818 & TRN & & \\
\hline CHEMBL1331200 & 688653 & 5.183 & 5.2027 & TRN & & \\
\hline CHEMBL1581674 & 688653 & 4.583 & 4.7549 & TRN & & \\
\hline CHEMBL1535032 & 688653 & 4.783 & 4.8407 & TST & & \\
\hline CHEMBL1522939 & 688653 & \multicolumn{3}{|c|}{5.332999999999999} & 4.9233 & TST \\
\hline CHEMBL1389740 & 688653 & 4.783 & 5.1059 & TST & & \\
\hline CHEMBL1429805 & 688653 & 5.033 & 5.2024 & TRN & & \\
\hline CHEMBL1594492 & 688653 & 4.883 & 5.0659 & TST & & \\
\hline CHEMBL3191452 & 688653 & 6.4829 & 5.5821 & TRN & & \\
\hline CHEMBL1450168 & 688653 & \multicolumn{3}{|c|}{ 5.382999999999999 } & 5.6644 & TRN \\
\hline CHEMBL1309268 & 688653 & \multicolumn{3}{|c|}{5.832999999999999} & 5.359 & TST \\
\hline CHEMBL1473949 & 688653 & \multicolumn{3}{|c|}{5.382999999999999} & 4.9199 & TRN \\
\hline CHEMBL1326124 & 688653 & 5.683 & 5.3963 & TRN & & \\
\hline CHEMBL1483995 & 688653 & 5.233 & 5.7162 & TRN & & \\
\hline CHEMBL1305329 & 688653 & \multicolumn{3}{|c|}{5.332999999999999} & 4.963 & TRN \\
\hline CHEMBL1559104 & 688653 & 5.733 & 5.2053 & TRN & & \\
\hline CHEMBL 211740 & 688653 & \multicolumn{3}{|c|}{6.2829999999999995} & 5.8789 & TRN \\
\hline CHEMBL1320555 & 688653 & 5.083 & 5.2146 & TRN & & \\
\hline CHEMBL1488200 & 688653 & 6.233 & 5.3514 & TRN & & \\
\hline CHEMBL1367432 & 688653 & 4.683 & 5.511 & TRN & & \\
\hline CHEMBL1372680 & 688653 & \multicolumn{3}{|c|}{4.7330000000000005} & 4.9706 & TRN \\
\hline CHEMBL3214455 & 688653 & \multicolumn{3}{|c|}{5.632999999999999} & 6.1518 & TRN \\
\hline CHEMBL1451293 & 688653 & 7.2328 & 5.9028 & TRN & & \\
\hline CHEMBL1410766 & 688653 & \multicolumn{3}{|c|}{5.882999999999999} & 5.5591 & TRN \\
\hline CHEMBL1325553 & 688653 & \multicolumn{3}{|c|}{5.332999999999999} & 5.501 & TRN \\
\hline CHEMBL1535520 & 688653 & 4.833 & 4.872 & TST & & \\
\hline CHEMBL1485560 & 688653 & & & TRN & & \\
\hline CHEMBL3198796 & 688653 & \multicolumn{3}{|c|}{5.882999999999999} & 5.2918 & TRN \\
\hline CHEMBL 3197783 & 688653 & 4.883 & 5.2397 & TRN & & \\
\hline CHEMBL1443173 & 688653 & 4.833 & 5.0696 & TRN & & \\
\hline CHEMBL11405 & 688653 & 5.683 & 5.4795 & TRN & & \\
\hline CHEMBL1530525 & 688653 & 4.883 & 5.1688 & TST & & \\
\hline
\end{tabular}




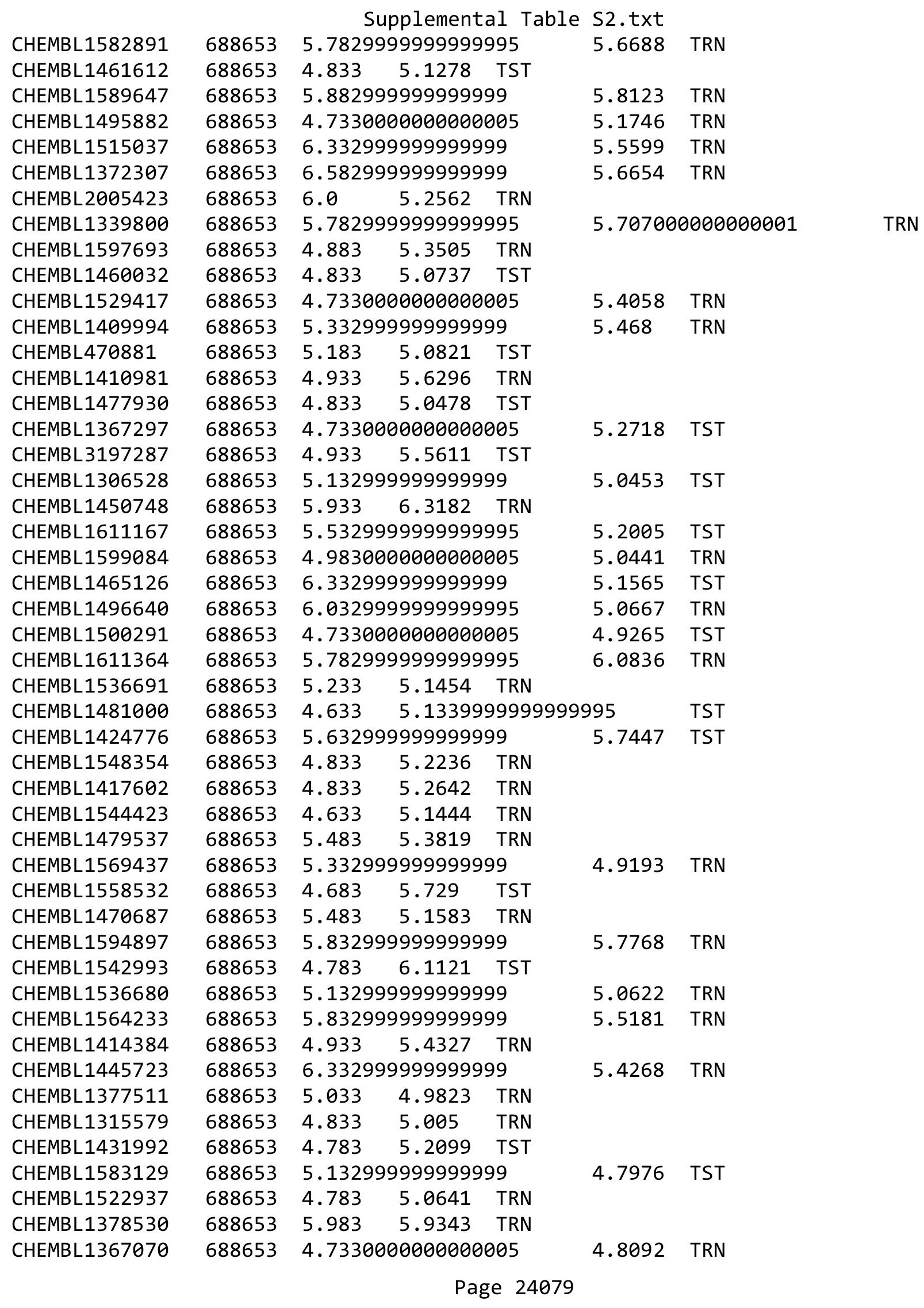




\begin{tabular}{|c|c|c|c|c|c|c|}
\hline \multirow{3}{*}{$\begin{array}{l}\text { CHEMBL1420487 } \\
\text { CHEMBL1602686 }\end{array}$} & \multirow{3}{*}{$\begin{array}{l}688653 \\
688653\end{array}$} & \multicolumn{5}{|c|}{ Supplemental Table S2.txt } \\
\hline & & \multicolumn{4}{|c|}{$5.2829999999999995 \quad 5.3302$} & \multirow{2}{*}{ TRA } \\
\hline & & 4.933 & 5.1886 & TRN & & \\
\hline CHEMBL1315149 & 688653 & \multicolumn{3}{|c|}{6.082999999999999} & 5.4919 & TRN \\
\hline CHEMBL1350943 & 688653 & \multicolumn{3}{|c|}{5.882999999999999} & 5.249 & TRN \\
\hline CHEMBL1440090 & 688653 & 4.883 & 5.4478 & TRN & & \\
\hline CHEMBL1400824 & 688653 & 4.933 & 5.0295 & TRN & & \\
\hline CHEMBL1440303 & 688653 & \multicolumn{3}{|c|}{4.9830000000000005} & 5.0773 & TRN \\
\hline CHEMBL1533982 & 688653 & 4.933 & 5.1861 & TRN & & \\
\hline CHEMBL1584061 & 688653 & 4.783 & 5.1515 & TRN & & \\
\hline CHEMBL1416658 & 688653 & 5.733 & 5.5134 & TST & & \\
\hline CHEMBL1424555 & 688653 & 5.733 & 5.7676 & TRN & & \\
\hline CHEMBL563294 & 688653 & \multicolumn{3}{|c|}{5.332999999999999} & 5.3414 & TRN \\
\hline CHEMBL1380764 & 688653 & 4.833 & 5.3133 & TRN & & \\
\hline CHEMBL1545955 & 688653 & \multicolumn{3}{|c|}{6.632999999999999} & 5.4695 & TRN \\
\hline CHEMBL1542328 & 688653 & 5.983 & 5.3273 & TST & & \\
\hline CHEMBL1368033 & 688653 & 4.783 & 5.1351 & TRN & & \\
\hline CHEMBL1340530 & 688653 & \multicolumn{3}{|c|}{5.832999999999999} & 5.4207 & TRN \\
\hline CHEMBL1444352 & 688653 & 4.833 & 5.357 & TRN & & \\
\hline CHEMBL1374508 & 688653 & 4.783 & 5.2491 & TRN & & \\
\hline CHEMBL1350956 & 688653 & \multicolumn{3}{|c|}{5.832999999999999} & 5.3429 & TRN \\
\hline CHEMBL1408390 & 688653 & 5.083 & 5.2042 & TRN & & \\
\hline CHEMBL1366027 & 688653 & 5.183 & 5.7474 & TRN & & \\
\hline CHEMBL1426866 & 688653 & \multicolumn{3}{|c|}{4.9830000000000005} & 5.2132 & TRN \\
\hline CHEMBL1479866 & 688653 & \multicolumn{3}{|c|}{4.7330000000000005} & 4.8475 & TRN \\
\hline CHEMBL1468353 & 688653 & \multicolumn{3}{|c|}{5.382999999999999} & 5.2069 & TRN \\
\hline CHEMBL1448637 & 688653 & \multicolumn{3}{|c|}{5.382999999999999} & 5.6951 & TRN \\
\hline CHEMBL1484849 & 688653 & \multicolumn{3}{|c|}{5.332999999999999} & 5.0849 & TRN \\
\hline CHEMBL1313028 & 688653 & 5.083 & 5.2529 & TST & & \\
\hline CHEMBL1325413 & 688653 & 5.433 & 5.9005 & TRN & & \\
\hline CHEMBL 2006611 & 688653 & 4.633 & 5.1227 & TRN & & \\
\hline CHEMBL1375105 & 688653 & \multicolumn{3}{|c|}{6.082999999999999} & 5.5537 & TST \\
\hline CHEMBL1323139 & 688653 & \multicolumn{3}{|c|}{4.9830000000000005} & 4.9436 & TST \\
\hline CHEMBL 1457445 & 688653 & 5.183 & 5.4865 & TST & & \\
\hline CHEMBL1459298 & 688653 & \multicolumn{3}{|c|}{4.9830000000000005} & 4.869 & TST \\
\hline CHEMBL1590717 & 688653 & 4.583 & 5.1026 & TRN & & \\
\hline CHEMBL1560684 & 688653 & \multicolumn{3}{|c|}{6.0329999999999995} & 5.5511 & TRN \\
\hline CHEMBL1411528 & 688653 & 4.7330 & 00000000 & 205 & 4.9421 & TRN \\
\hline CHEMBL1330058 & 688653 & 7.1331 & 6.3983 & TRN & & \\
\hline CHEMBL1881714 & 688653 & 5.183 & 5.3986 & TRN & & \\
\hline CHEMBL 3207375 & 688653 & 5.733 & 5.37 & TRN & & \\
\hline CHEMBL1495809 & 688653 & 4.933 & 5.0057 & TRN & & \\
\hline CHEMBL1421022 & 688653 & 6.0329 & 99999999 & 995 & 4.9602 & TST \\
\hline CHEMBL1584930 & 688653 & 5.683 & 5.529 & TRN & & \\
\hline CHEMBL1596656 & 688653 & 6.0329 & 99999999 & 995 & 5.8749 & TRN \\
\hline CHEMBL1562259 & 688653 & 5.183 & 5.2964 & TRN & & \\
\hline CHEMBL1436307 & 688653 & 4.633 & 5.1202 & TST & & \\
\hline CHEMBL1604747 & 688653 & 4.783 & 5.3276 & TRN & & \\
\hline CHEMBL1583909 & 688653 & 5.5829 & 99999999 & & 5.0145 & TRN \\
\hline
\end{tabular}




\begin{tabular}{|c|c|c|c|c|c|c|}
\hline \multirow[b]{2}{*}{ CHEMBL1539273 } & \multirow[b]{2}{*}{688653} & \multicolumn{5}{|c|}{ Supplemental Table S2.txt } \\
\hline & & \multicolumn{3}{|c|}{35.1634 TRN } & & \\
\hline CHEMBL1575504 & 688653 & 4.833 & 5.8393 & TRN & & \\
\hline CHEMBL1487466 & 688653 & \multicolumn{3}{|c|}{5.832999999999999} & 6.0152 & TRN \\
\hline CHEMBL1483229 & 688653 & 5.083 & 5.4771 & TRN & & \\
\hline CHEMBL3193405 & 688653 & 7.3325 & 5.9997 & TRN & & \\
\hline CHEMBL3212633 & 688653 & 5.083 & 4.9744 & TRN & & \\
\hline CHEMBL1345273 & 688653 & \multicolumn{3}{|c|}{5.632999999999999} & 5.2083 & TRN \\
\hline CHEMBL1418643 & 688653 & 4.833 & 5.3317 & TRN & & \\
\hline CHEMBL3199923 & 688653 & 4.833 & 5.1898 & TST & & \\
\hline CHEMBL1396895 & 688653 & 5.083 & 5.3031 & TST & & \\
\hline CHEMBL1529037 & 688653 & \multicolumn{3}{|c|}{5.132999999999999} & 5.1897 & TRN \\
\hline CHEMBL1461883 & 688653 & 5.233 & \multicolumn{3}{|c|}{5.4479999999999995} & TST \\
\hline CHEMBL1535257 & 688653 & 4.583 & 4.7087 & TRN & & \\
\hline CHEMBL1582357 & 688653 & 5.183 & 5.2978 & TST & & \\
\hline CHEMBL1327919 & 688653 & 4.783 & 5.3084 & TRN & & \\
\hline CHEMBL1455873 & 688653 & 4.583 & 5.0008 & TRN & & \\
\hline CHEMBL1339120 & 688653 & \multicolumn{3}{|c|}{5.7829999999999995} & 5.3461 & TRN \\
\hline CHEMBL1372802 & 688653 & \multicolumn{3}{|c|}{6.0329999999999995} & 5.4726 & TRN \\
\hline CHEMBL1555250 & 688653 & \multicolumn{3}{|c|}{5.882999999999999} & 5.9734 & TRN \\
\hline CHEMBL1545868 & 688653 & \multicolumn{3}{|c|}{6.0329999999999995} & 5.495 & TST \\
\hline CHEMBL1384623 & 688653 & 6.0 & 5.1086 & TST & & \\
\hline CHEMBL1372494 & 688653 & 5.933 & 5.17 & TRN & & \\
\hline CHEMBL1312909 & 688653 & \multicolumn{3}{|c|}{5.582999999999999} & 5.2775 & TST \\
\hline CHEMBL1311047 & 688653 & 5.733 & 5.0248 & TST & & \\
\hline CHEMBL1478975 & 688653 & \multicolumn{3}{|c|}{5.7829999999999995} & 5.5707 & TRN \\
\hline CHEMBL 206778 & 688653 & 5.083 & 5.1585 & TRN & & \\
\hline CHEMBL1534197 & 688653 & 5.733 & 5.6167 & TRN & & \\
\hline CHEMBL1573211 & 688653 & 5.433 & 5.7187 & TRN & & \\
\hline CHEMBL1982868 & 688653 & 4.783 & 4.9719 & TRN & & \\
\hline CHEMBL1564962 & 688653 & \multicolumn{3}{|c|}{6.832999999999999} & 5.8621 & TRN \\
\hline CHEMBL1607132 & 688653 & \multicolumn{3}{|c|}{6.5329999999999995} & 5.6639 & TRN \\
\hline CHEMBL1513547 & 688653 & 5.733 & 5.3534 & TRN & & \\
\hline CHEMBL1601730 & 688653 & & 5.6341 & TST & & \\
\hline CHEMBL1492814 & 688653 & \multicolumn{3}{|c|}{5.5329999999999995} & 5.3288 & TRN \\
\hline CHEMBL1583231 & 688653 & 5.183 & 5.5893 & TRN & & \\
\hline CHEMBL1515212 & 688653 & \multicolumn{3}{|c|}{4.9830000000000005} & 5.047 & TRN \\
\hline CHEMBL1429558 & 688653 & 5.483 & 5.354 & TRN & & \\
\hline CHEMBL3196933 & 688653 & \multicolumn{3}{|c|}{4.9830000000000005} & 5.2185 & TRN \\
\hline CHEMBL1438836 & 688653 & 5.733 & 5.5972 & TRN & & \\
\hline CHEMBL1591432 & 688653 & 5.683 & 4.97199 & 999999999 & 95 & TRN \\
\hline CHEMBL1464436 & 688653 & 4.633 & 4.7716 & TRN & & \\
\hline CHEMBL1474584 & 688653 & 5.233 & 5.7411 & TRN & & \\
\hline CHEMBL1987441 & 688653 & 5.733 & 5.5978 & TRN & & \\
\hline CHEMBL1500182 & 688653 & \multicolumn{3}{|c|}{4.7330000000000005} & 5.095 & TST \\
\hline CHEMBL1594268 & 688653 & 4.633 & 5.2732 & TRN & & \\
\hline CHEMBL2236983 & 688653 & 4.933 & 5.3465 & TRN & & \\
\hline CHEMBL1600081 & 688653 & 5.733 & 5.2239 & TRN & & \\
\hline CHEMBL1528246 & 688653 & 4.833 & 5.2697 & TRN & & \\
\hline
\end{tabular}




\begin{tabular}{|c|c|c|c|c|c|c|}
\hline \multirow[b]{2}{*}{ CHEMBL1504959 } & \multirow[b]{2}{*}{688653} & \multicolumn{5}{|c|}{ Supplemental Table S2.txt } \\
\hline & & \multicolumn{3}{|c|}{$5.083 \quad 5.2554$ TRN } & & \\
\hline CHEMBL1580312 & 688653 & 4.883 & 5.6088 & TRN & & \\
\hline CHEMBL1332512 & 688653 & \multicolumn{3}{|c|}{5.332999999999999} & \multirow[t]{3}{*}{5.6709} & \multirow[t]{3}{*}{ TRN } \\
\hline CHEMBL1966180 & 688653 & 6.7331 & 5.5108 & TRN & & \\
\hline CHEMBL1163763 & 688653 & 6.233 & 5.2033 & TRN & & \\
\hline CHEMBL1368072 & 688653 & \multicolumn{3}{|c|}{5.132999999999999} & 5.335 & TRN \\
\hline CHEMBL1541441 & 688653 & 4.833 & 4.9983 & TST & & \\
\hline CHEMBL1513809 & 688653 & \multicolumn{3}{|c|}{5.832999999999999} & 5.1316 & TRN \\
\hline CHEMBL1429609 & 688653 & 4.883 & 5.4035 & TST & & \\
\hline CHEMBL1513604 & 688653 & 4.783 & 5.188 & TRN & & \\
\hline CHEMBL1535869 & 688653 & 4.883 & 5.2426 & TRN & & \\
\hline CHEMBL1429817 & 688653 & 4.683 & 4.9913 & TRN & & \\
\hline CHEMBL1352038 & 688653 & 6.4829 & 5.8884 & TST & & \\
\hline CHEMBL1373305 & 688653 & 4.883 & 5.4938 & TRN & & \\
\hline CHEMBL1310946 & 688653 & 4.883 & 5.1249 & TST & & \\
\hline CHEMBL1341668 & 688653 & 5.433 & 5.7137 & TRN & & \\
\hline CHEMBL1577769 & 688653 & \multicolumn{3}{|c|}{4.9830000000000005} & 5.2895 & TST \\
\hline CHEMBL1380287 & 688653 & 4.783 & 5.2104 & TRN & & \\
\hline CHEMBL1442780 & 688653 & 5.983 & 5.3325 & TRN & & \\
\hline CHEMBL1353633 & 688653 & 4.783 & \multicolumn{3}{|c|}{4.9430000000000005} & TST \\
\hline CHEMBL1602567 & 688653 & \multicolumn{3}{|c|}{5.2829999999999995} & 5.9742 & TRN \\
\hline CHEMBL11709 & 688653 & 5.233 & 5.5139 & TRN & & \\
\hline CHEMBL1490871 & 688653 & 4.783 & 5.5661 & TRN & & \\
\hline CHEMBL549291 & 688653 & \multicolumn{3}{|c|}{4.7330000000000005} & 5.2835 & TRN \\
\hline CHEMBL3195806 & 688653 & \multicolumn{3}{|c|}{5.7829999999999995} & 5.2739 & TRN \\
\hline CHEMBL1997450 & 688653 & 5.183 & 5.8443 & TRN & & \\
\hline CHEMBL1511941 & 688653 & 4.633 & 5.278 & TST & & \\
\hline CHEMBL1498419 & 688653 & 4.783 & 5.0341 & TRN & & \\
\hline CHEMBL1510212 & 688653 & 5.183 & 5.1541 & TRN & & \\
\hline CHEMBL1392292 & 688653 & 5.683 & 5.7521 & TST & & \\
\hline CHEMBL1478307 & 688653 & \multicolumn{3}{|c|}{5.132999999999999} & 5.3346 & TRN \\
\hline CHEMBL1509104 & 688653 & 4.883 & 5.579 & TRN & & \\
\hline CHEMBL1465938 & 688653 & \multicolumn{3}{|c|}{4.7330000000000005} & 4.728 & TRN \\
\hline CHEMBL1573574 & 688653 & 4.833 & 5.2801 & TST & & \\
\hline CHEMBL1595927 & 688653 & \multicolumn{3}{|c|}{5.582999999999999} & 5.6084 & TRN \\
\hline CHEMBL1413986 & 688653 & 5.983 & 5.4945 & TRN & & \\
\hline CHEMBL1564713 & 688653 & 5.733 & 6.0523 & TRN & & \\
\hline CHEMBL1488919 & 688653 & 5.183 & 5.5806 & TRN & & \\
\hline CHEMBL1384146 & 688653 & \multicolumn{3}{|c|}{5.382999999999999} & 5.7089 & TRN \\
\hline CHEMBL1306437 & 688653 & 4.583 & 5.3088 & TRN & & \\
\hline CHEMBL3199794 & 688653 & \multicolumn{3}{|c|}{6.5329999999999995} & 6.1589 & TRN \\
\hline CHEMBL3212955 & 688653 & \multicolumn{3}{|c|}{4.7330000000000005} & 5.46 & TST \\
\hline CHEMBL1372990 & 688653 & \multicolumn{3}{|c|}{4.7330000000000005} & 4.9336 & TST \\
\hline CHEMBL1309478 & 688653 & 5.83299 & 99999999 & & 5.7553 & TRN \\
\hline CHEMBL1325034 & 688653 & 5.28299 & 99999999 & 995 & 5.7865 & TRN \\
\hline CHEMBL1408909 & 688653 & 4.933 & 5.4334 & TRN & & \\
\hline CHEMBL1536069 & 688653 & 4.833 & 5.0747 & TRN & & \\
\hline CHEMBL1418423 & 688653 & 5.033 & 4.9191 & TST & & \\
\hline
\end{tabular}




\begin{tabular}{|c|c|c|c|c|c|c|c|}
\hline \multicolumn{8}{|c|}{ Supplemental Table S2.txt } \\
\hline CHEMBL1388207 & 688653 & 4.833 & 5.0385 & TRN & & & \\
\hline CHEMBL1403097 & 688653 & \multicolumn{3}{|c|}{5.382999999999999} & 5.2256 & TRN & \\
\hline CHEMBL1527300 & 688653 & 4.633 & 4.8688 & TST & & & \\
\hline CHEMBL1366347 & 688653 & \multicolumn{3}{|c|}{5.132999999999999} & \multicolumn{2}{|c|}{6.343999999999999} & TRN \\
\hline CHEMBL1610286 & 688653 & 5.7 & 5.6796 & TRN & & & \\
\hline CHEMBL1389421 & 688653 & 4.833 & 5.3826 & TRN & & & \\
\hline CHEMBL1470617 & 688653 & 5.033 & 5.8578 & TRN & & & \\
\hline CHEMBL1349790 & 688653 & 4.833 & 5.2216 & TRN & & & \\
\hline CHEMBL1336046 & 688653 & \multicolumn{3}{|c|}{7.082999999999999} & 5.5324 & TRN & \\
\hline CHEMBL1483562 & 688653 & 4.833 & 5.1954 & TST & & & \\
\hline CHEMBL1385092 & 688653 & 5.983 & 5.6091 & TRN & & & \\
\hline CHEMBL1525289 & 688653 & 4.783 & 4.8943 & TRN & & & \\
\hline CHEMBL1487668 & 688653 & \multicolumn{3}{|c|}{5.382999999999999} & 5.1122 & TRN & \\
\hline CHEMBL1382288 & 688653 & 6.183 & 5.4193 & TRN & & & \\
\hline CHEMBL1417812 & 688653 & 4.683 & 4.6845 & TRN & & & \\
\hline CHEMBL1489455 & 688653 & 4.883 & 5.1958 & TST & & & \\
\hline CHEMBL1397514 & 688653 & 5.433 & 5.1555 & TRN & & & \\
\hline CHEMBL1370404 & 688653 & \multicolumn{3}{|c|}{5.7829999999999995} & 5.3062 & TRN & \\
\hline CHEMBL1477767 & 688653 & 5.183 & 5.1362 & TRN & & & \\
\hline CHEMBL388979 & 688653 & 4.683 & 4.9893 & TST & & & \\
\hline CHEMBL1366443 & 688653 & 6.183 & 5.3921 & TST & & & \\
\hline CHEMBL1302631 & 688653 & 4.883 & 4.8953 & TRN & & & \\
\hline CHEMBL3196277 & 688653 & 5.183 & 5.3517 & TRN & & & \\
\hline CHEMBL1570104 & 688653 & 4.683 & 5.3635 & TST & & & \\
\hline CHEMBL1591337 & 688653 & 4.633 & 5.3074 & TST & & & \\
\hline CHEMBL1497494 & 688653 & 4.833 & 5.6283 & TRN & & & \\
\hline CHEMBL1422896 & 688653 & 4.783 & 5.0346 & TST & & & \\
\hline CHEMBL1364270 & 688653 & 4.783 & 5.265 & TRN & & & \\
\hline CHEMBL1593915 & 688653 & 4.783 & 5.104 & TRN & & & \\
\hline CHEMBL1571312 & 688653 & \multicolumn{3}{|c|}{4.7330000000000005} & 5.3933 & TRN & \\
\hline CHEMBL3194091 & 688653 & \multicolumn{3}{|c|}{4.9830000000000005} & 5.0661 & TST & \\
\hline CHEMBL1508551 & 688653 & \multicolumn{3}{|c|}{6.382999999999999} & 5.3724 & TRN & \\
\hline CHEMBL1300898 & 688653 & 4.783 & 4.9808 & TRN & & & \\
\hline CHEMBL1337987 & 688653 & 4.883 & 5.2045 & TRN & & & \\
\hline CHEMBL1563249 & 688653 & 4.833 & 5.68 & TRN & & & \\
\hline CHEMBL1599929 & 688653 & 5.233 & 5.5146 & TST & & & \\
\hline CHEMBL1493488 & 688653 & \multicolumn{3}{|c|}{6.382999999999999} & \multicolumn{2}{|c|}{5.287000000000001} & TST \\
\hline CHEMBL3207419 & 688653 & \multicolumn{3}{|c|}{4.9830000000000005} & 5.1937 & TRN & \\
\hline CHEMBL1511667 & 688653 & \multicolumn{3}{|c|}{4.9830000000000005} & 5.2715 & TST & \\
\hline CHEMBL3194097 & 688653 & 5.733 & 5.2249 & TRN & & & \\
\hline CHEMBL3207781 & 688653 & 4.883 & 5.2072 & TRN & & & \\
\hline CHEMBL1321433 & 688653 & \multicolumn{3}{|c|}{4.7330000000000005} & 5.3192 & TRN & \\
\hline CHEMBL1423842 & 688653 & 5.083 & 5.1489 & TRN & & & \\
\hline CHEMBL1539438 & 688653 & 5.233 & 5.825 & TST & & & \\
\hline CHEMBL1513774 & 688653 & 4.633 & 4.7669 & TRN & & & \\
\hline CHEMBL1420759 & 688653 & \multicolumn{3}{|c|}{6.382999999999999} & 5.9031 & TRN & \\
\hline CHEMBL1507028 & 688653 & 5.233 & 5.3859 & TRN & & & \\
\hline CHEMBL1361489 & 688653 & 6.0329 & 99999999 & 995 & 5.7383 & TRN & \\
\hline
\end{tabular}




\begin{tabular}{|c|c|c|c|c|c|c|}
\hline & & \multicolumn{5}{|c|}{ Supplemental Table S2.txt } \\
\hline CHEMBL1378255 & 688653 & 4.783 & 5.1191 & TRN & & \\
\hline CHEMBL 3144938 & 688653 & 5.683 & 5.4442 & TST & & \\
\hline CHEMBL1479762 & 688653 & 4.783 & 5.4488 & TRN & & \\
\hline CHEMBL1613062 & 688653 & \multicolumn{3}{|c|}{4.7330000000000005} & 5.499 & TRN \\
\hline CHEMBL1580671 & 688653 & 5.683 & 5.6522 & TRN & & \\
\hline CHEMBL1534650 & 688653 & 4.783 & 5.1152 & TST & & \\
\hline CHEMBL1391555 & 688653 & 5.033 & 5.3014 & TRN & & \\
\hline CHEMBL1566543 & 688653 & 5.433 & 5.5047 & TRN & & \\
\hline CHEMBL1337282 & 688653 & 6.183 & 5.4256 & TRN & & \\
\hline CHEMBL1429052 & 688653 & \multicolumn{3}{|c|}{5.832999999999999} & 5.4449 & TRN \\
\hline CHEMBL3197565 & 688653 & \multicolumn{3}{|c|}{5.332999999999999} & 5.5135 & TRN \\
\hline CHEMBL1569645 & 688653 & \multicolumn{3}{|c|}{5.332999999999999} & 5.5279 & TRN \\
\hline CHEMBL3195082 & 688653 & \multicolumn{3}{|c|}{5.5329999999999995} & 5.6266 & TRN \\
\hline CHEMBL1318405 & 688653 & \multicolumn{3}{|c|}{4.9830000000000005} & 4.8366 & TST \\
\hline CHEMBL1391955 & 688653 & \multicolumn{3}{|c|}{5.832999999999999} & 5.7564 & TRN \\
\hline CHEMBL1449988 & 688653 & 4.933 & 5.2631 & TRN & & \\
\hline CHEMBL1554709 & 688653 & 4.633 & 4.9195 & TST & & \\
\hline CHEMBL1577660 & 688653 & 4.783 & 4.98 & TST & & \\
\hline CHEMBL1357571 & 688653 & 4.633 & 4.9622 & TST & & \\
\hline CHEMBL1505721 & 688653 & 5.183 & 5.8614 & TRN & & \\
\hline CHEMBL1547975 & 688653 & 5.683 & 5.3104 & TRN & & \\
\hline CHEMBL1370744 & 688653 & 4.933 & 5.1973 & TRN & & \\
\hline CHEMBL3211699 & 688653 & 5.483 & 5.7304 & TST & & \\
\hline CHEMBL3190993 & 688653 & \multicolumn{3}{|c|}{5.332999999999999} & 5.6003 & TRN \\
\hline CHEMBL1319821 & 688653 & 4.833 & 5.4377 & TRN & & \\
\hline CHEMBL1418814 & 688653 & 4.933 & 5.1606 & TST & & \\
\hline CHEMBL1478832 & 688653 & 4.783 & 4.9966 & TRN & & \\
\hline CHEMBL1430074 & 688653 & 5.233 & 4.8056 & TST & & \\
\hline CHEMBL1583989 & 688653 & \multicolumn{3}{|c|}{5.2829999999999995} & 5.5118 & TRN \\
\hline CHEMBL1491971 & 688653 & \multicolumn{3}{|c|}{5.5329999999999995} & 5.1704 & TRN \\
\hline CHEMBL1520870 & 688653 & 5.483 & 5.1589 & TRN & & \\
\hline CHEMBL1370615 & 688653 & \multicolumn{3}{|c|}{5.632999999999999} & 5.7596 & TRN \\
\hline CHEMBL1385055 & 688653 & 5.183 & 4.9758 & TRN & & \\
\hline CHEMBL1505229 & 688653 & \multicolumn{3}{|c|}{4.9830000000000005} & 5.0206 & TST \\
\hline CHEMBL1588310 & 688653 & 4.883 & 5.1026 & TRN & & \\
\hline CHEMBL1607862 & 688653 & 4.633 & \multicolumn{3}{|c|}{5.1610000000000005} & TRN \\
\hline CHEMBL1511424 & 688653 & 4.933 & 4.9172 & TRN & & \\
\hline CHEMBL1414188 & 688653 & 4.883 & 4.7565 & TST & & \\
\hline CHEMBL3211998 & 688653 & 4.583 & 5.7103 & TRN & & \\
\hline CHEMBL3195962 & 688653 & \multicolumn{3}{|c|}{5.132999999999999} & 5.2307 & TRN \\
\hline CHEMBL1329822 & 688653 & 5.683 & 5.3147 & TRN & & \\
\hline CHEMBL1275611 & 688653 & \multicolumn{3}{|c|}{4.7330000000000005} & 5.2688 & TRN \\
\hline CHEMBL1374725 & 688653 & 5.483 & 5.7348 & TRN & & \\
\hline CHEMBL1558697 & 688653 & 4.883 & 5.2116 & TRN & & \\
\hline CHEMBL1532177 & 688653 & 5.183 & 5.3068 & TRN & & \\
\hline CHEMBL600968 & 688653 & \multicolumn{3}{|c|}{5.632999999999999} & 5.4583 & TRN \\
\hline CHEMBL1544320 & 688653 & 4.683 & 5.1126 & TRN & & \\
\hline CHEMBL1467152 & 688653 & 5.483 & 5.6242 & TST & & \\
\hline
\end{tabular}




\begin{tabular}{|c|c|c|c|c|c|c|}
\hline \multirow[b]{2}{*}{ CHEMBL1590196 } & \multicolumn{6}{|c|}{ olemental } \\
\hline & 688653 & 4.783 & 5.3535 & TRN & & \\
\hline CHEMBL1543774 & 688653 & 4.933 & 4.9477 & TRN & & \\
\hline CHEMBL1536701 & 688653 & \multicolumn{3}{|c|}{4.7330000000000005} & 5.2851 & 12 \\
\hline CHEMBL1324156 & 688653 & 4.883 & 5.5433 & TST & & \\
\hline CHEMBL1404461 & 688653 & \multicolumn{3}{|c|}{5.832999999999999} & 5.3404 & \\
\hline CHEMBL 236897 & 688653 & 5.683 & 6.0266 & TRN & & \\
\hline CHEMBL1392842 & 688653 & \multicolumn{3}{|c|}{6.2829999999999995} & 6.1081 & \\
\hline CHEMBL1583952 & 688653 & 5.433 & 5.4761 & TRN & & \\
\hline CHEMBL1449750 & 688653 & \multicolumn{3}{|c|}{6.132999999999999} & 5.5144 & \\
\hline CHEMBL1501221 & 688653 & \multicolumn{3}{|c|}{5.5329999999999995} & & \\
\hline CHEMBL1340838 & 688653 & 6.183 & 5.5909 & TRN & & \\
\hline CHEMBL1515602 & 688653 & 5.733 & 5.1768 & TRN & & \\
\hline CHEMBL1345494 & 688653 & \multicolumn{3}{|c|}{6.632999999999999} & 5.4048 & \\
\hline CHEMBL1520043 & 6886 & 5.083 & 5.1931 & TRN & & \\
\hline CHEMBL1 & 688653 & 4.783 & 5.3815 & TRN & & \\
\hline CHEMBL14 & 688653 & 4.633 & 4.9854 & TST & & \\
\hline CHEMBL1451800 & 688653 & 4.883 & 4.9173 & TST & & \\
\hline CHEMBL1596982 & 688653 & \multicolumn{3}{|c|}{5.382999999999999} & 5.8422 & \\
\hline CHEMBL135 & 688 & 4.783 & 5.1938 & TST & & \\
\hline CHEMBL1 & 688 & 5.483 & \multicolumn{3}{|c|}{5.468999999999999} & \\
\hline CHEMBL1533477 & 688653 & \multicolumn{3}{|c|}{5.832999999999999} & 5.9806 & \\
\hline CHEMBL1428407 & 688653 & 4.683 & 4.683 & TRN & & \\
\hline CHEMBL1592398 & 688653 & 5.683 & 5.2873 & TRN & & \\
\hline CHEMBL1 & 688 & 4.783 & 5.1925 & TRN & & \\
\hline CHEMBL & 688 & \multicolumn{3}{|c|}{4.9830000000000005} & 5.1702 & \\
\hline CHEMBL 1378190 & 688 & 4.883 & 5.3804 & TRN & & \\
\hline CHEMBL1328025 & 688653 & 4.933 & 6.1086 & TRN & & \\
\hline CHEMBL1301188 & 6886 & 4.783 & 5.2143 & TRN & & \\
\hline CHEMB & 688 & \multicolumn{3}{|c|}{4.7330000000000005} & 3.2034 & \\
\hline CHEMBL1544967 & 688653 & \multicolumn{3}{|c|}{6.2829999999999995} & 5.403 & \\
\hline CHEMBL1329309 & 688 & 4.783 & 5.1582 & TRN & & \\
\hline CHEMBL1542287 & 688653 & \multicolumn{3}{|c|}{4.7330000000000005} & 5.2349 & \\
\hline CHEMBL1403294 & 688653 & 5.683 & 5.2751 & TST & & \\
\hline CHEME & 688 & \multicolumn{3}{|c|}{5.132999999999999} & 5.4121 & \\
\hline CHEMBL1534381 & 688653 & 4.833 & 5.2929 & TST & & \\
\hline CHEMBL3196261 & 688653 & \multicolumn{3}{|c|}{5.882999999999999} & & \\
\hline CHEMBL1401239 & 688653 & \multicolumn{3}{|c|}{4.7330000000000005} & 5.2293 & \\
\hline CHEMBL1541277 & 688653 & 5.683 & 5.3057 & TRN & & \\
\hline CHEMBL15 & 688 & \multirow{2}{*}{\multicolumn{2}{|c|}{$\begin{array}{ll}4.683 & 5.315 \\
5 & 1329999999999\end{array}$}} & TRN & & \\
\hline CHEMBL1536762 & 688653 & & & 5.132999999999999 & 5.0684 & \\
\hline CHEMBL1579313 & 688653 & 4.783 & 4.93267 & TRN & & \\
\hline CHEMBL1586486 & 688653 & \multirow{2}{*}{\multicolumn{2}{|c|}{$\begin{array}{ll}4.833 & 5.0507 \\
5 & 532999999990\end{array}$}} & TRN & & \\
\hline CHEMBL1329465 & 688653 & & & 995 & 5.513 & \\
\hline CHEMBL1489167 & 688653 & 4.783 & 5.2179 & TRN & & \\
\hline CHEMBL3189689 & 688653 & 5.38299 & 999999999 & & 5.1864 & \\
\hline CHEMBL1424928 & 688653 & 5.483 & 5.1057 & TRN & & \\
\hline CHEMBL1604446 & 688653 & 7.0329 & 5.8802 & TRN & & \\
\hline CHEMBL1545365 & 688653 & 4.883 & 5.028000 & 30000 & & \\
\hline & & & & e & & \\
\hline
\end{tabular}




\begin{tabular}{|c|c|c|c|c|c|c|}
\hline \multirow[b]{2}{*}{ CHEMBL1328595 } & \multirow[b]{2}{*}{688653} & \multicolumn{5}{|c|}{ Supplemental Table S2.txt } \\
\hline & & 5.033 & 5.2119 & TRN & & \\
\hline CHEMBL1449351 & 688653 & \multicolumn{3}{|c|}{5.332999999999999} & 5.2922 & TRN \\
\hline CHEMBL1517238 & 688653 & \multicolumn{3}{|c|}{5.132999999999999} & 5.0911 & \\
\hline CHEMBL1474599 & 688653 & 4.583 & 5.2182 & TST & & \\
\hline CHEMBL1521754 & 688653 & \multicolumn{3}{|c|}{5.2829999999999995} & 5.3455 & TST \\
\hline CHEMBL1491026 & 688653 & 5.683 & 5.5475 & TRN & & \\
\hline CHEMBL1546332 & 688653 & \multicolumn{3}{|c|}{6.382999999999999} & 5.2465 & \\
\hline CHEMBL1434318 & 688653 & 5.183 & 5.3505 & TRN & & \\
\hline CHEMBL1439976 & 688653 & 5.233 & 5.0903 & TRN & & \\
\hline CHEMBL1536204 & 688653 & 6.233 & 5.5334 & TRN & & \\
\hline CHEMBL1533776 & 688653 & 4.583 & 5.0182 & TST & & \\
\hline CHEMBL445153 & 688653 & 4.633 & 5.5312 & TRN & & \\
\hline CHEMBL1383461 & 688653 & \multicolumn{3}{|c|}{5.132999999999999} & 5.2428 & $\mathrm{~T}$ \\
\hline CHEMBL1319737 & 688653 & \multicolumn{3}{|c|}{5.882999999999999} & 5.1502 & \\
\hline CHEMBL1411784 & 688653 & 6.683 & 5.3474 & TRN & & \\
\hline CHEMBL1437157 & 688653 & 4.633 & 4.9845 & TRN & & \\
\hline CHEMBL1417917 & 688653 & \multicolumn{3}{|c|}{5.882999999999999} & 5.6926 & \\
\hline CHEMBL1547204 & 688653 & \multicolumn{3}{|c|}{5.7829999999999995} & 5.692 & \\
\hline CHEMBL1443734 & 688653 & \multicolumn{3}{|c|}{5.132999999999999} & 5.5959 & \\
\hline CHEMBL1564397 & 688653 & 5.733 & 5.2944 & TRN & & \\
\hline CHEMBL1604281 & 688653 & 4.683 & 5.4192 & TRN & & \\
\hline CHEMBL 3212698 & 688653 & 4.933 & 5.011 & TST & & \\
\hline CHEMBL 2 & 688653 & 5.233 & 5.2543 & TRN & & \\
\hline CHEMBL15 & 688653 & 6.433 & 5.5788 & TRN & & \\
\hline CHEMBL1605629 & 688653 & \multicolumn{3}{|c|}{5.7829999999999995} & 5.6873 & TRN \\
\hline CHEMBL1415253 & 688653 & \multicolumn{3}{|c|}{6.132999999999999} & 5.5935 & \\
\hline CHEMBL1503742 & 688653 & \multicolumn{3}{|c|}{5.5329999999999995} & 568 & \\
\hline CHEMBL1354660 & 688653 & \multicolumn{3}{|c|}{4.7330000000000005} & 5.2489 & \\
\hline CHEMBL1446070 & 688653 & 4.633 & 5.231 & TST & & \\
\hline CHEMBL1394077 & 688653 & 6.4829 & 5.3458 & TRN & & \\
\hline CHEMBL 3195350 & 688653 & 5.183 & 5.2741 & TRN & & \\
\hline CHEMBL14 & 688653 & 4.933 & 5.1947 & TRN & & \\
\hline CHEMBL14 & 688653 & \multicolumn{3}{|c|}{4.7330000000000005} & 4.8429 & $\mathrm{~T}$ \\
\hline CHEMBL1414717 & 688653 & 5.183 & 5.0883 & TRN & & \\
\hline CHEMBL1581528 & 688653 & \multicolumn{3}{|c|}{5.2829999999999995} & 5.0104 & \\
\hline CHEMBL2373661 & 688653 & 4.583 & 5.2542 & TST & & \\
\hline CHEMBL138 & 688653 & 5.483 & 5.1004 & TRN & & \\
\hline CHEMBL1480761 & 688653 & 6.8831 & 5.6786 & TRN & & \\
\hline CHEMBL3208114 & 688653 & 5.733 & 5.4637 & TRN & & \\
\hline CHEMBL1327779 & 688653 & 4.783 & 4.9306 & TRN & & \\
\hline CHEMBL1317531 & 688653 & 5.033 & 5.1091 & TST & & \\
\hline CHEMBL1404994 & 688653 & \multicolumn{3}{|c|}{4.9830000000000005} & 5.3902 & Tा \\
\hline CHEMBL1592927 & 688653 & \multicolumn{3}{|c|}{5.582999999999999} & 5.4177 & \\
\hline CHEMBL1529656 & 688653 & 6.8831 & 5.855 & TRN & & \\
\hline CHEMBL1537340 & 688653 & \multicolumn{3}{|c|}{4.7330000000000005} & 4.8958 & 13 \\
\hline CHEMBL1482712 & 688653 & 4.683 & 5.1103 & TST & & \\
\hline CHEMBL1358225 & 688653 & 6.6329 & 99999999 & & 5.7533 & \\
\hline CHEMBL1383700 & 688653 & 5.6329 & 99999999 & & 5.3644 & \\
\hline
\end{tabular}




\begin{tabular}{|c|c|c|c|c|c|c|}
\hline \multirow{3}{*}{$\begin{array}{l}\text { CHEMBL1392344 } \\
\text { CHEMBL1388684 }\end{array}$} & & \multicolumn{5}{|c|}{ Supplemental Table S2.txt } \\
\hline & 688653 & \multicolumn{3}{|c|}{5.7829999999999995} & 5.7574 & TRN \\
\hline & 688653 & 5.733 & 4.8101 & TRN & & \\
\hline CHEMBL1303184 & 688653 & \multicolumn{3}{|c|}{5.5329999999999995} & 5.2818 & TRN \\
\hline CHEMBL1314431 & 688653 & 4.683 & 4.9189 & TRN & & \\
\hline CHEMBL1607139 & 688653 & \multicolumn{3}{|c|}{5.382999999999999} & 5.4395 & TST \\
\hline CHEMBL1500117 & 688653 & 4.833 & 5.5689 & TRN & & \\
\hline CHEMBL1485333 & 688653 & \multicolumn{3}{|c|}{4.7330000000000005} & 5.0512 & TRN \\
\hline CHEMBL1560671 & 688653 & 6.7331 & 5.3312 & TST & & \\
\hline CHEMBL1412875 & 688653 & \multicolumn{3}{|c|}{5.132999999999999} & 5.2631 & TRN \\
\hline CHEMBL1489744 & 688653 & \multicolumn{3}{|c|}{6.382999999999999} & 5.4596 & TRN \\
\hline CHEMBL1578372 & 688653 & 5.983 & 5.6464 & TRN & & \\
\hline CHEMBL1608952 & 688653 & \multicolumn{3}{|c|}{6.382999999999999} & 5.822 & TRN \\
\hline CHEMBL1466087 & 688653 & \multicolumn{3}{|c|}{6.832999999999999} & 5.9749 & TRN \\
\hline CHEMBL3193741 & 688653 & 5.233 & 5.1543 & TRN & & \\
\hline CHEMBL1497078 & 688653 & 4.783 & 4.6539 & TRN & & \\
\hline CHEMBL1367463 & 688653 & \multicolumn{3}{|c|}{5.332999999999999} & 5.1967 & TRN \\
\hline CHEMBL 3212230 & 688653 & 5.183 & 5.1672 & TRN & & \\
\hline CHEMBL1511861 & 688653 & \multirow{2}{*}{\multicolumn{3}{|c|}{$\begin{array}{l}4.183 \quad 5.2184 \text { IRIN } \\
5.332999999999999\end{array}$}} & & \\
\hline CHEMBL1566311 & 688653 & & & & 5.654 & TRN \\
\hline CHEMBL1471351 & 688653 & 4.633 & 4.7861 & TRN & & \\
\hline CHEMBL1334922 & 688653 & \multicolumn{3}{|c|}{4.9830000000000005} & 4.9216 & TRN \\
\hline CHEMBL1533576 & 688653 & 4.783 & 5.5344 & TST & & \\
\hline CHEMBL1541490 & 688653 & \multicolumn{3}{|c|}{5.382999999999999} & 5.7004 & TST \\
\hline CHEMBL1498636 & 688653 & 5.733 & 5.7403 & TRN & & \\
\hline CHEMBL1609306 & 688653 & 5.183 & 5.1104 & TRN & & \\
\hline CHEMBL1426015 & 688653 & 4.683 & 5.48 & TRN & & \\
\hline CHEMBL1372880 & 688653 & 5.233 & 5.2258 & TST & & \\
\hline CHEMBL1530557 & 688653 & 4.933 & 4.6329 & TRN & & \\
\hline CHEMBL3207597 & 688653 & \multicolumn{3}{|c|}{5.2829999999999995} & 5.3636 & TRN \\
\hline CHEMBL3212843 & 688653 & 5.183 & 5.1569 & TRN & & \\
\hline CHEMBL1308027 & 688653 & 6.983 & 5.9801 & TRN & & \\
\hline CHEMBL3199236 & 688653 & 4.783 & 5.2698 & TRN & & \\
\hline CHEMBL1345587 & 688653 & 4.833 & 5.0794 & TRN & & \\
\hline CHEMBL1347011 & 688653 & 6.433 & 5.894 & TRN & & \\
\hline CHEMBL1590894 & 688653 & 4.783 & 5.2091 & TRN & & \\
\hline CHEMBL1470015 & 688653 & 5.183 & 5.5399 & TRN & & \\
\hline CHEMBL1324560 & 688653 & 5.183 & 5.7464 & TRN & & \\
\hline CHEMBL1309243 & 688653 & \multicolumn{3}{|c|}{5.7829999999999995} & 5.2993 & TRN \\
\hline CHEMBL1421287 & 688653 & \multicolumn{3}{|c|}{6.832999999999999} & 5.8205 & TRN \\
\hline CHEMBL1579839 & 688653 & 4.633 & 5.4971 & TRN & & \\
\hline CHEMBL1320794 & 688653 & 5.033 & 6.2931 & TRN & & \\
\hline CHEMBL1423442 & 688653 & 4.783 & 5.0634 & TST & & \\
\hline CHEMBL1609199 & 688653 & 5.933 & 5.5929 & TRN & & \\
\hline CHEMBL1520432 & 688653 & 5.083 & 4.9407 & TRN & & \\
\hline CHEMBL1452610 & 688653 & 4.583 & 4.7715 & TRN & & \\
\hline CHEMBL1347392 & 688653 & 5.933 & 5.54899 & 9999 & 995 & TRN \\
\hline CHEMBL1504679 & 688653 & 5.683 & 5.587006 & 2000 & 01 & TRN \\
\hline \multirow[t]{2}{*}{ CHEMBL1489591 } & 688653 & 5.183 & 5.4045 & TRN & & \\
\hline & & \multicolumn{4}{|c|}{ Page 2408} & \\
\hline
\end{tabular}




\begin{tabular}{|c|c|c|c|c|c|c|c|}
\hline \multicolumn{8}{|c|}{ Supplemental Table S2.txt } \\
\hline CHEMBL1452643 & 688653 & 4.783 & 5.0193 & TRN & & & \\
\hline CHEMBL1375473 & 688653 & 6.183 & 5.856 & TRN & & & \\
\hline CHEMBL576317 & 688653 & 5.183 & 5.2223 & TRN & & & \\
\hline CHEMBL1426681 & 688653 & 5.683 & 5.5522 & TRN & & & \\
\hline CHEMBL1390804 & 688653 & 4.783 & 5.1775 & TST & & & \\
\hline CHEMBL1512405 & 688653 & 5.183 & 5.3314 & TRN & & & \\
\hline CHEMBL1342790 & 688653 & 4.683 & 5.2927 & TRN & & & \\
\hline CHEMBL1337036 & 688653 & \multicolumn{3}{|c|}{5.382999999999999} & 4.8846 & TRN & \\
\hline CHEMBL1537713 & 688653 & 4.783 & 4.9306 & TRN & & & \\
\hline CHEMBL1598379 & 688653 & \multicolumn{3}{|c|}{5.2829999999999995} & 5.0488 & TRN & \\
\hline CHEMBL 3190834 & 688653 & \multicolumn{3}{|c|}{5.832999999999999} & 5.4337 & TST & \\
\hline CHEMBL1463885 & 688653 & 4.883 & 4.9112 & TRN & & & \\
\hline CHEMBL1548385 & 688653 & 5.683 & 5.1351 & TST & & & \\
\hline CHEMBL1303829 & 688653 & 4.833 & 5.1561 & TRN & & & \\
\hline CHEMBL1575832 & 688653 & 4.833 & 5.2907 & TRN & & & \\
\hline CHEMBL1501480 & 688653 & \multicolumn{3}{|c|}{6.632999999999999} & 5.8487 & TRN & \\
\hline CHEMBL1301119 & 688653 & 4.783 & 4.8124 & TST & & & \\
\hline CHEMBL1302966 & 688653 & 4.783 & 5.2369 & TST & & & \\
\hline CHEMBL1399459 & 688653 & 5.683 & 4.9732 & TRN & & & \\
\hline CHEMBL1346991 & 688653 & 4.783 & 5.3992 & TST & & & \\
\hline CHEMBL1314949 & 688653 & \multicolumn{3}{|c|}{4.9830000000000005} & \multicolumn{2}{|c|}{5.0889999999999995} & TRN \\
\hline CHEMBL1493661 & 688653 & 4.633 & 5.3005 & TST & & & \\
\hline CHEMBL1307777 & 688653 & 4.833 & 5.3717 & TRN & & & \\
\hline CHEMBL1511024 & 688653 & \multicolumn{3}{|c|}{5.882999999999999} & 5.504 & TRN & \\
\hline CHEMBL1982304 & 688653 & 4.883 & 5.5868 & TRN & & & \\
\hline CHEMBL3194292 & 688653 & 4.783 & 5.3496 & TRN & & & \\
\hline CHEMBL1351120 & 688653 & \multicolumn{3}{|c|}{4.7330000000000005} & 5.1701 & TRN & \\
\hline CHEMBL17201 & 688653 & 4.683 & 5.3847 & TRN & & & \\
\hline CHEMBL1438609 & 688653 & \multicolumn{3}{|c|}{4.9830000000000005} & 5.044 & TRN & \\
\hline CHEMBL1351441 & 688653 & 4.933 & 5.4466 & TST & & & \\
\hline CHEMBL1307163 & 688653 & \multicolumn{3}{|c|}{5.132999999999999} & 5.3029 & TST & \\
\hline CHEMBL1356127 & 688653 & 5.083 & 5.6234 & TRN & & & \\
\hline CHEMBL1393351 & 688653 & \multirow{2}{*}{\multicolumn{3}{|c|}{ 5.5329999999999995 }} & & & \\
\hline CHEMBL1559788 & 688653 & & & & 5.7354 & TRN & \\
\hline CHEMBL1350929 & 688653 & 5.733 & 6.2951 & TRN & & & \\
\hline CHEMBL1386791 & 688653 & 4.833 & 5.0111 & TST & & & \\
\hline CHEMBL1439686 & 688653 & 4.883 & 5.3994 & TRN & & & \\
\hline CHEMBL3193863 & 688653 & 5.433 & 5.7386 & TST & & & \\
\hline CHEMBL 3210321 & 688653 & \multicolumn{3}{|c|}{6.132999999999999} & \multicolumn{2}{|c|}{5.553999999999999} & TRN \\
\hline CHEMBL1366235 & 688653 & 4.933 & 4.6483 & TST & & & \\
\hline CHEMBL1390720 & 688653 & \multicolumn{3}{|c|}{4.7330000000000005} & 4.8961 & TST & \\
\hline CHEMBL1613147 & 688653 & 6.183 & 6.0276 & TRN & & & \\
\hline CHEMBL1349495 & 688653 & 4.883 & 4.8704 & TRN & & & \\
\hline CHEMBL3209756 & 688653 & 5.033 & 5.2852 & TST & & & \\
\hline CHEMBL1606351 & 688653 & \multicolumn{3}{|c|}{6.332999999999999} & 5.5365 & TRN & \\
\hline CHEMBL1417372 & 688653 & \multicolumn{3}{|c|}{4.7330000000000005} & 5.0897 & TRN & \\
\hline CHEMBL 1557640 & 688653 & 4.633 & 5.0306 & TRN & & & \\
\hline CHEMBL1480809 & 688653 & 5.2829 & 99999999 & 995 & 5.4537 & TRN & \\
\hline
\end{tabular}




\begin{tabular}{|c|c|c|c|c|c|c|}
\hline & & \multicolumn{5}{|c|}{ Supplemental Table S2.txt } \\
\hline CHEMBL1489005 & 688653 & 4.833 & 5.3946 & TRN & & \\
\hline CHEMBL1481085 & 688653 & 4.633 & 4.4747 & TRN & & \\
\hline CHEMBL1489702 & 688653 & 5.8329 & 999999999 & & 5.3029 & TRN \\
\hline CHEMBL1423390 & 688653 & 4.583 & 4.8202 & TST & & \\
\hline CHEMBL1454450 & 688653 & 4.9830 & 000000006 & 005 & 5.1975 & TRN \\
\hline CHEMBL1479977 & 688653 & 4.7330 & 000000006 & 005 & 5.0822 & \\
\hline CHEMBL1563190 & 688653 & 4.583 & 5.0158 & TRN & & \\
\hline CHEMBL1503136 & 688653 & 4.883 & 4.9679 & TRN & & \\
\hline CHEMBL1332698 & 688653 & 4.683 & 5.1855 & TST & & \\
\hline CHEMBL1461193 & 688653 & 5.183 & 5.6209 & TRN & & \\
\hline CHEMBL1497634 & 688653 & 5.733 & 5.4006 & TRN & & \\
\hline CHEMBL1601207 & 688653 & 5.433 & 5.4227 & TRN & & \\
\hline CHEMBL1441122 & 688653 & 5.6329 & 999999999 & & 5.0972 & \\
\hline CHEMBL1992918 & 688653 & 5.2829 & 999999999 & 995 & 5.3976 & \\
\hline CHEMBL1518426 & 688653 & 4.883 & 5.6988 & TST & & \\
\hline CHEMBL1333254 & 688653 & 6.1329 & 999999999 & & 5.8225 & \\
\hline CHEMBL69612 & 688653 & 4.9830 & 000000000 & 005 & 5.0685 & \\
\hline CHEMBL1515852 & 688653 & 4.9830 & 00000000 & 005 & 4.8829 & \\
\hline CHEMBL1559808 & 688653 & 5.7829 & 999999999 & 995 & 5.3866 & \\
\hline CHEMBL1543735 & 688653 & 5.233 & 5.2242 & TST & & \\
\hline CHEMBL1531962 & 688653 & 4.883 & 5.5548 & TRN & & \\
\hline CHEMBL1349881 & 688653 & 5.233 & 5.2834 & TRN & & \\
\hline CHEMBL1306558 & 688653 & 5.433 & 5.1929 & TRN & & \\
\hline CHEMBL1571570 & 688653 & 5.683 & 5.5606 & TST & & \\
\hline CHEMBL1584761 & 688653 & 6.5829 & 999999999 & & 5.8051 & \\
\hline CHEMBL1601966 & 688653 & 5.8829 & 999999999 & & 5.3764 & \\
\hline CHEMBL1518626 & 688653 & 5.733 & 5.6294 & TRN & & \\
\hline CHEMBL1388416 & 688653 & 5.3829 & 999999999 & & 5.1457 & \\
\hline CHEMBL1352417 & 688653 & 6.233 & 5.7547 & TRN & & \\
\hline CHEMBL1578805 & 688653 & 5.183 & 4.9028 & TRN & & \\
\hline CHEMBL1367246 & 688653 & 6.233 & 5.7336 & TRN & & \\
\hline CHEMBL1584676 & 688653 & 4.883 & 5.1248 & TST & & \\
\hline CHEMBL 2005486 & 688653 & 4.833 & 5.5121 & TST & & \\
\hline CHEMBL1551391 & 688653 & 6.8329 & 999999999 & & 5.9171 & \\
\hline CHEMBL1445486 & 688653 & 6.9329 & 5.8727 & TRN & & \\
\hline CHEMBL 3192023 & 688653 & 5.5329 & 999999999 & 995 & 5.3204 & \\
\hline CHEMBL54837 & 688653 & 4.933 & 5.0469 & TRN & & \\
\hline CHEMBL1453788 & 688653 & 4.783 & 5.2259 & TRN & & \\
\hline CHEMBL1490005 & 688653 & 5.6329 & 999999999 & & 5.3976 & TRN \\
\hline CHEMBL1532452 & 688653 & 4.783 & 5.0819 & TST & & \\
\hline CHEMBL 3195006 & 688653 & 5.483 & 5.4924 & TRN & & \\
\hline CHEMBL1588572 & 688653 & 5.433 & 5.7899 & TRN & & \\
\hline CHEMBL 2369193 & 688653 & 5.933 & 5.5314 & TRN & & \\
\hline CHEMBL1353454 & 688653 & 5.733 & 5.5038 & TRN & & \\
\hline CHEMBL 3193443 & 688653 & 5.683 & 5.1892 & TRN & & \\
\hline CHEMBL1439730 & 688653 & 6.433 & 5.4982 & TRN & & \\
\hline CHEMBL1548889 & 688653 & 4.7330 & 000000000 & 205 & 5.5846 & $\mathrm{~m}$ \\
\hline CHEMBL1386766 & 688653 & 4.933 & 4.9229 & TRN & & \\
\hline
\end{tabular}




\begin{tabular}{|c|c|c|c|c|c|c|c|}
\hline \multicolumn{8}{|c|}{ 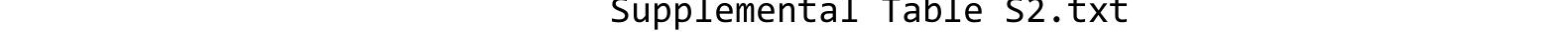 } \\
\hline CHEMBL3197612 & 688653 & 4.783 & 5.2563 & TRN & & & \\
\hline CHEMBL1322179 & 688653 & 5.983 & 5.1048 & TRN & & & \\
\hline CHEMBL1541261 & 688653 & 4.783 & 5.1061 & TRN & & & \\
\hline CHEMBL1450107 & 688653 & 5.733 & 5.4283 & TST & & & \\
\hline CHEMBL1435221 & 688653 & 6.8831 & 5.9298 & TRN & & & \\
\hline CHEMBL1558030 & 688653 & 5.53299 & 999999999 & 995 & 5.5123 & TRN & \\
\hline CHEMBL1495321 & 688653 & 4.933 & 5.0797 & TRN & & & \\
\hline CHEMBL1518491 & 688653 & 5.78299 & 999999999 & 995 & 5.3261 & TRN & \\
\hline CHEMBL1601128 & 688653 & 5.183 & 5.5222 & TRN & & & \\
\hline CHEMBL1370834 & 688653 & 5.183 & 5.7087 & TRN & & & \\
\hline CHEMBL1376254 & 688653 & 5.28299 & 999999999 & 995 & 5.5237 & TST & \\
\hline CHEMBL1580628 & 688653 & 4.883 & 5.6838 & TRN & & & \\
\hline CHEMBL1311826 & 688653 & 5.38299 & 999999999 & & 5.8929 & TRN & \\
\hline CHEMBL1596624 & 688653 & 5.183 & 5.3946 & TRN & & & \\
\hline CHEMBL1468793 & 688653 & 5.13299 & 999999999 & & 5.8314 & TST & \\
\hline CHEMBL1441118 & 688653 & 4.933 & 5.4703 & TRN & & & \\
\hline CHEMBL1386612 & 688653 & 4.73300 & 000000000 & 005 & 4.9566 & TRN & \\
\hline CHEMBL1514951 & 688653 & 6.683 & 6.2062 & TRN & & & \\
\hline CHEMBL1457006 & 688653 & 4.833 & 5.4441 & TRN & & & \\
\hline CHEMBL1299741 & 688653 & 4.833 & 5.3682 & TST & & & \\
\hline CHEMBL1381333 & 688653 & 4.633 & 5.0876 & TST & & & \\
\hline CHEMBL1525839 & 688653 & 4.683 & 5.382999 & 99999 & 99 & TST & \\
\hline CHEMBL 1343176 & 688653 & 5.38299 & 999999999 & & 5.3677 & TST & \\
\hline CHEMBL1452521 & 688653 & 5.83299 & 999999999 & & 5.7837 & TRN & \\
\hline CHEMBL1453229 & 688653 & 5.83299 & 999999999 & & 5.5632 & TRN & \\
\hline CHEMBL1335126 & 688653 & 5.53299 & 999999999 & 995 & 5.0803 & TRN & \\
\hline CHEMBL1342062 & 688653 & 4.783 & 4.7783 & TRN & & & \\
\hline CHEMBL1454996 & 688653 & 6.38299 & 999999999 & & 6.0370 & 0000000001 & TRN \\
\hline CHEMBL1585689 & 688653 & 4.583 & 5.0993 & TRN & & & \\
\hline CHEMBL1560235 & 688653 & 5.183 & 5.4924 & TRN & & & \\
\hline CHEMBL1443180 & 688653 & 4.833 & 4.9725 & TRN & & & \\
\hline CHEMBL589507 & 688653 & 5.53299 & 999999999 & 995 & 5.5815 & TRN & \\
\hline CHEMBL1603029 & 688653 & 4.783 & 4.8033 & TST & & & \\
\hline CHEMBL1606602 & 688653 & 5.78299 & 999999999 & 995 & 5.2428 & TST & \\
\hline CHEMBL1898908 & 688653 & 4.783 & 5.5708 & TST & & & \\
\hline CHEMBL1567271 & 688653 & 4.783 & 5.3646 & TST & & & \\
\hline CHEMBL1574298 & 688653 & 5.83299 & 999999999 & & 5.6041 & TRN & \\
\hline CHEMBL1360295 & 688653 & 7.1331 & 5.9064 & TRN & & & \\
\hline CHEMBL1449231 & 688653 & 4.883 & 5.1648 & TRN & & & \\
\hline CHEMBL1329938 & 688653 & 5.13299 & 999999999 & & 4.6476 & TST & \\
\hline CHEMBL1384746 & 688653 & 5.483 & 5.0592 & TRN & & & \\
\hline CHEMBL1303428 & 688653 & 4.783 & 5.2056 & TST & & & \\
\hline CHEMBL 1380537 & 688653 & 5.683 & 5.2498 & TRN & & & \\
\hline CHEMBL1494713 & 688653 & 4.833 & 4.8036 & TRN & & & \\
\hline CHEMBL1455190 & 688653 & 5.13299 & 999999999 & & 5.2722 & TRN & \\
\hline CHEMBL3198494 & 688653 & 4.833 & 5.4333 & TRN & & & \\
\hline CHEMBL1421477 & 688653 & 5.083 & 5.1312 & TRN & & & \\
\hline CHEMBL1310399 & 688653 & 4.73300 & 000000000 & 205 & 5.0674 & TRN & \\
\hline
\end{tabular}




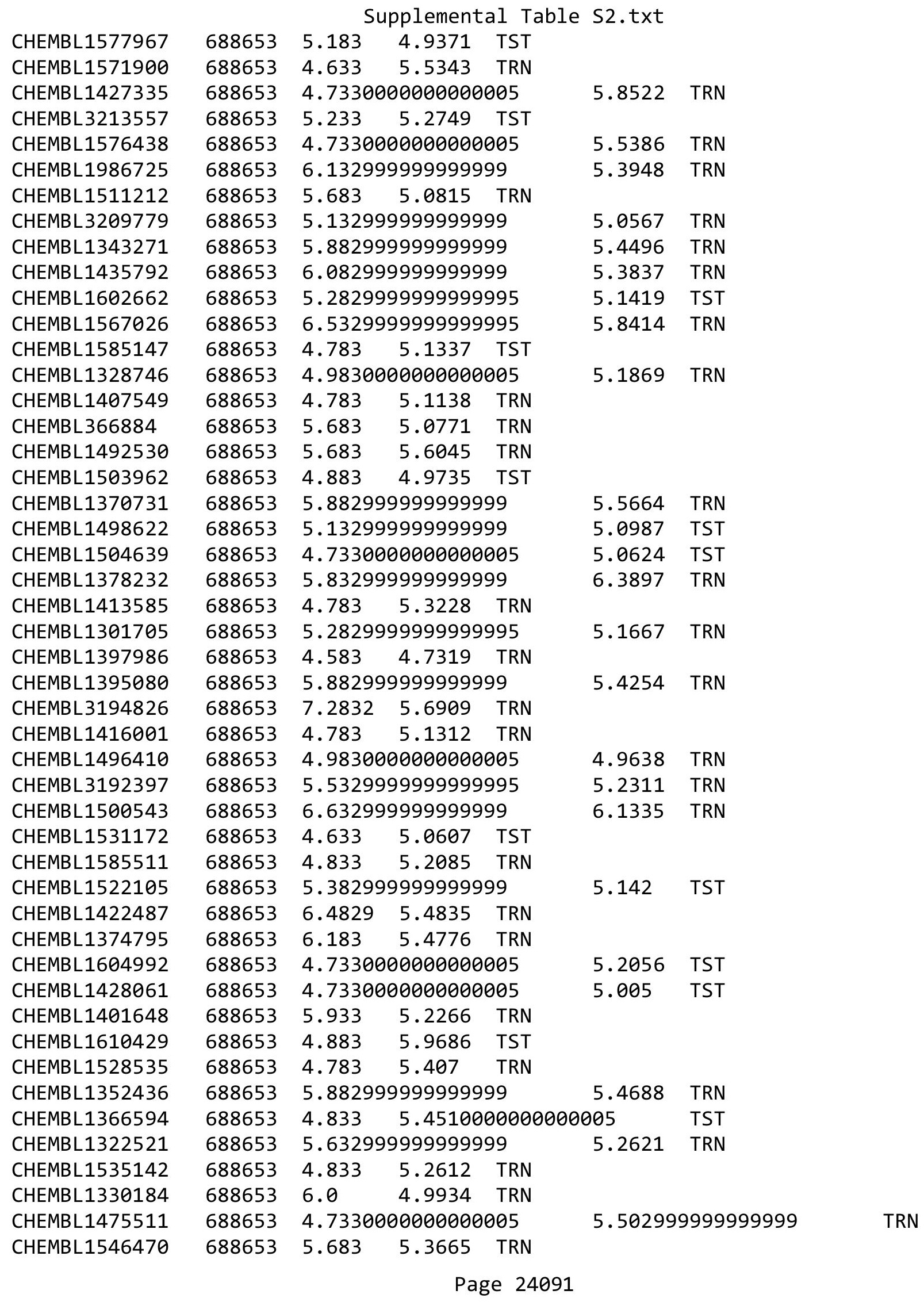




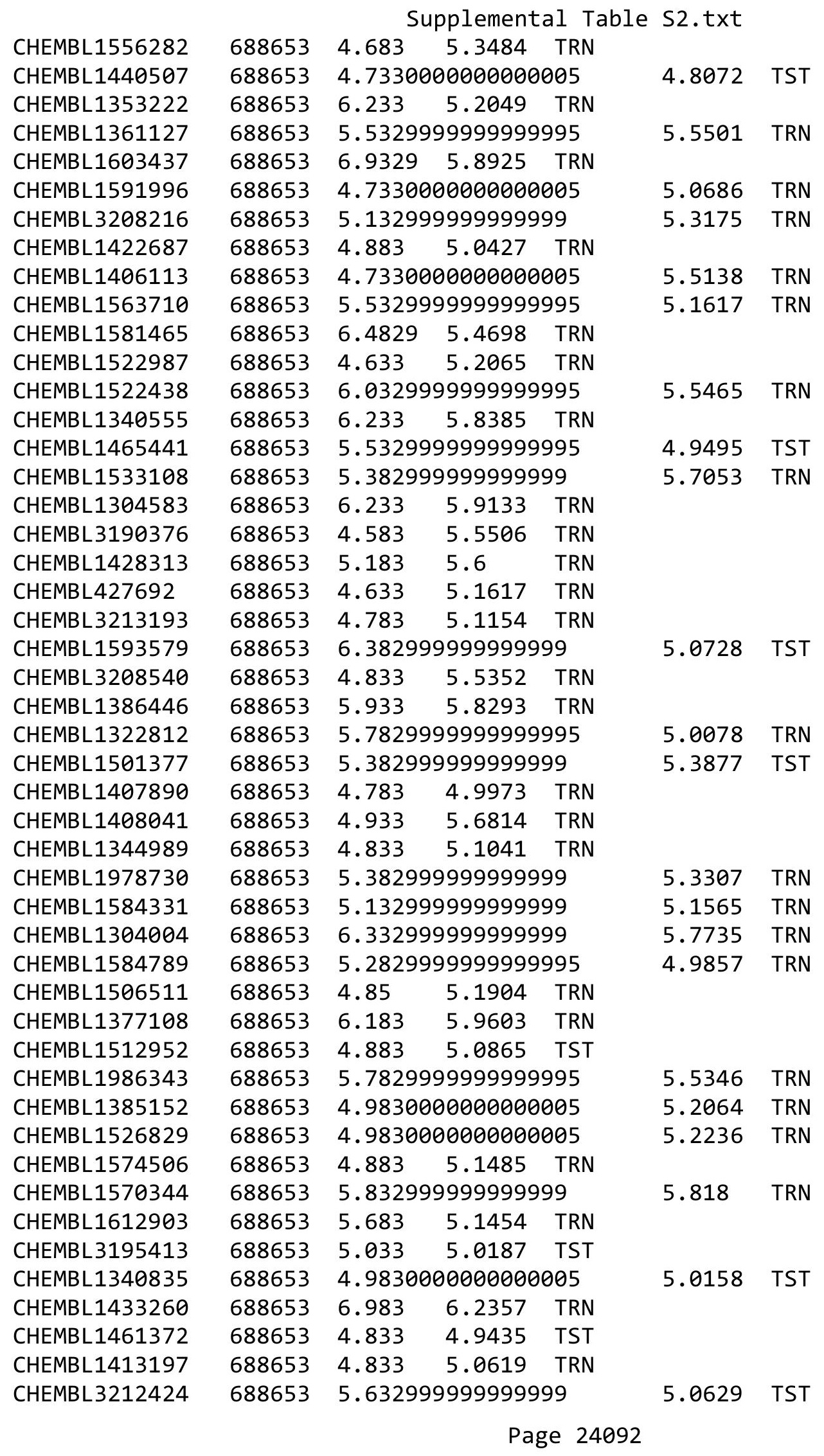




\begin{tabular}{|c|c|c|c|c|c|c|}
\hline \multirow[b]{2}{*}{ CHEMBL1581971 } & \\
\hline & 688653 & 4.783 & 5.0997 & TRN & & \\
\hline CHEMBL1429106 & 688653 & 6.983 & 5.7246 & TRN & & \\
\hline CHEMBL1303952 & 688653 & 4.783 & 4.977 & TRN & & \\
\hline CHEMBL 3214405 & 688653 & 5.733 & 5.1165 & TRN & & \\
\hline CHEMBL 3211095 & 688653 & 5.033 & 5.1017 & TST & & \\
\hline CHEMBL1597510 & 688653 & 5.483 & 4.9933 & TRN & & \\
\hline CHEMBL1487993 & 688653 & \multicolumn{3}{|c|}{4.7330000000000005} & 4.9029 & TRN \\
\hline CHEMBL1396894 & 688653 & \multicolumn{3}{|c|}{4.9830000000000005} & 4.6481 & \\
\hline CHEMBL3210106 & 688653 & 5.183 & 5.358 & TRN & & \\
\hline CHEMBL1482449 & 688653 & 5.733 & 5.8033 & TRN & & \\
\hline CHEMBL1372359 & 688653 & 5.983 & 5.8092 & TRN & & \\
\hline CHEMBL1366824 & 688653 & 5.433 & 5.3423 & TRN & & \\
\hline CHEMBL1410215 & 688653 & 6.0 & 4.7953 & TRN & & \\
\hline CHEMBL1537087 & 688653 & 5.083 & 4.8673 & TRN & & \\
\hline CHEMBL1360502 & 688653 & 5.083 & 5.4729 & TRN & & \\
\hline CHEMBL1428788 & 688653 & 5.183 & 5.1311 & TRN & & \\
\hline CHEMBL1320020 & 688653 & \multicolumn{3}{|c|}{4.7330000000000005} & 4.9605 & TST \\
\hline CHEMBL1389388 & 688653 & \multicolumn{3}{|c|}{4.7330000000000005} & 4.7826 & TST \\
\hline CHEMBL1577886 & 688653 & 4.683 & 4.9619 & TST & & \\
\hline CHEMBL1536395 & 688653 & 5.983 & 5.5788 & TRN & & \\
\hline CHEMBL1315894 & 688653 & 4.783 & 5.1627 & TRN & & \\
\hline CHEMBL1497853 & 688653 & 5.233 & 5.5118 & TRN & & \\
\hline CHEMBL1576330 & 688653 & 4.833 & 5.3192 & TRN & & \\
\hline CHEMBL1550961 & 688653 & 4.783 & 5.19 & TST & & \\
\hline CHEMBL1582785 & 688653 & 5.433 & 5.9908 & TRN & & \\
\hline CHEMBL1534204 & 688653 & 6.433 & \multicolumn{3}{|c|}{6.167999999999999} & $\mathrm{TR}$ \\
\hline CHEMBL1445389 & 688653 & 4.883 & 5.4571 & TST & & \\
\hline CHEMBL1420610 & 688653 & \multicolumn{3}{|c|}{6.2829999999999995} & 6.1561 & Thiv \\
\hline CHEMBL1365359 & 688653 & \multicolumn{3}{|c|}{5.382999999999999} & 5.4531 & $\mathrm{TR}$ \\
\hline CHEMBL1371871 & 688653 & 4.833 & 4.9283 & TST & & \\
\hline CHEMBL1446390 & 688653 & 4.883 & 5.0437 & TRN & & \\
\hline CHEMBL1371455 & 688653 & \multicolumn{3}{|c|}{5.7829999999999995} & 5.8708 & $\mathrm{TR}$ \\
\hline CHEMBL1458318 & 688653 & 5.233 & 5.2422 & TST & & \\
\hline CHEMBL1489312 & 688653 & \multicolumn{3}{|c|}{5.382999999999999} & 5.0693 & 13 \\
\hline CHEMBL1429317 & 688653 & 4.783 & 5.2285 & TST & & \\
\hline CHEMBL1493139 & 688653 & 4.633 & 4.6919 & TRN & & \\
\hline CHEMBL1391826 & 688653 & 4.883 & 4.7709 & TRN & & \\
\hline CHEMBL1574521 & 688653 & \multicolumn{3}{|c|}{5.2829999999999995} & 5.2304 & TST \\
\hline CHEMBL1381612 & 688653 & \multicolumn{3}{|c|}{4.9830000000000005} & 5.0175 & TST \\
\hline CHEMBL1452832 & 688653 & \multicolumn{3}{|c|}{6.2829999999999995} & 5.7982 & TRN \\
\hline CHEMBL1563225 & 688653 & 4.883 & 5.2586 & TST & & \\
\hline CHEMBL1531845 & 688653 & 4.833 & 5.3439 & TRN & & \\
\hline CHEMBL1412975 & 688653 & \multicolumn{3}{|c|}{5.2829999999999995} & 5.1428 & TS \\
\hline CHEMBL1526513 & 688653 & 4.883 & \multicolumn{3}{|c|}{4.861000000000001} & TR \\
\hline CHEMBL 377583 & 688653 & 6.983 & 6.2588 & TRN & & \\
\hline CHEMBL1350064 & 688653 & \multicolumn{3}{|c|}{4.7330000000000005} & 4.8174 & N \\
\hline CHEMBL1598740 & 688653 & 4.883 & 4.9492 & TST & & \\
\hline CHEMBL1495974 & 688653 & \multicolumn{3}{|c|}{4.7330000000000005} & 5.0534 & \\
\hline
\end{tabular}




\begin{tabular}{|c|c|c|c|c|c|c|c|}
\hline \multicolumn{8}{|c|}{ Supplemental Table S2.txt } \\
\hline CHEMBL1367779 & 688653 & 4.833 & 5.1984 & TST & & & \\
\hline CHEMBL1496409 & 688653 & 5.033 & 5.0997 & TRN & & & \\
\hline CHEMBL1403604 & 688653 & \multicolumn{3}{|c|}{5.382999999999999} & 5.1518 & TRN & \\
\hline CHEMBL1509227 & 688653 & 5.733 & 5.3396 & TRN & & & \\
\hline CHEMBL1449655 & 688653 & \multicolumn{3}{|c|}{5.5329999999999995} & 5.49 & TST & \\
\hline CHEMBL1988310 & 688653 & \multicolumn{3}{|c|}{7.082999999999999} & \multicolumn{2}{|c|}{5.502999999999999} & TRN \\
\hline CHEMBL1974640 & 688653 & 5.933 & 5.3339 & TRN & & & \\
\hline CHEMBL3207982 & 688653 & 4.583 & 5.4944 & TRN & & & \\
\hline CHEMBL1409219 & 688653 & 4.633 & 5.3895 & TST & & & \\
\hline CHEMBL1396869 & 688653 & 4.633 & 5.2365 & TRN & & & \\
\hline CHEMBL1319647 & 688653 & 5.183 & 5.3867 & TST & & & \\
\hline CHEMBL469424 & 688653 & 4.933 & 4.9771 & TST & & & \\
\hline CHEMBL530636 & 688653 & \multicolumn{3}{|c|}{5.7829999999999995} & 6.0701 & TRN & \\
\hline CHEMBL1564638 & 688653 & 4.933 & 5.1028 & TRN & & & \\
\hline CHEMBL1535055 & 688653 & 4.783 & 4.5256 & TRN & & & \\
\hline CHEMBL 2003172 & 688653 & 5.183 & 5.005 & TST & & & \\
\hline CHEMBL1579924 & 688653 & \multicolumn{3}{|c|}{5.332999999999999} & 5.2611 & TST & \\
\hline CHEMBL1333043 & 688653 & 4.883 & 4.6172 & TST & & & \\
\hline CHEMBL3209207 & 688653 & 4.583 & 4.9464 & TST & & & \\
\hline CHEMBL582715 & 688653 & 6.233 & 5.2344 & TRN & & & \\
\hline CHEMBL1412215 & 688653 & \multicolumn{3}{|c|}{5.5329999999999995} & 5.6466 & TRN & \\
\hline CHEMBL76144 & 688653 & \multicolumn{3}{|c|}{5.582999999999999} & 5.4274 & TRN & \\
\hline CHEMBL 3194846 & 688653 & \multicolumn{3}{|c|}{6.5329999999999995} & 6.1415 & TRN & \\
\hline CHEMBL1345392 & 688653 & \multicolumn{3}{|c|}{6.0329999999999995} & 5.7681 & TRN & \\
\hline CHEMBL1409066 & 688653 & \multicolumn{3}{|c|}{6.382999999999999} & 5.2886 & TRN & \\
\hline CHEMBL1356240 & 688653 & 5.733 & 5.5791 & TRN & & & \\
\hline CHEMBL1309006 & 688653 & \multicolumn{3}{|c|}{5.132999999999999} & 5.0293 & TRN & \\
\hline CHEMBL1964664 & 688653 & 5.433 & 5.3561 & TRN & & & \\
\hline CHEMBL609899 & 688653 & \multicolumn{3}{|c|}{4.7330000000000005} & 4.8892 & TRN & \\
\hline CHEMBL1518688 & 688653 & 4.783 & 5.4107 & TRN & & & \\
\hline CHEMBL1985680 & 688653 & 6.183 & 5.7038 & TRN & & & \\
\hline CHEMBL1318033 & 688653 & 4.583 & 4.6162 & TRN & & & \\
\hline CHEMBL1467432 & 688653 & 4.833 & 5.1464 & TRN & & & \\
\hline CHEMBL1493461 & 688653 & 5.183 & 5.2311 & TRN & & & \\
\hline CHEMBL3189883 & 688653 & \multicolumn{3}{|c|}{5.632999999999999} & 5.5042 & TRN & \\
\hline CHEMBL1505057 & 688653 & 4.633 & 5.2532 & TST & & & \\
\hline CHEMBL1455867 & 688653 & \multicolumn{3}{|c|}{5.832999999999999} & 5.4825 & TRN & \\
\hline CHEMBL1508884 & 688653 & \multicolumn{3}{|c|}{5.132999999999999} & 5.3708 & TRN & \\
\hline CHEMBL1595006 & 688653 & 4.883 & 5.2249 & TRN & & & \\
\hline CHEMBL1590210 & 688653 & \multirow{2}{*}{\multicolumn{3}{|c|}{$\begin{array}{lcc}4.783 & 5.1476 & \text { TST } \\
4.7330000000000005\end{array}$}} & & & \\
\hline CHEMBL1307057 & 688653 & & & & 5.1501 & TRN & \\
\hline CHEMBL1506606 & 688653 & 3.833 & 4.9344 & TST & & & \\
\hline CHEMBL1508616 & 688653 & 4.833 & 5.4108 & TST & & & \\
\hline CHEMBL473721 & 688653 & 7.1831 & 6.3326 & TRN & & & \\
\hline CHEMBL1567324 & 688653 & 5.33299 & 99999999 & & 5.1016 & TST & \\
\hline CHEMBL1301889 & 688653 & 6.03299 & 99999999 & 995 & 5.6273 & TRN & \\
\hline CHEMBL1528373 & 688653 & 5.683 & 5.271 & TRN & & & \\
\hline CHEMBL1320449 & 688653 & 5.33299 & 99999999 & & 5.2851 & TRN & \\
\hline
\end{tabular}




\begin{tabular}{|c|c|c|c|c|c|c|}
\hline \multirow[b]{2}{*}{ CHEMBL1497875 } & \multicolumn{6}{|c|}{ Supplemental Table S2.txt } \\
\hline & 688653 & 5.733 & 5.5229 & TRN & & \\
\hline CHEMBL1524749 & 688653 & \multicolumn{3}{|c|}{4.7330000000000005} & 5.2661 & $\mathrm{~T}$ \\
\hline CHEMBL1523019 & 688653 & \multicolumn{3}{|c|}{5.832999999999999} & 5.4389 & \\
\hline CHEMBL1518339 & 688653 & 5.233 & 5.7634 & TRN & & \\
\hline CHEMBL1407672 & 688653 & \multicolumn{3}{|c|}{6.632999999999999} & 5.4925 & TS \\
\hline CHEMBL3212216 & 688653 & \multicolumn{3}{|c|}{5.2829999999999995} & 5.171 & \\
\hline CHEMBL1587523 & 688653 & 4.783 & 5.4095 & TST & & \\
\hline CHEMBL1520607 & 688653 & \multicolumn{3}{|c|}{5.2829999999999995} & 5.3323 & \\
\hline CHEMBL1551318 & 688653 & 4.783 & 5.421 & TST & & \\
\hline CHEMBL1465435 & 688653 & 4.833 & 5.5029 & TRN & & \\
\hline CHEMBL1442136 & 688653 & 4.833 & 4.7952 & TRN & & \\
\hline CHEMBL1545241 & 688653 & \multicolumn{3}{|c|}{5.132999999999999} & 262 & \\
\hline CHEMBL142 & 688653 & 4.783 & 5.3322 & TRN & & \\
\hline CHEMBL132 & 688653 & 5.683 & 5.3976 & TRN & & \\
\hline CHEMBL19 & 588653 & 7.2328 & 5.6821 & TST & & \\
\hline CHEMBL153 & 688653 & \multicolumn{3}{|c|}{5.2829999999999995} & 71 & \\
\hline CHEMBL137 & 688653 & 4.883 & 4.7034 & TST & & \\
\hline CHEMBL1 & 688 & \multirow{2}{*}{\multicolumn{3}{|c|}{5.832999999999999}} & & \\
\hline CHEMBL1 & 688653 & & & & 5.3546 & \\
\hline CHEMBL1383238 & 688653 & 4.783 & 5.0567 & TRN & & \\
\hline CHEMBL1522344 & 688653 & \multicolumn{3}{|c|}{5.2829999999999995} & 892 & \\
\hline CHEMBL13 & 688653 & \multicolumn{3}{|c|}{6.382999999999999} & & \\
\hline CHEMBL1 & 688 & 5.033 & 4.928 & TRN & & \\
\hline CHEMBL1 & 688 & \multicolumn{3}{|c|}{5.7829999999999995} & 856 & \\
\hline CHEMBL151 & 688653 & 5.683 & 5.4886 & TRN & & \\
\hline CHEMBL13 & 6886 & 5.983 & \multicolumn{3}{|c|}{ 4.9239999999999995 } & \\
\hline CHEMBL3 & 6886 & \multicolumn{3}{|c|}{6.7829999999999995} & 553 & \\
\hline CHEMBL & 688 & \multicolumn{3}{|c|}{5.382999999999999} & & \\
\hline CHEMBL1 & 688653 & 5.733 & 5.8274 & TRN & & \\
\hline CHEMBL20e & 688653 & \multirow{2}{*}{\multicolumn{3}{|c|}{$\begin{array}{lrr}4.933 & 5.2743 & \text { TST } \\
5.5329999999999995\end{array}$}} & & \\
\hline CHEMBL142 & 688653 & & & & כצכש.כ & \\
\hline CHEI & $6 \varepsilon$ & \multicolumn{3}{|c|}{$\begin{array}{lcc}5.5329999999999995 \\
5.433 & 4.8441 & \text { TRN }\end{array}$} & & \\
\hline CHEMBL: & $68 \varepsilon$ & & & TST & & \\
\hline CHEMBL1542791 & 688653 & \multicolumn{3}{|c|}{5.7829999999999995} & 5.7204 & \\
\hline CHEMBL1594960 & 688653 & 5.433 & 5.1249 & TRN & & \\
\hline CHEMBL1543831 & 688653 & \multicolumn{3}{|c|}{4.9830000000000005} & 5.1566 & \\
\hline CHEMBL: & $6 \varepsilon$ & 4.633 & 4.6342 & TST & & \\
\hline CHEMBL 1 & $68 \varepsilon$ & \multirow{2}{*}{\multicolumn{3}{|c|}{$\begin{array}{lcc}4.583 & 4.9599 & \text { TRN } \\
5.5329999999999995\end{array}$}} & & \\
\hline CHEMBL1518543 & 688653 & & & & 4.7135 & \\
\hline CHEMBL1982107 & 688653 & 4.783 & 4.9991 & TRN & & \\
\hline CHEMBL134 & 688653 & 5.28299 & 99999999 & 995 & & \\
\hline CHEMBL1307371 & 688653 & 5.33299 & 99999999 & & 5.4356 & \\
\hline CHEMBL1516470 & 688653 & 4.833 & 5.0589 & TST & & \\
\hline CHEMBL3212304 & 688653 & 5.53299 & 99999999 & 995 & 5.6357 & \\
\hline CHEMBL1350429 & 688653 & 5.733 & 4.9246 & TST & & \\
\hline CHEMBL1587531 & 688653 & 4.833 & 5.4289 & TRN & & \\
\hline CHEMBL3212610 & 688653 & 4.883 & 5.32100 & 0000 & & \\
\hline CHEMBL1563211 & 688653 & 6.08299 & 99999999 & & 5.914 & \\
\hline
\end{tabular}




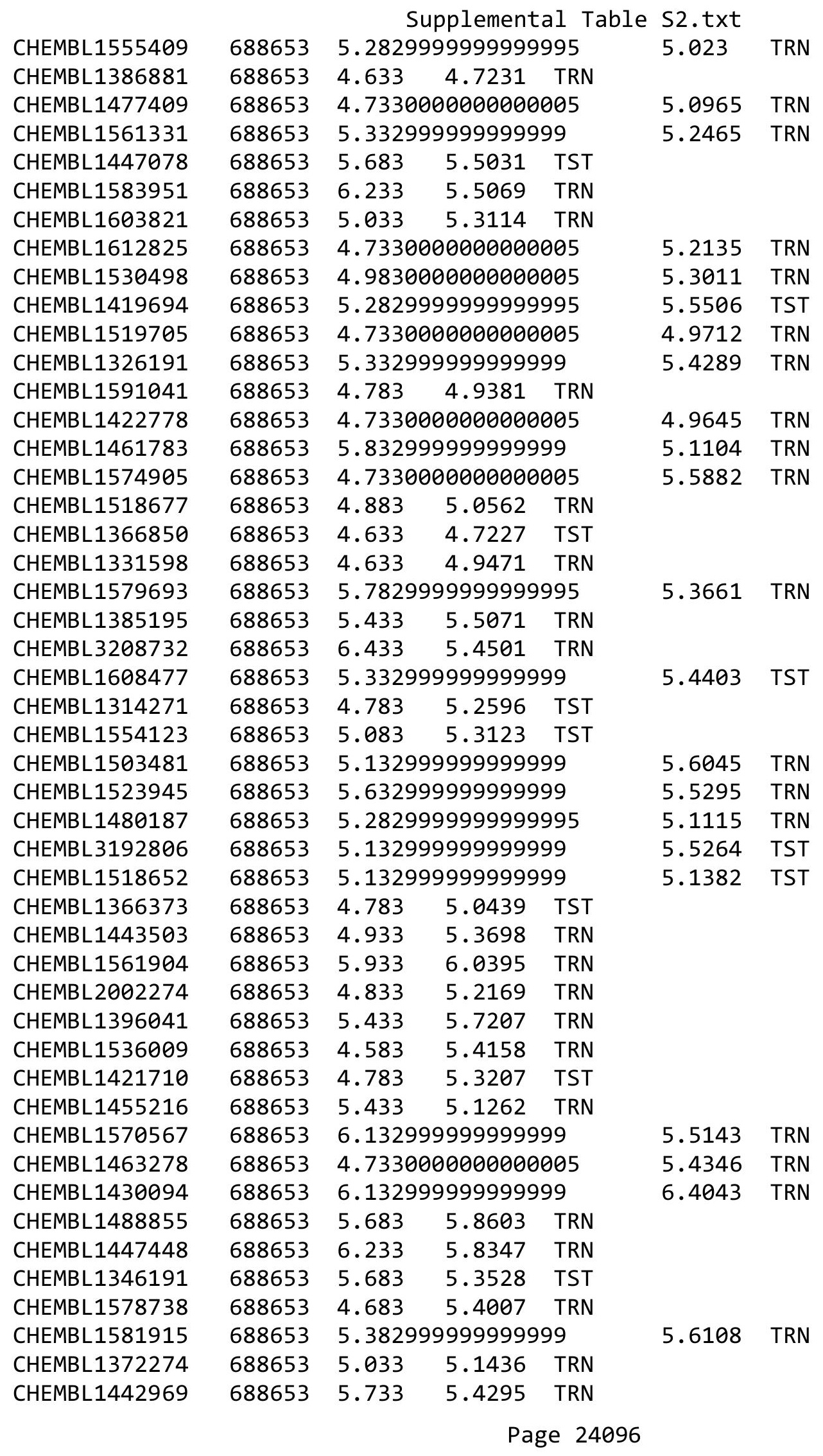




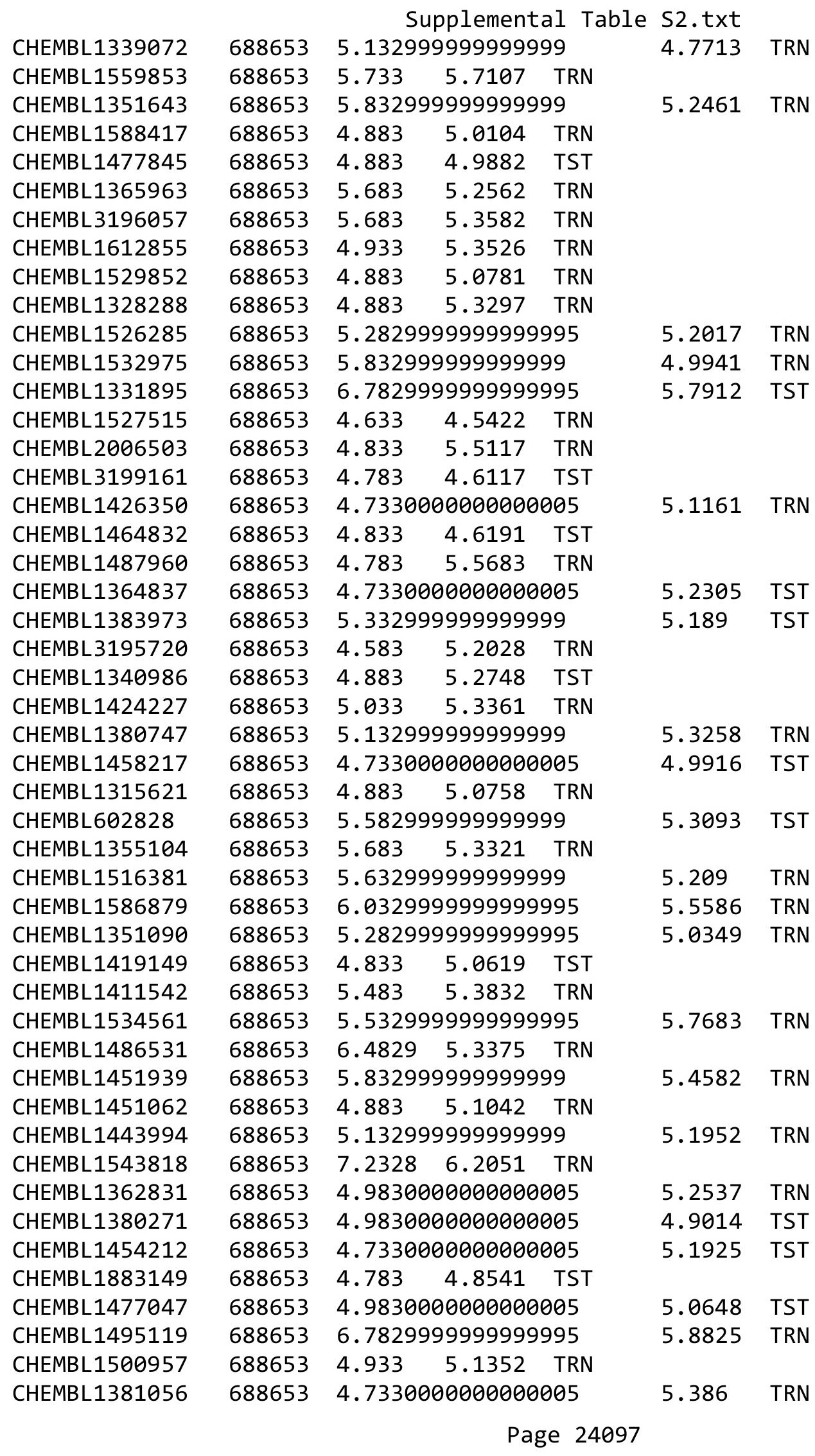




\begin{tabular}{|c|c|c|c|c|c|c|c|}
\hline \multicolumn{7}{|c|}{ Supplemental Table S2.txt } & \\
\hline CHEMBL 3197143 & 688653 & \multicolumn{3}{|c|}{5.132999999999999} & 5.7584 & TRN & \\
\hline CHEMBL1571963 & 688653 & \multicolumn{3}{|c|}{4.9830000000000005} & 5.1132 & TST & \\
\hline CHEMBL1506816 & 688653 & 4.783 & 5.0891 & TRN & & & \\
\hline CHEMBL1370883 & 688653 & \multicolumn{3}{|c|}{5.382999999999999} & 5.3963 & TRN & \\
\hline CHEMBL1432072 & 688653 & \multicolumn{3}{|c|}{5.2829999999999995} & 4.9907 & TRN & \\
\hline CHEMBL1420526 & 688653 & 4.833 & 5.4658 & TRN & & & \\
\hline CHEMBL1553169 & 688653 & 5.683 & 5.4118 & TRN & & & \\
\hline CHEMBL1549834 & 688653 & \multicolumn{3}{|c|}{5.132999999999999} & 4.9528 & TST & \\
\hline CHEMBL1456981 & 688653 & 5.683 & 4.9249 & TRN & & & \\
\hline CHEMBL1593522 & 688653 & 4.783 & 5.3076 & TST & & & \\
\hline CHEMBL1603017 & 688653 & \multicolumn{3}{|c|}{6.2829999999999995} & 5.1493 & TRN & \\
\hline CHEMBL3191696 & 688653 & 4.883 & 5.4214 & TRN & & & \\
\hline CHEMBL1346753 & 688653 & 5.733 & 5.4575 & TST & & & \\
\hline CHEMBL1450563 & 688653 & \multicolumn{3}{|c|}{4.7330000000000005} & 5.0628 & TRN & \\
\hline CHEMBL1609599 & 688653 & \multicolumn{3}{|c|}{5.2829999999999995} & 5.2954 & TRN & \\
\hline CHEMBL1380816 & 688653 & \multicolumn{3}{|c|}{6.382999999999999} & 5.9619 & TRN & \\
\hline CHEMBL1506627 & 688653 & 5.183 & 5.0084 & TRN & & & \\
\hline CHEMBL1381473 & 688653 & 6.433 & 5.5503 & TRN & & & \\
\hline CHEMBL1421398 & 688653 & \multicolumn{3}{|c|}{6.582999999999999} & 5.4448 & TRN & \\
\hline CHEMBL1381954 & 688653 & 5.233 & 5.2669 & TRN & & & \\
\hline CHEMBL1302425 & 688653 & \multicolumn{3}{|c|}{5.132999999999999} & 5.5044 & TST & \\
\hline CHEMBL1583176 & 688653 & \multicolumn{3}{|c|}{5.132999999999999} & 4.7386 & TRN & \\
\hline CHEMBL1542876 & 688653 & \multicolumn{3}{|c|}{6.582999999999999} & 5.0959 & TST & \\
\hline CHEMBL577662 & 688653 & \multicolumn{3}{|c|}{5.7829999999999995} & \multirow{2}{*}{\multicolumn{2}{|c|}{5.667999999999999}} & TRN \\
\hline CHEMBL1610120 & 688653 & 6.433 & 5.6117 & TRN & & & \\
\hline CHEMBL1371110 & 688653 & \multicolumn{3}{|c|}{6.132999999999999} & 5.325 & TST & \\
\hline CHEMBL1377821 & 688653 & \multicolumn{3}{|c|}{6.382999999999999} & 5.5721 & TRN & \\
\hline CHEMBL1552526 & 688653 & 4.583 & 4.8838 & TST & & & \\
\hline CHEMBL1398350 & 688653 & 6.183 & 5.4162 & TRN & & & \\
\hline CHEMBL1468360 & 688653 & \multicolumn{3}{|c|}{6.2829999999999995} & 5.6204 & TRN & \\
\hline CHEMBL1309377 & 688653 & 6.433 & 5.41799 & 999999999 & & TRN & \\
\hline CHEMBL1352868 & 688653 & \multicolumn{3}{|c|}{4.9830000000000005} & 5.32100 & 0000000001 & TRN \\
\hline CHEMBL1362589 & 688653 & 4.783 & 5.3 & TRN & & & \\
\hline CHEMBL1396361 & 688653 & \multicolumn{3}{|c|}{5.332999999999999} & 5.3901 & TST & \\
\hline CHEMBL1605300 & 688653 & 6.183 & 5.8115 & TRN & & & \\
\hline CHEMBL1511813 & 688653 & 4.833 & 5.36100 & 000000000 & & TST & \\
\hline CHEMBL1517954 & 688653 & 4.883 & 4.9905 & TRN & & & \\
\hline CHEMBL1576649 & 688653 & 5.8829 & 79999999 & & 5.6174 & TRN & \\
\hline CHEMBL203946 & 688653 & 5.033 & 5.056 & TRN & & & \\
\hline CHEMBL1574061 & 688653 & 5.1329 & 99999999 & & 5.3407 & TST & \\
\hline CHEMBL1589168 & 688653 & 4.683 & 4.8604 & TST & & & \\
\hline CHEMBL1336976 & 688653 & 5.3829 & 79999999 & & 5.2712 & TRN & \\
\hline CHEMBL1333771 & 688653 & 5.733 & 5.2927 & TRN & & & \\
\hline CHEMBL1592150 & 688653 & 4.633 & 5.1139 & TRN & & & \\
\hline CHEMBL1412396 & 688653 & 5.483 & 4.9865 & TRN & & & \\
\hline CHEMBL1312838 & 688653 & 5.683 & 5.504 & TRN & & & \\
\hline CHEMBL1378852 & 688653 & 5.433 & 5.9515 & TRN & & & \\
\hline CHEMBL1315431 & 688653 & 5.7829 & 79999999 & 995 & 5.1754 & TRN & \\
\hline
\end{tabular}




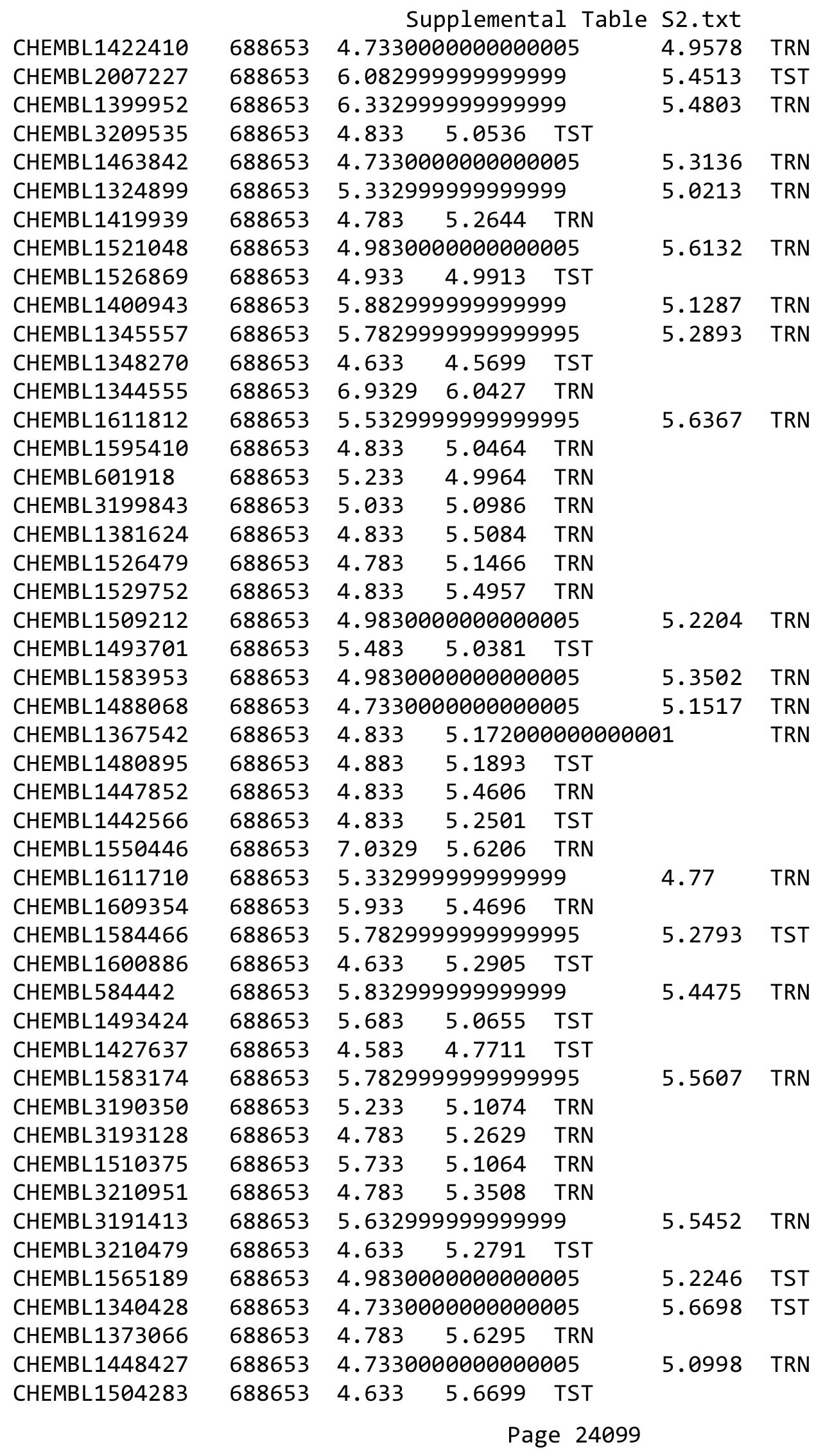




\begin{tabular}{|c|c|c|c|c|c|c|}
\hline \multirow{3}{*}{$\begin{array}{l}\text { CHEMBL1420871 } \\
\text { CHEMBL1422010 }\end{array}$} & \multirow{3}{*}{$\begin{array}{l}688653 \\
688653\end{array}$} & \multicolumn{5}{|c|}{ Supplemental Table S2.txt } \\
\hline & & \multicolumn{3}{|c|}{6.382999999999999} & 5.6832 & TRN \\
\hline & & 4.833 & 5.8068 & TRN & & \\
\hline CHEMBL3192095 & 688653 & 4.783 & 5.7626 & TRN & & \\
\hline CHEMBL1372398 & 688653 & \multicolumn{3}{|c|}{4.7330000000000005} & 4.4594 & TST \\
\hline CHEMBL1380078 & 688653 & \multicolumn{3}{|c|}{4.9830000000000005} & 5.1177 & TST \\
\hline CHEMBL3194019 & 688653 & 4.783 & 5.4076 & TST & & \\
\hline CHEMBL1368118 & 688653 & \multicolumn{3}{|c|}{5.582999999999999} & 5.5701 & TRN \\
\hline CHEMBL1497557 & 688653 & \multicolumn{3}{|c|}{6.632999999999999} & 5.369 & TRN \\
\hline CHEMBL1485168 & 688653 & 4.933 & 5.3824 & TST & & \\
\hline CHEMBL1384976 & 688653 & \multicolumn{3}{|c|}{6.0329999999999995} & 5.1836 & TRN \\
\hline CHEMBL1306900 & 688653 & 4.833 & 4.3158 & TRN & & \\
\hline CHEMBL1319537 & 688653 & 4.633 & 5.0463 & TRN & & \\
\hline CHEMBL1601073 & 688653 & 4.633 & 4.8268 & TRN & & \\
\hline CHEMBL1521694 & 688653 & 5.033 & 5.4944 & TRN & & \\
\hline CHEMBL1534638 & 688653 & \multicolumn{3}{|c|}{5.132999999999999} & 5.0559 & TRN \\
\hline CHEMBL1573167 & 688653 & 5.083 & 5.3343 & TRN & & \\
\hline CHEMBL1499980 & 688653 & \multirow{2}{*}{\multicolumn{3}{|c|}{$\begin{array}{l}4.933 \text { 3.4539 IRIN } \\
6.382999999999999\end{array}$}} & & \\
\hline CHEMBL1386804 & 688653 & & & & 5.9773 & TRN \\
\hline CHEMBL1558388 & 688653 & 5.233 & 5.8244 & TRN & & \\
\hline CHEMBL1453995 & 688653 & \multicolumn{3}{|c|}{5.132999999999999} & 5.2464 & TRN \\
\hline CHEMBL1333282 & 688653 & 6.233 & 5.88 & TRN & & \\
\hline CHEMBL1325039 & 688653 & 4.583 & 4.6597 & TRN & & \\
\hline CHEMBL1462028 & 688653 & 4.833 & 5.7194 & TRN & & \\
\hline CHEMBL1390889 & 688653 & \multicolumn{3}{|c|}{5.132999999999999} & 5.5709 & TRN \\
\hline CHEMBL1445607 & 688653 & 5.733 & 5.8327 & TRN & & \\
\hline CHEMBL1438451 & 688653 & 6.433 & 5.8325 & TRN & & \\
\hline CHEMBL3208621 & 688653 & 5.183 & 4.6854 & TRN & & \\
\hline CHEMBL1579916 & 688653 & 4.833 & 5.2621 & TST & & \\
\hline CHEMBL1507780 & 688653 & 5.233 & 5.2493 & TRN & & \\
\hline CHEMBL1509452 & 688653 & 5.933 & 5.6967 & TRN & & \\
\hline CHEMBL 3210480 & 688653 & \multicolumn{3}{|c|}{4.7330000000000005} & 5.2327 & TRN \\
\hline CHEMBL1473504 & 688653 & 4.633 & 5.1948 & TST & & \\
\hline CHEMBL1409218 & 688653 & \multicolumn{3}{|c|}{5.882999999999999} & 5.392 & TRN \\
\hline CHEMBL1508526 & 688653 & 4.6 & 4.7333 & TST & & \\
\hline CHEMBL1407731 & 688653 & 4.933 & 5.3484 & TRN & & \\
\hline CHEMBL1458435 & 688653 & \multicolumn{3}{|c|}{5.332999999999999} & 5.3568 & TRN \\
\hline CHEMBL3189265 & 688653 & 4.883 & 5.3535 & TRN & & \\
\hline CHEMBL138649 & 688653 & 5.483 & 5.4314 & TRN & & \\
\hline CHEMBL1429226 & 688653 & 4.933 & 5.1049 & TRN & & \\
\hline CHEMBL1468262 & 688653 & 4.783 & 5.6813 & TST & & \\
\hline CHEMBL1339696 & 688653 & 4.633 & 4.7333 & TST & & \\
\hline CHEMBL1490771 & 688653 & \multicolumn{3}{|c|}{5.832999999999999} & 5.3825 & TRN \\
\hline CHEMBL1551471 & 688653 & 4.783 & 5.3921 & TST & & \\
\hline CHEMBL1565328 & 688653 & \multicolumn{3}{|c|}{5.632999999999999} & 5.4468 & TRN \\
\hline CHEMBL1435457 & 688653 & & 5.1822 & TRN \\
\hline CHEMBL1497525 & 688653 & \multicolumn{3}{|c|}{$\begin{array}{l}4.7330000000000005 \\
5.183 \quad 5.366000000\end{array}$} & 005 & TRN \\
\hline CHEMBL1343279 & 688653 & 4.883 & 5.2983 & TRN & & \\
\hline CHEMBL1450720 & 688653 & \multicolumn{3}{|c|}{6.5329999999999995} & 5.6184 & TRN \\
\hline
\end{tabular}




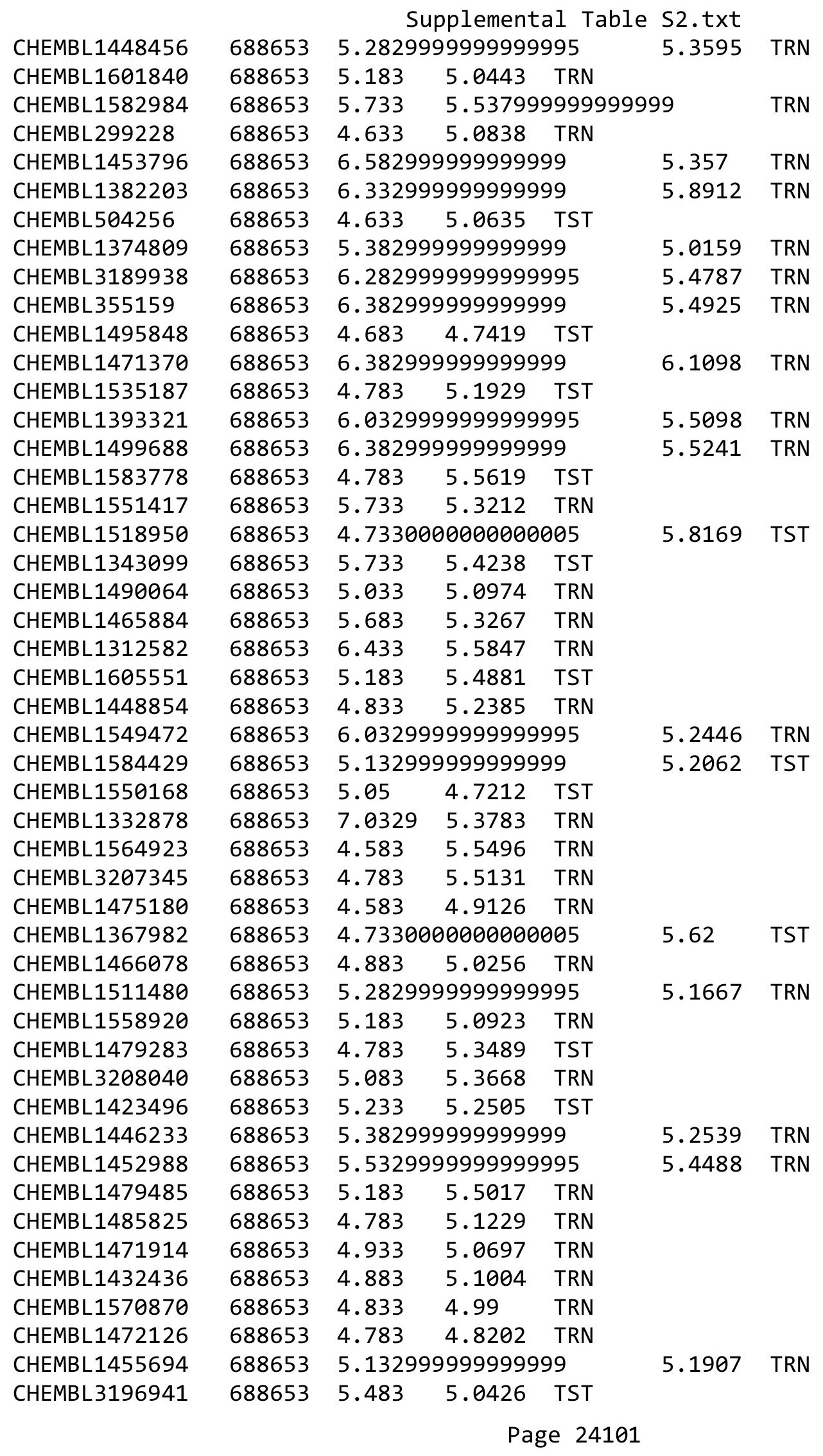




\begin{tabular}{|c|c|c|c|c|c|c|c|}
\hline \multirow[b]{2}{*}{ CHEMBL1536233 } & \multicolumn{6}{|c|}{ Supplemental Table S2.txt } & \\
\hline & 688653 & 4.933 & 5.0813 & TST & & & \\
\hline CHEMBL1341379 & 688653 & 4.783 & 5.1025 & TST & & & \\
\hline CHEMBL1530724 & 688653 & 6.6329 & 99999999 & & 6.16706 & 0000000001 & TRN \\
\hline CHEMBL1373690 & 688653 & 4.883 & 5.1169 & TRN & & & \\
\hline CHEMBL1471612 & 688653 & 4.633 & 5.035 & TRN & & & \\
\hline CHEMBL1580050 & 688653 & 5.8329 & 99999999 & & 5.3695 & TRN & \\
\hline CHEMBL1308979 & 688653 & 4.783 & 5.0526 & TRN & & & \\
\hline CHEMBL482604 & 688653 & 4.833 & 5.2313 & TRN & & & \\
\hline CHEMBL1414704 & 688653 & 4.783 & 4.7654 & TST & & & \\
\hline CHEMBL1340557 & 688653 & 4.633 & 5.2683 & TRN & & & \\
\hline CHEMBL1428452 & 688653 & 6.5829 & 99999999 & & 5.8872 & TRN & \\
\hline CHEMBL1400370 & 688653 & 5.183 & 4.8839 & TST & & & \\
\hline CHEMBL 2000945 & 688653 & 4.933 & 5.49 & TRN & & & \\
\hline CHEMBL1352266 & 688653 & 4.933 & 5.2634 & TST & & & \\
\hline CHEMBL1606927 & 688653 & 4.833 & 4.9262 & TST & & & \\
\hline CHEMBL1509299 & 688653 & 4.9830 & 00000000 & 005 & 4.8249 & TST & \\
\hline CHEMBL1511866 & 688653 & 4.683 & 4.8535 & TRN & & & \\
\hline CHEMBL1309762 & 688653 & 4.7330 & 00000000 & 005 & 5.4487 & TRN & \\
\hline CHEMBL3194612 & 688653 & 4.7330 & 20000000 & 005 & 5.521 & TST & \\
\hline CHEMBL1442861 & 688653 & 5.2829 & 99999999 & 995 & 5.6082 & TRN & \\
\hline CHEMBL1522577 & 688653 & 4.783 & 5.1873 & TRN & & & \\
\hline CHEMBL1469367 & 688653 & 5.6329 & 99999999 & & 5.0702 & TRN & \\
\hline CHEMBL1578341 & 688653 & 4.833 & 4.862 & TRN & & & \\
\hline CHEMBL1412640 & 688653 & 4.783 & 5.3009 & TRN & & & \\
\hline CHEMBL1408887 & 688653 & 4.7330 & 20000000 & 005 & 4.9836 & TST & \\
\hline CHEMBL1497081 & 688653 & 4.633 & 4.9924 & TST & & & \\
\hline CHEMBL1493162 & 688653 & 4.883 & 5.1441 & TST & & & \\
\hline CHEMBL1435594 & 688653 & 5.733 & 5.4325 & TRN & & & \\
\hline CHEMBL1433561 & 688653 & 5.8829 & 99999999 & & 5.3963 & TRN & \\
\hline CHEMBL1495607 & 688653 & 5.5829 & 99999999 & & 5.3007 & TRN & \\
\hline CHEMBL1598800 & 688653 & 5.5329 & 99999999 & 995 & 5.2976 & TST & \\
\hline CHEMBL1387835 & 688653 & 4.633 & 5.065 & TST & & & \\
\hline CHEMBL1469579 & 688653 & 4.833 & 5.6422 & TRN & & & \\
\hline CHEMBL1539240 & 688653 & 4.933 & 5.2212 & TRN & & & \\
\hline CHEMBL1552851 & 688653 & 5.483 & 5.5316 & TRN & & & \\
\hline CHEMBL3209023 & 688653 & 5.233 & 5.3256 & TRN & & & \\
\hline CHEMBL1602114 & 688653 & 4.783 & 5.0901 & TRN & & & \\
\hline CHEMBL1382268 & 688653 & 4.583 & 5.2426 & TST & & & \\
\hline CHEMBL1466726 & 688653 & 4.7330 & $\partial 0000000$ & 005 & 4.8931 & TRN & \\
\hline CHEMBL1507089 & 688653 & 4.883 & 5.5334 & TRN & & & \\
\hline CHEMBL1609800 & 688653 & 5.233 & 5.8545 & TRN & & & \\
\hline CHEMBL1333150 & 688653 & 4.783 & 4.9297 & TRN & & & \\
\hline CHEMBL1322852 & 688653 & 4.7330 & 00000000 & 005 & 5.2748 & TST & \\
\hline CHEMBL1368173 & 688653 & 4.7330 & $\partial 0000000$ & 005 & 5.027 & TRN & \\
\hline CHEMBL1521269 & 688653 & 4.933 & 5.095 & TRN & & & \\
\hline CHEMBL1476414 & 688653 & 4.583 & 5.0786 & TRN & & & \\
\hline CHEMBL1461786 & 688653 & 5.933 & 5.5349 & TRN & & & \\
\hline CHEMBL1363829 & 688653 & 5.8829 & 99999999 & & 5.4666 & TRN & \\
\hline
\end{tabular}




\begin{tabular}{|c|c|c|c|c|c|c|}
\hline \multirow{3}{*}{$\begin{array}{l}\text { CHEMBL } 3197109 \\
\text { CHEMBL1587473 }\end{array}$} & & \multicolumn{5}{|c|}{ Supplemental Table S2.txt } \\
\hline & 688653 & \multicolumn{3}{|c|}{5.2829999999999995} & \multirow[t]{3}{*}{6.1042} & \multirow[t]{2}{*}{ TRA } \\
\hline & 688653 & 4.633 & 4.8766 & TST & & \\
\hline CHEMBL1508783 & 688653 & 4.783 & 5.3097 & TST & & \\
\hline CHEMBL 3191734 & 688653 & \multicolumn{3}{|c|}{6.132999999999999} & 5.3499 & TRN \\
\hline CHEMBL 3145313 & 688653 & \multicolumn{3}{|c|}{4.7330000000000005} & 5.0784 & \\
\hline CHEMBL1590049 & 688653 & 6.4829 & 5.6372 & TRN & & \\
\hline CHEMBL1305154 & 688653 & 5.183 & 5.0446 & TRN & & \\
\hline CHEMBL3214518 & 688653 & 4.833 & 5.7425 & TST & & \\
\hline CHEMBL1359915 & 688653 & 5.933 & 5.9256 & TRN & & \\
\hline CHEMBL1419535 & 688653 & 4.683 & 5.5703 & TRN & & \\
\hline CHEMBL3193139 & 688653 & 4.783 & 5.371 & TRN & & \\
\hline CHEMBL1565255 & 688653 & 5.683 & 5.2313 & TRN & & \\
\hline CHEMBL1531188 & 688653 & \multicolumn{3}{|c|}{4.7330000000000005} & 4.9852 & \\
\hline CHEMBL1332133 & 688653 & 4.633 & 4.6142 & TRN & & \\
\hline CHEMBL1322476 & 688653 & \multicolumn{3}{|c|}{5.132999999999999} & 4.9519 & \\
\hline CHEMBL598885 & 688653 & 8.4318 & 5.8706 & TRN & & \\
\hline CHEMBL1 & 688653 & \multicolumn{3}{|c|}{6.382999999999999} & 5.0671 & \\
\hline CHEMBL1 & 688653 & \multicolumn{3}{|c|}{5.7829999999999995} & 5.165 & \\
\hline CHEMBL1343710 & 688653 & 4.833 & 4.967 & TST & & \\
\hline CHEMBL1400338 & 688653 & 5.183 & \multicolumn{3}{|c|}{5.367999999999999} & \\
\hline CHEMBL1367316 & 688653 & 4.833 & 4.8974 & TRN & & \\
\hline CHEMB & 688653 & \multicolumn{3}{|c|}{5.832999999999999} & $3.4 / 74$ & \\
\hline CHEMBL: & 688653 & 6.233 & 5.3635 & TST & & \\
\hline CHEMBL1371171 & 688653 & \multicolumn{3}{|c|}{6.5329999999999995} & 5.3905 & $\mathrm{~T}$ \\
\hline CHEMBL1554146 & 688653 & 4.633 & 4.6376 & TRN & & \\
\hline CHEMBL1569864 & 688653 & \multicolumn{3}{|c|}{5.2829999999999995} & 5.3631 & \\
\hline CHEME & 688 & 5.683 & 5.3607 & TRN & & \\
\hline CHEME & 688653 & 4.833 & 5.7292 & TST & & \\
\hline CHEMB & 688653 & 6.8831 & 5.9696 & TST & & \\
\hline CHEMBL1334327 & 688653 & \multicolumn{3}{|c|}{5.832999999999999} & 5.1936 & $\mathrm{TS}$ \\
\hline CHEMBL1351912 & 688653 & \multicolumn{3}{|c|}{5.132999999999999} & 5.1999 & \\
\hline CHEME & 688653 & 4.933 & 5.3031 & TRN & & \\
\hline CHEMB & 688653 & \multicolumn{3}{|c|}{4.7330000000000005} & 5.1328 & $\mathrm{TS}$ \\
\hline CHEMBL1503007 & 688653 & 4.683 & 5.2389 & TST & & \\
\hline CHEMBL3213886 & 688653 & 5.033 & 5.0252 & TRN & & \\
\hline CHEME & 688 & 5.733 & 5.6295 & TRN & & \\
\hline CHEMB & 688653 & \multicolumn{3}{|c|}{6.082999999999999} & 5.3229 & $T$ \\
\hline CHEMBL: & 688653 & 5.483 & 4.8424 & TST & & \\
\hline CHEMBL258853 & 688653 & 4.883 & 5.3928 & TST & & \\
\hline CHEMBL1424763 & 688653 & 5.483 & 5.2422 & TRN & & \\
\hline CHEMBL1322817 & 688653 & \multicolumn{3}{|c|}{4.7330000000000005} & 4.7645 & It \\
\hline CHEMBL1582551 & 688653 & 4.633 & 5.329 & TST & & \\
\hline CHEMBL1440300 & 688653 & 5.433 & 5.3721 & TRN & & \\
\hline CHEMBL1453273 & 688653 & \multicolumn{3}{|c|}{5.7829999999999995} & 5.4036 & $\mathrm{TI}$ \\
\hline CHEMBL 3145312 & 688653 & 6.1329 & 99999999 & & 5.2514 & \\
\hline CHEMBL1446527 & 688653 & 4.633 & 5.3432 & TRN & & \\
\hline CHEMBL1347792 & 688653 & 4.783 & 5.2811 & TRN & & \\
\hline CHEMBL1611840 & 688653 & 5.5329 & 99999999 & 95 & 5.2158 & 31 \\
\hline
\end{tabular}




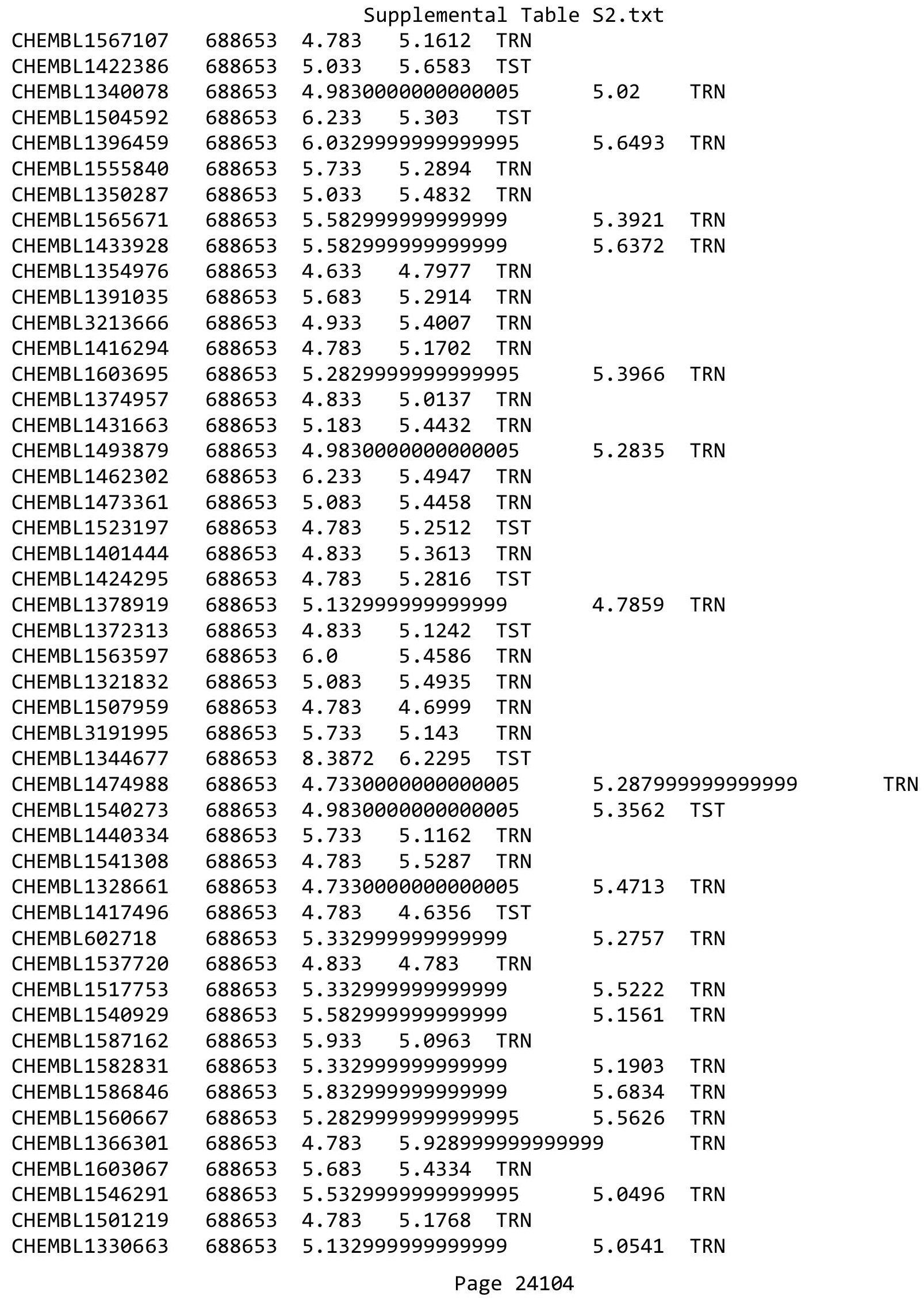




\begin{tabular}{|c|c|c|c|c|c|c|}
\hline \multicolumn{7}{|c|}{ Supplemental Table S2.txt } \\
\hline CHEMBL1489760 & 688653 & 5.083 & 5.1574 & TRN & & \\
\hline CHEMBL1326292 & 688653 & 5.58299 & 999999999 & & 5.6927 & 10 \\
\hline CHEMBL1577058 & 688653 & 4.833 & 4.7302 & TRN & & \\
\hline CHEMBL1311339 & 688653 & 4.98300 & 000000000 & 005 & 5.6165 & \\
\hline CHEMBL1314817 & 688653 & 4.633 & 4.9344 & TST & & \\
\hline CHEMBL1370394 & 688653 & 6.53299 & 999999999 & 995 & 5.4457 & \\
\hline CHEMBL1345338 & 688653 & 4.633 & 4.9253 & TRN & & \\
\hline CHEMBL1607487 & 688653 & 4.783 & 5.2839 & TST & & \\
\hline CHEMBL1420574 & 688653 & 5.28299 & 999999999 & 995 & 5.3717 & \\
\hline CHEMBL1348911 & 688653 & 4.73300 & 000000000 & 005 & 5.1005 & \\
\hline CHEMBL231699 & 688653 & 4.833 & 4.5025 & TRN & & \\
\hline CHEMBL1557386 & 688653 & 5.83299 & 999999999 & & 5.1603 & \\
\hline CHEMBL1554992 & 688653 & 5.88299 & 999999999 & & 5.2847 & \\
\hline CHEMBL1477419 & 688653 & 6.433 & 5.2914 & TST & & \\
\hline CHEMBL1368644 & 688653 & 5.483 & 5.1388 & TRN & & \\
\hline CHEMBL1591655 & 688653 & 4.883 & 5.5255 & TRN & & \\
\hline CHEMBL1331006 & 688653 & 5.233 & 5.0068 & TRN & & \\
\hline CHEMBL1452866 & 688653 & 5.683 & 5.497999 & 99999 & 99 & \\
\hline CHEMBL1405805 & 688653 & 4.73300 & 000000000 & 205 & 5.4675 & \\
\hline CHEMBL1581514 & 688653 & 4.73300 & 000000000 & 205 & 5.3837 & \\
\hline CHEMBL1606027 & 688653 & 4.783 & 5.0331 & TRN & & \\
\hline CHEMBL1443655 & 688653 & 4.833 & 4.6976 & TRN & & \\
\hline CHEMBL1607194 & 688653 & 6.38299 & 999999999 & & 6 & \\
\hline CHEMBL1420639 & 688653 & 6.183 & 5.4552 & TRN & & \\
\hline CHEMBL 3213348 & 688653 & 5.33299 & 999999999 & & 5.3913 & \\
\hline CHEMBL1483293 & 688653 & 4.783 & 5.7952 & TRN & & \\
\hline CHEMBL1473861 & 688653 & 5.983 & 5.1134 & TRN & & \\
\hline CHEMBL139 & 688 & 5.33299 & 999999999 & & 5.5908 & \\
\hline CHEMBL1582862 & 688653 & 5.53299 & 999999999 & 995 & 6.0315 & \\
\hline CHEMBL1498673 & 688653 & 5.433 & 5.2876 & TRN & & \\
\hline CHEMBL1377307 & 688653 & 5.083 & 4.9958 & TRN & & \\
\hline CHEMBL1504716 & 688653 & 4.98300 & 000000000 & 205 & 4.8195 & \\
\hline CHEMBL3 & 688653 & 5.13299 & 999999999 & & 5.4852 & \\
\hline CHEMBL1430358 & 688653 & 5.83299 & 999999999 & & 5.135 & \\
\hline CHEMBL1606532 & 688653 & 4.883 & 4.72 & TST & & \\
\hline CHEMBL1392348 & 688653 & 6.7331 & 5.7324 & TST & & \\
\hline CHEMBL1501060 & 688653 & 4.73300 & 000000000 & 205 & 5.3408 & \\
\hline CHEMBL1414146 & 688653 & 4.583 & 5.5281 & TRN & & \\
\hline CHEMBL1338958 & 688653 & 4.633 & 4.8928 & TRN & & \\
\hline CHEMBL1516980 & 688653 & 4.73300 & 000000000 & 305 & 4.817 & \\
\hline CHEMBL1368219 & 688653 & 5.983 & 5.3688 & TRN & & \\
\hline CHEMBL1309015 & 688653 & 5.58299 & 999999999 & & 5.3795 & \\
\hline CHEMBL1301945 & 688653 & 4.883 & 5.154 & TRN & & \\
\hline CHEMBL1490323 & 688653 & 5.683 & 5.2406 & TRN & & \\
\hline CHEMBL1537944 & 688653 & 5.033 & 4.9646 & TRN & & \\
\hline CHEMBL1607947 & 688653 & 4.783 & 4.9893 & TRN & & \\
\hline CHEMBL3199584 & 688653 & 4.583 & 5.2054 & TRN & & \\
\hline CHEMBL1426702 & 688653 & 4.883 & 5.0244 & TST & & \\
\hline
\end{tabular}




\begin{tabular}{|c|c|c|c|c|c|c|c|}
\hline \multirow[b]{2}{*}{ CHEMBL1328299 } & \multicolumn{6}{|c|}{ 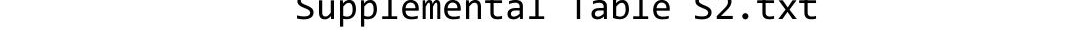 } & \\
\hline & 688653 & 5.7 & 5.4522 & TRN & & & \\
\hline CHEMBL1531920 & 688653 & 4.583 & 5.0859 & TRN & & & \\
\hline CHEMBL1547920 & 688653 & 4.933 & 5.1857 & TRN & & & \\
\hline CHEMBL1375043 & 688653 & 6.9329 & 5.7659 & TRN & & & \\
\hline CHEMBL1390302 & 688653 & 5.38299 & 999999999 & & 5.62700 & 0000000001 & TRN \\
\hline CHEMBL1560957 & 688653 & 4.783 & 5.3427 & TRN & & & \\
\hline CHEMBL1578086 & 688653 & 4.883 & 4.787 & TRN & & & \\
\hline CHEMBL1457952 & 688653 & 4.73300 & 000000000 & 005 & 5.3336 & TRN & \\
\hline CHEMBL1360255 & 688653 & 6.8831 & 5.6929 & TRN & & & \\
\hline CHEMBL1971120 & 688653 & 4.833 & 5.0221 & TST & & & \\
\hline CHEMBL1367079 & 688653 & 4.933 & 5.0709 & TRN & & & \\
\hline CHEMBL1539056 & 688653 & 5.58299 & 999999999 & & 4.96399 & 99999999995 & TST \\
\hline CHEMBL1558038 & 688653 & 4.633 & 5.2896 & TRN & & & \\
\hline CHEMBL3196420 & 688653 & 4.73300 & 000000000 & 005 & 5.3123 & TST & \\
\hline CHEMBL1561927 & 688653 & 4.683 & 5.3132 & TRN & & & \\
\hline CHEMBL1395238 & 688653 & 4.883 & 5.286000 & 000000000 & 205 & TRN & \\
\hline CHEMBL1328903 & 688653 & 5.233 & 5.0224 & TRN & & & \\
\hline CHEMBL1395199 & 688653 & 4.633 & 5.3598 & TST & & & \\
\hline CHEMBL1330126 & 688653 & 4.883 & 5.087 & TRN & & & \\
\hline CHEMBL3207793 & 688653 & 5.38299 & 999999999 & & 5.1508 & TRN & \\
\hline CHEMBL1601984 & 688653 & 4.98300 & 000000000 & 005 & 5.8264 & TRN & \\
\hline CHEMBL1346011 & 688653 & 4.73300 & 000000000 & 005 & 5.1326 & TRN & \\
\hline CHEMBL1440284 & 688653 & 5.683 & 5.5465 & TRN & & & \\
\hline CHEMBL1604402 & 688653 & 5.13299 & 999999999 & & 5.6747 & TRN & \\
\hline CHEMBL1376134 & 688653 & 5.28299 & 999999999 & 995 & 5.2159 & TRN & \\
\hline CHEMBL1369358 & 688653 & 5.83299 & 999999999 & & 5.4911 & TST & \\
\hline CHEMBL1386083 & 688653 & 5.183 & 5.2865 & TRN & & & \\
\hline CHEMBL1439235 & 688653 & 5.183 & 5.3864 & TRN & & & \\
\hline CHEMBL1586168 & 688653 & 5.433 & 5.0685 & TRN & & & \\
\hline CHEMBL1434576 & 688653 & 4.583 & 4.9475 & TRN & & & \\
\hline CHEMBL1552275 & 688653 & 5.33299 & 999999999 & & 5.043 & TRN & \\
\hline CHEMBL1542179 & 688653 & 5.933 & 5.5721 & TST & & & \\
\hline CHEMBL1541271 & 688653 & 6.58299 & 999999999 & & 5.3048 & TRN & \\
\hline CHEMBL452954 & 688653 & 5.28299 & 999999999 & 995 & 5.6625 & TRN & \\
\hline CHEMBL1427109 & 688653 & 4.883 & 5.0534 & TRN & & & \\
\hline CHEMBL1515969 & 688653 & 4.883 & 5.1732 & TST & & & \\
\hline CHEMBL1422395 & 688653 & 4.783 & 5.5027 & TST & & & \\
\hline CHEMBL1362340 & 688653 & 5.483 & 5.3825 & TRN & & & \\
\hline CHEMBL1384917 & 688653 & 6.53299 & 999999999 & 995 & 5.8331 & TRN & \\
\hline CHEMBL1605045 & 688653 & 5.183 & 5.296 & TRN & & & \\
\hline CHEMBL1302557 & 688653 & 5.033 & 5.0452 & TRN & & & \\
\hline CHEMBL600103 & 688653 & 5.83299 & 999999999 & & 5.2576 & TRN & \\
\hline CHEMBL1410510 & 688653 & 4.833 & 5.2104 & TRN & & & \\
\hline CHEMBL1474691 & 688653 & 4.583 & 5.0698 & TRN & & & \\
\hline CHEMBL1560191 & 688653 & 5.53299 & 999999999 & 995 & 5.3478 & TRN & \\
\hline CHEMBL3212280 & 688653 & 4.883 & 5.0629 & TRN & & & \\
\hline CHEMBL1410610 & 688653 & 5.83299 & 999999999 & & 5.6369 & TRN & \\
\hline CHEMBL1458170 & 688653 & 5.233 & 5.3993 & TST & & & \\
\hline
\end{tabular}




\begin{tabular}{|c|c|c|c|c|c|c|}
\hline & & \multicolumn{5}{|c|}{ Supplemental Table S2.txt } \\
\hline CHEMBL435392 & 688653 & 4.783 & 5.0378 & TST & & \\
\hline CHEMBL3197065 & 688653 & 6.683 & 5.5127 & TRN & & \\
\hline CHEMBL3196665 & 688653 & \multicolumn{3}{|c|}{5.882999999999999} & 5.3816 & TRN \\
\hline CHEMBL1567170 & 688653 & \multicolumn{3}{|c|}{5.7829999999999995} & 5.607 & TRN \\
\hline CHEMBL1424397 & 688653 & \multicolumn{3}{|c|}{4.7330000000000005} & 5.3317 & TRN \\
\hline CHEMBL1418686 & 688653 & 4.583 & 4.7905 & TRN & & \\
\hline CHEMBL3208441 & 688653 & \multicolumn{3}{|c|}{5.382999999999999} & 5.0996 & this \\
\hline CHEMBL1437375 & 688653 & 4.583 & 4.89 & TST & & \\
\hline CHEMBL1378418 & 688653 & 5.683 & 5.1371 & TST & & \\
\hline CHEMBL1608274 & 688653 & \multicolumn{3}{|c|}{4.7330000000000005} & 5.151 & $\mathrm{TP}$ \\
\hline CHEMBL1323799 & 688653 & 5.083 & 4.8659 & TRN & & \\
\hline CHEMBL1975959 & 688653 & \multicolumn{3}{|c|}{4.7330000000000005} & 5.4835 & TST \\
\hline CHEMBL1343821 & 688653 & 5.233 & 5.3537 & TRN & & \\
\hline CHEMBL580609 & 688653 & 5.433 & 5.138 & TRN & & \\
\hline CHEMBL1557045 & 688653 & \multicolumn{3}{|c|}{5.382999999999999} & 5.2248 & TRN \\
\hline CHEMBL1345311 & 688653 & \multicolumn{3}{|c|}{5.882999999999999} & 5.6318 & TRN \\
\hline CHEMBL1434637 & 688653 & 5.683 & 5.4598 & TRN & & \\
\hline CHEMBL1606948 & 688653 & 4.633 & 4.8856 & TRN & & \\
\hline CHEMBL1524681 & 688653 & \multicolumn{3}{|c|}{5.382999999999999} & 5.2737 & TST \\
\hline CHEMBL1396785 & 688653 & \multicolumn{3}{|c|}{5.582999999999999} & 5.4543 & TRN \\
\hline CHEMBL1440947 & 688653 & 4.933 & 5.0676 & TRN & & \\
\hline CHEMBL3199616 & 688653 & 4.883 & 5.05 & TRN & & \\
\hline CHEMBL14 & 688653 & 4.833 & 4.9706 & TST & & \\
\hline CHEMBL 3209674 & 688653 & 4.833 & 5.2286 & TST & & \\
\hline CHEMBL1326663 & 688653 & 5.483 & 5.3403 & TRN & & \\
\hline CHEMBL1322345 & 688653 & 4.883 & 5.7976 & TRN & & \\
\hline CHEMBL1343615 & 688653 & \multicolumn{3}{|c|}{4.7330000000000005} & 4.7468 & TST \\
\hline CHEMBL13 & 688 & \multicolumn{3}{|c|}{5.132999999999999} & & TRN \\
\hline CHEMBL1425001 & 688653 & \multicolumn{3}{|c|}{4.7330000000000005} & 5.3 & TST \\
\hline CHEMBL1378961 & 688653 & 4.633 & 5.0872 & TST & & \\
\hline CHEMBL1577745 & 688653 & 4.633 & 5.1135 & TRN & & \\
\hline CHEMBL1610821 & 688653 & 5.933 & 5.7286 & TRN & & \\
\hline CHEMBL13 & 688 & \multicolumn{3}{|c|}{5.7829999999999995} & 5.2 & TRN \\
\hline CHEMBL3193775 & 688653 & \multicolumn{3}{|c|}{4.9830000000000005} & 5.3212 & TRN \\
\hline CHEMBL1584143 & 688653 & \multicolumn{3}{|c|}{4.7330000000000005} & 4.9935 & TRN \\
\hline CHEMBL1522738 & 688653 & 4.783 & 5.0175 & TRN & & \\
\hline CHEMBL1516044 & 688653 & 4.633 & 4.8897 & TRN & & \\
\hline CHEMBL137 & 688653 & 4.833 & 5.4899 & TST & & \\
\hline CHEMBL1604973 & 688653 & 5.183 & 5.3751 & TRN & & \\
\hline CHEMBL1534728 & 688653 & \multicolumn{3}{|c|}{6.382999999999999} & 5.5453 & $\mathrm{TP}$ \\
\hline CHEMBL1334054 & 688653 & 4.683 & 4.9228 & TRN & & \\
\hline CHEMBL1399315 & 688653 & 5.183 & 5.3971 & TRN & & \\
\hline CHEMBL1376795 & 688653 & 5.733 & 5.0489 & TRN & & \\
\hline CHEMBL1403254 & 688653 & \multicolumn{3}{|c|}{5.382999999999999} & 5.1178 & TST \\
\hline CHEMBL1597082 & 688653 & \multicolumn{3}{|c|}{5.882999999999999} & 5.2713 & TRN \\
\hline CHEMBL1347295 & 688653 & 4.633 & 4.8439 & TST & & \\
\hline CHEMBL1305734 & 688653 & 4.833 & 4.9266 & TRN & & \\
\hline CHEMBL1432983 & 688653 & 4.883 & 5.2447 & TRN & & \\
\hline
\end{tabular}




\begin{tabular}{|c|c|c|c|c|c|c|c|}
\hline \multicolumn{8}{|c|}{ Supplemental Table S2.txt } \\
\hline CHEMBL1334289 & 688653 & 4.783 & 5.1935 & TRN & & & \\
\hline CHEMBL1441604 & 688653 & 5.233 & 4.9 & TRN & & & \\
\hline CHEMBL1350409 & 688653 & \multicolumn{3}{|c|}{5.132999999999999} & 5.0315 & TRN & \\
\hline CHEMBL1601024 & 688653 & \multicolumn{3}{|c|}{6.7829999999999995} & 5.7122 & TRN & \\
\hline CHEMBL1456777 & 688653 & 4.783 & 5.0139 & TRN & & & \\
\hline CHEMBL1511038 & 688653 & 4.783 & 5.2564 & TRN & & & \\
\hline CHEMBL1304926 & 688653 & \multicolumn{3}{|c|}{5.382999999999999} & 5.0248 & TRN & \\
\hline CHEMBL1551401 & 688653 & \multicolumn{3}{|c|}{6.0329999999999995} & 5.0634 & TRN & \\
\hline CHEMBL1418766 & 688653 & \multicolumn{3}{|c|}{4.7330000000000005} & \multicolumn{2}{|c|}{5.218999999999999} & TST \\
\hline CHEMBL3211961 & 688653 & 4.933 & 5.272 & TRN & & & \\
\hline CHEMBL1411113 & 688653 & 4.833 & 5.4444 & TST & & & \\
\hline CHEMBL1453452 & 688653 & \multicolumn{3}{|c|}{5.2829999999999995} & 5.1277 & TST & \\
\hline CHEMBL1438708 & 688653 & 5.033 & 4.6299 & TRN & & & \\
\hline CHEMBL143703 & 688653 & 5.233 & 5.9781 & TRN & & & \\
\hline CHEMBL1384045 & 688653 & 4.633 & 4.9675 & TRN & & & \\
\hline CHEMBL1514097 & 688653 & 6.433 & 6.3017 & TRN & & & \\
\hline CHEMBL3195445 & 688653 & \multicolumn{3}{|c|}{6.832999999999999} & 5.4261 & TST & \\
\hline CHEMBL1488923 & 688653 & 5.933 & 5.9194 & TRN & & & \\
\hline CHEMBL1562360 & 688653 & 6.4829 & 5.7089 & TRN & & & \\
\hline CHEMBL1569856 & 688653 & \multicolumn{3}{|c|}{4.7330000000000005} & 5.1102 & TST & \\
\hline CHEMBL1580096 & 688653 & \multicolumn{3}{|c|}{6.2829999999999995} & 5.8287 & TRN & \\
\hline CHEMBL1417082 & 688653 & \multicolumn{3}{|c|}{4.7330000000000005} & 4.9047 & TRN & \\
\hline CHEMBL1408080 & 688653 & \multicolumn{3}{|c|}{5.832999999999999} & 5.5256 & TRN & \\
\hline CHEMBL1356410 & 688653 & 4.783 & 5.0918 & TRN & & & \\
\hline CHEMBL1600093 & 688653 & 4.783 & 4.8338 & TRN & & & \\
\hline CHEMBL1528207 & 688653 & \multicolumn{3}{|c|}{5.5329999999999995} & 5.1196 & TRN & \\
\hline CHEMBL3207617 & 688653 & 4.783 & 5.3568 & TRN & & & \\
\hline CHEMBL1574685 & 688653 & 4.833 & 4.612 & TRN & & & \\
\hline CHEMBL1387187 & 688653 & 4.883 & 5.3743 & TST & & & \\
\hline CHEMBL1516336 & 688653 & 4.833 & 4.9297 & TRN & & & \\
\hline CHEMBL1339638 & 688653 & 4.833 & 4.9622 & TRN & & & \\
\hline CHEMBL1347974 & 688653 & \multicolumn{3}{|c|}{4.7330000000000005} & \multicolumn{2}{|c|}{5.162999999999999} & TRN \\
\hline CHEMBL1301280 & 688653 & \multicolumn{3}{|c|}{5.582999999999999} & 5.2572 & TRN & \\
\hline CHEMBL3196187 & 688653 & 4.783 & 5.1407 & TRN & & & \\
\hline CHEMBL1539747 & 688653 & \multicolumn{3}{|c|}{5.332999999999999} & 5.1502 & TST & \\
\hline CHEMBL1309247 & 688653 & \multicolumn{3}{|c|}{4.7330000000000005} & 4.7069 & TST & \\
\hline CHEMBL1511072 & 688653 & 4.933 & 5.3004 & TST & & & \\
\hline CHEMBL1451019 & 688653 & \multicolumn{3}{|c|}{5.7829999999999995} & 5.7194 & TRN & \\
\hline CHEMBL1364731 & 688653 & 4.833 & 5.4178 & TRN & & & \\
\hline CHEMBL1552311 & 688653 & 6.183 & 5.5207 & TRN & & & \\
\hline CHEMBL494255 & 688653 & \multicolumn{3}{|c|}{5.332999999999999} & 5.3798 & TRN & \\
\hline CHEMBL1476957 & 688653 & 6.3329 & 99999999 & & 5.7897 & TRN & \\
\hline CHEMBL1574242 & 688653 & 5.3329 & 99999999 & & 5.3999 & TRN & \\
\hline CHEMBL1398002 & 688653 & 5.2829 & 99999999 & 995 & 5.4523 & TRN & \\
\hline CHEMBL1409342 & 688653 & 4.783 & 5.0113 & TRN & & & \\
\hline CHEMBL1374547 & 688653 & 5.433 & 5.4998 & TRN & & & \\
\hline CHEMBL1390171 & 688653 & 5.5329 & 99999999 & 995 & 5.0312 & TRN & \\
\hline CHEMBL1527590 & 688653 & 5.1329 & 99999999 & & 5.4582 & TST & \\
\hline
\end{tabular}




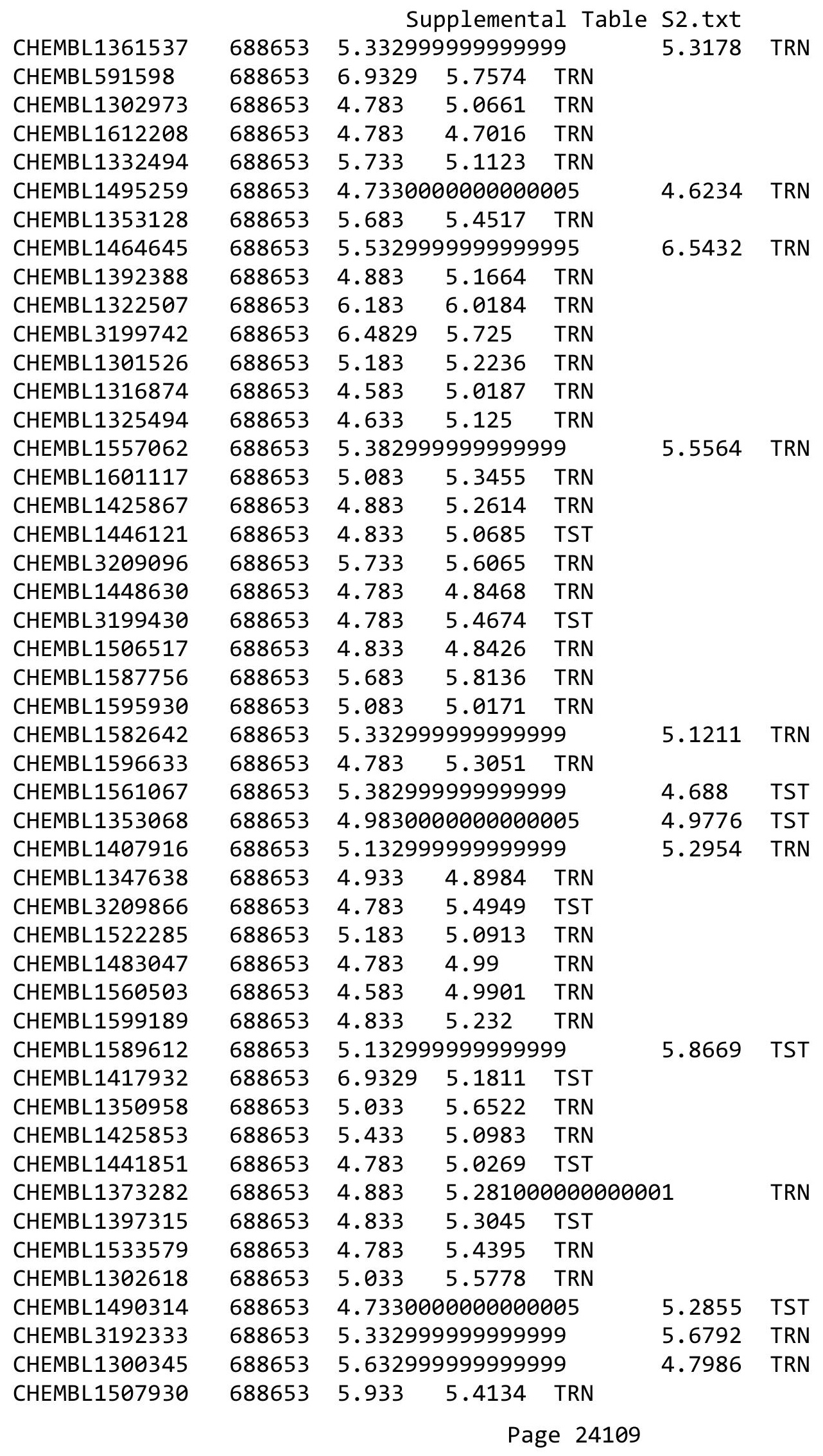




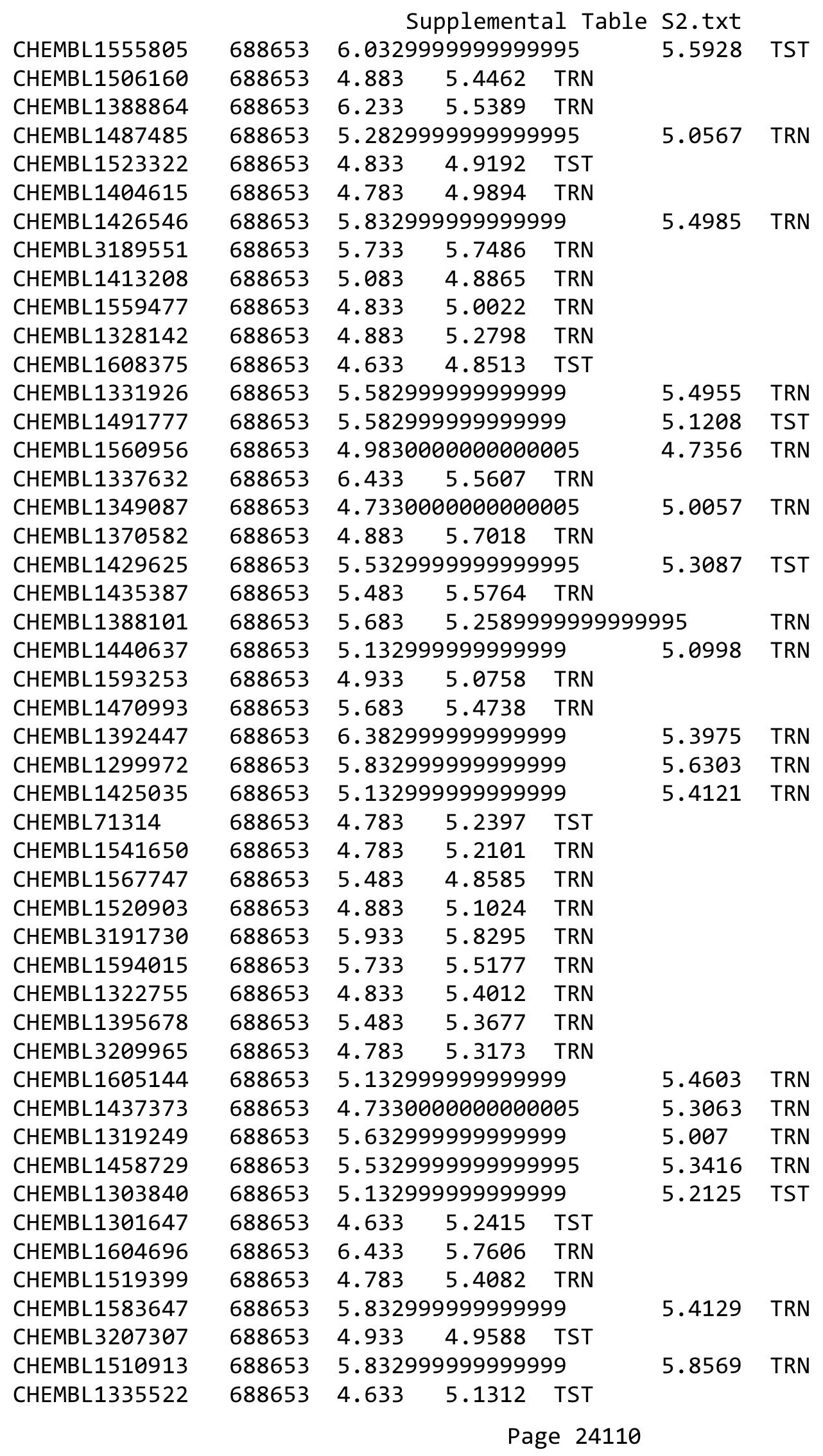




\begin{tabular}{|c|c|c|c|c|c|c|c|}
\hline \multicolumn{8}{|c|}{ Supplemental Table S2.txt } \\
\hline CHEMBL1422810 & 688653 & 5.933 & 5.2143 & TRN & & & \\
\hline CHEMBL1476676 & 688653 & 4.783 & 4.9783 & TRN & & & \\
\hline CHEMBL1564796 & 688653 & 4.833 & 5.36 & TST & & & \\
\hline CHEMBL1315803 & 688653 & \multicolumn{3}{|c|}{5.132999999999999} & 5.5992 & TRN & \\
\hline CHEMBL1351842 & 688653 & \multicolumn{3}{|c|}{4.7330000000000005} & 5.2412 & TRN & \\
\hline CHEMBL1316171 & 688653 & 4.633 & 4.9034 & TRN & & & \\
\hline CHEMBL1316261 & 688653 & 5.183 & \multicolumn{3}{|c|}{5.8389999999999995} & TRN & \\
\hline CHEMBL3199216 & 688653 & \multicolumn{3}{|c|}{6.632999999999999} & 5.8435 & TRN & \\
\hline CHEMBL1572931 & 688653 & 7.1831 & 5.8893 & TRN & & & \\
\hline CHEMBL1495537 & 688653 & \multicolumn{3}{|c|}{5.882999999999999} & 5.6825 & TRN & \\
\hline CHEMBL1308477 & 688653 & 4.933 & 5.311 & TRN & & & \\
\hline CHEMBL1444799 & 688653 & 4.783 & 5.0659 & TRN & & & \\
\hline CHEMBL1542050 & 688653 & \multicolumn{3}{|c|}{5.382999999999999} & 5.4705 & TRN & \\
\hline CHEMBL 3197676 & 688653 & \multicolumn{3}{|c|}{5.7829999999999995} & 5.5744 & TRN & \\
\hline CHEMBL1334273 & 688653 & 5.233 & 5.3739 & TRN & & & \\
\hline CHEMBL1387450 & 688653 & \multicolumn{3}{|c|}{5.132999999999999} & \multicolumn{2}{|c|}{5.167999999999999} & TRN \\
\hline CHEMBL1391887 & 688653 & \multicolumn{3}{|c|}{4.9830000000000005} & 5.3233 & TRN & \\
\hline CHEMBL1373585 & 688653 & \multicolumn{3}{|c|}{5.132999999999999} & 4.9016 & TRN & \\
\hline CHEMBL1495170 & 688653 & \multicolumn{3}{|c|}{4.9830000000000005} & 5.37799 & 9999999999 & TST \\
\hline CHEMBL1399938 & 688653 & \multicolumn{3}{|c|}{4.7330000000000005} & 4.9429 & TRN & \\
\hline CHEMBL1575512 & 688653 & 4.883 & 5.2893 & TST & & & \\
\hline CHEMBL1548850 & 688653 & 4.833 & 5.1327 & TST & & & \\
\hline CHEMBL1579380 & 688653 & \multicolumn{3}{|c|}{5.582999999999999} & 5.845 & TRN & \\
\hline CHEMBL1484821 & 688653 & 5.433 & 5.1995 & TRN & & & \\
\hline CHEMBL1499544 & 688653 & 4.833 & 4.8206 & TRN & & & \\
\hline CHEMBL1533373 & 688653 & 5.233 & 5.5359 & TRN & & & \\
\hline CHEMBL1409900 & 688653 & 6.0 & 5.1619 & TRN & & & \\
\hline CHEMBL1454853 & 688653 & 5.433 & 5.6505 & TRN & & & \\
\hline CHEMBL1573068 & 688653 & \multicolumn{3}{|c|}{5.332999999999999} & 4.9473 & TRN & \\
\hline CHEMBL1585377 & 688653 & 4.933 & 4.6603 & TRN & & & \\
\hline CHEMBL1308273 & 688653 & 6.983 & 5.4443 & TRN & & & \\
\hline CHEMBL1456587 & 688653 & 5.933 & 5.2113 & TRN & & & \\
\hline CHEMBL1509879 & 688653 & 4.833 & 5.0958 & TRN & & & \\
\hline CHEMBL1585420 & 688653 & \multicolumn{3}{|c|}{5.632999999999999} & 5.2948 & TST & \\
\hline CHEMBL1348307 & 688653 & 4.883 & 5.1168 & TRN & & & \\
\hline CHEMBL1334636 & 688653 & \multicolumn{3}{|c|}{5.132999999999999} & 5.3151 & TRN & \\
\hline CHEMBL1433022 & 688653 & 5.733 & 5.3092 & TRN & & & \\
\hline CHEMBL3199835 & 688653 & 4.783 & 5.4245 & TRN & & & \\
\hline CHEMBL1399406 & 688653 & 6.4829 & 5.3329 & TRN & & & \\
\hline CHEMBL1556365 & 688653 & \multicolumn{3}{|c|}{4.9830000000000005} & 5.2261 & TST & \\
\hline CHEMBL1456355 & 688653 & 4.883 & 5.4774 & TST & & & \\
\hline CHEMBL1998425 & 688653 & 4.883 & 4.9251 & TRN & & & \\
\hline CHEMBL1487064 & 688653 & 4.783 & 5.0053 & TRN & & & \\
\hline CHEMBL1355236 & 688653 & 5.183 & 5.0645 & TST & & & \\
\hline CHEMBL1501547 & 688653 & \multicolumn{3}{|c|}{6.582999999999999} & 5.8152 & TRN & \\
\hline CHEMBL1592648 & 688653 & 4.933 & 5.0934 & TRN & & & \\
\hline CHEMBL 7724 & 688653 & \multirow{2}{*}{\multicolumn{3}{|c|}{$\begin{array}{ll}6.183 & 5.8 / 84 \\
4.7330000000000005\end{array}$}} & & & \\
\hline CHEMBL1602544 & 688653 & & & & 4.8445 & TRN & \\
\hline
\end{tabular}




\begin{tabular}{|c|c|c|c|c|c|c|}
\hline \multirow{3}{*}{$\begin{array}{l}\text { CHEMBL1485951 } \\
\text { CHEMBL1396133 }\end{array}$} & \multirow{3}{*}{$\begin{array}{l}688653 \\
688653\end{array}$} & \multicolumn{4}{|c|}{ Supplemental Table S2.txt } & \multirow{2}{*}{ TRN } \\
\hline & & \multicolumn{3}{|c|}{5.582999999999999} & 5.263 & \\
\hline & & 4.583 & 4.9411 & TRN & & \\
\hline CHEMBL1407806 & 688653 & \multicolumn{3}{|c|}{5.2829999999999995} & 5.3537 & TRN \\
\hline CHEMBL1528094 & 688653 & 4.583 & 5.186 & TRN & & \\
\hline CHEMBL1537469 & 688653 & \multicolumn{3}{|c|}{5.632999999999999} & 5.4439 & TRN \\
\hline CHEMBL1604550 & 688653 & 5.683 & 5.4638 & TRN & & \\
\hline CHEMBL1536524 & 688653 & \multicolumn{3}{|c|}{4.7330000000000005} & 5.087 & TRN \\
\hline CHEMBL1487872 & 688653 & \multicolumn{3}{|c|}{6.382999999999999} & 6.0631 & TRN \\
\hline CHEMBL1538895 & 688653 & \multicolumn{3}{|c|}{6.332999999999999} & 5.5417 & TRN \\
\hline CHEMBL1434336 & 688653 & 4.833 & 5.4317 & TST & & \\
\hline CHEMBL1352111 & 688653 & 4.883 & 4.8979 & TRN & & \\
\hline CHEMBL1493131 & 688653 & \multicolumn{3}{|c|}{5.382999999999999} & 5.3255 & TST \\
\hline CHEMBL1525236 & 688653 & \multicolumn{3}{|c|}{4.9830000000000005} & 5.0489 & TRN \\
\hline CHEMBL1560308 & 688653 & \multicolumn{3}{|c|}{4.7330000000000005} & 4.7809 & TST \\
\hline CHEMBL1542722 & 688653 & \multicolumn{3}{|c|}{4.7330000000000005} & 5.2845 & TST \\
\hline CHEMBL1341733 & 688653 & 4.883 & 5.2233 & TRN & & \\
\hline CHEMBL1481911 & 688653 & 4.633 & 4.953 & TST & & \\
\hline CHEMBL3190397 & 688653 & 7.2832 & 6.136 & TRN & & \\
\hline CHEMBL1447359 & 688653 & 6.233 & 5.4293 & TRN & & \\
\hline CHEMBL1506233 & 688653 & 4.783 & 5.0577 & TRN & & \\
\hline CHEMBL1602267 & 688653 & \multicolumn{3}{|c|}{5.5329999999999995} & 5.061 & TRN \\
\hline CHEMBL3195157 & 688653 & 4.933 & 5.1905 & TRN & & \\
\hline CHEMBL1376048 & 688653 & 5.483 & 5.2995 & TST & & \\
\hline CHEMBL1403276 & 688653 & 7.3325 & 6.7428 & TRN & & \\
\hline CHEMBL1345888 & 688653 & 5.483 & 5.3582 & TRN & & \\
\hline CHEMBL592552 & 688653 & \multicolumn{3}{|c|}{4.9830000000000005} & 5.0804 & TRN \\
\hline CHEMBL 281980 & 688653 & \multicolumn{3}{|c|}{5.132999999999999} & 5.5951 & TRN \\
\hline CHEMBL1455809 & 688653 & \multicolumn{3}{|c|}{5.382999999999999} & 5.5207 & TST \\
\hline CHEMBL1335686 & 688653 & 4.783 & 5.0505 & TRN & & \\
\hline CHEMBL1380577 & 688653 & 4.683 & 5.6753 & TRN & & \\
\hline CHEMBL1426594 & 688653 & 5.483 & 5.5374 & TRN & & \\
\hline CHEMBL1470168 & 688653 & 4.933 & 5.1801 & TRN & & \\
\hline CHEMBL1413057 & 688653 & 5.233 & 5.4561 & TRN & & \\
\hline CHEMBL1516979 & 688653 & 4.883 & 5.1654 & TST & & \\
\hline CHEMBL1478720 & 688653 & 4.833 & 5.0771 & TRN & & \\
\hline CHEMBL1316753 & 688653 & \multicolumn{3}{|c|}{5.632999999999999} & 5.6448 & TRN \\
\hline CHEMBL1369677 & 688653 & \multicolumn{3}{|c|}{4.7330000000000005} & 4.9422 & TRN \\
\hline CHEMBL1604921 & 688653 & 4.883 & 4.9736 & TRN & & \\
\hline CHEMBL1309149 & 688653 & 5.733 & 5.1253 & TRN & & \\
\hline CHEMBL1544075 & 688653 & \multicolumn{3}{|c|}{4.7330000000000005} & 5.0789 & TST \\
\hline CHEMBL1390438 & 688653 & 5.483 & 5.7369 & TST & & \\
\hline CHEMBL1403950 & 688653 & 5.53299 & 99999999 & 995 & 5.3036 & TRN \\
\hline CHEMBL1423133 & 688653 & 5.28299 & 99999999 & 995 & 5.1609 & TRN \\
\hline CHEMBL1442155 & 688653 & 5.183 & 5.4443 & TST & & \\
\hline CHEMBL1490377 & 688653 & 6.33299 & 99999999 & & 5.2357 & TRN \\
\hline CHEMBL1469510 & 688653 & 5.13299 & 99999999 & & 5.6544 & TRN \\
\hline CHEMBL1549946 & 688653 & 4.583 & 5.1688 & TST & & \\
\hline CHEMBL1574127 & 688653 & 5.683 & 5.1026 & TRN & & \\
\hline & & & & & & \\
\hline
\end{tabular}




\begin{tabular}{|c|c|c|c|c|c|c|}
\hline \multirow[b]{2}{*}{ CHEMBL1335541 } & \multirow[b]{2}{*}{688653} & \multicolumn{5}{|c|}{ Supplemental Table s2.txt } \\
\hline & & 4.583 & 5.1636 & TRN & & \\
\hline CHEMBL1185172 & 688653 & \multicolumn{3}{|c|}{4.9830000000000005} & 4.7375 & TRN \\
\hline CHEMBL1376174 & 688653 & 4.833 & 5.355 & TST & & \\
\hline CHEMBL3195965 & 688653 & 5.083 & 5.3965 & TRN & & \\
\hline CHEMBL3197876 & 688653 & 4.783 & 5.4622 & TRN & & \\
\hline CHEMBL1269633 & 688653 & 4.833 & 5.3746 & TRN & & \\
\hline CHEMBL1538585 & 688653 & \multicolumn{3}{|c|}{5.2829999999999995} & 5.7246 & TRN \\
\hline CHEMBL1371579 & 688653 & 4.833 & 4.6418 & TRN & & \\
\hline CHEMBL1451512 & 688653 & \multicolumn{3}{|c|}{6.5329999999999995} & 5.2521 & TRN \\
\hline CHEMBL469976 & 688653 & \multicolumn{3}{|c|}{4.9830000000000005} & 5.2426 & TRN \\
\hline CHEMBL1572558 & 688653 & \multicolumn{3}{|c|}{5.382999999999999} & 5.2066 & TST \\
\hline CHEMBL1473495 & 688653 & 5.233 & 5.1333 & TRN & & \\
\hline CHEMBL1402573 & 688653 & \multicolumn{3}{|c|}{6.332999999999999} & 5.3296 & TST \\
\hline CHEMBL1302266 & 688653 & 6.9329 & 5.8718 & TRN & & \\
\hline CHEMBL3189498 & 688653 & \multicolumn{3}{|c|}{4.9830000000000005} & 5.1401 & TRN \\
\hline CHEMBL1511532 & 688653 & 5.483 & 4.9164 & TRN & & \\
\hline CHEMBL1369023 & 688653 & \multicolumn{3}{|c|}{5.882999999999999} & 5.6672 & TRN \\
\hline CHEMBL1409398 & 688653 & \multicolumn{3}{|c|}{5.2829999999999995} & 5.2051 & TST \\
\hline CHEMBL1513449 & 688653 & \multicolumn{3}{|c|}{4.7330000000000005} & 4.8674 & TRN \\
\hline CHEMBL1559232 & 688653 & \multicolumn{3}{|c|}{5.132999999999999} & 5.4288 & TRN \\
\hline CHEMBL1606984 & 688653 & 5.433 & 5.4022 & TRN & & \\
\hline CHEMBL1481425 & 688653 & 5.483 & 5.4685 & TRN & & \\
\hline CHEMBL1322187 & 688653 & 4.883 & 5.2106 & TST & & \\
\hline CHEMBL1401052 & 688653 & \multicolumn{3}{|c|}{5.582999999999999} & 5.1821 & TRN \\
\hline CHEMBL1562232 & 688653 & 5.933 & 5.0947 & TST & & \\
\hline CHEMBL1546600 & 688653 & \multicolumn{3}{|c|}{5.5329999999999995} & 5.5656 & TRN \\
\hline CHEMBL1493135 & 688653 & \multicolumn{3}{|c|}{4.7330000000000005} & 5.0342 & TST \\
\hline CHEMBL3210865 & 688653 & \multicolumn{3}{|c|}{5.332999999999999} & 5.5378 & TRN \\
\hline CHEMBL1368216 & 688653 & \multicolumn{3}{|c|}{5.832999999999999} & 5.3628 & TRN \\
\hline CHEMBL3196489 & 688653 & \multicolumn{3}{|c|}{5.882999999999999} & 5.1892 & TRN \\
\hline CHEMBL1501183 & 688653 & 4.833 & 5.4084 & TRN & & \\
\hline CHEMBL1610235 & 688653 & \multicolumn{3}{|c|}{5.2829999999999995} & 4.8175 & TRN \\
\hline CHEMBL1542941 & 688653 & 4.833 & 5.4034 & TST & & \\
\hline CHEMBL1396184 & 688653 & 7.0329 & 4.7292 & TRN & & \\
\hline CHEMBL1308639 & 688653 & 5.083 & 5.3989 & TRN & & \\
\hline CHEMBL3214026 & 688653 & 4.73300 & 20000000 & 005 & 5.4687 & TST \\
\hline CHEMBL1454365 & 688653 & 5.733 & 5.3642 & TRN & & \\
\hline CHEMBL1376693 & 688653 & 5.433 & 5.5255 & TRN & & \\
\hline CHEMBL1428363 & 688653 & 4.833 & 5.2259 & TRN & & \\
\hline CHEMBL1574505 & 688653 & 4.98300 & 00000000 & 005 & 5.2614 & TST \\
\hline CHEMBL1579704 & 688653 & 5.933 & 5.6587 & TRN & & \\
\hline CHEMBL1300635 & 688653 & 4.833 & 5.1046 & TST & & \\
\hline CHEMBL1395443 & 688653 & 5.033 & 5.2627 & TRN & & \\
\hline CHEMBL1530546 & 688653 & 5.183 & 5.1814 & TRN & & \\
\hline CHEMBL1531260 & 688653 & 5.88299 & 99999999 & 99 & 5.1767 & TRN \\
\hline CHEMBL1469859 & 688653 & 4.883 & 4.905 & TRN & & \\
\hline CHEMBL1458351 & 688653 & 5.683 & 5.3097 & TRN & & \\
\hline CHEMBL1332840 & 688653 & 4.883 & 5.0672 & TRN & & \\
\hline
\end{tabular}




\begin{tabular}{|c|c|c|c|c|c|c|}
\hline \multicolumn{7}{|c|}{ Supplemental Table S2.txt } \\
\hline CHEMBL1489749 & 688653 & 4.933 & 5.2918 & TRN & & \\
\hline CHEMBL 3211620 & 688653 & 6.683 & 6.0866 & TRN & & \\
\hline CHEMBL1607187 & 688653 & 5.433 & 5.3716 & TRN & & \\
\hline CHEMBL1482964 & 688653 & 6.183 & 5.8114 & TRN & & \\
\hline CHEMBL1429929 & 688653 & 4.833 & 4.7913 & TRN & & \\
\hline CHEMBL1535140 & 688653 & \multicolumn{3}{|c|}{4.7330000000000005} & 5.0317 & TRN \\
\hline CHEMBL1582020 & 688653 & 4.883 & 5.0461 & TRN & & \\
\hline CHEMBL1330202 & 688653 & 4.783 & 5.1875 & TRN & & \\
\hline CHEMBL1457048 & 688653 & 4.833 & 4.8558 & TRN & & \\
\hline CHEMBL1326021 & 688653 & \multicolumn{3}{|c|}{5.132999999999999} & 5.4684 & TST \\
\hline CHEMBL1312842 & 688653 & 4.933 & 5.3999 & TRN & & \\
\hline CHEMBL1314606 & 688653 & 4.783 & 5.2581 & TRN & & \\
\hline CHEMBL1399698 & 688653 & \multicolumn{3}{|c|}{6.332999999999999} & 5.3397 & TST \\
\hline CHEMBL1518682 & 688653 & \multicolumn{3}{|c|}{6.832999999999999} & 5.1399 & TRN \\
\hline CHEMBL1461718 & 688653 & 5.083 & 5.0186 & TRN & & \\
\hline CHEMBL 3190922 & 688653 & 4.783 & 5.0731 & TRN & & \\
\hline CHEMBL1597558 & 688653 & 5.233 & 5.3384 & TST & & \\
\hline CHEMBL1427443 & 688653 & 5.483 & 5.2782 & TRN & & \\
\hline CHEMBL1595659 & 688653 & 4.783 & 5.4303 & TRN & & \\
\hline CHEMBL1476263 & 688653 & \multicolumn{3}{|c|}{5.832999999999999} & 5.3413 & TRN \\
\hline CHEMBL1347437 & 688653 & \multicolumn{3}{|c|}{5.7829999999999995} & 5.3532 & TRN \\
\hline CHEMBL 3194273 & 688653 & 7.0329 & 6.0185 & TRN & & \\
\hline CHEMBL1545970 & 688653 & 4.933 & 5.1353 & TST & & \\
\hline CHEMBL1361694 & 688653 & \multicolumn{3}{|c|}{5.132999999999999} & 5.2494 & TST \\
\hline CHEMBL1312320 & 688653 & \multicolumn{3}{|c|}{5.632999999999999} & 5.311 & TST \\
\hline CHEMBL1419870 & 688653 & \multicolumn{3}{|c|}{5.132999999999999} & 5.5067 & TST \\
\hline CHEMBL1564717 & 688653 & 5.983 & 5.2446 & TRN & & \\
\hline CHEMBL1342602 & 688653 & \multicolumn{3}{|c|}{5.7829999999999995} & 5.6773 & Int \\
\hline CHEMBL1407114 & 688653 & 5.233 & 5.1087 & TST & & \\
\hline CHEMBL1413177 & 688653 & \multicolumn{3}{|c|}{5.132999999999999} & 5.0283 & $\mathrm{TR}$ \\
\hline CHEMBL 3189370 & 688653 & 4.883 & 5.0718 & TRN & & \\
\hline CHEMBL1584890 & 688653 & 5.083 & 4.8014 & TST & & \\
\hline CHEMBL1394430 & 688653 & 4.883 & 5.095 & TRN & & \\
\hline CHEMBL1362178 & 688653 & 4.783 & 4.9075 & TRN & & \\
\hline CHEMBL 3192821 & 688653 & 5.083 & 5.47 & TRN & & \\
\hline CHEMBL1582494 & 688653 & \multicolumn{3}{|c|}{6.382999999999999} & 5.6527 & $\mathrm{TP}$ \\
\hline CHEMBL1595727 & 688653 & \multicolumn{3}{|c|}{6.0329999999999995} & 5.3032 & I TाV \\
\hline CHEMBL1429930 & 688653 & \multicolumn{3}{|c|}{5.582999999999999} & 4.9212 & TST \\
\hline CHEMBL1523400 & 688653 & \multicolumn{3}{|c|}{5.7829999999999995} & 5.1763 & TRN \\
\hline CHEMBL1458622 & 688653 & 5.733 & 5.5478 & TRN & & \\
\hline CHEMBL1417528 & 688653 & 4.883 & 5.1888 & TRN & & \\
\hline CHEMBL1489256 & 688653 & 6.183 & 5.46 & TRN & & \\
\hline CHEMBL1557673 & 688653 & 4.833 & 5.4082 & TRN & & \\
\hline CHEMBL1466448 & 688653 & \multicolumn{3}{|c|}{5.2829999999999995} & 4.9607 & N \\
\hline CHEMBL1595408 & 688653 & 5.733 & 5.6167 & TRN & & \\
\hline CHEMBL1533676 & 688653 & 4.833 & 5.2522 & TST & & \\
\hline CHEMBL1377872 & 688653 & \multicolumn{3}{|c|}{6.582999999999999} & 5.5107 & RI \\
\hline CHEMBL1365696 & 688653 & 4.633 & 5.1364 & TRN & & \\
\hline
\end{tabular}




\begin{tabular}{|c|c|c|c|c|c|c|}
\hline \multirow[b]{2}{*}{ CHEMBL1513607 } & \multirow[b]{2}{*}{688653} & \multicolumn{5}{|c|}{ Supplemental Table s2.txt } \\
\hline & & 4.783 & 4.9001 & TST & & \\
\hline CHEMBL1515197 & 688653 & 4.633 & 4.9567 & TRN & & \\
\hline CHEMBL1569325 & 688653 & 5.233 & 5.1338 & TST & & \\
\hline CHEMBL 3196267 & 688653 & \multicolumn{3}{|c|}{6.332999999999999} & 5.6433 & TRN \\
\hline CHEMBL1422265 & 688653 & 6.233 & 5.6801 & TRN & & \\
\hline CHEMBL1606319 & 688653 & \multicolumn{3}{|c|}{6.5329999999999995} & 5.8969 & TRN \\
\hline CHEMBL1334840 & 688653 & 4.783 & 4.8485 & TST & & \\
\hline CHEMBL1598821 & 688653 & 4.883 & 5.1156 & TRN & & \\
\hline CHEMBL3211533 & 688653 & 5.083 & 5.0205 & TRN & & \\
\hline CHEMBL1603420 & 688653 & 4.833 & 4.7493 & TRN & & \\
\hline CHEMBL3195289 & 688653 & 4.783 & 5.6643 & TRN & & \\
\hline CHEMBL1407344 & 688653 & 4.833 & 5.5591 & TRN & & \\
\hline CHEMBL1356298 & 688653 & \multicolumn{3}{|c|}{5.7829999999999995} & 5.6825 & TST \\
\hline CHEMBL1522657 & 688653 & 5.683 & 5.66 & TRN & & \\
\hline CHEMBL1490493 & 688653 & 5.483 & 5.6361 & TST & & \\
\hline CHEMBL1305235 & 688653 & 4.883 & 5.1451 & TRN & & \\
\hline CHEMBL1597714 & 688653 & 6.233 & 5.3431 & TRN & & \\
\hline CHEMBL1501568 & 688653 & 4.833 & 4.801 & TRN & & \\
\hline CHEMBL1416927 & 688653 & \multicolumn{3}{|c|}{7.082999999999999} & 5.8274 & TRN \\
\hline CHEMBL1597184 & 688653 & 4.833 & 5.3506 & TST & & \\
\hline CHEMBL1565009 & 688653 & 5.233 & 5.0065 & TST & & \\
\hline CHEMBL1305393 & 688653 & 5.433 & 5.0272 & TRN & & \\
\hline CHEMBL1320319 & 688653 & 5.983 & 5.2774 & TST & & \\
\hline CHEMBL1579170 & 688653 & 4.633 & 5.1418 & TST & & \\
\hline CHEMBL1454209 & 688653 & \multicolumn{3}{|c|}{5.582999999999999} & 5.0291 & TRN \\
\hline CHEMBL1463869 & 688653 & \multicolumn{3}{|c|}{6.5329999999999995} & 6.2256 & TRN \\
\hline CHEMBL1487117 & 688653 & 4.633 & 4.982 & TST & & \\
\hline CHEMBL3195763 & 688653 & 5.933 & 5.9604 & TRN & & \\
\hline CHEMBL1336091 & 688653 & 6.4829 & 4.9133 & TST & & \\
\hline CHEMBL1539742 & 688653 & \multicolumn{3}{|c|}{5.7829999999999995} & 5.358 & TRN \\
\hline CHEMBL1569816 & 688653 & \multicolumn{3}{|c|}{6.382999999999999} & 5.6516 & TRN \\
\hline CHEMBL1539282 & 688653 & 4.833 & 4.9862 & TRN & & \\
\hline CHEMBL1972666 & 688653 & \multicolumn{3}{|c|}{5.382999999999999} & 5.5615 & TST \\
\hline CHEMBL1445681 & 688653 & 4.883 & 4.9651 & TST & & \\
\hline CHEMBL1564748 & 688653 & \multicolumn{3}{|c|}{5.132999999999999} & 5.371 & TRN \\
\hline CHEMBL1428508 & 688653 & 5.233 & 5.1245 & TRN & & \\
\hline CHEMBL3194199 & 688653 & 5.683 & 5.6335 & TRN & & \\
\hline CHEMBL1543381 & 688653 & 4.933 & 5.0202 & TRN & & \\
\hline CHEMBL1534574 & 688653 & 5.033 & 5.8427 & TRN & & \\
\hline CHEMBL3212388 & 688653 & 5.683 & 5.0866 & TRN & & \\
\hline CHEMBL1401424 & 688653 & 5.033 & 5.6515 & TST & & \\
\hline CHEMBL1368827 & 688653 & 5.183 & 5.2462 & TST & & \\
\hline CHEMBL1512359 & 688653 & 4.933 & 5.7764 & TRN & & \\
\hline CHEMBL1376387 & 688653 & \multicolumn{3}{|c|}{5.832999999999999} & 4.8608 & TRN \\
\hline CHEMBL1601345 & 688653 & 4.783 & 5.2293 & TRN & & \\
\hline CHEMBL1338072 & 688653 & 4.833 & 4.8384 & TRN & & \\
\hline CHEMBL1451236 & 688653 & 4.933 & 5.4595 & TRN & & \\
\hline CHEMBL1388672 & 688653 & 4.833 & 5.1692 & TST & & \\
\hline
\end{tabular}




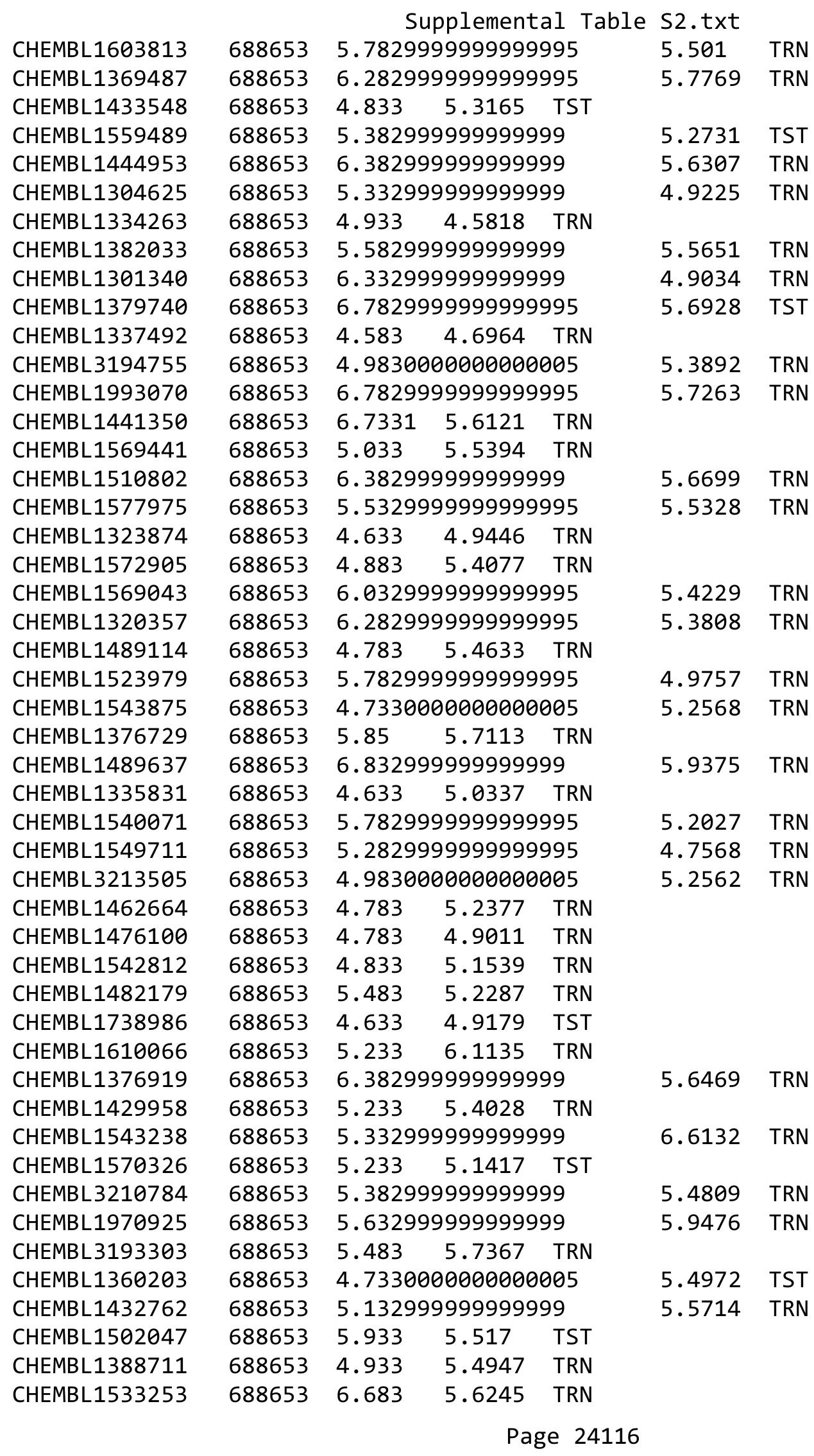




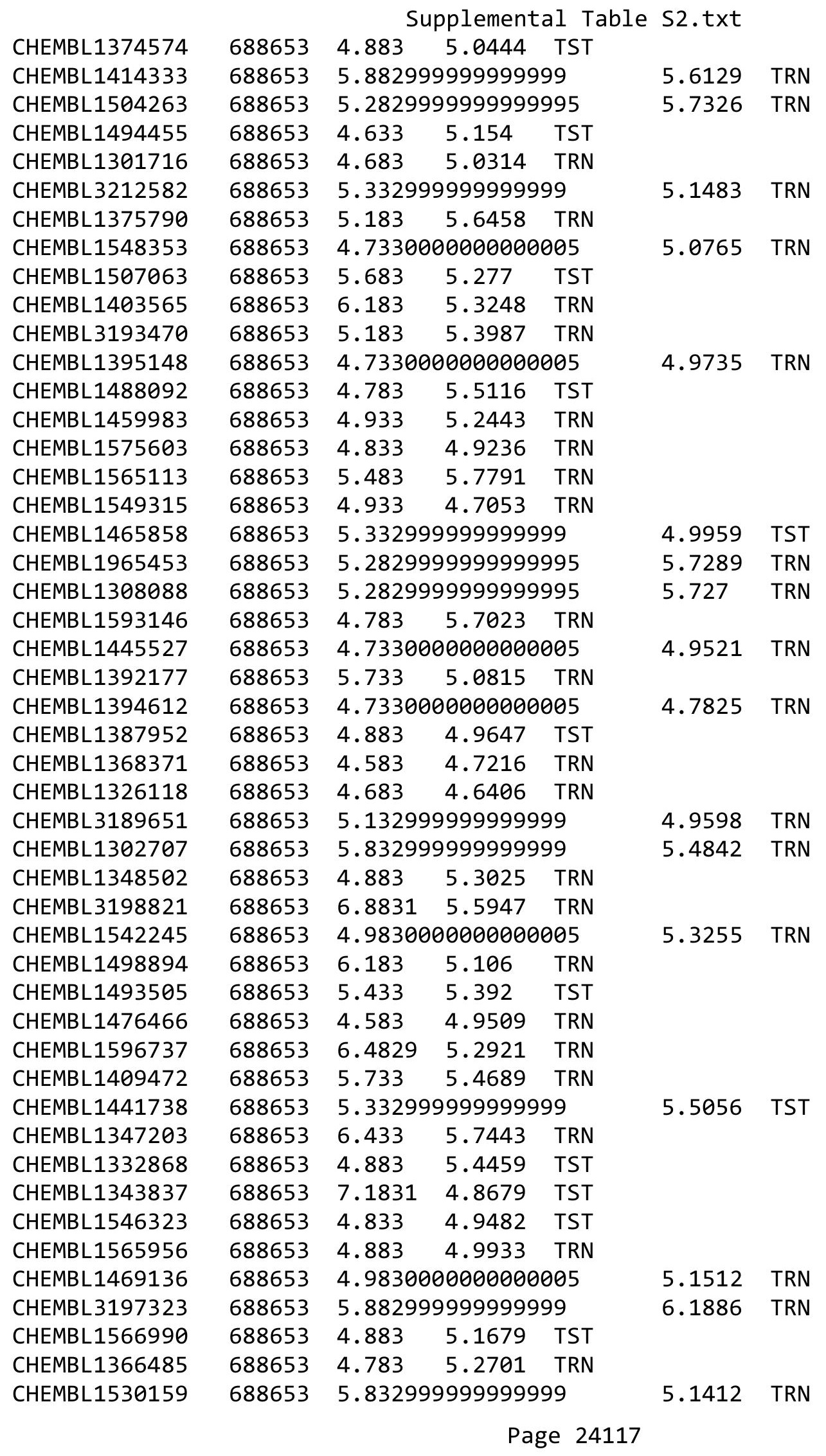




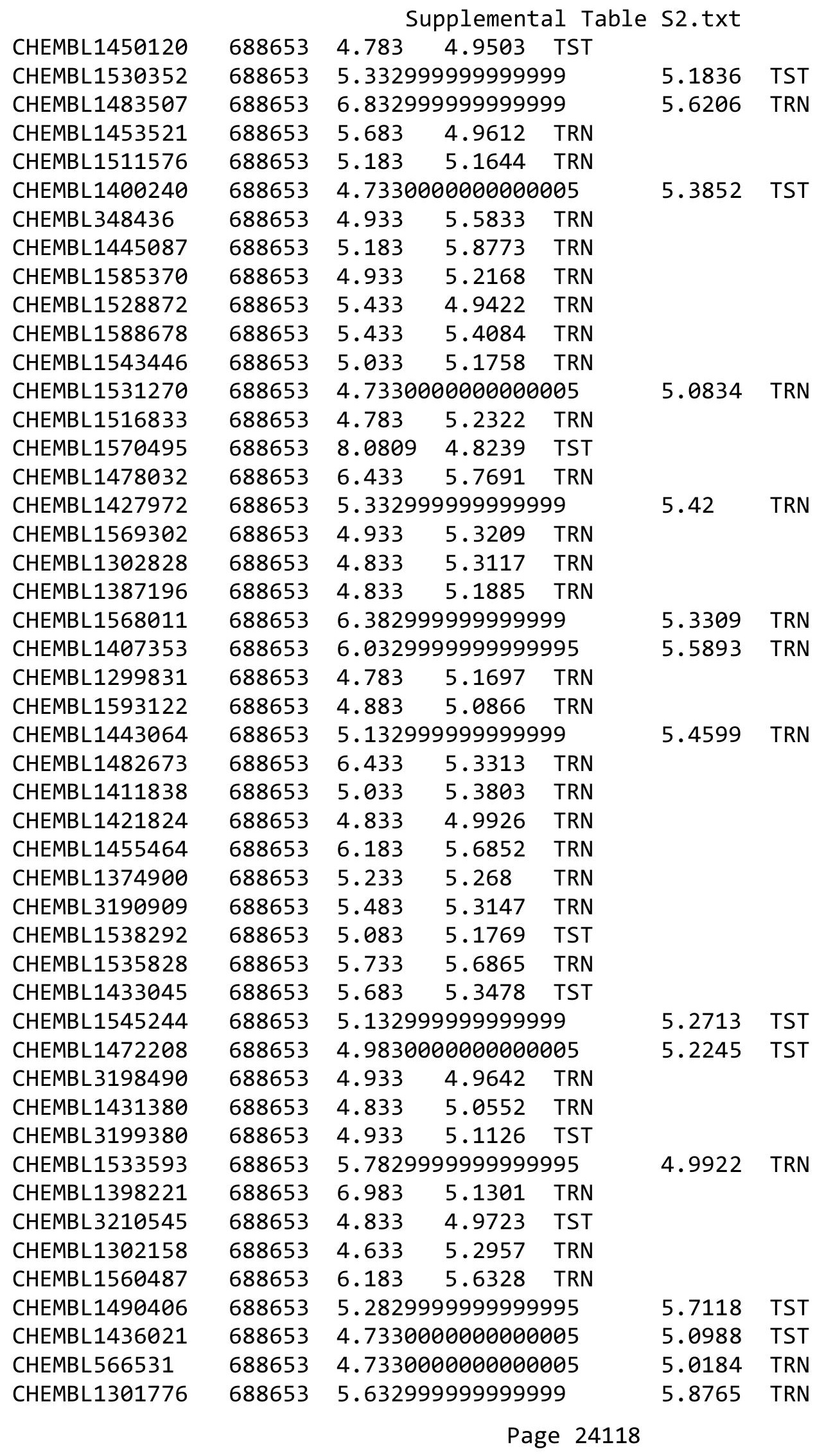




\begin{tabular}{|c|c|c|c|c|c|c|}
\hline & & \multicolumn{5}{|c|}{ Supplemental Table S2.txt } \\
\hline CHEMBL1328918 & 688653 & 4.883 & 5.3026 & TRN & & \\
\hline CHEMBL1483674 & 688653 & 4.833 & 5.294 & TST & & \\
\hline CHEMBL3194361 & 688653 & \multicolumn{3}{|c|}{6.382999999999999} & 5.8523 & TRN \\
\hline CHEMBL1367400 & 688653 & 5.683 & 5.2633 & TRN & & \\
\hline CHEMBL1579867 & 688653 & \multicolumn{3}{|c|}{4.9830000000000005} & 5.6162 & TST \\
\hline CHEMBL1477847 & 688653 & \multicolumn{3}{|c|}{5.132999999999999} & 5.3251 & TRN \\
\hline CHEMBL1512175 & 688653 & 4.883 & 4.7568 & TRN & & \\
\hline CHEMBL1597187 & 688653 & 5.233 & 5.0462 & TRN & & \\
\hline CHEMBL3199829 & 688653 & 5.183 & 5.5405 & TST & & \\
\hline CHEMBL1382867 & 688653 & \multicolumn{3}{|c|}{5.132999999999999} & 5.9535 & TRN \\
\hline CHEMBL1438570 & 688653 & \multicolumn{3}{|c|}{6.332999999999999} & 5.9152 & TRN \\
\hline CHEMBL1428673 & 688653 & 6.183 & 5.5686 & TRN & & \\
\hline CHEMBL1159655 & 688653 & 4.583 & 4.5719 & TST & & \\
\hline CHEMBL1507288 & 688653 & 4.833 & 4.8687 & TRN & & \\
\hline CHEMBL1568666 & 688653 & 6.5501 & 5.7023 & TRN & & \\
\hline CHEMBL1337243 & 688653 & 4.883 & 5.1718 & TRN & & \\
\hline CHEMBL1345801 & 688653 & \multicolumn{3}{|c|}{4.7330000000000005} & 5.2507 & TRN \\
\hline CHEMBL1334187 & 688653 & \multicolumn{3}{|c|}{5.132999999999999} & 5.311 & TRN \\
\hline CHEMBL1380586 & 688653 & 5.683 & 5.336 & TRN & & \\
\hline CHEMBL1585478 & 688653 & 4.933 & 4.8749 & TST & & \\
\hline CHEMBL1503190 & 688653 & 4.833 & 4.7641 & TST & & \\
\hline CHEMBL3197431 & 688653 & \multicolumn{3}{|c|}{7.082999999999999} & 6.0488 & TRN \\
\hline CHEMBL1493865 & 688653 & 4.783 & 5.0284 & TRN & & \\
\hline CHEMBL1474188 & 688653 & 4.783 & 4.7585 & TRN & & \\
\hline CHEMBL3190258 & 688653 & \multicolumn{3}{|c|}{4.7330000000000005} & 5.1787 & TRN \\
\hline CHEMBL3199098 & 688653 & \multicolumn{3}{|c|}{5.582999999999999} & 5.5838 & TRN \\
\hline CHEMBL1426361 & 688653 & \multicolumn{3}{|c|}{4.9830000000000005} & 5.2492 & TRN \\
\hline CHEMBL1529998 & 688653 & \multicolumn{3}{|c|}{5.7829999999999995} & 5.7587 & TRN \\
\hline CHEMBL1470985 & 688653 & 5.433 & 5.3494 & TRN & & \\
\hline CHEMBL1604094 & 688653 & \multicolumn{3}{|c|}{4.7330000000000005} & 4.8491 & TST \\
\hline CHEMBL1546246 & 688653 & \multicolumn{3}{|c|}{5.632999999999999} & 5.5822 & TRN \\
\hline CHEMBL1308467 & 688653 & 5.033 & 5.346 & TRN & & \\
\hline CHEMBL1608921 & 688653 & & & TRN & & \\
\hline CHEMBL600336 & 688653 & \multicolumn{3}{|c|}{6.2829999999999995} & 5.8452 & TRN \\
\hline CHEMBL3189405 & 688653 & \multicolumn{3}{|c|}{5.632999999999999} & 5.0678 & TST \\
\hline CHEMBL1584557 & 688653 & 7.2328 & 5.9391 & TST & & \\
\hline CHEMBL1428641 & 688653 & 4.783 & 5.5369 & TRN & & \\
\hline CHEMBL1538643 & 688653 & 4.633 & 4.6265 & TST & & \\
\hline CHEMBL1613560 & 688653 & \multicolumn{3}{|c|}{5.832999999999999} & 5.7068 & TRN \\
\hline CHEMBL1467190 & 688653 & \multicolumn{3}{|c|}{4.7330000000000005} & 4.8282 & TST \\
\hline CHEMBL1442084 & 688653 & \multicolumn{3}{|c|}{6.0329999999999995} & 5.9764 & TRN \\
\hline CHEMBL1516908 & 688653 & 6.183 & \multicolumn{3}{|c|}{5.7620000000000005} & TRN \\
\hline CHEMBL1425678 & 688653 & 5.433 & 5.2983 & TRN & & \\
\hline CHEMBL3197889 & 688653 & 4.933 & 4.9641 & TRN & & \\
\hline CHEMBL1508375 & 688653 & 6.0 & 5.3484 & TRN & & \\
\hline CHEMBL1374535 & 688653 & 5.983 & 5.8743 & TRN & & \\
\hline CHEMBL1369352 & 688653 & 4.883 & 5.4719 & TRN & & \\
\hline CHEMBL407501 & 688653 & 5.233 & 5.4158 & TRN & & \\
\hline
\end{tabular}




\begin{tabular}{|c|c|c|c|c|c|c|}
\hline & & \multicolumn{5}{|c|}{ Supplemental Table S2.txt } \\
\hline CHEMBL1311874 & 688653 & 4.833 & 5.3868 & TST & & \\
\hline CHEMBL1482798 & 688653 & 4.783 & 4.9925 & TRN & & \\
\hline CHEMBL1581425 & 688653 & 4.633 & 4.9314 & TST & & \\
\hline CHEMBL1578404 & 688653 & 5.033 & 5.5974 & TRN & & \\
\hline CHEMBL1328517 & 688653 & \multicolumn{3}{|c|}{4.9830000000000005} & 5.405 & TRN \\
\hline CHEMBL1580184 & 688653 & 4.833 & 5.3618 & TRN & & \\
\hline CHEMBL1524792 & 688653 & 4.883 & 5.2121 & TST & & \\
\hline CHEMBL1497812 & 688653 & 4.583 & 5.1102 & TST & & \\
\hline CHEMBL1471057 & 688653 & 5.183 & 5.5477 & TRN & & \\
\hline CHEMBL1479169 & 688653 & \multicolumn{3}{|c|}{5.7829999999999995} & 5.5499 & TRN \\
\hline CHEMBL1413432 & 688653 & 5.733 & 5.2262 & TRN & & \\
\hline CHEMBL1388701 & 688653 & 4.833 & 5.2404 & TRN & & \\
\hline CHEMBL1538438 & 688653 & 5.033 & 5.0711 & TRN & & \\
\hline CHEMBL1343828 & 688653 & 5.033 & 5.2328 & TRN & & \\
\hline CHEMBL1550561 & 688653 & \multicolumn{3}{|c|}{4.7330000000000005} & 5.2128 & TRN \\
\hline CHEMBL3199559 & 688653 & 4.833 & 4.8353 & TST & & \\
\hline CHEMBL3191527 & 688653 & 5.183 & 5.6457 & TRN & & \\
\hline CHEMBL1319525 & 688653 & 4.933 & 5.5582 & TST & & \\
\hline CHEMBL1311291 & 688653 & \multicolumn{3}{|c|}{5.132999999999999} & 4.8194 & TRN \\
\hline CHEMBL3211512 & 688653 & 4.933 & 5.5795 & TRN & & \\
\hline CHEMBL1441560 & 688653 & \multicolumn{3}{|c|}{5.882999999999999} & 9 & TRN \\
\hline CHEMBL3189963 & 688653 & \multicolumn{3}{|c|}{5.7829999999999995} & & TST \\
\hline CHEMBL1481061 & 688653 & 4.633 & 5.1721 & TST & & \\
\hline CHEMBL1441635 & 688653 & 4.883 & 5.1531 & TRN & & \\
\hline CHEMBL1517869 & 688653 & 5.733 & 5.305 & TRN & & \\
\hline CHEMBL1541062 & 688653 & 4.9 & 5.0523 & TRN & & \\
\hline CHEMBL1542137 & 688653 & 4.6 & 5.1427 & TRN & & \\
\hline CHEMBL1409776 & 688653 & 5.233 & 5.7598 & TRN & & \\
\hline CHEMBL1455934 & 688653 & 4.583 & 5.1185 & TRN & & \\
\hline CHEMBL1379675 & 688653 & \multicolumn{3}{|c|}{5.332999999999999} & 5.0933 & TRN \\
\hline CHEMBL1964467 & 688653 & 6.183 & \multicolumn{3}{|c|}{5.6160000000000005} & TRN \\
\hline CHEMBL 3213880 & 688653 & 4.883 & \multicolumn{3}{|c|}{5.497999999999999} & TRN \\
\hline CHEMBL 3194438 & 688653 & \multicolumn{3}{|c|}{5.332999999999999} & 5.1922 & TRN \\
\hline CHEMBL1309858 & 688653 & 5.683 & 5.2374 & TST & & \\
\hline CHEMBL1312443 & 688653 & 5.683 & 5.4538 & TRN & & \\
\hline CHEMBL1499266 & 688653 & 5.2 & 5.0596 & TRN & & \\
\hline CHEMBL1367179 & 688653 & & 5.1095 & TRN & & \\
\hline CHEMBL1301561 & 688653 & 5.233 & 5.0452 & TRN & & \\
\hline CHEMBL1475193 & 688653 & 4.583 & 4.5399 & TST & & \\
\hline CHEMBL1425227 & 688653 & \multicolumn{3}{|c|}{5.2829999999999995} & 5.1404 & TR \\
\hline CHEMBL1595912 & 688653 & 4.633 & 5.0633 & TST & & \\
\hline CHEMBL1305196 & 688653 & \multicolumn{3}{|c|}{4.7330000000000005} & 5.1725 & 3 \\
\hline CHEMBL1526223 & 688653 & 4.833 & 5.1933 & TST & & \\
\hline CHEMBL1353144 & 688653 & \multicolumn{3}{|c|}{5.832999999999999} & 5.6994 & $T_{10 \mathrm{I}}$ \\
\hline CHEMBL1533114 & 688653 & 5.483 & 5.6861 & TRN & & \\
\hline CHEMBL1488263 & 688653 & 5.733 & 5.444 & TRN & & \\
\hline CHEMBL1542576 & 688653 & \multicolumn{3}{|c|}{6.5329999999999995} & 5.7922 & IRIV \\
\hline CHEMBL1429784 & 688653 & \multicolumn{3}{|c|}{5.2829999999999995} & 5.2431 & TST \\
\hline
\end{tabular}




\begin{tabular}{|c|c|c|c|c|c|c|}
\hline \multirow[b]{2}{*}{ CHEMBL1510331 } & \multirow[b]{2}{*}{688653} & \multicolumn{5}{|c|}{ Supplemental Table S2.txt } \\
\hline & & \multicolumn{3}{|c|}{5.3634 TRN } & & \\
\hline CHEMBL1597854 & 688653 & 4.833 & 5.1438 & TRN & & \\
\hline CHEMBL1541480 & 688653 & \multicolumn{3}{|c|}{4.7330000000000005} & 5.2863 & TST \\
\hline CHEMBL1469143 & 688653 & \multirow{2}{*}{\multicolumn{3}{|c|}{$\begin{array}{ll}4.783 & 5.0436 \\
5.5329999999999995\end{array}$}} & & \\
\hline CHEMBL1414767 & 688653 & & & & 5.2316 & TRN \\
\hline CHEMBL1579271 & 688653 & \multicolumn{3}{|c|}{5.132999999999999} & 5.6657 & TRN \\
\hline CHEMBL1582298 & 688653 & \multicolumn{3}{|c|}{5.132999999999999} & 5.1721 & TRN \\
\hline CHEMBL585622 & 688653 & 4.633 & 4.7825 & TRN & & \\
\hline CHEMBL1377384 & 688653 & \multicolumn{3}{|c|}{6.632999999999999} & 5.8492 & TRN \\
\hline CHEMBL402053 & 688653 & 4.833 & 5.1001 & TRN & & \\
\hline CHEMBL1565933 & 688653 & \multicolumn{3}{|c|}{4.7330000000000005} & 5.2464 & TRN \\
\hline CHEMBL1515228 & 688653 & \multicolumn{3}{|c|}{5.2829999999999995} & 4.9492 & TRN \\
\hline CHEMBL1577230 & 688653 & 5.8 & 4.9178 & TRN & & \\
\hline CHEMBL1582061 & 688653 & 4.883 & \multicolumn{3}{|c|}{5.1770000000000005} & TRN \\
\hline CHEMBL1518283 & 688653 & 4.783 & 5.2738 & TST & & \\
\hline CHEMBL1451983 & 688653 & 4.783 & 5.1678 & TRN & & \\
\hline CHEMBL1381057 & 688653 & \multicolumn{3}{|c|}{2999999999999} & 5.0335 & TRN \\
\hline CHEMBL1494468 & 688653 & 5.183 & 5.4108 & TRN & & \\
\hline CHEMBL1459930 & 688653 & 6.0 & \multicolumn{3}{|c|}{5.292999999999999} & TRN \\
\hline CHEMBL1765369 & 688653 & 5.483 & 5.1827 & TST & & \\
\hline CHEMBL 3145378 & 688653 & 4.633 & 5.6782 & TRN & & \\
\hline CHEMBL3192474 & 688653 & \multicolumn{3}{|c|}{4.7330000000000005} & 4.9406 & TRN \\
\hline CHEMBL1306977 & 688653 & \multicolumn{3}{|c|}{5.632999999999999} & 5.8641 & TRN \\
\hline CHEMBL1531715 & 688653 & 5.033 & 5.114 & TST & & \\
\hline CHEMBL1381350 & 688653 & 4.933 & 4.947 & TRN & & \\
\hline CHEMBL1470253 & 688653 & 4.833 & 5.0055 & TRN & & \\
\hline CHEMBL1437528 & 688653 & 5.183 & 4.9431 & TST & & \\
\hline CHEMBL1333418 & 688653 & 4.783 & 4.9089 & TRN & & \\
\hline CHEMBL1351908 & 688653 & 4.933 & 6.7091 & TRN & & \\
\hline CHEMBL1516339 & 688653 & 5.433 & 6.0387 & TRN & & \\
\hline CHEMBL1509804 & 688653 & 4.833 & 5.5786 & TST & & \\
\hline CHEMBL1545569 & 688653 & \multicolumn{3}{|c|}{5.132999999999999} & 5.246 & TRN \\
\hline CHEMBL1581762 & 688653 & \multicolumn{3}{|c|}{4.9830000000000005} & 4.8757 & TST \\
\hline CHEMBL 270297 & 688653 & \multicolumn{3}{|c|}{5.882999999999999} & 5.5992 & TRN \\
\hline CHEMBL 3213280 & 688653 & \multicolumn{3}{|c|}{4.7330000000000005} & 5.2282 & TST \\
\hline CHEMBL1494181 & 688653 & \multicolumn{3}{|c|}{6.582999999999999} & 5.7482 & TRN \\
\hline CHEMBL1313313 & 688653 & 6.3829 & 99999999 & & 5.3072 & TRN \\
\hline CHEMBL 2000338 & 688653 & 5.3829 & 99999999 & & 5.8696 & TRN \\
\hline CHEMBL1429841 & 688653 & 5.483 & 6.0449 & TRN & & \\
\hline CHEMBL1568779 & 688653 & 5.3829 & 99999999 & 99 & 5.3623 & TRN \\
\hline CHEMBL3195686 & 688653 & 4.833 & 5.1663 & TST & & \\
\hline CHEMBL1612470 & 688653 & 5.1329 & 99999999 & & 5.3975 & TST \\
\hline CHEMBL1482683 & 688653 & 5.683 & 5.6996 & TRN & & \\
\hline CHEMBL1358032 & 688653 & 4.583 & 5.0941 & TRN & & \\
\hline CHEMBL1526182 & 688653 & 5.433 & 5.2312 & TRN & & \\
\hline CHEMBL 1357490 & 688653 & 4.583 & 4.6683 & TRN & & \\
\hline CHEMBL1430820 & 688653 & 5.8829 & 99999999 & & 5.5665 & TRN \\
\hline CHEMBL1347881 & 688653 & 4.833 & 5.0494 & TRN & & \\
\hline
\end{tabular}




\begin{tabular}{|c|c|c|c|c|c|c|}
\hline \multicolumn{7}{|c|}{ Supplemental Table S2.txt } \\
\hline CHEMBL1537425 & 688653 & 5.433 & 5.9663 & TRN & & \\
\hline CHEMBL1534177 & 688653 & 4.833 & 5.376 & TRN & & \\
\hline CHEMBL1423429 & 688653 & 5.033 & 5.0212 & TRN & & \\
\hline CHEMBL1342156 & 688653 & 4.883 & \multicolumn{3}{|c|}{5.2170000000000005} & $\mathrm{~T}$ \\
\hline CHEMBL1329798 & 688653 & 7.3325 & 6.7471 & TRN & & \\
\hline CHEMBL1485948 & 688653 & \multicolumn{3}{|c|}{5.5329999999999995} & 4.9546 & TI \\
\hline CHEMBL1599370 & 688653 & 5.233 & 5.3004 & TRN & & \\
\hline CHEMBL1395838 & 688653 & \multicolumn{3}{|c|}{6.0329999999999995} & 5.6506 & 11 \\
\hline CHEMBL 3193248 & 688653 & 4.783 & 5.2281 & TRN & & \\
\hline CHEMBL1309826 & 688653 & 4.833 & 4.8655 & TRN & & \\
\hline CHEMBL1465410 & 688653 & 4.783 & 5.3246 & TST & & \\
\hline CHEMBL1549650 & 588653 & \multicolumn{3}{|c|}{4.7330000000000005} & 4.7449 & TRN \\
\hline CHEMBL 3190414 & 688653 & \multicolumn{3}{|c|}{5.882999999999999} & 5.5984 & 17 \\
\hline CHEMBL1460250 & 688653 & \multicolumn{3}{|c|}{5.2829999999999995} & 5.3244 & TRN \\
\hline CHEMBL1584630 & 688653 & \multicolumn{3}{|c|}{5.332999999999999} & 5.1983 & \\
\hline CHEMBL1548033 & 688653 & 4.833 & 4.9138 & TRN & & \\
\hline CHEMBL1531600 & 688653 & 4.933 & 5.1434 & TRN & & \\
\hline CHEMBL1966316 & 688653 & 5.033 & 5.2283 & TRN & & \\
\hline CHEMBL3 & 688 & \multicolumn{3}{|c|}{4.7330000000000005} & 5.1373 & \\
\hline CHEMBL1 & 688 & 4.783 & 5.0029 & TRN & & \\
\hline CHEMBL1483494 & 688653 & 4.883 & 4.6512 & TST & & \\
\hline CHEMBL1568877 & 688653 & 5.933 & 5.3483 & TRN & & \\
\hline CHEMBL1564777 & 688653 & \multicolumn{3}{|c|}{6.0329999999999995} & 5.5768 & \\
\hline CHEMBL1 & 688 & \multicolumn{3}{|c|}{$5.733 \quad 5.33700000$} & 01 & \\
\hline CHEMBL & 688653 & \multirow{2}{*}{\multicolumn{3}{|c|}{$\begin{array}{lll}4.783 & 4.9637 & \text { TRN } \\
4.7330000000000005\end{array}$}} & & \\
\hline CHEMBL1608632 & 688653 & & & & 5.0515 & $T$ \\
\hline CHEMBL1613418 & 688653 & \multicolumn{3}{|c|}{$\begin{array}{lll}4.583 & 5.0988 & \text { TRN }\end{array}$} & & \\
\hline CHEMBL 1440556 & 688653 & 4.833 & 5.2264 & TRN & & \\
\hline CHEMBL & $68 \varepsilon$ & \multicolumn{3}{|c|}{5.832999999999999} & 5.425 & \\
\hline CHEMBL1 & 688653 & 4.833 & 4.9392 & TRN & & \\
\hline CHEMBL1310715 & 688653 & \multicolumn{3}{|c|}{5.382999999999999} & 5.0169 & TRN \\
\hline CHEMBL1610169 & 688653 & \multicolumn{3}{|c|}{5.7829999999999995} & 5.3065 & \\
\hline CHEMBL1337226 & 688 & & 4.8654 & TST & & \\
\hline CHEMBL: & 53 & 5 . & 5.2767 & TRN & & \\
\hline CHEMBL: & 688 & 4.8 & 5.223 & TRN & & \\
\hline CHEMBL1501064 & 688653 & 6.2 & 5.4394 & TRN & & \\
\hline CHEMBL3212709 & 688653 & 4.833 & 5.1064 & TRN & & \\
\hline CHEMBL3 & & & 5.39 & TRN & & \\
\hline CHEMBL1 & $68 \varepsilon$ & 4.633 & 5.4679 & TST & & \\
\hline CHEMBL1363396 & 688653 & \multicolumn{3}{|c|}{5.5329999999999995} & 5.1469 & $T$ \\
\hline CHEMBL1506434 & 688653 & 4.833 & 5.032 & TRN & & \\
\hline CHEMBL1343259 & 688653 & \multicolumn{3}{|c|}{4.7330000000000005} & $5 . €$ & TST \\
\hline CHEMBL1999768 & 688653 & \multicolumn{3}{|c|}{4.7330000000000005} & 4.7572 & \\
\hline CHEMBL1341504 & 688653 & 4.883 & 5.0432 & TRN & & \\
\hline CHEMBL1345220 & 688653 & 5.933 & 5.0668 & TRN & & \\
\hline CHEMBL1315605 & 688653 & 4.583 & 4.812 & TRN & & \\
\hline CHEMBL1541170 & 688653 & \multicolumn{3}{|c|}{5.382999999999999} & 5.4 & 10 \\
\hline CHEMBL1351639 & 688653 & 5.5329 & 99999999 & 995 & 5.3551 & \\
\hline
\end{tabular}




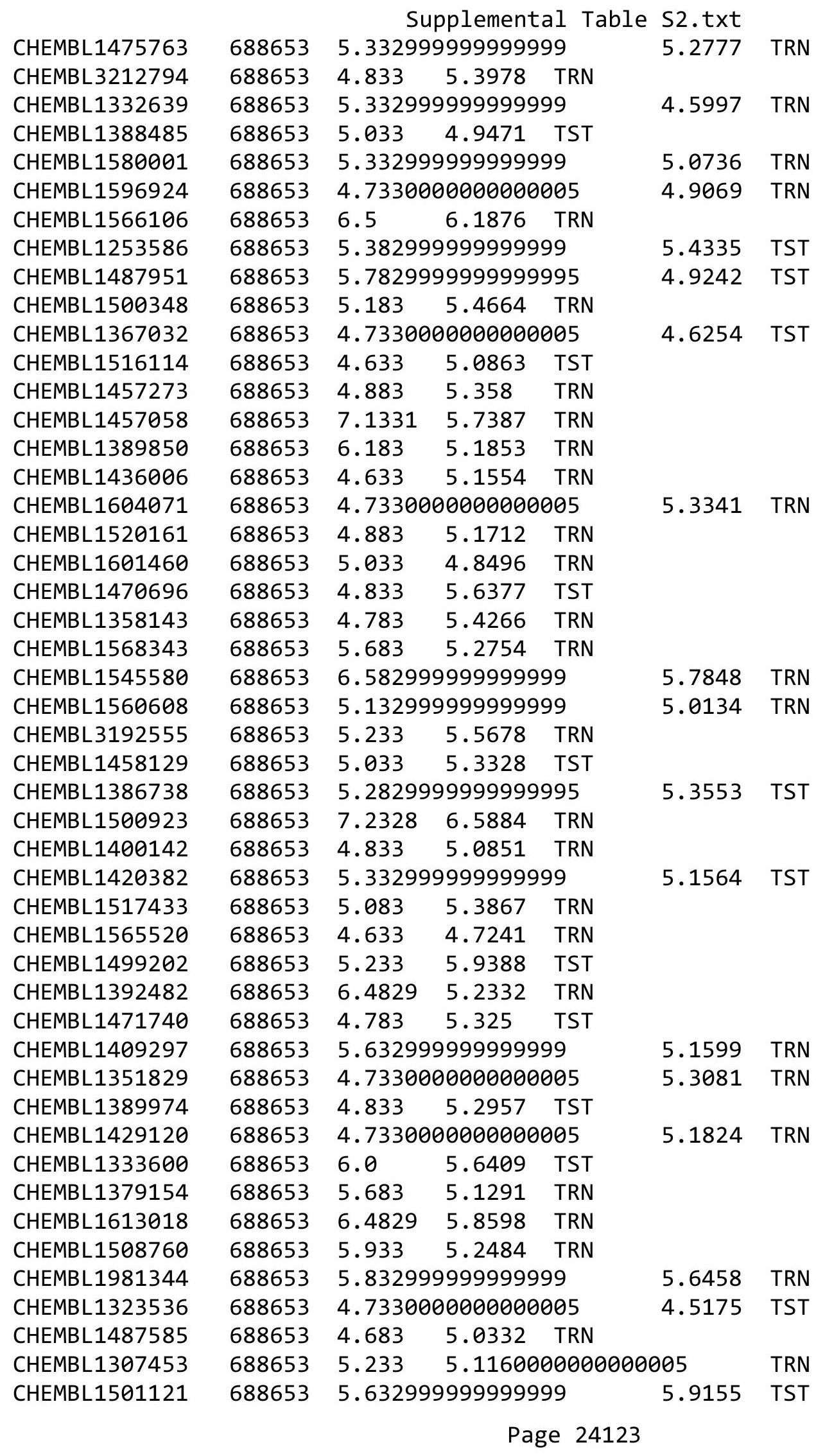




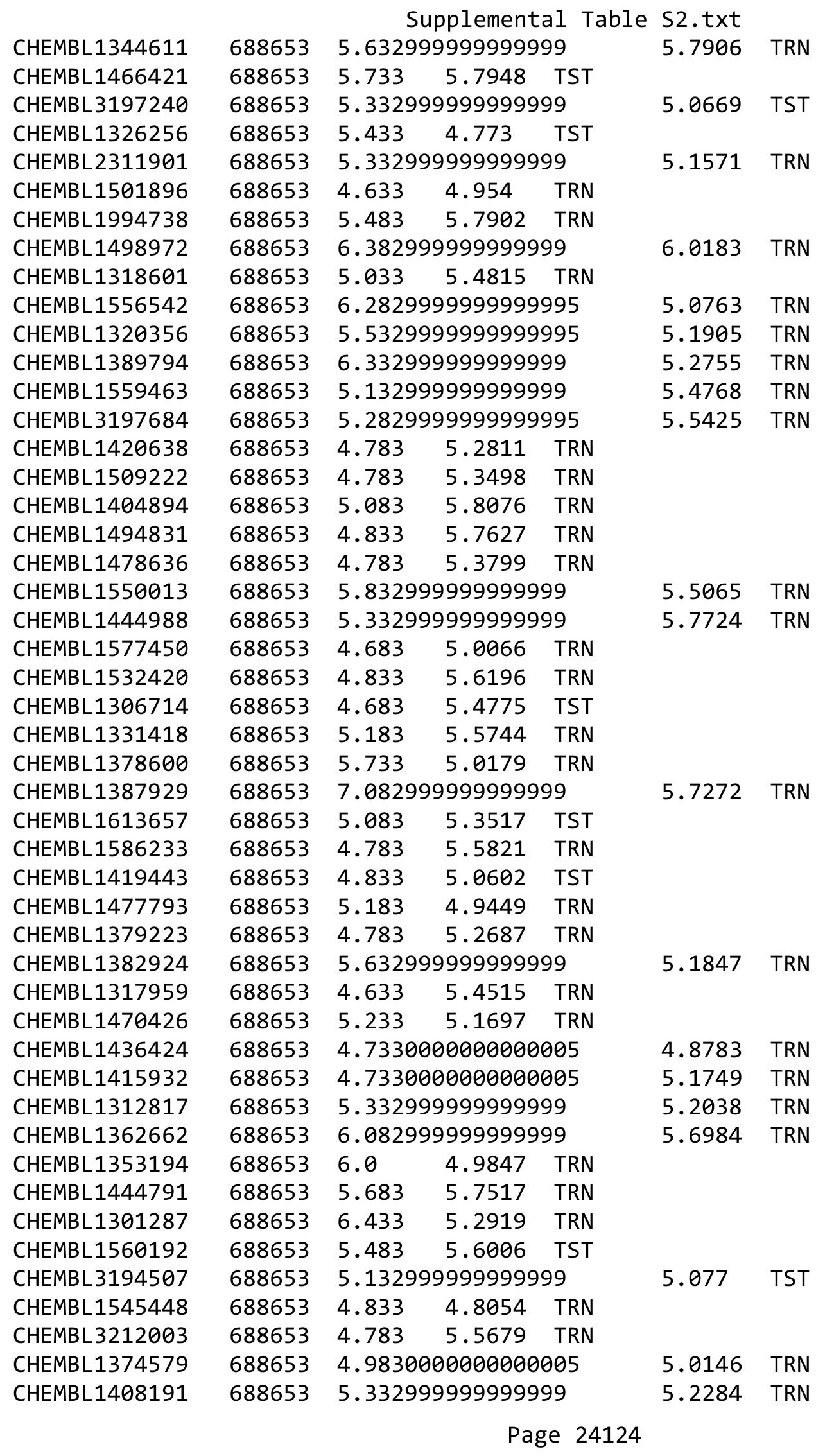




\begin{tabular}{|c|c|c|c|c|c|c|}
\hline \multirow[b]{2}{*}{ CHEMBL1371675 } & & \multicolumn{5}{|c|}{ Supplemental Table S2.txt } \\
\hline & 688653 & 4.833 & 5.2614 & TRN & & \\
\hline CHEMBL1606085 & 688653 & 5.683 & 5.2856 & TRN & & \\
\hline CHEMBL1520332 & 688653 & \multicolumn{3}{|c|}{5.2829999999999995} & 5.3042 & TRA \\
\hline CHEMBL1536427 & 688653 & \multicolumn{3}{|c|}{5.382999999999999} & 5.3723 & TRN \\
\hline CHEMBL 3213188 & 688653 & \multicolumn{3}{|c|}{4.9830000000000005} & 5.2629 & TRN \\
\hline CHEMBL1456654 & 688653 & \multicolumn{3}{|c|}{5.7829999999999995} & 5.8201 & TRN \\
\hline CHEMBL1314190 & 688653 & 4.583 & 5.3839 & TST & & \\
\hline CHEMBL3193809 & 688653 & 5.683 & 5.4588 & TRN & & \\
\hline CHEMBL1427531 & 688653 & \multicolumn{3}{|c|}{4.7330000000000005} & 5.4099 & TST \\
\hline CHEMBL1470829 & 688653 & 5.433 & 5.3172 & TRN & & \\
\hline CHEMBL1450979 & 688653 & 5.233 & 5.4632 & TRN & & \\
\hline CHEMBL1543215 & 688653 & 5.433 & 5.3442 & TRN & & \\
\hline CHEMBL1471159 & 688653 & \multicolumn{3}{|c|}{4.7330000000000005} & 4.7001 & TRA \\
\hline CHEMBL1523083 & 688653 & 5.033 & 5.0796 & TRN & & \\
\hline CHEMBL1534994 & 688653 & 4.633 & 4.9881 & TRN & & \\
\hline CHEMBL1499883 & 688653 & \multicolumn{3}{|c|}{5.7829999999999995} & 6.0135 & TRN \\
\hline CHEMBL1314557 & 688653 & 5.033 & 5.1067 & TST & & \\
\hline CHEMBL1366559 & 688653 & 5.233 & 5.2576 & TRN & & \\
\hline CHEMBL1357104 & 688653 & \multicolumn{3}{|c|}{4.9830000000000005} & 4.897 & TRN \\
\hline CHEMBL1313698 & 688653 & 5.683 & 5.3827 & TRN & & \\
\hline CHEMBL3196106 & 688653 & 5.083 & 5.3405 & TRN & & \\
\hline CHEMBL1528314 & 688653 & 4.833 & 4.8367 & TRN & & \\
\hline CHEMBL1551114 & 688653 & 4.883 & 5.1787 & TRN & & \\
\hline CHEMBL1595774 & 688653 & \multicolumn{3}{|c|}{5.7829999999999995} & 5.7866 & TRA \\
\hline CHEMBL1414183 & 688653 & 5.733 & 5.3755 & TRN & & \\
\hline CHEMBL1379003 & 688653 & \multicolumn{3}{|c|}{5.132999999999999} & 5.1677 & TRN \\
\hline CHEMBL1498788 & 688653 & 5.233 & 5.5333 & TST & & \\
\hline CHEMBL1461903 & 688653 & 4.933 & 5.2726 & TRN & & \\
\hline CHEMBL1351433 & 688653 & \multicolumn{3}{|c|}{6.2829999999999995} & 5.9148 & TRN \\
\hline CHEMBL1310221 & 688653 & \multicolumn{3}{|c|}{5.332999999999999} & 5.3856 & TRN \\
\hline CHEMBL1364803 & 688653 & \multicolumn{3}{|c|}{5.632999999999999} & 5.2812 & TRN \\
\hline CHEMBL1580951 & 688653 & 4.683 & 4.8924 & TRN & & \\
\hline CHEMBL1534196 & 688653 & \multicolumn{3}{|c|}{5.582999999999999} & 5.0485 & TRN \\
\hline CHEMBL1583149 & 688653 & 4.783 & 5.6622 & TST & & \\
\hline CHEMBL1299663 & 688653 & 5.083 & 5.3752 & TST & & \\
\hline CHEMBL1409203 & 688653 & 5.233 & 5.1144 & TRN & & \\
\hline CHEMBL1538864 & 688653 & 4.833 & 5.0184 & TRN & & \\
\hline CHEMBL1380100 & 688653 & 5.983 & 5.7686 & TRN & & \\
\hline CHEMBL1396642 & 688653 & \multicolumn{3}{|c|}{4.9830000000000005} & 4.9647 & TRA \\
\hline CHEMBL1535321 & 688653 & 4.633 & 4.8102 & TRN & & \\
\hline CHEMBL1595502 & 688653 & 5.433 & 5.0062 & TRN & & \\
\hline CHEMBL1552343 & 688653 & 4.883 & 5.6344 & TRN & & \\
\hline CHEMBL601137 & 688653 & 5.033 & 5.5226 & TST & & \\
\hline CHEMBL1376274 & 688653 & 4.683 & 5.0392 & TRN & & \\
\hline CHEMBL1351533 & 688653 & 4.633 & 4.9881 & TRN & & \\
\hline CHEMBL1452809 & 688653 & \multicolumn{3}{|c|}{4.7330000000000005} & 5.0027 & TRN \\
\hline CHEMBL1504208 & 688653 & 4.85 & 5.245 & TST & & \\
\hline CHEMBL1974389 & 688653 & 4.633 & 4.8108 & TRN & & \\
\hline
\end{tabular}




\begin{tabular}{|c|c|c|c|c|c|c|}
\hline & & \multicolumn{4}{|c|}{ Supplemental Table S2.txt } & \\
\hline CHEMBL1386061 & 688653 & \multicolumn{4}{|c|}{5.832999999999999} & TRN \\
\hline CHEMBL1517284 & 688653 & \multicolumn{3}{|c|}{6.632999999999999} & .9531 & \\
\hline CHEMBL1384668 & 688653 & 5.433 & 5.1662 & TRN & & \\
\hline CHEMBL1428354 & 688653 & 4.883 & 4.6543 & TRN & & \\
\hline CHEMBL1506252 & 688653 & \multicolumn{3}{|c|}{5.7829999999999995} & 5.1281 & \\
\hline CHEMBL1403202 & 688653 & 5.183 & 5.1889 & TST & & \\
\hline CHEMBL1524038 & 688653 & 5.733 & 5.5649 & TRN & & \\
\hline CHEMBL1305364 & 688653 & \multicolumn{3}{|c|}{4.7330000000000005} & 4.9737 & \\
\hline CHEMBL1408307 & 688653 & \multicolumn{3}{|c|}{5.132999999999999} & 6.0285 & \\
\hline CHEMBL1540914 & 688653 & \multicolumn{3}{|c|}{6.132999999999999} & 5.0448 & \\
\hline CHEMBL1588895 & 688653 & 4.883 & 4.8597 & TRN & & \\
\hline CHEMBL1599138 & 688653 & 4.833 & 5.0271 & TRN & & \\
\hline CHEMBL1418012 & 688653 & \multicolumn{3}{|c|}{5.132999999999999} & 5.1287 & \\
\hline CHEMBL1458464 & 688653 & \multicolumn{3}{|c|}{4.9830000000000005} & 4.9335 & \\
\hline CHEMBL1369849 & 688653 & \multicolumn{3}{|c|}{5.2829999999999995} & 5.5236 & \\
\hline CHEMBL1373064 & 688653 & \multicolumn{3}{|c|}{5.382999999999999} & 5.5495 & \\
\hline CHEMBL1460740 & 688653 & 4.833 & 5.4044 & TRN & & \\
\hline CHEMBL1600848 & 688653 & \multirow{2}{*}{\multicolumn{3}{|c|}{$\begin{array}{lll}5.683 & 5.5711 \\
4.7330000000000005\end{array}$}} & & \\
\hline CHEMBL1608219 & 688653 & & & & & \\
\hline CHEMBL1470064 & 688653 & 4.783 & 4.9094 & TRN & & \\
\hline CHEMBL1452998 & 688653 & \multicolumn{3}{|c|}{5.7829999999999995} & 5.1021 & \\
\hline CHEMBL1544122 & 688653 & \multicolumn{3}{|c|}{6.332999999999999} & 725 & \\
\hline CHEMBL1979665 & 688653 & 5.083 & 5.1041 & TRN & & \\
\hline CHEMBL1480817 & 688653 & 5.483 & 5.1641 & TRN & & \\
\hline CHEMBL1545621 & 688653 & \multicolumn{3}{|c|}{5.2829999999999995} & 246 & \\
\hline CHEMBL1356313 & 688653 & \multicolumn{3}{|c|}{5.7829999999999995} & 5.4914 & \\
\hline CHEMB & 688 & 7.0329 & 5.5411 & TRN & & \\
\hline CHEMBL1457855 & 688653 & \multicolumn{3}{|c|}{4.7330000000000005} & 4.7873 & \\
\hline CHEMBL1610912 & 688653 & 4.683 & 4.7728 & TST & & \\
\hline CHEMBL1504282 & 688653 & 4.833 & 4.9886 & TRN & & \\
\hline CHEMBL1363308 & 688653 & \multicolumn{3}{|c|}{5.832999999999999} & (1) & \\
\hline CHEMBL160 & 688653 & \multicolumn{3}{|c|}{4.7330000000000005} & 875 & \\
\hline CHEMBL1346114 & 688653 & \multicolumn{3}{|c|}{6.332999999999999} & 5.7615 & \\
\hline CHEMBL1566148 & 688653 & 6.233 & 5.476 & TRN & & \\
\hline CHEMBL1328819 & 688653 & \multirow{2}{*}{\multicolumn{3}{|c|}{$\begin{array}{lrr}6.683 & 5.7294 \\
5.882999999999999\end{array}$}} & & \\
\hline CHEMBL1308955 & 688653 & & & & 5.2583 & \\
\hline CHEMBL1423707 & 688653 & 5.083 & 4.9289 & TRN & & \\
\hline CHEMBL1401151 & 688653 & 4.833 & 5.1969 & TRN & & \\
\hline CHEMBL1391898 & 688653 & 5.033 & 4.9945 & TRN & & \\
\hline CHEMBL1570760 & 688653 & 5.3829 & 9999999 & & 4.9439 & 11 \\
\hline CHEMBL1383081 & 688653 & 5.3329 & 9999999 & & 5.3104 & \\
\hline CHEMBL1341999 & 688653 & 4.633 & 4.7081 & TRN & & \\
\hline CHEMBL1551247 & 688653 & 4.633 & 5.2074 & TRN & & \\
\hline CHEMBL1484245 & 688653 & 4.883 & 5.2637 & TST & & \\
\hline CHEMBL1391585 & 688653 & 4.833 & 5.394 & TRN & & \\
\hline CHEMBL1402048 & 688653 & 4.883 & 5.0988 & TST & & \\
\hline CHEMBL1362754 & 688653 & 5.2829 & 7999999 & 995 & 5.5 & \\
\hline CHEMBL1533357 & 688653 & 4.683 & 5.1237 & TST & & \\
\hline
\end{tabular}




\begin{tabular}{|c|c|c|c|c|c|c|c|}
\hline \multirow{3}{*}{$\begin{array}{l}\text { CHEMBL3193066 } \\
\text { CHEMBL1439006 }\end{array}$} & \multicolumn{6}{|c|}{ Supplemental T } & \multirow{4}{*}{ TRN } \\
\hline & 688653 & 5.083 & 5.4118 & TRN & \multirow{2}{*}{\multicolumn{2}{|c|}{5.872000000000001}} & \\
\hline & 688653 & \multicolumn{3}{|c|}{6.582999999999999} & & & \\
\hline CHEMBL1380802 & 688653 & 4.933 & 5.3869 & TRN & & & \\
\hline CHEMBL1443790 & 688653 & 4.783 & 5.0981 & TRN & & & \\
\hline CHEMBL1502354 & 688653 & \multicolumn{3}{|c|}{5.832999999999999} & 5.2657 & TRN & \\
\hline CHEMBL1397120 & 688653 & 5.933 & 5.735 & TRN & & & \\
\hline CHEMBL1339526 & 688653 & 4.933 & 5.1653 & TST & & & \\
\hline CHEMBL1369483 & 688653 & 5.983 & 5.8744 & TRN & & & \\
\hline CHEMBL1409509 & 688653 & \multicolumn{3}{|c|}{5.7829999999999995} & 5.495 & TRN & \\
\hline CHEMBL1552887 & 688653 & 5.183 & 4.8319 & TRN & & & \\
\hline CHEMBL1555217 & 688653 & 5.483 & 5.1406 & TRN & & & \\
\hline CHEMBL1425872 & 688653 & 6.4829 & 5.7088 & TRN & & & \\
\hline CHEMBL1463724 & 688653 & \multicolumn{3}{|c|}{4.9830000000000005} & 5.1217 & TRN & \\
\hline CHEMBL1324593 & 688653 & \multicolumn{3}{|c|}{4.7330000000000005} & 4.806 & TRN & \\
\hline CHEMBL 3209105 & 688653 & \multicolumn{3}{|c|}{6.582999999999999} & 5.3529 & TRN & \\
\hline CHEMBL 3194422 & 688653 & 5.433 & 5.6802 & TST & & & \\
\hline CHEMBL1548437 & 688653 & 5.183 & 5.4297 & TRN & & & \\
\hline CHEMBL1406436 & 688653 & 4.833 & 4.7912 & TRN & & & \\
\hline CHEMBL1379110 & 688653 & 6.683 & 6.0041 & TRN & & & \\
\hline CHEMBL1366749 & 688653 & 4.783 & 5.4499 & TRN & & & \\
\hline CHEMBL1408523 & 688653 & 5.233 & 5.1147 & TRN & & & \\
\hline CHEMBL1565242 & 688653 & \multicolumn{3}{|c|}{5.832999999999999} & 5.5283 & TRN & \\
\hline CHEMBL378903 & 688653 & 5.433 & 5.3317 & TRN & & & \\
\hline CHEMBL1453866 & 688653 & 4.783 & 5.3032 & TRN & & & \\
\hline CHEMBL1389237 & 688653 & 4.683 & 5.2183 & TST & & & \\
\hline CHEMBL1338683 & 688653 & 5.483 & 5.282 & TRN & & & \\
\hline CHEMBL1391631 & 688653 & 5.933 & 4.6458 & TST & & & \\
\hline CHEMBL1987483 & 688653 & 5.033 & 4.793 & TRN & & & \\
\hline CHEMBL1608900 & 688653 & \multicolumn{3}{|c|}{5.132999999999999} & 5.4675 & TRN & \\
\hline CHEMBL1486630 & 688653 & 4.783 & 5.1647 & TRN & & & \\
\hline CHEMBL1574677 & 688653 & \multicolumn{3}{|c|}{6.382999999999999} & 5.3777 & TRN & \\
\hline CHEMBL1310244 & 688653 & 4.583 & 5.5625 & TST & & & \\
\hline CHEMBL1305736 & 688653 & \multicolumn{3}{|c|}{5.2829999999999995} & 5.553 & TST & \\
\hline CHEMBL1516711 & 688653 & 4.883 & 5.3786 & TRN & & & \\
\hline CHEMBL1310326 & 688653 & 4.883 & 4.9026 & TRN & & & \\
\hline CHEMBL1537141 & 688653 & \multicolumn{3}{|c|}{6.332999999999999} & 5.487 & TST & \\
\hline CHEMBL1601355 & 688653 & \multicolumn{3}{|c|}{6.832999999999999} & 5.7621 & TRN & \\
\hline CHEMBL1598614 & 688653 & 7.1331 & 5.8287 & TRN & & & \\
\hline CHEMBL1398104 & 688653 & 4.883 & 5.0214 & TRN & & & \\
\hline CHEMBL1402556 & 688653 & 5.183 & 4.923 & TST & & & \\
\hline CHEMBL1430846 & 688653 & \multicolumn{3}{|c|}{5.7829999999999995} & 5.4528 & TRN & \\
\hline CHEMBL1517151 & 688653 & 4.783 & 5.3273 & TRN & & & \\
\hline CHEMBL1485763 & 688653 & 4.583 & 5.6364 & TRN & & & \\
\hline CHEMBL1424541 & 688653 & 5.183 & 5.1802 & TRN & & & \\
\hline CHEMBL1574999 & 688653 & \multicolumn{3}{|c|}{5.2829999999999995} & 5.8685 & TRN & \\
\hline CHEMBL1410344 & 688653 & 4.783 & 5.0338 & TRN & & & \\
\hline CHEMBL1506805 & 688653 & \multicolumn{3}{|c|}{4.7330000000000005} & 5.0292 & TRN & \\
\hline CHEMBL1435049 & 688653 & 5.033 & 5.5475 & TST & & & \\
\hline
\end{tabular}




\begin{tabular}{|c|c|c|c|c|c|c|}
\hline \multirow[b]{2}{*}{ CHEMBL1422429 } & \multirow[b]{2}{*}{688653} & \multicolumn{5}{|c|}{ Supplemental Table S2.txt } \\
\hline & & \multirow{2}{*}{\multicolumn{3}{|c|}{$\begin{array}{lrr}5.933 & 5.9528 & \text { TST } \\
5.7829999999999995\end{array}$}} & \multirow{2}{*}{5.1143} & \multirow[b]{2}{*}{ TRN } \\
\hline CHEMBL1445264 & 688653 & & & & & \\
\hline CHEMBL1492568 & 688653 & 6.233 & 5.2152 & TRN & & \\
\hline CHEMBL1379224 & 688653 & 5.733 & 5.6816 & TRN & & \\
\hline CHEMBL1318046 & 688653 & 4.633 & 4.8499 & TRN & & \\
\hline CHEMBL1609632 & 688653 & 5.733 & 5.103 & TRN & & \\
\hline CHEMBL1532892 & 688653 & \multicolumn{3}{|c|}{4.9830000000000005} & 5.0575 & TRN \\
\hline CHEMBL 3213340 & 688653 & 4.933 & 5.0606 & TRN & & \\
\hline CHEMBL1441974 & 688653 & 4.883 & 5.0591 & TST & & \\
\hline CHEMBL1463567 & 688653 & 5.033 & 5.5291 & TRN & & \\
\hline CHEMBL1526189 & 688653 & 6.233 & 6.0305 & TST & & \\
\hline CHEMBL1365560 & 688653 & 4.783 & 5.0262 & TRN & & \\
\hline CHEMBL1393143 & 688653 & \multicolumn{3}{|c|}{5.832999999999999} & 5.6782 & TRN \\
\hline CHEMBL1371275 & 688653 & \multicolumn{3}{|c|}{5.7829999999999995} & 5.7275 & TRN \\
\hline CHEMBL1588123 & 688653 & 5.45 & \multicolumn{3}{|c|}{5.4910000000000005} & TRN \\
\hline CHEMBL1450616 & 688653 & 4.933 & 5.1596 & TRN & & \\
\hline CHEMBL1302741 & 688653 & \multicolumn{3}{|c|}{5.882999999999999} & 5.9456 & TRN \\
\hline CHEMBL1312255 & 688653 & \multicolumn{3}{|c|}{5.832999999999999} & 5.5939 & TRN \\
\hline CHEMBL1362531 & 688653 & 4.833 & 5.3141 & TRN & & \\
\hline CHEMBL1995152 & 688653 & 4.583 & 5.3286 & TRN & & \\
\hline CHEMBL1407854 & 688653 & 4.933 & 5.4651 & TRN & & \\
\hline CHEMBL1467033 & 688653 & 5.483 & 5.1835 & TRN & & \\
\hline CHEMBL1434800 & 688653 & 5.683 & 5.2819 & TST & & \\
\hline CHEMBL1317872 & 688653 & 4.783 & 5.1695 & TST & & \\
\hline CHEMBL1393395 & 688653 & \multicolumn{3}{|c|}{5.7829999999999995} & 4.9835 & TRN \\
\hline CHEMBL1609903 & 688653 & \multicolumn{3}{|c|}{5.882999999999999} & 4.9146 & TST \\
\hline CHEMBL1583531 & 688653 & \multicolumn{3}{|c|}{6.632999999999999} & 5.4025 & TRN \\
\hline CHEMBL1387641 & 688653 & \multicolumn{3}{|c|}{6.832999999999999} & 6.146 & TRN \\
\hline CHEMBL1470745 & 688653 & 5.033 & 5.1178 & TRN & & \\
\hline CHEMBL2369291 & 688653 & 5.483 & 5.399 & TST & & \\
\hline CHEMBL3211613 & 688653 & 5.233 & 5.3251 & TRN & & \\
\hline CHEMBL1346543 & 688653 & 4.933 & 5.7442 & TRN & & \\
\hline CHEMBL1528225 & 688653 & \multicolumn{3}{|c|}{5.332999999999999} & 4.927 & TRN \\
\hline CHEMBL1425705 & 688653 & \multicolumn{3}{|c|}{5.132999999999999} & 5.5234 & TRN \\
\hline CHEMBL3189160 & 688653 & 4.583 & 5.3247 & TRN & & \\
\hline CHEMBL534535 & 688653 & 4.633 & 4.7064 & TST & & \\
\hline CHEMBL1585767 & 688653 & 4.633 & 5.1188 & TST & & \\
\hline CHEMBL1510621 & 688653 & \multicolumn{3}{|c|}{5.132999999999999} & 5.0899 & TRN \\
\hline CHEMBL1527757 & 688653 & 6.683 & 6.0665 & TRN & & \\
\hline CHEMBL1534367 & 688653 & 5.083 & 5.4614 & TST & & \\
\hline CHEMBL1333952 & 688653 & 4.783 & \multicolumn{3}{|c|}{5.172999999999999} & TRN \\
\hline CHEMBL1459869 & 688653 & \multicolumn{3}{|c|}{4.7330000000000005} & 5.2697 & TRN \\
\hline CHEMBL1492633 & 688653 & 4.883 & 5.2576 & TRN & & \\
\hline CHEMBL1549267 & 688653 & 4.933 & 5.5513 & TRN & & \\
\hline CHEMBL1550107 & 688653 & 5.0 & 4.9714 & TRN & & \\
\hline CHEMBL1987655 & 688653 & 6.5829 & 99999999 & 99 & 5.6577 & TRN \\
\hline CHEMBL3190034 & 688653 & 5.083 & 5.1191 & TRN & & \\
\hline CHEMBL1324102 & 688653 & 4.783 & 5.4313 & TRN & & \\
\hline
\end{tabular}




\begin{tabular}{|c|c|c|c|c|c|c|}
\hline \multirow{3}{*}{$\begin{array}{l}\text { CHEMBL1497933 } \\
\text { CHEMBL1597544 }\end{array}$} & \multicolumn{6}{|c|}{ Supplemental Table S2.txt } \\
\hline & 688653 & \multicolumn{3}{|c|}{5.132999999999999} & 5.2049 & TST \\
\hline & 688653 & 4.833 & 4.9829 & TRN & & \\
\hline CHEMBL1419578 & 688653 & \multicolumn{3}{|c|}{5.132999999999999} & 5.3473 & TRN \\
\hline CHEMBL1366214 & 688653 & \multicolumn{3}{|c|}{5.7829999999999995} & 5.2432 & \\
\hline CHEMBL1416713 & 688653 & 4.783 & 5.1582 & TST & & \\
\hline CHEMBL1445787 & 688653 & 4.633 & 5.2904 & TST & & \\
\hline CHEMBL1500265 & 688653 & \multicolumn{3}{|c|}{5.2829999999999995} & 5.1771 & $\mathrm{~T}$ \\
\hline CHEMBL1382265 & 688653 & 4.583 & 4.8063 & TRN & & \\
\hline CHEMBL1534986 & 688653 & 4.633 & 5.1238 & TRN & & \\
\hline CHEMBL598903 & 688653 & 4.583 & 5.0422 & TST & & \\
\hline CHEMBL1441217 & 688653 & \multicolumn{3}{|c|}{5.132999999999999} & 4.8514 & \\
\hline CHEMBL1454879 & 688653 & 4.833 & 5.5334 & TRN & & \\
\hline CHEMBL1585521 & 688653 & \multicolumn{3}{|c|}{5.832999999999999} & 5.7087 & TRN \\
\hline CHEMBL1564471 & 688653 & \multicolumn{3}{|c|}{6.5329999999999995} & 5.6997 & \\
\hline CHEMBL1575177 & 688653 & 4.833 & 5.2826 & TRN & & \\
\hline CHEMBL1380214 & 688653 & 5.983 & 5.4508 & TRN & & \\
\hline CHEMBL1420265 & 688653 & 5.683 & 5.6151 & TRN & & \\
\hline CHEMBL1510561 & 688653 & 4.683 & 5.3339 & TRN & & \\
\hline CHEMBL1388561 & 688653 & \multicolumn{3}{|c|}{4.7330000000000005} & 5.0574 & \\
\hline CHEMBL1579500 & 688653 & \multicolumn{3}{|c|}{5.382999999999999} & 5.1152 & \\
\hline CHEMBL1387511 & 688653 & 4.883 & 5.2971 & TST & & \\
\hline CHEMBL1363615 & 688653 & \multicolumn{3}{|c|}{5.7829999999999995} & 6.1226 & $\mathrm{~T}$ \\
\hline CHEMBL1466462 & 688653 & \multicolumn{3}{|c|}{5.5329999999999995} & 6.019 & \\
\hline CHEMBL1367508 & 688653 & 4.883 & 5.1424 & TRN & & \\
\hline CHEMBL1587981 & 688653 & 4.583 & 4.5269 & TRN & & \\
\hline CHEMBL1597445 & 688 & 5.683 & 5.147 & TST & & \\
\hline CHEMBL1429159 & 688653 & 5.033 & 5.1433 & TST & & \\
\hline CHEMBL1472059 & 688653 & 5.433 & 5.126 & TRN & & \\
\hline CHEMBL1385866 & 688653 & 4.883 & 5.3863 & TRN & & \\
\hline CHEMBL1465815 & 688 & 5.6 & 5.2727 & TRN & & \\
\hline CHEMBL 32 & $68 \varepsilon$ & 5.683 & 5.4431 & TRN & & \\
\hline CHEMBL1582369 & 688 & 5.033 & 5.3163 & TRN & & \\
\hline CHEMBL1335171 & 688653 & \multicolumn{3}{|c|}{5.2829999999999995} & 5.4797 & \\
\hline CHEMBL1391563 & 688653 & \multicolumn{3}{|c|}{5.7829999999999995} & 5.6701 & \\
\hline CHEMBL1511526 & $68 \varepsilon$ & & 4.7915 & TRN & & \\
\hline CHEMBL1479503 & 688 & 5.033 & 5.6292 & TRN & & \\
\hline CHEMBL3190669 & 688653 & 5.733 & 5.6747 & TRN & & \\
\hline CHEMBL1542691 & 688653 & 5.683 & 5.9402 & TST & & \\
\hline CHEMBL 242515 & 688653 & 5.233 & 5.1825 & TST & & \\
\hline CHEMBL1571190 & 688653 & \multicolumn{3}{|c|}{4.9830000000000005} & & - \\
\hline CHEMBL1361203 & 688653 & \multicolumn{3}{|c|}{5.832999999999999} & & \\
\hline CHEMBL1436721 & 688653 & 4.833 & 4.8845 & TRN & & \\
\hline CHEMBL1362432 & 688653 & 6.233 & 5.3742 & TRN & & \\
\hline CHEMBL1571602 & 688653 & 5.183 & 5.7402 & TRN & & \\
\hline CHEMBL1537574 & 688653 & \multicolumn{3}{|c|}{4.7330000000000005} & .3261 & \\
\hline CHEMBL1547325 & 688653 & 4.833 & 5.0846 & TRN & & \\
\hline CHEMBL1331595 & 688653 & \multicolumn{3}{|c|}{4.7330000000000005} & 5.265 & TRN \\
\hline CHEMBL1362660 & 688653 & \multicolumn{3}{|c|}{5.5329999999999995} & 5.4151 & \\
\hline
\end{tabular}




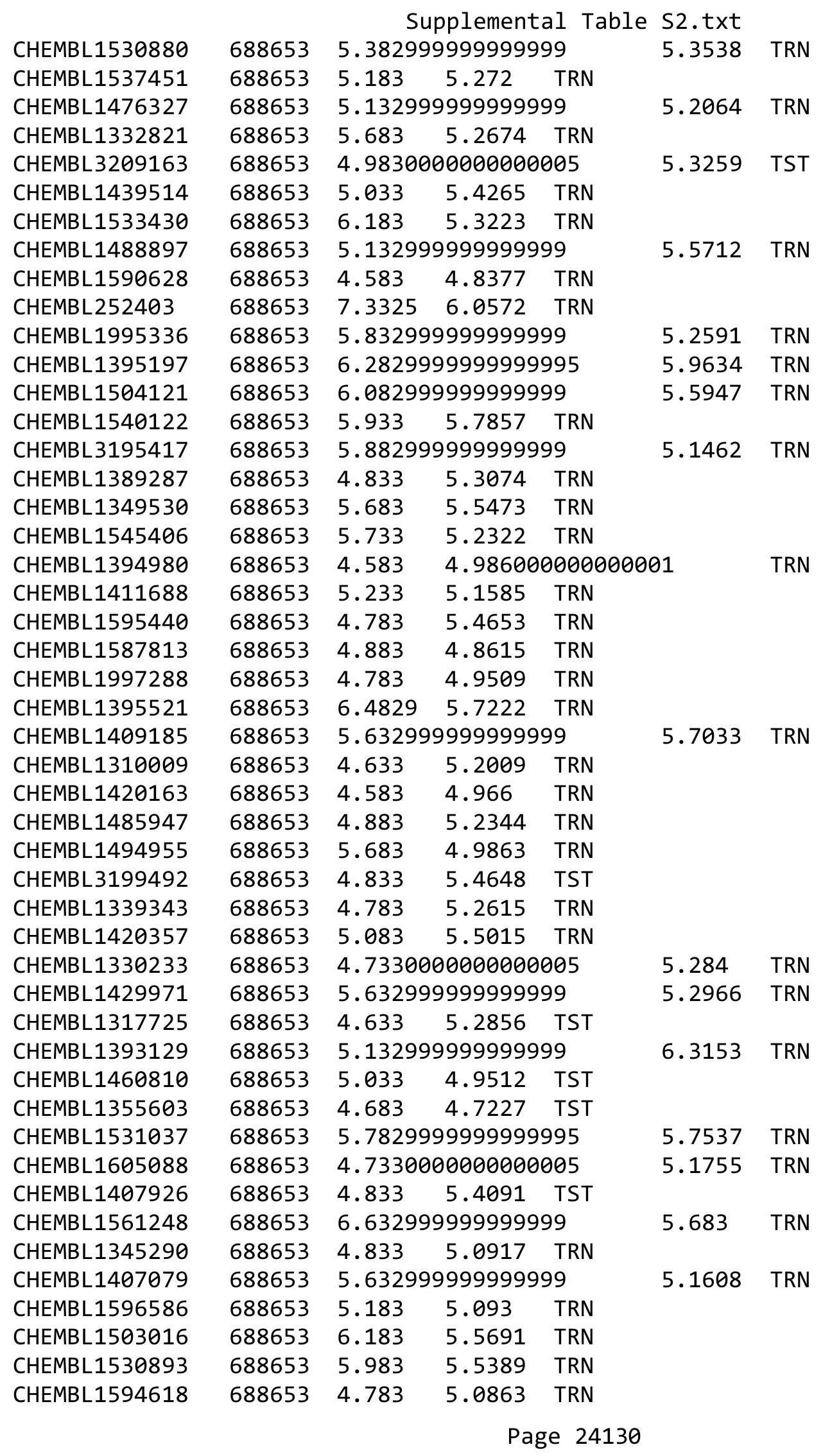




\begin{tabular}{|c|c|c|c|c|c|c|}
\hline \multirow[b]{2}{*}{ CHEMBL1363703 } & \multirow[b]{2}{*}{688653} & \multicolumn{5}{|c|}{ Supplemental Table S2.txt } \\
\hline & & 4.833 & 5.1692 & TST & & \\
\hline CHEMBL1372801 & 688653 & 4.883 & 4.669 & TST & & \\
\hline CHEMBL1358069 & 688653 & 4.933 & 5.2793 & TST & & \\
\hline CHEMBL1466224 & 688653 & 4.833 & 5.1223 & TST & & \\
\hline CHEMBL565269 & 688653 & \multicolumn{3}{|c|}{5.7829999999999995} & 5.4107 & TRN \\
\hline CHEMBL1553476 & 688653 & \multicolumn{3}{|c|}{6.2829999999999995} & 5.8609 & TRN \\
\hline CHEMBL1474736 & 688653 & 4.783 & 5.0291 & TRN & & \\
\hline CHEMBL1382853 & 688653 & 4.783 & 5.0803 & TST & & \\
\hline CHEMBL1377580 & 688653 & 5.433 & 5.4088 & TST & & \\
\hline CHEMBL1580946 & 688653 & \multicolumn{3}{|c|}{6.382999999999999} & 5.7527 & TRN \\
\hline CHEMBL1416417 & 688653 & 4.833 & 5.2568 & TST & & \\
\hline CHEMBL3190702 & 688653 & 5.033 & 5.4429 & TRN & & \\
\hline CHEMBL3207968 & 688653 & \multicolumn{3}{|c|}{6.382999999999999} & 5.5722 & TST \\
\hline CHEMBL3207641 & 688653 & 5.083 & 4.9442 & TST & & \\
\hline CHEMBL1579959 & 688653 & \multicolumn{3}{|c|}{4.7330000000000005} & 5.3992 & TRN \\
\hline CHEMBL1310737 & 688653 & 4.783 & 5.3131 & TRN & & \\
\hline CHEMBL1504833 & 688653 & 4.633 & 4.7962 & TRN & & \\
\hline CHEMBL1501607 & 688653 & \multicolumn{3}{|c|}{5.5329999999999995} & 5.5728 & TRN \\
\hline CHEMBL1425823 & 688653 & 7.2832 & 6.4232 & TRN & & \\
\hline CHEMBL587247 & 688653 & \multicolumn{3}{|c|}{4.7330000000000005} & 5.1316 & TRN \\
\hline CHEMBL3190635 & 688653 & 5.983 & 5.2552 & TRN & & \\
\hline CHEMBL1361526 & 688653 & 5.733 & 5.4405 & TRN & & \\
\hline CHEMBL1438160 & 688653 & \multicolumn{3}{|c|}{6.7829999999999995} & 5.1147 & TRN \\
\hline CHEMBL1395996 & 688653 & 4.933 & 5.5265 & TRN & & \\
\hline CHEMBL1601919 & 688653 & 4.833 & 5.2328 & TRN & & \\
\hline CHEMBL1533535 & 688653 & \multicolumn{3}{|c|}{6.2829999999999995} & 5.4881 & TRN \\
\hline CHEMBL1536341 & 688653 & 6.8831 & 5.7487 & TRN & & \\
\hline CHEMBL1480810 & 688653 & 4.633 & 4.6655 & TRN & & \\
\hline CHEMBL1519457 & 688653 & 4.633 & 4.9568 & TRN & & \\
\hline CHEMBL1300237 & 688653 & 5.733 & 5.9215 & TRN & & \\
\hline CHEMBL1599182 & 688653 & 4.583 & 5.0828 & TST & & \\
\hline CHEMBL 3194787 & 688653 & 4.833 & 5.3892 & TRN & & \\
\hline CHEMBL1582420 & 688653 & 5.433 & 5.3816 & TRN & & \\
\hline CHEMBL1309484 & 688653 & 5.183 & 5.4891 & TST & & \\
\hline CHEMBL1898790 & 688653 & 4.883 & 5.1078 & TST & & \\
\hline CHEMBL1444275 & 688653 & 4.933 & 4.8767 & TRN & & \\
\hline CHEMBL1408355 & 688653 & 5.733 & 5.8656 & TRN & & \\
\hline CHEMBL1544366 & 688653 & 5.683 & 5.6357 & TRN & & \\
\hline CHEMBL3189851 & 688653 & 4.883 & 5.3737 & TST & & \\
\hline CHEMBL1341509 & 688653 & 6.28299 & 99999999 & 995 & 5.8071 & TRN \\
\hline CHEMBL1509310 & 688653 & 4.73300 & 00000000 & 005 & 5.1152 & TRN \\
\hline CHEMBL525098 & 688653 & 5.13299 & 99999999 & & 5.3356 & TRN \\
\hline CHEMBL1449473 & 688653 & 5.58299 & 99999999 & & 5.5454 & TST \\
\hline CHEMBL1518971 & 688653 & 6.53299 & 99999999 & 995 & 5.0314 & TRN \\
\hline CHEMBL1445717 & 688653 & 5.083 & 4.5244 & TRN & & \\
\hline CHEMBL1569410 & 688653 & 4.583 & 5.3391 & TST & & \\
\hline CHEMBL1437560 & 688653 & 4.633 & 4.7039 & TST & & \\
\hline CHEMBL1351973 & 688653 & 6.183 & 5.5559 & TST & & \\
\hline
\end{tabular}




\begin{tabular}{|c|c|c|c|c|c|c|}
\hline \multicolumn{7}{|c|}{ Supplemental Table S2.txt } \\
\hline CHEMBL1603877 & 688653 & \multicolumn{3}{|c|}{4.7330000000000005} & 4.7651 & TRN \\
\hline CHEMBL1463690 & 688653 & \multicolumn{3}{|c|}{5.332999999999999} & 5.7629 & TRN \\
\hline CHEMBL1479486 & 688653 & 5.733 & 5.3085 & TRN & & \\
\hline CHEMBL3198373 & 688653 & \multicolumn{3}{|c|}{6.332999999999999} & 5.4204 & TRN \\
\hline CHEMBL1437588 & 688653 & 5.033 & 5.3364 & TRN & & \\
\hline CHEMBL1524484 & 688653 & \multicolumn{3}{|c|}{5.882999999999999} & 6.6656 & TRN \\
\hline CHEMBL1389915 & 688653 & 5.033 & 5.1158 & TRN & & \\
\hline CHEMBL1419814 & 688653 & 4.583 & 5.0064 & TRN & & \\
\hline CHEMBL1457606 & 688653 & 5.083 & 5.357 & TRN & & \\
\hline CHEMBL1436013 & 688653 & 4.583 & 4.9942 & TRN & & \\
\hline CHEMBL1308658 & 688653 & 5.733 & 5.9948 & TRN & & \\
\hline CHEMBL1546756 & 688653 & 4.933 & 5.1634 & TST & & \\
\hline CHEMBL1349459 & 688653 & \multicolumn{3}{|c|}{4.7330000000000005} & 5.0082 & TRN \\
\hline CHEMBL 2004183 & 688653 & 5.683 & 5.251 & TST & & \\
\hline CHEMBL1347975 & 688653 & 4.633 & 5.2584 & TST & & \\
\hline CHEMBL1320276 & 688653 & 4.933 & 5.3391 & TRN & & \\
\hline CHEMBL1349795 & 688653 & 5.183 & 5.0353 & TST & & \\
\hline CHEMBL1338769 & 688653 & \multicolumn{3}{|c|}{4.7330000000000005} & 5.3775 & TST \\
\hline CHEMBL1357934 & 688653 & 5.433 & 5.4991 & TRN & & \\
\hline CHEMBL1480635 & 688653 & 5.933 & 5.2672 & TST & & \\
\hline CHEMBL1536994 & 688653 & 5.733 & 5.2682 & TRN & & \\
\hline CHEMBL1465682 & 688653 & 4.883 & 5.2108 & TRN & & \\
\hline CHEMBL1388611 & 688653 & 5.183 & 5.5257 & TRN & & \\
\hline CHEMBL1433632 & 688653 & 4.633 & 5.1507 & TRN & & \\
\hline CHEMBL1563127 & 688653 & 4.783 & 5.3498 & TRN & & \\
\hline CHEMBL1592108 & 688653 & 6.4829 & 5.6027 & TRN & & \\
\hline CHEMBL1422119 & 688653 & \multicolumn{3}{|c|}{6.832999999999999} & 5.0384 & TST \\
\hline CHEMBL1509282 & 688653 & 5.033 & 4.8712 & TRN & & \\
\hline CHEMBL1483321 & 688653 & 4.583 & 5.436 & TST & & \\
\hline CHEMBL1311730 & 688653 & \multicolumn{3}{|c|}{5.382999999999999} & 5.5855 & TRN \\
\hline CHEMBL1409988 & 688653 & \multicolumn{3}{|c|}{4.7330000000000005} & 4.9269 & TRN \\
\hline CHEMBL1982569 & 688653 & \multicolumn{3}{|c|}{5.382999999999999} & 5.263990 & 9999999999 \\
\hline CHEMBL1394905 & 688653 & \multicolumn{3}{|c|}{4.9830000000000005} & 5.0975 & TST \\
\hline CHEMBL1580472 & 688653 & 4.933 & 5.1348 & TRN & & \\
\hline CHEMBL1352274 & 688653 & 4.933 & \multicolumn{3}{|c|}{5.111000000000001} & TRN \\
\hline CHEMBL1438799 & 688653 & \multicolumn{3}{|c|}{4.7330000000000005} & 5.0115 & TRN \\
\hline CHEMBL1542936 & 688653 & 4.833 & 4.5187 & TRN & & \\
\hline CHEMBL1341123 & 688653 & \multicolumn{3}{|c|}{5.632999999999999} & 5.2231 & TRN \\
\hline CHEMBL583578 & 688653 & \multicolumn{3}{|c|}{6.832999999999999} & 6.0026 & TRN \\
\hline CHEMBL1577228 & 688653 & \multicolumn{3}{|c|}{5.832999999999999} & 5.3697 & TRN \\
\hline CHEMBL1576382 & 688653 & 4.583 & 4.9046 & TRN & & \\
\hline CHEMBL1985343 & 688653 & \multicolumn{3}{|c|}{4.9830000000000005} & 5.3324 & TRN \\
\hline CHEMBL1487222 & 688653 & 5.033 & 5.2735 & TST & & \\
\hline CHEMBL 3211158 & 688653 & 5.683 & 6.1612 & TRN & & \\
\hline CHEMBL1570020 & 688653 & \multicolumn{3}{|c|}{4.7330000000000005} & 5.0349 & TRN \\
\hline CHEMBL 1438186 & 688653 & 6.683 & 5.7224 & TRN & & \\
\hline CHEMBL1466201 & 688653 & 4.633 & 5.0372 & TRN & & \\
\hline CHEMBL213017 & 688653 & 4.783 & 5.5882 & TST & & \\
\hline
\end{tabular}




\begin{tabular}{|c|c|c|c|c|c|c|}
\hline \multirow[b]{2}{*}{ CHEMBL1411457 } & \multirow[b]{2}{*}{688653} & \multicolumn{5}{|c|}{ Supplemental Table S2.txt } \\
\hline & & \multirow{2}{*}{\multicolumn{3}{|c|}{$\begin{array}{lrr}5.183 & 5.0905 & \text { TRN } \\
5.5329999999999995\end{array}$}} & & \\
\hline CHEMBL1588181 & 688653 & & & & 5.1322 & TRN \\
\hline CHEMBL1613359 & 688653 & \multicolumn{3}{|c|}{4.7330000000000005} & 5.2167 & \\
\hline CHEMBL1531322 & 688653 & \multicolumn{3}{|c|}{6.382999999999999} & 5.4838 & \\
\hline CHEMBL1452318 & 688653 & 5.683 & 5.2738 & TRN & & \\
\hline CHEMBL3190808 & 688653 & 4.783 & 5.2538 & TRN & & \\
\hline CHEMBL1526810 & 688653 & 5.733 & 5.5461 & TRN & & \\
\hline CHEMBL1604614 & 688653 & 4.583 & 5.3192 & TRN & & \\
\hline CHEMBL1303316 & 688653 & 4.583 & 5.5783 & TRN & & \\
\hline CHEMBL1493554 & 688653 & 4.833 & \multicolumn{3}{|c|}{5.4110000000000005} & \\
\hline CHEMBL1379878 & 688653 & 4.783 & 5.0588 & TST & & \\
\hline CHEMBL1552153 & 688653 & \multicolumn{3}{|c|}{5.332999999999999} & 5.0248 & \\
\hline CHEMBL1339909 & 688653 & 4.883 & 5.0345 & TRN & & \\
\hline CHEMBL1405567 & 688653 & \multicolumn{3}{|c|}{5.632999999999999} & 5.5673 & \\
\hline CHEMBL1530719 & 688653 & 4.833 & 4.9545 & TRN & & \\
\hline CHEMBL3192242 & 688653 & \multirow{2}{*}{\multicolumn{3}{|c|}{5.2829999999999995}} & & \\
\hline CHEMBL1453473 & 688653 & & & & 5.5801 & \\
\hline CHEMBL1397875 & 688653 & 6.683 & 4.9146 & TST & & \\
\hline CHEMBL1377109 & 688653 & 4.883 & 5.4993 & TRN & & \\
\hline CHEMBL3207673 & 688653 & 4.933 & 4.9985 & TST & & \\
\hline CHEMBL1570475 & 688653 & 5.9 & 5.3931 & TRN & & \\
\hline CHEMBL3 & 688653 & 4.783 & 5.5075 & TST & & \\
\hline CHEMBL3191356 & 688653 & \multicolumn{3}{|c|}{4.7330000000000005} & 5.7907 & \\
\hline CHEMBL1344988 & 688653 & 4.933 & 5.038 & TST & & \\
\hline CHEMBL1487527 & 688653 & 5.683 & 5.4635 & TRN & & \\
\hline CHEMBL1534326 & 688653 & \multicolumn{3}{|c|}{5.132999999999999} & 5.7463 & \\
\hline CHEMBL1 & 688653 & 4.583 & 4.4255 & TRN & & \\
\hline CHEMBL3197628 & 688653 & 5.183 & 5.0561 & TRN & & \\
\hline CHEMBL1382028 & 688653 & \multicolumn{3}{|c|}{6.7829999999999995} & 6.0159 & $\mathrm{~T}$ \\
\hline CHEMBL1321292 & 688653 & 5.683 & 5.0521 & TRN & & \\
\hline CHEMBL1594644 & 688653 & \multicolumn{3}{|c|}{4.9830000000000005} & 5.4495 & \\
\hline CHEMBL15 & 688653 & 4.583 & 5.2495 & TST & & \\
\hline CHEMBL1318793 & 688653 & \multicolumn{3}{|c|}{5.882999999999999} & 5.3743 & TRN \\
\hline CHEMBL1419445 & 688653 & \multicolumn{3}{|c|}{5.832999999999999} & 5.581 & TRN \\
\hline CHEMBL1541296 & 688653 & \multicolumn{3}{|c|}{5.2829999999999995} & 5.3119 & TRN \\
\hline CHEMBL1435513 & 688653 & \multicolumn{3}{|c|}{6.2829999999999995} & 5.6548 & TRN \\
\hline CHEMBL1422006 & 688653 & \multicolumn{3}{|c|}{5.882999999999999} & 5.12 & 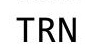 \\
\hline CHEMBL1481769 & 688653 & 5.233 & 5.2688 & TRN & & \\
\hline CHEMBL1452487 & 688653 & 4.633 & 4.824 & TRN & & \\
\hline CHEMBL1328522 & 688653 & 4.683 & 5.1024 & TST & & \\
\hline CHEMBL 1585752 & 688653 & \multicolumn{3}{|c|}{5.5329999999999995} & 5.091 & $1 \mathrm{~K}$ \\
\hline CHEMBL1317848 & 688653 & 4.933 & 4.724 & TRN & & \\
\hline CHEMBL1360177 & 688653 & 4.833 & 5.0779 & TST & & \\
\hline CHEMBL1444379 & 688653 & 4.783 & 4.9494 & TRN & & \\
\hline CHEMBL1431459 & 688653 & 4.783 & 5.1009 & TST & & \\
\hline CHEMBL1564863 & 688653 & 5.033 & 4.9135 & TRN & & \\
\hline CHEMBL1494788 & 688653 & 5.233 & 5.1279 & TRN & & \\
\hline CHEMBL1553504 & 688653 & 4.583 & 4.739 & TST & & \\
\hline
\end{tabular}




\begin{tabular}{|c|c|c|c|c|c|c|}
\hline & & \multicolumn{5}{|c|}{ Supplemental Table s2.txt } \\
\hline CHEMBL1348933 & 688653 & \multicolumn{4}{|c|}{5.5329999999999995} & TRN \\
\hline CHEMBL1580578 & 688653 & \multicolumn{3}{|c|}{6.2829999999999995} & 5.3907 & \\
\hline CHEMBL3195204 & 688653 & 5.483 & 5.4388 & TRN & & \\
\hline CHEMBL 3212255 & 688653 & 5.233 & 4.9184 & TST & & \\
\hline CHEMBL1444581 & 688653 & 4.833 & 4.9268 & TST & & \\
\hline CHEMBL1494328 & 688653 & \multicolumn{3}{|c|}{5.832999999999999} & 5.2089 & \\
\hline CHEMBL 8950 & 688653 & 4.633 & 5.6135 & TST & & \\
\hline CHEMBL1580401 & 688653 & 4.683 & 5.5062 & TST & & \\
\hline CHEMBL1611982 & 688653 & \multicolumn{3}{|c|}{5.2829999999999995} & 5.3801 & \\
\hline CHEMBL1396263 & 688653 & 5.083 & \multicolumn{3}{|c|}{5.1770000000000005} & \\
\hline CHEMBL1409513 & 688653 & 7.0329 & \multicolumn{3}{|c|}{5.763999999999999} & \\
\hline CHEMBL3197009 & 688653 & 4.833 & 5.0552 & TRN & & \\
\hline CHEMBL1500427 & 688653 & \multicolumn{3}{|c|}{5.132999999999999} & 5.6998 & \\
\hline CHEMBL1458746 & 688653 & 5.083 & 5.3118 & TRN & & \\
\hline CHEMBL1523441 & 688653 & \multicolumn{3}{|c|}{5.132999999999999} & 5.7837 & \\
\hline CHEMBL 233302 & 688653 & 5.9 & 5.2598 & TRN & & \\
\hline CHEMBL1399255 & 688653 & 4.783 & 5.1995 & TRN & & \\
\hline CHEMBL3193965 & 688653 & 4.783 & 5.0905 & TRN & & \\
\hline CHEMBL1375640 & 688653 & 5.083 & \multicolumn{3}{|c|}{5.4079999999999995} & \\
\hline CHEMBL1409630 & 688653 & \multicolumn{3}{|c|}{6.382999999999999} & 5.6009 & \\
\hline CHEMBL1600906 & 688653 & \multicolumn{3}{|c|}{5.382999999999999} & 5.3813 & \\
\hline CHEMBL1474777 & 688653 & 4.883 & 4.7216 & TRN & & \\
\hline CHEMBL1404372 & 688653 & \multicolumn{3}{|c|}{5.882999999999999} & 5.5712 & \\
\hline CHEMBL3194833 & 688653 & 4.583 & 4.9556 & TRN & & \\
\hline CHEMBL1522699 & 688653 & \multicolumn{3}{|c|}{6.2829999999999995} & 5.8104 & \\
\hline CHEMBL1339491 & 688653 & 4.783 & 5.2937 & TST & & \\
\hline CHEMBL1487859 & 688653 & \multicolumn{3}{|c|}{6.0329999999999995} & 5.523 & 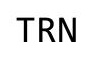 \\
\hline CHEMBL1975210 & 688653 & \multicolumn{3}{|c|}{5.582999999999999} & 5.4192 & \\
\hline CHEMBL3212261 & 688653 & 5.433 & 5.3969 & TST & & \\
\hline CHEMBL1550600 & 688653 & 4.633 & 5.2655 & TST & & \\
\hline CHEMBL1393174 & 688653 & 4.833 & 4.9373 & TRN & & \\
\hline CHEMBL1449788 & 688653 & 4.683 & 4.9449 & TRN & & \\
\hline CHEMBL1469755 & 688653 & 5.183 & 5.1508 & TRN & & \\
\hline CHEMBL1507679 & 688653 & 4.683 & 5.1997 & TRN & & \\
\hline CHEMBL1516672 & 688653 & \multicolumn{3}{|c|}{4.7330000000000005} & 5.2823 & \\
\hline CHEMBL1346227 & 688653 & 4.883 & 5.2991 & TRN & & \\
\hline CHEMBL1467600 & 688653 & 5.083 & 5.1006 & TST & & \\
\hline CHEMBL1572252 & 688653 & 4.933 & 4.7681 & TRN & & \\
\hline CHEMBL1314798 & 688653 & 6.983 & 5.5807 & TRN & & \\
\hline CHEMBL1536304 & 688653 & 4.583 & 5.5372 & TST & & \\
\hline CHEMBL3194014 & 688653 & 4.833 & 4.8815 & TRN & & \\
\hline CHEMBL1457591 & 688653 & 4.933 & 4.7419 & TST & & \\
\hline CHEMBL1403722 & 688653 & 5.683 & 5.3938 & TRN & & \\
\hline CHEMBL1316269 & 688653 & 5.433 & 5.0926 & TRN & & \\
\hline CHEMBL1435876 & 688653 & 4.583 & 4.8998 & TRN & & \\
\hline CHEMBL1533745 & 688653 & 4.783 & 5.3844 & TRN & & \\
\hline CHEMBL1456255 & 688653 & 5.433 & 5.6245 & TRN & & \\
\hline CHEMBL1331098 & 688653 & 4.883 & 4.8698 & TRN & & \\
\hline
\end{tabular}




\begin{tabular}{|c|c|c|c|c|c|c|}
\hline & & \multicolumn{5}{|c|}{ Supplemental Table S2.txt } \\
\hline CHEMBL1386367 & 688653 & 5.183 & 5.0846 & TRN & & \\
\hline CHEMBL600121 & 688653 & 5.53299 & 99999999 & 995 & 5.1781 & $\mathrm{~T}$ \\
\hline CHEMBL1467203 & 688653 & 5.083 & 5.2357 & TRN & & \\
\hline CHEMBL1457456 & 688653 & 5.033 & 5.2159 & TRN & & \\
\hline CHEMBL1485481 & 688653 & 4.783 & 5.1065 & TRN & & \\
\hline CHEMBL1467444 & 688653 & 4.783 & 5.5717 & TRN & & \\
\hline CHEMBL 1400780 & 688653 & 5.233 & 5.4665 & TRN & & \\
\hline CHEMBL1357810 & 688653 & .633 & 4.9025 & TRN & & \\
\hline CHEMBL1330522 & 688653 & 4.883 & 5.0473 & TST & & \\
\hline CHEMBL1529427 & 688653 & 4.633 & 5.0394 & TRN & & \\
\hline CHEMBL1586476 & 688653 & 6.03299 & 99999999 & 995 & 5.6014 & \\
\hline CHEMBL1322557 & 688653 & 4.73300 & 00000000 & 005 & 5.1302 & \\
\hline CHEMBL 3199631 & 688653 & 4.783 & 5.63299 & 999999999 & 99 & \\
\hline CHEMBL1341673 & 688653 & 5.433 & 5.5202 & TRN & & \\
\hline CHEMBL1344200 & 688653 & 4.73300 & 00000000 & 005 & 5.1342 & \\
\hline CHEMBL1325132 & 688653 & 4.783 & 5.3989 & TRN & & \\
\hline CHEMBL1532184 & 688653 & 4.933 & 4.6958 & TRN & & \\
\hline CHEMBL1458453 & 688653 & 5.83299 & 99999999 & & 5.4551 & \\
\hline CHEMBL1462991 & 688653 & 6.28299 & 99999999 & 995 & 5.6835 & \\
\hline CHEMBL1338530 & 688653 & 4.633 & 5.25899 & 9999 & 995 & \\
\hline CHEMBL1350031 & 688653 & 4.833 & 4.9284 & TRN & & \\
\hline CHEMBL1478550 & 688653 & 4.73300 & 00000000 & 005 & & \\
\hline CHEMBL1392604 & 688653 & 4.883 & 5.1936 & TST & & \\
\hline CHEMBL1346585 & 688653 & 6.683 & 5.9468 & TRN & & \\
\hline CHEMBL 3197265 & 688653 & 5.63299 & 99999999 & & 5.4783 & TRN \\
\hline CHEMBL3198072 & 688653 & 5.83299 & 99999999 & & 5.2446 & \\
\hline CHEMBL1518520 & 688653 & 5.233 & 5.3264 & TRN & & \\
\hline CHEMBL1529687 & 688653 & 4.833 & 5.1402 & TRN & & \\
\hline CHEMBL1381454 & 688653 & 5.683 & 5.4983 & TRN & & \\
\hline CHEMBL1525965 & 688653 & 6.28299 & 99999999 & 995 & 5.6708 & TP \\
\hline CHEMBL1599411 & 688653 & 5.933 & 5.7404 & TST & & \\
\hline CHEMBL1407778 & 688653 & 5.63299 & 99999999 & & נכו & (1) \\
\hline CHEMBL 3199408 & 688653 & 4.98300 & 00000000 & 005 & 5.2097 & TST \\
\hline CHEMBL1565709 & 688653 & 4.783 & 5.2112 & TRN & & \\
\hline CHEMBL1571483 & 688653 & 6.183 & 6.0881 & TRN & & \\
\hline CHEMBL1520126 & 688653 & 5.78299 & 99999999 & 995 & 7 & TRN \\
\hline CHEMBL1502052 & 688653 & 4.98300 & 00000000 & 005 & & \\
\hline CHEMBL1568650 & 688653 & 4.783 & 5.4241 & TRN & & \\
\hline CHEMBL1509200 & 688653 & 4.833 & 5.4051 & TRN & & \\
\hline CHEMBL1374910 & 688653 & 5.483 & 5.1596 & TRN & & \\
\hline CHEMBL1346510 & 688653 & 5.683 & 5.6259 & TRN & & \\
\hline CHEMBL1601466 & 688653 & 4.933 & 5.051 & TST & & \\
\hline CHEMBL1409534 & 688653 & 4.783 & 5.0252 & TRN & & \\
\hline CHEMBL1990027 & 688653 & 5.13299 & 99999999 & & 5.4834 & TाN \\
\hline CHEMBL1492533 & 688653 & 6.58299 & 99999999 & & 5.6145 & TRN \\
\hline CHEMBL1358526 & 688653 & 4.583 & 4.9746 & TST & & \\
\hline CHEMBL1452463 & 688653 & 6.0829 & 99999999 & 99 & 5.5276 & rRN \\
\hline CHEMBL1305603 & 688653 & 4.933 & 5.1567 & TST & & \\
\hline
\end{tabular}




\begin{tabular}{|c|c|c|c|c|c|c|}
\hline & & \multicolumn{4}{|c|}{ Supplemental Table S2.txt } & \\
\hline CHEMBL1332957 & 688653 & \multicolumn{4}{|c|}{5.132999999999999} & TRN \\
\hline CHEMBL1454395 & 688653 & \multicolumn{3}{|c|}{4.9830000000000005} & 2742 & \\
\hline CHEMBL405072 & 688653 & 4.783 & 5.4482 & TRN & & \\
\hline CHEMBL1440127 & 688653 & 5.183 & 5.1217 & TRN & & \\
\hline CHEMBL3210088 & 588653 & 7.0329 & 5.6835 & TRN & & \\
\hline CHEMBL1541090 & 588653 & 6.183 & 5.5025 & TST & & \\
\hline CHEMBL1462130 & 688653 & \multicolumn{3}{|c|}{4.9830000000000005} & 4.8757 & \\
\hline CHEMBL3211385 & 688653 & \multicolumn{3}{|c|}{5.5329999999999995} & 5.1396 & \\
\hline CHEMBL1327052 & 688653 & \multicolumn{3}{|c|}{4.7330000000000005} & 5.1047 & \\
\hline CHEMBL1517937 & 688653 & \multicolumn{3}{|c|}{4.9830000000000005} & 5.7058 & \\
\hline CHEMBL1576659 & 688653 & 6.183 & 5.7631 & TRN & & \\
\hline CHEMBL1605231 & 688653 & 4.783 & 4.9929 & TRN & & \\
\hline CHEMBL1484073 & 688653 & \multicolumn{3}{|c|}{4.7330000000000005} & 4.8758 & \\
\hline CHEMBL1372424 & 688653 & 4.833 & 5.0423 & TRN & & \\
\hline CHEMBL1417554 & 688653 & \multicolumn{3}{|c|}{5.582999999999999} & 5.6278 & \\
\hline CHEMBL3192939 & 688653 & \multicolumn{3}{|c|}{4.9830000000000005} & 5.0281 & \\
\hline CHEMBL1 & 688653 & 5.183 & 5.2154 & TRN & & \\
\hline CHEMBL1478035 & 688653 & \multicolumn{3}{|c|}{5.632999999999999} & 5.5591 & $\mathrm{~T}$ \\
\hline CHEMBL1411631 & 688653 & \multicolumn{3}{|c|}{5.382999999999999} & 4.7863 & \\
\hline CHEMBL1447111 & 688653 & \multicolumn{3}{|c|}{6.5329999999999995} & & \\
\hline CHEMBL1320192 & 688653 & 4.833 & 5.2502 & TRN & & \\
\hline CHEMBL1 & 688653 & \multicolumn{3}{|c|}{6.2829999999999995} & 5.2801 & ונדו \\
\hline CHEMBL1494384 & 688653 & \multicolumn{3}{|c|}{4.9830000000000005} & 5.3061 & \\
\hline CHEMBL1169821 & 688653 & 5.033 & 5.1332 & TRN & & \\
\hline CHEMBL1416701 & 688653 & \multicolumn{3}{|c|}{4.7330000000000005} & 967 & TST \\
\hline CHEMBL1508931 & 688653 & \multicolumn{3}{|c|}{5.132999999999999} & 5.6548 & \\
\hline CHEMBL & 688 & \multicolumn{3}{|c|}{5.332999999999999} & 4.9133 & TRN \\
\hline CHEMBL1 & 688653 & \multicolumn{3}{|c|}{4.9830000000000005} & 5.0672 & \\
\hline CHEMBL1344152 & 688653 & 4.933 & 5.4146 & TRN & & \\
\hline CHEMBL1570692 & 688653 & \multicolumn{3}{|c|}{6.132999999999999} & 5.7685 & \\
\hline CHEMBL1442615 & 688653 & 5.23 & 5.1299 & TRN & & \\
\hline CHEMBL: & 688 & 31 & 5.7 & TRN & & \\
\hline CHEMBL: & 688653 & 5.183 & 5.6067 & TST & & \\
\hline CHEMBL1570356 & 688653 & 5.033 & 5.3828 & TRN & & \\
\hline CHEMBL1330646 & 688653 & \multicolumn{3}{|c|}{5.132999999999999} & 5.1864 & $\mathrm{TI}$ \\
\hline CHEMBL1466696 & 688653 & 4.73300 & 00000000 & 005 & 5.011 & \\
\hline CHEMBL1 & 688653 & 5.083 & 5.8475 & TRN & & \\
\hline CHEMBL1611217 & 688653 & 4.98300 & 00000000 & 005 & 5.1562 & TR \\
\hline CHEMBL1358420 & 688653 & 5.083 & 5.2912 & TRN & & \\
\hline CHEMBL1547988 & 688653 & 4.783 & 5.0539 & TRN & & \\
\hline CHEMBL1507903 & 688653 & 4.883 & 5.0776 & TRN & & \\
\hline CHEMBL1573642 & 688653 & 6.03299 & 99999999 & 995 & 5.3481 & $\mathrm{Tt}$ \\
\hline CHEMBL1594185 & 688653 & 4.783 & 5.1573 & TRN & & \\
\hline CHEMBL1504150 & 688653 & 5.183 & 5.3756 & TRN & & \\
\hline CHEMBL1549543 & 688653 & 4.98300 & 00000000 & 005 & 5.3497 & 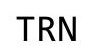 \\
\hline CHEMBL1448339 & 688653 & 4.783 & 4.9146 & TST & & \\
\hline CHEMBL1410697 & 688653 & 5.433 & 5.7861 & TST & & \\
\hline CHEMBL1420513 & 688653 & 6.33299 & 99999999 & & 5.092 & $\mathrm{INI}$ \\
\hline
\end{tabular}




\begin{tabular}{|c|c|c|c|c|c|c|}
\hline & & \multicolumn{5}{|c|}{ Supplemental Table S2.txt } \\
\hline CHEMBL1511689 & 688653 & 5.083 & 5.0713 & TRN & & \\
\hline CHEMBL1518077 & 688653 & 5.033 & 5.075 & TRN & & \\
\hline CHEMBL1527186 & 688653 & \multicolumn{3}{|c|}{6.582999999999999} & 6.0574 & TRN \\
\hline CHEMBL1567692 & 688653 & \multicolumn{3}{|c|}{6.082999999999999} & 5.5909 & TRN \\
\hline CHEMBL1533437 & 688653 & \multicolumn{3}{|c|}{5.882999999999999} & 5.2947 & TRN \\
\hline CHEMBL1476423 & 688653 & 4.633 & 5.1227 & TST & & \\
\hline CHEMBL1444181 & 688653 & \multicolumn{3}{|c|}{5.332999999999999} & 5.5251 & TRN \\
\hline CHEMBL1536928 & 688653 & 4.883 & 5.0386 & TST & & \\
\hline CHEMBL1544369 & 688653 & 5.683 & 5.7794 & TRN & & \\
\hline CHEMBL1354317 & 688653 & \multicolumn{3}{|c|}{6.5329999999999995} & 5.3187 & TRN \\
\hline CHEMBL 2004186 & 688653 & \multicolumn{3}{|c|}{5.132999999999999} & 5.2156 & TRN \\
\hline CHEMBL1510392 & 688653 & 4.783 & 5.0527 & TRN & & \\
\hline CHEMBL1440359 & 688653 & \multicolumn{3}{|c|}{4.7330000000000005} & 5.075 & 11 \\
\hline CHEMBL1319713 & 688653 & 5.033 & 4.9767 & TST & & \\
\hline CHEMBL1582736 & 688653 & 4.933 & 4.9432 & TST & & \\
\hline CHEMBL1401867 & 688653 & 5.683 & 5.8732 & TRN & & \\
\hline CHEMBL1403611 & 688653 & 4.883 & 5.2382 & TRN & & \\
\hline CHEMBL1406757 & 688653 & \multicolumn{3}{|c|}{5.132999999999999} & 5.2897 & TRN \\
\hline CHEMBL1420911 & 688653 & \multicolumn{3}{|c|}{4.7330000000000005} & 5.231 & TST \\
\hline CHEMBL1393635 & 688653 & \multicolumn{3}{|c|}{6.632999999999999} & 6.0865 & TRN \\
\hline CHEMBL1379283 & 688653 & 4.833 & 5.2566 & TRN & & \\
\hline CHEMBL1442877 & 688653 & 4.683 & 5.2505 & TST & & \\
\hline CHEMBL1486215 & 688653 & 4.683 & 5.3915 & TRN & & \\
\hline CHEMBL1384751 & 688653 & 5.083 & 4.9144 & TRN & & \\
\hline CHEMBL1405282 & 688653 & 4.783 & 5.5758 & TRN & & \\
\hline CHEMBL 3190453 & 688653 & 4.833 & 5.2478 & TRN & & \\
\hline CHEMBL1337266 & 688653 & 4.833 & 5.1995 & TST & & \\
\hline CHEMBL1467146 & 688653 & 4.833 & 5.322 & TST & & \\
\hline CHEMBL1328741 & 688653 & 4.633 & 5.5439 & TRN & & \\
\hline CHEMBL1490810 & 688653 & 4.783 & 4.783 & TST & & \\
\hline CHEMBL 2005671 & 688653 & 4.833 & 5.3557 & TRN & & \\
\hline CHEMBL1360165 & 688653 & \multicolumn{3}{|c|}{5.7829999999999995} & 08 & I K \\
\hline CHEMBL1371339 & 688653 & \multicolumn{3}{|c|}{5.132999999999999} & 6.3233 & TRN \\
\hline CHEMBL1579155 & 688653 & 5.233 & 5.4511 & TST & & \\
\hline CHEMBL69003 & 688653 & 4.783 & 4.862 & TST & & \\
\hline CHEMBL1453321 & 688653 & 4.933 & 5.0381 & TRN & & \\
\hline CHEMBL1460591 & 688653 & 5.483 & 5.0348 & TRN & & \\
\hline CHEMBL1495394 & 688653 & 6.183 & 5.6674 & TRN & & \\
\hline CHEMBL3191795 & 688653 & 4.933 & 4.727 & TRN & & \\
\hline CHEMBL1339145 & 688653 & 5.183 & 5.3909 & TRN & & \\
\hline CHEMBL1478916 & 688653 & \multicolumn{3}{|c|}{6.332999999999999} & 5.4708 & If \\
\hline CHEMBL1502185 & 688653 & 6.183 & 5.4183 & TRN & & \\
\hline CHEMBL1386394 & 688653 & \multicolumn{3}{|c|}{4.7330000000000005} & 5.2149 & TRN \\
\hline CHEMBL3194828 & 688653 & \multicolumn{3}{|c|}{6.0329999999999995} & 5.7247 & TRN \\
\hline CHEMBL1571028 & 688653 & 4.583 & 4.8618 & TRN & & \\
\hline CHEMBL1546818 & 688653 & \multicolumn{3}{|c|}{5.632999999999999} & 5. & TRN \\
\hline CHEMBL1364195 & 688653 & \multicolumn{3}{|c|}{5.5329999999999995} & 5.5636 & TST \\
\hline CHEMBL1528926 & 688653 & 5.483 & 5.5157 & TST & & \\
\hline
\end{tabular}




\begin{tabular}{|c|c|c|c|c|c|c|c|}
\hline & & & plement & al & s2.txt & & \\
\hline CHEMBL1428900 & 688653 & 4.73300 & j0000000e & 005 & 5.5995 & TST & \\
\hline CHEMBL1531101 & 688653 & 4.73300 & 000000006 & 005 & 5.1202 & TRN & \\
\hline CHEMBL1471016 & 688653 & 6.33299 & 999999994 & & 5.6606 & TRN & \\
\hline CHEMBL1355221 & 688653 & 5.13299 & 99999999 & & 5.1656 & TRN & \\
\hline CHEMBL1386715 & 688653 & 4.783 & 5.2754 & TST & & & \\
\hline CHEMBL1341879 & 688653 & 6.28299 & 99999999 & 995 & 6.0695 & TRN & \\
\hline CHEMBL3208981 & 688653 & 4.883 & 5.4178 & TRN & & & \\
\hline CHEMBL1489288 & 688653 & 4.73300 & 200000006 & 005 & 5.36299 & 99999999995 & TRN \\
\hline CHEMBL1427857 & 688653 & 6.0 & 5.4876 & TRN & & & \\
\hline CHEMBL1467987 & 688653 & 5.63299 & 99999999 & & 5.4761 & TST & \\
\hline CHEMBL1597627 & 688653 & 5.233 & 6.4529 & TRN & & & \\
\hline CHEMBL1325024 & 688653 & 4.833 & 5.09399 & 99999 & & TRN & \\
\hline CHEMBL1317352 & 688653 & 4.633 & 4.71899 & 99999 & 99 & TRN & \\
\hline CHEMBL1542408 & 688653 & 4.98300 & 20000000t & 005 & 5.1174 & TRN & \\
\hline CHEMBL1521122 & 688653 & 5.433 & 5.392 & TRN & & & \\
\hline CHEMBL3191729 & 688653 & 5.083 & 5.3879 & TRN & & & \\
\hline CHEMBL3208363 & 688653 & 4.933 & 5.4438 & TRN & & & \\
\hline CHEMBL1398721 & 688653 & 4.783 & 4.7001 & TRN & & & \\
\hline CHEMBL1317170 & 688653 & 4.583 & 4.7081 & TRN & & & \\
\hline CHEMBL1401926 & 688653 & 6.83299 & 99999999 & & 5.9556 & TRN & \\
\hline CHEMBL3183391 & 688653 & 5.13299 & 999999995 & & 5.234 & TST & \\
\hline CHEMBL1504878 & 688653 & 4.833 & 5.0649 & TRN & & & \\
\hline CHEMBL1442683 & 688653 & 5.183 & 5.4015 & TRN & & & \\
\hline CHEMBL1520533 & 688653 & 5.33299 & 99999999 & & 5.0072 & TRN & \\
\hline CHEMBL1599863 & 688653 & 6.28299 & 99999999 & 995 & 5.4278 & TST & \\
\hline CHEMBL1431340 & 688653 & 7.0329 & 6.0745 & TRN & & & \\
\hline CHEMBL1540473 & 688653 & 5.233 & 5.1413 & TRN & & & \\
\hline CHEMBL603522 & 688653 & 5.483 & 5.2657 & TST & & & \\
\hline CHEMBL1403628 & 688653 & 4.883 & 5.4697 & TST & & & \\
\hline CHEMBL1399667 & 688653 & 5.183 & 5.7535 & TRN & & & \\
\hline CHEMBL1340951 & 688653 & 4.783 & 5.4189 & TST & & & \\
\hline CHEMBL1575371 & 688653 & 4.683 & 5.2507 & TRN & & & \\
\hline CHEMBL3195856 & 688653 & 5.683 & 5.6937 & TST & & & \\
\hline CHEMBL1376796 & 688653 & 5.683 & 5.38399 & 99999 & 995 & TRN & \\
\hline CHEMBL1307267 & 688653 & 4.783 & 5.6773 & TRN & & & \\
\hline CHEMBL1344642 & 688653 & 5.13299 & 99999999 & & 5.0648 & TST & \\
\hline CHEMBL1465755 & 688653 & 4.98300 & 00000000 & 005 & 5.1852 & TRN & \\
\hline CHEMBL1583292 & 688653 & 5.38299 & 99999999 & & 5.2477 & TST & \\
\hline CHEMBL1455399 & 688653 & 4.883 & 5.6138 & TRN & & & \\
\hline CHEMBL1432657 & 688653 & 6.4829 & 5.7099 & TRN & & & \\
\hline CHEMBL1353871 & 688653 & 5.183 & 4.9958 & TRN & & & \\
\hline CHEMBL1462337 & 688653 & 4.783 & 4.9546 & TRN & & & \\
\hline CHEMBL1610836 & 688653 & 5.13299 & 99999999 & 99 & 5.0449 & TRN & \\
\hline CHEMBL1303968 & 688653 & 4.833 & 5.1107 & TRN & & & \\
\hline CHEMBL1358433 & 688653 & 4.833 & 4.7605 & TRN & & & \\
\hline CHEMBL1992261 & 688653 & 5.683 & 5.7815 & TRN & & & \\
\hline CHEMBL1372768 & 688653 & 4.98300 & 00000000 & 005 & 5.3869 & TST & \\
\hline CHEMBL3199578 & 688653 & 5.13299 & 99999999 & & 5.6505 & TRN & \\
\hline
\end{tabular}




\begin{tabular}{|c|c|c|c|c|c|c|c|}
\hline \multicolumn{7}{|c|}{ Supplemental Table S2.txt } & \\
\hline CHEMBL1323991 & 688653 & \multicolumn{3}{|c|}{5.582999999999999} & 5.4806 & TRN & \\
\hline CHEMBL1362428 & 688653 & 4.833 & 5.0684 & TRN & & & \\
\hline CHEMBL1489325 & 688653 & \multicolumn{3}{|c|}{4.9830000000000005} & 4.9644 & TST & \\
\hline CHEMBL1603311 & 688653 & \multicolumn{3}{|c|}{4.7330000000000005} & 4.9817 & TST & \\
\hline CHEMBL1467493 & 688653 & 6.183 & 5.7168 & TRN & & & \\
\hline CHEMBL1408414 & 688653 & 5.733 & 5.4688 & TRN & & & \\
\hline CHEMBL1347497 & 688653 & 4.583 & 4.8844 & TST & & & \\
\hline CHEMBL1418232 & 688653 & \multicolumn{3}{|c|}{4.7330000000000005} & 5.0129 & TST & \\
\hline CHEMBL1607684 & 688653 & \multicolumn{3}{|c|}{5.132999999999999} & 4.8027 & TRN & \\
\hline CHEMBL1316968 & 688653 & 4.933 & 5.3059 & TRN & & & \\
\hline CHEMBL1517787 & 688653 & 4.583 & \multicolumn{3}{|c|}{4.7780000000000005} & TRN & \\
\hline CHEMBL1404447 & 688653 & 5.683 & 5.1689 & TRN & & & \\
\hline CHEMBL1413901 & 688653 & 7.1831 & 5.8384 & TRN & & & \\
\hline CHEMBL1598110 & 688653 & 4.933 & \multicolumn{3}{|c|}{5.367000000000001} & TRN & \\
\hline CHEMBL1362651 & 688653 & 4.633 & 5.1829 & TRN & & & \\
\hline CHEMBL1337898 & 688653 & 7.2832 & 5.6289 & TRN & & & \\
\hline CHEMBL1481981 & 688653 & \multicolumn{3}{|c|}{4.9830000000000005} & 5.3013 & TST & \\
\hline CHEMBL1428758 & 688653 & 4.783 & 4.915 & TRN & & & \\
\hline CHEMBL3196561 & 688653 & 5.733 & 5.8381 & TST & & & \\
\hline CHEMBL 3212849 & 688653 & \multicolumn{3}{|c|}{4.7330000000000005} & 5.324 & TRN & \\
\hline CHEMBL1493953 & 688653 & 4.833 & 4.8012 & TRN & & & \\
\hline CHEMBL1495908 & 688653 & \multicolumn{3}{|c|}{5.382999999999999} & 5.1859 & TRN & \\
\hline CHEMBL1504690 & 688653 & \multicolumn{3}{|c|}{5.132999999999999} & 5.0454 & TRN & \\
\hline CHEMBL1394882 & 688653 & 4.833 & 4.9627 & TRN & & & \\
\hline CHEMBL1353518 & 688653 & 4.633 & 5.2914 & TST & & & \\
\hline CHEMBL1438282 & 688653 & \multicolumn{3}{|c|}{ 5. 2829999999999995} & 5.3724 & TRN & \\
\hline CHEMBL1307186 & 688653 & 4.883 & 5.0762 & TRN & & & \\
\hline CHEMBL 1384576 & 688653 & \multicolumn{3}{|c|}{6.332999999999999} & 5.3693 & TRN & \\
\hline CHEMBL 1487460 & 688653 & 5.233 & 5.1894 & TST & & & \\
\hline CHEMBL1300471 & 688653 & \multicolumn{3}{|c|}{5.332999999999999} & 5.1911 & TRN & \\
\hline CHEMBL1597432 & 688653 & \multicolumn{3}{|c|}{6.632999999999999} & 5.3575 & TRN & \\
\hline CHEMBL1444536 & 688653 & 5.233 & 5.5375 & TRN & & & \\
\hline CHEMBL1376945 & 688653 & \multicolumn{3}{|c|}{6.332999999999999} & 4.8799 & TST & \\
\hline CHEMBL 3198547 & 688653 & 4.783 & 4.8731 & TRN & & & \\
\hline CHEMBL1301573 & 688653 & \multicolumn{3}{|c|}{5.5329999999999995} & \multicolumn{2}{|c|}{5.667000000000001} & TST \\
\hline CHEMBL1381977 & 688653 & 5.033 & 5.6468 & TRN & & & \\
\hline CHEMBL 2006634 & 688653 & 4.583 & 5.2492 & TRN & & & \\
\hline CHEMBL1536562 & 688653 & \multicolumn{3}{|c|}{4.9830000000000005} & 5.4118 & TRN & \\
\hline CHEMBL1422577 & 688653 & 4.883 & 5.6065 & TRN & & & \\
\hline CHEMBL1431475 & 688653 & 4.833 & 4.6161 & TST & & & \\
\hline CHEMBL1532072 & 688653 & \multicolumn{3}{|c|}{4.7330000000000005} & 5.341 & TRN & \\
\hline CHEMBL 3197208 & 688653 & 5.683 & 5.6115 & TRN & & & \\
\hline CHEMBL1462690 & 688653 & 6.38299 & 99999999 & & 5.8066 & TRN & \\
\hline CHEMBL1470185 & 688653 & 4.633 & 5.1442 & TST & & & \\
\hline CHEMBL1256749 & 688653 & 4.633 & 5.052 & TST & & & \\
\hline CHEMBL1494080 & 688653 & 5.78299 & 99999999 & 995 & 6.1387 & TRN & \\
\hline CHEMBL1350032 & 688653 & 5.33299 & 99999999 & & 5.5666 & TRN & \\
\hline CHEMBL1421893 & 688653 & 4.95 & 4.9161 & TRN & & & \\
\hline
\end{tabular}




\begin{tabular}{|c|c|c|c|c|c|c|}
\hline \multirow[b]{2}{*}{ CHEMBL1462968 } & & \multicolumn{5}{|c|}{ Supplemental Table S2.txt } \\
\hline & 688653 & 4.583 & 5.0317 & TRN & & \\
\hline CHEMBL1513212 & 688653 & 5.033 & 5.1505 & TRN & & \\
\hline CHEMBL1372804 & 688653 & 5.28299 & 99999999 & 995 & 5.2101 & TRN \\
\hline CHEMBL1459538 & 688653 & 5.28299 & 99999999 & 995 & 5.2142 & TRN \\
\hline CHEMBL1357829 & 688653 & 4.73300 & $00000000 t$ & 005 & 5.093 & TST \\
\hline CHEMBL1559668 & 688653 & 4.73300 & 000000006 & 005 & 5.1861 & TRN \\
\hline CHEMBL1422329 & 688653 & 6.28299 & 99999999 & 995 & 5.6704 & TRN \\
\hline CHEMBL1437818 & 688653 & 5.683 & 5.2341 & TRN & & \\
\hline CHEMBL1369565 & 688653 & 5.233 & 5.2258 & TST & & \\
\hline CHEMBL1543847 & 688653 & 5.33299 & 999999995 & & 5.4938 & TRN \\
\hline CHEMBL1600075 & 688653 & 4.98300 & $00000000 t$ & 005 & 5.3546 & TRN \\
\hline CHEMBL1491703 & 688653 & 4.73300 & j00000006 & 005 & 5.1134 & TST \\
\hline CHEMBL1316301 & 688653 & 7.3325 & 5.7628 & TRN & & \\
\hline CHEMBL1330965 & 688653 & 6.08299 & 99999999 & & 5.2721 & TRN \\
\hline CHEMBL1415579 & 688653 & 5.233 & 5.0288 & TRN & & \\
\hline CHEMBL1349995 & 688653 & 4.73300 & $00000000 t$ & 005 & 5.2648 & TRN \\
\hline CHEMBL1575036 & 688653 & 6.233 & 5.4598 & TRN & & \\
\hline CHEMBL1538778 & 688653 & 5.13299 & 99999999 & & 4.9283 & TST \\
\hline CHEMBL3199809 & 688653 & 4.883 & 5.4864 & TRN & & \\
\hline CHEMBL3210398 & 688653 & 5.13299 & 99999999 & & 5.4898 & TST \\
\hline CHEMBL1418105 & 688653 & 4.73300 & $00000000 t$ & 005 & 5.2618 & TRN \\
\hline CHEMBL3192337 & 688653 & 6.33299 & 99999999 & & 5.2345 & TRN \\
\hline CHEMBL1486877 & 688653 & 5.733 & 5.6542 & TRN & & \\
\hline CHEMBL1367587 & 688653 & 4.883 & 5.3504 & TST & & \\
\hline CHEMBL1413568 & 688653 & 6.0 & 5.3643 & TRN & & \\
\hline CHEMBL1514284 & 688653 & 5.88299 & 99999999 & & 5.3099 & TST \\
\hline CHEMBL1585178 & 688653 & 4.783 & 5.0881 & TRN & & \\
\hline CHEMBL1360879 & 688653 & 5.933 & 5.3409 & TRN & & \\
\hline CHEMBL1563492 & 688653 & 4.933 & 5.2195 & TRN & & \\
\hline CHEMBL1589176 & 688653 & 5.033 & 5.2827 & TRN & & \\
\hline CHEMBL3191254 & 688653 & 4.73300 & 00000000 & 005 & 5.2757 & TRN \\
\hline CHEMBL3192519 & 688653 & 4.833 & 5.1111 & TRN & & \\
\hline CHEMBL3190328 & 688653 & 4.833 & 4.8369 & TRN & & \\
\hline CHEMBL1311226 & 688653 & 5.233 & 5.6468 & TRN & & \\
\hline CHEMBL1558957 & 688653 & 4.633 & 5.149 & TRN & & \\
\hline CHEMBL1530574 & 688653 & 4.933 & 5.4222 & TST & & \\
\hline CHEMBL3190998 & 688653 & 5.13299 & 99999999 & & 5.8001 & TRN \\
\hline CHEMBL1299319 & 688653 & 4.833 & 4.8589 & TST & & \\
\hline CHEMBL1597975 & 688653 & 4.783 & 5.4722 & TST & & \\
\hline CHEMBL1470314 & 688653 & 4.633 & 5.5462 & TST & & \\
\hline CHEMBL3196904 & 688653 & 5.33299 & 99999999 & & 5.1694 & TRN \\
\hline CHEMBL3195732 & 688653 & 5.733 & 5.6089 & TST & & \\
\hline CHEMBL1520180 & 688653 & 6.38299 & 99999999 & & 5.7417 & TST \\
\hline CHEMBL1414267 & 688653 & 4.883 & 4.9263 & TRN & & \\
\hline CHEMBL1423871 & 688653 & 4.833 & 5.1767 & TRN & & \\
\hline CHEMBL1587930 & 688653 & 4.73300 & 00000000 & 005 & 4.7497 & TRN \\
\hline CHEMBL1457469 & 688653 & 4.883 & 4.9586 & TST & & \\
\hline CHEMBL1453194 & 688653 & 5.433 & 5.9742 & TRN & & \\
\hline
\end{tabular}




\begin{tabular}{|c|c|c|c|c|c|c|}
\hline \multirow[b]{2}{*}{ CHEMBL1335100 } & \multicolumn{6}{|c|}{ Supplemental Table S2.txt } \\
\hline & 688653 & 5.683 & \multirow{2}{*}{\multicolumn{3}{|c|}{$\begin{array}{l}5.3583 \text { TRN } \\
5.382999999999999\end{array}$}} & \\
\hline CHEMBL1562029 & 688653 & 5.083 & & & & TRN \\
\hline CHEMBL1438758 & 688653 & 4.933 & 6.2439 & \multicolumn{2}{|l|}{ TRN } & \\
\hline CHEMBL1508071 & 688653 & \multicolumn{3}{|c|}{4.7330000000000005} & 5.358 & \\
\hline CHEMBL1605554 & 688653 & 4.933 & 5.002 & TST & & \\
\hline CHEMBL1558163 & 688653 & \multicolumn{3}{|c|}{6.582999999999999} & 5.7911 & \\
\hline CHEMBL1361858 & 688653 & 5.083 & 5.5591 & TRN & & \\
\hline CHEMBL 3145365 & 588653 & 5.433 & 5.4205 & TRN & & \\
\hline CHEMBL1382658 & 688653 & \multicolumn{3}{|c|}{5.2829999999999995} & 6.1174 & \\
\hline CHEMBL1459468 & 688653 & \multicolumn{3}{|c|}{5.832999999999999} & 6.3933 & \\
\hline CHEMBL602150 & 688653 & \multicolumn{3}{|c|}{5.332999999999999} & 5.0935 & \\
\hline CHEMBL1480704 & 688653 & \multicolumn{3}{|c|}{6.132999999999999} & 5.2898 & \\
\hline CHEMBL1469808 & 688653 & \multicolumn{3}{|c|}{5.2829999999999995} & 5.2612 & \\
\hline CHEMBL1433319 & 688653 & \multicolumn{3}{|c|}{5.2829999999999995} & 5.4294 & \\
\hline CHEMBL1514677 & 688653 & 7.3325 & 5.6349 & TRN & & \\
\hline CHEMBL1331106 & 688653 & 4.883 & 5.3501 & TRN & & \\
\hline CHEMBL1375767 & 688653 & 4.783 & 5.0913 & TRN & & \\
\hline CHEMBL13 & 688653 & \multicolumn{3}{|c|}{4.7330000000000005} & 4.7644 & \\
\hline CHEMBL1507312 & 688653 & \multicolumn{3}{|c|}{4.9830000000000005} & 5.2075 & \\
\hline CHEMBL1598540 & 688653 & 4.783 & 5.0287 & TST & & \\
\hline CHEMBL1341991 & 688653 & \multicolumn{3}{|c|}{4.7330000000000005} & 993 & \\
\hline CHEMBL1462179 & 688653 & 5.433 & 5.3536 & TRN & & \\
\hline CHEMBL15 & 688653 & \multirow{2}{*}{\multicolumn{3}{|c|}{$\begin{array}{lc}5.183 & 5.3792 \\
4.9830000000000005\end{array}$}} & & \\
\hline CHEMBL1525724 & 688653 & & & & 5.1581 & \\
\hline CHEMBL578716 & 688653 & 5.233 & 5.1493 & TST & & \\
\hline CHEMBL1381097 & 688653 & 5.183 & 5.3305 & TST & & \\
\hline CHEMBL1384533 & 688653 & 6.45 & 5.7101 & TRN & & \\
\hline CHEMBL14 & 688653 & 5.933 & 6.072 & TRN & & \\
\hline CHEMBL1462556 & 688653 & 5.933 & 5.729 & TRN & & \\
\hline CHEMBL1387022 & 688653 & \multicolumn{3}{|c|}{ 5.382999999999999 } & 5.5786 & \\
\hline CHEMBL1508552 & 688653 & 4.783 & 5.3028 & TST & & \\
\hline CHEMBL13 & 688653 & \multicolumn{3}{|c|}{5.332999999999999} & 5.3434 & \\
\hline CHEMBL14 & 688653 & 4.883 & 5.1536 & TST & & \\
\hline CHEMBL1603130 & 688653 & 5.233 & 5.5308 & TRN & & \\
\hline CHEMBL1532619 & 688653 & \multicolumn{3}{|c|}{5.5329999999999995} & 4.7893 & \\
\hline CHEMBL1372428 & 688653 & \multicolumn{3}{|c|}{6.632999999999999} & 6.1935 & \\
\hline CHEMBL1 & 68 & 4.683 & 5.3142 & TST & & \\
\hline CHEMBL1555728 & 688653 & & & TRN & & \\
\hline CHEMBL1528829 & 688653 & 5.3329 & 999999999 & & 5.2766 & \\
\hline CHEMBL1313954 & 688653 & 5.1329 & 999999999 & & 5.8476 & \\
\hline CHEMBL1364728 & 688653 & 5.6329 & 999999999 & & 5.2613 & \\
\hline CHEMBL1594554 & 688653 & 6.1329 & 999999999 & & 5.4602 & \\
\hline CHEMBL1464493 & 688653 & 5.733 & 5.1438 & TRN & & \\
\hline CHEMBL1474157 & 688653 & 5.1329 & 999999999 & & 5.3413 & T \\
\hline CHEMBL1539488 & 688653 & 4.933 & 5.6967 & TRN & & \\
\hline CHEMBL1493385 & 688653 & 5.683 & 5.1031 & TRN & & \\
\hline CHEMBL1603034 & 688653 & 5.2829 & 999999999 & 995 & 5.859 & \\
\hline CHEMBL1445523 & 688653 & 5.683 & 5.6803 & TRN & & \\
\hline
\end{tabular}




\begin{tabular}{|c|c|c|c|c|c|c|c|}
\hline \multicolumn{7}{|c|}{ Supplemental Table S2.txt } & \\
\hline CHEMBL1382123 & 688653 & \multicolumn{3}{|c|}{5.2829999999999995} & 5.2385 & TRN & \\
\hline CHEMBL1347668 & 688653 & \multicolumn{3}{|c|}{5.632999999999999} & 5.7316 & TRN & \\
\hline CHEMBL1364234 & 688653 & \multicolumn{3}{|c|}{5.632999999999999} & 5.0452 & TRN & \\
\hline CHEMBL1580091 & 688653 & 5.183 & 5.3456 & TRN & & & \\
\hline CHEMBL1393490 & 688653 & 5.733 & 5.3056 & TRN & & & \\
\hline CHEMBL3196535 & 688653 & 5.083 & 5.0461 & TRN & & & \\
\hline CHEMBL1599168 & 688653 & \multicolumn{3}{|c|}{5.132999999999999} & 5.7743 & TRN & \\
\hline CHEMBL1415245 & 688653 & \multicolumn{3}{|c|}{5.132999999999999} & 5.351 & TRN & \\
\hline CHEMBL1510949 & 688653 & 4.783 & 4.9681 & TST & & & \\
\hline CHEMBL1540471 & 688653 & 4.833 & 5.1812 & TRN & & & \\
\hline CHEMBL1528497 & 688653 & 4.933 & 4.9224 & TRN & & & \\
\hline CHEMBL1333734 & 688653 & 4.583 & 5.353 & TST & & & \\
\hline CHEMBL1402010 & 688653 & \multicolumn{3}{|c|}{5.832999999999999} & 5.4307 & TST & \\
\hline CHEMBL1383644 & 688653 & 5.183 & 5.3554 & TST & & & \\
\hline CHEMBL3207816 & 688653 & 4.883 & 5.6855 & TST & & & \\
\hline CHEMBL1565955 & 688653 & 5.933 & 4.9689 & TRN & & & \\
\hline CHEMBL3196374 & 688653 & 4.583 & 5.5395 & TRN & & & \\
\hline CHEMBL1509789 & 688653 & 4.883 & 5.5817 & TST & & & \\
\hline CHEMBL1442582 & 688653 & \multicolumn{3}{|c|}{4.7330000000000005} & 5.2769 & TRN & \\
\hline CHEMBL1414524 & 688653 & 4.883 & 4.9997 & TST & & & \\
\hline CHEMBL1625031 & 688653 & 4.683 & 4.6946 & TRN & & & \\
\hline CHEMBL1343311 & 688653 & 6.433 & 5.9576 & TST & & & \\
\hline CHEMBL 29213 & 688653 & 4.883 & 5.2327 & TST & & & \\
\hline CHEMBL1595125 & 688653 & 4.783 & 5.0975 & TRN & & & \\
\hline CHEMBL1313864 & 688653 & 4.833 & 5.4003 & TRN & & & \\
\hline CHEMBL1528144 & 688653 & 5.183 & 5.4286 & TRN & & & \\
\hline CHEMBL1413424 & 688653 & 5.033 & 5.3549 & TST & & & \\
\hline CHEMBL261799 & 688653 & \multicolumn{3}{|c|}{5.332999999999999} & 5.3089 & TRN & \\
\hline CHEMBL1463404 & 688653 & 5.483 & 5.205 & TRN & & & \\
\hline CHEMBL1554517 & 688653 & \multicolumn{3}{|c|}{5.832999999999999} & 5.1166 & TST & \\
\hline CHEMBL1612099 & 688653 & \multicolumn{3}{|c|}{4.7330000000000005} & 4.9423 & TRN & \\
\hline CHEMBL1518990 & 688653 & \multicolumn{3}{|c|}{4.9830000000000005} & 5.2707 & TRN & \\
\hline CHEMBL 2094789 & 688653 & \multicolumn{3}{|c|}{5.832999999999999} & 5.6882 & TRN & \\
\hline CHEMBL1524934 & 688653 & \multicolumn{3}{|c|}{4.7330000000000005} & 5.8071 & TRN & \\
\hline CHEMBL1518265 & 688653 & \multicolumn{3}{|c|}{4.7330000000000005} & 5.768 & TRN & \\
\hline CHEMBL1388012 & 688653 & 6.2 & 5.4925 & TRN & & & \\
\hline CHEMBL1578635 & 688653 & \multicolumn{3}{|c|}{4.9830000000000005} & 4.9587 & TRN & \\
\hline CHEMBL1402939 & 688653 & 5.183 & 5.3185 & TRN & & & \\
\hline CHEMBL1542825 & 688653 & \multicolumn{3}{|c|}{4.7330000000000005} & 5.2506 & TST & \\
\hline CHEMBL1580007 & 688653 & 5.483 & 5.3495 & TRN & & & \\
\hline CHEMBL1363210 & 688653 & 6.433 & 5.6141 & TRN & & & \\
\hline CHEMBL1561108 & 688653 & \multicolumn{3}{|c|}{5.2829999999999995} & 5.269 & TRN & \\
\hline CHEMBL1438778 & 688653 & 4.633 & 5.2764 & TST & & & \\
\hline CHEMBL1335682 & 688653 & \multicolumn{3}{|c|}{5.332999999999999} & 5.6560 & 0000000001 & TST \\
\hline CHEMBL1561748 & 688653 & \multicolumn{3}{|c|}{5.7829999999999995} & 5.1694 & TST & \\
\hline CHEMBL1311739 & 688653 & 4.883 & 5.4249 & TRN & & & \\
\hline CHEMBL1540117 & 688653 & 4.933 & 5.3156 & TRN & & & \\
\hline CHEMBL1557213 & 688653 & 4.683 & 5.0097 & TST & & & \\
\hline
\end{tabular}




\begin{tabular}{|c|c|c|c|c|c|c|}
\hline & & \multicolumn{5}{|c|}{ Supplemental Table s2.txt } \\
\hline CHEMBL1597541 & 688653 & \multicolumn{4}{|c|}{4.7330000000000005} & TRN \\
\hline CHEMBL1347724 & 688653 & \multicolumn{3}{|c|}{5.382999999999999} & 5.2508 & TRN \\
\hline CHEMBL1606263 & 688653 & 6.4829 & 5.6644 & TRN & & \\
\hline CHEMBL1450831 & 688653 & \multicolumn{3}{|c|}{5.832999999999999} & 5.5569 & TRN \\
\hline CHEMBL1422056 & 688653 & 6.0 & 5.3591 & TST & & \\
\hline CHEMBL1503294 & 688653 & 4.883 & 5.9161 & TRN & & \\
\hline CHEMBL1448611 & 688653 & \multicolumn{3}{|c|}{6.332999999999999} & 5.6989 & TST \\
\hline CHEMBL1989467 & 688653 & 5.233 & 5.3778 & TRN & & \\
\hline CHEMBL1465850 & 688653 & \multicolumn{3}{|c|}{6.0329999999999995} & 5.4423 & TRN \\
\hline CHEMBL1396810 & 688653 & 4.633 & 4.6812 & TRN & & \\
\hline CHEMBL1565099 & 688653 & 4.783 & \multicolumn{3}{|c|}{5.492000000000001} & TST \\
\hline CHEMBL1562762 & 688653 & \multicolumn{3}{|c|}{5.882999999999999} & 5.4251 & TRN \\
\hline CHEMBL1511716 & 688653 & \multicolumn{3}{|c|}{5.382999999999999} & 5.4108 & TRN \\
\hline CHEMBL1355883 & 688653 & \multicolumn{3}{|c|}{6.382999999999999} & 5.1556 & TRN \\
\hline CHEMBL1396506 & 688653 & 4.683 & 5.0708 & TST & & \\
\hline CHEMBL1554304 & 688653 & 4.783 & 4.9375 & TRN & & \\
\hline CHEMBL1328521 & 688653 & 4.883 & 4.9981 & TRN & & \\
\hline CHEMBL1436095 & 688653 & 4.883 & 5.3112 & TST & & \\
\hline CHEMBL1357178 & 688653 & 4.883 & 4.7732 & TRN & & \\
\hline CHEMBL1536255 & 688653 & \multicolumn{3}{|c|}{5.632999999999999} & 5.4164 & TST \\
\hline CHEMBL1487709 & 688653 & 5.483 & 5.1919 & TRN & & \\
\hline CHEMBL1512621 & 688653 & \multicolumn{3}{|c|}{5.832999999999999} & 5.4664 & TRN \\
\hline CHEMBL1366971 & 688653 & \multicolumn{3}{|c|}{5.582999999999999} & 5.2511 & TRN \\
\hline CHEMBL1458858 & 688653 & 4.633 & 4.9013 & TRN & & \\
\hline CHEMBL1554801 & 688653 & 4.883 & 4.8537 & TRN & & \\
\hline CHEMBL1579367 & 688653 & 5.033 & 4.9656 & TRN & & \\
\hline CHEMBL1532956 & 688653 & \multicolumn{3}{|c|}{4.7330000000000005} & 5.0065 & TST \\
\hline CHEMBL1450259 & 688653 & 4.883 & 5.2711 & TRN & & \\
\hline CHEMBL1375678 & 688653 & \multicolumn{3}{|c|}{5.832999999999999} & 5.8007 & TRN \\
\hline CHEMBL412603 & 688653 & \multicolumn{3}{|c|}{5.832999999999999} & 5.2841 & TRN \\
\hline CHEMBL1579437 & 688653 & 4.833 & 4.8953 & TRN & & \\
\hline CHEMBL1453801 & 688653 & 6.233 & 5.56 & TRN & & \\
\hline CHEMBL3197123 & 688653 & 5.433 & 5.6315 & TST & & \\
\hline CHEMBL1488483 & 688653 & 4.883 & 5.0011 & TRN & & \\
\hline CHEMBL1381226 & 688653 & 6.183 & 5.3927 & TRN & & \\
\hline CHEMBL1340223 & 688653 & 4.833 & 5.1437 & TRN & & \\
\hline CHEMBL3197450 & 688653 & 4.783 & 5.2719 & TRN & & \\
\hline CHEMBL1312205 & 688653 & 4.933 & 5.2668 & TRN & & \\
\hline CHEMBL14284 & 688653 & \multicolumn{3}{|c|}{6.5329999999999995} & 5.9302 & TRN \\
\hline CHEMBL3190668 & 688653 & 6.233 & 5.2255 & TRN & & \\
\hline CHEMBL1569305 & 688653 & \multicolumn{3}{|c|}{6.082999999999999} & 5.6894 & TRN \\
\hline CHEMBL1387110 & 688653 & 4.633 & 5.8422 & TRN & & \\
\hline CHEMBL1444961 & 688653 & \multicolumn{3}{|c|}{5.882999999999999} & 5.4118 & TST \\
\hline CHEMBL1364997 & 688653 & 4.633 & 4.4755 & TST & & \\
\hline CHEMBL1517034 & 688653 & 5.233 & 4.8888 & TRN & & \\
\hline CHEMBL1316794 & 688653 & 4.833 & 4.9645 & TRN & & \\
\hline CHEMBL1328837 & 688653 & 5.9218 & 5.1562 & TST & & \\
\hline CHEMBL1301891 & 688653 & 4.933 & 5.2327 & TST & & \\
\hline
\end{tabular}




\begin{tabular}{|c|c|c|c|c|c|c|}
\hline \multirow[b]{2}{*}{ CHEMBL3191007 } & & \multicolumn{5}{|c|}{ Supplemental Table s2.txt } \\
\hline & 688653 & 4.783 & 4.8812 & TST & & \\
\hline CHEMBL1414272 & 688653 & 4.883 & 5.3248 & TRN & & \\
\hline CHEMBL 71271 & 688653 & \multicolumn{3}{|c|}{5.332999999999999} & 5.8016 & TRN \\
\hline CHEMBL1519943 & 688653 & \multicolumn{3}{|c|}{5.382999999999999} & 5.1577 & TRN \\
\hline CHEMBL1558550 & 688653 & 5.233 & 5.3019 & TRN & & \\
\hline CHEMBL1610972 & 688653 & 6.4829 & 5.4594 & TST & & \\
\hline CHEMBL1519731 & 688653 & \multicolumn{3}{|c|}{5.582999999999999} & 6.3092 & TRN \\
\hline CHEMBL1378893 & 688653 & \multicolumn{3}{|c|}{5.382999999999999} & 5.0913 & TRN \\
\hline CHEMBL3191416 & 688653 & \multicolumn{3}{|c|}{7.382999999999999} & 5.9539 & TRN \\
\hline CHEMBL3196459 & 688653 & 4.833 & 5.322 & TRN & & \\
\hline CHEMBL1478565 & 688653 & 4.683 & 5.3959 & TST & & \\
\hline CHEMBL3190052 & 688653 & 5.183 & 5.4251 & TRN & & \\
\hline CHEMBL1577325 & 688653 & \multicolumn{3}{|c|}{4.7330000000000005} & 5.2512 & TRN \\
\hline CHEMBL1357951 & 688653 & 4.783 & 5.0618 & TRN & & \\
\hline CHEMBL1379619 & 688653 & 4.833 & 5.3504 & TRN & & \\
\hline CHEMBL1439954 & 688653 & \multicolumn{3}{|c|}{5.832999999999999} & 6.07 & TRN \\
\hline CHEMBL1541158 & 688653 & \multicolumn{3}{|c|}{4.7330000000000005} & 5.5535 & TRN \\
\hline CHEMBL1598184 & 688653 & \multicolumn{3}{|c|}{5.382999999999999} & 4.7992 & TRN \\
\hline CHEMBL1524381 & 688653 & \multicolumn{3}{|c|}{4.7330000000000005} & 5.3751 & TRN \\
\hline CHEMBL1371507 & 688653 & 6.683 & 5.977 & TRN & & \\
\hline CHEMBL1319574 & 688653 & \multicolumn{3}{|c|}{4.7330000000000005} & 4.894 & TRN \\
\hline CHEMBL1550087 & 688653 & 5.983 & 5.6218 & TRN & & \\
\hline CHEMBL1333751 & 688653 & \multicolumn{3}{|c|}{5.832999999999999} & 5.2948 & TRN \\
\hline CHEMBL1390467 & 688653 & 4.783 & 5.0463 & TST & & \\
\hline CHEMBL1330197 & 688653 & 4.883 & 5.4052 & TRN & & \\
\hline CHEMBL1359561 & 688653 & \multicolumn{3}{|c|}{5.2829999999999995} & 5.2929 & TST \\
\hline CHEMBL1403203 & 688653 & \multicolumn{3}{|c|}{4.9830000000000005} & 5.4425 & TST \\
\hline CHEMBL1348395 & 688653 & 4.883 & 5.1367 & TRN & & \\
\hline CHEMBL1433899 & 688653 & 4.633 & 4.7132 & TST & & \\
\hline CHEMBL1387440 & 688653 & 5.183 & 5.1075 & TRN & & \\
\hline CHEMBL1355362 & 688653 & 4.683 & 4.7518 & TRN & & \\
\hline CHEMBL 3214074 & 688653 & 4.783 & 4.8434 & TRN & & \\
\hline CHEMBL3197489 & 688653 & 4.633 & 4.651 & TST & & \\
\hline CHEMBL1365533 & 688653 & 4.883 & 5.0988 & TST & & \\
\hline CHEMBL1421125 & 688653 & 6.3329 & 99999999 & 99 & 5.4612 & TRN \\
\hline CHEMBL1452179 & 688653 & 4.883 & 5.3454 & TRN & & \\
\hline CHEMBL1499293 & 688653 & 4.783 & 5.282 & TRN & & \\
\hline CHEMBL1610045 & 688653 & 4.783 & 5.3063 & TRN & & \\
\hline CHEMBL1586373 & 688653 & 5.8829 & 99999999 & & 5.5335 & TRN \\
\hline CHEMBL1541915 & 688653 & 5.3829 & 99999999 & & 5.5578 & TRN \\
\hline CHEMBL1506340 & 688653 & 5.433 & 5.0412 & TST & & \\
\hline CHEMBL209699 & 688653 & 5.5329 & 99999999 & 995 & 5.6679 & TRN \\
\hline CHEMBL1445750 & 688653 & 6.433 & 5.4457 & TRN & & \\
\hline CHEMBL2369285 & 688653 & 6.433 & 5.5584 & TRN & & \\
\hline CHEMBL1531156 & 688653 & 4.783 & 5.1257 & TST & & \\
\hline CHEMBL1562685 & 688653 & 4.883 & 5.403 & TRN & & \\
\hline CHEMBL1587080 & 688653 & 4.783 & 5.3318 & TST & & \\
\hline CHEMBL1324894 & 688653 & 5.433 & 5.5574 & TST & & \\
\hline
\end{tabular}




\begin{tabular}{|c|c|c|c|c|c|c|c|}
\hline \multicolumn{8}{|c|}{ Supplemental Table S2.txt } \\
\hline CHEMBL3192129 & 688653 & 5.733 & 4.9078 & TST & & & \\
\hline CHEMBL1475345 & 688653 & 4.583 & 5.1591 & TRN & & & \\
\hline CHEMBL1546037 & 688653 & 6.08299 & 999999999 & & 5.74299 & 9999999999 & TRN \\
\hline CHEMBL1345197 & 688653 & 4.883 & 5.492999 & 999999999 & & TRN & \\
\hline CHEMBL3207762 & 688653 & 4.783 & 5.3667 & TST & & & \\
\hline CHEMBL1603319 & 688653 & 5.63299 & 999999999 & & 5.2055 & TST & \\
\hline CHEMBL1422229 & 688653 & 4.783 & 5.271 & TRN & & & \\
\hline CHEMBL1503529 & 688653 & 4.73300 & 000000006 & 005 & 5.2749 & TST & \\
\hline CHEMBL1396557 & 688653 & 5.683 & 5.3021 & TRN & & & \\
\hline CHEMBL1461728 & 688653 & 5.13299 & 99999999؛ & & 5.6504 & TRN & \\
\hline CHEMBL1420307 & 688653 & 5.38299 & 999999999 & & 5.3427 & TRN & \\
\hline CHEMBL1976649 & 688653 & 4.73300 & 000000006 & 005 & 5.2403 & TRN & \\
\hline CHEMBL454580 & 688653 & 4.633 & 5.4467 & TST & & & \\
\hline CHEMBL1420258 & 688653 & 4.683 & 4.7785 & TRN & & & \\
\hline CHEMBL1593187 & 688653 & 6.433 & 5.3065 & TRN & & & \\
\hline CHEMBL1372480 & 688653 & 5.183 & 5.5091 & TRN & & & \\
\hline CHEMBL1513797 & 688653 & 4.783 & 5.3187 & TRN & & & \\
\hline CHEMBL1593600 & 688653 & 4.98300 & 000000006 & 005 & 5.2778 & TRN & \\
\hline CHEMBL1578365 & 688653 & 4.833 & 5.4863 & TRN & & & \\
\hline CHEMBL1571075 & 688653 & 4.833 & 5.0125 & TRN & & & \\
\hline CHEMBL1451129 & 688653 & 4.783 & 5.2619 & TST & & & \\
\hline CHEMBL1547908 & 688653 & 4.783 & 5.7482 & TRN & & & \\
\hline CHEMBL1306451 & 688653 & 5.38299 & 999999999 & & 5.034 & TRN & \\
\hline CHEMBL1554178 & 688653 & 5.38299 & 999999995 & & 4.8693 & TST & \\
\hline CHEMBL1470900 & 688653 & 5.233 & 5.2374 & TRN & & & \\
\hline CHEMBL1448332 & 688653 & 6.78299 & 999999999 & 995 & 5.7334 & TRN & \\
\hline CHEMBL1572118 & 688653 & 5.733 & 5.3661 & TST & & & \\
\hline CHEMBL1421322 & 688653 & 4.73300 & 000000000 & 005 & 4.8982 & TST & \\
\hline CHEMBL1573326 & 688653 & 5.53299 & 999999999 & 995 & 5.4103 & TRN & \\
\hline CHEMBL1424903 & 688653 & 4.73300 & 000000000 & 005 & 5.2733 & TRN & \\
\hline CHEMBL1340941 & 688653 & 5.083 & 4.8851 & TRN & & & \\
\hline CHEMBL1463374 & 688653 & 4.883 & 5.1744 & TRN & & & \\
\hline CHEMBL1345922 & 688653 & 4.783 & 5.1946 & TRN & & & \\
\hline CHEMBL1410048 & 688653 & 5.63299 & 999999999 & & 5.11 & TRN & \\
\hline CHEMBL1575409 & 688653 & 4.783 & 4.8769 & TRN & & & \\
\hline CHEMBL1500142 & 688653 & 4.633 & 5.4251 & TRN & & & \\
\hline CHEMBL3196736 & 688653 & 5.183 & 5.3479 & TST & & & \\
\hline CHEMBL3199083 & 688653 & 5.33299 & 999999999 & & 5.2363 & TST & \\
\hline CHEMBL3192277 & 688653 & 5.233 & 5.3315 & TRN & & & \\
\hline CHEMBL1305233 & 688653 & 7.1831 & 6.0582 & TRN & & & \\
\hline CHEMBL1302038 & 688653 & 4.783 & 5.2028 & TRN & & & \\
\hline CHEMBL1334777 & 688653 & 5.28299 & 999999999 & 995 & 5.645 & TRN & \\
\hline CHEMBL1416171 & 688653 & 4.883 & 4.8336 & TST & & & \\
\hline CHEMBL1602962 & 688653 & 5.28299 & 999999999 & 995 & 5.1958 & TRN & \\
\hline CHEMBL1389022 & 688653 & 4.883 & 5.1253 & TRN & & & \\
\hline CHEMBL1451830 & 688653 & 4.933 & 5.1082 & TRN & & & \\
\hline CHEMBL1393551 & 688653 & 5.033 & 5.4178 & TRN & & & \\
\hline CHEMBL1376991 & 688653 & 5.33299 & 999999999 & 99 & 4.5415 & TST & \\
\hline
\end{tabular}




\begin{tabular}{|c|c|c|c|c|c|c|}
\hline & \multicolumn{5}{|c|}{ - } \\
\hline CHEMBL1528097 & 688653 & 4.95 & 4.7634 & TRN & & \\
\hline CHEMBL1406138 & 688653 & \multicolumn{3}{|c|}{6.632999999999999} & 5.5471 & TRN \\
\hline CHEMBL1503907 & 688653 & \multicolumn{3}{|c|}{5.132999999999999} & 5.5426 & TRN \\
\hline CHEMBL1453975 & 688653 & 4.833 & 5.4301 & TST & & \\
\hline CHEMBL1554111 & 688653 & 5.733 & 5.4574 & TRN & & \\
\hline CHEMBL1453723 & 688653 & 5.433 & 6.2703 & TRN & & \\
\hline CHEMBL1503130 & 688653 & 4.833 & 5.1689 & TRN & & \\
\hline CHEMBL1387309 & 688653 & 4.933 & 5.0222 & TRN & & \\
\hline CHEMBL1341822 & 688653 & 5.483 & 5.6233 & TRN & & \\
\hline CHEMBL1422471 & 688653 & \multicolumn{3}{|c|}{5.2829999999999995} & 5.2306 & TST \\
\hline CHEMBL1586895 & 688653 & \multicolumn{3}{|c|}{4.7330000000000005} & 5.0601 & TRN \\
\hline CHEMBL1327057 & 688653 & 5.183 & 5.2989 & TST & & \\
\hline CHEMBL1462675 & 688653 & \multicolumn{3}{|c|}{6.0329999999999995} & 5.5829 & TRN \\
\hline CHEMBL1431928 & 688653 & \multicolumn{3}{|c|}{4.7330000000000005} & 5.0677 & TRN \\
\hline CHEMBL1582309 & 688653 & \multicolumn{3}{|c|}{5.832999999999999} & 5.3087 & TRN \\
\hline CHEMBL1364267 & 688653 & 5.233 & 5.2867 & TST & & \\
\hline CHEMBL1492108 & 688653 & \multicolumn{3}{|c|}{6.2829999999999995} & 5.8345 & TRN \\
\hline CHEMBL1386152 & 688653 & \multicolumn{3}{|c|}{5.132999999999999} & 5.1016 & TRN \\
\hline CHEMBL1526511 & 688653 & 5.683 & 5.4563 & TRN & & \\
\hline CHEMBL1313535 & 688653 & \multirow{2}{*}{\multicolumn{3}{|c|}{4.7330000000000005}} & & \\
\hline CHEMBL1372587 & 688653 & & & & 5.4042 & TRN \\
\hline CHEMBL1377269 & 688653 & 4.883 & 5.0928 & TRN & & \\
\hline CHEMBL1600937 & 688653 & 4.583 & 4.971 & TRN & & \\
\hline CHEMBL1503492 & 688653 & 5.433 & 5.4621 & TRN & & \\
\hline CHEMBL1513901 & 688653 & \multicolumn{3}{|c|}{5.132999999999999} & 5.6191 & TRN \\
\hline CHEMBL3193361 & 688653 & \multicolumn{3}{|c|}{5.132999999999999} & 5.0174 & TST \\
\hline CHEMBL1582073 & 688653 & \multicolumn{3}{|c|}{5.132999999999999} & 5.3269 & TST \\
\hline CHEMBL1604119 & 688653 & 4.783 & 5.269 & TRN & & \\
\hline CHEMBL1994221 & 688653 & \multicolumn{3}{|c|}{5.5329999999999995} & 5.6653 & TRN \\
\hline CHEMBL1450833 & 688653 & 4.883 & 5.2282 & TST & & \\
\hline CHEMBL1332154 & 688653 & \multirow{2}{*}{\multicolumn{3}{|c|}{$\begin{array}{lcc}5.683 & 5.1278 & \text { TRN } \\
4.9830000000000005\end{array}$}} & & \\
\hline CHEMBL1605075 & 688653 & & & & 5.3014 & TRN \\
\hline CHEMBL1475359 & 688653 & \multicolumn{3}{|c|}{4.6334 .7677 TRN } & & \\
\hline CHEMBL1514957 & 688653 & \multicolumn{3}{|c|}{4.7330000000000005} & 5.1337 & TRN \\
\hline CHEMBL1608798 & 688653 & \multicolumn{3}{|c|}{5.882999999999999} & 5.5829 & TRN \\
\hline CHEMBL1429540 & 688653 & 5.683 & 5.6471 & TRN & & \\
\hline CHEMBL1345525 & 688653 & 4.783 & 5.6223 & TRN & & \\
\hline CHEMBL1319101 & 688653 & 5.033 & 5.2892 & TRN & & \\
\hline CHEMBL1425778 & 688653 & \multicolumn{3}{|c|}{6.332999999999999} & 5.5995 & TRN \\
\hline CHEMBL1513443 & 688653 & 5.7829 & 79999999 & 995 & 5.6761 & TST \\
\hline CHEMBL1503423 & 688653 & 4.783 & 5.0344 & TRN & & \\
\hline CHEMBL1567317 & 688653 & 7.0329 & 5.6858 & TRN & & \\
\hline CHEMBL3190025 & 688653 & 5.233 & 5.2715 & TRN & & \\
\hline CHEMBL1379011 & 688653 & 6.0 & 5.82799 & 99999 & 99 & TRN \\
\hline CHEMBL1359476 & 688653 & 5.6329 & و9999999 & & 5.4114 & TRN \\
\hline CHEMBL1555188 & 688653 & 4.7330 & 30000000 & 005 & 5.0669 & TRN \\
\hline CHEMBL1311280 & 688653 & 5.1329 & 99999999 & & 5.4956 & TST \\
\hline CHEMBL1561284 & 688653 & 4.783 & 5.1605 & TRN & & \\
\hline
\end{tabular}




\begin{tabular}{|c|c|c|c|c|c|c|}
\hline \multirow[b]{2}{*}{ CHEMBL1490979 } & \multirow[b]{2}{*}{688653} & \multicolumn{5}{|c|}{ Supplemental Table S2.txt } \\
\hline & & \multicolumn{5}{|c|}{$4.783 \quad 5.2034$ TRN } \\
\hline CHEMBL1431807 & 688653 & \multicolumn{3}{|c|}{4.7330000000000005} & 5.3347 & TRN \\
\hline CHEMBL1481284 & 688653 & \multicolumn{3}{|c|}{5.132999999999999} & 5.2491 & TRN \\
\hline CHEMBL1369200 & 688653 & 4.583 & 4.9863 & TRN & & \\
\hline CHEMBL1409054 & 688653 & \multicolumn{3}{|c|}{6.082999999999999} & 5.2134 & TRN \\
\hline CHEMBL1471728 & 688653 & 5.733 & 5.4719 & TRN & & \\
\hline CHEMBL1328510 & 688653 & 6.0 & 5.3144 & TRN & & \\
\hline CHEMBL1395993 & 688653 & \multicolumn{3}{|c|}{5.7829999999999995} & 5.664 & TRN \\
\hline CHEMBL1321361 & 688653 & 5.233 & 5.7254 & TRN & & \\
\hline CHEMBL1603278 & 688653 & \multicolumn{3}{|c|}{5.832999999999999} & 5.2504 & TRN \\
\hline CHEMBL1518533 & 688653 & 5.183 & 5.2093 & TRN & & \\
\hline CHEMBL1428507 & 688653 & 4.633 & 4.8562 & TRN & & \\
\hline CHEMBL1423968 & 688653 & \multicolumn{3}{|c|}{4.9830000000000005} & 5.4393 & TRN \\
\hline CHEMBL1512380 & 688653 & \multicolumn{3}{|c|}{5.882999999999999} & 5.2178 & TST \\
\hline CHEMBL1573978 & 688653 & 5.683 & 5.7945 & TST & & \\
\hline CHEMBL1349500 & 688653 & \multicolumn{3}{|c|}{6.382999999999999} & 5.6712 & TRN \\
\hline CHEMBL1358035 & 688653 & 5.683 & 5.1981 & TRN & & \\
\hline CHEMBL1504374 & 688653 & \multicolumn{3}{|c|}{4.7330000000000005} & 5.4311 & TRN \\
\hline CHEMBL1387945 & 688653 & 5.433 & 5.9285 & TRN & & \\
\hline CHEMBL1315560 & 688653 & 4.783 & 4.8347 & TRN & & \\
\hline CHEMBL3193067 & 688653 & 4.883 & 5.0392 & TRN & & \\
\hline CHEMBL1506690 & 688653 & 5.233 & \multicolumn{3}{|c|}{5.502000000000001} & TRN \\
\hline CHEMBL3190353 & 688653 & 5.483 & 5.9298 & TRN & & \\
\hline CHEMBL1546461 & 688653 & 5.183 & 5.6223 & TST & & \\
\hline CHEMBL1360765 & 688653 & 4.633 & 5.0014 & TST & & \\
\hline CHEMBL1403819 & 688653 & 7.2832 & 5.7757 & TRN & & \\
\hline CHEMBL1478339 & 688653 & 4.633 & 5.2013 & TRN & & \\
\hline CHEMBL1420866 & 688653 & 5.033 & 4.8507 & TST & & \\
\hline CHEMBL1500051 & 688653 & \multicolumn{3}{|c|}{6.332999999999999} & 6.0607 & TRN \\
\hline CHEMBL1506796 & 688653 & 7.2328 & 5.5065 & TRN & & \\
\hline CHEMBL1580695 & 688653 & \multicolumn{3}{|c|}{4.7330000000000005} & 5.1448 & TRN \\
\hline CHEMBL1553427 & 688653 & \multicolumn{3}{|c|}{5.832999999999999} & 5.6145 & TRN \\
\hline CHEMBL1599897 & 688653 & 5.933 & 5.9278 & TRN & & \\
\hline CHEMBL1599038 & 688653 & 5.233 & 5.5501 & TRN & & \\
\hline CHEMBL3199500 & 688653 & 4.833 & 5.4219 & TST & & \\
\hline CHEMBL1400469 & 688653 & 4.783 & 4.6727 & TRN & & \\
\hline CHEMBL1499935 & 688653 & 4.933 & 5.0574 & TST & & \\
\hline CHEMBL1531181 & 688653 & 4.633 & 5.0691 & TRN & & \\
\hline CHEMBL1596014 & 688653 & \multicolumn{3}{|c|}{4.7330000000000005} & 5.4571 & TST \\
\hline CHEMBL1305881 & 688653 & \multicolumn{3}{|c|}{4.7330000000000005} & 5.9917 & TRN \\
\hline CHEMBL1607346 & 688653 & 5.683 & 5.2484 & TRN & & \\
\hline CHEMBL1363746 & 688653 & \multicolumn{3}{|c|}{6.082999999999999} & 5.2 & TRN \\
\hline CHEMBL1411904 & 688653 & \multicolumn{3}{|c|}{5.632999999999999} & 5.5924 & TRN \\
\hline CHEMBL1563809 & 688653 & 4.933 & 5.7603 & TRN & & \\
\hline CHEMBL3193283 & 688653 & 5.233 & 5.5658 & TRN & & \\
\hline CHEMBL1498014 & 688653 & 5.183 & 5.046 & TRN & & \\
\hline CHEMBL1582115 & 688653 & 5.183 & 5.1196 & TRN & & \\
\hline CHEMBL1494802 & 688653 & 4.783 & 5.6865 & TST & & \\
\hline
\end{tabular}




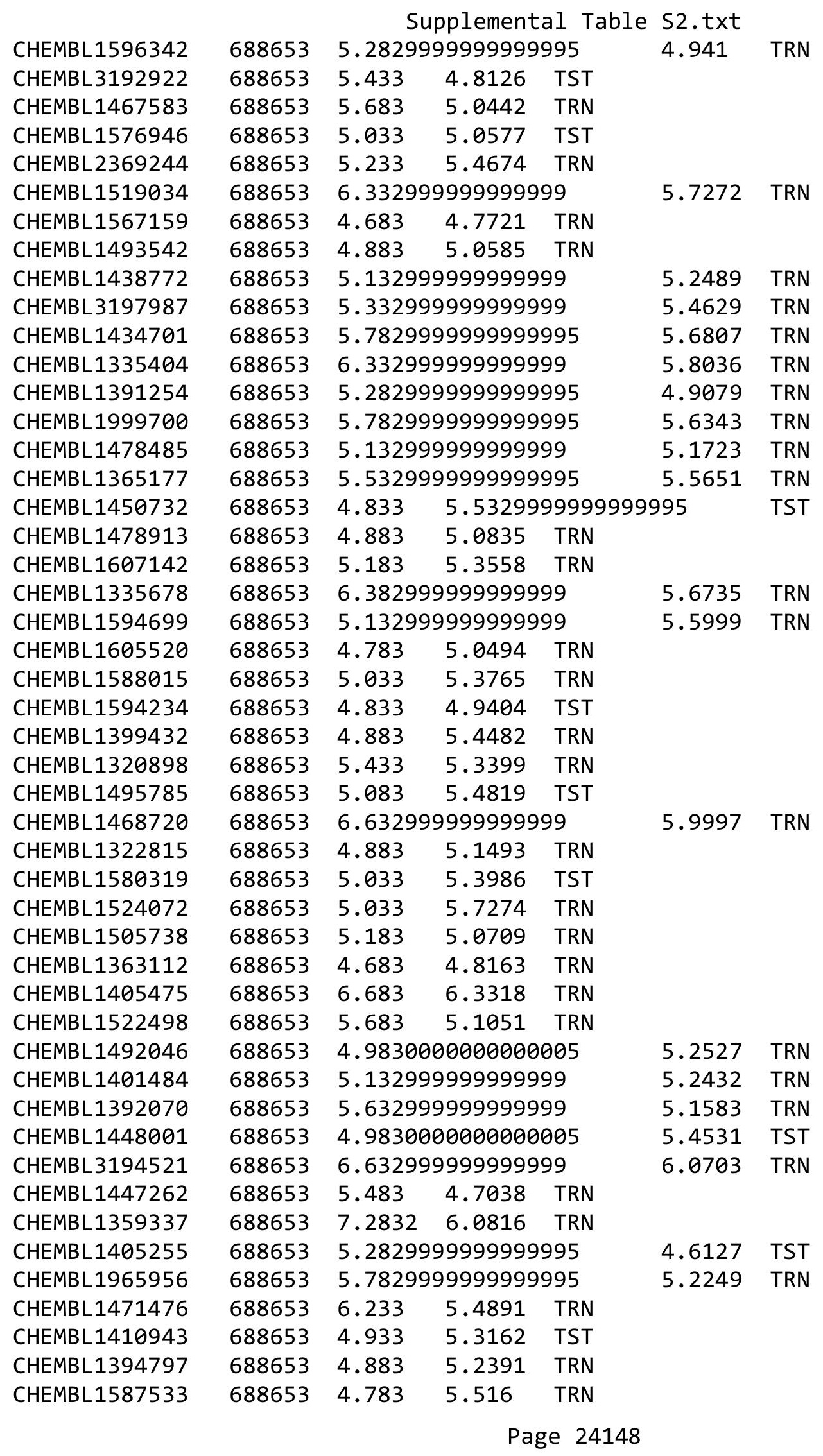




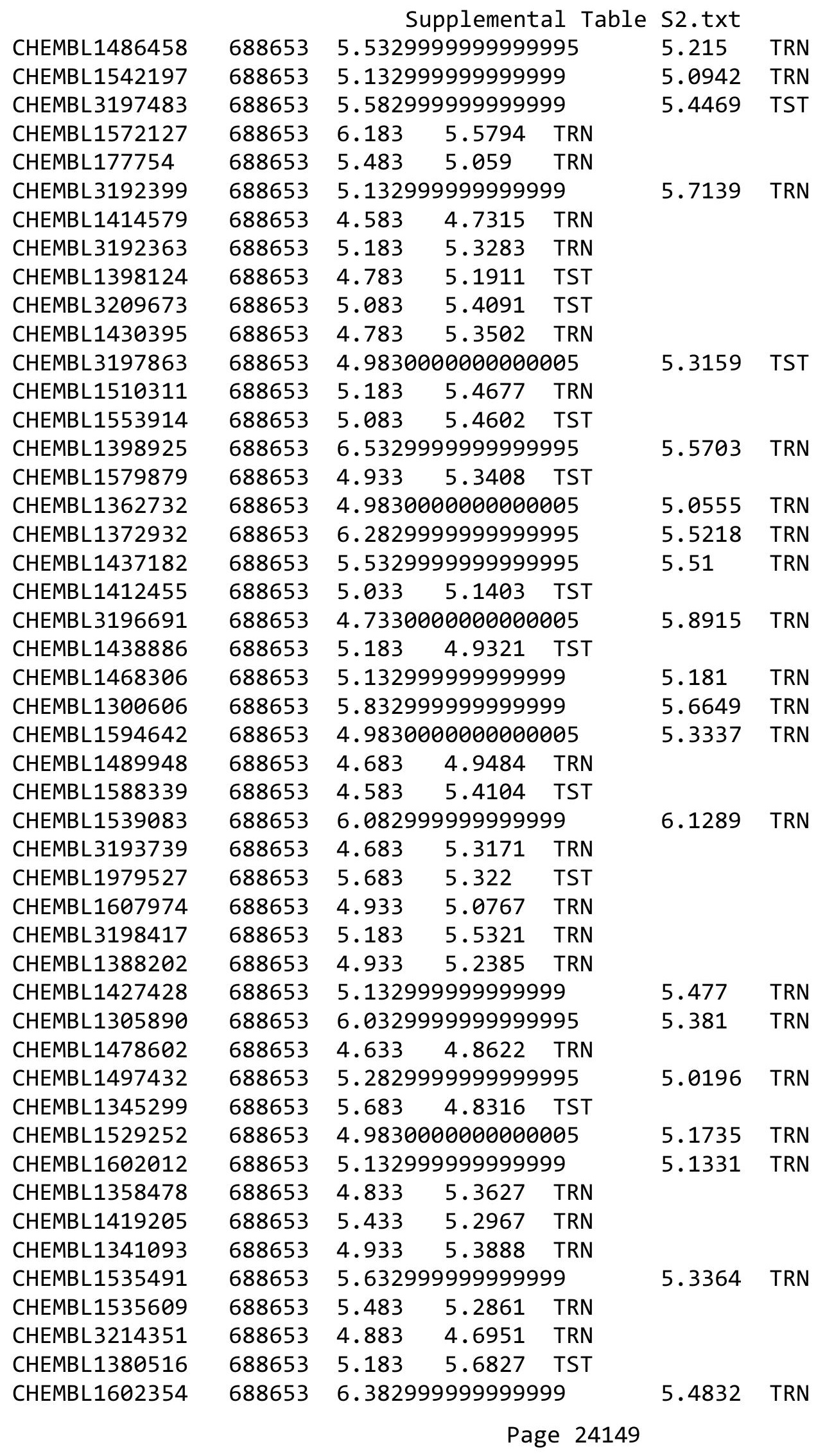




\begin{tabular}{|c|c|c|c|c|c|c|}
\hline \multirow[b]{2}{*}{ CHEMBL1404702 } & & \multicolumn{5}{|c|}{ Supplemental Table s2.txt } \\
\hline & 688653 & 4.883 & 4.8414 & TST & & \\
\hline CHEMBL3192746 & 688653 & 4.883 & 5.0562 & TRN & & \\
\hline CHEMBL1432018 & 688653 & 6.33299 & 99999999 & & 5.3772 & TRN \\
\hline CHEMBL1547504 & 688653 & 5.13299 & 99999999 & 99 & 5.7066 & TRN \\
\hline CHEMBL1476200 & 688653 & 4.633 & 5.0154 & TST & & \\
\hline CHEMBL1554533 & 688653 & 4.833 & 5.4402 & TRN & & \\
\hline CHEMBL1406600 & 688653 & 4.583 & 5.2467 & TRN & & \\
\hline CHEMBL3189975 & 688653 & 5.483 & 5.5184 & TRN & & \\
\hline CHEMBL1612240 & 688653 & 5.183 & 5.4196 & TST & & \\
\hline CHEMBL1326200 & 688653 & 4.883 & 5.2494 & TST & & \\
\hline CHEMBL1602161 & 688653 & 4.73300 & 00000000 & 005 & 4.9448 & TRN \\
\hline CHEMBL3196478 & 688653 & 5.88299 & 99999999 & & 5.2805 & TRN \\
\hline CHEMBL1505142 & 688653 & 4.833 & 4.8643 & TRN & & \\
\hline CHEMBL1503273 & 688653 & 5.233 & 5.5265 & TRN & & \\
\hline CHEMBL1457096 & 688653 & 5.083 & 6.0339 & TRN & & \\
\hline CHEMBL1521602 & 688653 & 4.833 & 5.087 & TRN & & \\
\hline CHEMBL1431326 & 688653 & 6.58299 & 99999999 & & 5.8043 & TRN \\
\hline CHEMBL1558531 & 688653 & 4.833 & 4.9303 & TST & & \\
\hline CHEMBL1359742 & 688653 & 5.683 & 5.3712 & TRN & & \\
\hline CHEMBL1376618 & 688653 & 5.233 & 5.7255 & TRN & & \\
\hline CHEMBL1578924 & 688653 & 6.03299 & 99999999 & 995 & 5.2436 & TRN \\
\hline CHEMBL1380797 & 688653 & 4.833 & 4.9782 & TRN & & \\
\hline CHEMBL1498608 & 688653 & 5.033 & 5.3994 & TRN & & \\
\hline CHEMBL1490577 & 688653 & 5.55 & 5.3383 & TRN & & \\
\hline CHEMBL1605111 & 688653 & 5.63299 & 99999999 & & 5.6277 & TRN \\
\hline CHEMBL1350153 & 688653 & 4.783 & 5.5321 & TST & & \\
\hline CHEMBL1556805 & 688653 & 5.63299 & 99999999 & & 5.7839 & TST \\
\hline CHEMBL1568395 & 688653 & 4.933 & 5.45799 & 999999999 & & TRN \\
\hline CHEMBL1514521 & 688653 & 4.833 & 5.01699 & 999999999 & 995 & TRN \\
\hline CHEMBL3197211 & 688653 & 4.783 & 5.1984 & TRN & & \\
\hline CHEMBL1300411 & 688653 & 6.8831 & 5.8861 & TRN & & \\
\hline CHEMBL1307600 & 688653 & 4.833 & 5.3741 & TRN & & \\
\hline CHEMBL1383436 & 688653 & 5.483 & 5.2887 & TRN & & \\
\hline CHEMBL1416856 & 688653 & 5.033 & 5.0619 & TST & & \\
\hline CHEMBL1449911 & 688653 & 5.983 & 5.4747 & TRN & & \\
\hline CHEMBL1988679 & 688653 & 5.033 & 5.307 & TRN & & \\
\hline CHEMBL1427323 & 688653 & 4.73300 & 00000000 & 005 & 4.819 & TRN \\
\hline CHEMBL1381446 & 688653 & 5.78299 & 99999999 & 995 & 5.4147 & TRN \\
\hline CHEMBL3213598 & 688653 & 5.83299 & 99999999 & & 4.607 & TST \\
\hline CHEMBL1582510 & 688653 & 6.33299 & 99999999 & & 5.8015 & TRN \\
\hline CHEMBL1314235 & 688653 & 4.783 & 5.2338 & TRN & & \\
\hline CHEMBL1469487 & 688653 & 4.833 & 5.4366 & TRN & & \\
\hline CHEMBL1418545 & 688653 & 5.78299 & 99999999 & 995 & 5.194 & TST \\
\hline CHEMBL1374522 & 688653 & 5.183 & 4.9267 & TST & & \\
\hline CHEMBL3211664 & 688653 & 4.683 & 5.3488 & TST & & \\
\hline CHEMBL1455894 & 688653 & 6.4829 & 5.6875 & TRN & & \\
\hline CHEMBL1473541 & 688653 & 4.783 & 5.1677 & TRN & & \\
\hline CHEMBL1517848 & 688653 & 4.95 & 5.4025 & TST & & \\
\hline
\end{tabular}




\begin{tabular}{|c|c|c|c|c|c|c|}
\hline \multirow[b]{2}{*}{ CHEMBL1601731 } & \multicolumn{6}{|c|}{ Supplemental Ta } \\
\hline & 688653 & 5.483 & 5.32 & TRN & & \\
\hline CHEMBL1341008 & 688653 & 4.683 & 4.8828 & TST & & \\
\hline CHEMBL1533602 & 688653 & 5.28299 & 999999999 & 995 & 5.6253 & Tाт \\
\hline CHEMBL1561802 & 688653 & 6.433 & 6.0193 & TRN & & \\
\hline CHEMBL1584605 & 688653 & 5.233 & 5.4173 & TRN & & \\
\hline CHEMBL1319859 & 688653 & 5.28299 & 999999999 & 995 & 4.8134 & TRN \\
\hline CHEMBL1412015 & 688653 & 5.78299 & 999999999 & 995 & 5.3235 & \\
\hline CHEMBL1437960 & 688653 & 5.433 & 5.6087 & TRN & & \\
\hline CHEMBL1489839 & 688653 & 4.73300 & 000000006 & 005 & 4.8497 & \\
\hline CHEMBL1410600 & 688653 & 4.883 & 5.0466 & TRN & & \\
\hline CHEMBL1584006 & 688653 & 4.833 & 4.9731 & TRN & & \\
\hline CHEMBL1346947 & 688653 & 5.183 & 5.4313 & TRN & & \\
\hline CHEMBL1570371 & 688653 & 5.033 & 6.1049 & TRN & & \\
\hline CHEMBL1445962 & 688653 & 4.583 & 4.7342 & TST & & \\
\hline CHEMBL1383057 & 688653 & 4.73300 & 000000006 & 005 & 5.8786 & \\
\hline CHEMBL1358973 & 688653 & 6.03299 & 999999999 & 995 & 5.3319 & \\
\hline CHEMBL1528333 & 688653 & 4.73300 & 000000000 & 005 & 5.1527 & \\
\hline CHEMBL1481638 & 688653 & 4.933 & 5.6124 & TRN & & \\
\hline CHEMBL1565953 & 688653 & 5.183 & 5.3554 & TRN & & \\
\hline CHEMBL1578502 & 688653 & 4.583 & 5.4222 & TRN & & \\
\hline CHEMBL1351657 & 688653 & 4.833 & 5.1528 & TRN & & \\
\hline CHEMBL1534731 & 688653 & 4.933 & 5.062 & TST & & \\
\hline CHEMBL1368888 & 688653 & 4.783 & 5.1446 & TRN & & \\
\hline CHEMBL1372039 & 688653 & 7.0329 & 5.92 & TRN & & \\
\hline CHEMBL1451846 & 688653 & 5.033 & 4.9632 & TRN & & \\
\hline CHEMBL 209410 & 688653 & 5.88299 & 999999999 & & 6.0056 & $\mathrm{Tr}$ \\
\hline CHEMBL1527010 & 688653 & 6.4829 & 5.1885 & TRN & & \\
\hline CHEMBL 233531 & 688653 & 6.4829 & 5.9327 & TRN & & \\
\hline CHEMBL1337087 & 688653 & 5.233 & 5.6312 & TRN & & \\
\hline CHEMBL1430719 & 688653 & 6.38299 & 999999999 & & 5.8099 & \\
\hline CHEMBL1311848 & 688653 & 5.183 & 5.4409 & TRN & & \\
\hline CHEMBL1579257 & 688653 & 5.38299 & 999999999 & & 5.271 & \\
\hline CHEMBL 3211008 & 688653 & 5.083 & 4.9973 & TRN & & \\
\hline CHEMBL1525407 & 688653 & 5.13299 & 999999999 & & 5.8385 & I RIN \\
\hline CHEMBL1373110 & 688653 & 5.13299 & 999999999 & & 5.5368 & \\
\hline CHEMBL1485445 & 688653 & 4.683 & 4.6452 & TRN & & \\
\hline CHEMBL1307170 & 688653 & 5.78299 & 999999999 & 995 & 5.23 & \\
\hline CHEMBL1530216 & 688653 & 4.73300 & 000000000 & 005 & 5.3579 & 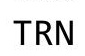 \\
\hline CHEMBL1575749 & 688653 & 6.13299 & 999999999 & & 5.7883 & TRN \\
\hline CHEMBL1301881 & 688653 & 4.833 & 5.2259 & TST & & \\
\hline CHEMBL1538408 & 688653 & 4.883 & 4.9406 & TST & & \\
\hline CHEMBL1543704 & 688653 & 4.883 & 5.087 & TST & & \\
\hline CHEMBL1605779 & 688653 & 5.683 & 5.4088 & TRN & & \\
\hline CHEMBL1540373 & 688653 & 4.833 & 5.5346 & TRN & & \\
\hline CHEMBL1429336 & 688653 & 4.833 & 5.3979 & TRN & & \\
\hline CHEMBL1451888 & 688653 & 4.633 & 4.9954 & TST & & \\
\hline CHEMBL1412371 & 688653 & 5.53299 & 999999999 & 995 & 5.2983 & Th \\
\hline CHEMBL1458284 & 688653 & 4.783 & 5.1569 & TST & & \\
\hline
\end{tabular}




\begin{tabular}{|c|c|c|c|c|c|c|c|}
\hline \multirow{3}{*}{$\begin{array}{l}\text { CHEMBL1373093 } \\
\text { CHEMBL1388252 }\end{array}$} & \multicolumn{6}{|c|}{ Supplemental Table S2.txt } & \\
\hline & 688653 & \multicolumn{3}{|c|}{5.7829999999999995} & \multirow[t]{2}{*}{4.9274} & \multicolumn{2}{|l|}{ TRN } \\
\hline & 688653 & 6.183 & 5.8327 & TRN & & & \\
\hline CHEMBL1481516 & 688653 & \multicolumn{3}{|c|}{5.132999999999999} & \multicolumn{2}{|c|}{5.1370000000000005} & TRN \\
\hline CHEMBL1578091 & 688653 & 4.883 & 5.6139 & TRN & & & \\
\hline CHEMBL1299889 & 688653 & 4.933 & 4.8832 & TST & & & \\
\hline CHEMBL1549929 & 688653 & 4.783 & 5.7241 & TST & & & \\
\hline CHEMBL1322894 & 688653 & 6.433 & 5.8598 & TRN & & & \\
\hline CHEMBL1430455 & 688653 & 5.683 & 5.3703 & TRN & & & \\
\hline CHEMBL1363600 & 688653 & 4.783 & 5.1564 & TRN & & & \\
\hline CHEMBL1603677 & 688653 & 4.833 & 5.1102 & TST & & & \\
\hline CHEMBL1421261 & 688653 & 4.833 & 5.18 & TRN & & & \\
\hline CHEMBL1599175 & 688653 & \multicolumn{3}{|c|}{4.7330000000000005} & 5.1987 & TST & \\
\hline CHEMBL1577171 & 688653 & 5.933 & 6.09 & TRN & & & \\
\hline CHEMBL1460449 & 688653 & \multicolumn{3}{|c|}{4.7330000000000005} & 4.9884 & TRN & \\
\hline CHEMBL1411726 & 688653 & \multicolumn{3}{|c|}{5.832999999999999} & 5.3985 & TRN & \\
\hline CHEMBL 3210983 & 688653 & \multicolumn{3}{|c|}{6.5329999999999995} & 5.8042 & TRN & \\
\hline CHEMBL1513000 & 688653 & 5.733 & 5.6296 & TRN & & & \\
\hline CHEMBL1448504 & 688653 & 4.783 & 5.2121 & TRN & & & \\
\hline CHEMBL1547182 & 688653 & \multicolumn{3}{|c|}{5.332999999999999} & 4.7906 & TST & \\
\hline CHEMBL1537753 & 688653 & 5.033 & 4.975 & TRN & & & \\
\hline CHEMBL1387020 & 688653 & 5.483 & 5.24 & TRN & & & \\
\hline CHEMBL1607497 & 688653 & 5.933 & 5.5478 & TRN & & & \\
\hline CHEMBL3192898 & 688653 & 4.583 & \multicolumn{3}{|c|}{5.303999999999999} & TRN & \\
\hline CHEMBL1467407 & 688653 & \multicolumn{3}{|c|}{4.9830000000000005} & 4.6724 & TRN & \\
\hline CHEMBL1579179 & 688653 & 4.783 & 5.3363 & TRN & & & \\
\hline CHEMBL1350986 & 688653 & \multicolumn{3}{|c|}{4.7330000000000005} & 5.2796 & TRN & \\
\hline CHEMBL570470 & 688653 & \multicolumn{3}{|c|}{6.332999999999999} & 5.4969 & TRN & \\
\hline CHEMBL1480085 & 688653 & 4.583 & 5.1342 & TST & & & \\
\hline CHEMBL1484344 & 688653 & \multicolumn{3}{|c|}{6.332999999999999} & 4.9404 & TST & \\
\hline CHEMBL1420139 & 688653 & 5.683 & 5.6432 & TRN & & & \\
\hline CHEMBL1371815 & 688653 & \multicolumn{3}{|c|}{6.582999999999999} & 5.6893 & TRN & \\
\hline CHEMBL1494389 & 688653 & \multicolumn{3}{|c|}{5.7829999999999995} & 5.4514 & TRN & \\
\hline CHEMBL3193608 & 688653 & \multicolumn{3}{|c|}{5.832999999999999} & 5.5849 & TRN & \\
\hline CHEMBL1442711 & 688653 & \multicolumn{3}{|c|}{5.132999999999999} & 5.3992 & TST & \\
\hline CHEMBL1354568 & 688653 & 4.683 & 4.9688 & TRN & & & \\
\hline CHEMBL1407458 & 688653 & 4.833 & 5.305 & TRN & & & \\
\hline CHEMBL1608293 & 688653 & 5.88299 & 99999999 & & 5.7028 & TRN & \\
\hline CHEMBL1325071 & 688653 & 6.28299 & 99999999 & 995 & 5.4695 & TRN & \\
\hline CHEMBL 3199178 & 688653 & 6.53299 & 99999999 & 995 & 5.9171 & TST & \\
\hline CHEMBL1425200 & 688653 & 5.63299 & 99999999 & & 5.209 & TST & \\
\hline CHEMBL1463660 & 688653 & 5.33299 & 99999999 & & 5.0656 & TRN & \\
\hline CHEMBL1555437 & 688653 & 5.033 & 5.2444 & TST & & & \\
\hline CHEMBL1437356 & 688653 & 6.8831 & 5.4682 & TRN & & & \\
\hline CHEMBL3213752 & 688653 & 4.883 & 5.1186 & TRN & & & \\
\hline CHEMBL1307682 & 688653 & 5.183 & 5.0102 & TRN & & & \\
\hline CHEMBL1574277 & 688653 & 4.933 & 5.3526 & TRN & & & \\
\hline CHEMBL1419759 & 688653 & 4.933 & 5.3046 & TRN & & & \\
\hline CHEMBL1565912 & 688653 & 5.53299 & 99999999 & 995 & 5.1322 & TST & \\
\hline
\end{tabular}




\begin{tabular}{|c|c|c|c|c|c|c|}
\hline & & \multicolumn{5}{|c|}{ Supplemental Table s2.txt } \\
\hline CHEMBL162808 & 688653 & 5.033 & 5.1755 & TRN & & \\
\hline CHEMBL1540377 & 688653 & 5.233 & 4.9768 & TST & & \\
\hline CHEMBL3197590 & 688653 & 4.883 & 5.1633 & TRN & & \\
\hline CHEMBL 259588 & 688653 & 4.783 & 5.5798 & TRN & & \\
\hline CHEMBL1609996 & 688653 & 5.483 & 5.2407 & TRN & & \\
\hline CHEMBL1510022 & 688653 & 5.683 & 5.7809 & TST & & \\
\hline CHEMBL1390479 & 688653 & 5.683 & 5.5146 & TRN & & \\
\hline CHEMBL1445209 & 688653 & 4.633 & 4.7176 & TST & & \\
\hline CHEMBL1426944 & 688653 & \multicolumn{3}{|c|}{6.382999999999999} & 5.3268 & TP \\
\hline CHEMBL3214065 & 688653 & 4.933 & 5.0616 & TST & & \\
\hline CHEMBL1432131 & 688653 & \multicolumn{3}{|c|}{6.382999999999999} & 5.4221 & TRN \\
\hline CHEMBL1403085 & 688653 & 5.033 & 5.1007 & TRN & & \\
\hline CHEMBL1452558 & 688653 & 5.683 & 5.2644 & TRN & & \\
\hline CHEMBL1509759 & 688653 & \multicolumn{3}{|c|}{5.382999999999999} & 5.4598 & TRN \\
\hline CHEMBL1492119 & 688653 & \multicolumn{3}{|c|}{5.5329999999999995} & 6.0704 & TRN \\
\hline CHEMBL1549103 & 688653 & \multicolumn{3}{|c|}{5.882999999999999} & 5.7318 & TRN \\
\hline CHEMBL1999960 & 688653 & \multicolumn{3}{|c|}{5.382999999999999} & 5.2472 & TST \\
\hline CHEMBL1426742 & 688653 & 5.683 & 4.8772 & TRN & & \\
\hline CHEMBL1489459 & 688653 & \multicolumn{3}{|c|}{4.7330000000000005} & 5.2732 & TRI \\
\hline CHEMBL3189573 & 688653 & 4.783 & 5.5245 & TRN & & \\
\hline CHEMBL1604854 & 688653 & 4.783 & 5.2791 & TST & & \\
\hline CHEMBL1548028 & 688653 & \multicolumn{3}{|c|}{5.832999999999999} & 5.3067 & Th \\
\hline CHEMBL1432642 & 688653 & 4.633 & 5.0843 & TRN & & \\
\hline CHEMBL1972959 & 688653 & \multicolumn{3}{|c|}{6.332999999999999} & 6.2321 & TRN \\
\hline CHEMBL1374458 & 688653 & \multicolumn{3}{|c|}{5.832999999999999} & 5.7077 & TRN \\
\hline CHEMBL1609015 & 688653 & 5.233 & 5.9568 & TST & & \\
\hline CHEMBL1312821 & 688653 & \multicolumn{3}{|c|}{5.132999999999999} & 35 & וכנו \\
\hline CHEMBL1399209 & 688653 & \multicolumn{3}{|c|}{5.632999999999999} & 5.7565 & TRN \\
\hline CHEMBL 3197847 & 688653 & 5.683 & 5.7405 & TRN & & \\
\hline CHEMBL1512205 & 688653 & 4.833 & 4.9395 & TST & & \\
\hline CHEMBL1390450 & 688653 & \multicolumn{3}{|c|}{5.882999999999999} & & \\
\hline CHEMBL1337672 & 688653 & \multicolumn{3}{|c|}{5.7829999999999995} & 5 . & Tार \\
\hline CHEMBL1527326 & 688653 & \multicolumn{3}{|c|}{5.132999999999999} & 5.0735 & TRN \\
\hline CHEMBL1323824 & 688653 & 4.883 & 5.1373 & TRN & & \\
\hline CHEMBL1438472 & 688653 & \multicolumn{3}{|c|}{6.2829999999999995} & & TRN \\
\hline CHEMBL1399453 & 688653 & \multicolumn{3}{|c|}{6.132999999999999} & 5.2 & $\mathrm{~T}$ \\
\hline CHEMBL1484188 & 688653 & \multicolumn{3}{|c|}{5.882999999999999} & 5.5392 & \\
\hline CHEMBL3190186 & 688653 & 4.833 & 4.9934 & TST & & \\
\hline CHEMBL3193893 & 688653 & \multicolumn{3}{|c|}{5.832999999999999} & 5.4689 & $\mathrm{TR}$ \\
\hline CHEMBL1408178 & 688653 & 5.683 & 5.3782 & TST & & \\
\hline CHEMBL1412563 & 688653 & 4.783 & 5.3859 & TST & & \\
\hline CHEMBL1473242 & 688653 & 5.733 & 5.3691 & TRN & & \\
\hline CHEMBL1328797 & 688653 & 5.083 & 5.1437 & TST & & \\
\hline CHEMBL1415042 & 688653 & 4.883 & 5.3199 & TRN & & \\
\hline CHEMBL1539786 & 688653 & \multicolumn{3}{|c|}{4.9830000000000005} & 5.2026 & TRN \\
\hline CHEMBL1530178 & 688653 & 5.3829 & 99999999 & & 5.3742 & \\
\hline CHEMBL1439014 & 688653 & 5.233 & 5.4906 & TRN & & \\
\hline CHEMBL1417731 & 688653 & 4.933 & 5.2491 & TST & & \\
\hline
\end{tabular}




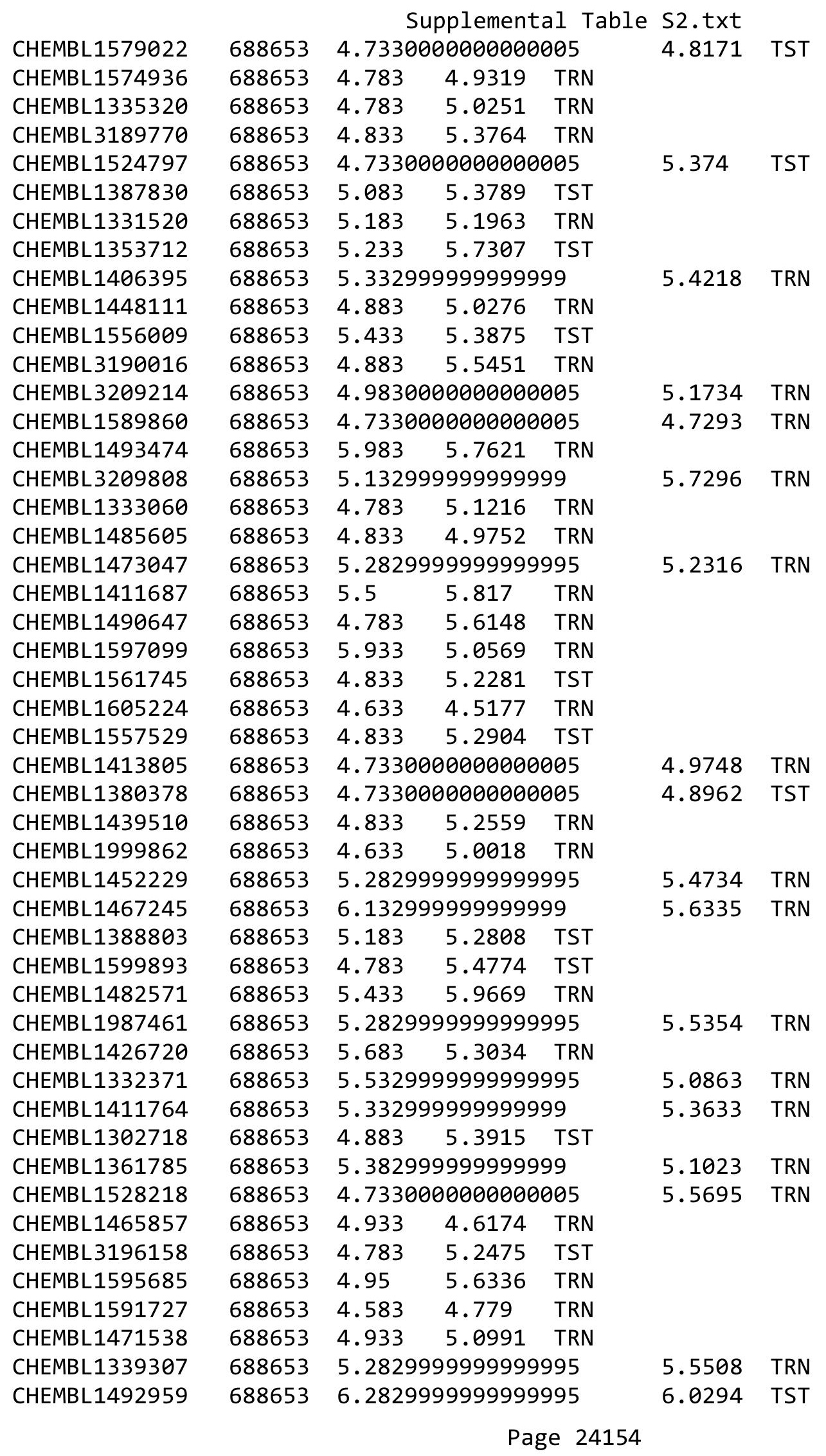




\begin{tabular}{|c|c|c|c|c|c|c|}
\hline \multirow[b]{2}{*}{ CHEMBL1447402 } & \multicolumn{6}{|c|}{ Supplemental Ta } \\
\hline & 688653 & 5.033 & 4.7928 & TRN & & \\
\hline CHEMBL1572026 & 688653 & 4.633 & 4.8906 & TRN & & \\
\hline CHEMBL 2369261 & 688653 & 5.83299 & 999999999 & & 5.7396 & ותנו \\
\hline CHEMBL1427485 & 688653 & 4.933 & 5.0511 & TRN & & \\
\hline CHEMBL1357485 & 688653 & 5.733 & 5.4486 & TRN & & \\
\hline CHEMBL 3198870 & 688653 & 6.28299 & 999999999 & 995 & 5.7626 & \\
\hline CHEMBL1439933 & 688653 & 4.73300 & 000000006 & 005 & 4.7594 & \\
\hline CHEMBL1329295 & 688653 & 4.683 & 5.3231 & TRN & & \\
\hline CHEMBL1525906 & 688653 & 5.13299 & 999999999 & & 5.4572 & \\
\hline CHEMBL1356105 & 688653 & 4.98300 & 000000000 & 005 & 5.0475 & \\
\hline CHEMBL1590906 & 688653 & 4.883 & 4.8528 & TRN & & \\
\hline CHEMBL1505462 & 688653 & 4.73300 & 000000006 & 005 & 5.4706 & \\
\hline CHEMBL1540112 & 688653 & 7.3325 & 6.1702 & TRN & & \\
\hline CHEMBL1528455 & 688653 & 5.13299 & 999999999 & & 5.2185 & \\
\hline CHEMBL1572746 & 688653 & 6.38299 & 999999999 & & 5.1274 & \\
\hline CHEMBL1521591 & 688653 & 5.733 & 5.1268 & TRN & & \\
\hline CHEMBL1414482 & 688653 & 4.98300 & 000000000 & 005 & 5.0796 & \\
\hline CHEMBL1376768 & 688653 & 4.783 & 5.1877 & TRN & & \\
\hline CHEMBL1495290 & 688653 & 5.53299 & 999999999 & 995 & 5 & \\
\hline CHEMBL1336874 & 688653 & 5.183 & 5.495 & TRN & & \\
\hline CHEMBL1314052 & 688653 & 6.03299 & 999999999 & 995 & 5.7819 & \\
\hline CHEMBL1546223 & 688653 & 4.883 & 4.883 & TST & & \\
\hline CHEMBL1380733 & 688653 & 5.683 & 5.3289 & TRN & & \\
\hline CHEMBL1446080 & 688653 & 4.73300 & 000000006 & 005 & 5.1503 & \\
\hline CHEMBL1542484 & 688653 & 5.38299 & 999999999 & & 5.3987 & \\
\hline CHEMBL1415430 & 688653 & 4.583 & 5.0379 & TST & & \\
\hline CHEMBL1443170 & 688653 & 5.38299 & 999999999 & & 5.2346 & \\
\hline CHEMBL1369424 & 688653 & 5.483 & 5.2997 & TST & & \\
\hline CHEMBL1982575 & 688653 & 6.38299 & 999999999 & & 5.7651 & TRN \\
\hline CHEMBL1418950 & 688653 & 5.483 & 4.8634 & TRN & & \\
\hline CHEMBL2369229 & 688653 & 4.933 & 5.3029 & TRN & & \\
\hline CHEMBL1503657 & 688653 & 6.78299 & 999999999 & 995 & 5.6098 & Tiv \\
\hline CHEMBL1472261 & 688653 & 4.883 & 5.2289 & TRN & & \\
\hline CHEMBL1434871 & 688653 & 4.583 & 4.99 & TST & & \\
\hline CHEMBL1339270 & 688653 & 5.733 & 6.3212 & TRN & & \\
\hline CHEMBL1413648 & 688653 & 5.88299 & 999999999 & & 5.5959 & TRN \\
\hline CHEMBL1386871 & 688653 & 6.08299 & 999999999 & & 5.1541 & $\mathrm{TP}$ \\
\hline CHEMBL1406194 & 688653 & 4.633 & 5.2926 & TRN & & \\
\hline CHEMBL1323129 & 688653 & 6.0 & 5.5307 & TRN & & \\
\hline CHEMBL1336158 & 688653 & 4.98300 & 000000000 & 205 & 4.8998 & TS \\
\hline CHEMBL1373420 & 688653 & 4.933 & 5.4684 & TRN & & \\
\hline CHEMBL3191903 & 688653 & 5.13299 & 999999999 & & 5.5549 & 13 \\
\hline CHEMBL1482199 & 688653 & 4.73300 & 000000000 & 005 & 5.6735 & . \\
\hline CHEMBL1585759 & 688653 & 5.983 & 5.5866 & TST & & \\
\hline CHEMBL1322324 & 688653 & 4.73300 & 000000000 & 205 & 5.0414 & N \\
\hline CHEMBL1556960 & 688653 & 5.733 & 5.6666 & TRN & & \\
\hline CHEMBL1556906 & 688653 & 5.433 & 4.8064 & TST & & \\
\hline CHEMBL1359861 & 688653 & 5.683 & 5.4776 & TST & & \\
\hline
\end{tabular}




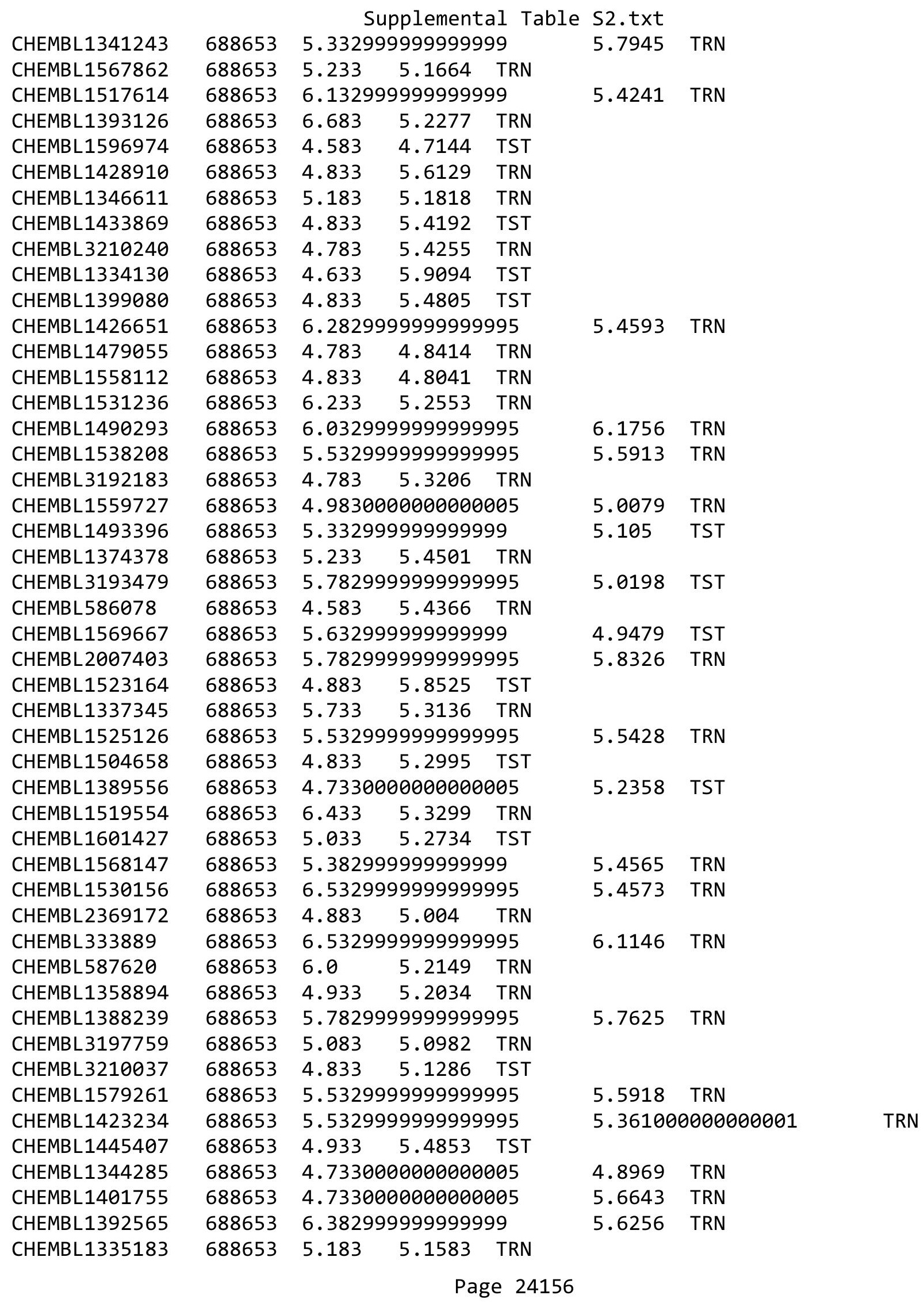




\begin{tabular}{|c|c|c|c|c|c|c|c|}
\hline \multicolumn{8}{|c|}{ Supplemental Table S2.txt } \\
\hline CHEMBL1337120 & 688653 & 5.083 & 4.9257 & TRN & & & \\
\hline CHEMBL1324664 & 688653 & 5.933 & 5.4324 & TRN & & & \\
\hline CHEMBL1610996 & 688653 & \multicolumn{3}{|c|}{4.7330000000000005} & 5.7864 & TRN & \\
\hline CHEMBL1326299 & 688653 & 6.183 & 5.1981 & TRN & & & \\
\hline CHEMBL1481978 & 688653 & 5.483 & 5.4819 & TRN & & & \\
\hline CHEMBL1608433 & 688653 & 4.633 & 4.6377 & TST & & & \\
\hline CHEMBL1488219 & 688653 & 4.933 & 5.3053 & TST & & & \\
\hline CHEMBL1528562 & 688653 & 4.833 & 5.53700 & 000000000 & & TRN & \\
\hline CHEMBL1318141 & 688653 & 6.4829 & 5.5163 & TRN & & & \\
\hline CHEMBL1604301 & 688653 & \multicolumn{3}{|c|}{4.9830000000000005} & \multicolumn{2}{|c|}{5.3020000000000005} & TRN \\
\hline CHEMBL1411317 & 688653 & 6.4829 & 5.9616 & TRN & & & \\
\hline CHEMBL1340820 & 688653 & \multicolumn{3}{|c|}{6.332999999999999} & \multicolumn{2}{|c|}{5.537999999999999} & TRN \\
\hline CHEMBL1329889 & 688653 & 4.783 & 5.2168 & TST & & & \\
\hline CHEMBL1439244 & 688653 & \multicolumn{3}{|c|}{6.632999999999999} & 6.0847 & TRN & \\
\hline CHEMBL3189326 & 688653 & \multicolumn{3}{|c|}{4.7330000000000005} & 4.6536 & TST & \\
\hline CHEMBL1379424 & 688653 & 5.033 & 5.2728 & TRN & & & \\
\hline CHEMBL1299870 & 688653 & \multicolumn{3}{|c|}{4.7330000000000005} & 4.9606 & TRN & \\
\hline CHEMBL1335818 & 688653 & \multicolumn{3}{|c|}{5.7829999999999995} & 5.3237 & TRN & \\
\hline CHEMBL1456543 & 688653 & 5.433 & 5.4943 & TRN & & & \\
\hline CHEMBL1368383 & 688653 & 6.983 & 5.8039 & TRN & & & \\
\hline CHEMBL1393851 & 688653 & 5.733 & 4.952 & TRN & & & \\
\hline CHEMBL1571934 & 688653 & \multicolumn{3}{|c|}{4.7330000000000005} & 4.565 & TST & \\
\hline CHEMBL1513779 & 688653 & 4.833 & 4.5979 & TST & & & \\
\hline CHEMBL1482799 & 688653 & 5.033 & 5.0825 & TST & & & \\
\hline CHEMBL3208179 & 688653 & \multicolumn{3}{|c|}{4.7330000000000005} & 5.0657 & TRN & \\
\hline CHEMBL1309107 & 688653 & 4.783 & 5.4422 & TST & & & \\
\hline CHEMBL1305980 & 688653 & 5.183 & 5.6192 & TRN & & & \\
\hline CHEMBL1410197 & 688653 & 6.8831 & 5.8314 & TRN & & & \\
\hline CHEMBL1594900 & 688653 & 4.883 & 5.4787 & TST & & & \\
\hline CHEMBL1497719 & 688653 & \multicolumn{3}{|c|}{4.9830000000000005} & 5.228 & TRN & \\
\hline CHEMBL1328956 & 688653 & 6.9329 & 5.3941 & TRN & & & \\
\hline CHEMBL1524862 & 688653 & 5.733 & 5.6614 & TRN & & & \\
\hline CHEMBL1330757 & 688653 & \multicolumn{3}{|c|}{4.7330000000000005} & 5.5229 & TRN & \\
\hline CHEMBL1495002 & 688653 & 5.183 & 5.439 & TRN & & & \\
\hline CHEMBL1336900 & 688653 & 4.933 & 5.1857 & TST & & & \\
\hline CHEMBL1566003 & 688653 & \multicolumn{3}{|c|}{5.882999999999999} & 5.6579 & TRN & \\
\hline CHEMBL3189645 & 688653 & 4.883 & 5.5158 & TRN & & & \\
\hline CHEMBL1360191 & 688653 & 6.0 & 4.8533 & TRN & & & \\
\hline CHEMBL1589655 & 688653 & 5.083 & 5.1093 & TRN & & & \\
\hline CHEMBL1313735 & 688653 & 4.833 & 5.4273 & TRN & & & \\
\hline CHEMBL1345948 & 688653 & 5.033 & 5.4064 & TRN & & & \\
\hline CHEMBL1306638 & 688653 & 6.8831 & 5.9625 & TRN & & & \\
\hline CHEMBL1473380 & 688653 & 4.883 & 5.1479 & TRN & & & \\
\hline CHEMBL1484568 & 688653 & \multicolumn{3}{|c|}{4.9830000000000005} & 5.0234 & TRN & \\
\hline CHEMBL1409958 & 688653 & 4.583 & 5.0321 & TRN & & & \\
\hline CHEMBL1165229 & 688653 & 4.833 & 5.1658 & TRN & & & \\
\hline CHEMBL1336211 & 688653 & \multicolumn{3}{|c|}{6.132999999999999} & 5.3367 & TRN & \\
\hline CHEMBL1532623 & 688653 & 6.433 & 5.1472 & TRN & & & \\
\hline
\end{tabular}




\begin{tabular}{|c|c|c|c|c|c|c|}
\hline \multirow[b]{2}{*}{ CHEMBL1483697 } & \multicolumn{6}{|c|}{ Supplemental Table S2.txt } \\
\hline & 688653 & 4.783 & 5.1131 & TRN & & \\
\hline CHEMBL1416356 & 688653 & 4.683 & 5.3759 & TST & & \\
\hline CHEMBL1399068 & 688653 & 4.833 & 5.6292 & TRN & & \\
\hline CHEMBL1450361 & 688653 & \multicolumn{3}{|c|}{4.7330000000000005} & 5.3137 & TRN \\
\hline CHEMBL 3198708 & 688653 & 4.933 & 5.0961 & TRN & & \\
\hline CHEMBL1340124 & 688653 & \multicolumn{3}{|c|}{4.9830000000000005} & 5.6421 & TST \\
\hline CHEMBL1399973 & 688653 & \multicolumn{3}{|c|}{5.832999999999999} & 5.5766 & \\
\hline CHEMBL1509919 & 688653 & 6.433 & 5.8344 & TRN & & \\
\hline CHEMBL 3207925 & 688653 & 5.433 & 5.3134 & TRN & & \\
\hline CHEMBL1563581 & 688653 & 6.5501 & 5.8201 & TRN & & \\
\hline CHEMBL1473602 & 688653 & 5.233 & \multicolumn{3}{|c|}{5.1610000000000005} & \\
\hline CHEMBL1358319 & 688653 & 5.683 & 5.2292 & TRN & & \\
\hline CHEMBL1443791 & 688653 & \multicolumn{3}{|c|}{4.9830000000000005} & 5.0835 & 等 \\
\hline CHEMBL1588953 & 688653 & \multicolumn{3}{|c|}{4.7330000000000005} & 5.2459 & \\
\hline CHEMBL1576009 & 688653 & 6.233 & 5.5902 & TRN & & \\
\hline CHEMBL1445997 & 688653 & 5.083 & \multicolumn{3}{|c|}{5.212000000000001} & \\
\hline CHEMBL1460273 & 688653 & 4.583 & 5.1789 & TRN & & \\
\hline CHEMBL1589122 & 688653 & 4.95 & 5.2591 & TRN & & \\
\hline CHEMBL 3208705 & 688653 & 4.783 & 5.3911 & TRN & & \\
\hline CHEMBL1542546 & 688653 & \multicolumn{3}{|c|}{5.332999999999999} & 5.6931 & ות \\
\hline CHEMBL1379303 & 688653 & 5.083 & 5.5923 & TRN & & \\
\hline CHEMBL1605295 & 688653 & 4.683 & 4.8216 & TST & & \\
\hline CHEMBL 3197351 & 688653 & 5.483 & 5.0789 & TRN & & \\
\hline CHEMBL13 & 688653 & 4.783 & 5.1564 & TRN & & \\
\hline CHEMBL1406696 & 688653 & 4.883 & 4.9042 & TST & & \\
\hline CHEMBL1409344 & 688653 & 4.783 & 5.3722 & TST & & \\
\hline CHEMBL1568813 & 688653 & \multicolumn{3}{|c|}{5.5329999999999995} & 5.0093 & \\
\hline CHEMBL 58 & 688653 & 4.583 & 4.7414 & TST & & \\
\hline CHEMBL1526871 & 688653 & 4.583 & 5.1659 & TST & & \\
\hline CHEMBL1490590 & 688653 & 4.783 & 5.3021 & TRN & & \\
\hline CHEMBL1443766 & 688653 & 6.4829 & 6.0222 & TRN & & \\
\hline CHEMBL1467324 & 688653 & \multicolumn{3}{|c|}{5.132999999999999} & 5.4897 & \\
\hline CHEMBL1332724 & 688653 & 5.033 & 5.3367 & TRN & & \\
\hline CHEMBL1474931 & 688653 & 4.833 & 5.4795 & TRN & & \\
\hline CHEMBL1521627 & 688653 & \multicolumn{3}{|c|}{4.7330000000000005} & 5.0455 & TR \\
\hline CHEMBL1200792 & 688653 & 4.633 & 4.8299 & TST & & \\
\hline CHEMBL15 & 688653 & 5.183 & 5.4239 & TRN & & \\
\hline CHEMBL1362679 & 688653 & 5.183 & 5.1321 & TRN & & \\
\hline CHEMBL1494161 & 688653 & 4.783 & 5.0828 & TRN & & \\
\hline CHEMBL1388987 & 688653 & \multicolumn{3}{|c|}{4.7330000000000005} & 5.3641 & TS \\
\hline CHEMBL1349215 & 688653 & 5.033 & 5.3392 & TRN & & \\
\hline CHEMBL1477325 & 688653 & 5.033 & 5.1633 & TRN & & \\
\hline CHEMBL 244445 & 688653 & 4.783 & 4.9739 & TRN & & \\
\hline CHEMBL1579042 & 688653 & \multicolumn{3}{|c|}{6.082999999999999} & 6.0804 & נו \\
\hline CHEMBL1565163 & 688653 & 5.733 & 5.3829 & TRN & & \\
\hline CHEMBL1600795 & 688653 & 4.633 & 5.2175 & TRN & & \\
\hline CHEMBL 2002248 & 688653 & \multicolumn{3}{|c|}{5.7829999999999995} & 5.7335 & 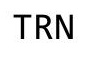 \\
\hline CHEMBL1303471 & 688653 & \multicolumn{3}{|c|}{5.132999999999999} & 5.4296 & \\
\hline
\end{tabular}




\begin{tabular}{|c|c|c|c|c|c|c|c|}
\hline \multicolumn{8}{|c|}{ Supplemental Table s2.txt } \\
\hline CHEMBL1472680 & 688653 & 4.833 & 5.0084 & TRN & & & \\
\hline CHEMBL1324646 & 688653 & 4.883 & 5.2053 & TRN & & & \\
\hline CHEMBL1547792 & 688653 & \multicolumn{3}{|c|}{6.332999999999999} & 6.2004 & TRN & \\
\hline CHEMBL1558486 & 688653 & 4.833 & 5.3034 & TRN & & & \\
\hline CHEMBL1585669 & 688653 & 4.883 & 5.0442 & TRN & & & \\
\hline CHEMBL1530387 & 688653 & 4.883 & \multicolumn{3}{|c|}{5.013999999999999} & TRN & \\
\hline CHEMBL1429220 & 688653 & \multicolumn{3}{|c|}{4.7330000000000005} & 5.1841 & TST & \\
\hline CHEMBL1421540 & 688653 & 5.183 & 5.3857 & TRN & & & \\
\hline CHEMBL1600781 & 688653 & \multicolumn{3}{|c|}{4.7330000000000005} & 5.0138 & TRN & \\
\hline CHEMBL1975032 & 688653 & 4.633 & 4.997 & TST & & & \\
\hline CHEMBL1567375 & 688653 & \multicolumn{3}{|c|}{5.332999999999999} & 5.4115 & TRN & \\
\hline CHEMBL1385060 & 688653 & \multicolumn{3}{|c|}{5.582999999999999} & 5.9013 & TRN & \\
\hline CHEMBL1339363 & 688653 & \multicolumn{3}{|c|}{6.382999999999999} & \multicolumn{2}{|c|}{5.218999999999999} & TRN \\
\hline CHEMBL1346776 & 688653 & 5.083 & 5.5352 & TST & & & \\
\hline CHEMBL1479139 & 688653 & 5.683 & 5.1908 & TST & & & \\
\hline CHEMBL1528978 & 688653 & \multicolumn{3}{|c|}{4.9830000000000005} & 5.2861 & TST & \\
\hline CHEMBL2369275 & 688653 & 4.583 & 5.2674 & TRN & & & \\
\hline CHEMBL3208846 & 688653 & 4.883 & 5.4122 & TRN & & & \\
\hline CHEMBL1309227 & 688653 & 4.783 & 5.1024 & TRN & & & \\
\hline CHEMBL1382723 & 688653 & 6.233 & 5.6793 & TRN & & & \\
\hline CHEMBL1575937 & 688653 & \multicolumn{3}{|c|}{6.5329999999999995} & 5.8617 & TRN & \\
\hline CHEMBL3194035 & 688653 & \multicolumn{3}{|c|}{4.9830000000000005} & 5.1427 & TRN & \\
\hline CHEMBL1328836 & 688653 & \multicolumn{3}{|c|}{4.7330000000000005} & 5.4204 & TRN & \\
\hline CHEMBL1324742 & 688653 & 4.833 & 4.9697 & TRN & & & \\
\hline CHEMBL1395405 & 688653 & 4.583 & 5.5971 & TRN & & & \\
\hline CHEMBL1578199 & 688653 & 4.833 & 5.1099 & TRN & & & \\
\hline CHEMBL1435099 & 688653 & \multicolumn{3}{|c|}{5.882999999999999} & 5.6176 & TRN & \\
\hline CHEMBL1610644 & 688653 & \multicolumn{3}{|c|}{6.332999999999999} & \multicolumn{2}{|c|}{5.372999999999999} & TRN \\
\hline CHEMBL1540547 & 688653 & 4.783 & 5.4712 & TRN & & & \\
\hline CHEMBL1499474 & 688653 & 5.683 & 5.4986 & TST & & & \\
\hline CHEMBL1491717 & 688653 & 4.833 & 5.0169 & TRN & & & \\
\hline CHEMBL1486585 & 688653 & \multicolumn{3}{|c|}{5.832999999999999} & 5.7567 & TRN & \\
\hline CHEMBL1369448 & 688653 & 4.883 & 5.2036 & TRN & & & \\
\hline CHEMBL492010 & 688653 & & & TRN & & & \\
\hline CHEMBL1557485 & 688653 & \multicolumn{3}{|c|}{4.7330000000000005} & 5.0153 & TST & \\
\hline CHEMBL1610042 & 688653 & 5.183 & 5.0766 & TRN & & & \\
\hline CHEMBL 1497608 & 688653 & 5.683 & 5.461 & TRN & & & \\
\hline CHEMBL1488237 & 688653 & 4.883 & 5.0707 & TRN & & & \\
\hline CHEMBL1460352 & 688653 & \multicolumn{3}{|c|}{5.2829999999999995} & 5.9056 & TRN & \\
\hline CHEMBL1491844 & 688653 & \multicolumn{3}{|c|}{5.2829999999999995} & 5.4752 & TRN & \\
\hline CHEMBL1438507 & 688653 & \multicolumn{3}{|c|}{6.0329999999999995} & 5.4288 & TRN & \\
\hline CHEMBL1404546 & 688653 & 5.3829 & 79999999 & & 5.3256 & TRN & \\
\hline CHEMBL1596699 & 688653 & 4.633 & 5.1081 & TRN & & & \\
\hline CHEMBL1519708 & 688653 & 5.033 & 5.3935 & TRN & & & \\
\hline CHEMBL1577426 & 688653 & 5.1329 & 79999999 & & 5.5255 & TRN & \\
\hline CHEMBL1300116 & 688653 & 6.0829 & 99999999 & & 4.952 & TRN & \\
\hline CHEMBL1378489 & 688653 & 4.633 & 5.0298 & TST & & & \\
\hline CHEMBL1520758 & 688653 & 4.7330 & 30000000 & 005 & 5.0795 & TRN & \\
\hline
\end{tabular}




\begin{tabular}{|c|c|c|c|c|c|c|c|}
\hline \multicolumn{7}{|c|}{ Supplemental Table S2.txt } & \\
\hline CHEMBL1569881 & 688653 & 5.483 & 4.6502 & TST & & & \\
\hline CHEMBL 1471990 & 688653 & 6.03299 & 99999999 & 995 & 5.3449 & TRN & \\
\hline CHEMBL1427298 & 688653 & 6.233 & 6.0361 & TRN & & & \\
\hline CHEMBL2369277 & 688653 & 4.583 & 5.0089 & TRN & & & \\
\hline CHEMBL1481930 & 688653 & 5.733 & 5.5252 & TST & & & \\
\hline CHEMBL1569243 & 688653 & 5.78299 & 99999999 & 995 & 5.2533 & TRN & \\
\hline CHEMBL3198350 & 688653 & 6.33299 & 99999999 & & 5.6417 & TRN & \\
\hline CHEMBL1995481 & 688653 & 6.33299 & 99999999 & & 5.4034 & TRN & \\
\hline CHEMBL1394404 & 688653 & 5.33299 & 99999999 & & 5.3891 & TST & \\
\hline CHEMBL1549857 & 688653 & 4.833 & 5.0476 & TST & & & \\
\hline CHEMBL1601310 & 688653 & 4.783 & 4.8468 & TST & & & \\
\hline CHEMBL1547530 & 688653 & 4.933 & 4.8547 & TST & & & \\
\hline CHEMBL1423674 & 688653 & 4.783 & 4.7427 & TRN & & & \\
\hline CHEMBL1431829 & 688653 & 6.433 & 4.8275 & TST & & & \\
\hline CHEMBL1408326 & 688653 & 4.833 & 5.3162 & TRN & & & \\
\hline CHEMBL1396641 & 688653 & 6.7331 & 5.5367 & TRN & & & \\
\hline CHEMBL1515545 & 688653 & 5.183 & 4.8806 & TRN & & & \\
\hline CHEMBL1444896 & 688653 & 4.783 & 5.3912 & TST & & & \\
\hline CHEMBL1327298 & 688653 & 7.08299 & 99999999 & 99 & 6.4032 & TST & \\
\hline CHEMBL587856 & 688653 & 4.783 & 5.6713 & TRN & & & \\
\hline CHEMBL1360115 & 688653 & 7.1831 & 5.6841 & TRN & & & \\
\hline CHEMBL1575407 & 688653 & 4.73300 & 30000000 & 005 & 5.1245 & TST & \\
\hline CHEMBL1299526 & 688653 & 5.433 & 4.9561 & TRN & & & \\
\hline CHEMBL1575850 & 688653 & 4.933 & 4.6774 & TRN & & & \\
\hline CHEMBL1896260 & 688653 & 5.53299 & 99999999 & 995 & 5.0035 & TRN & \\
\hline CHEMBL1530177 & 688653 & 4.633 & 5.1378 & TRN & & & \\
\hline CHEMBL1413081 & 688653 & 4.833 & 5.0296 & TRN & & & \\
\hline CHEMBL1308583 & 688653 & 5.13299 & 99999999 & & $4.8180 e$ & 00000000005 & TST \\
\hline CHEMBL1389420 & 688653 & 4.98300 & 00000000 & 005 & 5.034 & TRN & \\
\hline CHEMBL1601032 & 688653 & 6.233 & 5.3451 & TRN & & & \\
\hline CHEMBL1482670 & 688653 & 5.933 & 5.3673 & TRN & & & \\
\hline CHEMBL 3197570 & 688653 & 5.733 & 5.5737 & TST & & & \\
\hline CHEMBL 1504026 & 688653 & 6.9329 & 5.9065 & TRN & & & \\
\hline CHEMBL1419621 & 688653 & 5.933 & 5.5693 & TRN & & & \\
\hline CHEMBL1420064 & 688653 & 5.78299 & 99999999 & 995 & 5.3783 & TRN & \\
\hline CHEMBL1507708 & 688653 & 4.833 & 4.8876 & TRN & & & \\
\hline CHEMBL1500193 & 688653 & 6.03299 & 99999999 & 995 & 5.6783 & TRN & \\
\hline CHEMBL1587205 & 688653 & 4.683 & 5.3264 & TST & & & \\
\hline CHEMBL3192991 & 688653 & 4.683 & 5.3763 & TRN & & & \\
\hline CHEMBL1378491 & 688653 & 5.683 & 4.9796 & TRN & & & \\
\hline CHEMBL1419354 & 688653 & 4.783 & 5.651 & TST & & & \\
\hline CHEMBL1590790 & 688653 & 5.28299 & 99999999 & 995 & 5.4563 & TRN & \\
\hline CHEMBL1413823 & 688653 & 5.983 & 6.0816 & TRN & & & \\
\hline CHEMBL1608161 & 688653 & 4.783 & 5.3427 & TRN & & & \\
\hline CHEMBL1414691 & 688653 & 4.98300 & 00000000 & 005 & 5.3783 & TRN & \\
\hline CHEMBL42870 & 688653 & 6.83299 & 99999999 & & 5.5434 & TRN & \\
\hline CHEMBL1597869 & 688653 & 6.433 & 5.3846 & TRN & & & \\
\hline CHEMBL1374335 & 688653 & 4.833 & 5.0722 & TRN & & & \\
\hline
\end{tabular}




\begin{tabular}{|c|c|c|c|c|c|c|}
\hline & & \multicolumn{5}{|c|}{ Supplemental Table S2.txt } \\
\hline CHEMBL1360998 & 688653 & 4.833 & 5.0554 & TST & & \\
\hline CHEMBL1558351 & 688653 & 4.583 & 5.1085 & TRN & & \\
\hline CHEMBL1607801 & 688653 & 6.233 & 6.3416 & TRN & & \\
\hline CHEMBL1564238 & 688653 & 5.683 & 5.3329 & TRN & & \\
\hline CHEMBL1608066 & 688653 & 5.933 & 5.3972 & TRN & & \\
\hline CHEMBL1369287 & 688653 & 4.783 & 5.0134 & TRN & & \\
\hline CHEMBL1381216 & 688653 & 5.033 & 5.1064 & TST & & \\
\hline CHEMBL1516531 & 688653 & \multicolumn{3}{|c|}{4.7330000000000005} & 5.0582 & TRN \\
\hline CHEMBL3213113 & 688653 & 5.083 & 5.051 & TRN & & \\
\hline CHEMBL1498133 & 688653 & \multicolumn{3}{|c|}{5.2829999999999995} & 5.3634 & TST \\
\hline CHEMBL1382693 & 688653 & 4.783 & 5.4444 & TST & & \\
\hline CHEMBL1502801 & 688653 & 4.783 & 5.2158 & TRN & & \\
\hline CHEMBL1477851 & 688653 & 4.833 & 4.7819 & TRN & & \\
\hline CHEMBL1989170 & 688653 & 4.883 & 4.9781 & TRN & & \\
\hline CHEMBL1535734 & 688653 & 4.933 & 5.21 & TRN & & \\
\hline CHEMBL3209477 & 688653 & \multicolumn{3}{|c|}{5.582999999999999} & 5.5211 & TRN \\
\hline CHEMBL1426797 & 688653 & \multicolumn{3}{|c|}{6.382999999999999} & 5.5926 & TRN \\
\hline CHEMBL1381824 & 688653 & 6.233 & \multicolumn{3}{|c|}{5.9079999999999995} & TRN \\
\hline CHEMBL1466286 & 688653 & \multicolumn{3}{|c|}{4.9830000000000005} & 5.1553 & TRN \\
\hline CHEMBL1468908 & 688653 & 5.483 & 5.2032 & TST & & \\
\hline CHEMBL1480323 & 688653 & \multicolumn{3}{|c|}{5.7829999999999995} & 5.2883 & TRN \\
\hline CHEMBL1327318 & 688653 & \multicolumn{3}{|c|}{6.2829999999999995} & 5.6828 & TRN \\
\hline CHEMBL3195186 & 688653 & \multicolumn{3}{|c|}{6.0329999999999995} & 5.1804 & TRN \\
\hline CHEMBL3192125 & 688653 & \multicolumn{3}{|c|}{5.2829999999999995} & 5.2068 & TRN \\
\hline CHEMBL1365095 & 688653 & \multicolumn{3}{|c|}{5.832999999999999} & 5.4654 & TRN \\
\hline CHEMBL1426767 & 688653 & 5.233 & 5.3434 & TST & & \\
\hline CHEMBL1443573 & 688653 & 4.583 & 5.0181 & TRN & & \\
\hline CHEMBL3208952 & 688653 & 4.783 & 5.3878 & TRN & & \\
\hline CHEMBL1415983 & 688653 & 5.033 & 5.0581 & TRN & & \\
\hline CHEMBL1387896 & 688653 & \multicolumn{3}{|c|}{5.882999999999999} & 5.1141 & TRN \\
\hline CHEMBL1611922 & 688653 & 4.833 & 4.9825 & TRN & & \\
\hline CHEMBL1531589 & 688653 & 4.583 & 5.0315 & TRN & & \\
\hline CHEMBL1378171 & 688653 & \multicolumn{3}{|c|}{4.9830000000000005} & 5.7567 & TRN \\
\hline CHEMBL1448104 & 688653 & \multicolumn{3}{|c|}{4.7330000000000005} & 4.9787 & TRN \\
\hline CHEMBL1433083 & 688653 & 4.883 & 5.4638 & TST & & \\
\hline CHEMBL1493166 & 688653 & 5.083 & 5.1261 & TRN & & \\
\hline CHEMBL1382623 & 688653 & 4.833 & 4.85 & TRN & & \\
\hline CHEMBL1531389 & 688653 & 5.183 & 4.8774 & TRN & & \\
\hline CHEMBL1377370 & 688653 & 4.783 & 5.4494 & TRN & & \\
\hline CHEMBL1414244 & 688653 & \multicolumn{3}{|c|}{5.132999999999999} & 5.2491 & TRN \\
\hline CHEMBL1374433 & 688653 & 5.733 & 5.7878 & TST & & \\
\hline CHEMBL1545616 & 688653 & 5.733 & 5.3677 & TST & & \\
\hline CHEMBL1309389 & 688653 & 4.833 & 5.0256 & TRN & & \\
\hline CHEMBL3193485 & 688653 & 4.833 & 5.1029 & TRN & & \\
\hline CHEMBL1378441 & 688653 & 4.833 & 5.1415 & TRN & & \\
\hline CHEMBL1977763 & 688653 & 5.083 & 5.4386 & TRN & & \\
\hline CHEMBL1472430 & 688653 & \multicolumn{3}{|c|}{5.132999999999999} & 5.5914 & TRN \\
\hline \multirow[t]{2}{*}{ CHEMBL1575233 } & 688653 & \multicolumn{3}{|c|}{6.082999999999999} & 5.0529 & TST \\
\hline & & \multicolumn{5}{|c|}{ Page 24161} \\
\hline
\end{tabular}




\begin{tabular}{|c|c|c|c|c|c|c|c|}
\hline \multicolumn{8}{|c|}{ Supplemental Table S2.txt } \\
\hline CHEMBL1464105 & 688653 & 4.833 & 5.2538 & TRN & & & \\
\hline CHEMBL1531253 & 688653 & 5.033 & 5.3222 & TST & & & \\
\hline CHEMBL1407187 & 688653 & 4.783 & 5.1262 & TRN & & & \\
\hline CHEMBL1438232 & 688653 & \multicolumn{3}{|c|}{5.5329999999999995} & 5.5808 & TRN & \\
\hline CHEMBL3207771 & 688653 & 4.783 & 4.8924 & TST & & & \\
\hline CHEMBL1548970 & 688653 & \multicolumn{3}{|c|}{5.2829999999999995} & 5.0113 & TRN & \\
\hline CHEMBL1300398 & 688653 & 4.883 & 5.2029 & TRN & & & \\
\hline CHEMBL1547177 & 688653 & 4.833 & 5.1885 & TST & & & \\
\hline CHEMBL 1468270 & 688653 & 5.733 & 5.5663 & TRN & & & \\
\hline CHEMBL1325056 & 688653 & \multicolumn{3}{|c|}{5.7829999999999995} & 5.2691 & TRN & \\
\hline CHEMBL1539537 & 688653 & 4.833 & 5.0467 & TST & & & \\
\hline CHEMBL1505217 & 688653 & 5.233 & 5.5164 & TRN & & & \\
\hline CHEMBL1404163 & 688653 & \multicolumn{3}{|c|}{5.7829999999999995} & 5.6478 & TRN & \\
\hline CHEMBL1368714 & 688653 & 5.083 & 5.9478 & TRN & & & \\
\hline CHEMBL3193017 & 688653 & 5.483 & 5.2503 & TRN & & & \\
\hline CHEMBL3209007 & 688653 & \multicolumn{3}{|c|}{5.5329999999999995} & 5.1619 & TST & \\
\hline CHEMBL1313764 & 688653 & 4.633 & 5.1961 & TRN & & & \\
\hline CHEMBL1355627 & 688653 & 4.783 & 4.9767 & TRN & & & \\
\hline CHEMBL1357262 & 688653 & 4.833 & 5.0143 & TST & & & \\
\hline CHEMBL1377682 & 688653 & 4.833 & 4.5749 & TRN & & & \\
\hline CHEMBL3212950 & 688653 & 4.583 & 5.0224 & TST & & & \\
\hline CHEMBL1488449 & 688653 & \multicolumn{3}{|c|}{5.132999999999999} & 5.1876 & TRN & \\
\hline CHEMBL1371027 & 688653 & 4.883 & 4.8636 & TRN & & & \\
\hline CHEMBL1341938 & 688653 & 6.433 & 5.1362 & TRN & & & \\
\hline CHEMBL1535225 & 688653 & 7.2328 & 6.2764 & TRN & & & \\
\hline CHEMBL1514008 & 688653 & 4.583 & 5.0794 & TRN & & & \\
\hline CHEMBL1471201 & 688653 & 5.683 & 5.8615 & TRN & & & \\
\hline CHEMBL1472147 & 688653 & \multicolumn{3}{|c|}{4.7330000000000005} & 5.3523 & TST & \\
\hline CHEMBL1565441 & 688653 & \multicolumn{3}{|c|}{6.582999999999999} & 5.9295 & TRN & \\
\hline CHEMBL1595047 & 688653 & \multicolumn{3}{|c|}{5.882999999999999} & 5.4057 & TRN & \\
\hline CHEMBL 292785 & 688653 & 6.183 & 5.7915 & TRN & & & \\
\hline CHEMBL1365929 & 688653 & 4.783 & 5.3703 & TRN & & & \\
\hline CHEMBL1458698 & 688653 & 4.933 & 5.0355 & TRN & & & \\
\hline CHEMBL1333878 & 688653 & 5.033 & 5.2703 & TST & & & \\
\hline CHEMBL1503463 & 688653 & \multicolumn{3}{|c|}{6.632999999999999} & 5.4113 & TST & \\
\hline CHEMBL1329597 & 688653 & 4.583 & 5.1351 & TST & & & \\
\hline CHEMBL3191096 & 688653 & \multicolumn{3}{|c|}{4.7330000000000005} & 5.0374 & TRN & \\
\hline CHEMBL1490190 & 688653 & \multicolumn{3}{|c|}{5.132999999999999} & 5.3949 & TRN & \\
\hline CHEMBL1541791 & 688653 & 5.033 & 5.0185 & TST & & & \\
\hline CHEMBL1388892 & 688653 & 4.783 & 5.2047 & TRN & & & \\
\hline CHEMBL1443120 & 688653 & \multicolumn{3}{|c|}{5.882999999999999} & 5.2897 & TST & \\
\hline CHEMBL1397876 & 688653 & 5.483 & 4.9809 & TRN & & & \\
\hline CHEMBL1436476 & 688653 & \multicolumn{3}{|c|}{4.9830000000000005} & 5.4017 & TRN & \\
\hline CHEMBL1504239 & 688653 & \multicolumn{3}{|c|}{6.5329999999999995} & 5.45200 & 0000000001 & TRN \\
\hline CHEMBL1338885 & 688653 & 4.583 & 4.5874 & TRN & & & \\
\hline CHEMBL1486109 & 688653 & \multicolumn{3}{|c|}{5.832999999999999} & 6.6284 & TRN & \\
\hline CHEMBL1519571 & 688653 & \multicolumn{3}{|c|}{5.132999999999999} & 5.42899 & 9999999999 & TRN \\
\hline CHEMBL1395731 & 688653 & \multicolumn{3}{|c|}{5.832999999999999} & 5.1935 & TRN & \\
\hline
\end{tabular}




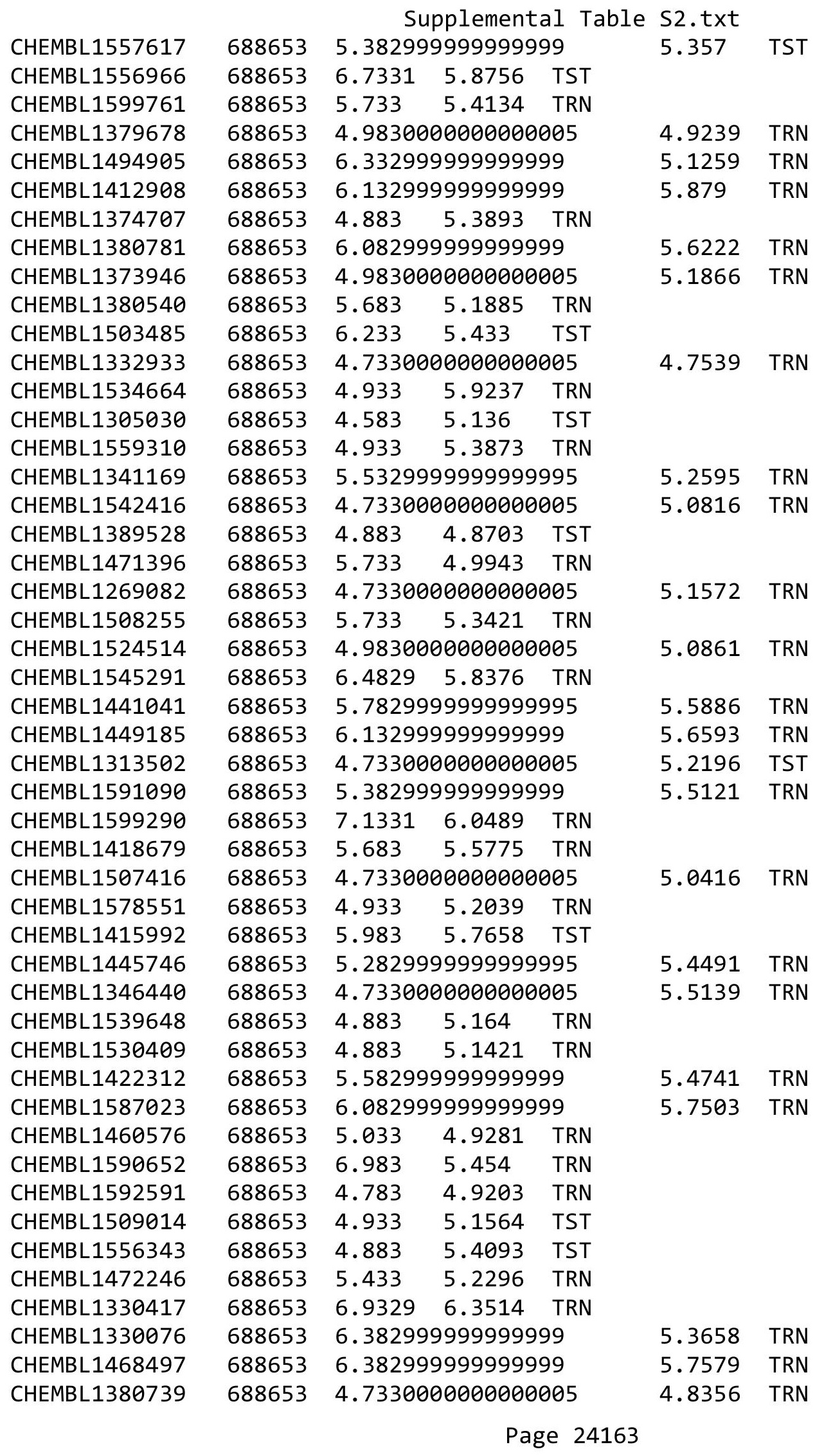




\begin{tabular}{|c|c|c|c|c|c|c|}
\hline & & \multicolumn{5}{|c|}{ Supplemental Table s2.txt } \\
\hline CHEMBL1340587 & 688653 & 4.583 & 5.2553 & TST & & \\
\hline CHEMBL1442562 & 688653 & 4.783 & 5.1748 & TRN & & \\
\hline CHEMBL1382411 & 688653 & 5.733 & 5.5266 & TRN & & \\
\hline CHEMBL1339380 & 688653 & 5.183 & 5.396 & TRN & & \\
\hline CHEMBL1559461 & 688653 & \multicolumn{3}{|c|}{6.832999999999999} & 6.0143 & TRN \\
\hline CHEMBL1413209 & 688653 & 4.883 & 5.2862 & TST & & \\
\hline CHEMBL492116 & 688653 & 5.483 & \multicolumn{3}{|c|}{5.0489999999999995} & TRN \\
\hline CHEMBL1338322 & 688653 & 4.783 & 5.1367 & TRN & & \\
\hline CHEMBL1576840 & 688653 & 5.683 & 5.1138 & TRN & & \\
\hline CHEMBL1448466 & 688653 & \multicolumn{3}{|c|}{5.832999999999999} & 5.6725 & TRN \\
\hline CHEMBL1534171 & 688653 & 5.233 & 5.0827 & TRN & & \\
\hline CHEMBL1355423 & 688653 & 4.883 & 5.2401 & TST & & \\
\hline CHEMBL1447750 & 688653 & 6.433 & 5.3048 & TRN & & \\
\hline CHEMBL3189944 & 688653 & 5.033 & 5.2741 & TST & & \\
\hline CHEMBL1583961 & 688653 & 4.883 & 5.034 & TST & & \\
\hline CHEMBL3190582 & 688653 & 4.683 & 5.0136 & TRN & & \\
\hline CHEMBL1524971 & 688653 & 4.683 & 4.9889 & TST & & \\
\hline CHEMBL3198651 & 688653 & 5.733 & 5.7664 & TRN & & \\
\hline CHEMBL1546279 & 688653 & 6.433 & 5.1479 & TRN & & \\
\hline CHEMBL3190289 & 688653 & \multicolumn{3}{|c|}{4.7330000000000005} & 5.2631 & TST \\
\hline CHEMBL1318869 & 688653 & 4.633 & 4.8019 & TRN & & \\
\hline CHEMBL1390567 & 688653 & 5.183 & 5.7438 & TST & & \\
\hline CHEMBL1369217 & 688653 & 5.033 & 5.5207 & TRN & & \\
\hline CHEMBL1472311 & 688653 & 5.233 & 5.7677 & TRN & & \\
\hline CHEMBL1526995 & 688653 & 4.933 & 5.1445 & TST & & \\
\hline CHEMBL1361994 & 688653 & \multicolumn{3}{|c|}{6.582999999999999} & 5.7531 & TST \\
\hline CHEMBL1443326 & 688653 & \multicolumn{3}{|c|}{5.2829999999999995} & 5.5903 & TRN \\
\hline CHEMBL1446192 & 688653 & 4.633 & 4.9288 & TRN & & \\
\hline CHEMBL1413661 & 688653 & \multicolumn{3}{|c|}{5.382999999999999} & 5.3546 & TRN \\
\hline CHEMBL3208511 & 688653 & \multicolumn{3}{|c|}{5.2829999999999995} & 5.1876 & TST \\
\hline CHEMBL1467426 & 688653 & 4.783 & 5.1464 & TRN & & \\
\hline CHEMBL1379756 & 688653 & 4.933 & 5.3349 & TRN & & \\
\hline CHEMBL1555344 & 688653 & \multicolumn{3}{|c|}{5.632999999999999} & 5.1808 & TRN \\
\hline CHEMBL1580883 & 688653 & 5.433 & 5.289 & TRN & & \\
\hline CHEMBL3190577 & 688653 & 5.183 & 5.7207 & TST & & \\
\hline CHEMBL1547714 & 688653 & 5.733 & 5.5316 & TRN & & \\
\hline CHEMBL1601374 & 688653 & \multicolumn{3}{|c|}{4.7330000000000005} & 5.3524 & TRN \\
\hline CHEMBL1527546 & 688653 & \multicolumn{3}{|c|}{5.332999999999999} & 5.0291 & TST \\
\hline CHEMBL1431743 & 688653 & \multicolumn{3}{|c|}{5.382999999999999} & 5.2603 & TST \\
\hline CHEMBL1309122 & 688653 & 4.783 & 5.3795 & TRN & & \\
\hline CHEMBL1348781 & 688653 & \multicolumn{3}{|c|}{5.632999999999999} & 5.255 & TRN \\
\hline CHEMBL1345315 & 688653 & 5.083 & 4.8973 & TRN & & \\
\hline CHEMBL1454347 & 688653 & 4.783 & 5.0668 & TRN & & \\
\hline CHEMBL1392444 & 688653 & 4.783 & 5.4313 & TST & & \\
\hline CHEMBL1503688 & 688653 & 4.933 & 5.2861 & TRN & & \\
\hline CHEMBL1300618 & 688653 & 4.583 & 4.8591 & TST & & \\
\hline CHEMBL1344186 & 688653 & 5.183 & 5.0594 & TRN & & \\
\hline CHEMBL1546843 & 688653 & 5.033 & 5.0677 & TST & & \\
\hline
\end{tabular}




\begin{tabular}{|c|c|c|c|c|c|c|}
\hline \multirow{3}{*}{$\begin{array}{l}\text { CHEMBL1461626 } \\
\text { CHEMBL1424911 }\end{array}$} & \multirow{3}{*}{$\begin{array}{l}688653 \\
688653\end{array}$} & \multicolumn{5}{|c|}{ Supplemental Table S2.txt } \\
\hline & & \multicolumn{3}{|c|}{5.382999999999999} & \multirow[t]{3}{*}{5.4073} & \multirow[t]{2}{*}{ TRA } \\
\hline & & 5.183 & 5.3683 & TRN & & \\
\hline CHEMBL1528309 & 688653 & 5.233 & 5.6373 & TST & & \\
\hline CHEMBL1409532 & 688653 & \multicolumn{3}{|c|}{5.382999999999999} & 4.7925 & $T$ \\
\hline CHEMBL1215100 & 688653 & 4.833 & 5.4986 & TRN & & \\
\hline CHEMBL262627 & 588653 & \multicolumn{3}{|c|}{5.332999999999999} & 5.2278 & \\
\hline CHEMBL1354123 & 688653 & \multicolumn{3}{|c|}{4.7330000000000005} & 5.3775 & \\
\hline CHEMBL1341915 & 688653 & 5.733 & 5.2645 & TRN & & \\
\hline CHEMBL1610215 & 688653 & \multicolumn{3}{|c|}{5.2829999999999995} & 5.4411 & \\
\hline CHEMBL1432649 & 688653 & 5.183 & 5.4004 & TST & & \\
\hline CHEMBL3213941 & 688653 & 5.483 & 4.7837 & TST & & \\
\hline CHEMBL1356020 & 688653 & 4.633 & 4.9656 & TRN & & \\
\hline CHEMBL1327234 & 688653 & \multicolumn{3}{|c|}{6.5329999999999995} & 5.3276 & TS \\
\hline CHEMBL1458423 & 688653 & 4.933 & 5.4532 & TST & & \\
\hline CHEMBL1520402 & 688653 & 5.733 & 5.2223 & TRN & & \\
\hline CHEMBL1 & 688 & 5.683 & 5.8798 & TRN & & \\
\hline CHEMBL1 & 688 & \multicolumn{3}{|c|}{5.2829999999999995} & 4.9391 & 1. \\
\hline CHEMBL1989636 & 688653 & 5.733 & 5.6124 & TRN & & \\
\hline CHEMBL1502787 & 688653 & \multicolumn{3}{|c|}{5.2829999999999995} & 6129 & \\
\hline CHEMBL1537051 & 688653 & 5.65 & 5.0604 & TRN & & \\
\hline CHEMBL & 688 & \multirow{2}{*}{\multicolumn{3}{|c|}{ א.132999999999999 }} & & \\
\hline CHEMBL 1 & 688 & & & & 5.0121 & $\mathrm{TI}$ \\
\hline CHEMBL1418104 & 688653 & 5.433 & 5.7652 & TRN & & \\
\hline CHEMBL1337634 & 6886 & 5.683 & 5.6523 & TRN & & \\
\hline CHEMBL31S & 688653 & \multicolumn{3}{|c|}{4.7330000000000005} & 4.985 & \\
\hline CHEMBL1 & 688 & 4.683 & 5.2345 & TRN & & \\
\hline CHEMBL1368198 & 688653 & \multicolumn{3}{|c|}{4.7330000000000005} & 5.4308 & $\mathrm{TS}$ \\
\hline CHEMBL1424864 & 688653 & 5.733 & 5.32 & TST & & \\
\hline CHEMBL3189201 & 688653 & 6.4829 & 5.9842 & TRN & & \\
\hline CHEMBL145 & 688 & \multicolumn{3}{|c|}{4.7330000000000005} & גנכסינ & \\
\hline CHEMBL: & $68 \varepsilon$ & 4.583 & 5.0249 & TRN & & \\
\hline CHEMBL1557191 & 688 & 6. & 6.1142 & TRN & & \\
\hline CHEMBL1545922 & 688653 & 4.833 & 5.3565 & TRN & & \\
\hline CHEMBL1372701 & 688653 & \multicolumn{3}{|c|}{5.632999999999999} & גנכנ. & TP \\
\hline CHEMBL: & 688 & \multicolumn{3}{|c|}{5.2829999999999995} & 5.7923 & \\
\hline CHEMBL1504704 & 688 & 5.483 & 5.0589 & TST & & \\
\hline CHEMBL1545180 & 688653 & 4.783 & 5.3851 & TRN & & \\
\hline CHEMBL1422008 & 688653 & 5.65 & 5.4253 & TST & & \\
\hline CHEMBL1427072 & 688653 & 5.433 & 6.2359 & TRN & & \\
\hline CHEMBL15e & 688 & \multicolumn{3}{|c|}{5.832999999999999} & 5.3451 & TST \\
\hline CHEMBL1341706 & 688653 & 4.883 & 5.0726 & TRN & & \\
\hline CHEMBL1565737 & 688653 & \multicolumn{3}{|c|}{5.832999999999999} & 5.1955 & 10 \\
\hline CHEMBL1539023 & 688653 & 4.783 & 5.058 & TRN & & \\
\hline CHEMBL1544108 & 688653 & 5.5829 & 99999999 & & 5 & 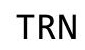 \\
\hline CHEMBL1510508 & 688653 & 5.1329 & 99999999 & & 5.0262 & . \\
\hline CHEMBL1548449 & 688653 & 5.8829 & 99999999 & & 5.6801 & TRN \\
\hline CHEMBL1520639 & 688653 & 5.3329 & 99999999 & & 5.864 & TRN \\
\hline CHEMBL1561456 & 688653 & 6.0829 & 99999999 & & 5.646 & \\
\hline
\end{tabular}




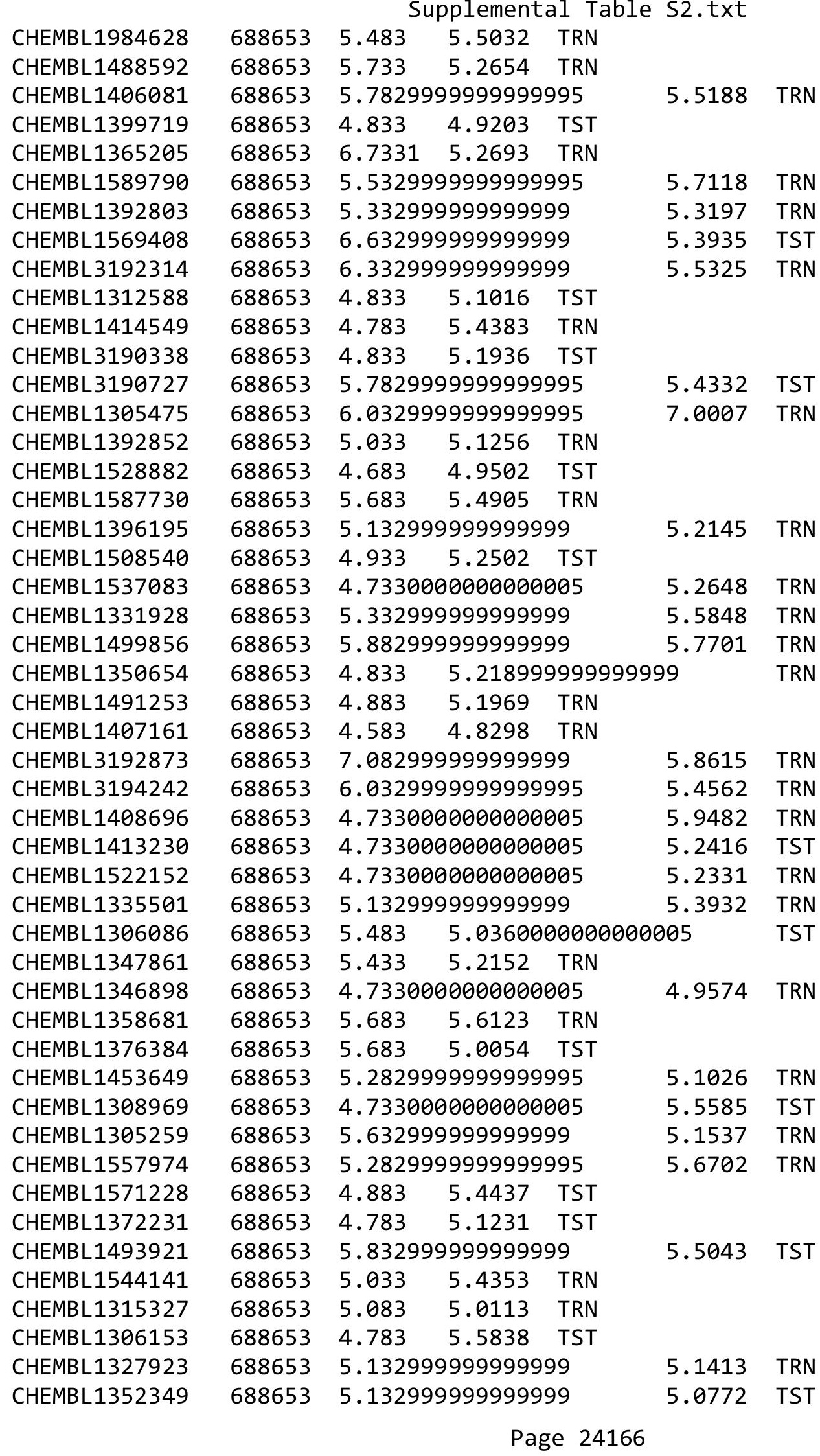




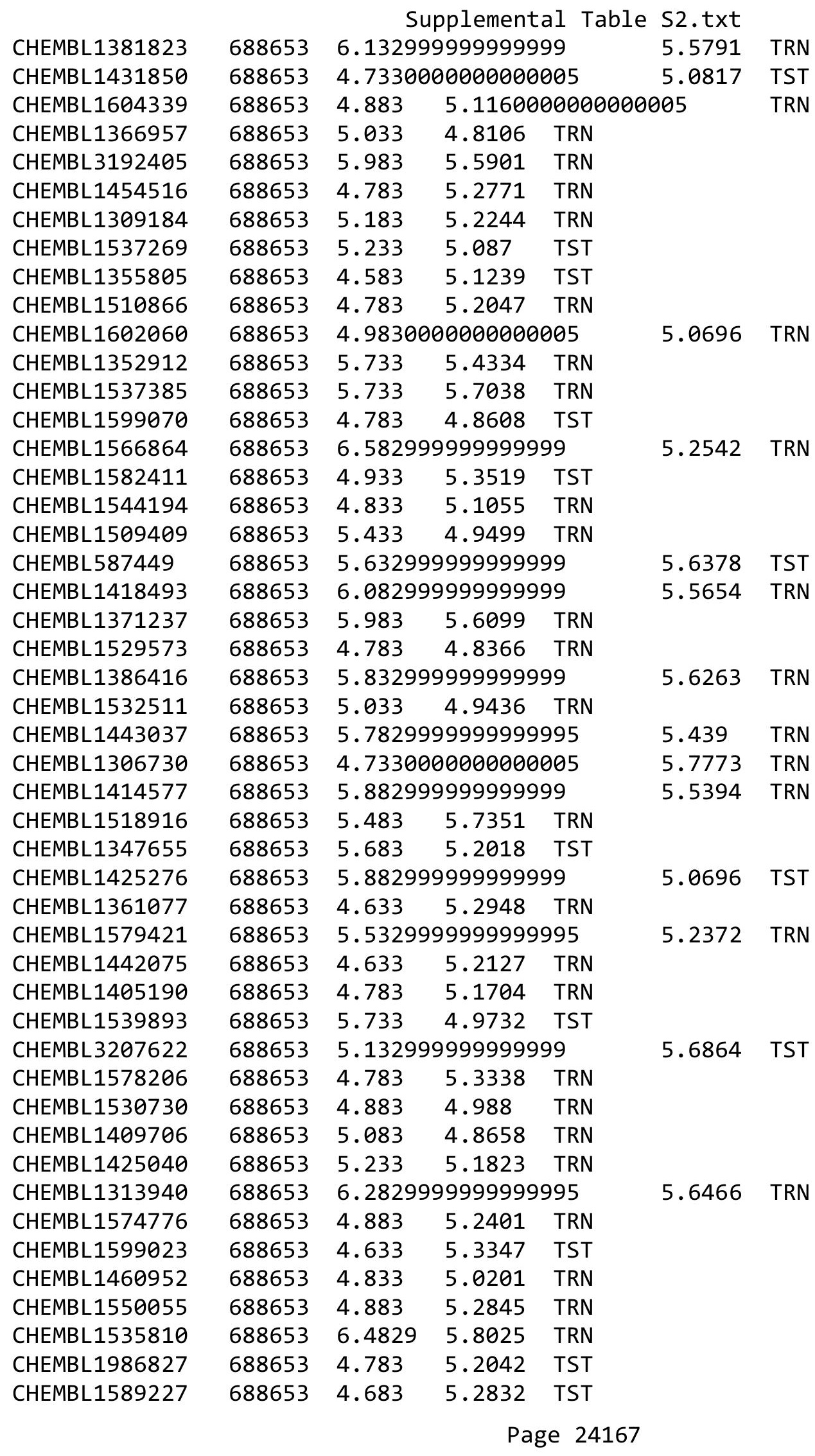




\begin{tabular}{|c|c|c|c|c|c|c|}
\hline \multirow[b]{2}{*}{ CHEMBL3199409 } & \\
\hline & 688653 & 7.0329 & 5.3541 & TRN & & \\
\hline CHEMBL1417573 & 688653 & \multicolumn{3}{|c|}{6.2829999999999995} & 5.4163 & $\mathrm{Tr}$ \\
\hline CHEMBL1333568 & 688653 & \multicolumn{3}{|c|}{4.9830000000000005} & 5.1366 & \\
\hline CHEMBL19954 & 688653 & \multicolumn{3}{|c|}{5.5329999999999995} & 5.2666 & \\
\hline CHEMBL60718 & 588653 & 4.783 & 4.7217 & TST & & \\
\hline CHEMBL1393205 & 688653 & 4.783 & \multicolumn{3}{|c|}{5.207000000000001} & \\
\hline CHEMBL1323478 & 688653 & \multicolumn{3}{|c|}{5.132999999999999} & 5.1869 & \\
\hline CHEMBL1497635 & 688653 & \multicolumn{3}{|c|}{6.382999999999999} & 5.8862 & \\
\hline CHEMBL1587605 & 688653 & 4.783 & 5.13 & TRN & & \\
\hline CHEMBL1453239 & 688653 & \multicolumn{3}{|c|}{4.7330000000000005} & 5.3349 & \\
\hline CHEMBL1328077 & 688653 & 4.633 & 4.9606 & TRN & & \\
\hline CHEMBL1515582 & 688653 & \multicolumn{3}{|c|}{5.582999999999999} & 5.1783 & \\
\hline CHEMBL1443234 & 688653 & 5.083 & 5.2578 & TRN & & \\
\hline CHEMBL1396542 & 688653 & 4.583 & 4.9661 & TRN & & \\
\hline CHEMBL1590714 & 688653 & \multicolumn{3}{|c|}{6.382999999999999} & 522 & \\
\hline CHEMBL1499320 & 688653 & 4.633 & 5.4902 & TRN & & \\
\hline CHEMBL1422295 & 688653 & 4.783 & 5.2859 & TRN & & \\
\hline CHEMBL1342461 & 688653 & \multicolumn{3}{|c|}{5.132999999999999} & 367 & \\
\hline CHEMBL1399985 & 688653 & \multicolumn{3}{|c|}{5.132999999999999} & 445 & \\
\hline CHEMBL1340332 & 688653 & \multicolumn{3}{|c|}{6.332999999999999} & 5.5384 & \\
\hline CHEMBL14: & 688653 & \multicolumn{3}{|c|}{4.7330000000000005} & $\partial 64$ & \\
\hline CHEMBL1533611 & 688653 & \multicolumn{3}{|c|}{5.882999999999999} & 5. & \\
\hline CHEMBL 1566026 & 688653 & \multicolumn{3}{|c|}{6.332999999999999} & 5.7029 & \\
\hline CHEMBL1567032 & 688653 & \multicolumn{3}{|c|}{5.632999999999999} & & \\
\hline CHEMBL 1493793 & 688653 & 4.833 & 5.4154 & TRN & & \\
\hline CHEMBL17 & 688 & \multirow{2}{*}{\multicolumn{3}{|c|}{$\begin{array}{lr}5.683 & 5.4187 \\
4.7330000000900005\end{array}$}} & & \\
\hline CHEMBL 1429724 & 688653 & & & & 4.829 & \\
\hline CHEMBL1520582 & 688653 & \multicolumn{3}{|c|}{5.632999999999999} & 5.5238 & \\
\hline CHEMBL1348299 & 688653 & 4.9830 & 00000000 & 005 & 5.1547 & \\
\hline CHEMBL 1403009 & 688653 & 6.3829 & 99999999 & & 5.4438 & \\
\hline CHEMBL13 & 688653 & 5.233 & 5.4475 & TRN & & \\
\hline CHEMBL 1576553 & 688653 & 4.833 & 5.0058 & TST & & \\
\hline CHEMBL1429722 & 688653 & 6.1329 & 99999999 & & 5.3006 & $\mathrm{TH}$ \\
\hline CHEMBL1568662 & 688653 & 5.433 & 5.3554 & TRN & & \\
\hline CHEMBL1565105 & 688653 & 4.7330 & 00000000 & 005 & 4.8924 & \\
\hline CHEMBL & 688653 & 5.2 & 5.3602 & TRN & & \\
\hline CHEMBL1492461 & 688653 & 6.4829 & 5.61100 & 0000 & & TRN \\
\hline CHEMBL1493291 & 688653 & 5.233 & 5.5118 & TRN & & \\
\hline CHEMBL1593939 & 688653 & 4.633 & 4.801 & TRN & & \\
\hline CHEMBL13 & 688653 & 5.033 & 5.2 & TRN & & \\
\hline CHEMBL1439189 & 688653 & 4.583 & 5.3202 & TST & & \\
\hline CHEMBL 1563222 & 688653 & 5.2829 & 99999999 & 995 & 5.3231 & TRN \\
\hline CHEMBL1404601 & 688653 & 5.7829 & 99999999 & 995 & 5.5766 & $\pi$ \\
\hline CHEMBL1363074 & 688653 & 5.083 & 5.1289 & TRN & & \\
\hline CHEMBL1533584 & 688653 & 5.083 & 5.266 & TRN & & \\
\hline CHEMBL1307326 & 688653 & 5.183 & 5.5064 & TRN & & \\
\hline CHEMBL 1498514 & 688653 & 4.9830 & 00000000 & 005 & 5.005 & 10 \\
\hline CHEMBL1403152 & 688653 & 5.1329 & 99999999 & & 5.0758 & TR \\
\hline
\end{tabular}




\begin{tabular}{|c|c|c|c|c|c|c|}
\hline & & \multicolumn{5}{|c|}{ Supplemental Table S2.txt } \\
\hline CHEMBL1317655 & 688653 & 4.583 & 5.0599 & TRN & & \\
\hline CHEMBL3191871 & 688653 & 5.183 & 6.4519 & TRN & & \\
\hline CHEMBL1596866 & 688653 & \multicolumn{3}{|c|}{4.7330000000000005} & 5.0065 & TRN \\
\hline CHEMBL1484093 & 688653 & \multicolumn{3}{|c|}{5.2829999999999995} & 5.093 & TRN \\
\hline CHEMBL1558789 & 688653 & \multicolumn{3}{|c|}{5.5329999999999995} & 5.4203 & TRN \\
\hline CHEMBL1338596 & 688653 & \multicolumn{3}{|c|}{5.332999999999999} & 5.0788 & \\
\hline CHEMBL1527295 & 688653 & \multicolumn{3}{|c|}{4.7330000000000005} & 5.4534 & \\
\hline CHEMBL1560223 & 688653 & 5.9 & 5.6891 & TRN & & \\
\hline CHEMBL1501376 & 688653 & 4.583 & 5.2284 & TST & & \\
\hline CHEMBL3190332 & 688653 & \multicolumn{3}{|c|}{6.0329999999999995} & 5.2663 & TRN \\
\hline CHEMBL1597668 & 688653 & \multicolumn{3}{|c|}{5.382999999999999} & 5.3254 & \\
\hline CHEMBL199194 & 688653 & 5.233 & 5.8954 & TST & & \\
\hline CHEMBL1382833 & 688653 & \multicolumn{3}{|c|}{5.7829999999999995} & 5.4011 & \\
\hline CHEMBL1493414 & 688653 & \multicolumn{3}{|c|}{4.7330000000000005} & 4.9415 & \\
\hline CHEMBL1456179 & 688653 & 6.0 & 5.5454 & TRN & & \\
\hline CHEMBL1603890 & 688653 & 4.833 & 5.1775 & TST & & \\
\hline CHEMBL1436755 & 688653 & 4.783 & 4.8746 & TST & & \\
\hline CHEMBL1601285 & 688653 & 5.233 & 5.3003 & TRN & & \\
\hline CHEMBL1569172 & 688653 & 5.183 & 5.2484 & TRN & & \\
\hline CHEMBL1578877 & 688653 & 4.783 & 5.2344 & TRN & & \\
\hline CHEMBL1474556 & 688653 & 4.583 & 4.9366 & TRN & & \\
\hline CHEMBL1599559 & 688653 & \multicolumn{3}{|c|}{6.132999999999999} & 5.4817 & \\
\hline CHEMBL408563 & 688653 & 7.1831 & 5.9229 & TRN & & \\
\hline CHEMBL1545093 & 688653 & 4.783 & 5.0718 & TST & & \\
\hline CHEMBL1576110 & 688653 & 4.683 & 5.0734 & TRN & & \\
\hline CHEMBL1371531 & 688653 & \multicolumn{3}{|c|}{4.9830000000000005} & 152 & \\
\hline CHEMBL1494629 & 688653 & 4.883 & 4.8314 & TRN & & \\
\hline CHEMBL1532195 & 688653 & \multicolumn{3}{|c|}{5.632999999999999} & 5.7799 & 10 \\
\hline CHEMBL1379668 & 688653 & 5.183 & 5.2622 & TRN & & \\
\hline CHEMBL1380894 & 688653 & 5.483 & 5.225 & TRN & & \\
\hline CHEMBL3197310 & 688653 & 5.683 & 5.4612 & TRN & & \\
\hline CHEMBL1430883 & 688 & 4.833 & 4.8 & TST & & \\
\hline CHEMBL1540841 & 688653 & 5.733 & 5.5387 & TRN & & \\
\hline CHEMBL1517132 & 688653 & 6.183 & 5.8634 & TRN & & \\
\hline CHEMBL1340958 & 688653 & \multicolumn{3}{|c|}{4.7330000000000005} & & TST \\
\hline CHEMBL1440215 & 688653 & \multicolumn{3}{|c|}{5.832999999999999} & 5.5003 & \\
\hline CHEMBL1369569 & 688653 & 5.983 & 6.0059 & TRN & & \\
\hline CHEMBL1431090 & 688653 & & 5.2537 & & & \\
\hline CHEMBL1418770 & 688653 & \multicolumn{3}{|c|}{4.7330000000000005} & 5.325 & TRN \\
\hline CHEMBL1469489 & 688653 & \multicolumn{3}{|c|}{4.9830000000000005} & 5.1921 & TRN \\
\hline CHEMBL3210893 & 688653 & \multicolumn{3}{|c|}{5.5329999999999995} & 5.364 & \\
\hline CHEMBL1551327 & 688653 & 4.833 & 4.8245 & TRN & & \\
\hline CHEMBL1452153 & 688653 & 4.833 & 5.5596 & TRN & & \\
\hline CHEMBL1415226 & 688653 & 4.833 & 5.2739 & TRN & & \\
\hline CHEMBL1416060 & 688653 & \multicolumn{3}{|c|}{4.7330000000000005} & 5.1368 & $1 \mathrm{~K}$ \\
\hline CHEMBL1586822 & 688653 & 4.933 & 5.0169 & TRN & & \\
\hline CHEMBL3192055 & 688653 & \multicolumn{3}{|c|}{5.332999999999999} & 3202 & TRN \\
\hline CHEMBL1406639 & 688653 & 5.433 & 4.6697 & TST & & \\
\hline
\end{tabular}




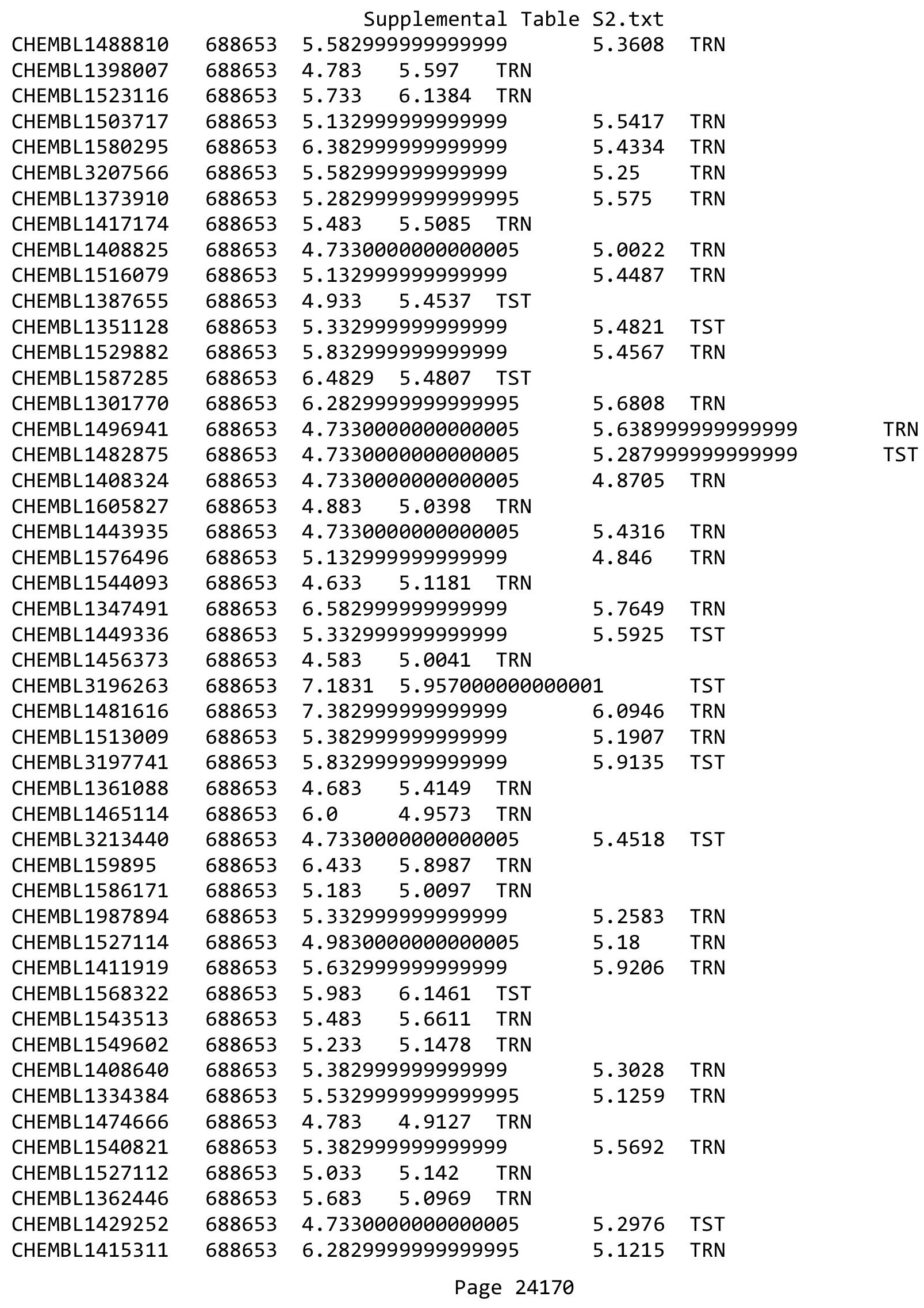




\begin{tabular}{|c|c|c|c|c|c|c|c|}
\hline \multicolumn{7}{|c|}{ Supplemental Table S2.txt } & \\
\hline CHEMBL1483298 & 688653 & 4.933 & 5.1485 & TRN & & & \\
\hline CHEMBL1394400 & 688653 & 4.783 & 5.2803 & TRN & & & \\
\hline CHEMBL1373897 & 688653 & 5.88299 & 99999999 & & 5.4251 & TRN & \\
\hline CHEMBL1483039 & 688653 & 4.883 & 5.0594 & TRN & & & \\
\hline CHEMBL1342907 & 688653 & 5.38299 & 99999999 & & 5.0782 & TRN & \\
\hline CHEMBL3197851 & 688653 & 5.38299 & 99999999 & & 5.3596 & TST & \\
\hline CHEMBL1454819 & 688653 & 4.633 & 4.9611 & TRN & & & \\
\hline CHEMBL 3194283 & 688653 & 5.38299 & 99999999 & & 5.4973 & TRN & \\
\hline CHEMBL1426911 & 688653 & 6.38299 & 99999999 & & 5.2191 & TRN & \\
\hline CHEMBL 1303740 & 688653 & 4.783 & 5.4047 & TRN & & & \\
\hline CHEMBL1600857 & 688653 & 5.78299 & 99999999 & 995 & 5.1677 & TRN & \\
\hline CHEMBL1301679 & 688653 & 4.73300 & 00000000 & 005 & 5.3838 & TST & \\
\hline CHEMBL1547030 & 688653 & 4.73300 & 00000000 & 005 & 5.13399 & 99999999995 & TRN \\
\hline CHEMBL1336911 & 688653 & 5.433 & 4.7547 & TRN & & & \\
\hline CHEMBL1430372 & 688653 & 4.633 & 5.4046 & TST & & & \\
\hline CHEMBL3190064 & 688653 & 5.28299 & 99999999 & 995 & 5.3768 & TRN & \\
\hline CHEMBL1449642 & 688653 & 5.233 & 5.0789 & TRN & & & \\
\hline CHEMBL1583356 & 688653 & 5.233 & 5.2624 & TRN & & & \\
\hline CHEMBL1384998 & 688653 & 5.733 & 5.4151 & TST & & & \\
\hline CHEMBL1328629 & 688653 & 4.883 & 5.3117 & TST & & & \\
\hline CHEMBL1583650 & 688653 & 6.53299 & 99999999 & 995 & 5.8798 & TRN & \\
\hline CHEMBL1318479 & 688653 & 4.583 & 5.5591 & TRN & & & \\
\hline CHEMBL1502260 & 688653 & 5.53299 & 99999999 & 995 & 5.4745 & TRN & \\
\hline CHEMBL1398217 & 688653 & 4.633 & 5.5119 & TST & & & \\
\hline CHEMBL1342150 & 688653 & 5.38299 & 99999999 & & 5.3249 & TRN & \\
\hline CHEMBL1512285 & 688653 & 5.63299 & 99999999 & & 5.2225 & TST & \\
\hline CHEMBL1486352 & 688653 & 6.08299 & 99999999 & & 5.2389 & TRN & \\
\hline CHEMBL1342003 & 688653 & 4.783 & 5.0214 & TRN & & & \\
\hline CHEMBL1595690 & 688653 & 4.98300 & 00000000 & 005 & 5.0329 & TRN & \\
\hline CHEMBL1522762 & 688653 & 4.683 & 5.0767 & TST & & & \\
\hline CHEMBL1501288 & 688653 & 5.483 & 5.4144 & TST & & & \\
\hline CHEMBL1405197 & 688653 & 5.033 & 4.9874 & TRN & & & \\
\hline CHEMBL1339995 & 688653 & 5.63299 & 99999999 & & 5.54299 & 9999999999 & TRN \\
\hline CHEMBL3197063 & 688653 & 6.03299 & 99999999 & 995 & 5.8456 & TRN & \\
\hline CHEMBL1353364 & 688653 & 5.13299 & 99999999 & 99 & 5.3756 & TRN & \\
\hline CHEMBL1496004 & 688653 & 4.883 & 5.1156 & TRN & & & \\
\hline CHEMBL1545892 & 688653 & 4.933 & 5.3888 & TRN & & & \\
\hline CHEMBL3194403 & 688653 & 5.38299 & 99999999 & 99 & 5.3061 & TRN & \\
\hline CHEMBL1337023 & 688653 & 4.783 & 5.7276 & TRN & & & \\
\hline CHEMBL1321603 & 688653 & 5.63299 & 99999999 & & 5.7641 & TRN & \\
\hline CHEMBL1395906 & 688653 & 4.73300 & 00000000 & 005 & 5.6131 & TRN & \\
\hline CHEMBL1483243 & 688653 & 4.883 & 5.3842 & TRN & & & \\
\hline CHEMBL1538484 & 688653 & 5.483 & 5.4978 & TRN & & & \\
\hline CHEMBL1358438 & 688653 & 4.73300 & 00000000 & 005 & 5.4499 & TRN & \\
\hline CHEMBL1341826 & 688653 & 4.783 & 5.5048 & TRN & & & \\
\hline CHEMBL1370450 & 688653 & 5.083 & 5.3071 & TST & & & \\
\hline CHEMBL1479897 & 688653 & 4.633 & 5.1477 & TRN & & & \\
\hline CHEMBL1465074 & 688653 & 6.05 & 5.9318 & TRN & & & \\
\hline
\end{tabular}




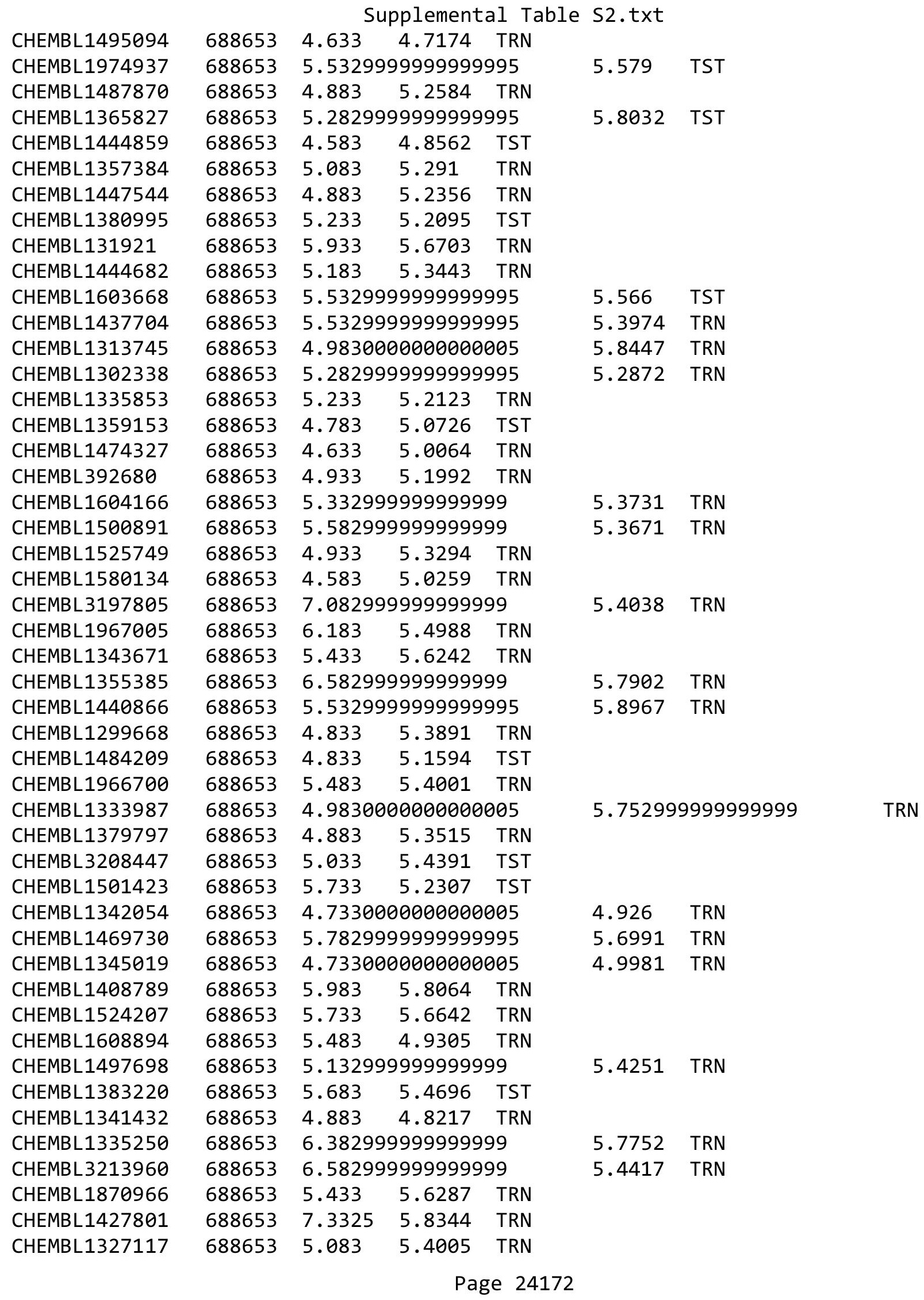




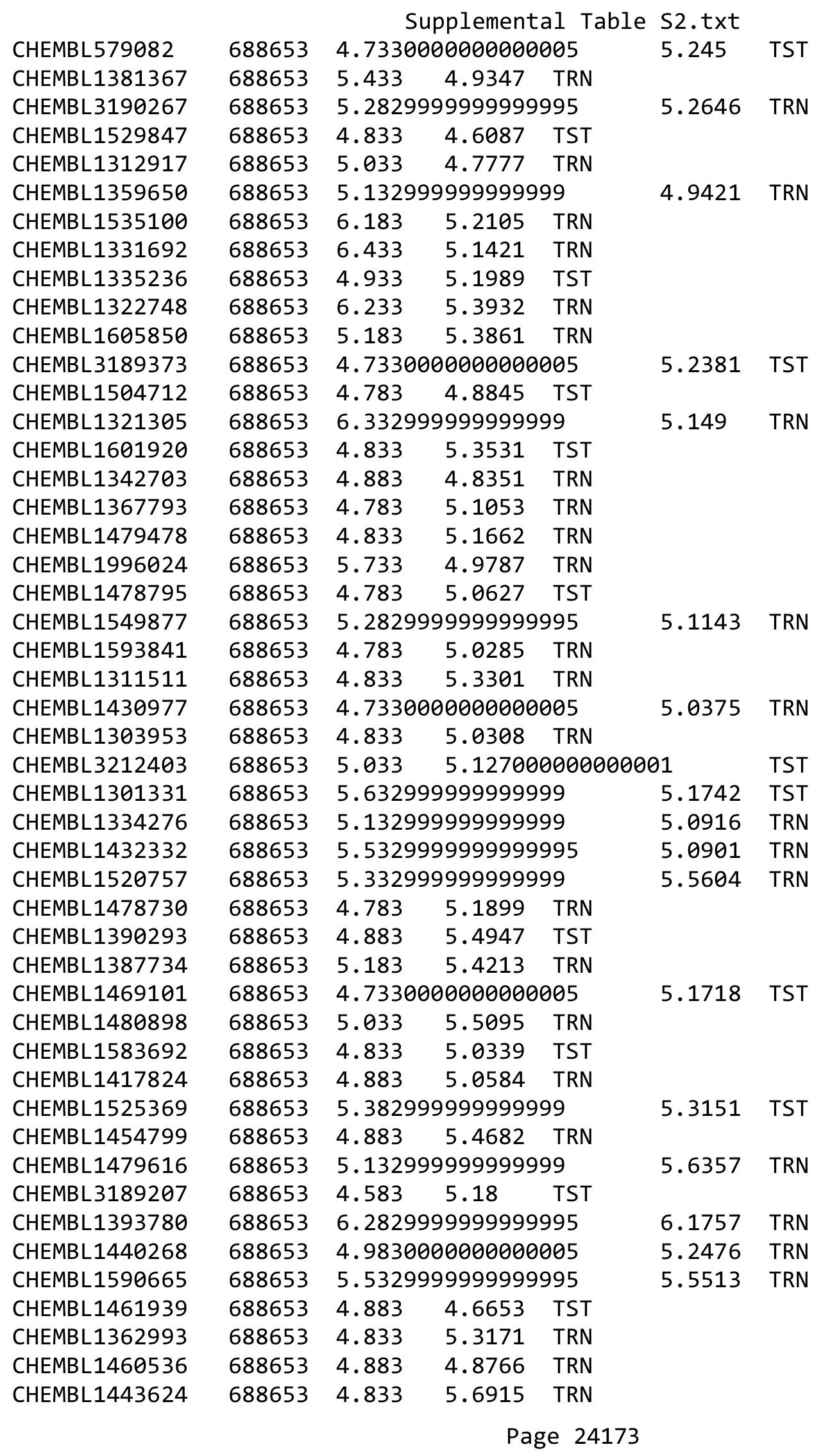




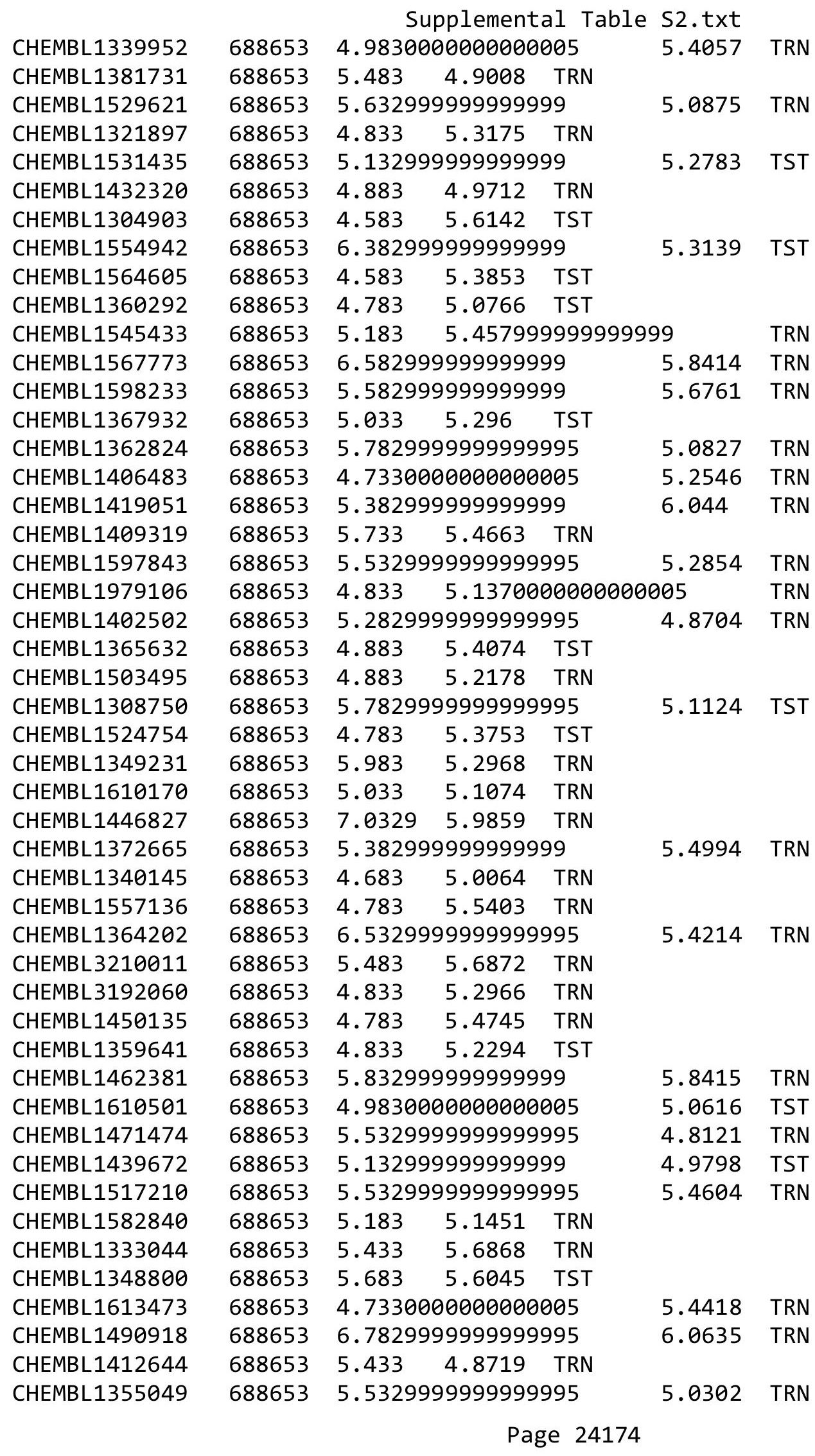




\begin{tabular}{|c|c|c|c|c|c|c|}
\hline \multirow[b]{2}{*}{ CHEMBL1580010 } & \multicolumn{6}{|c|}{ Supplemental Table S2.txt } \\
\hline & 688653 & 4.883 & 5.2091 & TRN & & \\
\hline CHEMBL1368999 & 688653 & 4.633 & 4.631 & TST & & \\
\hline CHEMBL1465699 & 688653 & 5.233 & 5.702999 & 99999 & 99 & TRN \\
\hline CHEMBL1990093 & 688653 & 5.6329 & 999999999 & 99 & 5.7149 & \\
\hline CHEMBL1581662 & 688653 & 5.233 & 4.8806 & TRN & & \\
\hline CHEMBL1413278 & 688653 & 5.733 & 5.6457 & TRN & & \\
\hline CHEMBL1390713 & 688653 & 6.433 & 6.1351 & TRN & & \\
\hline CHEMBL1558942 & 688653 & 4.583 & 4.6054 & TRN & & \\
\hline CHEMBL1520393 & 688653 & 5.8829 & 999999999 & & 5.5417 & TRN \\
\hline CHEMBL3198589 & 688653 & 5.483 & 5.6484 & TRN & & \\
\hline CHEMBL3193844 & 688653 & 6.3329 & 999999999 & & 6.0778 & \\
\hline CHEMBL1361943 & 688653 & 4.7330 & 000000000 & 005 & 5.4884 & \\
\hline CHEMBL1461497 & 688653 & 5.0 & 4.9111 & TST & & \\
\hline CHEMBL1555048 & 688653 & 4.833 & 5.0602 & TST & & \\
\hline CHEMBL1364306 & 688653 & 5.683 & 5.5138 & TRN & & \\
\hline CHEMBL1337548 & 688653 & 4.633 & 5.2198 & TRN & & \\
\hline CHEMBL1578822 & 688653 & 4.883 & 5.044 & TRN & & \\
\hline CHEMBL1463480 & 688653 & 5.3329 & 999999999 & & 5.2677 & \\
\hline CHEMBL1513803 & 688653 & 4.883 & 5.1005 & TST & & \\
\hline CHEMBL1499948 & 688653 & 5.3829 & 999999999 & & 526 & \\
\hline CHEMBL1546205 & 688653 & 4.833 & 4.7937 & TST & & \\
\hline CHEMBL1425958 & 688653 & 5.3329 & 999999999 & & 5.578 & \\
\hline CHEMBL1494088 & 688653 & 5.183 & 5.3259 & TRN & & \\
\hline CHEMBL1362424 & 688653 & 5.6329 & 999999999 & & 5.1164 & TRN \\
\hline CHEMBL1612828 & 688653 & 5.2829 & 999999999 & 995 & & \\
\hline CHEMBL3190652 & 688653 & 5.733 & 5.6932 & TRN & & \\
\hline CHEMBL1448729 & 688653 & 6.1329 & 999999999 & & 5.6431 & \\
\hline CHEMBL1329598 & 688653 & 5.683 & 5.1771 & TRN & & \\
\hline CHEMBL1435576 & 688653 & 4.783 & 4.7409 & TRN & & \\
\hline CHEMBL1360318 & 688653 & 4.9830 & 000000000 & 205 & 5.3856 & \\
\hline CHEMBL1557320 & 688653 & 5.083 & 5.4011 & TST & & \\
\hline CHEMBL1343361 & 688653 & 4.7330 & 000000000 & 205 & 5.5189 & TRN \\
\hline CHEMBL 3190273 & 688653 & 5.3329 & 999999999 & 99 & 5.7386 & \\
\hline CHEMBL1571455 & 688653 & 4.833 & 4.8608 & TRN & & \\
\hline CHEMBL1589334 & 688653 & 5.683 & 5.9987 & TRN & & \\
\hline CHEMBL1484355 & 53 & 4.833 & 5.0694 & TRN & & \\
\hline CHEMBL1589937 & 688653 & 4.783 & 5.0442 & TRN & & \\
\hline CHEMBL1387481 & 688653 & 4.783 & 4.9043 & TRN & & \\
\hline CHEMBL1463966 & 688653 & 6.233 & 5.1272 & TRN & & \\
\hline CHEMBL1605182 & 688653 & 4.833 & 4.9983 & TRN & & \\
\hline CHEMBL1502535 & 688653 & 5.1329 & 999999999 & & 5.1136 & w \\
\hline CHEMBL1422911 & 688653 & 4.833 & 5.3295 & TRN & & \\
\hline CHEMBL1387825 & 688653 & 5.183 & 5.0988 & TRN & & \\
\hline CHEMBL1582419 & 688653 & 4.583 & 5.0755 & TRN & & \\
\hline CHEMBL1440703 & 688653 & 5.3329 & 999999999 & & 96 & \\
\hline CHEMBL1425649 & 688653 & 4.7330 & 000000000 & 305 & 5.3681 & \\
\hline CHEMBL1404570 & 688653 & 4.783 & 5.3597 & TRN & & \\
\hline CHEMBL1566884 & 688653 & 4.7330 & 000000000 & 005 & 4.9663 & RIV \\
\hline
\end{tabular}




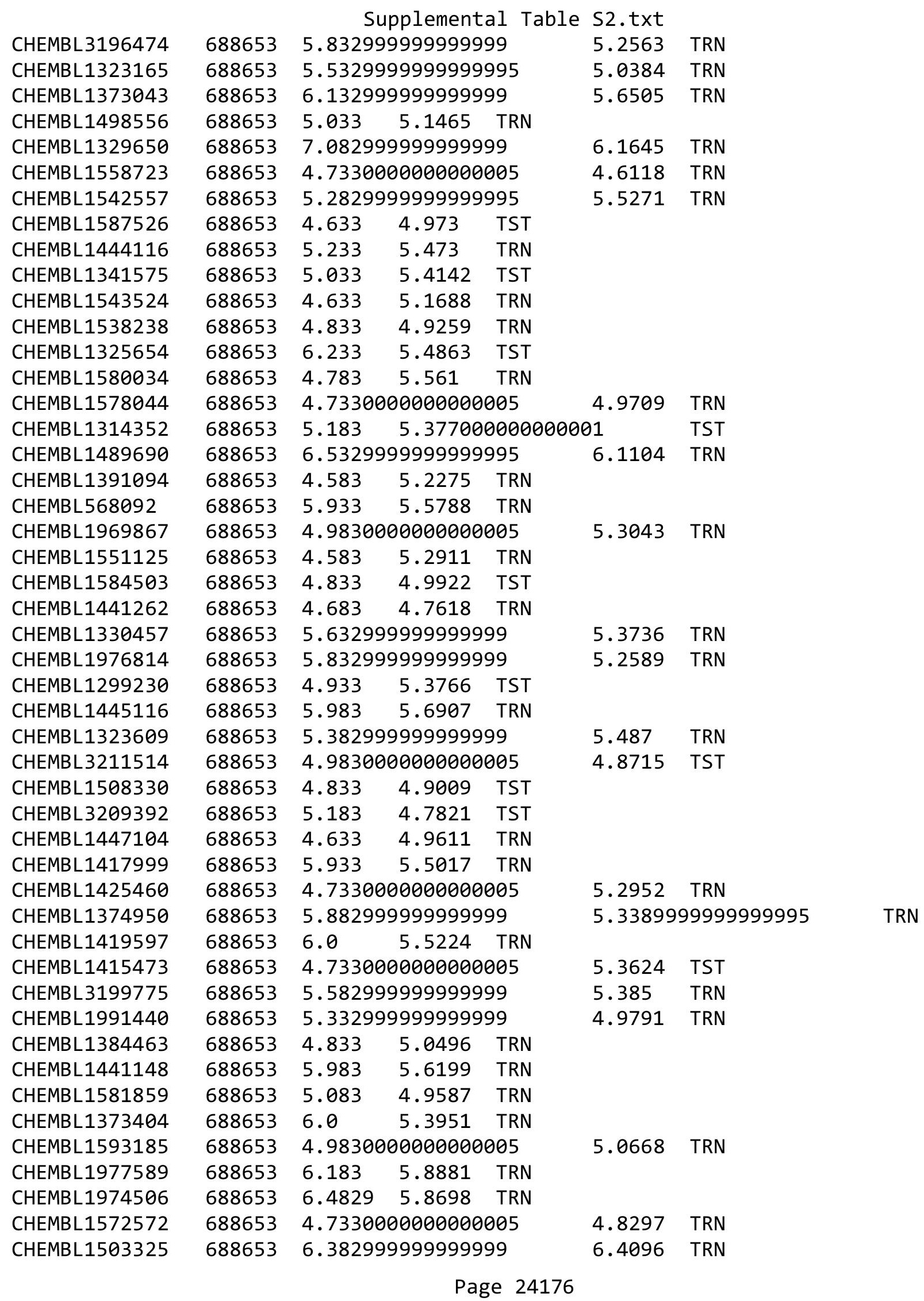




\begin{tabular}{|c|c|c|c|c|c|c|c|}
\hline & & & pplement & al Table & s2.txt & & \\
\hline CHEMBL1604150 & 688653 & 4.98300 & 00000000 & 005 & 5.1646 & TRN & \\
\hline CHEMBL3193476 & 688653 & 4.883 & 5.5798 & TRN & & & \\
\hline CHEMBL1508620 & 688653 & 5.78299 & 99999999 & 995 & 5.715 & TRN & \\
\hline CHEMBL1603127 & 688653 & 4.883 & 5.0141 & TST & & & \\
\hline CHEMBL1582677 & 688653 & 4.833 & 5.1389 & TRN & & & \\
\hline CHEMBL3207845 & 688653 & 6.38299 & 99999999 & & 5.3751 & TRN & \\
\hline CHEMBL1321786 & 688653 & 5.28299 & 99999999 & 995 & 5.0083 & TRN & \\
\hline CHEMBL1532930 & 688653 & 4.633 & 5.0139 & TRN & & & \\
\hline CHEMBL1511217 & 688653 & 6.183 & 5.1644 & TRN & & & \\
\hline CHEMBL1325980 & 688653 & 6.0 & 5.8391 & TRN & & & \\
\hline CHEMBL1427964 & 688653 & 5.483 & 5.0661 & TRN & & & \\
\hline CHEMBL1408121 & 688653 & 6.03299 & 99999999 & 995 & 5.8208 & TRN & \\
\hline CHEMBL1570661 & 688653 & 5.78299 & 99999999 & 995 & 5.5793 & TST & \\
\hline CHEMBL1341142 & 688653 & 5.033 & 5.7502 & TRN & & & \\
\hline CHEMBL1542405 & 688653 & 5.683 & 5.9452 & TRN & & & \\
\hline CHEMBL1528977 & 688653 & 4.73300 & 00000000 & 005 & 5.3469 & TST & \\
\hline CHEMBL1433066 & 688653 & 4.833 & 5.348 & TST & & & \\
\hline CHEMBL1483163 & 688653 & 5.78299 & 99999999 & 995 & 5.8124 & TRN & \\
\hline CHEMBL1338698 & 688653 & 6.28299 & 99999999 & 995 & 5.3149 & TST & \\
\hline CHEMBL1608377 & 688653 & 4.95 & 5.4261 & TRN & & & \\
\hline CHEMBL1482247 & 688653 & 7.1831 & 5.43 & TRN & & & \\
\hline CHEMBL 3211125 & 688653 & 4.783 & 5.1008 & TRN & & & \\
\hline CHEMBL1366816 & 688653 & 5.683 & 5.6142 & TRN & & & \\
\hline CHEMBL1547600 & 688653 & 5.38299 & 99999999 & & 5.3307 & TRN & \\
\hline CHEMBL1466167 & 688653 & 5.78299 & 99999999 & 995 & 5.7865 & TRN & \\
\hline CHEMBL1412676 & 688653 & 4.783 & 5.4186 & TST & & & \\
\hline CHEMBL1334616 & 688653 & 4.633 & 5.1251 & TST & & & \\
\hline CHEMBL1400505 & 688653 & 6.183 & 5.8683 & TRN & & & \\
\hline CHEMBL1369721 & 688653 & 6.9329 & 5.6611 & TRN & & & \\
\hline CHEMBL1395020 & 688653 & 4.833 & 5.5678 & TRN & & & \\
\hline CHEMBL1520674 & 688653 & 5.33299 & 99999999 & & 5.454 & TRN & \\
\hline CHEMBL1603537 & 688653 & 4.883 & 4.9485 & TST & & & \\
\hline CHEMBL1583053 & 688653 & 4.73300 & 00000000 & 005 & 5.1188 & TRN & \\
\hline CHEMBL1488204 & 688653 & 6.63299 & 99999999 & & 6.0893 & TRN & \\
\hline CHEMBL1566346 & 688653 & 5.183 & 5.2091 & TRN & & & \\
\hline CHEMBL1361413 & 688653 & 5.55 & 5.0764 & TRN & & & \\
\hline CHEMBL1504227 & 688653 & 5.483 & 5.2937 & TRN & & & \\
\hline CHEMBL1458893 & 688653 & 4.583 & 5.1591 & TRN & & & \\
\hline CHEMBL1563171 & 688653 & 5.733 & 5.7335 & TRN & & & \\
\hline CHEMBL1588757 & 688653 & 4.783 & 4.9247 & TRN & & & \\
\hline CHEMBL1548865 & 688653 & 5.483 & 5.4826 & TRN & & & \\
\hline CHEMBL566489 & 688653 & 5.38299 & 99999999 & & 5.21399 & 99999999995 & TRN \\
\hline CHEMBL3214522 & 688653 & 5.33299 & 99999999 & & 5.6562 & TRN & \\
\hline CHEMBL3194300 & 688653 & 4.833 & 5.6809 & TRN & & & \\
\hline CHEMBL1589018 & 688653 & 4.883 & 4.9687 & TRN & & & \\
\hline CHEMBL1439938 & 688653 & 5.83299 & 99999999 & & 5.1518 & TRN & \\
\hline CHEMBL1431650 & 688653 & 4.683 & 5.1442 & TRN & & & \\
\hline CHEMBL1477383 & 688653 & 5.38299 & 99999999 & & 5.3681 & TST & \\
\hline
\end{tabular}




\begin{tabular}{|c|c|c|c|c|c|c|}
\hline & & \multicolumn{5}{|c|}{ Supplemental Table s2.txt } \\
\hline CHEMBL1487137 & 688653 & 4.833 & 4.9724 & TRN & & \\
\hline CHEMBL3199213 & 688653 & 5.183 & 5.1259 & TRN & & \\
\hline CHEMBL1501576 & 688653 & 4.683 & 4.8986 & TRN & & \\
\hline CHEMBL1430772 & 688653 & 4.583 & 5.0882 & TRN & & \\
\hline CHEMBL1607390 & 688653 & 5.183 & \multicolumn{3}{|c|}{5.912999999999999} & TRN \\
\hline CHEMBL1536018 & 688653 & \multicolumn{3}{|c|}{5.132999999999999} & 5.3905 & TST \\
\hline CHEMBL1480801 & 688653 & \multicolumn{3}{|c|}{6.2829999999999995} & 6.0261 & TRN \\
\hline CHEMBL1467184 & 688653 & \multicolumn{3}{|c|}{6.2829999999999995} & 5.932 & TRN \\
\hline CHEMBL1558845 & 688653 & \multicolumn{3}{|c|}{5.132999999999999} & 5.5489 & TRN \\
\hline CHEMBL1389263 & 688653 & 4.783 & 5.1373 & TST & & \\
\hline CHEMBL1975622 & 688653 & 4.933 & 5.2727 & TRN & & \\
\hline CHEMBL1603181 & 688653 & 5.933 & 5.2583 & TRN & & \\
\hline CHEMBL1416292 & 688653 & \multicolumn{3}{|c|}{5.132999999999999} & 5.3406 & TST \\
\hline CHEMBL1380932 & 688653 & 4.833 & 5.0808 & TRN & & \\
\hline CHEMBL1431338 & 688653 & 5.433 & 5.4156 & TRN & & \\
\hline CHEMBL1336922 & 688653 & \multicolumn{3}{|c|}{4.9830000000000005} & 5.4662 & TRN \\
\hline CHEMBL1496826 & 688653 & 5.683 & 5.7302 & TRN & & \\
\hline CHEMBL1578022 & 688653 & \multicolumn{3}{|c|}{5.132999999999999} & 4.9567 & TRN \\
\hline CHEMBL1342888 & 688653 & \multicolumn{3}{|c|}{5.632999999999999} & 5.3419 & TST \\
\hline CHEMBL1603031 & 688653 & \multicolumn{3}{|c|}{5.332999999999999} & 5.0454 & TRN \\
\hline CHEMBL1315110 & 688653 & 5.233 & 5.0785 & TRN & & \\
\hline CHEMBL1611371 & 688653 & 4.833 & 4.8693 & TRN & & \\
\hline CHEMBL1558608 & 688653 & 4.783 & 5.2401 & TRN & & \\
\hline CHEMBL1549133 & 688653 & \multicolumn{3}{|c|}{4.9830000000000005} & 4.9582 & TRN \\
\hline CHEMBL1503246 & 688653 & \multicolumn{3}{|c|}{5.332999999999999} & 5.575 & TRN \\
\hline CHEMBL1393156 & 688653 & \multicolumn{3}{|c|}{5.2829999999999995} & 4.9979 & TRN \\
\hline CHEMBL1491017 & 688653 & 4.783 & 4.9336 & TRN & & \\
\hline CHEMBL1520222 & 688653 & 4.933 & 5.3028 & TRN & & \\
\hline CHEMBL1436168 & 688653 & 5.733 & 5.176 & TRN & & \\
\hline CHEMBL3193031 & 688653 & 4.683 & 5.2721 & TRN & & \\
\hline CHEMBL600107 & 688653 & 4.633 & 5.2141 & TST & & \\
\hline CHEMBL1605089 & 688653 & \multicolumn{3}{|c|}{6.2829999999999995} & 4.9413 & TRN \\
\hline CHEMBL1358295 & 688653 & 4.833 & 5.1167 & TST & & \\
\hline CHEMBL3192130 & 688653 & 4.883 & 5.0261 & TRN & & \\
\hline CHEMBL3199473 & 688653 & 4.833 & 5.3754 & TRN & & \\
\hline CHEMBL1382027 & 688653 & \multicolumn{3}{|c|}{5.632999999999999} & 5.5465 & TST \\
\hline CHEMBL1573912 & 688653 & \multicolumn{3}{|c|}{4.7330000000000005} & 5.2475 & TST \\
\hline CHEMBL1583911 & 688653 & 4.883 & 5.2955 & TRN & & \\
\hline CHEMBL1572867 & 688653 & 5.483 & 5.1271 & TRN & & \\
\hline CHEMBL1455243 & 688653 & 4.883 & 5.3597 & TRN & & \\
\hline CHEMBL1328367 & 688653 & 4.833 & 4.7981 & TST & & \\
\hline CHEMBL1588543 & 688653 & 4.783 & 5.1635 & TRN & & \\
\hline CHEMBL1319427 & 688653 & \multicolumn{3}{|c|}{5.382999999999999} & 5.2023 & TRN \\
\hline CHEMBL1393722 & 688653 & \multicolumn{3}{|c|}{4.7330000000000005} & 5.2528 & TRN \\
\hline CHEMBL1608010 & 688653 & \multicolumn{3}{|c|}{6.382999999999999} & 5.9142 & TRN \\
\hline CHEMBL1317343 & 688653 & \multicolumn{3}{|c|}{5.882999999999999} & 5.4231 & TST \\
\hline CHEMBL1358321 & 688653 & 4.783 & 5.4748 & TRN & & \\
\hline CHEMBL1497650 & 688653 & 4.783 & 5.8053 & TST & & \\
\hline
\end{tabular}




\begin{tabular}{|c|c|c|c|c|c|c|}
\hline \multirow[b]{2}{*}{ CHEMBL1323491 } & & \multicolumn{5}{|c|}{ S2.txt } \\
\hline & 688653 & 6.4829 & 5.9127 & TRN & & \\
\hline CHEMBL1383650 & 688653 & \multicolumn{3}{|c|}{5.132999999999999} & 5.0679 & TRI \\
\hline CHEMBL1379622 & 688653 & 4.633 & 5.1282 & TST & & \\
\hline CHEMBL1608932 & 688653 & \multicolumn{3}{|c|}{4.7330000000000005} & 4.6167 & \\
\hline CHEMBL1530804 & 688653 & 4.883 & 5.2032 & TRN & & \\
\hline CHEMBL1384103 & 688653 & 5.433 & 5.4276 & TRN & & \\
\hline CHEMBL1458414 & 688653 & 5.233 & 5.074 & TRN & & \\
\hline CHEMBL1365841 & 688653 & 4.783 & 5.0741 & TRN & & \\
\hline CHEMBL1510937 & 688653 & \multicolumn{3}{|c|}{6.132999999999999} & 5.6577 & \\
\hline CHEMBL1449267 & 688653 & 4.783 & 4.9867 & TRN & & \\
\hline CHEMBL1320405 & 688653 & 4.783 & 5.1284 & TRN & & \\
\hline CHEMBL1592136 & 688653 & 4.783 & 4.7431 & TRN & & \\
\hline CHEMBL579318 & 688653 & \multicolumn{3}{|c|}{5.5329999999999995} & 5.4856 & \\
\hline CHEMBL1528991 & 688653 & \multicolumn{3}{|c|}{5.2829999999999995} & 5.2974 & \\
\hline CHEMBL1441655 & 688653 & 6.433 & 4.9763 & TRN & & \\
\hline CHEMBL1385216 & 688653 & 4.883 & 5.3487 & TRN & & \\
\hline CHEMBL1344225 & 688653 & 6.183 & 5.4674 & TRN & & \\
\hline CHEMBL1536104 & 688653 & 5.733 & 5.9111 & TRN & & \\
\hline CHEMBL 3208474 & 688653 & 4.783 & 5.4204 & TRN & & \\
\hline CHEMBL 3195508 & 688653 & 4.833 & \multicolumn{3}{|c|}{5.252000000000001} & \\
\hline CHEMBL1588245 & 688653 & 4.833 & 4.9085 & TST & & \\
\hline CHEMBL1573062 & 688653 & 4.883 & 5.2577 & TST & & \\
\hline CHEMBL1567359 & 688653 & 5.433 & 5.037 & TRN & & \\
\hline CHEMBL1358862 & 688653 & \multicolumn{3}{|c|}{5.832999999999999} & 5.4727 & \\
\hline CHEMBL1512962 & 688653 & \multicolumn{3}{|c|}{4.7330000000000005} & 5.3135 & \\
\hline CHEMBL1350356 & 688653 & 5.483 & 5.2922 & TRN & & \\
\hline CHEMBL1551707 & 688653 & \multicolumn{3}{|c|}{5.832999999999999} & 5.0305 & \\
\hline CHEMBL1355069 & 688653 & 5.433 & 5.3336 & TRN & & \\
\hline CHEMBL1462518 & 688653 & \multicolumn{3}{|c|}{5.632999999999999} & 5.3212 & \\
\hline CHEMBL1306554 & 688653 & 5.683 & 5.2911 & TRN & & \\
\hline CHEMBL1575768 & 688653 & \multicolumn{3}{|c|}{5.832999999999999} & 5.2354 & $\mathrm{TP}$ \\
\hline CHEMBL1440683 & 688653 & \multicolumn{3}{|c|}{5.382999999999999} & 5.4881 & \\
\hline CHEMBL 3193604 & 688653 & 5.033 & 4.5236 & TRN & & \\
\hline CHEMBL1565640 & 688653 & \multicolumn{3}{|c|}{4.7330000000000005} & 5.5212 & $1 \mathrm{RT}$ \\
\hline CHEMBL1403215 & 688653 & 5.183 & 5.0539 & TRN & & \\
\hline CHEMBL1416154 & 688653 & 4.783 & 5.6006 & TRN & & \\
\hline CHEMBL1385800 & 688653 & 4.783 & 5.0467 & TST & & \\
\hline CHEMBL1448294 & 688653 & \multicolumn{3}{|c|}{4.7330000000000005} & 5.0434 & TRN \\
\hline CHEMBL1380300 & 688653 & 4.633 & 4.8575 & TRN & & \\
\hline CHEMBL475813 & 688653 & 4.833 & 5.5228 & TST & & \\
\hline CHEMBL1416206 & 688653 & 4.833 & 5.2859 & TRN & & \\
\hline CHEMBL1466753 & 688653 & \multicolumn{3}{|c|}{5.132999999999999} & 5.2316 & 11 \\
\hline CHEMBL1481651 & 688653 & \multicolumn{3}{|c|}{6.132999999999999} & 5.1811 & \\
\hline CHEMBL1371014 & 688653 & 6.0 & 5.8335 & TRN & & \\
\hline CHEMBL1434958 & 688653 & 5.983 & 5.4305 & TRN & & \\
\hline CHEMBL1521352 & 688653 & 4.933 & 5.3845 & TRN & & \\
\hline CHEMBL1434180 & 688653 & 4.583 & 4.7284 & TRN & & \\
\hline CHEMBL1455335 & 688653 & 4.783 & 5.3863 & TRN & & \\
\hline
\end{tabular}




\begin{tabular}{|c|c|c|c|c|c|c|}
\hline \multirow[b]{2}{*}{ CHEMBL1590169 } & \multicolumn{6}{|c|}{ Supplemental Table S2.txt } \\
\hline & 688653 & 6.7331 & 5.4893 & TRN & & \\
\hline CHEMBL3210363 & 688653 & 4.933 & 5.2176 & TST & & \\
\hline CHEMBL1999900 & 688653 & 5.933 & 5.7182 & TST & & \\
\hline CHEMBL1461293 & 688653 & 4.683 & 5.1275 & TST & & \\
\hline CHEMBL1349331 & 688653 & 5.733 & 5.3357 & TST & & \\
\hline CHEMBL1322896 & 688653 & 5.233 & 5.2242 & TRN & & \\
\hline CHEMBL1565691 & 688653 & \multicolumn{3}{|c|}{5.132999999999999} & 5.7748 & TRN \\
\hline CHEMBL1340541 & 688653 & \multicolumn{3}{|c|}{6.382999999999999} & 5.2548 & \\
\hline CHEMBL1409104 & 688653 & 4.783 & 5.2718 & TRN & & \\
\hline CHEMBL1432569 & 688653 & \multicolumn{3}{|c|}{4.7330000000000005} & 4.7997 & TRN \\
\hline CHEMBL1552501 & 688653 & \multicolumn{3}{|c|}{4.7330000000000005} & 5.3396 & \\
\hline CHEMBL1350733 & 688653 & 5.033 & 4.9221 & TRN & & \\
\hline CHEMBL1582062 & 688653 & 4.783 & 5.3327 & TRN & & \\
\hline CHEMBL1492720 & 688653 & \multicolumn{3}{|c|}{5.132999999999999} & 5.6663 & TRN \\
\hline CHEMBL1596277 & 688653 & \multicolumn{3}{|c|}{5.882999999999999} & 5.1164 & TRN \\
\hline CHEMBL1585864 & 688653 & \multicolumn{3}{|c|}{5.2829999999999995} & 5.3034 & TRN \\
\hline CHEMBL1587067 & 688653 & 4.883 & 5.0177 & TRN & & \\
\hline CHEMBL1306590 & 688653 & 6.4829 & 6.029 & TRN & & \\
\hline CHEMBL1578485 & 688653 & 4.833 & 5.3829 & TST & & \\
\hline CHEMBL3208086 & 688653 & \multicolumn{3}{|c|}{5.132999999999999} & 5.4566 & TRN \\
\hline CHEMBL1525012 & 688653 & 5.683 & 5.5019 & TRN & & \\
\hline CHEMBL1479116 & 688653 & 5.033 & 5.0577 & TRN & & \\
\hline CHEMBL1521892 & 688653 & 4.783 & 4.802 & TRN & & \\
\hline CHEMBL1313001 & 688653 & 4.783 & 5.4934 & TST & & \\
\hline CHEMBL582473 & 688653 & 5.733 & 4.9867 & TRN & & \\
\hline CHEMBL1603928 & 688653 & 4.933 & 5.2973 & TRN & & \\
\hline CHEMBL1411551 & 688653 & \multicolumn{3}{|c|}{5.7829999999999995} & 5.6963 & \\
\hline CHEMBL1299300 & 688653 & \multicolumn{3}{|c|}{5.132999999999999} & 4.7792 & \\
\hline CHEMBL3191163 & 688653 & 4.683 & 5.2625 & TRN & & \\
\hline CHEMBL1379684 & 688653 & \multicolumn{3}{|c|}{5.332999999999999} & 5.2596 & TRN \\
\hline CHEMBL3208777 & 688653 & \multicolumn{3}{|c|}{5.632999999999999} & 4.9032 & TRN \\
\hline CHEMBL1384275 & 688653 & \multicolumn{3}{|c|}{4.7330000000000005} & 912 & TRN \\
\hline CHEMBL1556113 & 688653 & \multicolumn{3}{|c|}{5.132999999999999} & 4.9315 & TRN \\
\hline CHEMBL1337976 & 688653 & \multicolumn{3}{|c|}{4.9830000000000005} & 5.8079 & TRN \\
\hline CHEMBL1386963 & 688653 & \multicolumn{3}{|c|}{5.832999999999999} & 5.0636 & TRN \\
\hline CHEMBL1360866 & 688653 & \multicolumn{3}{|c|}{5.5329999999999995} & 5.2168 & TST \\
\hline CHEMBL1560581 & 688653 & 4.883 & 5.3014 & TRN & & \\
\hline CHEMBL1513139 & 688653 & 4.633 & 4.8313 & TRN & & \\
\hline CHEMBL1305561 & 688653 & 5.183 & 4.7967 & TRN & & \\
\hline CHEMBL1309219 & 688653 & 5.53299 & э9999999 & 995 & 5.1459 & $\mathrm{~T}$ \\
\hline CHEMBL204914 & 688653 & 4.633 & 5.0667 & TST & & \\
\hline CHEMBL1396290 & 688653 & 4.683 & 5.2748 & TRN & & \\
\hline CHEMBL1554365 & 688653 & 6.38299 & 79999999 & & 5.204 & $T$ \\
\hline CHEMBL1580979 & 688653 & 4.783 & 5.0812 & TST & & \\
\hline CHEMBL1385733 & 688653 & 4.883 & 5.2655 & TRN & & \\
\hline CHEMBL1170087 & 688653 & 5.683 & 5.194 & TRN & & \\
\hline CHEMBL483633 & 688653 & 5.88299 & 79999999 & & 5.6974 & TRIV \\
\hline CHEMBL1507986 & 688653 & 5.38299 & 79999999 & & 5.5905 & \\
\hline
\end{tabular}




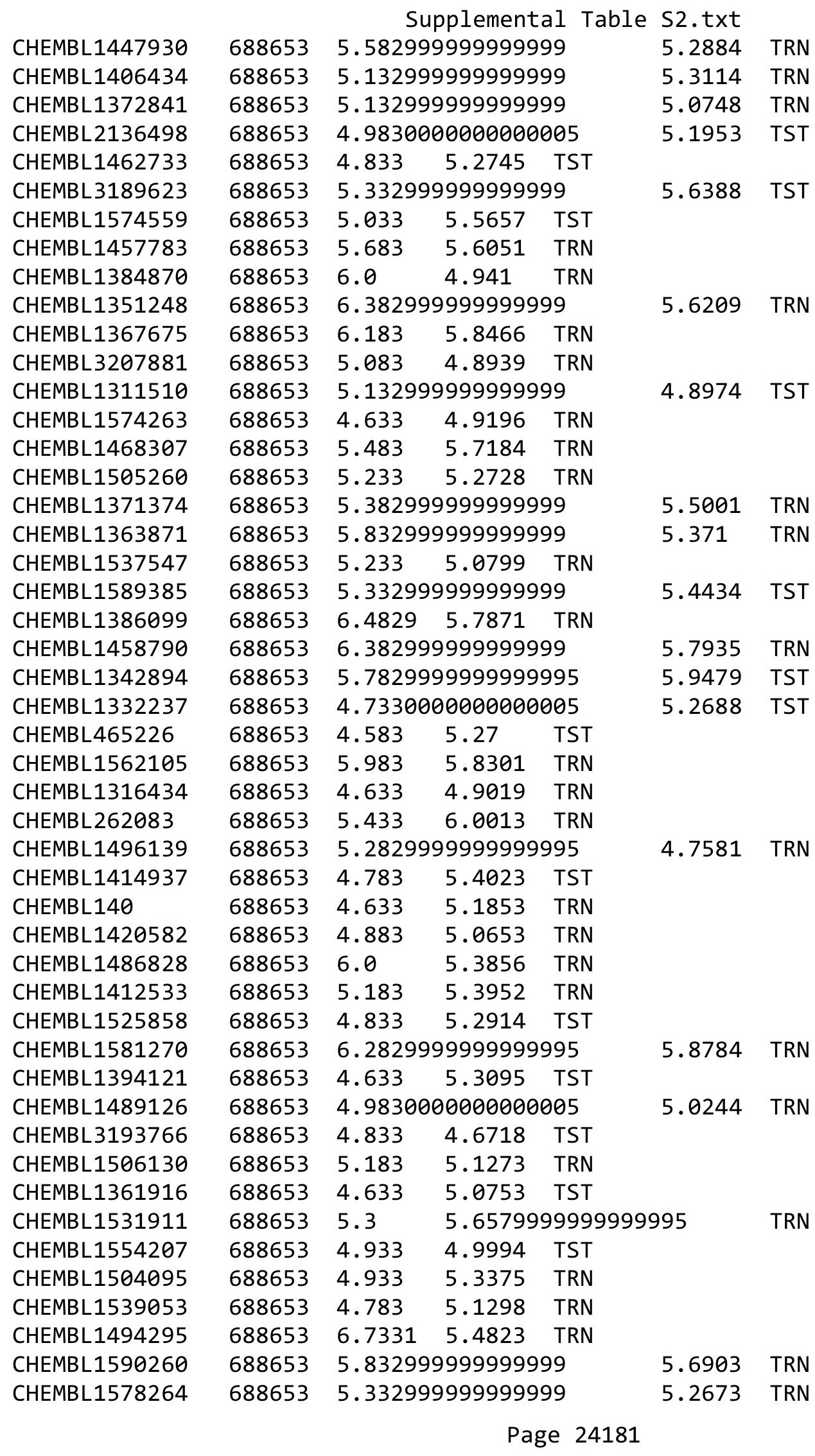




\begin{tabular}{|c|c|c|c|c|c|c|}
\hline & & \multicolumn{4}{|c|}{ Supplemental Table s2.txt } & \\
\hline CHEMBL1488090 & 688653 & \multicolumn{3}{|c|}{6.0329999999999995} & 5.5264 & TRN \\
\hline CHEMBL1510229 & 688653 & 5.483 & 5.5385 & TRN & & \\
\hline CHEMBL1385377 & 688653 & \multicolumn{3}{|c|}{5.132999999999999} & 5.1367 & TRN \\
\hline CHEMBL1476194 & 688653 & 4.583 & 4.7266 & TRN & & \\
\hline CHEMBL1588401 & 688653 & \multicolumn{3}{|c|}{6.582999999999999} & 6.1194 & TST \\
\hline CHEMBL1525698 & 688653 & 4.783 & 5.0131 & TRN & & \\
\hline CHEMBL1546771 & 688653 & 4.683 & 5.4025 & TRN & & \\
\hline CHEMBL1305344 & 688653 & 5.5 & 5.2031 & TST & & \\
\hline CHEMBL1321350 & 688653 & 5.083 & 5.1631 & TST & & \\
\hline CHEMBL1365755 & 688653 & 4.783 & 4.8089 & TST & & \\
\hline CHEMBL1476026 & 688653 & 5.983 & 5.1725 & TRN & & \\
\hline CHEMBL1378500 & 688653 & \multicolumn{3}{|c|}{5.132999999999999} & 5.687 & TST \\
\hline CHEMBL1314638 & 688653 & \multicolumn{3}{|c|}{4.7330000000000005} & 5.1658 & TRN \\
\hline CHEMBL1346838 & 688653 & \multicolumn{3}{|c|}{5.832999999999999} & 5.7002 & TRN \\
\hline CHEMBL1587336 & 688653 & \multicolumn{3}{|c|}{4.7330000000000005} & 5.5466 & TRN \\
\hline CHEMBL1320882 & 688653 & 5.433 & 4.9904 & TRN & & \\
\hline CHEMBL1606553 & 688653 & 4.633 & 4.8653 & TRN & & \\
\hline CHEMBL3213503 & 688653 & 5.183 & 4.9729 & TST & & \\
\hline CHEMBL3212543 & 688653 & 5.733 & 5.6095 & TST & & \\
\hline CHEMBL1440541 & 688653 & 4.783 & 5.3386 & TRN & & \\
\hline CHEMBL1316725 & 688653 & 4.633 & 5.0438 & TRN & & \\
\hline CHEMBL3208093 & 688653 & 4.933 & 5.6788 & TRN & & \\
\hline CHEMBL1477846 & 688653 & \multicolumn{3}{|c|}{6.632999999999999} & 6.0709 & TRN \\
\hline CHEMBL1443435 & 688653 & \multicolumn{3}{|c|}{5.7829999999999995} & 5.3395 & TRN \\
\hline CHEMBL1550909 & 688653 & \multicolumn{3}{|c|}{5.132999999999999} & 5.4051 & TRN \\
\hline CHEMBL1397690 & 688653 & \multicolumn{3}{|c|}{5.132999999999999} & 5.1533 & TRN \\
\hline CHEMBL3198514 & 688653 & 4.633 & 5.0177 & TRN & & \\
\hline CHEMBL1301826 & 688653 & 5.033 & 5.3348 & TRN & & \\
\hline CHEMBL1490454 & 688653 & 4.783 & 4.9739 & TRN & & \\
\hline CHEMBL 3198034 & 688653 & \multicolumn{3}{|c|}{5.832999999999999} & 5.7241 & TRN \\
\hline CHEMBL1568934 & 688653 & 4.633 & 5.0185 & TRN & & \\
\hline CHEMBL1380428 & 688653 & \multicolumn{3}{|c|}{4.7330000000000005} & 5.0933 & TRN \\
\hline CHEMBL1335444 & 688653 & 4.633 & 4.9187 & TRN & & \\
\hline CHEMBL1380174 & 688653 & \multicolumn{3}{|c|}{4.7330000000000005} & 5.2001 & TST \\
\hline CHEMBL1307303 & 688653 & 5.683 & 5.8189 & TRN & & \\
\hline CHEMBL1429300 & 688653 & \multicolumn{3}{|c|}{6.332999999999999} & 5.3101 & TRN \\
\hline CHEMBL1577036 & 688653 & 5.033 & 5.8435 & TRN & & \\
\hline CHEMBL3197340 & 688653 & \multicolumn{3}{|c|}{5.382999999999999} & 5.3114 & TRN \\
\hline CHEMBL1554736 & 688653 & 5.033 & 4.8834 & TRN & & \\
\hline CHEMBL1573186 & 688653 & 4.633 & 5.8829 & TRN & & \\
\hline CHEMBL1304922 & 688653 & \multicolumn{3}{|c|}{5.332999999999999} & 5.3193 & TRN \\
\hline CHEMBL1536588 & 688653 & 4.633 & 5.1708 & TRN & & \\
\hline CHEMBL1353455 & 688653 & 5.183 & 6.0359 & TST & & \\
\hline CHEMBL1386224 & 688653 & 4.583 & 5.0521 & TRN & & \\
\hline CHEMBL1342395 & 688653 & 4.883 & 4.8564 & TRN & & \\
\hline CHEMBL1497953 & 688653 & 4.783 & 4.8932 & TST & & \\
\hline CHEMBL3212549 & 688653 & \multicolumn{3}{|c|}{5.132999999999999} & 5.2311 & TST \\
\hline CHEMBL1380103 & 688653 & 5.233 & 5.223 & TRN & & \\
\hline
\end{tabular}




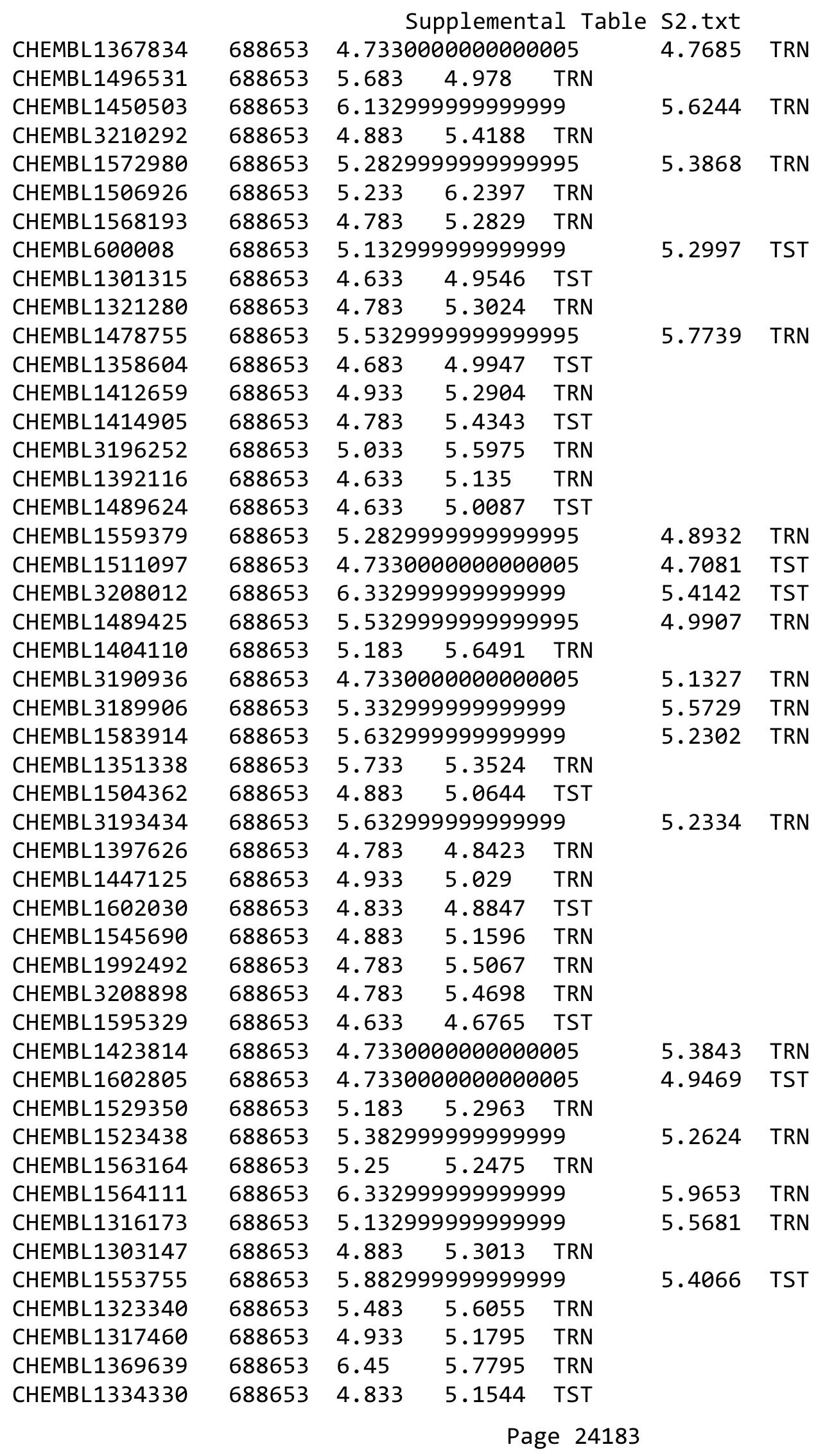




\begin{tabular}{|c|c|c|c|c|c|c|c|}
\hline \multirow[b]{2}{*}{ CHEMBL1583901 } & & \\
\hline & 688653 & 4.783 & 4.8841 & TST & & & \\
\hline CHEMBL1595208 & 688653 & 4.783 & 5.0122 & TRN & & & \\
\hline CHEMBL1466041 & 688653 & 5.78299 & 99999999 & 995 & 5.3918 & TRN & \\
\hline CHEMBL1512126 & 688653 & 4.933 & 5.1644 & TST & & & \\
\hline CHEMBL1520565 & 688653 & 5.733 & 5.279 & TRN & & & \\
\hline CHEMBL1575440 & 688653 & 4.633 & 4.6526 & TST & & & \\
\hline CHEMBL1385381 & 688653 & 5.033 & 5.2531 & TRN & & & \\
\hline CHEMBL1303677 & 688653 & 4.683 & 5.1992 & TST & & & \\
\hline CHEMBL1409101 & 688653 & 7.2328 & 6.0071 & TRN & & & \\
\hline CHEMBL1481816 & 688653 & 6.13299 & 99999999 & & 4.989 & TRN & \\
\hline CHEMBL1393320 & 688653 & 4.73300 & 00000000 & 005 & 5.0141 & TRN & \\
\hline CHEMBL1384654 & 688653 & 6.983 & 5.7872 & TRN & & & \\
\hline CHEMBL1538399 & 688653 & 5.683 & 4.8008 & TST & & & \\
\hline CHEMBL1555359 & 688653 & 5.733 & 5.499 & TRN & & & \\
\hline CHEMBL1531825 & 688653 & 4.633 & 4.5827 & TRN & & & \\
\hline CHEMBL1315216 & 688653 & 5.13299 & 99999999 & & 5.7849 & TRN & \\
\hline CHEMBL1499123 & 688653 & 4.633 & 5.0253 & TST & & & \\
\hline CHEMBL1320672 & 688653 & 6.433 & 5.1703 & TRN & & & \\
\hline CHEMBL1322708 & 688653 & 6.33299 & 99999999 & & 5.7822 & TRN & \\
\hline CHEMBL1300212 & 688653 & 5.233 & 5.0684 & TRN & & & \\
\hline CHEMBL1328551 & 688653 & 4.73300 & 00000000 & 005 & 5.2563 & TRN & \\
\hline CHEMBL1471899 & 688653 & 5.13299 & 99999999 & & 6.1753 & TST & \\
\hline CHEMBL 3211707 & 688653 & 5.13299 & 99999999 & & 4.9645 & TST & \\
\hline CHEMBL1610964 & 688653 & 5.033 & 5.0923 & TRN & & & \\
\hline CHEMBL 3198282 & 688653 & 4.833 & 4.9304 & TST & & & \\
\hline CHEMBL1353077 & 688653 & 4.73300 & 00000000 & 005 & 4.6827 & TRN & \\
\hline CHEMBL1595352 & 688653 & 5.433 & 5.1646 & TRN & & & \\
\hline CHEMBL1372459 & 688653 & 4.783 & 5.069 & TRN & & & \\
\hline CHEMBL1419163 & 688653 & 5.933 & 5.3614 & TRN & & & \\
\hline CHEMBL1428295 & 688653 & 5.183 & 5.5171 & TRN & & & \\
\hline CHEMBL1481525 & 688653 & 4.833 & 4.6354 & TST & & & \\
\hline CHEMBL 3192231 & 688653 & 5.53299 & 99999999 & 995 & 5.1441 & TRN & \\
\hline CHEMBL1452227 & 688653 & 5.88299 & 99999999 & & 5.82600 & 20000000005 & TRN \\
\hline CHEMBL1576566 & 688653 & 4.583 & 4.6972 & TST & & & \\
\hline CHEMBL1547434 & 688653 & 5.033 & 5.2754 & TRN & & & \\
\hline CHEMBL1567671 & 688653 & 5.233 & 5.0384 & TST & & & \\
\hline CHEMBL1320219 & 688653 & 5.233 & 5.4496 & TRN & & & \\
\hline CHEMBL1525249 & 688653 & 5.28299 & 99999999 & 995 & 5.0529 & TRN & \\
\hline CHEMBL1388168 & 688653 & 5.683 & 5.2469 & TRN & & & \\
\hline CHEMBL1349829 & 688653 & 4.833 & 5.0904 & TRN & & & \\
\hline CHEMBL1465619 & 688653 & 4.883 & 4.8409 & TRN & & & \\
\hline CHEMBL1478592 & 688653 & 4.783 & 5.7435 & TRN & & & \\
\hline CHEMBL3213953 & 688653 & 5.983 & 5.1985 & TRN & & & \\
\hline CHEMBL1442882 & 688653 & 4.633 & 5.5504 & TST & & & \\
\hline CHEMBL1379046 & 688653 & 4.73300 & 00000000 & 005 & 5.5336 & TRN & \\
\hline CHEMBL1388292 & 688653 & 6.03299 & 99999999 & 995 & 5.5832 & TRN & \\
\hline CHEMBL1498085 & 688653 & 5.78299 & 99999999 & & 5.6884 & TRN & \\
\hline CHEMBL1590202 & 688653 & 5.78299 & 99999999 & 995 & 4.9869 & TRN & \\
\hline
\end{tabular}




\begin{tabular}{|c|c|c|c|c|c|c|c|}
\hline \multicolumn{8}{|c|}{ Supplemental Table S2.txt } \\
\hline CHEMBL1591007 & 688653 & 5.183 & 5.0067 & TRN & & & \\
\hline CHEMBL1520524 & 688653 & 5.733 & 5.8901 & TRN & & & \\
\hline CHEMBL1391973 & 688653 & \multicolumn{3}{|c|}{6.132999999999999} & 6.3011 & TRN & \\
\hline CHEMBL1464993 & 688653 & 5.733 & 5.5115 & TRN & & & \\
\hline CHEMBL1343700 & 688653 & \multicolumn{3}{|c|}{5.632999999999999} & \multicolumn{2}{|c|}{5.7379999999999995} & TRN \\
\hline CHEMBL1413075 & 688653 & \multicolumn{3}{|c|}{7.082999999999999} & 5.8804 & TRN & \\
\hline CHEMBL1437736 & 688653 & 4.933 & 5.065 & TRN & & & \\
\hline CHEMBL1338542 & 688653 & 4.883 & 5.3818 & TRN & & & \\
\hline CHEMBL1319584 & 688653 & 5.683 & 5.4598 & TST & & & \\
\hline CHEMBL1517532 & 688653 & 5.983 & 5.7309 & TRN & & & \\
\hline CHEMBL1403939 & 688653 & 5.083 & 4.806 & TRN & & & \\
\hline CHEMBL1556323 & 688653 & 5.433 & 5.0056 & TRN & & & \\
\hline CHEMBL1327755 & 688653 & 4.783 & 5.0456 & TRN & & & \\
\hline CHEMBL1494012 & 688653 & \multicolumn{3}{|c|}{4.7330000000000005} & 5.0308 & TRN & \\
\hline CHEMBL1392461 & 688653 & 4.783 & 5.1738 & TST & & & \\
\hline CHEMBL1419591 & 688653 & 4.633 & 5.0236 & TST & & & \\
\hline CHEMBL1476812 & 688653 & \multicolumn{3}{|c|}{4.7330000000000005} & 4.9659 & TRN & \\
\hline CHEMBL1313588 & 688653 & \multicolumn{3}{|c|}{5.382999999999999} & 5.8431 & TRN & \\
\hline CHEMBL1537846 & 688653 & 4.833 & 5.4708 & TST & & & \\
\hline CHEMBL1481139 & 688653 & \multicolumn{3}{|c|}{5.332999999999999} & 5.1586 & TRN & \\
\hline CHEMBL1490828 & 688653 & \multicolumn{3}{|c|}{4.7330000000000005} & 5.2603 & TRN & \\
\hline CHEMBL1348981 & 688653 & 6.433 & 5.3277 & TST & & & \\
\hline CHEMBL1334799 & 688653 & \multicolumn{3}{|c|}{5.7829999999999995} & 5.4242 & TRN & \\
\hline CHEMBL77928 & 688653 & 4.783 & 5.5376 & TRN & & & \\
\hline CHEMBL3207874 & 688653 & \multicolumn{3}{|c|}{5.7829999999999995} & 5.7707 & TST & \\
\hline CHEMBL1985598 & 688653 & 4.833 & 5.0217 & TRN & & & \\
\hline CHEMBL1514498 & 688653 & 4.583 & 4.4791 & TRN & & & \\
\hline CHEMBL1592544 & 688653 & \multicolumn{3}{|c|}{5.5329999999999995} & 5.2832 & TRN & \\
\hline CHEMBL1521259 & 688653 & 4.583 & 4.8409 & TRN & & & \\
\hline CHEMBL1334844 & 688653 & 5.683 & 5.782 & TRN & & & \\
\hline CHEMBL3195168 & 688653 & 5.083 & 5.2763 & TRN & & & \\
\hline CHEMBL1456751 & 688653 & \multicolumn{3}{|c|}{5.5329999999999995} & 5.8022 & TRN & \\
\hline CHEMBL1342491 & 688653 & 5.733 & 5.341 & TRN & & & \\
\hline CHEMBL1472015 & 688653 & \multicolumn{3}{|c|}{5.2829999999999995} & 5.3689 & TRN & \\
\hline CHEMBL1483288 & 688653 & \multicolumn{3}{|c|}{5.632999999999999} & 5.7912 & TRN & \\
\hline CHEMBL1324243 & 688653 & 4.583 & 4.8867 & TST & & & \\
\hline CHEMBL3198340 & 688653 & 4.833 & 5.0045 & TRN & & & \\
\hline CHEMBL1606862 & 688653 & 5.483 & 5.5089 & TRN & & & \\
\hline CHEMBL1601439 & 688653 & 6.0 & 5.3407 & TRN & & & \\
\hline CHEMBL1496455 & 688653 & \multicolumn{3}{|c|}{6.632999999999999} & 5.5062 & TRN & \\
\hline CHEMBL1413306 & 688653 & \multicolumn{3}{|c|}{4.9830000000000005} & 5.6164 & TRN & \\
\hline CHEMBL1389928 & 688653 & \multicolumn{3}{|c|}{6.382999999999999} & 5.5907 & TRN & \\
\hline CHEMBL1584862 & 688653 & 4.833 & 4.9558 & TRN & & & \\
\hline CHEMBL1498536 & 688653 & \multicolumn{3}{|c|}{4.9830000000000005} & 4.7345 & TRN & \\
\hline CHEMBL1534673 & 688653 & \multicolumn{3}{|c|}{5.2829999999999995} & 5.3726 & TRN & \\
\hline CHEMBL1444977 & 688653 & 5.033 & 5.5006 & TRN & & & \\
\hline CHEMBL1552375 & 688653 & 4.583 & 4.8849 & TST & & & \\
\hline CHEMBL1362398 & 688653 & 5.233 & 5.3246 & TRN & & & \\
\hline
\end{tabular}




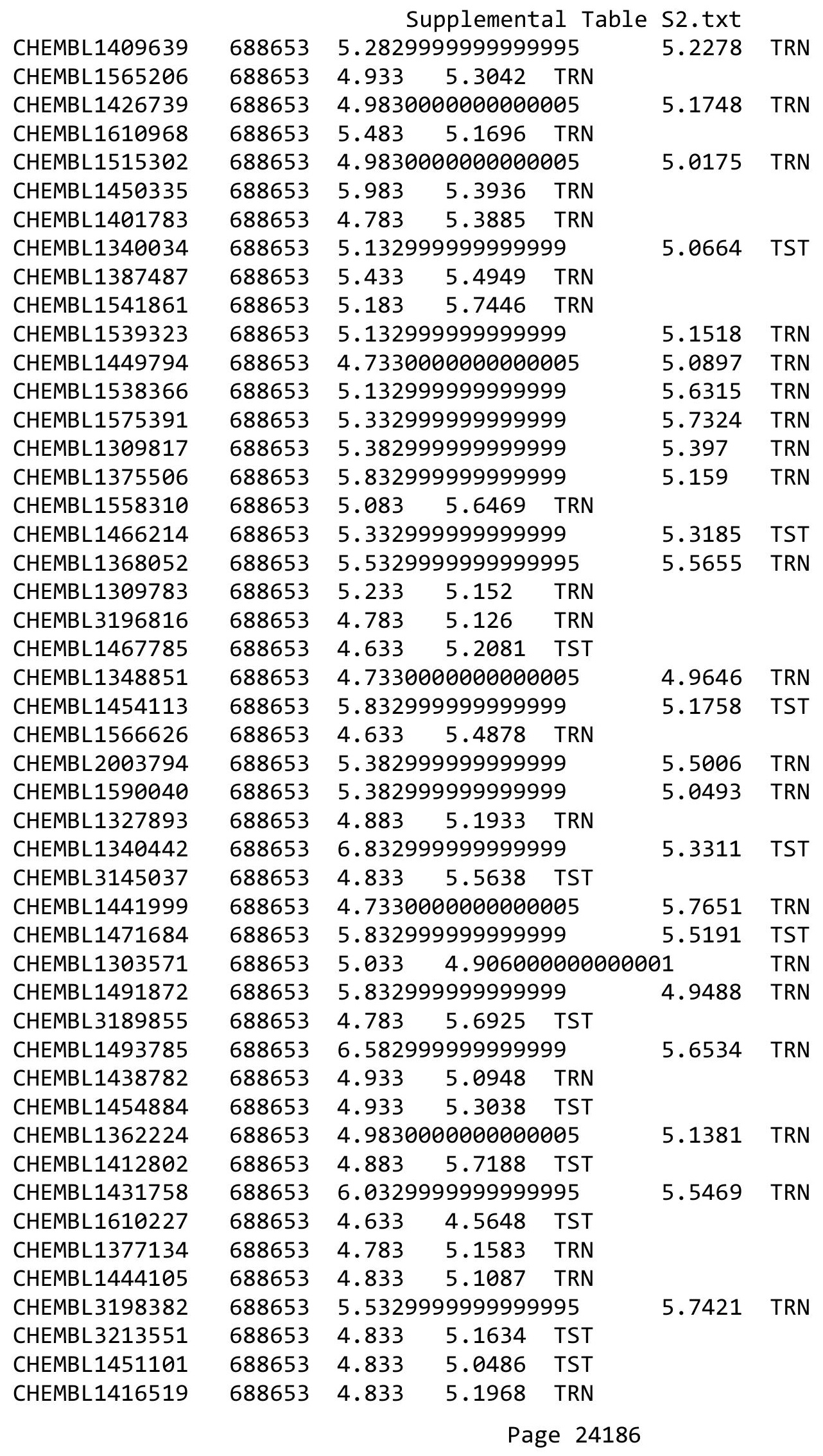




\begin{tabular}{|c|c|c|c|c|c|c|}
\hline & & \multicolumn{5}{|c|}{ Supplemental Table S2.txt } \\
\hline CHEMBL1528266 & 688653 & 5.033 & 4.8205 & TRN & & \\
\hline CHEMBL1461524 & 688653 & 4.683 & 5.7326 & TRN & & \\
\hline CHEMBL1507441 & 688653 & 4.633 & 4.9155 & TRN & & \\
\hline CHEMBL1534181 & 688653 & 4.783 & 5.2919 & TRN & & \\
\hline CHEMBL3208406 & 688653 & 4.683 & 5.0275 & TST & & \\
\hline CHEMBL1324046 & 688653 & \multicolumn{3}{|c|}{4.9830000000000005} & 5.1937 & TRN \\
\hline CHEMBL1452167 & 688653 & 5.033 & 5.6414 & TRN & & \\
\hline CHEMBL1316818 & 688653 & \multicolumn{3}{|c|}{6.5329999999999995} & 5.3054 & $\mathrm{~T}$ \\
\hline CHEMBL1453757 & 688653 & 6.7331 & 6.0168 & TRN & & \\
\hline CHEMBL3196118 & 688653 & 6.233 & 5.4295 & TRN & & \\
\hline CHEMBL1407577 & 688653 & 5.683 & 5.7282 & TRN & & \\
\hline CHEMBL1570507 & 688653 & 5.233 & 5.2758 & TRN & & \\
\hline CHEMBL1431917 & 688653 & \multicolumn{3}{|c|}{5.2829999999999995} & 5.0486 & \\
\hline CHEMBL1322350 & 688653 & 4.633 & 4.5795 & TRN & & \\
\hline CHEMBL1453113 & 688653 & 5.683 & 5.4261 & TST & & \\
\hline CHEMBL1432640 & 688653 & 5.233 & 5.3653 & TRN & & \\
\hline CHEMBL1419786 & 688653 & 6.233 & 5.2178 & TRN & & \\
\hline CHEMBL1322180 & 688653 & 4.783 & 4.9595 & TST & & \\
\hline CHEMBL1378790 & 688653 & \multicolumn{3}{|c|}{5.882999999999999} & 5.2604 & TRN \\
\hline CHEMBL1321410 & 688653 & \multicolumn{3}{|c|}{6.382999999999999} & 5.6919 & \\
\hline CHEMBL1486195 & 688653 & 5.483 & 5.3771 & TRN & & \\
\hline CHEMBL1383824 & 688653 & 5.733 & 5.2599 & TST & & \\
\hline CHEMBL1372027 & 688653 & 4.883 & 5.1554 & TST & & \\
\hline CHEMBL1574623 & 688653 & 4.783 & 4.6502 & TRN & & \\
\hline CHEMBL1320060 & 688653 & 4.783 & 5.0478 & TRN & & \\
\hline CHEMBL3209498 & 688653 & 6.683 & 5.7745 & TRN & & \\
\hline CHEMBL3208696 & 688653 & 5.233 & 5.7259 & TRN & & \\
\hline CHEMBL 3210176 & 688653 & 5.483 & 5.6903 & TRN & & \\
\hline CHEMBL1501925 & 688653 & 5.433 & 5.1775 & TST & & \\
\hline CHEMBL1608540 & 688653 & \multicolumn{3}{|c|}{6.2829999999999995} & 5.5069 & \\
\hline CHEMBL1327780 & 688653 & 5.733 & 5.9069 & TRN & & \\
\hline CHEMBL1534459 & 688653 & \multicolumn{3}{|c|}{6.332999999999999} & 5.7465 & TRN \\
\hline CHEMBL528181 & 688653 & 4.683 & 4.9813 & TRN & & \\
\hline CHEMBL1489311 & 688653 & \multicolumn{3}{|c|}{4.7330000000000005} & 5.1373 & TRI \\
\hline CHEMBL1569671 & 688653 & 5.733 & 5.157 & TST & & \\
\hline CHEMBL1546642 & 688653 & 4.85 & 4.8723 & TRN & & \\
\hline CHEMBL1392037 & 688653 & \multicolumn{3}{|c|}{5.832999999999999} & 5.4788 & 15 \\
\hline CHEMBL1543654 & 688653 & 4.583 & 5.1855 & TRN & & \\
\hline CHEMBL1477995 & 688653 & 4.833 & 5.4084 & TRN & & \\
\hline CHEMBL1574283 & 688653 & 5.183 & 5.9387 & TRN & & \\
\hline CHEMBL1318968 & 688653 & \multicolumn{3}{|c|}{6.332999999999999} & 5.5496 & TRN \\
\hline CHEMBL1611868 & 688653 & \multicolumn{3}{|c|}{4.7330000000000005} & 5.1541 & 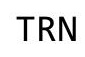 \\
\hline CHEMBL1452029 & 688653 & 5.083 & 4.9768 & TRN & & \\
\hline CHEMBL1439513 & 688653 & \multicolumn{3}{|c|}{5.832999999999999} & 5.1083 & TRN \\
\hline CHEMBL1584850 & 688653 & \multicolumn{3}{|c|}{5.832999999999999} & 5.0123 & TST \\
\hline CHEMBL1609498 & 688653 & \multicolumn{3}{|c|}{5.832999999999999} & 5.8935 & TRN \\
\hline CHEMBL1505918 & 688653 & \multicolumn{3}{|c|}{4.9830000000000005} & 4.9646 & TST \\
\hline CHEMBL1568189 & 688653 & 4.683 & 4.8675 & TST & & \\
\hline
\end{tabular}




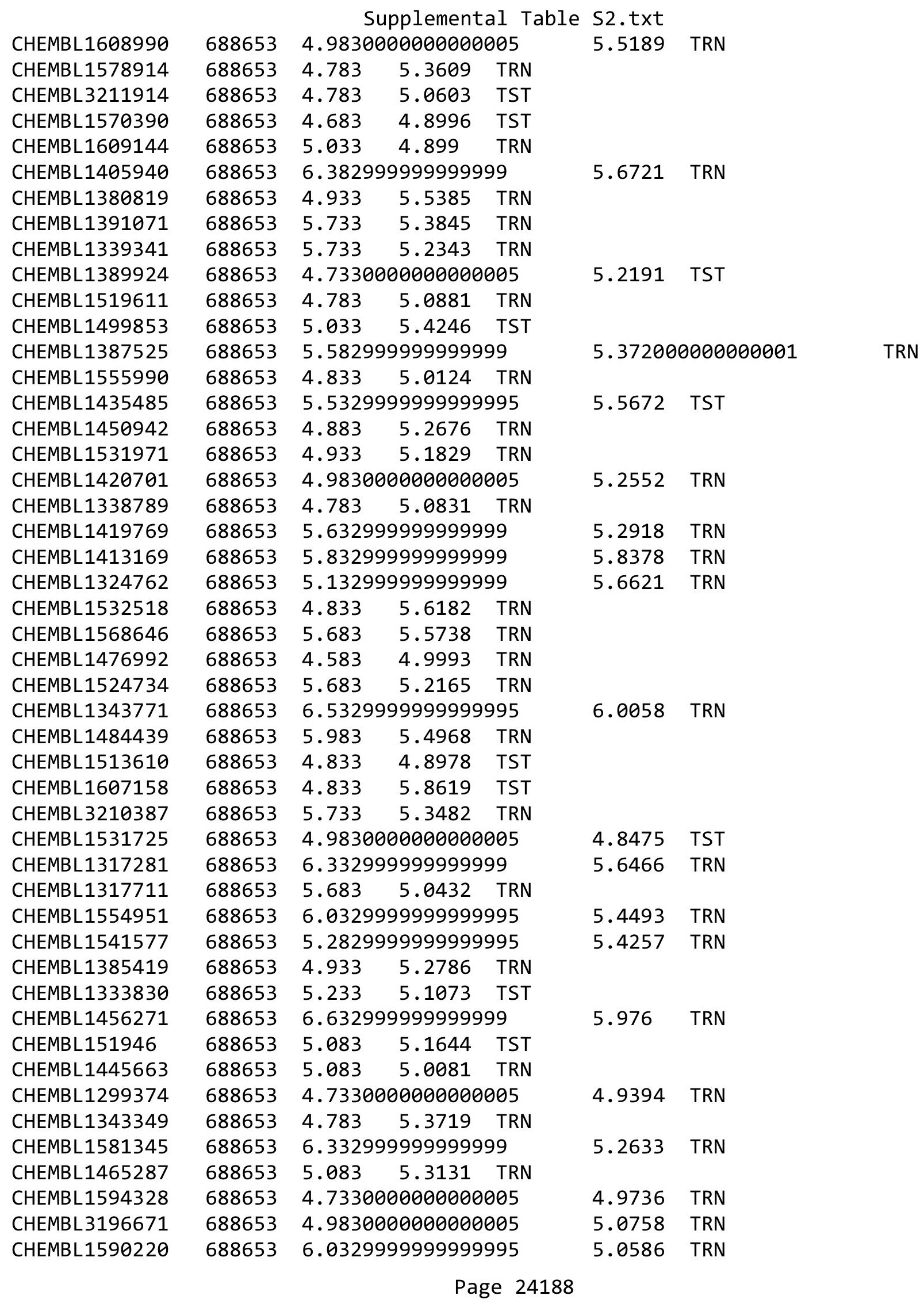




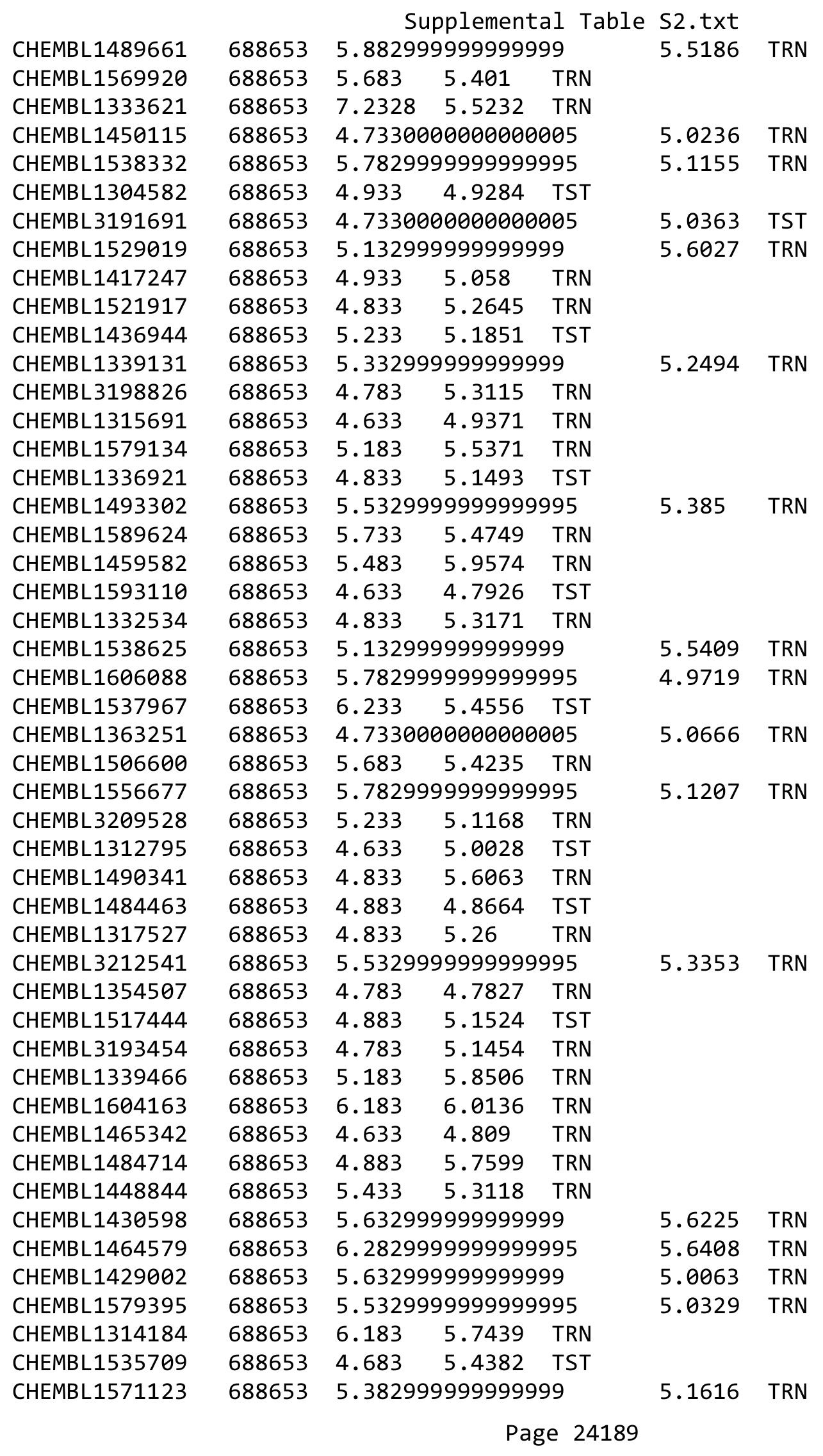




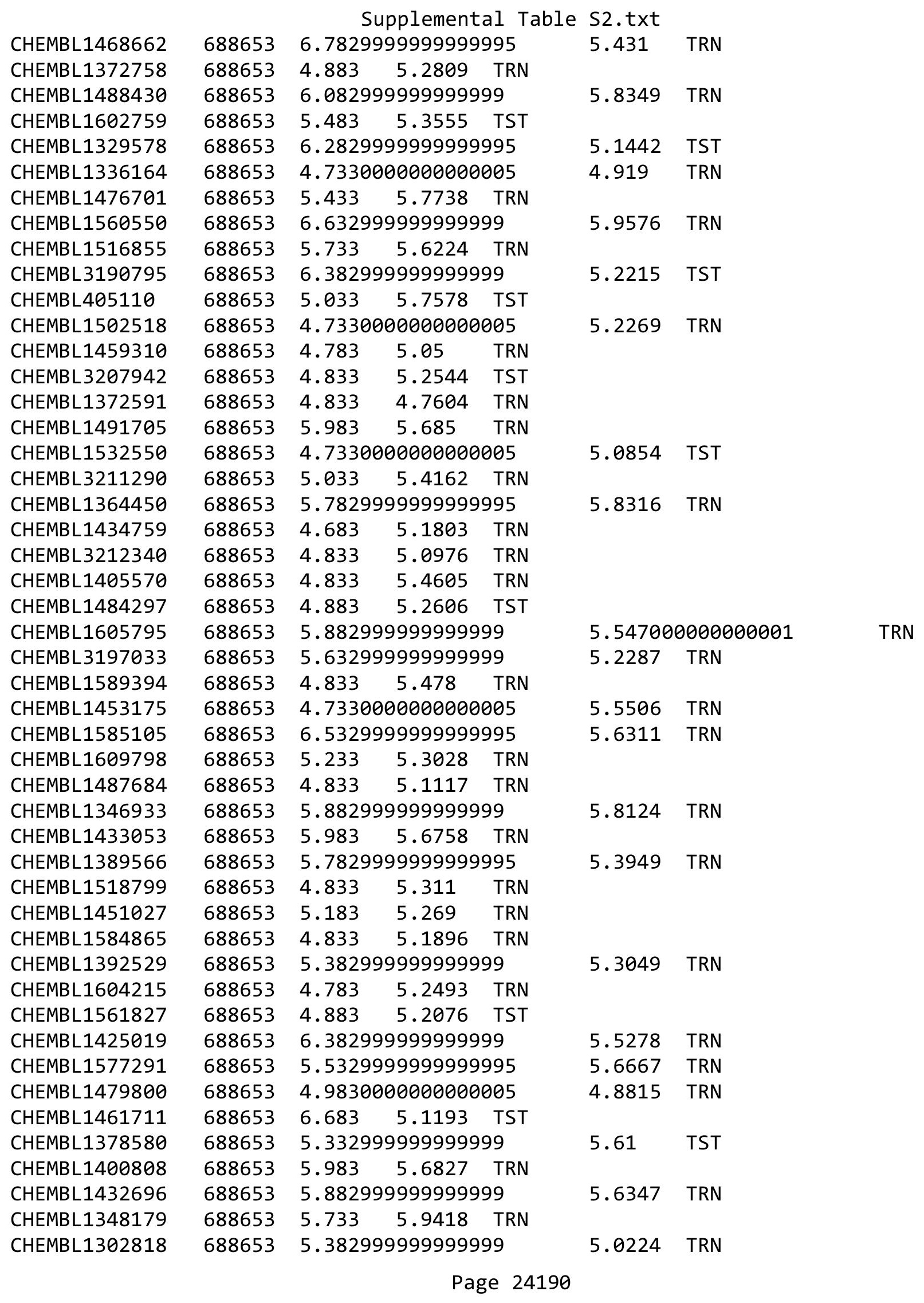




\begin{tabular}{|c|c|c|c|c|c|c|}
\hline & & \multicolumn{5}{|c|}{ Supplemental Table s2.txt } \\
\hline CHEMBL3212292 & 688653 & 5.483 & 5.0425 & TST & & \\
\hline CHEMBL1320424 & 688653 & 5.183 & 5.7491 & TRN & & \\
\hline CHEMBL1391409 & 688653 & \multicolumn{3}{|c|}{5.382999999999999} & 5.2125 & TRN \\
\hline CHEMBL1437740 & 688653 & 4.583 & 4.955 & TRN & & \\
\hline CHEMBL1495355 & 688653 & \multicolumn{3}{|c|}{5.332999999999999} & 5.3468 & TRN \\
\hline CHEMBL1425271 & 688653 & 5.733 & 5.2212 & TRN & & \\
\hline CHEMBL1480062 & 688653 & 4.683 & 5.0801 & TRN & & \\
\hline CHEMBL1420922 & 688653 & \multicolumn{3}{|c|}{5.7829999999999995} & 5.7043 & TRN \\
\hline CHEMBL1383128 & 688653 & \multicolumn{3}{|c|}{6.132999999999999} & 5.4998 & TST \\
\hline CHEMBL1449243 & 688653 & 6.683 & 5.1832 & TRN & & \\
\hline CHEMBL1304708 & 688653 & 4.833 & 4.838 & TRN & & \\
\hline CHEMBL1518284 & 688653 & 4.783 & 4.7192 & TRN & & \\
\hline CHEMBL3195870 & 688653 & 5.483 & 5.4581 & TRN & & \\
\hline CHEMBL1425034 & 688653 & 5.033 & 6.3994 & TRN & & \\
\hline CHEMBL3191668 & 688653 & 8.1805 & 5.4145 & TRN & & \\
\hline CHEMBL1418304 & 688653 & 4.783 & 5.0218 & TRN & & \\
\hline CHEMBL609030 & 688653 & 4.833 & 5.2562 & TST & & \\
\hline CHEMBL1421270 & 688653 & 5.983 & 5.6769 & TST & & \\
\hline CHEMBL1611123 & 688653 & 5.733 & 5.9528 & TRN & & \\
\hline CHEMBL1424857 & 688653 & 4.883 & 4.9543 & TST & & \\
\hline CHEMBL1610361 & 688653 & 4.883 & 5.3084 & TRN & & \\
\hline CHEMBL1524783 & 688653 & \multicolumn{3}{|c|}{5.632999999999999} & 5.6128 & TRN \\
\hline CHEMBL1323791 & 688653 & 6.183 & 5.2592 & TRN & & \\
\hline CHEMBL1375643 & 688653 & 4.783 & 5.0451 & TRN & & \\
\hline CHEMBL171279 & 688653 & 4.683 & 4.989 & TRN & & \\
\hline CHEMBL464859 & 688653 & 7.9318 & 5.8945 & TRN & & \\
\hline CHEMBL1390665 & 688653 & 4.783 & 5.5233 & TST & & \\
\hline CHEMBL1527316 & 688653 & 5.25 & 5.2563 & TRN & & \\
\hline CHEMBL1302934 & 688653 & 4.783 & \multicolumn{3}{|c|}{5.162000000000001} & TRN \\
\hline CHEMBL1589241 & 688653 & 4.683 & 5.1163 & TRN & & \\
\hline CHEMBL1421574 & 688653 & \multicolumn{3}{|c|}{5.632999999999999} & 5.0424 & TRN \\
\hline CHEMBL1447882 & 688653 & \multicolumn{3}{|c|}{5.5329999999999995} & 5.4898 & TRN \\
\hline CHEMBL1417964 & 688653 & \multicolumn{3}{|c|}{ 5.332999999999999 } & 5.5735 & TRN \\
\hline CHEMBL1573766 & 688653 & 6.983 & 5.9035 & TRN & & \\
\hline CHEMBL1442212 & 688653 & 5.683 & 5.6207 & TST & & \\
\hline CHEMBL1610029 & 688653 & 4.583 & 5.0832 & TST & & \\
\hline CHEMBL1432213 & 688653 & 6.233 & 5.569 & TRN & & \\
\hline CHEMBL1492237 & 688653 & 5.033 & 4.9015 & TRN & & \\
\hline CHEMBL1558494 & 688653 & 4.783 & 5.2138 & TRN & & \\
\hline CHEMBL1328952 & 688653 & \multicolumn{3}{|c|}{6.332999999999999} & 5.9586 & TRN \\
\hline CHEMBL1524508 & 688653 & 4.683 & 4.5791 & TST & & \\
\hline CHEMBL1309260 & 688653 & \multicolumn{3}{|c|}{6.832999999999999} & 5.7769 & TRN \\
\hline CHEMBL1506379 & 688653 & 5.433 & 5.4116 & TRN & & \\
\hline CHEMBL1505536 & 688653 & 4.783 & 5.0741 & TRN & & \\
\hline CHEMBL3209911 & 688653 & 5.483 & 5.3858 & TRN & & \\
\hline CHEMBL1465089 & 688653 & 4.683 & 5.1582 & TRN & & \\
\hline CHEMBL1384417 & 688653 & 4.933 & 5.0397 & TRN & & \\
\hline CHEMBL1444426 & 688653 & 4.883 & 5.0407 & TRN & & \\
\hline
\end{tabular}




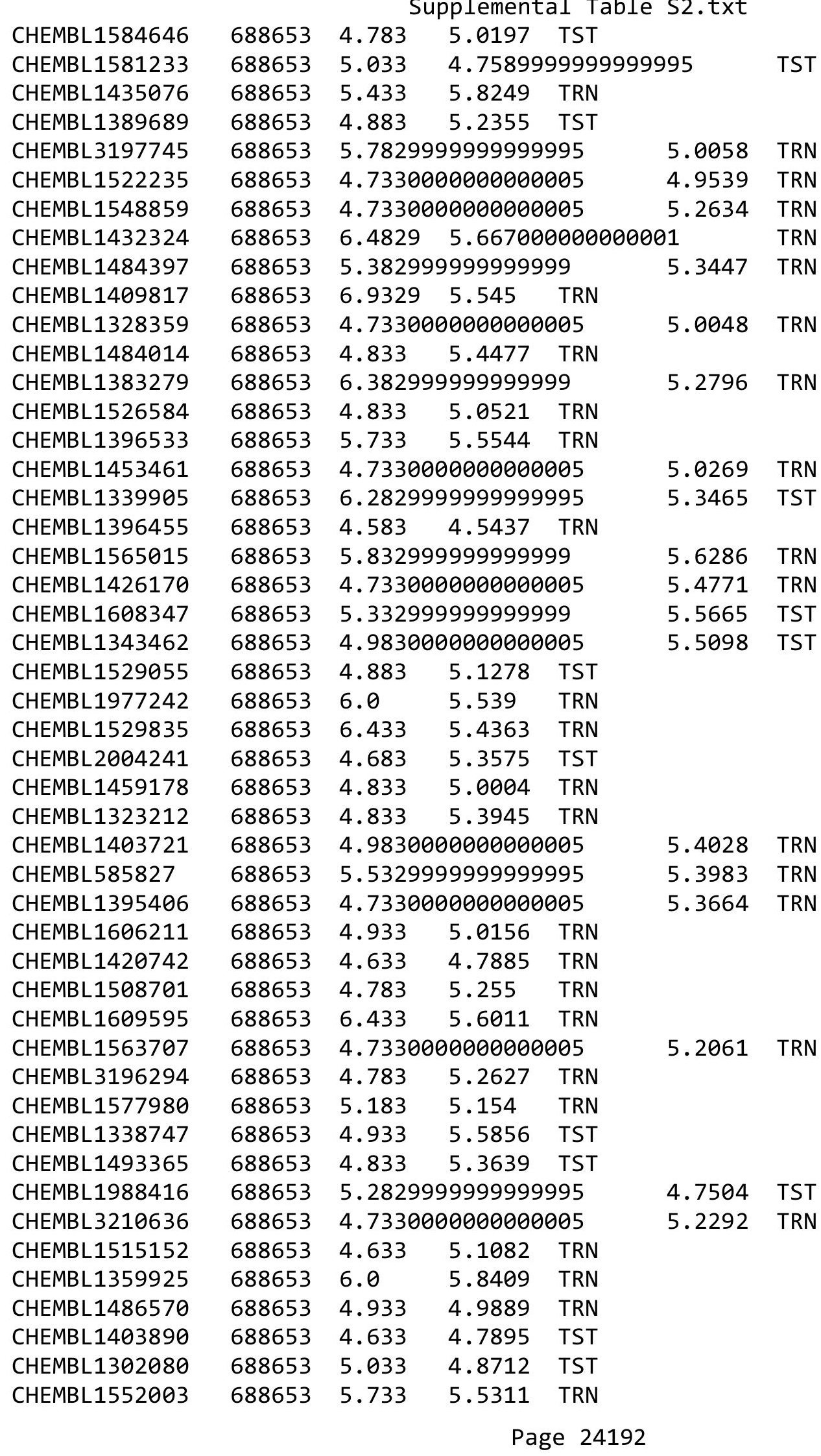




\begin{tabular}{|c|c|c|c|c|c|c|c|}
\hline \multicolumn{8}{|c|}{ Supplemental Table S2.txt } \\
\hline CHEMBL1308091 & 688653 & 4.783 & 5.4588 & TST & & & \\
\hline CHEMBL1347564 & 688653 & 4.98300 & 00000000 & 005 & 5.0548 & TRN & \\
\hline CHEMBL1319873 & 688653 & 6.4829 & 5.7469 & TRN & & & \\
\hline CHEMBL1494863 & 688653 & 4.783 & 5.3397 & TRN & & & \\
\hline CHEMBL1304008 & 688653 & 5.433 & 5.6599 & TRN & & & \\
\hline CHEMBL1485838 & 688653 & \multicolumn{3}{|c|}{4.9830000000000005} & 4.7915 & TRN & \\
\hline CHEMBL1417300 & 688653 & 5.433 & 5.1383 & TRN & & & \\
\hline CHEMBL1406456 & 688653 & 4.933 & 5.7489 & TRN & & & \\
\hline CHEMBL329836 & 688653 & \multicolumn{3}{|c|}{4.7330000000000005} & 5.4609 & TRN & \\
\hline CHEMBL1495176 & 688653 & \multicolumn{3}{|c|}{5.7829999999999995} & 5.1452 & TRN & \\
\hline CHEMBL1441921 & 688653 & \multicolumn{3}{|c|}{5.5329999999999995} & 5.5456 & TRN & \\
\hline CHEMBL3211023 & 688653 & 4.833 & 4.9636 & TRN & & & \\
\hline CHEMBL1549578 & 688653 & 4.783 & 5.2348 & TST & & & \\
\hline CHEMBL1368397 & 688653 & 4.783 & 5.1125 & TRN & & & \\
\hline CHEMBL1404568 & 688653 & \multicolumn{3}{|c|}{5.582999999999999} & \multicolumn{2}{|c|}{5.2860000000000005} & TRN \\
\hline CHEMBL3210259 & 688653 & \multicolumn{3}{|c|}{5.832999999999999} & 5.1927 & TRN & \\
\hline CHEMBL1436395 & 688653 & 4.833 & 5.2064 & TRN & & & \\
\hline CHEMBL1416844 & 688653 & 4.633 & 5.1519 & TST & & & \\
\hline CHEMBL1418610 & 688653 & 4.833 & 5.3847 & TRN & & & \\
\hline CHEMBL1329038 & 688653 & 4.783 & 4.7758 & TRN & & & \\
\hline CHEMBL1581759 & 688653 & \multicolumn{3}{|c|}{5.7829999999999995} & 5.1725 & TRN & \\
\hline CHEMBL1428947 & 688653 & 4.633 & 5.0419 & TRN & & & \\
\hline CHEMBL1534478 & 688653 & 5.033 & 5.4101 & TST & & & \\
\hline CHEMBL1360949 & 688653 & 4.783 & 5.3805 & TRN & & & \\
\hline CHEMBL1338413 & 688653 & 4.783 & 4.8471 & TRN & & & \\
\hline CHEMBL1498130 & 688653 & 5.083 & 5.4804 & TST & & & \\
\hline CHEMBL1426363 & 688653 & \multicolumn{3}{|c|}{5.132999999999999} & 5.1212 & TRN & \\
\hline CHEMBL1593295 & 688653 & \multicolumn{3}{|c|}{4.9830000000000005} & 5.15600 & 0000000001 & TST \\
\hline CHEMBL1594984 & 688653 & \multicolumn{3}{|c|}{5.882999999999999} & 5.5775 & TRN & \\
\hline CHEMBL1400174 & 688653 & \multicolumn{3}{|c|}{5.5329999999999995} & 5.9002 & TRN & \\
\hline CHEMBL1577530 & 688653 & \multicolumn{3}{|c|}{4.7330000000000005} & 5.7055 & TRN & \\
\hline CHEMBL1593330 & 688653 & \multicolumn{3}{|c|}{4.7330000000000005} & 5.2568 & TRN & \\
\hline CHEMBL1321224 & 688653 & \multicolumn{3}{|c|}{4.9830000000000005} & 4.7555 & TRN & \\
\hline CHEMBL1584570 & 688653 & 5.3 & 5.56 & TST & & & \\
\hline CHEMBL1326990 & 688653 & 4.633 & 4.8695 & TRN & & & \\
\hline CHEMBL1604016 & 688653 & 5.683 & 5.3062 & TRN & & & \\
\hline CHEMBL1556513 & 688653 & 4.633 & 5.2222 & TRN & & & \\
\hline CHEMBL3191183 & 688653 & 5.183 & 5.1784 & TRN & & & \\
\hline CHEMBL1520559 & 688653 & 5.53299 & 99999999 & 995 & 5.6964 & TRN & \\
\hline CHEMBL1470135 & 688653 & 5.433 & 4.8575 & TRN & & & \\
\hline CHEMBL3208674 & 688653 & 4.683 & 5.189 & TST & & & \\
\hline CHEMBL1594990 & 688653 & 4.783 & 5.1074 & TST & & & \\
\hline CHEMBL1446422 & 688653 & 6.233 & 4.9737 & TST & & & \\
\hline CHEMBL1383395 & 688653 & 5.683 & 5.1873 & TST & & & \\
\hline CHEMBL2003651 & 688653 & 5.683 & 5.2393 & TRN & & & \\
\hline CHEMBL1411887 & 688653 & 5.53299 & 99999999 & 995 & 5.2482 & TRN & \\
\hline CHEMBL1489764 & 688653 & 5.983 & 5.4937 & TRN & & & \\
\hline CHEMBL3198327 & 688653 & 4.933 & 5.4956 & TRN & & & \\
\hline
\end{tabular}




\begin{tabular}{|c|c|c|c|c|c|c|}
\hline \multirow[b]{2}{*}{ CHEMBL1403905 } & & \multicolumn{5}{|c|}{ Supplemental Table s2.txt } \\
\hline & 688653 & 4.633 & 4.7905 & TST & & \\
\hline CHEMBL1469953 & 688653 & 4.583 & 5.0566 & TST & & \\
\hline CHEMBL1358378 & 688653 & 4.583 & 5.2301 & TRN & & \\
\hline CHEMBL1421628 & 688653 & \multicolumn{3}{|c|}{4.9830000000000005} & 5.0578 & TST \\
\hline CHEMBL379179 & 688653 & 6.8831 & 6.0597 & TRN & & \\
\hline CHEMBL1448753 & 688653 & \multicolumn{3}{|c|}{4.7330000000000005} & 5.2037 & TRN \\
\hline CHEMBL1447992 & 688653 & 4.833 & 5.0592 & TRN & & \\
\hline CHEMBL1423379 & 688653 & \multicolumn{3}{|c|}{4.7330000000000005} & 5.1738 & TRN \\
\hline CHEMBL1593580 & 688653 & 4.583 & 5.1559 & TST & & \\
\hline CHEMBL1440455 & 688653 & \multicolumn{3}{|c|}{6.2829999999999995} & 5.6694 & TRN \\
\hline CHEMBL1364520 & 688653 & 4.783 & 5.1093 & TRN & & \\
\hline CHEMBL1512157 & 688653 & 4.583 & 4.9382 & TST & & \\
\hline CHEMBL66874 & 688653 & 4.783 & 5.5738 & TST & & \\
\hline CHEMBL3195032 & 688653 & \multicolumn{3}{|c|}{5.7829999999999995} & 5.6585 & TRN \\
\hline CHEMBL1347319 & 688653 & 4.95 & 4.915 & TRN & & \\
\hline CHEMBL1325798 & 688653 & 5.083 & 5.1832 & TST & & \\
\hline CHEMBL1447093 & 688653 & 5.683 & 5.567 & TRN & & \\
\hline CHEMBL1546145 & 688653 & 5.683 & 5.3681 & TST & & \\
\hline CHEMBL1574154 & 688653 & \multicolumn{3}{|c|}{5.132999999999999} & 5.1168 & TST \\
\hline CHEMBL1385338 & 688653 & 5.433 & 4.9423 & TRN & & \\
\hline CHEMBL1300086 & 688653 & 4.833 & 5.4706 & TST & & \\
\hline CHEMBL1354646 & 688653 & 4.633 & 5.0393 & TRN & & \\
\hline CHEMBL1497490 & 688653 & 5.233 & 5.266 & TRN & & \\
\hline CHEMBL1445932 & 688653 & 5.033 & 5.4664 & TRN & & \\
\hline CHEMBL1323821 & 688653 & 4.783 & 5.098 & TST & & \\
\hline CHEMBL1395609 & 688653 & 5.233 & 5.4609 & TST & & \\
\hline CHEMBL1407880 & 688653 & 5.483 & 5.2085 & TST & & \\
\hline CHEMBL1319818 & 688653 & \multicolumn{3}{|c|}{4.9830000000000005} & 5.5738 & TRN \\
\hline CHEMBL1613251 & 688653 & 4.783 & 5.1576 & TST & & \\
\hline CHEMBL1365902 & 688653 & 4.583 & 4.883 & TRN & & \\
\hline CHEMBL1523432 & 688653 & 4.783 & 4.749 & TRN & & \\
\hline CHEMBL1485865 & 688653 & 5.233 & 5.0026 & TST & & \\
\hline CHEMBL1319534 & 688653 & \multicolumn{3}{|c|}{5.132999999999999} & 5.3492 & TRN \\
\hline CHEMBL3192631 & 688653 & 4.833 & 5.1599 & TRN & & \\
\hline CHEMBL1568788 & 688653 & 5.233 & 4.6094 & TRN & & \\
\hline CHEMBL1503613 & 688653 & 6.4829 & 5.4981 & TRN & & \\
\hline CHEMBL1313072 & 688653 & 6.233 & 5.3827 & TRN & & \\
\hline CHEMBL1412457 & 688653 & 4.783 & 5.2044 & TRN & & \\
\hline CHEMBL1515951 & 688653 & 4.833 & 5.0924 & TRN & & \\
\hline CHEMBL3211554 & 688653 & 6.4829 & 5.63899 & 999999999 & 99 & TST \\
\hline CHEMBL1603383 & 688653 & 4.783 & 5.2995 & TST & & \\
\hline CHEMBL1337721 & 688653 & 4.833 & 5.6202 & TRN & & \\
\hline CHEMBL1573634 & 688653 & 4.933 & 5.7158 & TRN & & \\
\hline CHEMBL1543332 & 688653 & 5.083 & 5.0101 & TRN & & \\
\hline CHEMBL1505177 & 688653 & 5.033 & 5.455 & TRN & & \\
\hline CHEMBL1313738 & 688653 & \multicolumn{3}{|c|}{5.832999999999999} & 5.7274 & TRN \\
\hline CHEMBL1464077 & 688653 & 4.783 & 5.3666 & TST & & \\
\hline CHEMBL1380704 & 688653 & 4.783 & 5.165 & TRN & & \\
\hline
\end{tabular}




\begin{tabular}{|c|c|c|c|c|c|c|}
\hline \multirow[b]{2}{*}{ CHEMBL1338803 } & \multirow[b]{2}{*}{688653} & \multicolumn{5}{|c|}{ Supplemental Table s2.txt } \\
\hline & & \multicolumn{3}{|c|}{$\begin{array}{lll}4.783 & 4.5108 & \text { TST }\end{array}$} & & \\
\hline CHEMBL1339565 & 688653 & 4.633 & 4.7417 & TRN & & \\
\hline CHEMBL1329318 & 688653 & \multicolumn{3}{|c|}{5.5329999999999995} & 5.5571 & TRN \\
\hline CHEMBL1582472 & 688653 & 6.183 & 5.4434 & TRN & & \\
\hline CHEMBL1588055 & 688653 & \multicolumn{3}{|c|}{5.7829999999999995} & 5.0753 & TRN \\
\hline CHEMBL1396544 & 688653 & 4.583 & 4.9302 & TRN & & \\
\hline CHEMBL1360192 & 688653 & \multicolumn{3}{|c|}{5.7829999999999995} & 4.9122 & TRN \\
\hline CHEMBL1367262 & 688653 & 4.583 & 4.6845 & TST & & \\
\hline CHEMBL1559622 & 688653 & \multicolumn{3}{|c|}{4.7330000000000005} & 4.6402 & TRN \\
\hline CHEMBL1473368 & 688653 & 5.433 & 5.2762 & TRN & & \\
\hline CHEMBL1328606 & 688653 & 4.883 & 4.6716 & TRN & & \\
\hline CHEMBL1519103 & 688653 & \multicolumn{3}{|c|}{4.7330000000000005} & 5.8365 & TRN \\
\hline CHEMBL1576677 & 688653 & 7.1331 & 5.4502 & TRN & & \\
\hline CHEMBL1404865 & 688653 & 5.033 & 5.2953 & TRN & & \\
\hline CHEMBL1479763 & 688653 & 5.483 & 5.3245 & TRN & & \\
\hline CHEMBL1378076 & 688653 & 4.883 & 5.2298 & TRN & & \\
\hline CHEMBL1413385 & 688653 & \multicolumn{3}{|c|}{4.7330000000000005} & 5.4315 & TST \\
\hline CHEMBL1491158 & 688653 & \multicolumn{3}{|c|}{4.9830000000000005} & 5.6251 & TST \\
\hline CHEMBL1510014 & 688653 & \multicolumn{3}{|c|}{5.882999999999999} & 5.1621 & TRN \\
\hline CHEMBL1324360 & 688653 & 4.783 & 5.1146 & TRN & & \\
\hline CHEMBL1526740 & 688653 & \multirow{2}{*}{\multicolumn{3}{|c|}{$\begin{array}{lcc}4.883 & 5.4555 & \text { TRN } \\
5.832999999999999\end{array}$}} & & \\
\hline CHEMBL1595601 & 688653 & & & & 5.3493 & TRN \\
\hline CHEMBL1478611 & 688653 & 4.833 & 5.1992 & TRN & & \\
\hline CHEMBL1441479 & 688653 & 4.933 & 5.1137 & TRN & & \\
\hline CHEMBL1508411 & 688653 & 5.683 & 5.1594 & TRN & & \\
\hline CHEMBL1366608 & 688653 & \multicolumn{3}{|c|}{4.9830000000000005} & 4.887 & TRN \\
\hline CHEMBL1377608 & 688653 & \multicolumn{3}{|c|}{5.382999999999999} & 5.0706 & TST \\
\hline CHEMBL1420109 & 688653 & 5.0 & 4.9568 & TRN & & \\
\hline CHEMBL1309645 & 688653 & \multirow{2}{*}{\multicolumn{3}{|c|}{ 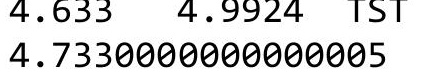 }} & & \\
\hline CHEMBL1350275 & 688653 & & & & 4.6702 & TRN \\
\hline CHEMBL1497763 & 688653 & 5.033 & 5.559 & TRN & & \\
\hline CHEMBL1601796 & 688653 & 5.433 & 5.2496 & TST & & \\
\hline CHEMBL1432474 & 688653 & 5.183 & 5.0573 & TRN & & \\
\hline CHEMBL3198914 & 688653 & 4.583 & 5.1897 & TRN & & \\
\hline CHEMBL1535506 & 688653 & 5.083 & 5.229 & TST & & \\
\hline CHEMBL1329095 & 688653 & 5.233 & 5.2711 & TRN & & \\
\hline CHEMBL1451784 & 688653 & 4.883 & 5.2959 & TRN & & \\
\hline CHEMBL1598978 & 688653 & \multicolumn{3}{|c|}{5.132999999999999} & 5.1869 & TRN \\
\hline CHEMBL85321 & 688653 & 5.233 & 5.1206 & TST & & \\
\hline CHEMBL1432008 & 688653 & \multicolumn{3}{|c|}{5.5329999999999995} & 5.4217 & TRN \\
\hline CHEMBL1467999 & 688653 & 5.183 & 4.96 & TRN & & \\
\hline CHEMBL1598214 & 688653 & 4.933 & 5.1108 & TRN & & \\
\hline CHEMBL1336947 & 688653 & 4.833 & 5.4106 & TRN & & \\
\hline CHEMBL1523422 & 688653 & \multicolumn{3}{|c|}{5.382999999999999} & 5.2166 & TRN \\
\hline CHEMBL1561900 & 688653 & 5.033 & 5.2191 & TRN & & \\
\hline CHEMBL1360351 & 688653 & \multicolumn{3}{|c|}{5.382999999999999} & 5.3458 & TRN \\
\hline CHEMBL3196606 & 688653 & 5.683 & 5.2752 & TRN & & \\
\hline CHEMBL1427079 & 688653 & 4.883 & 5.3992 & TST & & \\
\hline
\end{tabular}




\begin{tabular}{|c|c|c|c|c|c|c|}
\hline & & \multicolumn{5}{|c|}{ Supplemental Table S2.txt } \\
\hline CHEMBL1390385 & 688653 & 5.183 & 5.2102 & TRN & & \\
\hline CHEMBL1545981 & 688653 & 4.783 & 5.1877 & TST & & \\
\hline CHEMBL3196834 & 688653 & 4.833 & 5.8055 & TST & & \\
\hline CHEMBL1576203 & 688653 & \multicolumn{3}{|c|}{5.132999999999999} & 5.4262 & TST \\
\hline CHEMBL1360553 & 688653 & 4.883 & 4.9504 & TST & & \\
\hline CHEMBL3211166 & 688653 & 5.183 & 5.1366 & TST & & \\
\hline CHEMBL1514737 & 688653 & 7.3325 & 6.0969 & TRN & & \\
\hline CHEMBL1299791 & 688653 & 5.933 & 5.23 & TST & & \\
\hline CHEMBL1461574 & 688653 & 4.833 & 5.2675 & TST & & \\
\hline CHEMBL1357107 & 688653 & 5.183 & 5.1435 & TRN & & \\
\hline CHEMBL1483169 & 688653 & 4.833 & 4.856 & TRN & & \\
\hline CHEMBL1497430 & 688653 & \multicolumn{3}{|c|}{5.832999999999999} & & \\
\hline CHEMBL1474862 & 688653 & 5.483 & 5.341 & TRN & & \\
\hline CHEMBL3197649 & 688653 & \multicolumn{3}{|c|}{5.382999999999999} & 5.1425 & TRN \\
\hline CHEMBL1606631 & 688653 & \multicolumn{3}{|c|}{5.832999999999999} & 5.5863 & TRN \\
\hline CHEMBL1599915 & 688653 & 5.083 & 5.9419 & TRN & & \\
\hline CHEMBL1315381 & 688653 & \multicolumn{3}{|c|}{5.2829999999999995} & 5.3713 & TRN \\
\hline CHEMBL144472 & 688653 & \multicolumn{3}{|c|}{6.5329999999999995} & 5.5232 & TST \\
\hline CHEMBL1485628 & 688653 & \multicolumn{3}{|c|}{4.9830000000000005} & 4.9862 & TRN \\
\hline CHEMBL3198461 & 688653 & \multicolumn{3}{|c|}{4.7330000000000005} & 5.1928 & TRN \\
\hline CHEMBL1546132 & 688653 & 5.733 & 5.5423 & TST & & \\
\hline CHEMBL1391920 & 688653 & \multicolumn{3}{|c|}{5.5329999999999995} & 5.5838 & 1. \\
\hline CHEMBL1384620 & 688653 & 6.183 & 5.7464 & TRN & & \\
\hline CHEMBL1507537 & 688653 & \multirow{2}{*}{\multicolumn{3}{|c|}{$\begin{array}{l}5.433 \quad 5.4354 \quad \text { TRN } \\
5.5329999999999995\end{array}$}} & & \\
\hline CHEMBL1301586 & 688653 & & & & 5.5139 & TRI \\
\hline CHEMBL1462686 & 688653 & 5.683 & 5.1304 & TST & & \\
\hline CHEMBL600773 & 688653 & \multicolumn{3}{|c|}{5.332999999999999} & 5.2235 & TIN \\
\hline CHEMBL1501691 & 688653 & \multicolumn{3}{|c|}{4.7330000000000005} & 5.4033 & TRN \\
\hline CHEMBL1353463 & 688653 & \multicolumn{3}{|c|}{5.132999999999999} & 5.5639 & TRN \\
\hline CHEMBL1483686 & 688653 & \multicolumn{3}{|c|}{5.2829999999999995} & 5.0811 & TRN \\
\hline CHEMBL1452459 & 688653 & \multicolumn{3}{|c|}{4.7330000000000005} & 4.8534 & TRN \\
\hline CHEMBL133 & 688 & 5.183 & 5.2904 & TRN & & \\
\hline CHEMBL1990071 & 688653 & \multicolumn{3}{|c|}{5.882999999999999} & 5.4049 & TS \\
\hline CHEMBL1559802 & 688653 & 5.983 & 5.157 & TRN & & \\
\hline CHEMBL1346014 & 688653 & 5.733 & 5.3789 & TRN & & \\
\hline CHEMBL1320008 & 688653 & \multicolumn{3}{|c|}{6.2829999999999995} & & $\mathrm{TI}$ \\
\hline CHEMBL1393211 & 688653 & \multicolumn{3}{|c|}{5.7829999999999995} & & ТК \\
\hline CHEMBL1484410 & 688653 & \multicolumn{3}{|c|}{5.582999999999999} & 5.3447 & TRN \\
\hline CHEMBL1460564 & 688653 & \multicolumn{3}{|c|}{6.082999999999999} & 5.6938 & TRN \\
\hline CHEMBL1455505 & 688653 & 4.7330 & 00000000 & 005 & 5.3459 & TRN \\
\hline CHEMBL3198626 & 688653 & 4.7330 & 00000000 & 005 & 5.0993 & $\mathrm{TR}$ \\
\hline CHEMBL1507963 & 688653 & 4.783 & 5.7866 & TRN & & \\
\hline CHEMBL1415176 & 688653 & 5.033 & 5.1315 & TRN & & \\
\hline CHEMBL1328321 & 688653 & 4.633 & 5.2799 & TRN & & \\
\hline CHEMBL1339746 & 688653 & 4.883 & 5.442 & TST & & \\
\hline CHEMBL1339913 & 688653 & 4.583 & 4.8037 & TST & & \\
\hline CHEMBL1383812 & 688653 & 4.7330 & 00000000 & 005 & 5.3346 & ISI \\
\hline CHEMBL1466758 & 688653 & 5.7829 & 99999999 & 995 & 5.2103 & \\
\hline
\end{tabular}




\begin{tabular}{|c|c|c|c|c|c|c|c|}
\hline \multicolumn{7}{|c|}{ Supplemental Table S2.txt } & \\
\hline CHEMBL1556263 & 688653 & 4.783 & 5.2114 & TRN & & & \\
\hline CHEMBL1391694 & 688653 & 5.88299 & 99999999 & & 5.5025 & TRN & \\
\hline CHEMBL1567527 & 688653 & 4.883 & 4.813 & TST & & & \\
\hline CHEMBL1503604 & 688653 & 4.583 & 5.0612 & TRN & & & \\
\hline CHEMBL1373016 & 688653 & 5.033 & 5.1634 & TRN & & & \\
\hline CHEMBL563503 & 688653 & 5.28299 & 99999999 & 995 & 5.1977 & TRN & \\
\hline CHEMBL1392415 & 688653 & 4.883 & 5.25 & TRN & & & \\
\hline CHEMBL1437230 & 688653 & 4.833 & 5.0291 & TRN & & & \\
\hline CHEMBL1581866 & 688653 & 4.883 & 4.8981 & TRN & & & \\
\hline CHEMBL1328462 & 688653 & 6.0 & 4.4793 & TRN & & & \\
\hline CHEMBL1379054 & 688653 & 6.28299 & 99999999 & 995 & 5.511 & TRN & \\
\hline CHEMBL273891 & 688653 & 5.78299 & 99999999 & 995 & 5.567 & TRN & \\
\hline CHEMBL1384565 & 688653 & 5.233 & 5.2501 & TRN & & & \\
\hline CHEMBL1449808 & 688653 & 5.88299 & 99999999 & & 5.82700 & 0000000001 & TRN \\
\hline CHEMBL1544929 & 688653 & 5.183 & 5.5001 & TRN & & & \\
\hline CHEMBL1378912 & 688653 & 6.33299 & 99999999 & & 5.7203 & TST & \\
\hline CHEMBL1609203 & 688653 & 4.633 & 5.0294 & TRN & & & \\
\hline CHEMBL1319613 & 688653 & 5.13299 & 99999999 & & 5.6801 & TRN & \\
\hline CHEMBL1548211 & 688653 & 6.38299 & 99999999 & & 5.1692 & TRN & \\
\hline CHEMBL3194047 & 688653 & 4.833 & 5.1259 & TST & & & \\
\hline CHEMBL1324818 & 688653 & 5.38299 & 99999999 & & 4.8802 & TST & \\
\hline CHEMBL3212796 & 688653 & 5.13299 & 99999999 & & 5.0396 & TRN & \\
\hline CHEMBL1611086 & 688653 & 5.13299 & 99999999 & & 4.9832 & TRN & \\
\hline CHEMBL1486925 & 688653 & 4.883 & 4.9249 & TRN & & & \\
\hline CHEMBL1613243 & 688653 & 4.73300 & 00000000 & 005 & 5.1661 & TRN & \\
\hline CHEMBL1600759 & 688653 & 4.783 & 4.9382 & TST & & & \\
\hline CHEMBL1590235 & 688653 & 4.883 & 5.5047 & TRN & & & \\
\hline CHEMBL1555330 & 688653 & 4.883 & 5.1708 & TRN & & & \\
\hline CHEMBL1527207 & 688653 & 4.98300 & 00000000 & 005 & 5.0904 & TRN & \\
\hline CHEMBL1319817 & 688653 & 4.73300 & 00000000 & 005 & 5.2081 & TRN & \\
\hline CHEMBL1546177 & 688653 & 5.83299 & 99999999 & & 5.755 & TRN & \\
\hline CHEMBL1486984 & 688653 & 5.58299 & 99999999 & & 5.4359 & TRN & \\
\hline CHEMBL1321657 & 688653 & 5.033 & 5.4216 & TRN & & & \\
\hline CHEMBL1603382 & 688653 & 4.98300 & 00000000 & 005 & 5.1547 & TRN & \\
\hline CHEMBL1195425 & 688653 & 4.833 & 5.4907 & TRN & & & \\
\hline CHEMBL1481868 & 688653 & 4.633 & 5.01 & TST & & & \\
\hline CHEMBL1315044 & 688653 & 5.483 & 5.3789 & TRN & & & \\
\hline CHEMBL1423203 & 688653 & 5.63299 & 99999999 & & 5.7118 & TRN & \\
\hline CHEMBL1543724 & 688653 & 4.883 & 5.1926 & TST & & & \\
\hline CHEMBL1356806 & 688653 & 5.58299 & 99999999 & & 5.1497 & TRN & \\
\hline CHEMBL1481384 & 688653 & 6.38299 & 99999999 & & 5.8133 & TRN & \\
\hline CHEMBL1327588 & 688653 & 4.833 & 4.7922 & TRN & & & \\
\hline CHEMBL1343527 & 688653 & 6.0 & 6.07600 & 000000000 & 205 & TRN & \\
\hline CHEMBL1312050 & 688653 & 4.633 & 5.3406 & TST & & & \\
\hline CHEMBL2005998 & 688653 & 4.683 & 5.6577 & TST & & & \\
\hline CHEMBL1452003 & 688653 & 5.28299 & 99999999 & 995 & 5.5179 & TRN & \\
\hline CHEMBL1440037 & 688653 & 4.783 & 5.5657 & TRN & & & \\
\hline CHEMBL1542594 & 688653 & 5.033 & 5.2017 & TRN & & & \\
\hline
\end{tabular}




\begin{tabular}{|c|c|c|c|c|c|c|}
\hline & & \multicolumn{5}{|c|}{ Supplemental Table S2.txt } \\
\hline CHEMBL1401264 & 688653 & 5.933 & 5.7397 & TST & & \\
\hline CHEMBL1609331 & 688653 & 4.883 & 4.824 & TST & & \\
\hline CHEMBL1386313 & 688653 & 5.183 & 5.114 & TRN & & \\
\hline CHEMBL1379214 & 688653 & 4.683 & 5.1713 & TRN & & \\
\hline CHEMBL1496611 & 688653 & \multicolumn{3}{|c|}{6.382999999999999} & 5.7577 & TRN \\
\hline CHEMBL1533085 & 688653 & \multicolumn{3}{|c|}{4.7330000000000005} & 5.1954 & \\
\hline CHEMBL1519018 & 688653 & 4.833 & 5.0761 & TST & & \\
\hline CHEMBL1612086 & 688653 & \multicolumn{3}{|c|}{4.7330000000000005} & 5.5953 & TST \\
\hline CHEMBL1412660 & 688653 & 5.683 & 5.1298 & TRN & & \\
\hline CHEMBL3198844 & 688653 & 4.683 & 5.2555 & TST & & \\
\hline CHEMBL1541251 & 688653 & 6.0 & 5.0776 & TRN & & \\
\hline CHEMBL1546765 & 688653 & 4.783 & 5.3038 & TRN & & \\
\hline CHEMBL3213363 & 688653 & 4.833 & 5.2437 & TRN & & \\
\hline CHEMBL1574508 & 688653 & 5.483 & 4.9636 & TST & & \\
\hline CHEMBL1364277 & 688653 & 4.833 & 4.9732 & TST & & \\
\hline CHEMBL1352679 & 688653 & 5.683 & 5.6586 & TRN & & \\
\hline CHEMBL1361798 & 688653 & 4.783 & 5.4312 & TST & & \\
\hline CHEMBL1396437 & 688653 & 4.633 & 5.2284 & TRN & & \\
\hline CHEMBL1572578 & 688653 & 5.483 & 5.4296 & TRN & & \\
\hline CHEMBL1344529 & 688653 & \multicolumn{3}{|c|}{6.632999999999999} & 5.8869 & \\
\hline CHEMBL1450799 & 688653 & 4.633 & 4.9215 & TRN & & \\
\hline CHEMBL1520063 & 688653 & 4.783 & 4.8069 & TST & & \\
\hline CHEMBL1550842 & 688653 & 5.233 & 5.006 & TRN & & \\
\hline CHEMBL1613591 & 688653 & \multicolumn{3}{|c|}{6.0329999999999995} & 5.6416 & \\
\hline CHEMBL1597726 & 688653 & 6.983 & 6.428 & TRN & & \\
\hline CHEMBL1332043 & 688653 & \multicolumn{3}{|c|}{5.5329999999999995} & 352 & \\
\hline CHEMBL3195001 & 688653 & 5.683 & 5.4737 & TRN & & \\
\hline CHEMBL1366983 & 688653 & 4.85 & 5.0796 & TRN & & \\
\hline CHEMBL 3192560 & 688653 & 4.683 & 5.4383 & TRN & & \\
\hline CHEMBL1543792 & 688653 & 4.933 & 4.8885 & TRN & & \\
\hline CHEMBL1440833 & 688653 & \multicolumn{3}{|c|}{6.332999999999999} & .5351 & TRN \\
\hline CHEMBL1570398 & 688653 & \multicolumn{3}{|c|}{5.382999999999999} & & \\
\hline CHEMBL2369262 & 688653 & 4.883 & 5.1995 & TRN & & \\
\hline CHEMBL1432528 & 688653 & 4.783 & 5.2521 & TRN & & \\
\hline CHEMBL1445415 & 688653 & 4.783 & 5.2002 & TRN & & \\
\hline CHEMBL1316015 & 688653 & 4.633 & 4.8728 & TST & & \\
\hline CHEMBL1549243 & 688653 & \multicolumn{3}{|c|}{6.332999999999999} & 5.0446 & $\mathrm{TI}$ \\
\hline CHEMBL1348667 & 688653 & 5.433 & 5.4179 & TRN & & \\
\hline CHEMBL1309323 & 688653 & \multicolumn{3}{|c|}{5.332999999999999} & 5.2924 & TRN \\
\hline CHEMBL1457941 & 688653 & \multicolumn{3}{|c|}{6.382999999999999} & 6.0625 & $\mathrm{TR}$ \\
\hline CHEMBL464433 & 688653 & \multicolumn{3}{|c|}{6.082999999999999} & 5.5999 & TRI \\
\hline CHEMBL1451031 & 688653 & 4.783 & 4.9546 & TRN & & \\
\hline CHEMBL1565686 & 688653 & 6.4829 & 5.6379 & TRN & & \\
\hline CHEMBL1456323 & 688653 & 4.833 & 5.6068 & TST & & \\
\hline CHEMBL1359529 & 688653 & \multicolumn{3}{|c|}{6.082999999999999} & 5.4166 & $\mathrm{TR}$ \\
\hline CHEMBL1426565 & 688653 & 4.583 & 4.8662 & TST & & \\
\hline CHEMBL1368400 & 688653 & \multicolumn{3}{|c|}{6.2829999999999995} & 5.4237 & TRN \\
\hline CHEMBL1475709 & 688653 & \multicolumn{3}{|c|}{4.7330000000000005} & 5.2023 & \\
\hline
\end{tabular}




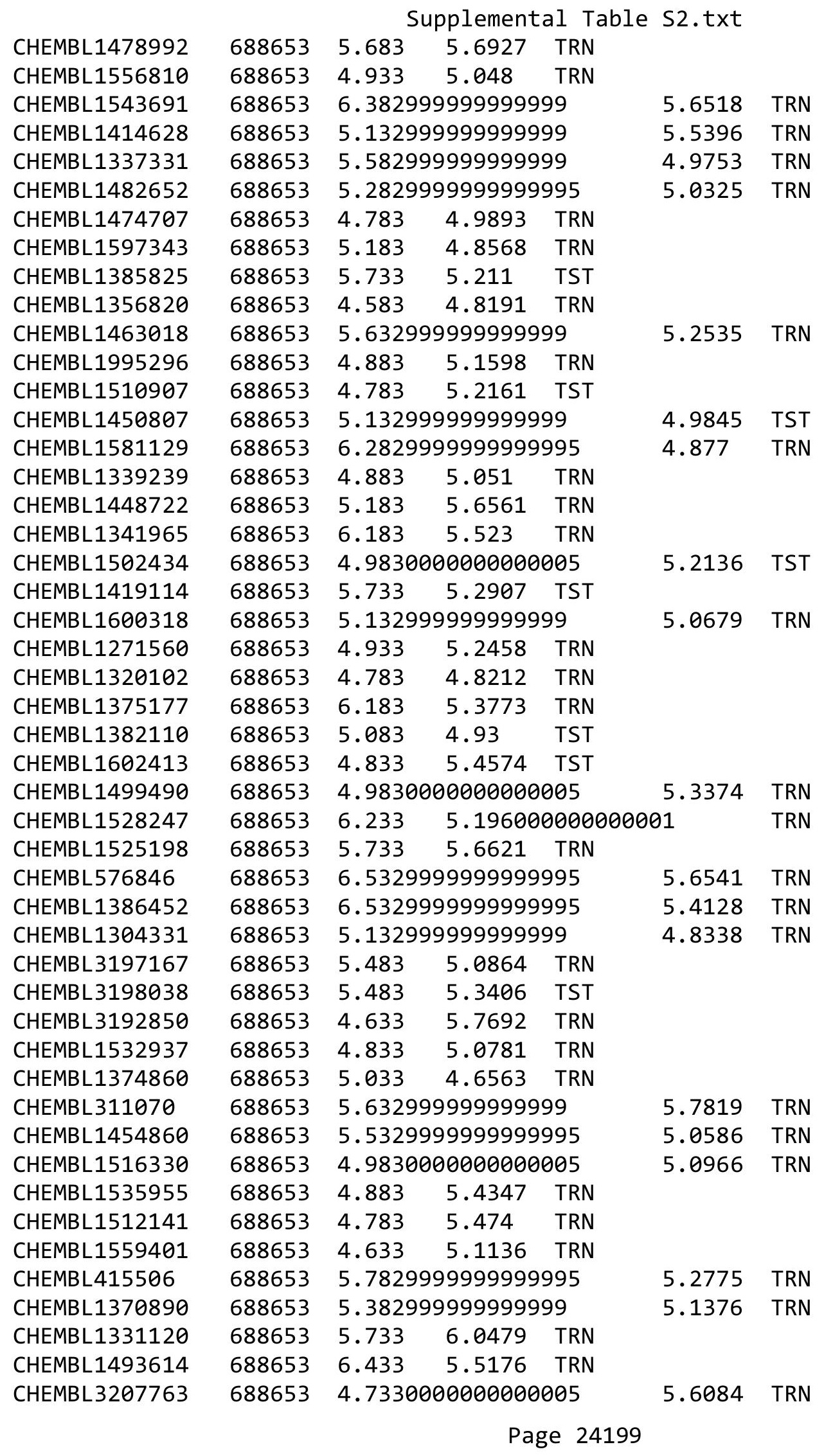




\begin{tabular}{|c|c|c|c|c|c|c|c|}
\hline \multicolumn{8}{|c|}{ oplemental lable s2.txt } \\
\hline CHEMBL1450998 & 688653 & 5.483 & 5.2152 & TRN & & & \\
\hline CHEMBL1604296 & 688653 & \multicolumn{3}{|c|}{5.882999999999999} & 5.3972 & TST & \\
\hline CHEMBL1412123 & 688653 & \multicolumn{3}{|c|}{6.132999999999999} & 5.7132 & TRN & \\
\hline CHEMBL1568658 & 688653 & 4.583 & \multicolumn{3}{|c|}{4.718999999999999} & TST & \\
\hline CHEMBL1456203 & 688653 & 4.833 & 5.0295 & TRN & & & \\
\hline CHEMBL1409618 & 688653 & \multicolumn{3}{|c|}{5.632999999999999} & 5.5049 & TRN & \\
\hline CHEMBL1343363 & 688653 & 4.583 & 5.126 & TRN & & & \\
\hline CHEMBL1349481 & 688653 & 4.783 & 5.2435 & TRN & & & \\
\hline CHEMBL1339671 & 688653 & 6.0 & 5.6366 & TRN & & & \\
\hline CHEMBL2369186 & 688653 & \multicolumn{3}{|c|}{6.2829999999999995} & 5.2171 & TRN & \\
\hline CHEMBL1503648 & 688653 & 4.683 & 5.0444 & TRN & & & \\
\hline CHEMBL1399860 & 688653 & 4.883 & 5.1755 & TST & & & \\
\hline CHEMBL1524052 & 688653 & \multicolumn{3}{|c|}{4.7330000000000005} & 4.832 & TST & \\
\hline CHEMBL1316940 & 688653 & 4.783 & 5.7607 & TST & & & \\
\hline CHEMBL1470904 & 688653 & \multicolumn{3}{|c|}{7.082999999999999} & 5.9124 & TRN & \\
\hline CHEMBL1976304 & 688653 & 4.683 & 4.9385 & TST & & & \\
\hline CHEMBL1543248 & 688653 & 5.183 & 5.1439 & TST & & & \\
\hline CHEMBL1568979 & 688653 & 7.3325 & 5.9872 & TRN & & & \\
\hline CHEMBL1320375 & 688653 & 4.683 & 5.2846 & TRN & & & \\
\hline CHEMBL1383379 & 688653 & 5.733 & 5.8038 & TRN & & & \\
\hline CHEMBL1430376 & 688653 & 4.583 & 5.1233 & TRN & & & \\
\hline CHEMBL1319618 & 688653 & 4.783 & 4.72 & TRN & & & \\
\hline CHEMBL1429687 & 688653 & 4.633 & 4.9912 & TRN & & & \\
\hline CHEMBL1452651 & 688653 & 4.833 & 5.1658 & TRN & & & \\
\hline CHEMBL1499459 & 688653 & 4.833 & 5.2195 & TRN & & & \\
\hline CHEMBL1438924 & 688653 & 5.233 & 4.7546 & TST & & & \\
\hline CHEMBL1313741 & 688653 & 5.683 & 5.1201 & TRN & & & \\
\hline CHEMBL1379301 & 688653 & 5.933 & 5.2051 & TRN & & & \\
\hline CHEMBL1420467 & 688653 & 5.233 & 5.3078 & TST & & & \\
\hline CHEMBL1502629 & 688653 & \multicolumn{3}{|c|}{5.332999999999999} & 4.9325 & TST & \\
\hline CHEMBL1411388 & 688653 & \multicolumn{3}{|c|}{5.882999999999999} & 5.1413 & TST & \\
\hline CHEMBL1497012 & 688653 & \multicolumn{3}{|c|}{6.382999999999999} & 5.6524 & TRN & \\
\hline CHEMBL1477229 & 688653 & \multicolumn{3}{|c|}{4.7330000000000005} & 5.0501 & TST & \\
\hline CHEMBL1502133 & 688653 & 6.9329 & 6.0794 & TRN & & & \\
\hline CHEMBL1472242 & 688653 & 4.883 & 5.2536 & TST & & & \\
\hline CHEMBL1488645 & 688653 & \multicolumn{3}{|c|}{4.7330000000000005} & 4.846 & TST & \\
\hline CHEMBL1370224 & 688653 & 6.9329 & 5.3468 & TRN & & & \\
\hline CHEMBL1551283 & 688653 & 4.833 & 5.0314 & TRN & & & \\
\hline CHEMBL3194176 & 688653 & \multicolumn{3}{|c|}{5.332999999999999} & 5.4733 & TST & \\
\hline CHEMBL3213270 & 688653 & \multicolumn{3}{|c|}{4.7330000000000005} & \multicolumn{2}{|c|}{5.707000000000001} & TRN \\
\hline CHEMBL1516667 & 688653 & 4.783 & 5.0928 & TRN & & & \\
\hline CHEMBL1320838 & 688653 & 4.783 & 4.9505 & TRN & & & \\
\hline CHEMBL1448931 & 688653 & 4.583 & 5.1861 & TRN & & & \\
\hline CHEMBL1535952 & 688653 & 4.883 & 5.3102 & TST & & & \\
\hline CHEMBL1464530 & 688653 & \multicolumn{3}{|c|}{5.132999999999999} & \multicolumn{2}{|c|}{5.4670000000000005} & TRN \\
\hline CHEMBL1453539 & 688653 & \multicolumn{3}{|c|}{5.332999999999999} & 5.3089 & TRN & \\
\hline CHEMBL1462244 & 688653 & 5.933 & 6.055 & TRN & & & \\
\hline CHEMBL1362013 & 688653 & 6.683 & 5.6994 & TST & & & \\
\hline
\end{tabular}




\begin{tabular}{|c|c|c|c|c|c|c|c|}
\hline \multicolumn{8}{|c|}{ Supplemental Table S2.txt } \\
\hline CHEMBL1366370 & 688653 & 4.583 & 4.9473 & TRN & & & \\
\hline CHEMBL1356144 & 688653 & 4.683 & 4.8336 & TRN & & & \\
\hline CHEMBL1476510 & 688653 & 5.933 & 5.9391 & TRN & & & \\
\hline CHEMBL1337662 & 688653 & \multicolumn{3}{|c|}{5.832999999999999} & 5.5116 & TRN & \\
\hline CHEMBL1306412 & 688653 & 4.833 & 4.8879 & TST & & & \\
\hline CHEMBL1449740 & 688653 & \multicolumn{3}{|c|}{5.7829999999999995} & 5.2628 & TRN & \\
\hline CHEMBL1477136 & 688653 & 4.633 & 5.3069 & TRN & & & \\
\hline CHEMBL1362566 & 688653 & \multicolumn{3}{|c|}{5.382999999999999} & 4.539 & TRN & \\
\hline CHEMBL1509578 & 688653 & \multicolumn{3}{|c|}{4.9830000000000005} & 4.9987 & TRN & \\
\hline CHEMBL1500271 & 688653 & \multicolumn{3}{|c|}{5.132999999999999} & 5.1177 & TRN & \\
\hline CHEMBL1603922 & 688653 & 5.083 & 5.2985 & TRN & & & \\
\hline CHEMBL1604871 & 688653 & 4.833 & 5.3333 & TST & & & \\
\hline CHEMBL1502358 & 688653 & 4.633 & 5.3108 & TST & & & \\
\hline CHEMBL1498306 & 688653 & 5.183 & 5.6426 & TRN & & & \\
\hline CHEMBL1458674 & 688653 & 5.083 & 5.1965 & TRN & & & \\
\hline CHEMBL1402539 & 688653 & \multicolumn{3}{|c|}{5.2829999999999995} & 5.0601 & TST & \\
\hline CHEMBL1981002 & 688653 & 4.833 & 5.0224 & TST & & & \\
\hline CHEMBL1397788 & 688653 & 4.833 & 5.7419 & TRN & & & \\
\hline CHEMBL1584752 & 688653 & 4.783 & 4.8927 & TRN & & & \\
\hline CHEMBL3190739 & 688653 & 4.833 & 4.8867 & TST & & & \\
\hline CHEMBL1471716 & 688653 & 4.783 & 5.4033 & TRN & & & \\
\hline CHEMBL1476345 & 688653 & 4.633 & 5.2897 & TRN & & & \\
\hline CHEMBL1505167 & 688653 & \multicolumn{3}{|c|}{6.332999999999999} & 5.1051 & TST & \\
\hline CHEMBL1340097 & 688653 & \multicolumn{3}{|c|}{6.0329999999999995} & 5.9178 & TRN & \\
\hline CHEMBL1409781 & 688653 & 5.733 & 4.9092 & TRN & & & \\
\hline CHEMBL1390975 & 688653 & \multicolumn{3}{|c|}{5.882999999999999} & 5.9327 & TRN & \\
\hline CHEMBL1380222 & 688653 & \multicolumn{3}{|c|}{4.7330000000000005} & 5.2645 & TRN & \\
\hline CHEMBL1528690 & 688653 & \multicolumn{3}{|c|}{5.882999999999999} & \multicolumn{2}{|c|}{5.162999999999999} & TRN \\
\hline CHEMBL 3213278 & 688653 & 4.783 & 5.1887 & TST & & & \\
\hline CHEMBL3212892 & 688653 & 4.633 & 5.2084 & TST & & & \\
\hline CHEMBL1568494 & 688653 & 4.783 & 4.9027 & TRN & & & \\
\hline CHEMBL1314580 & 688653 & \multicolumn{3}{|c|}{5.132999999999999} & 5.0787 & TRN & \\
\hline CHEMBL1331218 & 688653 & 5.233 & 5.2056 & TRN & & & \\
\hline CHEMBL1308404 & 688653 & \multicolumn{3}{|c|}{5.2829999999999995} & 4.6539 & TRN & \\
\hline CHEMBL1437103 & 688653 & \multicolumn{3}{|c|}{6.132999999999999} & 5.7187 & TST & \\
\hline CHEMBL469058 & 688653 & 4.933 & 5.2233 & TRN & & & \\
\hline CHEMBL1570812 & 688653 & \multicolumn{3}{|c|}{5.882999999999999} & 5.1489 & TST & \\
\hline CHEMBL1337225 & 688653 & 6.183 & 5.3442 & TRN & & & \\
\hline CHEMBL1480241 & 688653 & 4.783 & 5.029 & TRN & & & \\
\hline CHEMBL1300344 & 688653 & 5.083 & 5.2391 & TST & & & \\
\hline CHEMBL1461585 & 688653 & 4.833 & 4.7174 & TRN & & & \\
\hline CHEMBL1388764 & 688653 & 5.083 & 4.8946 & TRN & & & \\
\hline CHEMBL1437858 & 688653 & 4.883 & 5.4333 & TRN & & & \\
\hline CHEMBL1376611 & 688653 & \multicolumn{3}{|c|}{6.332999999999999} & \multicolumn{2}{|c|}{5.462000000000001} & TRN \\
\hline CHEMBL1497714 & 688653 & 4.833 & 5.2433 & TRN & & & \\
\hline CHEMBL1536068 & 688653 & 4.833 & 5.442 & TRN & & & \\
\hline CHEMBL1493362 & 688653 & \multicolumn{3}{|c|}{5.7829999999999995} & 5.3965 & TRN & \\
\hline CHEMBL3208374 & 688653 & 4.833 & 5.2663 & TST & & & \\
\hline
\end{tabular}




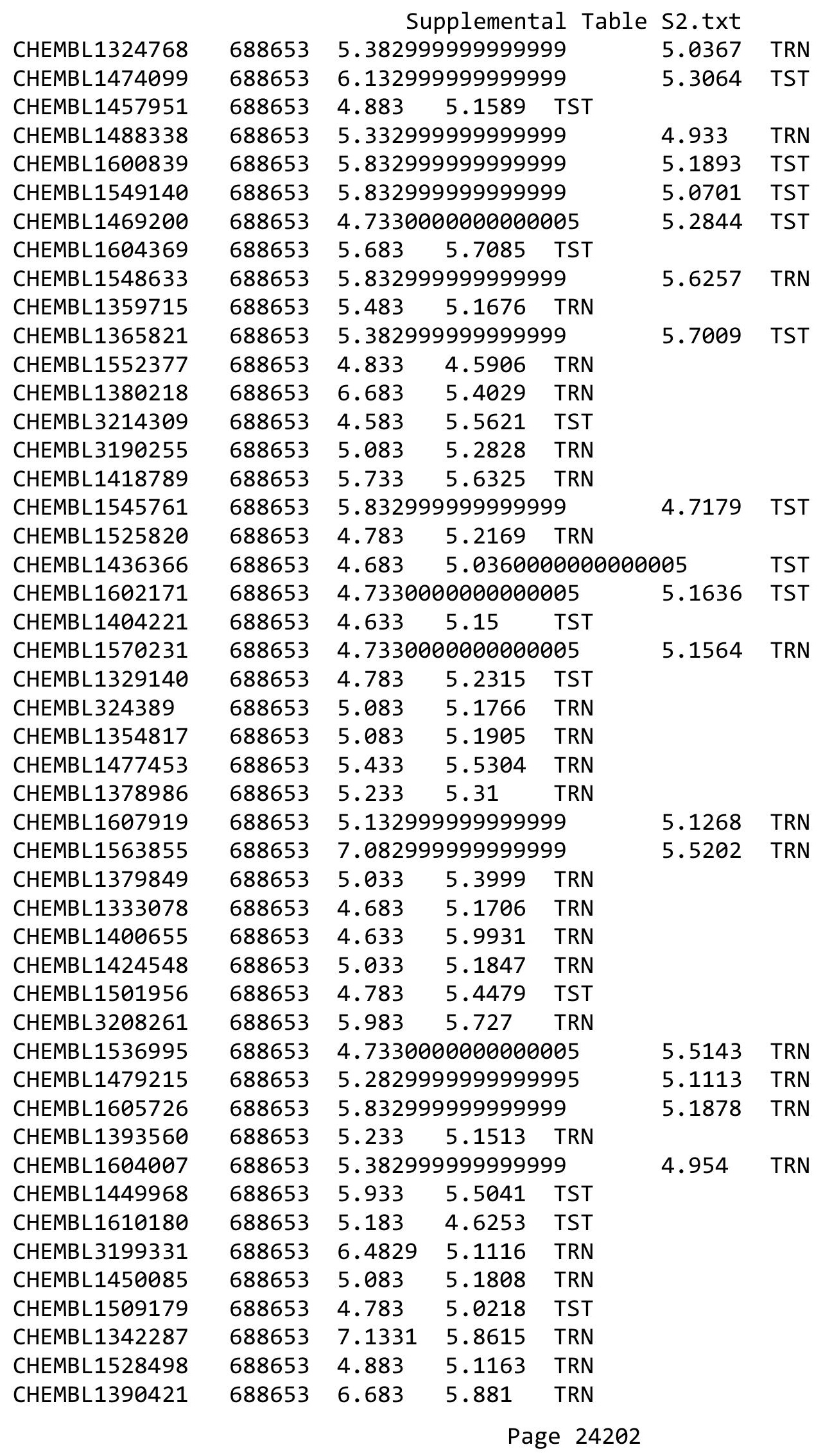




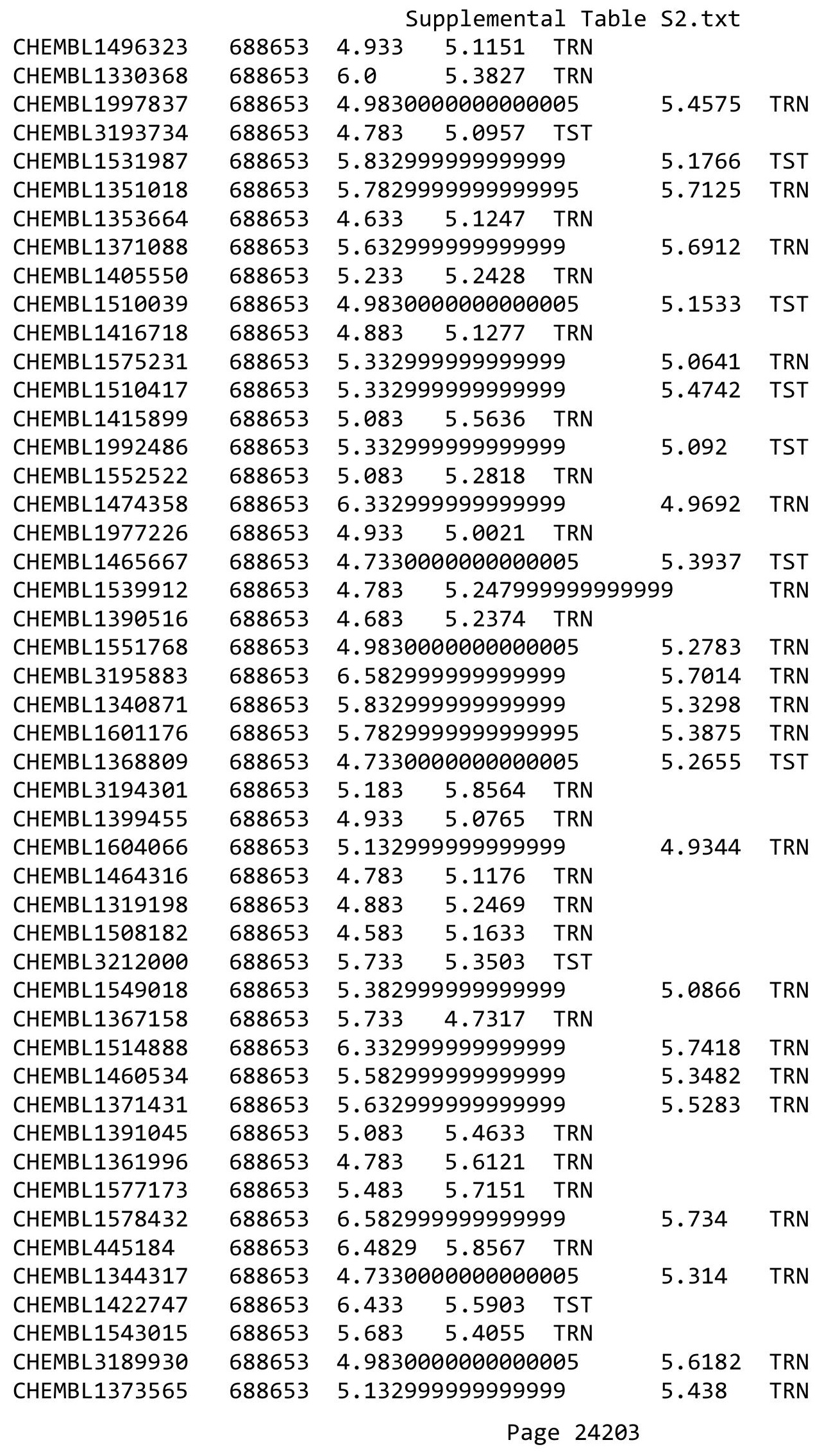




\begin{tabular}{|c|c|c|c|c|c|c|}
\hline \multirow[b]{2}{*}{ CHEMBL1335083 } & \multirow[b]{2}{*}{688653} & \multicolumn{5}{|c|}{ Supplemental Table s2.txt } \\
\hline & & 5.55 & 5.4184 & TRN & & \\
\hline CHEMBL1486376 & 688653 & 4.783 & 5.1326 & TRN & & \\
\hline CHEMBL1350768 & 688653 & 4.583 & 5.4511 & TST & & \\
\hline CHEMBL1323071 & 688653 & 4.783 & 5.3535 & TST & & \\
\hline CHEMBL1473441 & 688653 & \multicolumn{3}{|c|}{5.5329999999999995} & 5.0955 & TRN \\
\hline CHEMBL 78010 & 688653 & 6.183 & 5.8823 & TRN & & \\
\hline CHEMBL1523565 & 688653 & 5.983 & 5.5348 & TRN & & \\
\hline CHEMBL3196521 & 688653 & \multicolumn{3}{|c|}{5.7829999999999995} & 5.6893 & TST \\
\hline CHEMBL1464595 & 688653 & \multicolumn{3}{|c|}{5.5329999999999995} & 5.1488 & TST \\
\hline CHEMBL1479296 & 688653 & 7.0329 & 6.1019 & TRN & & \\
\hline CHEMBL1372286 & 688653 & 5.433 & 5.4665 & TRN & & \\
\hline CHEMBL1358265 & 688653 & 4.883 & 4.7661 & TRN & & \\
\hline CHEMBL1310411 & 688653 & 5.083 & 5.0735 & TST & & \\
\hline CHEMBL1365330 & 688653 & \multicolumn{3}{|c|}{5.7829999999999995} & 4.88 & TRN \\
\hline CHEMBL1533199 & 688653 & \multicolumn{3}{|c|}{4.7330000000000005} & 5.1257 & TRN \\
\hline CHEMBL1527857 & 688653 & \multicolumn{3}{|c|}{6.5329999999999995} & 5.7276 & TRN \\
\hline CHEMBL1416195 & 688653 & 4.783 & 5.7567 & TST & & \\
\hline CHEMBL1563317 & 688653 & 4.783 & 5.0045 & TRN & & \\
\hline CHEMBL1595444 & 688653 & 4.683 & 5.0017 & TRN & & \\
\hline CHEMBL1444860 & 688653 & 4.783 & 5.2138 & TST & & \\
\hline CHEMBL1335581 & 688653 & \multicolumn{3}{|c|}{5.582999999999999} & 5.2563 & TST \\
\hline CHEMBL1402321 & 688653 & 5.183 & 4.9597 & TRN & & \\
\hline CHEMBL1601133 & 688653 & \multicolumn{3}{|c|}{5.5329999999999995} & 5.2387 & TRN \\
\hline CHEMBL1361343 & 688653 & 4.883 & 5.3482 & TRN & & \\
\hline CHEMBL3195420 & 688653 & \multicolumn{3}{|c|}{5.132999999999999} & 5.1046 & TST \\
\hline CHEMBL1611164 & 688653 & \multicolumn{3}{|c|}{4.7330000000000005} & 5.4336 & TRN \\
\hline CHEMBL1530203 & 688653 & 6.4829 & 5.9432 & TRN & & \\
\hline CHEMBL3189196 & 688653 & \multicolumn{3}{|c|}{5.332999999999999} & 5.0898 & TST \\
\hline CHEMBL463763 & 688653 & 7.7328 & 6.2308 & TST & & \\
\hline CHEMBL1347505 & 688653 & \multicolumn{3}{|c|}{5.132999999999999} & 5.3909 & TST \\
\hline CHEMBL1451655 & 688653 & 4.783 & 5.1906 & TRN & & \\
\hline CHEMBL1380580 & 688653 & 5.233 & 5.7427 & TRN & & \\
\hline CHEMBL1327816 & 688653 & 4.633 & 5.0945 & TRN & & \\
\hline CHEMBL1542067 & 688653 & 6.4829 & 5.7986 & TRN & & \\
\hline CHEMBL1467006 & 688653 & 5.033 & 5.4867 & TRN & & \\
\hline CHEMBL1468063 & 688653 & 4.783 & 5.3503 & TRN & & \\
\hline CHEMBL1607469 & 688653 & \multicolumn{3}{|c|}{5.5329999999999995} & 5.3227 & TRN \\
\hline CHEMBL1432720 & 688653 & 4.783 & 4.8424 & TRN & & \\
\hline CHEMBL1372902 & 688653 & \multicolumn{3}{|c|}{5.7829999999999995} & 5.5548 & TRN \\
\hline CHEMBL2374092 & 688653 & 5.6718 & 5.2297 & TST & & \\
\hline CHEMBL1371655 & 688653 & 5.433 & 5.3844 & TST & & \\
\hline CHEMBL1399122 & 688653 & 4.883 & 5.2943 & TRN & & \\
\hline CHEMBL1356053 & 688653 & \multicolumn{3}{|c|}{5.382999999999999} & 4.8203 & TST \\
\hline CHEMBL1321156 & 688653 & 5.983 & 5.2796 & TRN & & \\
\hline CHEMBL1304969 & 688653 & 5.183 & 5.2251 & TRN & & \\
\hline CHEMBL1547377 & 688653 & 4.783 & 5.0315 & TST & & \\
\hline CHEMBL1590707 & 688653 & 4.633 & 5.0954 & TST & & \\
\hline CHEMBL1418191 & 688653 & 4.583 & 4.8761 & TRN & & \\
\hline
\end{tabular}




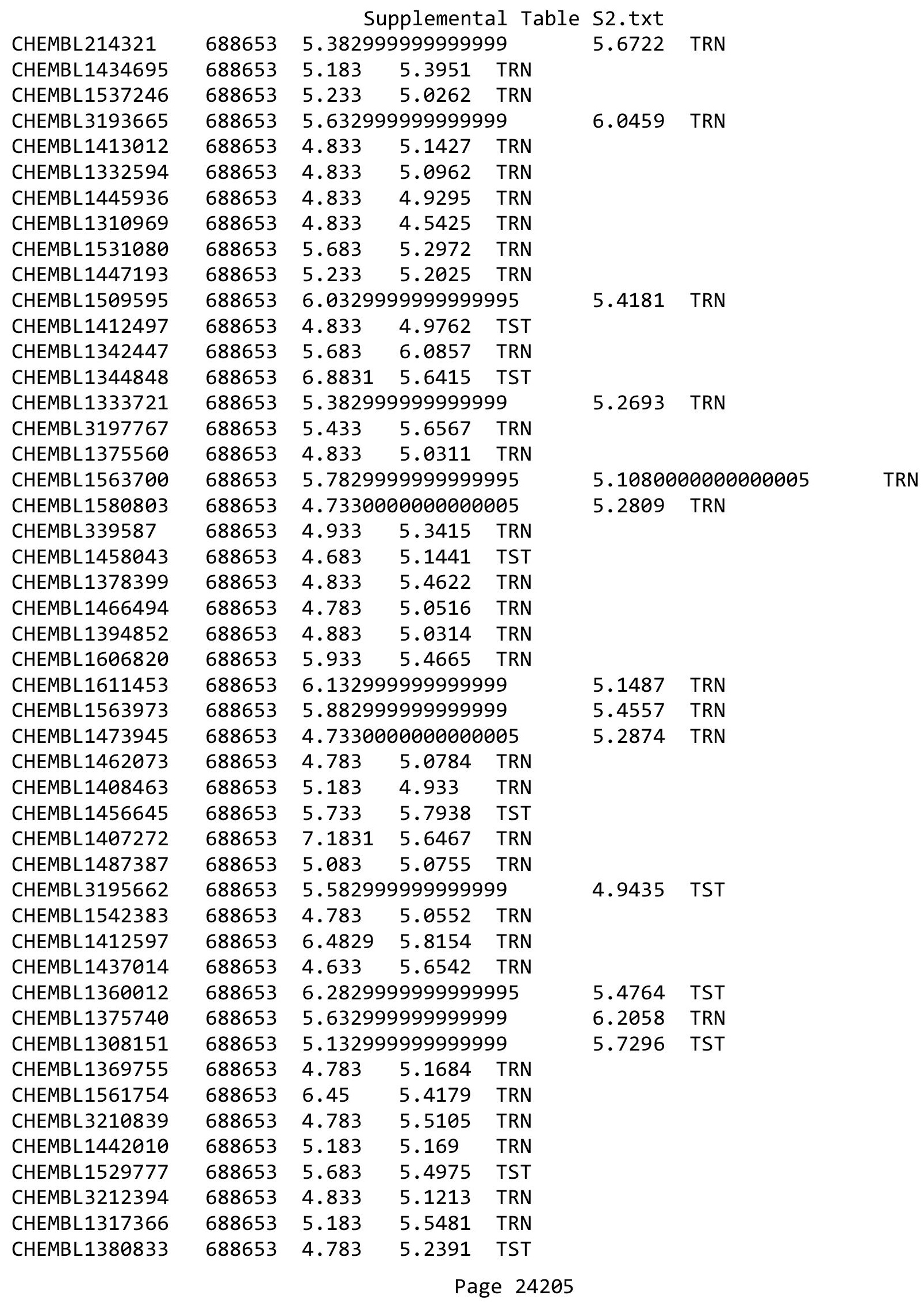




\begin{tabular}{|c|c|c|c|c|c|c|}
\hline \multirow[b]{2}{*}{ CHEMBL1342613 } & \multicolumn{6}{|c|}{ Supplemental Table S2.txt } \\
\hline & 688653 & 4.783 & 5.1074 & TRN & & \\
\hline CHEMBL1328190 & 688653 & 4.783 & 4.6926 & TRN & & \\
\hline CHEMBL1328639 & 688653 & 5.6329 & 99999999 & & 4.9538 & TRN \\
\hline CHEMBL1420155 & 688653 & 6.5829 & 99999999 & 99 & 5.5585 & TRN \\
\hline CHEMBL1380456 & 688653 & 5.083 & 5.4658 & TST & & \\
\hline CHEMBL1367092 & 688653 & 4.7330 & 00000000 & 005 & 4.8022 & \\
\hline CHEMBL 3195550 & 688653 & 5.233 & 5.289 & TRN & & \\
\hline CHEMBL1522641 & 688653 & 4.833 & 5.0563 & TRN & & \\
\hline CHEMBL1438637 & 688653 & 4.783 & 4.9086 & TRN & & \\
\hline CHEMBL1533120 & 688653 & 5.5329 & 99999999 & 995 & 5.3288 & Th \\
\hline CHEMBL1379819 & 688653 & 4.833 & 5.4242 & TRN & & \\
\hline CHEMBL1385287 & 688653 & 4.783 & 5.6312 & TRN & & \\
\hline CHEMBL1505109 & 688653 & 5.5829 & 99999999 & & 5.1452 & \\
\hline CHEMBL1401476 & 688653 & 4.633 & 5.1146 & TRN & & \\
\hline CHEMBL1565578 & 688653 & 5.433 & 5.2442 & TST & & \\
\hline CHEMBL1532501 & 688653 & 6.0329 & 99999999 & 995 & 5.3521 & \\
\hline CHEMBL1558170 & 688653 & 4.883 & 5.1778 & TRN & & \\
\hline CHEMBL1452706 & 688653 & 4.783 & 5.9224 & TST & & \\
\hline CHEMBL 3198130 & 688653 & 5.3329 & 99999999 & & 5.4438 & \\
\hline CHEMBL1382290 & 688653 & 5.433 & 5.6156 & TRN & & \\
\hline CHEMBL1495825 & 688653 & 4.7330 & 00000000 & 005 & 5615 & \\
\hline CHEMBL1525437 & 688653 & 4.783 & 4.9624 & TRN & & \\
\hline CHEMBL1612666 & 688653 & 4.883 & 5.2927 & TRN & & \\
\hline CHEMBL1317615 & 688653 & 4.633 & 5.0144 & TRN & & \\
\hline CHEMBL1552163 & 688653 & 5.5329 & 99999999 & 995 & 5.4938 & TRN \\
\hline CHEMBL1344968 & 688653 & 4.7330 & 00000000 & 005 & & \\
\hline CHEMBL1440907 & 688653 & 5.233 & 5.1351 & TRN & & \\
\hline CHEMBL1439278 & 688653 & 4.833 & 5.0583 & TST & & \\
\hline CHEMBL 260451 & 688653 & 7.2832 & 6.3475 & TRN & & \\
\hline CHEMBL1590587 & 688653 & 5.233 & 5.3636 & TRN & & \\
\hline CHEMBL1484293 & 688653 & 5.233 & 5.1767 & TRN & & \\
\hline CHEMBL1367568 & 688653 & 5.233 & 5.012 & TRN & & \\
\hline CHEMBL1532631 & 688653 & 5.233 & 5.1632 & TST & & \\
\hline CHEMBL 3197922 & 688653 & 5.5829 & 99999999 & & 5.4027 & TRN \\
\hline CHEMBL1410437 & 688653 & 5.8829 & 99999999 & & 5.4844 & $\mathrm{TR}$ \\
\hline CHEMBL1466913 & 688653 & 5.3829 & 99999999 & & 5.4195 & \\
\hline CHEMBL 3211021 & 688653 & 5.1329 & 99999999 & & 5.079 & \\
\hline CHEMBL 3191619 & 688653 & 5.933 & 5.2618 & TRN & & \\
\hline CHEMBL1313826 & 688653 & 5.1329 & 99999999 & & 4.7822 & TRI \\
\hline CHEMBL1421652 & 688653 & 5.3329 & 99999999 & & 5.5267 & TR \\
\hline CHEMBL1405816 & 688653 & 5.3829 & 99999999 & & 4.7842 & \\
\hline CHEMBL1444924 & 688653 & 5.7829 & 99999999 & 995 & 5.1458 & TRा \\
\hline CHEMBL1526153 & 688653 & 5.1329 & 99999999 & & 4.9221 & TRA \\
\hline CHEMBL1549911 & 688653 & 5.683 & 4.976 & TRN & & \\
\hline CHEMBL1549051 & 688653 & 5.183 & 5.0721 & TRN & & \\
\hline CHEMBL1528826 & 688653 & 4.883 & 5.29799 & 99999 & 99 & \\
\hline CHEMBL1513214 & 688653 & 4.583 & 4.7667 & TRN & & \\
\hline CHEMBL 3193098 & 688653 & 6.2829 & 99999999 & 995 & 6.018 & \\
\hline
\end{tabular}




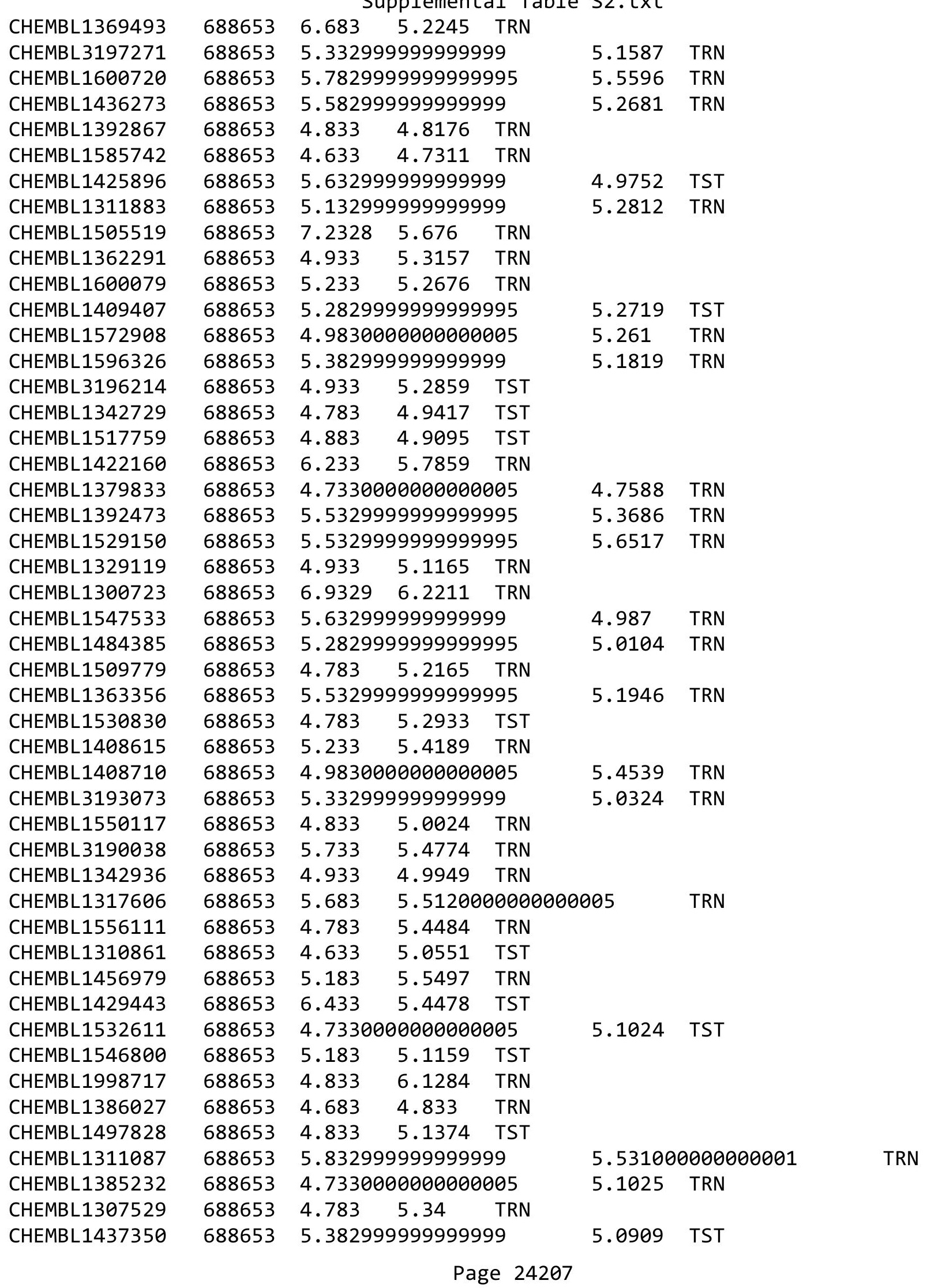




\begin{tabular}{|c|c|c|c|c|c|c|}
\hline & & \multicolumn{5}{|c|}{ Supplemental Table S2.txt } \\
\hline CHEMBL3208941 & 688653 & 5.683 & 5.1101 & TRN & & \\
\hline CHEMBL1386854 & 688653 & 4.883 & 5.3086 & TST & & \\
\hline CHEMBL1570542 & 688653 & 5.683 & 5.6167 & TRN & & \\
\hline CHEMBL1428467 & 688653 & 4.833 & 5.1748 & TRN & & \\
\hline CHEMBL3193959 & 688653 & 5.233 & 5.5018 & TRN & & \\
\hline CHEMBL1299352 & 688653 & 4.633 & 5.4956 & TST & & \\
\hline CHEMBL1383572 & 688653 & 4.883 & 5.1839 & TRN & & \\
\hline CHEMBL1334984 & 688653 & \multicolumn{3}{|c|}{5.332999999999999} & 5.0985 & TR \\
\hline CHEMBL3198155 & 688653 & 5.433 & 5.114 & TRN & & \\
\hline CHEMBL1556143 & 688653 & 5.233 & 5.5929 & TRN & & \\
\hline CHEMBL1497047 & 688653 & 4.883 & \multicolumn{3}{|c|}{5.531000000000001} & $1 \mathrm{nN}$ \\
\hline CHEMBL1310646 & 688653 & 5.083 & 5.166 & TRN & & \\
\hline CHEMBL1327129 & 688653 & 4.633 & 4.6591 & TRN & & \\
\hline CHEMBL1414663 & 688653 & 4.833 & 5.011 & TRN & & \\
\hline CHEMBL1558236 & 688653 & 5.083 & 5.4573 & TRN & & \\
\hline CHEMBL1368263 & 688653 & 5.233 & 4.68 & TRN & & \\
\hline CHEMBL1562114 & 688653 & \multicolumn{3}{|c|}{5.132999999999999} & 4.7871 & TRN \\
\hline CHEMBL1430237 & 688653 & \multicolumn{3}{|c|}{4.7330000000000005} & 5.0164 & TST \\
\hline CHEMBL1467256 & 688653 & \multicolumn{3}{|c|}{4.7330000000000005} & 5.271 & TRN \\
\hline CHEMBL3192493 & 688653 & \multicolumn{3}{|c|}{5.7829999999999995} & 5.07 & TST \\
\hline CHEMBL1499792 & 688653 & \multicolumn{3}{|c|}{5.132999999999999} & 5.2241 & TST \\
\hline CHEMBL1600510 & 688653 & 5.033 & 5.2861 & TRN & & \\
\hline CHEMBL1383312 & 688653 & 5.483 & 7.2249 & TRN & & \\
\hline CHEMBL1349166 & 688653 & 4.833 & 5.2547 & TRN & & \\
\hline CHEMBL1469288 & 688653 & 4.633 & 5.2552 & TRN & & \\
\hline CHEMBL1384333 & 688653 & 6.233 & 5.9718 & TST & & \\
\hline CHEMBL3197908 & 688653 & \multicolumn{3}{|c|}{4.9830000000000005} & 5.4093 & III \\
\hline CHEMBL1610384 & 688653 & 4.783 & 4.9528 & TRN & & \\
\hline CHEMBL 3197504 & 688653 & \multicolumn{3}{|c|}{5.382999999999999} & 4.7096 & TRN \\
\hline CHEMBL1566229 & 688653 & \multicolumn{3}{|c|}{5.7829999999999995} & 5.8843 & TRN \\
\hline CHEMBL1400666 & 688653 & \multicolumn{3}{|c|}{4.7330000000000005} & 5.1564 & TST \\
\hline CHEMBL3196815 & 688 & & 5.2025 & TRN & & \\
\hline CHEMBL1348445 & 688653 & \multirow{2}{*}{\multicolumn{3}{|c|}{4.7330000000000005}} & & \\
\hline CHEMBL1339997 & 688653 & & & & 5.1521 & TS \\
\hline CHEMBL1300838 & 688653 & 4.833 & 5.2272 & TRN & & \\
\hline CHEMBL1490935 & 688653 & & 4.9307 & TRN & & \\
\hline CHEMBL1375907 & 688653 & & \multicolumn{3}{|c|}{5.093999999999999} & . \\
\hline CHEMBL1536287 & 688653 & 5.683 & 5.2387 & TRN & & \\
\hline CHEMBL1304065 & 688653 & 4.633 & 5.0013 & TRN & & \\
\hline CHEMBL1488385 & 688653 & 5.033 & 4.8512 & TRN & & \\
\hline CHEMBL1568820 & 688653 & \multicolumn{3}{|c|}{4.7330000000000005} & 5.2906 & IRIN \\
\hline CHEMBL3212397 & 688653 & \multicolumn{3}{|c|}{5.132999999999999} & 5.5388 & Tार \\
\hline CHEMBL1550325 & 688653 & \multicolumn{3}{|c|}{5.5329999999999995} & 5.5213 & TRN \\
\hline CHEMBL1497102 & 688653 & \multicolumn{3}{|c|}{5.5329999999999995} & 5.937 & TRN \\
\hline CHEMBL1535049 & 688653 & \multicolumn{3}{|c|}{4.7330000000000005} & 4.895 & TST \\
\hline CHEMBL1303165 & 688653 & 5.033 & 5.1134 & TST & & \\
\hline CHEMBL1534136 & 688653 & \multicolumn{3}{|c|}{6.382999999999999} & .0712 & RN \\
\hline CHEMBL1464688 & 688653 & 4.783 & 5.175 & TST & & \\
\hline
\end{tabular}




\begin{tabular}{|c|c|c|c|c|c|c|}
\hline & \multicolumn{5}{|c|}{ plemen } \\
\hline CHEMBL1366274 & 688653 & 5.033 & 5.1831 & TRN & & \\
\hline CHEMBL1555045 & 688653 & \multicolumn{3}{|c|}{4.7330000000000005} & 4.9456 & TST \\
\hline CHEMBL 2001381 & 688653 & \multicolumn{3}{|c|}{4.7330000000000005} & 5.419 & \\
\hline CHEMBL1377469 & 688653 & 6.233 & 5.4658 & TRN & & \\
\hline CHEMBL1304741 & 688653 & 4.933 & 4.8879 & TST & & \\
\hline CHEMBL1538515 & 688653 & \multicolumn{3}{|c|}{6.332999999999999} & 5.379 & \\
\hline CHEMBL1475635 & 688653 & \multicolumn{3}{|c|}{4.7330000000000005} & 5.1997 & \\
\hline CHEMBL1418583 & 688653 & 4.783 & 5.3687 & TRN & & \\
\hline CHEMBL1336808 & 688653 & \multicolumn{3}{|c|}{5.882999999999999} & 7307 & \\
\hline CHEMBL1403068 & 688653 & 4.883 & 5.3506 & TST & & \\
\hline CHEMBL1601158 & 688653 & \multicolumn{3}{|c|}{5.5329999999999995} & 5.1964 & \\
\hline CHEMBL1320578 & 688653 & 4.883 & 5.3034 & TRN & & \\
\hline CHEMBL1425572 & 688653 & 6.683 & 5.7886 & TRN & & \\
\hline CHEMBL1464220 & 688653 & 4.783 & 4.9785 & TRN & & \\
\hline CHEMBL1457648 & 688653 & \multicolumn{3}{|c|}{4.7330000000000005} & 5.1898 & \\
\hline CHEMBL1524347 & 688653 & 5.683 & 5.7 & TRN & & \\
\hline CHEMBL 3195878 & 688653 & \multicolumn{3}{|c|}{5.382999999999999} & 2466 & \\
\hline CHEMBL1320247 & 688653 & \multicolumn{3}{|c|}{4.7330000000000005} & 5.4745 & \\
\hline CHEMBL1498004 & 688653 & \multicolumn{3}{|c|}{5.132999999999999} & 251 & \\
\hline CHEMBL14 & 688653 & \multicolumn{3}{|c|}{5.2829999999999995} & 376 & \\
\hline CHEMBL1364577 & 688653 & \multicolumn{3}{|c|}{7.082999999999999} & 5.8435 & \\
\hline CHEMBL1479906 & 688653 & \multicolumn{3}{|c|}{5.582999999999999} & 5.347 & \\
\hline CHEMBL1513131 & 688653 & 5.733 & 5.2697 & TRN & & \\
\hline CHEMBL14 & 688 & \multirow{2}{*}{\multicolumn{3}{|c|}{$\begin{array}{lcc}5.1 & 5.3527 & \text { TRN } \\
6.832999999999999\end{array}$}} & & \\
\hline CHEMBL1516542 & 688653 & & & & 6.2686 & \\
\hline CHEMBL1450185 & 688653 & \multicolumn{3}{|c|}{$\begin{array}{lll}5.183 & 5.3236 & \text { TST }\end{array}$} & & \\
\hline CHEMBL1539670 & 688653 & 5.683 & 5.3379 & TRN & & \\
\hline CHEMBL1351769 & 688653 & \multicolumn{3}{|c|}{6.2829999999999995} & & \\
\hline CHEMBL14 & 688 & \multicolumn{3}{|c|}{6.0329999999999995} & & \\
\hline CHEMBL 3192279 & 688653 & & 5.0832 & \\
\hline CHEMBL1415300 & 688653 & \multicolumn{3}{|c|}{$\begin{array}{l}5.7829999999999995 \\
4.883 \quad 5.1973 \quad \text { TRN }\end{array}$} & & \\
\hline CHEMBL 3199873 & 688653 & 4.833 & 5.1281 & TRN & & \\
\hline CHEMBL1548896 & 688653 & 5.1329 & 9999999 & & & \\
\hline CHEMBL1 & 688653 & 6.5829 & ( & & 97 & \\
\hline CHEMBL1557451 & 688653 & 5.3829 & 9999999 & & 5.9682 & \\
\hline CHEMBL1398967 & 688653 & 5.8329 & 9999999 & & 5.4132 & $\mathrm{TH}$ \\
\hline CHEMBL1507975 & 688653 & 4.783 & 4.9658 & TST & & \\
\hline CHEMBL1354470 & 688653 & 5.8329 & 9999999 & & & \\
\hline CHEMBL1533140 & 688653 & 4.7330 & $\partial 000000$ & 005 & 5.2005 & \\
\hline CHEMBL1524688 & 688653 & 6.433 & 5.69 & TRN & & \\
\hline CHEMBL1394298 & 688653 & 5.2829 & 9999999 & 995 & 4.9247 & 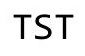 \\
\hline CHEMBL1599375 & 688653 & 4.783 & 5.4079 & TRN & & \\
\hline CHEMBL1405633 & 688653 & 5.8829 & 9999999 & & & T \\
\hline CHEMBL 3208246 & 688653 & 4.9830 & $\partial 000000$ & 005 & 5.0894 & \\
\hline CHEMBL 3192394 & 688653 & 5.3829 & 9999999 & & 5.1027 & TRN \\
\hline CHEMBL1439309 & 688653 & 4.583 & 5.1495 & TST & & \\
\hline CHEMBL1426292 & 688653 & 5.033 & 5.1208 & TST & & \\
\hline CHEMBL1414176 & 688653 & 5.1329 & 9999999 & & 5.1472 & \\
\hline
\end{tabular}




\begin{tabular}{|c|c|c|c|c|c|c|}
\hline & & \multicolumn{5}{|c|}{ Supplemental Table S2.txt } \\
\hline CHEMBL1576977 & 688653 & \multicolumn{3}{|c|}{5.2829999999999995} & 5.6448 & TRN \\
\hline CHEMBL1588285 & 588653 & 5.933 & 5.4475 & TST & & \\
\hline CHEMBL1591234 & 688653 & \multicolumn{3}{|c|}{4.7330000000000005} & 5.0575 & in \\
\hline CHEMBL1529111 & 688653 & \multicolumn{3}{|c|}{5.7829999999999995} & 5.2774 & \\
\hline CHEMBL1607865 & 688653 & 6.183 & 5.8359 & TRN & & \\
\hline CHEMBL1484754 & 688653 & \multicolumn{3}{|c|}{5.2829999999999995} & 5.2509 & 13 \\
\hline CHEMBL1597227 & 688653 & 4.933 & 5.1848 & TRN & & \\
\hline CHEMBL1603501 & 588653 & 4.783 & 5.1555 & TRN & & \\
\hline CHEMBL3189662 & 688653 & \multicolumn{3}{|c|}{5.632999999999999} & 5.1239 & Th \\
\hline CHEMBL1535024 & 688653 & 4.883 & 5.2598 & TRN & & \\
\hline CHEMBL1399652 & 688653 & 4.633 & 5.0341 & TRN & & \\
\hline HEMBL1594576 & 588653 & 4.933 & 4.5627 & TRN & & \\
\hline CHEMBL3194126 & $68 \varepsilon$ & \multicolumn{3}{|c|}{5.382999999999999} & 5.659 & $T$ \\
\hline CHEMBL1341628 & 688653 & \multicolumn{3}{|c|}{5.2829999999999995} & 4.9964 & \\
\hline HEMBL3211173 & 588653 & \multicolumn{3}{|c|}{5.132999999999999} & 5.2589 & \\
\hline CHEMBL1565917 & 688653 & \multicolumn{3}{|c|}{5.132999999999999} & 5.2766 & \\
\hline CHEMBL1545407 & 688 & 5.083 & 5.2215 & TRN & & \\
\hline CHEMBL138 & $68 \varepsilon$ & \multicolumn{3}{|c|}{5.5329999999999995} & 5.2144 & 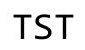 \\
\hline CHEMBL1444869 & 688 & \multicolumn{3}{|c|}{5.382999999999999} & 5.3533 & \\
\hline CHEMBL1365724 & 688653 & \multicolumn{3}{|c|}{5.882999999999999} & 5.4712 & \\
\hline CHEMBL1445664 & 688653 & 4.883 & 5.5826 & TST & & \\
\hline CHEMBL1402732 & 688653 & \multicolumn{3}{|c|}{6.382999999999999} & 5 & \\
\hline CHEMBL140 & 68 & 4.883 & 5.5126 & TST & & \\
\hline CHEMBL3191969 & $68 \varepsilon$ & \multicolumn{3}{|c|}{5.382999999999999} & 517 & \\
\hline HEMBL1582711 & 688653 & \multicolumn{3}{|c|}{6.332999999999999} & 5.8137 & \\
\hline CHEMBL1300536 & 688653 & \multicolumn{3}{|c|}{4.7330000000000005} & 5.4928 & TST \\
\hline CHEMBL15 & 688653 & \multicolumn{3}{|c|}{5.132999999999999} & 5.4939 & \\
\hline CHEMBL3 & 68 & 5.483 & 5.0222 & TST & & \\
\hline CHEMBL1414933 & 68 & \multirow{2}{*}{\multicolumn{3}{|c|}{$\begin{array}{lcc}4.833 & 5.3553 & \text { TRN } \\
5.5329999999999995\end{array}$}} & & \\
\hline CHEMBL1427228 & 688653 & & & & 5.7687 & \\
\hline CHEMBL1495815 & 688653 & \multicolumn{3}{|c|}{$\begin{array}{lll}4.933 & 5.0647 & \text { TRN }\end{array}$} & & \\
\hline CHEMBL & 3 & 5.18 & 5.1666 & TRN & & \\
\hline CHEMBL: & 53 & 7.1331 & 5.7837 & TST & & \\
\hline CHEMBL1459767 & & 5.233 & 6.1377 & TST & & \\
\hline CHEMBL1432251 & 688653 & \multicolumn{3}{|c|}{5.382999999999999} & 5.4143 & \\
\hline CHEMBL1481118 & 688653 & 4.783 & 5.0675 & TRN & & \\
\hline CHEMBL & & 5.683 & 5.2275 & TRN & & \\
\hline CHEMBL14 & 53 & 4.883 & 5.1527 & TRN & & \\
\hline CHEMBL1389343 & 688653 & 4.73300 & 00000000 & 305 & 5.0319 & \\
\hline CHEMBL1386377 & 688653 & 5.83299 & 99999999 & & 5.686 & \\
\hline CHEMBL1455617 & 688653 & 5.33299 & 99999999 & & 5.034 & \\
\hline CHEMBL1497438 & 688653 & 5.78299 & 9999999 & 995 & 5.358 & וצנו \\
\hline CHEMBL1460565 & 688653 & 6.03299 & 99999999 & 995 & 5.0866 & TST \\
\hline CHEMBL1571615 & 688653 & 5.13299 & 99999999 & & 5.891 & TRN \\
\hline CHEMBL1604091 & 688653 & 4.783 & 5.1128 & TR & & \\
\hline CHEMBL1612355 & 688653 & 4.933 & 5.0945 & TST & & \\
\hline CHEMBL1436326 & 688653 & 6.33299 & 99999999 & & 5.5637 & \\
\hline CHEMBL1403279 & 688653 & 5.733 & 5.0589 & TR & & \\
\hline
\end{tabular}




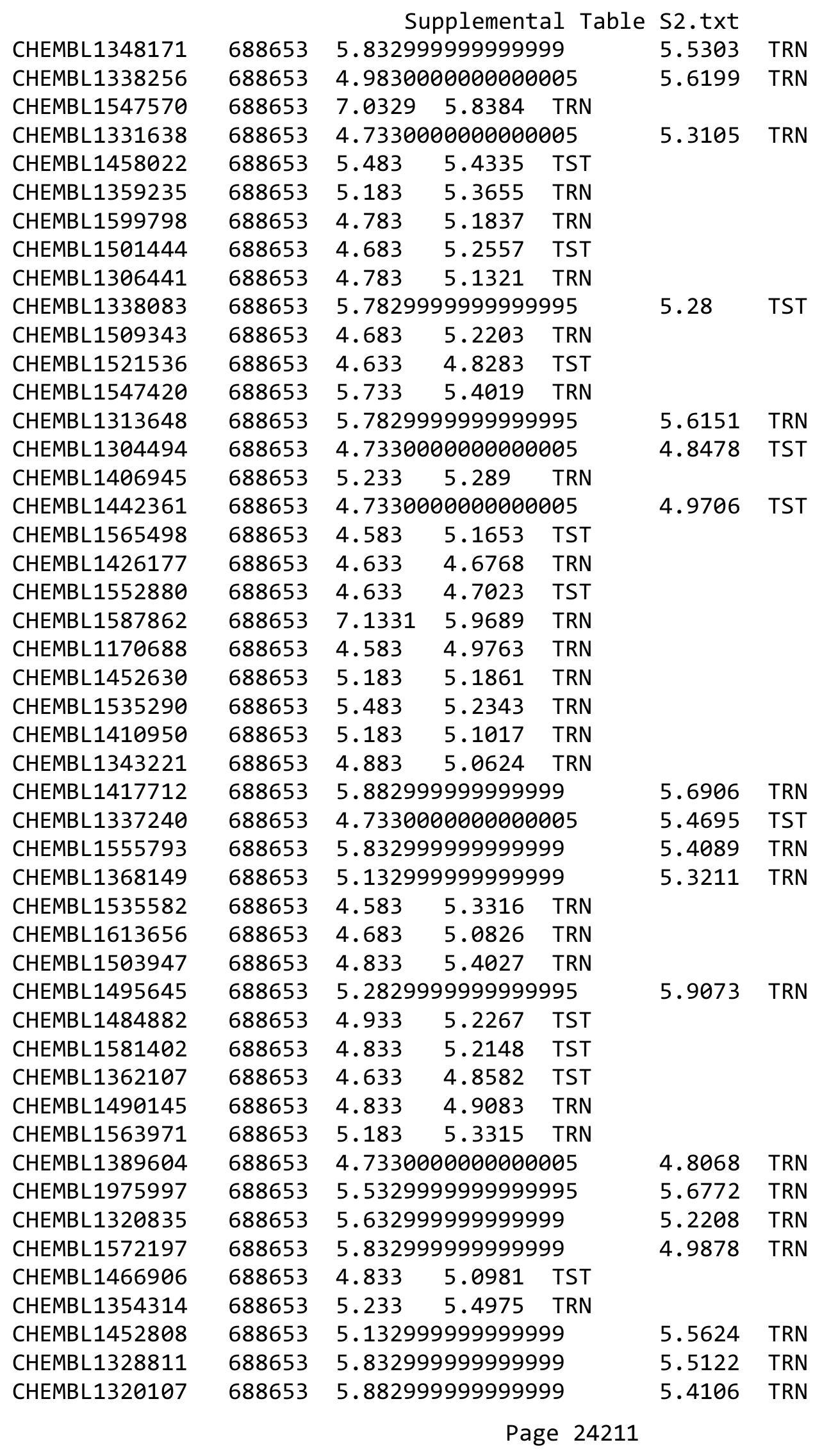




\begin{tabular}{|c|c|c|c|c|c|c|}
\hline \multicolumn{7}{|c|}{ Supplemental Table S2.txt } \\
\hline CHEMBL1347250 & 688653 & 5.933 & \multicolumn{3}{|c|}{5.252999999999999} & TRN \\
\hline CHEMBL1412422 & 688653 & 4.933 & 4.9094 & TRN & & \\
\hline CHEMBL1390519 & 688653 & 4.783 & 5.0657 & TST & & \\
\hline CHEMBL1582569 & 688653 & \multicolumn{3}{|c|}{5.832999999999999} & 5.3008 & TST \\
\hline CHEMBL1350324 & 688653 & \multicolumn{3}{|c|}{5.832999999999999} & 4.9944 & TRN \\
\hline CHEMBL1355804 & 688653 & 4.583 & 4.9054 & TST & & \\
\hline CHEMBL1470236 & 688653 & \multicolumn{3}{|c|}{6.382999999999999} & 5.3367 & TST \\
\hline CHEMBL1401914 & 688653 & 4.933 & 5.2103 & TRN & & \\
\hline CHEMBL1462363 & 688653 & 5.9 & 5.4671 & TRN & & \\
\hline CHEMBL1302639 & 688653 & \multicolumn{3}{|c|}{4.7330000000000005} & 4.8698 & TST \\
\hline CHEMBL1456092 & 688653 & 4.583 & 5.3027 & TST & & \\
\hline CHEMBL1554504 & 688653 & 4.683 & 5.1484 & TRN & & \\
\hline CHEMBL1527382 & 688653 & 5.683 & 5.3921 & TRN & & \\
\hline CHEMBL1461809 & 688653 & 5.233 & 5.1146 & TST & & \\
\hline CHEMBL3213930 & 688653 & \multicolumn{3}{|c|}{6.2829999999999995} & 5.6151 & TST \\
\hline CHEMBL1317796 & 688653 & 5.233 & 5.0046 & TST & & \\
\hline CHEMBL1467543 & 688653 & 5.033 & 5.3472 & TST & & \\
\hline CHEMBL1427138 & 688653 & 5.683 & 5.4131 & TRN & & \\
\hline CHEMBL1301862 & 688653 & 4.833 & 4.9551 & TRN & & \\
\hline CHEMBL1529921 & 688653 & 4.933 & 5.0816 & TRN & & \\
\hline CHEMBL1409078 & 688653 & 4.783 & 5.2058 & TRN & & \\
\hline CHEMBL1513079 & 688653 & \multicolumn{3}{|c|}{6.632999999999999} & 5.8069 & TRN \\
\hline CHEMBL1504573 & 688653 & \multicolumn{3}{|c|}{5.132999999999999} & 5.3137 & TRN \\
\hline CHEMBL1422327 & 688653 & \multicolumn{3}{|c|}{5.2829999999999995} & 5.0743 & TRN \\
\hline CHEMBL1489218 & 688653 & 4.933 & 5.1905 & TST & & \\
\hline CHEMBL1534798 & 688653 & 5.433 & 5.2075 & TRN & & \\
\hline CHEMBL1305304 & 688653 & \multicolumn{3}{|c|}{5.832999999999999} & \multicolumn{2}{|c|}{5.582999999999999} \\
\hline CHEMBL 3211557 & 688653 & 4.783 & 5.3513 & TST & & \\
\hline CHEMBL 1348386 & 688653 & 4.933 & 4.8462 & TRN & & \\
\hline CHEMBL1579841 & 688653 & \multicolumn{3}{|c|}{5.582999999999999} & 5.5197 & TRN \\
\hline CHEMBL 3198982 & 688653 & \multicolumn{3}{|c|}{5.332999999999999} & 5.2564 & TST \\
\hline CHEMBL1402105 & 688653 & \multicolumn{3}{|c|}{5.632999999999999} & 5.1787 & TST \\
\hline CHEMBL1222385 & 688653 & \multicolumn{3}{|c|}{6.2829999999999995} & 5.3803 & TRN \\
\hline CHEMBL1972436 & 688653 & \multicolumn{3}{|c|}{5.632999999999999} & 5.643 & TST \\
\hline CHEMBL1413154 & 688653 & 4.883 & 5.3555 & TRN & & \\
\hline CHEMBL1432841 & 688653 & \multicolumn{3}{|c|}{4.7330000000000005} & 4.9272 & TRN \\
\hline CHEMBL1487549 & 688653 & 4.783 & 5.3906 & TRN & & \\
\hline CHEMBL1549837 & 688653 & \multicolumn{3}{|c|}{5.132999999999999} & 5.1602 & TRN \\
\hline CHEMBL1985529 & 688653 & \multicolumn{3}{|c|}{4.7330000000000005} & 5.3641 & TST \\
\hline CHEMBL1460651 & 688653 & 4.783 & 4.5958 & TRN & & \\
\hline CHEMBL1488608 & 688653 & \multicolumn{3}{|c|}{6.5329999999999995} & 5.4095 & TRN \\
\hline CHEMBL1344387 & 688653 & \multicolumn{3}{|c|}{5.632999999999999} & 5.1715 & TRN \\
\hline CHEMBL 3198569 & 688653 & 4.683 & 4.9297 & TRN & & \\
\hline CHEMBL1387028 & 688653 & 6.13299 & 99999999 & & 5.1159 & TST \\
\hline CHEMBL 1581570 & 688653 & 5.58299 & 99999999 & & 5.0973 & TST \\
\hline CHEMBL1437193 & 688653 & 5.983 & 5.4847 & TST & & \\
\hline CHEMBL1409167 & 688653 & 5.033 & 5.1302 & TRN & & \\
\hline
\end{tabular}




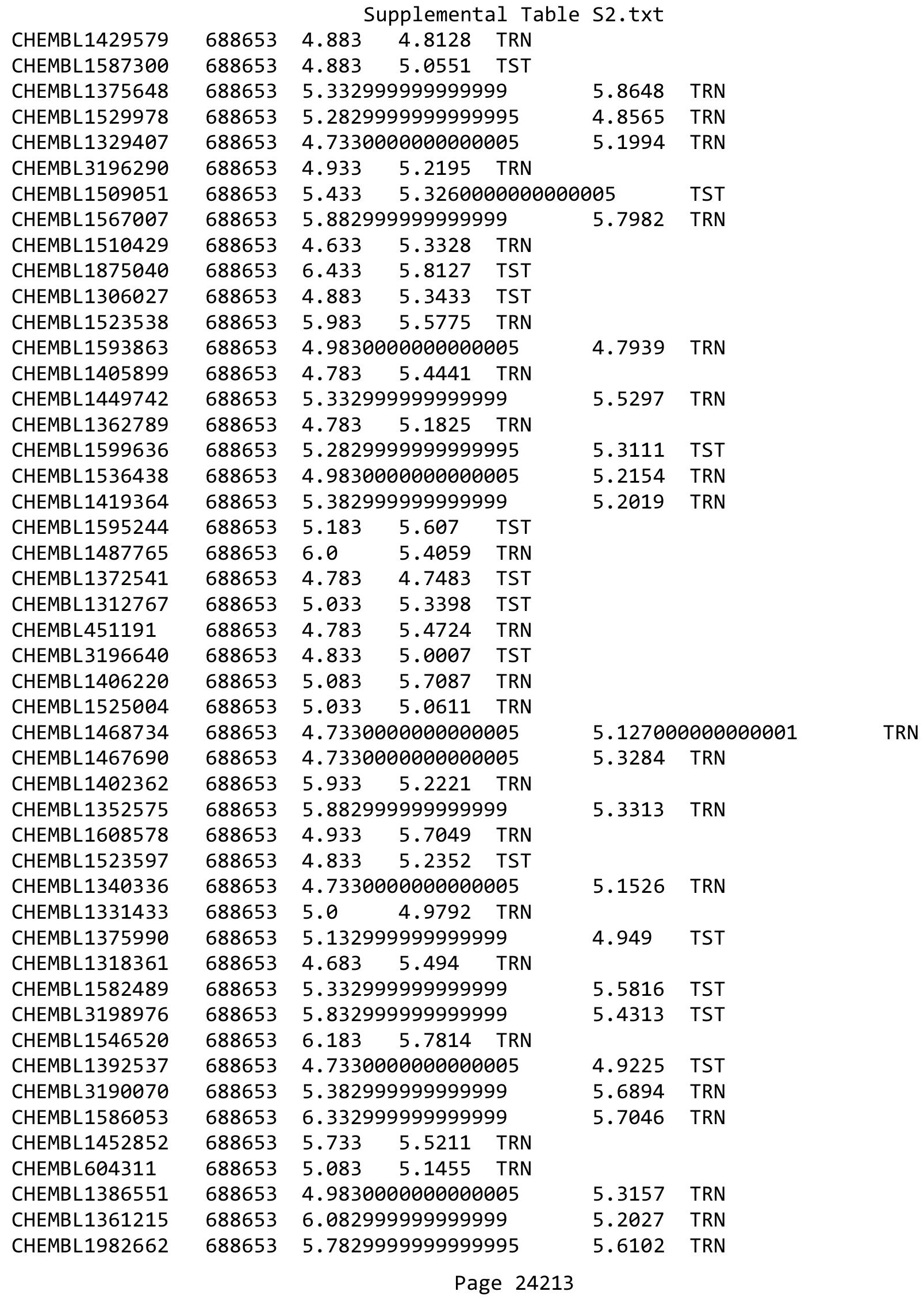




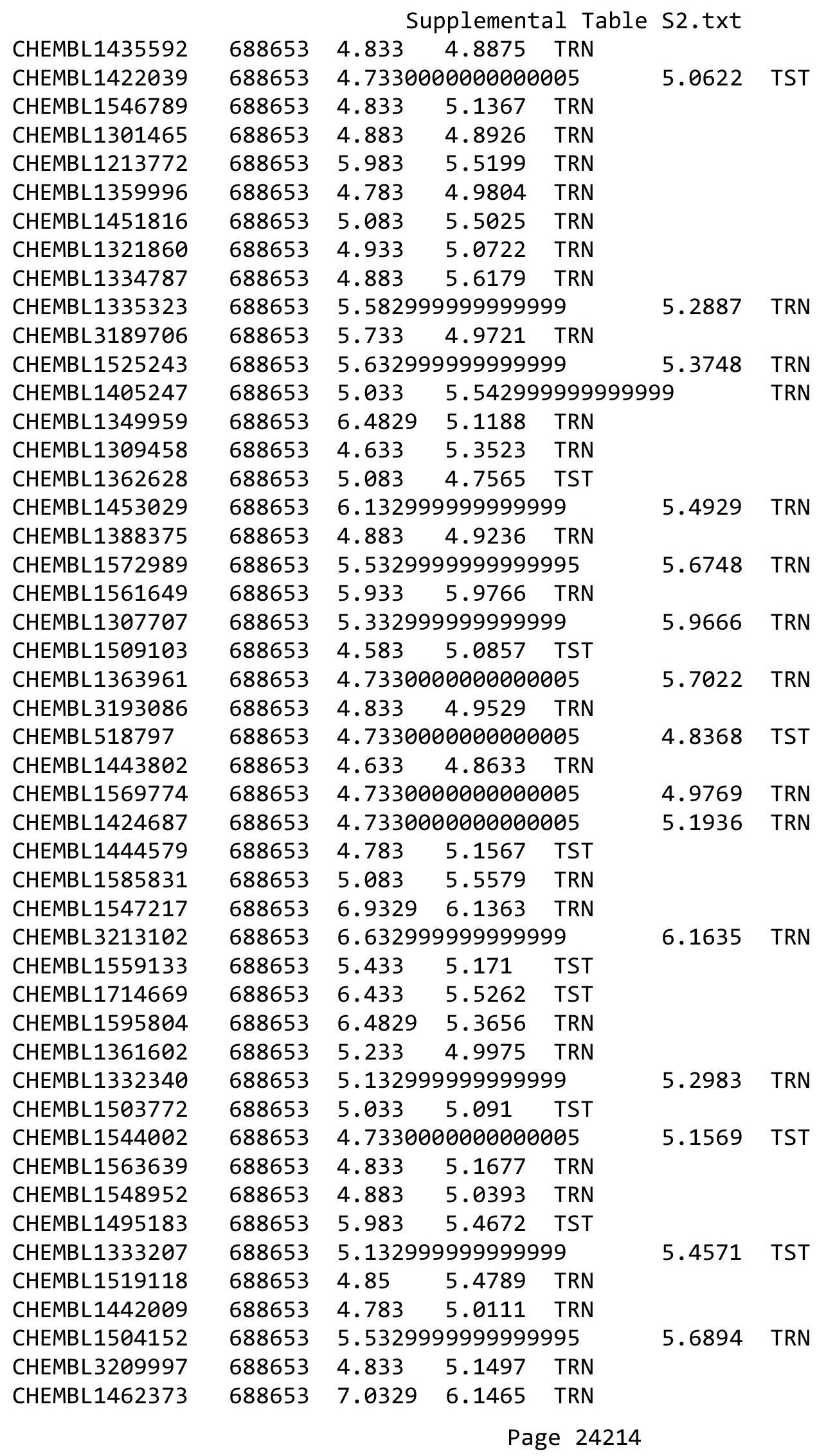




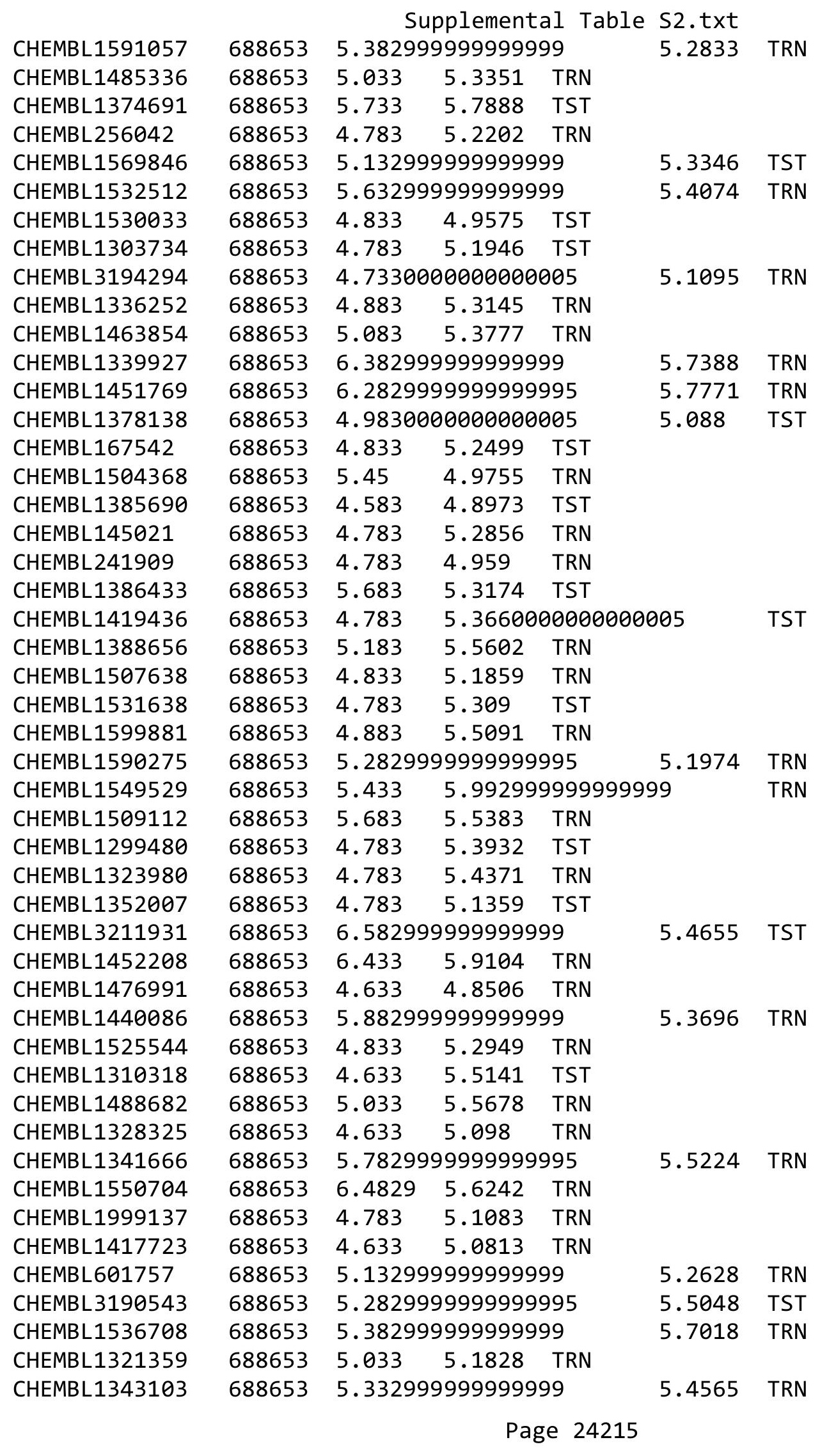




\begin{tabular}{|c|c|c|c|c|c|c|}
\hline & & \multicolumn{5}{|c|}{ Supplemental Table s2.txt } \\
\hline CHEMBL1402185 & 688653 & 5.183 & 5.4932 & TRN & & \\
\hline CHEMBL1214525 & 688653 & 6.2 & 5.6291 & TRN & & \\
\hline CHEMBL1488459 & 688653 & 4.933 & 5.5325 & TST & & \\
\hline CHEMBL1374010 & 688653 & 4.633 & 5.1141 & TRN & & \\
\hline CHEMBL1567682 & 688653 & 5.733 & 5.1972 & TRN & & \\
\hline CHEMBL1545159 & 688653 & \multicolumn{3}{|c|}{4.7330000000000005} & 4.691 & TRN \\
\hline CHEMBL1342992 & 688653 & 4.783 & 4.9906 & TST & & \\
\hline CHEMBL1487639 & 688653 & 4.783 & 5.5131 & TRN & & \\
\hline CHEMBL1584917 & 688653 & \multicolumn{3}{|c|}{5.582999999999999} & 5.7662 & TST \\
\hline CHEMBL1442846 & 688653 & 5.183 & 5.1827 & TST & & \\
\hline CHEMBL1475976 & 688653 & 4.883 & 4.8483 & TRN & & \\
\hline CHEMBL1449854 & 688653 & 4.833 & 4.9857 & TRN & & \\
\hline CHEMBL1486920 & 688653 & 4.933 & 5.3703 & TRN & & \\
\hline CHEMBL1539194 & 688653 & 4.883 & 5.1162 & TST & & \\
\hline CHEMBL1428003 & 688653 & 4.633 & 4.4796 & TRN & & \\
\hline CHEMBL1359059 & 688653 & 5.233 & 5.3397 & TRN & & \\
\hline CHEMBL1409255 & 688653 & 4.883 & 5.1324 & TRN & & \\
\hline CHEMBL1290401 & 688653 & 5.233 & 5.3778 & TRN & & \\
\hline CHEMBL1301786 & 688653 & 4.783 & 5.2714 & TST & & \\
\hline CHEMBL1592618 & 688653 & \multicolumn{3}{|c|}{6.2829999999999995} & 5.2206 & TRN \\
\hline CHEMBL1302837 & 688653 & 5.183 & 5.3301 & TRN & & \\
\hline CHEMBL1499314 & 688653 & \multicolumn{3}{|c|}{4.7330000000000005} & 5.4473 & TRN \\
\hline CHEMBL1517603 & 688653 & \multicolumn{3}{|c|}{6.0329999999999995} & 5.6296 & TRN \\
\hline CHEMBL1408108 & 688653 & 5.033 & 5.0899 & TST & & \\
\hline CHEMBL1597688 & 688653 & \multicolumn{3}{|c|}{4.9830000000000005} & 4.9229 & TRN \\
\hline CHEMBL1380195 & 688653 & 4.783 & 5.4145 & TST & & \\
\hline CHEMBL1546325 & 688653 & \multicolumn{3}{|c|}{5.5329999999999995} & 5.5187 & TRN \\
\hline CHEMBL1458067 & 688653 & 5.233 & \multicolumn{3}{|c|}{5.6129999999999995} & TRN \\
\hline CHEMBL1985165 & 688653 & 5.033 & 5.5063 & TRN & & \\
\hline CHEMBL1579291 & 688653 & 4.833 & 5.2859 & TRN & & \\
\hline CHEMBL1490789 & 688653 & 5.983 & 4.9054 & TST & & \\
\hline CHEMBL3213344 & 688653 & \multicolumn{3}{|c|}{5.2829999999999995} & 5.1577 & TRN \\
\hline CHEMBL1550734 & 688653 & 7.6326 & 6.7253 & TRN & & \\
\hline CHEMBL1330670 & 688653 & 5.233 & 5.8119 & TRN & & \\
\hline CHEMBL1584190 & 688653 & 5.683 & 5.6519 & TRN & & \\
\hline CHEMBL1399869 & 688653 & 4.883 & 5.0472 & TRN & & \\
\hline CHEMBL1989372 & 688653 & 6.183 & 6.0753 & TRN & & \\
\hline CHEMBL1581016 & 688653 & \multicolumn{3}{|c|}{4.7330000000000005} & 5.4926 & TRN \\
\hline CHEMBL1448612 & 688653 & \multicolumn{3}{|c|}{4.7330000000000005} & 5.1884 & TST \\
\hline CHEMBL1497295 & 688653 & \multicolumn{3}{|c|}{4.7330000000000005} & 5.2663 & TRN \\
\hline CHEMBL1473261 & 688653 & 5.683 & 5.3779 & TRN & & \\
\hline CHEMBL1400318 & 688653 & 6.7331 & \multicolumn{3}{|c|}{5.6339999999999995} & TST \\
\hline CHEMBL3207825 & 688653 & \multicolumn{3}{|c|}{6.2829999999999995} & 5.7876 & TRN \\
\hline CHEMBL451748 & 688653 & \multicolumn{3}{|c|}{6.2829999999999995} & 5.4938 & TRN \\
\hline CHEMBL1494624 & 688653 & \multicolumn{3}{|c|}{5.7829999999999995} & 5.5414 & TRN \\
\hline CHEMBL1490017 & 688653 & 6.4829 & 5.7457 & TRN & & \\
\hline \multirow{2}{*}{ CHEMBL1548614 } & 688653 & 5.083 & 5.6081 & TRN & & \\
\hline & 688653 & 5.033 & 5.5962 & TRN & & \\
\hline
\end{tabular}





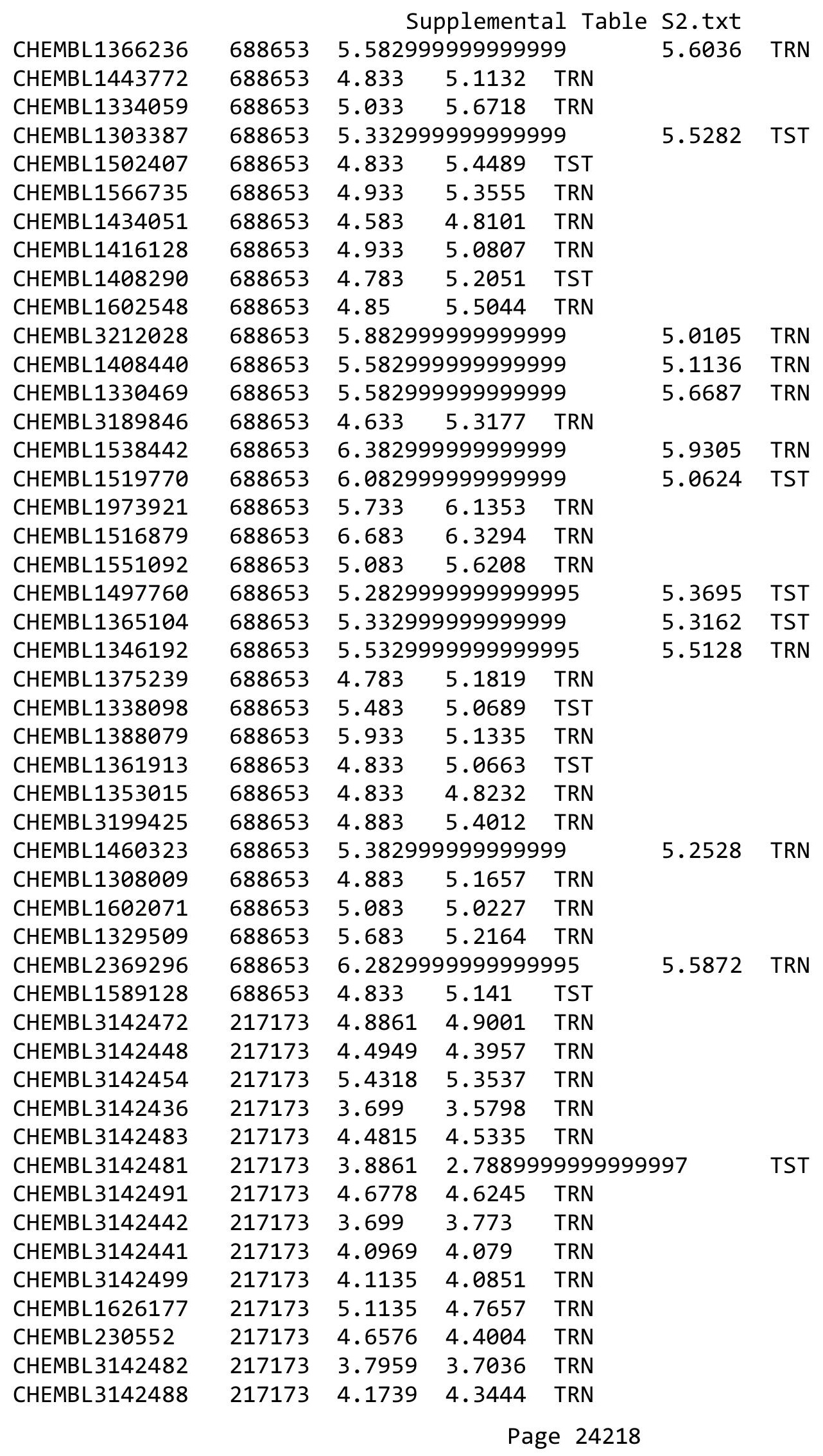




\begin{tabular}{|c|c|c|c|c|}
\hline \multicolumn{5}{|c|}{ Supplemental Table S2.txt } \\
\hline CHEMBL3142462 & 217173 & 4.4318 & 3.2833 & TST \\
\hline CHEMBL3142478 & 217173 & 5.2518 & 5.3493 & TRN \\
\hline CHEMBL3142437 & 217173 & 3.4815 & 2.9888 & TST \\
\hline CHEMBL 3142467 & 217173 & 4.7212 & 4.965 & TRN \\
\hline CHEMBL 3142490 & 217173 & 5.4437 & 5.4028 & TRN \\
\hline CHEMBL 3142451 & 217173 & 5.2518 & 5.1421 & TRN \\
\hline CHEMBL3142492 & 217173 & 4.2218 & 4.4292 & TRN \\
\hline CHEMBL3142430 & 217173 & 5.041 & 4.7951 & TRN \\
\hline CHEMBL 3142440 & 217173 & 4.1739 & 3.5182 & TST \\
\hline CHEMBL3142463 & 217173 & 4.9586 & 5.0852 & TRN \\
\hline CHEMBL 3142485 & 217173 & 3.5376 & 3.4167 & TRN \\
\hline CHEMBL 3142464 & 217173 & 5.0 & 4.7239 & TRN \\
\hline CHEMBL3142501 & 217173 & 3.5376 & 3.7249 & TRN \\
\hline CHEMBL 3142445 & 217173 & 3.7696 & 3.6659 & TRN \\
\hline CHEMBL3142479 & 217173 & 4.2757 & 4.394 & TRN \\
\hline CHEMBL 3142453 & 217173 & 4.2518 & 4.4763 & TRN \\
\hline CHEMBL3142439 & 217173 & 4.301 & 4.4829 & TRN \\
\hline CHEMBL3142438 & 217173 & 4.301 & 4.3417 & TST \\
\hline CHEMBL3142449 & 217173 & 4.1739 & 4.1954 & TRN \\
\hline CHEMBL3142470 & 217173 & 4.7696 & 4.6222 & TRN \\
\hline CHEMBL3142433 & 217173 & 3.301 & 3.4883 & TRN \\
\hline CHEMBL3142446 & 217173 & 4.4815 & 3.1832 & TST \\
\hline CHEMBL3142497 & 217173 & 3.7696 & 3.826 & TRN \\
\hline CHEMBL3142469 & 217173 & 4.9586 & 4.9022 & TRN \\
\hline CHEMBL3142495 & 217173 & 4.7447 & 4.8693 & TRN \\
\hline CHEMBL 3142447 & 217173 & 4.2518 & 4.2454 & TRN \\
\hline CHEMBL3142435 & 217173 & 4.1135 & 4.2804 & TST \\
\hline CHEMBL3142456 & 217173 & 5.2518 & 5.0915 & TRN \\
\hline CHEMBL3142502 & 217173 & 5.1135 & 5.3055 & TRN \\
\hline CHEMBL3142503 & 217173 & 4.4815 & 4.6068 & TRN \\
\hline CHEMBL3306988 & 217173 & 4.6198 & 4.3689 & TRN \\
\hline CHEMBL 3142500 & 217173 & 3.6021 & 3.5372 & TRN \\
\hline CHEMBL3142471 & 217173 & 4.8539 & 4.7478 & TRN \\
\hline CHEMBL 3142444 & 217173 & 4.4815 & 4.4483 & TRN \\
\hline CHEMBL3142498 & 217173 & 4.8861 & 4.8379 & TRN \\
\hline CHEMBL3142480 & 217173 & 4.9208 & 5.0927 & TRN \\
\hline CHEMBL 3142461 & 217173 & 4.0809 & 3.9384 & TST \\
\hline CHEMBL 3142443 & 217173 & 3.5086 & 3.6159 & TRN \\
\hline CHEMBL 3142465 & 217173 & 4.4815 & 4.5164 & TRN \\
\hline CHEMBL3142466 & 217173 & 4.4815 & 4.4637 & TRN \\
\hline CHEMBL3142477 & 217173 & 5.0809 & 5.1349 & TRN \\
\hline CHEMBL3142486 & 217173 & 4.3188 & 4.4279 & TRN \\
\hline CHEMBL 3142434 & 217173 & 4.5376 & 5.1803 & TST \\
\hline CHEMBL3142475 & 217173 & 4.1249 & 4.3111 & TST \\
\hline CHEMBL3142496 & 217173 & 4.5376 & 4.3126 & TST \\
\hline CHEMBL 3142460 & 217173 & 5.5086 & 5.4257 & TST \\
\hline CHEMBL 3142493 & 217173 & 4.5686 & 4.5895 & TST \\
\hline CHEMBL3142489 & 217173 & 4.1135 & 4.1044 & TST \\
\hline
\end{tabular}


Supplemental Table S2.txt

\begin{tabular}{|c|c|c|c|c|}
\hline CHEMBL3142484 & 217173 & 5.0809 & 4.7001 & TST \\
\hline CHEMBL3142452 & 217173 & 4.4815 & 4.106 & TST \\
\hline CHEMBL3650904 & 1536022 & 6.5229 & 6.3469 & TST \\
\hline CHEMBL3650939 & 1536022 & 7.5086 & 7.2926 & TRN \\
\hline CHEMBL 3654272 & 1536022 & 6.8861 & 6.68 & TRN \\
\hline CHEMBL3654282 & 1536022 & 6.8861 & \multicolumn{2}{|c|}{6.7620000000000005} \\
\hline CHEMBL3654268 & 1536022 & 7.0 & 6.9868 & TRN \\
\hline CHEMBL3650888 & 1536022 & 7.2291 & 7.1667 & TRN \\
\hline CHEMBL3650950 & 1536022 & 6.8239 & 7.0619 & TRN \\
\hline CHEMBL3654281 & 1536022 & 6.9586 & 7.1376 & TRN \\
\hline CHEMBL3650924 & 1536022 & 7.0 & 6.8503 & TRN \\
\hline CHEMBL3654297 & 1536022 & 7.1427 & 6.9627 & TRN \\
\hline CHEMBL3650972 & 1536022 & 6.0 & 6.2265 & TRN \\
\hline CHEMBL3650893 & 1536022 & 7.0506 & 6.8669 & TST \\
\hline CHEMBL 3654280 & 1536022 & 6.7959 & 6.8743 & TRN \\
\hline CHEMBL3654308 & 1536022 & 6.0 & 6.6914 & TRN \\
\hline CHEMBL3654273 & 1536022 & 6.8239 & 6.6623 & TRN \\
\hline CHEMBL3650930 & 1536022 & 7.0177 & 6.8874 & TRN \\
\hline CHEMBL 3654274 & 1536022 & 6.5686 & 6.5077 & TRN \\
\hline CHEMBL3650943 & 1536022 & 6.9208 & 6.9926 & TRN \\
\hline CHEMBL3650906 & 1536022 & 6.8861 & 6.6304 & TRN \\
\hline CHEMBL3654267 & 1536022 & 6.8861 & 7.0238 & TRN \\
\hline CHEMBL3650915 & 1536022 & 6.9586 & 6.657 & TRN \\
\hline CHEMBL3654263 & 1536022 & 6.0 & 6.4035 & TRN \\
\hline CHEMBL3650871 & 1536022 & 6.0 & 6.0722 & TRN \\
\hline CHEMBL3650925 & 1536022 & 6.9208 & 6.7327 & TRN \\
\hline CHEMBL3650976 & 1536022 & 6.0 & 6.7333 & TRN \\
\hline CHEMBL3650955 & 1536022 & 7.8539 & 7.8758 & TST \\
\hline CHEMBL3654293 & 1536022 & 7.8861 & 7.6287 & TRN \\
\hline CHEMBL3650914 & 1536022 & 6.8861 & 6.5711 & TRN \\
\hline CHEMBL3979131 & 1536022 & 7.6383 & 7.5395 & TST \\
\hline CHEMBL3650932 & 1536022 & 7.2111 & 7.4624 & TRN \\
\hline CHEMBL3650891 & 1536022 & 6.8239 & 6.581 & TRN \\
\hline CHEMBL3654307 & 1536022 & 7.4437 & 7.4462 & TRN \\
\hline CHEMBL3654276 & 1536022 & 6.7212 & 6.8477 & TRN \\
\hline CHEMBL3654269 & 1536022 & 6.6198 & 6.6313 & TRN \\
\hline CHEMBL3650889 & 1536022 & 6.0 & 6.0613 & TST \\
\hline CHEMBL3650890 & 1536022 & 7.1192 & 7.1887 & TRN \\
\hline CHEMBL3654319 & 1536022 & 6.7696 & 6.5902 & TST \\
\hline CHEMBL3650892 & 1536022 & 7.0706 & 6.974 & TST \\
\hline CHEMBL3650916 & 1536022 & 7.5528 & 7.4158 & TST \\
\hline CHEMBL 3650960 & 1536022 & 7.3372 & 7.3519 & TRN \\
\hline CHEMBL3654264 & 1536022 & 7.0969 & 6.8818 & TRN \\
\hline CHEMBL3654265 & 1536022 & 6.8861 & 6.6652 & TRN \\
\hline CHEMBL3650897 & 1536022 & 6.5528 & 6.4783 & TRN \\
\hline CHEMBL3650886 & 1536022 & 6.9586 & 7.0406 & TRN \\
\hline CHEMBL3654302 & 1536022 & 7.0458 & 6.9639 & TRN \\
\hline CHEMBL3961497 & 1536022 & 6.0 & 6.1442 & TRN \\
\hline
\end{tabular}


Supplemental Table S2.txt

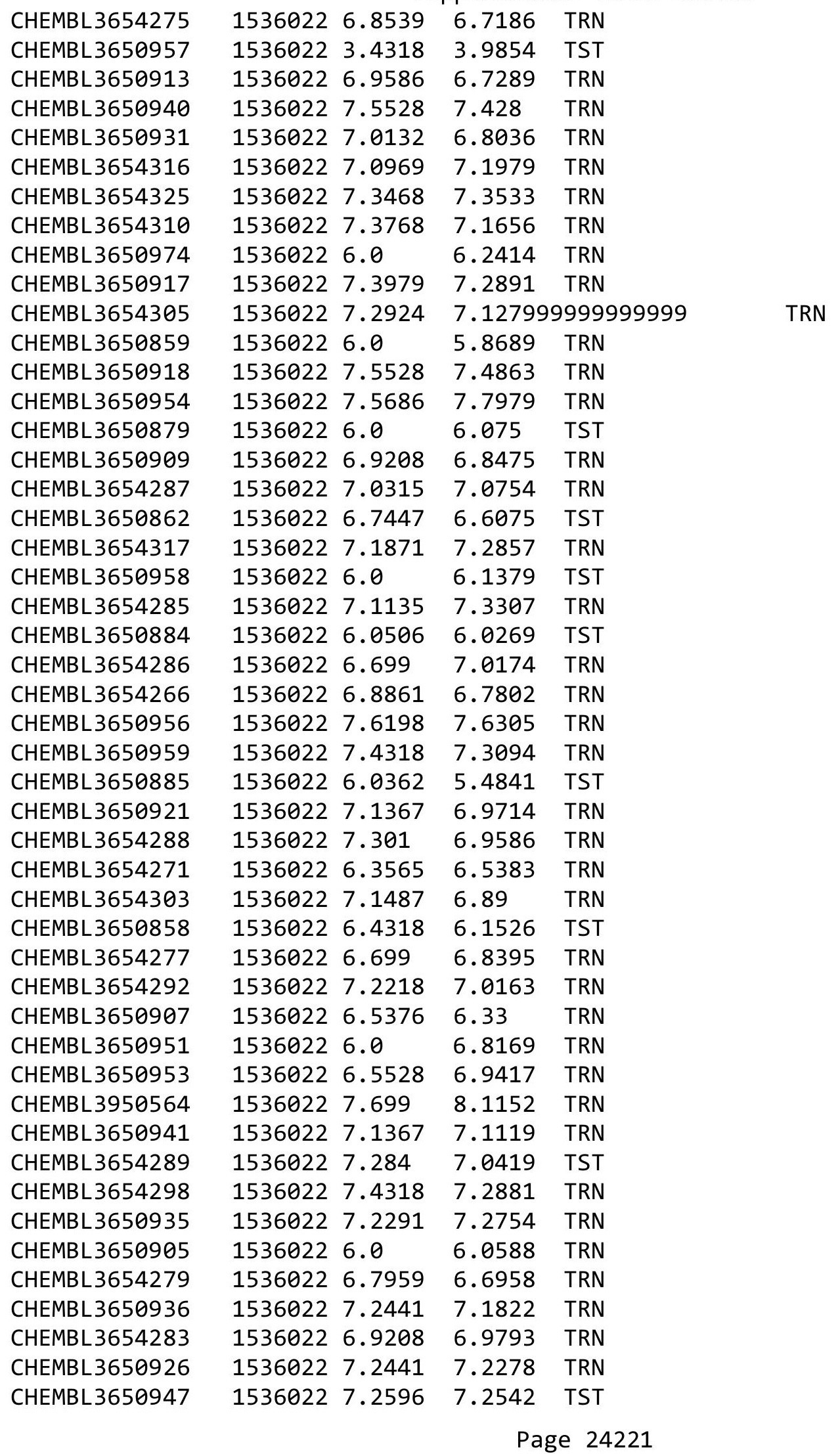


Supplemental Table S2.txt

\begin{tabular}{|c|c|c|c|c|}
\hline CHEMBL 3654306 & 1536022 & 7.1249 & 6.7461 & TRN \\
\hline CHEMBL 3650927 & 1536022 & 7.0655 & 7.0916 & TST \\
\hline CHEMBL3650975 & 1536022 & 7.2757 & 7.2954 & TRN \\
\hline CHEMBL 3650895 & 1536022 & 6.5528 & 6.7082 & TRN \\
\hline CHEMBL 3654301 & 1536022 & 6.0 & 5.9847 & TRN \\
\hline CHEMBL 3650908 & 1536022 & 6.3188 & 6.3181 & TST \\
\hline CHEMBL 3650928 & 1536022 & 7.4437 & \multicolumn{2}{|c|}{7.20100000000} \\
\hline CHEMBL 3650948 & 1536022 & 6.0 & 6.1771 & TRN \\
\hline CHEMBL3650969 & 1536022 & 6.0 & 6.2785 & TRN \\
\hline CHEMBL3650971 & 1536022 & 3.4318 & 6.1556 & TST \\
\hline CHEMBL 3650966 & 1536022 & 6.0 & 6.1559 & TRN \\
\hline CHEMBL 3654284 & 1536022 & 7.1192 & 7.0369 & TRN \\
\hline CHEMBL 3650922 & 1536022 & 6.699 & 6.5977 & TRN \\
\hline CHEMBL3650946 & 1536022 & 7.4437 & 7.4737 & TRN \\
\hline CHEMBL3650934 & 1536022 & 7.3565 & 7.3205 & TRN \\
\hline CHEMBL 3650961 & 1536022 & 7.4949 & 7.4193 & TRN \\
\hline CHEMBL3654294 & 1536022 & 7.0315 & 7.0296 & TRN \\
\hline CHEMBL 3650942 & 1536022 & 6.0969 & 6.3766 & TRN \\
\hline CHEMBL3650894 & 1536022 & 6.9586 & 6.9055 & TRN \\
\hline CHEMBL 3650883 & 1536022 & 6.3279 & 6.0193 & TRN \\
\hline CHEMBL 3650881 & 1536022 & 6.0 & 5.9999 & TRN \\
\hline CHEMBL3650896 & 1536022 & 7.0 & 7.0871 & TRN \\
\hline CHEMBL 3650929 & 1536022 & 7.0132 & 6.8439 & TRN \\
\hline CHEMBL3926752 & 1536022 & 6.9208 & 6.9907 & TRN \\
\hline CHEMBL 3654295 & 1536022 & 6.9586 & 6.914 & TRN \\
\hline CHEMBL 3650933 & 1536022 & 7.7959 & 7.6764 & TST \\
\hline CHEMBL 3654300 & 1536022 & 7.5229 & 7.2949 & TRN \\
\hline CHEMBL 3654326 & 1536022 & 7.4089 & 7.2764 & TST \\
\hline CHEMBL3654309 & 1536022 & 7.2147 & 7.0246 & TST \\
\hline CHEMBL 3937587 & 1536022 & 6.0 & 6.0243 & TST \\
\hline CHEMBL 3654278 & 1536022 & 6.9208 & 6.9849 & TST \\
\hline CHEMBL 3650878 & 1536022 & 6.6021 & 6.4552 & TST \\
\hline CHEMBL 3650887 & 1536022 & 6.7959 & 6.8061 & TST \\
\hline CHEMBL3654296 & 1536022 & 7.0605 & 7.2883 & TST \\
\hline CHEMBL3650903 & 1536022 & 6.9208 & 6.7671 & TST \\
\hline CHEMBL 3650962 & 1536022 & 7.4202 & 7.0955 & TST \\
\hline CHEMBL3650856 & 1536022 & 6.284 & 6.131 & TST \\
\hline CHEMBL 3654270 & 1536022 & 6.9208 & 6.6743 & TST \\
\hline CHEMBL 3654318 & 1536022 & 7.7959 & 8.1344 & TST \\
\hline CHEMBL3946839 & 1641409 & 8.8861 & 9.0283 & TRN \\
\hline CHEMBL3960404 & 1641409 & 8.1549 & 8.879 & TRN \\
\hline CHEMBL3938427 & 1641409 & 8.8861 & 8.5864 & TRN \\
\hline CHEMBL3901806 & 1641409 & 9.5229 & 8.9286 & TST \\
\hline CHEMBL3906897 & 1641409 & 8.1549 & 8.6064 & TRN \\
\hline CHEMBL3967351 & 1641409 & 9.5229 & 9.0802 & TRN \\
\hline CHEMBL 3890630 & 1641409 & 8.301 & 8.8532 & TRN \\
\hline CHEMBL3962646 & 1641409 & 8.301 & 8.6847 & TRN \\
\hline CHEMBL3935608 & 1641409 & 8.6778 & 9.0534 & TRN \\
\hline
\end{tabular}

Page 24222 
Supplemental Table S2.txt

\begin{tabular}{|c|c|c|c|c|}
\hline IE & 99 & & & \\
\hline HЕMPI 2099151 & 641409 & 7.5229 & .2936 & \\
\hline ITS & & & & \\
\hline HEMBL390 & 409 & 969 & 8884 & \\
\hline AEMBL3892626 & 641409 & 229 & 379 & \\
\hline HEMBL3970809 & 641409 & 9.5229 & .4169 & \\
\hline HEMBL 393 & 09 & & 869 & \\
\hline IFMBI 39 & & & & \\
\hline AEMBL3900097 & 409 & & .5006 & \\
\hline HEMBL3981875 & 409 & 8 . & 8193 & \\
\hline HEMBL3908507 & 409 & 7.8861 & .0449 & \\
\hline AEMBL39 & $\partial 9$ & 79 & .2455 & \\
\hline AEMBL3S & & & & \\
\hline HEMBL391 & 109 & & 9.0895 & \\
\hline HEMBL392 & 09 & & 4117 & \\
\hline AEMBL39 & 99 & 9 & .316 & \\
\hline HEMBL39 & 99 & & 5797 & \\
\hline HEMBL38 & & & & \\
\hline HEMBL38 & & & .5437 & \\
\hline AEMBL3S & 09 & & & \\
\hline AEMBL3 & 99 & & 98 & \\
\hline AEMBL & 19 & & 37 & \\
\hline HEMBL & & 9 & 93 & \\
\hline 99 & & & 5976 & RN \\
\hline AEMBL3S & & & & RIV \\
\hline HEMBL38 & 39 & & 18 & RN \\
\hline HEMBL3 & & & & IRN \\
\hline$H F M B I=$ & & & 883 & RN \\
\hline HEMBL3S & & 9. & 6153 & RIV \\
\hline HEMBL3908533 & & & 3688 & RN \\
\hline HEMBL3S & & & 1833 & RN \\
\hline HEMBL; & & & 11 & \\
\hline HEMBL; & & & 018 & RN \\
\hline HEMBL395 & & & 9.2264 & IRN \\
\hline HEMBL3892303 & $\partial 9$ & & 9.1417 & $\Gamma \mathrm{RN}$ \\
\hline HEMBL3 & & & 2868 & rRN \\
\hline HFMRI $=2$ & & & & RN \\
\hline HEMBL3 & & & 3093 & TST \\
\hline HEMBL $397 \varepsilon$ & $\partial 9$ & 8. & .6936 & TST \\
\hline IEMBL3 & & & .2571 & RN \\
\hline HEMBL39 & 39 & & .7678 & \\
\hline CHEMBL39 & & & 8.5243 & RN \\
\hline HEMBL3986284 & 09 & 8.0969 & 8.7235 & TST \\
\hline HEMBL3894811 & 09 & 8.3979 & .3282 & TRN \\
\hline $\mathrm{MBI} 3$ & & & & \\
\hline HEMBL3S & & & .9401 & \\
\hline CHEMBL393 & & 8.5229 & .6779 & \\
\hline CHEMBL3909622 & 1641409 & 9.5229 & 9.0453 & ГST \\
\hline
\end{tabular}

Page 24223 
Supplemental Table S2.txt

\begin{tabular}{|c|c|c|c|c|}
\hline - & 1409 & 7959 & & \\
\hline & 641409 & 8.2007 & & \\
\hline 3302 & & & & \\
\hline AEMBL & 409 & 0757 & & \\
\hline AEMBL3971079 & 409 & .5229 & 8387 & \\
\hline HEMBL3915104 & 641409 & 9.5229 & 6157 & \\
\hline & & 29 & 7635 & \\
\hline IFMRI = & & & & \\
\hline AEMBL391 & & 7.7212 & 8076 & \\
\hline HEMBL3930996 & 409 & 29 & 8701 & \\
\hline HEMBL3903657 & 409 & 8. & .9648 & \\
\hline IEMBL39 & $\partial 9$ & 9. & 008 & \\
\hline AEMBL3S & & 9. & & \\
\hline HEMBL396 & & & 0833 & \\
\hline AEMBL3S & 09 & & 9561 & \\
\hline AEMBL39 & 99 & 9. & 356 & \\
\hline AEMBL3S & 9 & & 326 & \\
\hline HEMBL3S & & & & \\
\hline HEMBL39 & & & 9804 & \\
\hline AEMBL3S & 09 & & 3043 & \\
\hline HEIMBLSS & 99 & & 322 & Niv \\
\hline AEMBL: & & & 118 & RN \\
\hline HEMBL & & & 018 & \\
\hline 296 & & & 3798 & \\
\hline AEMBL3S & & & & ISI \\
\hline HEMBL3S & 39 & & 7597 & RN \\
\hline HEMBL & & & 536 & וזנה \\
\hline$H F M B I=$ & & & 14 & \\
\hline HEMBL3 & & & & RIV \\
\hline HEMBL 390 & & & 1074 & I RN \\
\hline HEMBL3S & & & 376 & RN \\
\hline HEMBL & & & 247 & RN \\
\hline HEMBL. & & 9. & 779 & TRN \\
\hline HEMBL391 & $\partial 9$ & & 9569 & Th \\
\hline HEMBL3951931 & 39 & 7. & 1583 & TRN \\
\hline HEMBL3 & & & 722 & קט \\
\hline HFMRI & & 9. & 782 & \\
\hline HEMBL3 & & 9. & 149 & IR \\
\hline HEMBL3898289 & & 7.7 & 7755 & TRN \\
\hline IEMBL3 & & & 124 & RN \\
\hline HEMBL3S & 99 & & 954 & \\
\hline HEMBL 38 & & & & RN \\
\hline HEMBL3S & & 9.5229 & 8.9404 & TST \\
\hline HEMBL3894547 & 109 & 9. & 0645 & TST \\
\hline $\mathrm{MRI}=$ & & 9 & & I \\
\hline HEMBL3\& & & & 3242 & \\
\hline LHEMBL 3901390 & & 7.9208 & 8.2686 & \\
\hline LHEMBL3942117 & 1641409 & 8.699 & 8.8901 & ГST \\
\hline
\end{tabular}

Page 24224 
Supplemental Table S2.txt

\begin{tabular}{|c|c|c|c|c|c|}
\hline CHEMBL 3893263 & 1641409 & 9.5229 & 8.8044 & TST & \\
\hline CHEMBL3908795 & 1641409 & 8.5229 & 9.1824 & TST & \\
\hline CHEMBL3902865 & 1641409 & 8.6198 & 9.2446 & TRN & \\
\hline CHEMBL 3936455 & 1641409 & 7.7696 & 8.4815 & TRN & \\
\hline CHEMBL3933733 & 1641409 & 8.699 & 8.7035 & TRN & \\
\hline CHEMBL3939870 & 1641409 & 9.5229 & 8.632 & TST & \\
\hline CHEMBL3931127 & 1641409 & 8.0809 & 8.9817 & TST & \\
\hline CHEMBL 3897785 & 1641409 & 8.3979 & 8.6197 & TRN & \\
\hline CHEMBL3932002 & 1641409 & 9.0 & 8.8925 & TRN & \\
\hline CHEMBL3906333 & 1641409 & 8.2218 & 8.4578 & TRN & \\
\hline CHEMBL3936031 & 1641409 & 8.5229 & 8.3488 & TRN & \\
\hline CHEMBL3976976 & 1641409 & 9.5229 & 9.0686 & TRN & \\
\hline CHEMBL 3892160 & 1641409 & 8.699 & 9.0705 & TRN & \\
\hline CHEMBL3921200 & 1641409 & 8.2924 & \multicolumn{2}{|c|}{8.357000000000001} & TRN \\
\hline CHEMBL 3927461 & 1641409 & 8.699 & 8.5049 & TRN & \\
\hline CHEMBL3909587 & 1641409 & 9.2218 & 8.7401 & TRN & \\
\hline CHEMBL3952322 & 1641409 & 9.5229 & 9.0245 & TST & \\
\hline CHEMBL 3908954 & 1641409 & 8.301 & 8.8975 & TRN & \\
\hline CHEMBL3960726 & 1641409 & 9.5229 & 8.712 & TRN & \\
\hline CHEMBL3912930 & 1641409 & 8.5229 & 8.7878 & TRN & \\
\hline CHEMBL 3891752 & 1641409 & 9.5229 & \multicolumn{2}{|c|}{ 8.927999999999999 } & TRN \\
\hline CHEMBL3904200 & 1641409 & 9.0 & 8.8901 & TRN & \\
\hline CHEMBL 3892840 & 1641409 & 9.5229 & 8.6622 & TRN & \\
\hline CHEMBL3960642 & 1641409 & 8.0 & 8.6412 & TRN & \\
\hline CHEMBL 3890055 & 1641409 & 9.5229 & 8.7199 & TRN & \\
\hline CHEMBL 3977220 & 1641409 & 9.0 & 9.0855 & TST & \\
\hline CHEMBL3961194 & 1641409 & 9.5229 & 8.647 & TRN & \\
\hline CHEMBL 3909640 & 1641409 & 8.301 & 8.2385 & TRN & \\
\hline CHEMBL3954586 & 1641409 & 8.5229 & 8.7002 & TST & \\
\hline CHEMBL3907285 & 1641409 & 9.5229 & 8.7536 & TRN & \\
\hline CHEMBL3907859 & 1641409 & 8.301 & 8.4048 & TRN & \\
\hline CHEMBL 3894405 & 1641409 & 8.5229 & 8.5343 & TRN & \\
\hline CHEMBL 3927318 & 1641409 & 8.2218 & 8.9659 & TRN & \\
\hline CHEMBL3932037 & 1641409 & 8.699 & 8.7698 & TRN & \\
\hline CHEMBL 3898364 & 1641409 & 8.5686 & 8.7867 & TRN & \\
\hline CHEMBL3901163 & 1641409 & 9.5229 & 9.2175 & TRN & \\
\hline CHEMBL 3894070 & 1641409 & 8.1549 & 8.8626 & TRN & \\
\hline CHEMBL3982373 & 1641409 & 9.5229 & 8.5174 & TRN & \\
\hline CHEMBL3968724 & 1641409 & 7.9586 & 8.6248 & TST & \\
\hline CHEMBL3945997 & 1641409 & 8.5229 & 8.8224 & TRN & \\
\hline CHEMBL 3902822 & 1641409 & 9.5229 & 8.895 & TRN & \\
\hline CHEMBL 3895283 & 1641409 & 8.1549 & 8.5674 & TRN & \\
\hline CHEMBL3976713 & 1641409 & 9.5229 & 8.3067 & TRN & \\
\hline CHEMBL3950224 & 1641409 & 9.5229 & 8.921 & TRN & \\
\hline CHEMBL3917548 & 1641409 & 8.2924 & 8.84799 & & TRN \\
\hline CHEMBL 3892952 & 1641409 & 7.9208 & 8.8214 & TST & \\
\hline CHEMBL3953905 & 1641409 & 8.3979 & 8.6045 & TRN & \\
\hline CHEMBL3954688 & 1641409 & 8.3768 & 9.0988 & TRN & \\
\hline
\end{tabular}

Page 24225 

Supplemental Table S2.txt

\begin{tabular}{|c|c|c|c|c|c|}
\hline CHEMBL3908721 & 1641409 & 9.5229 & 9.1427 & TRN & \\
\hline CHEMBL3967765 & 1641409 & 8.1549 & 8.5646 & TRN & \\
\hline CHEMBL3904036 & 1641409 & 8.3979 & 8.6892 & TRN & \\
\hline CHEMBL3953135 & 1641409 & 8.3979 & 8.6047 & TRN & \\
\hline CHEMBL3954742 & 1641409 & 8.3979 & 8.508 & TRN & \\
\hline CHEMBL3932233 & 1641409 & 9.5229 & 8.6842 & TST & \\
\hline CHEMBL3967475 & 1641409 & 9.5229 & 9.257 & TST & \\
\hline CHEMBL3896686 & 1641409 & 7.7959 & 8.0113 & TST & \\
\hline CHEMBL3925052 & 1641409 & 8.699 & 8.8089 & TST & \\
\hline CHEMBL3911270 & 1641409 & 8.5229 & 8.5689 & TRN & \\
\hline CHEMBL3961426 & 1641409 & 9.5229 & 8.2012 & TST & \\
\hline CHEMBL3907237 & 1641409 & 7.9208 & 8.7887 & TST & \\
\hline CHEMBL3975987 & 1641409 & 9.5229 & 9.0219 & TRN & \\
\hline CHEMBL3899456 & 1641409 & 9.5229 & 9.2066 & TRN & \\
\hline CHEMBL3944291 & 1641409 & 8.0 & 8.7379 & TST & \\
\hline CHEMBL3933980 & 1641409 & 9.5229 & 8.9508 & TRN & \\
\hline CHEMBL3927811 & 1641409 & 8.301 & 8.9847 & TRN & \\
\hline CHEMBL3945801 & 1641409 & 8.0969 & 8.0488 & TRN & \\
\hline CHEMBL3971948 & 1641409 & 8.2291 & 8.3073 & TRN & \\
\hline CHEMBL3982067 & 1641409 & 8.5229 & 8.2741 & TRN & \\
\hline CHEMBL3941486 & 1641409 & 11.0 & 8.9062 & TRN & \\
\hline CHEMBL3915545 & 1641409 & 9.0458 & 9.0779 & TRN & \\
\hline CHEMBL94069 & 206484 & 5.8928 & 5.8926 & TRN & \\
\hline CHEMBL316101 & 206484 & 5.1805 & 5.1804 & TRN & \\
\hline CHEMBL327821 & 206484 & 6.2676 & 6.2677 & TRN & \\
\hline CHEMBL91442 & 206484 & 6.7959 & 6.7959 & TRN & \\
\hline CHEMBL327464 & 206484 & 5.752000 & 000000000 & $\partial 1$ & 5.7522 \\
\hline CHEMBL316102 & 206484 & 5.5784 & 5.5783 & TRN & \\
\hline CHEMBL88358 & 206484 & 6.5686 & 6.5684 & TRN & \\
\hline CHEMBL91236 & 206484 & 6.5528 & 5.6778 & TST & \\
\hline CHEMBL90589 & 206484 & 6.3979 & 6.3979 & TRN & \\
\hline CHEMBL329442 & 206484 & 5.1232 & 6.4042 & TST & \\
\hline CHEMBL90268 & 206484 & 5.5143 & 5.5144 & TRN & \\
\hline CHEMBL329787 & 206484 & 5.8996 & 6.1668 & TST & \\
\hline CHEMBL330294 & 206484 & 5.5575 & 6.4124 & TST & \\
\hline CHEMBL93960 & 206484 & 5.7328 & 5.733 & TRN & \\
\hline CHEMBL92494 & 206484 & 5.1818 & 5.1818 & TRN & \\
\hline CHEMBL315954 & 206484 & 6.2441 & 6.2441 & TRN & \\
\hline CHEMBL328988 & 206484 & 5.9101 & 5.91 & TRN & \\
\hline CHEMBL313159 & 206484 & 5.9508 & 5.9506 & TRN & \\
\hline CHEMBL314096 & 206484 & 5.8239 & 5.824 & TRN & \\
\hline CHEMBL327683 & 206484 & 5.7471 & 5.7472 & TRN & \\
\hline CHEMBL92029 & 206484 & 6.1079 & 6.108 & TRN & \\
\hline CHEMBL327458 & 206484 & 5.7328 & 5.7327 & TRN & \\
\hline CHEMBL313158 & 206484 & 6.2147 & 6.2145 & TRN & \\
\hline CHEMBL1199648 & 206484 & 5.8447 & 5.8446 & TRN & \\
\hline CHEMBL88467 & 206484 & 5.1129 & 5.113 & TRN & \\
\hline CHEMBL315868 & 206484 & 6.4202 & 6.4203 & TRN & \\
\hline
\end{tabular}




\begin{tabular}{|c|c|c|c|c|c|c|}
\hline & & \multicolumn{5}{|c|}{ Supplemental Table S2.txt } \\
\hline CHEMBL88795 & 206484 & 7.0458 & 7.0459 & TRN & & \\
\hline CHEMBL327211 & 206484 & 6.2441 & 6.2443 & TRN & & \\
\hline CHEMBL91303 & 206484 & 5.8268 & 5.6336 & TST & & \\
\hline CHEMBL90516 & 206484 & 6.1675 & 6.1673 & TRN & & \\
\hline CHEMBL327207 & 206484 & 7.1549 & 7.1549 & TRN & & \\
\hline CHEMBL88517 & 206484 & 5.8416 & 6.2701 & TST & & \\
\hline CHEMBL328066 & 206484 & 6.7447 & 6.7447 & TRN & & \\
\hline CHEMBL93177 & 206484 & 6.2007 & 6.2005 & TRN & & \\
\hline CHEMBL92848 & 206484 & 6.7959 & 6.7958 & TRN & & \\
\hline CHEMBL314932 & 206484 & 4.6548 & 5.7536 & TST & & \\
\hline CHEMBL313390 & 206484 & 6.0315 & 6.3837 & TST & & \\
\hline CHEMBL328505 & 206484 & 5.7144 & 5.7145 & TRN & & \\
\hline CHEMBL316289 & 206484 & 5.9788 & 5.979 & TRN & & \\
\hline CHEMBL91279 & 206484 & 6.1427 & 6.1426 & TRN & & \\
\hline CHEMBL91305 & 206484 & 6.6021 & 5.2645 & TST & & \\
\hline CHEMBL90750 & 206484 & 5.0809 & 5.0809 & TRN & & \\
\hline CHEMBL90293 & 206484 & $5.8210 e$ & 00000000 & $\partial 1$ & 5.8211 & TRN \\
\hline CHEMBL92317 & 206484 & 6.1549 & 6.155 & TRN & & \\
\hline CHEMBL90914 & 206484 & 6.3188 & 6.3188 & TRN & & \\
\hline CHEMBL93053 & 206484 & 3.4948 & 3.4948 & TRN & & \\
\hline CHEMBL330110 & 206484 & 6.4318 & 6.4317 & TRN & & \\
\hline CHEMBL91032 & 206484 & 6.1805 & 6.1806 & TRN & & \\
\hline CHEMBL91281 & 206484 & 6.1871 & 6.1871 & TRN & & \\
\hline CHEMBL314733 & 206484 & 5.9172 & 5.9173 & TRN & & \\
\hline CHEMBL92355 & 206484 & 6.7696 & 6.7696 & TRN & & \\
\hline CHEMBL316450 & 206484 & 7.0969 & 7.097 & TRN & & \\
\hline CHEMBL1199895 & 206484 & 5.2464 & 5.2465 & TRN & & \\
\hline CHEMBL90185 & 206484 & 6.0862 & 6.0861 & TRN & & \\
\hline CHEMBL88719 & 206484 & 6.6576 & 5.9882 & TST & & \\
\hline CHEMBL91825 & 206484 & 6.3279 & 6.4018 & TST & & \\
\hline CHEMBL91406 & 206484 & 6.3872 & 5.5189 & TST & & \\
\hline CHEMBL88786 & 206484 & 5.9586 & 5.8362 & TST & & \\
\hline CHEMBL330534 & 206484 & 5.5361 & 5.8949 & TST & & \\
\hline CHEMBL90648 & 206484 & 5.4559 & 6.0102 & TST & & \\
\hline CHEMBL1199647 & 206484 & 5.8416 & 5.2959 & TST & & \\
\hline CHEMBL494722 & 538760 & 3.9208 & 4.1139 & TRN & & \\
\hline CHEMBL494081 & 538760 & 4.4089 & 4.387 & TRN & & \\
\hline CHEMBL492294 & 538760 & 4.8539 & 4.1043 & TRN & & \\
\hline CHEMBL494931 & 538760 & 4.3372 & 4.3003 & TRN & & \\
\hline CHEMBL492236 & 538760 & 4.3872 & 3.907 & TST & & \\
\hline CHEMBL493922 & 538760 & 3.7959 & 4.0364 & TRN & & \\
\hline CHEMBL521673 & 538760 & 3.8447 & 3.8407 & TRN & & \\
\hline CHEMBL492293 & 538760 & 4.8861 & 4.7679 & TRN & & \\
\hline CHEMBL507828 & 538760 & 4.6021 & 4.6519 & TRN & & \\
\hline CHEMBL493435 & 538760 & 5.1308 & 3.8961 & TRN & & \\
\hline CHEMBL501131 & 538760 & 4.4949 & 5.0906 & TRN & & \\
\hline CHEMBL495288 & 538760 & 4.3372 & 4.7104 & TRN & & \\
\hline CHEMBL494079 & 538760 & 4.5229 & 4.4819 & TRN & & \\
\hline
\end{tabular}


Supplemental Table S2.txt

\begin{tabular}{|c|c|c|c|c|}
\hline CHEMBL521521 & 38760 & 4.0223 & 4.2096 & TST \\
\hline CHEMBL523663 & 38760 & 3.4271 & 4.0342 & TRN \\
\hline HEMBL523387 & 38760 & 4.6021 & 5395 & TPN \\
\hline HEMBL443080 & 38760 & 3.15 & 4.13 & \\
\hline HEMBL494487 & 38760 & 6.301 & 5.4141 & TRN \\
\hline HEMBL500836 & 38760 & 4.5229 & 4.5235 & \\
\hline HEMBL493866 & 38760 & 5.1367 & 4.9211 & RN \\
\hline CHEMBL494113 & 38760 & 4.3279 & 4.5997 & RN \\
\hline HEMBL492278 & 38760 & 3.1952 & 3.9943 & IN \\
\hline HEMBL522005 & 38760 & 4.7212 & 4.5728 & TRN \\
\hline CHEMBL494310 & 38760 & 4.1487 & 4.1997 & \\
\hline HEMBL450135 & 38760 & 4.2007 & 4.186 & RN \\
\hline HEMBL4 & 760 & 5.1308 & 999 & \\
\hline HEMBL493923 & 38760 & 3.6021 & 3.8309 & TRN \\
\hline HEMBL493691 & 760 & 4.6778 & 5486 & TRN \\
\hline CHEMBL494725 & 60 & 4.3665 & 4.0118 & \\
\hline HEMBL492235 & 60 & 4 & 4.6717 & RN \\
\hline HEMBL5 & 760 & 5.3979 & 5.012 & TRN \\
\hline HEMBL115145 & 760 & 4.2924 & 3.8717 & TRN \\
\hline CHEMBL493698 & 60 & 4.5 & 4.8219 & TRN \\
\hline CHEMBL4 & 60 & 4. & 3.6877 & RN \\
\hline HEMBL4 & 60 & 4. & 4.3831 & TRN \\
\hline CHEMBL4 & 760 & 5.3872 & 5.1488 & TRN \\
\hline CHEMBL523359 & 760 & 5. & 4.7708 & TRN \\
\hline CHEMBL493889 & 60 & 5.4 & 074 & I RN \\
\hline CHEMBL492 & 60 & 3. & 1586 & TRN \\
\hline CHEMBL4 & 60 & 4. & 5558 & TRN \\
\hline CHEMBL 5 & 760 & 5.2757 & 4.9155 & TRN \\
\hline CHEMBL492475 & & 3.5 & 4.3729 & TRN \\
\hline HEMBL446815 & 3760 & 5.301 & 4.8586 & TRN \\
\hline HEMBL4 & 60 & 4.2 & 4.3905 & TRN \\
\hline CHEMBL 5 & 60 & 71 & 2848 & TRN \\
\hline CHEMBL4 & & 4.284 & 4.268 & TRN \\
\hline CHEMBL522696 & 60 & 4.5229 & 4.0661 & TRN \\
\hline CHEMBL492833 & 760 & 4.7447 & 4.7468 & TRN \\
\hline HEMBL4 & 60 & 5. & 1658 & TST \\
\hline CHEMBL4 & 60 & 4. & 4.8446 & TRN \\
\hline CHEMBL522832 & 760 & 3.8894 & 4.5646 & TRN \\
\hline CHEMBL494112 & 8760 & 4.3372 & 4.9127 & TRN \\
\hline CHEMBL4S & & 68 & 3.6651 & TRN \\
\hline CHEMBL523003 & 760 & 3.8477 & 4.3349 & TRN \\
\hline CHEMBL493659 & 38760 & 4.3768 & 4.563 & TRN \\
\hline CHEMBL522686 & 38760 & 4.6021 & 4.5884 & TRN \\
\hline CHEMBL494045 & 3760 & 4.6021 & 4.5982 & TRN \\
\hline CHEMBL5 & & 4.4949 & 4.2286 & $\mathrm{TR}$ \\
\hline CHEMBL213432 & 538760 & 4.0 & 3.8859 & \\
\hline CHEMBL494474 & 538760 & 5.0 & 4.6773 & TRN \\
\hline CHEMBL494668 & 538760 & 5.2291 & 5.4256 & $\mathrm{~K}$ \\
\hline
\end{tabular}

Page 24229 


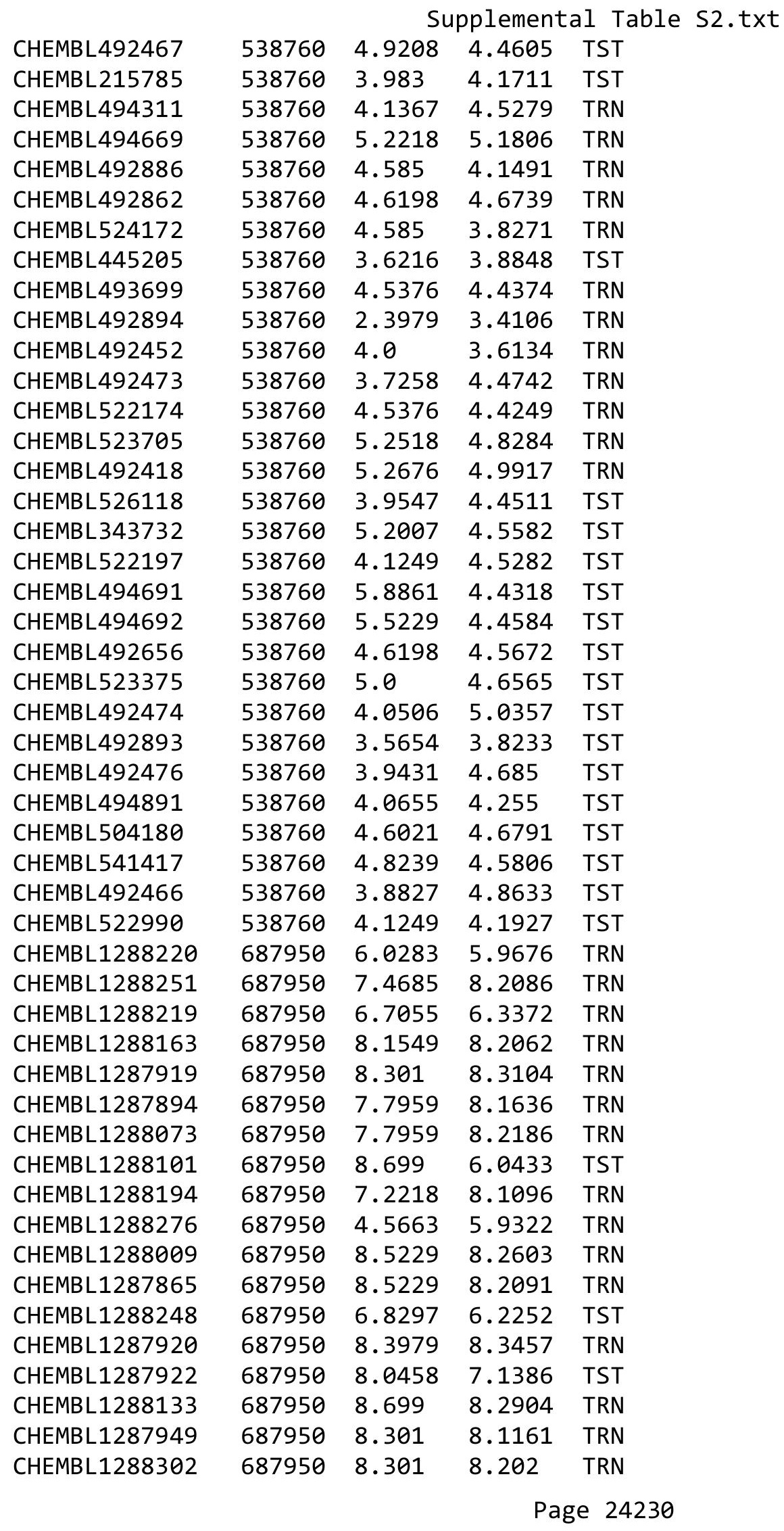




\begin{tabular}{|c|c|c|c|c|c|}
\hline \multicolumn{6}{|c|}{ Supplemental Table S2.txt } \\
\hline CHEMBL1288191 & 687950 & 8.1549 & 5.8135 & TST & \\
\hline CHEMBL1287948 & 687950 & 7.6778 & 7.6327 & TRN & \\
\hline CHEMBL1287892 & 687950 & 8.699 & 7.9275 & TRN & \\
\hline CHEMBL1288277 & 687950 & 7.6198 & 8.1548 & TRN & \\
\hline CHEMBL1287891 & 687950 & 8.5229 & 8.2523 & TRN & \\
\hline CHEMBL1288161 & 687950 & 6.1273 & 6.2517 & TST & \\
\hline CHEMBL1287862 & 687950 & 8.699 & 8.3852 & TRN & \\
\hline CHEMBL1288307 & 687950 & 6.1445 & 8.0258 & TRN & \\
\hline CHEMBL1288130 & 687950 & 7.8539 & 7.0697 & TRN & \\
\hline CHEMBL1288132 & 687950 & 8.301 & 8.3436 & TRN & \\
\hline CHEMBL1287921 & 687950 & 5.3389 & 7.1238 & TRN & \\
\hline CHEMBL1288279 & 687950 & 8.301 & 8.3171 & TRN & \\
\hline CHEMBL1288010 & 687950 & 8.5229 & 8.2952 & TRN & \\
\hline CHEMBL1288306 & 687950 & 7.2518 & 7.9061 & TRN & \\
\hline CHEMBL1287864 & 687950 & 9.0 & 8.2753 & TRN & \\
\hline CHEMBL1288164 & 687950 & 8.301 & 8.2757 & TRN & \\
\hline CHEMBL1288193 & 687950 & 8.0458 & 8.3262 & TRN & \\
\hline CHEMBL1288042 & 687950 & 8.3979 & 8.24 & TRN & \\
\hline CHEMBL 1288222 & 687950 & 8.699 & 8.2106 & TRN & \\
\hline CHEMBL1288072 & 687950 & 7.2218 & 8.1791 & TRN & \\
\hline CHEMBL1231624 & 687950 & 9.0 & 7.3483 & TRN & \\
\hline CHEMBL1288278 & 687950 & 9.0 & 8.3209 & TRN & \\
\hline CHEMBL1288192 & 687950 & 6.5346 & 6.2222 & TRN & \\
\hline CHEMBL1288162 & 687950 & 8.5229 & 7.0757 & TRN & \\
\hline CHEMBL1287893 & 687950 & 7.699 & 8.2906 & TRN & \\
\hline CHEMBL1288221 & 687950 & 8.3979 & 7.4383 & TRN & \\
\hline CHEMBL1288131 & 687950 & 6.1506 & 6.6126 & TRN & \\
\hline CHEMBL1288103 & 687950 & 8.0458 & 7.6046 & TRN & \\
\hline CHEMBL1288305 & 687950 & 8.5229 & 8.342 & TST & \\
\hline CHEMBL1288250 & 687950 & 7.1739 & 8.0496 & TST & \\
\hline CHEMBL1288304 & 687950 & 8.0969 & 8.2583 & TST & \\
\hline CHEMBL1287863 & 687950 & 8.699 & 8.3385 & TST & \\
\hline CHEMBL1288102 & 687950 & 8.0458 & 7.985 & TST & \\
\hline CHEMBL1287978 & 687950 & 7.7212 & 8.1804 & TST & \\
\hline CHEMBL1288303 & 687950 & 8.3979 & 7.5164 & TST & \\
\hline CHEMBL1287979 & 687950 & 8.5229 & 8.3747 & TST & \\
\hline CHEMBL1288043 & 687950 & 8.3979 & 8.3021 & TST & \\
\hline CHEMBL449158 & 954525 & 6.4251 & 6.6286 & TST & \\
\hline CHEMBL202721 & 954525 & 5.852 & 5.75700 & 0000000001 & TRN \\
\hline CHEMBL213100 & 954525 & 3.9014 & 3.7128 & TRN & \\
\hline CHEMBL512504 & 954525 & 6.7657 & 6.8247 & TRN & \\
\hline CHEMBL1909414 & 954525 & 4.1338 & 4.2352 & TRN & \\
\hline CHEMBL240954 & 954525 & 3.6404 & 4.0991 & TST & \\
\hline CHEMBL258844 & 954525 & 3.5248 & 3.8446 & TRN & \\
\hline CHEMBL1590308 & 954525 & 3.7698 & 3.8241 & TST & \\
\hline CHEMBL1673039 & 954525 & 5.2465 & 5.2396 & TRN & \\
\hline CHEMBL1404918 & 954525 & 3.1913 & 3.0885 & TRN & \\
\hline CHEMBL92309 & 954525 & 3.9989 & 3.8629 & TST & \\
\hline
\end{tabular}


Supplemental Table S2.txt

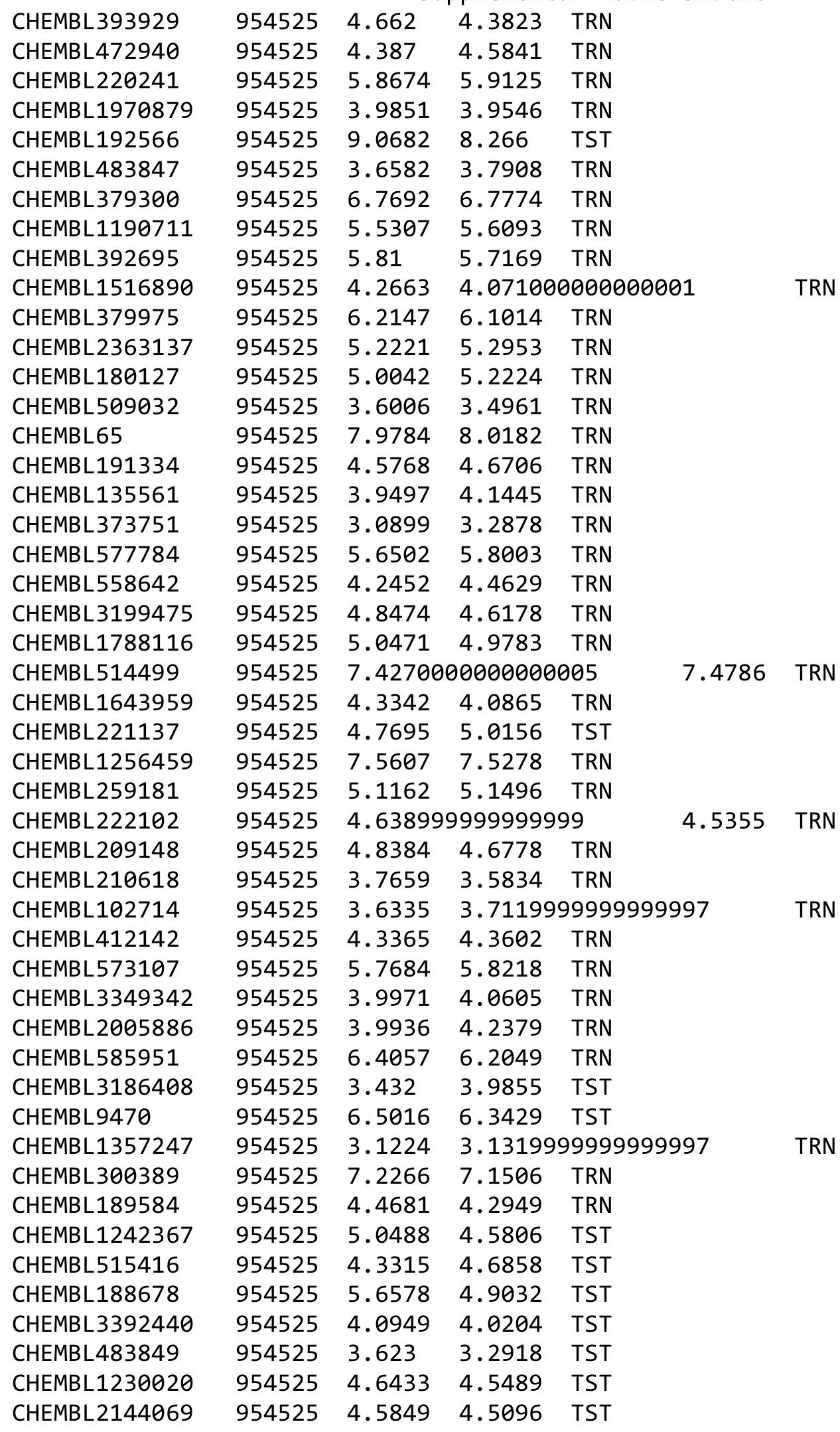

Page 24232 
Supplemental Table S2.txt

\begin{tabular}{|c|c|c|c|c|c|}
\hline CHEMBL3632984 & 1526873 & 8.9586 & 8.4585 & TST & \\
\hline CHEMBL3632973 & 1526873 & 8.5528 & 8.48899 & 7999999999 & TST \\
\hline CHEMBL3632981 & 1526873 & 7.8861 & 7.6943 & TST & \\
\hline CHEMBL 3632971 & 1526873 & 8.5086 & 8.5463 & TST & \\
\hline CHEMBL3581641 & 1526873 & 8.585 & 8.5816 & TRN & \\
\hline CHEMBL3633215 & 1526873 & 7.2676 & 7.25 & TRN & \\
\hline CHEMBL3633225 & 1526873 & 8.5229 & 8.5653 & TRN & \\
\hline CHEMBL3632967 & 1526873 & 5.0 & 4.9912 & TRN & \\
\hline CHEMBL 3633227 & 1526873 & 9.5229 & 9.5174 & TRN & \\
\hline CHEMBL3632966 & 1526873 & 7.3279 & 7.3197 & TRN & \\
\hline CHEMBL 3633224 & 1526873 & 9.3979 & 9.3844 & TRN & \\
\hline CHEMBL3632986 & 1526873 & 7.1938 & 7.1661 & TRN & \\
\hline CHEMBL3633229 & 1526873 & 9.5229 & 9.5412 & TRN & \\
\hline CHEMBL 3632980 & 1526873 & 6.4522 & 6.4183 & TST & \\
\hline CHEMBL3633412 & 1526873 & 8.8861 & 8.8798 & TRN & \\
\hline CHEMBL3632979 & 1526873 & 6.9355 & 6.9284 & TRN & \\
\hline CHEMBL3632968 & 1526873 & 8.8539 & 8.8588 & TRN & \\
\hline CHEMBL3632974 & 1526873 & 9.5229 & 8.9952 & TST & \\
\hline CHEMBL 3632798 & 1526873 & 7.9586 & 7.9807 & TRN & \\
\hline CHEMBL3633222 & 1526873 & 9.5229 & 9.5195 & TRN & \\
\hline CHEMBL3632983 & 1526873 & 7.7212 & 7.7176 & TRN & \\
\hline CHEMBL3632978 & 1526873 & 6.4157 & 6.4269 & TRN & \\
\hline CHEMBL3633213 & 1526873 & 6.9914 & 7.4746 & TST & \\
\hline CHEMBL3632969 & 1526873 & 8.8539 & 8.8695 & TRN & \\
\hline CHEMBL3632976 & 1526873 & 7.6021 & 8.2705 & TST & \\
\hline CHEMBL3633228 & 1526873 & 9.5229 & 9.52 & TRN & \\
\hline CHEMBL3633217 & 1526873 & 7.7212 & 7.7361 & TST & \\
\hline CHEMBL3633406 & 1526873 & 8.1192 & 8.1307 & TRN & \\
\hline CHEMBL 3633226 & 1526873 & 9.5229 & 9.5259 & TRN & \\
\hline CHEMBL3632982 & 1526873 & 6.5654 & 6.5869 & TRN & \\
\hline CHEMBL3632985 & 1526873 & 9.0458 & 8.5861 & TST & \\
\hline CHEMBL3632797 & 1526873 & 8.3372 & 8.3523 & TRN & \\
\hline CHEMBL 3633410 & 1526873 & 9.2218 & 9.2441 & TRN & \\
\hline CHEMBL3633405 & 1526873 & 8.9586 & 8.9677 & TRN & \\
\hline CHEMBL3632972 & 1526873 & 8.3665 & 8.3606 & TRN & \\
\hline CHEMBL3633408 & 1526873 & 9.0969 & 9.0781 & TRN & \\
\hline CHEMBL3633216 & 1526873 & 7.7447 & 7.7492 & TRN & \\
\hline CHEMBL3633219 & 1526873 & 9.3979 & \multicolumn{2}{|c|}{9.402000000000001} & TRN \\
\hline CHEMBL 3633407 & 1526873 & 9.5229 & 9.5247 & TRN & \\
\hline CHEMBL 3632977 & 1526873 & 7.699 & 7.7091 & TRN & \\
\hline CHEMBL3633409 & 1526873 & 9.5229 & 9.5172 & TRN & \\
\hline CHEMBL3633231 & 1526873 & 9.5229 & 9.4972 & TRN & \\
\hline CHEMBL3633230 & 1526873 & 9.3979 & 9.3669 & TRN & \\
\hline CHEMBL 3632796 & 1526873 & 7.585 & 7.5845 & TRN & \\
\hline CHEMBL 3633220 & 1526873 & 9.2218 & 9.2337 & TRN & \\
\hline CHEMBL3633218 & 1526873 & 9.301 & 8.8625 & TST & \\
\hline CHEMBL3633223 & 1526873 & 9.0969 & 9.077 & TRN & \\
\hline CHEMBL3633214 & 1526873 & 9.0969 & 8.8311 & TST & \\
\hline
\end{tabular}


Supplemental Table S2.txt

\begin{tabular}{|c|c|c|c|c|}
\hline HEMB I & 526873 & 8.3279 & & $\mathrm{TR}$ \\
\hline & 526873 & 7.4559 & & \\
\hline 2 & & & & \\
\hline AEMBL & 26873 & 38 & 0063 & \\
\hline AEMBL3633413 & 526873 & & 4154 & \\
\hline HEMBL3633411 & 526873 & 9.0969 & .102 & \\
\hline HEMBL & 526873 & & 5567 & \\
\hline IEMBL3 & 540426 & & & RN \\
\hline AEMBL3926631 & 640426 & 9.0 & . 1897 & PN \\
\hline HEMBL3942451 & 640426 & 10.0 & .7285 & \\
\hline HEMBL3929671 & 640426 & & .1547 & \\
\hline IEMBL392e & 26 & & 9517 & \\
\hline AEMBL 389 & & & 1047 & RN \\
\hline HEMBL3938790 & 640426 & & .8072 & \\
\hline AEMBL3918 & 640426 & & 3527 & \\
\hline AEMBL3963 & 640426 & & .5714 & \\
\hline AEMBL3 & 26 & & 39 & 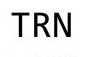 \\
\hline HEMBL3S & & 861 & 497 & \\
\hline HEMBL390 & 640426 & 9.0 & 8.805 & \\
\hline AEMBL390 & 426 & & 31 & ST \\
\hline AEMBL 397 & 640426 & 959 & 54 & NIV \\
\hline HEMBL390 & 26 & & 94 & RN \\
\hline HEMBL3898 & 26 & 218 & 89 & \\
\hline HEMBL391: & 640426 & 8 . & 995 & $\Gamma \mathrm{RN}$ \\
\hline HEMBL 389 & & & & TRN \\
\hline HEMBL3S & 640426 & 9 & 06 & SI \\
\hline HEMBL; & & & 468 & RN \\
\hline $\mathrm{AFMBI}=$ & 26 & 9 & 18 & ST \\
\hline HEMBL 3972 & 640426 & 9. & 208 & TRN \\
\hline HEMBL39026 & 640426 & 9 & & RIN \\
\hline HEMBL 334 & 640426 & & & RN \\
\hline HEMBL & 26 & & & RN \\
\hline HEMBL3 & 26 & & 06 & RN \\
\hline HEMBL3982691 & 540426 & 7.886 & 311 & IRN \\
\hline HEMBL3919503 & 640426 & & 478 & TRN \\
\hline HEMBL3S & 26 & & 29 & RN \\
\hline HFMRI 3 & 6 & 9. & 55 & זRN \\
\hline HEMBL3 & & 8.3979 & 1082 & ГST \\
\hline HEMBL3922863 & 640426 & 10.0 & 493 & TRN \\
\hline HEMBL 395 & 540426 & 9. & 343 & RN \\
\hline HEMBL 39 & 640426 & 8 & 806 & PA $>$ \\
\hline CHEMBL39 & 1640426 & & & TRN \\
\hline HEMBL392 & 1640426 & 8.69 & 8.3579 & RN \\
\hline HEMBL3934000 & 640426 & 7.7696 & 1764 & TST \\
\hline MBL388 & & 3539 & 025 & RN \\
\hline HEMBL3907 & 640426 & 10.0 & 0.2427 & \\
\hline CHEMBL 391 & 640426 & 9.0 & 9.6943 & 促 \\
\hline LHEMBL3935416 & 1640426 & 8.699 & 8.8341 & RN \\
\hline
\end{tabular}

Page 24234 


\begin{tabular}{|c|c|c|c|c|c|c|}
\hline \multicolumn{7}{|c|}{ Supplemental Table S2.txt } \\
\hline CHEMBL3901565 & 1640426 & 9.0 & 9.0053 & TRN & & \\
\hline CHEMBL 3963767 & 1640426 & 7.6383 & 8.0527 & TRN & & \\
\hline CHEMBL 3933665 & 1640426 & 10.0 & 9.6219 & TRN & & \\
\hline CHEMBL 3980137 & 1640426 & 8.3979 & 8.3021 & TST & & \\
\hline CHEMBL 3944738 & 1640426 & 9.0 & 8.9202 & TST & & \\
\hline CHEMBL 3945540 & 1640426 & 9.0 & 8.9373 & TST & & \\
\hline CHEMBL 3901683 & 1640426 & 8.5229 & 8.6504 & TST & & \\
\hline CHEMBL 3947661 & 1640426 & 10.0 & 8.5504 & TST & & \\
\hline CHEMBL 3911341 & 1640426 & 9.0 & 8.8281 & TST & & \\
\hline CHEMBL3973301 & 1640426 & 8.1549 & 9.134 & TST & & \\
\hline CHEMBL3979685 & 1640426 & 7.6576 & 7.9938 & TST & & \\
\hline CHEMBL3959299 & 1641467 & 6.0809 & 6.7559 & TRN & & \\
\hline CHEMBL3915047 & 1641467 & 7.4034 & 7.0697 & TST & & \\
\hline CHEMBL3893308 & 1641467 & 6.38200 & 00000000 & $\partial 1$ & 6.2097 & TRN \\
\hline CHEMBL 3984857 & 1641467 & 8.1249 & 7.3361 & TST & & \\
\hline CHEMBL3955584 & 1641467 & 7.7447 & 6.9117 & TRN & & \\
\hline CHEMBL3931803 & 1641467 & 4.9508 & 6.8889 & TST & & \\
\hline CHEMBL3894613 & 1641467 & 5.6904 & 6.9577 & TST & & \\
\hline CHEMBL 3932268 & 1641467 & 7.1481 & 7.2139 & TST & & \\
\hline CHEMBL3956842 & 1641467 & 8.4698 & 8.1404 & TRN & & \\
\hline CHEMBL3941441 & 1641467 & 7.5114 & 6.9527 & TRN & & \\
\hline CHEMBL 3952927 & 1641467 & 6.5421 & 7.369 & TST & & \\
\hline CHEMBL3975973 & 1641467 & 7.2684 & 7.04799 & 9999999999 & & TRN \\
\hline CHEMBL 3943403 & 1641467 & 7.3316 & 7.3004 & TRN & & \\
\hline CHEMBL3903331 & 1641467 & 7.4179 & 7.2485 & TRN & & \\
\hline CHEMBL3980497 & 1641467 & 7.8268 & 7.3316 & TRN & & \\
\hline CHEMBL3961182 & 1641467 & 4.9547 & 6.6253 & TST & & \\
\hline CHEMBL3909524 & 1641467 & 6.9393 & 7.2694 & TRN & & \\
\hline CHEMBL 3960268 & 1641467 & 6.7545 & 7.1426 & TRN & & \\
\hline CHEMBL3935810 & 1641467 & 7.4425 & 7.2191 & TRN & & \\
\hline CHEMBL 3967874 & 1641467 & 7.1586 & 7.2752 & TRN & & \\
\hline CHEMBL3945100 & 1641467 & 7.2351 & 7.1429 & TRN & & \\
\hline CHEMBL3902211 & 1641467 & 7.0545 & 6.7991 & TST & & \\
\hline CHEMBL 3890239 & 1641467 & 6.4449 & 6.9755 & TRN & & \\
\hline CHEMBL3938815 & 1641467 & 6.6925 & 7.0545 & TRN & & \\
\hline CHEMBL3899181 & 1641467 & 7.2464 & 7.3495 & TRN & & \\
\hline CHEMBL3902013 & 1641467 & 6.9957 & 7.011 & TRN & & \\
\hline CHEMBL3972491 & 1641467 & 6.7471 & 6.9342 & TRN & & \\
\hline CHEMBL3918436 & 1641467 & 7.1002 & 6.944 & TST & & \\
\hline CHEMBL 3954182 & 1641467 & 7.7747 & 7.4405 & TRN & & \\
\hline CHEMBL3953911 & 1641467 & 7.61799 & 99999999 & 99 & 7.2662 & TRN \\
\hline CHEMBL 3926725 & 1641467 & 7.3872 & 7.4629 & TST & & \\
\hline CHEMBL3929279 & 1641467 & 7.1543 & 6.8916 & TRN & & \\
\hline CHEMBL3899359 & 1641467 & 7.1349 & 7.3659 & TRN & & \\
\hline CHEMBL3955776 & 1641467 & 6.5986 & 6.8431 & TRN & & \\
\hline CHEMBL3950600 & 1641467 & 6.4989 & 6.7814 & TRN & & \\
\hline CHEMBL3941366 & 1641467 & 7.6925 & 6.9959 & TRN & & \\
\hline CHEMBL3896504 & 1641467 & 7.8327 & 8.0447 & TST & & \\
\hline
\end{tabular}


Supplemental Table S2.txt

\begin{tabular}{|c|c|c|c|c|c|}
\hline CHEMBL3900495 & 1641467 & 6.9208 & 6.9326 & TST & \\
\hline CHEMBL3954295 & 1641467 & 7.1427 & 7.2146 & TRN & \\
\hline CHEMBL3936178 & 1641467 & 7.2111 & 7.5168 & TRN & \\
\hline CHEMBL3959477 & 1641467 & 7.1379 & 7.1926 & TRN & \\
\hline CHEMBL3913647 & 1641467 & 5.0052 & 7.1567 & TST & \\
\hline CHEMBL3963374 & 1641467 & 6.3372 & 7.2478 & TRN & \\
\hline CHEMBL3986968 & 1641467 & 8.1221 & 8.0484 & TRN & \\
\hline CHEMBL3896390 & 1641467 & 7.9586 & 7.3308 & TRN & \\
\hline CHEMBL3979773 & 1641467 & 5.684 & 5.5162 & TRN & \\
\hline CHEMBL3953476 & 1641467 & 7.9101 & 7.8704 & TRN & \\
\hline CHEMBL3904380 & 1641467 & 7.6271 & 6.91100 & 90000000005 & TST \\
\hline CHEMBL3910560 & 1641467 & 7.3936 & 7.4573 & TRN & \\
\hline CHEMBL3925337 & 1641467 & 6.3116 & 7.0729 & TRN & \\
\hline CHEMBL3981239 & 1641467 & 7.1778 & 7.0608 & TRN & \\
\hline CHEMBL3945457 & 1641467 & 7.426 & 7.075 & TRN & \\
\hline CHEMBL3891034 & 1641467 & 7.2218 & 7.1079 & TST & \\
\hline CHEMBL3908836 & 1641467 & 7.4318 & 7.1632 & TRN & \\
\hline CHEMBL3966951 & 1641467 & 7.1952 & 7.2719 & TRN & \\
\hline CHEMBL3918406 & 1641467 & 8.0114 & 7.9418 & TRN & \\
\hline CHEMBL3944747 & 1641467 & 8.0535 & 7.3529 & TRN & \\
\hline CHEMBL3905814 & 1641467 & 5.7721 & 6.8094 & TRN & \\
\hline CHEMBL3921699 & 1641467 & 6.8097 & 6.9217 & TRN & \\
\hline CHEMBL3962028 & 1641467 & 8.057 & 7.1516 & TRN & \\
\hline CHEMBL3939635 & 1641467 & 6.7305 & 6.8022 & TST & \\
\hline CHEMBL3925570 & 1641467 & 7.2865 & 7.2056 & TRN & \\
\hline CHEMBL3982277 & 1641467 & 8.0 & 7.3997 & TRN & \\
\hline CHEMBL3901772 & 1641467 & 6.0 & 7.1747 & TRN & \\
\hline CHEMBL3926956 & 1641467 & 7.6498 & 7.395 & TRN & \\
\hline CHEMBL3917786 & 1641467 & 7.4034 & 7.5746 & TRN & \\
\hline CHEMBL3902033 & 1641467 & 7.3072 & 7.4794 & TRN & \\
\hline CHEMBL3928251 & 1641467 & 4.9136 & 6.8949 & TST & \\
\hline CHEMBL3976248 & 1641467 & 7.3098 & 7.3763 & TRN & \\
\hline CHEMBL 3890237 & 1641467 & 6.1079 & 6.8743 & TRN & \\
\hline CHEMBL3921821 & 1641467 & 7.3513 & 7.1464 & TRN & \\
\hline CHEMBL3920507 & 1641467 & 6.5498 & 6.2366 & TRN & \\
\hline CHEMBL3924694 & 1641467 & 6.0 & 6.2685 & TRN & \\
\hline CHEMBL3910386 & 1641467 & 7.8239 & 7.5896 & TRN & \\
\hline CHEMBL3901617 & 1641467 & 8.3116 & 7.9686 & TRN & \\
\hline CHEMBL3942792 & 1641467 & \multicolumn{3}{|c|}{8.556000000000001} & TRN \\
\hline CHEMBL3935370 & 1641467 & 7.6757 & 7.176 & TRN & \\
\hline CHEMBL3975950 & 1641467 & 6.2807 & 6.8044 & TRN & \\
\hline CHEMBL3960840 & 1641467 & 8.0458 & 7.7147 & TRN & \\
\hline CHEMBL3906765 & 1641467 & 7.3893 & 6.8963 & TRN & \\
\hline CHEMBL3928984 & 1641467 & 7.7077 & 7.8384 & TRN & \\
\hline CHEMBL3984524 & 1641467 & 6.0645 & 5.4588 & TST & \\
\hline CHEMBL3913658 & 1641467 & 6.5544 & 6.4414 & TRN & \\
\hline CHEMBL3893317 & 1641467 & 8.4413 & 7.9475 & TRN & \\
\hline CHEMBL3982601 & 1641467 & 5.9872 & 7.3575 & TRN & \\
\hline
\end{tabular}

Page 24236 


\begin{tabular}{|c|c|c|c|c|c|c|c|}
\hline \multicolumn{7}{|c|}{ Supplemental Table S2.txt } & \\
\hline CHEMBL3934082 & 1641467 & 6.382999 & 99999999 & & 6.7941 & TRN & \\
\hline CHEMBL3904685 & 1641467 & 7.6946 & 7.0164 & TRN & & & \\
\hline CHEMBL3904824 & 1641467 & 7.8996 & 7.8146 & TRN & & & \\
\hline CHEMBL3924669 & 1641467 & 6.3605 & 7.0328 & TST & & & \\
\hline CHEMBL 3894731 & 1641467 & 8.0585 & 7.6689 & TRN & & & \\
\hline CHEMBL 3969024 & 1641467 & 7.2211 & 6.9559 & TRN & & & \\
\hline CHEMBL 3894362 & 1641467 & 7.9508 & 7.49299 & 9999999999 & & TRN & \\
\hline CHEMBL 3892278 & 1641467 & 7.4737 & 7.8271 & TRN & & & \\
\hline CHEMBL 3976417 & 1641467 & 6.0757 & 7.2093 & TST & & & \\
\hline CHEMBL3894253 & 1641467 & 8.5017 & 7.5938 & TRN & & & \\
\hline CHEMBL 3921721 & 1641467 & 7.2782 & 6.9157 & TST & & & \\
\hline CHEMBL 3894641 & 1641467 & 7.8356 & 6.5048 & TRN & & & \\
\hline CHEMBL3908237 & 1641467 & 8.209 & 7.2036 & TRN & & & \\
\hline CHEMBL 3934083 & 1641467 & 6.7167 & 6.7525 & TRN & & & \\
\hline CHEMBL3910029 & 1641467 & 7.5045 & 6.9938 & TST & & & \\
\hline CHEMBL 3908307 & 1641467 & 6.4377 & 7.3213 & TRN & & & \\
\hline CHEMBL3900326 & 1641467 & 5.1884 & 7.1169 & TST & & & \\
\hline CHEMBL3969053 & 1641467 & 8.0846 & 6.392 & TRN & & & \\
\hline CHEMBL3960119 & 1641467 & 7.7375 & 7.5507 & TRN & & & \\
\hline CHEMBL3949547 & 1641467 & 7.9172 & 7.2008 & TRN & & & \\
\hline CHEMBL3955900 & 1641467 & 6.4698 & 6.7297 & TRN & & & \\
\hline CHEMBL3986269 & 1641467 & 5.3152 & 6.5572 & TST & & & \\
\hline CHEMBL3977711 & 1641467 & 5.6402 & 6.9444 & TRN & & & \\
\hline CHEMBL3955212 & 1641467 & 6.342006 & 30000000 & 205 & 6.861 & 00000001 & TRN \\
\hline CHEMBL 3980543 & 1641467 & 7.2716 & 7.1157 & TST & & & \\
\hline CHEMBL 3925651 & 1641467 & 8.118 & 7.9612 & TST & & & \\
\hline CHEMBL3943725 & 1641467 & 7.1772 & 7.108 & TRN & & & \\
\hline CHEMBL 3967018 & 1641467 & 6.5331 & 6.7439 & TRN & & & \\
\hline CHEMBL3951469 & 1641467 & 7.4377 & 7.0343 & TRN & & & \\
\hline CHEMBL 3967144 & 1641467 & 7.8601 & 7.3105 & TRN & & & \\
\hline CHEMBL 3973896 & 1641467 & 7.1198 & 6.9105 & TRN & & & \\
\hline CHEMBL3945181 & 1641467 & 7.6055 & 7.2851 & TRN & & & \\
\hline CHEMBL 3954851 & 1641467 & 5.7799 & 6.7592 & TRN & & & \\
\hline CHEMBL3936000 & 1641467 & 7.1979 & 7.0076 & TRN & & & \\
\hline CHEMBL3930840 & 1641467 & 7.5735 & 7.5828 & TRN & & & \\
\hline CHEMBL 3980234 & 1641467 & 7.4724 & 7.3967 & TRN & & & \\
\hline CHEMBL3928768 & 1641467 & 8.0516 & 7.70299 & 9999999999 & & TRN & \\
\hline CHEMBL3895967 & 1641467 & 7.067 & 6.7718 & TRN & & & \\
\hline CHEMBL3967619 & 1641467 & 7.9208 & 7.1147 & TRN & & & \\
\hline CHEMBL 3895350 & 1641467 & 8.3851 & 7.7639 & TRN & & & \\
\hline CHEMBL 3928645 & 1641467 & 6.3665 & 6.7247 & TST & & & \\
\hline CHEMBL 3963498 & 1641467 & 7.0899 & 6.7655 & TST & & & \\
\hline CHEMBL 3895874 & 1641467 & 7.8508 & 7.6163 & TRN & & & \\
\hline CHEMBL3923900 & 1641467 & 6.9666 & 7.3654 & TRN & & & \\
\hline CHEMBL3899360 & 1641467 & 6.9666 & 6.8254 & TRN & & & \\
\hline CHEMBL 3955814 & 1641467 & 8.214 & 8.001 & TRN & & & \\
\hline CHEMBL3929033 & 1641467 & 6.8508 & 6.8926 & TRN & & & \\
\hline CHEMBL3967365 & 1641467 & 7.7305 & 7.3797 & TST & & & \\
\hline
\end{tabular}

Page 24237 
Supplemental Table S2.txt

\begin{tabular}{|c|c|c|c|c|c|}
\hline CHEMBL 3969268 & 1641467 & 6.2848 & 5.8367 & TRN & \\
\hline CHEMBL 3945879 & 1641467 & 7.1203 & 7.0753 & TRN & \\
\hline CHEMBL3953500 & 1641467 & 7.1537 & 7.3384 & TST & \\
\hline CHEMBL 3961061 & 1641467 & 6.5768 & 6.6604 & TST & \\
\hline CHEMBL3954458 & 1641467 & 7.9586 & 7.1484 & TRN & \\
\hline CHEMBL 3949198 & 1641467 & 7.9788 & 7.2603 & TST & \\
\hline CHEMBL 3890164 & 1641467 & 7.9031 & 7.3733 & TRN & \\
\hline CHEMBL 3905794 & 1641467 & 8.5575 & 8.5149 & TST & \\
\hline CHEMBL 3929108 & 1641467 & 7.5834 & 7.1487 & TRN & \\
\hline CHEMBL3967676 & 1641467 & 8.5498 & 8.5953 & TST & \\
\hline CHEMBL 3964496 & 1641467 & 7.3382 & 7.5921 & TRN & \\
\hline CHEMBL 3920700 & 1641467 & 6.9431 & 7.2021 & TST & \\
\hline CHEMBL 3976952 & 1641467 & 6.109 & 6.6058 & TRN & \\
\hline CHEMBL 3911865 & 1641467 & 7.2692 & 7.0951 & TST & \\
\hline CHEMBL3928174 & 1641467 & 5.3089 & 6.5946 & TST & \\
\hline CHEMBL 3921797 & 1641467 & 8.4283 & 6.8797 & TST & \\
\hline CHEMBL3933608 & 1641467 & 6.5735 & 6.8945 & TRN & \\
\hline CHEMBL 3913092 & 1641467 & 8.3372 & 8.1138 & TRN & \\
\hline CHEMBL 3986386 & 1641467 & 7.1427 & 6.9117 & TRN & \\
\hline CHEMBL 3948093 & 1641467 & 7.3363 & 7.7505 & TRN & \\
\hline CHEMBL 3947044 & 1641467 & 6.0 & 7.1103 & TRN & \\
\hline CHEMBL3950599 & 1641467 & 5.8665 & 6.722 & TRN & \\
\hline CHEMBL 3944806 & 1641467 & 8.1175 & 7.301 & TST & \\
\hline CHEMBL 3947412 & 1641467 & 7.3747 & 7.047999 & 7999999999 & TRN \\
\hline CHEMBL 3931632 & 1641467 & 7.0057 & 6.045 & TST & \\
\hline CHEMBL 3943701 & 1641467 & 8.3197 & 7.9393 & TRN & \\
\hline CHEMBL 3901352 & 1641467 & 5.4045 & 6.8407 & TST & \\
\hline CHEMBL 3983160 & 1641467 & 7.4034 & 7.2431 & TRN & \\
\hline CHEMBL 3891252 & 1641467 & 7.2907 & 6.857 & TST & \\
\hline CHEMBL 3942881 & 1641467 & 6.7471 & 6.8793 & TST & \\
\hline CHEMBL 3977808 & 1641467 & 6.5258 & 7.4784 & TRN & \\
\hline CHEMBL 3964742 & 1641467 & 8.4802 & 8.1722 & TRN & \\
\hline CHEMBL 3978638 & 1641467 & 5.7878 & 6.8194 & TRN & \\
\hline CHEMBL 3931519 & 1641467 & 8.3615 & 7.3193 & TRN & \\
\hline CHEMBL 3896608 & 1641467 & 7.1427 & 7.093 & TRN & \\
\hline CHEMBL 3907811 & 1641467 & 8.3516 & 8.1109 & TRN & \\
\hline CHEMBL 3892230 & 1641467 & 7.7055 & 7.3888 & TRN & \\
\hline CHEMBL 3922932 & 1641467 & 7.8386 & 7.915 & TRN & \\
\hline CHEMBL 3940058 & 1641467 & 7.4962 & 6.8674 & TST & \\
\hline CHEMBL 3900704 & 1641467 & 6.7352 & 6.6823 & TRN & \\
\hline CHEMBL 3985246 & 1641467 & 8.129 & 7.7987 & TRN & \\
\hline CHEMBL 3939846 & 1641467 & 7.5918 & 7.9664 & TRN & \\
\hline CHEMBL3919686 & 1641467 & 8.2993 & 8.0142 & TRN & \\
\hline CHEMBL 3961580 & 1641467 & 6.7033 & 6.9831 & TST & \\
\hline CHEMBL 3956224 & 1641467 & 6.3768 & 6.6947 & TRN & \\
\hline CHEMBL 3932952 & 1641467 & 8.55600 & 000000000 & 8.0687 & TRN \\
\hline CHEMBL 3938322 & 1641467 & 7.1599 & 7.5057 & TRN & \\
\hline CHEMBL 3901177 & 1641467 & 6.567 & 7.0537 & TRN & \\
\hline
\end{tabular}


Supplemental Table S2.txt

\begin{tabular}{|c|c|c|c|c|}
\hline 㱠 & 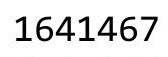 & 5073 & & \\
\hline HEMBL3969029 & 641467 & 7.9355 & 7.2263 & \\
\hline 643 & & & & \\
\hline 86924 & 467 & & 498 & \\
\hline AEMBL3977609 & 641467 & 6.6596 & 7511 & \\
\hline HEMBL3933582 & 641467 & 8.6882 & 6915 & \\
\hline HEMBL3938612 & 641467 & .3893 & 3357 & \\
\hline IEMBL3 & 57 & & & \\
\hline IEMBL 3894478 & & 7.1938 & 3637 & \\
\hline HEMBL3916356 & 167 & 6.9066 & 0168 & \\
\hline HEMBL3895728 & 467 & 6.5302 & 7459 & \\
\hline HEMBL3972642 & 467 & 6.7235 & 1331 & \\
\hline HEMBL3 & & .8297 & & \\
\hline HEMBL3E & & 6.2328 & & \\
\hline HEMBL3969804 & 67 & 8.2541 & 9058 & \\
\hline AEMBL397 & 57 & 4776 & & \\
\hline AEMBL38 & 67 & 99 & 54 & \\
\hline HEMBL3 & & & & \\
\hline HEMBL3 & & & & \\
\hline HEMBL3S & 67 & 82 & & \\
\hline AEMBL3951083 & 57 & 6. & 51 & \\
\hline HEMBL3S & 7 & 7. & 83 & \\
\hline HEMBL3 & & & & \\
\hline 676 & & & & \\
\hline AEMBL39 & & & & RN \\
\hline HEMBL3959204 & 7 & 6. & 54 & 1 \\
\hline HEMBL3903773 & 6 & 7. & 12 & 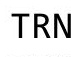 \\
\hline HEMBL3 & & 51 & & \\
\hline 516 & & & & RN \\
\hline AEMBL38 & & & & RIN \\
\hline HEMBL3915788 & 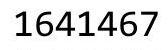 & & 07 & ST \\
\hline HEMBL3946294 & 6 & 5 & & KIV \\
\hline HEMBL39 & & 8. & & ST \\
\hline HEMBL39 & & 6 & & RN \\
\hline HEMBL3912421 & 57 & & 02 & ST \\
\hline HEMBL3955731 & 57 & & 71 & $\mathrm{RN}$ \\
\hline HEMBL3959889 & 57 & 7. & 566 & Niv \\
\hline 518 & & & & $S 1$ \\
\hline HEMBL3924279 & & & 262 & $\mathrm{RN}$ \\
\hline HEMBL3978179 & 57 & & 927 & RN \\
\hline HEMBL3974810 & 164 & 179 & 359 & \\
\hline CHEMBL 3928853 & & & 5857 & RIV \\
\hline CHEMBL3927514 & & & 3738 & RN \\
\hline HEMBL3896775 & 67 & 7.2 & 9383 & ST \\
\hline AEMBL3927403 & 57 & 5 . & 624 & F \\
\hline 091 & & & & \\
\hline 966 & & 8.7799 & & \\
\hline 393834 & 6414 & 5.991 & & \\
\hline
\end{tabular}

Page 24239 
Supplemental Table S2.txt

\begin{tabular}{|c|c|c|c|c|c|}
\hline CHEMBL3976744 & 1641467 & 6.7696 & 5.9594 & TST & \\
\hline CHEMBL3929951 & 1641467 & 6.0 & 7.3398 & TRN & \\
\hline CHEMBL3918775 & 1641467 & 7.3851 & 6.9233 & TRN & \\
\hline CHEMBL3959913 & 1641467 & 8.0926 & 7.8259 & TRN & \\
\hline CHEMBL3980195 & 1641467 & 7.8041 & 7.1589 & TRN & \\
\hline CHEMBL3937885 & 1641467 & 7.7852 & 7.6038 & TRN & \\
\hline CHEMBL3946310 & 1641467 & 5.8996 & 6.9992 & TST & \\
\hline CHEMBL3975810 & 1641467 & 7.3179 & 7.2316 & TRN & \\
\hline CHEMBL3957123 & 1641467 & 6.1385 & 6.0955 & TST & \\
\hline CHEMBL3896417 & 1641467 & 7.0132 & 7.1253 & TST & \\
\hline CHEMBL 3947767 & 1641467 & 6.057 & 6.6998 & TRN & \\
\hline CHEMBL3908772 & 1641467 & 6.6757 & 6.5929 & TRN & \\
\hline CHEMBL3901122 & 1641467 & 6.9957 & 7.1457 & TRN & \\
\hline CHEMBL3965057 & 1641467 & 7.0004 & 7.4267 & TRN & \\
\hline CHEMBL3894636 & 1641467 & 5.6498 & 6.7861 & TRN & \\
\hline CHEMBL3917565 & 1641467 & 6.9393 & 7.1536 & TRN & \\
\hline CHEMBL3967329 & 1641467 & 6.433 & 6.4088 & TRN & \\
\hline CHEMBL 3904786 & 1641467 & 7.7399 & 7.575 & TRN & \\
\hline CHEMBL3909194 & 1641467 & 8.3979 & 8.5352 & TST & \\
\hline CHEMBL3945484 & 1641467 & 7.4056 & 7.051 & TRN & \\
\hline CHEMBL3939123 & 1641467 & 6.8761 & 6.7859 & TRN & \\
\hline CHEMBL3906668 & 1641467 & 6.4609 & 6.1944 & TST & \\
\hline CHEMBL 3890173 & 1641467 & 7.7423 & 7.76399 & 9999999999 & TRN \\
\hline CHEMBL3939177 & 1641467 & 7.5214 & 7.0591 & TRN & \\
\hline CHEMBL3913274 & 1641467 & 7.8268 & 7.8078 & TRN & \\
\hline CHEMBL3920029 & 1641467 & 6.0 & 7.2642 & TRN & \\
\hline CHEMBL3967960 & 1641467 & 7.7144 & 8.0157 & TRN & \\
\hline CHEMBL3932831 & 1641467 & 8.224 & 7.9285 & TRN & \\
\hline CHEMBL3918223 & 1641467 & 7.4868 & 6.9727 & TST & \\
\hline CHEMBL3902711 & 1641467 & 7.4815 & 7.2074 & TRN & \\
\hline CHEMBL3962855 & 1641467 & 6.8928 & 7.25299 & 9999999999 & TRN \\
\hline CHEMBL3960333 & 1641467 & 7.9208 & 7.1496 & TRN & \\
\hline CHEMBL3950114 & 1641467 & 7.8508 & 7.0694 & TRN & \\
\hline CHEMBL 3901650 & 1641467 & 5.6968 & 7.0058 & TST & \\
\hline CHEMBL 3970443 & 1641467 & 6.5513 & 6.9885 & TRN & \\
\hline CHEMBL3959328 & 1641467 & 7.0894 & 6.8379 & TRN & \\
\hline CHEMBL3967021 & 1641467 & 7.7055 & 6.8762 & TRN & \\
\hline CHEMBL3922299 & 1641467 & 6.9872 & 7.2282 & TRN & \\
\hline CHEMBL3961527 & 1641467 & 8.3716 & 6.8889 & TST & \\
\hline CHEMBL3975499 & 1641467 & 6.5622 & 6.3875 & TRN & \\
\hline CHEMBL3969823 & 1641467 & 7.0575 & 6.6955 & TRN & \\
\hline CHEMBL 3950120 & 1641467 & 7.8041 & 7.2919 & TRN & \\
\hline CHEMBL3956551 & 1641467 & 7.2857 & 7.2975 & TRN & \\
\hline CHEMBL3946258 & 1641467 & 6.8539 & 7.4014 & TRN & \\
\hline CHEMBL3903082 & 1641467 & 7.6517 & 7.1571 & TST & \\
\hline CHEMBL3946600 & 1641467 & 7.3925 & 7.2587 & TST & \\
\hline CHEMBL3949503 & 1641467 & 7.129 & 6.0016 & TST & \\
\hline CHEMBL3950440 & 1641467 & 8.7167 & 8.5031 & TRN & \\
\hline
\end{tabular}

Page 24240 
Supplemental Table S2.txt

\begin{tabular}{|c|c|c|c|c|c|c|}
\hline CHEMBL 3944521 & 1641467 & 6.8356 & 6.7723 & TRN & & \\
\hline CHEMBL 3917279 & 1641467 & 7.6073 & 7.3392 & TRN & & \\
\hline CHEMBL3914871 & 1641467 & 6.9586 & 7.2129 & TST & & \\
\hline CHEMBL 3919251 & 1641467 & 6.61799 & 999999999 & 99 & 7.0646 & TST \\
\hline CHEMBL 3936299 & 1641467 & 6.7496 & 7.017 & TRN & & \\
\hline CHEMBL 3894140 & 1641467 & 6.7645 & 6.64 & TST & & \\
\hline CHEMBL 3925757 & 1641467 & 8.342 & 7.9131 & TRN & & \\
\hline CHEMBL 3907814 & 1641467 & 7.5867 & 7.0736 & TRN & & \\
\hline CHEMBL 3909335 & 1641467 & 6.8239 & 7.0431 & TRN & & \\
\hline CHEMBL3933676 & 1641467 & 7.556 & 7.0239 & TRN & & \\
\hline CHEMBL 3972641 & 1641467 & 6.3401 & 6.6649 & TST & & \\
\hline CHEMBL3920599 & 1641467 & 7.4763 & 7.2755 & TRN & & \\
\hline CHEMBL 3891065 & 1641467 & 7.7932 & 7.5407 & TRN & & \\
\hline CHEMBL3972460 & 1641467 & 8.0969 & 8.4356 & TRN & & \\
\hline CHEMBL 3933558 & 1641467 & 7.5575 & 7.24 & TST & & \\
\hline CHEMBL 3916582 & 1641467 & 6.8386 & 6.6644 & TRN & & \\
\hline CHEMBL 3894095 & 1641467 & 6.7282 & 7.2141 & TRN & & \\
\hline CHEMBL 3986459 & 1641467 & 6.6003 & 7.1008 & TRN & & \\
\hline CHEMBL 3931536 & 1641467 & 7.4547 & 7.0674 & TST & & \\
\hline CHEMBL 3952449 & 1641467 & 7.1831 & 7.1078 & TRN & & \\
\hline CHEMBL 3961943 & 1641467 & 7.3152 & 7.2707 & TRN & & \\
\hline CHEMBL 3945168 & 1641467 & 6.0 & 7.8806 & TRN & & \\
\hline CHEMBL 3966003 & 1641467 & 5.7167 & 6.9208 & TRN & & \\
\hline CHEMBL 3902858 & 1641467 & 7.5884 & 6.9994 & TRN & & \\
\hline CHEMBL 3930904 & 1641467 & 6.7144 & 6.9009 & TST & & \\
\hline CHEMBL 3962298 & 1641467 & 7.4949 & 7.2293 & TRN & & \\
\hline CHEMBL 3897667 & 1641467 & 7.6737 & 7.7125 & TRN & & \\
\hline CHEMBL 3967438 & 1641467 & 6.2411 & 6.5998 & TRN & & \\
\hline CHEMBL3922276 & 1641467 & 8.3768 & 7.7053 & TRN & & \\
\hline CHEMBL 3897661 & 1641467 & 6.0 & 5.7637 & TST & & \\
\hline CHEMBL3914997 & 1641467 & 7.1506 & 6.8039 & TST & & \\
\hline CHEMBL 3920730 & 1641467 & 7.2125 & 7.1807 & TRN & & \\
\hline CHEMBL 3944862 & 1641467 & 8.0731 & 7.7175 & TRN & & \\
\hline CHEMBL3911520 & 1641467 & 6.0 & 7.1364 & TRN & & \\
\hline CHEMBL 3980520 & 1641467 & 6.7399 & 7.2823 & TRN & & \\
\hline CHEMBL3911220 & 1641467 & 7.5143 & 7.6133 & TRN & & \\
\hline CHEMBL3923436 & 1641467 & 7.7595 & 7.4908 & TRN & & \\
\hline CHEMBL 3896711 & 1641467 & 7.5302 & 7.0558 & TRN & & \\
\hline CHEMBL 3957895 & 1641467 & 7.4034 & 7.2271 & TRN & & \\
\hline CHEMBL 3920303 & 1641467 & 7.1046 & 7.276 & TRN & & \\
\hline CHEMBL 3893714 & 1641467 & 7.0953 & 6.7824 & TST & & \\
\hline CHEMBL 3943589 & 1641467 & 5.7352 & 5.1743 & TST & & \\
\hline CHEMBL3956607 & 1641467 & 8.3575 & 8.5086 & TST & & \\
\hline CHEMBL3916076 & 1641467 & 5.4413 & 7.1373 & TRN & & \\
\hline CHEMBL 3978751 & 1641467 & 6.4123 & 7.3154 & TRN & & \\
\hline CHEMBL 3964481 & 1641467 & 7.7305 & 7.1716 & TST & & \\
\hline CHEMBL 3949475 & 1641467 & 7.71899 & 999999999 & & 7.1775 & \\
\hline CHEMBL3890168 & 1641467 & 7.4962 & 7.4837 & TRN & & \\
\hline
\end{tabular}

Page 24241 
Supplemental Table S2.txt

\begin{tabular}{|c|c|c|c|c|c|c|c|}
\hline CHEMBL3890401 & 1641467 & 7.1445 & 7.4432 & TRN & & & \\
\hline CHEMBL3971905 & 1641467 & 6.5654 & 6.9604 & TST & & & \\
\hline CHEMBL3966419 & 1641467 & 7.4498 & 7.5822 & TRN & & & \\
\hline CHEMBL3891301 & 1641467 & 6.9788 & \multicolumn{2}{|c|}{6.656000000000001} & & TST & \\
\hline CHEMBL3917263 & 1641467 & 7.6253 & 7.5879 & TRN & & & \\
\hline CHEMBL3894699 & 1641467 & 7.5935 & 6.7289 & TST & & & \\
\hline CHEMBL 3906020 & 1641467 & 5.2441 & 5.3458 & TST & & & \\
\hline CHEMBL 3973887 & 1641467 & 6.8539 & 7.1638 & TRN & & & \\
\hline CHEMBL 3958247 & 1641467 & \multicolumn{3}{|c|}{5.718999999999999} & \multicolumn{2}{|c|}{ 7. 382999999999999} & TRN \\
\hline CHEMBL3963419 & 1641467 & 6.6038 & 7.2715 & TST & & & \\
\hline CHEMBL3902199 & 1641467 & 7.5467 & 7.4903 & TRN & & & \\
\hline CHEMBL3947124 & 1641467 & 6.6655 & 7.1921 & TST & & & \\
\hline CHEMBL3945634 & 1641467 & 7.3325 & 7.129 & TRN & & & \\
\hline CHEMBL3900952 & 1641467 & 7.27 & 7.3105 & TRN & & & \\
\hline CHEMBL3930766 & 1641467 & 7.2573 & 7.1716 & TRN & & & \\
\hline CHEMBL3942911 & 1641467 & 7.0448 & 6.9416 & TST & & & \\
\hline CHEMBL3901372 & 1641467 & 7.0726 & 7.2961 & TRN & & & \\
\hline CHEMBL3904531 & 1641467 & 7.5901 & 7.3509 & TRN & & & \\
\hline CHEMBL3904179 & 1641467 & 8.4101 & 7.9968 & TRN & & & \\
\hline CHEMBL3940346 & 1641467 & 7.4191 & 7.6035 & TRN & & & \\
\hline CHEMBL3915114 & 1641467 & 7.3605 & 7.3077 & TRN & & & \\
\hline CHEMBL3901623 & 1641467 & 6.2976 & 6.7907 & TRN & & & \\
\hline CHEMBL3929707 & 1641467 & 7.6198 & 7.2912 & TRN & & & \\
\hline CHEMBL3940843 & 1641467 & 6.7986 & 7.0368 & TRN & & & \\
\hline CHEMBL3932815 & 1641467 & 6.52 & 7.20799 & 799999999 & & TRN & \\
\hline CHEMBL3892161 & 1641467 & 7.1838 & 7.3553 & TRN & & & \\
\hline CHEMBL3983114 & 1641467 & 6.5017 & 6.93 & TST & & & \\
\hline CHEMBL3975508 & 1641467 & 6.0 & 7.4061 & TRN & & & \\
\hline CHEMBL3904266 & 1641467 & 7.055 & 6.9011 & TST & & & \\
\hline CHEMBL3982876 & 1641467 & 7.0788 & 6.8384 & TRN & & & \\
\hline CHEMBL3932770 & 1641467 & 7.1993 & 6.8184 & TRN & & & \\
\hline CHEMBL3977501 & 1641467 & 7.6676 & 7.8498 & TRN & & & \\
\hline CHEMBL3970175 & 1641467 & 6.6216 & 7.1046 & TST & & & \\
\hline CHEMBL 3925932 & 1641467 & 7.6402 & 7.6971 & TRN & & & \\
\hline CHEMBL3963919 & 1641467 & 7.0778 & 6.9677 & TST & & & \\
\hline CHEMBL3945307 & 1641467 & 6.0137 & 6.9123 & TRN & & & \\
\hline CHEMBL3937775 & 1641467 & 7.7595 & 6.9204 & TRN & & & \\
\hline CHEMBL3931634 & 1641467 & 6.9872 & 7.3012 & TRN & & & \\
\hline CHEMBL3934532 & 1641467 & 8.4306 & 7.954 & TRN & & & \\
\hline CHEMBL3962263 & 1641467 & 7.0665 & 7.2852 & TRN & & & \\
\hline CHEMBL3894761 & 1641467 & 7.08299 & 99999999 & & 7.2712 & TRN & \\
\hline CHEMBL3973273 & 1641467 & 6.7747 & 6.9073 & TRN & & & \\
\hline CHEMBL3900549 & 1641467 & 8.0931 & 7.4921 & TRN & & & \\
\hline CHEMBL3976018 & 1641467 & 7.8182 & 7.3254 & TRN & & & \\
\hline CHEMBL3954816 & 1641467 & 8.2807 & 7.8077 & TST & & & \\
\hline CHEMBL3949048 & 1641467 & 6.6478 & 7.1463 & TRN & & & \\
\hline CHEMBL3933101 & 1641467 & 6.5751 & 6.3011 & TST & & & \\
\hline CHEMBL3914160 & 1641467 & 6.2815 & 6.9109 & TRN & & & \\
\hline
\end{tabular}


Supplemental Table S2.txt

\begin{tabular}{|c|c|c|c|c|}
\hline CHEMBL3971631 & 1641467 & 6.9208 & 7.3028 & TRN \\
\hline CHEMBL3922721 & 1641467 & 8.6861 & 8.0682 & TRN \\
\hline CHEMBL3933820 & 1641467 & 8.6716 & 8.6388 & TRN \\
\hline CHEMBL 3924753 & 1641467 & 7.5331 & 7.1057 & TRN \\
\hline CHEMBL3951615 & 1641467 & 7.4023 & 7.41700 & 0000000001 \\
\hline CHEMBL3919961 & 1641467 & 8.4789 & 6.4636 & TRN \\
\hline CHEMBL3943749 & 1641467 & 8.8386 & 6.9789 & TRN \\
\hline CHEMBL 3981575 & 1641467 & 7.3979 & 6.9801 & TST \\
\hline CHEMBL3921117 & 1641467 & 6.7375 & 6.9464 & TST \\
\hline CHEMBL3922688 & 1641467 & 7.0052 & 6.5965 & TST \\
\hline CHEMBL3973403 & 1641467 & 6.2218 & 6.7959 & TRN \\
\hline CHEMBL 3947487 & 1641467 & 8.2798 & 7.6577 & TRN \\
\hline CHEMBL3951228 & 1641467 & 8.0969 & 7.5079 & TRN \\
\hline CHEMBL 3918774 & 1641467 & 6.9066 & 7.1157 & TST \\
\hline CHEMBL3923017 & 1641467 & 7.1192 & 6.9906 & TRN \\
\hline CHEMBL3906465 & 1641467 & 7.6778 & 6.8909 & TRN \\
\hline CHEMBL3985843 & 1641467 & 5.5452 & 7.4882 & TRN \\
\hline CHEMBL3986440 & 1641467 & 5.3279 & 6.9691 & TRN \\
\hline CHEMBL3953272 & 1641467 & 7.6778 & 8.2432 & TST \\
\hline CHEMBL3944278 & 1641467 & 6.7055 & 7.49 & TRN \\
\hline CHEMBL3963031 & 1641467 & 7.8794 & 7.7575 & TRN \\
\hline CHEMBL3949576 & 1641467 & 5.8041 & 6.7493 & TRN \\
\hline CHEMBL3941284 & 1641467 & 7.7496 & 7.5682 & TRN \\
\hline CHEMBL3909474 & 1641467 & 6.5901 & 6.9313 & TST \\
\hline CHEMBL3948387 & 1641467 & 6.6655 & 6.6277 & TRN \\
\hline CHEMBL3952161 & 1641467 & 7.7545 & 7.3356 & TRN \\
\hline CHEMBL3896619 & 1641467 & 5.9245 & 7.5666 & TST \\
\hline CHEMBL3906840 & 1641467 & 7.5287 & 7.0513 & TRN \\
\hline CHEMBL3922716 & 1641467 & 8.0931 & 7.3382 & TRN \\
\hline CHEMBL3911601 & 1641467 & 7.4342 & 7.6959 & TST \\
\hline CHEMBL3979549 & 1641467 & 6.8125 & 6.7986 & TRN \\
\hline CHEMBL3905545 & 1641467 & 6.2175 & 6.9325 & TST \\
\hline CHEMBL3953024 & 1641467 & 6.5317 & 7.2293 & TRN \\
\hline CHEMBL3960365 & 1641467 & 7.6904 & 7.4057 & TRN \\
\hline CHEMBL3930482 & 1641467 & 7.2168 & 7.18 & TRN \\
\hline CHEMBL3948127 & 1641467 & 7.1158 & 7.182 & TRN \\
\hline CHEMBL3958262 & 1641467 & 8.3969 & 8.1473 & TRN \\
\hline CHEMBL 3893908 & 1641467 & 7.5638 & 6.9288 & TRN \\
\hline CHEMBL3954318 & 1641467 & 6.3936 & 7.2139 & TST \\
\hline CHEMBL3985582 & 1641467 & 7.4789 & 7.4033 & TRN \\
\hline CHEMBL3907234 & 1641467 & 5.9914 & 7.4783 & TRN \\
\hline CHEMBL3974871 & 1641467 & 7.0975 & 7.0868 & TRN \\
\hline CHEMBL3949604 & 1641467 & 7.4168 & 7.2604 & TRN \\
\hline CHEMBL3931960 & 1641467 & 6.5719 & 6.9009 & TST \\
\hline CHEMBL3919342 & 1641467 & 9.0241 & 8.8266 & TST \\
\hline CHEMBL3924865 & 1641467 & 6.8041 & 6.9746 & TRN \\
\hline CHEMBL 3908378 & 1641467 & 6.5272 & 6.9199 & TRN \\
\hline CHEMBL3984550 & 1641467 & 7.295 & 6.7503 & TRN \\
\hline
\end{tabular}


Supplemental Table S2.txt

\begin{tabular}{|c|c|c|c|c|c|c|c|}
\hline CHEMBL3922300 & 1641467 & 8.0835 & 7.6518 & TRN & & & \\
\hline CHEMBL3921818 & 1641467 & 7.2464 & 7.3548 & TRN & & & \\
\hline CHEMBL3931034 & 1641467 & 8.2668 & 8.3692 & TST & & & \\
\hline CHEMBL3944138 & 1641467 & 6.0 & 7.8209 & TRN & & & \\
\hline CHEMBL3926822 & 1641467 & 7.9586 & 7.7817 & TRN & & & \\
\hline CHEMBL3944863 & 1641467 & 7.7799 & 7.4006 & TRN & & & \\
\hline CHEMBL3951556 & 1641467 & 6.7852 & 6.147 & TRN & & & \\
\hline CHEMBL3976717 & 1641467 & \multicolumn{3}{|c|}{7.821000000000001} & 7.5692 & TRN & \\
\hline CHEMBL3946158 & 1641467 & 8.1831 & 7.3237 & TST & & & \\
\hline CHEMBL3924390 & 1641467 & 7.3757 & 7.9464 & TST & & & \\
\hline CHEMBL3894355 & 1641467 & 7.3116 & 7.0797 & TRN & & & \\
\hline CHEMBL3894286 & 1641467 & 6.8665 & 7.1207 & TRN & & & \\
\hline CHEMBL3916102 & 1641467 & 6.6925 & 7.1318 & TRN & & & \\
\hline CHEMBL3908312 & 1641467 & 7.983 & 7.4939 & TRN & & & \\
\hline CHEMBL3931219 & 1641467 & 8.2434 & 7.2598 & TRN & & & \\
\hline CHEMBL3947869 & 1641467 & 6.4449 & 6.7989 & TRN & & & \\
\hline CHEMBL3889707 & 1641467 & 6.284 & 6.7945 & TRN & & & \\
\hline CHEMBL3916813 & 1641467 & 7.1051 & 7.3017 & TRN & & & \\
\hline CHEMBL3890324 & 1641467 & 6.9101 & 7.2515 & TRN & & & \\
\hline CHEMBL3957989 & 1641467 & \multicolumn{3}{|c|}{6.718999999999999} & \multicolumn{2}{|c|}{7.257000000000001} & TRN \\
\hline CHEMBL3910353 & 1641467 & 6.2958 & 7.1407 & TRN & & & \\
\hline CHEMBL3934028 & 1641467 & 8.1599 & 8.1258 & TRN & & & \\
\hline CHEMBL3919264 & 1641467 & 4.9031 & 6.8858 & TST & & & \\
\hline CHEMBL3963731 & 1641467 & 7.2832 & 7.1522 & TRN & & & \\
\hline CHEMBL3934444 & 1641467 & 7.3179 & 7.0685 & TRN & & & \\
\hline CHEMBL3907653 & 1641467 & 7.0424 & 6.8068 & TRN & & & \\
\hline CHEMBL3945252 & 1641467 & 6.3665 & 6.7976 & TST & & & \\
\hline CHEMBL3940548 & 1641467 & 7.1409 & 7.0566 & TRN & & & \\
\hline CHEMBL3911374 & 1641467 & 8.52 & 8.6381 & TRN & & & \\
\hline CHEMBL3944711 & 1641467 & 8.4935 & 8.3305 & TRN & & & \\
\hline CHEMBL3934228 & 1641467 & 6.4145 & 7.2265 & TRN & & & \\
\hline CHEMBL3907075 & 1641467 & 8.3497 & 7.4473 & TRN & & & \\
\hline CHEMBL3890734 & 1641467 & 6.2048 & 6.9287 & TRN & & & \\
\hline CHEMBL3933851 & 1641467 & \multicolumn{3}{|c|}{6.2620000000000005} & 5.995 & TST & \\
\hline CHEMBL3923664 & 1641467 & 7.1765 & 7.2941 & TRN & & & \\
\hline CHEMBL3912789 & 1641467 & 7.0926 & 7.0664 & TRN & & & \\
\hline CHEMBL3956537 & 1641467 & 8.172 & 7.246 & TST & & & \\
\hline CHEMBL3922963 & 1641467 & 7.7328 & 7.0069 & TRN & & & \\
\hline CHEMBL3909496 & 1641467 & 5.2993 & 7.3321 & TRN & & & \\
\hline CHEMBL3981869 & 1641467 & 6.5272 & 7.1083 & TST & & & \\
\hline CHEMBL3953218 & 1641467 & 6.8477 & 6.8439 & TRN & & & \\
\hline CHEMBL3950118 & 1641467 & 7.6737 & 7.4944 & TRN & & & \\
\hline CHEMBL3954583 & 1641467 & 7.0141 & 7.3105 & TRN & & & \\
\hline CHEMBL3977474 & 1641467 & 7.9101 & 7.6388 & TRN & & & \\
\hline CHEMBL3947820 & 1641467 & 6.129 & 7.2074 & TRN & & & \\
\hline CHEMBL3968828 & 1641467 & 5.7352 & 5.7411 & TST & & & \\
\hline CHEMBL3946775 & 1641467 & 7.6234 & 7.0024 & TRN & & & \\
\hline CHEMBL3982113 & 1641467 & 7.0443 & 6.7983 & TST & & & \\
\hline
\end{tabular}


Supplemental Table S2.txt

\begin{tabular}{|c|c|c|c|c|c|}
\hline CHEMBL3978728 & 1641467 & 7.308 & 7.4932 & TRN & \\
\hline CHEMBL3954769 & 1641467 & 6.4802 & 6.5227 & TST & \\
\hline CHEMBL3895526 & 1641467 & 7.5214 & 7.3956 & TRN & \\
\hline CHEMBL3898074 & 1641467 & 6.4776 & 6.76 & TST & \\
\hline CHEMBL3969129 & 1641467 & 8.0835 & 7.9288 & TST & \\
\hline CHEMBL3934481 & 1641467 & 7.0883 & 7.3467 & TRN & \\
\hline CHEMBL3929975 & 1641467 & 6.1062 & 6.8815 & TST & \\
\hline CHEMBL3916836 & 1641467 & 8.3279 & 8.0922 & TRN & \\
\hline CHEMBL3943678 & 1641467 & 7.8239 & \multicolumn{2}{|c|}{6.622999999999999} & TRN \\
\hline CHEMBL 3893825 & 1641467 & 7.2418 & 7.2292 & TRN & \\
\hline CHEMBL 3945678 & 1641467 & 7.4012 & 7.2582 & TRN & \\
\hline CHEMBL3934791 & 1641467 & 7.9172 & 7.6745 & TRN & \\
\hline CHEMBL3941298 & 1641467 & 8.0017 & 7.2805 & TRN & \\
\hline CHEMBL3917863 & 1641467 & 7.9586 & 7.5338 & TRN & \\
\hline CHEMBL 3892281 & 1641467 & 8.1707 & 7.9842 & TRN & \\
\hline CHEMBL 3978579 & 1641467 & 6.6517 & \multicolumn{2}{|c|}{6.8420000000000005} & TRN \\
\hline CHEMBL3923751 & 1641467 & \multicolumn{3}{|c|}{$7.4510000000000005 \quad 7.1621$} & TRN \\
\hline CHEMBL3963819 & 1641467 & 7.4609 & 6.7843 & TST & \\
\hline CHEMBL3928919 & 1641467 & 7.2684 & 7.381 & TRN & \\
\hline CHEMBL 3914763 & 1641467 & 7.7959 & 7.6875 & TRN & \\
\hline CHEMBL 3920095 & 1641467 & 7.2916 & 7.2006 & TRN & \\
\hline CHEMBL3892163 & 1641467 & 7.0311 & 7.0891 & TRN & \\
\hline CHEMBL3929087 & 1641467 & 6.9788 & 7.5639 & TRN & \\
\hline CHEMBL 3935764 & 1641467 & \multicolumn{3}{|c|}{8.091000000000001} & This \\
\hline CHEMBL 3940780 & 1641467 & 7.5952 & 7.1488 & TRN & \\
\hline CHEMBL 3907391 & 1641467 & 8.7077 & 8.7088 & TST & \\
\hline CHEMBL3938336 & 1641467 & 7.3028 & 7.0285 & TRN & \\
\hline CHEMBL 3958714 & 1641467 & 8.2916 & 8.0059 & TRN & \\
\hline CHEMBL3976603 & 1641467 & 6.0 & 6.7463 & TRN & \\
\hline CHEMBL3908234 & 1641467 & 7.2104 & 6.7162 & TST & \\
\hline CHEMBL 3951284 & 1641467 & 7.2628 & 7.2058 & TST & \\
\hline CHEMBL3974051 & 1641467 & 6.8268 & 6.9816 & TRN & \\
\hline CHEMBL3898906 & 1641467 & 7.6478 & 7.7267 & TRN & \\
\hline CHEMBL3917230 & 1641467 & 5.6946 & 6.4918 & TST & \\
\hline CHEMBL3938019 & 1641467 & 7.9031 & \multicolumn{2}{|c|}{7.332999999999999} & TRN \\
\hline CHEMBL3899881 & 1641467 & 7.2358 & 7.4017 & TRN & \\
\hline CHEMBL3896179 & 1641467 & 7.9245 & 7.7462 & TRN & \\
\hline CHEMBL3980305 & 1641467 & 8.6216 & 8.7336 & TST & \\
\hline CHEMBL 3894870 & 1641467 & 6.2381 & 7.0492 & TST & \\
\hline CHEMBL3956902 & 1641467 & 6.308 & 6.2239 & TST & \\
\hline CHEMBL3893234 & 1641467 & 7.065 & 6.9046 & TRN & \\
\hline CHEMBL3939488 & 1641467 & 7.7825 & 7.4101 & TRN & \\
\hline CHEMBL3978025 & 1641467 & 6.8827 & 7.1621 & TRN & \\
\hline CHEMBL3931666 & 1641467 & 6.7471 & 7.5048 & TRN & \\
\hline CHEMBL3906515 & 1641467 & 6.0 & 7.4122 & TRN & \\
\hline CHEMBL3928196 & 1641467 & 8.209 & 7.8514 & TRN & \\
\hline CHEMBL3901803 & 1641467 & 6.7305 & 7.2189 & TRN & \\
\hline CHEMBL 3940426 & 1641467 & 8.0039 & 7.1156 & TRN & \\
\hline
\end{tabular}

Page 24245 
Supplemental Table S2.txt

\begin{tabular}{|c|c|c|c|c|c|}
\hline CHEMBL3902011 & 1641467 & 6.8539 & 6.6041 & TRN & \\
\hline CHEMBL3955004 & 1641467 & 8.0809 & 8.1256 & TST & \\
\hline CHEMBL3977469 & 1641467 & 6.7282 & 7.1589 & TRN & \\
\hline CHEMBL 3925062 & 1641467 & 7.3516 & 7.1423 & TRN & \\
\hline CHEMBL3949095 & 1641467 & 7.6308 & 7.6556 & TRN & \\
\hline CHEMBL3960317 & 1641467 & 8.6576 & 8.0193 & TST & \\
\hline CHEMBL3959812 & 1641467 & 6.209 & 6.5678 & TRN & \\
\hline CHEMBL3912166 & 1641467 & 5.7235 & 5.6238 & TST & \\
\hline CHEMBL 3908320 & 1641467 & 7.6055 & 7.6606 & TRN & \\
\hline CHEMBL3953587 & 1641467 & 8.1586 & 7.8916 & TRN & \\
\hline CHEMBL3956181 & 1641467 & 8.1831 & 6.9593 & TST & \\
\hline CHEMBL3945120 & 1641467 & 7.475 & 7.3758 & TRN & \\
\hline CHEMBL3915434 & 1641467 & 7.9586 & 7.08 & TRN & \\
\hline CHEMBL3937353 & 1641467 & 7.8239 & 7.6512 & TRN & \\
\hline CHEMBL3898462 & 1641467 & 7.9872 & 7.1467 & TRN & \\
\hline CHEMBL3932411 & 1641467 & 8.0395 & 7.7074 & TRN & \\
\hline CHEMBL3918356 & 1641467 & 7.5622 & 7.4012 & TRN & \\
\hline CHEMBL3970983 & 1641467 & 7.8601 & 7.8411 & TRN & \\
\hline CHEMBL3952764 & 1641467 & 7.3516 & 6.784 & TRN & \\
\hline CHEMBL3983478 & 1641467 & 6.5467 & 6.70100 & 00000000005 & TRN \\
\hline CHEMBL3958422 & 1641467 & 8.51 & 8.5412 & TRN & \\
\hline CHEMBL3961965 & 1641467 & 6.5751 & 7.4485 & TRN & \\
\hline CHEMBL3907205 & 1641467 & 7.4855 & 6.7908 & TST & \\
\hline CHEMBL3978418 & 1641467 & 7.9747 & 7.8031 & TRN & \\
\hline CHEMBL 3937583 & 1641467 & 6.8356 & 6.5809 & TRN & \\
\hline CHEMBL3903584 & 1641467 & 5.5607 & 6.4174 & TRN & \\
\hline CHEMBL 3932844 & 1641467 & 5.8069 & 6.8411 & TRN & \\
\hline CHEMBL3906004 & 1641467 & 6.6517 & 6.7539 & TRN & \\
\hline CHEMBL3978194 & 1641467 & 7.0491 & 6.7922 & TRN & \\
\hline CHEMBL3905031 & 1641467 & 7.3325 & 7.4591 & TRN & \\
\hline CHEMBL3916052 & 1641467 & 7.3565 & 7.1147 & TRN & \\
\hline CHEMBL 3402474 & 1466703 & 8.0706 & 8.0184 & TRN & \\
\hline CHEMBL 3402446 & 1466703 & 8.5229 & 8.5994 & TRN & \\
\hline CHEMBL2332099 & 1466703 & 9.0 & 8.8895 & TRN & \\
\hline CHEMBL 3402441 & 1466703 & 7.585 & 7.599 & TRN & \\
\hline CHEMBL2332074 & 1466703 & 8.3979 & 8.2353 & TRN & \\
\hline CHEMBL 2332060 & 1466703 & 9.0 & 9.0727 & TRN & \\
\hline CHEMBL2332058 & 1466703 & 8.699 & 7.6522 & TST & \\
\hline CHEMBL2332072 & 1466703 & 8.3979 & 8.1871 & TRN & \\
\hline CHEMBL 3402449 & 1466703 & 7.8861 & 7.76 & TRN & \\
\hline CHEMBL2332071 & 1466703 & 7.8861 & 8.1831 & TRN & \\
\hline CHEMBL2332056 & 1466703 & 8.699 & 8.56 & TST & \\
\hline CHEMBL 3402444 & 1466703 & 8.5229 & 8.7399 & TRN & \\
\hline CHEMBL3402463 & 1466703 & 10.0 & 9.6179 & TRN & \\
\hline CHEMBL3402462 & 1466703 & 8.5229 & 8.8034 & TRN & \\
\hline CHEMBL3402455 & 1466703 & 10.0 & 9.7337 & TRN & \\
\hline CHEMBL2332097 & 1466703 & 9.0 & 9.167 & TRN & \\
\hline CHEMBL 3402464 & 1466703 & 8.2218 & 8.4542 & TRN & \\
\hline
\end{tabular}

Page 24246 


\begin{tabular}{|c|c|c|c|c|c|c|}
\hline \multicolumn{7}{|c|}{ Supplemental Table S2.txt } \\
\hline CHEMBL2332091 & 1466703 & 6.4473 & 6.5872 & TRN & & \\
\hline CHEMBL 2332066 & 1466703 & 7.7696 & 7.9197 & TRN & & \\
\hline CHEMBL3402454 & 1466703 & 10.0 & 9.9355 & TRN & & \\
\hline CHEMBL 3402457 & 1466703 & 10.0 & 10.3162 & TRN & & \\
\hline CHEMBL3402451 & 1466703 & 6.7258 & 8.0454 & TST & & \\
\hline CHEMBL3402468 & 1466703 & 6.21399 & $79999999 \subseteq$ & 995 & 7.1186 & TST \\
\hline CHEMBL 2332085 & 1466703 & 6.5969 & 6.6037 & TRN & & \\
\hline CHEMBL3402475 & 1466703 & 8.0969 & 8.0772 & TRN & & \\
\hline CHEMBL 3402458 & 1466703 & 10.0 & 9.5486 & TRN & & \\
\hline CHEMBL2332084 & 1466703 & 6.1244 & 5.6997 & TST & & \\
\hline CHEMBL2332070 & 1466703 & 8.301 & 8.5014 & TRN & & \\
\hline CHEMBL2332068 & 1466703 & 9.0 & 8.4539 & TRN & & \\
\hline CHEMBL2332073 & 1466703 & 8.301 & 8.3796 & TRN & & \\
\hline CHEMBL3402452 & 1466703 & 10.0 & 10.2447 & TRN & & \\
\hline CHEMBL2332089 & 1466703 & 6.3716 & 6.355 & TRN & & \\
\hline CHEMBL 3402450 & 1466703 & 7.3565 & 7.1346 & TRN & & \\
\hline CHEMBL2332079 & 1466703 & 5.9927 & 6.0314 & TRN & & \\
\hline CHEMBL 2332086 & 1466703 & 6.4802 & 6.5865 & TRN & & \\
\hline CHEMBL3402465 & 1466703 & 7.7447 & 7.7771 & TRN & & \\
\hline CHEMBL 2332090 & 1466703 & 6.5513 & 6.4629 & TRN & & \\
\hline CHEMBL3402445 & 1466703 & 7.7696 & 7.8837 & TRN & & \\
\hline CHEMBL3402453 & 1466703 & 10.0 & 10.2364 & TRN & & \\
\hline CHEMBL3402473 & 1466703 & 8.2518 & 8.1538 & TRN & & \\
\hline CHEMBL3402460 & 1466703 & 10.0 & 9.7689 & TRN & & \\
\hline CHEMBL2332057 & 1466703 & 9.0 & 7.8367 & TST & & \\
\hline CHEMBL3402459 & 1466703 & 10.0 & 9.3757 & TRN & & \\
\hline CHEMBL3402472 & 1466703 & 6.7696 & 7.1358 & TRN & & \\
\hline CHEMBL3402466 & 1466703 & 8.699 & 8.9086 & TRN & & \\
\hline CHEMBL 3402467 & 1466703 & 7.0605 & 6.3244 & TST & & \\
\hline CHEMBL2332087 & 1466703 & 6.2441 & 6.3583 & TRN & & \\
\hline CHEMBL2332075 & 1466703 & 7.8539 & 8.1484 & TRN & & \\
\hline CHEMBL2332083 & 1466703 & 6.5528 & 6.8986 & TST & & \\
\hline CHEMBL 2332067 & 1466703 & 10.0 & 10.162 & TRN & & \\
\hline CHEMBL 3402448 & 1466703 & 8.301 & 8.2554 & TRN & & \\
\hline CHEMBL3402469 & 1466703 & 5.5252 & 6.5349 & TST & & \\
\hline CHEMBL3402471 & 1466703 & 10.0 & 9.4506 & TRN & & \\
\hline CHEMBL2331562 & 1466703 & 7.9208 & 8.212 & TST & & \\
\hline CHEMBL 3402470 & 1466703 & 5.4783 & 6.4058 & TST & & \\
\hline CHEMBL2332098 & 1466703 & 9.0 & 8.7895 & TST & & \\
\hline CHEMBL 3402442 & 1466703 & 5.5607 & 5.4556 & TRN & & \\
\hline CHEMBL2332059 & 1466703 & 8.699 & 6.7067 & TST & & \\
\hline CHEMBL2332078 & 1466703 & 7.0555 & 6.92899 & 9999999999 & & S \\
\hline CHEMBL2332065 & 1466703 & 9.0 & 9.3693 & TST & & \\
\hline CHEMBL 2332088 & 1466703 & 6.0343 & 5.8601 & TRN & & \\
\hline CHEMBL2332064 & 1466703 & 8.5229 & 9.5548 & TST & & \\
\hline CHEMBL2332076 & 1466703 & 8.699 & 8.2592 & TST & & \\
\hline CHEMBL3402447 & 1466703 & 8.699 & 8.7274 & TRN & & \\
\hline CHEMBL3402456 & 1466703 & 10.0 & 10.0677 & TRN & & \\
\hline
\end{tabular}


Supplemental Table S2.txt

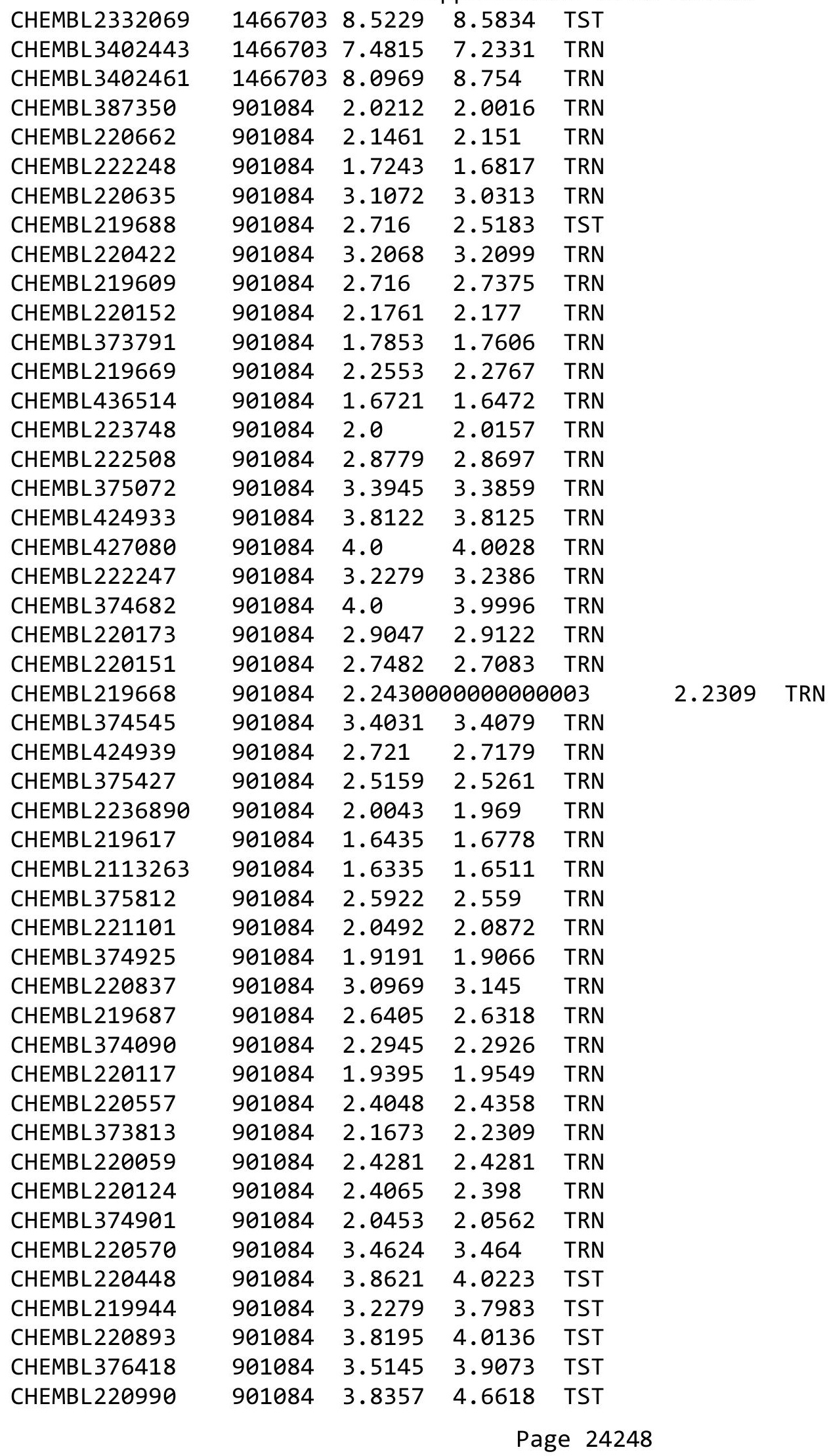




\begin{tabular}{|c|c|c|c|c|c|c|}
\hline & & \multicolumn{5}{|c|}{ Supplemental Table S2.txt } \\
\hline CHEMBL219817 & 901084 & 3.9638 & 3.998 & TST & & \\
\hline CHEMBL375747 & 901084 & 3.8951 & 3.8909 & TRN & & \\
\hline CHEMBL220681 & 901084 & 2.8451 & 2.8308 & TST & & \\
\hline CHEMBL219661 & 901084 & 3.5966 & 3.5838 & TST & & \\
\hline CHEMBL219686 & 901084 & 3.0569 & 2.7409 & TST & & \\
\hline CHEMBL220785 & 901084 & 3.9713 & 4.2589 & TST & & \\
\hline CHEMBL220508 & 901084 & 3.7559 & 4.0989 & TST & & \\
\hline CHEMBL373605 & 901084 & 3.8325 & 3.8007 & TST & & \\
\hline CHEMBL220421 & 901084 & 3.2966 & 3.5098 & TST & & \\
\hline CHEMBL3967996 & 1641654 & 8.0347 & 7.9381 & TRN & & \\
\hline CHEMBL3958986 & 1641654 & 7.0337 & 7.2306 & TRN & & \\
\hline CHEMBL3394062 & 1641654 & 6.63 & 6.1866 & TST & & \\
\hline CHEMBL3981553 & 1641654 & 7.9439 & 7.9491 & TRN & & \\
\hline CHEMBL3981772 & 1641654 & 7.9234 & 7.8774 & TRN & & \\
\hline CHEMBL3918188 & 1641654 & 8.2369 & 8.3704 & TRN & & \\
\hline CHEMBL3960298 & 1641654 & 8.4175 & 8.7803 & TRN & & \\
\hline CHEMBL3394164 & 1641654 & 8.8233 & 8.6755 & TRN & & \\
\hline CHEMBL3942435 & 1641654 & 8.71600 & 00000000 & $\partial 1$ & 8.6322 & TRN \\
\hline CHEMBL 3918784 & 1641654 & 6.2585 & 6.4693 & TRN & & \\
\hline CHEMBL3964497 & 1641654 & 8.0571 & 8.3328 & TST & & \\
\hline CHEMBL3980131 & 1641654 & 9.1463 & 8.9349 & TRN & & \\
\hline CHEMBL3941897 & 1641654 & 7.3378 & 7.3347 & TRN & & \\
\hline CHEMBL3970964 & 1641654 & 6.5541 & 6.6883 & TST & & \\
\hline CHEMBL3918913 & 1641654 & 7.0816 & 7.1546 & TRN & & \\
\hline CHEMBL3983191 & 1641654 & 6.1152 & 6.1306 & TRN & & \\
\hline CHEMBL3948403 & 1641654 & 6.1283 & 6.0633 & TRN & & \\
\hline CHEMBL3935173 & 1641654 & 7.7479 & 8.1046 & TST & & \\
\hline CHEMBL3912741 & 1641654 & 8.8236 & 9.0234 & TRN & & \\
\hline CHEMBL3394070 & 1641654 & 6.9597 & 7.0144 & TRN & & \\
\hline CHEMBL3917311 & 1641654 & 8.9961 & 9.0495 & TRN & & \\
\hline CHEMBL3959316 & 1641654 & 7.6929 & 7.9315 & TRN & & \\
\hline CHEMBL3976832 & 1641654 & 7.9292 & 7.8496 & TRN & & \\
\hline CHEMBL3912927 & 1641654 & 6.9181 & 6.6976 & TRN & & \\
\hline CHEMBL3958501 & 1641654 & 5.8827 & 5.6545 & TRN & & \\
\hline CHEMBL3932794 & 1641654 & 8.2256 & 8.2959 & TRN & & \\
\hline CHEMBL3981312 & 1641654 & 6.9885 & 6.8633 & TST & & \\
\hline CHEMBL 3901582 & 1641654 & 8.3542 & 8.3947 & TRN & & \\
\hline CHEMBL3394169 & 1641654 & 7.392 & 7.3841 & TRN & & \\
\hline CHEMBL3941198 & 1641654 & 8.5967 & 8.326 & TRN & & \\
\hline CHEMBL3901121 & 1641654 & 5.9018 & 5.9191 & TRN & & \\
\hline CHEMBL3937933 & 1641654 & 7.6975 & 7.7384 & TRN & & \\
\hline CHEMBL3394067 & 1641654 & 6.0 & 6.3385 & TRN & & \\
\hline CHEMBL3933275 & 1641654 & 7.289 & 7.2369 & TRN & & \\
\hline CHEMBL 3894736 & 1641654 & 6.0 & 5.8953 & TRN & & \\
\hline CHEMBL3945136 & 1641654 & 7.5039 & 7.5583 & TRN & & \\
\hline CHEMBL3900171 & 1641654 & 6.0 & 6.5807 & TRN & & \\
\hline CHEMBL3939297 & 1641654 & 7.131 & 7.2601 & TRN & & \\
\hline CHEMBL3965804 & 1641654 & 7.0333 & 7.1413 & TRN & & \\
\hline
\end{tabular}

Page 24249 
Supplemental Table S2.txt

\begin{tabular}{|c|c|c|c|c|c|c|}
\hline CHEMBL 3893572 & 1641654 & 8.1693 & 8.2205 & TST & & \\
\hline CHEMBL3920604 & 1641654 & 5.9975 & 5.8897 & TRN & & \\
\hline CHEMBL3925503 & 1641654 & 7.287000 & 000000000 & & 7.4709 & TRN \\
\hline CHEMBL 3898847 & 1641654 & 7.1357 & 7.5665 & TST & & \\
\hline CHEMBL3932201 & 1641654 & 8.856 & 8.4541 & TRN & & \\
\hline CHEMBL3950989 & 1641654 & 6.9781 & 7.5524 & TST & & \\
\hline CHEMBL3911670 & 1641654 & 6.1968 & 6.2037 & TRN & & \\
\hline CHEMBL3947565 & 1641654 & 8.1204 & 8.2055 & TRN & & \\
\hline CHEMBL 3944528 & 1641654 & 8.3703 & 7.7513 & TRN & & \\
\hline CHEMBL3394171 & 1641654 & 6.0 & 6.322 & TRN & & \\
\hline CHEMBL3916074 & 1641654 & 7.3669 & 7.3942 & TRN & & \\
\hline CHEMBL 3904314 & 1641654 & 7.8122 & 7.6291 & TST & & \\
\hline CHEMBL3930004 & 1641654 & 8.2951 & 8.2351 & TRN & & \\
\hline CHEMBL 3951344 & 1641654 & 6.8114 & 6.9373 & TRN & & \\
\hline CHEMBL3919337 & 1641654 & 6.0 & 6.5392 & TRN & & \\
\hline CHEMBL3965588 & 1641654 & 6.0 & 5.8123 & TRN & & \\
\hline CHEMBL3981514 & 1641654 & 8.9245 & 8.5771 & TRN & & \\
\hline CHEMBL3934994 & 1641654 & 7.6112 & 7.6981 & TRN & & \\
\hline CHEMBL 3947201 & 1641654 & 8.5967 & 8.5683 & TRN & & \\
\hline CHEMBL3957552 & 1641654 & 7.8781 & 8.0768 & TRN & & \\
\hline CHEMBL3892029 & 1641654 & 8.6981 & 8.6924 & TRN & & \\
\hline CHEMBL3930916 & 1641654 & 7.757999 & 999999999 & 99 & 7.7601 & TRN \\
\hline CHEMBL3912493 & 1641654 & 6.5719 & 6.568 & TRN & & \\
\hline CHEMBL3910677 & 1641654 & 7.8765 & 7.9839 & TRN & & \\
\hline CHEMBL3938446 & 1641654 & 7.8184 & 7.8619 & TRN & & \\
\hline CHEMBL3903410 & 1641654 & 6.6496 & 6.716 & TRN & & \\
\hline CHEMBL3973417 & 1641654 & 8.2232 & 8.1688 & TRN & & \\
\hline CHEMBL3394060 & 1641654 & 6.5511 & 5.831 & TST & & \\
\hline CHEMBL3951087 & 1641654 & 6.7672 & 6.4573 & TST & & \\
\hline CHEMBL3981344 & 1641654 & 8.217 & 8.2811 & TRN & & \\
\hline CHEMBL3956364 & 1641654 & 6.3045 & 6.1563 & TRN & & \\
\hline CHEMBL3913921 & 1641654 & 6.7301 & 6.6295 & TRN & & \\
\hline CHEMBL3963322 & 1641654 & 6.0417 & 6.0879 & TRN & & \\
\hline CHEMBL3939931 & 1641654 & 5.5529 & 5.3242 & TRN & & \\
\hline CHEMBL3969190 & 1641654 & 6.2688 & 6.2069 & TRN & & \\
\hline CHEMBL3394165 & 1641654 & 8.5017 & 8.4079 & TRN & & \\
\hline CHEMBL3927492 & 1641654 & 7.3906 & 7.4914 & TRN & & \\
\hline CHEMBL 3944661 & 1641654 & 7.1357 & 6.9935 & TST & & \\
\hline CHEMBL 3933697 & 1641654 & 7.8173 & 7.6664 & TRN & & \\
\hline CHEMBL3921086 & 1641654 & 6.9979 & 6.7125 & TRN & & \\
\hline CHEMBL3895040 & 1641654 & 8.5952 & 8.472000 & 0000000001 & & TRN \\
\hline CHEMBL3890422 & 1641654 & 7.2443 & 7.2991 & TRN & & \\
\hline CHEMBL3914520 & 1641654 & 7.9646 & 7.8669 & TRN & & \\
\hline CHEMBL3956673 & 1641654 & 7.2385 & 7.2417 & TRN & & \\
\hline CHEMBL3911316 & 1641654 & 8.7474 & 8.5943 & TRN & & \\
\hline CHEMBL3963493 & 1641654 & 6.4911 & 6.4435 & TRN & & \\
\hline CHEMBL3906747 & 1641654 & 7.572999 & 799999999 & 995 & 7.5329 & TRN \\
\hline CHEMBL3986124 & 1641654 & 8.3399 & 8.1781 & TRN & & \\
\hline
\end{tabular}


Supplemental Table S2.txt

\begin{tabular}{|c|c|c|c|c|c|}
\hline CHEMBL3911843 & 1641654 & 7.4585 & 7.317 & TRN & \\
\hline CHEMBL3965029 & 1641654 & 7.8955 & 7.9844 & TRN & \\
\hline CHEMBL3902931 & 1641654 & 5.6984 & 5.8867 & TST & \\
\hline CHEMBL3943596 & 1641654 & 6.6821 & 6.8027 & TRN & \\
\hline CHEMBL3899208 & 1641654 & 7.7051 & 7.9004 & TRN & \\
\hline CHEMBL3899451 & 1641654 & 7.5177 & 7.8315 & TRN & \\
\hline CHEMBL3922724 & 1641654 & 7.9014 & 8.0194 & TRN & \\
\hline CHEMBL3918311 & 1641654 & 6.4103 & 6.1629 & TST & \\
\hline CHEMBL3963678 & 1641654 & 5.6446 & 5.5125 & TRN & \\
\hline CHEMBL3892287 & 1641654 & 7.7215 & 7.8223 & TRN & \\
\hline CHEMBL3969942 & 1641654 & 8.8019 & 8.6969 & TRN & \\
\hline CHEMBL3968456 & 1641654 & 8.0571 & 7.8432 & TRN & \\
\hline CHEMBL 3983984 & 1641654 & 6.1469 & 5.9352 & TRN & \\
\hline CHEMBL 3985653 & 1641654 & 6.5851 & 6.9171 & TST & \\
\hline CHEMBL3985673 & 1641654 & 6.0245 & 6.1838 & TRN & \\
\hline CHEMBL3956256 & 1641654 & 8.4168 & 8.1197 & TST & \\
\hline CHEMBL3394170 & 1641654 & 7.7049 & 7.6665 & TRN & \\
\hline CHEMBL3952291 & 1641654 & 6.9671 & 7.0206 & TRN & \\
\hline CHEMBL3978285 & 1641654 & 8.5967 & 8.7176 & TRN & \\
\hline CHEMBL3957441 & 1641654 & 7.8024 & 7.9066 & TRN & \\
\hline CHEMBL3910491 & 1641654 & 6.9781 & 6.8434 & TRN & \\
\hline CHEMBL3919558 & 1641654 & 7.3396 & 7.3273 & TRN & \\
\hline CHEMBL3952591 & 1641654 & 8.0266 & 8.1573 & TRN & \\
\hline CHEMBL3394068 & 1641654 & 7.6799 & 7.8532 & TRN & \\
\hline CHEMBL3394074 & 1641654 & 8.756 & 8.634 & TRN & \\
\hline CHEMBL3922191 & 1641654 & 5.9452 & 5.8036 & TST & \\
\hline CHEMBL3970104 & 1641654 & 8.0034 & 8.0191 & TRN & \\
\hline CHEMBL3965031 & 1641654 & 8.1646 & 8.2804 & TRN & \\
\hline CHEMBL3915388 & 1641654 & 6.3735 & 6.4048 & TRN & \\
\hline CHEMBL3955578 & 1641654 & 5.7235 & 5.7947 & TRN & \\
\hline CHEMBL3947790 & 1641654 & 6.2588 & 6.5 & TRN & \\
\hline CHEMBL3907899 & 1641654 & 7.4166 & 7.63299 & 9999999999 & TRN \\
\hline CHEMBL3946064 & 1641654 & 5.0 & 5.532 & TRN & \\
\hline CHEMBL 3975552 & 1641654 & 7.5536 & 7.4009 & TRN & \\
\hline CHEMBL3957081 & 1641654 & 6.0077 & 5.7441 & TRN & \\
\hline CHEMBL3904737 & 1641654 & 7.9751 & 8.0591 & TRN & \\
\hline CHEMBL3913006 & 1641654 & 8.9208 & 8.8703 & TRN & \\
\hline CHEMBL3909365 & 1641654 & 7.1738 & 7.2862 & TRN & \\
\hline CHEMBL3924622 & 1641654 & 6.5118 & 6.79899 & 99999999995 & TRN \\
\hline CHEMBL3961142 & 1641654 & 6.2898 & 6.3989 & TRN & \\
\hline CHEMBL3910718 & 1641654 & 6.3969 & 6.4233 & TRN & \\
\hline CHEMBL3942045 & 1641654 & 5.6115 & 5.4866 & TRN & \\
\hline CHEMBL3901647 & 1641654 & 6.0 & 6.5252 & TST & \\
\hline CHEMBL3889589 & 1641654 & 6.2933 & 6.2376 & TRN & \\
\hline CHEMBL3912113 & 1641654 & 8.2369 & 8.3541 & TRN & \\
\hline CHEMBL3980995 & 1641654 & 7.0124 & 6.2562 & TST & \\
\hline CHEMBL3915618 & 1641654 & 7.4174 & 7.6843 & TST & \\
\hline CHEMBL 3932720 & 1641654 & 7.0548 & 7.3242 & TRN & \\
\hline
\end{tabular}

Page 24251 
Supplemental Table S2.txt

\begin{tabular}{|c|c|c|c|c|}
\hline (L) & 541654 & 6.9547 & & \\
\hline & & & & \\
\hline IFM & 654 & & & \\
\hline HEMBL & & 1516 & & \\
\hline AEMBL3910525 & 641654 & 6.7923 & 7332 & \\
\hline HEMBL3959910 & 54 & 7.4067 & 5867 & \\
\hline 37 & 54 & 6.57 & & \\
\hline AEMBL3 & & & & \\
\hline HEMBL3981152 & 554 & 7.4029 & 3384 & \\
\hline HEMBL3961249 & 554 & 7.8626 & 565 & \\
\hline HEMBL3959112 & 64 & 7.8726 & 7749 & \\
\hline HEMBL3 & 54 & 574 & 9594 & \\
\hline HEMBL3 & & & & \\
\hline HEMBL3892162 & 554 & 6.1097 & 041 & \\
\hline HEMBL3954897 & 554 & 6.5653 & & \\
\hline HEMBL3S & 6 & 6. & 701 & \\
\hline HEMBL3 & & & & 等 \\
\hline HEMBL3 & & & 891 & \\
\hline HEMBL 394 & & & & \\
\hline HEMBL396 & & 177 & & \\
\hline HEMBL3 & 4 & 7. & & SI \\
\hline HEM & & & & RN \\
\hline HEMBL & 4 & 6 & & ST \\
\hline HEMBL3 & & & & \\
\hline HEMBL398 & & & 88 & IRN \\
\hline HEMBL3 & & & & RN \\
\hline HEMBL & & & & KIV \\
\hline HEMPI & & 31 & & 「RN \\
\hline HEMBL 392 & & & & IRIN \\
\hline HEMBL339 & & 95 & 923 & TRN \\
\hline HEMBL3 & & 74 & 45 & RN \\
\hline HFM & & & & 「RN \\
\hline נ & & & & RN \\
\hline HEMBL 398 & & & & 「RN \\
\hline HEMBL3927342 & 54 & 914 & & ГST \\
\hline AEMRI 2 & & 39 & & TRN \\
\hline 8 & & 27 & & ГRN \\
\hline HEMBL395 & & & & TST \\
\hline HEMBL 395 & & & & $\mathrm{RN}$ \\
\hline HEMBL; & & & & RN \\
\hline HEMBL3 & & 8 . & 26 & RN \\
\hline HEMBL3 & & 5. & 994 & ST \\
\hline HEMBL3 & & 7.5099 & 4372 & TRN \\
\hline HEMBL3 & 54 & 49 & & TR \\
\hline 99 & & & & \\
\hline HEMBL3 & & & & \\
\hline HEMBL 391 & 16 & 6.7548 & 5.8211 & RN \\
\hline CHEMBL3915900 & 1641654 & 6.4002 & 6.4251 & \\
\hline
\end{tabular}

Page 24252 
Supplemental Table S2.txt

\begin{tabular}{|c|c|c|c|c|c|}
\hline CHEMBL3942496 & 1641654 & 7.0854 & 7.2577 & TRN & \\
\hline CHEMBL3945846 & 1641654 & 7.7986 & 7.9498 & TRN & \\
\hline CHEMBL3964167 & 1641654 & 7.3834 & 7.3574 & TRN & \\
\hline CHEMBL 3903651 & 1641654 & 5.0 & 5.4176 & TRN & \\
\hline CHEMBL3957476 & 1641654 & 6.6326 & 7.082006 & 0000000001 & TST \\
\hline CHEMBL3972180 & 1641654 & 7.38700 & 20000000 & 7.4449 & TRN \\
\hline CHEMBL3968679 & 1641654 & 6.4743 & 6.7054 & TRN & \\
\hline CHEMBL 3891490 & 1641654 & 7.2128 & 6.9312 & TRN & \\
\hline CHEMBL 3927004 & 1641654 & 8.3776 & 8.2044 & TRN & \\
\hline CHEMBL3889658 & 1641654 & 6.9936 & 7.1002 & TST & \\
\hline CHEMBL3977572 & 1641654 & 5.6848 & 5.2929 & TRN & \\
\hline CHEMBL 3971473 & 1641654 & 8.1925 & 8.1934 & TRN & \\
\hline CHEMBL3974156 & 1641654 & 6.6472 & 6.9296 & TRN & \\
\hline CHEMBL 3925863 & 1641654 & 8.7528 & 8.5008 & TRN & \\
\hline CHEMBL3900578 & 1641654 & 6.0 & 6.3792 & TST & \\
\hline CHEMBL3970168 & 1641654 & 8.2596 & 8.3101 & TRN & \\
\hline CHEMBL3941886 & 1641654 & 6.5726 & 6.4156 & TRN & \\
\hline CHEMBL 3967448 & 1641654 & 6.4886 & 6.6678 & TRN & \\
\hline CHEMBL3900527 & 1641654 & 7.7303 & 8.4387 & TST & \\
\hline CHEMBL3914961 & 1641654 & 8.039 & 7.7871 & TRN & \\
\hline CHEMBL3946988 & 1641654 & 6.5742 & 6.2168 & TST & \\
\hline CHEMBL3972727 & 1641654 & 7.4268 & 7.4629 & TRN & \\
\hline CHEMBL3904783 & 1641654 & 8.7122 & 8.8758 & TRN & \\
\hline CHEMBL3921252 & 1641654 & 7.065 & 7.2639 & TRN & \\
\hline CHEMBL 3896794 & 1641654 & 8.3621 & 8.30600 & 0000000001 & TRN \\
\hline CHEMBL3894390 & 1641654 & 7.2272 & 6.9437 & TRN & \\
\hline CHEMBL3951570 & 1641654 & 7.819 & 7.9843 & TRN & \\
\hline CHEMBL3974432 & 1641654 & 6.6519 & 6.4096 & TRN & \\
\hline CHEMBL3394061 & 1641654 & 6.7507 & 6.0725 & TST & \\
\hline CHEMBL 3982628 & 1641654 & 6.803 & 6.6585 & TRN & \\
\hline CHEMBL 3945003 & 1641654 & 7.6055 & 7.7398 & TRN & \\
\hline CHEMBL3918394 & 1641654 & 7.5412 & 7.6622 & TRN & \\
\hline CHEMBL3905618 & 1641654 & 8.8732 & 9.0413 & TRN & \\
\hline CHEMBL 3949902 & 1641654 & 6.7305 & 6.8655 & TRN & \\
\hline CHEMBL3394166 & 1641654 & 7.8324 & 7.836 & TRN & \\
\hline CHEMBL 3975848 & 1641654 & 7.1836 & 7.7176 & TRN & \\
\hline CHEMBL3975438 & 1641654 & 5.9776 & 5.7634 & TRN & \\
\hline CHEMBL 3924284 & 1641654 & 6.2381 & 6.2695 & TRN & \\
\hline CHEMBL3940389 & 1641654 & 9.3904 & 9.2321 & TRN & \\
\hline CHEMBL3971664 & 1641654 & 8.3297 & 8.3392 & TRN & \\
\hline CHEMBL3394064 & 1641654 & 6.7008 & 6.4064 & TST & \\
\hline CHEMBL3985000 & 1641654 & 5.0 & 5.0938 & TRN & \\
\hline CHEMBL3394065 & 1641654 & 6.1517 & 6.1861 & TRN & \\
\hline CHEMBL3984463 & 1641654 & 6.4372 & 6.4684 & TRN & \\
\hline CHEMBL3915869 & 1641654 & 6.6185 & 6.7596 & TRN & \\
\hline CHEMBL3937821 & 1641654 & 6.6428 & 6.5116 & TRN & \\
\hline CHEMBL 3896741 & 1641654 & 7.1719 & 7.3741 & TRN & \\
\hline CHEMBL3935080 & 1641654 & 7.2749 & 7.3452 & TST & \\
\hline
\end{tabular}


Supplemental Table S2.txt

\begin{tabular}{|c|c|c|c|c|c|c|}
\hline CHEMBL3394071 & 1641654 & 6.8472 & 6.8124 & TRN & & \\
\hline CHEMBL 3897123 & 1641654 & 6.6185 & 6.8678 & TRN & & \\
\hline CHEMBL3926288 & 1641654 & 6.9781 & 6.9725 & TRN & & \\
\hline CHEMBL 3957078 & 1641654 & 5.9414 & 5.8465 & TRN & & \\
\hline CHEMBL 3895619 & 1641654 & 7.5869 & 7.5535 & TRN & & \\
\hline CHEMBL 3906121 & 1641654 & 6.6175 & 6.4941 & TRN & & \\
\hline CHEMBL3936450 & 1641654 & 7.15799 & 99999999 & 995 & 6.9446 & TRN \\
\hline CHEMBL 3908000 & 1641654 & 8.1608 & 8.6752 & TST & & \\
\hline CHEMBL3938424 & 1641654 & 6.7983 & 6.8908 & TST & & \\
\hline CHEMBL 3916044 & 1641654 & 5.6269 & 5.7508 & TRN & & \\
\hline CHEMBL 3954270 & 1641654 & 8.2369 & 8.3125 & TRN & & \\
\hline CHEMBL 3950988 & 1641654 & 8.382 & 8.5216 & TRN & & \\
\hline CHEMBL 3901441 & 1641654 & 8.3823 & 8.1182 & TRN & & \\
\hline CHEMBL3949278 & 1641654 & 8.0151 & 8.0733 & TRN & & \\
\hline CHEMBL 3947592 & 1641654 & 6.1476 & 6.3489 & TRN & & \\
\hline CHEMBL 3898134 & 1641654 & 6.0312 & 6.0471 & TRN & & \\
\hline CHEMBL 3982237 & 1641654 & 7.5324 & 7.3795 & TST & & \\
\hline CHEMBL 3946212 & 1641654 & 8.5357 & 8.5809 & TRN & & \\
\hline CHEMBL3965530 & 1641654 & 6.7274 & 6.5102 & TST & & \\
\hline CHEMBL 3910838 & 1641654 & 7.6741 & 7.6623 & TRN & & \\
\hline CHEMBL3962369 & 1641654 & 7.1541 & 6.6987 & TST & & \\
\hline CHEMBL 3960208 & 1641654 & 7.9598 & 7.8316 & TRN & & \\
\hline CHEMBL 3942256 & 1641654 & 8.1884 & 7.9938 & TRN & & \\
\hline CHEMBL 3890347 & 1641654 & 8.2282 & 8.2195 & TRN & & \\
\hline CHEMBL 3960832 & 1641654 & 7.3284 & 7.2372 & TST & & \\
\hline CHEMBL 3970756 & 1641654 & 7.6975 & 7.8821 & TRN & & \\
\hline CHEMBL 3891857 & 1641654 & 6.4386 & 6.99299 & 999999999s & & TST \\
\hline CHEMBL 3943672 & 1641654 & 6.2865 & 6.476 & TST & & \\
\hline CHEMBL3962494 & 1641654 & 7.4201 & 7.8696 & TST & & \\
\hline CHEMBL 3962808 & 1641654 & 8.6949 & 8.6954 & TST & & \\
\hline CHEMBL3913009 & 1641654 & 7.3931 & 7.5968 & TST & & \\
\hline CHEMBL 3943843 & 1641654 & 7.7765 & 7.4306 & TST & & \\
\hline CHEMBL 3923772 & 1641654 & 7.6419 & 6.8395 & TST & & \\
\hline CHEMBL3940277 & 1641654 & 7.5906 & 7.7868 & TST & & \\
\hline CHEMBL 3899690 & 1641654 & 6.1778 & 6.6875 & TST & & \\
\hline CHEMBL3899404 & 1641654 & 8.0265 & 8.5656 & TST & & \\
\hline CHEMBL3394069 & 1641654 & 7.9055 & 7.6384 & TST & & \\
\hline CHEMBL 3977709 & 1641654 & 6.9168 & 7.1184 & TST & & \\
\hline CHEMBL3952167 & 1641654 & 7.1882 & 6.2964 & TST & & \\
\hline CHEMBL 3900255 & 1641654 & 6.9882 & 6.9562 & TST & & \\
\hline CHEMBL3964669 & 1641654 & 8.0499 & 8.4813 & TST & & \\
\hline CHEMBL3919198 & 1641654 & 6.8384 & 6.4108 & TST & & \\
\hline CHEMBL 3976511 & 1641654 & 7.7836 & 7.2126 & TST & & \\
\hline CHEMBL 3925450 & 1641654 & 7.15799 & 99999999 & 995 & 7.1921 & ו \\
\hline CHEMBL3965556 & 1641654 & 8.6126 & 8.3166 & TST & & \\
\hline CHEMBL 3930132 & 1641654 & 7.3692 & 7.4276 & TST & & \\
\hline CHEMBL 3897313 & 1641654 & 7.3378 & 7.2548 & TST & & \\
\hline CHEMBL3394172 & 1641654 & 7.9796 & 8.0416 & TST & & \\
\hline
\end{tabular}


Supplemental Table S2.txt

\begin{tabular}{|c|c|c|c|c|c|}
\hline CHEMBL3891145 & 1641654 & 6.1011 & 6.6713 & TST & \\
\hline CHEMBL3394168 & 1641654 & 7.8333 & 7.6339 & TST & \\
\hline CHEMBL3953116 & 1641654 & 7.3378 & 7.442 & TST & \\
\hline CHEMBL3939836 & 1641654 & 7.4365 & 7.3692 & TST & \\
\hline CHEMBL 3931494 & 1641654 & 6.5867 & 6.4864 & TST & \\
\hline CHEMBL3904923 & 1641654 & \multicolumn{2}{|c|}{7.1579999999999995} & 7.4372 & TST \\
\hline CHEMBL3972469 & 1641654 & 7.0082 & 6.8029 & TST & \\
\hline CHEMBL3937321 & 1641654 & 7.5177 & 7.7506 & TST & \\
\hline CHEMBL3947675 & 1641654 & 7.2351 & 7.2742 & TST & \\
\hline CHEMBL126731 & 149059 & 3.0 & 3.252 & TST & \\
\hline CHEMBL127119 & 149059 & 5.0 & 5.2508 & TST & \\
\hline CHEMBL126194 & 149059 & 4.0 & 4.7564 & TST & \\
\hline CHEMBL126195 & 149059 & 5.2218 & 5.2124 & TRN & \\
\hline CHEMBL126232 & 149059 & 4.0 & \multicolumn{2}{|c|}{4.6419999999999995} & TST \\
\hline CHEMBL338814 & 149059 & 4.0 & 3.92 & TRN & \\
\hline CHEMBL338605 & 149059 & 5.0 & 4.8714 & TRN & \\
\hline CHEMBL126565 & 149059 & 5.5229 & 5.4203 & TRN & \\
\hline CHEMBL340897 & 149059 & 4.0 & 3.9305 & TRN & \\
\hline CHEMBL125748 & 149059 & 5.4318 & 5.3551 & TRN & \\
\hline CHEMBL129708 & 149059 & 4.0 & 3.9142 & TRN & \\
\hline CHEMBL126824 & 149059 & 5.2076 & 5.3002 & TRN & \\
\hline CHEMBL130695 & 149059 & 6.4559 & 6.5638 & TRN & \\
\hline CHEMBL129246 & 149059 & 5.1938 & 4.7669 & TST & \\
\hline CHEMBL340589 & 149059 & 5.5229 & 6.2117 & TST & \\
\hline CHEMBL 338170 & 149059 & 5.6383 & 5.6319 & TRN & \\
\hline CHEMBL129001 & 149059 & 4.0 & 5.6265 & TST & \\
\hline CHEMBL127016 & 149059 & 6.0 & 5.9502 & TRN & \\
\hline CHEMBL126999 & 149059 & 6.4685 & 6.1261 & TRN & \\
\hline CHEMBL126371 & 149059 & 5.5229 & 5.4832 & TRN & \\
\hline CHEMBL341490 & 149059 & 5.3979 & 5.4217 & TRN & \\
\hline CHEMBL340141 & 149059 & 4.0 & 4.0546 & TRN & \\
\hline CHEMBL130186 & 149059 & 4.0 & 4.0051 & TRN & \\
\hline CHEMBL129581 & 149059 & 5.2076 & 5.4341 & TRN & \\
\hline CHEMBL339866 & 149059 & 4.0 & 4.4453 & TST & \\
\hline CHEMBL13477 & 149059 & 4.0 & 4.0098 & TRN & \\
\hline CHEMBL127957 & 149059 & 4.0 & 4.2212 & TST & \\
\hline CHEMBL126773 & 149059 & 3.0 & 3.0553 & TRN & \\
\hline CHEMBL341119 & 149059 & 4.0 & \multicolumn{2}{|c|}{3.9930000000000003} & TRN \\
\hline CHEMBL129498 & 149059 & 5.6383 & 5.6324 & TRN & \\
\hline CHEMBL126717 & 149059 & 5.9586 & \multicolumn{2}{|c|}{6.007999999999999} & TRN \\
\hline CHEMBL269624 & 149059 & 5.4685 & 5.395 & TRN & \\
\hline CHEMBL125358 & 149059 & 5.0 & 5.0479 & TRN & \\
\hline CHEMBL340581 & 149059 & 4.0 & 3.9103 & TRN & \\
\hline CHEMBL340531 & 149059 & 4.0 & 3.9269 & TRN & \\
\hline CHEMBL334953 & 149059 & 6.0 & \multicolumn{2}{|c|}{6.1979999999999995} & TRN \\
\hline CHEMBL125343 & 149059 & 4.0 & 3.9611 & TRN & \\
\hline CHEMBL341077 & 149059 & 5.301 & 4.5626 & TST & \\
\hline CHEMBL126025 & 149059 & 4.0 & 4.2647 & TRN & \\
\hline
\end{tabular}




\begin{tabular}{|c|c|c|c|c|c|}
\hline \multicolumn{6}{|c|}{ Supplemental Table S2.txt } \\
\hline CHEMBL126796 & 149059 & 5.0 & 4.9957 & TRN & \\
\hline CHEMBL127117 & 149059 & 5.2441 & 5.255 & TRN & \\
\hline CHEMBL340102 & 149059 & 6.0 & 6.2222 & TRN & \\
\hline CHEMBL129031 & 149059 & 4.0 & 4.0486 & TRN & \\
\hline CHEMBL 340153 & 149059 & 6.3372 & 6.2129 & TRN & \\
\hline CHEMBL341482 & 149059 & 3.0 & 2.9254 & TRN & \\
\hline CHEMBL338409 & 149059 & 6.0506 & 6.0472 & TRN & \\
\hline CHEMBL341021 & 149059 & 4.6576 & 4.975 & TST & \\
\hline CHEMBL125350 & 149059 & 4.0 & 4.0708 & TRN & \\
\hline CHEMBL339472 & 149059 & 3.0 & 3.1723 & TRN & \\
\hline CHEMBL129104 & 149059 & 6.2218 & 6.1851 & TRN & \\
\hline CHEMBL127063 & 149059 & 5.8861 & 6.0527 & TRN & \\
\hline CHEMBL126883 & 149059 & 3.5229 & 3.6105 & TRN & \\
\hline CHEMBL434825 & 149059 & 5.2676 & 5.1403 & TRN & \\
\hline CHEMBL129268 & 149059 & 5.9586 & 5.7742 & TRN & \\
\hline CHEMBL126708 & 149059 & 5.0706 & 5.0646 & TRN & \\
\hline CHEMBL338235 & 149059 & 6.2007 & 6.2748 & TRN & \\
\hline CHEMBL338570 & 149059 & 3.5229 & 3.4715 & TRN & \\
\hline CHEMBL340465 & 149059 & 5.1871 & 5.3058 & TRN & \\
\hline CHEMBL341339 & 149059 & 6.1079 & 6.0563 & TRN & \\
\hline CHEMBL407977 & 149059 & 4.0 & 5.2835 & TST & \\
\hline CHEMBL420144 & 149059 & 6.0 & 5.8054 & TRN & \\
\hline CHEMBL337976 & 149059 & 5.0 & 4.0877 & TST & \\
\hline CHEMBL340695 & 149059 & 4.0 & 3.9963 & TRN & \\
\hline CHEMBL 340920 & 149059 & 5.4685 & 5.7241 & TST & \\
\hline CHEMBL419422 & 149059 & 5.8539 & 5.9189 & TRN & \\
\hline CHEMBL339093 & 149059 & 5.6576 & 5.2399 & TST & \\
\hline CHEMBL419603 & 149059 & 4.0 & 3.8177 & TRN & \\
\hline CHEMBL126029 & 149059 & 4.0 & 4.0829 & TRN & \\
\hline CHEMBL341039 & 149059 & 4.0 & 3.9706 & TRN & \\
\hline CHEMBL126785 & 149059 & 4.0 & 3.9924 & TRN & \\
\hline CHEMBL340149 & 149059 & 5.0 & 4.4355 & TST & \\
\hline CHEMBL126453 & 149059 & 4.7959 & 5.02800 & 00000000005 & TRN \\
\hline CHEMBL338470 & 149059 & 4.0 & 5.0137 & TST & \\
\hline CHEMBL131499 & 149059 & 6.1135 & 6.1514 & TRN & \\
\hline CHEMBL129413 & 149059 & 5.0 & 3.6433 & TST & \\
\hline CHEMBL338757 & 149059 & 5.9208 & 5.8406 & TRN & \\
\hline CHEMBL340588 & 149059 & 5.1192 & 5.1913 & TRN & \\
\hline CHEMBL129647 & 149059 & 4.0 & 3.7447 & TST & \\
\hline CHEMBL128978 & 149059 & 5.1192 & 5.0596 & TRN & \\
\hline CHEMBL 2111847 & 149059 & 6.0 & 5.9027 & TRN & \\
\hline CHEMBL126381 & 149059 & 4.0 & 4.2929 & TST & \\
\hline CHEMBL341108 & 149059 & 5.1487 & 5.7447 & TST & \\
\hline CHEMBL1080986 & 622939 & 6.0 & 5.71 & TRN & \\
\hline CHEMBL1076284 & 622939 & 8.699 & 8.1969 & TRN & \\
\hline CHEMBL1076287 & 622939 & 6.6576 & 7.8917 & TRN & \\
\hline CHEMBL1079556 & 622939 & 6.0 & 5.6025 & TRN & \\
\hline CHEMBL1079761 & 622939 & 8.3979 & 7.99799 & 9999999999 & TRN \\
\hline & & & & 24256 & \\
\hline
\end{tabular}




\begin{tabular}{|c|c|c|c|c|}
\hline \multicolumn{5}{|c|}{ Supplemental Table S2.txt } \\
\hline CHEMBL1076425 & 622939 & 8.2218 & 8.2045 & TRN \\
\hline CHEMBL1076282 & 622939 & 6.6198 & 7.6312 & TRN \\
\hline CHEMBL1076283 & 622939 & 8.699 & 8.1615 & TRN \\
\hline CHEMBL1076351 & 622939 & 6.0 & 5.6586 & TRN \\
\hline CHEMBL1076429 & 622939 & 9.0969 & 8.4158 & TRN \\
\hline CHEMBL1076422 & 622939 & 6.0 & 5.2421 & TRN \\
\hline CHEMBL1081529 & 622939 & 9.0 & 8.5143 & TRN \\
\hline CHEMBL1079753 & 622939 & 6.0 & 6.4074 & TRN \\
\hline CHEMBL1079778 & 622939 & 7.0969 & 7.5607 & TRN \\
\hline CHEMBL1079587 & 622939 & 7.5376 & 7.5305 & TST \\
\hline CHEMBL1076290 & 622939 & 9.0 & 8.2619 & TRN \\
\hline CHEMBL1076346 & 622939 & 6.0 & 5.6216 & TRN \\
\hline CHEMBL1079570 & 622939 & 8.1549 & 7.7871 & TST \\
\hline CHEMBL477014 & 622939 & 7.6383 & 7.8719 & TST \\
\hline CHEMBL1076303 & 622939 & 5.9586 & 7.0387 & TRN \\
\hline CHEMBL1081562 & 622939 & 7.6198 & 7.6845 & TRN \\
\hline CHEMBL1076302 & 622939 & 7.5086 & 7.9299 & TRN \\
\hline CHEMBL1076414 & 622939 & 6.0 & 5.6778 & TRN \\
\hline CHEMBL1076411 & 622939 & 6.0 & 6.3722 & TRN \\
\hline CHEMBL1076410 & 622939 & 6.0 & 6.2341 & TRN \\
\hline CHEMBL1076421 & 622939 & 6.0 & 6.4646 & TRN \\
\hline CHEMBL1076293 & 622939 & 7.0969 & 7.6112 & TRN \\
\hline CHEMBL1080462 & 622939 & 6.0 & 5.9337 & TRN \\
\hline CHEMBL1076416 & 622939 & 6.0 & 6.3151 & TRN \\
\hline CHEMBL1076285 & 622939 & 8.699 & 8.1737 & TRN \\
\hline CHEMBL1076426 & 622939 & 6.0 & 6.5009 & TRN \\
\hline CHEMBL1076420 & 622939 & 6.0 & 5.9914 & TRN \\
\hline CHEMBL1076280 & 622939 & 8.699 & 8.0391 & TRN \\
\hline CHEMBL1076291 & 622939 & 6.4089 & 7.1576 & TRN \\
\hline CHEMBL1076294 & 622939 & 7.585 & 7.9236 & TRN \\
\hline CHEMBL1076417 & 622939 & 6.0 & 6.0959 & TRN \\
\hline CHEMBL1079952 & 622939 & 8.2218 & 7.8865 & TRN \\
\hline CHEMBL1076412 & 622939 & 6.0 & 6.1936 & TRN \\
\hline CHEMBL1076296 & 622939 & 8.3979 & 8.446 & TRN \\
\hline CHEMBL1076281 & 622939 & 8.0969 & 7.6077 & TRN \\
\hline CHEMBL1076418 & 622939 & 6.0 & 5.6558 & TRN \\
\hline CHEMBL1076413 & 622939 & 6.0 & 5.769 & TRN \\
\hline CHEMBL1076415 & 622939 & 6.0 & 5.6834 & TST \\
\hline CHEMBL1076289 & 622939 & 7.0862 & 7.6226 & TST \\
\hline CHEMBL1076295 & 622939 & 7.7696 & 7.9648 & TST \\
\hline CHEMBL1079586 & 622939 & 7.9586 & 7.5767 & TST \\
\hline CHEMBL1076409 & 622939 & 6.0 & 6.1752 & TST \\
\hline CHEMBL1079953 & 622939 & 5.4815 & 7.9457 & TST \\
\hline CHEMBL1076424 & 622939 & 6.0 & 5.9413 & TST \\
\hline CHEMBL1076427 & 622939 & 6.0 & 5.9272 & TST \\
\hline CHEMBL1076286 & 622939 & 8.699 & 7.7434 & TST \\
\hline CHEMBL1081891 & 622939 & 6.0 & 5.6437 & TST \\
\hline CHEMBL1076292 & 622939 & 8.301 & 8.0227 & TST \\
\hline
\end{tabular}




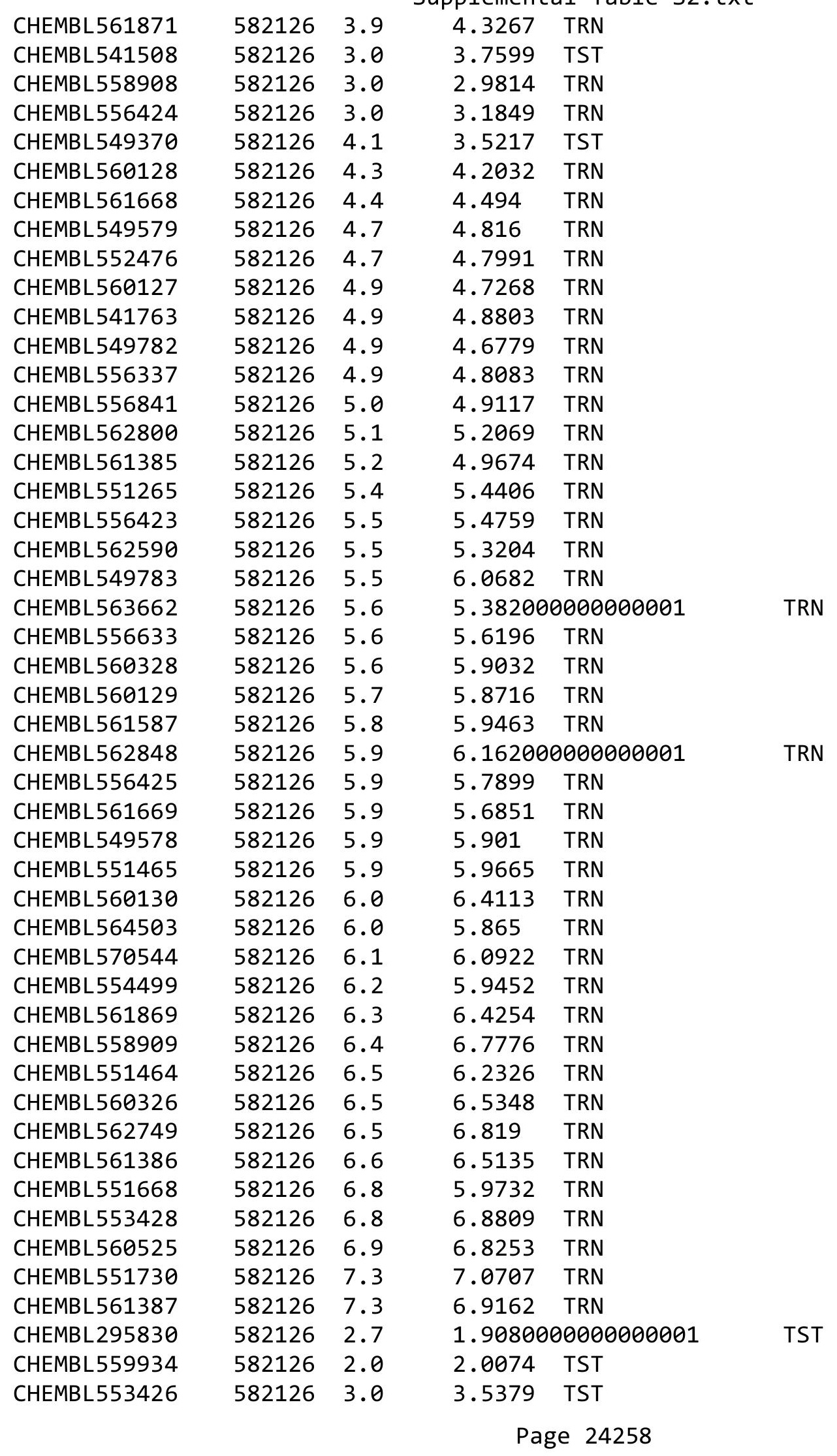




\begin{tabular}{|c|c|c|c|c|c|c|}
\hline & & & & & & \\
\hline CHEMBL539702 & 582126 & 3.0 & 3.0694 & TST & & \\
\hline CHEMBL554311 & 582126 & 3.0 & 3.2531 & TST & & \\
\hline CHEMBL559933 & 582126 & 3.0 & 3.0335 & TST & & \\
\hline CHEMBL131244 & 582126 & 4.8 & 1.7018 & TST & & \\
\hline CHEMBL571004 & 582126 & 5.4 & 4.9149 & TST & & \\
\hline CHEMBL540208 & 582126 & 5.9 & 5.794 & TST & & \\
\hline CHEMBL66693 & 582126 & 6.2 & 3.437 & TST & & \\
\hline CHEMBL285123 & 582126 & 6.5 & 3.4315 & TST & & \\
\hline CHEMBL553701 & 582126 & 6.6 & 4.6226 & TST & & \\
\hline CHEMBL1255660 & 582126 & 6.8 & 1.9229 & TST & & \\
\hline CHEMBL584136 & 592450 & 3.6021 & 3.5918 & TRN & & \\
\hline CHEMBL573231 & 592450 & 5.5086 & 5.5536 & TRN & & \\
\hline CHEMBL572849 & 592450 & 4.7721 & 4.3571 & TST & & \\
\hline CHEMBL583517 & 592450 & 4.8153 & 4.4454 & TST & & \\
\hline CHEMBL583521 & 592450 & 3.6021 & 3.8321 & TST & & \\
\hline CHEMBL583722 & 592450 & 4.618 & 4.283 & TST & & \\
\hline CHEMBL573230 & 592450 & 5.2007 & 5.1807 & TRN & & \\
\hline CHEMBL574014 & 592450 & 4.8665 & 4.8608 & TRN & & \\
\hline CHEMBL583935 & 592450 & 3.6021 & 3.6074 & TRN & & \\
\hline CHEMBL584135 & 592450 & 3.6021 & 3.5783 & TRN & & \\
\hline CHEMBL573228 & 592450 & 3.6021 & 3.6268 & TRN & & \\
\hline CHEMBL582907 & 592450 & 3.6021 & 3.6234 & TRN & & \\
\hline CHEMBL583516 & 592450 & 4.76699 & 79999999ऽ & 995 & 4.9435 & TRN \\
\hline CHEMBL583936 & 592450 & 3.6021 & 3.596 & TRN & & \\
\hline CHEMBL584144 & 592450 & 4.9318 & 4.9443 & TRN & & \\
\hline CHEMBL583313 & 592450 & 3.6021 & 3.5952 & TRN & & \\
\hline CHEMBL583112 & 592450 & 3.6021 & 3.6016 & TRN & & \\
\hline CHEMBL573005 & 592450 & 3.6021 & 3.6068 & TRN & & \\
\hline CHEMBL582909 & 592450 & 3.6021 & 3.6195 & TRN & & \\
\hline CHEMBL584348 & 592450 & 3.6021 & 3.6236 & TRN & & \\
\hline CHEMBL584349 & 592450 & 3.6021 & 3.5982 & TRN & & \\
\hline CHEMBL583724 & 592450 & 4.7033 & 4.7144 & TRN & & \\
\hline CHEMBL584134 & 592450 & 3.6021 & 3.6198 & TRN & & \\
\hline CHEMBL583515 & 592450 & 3.6021 & 3.8652 & TST & & \\
\hline CHEMBL583940 & 592450 & 3.6021 & 3.6023 & TRN & & \\
\hline CHEMBL583931 & 592450 & 3.6021 & 3.5991 & TRN & & \\
\hline CHEMBL573549 & 592450 & 4.9245 & 4.9504 & TRN & & \\
\hline CHEMBL573129 & 592450 & 3.6021 & 3.6041 & TRN & & \\
\hline CHEMBL583938 & 592450 & 4.9469 & 4.9237 & TRN & & \\
\hline CHEMBL584133 & 592450 & 3.6021 & 3.6141 & TRN & & \\
\hline CHEMBL583518 & 592450 & 4.7328 & 4.6322 & TST & & \\
\hline CHEMBL584347 & 592450 & 3.6021 & 3.5901 & TRN & & \\
\hline CHEMBL584142 & 592450 & 5.6778 & 5.667006 & 0000000001 & & TRN \\
\hline CHEMBL583721 & 592450 & 4.6696 & 4.6323 & TST & & \\
\hline CHEMBL583943 & 592450 & 3.6021 & 3.608 & TRN & & \\
\hline CHEMBL573227 & 592450 & 3.6021 & 3.9236 & TST & & \\
\hline CHEMBL583720 & 592450 & 4.9788 & 4.6177 & TST & & \\
\hline CHEMBL582906 & 592450 & 3.6021 & 3.5957 & TRN & & \\
\hline
\end{tabular}

Page 24259 


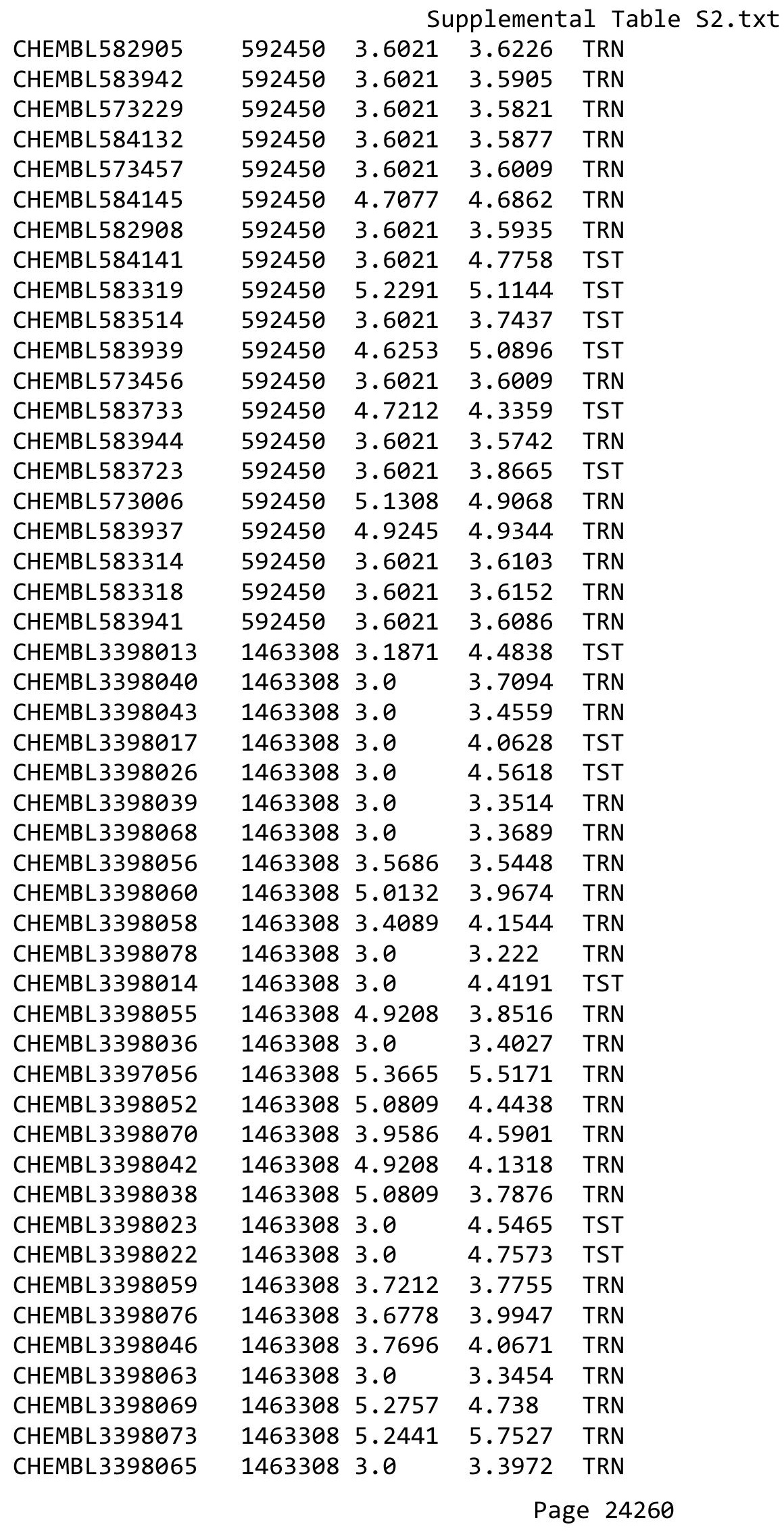


Supplemental Table S2.txt

\begin{tabular}{|c|c|c|c|c|}
\hline CHEMBL3398037 & 1463308 & 3.0 & 3.4899 & TRN \\
\hline CHEMBL3398027 & 1463308 & 4.4949 & 4.4487 & TST \\
\hline CHEMBL3398061 & 1463308 & 3.6021 & 3.717 & TRN \\
\hline CHEMBL3398067 & 1463308 & 3.4437 & \multicolumn{2}{|c|}{3.5269999999999997} \\
\hline CHEMBL3398074 & 1463308 & 3.9208 & 4.2578 & TRN \\
\hline CHEMBL3398077 & 1463308 & 3.0 & 3.3084 & TRN \\
\hline CHEMBL3398051 & 1463308 & 4.6383 & 4.6083 & TRN \\
\hline CHEMBL3398075 & 1463308 & 4.2007 & 4.6838 & TRN \\
\hline CHEMBL3398012 & 1463308 & 3.0 & 4.6302 & TST \\
\hline CHEMBL3398079 & 1463308 & 5.4437 & 5.3569 & TST \\
\hline CHEMBL3398053 & 1463308 & 4.6198 & 4.604 & TRN \\
\hline CHEMBL3398035 & 1463308 & 4.6021 & 3.8446 & TRN \\
\hline CHEMBL3398033 & 1463308 & 3.0 & 3.4419 & TRN \\
\hline CHEMBL3398020 & 1463308 & 4.6576 & 4.6108 & TST \\
\hline CHEMBL 3398021 & 1463308 & 5.1739 & 4.3437 & TRN \\
\hline CHEMBL3398071 & 1463308 & 4.4815 & 4.7578 & TRN \\
\hline CHEMBL3398062 & 1463308 & 3.3468 & 3.3624 & TRN \\
\hline CHEMBL3398080 & 1463308 & 5.7212 & 5.6777 & TST \\
\hline CHEMBL3398072 & 1463308 & 5.3188 & 5.681 & TRN \\
\hline CHEMBL3398034 & 1463308 & 3.5528 & 4.1217 & TST \\
\hline CHEMBL3398007 & 1463308 & 5.5229 & 5.019 & TST \\
\hline CHEMBL3398057 & 1463308 & 5.0809 & 3.9095 & TRN \\
\hline CHEMBL3398081 & 1463308 & 4.5376 & 4.5266 & TST \\
\hline CHEMBL3398064 & 1463308 & 4.6383 & 3.8205 & TRN \\
\hline CHEMBL3398041 & 1463308 & 3.7447 & 3.8929 & TRN \\
\hline CHEMBL437981 & 468873 & 5.1427 & 4.9822 & TRN \\
\hline CHEMBL402241 & 468873 & 5.0458 & 4.4003 & TRN \\
\hline CHEMBL 258341 & 468873 & 3.0 & 4.5356 & TRN \\
\hline CHEMBL 272746 & 468873 & 5.0605 & 4.3784 & TRN \\
\hline CHEMBL404198 & 468873 & 3.0 & 4.3784 & TRN \\
\hline CHEMBL 258343 & 468873 & 5.0132 & 4.5356 & TRN \\
\hline CHEMBL 270789 & 468873 & 4.8633 & 4.3784 & TRN \\
\hline CHEMBL405941 & 468873 & 4.9747 & 4.4916 & TRN \\
\hline CHEMBL428243 & 468873 & 3.0 & 4.9458 & TST \\
\hline CHEMBL403437 & 468873 & 4.9355 & 4.499 & TRN \\
\hline CHEMBL 256582 & 468873 & 4.9706 & 4.6907 & TST \\
\hline CHEMBL403872 & 468873 & 5.0757 & 4.989 & TST \\
\hline CHEMBL 272534 & 468873 & 4.9872 & 4.3784 & TRN \\
\hline CHEMBL 271002 & 468873 & 4.3585 & 4.4003 & TRN \\
\hline CHEMBL258299 & 468873 & 5.1367 & 4.5356 & TRN \\
\hline CHEMBL 256164 & 468873 & 5.041 & 4.6198 & TRN \\
\hline CHEMBL 258339 & 468873 & 5.0915 & 5.0056 & TST \\
\hline CHEMBL270787 & 468873 & 5.0706 & 4.499 & TRN \\
\hline CHEMBL438167 & 468873 & 5.0706 & 4.499 & TRN \\
\hline CHEMBL 270855 & 468873 & 4.9626 & 4.9011 & TRN \\
\hline CHEMBL407562 & 468873 & 4.5391 & 4.9087 & TRN \\
\hline CHEMBL401724 & 468873 & 5.2924 & 4.7888 & TRN \\
\hline CHEMBL401761 & 468873 & 5.0757 & 4.4003 & TRN \\
\hline
\end{tabular}




\begin{tabular}{|c|c|c|c|c|c|c|}
\hline & & \multicolumn{5}{|c|}{ Supplemental Table S2.txt } \\
\hline CHEMBL271719 & 468873 & 4.6904 & 5.0381 & TST & & \\
\hline CHEMBL404844 & 468873 & 4.6676 & 4.9197 & TST & & \\
\hline CHEMBL257266 & 468873 & 3.0 & 4.4003 & TRN & & \\
\hline CHEMBL256435 & 468873 & 3.0 & 4.3784 & TRN & & \\
\hline CHEMBL404724 & 468873 & 5.1079 & 4.9887 & TST & & \\
\hline CHEMBL258280 & 468873 & $4.9830 e$ & 00000000 & 005 & 4.9651 & TRN \\
\hline CHEMBL272747 & 468873 & 4.6676 & 4.8414 & TRN & & \\
\hline CHEMBL256905 & 468873 & 5.1612 & 4.5356 & TST & & \\
\hline CHEMBL403092 & 468873 & 4.8861 & 4.9784 & TRN & & \\
\hline CHEMBL403859 & 468873 & 4.567 & 4.6419 & TRN & & \\
\hline CHEMBL437022 & 468873 & 5.1024 & 4.9467 & TRN & & \\
\hline CHEMBL401760 & 468873 & 5.2441 & 4.5356 & TST & & \\
\hline CHEMBL256896 & 468873 & 4.9788 & 4.499 & TRN & & \\
\hline CHEMBL255844 & 468873 & 5.0 & 4.9326 & TRN & & \\
\hline CHEMBL271001 & 468873 & 4.9066 & 4.6375 & TRN & & \\
\hline CHEMBL256898 & 468873 & 5.2291 & 4.5121 & TRN & & \\
\hline CHEMBL256583 & 468873 & 3.0 & 4.6163 & TRN & & \\
\hline CHEMBL257837 & 468873 & 5.2007 & 4.9587 & TST & & \\
\hline CHEMBL272066 & 468873 & 5.0809 & 4.9593 & TRN & & \\
\hline CHEMBL271003 & 468873 & 4.8861 & 4.4003 & TRN & & \\
\hline CHEMBL258307 & 468873 & 4.2807 & 4.499 & TRN & & \\
\hline CHEMBL256897 & 468873 & 4.5686 & 4.3784 & TRN & & \\
\hline CHEMBL403617 & 468873 & 4.9208 & 4.6437 & TRN & & \\
\hline CHEMBL258308 & 468873 & 5.1805 & 5.0413 & TST & & \\
\hline CHEMBL402948 & 468873 & 5.1739 & 5.0122 & TST & & \\
\hline CHEMBL258306 & 468873 & 3.0 & 4.3784 & TRN & & \\
\hline CHEMBL272489 & 468873 & 4.0691 & 5.0261 & TST & & \\
\hline CHEMBL256791 & 468873 & 4.857 & 4.6524 & TRN & & \\
\hline CHEMBL272554 & 468873 & 4.3224 & 4.8882 & TRN & & \\
\hline CHEMBL255853 & 468873 & 5.3468 & 4.6546 & TST & & \\
\hline CHEMBL271000 & 468873 & 4.7799 & 4.6546 & TRN & & \\
\hline CHEMBL270854 & 468873 & 3.0 & 4.499 & TRN & & \\
\hline CHEMBL270856 & 468873 & 4.7122 & 4.4003 & TRN & & \\
\hline CHEMBL403618 & 468873 & 4.9626 & 4.9205 & TRN & & \\
\hline CHEMBL256165 & 468873 & 4.857 & 4.7459 & TRN & & \\
\hline CHEMBL257633 & 468873 & 4.6904 & 4.9897 & TRN & & \\
\hline CHEMBL404111 & 468873 & 4.857 & 4.789 & TRN & & \\
\hline CHEMBL257472 & 468873 & 5.1024 & 4.4003 & TRN & & \\
\hline CHEMBL255573 & 468873 & 4.9706 & 4.6793 & TRN & & \\
\hline CHEMBL403964 & 468873 & 3.8327 & 5.0574 & TST & & \\
\hline CHEMBL271074 & 468873 & 5.3979 & 4.5356 & TST & & \\
\hline CHEMBL3961835 & 1641813 & 7.2924 & 6.864 & TRN & & \\
\hline CHEMBL3980327 & 1641813 & 8.0458 & 8.4319 & TST & & \\
\hline CHEMBL 3914412 & 1641813 & 7.3372 & 6.6444 & TST & & \\
\hline CHEMBL 3899397 & 1641813 & 7.7959 & 7.50799 & 9999999999 & & $1 \mathrm{~K}$ \\
\hline CHEMBL3937083 & 1641813 & 8.0458 & 8.1864 & TRN & & \\
\hline CHEMBL3917152 & 1641813 & 8.1549 & 6.9882 & TRN & & \\
\hline CHEMBL 3932052 & 1641813 & 8.0 & 7.5743 & TRN & & \\
\hline
\end{tabular}


Supplemental Table S2.txt

\begin{tabular}{|c|c|c|c|c|c|}
\hline CHEMBL3937383 & 1641813 & 8.301 & 8.4104 & TST & \\
\hline CHEMBL3931288 & 1641813 & 8.0969 & 7.8256 & TRN & \\
\hline CHEMBL3932128 & 1641813 & 8.699 & 8.6401 & TRN & \\
\hline CHEMBL3914800 & 1641813 & 8.2218 & 8.3349 & TRN & \\
\hline CHEMBL3935304 & 1641813 & 7.2366 & 6.9689 & TRN & \\
\hline CHEMBL3952551 & 1641813 & 8.1549 & 8.1198 & TRN & \\
\hline CHEMBL3969647 & 1641813 & 7.8861 & 7.027 & TRN & \\
\hline CHEMBL3915441 & 1641813 & 8.5229 & 8.1835 & TST & \\
\hline CHEMBL3903465 & 1641813 & 8.301 & 7.4502 & TST & \\
\hline CHEMBL3905507 & 1641813 & 7.2007 & 7.1008 & TRN & \\
\hline CHEMBL3912986 & 1641813 & 6.58 & 6.5336 & TST & \\
\hline CHEMBL3982456 & 1641813 & 7.7959 & 8.5514 & TRN & \\
\hline CHEMBL3932172 & 1641813 & 6.9666 & 7.4349 & TST & \\
\hline CHEMBL3890172 & 1641813 & 7.2007 & 6.4057 & TRN & \\
\hline CHEMBL3976454 & 1641813 & 6.4449 & 6.8502 & TRN & \\
\hline CHEMBL3949934 & 1641813 & 6.0 & 6.6685 & TRN & \\
\hline CHEMBL3957197 & 1641813 & 8.5229 & 7.7918 & TRN & \\
\hline CHEMBL3889860 & 1641813 & 7.7447 & 7.6075 & TRN & \\
\hline CHEMBL3928381 & 1641813 & 8.301 & 8.6536 & TRN & \\
\hline CHEMBL 3942657 & 1641813 & 6.0 & 6.3264 & TRN & \\
\hline CHEMBL3942800 & 1641813 & 8.3979 & 8.3165 & TRN & \\
\hline CHEMBL3889732 & 1641813 & 7.6021 & 7.7054 & TRN & \\
\hline CHEMBL3937536 & 1641813 & 6.8729 & 7.0934 & TRN & \\
\hline CHEMBL3940081 & 1641813 & 6.0 & 5.9455 & TRN & \\
\hline CHEMBL3948630 & 1641813 & 7.9208 & 7.2793 & TRN & \\
\hline CHEMBL3936391 & 1641813 & 6.0 & 7.3084 & TRN & \\
\hline CHEMBL3975915 & 1641813 & 8.0969 & 7.53600 & 00000000005 & TRN \\
\hline CHEMBL3939276 & 1641813 & 8.699 & 8.2236 & TRN & \\
\hline CHEMBL3946477 & 1641813 & 6.0 & 6.1216 & TRN & \\
\hline CHEMBL 3925844 & 1641813 & 7.9586 & 7.9053 & TRN & \\
\hline CHEMBL3950123 & 1641813 & 7.7959 & 7.7081 & TRN & \\
\hline CHEMBL3926004 & 1641813 & 7.8539 & 7.2264 & TRN & \\
\hline CHEMBL3950551 & 1641813 & 6.0 & 6.4371 & TRN & \\
\hline CHEMBL3909698 & 1641813 & 8.3979 & 8.6652 & TRN & \\
\hline CHEMBL3982287 & 1641813 & 8.0 & 7.4027 & TST & \\
\hline CHEMBL3955850 & 1641813 & 7.6021 & 7.21399 & 99999999995 & TRN \\
\hline CHEMBL3949299 & 1641813 & 8.3979 & 6.9756 & TST & \\
\hline CHEMBL3977315 & 1641813 & 6.0 & 7.0441 & TST & \\
\hline CHEMBL3909891 & 1641813 & 6.0 & 6.5505 & TRN & \\
\hline CHEMBL3907043 & 1641813 & 8.0458 & 8.4738 & TRN & \\
\hline CHEMBL3916990 & 1641813 & 8.5229 & 8.2854 & TRN & \\
\hline CHEMBL3891556 & 1641813 & 6.0 & 6.9874 & TRN & \\
\hline CHEMBL3954808 & 1641813 & 7.4815 & 6.6303 & TST & \\
\hline CHEMBL3970017 & 1641813 & 8.0 & 8.2515 & TRN & \\
\hline CHEMBL3921754 & 1641813 & 6.0 & 7.0402 & TRN & \\
\hline CHEMBL3970121 & 1641813 & 8.699 & 8.8994 & TRN & \\
\hline CHEMBL3905709 & 1641813 & 6.7959 & 6.7975 & TRN & \\
\hline CHEMBL3922616 & 1641813 & 6.0 & 6.8639 & TRN & \\
\hline
\end{tabular}


Supplemental Table S2.txt

\begin{tabular}{|c|c|c|c|c|c|}
\hline CHEMBL 3986578 & 1641813 & 8.699 & 8.2311 & TRN & \\
\hline CHEMBL 3950932 & 1641813 & 8.0 & 7.99 & TRN & \\
\hline CHEMBL3930941 & 1641813 & 7.4202 & 7.1454 & TRN & \\
\hline CHEMBL 3905803 & 1641813 & 8.699 & 8.1615 & TST & \\
\hline CHEMBL3944131 & 1641813 & 7.8539 & 8.0117 & TRN & \\
\hline CHEMBL3985671 & 1641813 & 7.6778 & 7.2605 & TRN & \\
\hline CHEMBL3931614 & 1641813 & 8.699 & 7.8702 & TST & \\
\hline CHEMBL3961661 & 1641813 & 8.5229 & 7.7711 & TRN & \\
\hline CHEMBL 3891845 & 1641813 & 7.6383 & 7.9018 & TRN & \\
\hline CHEMBL3924297 & 1641813 & 8.1549 & 8.6307 & TRN & \\
\hline CHEMBL3951761 & 1641813 & 6.0 & 6.44799 & 99999999995 & TRN \\
\hline CHEMBL3957005 & 1641813 & 8.3979 & 8.7229 & TRN & \\
\hline CHEMBL3909935 & 1641813 & 7.9208 & 7.9908 & TRN & \\
\hline CHEMBL 3940479 & 1641813 & 8.3979 & 7.8479 & TRN & \\
\hline CHEMBL 3964533 & 1641813 & 8.301 & 6.5875 & TST & \\
\hline CHEMBL3973377 & 1641813 & 7.4685 & 7.7229 & TRN & \\
\hline CHEMBL3899115 & 1641813 & 6.8239 & 6.9671 & TRN & \\
\hline CHEMBL3926567 & 1641813 & 7.7447 & 7.7135 & TRN & \\
\hline CHEMBL 3922926 & 1641813 & 8.2218 & 7.849 & TRN & \\
\hline CHEMBL3902548 & 1641813 & 7.9586 & 8.1093 & TRN & \\
\hline CHEMBL 3901046 & 1641813 & 6.6364 & 6.2997 & TRN & \\
\hline CHEMBL 3944920 & 1641813 & 6.0 & 6.4079 & TRN & \\
\hline CHEMBL3966434 & 1641813 & 6.8125 & 6.4508 & TRN & \\
\hline CHEMBL 3947400 & 1641813 & 8.3979 & 7.8892 & TRN & \\
\hline CHEMBL3936794 & 1641813 & 8.5229 & 6.9138 & TRN & \\
\hline CHEMBL 3910503 & 1641813 & 7.7696 & 7.1548 & TST & \\
\hline CHEMBL3984519 & 1641813 & 7.9586 & 8.1571 & TRN & \\
\hline CHEMBL3934334 & 1641813 & 6.0 & 5.9352 & TRN & \\
\hline CHEMBL 3913241 & 1641813 & 7.4949 & 7.3884 & TRN & \\
\hline CHEMBL3909591 & 1641813 & 6.8697 & 6.9218 & TRN & \\
\hline CHEMBL 3967189 & 1641813 & 8.2218 & 8.3838 & TRN & \\
\hline CHEMBL3912771 & 1641813 & 7.6576 & 8.0479 & TST & \\
\hline CHEMBL3944926 & 1641813 & 8.0458 & 7.9526 & TRN & \\
\hline CHEMBL3968813 & 1641813 & 7.3468 & 7.3609 & TRN & \\
\hline CHEMBL3955958 & 1641813 & 8.3979 & 7.8692 & TRN & \\
\hline CHEMBL 3890190 & 1641813 & 6.0 & 6.3991 & TST & \\
\hline CHEMBL3911781 & 1641813 & 6.0 & 8.7531 & TST & \\
\hline CHEMBL3939871 & 1641813 & 8.0458 & 7.9157 & TRN & \\
\hline CHEMBL 3952024 & 1641813 & 6.0 & 6.4843 & TST & \\
\hline CHEMBL3974464 & 1641813 & 8.1549 & 7.5192 & TRN & \\
\hline CHEMBL3901309 & 1641813 & 7.6778 & 7.4615 & TRN & \\
\hline CHEMBL3981022 & 1641813 & 7.6383 & 6.5822 & TST & \\
\hline CHEMBL3971831 & 1641813 & 7.9208 & 7.3154 & TRN & \\
\hline CHEMBL 3949405 & 1641813 & 7.8861 & 6.9126 & TRN & \\
\hline CHEMBL3936807 & 1641813 & 7.8861 & 7.909 & TRN & \\
\hline CHEMBL 3914172 & 1641813 & 6.0 & 5.7811 & TST & \\
\hline CHEMBL 3894281 & 1641813 & 8.699 & 8.1982 & TRN & \\
\hline CHEMBL3953986 & 1641813 & 7.3565 & 7.886 & TRN & \\
\hline
\end{tabular}


Supplemental Table S2.txt

\begin{tabular}{|c|c|c|c|c|c|}
\hline CHEMBL3915515 & 1641813 & 7.3768 & 7.0781 & TRN & \\
\hline CHEMBL3980505 & 1641813 & 8.3979 & 8.2593 & TRN & \\
\hline CHEMBL3973307 & 1641813 & 8.5229 & 8.3028 & TST & \\
\hline CHEMBL 3943477 & 1641813 & 7.1805 & 6.9091 & TST & \\
\hline CHEMBL3957015 & 1641813 & 7.585 & 8.546 & TST & \\
\hline CHEMBL3895128 & 1641813 & 7.8539 & 7.9109 & TRN & \\
\hline CHEMBL3950194 & 1641813 & 6.7905 & 7.0196 & TRN & \\
\hline CHEMBL 3936014 & 1641813 & 8.2218 & 8.2886 & TST & \\
\hline CHEMBL 3986729 & 1641813 & 8.5229 & 8.6742 & TRN & \\
\hline CHEMBL3949772 & 1641813 & 6.0 & 8.0193 & TRN & \\
\hline CHEMBL3903532 & 1641813 & 7.9586 & 7.9998 & TRN & \\
\hline CHEMBL3983086 & 1641813 & 7.9208 & 7.8161 & TRN & \\
\hline CHEMBL3984364 & 1641813 & 8.3979 & \multicolumn{2}{|c|}{ 7.957999999999999 } & TRN \\
\hline CHEMBL3900106 & 1641813 & 7.4559 & 7.8226 & TRN & \\
\hline CHEMBL3916840 & 1641813 & 8.0969 & 8.0054 & TRN & \\
\hline CHEMBL3946711 & 1641813 & 8.301 & 8.3755 & TRN & \\
\hline CHEMBL3958105 & 1641813 & 6.4685 & 6.8373 & TST & \\
\hline CHEMBL3899771 & 1641813 & 7.6576 & 7.8075 & TRN & \\
\hline CHEMBL3961233 & 1641813 & 7.7447 & 7.7059 & TRN & \\
\hline CHEMBL3901449 & 1641813 & 8.5229 & 8.7054 & TRN & \\
\hline CHEMBL3927329 & 1641813 & 6.0 & 6.487 & TRN & \\
\hline CHEMBL3901016 & 1641813 & 8.699 & 8.5813 & TRN & \\
\hline CHEMBL 3978472 & 1641813 & 8.0 & 8.4509 & TRN & \\
\hline CHEMBL3911412 & 1641813 & 6.0 & 7.4035 & TRN & \\
\hline CHEMBL3923101 & 1641813 & 7.3979 & 7.1393 & TRN & \\
\hline CHEMBL3986840 & 1641813 & 8.3979 & 8.1638 & TST & \\
\hline CHEMBL3891521 & 1641813 & 8.5229 & 8.0639 & TRN & \\
\hline CHEMBL3920996 & 1641813 & 6.0 & 6.1795 & TRN & \\
\hline CHEMBL3982350 & 1641813 & 8.0 & 8.0478 & TRN & \\
\hline CHEMBL3977406 & 1641813 & 8.699 & 8.567 & TRN & \\
\hline CHEMBL3914933 & 1641813 & 7.8539 & 6.6241 & TST & \\
\hline CHEMBL3953823 & 1641813 & 7.1192 & 6.5537 & TRN & \\
\hline CHEMBL3906766 & 1641813 & 8.699 & 8.5933 & TRN & \\
\hline CHEMBL3982655 & 1641813 & 7.5376 & 7.9293 & TST & \\
\hline CHEMBL 3898068 & 1641813 & 6.8539 & 6.6306 & TRN & \\
\hline CHEMBL3916365 & 1641813 & 7.6383 & 7.6492 & TRN & \\
\hline CHEMBL3987127 & 1641813 & 8.2218 & 7.8122 & TRN & \\
\hline CHEMBL 3915242 & 1641813 & 6.0 & 6.3233 & TST & \\
\hline CHEMBL3907213 & 1641813 & 8.0 & 8.0957 & TRN & \\
\hline CHEMBL3962943 & 1641813 & 7.4089 & 7.38 & TRN & \\
\hline CHEMBL3915321 & 1641813 & 8.1549 & 5.8487 & TST & \\
\hline CHEMBL3930782 & 1641813 & 8.699 & 8.2602 & TRN & \\
\hline CHEMBL3977822 & 1641813 & 8.0458 & 7.8155 & TRN & \\
\hline CHEMBL3905125 & 1641813 & 8.2218 & 7.4963 & TST & \\
\hline CHEMBL3927110 & 1641813 & 7.3979 & 7.1117 & TRN & \\
\hline CHEMBL3934827 & 1641813 & 7.585 & 6.5795 & TST & \\
\hline CHEMBL3981585 & 1641813 & 6.0 & 7.1995 & TRN & \\
\hline CHEMBL3892450 & 1641813 & 8.1549 & 7.8568 & TRN & \\
\hline
\end{tabular}

Page 24265 
Supplemental Table S2.txt

\begin{tabular}{|c|c|c|c|c|}
\hline CHEMBL3946522 & 1641813 & 6.9788 & 7.473 & TST \\
\hline CHEMBL3976666 & 1641813 & 6.0 & 8.0372 & TST \\
\hline CHEMBL3892222 & 1641813 & 6.5735 & 7.1705 & TRN \\
\hline CHEMBL3935165 & 1641813 & 7.9586 & 7.851 & TRN \\
\hline CHEMBL3895428 & 1641813 & 9.0 & 8.314 & TRN \\
\hline CHEMBL3936425 & 1641813 & 7.5528 & 7.5279 & TRN \\
\hline CHEMBL3948067 & 1641813 & 8.0 & 6.0923 & TST \\
\hline CHEMBL3974412 & 1641813 & 7.7447 & 7.2625 & TST \\
\hline CHEMBL3943517 & 1641813 & 7.7447 & 6.9567 & TRN \\
\hline CHEMBL3909602 & 1641813 & 7.4685 & 7.4588 & TST \\
\hline CHEMBL3951536 & 1641813 & 6.0 & 6.7164 & TRN \\
\hline CHEMBL3905728 & 1641813 & 6.0 & 5.7424 & TST \\
\hline CHEMBL3893487 & 1641813 & 6.0 & 7.1675 & TRN \\
\hline CHEMBL3906786 & 1641813 & 8.3979 & 8.2482 & TRN \\
\hline CHEMBL3896719 & 1641813 & 6.9208 & 7.1566 & TRN \\
\hline CHEMBL3958896 & 1641813 & 8.1549 & 8.0569 & TRN \\
\hline CHEMBL3941005 & 1641813 & 7.6576 & 7.3382 & TST \\
\hline CHEMBL3952193 & 1641813 & 6.0 & 6.5991 & TRN \\
\hline CHEMBL3931703 & 1641813 & 8.5229 & 8.6369 & TRN \\
\hline CHEMBL3934762 & 1641813 & 8.699 & 8.112 & TST \\
\hline CHEMBL3975371 & 1641813 & 6.0 & 6.518 & TRN \\
\hline CHEMBL3976422 & 1641813 & 6.0 & 5.9981 & TRN \\
\hline CHEMBL3919733 & 1641813 & 7.6383 & 8.0983 & TRN \\
\hline CHEMBL3959249 & 1641813 & 6.0 & 6.1248 & TRN \\
\hline CHEMBL3964937 & 1641813 & 7.8539 & 6.3887 & TST \\
\hline CHEMBL3923957 & 1641813 & 7.3372 & 7.2994 & TST \\
\hline CHEMBL3891563 & 1641813 & 6.0 & 6.5942 & TRN \\
\hline CHEMBL3928584 & 1641813 & 6.0 & 6.4579 & TRN \\
\hline CHEMBL3944015 & 1641813 & 8.0458 & 8.1405 & TST \\
\hline CHEMBL3935258 & 1641813 & 7.1871 & 7.1121 & TRN \\
\hline CHEMBL3945839 & 1641813 & 8.0969 & 8.7675 & TST \\
\hline CHEMBL3891897 & 1641813 & 7.0969 & 7.3097 & TST \\
\hline CHEMBL3986253 & 1641813 & 7.0915 & 6.7698 & TST \\
\hline CHEMBL3946941 & 1641813 & 6.0 & 7.2206 & TRN \\
\hline CHEMBL3896300 & 1641813 & 8.699 & 8.4564 & TRN \\
\hline CHEMBL3945056 & 1641813 & 7.8539 & 6.6991 & TST \\
\hline CHEMBL3909740 & 1641813 & 6.4622 & 7.1089 & TST \\
\hline CHEMBL3955217 & 1641813 & 7.4318 & 7.5917 & TRN \\
\hline CHEMBL3956914 & 1641813 & 7.7212 & 7.1166 & TRN \\
\hline CHEMBL3965913 & 1641813 & 8.699 & 8.6477 & TRN \\
\hline CHEMBL3918669 & 1641813 & 8.1549 & 8.1142 & TRN \\
\hline CHEMBL3976187 & 1641813 & 7.7696 & 6.4019 & TST \\
\hline CHEMBL3972266 & 1641813 & 7.284 & 6.7286 & TST \\
\hline CHEMBL3958056 & 1641813 & 7.1367 & 7.6949 & TRN \\
\hline CHEMBL3967278 & 1641813 & 8.301 & 8.3226 & TRN \\
\hline CHEMBL3900736 & 1641813 & 7.1675 & 6.5487 & TST \\
\hline CHEMBL3945810 & 1641813 & 7.7696 & 8.0927 & TRN \\
\hline CHEMBL3892665 & 1641813 & 8.3979 & 8.12 & TRN \\
\hline
\end{tabular}


Supplemental Table S2.txt

\begin{tabular}{|c|c|c|c|c|c|}
\hline CHEMBL3894013 & 1641813 & 7.301 & 7.3934 & TRN & \\
\hline CHEMBL3930286 & 1641813 & 7.7212 & 7.914 & TRN & \\
\hline CHEMBL3975100 & 1641813 & 7.6778 & 7.6631 & TRN & \\
\hline CHEMBL 3914124 & 1641813 & 7.5229 & 7.4506 & TRN & \\
\hline CHEMBL3950777 & 1641813 & 7.1739 & 7.4155 & TRN & \\
\hline CHEMBL3892413 & 1641813 & 8.301 & 8.1158 & TRN & \\
\hline CHEMBL3938894 & 1641813 & 8.0 & 7.1861 & TRN & \\
\hline CHEMBL3934035 & 1641813 & 6.0 & 6.6937 & TRN & \\
\hline CHEMBL3974354 & 1641813 & 7.6383 & 7.6956 & TRN & \\
\hline CHEMBL3914316 & 1641813 & 8.1549 & 8.3582 & TRN & \\
\hline CHEMBL3913109 & 1641813 & 6.2765 & 6.32299 & 99999999995 & TRN \\
\hline CHEMBL3979282 & 1641813 & 8.699 & 7.6956 & TST & \\
\hline CHEMBL3930564 & 1641813 & 7.7696 & 7.7037 & TRN & \\
\hline CHEMBL3899136 & 1641813 & 6.0 & 6.6498 & TST & \\
\hline CHEMBL3947653 & 1641813 & 8.699 & 8.9394 & TRN & \\
\hline CHEMBL3928228 & 1641813 & 6.5243 & 7.1585 & TST & \\
\hline CHEMBL3968935 & 1641813 & 8.5229 & 8.6358 & TRN & \\
\hline CHEMBL3961379 & 1641813 & 7.6198 & 7.2692 & TRN & \\
\hline CHEMBL 3931543 & 1641813 & 8.2218 & 7.2784 & TRN & \\
\hline CHEMBL3952917 & 1641813 & 8.1549 & 7.9599 & TRN & \\
\hline CHEMBL3901703 & 1641813 & 6.0 & 5.9384 & TST & \\
\hline CHEMBL3986215 & 1641813 & 7.7447 & 7.223 & TST & \\
\hline CHEMBL3927881 & 1641813 & 8.699 & 8.7015 & TRN & \\
\hline CHEMBL3911555 & 1641813 & 8.5229 & 8.5404 & TRN & \\
\hline CHEMBL3924492 & 1641813 & 7.1487 & 7.3351 & TRN & \\
\hline CHEMBL3941172 & 1641813 & 8.3979 & 7.985 & TRN & \\
\hline CHEMBL3910185 & 1641813 & 6.0 & 6.72 & TRN & \\
\hline CHEMBL3900550 & 1641813 & 7.4685 & 7.2006 & TRN & \\
\hline CHEMBL3925984 & 1641813 & 9.0 & 8.724 & TST & \\
\hline CHEMBL3964277 & 1641813 & 8.301 & 7.8838 & TRN & \\
\hline CHEMBL3933695 & 1641813 & 6.8386 & 7.1066 & TRN & \\
\hline CHEMBL3960205 & 1641813 & 7.2676 & 7.0594 & TST & \\
\hline CHEMBL3925740 & 1641813 & 7.7447 & 7.7729 & TRN & \\
\hline CHEMBL3908479 & 1641813 & 6.4123 & 7.1922 & TST & \\
\hline CHEMBL3900432 & 1641813 & 8.3979 & 8.7395 & TRN & \\
\hline CHEMBL3983218 & 1641813 & 8.2218 & 8.1029 & TRN & \\
\hline CHEMBL3973299 & 1641813 & 8.2218 & 7.9888 & TRN & \\
\hline CHEMBL3971688 & 1641813 & 7.1739 & 7.405 & TRN & \\
\hline CHEMBL 3964552 & 1641813 & 7.9586 & 7.8688 & TRN & \\
\hline CHEMBL 3922021 & 1641813 & \multicolumn{3}{|c|}{6.4510000000000005} & TST \\
\hline CHEMBL3927411 & 1641813 & 7.5686 & 7.8769 & TRN & \\
\hline CHEMBL3980314 & 1641813 & 7.2441 & 7.3111 & TRN & \\
\hline CHEMBL3910530 & 1641813 & 6.0 & 7.4117 & TST & \\
\hline CHEMBL 3986811 & 1641813 & 8.5229 & 7.3978 & TST & \\
\hline CHEMBL 3935977 & 1641813 & 6.6799 & 6.5855 & TRN & \\
\hline CHEMBL3927153 & 1641813 & 7.3665 & 7.2467 & TRN & \\
\hline CHEMBL3910318 & 1641813 & 7.6383 & 6.655 & TRN & \\
\hline CHEMBL3973541 & 1641813 & 8.699 & 8.5067 & TRN & \\
\hline
\end{tabular}

Page 24267 


\begin{tabular}{|c|c|c|c|c|c|}
\hline \multirow[b]{2}{*}{ CHEMBL3929703 } & \multicolumn{5}{|c|}{ Supplemental Table s2.txt } \\
\hline & 1641813 & 8.301 & 7.1142 & TRN & \\
\hline CHEMBL3960701 & 1641813 & 8.5229 & 8.65200 & 0000000001 & TST \\
\hline CHEMBL3912564 & 1641813 & 8.301 & 7.9897 & TRN & \\
\hline CHEMBL 3923161 & 1641813 & 6.6108 & 6.3328 & TRN & \\
\hline CHEMBL 3898770 & 1641813 & 8.301 & 7.9944 & TRN & \\
\hline CHEMBL3986854 & 1641813 & 8.699 & 8.9586 & TRN & \\
\hline CHEMBL3940979 & 1641813 & 9.0 & 9.0831 & TRN & \\
\hline CHEMBL3928977 & 1641813 & 8.5229 & 8.5587 & TRN & \\
\hline CHEMBL 3963790 & 1641813 & 7.9586 & 8.2238 & TRN & \\
\hline CHEMBL3900561 & 1641813 & 6.6144 & 6.5748 & TST & \\
\hline CHEMBL 3984585 & 1641813 & 8.0 & 7.6981 & TRN & \\
\hline CHEMBL3891625 & 1641813 & 6.1314 & 6.7079 & TST & \\
\hline CHEMBL3951378 & 1641813 & 7.3098 & 7.3987 & TRN & \\
\hline CHEMBL3900893 & 1641813 & 8.2218 & 8.0615 & TST & \\
\hline CHEMBL 3933404 & 1641813 & 7.5528 & 7.9421 & TRN & \\
\hline CHEMBL3931101 & 1641813 & 7.3565 & 7.7799 & TST & \\
\hline CHEMBL3898047 & 1641813 & 6.3439 & 6.2268 & TRN & \\
\hline CHEMBL3924851 & 1641813 & 8.0969 & 7.6022 & TRN & \\
\hline CHEMBL 3892754 & 1641813 & 6.0 & 7.6019 & TRN & \\
\hline CHEMBL3912966 & 1641813 & 8.3979 & 7.8868 & TRN & \\
\hline CHEMBL3891248 & 1641813 & 6.0 & 6.4714 & TRN & \\
\hline CHEMBL3976667 & 1641813 & 7.6198 & 7.3502 & TRN & \\
\hline CHEMBL3194607 & 954336 & 5.3809 & 5.4724 & TRN & \\
\hline CHEMBL1477039 & 954336 & 4.7447 & 5.0928 & TRN & \\
\hline CHEMBL1502954 & 954336 & 4.8564 & 4.9227 & TST & \\
\hline CHEMBL1902709 & 954336 & 5.4056 & 5.1735 & TRN & \\
\hline CHEMBL1439132 & 954336 & 4.7657 & 4.9298 & TRN & \\
\hline CHEMBL1898779 & 954336 & 5.1261 & 4.9366 & TST & \\
\hline CHEMBL1438881 & 954336 & 5.4353 & 5.2733 & TRN & \\
\hline CHEMBL596633 & 954336 & 5.1701 & 4.9282 & TRN & \\
\hline CHEMBL1256995 & 954336 & 4.6726 & 4.9318 & TRN & \\
\hline CHEMBL1407955 & 954336 & 5.9706 & 5.01399 & 9999999999 & TRN \\
\hline CHEMBL493691 & 954336 & 4.7802 & 5.4494 & TRN & \\
\hline CHEMBL1443133 & 954336 & 5.0516 & 4.9282 & TST & \\
\hline CHEMBL1456796 & 954336 & 4.6223 & 4.9239 & TRN & \\
\hline CHEMBL1708988 & 954336 & 5.0453 & 4.8719 & TRN & \\
\hline CHEMBL2354899 & 954336 & 4.8176 & 5.2292 & TRN & \\
\hline CHEMBL1350563 & 954336 & 5.066 & 4.9358 & TRN & \\
\hline CHEMBL1444462 & 954336 & 5.3363 & 4.9262 & TST & \\
\hline CHEMBL1382265 & 954336 & 5.301 & 4.9868 & TRN & \\
\hline CHEMBL326967 & 954336 & 4.9169 & 5.1421 & TST & \\
\hline CHEMBL1394831 & 954336 & 4.6955 & 4.9969 & TST & \\
\hline CHEMBL1390351 & 954336 & 5.1844 & 4.862 & TRN & \\
\hline CHEMBL1893851 & 954336 & 5.2226 & 5.3269 & TRN & \\
\hline CHEMBL547833 & 954336 & 4.8758 & 5.53600 & 00000000005 & TRN \\
\hline CHEMBL1524147 & 954336 & 5.2941 & 5.30399 & 9999999999 & TRN \\
\hline CHEMBL1307663 & 954336 & 5.426 & 4.8525 & TRN & \\
\hline CHEMBL1557130 & 954336 & 4.9352 & 5.1621 & TRN & \\
\hline
\end{tabular}




\begin{tabular}{|c|c|c|c|c|c|c|}
\hline & & \multicolumn{5}{|c|}{ Supplemental Table S2.txt } \\
\hline CHEMBL1995152 & 954336 & 4.9666 & 5.1843 & TRN & & \\
\hline CHEMBL1561091 & 954336 & 5.644 & 5.0333 & TRN & & \\
\hline CHEMBL1605224 & 954336 & 4.8752 & 4.9708 & TRN & & \\
\hline CHEMBL1454364 & 954336 & 4.8617 & 5.0475 & TRN & & \\
\hline CHEMBL582471 & 954336 & 5.05699 & 99999999 & 995 & 5.499 & TRN \\
\hline CHEMBL1444553 & 954336 & 4.8066 & 4.7505 & TST & & \\
\hline CHEMBL1558725 & 954336 & 4.9496 & 4.8645 & TRN & & \\
\hline CHEMBL1385806 & 954336 & 5.4535 & 5.4041 & TRN & & \\
\hline CHEMBL1901861 & 954336 & 5.3089 & 5.3817 & TRN & & \\
\hline CHEMBL1864833 & 954336 & 4.7176 & 5.1218 & TRN & & \\
\hline CHEMBL 2360086 & 954336 & 4.7158 & 5.3114 & TST & & \\
\hline CHEMBL1430644 & 954336 & 4.9066 & 5.1475 & TRN & & \\
\hline CHEMBL1560273 & 954336 & 5.1904 & 5.0919 & TRN & & \\
\hline CHEMBL1789994 & 954336 & 6.2411 & 5.2725 & TRN & & \\
\hline CHEMBL1578788 & 954336 & 4.7647 & 4.9068 & TRN & & \\
\hline CHEMBL1547667 & 954336 & 5.2526 & 5.5283 & TRN & & \\
\hline CHEMBL3197538 & 954336 & 5.2708 & 5.8001 & TRN & & \\
\hline CHEMBL568092 & 954336 & 4.8286 & 5.0186 & TRN & & \\
\hline CHEMBL1530087 & 954336 & 5.1593 & 5.0504 & TRN & & \\
\hline CHEMBL 3191149 & 954336 & 5.6421 & 5.734 & TRN & & \\
\hline CHEMBL1460273 & 954336 & 4.7018 & 5.2376 & TRN & & \\
\hline CHEMBL1725136 & 954336 & 5.983 & 5.6365 & TRN & & \\
\hline CHEMBL1330113 & 954336 & 4.7587 & 5.2719 & TST & & \\
\hline CHEMBL1612393 & 954336 & 4.6629 & 4.9279 & TRN & & \\
\hline CHEMBL 3392078 & 954336 & 4.782 & 5.0876 & TST & & \\
\hline CHEMBL1480915 & 954336 & 4.684 & 4.7771 & TRN & & \\
\hline CHEMBL492468 & 954336 & 5.0804 & 5.0079 & TRN & & \\
\hline CHEMBL1734563 & 954336 & 6.4437 & 5.5891 & TRN & & \\
\hline CHEMBL577887 & 954336 & 4.9465 & 5.218 & TRN & & \\
\hline CHEMBL1501307 & 954336 & 6.0101 & 5.651 & TRN & & \\
\hline CHEMBL1359141 & 954336 & 5.0092 & 5.0945 & TRN & & \\
\hline CHEMBL1409219 & 954336 & 5.2765 & 5.0589 & TRN & & \\
\hline CHEMBL22062 & 954336 & 5.6556 & 5.6718 & TRN & & \\
\hline CHEMBL1701562 & 954336 & 4.777 & 4.6591 & TRN & & \\
\hline CHEMBL1339810 & 954336 & 5.3497 & 5.1569 & TRN & & \\
\hline CHEMBL1380645 & 954336 & 4.9385 & 4.9276 & TRN & & \\
\hline CHEMBL1609129 & 954336 & 5.8601 & 5.369 & TRN & & \\
\hline CHEMBL1463926 & 954336 & 5.1518 & 5.3586 & TRN & & \\
\hline CHEMBL1378768 & 954336 & 5.011 & 5.0584 & TRN & & \\
\hline CHEMBL1723149 & 954336 & 4.7249 & 5.3283 & TRN & & \\
\hline CHEMBL1611486 & 954336 & 4.761 & 4.8821 & TRN & & \\
\hline CHEMBL478754 & 954336 & 5.9281 & 5.1575 & TRN & & \\
\hline CHEMBL1334156 & 954336 & 4.7409 & 5.2406 & TRN & & \\
\hline CHEMBL 2360949 & 954336 & 4.8755 & 5.067 & TRN & & \\
\hline CHEMBL1583807 & 954336 & 5.0825 & 5.2268 & TRN & & \\
\hline CHEMBL1353553 & 954336 & 4.6765 & 4.8874 & TRN & & \\
\hline CHEMBL2359297 & 954336 & 4.5493 & 4.7994 & TST & & \\
\hline CHEMBL1346908 & 954336 & 4.7592 & 5.1034 & TRN & & \\
\hline
\end{tabular}


Supplemental Table S2.txt

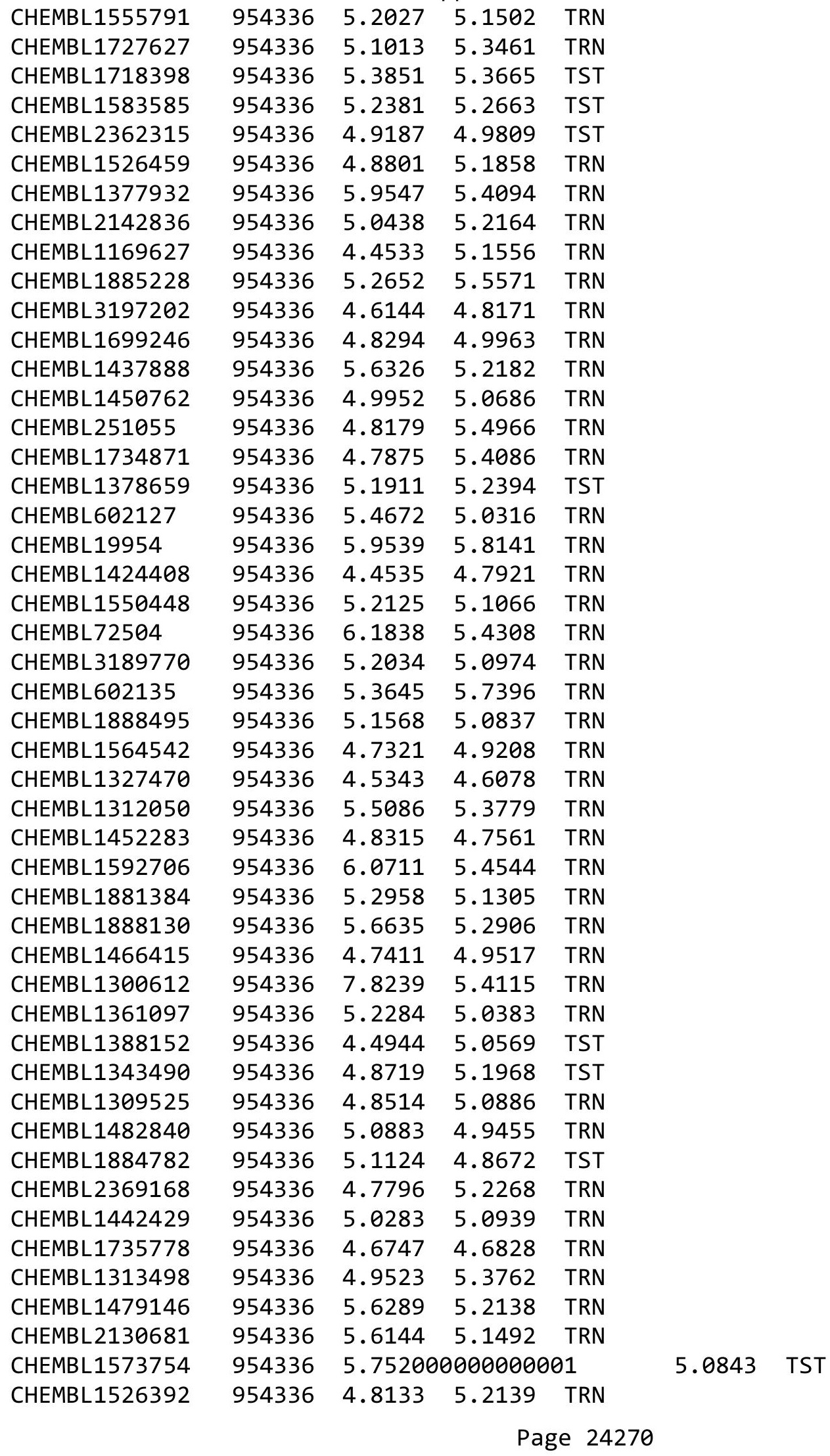


Supplemental Table S2.txt

\begin{tabular}{|c|c|c|c|c|}
\hline 363 & 6 & 6.1068 & & 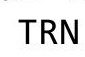 \\
\hline & & .1675 & & \\
\hline HEMR I 1 & & 801 & & \\
\hline HEMBL1\& & & 336 & & \\
\hline AEMBL1474571 & 36 & 3196 & 1258 & \\
\hline HEMBL1200847 & 36 & 6.15 & .2029 & \\
\hline 3779 & & 823 & 72 & \\
\hline AEMBL1337416 & & & & DN \\
\hline HEMBL1256655 & 36 & 1656 & 7593 & \\
\hline HEMBL1588889 & 36 & 98 & & \\
\hline HEMBL1883601 & & 129 & 19 & \\
\hline 180 & & & & \\
\hline AEMBL1 & & & & \\
\hline HEMBL1325721 & 36 & .71 & & \\
\hline HEMBL1507599 & & 708 & & \\
\hline HEMBL1889458 & & 79 & & RN \\
\hline HEMBL1 & & & & s \\
\hline HEMBL1321398 & & & & \\
\hline HEMBL1451649 & & & & \\
\hline AEMBL5 & & & 03 & I KIV \\
\hline HEMBL: & & & & $2 \mathrm{~N}$ \\
\hline HEM & & & & TIV \\
\hline AEMBL 2 & & & & \\
\hline HEMBL1 & & & & \\
\hline HEMBL 2142209 & & 54 & & IRN \\
\hline HEMBL1 & & & & 「RN \\
\hline HEMBL 1 & & & & KIN \\
\hline 91 & & 57 & & CRN \\
\hline AEMBL1 & & & & IK \\
\hline AEMBL532452 & & 99 & 63 & TRN \\
\hline AEMBL & & 39 & & 「RN \\
\hline 31 & & & & \\
\hline 059 & & 4 & & 「RN \\
\hline HEMBL1512668 & & & & TST \\
\hline HEMBL1491258 & & & & ГRN \\
\hline 156 & & & & TRN \\
\hline 43 & & & & IST \\
\hline HEMBL1483235 & & & & TRN \\
\hline HEMBL1479940 & & 86 & & $\Gamma R$ \\
\hline EOS & & & & IST \\
\hline 96726 & & & & 「RN \\
\hline HEMBL1366987 & & & & IST \\
\hline HEMBL1713613 & & 5.5017 & & TRN \\
\hline HEMBL6 & & & & TR \\
\hline CHFMRI 587626 & & & & RN \\
\hline HEMBL1 & & & & \\
\hline CHEMBL 157964 & & 5.9747 & 5.4591 & \\
\hline CHEMBL214298 & 954336 & 4.8207 & 4.9011 & \\
\hline
\end{tabular}

Page 24271 


\begin{tabular}{|c|c|c|c|c|c|c|}
\hline & & \multicolumn{5}{|c|}{ Supplemental Table S2.txt } \\
\hline CHEMBL 2131347 & 954336 & 4.7711 & 5.5501 & TST & & \\
\hline CHEMBL581868 & 954336 & 4.8222 & 5.0145 & TRN & & \\
\hline CHEMBL1504869 & 954336 & 5.21899 & 99999999 & 99 & 4.9339 & TRN \\
\hline CHEMBL1315902 & 954336 & 5.4935 & 4.9887 & TRN & & \\
\hline CHEMBL1453126 & 954336 & 5.6498 & 5.62700 & 0000000001 & & TRN \\
\hline CHEMBL1471266 & 954336 & 5.2604 & 5.4272 & TRN & & \\
\hline CHEMBL463783 & 954336 & 7.8239 & 5.4543 & TRN & & \\
\hline CHEMBL1467326 & 954336 & 5.1549 & 5.4162 & TST & & \\
\hline CHEMBL1404909 & 954336 & 4.7711 & 5.1633 & TRN & & \\
\hline CHEMBL1486042 & 954336 & 4.9594 & 5.1849 & TRN & & \\
\hline CHEMBL1467492 & 954336 & 5.062 & 4.9347 & TRN & & \\
\hline CHEMBL1548292 & 954336 & 4.8703 & 5.0581 & TRN & & \\
\hline CHEMBL1522153 & 954336 & 5.2668 & 5.3775 & TRN & & \\
\hline CHEMBL1505549 & 954336 & 5.279 & 4.9839 & TRN & & \\
\hline CHEMBL1301758 & 954336 & 5.3675 & 5.3242 & TRN & & \\
\hline CHEMBL1495160 & 954336 & 4.9352 & 4.6157 & TRN & & \\
\hline CHEMBL1369585 & 954336 & 4.6582 & 4.9883 & TRN & & \\
\hline CHEMBL1301817 & 954336 & 4.76399 & 99999999 & & 4.9681 & TRN \\
\hline CHEMBL1888857 & 954336 & 6.1656 & 5.5743 & TRN & & \\
\hline CHEMBL1503520 & 954336 & 4.6737 & 4.6381 & TRN & & \\
\hline CHEMBL602365 & 954336 & 4.8636 & 5.4133 & TRN & & \\
\hline CHEMBL1733684 & 954336 & 7.4389 & 5.3707 & TRN & & \\
\hline CHEMBL 2144470 & 954336 & 5.3197 & 5.2215 & TRN & & \\
\hline CHEMBL606456 & 954336 & 5.2248 & 4.999 & TRN & & \\
\hline CHEMBL1552591 & 954336 & 5.0052 & 5.6179 & TST & & \\
\hline CHEMBL3391727 & 954336 & 5.8962 & 4.7141 & TST & & \\
\hline CHEMBL1433972 & 954336 & 4.6041 & 4.9069 & TRN & & \\
\hline CHEMBL1705375 & 954336 & 5.0 & 5.49 & TRN & & \\
\hline CHEMBL1478968 & 954336 & 5.21399 & 99999999 & 995 & 5.2345 & TRN \\
\hline CHEMBL1462215 & 954336 & 5.0862 & 5.1772 & TST & & \\
\hline CHEMBL1256661 & 954336 & 4.5035 & 4.9341 & TRN & & \\
\hline CHEMBL1898974 & 954336 & 4.7167 & 5.1288 & TRN & & \\
\hline CHEMBL1593516 & 954336 & 4.9172 & 5.0707 & TRN & & \\
\hline CHEMBL1340872 & 954336 & 4.4932 & 4.9885 & TRN & & \\
\hline CHEMBL1338805 & 954336 & 5.0414 & 5.8441 & TRN & & \\
\hline CHEMBL1445287 & 954336 & 5.3655 & 5.222 & TRN & & \\
\hline CHEMBL3349050 & 954336 & 4.8891 & 4.8264 & TRN & & \\
\hline CHEMBL1367706 & 954336 & 4.8716 & 4.7427 & TRN & & \\
\hline CHEMBL1565558 & 954336 & 5.0448 & 5.0464 & TRN & & \\
\hline CHEMBL1717770 & 954336 & 5.2774 & 5.0468 & TRN & & \\
\hline CHEMBL1367933 & 954336 & 4.8567 & 5.3276 & TST & & \\
\hline CHEMBL1299925 & 954336 & 4.7484 & 4.8956 & TRN & & \\
\hline CHEMBL 2360026 & 954336 & 5.3391 & 4.9747 & TST & & \\
\hline CHEMBL1592159 & 954336 & 4.95 & 5.29 & TRN & & \\
\hline CHEMBL1715362 & 954336 & 5.4535 & 5.0448 & TST & & \\
\hline CHEMBL1190214 & 954336 & 5.6676 & 5.2763 & TST & & \\
\hline CHEMBL 1384387 & 954336 & 4.9905 & 4.9999 & TRN & & \\
\hline CHEMBL1342835 & 954336 & 4.8239 & 4.9876 & TRN & & \\
\hline
\end{tabular}




\begin{tabular}{|c|c|c|c|c|c|}
\hline \multicolumn{6}{|c|}{ Supplemental Table S2.txt } \\
\hline CHEMBL335782 & 954336 & 6.2534 & 5.5237 & TRN & \\
\hline CHEMBL1201074 & 954336 & 4.8271 & 4.9637 & TRN & \\
\hline CHEMBL1326957 & 954336 & 5.2062 & 5.5053 & TRN & \\
\hline CHEMBL1599959 & 954336 & 4.6629 & 5.3127 & TRN & \\
\hline CHEMBL1992564 & 954336 & 4.7359 & 5.2588 & TST & \\
\hline CHEMBL1370095 & 954336 & 5.8327 & 5.2095 & TRN & \\
\hline CHEMBL1546470 & 954336 & 5.3585 & 5.2755 & TRN & \\
\hline CHEMBL 2362913 & 954336 & 5.1226 & 4.9117 & TST & \\
\hline CHEMBL1564293 & 954336 & 4.7222 & 4.9579 & TRN & \\
\hline CHEMBL1424003 & 954336 & 5.6073 & 5.4753 & TRN & \\
\hline CHEMBL1727822 & 954336 & 4.6844 & 5.1591 & TRN & \\
\hline CHEMBL1900417 & 954336 & 5.3125 & 4.9463 & TST & \\
\hline CHEMBL580076 & 954336 & 5.8962 & 5.516 & TRN & \\
\hline CHEMBL1901040 & 954336 & 5.8125 & 5.4064 & TRN & \\
\hline CHEMBL1343182 & 954336 & 5.4647 & 5.1177 & TRN & \\
\hline CHEMBL1709546 & 954336 & 4.7625 & 4.5739 & TRN & \\
\hline CHEMBL3196990 & 954336 & 5.6517 & 5.2347 & TRN & \\
\hline CHEMBL1310009 & 954336 & 4.7319 & 4.8926 & TRN & \\
\hline CHEMBL1550957 & 954336 & 5.341 & 5.604 & TST & \\
\hline CHEMBL1304963 & 954336 & 4.7404 & 5.2651 & TRN & \\
\hline CHEMBL 2356337 & 954336 & 5.0665 & 5.2316 & TRN & \\
\hline CHEMBL1890894 & 954336 & 5.6326 & 5.4223 & TRN & \\
\hline CHEMBL1502559 & 954336 & 4.76399 & 99999999 & 5.2669 & TRN \\
\hline CHEMBL1702107 & 954336 & 5.0516 & 4.8314 & TRN & \\
\hline CHEMBL 1304273 & 954336 & 4.7192 & 5.6191 & TRN & \\
\hline CHEMBL1304200 & 954336 & 4.8005 & 4.8425 & TST & \\
\hline CHEMBL1466074 & 954336 & 5.433 & 5.0801 & TRN & \\
\hline CHEMBL1887373 & 954336 & 4.8794 & 5.3134 & TRN & \\
\hline CHEMBL1335217 & 954336 & 4.6586 & 5.0844 & TRN & \\
\hline CHEMBL1339512 & 954336 & 5.2175 & 5.41200 & $\partial 000000001$ & TRN \\
\hline CHEMBL1427087 & 954336 & 4.914 & 4.8569 & TRN & \\
\hline CHEMBL1606217 & 954336 & 5.2343 & 4.8375 & TRN & \\
\hline CHEMBL1376732 & 954336 & 5.5114 & 5.7564 & TRN & \\
\hline CHEMBL 2143570 & 954336 & 5.8069 & 5.1893 & TRN & \\
\hline CHEMBL1256735 & 954336 & 4.9706 & 5.3259 & TRN & \\
\hline CHEMBL1463198 & 954336 & 4.7333 & 5.3218 & TST & \\
\hline CHEMBL1311005 & 954336 & 5.0137 & 5.4566 & TRN & \\
\hline CHEMBL1545614 & 954336 & 4.8551 & 5.0498 & TRN & \\
\hline CHEMBL1380497 & 954336 & 5.51 & 5.7402 & TRN & \\
\hline CHEMBL1556655 & 954336 & 4.9821 & 5.3686 & TRN & \\
\hline CHEMBL353764 & 954336 & 4.9219 & 5.5249 & TST & \\
\hline CHEMBL1415090 & 954336 & 5.3002 & 4.9105 & TRN & \\
\hline CHEMBL1509380 & 954336 & 5.15 & 4.95 & TRN & \\
\hline CHEMBL1459150 & 954336 & 5.0255 & 5.1951 & TRN & \\
\hline CHEMBL1713454 & 954336 & 5.2596 & 4.9999 & TRN & \\
\hline CHEMBL1391330 & 954336 & 5.9508 & 5.4123 & TRN & \\
\hline CHEMBL1373317 & 954336 & 5.4449 & 5.1016 & TRN & \\
\hline CHEMBL1488420 & 954336 & 7.1669 & 5.4632 & TRN & \\
\hline
\end{tabular}




\begin{tabular}{|c|c|c|c|c|c|}
\hline \multicolumn{6}{|c|}{ Supplemental Table S2.txt } \\
\hline CHEMBL1328193 & 954336 & 5.0232 & 5.4024 & TST & \\
\hline CHEMBL1427899 & 954336 & 4.66 & 4.6507 & TRN & \\
\hline CHEMBL1968290 & 954336 & 5.5045 & 5.5331 & TST & \\
\hline CHEMBL1730458 & 954336 & 5.2457 & 5.3892 & TRN & \\
\hline CHEMBL1704186 & 954336 & 5.1986 & 4.7827 & TRN & \\
\hline CHEMBL1888824 & 954336 & 6.1314 & 5.2251 & TST & \\
\hline CHEMBL 2360295 & 954336 & 4.6103 & 5.0194 & TST & \\
\hline CHEMBL1414834 & 954336 & 6.0311 & 5.2587 & TRN & \\
\hline CHEMBL1490332 & 954336 & 5.6799 & 5.4451 & TRN & \\
\hline CHEMBL1611191 & 954336 & 4.9059 & 5.5644 & TRN & \\
\hline CHEMBL1734579 & 954336 & 4.9638 & 4.8412 & TRN & \\
\hline CHEMBL1731722 & 954336 & 6.2291 & 5.5596 & TRN & \\
\hline CHEMBL1530967 & 954336 & 4.8508 & 5.2189 & TRN & \\
\hline CHEMBL1872977 & 954336 & 5.1024 & 5.0707 & TRN & \\
\hline CHEMBL1509103 & 954336 & 4.8216 & 5.2906 & TRN & \\
\hline CHEMBL1509181 & 954336 & 4.9759 & 5.107 & TRN & \\
\hline CHEMBL1878215 & 954336 & 5.0778 & 5.3112 & TRN & \\
\hline CHEMBL1407863 & 954336 & 4.8649 & 5.2573 & TRN & \\
\hline CHEMBL1868173 & 954336 & 6.0214 & 4.7083 & TST & \\
\hline CHEMBL1520689 & 954336 & 4.9809 & 5.1063 & TRN & \\
\hline CHEMBL1434448 & 954336 & 4.6676 & 5.03600 & 00000000005 & TRN \\
\hline CHEMBL1600855 & 954336 & 5.059 & 4.9936 & TRN & \\
\hline CHEMBL1439686 & 954336 & 4.9876 & 5.1675 & TRN & \\
\hline CHEMBL1541609 & 954336 & 4.8303 & 4.9774 & TST & \\
\hline CHEMBL1376708 & 954336 & 4.567 & 5.2221 & TST & \\
\hline CHEMBL1871772 & 954336 & 5.15 & 5.4278 & TRN & \\
\hline CHEMBL1200792 & 954336 & 4.8976 & 4.8358 & TRN & \\
\hline CHEMBL1502199 & 954336 & 5.0 & 4.7072 & TRN & \\
\hline CHEMBL1971727 & 954336 & 6.0273 & 5.6016 & TRN & \\
\hline CHEMBL297954 & 954336 & 5.1409 & 5.8236 & TRN & \\
\hline CHEMBL1603356 & 954336 & 4.4733 & 4.7843 & TRN & \\
\hline CHEMBL 2362789 & 954336 & 4.9918 & 5.1097 & TRN & \\
\hline CHEMBL1368458 & 954336 & 4.7433 & 4.9473 & TRN & \\
\hline CHEMBL1405449 & 954336 & 4.9348 & 5.09 & TRN & \\
\hline CHEMBL1389370 & 954336 & 5.3116 & 4.8589 & TRN & \\
\hline CHEMBL1560080 & 954336 & 5.4921 & 4.9555 & TRN & \\
\hline CHEMBL1301755 & 954336 & 4.8887 & 4.9663 & TRN & \\
\hline CHEMBL1612743 & 954336 & 4.636 & 5.185 & TRN & \\
\hline CHEMBL578944 & 954336 & 4.5051 & 5.1727 & TRN & \\
\hline CHEMBL 2137112 & 954336 & 5.8041 & 5.2312 & TRN & \\
\hline CHEMBL1308088 & 954336 & 5.6055 & 5.7297 & TRN & \\
\hline CHEMBL 2139018 & 954336 & 4.8102 & 5.3217 & TST & \\
\hline CHEMBL1865717 & 954336 & 5.3625 & 5.1939 & TRN & \\
\hline CHEMBL1534121 & 954336 & 5.6216 & 5.521 & TRN & \\
\hline CHEMBL1562066 & 954336 & 4.7199 & 5.1937 & TST & \\
\hline CHEMBL1323186 & 954336 & 4.8536 & 4.8884 & TRN & \\
\hline CHEMBL1422453 & 954336 & 4.6629 & 4.9556 & TRN & \\
\hline CHEMBL583824 & 954336 & 5.0273 & 5.3746 & TRN & \\
\hline
\end{tabular}




\begin{tabular}{|c|c|c|c|c|c|c|}
\hline & & \multicolumn{5}{|c|}{ Supplemental Table S2.txt } \\
\hline CHEMBL1387977 & 954336 & 5.0429 & 5.3402 & TST & & \\
\hline CHEMBL596836 & 954336 & 5.1391 & 5.5406 & TRN & & \\
\hline CHEMBL 2357282 & 954336 & 5.3478 & 5.2188 & TRN & & \\
\hline CHEMBL1437823 & 954336 & 5.1844 & 4.6883 & TRN & & \\
\hline CHEMBL1721555 & 954336 & 4.9423 & 4.8802 & TRN & & \\
\hline CHEMBL3195455 & 954336 & 4.9686 & 5.2078 & TST & & \\
\hline CHEMBL1711432 & 954336 & 6.0605 & 5.8243 & TRN & & \\
\hline CHEMBL1496743 & 954336 & 4.8505 & 5.1103 & TRN & & \\
\hline CHEMBL1701486 & 954336 & 4.9066 & 4.4726 & TRN & & \\
\hline CHEMBL1374245 & 954336 & 5.8013 & 5.431 & TRN & & \\
\hline CHEMBL1897619 & 954336 & 5.3429 & 5.5413 & TRN & & \\
\hline CHEMBL1393446 & 954336 & \multicolumn{3}{|c|}{5.7620000000000005} & .3064 & TRN \\
\hline CHEMBL1719620 & 954336 & 5.5391 & 5.5462 & TRN & & \\
\hline CHEMBL1584799 & 954336 & 4.7755 & 5.1269 & TRN & & \\
\hline CHEMBL1538277 & 954336 & 5.0348 & 5.4459 & TRN & & \\
\hline CHEMBL1496982 & 954336 & 4.7077 & 4.8401 & TRN & & \\
\hline CHEMBL1565749 & 954336 & 4.8545 & 4.9764 & TRN & & \\
\hline CHEMBL1092473 & 954336 & 6.0 & 5.1043 & TST & & \\
\hline CHEMBL1518634 & 954336 & 4.8517 & 4.7381 & TRN & & \\
\hline CHEMBL1540339 & 954336 & 5.2487 & 5.1938 & TRN & & \\
\hline CHEMBL1499216 & 954336 & 5.5229 & 5.0267 & TRN & & \\
\hline CHEMBL1712646 & 954336 & 6.4401 & 5.4538 & TRN & & \\
\hline CHEMBL1501398 & 954336 & 4.9234 & 5.1534 & TST & & \\
\hline CHEMBL1304174 & 954336 & 5.8827 & 5.0796 & TRN & & \\
\hline CHEMBL1375045 & 954336 & 5.0467 & 5.0011 & TRN & & \\
\hline CHEMBL1736358 & 954336 & 4.7247 & 5.3625 & TST & & \\
\hline CHEMBL1355406 & 954336 & 4.6992 & 5.0722 & TRN & & \\
\hline CHEMBL72964 & 954336 & 6.4949 & 5.5108 & TRN & & \\
\hline CHEMBL1256737 & 954336 & 4.7293 & 5.1169 & TRN & & \\
\hline CHEMBL1874966 & 954336 & 4.7592 & 4.7245 & TRN & & \\
\hline CHEMBL1343338 & 954336 & 5.4572 & 5.1176 & TST & & \\
\hline CHEMBL1427032 & 954336 & 4.9416 & 5.0433 & TRN & & \\
\hline CHEMBL1340203 & 954336 & 4.6417 & 5.16700 & 0000000001 & & TRN \\
\hline CHEMBL1181670 & 954336 & 5.2848 & 5.3599 & TST & & \\
\hline CHEMBL1402502 & 954336 & 5.1355 & 5.124 & TRN & & \\
\hline CHEMBL1899959 & 954336 & 5.3969 & 5.3488 & TRN & & \\
\hline CHEMBL1382884 & 954336 & 5.2765 & 4.9887 & TRN & & \\
\hline CHEMBL1705020 & 954336 & 4.4686 & 4.8031 & TST & & \\
\hline CHEMBL1307163 & 954336 & 4.8462 & 5.6512 & TRN & & \\
\hline CHEMBL52101 & 954336 & 5.7212 & 5.8409 & TRN & & \\
\hline CHEMBL1730686 & 954336 & 5.0516 & 4.8323 & TRN & & \\
\hline CHEMBL509999 & 954336 & 5.032 & 5.2449 & TRN & & \\
\hline CHEMBL1714580 & 954336 & 4.8111 & 4.9999 & TST & & \\
\hline CHEMBL1308687 & 954336 & 4.9038 & 4.9745 & TRN & & \\
\hline CHEMBL492418 & 954336 & 5.8894 & 5.3947 & TRN & & \\
\hline CHEMBL1868212 & 954336 & 4.5923 & 5.5293 & TST & & \\
\hline CHEMBL1429174 & 954336 & 4.8348 & 5.3003 & TRN & & \\
\hline CHEMBL1465672 & 954336 & 5.767 & 5.0096 & TRN & & \\
\hline
\end{tabular}


Supplemental Table S2.txt

\begin{tabular}{|c|c|c|c|c|c|c|}
\hline CHEMBL1335850 & 954336 & 5.1175 & 5.0911 & TRN & & \\
\hline CHEMBL 3194737 & 954336 & 5.5918 & 5.7467 & TRN & & \\
\hline CHEMBL1471941 & 954336 & 5.3478 & 5.0304 & TRN & & \\
\hline CHEMBL 2135136 & 954336 & 5.2765 & 5.3772 & TRN & & \\
\hline CHEMBL295786 & 954336 & 4.7844 & 5.3865 & TRN & & \\
\hline CHEMBL1701600 & 954336 & 4.8844 & 4.8759 & TST & & \\
\hline CHEMBL1398645 & 954336 & 5.7595 & 5.2668 & TST & & \\
\hline CHEMBL1444501 & 954336 & 4.637 & 4.7415 & TRN & & \\
\hline CHEMBL1428009 & 954336 & 5.224 & 5.0438 & TRN & & \\
\hline CHEMBL1399523 & 954336 & 5.4584 & 5.3581 & TRN & & \\
\hline CHEMBL461193 & 954336 & 5.6108 & 5.4629 & TST & & \\
\hline CHEMBL1503928 & 954336 & 4.7162 & 5.0044 & TRN & & \\
\hline CHEMBL1521371 & 954336 & 5.05399 & 79999999 & 99 & 5.1163 & TRN \\
\hline CHEMBL 2369333 & 954336 & 4.8955 & 5.1513 & TST & & \\
\hline CHEMBL1362949 & 954336 & 4.9 & 5.2945 & TRN & & \\
\hline CHEMBL 3391752 & 954336 & 5.7144 & 4.6508 & TST & & \\
\hline CHEMBL1488905 & 954336 & 4.7055 & 4.8677 & TRN & & \\
\hline CHEMBL1427814 & 954336 & 5.45100 & 0000000 & 305 & 5.335 & TRN \\
\hline CHEMBL1978479 & 954336 & 5.8928 & 5.154 & TRN & & \\
\hline CHEMBL1485340 & 954336 & 5.3645 & 5.21200 & 0000000001 & & TRN \\
\hline CHEMBL1902535 & 954336 & 5.2248 & 5.2349 & TRN & & \\
\hline CHEMBL1967371 & 954336 & 4.5481 & 4.876 & TRN & & \\
\hline CHEMBL1470728 & 954336 & 6.4295 & 5.6198 & TRN & & \\
\hline CHEMBL1889079 & 954336 & 5.1524 & 5.3028 & TRN & & \\
\hline CHEMBL1475528 & 954336 & 5.0458 & 5.3244 & TRN & & \\
\hline CHEMBL994 & 954336 & 5.2557 & 5.5879 & TRN & & \\
\hline CHEMBL1438731 & 954336 & 4.9698 & 5.0851 & TRN & & \\
\hline CHEMBL1612974 & 954336 & 4.988 & 4.8375 & TRN & & \\
\hline CHEMBL528724 & 954336 & 5.4672 & 5.3592 & TRN & & \\
\hline CHEMBL 2137493 & 954336 & 5.5686 & 5.3427 & TRN & & \\
\hline CHEMBL1904111 & 954336 & 5.9431 & 5.3129 & TRN & & \\
\hline CHEMBL1391171 & 954336 & 4.6938 & 5.3862 & TRN & & \\
\hline CHEMBL1092508 & 954336 & 5.4855 & 5.4175 & TRN & & \\
\hline CHEMBL1559767 & 954336 & 5.2168 & 5.1862 & TRN & & \\
\hline CHEMBL1716796 & 954336 & 4.7104 & 4.5711 & TRN & & \\
\hline CHEMBL129542 & 954336 & 4.9889 & 5.0081 & TRN & & \\
\hline CHEMBL1710 & 954336 & 4.6474 & 4.8154 & TRN & & \\
\hline CHEMBL1612163 & 954336 & 5.5129 & 5.1841 & TRN & & \\
\hline CHEMBL1467036 & 954336 & 4.6857 & 5.2158 & TRN & & \\
\hline CHEMBL1429512 & 954336 & \multicolumn{3}{|c|}{5.2620000000000005} & 5.5726 & TRN \\
\hline CHEMBL1875294 & 954336 & 4.6772 & 5.1191 & TRN & & \\
\hline CHEMBL1435332 & 954336 & 4.8002 & 4.9526 & TRN & & \\
\hline CHEMBL1598234 & 954336 & 5.0511 & 4.9223 & TRN & & \\
\hline CHEMBL1312371 & 954336 & 4.815 & 5.0144 & TRN & & \\
\hline CHEMBL1902072 & 954336 & 5.5513 & 5.4577 & TRN & & \\
\hline CHEMBL1362150 & 954336 & 4.8156 & 4.9928 & TRN & & \\
\hline CHEMBL1903878 & 954336 & 5.6198 & 5.1939 & TRN & & \\
\hline CHEMBL1554856 & 954336 & 5.3152 & 5.3514 & TRN & & \\
\hline
\end{tabular}


Supplemental Table S2.txt

\begin{tabular}{|c|c|c|c|c|}
\hline CHEMBL1467801 & 954336 & 4.9031 & 5.0919 & TRN \\
\hline CHEMBL1905246 & 954336 & 5.1057 & 5.1557 & TRN \\
\hline CHEMBL1899451 & 954336 & 4.9516 & 5.1011 & TST \\
\hline CHEMBL1699154 & 954336 & 4.6698 & 5.6016 & TRN \\
\hline CHEMBL1430970 & 954336 & 4.7937 & 5.1651 & TRN \\
\hline CHEMBL1470912 & 954336 & 4.4819 & 4.9912 & TRN \\
\hline CHEMBL1864636 & 954336 & 5.1421 & 5.3063 & TRN \\
\hline CHEMBL1496705 & 954336 & 5.0237 & 4.9334 & TRN \\
\hline CHEMBL1548574 & 954336 & 5.6498 & 5.2924 & TRN \\
\hline CHEMBL1388553 & 954336 & 5.8894 & 5.0509 & TRN \\
\hline CHEMBL1402724 & 954336 & 5.0888 & 5.1746 & TRN \\
\hline CHEMBL1453201 & 954336 & 4.7305 & 5.2743 & TRN \\
\hline CHEMBL1394750 & 954336 & 4.8336 & 4.5298 & TRN \\
\hline CHEMBL1714988 & 954336 & 5.1524 & 5.1203 & TRN \\
\hline CHEMBL1590902 & 954336 & 5.2284 & 4.8313 & TST \\
\hline CHEMBL573214 & 954336 & 4.9566 & 4.9062 & TST \\
\hline CHEMBL1893072 & 954336 & 4.9504 & 5.1423 & TRN \\
\hline CHEMBL609036 & 954336 & 5.2832 & 5.5037 & TRN \\
\hline CHEMBL1701401 & 954336 & 5.5173 & 4.8962 & TRN \\
\hline CHEMBL 2135878 & 954336 & 5.6108 & 5.1352 & TRN \\
\hline CHEMBL1424729 & 954336 & 5.1549 & 4.9468 & TRN \\
\hline CHEMBL1718507 & 954336 & 5.2457 & 5.2303 & TRN \\
\hline CHEMBL1415634 & 954336 & 4.6594 & 5.3612 & TRN \\
\hline CHEMBL1372118 & 954336 & 4.8041 & 4.9636 & TST \\
\hline CHEMBL1892713 & 954336 & 5.5935 & 5.4667 & TRN \\
\hline CHEMBL1584280 & 954336 & 4.9634 & 5.1748 & TRN \\
\hline CHEMBL1864723 & 954336 & 4.9034 & 5.3585 & TRN \\
\hline CHEMBL1705808 & 954336 & 4.9496 & 4.8593 & TST \\
\hline CHEMBL1992308 & 954336 & 4.9817 & 5.439 & TST \\
\hline CHEMBL 2136048 & 954336 & 4.5339 & 4.8487 & TRN \\
\hline CHEMBL1706173 & 954336 & 5.2321 & 5.0832 & TST \\
\hline CHEMBL1469738 & 954336 & 4.654 & 4.9613 & TRN \\
\hline CHEMBL1319771 & 954336 & 5.0862 & 5.1074 & TRN \\
\hline CHEMBL1906593 & 954336 & 5.2449 & 5.4048 & TRN \\
\hline CHEMBL1424691 & 954336 & 4.7948 & 4.9371 & TRN \\
\hline CHEMBL1731419 & 954336 & 4.776 & 5.1769 & TRN \\
\hline CHEMBL1873630 & 954336 & 5.15 & 5.1811 & TST \\
\hline CHEMBL1384942 & 954336 & 4.6882 & 4.905 & TRN \\
\hline CHEMBL1714502 & 954336 & 4.4647 & 5.0197 & TRN \\
\hline CHEMBL501131 & 954336 & 5.3134 & 5.4358 & TRN \\
\hline CHEMBL1342991 & 954336 & 4.8245 & 5.2173 & TRN \\
\hline CHEMBL1327262 & 954336 & 5.0716 & 5.5053 & TRN \\
\hline CHEMBL1600045 & 954336 & 4.6325 & 4.7813 & TRN \\
\hline CHEMBL608105 & 954336 & 4.9333 & 4.853 & TRN \\
\hline CHEMBL599943 & 954336 & 4.8383 & 5.0222 & TRN \\
\hline CHEMBL578719 & 954336 & 5.8539 & 5.5213 & TRN \\
\hline CHEMBL1427763 & 954336 & 4.9626 & $4.99100 e$ & 00000000005 \\
\hline CHEMBL1464230 & 954336 & 5.4056 & 5.1078 & TRN \\
\hline
\end{tabular}




\begin{tabular}{|c|c|c|c|c|c|}
\hline & & & oplement & al Table S2. & \\
\hline CHEMBL1886349 & 954336 & 4.9024 & 5.07600 & 20000000005 & TST \\
\hline CHEMBL1556245 & 954336 & 4.9245 & 5.38899 & 9999999999 & TRN \\
\hline CHEMBL1198307 & 954336 & 5.8041 & 5.5837 & TRN & \\
\hline CHEMBL1736406 & 954336 & 5.06 & 5.0033 & TST & \\
\hline CHEMBL1478755 & 954336 & 5.9101 & 5.5023 & TRN & \\
\hline CHEMBL1708493 & 954336 & 7.8239 & 5.7109 & TRN & \\
\hline CHEMBL1522786 & 954336 & 5.1537 & 5.4776 & TRN & \\
\hline CHEMBL1699532 & 954336 & 6.0726 & 5.4575 & TRN & \\
\hline CHEMBL1350514 & 954336 & 4.6073 & 4.9768 & TRN & \\
\hline CHEMBL1731074 & 954336 & 5.0472 & 4.795 & TST & \\
\hline CHEMBL522887 & 954336 & 5.2874 & 5.3769 & TRN & \\
\hline CHEMBL1507774 & 954336 & 5.2815 & 4.96899 & 9999999999 & TRN \\
\hline CHEMBL35228 & 954336 & 7.4547 & 5.4026 & TRN & \\
\hline CHEMBL1407082 & 954336 & 4.7693 & 5.0184 & TRN & \\
\hline CHEMBL1535375 & 954336 & 5.9393 & 5.6181 & TRN & \\
\hline CHEMBL1361110 & 954336 & 4.5722 & 5.2601 & TRN & \\
\hline CHEMBL1415258 & 954336 & 5.4461 & 5.269 & TRN & \\
\hline CHEMBL1583901 & 954336 & 4.808 & 4.9372 & TRN & \\
\hline CHEMBL1501995 & 954336 & 4.8719 & 5.3743 & TRN & \\
\hline CHEMBL1865745 & 954336 & 5.6737 & 5.3026 & TRN & \\
\hline CHEMBL1460349 & 954336 & 5.3883 & 5.6073 & TRN & \\
\hline CHEMBL1903596 & 954336 & 5.433 & 5.4309 & TRN & \\
\hline CHEMBL1588483 & 954336 & 4.8097 & 4.9841 & TRN & \\
\hline CHEMBL1256660 & 954336 & 4.6482 & 5.0937 & TRN & \\
\hline CHEMBL1566354 & 954336 & 4.5133 & 4.6521 & TRN & \\
\hline CHEMBL 2374259 & 954336 & 5.0742 & 5.0089 & TST & \\
\hline CHEMBL590168 & 954336 & 5.4145 & 5.0727 & TRN & \\
\hline CHEMBL1885654 & 954336 & 5.2628 & 5.5351 & TRN & \\
\hline CHEMBL1404004 & 954336 & 4.9112 & 4.9851 & TST & \\
\hline CHEMBL1586819 & 954336 & 5.0334 & 5.5461 & TRN & \\
\hline CHEMBL1320254 & 954336 & 5.1186 & 5.5942 & TRN & \\
\hline CHEMBL2358631 & 954336 & 4.7027 & 5.0829 & TRN & \\
\hline CHEMBL3391979 & 954336 & 5.8182 & 5.2843 & TRN & \\
\hline CHEMBL1890104 & 954336 & 4.8462 & 5.3308 & TRN & \\
\hline CHEMBL589924 & 954336 & 5.4214 & 5.2659 & TRN & \\
\hline CHEMBL416556 & 954336 & 5.6003 & 5.5801 & TRN & \\
\hline CHEMBL1541987 & 954336 & 5.8069 & 5.3805 & TRN & \\
\hline CHEMBL1906617 & 954336 & 5.9706 & 5.4497 & TRN & \\
\hline CHEMBL1324723 & 954336 & 5.1331 & 5.1796 & TRN & \\
\hline CHEMBL1414890 & 954336 & 4.6312 & 4.935 & TRN & \\
\hline CHEMBL1436792 & 954336 & 5.7799 & 5.3803 & TRN & \\
\hline CHEMBL600841 & 954336 & 4.9523 & 5.0645 & TRN & \\
\hline CHEMBL2361749 & 954336 & 5.0339 & 5.3495 & TRN & \\
\hline CHEMBL585622 & 954336 & 5.8508 & 5.6878 & TRN & \\
\hline CHEMBL1534889 & 954336 & 5.1952 & 5.6457 & TRN & \\
\hline CHEMBL 2358958 & 954336 & 4.5585 & 5.1222 & TRN & \\
\hline CHEMBL1256656 & 954336 & 5.1129 & 5.17399 & 99999999995 & TRN \\
\hline CHEMBL1468340 & 954336 & 4.9101 & 5.4149 & TRN & \\
\hline & & & & 4278 & \\
\hline
\end{tabular}




\begin{tabular}{|c|c|c|c|c|c|}
\hline \multicolumn{6}{|c|}{ Supplemental Table S2.txt } \\
\hline CHEMBL1587558 & 954336 & 5.2865 & 5.8476 & TRN & \\
\hline CHEMBL1718911 & 954336 & 5.3028 & 5.0468 & TRN & \\
\hline CHEMBL1609756 & 954336 & 4.5782 & 4.8901 & TRN & \\
\hline CHEMBL1519064 & 954336 & 4.9378 & 5.2068 & TRN & \\
\hline CHEMBL368457 & 954336 & 4.6975 & 5.26399 & 9999999999 & TRN \\
\hline CHEMBL1347600 & 954336 & 5.3054 & 4.8413 & TST & \\
\hline CHEMBL1347637 & 954336 & 5.4023 & 5.4366 & TRN & \\
\hline CHEMBL1317267 & 954336 & 5.4962 & 5.4607 & TRN & \\
\hline CHEMBL1580286 & 954336 & 4.5491 & 5.0447 & TRN & \\
\hline CHEMBL1563079 & 954336 & 5.3686 & 5.181 & TRN & \\
\hline CHEMBL1256020 & 954336 & 4.7452 & 5.1285 & TST & \\
\hline CHEMBL1882117 & 954336 & 5.3595 & 5.2948 & TRN & \\
\hline CHEMBL1574730 & 954336 & 4.7552 & 4.878 & TST & \\
\hline CHEMBL1893767 & 954336 & 5.6162 & 5.4821 & TRN & \\
\hline CHEMBL1877424 & 954336 & 5.4647 & 5.4933 & TRN & \\
\hline CHEMBL602977 & 954336 & 4.8069 & 5.3543 & TRN & \\
\hline CHEMBL274189 & 954336 & 5.2848 & 5.4616 & TRN & \\
\hline CHEMBL1892757 & 954336 & 5.2426 & 5.3909 & TRN & \\
\hline CHEMBL1408030 & 954336 & 5.6108 & 5.3039 & TRN & \\
\hline CHEMBL1506662 & 954336 & 4.9796 & 4.9152 & TRN & \\
\hline CHEMBL1542113 & 954336 & 5.1337 & 5.1725 & TRN & \\
\hline CHEMBL1609956 & 954336 & 5.4711 & 5.2574 & TRN & \\
\hline CHEMBL1467211 & 954336 & 5.02 & 4.8161 & TRN & \\
\hline CHEMBL1703466 & 954336 & 5.0804 & 5.1915 & TRN & \\
\hline CHEMBL1891116 & 954336 & 5.3098 & 5.272 & TRN & \\
\hline CHEMBL197027 & 954336 & 5.109 & 5.16799 & 9999999999 & TST \\
\hline CHEMBL1589663 & 954336 & 4.7053 & 4.7243 & TRN & \\
\hline CHEMBL 2362043 & 954336 & 4.9551 & 5.2159 & TRN & \\
\hline CHEMBL1899457 & 954336 & 4.9278 & 4.7319 & TRN & \\
\hline CHEMBL1724223 & 954336 & 4.7967 & 4.9204 & TST & \\
\hline CHEMBL3191826 & 954336 & 4.7873 & 5.2591 & TRN & \\
\hline CHEMBL 2369275 & 954336 & 5.4145 & 5.1092 & TRN & \\
\hline CHEMBL1863579 & 954336 & 5.6556 & 5.3122 & TRN & \\
\hline CHEMBL1548026 & 954336 & 4.7219 & 5.092 & TRN & \\
\hline CHEMBL405110 & 954336 & 6.0287 & 5.0914 & TST & \\
\hline CHEMBL1532999 & 954336 & 4.6149 & 5.005 & TST & \\
\hline CHEMBL1361099 & 954336 & 5.4895 & 4.8796 & TST & \\
\hline CHEMBL1790033 & 954336 & 5.8729 & 5.5463 & TST & \\
\hline CHEMBL1971151 & 954336 & 4.6381 & 5.0601 & TST & \\
\hline CHEMBL 2357974 & 954336 & 5.3595 & 5.0876 & TST & \\
\hline CHEMBL124006 & 954336 & 6.567 & 5.6656 & TST & \\
\hline CHEMBL1588550 & 954336 & 5.1733 & 5.3993 & TST & \\
\hline CHEMBL1789983 & 954336 & 6.2958 & 5.2319 & TST & \\
\hline CHEMBL1715809 & 954336 & 4.8921 & 5.1104 & TST & \\
\hline CHEMBL1542895 & 954336 & 5.2857 & 4.8579 & TST & \\
\hline CHEMBL 2134849 & 954336 & 4.791 & 5.1488 & TST & \\
\hline CHEMBL1698009 & 954336 & 4.6366 & 4.9761 & TST & \\
\hline CHEMBL1709989 & 954336 & 5.0353 & 4.7872 & TST & \\
\hline
\end{tabular}


Supplemental Table S2.txt

\begin{tabular}{|c|c|c|c|c|c|}
\hline CHEMBL1364603 & 954336 & 4.9303 & 4.8668 & TST & \\
\hline CHEMBL1380684 & 954336 & 5.1487 & 5.3053 & TST & \\
\hline CHEMBL1308975 & 954336 & 5.5575 & 5.3875 & TST & \\
\hline CHEMBL1731329 & 954336 & 7.8239 & 5.553 & TST & \\
\hline CHEMBL1713029 & 954336 & 5.3344 & 5.4517 & TST & \\
\hline CHEMBL1571792 & 954336 & 5.2684 & 5.106 & TST & \\
\hline CHEMBL1572896 & 954336 & 4.766 & 5.1896 & TST & \\
\hline CHEMBL 2360126 & 954336 & 4.51699 & 99999999 & 5.0924 & TST \\
\hline CHEMBL 2358398 & 954336 & 4.5426 & 5.0704 & TST & \\
\hline CHEMBL1427859 & 954336 & 5.0429 & 4.9901 & TST & \\
\hline CHEMBL1573162 & 954336 & 5.4609 & 5.1327 & TST & \\
\hline CHEMBL1462720 & 954336 & 5.3344 & 5.20299 & 9999999999 & ונו \\
\hline CHEMBL1424941 & 954336 & 5.0625 & 5.3228 & TST & \\
\hline CHEMBL1550238 & 954336 & 5.3261 & 4.8425 & TST & \\
\hline CHEMBL1704543 & 954336 & 5.0022 & 5.3769 & TST & \\
\hline CHEMBL1901645 & 954336 & 6.2899 & 5.6327 & TST & \\
\hline CHEMBL1325789 & 954336 & 4.9169 & 5.206 & TST & \\
\hline CHEMBL1536569 & 954336 & 6.1618 & 5.2222 & TST & \\
\hline CHEMBL584442 & 954336 & 5.0878 & 5.1283 & TST & \\
\hline CHEMBL1544336 & 954336 & 4.8245 & 5.7414 & TST & \\
\hline CHEMBL1413740 & 954336 & 6.556 & 5.229 & TST & \\
\hline CHEMBL1357528 & 954336 & 5.1013 & 5.2675 & TST & \\
\hline CHEMBL1374340 & 954336 & 4.6887 & 5.3662 & TST & \\
\hline CHEMBL1707355 & 954336 & 5.0846 & 4.9318 & TST & \\
\hline CHEMBL3196206 & 954336 & 5.059 & 4.8916 & TST & \\
\hline CHEMBL1388090 & 954336 & 5.0809 & 5.1535 & TST & \\
\hline CHEMBL1457157 & 954336 & 5.3706 & 5.3833 & TST & \\
\hline CHEMBL1359356 & 954336 & 5.7167 & 5.0324 & TST & \\
\hline CHEMBL1439554 & 954336 & 4.688 & 5.4673 & TST & \\
\hline CHEMBL1613238 & 954336 & 5.6556 & \multicolumn{2}{|c|}{5.377000000000001} & TST \\
\hline CHEMBL1731759 & 954336 & 6.3002 & 5.5615 & TST & \\
\hline CHEMBL1888507 & 954336 & 5.4023 & 5.3538 & TST & \\
\hline CHEMBL1401821 & 954336 & 4.9161 & 5.6038 & TST & \\
\hline CHEMBL1389885 & 954336 & 5.3002 & 5.0417 & TST & \\
\hline CHEMBL1537300 & 954336 & 5.0862 & 4.895 & TST & \\
\hline CHEMBL1577103 & 954336 & 5.1073 & 4.73600 & 0000000001 & TS \\
\hline CHEMBL1340432 & 954336 & 4.5867 & 5.0018 & TST & \\
\hline CHEMBL1721330 & 954336 & 6.0391 & 5.221 & TST & \\
\hline CHEMBL1357648 & 954336 & 4.9987 & 5.5432 & TST & \\
\hline CHEMBL1476899 & 954336 & 4.9952 & 4.9079 & TST & \\
\hline CHEMBL1879869 & 954336 & 5.3958 & 5.0737 & TST & \\
\hline CHEMBL1432498 & 954336 & 6.1013 & 5.0312 & TST & \\
\hline CHEMBL1499676 & 954336 & 4.8514 & 4.915 & TST & \\
\hline CHEMBL1441948 & 954336 & 4.9527 & 4.676 & TST & \\
\hline CHEMBL1432479 & 954336 & 4.8022 & 5.0888 & TST & \\
\hline CHEMBL1340289 & 954336 & 4.7943 & 4.918 & TST & \\
\hline CHEMBL1318843 & 954336 & 5.0057 & 5.0895 & TST & \\
\hline CHEMBL1343778 & 954336 & 4.9735 & 5.1813 & TST & \\
\hline
\end{tabular}




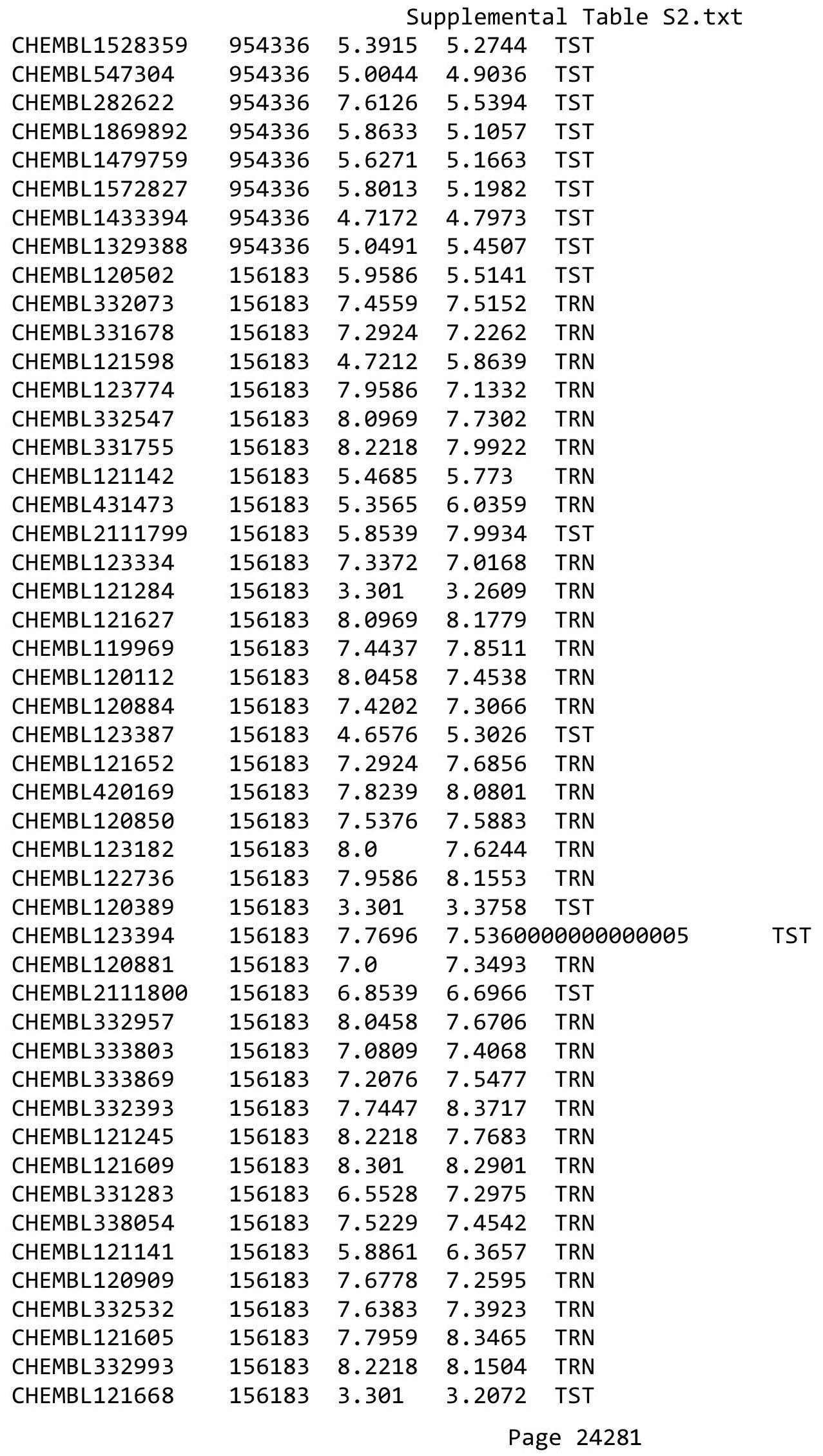




\begin{tabular}{|c|c|c|c|c|c|}
\hline \multicolumn{6}{|c|}{ Supplemental Table S2.txt } \\
\hline CHEMBL121818 & 156183 & 3.301 & 3.1327 & TRN & \\
\hline CHEMBL121422 & 156183 & 7.7696 & 7.8247 & TRN & \\
\hline CHEMBL414424 & 156183 & 8.0 & 7.5102 & TRN & \\
\hline CHEMBL120553 & 156183 & 7.6778 & 7.9095 & TRN & \\
\hline CHEMBL121664 & 156183 & 7.3665 & 7.1632 & TRN & \\
\hline CHEMBL121519 & 156183 & 5.1805 & 6.6343 & TRN & \\
\hline CHEMBL 2111798 & 156183 & 6.6198 & 6.8966 & TST & \\
\hline CHEMBL120899 & 156183 & 7.3372 & 7.0307 & TRN & \\
\hline CHEMBL 330844 & 156183 & 7.6383 & 7.2595 & TRN & \\
\hline CHEMBL332877 & 156183 & 7.0969 & 6.4842 & TRN & \\
\hline CHEMBL123343 & 156183 & 7.3565 & 6.7116 & TRN & \\
\hline CHEMBL121152 & 156183 & 6.9208 & 7.8169 & TST & \\
\hline CHEMBL123384 & 156183 & 7.8861 & 6.6354 & TRN & \\
\hline CHEMBL 330987 & 156183 & 7.8539 & 7.6016 & TRN & \\
\hline CHEMBL 121030 & 156183 & 7.8861 & 7.6945 & TRN & \\
\hline CHEMBL121481 & 156183 & 7.8539 & 8.1499 & TRN & \\
\hline CHEMBL120111 & 156183 & 7.7696 & 7.8175 & TRN & \\
\hline CHEMBL121645 & 156183 & 8.0458 & 7.7858 & TST & \\
\hline CHEMBL121199 & 156183 & 7.8239 & 7.0643 & TST & \\
\hline CHEMBL333691 & 156183 & 6.699 & 5.5778 & TST & \\
\hline CHEMBL121617 & 156183 & 8.0969 & 7.3246 & TST & \\
\hline CHEMBL122718 & 156183 & 7.0969 & 6.4974 & TST & \\
\hline CHEMBL334242 & 156183 & 7.7212 & 7.3417 & TST & \\
\hline CHEMBL 331184 & 156183 & 7.6021 & 6.5032 & TST & \\
\hline CHEMBL 2440976 & 990201 & 7.0799 & 7.075 & TRN & \\
\hline CHEMBL 2440956 & 990201 & 6.1636 & 5.4626 & TST & \\
\hline CHEMBL 2441001 & 990201 & 7.4365 & 7.7226 & TRN & \\
\hline CHEMBL 2440970 & 990201 & 9.3979 & 9.4284 & TRN & \\
\hline CHEMBL 2440944 & 990201 & 8.8539 & 8.48200 & 0000000001 & TRN \\
\hline CHEMBL 2440982 & 990201 & 8.2291 & 7.9779 & TRN & \\
\hline CHEMBL 2440997 & 990201 & 7.9586 & 7.8981 & TRN & \\
\hline CHEMBL 2440993 & 990201 & 7.2757 & 7.33700 & 3000000001 & TRN \\
\hline CHEMBL 2440960 & 990201 & 7.6108 & 7.3457 & TRN & \\
\hline CHEMBL 2440984 & 990201 & 5.0 & 4.9716 & TRN & \\
\hline CHEMBL 2440967 & 990201 & 8.4202 & 8.7534 & TRN & \\
\hline CHEMBL 2441007 & 990201 & 7.7144 & 7.6916 & TRN & \\
\hline CHEMBL 2440973 & 990201 & 6.5654 & 6.6546 & TRN & \\
\hline CHEMBL 2440968 & 990201 & 9.2218 & 9.1341 & TRN & \\
\hline CHEMBL 2440979 & 990201 & 7.4191 & 7.3691 & TRN & \\
\hline CHEMBL 2440939 & 990201 & 8.4949 & 8.657 & TRN & \\
\hline CHEMBL 2440994 & 990201 & 7.3098 & 7.3712 & TRN & \\
\hline CHEMBL 2440952 & 990201 & 6.4776 & 6.8168 & TST & \\
\hline CHEMBL 2440981 & 990201 & 7.4547 & 7.4622 & TRN & \\
\hline CHEMBL 2441004 & 990201 & 7.2708 & 7.5548 & TRN & \\
\hline CHEMBL 2440951 & 990201 & 5.0 & 9.0488 & TST & \\
\hline CHEMBL 2441009 & 990201 & 7.1226 & 7.1299 & TRN & \\
\hline CHEMBL 2440959 & 990201 & 7.0605 & 7.4241 & TRN & \\
\hline CHEMBL 2440999 & 990201 & 8.7959 & 8.719 & TRN & \\
\hline
\end{tabular}


Supplemental Table S2.txt

\begin{tabular}{|c|c|c|c|c|c|c|}
\hline CHEMBL 2441003 & 990201 & 7.5171 & 7.3048 & TRN & & \\
\hline CHEMBL 2440975 & 990201 & \multicolumn{3}{|c|}{6.4510000000000005} & 6.3853 & TRN \\
\hline CHEMBL 2440942 & 990201 & 8.8239 & 8.7288 & TRN & & \\
\hline CHEMBL 2440964 & 990201 & 8.0458 & 8.4482 & TRN & & \\
\hline CHEMBL 2441012 & 990201 & 7.3143 & 7.6002 & TRN & & \\
\hline CHEMBL 2440948 & 990201 & 6.4461 & 7.4336 & TST & & \\
\hline CHEMBL 2440989 & 990201 & 6.4992 & 7.5498 & TST & & \\
\hline CHEMBL 2440977 & 990201 & 7.585 & 7.4967 & TRN & & \\
\hline CHEMBL 2440995 & 990201 & 7.3372 & 7.221 & TRN & & \\
\hline CHEMBL 2440988 & 990201 & 6.9385 & 6.9752 & TST & & \\
\hline CHEMBL 2440962 & 990201 & 7.7212 & 7.5749 & TRN & & \\
\hline CHEMBL 2440941 & 990201 & 9.3979 & 9.23299 & 9999999999 & & TRN \\
\hline CHEMBL 2440966 & 990201 & 8.301 & 8.3765 & TRN & & \\
\hline CHEMBL503486 & 990201 & 7.699 & 7.6201 & TRN & & \\
\hline CHEMBL221532 & 990201 & 9.0 & 8.9862 & TRN & & \\
\hline CHEMBL 2440978 & 990201 & 7.3125 & 7.2607 & TRN & & \\
\hline CHEMBL 2441002 & 990201 & 7.5654 & 7.5158 & TST & & \\
\hline CHEMBL 2440969 & 990201 & 8.6778 & 8.6026 & TRN & & \\
\hline CHEMBL 2440992 & 990201 & 7.1537 & 7.2342 & TRN & & \\
\hline CHEMBL 2441000 & 990201 & 7.4949 & 7.4946 & TRN & & \\
\hline CHEMBL 2440974 & 990201 & 6.6737 & 6.6639 & TRN & & \\
\hline CHEMBL 2440987 & 990201 & 7.4535 & 7.3729 & TST & & \\
\hline CHEMBL 2440955 & 990201 & 5.0 & 6.9432 & TST & & \\
\hline CHEMBL 2440953 & 990201 & 6.4776 & 6.9699 & TST & & \\
\hline CHEMBL 2440996 & 990201 & 8.2676 & 8.1201 & TRN & & \\
\hline CHEMBL 2440986 & 990201 & 5.0 & 9.01799 & 9999999999 & & TST \\
\hline CHEMBL 2440947 & 990201 & 6.6334 & 6.6243 & TRN & & \\
\hline CHEMBL 2440990 & 990201 & 6.7122 & 7.261 & TST & & \\
\hline CHEMBL 2440972 & 990201 & 9.0969 & 9.0381 & TRN & & \\
\hline CHEMBL 2441011 & 990201 & 7.301 & 7.4169 & TRN & & \\
\hline CHEMBL 2440943 & 990201 & 8.2366 & 8.2455 & TST & & \\
\hline CHEMBL 2440127 & 990201 & 7.0114 & 7.6195 & TST & & \\
\hline CHEMBL 2440991 & 990201 & 7.9208 & 7.6058 & TRN & & \\
\hline CHEMBL 2440946 & 990201 & 7.8928 & 8.2292 & TRN & & \\
\hline CHEMBL 2441010 & 990201 & 6.9094 & 6.8989 & TRN & & \\
\hline CHEMBL 2441008 & 990201 & 7.9547 & 8.0254 & TRN & & \\
\hline CHEMBL 2440980 & 990201 & 7.9318 & 7.9204 & TRN & & \\
\hline CHEMBL 2440961 & 990201 & 7.6819 & 7.6423 & TRN & & \\
\hline CHEMBL 2440945 & 990201 & 7.8386 & 7.9038 & TRN & & \\
\hline CHEMBL 2440963 & 990201 & 9.5229 & 9.7076 & TRN & & \\
\hline CHEMBL 2440958 & 990201 & 9.699 & 7.9231 & TST & & \\
\hline CHEMBL 2440949 & 990201 & 5.0 & 9.1572 & TST & & \\
\hline CHEMBL 2440983 & 990201 & 7.0491 & 7.6331 & TRN & & \\
\hline CHEMBL 2440957 & 990201 & 7.9031 & 6.4125 & TST & & \\
\hline CHEMBL 2440971 & 990201 & 8.9208 & 8.7739 & TRN & & \\
\hline CHEMBL 2440950 & 990201 & 5.0 & 9.1517 & TST & & \\
\hline CHEMBL 2440985 & 990201 & 7.5654 & 7.2825 & TRN & & \\
\hline CHEMBL 2440940 & 990201 & 8.9586 & 8.6713 & TRN & & \\
\hline
\end{tabular}




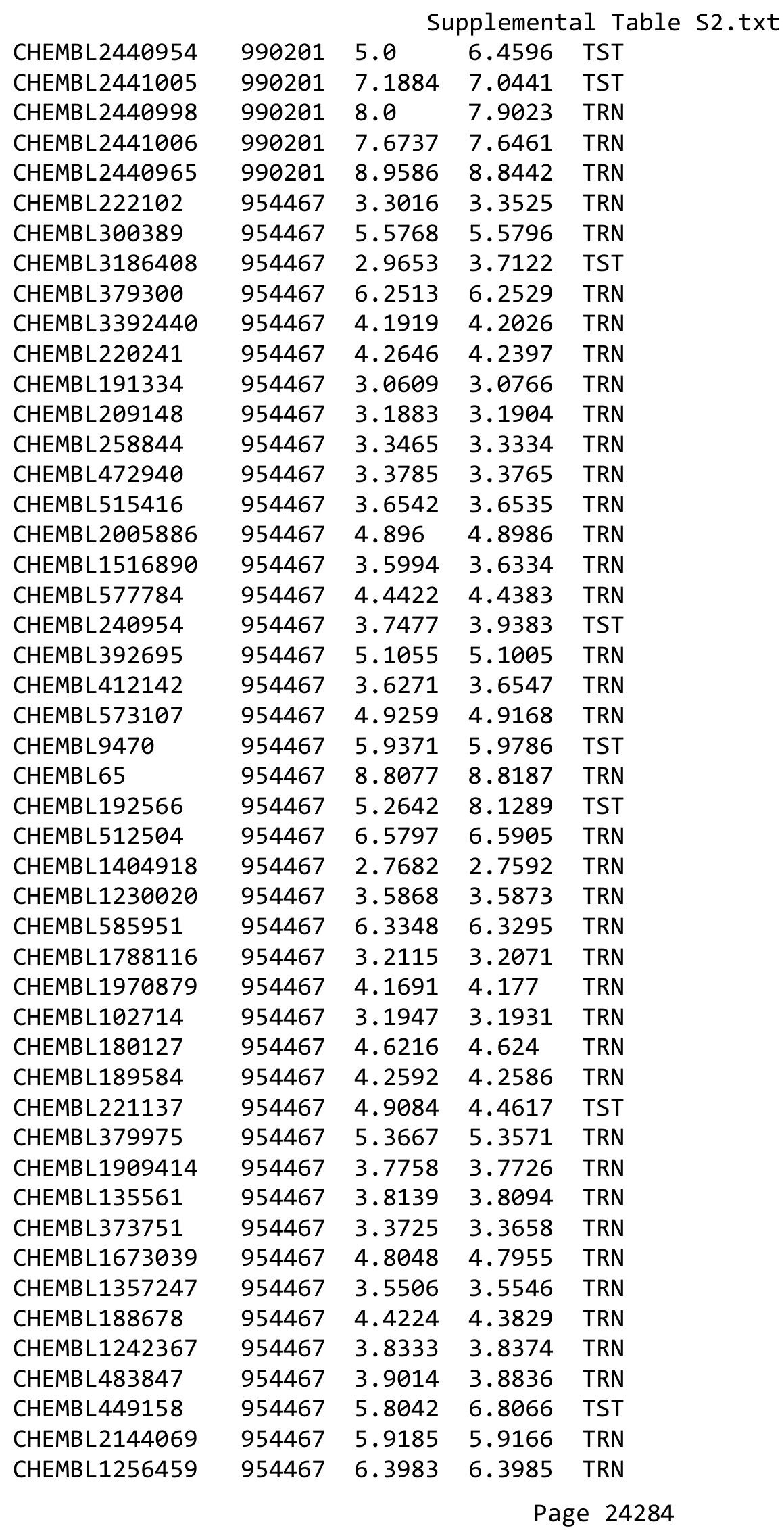




\begin{tabular}{|c|c|c|c|c|c|}
\hline & & \multicolumn{4}{|c|}{ Supplemental Table S2.txt } \\
\hline CHEMBL1590308 & 954467 & 3.7379 & 3.237 & TST & \\
\hline CHEMBL259181 & 954467 & 4.688 & 4.6728 & TRN & \\
\hline CHEMBL 213100 & 954467 & 3.1781 & 3.1788 & TRN & \\
\hline CHEMBL509032 & 954467 & 5.6622 & 5.6832 & TRN & \\
\hline CHEMBL1643959 & 954467 & 3.1528 & 3.1505 & TRN & \\
\hline CHEMBL558642 & 954467 & 3.8278 & 3.8183 & TRN & \\
\hline CHEMBL3199475 & 954467 & 5.0125 & 5.0018 & TRN & \\
\hline CHEMBL202721 & 954467 & 5.8642 & 5.8631 & TRN & \\
\hline CHEMBL3349342 & 954467 & 6.8624 & 4.7762 & TST & \\
\hline CHEMBL92309 & 954467 & 3.8135 & 2.4805 & TST & \\
\hline CHEMBL210618 & 954467 & 3.3962 & 3.0114 & TST & \\
\hline CHEMBL483849 & 954467 & 3.0719 & 1.9865 & TST & \\
\hline CHEMBL1190711 & 954467 & 5.1322 & 4.8056 & TST & \\
\hline CHEMBL393929 & 954467 & 3.5858 & 3.3798 & TST & \\
\hline CHEMBL2363137 & 954467 & 5.2069 & 4.948 & TST & \\
\hline CHEMBL514499 & 954467 & 6.2586 & 6.605 & TST & \\
\hline CHEMBL1917661 & 787662 & 3.0 & 3.3846 & TRN & \\
\hline CHEMBL572236 & 787662 & 3.0 & 3.3572 & TRN & \\
\hline CHEMBL1914493 & 787662 & 4.7943 & 3.1584 & TST & \\
\hline CHEMBL1917670 & 787662 & 3.0 & 3.2921 & TRN & \\
\hline CHEMBL1917656 & 787662 & 4.7688 & 5.0281 & TRN & \\
\hline CHEMBL1917669 & 787662 & 4.013 & 3.7808 & TRN & \\
\hline CHEMBL1917660 & 787662 & 4.7317 & 4.6078 & TRN & \\
\hline CHEMBL1917829 & 787662 & 3.0 & 2.3991 & TST & \\
\hline CHEMBL1917658 & 787662 & 3.0 & 2.5966 & TRN & \\
\hline CHEMBL1917828 & 787662 & 4.9329 & 4.4068 & TRN & \\
\hline CHEMBL584953 & 787662 & 3.0 & 2.9663 & TRN & \\
\hline CHEMBL571146 & 787662 & 4.5274 & 4.2022 & TRN & \\
\hline CHEMBL1917839 & 787662 & 3.0 & 2.2175 & TST & \\
\hline CHEMBL1917655 & 787662 & 3.0 & 4.6433 & TRN & \\
\hline CHEMBL1917838 & 787662 & 3.0 & 2.91399 & 99999999997 & TST \\
\hline CHEMBL1917659 & 787662 & 5.5607 & 5.2737 & TRN & \\
\hline CHEMBL1917663 & 787662 & 4.8251 & 4.683 & TRN & \\
\hline CHEMBL576070 & 787662 & 5.0186 & 4.7328 & TRN & \\
\hline CHEMBL1917827 & 787662 & 3.0 & 2.6486 & TRN & \\
\hline CHEMBL1917836 & 787662 & 5.9066 & 3.7935 & TST & \\
\hline CHEMBL1917665 & 787662 & 4.1379 & 3.1271 & TRN & \\
\hline CHEMBL570466 & 787662 & 4.0298 & 4.1851 & TRN & \\
\hline CHEMBL578814 & 787662 & 5.6655 & 5.0628 & TRN & \\
\hline CHEMBL569115 & 787662 & 7.3979 & 6.5606 & TRN & \\
\hline CHEMBL572026 & 787662 & 3.0 & 2.6508 & TRN & \\
\hline CHEMBL570511 & 787662 & 3.0 & 2.8369 & TRN & \\
\hline CHEMBL1917666 & 787662 & 4.6107 & 4.5845 & TRN & \\
\hline CHEMBL1917837 & 787662 & 5.857 & 2.1411 & TST & \\
\hline CHEMBL583335 & 787662 & 4.5246 & 4.6931 & TRN & \\
\hline CHEMBL569338 & 787662 & 4.2077 & 4.2592 & TRN & \\
\hline CHEMBL1917832 & 787662 & 4.6148 & 3.52600 & 00000000002 & TST \\
\hline CHEMBL572024 & 787662 & 5.4921 & 6.0439 & TRN & \\
\hline
\end{tabular}




\begin{tabular}{|c|c|c|c|c|c|}
\hline \\
\hline CHEMBL569557 & 787662 & 3.0 & 3.7596 & TRN & \\
\hline CHEMBL569558 & 787662 & 3.0 & 3.9475 & TRN & \\
\hline CHEMBL1917831 & 787662 & 4.1549 & 3.3308 & TST & \\
\hline CHEMBL1917834 & 787662 & 3.0 & 2.5078 & TST & \\
\hline CHEMBL570465 & 787662 & 3.0 & 2.6679 & TRN & \\
\hline CHEMBL571359 & 787662 & 4.8511 & 3.9475 & TRN & \\
\hline CHEMBL570059 & 787662 & 5.3645 & 5.0335 & TRN & \\
\hline CHEMBL1917654 & 787662 & 5.4248 & 5.5728 & TRN & \\
\hline CHEMBL1917671 & 787662 & 3.0 & 3.6398 & TRN & \\
\hline CHEMBL570510 & 787662 & 3.0 & 3.3972 & TRN & \\
\hline CHEMBL1917667 & 787662 & 3.0 & 3.1899 & TRN & \\
\hline CHEMBL1917662 & 787662 & 3.0 & 3.2178 & TRN & \\
\hline CHEMBL1917657 & 787662 & 5.5986 & 5.581 & TRN & \\
\hline CHEMBL1917664 & 787662 & 3.0 & 3.12100 & 00000000004 & TRN \\
\hline CHEMBL1917833 & 787662 & 4.5766 & 3.9134 & TST & \\
\hline CHEMBL1917830 & 787662 & 3.0 & 2.9517 & TST & \\
\hline CHEMBL1917668 & 787662 & 3.0 & 2.8792 & TST & \\
\hline CHEMBL1917835 & 787662 & 3.0 & 3.9125 & TST & \\
\hline CHEMBL 2403539 & 971016 & 3.301 & 3.5888 & TST & \\
\hline CHEMBL 2403523 & 971016 & 3.301 & 3.2894 & TST & \\
\hline CHEMBL 2401757 & 971016 & 3.301 & 3.2974 & TRN & \\
\hline CHEMBL 2403524 & 971016 & 3.301 & 3.3173 & TRN & \\
\hline CHEMBL 2403532 & 971016 & 4.5979 & 4.3286 & TRN & \\
\hline CHEMBL 2403611 & 971016 & 4.5874 & 4.5778 & TRN & \\
\hline CHEMBL 2403537 & 971016 & 3.301 & 3.266 & TRN & \\
\hline CHEMBL 2403525 & 971016 & 3.0458 & 3.2255 & TRN & \\
\hline CHEMBL 2403542 & 971016 & 3.301 & 3.335 & TRN & \\
\hline CHEMBL 2403606 & 971016 & 3.301 & 3.1798 & TRN & \\
\hline CHEMBL 2403526 & 971016 & 3.0458 & 3.1732 & TRN & \\
\hline CHEMBL 2403536 & 971016 & 4.4293 & 4.4379 & TRN & \\
\hline CHEMBL 2403547 & 971016 & 3.301 & 3.3167 & TRN & \\
\hline CHEMBL2403521 & 971016 & 3.301 & 3.1879 & TRN & \\
\hline CHEMBL2403535 & 971016 & 3.301 & 3.30800 & 00000000003 & TRN \\
\hline CHEMBL 2403530 & 971016 & 2.9031 & 2.9091 & TRN & \\
\hline CHEMBL 2403528 & 971016 & 3.0458 & 2.7752 & TRN & \\
\hline CHEMBL 2403607 & 971016 & 4.739 & 4.7519 & TRN & \\
\hline CHEMBL2403533 & 971016 & 3.301 & 3.39899 & 99999999996 & TRN \\
\hline CHEMBL2403599 & 971016 & 3.301 & 3.321 & TRN & \\
\hline CHEMBL 2403600 & 971016 & 3.301 & 3.3866 & TRN & \\
\hline CHEMBL 2403534 & 971016 & 3.301 & 3.4863 & TST & \\
\hline CHEMBL 2403612 & 971016 & 3.301 & 3.4831 & TRN & \\
\hline CHEMBL 2403546 & 971016 & 3.301 & 3.1805 & TRN & \\
\hline CHEMBL 2403608 & 971016 & 3.301 & 3.5024 & TRN & \\
\hline CHEMBL 2403522 & 971016 & 4.6981 & 4.7021 & TRN & \\
\hline CHEMBL51434 & 971016 & 3.301 & 3.0946 & TST & \\
\hline CHEMBL 2403605 & 971016 & 3.301 & 3.3436 & TRN & \\
\hline CHEMBL 2403520 & 971016 & 3.301 & 3.2557 & TRN & \\
\hline CHEMBL 2403610 & 971016 & 3.301 & 3.2385 & TRN & \\
\hline
\end{tabular}




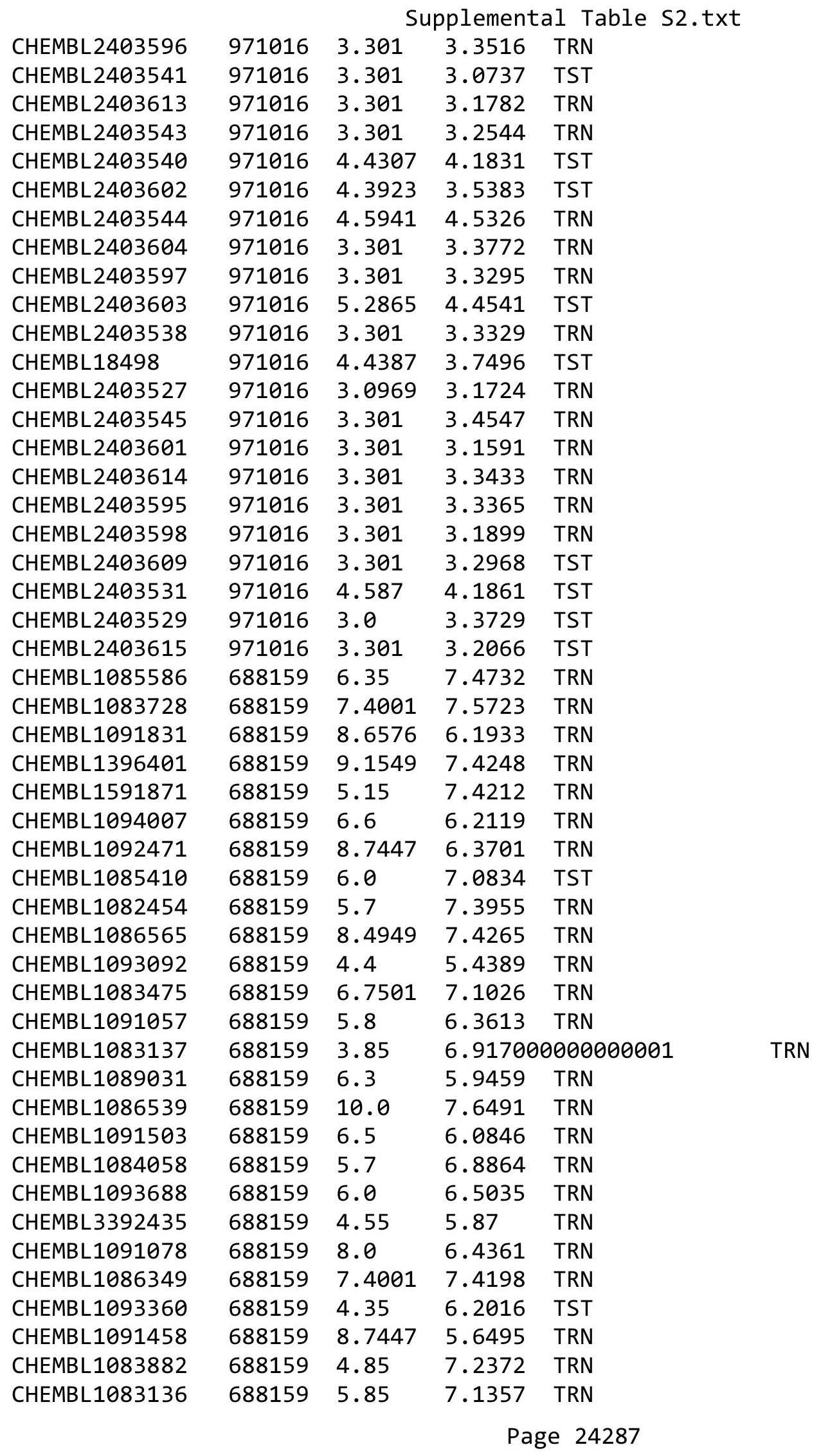




\begin{tabular}{|c|c|c|c|c|c|}
\hline \multicolumn{6}{|c|}{ Supplemental Table S2.txt } \\
\hline CHEMBL1084899 & 688159 & 5.1 & 7.4132 & TRN & \\
\hline CHEMBL1082457 & 688159 & 7.4001 & 7.4429 & TRN & \\
\hline CHEMBL1092462 & 688159 & 6.5 & 6.0895 & TRN & \\
\hline CHEMBL1085412 & 688159 & 4.55 & 7.2514 & TRN & \\
\hline CHEMBL1435175 & 688159 & 8.9586 & 8.2992 & TRN & \\
\hline CHEMBL1085411 & 688159 & 7.15 & 7.3146 & TRN & \\
\hline CHEMBL1085648 & 688159 & 4.45 & 7.17700 & 00000000005 & TRN \\
\hline CHEMBL1555167 & 688159 & 4.35 & 6.0887 & TRN & \\
\hline CHEMBL1092480 & 688159 & 10.4001 & 7.0319 & TRN & \\
\hline CHEMBL1551624 & 688159 & 7.8508 & 6.9572 & TST & \\
\hline CHEMBL1323190 & 688159 & 6.95 & 7.282 & TRN & \\
\hline CHEMBL1524808 & 688159 & 10.4001 & 7.8443 & TRN & \\
\hline CHEMBL1093687 & 688159 & 6.95 & 6.237 & TRN & \\
\hline CHEMBL1093996 & 688159 & 6.0 & 6.3669 & TST & \\
\hline CHEMBL1085647 & 688159 & 10.5003 & 7.5145 & TRN & \\
\hline CHEMBL1085794 & 688159 & 6.5501 & 7.3903 & TST & \\
\hline CHEMBL1086540 & 688159 & 6.15 & 7.5655 & TST & \\
\hline CHEMBL1084057 & 688159 & 4.4 & 6.7798 & TST & \\
\hline CHEMBL1082796 & 688159 & 10.7496 & 7.6183 & TST & \\
\hline CHEMBL1090753 & 688159 & 6.1 & 6.4083 & TRN & \\
\hline CHEMBL1085147 & 688159 & 7.8508 & 7.5237 & TST & \\
\hline CHEMBL1093096 & 688159 & 8.2007 & 6.4839 & TRN & \\
\hline CHEMBL1090777 & 688159 & 7.2 & 6.1792 & TRN & \\
\hline CHEMBL1091504 & 688159 & 4.6 & 6.1954 & TRN & \\
\hline CHEMBL1092472 & 688159 & 4.2 & 6.3116 & TRN & \\
\hline CHEMBL1083165 & 688159 & 7.3497 & 7.2706 & TST & \\
\hline CHEMBL1091795 & 688159 & 4.35 & 5.4949 & TRN & \\
\hline CHEMBL1090775 & 688159 & 4.45 & 5.8932 & TRN & \\
\hline CHEMBL1086566 & 688159 & 5.1 & 7.3419 & TST & \\
\hline CHEMBL1092297 & 688159 & 8.0 & 6.0594 & TRN & \\
\hline CHEMBL1093049 & 688159 & 4.6 & 6.3105 & TRN & \\
\hline CHEMBL1091457 & 688159 & 6.25 & 6.1916 & TRN & \\
\hline CHEMBL1093361 & 688159 & 6.25 & 6.8138 & TRN & \\
\hline CHEMBL1085649 & 688159 & 4.8 & 7.3939 & TST & \\
\hline CHEMBL1082456 & 688159 & 7.2503 & 7.4777 & TST & \\
\hline CHEMBL1093369 & 688159 & 6.0 & 6.4239 & TST & \\
\hline CHEMBL1088748 & 688159 & 10.5498 & 6.811 & TRN & \\
\hline CHEMBL1360157 & 688159 & 8.2007 & 7.0568 & TST & \\
\hline CHEMBL1086350 & 688159 & 5.2 & 7.4212 & TST & \\
\hline CHEMBL1082455 & 688159 & 7.4001 & 7.7373 & TST & \\
\hline CHEMBL1089366 & 688159 & 6.25 & 6.5464 & TST & \\
\hline CHEMBL1094006 & 688159 & 5.7 & 5.4619 & TRN & \\
\hline CHEMBL1315562 & 688159 & 7.3002 & 6.2639 & TRN & \\
\hline CHEMBL1093091 & 688159 & 5.55 & 5.4389 & TRN & \\
\hline CHEMBL1090774 & 688159 & 6.4 & 5.8448 & TRN & \\
\hline CHEMBL1085413 & 688159 & 4.6 & 7.0471 & TST & \\
\hline CHEMBL1091794 & 688159 & 4.4 & 5.5234 & TRN & \\
\hline CHEMBL1090711 & 688159 & 6.0 & 6.6656 & TST & \\
\hline
\end{tabular}





\begin{tabular}{|c|c|c|c|c|c|}
\hline \multicolumn{6}{|c|}{ Supplemental Table S2.txt } \\
\hline CHEMBL419303 & 157195 & 7.7 & 7.8073 & TRN & \\
\hline CHEMBL312201 & 157195 & 7.9 & 8.0905 & TRN & \\
\hline CHEMBL82393 & 157195 & 7.0 & 6.7436 & TRN & \\
\hline CHEMBL83199 & 157195 & 7.6 & 7.971 & TRN & \\
\hline CHEMBL85941 & 157195 & 7.5 & 7.1958 & TST & \\
\hline CHEMBL85940 & 157195 & 7.2 & 7.1014 & TST & \\
\hline CHEMBL86156 & 157195 & 7.6 & 7.2513 & TST & \\
\hline CHEMBL82017 & 157195 & 9.2 & 8.6064 & TST & \\
\hline CHEMBL85056 & 157195 & 8.0 & 7.7758 & TST & \\
\hline CHEMBL86181 & 157195 & 7.0 & 6.7184 & TST & \\
\hline CHEMBL83994 & 157195 & 7.8 & 7.1636 & TST & \\
\hline CHEMBL84099 & 157195 & 7.8 & 7.4908 & TST & \\
\hline CHEMBL1467966 & 688606 & 4.9 & 5.1016 & TRN & \\
\hline CHEMBL1593464 & 688606 & 4.95 & 5.145 & TRN & \\
\hline CHEMBL1394846 & 688606 & 5.4 & 5.5133 & TRN & \\
\hline CHEMBL1412703 & 688606 & 4.8 & 5.2639 & TRN & \\
\hline CHEMBL1928491 & 688606 & 5.3 & 5.2664 & TRN & \\
\hline CHEMBL1420442 & 688606 & 6.2 & 6.2483 & TRN & \\
\hline CHEMBL1589848 & 688606 & 6.5501 & 5.5814 & TRN & \\
\hline CHEMBL994 & 688606 & 4.55 & 4.372 & TRN & \\
\hline CHEMBL1420885 & 688606 & 5.55 & 5.529 & TRN & \\
\hline CHEMBL1590890 & 688606 & 5.1 & 5.2470 & 0000000001 & TRN \\
\hline CHEMBL1321317 & 688606 & 4.9 & 4.7462 & TST & \\
\hline CHEMBL1313846 & 688606 & 4.5 & 4.1691 & TRN & \\
\hline CHEMBL1447768 & 688606 & 5.25 & 4.9286 & TRN & \\
\hline CHEMBL1386933 & 688606 & 5.2 & 5.3457 & TRN & \\
\hline CHEMBL1428894 & 688606 & 5.1 & 5.0243 & TRN & \\
\hline CHEMBL1390112 & 688606 & 5.45 & 5.6594 & TRN & \\
\hline CHEMBL1309434 & 688606 & 5.45 & 5.0388 & TST & \\
\hline CHEMBL1316462 & 688606 & 4.95 & 4.7387 & TRN & \\
\hline CHEMBL1545902 & 688606 & 4.45 & 4.0248 & TRN & \\
\hline CHEMBL3199569 & 688606 & 5.5 & 4.7403 & TST & \\
\hline CHEMBL1514557 & 688606 & 4.95 & 4.7817 & TRN & \\
\hline CHEMBL1309645 & 688606 & 5.3 & 5.5979 & TRN & \\
\hline CHEMBL3197879 & 688606 & 4.75 & 4.8558 & TRN & \\
\hline CHEMBL3192542 & 688606 & 4.85 & 5.2969 & TST & \\
\hline CHEMBL1378873 & 688606 & 4.95 & 5.1983 & TRN & \\
\hline CHEMBL1571290 & 688606 & 5.1 & 5.4221 & TRN & \\
\hline CHEMBL1594010 & 688606 & 4.8 & 4.9726 & TRN & \\
\hline CHEMBL1540377 & 688606 & 5.05 & 4.8732 & TRN & \\
\hline CHEMBL1433540 & 688606 & 5.15 & 5.3752 & TRN & \\
\hline CHEMBL1428944 & 688606 & 5.35 & 5.2979 & 9999999999 & TRN \\
\hline CHEMBL1436023 & 688606 & 4.85 & 4.7843 & TRN & \\
\hline CHEMBL1326132 & 688606 & 5.3 & 4.8871 & TRN & \\
\hline CHEMBL1608077 & 688606 & 7.8996 & 7.8593 & TRN & \\
\hline CHEMBL1586581 & 688606 & 4.8 & 5.0685 & TST & \\
\hline CHEMBL1477366 & 688606 & 8.8861 & 8.5553 & TRN & \\
\hline CHEMBL1547169 & 688606 & 6.7501 & 7.0321 & TRN & \\
\hline
\end{tabular}

Page 24290 


\begin{tabular}{|c|c|c|c|c|c|}
\hline \multicolumn{6}{|c|}{ Supplemental Table S2.txt } \\
\hline CHEMBL1532544 & 688606 & 5.15 & 4.8769 & TRN & \\
\hline CHEMBL1535351 & 688606 & 5.2 & 5.0503 & TRN & \\
\hline CHEMBL1513325 & 688606 & 5.05 & 5.0734 & TRN & \\
\hline CHEMBL1412578 & 688606 & 5.55 & 6.2279 & TRN & \\
\hline CHEMBL1365585 & 688606 & 5.4 & 5.8715 & TRN & \\
\hline CHEMBL1574454 & 688606 & 4.45 & 5.3684 & TRN & \\
\hline CHEMBL1486253 & 688606 & 5.2 & 5.2212 & TRN & \\
\hline CHEMBL1604854 & 688606 & 5.1 & 4.7821 & TRN & \\
\hline CHEMBL1546303 & 688606 & 4.95 & 4.6553 & TRN & \\
\hline CHEMBL1475254 & 688606 & 5.0 & 5.2311 & TRN & \\
\hline CHEMBL1314792 & 688606 & 5.3 & 4.8355 & TRN & \\
\hline CHEMBL1171204 & 688606 & 5.5 & 5.7634 & TRN & \\
\hline CHEMBL1560783 & 688606 & 5.1 & 5.1283 & TRN & \\
\hline CHEMBL1565180 & 688606 & 4.85 & 4.7713 & TRN & \\
\hline CHEMBL1593815 & 688606 & 6.4 & 4.827 & TST & \\
\hline CHEMBL1584502 & 688606 & 5.1 & 4.6424 & TRN & \\
\hline CHEMBL1395532 & 688606 & 9.3979 & 6.6308 & TRN & \\
\hline CHEMBL1332139 & 688606 & 4.6 & 4.8841 & TRN & \\
\hline CHEMBL1483593 & 688606 & 5.5 & 5.5037 & TRN & \\
\hline CHEMBL1597972 & 688606 & 4.55 & 5.1175 & TRN & \\
\hline CHEMBL1595402 & 688606 & 4.5 & 4.6329 & TRN & \\
\hline CHEMBL1473289 & 688606 & 5.65 & 5.3267 & TRN & \\
\hline CHEMBL567422 & 688606 & 5.5 & 4.4842 & TST & \\
\hline CHEMBL1475058 & 688606 & 5.15 & 5.2154 & TRN & \\
\hline CHEMBL1595564 & 688606 & 4.85 & 4.7759 & TRN & \\
\hline CHEMBL1604296 & 688606 & 5.1 & 4.686 & TRN & \\
\hline CHEMBL1965348 & 688606 & 5.9 & 5.9263 & TRN & \\
\hline CHEMBL1303819 & 688606 & 4.9 & 5.269 & TRN & \\
\hline CHEMBL1486095 & 688606 & 5.65 & 5.91799 & 9999999999 & TRN \\
\hline CHEMBL1316409 & 688606 & 4.85 & 5.0994 & TRN & \\
\hline CHEMBL1475698 & 688606 & 5.6 & 4.7149 & TST & \\
\hline CHEMBL1342018 & 688606 & 4.45 & 4.3802 & TRN & \\
\hline CHEMBL1435126 & 688606 & 5.0 & 5.1453 & TRN & \\
\hline CHEMBL1402895 & 688606 & 5.1 & 4.9787 & TRN & \\
\hline CHEMBL1397601 & 688606 & 5.0 & 5.1014 & TRN & \\
\hline CHEMBL567332 & 688606 & 4.8 & 5.2709 & TRN & \\
\hline CHEMBL1362520 & 688606 & 4.45 & 4.9507 & TRN & \\
\hline CHEMBL1588205 & 688606 & 5.15 & 5.0307 & TRN & \\
\hline CHEMBL1564800 & 688606 & 5.05 & 5.1844 & TRN & \\
\hline CHEMBL1325047 & 688606 & 4.5 & 4.5961 & TRN & \\
\hline CHEMBL583200 & 688606 & 6.6 & 5.5683 & TRN & \\
\hline CHEMBL 1358722 & 688606 & 5.3 & 4.522 & TST & \\
\hline CHEMBL1533778 & 688606 & 4.9 & 5.5801 & TRN & \\
\hline CHEMBL1368430 & 688606 & 5.0 & 5.1043 & TST & \\
\hline CHEMBL1472877 & 688606 & 5.45 & 5.5859 & TRN & \\
\hline CHEMBL1333548 & 688606 & 5.65 & 4.9926 & TST & \\
\hline CHEMBL1359674 & 688606 & 5.1 & 4.5305 & TRN & \\
\hline CHEMBL1320641 & 688606 & 6.7001 & 6.8818 & TRN & \\
\hline
\end{tabular}

Page 24291 


\begin{tabular}{|c|c|c|c|c|}
\hline \multicolumn{5}{|c|}{ Supplemental Table S2.txt } \\
\hline CHEMBL1304647 & 688606 & 5.1 & 5.2132 & TRN \\
\hline CHEMBL576349 & 688606 & 5.05 & 4.7711 & TST \\
\hline CHEMBL1530756 & 688606 & 5.3 & 5.4234 & TRN \\
\hline CHEMBL566293 & 688606 & 5.6 & 5.6083 & TRN \\
\hline CHEMBL16671 & 688606 & 6.8 & 4.2827 & TST \\
\hline CHEMBL1351576 & 688606 & 5.3 & 5.6765 & TRN \\
\hline CHEMBL530049 & 688606 & 5.7 & 5.7043 & TRN \\
\hline CHEMBL1465744 & 688606 & 5.05 & 5.3014 & TRN \\
\hline CHEMBL1486345 & 688606 & 5.35 & 5.4766 & TRN \\
\hline CHEMBL1359510 & 688606 & 5.05 & 5.1593 & TRN \\
\hline CHEMBL1530229 & 688606 & 5.4 & 5.5867 & TST \\
\hline CHEMBL1397436 & 688606 & 4.85 & 5.1828 & TST \\
\hline CHEMBL1478067 & 688606 & 6.1 & 4.9059 & TST \\
\hline CHEMBL1533757 & 688606 & 5.0 & 5.6394 & TST \\
\hline CHEMBL1376974 & 688606 & 8.301 & 5.0962 & TST \\
\hline CHEMBL98350 & 688606 & 5.15 & 5.0961 & TST \\
\hline CHEMBL1478882 & 688606 & 4.85 & 4.5779 & TST \\
\hline CHEMBL1571030 & 688606 & 4.95 & 5.3278 & TST \\
\hline CHEMBL1557928 & 688606 & 5.4 & 5.3538 & TST \\
\hline CHEMBL1555364 & 688606 & 5.8 & 6.2114 & TST \\
\hline CHEMBL1567613 & 688606 & 5.3 & 5.1658 & TST \\
\hline CHEMBL1371147 & 688606 & 4.55 & 5.3164 & TST \\
\hline CHEMBL1560379 & 688606 & 4.5 & 4.5952 & TST \\
\hline CHEMBL1369655 & 688606 & 5.5 & 4.9075 & TST \\
\hline CHEMBL1523600 & 688606 & 4.65 & 5.593 & TST \\
\hline CHEMBL262065 & 467654 & 6.6576 & 6.6694 & TRN \\
\hline CHEMBL411288 & 467654 & 7.3279 & 7.3183 & TRN \\
\hline CHEMBL262327 & 467654 & 7.5086 & 7.4957 & TRN \\
\hline CHEMBL256949 & 467654 & 7.7212 & 7.7279 & TRN \\
\hline CHEMBL259995 & 467654 & 9.0 & 8.9902 & TRN \\
\hline CHEMBL404720 & 467654 & 5.4949 & 5.5035 & TRN \\
\hline CHEMBL 260255 & 467654 & 6.5528 & 6.5588 & TRN \\
\hline CHEMBL409248 & 467654 & 9.0 & 9.0624 & TRN \\
\hline CHEMBL410688 & 467654 & 7.5376 & 7.5501 & TRN \\
\hline CHEMBL256741 & 467654 & 9.0 & 8.8997 & TRN \\
\hline CHEMBL258236 & 467654 & 7.7447 & 7.7711 & TRN \\
\hline CHEMBL 255240 & 467654 & 7.3468 & 7.3662 & TRN \\
\hline CHEMBL258027 & 467654 & 7.9586 & 7.9573 & TRN \\
\hline CHEMBL401769 & 467654 & 6.5376 & 5.926 & TST \\
\hline CHEMBL256918 & 467654 & 7.3468 & 7.3409 & TRN \\
\hline CHEMBL403641 & 467654 & 9.0 & 8.9402 & TRN \\
\hline CHEMBL 256323 & 467654 & 7.9208 & 7.9211 & TRN \\
\hline CHEMBL408675 & 467654 & 7.3098 & 7.2445 & TST \\
\hline CHEMBL265447 & 467654 & 6.8539 & 6.8484 & TRN \\
\hline CHEMBL403642 & 467654 & 7.5229 & 7.5193 & TRN \\
\hline CHEMBL261300 & 467654 & 7.9586 & 7.9508 & TRN \\
\hline CHEMBL 254164 & 467654 & 6.8239 & 6.4542 & TST \\
\hline CHEMBL256948 & 467654 & 7.0 & 7.0045 & TRN \\
\hline
\end{tabular}




\begin{tabular}{|c|c|c|c|c|c|}
\hline \multirow[b]{2}{*}{ CHEMBL 258237} & \multicolumn{5}{|c|}{ Supplemental Table S2.txt } \\
\hline & 467654 & 6.7696 & 6.7691 & TRN & \\
\hline CHEMBL 257408 & 467654 & 7.8539 & 7.8384 & TRN & \\
\hline CHEMBL402906 & 467654 & 6.6021 & 6.5861 & TRN & \\
\hline CHEMBL 257409 & 467654 & 7.5686 & 7.5769 & TRN & \\
\hline CHEMBL259781 & 467654 & 8.0 & 7.4987 & TST & \\
\hline CHEMBL436646 & 467654 & 7.1192 & 7.1256 & TRN & \\
\hline CHEMBL261298 & 467654 & 9.0 & 9.0967 & TRN & \\
\hline CHEMBL409672 & 467654 & 7.2441 & 6.5548 & TST & \\
\hline CHEMBL 258028 & 467654 & 6.7212 & 6.7299 & TRN & \\
\hline CHEMBL261698 & 467654 & 7.5686 & 7.5839 & TRN & \\
\hline CHEMBL256324 & 467654 & 7.4815 & 7.4902 & TRN & \\
\hline CHEMBL402234 & 467654 & 9.0 & 8.9908 & TRN & \\
\hline CHEMBL260084 & 467654 & 6.7447 & 6.2794 & TST & \\
\hline CHEMBL399631 & 467654 & 7.1549 & 6.5035 & TST & \\
\hline CHEMBL253963 & 467654 & 7.5229 & 7.5282 & TRN & \\
\hline CHEMBL401770 & 467654 & 5.4949 & 5.4973 & TRN & \\
\hline CHEMBL258899 & 467654 & 6.8861 & 6.9668 & TST & \\
\hline CHEMBL255239 & 467654 & 9.0 & 8.9964 & TRN & \\
\hline CHEMBL 253964 & 467654 & 6.5229 & 6.5333 & TRN & \\
\hline CHEMBL411407 & 467654 & 7.7212 & 7.7234 & TRN & \\
\hline CHEMBL 265190 & 467654 & 7.2147 & 5.8543 & TST & \\
\hline CHEMBL401595 & 467654 & 7.6383 & 7.6372 & TRN & \\
\hline CHEMBL261686 & 467654 & 6.2291 & 6.2144 & TRN & \\
\hline CHEMBL 260083 & 467654 & 6.7696 & 6.6494 & TST & \\
\hline CHEMBL 255441 & 467654 & 6.0 & 5.98600 & 0000000001 & TRN \\
\hline CHEMBL265924 & 467654 & 7.5376 & 7.6698 & TST & \\
\hline CHEMBL402191 & 467654 & 6.6198 & 6.6095 & TRN & \\
\hline CHEMBL259335 & 467654 & 6.8861 & 7.8931 & TST & \\
\hline CHEMBL 259349 & 467654 & 7.1487 & 7.7185 & TST & \\
\hline CHEMBL401825 & 467654 & 9.0 & 7.4386 & TST & \\
\hline CHEMBL258459 & 467654 & 8.0 & 8.0076 & TRN & \\
\hline CHEMBL 257195 & 467654 & 8.0 & 7.9685 & TRN & \\
\hline CHEMBL 259741 & 467654 & 7.6198 & 7.624 & TRN & \\
\hline CHEMBL 254163 & 467654 & 9.0 & 9.0087 & TRN & \\
\hline CHEMBL261697 & 467654 & 7.5686 & 7.5774 & TRN & \\
\hline CHEMBL402125 & 467654 & 7.4202 & 7.4187 & TRN & \\
\hline CHEMBL 255901 & 467654 & 8.0 & 7.232 & TST & \\
\hline CHEMBL410687 & 467654 & 7.0 & 7.2882 & TST & \\
\hline CHEMBL403189 & 467654 & 7.8861 & 7.8679 & TRN & \\
\hline CHEMBL65 & 954604 & 8.3913 & 8.2296 & TRN & \\
\hline CHEMBL1909414 & 954604 & 4.8287 & 4.7904 & TRN & \\
\hline CHEMBL188678 & 954604 & 5.1366 & 4.9282 & TRN & \\
\hline CHEMBL392695 & 954604 & 5.9716 & 6.0413 & TRN & \\
\hline CHEMBL 259181 & 954604 & 4.7534 & 4.6028 & TRN & \\
\hline CHEMBL1242367 & 954604 & 4.9111 & 4.5897 & TRN & \\
\hline CHEMBL1516890 & 954604 & 4.7155 & 4.8408 & TRN & \\
\hline CHEMBL9470 & 954604 & 7.2202 & 6.3608 & TST & \\
\hline CHEMBL151176 & 954604 & 5.5995 & 5.5536 & TRN & \\
\hline
\end{tabular}

Page 24293 


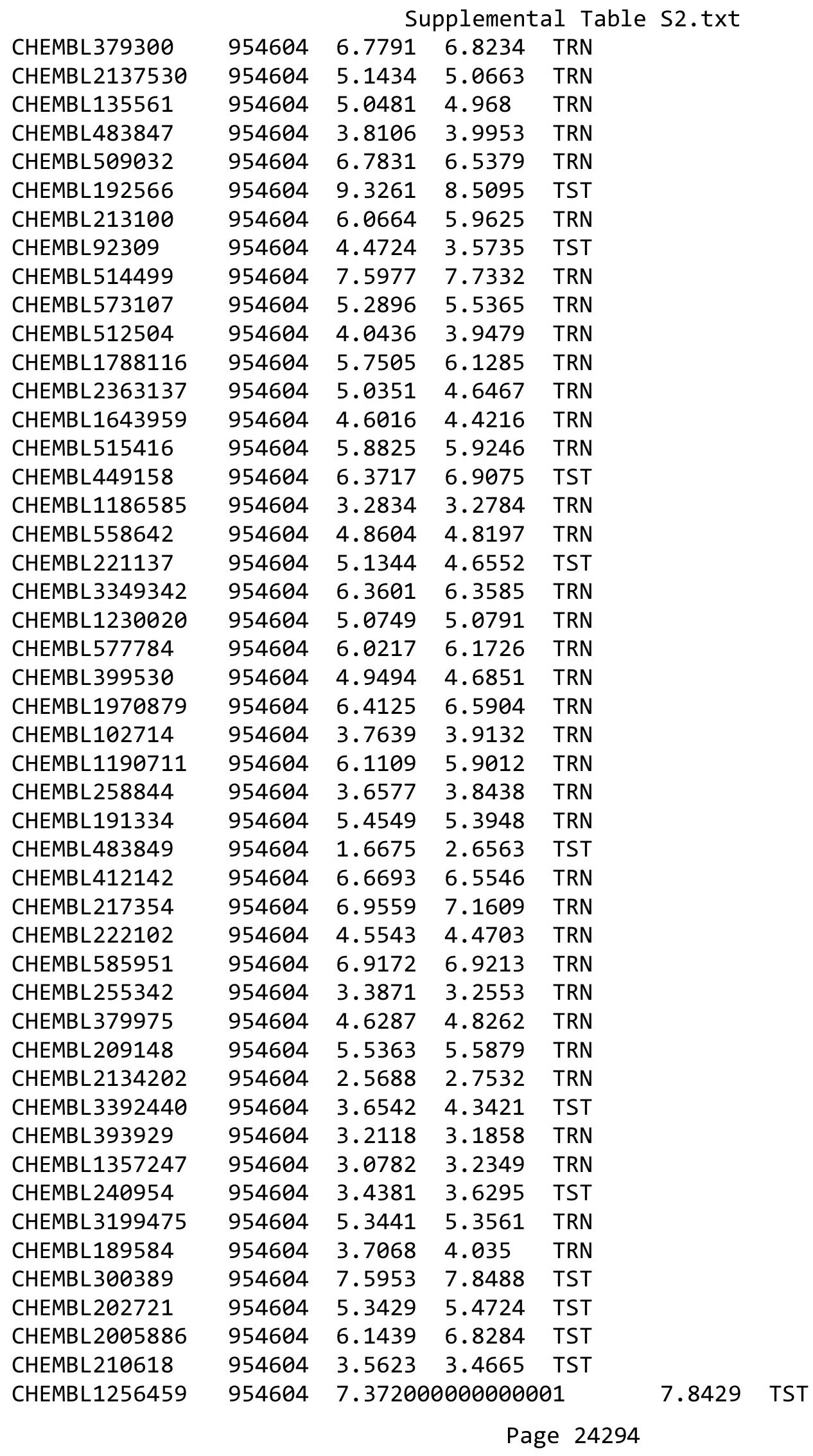


Supplemental Table S2.txt

\begin{tabular}{|c|c|c|c|c|c|c|}
\hline CHEMBL1404918 & 954604 & 2.8891 & 2.7338 & TST & & \\
\hline CHEMBL472940 & 954604 & 3.9484 & 3.6512 & TST & & \\
\hline CHEMBL28471 & 43727 & 4.9431 & 4.7712 & TRN & & \\
\hline CHEMBL30096 & 43727 & 3.8633 & 4.0072 & TST & & \\
\hline CHEMBL29733 & 43727 & 3.3372 & 3.2919 & TRN & & \\
\hline CHEMBL28613 & 43727 & 3.8928 & 3.7329 & TST & & \\
\hline CHEMBL 286526 & 43727 & 4.3925 & 4.2929 & TST & & \\
\hline CHEMBL28251 & 43727 & 5.7825 & 5.5426 & TRN & & \\
\hline CHEMBL29563 & 43727 & 5.056 & 4.809 & TRN & & \\
\hline CHEMBL281980 & 43727 & 2.301 & 2.1563 & TRN & & \\
\hline CHEMBL417299 & 43727 & 5.0223 & 4.66 & TRN & & \\
\hline CHEMBL 284405 & 43727 & \multicolumn{3}{|c|}{4.821000000000001} & 4.71 & TRN \\
\hline CHEMBL29542 & 43727 & 5.0565 & 4.8758 & TRN & & \\
\hline CHEMBL25902 & 43727 & 4.3615 & 4.3527 & TST & & \\
\hline CHEMBL281551 & 43727 & 3.6498 & 3.7891 & TST & & \\
\hline CHEMBL 29493 & 43727 & 4.4401 & 3.8179 & TST & & \\
\hline CHEMBL28855 & 43727 & 4.3872 & 4.5447 & TRN & & \\
\hline CHEMBL286704 & 43727 & \multicolumn{3}{|c|}{ 4.7669999999999995 } & 4.4724 & TP \\
\hline CHEMBL 27535 & 43727 & 4.699 & 4.7969 & TRN & & \\
\hline CHEMBL413538 & 43727 & 4.4976 & 4.8403 & TRN & & \\
\hline CHEMBL 29737 & 43727 & 4.3458 & 4.4639 & TST & & \\
\hline CHEMBL 282370 & 43727 & 3.5467 & 3.2564 & TRN & & \\
\hline CHEMBL28689 & 43727 & 5.1296 & 4.6318 & TRN & & \\
\hline CHEMBL29170 & 43727 & 4.4895 & 4.4264 & TRN & & \\
\hline CHEMBL29573 & 43727 & 5.025 & 5.0295 & TRN & & \\
\hline CHEMBL28667 & 43727 & 4.3686 & 4.2122 & TST & & \\
\hline CHEMBL30098 & 43727 & 4.3747 & 4.5241 & TRN & & \\
\hline CHEMBL280639 & 43727 & 3.5467 & 3.5806 & TRN & & \\
\hline CHEMBL 29701 & 43727 & 3.9586 & 3.9731 & TST & & \\
\hline CHEMBL417294 & 43727 & 4.5391 & 4.7728 & TRN & & \\
\hline CHEMBL 282399 & 43727 & 5.1124 & 5.2312 & TRN & & \\
\hline CHEMBL 28190 & 43727 & 4.1733 & 3.4331 & TRN & & \\
\hline CHEMBL282326 & 43727 & 2.301 & 2.2364 & TRN & & \\
\hline CHEMBL 281704 & 43727 & 3.7696 & 3.8378 & TST & & \\
\hline CHEMBL 28861 & 43727 & 2.301 & 2.5207 & TRN & & \\
\hline CHEMBL444786 & 43727 & 3.7033 & 3.8943 & TST & & \\
\hline CHEMBL 281870 & 43727 & 5.0535 & 5.1994 & TRN & & \\
\hline CHEMBL 30145 & 43727 & 4.4868 & 4.3926 & TRN & & \\
\hline CHEMBL30095 & 43727 & 5.2757 & 5.0447 & TRN & & \\
\hline CHEMBL 283707 & 43727 & 5.0506 & 5.0486 & TRN & & \\
\hline CHEMBL 284878 & 43727 & \multicolumn{3}{|c|}{ 4. 3839999999999995} & 4.6162 & 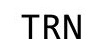 \\
\hline CHEMBL 282962 & 43727 & 4.4067 & 4.7654 & TRN & & \\
\hline CHEMBL30247 & 43727 & 5.0964 & 5.2147 & TRN & & \\
\hline CHEMBL 282831 & 43727 & 4.5214 & 4.6936 & TST & & \\
\hline CHEMBL29539 & 43727 & 6.4559 & 6.5285 & TRN & & \\
\hline CHEMBL 287179 & 43727 & 2.301 & 3.1732 & TRN & & \\
\hline CHEMBL29351 & 43727 & 5.0367 & 4.8629 & TRN & & \\
\hline CHEMBL29077 & 43727 & 3.7122 & 4.0004 & TST & & \\
\hline
\end{tabular}




\begin{tabular}{|c|c|c|c|c|c|c|}
\hline \multirow[b]{2}{*}{ CHEMBL 29845} & \multicolumn{6}{|c|}{ Supplemental Table S2.txt } \\
\hline & 43727 & 4.317 & 3.5964 & TRN & & \\
\hline CHEMBL28591 & 43727 & 4.38399 & 99999999 & 995 & 4.5172 & TRN \\
\hline CHEMBL282171 & 43727 & 4.9508 & 4.92399 & 9999999999 & & TRN \\
\hline CHEMBL28189 & 43727 & 2.301 & 3.3122 & TRN & & \\
\hline CHEMBL 28755 & 43727 & 4.4763 & 4.6718 & TRN & & \\
\hline CHEMBL 28614 & 43727 & 2.301 & 2.7294 & TST & & \\
\hline CHEMBL 29042 & 43727 & 3.6536 & 3.6572 & TRN & & \\
\hline CHEMBL 29251 & 43727 & 5.0264 & 4.769 & TRN & & \\
\hline CHEMBL 29787 & 43727 & 4.8013 & 4.9118 & TRN & & \\
\hline CHEMBL 30022 & 43727 & 5.5157 & 5.8633 & TRN & & \\
\hline CHEMBL225788 & 587680 & 6.0209 & 5.9226 & TRN & & \\
\hline CHEMBL574764 & 587680 & 8.4089 & 8.1232 & TRN & & \\
\hline CHEMBL572418 & 587680 & 7.7447 & 7.5784 & TRN & & \\
\hline CHEMBL225789 & 587680 & 8.1487 & 8.1582 & TRN & & \\
\hline CHEMBL382379 & 587680 & 5.1568 & 5.1624 & TRN & & \\
\hline CHEMBL576565 & 587680 & 5.6946 & 5.7485 & TRN & & \\
\hline CHEMBL573133 & 587680 & 8.4089 & 8.2021 & TRN & & \\
\hline CHEMBL207671 & 587680 & 5.6655 & 5.6858 & TRN & & \\
\hline CHEMBL516429 & 587680 & 6.7471 & 6.3607 & TRN & & \\
\hline CHEMBL576348 & 587680 & 8.8239 & 8.3907 & TRN & & \\
\hline CHEMBL440560 & 587680 & 5.5187 & 5.2691 & TST & & \\
\hline CHEMBL572884 & 587680 & 9.0458 & 8.7505 & TRN & & \\
\hline CHEMBL572629 & 587680 & 5.9987 & 5.6565 & TST & & \\
\hline CHEMBL573355 & 587680 & 7.1838 & 7.4067 & TRN & & \\
\hline CHEMBL574269 & 587680 & 8.4815 & 8.2919 & TRN & & \\
\hline CHEMBL180231 & 587680 & 7.0706 & 5.8861 & TST & & \\
\hline CHEMBL376569 & 587680 & 9.4685 & 8.2908 & TRN & & \\
\hline CHEMBL375985 & 587680 & 5.3098 & 5.8675 & TST & & \\
\hline CHEMBL381610 & 587680 & 6.8327 & 6.8723 & TRN & & \\
\hline CHEMBL 210544 & 587680 & 6.5157 & 7.1258 & TRN & & \\
\hline CHEMBL388729 & 587680 & 7.2924 & 7.3253 & TRN & & \\
\hline CHEMBL222254 & 587680 & 4.9066 & 6.2179 & TST & & \\
\hline CHEMBL 205410 & 587680 & 6.4949 & 6.7098 & TRN & & \\
\hline CHEMBL208199 & 587680 & 6.6108 & 6.6911 & TRN & & \\
\hline CHEMBL 209513 & 587680 & 8.699 & 8.5818 & TRN & & \\
\hline CHEMBL575838 & 587680 & 4.6737 & 5.6302 & TST & & \\
\hline CHEMBL574995 & 587680 & 8.0088 & 8.395 & TRN & & \\
\hline CHEMBL203384 & 587680 & 7.1024 & 6.3439 & TST & & \\
\hline CHEMBL574262 & 587680 & 8.3979 & 8.2672 & TRN & & \\
\hline CHEMBL 210390 & 587680 & 8.4685 & 8.2055 & TRN & & \\
\hline CHEMBL584181 & 587680 & 4.7959 & 6.6771 & TST & & \\
\hline CHEMBL577792 & 587680 & 5.8239 & 5.2691 & TST & & \\
\hline CHEMBL439340 & 587680 & 5.8386 & 6.1014 & TRN & & \\
\hline CHEMBL381829 & 587680 & 5.0958 & 5.6693 & TRN & & \\
\hline CHEMBL203329 & 587680 & 6.7033 & 6.3833 & TST & & \\
\hline CHEMBL202972 & 587680 & 5.4353 & 5.474 & TRN & & \\
\hline CHEMBL575646 & 587680 & 6.6778 & 6.6877 & TRN & & \\
\hline CHEMBL573394 & 587680 & 6.6676 & 6.3608 & TRN & & \\
\hline
\end{tabular}




\begin{tabular}{|c|c|c|c|c|c|}
\hline \multirow[b]{2}{*}{ CHEMBL178133 } & \multicolumn{5}{|c|}{ clicas } \\
\hline & 587680 & 4.6641 & 5.2697 & TST & \\
\hline CHEMBL206236 & 587680 & 5.3936 & 5.7253 & TRN & \\
\hline CHEMBL574268 & 587680 & 8.2676 & 7.9858 & TRN & \\
\hline CHEMBL572670 & 587680 & 8.9208 & 8.6251 & TRN & \\
\hline CHEMBL208499 & 587680 & 5.7802 & 6.1957 & TRN & \\
\hline CHEMBL208962 & 587680 & 6.7258 & 7.0892 & TRN & \\
\hline CHEMBL375142 & 587680 & 4.9281 & 6.3327 & TST & \\
\hline CHEMBL577379 & 587680 & 8.2291 & 8.1072 & TRN & \\
\hline CHEMBL577377 & 587680 & 8.8239 & 8.7888 & TRN & \\
\hline CHEMBL574774 & 587680 & 5.7333 & 7.1846 & TRN & \\
\hline CHEMBL564795 & 587680 & 5.9519 & 6.9974 & TRN & \\
\hline CHEMBL574476 & 587680 & 7.2007 & 4.5001 & TST & \\
\hline CHEMBL575428 & 587680 & 6.1244 & 6.5106 & TRN & \\
\hline CHEMBL226848 & 587680 & 7.7959 & 8.2847 & TRN & \\
\hline CHEMBL577567 & 587680 & 7.3947 & 7.6916 & TRN & \\
\hline CHEMBL575427 & 587680 & 8.2218 & 8.5155 & TRN & \\
\hline CHEMBL379209 & 587680 & 8.3372 & 8.8332 & TRN & \\
\hline CHEMBL207496 & 587680 & 6.7212 & 6.392 & TRN & \\
\hline CHEMBL576733 & 587680 & 8.8861 & 9.0032 & TRN & \\
\hline CHEMBL178397 & 587680 & 6.1192 & 5.6565 & TST & \\
\hline CHEMBL205871 & 587680 & 6.4895 & 6.3163 & TRN & \\
\hline CHEMBL573592 & 587680 & 8.0757 & 8.0032 & TRN & \\
\hline CHEMBL574289 & 587680 & 7.699 & 4.5001 & TST & \\
\hline CHEMBL374808 & 587680 & 8.7447 & 8.746 & TRN & \\
\hline CHEMBL 381785 & 587680 & 6.644 & 6.2057 & TRN & \\
\hline CHEMBL576386 & 587680 & 7.983 & 7.5393 & TRN & \\
\hline CHEMBL573393 & 587680 & 6.5058 & 6.0258 & TRN & \\
\hline CHEMBL210246 & 587680 & 8.4559 & 8.0427 & TRN & \\
\hline CHEMBL374805 & 587680 & 8.8239 & 8.0751 & TRN & \\
\hline CHEMBL382914 & 587680 & 6.7878 & 6.8031 & TRN & \\
\hline CHEMBL374701 & 587680 & 4.857 & 6.4104 & TST & \\
\hline CHEMBL575824 & 587680 & 8.3665 & 8.1893 & TRN & \\
\hline CHEMBL206382 & 587680 & 4.8324 & 4.8249 & TST & \\
\hline CHEMBL203673 & 587680 & 6.1612 & 6.13299 & 9999999999 & TRN \\
\hline CHEMBL575631 & 587680 & 9.1549 & 9.1423 & TRN & \\
\hline CHEMBL226332 & 587680 & 7.2291 & 7.636 & TRN & \\
\hline CHEMBL206819 & 587680 & 6.5229 & 6.9431 & TRN & \\
\hline CHEMBL 272292 & 587680 & 6.6198 & 3.6359 & TST & \\
\hline CHEMBL583705 & 587680 & 8.0862 & 7.9325 & TRN & \\
\hline CHEMBL 362455 & 587680 & 5.4685 & 5.5938 & TST & \\
\hline CHEMBL576135 & 587680 & 7.8539 & 7.9253 & TRN & \\
\hline CHEMBL572905 & 587680 & 7.7447 & 8.2486 & TRN & \\
\hline CHEMBL378823 & 587680 & 5.1904 & 5.3761 & TRN & \\
\hline CHEMBL226382 & 587680 & 7.8861 & 7.4001 & TRN & \\
\hline CHEMBL577186 & 587680 & 4.9638 & 5.2161 & TST & \\
\hline CHEMBL207215 & 587680 & 5.9905 & 5.9517 & TRN & \\
\hline CHEMBL377764 & 587680 & 7.6576 & 7.7714 & TRN & \\
\hline CHEMBL226148 & 587680 & 9.0 & 8.9558 & TRN & \\
\hline & & & & 24297 & \\
\hline
\end{tabular}


Supplemental Table S2.txt

\begin{tabular}{|c|c|c|c|c|}
\hline CHEMBL383264 & 587680 & 8.699 & 7.7396 & TRN \\
\hline CHEMBL573326 & 587680 & 9.7696 & 9.4414 & TRN \\
\hline CHEMBL381075 & 587680 & 6.9172 & 6.6363 & TRN \\
\hline CHEMBL376570 & 587680 & 7.8539 & 8.0101 & TRN \\
\hline CHEMBL572417 & 587680 & 7.4089 & 7.1245 & TRN \\
\hline CHEMBL204059 & 587680 & \multicolumn{3}{|c|}{ 4.7139999999999995 } \\
\hline CHEMBL202787 & 587680 & 6.7545 & 6.9228 & TRN \\
\hline CHEMBL577795 & 587680 & 8.5376 & 8.6409 & TRN \\
\hline CHEMBL380196 & 587680 & 7.8239 & 7.43 & TRN \\
\hline CHEMBL572908 & 587680 & 9.0969 & 8.5796 & TRN \\
\hline CHEMBL573096 & 587680 & 6.8153 & 7.9389 & TRN \\
\hline CHEMBL577797 & 587680 & 8.0 & 9.0382 & TRN \\
\hline CHEMBL575811 & 587680 & 8.8539 & 9.0358 & TST \\
\hline CHEMBL581848 & 587680 & 6.4802 & 6.4046 & TRN \\
\hline CHEMBL572859 & 587680 & 5.9508 & 5.7194 & TRN \\
\hline CHEMBL383527 & 587680 & 6.1752 & 5.7407 & TST \\
\hline CHEMBL573334 & 587680 & 7.9872 & 7.7316 & TRN \\
\hline CHEMBL203434 & 587680 & 6.5638 & 6.0795 & TRN \\
\hline CHEMBL 388311 & 587680 & 9.2218 & 8.4445 & TST \\
\hline CHEMBL206708 & 587680 & 5.4763 & 5.433 & TRN \\
\hline CHEMBL206328 & 587680 & 4.4915 & 5.2763 & TST \\
\hline CHEMBL206732 & 587680 & 6.6778 & 5.6928 & TST \\
\hline CHEMBL383541 & 587680 & 6.4437 & 6.5362 & TRN \\
\hline CHEMBL574087 & 587680 & 8.9393 & 8.8908 & TRN \\
\hline CHEMBL204892 & 587680 & 4.5047 & 4.4375 & TRN \\
\hline CHEMBL572907 & 587680 & 8.585 & 8.6452 & TRN \\
\hline CHEMBL577375 & 587680 & 7.2782 & 7.8377 & TRN \\
\hline CHEMBL576761 & 587680 & 5.3956 & 5.7933 & TRN \\
\hline CHEMBL202893 & 587680 & 5.9586 & 5.3172 & TRN \\
\hline CHEMBL574979 & 587680 & 7.3279 & 7.3081 & TRN \\
\hline CHEMBL210089 & 587680 & 7.9208 & 7.9668 & TRN \\
\hline CHEMBL378843 & 587680 & 8.8239 & 9.2585 & TRN \\
\hline CHEMBL204012 & 587680 & 6.301 & 6.4374 & TRN \\
\hline CHEMBL377294 & 587680 & 5.5735 & 5.3057 & TRN \\
\hline CHEMBL205781 & 587680 & 5.6635 & 5.4094 & TRN \\
\hline CHEMBL574978 & 587680 & 5.8665 & 6.2969 & TRN \\
\hline CHEMBL573778 & 587680 & 8.301 & 7.8522 & TRN \\
\hline CHEMBL260397 & 587680 & 6.5376 & 4.6279 & TST \\
\hline CHEMBL573359 & 587680 & 8.6021 & 8.2257 & TRN \\
\hline CHEMBL 206746 & 587680 & 5.857 & 5.55200 & 00000000005 \\
\hline CHEMBL579246 & 587680 & 8.4949 & 8.6433 & TRN \\
\hline CHEMBL577134 & 587680 & 7.0044 & 7.1226 & TRN \\
\hline CHEMBL574986 & 587680 & 7.9208 & 8.3028 & TRN \\
\hline CHEMBL 379300 & 587680 & 9.7959 & 9.5922 & TRN \\
\hline CHEMBL 273160 & 587680 & 6.7799 & 3.6359 & TST \\
\hline CHEMBL 220006 & 587680 & 4.8013 & 6.9633 & TST \\
\hline CHEMBL576372 & 587680 & 8.1675 & 7.7655 & TRN \\
\hline CHEMBL 205514 & 587680 & 5.4949 & 5.4029 & TST \\
\hline
\end{tabular}




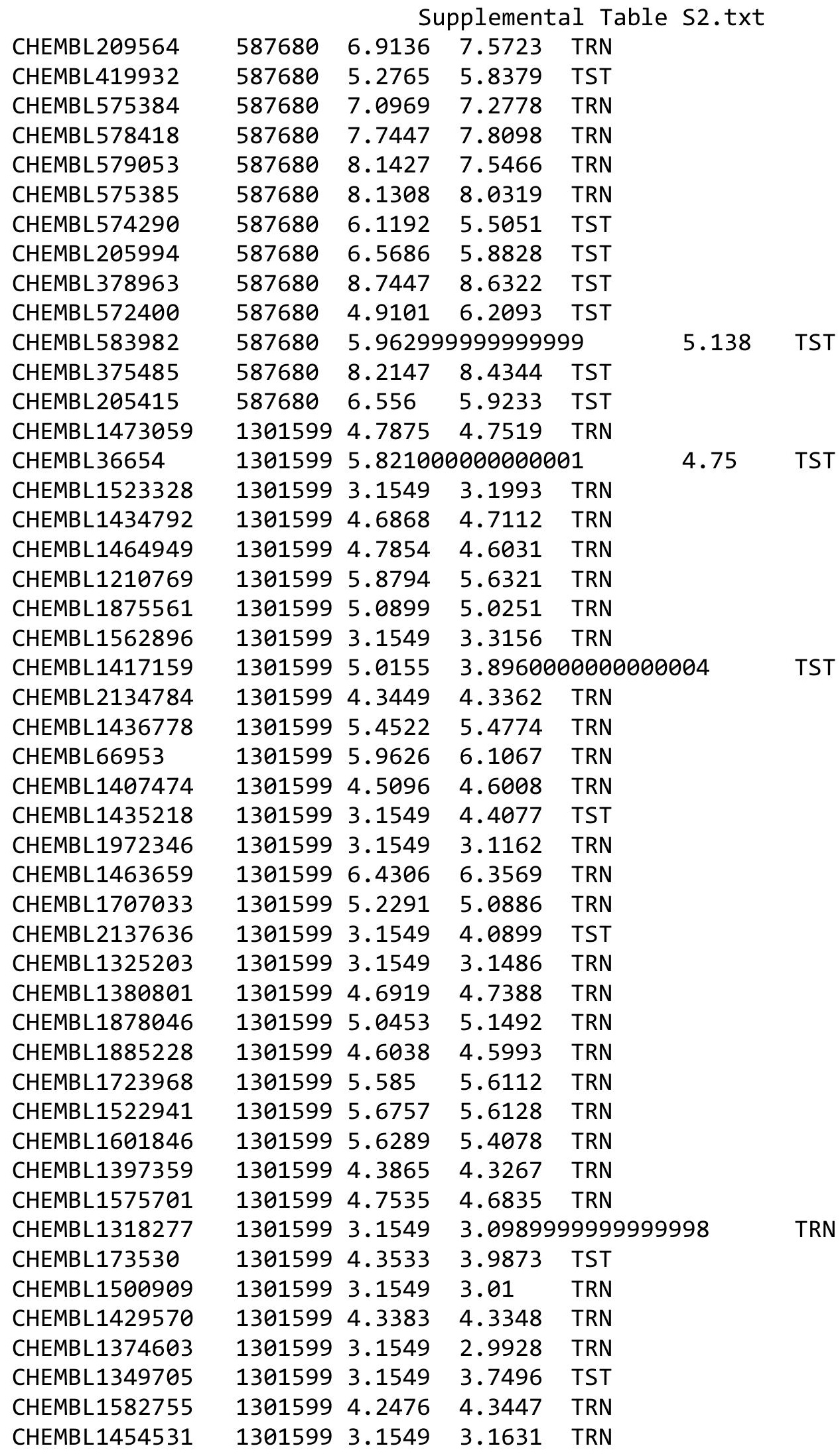

Page 24299 
Supplemental Table S2.txt

\begin{tabular}{|c|c|c|c|c|c|}
\hline CHEMBL1512376 & 1301599 & 3.1549 & 3.2715 & TRN & \\
\hline CHEMBL1983033 & 1301599 & 5.0645 & 5.098 & TRN & \\
\hline CHEMBL1376200 & 1301599 & 4.2237 & 4.4193 & TRN & \\
\hline CHEMBL1702248 & 1301599 & 3.1549 & 3.0761 & TRN & \\
\hline CHEMBL1346909 & 1301599 & 4.5938 & 4.5912 & TRN & \\
\hline CHEMBL 210208 & 1301599 & 3.1549 & 3.191999 & 99999999997 & TRN \\
\hline CHEMBL1535375 & 1301599 & 5.1215 & 5.1594 & TRN & \\
\hline CHEMBL1397916 & 1301599 & 3.1549 & 3.2067 & TRN & \\
\hline CHEMBL1605660 & 1301599 & 4.1646 & 4.3495 & TRN & \\
\hline CHEMBL 2137294 & 1301599 & 5.3316 & 5.3573 & TRN & \\
\hline CHEMBL1347633 & 1301599 & 3.1549 & 3.3 & TRN & \\
\hline CHEMBL164 & 1301599 & 5.2676 & 5.2939 & TRN & \\
\hline CHEMBL1321993 & 1301599 & 3.1549 & 3.2333 & TRN & \\
\hline CHEMBL1456035 & 1301599 & 4.467 & 4.4129 & TRN & \\
\hline CHEMBL 3182623 & 1301599 & 4.5267 & 4.5319 & TST & \\
\hline CHEMBL1518827 & 1301599 & 5.011 & 4.9546 & TRN & \\
\hline CHEMBL1504853 & 1301599 & 4.758999 & 999999999 & 4.8011 & TRN \\
\hline CHEMBL994 & 1301599 & 5.3904 & \multicolumn{2}{|c|}{5.382000000000001} & TRN \\
\hline CHEMBL1473982 & 1301599 & 3.1549 & 3.4454 & TRN & \\
\hline CHEMBL1719459 & 1301599 & 4.9136 & 5.2029 & TRN & \\
\hline CHEMBL1978925 & 1301599 & 3.1549 & 3.0854 & TRN & \\
\hline CHEMBL1613638 & 1301599 & 4.6979 & 4.6815 & TRN & \\
\hline CHEMBL1329425 & 1301599 & 3.1549 & 3.1637 & TRN & \\
\hline CHEMBL1364567 & 1301599 & 4.9245 & 4.6149 & TRN & \\
\hline CHEMBL1540929 & 1301599 & 5.0605 & 5.1033 & TRN & \\
\hline CHEMBL1563898 & 1301599 & 5.8761 & \multicolumn{2}{|c|}{5.917000000000001} & TRN \\
\hline CHEMBL1271266 & 1301599 & 4.5204 & 4.458 & TRN & \\
\hline CHEMBL1521600 & 1301599 & 4.8362 & 4.9061 & TRN & \\
\hline CHEMBL1492590 & 1301599 & 4.7572 & 4.8341 & TRN & \\
\hline CHEMBL1478064 & 1301599 & 3.6576 & 3.2803 & TRN & \\
\hline CHEMBL1602693 & 1301599 & 3.1549 & 4.527 & TST & \\
\hline CHEMBL1448387 & 1301599 & 4.1644 & 4.5451 & TST & \\
\hline CHEMBL1458444 & 1301599 & 3.6576 & 3.6935 & TRN & \\
\hline CHEMBL1872366 & 1301599 & 4.6975 & 4.7131 & TRN & \\
\hline CHEMBL1517216 & 1301599 & 3.1549 & 2.8281 & TST & \\
\hline CHEMBL1357064 & 1301599 & 4.6343 & 5.0559 & TST & \\
\hline CHEMBL1520233 & 1301599 & 4.6639 & 4.0856 & TST & \\
\hline CHEMBL1473428 & 1301599 & 4.8353 & 3.9598 & TST & \\
\hline CHEMBL1709883 & 1301599 & 6.0462 & 4.8352 & TST & \\
\hline CHEMBL1409628 & 1301599 & 3.1549 & 5.1532 & TST & \\
\hline CHEMBL1435948 & 1301599 & 3.6576 & 3.2628 & TST & \\
\hline CHEMBL1902287 & 1301599 & 3.1549 & 4.2544 & TST & \\
\hline CHEMBL1434555 & 1301599 & 3.1549 & 2.8636 & TST & \\
\hline CHEMBL1497070 & 1301599 & \multicolumn{3}{|c|}{5.752000000000001} & TST \\
\hline CHEMBL1606013 & 1301599 & 4.2906 & 3.6303 & TST & \\
\hline CHEMBL445304 & 1301599 & 5.2118 & 4.0155 & TST & \\
\hline CHEMBL11581 & 61740 & 7.0315 & 7.1208 & TRN & \\
\hline CHEMBL542784 & 61740 & 5.0 & 5.5936 & TST & \\
\hline
\end{tabular}




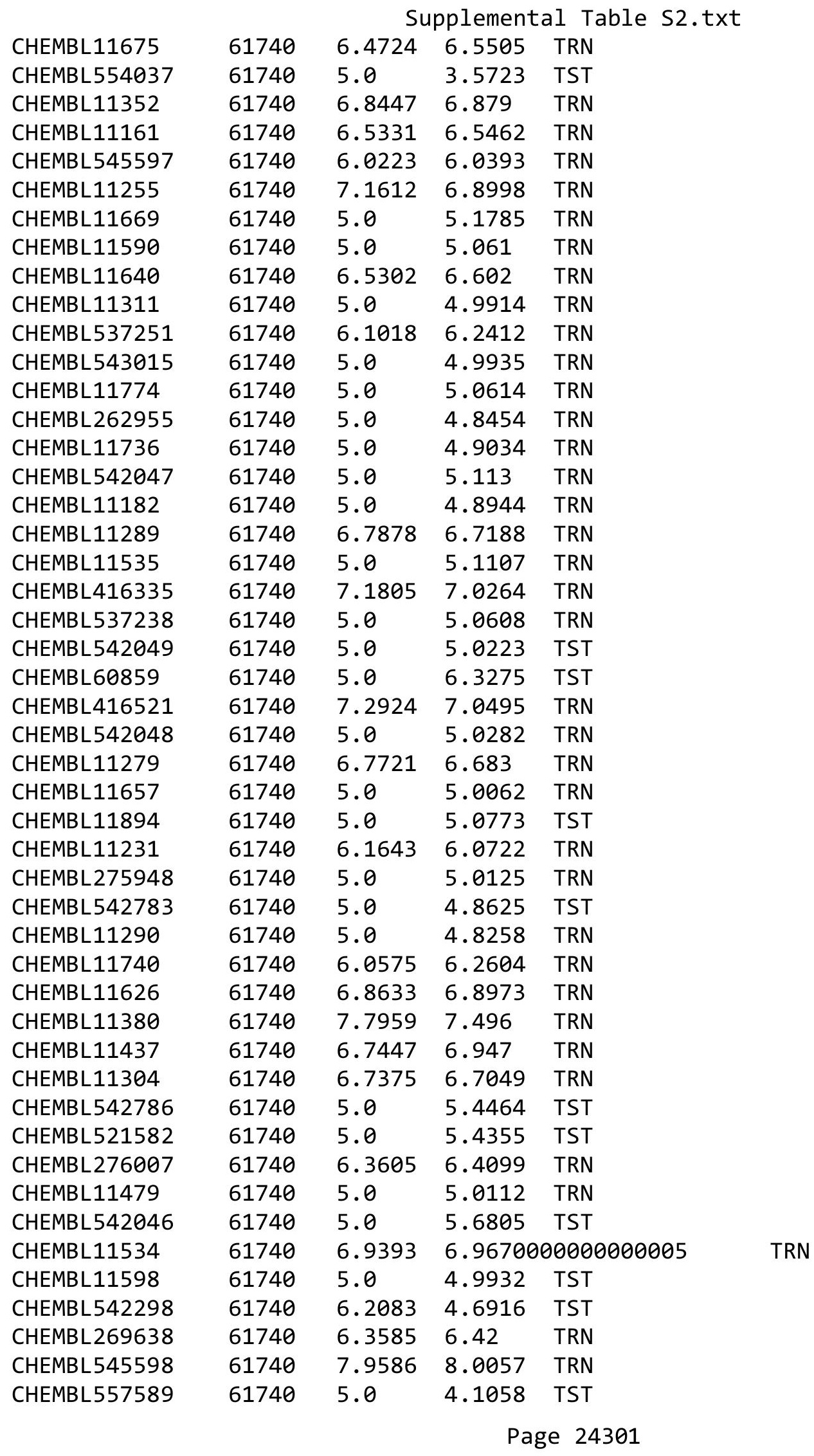




\begin{tabular}{|c|c|c|c|c|c|}
\hline \multicolumn{6}{|c|}{ Supplemental Table S2.txt } \\
\hline CHEMBL12107 & 61740 & 5.0 & 4.9269 & TST & \\
\hline CHEMBL11474 & 61740 & 5.0 & 4.9212 & TRN & \\
\hline CHEMBL542295 & 61740 & 6.1675 & 4.8544 & TST & \\
\hline CHEMBL11735 & 61740 & 5.0 & 5.0193 & TRN & \\
\hline CHEMBL542785 & 61740 & 5.0 & 5.6146 & TST & \\
\hline CHEMBL11803 & 61740 & 6.9508 & 6.8521 & TRN & \\
\hline CHEMBL542542 & 61740 & 7.0555 & 7.3666 & TRN & \\
\hline CHEMBL11637 & 61740 & 5.0 & 4.923 & TRN & \\
\hline CHEMBL1455253 & 736836 & 6.1921 & 5.311 & TRN & \\
\hline CHEMBL1345078 & 736836 & 4.8292 & 4.67899 & 9999999999 & TRN \\
\hline CHEMBL1424834 & 736836 & 5.185 & 5.1439 & TRN & \\
\hline CHEMBL1388369 & 736836 & 5.4466 & 5.3959 & TST & \\
\hline CHEMBL1414655 & 736836 & 4.7791 & 4.5223 & TRN & \\
\hline CHEMBL1451569 & 736836 & 4.6117 & 4.7849 & TRN & \\
\hline CHEMBL1352774 & 736836 & 6.0067 & 5.3292 & TRN & \\
\hline CHEMBL1388377 & 736836 & 5.037 & 4.7247 & TRN & \\
\hline CHEMBL1485923 & 736836 & 4.963 & 4.5973 & TRN & \\
\hline CHEMBL1510853 & 736836 & 5.0179 & 4.7363 & TRN & \\
\hline CHEMBL1546422 & 736836 & 5.2865 & 4.4922 & TRN & \\
\hline CHEMBL1715775 & 736836 & 5.2196 & 4.8264 & TRN & \\
\hline CHEMBL1469535 & 736836 & 4.7817 & 4.798 & TRN & \\
\hline CHEMBL1359891 & 736836 & 5.0708 & 5.1166 & TST & \\
\hline CHEMBL1405851 & 736836 & 4.6364 & 4.7904 & TRN & \\
\hline CHEMBL1388596 & 736836 & 4.971 & 4.9221 & TST & \\
\hline CHEMBL1343305 & 736836 & 4.9208 & 5.1234 & TRN & \\
\hline CHEMBL1527323 & 736836 & 4.6692 & 4.9219 & TRN & \\
\hline CHEMBL1540947 & 736836 & 5.0075 & 4.8221 & TRN & \\
\hline CHEMBL 3194374 & 736836 & 5.3454 & 4.7493 & TRN & \\
\hline CHEMBL1518304 & 736836 & 5.6313 & 5.6258 & TRN & \\
\hline CHEMBL1312600 & 736836 & 5.3761 & 4.8251 & TST & \\
\hline CHEMBL1403346 & 736836 & 4.8719 & 4.8917 & TRN & \\
\hline CHEMBL1339887 & 736836 & 4.3272 & 5.0933 & TST & \\
\hline CHEMBL1563513 & 736836 & 4.6286 & 5.0864 & TRN & \\
\hline CHEMBL 3208660 & 736836 & 5.5525 & 5.1879 & TRN & \\
\hline CHEMBL1582317 & 736836 & 5.1653 & 5.1558 & TRN & \\
\hline CHEMBL1400666 & 736836 & 5.5637 & 4.6756 & TRN & \\
\hline CHEMBL1400195 & 736836 & 4.7474 & 4.513 & TST & \\
\hline CHEMBL1555914 & 736836 & 5.2027 & 4.853 & TST & \\
\hline CHEMBL1568729 & 736836 & 4.5488 & 4.8986 & TRN & \\
\hline CHEMBL1419900 & 736836 & 5.2224 & 4.8167 & TRN & \\
\hline CHEMBL512935 & 736836 & 4.4211 & 4.607 & TRN & \\
\hline CHEMBL 1440225 & 736836 & 4.9496 & 4.6895 & TRN & \\
\hline CHEMBL1561078 & 736836 & 5.3405 & 4.7349 & TST & \\
\hline CHEMBL1330989 & 736836 & 5.4588 & 5.1595 & TRN & \\
\hline CHEMBL1550191 & 736836 & 4.815 & 4.8548 & TRN & \\
\hline CHEMBL1562317 & 736836 & 4.8413 & 5.0085 & TRN & \\
\hline CHEMBL1530208 & 736836 & 5.3555 & 4.9085 & TRN & \\
\hline CHEMBL1606872 & 736836 & 5.0001 & 5.3308 & TRN & \\
\hline
\end{tabular}




\begin{tabular}{|c|c|c|c|c|c|c|}
\hline & & & & & & \\
\hline CHEMBL1493766 & 736836 & 5.4031 & 4.91 & TRN & & \\
\hline CHEMBL1577620 & 736836 & 4.919 & 4.8127 & TRN & & \\
\hline CHEMBL1575796 & 736836 & 4.7312 & 4.9266 & TST & & \\
\hline CHEMBL1398061 & 736836 & 5.4021 & 5.0635 & TRN & & \\
\hline CHEMBL1356182 & 736836 & 5.5799 & 5.4557 & TRN & & \\
\hline CHEMBL 3189821 & 736836 & 5.1408 & 5.5022 & TRN & & \\
\hline CHEMBL1369595 & 736836 & 4.8517 & 4.8246 & TRN & & \\
\hline CHEMBL1544333 & 736836 & 4.7926 & 4.6988 & TRN & & \\
\hline CHEMBL1455059 & 736836 & 4.7693 & 5.04899 & 99999999995 & & TRN \\
\hline CHEMBL1396464 & 736836 & 5.5575 & 5.5208 & TRN & & \\
\hline CHEMBL1542449 & 736836 & 4.8925 & 4.7987 & TST & & \\
\hline CHEMBL1338580 & 736836 & 4.8814 & 4.7311 & TRN & & \\
\hline CHEMBL1351626 & 736836 & 5.0052 & 4.8738 & TRN & & \\
\hline CHEMBL1461780 & 736836 & 4.9219 & 4.7948 & TRN & & \\
\hline CHEMBL1303197 & 736836 & 5.058 & 4.882 & TRN & & \\
\hline CHEMBL1305158 & 736836 & 5.01699 & 99999999 & 995 & .9398 & TRN \\
\hline CHEMBL1540096 & 736836 & 4.8438 & 4.8572 & TST & & \\
\hline CHEMBL1496095 & 736836 & 4.9796 & 5.0731 & TRN & & \\
\hline CHEMBL1339993 & 736836 & 3.0 & 4.1584 & TRN & & \\
\hline CHEMBL1517146 & 736836 & 4.9382 & 5.0183 & TRN & & \\
\hline CHEMBL1427189 & 736836 & 4.8891 & 4.7812 & TRN & & \\
\hline CHEMBL1594238 & 736836 & 5.3586 & 5.0432 & TRN & & \\
\hline CHEMBL486706 & 736836 & 4.9516 & 4.9767 & TRN & & \\
\hline CHEMBL1448901 & 736836 & 5.1719 & 4.3353 & TRN & & \\
\hline CHEMBL1550764 & 736836 & 4.908 & 4.8706 & TRN & & \\
\hline CHEMBL1349802 & 736836 & 4.7937 & 5.1293 & TRN & & \\
\hline CHEMBL1716272 & 736836 & 4.9666 & 4.7601 & TST & & \\
\hline CHEMBL1388124 & 736836 & 4.9194 & 4.7966 & TST & & \\
\hline CHEMBL1542284 & 736836 & 4.8677 & 5.3169 & TRN & & \\
\hline CHEMBL1509422 & 736836 & 4.9838 & 5.4764 & TRN & & \\
\hline CHEMBL1366764 & 736836 & 4.05699 & 99999999 & 995 & 3271 & TRN \\
\hline CHEMBL1595948 & 736836 & 5.099 & 5.0794 & TRN & & \\
\hline CHEMBL1468612 & 736836 & 4.1123 & 4.32600 & 00000000005 & & TRN \\
\hline CHEMBL1392763 & 736836 & 4.4683 & 4.874 & TRN & & \\
\hline CHEMBL1402907 & 736836 & 4.8579 & 5.3184 & TRN & & \\
\hline CHEMBL1561245 & 736836 & 4.7055 & 4.8477 & TRN & & \\
\hline CHEMBL1598744 & 736836 & 4.7115 & 5.1424 & TRN & & \\
\hline CHEMBL1338004 & 736836 & 5.2878 & 5.2708 & TST & & \\
\hline CHEMBL1406272 & 736836 & 5.3515 & 5.3815 & TRN & & \\
\hline CHEMBL1526632 & 736836 & 4.4817 & 4.5782 & TRN & & \\
\hline CHEMBL540851 & 736836 & 5.0316 & 4.9727 & TST & & \\
\hline CHEMBL 1406536 & 736836 & 4.8962 & 4.9004 & TRN & & \\
\hline CHEMBL1464645 & 736836 & 4.2225 & 4.8323 & TRN & & \\
\hline CHEMBL1340840 & 736836 & 4.4891 & 4.5204 & TRN & & \\
\hline CHEMBL1382643 & 736836 & 4.8502 & 4.9704 & TRN & & \\
\hline CHEMBL1546248 & 736836 & 3.0 & 4.7326 & TRN & & \\
\hline CHEMBL1444617 & 736836 & 5.2444 & 4.9273 & TRN & & \\
\hline CHEMBL1425691 & 736836 & 4.8821 & 5.1267 & TRN & & \\
\hline
\end{tabular}




\begin{tabular}{|c|c|c|c|c|c|c|}
\hline & & & & & & \\
\hline CHEMBL1370134 & 736836 & 5.0211 & 4.9413 & TRN & & \\
\hline CHEMBL1606939 & 736836 & 4.9423 & 4.7952 & TRN & & \\
\hline CHEMBL1313808 & 736836 & 4.6951 & 5.0852 & TST & & \\
\hline CHEMBL1447981 & 736836 & 5.8204 & 5.0359 & TRN & & \\
\hline CHEMBL1574523 & 736836 & 5.016 & 4.7044 & TRN & & \\
\hline CHEMBL1706291 & 736836 & 5.1772 & 4.6839 & TRN & & \\
\hline CHEMBL1407834 & 736836 & 5.12299 & 99999999 & 99 & 5.0269 & TRN \\
\hline CHEMBL1717382 & 736836 & 3.0 & 4.4347 & TRN & & \\
\hline CHEMBL1496854 & 736836 & 5.24100 & 30000000 & 005 & 4.7818 & TRN \\
\hline CHEMBL1542752 & 736836 & 4.6185 & 4.9518 & TST & & \\
\hline CHEMBL1360994 & 736836 & 4.1097 & 4.636 & TRN & & \\
\hline CHEMBL1710103 & 736836 & 4.8831 & 5.1523 & TRN & & \\
\hline CHEMBL3193715 & 736836 & 5.0935 & 5.0034 & TRN & & \\
\hline CHEMBL1559767 & 736836 & 5.002 & 5.0921 & TRN & & \\
\hline CHEMBL1392593 & 736836 & 4.1376 & 5.2483 & TST & & \\
\hline CHEMBL1384282 & 736836 & 5.364 & 5.3427 & TRN & & \\
\hline CHEMBL1560731 & 736836 & 4.9048 & 4.7153 & TRN & & \\
\hline CHEMBL1522909 & 736836 & 4.7612 & 5.25200 & 0000000001 & & TRN \\
\hline CHEMBL1701468 & 736836 & 5.0082 & 4.9913 & TRN & & \\
\hline CHEMBL1299499 & 736836 & 5.2274 & 4.4344 & TRN & & \\
\hline CHEMBL1365611 & 736836 & 4.794 & 5.4495 & TRN & & \\
\hline CHEMBL1385576 & 736836 & 4.8147 & 4.7281 & TRN & & \\
\hline CHEMBL1565099 & 736836 & 5.4973 & 5.0508 & TRN & & \\
\hline CHEMBL1340346 & 736836 & 4.965 & 4.5872 & TST & & \\
\hline CHEMBL1523930 & 736836 & 5.2802 & 5.0604 & TRN & & \\
\hline CHEMBL1364803 & 736836 & 5.4642 & 5.4451 & TRN & & \\
\hline CHEMBL1422664 & 736836 & 4.3128 & 4.7621 & TRN & & \\
\hline CHEMBL1540876 & 736836 & 5.1033 & 4.8188 & TRN & & \\
\hline CHEMBL 2003901 & 736836 & 4.4647 & 5.081 & TRN & & \\
\hline CHEMBL1494764 & 736836 & 5.0163 & 4.8992 & TRN & & \\
\hline CHEMBL406121 & 736836 & 4.3462 & 4.3375 & TRN & & \\
\hline CHEMBL1430604 & 736836 & 4.7959 & 4.9091 & TRN & & \\
\hline CHEMBL1464388 & 736836 & 5.0863 & 4.5419 & TRN & & \\
\hline CHEMBL 88584 & 736836 & 5.8511 & 4.9596 & TST & & \\
\hline CHEMBL1326644 & 736836 & 3.0 & 4.2192 & TRN & & \\
\hline CHEMBL1401460 & 736836 & 5.0936 & 4.5425 & TRN & & \\
\hline CHEMBL1392642 & 736836 & 5.2375 & 4.6179 & TST & & \\
\hline CHEMBL1612826 & 736836 & 4.6645 & 4.9774 & TRN & & \\
\hline CHEMBL1527578 & 736836 & 5.4458 & 4.8259 & TRN & & \\
\hline CHEMBL1307244 & 736836 & 4.9069 & 4.6418 & TRN & & \\
\hline CHEMBL1449269 & 736836 & 4.3823 & 4.9016 & TRN & & \\
\hline CHEMBL252925 & 736836 & 5.0097 & 5.1085 & TRN & & \\
\hline CHEMBL1335846 & 736836 & 4.6232 & 4.9252 & TRN & & \\
\hline CHEMBL1458952 & 736836 & 5.7655 & 4.7694 & TRN & & \\
\hline CHEMBL1561659 & 736836 & 5.4817 & 4.7969 & TRN & & \\
\hline CHEMBL1457199 & 736836 & 5.0414 & 5.1311 & TRN & & \\
\hline CHEMBL1545902 & 736836 & 5.1117 & 4.9381 & TRN & & \\
\hline CHEMBL1457908 & 736836 & 5.5424 & 5.0782 & TRN & & \\
\hline
\end{tabular}




\begin{tabular}{|c|c|c|c|c|c|}
\hline \multicolumn{6}{|c|}{ Supplemental Table S2.txt } \\
\hline CHEMBL1328939 & 736836 & 3.0 & 4.1467 & TRN & \\
\hline CHEMBL1574542 & 736836 & 4.1699 & 4.2327 & TRN & \\
\hline CHEMBL1502451 & 736836 & 5.2787 & 4.8472 & TRN & \\
\hline CHEMBL 3190607 & 736836 & 5.1531 & 4.8805 & TRN & \\
\hline CHEMBL 295786 & 736836 & 4.4207 & 5.1726 & TST & \\
\hline CHEMBL1523678 & 736836 & 4.6275 & 4.4889 & TRN & \\
\hline CHEMBL3197063 & 736836 & 4.8595 & 4.3908 & TRN & \\
\hline CHEMBL3210528 & 736836 & 5.2224 & 5.0137 & TRN & \\
\hline CHEMBL1508764 & 736836 & 5.3235 & 4.8877 & TRN & \\
\hline CHEMBL1417888 & 736836 & 5.4763 & 4.5908 & TRN & \\
\hline CHEMBL1320465 & 736836 & 5.4526 & 5.0906 & TRN & \\
\hline CHEMBL3212885 & 736836 & 5.1252 & 4.6869 & TRN & \\
\hline CHEMBL1532635 & 736836 & 4.4383 & 4.8978 & TST & \\
\hline CHEMBL3190356 & 736836 & 5.1394 & 5.478 & TRN & \\
\hline CHEMBL1348562 & 736836 & 4.5455 & 4.7215 & TRN & \\
\hline CHEMBL1729477 & 736836 & 5.1539 & 4.9727 & TRN & \\
\hline CHEMBL1300631 & 736836 & 3.0 & 4.3457 & TRN & \\
\hline CHEMBL1349755 & 736836 & 5.1539 & 4.9924 & TRN & \\
\hline CHEMBL1429574 & 736836 & 5.6247 & 4.79899 & 99999999995 & TRN \\
\hline CHEMBL1424504 & 736836 & 4.7251 & 4.7673 & TRN & \\
\hline CHEMBL1733342 & 736836 & 4.2531 & 4.6758 & TRN & \\
\hline CHEMBL1508547 & 736836 & 5.2712 & 4.9455 & TRN & \\
\hline CHEMBL1417963 & 736836 & 4.9248 & 4.5196 & TRN & \\
\hline CHEMBL1356140 & 736836 & 5.0216 & 4.8556 & TRN & \\
\hline CHEMBL1582665 & 736836 & 4.9805 & 4.4826 & TRN & \\
\hline CHEMBL1200847 & 736836 & 5.5011 & 5.1238 & TST & \\
\hline CHEMBL1556020 & 736836 & 6.0048 & 5.0262 & TRN & \\
\hline CHEMBL1438058 & 736836 & 4.8097 & 4.7121 & TST & \\
\hline CHEMBL1707746 & 736836 & 5.0986 & 5.06 & TRN & \\
\hline CHEMBL1516464 & 736836 & 3.0 & 4.7384 & TRN & \\
\hline CHEMBL1449107 & 736836 & 4.8925 & 5.0175 & TRN & \\
\hline CHEMBL 217920 & 736836 & 4.1935 & 4.638 & TRN & \\
\hline CHEMBL1382265 & 736836 & 4.9855 & 5.14 & TRN & \\
\hline CHEMBL1306389 & 736836 & 5.0781 & 5.063 & TST & \\
\hline CHEMBL1441135 & 736836 & 4.6511 & 5.0416 & TRN & \\
\hline CHEMBL1305718 & 736836 & 4.9337 & 5.4985 & TRN & \\
\hline CHEMBL1413681 & 736836 & 4.0953 & 4.734 & TRN & \\
\hline CHEMBL1547025 & 736836 & 4.8671 & 4.9572 & TRN & \\
\hline CHEMBL1164316 & 736836 & 4.8765 & 4.9805 & TST & \\
\hline CHEMBL1576338 & 736836 & 3.0 & 5.2459 & TST & \\
\hline CHEMBL1370674 & 736836 & 5.1369 & 4.9809 & TRN & \\
\hline CHEMBL1449029 & 736836 & 5.0311 & 4.8665 & TRN & \\
\hline CHEMBL1340445 & 736836 & 4.6724 & 5.0901 & TRN & \\
\hline CHEMBL1714370 & 736836 & 5.145 & 5.3272 & TRN & \\
\hline CHEMBL1458545 & 736836 & 5.1316 & 4.9828 & TRN & \\
\hline CHEMBL1300620 & 736836 & 4.9876 & 4.9966 & TRN & \\
\hline CHEMBL1560459 & 736836 & 4.9686 & 5.0185 & TRN & \\
\hline CHEMBL1442384 & 736836 & 5.1428 & 4.955 & TRN & \\
\hline
\end{tabular}




\begin{tabular}{|c|c|c|c|c|c|c|}
\hline & & \multicolumn{5}{|c|}{ Supplemental Table S2.txt } \\
\hline CHEMBL1596326 & 736836 & 5.2191 & 5.0771 & TST & & \\
\hline CHEMBL3191783 & 736836 & 4.7447 & 5.0396 & TRN & & \\
\hline CHEMBL1537034 & 736836 & 4.6651 & 5.1041 & TRN & & \\
\hline CHEMBL1519308 & 736836 & 4.7055 & 5.1415 & TRN & & \\
\hline CHEMBL1362624 & 736836 & 3.0 & 4.4756 & TRN & & \\
\hline CHEMBL1501755 & 736836 & 5.6392 & 4.7961 & TRN & & \\
\hline CHEMBL1526266 & 736836 & 5.2302 & 4.6747 & TRN & & \\
\hline CHEMBL1725896 & 736836 & 5.0354 & 5.331 & TRN & & \\
\hline CHEMBL1532234 & 736836 & 4.6708 & 4.7744 & TST & & \\
\hline CHEMBL1408253 & 736836 & 5.1842 & 4.5399 & TST & & \\
\hline CHEMBL1580028 & 736836 & 5.3305 & 4.7096 & TST & & \\
\hline CHEMBL1329111 & 736836 & 5.1563 & 4.9482 & TRN & & \\
\hline CHEMBL1509494 & 736836 & 5.2149 & 4.9717 & TRN & & \\
\hline CHEMBL1537562 & 736836 & 5.0263 & 5.2704 & TRN & & \\
\hline CHEMBL1577174 & 736836 & 5.2096 & 5.1056 & TRN & & \\
\hline CHEMBL1409121 & 736836 & 4.3528 & 4.834 & TRN & & \\
\hline CHEMBL1489610 & 736836 & 4.8948 & 4.989 & TRN & & \\
\hline CHEMBL1453858 & 736836 & 5.0659 & 5.1291 & TRN & & \\
\hline CHEMBL1508257 & 736836 & 4.601 & 4.8742 & TST & & \\
\hline CHEMBL1362012 & 736836 & 5.0163 & 4.8598 & TRN & & \\
\hline CHEMBL1299361 & 736836 & 5.0152 & 4.9101 & TST & & \\
\hline CHEMBL1346897 & 736836 & \multicolumn{3}{|c|}{4.638999999999999} & 4.9554 & TRN \\
\hline CHEMBL1429947 & 736836 & 4.8456 & 4.8865 & TST & & \\
\hline CHEMBL1523485 & 736836 & 5.0816 & 4.7328 & TST & & \\
\hline CHEMBL1363179 & 736836 & 4.8914 & 4.458 & TST & & \\
\hline CHEMBL1432215 & 736836 & 4.0894 & 4.5865 & TST & & \\
\hline CHEMBL1499903 & 736836 & 5.7587 & 4.663 & TST & & \\
\hline CHEMBL1704776 & 736836 & 4.5648 & 4.9231 & TST & & \\
\hline CHEMBL1566885 & 736836 & 4.9176 & \multicolumn{3}{|c|}{5.0889999999999995} & TST \\
\hline CHEMBL1381136 & 736836 & 4.9547 & 4.8068 & TST & & \\
\hline CHEMBL1607592 & 736836 & 5.2853 & 5.1648 & TST & & \\
\hline CHEMBL1575013 & 736836 & 5.0426 & 4.7993 & TST & & \\
\hline CHEMBL1346802 & 736836 & 5.0429 & 4.9132 & TST & & \\
\hline CHEMBL1326648 & 736836 & 5.3663 & 4.8455 & TST & & \\
\hline CHEMBL1480899 & 736836 & 5.2674 & 5.0688 & TST & & \\
\hline CHEMBL1562550 & 736836 & 4.9259 & 5.0192 & TST & & \\
\hline CHEMBL1604346 & 736836 & 5.4077 & 5.4073 & TST & & \\
\hline CHEMBL1437349 & 736836 & 4.5872 & 4.7127 & TST & & \\
\hline CHEMBL1436748 & 736836 & 5.5706 & 5.1527 & TST & & \\
\hline CHEMBL1501309 & 736836 & 4.4069 & 4.6451 & TST & & \\
\hline CHEMBL1404438 & 736836 & 4.9031 & 4.8131 & TST & & \\
\hline CHEMBL1454924 & 736836 & \multicolumn{3}{|c|}{5.162000000000001} & 5.25 & TST \\
\hline CHEMBL1378435 & 736836 & 5.0195 & 5.1036 & TST & & \\
\hline CHEMBL1569484 & 736836 & 5.3422 & 4.8218 & TST & & \\
\hline CHEMBL1557929 & 736836 & 4.6946 & 4.5919 & TST & & \\
\hline CHEMBL1444904 & 736836 & 4.7796 & 4.5155 & TST & & \\
\hline CHEMBL120826 & 305629 & 7.5686 & 7.7931 & TST & & \\
\hline CHEMBL342555 & 305629 & 5.9586 & 6.1468 & TRN & & \\
\hline
\end{tabular}




\begin{tabular}{|c|c|c|c|c|c|}
\hline & & & च & & \\
\hline CHEMBL264386 & 305629 & 8.1367 & 7.8795 & TRN & \\
\hline CHEMBL123276 & 305629 & 7.5229 & 7.6447 & TST & \\
\hline CHEMBL17431 & 305629 & 5.585 & 5.6068 & TRN & \\
\hline CHEMBL34337 & 305629 & 6.0362 & 6.1817 & TRN & \\
\hline CHEMBL283311 & 305629 & 4.9355 & 4.4529 & TST & \\
\hline CHEMBL123043 & 305629 & 7.6576 & 7.7059 & TRN & \\
\hline CHEMBL292634 & 305629 & 7.301 & 7.1973 & TRN & \\
\hline CHEMBL367802 & 305629 & 7.6778 & 7.176 & TRN & \\
\hline CHEMBL54732 & 305629 & 7.301 & 7.2916 & TRN & \\
\hline CHEMBL82975 & 305629 & 7.5686 & 7.3404 & TRN & \\
\hline CHEMBL279914 & 305629 & 4.4202 & 4.0266 & TST & \\
\hline CHEMBL142624 & 305629 & 6.699 & 6.6699 & TRN & \\
\hline CHEMBL32583 & 305629 & 6.7122 & 6.6128 & TRN & \\
\hline CHEMBL300886 & 305629 & 6.8861 & 7.1471 & TST & \\
\hline CHEMBL68439 & 305629 & 5.3665 & 5.256 & TRN & \\
\hline CHEMBL121319 & 305629 & 7.0132 & 7.2035 & TST & \\
\hline CHEMBL179319 & 305629 & 8.2007 & 8.004 & TRN & \\
\hline CHEMBL278013 & 305629 & 6.0 & 5.8497 & TST & \\
\hline CHEMBL32635 & 305629 & 6.0088 & 6.1649 & TRN & \\
\hline CHEMBL52688 & 305629 & 7.3565 & 7.5728 & TRN & \\
\hline CHEMBL52947 & 305629 & 6.9208 & 6.8998 & TRN & \\
\hline CHEMBL33208 & 305629 & 6.4559 & 6.38399 & 99999999995 & TRN \\
\hline CHEMBL80066 & 305629 & 7.9586 & 8.0188 & TRN & \\
\hline CHEMBL138252 & 305629 & 6.0809 & 5.7937 & TRN & \\
\hline CHEMBL57682 & 305629 & 6.0 & 6.86799 & 9999999999 & TST \\
\hline CHEMBL141260 & 305629 & 6.1367 & 6.063 & TRN & \\
\hline CHEMBL299174 & 305629 & 7.8539 & 7.7625 & TRN & \\
\hline CHEMBL53318 & 305629 & 7.8239 & 7.7973 & TRN & \\
\hline CHEMBL32769 & 305629 & 6.1367 & 6.1374 & TRN & \\
\hline CHEMBL142081 & 305629 & 7.2366 & 7.3368 & TST & \\
\hline CHEMBL296382 & 305629 & 6.8539 & 6.8315 & TRN & \\
\hline CHEMBL312348 & 305629 & 7.9208 & 7.9808 & TRN & \\
\hline CHEMBL 23867 & 305629 & 7.8386 & 7.8163 & TRN & \\
\hline CHEMBL23846 & 305629 & 4.4318 & 4.0954 & TST & \\
\hline CHEMBL55928 & 305629 & 7.0458 & 7.0737 & TRN & \\
\hline CHEMBL 22623 & 305629 & 7.2366 & 7.3225 & TRN & \\
\hline CHEMBL33136 & 305629 & 5.3516 & 5.5386 & TRN & \\
\hline CHEMBL55179 & 305629 & 7.3979 & 7.3165 & TRN & \\
\hline CHEMBL278261 & 305629 & 6.0605 & 5.9159 & TST & \\
\hline CHEMBL423560 & 305629 & 7.3098 & 6.996 & TST & \\
\hline CHEMBL420224 & 305629 & 7.9208 & 7.9043 & TRN & \\
\hline CHEMBL80065 & 305629 & 8.0223 & 7.9567 & TRN & \\
\hline CHEMBL142741 & 305629 & 8.0458 & 7.8663 & TRN & \\
\hline CHEMBL145068 & 305629 & 6.699 & 6.6494 & TRN & \\
\hline CHEMBL116200 & 305629 & 6.7696 & 6.8814 & TRN & \\
\hline CHEMBL 35222 & 305629 & 7.585 & 7.7053 & TRN & \\
\hline CHEMBL178888 & 305629 & 7.1675 & 7.3359 & TST & \\
\hline CHEMBL32754 & 305629 & 6.6383 & 6.2589 & TRN & \\
\hline
\end{tabular}




\begin{tabular}{|c|c|c|c|c|c|c|}
\hline & & & oplement & $a \perp$ labl & $2 \cdot t$ & \\
\hline CHEMBL178684 & 305629 & 6.4815 & 6.8553 & TRN & & \\
\hline CHEMBL54618 & 305629 & 6.8861 & 7.0838 & TRN & & \\
\hline CHEMBL36245 & 305629 & 7.5086 & 7.4931 & TRN & & \\
\hline CHEMBL 276734 & 305629 & 5.9586 & 5.7951 & TST & & \\
\hline CHEMBL57624 & 305629 & 8.0088 & 8.1797 & TRN & & \\
\hline CHEMBL55191 & 305629 & 7.6021 & 7.5071 & TRN & & \\
\hline CHEMBL141585 & 305629 & 6.1675 & 5.7983 & TRN & & \\
\hline CHEMBL284849 & 305629 & 6.3188 & 6.2519 & TRN & & \\
\hline CHEMBL52836 & 305629 & 7.0 & 6.9856 & TRN & & \\
\hline CHEMBL325434 & 305629 & 7.5229 & 7.806 & TRN & & \\
\hline CHEMBL333791 & 305629 & 8.0044 & 8.0308 & TST & & \\
\hline CHEMBL23532 & 305629 & 8.1308 & 8.2146 & TRN & & \\
\hline CHEMBL32190 & 305629 & 7.8539 & 7.8643 & TRN & & \\
\hline CHEMBL 292143 & 305629 & 7.3188 & 7.313 & TST & & \\
\hline CHEMBL49454 & 305629 & 8.1135 & 8.2176 & TRN & & \\
\hline CHEMBL33038 & 305629 & 7.4949 & 7.4431 & TRN & & \\
\hline CHEMBL53693 & 305629 & 8.1739 & 8.3882 & TRN & & \\
\hline CHEMBL120939 & 305629 & 6.8539 & 7.0758 & TRN & & \\
\hline CHEMBL138452 & 305629 & 5.6198 & 5.6318 & TRN & & \\
\hline CHEMBL54523 & 305629 & 6.9208 & 6.9328 & TRN & & \\
\hline CHEMBL113999 & 305629 & 7.0757 & 7.1781 & TRN & & \\
\hline CHEMBL23416 & 305629 & 7.7212 & 7.7235 & TRN & & \\
\hline CHEMBL121868 & 305629 & 7.8239 & 7.91799 & 999999999 & & TRN \\
\hline CHEMBL68673 & 305629 & 5.2218 & 5.192 & TRN & & \\
\hline CHEMBL115474 & 305629 & 6.4949 & 6.8161 & TRN & & \\
\hline CHEMBL116637 & 305629 & 6.7212 & 6.8664 & TRN & & \\
\hline CHEMBL81119 & 305629 & 8.1487 & 8.0672 & TRN & & \\
\hline CHEMBL145528 & 305629 & 6.6021 & 6.4719 & TRN & & \\
\hline CHEMBL415962 & 305629 & 7.7959 & 7.7715 & TRN & & \\
\hline CHEMBL32266 & 305629 & 5.9208 & 5.9608 & TRN & & \\
\hline CHEMBL23960 & 305629 & 4.3429 & 4.0814 & TST & & \\
\hline CHEMBL32708 & 305629 & 6.5086 & 6.4548 & TRN & & \\
\hline CHEMBL54913 & 305629 & 7.5528 & 7.5212 & TRN & & \\
\hline CHEMBL23844 & 305629 & 7.0 & 6.9205 & TRN & & \\
\hline CHEMBL145005 & 305629 & 5.8239 & 5.6535 & TRN & & \\
\hline CHEMBL301105 & 305629 & 6.6021 & 7.5849 & TRN & & \\
\hline CHEMBL 7263 & 305629 & 6.7423 & 7.0689 & TST & & \\
\hline CHEMBL178119 & 305629 & 6.0223 & 6.3097 & TRN & & \\
\hline CHEMBL281803 & 305629 & 7.5214 & 7.2757 & TRN & & \\
\hline CHEMBL121348 & 305629 & 7.6383 & 8.0073 & TST & & \\
\hline CHEMBL 279983 & 305629 & 7.24799 & 99999999 & 99 & 7.3969 & TRN \\
\hline CHEMBL32220 & 305629 & 6.4202 & 6.345 & TRN & & \\
\hline CHEMBL120821 & 305629 & 7.9208 & 8.1762 & TST & & \\
\hline CHEMBL300603 & 305629 & 7.5686 & 7.6403 & TRN & & \\
\hline CHEMBL17873 & 305629 & 5.8539 & 5.6588 & TRN & & \\
\hline CHEMBL116815 & 305629 & 6.9208 & 7.0121 & TRN & & \\
\hline CHEMBL137981 & 305629 & 7.7212 & 7.6347 & TST & & \\
\hline CHEMBL23569 & 305629 & 8.3188 & 8.1891 & TRN & & \\
\hline
\end{tabular}

Page 24308 


\begin{tabular}{|c|c|c|c|c|c|}
\hline \multicolumn{6}{|c|}{ Supplemental Table S2.txt } \\
\hline CHEMBL81820 & 305629 & 7.5528 & 7.5651 & TRN & \\
\hline CHEMBL178512 & 305629 & 6.2218 & 6.3003 & TST & \\
\hline CHEMBL179131 & 305629 & 7.4815 & 7.2849 & TST & \\
\hline CHEMBL337746 & 305629 & 6.6778 & 6.7809 & TST & \\
\hline CHEMBL283515 & 305629 & 4.7212 & 4.625 & TST & \\
\hline CHEMBL115804 & 305629 & 7.4089 & 7.5864 & TRN & \\
\hline CHEMBL121264 & 305629 & 7.4437 & 7.6945 & TST & \\
\hline CHEMBL53420 & 305629 & 7.0605 & 7.1426 & TRN & \\
\hline CHEMBL139188 & 305629 & 6.5229 & 6.3585 & TRN & \\
\hline CHEMBL52777 & 305629 & 7.2676 & 7.1969 & TRN & \\
\hline CHEMBL179102 & 305629 & 7.0044 & 7.1489 & TRN & \\
\hline CHEMBL53165 & 305629 & 6.9586 & 7.1931 & TRN & \\
\hline CHEMBL278110 & 305629 & 4.6676 & 4.3019 & TST & \\
\hline CHEMBL55727 & 305629 & 7.7959 & 7.8253 & TRN & \\
\hline CHEMBL286700 & 305629 & 6.284 & 6.1936 & TRN & \\
\hline CHEMBL115788 & 305629 & 7.8861 & 7.6983 & TRN & \\
\hline CHEMBL310880 & 305629 & 6.0 & 7.1845 & TRN & \\
\hline CHEMBL334271 & 305629 & 7.0269 & 6.8379 & TRN & \\
\hline CHEMBL33187 & 305629 & 5.4318 & 5.5568 & TRN & \\
\hline CHEMBL52698 & 305629 & 7.4202 & 7.4327 & TRN & \\
\hline CHEMBL117750 & 305629 & 7.7696 & 7.8468 & TRN & \\
\hline CHEMBL17430 & 305629 & 4.9355 & 5.0558 & TRN & \\
\hline CHEMBL23288 & 305629 & 6.5229 & 6.6154 & TRN & \\
\hline CHEMBL113816 & 305629 & 8.0315 & 7.9574 & TRN & \\
\hline CHEMBL180476 & 305629 & 7.1249 & 6.8155 & TST & \\
\hline CHEMBL53903 & 305629 & 7.6383 & 7.7828 & TRN & \\
\hline CHEMBL54733 & 305629 & 7.0706 & 7.2147 & TRN & \\
\hline CHEMBL275893 & 305629 & 5.0362 & 5.1081 & TRN & \\
\hline CHEMBL121683 & 305629 & 7.7696 & 7.9976 & TST & \\
\hline CHEMBL358297 & 305629 & 7.1135 & 7.0306 & TST & \\
\hline CHEMBL147886 & 305629 & 6.9586 & 6.9804 & TST & \\
\hline CHEMBL178904 & 305629 & 7.1079 & 7.4679 & TST & \\
\hline CHEMBL292427 & 305629 & 7.2441 & 7.1715 & TRN & \\
\hline CHEMBL35569 & 305629 & 6.4559 & 6.3062 & TRN & \\
\hline CHEMBL23705 & 305629 & 7.4202 & 7.2591 & TRN & \\
\hline CHEMBL53974 & 305629 & 7.585 & 7.6073 & TRN & \\
\hline CHEMBL 292212 & 305629 & 7.041 & 7.022 & TRN & \\
\hline CHEMBL116816 & 305629 & 6.7959 & 6.92899 & 9999999999 & TRN \\
\hline CHEMBL 279679 & 305629 & 7.7696 & 7.8293 & TRN & \\
\hline CHEMBL141708 & 305629 & 5.8539 & 5.8018 & TRN & \\
\hline CHEMBL52433 & 305629 & 8.5686 & 8.3378 & TRN & \\
\hline CHEMBL121433 & 305629 & 7.6778 & 7.7215 & TST & \\
\hline CHEMBL51706 & 305629 & 7.3372 & 7.3566 & TRN & \\
\hline CHEMBL120994 & 305629 & 6.9586 & 7.1514 & TST & \\
\hline CHEMBL264548 & 305629 & 7.7696 & 7.8329 & TST & \\
\hline CHEMBL 7488 & 305629 & 7.2676 & 7.4049 & TST & \\
\hline CHEMBL141218 & 305629 & 5.5528 & 5.4772 & TRN & \\
\hline CHEMBL299927 & 305629 & 6.5376 & 6.6065 & TST & \\
\hline
\end{tabular}




\begin{tabular}{|c|c|c|c|c|c|}
\hline \multirow[b]{2}{*}{ CHEMBL32113 } & \multicolumn{5}{|c|}{ Supplemental Table S2.txt } \\
\hline & 305629 & 8.2007 & 8.0035 & TRN & \\
\hline CHEMBL23297 & 305629 & 4.4895 & 4.2499 & TST & \\
\hline CHEMBL123122 & 305629 & 8.1549 & 8.2144 & TST & \\
\hline CHEMBL368645 & 305629 & 6.1192 & 6.3329 & TST & \\
\hline CHEMBL445359 & 305629 & 7.5229 & \multicolumn{2}{|c|}{7.547000000000001} & TRN \\
\hline CHEMBL 22561 & 305629 & 4.6271 & 4.2813 & TST & \\
\hline CHEMBL54792 & 305629 & 7.8239 & 7.834 & TRN & \\
\hline CHEMBL114833 & 305629 & 6.9066 & 6.9515 & TRN & \\
\hline CHEMBL140705 & 305629 & 6.3372 & 6.2008 & TRN & \\
\hline CHEMBL17323 & 305629 & 5.7696 & 5.7314 & TRN & \\
\hline CHEMBL116614 & 305629 & 7.0809 & 6.858 & TRN & \\
\hline CHEMBL23021 & 305629 & 7.7959 & 7.8534 & TRN & \\
\hline CHEMBL55656 & 305629 & 7.3098 & 7.5427 & TST & \\
\hline CHEMBL417746 & 305629 & 6.7959 & 6.8325 & TRN & \\
\hline CHEMBL55063 & 305629 & 9.0757 & 8.0683 & TRN & \\
\hline CHEMBL 279680 & 305629 & 7.5376 & 7.5057 & TRN & \\
\hline CHEMBL17479 & 305629 & 6.0915 & 6.1144 & TRN & \\
\hline CHEMBL283518 & 305629 & 8.0555 & 7.9569 & TRN & \\
\hline CHEMBL79347 & 305629 & 7.5229 & 7.4313 & TRN & \\
\hline CHEMBL137844 & 305629 & 7.3468 & 7.4181 & TST & \\
\hline CHEMBL50514 & 305629 & 9.2366 & 8.8187 & TRN & \\
\hline CHEMBL54538 & 305629 & 7.7447 & 7.8274 & TRN & \\
\hline CHEMBL 299140 & 305629 & 7.585 & 7.5778 & TRN & \\
\hline CHEMBL356490 & 305629 & 7.3098 & 7.3124 & TRN & \\
\hline CHEMBL218962 & 873932 & 7.301 & 7.4938 & TST & \\
\hline CHEMBL 2182102 & 873932 & 6.0132 & 5.9264 & TRN & \\
\hline CHEMBL 2182071 & 873932 & 8.0458 & 7.874 & TRN & \\
\hline CHEMBL 2182073 & 873932 & 7.5376 & 7.6328 & TRN & \\
\hline CHEMBL 2182081 & 873932 & 7.4949 & 7.8152 & TRN & \\
\hline CHEMBL 2177221 & 873932 & 7.7696 & 7.3889 & TRN & \\
\hline CHEMBL 2182085 & 873932 & 8.5229 & 8.321 & TRN & \\
\hline CHEMBL2182080 & 873932 & 6.6576 & 6.4329 & TST & \\
\hline CHEMBL 2177222 & 873932 & 7.6198 & 7.5775 & TRN & \\
\hline CHEMBL 2182107 & 873932 & 6.0706 & 6.4511 & TRN & \\
\hline CHEMBL2182100 & 873932 & 6.5229 & 7.15600 & 0000000001 & TRN \\
\hline CHEMBL2182079 & 873932 & 6.0044 & 6.25700 & 0000000001 & TST \\
\hline CHEMBL 2177209 & 873932 & 7.8239 & 6.6744 & TRN & \\
\hline CHEMBL 2177212 & 873932 & 7.4559 & 7.6907 & TRN & \\
\hline CHEMBL2177213 & 873932 & 7.8539 & 7.9379 & TRN & \\
\hline CHEMBL2182088 & 873932 & 7.9586 & 7.8598 & TRN & \\
\hline CHEMBL 2182087 & 873932 & 7.699 & 7.6542 & TRN & \\
\hline CHEMBL2182084 & 873932 & 7.7696 & 8.1451 & TRN & \\
\hline CHEMBL2182099 & 873932 & 7.8861 & 7.3909 & TRN & \\
\hline CHEMBL2182093 & 873932 & 5.3279 & 5.1646 & TRN & \\
\hline CHEMBL2182086 & 873932 & 7.3979 & 7.445 & TRN & \\
\hline CHEMBL 2177217 & 873932 & 7.8539 & 7.3122 & TRN & \\
\hline CHEMBL2182066 & 873932 & 5.1675 & 6.94799 & 99999999995 & TST \\
\hline CHEMBL2182091 & 873932 & 5.2076 & 5.7879 & TRN & \\
\hline & & & & 24310 & \\
\hline
\end{tabular}


Supplemental Table S2.txt

\begin{tabular}{|c|c|c|c|c|c|}
\hline CHEMBL 2182110 & 873932 & 7.0757 & 7.0965 & TRN & \\
\hline CHEMBL 2177205 & 873932 & 7.3979 & 7.00899 & 99999999995 & TRN \\
\hline CHEMBL 2182106 & 873932 & 5.7959 & 6.0281 & TRN & \\
\hline CHEMBL 2182089 & 873932 & 8.0 & 8.1332 & TRN & \\
\hline CHEMBL 2182109 & 873932 & 6.7959 & 6.9813 & TRN & \\
\hline CHEMBL 2177204 & 873932 & 6.6778 & 6.6455 & TRN & \\
\hline CHEMBL 2177226 & 873932 & 6.699 & 6.4376 & TRN & \\
\hline CHEMBL 2177224 & 873932 & 7.699 & 7.3816 & TRN & \\
\hline CHEMBL 2182108 & 873932 & 6.6576 & 6.9338 & TST & \\
\hline CHEMBL 2177206 & 873932 & 6.8861 & 7.0696 & TRN & \\
\hline CHEMBL 2177219 & 873932 & 7.4559 & 7.2733 & TRN & \\
\hline CHEMBL 2182076 & 873932 & 5.4815 & 5.4607 & TRN & \\
\hline CHEMBL 2177207 & 873932 & 5.3188 & 5.436 & TRN & \\
\hline CHEMBL 2177106 & 873932 & 7.9208 & 7.5019 & TRN & \\
\hline CHEMBL 2182095 & 873932 & 5.4202 & 6.0176 & TRN & \\
\hline CHEMBL 2182082 & 873932 & 7.9208 & 7.6413 & TRN & \\
\hline CHEMBL 2182101 & 873932 & 7.3979 & 7.5395 & TRN & \\
\hline CHEMBL 2182094 & 873932 & 7.0 & 5.8244 & TRN & \\
\hline CHEMBL 2177227 & 873932 & 5.699 & 5.6928 & TRN & \\
\hline CHEMBL 2182098 & 873932 & 6.4559 & 7.0473 & TRN & \\
\hline CHEMBL 2182083 & 873932 & 7.5686 & 8.092 & TRN & \\
\hline CHEMBL 2177218 & 873932 & 6.9208 & 7.0437 & TRN & \\
\hline CHEMBL 2177220 & 873932 & 7.2596 & 6.8874 & TRN & \\
\hline CHEMBL 2182103 & 873932 & 7.3768 & 7.3789 & TRN & \\
\hline CHEMBL 2177211 & 873932 & 7.4437 & 7.1707 & TRN & \\
\hline CHEMBL 2182092 & 873932 & 5.3188 & 5.7604 & TRN & \\
\hline CHEMBL 2182069 & 873932 & 7.0809 & 6.8451 & TST & \\
\hline CHEMBL 2182078 & 873932 & 5.3565 & 5.4034 & TRN & \\
\hline CHEMBL 2177208 & 873932 & 6.8861 & 6.4333 & TST & \\
\hline CHEMBL 2182105 & 873932 & 5.5686 & 5.9703 & TRN & \\
\hline CHEMBL 2177228 & 873932 & 5.8239 & 6.2929 & TRN & \\
\hline CHEMBL 2182090 & 873932 & 7.9208 & 8.1936 & TRN & \\
\hline CHEMBL 2177154 & 873932 & 5.3665 & 5.2216 & TRN & \\
\hline CHEMBL 2182070 & 873932 & 7.5686 & 6.8475 & TST & \\
\hline CHEMBL 2182072 & 873932 & 8.3979 & 8.4142 & TRN & \\
\hline CHEMBL 2177215 & 873932 & 8.301 & 7.7393 & TST & \\
\hline CHEMBL 2182068 & 873932 & 5.5086 & 5.28 & TST & \\
\hline CHEMBL 2182067 & 873932 & 7.5229 & 6.6471 & TST & \\
\hline CHEMBL 2177225 & 873932 & 5.9208 & 6.3369 & TST & \\
\hline CHEMBL 2177210 & 873932 & 6.7447 & 6.8127 & TST & \\
\hline CHEMBL 2177223 & 873932 & 7.6021 & 7.1581 & TST & \\
\hline CHEMBL 2177214 & 873932 & 8.0 & 7.4612 & TST & \\
\hline CHEMBL 2182074 & 873932 & 8.0 & 7.9975 & TST & \\
\hline CHEMBL10 & 873932 & 7.4318 & 7.5478 & TST & \\
\hline CHEMBL 2177216 & 873932 & 7.4318 & 6.6802 & TST & \\
\hline CHEMBL3823595 & 1587725 & 9.5229 & 9.5127 & TRN & \\
\hline CHEMBL 3824299 & 1587725 & 8.3979 & 8.3566 & TRN & \\
\hline CHEMBL3822915 & 1587725 & 9.699 & 9.195 & TST & \\
\hline
\end{tabular}




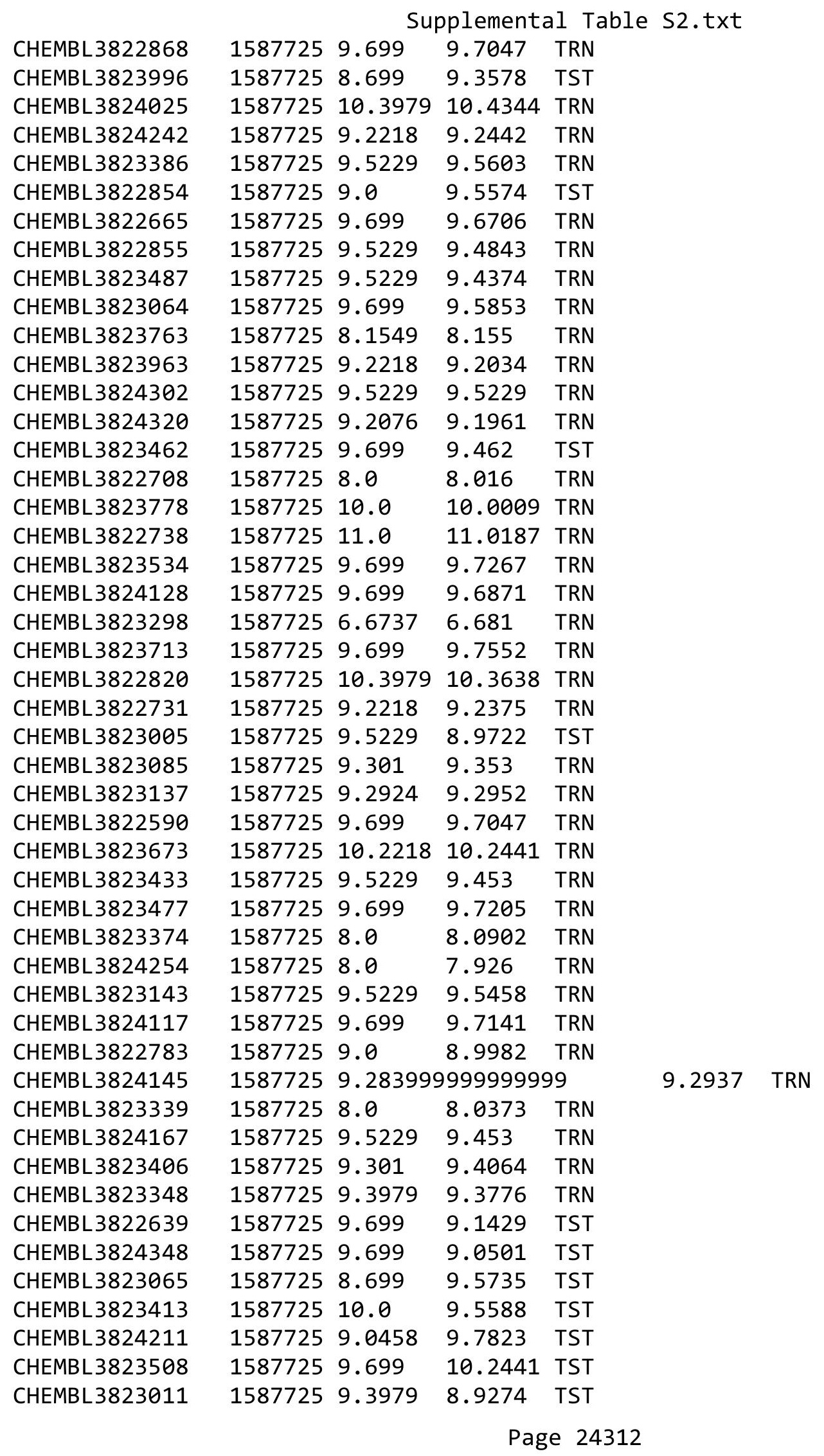




\begin{tabular}{|c|c|c|c|c|c|c|}
\hline \multicolumn{7}{|c|}{ Supplemental Table S2.txt } \\
\hline CHEMBL3822649 & 1587725 & 10.0 & 9.2345 & TST & & \\
\hline CHEMBL 3824360 & 1587725 & 10.6990 & 00000000 & 302 & 9.389 & TST \\
\hline CHEMBL3897270 & 1642432 & 5.4295 & 5.2049 & TRN & & \\
\hline CHEMBL3921248 & 1642432 & 5.0931 & 5.4206 & TRN & & \\
\hline CHEMBL 3929828 & 1642432 & 5.5702 & 5.5965 & TRN & & \\
\hline CHEMBL3950413 & 1642432 & 5.5544 & 4.7674 & TST & & \\
\hline CHEMBL3985558 & 1642432 & 5.6021 & 5.6732 & TRN & & \\
\hline CHEMBL3967095 & 1642432 & 5.7471 & 5.4641 & TRN & & \\
\hline CHEMBL3945510 & 1642432 & 5.4789 & 5.4439 & TRN & & \\
\hline CHEMBL3919679 & 1642432 & 6.2269 & 5.541 & TRN & & \\
\hline CHEMBL3952831 & 1642432 & 6.2262 & 6.1868 & TRN & & \\
\hline CHEMBL3939152 & 1642432 & 6.4486 & 6.21 & TRN & & \\
\hline CHEMBL3935612 & 1642432 & 5.1475 & 4.6701 & TRN & & \\
\hline CHEMBL3960456 & 1642432 & 6.0 & 5.6753 & TRN & & \\
\hline CHEMBL3986039 & 1642432 & 5.6556 & 5.4458 & TRN & & \\
\hline CHEMBL3922366 & 1642432 & 5.21399 & 99999999 & 995 & 4.7611 & TST \\
\hline CHEMBL3936763 & 1642432 & 6.0 & 6.0086 & TRN & & \\
\hline CHEMBL3940887 & 1642432 & 4.9101 & 5.3301 & TRN & & \\
\hline CHEMBL3940851 & 1642432 & 3.699 & 4.561 & TST & & \\
\hline CHEMBL3907137 & 1642432 & 6.0101 & 5.5754 & TRN & & \\
\hline CHEMBL3905547 & 1642432 & 5.4318 & 5.6326 & TRN & & \\
\hline CHEMBL3952300 & 1642432 & 6.4634 & 6.7474 & TRN & & \\
\hline CHEMBL3954229 & 1642432 & 6.45100 & 00000000 & 305 & 6.6138 & TRN \\
\hline CHEMBL3938360 & 1642432 & 6.1158 & 6.0198 & TST & & \\
\hline CHEMBL3970146 & 1642432 & 5.8069 & 5.7831 & TRN & & \\
\hline CHEMBL3899787 & 1642432 & 6.2716 & 5.7965 & TRN & & \\
\hline CHEMBL3923868 & 1642432 & 5.4634 & 5.666 & TRN & & \\
\hline CHEMBL3967488 & 1642432 & 5.5513 & 5.4019 & TRN & & \\
\hline CHEMBL3957112 & 1642432 & 5.6308 & 5.4393 & TRN & & \\
\hline CHEMBL3937873 & 1642432 & 4.8996 & 5.1599 & TRN & & \\
\hline CHEMBL3928353 & 1642432 & 5.9957 & 5.8983 & TRN & & \\
\hline CHEMBL3925318 & 1642432 & 5.2457 & 5.2076 & TRN & & \\
\hline CHEMBL3967064 & 1642432 & 5.9914 & 6.2296 & TRN & & \\
\hline CHEMBL3910053 & 1642432 & 5.3737 & 4.8596 & TRN & & \\
\hline CHEMBL3912859 & 1642432 & 6.025 & 5.7935 & TRN & & \\
\hline CHEMBL3927533 & 1642432 & 6.0405 & 5.9828 & TRN & & \\
\hline CHEMBL3948725 & 1642432 & 5.6198 & 5.2242 & TRN & & \\
\hline CHEMBL3918342 & 1642432 & 6.0747 & 6.282 & TST & & \\
\hline CHEMBL3934211 & 1642432 & 5.8928 & 5.8928 & TRN & & \\
\hline CHEMBL3972901 & 1642432 & 5.5935 & 5.5116 & TST & & \\
\hline CHEMBL3966315 & 1642432 & 5.3686 & 5.4619 & TST & & \\
\hline CHEMBL3909839 & 1642432 & 5.51 & 5.1723 & TRN & & \\
\hline CHEMBL3928592 & 1642432 & 6.1073 & 5.8635 & TRN & & \\
\hline CHEMBL3912110 & 1642432 & 6.1343 & 6.0727 & TST & & \\
\hline CHEMBL3906597 & 1642432 & 3.699 & 4.5807 & TRN & & \\
\hline CHEMBL3979650 & 1642432 & 6.6861 & 6.5621 & TRN & & \\
\hline CHEMBL3972494 & 1642432 & 3.699 & 5.1544 & TRN & & \\
\hline CHEMBL3971991 & 1642432 & 5.7932 & 5.473 & TRN & & \\
\hline
\end{tabular}


Supplemental Table S2.txt

\begin{tabular}{|c|c|c|c|c|}
\hline CHEMBL3941269 & 1642432 & 5.0306 & 5.2217 & TRN \\
\hline CHEMBL3941492 & 1642432 & 6.0 & 5.5728 & TRN \\
\hline CHEMBL3948190 & 1642432 & 6.0675 & 6.2112 & TRN \\
\hline CHEMBL3940431 & 1642432 & 6.5452 & 6.0512 & TRN \\
\hline CHEMBL3971374 & 1642432 & 5.5918 & 5.46 & TRN \\
\hline CHEMBL3932775 & 1642432 & 6.2541 & 5.9413 & TRN \\
\hline CHEMBL3928218 & 1642432 & 3.699 & 5.0796 & TST \\
\hline CHEMBL3896715 & 1642432 & 5.3019 & 5.1796 & TRN \\
\hline CHEMBL3930871 & 1642432 & 3.699 & 4.4423 & TST \\
\hline CHEMBL3986012 & 1642432 & 6.1624 & 5.9943 & TST \\
\hline CHEMBL3933452 & 1642432 & 6.0 & 5.5792 & TRN \\
\hline CHEMBL3951852 & 1642432 & 5.7144 & 5.4855 & TRN \\
\hline CHEMBL3893721 & 1642432 & 5.0841 & 4.8909 & TST \\
\hline CHEMBL3959890 & 1642432 & 5.7077 & 5.7418 & TST \\
\hline CHEMBL 3957043 & 1642432 & 6.3925 & 6.4952 & TRN \\
\hline CHEMBL3973892 & 1642432 & 3.699 & 4.2713 & TRN \\
\hline CHEMBL3907510 & 1642432 & 5.5143 & 5.4036 & TST \\
\hline CHEMBL3911242 & 1642432 & 4.9208 & 5.5763 & TRN \\
\hline CHEMBL3976328 & 1642432 & 5.066 & 5.0543 & TRN \\
\hline CHEMBL3978848 & 1642432 & 6.279 & 6.2811 & TRN \\
\hline CHEMBL3929990 & 1642432 & 5.4698 & 5.532 & TRN \\
\hline CHEMBL3954938 & 1642432 & 5.3002 & 5.6784 & TRN \\
\hline CHEMBL3972462 & 1642432 & 5.5406 & 5.6492 & TRN \\
\hline CHEMBL 3902762 & 1642432 & 6.2182 & 5.5989 & TRN \\
\hline CHEMBL3890443 & 1642432 & 5.5129 & 5.1595 & TRN \\
\hline CHEMBL3917050 & 1642432 & 5.4597 & 6.12700 & 0000000001 \\
\hline CHEMBL3891536 & 1642432 & 5.1838 & 5.40600 & 0000000001 \\
\hline CHEMBL3984984 & 1642432 & 5.1772 & 4.8604 & TRN \\
\hline CHEMBL3912584 & 1642432 & 5.9393 & 5.8285 & TRN \\
\hline CHEMBL3943108 & 1642432 & 3.699 & 4.1192 & TRN \\
\hline CHEMBL3978968 & 1642432 & 4.7852 & 4.927 & TRN \\
\hline CHEMBL3938950 & 1642432 & 5.9586 & 5.1804 & TRN \\
\hline CHEMBL3943521 & 1642432 & 6.0 & 5.4145 & TRN \\
\hline CHEMBL3936133 & 1642432 & 5.5017 & 5.5376 & TRN \\
\hline CHEMBL3926398 & 1642432 & 6.0958 & 5.9061 & TRN \\
\hline CHEMBL3905520 & 1642432 & 6.6345 & 5.5348 & TRN \\
\hline CHEMBL 3895682 & 1642432 & 6.3575 & 5.9375 & TRN \\
\hline CHEMBL 3972232 & 1642432 & 3.699 & 4.8882 & TST \\
\hline CHEMBL3912423 & 1642432 & 5.1302 & 5.3491 & TRN \\
\hline CHEMBL3947741 & 1642432 & 6.1024 & 5.3247 & TRN \\
\hline CHEMBL3896977 & 1642432 & 5.5686 & 5.6768 & TRN \\
\hline CHEMBL3966529 & 1642432 & 3.699 & 4.9151 & TRN \\
\hline CHEMBL3920242 & 1642432 & 6.0 & 5.6223 & TRN \\
\hline CHEMBL3931067 & 1642432 & 6.0526 & 5.9379 & TRN \\
\hline CHEMBL3906035 & 1642432 & 5.5784 & 5.1682 & TST \\
\hline CHEMBL3936552 & 1642432 & 6.5331 & 5.5044 & TST \\
\hline CHEMBL 3980410 & 1642432 & 5.699 & 5.6126 & TRN \\
\hline CHEMBL3904231 & 1642432 & 5.7986 & 5.8071 & TRN \\
\hline
\end{tabular}


Supplemental Table S2.txt

\begin{tabular}{|c|c|c|c|c|c|}
\hline CHEMBL3934423 & 1642432 & 6.2449 & 5.9244 & TRN & \\
\hline CHEMBL3984637 & 1642432 & 5.5214 & 5.5697 & TRN & \\
\hline CHEMBL3975041 & 1642432 & 3.699 & 5.1042 & TRN & \\
\hline CHEMBL3930533 & 1642432 & 6.2899 & 5.7256 & TRN & \\
\hline CHEMBL3974712 & 1642432 & 6.1612 & 5.5742 & TRN & \\
\hline CHEMBL3927426 & 1642432 & 5.51 & 5.4693 & TST & \\
\hline CHEMBL3958160 & 1642432 & 5.4949 & 5.124 & TRN & \\
\hline CHEMBL3946281 & 1642432 & 3.699 & 5.1129 & TRN & \\
\hline CHEMBL3958155 & 1642432 & 4.7799 & 5.1445 & TRN & \\
\hline CHEMBL3956892 & 1642432 & 5.58 & 5.9596 & TRN & \\
\hline CHEMBL3921120 & 1642432 & 4.8386 & 5.2042 & TRN & \\
\hline CHEMBL3955469 & 1642432 & 5.1198 & 5.9505 & TRN & \\
\hline CHEMBL3903933 & 1642432 & 5.5575 & 5.6732 & TST & \\
\hline CHEMBL3921238 & 1642432 & 6.2321 & 5.5611 & TRN & \\
\hline CHEMBL3944319 & 1642432 & 5.0991 & 5.3189 & TRN & \\
\hline CHEMBL3920541 & 1642432 & 5.7773 & 5.9708 & TRN & \\
\hline CHEMBL3950947 & 1642432 & 5.6038 & 6.1384 & TST & \\
\hline CHEMBL3918972 & 1642432 & 4.8416 & 5.3288 & TRN & \\
\hline CHEMBL3945172 & 1642432 & 6.0 & 5.2747 & TRN & \\
\hline CHEMBL3926656 & 1642432 & 6.0448 & 5.4223 & TRN & \\
\hline CHEMBL3939672 & 1642432 & 6.2526 & 5.8748 & TRN & \\
\hline CHEMBL3893710 & 1642432 & 5.8539 & 5.9004 & TRN & \\
\hline CHEMBL3974139 & 1642432 & 5.5317 & 4.6923 & TRN & \\
\hline CHEMBL3935861 & 1642432 & 5.9245 & 5.9798 & TRN & \\
\hline CHEMBL3985513 & 1642432 & 5.3468 & 5.6276 & TRN & \\
\hline CHEMBL3913522 & 1642432 & 6.5302 & 5.9413 & TRN & \\
\hline CHEMBL3978298 & 1642432 & 5.5258 & 5.25 & TRN & \\
\hline CHEMBL3973981 & 1642432 & 4.8794 & 5.0941 & TRN & \\
\hline CHEMBL 3917845 & 1642432 & 3.699 & 5.7499 & TST & \\
\hline CHEMBL3909018 & 1642432 & 6.4881 & 6.8842 & TRN & \\
\hline CHEMBL3895310 & 1642432 & 5.6003 & 5.6031 & TRN & \\
\hline CHEMBL3920990 & 1642432 & 6.0348 & 5.2659 & TRN & \\
\hline CHEMBL3890890 & 1642432 & 4.9208 & 5.3052 & TRN & \\
\hline CHEMBL3976532 & 1642432 & 6.1337 & 5.6182 & TRN & \\
\hline CHEMBL 3890578 & 1642432 & 5.9666 & 6.1407 & TRN & \\
\hline CHEMBL3894872 & 1642432 & 6.0665 & 6.0021 & TST & \\
\hline CHEMBL3935365 & 1642432 & 5.4828 & 5.3838 & TRN & \\
\hline CHEMBL 3924424 & 1642432 & 5.4962 & 5.241006 & 00000000005 & TRN \\
\hline CHEMBL 3922241 & 1642432 & 4.8665 & 5.3395 & TRN & \\
\hline CHEMBL3960313 & 1642432 & 6.0 & 6.0172 & TRN & \\
\hline CHEMBL3955525 & 1642432 & 5.7721 & 5.6681 & TST & \\
\hline CHEMBL3944481 & 1642432 & 5.0424 & 5.3691 & TRN & \\
\hline CHEMBL3964450 & 1642432 & 5.9031 & 5.5211 & TRN & \\
\hline CHEMBL3968558 & 1642432 & 5.4377 & 5.2799 & TRN & \\
\hline CHEMBL3956647 & 1642432 & 6.0531 & 5.9058 & TST & \\
\hline CHEMBL3902687 & 1642432 & 3.699 & 5.6984 & TST & \\
\hline CHEMBL3970942 & 1642432 & $6.3270 e$ & 00000006 & 5.8174 & TRN \\
\hline CHEMBL3891357 & 1642432 & 5.4191 & 5.3072 & TRN & \\
\hline
\end{tabular}


Supplemental Table S2.txt

\begin{tabular}{|c|c|c|c|c|}
\hline CHEMBL3957193 & 1642432 & 6.0405 & 5.2708 & TRN \\
\hline CHEMBL3932839 & 1642432 & 6.0 & 5.8085 & TRN \\
\hline CHEMBL3917623 & 1642432 & 5.6882 & 5.4303 & TST \\
\hline CHEMBL3927782 & 1642432 & 5.9136 & 5.9206 & TRN \\
\hline CHEMBL3906631 & 1642432 & 4.7905 & 5.3524 & TRN \\
\hline CHEMBL3979871 & 1642432 & 5.5952 & 5.6815 & TRN \\
\hline CHEMBL3906877 & 1642432 & 5.6556 & 5.4734 & TRN \\
\hline CHEMBL3931525 & 1642432 & 6.0 & 6.0767 & TRN \\
\hline CHEMBL3893747 & 1642432 & 5.5421 & 5.8305 & TRN \\
\hline CHEMBL 3924068 & 1642432 & 5.3019 & 5.9031 & TRN \\
\hline CHEMBL3899789 & 1642432 & 5.1397 & 6.3587 & TST \\
\hline CHEMBL3945788 & 1642432 & 5.7077 & \multicolumn{2}{|c|}{5.9110000000000005} \\
\hline CHEMBL 3963450 & 1642432 & 5.4473 & 5.4276 & TRN \\
\hline CHEMBL 3891843 & 1642432 & 5.9706 & 5.5139 & TRN \\
\hline CHEMBL3910194 & 1642432 & 6.0 & 6.4208 & TRN \\
\hline CHEMBL3894019 & 1642432 & 5.5031 & 4.9886 & TRN \\
\hline CHEMBL3949462 & 1642432 & 5.8386 & 5.928 & TRN \\
\hline CHEMBL3935527 & 1642432 & 5.5243 & 4.9373 & TRN \\
\hline CHEMBL 3897837 & 1642432 & 6.0 & 5.7893 & TRN \\
\hline CHEMBL3929695 & 1642432 & 3.699 & 5.6261 & TST \\
\hline CHEMBL3952964 & 1642432 & 4.9508 & 5.3459 & TST \\
\hline CHEMBL3912336 & 1642432 & 5.5686 & 5.6755 & TRN \\
\hline CHEMBL3898654 & 1642432 & 6.6615 & 5.8663 & TRN \\
\hline CHEMBL3959876 & 1642432 & 5.7595 & 5.9223 & TRN \\
\hline CHEMBL3917696 & 1642432 & 4.8761 & 4.7047 & TRN \\
\hline CHEMBL3933233 & 1642432 & 3.699 & 3.2869 & TRN \\
\hline CHEMBL3897701 & 1642432 & 5.9393 & 5.6003 & TRN \\
\hline CHEMBL3910542 & 1642432 & 3.699 & 6.585 & TST \\
\hline CHEMBL3893055 & 1642432 & 5.5229 & 5.5014 & TST \\
\hline CHEMBL3977732 & 1642432 & 6.3487 & 6.1001 & TRN \\
\hline CHEMBL3916776 & 1642432 & 4.8356 & 5.3088 & TRN \\
\hline CHEMBL3921786 & 1642432 & 4.9957 & 5.0572 & TRN \\
\hline CHEMBL3950084 & 1642432 & 6.0 & 5.4193 & TRN \\
\hline CHEMBL3927959 & 1642432 & 3.699 & 4.7179 & TRN \\
\hline CHEMBL3978098 & 1642432 & 5.9245 & 5.6539 & TRN \\
\hline CHEMBL3895066 & 1642432 & 6.0809 & 6.1024 & TRN \\
\hline CHEMBL3944781 & 1642432 & 5.4868 & 5.2794 & TRN \\
\hline CHEMBL3944043 & 1642432 & 6.041 & 6.2079 & TRN \\
\hline CHEMBL3904346 & 1642432 & 5.3947 & 5.3019 & TRN \\
\hline CHEMBL3894438 & 1642432 & 5.7595 & 6.0346 & TST \\
\hline CHEMBL3976973 & 1642432 & 4.9393 & 5.1363 & TRN \\
\hline CHEMBL3910299 & 1642432 & 6.4318 & 6.3741 & TRN \\
\hline CHEMBL3920587 & 1642432 & 3.699 & 4.8018 & TRN \\
\hline CHEMBL3973921 & 1642432 & 4.8633 & 5.4917 & TRN \\
\hline CHEMBL 3908675 & 1642432 & 5.6696 & 6.0337 & TST \\
\hline CHEMBL3915123 & 1642432 & 3.699 & 5.9538 & TST \\
\hline CHEMBL3918289 & 1642432 & 3.699 & 4.8229 & TRN \\
\hline CHEMBL 3974892 & 1642432 & 5.4868 & 5.2828 & TRN \\
\hline
\end{tabular}

Page 24316 
Supplemental Table S2.txt

\begin{tabular}{|c|c|c|c|c|c|}
\hline CHEMBL3969937 & 1642432 & 5.6799 & 5.4415 & TRN & \\
\hline CHEMBL3921069 & 1642432 & 5.4672 & 4.8144 & TRN & \\
\hline CHEMBL3948505 & 1642432 & 5.51 & 5.8166 & TRN & \\
\hline CHEMBL3958652 & 1642432 & 6.1772 & 5.7119 & TRN & \\
\hline CHEMBL3903319 & 1642432 & 4.7773 & 5.5439 & TRN & \\
\hline CHEMBL3916372 & 1642432 & 5.983 & 5.7366 & TRN & \\
\hline CHEMBL3912212 & 1642432 & 3.699 & 5.3885 & TRN & \\
\hline CHEMBL3918597 & 1642432 & 5.7033 & 5.7102 & TRN & \\
\hline CHEMBL 3943126 & 1642432 & 4.8601 & 5.4177 & TRN & \\
\hline CHEMBL3970931 & 1642432 & 5.2534 & 6.0996 & TRN & \\
\hline CHEMBL3907618 & 1642432 & 3.699 & 4.7998 & TST & \\
\hline CHEMBL3938465 & 1642432 & 3.699 & 5.3318 & TRN & \\
\hline CHEMBL3918990 & 1642432 & 5.58 & 5.6139 & TRN & \\
\hline CHEMBL3911349 & 1642432 & 4.9066 & 4.7684 & TRN & \\
\hline CHEMBL3970671 & 1642432 & 5.4935 & 5.9476 & TRN & \\
\hline CHEMBL3948796 & 1642432 & 3.699 & 4.8616 & TRN & \\
\hline CHEMBL3908904 & 1642432 & 6.0 & 5.6253 & TST & \\
\hline CHEMBL3932370 & 1642432 & 5.4989 & 5.8259 & TRN & \\
\hline CHEMBL3980008 & 1642432 & 5.2284 & 5.9631 & TRN & \\
\hline CHEMBL3893582 & 1642432 & 5.4841 & 6.1765 & TRN & \\
\hline CHEMBL3983843 & 1642432 & 4.8601 & 5.1452 & TRN & \\
\hline CHEMBL3908609 & 1642432 & 6.0 & 5.0398 & TST & \\
\hline CHEMBL3932097 & 1642432 & 3.699 & 4.5759 & TRN & \\
\hline CHEMBL3913714 & 1642432 & 6.0 & 6.1896 & TRN & \\
\hline CHEMBL3945297 & 1642432 & 3.699 & 5.1065 & TRN & \\
\hline CHEMBL3963162 & 1642432 & 4.9431 & 5.0836 & TRN & \\
\hline CHEMBL3949517 & 1642432 & 5.0975 & 5.5515 & TRN & \\
\hline CHEMBL3927705 & 1642432 & 6.0278 & 5.8163 & TRN & \\
\hline CHEMBL3962158 & 1642432 & 5.5406 & 5.8144 & TST & \\
\hline CHEMBL3950298 & 1642432 & 5.4622 & 5.2964 & TRN & \\
\hline CHEMBL3932809 & 1642432 & 5.699 & 5.0578 & TRN & \\
\hline CHEMBL3978850 & 1642432 & 5.6968 & 5.4149 & TRN & \\
\hline CHEMBL3918351 & 1642432 & 5.05699 & 999999999 & 4.9612 & TRN \\
\hline CHEMBL3924612 & 1642432 & 5.8477 & 5.3344 & TRN & \\
\hline CHEMBL3954588 & 1642432 & 5.61799 & 799999999 & 6.1988 & TST \\
\hline CHEMBL3893967 & 1642432 & 3.699 & 4.6662 & TRN & \\
\hline CHEMBL3931145 & 1642432 & 5.3904 & 5.7004 & TST & \\
\hline CHEMBL3938479 & 1642432 & 3.699 & 5.7733 & TST & \\
\hline CHEMBL3970045 & 1642432 & 6.0 & 6.237999 & 99999999995 & TRN \\
\hline CHEMBL3913536 & 1642432 & 6.05399 & 999999999 & 5.3943 & TRN \\
\hline CHEMBL3956844 & 1642432 & 5.5686 & 6.0544 & TRN & \\
\hline CHEMBL3939702 & 1642432 & 5.4461 & 5.207000 & 0000000001 & TRN \\
\hline CHEMBL3931153 & 1642432 & 5.5072 & 5.3079 & TRN & \\
\hline CHEMBL3896768 & 1642432 & 5.6778 & 5.6947 & TRN & \\
\hline CHEMBL3936733 & 1642432 & 4.9431 & 5.3843 & TRN & \\
\hline CHEMBL3950690 & 1642432 & 6.0 & 6.1052 & TRN & \\
\hline CHEMBL3935792 & 1642432 & 5.2581 & 4.713999 & 99999999995 & TRN \\
\hline CHEMBL3959208 & 1642432 & 3.699 & 5.2324 & TRN & \\
\hline
\end{tabular}




\begin{tabular}{|c|c|c|c|c|c|}
\hline \multicolumn{6}{|c|}{ Supplemental Table S2.txt } \\
\hline CHEMBL3961658 & 1642432 & 6.0 & 5.6651 & TST & \\
\hline CHEMBL 3986304 & 1642432 & 5.6198 & 5.7233 & TRN & \\
\hline CHEMBL 3957685 & 1642432 & 6.0 & 6.1657 & TST & \\
\hline CHEMBL 3929978 & 1642432 & 5.9508 & 5.7802 & TRN & \\
\hline CHEMBL 3979409 & 1642432 & 6.0 & 5.1718 & TRN & \\
\hline CHEMBL 3944250 & 1642432 & 4.9136 & 5.2125 & TST & \\
\hline CHEMBL 3898482 & 1642432 & 6.0 & 5.2535 & TST & \\
\hline CHEMBL 3926689 & 1642432 & 5.2132 & 5.1611 & TRN & \\
\hline CHEMBL3971933 & 1642432 & 5.041 & 5.17299 & 9999999999 & TRN \\
\hline CHEMBL3899704 & 1642432 & 6.0794 & 5.1255 & TST & \\
\hline CHEMBL3947943 & 1642432 & 5.0264 & 4.8656 & TRN & \\
\hline CHEMBL 3954256 & 1642432 & 6.0 & 6.1664 & TRN & \\
\hline CHEMBL3968129 & 1642432 & 3.699 & 4.3447 & TRN & \\
\hline CHEMBL 3946807 & 1642432 & 4.7011 & 5.3414 & TST & \\
\hline CHEMBL3930563 & 1642432 & 5.5214 & 5.5305 & TRN & \\
\hline CHEMBL3896736 & 1642432 & 3.699 & 4.9899 & TRN & \\
\hline CHEMBL 3948233 & 1642432 & 5.4881 & 5.2204 & TRN & \\
\hline CHEMBL3934494 & 1642432 & 4.82100 & $\partial 0000000$ & 5.3656 & TST \\
\hline CHEMBL 3963026 & 1642432 & 5.857 & 5.318 & TRN & \\
\hline CHEMBL3984955 & 1642432 & 6.0 & 5.7549 & TST & \\
\hline CHEMBL3913340 & 1642432 & 5.7055 & 5.21899 & 9999999999 & TRN \\
\hline CHEMBL 3904478 & 1642432 & 5.6576 & 5.0611 & TRN & \\
\hline CHEMBL3930075 & 1642432 & 5.5452 & 6.0735 & TST & \\
\hline CHEMBL 3954283 & 1642432 & 4.762 & 5.3633 & TRN & \\
\hline CHEMBL3896495 & 1642432 & 5.6198 & 5.7826 & TRN & \\
\hline CHEMBL3965189 & 1642432 & 6.0 & 5.9816 & TRN & \\
\hline CHEMBL 3893364 & 1642432 & 5.8182 & 5.9542 & TST & \\
\hline CHEMBL3898367 & 1642432 & 3.699 & 6.1468 & TST & \\
\hline CHEMBL 3935362 & 1642432 & 3.699 & 4.751 & TRN & \\
\hline CHEMBL3976992 & 1642432 & 5.0061 & 5.1704 & TRN & \\
\hline CHEMBL3971399 & 1642432 & 5.5591 & 5.7334 & TRN & \\
\hline CHEMBL 3932458 & 1642432 & 5.4698 & 4.9592 & TRN & \\
\hline CHEMBL3964900 & 1642432 & 5.8297 & 5.1212 & TRN & \\
\hline CHEMBL 3962274 & 1642432 & 5.4711 & 4.8766 & TST & \\
\hline CHEMBL3895487 & 1642432 & 6.0 & 5.3491 & TRN & \\
\hline CHEMBL3921807 & 1642432 & 5.9666 & 6.0482 & TST & \\
\hline CHEMBL3948100 & 1642432 & 5.5654 & 5.851 & TRN & \\
\hline CHEMBL3965849 & 1642432 & 5.9101 & 5.9606 & TST & \\
\hline CHEMBL3916452 & 1642432 & 6.0 & 5.5335 & TRN & \\
\hline CHEMBL 3889843 & 1642432 & 5.9469 & 5.8934 & TRN & \\
\hline CHEMBL3966293 & 1642432 & 6.0 & 5.3184 & TST & \\
\hline CHEMBL3927319 & 1642432 & 5.0665 & 5.7604 & TRN & \\
\hline CHEMBL3985423 & 1642432 & 3.699 & 5.4032 & TST & \\
\hline CHEMBL 3904496 & 1642432 & 6.0 & 6.0238 & TRN & \\
\hline CHEMBL3904604 & 1642432 & 3.699 & 5.2006 & TST & \\
\hline CHEMBL3935283 & 1642432 & 5.58 & 5.3266 & TRN & \\
\hline CHEMBL3900843 & 1642432 & 5.2993 & 5.2591 & TRN & \\
\hline CHEMBL3921684 & 1642432 & 5.7033 & 5.7445 & TRN & \\
\hline
\end{tabular}


Supplemental Table S2.txt

\begin{tabular}{|c|c|c|c|c|}
\hline & & 074 & & 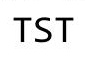 \\
\hline HEMBL3 & 642432 & 4.8601 & 4.7157 & \\
\hline & & & & \\
\hline 666 & 32 & & & \\
\hline 0097 & 432 & 426 & נצס & \\
\hline IEMBL3911359 & 642432 & 6.5317 & 499 & \\
\hline EMBL3918249 & & 5.2798 & 81 & \\
\hline 139 & 32 & 39 & 531 & \\
\hline 75363 & 32 & 478 & 06 & \\
\hline AEMBL3980408 & 32 & 5.5969 & 3589 & \\
\hline HEMBL3985565 & 32 & 3508 & 5.4108 & \\
\hline EMBL3909317 & 32 & 556 & 633 & \\
\hline EME & & 214 & & \\
\hline IEMBL 3933025 & 32 & 5.4935 & 399 & \\
\hline EMBL3967307 & 32 & 5.4473 & 58 & \\
\hline IEMBL395 & 32 & 71 & 7 & \\
\hline EMBL3929628 & 2 & & 153 & \\
\hline IEMBL 3942987 & 2 & & 317 & \\
\hline EMBL3921141 & 32 & 7122 & 908 & \\
\hline EMBL 3896612 & 32 & & 77 & \\
\hline EMBL3933392 & 2 & 73 & 904 & \\
\hline EMBL396 & 2 & .77 & 439 & \\
\hline EMBL394 & 2 & & 917 & \\
\hline 948959 & & & & \\
\hline EMBL3942075 & 2 & & & \\
\hline MBL3902733 & 2 & 45 & 88 & s \\
\hline EMBL3904780 & 2 & 45 & 131 & \\
\hline 206 & 2 & 99 & 11 & \\
\hline 310 & & & & \\
\hline EMBL 3938301 & 2 & & & \\
\hline 4879 & 16 & 36 & 17 & RI \\
\hline 3161 & 2 & 5 & 85 & \\
\hline 587 & 2 & & & \\
\hline 132 & & & & \\
\hline IEMBL 3972071 & 2 & & & \\
\hline 925 & 2 & & 49 & $\mathrm{R}$ \\
\hline 516 & 16 & 52 & 501 & \\
\hline & 2 & & 843 & \\
\hline EMBL3980943 & 32 & 575 & 959 & $\mathrm{R}$ \\
\hline EMBL3928398 & 2 & & & \\
\hline EMBL3959027 & 16 & & 616 & $\mathbf{K}$ \\
\hline HEMBL3980105 & 16 & & 268 & \\
\hline EMBL3937607 & 32 & 5.4622 & 2354 & R \\
\hline MBL 3925250 & 32 & & 706 & \\
\hline a72 & 2 & 007 & & \\
\hline MBL 3925471 & 164 & & 3906 & \\
\hline CHEMBL3951324 & 164 & 5331 & 5.5184 & \\
\hline CHEMBL3895724 & 1642432 & 5.8962 & 5.6262 & \\
\hline
\end{tabular}

Page 24319 
Supplemental Table S2.txt

\begin{tabular}{|c|c|c|c|c|}
\hline CHEMBL3953769 & 1642432 & 6.7799 & 6.7356 & TRN \\
\hline CHEMBL 3890294 & 1642432 & 6.5171 & 6.0698 & TRN \\
\hline CHEMBL 3924034 & 1642432 & 5.9747 & 5.3758 & TRN \\
\hline CHEMBL3976095 & 1642432 & 5.8996 & 5.1456 & TRN \\
\hline CHEMBL 3985075 & 1642432 & 3.699 & 4.1378 & TRN \\
\hline CHEMBL3961975 & 1642432 & 6.2097 & 6.3527 & TRN \\
\hline CHEMBL 3932642 & 1642432 & 6.056 & 5.4365 & TST \\
\hline CHEMBL3975895 & 1642432 & 6.0 & 5.7449 & TST \\
\hline CHEMBL 3938475 & 1642432 & 6.0 & 5.6776 & TRN \\
\hline CHEMBL 3896584 & 1642432 & 5.3372 & 5.48799 & 99999999995 \\
\hline CHEMBL3934180 & 1642432 & 4.7595 & 5.1156 & TRN \\
\hline CHEMBL 3891495 & 1642432 & 5.4815 & 5.1756 & TRN \\
\hline CHEMBL3977282 & 1642432 & 5.1101 & 5.6043 & TRN \\
\hline CHEMBL3933358 & 1642432 & 5.2588 & 5.4906 & TRN \\
\hline CHEMBL 3904884 & 1642432 & 6.0 & 5.4735 & TST \\
\hline CHEMBL3901135 & 1642432 & 5.4634 & 5.8533 & TRN \\
\hline CHEMBL3971026 & 1642432 & 6.6234 & 5.774 & TST \\
\hline CHEMBL 3980273 & 1642432 & 6.2832 & 6.393 & TRN \\
\hline CHEMBL3960819 & 1642432 & 5.4067 & 5.2566 & TRN \\
\hline CHEMBL3919860 & 1642432 & 5.6345 & 5.5392 & TRN \\
\hline CHEMBL3916110 & 1642432 & 5.4868 & 5.4119 & TRN \\
\hline CHEMBL 3983441 & 1642432 & 5.9626 & 5.1547 & TRN \\
\hline CHEMBL 3904278 & 1642432 & 6.153 & 5.9184 & TRN \\
\hline CHEMBL 3921833 & 1642432 & 6.1549 & 5.7933 & TRN \\
\hline CHEMBL 3894503 & 1642432 & 5.3478 & 5.5333 & TRN \\
\hline CHEMBL3955517 & 1642432 & 5.2262 & 5.3992 & TRN \\
\hline CHEMBL3986446 & 1642432 & 4.8539 & 4.9003 & TST \\
\hline CHEMBL3904997 & 1642432 & 6.2111 & 5.6518 & TRN \\
\hline CHEMBL 3951748 & 1642432 & 6.4067 & 5.7373 & TRN \\
\hline CHEMBL 3929432 & 1642432 & 6.0 & 5.6617 & TRN \\
\hline CHEMBL3915627 & 1642432 & 5.644 & 5.4171 & TRN \\
\hline CHEMBL 3933413 & 1642432 & 5.4012 & 5.6206 & TRN \\
\hline CHEMBL3933559 & 1642432 & 3.699 & 4.4715 & TRN \\
\hline CHEMBL3949037 & 1642432 & 4.7033 & 4.8979 & TRN \\
\hline CHEMBL 3928427 & 1642432 & 4.8297 & 5.4157 & TRN \\
\hline CHEMBL3946456 & 1642432 & 4.9508 & 5.0753 & TRN \\
\hline CHEMBL 3982531 & 1642432 & 5.9172 & 6.0005 & TRN \\
\hline CHEMBL 3982853 & 1642432 & 5.7878 & 5.5331 & TRN \\
\hline CHEMBL3912811 & 1642432 & 6.0 & 5.5314 & TRN \\
\hline CHEMBL3969245 & 1642432 & 5.2815 & 4.984 & TST \\
\hline CHEMBL3938244 & 1642432 & 5.9626 & 4.8848 & TST \\
\hline CHEMBL3971659 & 1642432 & 6.0057 & 6.1537 & TRN \\
\hline CHEMBL 3936297 & 1642432 & 3.699 & 5.516 & TST \\
\hline CHEMBL3958367 & 1642432 & 5.7282 & 5.5153 & TRN \\
\hline CHEMBL3917558 & 1642432 & 4.9172 & 5.3951 & TRN \\
\hline CHEMBL3960905 & 1642432 & 6.0 & 5.5663 & TRN \\
\hline CHEMBL 3918176 & 1642432 & 5.4401 & 5.3058 & TRN \\
\hline CHEMBL3913976 & 1642432 & 6.0123 & 6.061 & TRN \\
\hline
\end{tabular}


Supplemental Table S2.txt

\begin{tabular}{|c|c|c|c|c|c|}
\hline CHEMBL 3966603 & 1642432 & 5.7545 & 5.6859 & TRN & \\
\hline CHEMBL3950234 & 1642432 & 4.9957 & 5.4723 & TRN & \\
\hline CHEMBL3898321 & 1642432 & 5.5406 & 5.3098 & TRN & \\
\hline CHEMBL 3894968 & 1642432 & 6.2815 & 5.2525 & TRN & \\
\hline CHEMBL3932105 & 1642432 & 4.9914 & 5.8907 & TRN & \\
\hline CHEMBL 3893899 & 1642432 & 5.5719 & 5.1595 & TRN & \\
\hline CHEMBL 3958619 & 1642432 & 6.0 & 5.9531 & TRN & \\
\hline CHEMBL3915152 & 1642432 & 4.9872 & 5.5531 & TRN & \\
\hline CHEMBL3907776 & 1642432 & 5.8097 & 6.1608 & TST & \\
\hline CHEMBL3939555 & 1642432 & 5.9872 & 5.6867 & TRN & \\
\hline CHEMBL 3919465 & 1642432 & 4.9957 & 4.8452 & TRN & \\
\hline CHEMBL 3902587 & 1642432 & 5.3063 & 5.4347 & TRN & \\
\hline CHEMBL 3889889 & 1642432 & 5.2321 & 4.9887 & TRN & \\
\hline CHEMBL 3983227 & 1642432 & 6.1805 & 6.1709 & TST & \\
\hline CHEMBL 3972480 & 1642432 & 5.5157 & 5.0772 & TST & \\
\hline CHEMBL3972053 & 1642432 & 4.9066 & 5.1641 & TRN & \\
\hline CHEMBL3950338 & 1642432 & 5.5302 & 5.3105 & TRN & \\
\hline CHEMBL 3961485 & 1642432 & 4.9066 & 5.0998 & TRN & \\
\hline CHEMBL 3908828 & 1642432 & 5.3851 & 5.841 & TST & \\
\hline CHEMBL3953407 & 1642432 & 3.699 & 4.7342 & TRN & \\
\hline CHEMBL3897261 & 1642432 & 5.4828 & 5.7249 & TRN & \\
\hline CHEMBL3945991 & 1642432 & 5.6055 & 5.3502 & TRN & \\
\hline CHEMBL 3982482 & 1642432 & 6.1612 & 6.2541 & TRN & \\
\hline CHEMBL 3934019 & 1642432 & 5.4377 & 5.2779 & TRN & \\
\hline CHEMBL 3896114 & 1642432 & 5.6144 & 5.7846 & TRN & \\
\hline CHEMBL 3926232 & 1642432 & 5.6676 & 5.1416 & TRN & \\
\hline CHEMBL3971777 & 1642432 & 6.0915 & 4.8634 & TRN & \\
\hline CHEMBL 3927912 & 1642432 & 5.9706 & 5.8178 & TRN & \\
\hline CHEMBL 3948882 & 1642432 & 6.3675 & 6.8122 & TRN & \\
\hline CHEMBL 3986805 & 1642432 & 5.8928 & 5.5408 & TRN & \\
\hline CHEMBL 3923685 & 1642432 & 5.7799 & 6.1605 & TRN & \\
\hline CHEMBL3976880 & 1642432 & 5.9872 & 6.0145 & TST & \\
\hline CHEMBL 3918265 & 1642432 & 6.3979 & $5.83200 e$ & 0000000001 & TRN \\
\hline CHEMBL3973701 & 1642432 & 5.5331 & 5.6463 & TRN & \\
\hline CHEMBL 3968608 & 1642432 & 5.4078 & 5.6443 & TRN & \\
\hline CHEMBL3909172 & 1642432 & 6.0009 & 6.0304 & TRN & \\
\hline CHEMBL3985395 & 1642432 & 4.8894 & 4.5585 & TRN & \\
\hline CHEMBL3921602 & 1642432 & 5.6253 & 5.5894 & TRN & \\
\hline CHEMBL 3977009 & 1642432 & 5.5143 & 5.2315 & TRN & \\
\hline CHEMBL3954227 & 1642432 & 6.0 & 5.635 & TST & \\
\hline CHEMBL3971533 & 1642432 & 5.4597 & 5.0066 & TRN & \\
\hline CHEMBL3930151 & 1642432 & 5.8356 & 5.6131 & TRN & \\
\hline CHEMBL3935101 & 1642432 & 5.2967 & 5.8413 & TST & \\
\hline CHEMBL 3966123 & 1642432 & 3.699 & 3.5541 & TRN & \\
\hline CHEMBL3980097 & 1642432 & 5.0521 & 4.7837 & TST & \\
\hline CHEMBL 3967767 & 1642432 & 5.7932 & 5.2808 & TRN & \\
\hline CHEMBL3891190 & 1642432 & 3.699 & 3.4887 & TRN & \\
\hline CHEMBL3948199 & 1642432 & 6.2549 & 6.0604 & TST & \\
\hline
\end{tabular}


Supplemental Table S2.txt

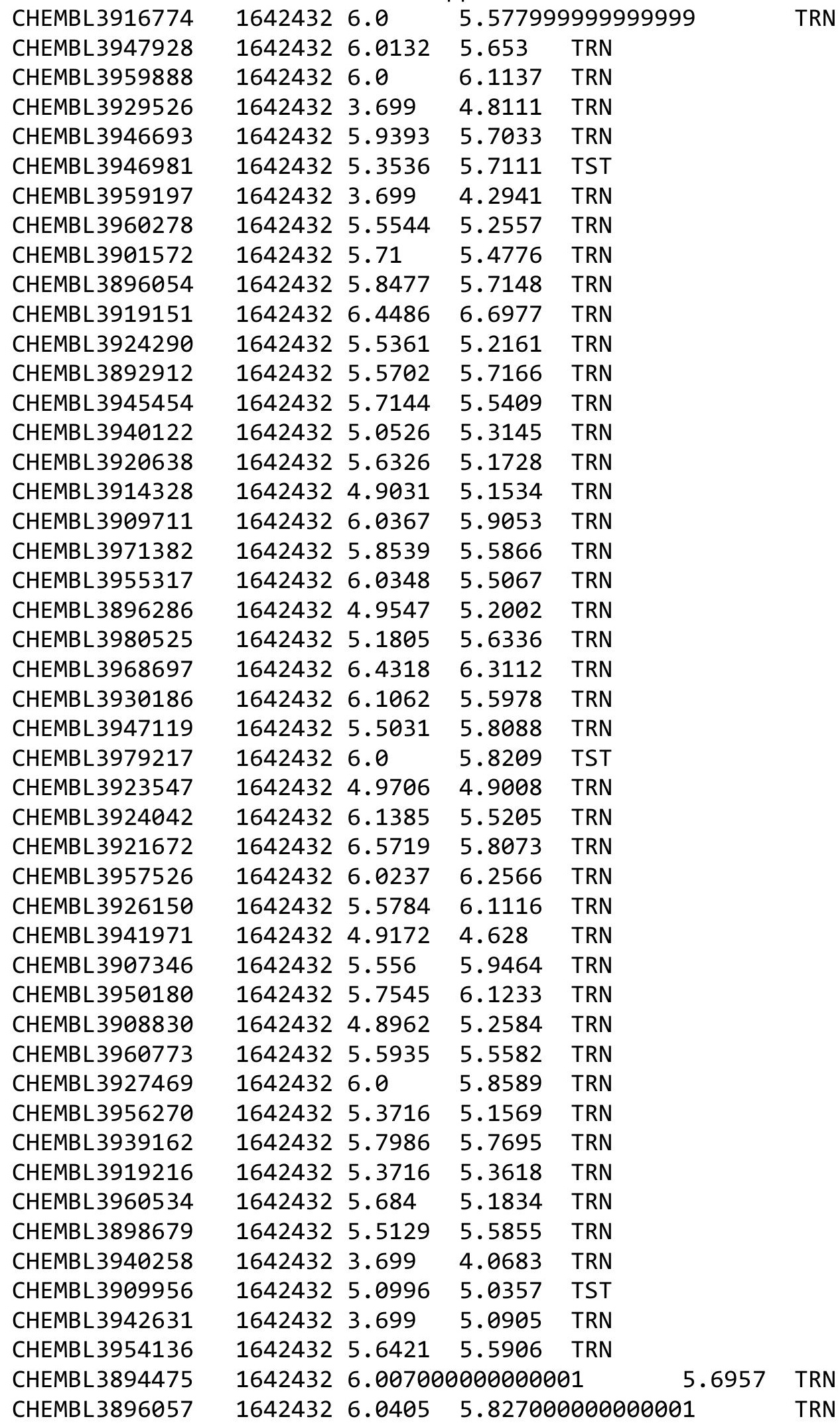

Page 24322 
Supplemental Table S2.txt

\begin{tabular}{|c|c|c|c|c|c|}
\hline CHEMBL 3918873 & 1642432 & 4.7645 & 5.0877 & TST & \\
\hline CHEMBL 3925780 & 1642432 & 5.8827 & 5.4 & TRN & \\
\hline CHEMBL 3893530 & 1642432 & 5.6253 & 5.166 & TRN & \\
\hline CHEMBL 3901472 & 1642432 & 5.8827 & 5.9361 & TRN & \\
\hline CHEMBL3957969 & 1642432 & 5.4841 & 5.4815 & TRN & \\
\hline CHEMBL3905006 & 1642432 & 5.5346 & 5.376 & TRN & \\
\hline CHEMBL 3905717 & 1642432 & 4.8182 & 5.7851 & TRN & \\
\hline CHEMBL 3971443 & 1642432 & 5.0386 & 4.7753 & TRN & \\
\hline CHEMBL 3924696 & 1642432 & 6.1029 & 5.8827 & TRN & \\
\hline CHEMBL3923007 & 1642432 & 5.2 & 5.048 & TRN & \\
\hline CHEMBL3975752 & 1642432 & 5.5114 & 5.4241 & TRN & \\
\hline CHEMBL 3960616 & 1642432 & 6.0 & 6.0813 & TRN & \\
\hline CHEMBL 3978052 & 1642432 & 3.699 & $4.85800 e$ & 30000000005 & TRN \\
\hline CHEMBL 3912050 & 1642432 & 4.9172 & 5.0241 & TRN & \\
\hline CHEMBL3979669 & 1642432 & 6.1013 & 6.3483 & TRN & \\
\hline CHEMBL 3904857 & 1642432 & 5.0953 & 5.5534 & TST & \\
\hline CHEMBL3930780 & 1642432 & 5.2692 & 4.2955 & TRN & \\
\hline CHEMBL 3974623 & 1642432 & 3.699 & 3.3658 & TRN & \\
\hline CHEMBL3976392 & 1642432 & 4.8508 & 5.3647 & TST & \\
\hline CHEMBL3974269 & 1642432 & 5.5513 & 5.5776 & TRN & \\
\hline CHEMBL3946117 & 1642432 & 4.9788 & 5.5258 & TRN & \\
\hline CHEMBL 3938190 & 1642432 & 6.0 & 5.3314 & TRN & \\
\hline CHEMBL 3963358 & 1642432 & 5.4437 & $4.91100 e$ & 30000000005 & TRN \\
\hline CHEMBL 3948686 & 1642432 & 3.699 & 5.2301 & TST & \\
\hline CHEMBL 3962762 & 1642432 & 5.7696 & 4.6388 & TST & \\
\hline CHEMBL 3982278 & 1642432 & 5.6162 & 5.5241 & TST & \\
\hline CHEMBL 3918961 & 1642432 & 3.699 & 5.2236 & TST & \\
\hline CHEMBL 3983790 & 1642432 & 5.5258 & 5.0331 & TST & \\
\hline CHEMBL 3940189 & 1642432 & 6.0 & 5.3892 & TST & \\
\hline CHEMBL 3906669 & 1642432 & 5.4976 & 5.3018 & TST & \\
\hline CHEMBL 3917867 & 1642432 & 4.766999 & 99999999 & 4.564 & TST \\
\hline CHEMBL 3980177 & 1642432 & 5.5376 & 5.565 & TST & \\
\hline CHEMBL 3923897 & 1642432 & 5.8996 & 5.846 & TST & \\
\hline CHEMBL3903399 & 1642432 & 3.699 & 5.6578 & TST & \\
\hline CHEMBL 3959613 & 1642432 & 5.2396 & 5.5388 & TST & \\
\hline CHEMBL 3903851 & 1642432 & 3.699 & 5.1571 & TST & \\
\hline CHEMBL 3941849 & 1642432 & 6.4828 & 6.4099 & TST & \\
\hline CHEMBL 3895032 & 1642432 & 5.983 & 5.717006 & 30000000005 & TST \\
\hline CHEMBL 3977869 & 1642432 & 3.699 & 5.6196 & TST & \\
\hline CHEMBL 3934139 & 1642432 & 5.4647 & 6.1087 & TST & \\
\hline CHEMBL 3920923 & 1642432 & 3.699 & 5.0212 & TST & \\
\hline CHEMBL 3974190 & 1642432 & 4.9788 & 4.9213 & TST & \\
\hline CHEMBL 3908457 & 1642432 & 5.2676 & 5.3979 & TST & \\
\hline CHEMBL 3973928 & 1642432 & 5.0146 & 5.3964 & TST & \\
\hline CHEMBL 3897089 & 1642432 & 5.6615 & 5.5857 & TST & \\
\hline CHEMBL 3967202 & 1642432 & 5.8125 & 5.5515 & TST & \\
\hline CHEMBL 3946193 & 1642432 & 3.699 & 5.0088 & TST & \\
\hline CHEMBL 3984908 & 1642432 & 6.2684 & 5.7457 & TST & \\
\hline
\end{tabular}

Page 24323 
Supplemental Table S2.txt

\begin{tabular}{|c|c|c|c|c|}
\hline CHEMBL 3963035 & 1642432 & 6.0405 & 5.6256 & TST \\
\hline CHEMBL 3960413 & 1642432 & 5.9747 & 5.7334 & TST \\
\hline CHEMBL3944766 & 1642432 & 6.0 & 5.7772 & TST \\
\hline CHEMBL3903188 & 1642432 & 3.699 & 4.7085 & TST \\
\hline CHEMBL 3980540 & 1642432 & 5.4089 & 5.4034 & TST \\
\hline CHEMBL 3958532 & 1642432 & 5.5129 & \multicolumn{2}{|c|}{5.3020000000000005} \\
\hline CHEMBL 3978612 & 1642432 & 6.2765 & 6.1689 & TST \\
\hline CHEMBL 3970944 & 1642432 & 3.699 & 5.8046 & TST \\
\hline CHEMBL 3906532 & 1642432 & 5.0209 & 5.1811 & TST \\
\hline CHEMBL 3970762 & 1642432 & 5.9747 & 5.7482 & TST \\
\hline CHEMBL 3933564 & 1642432 & 5.9355 & 6.2016 & TST \\
\hline CHEMBL 3969113 & 1642432 & 5.7696 & 5.9126 & TST \\
\hline CHEMBL 3921936 & 1642432 & 6.6536 & 6.4543 & TST \\
\hline CHEMBL 3899383 & 1642432 & 6.0799 & \multicolumn{2}{|c|}{5.797000000000001} \\
\hline CHEMBL 3897463 & 1642432 & 5.1035 & 5.2034 & TST \\
\hline CHEMBL 3920998 & 1642432 & 5.0269 & 5.4364 & TST \\
\hline CHEMBL3962962 & 1642432 & 3.699 & 4.9953 & TST \\
\hline CHEMBL 3945672 & 1642432 & 3.699 & 5.3302 & TST \\
\hline CHEMBL 3921067 & 1642432 & 6.2321 & 5.8074 & TST \\
\hline CHEMBL 3942780 & 1642432 & 5.5058 & 5.7351 & TST \\
\hline CHEMBL3956615 & 1642432 & 4.9872 & 5.3053 & TST \\
\hline CHEMBL3981930 & 1642432 & 5.3089 & \multicolumn{2}{|c|}{5.1339999999999995} \\
\hline CHEMBL 3985291 & 1642432 & 5.767 & 5.8919 & TST \\
\hline CHEMBL 3962010 & 1642432 & 6.0 & 5.4206 & TST \\
\hline CHEMBL575426 & 587660 & 3.0 & 2.9126 & TRN \\
\hline CHEMBL572646 & 587660 & 3.0458 & 3.0526 & TRN \\
\hline CHEMBL583512 & 587660 & 3.699 & 4.1061 & TRN \\
\hline CHEMBL573607 & 587660 & 3.5229 & 4.1352 & TRN \\
\hline CHEMBL575656 & 587660 & 3.0 & 3.9447 & TST \\
\hline CHEMBL573372 & 587660 & 3.0 & 3.3657 & TRN \\
\hline CHEMBL572449 & 587660 & 3.0 & 3.0201 & TRN \\
\hline CHEMBL573850 & 587660 & 3.0969 & 2.8834 & TRN \\
\hline CHEMBL575210 & 587660 & 3.0809 & 2.8447 & TRN \\
\hline CHEMBL573370 & 587660 & 4.1487 & 3.56 & TST \\
\hline CHEMBL574095 & 587660 & 5.2218 & 4.0697 & TRN \\
\hline CHEMBL573864 & 587660 & 3.0458 & 2.8025 & TRN \\
\hline CHEMBL573618 & 587660 & 4.9208 & 4.1244 & TRN \\
\hline CHEMBL573608 & 587660 & 3.8239 & 3.3774 & TST \\
\hline CHEMBL577182 & 587660 & 3.0969 & 3.912 & TRN \\
\hline CHEMBL572677 & 587660 & 4.8861 & 3.7042 & TRN \\
\hline CHEMBL583948 & 587660 & 4.301 & 3.6874 & TRN \\
\hline CHEMBL575861 & 587660 & 3.2218 & 3.5693 & TST \\
\hline CHEMBL573542 & 587660 & 3.0458 & 3.0931 & TRN \\
\hline CHEMBL573371 & 587660 & 4.5229 & 3.8442 & TRN \\
\hline CHEMBL573852 & 587660 & 3.0969 & 3.3591 & TST \\
\hline CHEMBL583763 & 587660 & 3.2366 & 3.7285 & TRN \\
\hline CHEMBL575433 & 587660 & 3.2218 & 3.4925 & TRN \\
\hline CHEMBL575208 & 587660 & 3.0969 & 3.3896 & TST \\
\hline
\end{tabular}




\begin{tabular}{|c|c|c|c|c|}
\hline \multirow[b]{2}{*}{ CHEMBL573619 } & \multicolumn{4}{|c|}{ Supplemental Table S2.txt } \\
\hline & 587660 & 3.0 & 3.2576 & TRN \\
\hline CHEMBL573369 & 587660 & 4.8539 & 3.7534 & TRN \\
\hline CHEMBL573624 & 587660 & 3.0 & 2.9431 & TRN \\
\hline CHEMBL 574100 & 587660 & 3.0 & 3.4588 & TRN \\
\hline CHEMBL574101 & 587660 & 3.0 & 2.9788 & TRN \\
\hline CHEMBL573611 & 587660 & 5.0969 & 4.0883 & TRN \\
\hline CHEMBL574322 & 587660 & 3.0969 & 3.5711 & TST \\
\hline CHEMBL575657 & 587660 & 3.1249 & 3.6484 & TRN \\
\hline CHEMBL 575652 & 587660 & 3.0 & 3.9109 & TRN \\
\hline CHEMBL585009 & 587660 & 3.2596 & 3.1664 & TRN \\
\hline CHEMBL574549 & 587660 & 3.301 & 3.3689 & TST \\
\hline CHEMBL575432 & 587660 & 3.0 & 3.6651 & TRN \\
\hline CHEMBL 573752 & 587660 & 4.4559 & 3.3089 & TST \\
\hline CHEMBL583379 & 587660 & 3.3979 & 3.6977 & TRN \\
\hline CHEMBL573626 & 587660 & 3.0 & 3.9574 & TRN \\
\hline CHEMBL573606 & 587660 & 3.5229 & 3.9416 & TRN \\
\hline CHEMBL573609 & 587660 & 3.1871 & 3.9149 & TRN \\
\hline CHEMBL573132 & 587660 & 3.3979 & 3.6955 & TRN \\
\hline CHEMBL 575862 & 587660 & 3.4815 & 3.6356 & TRN \\
\hline CHEMBL 573842 & 587660 & 4.9586 & 3.5514 & TRN \\
\hline CHEMBL575651 & 587660 & 5.0458 & 4.109 & TRN \\
\hline CHEMBL564201 & 587660 & 3.699 & 3.4673 & TST \\
\hline CHEMBL575209 & 587660 & 4.1549 & 4.1483 & TRN \\
\hline CHEMBL573541 & 587660 & 3.0 & 3.0126 & TRN \\
\hline CHEMBL573627 & 587660 & 3.0 & 3.4973 & TRN \\
\hline CHEMBL575650 & 587660 & 3.5229 & 3.9139 & TRN \\
\hline CHEMBL575655 & 587660 & 5.0 & 3.7551 & TRN \\
\hline CHEMBL573628 & 587660 & 3.0 & 2.9938 & TRN \\
\hline CHEMBL573352 & 587660 & 4.6198 & 3.3973 & TST \\
\hline CHEMBL573625 & 587660 & 3.301 & 3.8768 & TRN \\
\hline CHEMBL584804 & 587660 & 3.0 & 3.5 & TRN \\
\hline CHEMBL584359 & 587660 & 3.301 & 3.7011 & TRN \\
\hline CHEMBL574096 & 587660 & 3.2366 & 2.9052 & TST \\
\hline CHEMBL573540 & 587660 & 3.0458 & 4.0352 & TST \\
\hline CHEMBL573539 & 587660 & 3.0706 & 2.9886 & TST \\
\hline CHEMBL418899 & 587660 & 4.699 & 3.4729 & TST \\
\hline CHEMBL583739 & 587660 & 4.6021 & 2.9651 & TST \\
\hline CHEMBL 3983082 & 1625735 & 4.0 & 4.3753 & TRN \\
\hline CHEMBL 3986751 & 1625735 & 5.0757 & 5.092 & TRN \\
\hline CHEMBL 3977048 & 1625735 & 4.0 & 4.3592 & TST \\
\hline CHEMBL3929358 & 1625735 & 4.0 & 4.9053 & TRN \\
\hline CHEMBL 3105681 & 1625735 & 4.0 & 4.6085 & TST \\
\hline CHEMBL3911834 & 1625735 & 4.0 & 3.9732 & TRN \\
\hline CHEMBL 3957141 & 1625735 & 5.1675 & 5.1273 & TRN \\
\hline CHEMBL 3943864 & 1625735 & 4.0 & 5.016 & TRN \\
\hline CHEMBL3961289 & 1625735 & 4.0 & 4.0837 & TRN \\
\hline CHEMBL3947885 & 1625735 & 5.3468 & 4.9415 & TRN \\
\hline CHEMBL 3914641 & 1625735 & 4.0 & 3.8896 & TRN \\
\hline
\end{tabular}


Supplemental Table S2.txt

\begin{tabular}{|c|c|c|c|c|c|}
\hline CHEMBL3933815 & 1625735 & 5.2518 & \multicolumn{2}{|c|}{5.1339999999999995} & TRN \\
\hline CHEMBL3982499 & 1625735 & 5.2441 & 5.0092 & TST & \\
\hline CHEMBL3905660 & 1625735 & 5.3872 & 4.6595 & TRN & \\
\hline CHEMBL3979349 & 1625735 & 4.0 & 4.579 & TRN & \\
\hline CHEMBL3948459 & 1625735 & 5.4559 & 4.2273 & TRN & \\
\hline CHEMBL3922245 & 1625735 & 4.0 & 4.9773 & TRN & \\
\hline CHEMBL3896717 & 1625735 & 4.0 & 4.1679 & TRN & \\
\hline CHEMBL3924898 & 1625735 & 4.0 & \multicolumn{2}{|c|}{4.2989999999999995} & TST \\
\hline CHEMBL3920454 & 1625735 & 5.2076 & 4.993 & TRN & \\
\hline CHEMBL3956929 & 1625735 & 5.1675 & 5.1671 & TRN & \\
\hline CHEMBL3951385 & 1625735 & 5.5686 & 4.718 & TRN & \\
\hline CHEMBL3894222 & 1625735 & 6.0969 & 5.0503 & TRN & \\
\hline CHEMBL3976477 & 1625735 & 5.041 & 5.0018 & TST & \\
\hline CHEMBL3942648 & 1625735 & 4.0 & 3.8743 & TRN & \\
\hline CHEMBL3939711 & 1625735 & 4.0 & 4.0281 & TRN & \\
\hline CHEMBL3948265 & 1625735 & 4.0 & 4.9471 & TRN & \\
\hline CHEMBL3938602 & 1625735 & 4.0 & 4.173 & TRN & \\
\hline CHEMBL3947182 & 1625735 & 4.0 & 5.0097 & TRN & \\
\hline CHEMBL3928131 & 1625735 & 5.9586 & 5.0238 & TRN & \\
\hline CHEMBL3924764 & 1625735 & 4.0 & 4.0941 & TRN & \\
\hline CHEMBL3938989 & 1625735 & 4.0 & 4.0358 & TRN & \\
\hline CHEMBL3933686 & 1625735 & 4.0 & 4.6581 & TRN & \\
\hline CHEMBL3929577 & 1625735 & 4.0 & 4.2541 & TRN & \\
\hline CHEMBL3923672 & 1625735 & 4.0 & 4.0767 & TRN & \\
\hline CHEMBL3915908 & 1625735 & 4.0 & 4.0809 & TRN & \\
\hline CHEMBL3920663 & 1625735 & 4.0 & 4.0818 & TRN & \\
\hline CHEMBL3911731 & 1625735 & 4.0 & 4.1097 & TRN & \\
\hline CHEMBL3912204 & 1625735 & 4.0 & 4.186 & TRN & \\
\hline CHEMBL3968165 & 1625735 & 5.8539 & 5.2024 & TRN & \\
\hline CHEMBL3967961 & 1625735 & 5.7212 & 5.1749 & TRN & \\
\hline CHEMBL3931161 & 1625735 & 5.1427 & 4.3139 & TRN & \\
\hline CHEMBL3956564 & 1625735 & 4.0 & 4.2061 & TST & \\
\hline CHEMBL3950318 & 1625735 & 5.3768 & 4.5593 & TST & \\
\hline CHEMBL3940207 & 1625735 & 5.1135 & 4.5623 & TST & \\
\hline CHEMBL3942787 & 1625735 & 5.3565 & 5.0098 & TST & \\
\hline CHEMBL3938404 & 1625735 & 5.4202 & 5.1283 & TST & \\
\hline CHEMBL3977144 & 1625735 & 5.8539 & 4.9482 & TST & \\
\hline CHEMBL3218921 & 1625735 & 5.8861 & 5.1255 & TST & \\
\hline CHEMBL3913238 & 1625735 & 5.1192 & 4.9637 & TST & \\
\hline CHEMBL1522986 & 752406 & 4.7077 & 4.0071 & TRN & \\
\hline CHEMBL1380676 & 752406 & 3.9487 & 4.0665 & TRN & \\
\hline CHEMBL1412067 & 752406 & 5.7986 & 6.4741 & TRN & \\
\hline CHEMBL1416556 & 752406 & 4.9477 & 4.5904 & TRN & \\
\hline CHEMBL1725771 & 752406 & 5.5467 & 6.12299 & 9999999999 & TRN \\
\hline CHEMBL1544136 & 752406 & 4.9682 & 4.426 & TST & \\
\hline CHEMBL498373 & 752406 & 5.0851 & 4.3192 & TST & \\
\hline CHEMBL1524257 & 752406 & 5.7471 & 5.92399 & 99999999995 & TRN \\
\hline CHEMBL3191733 & 752406 & 2.301 & 3.5672 & TRN & \\
\hline
\end{tabular}




\begin{tabular}{|c|c|c|c|c|c|}
\hline & & & & & \\
\hline CHEMBL1426267 & 752406 & 4.3593 & 4.0988 & TRN & \\
\hline CHEMBL1500251 & 752406 & 5.5045 & 5.9822 & TRN & \\
\hline CHEMBL1398345 & 752406 & 5.8327 & 6.1976 & TRN & \\
\hline CHEMBL1569232 & 752406 & 5.9208 & 6.1565 & TRN & \\
\hline CHEMBL1428985 & 752406 & 2.301 & 4.1448 & TRN & \\
\hline CHEMBL1494852 & 752406 & 5.6402 & 4.8537 & TRN & \\
\hline CHEMBL1441284 & 752406 & 3.5768 & 4.0206 & TST & \\
\hline CHEMBL1473205 & 752406 & 5.2299 & $4.60800 t$ & 00000000005 & TST \\
\hline CHEMBL1374927 & 752406 & 4.414 & 3.9301 & TST & \\
\hline CHEMBL1439525 & 752406 & 3.7522 & 3.8297 & TST & \\
\hline CHEMBL1508452 & 752406 & 4.2314 & 5.0499 & TRN & \\
\hline CHEMBL1374066 & 752406 & 5.0996 & 4.6678 & TST & \\
\hline CHEMBL391877 & 752406 & 4.2863 & 4.255 & TRN & \\
\hline CHEMBL1434843 & 752406 & 4.1406 & 4.128 & TRN & \\
\hline CHEMBL1394204 & 752406 & 4.0847 & 4.2274 & TRN & \\
\hline CHEMBL1304357 & 752406 & 4.2365 & 4.1574 & TST & \\
\hline CHEMBL1606122 & 752406 & 6.2154 & 5.9054 & TRN & \\
\hline CHEMBL1300474 & 752406 & 6.6968 & 3.9686 & TST & \\
\hline CHEMBL1423797 & 752406 & 4.0063 & 4.0172 & TRN & \\
\hline CHEMBL1864540 & 752406 & 5.1226 & 4.0593 & TRN & \\
\hline CHEMBL1313968 & 752406 & 5.2815 & 4.4378 & TRN & \\
\hline CHEMBL1713654 & 752406 & 5.4157 & 5.0187 & TRN & \\
\hline CHEMBL1401536 & 752406 & 3.5076 & 4.4647 & TRN & \\
\hline CHEMBL1390056 & 752406 & 4.4989 & 4.2653 & TRN & \\
\hline CHEMBL1400992 & 752406 & 3.6997 & 3.7279 & TRN & \\
\hline CHEMBL1416195 & 752406 & 3.6066 & 3.9249 & TRN & \\
\hline CHEMBL1412077 & 752406 & 6.4486 & 5.5968 & TRN & \\
\hline CHEMBL1506185 & 752406 & 6.2848 & 5.921 & TRN & \\
\hline CHEMBL1436864 & 752406 & 5.2269 & 4.2173 & TRN & \\
\hline CHEMBL1390971 & 752406 & 5.857 & 6.1778 & TRN & \\
\hline CHEMBL1370536 & 752406 & 4.198 & 4.375 & TST & \\
\hline CHEMBL1316831 & 752406 & 4.8536 & 4.2275 & TST & \\
\hline CHEMBL1868202 & 752406 & 3.7963 & 3.6254 & TRN & \\
\hline CHEMBL601385 & 752406 & 3.8386 & 4.0922 & TRN & \\
\hline CHEMBL1428663 & 752406 & 3.9423 & 4.4797 & TRN & \\
\hline CHEMBL1891482 & 752406 & 3.3736 & 4.0497 & TST & \\
\hline CHEMBL 2003304 & 752406 & 6.0615 & 5.7832 & TRN & \\
\hline CHEMBL1342725 & 752406 & 4.1548 & 3.8815 & TRN & \\
\hline CHEMBL1352113 & 752406 & 5.5784 & 5.0063 & TRN & \\
\hline CHEMBL1370447 & 752406 & 3.889 & 4.396 & TRN & \\
\hline CHEMBL1590632 & 752406 & 4.3203 & 4.1433 & TRN & \\
\hline CHEMBL1999960 & 752406 & 3.8302 & 4.0154 & TST & \\
\hline CHEMBL1517883 & 752406 & 5.71899 & 99999999 & 6.0787 & TRN \\
\hline CHEMBL1598570 & 752406 & 4.0415 & 3.7919 & TST & \\
\hline CHEMBL1496231 & 752406 & 5.5544 & 4.903006 & 20000000005 & TRN \\
\hline CHEMBL1725731 & 752406 & 2.301 & 3.5264 & TRN & \\
\hline CHEMBL2001481 & 752406 & 4.1663 & 4.4156 & TRN & \\
\hline CHEMBL1419680 & 752406 & 4.5426 & 4.0843 & TRN & \\
\hline
\end{tabular}




\begin{tabular}{|c|c|c|c|c|c|}
\hline & & & & & \\
\hline CHEMBL1340920 & 752406 & 4.3341 & 3.9758 & TRN & \\
\hline CHEMBL1522563 & 752406 & 5.4112 & 5.2793 & TRN & \\
\hline CHEMBL1501987 & 752406 & 5.6162 & 5.0854 & TRN & \\
\hline CHEMBL1351229 & 752406 & 4.3779 & 4.3895 & TRN & \\
\hline CHEMBL1420548 & 752406 & 4.3464 & 4.1309 & TRN & \\
\hline CHEMBL1521250 & 752406 & 3.7673 & 4.0419 & TRN & \\
\hline CHEMBL1538590 & 752406 & 4.038 & 4.3043 & TRN & \\
\hline CHEMBL1713905 & 752406 & 6.1367 & 5.9006 & TRN & \\
\hline CHEMBL1429070 & 752406 & 5.4473 & 5.3024 & TRN & \\
\hline CHEMBL1990694 & 752406 & 5.983 & 5.7597 & TRN & \\
\hline CHEMBL1510317 & 752406 & 5.6326 & 5.0981 & TRN & \\
\hline CHEMBL1503134 & 752406 & 4.3554 & 3.997 & TRN & \\
\hline CHEMBL1402956 & 752406 & 3.8887 & 4.3089 & TST & \\
\hline CHEMBL1492232 & 752406 & 3.8208 & 4.7675 & TRN & \\
\hline CHEMBL1469444 & 752406 & 4.265 & 4.3939 & TRN & \\
\hline CHEMBL1459162 & 752406 & 4.184 & 4.1326 & TRN & \\
\hline CHEMBL1498441 & 752406 & 4.4472 & 4.1392 & TRN & \\
\hline CHEMBL1464060 & 752406 & 4.7158 & 4.5198 & TRN & \\
\hline CHEMBL1734889 & 752406 & 4.2793 & 4.1093 & TST & \\
\hline CHEMBL1727779 & 752406 & 5.2336 & 4.2028 & TST & \\
\hline CHEMBL1476797 & 752406 & 4.1431 & 4.7954 & TST & \\
\hline CHEMBL1320447 & 752406 & 3.9692 & 3.9564 & TST & \\
\hline CHEMBL1537601 & 752406 & 4.4939 & 4.0652 & TST & \\
\hline CHEMBL3667634 & 1528772 & 7.4647 & 7.7243 & TRN & \\
\hline CHEMBL3667627 & 1528772 & 8.3565 & 8.0775 & TRN & \\
\hline CHEMBL3667655 & 1528772 & 8.8861 & 8.3898 & TST & \\
\hline CHEMBL3667644 & 1528772 & 8.5086 & 7.6703 & TST & \\
\hline CHEMBL3667651 & 1528772 & 8.8239 & 9.0276 & TST & \\
\hline CHEMBL3667641 & 1528772 & 8.8239 & 8.2966 & TRN & \\
\hline CHEMBL3667647 & 1528772 & 8.8239 & 8.9185 & TRN & \\
\hline CHEMBL3639664 & 1528772 & 8.6383 & 8.6072 & TRN & \\
\hline CHEMBL3667618 & 1528772 & 8.9208 & 8.6686 & TRN & \\
\hline CHEMBL3667639 & 1528772 & 9.301 & 8.2343 & TRN & \\
\hline CHEMBL3667625 & 1528772 & 7.7055 & 8.0221 & TRN & \\
\hline CHEMBL3667648 & 1528772 & 9.1549 & 8.8508 & TST & \\
\hline CHEMBL3667615 & 1528772 & 8.041 & 8.5299 & TRN & \\
\hline CHEMBL3667628 & 1528772 & 6.5065 & 7.99200 & 0000000001 & TRN \\
\hline CHEMBL3667649 & 1528772 & 8.3872 & 8.8479 & TST & \\
\hline CHEMBL3667660 & 1528772 & 5.9508 & 8.7286 & TST & \\
\hline CHEMBL3667621 & 1528772 & 8.7959 & 8.8656 & TRN & \\
\hline CHEMBL3667637 & 1528772 & 9.0969 & 8.045 & TST & \\
\hline CHEMBL3667613 & 1528772 & 9.0 & 8.6587 & TRN & \\
\hline CHEMBL3667662 & 1528772 & 10.0 & 9.1729 & TRN & \\
\hline CHEMBL3667614 & 1528772 & 7.8013 & 8.0276 & TRN & \\
\hline CHEMBL3667638 & 1528772 & 9.0458 & 8.0517 & TST & \\
\hline CHEMBL3667636 & 1528772 & 8.3279 & 8.3796 & TRN & \\
\hline CHEMBL3667632 & 1528772 & 8.9586 & 8.9236 & TRN & \\
\hline CHEMBL3667635 & 1528772 & 8.1739 & 8.2889 & TRN & \\
\hline
\end{tabular}

Page 24328 
Supplemental Table S2.txt

\begin{tabular}{|c|c|c|c|c|c|}
\hline CHEMBL 3667620 & 1528772 & 8.2676 & 8.4943 & TRN & \\
\hline CHEMBL3667626 & 1528772 & 7.8894 & 7.235 & TRN & \\
\hline CHEMBL3667616 & 1528772 & 8.4318 & 8.5801 & TRN & \\
\hline CHEMBL3667623 & 1528772 & 8.1549 & 7.8323 & TRN & \\
\hline CHEMBL3667619 & 1528772 & 7.8539 & 8.6281 & TRN & \\
\hline CHEMBL3667611 & 1528772 & 8.4949 & 8.3912 & TRN & \\
\hline CHEMBL3667642 & 1528772 & 8.7959 & 8.4213 & TRN & \\
\hline CHEMBL3667652 & 1528772 & 8.7696 & 9.1598 & TRN & \\
\hline CHEMBL3667609 & 1528772 & 9.1549 & 8.8519 & TRN & \\
\hline CHEMBL3667650 & 1528772 & 8.7447 & 9.0842 & TRN & \\
\hline CHEMBL 3667640 & 1528772 & 8.2147 & 8.2217 & TST & \\
\hline CHEMBL3667654 & 1528772 & 8.4949 & 8.4064 & TST & \\
\hline CHEMBL3667629 & 1528772 & 7.3497 & 7.8141 & TRN & \\
\hline CHEMBL3667608 & 1528772 & 9.5229 & 9.0984 & TRN & \\
\hline CHEMBL3667631 & 1528772 & 9.1549 & 8.3287 & TRN & \\
\hline CHEMBL3667653 & 1528772 & 9.3979 & 9.2229 & TST & \\
\hline CHEMBL3667643 & 1528772 & 7.8794 & 7.7005 & TST & \\
\hline CHEMBL 3667645 & 1528772 & 9.0458 & 9.2344 & TRN & \\
\hline CHEMBL3667610 & 1528772 & 8.4089 & 8.4686 & TRN & \\
\hline CHEMBL3667659 & 1528772 & 8.2147 & 9.1668 & TST & \\
\hline CHEMBL3667656 & 1528772 & 7.6021 & 8.5839 & TRN & \\
\hline CHEMBL3667633 & 1528772 & 8.5686 & 8.3878 & TRN & \\
\hline CHEMBL3667646 & 1528772 & 9.0458 & 8.9055 & TRN & \\
\hline CHEMBL3667624 & 1528772 & 8.6383 & 8.2743 & TRN & \\
\hline CHEMBL3667617 & 1528772 & 8.9208 & 8.8876 & TRN & \\
\hline CHEMBL3667658 & 1528772 & 8.2518 & 8.32 & TST & \\
\hline CHEMBL3667630 & 1528772 & 7.6556 & 7.8798 & TRN & \\
\hline CHEMBL3667612 & 1528772 & 8.8861 & 9.0677 & TRN & \\
\hline CHEMBL 290331 & 933062 & 10.22 & 10.2682 & TRN & \\
\hline CHEMBL 2296983 & 933062 & 10.1 & 10.0691 & TRN & \\
\hline CHEMBL 2296982 & 933062 & 7.36 & 7.412000 & 0000000001 & TRN \\
\hline CHEMBL 2296981 & 933062 & 10.52 & 8.6231 & TST & \\
\hline CHEMBL113884 & 933062 & 10.1 & 8.7874 & TST & \\
\hline CHEMBL286390 & 933062 & 9.6 & 9.3134 & TRN & \\
\hline CHEMBL 2296978 & 933062 & 7.85 & 7.8516 & TRN & \\
\hline CHEMBL 2296977 & 933062 & 7.0 & 7.0096 & TRN & \\
\hline CHEMBL 2296976 & 933062 & 10.0 & 9.8462 & TRN & \\
\hline CHEMBL289393 & 933062 & 8.8 & 8.9122 & TRN & \\
\hline CHEMBL 2296974 & 933062 & 9.89 & 9.9438 & TRN & \\
\hline CHEMBL 2296973 & 933062 & 9.55 & 9.8701 & TRN & \\
\hline CHEMBL 2296972 & 933062 & 9.19 & 9.2956 & TRN & \\
\hline CHEMBL287520 & 933062 & 7.4 & 7.3684 & TRN & \\
\hline CHEMBL289934 & 933062 & 7.48 & 7.3684 & TRN & \\
\hline CHEMBL 37472 & 933062 & 8.92 & 8.7585 & TRN & \\
\hline CHEMBL 2296968 & 933062 & 9.42 & 9.165 & TRN & \\
\hline CHEMBL416964 & 933062 & 8.85 & 9.0652 & TRN & \\
\hline CHEMBL286159 & 933062 & 9.62 & 9.7395 & TRN & \\
\hline CHEMBL37701 & 933062 & 7.85 & 7.8064 & TRN & \\
\hline
\end{tabular}




\begin{tabular}{|c|c|c|c|c|c|}
\hline \multicolumn{6}{|c|}{ Supplemental Table S2.txt } \\
\hline CHEMBL38281 & 933062 & 8.25 & 8.2095 & TRN & \\
\hline CHEMBL 287818 & 933062 & 6.96 & 7.0668 & TRN & \\
\hline CHEMBL37033 & 933062 & 7.96 & 7.8799 & TRN & \\
\hline CHEMBL 37313 & 933062 & 7.92 & 7.9152 & TRN & \\
\hline CHEMBL2296960 & 933062 & 10.52 & 10.2066 & TRN & \\
\hline CHEMBL290254 & 933062 & 10.0 & 10.2137 & TRN & \\
\hline CHEMBL 288254 & 933062 & 10.22 & 10.3673 & TRN & \\
\hline CHEMBL2296957 & 933062 & 10.0 & 9.0152 & TST & \\
\hline CHEMBL 285282 & 933062 & 7.64 & 7.6237 & TRN & \\
\hline CHEMBL39592 & 933062 & 8.1 & 8.3356 & TRN & \\
\hline CHEMBL36862 & 933062 & 8.77 & 8.9704 & TRN & \\
\hline CHEMBL2296699 & 933062 & 10.22 & 10.1155 & TRN & \\
\hline CHEMBL2296698 & 933062 & 11.0 & 10.9586 & TRN & \\
\hline CHEMBL2296697 & 933062 & 10.7 & 10.5464 & TRN & \\
\hline CHEMBL2296696 & 933062 & 10.7 & 10.82 & TRN & \\
\hline CHEMBL 288261 & 933062 & 9.82 & 9.9113 & TRN & \\
\hline CHEMBL284941 & 933062 & 9.51 & 9.4658 & TRN & \\
\hline CHEMBL 284340 & 933062 & 10.05 & 9.8863 & TRN & \\
\hline CHEMBL 286693 & 933062 & 9.04 & 8.9083 & TRN & \\
\hline CHEMBL38339 & 933062 & 7.96 & 7.9758 & TRN & \\
\hline CHEMBL 288513 & 933062 & 8.21 & 7.1261 & TST & \\
\hline CHEMBL 286794 & 933062 & 6.8 & 7.584 & TST & \\
\hline CHEMBL37639 & 933062 & 7.82 & 7.5088 & TST & \\
\hline CHEMBL288239 & 933062 & 7.18 & 6.6131 & TST & \\
\hline CHEMBL39432 & 933062 & 6.49 & 6.2593 & TST & \\
\hline CHEMBL 2296685 & 933062 & 6.27 & 7.1881 & TST & \\
\hline CHEMBL39747 & 933062 & 6.73 & 6.7786 & TST & \\
\hline CHEMBL36481 & 933062 & 6.01 & 5.6203 & TST & \\
\hline CHEMBL2296986 & 933062 & 7.64 & 7.671 & TST & \\
\hline CHEMBL39749 & 933062 & 7.82 & 7.3973 & TST & \\
\hline CHEMBL142738 & 124418 & 6.72 & 5.989 & TST & \\
\hline CHEMBL143555 & 124418 & 8.24 & 8.0468 & TRN & \\
\hline CHEMBL357614 & 124418 & 8.23 & 8.1709 & TRN & \\
\hline CHEMBL 356977 & 124418 & 8.59 & 8.2645 & TRN & \\
\hline CHEMBL146439 & 124418 & 5.59 & 5.7766 & TRN & \\
\hline CHEMBL145007 & 124418 & 4.23 & 4.8673 & TRN & \\
\hline CHEMBL142923 & 124418 & 8.13 & 8.0373 & TRN & \\
\hline CHEMBL356734 & 124418 & 6.3 & 5.9385 & TST & \\
\hline CHEMBL 356714 & 124418 & 7.97 & 8.06200 & 3000000001 & TRN \\
\hline CHEMBL145217 & 124418 & 8.19 & 8.1112 & TRN & \\
\hline CHEMBL359392 & 124418 & 6.49 & 6.4567 & TRN & \\
\hline CHEMBL109018 & 124418 & 8.48 & 8.8051 & TRN & \\
\hline CHEMBL143274 & 124418 & 5.17 & 5.3685 & TRN & \\
\hline CHEMBL145781 & 124418 & 7.26 & 6.6344 & TRN & \\
\hline CHEMBL342724 & 124418 & 5.51 & 5.2606 & TRN & \\
\hline CHEMBL342327 & 124418 & 7.64 & 7.7433 & TRN & \\
\hline CHEMBL145792 & 124418 & 8.43 & 8.2686 & TRN & \\
\hline CHEMBL109084 & 124418 & 8.25 & 8.2465 & TRN & \\
\hline
\end{tabular}




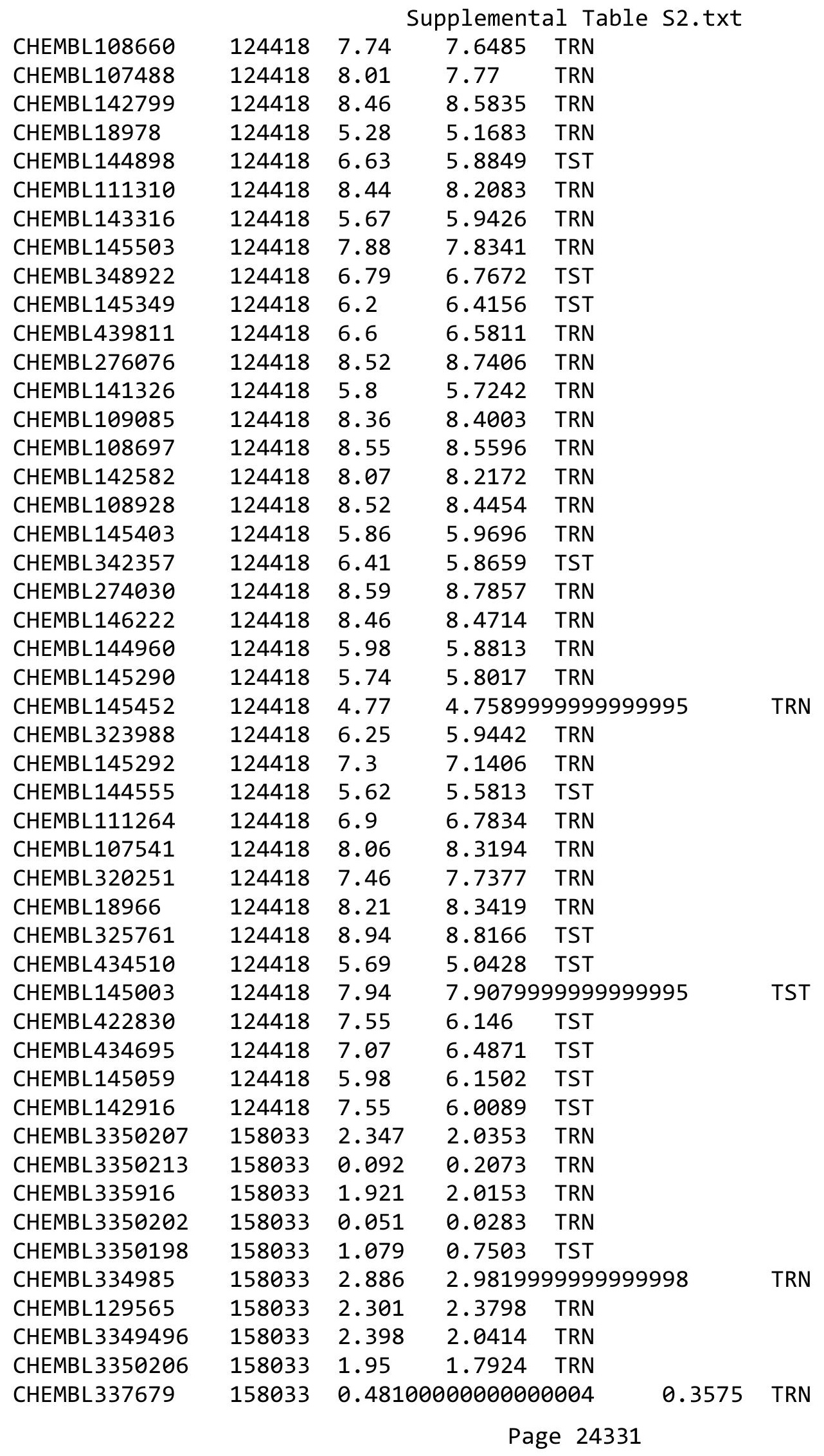




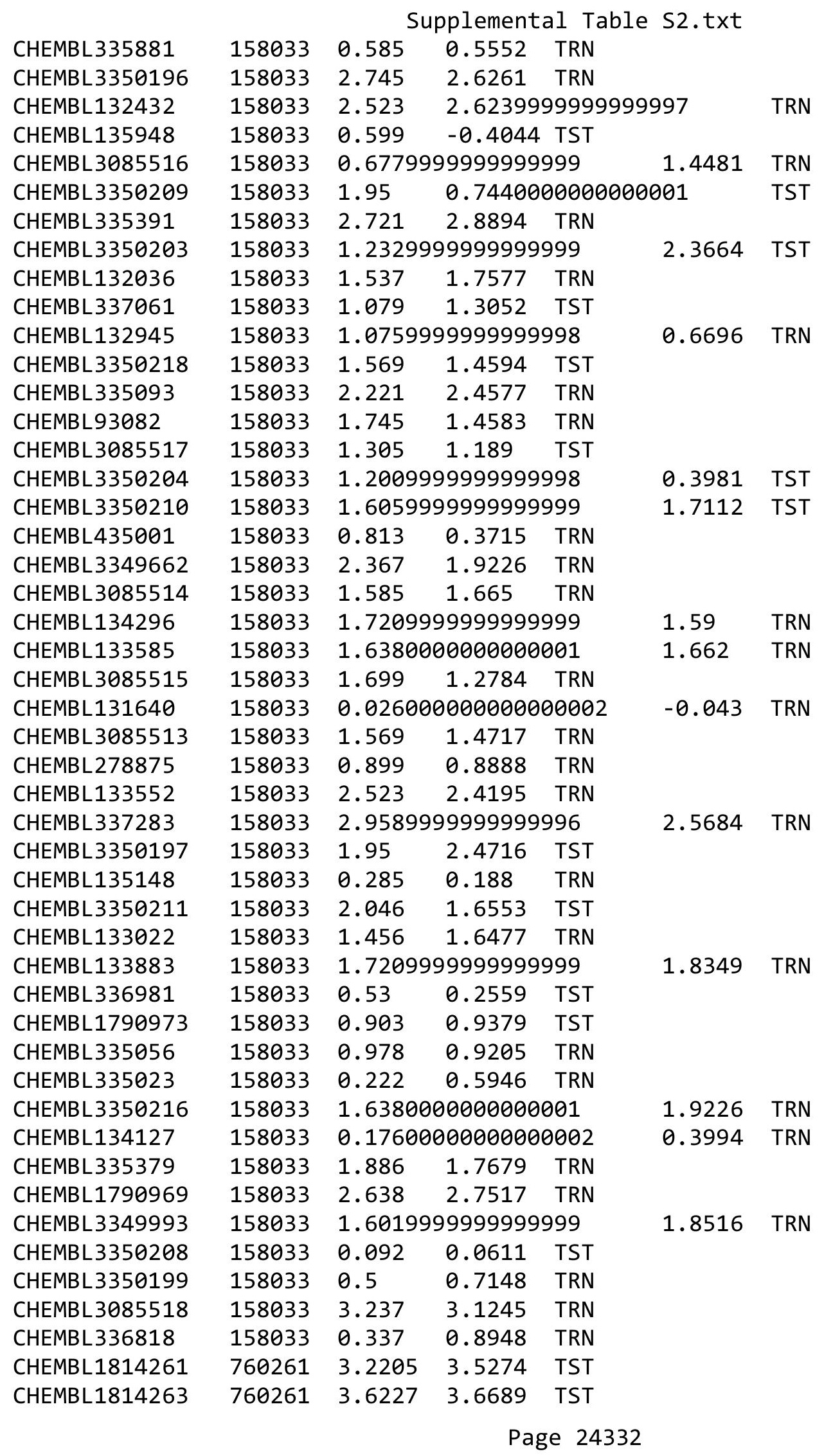


Supplemental Table S2.txt

\begin{tabular}{|c|c|c|c|c|}
\hline & & & & \\
\hline HEMBL1814372 & 60261 & 2.0969 & & \\
\hline HEMBL1814029 & 0261 & 3311 & & \\
\hline 1214 & 0261 & 972 & & \\
\hline EMBL18 & 0261 & 1739 & & \\
\hline AEMBL1814018 & 50261 & 8633 & & \\
\hline HEMBL1814212 & 60261 & .2774 & 4.8879 & \\
\hline HEMBL1814034 & 50261 & .1805 & & \\
\hline IEMBL1 & 50261 & 0969 & & \\
\hline IEMBL] & 50261 & .5607 & & \\
\hline HEMBL1814376 & 50261 & .7183 & 031 & \\
\hline HEMBL1814021 & 60261 & .7375 & & \\
\hline HEMBL1\& & 60261 & 5002 & & \\
\hline IEMBL: & 50261 & .0883 & & \\
\hline AEMBL: & 60261 & 3979 & & \\
\hline AEMBL1814030 & 60261 & .5334 & 074 & \\
\hline AEMBL1814373 & 60261 & & & \\
\hline HEMBL: & 60261 & 4.6308 & & \\
\hline AEMBL: & 60261 & 24 & & \\
\hline AEMBL: & 51 & 565 & & \\
\hline IEMBL1 & 50261 & .279 & & \\
\hline AEMBL1\& & 60261 & 56 & & \\
\hline HEMBLI & 60261 & 49 & & \\
\hline EMBL & 60261 & 38 & & \\
\hline AEMB & 51 & 88 & & \\
\hline IEMBL: & 50261 & 3.423 & & \\
\hline AEMBL1\& & 60261 & & & \\
\hline HEMBL: & 60261 & 3.7878 & & \\
\hline IEMB & 51 & 96 & & \\
\hline EMB & 51 & 3.5025 & & \\
\hline IEMBL: & & & & \\
\hline AEMBL1 & 60261 & 3.201 & & \\
\hline AEMBL & 61 & 59 & & \\
\hline $15 \mathrm{MC}$ & 1 & 51 & & \\
\hline EM & 51 & 44 & & RN \\
\hline EMBL1 & & & & \\
\hline AEMBL1 & 60261 & 2.0969 & & \\
\hline-17 & 51 & & & \\
\hline 4 & 51 & 05 & & \\
\hline & & & & $\mathrm{RN}$ \\
\hline AEMBL1 & 60261 & 353 & & \\
\hline AEMBL: & 60261 & 4. & & \\
\hline CHEME & & & & \\
\hline CHEMBL: & 60261 & & & \\
\hline CHEMBL & 60261 & & & $\mathrm{RI}$ \\
\hline IEMBL: & 50261 & 2.0969 & 85 & \\
\hline HEMBL: & $6 e$ & 3.9219 & & \\
\hline CHEMBL1 & & & 5.1678 & \\
\hline
\end{tabular}

Page 24333 


\begin{tabular}{|c|c|c|c|c|}
\hline & & & oplemen & al $\mathrm{T}$ \\
\hline CHEMBL1814028 & 760261 & 3.2375 & 3.5099 & TRN \\
\hline CHEMBL1814036 & 760261 & 2.7387 & 2.6188 & TRN \\
\hline CHEMBL1649775 & 760261 & 2.0969 & 3.7698 & TST \\
\hline CHEMBL1814238 & 760261 & 4.5969 & 3.9206 & TRN \\
\hline CHEMBL1814383 & 760261 & 3.5834 & 4.7095 & TST \\
\hline CHEMBL1814244 & 760261 & 3.7685 & 4.0273 & TRN \\
\hline CHEMBL1814223 & 760261 & 4.8996 & 4.6933 & TRN \\
\hline CHEMBL1814027 & 760261 & 3.156 & 2.9068 & TRN \\
\hline CHEMBL1814213 & 760261 & 5.1487 & 5.5101 & TRN \\
\hline CHEMBL1814004 & 760261 & 3.5556 & 4.2634 & TRN \\
\hline CHEMBL1814235 & 760261 & 4.9066 & 4.4888 & TRN \\
\hline CHEMBL1814227 & 760261 & 5.0555 & 4.5688 & TRN \\
\hline CHEMBL1814009 & 760261 & 4.8239 & 4.3487 & TRN \\
\hline CHEMBL1814024 & 760261 & 3.9133 & 4.1886 & TRN \\
\hline CHEMBL1814226 & 760261 & 6.2007 & 5.165 & TRN \\
\hline CHEMBL1814023 & 760261 & 4.2083 & 4.1886 & TRN \\
\hline CHEMBL1814211 & 760261 & 4.2197 & 4.7029 & TRN \\
\hline CHEMBL1814247 & 760261 & 5.4202 & 5.2162 & TRN \\
\hline CHEMBL1814221 & 760261 & 4.4815 & 4.6933 & TRN \\
\hline CHEMBL1814010 & 760261 & 4.6091 & 4.3487 & TRN \\
\hline CHEMBL1649757 & 760261 & 3.8854 & 3.5109 & TST \\
\hline CHEMBL1814369 & 760261 & 4.9281 & 5.3654 & TST \\
\hline CHEMBL1814366 & 760261 & 4.3503 & 4.6135 & TRN \\
\hline CHEMBL1814233 & 760261 & 3.978 & 4.0067 & TRN \\
\hline CHEMBL1814022 & 760261 & 4.2899 & 4.1886 & TRN \\
\hline CHEMBL1814380 & 760261 & 2.0969 & 4.7973 & TST \\
\hline CHEMBL1814043 & 760261 & 3.2489 & 2.9772 & TRN \\
\hline CHEMBL1814259 & 760261 & 5.6576 & 4.7032 & TRN \\
\hline CHEMBL1814217 & 760261 & 4.2336 & 4.5405 & TRN \\
\hline CHEMBL1814237 & 760261 & 4.27 & 4.555 & TST \\
\hline CHEMBL1814203 & 760261 & 4.9788 & 4.2675 & TRN \\
\hline CHEMBL1814014 & 760261 & 3.6478 & 2.4931 & TRN \\
\hline CHEMBL1814256 & 760261 & 5.7212 & 4.5171 & TRN \\
\hline CHEMBL1649771 & 760261 & 4.0737 & 3.5318 & TST \\
\hline CHEMBL1814248 & 760261 & 4.9626 & 4.1703 & TRN \\
\hline CHEMBL1814251 & 760261 & 2.3979 & 3.5159 & TRN \\
\hline CHEMBL1814033 & 760261 & 4.262 & 4.8063 & TRN \\
\hline CHEMBL1814240 & 760261 & 5.699 & 4.3343 & TST \\
\hline CHEMBL1811944 & 760261 & 4.9626 & 4.8154 & TRN \\
\hline CHEMBL1814241 & 760261 & 2.3979 & 3.1742 & TRN \\
\hline CHEMBL1814040 & 760261 & 4.0453 & 4.878 & TRN \\
\hline CHEMBL1814218 & 760261 & 4.0825 & 3.7144 & TRN \\
\hline CHEMBL1649773 & 760261 & 4.3197 & 4.5111 & TST \\
\hline CHEMBL1814236 & 760261 & 4.7645 & 4.323 & TST \\
\hline CHEMBL1814239 & 760261 & 5.3098 & 4.744 & TST \\
\hline CHEMBL1814254 & 760261 & 5.5376 & 5.7664 & TST \\
\hline CHEMBL1814032 & 760261 & 3.6755 & 3.6112 & TRN \\
\hline CHEMBL1814225 & 760261 & 3.9027 & 4.2039 & TRN \\
\hline
\end{tabular}

Page 24334 
Supplemental Table S2.txt

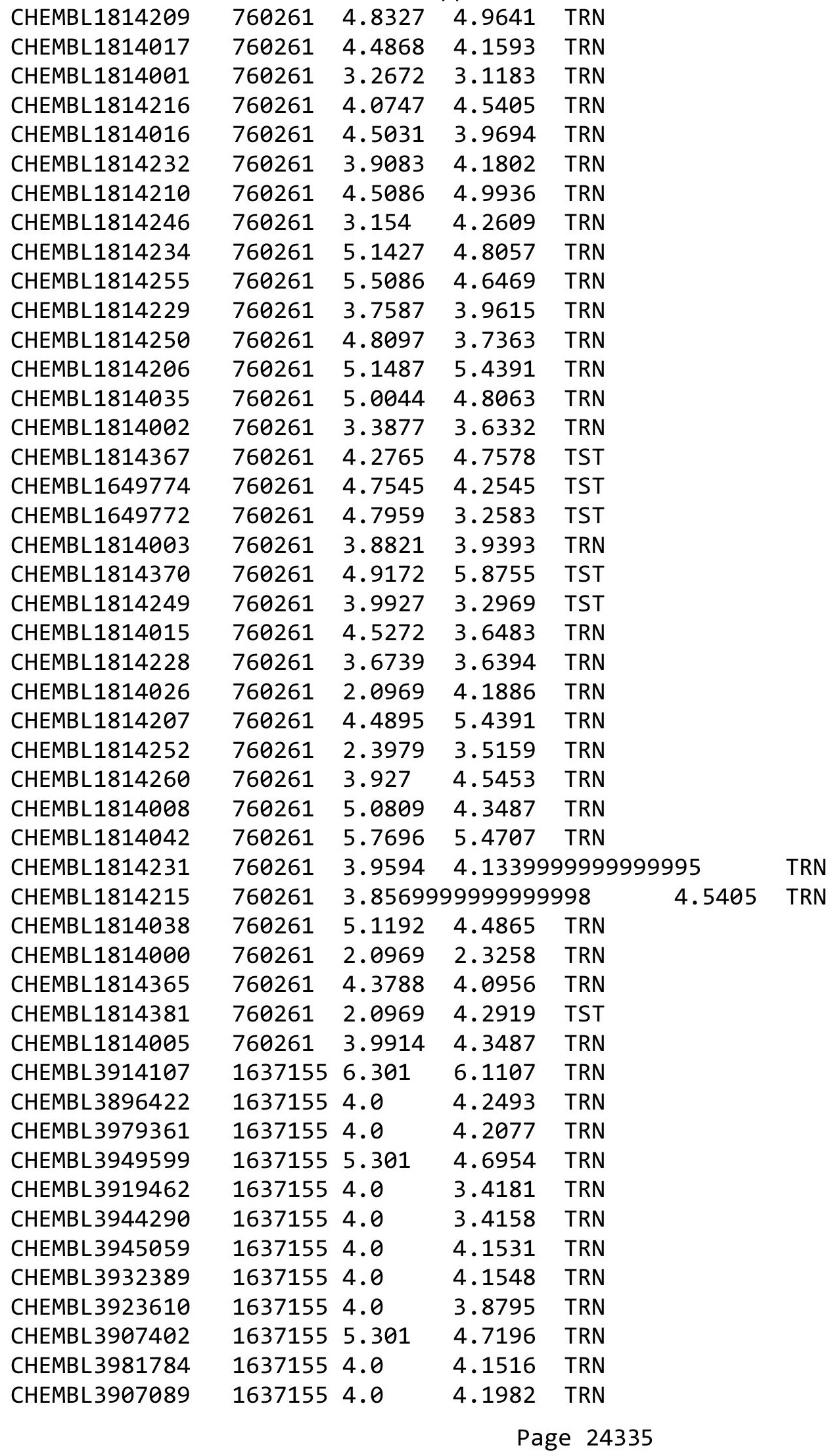


Supplemental Table S2.txt

\begin{tabular}{|c|c|c|c|c|c|}
\hline CHEMBL3971807 & 1637155 & 4.0 & 4.3205 & TRN & \\
\hline CHEMBL3949992 & 1637155 & 5.301 & 4.3286 & TST & \\
\hline CHEMBL3918722 & 1637155 & 4.0 & 4.2447 & TRN & \\
\hline CHEMBL3966021 & 1637155 & 4.0 & 4.2692 & TRN & \\
\hline CHEMBL3916725 & 1637155 & 4.0 & 4.2951 & TRN & \\
\hline CHEMBL3985076 & 1637155 & 6.301 & \multicolumn{2}{|c|}{4.7589999999999995} & TRN \\
\hline CHEMBL3957835 & 1637155 & 4.0 & 3.95 & TRN & \\
\hline CHEMBL3955478 & 1637155 & 4.0 & 4.2689 & TRN & \\
\hline CHEMBL3911079 & 1637155 & 4.0 & 4.258 & TST & \\
\hline CHEMBL3977421 & 1637155 & 6.301 & 6.3997 & TRN & \\
\hline CHEMBL3968460 & 1637155 & 6.301 & 4.8329 & TRN & \\
\hline CHEMBL3921859 & 1637155 & 6.301 & 5.2359 & TRN & \\
\hline CHEMBL3913674 & 1637155 & 4.0 & 4.276 & TST & \\
\hline CHEMBL3928847 & 1637155 & 4.0 & 4.0082 & TRN & \\
\hline CHEMBL3948750 & 1637155 & 5.301 & 4.6929 & TRN & \\
\hline CHEMBL3899027 & 1637155 & 4.0 & 4.1979 & TRN & \\
\hline CHEMBL3981425 & 1637155 & 4.0 & 4.3006 & TRN & \\
\hline CHEMBL3951586 & 1637155 & 4.0 & 4.158 & TRN & \\
\hline CHEMBL3979042 & 1637155 & 4.0 & 4.404 & TST & \\
\hline CHEMBL3928075 & 1637155 & 4.0 & 4.3017 & TRN & \\
\hline CHEMBL3935744 & 1637155 & 4.0 & 4.0462 & TRN & \\
\hline CHEMBL3964025 & 1637155 & 4.0 & 4.1353 & TRN & \\
\hline CHEMBL3935100 & 1637155 & 4.0 & 4.4298 & TRN & \\
\hline CHEMBL3958968 & 1637155 & 4.0 & 4.2992 & TST & \\
\hline CHEMBL3968497 & 1637155 & 4.0 & 3.6875 & TRN & \\
\hline CHEMBL3917962 & 1637155 & 4.0 & 3.7516 & TRN & \\
\hline CHEMBL3981313 & 1637155 & 4.0 & 4.5598 & TST & \\
\hline CHEMBL3899101 & 1637155 & 4.0 & 3.9057 & TST & \\
\hline CHEMBL3904645 & 1637155 & 5.301 & \multicolumn{2}{|c|}{4.5489999999999995} & TRN \\
\hline CHEMBL3890467 & 1637155 & 5.301 & 5.8761 & TST & \\
\hline CHEMBL3942381 & 1637155 & 4.0 & 4.5109 & TRN & \\
\hline CHEMBL3941565 & 1637155 & 4.0 & 4.2581 & TST & \\
\hline CHEMBL3952336 & 1637155 & 4.0 & 4.6275 & TST & \\
\hline CHEMBL3896589 & 1637155 & 4.0 & 4.2082 & TRN & \\
\hline CHEMBL3899285 & 1637155 & 4.0 & 4.1682 & TRN & \\
\hline CHEMBL3904980 & 1637155 & 4.0 & 4.1823 & TRN & \\
\hline CHEMBL3985717 & 1637155 & 4.0 & 4.473 & TST & \\
\hline CHEMBL3945707 & 1637155 & 5.301 & 4.5927 & TST & \\
\hline CHEMBL3980636 & 1637155 & 4.0 & 5.2819 & TRN & \\
\hline CHEMBL3931676 & 1637155 & 4.0 & 3.8185 & TRN & \\
\hline CHEMBL3968167 & 1637155 & 6.301 & 6.1085 & TRN & \\
\hline CHEMBL3956999 & 1637155 & 4.0 & 4.006 & TRN & \\
\hline CHEMBL3904333 & 1637155 & 4.0 & 4.1607 & TRN & \\
\hline CHEMBL3926189 & 1637155 & 4.0 & 4.1033 & TST & \\
\hline CHEMBL3920821 & 1637155 & 4.0 & 4.6122 & TRN & \\
\hline CHEMBL3954395 & 1637155 & 4.0 & 3.8485 & TRN & \\
\hline CHEMBL3967303 & 1637155 & 6.301 & 5.745 & TRN & \\
\hline CHEMBL3954978 & 1637155 & 6.301 & 4.3985 & TST & \\
\hline
\end{tabular}




\begin{tabular}{|c|c|c|c|c|}
\hline & & & & \\
\hline CHEMBL3928507 & 1637155 & 4.0 & 4.2637 & TRN \\
\hline CHEMBL3890797 & 1637155 & 4.0 & 3.9522 & TST \\
\hline CHEMBL3903656 & 1637155 & 4.0 & 3.6576 & TRN \\
\hline CHEMBL3969082 & 1637155 & 4.0 & 4.4671 & TRN \\
\hline CHEMBL3940360 & 1637155 & 4.0 & 3.8641 & TRN \\
\hline CHEMBL 3934437 & 1637155 & 4.0 & 3.8246 & TST \\
\hline CHEMBL3919966 & 1637155 & 4.0 & 4.3352 & TRN \\
\hline CHEMBL3941703 & 1637155 & 4.0 & 3.6125 & TRN \\
\hline CHEMBL3968095 & 1637155 & 4.0 & 5.0143 & TRN \\
\hline CHEMBL3986998 & 1637155 & 4.0 & 4.0938 & TRN \\
\hline CHEMBL 3947313 & 1637155 & 4.0 & 4.172 & TRN \\
\hline CHEMBL3893235 & 1637155 & 4.0 & 5.7812 & TST \\
\hline CHEMBL3904681 & 1637155 & 4.0 & 3.9312 & TRN \\
\hline CHEMBL 3897700 & 1637155 & 4.0 & 4.3624 & TRN \\
\hline CHEMBL3939013 & 1637155 & 4.0 & 3.8059 & TRN \\
\hline CHEMBL 3971789 & 1637155 & 4.0 & 3.9235 & TRN \\
\hline CHEMBL3896039 & 1637155 & 5.301 & 4.5992 & TST \\
\hline CHEMBL3933168 & 1637155 & 4.0 & 4.6273 & TRN \\
\hline CHEMBL3956565 & 1637155 & 6.301 & 4.9574 & TST \\
\hline CHEMBL 3912374 & 1637155 & 4.0 & 4.244 & TRN \\
\hline CHEMBL3942988 & 1637155 & 4.0 & 4.3242 & TRN \\
\hline CHEMBL3979607 & 1637155 & 4.0 & 4.4121 & TST \\
\hline CHEMBL3895266 & 1637155 & 4.0 & 3.773 & TRN \\
\hline CHEMBL3917210 & 1637155 & 4.0 & 4.4319 & TST \\
\hline CHEMBL 3948349 & 1637155 & 5.301 & 4.6488 & TST \\
\hline CHEMBL 2418024 & 977506 & 2.2269 & 1.8691 & TRN \\
\hline CHEMBL3215696 & 977506 & 2.082 & 1.4802 & TST \\
\hline CHEMBL 2418026 & 977506 & 1.857 & 2.303 & TRN \\
\hline CHEMBL3217032 & 977506 & -0.2788 & 0.0982 & TRN \\
\hline CHEMBL 2418010 & 977506 & 1.7144 & 1.4851 & TRN \\
\hline CHEMBL 3217251 & 977506 & 1.5607 & 0.8691 & TRN \\
\hline CHEMBL3217033 & 977506 & 1.8416 & 2.0272 & TRN \\
\hline CHEMBL90971 & 977506 & 0.8069 & 0.9815 & TRN \\
\hline CHEMBL 2418029 & 977506 & 1.8041 & 2.2568 & TRN \\
\hline CHEMBL 2418051 & 977506 & 2.1574 & 1.6929 & TRN \\
\hline CHEMBL 2418015 & 977506 & 2.2757 & 2.2356 & TRN \\
\hline CHEMBL3216586 & 977506 & 1.2457 & 0.8102 & TRN \\
\hline CHEMBL3216826 & 977506 & -0.2742 & 0.3927 & TRN \\
\hline CHEMBL 2417998 & 977506 & 1.7144 & 2.0793 & TRN \\
\hline CHEMBL 2418038 & 977506 & 2.3279 & 2.0809 & TRN \\
\hline CHEMBL3216144 & 977506 & 1.0915 & 1.0974 & TRN \\
\hline CHEMBL3215927 & 977506 & 0.6799 & 0.948 & TRN \\
\hline CHEMBL 2418055 & 977506 & 2.4948 & 2.2684 & TRN \\
\hline CHEMBL 2418034 & 977506 & 1.0685 & 1.2337 & TRN \\
\hline CHEMBL3707184 & 977506 & 1.7305 & 1.5891 & TRN \\
\hline CHEMBL 2418052 & 977506 & -0.1584 & 0.9904 & TST \\
\hline CHEMBL 2418019 & 977506 & 1.6676 & 2.0163 & TRN \\
\hline CHEMBL3216588 & 977506 & 2.3251 & 2.2971 & TRN \\
\hline
\end{tabular}

Page 24337 


\begin{tabular}{|c|c|c|c|c|c|}
\hline \multirow[b]{2}{*}{ CHEMBL3217038 } & \multicolumn{5}{|c|}{ Supplemental Table S2.txt } \\
\hline & 977506 & 1.4935 & 1.5921 & TRN & \\
\hline CHEMBL 2418044 & 977506 & 1.1013 & 1.5984 & TST & \\
\hline CHEMBL2418011 & 977506 & 1.6198 & 1.5042 & TST & \\
\hline CHEMBL3215691 & 977506 & 1.0625 & 0.8411 & TRN & \\
\hline CHEMBL 2418040 & 977506 & 0.8962 & 1.1614 & TST & \\
\hline CHEMBL 2418046 & 977506 & 2.2708 & 1.3199 & TST & \\
\hline CHEMBL3217029 & 977506 & 2.1805 & 2.1127 & TRN & \\
\hline CHEMBL 2418048 & 977506 & -0.433 & 1.4566 & TST & \\
\hline CHEMBL 2418018 & 977506 & 1.5452 & 2.0402 & TRN & \\
\hline CHEMBL 2418041 & 977506 & 1.9706 & 2.0624 & TRN & \\
\hline CHEMBL 24057 & 977506 & 2.1938 & 1.679 & TST & \\
\hline CHEMBL 2418047 & 977506 & 0.8447 & 1.0591 & TST & \\
\hline CHEMBL 2418032 & 977506 & 2.2175 & 2.2842 & TRN & \\
\hline CHEMBL 3217249 & 977506 & 1.262 & 0.8556 & TRN & \\
\hline CHEMBL3217034 & 977506 & 0.9666 & 0.8456 & TRN & \\
\hline CHEMBL 2418049 & 977506 & 1.2381 & 1.54199 & 99999999998 & TST \\
\hline CHEMBL3217039 & 977506 & 1.0894 & 0.8105 & TRN & \\
\hline CHEMBL 3217030 & 977506 & 0.9957 & 0.8574 & TRN & \\
\hline CHEMBL 3216142 & 977506 & 1.9666 & 1.9486 & TST & \\
\hline CHEMBL 2418035 & 977506 & 3.2441 & 2.0972 & TRN & \\
\hline CHEMBL 2418020 & 977506 & 1.8601 & 2.0518 & TRN & \\
\hline CHEMBL3215690 & 977506 & 1.7423 & 2.08699 & 99999999997 & TRN \\
\hline CHEMBL3216143 & 977506 & 2.6459 & 2.3116 & TRN & \\
\hline CHEMBL3216825 & 977506 & 1.0177 & 1.0743 & TRN & \\
\hline CHEMBL3216823 & 977506 & 1.8013 & 2.0252 & TRN & \\
\hline CHEMBL 2418012 & 977506 & 2.3019 & 2.2176 & TRN & \\
\hline CHEMBL 2418043 & 977506 & 0.7773 & 1.0901 & TST & \\
\hline CHEMBL3216587 & 977506 & -0.3502 & 0.1876 & TRN & \\
\hline CHEMBL 3217243 & 977506 & 2.3575 & 2.2933 & TRN & \\
\hline CHEMBL 3217253 & 977506 & 1.1518 & 0.78 & TRN & \\
\hline CHEMBL3216355 & 977506 & 1.5391 & 1.5911 & TRN & \\
\hline CHEMBL 2418050 & 977506 & 0.983 & 1.6337 & TST & \\
\hline CHEMBL3216596 & 977506 & 1.1506 & 1.0932 & TRN & \\
\hline CHEMBL3215697 & 977506 & 1.0026 & 1.0845 & TRN & \\
\hline CHEMBL 2418045 & 977506 & 1.684006 & 30000000 & 2.0039 & TST \\
\hline CHEMBL 3217252 & 977506 & 1.6655 & 1.5742 & TRN & \\
\hline CHEMBL3217035 & 977506 & 1.5719 & 2.0497 & TRN & \\
\hline CHEMBL3217240 & 977506 & 1.0477 & 1.1193 & TRN & \\
\hline CHEMBL 2418042 & 977506 & 2.1124 & 1.8355 & TST & \\
\hline CHEMBL91187 & 977506 & 1.1029 & 1.403 & TST & \\
\hline CHEMBL3927036 & 1642262 & 6.8239 & 6.2586 & TRN & \\
\hline CHEMBL 3902568 & 1642262 & 6.0555 & 5.9855 & TRN & \\
\hline CHEMBL3986372 & 1642262 & 6.4559 & 7.1145 & TST & \\
\hline CHEMBL 3934879 & 1642262 & 6.0362 & 5.8363 & TRN & \\
\hline CHEMBL 3907560 & 1642262 & 6.1675 & 6.5323 & TRN & \\
\hline CHEMBL3920297 & 1642262 & 6.4559 & 6.0446 & TRN & \\
\hline CHEMBL 3983174 & 1642262 & 6.041 & 5.9859 & TRN & \\
\hline CHEMBL 3983825 & 1642262 & 4.7212 & 5.3919 & TRN & \\
\hline
\end{tabular}

Page 24338 
Supplemental Table S2.txt

\begin{tabular}{|c|c|c|c|c|}
\hline CHEMBL 3952772 & 1642262 & 6.0 & 6.1586 & TRN \\
\hline CHEMBL 3961294 & 1642262 & 6.9208 & 7.0238 & TRN \\
\hline CHEMBL3913619 & 1642262 & 6.2291 & 6.0726 & TRN \\
\hline CHEMBL 3950181 & 1642262 & 5.6383 & 5.4633 & TRN \\
\hline CHEMBL 3912968 & 1642262 & 7.4949 & 6.3314 & TST \\
\hline CHEMBL 3916988 & 1642262 & 6.9586 & 6.8588 & TRN \\
\hline CHEMBL 3923002 & 1642262 & 5.4949 & 5.4245 & TRN \\
\hline CHEMBL 3937418 & 1642262 & 6.1612 & 6.2575 & TST \\
\hline CHEMBL 3922458 & 1642262 & 6.0809 & 5.5661 & TRN \\
\hline CHEMBL3933100 & 1642262 & 6.7696 & 6.677006 & 0000000005 \\
\hline CHEMBL 3958885 & 1642262 & 5.1427 & 6.3682 & TST \\
\hline CHEMBL 3975454 & 1642262 & 5.7959 & 6.17399 & 9999999995 \\
\hline CHEMBL 3984671 & 1642262 & 6.5686 & 6.1803 & TRN \\
\hline CHEMBL 3966723 & 1642262 & 5.7447 & 5.979 & TRN \\
\hline CHEMBL 3931540 & 1642262 & 5.0605 & 4.8773 & TRN \\
\hline CHEMBL 3910295 & 1642262 & 6.6383 & 5.5425 & TST \\
\hline CHEMBL3913624 & 1642262 & 6.4089 & 6.3191 & TST \\
\hline CHEMBL 3939548 & 1642262 & 6.1549 & 5.9656 & TST \\
\hline CHEMBL3964686 & 1642262 & 7.284 & 6.7892 & TST \\
\hline CHEMBL 3924528 & 1642262 & 7.3979 & 6.4965 & TST \\
\hline CHEMBL 3967225 & 1642262 & 5.1938 & 5.5906 & TRN \\
\hline CHEMBL3920323 & 1642262 & 6.7959 & 6.4928 & TRN \\
\hline CHEMBL 3946847 & 1642262 & 5.8861 & 5.6826 & TRN \\
\hline CHEMBL 3975258 & 1642262 & 7.284 & 6.4138 & TST \\
\hline CHEMBL 3891424 & 1642262 & 5.6778 & 5.8118 & TRN \\
\hline CHEMBL3949340 & 1642262 & 7.041 & 7.1555 & TRN \\
\hline CHEMBL 3904008 & 1642262 & 6.4949 & 7.1784 & TRN \\
\hline CHEMBL3910396 & 1642262 & 6.8861 & 6.8469 & TRN \\
\hline CHEMBL 3944913 & 1642262 & 4.3665 & 5.6115 & TRN \\
\hline CHEMBL3923844 & 1642262 & 6.0458 & 5.9712 & TST \\
\hline CHEMBL3956515 & 1642262 & 6.8239 & 6.9316 & TRN \\
\hline CHEMBL3947279 & 1642262 & 6.5528 & 7.08 & TRN \\
\hline CHEMBL3978376 & 1642262 & 5.6576 & 5.6401 & TST \\
\hline CHEMBL 3895881 & 1642262 & 6.8539 & 6.4605 & TRN \\
\hline CHEMBL3953243 & 1642262 & 6.0458 & 6.0463 & TST \\
\hline CHEMBL3967080 & 1642262 & 5.2076 & 5.2808 & TRN \\
\hline CHEMBL3983644 & 1642262 & 6.0506 & 5.6927 & TST \\
\hline CHEMBL3937361 & 1642262 & 6.5376 & 6.4261 & TRN \\
\hline CHEMBL 3979310 & 1642262 & 7.6576 & 6.2581 & TRN \\
\hline CHEMBL3961377 & 1642262 & 6.8861 & 6.5425 & TRN \\
\hline CHEMBL3916480 & 1642262 & 6.7959 & 6.7307 & TRN \\
\hline CHEMBL3977662 & 1642262 & 6.4949 & 6.794 & TRN \\
\hline CHEMBL3938221 & 1642262 & 5.1487 & 5.6126 & TRN \\
\hline CHEMBL3956055 & 1642262 & 6.5376 & 6.3299 & TRN \\
\hline CHEMBL 3907871 & 1642262 & 5.0 & \multicolumn{2}{|c|}{5.111000000000001} \\
\hline CHEMBL 3982473 & 1642262 & 6.8539 & 6.8373 & TRN \\
\hline CHEMBL3965493 & 1638422 & 5.7773 & 5.9836 & TST \\
\hline CHEMBL3959676 & 1638422 & 6.4685 & 6.2029 & TST \\
\hline
\end{tabular}


Supplemental Table S2.txt

\begin{tabular}{|c|c|c|c|c|c|c|}
\hline CHEMBL3978593 & 1638422 & 7.2218 & 5.8472 & TST & & \\
\hline CHEMBL3910006 & 1638422 & 6.0506 & 5.7282 & TRN & & \\
\hline CHEMBL3907713 & 1638422 & 5.71 & 6.1024 & TST & & \\
\hline CHEMBL 3962820 & 1638422 & 5.0088 & 5.232 & TRN & & \\
\hline CHEMBL3940637 & 1638422 & 4.9796 & 5.544 & TRN & & \\
\hline CHEMBL3923656 & 1638422 & 5.2749 & 5.232 & TRN & & \\
\hline CHEMBL 3902164 & 1638422 & 5.1457 & 5.0834 & TRN & & \\
\hline CHEMBL 3899025 & 1638422 & 6.5528 & 5.7282 & TRN & & \\
\hline CHEMBL3945156 & 1638422 & 4.71899 & 999999999 & 99 & 4.8163 & TRN \\
\hline CHEMBL3918514 & 1638422 & 5.0747 & 4.8163 & TRN & & \\
\hline CHEMBL3912278 & 1638422 & 5.9101 & 5.6628 & TRN & & \\
\hline CHEMBL3966877 & 1638422 & 4.7698 & 4.8163 & TRN & & \\
\hline CHEMBL3981290 & 1638422 & 6.4202 & 5.7178 & TRN & & \\
\hline CHEMBL3908028 & 1638422 & 5.5575 & 5.9053 & TRN & & \\
\hline CHEMBL3914919 & 1638422 & 5.6289 & 5.544 & TRN & & \\
\hline CHEMBL3962979 & 1638422 & 5.7167 & 5.8935 & TST & & \\
\hline CHEMBL3891294 & 1638422 & 5.6536 & 5.0834 & TRN & & \\
\hline CHEMBL3976722 & 1638422 & 5.9172 & 5.3254 & TST & & \\
\hline CHEMBL3975010 & 1638422 & 5.4001 & 5.544 & TRN & & \\
\hline CHEMBL3940709 & 1638422 & 5.7447 & 5.4494 & TRN & & \\
\hline CHEMBL3937793 & 1638422 & 4.3201 & 5.1942 & TRN & & \\
\hline CHEMBL3924289 & 1638422 & 5.4711 & 5.5214 & TST & & \\
\hline CHEMBL 3896444 & 1638422 & 5.6402 & 5.7282 & TRN & & \\
\hline CHEMBL3969514 & 1638422 & 5.6162 & 5.5879 & TRN & & \\
\hline CHEMBL3955549 & 1638422 & 5.0555 & 5.0834 & TRN & & \\
\hline CHEMBL3965139 & 1638422 & 5.5719 & 5.7282 & TRN & & \\
\hline CHEMBL3938403 & 1638422 & 5.1062 & 5.1361 & TRN & & \\
\hline CHEMBL 3895146 & 1638422 & 6.0915 & 6.1407 & TRN & & \\
\hline CHEMBL3969991 & 1638422 & 5.0615 & 4.8163 & TRN & & \\
\hline CHEMBL3979709 & 1638422 & 5.7212 & 5.544 & TRN & & \\
\hline CHEMBL3971964 & 1638422 & 4.3743 & 4.8163 & TRN & & \\
\hline CHEMBL3935011 & 1638422 & 5.0443 & 5.232 & TRN & & \\
\hline CHEMBL 3920390 & 1638422 & 4.583 & 4.8163 & TRN & & \\
\hline CHEMBL3973898 & 1638422 & 5.0595 & 5.232 & TRN & & \\
\hline CHEMBL3918432 & 1638422 & 5.06800 & & 305 & 5.232 & TRN \\
\hline CHEMBL3974158 & 1638422 & 6.1024 & \multicolumn{3}{|c|}{6.327999999999999} & TRN \\
\hline CHEMBL3963690 & 1638422 & 4.8904 & 5.232 & TRN & & \\
\hline CHEMBL 3907724 & 1638422 & 5.3851 & 5.7282 & TRN & & \\
\hline CHEMBL3980958 & 1638422 & 5.7773 & 6.1111 & TST & & \\
\hline CHEMBL3919840 & 1638422 & 5.3585 & 5.2883 & TRN & & \\
\hline CHEMBL3971205 & 1638422 & 5.06 & 5.4063 & TST & & \\
\hline CHEMBL3937894 & 1638422 & 5.4295 & 5.5842 & TRN & & \\
\hline CHEMBL 3932312 & 1638422 & 5.5331 & 5.232 & TRN & & \\
\hline CHEMBL3968265 & 1638422 & 5.5376 & 5.544 & TRN & & \\
\hline CHEMBL3935596 & 1638422 & 5.9547 & 5.9937 & TRN & & \\
\hline CHEMBL3965457 & 1638422 & 5.8697 & 5.308 & TRN & & \\
\hline CHEMBL3958577 & 1638422 & 5.3107 & 4.8163 & TRN & & \\
\hline CHEMBL3949081 & 1638422 & 4.6942 & 5.0834 & TRN & & \\
\hline
\end{tabular}

Page 24340 
Supplemental Table S2.txt

\begin{tabular}{|c|c|c|c|c|c|}
\hline CHEMBL3909282 & 1638422 & 4.8752 & 4.8163 & TRN & \\
\hline CHEMBL3975606 & 1638422 & 5.1203 & 4.9356 & TST & \\
\hline CHEMBL3937994 & 1638422 & 5.9469 & 5.8452 & TST & \\
\hline CHEMBL 3982744 & 1638422 & 4.9161 & 4.6339 & TST & \\
\hline CHEMBL 3910529 & 1638422 & 5.7905 & 5.232 & TST & \\
\hline CHEMBL3966351 & 1638422 & 5.983 & 6.3028 & TST & \\
\hline CHEMBL3940275 & 1638422 & 5.8268 & 5.7772 & TST & \\
\hline CHEMBL1565378 & 688201 & 5.3294 & 5.5346 & TRN & \\
\hline CHEMBL1435494 & 688201 & 5.1244 & 5.4654 & TRN & \\
\hline CHEMBL1469441 & 688201 & 6.1451 & 5.9706 & TRN & \\
\hline CHEMBL1381292 & 688201 & 5.3946 & 5.4772 & TRN & \\
\hline CHEMBL1431535 & 688201 & 4.7549 & 5.3522 & TST & \\
\hline CHEMBL1414554 & 688201 & 6.0645 & 5.9331 & TRN & \\
\hline CHEMBL1376656 & 688201 & 5.3347 & 4.8526 & TRN & \\
\hline CHEMBL 3194162 & 688201 & 5.9352 & 5.6361 & TRN & \\
\hline CHEMBL 3191768 & 688201 & 5.6714 & 5.7251 & TRN & \\
\hline CHEMBL1492629 & 688201 & 6.9202 & 6.1891 & TRN & \\
\hline CHEMBL1371319 & 688201 & 6.1549 & 5.9312 & TRN & \\
\hline CHEMBL1596878 & 688201 & 5.0685 & 5.426 & TST & \\
\hline CHEMBL1410338 & 688201 & 4.9973 & 4.7564 & TRN & \\
\hline CHEMBL1326008 & 688201 & 5.813 & 5.7632 & TST & \\
\hline CHEMBL1345175 & 688201 & 5.393 & 5.5216 & TRN & \\
\hline CHEMBL335619 & 688201 & 5.3942 & 5.5172 & TRN & \\
\hline CHEMBL1556501 & 688201 & 5.3144 & \multicolumn{2}{|c|}{5.5760000000000005} & TST \\
\hline CHEMBL1597507 & 688201 & 5.3474 & 5.6988 & TST & \\
\hline CHEMBL1498006 & 688201 & 5.7069 & 5.7396 & TRN & \\
\hline CHEMBL1605748 & 688201 & 5.4176 & 5.5476 & TRN & \\
\hline CHEMBL3194647 & 688201 & 4.1787 & 4.8871 & TRN & \\
\hline CHEMBL1389969 & 688201 & 5.4542 & 5.6641 & TRN & \\
\hline CHEMBL1574794 & 688201 & 5.6801 & 5.6708 & TST & \\
\hline CHEMBL1458632 & 688201 & 5.2784 & 5.5569 & TRN & \\
\hline CHEMBL1551022 & 688201 & 5.0422 & 5.3602 & TRN & \\
\hline CHEMBL1573007 & 688201 & 6.6112 & 6.0261 & TST & \\
\hline CHEMBL1541211 & 688201 & 5.251 & 5.5668 & TRN & \\
\hline CHEMBL1424340 & 688201 & 5.4425 & 5.5462 & TRN & \\
\hline CHEMBL1340014 & 688201 & 5.0149 & 5.3803 & TRN & \\
\hline CHEMBL 3194460 & 688201 & 6.0531 & 5.6192 & TRN & \\
\hline CHEMBL1556931 & 688201 & 5.3815 & \multicolumn{2}{|c|}{5.428999999999999} & I RI \\
\hline CHEMBL1483727 & 688201 & 5.2714 & 5.3369 & TRN & \\
\hline CHEMBL1415903 & 688201 & \multicolumn{3}{|c|}{5.3020000000000005} & TRN \\
\hline CHEMBL 3193161 & 688201 & 5.6015 & 5.5081 & TRN & \\
\hline CHEMBL1397449 & 688201 & 5.0475 & 5.49100 & 00000000005 & ובנו \\
\hline CHEMBL1537972 & 688201 & 5.2312 & 5.5307 & TRN & \\
\hline CHEMBL1388851 & 688201 & 5.8586 & 5.7448 & TRN & \\
\hline CHEMBL1452412 & 688201 & 5.0808 & 5.2911 & TRN & \\
\hline CHEMBL1415221 & 688201 & 5.9201 & 5.6782 & TRN & \\
\hline CHEMBL1576713 & 688201 & 6.1113 & 5.2767 & TRN & \\
\hline CHEMBL1516970 & 688201 & 5.8827 & 5.7004 & TRN & \\
\hline
\end{tabular}

Page 24341 
Supplemental Table S2.txt

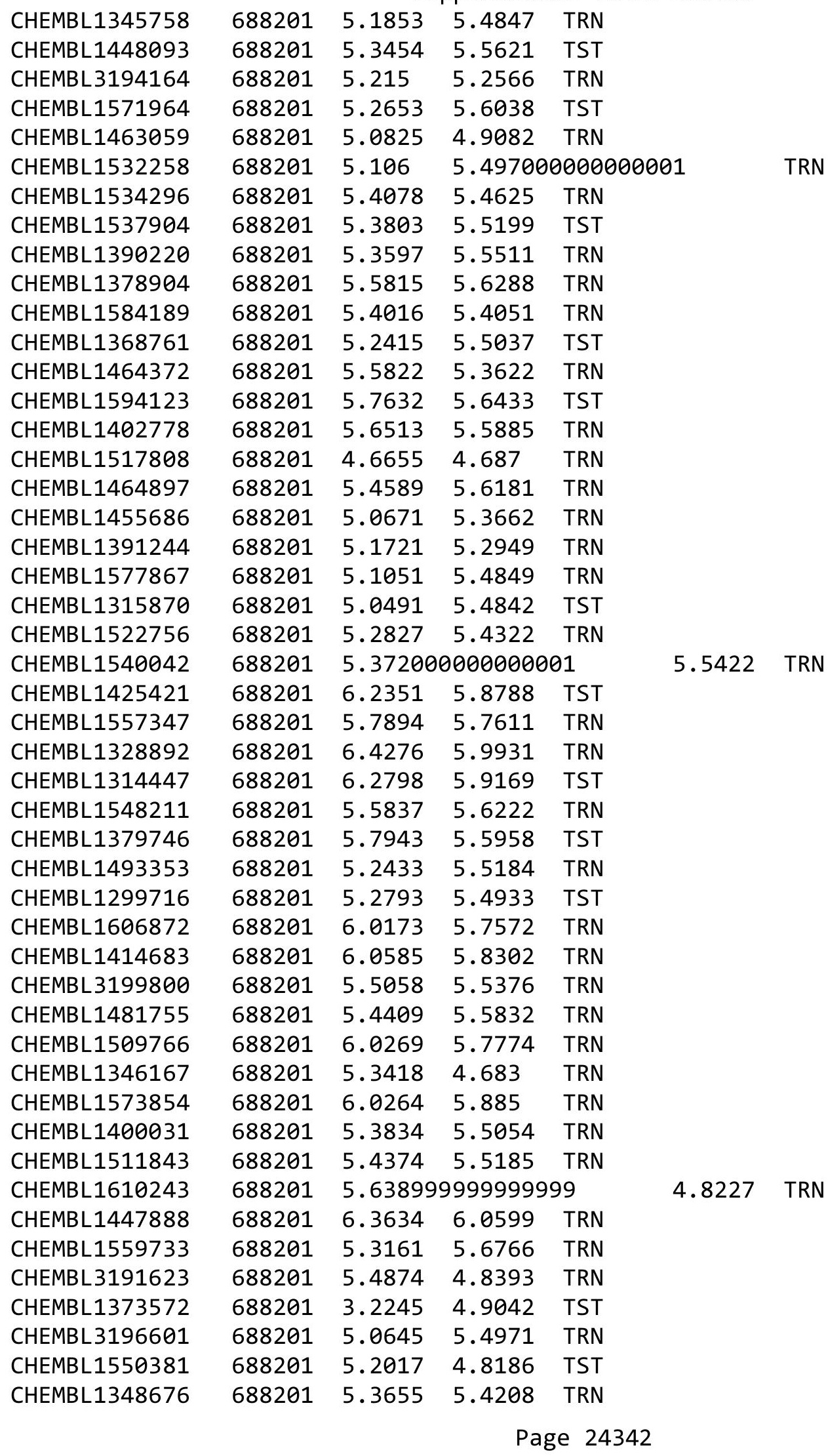


Supplemental Table S2.txt

\begin{tabular}{|c|c|c|c|c|c|}
\hline CHEMBL1579462 & 688201 & 5.3524 & 5.4876 & TRN & \\
\hline CHEMBL1591156 & 688201 & 5.3071 & 5.5539 & TST & \\
\hline CHEMBL1445684 & 688201 & 5.1012 & 5.2349 & TRN & \\
\hline CHEMBL1554968 & 688201 & 5.2751 & 5.5976 & TST & \\
\hline CHEMBL1558250 & 688201 & 5.7005 & 5.742000 & 0000000001 & TRI \\
\hline CHEMBL1358969 & 688201 & 5.3351 & 5.529 & TRN & \\
\hline CHEMBL1401466 & 688201 & 5.6635 & 5.8092 & TRN & \\
\hline CHEMBL1422515 & 688201 & 5.4067 & 5.5691 & TRN & \\
\hline CHEMBL3190779 & 688201 & 6.4754 & 5.9892 & TRN & \\
\hline CHEMBL1555759 & 688201 & 5.1568 & 5.5013 & TST & \\
\hline CHEMBL1445447 & 688201 & 5.4247 & 5.6246 & TRN & \\
\hline CHEMBL1455265 & 688201 & 5.8216 & 5.7174 & TST & \\
\hline CHEMBL1411914 & 688201 & 5.0088 & 5.3922 & TST & \\
\hline CHEMBL1431288 & 688201 & 5.5619 & 5.6321 & TST & \\
\hline CHEMBL3213100 & 688201 & 5.8356 & 5.7779 & TRN & \\
\hline CHEMBL1538097 & 688201 & 5.4297 & 5.4759 & TRN & \\
\hline CHEMBL1423602 & 688201 & 5.3757 & 5.5913 & TST & \\
\hline CHEMBL1328086 & 688201 & 3.2245 & 5.0368 & TST & \\
\hline CHEMBL1606520 & 688201 & 5.9523 & 5.7041 & TRN & \\
\hline CHEMBL1577281 & 688201 & 6.1618 & 5.925 & TRN & \\
\hline CHEMBL1527705 & 688201 & 5.3763 & 4.8036 & TRN & \\
\hline CHEMBL1578600 & 688201 & 7.4693 & 6.3983 & TST & \\
\hline CHEMBL1538815 & 688201 & 5.6645 & 5.6638 & TRN & \\
\hline CHEMBL3197536 & 688201 & 5.6824 & 5.7135 & TRN & \\
\hline CHEMBL1419367 & 688201 & 5.0776 & 5.4614 & TRN & \\
\hline CHEMBL1371432 & 688201 & 5.2111 & 5.542999 & 9999999999 & TRN \\
\hline CHEMBL1587451 & 688201 & 5.4411 & 5.5538 & TRN & \\
\hline CHEMBL1438203 & 688201 & 5.5297 & 5.6131 & TST & \\
\hline CHEMBL1549144 & 688201 & 5.1778 & 5.546 & TRN & \\
\hline CHEMBL1456096 & 688201 & 6.0511 & 5.7848 & TRN & \\
\hline CHEMBL1324305 & 688201 & 5.2043 & 5.4751 & TRN & \\
\hline CHEMBL3196939 & 688201 & 6.4785 & 5.8711 & TRN & \\
\hline CHEMBL1442450 & 688201 & 5.046 & 5.4207 & TRN & \\
\hline CHEMBL1603777 & 688201 & 5.3015 & 5.5263 & TST & \\
\hline CHEMBL 2348829 & 1620947 & 5.9718 & 6.1013 & TRN & \\
\hline CHEMBL3901608 & 1620947 & 4.8649 & 4.8814 & TRN & \\
\hline CHEMBL3965817 & 1620947 & 4.3979 & 4.3998 & TRN & \\
\hline CHEMBL 3893332 & 1620947 & 6.2857 & 6.2862 & TRN & \\
\hline CHEMBL3891346 & 1620947 & 5.4806 & 5.4128 & TRN & \\
\hline CHEMBL3970270 & 1620947 & 6.1636 & 6.1744 & TRN & \\
\hline CHEMBL3979616 & 1620947 & 6.8297 & 6.8511 & TRN & \\
\hline CHEMBL 255822 & 1620947 & 5.76200 & 000000000 & 5.7721 & $1 \mathrm{KI}$ \\
\hline CHEMBL3948168 & 1620947 & 6.041 & 6.0143 & TRN & \\
\hline CHEMBL3909388 & 1620947 & 5.9136 & 5.9303 & TRN & \\
\hline CHEMBL 3938874 & 1620947 & 5.224 & 5.1086 & TRN & \\
\hline CHEMBL1823804 & 1620947 & 5.2815 & 5.2822 & TRN & \\
\hline CHEMBL 2218926 & 1620947 & 5.7447 & 5.7329 & TRN & \\
\hline CHEMBL 3967845 & 1620947 & 5.4829 & 5.5154 & TRN & \\
\hline
\end{tabular}


Supplemental Table S2.txt

\begin{tabular}{|c|c|c|c|c|}
\hline HEMBL & & 784 & 5667 & TRN \\
\hline HEMBL3956710 & 620947 & 5.5331 & 5.5149 & \\
\hline HEMBL 224467 & 520947 & & & \\
\hline HEMBL 392725 & 620947 & 136 & 4057 & \\
\hline HEMBL1061 & 620947 & 4.8539 & .8576 & \\
\hline HEMBL 568596 & 520947 & 281 & 4398 & \\
\hline HEMBL150 & & 5.5086 & .5101 & 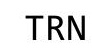 \\
\hline HEMBL1208633 & 620947 & 737 & 4589 & \\
\hline HEMBL 231616 & 620947 & 5.042 & .9933 & \\
\hline HEMBL 500110 & 620947 & 4.8204 & 4.7931 & \\
\hline HEMBL 201 & 620947 & 5.7069 & .7202 & \\
\hline HEMBL 392 & & & .8772 & \\
\hline HEMBL3982310 & 620 & 815 & 5.7748 & \\
\hline HEMBL3945250 & 620 & 5.4617 & 3.9781 & \\
\hline HEMBL3917957 & 620 & 5.0978 & 5.0985 & \\
\hline AEMBL3S & 7 & 244 & 381 & \\
\hline HEMBL1 & 7 & 95 & 89 & RN \\
\hline HEMBL 392 & 62 & 113 & 7133 & RN \\
\hline HEMBL 23 & 47 & 6. & 8887 & \\
\hline AEMBL 602048 & 17 & 31 & 5.1507 & KIV \\
\hline HEMBL3S & 47 & 23 & 607 & RN \\
\hline HEMBL3 & 7 & & 13 & RN \\
\hline HEMBL18 & 17 & & 1723 & BN \\
\hline HEMBL3S & & & 1983 & 「RN \\
\hline AEMBL49 & 17 & 6. & 544 & RN \\
\hline HEMBL2 & 17 & $\partial 2$ & 675 & ST \\
\hline HEMBL1 & 7 & 71 & 05 & 「RN \\
\hline HEMBL: & & 48 & 164 & $\pi \sigma^{-1}$ \\
\hline HEMBL38 & & & & ГST \\
\hline HEMBL 305 & .7 & 5. & 5631 & TST \\
\hline HEMBL3 & 17 & 97 & 909 & IST \\
\hline HEM & & & 24 & ST \\
\hline HEMBL & & & 3577 & TST \\
\hline HEMBL393 & & & 241 & TST \\
\hline HEMBL 2242 & 17 & 4. & 557 & TST \\
\hline HEMBL3 & 17 & 66 & 895 & TST \\
\hline A & & & & $\Gamma \mathrm{RN}$ \\
\hline HEMBL18 & & & 6.2674 & TRN \\
\hline HEMBL184102 & 9 & 6. & 177 & 「RN \\
\hline HEMBL18 & $y$ & 366 & 064 & 「RN \\
\hline HEMBL 36 & $\theta 6$ & & 5.2513 & IRN \\
\hline HEMBL 36 & & & 6.1788 & RN \\
\hline HEMBL364104 & 306 & & 1246 & TRN \\
\hline JEMBL18 & 306 & 086 & 3592 & TST \\
\hline EMBL4 & 306 & & 7934 & TRN \\
\hline CHEMBL363011 & 306739 & & 5.5205 & \\
\hline CHEMBL187165 & 306739 & 6.1415 & 5.9687 & \\
\hline CHEMBL186547 & 306739 & 5.7852 & 6.0986 & ГRN \\
\hline
\end{tabular}

Page 24344 


\begin{tabular}{|c|c|c|c|c|c|}
\hline \multirow[b]{2}{*}{ CHEMBL187859 } & \multicolumn{5}{|c|}{ Supplemental Table S2.txt } \\
\hline & 306739 & 6.5143 & 7.3758 & TRN & \\
\hline CHEMBL184001 & 306739 & 5.9706 & 6.5963 & TRN & \\
\hline CHEMBL186818 & 306739 & 6.7595 & 6.8056 & TRN & \\
\hline CHEMBL185065 & 306739 & 4.699 & 4.5041 & TRN & \\
\hline CHEMBL119647 & 306739 & 4.699 & 5.5096 & TST & \\
\hline CHEMBL364818 & 306739 & 4.699 & 6.8822 & TST & \\
\hline CHEMBL77072 & 306739 & 5.7986 & 5.3507 & TRN & \\
\hline CHEMBL185235 & 306739 & 6.4425 & 6.4588 & TRN & \\
\hline CHEMBL 364377 & 306739 & 7.0458 & 6.8855 & TRN & \\
\hline CHEMBL185096 & 306739 & 6.4868 & 6.4132 & TRN & \\
\hline CHEMBL183739 & 306739 & 6.0846 & 6.3009 & TRN & \\
\hline CHEMBL184394 & 306739 & 6.8633 & 6.4588 & TRN & \\
\hline CHEMBL184573 & 306739 & 6.4572 & 6.0712 & TRN & \\
\hline CHEMBL187295 & 306739 & 6.0872 & 5.9189 & TRN & \\
\hline CHEMBL184520 & 306739 & 7.2218 & 7.4524 & TST & \\
\hline CHEMBL183932 & 306739 & 6.1938 & 6.2587 & TRN & \\
\hline CHEMBL363103 & 306739 & 4.699 & 5.9454 & TRN & \\
\hline CHEMBL366307 & 306739 & 4.699 & 5.0332 & TRN & \\
\hline CHEMBL186770 & 306739 & 7.2757 & 6.4017 & TRN & \\
\hline CHEMBL186659 & 306739 & 6.1029 & 5.70299 & 9999999999 & TRN \\
\hline CHEMBL184754 & 306739 & 4.699 & 6.8015 & TST & \\
\hline CHEMBL 187702 & 306739 & 6.9788 & 6.9815 & TRN & \\
\hline CHEMBL184099 & 306739 & 4.699 & 7.1901 & TST & \\
\hline CHEMBL 361902 & 306739 & 4.699 & 5.6286 & TRN & \\
\hline CHEMBL365254 & 306739 & 6.3595 & 6.337006 & 0000000001 & TRN \\
\hline CHEMBL434162 & 306739 & 4.699 & 6.6692 & TST & \\
\hline CHEMBL185187 & 306739 & 4.699 & 4.4553 & TRN & \\
\hline CHEMBL186750 & 306739 & 6.8633 & 6.3969 & TRN & \\
\hline CHEMBL186949 & 306739 & 6.308 & 5.6563 & TRN & \\
\hline CHEMBL362713 & 306739 & 7.4949 & 6.7762 & TRN & \\
\hline CHEMBL181798 & 306739 & 4.699 & 6.0176 & TRN & \\
\hline CHEMBL184476 & 306739 & 6.2118 & 6.0086 & TRN & \\
\hline CHEMBL183532 & 306739 & 4.699 & 7.0476 & TST & \\
\hline CHEMBL 362720 & 306739 & 7.4437 & 6.7969 & TRN & \\
\hline CHEMBL363120 & 306739 & 4.699 & 5.5558 & TST & \\
\hline CHEMBL366041 & 306739 & 4.699 & 5.8769 & TRN & \\
\hline CHEMBL184086 & 306739 & 4.699 & 4.6844 & TRN & \\
\hline CHEMBL184980 & 306739 & 6.3645 & 6.0815 & TST & \\
\hline CHEMBL365459 & 306739 & 6.71899 & 99999999 & 6.4116 & TST \\
\hline CHEMBL186771 & 306739 & 4.699 & 5.6823 & TST & \\
\hline CHEMBL183631 & 306739 & 4.699 & 4.4799 & TST & \\
\hline CHEMBL363311 & 306739 & 6.9393 & 5.4749 & TST & \\
\hline CHEMBL1343532 & 737259 & 4.1811 & 4.6097 & TRN & \\
\hline CHEMBL1608727 & 737259 & 4.5347 & 4.7353 & TRN & \\
\hline CHEMBL1556737 & 737259 & 4.3059 & 4.8104 & TRN & \\
\hline CHEMBL1413510 & 737259 & 5.4079 & 5.4006 & TRN & \\
\hline CHEMBL1412077 & 737259 & 6.1379 & 6.3351 & TRN & \\
\hline CHEMBL1429070 & 737259 & 5.4331 & 5.3891 & TRN & \\
\hline
\end{tabular}




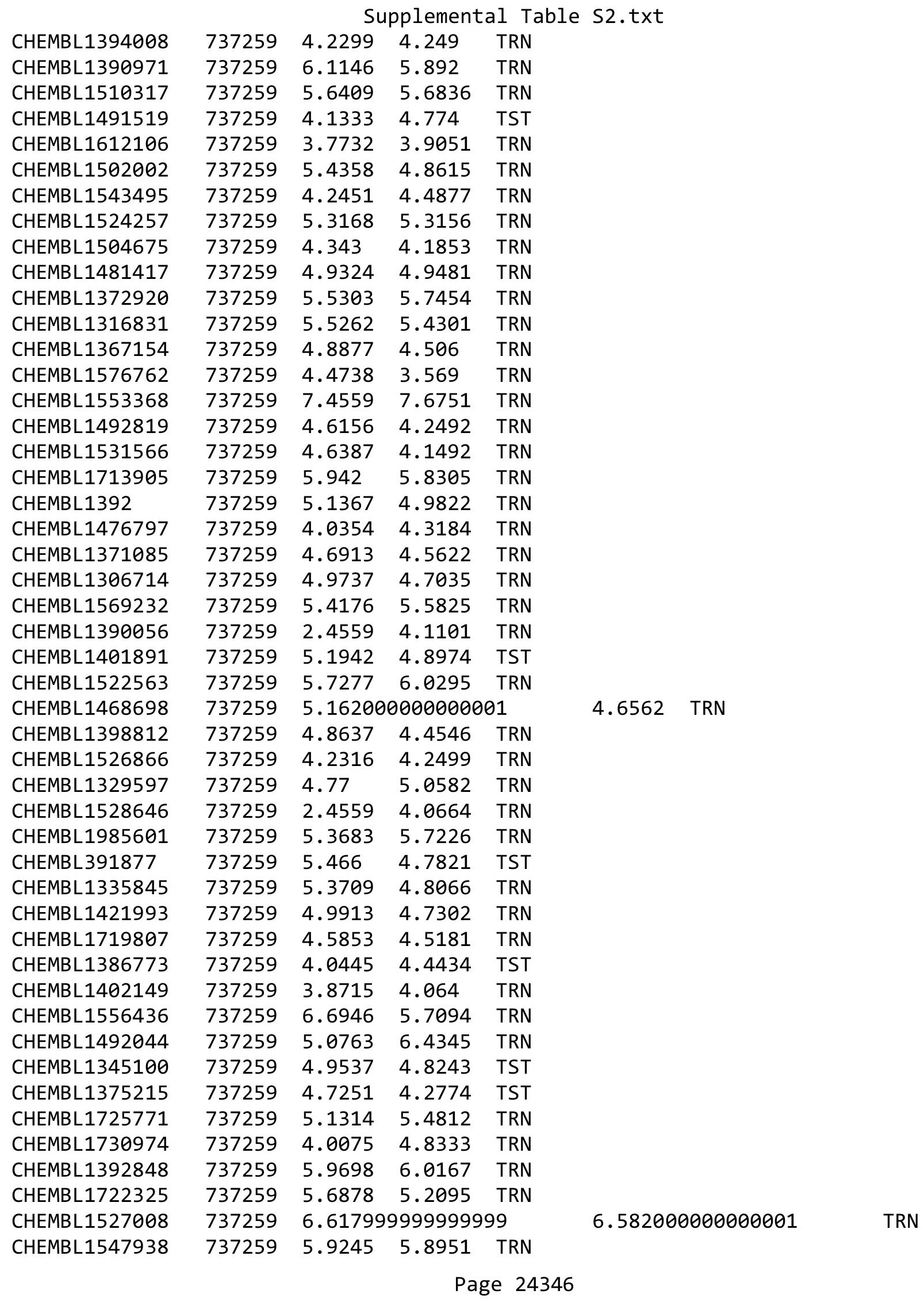




\begin{tabular}{|c|c|c|c|c|}
\hline & & & oplement & al $\mathrm{T}$ \\
\hline CHEMBL1548506 & 737259 & 4.8289 & 4.7527 & TRN \\
\hline CHEMBL1501987 & 737259 & 5.4263 & 5.4908 & TRN \\
\hline CHEMBL1501132 & 737259 & 4.1997 & 4.4093 & TRN \\
\hline CHEMBL1509989 & 737259 & 4.7443 & 4.7759 & TST \\
\hline CHEMBL1996555 & 737259 & 3.9948 & 4.5831 & TRN \\
\hline CHEMBL1455256 & 737259 & 4.1022 & 4.3408 & TST \\
\hline CHEMBL1385512 & 737259 & 4.8719 & 4.9566 & TRN \\
\hline CHEMBL1709562 & 737259 & 5.0615 & 5.2205 & TRN \\
\hline CHEMBL1367036 & 737259 & 6.466 & 6.0027 & TRN \\
\hline CHEMBL1545832 & 737259 & 4.6008 & 4.4566 & TRN \\
\hline CHEMBL1331195 & 737259 & 7.1871 & 6.5373 & TRN \\
\hline CHEMBL1409608 & 737259 & 5.7627 & 5.5828 & TRN \\
\hline CHEMBL1374066 & 737259 & 5.0957 & 5.157 & TRN \\
\hline CHEMBL1522155 & 737259 & 4.802 & 4.7534 & TRN \\
\hline CHEMBL1498441 & 737259 & 5.0658 & 4.9873 & TRN \\
\hline CHEMBL1500251 & 737259 & 5.2397 & 5.5186 & TRN \\
\hline CHEMBL1416556 & 737259 & 4.4459 & 4.177 & TRN \\
\hline CHEMBL1990694 & 737259 & 5.6469 & 5.5352 & TRN \\
\hline CHEMBL1730473 & 737259 & 4.4702 & 3.8817 & TRN \\
\hline CHEMBL1352113 & 737259 & 5.4965 & 5.6078 & TRN \\
\hline CHEMBL1575701 & 737259 & 5.6183 & 5.1425 & TRN \\
\hline CHEMBL1473205 & 737259 & 5.4275 & 5.3729 & TRN \\
\hline CHEMBL1345866 & 737259 & 5.3963 & 5.3492 & TRN \\
\hline CHEMBL68096 & 737259 & 5.5971 & 4.5342 & TRN \\
\hline CHEMBL1502018 & 737259 & 4.4224 & 4.7974 & TRN \\
\hline CHEMBL1474143 & 737259 & 5.0786 & 5.1336 & TRN \\
\hline CHEMBL1478303 & 737259 & 3.677 & 4.0734 & TST \\
\hline CHEMBL1387366 & 737259 & 6.0595 & 6.0504 & TRN \\
\hline CHEMBL3189581 & 737259 & 6.4647 & 5.6285 & TRN \\
\hline CHEMBL1532953 & 737259 & 4.3591 & 4.3609 & TRN \\
\hline CHEMBL1544136 & 737259 & 5.1633 & 4.7849 & TRN \\
\hline CHEMBL1300398 & 737259 & 3.5456 & 4.2628 & TRN \\
\hline CHEMBL1313968 & 737259 & 5.2801 & 4.8444 & TRN \\
\hline CHEMBL1390636 & 737259 & 4.931 & 4.4746 & TST \\
\hline CHEMBL1423797 & 737259 & 4.6951 & 4.4579 & TRN \\
\hline CHEMBL1732657 & 737259 & 5.1603 & 5.4897 & TRN \\
\hline CHEMBL1398964 & 737259 & 3.8996 & 5.1251 & TST \\
\hline CHEMBL1506185 & 737259 & 5.5246 & 5.4381 & TRN \\
\hline CHEMBL1345017 & 737259 & 4.8202 & 4.7422 & TST \\
\hline CHEMBL1550323 & 737259 & 4.1542 & 4.6394 & TRN \\
\hline CHEMBL1709883 & 737259 & 6.5003 & 6.1638 & TRN \\
\hline CHEMBL1469444 & 737259 & 4.5274 & 4.5928 & TRN \\
\hline CHEMBL1547448 & 737259 & 4.2746 & 4.3415 & TRN \\
\hline CHEMBL1326833 & 737259 & 5.7913 & 5.82 & TRN \\
\hline CHEMBL1713654 & 737259 & 5.8492 & 5.6899 & TRN \\
\hline CHEMBL1448906 & 737259 & 5.16 & 5.4254 & TRN \\
\hline CHEMBL1549687 & 737259 & 4.7227 & 4.728 & TRN \\
\hline CHEMBL1370068 & 737259 & 4.1652 & 4.1913 & TRN \\
\hline
\end{tabular}




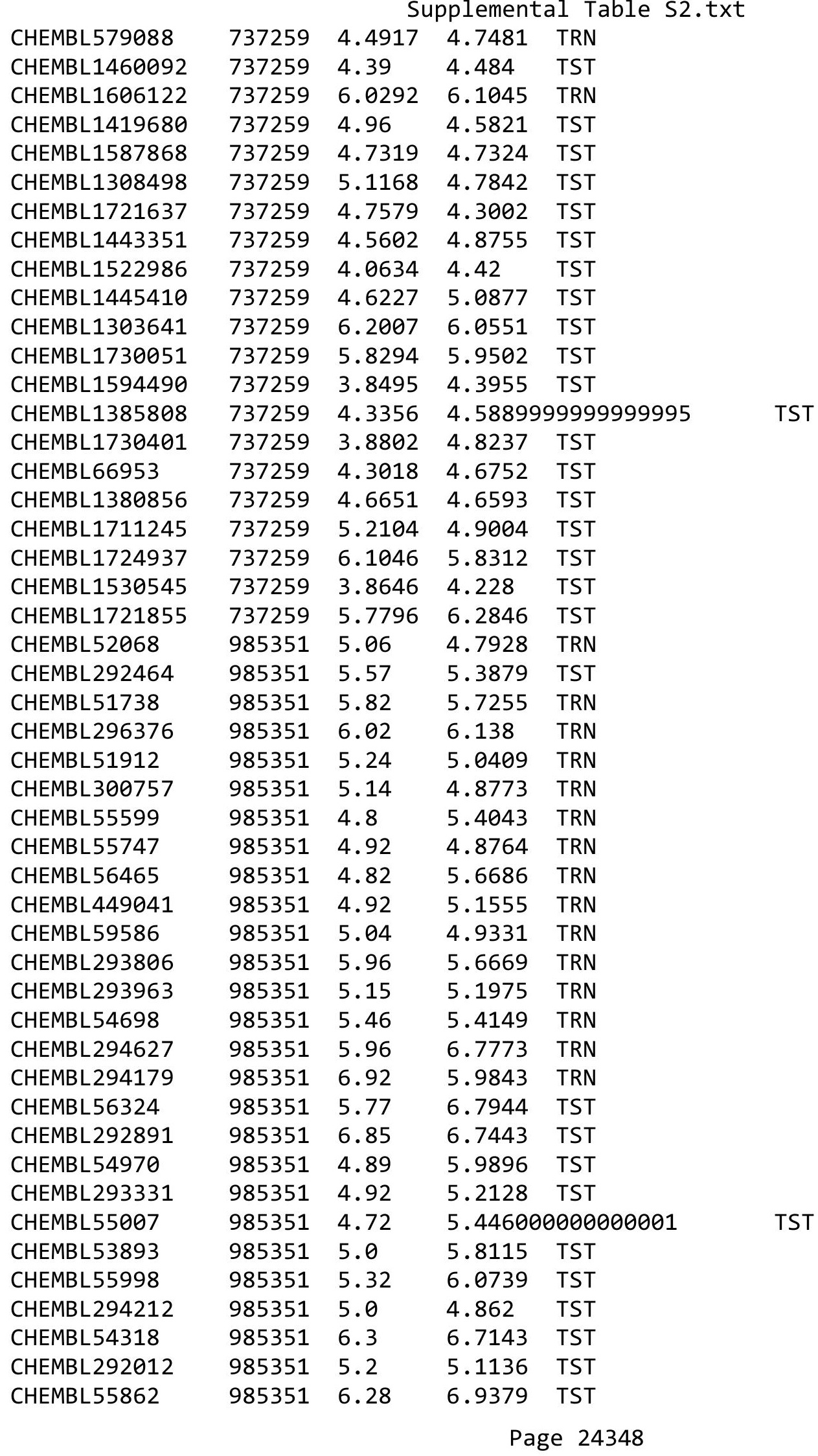




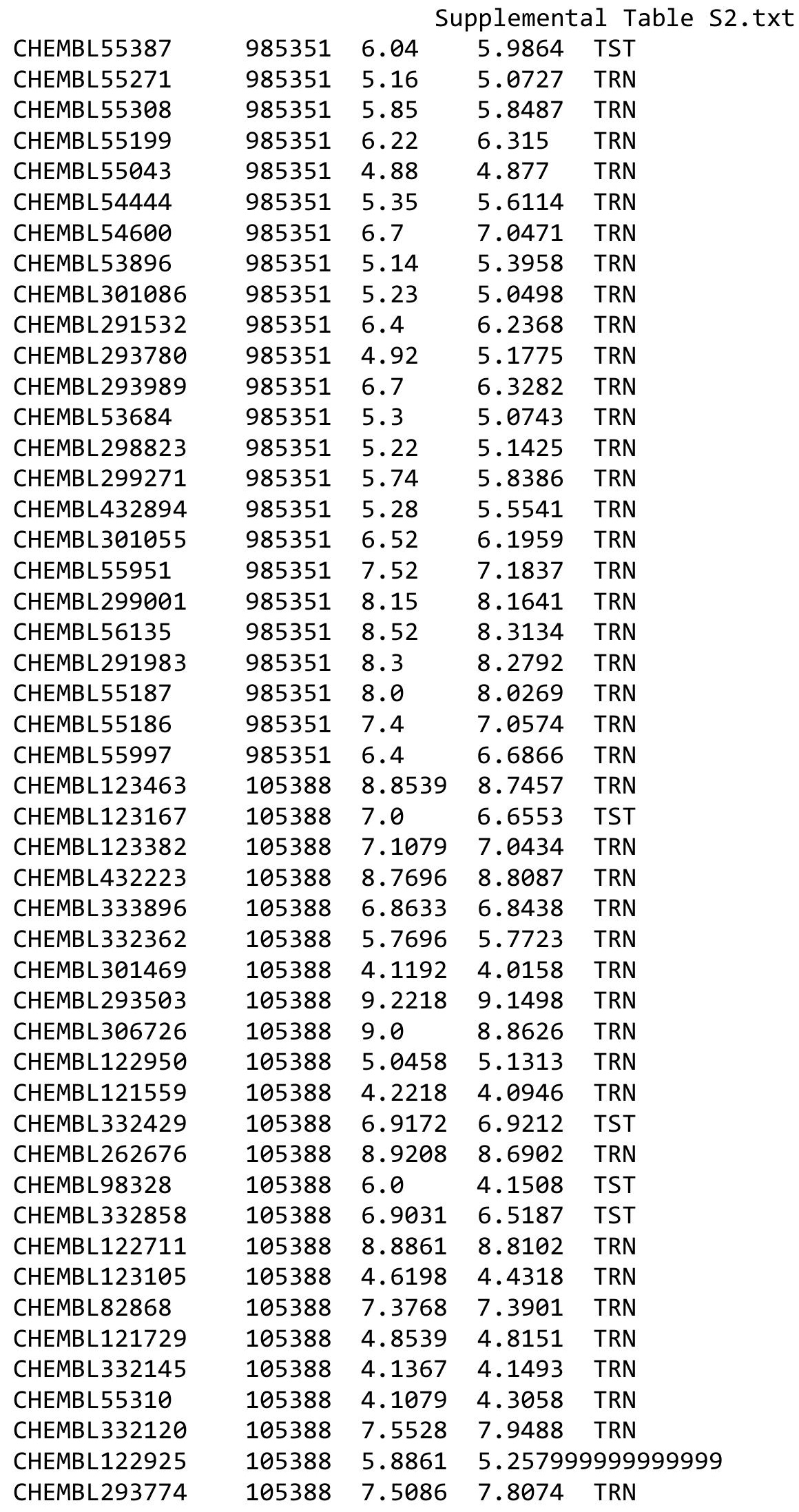




\begin{tabular}{|c|c|c|c|c|c|}
\hline \multicolumn{6}{|c|}{ Supplemental Table S2.txt } \\
\hline CHEMBL 304281 & 105388 & 8.3565 & 8.4281 & TRN & \\
\hline CHEMBL333122 & 105388 & 4.0809 & 5.345 & TST & \\
\hline CHEMBL331311 & 105388 & 8.3979 & 8.7291 & TRN & \\
\hline CHEMBL123233 & 105388 & 5.0 & 5.1361 & TRN & \\
\hline CHEMBL441084 & 105388 & 8.301 & 8.298 & TRN & \\
\hline CHEMBL330857 & 105388 & 8.3665 & 8.34 & TRN & \\
\hline CHEMBL123064 & 105388 & 4.4685 & 4.783 & TST & \\
\hline CHEMBL55110 & 105388 & 8.699 & 8.6634 & TRN & \\
\hline CHEMBL332406 & 105388 & 7.0506 & 6.9991 & TRN & \\
\hline CHEMBL122831 & 105388 & 8.301 & 8.3472 & TRN & \\
\hline CHEMBL124237 & 105388 & 3.0 & 3.8719 & TST & \\
\hline CHEMBL123443 & 105388 & 7.4437 & 7.1593 & TST & \\
\hline CHEMBL332439 & 105388 & 4.6778 & 4.9217 & TST & \\
\hline CHEMBL311336 & 105388 & 7.5686 & 7.6619 & TRN & \\
\hline CHEMBL122836 & 105388 & 8.8239 & 8.6112 & TRN & \\
\hline CHEMBL122109 & 105388 & 4.6778 & 4.9877 & TST & \\
\hline CHEMBL123775 & 105388 & 9.2218 & 9.1335 & TRN & \\
\hline CHEMBL330950 & 105388 & 3.0 & 3.8212 & TST & \\
\hline CHEMBL440714 & 105388 & 7.5086 & 7.62299 & 9999999999 & TRN \\
\hline CHEMBL123041 & 105388 & 8.3665 & 8.3209 & TRN & \\
\hline CHEMBL450327 & 105388 & 7.6198 & 7.6737 & TRN & \\
\hline CHEMBL122651 & 105388 & 7.4089 & 7.4865 & TRN & \\
\hline CHEMBL121592 & 105388 & 4.8861 & 4.9485 & TRN & \\
\hline CHEMBL122719 & 105388 & 8.3372 & 8.4231 & TRN & \\
\hline CHEMBL123404 & 105388 & 4.1805 & 4.148 & TRN & \\
\hline CHEMBL121916 & 105388 & 6.8996 & 6.9312 & TRN & \\
\hline CHEMBL120934 & 105388 & 4.1612 & 4.2517 & TRN & \\
\hline CHEMBL331308 & 105388 & 3.0 & 4.2239 & TST & \\
\hline CHEMBL120049 & 105388 & 6.9136 & 7.0458 & TRN & \\
\hline CHEMBL340461 & 105388 & 8.9586 & 9.221 & TRN & \\
\hline CHEMBL331342 & 105388 & 8.8861 & 8.1357 & TRN & \\
\hline CHEMBL316169 & 105388 & 7.4559 & 7.5725 & TRN & \\
\hline CHEMBL331669 & 105388 & 7.0177 & 6.9018 & TRN & \\
\hline CHEMBL 333532 & 105388 & 7.0 & 7.1265 & TRN & \\
\hline CHEMBL121501 & 105388 & 4.6383 & 5.2635 & TST & \\
\hline CHEMBL122868 & 105388 & 4.9208 & 4.8481 & TRN & \\
\hline CHEMBL333248 & 105388 & 6.9208 & 7.0178 & TST & \\
\hline CHEMBL332755 & 105388 & 8.9208 & 8.7899 & TRN & \\
\hline CHEMBL 331114 & 105388 & 4.8861 & 4.7393 & TRN & \\
\hline CHEMBL83508 & 105388 & 6.8447 & 6.3879 & TST & \\
\hline CHEMBL 3747746 & 1546332 & 4.0 & 4.021 & TRN & \\
\hline CHEMBL3747113 & 1546332 & 6.7959 & 4.9718 & TST & \\
\hline CHEMBL3747563 & 1546332 & 4.0 & 3.9932 & TRN & \\
\hline CHEMBL 3747297 & 1546332 & 4.0 & 4.012 & TRN & \\
\hline CHEMBL3747633 & 1546332 & 6.6757 & 6.6609 & TRN & \\
\hline CHEMBL 3747028 & 1546332 & 4.0 & 3.9784 & TRN & \\
\hline CHEMBL3746921 & 1546332 & 4.0 & 3.9894 & TRN & \\
\hline CHEMBL3747413 & 1546332 & 5.109 & 5.1108 & TRN & \\
\hline
\end{tabular}




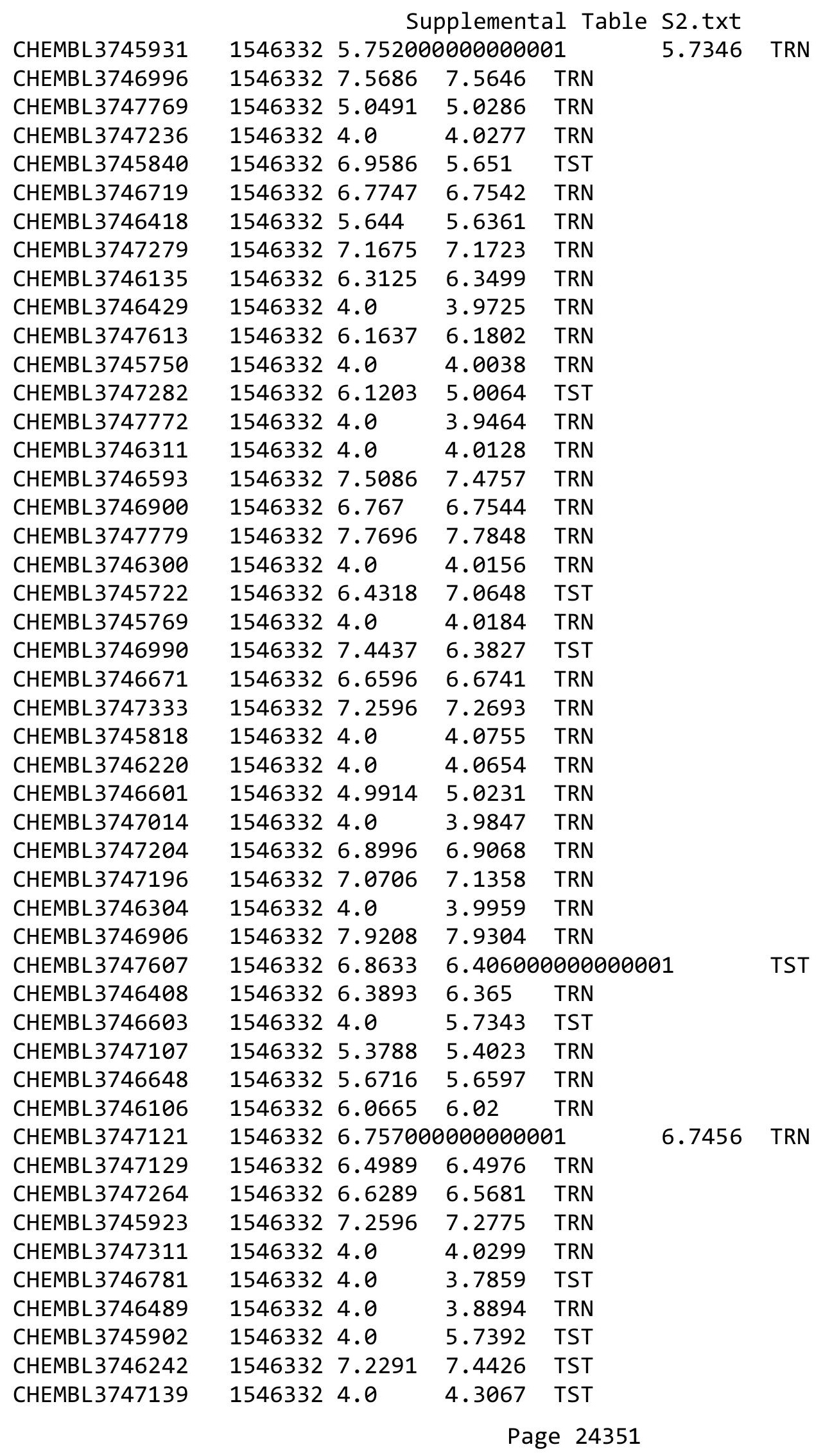


Supplemental Table S2.txt

\begin{tabular}{|c|c|c|c|c|c|c|}
\hline CHEMBL3746919 & 1546332 & 7.7447 & 6.2455 & TST & & \\
\hline CHEMBL3747471 & 1546332 & 4.0 & 6.2248 & TST & & \\
\hline CHEMBL3746725 & 1546332 & 4.98300 & 00000000 & 005 & 5.8351 & TST \\
\hline CHEMBL 3746093 & 1546332 & 5.75700 & 00000000 & 01 & 5.7857 & TST \\
\hline CHEMBL3747427 & 1546332 & 6.7423 & 6.6035 & TST & & \\
\hline CHEMBL504170 & 573581 & 8.2924 & 8.3006 & TRN & & \\
\hline CHEMBL537956 & 573581 & 8.1512 & 8.1394 & TRN & & \\
\hline CHEMBL553662 & 573581 & 8.2941 & 8.5139 & TRN & & \\
\hline CHEMBL450892 & 573581 & 7.8297 & \multicolumn{3}{|c|}{8.357000000000001} & D \\
\hline CHEMBL564755 & 573581 & 6.8894 & 7.3007 & TST & & \\
\hline CHEMBL553898 & 573581 & 8.5952 & 8.6477 & TRN & & \\
\hline CHEMBL555197 & 573581 & 7.8996 & 8.0733 & TRN & & \\
\hline CHEMBL502986 & 573581 & 7.9208 & 7.7386 & TRN & & \\
\hline CHEMBL503601 & 573581 & 8.8861 & 8.9102 & TRN & & \\
\hline CHEMBL540690 & 573581 & 8.308 & 8.3527 & TRN & & \\
\hline CHEMBL507683 & 573581 & 8.7447 & 8.2995 & TRN & & \\
\hline CHEMBL553932 & 573581 & 8.9393 & 8.2255 & TST & & \\
\hline CHEMBL442936 & 573581 & 8.6198 & 8.4384 & TST & & \\
\hline CHEMBL504333 & 573581 & 8.9586 & 8.5296 & TST & & \\
\hline CHEMBL502100 & 573581 & 8.0757 & 8.5293 & TRN & & \\
\hline CHEMBL540215 & 573581 & 8.2541 & 8.1978 & TRN & & \\
\hline CHEMBL538440 & 573581 & 8.2541 & 8.1129 & TRN & & \\
\hline CHEMBL362146 & 573581 & 8.5686 & 8.5808 & TRN & & \\
\hline CHEMBL453709 & 573581 & 7.8601 & 8.1258 & TRN & & \\
\hline CHEMBL501006 & 573581 & 8.585 & 8.3119 & TRN & & \\
\hline CHEMBL510098 & 573581 & 7.6925 & 8.1787 & TRN & & \\
\hline CHEMBL509534 & 573581 & 9.3979 & 8.6032 & TRN & & \\
\hline CHEMBL505678 & 573581 & 8.5376 & 8.7991 & TRN & & \\
\hline CHEMBL503845 & 573581 & 7.9208 & 8.0679 & TRN & & \\
\hline CHEMBL445812 & 573581 & 8.6778 & 8.5728 & TRN & & \\
\hline CHEMBL502417 & 573581 & 7.8182 & 7.9786 & TRN & & \\
\hline CHEMBL453702 & 573581 & 7.8539 & 7.749 & TST & & \\
\hline CHEMBL502482 & 573581 & 7.8539 & 7.6459 & TRN & & \\
\hline CHEMBL445708 & 573581 & 8.9208 & 8.5448 & TST & & \\
\hline CHEMBL539196 & 573581 & 8.3726 & 8.4557 & TRN & & \\
\hline CHEMBL507250 & 573581 & 8.2441 & 8.2626 & TRN & & \\
\hline CHEMBL444419 & 573581 & 8.7959 & 8.5752 & TRN & & \\
\hline CHEMBL537955 & 573581 & 8.327 & 8.5532 & TRN & & \\
\hline CHEMBL554540 & 573581 & 8.3696 & 8.3161 & TRN & & \\
\hline CHEMBL454522 & 573581 & 7.7447 & 7.5913 & TRN & & \\
\hline CHEMBL557957 & 573581 & 6.209 & 7.4039 & TST & & \\
\hline CHEMBL527105 & 573581 & 7.7773 & 7.8619 & TRN & & \\
\hline CHEMBL449870 & 573581 & 7.4157 & 8.0082 & TRN & & \\
\hline CHEMBL510418 & 573581 & 8.1487 & 8.5163 & TRN & & \\
\hline CHEMBL564422 & 573581 & 8.7399 & 8.4169 & TRN & & \\
\hline CHEMBL506232 & 573581 & 8.3279 & 7.9938 & TRN & & \\
\hline CHEMBL503627 & 573581 & 7.8182 & 7.9925 & TRN & & \\
\hline CHEMBL555198 & 573581 & 8.3487 & 8.2449 & TRN & & \\
\hline
\end{tabular}

Page 24352 
Supplemental Table S2.txt

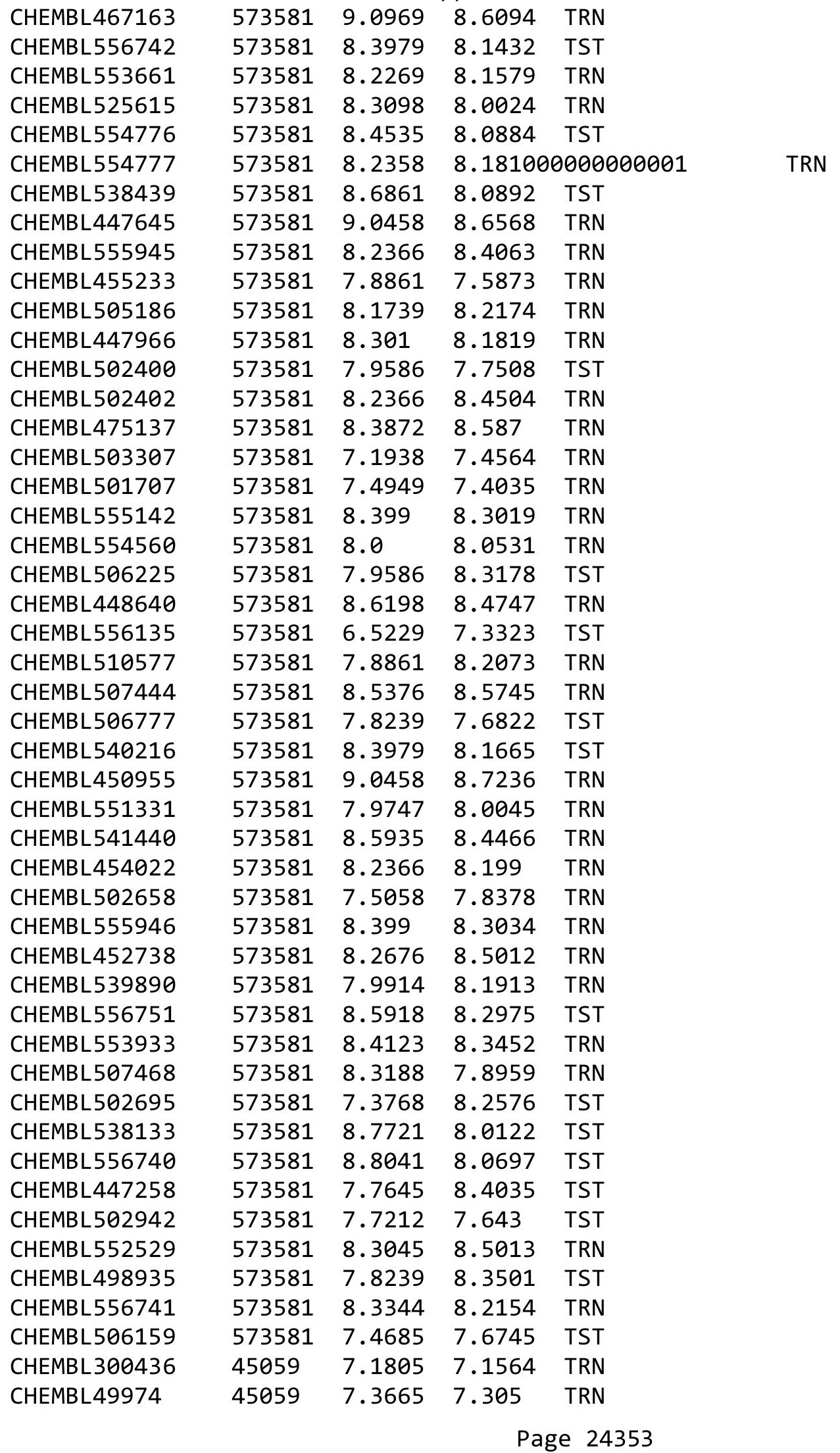




\begin{tabular}{|c|c|c|c|c|c|}
\hline & & \multicolumn{4}{|c|}{ Supplemental Table s2.txt } \\
\hline CHEMBL51437 & 45059 & 6.3979 & 6.357 & TRN & \\
\hline CHEMBL50045 & 45059 & 7.301 & 7.3646 & TRN & \\
\hline CHEMBL51416 & 45059 & 6.5376 & 6.3814 & TRN & \\
\hline CHEMBL 299160 & 45059 & 7.1249 & 7.1569 & TRN & \\
\hline CHEMBL51213 & 45059 & 6.3872 & 6.4734 & TRN & \\
\hline CHEMBL51719 & 45059 & 7.6778 & 7.6739 & TRN & \\
\hline CHEMBL50128 & 45059 & 8.0 & 6.6237 & TST & \\
\hline CHEMBL299744 & 45059 & 6.6021 & 6.6744 & TRN & \\
\hline CHEMBL 2113715 & 45059 & 6.7959 & 6.7729 & TRN & \\
\hline CHEMBL50000 & 45059 & 8.301 & 7.185 & TST & \\
\hline CHEMBL49182 & 45059 & 7.4437 & 7.4374 & TRN & \\
\hline CHEMBL53135 & 45059 & 6.9208 & 6.976 & TRN & \\
\hline CHEMBL 300020 & 45059 & 7.4437 & 7.3347 & TRN & \\
\hline CHEMBL52550 & 45059 & 7.4202 & \multicolumn{2}{|c|}{7.4079999999999995} & TRN \\
\hline CHEMBL 300265 & 45059 & 7.3979 & 7.3347 & TRN & \\
\hline CHEMBL52227 & 45059 & 8.0 & 7.9883 & TRN & \\
\hline CHEMBL51575 & 45059 & 6.4815 & 6.4712 & TRN & \\
\hline CHEMBL50481 & 45059 & 6.9586 & 6.97 & TRN & \\
\hline CHEMBL51534 & 45059 & 7.0706 & 7.2723 & TST & \\
\hline CHEMBL50776 & 45059 & 7.7959 & 7.9262 & TRN & \\
\hline CHEMBL 298110 & 45059 & 8.0458 & \multicolumn{2}{|c|}{7.992999999999999} & TRN \\
\hline CHEMBL 298132 & 45059 & 6.9393 & 6.9057 & TRN & \\
\hline CHEMBL51143 & 45059 & 6.284 & 6.2997 & TRN & \\
\hline CHEMBL48292 & 45059 & 8.5229 & 7.2601 & TST & \\
\hline CHEMBL53607 & 45059 & 7.585 & 6.8683 & TST & \\
\hline CHEMBL50365 & 45059 & 7.5528 & 6.8888 & TST & \\
\hline CHEMBL50921 & 45059 & 7.1367 & 7.1583 & TRN & \\
\hline CHEMBL445615 & 45059 & 7.2076 & 7.1429 & TRN & \\
\hline CHEMBL51586 & 45059 & 7.1308 & 7.1171 & TRN & \\
\hline CHEMBL50881 & 45059 & 6.5229 & 6.5065 & TRN & \\
\hline CHEMBL 298755 & 45059 & 7.2924 & 7.3216 & TRN & \\
\hline CHEMBL51346 & 45059 & 8.0458 & 8.0206 & TRN & \\
\hline CHEMBL54235 & 45059 & 8.0 & 6.816 & TST & \\
\hline CHEMBL50897 & 45059 & 7.1308 & 7.1174 & TRN & \\
\hline CHEMBL51787 & 45059 & 6.5157 & 6.5348 & TRN & \\
\hline CHEMBL52375 & 45059 & 7.3565 & 7.3299 & TRN & \\
\hline CHEMBL2113714 & 45059 & 7.3188 & 7.3047 & TRN & \\
\hline CHEMBL417728 & 45059 & 7.3468 & 7.3009 & TRN & \\
\hline CHEMBL51517 & 45059 & 6.3098 & 6.2936 & TRN & \\
\hline CHEMBL296390 & 45059 & 7.9208 & 7.9903 & TRN & \\
\hline CHEMBL51200 & 45059 & 7.1427 & 7.17899 & 9999999999 & TRN \\
\hline CHEMBL431742 & 45059 & 7.3768 & 7.745 & TST & \\
\hline CHEMBL53407 & 45059 & 7.9586 & 6.5502 & TST & \\
\hline CHEMBL48857 & 45059 & 6.4685 & 6.4791 & TRN & \\
\hline CHEMBL51455 & 45059 & 7.0706 & 7.032 & TRN & \\
\hline CHEMBL50195 & 45059 & 6.5157 & 6.539 & TRN & \\
\hline CHEMBL53972 & 45059 & 7.284 & 7.31 & TRN & \\
\hline CHEMBL51506 & 45059 & 8.1549 & 7.3711 & TST & \\
\hline
\end{tabular}




\begin{tabular}{|c|c|c|c|c|c|}
\hline & & \multicolumn{4}{|c|}{ Supplemental Table S2.txt } \\
\hline CHEMBL48697 & 45059 & 6.3468 & 6.5126 & TST & \\
\hline CHEMBL49062 & 45059 & 7.2757 & 7.2508 & TRN & \\
\hline CHEMBL418085 & 45059 & 7.1367 & 7.0983 & TST & \\
\hline CHEMBL51385 & 45059 & 7.0706 & 7.556 & TST & \\
\hline CHEMBL51668 & 45059 & 8.301 & 7.3301 & TST & \\
\hline CHEMBL50446 & 45059 & 7.1024 & 7.1162 & TRN & \\
\hline CHEMBL52542 & 45059 & 6.6021 & 6.6364 & TRN & \\
\hline CHEMBL 295343 & 45059 & 7.5229 & 6.4193 & TST & \\
\hline CHEMBL51725 & 45059 & 6.3768 & 6.3876 & TRN & \\
\hline CHEMBL51456 & 45059 & 6.6198 & 6.6575 & TRN & \\
\hline CHEMBL 297706 & 45059 & 6.6778 & 6.7053 & TRN & \\
\hline CHEMBL297892 & 45059 & 6.3468 & 6.7848 & TST & \\
\hline CHEMBL301071 & 45059 & 6.5528 & 6.6406 & TRN & \\
\hline CHEMBL 295779 & 45059 & 6.5607 & 6.555 & TRN & \\
\hline CHEMBL1565806 & 809060 & 5.52 & 4.838 & TRN & \\
\hline CHEMBL1580946 & 809060 & 3.0044 & 4.0428 & TRN & \\
\hline CHEMBL1965501 & 809060 & 3.0044 & 3.5598 & TRN & \\
\hline CHEMBL1323644 & 809060 & 6.0472 & 4.0921 & TST & \\
\hline CHEMBL1993417 & 809060 & 3.0044 & 3.1033 & TRN & \\
\hline CHEMBL1970462 & 809060 & 3.0044 & 3.3749 & TRN & \\
\hline CHEMBL1995649 & 809060 & 4.1608 & 4.0924 & TRN & \\
\hline CHEMBL1327501 & 809060 & 4.9208 & 4.6886 & TRN & \\
\hline CHEMBL1964510 & 809060 & 4.1715 & 3.4089 & TRN & \\
\hline CHEMBL 2006017 & 809060 & 5.8182 & 5.5678 & TRN & \\
\hline CHEMBL1968268 & 809060 & 4.2375 & 4.9093 & TRN & \\
\hline CHEMBL1372180 & 809060 & 4.1437 & 4.2044 & TRN & \\
\hline CHEMBL1988067 & 809060 & 4.1725 & 4.1137 & TRN & \\
\hline CHEMBL1969207 & 809060 & 5.8477 & 4.3385 & TST & \\
\hline CHEMBL1571839 & 809060 & 5.9747 & 5.41799 & 9999999999 & TRN \\
\hline CHEMBL1966161 & 809060 & 4.3543 & 3.6537 & TRN & \\
\hline CHEMBL1993743 & 809060 & 3.0044 & 4.4916 & TRN & \\
\hline CHEMBL1976967 & 809060 & 4.5287 & 3.8759 & TRN & \\
\hline CHEMBL1964901 & 809060 & 4.3008 & 4.7393 & TRN & \\
\hline CHEMBL1993846 & 809060 & 4.2913 & 4.327 & TRN & \\
\hline CHEMBL1990867 & 809060 & 4.3536 & 4.7211 & TST & \\
\hline CHEMBL1993650 & 809060 & 4.2782 & 3.8115 & TRN & \\
\hline CHEMBL 2002845 & 809060 & 3.0044 & 3.2582 & TRN & \\
\hline CHEMBL1977479 & 809060 & 3.0044 & 4.1677 & TST & \\
\hline CHEMBL1579264 & 809060 & 4.8861 & 4.2729 & TRN & \\
\hline CHEMBL1976098 & 809060 & 3.0044 & 3.9858 & TRN & \\
\hline CHEMBL1973984 & 809060 & 4.3185 & 3.7337 & TRN & \\
\hline CHEMBL1967430 & 809060 & 4.3686 & 3.3856 & TRN & \\
\hline CHEMBL1999938 & 809060 & 3.0044 & 4.0799 & TST & \\
\hline CHEMBL1410842 & 809060 & 3.0044 & 2.9672 & TRN & \\
\hline CHEMBL1976235 & 809060 & 4.0367 & 4.1064 & TRN & \\
\hline CHEMBL1986991 & 809060 & 3.0044 & 4.1161 & TRN & \\
\hline CHEMBL1977950 & 809060 & 4.7189 & 79999999 & 4.6092 & TRN \\
\hline CHEMBL1974026 & 809060 & 3.0044 & 3.4739 & TRN & \\
\hline
\end{tabular}




\begin{tabular}{|c|c|c|c|c|c|}
\hline \multirow[b]{2}{*}{ CHEMBL1972310 } & & \multicolumn{4}{|c|}{ Supplemental Table S2.txt } \\
\hline & 809060 & 4.2211 & 4.4815 & TRN & \\
\hline CHEMBL1968721 & 809060 & 4.1758 & 3.6172 & TRN & \\
\hline CHEMBL 2002071 & 809060 & 4.4667 & 5.0926 & TRN & \\
\hline CHEMBL1965201 & 809060 & 3.0044 & 3.3471 & TRN & \\
\hline CHEMBL 2002308 & 809060 & 4.112 & 3.76899 & 99999999997 & TRN \\
\hline CHEMBL 2005366 & 809060 & 3.0044 & 3.8905 & TRN & \\
\hline CHEMBL 2000042 & 809060 & 4.1537 & 3.6243 & TRN & \\
\hline CHEMBL1995451 & 809060 & 3.0044 & 3.8032 & TST & \\
\hline CHEMBL1995952 & 809060 & 4.1791 & 4.8272 & TRN & \\
\hline CHEMBL2007065 & 809060 & 3.0044 & 3.7876 & TRN & \\
\hline CHEMBL1500169 & 809060 & 4.6655 & 4.2742 & TST & \\
\hline CHEMBL1966622 & 809060 & 5.6383 & 4.6242 & TST & \\
\hline CHEMBL1311971 & 809060 & 4.7878 & 2.9242 & TRN & \\
\hline CHEMBL1392335 & 809060 & 5.6126 & 4.7847 & TST & \\
\hline CHEMBL1987661 & 809060 & 5.433 & 5.3311 & TRN & \\
\hline CHEMBL 2003811 & 809060 & 5.3429 & 4.5859 & TRN & \\
\hline CHEMBL1533040 & 809060 & 4.4768 & 4.5815 & TRN & \\
\hline CHEMBL1983833 & 809060 & 3.0044 & 3.1164 & TRN & \\
\hline CHEMBL1992176 & 809060 & 6.2097 & 5.004 & TRN & \\
\hline CHEMBL1581799 & 809060 & 4.4657 & 4.9445 & TRN & \\
\hline CHEMBL1700836 & 809060 & 4.7959 & 4.4865 & TST & \\
\hline CHEMBL1989640 & 809060 & 3.0044 & 3.6373 & TRN & \\
\hline CHEMBL1977692 & 809060 & 4.112 & 3.893006 & 00000000002 & TRN \\
\hline CHEMBL 2000599 & 809060 & 3.0044 & 3.5274 & TST & \\
\hline CHEMBL1368914 & 809060 & 3.0044 & 2.9925 & TRN & \\
\hline CHEMBL1995255 & 809060 & 4.0804 & 3.8351 & TRN & \\
\hline CHEMBL1967566 & 809060 & 4.9508 & 4.4625 & TST & \\
\hline CHEMBL 2001041 & 809060 & 5.6253 & 5.008 & TRN & \\
\hline CHEMBL1507840 & 809060 & 3.0044 & 3.6257 & TST & \\
\hline CHEMBL1993943 & 809060 & 5.8297 & 5.0911 & TRN & \\
\hline CHEMBL1979068 & 809060 & 3.0044 & 3.8963 & TRN & \\
\hline CHEMBL1525481 & 809060 & 6.0545 & 4.3423 & TST & \\
\hline CHEMBL1979770 & 809060 & 3.0044 & 3.3515 & TRN & \\
\hline CHEMBL1985970 & 809060 & 3.0044 & 4.4038 & TRN & \\
\hline CHEMBL 2006869 & 809060 & 3.0044 & 3.9187 & TST & \\
\hline CHEMBL1608436 & 809060 & 5.433 & 4.2182 & TRN & \\
\hline CHEMBL1985596 & 809060 & 3.0044 & 3.7094 & TRN & \\
\hline CHEMBL1309497 & 809060 & 6.3382 & 4.2153 & TST & \\
\hline CHEMBL1974840 & 809060 & 3.0044 & 3.6848 & TST & \\
\hline CHEMBL1974521 & 809060 & 5.16299 & 99999999 & 4.7959 & TST \\
\hline CHEMBL1528822 & 809060 & 4.762 & 4.4944 & TRN & \\
\hline CHEMBL1997796 & 809060 & 3.0044 & 3.4538 & TRN & \\
\hline CHEMBL1476102 & 809060 & 3.0044 & 3.5827 & TRN & \\
\hline CHEMBL1370417 & 809060 & 3.0044 & 3.5371 & TST & \\
\hline CHEMBL1520311 & 809060 & 5.7645 & 4.5837 & TST & \\
\hline CHEMBL1501937 & 809060 & 4.2314 & 4.918 & TRN & \\
\hline CHEMBL1989549 & 809060 & 4.4786 & 4.5217 & TRN & \\
\hline CHEMBL1988776 & 809060 & 3.0044 & 3.678 & TRN & \\
\hline
\end{tabular}




\begin{tabular}{|c|c|c|c|c|c|c|}
\hline & & \multicolumn{5}{|c|}{ Supplemental Table s2.txt } \\
\hline CHEMBL1475485 & 809060 & 4.2905 & 3.9152 & TRN & & \\
\hline CHEMBL1973444 & 809060 & 3.0044 & 3.2773 & TRN & & \\
\hline CHEMBL1305910 & 809060 & 4.7825 & 4.1368 & TRN & & \\
\hline CHEMBL1336933 & 809060 & 3.0044 & 2.9003 & TRN & & \\
\hline CHEMBL1991688 & 809060 & 3.0044 & 4.0849 & TRN & & \\
\hline CHEMBL1993130 & 809060 & 4.4733 & 5.5088 & TRN & & \\
\hline CHEMBL1351403 & 809060 & 4.2328 & 4.2303 & TRN & & \\
\hline CHEMBL1490308 & 809060 & 4.2844 & 4.5934 & TST & & \\
\hline CHEMBL1992480 & 809060 & 4.3154 & 4.0403 & TRN & & \\
\hline CHEMBL1995310 & 809060 & 3.0044 & 3.1836 & TRN & & \\
\hline CHEMBL1438570 & 809060 & 4.298 & 4.5441 & TRN & & \\
\hline CHEMBL1997123 & 809060 & 3.0044 & 3.3333 & TRN & & \\
\hline CHEMBL1983298 & 809060 & 3.0044 & 3.8216 & TRN & & \\
\hline CHEMBL1969580 & 809060 & 4.1766 & 4.5862 & TRN & & \\
\hline CHEMBL1992193 & 809060 & 4.1213 & 3.4998 & TST & & \\
\hline CHEMBL1347563 & 809060 & 4.228 & 4.5219 & TRN & & \\
\hline CHEMBL1985704 & 809060 & 4.8297 & 4.9356 & TRN & & \\
\hline CHEMBL1385744 & 809060 & 4.104 & 3.9656 & TRN & & \\
\hline CHEMBL1353222 & 809060 & 3.0044 & 3.6187 & TST & & \\
\hline CHEMBL1993276 & 809060 & 5.8041 & 5.5935 & TRN & & \\
\hline CHEMBL 246655 & 809060 & 5.5376 & 4.5164 & TST & & \\
\hline CHEMBL1985130 & 809060 & 6.104 & 4.6637 & TRN & & \\
\hline CHEMBL1594483 & 809060 & 4.7423 & 4.018 & TRN & & \\
\hline CHEMBL1993844 & 809060 & 3.0044 & 3.2096 & TRN & & \\
\hline CHEMBL1999373 & 809060 & 3.0044 & 3.5867 & TST & & \\
\hline CHEMBL1973048 & 809060 & 4.7986 & 3.6579 & TRN & & \\
\hline CHEMBL2001665 & 809060 & 4.2336 & 3.2716 & TRN & & \\
\hline CHEMBL 2006714 & 809060 & 5.8297 & 5.0822 & TRN & & \\
\hline CHEMBL1975135 & 809060 & 3.0044 & 3.8177 & TRN & & \\
\hline CHEMBL1549870 & 809060 & 4.2785 & 4.6769 & TST & & \\
\hline CHEMBL 2003655 & 809060 & 6.2441 & 4.4545 & TRN & & \\
\hline CHEMBL1992722 & 809060 & 4.4765 & 4.4121 & TRN & & \\
\hline CHEMBL1558834 & 809060 & 3.0044 & 3.3554 & TRN & & \\
\hline CHEMBL1989875 & 809060 & 4.1611 & 3.1612 & TRN & & \\
\hline CHEMBL1975823 & 809060 & 3.0044 & 3.2063 & TRN & & \\
\hline CHEMBL2006198 & 809060 & 4.1211 & 4.0343 & TRN & & \\
\hline CHEMBL1869416 & 809060 & 3.0044 & 3.5099 & TRN & & \\
\hline CHEMBL1981206 & 809060 & 4.3372 & 4.052 & TST & & \\
\hline CHEMBL2001815 & 809060 & 5.5768 & 5.4117 & TST & & \\
\hline CHEMBL1972780 & 809060 & 3.0044 & 4.1592 & TST & & \\
\hline CHEMBL1709744 & 809060 & 6.0057 & 3.7041 & TST & & \\
\hline CHEMBL1363112 & 809060 & $5.7570 e$ & 00000000 & 01 & 4.4061 & TST \\
\hline CHEMBL66966 & 688453 & 6.0 & 5.1135 & TRN & & \\
\hline CHEMBL1346879 & 688453 & 4.4 & 4.9359 & TRN & & \\
\hline CHEMBL1573347 & 688453 & 4.9 & 5.1239 & TRN & & \\
\hline CHEMBL1574417 & 688453 & 4.4 & 5.03100 & 0000000001 & & TST \\
\hline CHEMBL1580845 & 688453 & 4.5 & 4.6761 & TRN & & \\
\hline CHEMBL1539637 & 688453 & 4.8 & 5.0417 & TRN & & \\
\hline
\end{tabular}




\begin{tabular}{|c|c|c|c|c|c|}
\hline \multicolumn{6}{|c|}{ Supplemental Table S2.txt } \\
\hline CHEMBL434778 & 688453 & 4.95 & 5.1276 & TRN & \\
\hline CHEMBL1531125 & 688453 & 4.6 & 4.5572 & TRN & \\
\hline CHEMBL1491936 & 688453 & 4.4 & 5.1636 & TRN & \\
\hline CHEMBL1326833 & 688453 & 4.45 & 4.9297 & TRN & \\
\hline CHEMBL1492622 & 688453 & 4.7 & 4.5426 & TRN & \\
\hline CHEMBL1447002 & 688453 & 5.2 & 4.6066 & TRN & \\
\hline CHEMBL1333824 & 688453 & 4.4 & 5.1333 & TRN & \\
\hline CHEMBL1575881 & 688453 & 4.65 & 4.7895 & TRN & \\
\hline CHEMBL1541894 & 688453 & 4.5 & 5.1422 & TRN & \\
\hline CHEMBL1340514 & 688453 & 4.4 & 5.0205 & TRN & \\
\hline CHEMBL1561360 & 688453 & 4.6 & 4.9084 & TRN & \\
\hline CHEMBL1463100 & 688453 & 4.65 & 5.1688 & TRN & \\
\hline CHEMBL243677 & 688453 & 4.6 & 5.0909 & TRN & \\
\hline CHEMBL1415381 & 688453 & 5.85 & 5.2607 & TRN & \\
\hline CHEMBL1492926 & 688453 & 4.45 & 4.5436 & TRN & \\
\hline CHEMBL1438232 & 688453 & 4.4 & 5.091 & TRN & \\
\hline CHEMBL1387750 & 688453 & 4.65 & 5.0797 & TRN & \\
\hline CHEMBL 2002767 & 688453 & 4.45 & 4.825 & TRN & \\
\hline CHEMBL1544633 & 688453 & 4.5 & 4.8751 & TRN & \\
\hline CHEMBL1462707 & 688453 & 4.4 & 5.0 & TRN & \\
\hline CHEMBL1612797 & 688453 & 6.7001 & 5.2402 & TRN & \\
\hline CHEMBL1452254 & 688453 & 4.5 & 4.7092 & TRN & \\
\hline CHEMBL1458563 & 688453 & 4.9 & 4.71899 & 9999999999 & TRN \\
\hline CHEMBL1459161 & 688453 & 4.45 & 4.8388 & TRN & \\
\hline CHEMBL1308611 & 688453 & 4.6 & 5.0168 & TST & \\
\hline CHEMBL1380958 & 688453 & 4.65 & 5.2908 & TRN & \\
\hline CHEMBL1507894 & 688453 & 5.5 & 5.0857 & TRN & \\
\hline CHEMBL1997827 & 688453 & 4.55 & 4.8951 & TRN & \\
\hline CHEMBL1486100 & 688453 & 5.4 & 5.5802 & TRN & \\
\hline CHEMBL1516858 & 688453 & 4.85 & 4.8191 & TRN & \\
\hline CHEMBL1502381 & 688453 & 4.6 & 5.3154 & TRN & \\
\hline CHEMBL1385088 & 688453 & 4.65 & 5.0097 & TRN & \\
\hline CHEMBL1406197 & 688453 & 4.45 & 4.9402 & TRN & \\
\hline CHEMBL1383474 & 688453 & 4.3 & 5.0613 & TRN & \\
\hline CHEMBL1375570 & 688453 & 4.4 & 5.1156 & TRN & \\
\hline CHEMBL493863 & 688453 & 4.65 & 5.0138 & TRN & \\
\hline CHEMBL1411232 & 688453 & 5.2 & 4.8775 & TRN & \\
\hline CHEMBL1560128 & 688453 & 4.95 & 5.1255 & TRN & \\
\hline CHEMBL1311130 & 688453 & 7.6003 & 5.3402 & TRN & \\
\hline CHEMBL1607650 & 688453 & 4.45 & 4.9192 & TRN & \\
\hline CHEMBL1442869 & 688453 & 5.2 & 4.9461 & TST & \\
\hline CHEMBL1365118 & 688453 & 4.4 & 5.0519 & TRN & \\
\hline CHEMBL1607586 & 688453 & 4.65 & 4.9582 & TRN & \\
\hline CHEMBL1483278 & 688453 & 4.45 & 5.1148 & TRN & \\
\hline CHEMBL1325961 & 688453 & 5.05 & 5.0453 & TRN & \\
\hline CHEMBL1256623 & 688453 & 5.3 & 5.3123 & TRN & \\
\hline CHEMBL1372613 & 688453 & 4.45 & 4.9655 & TRN & \\
\hline CHEMBL1608990 & 688453 & 4.5 & 5.0451 & TRN & \\
\hline
\end{tabular}




\begin{tabular}{|c|c|c|c|c|}
\hline \multicolumn{5}{|c|}{ Supplemental Table S2.txt } \\
\hline CHEMBL1535540 & 688453 & 4.45 & 5.1154 & TRN \\
\hline CHEMBL1472066 & 688453 & 5.3 & 4.9066 & TRN \\
\hline CHEMBL1599723 & 688453 & 4.7 & 4.4308 & TRN \\
\hline CHEMBL1301348 & 688453 & 6.25 & 5.2171 & TRN \\
\hline CHEMBL3189778 & 688453 & 4.4 & 4.9787 & TRN \\
\hline CHEMBL1343805 & 688453 & 6.4 & 4.8287 & TRN \\
\hline CHEMBL1430139 & 688453 & 4.4 & 5.2787 & TRN \\
\hline CHEMBL1299341 & 688453 & 4.65 & 4.7688 & TRN \\
\hline CHEMBL1439668 & 688453 & 4.55 & 4.8935 & TRN \\
\hline CHEMBL1587856 & 688453 & 6.8499 & 5.3492 & TRN \\
\hline CHEMBL1464392 & 688453 & 4.45 & 4.7287 & TRN \\
\hline CHEMBL1449331 & 688453 & 4.4 & 5.2531 & TRN \\
\hline CHEMBL1999473 & 688453 & 4.4 & 4.8409 & TRN \\
\hline CHEMBL1533549 & 688453 & 4.4 & 4.7368 & TRN \\
\hline CHEMBL1544287 & 688453 & 5.2 & 5.1561 & TST \\
\hline CHEMBL1534353 & 688453 & 6.4 & 5.3564 & TST \\
\hline CHEMBL1543630 & 688453 & 4.4 & 4.6318 & TRN \\
\hline CHEMBL 2007227 & 688453 & 4.4 & 5.0221 & TRN \\
\hline CHEMBL1502245 & 688453 & 5.55 & 4.8582 & TST \\
\hline CHEMBL1432627 & 688453 & 5.35 & 4.6641 & TRN \\
\hline CHEMBL1313485 & 688453 & 5.85 & 5.2739 & TRN \\
\hline CHEMBL1453292 & 688453 & 6.05 & 5.0475 & TRN \\
\hline CHEMBL1530883 & 688453 & 4.55 & 4.8529 & TRN \\
\hline CHEMBL1543956 & 688453 & 4.8 & 5.1016 & TRN \\
\hline CHEMBL 3192501 & 688453 & 6.95 & 5.1657 & TRN \\
\hline CHEMBL1586490 & 688453 & 7.5003 & 5.3104 & TRN \\
\hline CHEMBL1584278 & 688453 & 4.45 & 4.848 & TRN \\
\hline CHEMBL1600921 & 688453 & 5.2 & 4.9076 & TRN \\
\hline CHEMBL1401239 & 688453 & 4.65 & 4.9869 & TRN \\
\hline CHEMBL1431104 & 688453 & 4.5 & 5.1712 & TST \\
\hline CHEMBL462880 & 688453 & 4.6 & 5.0231 & TST \\
\hline CHEMBL1500235 & 688453 & 4.95 & 5.0226 & TRN \\
\hline CHEMBL1518926 & 688453 & 4.5 & 4.838 & TRN \\
\hline CHEMBL1569232 & 688453 & 4.7 & 4.6609 & TRN \\
\hline CHEMBL1509872 & 688453 & 4.35 & 5.1445 & TRN \\
\hline CHEMBL1369226 & 688453 & 4.4 & 5.1141 & TRN \\
\hline CHEMBL1351364 & 688453 & 6.8 & 5.1365 & TRN \\
\hline CHEMBL1344388 & 688453 & 6.0 & 4.7686 & TRN \\
\hline CHEMBL1605659 & 688453 & 6.8 & 5.2052 & TRN \\
\hline CHEMBL1536025 & 688453 & 6.25 & 5.1757 & TST \\
\hline CHEMBL1374043 & 688453 & 5.2 & 5.1282 & TRN \\
\hline CHEMBL1323736 & 688453 & 5.05 & 4.9089 & TRN \\
\hline CHEMBL1416424 & 688453 & 5.2 & 5.0793 & TRN \\
\hline CHEMBL1392252 & 688453 & 4.65 & 5.0035 & TRN \\
\hline CHEMBL1477193 & 688453 & 5.85 & 4.987 & TRN \\
\hline CHEMBL187266 & 688453 & 4.4 & 4.9579 & TST \\
\hline CHEMBL1560726 & 688453 & 6.4 & 5.0096 & TST \\
\hline CHEMBL1409713 & 688453 & 4.55 & 5.2832 & TST \\
\hline
\end{tabular}




\begin{tabular}{|c|c|c|c|c|}
\hline \multicolumn{5}{|c|}{ Supplemental Table S2.txt } \\
\hline CHEMBL1610056 & 688453 & 4.4 & 5.0661 & TST \\
\hline CHEMBL1466558 & 688453 & 4.45 & 5.0573 & TRN \\
\hline CHEMBL1309506 & 688453 & 5.05 & 4.7402 & TRN \\
\hline CHEMBL1588660 & 688453 & 4.6 & 4.9366 & TRN \\
\hline CHEMBL15594 & 688453 & 6.0 & 5.2811 & TRN \\
\hline CHEMBL1455277 & 688453 & 4.6 & 5.1863 & TST \\
\hline CHEMBL1327800 & 688453 & 5.25 & 4.7305 & TRN \\
\hline CHEMBL1422234 & 688453 & 4.45 & 4.9852 & TRN \\
\hline CHEMBL1486503 & 688453 & 4.55 & 4.6905 & TRN \\
\hline CHEMBL1986381 & 688453 & 4.65 & 4.9105 & TRN \\
\hline CHEMBL1541438 & 688453 & 4.4 & 5.0036 & TRN \\
\hline CHEMBL1462808 & 688453 & 4.85 & 5.0127 & TST \\
\hline CHEMBL1407667 & 688453 & 4.9 & 4.9325 & TRN \\
\hline CHEMBL1311587 & 688453 & 4.5 & 5.1038 & TRN \\
\hline CHEMBL1373432 & 688453 & 5.4 & 4.9544 & TRN \\
\hline CHEMBL1370073 & 688453 & 4.9 & 4.9921 & TRN \\
\hline CHEMBL1598101 & 688453 & 4.45 & 5.0058 & TRN \\
\hline CHEMBL1575672 & 688453 & 6.45 & 5.2578 & TRN \\
\hline CHEMBL1511067 & 688453 & 5.0 & 4.9137 & TRN \\
\hline CHEMBL1445646 & 688453 & 4.45 & 5.1121 & TST \\
\hline CHEMBL1471867 & 688453 & 5.95 & 4.7374 & TRN \\
\hline CHEMBL1334684 & 688453 & 5.1 & 5.1073 & TST \\
\hline CHEMBL1482827 & 688453 & 5.05 & 4.8818 & TRN \\
\hline CHEMBL1604118 & 688453 & 5.95 & 5.1469 & TRN \\
\hline CHEMBL1386598 & 688453 & 4.4 & 4.9243 & TRN \\
\hline CHEMBL1470936 & 688453 & 5.5 & 4.8661 & TRN \\
\hline CHEMBL1465640 & 688453 & 5.45 & 5.3931 & TRN \\
\hline CHEMBL3190370 & 688453 & 5.3 & 4.5902 & TRN \\
\hline CHEMBL182461 & 688453 & 6.7501 & 5.4081 & TST \\
\hline CHEMBL1520891 & 688453 & 4.5 & 5.1222 & TRN \\
\hline CHEMBL1498032 & 688453 & 6.8 & 5.1883 & TRN \\
\hline CHEMBL1467244 & 688453 & 4.65 & 4.7974 & TRN \\
\hline CHEMBL1373101 & 688453 & 6.1 & 5.3292 & TRN \\
\hline CHEMBL222519 & 688453 & 5.85 & 4.9088 & TRN \\
\hline CHEMBL1558621 & 688453 & 6.0 & 5.0986 & TST \\
\hline CHEMBL1590156 & 688453 & 4.4 & 5.1116 & TRN \\
\hline CHEMBL1440632 & 688453 & 5.1 & 5.2783 & TRN \\
\hline CHEMBL3191560 & 688453 & 4.4 & 4.9867 & TST \\
\hline CHEMBL1607897 & 688453 & 4.4 & 4.7701 & TRN \\
\hline CHEMBL3214236 & 688453 & 4.4 & 4.9069 & TRN \\
\hline CHEMBL1271971 & 688453 & 4.45 & 5.125 & TRN \\
\hline CHEMBL1429633 & 688453 & 4.4 & 5.2808 & TRN \\
\hline CHEMBL1334889 & 688453 & 4.4 & 4.9695 & TRN \\
\hline CHEMBL1385027 & 688453 & 4.4 & 4.7947 & TRN \\
\hline CHEMBL1556350 & 688453 & 4.6 & 4.9754 & TST \\
\hline CHEMBL1560052 & 688453 & 4.4 & 4.6717 & TRN \\
\hline CHEMBL1373527 & 688453 & 4.95 & 5.0522 & TRN \\
\hline CHEMBL3191780 & 688453 & 5.0 & 4.9314 & TRN \\
\hline
\end{tabular}




\begin{tabular}{|c|c|c|c|c|c|}
\hline \multicolumn{6}{|c|}{ Supplemental Table S2.txt } \\
\hline CHEMBL1452686 & 688453 & 4.45 & 5.0186 & TRN & \\
\hline CHEMBL1364039 & 688453 & 4.6 & 5.0427 & TRN & \\
\hline CHEMBL1482979 & 688453 & 5.4 & 4.8171 & TRN & \\
\hline CHEMBL1429570 & 688453 & 4.9 & 4.7849 & TRN & \\
\hline CHEMBL1393468 & 688453 & 6.35 & 5.2922 & TRN & \\
\hline CHEMBL1441950 & 688453 & 4.5 & 5.2689 & TRN & \\
\hline CHEMBL 2003887 & 688453 & 4.85 & 4.6001 & TRN & \\
\hline CHEMBL 3207873 & 688453 & 4.4 & 5.0563 & TRN & \\
\hline CHEMBL1307692 & 688453 & 4.55 & 4.6342 & TRN & \\
\hline CHEMBL1301796 & 688453 & 5.35 & 4.9317 & TRN & \\
\hline CHEMBL1580407 & 688453 & 4.4 & 4.5541 & TRN & \\
\hline CHEMBL1430672 & 688453 & 5.85 & 5.1823 & TRN & \\
\hline CHEMBL1467262 & 688453 & 4.4 & 5.24100 & 00000000005 & TST \\
\hline CHEMBL1368366 & 688453 & 4.5 & 5.1599 & TST & \\
\hline CHEMBL1344101 & 688453 & 4.6 & 4.914 & TRN & \\
\hline CHEMBL1373868 & 688453 & 4.5 & 4.7502 & TRN & \\
\hline CHEMBL1604398 & 688453 & 5.4 & 4.8454 & TRN & \\
\hline CHEMBL1496441 & 688453 & 4.95 & 5.0999 & TRN & \\
\hline CHEMBL1475166 & 688453 & 4.5 & 5.0897 & TRN & \\
\hline CHEMBL1508600 & 688453 & 4.65 & 5.0688 & TRN & \\
\hline CHEMBL1443301 & 688453 & 6.8499 & 5.1449 & TRN & \\
\hline CHEMBL 547833 & 688453 & 4.65 & 4.9599 & TRN & \\
\hline CHEMBL1346870 & 688453 & 5.2 & 5.1342 & TST & \\
\hline CHEMBL1556769 & 688453 & 5.85 & 4.82100 & 0000000001 & TRN \\
\hline CHEMBL1537534 & 688453 & 4.35 & 4.8229 & TRN & \\
\hline CHEMBL1381795 & 688453 & 4.75 & 5.1353 & TRN & \\
\hline CHEMBL1581251 & 688453 & 4.85 & 4.9275 & TRN & \\
\hline CHEMBL3193830 & 688453 & 5.25 & 4.9778 & TRN & \\
\hline CHEMBL1548422 & 688453 & 4.4 & 4.7878 & TRN & \\
\hline CHEMBL1386891 & 688453 & 4.6 & 5.2102 & TRN & \\
\hline CHEMBL3193151 & 688453 & 4.45 & 4.5272 & TRN & \\
\hline CHEMBL477139 & 688453 & 4.4 & 5.0124 & TRN & \\
\hline CHEMBL3211304 & 688453 & 4.4 & 4.7688 & TST & \\
\hline CHEMBL1344944 & 688453 & 4.5 & 5.0991 & TRN & \\
\hline CHEMBL1299742 & 688453 & 4.5 & 5.0913 & TRN & \\
\hline CHEMBL1318708 & 688453 & 5.05 & 4.9605 & TST & \\
\hline CHEMBL1465297 & 688453 & 4.4 & 4.5876 & TRN & \\
\hline CHEMBL3197894 & 688453 & 5.1 & 5.1935 & TRN & \\
\hline CHEMBL3194702 & 688453 & 4.4 & 5.1367 & TRN & \\
\hline CHEMBL1421172 & 688453 & 4.85 & 4.5112 & TRN & \\
\hline CHEMBL1612236 & 688453 & 5.45 & 5.0237 & TRN & \\
\hline CHEMBL1411246 & 688453 & 4.5 & 5.4721 & TST & \\
\hline CHEMBL1477068 & 688453 & 4.6 & 4.8763 & TRN & \\
\hline CHEMBL257359 & 688453 & 4.5 & 4.5764 & TRN & \\
\hline CHEMBL1541487 & 688453 & 4.5 & 4.6927 & TRN & \\
\hline CHEMBL3211246 & 688453 & 5.55 & 5.209 & TRN & \\
\hline CHEMBL1413895 & 688453 & 6.8 & 5.2117 & TRN & \\
\hline CHEMBL1404133 & 688453 & 4.55 & 5.3707 & TRN & \\
\hline
\end{tabular}




\begin{tabular}{|c|c|c|c|c|c|}
\hline \multicolumn{6}{|c|}{ Supplemental Table S2.txt } \\
\hline CHEMBL1582210 & 688453 & 4.4 & 5.0009 & TRN & \\
\hline CHEMBL68534 & 688453 & 4.95 & 4.9502 & TRN & \\
\hline CHEMBL1301115 & 688453 & 4.85 & 4.9631 & TRN & \\
\hline CHEMBL131091 & 688453 & 6.0 & 4.893 & TST & \\
\hline CHEMBL1536878 & 688453 & 4.4 & 4.7358 & TRN & \\
\hline CHEMBL1398944 & 688453 & 4.4 & 5.0663 & TRN & \\
\hline CHEMBL1370814 & 688453 & 6.0 & 5.2268 & TRN & \\
\hline CHEMBL1368261 & 688453 & 5.35 & 4.9832 & TST & \\
\hline CHEMBL1385987 & 688453 & 4.4 & 4.7737 & TRN & \\
\hline CHEMBL1990772 & 688453 & 4.4 & 5.0956 & TRN & \\
\hline CHEMBL1394337 & 688453 & 5.35 & 5.17399 & 99999999995 & TRN \\
\hline CHEMBL1439414 & 688453 & 4.9 & 4.5689 & TRN & \\
\hline CHEMBL1548937 & 688453 & 6.2 & 5.2038 & TRN & \\
\hline CHEMBL1546190 & 688453 & 4.4 & 4.9747 & TRN & \\
\hline CHEMBL584759 & 688453 & 6.0 & 4.8918 & TRN & \\
\hline CHEMBL1441415 & 688453 & 4.45 & 5.012 & TRN & \\
\hline CHEMBL1423277 & 688453 & 5.15 & 5.0544 & TRN & \\
\hline CHEMBL1407928 & 688453 & 4.4 & 5.2231 & TST & \\
\hline CHEMBL1584280 & 688453 & 4.65 & 5.0083 & TRN & \\
\hline CHEMBL59451 & 688453 & 6.0 & 5.39 & TST & \\
\hline CHEMBL402053 & 688453 & 4.4 & 4.4756 & TRN & \\
\hline CHEMBL1374573 & 688453 & 4.6 & 4.6834 & TRN & \\
\hline CHEMBL1485713 & 688453 & 5.0 & 5.1261 & TRN & \\
\hline CHEMBL1594634 & 688453 & 4.6 & 4.8042 & TRN & \\
\hline CHEMBL1320868 & 688453 & 4.6 & 4.7077 & TRN & \\
\hline CHEMBL1408320 & 688453 & 5.0 & 4.6245 & TRN & \\
\hline CHEMBL3716478 & 688453 & 4.4 & 4.9541 & TST & \\
\hline CHEMBL1588295 & 688453 & 5.15 & 5.24799 & 9999999999 & TST \\
\hline CHEMBL1494937 & 688453 & 4.85 & 5.2683 & TRN & \\
\hline CHEMBL1596778 & 688453 & 5.05 & 5.2829 & TRN & \\
\hline CHEMBL1540584 & 688453 & 4.4 & 4.8303 & TST & \\
\hline CHEMBL1445157 & 688453 & 5.25 & 5.1986 & TRN & \\
\hline CHEMBL1706619 & 688453 & 4.4 & 4.5659 & TRN & \\
\hline CHEMBL1486283 & 688453 & 4.5 & 5.0782 & TST & \\
\hline CHEMBL1563429 & 688453 & 5.25 & 5.1809 & TRN & \\
\hline CHEMBL1505482 & 688453 & 5.4 & 4.8315 & TRN & \\
\hline CHEMBL3195888 & 688453 & 5.6 & 4.6465 & TRN & \\
\hline CHEMBL1421888 & 688453 & 4.45 & 5.0863 & TRN & \\
\hline CHEMBL1351342 & 688453 & 4.6 & 5.0594 & TRN & \\
\hline CHEMBL1383575 & 688453 & 8.0 & 5.4727 & TRN & \\
\hline CHEMBL1544691 & 688453 & 4.65 & 5.0836 & TRN & \\
\hline CHEMBL1508984 & 688453 & 4.4 & 5.0883 & TRN & \\
\hline CHEMBL351042 & 688453 & 6.0 & 5.4276 & TRN & \\
\hline CHEMBL1359236 & 688453 & 5.15 & 5.149 & TRN & \\
\hline CHEMBL1613634 & 688453 & 4.85 & 4.7913 & TRN & \\
\hline CHEMBL1415592 & 688453 & 5.45 & 5.1312 & TRN & \\
\hline CHEMBL1360585 & 688453 & 4.75 & 4.9099 & TST & \\
\hline CHEMBL1568563 & 688453 & 4.4 & 5.0033 & TRN & \\
\hline
\end{tabular}




\begin{tabular}{|c|c|c|c|c|}
\hline \multicolumn{5}{|c|}{ Supplemental Table S2.txt } \\
\hline CHEMBL1451841 & 688453 & 4.4 & 5.0918 & TST \\
\hline CHEMBL1307354 & 688453 & 4.6 & 4.6757 & TRN \\
\hline CHEMBL1575558 & 688453 & 4.4 & 5.2053 & TST \\
\hline CHEMBL1359354 & 688453 & 4.4 & 4.7964 & TRN \\
\hline CHEMBL1485734 & 688453 & 7.5003 & 5.1154 & TST \\
\hline CHEMBL119171 & 688453 & 4.55 & 5.1779 & TST \\
\hline CHEMBL3216654 & 688453 & 4.4 & 5.2137 & TST \\
\hline CHEMBL1497651 & 688453 & 5.5 & 4.6762 & TRN \\
\hline CHEMBL1408483 & 688453 & 5.55 & 5.0883 & TRN \\
\hline CHEMBL1529285 & 688453 & 4.4 & 4.8586 & TST \\
\hline CHEMBL1404424 & 688453 & 4.5 & 4.9221 & TRN \\
\hline CHEMBL1344064 & 688453 & 4.4 & 5.1743 & TRN \\
\hline CHEMBL1339340 & 688453 & 4.45 & 5.0227 & TRN \\
\hline CHEMBL1388509 & 688453 & 4.6 & 4.9013 & TRN \\
\hline CHEMBL578512 & 688453 & 5.3 & 5.0072 & TRN \\
\hline CHEMBL1990418 & 688453 & 4.45 & 4.8514 & TST \\
\hline CHEMBL1608986 & 688453 & 7.6003 & 5.5124 & TRN \\
\hline CHEMBL3193582 & 688453 & 4.4 & 4.9411 & TRN \\
\hline CHEMBL1331136 & 688453 & 6.1 & 5.1053 & TRN \\
\hline CHEMBL109037 & 688453 & 6.2 & 5.461 & TRN \\
\hline CHEMBL6291 & 688453 & 4.4 & 4.9617 & TST \\
\hline CHEMBL1463506 & 688453 & 6.15 & 5.1782 & TRN \\
\hline CHEMBL1526171 & 688453 & 5.0 & 4.9445 & TRN \\
\hline CHEMBL1464538 & 688453 & 6.8 & 5.0979 & TRN \\
\hline CHEMBL1502731 & 688453 & 4.45 & 4.711 & TRN \\
\hline CHEMBL1457362 & 688453 & 4.4 & 4.7054 & TRN \\
\hline CHEMBL1995879 & 688453 & 4.5 & 4.9689 & TRN \\
\hline CHEMBL1526949 & 688453 & 5.45 & 5.2589 & TRN \\
\hline CHEMBL1374949 & 688453 & 7.6003 & 5.5515 & TRN \\
\hline CHEMBL1545156 & 688453 & 4.4 & 5.2902 & TST \\
\hline CHEMBL428496 & 688453 & 6.0 & 5.1223 & TST \\
\hline CHEMBL1427190 & 688453 & 5.3 & 5.0894 & TRN \\
\hline CHEMBL1391479 & 688453 & 4.45 & 4.7313 & TRN \\
\hline CHEMBL1382785 & 688453 & 5.95 & 4.7833 & TRN \\
\hline CHEMBL1448234 & 688453 & 6.45 & 5.0655 & TRN \\
\hline CHEMBL1365290 & 688453 & 4.55 & 4.5824 & TRN \\
\hline CHEMBL 2003304 & 688453 & 4.7 & 4.9811 & TST \\
\hline CHEMBL41092 & 688453 & 5.15 & 5.0371 & TRN \\
\hline CHEMBL1422618 & 688453 & 6.7501 & 5.1342 & TST \\
\hline CHEMBL1521091 & 688453 & 4.6 & 4.9772 & TRN \\
\hline CHEMBL1411777 & 688453 & 4.45 & 4.7003 & TRN \\
\hline CHEMBL1380374 & 688453 & 6.8 & 5.0148 & TRN \\
\hline CHEMBL2005973 & 688453 & 5.35 & 4.7669 & TRN \\
\hline CHEMBL1375934 & 688453 & 4.4 & 5.0195 & TRN \\
\hline CHEMBL1306199 & 688453 & 4.45 & 4.9347 & TRN \\
\hline CHEMBL 2007178 & 688453 & 4.8 & 4.7654 & TRN \\
\hline CHEMBL 256097 & 688453 & 4.4 & 4.6721 & TRN \\
\hline CHEMBL1565805 & 688453 & 4.9 & 5.2047 & TRN \\
\hline
\end{tabular}




\begin{tabular}{|c|c|c|c|c|c|}
\hline \multicolumn{6}{|c|}{ Supplemental Table S2.txt } \\
\hline CHEMBL 244707 & 688453 & 5.5 & 5.0144 & TRN & \\
\hline CHEMBL 3193897 & 688453 & 5.35 & 4.6427 & TRN & \\
\hline CHEMBL1536196 & 688453 & 4.95 & 5.2966 & TST & \\
\hline CHEMBL1548326 & 688453 & 4.5 & 5.01 & TRN & \\
\hline CHEMBL1586692 & 688453 & 5.45 & 5.2492 & TRN & \\
\hline CHEMBL1461967 & 688453 & 4.75 & 4.8863 & TRN & \\
\hline CHEMBL1358778 & 688453 & 4.7 & 5.1168 & TRN & \\
\hline CHEMBL1493011 & 688453 & 4.85 & 5.1827 & TST & \\
\hline CHEMBL 3198927 & 688453 & 4.55 & 4.871 & TRN & \\
\hline CHEMBL1382357 & 688453 & 5.2 & 4.7807 & TST & \\
\hline CHEMBL1605033 & 688453 & 5.4 & 5.1238 & TRN & \\
\hline CHEMBL1521259 & 688453 & 4.85 & 4.7781 & TRN & \\
\hline CHEMBL502044 & 688453 & 6.0 & 5.2835 & TST & \\
\hline CHEMBL1319441 & 688453 & 4.6 & 4.6896 & TRN & \\
\hline CHEMBL1415028 & 688453 & 5.45 & 5.2837 & TRN & \\
\hline CHEMBL1444222 & 688453 & 5.35 & 5.095 & TRN & \\
\hline CHEMBL1538096 & 688453 & 5.2 & 4.971 & TST & \\
\hline CHEMBL3194876 & 688453 & 5.45 & 5.0603 & TRN & \\
\hline CHEMBL1398262 & 688453 & 4.4 & 5.3382 & TST & \\
\hline CHEMBL1553859 & 688453 & 4.5 & 4.9393 & TRN & \\
\hline CHEMBL1501307 & 688453 & 4.7 & 5.151 & TRN & \\
\hline CHEMBL1336788 & 688453 & 4.85 & 4.579 & TRN & \\
\hline CHEMBL1347992 & 688453 & 4.55 & 4.8841 & TRN & \\
\hline CHEMBL1722566 & 688453 & 4.8 & 4.6758 & TRN & \\
\hline CHEMBL1486131 & 688453 & 4.6 & 4.7203 & TRN & \\
\hline CHEMBL1486228 & 688453 & 6.1 & 5.2453 & TRN & \\
\hline CHEMBL571296 & 688453 & 4.5 & 4.9985 & TRN & \\
\hline CHEMBL1489074 & 688453 & 4.45 & 5.1246 & TRN & \\
\hline CHEMBL1490441 & 688453 & 5.45 & 4.94606 & 0000000001 & TRN \\
\hline CHEMBL1518905 & 688453 & 4.55 & 4.9479 & TRN & \\
\hline CHEMBL1445531 & 688453 & 4.4 & 5.1159 & TRN & \\
\hline CHEMBL1400620 & 688453 & 4.5 & 4.5347 & TRN & \\
\hline CHEMBL1451725 & 688453 & 4.45 & 5.0094 & TRN & \\
\hline CHEMBL1437486 & 688453 & 6.0 & 4.8552 & TST & \\
\hline CHEMBL1320839 & 688453 & 4.4 & 5.1255 & TRN & \\
\hline CHEMBL1427512 & 688453 & 7.0501 & 5.3695 & TRN & \\
\hline CHEMBL1329465 & 688453 & 4.4 & 4.9087 & TRN & \\
\hline CHEMBL1371999 & 688453 & 4.45 & 5.0733 & TST & \\
\hline CHEMBL1361498 & 688453 & 4.45 & 4.6702 & TRN & \\
\hline CHEMBL605003 & 688453 & 4.45 & 4.8168 & TST & \\
\hline CHEMBL1583598 & 688453 & 4.4 & 4.6232 & TRN & \\
\hline CHEMBL 78257 & 688453 & 4.4 & 5.0711 & TRN & \\
\hline CHEMBL 22304 & 688453 & 5.6 & 5.3012 & TST & \\
\hline CHEMBL1366112 & 688453 & 4.4 & 4.7085 & TRN & \\
\hline CHEMBL1469970 & 688453 & 6.7001 & 5.3741 & TRN & \\
\hline CHEMBL568651 & 688453 & 4.55 & 5.2813 & TRN & \\
\hline CHEMBL 1435787 & 688453 & 4.75 & 5.2087 & TRN & \\
\hline CHEMBL1452749 & 688453 & 4.4 & 5.0772 & TRN & \\
\hline
\end{tabular}




\begin{tabular}{|c|c|c|c|c|c|}
\hline \multicolumn{6}{|c|}{ Supplemental Table s2.txt } \\
\hline CHEMBL1335321 & 688453 & 5.0 & 4.8751 & TRN & \\
\hline CHEMBL1343439 & 688453 & 4.35 & 5.1705 & TRN & \\
\hline CHEMBL1570790 & 688453 & 6.8 & 5.369 & TRN & \\
\hline CHEMBL1462988 & 688453 & 4.4 & 5.1166 & TRN & \\
\hline CHEMBL1525462 & 688453 & 4.6 & 5.056 & TRN & \\
\hline CHEMBL3195048 & 688453 & 4.65 & 5.0237 & TRN & \\
\hline CHEMBL1313909 & 688453 & 4.6 & 4.9833 & TRN & \\
\hline CHEMBL1466446 & 688453 & 7.5003 & 5.0071 & TRN & \\
\hline CHEMBL1322401 & 688453 & 4.4 & 4.7629 & TRN & \\
\hline CHEMBL1402569 & 688453 & 5.15 & 5.003 & TRN & \\
\hline CHEMBL1420000 & 688453 & 6.5501 & 4.992 & TST & \\
\hline CHEMBL1454423 & 688453 & 4.4 & 5.08899 & 99999999995 & TRN \\
\hline CHEMBL1391895 & 688453 & 5.1 & 4.9689 & TRN & \\
\hline CHEMBL1342331 & 688453 & 4.8 & 5.2501 & TST & \\
\hline CHEMBL1577757 & 688453 & 4.4 & 4.9662 & TRN & \\
\hline CHEMBL1350393 & 688453 & 4.55 & 4.8444 & TST & \\
\hline CHEMBL1478326 & 688453 & 4.45 & 5.1508 & TRN & \\
\hline CHEMBL1458059 & 688453 & 4.85 & 5.1156 & TRN & \\
\hline CHEMBL1578456 & 688453 & 4.4 & 5.0082 & TRN & \\
\hline CHEMBL1605419 & 688453 & 4.55 & 4.545 & TRN & \\
\hline CHEMBL598663 & 688453 & 4.6 & 5.0632 & TRN & \\
\hline CHEMBL1499365 & 688453 & 4.6 & 4.9703 & TRN & \\
\hline CHEMBL1365380 & 688453 & 4.95 & 5.067 & TRN & \\
\hline CHEMBL1578278 & 688453 & 6.8499 & 5.1515 & TRN & \\
\hline CHEMBL1389020 & 688453 & 4.4 & 4.7586 & TRN & \\
\hline CHEMBL1577506 & 688453 & 5.05 & 5.0746 & TRN & \\
\hline CHEMBL1425322 & 688453 & 6.8499 & 5.2911 & TRN & \\
\hline CHEMBL1482115 & 688453 & 4.45 & 5.0498 & TRN & \\
\hline CHEMBL1477672 & 688453 & 4.45 & 4.8012 & TRN & \\
\hline CHEMBL1364621 & 688453 & 4.5 & 5.1091 & TRN & \\
\hline CHEMBL1381306 & 688453 & 4.4 & 5.2493 & TRN & \\
\hline CHEMBL1456386 & 688453 & 5.1 & 5.1219 & TRN & \\
\hline CHEMBL1407556 & 688453 & 5.35 & 5.1441 & TRN & \\
\hline CHEMBL3198716 & 688453 & 4.4 & 4.8154 & TRN & \\
\hline CHEMBL1457058 & 688453 & 6.25 & 5.1463 & TRN & \\
\hline CHEMBL1443157 & 688453 & 5.5 & 5.0863 & TST & \\
\hline CHEMBL1463368 & 688453 & 6.8 & 4.9403 & TRN & \\
\hline CHEMBL3194626 & 688453 & 4.75 & 4.842 & TRN & \\
\hline CHEMBL1456647 & 688453 & 4.4 & 5.1981 & TRN & \\
\hline CHEMBL1422647 & 688453 & 5.2 & 5.1761 & TRN & \\
\hline CHEMBL1392793 & 688453 & 4.4 & 5.1658 & TRN & \\
\hline CHEMBL3209943 & 688453 & 4.5 & 4.9051 & TST & \\
\hline CHEMBL1382043 & 688453 & 5.45 & 5.4437 & TST & \\
\hline CHEMBL1312714 & 688453 & 4.9 & 4.9686 & TRN & \\
\hline CHEMBL1341308 & 688453 & 4.45 & 4.7778 & TRN & \\
\hline CHEMBL1438598 & 688453 & 4.5 & 4.4744 & TRN & \\
\hline CHEMBL1431206 & 688453 & 4.45 & 4.9254 & TRN & \\
\hline CHEMBL3199033 & 688453 & 4.6 & 4.6294 & TRN & \\
\hline
\end{tabular}




\begin{tabular}{|c|c|c|c|c|}
\hline \multicolumn{5}{|c|}{ Supplemental Table S2.txt } \\
\hline CHEMBL1321017 & 688453 & 5.2 & 4.9369 & TRN \\
\hline CHEMBL1584057 & 688453 & 4.45 & 5.0078 & TRN \\
\hline CHEMBL1342842 & 688453 & 4.4 & 5.042 & TRN \\
\hline CHEMBL1985321 & 688453 & 4.55 & 4.7286 & TRN \\
\hline CHEMBL 1735892 & 688453 & 4.7 & 4.8723 & TRN \\
\hline CHEMBL1521608 & 688453 & 6.15 & 5.0727 & TST \\
\hline CHEMBL3210850 & 688453 & 4.4 & 4.789 & TRN \\
\hline CHEMBL1489773 & 688453 & 5.9 & 4.762 & TRN \\
\hline CHEMBL1302085 & 688453 & 5.35 & 4.9969 & TRN \\
\hline CHEMBL1346592 & 688453 & 4.85 & 4.7374 & TRN \\
\hline CHEMBL87791 & 688453 & 4.65 & 4.7996 & TST \\
\hline CHEMBL1367732 & 688453 & 5.2 & 5.1744 & TRN \\
\hline CHEMBL1304456 & 688453 & 4.45 & 4.8418 & TRN \\
\hline CHEMBL 3193785 & 688453 & 5.0 & 5.0173 & TST \\
\hline CHEMBL1425680 & 688453 & 6.0 & 4.8458 & TRN \\
\hline CHEMBL1405365 & 688453 & 5.2 & 5.3105 & TST \\
\hline CHEMBL1559333 & 688453 & 4.55 & 5.0346 & TST \\
\hline CHEMBL1484049 & 688453 & 4.65 & 4.7024 & TRN \\
\hline CHEMBL1423633 & 688453 & 4.4 & 4.8271 & TRN \\
\hline CHEMBL1449704 & 688453 & 5.45 & 5.1294 & TRN \\
\hline CHEMBL1499926 & 688453 & 4.4 & 4.9927 & TST \\
\hline CHEMBL1580041 & 688453 & 4.45 & 5.1109 & TRN \\
\hline CHEMBL1360251 & 688453 & 4.7 & 4.9848 & TRN \\
\hline CHEMBL1539589 & 688453 & 6.05 & 5.3985 & TRN \\
\hline CHEMBL1544332 & 688453 & 4.5 & 4.995 & TRN \\
\hline CHEMBL1987514 & 688453 & 4.4 & 4.7495 & TRN \\
\hline CHEMBL1370619 & 688453 & 4.4 & 4.9358 & TRN \\
\hline CHEMBL1497159 & 688453 & 4.5 & 4.9595 & TRN \\
\hline CHEMBL1447148 & 688453 & 4.5 & 4.9975 & TRN \\
\hline CHEMBL1534809 & 688453 & 7.5498 & 5.3564 & TST \\
\hline CHEMBL1535227 & 688453 & 4.4 & 5.0856 & TRN \\
\hline CHEMBL1360265 & 688453 & 4.4 & 5.1109 & TRN \\
\hline CHEMBL1440138 & 688453 & 5.1 & 5.1472 & TRN \\
\hline CHEMBL3196823 & 688453 & 4.4 & 5.0617 & TST \\
\hline CHEMBL1383400 & 688453 & 5.2 & 5.197 & TRN \\
\hline CHEMBL1606671 & 688453 & 4.6 & 4.7812 & TRN \\
\hline CHEMBL1529511 & 688453 & 4.65 & 4.9354 & TRN \\
\hline CHEMBL1384398 & 688453 & 4.8 & 5.3845 & TRN \\
\hline CHEMBL1453856 & 688453 & 4.4 & 5.2481 & TRN \\
\hline CHEMBL1379418 & 688453 & 4.6 & 5.0606 & TRN \\
\hline CHEMBL1575272 & 688453 & 4.65 & 4.8224 & TRN \\
\hline CHEMBL1422807 & 688453 & 4.4 & 4.7244 & TRN \\
\hline CHEMBL1608489 & 688453 & 4.45 & 4.8126 & TRN \\
\hline CHEMBL1336680 & 688453 & 5.05 & 5.0018 & TRN \\
\hline CHEMBL1602360 & 688453 & 4.85 & 5.1404 & TRN \\
\hline CHEMBL1546270 & 688453 & 6.7501 & 5.1534 & TRN \\
\hline CHEMBL1384581 & 688453 & 5.0 & 4.9143 & TRN \\
\hline CHEMBL1486180 & 688453 & 4.6 & 4.9287 & TRN \\
\hline
\end{tabular}




\begin{tabular}{|c|c|c|c|c|c|}
\hline & & \multicolumn{4}{|c|}{ Supplemental Table s2.txt } \\
\hline CHEMBL1599728 & 688453 & 4.85 & 5.0849 & TRN & \\
\hline CHEMBL1461231 & 688453 & 4.7 & 4.9877 & TRN & \\
\hline CHEMBL600765 & 688453 & 4.4 & 5.1008 & TST & \\
\hline CHEMBL1500231 & 688453 & 4.5 & 5.0064 & TST & \\
\hline CHEMBL1327596 & 688453 & 6.8 & 5.2585 & TRN & \\
\hline CHEMBL1409603 & 688453 & 4.7 & 4.7879 & TRN & \\
\hline CHEMBL3196373 & 688453 & 4.4 & 4.6263 & TRN & \\
\hline CHEMBL1604389 & 688453 & 5.15 & 4.9313 & TRN & \\
\hline CHEMBL1393875 & 688453 & 4.7 & 5.0027 & TRN & \\
\hline CHEMBL1613708 & 688453 & 4.85 & 4.5752 & TRN & \\
\hline CHEMBL1547684 & 688453 & 4.95 & 5.2757 & TRN & \\
\hline CHEMBL1612584 & 688453 & 4.4 & 5.2167 & TRN & \\
\hline CHEMBL1594374 & 688453 & 5.0 & 5.1851 & TRN & \\
\hline CHEMBL1507441 & 688453 & 7.0 & 4.9992 & TRN & \\
\hline CHEMBL1366812 & 688453 & 5.0 & 4.7968 & TRN & \\
\hline CHEMBL1402456 & 688453 & 4.4 & 5.0419 & TRN & \\
\hline CHEMBL1443162 & 688453 & 5.45 & 5.1331 & TRN & \\
\hline CHEMBL1432302 & 688453 & 4.4 & 5.0995 & TRN & \\
\hline CHEMBL1539720 & 688453 & 4.5 & 5.1394 & TRN & \\
\hline CHEMBL1495778 & 688453 & 5.05 & 4.9255 & TRN & \\
\hline CHEMBL1363368 & 688453 & 6.05 & 4.9704 & TRN & \\
\hline CHEMBL1555938 & 688453 & 5.45 & 4.9103 & TRN & \\
\hline CHEMBL1364573 & 688453 & 4.9 & 5.1098 & TRN & \\
\hline CHEMBL1516006 & 688453 & 4.4 & 4.9919 & TRN & \\
\hline CHEMBL580421 & 688453 & 6.0 & 5.1432 & TRN & \\
\hline CHEMBL11475 & 688453 & 5.45 & 5.1849 & TRN & \\
\hline CHEMBL1496101 & 688453 & 4.6 & 4.8822 & TRN & \\
\hline CHEMBL3208363 & 688453 & 5.45 & 5.2039 & TRN & \\
\hline CHEMBL1385808 & 688453 & 4.4 & 4.9963 & TST & \\
\hline CHEMBL1504802 & 688453 & 6.3 & 5.0389 & TRN & \\
\hline CHEMBL1337174 & 688453 & 5.55 & 4.9584 & TRN & \\
\hline CHEMBL1998184 & 688453 & 4.45 & 4.8312 & TRN & \\
\hline CHEMBL1458441 & 688453 & 4.55 & 4.60800 & 00000000005 & TRN \\
\hline CHEMBL1301832 & 688453 & 7.0 & 5.1482 & TRN & \\
\hline CHEMBL578585 & 688453 & 4.6 & 5.1237 & TRN & \\
\hline CHEMBL1478548 & 688453 & 6.95 & 5.0855 & TRN & \\
\hline CHEMBL1495485 & 688453 & 4.45 & 4.9793 & TRN & \\
\hline CHEMBL1597993 & 688453 & 4.85 & 4.9891 & TST & \\
\hline CHEMBL3210993 & 688453 & 4.4 & 4.9742 & TRN & \\
\hline CHEMBL1417159 & 688453 & 4.6 & 5.2991 & TRN & \\
\hline CHEMBL1438370 & 688453 & 4.6 & 5.1195 & TST & \\
\hline CHEMBL1338986 & 688453 & 4.45 & 5.2143 & TRN & \\
\hline CHEMBL1430255 & 688453 & 4.4 & 4.9667 & TRN & \\
\hline CHEMBL1487716 & 688453 & 4.5 & 4.9607 & TRN & \\
\hline CHEMBL3194805 & 688453 & 4.75 & 4.7216 & TRN & \\
\hline CHEMBL3193269 & 688453 & 4.4 & 4.6941 & TRN & \\
\hline CHEMBL1368067 & 688453 & 5.45 & 4.9764 & TRN & \\
\hline CHEMBL3194109 & 688453 & 4.4 & 4.7709 & TRN & \\
\hline
\end{tabular}




\begin{tabular}{|c|c|c|c|c|c|}
\hline \multicolumn{6}{|c|}{ Supplemental Table S2.txt } \\
\hline CHEMBL1516913 & 688453 & 4.45 & 4.7183 & TRN & \\
\hline CHEMBL 3190650 & 688453 & 6.8499 & 4.9938 & TST & \\
\hline CHEMBL1546109 & 688453 & 4.4 & 5.0454 & TRN & \\
\hline CHEMBL1452766 & 688453 & 4.4 & 4.9198 & TRN & \\
\hline CHEMBL1506948 & 688453 & 4.4 & 5.0355 & TST & \\
\hline CHEMBL1544120 & 688453 & 5.4 & 4.8765 & TRN & \\
\hline CHEMBL1451087 & 688453 & 5.2 & 5.1268 & TST & \\
\hline CHEMBL3191409 & 688453 & 6.2 & 5.0021 & TST & \\
\hline CHEMBL1359064 & 688453 & 6.7501 & 4.9302 & TRN & \\
\hline CHEMBL1423909 & 688453 & 4.6 & 5.0235 & TRN & \\
\hline CHEMBL1571649 & 688453 & 5.8 & 5.0137 & TST & \\
\hline CHEMBL1471965 & 688453 & 5.85 & 4.7776 & TRN & \\
\hline CHEMBL1540698 & 688453 & 6.05 & 5.0603 & TRN & \\
\hline CHEMBL1393605 & 688453 & 4.5 & 4.8227 & TRN & \\
\hline CHEMBL1483974 & 688453 & 5.2 & 5.0638 & TRN & \\
\hline CHEMBL1981464 & 688453 & 4.45 & 4.9666 & TRN & \\
\hline CHEMBL1388072 & 688453 & 4.45 & 5.1759 & TRN & \\
\hline CHEMBL1393131 & 688453 & 5.5 & 4.71899 & 9999999999 & TRN \\
\hline CHEMBL 34241 & 688453 & 6.0 & 4.7681 & TST & \\
\hline CHEMBL1573528 & 688453 & 5.15 & 4.8889 & TRN & \\
\hline CHEMBL1419443 & 688453 & 4.8 & 4.8331 & TRN & \\
\hline CHEMBL1397270 & 688453 & 5.5 & 4.9522 & TST & \\
\hline CHEMBL1585030 & 688453 & 5.25 & 4.8826 & TST & \\
\hline CHEMBL1542944 & 688453 & 4.45 & 4.6198 & TRN & \\
\hline CHEMBL1355965 & 688453 & 4.5 & 5.294 & TST & \\
\hline CHEMBL1312576 & 688453 & 4.6 & 4.9138 & TRN & \\
\hline CHEMBL1612167 & 688453 & 4.4 & 4.8653 & TRN & \\
\hline CHEMBL1359634 & 688453 & 6.0 & 5.25799 & 9999999999 & TST \\
\hline CHEMBL1534614 & 688453 & 5.05 & 5.4308 & TRN & \\
\hline CHEMBL1305289 & 688453 & 4.8 & 4.6886 & TRN & \\
\hline CHEMBL1304952 & 688453 & 4.55 & 5.1098 & TRN & \\
\hline CHEMBL1566097 & 688453 & 6.8 & 5.5314 & TRN & \\
\hline CHEMBL1393847 & 688453 & 4.45 & 4.985 & TRN & \\
\hline CHEMBL1537149 & 688453 & 4.4 & 4.9095 & TRN & \\
\hline CHEMBL1541418 & 688453 & 5.2 & 5.4128 & TRN & \\
\hline CHEMBL1405459 & 688453 & 6.05 & 5.2843 & TST & \\
\hline CHEMBL1611800 & 688453 & 4.8 & 5.1913 & TST & \\
\hline CHEMBL1481192 & 688453 & 4.65 & 4.5759 & TRN & \\
\hline CHEMBL1461019 & 688453 & 4.4 & 5.1956 & TRN & \\
\hline CHEMBL1520155 & 688453 & 4.85 & 4.8507 & TRN & \\
\hline CHEMBL1432715 & 688453 & 4.4 & 5.1573 & TRN & \\
\hline CHEMBL1496585 & 688453 & 4.4 & 4.8766 & TRN & \\
\hline CHEMBL1318764 & 688453 & 5.5 & 5.0404 & TRN & \\
\hline CHEMBL3195810 & 688453 & 6.7501 & 4.9832 & TST & \\
\hline CHEMBL1475562 & 688453 & 4.45 & 5.0813 & TRN & \\
\hline CHEMBL1606751 & 688453 & 4.55 & 4.9669 & TRN & \\
\hline CHEMBL1580646 & 688453 & 5.45 & 5.0503 & TRN & \\
\hline CHEMBL1521196 & 688453 & 4.85 & 4.9971 & TRN & \\
\hline
\end{tabular}




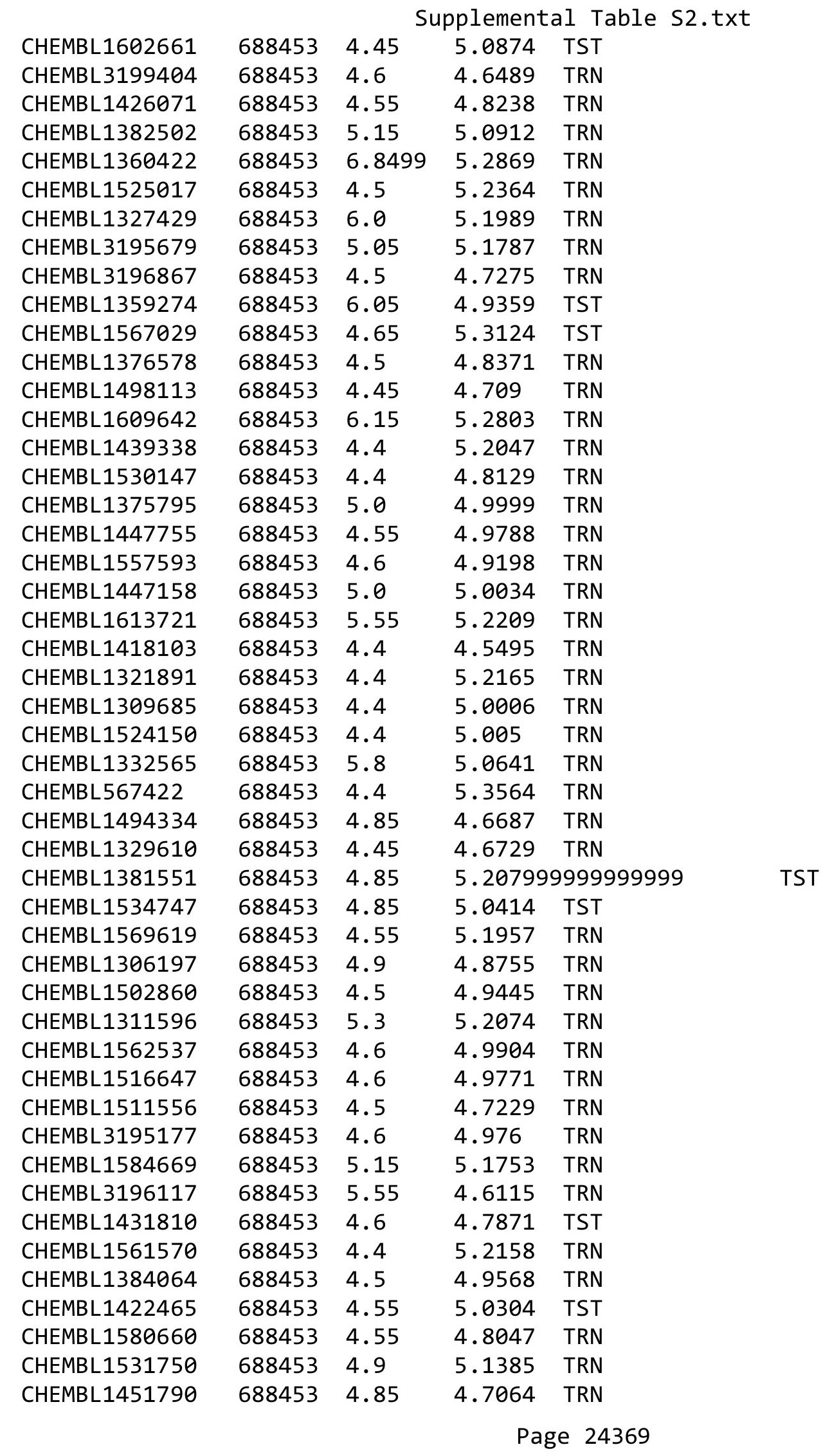




\begin{tabular}{|c|c|c|c|c|}
\hline \multicolumn{5}{|c|}{ Supplemental Table S2.txt } \\
\hline CHEMBL1498566 & 688453 & 4.5 & 5.0877 & TRN \\
\hline CHEMBL1441583 & 688453 & 4.65 & 4.5405 & TRN \\
\hline CHEMBL1321401 & 688453 & 5.15 & 5.3786 & TRN \\
\hline CHEMBL1560775 & 688453 & 4.5 & 4.5311 & TRN \\
\hline CHEMBL1411304 & 688453 & 5.05 & 4.7049 & TRN \\
\hline CHEMBL3197935 & 688453 & 4.4 & 4.8376 & TRN \\
\hline CHEMBL1579321 & 688453 & 5.4 & 5.1432 & TRN \\
\hline CHEMBL1463326 & 688453 & 4.65 & 4.8401 & TRN \\
\hline CHEMBL240836 & 688453 & 4.4 & 4.637 & TRN \\
\hline CHEMBL1467450 & 688453 & 6.35 & 5.3783 & TRN \\
\hline CHEMBL1465450 & 688453 & 4.5 & 4.9653 & TST \\
\hline CHEMBL1362324 & 688453 & 6.35 & 5.2458 & TST \\
\hline CHEMBL3212089 & 688453 & 6.0 & 4.8863 & TRN \\
\hline CHEMBL1975746 & 688453 & 4.45 & 4.822 & TRN \\
\hline CHEMBL 3145086 & 688453 & 4.45 & 4.9743 & TRN \\
\hline CHEMBL1446510 & 688453 & 4.4 & 5.2497 & TRN \\
\hline CHEMBL1390206 & 688453 & 4.45 & 4.7345 & TRN \\
\hline CHEMBL1420189 & 688453 & 4.4 & 4.8369 & TRN \\
\hline CHEMBL 3190368 & 688453 & 4.75 & 4.7295 & TRN \\
\hline CHEMBL1389955 & 688453 & 4.45 & 5.2513 & TRN \\
\hline CHEMBL1499111 & 688453 & 4.45 & 4.558 & TRN \\
\hline CHEMBL1411288 & 688453 & 5.4 & 5.1875 & TRN \\
\hline CHEMBL1575715 & 688453 & 5.3 & 5.2047 & TRN \\
\hline CHEMBL1457702 & 688453 & 4.45 & 4.9167 & TRN \\
\hline CHEMBL1595914 & 688453 & 4.5 & 5.3735 & TRN \\
\hline CHEMBL1325973 & 688453 & 5.35 & 5.0594 & TST \\
\hline CHEMBL1546095 & 688453 & 4.4 & 5.039 & TRN \\
\hline CHEMBL1468982 & 688453 & 4.95 & 4.743 & TRN \\
\hline CHEMBL1420462 & 688453 & 5.15 & 5.0337 & TST \\
\hline CHEMBL1402089 & 688453 & 4.4 & 5.2356 & TRN \\
\hline CHEMBL1318962 & 688453 & 4.5 & 5.1233 & TST \\
\hline CHEMBL1578026 & 688453 & 7.5498 & 5.3987 & TRN \\
\hline CHEMBL1481577 & 688453 & 4.5 & 5.2571 & TRN \\
\hline CHEMBL1969593 & 688453 & 4.4 & 4.9259 & TRN \\
\hline CHEMBL1426096 & 688453 & 4.4 & 4.8849 & TRN \\
\hline CHEMBL1446519 & 688453 & 4.4 & 5.0518 & TST \\
\hline CHEMBL 295316 & 688453 & 4.65 & 5.1423 & TRN \\
\hline CHEMBL1526447 & 688453 & 5.8 & 5.0817 & TRN \\
\hline CHEMBL 242171 & 688453 & 5.2 & 5.0435 & TRN \\
\hline CHEMBL1347211 & 688453 & 4.45 & 4.8537 & TRN \\
\hline CHEMBL1418068 & 688453 & 4.5 & 5.072 & TRN \\
\hline CHEMBL1389163 & 688453 & 4.85 & 5.0352 & TRN \\
\hline CHEMBL1549629 & 688453 & 4.9 & 4.9773 & TRN \\
\hline CHEMBL1371777 & 688453 & 4.45 & 4.7902 & TRN \\
\hline CHEMBL1402957 & 688453 & 4.7 & 4.7929 & TST \\
\hline CHEMBL1598435 & 688453 & 4.4 & 5.1979 & TRN \\
\hline CHEMBL1366939 & 688453 & 4.45 & 4.9714 & TRN \\
\hline CHEMBL1418573 & 688453 & 5.95 & 4.8151 & TRN \\
\hline
\end{tabular}




\begin{tabular}{|c|c|c|c|c|c|}
\hline & & \multicolumn{4}{|c|}{ Supplemental Table S2.txt } \\
\hline CHEMBL1320897 & 688453 & 4.55 & 4.9146 & TRN & \\
\hline CHEMBL370152 & 688453 & 4.45 & 5.1351 & TST & \\
\hline CHEMBL1605450 & 688453 & 6.8499 & 5.1084 & TRN & \\
\hline CHEMBL1458891 & 688453 & 5.45 & 4.8523 & TST & \\
\hline CHEMBL168276 & 688453 & 6.0 & 5.2099 & TRN & \\
\hline CHEMBL1359716 & 688453 & 5.3 & 5.0524 & TRN & \\
\hline CHEMBL1474286 & 688453 & 4.55 & 5.0222 & TRN & \\
\hline CHEMBL1402221 & 688453 & 4.45 & 4.97 & TRN & \\
\hline CHEMBL1491702 & 688453 & 4.85 & 5.1808 & TRN & \\
\hline CHEMBL1968540 & 688453 & 5.45 & 4.9984 & TRN & \\
\hline CHEMBL1482574 & 688453 & 4.6 & 5.0039 & TRN & \\
\hline CHEMBL3198790 & 688453 & 4.45 & 4.8824 & TRN & \\
\hline CHEMBL1559225 & 688453 & 5.85 & 4.9964 & TRN & \\
\hline CHEMBL1543646 & 688453 & 4.5 & 5.0336 & TRN & \\
\hline CHEMBL1404770 & 688453 & 4.6 & 5.0229 & TST & \\
\hline CHEMBL3199283 & 688453 & 4.55 & 4.8724 & TRN & \\
\hline CHEMBL1543216 & 688453 & 4.55 & 4.7435 & TRN & \\
\hline CHEMBL1374242 & 688453 & 5.1 & 4.8061 & TRN & \\
\hline CHEMBL1376091 & 688453 & 4.45 & 5.25 & TRN & \\
\hline CHEMBL1523510 & 688453 & 4.45 & 4.9307 & TRN & \\
\hline CHEMBL1965565 & 688453 & 5.2 & 4.9892 & TRN & \\
\hline CHEMBL1315457 & 688453 & 4.5 & 5.1862 & TST & \\
\hline CHEMBL1385676 & 688453 & 4.95 & 5.1919 & TRN & \\
\hline CHEMBL1360310 & 688453 & 4.6 & 5.0502 & TRN & \\
\hline CHEMBL560073 & 688453 & 4.5 & 4.8233 & TRN & \\
\hline CHEMBL1500751 & 688453 & 4.85 & 5.0615 & TST & \\
\hline CHEMBL1393351 & 688453 & 6.8499 & 5.1397 & TRN & \\
\hline CHEMBL1444415 & 688453 & 4.5 & 5.2742 & TRN & \\
\hline CHEMBL1428997 & 688453 & 4.55 & 4.4591 & TRN & \\
\hline CHEMBL1438913 & 688453 & 4.4 & 5.1091 & TRN & \\
\hline CHEMBL1563529 & 688453 & 4.4 & 5.1059 & TRN & \\
\hline CHEMBL1441601 & 688453 & 4.4 & 5.1648 & TRN & \\
\hline CHEMBL1451032 & 688453 & 4.4 & 4.6921 & TRN & \\
\hline CHEMBL1330213 & 688453 & 5.2 & $5.2410 e$ & 00000000005 & TST \\
\hline CHEMBL1406758 & 688453 & 4.7 & 4.5889 & TRN & \\
\hline CHEMBL1510946 & 688453 & 7.0501 & 5.08899 & 99999999995 & TRN \\
\hline CHEMBL1354086 & 688453 & 6.25 & 5.434 & TRN & \\
\hline CHEMBL1453534 & 688453 & 5.45 & 5.1479 & TRN & \\
\hline CHEMBL1501526 & 688453 & 4.5 & 5.0773 & TRN & \\
\hline CHEMBL1568055 & 688453 & 4.9 & 4.97199 & 99999999995 & TRN \\
\hline CHEMBL1387357 & 688453 & 4.65 & 5.0478 & TRN & \\
\hline CHEMBL1973525 & 688453 & 4.5 & 4.7725 & TST & \\
\hline CHEMBL3209701 & 688453 & 5.95 & 5.2539 & TST & \\
\hline CHEMBL1387712 & 688453 & 4.45 & 5.1176 & TRN & \\
\hline CHEMBL1309198 & 688453 & 4.55 & 4.5545 & TRN & \\
\hline CHEMBL1354033 & 688453 & 4.45 & 5.1023 & TRN & \\
\hline CHEMBL1480378 & 688453 & 4.6 & 4.8345 & TRN & \\
\hline CHEMBL1446151 & 688453 & 5.05 & 4.8974 & TRN & \\
\hline
\end{tabular}




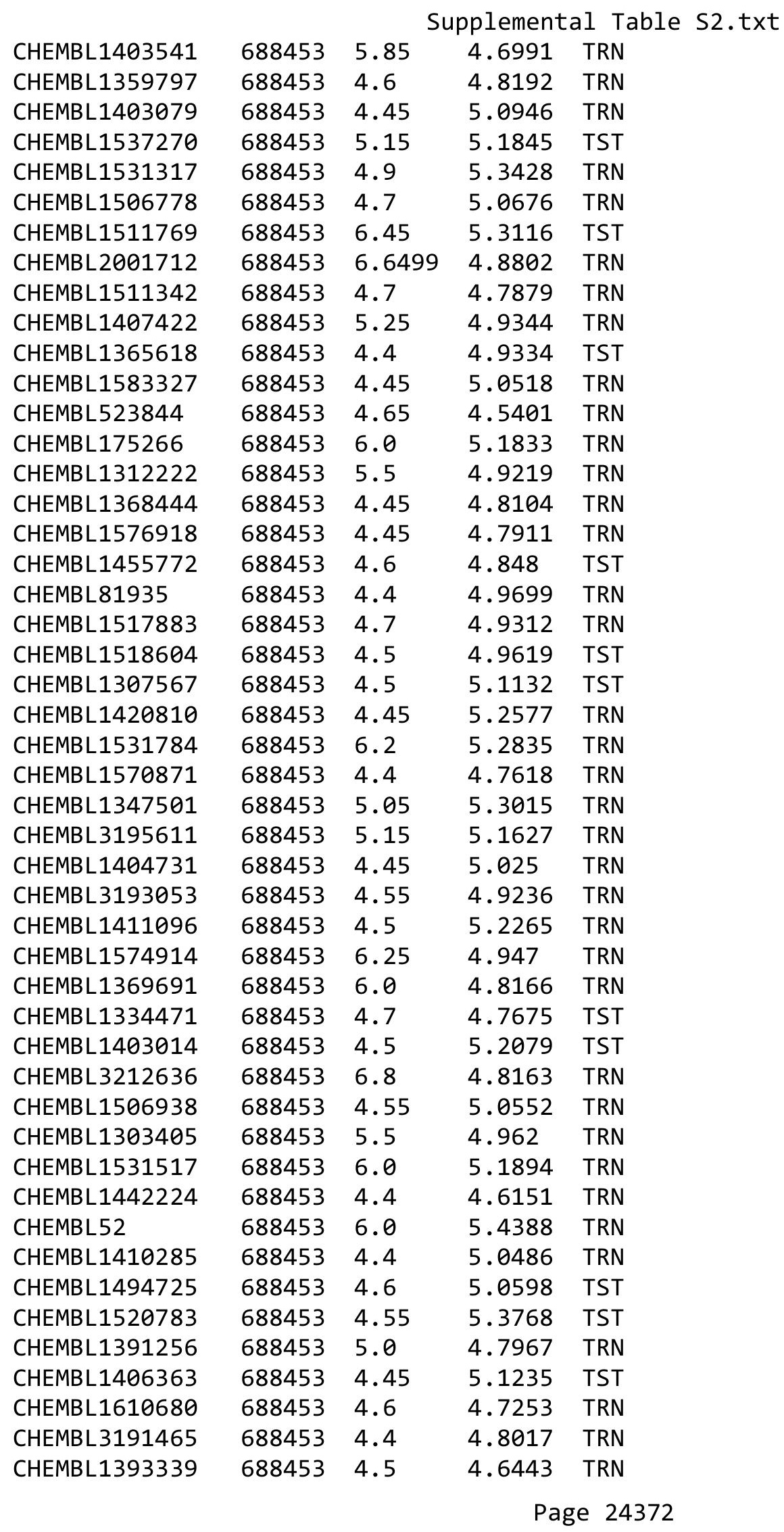




\begin{tabular}{|c|c|c|c|c|c|}
\hline \multicolumn{6}{|c|}{ Supplemental Table S2.txt } \\
\hline CHEMBL1582012 & 688453 & 5.2 & 5.2166 & TRN & \\
\hline CHEMBL1560502 & 688453 & 4.5 & 4.9204 & TST & \\
\hline CHEMBL1419268 & 688453 & 6.0 & 5.0479 & TST & \\
\hline CHEMBL1534619 & 688453 & 6.7501 & 5.1105 & TRN & \\
\hline CHEMBL3198809 & 688453 & 4.45 & 5.0155 & TRN & \\
\hline CHEMBL1386620 & 688453 & 4.4 & 5.1588 & TST & \\
\hline CHEMBL1419826 & 688453 & 4.45 & 4.8322 & TST & \\
\hline CHEMBL1420591 & 688453 & 4.45 & 4.6836 & TRN & \\
\hline CHEMBL1420206 & 688453 & 4.75 & 5.0857 & TRN & \\
\hline CHEMBL3392035 & 688453 & 4.4 & 5.2461 & TRN & \\
\hline CHEMBL 3210178 & 688453 & 6.0 & 5.4578 & TRN & \\
\hline CHEMBL1455554 & 688453 & 6.05 & 5.2245 & TRN & \\
\hline CHEMBL1545737 & 688453 & 4.9 & 5.2721 & TRN & \\
\hline CHEMBL 2132953 & 688453 & 4.55 & 5.2217 & TST & \\
\hline CHEMBL1458972 & 688453 & 5.8 & 5.2889 & TRN & \\
\hline CHEMBL1347763 & 688453 & 7.0501 & 5.1759 & TRN & \\
\hline CHEMBL586058 & 688453 & 5.15 & 4.8393 & TST & \\
\hline CHEMBL576932 & 688453 & 4.8 & 4.7906 & TRN & \\
\hline CHEMBL1488898 & 688453 & 4.5 & 4.9665 & TRN & \\
\hline CHEMBL1365005 & 688453 & 4.45 & 5.1102 & TST & \\
\hline CHEMBL1467442 & 688453 & 4.45 & 5.0255 & TRN & \\
\hline CHEMBL3145034 & 688453 & 4.45 & 5.0566 & TRN & \\
\hline CHEMBL1613557 & 688453 & 5.2 & 4.5859 & TRN & \\
\hline CHEMBL1369513 & 688453 & 5.85 & 4.7216 & TRN & \\
\hline CHEMBL1301960 & 688453 & 4.55 & 5.0221 & TRN & \\
\hline CHEMBL1547896 & 688453 & 4.4 & 4.8562 & TRN & \\
\hline CHEMBL3209471 & 688453 & 5.45 & 4.5787 & TRN & \\
\hline CHEMBL1564477 & 688453 & 4.65 & 5.0134 & TRN & \\
\hline CHEMBL1482369 & 688453 & 4.45 & 4.8794 & TST & \\
\hline CHEMBL1492716 & 688453 & 5.4 & 4.7692 & TRN & \\
\hline CHEMBL1459809 & 688453 & 4.5 & 4.4956 & TRN & \\
\hline CHEMBL1461136 & 688453 & 5.5 & 5.0414 & TRN & \\
\hline CHEMBL1484194 & 688453 & 4.65 & 5.2439 & TRN & \\
\hline CHEMBL1489892 & 688453 & 6.9 & 5.0433 & TRN & \\
\hline CHEMBL1527074 & 688453 & 6.3 & 5.2931 & TRN & \\
\hline CHEMBL1539845 & 688453 & 6.45 & 5.3197 & TST & \\
\hline CHEMBL1576131 & 688453 & 7.5498 & 5.2435 & TST & \\
\hline CHEMBL169 & 688453 & 6.8 & 5.1063 & TST & \\
\hline CHEMBL1493027 & 688453 & 4.6 & 5.2182 & TRN & \\
\hline CHEMBL1517146 & 688453 & 6.8499 & 5.1326 & TRN & \\
\hline CHEMBL 213432 & 688453 & 4.45 & 5.1241 & TRN & \\
\hline CHEMBL1417268 & 688453 & 4.7 & 4.9077 & TST & \\
\hline CHEMBL1490807 & 688453 & 6.0 & 5.2125 & TRN & \\
\hline CHEMBL1581746 & 688453 & 4.6 & 4.5686 & TRN & \\
\hline CHEMBL1305292 & 688453 & 4.5 & 4.7997 & TRN & \\
\hline CHEMBL1326485 & 688453 & 4.65 & 4.5777 & TRN & \\
\hline CHEMBL1334633 & 688453 & 5.05 & 5.2119 & TST & \\
\hline CHEMBL1351226 & 688453 & 4.45 & $5.3020 e$ & 00000000005 & TRN \\
\hline & & & & 24373 & \\
\hline
\end{tabular}




\begin{tabular}{|c|c|c|c|c|c|}
\hline \multirow{3}{*}{$\begin{array}{l}\text { CHEMBL1423479 } \\
\text { CHEMBL1469647 }\end{array}$} & \multirow{3}{*}{$\begin{array}{l}688453 \\
688453\end{array}$} & \multicolumn{4}{|c|}{ Supplemental Table S2.txt } \\
\hline & & 4.45 & 5.11100 & 0000000001 & TST \\
\hline & & 4.8 & 4.8644 & TRN & \\
\hline CHEMBL3145287 & 688453 & 4.55 & 4.7831 & TRN & \\
\hline CHEMBL1495231 & 688453 & 5.1 & 5.2125 & TRN & \\
\hline CHEMBL1410696 & 688453 & 4.4 & 5.0768 & TST & \\
\hline CHEMBL1366858 & 688453 & 4.9 & 5.5192 & TRN & \\
\hline CHEMBL1511094 & 688453 & 4.65 & 5.271 & TRN & \\
\hline CHEMBL1488072 & 688453 & 4.8 & 4.8668 & TRN & \\
\hline CHEMBL1508716 & 688453 & 4.4 & 5.0731 & TRN & \\
\hline CHEMBL1350914 & 688453 & 4.4 & 4.9427 & TRN & \\
\hline CHEMBL1333867 & 688453 & 4.6 & 5.0276 & TRN & \\
\hline CHEMBL1301591 & 688453 & 4.85 & 5.2258 & TRN & \\
\hline CHEMBL1556134 & 688453 & 6.5501 & 5.0954 & TRN & \\
\hline CHEMBL1489145 & 688453 & 4.65 & 4.7645 & TRN & \\
\hline CHEMBL1591009 & 688453 & 4.4 & 4.9356 & TST & \\
\hline CHEMBL1427633 & 688453 & 5.8 & 4.7065 & TRN & \\
\hline CHEMBL1443429 & 688453 & 7.5498 & 5.1721 & TRN & \\
\hline CHEMBL1474468 & 688453 & 5.5 & 5.12 & TRN & \\
\hline CHEMBL1575190 & 688453 & 4.35 & 4.9993 & TRN & \\
\hline CHEMBL1353481 & 688453 & 6.7501 & 4.941 & TRN & \\
\hline CHEMBL375655 & 688453 & 5.4 & 5.1438 & TST & \\
\hline CHEMBL1449253 & 688453 & 4.7 & 4.9484 & TRN & \\
\hline CHEMBL1429070 & 688453 & 5.1 & 5.0468 & TST & \\
\hline CHEMBL1525657 & 688453 & 6.8499 & 5.3156 & TRN & \\
\hline CHEMBL1520532 & 688453 & 4.45 & 4.9686 & TRN & \\
\hline CHEMBL1561877 & 688453 & 4.45 & 4.4984 & TRN & \\
\hline CHEMBL1518886 & 688453 & 4.55 & 5.1504 & TST & \\
\hline CHEMBL1373377 & 688453 & 4.8 & 5.1467 & TRN & \\
\hline CHEMBL1381419 & 688453 & 4.55 & 4.418 & TRN & \\
\hline CHEMBL1501577 & 688453 & 4.5 & 5.2102 & TRN & \\
\hline CHEMBL1344643 & 688453 & 4.45 & 4.9304 & TRN & \\
\hline CHEMBL 2005497 & 688453 & 4.6 & 4.7404 & TRN & \\
\hline CHEMBL1496066 & 688453 & 5.1 & 5.1983 & TRN & \\
\hline CHEMBL1470357 & 688453 & 4.4 & 5.1711 & TRN & \\
\hline CHEMBL1371781 & 688453 & 4.8 & 5.2872 & TRN & \\
\hline CHEMBL1557985 & 688453 & 6.8 & 5.1099 & TRN & \\
\hline CHEMBL1303927 & 688453 & 4.45 & 5.2103 & TST & \\
\hline CHEMBL1343972 & 688453 & 6.15 & 5.0488 & TST & \\
\hline CHEMBL1351174 & 688453 & 6.9 & 5.0829 & TST & \\
\hline CHEMBL1494390 & 688453 & 4.65 & 5.0996 & TRN & \\
\hline CHEMBL1463659 & 688453 & 5.35 & 4.9082 & TRN & \\
\hline CHEMBL1497894 & 688453 & 4.55 & 4.8547 & TRN & \\
\hline CHEMBL1514486 & 688453 & 5.4 & 5.0263 & TRN & \\
\hline CHEMBL1327587 & 688453 & 5.05 & 5.0359 & TRN & \\
\hline CHEMBL1575072 & 688453 & 4.65 & 5.0846 & TRN & \\
\hline CHEMBL1546136 & 688453 & 4.75 & 4.8452 & TRN & \\
\hline CHEMBL3190570 & 688453 & 4.4 & 4.7007 & TRN & \\
\hline CHEMBL1607967 & 688453 & 5.4 & 5.0275 & TRN & \\
\hline
\end{tabular}




\begin{tabular}{|c|c|c|c|c|c|}
\hline \multicolumn{6}{|c|}{ Supplemental Table S2.txt } \\
\hline CHEMBL1425536 & 688453 & 4.5 & 5.0888 & TRN & \\
\hline CHEMBL1608979 & 688453 & 4.9 & 5.0038 & TRN & \\
\hline CHEMBL1350617 & 688453 & 5.4 & 5.1837 & TRN & \\
\hline CHEMBL1604831 & 688453 & 4.5 & 4.7699 & TRN & \\
\hline CHEMBL1410548 & 688453 & 4.45 & 4.651 & TRN & \\
\hline CHEMBL1538146 & 688453 & 5.15 & 5.19 & TST & \\
\hline CHEMBL1482837 & 688453 & 5.2 & 5.1495 & TRN & \\
\hline CHEMBL1411505 & 688453 & 4.5 & 5.1155 & TRN & \\
\hline CHEMBL1419100 & 688453 & 4.5 & $5.0760 e$ & 00000000005 & TRN \\
\hline CHEMBL1550238 & 688453 & 4.4 & 4.9318 & TST & \\
\hline CHEMBL1549812 & 688453 & 4.5 & 4.7884 & TRN & \\
\hline CHEMBL189438 & 688453 & 5.15 & 5.141 & TST & \\
\hline CHEMBL1400255 & 688453 & 5.1 & 5.3131 & TST & \\
\hline CHEMBL1504113 & 688453 & 5.5 & 4.9871 & TST & \\
\hline CHEMBL1587670 & 688453 & 4.45 & 4.842 & TRN & \\
\hline CHEMBL3193251 & 688453 & 4.6 & 5.1018 & TRN & \\
\hline CHEMBL1545437 & 688453 & 6.1 & 5.1516 & TRN & \\
\hline CHEMBL1329848 & 688453 & 4.45 & 4.7187 & TRN & \\
\hline CHEMBL1450371 & 688453 & 4.65 & 5.0603 & TRN & \\
\hline CHEMBL1381289 & 688453 & 4.45 & 4.5505 & TRN & \\
\hline CHEMBL1592095 & 688453 & 6.0 & 4.931 & TST & \\
\hline CHEMBL1597805 & 688453 & 5.1 & 4.967 & TRN & \\
\hline CHEMBL1440162 & 688453 & 4.4 & 4.7259 & TRN & \\
\hline CHEMBL399043 & 688453 & 5.05 & 5.0279 & TST & \\
\hline CHEMBL1540557 & 688453 & 5.05 & 4.8554 & TST & \\
\hline CHEMBL1521099 & 688453 & 6.35 & 5.0663 & TRN & \\
\hline CHEMBL1509389 & 688453 & 4.5 & 5.0459 & TRN & \\
\hline CHEMBL1583872 & 688453 & 4.55 & 5.1504 & TST & \\
\hline CHEMBL1550867 & 688453 & 4.6 & 5.2659 & TRN & \\
\hline CHEMBL1352170 & 688453 & 4.65 & 4.8591 & TRN & \\
\hline CHEMBL1525405 & 688453 & 4.45 & 5.0591 & TRN & \\
\hline CHEMBL1330256 & 688453 & 5.45 & 4.9631 & TRN & \\
\hline CHEMBL1369287 & 688453 & 5.45 & 5.3519 & TST & \\
\hline CHEMBL1377249 & 688453 & 4.4 & 4.6986 & TRN & \\
\hline CHEMBL1547042 & 688453 & 4.5 & 5.0457 & TRN & \\
\hline CHEMBL309917 & 688453 & 4.85 & 5.2845 & TST & \\
\hline CHEMBL 1356826 & 688453 & 4.65 & 4.8787 & TRN & \\
\hline CHEMBL1981008 & 688453 & 4.65 & 5.0703 & TRN & \\
\hline CHEMBL170405 & 688453 & 5.35 & 5.1552 & TRN & \\
\hline CHEMBL1333826 & 688453 & 4.4 & 4.7137 & TRN & \\
\hline CHEMBL1460639 & 688453 & 4.4 & 5.0351 & TRN & \\
\hline CHEMBL1460461 & 688453 & 6.7501 & 4.595 & TRN & \\
\hline CHEMBL1507532 & 688453 & 7.0501 & 5.1671 & TRN & \\
\hline CHEMBL1547311 & 688453 & 4.45 & 5.0539 & TRN & \\
\hline CHEMBL 307782 & 688453 & 6.8499 & 5.2314 & TRN & \\
\hline CHEMBL3196348 & 688453 & 4.6 & 4.9158 & TRN & \\
\hline CHEMBL 1417120 & 688453 & 4.75 & 4.775 & TRN & \\
\hline CHEMBL1302827 & 688453 & 5.05 & 4.4615 & TRN & \\
\hline
\end{tabular}




\begin{tabular}{|c|c|c|c|c|}
\hline \multicolumn{5}{|c|}{ Supplemental Table S2.txt } \\
\hline CHEMBL1430175 & 688453 & 5.05 & 4.4115 & TRN \\
\hline CHEMBL1349129 & 688453 & 4.5 & 4.9191 & TRN \\
\hline CHEMBL1325576 & 688453 & 4.4 & 4.7499 & TRN \\
\hline CHEMBL1548383 & 688453 & 5.4 & 5.2318 & TRN \\
\hline CHEMBL1333011 & 688453 & 5.15 & 5.1902 & TST \\
\hline CHEMBL1407035 & 688453 & 5.2 & 4.9197 & TRN \\
\hline CHEMBL1583372 & 688453 & 5.65 & 5.1715 & TST \\
\hline CHEMBL1388061 & 688453 & 5.55 & 5.0147 & TRN \\
\hline CHEMBL1561156 & 688453 & 4.4 & 5.1362 & TRN \\
\hline CHEMBL1506716 & 688453 & 4.5 & 5.0937 & TST \\
\hline CHEMBL1606441 & 688453 & 5.25 & 5.2359 & TRN \\
\hline CHEMBL1548323 & 688453 & 4.45 & 5.0514 & TRN \\
\hline CHEMBL1386969 & 688453 & 4.4 & 4.4083 & TRN \\
\hline CHEMBL1568018 & 688453 & 4.65 & 5.1898 & TST \\
\hline CHEMBL3190913 & 688453 & 5.2 & 5.0368 & TRN \\
\hline CHEMBL7976 & 688453 & 5.35 & 5.0636 & TRN \\
\hline CHEMBL1437761 & 688453 & 5.2 & 4.9242 & TRN \\
\hline CHEMBL1559341 & 688453 & 4.6 & $4.9460 e$ & 0000000001 \\
\hline CHEMBL1363755 & 688453 & 5.2 & 4.6909 & TST \\
\hline CHEMBL1528710 & 688453 & 4.4 & 5.2766 & TRN \\
\hline CHEMBL1302893 & 688453 & 4.4 & 5.0569 & TRN \\
\hline CHEMBL1334647 & 688453 & 6.5 & 5.1679 & TRN \\
\hline CHEMBL1968732 & 688453 & 4.4 & 4.8639 & TST \\
\hline CHEMBL1578546 & 688453 & 4.45 & 5.0903 & TRN \\
\hline CHEMBL1497095 & 688453 & 6.8 & 5.1854 & TRN \\
\hline CHEMBL1324958 & 688453 & 5.45 & 5.2957 & TRN \\
\hline CHEMBL1336519 & 688453 & 4.45 & 5.3639 & TRN \\
\hline CHEMBL1322015 & 688453 & 4.4 & 5.1004 & TRN \\
\hline CHEMBL1301906 & 688453 & 4.6 & 4.9369 & TRN \\
\hline CHEMBL1398855 & 688453 & 4.4 & 5.0051 & TRN \\
\hline CHEMBL3208465 & 688453 & 4.7 & 5.0997 & TRN \\
\hline CHEMBL1384972 & 688453 & 4.5 & 5.2035 & TRN \\
\hline CHEMBL1468863 & 688453 & 5.45 & 5.1213 & TRN \\
\hline CHEMBL494668 & 688453 & 4.85 & 4.9065 & TST \\
\hline CHEMBL1588557 & 688453 & 4.45 & 5.1089 & TRN \\
\hline CHEMBL1345754 & 688453 & 4.6 & 4.6805 & TRN \\
\hline CHEMBL1597190 & 688453 & 6.0 & 5.1154 & TRN \\
\hline CHEMBL1412163 & 688453 & 4.95 & 5.0073 & TRN \\
\hline CHEMBL1458061 & 688453 & 5.4 & 5.3854 & TRN \\
\hline CHEMBL1517511 & 688453 & 4.45 & 4.961 & TRN \\
\hline CHEMBL1451483 & 688453 & 6.5501 & 5.1095 & TRN \\
\hline CHEMBL1484108 & 688453 & 4.4 & 4.9993 & TRN \\
\hline CHEMBL1349410 & 688453 & 4.55 & 4.9212 & TRN \\
\hline CHEMBL1420974 & 688453 & 7.5498 & 5.1694 & TRN \\
\hline CHEMBL1533415 & 688453 & 4.4 & 4.7109 & TRN \\
\hline CHEMBL1405265 & 688453 & 4.4 & 5.1406 & TRN \\
\hline CHEMBL505670 & 688453 & 4.45 & 4.7934 & TRN \\
\hline CHEMBL1562077 & 688453 & 4.5 & 5.0752 & TRN \\
\hline
\end{tabular}




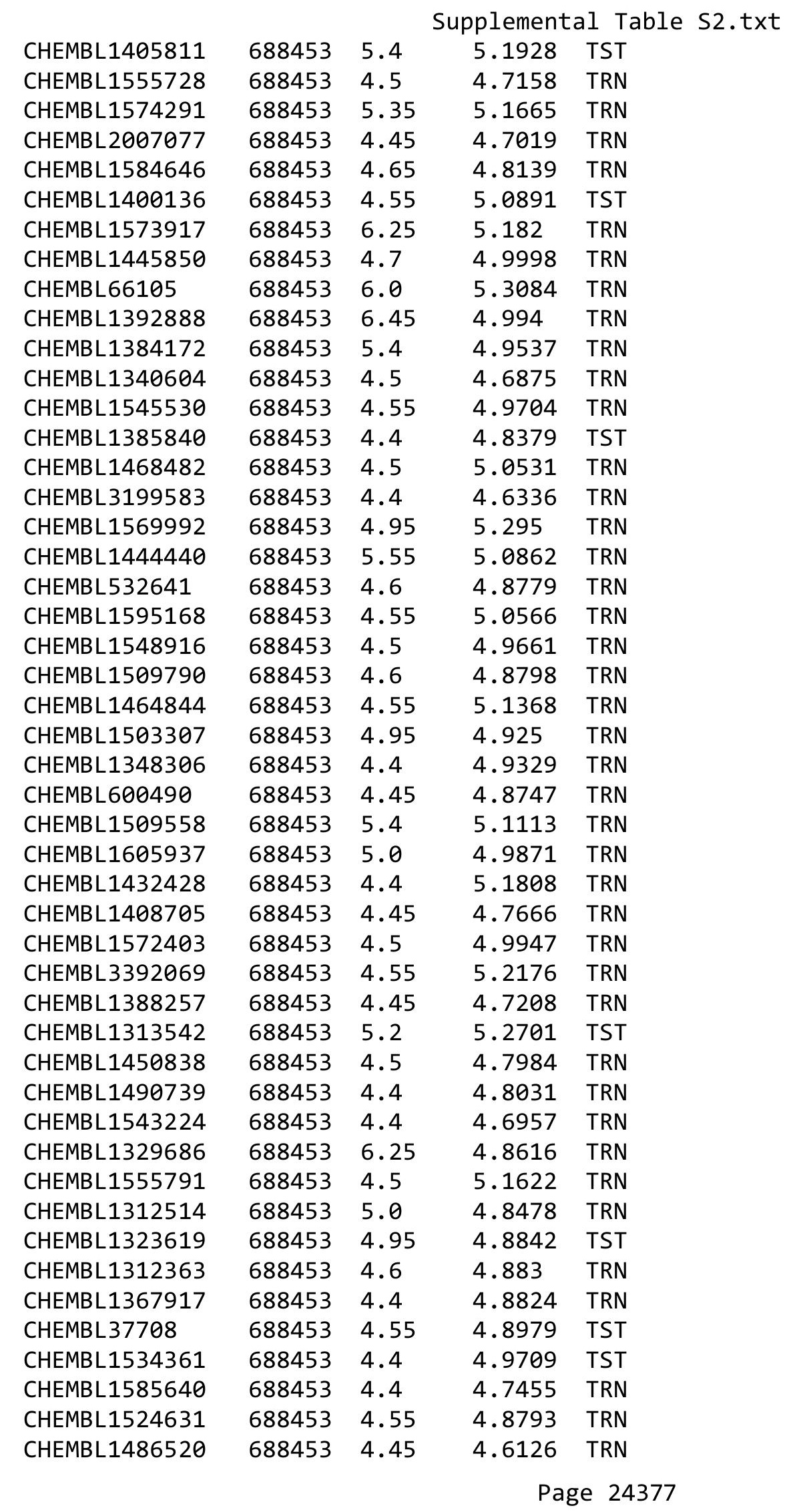




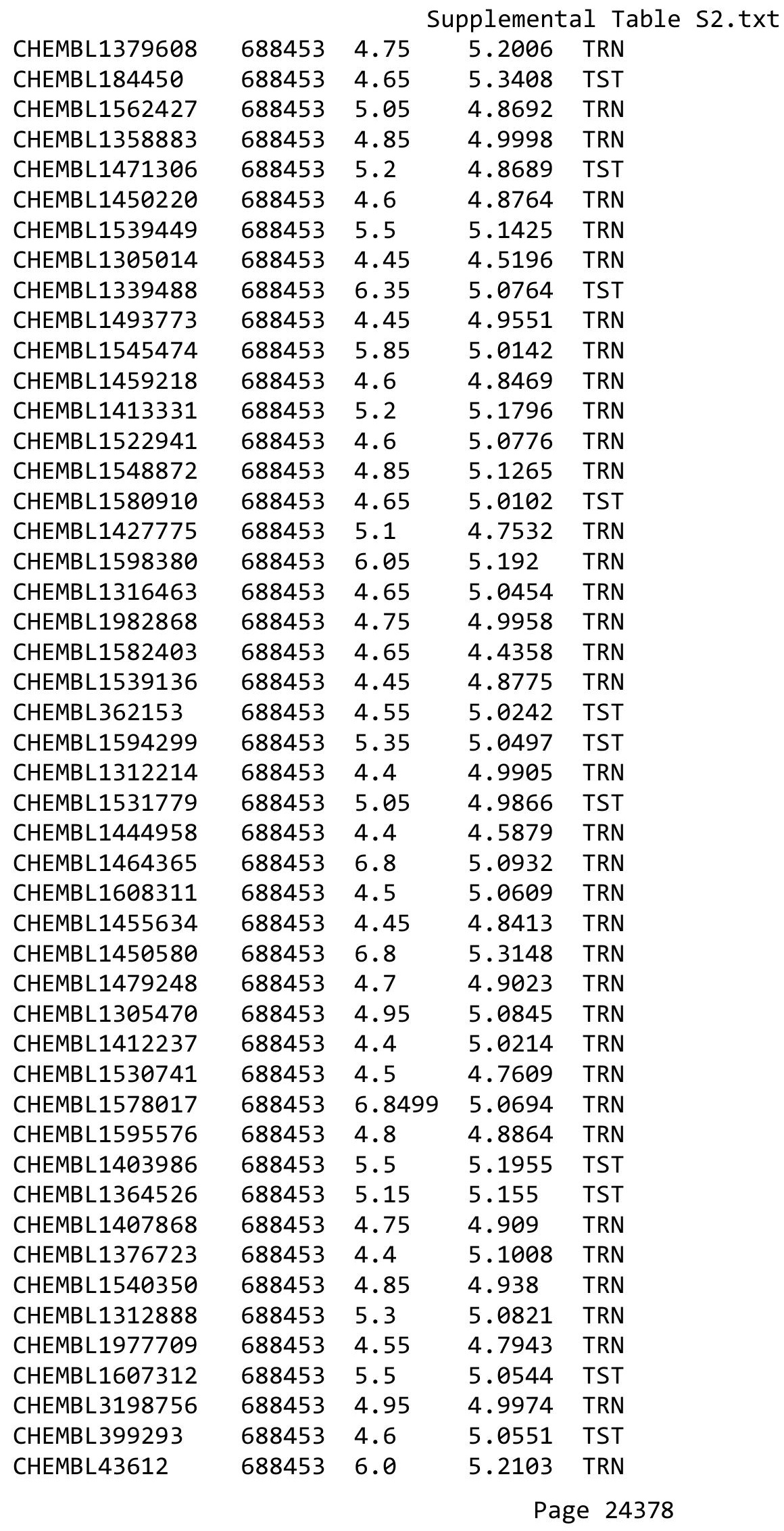




\begin{tabular}{|c|c|c|c|c|}
\hline \multicolumn{5}{|c|}{ Supplemental Table S2.txt } \\
\hline CHEMBL1417901 & 688453 & 4.5 & 5.1419 & TRN \\
\hline CHEMBL1407306 & 688453 & 4.65 & 4.9775 & TRN \\
\hline CHEMBL1460886 & 688453 & 6.3 & 5.0426 & TRN \\
\hline CHEMBL1591600 & 688453 & 4.55 & 5.0084 & TRN \\
\hline CHEMBL1372819 & 688453 & 4.65 & 4.9062 & TRN \\
\hline CHEMBL1300727 & 688453 & 5.15 & 5.1585 & TRN \\
\hline CHEMBL1330042 & 688453 & 4.45 & 4.9529 & TRN \\
\hline CHEMBL1477633 & 688453 & 5.85 & 4.9534 & TRN \\
\hline CHEMBL1464805 & 688453 & 4.5 & 4.8671 & TRN \\
\hline CHEMBL1366599 & 688453 & 6.5501 & 5.1129 & TRN \\
\hline CHEMBL1541153 & 688453 & 6.8499 & 5.1569 & TRN \\
\hline CHEMBL1450087 & 688453 & 5.3 & 5.1133 & TST \\
\hline CHEMBL1410466 & 688453 & 6.8499 & 4.928 & TRN \\
\hline CHEMBL1360493 & 688453 & 4.4 & 5.0291 & TST \\
\hline CHEMBL1578826 & 688453 & 4.45 & 4.9667 & TRN \\
\hline CHEMBL1361596 & 688453 & 6.0 & 4.7993 & TST \\
\hline CHEMBL1898790 & 688453 & 4.6 & 4.6804 & TRN \\
\hline CHEMBL483768 & 688453 & 4.45 & 4.9863 & TRN \\
\hline CHEMBL 3195832 & 688453 & 6.0 & 4.8077 & TRN \\
\hline CHEMBL1470395 & 688453 & 4.4 & 4.8583 & TRN \\
\hline CHEMBL1339328 & 688453 & 4.5 & 4.9767 & TRN \\
\hline CHEMBL1318948 & 688453 & 4.45 & 5.0213 & TRN \\
\hline CHEMBL1235717 & 688453 & 4.55 & 5.1745 & TRN \\
\hline CHEMBL1564753 & 688453 & 4.5 & 5.0294 & TRN \\
\hline CHEMBL1470481 & 688453 & 4.45 & 5.0064 & TST \\
\hline CHEMBL469424 & 688453 & 4.65 & 5.1257 & TRN \\
\hline CHEMBL1466239 & 688453 & 4.5 & 4.7736 & TRN \\
\hline CHEMBL1376700 & 688453 & 4.4 & 5.3983 & TST \\
\hline CHEMBL1491678 & 688453 & 6.8 & 5.1759 & TRN \\
\hline CHEMBL1378659 & 688453 & 5.95 & 5.4543 & TRN \\
\hline CHEMBL1456323 & 688453 & 4.6 & 5.2297 & TRN \\
\hline CHEMBL1468011 & 688453 & 4.4 & 4.9757 & TRN \\
\hline CHEMBL1307743 & 688453 & 5.15 & 5.0746 & TRN \\
\hline CHEMBL 3212648 & 688453 & 4.4 & 4.7919 & TRN \\
\hline CHEMBL1532193 & 688453 & 4.45 & 5.3047 & TRN \\
\hline CHEMBL1417952 & 688453 & 4.6 & 5.1735 & TRN \\
\hline CHEMBL 3214310 & 688453 & 5.05 & 4.6934 & TRN \\
\hline CHEMBL1388553 & 688453 & 4.65 & 5.1467 & TRN \\
\hline CHEMBL 3193527 & 688453 & 4.5 & 4.8096 & TRN \\
\hline CHEMBL1338546 & 688453 & 4.55 & 5.1837 & TRN \\
\hline CHEMBL1534425 & 688453 & 4.45 & 4.6905 & TRN \\
\hline CHEMBL1492642 & 688453 & 4.4 & 4.6707 & TRN \\
\hline CHEMBL1557425 & 688453 & 6.05 & 5.2142 & TRN \\
\hline CHEMBL1976631 & 688453 & 4.4 & 5.2677 & TRN \\
\hline CHEMBL358546 & 688453 & 4.7 & 5.0414 & TRN \\
\hline CHEMBL3199796 & 688453 & 4.5 & 4.7473 & TRN \\
\hline CHEMBL 1600674 & 688453 & 4.4 & 4.8601 & TRN \\
\hline CHEMBL1398763 & 688453 & 4.5 & 4.9144 & TST \\
\hline
\end{tabular}




\begin{tabular}{|c|c|c|c|c|c|}
\hline \multicolumn{6}{|c|}{ Supplemental Table S2.txt } \\
\hline CHEMBL1586973 & 688453 & 4.8 & 4.7704 & TRN & \\
\hline CHEMBL1486430 & 688453 & 4.85 & 4.9708 & TRN & \\
\hline CHEMBL1339927 & 688453 & 4.65 & 4.9878 & TRN & \\
\hline CHEMBL1419721 & 688453 & 5.5 & 4.71399 & 99999999995 & TRN \\
\hline CHEMBL1520582 & 688453 & 4.5 & 5.2114 & TST & \\
\hline CHEMBL1526959 & 688453 & 4.4 & 5.0785 & TRN & \\
\hline CHEMBL1399262 & 688453 & 5.05 & 5.2308 & TRN & \\
\hline CHEMBL 210833 & 688453 & 4.9 & 5.0455 & TRN & \\
\hline CHEMBL1501230 & 688453 & 5.1 & 5.2081 & TRN & \\
\hline CHEMBL1380847 & 688453 & 4.55 & 4.8032 & TRN & \\
\hline CHEMBL1539796 & 688453 & 5.95 & 5.3356 & TRN & \\
\hline CHEMBL1490194 & 688453 & 4.6 & 4.8919 & TRN & \\
\hline CHEMBL1348060 & 688453 & 4.4 & 4.9364 & TRN & \\
\hline CHEMBL1545634 & 688453 & 4.4 & 4.9665 & TST & \\
\hline CHEMBL1367305 & 688453 & 4.4 & 4.614 & TRN & \\
\hline CHEMBL1524943 & 688453 & 4.55 & 4.9991 & TRN & \\
\hline CHEMBL1535879 & 688453 & 7.2503 & 5.33799 & 9999999999 & TRN \\
\hline CHEMBL1439221 & 688453 & 7.6003 & 5.221 & TST & \\
\hline CHEMBL1321832 & 688453 & 4.5 & 5.1358 & TRN & \\
\hline CHEMBL1343654 & 688453 & 4.45 & 5.1027 & TRN & \\
\hline CHEMBL1566565 & 688453 & 4.45 & 5.2362 & TRN & \\
\hline CHEMBL18879 & 688453 & 5.0 & 4.7995 & TST & \\
\hline CHEMBL286494 & 688453 & 6.0 & 5.3057 & TRN & \\
\hline CHEMBL1438350 & 688453 & 6.1 & 4.931 & TRN & \\
\hline CHEMBL1526624 & 688453 & 5.1 & 4.8458 & TRN & \\
\hline CHEMBL1505750 & 688453 & 5.4 & 5.4952 & TRN & \\
\hline CHEMBL1427016 & 688453 & 5.35 & 5.1525 & TRN & \\
\hline CHEMBL1422112 & 688453 & 4.4 & 5.047 & TRN & \\
\hline CHEMBL 547407 & 688453 & 5.9 & 5.2207 & TRN & \\
\hline CHEMBL1567423 & 688453 & 4.45 & 4.7662 & TRN & \\
\hline CHEMBL1588323 & 688453 & 4.6 & 5.1172 & TRN & \\
\hline CHEMBL 1383348 & 688453 & 5.9 & 5.2415 & TRN & \\
\hline CHEMBL1605099 & 688453 & 4.5 & 4.5316 & TRN & \\
\hline CHEMBL1383812 & 688453 & 4.55 & 4.9646 & TST & \\
\hline CHEMBL1371473 & 688453 & 4.5 & 5.1379 & TST & \\
\hline CHEMBL3195977 & 688453 & 5.05 & 5.0432 & TST & \\
\hline CHEMBL1511733 & 688453 & 5.6 & 5.2852 & TRN & \\
\hline CHEMBL1459914 & 688453 & 4.5 & 4.6617 & TRN & \\
\hline CHEMBL1350188 & 688453 & 4.9 & 5.0271 & TRN & \\
\hline CHEMBL1570161 & 688453 & 4.55 & 5.2191 & TRN & \\
\hline CHEMBL1336739 & 688453 & 5.05 & 5.1317 & TRN & \\
\hline CHEMBL1565317 & 688453 & 7.6003 & 5.0479 & TST & \\
\hline CHEMBL1523224 & 688453 & 4.4 & 5.1259 & TRN & \\
\hline CHEMBL 255881 & 688453 & 5.2 & 4.6078 & TRN & \\
\hline CHEMBL1462800 & 688453 & 4.4 & 4.7428 & TRN & \\
\hline CHEMBL1521960 & 688453 & 4.55 & 4.8331 & TRN & \\
\hline CHEMBL592124 & 688453 & 4.4 & 4.9552 & TST & \\
\hline CHEMBL1464053 & 688453 & 4.65 & 4.7609 & TRN & \\
\hline
\end{tabular}




\begin{tabular}{|c|c|c|c|c|}
\hline \multicolumn{5}{|c|}{ Supplemental Table s2.txt } \\
\hline CHEMBL1307604 & 688453 & 4.5 & 4.9296 & TRN \\
\hline CHEMBL1520502 & 688453 & 4.4 & 5.0438 & TRN \\
\hline CHEMBL1602213 & 688453 & 5.0 & 4.9885 & TRN \\
\hline CHEMBL1552984 & 688453 & 5.55 & 5.4574 & TRN \\
\hline CHEMBL1403497 & 688453 & 4.6 & 4.8391 & TRN \\
\hline CHEMBL1326167 & 688453 & 4.9 & 4.5665 & TRN \\
\hline CHEMBL3194187 & 688453 & 6.0 & 5.0512 & TRN \\
\hline CHEMBL1612230 & 688453 & 6.25 & 5.1029 & TRN \\
\hline CHEMBL1555694 & 688453 & 4.45 & 4.8261 & TRN \\
\hline CHEMBL3198877 & 688453 & 4.4 & 4.9212 & TRN \\
\hline CHEMBL1365599 & 688453 & 6.0 & 4.966 & TRN \\
\hline CHEMBL1440703 & 688453 & 5.3 & 5.269 & TST \\
\hline CHEMBL1878162 & 688453 & 5.05 & 4.5449 & TRN \\
\hline CHEMBL1308037 & 688453 & 4.4 & 4.7241 & TRN \\
\hline CHEMBL1570195 & 688453 & 6.8499 & 5.2808 & TRN \\
\hline CHEMBL1448333 & 688453 & 6.8 & 5.1482 & TST \\
\hline CHEMBL35479 & 688453 & 4.45 & 5.0878 & TST \\
\hline CHEMBL1377441 & 688453 & 4.4 & 4.6557 & TRN \\
\hline CHEMBL1493592 & 688453 & 4.4 & 4.9498 & TRN \\
\hline CHEMBL1596516 & 688453 & 4.7 & 5.0042 & TRN \\
\hline CHEMBL 276168 & 688453 & 5.05 & 5.4047 & TRN \\
\hline CHEMBL1538505 & 688453 & 4.7 & 4.7372 & TRN \\
\hline CHEMBL1364967 & 688453 & 4.45 & 5.005 & TRN \\
\hline CHEMBL1571361 & 688453 & 4.45 & 5.1879 & TRN \\
\hline CHEMBL578502 & 688453 & 4.65 & 5.151 & TRN \\
\hline CHEMBL1496995 & 688453 & 4.8 & 4.783 & TRN \\
\hline CHEMBL1390427 & 688453 & 5.0 & 4.6971 & TRN \\
\hline CHEMBL523200 & 688453 & 5.6 & 4.8767 & TRN \\
\hline CHEMBL1303809 & 688453 & 5.4 & 5.3103 & TST \\
\hline CHEMBL1382040 & 688453 & 4.4 & 4.8848 & TRN \\
\hline CHEMBL1460558 & 688453 & 6.7001 & 5.3067 & TST \\
\hline CHEMBL1358777 & 688453 & 5.45 & 5.1892 & TRN \\
\hline CHEMBL1602728 & 688453 & 5.9 & 5.2388 & TRN \\
\hline CHEMBL3197704 & 688453 & 4.4 & 4.6625 & TRN \\
\hline CHEMBL567331 & 688453 & 4.4 & 4.9405 & TRN \\
\hline CHEMBL1579441 & 688453 & 4.55 & 4.8623 & TRN \\
\hline CHEMBL1408237 & 688453 & 5.85 & 4.712 & TRN \\
\hline CHEMBL 233760 & 688453 & 4.45 & 5.1809 & TRN \\
\hline CHEMBL1308104 & 688453 & 5.4 & 4.8588 & TRN \\
\hline CHEMBL1423852 & 688453 & 4.4 & 4.8282 & TRN \\
\hline CHEMBL1415045 & 688453 & 6.05 & 4.9703 & TST \\
\hline CHEMBL1527520 & 688453 & 5.4 & 5.0959 & TST \\
\hline CHEMBL1405054 & 688453 & 4.55 & 4.6268 & TRN \\
\hline CHEMBL1475739 & 688453 & 4.5 & 5.044 & TST \\
\hline CHEMBL1303580 & 688453 & 4.4 & 4.8423 & TRN \\
\hline CHEMBL1516564 & 688453 & 5.85 & 5.2997 & TST \\
\hline CHEMBL1442915 & 688453 & 4.4 & 5.1171 & TRN \\
\hline CHEMBL1408165 & 688453 & 6.7501 & 5.5332 & TRN \\
\hline
\end{tabular}

Page 24381 


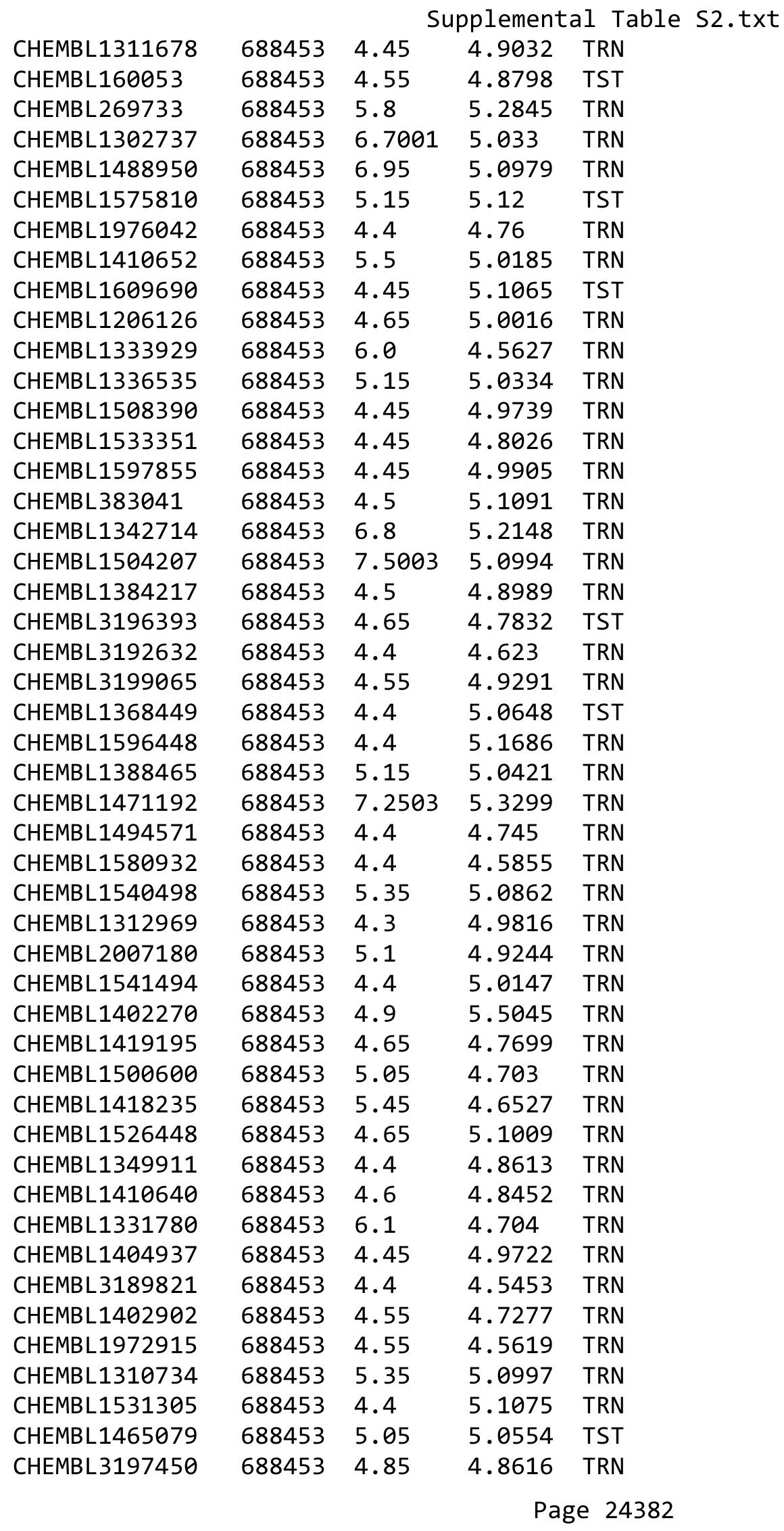




\begin{tabular}{|c|c|c|c|c|c|}
\hline \multicolumn{6}{|c|}{ Supplemental Table S2.txt } \\
\hline CHEMBL3144961 & 688453 & 4.55 & 5.1511 & TRN & \\
\hline CHEMBL1352147 & 688453 & 4.65 & 5.0198 & TRN & \\
\hline CHEMBL1490525 & 688453 & 4.4 & 5.0499 & TRN & \\
\hline CHEMBL1586196 & 688453 & 4.7 & 5.0909 & TRN & \\
\hline CHEMBL1976049 & 688453 & 4.6 & 4.7427 & TRN & \\
\hline CHEMBL3208267 & 688453 & 4.65 & 5.0598 & TRN & \\
\hline CHEMBL1448381 & 688453 & 4.4 & 4.949 & TRN & \\
\hline CHEMBL1341397 & 688453 & 4.85 & 5.0892 & TRN & \\
\hline CHEMBL1360155 & 688453 & 4.4 & 4.628 & TRN & \\
\hline CHEMBL1373095 & 688453 & 4.95 & 4.5515 & TRN & \\
\hline CHEMBL1523023 & 688453 & 6.05 & 5.0577 & TST & \\
\hline CHEMBL1326813 & 688453 & 6.7501 & 4.8415 & TST & \\
\hline CHEMBL1410106 & 688453 & 4.8 & 5.3121 & TRN & \\
\hline CHEMBL1584363 & 688453 & 6.1 & 4.8367 & TRN & \\
\hline CHEMBL1392012 & 688453 & 4.65 & 4.5463 & TRN & \\
\hline CHEMBL1305391 & 688453 & 4.5 & 4.9988 & TRN & \\
\hline CHEMBL1372603 & 688453 & 4.5 & 4.9161 & TST & \\
\hline CHEMBL1501269 & 688453 & 4.55 & 5.1211 & TRN & \\
\hline CHEMBL3213009 & 688453 & 5.2 & 5.1872 & TRN & \\
\hline CHEMBL1433062 & 688453 & 4.55 & 4.9321 & TST & \\
\hline CHEMBL1577388 & 688453 & 5.9 & 5.2287 & TRN & \\
\hline CHEMBL1529066 & 688453 & 6.8499 & 5.1769 & TRN & \\
\hline CHEMBL1572677 & 688453 & 4.4 & 5.0148 & TRN & \\
\hline CHEMBL1353440 & 688453 & 6.4 & 5.0901 & TRN & \\
\hline CHEMBL1503945 & 688453 & 4.55 & 5.1247 & TRN & \\
\hline CHEMBL1984240 & 688453 & 5.05 & 4.6469 & TRN & \\
\hline CHEMBL482477 & 688453 & 6.0 & 5.1004 & TRN & \\
\hline CHEMBL1467504 & 688453 & 4.4 & 5.0368 & TRN & \\
\hline CHEMBL1461389 & 688453 & 4.4 & 5.0468 & TRN & \\
\hline CHEMBL1368963 & 688453 & 5.2 & 5.20299 & 9999999999 & TRN \\
\hline CHEMBL1523733 & 688453 & 4.4 & 4.9883 & TRN & \\
\hline CHEMBL1540619 & 688453 & 5.85 & 5.2993 & TRN & \\
\hline CHEMBL1503652 & 688453 & 4.5 & 4.643 & TRN & \\
\hline CHEMBL1599965 & 688453 & 4.65 & 5.1832 & TRN & \\
\hline CHEMBL1421453 & 688453 & 5.35 & 5.1001 & TRN & \\
\hline CHEMBL1965376 & 688453 & 5.2 & 4.8509 & TRN & \\
\hline CHEMBL1585236 & 688453 & 5.05 & 5.346 & TRN & \\
\hline CHEMBL365356 & 688453 & 5.9 & 5.1652 & TRN & \\
\hline CHEMBL1535349 & 688453 & 4.85 & 5.1365 & TRN & \\
\hline CHEMBL463175 & 688453 & 4.75 & 5.2073 & TRN & \\
\hline CHEMBL1402596 & 688453 & 4.45 & 4.982 & TST & \\
\hline CHEMBL1599336 & 688453 & 4.55 & 4.9761 & TRN & \\
\hline CHEMBL1448306 & 688453 & 4.4 & 4.9186 & TST & \\
\hline CHEMBL1348074 & 688453 & 4.85 & 4.9886 & TST & \\
\hline CHEMBL1977747 & 688453 & 4.4 & 4.9111 & TRN & \\
\hline CHEMBL3194745 & 688453 & 4.55 & 4.9645 & TRN & \\
\hline CHEMBL1497174 & 688453 & 4.45 & 5.0138 & TRN & \\
\hline CHEMBL1558711 & 688453 & 4.45 & 5.1471 & TRN & \\
\hline
\end{tabular}




\begin{tabular}{|c|c|c|c|c|}
\hline \multicolumn{5}{|c|}{ Supplemental Table S2.txt } \\
\hline CHEMBL1451307 & 688453 & 5.2 & 4.5408 & TRN \\
\hline CHEMBL1500368 & 688453 & 4.4 & 4.9997 & TRN \\
\hline CHEMBL1540272 & 688453 & 5.1 & 4.743 & TRN \\
\hline CHEMBL1317098 & 688453 & 4.45 & 5.1312 & TRN \\
\hline CHEMBL1538637 & 688453 & 4.55 & 5.0736 & TRN \\
\hline CHEMBL1469246 & 688453 & 4.4 & 4.9861 & TRN \\
\hline CHEMBL 3199850 & 688453 & 4.4 & 4.8392 & TRN \\
\hline CHEMBL1446521 & 688453 & 6.5 & 5.2226 & TRN \\
\hline CHEMBL 3190625 & 688453 & 4.6 & 4.9619 & TST \\
\hline CHEMBL1484155 & 688453 & 6.3 & 5.2052 & TRN \\
\hline CHEMBL1380511 & 688453 & 4.85 & 4.8332 & TRN \\
\hline CHEMBL1517633 & 688453 & 6.1 & 5.1156 & TRN \\
\hline CHEMBL1574133 & 688453 & 4.7 & 4.8401 & TRN \\
\hline CHEMBL15192 & 688453 & 6.0 & 5.1185 & TRN \\
\hline CHEMBL1340328 & 688453 & 4.9 & 5.2157 & TRN \\
\hline CHEMBL553503 & 688453 & 4.45 & 5.0922 & TST \\
\hline CHEMBL429773 & 688453 & 4.6 & 5.4745 & TRN \\
\hline CHEMBL1368642 & 688453 & 5.95 & 5.1514 & TRN \\
\hline CHEMBL1313396 & 688453 & 4.6 & 5.0331 & TRN \\
\hline CHEMBL1523789 & 688453 & 6.2 & 5.2051 & TST \\
\hline CHEMBL1463279 & 688453 & 5.45 & 4.944 & TRN \\
\hline CHEMBL1334291 & 688453 & 4.4 & 5.1508 & TST \\
\hline CHEMBL1542128 & 688453 & 5.0 & 4.4361 & TRN \\
\hline CHEMBL1339695 & 688453 & 4.45 & 4.6967 & TRN \\
\hline CHEMBL1547938 & 688453 & 4.4 & 4.7666 & TRN \\
\hline CHEMBL1470962 & 688453 & 5.2 & 5.2621 & TRN \\
\hline CHEMBL601952 & 688453 & 4.85 & 5.2887 & TRN \\
\hline CHEMBL1479886 & 688453 & 6.35 & 5.4072 & TRN \\
\hline CHEMBL1606897 & 688453 & 4.45 & 5.2003 & TRN \\
\hline CHEMBL3195751 & 688453 & 4.4 & 4.9043 & TRN \\
\hline CHEMBL449362 & 688453 & 4.45 & 5.4844 & TST \\
\hline CHEMBL1305537 & 688453 & 4.4 & 5.056 & TRN \\
\hline CHEMBL1578687 & 688453 & 5.5 & 5.0419 & TRN \\
\hline CHEMBL29711 & 688453 & 5.25 & 5.2578 & TST \\
\hline CHEMBL1505878 & 688453 & 4.4 & 5.0943 & TRN \\
\hline CHEMBL1337913 & 688453 & 5.45 & 4.9433 & TRN \\
\hline CHEMBL3191489 & 688453 & 4.85 & 5.0725 & TST \\
\hline CHEMBL1323944 & 688453 & 4.75 & 4.9211 & TRN \\
\hline CHEMBL1461051 & 688453 & 4.4 & 4.9721 & TRN \\
\hline CHEMBL1416177 & 688453 & 4.6 & 4.8875 & TRN \\
\hline CHEMBL1391063 & 688453 & 6.95 & 5.0511 & TRN \\
\hline CHEMBL1439735 & 688453 & 5.05 & 5.0536 & TRN \\
\hline CHEMBL1551915 & 688453 & 4.5 & 5.05 & TRN \\
\hline CHEMBL1422133 & 688453 & 4.4 & 5.09 & TRN \\
\hline CHEMBL1347385 & 688453 & 4.7 & 4.7015 & TRN \\
\hline CHEMBL1426626 & 688453 & 5.25 & 5.103 & TRN \\
\hline CHEMBL1348374 & 688453 & 5.05 & 5.2456 & TRN \\
\hline CHEMBL1379737 & 688453 & 4.4 & 4.7915 & TRN \\
\hline
\end{tabular}




\begin{tabular}{|c|c|c|c|c|c|}
\hline \multirow[b]{2}{*}{ CHEMBL1305903 } & \multicolumn{5}{|c|}{ Supplemental Table S2.txt } \\
\hline & 688453 & 7.3497 & 5.153 & TRN & \\
\hline CHEMBL1361585 & 688453 & 5.3 & 5.0987 & TST & \\
\hline CHEMBL1459778 & 688453 & 4.65 & 4.9148 & TST & \\
\hline CHEMBL 3199720 & 688453 & 6.5501 & 4.5539 & TRN & \\
\hline CHEMBL1571480 & 688453 & 4.4 & 4.5468 & TRN & \\
\hline CHEMBL1421528 & 688453 & 6.7501 & 4.5776 & TRN & \\
\hline CHEMBL1449344 & 688453 & 4.7 & 5.2501 & TRN & \\
\hline CHEMBL1471952 & 688453 & 6.8499 & 5.0081 & TST & \\
\hline CHEMBL187460 & 688453 & 6.0 & 5.0344 & TST & \\
\hline CHEMBL1371498 & 688453 & 4.7 & 5.0223 & TRN & \\
\hline CHEMBL1540505 & 688453 & 4.6 & \multicolumn{2}{|c|}{5.257000000000001} & TST \\
\hline CHEMBL1453076 & 688453 & 6.4 & 5.1607 & TRN & \\
\hline CHEMBL1584567 & 688453 & 4.55 & 4.8998 & TRN & \\
\hline CHEMBL1430727 & 688453 & 4.45 & 4.8389 & TRN & \\
\hline CHEMBL1370038 & 688453 & 4.45 & 5.1431 & TRN & \\
\hline CHEMBL1404493 & 688453 & 4.4 & 4.8345 & TRN & \\
\hline CHEMBL1383196 & 688453 & 5.15 & 5.1313 & TRN & \\
\hline CHEMBL338790 & 688453 & 4.6 & 5.0842 & TRN & \\
\hline CHEMBL1392164 & 688453 & 4.45 & 4.6334 & TRN & \\
\hline CHEMBL1533694 & 688453 & 4.4 & 4.5638 & TRN & \\
\hline CHEMBL1568458 & 688453 & 4.4 & 5.1796 & TRN & \\
\hline CHEMBL1990694 & 688453 & 4.5 & 4.8873 & TST & \\
\hline CHEMBL52347 & 688453 & 4.55 & 5.1833 & TRN & \\
\hline CHEMBL1304408 & 688453 & 4.45 & 4.629 & TRN & \\
\hline CHEMBL1331238 & 688453 & 5.2 & 5.1135 & TRN & \\
\hline CHEMBL1479899 & 688453 & 4.4 & 5.3001 & TST & \\
\hline CHEMBL1385413 & 688453 & 6.0 & 4.6021 & TRN & \\
\hline CHEMBL1536311 & 688453 & 6.7001 & 5.0234 & TRN & \\
\hline CHEMBL254255 & 688453 & 4.9 & 5.0734 & TRN & \\
\hline CHEMBL1414009 & 688453 & 4.5 & \multicolumn{2}{|c|}{5.178999999999999} & TRN \\
\hline CHEMBL1353221 & 688453 & 4.8 & 4.9792 & TST & \\
\hline CHEMBL1488083 & 688453 & 4.6 & 5.1871 & TRN & \\
\hline CHEMBL1500010 & 688453 & 4.4 & 4.9375 & TST & \\
\hline CHEMBL1549316 & 688453 & 4.5 & 5.2895 & TRN & \\
\hline CHEMBL1601599 & 688453 & 4.45 & 5.0463 & TRN & \\
\hline CHEMBL3190566 & 688453 & 5.45 & 4.6154 & TRN & \\
\hline CHEMBL1606726 & 688453 & 4.4 & 5.0493 & TRN & \\
\hline CHEMBL1524831 & 688453 & 5.85 & 5.0524 & TRN & \\
\hline CHEMBL1329925 & 688453 & 4.45 & 4.9449 & TRN & \\
\hline CHEMBL1565911 & 688453 & 4.95 & 5.1248 & TRN & \\
\hline CHEMBL1388432 & 688453 & 4.8 & 4.9346 & TRN & \\
\hline CHEMBL1350028 & 688453 & 4.45 & 4.9984 & TRN & \\
\hline CHEMBL1584560 & 688453 & 5.15 & 5.0505 & TST & \\
\hline CHEMBL1352844 & 688453 & 4.9 & 4.8308 & TRN & \\
\hline CHEMBL3193859 & 688453 & 6.0 & 4.8281 & TRN & \\
\hline CHEMBL 388054 & 688453 & 5.1 & 5.3634 & TRN & \\
\hline \multirow{3}{*}{$\begin{array}{l}\text { CHEMBL3210729 } \\
\text { CHEMBL1457745 }\end{array}$} & 688453 & 5.35 & \multicolumn{2}{|c|}{ 4.92399999999999955 } & TRN \\
\hline & 688453 & 4.45 & 4.9993 & TRN & \\
\hline & & & & 24385 & \\
\hline
\end{tabular}




\begin{tabular}{|c|c|c|c|c|c|}
\hline \multicolumn{6}{|c|}{ Supplemental Table S2.txt } \\
\hline CHEMBL1429928 & 688453 & 5.2 & 4.9323 & TST & \\
\hline CHEMBL3208711 & 688453 & 5.5 & 5.058 & TRN & \\
\hline CHEMBL1407056 & 688453 & 4.45 & 4.8194 & TRN & \\
\hline CHEMBL1362481 & 688453 & 5.2 & 5.1729 & TST & \\
\hline CHEMBL1447964 & 688453 & 5.95 & 5.2178 & TRN & \\
\hline CHEMBL1160160 & 688453 & 5.0 & 4.9454 & TRN & \\
\hline CHEMBL 3192575 & 688453 & 4.55 & 5.0249 & TRN & \\
\hline CHEMBL1588521 & 688453 & 5.85 & 5.115 & TRN & \\
\hline CHEMBL1437942 & 688453 & 4.7 & 5.1648 & TRN & \\
\hline CHEMBL1612127 & 688453 & 5.3 & 5.2123 & TRN & \\
\hline CHEMBL1438738 & 688453 & 6.1 & 4.766 & TRN & \\
\hline CHEMBL1451156 & 688453 & 4.45 & 4.953 & TRN & \\
\hline CHEMBL1532154 & 688453 & 5.15 & 5.2215 & TRN & \\
\hline CHEMBL1432905 & 688453 & 4.65 & 4.8207 & TRN & \\
\hline CHEMBL1336050 & 688453 & 4.4 & 4.7776 & TRN & \\
\hline CHEMBL1255967 & 688453 & 5.4 & 5.4215 & TST & \\
\hline CHEMBL1966952 & 688453 & 4.4 & 4.9015 & TRN & \\
\hline CHEMBL1321931 & 688453 & 5.85 & 5.2157 & TRN & \\
\hline CHEMBL1455978 & 688453 & 4.45 & 4.5484 & TRN & \\
\hline CHEMBL1419273 & 688453 & 4.8 & 5.0269 & TST & \\
\hline CHEMBL1405421 & 688453 & 4.4 & 5.2695 & TRN & \\
\hline CHEMBL1480560 & 688453 & 7.5498 & 5.145 & TST & \\
\hline CHEMBL1548050 & 688453 & 5.2 & 5.2263 & TRN & \\
\hline CHEMBL1311807 & 688453 & 7.0 & 5.1298 & TRN & \\
\hline CHEMBL1473755 & 688453 & 4.5 & 4.9218 & TRN & \\
\hline CHEMBL522983 & 688453 & 4.55 & 5.0843 & TRN & \\
\hline CHEMBL312163 & 688453 & 5.7 & 5.1177 & TRN & \\
\hline CHEMBL1566661 & 688453 & 4.6 & 5.1492 & TRN & \\
\hline CHEMBL1346030 & 688453 & 4.45 & 4.7049 & TRN & \\
\hline CHEMBL1528895 & 688453 & 5.25 & 5.2139 & TRN & \\
\hline CHEMBL 376503 & 688453 & 4.5 & 4.8708 & TRN & \\
\hline CHEMBL3191480 & 688453 & 4.4 & 5.1177 & TRN & \\
\hline CHEMBL1385113 & 688453 & 4.75 & 5.1868 & TRN & \\
\hline CHEMBL67311 & 688453 & 9.0 & 5.2116 & TST & \\
\hline CHEMBL1375018 & 688453 & 4.5 & 5.1355 & TST & \\
\hline CHEMBL1422876 & 688453 & 4.65 & 5.1248 & TRN & \\
\hline CHEMBL1533099 & 688453 & 5.05 & 5.0172 & TRN & \\
\hline CHEMBL484640 & 688453 & 4.6 & 5.17299 & 9999999999 & TRN \\
\hline CHEMBL1574258 & 688453 & 4.6 & 5.1024 & TRN & \\
\hline CHEMBL1521335 & 688453 & 5.45 & 5.2663 & TRN & \\
\hline CHEMBL1586326 & 688453 & 4.7 & 4.6342 & TRN & \\
\hline CHEMBL1301398 & 688453 & 4.8 & 5.1721 & TRN & \\
\hline CHEMBL1305632 & 688453 & 4.4 & 4.817 & TRN & \\
\hline CHEMBL1342607 & 688453 & 4.4 & 4.7738 & TRN & \\
\hline CHEMBL1428760 & 688453 & 4.8 & 4.8548 & TRN & \\
\hline CHEMBL1439368 & 688453 & 4.55 & 5.0147 & TST & \\
\hline CHEMBL2357911 & 688453 & 5.8 & 4.9068 & TRN & \\
\hline CHEMBL3198659 & 688453 & 5.7 & 4.9784 & TRN & \\
\hline
\end{tabular}




\begin{tabular}{|c|c|c|c|c|c|}
\hline \multicolumn{6}{|c|}{ Supplemental Table S2.txt } \\
\hline CHEMBL61133 & 688453 & 4.45 & 5.1897 & TRN & \\
\hline CHEMBL1363505 & 688453 & 4.45 & 5.3291 & TRN & \\
\hline CHEMBL1309912 & 688453 & 4.4 & 5.0818 & TST & \\
\hline CHEMBL77387 & 688453 & 4.4 & 4.9182 & TRN & \\
\hline CHEMBL1584673 & 688453 & 4.4 & 5.3162 & TRN & \\
\hline CHEMBL1498884 & 688453 & 5.15 & 5.0929 & TRN & \\
\hline CHEMBL1566940 & 688453 & 4.4 & 4.9219 & TRN & \\
\hline CHEMBL587884 & 688453 & 4.45 & 5.3503 & TST & \\
\hline CHEMBL1456052 & 688453 & 4.6 & 4.9588 & TST & \\
\hline CHEMBL1535738 & 688453 & 5.05 & 5.1551 & TRN & \\
\hline CHEMBL259355 & 688453 & 4.9 & 5.33200 & 0000000001 & TRN \\
\hline CHEMBL1413473 & 688453 & 4.4 & 5.1199 & TST & \\
\hline CHEMBL1494599 & 688453 & 4.4 & 4.7928 & TRN & \\
\hline CHEMBL1577840 & 688453 & 5.0 & 5.0379 & TRN & \\
\hline CHEMBL 2006418 & 688453 & 5.55 & 4.7999 & TRN & \\
\hline CHEMBL1346749 & 688453 & 5.05 & 4.7482 & TRN & \\
\hline CHEMBL1561234 & 688453 & 4.4 & 4.7275 & TRN & \\
\hline CHEMBL3197979 & 688453 & 6.8 & 4.8801 & TRN & \\
\hline CHEMBL1494996 & 688453 & 4.4 & 4.817 & TRN & \\
\hline CHEMBL429095 & 688453 & 6.0 & 5.335 & TRN & \\
\hline CHEMBL403419 & 688453 & 4.5 & 4.6094 & TRN & \\
\hline CHEMBL1601387 & 688453 & 5.15 & 5.1611 & TRN & \\
\hline CHEMBL1372140 & 688453 & 5.0 & 4.9349 & TRN & \\
\hline CHEMBL1324333 & 688453 & 7.4498 & 5.1269 & TRN & \\
\hline CHEMBL1500636 & 688453 & 4.5 & 4.8559 & TRN & \\
\hline CHEMBL3193163 & 688453 & 4.9 & 5.1524 & TST & \\
\hline CHEMBL1446243 & 688453 & 4.4 & 4.9973 & TRN & \\
\hline CHEMBL1360140 & 688453 & 4.45 & 4.9683 & TRN & \\
\hline CHEMBL1612774 & 688453 & 5.15 & 4.973 & TRN & \\
\hline CHEMBL1365523 & 688453 & 6.8 & 4.6689 & TRN & \\
\hline CHEMBL1540343 & 688453 & 4.4 & 4.9626 & TRN & \\
\hline CHEMBL1478023 & 688453 & 4.6 & 4.9188 & TRN & \\
\hline CHEMBL1423950 & 688453 & 6.8 & 5.3764 & TRN & \\
\hline CHEMBL1508847 & 688453 & 5.4 & 4.5841 & TRN & \\
\hline CHEMBL1335923 & 688453 & 7.0 & 5.4395 & TRN & \\
\hline CHEMBL1359782 & 688453 & 4.45 & 4.3071 & TRN & \\
\hline CHEMBL1533653 & 688453 & 6.8499 & 5.0769 & TRN & \\
\hline CHEMBL1308547 & 688453 & 4.4 & 4.9257 & TRN & \\
\hline CHEMBL1521090 & 688453 & 4.9 & 5.0545 & TST & \\
\hline CHEMBL1350132 & 688453 & 4.4 & 5.063 & TRN & \\
\hline CHEMBL1605685 & 688453 & 5.9 & 5.0968 & TRN & \\
\hline CHEMBL1342429 & 688453 & 4.4 & 4.8125 & TRN & \\
\hline CHEMBL1509306 & 688453 & 4.5 & 5.0905 & TRN & \\
\hline CHEMBL1348043 & 688453 & 4.45 & 5.0158 & TST & \\
\hline CHEMBL1533561 & 688453 & 4.65 & 4.8854 & TRN & \\
\hline CHEMBL3198693 & 688453 & 4.55 & 4.9301 & TRN & \\
\hline CHEMBL 1459949 & 688453 & 4.4 & 4.6691 & TRN & \\
\hline CHEMBL1412409 & 688453 & 5.45 & 5.0981 & TRN & \\
\hline
\end{tabular}




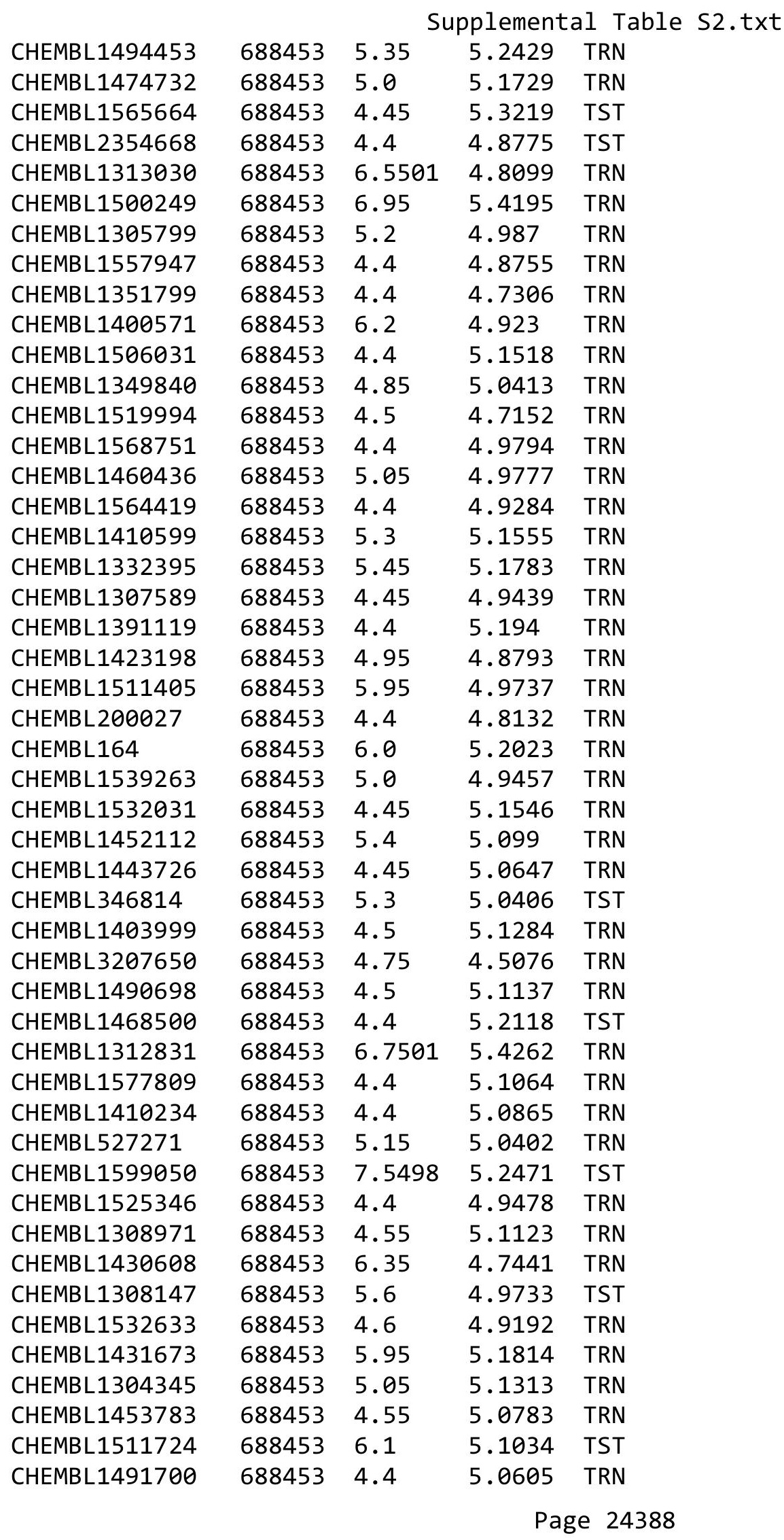




\begin{tabular}{|c|c|c|c|c|}
\hline \multicolumn{5}{|c|}{ Supplemental Table S2.txt } \\
\hline CHEMBL1450349 & 688453 & 4.45 & 5.1854 & TST \\
\hline CHEMBL1323320 & 688453 & 4.55 & 4.6032 & TRN \\
\hline CHEMBL1508925 & 688453 & 4.55 & 5.0616 & TST \\
\hline CHEMBL1419305 & 688453 & 4.4 & 5.2004 & TST \\
\hline CHEMBL1603460 & 688453 & 6.1 & 4.8753 & TRN \\
\hline CHEMBL1569742 & 688453 & 4.6 & 4.9786 & TRN \\
\hline CHEMBL 3189545 & 688453 & 4.6 & 4.6766 & TRN \\
\hline CHEMBL1458080 & 688453 & 4.7 & 5.086 & TRN \\
\hline CHEMBL1597042 & 688453 & 5.0 & 4.5271 & TRN \\
\hline CHEMBL1552277 & 688453 & 4.7 & 5.0324 & TRN \\
\hline CHEMBL1581755 & 688453 & 4.4 & 5.2553 & TST \\
\hline CHEMBL1516658 & 688453 & 4.45 & 5.2814 & TRN \\
\hline CHEMBL 2006441 & 688453 & 4.45 & 4.9973 & TST \\
\hline CHEMBL 29898 & 688453 & 4.5 & 5.1666 & TRN \\
\hline CHEMBL1331809 & 688453 & 4.4 & 4.9889 & TRN \\
\hline CHEMBL1490513 & 688453 & 5.15 & 4.5666 & TRN \\
\hline CHEMBL1449613 & 688453 & 7.1002 & 5.2019 & TRN \\
\hline CHEMBL1607187 & 688453 & 4.65 & 4.9928 & TRN \\
\hline CHEMBL1324034 & 688453 & 5.45 & 5.0387 & TRN \\
\hline CHEMBL1999019 & 688453 & 5.25 & 5.1599 & TST \\
\hline CHEMBL1509648 & 688453 & 4.55 & 4.7638 & TRN \\
\hline CHEMBL1335945 & 688453 & 4.4 & 4.9935 & TRN \\
\hline CHEMBL1571612 & 688453 & 6.8 & 5.3697 & TRN \\
\hline CHEMBL1608122 & 688453 & 6.8 & 5.2753 & TRN \\
\hline CHEMBL1361823 & 688453 & 4.6 & 5.0868 & TRN \\
\hline CHEMBL1352896 & 688453 & 6.6 & 5.1854 & TRN \\
\hline CHEMBL172350 & 688453 & 6.0 & 5.0032 & TRN \\
\hline CHEMBL1508612 & 688453 & 4.45 & 5.0817 & TRN \\
\hline CHEMBL 2002162 & 688453 & 4.6 & 5.0551 & TST \\
\hline CHEMBL1561729 & 688453 & 4.6 & 4.7207 & TRN \\
\hline CHEMBL1528227 & 688453 & 5.2 & 4.9863 & TRN \\
\hline CHEMBL1534873 & 688453 & 6.15 & 5.0733 & TRN \\
\hline CHEMBL1356280 & 688453 & 4.45 & 5.1016 & TST \\
\hline CHEMBL1480753 & 688453 & 4.4 & 4.5864 & TRN \\
\hline CHEMBL1981243 & 688453 & 4.65 & 4.5933 & TRN \\
\hline CHEMBL1348173 & 688453 & 4.4 & 4.8329 & TRN \\
\hline CHEMBL3212628 & 688453 & 4.35 & 4.8485 & TST \\
\hline CHEMBL1421887 & 688453 & 5.0 & 4.9884 & TRN \\
\hline CHEMBL1304007 & 688453 & 4.45 & 4.7206 & TRN \\
\hline CHEMBL1531622 & 688453 & 5.85 & 5.2339 & TRN \\
\hline CHEMBL1468365 & 688453 & 5.45 & 5.0484 & TRN \\
\hline CHEMBL1379075 & 688453 & 5.8 & 5.1963 & TST \\
\hline CHEMBL1332210 & 688453 & 4.4 & 4.9103 & TST \\
\hline CHEMBL1465727 & 688453 & 4.4 & 4.7113 & TRN \\
\hline CHEMBL161343 & 688453 & 5.45 & 5.3166 & TRN \\
\hline CHEMBL1570795 & 688453 & 5.15 & 5.1366 & TRN \\
\hline CHEMBL1521711 & 688453 & 4.75 & 4.9501 & TRN \\
\hline CHEMBL1986444 & 688453 & 6.3 & 4.8801 & TRN \\
\hline
\end{tabular}




\begin{tabular}{|c|c|c|c|c|c|}
\hline \multicolumn{6}{|c|}{ Supplemental Table S2.txt } \\
\hline CHEMBL1364496 & 688453 & 4.9 & 5.352 & TRN & \\
\hline CHEMBL1575502 & 688453 & 4.4 & 4.8255 & TRN & \\
\hline CHEMBL1498627 & 688453 & 4.4 & 4.9287 & TRN & \\
\hline CHEMBL1491039 & 688453 & 7.5498 & 5.0797 & TRN & \\
\hline CHEMBL3191392 & 688453 & 4.6 & 4.8002 & TRN & \\
\hline CHEMBL1417188 & 688453 & 4.4 & 4.8486 & TRN & \\
\hline CHEMBL1479502 & 688453 & 6.8499 & 5.19799 & 99999999995 & TRN \\
\hline CHEMBL1335044 & 688453 & 4.65 & 5.0628 & TST & \\
\hline CHEMBL1576458 & 688453 & 4.4 & 5.0055 & TRN & \\
\hline CHEMBL338115 & 688453 & 5.0 & 5.1561 & TRN & \\
\hline CHEMBL1406350 & 688453 & 4.35 & 4.666 & TRN & \\
\hline CHEMBL1431851 & 688453 & 4.5 & 4.6847 & TRN & \\
\hline CHEMBL1438695 & 688453 & 5.15 & 5.2162 & TRN & \\
\hline CHEMBL408850 & 688453 & 7.5498 & 4.9236 & TRN & \\
\hline CHEMBL1493956 & 688453 & 4.75 & 4.9497 & TRN & \\
\hline CHEMBL1482180 & 688453 & 4.55 & 5.1987 & TRN & \\
\hline CHEMBL1535281 & 688453 & 5.5 & 5.1844 & TST & \\
\hline CHEMBL1418460 & 688453 & 4.45 & 5.2357 & TST & \\
\hline CHEMBL1540523 & 688453 & 4.4 & 5.0412 & TST & \\
\hline CHEMBL 294264 & 688453 & 6.0 & 5.1876 & TRN & \\
\hline CHEMBL1419871 & 688453 & 6.5 & 5.2254 & TST & \\
\hline CHEMBL1326191 & 688453 & 5.35 & 5.1065 & TRN & \\
\hline CHEMBL1466297 & 688453 & 4.6 & 5.3381 & TRN & \\
\hline CHEMBL1569834 & 688453 & 6.1 & 5.1675 & TRN & \\
\hline CHEMBL1402943 & 688453 & 5.45 & 5.0899 & TRN & \\
\hline CHEMBL1570316 & 688453 & 5.4 & 5.3132 & TRN & \\
\hline CHEMBL1501891 & 688453 & 6.95 & 5.0533 & TRN & \\
\hline CHEMBL1464140 & 688453 & 5.5 & 5.1457 & TRN & \\
\hline CHEMBL1500504 & 688453 & 6.15 & 5.0358 & TRN & \\
\hline CHEMBL1306655 & 688453 & 4.4 & 4.68199 & 99999999995 & TRN \\
\hline CHEMBL1393630 & 688453 & 4.55 & 5.2174 & TST & \\
\hline CHEMBL1342281 & 688453 & 6.05 & 5.1557 & TRN & \\
\hline CHEMBL1972037 & 688453 & 5.5 & 4.8226 & TRN & \\
\hline CHEMBL3197583 & 688453 & 6.25 & 4.8875 & TRN & \\
\hline CHEMBL1340286 & 688453 & 4.4 & 5.4944 & TRN & \\
\hline CHEMBL1465037 & 688453 & 5.3 & 5.0398 & TRN & \\
\hline CHEMBL1343418 & 688453 & 6.3 & 5.3288 & TRN & \\
\hline CHEMBL1386161 & 688453 & 4.5 & 4.5077 & TRN & \\
\hline CHEMBL1580370 & 688453 & 5.6 & 5.1321 & TST & \\
\hline CHEMBL1200462 & 688453 & 4.55 & 5.1955 & TST & \\
\hline CHEMBL1390068 & 688453 & 4.45 & 5.09699 & 99999999995 & TRN \\
\hline CHEMBL1415195 & 688453 & 5.95 & 5.0102 & TRN & \\
\hline CHEMBL1467798 & 688453 & 5.35 & 5.1701 & TRN & \\
\hline CHEMBL1519992 & 688453 & 4.7 & 4.7656 & TRN & \\
\hline CHEMBL1529334 & 688453 & 4.7 & 4.5537 & TRN & \\
\hline CHEMBL1613238 & 688453 & 4.45 & 4.9854 & TRN & \\
\hline CHEMBL1584818 & 688453 & 4.55 & 4.9084 & TRN & \\
\hline CHEMBL1417879 & 688453 & 4.5 & 5.0445 & TRN & \\
\hline
\end{tabular}




\begin{tabular}{|c|c|c|c|c|c|}
\hline \multicolumn{6}{|c|}{ Supplemental Table S2.txt } \\
\hline CHEMBL1430005 & 688453 & 4.4 & 5.1449 & TST & \\
\hline CHEMBL1507419 & 688453 & 5.4 & 4.8868 & TST & \\
\hline CHEMBL1452952 & 688453 & 4.85 & 4.8048 & TRN & \\
\hline CHEMBL1422017 & 688453 & 4.55 & 5.0691 & TRN & \\
\hline CHEMBL1506510 & 688453 & 6.15 & 5.1721 & TRN & \\
\hline CHEMBL1580066 & 688453 & 4.5 & 4.9338 & TRN & \\
\hline CHEMBL1391393 & 688453 & 4.5 & 4.9324 & TRN & \\
\hline CHEMBL1349449 & 688453 & 4.45 & 4.746 & TRN & \\
\hline CHEMBL1413423 & 688453 & 4.65 & 5.0938 & TRN & \\
\hline CHEMBL1306497 & 688453 & 6.1 & 5.3857 & TST & \\
\hline CHEMBL1413079 & 688453 & 4.55 & 5.1722 & TRN & \\
\hline CHEMBL1423732 & 688453 & 4.45 & 4.9383 & TRN & \\
\hline CHEMBL1563317 & 688453 & 4.55 & 4.8668 & TRN & \\
\hline CHEMBL3145019 & 688453 & 5.15 & 5.0466 & TST & \\
\hline CHEMBL1341830 & 688453 & 6.1 & 5.1417 & TRN & \\
\hline CHEMBL542493 & 688453 & 5.45 & 4.9882 & TST & \\
\hline CHEMBL1341913 & 688453 & 4.45 & 4.9311 & TST & \\
\hline CHEMBL1381058 & 688453 & 4.45 & 5.28799 & 9999999999 & TRN \\
\hline CHEMBL225513 & 688453 & 5.35 & 4.9871 & TRN & \\
\hline CHEMBL1484380 & 688453 & 6.35 & 5.0425 & TRN & \\
\hline CHEMBL1366681 & 688453 & 4.45 & 4.5702 & TRN & \\
\hline CHEMBL1419637 & 688453 & 5.15 & 5.2233 & TRN & \\
\hline CHEMBL1606122 & 688453 & 5.45 & 4.997 & TRN & \\
\hline CHEMBL1437258 & 688453 & 4.4 & 4.9665 & TRN & \\
\hline CHEMBL1583199 & 688453 & 4.65 & 5.0081 & TRN & \\
\hline CHEMBL1964535 & 688453 & 4.4 & 4.7299 & TRN & \\
\hline CHEMBL1481642 & 688453 & 6.1 & 5.0182 & TRN & \\
\hline CHEMBL1584236 & 688453 & 4.4 & 4.9706 & TRN & \\
\hline CHEMBL69612 & 688453 & 4.9 & 4.708 & TRN & \\
\hline CHEMBL1409548 & 688453 & 5.5 & 5.2076 & TRN & \\
\hline CHEMBL1390229 & 688453 & 5.2 & 5.0171 & TRN & \\
\hline CHEMBL1566067 & 688453 & 4.6 & 5.187 & TRN & \\
\hline CHEMBL1335386 & 688453 & 6.0 & 5.0016 & TRN & \\
\hline CHEMBL1269084 & 688453 & 4.95 & 4.8086 & TRN & \\
\hline CHEMBL1307425 & 688453 & 5.2 & 5.2138 & TST & \\
\hline CHEMBL1446668 & 688453 & 4.45 & 4.8597 & TRN & \\
\hline CHEMBL1566203 & 688453 & 4.4 & 4.7108 & TRN & \\
\hline CHEMBL1528371 & 688453 & 6.8499 & 5.1444 & TRN & \\
\hline CHEMBL1612543 & 688453 & 4.4 & 5.098 & TRN & \\
\hline CHEMBL1330161 & 688453 & 4.9 & 4.8154 & TRN & \\
\hline CHEMBL1470512 & 688453 & 4.4 & 4.9587 & TRN & \\
\hline CHEMBL1450571 & 688453 & 6.7501 & 4.9827 & TRN & \\
\hline CHEMBL3195384 & 688453 & 4.55 & 4.941 & TRN & \\
\hline CHEMBL1556539 & 688453 & 5.35 & 4.8092 & TRN & \\
\hline CHEMBL1338216 & 688453 & 4.45 & 5.0278 & TST & \\
\hline CHEMBL1535285 & 688453 & 4.45 & 4.5373 & TRN & \\
\hline CHEMBL1331862 & 688453 & 4.45 & 5.4682 & TRN & \\
\hline CHEMBL1382015 & 688453 & 6.8 & 5.1069 & TST & \\
\hline
\end{tabular}




\begin{tabular}{|c|c|c|c|c|c|}
\hline \multicolumn{6}{|c|}{ Supplemental Table S2.txt } \\
\hline CHEMBL1563559 & 688453 & 4.55 & 4.9646 & TRN & \\
\hline CHEMBL1524439 & 688453 & 4.4 & 5.007 & TRN & \\
\hline CHEMBL1310746 & 688453 & 4.55 & 4.9018 & TRN & \\
\hline CHEMBL1567045 & 688453 & 4.4 & 5.1272 & TRN & \\
\hline CHEMBL8320 & 688453 & 4.4 & 5.4403 & TST & \\
\hline CHEMBL1452185 & 688453 & 4.5 & 4.9848 & TRN & \\
\hline CHEMBL1572788 & 688453 & 4.45 & 5.0169 & TRN & \\
\hline CHEMBL1560762 & 688453 & 6.8499 & 5.3124 & TRN & \\
\hline CHEMBL1306729 & 688453 & 6.2 & 5.3442 & TST & \\
\hline CHEMBL1499276 & 688453 & 6.8 & 4.98 & TRN & \\
\hline CHEMBL1512912 & 688453 & 4.45 & 5.26200 & 00000000005 & TRN \\
\hline CHEMBL1496320 & 688453 & 4.6 & 4.9516 & TRN & \\
\hline CHEMBL1576140 & 688453 & 5.05 & 5.0251 & TRN & \\
\hline CHEMBL1526013 & 688453 & 6.45 & 5.4302 & TRN & \\
\hline CHEMBL1410192 & 688453 & 5.2 & 4.7287 & TRN & \\
\hline CHEMBL1391517 & 688453 & 6.15 & 4.9933 & TRN & \\
\hline CHEMBL1516758 & 688453 & 6.1 & 4.7155 & TRN & \\
\hline CHEMBL1317451 & 688453 & 4.45 & 4.96 & TRN & \\
\hline CHEMBL1562963 & 688453 & 4.65 & 5.0229 & TRN & \\
\hline CHEMBL1374171 & 688453 & 5.2 & 5.1753 & TRN & \\
\hline CHEMBL1496753 & 688453 & 4.45 & 4.5866 & TRN & \\
\hline CHEMBL1524434 & 688453 & 6.8499 & 5.1832 & TST & \\
\hline CHEMBL458328 & 688453 & 6.0 & 5.2636 & TRN & \\
\hline CHEMBL1453652 & 688453 & 4.45 & 4.8293 & TRN & \\
\hline CHEMBL1384515 & 688453 & 4.55 & 4.9825 & TRN & \\
\hline CHEMBL1420053 & 688453 & 4.85 & 5.048 & TRN & \\
\hline CHEMBL1474151 & 688453 & 4.4 & 5.0912 & TRN & \\
\hline CHEMBL1343146 & 688453 & 6.95 & 5.2248 & TRN & \\
\hline CHEMBL1460220 & 688453 & 6.7001 & 5.2346 & TRN & \\
\hline CHEMBL1339670 & 688453 & 4.85 & 4.7128 & TRN & \\
\hline CHEMBL1996858 & 688453 & 4.8 & 4.9862 & TRN & \\
\hline CHEMBL1441401 & 688453 & 4.5 & 4.711 & TRN & \\
\hline CHEMBL1543088 & 688453 & 5.45 & 5.0246 & TRN & \\
\hline CHEMBL1302143 & 688453 & 6.7001 & 5.3204 & TRN & \\
\hline CHEMBL1377223 & 688453 & 4.65 & 4.755 & TRN & \\
\hline CHEMBL1443098 & 688453 & 6.05 & 5.2978 & TRN & \\
\hline CHEMBL1468844 & 688453 & 5.45 & 5.1579 & TRN & \\
\hline CHEMBL1612657 & 688453 & 5.45 & 4.7147 & TRN & \\
\hline CHEMBL1483453 & 688453 & 5.15 & 5.0801 & TRN & \\
\hline CHEMBL1432560 & 688453 & 4.45 & 4.7506 & TRN & \\
\hline CHEMBL1413013 & 688453 & 4.65 & 5.1885 & TRN & \\
\hline CHEMBL1537752 & 688453 & 5.5 & 4.7787 & TRN & \\
\hline CHEMBL 3193400 & 688453 & 4.9 & 4.994 & TRN & \\
\hline CHEMBL 343002 & 688453 & 6.0 & 5.109 & TRN & \\
\hline CHEMBL1504655 & 688453 & 4.7 & 5.1349 & TRN & \\
\hline CHEMBL525239 & 688453 & 5.55 & 5.1609 & TST & \\
\hline CHEMBL1524942 & 688453 & 4.6 & 4.698 & TRN & \\
\hline CHEMBL1342890 & 688453 & 5.15 & 5.276 & TST & \\
\hline
\end{tabular}




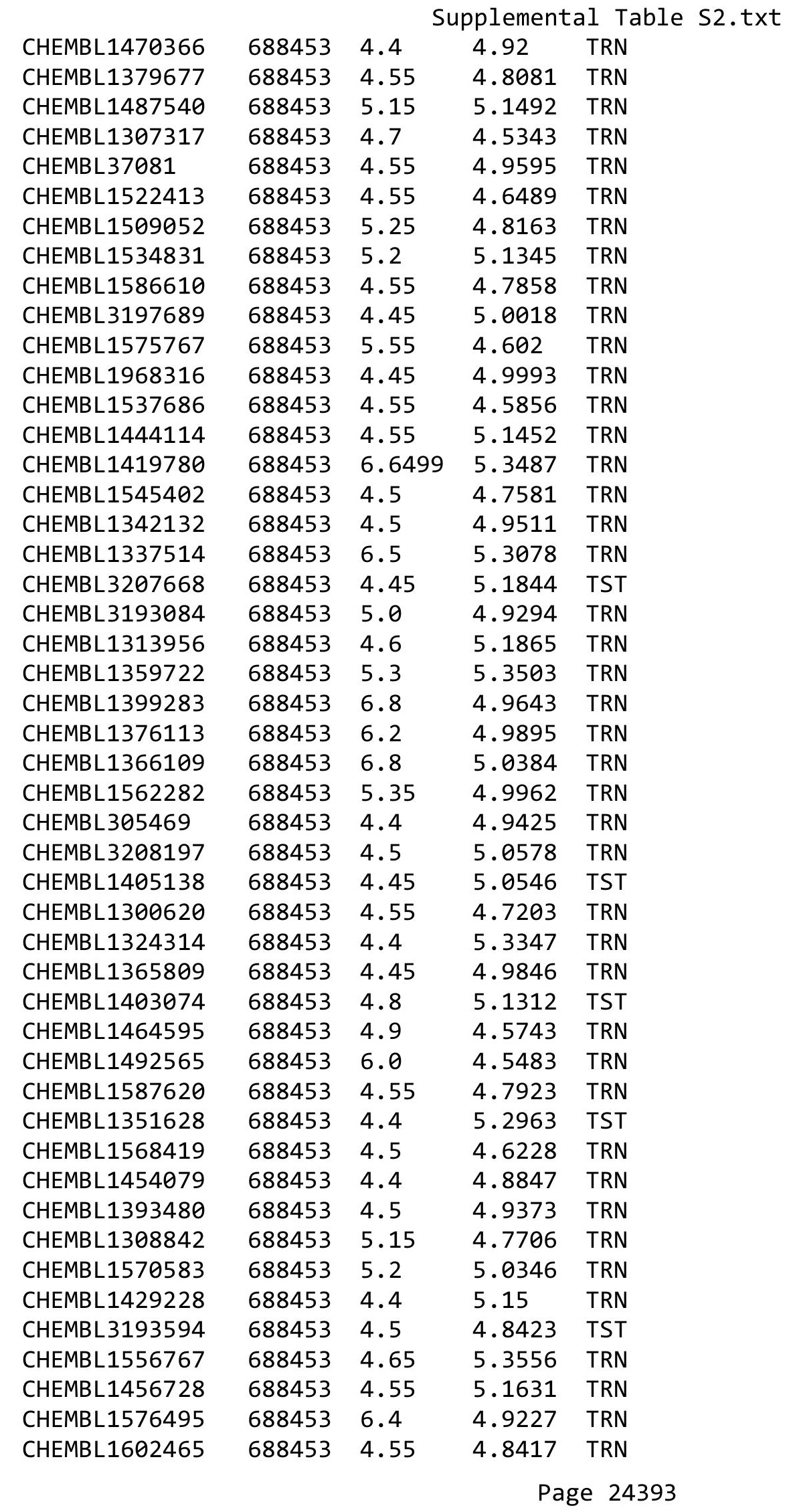




\begin{tabular}{|c|c|c|c|c|c|}
\hline & & \multicolumn{4}{|c|}{ Supplemental Table S2.txt } \\
\hline CHEMBL1348796 & 688453 & 4.4 & 4.7644 & TRN & \\
\hline CHEMBL1390621 & 688453 & 6.7501 & 5.1411 & TRN & \\
\hline CHEMBL490355 & 688453 & 6.0 & 4.9225 & TRN & \\
\hline CHEMBL1572785 & 688453 & 4.6 & 5.0105 & TRN & \\
\hline CHEMBL1304495 & 688453 & 4.45 & 5.0394 & TRN & \\
\hline CHEMBL 3192585 & 688453 & 5.4 & 4.8263 & TRN & \\
\hline CHEMBL1482102 & 688453 & 6.8 & 5.19600 & 2000000001 & TRN \\
\hline CHEMBL1971588 & 688453 & 4.45 & 4.9019 & TRN & \\
\hline CHEMBL1548678 & 688453 & 4.45 & 4.7311 & TRN & \\
\hline CHEMBL1379164 & 688453 & 4.45 & 5.1756 & TST & \\
\hline CHEMBL 3197293 & 688453 & 4.4 & 5.0305 & TST & \\
\hline CHEMBL1560638 & 688453 & 4.55 & 5.3152 & TRN & \\
\hline CHEMBL1508875 & 688453 & 4.5 & 5.0886 & TRN & \\
\hline CHEMBL1462570 & 688453 & 4.9 & 5.2863 & TRN & \\
\hline CHEMBL1478173 & 688453 & 4.9 & 4.9509 & TRN & \\
\hline CHEMBL1508502 & 688453 & 4.4 & 4.9693 & TRN & \\
\hline CHEMBL1584519 & 688453 & 5.1 & 5.4294 & TRN & \\
\hline CHEMBL1424602 & 688453 & 4.45 & 5.1275 & TST & \\
\hline CHEMBL3197851 & 688453 & 4.75 & 4.8104 & TST & \\
\hline CHEMBL3199590 & 688453 & 6.0 & 4.7201 & TRN & \\
\hline CHEMBL1558021 & 688453 & 4.5 & 5.2072 & TRN & \\
\hline CHEMBL1096009 & 688453 & 4.4 & 5.3208 & TST & \\
\hline CHEMBL1544178 & 688453 & 4.55 & 4.6706 & TRN & \\
\hline CHEMBL1420063 & 688453 & 4.4 & 5.0871 & TRN & \\
\hline CHEMBL1449836 & 688453 & 4.95 & 4.8754 & TRN & \\
\hline CHEMBL1610587 & 688453 & 4.55 & 4.7976 & TST & \\
\hline CHEMBL1345441 & 688453 & 5.4 & 5.314 & TRN & \\
\hline CHEMBL1558533 & 688453 & 4.4 & 4.796 & TRN & \\
\hline CHEMBL1517774 & 688453 & 4.55 & 4.8019 & TRN & \\
\hline CHEMBL1350435 & 688453 & 4.9 & 4.5808 & TRN & \\
\hline CHEMBL1539325 & 688453 & 4.95 & 5.0327 & TRN & \\
\hline CHEMBL1389473 & 688453 & 4.6 & 4.7595 & TRN & \\
\hline CHEMBL1337954 & 688453 & 4.45 & 5.3198 & TRN & \\
\hline CHEMBL1336709 & 688453 & 5.05 & 5.0734 & TRN & \\
\hline CHEMBL3198293 & 688453 & 6.8 & 5.2994 & TST & \\
\hline CHEMBL1336287 & 688453 & 4.45 & 5.3181 & TRN & \\
\hline CHEMBL1451023 & 688453 & 6.8 & 4.9647 & TST & \\
\hline CHEMBL1303094 & 688453 & 6.8 & 5.1181 & TRN & \\
\hline CHEMBL1705092 & 688453 & 4.6 & 4.7886 & TRN & \\
\hline CHEMBL123 & 688453 & 5.35 & 5.2305 & TRN & \\
\hline CHEMBL1606096 & 688453 & 4.7 & 5.1309 & TRN & \\
\hline CHEMBL1322453 & 688453 & 5.2 & 5.2797 & TRN & \\
\hline CHEMBL1580062 & 688453 & 5.3 & 4.8857 & TRN & \\
\hline CHEMBL1381627 & 688453 & 5.75 & 4.9671 & TRN & \\
\hline CHEMBL330756 & 688453 & 6.9 & 5.2437 & TST & \\
\hline CHEMBL1438907 & 688453 & 4.55 & 5.0892 & TRN & \\
\hline CHEMBL1348795 & 688453 & 4.45 & 4.9489 & TRN & \\
\hline CHEMBL1549405 & 688453 & 4.4 & 5.2017 & TRN & \\
\hline
\end{tabular}




\begin{tabular}{|c|c|c|c|c|}
\hline \multicolumn{5}{|c|}{ Supplemental Table S2.txt } \\
\hline CHEMBL1364731 & 688453 & 4.4 & 5.0548 & TRN \\
\hline CHEMBL1492710 & 688453 & 4.4 & 5.084 & TRN \\
\hline CHEMBL1610129 & 688453 & 4.4 & 4.7342 & TST \\
\hline CHEMBL1390674 & 688453 & 5.35 & 5.1399 & TRN \\
\hline CHEMBL1441538 & 688453 & 4.4 & 5.2188 & TRN \\
\hline CHEMBL1389052 & 688453 & 4.6 & 5.0147 & TRN \\
\hline CHEMBL1999900 & 688453 & 4.45 & 5.0741 & TRN \\
\hline CHEMBL1731995 & 688453 & 5.45 & 4.8458 & TRN \\
\hline CHEMBL1464853 & 688453 & 4.8 & 4.9833 & TRN \\
\hline CHEMBL1975615 & 688453 & 4.4 & 4.9248 & TRN \\
\hline CHEMBL3199475 & 688453 & 4.65 & 5.0037 & TRN \\
\hline CHEMBL1562712 & 688453 & 4.7 & 4.8306 & TRN \\
\hline CHEMBL1600232 & 688453 & 6.0 & 4.9154 & TST \\
\hline CHEMBL1428399 & 688453 & 4.55 & 5.0461 & TRN \\
\hline CHEMBL1377627 & 688453 & 6.05 & 5.0387 & TRN \\
\hline CHEMBL497781 & 688453 & 5.35 & 4.9432 & TRN \\
\hline CHEMBL3192831 & 688453 & 5.35 & 4.8215 & TRN \\
\hline CHEMBL1581396 & 688453 & 4.55 & 4.8514 & TRN \\
\hline CHEMBL1395431 & 688453 & 4.55 & 4.9239 & TRN \\
\hline CHEMBL1420312 & 688453 & 4.85 & 4.9131 & TRN \\
\hline CHEMBL1467640 & 688453 & 6.25 & 4.9878 & TRN \\
\hline CHEMBL1340905 & 688453 & 4.6 & 4.8317 & TRN \\
\hline CHEMBL1359359 & 688453 & 6.5 & 5.2628 & TST \\
\hline CHEMBL 2006431 & 688453 & 4.4 & 4.6757 & TRN \\
\hline CHEMBL1322185 & 688453 & 4.5 & 4.9982 & TRN \\
\hline CHEMBL1589300 & 688453 & 5.1 & 4.6839 & TRN \\
\hline CHEMBL1584917 & 688453 & 4.55 & 5.0963 & TRN \\
\hline CHEMBL 3199451 & 688453 & 4.95 & 4.7735 & TRN \\
\hline CHEMBL1984190 & 688453 & 5.25 & 4.8963 & TRN \\
\hline CHEMBL1439715 & 688453 & 6.1 & 4.9311 & TRN \\
\hline CHEMBL1235157 & 688453 & 4.4 & 5.3649 & TST \\
\hline CHEMBL1447034 & 688453 & 6.0 & 5.1945 & TST \\
\hline CHEMBL1393008 & 688453 & 4.4 & 4.6722 & TRN \\
\hline CHEMBL1493064 & 688453 & 6.2 & 5.3003 & TRN \\
\hline CHEMBL1333421 & 688453 & 4.4 & 5.1243 & TRN \\
\hline CHEMBL1572517 & 688453 & 7.4001 & 5.0303 & TRN \\
\hline CHEMBL1610552 & 688453 & 5.8 & 5.3873 & TRN \\
\hline CHEMBL1453350 & 688453 & 5.15 & 5.2047 & TRN \\
\hline CHEMBL1531564 & 688453 & 6.8 & 4.9059 & TRN \\
\hline CHEMBL1506100 & 688453 & 6.8 & 4.954 & TRN \\
\hline CHEMBL1399010 & 688453 & 4.55 & 5.2606 & TRN \\
\hline CHEMBL477396 & 688453 & 5.55 & 5.0561 & TST \\
\hline CHEMBL1375876 & 688453 & 4.45 & 4.9901 & TRN \\
\hline CHEMBL1367212 & 688453 & 4.45 & 4.8636 & TRN \\
\hline CHEMBL1522763 & 688453 & 6.7501 & 5.1131 & TRN \\
\hline CHEMBL1535216 & 688453 & 4.4 & 4.9449 & TRN \\
\hline CHEMBL1431609 & 688453 & 4.6 & 5.1273 & TRN \\
\hline CHEMBL1372404 & 688453 & 4.8 & 5.2552 & TRN \\
\hline
\end{tabular}




\begin{tabular}{|c|c|c|c|c|c|}
\hline \multicolumn{6}{|c|}{ Supplemental Table S2.txt } \\
\hline CHEMBL1981657 & 688453 & 4.9 & 4.7619 & TRN & \\
\hline CHEMBL1391169 & 688453 & 4.45 & 5.0908 & TRN & \\
\hline CHEMBL1399905 & 688453 & 6.35 & 5.0841 & TRN & \\
\hline CHEMBL1197556 & 688453 & 4.4 & 4.8112 & TRN & \\
\hline CHEMBL1392372 & 688453 & 5.45 & 4.89199 & 99999999995 & TRN \\
\hline CHEMBL1561230 & 688453 & 4.4 & 4.8174 & TST & \\
\hline CHEMBL1348714 & 688453 & 6.8499 & 4.915 & TRN & \\
\hline CHEMBL1497427 & 688453 & 4.55 & 4.7676 & TRN & \\
\hline CHEMBL1586066 & 688453 & 4.45 & 4.6654 & TRN & \\
\hline CHEMBL541505 & 688453 & 4.4 & 5.3741 & TST & \\
\hline CHEMBL3198658 & 688453 & 4.6 & 4.4242 & TRN & \\
\hline CHEMBL1519229 & 688453 & 4.55 & 4.7528 & TRN & \\
\hline CHEMBL1443088 & 688453 & 4.6 & 4.5556 & TRN & \\
\hline CHEMBL1312235 & 688453 & 4.55 & 4.51399 & 9999999999 & TRN \\
\hline CHEMBL1378504 & 688453 & 4.55 & 5.1045 & TRN & \\
\hline CHEMBL1424694 & 688453 & 4.5 & 4.6528 & TRN & \\
\hline CHEMBL1495539 & 688453 & 4.85 & 4.9961 & TRN & \\
\hline CHEMBL1965184 & 688453 & 4.55 & 4.8514 & TST & \\
\hline CHEMBL1730100 & 688453 & 6.0 & 5.1296 & TST & \\
\hline CHEMBL1339673 & 688453 & 7.3497 & 5.3152 & TRN & \\
\hline CHEMBL1323213 & 688453 & 4.4 & 5.1631 & TST & \\
\hline CHEMBL335619 & 688453 & 4.5 & 5.1807 & TRN & \\
\hline CHEMBL1349382 & 688453 & 6.2 & 4.8611 & TRN & \\
\hline CHEMBL1567597 & 688453 & 4.85 & 5.1185 & TRN & \\
\hline CHEMBL1409700 & 688453 & 4.5 & 4.8754 & TRN & \\
\hline CHEMBL1412429 & 688453 & 4.45 & 5.087 & TRN & \\
\hline CHEMBL1471466 & 688453 & 4.4 & 4.9453 & TRN & \\
\hline CHEMBL1488428 & 688453 & 6.7501 & 5.3153 & TRN & \\
\hline CHEMBL1539557 & 688453 & 4.45 & 4.7874 & TRN & \\
\hline CHEMBL1311773 & 688453 & 4.4 & 5.0898 & TST & \\
\hline CHEMBL3193391 & 688453 & 4.45 & 4.8122 & TRN & \\
\hline CHEMBL1353412 & 688453 & 4.5 & 4.98600 & 0000000001 & TRN \\
\hline CHEMBL1532186 & 688453 & 5.05 & 5.0151 & TRN & \\
\hline CHEMBL3191063 & 688453 & 5.35 & 4.8534 & TRN & \\
\hline CHEMBL1340724 & 688453 & 4.8 & 4.8079 & TRN & \\
\hline CHEMBL3189663 & 688453 & 4.45 & 5.0598 & TRN & \\
\hline CHEMBL1409518 & 688453 & 6.4 & 5.3493 & TRN & \\
\hline CHEMBL1543296 & 688453 & 5.3 & 5.001 & TRN & \\
\hline CHEMBL1310944 & 688453 & 4.4 & 4.842 & TRN & \\
\hline CHEMBL1400852 & 688453 & 4.6 & 4.7048 & TRN & \\
\hline CHEMBL1413657 & 688453 & 4.85 & 5.1154 & TRN & \\
\hline CHEMBL345124 & 688453 & 6.0 & 5.0129 & TST & \\
\hline CHEMBL1345094 & 688453 & 5.2 & 5.3108 & TRN & \\
\hline CHEMBL1531340 & 688453 & 5.85 & 5.0189 & TRN & \\
\hline CHEMBL1550676 & 688453 & 5.0 & 5.0635 & TRN & \\
\hline CHEMBL1448882 & 688453 & 4.4 & 5.0753 & TRN & \\
\hline CHEMBL56393 & 688453 & 5.8 & 5.0466 & TRN & \\
\hline CHEMBL1323890 & 688453 & 5.1 & 5.0245 & TRN & \\
\hline
\end{tabular}




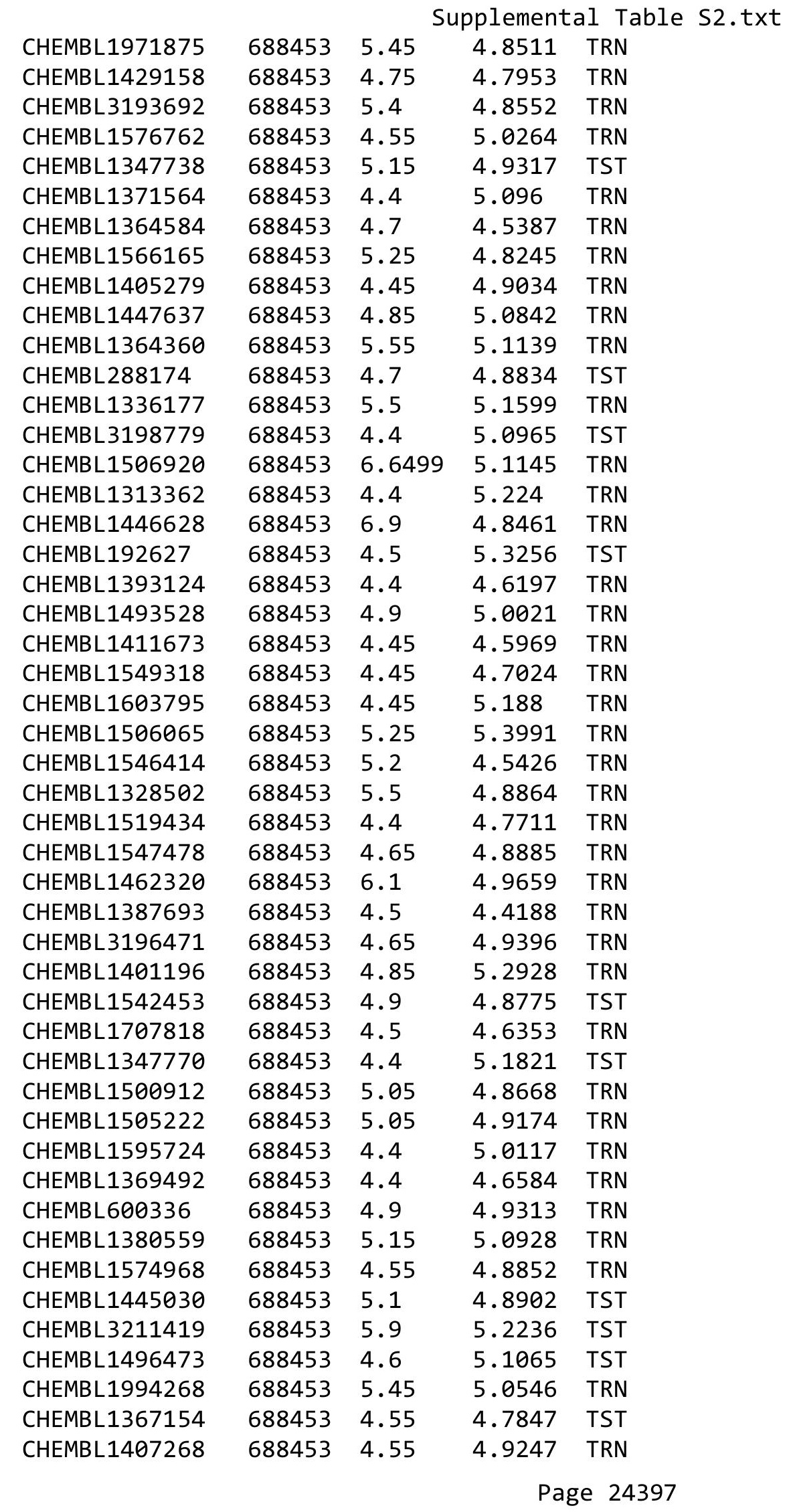




\begin{tabular}{|c|c|c|c|c|c|}
\hline \multirow[b]{2}{*}{ CHEMBL1480933 } & & \multicolumn{4}{|c|}{ Supplemental Table S2.txt } \\
\hline & 688453 & 6.1 & 4.89199 & 99999999995 & TRN \\
\hline CHEMBL1348826 & 688453 & 6.05 & 5.2385 & TRN & \\
\hline CHEMBL1465435 & 688453 & 4.5 & 4.9913 & TRN & \\
\hline CHEMBL1362714 & 688453 & 4.4 & 4.9787 & TST & \\
\hline CHEMBL1345979 & 688453 & 4.4 & 5.2619 & TST & \\
\hline CHEMBL1429131 & 688453 & 6.8 & 5.23799 & 99999999995 & TRN \\
\hline CHEMBL1307507 & 688453 & 6.8 & 5.143 & TRN & \\
\hline CHEMBL1306487 & 688453 & 5.4 & 5.2131 & TRN & \\
\hline CHEMBL 2003436 & 688453 & 4.4 & 4.9331 & TRN & \\
\hline CHEMBL1542814 & 688453 & 4.5 & 5.1286 & TST & \\
\hline CHEMBL1577037 & 688453 & 6.7501 & 5.0436 & TRN & \\
\hline CHEMBL1600902 & 688453 & 5.8 & 5.0156 & TST & \\
\hline CHEMBL1421590 & 688453 & 5.2 & 4.7917 & TRN & \\
\hline CHEMBL1502014 & 688453 & 4.85 & 4.8444 & TST & \\
\hline CHEMBL1572807 & 688453 & 4.5 & 4.7174 & TRN & \\
\hline CHEMBL1612548 & 688453 & 6.8 & 5.0793 & TRN & \\
\hline CHEMBL1427699 & 688453 & 4.5 & 5.0691 & TRN & \\
\hline CHEMBL1357090 & 688453 & 4.95 & 5.0367 & TRN & \\
\hline CHEMBL1346456 & 688453 & 4.95 & 5.0948 & TRN & \\
\hline CHEMBL1581151 & 688453 & 4.55 & 5.0156 & TRN & \\
\hline CHEMBL1558087 & 688453 & 4.8 & 4.8172 & TRN & \\
\hline CHEMBL1525600 & 688453 & 6.8 & 4.7714 & TRN & \\
\hline CHEMBL1431456 & 688453 & 4.85 & 4.9349 & TRN & \\
\hline CHEMBL1342299 & 688453 & 4.5 & 5.0044 & TRN & \\
\hline CHEMBL1478000 & 688453 & 4.4 & 5.1966 & TST & \\
\hline CHEMBL1546814 & 688453 & 4.6 & 5.2131 & TRN & \\
\hline CHEMBL3194447 & 688453 & 5.2 & 4.988 & TRN & \\
\hline CHEMBL1390716 & 688453 & 4.75 & 4.7715 & TRN & \\
\hline CHEMBL1429782 & 688453 & 4.65 & 5.0884 & TRN & \\
\hline CHEMBL499968 & 688453 & 5.05 & 5.0978 & TST & \\
\hline CHEMBL1325390 & 688453 & 5.6 & 5.1311 & TRN & \\
\hline CHEMBL1460445 & 688453 & 4.85 & 5.2054 & TRN & \\
\hline CHEMBL1988535 & 688453 & 4.4 & 5.0932 & TRN & \\
\hline CHEMBL1390204 & 688453 & 4.5 & 4.9859 & TRN & \\
\hline CHEMBL1348698 & 688453 & 7.6003 & 5.0111 & TRN & \\
\hline CHEMBL495123 & 688453 & 5.0 & 5.1668 & TRN & \\
\hline CHEMBL1465739 & 688453 & 4.4 & 5.0314 & TRN & \\
\hline CHEMBL1485865 & 688453 & 5.2 & 4.8949 & TST & \\
\hline CHEMBL1532477 & 688453 & 4.65 & 4.7231 & TRN & \\
\hline CHEMBL1334698 & 688453 & 4.4 & 5.1965 & TRN & \\
\hline CHEMBL1549120 & 688453 & 4.5 & 4.5276 & TRN & \\
\hline CHEMBL3196141 & 688453 & 4.4 & 4.9621 & TRN & \\
\hline CHEMBL1347607 & 688453 & 4.5 & 5.0283 & TRN & \\
\hline CHEMBL1453479 & 688453 & 4.4 & 5.2998 & TRN & \\
\hline CHEMBL1383110 & 688453 & 5.5 & 5.1758 & TRN & \\
\hline CHEMBL71851 & 688453 & 4.5 & 5.1133 & TRN & \\
\hline CHEMBL212414 & 688453 & 4.5 & 4.705 & TRN & \\
\hline CHEMBL1472067 & 688453 & 4.4 & 4.9244 & TRN & \\
\hline
\end{tabular}




\begin{tabular}{|c|c|c|c|c|c|}
\hline & & \multicolumn{4}{|c|}{ Supplemental Table s2.txt } \\
\hline CHEMBL547269 & 688453 & 4.65 & 4.985 & TRN & \\
\hline CHEMBL1563029 & 688453 & 4.55 & 5.0885 & TRN & \\
\hline CHEMBL1301692 & 688453 & 4.55 & 4.7501 & TRN & \\
\hline CHEMBL1561199 & 688453 & 4.5 & 4.9515 & TRN & \\
\hline CHEMBL1503050 & 688453 & 4.5 & 5.2792 & TRN & \\
\hline CHEMBL1491434 & 688453 & 4.4 & 4.9728 & TST & \\
\hline CHEMBL1345692 & 688453 & 5.2 & 4.8047 & TST & \\
\hline CHEMBL1565830 & 688453 & 6.0 & 4.6305 & TRN & \\
\hline CHEMBL303429 & 688453 & 5.25 & 5.5533 & TST & \\
\hline CHEMBL1302410 & 688453 & 5.1 & 4.9442 & TRN & \\
\hline CHEMBL1537764 & 688453 & 5.25 & 4.904 & TRN & \\
\hline CHEMBL1505129 & 688453 & 4.4 & 5.336 & TRN & \\
\hline CHEMBL1445028 & 688453 & 4.45 & 5.0647 & TRN & \\
\hline CHEMBL1533166 & 688453 & 4.5 & 5.0315 & TRN & \\
\hline CHEMBL1984001 & 688453 & 4.5 & 5.1072 & TRN & \\
\hline CHEMBL1340051 & 688453 & 4.5 & 4.7465 & TRN & \\
\hline CHEMBL1585112 & 688453 & 4.45 & 4.9078 & TRN & \\
\hline CHEMBL1553873 & 688453 & 5.0 & 5.0411 & TRN & \\
\hline CHEMBL1588790 & 688453 & 6.8 & 5.1278 & TRN & \\
\hline CHEMBL1463312 & 688453 & 4.4 & 4.8672 & TRN & \\
\hline CHEMBL1540048 & 688453 & 5.85 & 4.8224 & TRN & \\
\hline CHEMBL3212028 & 688453 & 5.15 & 4.971 & TRN & \\
\hline CHEMBL 3187257 & 688453 & 5.2 & 4.8061 & TRN & \\
\hline CHEMBL1308710 & 688453 & 4.45 & 4.7958 & TRN & \\
\hline CHEMBL 290914 & 688453 & 4.45 & 5.027 & TRN & \\
\hline CHEMBL418068 & 688453 & 5.5 & 4.9678 & TRN & \\
\hline CHEMBL1563691 & 688453 & 4.5 & 5.0064 & TRN & \\
\hline CHEMBL1502779 & 688453 & 4.85 & 4.9004 & TST & \\
\hline CHEMBL1363197 & 688453 & 4.4 & 4.6886 & TRN & \\
\hline CHEMBL1415264 & 688453 & 5.15 & 5.239 & TRN & \\
\hline CHEMBL1971410 & 688453 & 5.45 & 4.7417 & TRN & \\
\hline CHEMBL1331245 & 688453 & 5.4 & 5.2879 & TRN & \\
\hline CHEMBL1528171 & 688453 & 4.4 & 4.7633 & TRN & \\
\hline CHEMBL1299338 & 688453 & 5.45 & 5.2324 & TRN & \\
\hline CHEMBL1978120 & 688453 & 4.4 & 4.9039 & TRN & \\
\hline CHEMBL1544386 & 688453 & 4.5 & 5.1513 & TRN & \\
\hline CHEMBL1502633 & 688453 & 4.45 & 4.9197 & TRN & \\
\hline CHEMBL1351250 & 688453 & 4.75 & 4.8577 & TRN & \\
\hline CHEMBL1464334 & 688453 & 5.5 & 4.9855 & TST & \\
\hline CHEMBL1577742 & 688453 & 4.45 & 4.97199 & 99999999995 & TRN \\
\hline CHEMBL1302271 & 688453 & 4.8 & 5.1582 & TST & \\
\hline CHEMBL1405177 & 688453 & 4.5 & 4.9389 & TRN & \\
\hline CHEMBL1386982 & 688453 & 4.55 & 5.1344 & TRN & \\
\hline CHEMBL1460315 & 688453 & 5.15 & 5.1437 & TST & \\
\hline CHEMBL1499653 & 688453 & 6.0 & 4.9548 & TRN & \\
\hline CHEMBL1370165 & 688453 & 5.2 & 4.9909 & TRN & \\
\hline CHEMBL3145028 & 688453 & 4.45 & 5.0141 & TRN & \\
\hline CHEMBL1453134 & 688453 & 4.4 & 4.6783 & TRN & \\
\hline
\end{tabular}




\begin{tabular}{|c|c|c|c|c|}
\hline \multicolumn{5}{|c|}{ Supplemental Table S2.txt } \\
\hline CHEMBL1492667 & 688453 & 5.3 & 5.2309 & TRN \\
\hline CHEMBL1422848 & 688453 & 5.45 & 4.8134 & TRN \\
\hline CHEMBL1393455 & 688453 & 6.1 & 5.2101 & TRN \\
\hline CHEMBL1586339 & 688453 & 5.25 & 5.3047 & TRN \\
\hline CHEMBL1490548 & 688453 & 6.8 & 5.1697 & TRN \\
\hline CHEMBL1423709 & 688453 & 4.6 & 4.8071 & TRN \\
\hline CHEMBL1326282 & 688453 & 5.15 & 4.9567 & TRN \\
\hline CHEMBL1604163 & 688453 & 5.05 & 4.7309 & TRN \\
\hline CHEMBL1484818 & 688453 & 4.45 & 5.033 & TRN \\
\hline CHEMBL1325945 & 688453 & 4.4 & 5.0188 & TRN \\
\hline CHEMBL1299502 & 688453 & 4.55 & 4.8577 & TRN \\
\hline CHEMBL1546048 & 688453 & 4.4 & 4.4913 & TRN \\
\hline CHEMBL3193557 & 688453 & 5.5 & 4.9343 & TST \\
\hline CHEMBL1449488 & 688453 & 4.4 & 4.9518 & TRN \\
\hline CHEMBL1498887 & 688453 & 4.4 & 4.8216 & TRN \\
\hline CHEMBL1335077 & 688453 & 4.45 & 4.9543 & TRN \\
\hline CHEMBL1307266 & 688453 & 6.15 & 5.3604 & TRN \\
\hline CHEMBL1559715 & 688453 & 4.5 & 4.9068 & TRN \\
\hline CHEMBL 3194385 & 688453 & 5.05 & 5.0245 & TRN \\
\hline CHEMBL1363678 & 688453 & 4.45 & 4.9514 & TRN \\
\hline CHEMBL 22062 & 688453 & 4.85 & 5.1514 & TRN \\
\hline CHEMBL1352778 & 688453 & 4.6 & 4.9672 & TRN \\
\hline CHEMBL1393087 & 688453 & 4.55 & 4.9388 & TRN \\
\hline CHEMBL1530049 & 688453 & 4.55 & 4.8596 & TRN \\
\hline CHEMBL1481914 & 688453 & 5.1 & 4.7107 & TRN \\
\hline CHEMBL1509676 & 688453 & 4.45 & 4.5787 & TRN \\
\hline CHEMBL1504516 & 688453 & 4.55 & 4.8425 & TRN \\
\hline CHEMBL3191420 & 688453 & 6.9 & 5.0172 & TRN \\
\hline CHEMBL1454770 & 688453 & 5.3 & 5.0734 & TRN \\
\hline CHEMBL1314174 & 688453 & 5.55 & 5.2928 & TST \\
\hline CHEMBL1347052 & 688453 & 4.45 & 4.6284 & TRN \\
\hline CHEMBL1460015 & 688453 & 4.4 & 4.933 & TRN \\
\hline CHEMBL1442841 & 688453 & 4.65 & 4.8289 & TRN \\
\hline CHEMBL3198982 & 688453 & 5.15 & 4.9087 & TRN \\
\hline CHEMBL1508837 & 688453 & 5.0 & 4.9549 & TRN \\
\hline CHEMBL1457514 & 688453 & 4.6 & 4.7464 & TRN \\
\hline CHEMBL3189657 & 688453 & 5.2 & 5.0072 & TRN \\
\hline CHEMBL1299642 & 688453 & 5.15 & 4.8232 & TRN \\
\hline CHEMBL1333388 & 688453 & 6.15 & 5.0541 & TRN \\
\hline CHEMBL1535210 & 688453 & 5.2 & 5.1079 & TRN \\
\hline CHEMBL3208819 & 688453 & 5.15 & 5.3142 & TRN \\
\hline CHEMBL1559100 & 688453 & 4.75 & 4.8688 & TRN \\
\hline CHEMBL1883149 & 688453 & 4.4 & 4.7561 & TRN \\
\hline CHEMBL1461801 & 688453 & 4.7 & 5.0105 & TST \\
\hline CHEMBL1505467 & 688453 & 5.55 & 4.9209 & TRN \\
\hline CHEMBL1483590 & 688453 & 4.6 & 5.2274 & TRN \\
\hline CHEMBL1501200 & 688453 & 4.4 & 4.9776 & TRN \\
\hline CHEMBL1409731 & 688453 & 4.4 & 5.0075 & TRN \\
\hline
\end{tabular}




\begin{tabular}{|c|c|c|c|c|c|}
\hline \multicolumn{6}{|c|}{ Supplemental Table S2.txt } \\
\hline CHEMBL1455231 & 688453 & 4.65 & 5.1536 & TRN & \\
\hline CHEMBL1568038 & 688453 & 4.4 & 4.8109 & TRN & \\
\hline CHEMBL1527393 & 688453 & 4.4 & 4.6104 & TRN & \\
\hline CHEMBL1493191 & 688453 & 4.95 & 4.4822 & TRN & \\
\hline CHEMBL1303553 & 688453 & 5.2 & 5.0936 & TRN & \\
\hline CHEMBL1542467 & 688453 & 6.6499 & 5.192 & TRN & \\
\hline CHEMBL1967540 & 688453 & 4.55 & 4.6874 & TRN & \\
\hline CHEMBL1542543 & 688453 & 4.45 & 5.0335 & TRN & \\
\hline CHEMBL1609179 & 688453 & 5.95 & 5.2154 & TST & \\
\hline CHEMBL1328650 & 688453 & 5.4 & 5.30399 & 9999999999 & TRN \\
\hline CHEMBL1330951 & 688453 & 4.45 & 5.1186 & TST & \\
\hline CHEMBL1522300 & 688453 & 5.0 & 4.8049 & TRN & \\
\hline CHEMBL1372545 & 688453 & 4.9 & 5.2784 & TRN & \\
\hline CHEMBL1728023 & 688453 & 5.5 & 5.1173 & TRN & \\
\hline CHEMBL1318778 & 688453 & 4.4 & 4.8465 & TRN & \\
\hline CHEMBL1440834 & 688453 & 4.95 & 4.9739 & TRN & \\
\hline CHEMBL80658 & 688453 & 6.0 & 4.6713 & TRN & \\
\hline CHEMBL1303320 & 688453 & 4.85 & 4.8397 & TRN & \\
\hline CHEMBL1537509 & 688453 & 4.55 & 4.7455 & TST & \\
\hline CHEMBL1332802 & 688453 & 5.4 & 5.2173 & TRN & \\
\hline CHEMBL1343952 & 688453 & 4.6 & 5.0305 & TRN & \\
\hline CHEMBL1503980 & 688453 & 6.4 & 4.9519 & TST & \\
\hline CHEMBL3195576 & 688453 & 4.4 & 4.8878 & TST & \\
\hline CHEMBL1583406 & 688453 & 4.45 & 4.6044 & TRN & \\
\hline CHEMBL1351915 & 688453 & 4.5 & 5.2103 & TRN & \\
\hline CHEMBL1440320 & 688453 & 4.4 & 5.0588 & TRN & \\
\hline CHEMBL1545406 & 688453 & 6.45 & 5.072 & TRN & \\
\hline CHEMBL1322657 & 688453 & 4.45 & 4.6966 & TRN & \\
\hline CHEMBL1569215 & 688453 & 4.65 & 4.5408 & TRN & \\
\hline CHEMBL1339178 & 688453 & 4.45 & 5.1761 & TST & \\
\hline CHEMBL1612406 & 688453 & 4.8 & 5.182 & TST & \\
\hline CHEMBL1341271 & 688453 & 6.8499 & 5.0668 & TRN & \\
\hline CHEMBL1544265 & 688453 & 5.2 & 4.9163 & TRN & \\
\hline CHEMBL1978236 & 688453 & 4.65 & 5.0127 & TST & \\
\hline CHEMBL1352616 & 688453 & 4.6 & 4.877 & TRN & \\
\hline CHEMBL1489354 & 688453 & 4.25 & 5.1079 & TRN & \\
\hline CHEMBL29097 & 688453 & 4.55 & 5.0807 & TST & \\
\hline CHEMBL1369028 & 688453 & 4.45 & 5.285 & TST & \\
\hline CHEMBL1307577 & 688453 & 5.2 & 5.2859 & TRN & \\
\hline CHEMBL1452723 & 688453 & 7.0 & 4.9176 & TRN & \\
\hline CHEMBL1410381 & 688453 & 4.4 & 5.0501 & TRN & \\
\hline CHEMBL1351245 & 688453 & 4.55 & 5.03 & TRN & \\
\hline CHEMBL3198479 & 688453 & 5.2 & 4.9844 & TST & \\
\hline CHEMBL1323287 & 688453 & 4.4 & 5.1559 & TST & \\
\hline CHEMBL1482257 & 688453 & 4.4 & 5.4221 & TRN & \\
\hline CHEMBL1558442 & 688453 & 4.8 & 4.9739 & TRN & \\
\hline CHEMBL3192270 & 688453 & 4.45 & 4.867 & TRN & \\
\hline CHEMBL3190112 & 688453 & 4.45 & 4.7398 & TRN & \\
\hline
\end{tabular}




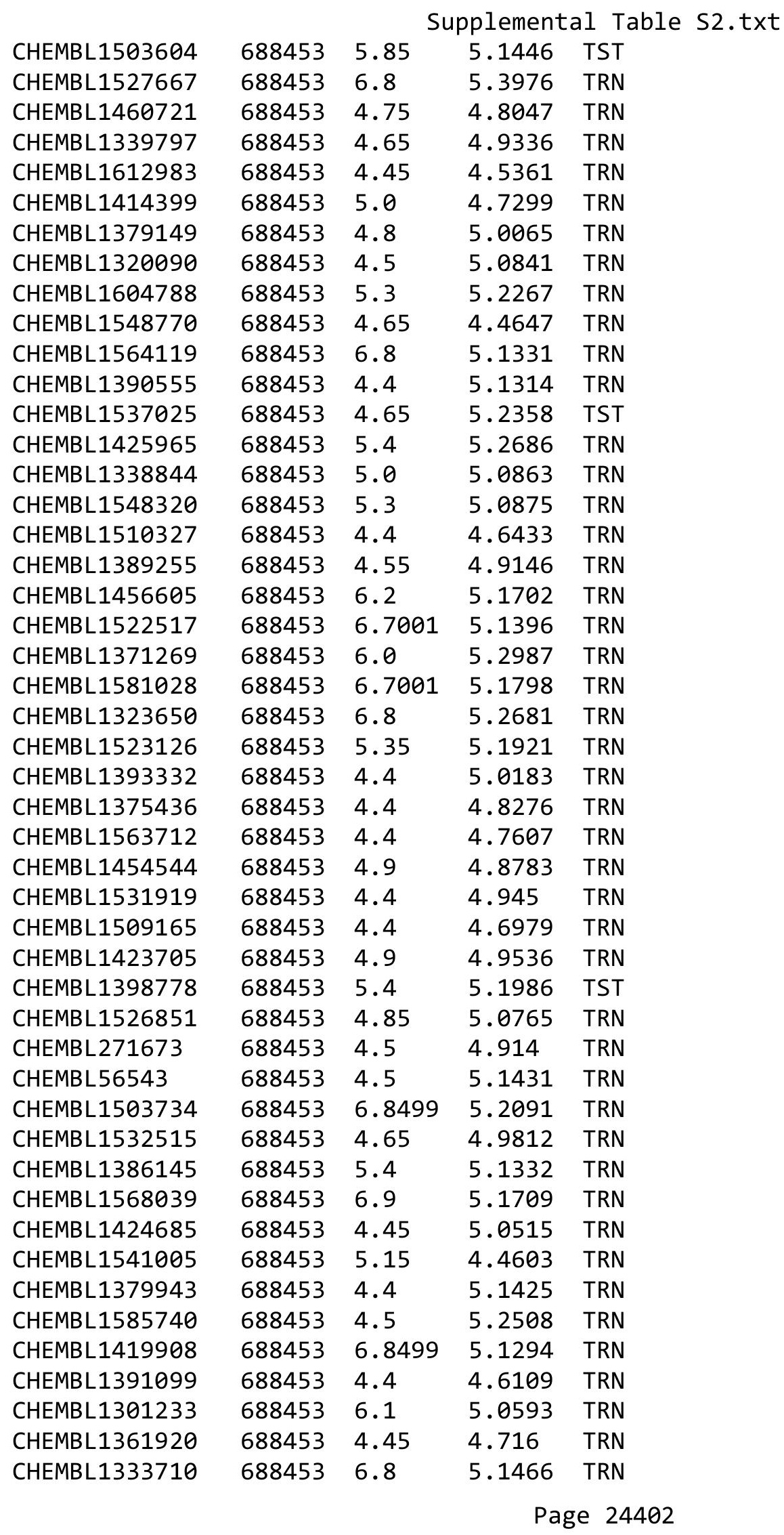




\begin{tabular}{|c|c|c|c|c|}
\hline \multicolumn{5}{|c|}{ Supplemental Table S2.txt } \\
\hline CHEMBL1606403 & 688453 & 4.4 & 4.6209 & TRN \\
\hline CHEMBL1334149 & 688453 & 4.4 & 5.1294 & TST \\
\hline CHEMBL1478395 & 688453 & 5.1 & 5.0986 & TST \\
\hline CHEMBL1340288 & 688453 & 4.45 & 4.8396 & TRN \\
\hline CHEMBL1570356 & 688453 & 4.45 & 5.1314 & TRN \\
\hline CHEMBL1508004 & 688453 & 5.25 & 5.0896 & TRN \\
\hline CHEMBL1526174 & 688453 & 4.5 & 4.9625 & TRN \\
\hline CHEMBL1443679 & 688453 & 4.45 & 4.9545 & TRN \\
\hline CHEMBL1327002 & 688453 & 5.15 & 5.0857 & TST \\
\hline CHEMBL1576746 & 688453 & 4.4 & 4.8808 & TST \\
\hline CHEMBL1587837 & 688453 & 4.55 & 4.7747 & TRN \\
\hline CHEMBL1577661 & 688453 & 4.65 & 5.1698 & TRN \\
\hline CHEMBL1487908 & 688453 & 4.45 & 5.4063 & TRN \\
\hline CHEMBL1394046 & 688453 & 4.45 & 4.717 & TRN \\
\hline CHEMBL1403663 & 688453 & 4.4 & 4.749 & TRN \\
\hline CHEMBL1366479 & 688453 & 4.5 & 4.6512 & TRN \\
\hline CHEMBL1537634 & 688453 & 4.5 & 5.1584 & TRN \\
\hline CHEMBL1441444 & 688453 & 6.8 & 4.9757 & TRN \\
\hline CHEMBL131199 & 688453 & 4.95 & 5.1272 & TST \\
\hline CHEMBL1471980 & 688453 & 5.0 & 5.0495 & TRN \\
\hline CHEMBL85194 & 688453 & 5.1 & 5.1668 & TRN \\
\hline CHEMBL1448387 & 688453 & 6.0 & 5.176 & TST \\
\hline CHEMBL1419151 & 688453 & 4.4 & 5.2475 & TST \\
\hline CHEMBL1598383 & 688453 & 4.45 & 4.9084 & TST \\
\hline CHEMBL1330322 & 688453 & 4.4 & 5.2219 & TRN \\
\hline CHEMBL1461262 & 688453 & 7.5003 & 4.9826 & TST \\
\hline CHEMBL1556868 & 688453 & 4.65 & 4.7565 & TRN \\
\hline CHEMBL1308224 & 688453 & 4.45 & 5.0299 & TRN \\
\hline CHEMBL1337310 & 688453 & 4.7 & 4.9475 & TRN \\
\hline CHEMBL1255648 & 688453 & 5.45 & 5.3072 & TRN \\
\hline CHEMBL1441886 & 688453 & 4.4 & 5.2275 & TRN \\
\hline CHEMBL1329673 & 688453 & 4.4 & 5.3954 & TRN \\
\hline CHEMBL1430204 & 688453 & 4.4 & 5.1241 & TRN \\
\hline CHEMBL1539251 & 688453 & 4.8 & 5.0495 & TRN \\
\hline CHEMBL1968421 & 688453 & 4.4 & 5.0851 & TRN \\
\hline CHEMBL1432044 & 688453 & 4.4 & 4.6919 & TRN \\
\hline CHEMBL3190095 & 688453 & 5.05 & 5.0078 & TST \\
\hline CHEMBL1353033 & 688453 & 4.7 & 4.5098 & TRN \\
\hline CHEMBL1544660 & 688453 & 4.6 & 5.1236 & TRN \\
\hline CHEMBL399982 & 688453 & 4.5 & 4.6587 & TRN \\
\hline CHEMBL3209347 & 688453 & 4.6 & 4.9455 & TRN \\
\hline CHEMBL1396296 & 688453 & 5.45 & 5.0319 & TRN \\
\hline CHEMBL1406067 & 688453 & 6.8 & 4.8686 & TRN \\
\hline CHEMBL1526201 & 688453 & 6.7001 & 5.033 & TRN \\
\hline CHEMBL3194042 & 688453 & 5.05 & 5.1933 & TRN \\
\hline CHEMBL1489700 & 688453 & 4.4 & 5.088 & TRN \\
\hline CHEMBL1437867 & 688453 & 4.5 & 5.1491 & TST \\
\hline CHEMBL1467245 & 688453 & 4.4 & 5.0554 & TRN \\
\hline
\end{tabular}




\begin{tabular}{|c|c|c|c|c|c|}
\hline \multicolumn{6}{|c|}{ Supplemental Table S2.txt } \\
\hline CHEMBL1334484 & 688453 & 5.0 & 4.734 & TRN & \\
\hline CHEMBL1345784 & 688453 & 6.6499 & 5.2117 & TRN & \\
\hline CHEMBL1306897 & 688453 & 4.45 & 4.9197 & TRN & \\
\hline CHEMBL3191399 & 688453 & 4.4 & 4.7545 & TRN & \\
\hline CHEMBL3190135 & 688453 & 5.3 & 4.8258 & TRN & \\
\hline CHEMBL1160028 & 688453 & 4.65 & 4.912 & TRN & \\
\hline CHEMBL1345567 & 688453 & 4.4 & 5.112 & TRN & \\
\hline CHEMBL3213353 & 688453 & 4.4 & 4.9975 & TST & \\
\hline CHEMBL1475999 & 688453 & 6.0 & 4.9515 & TST & \\
\hline CHEMBL1488280 & 688453 & 4.4 & 4.6364 & TRN & \\
\hline CHEMBL1450008 & 688453 & 5.05 & 4.7903 & TRN & \\
\hline CHEMBL1492311 & 688453 & 4.45 & 5.2477 & TRN & \\
\hline CHEMBL1392517 & 688453 & 4.45 & 4.8371 & TRN & \\
\hline CHEMBL1481146 & 688453 & 6.1 & 5.2362 & TST & \\
\hline CHEMBL1391132 & 688453 & 4.6 & 4.9293 & TRN & \\
\hline CHEMBL1349942 & 688453 & 4.45 & 5.30200 & 00000000005 & TRN \\
\hline CHEMBL1531320 & 688453 & 4.4 & 4.8197 & TRN & \\
\hline CHEMBL1501635 & 688453 & 4.45 & 4.9532 & TRN & \\
\hline CHEMBL1506999 & 688453 & 6.05 & 5.1724 & TRN & \\
\hline CHEMBL1607437 & 688453 & 4.4 & 5.405 & TRN & \\
\hline CHEMBL1323965 & 688453 & 5.95 & 4.9744 & TRN & \\
\hline CHEMBL1988210 & 688453 & 4.75 & 4.8116 & TRN & \\
\hline CHEMBL1346536 & 688453 & 4.6 & 5.0421 & TRN & \\
\hline CHEMBL1329083 & 688453 & 4.55 & 4.9676 & TRN & \\
\hline CHEMBL1581193 & 688453 & 5.05 & 5.0553 & TRN & \\
\hline CHEMBL1452821 & 688453 & 4.4 & 4.9466 & TST & \\
\hline CHEMBL1516670 & 688453 & 6.7501 & 5.0272 & TRN & \\
\hline CHEMBL1438439 & 688453 & 5.9 & 5.1839 & TRN & \\
\hline CHEMBL1500840 & 688453 & 6.0 & 4.9284 & TRN & \\
\hline CHEMBL1348579 & 688453 & 5.55 & 4.7932 & TRN & \\
\hline CHEMBL1556476 & 688453 & 4.4 & 5.2205 & TRN & \\
\hline CHEMBL3190777 & 688453 & 6.5 & 4.9387 & TRN & \\
\hline CHEMBL1306876 & 688453 & 4.4 & 5.12299 & 9999999999 & TRN \\
\hline CHEMBL1608535 & 688453 & 4.6 & 5.2317 & TRN & \\
\hline CHEMBL 293749 & 688453 & 4.4 & 5.1591 & TRN & \\
\hline CHEMBL1542910 & 688453 & 4.6 & 5.2799 & TRN & \\
\hline CHEMBL1456412 & 688453 & 4.75 & 4.8686 & TST & \\
\hline CHEMBL1391326 & 688453 & 4.65 & 5.1881 & TRN & \\
\hline CHEMBL1560833 & 688453 & 4.4 & 4.7585 & TRN & \\
\hline CHEMBL1493518 & 688453 & 4.4 & 5.2263 & TRN & \\
\hline CHEMBL1420111 & 688453 & 4.45 & 4.8358 & TRN & \\
\hline CHEMBL1307301 & 688453 & 4.55 & 5.193 & TRN & \\
\hline CHEMBL1312255 & 688453 & 5.45 & 5.294 & TRN & \\
\hline CHEMBL1342736 & 688453 & 4.6 & 4.5844 & TRN & \\
\hline CHEMBL1407474 & 688453 & 5.45 & 5.318 & TRN & \\
\hline CHEMBL1991573 & 688453 & 4.55 & 4.5071 & TRN & \\
\hline CHEMBL1585912 & 688453 & 4.4 & 4.8874 & TRN & \\
\hline CHEMBL1370045 & 688453 & 6.6 & 5.226 & TRN & \\
\hline
\end{tabular}




\begin{tabular}{|c|c|c|c|c|c|}
\hline \multicolumn{6}{|c|}{ Supplemental Table S2.txt } \\
\hline CHEMBL1975120 & 688453 & 4.4 & 4.8124 & TRN & \\
\hline CHEMBL1590048 & 688453 & 6.0 & 5.3208 & TRN & \\
\hline CHEMBL1349475 & 688453 & 4.6 & 4.8341 & TRN & \\
\hline CHEMBL1379324 & 688453 & 6.6499 & 5.1116 & TST & \\
\hline CHEMBL1367444 & 688453 & 5.75 & 4.9218 & TRN & \\
\hline CHEMBL1421559 & 688453 & 4.4 & 4.9894 & TST & \\
\hline CHEMBL1424399 & 688453 & 6.8499 & 5.1806 & TST & \\
\hline CHEMBL1173475 & 688453 & 6.0 & 5.1276 & TRN & \\
\hline CHEMBL 3213542 & 688453 & 4.4 & 4.9656 & TRN & \\
\hline CHEMBL1545251 & 688453 & 4.45 & 5.4005 & TST & \\
\hline CHEMBL1510676 & 688453 & 4.45 & 4.6736 & TRN & \\
\hline CHEMBL1582263 & 688453 & 5.5 & 5.1328 & TRN & \\
\hline CHEMBL1994935 & 688453 & 4.4 & 4.8226 & TRN & \\
\hline CHEMBL1439364 & 688453 & 4.55 & 4.90300 & 00000000005 & TRN \\
\hline CHEMBL1543251 & 688453 & 4.6 & 4.6793 & TRN & \\
\hline CHEMBL1440540 & 688453 & 4.4 & 5.0074 & TRN & \\
\hline CHEMBL1546943 & 688453 & 4.4 & 4.8782 & TRN & \\
\hline CHEMBL1511189 & 688453 & 5.2 & 5.1219 & TRN & \\
\hline CHEMBL1565213 & 688453 & 6.2 & 5.1997 & TRN & \\
\hline CHEMBL1523286 & 688453 & 4.4 & 4.7858 & TST & \\
\hline CHEMBL1449868 & 688453 & 4.45 & 4.7106 & TRN & \\
\hline CHEMBL1480651 & 688453 & 5.95 & 4.8108 & TRN & \\
\hline CHEMBL1568805 & 688453 & 4.45 & 5.1424 & TRN & \\
\hline CHEMBL1580759 & 688453 & 5.3 & 4.9371 & TRN & \\
\hline CHEMBL1443988 & 688453 & 6.45 & 5.3638 & TRN & \\
\hline CHEMBL1370375 & 688453 & 6.0 & 4.7761 & TRN & \\
\hline CHEMBL1347567 & 688453 & 5.4 & 5.3464 & TST & \\
\hline CHEMBL1393628 & 688453 & 4.45 & 4.5671 & TRN & \\
\hline CHEMBL1541904 & 688453 & 4.4 & 5.1859 & TRN & \\
\hline CHEMBL1434137 & 688453 & 4.7 & 5.0069 & TST & \\
\hline CHEMBL1400870 & 688453 & 5.35 & 5.1878 & TRN & \\
\hline CHEMBL1347829 & 688453 & 5.2 & 4.5902 & TRN & \\
\hline CHEMBL1500067 & 688453 & 5.3 & 4.8861 & TRN & \\
\hline CHEMBL274070 & 688453 & 4.4 & 4.7456 & TST & \\
\hline CHEMBL1406457 & 688453 & 4.9 & 5.153 & TRN & \\
\hline CHEMBL1381720 & 688453 & 4.65 & 5.0503 & TST & \\
\hline CHEMBL3902037 & 688453 & 4.85 & 4.5885 & TRN & \\
\hline CHEMBL1472148 & 688453 & 4.85 & 4.8805 & TRN & \\
\hline CHEMBL1455960 & 688453 & 4.4 & 4.6571 & TRN & \\
\hline CHEMBL3194662 & 688453 & 6.7001 & 4.8601 & TRN & \\
\hline CHEMBL1454269 & 688453 & 4.7 & 5.2806 & TRN & \\
\hline CHEMBL1322297 & 688453 & 4.55 & 4.5581 & TRN & \\
\hline CHEMBL1596108 & 688453 & 4.4 & 4.7697 & TRN & \\
\hline CHEMBL355496 & 688453 & 4.55 & 4.9565 & TST & \\
\hline CHEMBL1541324 & 688453 & 6.2 & 5.0279 & TST & \\
\hline CHEMBL1409077 & 688453 & 5.8 & 5.0932 & TST & \\
\hline CHEMBL1384365 & 688453 & 4.4 & 4.849 & TRN & \\
\hline CHEMBL1570395 & 688453 & 5.95 & 5.0794 & TRN & \\
\hline
\end{tabular}




\begin{tabular}{|c|c|c|c|c|}
\hline \multicolumn{5}{|c|}{ Supplemental Table S2.txt } \\
\hline CHEMBL1350798 & 688453 & 7.0 & 5.0622 & TST \\
\hline CHEMBL3197737 & 688453 & 4.5 & 4.9447 & TRN \\
\hline CHEMBL1533103 & 688453 & 4.45 & 5.0759 & TRN \\
\hline CHEMBL1430976 & 688453 & 4.9 & 4.8549 & TRN \\
\hline CHEMBL1386676 & 688453 & 4.9 & 4.7849 & TRN \\
\hline CHEMBL1366948 & 688453 & 4.45 & 4.9349 & TRN \\
\hline CHEMBL1369929 & 688453 & 6.1 & 4.6773 & TRN \\
\hline CHEMBL307893 & 688453 & 4.45 & 5.1949 & TRN \\
\hline CHEMBL1349498 & 688453 & 5.4 & 4.9833 & TST \\
\hline CHEMBL1463011 & 688453 & 6.8 & 5.0179 & TRN \\
\hline CHEMBL1577300 & 688453 & 5.15 & 5.2224 & TRN \\
\hline CHEMBL1572280 & 688453 & 4.6 & 4.7737 & TRN \\
\hline CHEMBL1402401 & 688453 & 6.45 & 5.1992 & TST \\
\hline CHEMBL1348933 & 688453 & 5.1 & 5.0642 & TRN \\
\hline CHEMBL1543892 & 688453 & 5.4 & 5.0288 & TRN \\
\hline CHEMBL1423078 & 688453 & 6.7501 & 5.2236 & TST \\
\hline CHEMBL1426907 & 688453 & 5.95 & 5.0278 & TRN \\
\hline CHEMBL1335687 & 688453 & 4.85 & 4.5682 & TRN \\
\hline CHEMBL1467961 & 688453 & 4.5 & 4.8728 & TST \\
\hline CHEMBL1343951 & 688453 & 4.4 & 4.8625 & TRN \\
\hline CHEMBL1506499 & 688453 & 4.45 & 4.5203 & TRN \\
\hline CHEMBL3199110 & 688453 & 6.5501 & 5.0666 & TRN \\
\hline CHEMBL1499320 & 688453 & 4.4 & 5.2535 & TRN \\
\hline CHEMBL1302721 & 688453 & 4.45 & 5.0515 & TRN \\
\hline CHEMBL3348955 & 688453 & 5.9 & 4.8437 & TST \\
\hline CHEMBL1308571 & 688453 & 6.05 & 5.2185 & TST \\
\hline CHEMBL515252 & 688453 & 4.9 & 4.8672 & TRN \\
\hline CHEMBL1544016 & 688453 & 5.2 & 5.2199 & TRN \\
\hline CHEMBL1346056 & 688453 & 4.7 & 5.1014 & TST \\
\hline CHEMBL3198782 & 688453 & 4.95 & 4.9622 & TRN \\
\hline CHEMBL1324442 & 688453 & 4.4 & 5.0885 & TRN \\
\hline CHEMBL1364430 & 688453 & 6.25 & 5.2308 & TRN \\
\hline CHEMBL1578235 & 688453 & 4.55 & 4.7063 & TRN \\
\hline CHEMBL1370482 & 688453 & 4.5 & 5.0445 & TRN \\
\hline CHEMBL1330752 & 688453 & 4.5 & 5.2966 & TRN \\
\hline CHEMBL1221925 & 688453 & 4.5 & 5.3436 & TRN \\
\hline CHEMBL1609687 & 688453 & 4.4 & 5.1266 & TRN \\
\hline CHEMBL1325946 & 688453 & 4.9 & 4.9354 & TRN \\
\hline CHEMBL1602385 & 688453 & 4.8 & 4.9671 & TRN \\
\hline CHEMBL1537165 & 688453 & 4.45 & 4.8793 & TRN \\
\hline CHEMBL1427879 & 688453 & 4.45 & 5.2227 & TRN \\
\hline CHEMBL1462855 & 688453 & 4.4 & 5.1501 & TRN \\
\hline CHEMBL1091723 & 688453 & 4.65 & 4.9175 & TRN \\
\hline CHEMBL1607905 & 688453 & 5.05 & 5.0708 & TST \\
\hline CHEMBL66 & 688453 & 6.0 & 5.1072 & TRN \\
\hline CHEMBL1527924 & 688453 & 5.4 & 5.1709 & TRN \\
\hline CHEMBL1586198 & 688453 & 6.25 & 5.0201 & TRN \\
\hline CHEMBL1443059 & 688453 & 4.75 & 4.5703 & TRN \\
\hline
\end{tabular}




\begin{tabular}{|c|c|c|c|c|}
\hline \multicolumn{5}{|c|}{ Supplemental Table S2.txt } \\
\hline CHEMBL1518342 & 688453 & 5.2 & 5.2971 & TRN \\
\hline CHEMBL1585997 & 688453 & 4.5 & 4.7206 & TRN \\
\hline CHEMBL1491928 & 688453 & 4.6 & 4.6722 & TRN \\
\hline CHEMBL1353015 & 688453 & 7.0 & 5.3772 & TRN \\
\hline CHEMBL1309763 & 688453 & 5.25 & 4.9438 & TRN \\
\hline CHEMBL1440119 & 688453 & 6.0 & 5.0806 & TRN \\
\hline CHEMBL607309 & 688453 & 4.4 & 5.0844 & TRN \\
\hline CHEMBL1430270 & 688453 & 4.6 & 4.9919 & TRN \\
\hline CHEMBL1527994 & 688453 & 5.05 & 5.055 & TRN \\
\hline CHEMBL1533772 & 688453 & 4.6 & 4.6615 & TRN \\
\hline CHEMBL3196801 & 688453 & 4.9 & 5.0683 & TRN \\
\hline CHEMBL1425060 & 688453 & 4.7 & 5.1452 & TRN \\
\hline CHEMBL1419952 & 688453 & 4.6 & 5.2446 & TRN \\
\hline CHEMBL1445396 & 688453 & 7.0 & 4.7528 & TRN \\
\hline CHEMBL1585318 & 688453 & 4.85 & 4.7337 & TRN \\
\hline CHEMBL1303139 & 688453 & 4.5 & 5.2128 & TRN \\
\hline CHEMBL146710 & 688453 & 4.4 & 4.9649 & TRN \\
\hline CHEMBL1573985 & 688453 & 7.6003 & 5.4474 & TRN \\
\hline CHEMBL1345825 & 688453 & 5.05 & 4.5642 & TRN \\
\hline CHEMBL1469723 & 688453 & 4.4 & 5.2341 & TRN \\
\hline CHEMBL1458486 & 688453 & 5.1 & 4.8352 & TRN \\
\hline CHEMBL1505341 & 688453 & 4.6 & 4.7704 & TRN \\
\hline CHEMBL3193823 & 688453 & 4.45 & 4.8256 & TRN \\
\hline CHEMBL1347789 & 688453 & 4.5 & 4.7719 & TRN \\
\hline CHEMBL1490580 & 688453 & 5.5 & 5.0235 & TRN \\
\hline CHEMBL1448410 & 688453 & 4.4 & 4.5569 & TRN \\
\hline CHEMBL1578885 & 688453 & 4.4 & 4.9756 & TRN \\
\hline CHEMBL3194654 & 688453 & 5.95 & 4.9069 & TRN \\
\hline CHEMBL1372912 & 688453 & 4.4 & 5.0616 & TRN \\
\hline CHEMBL1520677 & 688453 & 4.45 & 4.9404 & TRN \\
\hline CHEMBL1531893 & 688453 & 6.05 & 5.1762 & TRN \\
\hline CHEMBL3191714 & 688453 & 4.85 & 5.1783 & TRN \\
\hline CHEMBL1423708 & 688453 & 4.6 & 5.3185 & TRN \\
\hline CHEMBL1431569 & 688453 & 6.15 & 4.8596 & TST \\
\hline CHEMBL 273291 & 688453 & 5.35 & 5.1866 & TST \\
\hline CHEMBL1519264 & 688453 & 5.85 & 5.1697 & TST \\
\hline CHEMBL3193853 & 688453 & 4.45 & 5.0342 & TRN \\
\hline CHEMBL1431314 & 688453 & 6.7001 & 4.9641 & TRN \\
\hline CHEMBL1366826 & 688453 & 5.0 & 5.0165 & TRN \\
\hline CHEMBL1442824 & 688453 & 5.45 & 5.1818 & TRN \\
\hline CHEMBL1541613 & 688453 & 4.4 & 5.1374 & TRN \\
\hline CHEMBL1420621 & 688453 & 5.15 & 4.9712 & TRN \\
\hline CHEMBL247484 & 688453 & 6.15 & 5.1244 & TRN \\
\hline CHEMBL1381723 & 688453 & 4.45 & 4.9735 & TRN \\
\hline CHEMBL498373 & 688453 & 4.85 & 5.0304 & TRN \\
\hline CHEMBL1458524 & 688453 & 5.35 & 4.864 & TRN \\
\hline CHEMBL1576814 & 688453 & 4.95 & 4.6857 & TRN \\
\hline CHEMBL1520160 & 688453 & 5.35 & 5.3184 & TRN \\
\hline
\end{tabular}




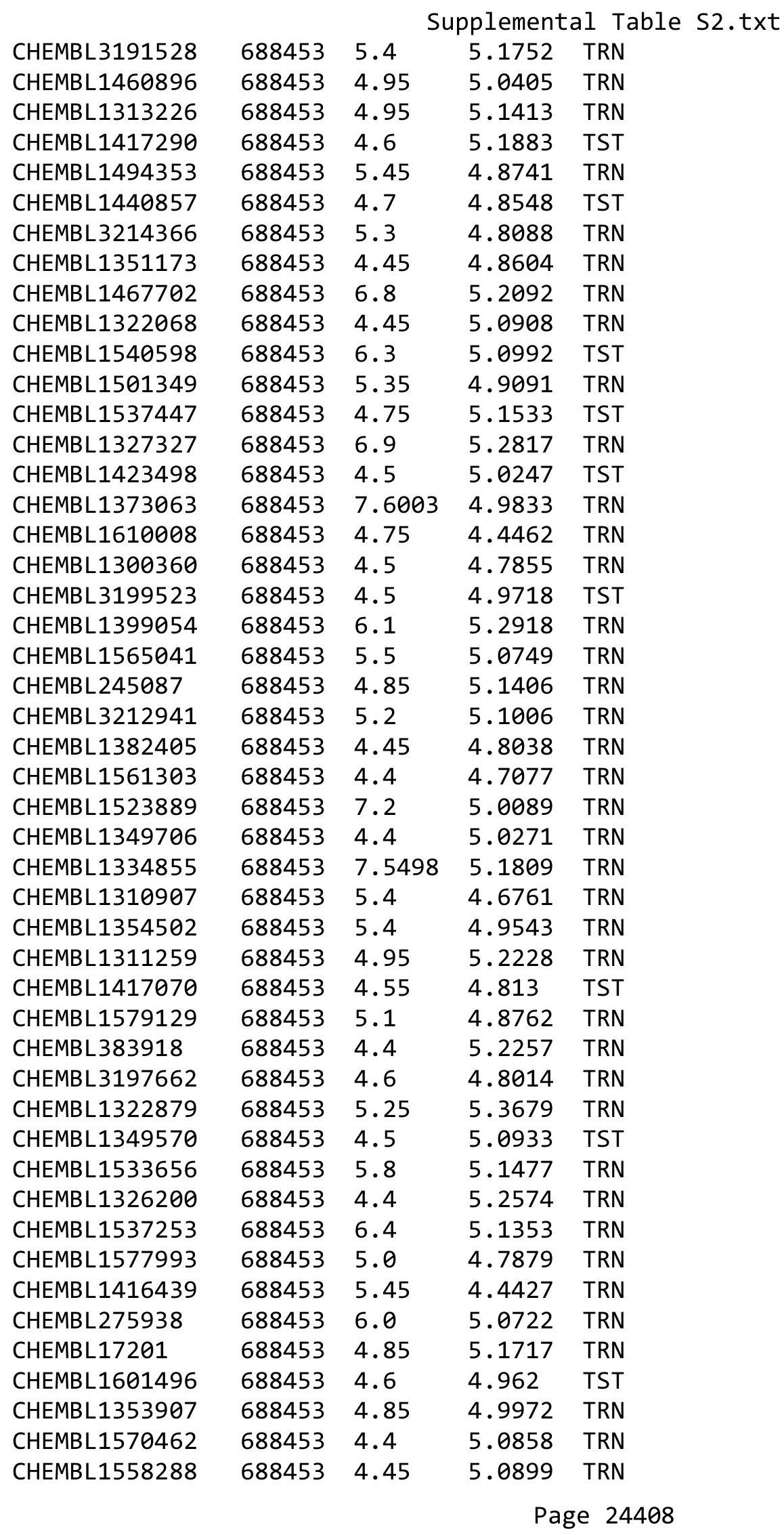




\begin{tabular}{|c|c|c|c|c|c|}
\hline \multicolumn{6}{|c|}{ Supplemental Table S2.txt } \\
\hline CHEMBL1300052 & 688453 & 4.55 & 5.1243 & TRN & \\
\hline CHEMBL1480797 & 688453 & 5.0 & 5.2198 & TRN & \\
\hline CHEMBL1378546 & 688453 & 5.8 & 5.1574 & TRN & \\
\hline CHEMBL 263972 & 688453 & 4.4 & 5.083 & TRN & \\
\hline CHEMBL1375358 & 688453 & 5.3 & 5.3366 & TST & \\
\hline CHEMBL1326108 & 688453 & 6.8 & 5.0098 & TRN & \\
\hline CHEMBL1546947 & 688453 & 4.45 & 4.8724 & TRN & \\
\hline CHEMBL1485208 & 688453 & 4.55 & 4.8355 & TRN & \\
\hline CHEMBL1457669 & 688453 & 4.45 & 4.88399 & 99999999995 & TRN \\
\hline CHEMBL1521042 & 688453 & 5.2 & 5.3261 & TRN & \\
\hline CHEMBL518430 & 688453 & 4.5 & 5.0693 & TRN & \\
\hline CHEMBL1406195 & 688453 & 5.15 & 5.0457 & TRN & \\
\hline CHEMBL1517757 & 688453 & 7.15 & 5.2809 & TRN & \\
\hline CHEMBL 1376770 & 688453 & 4.6 & 5.1681 & TRN & \\
\hline CHEMBL1415967 & 688453 & 7.2503 & 5.4719 & TRN & \\
\hline CHEMBL1463261 & 688453 & 5.15 & 4.6824 & TRN & \\
\hline CHEMBL1588566 & 688453 & 4.75 & 5.1124 & TRN & \\
\hline CHEMBL1370873 & 688453 & 4.5 & 4.8163 & TRN & \\
\hline CHEMBL1476362 & 688453 & 4.9 & 4.9686 & TST & \\
\hline CHEMBL1494800 & 688453 & 4.4 & 5.1195 & TRN & \\
\hline CHEMBL1381247 & 688453 & 4.4 & 5.0977 & TRN & \\
\hline CHEMBL1352173 & 688453 & 4.45 & 4.8306 & TRN & \\
\hline CHEMBL1457747 & 688453 & 4.5 & 4.7401 & TRN & \\
\hline CHEMBL1310969 & 688453 & 4.8 & 4.9602 & TRN & \\
\hline CHEMBL1563370 & 688453 & 4.4 & 5.056 & TST & \\
\hline CHEMBL1504502 & 688453 & 5.45 & 4.9666 & TRN & \\
\hline CHEMBL1486495 & 688453 & 4.4 & 4.8856 & TRN & \\
\hline CHEMBL555689 & 688453 & 5.45 & 4.842 & TRN & \\
\hline CHEMBL1420114 & 688453 & 4.95 & 4.8775 & TRN & \\
\hline CHEMBL1351158 & 688453 & 4.5 & 5.0018 & TRN & \\
\hline CHEMBL1489707 & 688453 & 4.5 & 4.8433 & TRN & \\
\hline CHEMBL3192197 & 688453 & 4.4 & 4.7278 & TRN & \\
\hline CHEMBL3198496 & 688453 & 5.2 & 4.8422 & TRN & \\
\hline CHEMBL1527340 & 688453 & 4.4 & 5.0724 & TRN & \\
\hline CHEMBL1461684 & 688453 & 6.7501 & 5.1383 & TRN & \\
\hline CHEMBL1325440 & 688453 & 5.15 & 4.8637 & TRN & \\
\hline CHEMBL1588339 & 688453 & 4.5 & 5.0495 & TRN & \\
\hline CHEMBL1442633 & 688453 & 5.55 & 4.8137 & TRN & \\
\hline CHEMBL1325920 & 688453 & 5.85 & 4.6326 & TRN & \\
\hline CHEMBL3191402 & 688453 & 4.6 & 5.0657 & TST & \\
\hline CHEMBL1416703 & 688453 & 6.1 & 5.1577 & TRN & \\
\hline CHEMBL1979747 & 688453 & 4.6 & 4.8564 & TRN & \\
\hline CHEMBL1312717 & 688453 & 4.4 & 4.9219 & TRN & \\
\hline CHEMBL1324748 & 688453 & 5.9 & 4.9723 & TRN & \\
\hline CHEMBL1408802 & 688453 & 4.4 & 4.7399 & TRN & \\
\hline CHEMBL1581596 & 688453 & 4.5 & 4.7391 & TRN & \\
\hline CHEMBL1578463 & 688453 & 4.4 & 4.8759 & TST & \\
\hline CHEMBL1422457 & 688453 & 4.95 & 5.1504 & TRN & \\
\hline
\end{tabular}




\begin{tabular}{|c|c|c|c|c|c|}
\hline \multicolumn{6}{|c|}{ Supplemental Table S2.txt } \\
\hline CHEMBL 2000670 & 688453 & 4.4 & 5.101 & TRN & \\
\hline CHEMBL1417924 & 688453 & 4.6 & 4.6623 & TRN & \\
\hline CHEMBL1488001 & 688453 & 5.2 & 5.1168 & TRN & \\
\hline CHEMBL1972621 & 688453 & 4.45 & 4.819 & TRN & \\
\hline CHEMBL1306955 & 688453 & 4.55 & 5.1609 & TRN & \\
\hline CHEMBL1530127 & 688453 & 4.45 & 5.3261 & TRN & \\
\hline CHEMBL1451216 & 688453 & 5.45 & 5.1654 & TST & \\
\hline CHEMBL1361276 & 688453 & 4.4 & 5.086 & TRN & \\
\hline CHEMBL1343403 & 688453 & 5.85 & 5.0287 & TRN & \\
\hline CHEMBL1310358 & 688453 & 4.4 & 4.7579 & TRN & \\
\hline CHEMBL1539909 & 688453 & 4.4 & 5.0694 & TRN & \\
\hline CHEMBL1311844 & 688453 & 5.05 & 5.2502 & TRN & \\
\hline CHEMBL1597345 & 688453 & 4.65 & 5.091 & TRN & \\
\hline CHEMBL1299355 & 688453 & 4.4 & 4.9598 & TRN & \\
\hline CHEMBL1588106 & 688453 & 4.4 & 4.6543 & TRN & \\
\hline CHEMBL1303718 & 688453 & 6.8 & 5.1774 & TRN & \\
\hline CHEMBL1339598 & 688453 & 4.5 & 4.9004 & TRN & \\
\hline CHEMBL1322489 & 688453 & 6.1 & 5.0606 & TRN & \\
\hline CHEMBL1414494 & 688453 & 4.5 & 5.33700 & 0000000001 & TST \\
\hline CHEMBL1542864 & 688453 & 5.45 & 5.2155 & TRN & \\
\hline CHEMBL3193501 & 688453 & 4.65 & 4.8824 & TRN & \\
\hline CHEMBL1504791 & 688453 & 4.5 & 5.1775 & TRN & \\
\hline CHEMBL1320536 & 688453 & 5.45 & 5.1965 & TRN & \\
\hline CHEMBL1458498 & 688453 & 4.5 & 5.2353 & TRN & \\
\hline CHEMBL1561017 & 688453 & 5.05 & 5.2106 & TRN & \\
\hline CHEMBL1547055 & 688453 & 4.55 & 4.6258 & TRN & \\
\hline CHEMBL1373997 & 688453 & 4.45 & 4.8103 & TRN & \\
\hline CHEMBL1463600 & 688453 & 4.55 & 4.6087 & TRN & \\
\hline CHEMBL1498940 & 688453 & 5.65 & 5.0806 & TRN & \\
\hline CHEMBL1505169 & 688453 & 4.4 & 5.0561 & TRN & \\
\hline CHEMBL3191244 & 688453 & 5.25 & 5.0802 & TRN & \\
\hline CHEMBL1504577 & 688453 & 4.4 & 4.6727 & TRN & \\
\hline CHEMBL1522044 & 688453 & 4.55 & 5.2381 & TRN & \\
\hline CHEMBL1310067 & 688453 & 4.45 & 4.9523 & TRN & \\
\hline CHEMBL1333874 & 688453 & 4.4 & 4.9767 & TRN & \\
\hline CHEMBL1532607 & 688453 & 4.4 & 5.1631 & TRN & \\
\hline CHEMBL1478015 & 688453 & 4.45 & 5.1374 & TRN & \\
\hline CHEMBL1463829 & 688453 & 4.45 & 4.8751 & TRN & \\
\hline CHEMBL1458047 & 688453 & 4.6 & 5.0319 & TRN & \\
\hline CHEMBL1586269 & 688453 & 5.2 & 4.7231 & TRN & \\
\hline CHEMBL1464522 & 688453 & 4.4 & 4.7024 & TRN & \\
\hline CHEMBL1462803 & 688453 & 4.4 & 4.5834 & TRN & \\
\hline CHEMBL1363056 & 688453 & 5.85 & 5.0801 & TRN & \\
\hline CHEMBL 2373648 & 688453 & 5.45 & 5.2451 & TST & \\
\hline CHEMBL1406485 & 688453 & 5.45 & 5.0874 & TST & \\
\hline CHEMBL1575649 & 688453 & 4.85 & 4.6606 & TRN & \\
\hline CHEMBL1498702 & 688453 & 4.45 & 4.9968 & TRN & \\
\hline CHEMBL1573353 & 688453 & 5.05 & 5.2575 & TRN & \\
\hline
\end{tabular}




\begin{tabular}{|c|c|c|c|c|c|}
\hline \multicolumn{6}{|c|}{ Supplemental Table S2.txt } \\
\hline CHEMBL1601394 & 688453 & 4.45 & 4.9878 & TRN & \\
\hline CHEMBL1309915 & 688453 & 5.45 & 5.1979 & TST & \\
\hline CHEMBL1467939 & 688453 & 4.4 & 5.1098 & TRN & \\
\hline CHEMBL1576254 & 688453 & 4.4 & 5.397 & TRN & \\
\hline CHEMBL1561724 & 688453 & 4.4 & 5.2965 & TRN & \\
\hline CHEMBL1391426 & 688453 & 4.9 & 4.8323 & TRN & \\
\hline CHEMBL1347577 & 688453 & 4.4 & 5.0536 & TST & \\
\hline CHEMBL1448744 & 688453 & 4.4 & 4.8255 & TRN & \\
\hline CHEMBL1422657 & 688453 & 4.45 & 4.9554 & TRN & \\
\hline CHEMBL1347387 & 688453 & 4.4 & 4.9322 & TRN & \\
\hline CHEMBL1559883 & 688453 & 4.55 & 4.6185 & TRN & \\
\hline CHEMBL1438401 & 688453 & 4.4 & 4.7048 & TRN & \\
\hline CHEMBL1332522 & 688453 & 4.85 & 5.2326 & TST & \\
\hline CHEMBL1486055 & 688453 & 4.4 & 4.8901 & TRN & \\
\hline CHEMBL1556956 & 688453 & 4.4 & 4.4362 & TRN & \\
\hline CHEMBL1401032 & 688453 & 4.5 & 5.0429 & TRN & \\
\hline CHEMBL1308840 & 688453 & 4.4 & 5.1044 & TRN & \\
\hline CHEMBL 30707 & 688453 & 6.0 & 5.0733 & TRN & \\
\hline CHEMBL1613644 & 688453 & 4.4 & 4.9135 & TRN & \\
\hline CHEMBL1548374 & 688453 & 4.85 & 4.4698 & TRN & \\
\hline CHEMBL1544146 & 688453 & 4.4 & 5.2529 & TRN & \\
\hline CHEMBL8197 & 688453 & 4.45 & 5.2473 & TRN & \\
\hline CHEMBL1468239 & 688453 & 5.15 & 5.0297 & TRN & \\
\hline CHEMBL1346664 & 688453 & 4.55 & 4.705 & TRN & \\
\hline CHEMBL1578345 & 688453 & 4.5 & 5.01699 & 99999999995 & TRN \\
\hline CHEMBL3198435 & 688453 & 5.35 & 4.982 & TRN & \\
\hline CHEMBL1585143 & 688453 & 4.4 & 5.0725 & TRN & \\
\hline CHEMBL 8747 & 688453 & 4.55 & 5.1699 & TST & \\
\hline CHEMBL 1545540 & 688453 & 5.15 & 5.3324 & TRN & \\
\hline CHEMBL1366801 & 688453 & 4.7 & 5.2393 & TRN & \\
\hline CHEMBL1312532 & 688453 & 6.7001 & 5.1238 & TRN & \\
\hline CHEMBL1513392 & 688453 & 5.55 & 5.4908 & TRN & \\
\hline CHEMBL1448221 & 688453 & 6.8 & 5.183 & TRN & \\
\hline CHEMBL1387426 & 688453 & 5.1 & 5.0435 & TRN & \\
\hline CHEMBL3195011 & 688453 & 4.4 & 4.851 & TRN & \\
\hline CHEMBL1520133 & 688453 & 4.7 & 4.73 & TRN & \\
\hline CHEMBL53898 & 688453 & 6.0 & 5.1332 & TRN & \\
\hline CHEMBL1509525 & 688453 & 5.15 & 5.1254 & TRN & \\
\hline CHEMBL1606809 & 688453 & 4.45 & 4.5306 & TRN & \\
\hline CHEMBL1487460 & 688453 & 4.4 & 5.0786 & TRN & \\
\hline CHEMBL1455560 & 688453 & 5.15 & 5.2584 & TRN & \\
\hline CHEMBL1582074 & 688453 & 4.4 & 5.0754 & TRN & \\
\hline CHEMBL1321329 & 688453 & 4.6 & 5.2799 & TRN & \\
\hline CHEMBL1442405 & 688453 & 4.5 & 4.9362 & TRN & \\
\hline CHEMBL487203 & 688453 & 5.5 & 5.1989 & TRN & \\
\hline CHEMBL3193878 & 688453 & 4.45 & 4.997 & TRN & \\
\hline CHEMBL305978 & 688453 & 4.4 & 4.8614 & TRN & \\
\hline CHEMBL1346943 & 688453 & 4.4 & 5.1195 & TRN & \\
\hline
\end{tabular}




\begin{tabular}{|c|c|c|c|c|c|}
\hline \multicolumn{6}{|c|}{ Supplemental Table S2.txt } \\
\hline CHEMBL1391430 & 688453 & 6.95 & 5.1677 & TRN & \\
\hline CHEMBL1300195 & 688453 & 4.45 & 5.0259 & TRN & \\
\hline CHEMBL1496950 & 688453 & 4.4 & 5.0428 & TRN & \\
\hline CHEMBL1526107 & 688453 & 7.0501 & 5.246 & TRN & \\
\hline CHEMBL1576702 & 688453 & 4.55 & 5.1402 & TRN & \\
\hline CHEMBL1579356 & 688453 & 5.05 & 4.9816 & TRN & \\
\hline CHEMBL3211633 & 688453 & 4.4 & 4.8543 & TST & \\
\hline CHEMBL1364903 & 688453 & 5.0 & 4.7163 & TRN & \\
\hline CHEMBL1345213 & 688453 & 4.75 & 5.0805 & TRN & \\
\hline CHEMBL1399008 & 688453 & 5.4 & 4.8831 & TRN & \\
\hline CHEMBL1531711 & 688453 & 5.25 & 5.1656 & TRN & \\
\hline CHEMBL1350596 & 688453 & 5.0 & 5.1237 & TRN & \\
\hline CHEMBL1429485 & 688453 & 6.95 & 4.9384 & TRN & \\
\hline CHEMBL1374916 & 688453 & 4.4 & 5.2898 & TRN & \\
\hline CHEMBL1412123 & 688453 & 4.4 & 5.0981 & TRN & \\
\hline CHEMBL1388018 & 688453 & 4.4 & 5.2868 & TRN & \\
\hline CHEMBL1399979 & 688453 & 4.85 & 4.856 & TRN & \\
\hline CHEMBL1332241 & 688453 & 4.45 & 4.6552 & TRN & \\
\hline CHEMBL1439356 & 688453 & 4.6 & 5.0407 & TRN & \\
\hline CHEMBL1557372 & 688453 & 5.75 & 5.13299 & 9999999999 & TRN \\
\hline CHEMBL1420642 & 688453 & 4.6 & 4.7588 & TRN & \\
\hline CHEMBL1454334 & 688453 & 4.45 & 5.2414 & TRN & \\
\hline CHEMBL1518838 & 688453 & 4.95 & 4.9994 & TRN & \\
\hline CHEMBL1346033 & 688453 & 5.3 & 5.0081 & TRN & \\
\hline CHEMBL1520852 & 688453 & 5.95 & 5.17 & TRN & \\
\hline CHEMBL1573595 & 688453 & 6.95 & 5.4344 & TRN & \\
\hline CHEMBL1489885 & 688453 & 4.4 & 5.1794 & TRN & \\
\hline CHEMBL106525 & 688453 & 4.9 & 4.9478 & TRN & \\
\hline CHEMBL1438434 & 688453 & 4.7 & 4.7814 & TRN & \\
\hline CHEMBL1540526 & 688453 & 4.4 & 4.878 & TRN & \\
\hline CHEMBL1410171 & 688453 & 4.45 & 4.8752 & TRN & \\
\hline CHEMBL1570251 & 688453 & 4.65 & 5.1196 & TRN & \\
\hline CHEMBL1603577 & 688453 & 5.15 & 5.187 & TRN & \\
\hline CHEMBL3856144 & 688453 & 5.4 & 4.9335 & TST & \\
\hline CHEMBL1358491 & 688453 & 5.5 & 4.8545 & TRN & \\
\hline CHEMBL446240 & 688453 & 4.7 & 5.15799 & 99999999995 & TRN \\
\hline CHEMBL1420711 & 688453 & 4.4 & 4.7854 & TRN & \\
\hline CHEMBL1304270 & 688453 & 5.05 & 5.2392 & TRN & \\
\hline CHEMBL1460037 & 688453 & 4.6 & 4.4273 & TRN & \\
\hline CHEMBL1308068 & 688453 & 4.95 & 4.8716 & TRN & \\
\hline CHEMBL59030 & 688453 & 4.45 & 5.1468 & TST & \\
\hline CHEMBL1424412 & 688453 & 5.1 & 5.1052 & TRN & \\
\hline CHEMBL1613481 & 688453 & 6.5501 & 5.087 & TRN & \\
\hline CHEMBL1347346 & 688453 & 4.45 & 4.8579 & TRN & \\
\hline CHEMBL3191740 & 688453 & 5.2 & 4.7521 & TST & \\
\hline CHEMBL1544000 & 688453 & 5.45 & 5.2325 & TRN & \\
\hline CHEMBL171637 & 688453 & 4.8 & 4.9591 & TST & \\
\hline CHEMBL1368891 & 688453 & 5.95 & 4.9904 & TRN & \\
\hline
\end{tabular}




\begin{tabular}{|c|c|c|c|c|}
\hline \multicolumn{5}{|c|}{ Supplemental Table S2.txt } \\
\hline CHEMBL1344963 & 688453 & 4.4 & 5.0085 & TRN \\
\hline CHEMBL1340399 & 688453 & 4.6 & 4.8847 & TRN \\
\hline CHEMBL1595761 & 688453 & 4.6 & 4.7387 & TRN \\
\hline CHEMBL1486174 & 688453 & 4.55 & 4.8567 & TRN \\
\hline CHEMBL1588389 & 688453 & 4.75 & 4.7682 & TRN \\
\hline CHEMBL1573731 & 688453 & 4.35 & 4.5715 & TRN \\
\hline CHEMBL1492305 & 688453 & 4.45 & 4.4689 & TRN \\
\hline CHEMBL1499258 & 688453 & 4.5 & 4.6077 & TRN \\
\hline CHEMBL1596574 & 688453 & 4.5 & 5.1735 & TRN \\
\hline CHEMBL1362935 & 688453 & 5.7 & 5.016 & TRN \\
\hline CHEMBL1392030 & 688453 & 4.4 & 4.6813 & TRN \\
\hline CHEMBL1304617 & 688453 & 4.4 & 5.2735 & TRN \\
\hline CHEMBL1589253 & 688453 & 4.55 & 5.0035 & TRN \\
\hline CHEMBL1418885 & 688453 & 4.5 & 4.9128 & TRN \\
\hline CHEMBL1365799 & 688453 & 6.05 & 5.129 & TRN \\
\hline CHEMBL1546134 & 688453 & 5.35 & 4.727 & TRN \\
\hline CHEMBL1612333 & 688453 & 4.45 & 5.1247 & TRN \\
\hline CHEMBL1342894 & 688453 & 4.75 & 4.7923 & TRN \\
\hline CHEMBL1564810 & 688453 & 4.6 & 4.6537 & TRN \\
\hline CHEMBL1410964 & 688453 & 4.4 & 4.9073 & TRN \\
\hline CHEMBL1448630 & 688453 & 6.05 & 5.2375 & TRN \\
\hline CHEMBL1583534 & 688453 & 4.65 & 4.817 & TST \\
\hline CHEMBL3193466 & 688453 & 6.05 & 5.1644 & TRN \\
\hline CHEMBL1537553 & 688453 & 4.4 & 5.2196 & TRN \\
\hline CHEMBL1597361 & 688453 & 4.45 & 5.2461 & TST \\
\hline CHEMBL1508080 & 688453 & 4.45 & 4.8867 & TRN \\
\hline CHEMBL1482554 & 688453 & 4.6 & 4.643 & TRN \\
\hline CHEMBL1460667 & 688453 & 6.2 & 5.0644 & TRN \\
\hline CHEMBL1300008 & 688453 & 4.9 & 4.698 & TRN \\
\hline CHEMBL530280 & 688453 & 4.85 & 4.9046 & TRN \\
\hline CHEMBL1332402 & 688453 & 4.85 & 4.5702 & TRN \\
\hline CHEMBL1582505 & 688453 & 4.55 & 5.3367 & TRN \\
\hline CHEMBL1485984 & 688453 & 5.55 & 5.012 & TST \\
\hline CHEMBL1391193 & 688453 & 4.55 & 4.5217 & TRN \\
\hline CHEMBL3197156 & 688453 & 4.45 & 4.8268 & TRN \\
\hline CHEMBL 3208500 & 688453 & 5.15 & 5.0712 & TRN \\
\hline CHEMBL 1430266 & 688453 & 4.85 & 4.8791 & TRN \\
\hline CHEMBL1462462 & 688453 & 6.6499 & 5.053 & TST \\
\hline CHEMBL3196704 & 688453 & 5.2 & 4.6125 & TRN \\
\hline CHEMBL1326892 & 688453 & 5.45 & 4.9176 & TRN \\
\hline CHEMBL1411396 & 688453 & 4.95 & 4.8558 & TRN \\
\hline CHEMBL1451353 & 688453 & 5.2 & 5.3407 & TRN \\
\hline CHEMBL1440137 & 688453 & 5.0 & 5.0279 & TRN \\
\hline CHEMBL1334993 & 688453 & 6.8499 & 5.1985 & TRN \\
\hline CHEMBL1505201 & 688453 & 6.8499 & 5.1816 & TST \\
\hline CHEMBL1556610 & 688453 & 5.15 & 5.1821 & TRN \\
\hline CHEMBL1324111 & 688453 & 4.65 & 5.0813 & TST \\
\hline CHEMBL1499361 & 688453 & 4.35 & 5.1088 & TRN \\
\hline
\end{tabular}




\begin{tabular}{|c|c|c|c|c|c|}
\hline & & \multicolumn{4}{|c|}{ Supplemental Table S2.txt } \\
\hline CHEMBL1458236 & 688453 & 9.0458 & 4.996 & TRN & \\
\hline CHEMBL1390889 & 688453 & 6.1 & 5.0824 & TRN & \\
\hline CHEMBL3212703 & 688453 & 4.5 & 4.7837 & TRN & \\
\hline CHEMBL1364062 & 688453 & 4.9 & 4.8638 & TST & \\
\hline CHEMBL20936 & 688453 & 4.85 & 5.3623 & TST & \\
\hline CHEMBL1469625 & 688453 & 6.95 & 5.3279 & TRN & \\
\hline CHEMBL1584366 & 688453 & 4.45 & 4.8496 & TRN & \\
\hline CHEMBL1310309 & 688453 & 4.85 & 5.0322 & TRN & \\
\hline CHEMBL1606222 & 688453 & 4.6 & 5.2639 & TRN & \\
\hline CHEMBL1323674 & 688453 & 4.4 & 5.078 & TRN & \\
\hline CHEMBL1415959 & 688453 & 5.1 & 5.079 & TRN & \\
\hline CHEMBL3199114 & 688453 & 4.4 & 4.8341 & TRN & \\
\hline CHEMBL1380969 & 688453 & 4.4 & 5.1917 & TRN & \\
\hline CHEMBL163316 & 688453 & 4.75 & 5.0587 & TRN & \\
\hline CHEMBL1424340 & 688453 & 4.7 & 4.9987 & TRN & \\
\hline CHEMBL1310655 & 688453 & 4.45 & 5.0984 & TRN & \\
\hline CHEMBL1604547 & 688453 & 4.4 & 4.8743 & TRN & \\
\hline CHEMBL1301238 & 688453 & 4.85 & 4.8428 & TRN & \\
\hline CHEMBL1403448 & 688453 & 4.4 & 4.8364 & TRN & \\
\hline CHEMBL1550129 & 688453 & 4.7 & 5.084 & TRN & \\
\hline CHEMBL1500713 & 688453 & 6.95 & 5.0895 & TRN & \\
\hline CHEMBL3193592 & 688453 & 4.45 & 4.6855 & TRN & \\
\hline CHEMBL1433158 & 688453 & 4.7 & 4.8581 & TST & \\
\hline CHEMBL1551284 & 688453 & 4.45 & 4.7394 & TRN & \\
\hline CHEMBL1478964 & 688453 & 5.0 & 5.2219 & TRN & \\
\hline CHEMBL1413583 & 688453 & 4.4 & 4.945 & TRN & \\
\hline CHEMBL1987136 & 688453 & 4.5 & 4.5806 & TRN & \\
\hline CHEMBL1351069 & 688453 & 4.5 & 5.0555 & TRN & \\
\hline CHEMBL1316979 & 688453 & 4.65 & 4.9754 & TRN & \\
\hline CHEMBL1375393 & 688453 & 5.3 & 5.1095 & TRN & \\
\hline CHEMBL1448262 & 688453 & 5.05 & 4.89 & TRN & \\
\hline CHEMBL1381264 & 688453 & 5.4 & 4.415 & TRN & \\
\hline CHEMBL3192160 & 688453 & 4.75 & 4.68199 & 99999999995 & TRN \\
\hline CHEMBL1517677 & 688453 & 4.55 & 5.232 & TRN & \\
\hline CHEMBL1501132 & 688453 & 5.05 & 4.8433 & TRN & \\
\hline CHEMBL1584923 & 688453 & 4.45 & 4.9744 & TRN & \\
\hline CHEMBL1421324 & 688453 & 6.8 & 5.1358 & TST & \\
\hline CHEMBL3194143 & 688453 & 4.65 & 4.7202 & TRN & \\
\hline CHEMBL1507021 & 688453 & 4.6 & 4.5445 & TRN & \\
\hline CHEMBL1401747 & 688453 & 5.45 & 4.6072 & TRN & \\
\hline CHEMBL1352607 & 688453 & 4.5 & 4.743 & TRN & \\
\hline CHEMBL1331027 & 688453 & 4.9 & 5.0465 & TRN & \\
\hline CHEMBL1454394 & 688453 & 5.4 & 5.0527 & TST & \\
\hline CHEMBL1458130 & 688453 & 4.45 & 4.8986 & TRN & \\
\hline CHEMBL1533944 & 688453 & 5.4 & 5.0753 & TRN & \\
\hline CHEMBL1323290 & 688453 & 4.4 & 4.7089 & TST & \\
\hline CHEMBL1316265 & 688453 & 5.15 & 5.1594 & TRN & \\
\hline CHEMBL366861 & 688453 & 5.4 & 4.8013 & TST & \\
\hline
\end{tabular}




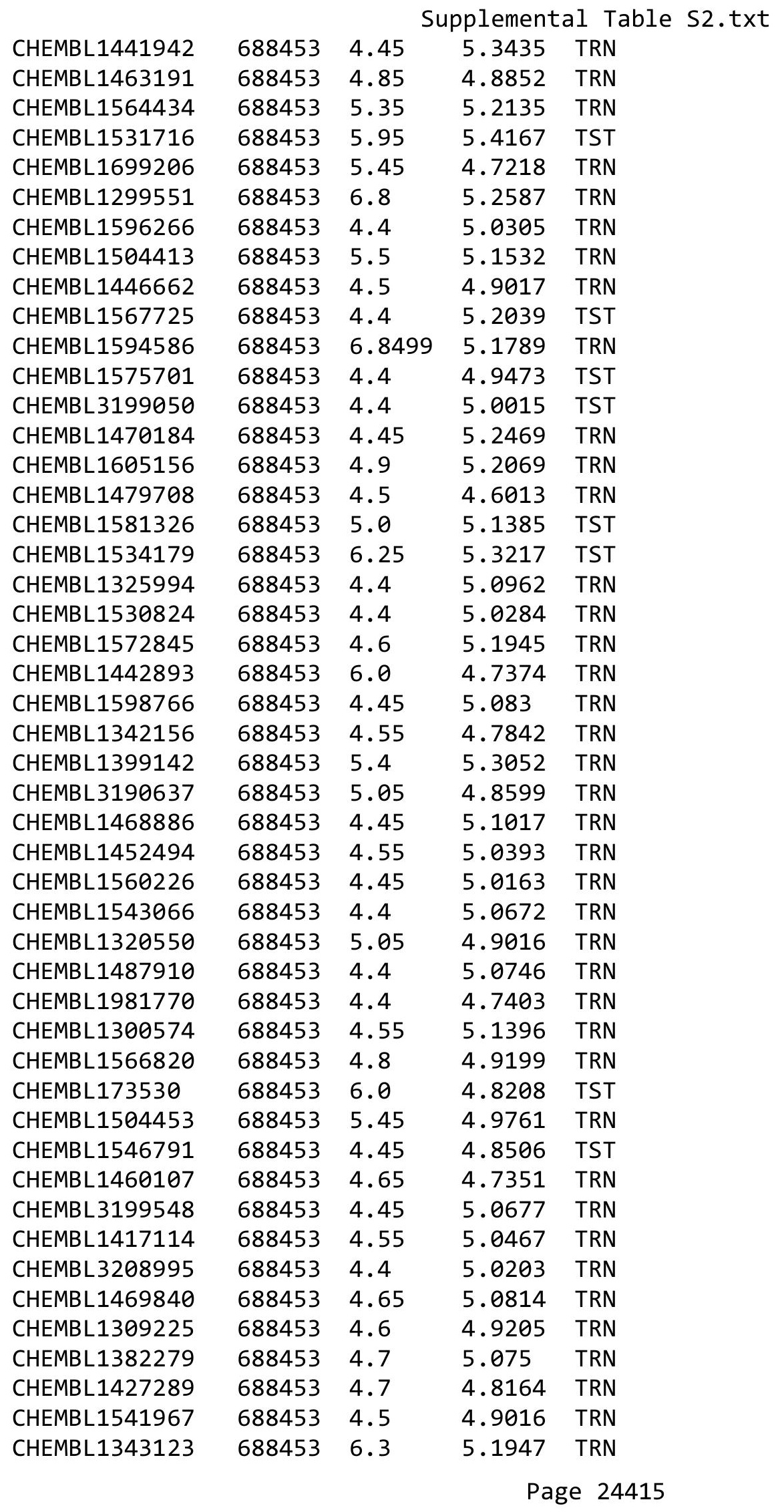




\begin{tabular}{|c|c|c|c|c|}
\hline \multicolumn{5}{|c|}{ Supplemental Table } \\
\hline CHEMBL1579827 & 688453 & 4.55 & 4.9744 & TRN \\
\hline CHEMBL1353420 & 688453 & 4.85 & 4.8848 & TRN \\
\hline CHEMBL1571510 & 688453 & 4.45 & 4.9089 & TRN \\
\hline CHEMBL1386372 & 688453 & 4.45 & 4.5886 & TRN \\
\hline CHEMBL1412367 & 688453 & 4.45 & 4.7367 & TRN \\
\hline CHEMBL1502839 & 688453 & 5.0 & 4.9617 & TRN \\
\hline CHEMBL 3193784 & 688453 & 4.75 & 5.0769 & TRN \\
\hline CHEMBL1360931 & 688453 & 7.2 & 5.0313 & TST \\
\hline CHEMBL 78573 & 688453 & 6.15 & 5.1781 & TRN \\
\hline CHEMBL3213025 & 688453 & 6.0 & 4.9829 & TRN \\
\hline CHEMBL1434411 & 688453 & 4.45 & 4.8232 & TRN \\
\hline CHEMBL3192665 & 688453 & 4.85 & 5.1742 & TRN \\
\hline CHEMBL1416847 & 688453 & 5.05 & 5.0878 & TRN \\
\hline CHEMBL1979849 & 688453 & 6.0 & 5.0702 & TRN \\
\hline CHEMBL1486967 & 688453 & 5.45 & 5.1622 & TST \\
\hline CHEMBL1425265 & 688453 & 5.35 & 4.8882 & TRN \\
\hline CHEMBL3196105 & 688453 & 4.45 & 4.994 & TRN \\
\hline CHEMBL1494440 & 688453 & 4.45 & 5.1564 & TRN \\
\hline CHEMBL1306724 & 688453 & 4.4 & 5.2492 & TRN \\
\hline CHEMBL1450985 & 688453 & 5.45 & 5.2765 & TRN \\
\hline CHEMBL1447632 & 688453 & 4.4 & 5.0869 & TRN \\
\hline CHEMBL1416493 & 688453 & 4.55 & 4.6093 & TRN \\
\hline CHEMBL1494667 & 688453 & 4.8 & 5.1061 & TRN \\
\hline CHEMBL1451643 & 688453 & 7.15 & 5.2923 & TRN \\
\hline CHEMBL1613004 & 688453 & 5.6 & 5.0456 & TRN \\
\hline CHEMBL1580019 & 688453 & 4.6 & 4.8062 & TRN \\
\hline CHEMBL1517702 & 688453 & 4.4 & 4.9918 & TRN \\
\hline CHEMBL3208368 & 688453 & 5.05 & 5.1679 & TST \\
\hline CHEMBL 247378 & 688453 & 4.55 & 5.1146 & TRN \\
\hline CHEMBL1373950 & 688453 & 4.7 & 5.3107 & TST \\
\hline CHEMBL1374536 & 688453 & 6.0 & 4.6245 & TRN \\
\hline CHEMBL1456580 & 688453 & 4.4 & 4.9524 & TRN \\
\hline CHEMBL162783 & 688453 & 4.6 & 5.1022 & TRN \\
\hline CHEMBL1436925 & 688453 & 4.6 & 4.7712 & TRN \\
\hline CHEMBL1607218 & 688453 & 4.35 & 5.2156 & TRN \\
\hline CHEMBL3190722 & 688453 & 6.05 & 5.28 & TST \\
\hline CHEMBL1419563 & 688453 & 4.55 & 5.0285 & TRN \\
\hline CHEMBL126077 & 688453 & 4.5 & 5.1006 & TST \\
\hline CHEMBL1594286 & 688453 & 4.45 & 5.0608 & TST \\
\hline CHEMBL1607532 & 688453 & 4.6 & 4.9134 & TRN \\
\hline CHEMBL1531677 & 688453 & 4.55 & 5.0232 & TRN \\
\hline CHEMBL539947 & 688453 & 4.55 & 4.9959 & TRN \\
\hline CHEMBL1337587 & 688453 & 4.45 & 4.6411 & TRN \\
\hline CHEMBL1343116 & 688453 & 4.9 & 5.3377 & TRN \\
\hline CHEMBL1349350 & 688453 & 5.95 & 4.8711 & TRN \\
\hline CHEMBL1450555 & 688453 & 4.55 & 4.9083 & TRN \\
\hline CHEMBL1322542 & 688453 & 5.55 & 5.3055 & TRN \\
\hline CHEMBL1594692 & 688453 & 5.1 & 5.1115 & TRN \\
\hline
\end{tabular}




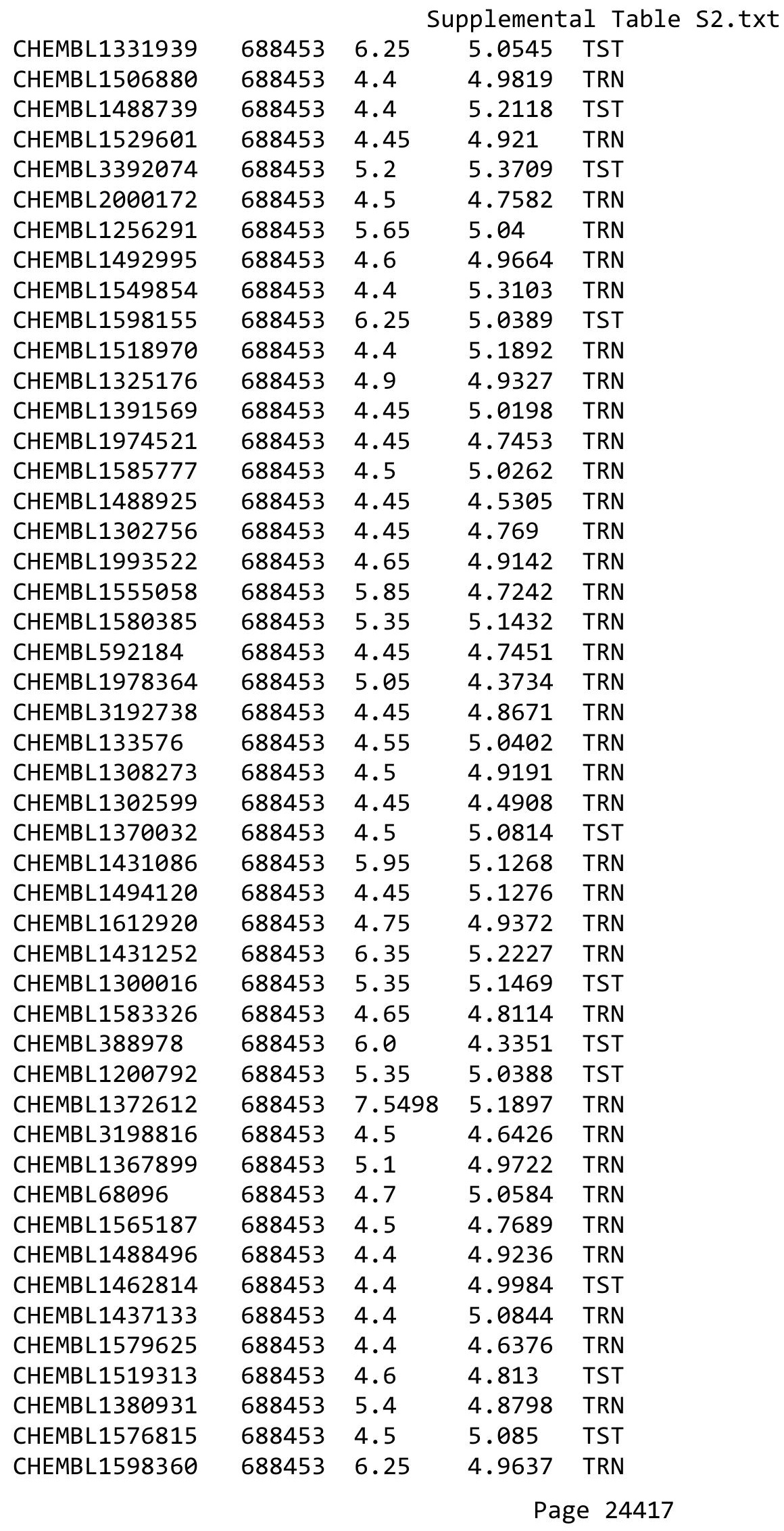




\begin{tabular}{|c|c|c|c|c|}
\hline \multicolumn{5}{|c|}{ Supplemental Table S2.txt } \\
\hline CHEMBL78150 & 688453 & 4.5 & 5.0626 & TRN \\
\hline CHEMBL1517897 & 688453 & 4.65 & 5.4354 & TRN \\
\hline CHEMBL1382548 & 688453 & 5.8 & 5.2549 & TRN \\
\hline CHEMBL323356 & 688453 & 6.5501 & 5.0883 & TRN \\
\hline CHEMBL1482991 & 688453 & 4.55 & 4.9896 & TRN \\
\hline CHEMBL1523860 & 688453 & 5.55 & 5.1699 & TRN \\
\hline CHEMBL1363854 & 688453 & 4.85 & 4.9266 & TRN \\
\hline CHEMBL1611600 & 688453 & 4.4 & 5.216 & TRN \\
\hline CHEMBL1548543 & 688453 & 4.4 & 4.9813 & TRN \\
\hline CHEMBL3189887 & 688453 & 5.4 & 5.0118 & TRN \\
\hline CHEMBL1576658 & 688453 & 5.75 & 4.8855 & TRN \\
\hline CHEMBL3198838 & 688453 & 4.45 & 5.0879 & TRN \\
\hline CHEMBL1436832 & 688453 & 4.4 & 5.0422 & TRN \\
\hline CHEMBL1414335 & 688453 & 4.4 & 4.9269 & TRN \\
\hline CHEMBL1441874 & 688453 & 4.4 & 4.9604 & TRN \\
\hline CHEMBL1426947 & 688453 & 4.85 & 5.0393 & TRN \\
\hline CHEMBL1367915 & 688453 & 4.5 & 4.6113 & TRN \\
\hline CHEMBL97453 & 688453 & 6.0 & 5.1235 & TRN \\
\hline CHEMBL1257041 & 688453 & 4.7 & 5.0972 & TST \\
\hline CHEMBL1485442 & 688453 & 5.5 & 5.2094 & TRN \\
\hline CHEMBL1363949 & 688453 & 5.05 & 4.973 & TRN \\
\hline CHEMBL1500884 & 688453 & 4.85 & 5.0406 & TRN \\
\hline CHEMBL1561092 & 688453 & 4.4 & 4.8813 & TRN \\
\hline CHEMBL1566566 & 688453 & 4.4 & 5.2105 & TRN \\
\hline CHEMBL3198096 & 688453 & 4.4 & 4.5817 & TRN \\
\hline CHEMBL1402228 & 688453 & 5.6 & 5.2351 & TST \\
\hline CHEMBL1498430 & 688453 & 4.65 & 4.8524 & TRN \\
\hline CHEMBL1303045 & 688453 & 4.85 & 4.9896 & TRN \\
\hline CHEMBL1256646 & 688453 & 6.0 & 5.1315 & TST \\
\hline CHEMBL3199718 & 688453 & 4.4 & 4.8666 & TRN \\
\hline CHEMBL 21241 & 688453 & 4.5 & 5.4604 & TST \\
\hline CHEMBL1353627 & 688453 & 6.05 & 5.1032 & TRN \\
\hline CHEMBL122701 & 688453 & 5.65 & 5.125 & TRN \\
\hline CHEMBL1523546 & 688453 & 4.4 & 5.1164 & TRN \\
\hline CHEMBL1516742 & 688453 & 5.8 & 5.0523 & TRN \\
\hline CHEMBL1580632 & 688453 & 6.7501 & 5.1316 & TRN \\
\hline CHEMBL1373289 & 688453 & 4.65 & 4.7786 & TRN \\
\hline CHEMBL1504151 & 688453 & 6.1 & 5.3332 & TRN \\
\hline CHEMBL1478509 & 688453 & 5.0 & 5.0284 & TRN \\
\hline CHEMBL1380684 & 688453 & 4.5 & 5.0915 & TST \\
\hline CHEMBL1525358 & 688453 & 4.5 & 5.0204 & TRN \\
\hline CHEMBL1389452 & 688453 & 4.45 & 4.9881 & TRN \\
\hline CHEMBL1300408 & 688453 & 4.4 & 5.0418 & TRN \\
\hline CHEMBL1532779 & 688453 & 5.05 & 5.1072 & TRN \\
\hline CHEMBL1522701 & 688453 & 4.4 & 5.2066 & TST \\
\hline CHEMBL1543245 & 688453 & 4.4 & 4.8785 & TRN \\
\hline CHEMBL1597650 & 688453 & 4.55 & 5.0571 & TRN \\
\hline CHEMBL1578509 & 688453 & 4.45 & 5.1051 & TRN \\
\hline
\end{tabular}




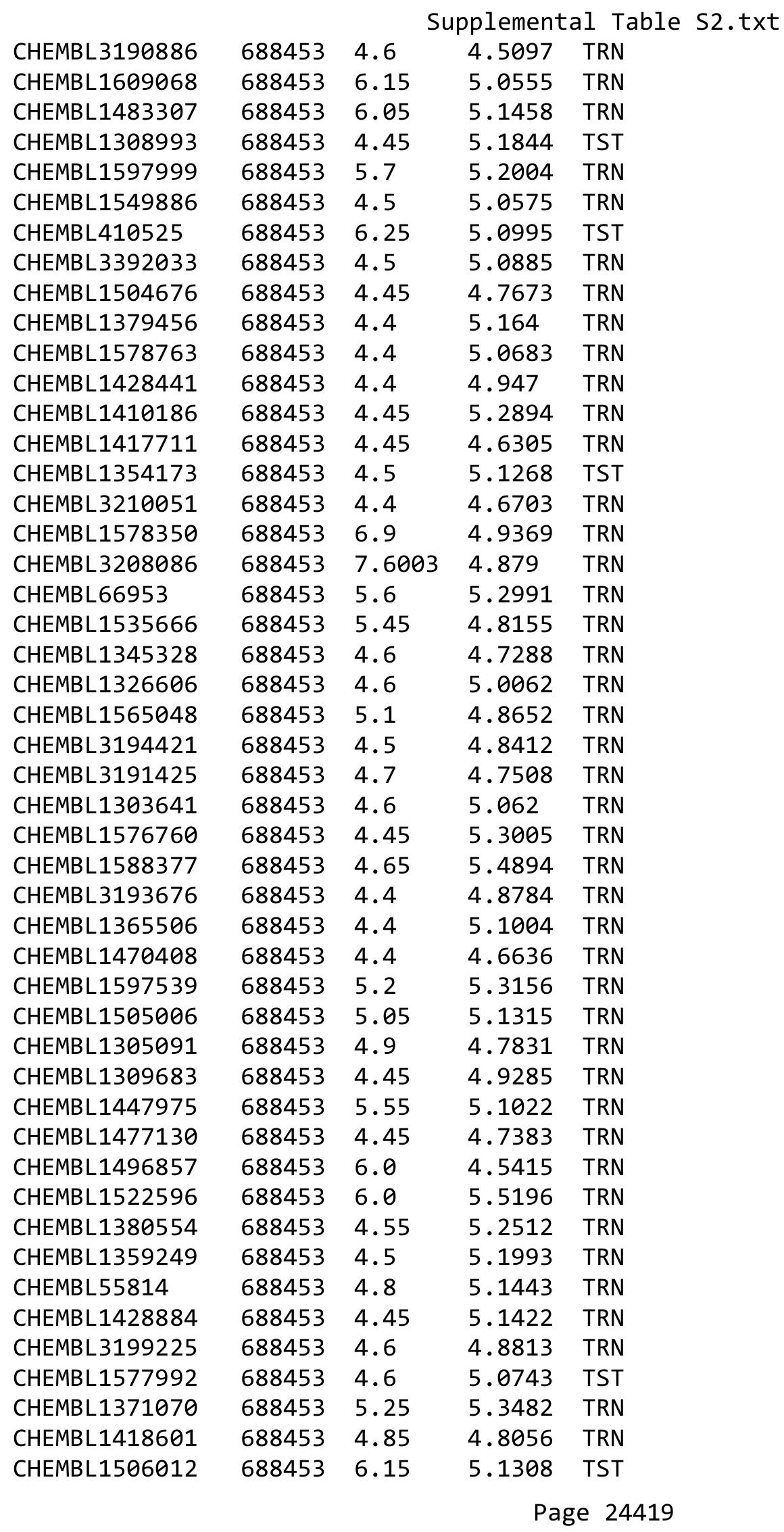




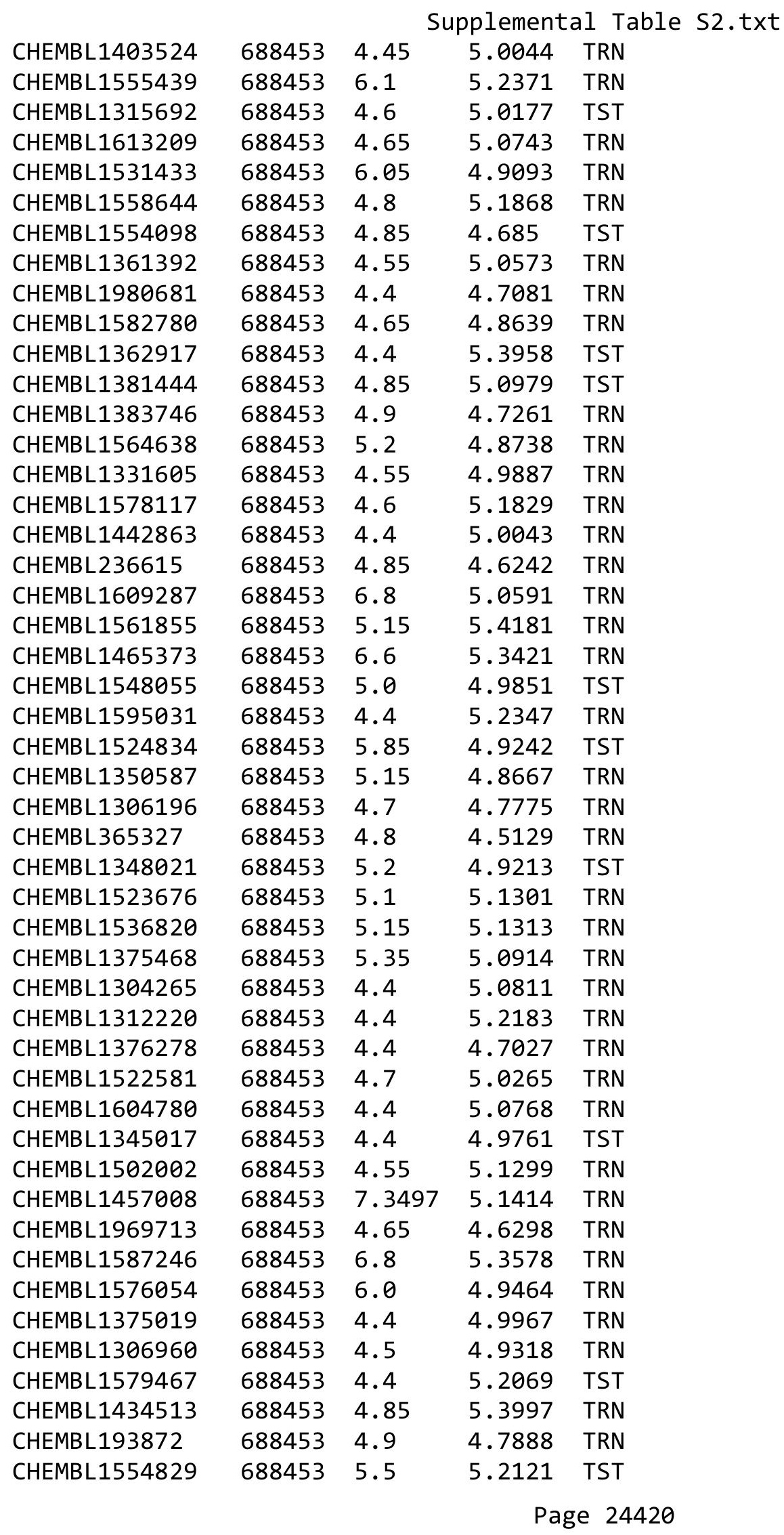




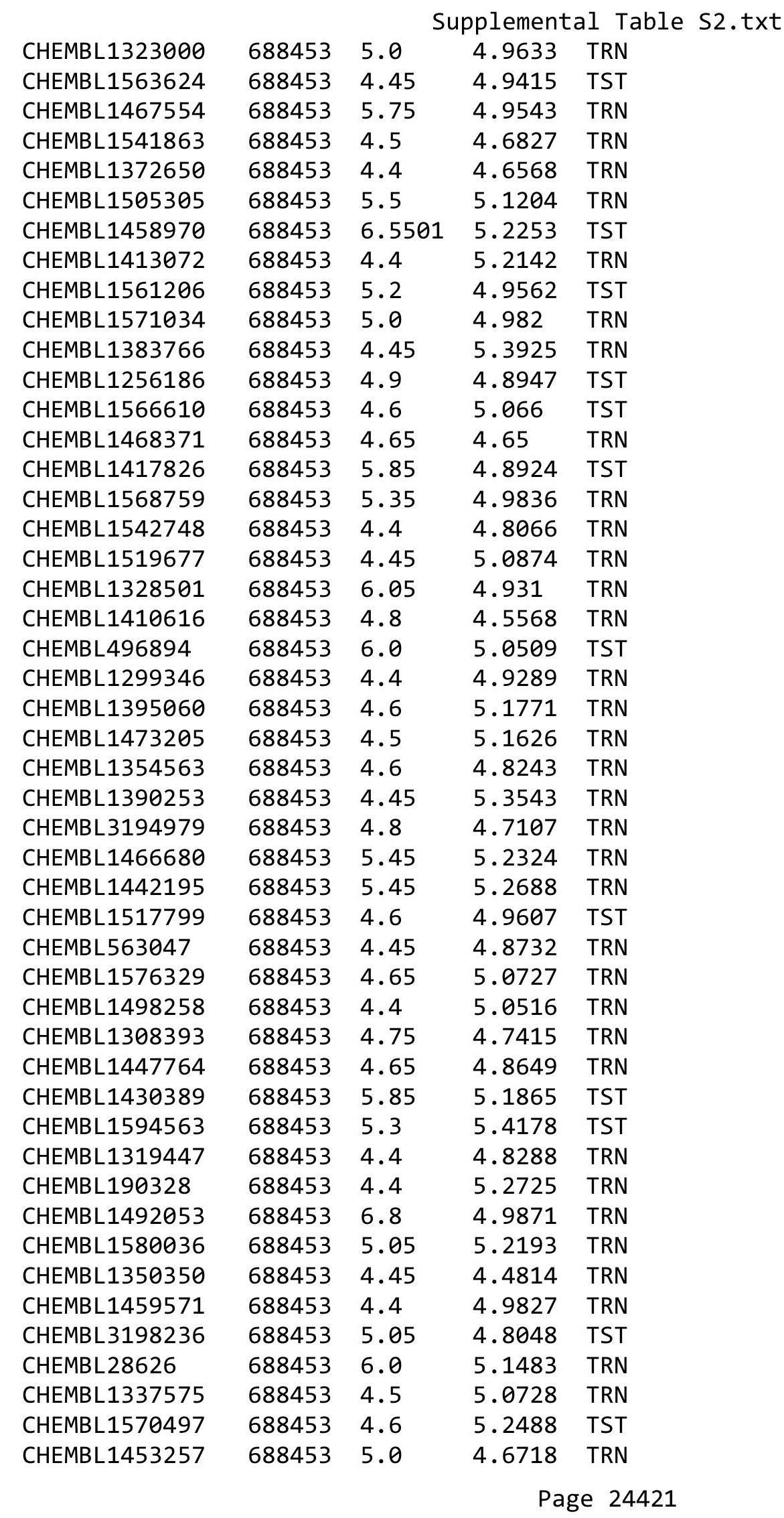




\begin{tabular}{|c|c|c|c|c|}
\hline \multicolumn{5}{|c|}{ Supplemental Table S2.txt } \\
\hline CHEMBL1338091 & 688453 & 4.45 & 5.0024 & TRN \\
\hline CHEMBL115600 & 688453 & 5.15 & 5.2462 & TST \\
\hline CHEMBL 3213098 & 688453 & 4.55 & 4.8117 & TRN \\
\hline CHEMBL1450458 & 688453 & 4.9 & 4.7368 & TRN \\
\hline CHEMBL1560831 & 688453 & 6.95 & 5.2347 & TST \\
\hline CHEMBL1545229 & 688453 & 4.55 & 5.006 & TRN \\
\hline CHEMBL1431643 & 688453 & 4.9 & 5.1572 & TRN \\
\hline CHEMBL1369967 & 688453 & 4.7 & 5.12 & TRN \\
\hline CHEMBL95925 & 688453 & 4.45 & 5.041 & TST \\
\hline CHEMBL 1452158 & 688453 & 4.55 & 5.3987 & TRN \\
\hline CHEMBL1490376 & 688453 & 5.4 & 4.8189 & TRN \\
\hline CHEMBL1443529 & 688453 & 4.45 & 4.9726 & TRN \\
\hline CHEMBL177820 & 688453 & 4.4 & 5.2323 & TST \\
\hline CHEMBL1387827 & 688453 & 4.65 & 4.9486 & TRN \\
\hline CHEMBL1414210 & 688453 & 4.45 & 5.0426 & TRN \\
\hline CHEMBL1601175 & 688453 & 4.4 & 4.8033 & TRN \\
\hline CHEMBL1386015 & 688453 & 4.6 & 4.8305 & TRN \\
\hline CHEMBL1506083 & 688453 & 4.4 & 4.9177 & TRN \\
\hline CHEMBL1508974 & 688453 & 6.0 & 5.0953 & TST \\
\hline CHEMBL1368835 & 688453 & 4.45 & 4.9991 & TRN \\
\hline CHEMBL1322028 & 688453 & 4.6 & 5.0294 & TRN \\
\hline CHEMBL1383060 & 688453 & 4.9 & 5.0058 & TRN \\
\hline CHEMBL1477071 & 688453 & 5.35 & 5.0272 & TRN \\
\hline CHEMBL1433297 & 688453 & 6.8499 & 5.1612 & TRN \\
\hline CHEMBL1492984 & 688453 & 4.5 & 5.2438 & TRN \\
\hline CHEMBL1489178 & 688453 & 4.85 & 5.2872 & TRN \\
\hline CHEMBL3191761 & 688453 & 4.4 & 4.7033 & TRN \\
\hline CHEMBL1388128 & 688453 & 6.05 & 5.346 & TST \\
\hline CHEMBL1364454 & 688453 & 4.5 & 4.8854 & TRN \\
\hline CHEMBL1385694 & 688453 & 4.85 & 5.0208 & TRN \\
\hline CHEMBL1468714 & 688453 & 4.65 & 5.0908 & TST \\
\hline CHEMBL1334586 & 688453 & 4.45 & 5.1198 & TST \\
\hline CHEMBL1585488 & 688453 & 4.4 & 5.1992 & TRN \\
\hline CHEMBL1378136 & 688453 & 4.7 & 4.7017 & TRN \\
\hline CHEMBL1442537 & 688453 & 5.15 & 4.9438 & TRN \\
\hline CHEMBL546257 & 688453 & 4.4 & 5.0788 & TST \\
\hline CHEMBL3198999 & 688453 & 4.55 & 4.9508 & TRN \\
\hline CHEMBL3195409 & 688453 & 5.55 & 5.063 & TRN \\
\hline CHEMBL1413526 & 688453 & 4.4 & 4.8366 & TRN \\
\hline CHEMBL1570051 & 688453 & 4.4 & 4.8095 & TRN \\
\hline CHEMBL1415665 & 688453 & 4.4 & 5.058 & TRN \\
\hline CHEMBL1586026 & 688453 & 4.45 & 4.7914 & TRN \\
\hline CHEMBL1531933 & 688453 & 5.95 & 5.0512 & TRN \\
\hline CHEMBL1324828 & 688453 & 5.3 & 4.988 & TRN \\
\hline CHEMBL1432808 & 688453 & 4.4 & 5.1157 & TST \\
\hline CHEMBL1348572 & 688453 & 4.8 & 4.7847 & TRN \\
\hline CHEMBL1307820 & 688453 & 5.2 & 5.2522 & TRN \\
\hline CHEMBL3212135 & 688453 & 4.5 & 5.1876 & TRN \\
\hline
\end{tabular}




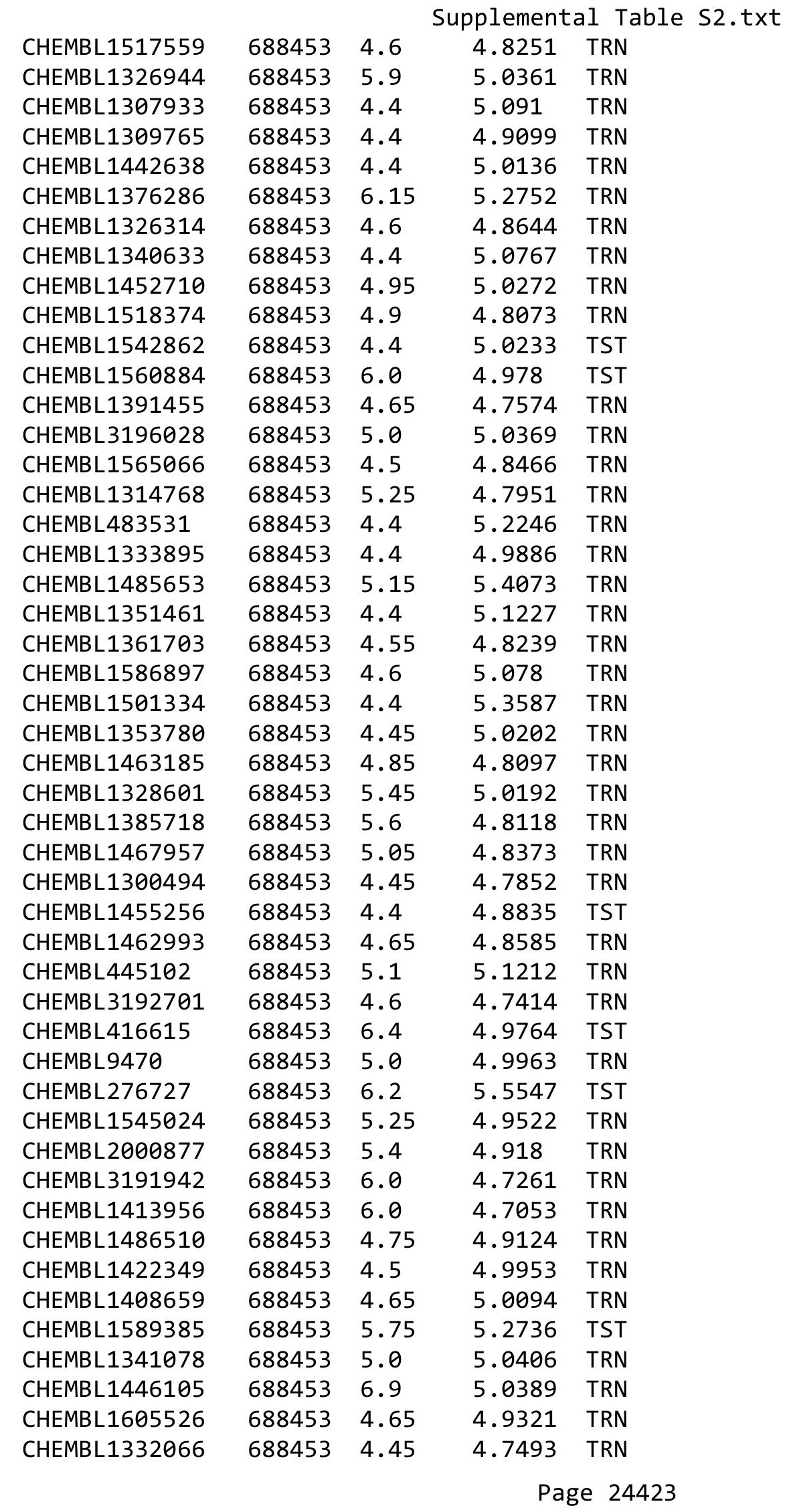




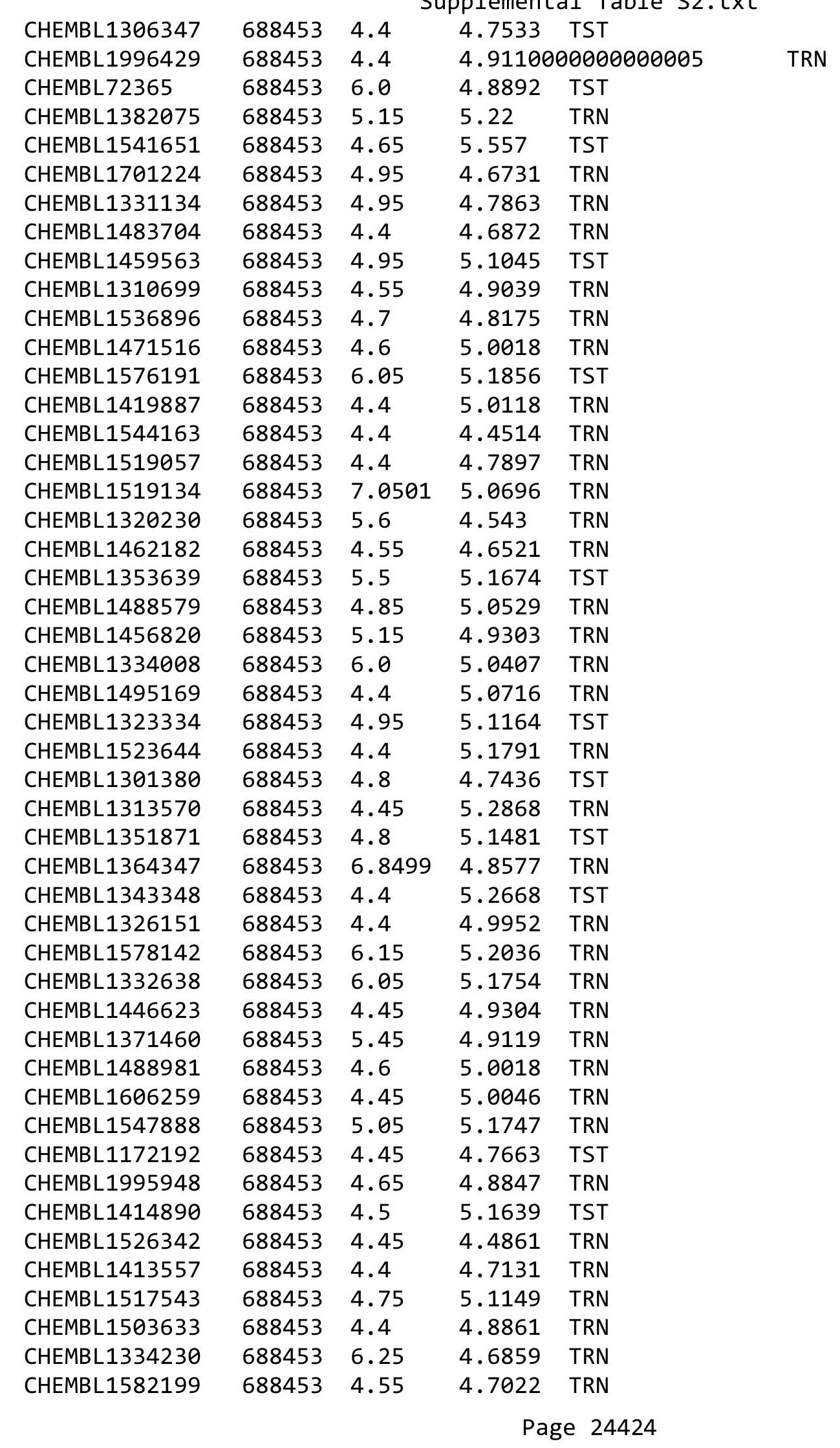




\begin{tabular}{|c|c|c|c|c|c|}
\hline \multicolumn{6}{|c|}{ Supplemental Table S2.txt } \\
\hline CHEMBL1403572 & 688453 & 5.5 & 4.9577 & TRN & \\
\hline CHEMBL1430487 & 688453 & 5.55 & 5.1633 & TRN & \\
\hline CHEMBL1481115 & 688453 & 6.05 & 5.2218 & TRN & \\
\hline CHEMBL1466492 & 688453 & 4.4 & 4.577 & TRN & \\
\hline CHEMBL1305441 & 688453 & 4.7 & 4.499 & TRN & \\
\hline CHEMBL1540034 & 688453 & 5.5 & 5.1364 & TRN & \\
\hline CHEMBL1455997 & 688453 & 4.65 & 5.16299 & 9999999999 & TRN \\
\hline CHEMBL1526751 & 688453 & 5.2 & 5.06 & TST & \\
\hline CHEMBL 1447678 & 688453 & 4.45 & 4.6406 & TRN & \\
\hline CHEMBL1365693 & 688453 & 6.2 & 5.0165 & TST & \\
\hline CHEMBL1443651 & 688453 & 4.5 & 4.7428 & TRN & \\
\hline CHEMBL1396203 & 688453 & 4.45 & 4.987 & TRN & \\
\hline CHEMBL1303508 & 688453 & 4.4 & 4.7866 & TRN & \\
\hline CHEMBL551842 & 688453 & 4.4 & 4.9062 & TST & \\
\hline CHEMBL1507341 & 688453 & 4.4 & 5.1318 & TST & \\
\hline CHEMBL1486827 & 688453 & 5.5 & 5.1449 & TRN & \\
\hline CHEMBL318457 & 688453 & 4.5 & 4.8588 & TST & \\
\hline CHEMBL1549076 & 688453 & 6.6499 & 5.2459 & TRN & \\
\hline CHEMBL1359071 & 688453 & 4.65 & 5.0926 & TRN & \\
\hline CHEMBL3145244 & 688453 & 4.4 & 4.6971 & TRN & \\
\hline CHEMBL1491402 & 688453 & 4.6 & 4.7484 & TRN & \\
\hline CHEMBL1387011 & 688453 & 4.6 & 4.835 & TRN & \\
\hline CHEMBL1579932 & 688453 & 5.55 & 5.1565 & TRN & \\
\hline CHEMBL 1300344 & 688453 & 4.45 & 4.8584 & TRN & \\
\hline CHEMBL1495790 & 688453 & 5.4 & 4.9264 & TRN & \\
\hline CHEMBL1439454 & 688453 & 6.1 & 5.2153 & TRN & \\
\hline CHEMBL1309136 & 688453 & 5.15 & 5.144 & TRN & \\
\hline CHEMBL1385176 & 688453 & 6.95 & 5.28299 & 99999999995 & TRN \\
\hline CHEMBL 3192400 & 688453 & 5.3 & 5.0727 & TRN & \\
\hline CHEMBL1379200 & 688453 & 4.4 & 4.4754 & TRN & \\
\hline CHEMBL1407289 & 688453 & 4.4 & 5.3047 & TRN & \\
\hline CHEMBL1419996 & 688453 & 5.15 & 5.0878 & TRN & \\
\hline CHEMBL1556581 & 688453 & 5.15 & 5.0884 & TST & \\
\hline CHEMBL1594984 & 688453 & 5.45 & 4.6638 & TRN & \\
\hline CHEMBL1399332 & 688453 & 5.3 & 4.8325 & TRN & \\
\hline CHEMBL1594186 & 688453 & 4.4 & 5.0513 & TRN & \\
\hline CHEMBL1464373 & 688453 & 4.85 & 4.731 & TRN & \\
\hline CHEMBL1992880 & 688453 & 4.65 & 4.7678 & TRN & \\
\hline CHEMBL193627 & 688453 & 4.4 & 4.8351 & TRN & \\
\hline CHEMBL1389446 & 688453 & 4.4 & 4.9944 & TRN & \\
\hline CHEMBL1587708 & 688453 & 4.5 & 4.6533 & TRN & \\
\hline CHEMBL405110 & 688453 & 4.5 & 5.0043 & TST & \\
\hline CHEMBL1533766 & 688453 & 4.4 & 4.8078 & TRN & \\
\hline CHEMBL1444824 & 688453 & 4.85 & 4.8594 & TRN & \\
\hline CHEMBL1361177 & 688453 & 6.7501 & 5.2989 & TRN & \\
\hline CHEMBL1352280 & 688453 & 4.4 & 4.8509 & TRN & \\
\hline CHEMBL1304807 & 688453 & 4.85 & 4.8393 & TRN & \\
\hline CHEMBL1383074 & 688453 & 4.5 & 5.2865 & TST & \\
\hline
\end{tabular}




\begin{tabular}{|c|c|c|c|c|c|}
\hline & & & & & \\
\hline CHEMBL1581410 & 688453 & 4.5 & 5.0697 & TRN & \\
\hline CHEMBL1502837 & 688453 & 6.8 & 5.061 & TRN & \\
\hline CHEMBL1346172 & 688453 & 4.8 & 4.8095 & TRN & \\
\hline CHEMBL1405834 & 688453 & 5.3 & 4.4962 & TRN & \\
\hline CHEMBL1361552 & 688453 & 4.45 & 5.0866 & TRN & \\
\hline CHEMBL1516525 & 688453 & 4.45 & 5.05399 & 9999999999 & TRN \\
\hline CHEMBL1576863 & 688453 & 6.9 & 4.9049 & TST & \\
\hline CHEMBL1495071 & 688453 & 5.1 & 5.0511 & TST & \\
\hline CHEMBL1349705 & 688453 & 4.5 & 5.1604 & TRN & \\
\hline CHEMBL1489693 & 688453 & 4.5 & 5.0238 & TRN & \\
\hline CHEMBL485258 & 688453 & 4.6 & 5.2895 & TRN & \\
\hline CHEMBL1364873 & 688453 & 4.65 & 4.9012 & TRN & \\
\hline CHEMBL1487424 & 688453 & 5.2 & 5.0209 & TRN & \\
\hline CHEMBL1490257 & 688453 & 4.4 & 5.0113 & TRN & \\
\hline CHEMBL1505663 & 688453 & 4.85 & 5.0605 & TRN & \\
\hline CHEMBL1533230 & 688453 & 5.85 & 5.2534 & TST & \\
\hline CHEMBL1588661 & 688453 & 4.45 & 5.0715 & TST & \\
\hline CHEMBL1465322 & 688453 & 4.6 & 4.7638 & TRN & \\
\hline CHEMBL1517112 & 688453 & 4.4 & 5.0064 & TRN & \\
\hline CHEMBL1414236 & 688453 & 4.6 & 4.8536 & TST & \\
\hline CHEMBL1571250 & 688453 & 5.35 & 5.3305 & TST & \\
\hline CHEMBL1361370 & 688453 & 6.25 & 5.2505 & TST & \\
\hline CHEMBL1499783 & 688453 & 4.45 & 4.9039 & TRN & \\
\hline CHEMBL1242180 & 688453 & 4.4 & 4.9455 & TRN & \\
\hline CHEMBL1423092 & 688453 & 5.4 & 5.3959 & TRN & \\
\hline CHEMBL1482275 & 688453 & 4.4 & 4.9909 & TRN & \\
\hline CHEMBL1484167 & 688453 & 4.55 & 4.918 & TRN & \\
\hline CHEMBL1566134 & 688453 & 4.4 & 5.2504 & TST & \\
\hline CHEMBL1509585 & 688453 & 4.4 & 4.6715 & TRN & \\
\hline CHEMBL1409064 & 688453 & 4.45 & 4.8368 & TRN & \\
\hline CHEMBL1448446 & 688453 & 4.5 & 5.0223 & TRN & \\
\hline CHEMBL1506749 & 688453 & 4.4 & 5.1226 & TRN & \\
\hline CHEMBL1482679 & 688453 & 6.8499 & 5.1784 & TRN & \\
\hline CHEMBL1589239 & 688453 & 5.55 & 5.1552 & TRN & \\
\hline CHEMBL1576333 & 688453 & 6.7501 & 4.9727 & TRN & \\
\hline CHEMBL1558364 & 688453 & 4.7 & 5.086 & TRN & \\
\hline CHEMBL1599659 & 688453 & 4.45 & 4.9953 & TRN & \\
\hline CHEMBL1398194 & 688453 & 6.0 & 4.9406 & TRN & \\
\hline CHEMBL1384567 & 688453 & 4.4 & 4.8116 & TRN & \\
\hline CHEMBL1427849 & 688453 & 6.9 & 5.1113 & TRN & \\
\hline CHEMBL1562466 & 688453 & 4.4 & 5.1708 & TRN & \\
\hline CHEMBL1984703 & 688453 & 4.5 & 4.4641 & TRN & \\
\hline CHEMBL1601512 & 688453 & 4.65 & 5.0568 & TRN & \\
\hline CHEMBL3198342 & 688453 & 4.4 & 4.7521 & TRN & \\
\hline CHEMBL1597177 & 688453 & 4.4 & 4.9685 & TRN & \\
\hline CHEMBL1461649 & 688453 & 4.55 & 4.8479 & TRN & \\
\hline CHEMBL1516859 & 688453 & 4.4 & 5.0404 & TRN & \\
\hline CHEMBL1439291 & 688453 & 4.4 & 4.9185 & TRN & \\
\hline & & & & 24426 & \\
\hline
\end{tabular}




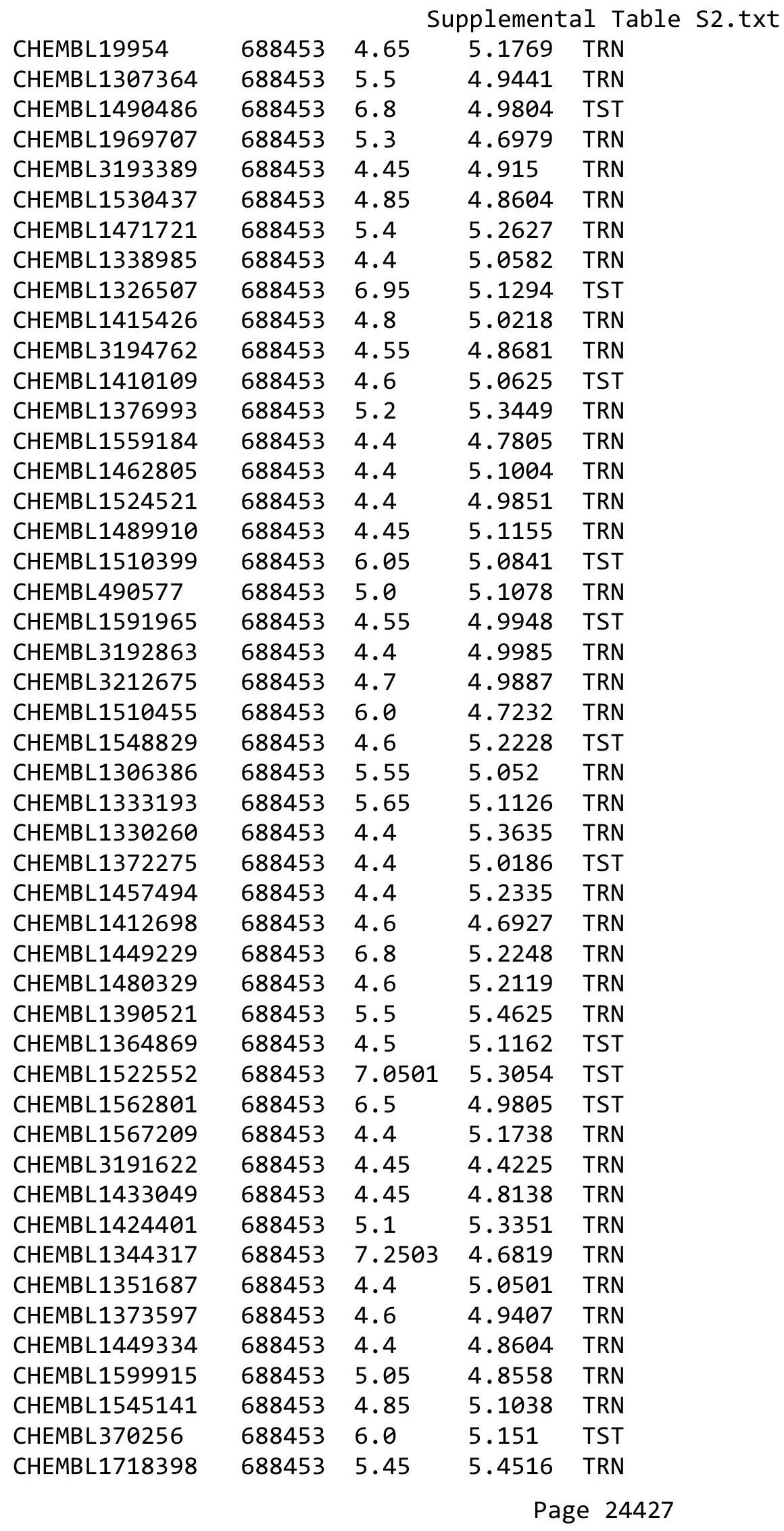




\begin{tabular}{|c|c|c|c|c|c|}
\hline \multicolumn{6}{|c|}{ Supplemental Table s2.txt } \\
\hline CHEMBL3191615 & 688453 & 5.05 & 5.2858 & TRN & \\
\hline CHEMBL1375499 & 688453 & 4.55 & 4.5188 & TRN & \\
\hline CHEMBL1566010 & 688453 & 4.45 & 4.9574 & TRN & \\
\hline CHEMBL3191186 & 688453 & 4.4 & 4.7891 & TRN & \\
\hline CHEMBL3195924 & 688453 & 4.4 & 4.9691 & TRN & \\
\hline CHEMBL1509377 & 688453 & 4.75 & 4.9689 & TST & \\
\hline CHEMBL1376308 & 688453 & 4.55 & 4.6444 & TRN & \\
\hline CHEMBL1450647 & 688453 & 4.8 & 5.051 & TRN & \\
\hline CHEMBL1499658 & 688453 & 4.6 & 4.9136 & TRN & \\
\hline CHEMBL1561148 & 688453 & 5.0 & 5.0795 & TRN & \\
\hline CHEMBL1429479 & 688453 & 6.0 & 4.7674 & TRN & \\
\hline CHEMBL1340998 & 688453 & 6.0 & 5.1453 & TRN & \\
\hline CHEMBL1403191 & 688453 & 5.15 & 4.9485 & TRN & \\
\hline CHEMBL1307247 & 688453 & 4.55 & 4.8292 & TRN & \\
\hline CHEMBL1581951 & 688453 & 4.7 & 5.2887 & TRN & \\
\hline CHEMBL3214629 & 688453 & 6.05 & 5.2152 & TRN & \\
\hline CHEMBL1550336 & 688453 & 4.5 & 4.9495 & TST & \\
\hline CHEMBL1568803 & 688453 & 4.75 & 5.0304 & TRN & \\
\hline CHEMBL1305736 & 688453 & 4.4 & 5.1147 & TRN & \\
\hline CHEMBL1594376 & 688453 & 5.6 & 4.6557 & TRN & \\
\hline CHEMBL1416649 & 688453 & 5.2 & 4.6954 & TRN & \\
\hline CHEMBL1301574 & 688453 & 5.45 & 5.1404 & TRN & \\
\hline CHEMBL1498822 & 688453 & 4.5 & 4.9925 & TRN & \\
\hline CHEMBL1379371 & 688453 & 4.4 & 4.9397 & TRN & \\
\hline CHEMBL1388435 & 688453 & 5.9 & 5.2773 & TRN & \\
\hline CHEMBL1389510 & 688453 & 4.4 & 4.9024 & TRN & \\
\hline CHEMBL1324982 & 688453 & 5.1 & 4.8799 & TRN & \\
\hline CHEMBL3351065 & 688453 & 5.4 & 4.9572 & TST & \\
\hline CHEMBL1364617 & 688453 & 4.55 & 5.2137 & TRN & \\
\hline CHEMBL1548074 & 688453 & 4.45 & 4.7471 & TRN & \\
\hline CHEMBL1601573 & 688453 & 4.6 & 4.9898 & TRN & \\
\hline CHEMBL1572323 & 688453 & 4.65 & 5.2872 & TST & \\
\hline CHEMBL1430473 & 688453 & 5.75 & 4.9692 & TST & \\
\hline CHEMBL1548087 & 688453 & 4.55 & 5.1498 & TRN & \\
\hline CHEMBL1569094 & 688453 & 4.45 & 4.6202 & TRN & \\
\hline CHEMBL1582121 & 688453 & 4.45 & 4.6325 & TRN & \\
\hline CHEMBL1998651 & 688453 & 6.7501 & 4.9837 & TRN & \\
\hline CHEMBL1490809 & 688453 & 5.15 & 5.1103 & TRN & \\
\hline CHEMBL1381005 & 688453 & 4.9 & 5.0788 & TRN & \\
\hline CHEMBL 2006519 & 688453 & 4.4 & 4.6974 & TRN & \\
\hline CHEMBL1367105 & 688453 & 5.0 & 5.356 & TST & \\
\hline CHEMBL1585191 & 688453 & 4.4 & 4.6278 & TRN & \\
\hline CHEMBL1507308 & 688453 & 4.55 & 4.8786 & TRN & \\
\hline CHEMBL1609550 & 688453 & 5.05 & 4.5427 & TRN & \\
\hline CHEMBL1501800 & 688453 & 4.5 & 5.1220 & 0000000001 & TRN \\
\hline CHEMBL1520077 & 688453 & 4.65 & 4.7289 & TRN & \\
\hline CHEMBL1305450 & 688453 & 4.85 & 4.8437 & TRN & \\
\hline CHEMBL1965155 & 688453 & 5.05 & 4.8802 & TRN & \\
\hline
\end{tabular}




\begin{tabular}{|c|c|c|c|c|c|}
\hline & & \multicolumn{4}{|c|}{ Supplemental Table S2.txt } \\
\hline CHEMBL1531925 & 688453 & 5.05 & 4.8412 & TRN & \\
\hline CHEMBL1338441 & 688453 & 4.4 & 4.9422 & TRN & \\
\hline CHEMBL1384778 & 688453 & 4.8 & 5.3558 & TRN & \\
\hline CHEMBL1323795 & 688453 & 5.9 & 4.76399 & 9999999999 & TRN \\
\hline CHEMBL1564066 & 688453 & 4.5 & 4.966 & TRN & \\
\hline CHEMBL1524286 & 688453 & 4.45 & 5.0137 & TRN & \\
\hline CHEMBL1576143 & 688453 & 6.8 & 5.1438 & TST & \\
\hline CHEMBL1505816 & 688453 & 5.8 & 5.1754 & TRN & \\
\hline CHEMBL181633 & 688453 & 5.1 & 5.0585 & TRN & \\
\hline CHEMBL1404955 & 688453 & 6.9 & 5.0045 & TRN & \\
\hline CHEMBL1606736 & 688453 & 4.45 & 5.1192 & TRN & \\
\hline CHEMBL1558007 & 688453 & 4.45 & 4.7476 & TRN & \\
\hline CHEMBL1442597 & 688453 & 5.35 & 5.0292 & TST & \\
\hline CHEMBL1736377 & 688453 & 4.45 & 4.5843 & TRN & \\
\hline CHEMBL1327923 & 688453 & 4.55 & 5.0098 & TRN & \\
\hline CHEMBL504791 & 688453 & 5.2 & 4.8236 & TRN & \\
\hline CHEMBL1490919 & 688453 & 4.4 & 4.8766 & TST & \\
\hline CHEMBL1304478 & 688453 & 4.9 & 5.0869 & TST & \\
\hline CHEMBL1533336 & 688453 & 4.5 & 5.2038 & TRN & \\
\hline CHEMBL3191066 & 688453 & 4.7 & 5.0027 & TRN & \\
\hline CHEMBL1379048 & 688453 & 4.4 & 5.1512 & TRN & \\
\hline CHEMBL1377118 & 688453 & 4.5 & 5.0751 & TRN & \\
\hline CHEMBL 3195772 & 688453 & 4.4 & 4.8213 & TRN & \\
\hline CHEMBL1312458 & 688453 & 5.6 & 5.2004 & TRN & \\
\hline CHEMBL1468919 & 688453 & 4.85 & 5.0044 & TRN & \\
\hline CHEMBL1366942 & 688453 & 4.7 & 4.9429 & TRN & \\
\hline CHEMBL1348185 & 688453 & 6.45 & 5.1426 & TST & \\
\hline CHEMBL1378879 & 688453 & 4.6 & 5.1329 & TST & \\
\hline CHEMBL 3209157 & 688453 & 6.0 & 4.8446 & TRN & \\
\hline CHEMBL1510372 & 688453 & 5.45 & 5.2 & TRN & \\
\hline CHEMBL1381676 & 688453 & 5.15 & 4.548 & TRN & \\
\hline CHEMBL1349987 & 688453 & 4.4 & 4.9342 & TRN & \\
\hline CHEMBL1570361 & 688453 & 4.75 & 5.05399 & 9999999999 & TST \\
\hline CHEMBL 3212082 & 688453 & 5.05 & 5.0057 & TRN & \\
\hline CHEMBL463563 & 688453 & 4.9 & 4.9079 & TRN & \\
\hline CHEMBL567959 & 688453 & 6.8 & 5.005 & TRN & \\
\hline CHEMBL1446955 & 688453 & 6.0 & 4.9901 & TRN & \\
\hline CHEMBL1387843 & 688453 & 4.4 & 5.2174 & TST & \\
\hline CHEMBL1489151 & 688453 & 4.4 & 4.8895 & TRN & \\
\hline CHEMBL1316831 & 688453 & 4.85 & 4.7636 & TRN & \\
\hline CHEMBL1410280 & 688453 & 4.85 & 4.9045 & TRN & \\
\hline CHEMBL1411403 & 688453 & 4.5 & 4.5301 & TRN & \\
\hline CHEMBL1413112 & 688453 & 4.4 & 5.0598 & TRN & \\
\hline CHEMBL1478754 & 688453 & 4.5 & 4.9646 & TST & \\
\hline CHEMBL 3193312 & 688453 & 4.4 & 5.003 & TRN & \\
\hline CHEMBL1526090 & 688453 & 7.6003 & 5.2346 & TRN & \\
\hline CHEMBL102714 & 688453 & 4.5 & 4.9406 & TST & \\
\hline CHEMBL1312190 & 688453 & 4.4 & 5.0871 & TRN & \\
\hline
\end{tabular}




\begin{tabular}{|c|c|c|c|c|c|}
\hline \\
\hline CHEMBL1970896 & 688453 & 4.8 & 4.941 & TRN & \\
\hline CHEMBL1305771 & 688453 & 5.0 & 4.7252 & TRN & \\
\hline CHEMBL1464288 & 688453 & 4.4 & 5.1093 & TRN & \\
\hline CHEMBL1587260 & 688453 & 4.55 & 4.7706 & TRN & \\
\hline CHEMBL1344422 & 688453 & 4.8 & 4.7278 & TRN & \\
\hline CHEMBL1391248 & 688453 & 4.4 & 4.8426 & TRN & \\
\hline CHEMBL3194381 & 688453 & 4.4 & 4.876 & TRN & \\
\hline CHEMBL1522129 & 688453 & 4.75 & 4.8471 & TRN & \\
\hline CHEMBL1489288 & 688453 & 5.45 & 5.0007 & TRN & \\
\hline CHEMBL1353867 & 688453 & 6.7001 & 5.1346 & TST & \\
\hline CHEMBL1463964 & 688453 & 4.75 & 4.7139 & TRN & \\
\hline CHEMBL3192810 & 688453 & 4.4 & 4.7479 & TRN & \\
\hline CHEMBL1594542 & 688453 & 4.6 & 5.0069 & TRN & \\
\hline CHEMBL1532453 & 688453 & 5.5 & 5.1036 & TST & \\
\hline CHEMBL1463663 & 688453 & 4.6 & 4.904 & TRN & \\
\hline CHEMBL1449354 & 688453 & 5.15 & 4.7932 & TRN & \\
\hline CHEMBL1441064 & 688453 & 4.4 & 5.1396 & TST & \\
\hline CHEMBL1320317 & 688453 & 4.4 & 4.9604 & TRN & \\
\hline CHEMBL1556215 & 688453 & 4.55 & 4.7658 & TRN & \\
\hline CHEMBL 234338 & 688453 & 4.9 & 5.0294 & TRN & \\
\hline CHEMBL1339534 & 688453 & 4.5 & 4.9134 & TRN & \\
\hline CHEMBL1307046 & 688453 & 4.4 & 5.05699 & 99999999995 & TRN \\
\hline CHEMBL1537381 & 688453 & 4.55 & 4.9283 & TRN & \\
\hline CHEMBL3192785 & 688453 & 4.5 & 4.9975 & TRN & \\
\hline CHEMBL1390169 & 688453 & 6.05 & 5.0794 & TRN & \\
\hline CHEMBL1464863 & 688453 & 4.55 & 5.0252 & TRN & \\
\hline CHEMBL1448466 & 688453 & 4.5 & 5.2147 & TRN & \\
\hline CHEMBL353187 & 688453 & 5.15 & 5.3369 & TRN & \\
\hline CHEMBL504977 & 688453 & 4.45 & 4.5342 & TRN & \\
\hline CHEMBL 1441782 & 688453 & 5.9 & 5.0283 & TRN & \\
\hline CHEMBL1404718 & 688453 & 6.95 & 5.2937 & TRN & \\
\hline CHEMBL1324556 & 688453 & 5.15 & 4.8149 & TRN & \\
\hline CHEMBL1600163 & 688453 & 4.9 & 4.9774 & TST & \\
\hline CHEMBL1539159 & 688453 & 4.55 & 5.0794 & TRN & \\
\hline CHEMBL1570922 & 688453 & 5.95 & 5.0022 & TRN & \\
\hline CHEMBL1310401 & 688453 & 4.4 & 5.006 & TRN & \\
\hline CHEMBL3197063 & 688453 & 4.4 & 4.9077 & TRN & \\
\hline CHEMBL1539384 & 688453 & 4.85 & 5.05399 & 9999999999 & TRN \\
\hline CHEMBL1402286 & 688453 & 4.4 & 4.4994 & TRN & \\
\hline CHEMBL580819 & 688453 & 4.45 & 4.7367 & TRN & \\
\hline CHEMBL1464280 & 688453 & 5.0 & 4.9616 & TST & \\
\hline CHEMBL1334940 & 688453 & 4.4 & 4.9222 & TRN & \\
\hline CHEMBL498423 & 688453 & 4.65 & 5.0418 & TRN & \\
\hline CHEMBL1372661 & 688453 & 4.4 & 5.0889 & TST & \\
\hline CHEMBL1494724 & 688453 & 6.8 & 5.1439 & TST & \\
\hline CHEMBL1603442 & 688453 & 4.5 & 4.9347 & TRN & \\
\hline CHEMBL1339860 & 688453 & 4.55 & 4.675 & TRN & \\
\hline CHEMBL1554479 & 688453 & 4.45 & 5.2102 & TST & \\
\hline
\end{tabular}




\begin{tabular}{|c|c|c|c|c|}
\hline \multicolumn{5}{|c|}{ Supplemental Table S2.txt } \\
\hline CHEMBL 3191340 & 688453 & 4.4 & 4.8844 & TRN \\
\hline CHEMBL1489794 & 688453 & 5.2 & 5.0739 & TRN \\
\hline CHEMBL1351838 & 688453 & 4.45 & 4.8084 & TST \\
\hline CHEMBL1575074 & 688453 & 6.45 & 4.9056 & TST \\
\hline CHEMBL1525168 & 688453 & 5.05 & 5.2418 & TRN \\
\hline CHEMBL3191661 & 688453 & 4.4 & 4.7736 & TRN \\
\hline CHEMBL1373339 & 688453 & 4.5 & 4.6393 & TRN \\
\hline CHEMBL1365553 & 688453 & 6.05 & 4.7648 & TRN \\
\hline CHEMBL1573700 & 688453 & 4.95 & 5.4238 & TRN \\
\hline CHEMBL1439844 & 688453 & 4.8 & 4.9711 & TRN \\
\hline CHEMBL3196701 & 688453 & 4.45 & 4.8465 & TRN \\
\hline CHEMBL1331195 & 688453 & 4.6 & 4.9311 & TRN \\
\hline CHEMBL1469320 & 688453 & 5.05 & 4.9467 & TRN \\
\hline CHEMBL1532309 & 688453 & 5.1 & 5.0923 & TST \\
\hline CHEMBL1313506 & 688453 & 4.9 & 5.2502 & TRN \\
\hline CHEMBL1461843 & 688453 & 5.0 & 4.9149 & TRN \\
\hline CHEMBL1531365 & 688453 & 4.4 & 4.8573 & TRN \\
\hline CHEMBL1423392 & 688453 & 5.0 & 5.1914 & TRN \\
\hline CHEMBL1424036 & 688453 & 4.6 & 4.9822 & TRN \\
\hline CHEMBL1337132 & 688453 & 5.95 & 5.1935 & TRN \\
\hline CHEMBL165064 & 688453 & 4.85 & 5.0264 & TRN \\
\hline CHEMBL1537100 & 688453 & 4.45 & 4.7205 & TRN \\
\hline CHEMBL1338474 & 688453 & 4.4 & 4.9743 & TRN \\
\hline CHEMBL3197008 & 688453 & 4.4 & 5.047 & TRN \\
\hline CHEMBL1964891 & 688453 & 4.45 & 4.6666 & TRN \\
\hline CHEMBL1978193 & 688453 & 4.4 & 4.8818 & TRN \\
\hline CHEMBL1501748 & 688453 & 5.3 & 4.8625 & TRN \\
\hline CHEMBL1332063 & 688453 & 4.4 & 4.7457 & TRN \\
\hline CHEMBL1305110 & 688453 & 5.2 & 5.2933 & TRN \\
\hline CHEMBL1390210 & 688453 & 4.4 & 5.1563 & TRN \\
\hline CHEMBL1468925 & 688453 & 4.55 & 5.4487 & TST \\
\hline CHEMBL1583049 & 688453 & 4.45 & 4.8911 & TRN \\
\hline CHEMBL1985664 & 688453 & 5.75 & 4.8929 & TRN \\
\hline CHEMBL1403245 & 688453 & 4.7 & 5.0907 & TRN \\
\hline CHEMBL1487945 & 688453 & 4.45 & 4.9309 & TRN \\
\hline CHEMBL152557 & 688453 & 4.4 & 5.1225 & TST \\
\hline CHEMBL1305433 & 688453 & 6.8 & 5.0777 & TRN \\
\hline CHEMBL1534763 & 688453 & 4.4 & 4.7075 & TRN \\
\hline CHEMBL1575299 & 688453 & 4.4 & 5.3042 & TRN \\
\hline CHEMBL429023 & 688453 & 5.5 & 5.0093 & TST \\
\hline CHEMBL1340834 & 688453 & 4.65 & 4.5609 & TRN \\
\hline CHEMBL1366071 & 688453 & 4.5 & 5.1198 & TST \\
\hline CHEMBL3213768 & 688453 & 4.45 & 4.8068 & TRN \\
\hline CHEMBL1445663 & 688453 & 4.4 & 5.1452 & TRN \\
\hline CHEMBL1604803 & 688453 & 4.8 & 4.9385 & TRN \\
\hline CHEMBL1561481 & 688453 & 4.45 & 5.0414 & TRN \\
\hline CHEMBL1424746 & 688453 & 5.05 & 4.6785 & TRN \\
\hline CHEMBL1546656 & 688453 & 5.05 & 4.4314 & TRN \\
\hline
\end{tabular}




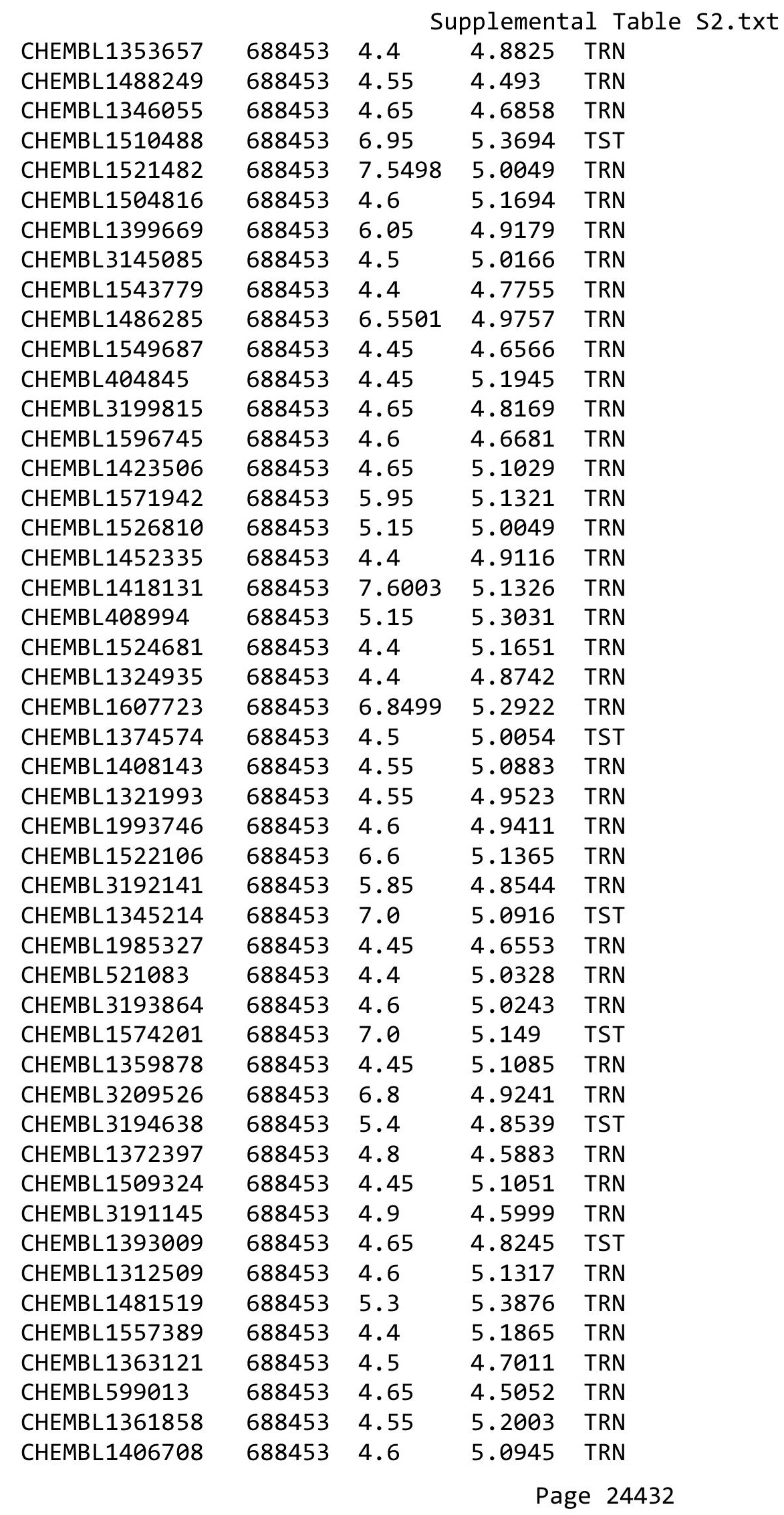




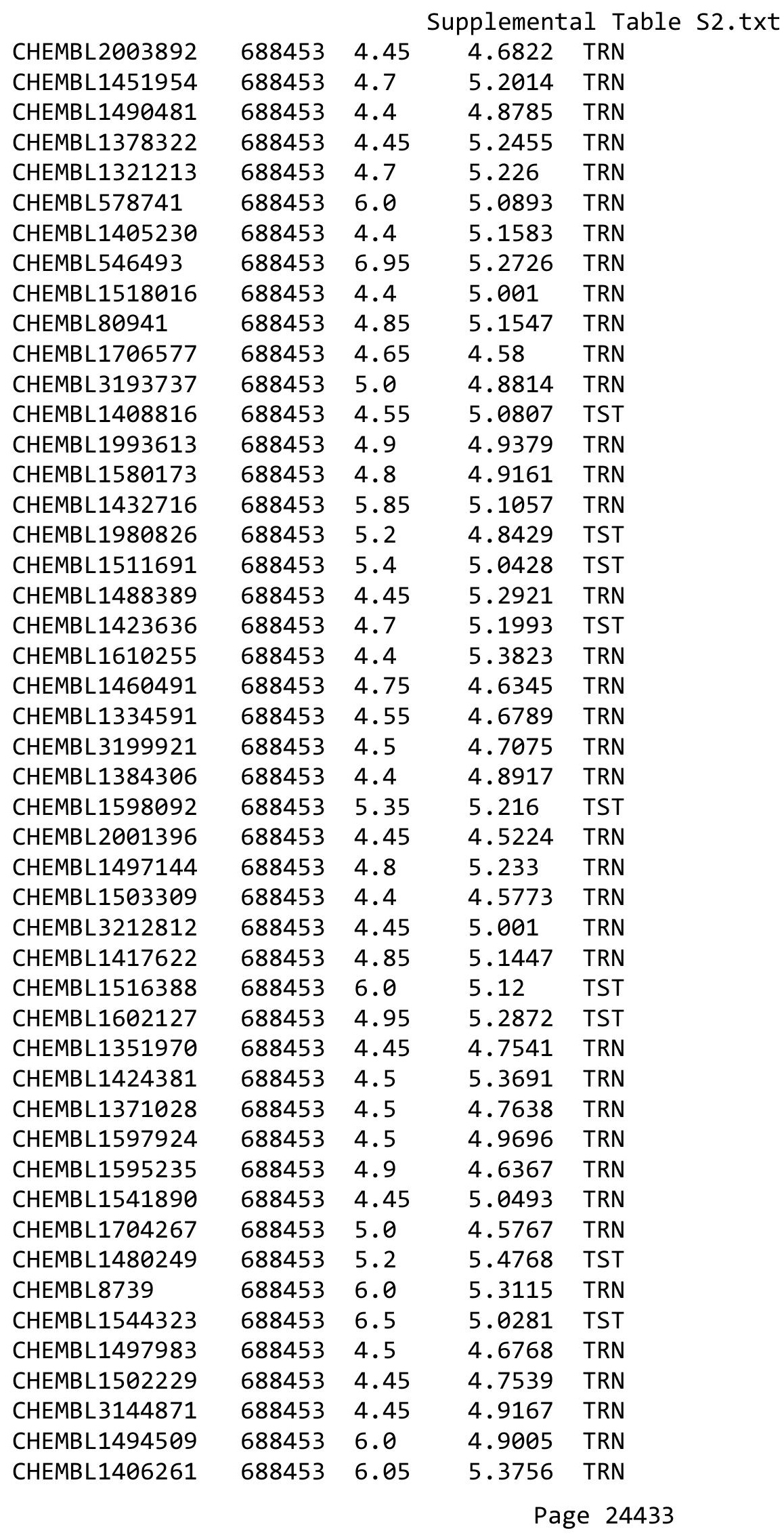




\begin{tabular}{|c|c|c|c|c|c|}
\hline & & \multicolumn{4}{|c|}{ Supplemental Table S2.txt } \\
\hline CHEMBL1380001 & 688453 & 6.7501 & 5.5676 & TRN & \\
\hline CHEMBL1455701 & 688453 & 4.45 & 4.8737 & TRN & \\
\hline CHEMBL1446805 & 688453 & 4.4 & 4.9115 & TRN & \\
\hline CHEMBL592414 & 688453 & 4.4 & 4.9923 & TST & \\
\hline CHEMBL1595525 & 688453 & 4.4 & 4.69600 & 3000000001 & TRN \\
\hline CHEMBL1562756 & 688453 & 4.55 & 5.0316 & TST & \\
\hline CHEMBL1387761 & 688453 & 6.45 & 5.0635 & TRN & \\
\hline CHEMBL1305050 & 688453 & 5.2 & 4.9786 & TRN & \\
\hline CHEMBL1521086 & 688453 & 4.4 & 5.2011 & TRN & \\
\hline CHEMBL1406712 & 688453 & 4.6 & 5.0314 & TRN & \\
\hline CHEMBL1400657 & 688453 & 4.95 & 4.8329 & TRN & \\
\hline CHEMBL1411860 & 688453 & 6.5501 & 5.1545 & TRN & \\
\hline CHEMBL1529871 & 688453 & 4.4 & 4.7501 & TST & \\
\hline CHEMBL1455524 & 688453 & 4.4 & 5.005 & TRN & \\
\hline CHEMBL1406158 & 688453 & 6.6 & 5.0746 & TRN & \\
\hline CHEMBL1363790 & 688453 & 4.45 & 4.8101 & TRN & \\
\hline CHEMBL1536626 & 688453 & 5.0 & 5.048 & TRN & \\
\hline CHEMBL1455429 & 688453 & 5.5 & 5.2716 & TRN & \\
\hline CHEMBL1333151 & 688453 & 7.0 & 4.9382 & TRN & \\
\hline CHEMBL1308606 & 688453 & 4.4 & 4.7708 & TRN & \\
\hline CHEMBL1453978 & 688453 & 4.8 & 5.171 & TRN & \\
\hline CHEMBL1416441 & 688453 & 6.05 & 5.0076 & TRN & \\
\hline CHEMBL1424468 & 688453 & 4.55 & 5.0535 & TRN & \\
\hline CHEMBL1446986 & 688453 & 5.05 & 5.1306 & TRN & \\
\hline CHEMBL1437964 & 688453 & 4.4 & 5.1888 & TRN & \\
\hline CHEMBL1454722 & 688453 & 4.4 & 5.2426 & TRN & \\
\hline CHEMBL1331485 & 688453 & 7.4498 & 5.1769 & TRN & \\
\hline CHEMBL1896972 & 688453 & 4.65 & 4.6431 & TRN & \\
\hline CHEMBL1585234 & 688453 & 4.6 & 4.9229 & TRN & \\
\hline CHEMBL453388 & 688453 & 6.0 & 5.0818 & TST & \\
\hline CHEMBL1364325 & 688453 & 4.5 & 5.0961 & TRN & \\
\hline CHEMBL1330249 & 688453 & 6.0 & 5.0266 & TRN & \\
\hline CHEMBL1562650 & 688453 & 5.5 & 5.0704 & TRN & \\
\hline CHEMBL7463 & 688453 & 4.55 & 4.9744 & TST & \\
\hline CHEMBL1378418 & 688453 & 4.6 & 5.024 & TRN & \\
\hline CHEMBL1406667 & 688453 & 4.5 & 4.8687 & TRN & \\
\hline CHEMBL1334307 & 688453 & 4.9 & 5.106 & TRN & \\
\hline CHEMBL1977384 & 688453 & 4.4 & 4.7122 & TRN & \\
\hline CHEMBL1392335 & 688453 & 4.6 & 4.6115 & TRN & \\
\hline CHEMBL1317166 & 688453 & 4.7 & 5.0686 & TRN & \\
\hline CHEMBL1455868 & 688453 & 6.4 & 5.1222 & TRN & \\
\hline CHEMBL1546783 & 688453 & 4.9 & 5.1214 & TRN & \\
\hline CHEMBL1518732 & 688453 & 6.0 & 5.317 & TST & \\
\hline CHEMBL1343322 & 688453 & 4.4 & 5.082 & TRN & \\
\hline CHEMBL1526913 & 688453 & 5.05 & 5.1632 & TST & \\
\hline CHEMBL1445279 & 688453 & 7.699 & 5.0725 & TRN & \\
\hline CHEMBL 3198785 & 688453 & 7.0501 & 4.9298 & TST & \\
\hline CHEMBL1479937 & 688453 & 6.7001 & 5.4106 & TRN & \\
\hline
\end{tabular}




\begin{tabular}{|c|c|c|c|c|}
\hline \multicolumn{5}{|c|}{ Supplemental Table S2.txt } \\
\hline CHEMBL1305393 & 688453 & 4.75 & 5.2393 & TRN \\
\hline CHEMBL1332715 & 688453 & 5.5 & 5.154 & TRN \\
\hline CHEMBL1599161 & 688453 & 5.0 & 4.6506 & TRN \\
\hline CHEMBL3193997 & 688453 & 4.85 & 4.7765 & TRN \\
\hline CHEMBL1439861 & 688453 & 4.4 & 5.0559 & TRN \\
\hline CHEMBL1423197 & 688453 & 4.45 & 5.2522 & TST \\
\hline CHEMBL1466298 & 688453 & 5.95 & 5.3541 & TRN \\
\hline CHEMBL1472249 & 688453 & 4.95 & 5.045 & TRN \\
\hline CHEMBL1417815 & 688453 & 4.4 & 5.0394 & TRN \\
\hline CHEMBL240331 & 688453 & 5.05 & 5.0132 & TRN \\
\hline CHEMBL1321572 & 688453 & 4.8 & 4.7278 & TRN \\
\hline CHEMBL1339018 & 688453 & 4.45 & 5.0732 & TRN \\
\hline CHEMBL1383878 & 688453 & 4.5 & 4.6119 & TRN \\
\hline CHEMBL1419228 & 688453 & 4.4 & 4.9731 & TRN \\
\hline CHEMBL1420383 & 688453 & 5.2 & 5.0773 & TRN \\
\hline CHEMBL1588434 & 688453 & 5.1 & 4.7018 & TRN \\
\hline CHEMBL1547446 & 688453 & 4.45 & 4.5134 & TRN \\
\hline CHEMBL1388278 & 688453 & 4.6 & 4.7711 & TRN \\
\hline CHEMBL1512517 & 688453 & 4.4 & 5.0469 & TRN \\
\hline CHEMBL1575869 & 688453 & 4.45 & 4.8579 & TRN \\
\hline CHEMBL1508528 & 688453 & 4.4 & 5.0188 & TRN \\
\hline CHEMBL1540803 & 688453 & 5.55 & 5.2081 & TRN \\
\hline CHEMBL1512440 & 688453 & 5.5 & 5.0659 & TRN \\
\hline CHEMBL1488358 & 688453 & 4.4 & 5.0552 & TRN \\
\hline CHEMBL1489025 & 688453 & 4.45 & 4.7686 & TST \\
\hline CHEMBL1478258 & 688453 & 4.4 & 5.1525 & TRN \\
\hline CHEMBL1441804 & 688453 & 4.45 & 5.1625 & TRN \\
\hline CHEMBL1431490 & 688453 & 5.0 & 4.8382 & TRN \\
\hline CHEMBL1485279 & 688453 & 5.1 & 5.4952 & TRN \\
\hline CHEMBL446827 & 688453 & 4.55 & 4.8277 & TRN \\
\hline CHEMBL1600209 & 688453 & 4.7 & 5.0054 & TST \\
\hline CHEMBL1572068 & 688453 & 4.4 & 5.1665 & TST \\
\hline CHEMBL1532909 & 688453 & 4.45 & 5.1936 & TRN \\
\hline CHEMBL1312956 & 688453 & 6.05 & 5.2418 & TRN \\
\hline CHEMBL2004070 & 688453 & 5.25 & 5.0081 & TRN \\
\hline CHEMBL1451968 & 688453 & 4.45 & 5.0227 & TRN \\
\hline CHEMBL1416616 & 688453 & 4.7 & 5.3465 & TST \\
\hline CHEMBL1346868 & 688453 & 5.1 & 5.4434 & TST \\
\hline CHEMBL1364268 & 688453 & 6.1 & 4.9671 & TST \\
\hline CHEMBL1505673 & 688453 & 6.0 & 4.9844 & TRN \\
\hline CHEMBL1547386 & 688453 & 6.05 & 5.1952 & TRN \\
\hline CHEMBL1724937 & 688453 & 4.65 & 4.9429 & TST \\
\hline CHEMBL1496657 & 688453 & 6.8 & 4.9551 & TRN \\
\hline CHEMBL1462153 & 688453 & 5.1 & 5.2069 & TRN \\
\hline CHEMBL3190746 & 688453 & 4.55 & 5.0871 & TRN \\
\hline CHEMBL3194390 & 688453 & 6.0 & 5.0193 & TRN \\
\hline CHEMBL1610116 & 688453 & 5.4 & 5.0527 & TRN \\
\hline CHEMBL1335040 & 688453 & 4.4 & 5.24 & TRN \\
\hline
\end{tabular}




\begin{tabular}{|c|c|c|c|c|c|}
\hline \multicolumn{6}{|c|}{ Supplemental Table S2.txt } \\
\hline CHEMBL1378735 & 688453 & 4.5 & 4.7851 & TRN & \\
\hline CHEMBL1449662 & 688453 & 6.25 & 5.3015 & TRN & \\
\hline CHEMBL1489226 & 688453 & 5.5 & 4.8519 & TRN & \\
\hline CHEMBL546649 & 688453 & 5.1 & 4.9208 & TRN & \\
\hline CHEMBL216504 & 688453 & 4.7 & 4.9822 & TRN & \\
\hline CHEMBL3191927 & 688453 & 5.85 & 4.7939 & TRN & \\
\hline CHEMBL1469743 & 688453 & 4.9 & 4.8121 & TST & \\
\hline CHEMBL3192002 & 688453 & 4.4 & 4.7214 & TST & \\
\hline CHEMBL1371524 & 688453 & 6.8499 & 4.8281 & TRN & \\
\hline CHEMBL1580375 & 688453 & 4.55 & 4.9529 & TRN & \\
\hline CHEMBL1478583 & 688453 & 4.4 & 5.0223 & TRN & \\
\hline CHEMBL1404761 & 688453 & 4.55 & 4.3848 & TRN & \\
\hline CHEMBL1586842 & 688453 & 4.5 & 5.0417 & TRN & \\
\hline CHEMBL1374733 & 688453 & 4.4 & 4.959 & TRN & \\
\hline CHEMBL1543149 & 688453 & 4.4 & 5.2799 & TRN & \\
\hline CHEMBL1544430 & 688453 & 6.8 & 4.937 & TST & \\
\hline CHEMBL1471583 & 688453 & 4.9 & 5.1027 & TRN & \\
\hline CHEMBL1447211 & 688453 & 4.95 & 4.6787 & TRN & \\
\hline CHEMBL1363028 & 688453 & 4.45 & 5.21399 & 99999999995 & TRN \\
\hline CHEMBL1609070 & 688453 & 4.4 & 5.2297 & TRN & \\
\hline CHEMBL1442760 & 688453 & 5.8 & 5.289 & TRN & \\
\hline CHEMBL1344392 & 688453 & 5.2 & 4.7546 & TRN & \\
\hline CHEMBL1543673 & 688453 & 4.95 & 4.9709 & TST & \\
\hline CHEMBL1601258 & 688453 & 4.55 & 4.8308 & TRN & \\
\hline CHEMBL1571837 & 688453 & 7.5498 & 5.0894 & TRN & \\
\hline CHEMBL 2003358 & 688453 & 4.45 & 4.7608 & TRN & \\
\hline CHEMBL1572208 & 688453 & 5.4 & 5.154 & TST & \\
\hline CHEMBL1404403 & 688453 & 5.05 & 5.1567 & TRN & \\
\hline CHEMBL1525878 & 688453 & 6.7001 & 5.1811 & TRN & \\
\hline CHEMBL1344121 & 688453 & 5.45 & 4.7906 & TRN & \\
\hline CHEMBL172439 & 688453 & 5.4 & 4.8638 & TST & \\
\hline CHEMBL1400469 & 688453 & 4.7 & 5.0824 & TRN & \\
\hline CHEMBL1462597 & 688453 & 4.45 & 5.255 & TRN & \\
\hline CHEMBL1549284 & 688453 & 4.65 & 4.8387 & TRN & \\
\hline CHEMBL1494805 & 688453 & 4.5 & 5.0669 & TRN & \\
\hline CHEMBL1530561 & 688453 & 4.65 & 5.0332 & TRN & \\
\hline CHEMBL1390971 & 688453 & 4.5 & 4.9377 & TRN & \\
\hline CHEMBL1300405 & 688453 & 4.4 & 4.8094 & TRN & \\
\hline CHEMBL1423982 & 688453 & 5.4 & 4.965 & TRN & \\
\hline CHEMBL1582834 & 688453 & 4.65 & 4.8822 & TRN & \\
\hline CHEMBL1407291 & 688453 & 5.9 & 4.9924 & TRN & \\
\hline CHEMBL1482670 & 688453 & 5.85 & 4.8327 & TRN & \\
\hline CHEMBL1364549 & 688453 & 4.6 & 5.319 & TRN & \\
\hline CHEMBL1498952 & 688453 & 4.7 & 4.9436 & TRN & \\
\hline CHEMBL1367079 & 688453 & 6.7001 & 4.8955 & TST & \\
\hline CHEMBL1413400 & 688453 & 4.45 & 5.1154 & TRN & \\
\hline CHEMBL1303212 & 688453 & 4.45 & 4.6442 & TRN & \\
\hline CHEMBL1541295 & 688453 & 4.75 & 4.5328 & TRN & \\
\hline
\end{tabular}




\begin{tabular}{|c|c|c|c|c|c|}
\hline & & \multicolumn{4}{|c|}{ Supplemental Table s2.txt } \\
\hline CHEMBL1493155 & 688453 & 4.45 & 4.833 & TRN & \\
\hline CHEMBL1416898 & 688453 & 4.4 & 4.7995 & TRN & \\
\hline CHEMBL1367122 & 688453 & 5.4 & 4.9223 & TRN & \\
\hline CHEMBL1452131 & 688453 & 4.4 & 5.2545 & TRN & \\
\hline CHEMBL3193641 & 688453 & 5.8 & 5.0785 & TRN & \\
\hline CHEMBL1485407 & 688453 & 6.35 & 4.8933 & TRN & \\
\hline CHEMBL1518767 & 688453 & 4.65 & 4.8605 & TRN & \\
\hline CHEMBL1604012 & 688453 & 4.65 & 4.5895 & TRN & \\
\hline CHEMBL1419164 & 688453 & 4.75 & 5.1178 & TRN & \\
\hline CHEMBL1574145 & 688453 & 4.65 & 5.1758 & TRN & \\
\hline CHEMBL1343718 & 688453 & 4.4 & 5.2613 & TRN & \\
\hline CHEMBL1318425 & 688453 & 4.95 & 4.9315 & TRN & \\
\hline CHEMBL1427549 & 688453 & 4.5 & 5.3087 & TRN & \\
\hline CHEMBL3191320 & 688453 & 4.6 & 5.0365 & TRN & \\
\hline CHEMBL1585589 & 688453 & 4.55 & 4.9057 & TST & \\
\hline CHEMBL1560349 & 688453 & 4.4 & 5.1445 & TRN & \\
\hline CHEMBL1441597 & 688453 & 6.4 & 5.1311 & TRN & \\
\hline CHEMBL1562005 & 688453 & 4.65 & 4.8789 & TRN & \\
\hline CHEMBL39 & 688453 & 4.4 & 5.2570 & 0000000001 & TRN \\
\hline CHEMBL1408468 & 688453 & 4.7 & 4.7313 & TRN & \\
\hline CHEMBL1458082 & 688453 & 4.4 & 5.1249 & TRN & \\
\hline CHEMBL1328245 & 688453 & 6.8 & 4.9943 & TRN & \\
\hline CHEMBL1546490 & 688453 & 6.95 & 5.1849 & TRN & \\
\hline CHEMBL1421468 & 688453 & 4.5 & 4.6831 & TRN & \\
\hline CHEMBL1340909 & 688453 & 4.4 & 5.2852 & TRN & \\
\hline CHEMBL1582927 & 688453 & 4.5 & 4.7912 & TRN & \\
\hline CHEMBL1403564 & 688453 & 4.4 & 5.0547 & TRN & \\
\hline CHEMBL1462701 & 688453 & 4.6 & 5.0948 & TRN & \\
\hline CHEMBL1464544 & 688453 & 4.5 & 4.8516 & TRN & \\
\hline CHEMBL1541779 & 688453 & 4.6 & 4.9721 & TRN & \\
\hline CHEMBL1324503 & 688453 & 4.45 & 5.075 & TRN & \\
\hline CHEMBL1448671 & 688453 & 4.45 & 4.6325 & TRN & \\
\hline CHEMBL1601302 & 688453 & 4.5 & 4.7859 & TRN & \\
\hline CHEMBL1471289 & 688453 & 4.9 & 5.0755 & TST & \\
\hline CHEMBL3187596 & 688453 & 4.75 & 4.7297 & TRN & \\
\hline CHEMBL1429861 & 688453 & 4.4 & 5.0956 & TRN & \\
\hline CHEMBL1200567 & 688453 & 5.85 & 4.9809 & TST & \\
\hline CHEMBL1378943 & 688453 & 5.6 & 4.9932 & TST & \\
\hline CHEMBL1393080 & 688453 & 5.4 & 5.2127 & TRN & \\
\hline CHEMBL1445603 & 688453 & 4.5 & 4.8385 & TRN & \\
\hline CHEMBL1529997 & 688453 & 6.8 & 5.38 & TRN & \\
\hline CHEMBL1452184 & 688453 & 4.45 & 5.2122 & TRN & \\
\hline CHEMBL1301096 & 688453 & 4.45 & 4.7873 & TRN & \\
\hline CHEMBL1412131 & 688453 & 4.45 & 4.702 & TRN & \\
\hline CHEMBL3193247 & 688453 & 4.55 & 4.5282 & TRN & \\
\hline CHEMBL1479830 & 688453 & 5.45 & 5.0925 & TST & \\
\hline CHEMBL549640 & 688453 & 4.6 & 4.5276 & TRN & \\
\hline CHEMBL1469880 & 688453 & 4.4 & 5.193 & TRN & \\
\hline
\end{tabular}




\begin{tabular}{|c|c|c|c|c|c|}
\hline \multicolumn{6}{|c|}{ Supplemental Table s2.txt } \\
\hline CHEMBL1480327 & 688453 & 5.9 & 5.0498 & TRN & \\
\hline CHEMBL1426003 & 688453 & 4.45 & 5.0191 & TRN & \\
\hline CHEMBL1531537 & 688453 & 5.15 & 4.8407 & TST & \\
\hline CHEMBL1333391 & 688453 & 4.45 & 5.3179 & TRN & \\
\hline CHEMBL1441738 & 688453 & 4.5 & 4.6967 & TST & \\
\hline CHEMBL1459173 & 688453 & 6.4 & 5.40799 & 99999999995 & TRN \\
\hline CHEMBL192600 & 688453 & 4.8 & 5.0352 & TRN & \\
\hline CHEMBL3194162 & 688453 & 5.2 & 4.8785 & TRN & \\
\hline CHEMBL1330390 & 688453 & 4.5 & 4.7427 & TRN & \\
\hline CHEMBL1519507 & 688453 & 4.65 & 4.9875 & TRN & \\
\hline CHEMBL1588707 & 688453 & 4.4 & 4.8056 & TRN & \\
\hline CHEMBL1588836 & 688453 & 7.3002 & 5.2943 & TRN & \\
\hline CHEMBL1556061 & 688453 & 6.8 & 5.2477 & TRN & \\
\hline CHEMBL 3208556 & 688453 & 4.4 & 4.7695 & TRN & \\
\hline CHEMBL1530112 & 688453 & 4.4 & 5.0785 & TRN & \\
\hline CHEMBL3195717 & 688453 & 4.8 & 4.4875 & TRN & \\
\hline CHEMBL1562121 & 688453 & 4.4 & 5.044 & TRN & \\
\hline CHEMBL1360878 & 688453 & 4.5 & 5.0787 & TRN & \\
\hline CHEMBL3197060 & 688453 & 4.4 & 4.9809 & TST & \\
\hline CHEMBL1439429 & 688453 & 5.15 & 5.0859 & TRN & \\
\hline CHEMBL1415497 & 688453 & 4.5 & 4.9543 & TRN & \\
\hline CHEMBL3198837 & 688453 & 4.6 & 4.6907 & TRN & \\
\hline CHEMBL1580876 & 688453 & 4.9 & 4.98600 & 0000000001 & TRN \\
\hline CHEMBL 267548 & 688453 & 6.0 & 4.9793 & TST & \\
\hline CHEMBL1424878 & 688453 & 5.45 & 4.8142 & TRN & \\
\hline CHEMBL1548613 & 688453 & 4.45 & 4.9714 & TST & \\
\hline CHEMBL1604290 & 688453 & 6.7501 & 5.0319 & TRN & \\
\hline CHEMBL1452282 & 688453 & 5.25 & 5.101 & TRN & \\
\hline CHEMBL1399046 & 688453 & 4.4 & 5.2038 & TRN & \\
\hline CHEMBL1578537 & 688453 & 5.4 & 4.6866 & TRN & \\
\hline CHEMBL1372654 & 688453 & 6.8499 & 5.1819 & TRN & \\
\hline CHEMBL1448985 & 688453 & 4.6 & 4.8655 & TST & \\
\hline CHEMBL1373732 & 688453 & 4.4 & 5.2379 & TST & \\
\hline CHEMBL3192740 & 688453 & 5.05 & 4.7654 & TST & \\
\hline CHEMBL1447682 & 688453 & 5.1 & 5.2138 & TST & \\
\hline CHEMBL1347850 & 688453 & 4.6 & 5.0891 & TST & \\
\hline CHEMBL1432884 & 688453 & 4.6 & 4.8584 & TST & \\
\hline CHEMBL3191201 & 688453 & 5.4 & 4.7662 & TST & \\
\hline CHEMBL1463767 & 688453 & 6.6 & 5.0314 & TST & \\
\hline CHEMBL1423271 & 688453 & 4.45 & 4.9194 & TST & \\
\hline CHEMBL1352624 & 688453 & 4.5 & 4.4568 & TST & \\
\hline CHEMBL1599132 & 688453 & 4.5 & 4.9531 & TST & \\
\hline CHEMBL1608604 & 688453 & 4.4 & 4.9266 & TST & \\
\hline CHEMBL1404357 & 688453 & 4.65 & 5.2094 & TST & \\
\hline CHEMBL1547073 & 688453 & 6.35 & 4.9874 & TST & \\
\hline CHEMBL1471220 & 688453 & 4.65 & 5.1256 & TST & \\
\hline CHEMBL1341334 & 688453 & 4.4 & 5.0494 & TST & \\
\hline CHEMBL1488063 & 688453 & 4.4 & 5.0326 & TST & \\
\hline
\end{tabular}




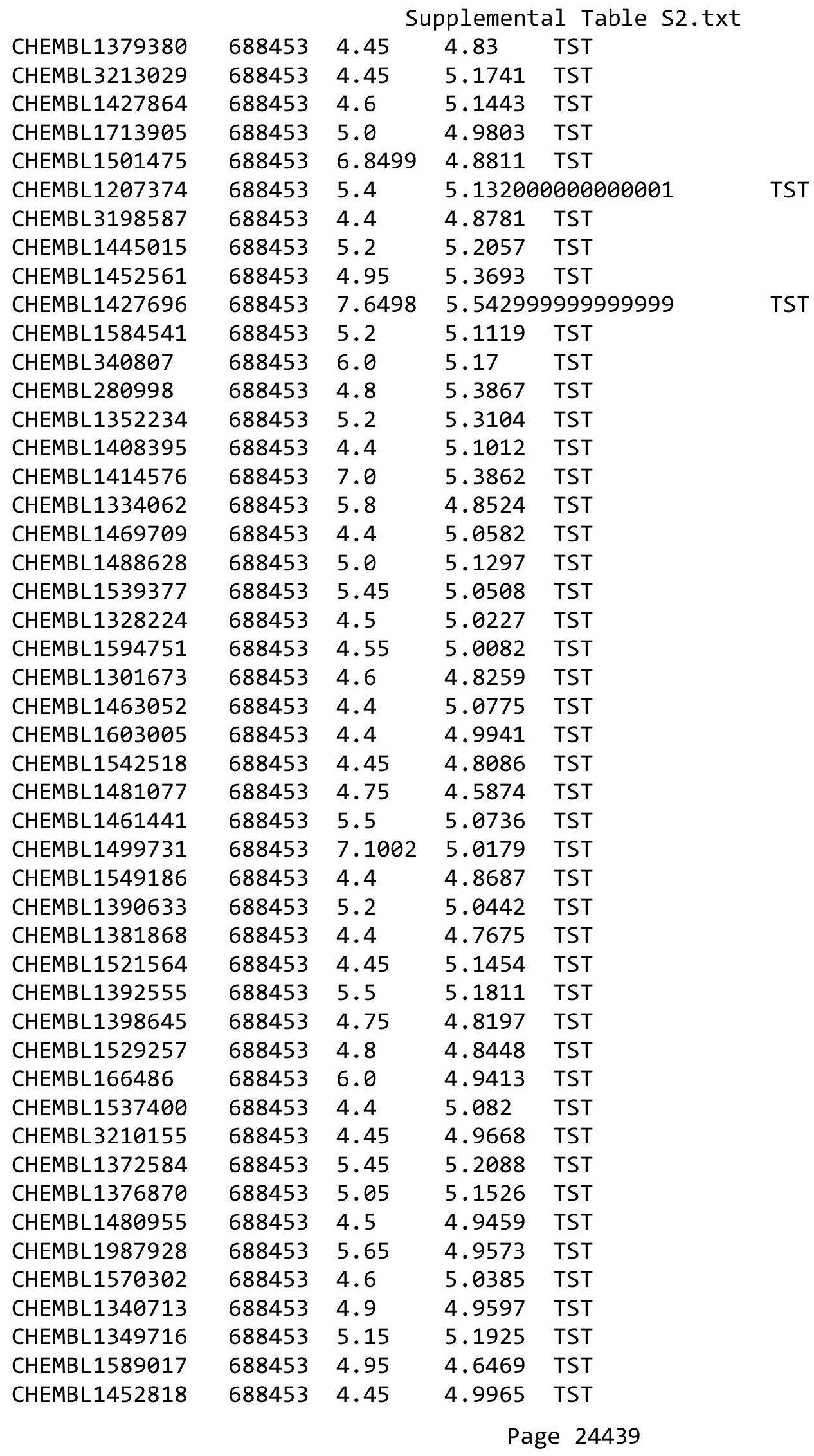




\begin{tabular}{|c|c|c|c|c|}
\hline \multicolumn{5}{|c|}{ Supplemental Table S2.txt } \\
\hline CHEMBL1402056 & 688453 & 4.65 & 4.8365 & TST \\
\hline CHEMBL1549660 & 688453 & 4.55 & 4.8314 & TST \\
\hline CHEMBL1571348 & 688453 & 4.45 & 4.5693 & TST \\
\hline CHEMBL1208858 & 688453 & 4.6 & 5.0306 & TST \\
\hline CHEMBL1579424 & 688453 & 4.45 & 5.2258 & TST \\
\hline CHEMBL1439895 & 688453 & 4.6 & 4.7337 & TST \\
\hline CHEMBL1421724 & 688453 & 6.8 & 5.1803 & TST \\
\hline CHEMBL1599535 & 688453 & 5.45 & 5.1521 & TST \\
\hline CHEMBL1340228 & 688453 & 4.6 & 4.7083 & TST \\
\hline CHEMBL 2007318 & 688453 & 4.8 & 4.8771 & TST \\
\hline CHEMBL23194 & 688453 & 4.5 & 5.5196 & TST \\
\hline CHEMBL1422601 & 688453 & 4.6 & 4.9356 & TST \\
\hline CHEMBL1562034 & 688453 & 6.15 & 5.0044 & TST \\
\hline CHEMBL1354529 & 688453 & 4.4 & 5.0238 & TST \\
\hline CHEMBL1502458 & 688453 & 4.6 & 5.1481 & TST \\
\hline CHEMBL1416846 & 688453 & 4.4 & 4.8236 & TST \\
\hline CHEMBL1224512 & 688453 & 6.1 & 4.9615 & TST \\
\hline CHEMBL1380386 & 688453 & 4.65 & 5.3944 & TST \\
\hline CHEMBL1531174 & 688453 & 5.1 & 4.9397 & TST \\
\hline CHEMBL1343466 & 688453 & 6.7001 & 5.1006 & TST \\
\hline CHEMBL1350426 & 688453 & 4.45 & 4.779 & TST \\
\hline CHEMBL3196993 & 688453 & 5.5 & 5.0089 & TST \\
\hline CHEMBL1442956 & 688453 & 4.4 & 4.885 & TST \\
\hline CHEMBL1370295 & 688453 & 4.4 & 5.2296 & TST \\
\hline CHEMBL1466912 & 688453 & 4.4 & 4.5998 & TST \\
\hline CHEMBL1442764 & 688453 & 4.55 & 4.6829 & TST \\
\hline CHEMBL1504166 & 688453 & 4.5 & 4.9422 & TST \\
\hline CHEMBL1996233 & 688453 & 4.65 & 4.7408 & TST \\
\hline CHEMBL1442104 & 688453 & 4.45 & 5.0093 & TST \\
\hline CHEMBL1528814 & 688453 & 5.05 & 5.0949 & TST \\
\hline CHEMBL1400132 & 688453 & 4.75 & 4.9425 & TST \\
\hline CHEMBL1336564 & 688453 & 4.5 & 5.0809 & TST \\
\hline CHEMBL1491389 & 688453 & 4.6 & 5.2537 & TST \\
\hline CHEMBL1533852 & 688453 & 6.5501 & 5.2891 & TST \\
\hline CHEMBL1534707 & 688453 & 5.05 & 4.9896 & TST \\
\hline CHEMBL1591874 & 688453 & 4.75 & 4.9268 & TST \\
\hline CHEMBL1346889 & 688453 & 4.45 & 5.0782 & TST \\
\hline CHEMBL1601846 & 688453 & 5.35 & 5.2344 & TST \\
\hline CHEMBL1309624 & 688453 & 4.4 & 5.1137 & TST \\
\hline CHEMBL1408586 & 688453 & 6.8 & 4.9702 & TST \\
\hline CHEMBL1411252 & 688453 & 4.4 & 4.9607 & TST \\
\hline CHEMBL131921 & 688453 & 5.9 & 4.9995 & TST \\
\hline CHEMBL1556041 & 688453 & 5.45 & 5.033 & TST \\
\hline CHEMBL1362572 & 688453 & 4.45 & 4.6381 & TST \\
\hline CHEMBL1429133 & 688453 & 4.4 & 5.2632 & TST \\
\hline CHEMBL1560414 & 688453 & 6.7501 & 5.0972 & TST \\
\hline CHEMBL1483257 & 688453 & 6.4 & 5.379 & TST \\
\hline CHEMBL1373183 & 688453 & 4.65 & 4.7143 & TST \\
\hline
\end{tabular}




\begin{tabular}{|c|c|c|c|c|c|}
\hline \multicolumn{6}{|c|}{ Supplemental Table S2.txt } \\
\hline CHEMBL45068 & 688453 & 4.9 & 5.2577 & TST & \\
\hline CHEMBL1481992 & 688453 & 4.4 & 5.0713 & TST & \\
\hline CHEMBL3195461 & 688453 & 5.05 & 4.8722 & TST & \\
\hline CHEMBL 3192475 & 688453 & 4.4 & 4.84 & TST & \\
\hline CHEMBL1502374 & 688453 & 4.75 & 4.9356 & TST & \\
\hline CHEMBL1383603 & 688453 & 4.45 & 5.1054 & TST & \\
\hline CHEMBL3189598 & 688453 & 5.2 & 5.2075 & TST & \\
\hline CHEMBL1540453 & 688453 & 4.45 & 4.8803 & TST & \\
\hline CHEMBL1452827 & 688453 & 4.45 & 4.9218 & TST & \\
\hline CHEMBL1482057 & 688453 & 5.45 & 5.1221 & TST & \\
\hline CHEMBL1256686 & 688453 & 6.0 & 4.8213 & TST & \\
\hline CHEMBL1368934 & 688453 & 4.4 & 5.0185 & TST & \\
\hline CHEMBL1559494 & 688453 & 4.5 & 4.9796 & TST & \\
\hline CHEMBL1458900 & 688453 & 4.45 & 5.1075 & TST & \\
\hline CHEMBL1588482 & 688453 & 5.4 & 5.1138 & TST & \\
\hline CHEMBL1436272 & 688453 & 4.55 & 4.9981 & TST & \\
\hline CHEMBL1536598 & 688453 & 5.3 & 4.7013 & TST & \\
\hline CHEMBL1527095 & 688453 & 4.65 & 4.6827 & TST & \\
\hline CHEMBL1606247 & 688453 & 6.7001 & 4.9571 & TST & \\
\hline CHEMBL1502893 & 688453 & 7.6003 & 5.1924 & TST & \\
\hline CHEMBL1347145 & 688453 & 4.4 & 5.1498 & TST & \\
\hline CHEMBL1457476 & 688453 & 4.6 & 4.9973 & TST & \\
\hline CHEMBL1374841 & 688453 & 4.55 & 4.6489 & TST & \\
\hline CHEMBL1415500 & 688453 & 4.4 & 4.9488 & TST & \\
\hline CHEMBL1410476 & 688453 & 5.35 & 5.2617 & TST & \\
\hline CHEMBL1966792 & 688453 & 4.55 & 4.4719 & TST & \\
\hline CHEMBL3190287 & 688453 & 4.4 & 4.6215 & TST & \\
\hline CHEMBL1542726 & 688453 & 5.85 & 4.8456 & TST & \\
\hline CHEMBL3196212 & 688453 & 4.45 & 4.8315 & TST & \\
\hline CHEMBL1376685 & 688453 & 4.4 & 5.1837 & TST & \\
\hline CHEMBL1435886 & 688453 & 6.2 & 5.1168 & TST & \\
\hline CHEMBL3192605 & 688453 & 5.05 & 4.9672 & TST & \\
\hline CHEMBL 2448500 & 688453 & 4.45 & 5.2739 & TST & \\
\hline CHEMBL1519330 & 688453 & 5.2 & 5.0029 & TST & \\
\hline CHEMBL1310336 & 688453 & 4.45 & 4.713 & TST & \\
\hline CHEMBL1383193 & 688453 & 4.45 & $5.4920 e$ & 0000000001 & TST \\
\hline CHEMBL1415088 & 688453 & 4.45 & 4.753 & TST & \\
\hline CHEMBL1429802 & 688453 & 5.35 & 4.9715 & TST & \\
\hline CHEMBL1326180 & 688453 & 4.95 & 5.0888 & TST & \\
\hline CHEMBL1379222 & 688453 & 5.05 & 4.9465 & TST & \\
\hline CHEMBL1333249 & 688453 & 6.0 & 4.6253 & TST & \\
\hline CHEMBL1547092 & 688453 & 4.4 & 4.8327 & TST & \\
\hline CHEMBL1416169 & 688453 & 4.6 & 4.7265 & TST & \\
\hline CHEMBL1414859 & 688453 & 5.95 & 5.1145 & TST & \\
\hline CHEMBL1300503 & 688453 & 5.3 & 5.0023 & TST & \\
\hline CHEMBL1370836 & 688453 & 4.45 & 4.7637 & TST & \\
\hline CHEMBL1353840 & 688453 & 4.4 & 4.8108 & TST & \\
\hline CHEMBL1303782 & 688453 & 4.4 & 5.0419 & TST & \\
\hline
\end{tabular}




\begin{tabular}{|c|c|c|c|c|c|}
\hline \multicolumn{6}{|c|}{ Supplemental Table s2.txt } \\
\hline CHEMBL1438006 & 688453 & 4.55 & 5.0046 & TST & \\
\hline CHEMBL1386978 & 688453 & 4.4 & 4.8956 & TST & \\
\hline CHEMBL1350120 & 688453 & 4.45 & 5.0723 & TST & \\
\hline CHEMBL1608603 & 688453 & 4.7 & 4.6802 & TST & \\
\hline CHEMBL1496627 & 688453 & 4.45 & 5.13899 & 9999999999 & TST \\
\hline CHEMBL1588047 & 688453 & 4.55 & 4.7899 & TST & \\
\hline CHEMBL1503129 & 688453 & 4.4 & 5.0532 & TST & \\
\hline CHEMBL3190701 & 688453 & 5.3 & 5.0763 & TST & \\
\hline CHEMBL1352976 & 688453 & 6.1 & 5.2038 & TST & \\
\hline CHEMBL1431779 & 688453 & 6.5501 & 5.09699 & 99999999995 & TST \\
\hline CHEMBL337173 & 688453 & 6.0 & 5.0748 & TST & \\
\hline CHEMBL1509862 & 688453 & 4.45 & 4.8813 & TST & \\
\hline CHEMBL1365055 & 688453 & 4.4 & 5.2553 & TST & \\
\hline CHEMBL1405330 & 688453 & 7.2503 & 4.9658 & TST & \\
\hline CHEMBL1406027 & 688453 & 4.4 & 5.2944 & TST & \\
\hline CHEMBL3213938 & 688453 & 5.35 & 5.1544 & TST & \\
\hline CHEMBL1507172 & 688453 & 4.6 & 4.7216 & TST & \\
\hline CHEMBL1512190 & 688453 & 4.45 & 4.9968 & TST & \\
\hline CHEMBL416657 & 688453 & 4.5 & 5.0542 & TST & \\
\hline CHEMBL1533488 & 688453 & 4.5 & 5.3727 & TST & \\
\hline CHEMBL1480658 & 688453 & 4.4 & 5.1194 & TST & \\
\hline CHEMBL51931 & 688453 & 4.4 & 5.32799 & 9999999999 & \\
\hline CHEMBL1581065 & 688453 & 4.55 & 4.9964 & TST & \\
\hline CHEMBL1320975 & 688453 & 4.85 & 4.8296 & TST & \\
\hline CHEMBL3199284 & 688453 & 4.6 & 4.7428 & TST & \\
\hline CHEMBL1392546 & 688453 & 4.6 & 4.996 & TST & \\
\hline CHEMBL1504738 & 688453 & 4.45 & 5.0581 & TST & \\
\hline CHEMBL1583312 & 688453 & 4.75 & 5.1373 & TST & \\
\hline CHEMBL1366848 & 688453 & 4.85 & 5.206 & TST & \\
\hline CHEMBL3213660 & 688453 & 4.45 & 4.8139 & TST & \\
\hline CHEMBL3199408 & 688453 & 4.55 & 5.1454 & TST & \\
\hline CHEMBL1400644 & 688453 & 6.5501 & 5.1065 & TST & \\
\hline CHEMBL1522018 & 688453 & 4.6 & 4.5764 & TST & \\
\hline CHEMBL1422472 & 688453 & 4.4 & 4.7507 & TST & \\
\hline CHEMBL1487660 & 688453 & 4.5 & 4.6962 & TST & \\
\hline CHEMBL1570962 & 688453 & 5.2 & 5.2298 & TST & \\
\hline CHEMBL1529213 & 688453 & 4.4 & 5.0777 & TST & \\
\hline CHEMBL1477236 & 688453 & 4.45 & 5.1655 & TST & \\
\hline CHEMBL1399897 & 688453 & 5.55 & 5.3178 & TST & \\
\hline CHEMBL1607991 & 688453 & 4.45 & 4.6959 & TST & \\
\hline CHEMBL3191231 & 688453 & 5.55 & 5.0527 & TST & \\
\hline CHEMBL1567682 & 688453 & 4.6 & 4.8795 & TST & \\
\hline CHEMBL1461753 & 688453 & 4.45 & 5.2106 & TST & \\
\hline CHEMBL1965814 & 688453 & 4.65 & 5.0626 & TST & \\
\hline CHEMBL1321592 & 688453 & 4.4 & 5.2327 & TST & \\
\hline CHEMBL1511437 & 688453 & 5.45 & 5.0046 & TST & \\
\hline CHEMBL1542241 & 688453 & 4.4 & 4.9874 & TST & \\
\hline CHEMBL1369950 & 688453 & 5.75 & 5.1543 & TST & \\
\hline
\end{tabular}




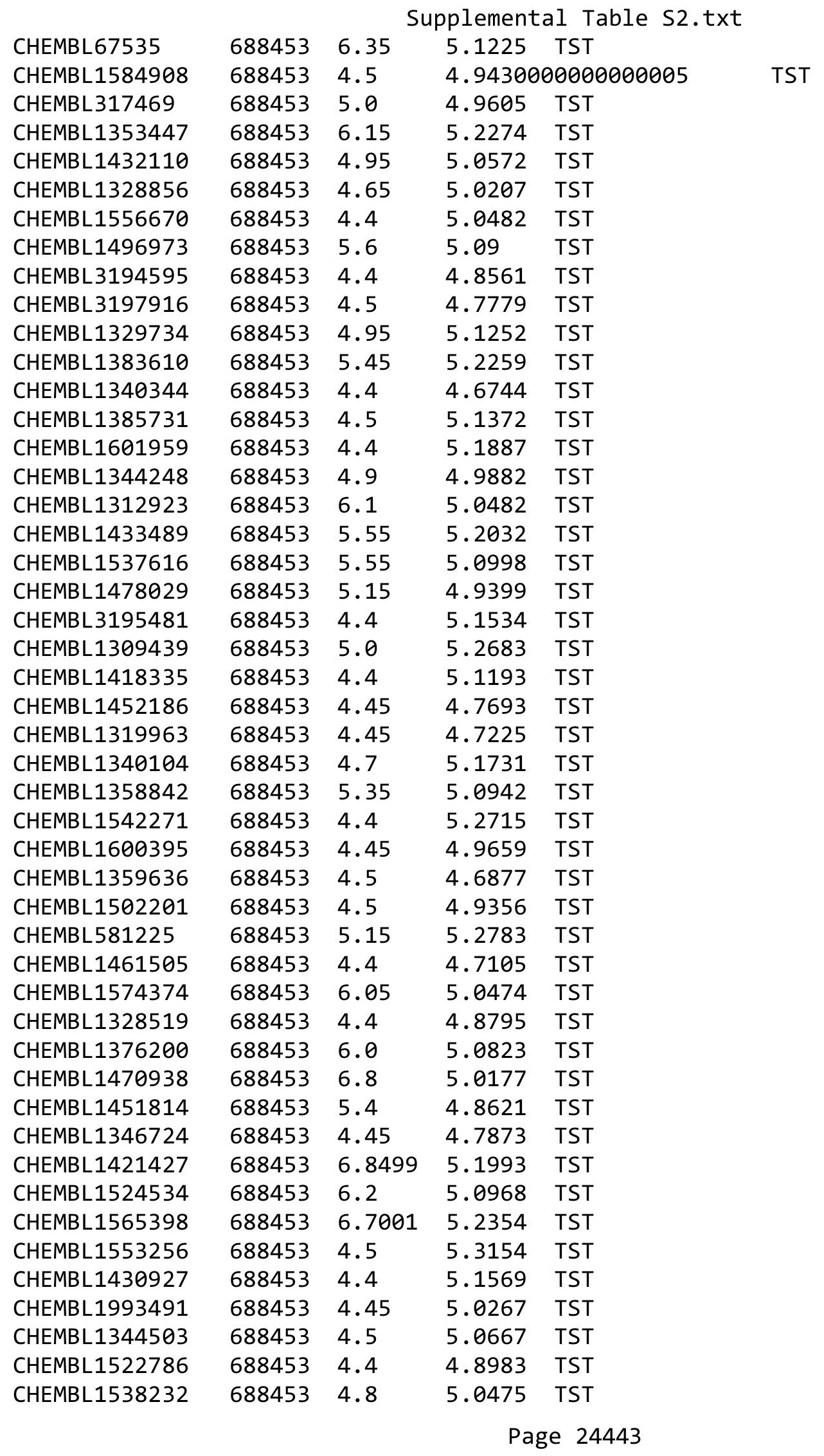




\begin{tabular}{|c|c|c|c|c|c|}
\hline \multicolumn{6}{|c|}{ Supplemental Table S2.txt } \\
\hline CHEMBL1330934 & 688453 & 6.1 & 5.1013 & TST & \\
\hline CHEMBL1369100 & 688453 & 4.4 & 5.1122 & TST & \\
\hline CHEMBL1555486 & 688453 & 4.45 & 4.9106 & TST & \\
\hline CHEMBL1417389 & 688453 & 4.45 & 5.1048 & TST & \\
\hline CHEMBL1362307 & 688453 & 4.7 & 4.8427 & TST & \\
\hline CHEMBL1384797 & 688453 & 4.5 & 5.0367 & TST & \\
\hline CHEMBL1531948 & 688453 & 6.8 & 5.3145 & TST & \\
\hline CHEMBL1563341 & 688453 & 4.4 & 4.6764 & TST & \\
\hline CHEMBL1358724 & 688453 & 4.4 & 5.1137 & TST & \\
\hline CHEMBL1477786 & 688453 & 4.45 & 4.7792 & TST & \\
\hline CHEMBL1398604 & 688453 & 4.55 & 5.2935 & TST & \\
\hline CHEMBL1522579 & 688453 & 4.8 & 5.0096 & TST & \\
\hline CHEMBL1597171 & 688453 & 6.05 & 5.2411 & TST & \\
\hline CHEMBL3212668 & 688453 & 7.6498 & 5.2319 & TST & \\
\hline CHEMBL3210043 & 688453 & 4.45 & 4.9522 & TST & \\
\hline CHEMBL1445414 & 688453 & 7.5498 & 5.0536 & TST & \\
\hline CHEMBL1365795 & 688453 & 5.2 & 5.4295 & TST & \\
\hline CHEMBL1510803 & 688453 & 4.5 & 4.8316 & TST & \\
\hline CHEMBL1517521 & 688453 & 4.35 & 4.9727 & TST & \\
\hline CHEMBL1313195 & 688453 & 4.95 & 4.9029 & TST & \\
\hline CHEMBL1426768 & 688453 & 4.45 & 4.9239 & TST & \\
\hline CHEMBL500996 & 688453 & 4.4 & 5.3489 & TST & \\
\hline CHEMBL1303536 & 688453 & 4.85 & 4.8252 & TST & \\
\hline CHEMBL1374385 & 688453 & 4.65 & 4.9728 & TST & \\
\hline CHEMBL1407122 & 688453 & 4.4 & 5.2772 & TST & \\
\hline CHEMBL1459529 & 688453 & 4.45 & 5.1217 & TST & \\
\hline CHEMBL1375487 & 688453 & 4.4 & 4.9734 & TST & \\
\hline CHEMBL1327545 & 688453 & 4.6 & 4.992 & TST & \\
\hline CHEMBL1580966 & 688453 & 4.55 & 5.0783 & TST & \\
\hline CHEMBL1362933 & 688453 & 4.55 & 5.1942 & TST & \\
\hline CHEMBL3191804 & 688453 & 5.15 & 5.023 & TST & \\
\hline CHEMBL1440706 & 688453 & 4.55 & 4.9111 & TST & \\
\hline CHEMBL1604189 & 688453 & 4.6 & 5.0433 & TST & \\
\hline CHEMBL1480886 & 688453 & 4.5 & 5.1112 & TST & \\
\hline CHEMBL3191928 & 688453 & 4.45 & 4.8778 & TST & \\
\hline CHEMBL1545337 & 688453 & 5.2 & 5.1803 & TST & \\
\hline CHEMBL1569332 & 688453 & 6.95 & 5.2338 & TST & \\
\hline CHEMBL1515417 & 688453 & 4.6 & 4.94300 & 00000000005 & TS \\
\hline CHEMBL261641 & 688453 & 4.55 & 4.6752 & TST & \\
\hline CHEMBL1322088 & 688453 & 4.45 & 4.8753 & TST & \\
\hline CHEMBL1606258 & 688453 & 5.2 & 5.2613 & TST & \\
\hline CHEMBL1909455 & 688453 & 4.55 & 4.8861 & TST & \\
\hline CHEMBL1478382 & 688453 & 4.65 & 4.9865 & TST & \\
\hline CHEMBL507824 & 688453 & 4.7 & 4.9813 & TST & \\
\hline CHEMBL1453654 & 688453 & 4.4 & 5.0013 & TST & \\
\hline CHEMBL1421414 & 688453 & 4.4 & 5.0466 & TST & \\
\hline CHEMBL1358284 & 688453 & 4.5 & 5.1907 & TST & \\
\hline CHEMBL1300312 & 688453 & 4.65 & 4.8314 & TST & \\
\hline
\end{tabular}




\begin{tabular}{|c|c|c|c|c|c|}
\hline \multicolumn{6}{|c|}{ Supplemental Table s2.txt } \\
\hline CHEMBL1308332 & 688453 & 4.4 & 5.1672 & TST & \\
\hline CHEMBL 2003564 & 688453 & 4.5 & 4.877 & TST & \\
\hline CHEMBL1564253 & 688453 & 4.55 & 4.92 & TST & \\
\hline CHEMBL1392149 & 688453 & 6.8 & 5.1935 & TST & \\
\hline CHEMBL1310971 & 688453 & 6.5501 & 5.0873 & TST & \\
\hline CHEMBL1447308 & 688453 & 4.4 & 5.1626 & TST & \\
\hline CHEMBL1315981 & 688453 & 5.95 & 4.963 & TST & \\
\hline CHEMBL1327403 & 688453 & 6.9 & 5.1267 & TST & \\
\hline CHEMBL1491029 & 688453 & 6.0 & 5.3027 & TST & \\
\hline CHEMBL 3144868 & 688453 & 4.4 & 4.9426 & TST & \\
\hline CHEMBL602573 & 688453 & 5.5 & 4.7183 & TST & \\
\hline CHEMBL1472085 & 688453 & 4.4 & 5.0978 & TST & \\
\hline CHEMBL2369209 & 688453 & 4.6 & 5.0227 & TST & \\
\hline CHEMBL1449018 & 688453 & 4.75 & 5.2167 & TST & \\
\hline CHEMBL1389034 & 688453 & 4.5 & 4.90300 & 00000000005 & TST \\
\hline CHEMBL1433441 & 688453 & 4.5 & 5.2728 & TST & \\
\hline CHEMBL1321473 & 688453 & 4.45 & 4.838 & TST & \\
\hline CHEMBL 2093214 & 688453 & 5.45 & 5.0914 & TST & \\
\hline CHEMBL 3189251 & 688453 & 4.5 & 4.7063 & TST & \\
\hline CHEMBL1399606 & 688453 & 4.4 & 5.0593 & TST & \\
\hline CHEMBL1428673 & 688453 & 5.35 & 5.2721 & TST & \\
\hline CHEMBL1452397 & 688453 & 4.65 & 4.9031 & TST & \\
\hline CHEMBL1300662 & 688453 & 4.4 & 4.8466 & TST & \\
\hline CHEMBL1313635 & 688453 & 4.95 & 5.1523 & TST & \\
\hline CHEMBL1471354 & 688453 & 5.95 & 5.4095 & TST & \\
\hline CHEMBL1429083 & 688453 & 4.55 & 4.3985 & TST & \\
\hline CHEMBL1338776 & 688453 & 6.95 & 4.805 & TST & \\
\hline CHEMBL1609128 & 688453 & 4.4 & 4.8631 & TST & \\
\hline CHEMBL1547225 & 688453 & 4.4 & 5.2349 & TST & \\
\hline CHEMBL151 & 688453 & 6.0 & 5.0768 & TST & \\
\hline CHEMBL1451059 & 688453 & 4.6 & 5.3935 & TST & \\
\hline CHEMBL1487253 & 688453 & 4.45 & 5.0921 & TST & \\
\hline CHEMBL1903762 & 688453 & 4.6 & 4.9069 & TST & \\
\hline CHEMBL 3211277 & 688453 & 4.4 & 5.0345 & TST & \\
\hline CHEMBL3197786 & 688453 & 4.6 & 4.8473 & TST & \\
\hline CHEMBL1511665 & 688453 & 4.4 & 4.9502 & TST & \\
\hline CHEMBL1327418 & 688453 & 4.7 & 4.5459 & TST & \\
\hline CHEMBL139935 & 688453 & 4.4 & 5.0539 & TST & \\
\hline CHEMBL1570479 & 688453 & 6.15 & 5.0136 & TST & \\
\hline CHEMBL3195625 & 688453 & 4.45 & 5.0611 & TST & \\
\hline CHEMBL1501922 & 688453 & 4.75 & 5.3094 & TST & \\
\hline CHEMBL1580510 & 688453 & 4.5 & 5.0922 & TST & \\
\hline CHEMBL1504875 & 688453 & 4.7 & 5.0547 & TST & \\
\hline CHEMBL1329140 & 688453 & 4.4 & 4.9828 & TST & \\
\hline CHEMBL77030 & 688453 & 6.0 & 5.0312 & TST & \\
\hline CHEMBL1332007 & 688453 & 5.8 & 5.1615 & TST & \\
\hline CHEMBL1372204 & 688453 & 6.8499 & 4.9455 & TST & \\
\hline CHEMBL1458400 & 688453 & 4.4 & 5.1558 & TST & \\
\hline
\end{tabular}




\begin{tabular}{|c|c|c|c|c|}
\hline \multicolumn{5}{|c|}{ Supplemental Table S2.txt } \\
\hline CHEMBL1301635 & 688453 & 5.35 & 4.8908 & TST \\
\hline CHEMBL1326683 & 688453 & 4.4 & 5.1501 & TST \\
\hline CHEMBL1505616 & 688453 & 5.9 & 5.0114 & TST \\
\hline CHEMBL1397534 & 688453 & 5.2 & 5.0599 & TST \\
\hline CHEMBL1400764 & 688453 & 4.55 & 5.0632 & TST \\
\hline CHEMBL1310531 & 688453 & 4.4 & 5.2863 & TST \\
\hline CHEMBL1561713 & 688453 & 4.45 & 5.0631 & TST \\
\hline CHEMBL1491530 & 688453 & 4.55 & 4.8387 & TST \\
\hline CHEMBL1432535 & 688453 & 4.8 & 4.8179 & TST \\
\hline CHEMBL1584223 & 688453 & 5.4 & 5.1123 & TST \\
\hline CHEMBL1319476 & 688453 & 4.55 & 4.9328 & TST \\
\hline CHEMBL1431971 & 688453 & 4.5 & 5.011 & TST \\
\hline CHEMBL1445168 & 688453 & 6.05 & 4.7321 & TST \\
\hline CHEMBL3213103 & 688453 & 4.6 & 4.5935 & TST \\
\hline CHEMBL1607164 & 688453 & 6.8 & 5.3766 & TST \\
\hline CHEMBL1468914 & 688453 & 7.15 & 5.3847 & TST \\
\hline CHEMBL1728821 & 688453 & 4.45 & 4.5586 & TST \\
\hline CHEMBL1571868 & 688453 & 6.1 & 5.3268 & TST \\
\hline CHEMBL2448501 & 688453 & 5.4 & 5.2783 & TST \\
\hline CHEMBL1419301 & 688453 & 4.4 & 4.6704 & TST \\
\hline CHEMBL1399533 & 688453 & 4.55 & 4.8898 & TST \\
\hline CHEMBL1509301 & 688453 & 4.4 & 5.334 & TST \\
\hline CHEMBL1361191 & 688453 & 4.45 & 5.0005 & TST \\
\hline CHEMBL1973501 & 688453 & 4.5 & 4.8071 & TST \\
\hline CHEMBL1492463 & 688453 & 4.5 & 5.2034 & TST \\
\hline CHEMBL1329286 & 688453 & 4.55 & 4.8755 & TST \\
\hline CHEMBL1427330 & 688453 & 6.5 & 4.7467 & TST \\
\hline CHEMBL1534959 & 688453 & 6.0 & 4.6199 & TST \\
\hline CHEMBL1417273 & 688453 & 7.6003 & 5.0503 & TST \\
\hline CHEMBL1538062 & 688453 & 6.4 & 5.0014 & TST \\
\hline CHEMBL1366408 & 688453 & 6.0 & 5.0469 & TST \\
\hline CHEMBL1303309 & 688453 & 6.6499 & 4.9011 & TST \\
\hline CHEMBL1541638 & 688453 & 4.4 & 5.3874 & TST \\
\hline CHEMBL1380353 & 688453 & 5.15 & 5.0583 & TST \\
\hline CHEMBL1484034 & 688453 & 6.25 & 5.3208 & TST \\
\hline CHEMBL1578082 & 688453 & 4.5 & 4.9209 & TST \\
\hline CHEMBL 223453 & 688453 & 4.45 & 4.7604 & TST \\
\hline CHEMBL1257003 & 688453 & 6.05 & 4.9046 & TST \\
\hline CHEMBL1319467 & 688453 & 4.6 & 4.8957 & TST \\
\hline CHEMBL1562723 & 688453 & 4.4 & 4.7406 & TST \\
\hline CHEMBL 2373677 & 688453 & 4.55 & 5.2982 & TST \\
\hline CHEMBL1360179 & 688453 & 6.25 & 5.2901 & TST \\
\hline CHEMBL1371869 & 688453 & 4.85 & 4.5248 & TST \\
\hline CHEMBL1320902 & 688453 & 6.0 & 5.3202 & TST \\
\hline CHEMBL1423437 & 688453 & 6.6499 & 4.9858 & TST \\
\hline CHEMBL1397050 & 688453 & 5.95 & 5.2768 & TST \\
\hline CHEMBL1483557 & 688453 & 6.05 & 5.3605 & TST \\
\hline CHEMBL1595962 & 688453 & 4.6 & 5.1236 & TST \\
\hline
\end{tabular}




\begin{tabular}{|c|c|c|c|c|c|}
\hline \\
\hline CHEMBL1439498 & 688453 & 5.4 & 5.1235 & TST & \\
\hline CHEMBL1498401 & 688453 & 4.5 & 5.003 & TST & \\
\hline CHEMBL1443128 & 688453 & 4.7 & 5.1133 & TST & \\
\hline CHEMBL1349813 & 688453 & 4.5 & 4.6784 & TST & \\
\hline CHEMBL1498555 & 688453 & 4.4 & 5.0842 & TST & \\
\hline CHEMBL1335249 & 688453 & 7.5498 & 5.0444 & TST & \\
\hline CHEMBL1495606 & 688453 & 6.5501 & 5.0822 & TST & \\
\hline CHEMBL1481580 & 688453 & 6.5501 & 5.2326 & TST & \\
\hline CHEMBL1556914 & 688453 & 5.05 & 5.24799 & 9999999999 & TST \\
\hline CHEMBL1431081 & 688453 & 4.45 & 4.9261 & TST & \\
\hline CHEMBL1424208 & 688453 & 4.4 & 4.5658 & TST & \\
\hline CHEMBL 8260 & 688453 & 6.0 & 5.1093 & TST & \\
\hline CHEMBL1305475 & 688453 & 4.45 & 5.0664 & TST & \\
\hline CHEMBL3197462 & 688453 & 4.6 & 4.6791 & TST & \\
\hline CHEMBL1536162 & 688453 & 6.7501 & 5.1478 & TST & \\
\hline CHEMBL1376754 & 688453 & 4.4 & 4.7319 & TST & \\
\hline CHEMBL1535989 & 688453 & 5.95 & 5.0911 & TST & \\
\hline CHEMBL1609634 & 688453 & 5.95 & 5.1172 & TST & \\
\hline CHEMBL1608853 & 688453 & 4.4 & 4.6684 & TST & \\
\hline CHEMBL1417521 & 688453 & 5.35 & 4.6237 & TST & \\
\hline CHEMBL1571442 & 688453 & 5.5 & 5.0269 & TST & \\
\hline CHEMBL1557688 & 688453 & 4.65 & 4.7138 & TST & \\
\hline CHEMBL1559248 & 688453 & 4.65 & 5.0751 & TST & \\
\hline CHEMBL1323617 & 688453 & 5.5 & 5.0334 & TST & \\
\hline CHEMBL3199324 & 688453 & 4.45 & 4.681 & TST & \\
\hline CHEMBL1486709 & 688453 & 5.55 & 5.1851 & TST & \\
\hline CHEMBL1512786 & 688453 & 4.55 & 4.8993 & TST & \\
\hline CHEMBL1490793 & 688453 & 6.25 & 5.2334 & TST & \\
\hline CHEMBL1411573 & 688453 & 6.05 & 5.0125 & TST & \\
\hline CHEMBL1416148 & 688453 & 4.45 & 4.8873 & TST & \\
\hline CHEMBL1409576 & 688453 & 6.8 & 4.9654 & TST & \\
\hline CHEMBL1978449 & 688453 & 5.4 & 5.0581 & TST & \\
\hline CHEMBL1433752 & 688453 & 4.5 & 4.8138 & TST & \\
\hline CHEMBL1583412 & 688453 & 6.2 & 5.16 & TST & \\
\hline CHEMBL1496575 & 688453 & 4.7 & 4.8825 & TST & \\
\hline CHEMBL1397833 & 688453 & 6.0 & 5.064 & TST & \\
\hline CHEMBL1313554 & 688453 & 4.4 & 5.0559 & TST & \\
\hline CHEMBL1331181 & 688453 & 5.95 & 4.97 & TST & \\
\hline CHEMBL1539793 & 688453 & 4.4 & 4.9971 & TST & \\
\hline CHEMBL1332534 & 688453 & 6.6 & 5.24299 & 9999999999 & TST \\
\hline CHEMBL1471345 & 688453 & 4.6 & 4.8987 & TST & \\
\hline CHEMBL1538611 & 688453 & 4.6 & 4.7701 & TST & \\
\hline CHEMBL1200938 & 688453 & 6.0 & 5.1098 & TST & \\
\hline CHEMBL1367018 & 688453 & 4.45 & 5.2801 & TST & \\
\hline CHEMBL1479786 & 688453 & 4.4 & 5.0728 & TST & \\
\hline CHEMBL1311053 & 688453 & 5.5 & 5.0116 & TST & \\
\hline CHEMBL1341913 & 688329 & 3.8 & 3.9381 & TRN & \\
\hline CHEMBL1339461 & 688329 & 10.0 & 7.8401 & TRN & \\
\hline
\end{tabular}




\begin{tabular}{|c|c|c|c|c|}
\hline \multicolumn{5}{|c|}{ Supplemental Table S2.txt } \\
\hline CHEMBL1432973 & 688329 & 4.2 & 5.5175 & TRN \\
\hline CHEMBL1570497 & 688329 & 4.15 & 4.6561 & TRN \\
\hline CHEMBL3216654 & 688329 & 4.3 & 4.0722 & TRN \\
\hline CHEMBL1312989 & 688329 & 4.5 & 5.2936 & TRN \\
\hline CHEMBL 1471350 & 688329 & 7.5003 & 6.6615 & TRN \\
\hline CHEMBL1446063 & 688329 & 8.1487 & 7.5047 & TRN \\
\hline CHEMBL3144999 & 688329 & 4.4 & 3.3905 & TRN \\
\hline CHEMBL 3145176 & 688329 & 4.1 & 4.7094 & TRN \\
\hline CHEMBL1340437 & 688329 & 4.3 & 5.9485 & TRN \\
\hline CHEMBL1306199 & 688329 & 4.2 & 5.1581 & TRN \\
\hline CHEMBL1514936 & 688329 & 4.05 & 3.8429 & TST \\
\hline CHEMBL3192098 & 688329 & 4.5 & 4.1248 & TRN \\
\hline CHEMBL1356812 & 688329 & 3.9 & 4.6271 & TRN \\
\hline CHEMBL1421993 & 688329 & 4.45 & 4.8298 & TRN \\
\hline CHEMBL1430956 & 688329 & 4.45 & 5.6677 & TRN \\
\hline CHEMBL1350237 & 688329 & 9.699 & 7.9049 & TRN \\
\hline CHEMBL1349942 & 688329 & 4.45 & 4.6597 & TRN \\
\hline CHEMBL1561548 & 688329 & 5.5 & 4.0576 & TST \\
\hline CHEMBL1497953 & 688329 & 4.25 & 5.5637 & TRN \\
\hline CHEMBL1388300 & 688329 & 4.95 & 3.799 & TRN \\
\hline CHEMBL1503523 & 688329 & 7.6003 & 6.1502 & TRN \\
\hline CHEMBL1397706 & 688329 & 4.6 & 4.2843 & TRN \\
\hline CHEMBL1499258 & 688329 & 9.699 & 7.4398 & TRN \\
\hline CHEMBL346516 & 688329 & 4.6 & 4.5529 & TRN \\
\hline CHEMBL3209291 & 688329 & 7.0501 & 8.0984 & TRN \\
\hline CHEMBL1525860 & 688329 & 6.5501 & 5.0824 & TRN \\
\hline CHEMBL1305427 & 688329 & 4.5 & 6.7553 & TRN \\
\hline CHEMBL1504611 & 688329 & 4.5 & 5.6421 & TRN \\
\hline CHEMBL1591431 & 688329 & 4.8 & 3.5684 & TRN \\
\hline CHEMBL1584739 & 688329 & 4.95 & 6.3786 & TRN \\
\hline CHEMBL1491456 & 688329 & 9.2218 & 4.3179 & TST \\
\hline CHEMBL1470333 & 688329 & 8.0506 & 4.5998 & TST \\
\hline CHEMBL1573910 & 688329 & 4.7 & 4.334 & TRN \\
\hline CHEMBL1541259 & 688329 & 5.1 & 5.847 & TRN \\
\hline CHEMBL1566927 & 688329 & 7.6003 & 6.4908 & TRN \\
\hline CHEMBL1332240 & 688329 & 4.45 & 6.3401 & TRN \\
\hline CHEMBL1590938 & 688329 & 5.0 & 6.0422 & TRN \\
\hline CHEMBL 22304 & 688329 & 8.4949 & 4.7404 & TST \\
\hline CHEMBL1477505 & 688329 & 8.7959 & 5.6404 & TST \\
\hline CHEMBL1436782 & 688329 & 8.7447 & 6.4383 & TRN \\
\hline CHEMBL1457022 & 688329 & 4.85 & 5.1009 & TRN \\
\hline CHEMBL1596192 & 688329 & 9.3979 & 7.7453 & TRN \\
\hline CHEMBL1537149 & 688329 & 4.6 & 4.0893 & TRN \\
\hline CHEMBL1325945 & 688329 & 6.2 & 5.625 & TST \\
\hline CHEMBL1368166 & 688329 & 4.4 & 4.8554 & TRN \\
\hline CHEMBL1522941 & 688329 & 4.35 & 3.5291 & TRN \\
\hline CHEMBL1383058 & 688329 & 4.4 & 4.5285 & TRN \\
\hline CHEMBL1492541 & 688329 & 4.35 & 2.8533 & TRN \\
\hline
\end{tabular}




\begin{tabular}{|c|c|c|c|c|c|}
\hline \multicolumn{6}{|c|}{ Supplemental Table S2.txt } \\
\hline CHEMBL1528757 & 688329 & 4.1 & 5.2016 & TST & \\
\hline CHEMBL1595323 & 688329 & 3.85 & 5.1446 & TRN & \\
\hline CHEMBL1383986 & 688329 & 7.2503 & 6.2787 & TRN & \\
\hline CHEMBL1301005 & 688329 & 4.1 & 4.2759 & TRN & \\
\hline CHEMBL1335040 & 688329 & 8.0 & 7.8115 & TRN & \\
\hline CHEMBL1596811 & 688329 & 4.45 & 6.3685 & TST & \\
\hline CHEMBL3190629 & 688329 & 4.55 & 3.5875 & TRN & \\
\hline CHEMBL1418852 & 688329 & 4.1 & 4.851 & TRN & \\
\hline CHEMBL3191078 & 688329 & 4.15 & 4.9448 & TRN & \\
\hline CHEMBL1346049 & 688329 & 4.45 & 5.5561 & TRN & \\
\hline CHEMBL1572845 & 688329 & 6.0 & 5.1285 & TRN & \\
\hline CHEMBL3191525 & 688329 & 4.65 & 4.7233 & TRN & \\
\hline CHEMBL1550129 & 688329 & 4.15 & 5.4676 & TST & \\
\hline CHEMBL1465144 & 688329 & 4.75 & 6.2585 & TRN & \\
\hline CHEMBL1598092 & 688329 & 8.4949 & 6.4594 & TRN & \\
\hline CHEMBL1362933 & 688329 & 4.1 & 4.99 & TST & \\
\hline CHEMBL1402456 & 688329 & 4.45 & 3.3244 & TRN & \\
\hline CHEMBL1382733 & 688329 & 4.85 & 5.0391 & TRN & \\
\hline CHEMBL3193855 & 688329 & 3.5 & 5.5659 & TRN & \\
\hline CHEMBL1321739 & 688329 & 4.75 & 5.166 & TRN & \\
\hline CHEMBL1401379 & 688329 & 7.5498 & 7.9907 & TRN & \\
\hline CHEMBL1446211 & 688329 & 4.7 & 4.3043 & TRN & \\
\hline CHEMBL1401841 & 688329 & 4.0 & 4.356 & TRN & \\
\hline CHEMBL1596010 & 688329 & 3.95 & 4.3558 & TRN & \\
\hline CHEMBL1990342 & 688329 & 7.0501 & 5.0683 & TST & \\
\hline CHEMBL1483809 & 688329 & 4.15 & 3.1498 & TST & \\
\hline CHEMBL1376246 & 688329 & 6.8 & 6.3744 & TST & \\
\hline CHEMBL1370416 & 688329 & 5.0 & 6.1852 & TST & \\
\hline CHEMBL1489362 & 688329 & 5.0 & 6.6526 & TST & \\
\hline CHEMBL1368433 & 688329 & 5.3 & 5.5418 & TST & \\
\hline CHEMBL1358678 & 688329 & 4.5 & 5.6899 & TST & \\
\hline CHEMBL1974319 & 688329 & 4.55 & 4.4297 & TST & \\
\hline CHEMBL3193322 & 688329 & 4.55 & 3.8814 & TST & \\
\hline CHEMBL1502095 & 688329 & 7.3497 & 7.0985 & TST & \\
\hline CHEMBL1383671 & 688329 & 6.0 & 6.4817 & TST & \\
\hline CHEMBL1682822 & 728398 & 6.9698 & 6.7888 & TRN & \\
\hline CHEMBL1682791 & 728398 & 7.0367 & 7.2234 & TRN & \\
\hline CHEMBL1682801 & 728398 & 6.9465 & 7.3395 & TST & \\
\hline CHEMBL1682829 & 728398 & 7.9101 & 6.7995 & TRN & \\
\hline CHEMBL1682797 & 728398 & 6.93 & 7.2711 & TST & \\
\hline CHEMBL1682815 & 728398 & 6.6801 & 6.41200 & 0000000001 & TRN \\
\hline CHEMBL1681799 & 728398 & 7.3002 & 6.4652 & TRN & \\
\hline CHEMBL1682798 & 728398 & 7.5302 & 7.4096 & TRN & \\
\hline CHEMBL1682805 & 728398 & 6.965 & 7.2185 & TRN & \\
\hline CHEMBL1682792 & 728398 & 7.9393 & 6.9926 & TRN & \\
\hline CHEMBL1682823 & 728398 & 6.6851 & 6.7888 & TRN & \\
\hline CHEMBL1682789 & 728398 & 7.52 & 7.0431 & TRN & \\
\hline CHEMBL1682811 & 728398 & 7.6925 & 7.1153 & TRN & \\
\hline
\end{tabular}




\begin{tabular}{|c|c|c|c|c|c|}
\hline \multirow[b]{2}{*}{ CHEMBL1682796 } & \multicolumn{5}{|c|}{ Supplemental Table S2.txt } \\
\hline & 728398 & 7.5243 & 7.2059 & TRN & \\
\hline CHEMBL1682827 & 728398 & 6.3433 & 6.6219 & TRN & \\
\hline CHEMBL1682836 & 728398 & 6.08 & 6.3864 & TRN & \\
\hline CHEMBL1682802 & 728398 & 6.2466 & 6.9945 & TST & \\
\hline CHEMBL1682814 & 728398 & 6.125 & 6.3406 & TRN & \\
\hline CHEMBL1682826 & 728398 & 6.806 & 6.5138 & TRN & \\
\hline CHEMBL1682807 & 728398 & 7.7595 & 7.3683 & TRN & \\
\hline CHEMBL1682820 & 728398 & 6.4567 & 6.5869 & TRN & \\
\hline CHEMBL1682816 & 728398 & 6.5444 & 6.3982 & TRN & \\
\hline CHEMBL1682803 & 728398 & 6.3966 & 7.2218 & TST & \\
\hline CHEMBL 1682834 & 728398 & 6.1467 & 6.3378 & TRN & \\
\hline CHEMBL1682830 & 728398 & 7.2197 & 6.44 & TRN & \\
\hline CHEMBL1682809 & 728398 & 6.5117 & 7.0888 & TST & \\
\hline CHEMBL1682825 & 728398 & 6.28 & 6.6877 & TRN & \\
\hline CHEMBL1682813 & 728398 & 7.2097 & 6.7874 & TRN & \\
\hline CHEMBL1682804 & 728398 & 7.8013 & 7.2593 & TRN & \\
\hline CHEMBL1682812 & 728398 & 3.6021 & 6.8124 & TRN & \\
\hline CHEMBL1682835 & 728398 & 6.1574 & 6.7098 & TRN & \\
\hline CHEMBL1682794 & 728398 & 6.285 & 7.3918 & TRN & \\
\hline CHEMBL1682821 & 728398 & 7.5243 & 6.9481 & TRN & \\
\hline CHEMBL1682832 & 728398 & 6.3233 & 6.3913 & TRN & \\
\hline CHEMBL1682833 & 728398 & 6.215 & 6.4318 & TRN & \\
\hline CHEMBL1682795 & 728398 & 6.23 & 7.3399 & TRN & \\
\hline CHEMBL1682831 & 728398 & 6.3367 & 6.404 & TRN & \\
\hline CHEMBL1682817 & 728398 & 6.53 & 6.5792 & TRN & \\
\hline CHEMBL1682800 & 728398 & 6.7399 & 7.2861 & TST & \\
\hline CHEMBL1682799 & 728398 & 7.3536 & 7.3796 & TRN & \\
\hline CHEMBL1682808 & 728398 & 6.6649 & 7.1141 & TRN & \\
\hline CHEMBL1682824 & 728398 & 6.6149 & 6.8796 & TRN & \\
\hline CHEMBL1682790 & 728398 & 7.9355 & 7.4863 & TRN & \\
\hline CHEMBL 252956 & 728398 & 7.8539 & 7.1628 & TRN & \\
\hline CHEMBL1682793 & 728398 & 7.2741 & 7.3044 & TST & \\
\hline CHEMBL1682806 & 728398 & 7.4295 & 7.3598 & TRN & \\
\hline CHEMBL1682818 & 728398 & 6.2425 & 6.4662 & TST & \\
\hline CHEMBL1682819 & 728398 & 6.11 & 6.3981 & TST & \\
\hline CHEMBL1348198 & 728398 & 6.7749 & 6.4994 & TST & \\
\hline CHEMBL505105 & 728398 & 7.5129 & 7.2659 & TST & \\
\hline CHEMBL 1682828 & 728398 & 6.43 & 6.5317 & TST & \\
\hline CHEMBL1682810 & 728398 & 7.2464 & 6.8576 & TST & \\
\hline CHEMBL 2172136 & 864186 & 4.301 & 4.2983 & TRN & \\
\hline CHEMBL 2172266 & 864186 & 6.3233 & 6.3209 & TRN & \\
\hline CHEMBL3145352 & 864186 & 4.0 & 3.2832 & TST & \\
\hline CHEMBL 2172280 & 864186 & 5.585 & 5.2292 & TST & \\
\hline CHEMBL 2172265 & 864186 & 5.8356 & 5.83799 & 9999999999 & TRN \\
\hline CHEMBL 2172142 & 864186 & 4.301 & 4.3031 & TRN & \\
\hline CHEMBL 2172139 & 864186 & 7.0458 & 7.0532 & TRN & \\
\hline CHEMBL 2172133 & 864186 & 7.0362 & 7.0314 & TRN & \\
\hline CHEMBL 2172141 & 864186 & 5.7258 & 5.7222 & TRN & \\
\hline
\end{tabular}

Page 24450 


\begin{tabular}{|c|c|c|c|c|c|}
\hline \multicolumn{6}{|c|}{ Supplemental Table S2.txt } \\
\hline CHEMBL 2172156 & 864186 & 7.0 & 6.9994 & TRN & \\
\hline CHEMBL 2172147 & 864186 & 5.9666 & 5.9676 & TRN & \\
\hline CHEMBL 2172132 & 864186 & 6.6778 & 6.6858 & TRN & \\
\hline CHEMBL 2172283 & 864186 & 4.0 & 3.0627 & TST & \\
\hline CHEMBL 2172135 & 864186 & 5.4425 & 5.4453 & TRN & \\
\hline CHEMBL 2172284 & 864186 & 5.8633 & 4.8529 & TST & \\
\hline CHEMBL 2172144 & 864186 & 5.8761 & 5.8758 & TRN & \\
\hline CHEMBL 2172140 & 864186 & 7.5229 & 7.5133 & TRN & \\
\hline CHEMBL 2172137 & 864186 & 5.7212 & 5.7218 & TRN & \\
\hline CHEMBL 2172272 & 864186 & 7.6021 & 7.586 & TRN & \\
\hline CHEMBL 2172128 & 864186 & 7.3979 & 7.3987 & TRN & \\
\hline CHEMBL 2172278 & 864186 & 5.6478 & 4.535 & TST & \\
\hline CHEMBL 2172277 & 864186 & 5.4815 & 5.5167 & TST & \\
\hline CHEMBL 2172134 & 864186 & 5.6198 & 5.6193 & TRN & \\
\hline CHEMBL 2172149 & 864186 & 7.7212 & 7.7426 & TRN & \\
\hline CHEMBL 2172155 & 864186 & 5.9208 & 5.9239 & TRN & \\
\hline CHEMBL 2172162 & 864186 & 6.4202 & 6.42200 & 0000000001 & TRN \\
\hline CHEMBL 2172268 & 864186 & 7.3979 & 7.3951 & TRN & \\
\hline CHEMBL 2172157 & 864186 & 7.1192 & 7.1204 & TRN & \\
\hline CHEMBL 2172164 & 864186 & 4.301 & 4.3014 & TRN & \\
\hline CHEMBL 2172146 & 864186 & 6.9066 & 6.9079 & TRN & \\
\hline CHEMBL 2172163 & 864186 & 6.5376 & 6.5371 & TRN & \\
\hline CHEMBL 2172129 & 864186 & 7.301 & 7.2981 & TRN & \\
\hline CHEMBL 2172165 & 864186 & 6.2557 & 6.2555 & TRN & \\
\hline CHEMBL 2172148 & 864186 & 7.6778 & 7.6746 & TRN & \\
\hline CHEMBL 2172160 & 864186 & 6.2218 & 6.22 & TRN & \\
\hline CHEMBL 2172281 & 864186 & 5.1302 & 4.9406 & TST & \\
\hline CHEMBL2172159 & 864186 & 5.5317 & 5.5276 & TRN & \\
\hline CHEMBL 2172143 & 864186 & 6.1024 & 6.1023 & TRN & \\
\hline CHEMBL 2172275 & 864186 & 5.585 & 4.9742 & TST & \\
\hline CHEMBL 2172279 & 864186 & 5.4283 & 4.9494 & TST & \\
\hline CHEMBL 2172161 & 864186 & 7.1549 & 7.1612 & TRN & \\
\hline CHEMBL 2172274 & 864186 & 6.6576 & 6.659 & TRN & \\
\hline CHEMBL 2172273 & 864186 & 7.8861 & 7.88399 & 99999999995 & TRN \\
\hline CHEMBL 2172282 & 864186 & 5.0434 & 3.6769 & TST & \\
\hline CHEMBL 2172270 & 864186 & 7.8861 & 7.8881 & TRN & \\
\hline CHEMBL 2172131 & 864186 & 6.1707 & 6.1672 & TRN & \\
\hline CHEMBL 2172158 & 864186 & 5.5045 & 5.5061 & TRN & \\
\hline CHEMBL 2172130 & 864186 & 5.4237 & 5.4243 & TRN & \\
\hline CHEMBL 2172267 & 864186 & 7.2366 & 7.2373 & TRN & \\
\hline CHEMBL 2172150 & 864186 & 7.8539 & 7.8514 & TRN & \\
\hline CHEMBL 2172166 & 864186 & 6.0458 & 5.178 & TST & \\
\hline CHEMBL 2172138 & 864186 & 5.6556 & 5.6556 & TRN & \\
\hline CHEMBL 2172264 & 864186 & 5.5086 & 5.5063 & TRN & \\
\hline CHEMBL 2172145 & 864186 & 5.9101 & 5.9718 & TST & \\
\hline CHEMBL 2172127 & 864186 & 6.8861 & 5.9093 & TST & \\
\hline CHEMBL2172269 & 864186 & 7.7696 & 7.0779 & TST & \\
\hline CHEMBL3958057 & 1642307 & 7.0458 & 7.3186 & TRN & \\
\hline
\end{tabular}


Supplemental Table S2.txt

\begin{tabular}{|c|c|c|c|c|c|}
\hline CHEMBL3904838 & 1642307 & 6.2518 & 6.7299 & TRN & \\
\hline CHEMBL3934796 & 1642307 & 6.2495 & 6.6449 & TRN & \\
\hline CHEMBL3969487 & 1642307 & 7.0655 & 6.7636 & TRN & \\
\hline CHEMBL3967660 & 1642307 & 6.5376 & 6.7714 & TRN & \\
\hline CHEMBL3932149 & 1642307 & 6.1831 & 7.4009 & TST & \\
\hline CHEMBL3932319 & 1642307 & 6.8097 & 6.6656 & TRN & \\
\hline CHEMBL3937695 & 1642307 & 7.4437 & 7.5115 & TRN & \\
\hline CHEMBL3919678 & 1642307 & 7.4949 & 7.5933 & TRN & \\
\hline CHEMBL3906994 & 1642307 & 6.8013 & 6.7395 & TRN & \\
\hline CHEMBL3980663 & 1642307 & 6.3883 & 7.1767 & TRN & \\
\hline CHEMBL3958102 & 1642307 & 7.2076 & 7.3487 & TRN & \\
\hline CHEMBL3951182 & 1642307 & 7.6778 & 7.6131 & TRN & \\
\hline CHEMBL3902338 & 1642307 & 6.4157 & 6.5823 & TST & \\
\hline CHEMBL 3892261 & 1642307 & 7.6576 & 7.5269 & TRN & \\
\hline CHEMBL3895738 & 1642307 & 7.0269 & 7.3311 & TRN & \\
\hline CHEMBL3942448 & 1642307 & 7.3279 & 7.5018 & TRN & \\
\hline CHEMBL3914442 & 1642307 & 7.5686 & 7.5594 & TRN & \\
\hline CHEMBL 3890242 & 1642307 & 7.5528 & 7.4007 & TRN & \\
\hline CHEMBL3967025 & 1642307 & 6.9208 & 6.8308 & TRN & \\
\hline CHEMBL3968975 & 1642307 & 7.9208 & 7.5223 & TRN & \\
\hline CHEMBL3969402 & 1642307 & 7.0969 & 6.6873 & TRN & \\
\hline CHEMBL3950526 & 1642307 & 7.0655 & 6.8626 & TST & \\
\hline CHEMBL3935864 & 1642307 & 7.1739 & 7.4532 & TRN & \\
\hline CHEMBL3944079 & 1642307 & 5.4685 & 6.5035 & TRN & \\
\hline CHEMBL3966717 & 1642307 & 7.1675 & 6.84200 & 00000000005 & TST \\
\hline CHEMBL3962722 & 1642307 & 7.301 & 7.2311 & TRN & \\
\hline CHEMBL3926347 & 1642307 & 7.0809 & 7.23600 & 0000000001 & TRN \\
\hline CHEMBL3929310 & 1642307 & 7.3872 & 7.5313 & TRN & \\
\hline CHEMBL3922636 & 1642307 & 6.4855 & 6.6168 & TRN & \\
\hline CHEMBL3903616 & 1642307 & 6.4559 & 6.6072 & TRN & \\
\hline CHEMBL3961416 & 1642307 & 6.8239 & 6.8722 & TRN & \\
\hline CHEMBL3938072 & 1642307 & 6.5229 & 6.8683 & TST & \\
\hline CHEMBL3971935 & 1642307 & 7.0862 & 6.7084 & TRN & \\
\hline CHEMBL3891872 & 1642307 & 6.6778 & 6.8215 & TST & \\
\hline CHEMBL3917950 & 1642307 & 7.8861 & 7.6123 & TRN & \\
\hline CHEMBL3918968 & 1642307 & 7.2676 & 7.2064 & TRN & \\
\hline CHEMBL 3976164 & 1642307 & 6.6198 & 6.8978 & TST & \\
\hline CHEMBL3914708 & 1642307 & 7.2007 & 7.5214 & TRN & \\
\hline CHEMBL 3957944 & 1642307 & 7.0655 & 7.6005 & TST & \\
\hline CHEMBL 3932840 & 1642307 & 8.0969 & 7.6461 & TRN & \\
\hline CHEMBL3945195 & 1642307 & 6.9208 & 6.6427 & TRN & \\
\hline CHEMBL3965399 & 1642307 & 6.6968 & 7.4724 & TST & \\
\hline CHEMBL3910728 & 1642307 & 6.8729 & 6.8178 & TRN & \\
\hline CHEMBL 3897083 & 1642307 & 6.6819 & 6.522 & TRN & \\
\hline CHEMBL3943470 & 1642307 & 6.4437 & 6.6766 & TST & \\
\hline CHEMBL3896450 & 1642307 & 6.8697 & 7.3664 & TRN & \\
\hline CHEMBL3903903 & 1642307 & 7.6021 & 7.3509 & TRN & \\
\hline CHEMBL 3938287 & 1642307 & 7.3098 & 7.41799 & 99999999999 & Trov \\
\hline
\end{tabular}

Page 24452 
Supplemental Table S2.txt

\begin{tabular}{|c|c|c|c|c|}
\hline 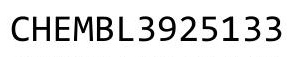 & & & 6.7743 & \\
\hline HEMBL3902442 & 642307 & 7.2147 & 7.4912 & \\
\hline & 307 & & & \\
\hline IEMBL 3946166 & 307 & 83 & 5785 & \\
\hline AEMBL3964599 & 642307 & 8.0 & 8369 & \\
\hline AEMBL3972895 & 642307 & 7.7212 & 5236 & \\
\hline HEMBL3981133 & 642307 & 6.4295 & 458 & \\
\hline IEMBL39 & 307 & & & \\
\hline EMBL3934013 & 307 & & & \\
\hline AEMBL3963269 & 307 & 6.8153 & & \\
\hline AEMBL3963563 & 307 & 7.4318 & 466 & \\
\hline HEMBL3949396 & 307 & 6.9586 & 012 & \\
\hline AEMBL39 & & & & \\
\hline HEMBL3S & & & & \\
\hline AEMBL3931022 & 307 & 7.8861 & 079 & \\
\hline AEMBL3967919 & 27 & 98 & 91 & \\
\hline AEMBL3S & 07 & 021 & 034 & \\
\hline HEMBL3S & & 84 & & \\
\hline HEMBL 2 & & 229 & & \\
\hline AEMBL2] & & 3.5229 & & \\
\hline IEMBL $21 / 2 \theta / 6$ & 6 & 229 & 54 & I \\
\hline HEMBL21 & 6 & 229 & 24 & \\
\hline HEMBL 21 & & 229 & & \\
\hline AFMBL 21 & & 229 & & KIV \\
\hline HEMBL 217 & & 29 & & RN \\
\hline HEMBL2172087 & 6 & 29 & & KIV \\
\hline HEMBL2172081 & 6 & 239 & 31 & \\
\hline HEMBL217 & & 29 & & ST \\
\hline L21 & & 91 & & RN \\
\hline IEMBL 217 & 6 & 3 & & RIN \\
\hline HEMBL 217 & & 29 & & ST \\
\hline HEMBL 2172063 & & 29 & 399 & ST \\
\hline HEMBL21€ & & & & ST \\
\hline HEMBL 217 & & & & $\mathrm{RN}$ \\
\hline IEMBL21720 & $\partial$ & 36 & 48 & ST \\
\hline EMBL 217 & & 67 & 399 & ST \\
\hline HEMBL 2172086 & & 29 & 08 & RN \\
\hline & & & & RN \\
\hline HEMBL 2172225 & & & 535 & $\mathrm{RN}$ \\
\hline AEMBL2172072 & 6 & 29 & & RN \\
\hline IEMBL1443272 & & & 075 & \\
\hline HEMBL2172069 & & & & \\
\hline HEMBL2172220 & & & & $\mathrm{RN}$ \\
\hline HEMBL2172109 & & 229 & 108 & RN \\
\hline IEMBL21721 & & 51 & & $\mathrm{~N}$ \\
\hline HEMBL 217 & & & & \\
\hline HEMBL 217211 & & 3.5229 & .0163 & \\
\hline - 217212 & 364146 & 3.5229 & 4.0199 & \\
\hline
\end{tabular}

Page 24453 
Supplemental Table S2.txt

\begin{tabular}{|c|c|c|c|c|c|}
\hline CHEMBL 2172106 & 864146 & 3.5229 & 3.8869 & TRN & \\
\hline CHEMBL 2172085 & 864146 & 3.5229 & 3.5331 & TRN & \\
\hline CHEMBL2172222 & 864146 & 3.5229 & 3.1309 & TRN & \\
\hline CHEMBL2172123 & 864146 & 4.857 & 3.9004 & TRN & \\
\hline CHEMBL2172110 & 864146 & 3.5229 & 4.4211 & TRN & \\
\hline CHEMBL 2172113 & 864146 & 3.5229 & 3.8466 & TRN & \\
\hline CHEMBL 2172083 & 864146 & 3.5229 & 3.7832 & TRN & \\
\hline CHEMBL 2172224 & 864146 & 3.5229 & 3.9112 & TRN & \\
\hline CHEMBL 2172120 & 864146 & 4.7545 & 3.9134 & TRN & \\
\hline CHEMBL2172068 & 864146 & 3.5229 & 3.6318 & TRN & \\
\hline CHEMBL2172097 & 864146 & 3.5229 & 3.9493 & TST & \\
\hline CHEMBL 2172061 & 864146 & 3.5229 & 3.7669 & TST & \\
\hline CHEMBL 2172093 & 864146 & 3.5229 & 3.756006 & 00000000002 & TRN \\
\hline CHEMBL2172099 & 864146 & 3.5229 & 3.8923 & TST & \\
\hline CHEMBL2172075 & 864146 & 3.5229 & 4.1762 & TRN & \\
\hline CHEMBL 2172223 & 864146 & 3.5229 & 3.2802 & TST & \\
\hline CHEMBL2172221 & 864146 & 3.5229 & 3.3889 & TRN & \\
\hline CHEMBL 2172118 & 864146 & 3.5229 & 3.8657 & TRN & \\
\hline CHEMBL1698807 & 864146 & 3.5229 & 3.4933 & TRN & \\
\hline CHEMBL2172084 & 864146 & 3.5229 & 3.7001 & TRN & \\
\hline CHEMBL2172060 & 864146 & 4.9586 & 3.9281 & TST & \\
\hline CHEMBL2172125 & 864146 & 3.5229 & 3.8654 & TRN & \\
\hline CHEMBL1871992 & 864146 & 3.5229 & 3.90199 & 99999999997 & TST \\
\hline CHEMBL2172090 & 864146 & 3.5229 & 3.3623 & TRN & \\
\hline CHEMBL2172098 & 864146 & 3.5229 & 3.9361 & TST & \\
\hline CHEMBL2172088 & 864146 & 3.5229 & 3.5263 & TRN & \\
\hline CHEMBL 2172111 & 864146 & 3.5229 & 3.9419 & TRN & \\
\hline CHEMBL2172089 & 864146 & 3.5229 & 3.5923 & TRN & \\
\hline CHEMBL2172070 & 864146 & 3.5229 & 3.7988 & TRN & \\
\hline CHEMBL 2172107 & 864146 & 3.5229 & 4.3514 & TST & \\
\hline CHEMBL1566492 & 864146 & 4.6925 & 3.7629 & TRN & \\
\hline CHEMBL 2172100 & 864146 & 3.5229 & 3.7964 & TST & \\
\hline CHEMBL 2172091 & 864146 & 6.1308 & 4.6875 & TRN & \\
\hline CHEMBL2172124 & 864146 & 3.5229 & 3.9885 & TRN & \\
\hline CHEMBL 2172067 & 864146 & 3.5229 & 3.7547 & TRN & \\
\hline CHEMBL2172114 & 864146 & 3.5229 & 3.9914 & TRN & \\
\hline CHEMBL148201 & 41497 & 6.1427 & 6.3543 & TST & \\
\hline CHEMBL146587 & 41497 & 6.9208 & 6.9766 & TRN & \\
\hline CHEMBL93812 & 41497 & 4.2355 & 5.1712 & TST & \\
\hline CHEMBL357836 & 41497 & 6.9586 & 6.8228 & TRN & \\
\hline CHEMBL145992 & 41497 & 5.1637 & 5.0981 & TRN & \\
\hline CHEMBL149548 & 41497 & 3.9293 & 3.9064 & TRN & \\
\hline CHEMBL95119 & 41497 & 6.7447 & 6.8384 & TRN & \\
\hline CHEMBL96457 & 41497 & 5.7399 & 5.9256 & TRN & \\
\hline CHEMBL148032 & 41497 & 5.5482 & 5.4503 & TRN & \\
\hline CHEMBL149234 & 41497 & 5.1891 & 5.517 & TST & \\
\hline CHEMBL146211 & 41497 & 6.6383 & 6.5521 & TRN & \\
\hline CHEMBL319952 & 41497 & 6.1675 & 6.0934 & TRN & \\
\hline
\end{tabular}




\begin{tabular}{|c|c|c|c|c|c|}
\hline \multicolumn{6}{|c|}{ Supplemental Table S2.txt } \\
\hline CHEMBL147055 & 41497 & 7.1549 & 7.2972 & TRN & \\
\hline CHEMBL420815 & 41497 & 6.3098 & 6.3036 & TRN & \\
\hline CHEMBL141331 & 41497 & 3.3579 & 4.6098 & TST & \\
\hline CHEMBL147643 & 41497 & 6.1249 & 6.2916 & TST & \\
\hline CHEMBL147496 & 41497 & 5.8665 & 5.83 & TRN & \\
\hline CHEMBL147865 & 41497 & 5.7447 & 5.5688 & TRN & \\
\hline CHEMBL344785 & 41497 & 6.4202 & 6.3668 & TRN & \\
\hline CHEMBL96713 & 41497 & 6.5086 & 6.3317 & TRN & \\
\hline CHEMBL142339 & 41497 & 5.4157 & 5.3106 & TRN & \\
\hline CHEMBL141547 & 41497 & 5.0675 & 5.17899 & 9999999999 & TST \\
\hline CHEMBL148196 & 41497 & 5.6383 & 5.6063 & TRN & \\
\hline CHEMBL148318 & 41497 & 6.3768 & 6.437 & TRN & \\
\hline CHEMBL1264 & 41497 & 5.52 & 5.5848 & TRN & \\
\hline CHEMBL318061 & 41497 & 6.8539 & 6.8766 & TRN & \\
\hline CHEMBL 357023 & 41497 & 6.2676 & 6.3649 & TRN & \\
\hline CHEMBL344313 & 41497 & 7.0969 & 7.0503 & TRN & \\
\hline CHEMBL359190 & 41497 & 5.9914 & 5.9124 & TST & \\
\hline CHEMBL147997 & 41497 & 4.1198 & 4.2933 & TRN & \\
\hline CHEMBL343262 & 41497 & 6.1427 & 6.3123 & TST & \\
\hline CHEMBL149228 & 41497 & 4.9446 & 4.9764 & TRN & \\
\hline CHEMBL341881 & 41497 & 6.7696 & 6.6781 & TRN & \\
\hline CHEMBL96072 & 41497 & 5.426 & 5.4431 & TRN & \\
\hline CHEMBL143061 & 41497 & 3.6836 & 4.0265 & TRN & \\
\hline CHEMBL93496 & 41497 & 6.041 & 6.0879 & TRN & \\
\hline CHEMBL356974 & 41497 & 5.7595 & 5.7825 & TST & \\
\hline CHEMBL357613 & 41497 & 6.0555 & 5.9576 & TST & \\
\hline CHEMBL147781 & 41497 & 5.1649 & 4.9977 & TRN & \\
\hline CHEMBL357004 & 41497 & 5.0424 & 4.9941 & TRN & \\
\hline CHEMBL445381 & 41497 & 6.5229 & 6.5574 & TRN & \\
\hline CHEMBL358299 & 41497 & 5.8729 & 5.8297 & TRN & \\
\hline CHEMBL146135 & 41497 & 6.4089 & 6.3921 & TRN & \\
\hline CHEMBL146996 & 41497 & 6.1739 & 6.1697 & TRN & \\
\hline CHEMBL148001 & 41497 & 6.9586 & 6.9132 & TRN & \\
\hline CHEMBL149235 & 41497 & 5.983 & 5.9572 & TRN & \\
\hline CHEMBL146671 & 41497 & 3.5199 & 3.5192 & TRN & \\
\hline CHEMBL146084 & 41497 & 5.9508 & 6.0372 & TRN & \\
\hline CHEMBL96597 & 41497 & 7.301 & 7.3459 & TRN & \\
\hline CHEMBL147852 & 41497 & 5.5969 & 5.8613 & TST & \\
\hline CHEMBL146565 & 41497 & 4.9248 & 4.811 & TRN & \\
\hline CHEMBL145168 & 41497 & 6.1192 & 6.0061 & TST & \\
\hline CHEMBL422315 & 41497 & 6.1675 & 6.1253 & TRN & \\
\hline CHEMBL144148 & 41497 & 6.9208 & 7.041 & TRN & \\
\hline CHEMBL344278 & 41497 & 7.1549 & 7.2573 & TRN & \\
\hline CHEMBL145120 & 41497 & 4.6949 & 5.3706 & TST & \\
\hline CHEMBL143963 & 41497 & 4.7791 & 5.6254 & TST & \\
\hline CHEMBL147839 & 41497 & 6.2757 & 6.1379 & TRN & \\
\hline CHEMBL145861 & 41497 & 7.0458 & 6.21700 & 00000000005 & IST \\
\hline CHEMBL146159 & 41497 & 6.1805 & 6.2071 & TST & \\
\hline
\end{tabular}




\begin{tabular}{|c|c|c|c|c|c|}
\hline \multicolumn{6}{|c|}{ Supplemental Table S2.txt } \\
\hline CHEMBL148235 & 41497 & 5.5969 & 5.5818 & TRN & \\
\hline CHEMBL146081 & 41497 & 6.4685 & 6.5093 & TST & \\
\hline CHEMBL358568 & 41497 & 5.0205 & 4.9757 & TRN & \\
\hline CHEMBL 343400 & 41497 & 6.7696 & 6.6988 & TRN & \\
\hline CHEMBL148260 & 41497 & 6.7212 & 6.6514 & TRN & \\
\hline CHEMBL147788 & 41497 & 6.6778 & 6.7117 & TRN & \\
\hline CHEMBL147724 & 41497 & 6.0362 & 6.1321 & TRN & \\
\hline CHEMBL146558 & 41497 & 6.1135 & 6.3129 & TRN & \\
\hline CHEMBL142319 & 41497 & 5.5784 & 5.9658 & TST & \\
\hline CHEMBL3644316 & 1642491 & 9.0 & 8.9784 & TRN & \\
\hline CHEMBL3644332 & 1642491 & 7.9208 & 7.9387 & TRN & \\
\hline CHEMBL 3644298 & 1642491 & 7.4949 & 7.4999 & TRN & \\
\hline CHEMBL 3644317 & 1642491 & 8.1549 & 8.1487 & TRN & \\
\hline CHEMBL 3644360 & 1642491 & 6.8386 & 6.8364 & TRN & \\
\hline CHEMBL 3644291 & 1642491 & 7.5229 & 7.5236 & TRN & \\
\hline CHEMBL3644352 & 1642491 & 7.1938 & 7.1722 & TRN & \\
\hline CHEMBL3646863 & 1642491 & 8.0969 & 8.1056 & TRN & \\
\hline CHEMBL3949976 & 1642491 & 7.3979 & 7.3978 & TRN & \\
\hline CHEMBL 3646850 & 1642491 & 7.7212 & 7.6939 & TRN & \\
\hline CHEMBL 3644337 & 1642491 & 6.9469 & 6.934 & TRN & \\
\hline CHEMBL3904001 & 1642491 & 8.5229 & 8.0518 & TST & \\
\hline CHEMBL 3644314 & 1642491 & 7.0969 & 7.1134 & TRN & \\
\hline CHEMBL3644361 & 1642491 & 8.5229 & 8.5207 & TRN & \\
\hline CHEMBL 3644283 & 1642491 & 5.6887 & 5.6841 & TRN & \\
\hline CHEMBL 3644350 & 1642491 & 8.0458 & 8.0544 & TRN & \\
\hline CHEMBL3646859 & 1642491 & 8.3979 & 8.3891 & TRN & \\
\hline CHEMBL 3644302 & 1642491 & 7.4318 & 7.7118 & TRN & \\
\hline CHEMBL3963781 & 1642491 & 9.0 & 7.6711 & TST & \\
\hline CHEMBL 3644355 & 1642491 & 8.2218 & 8.2099 & TRN & \\
\hline CHEMBL3644353 & 1642491 & 7.4685 & 7.4769 & TRN & \\
\hline CHEMBL3971788 & 1642491 & 7.6198 & 7.7158 & TST & \\
\hline CHEMBL 3644284 & 1642491 & 6.2733 & 6.2715 & TRN & \\
\hline CHEMBL3895073 & 1642491 & 8.3979 & 7.8725 & TST & \\
\hline CHEMBL 3955264 & 1642491 & 6.767 & 6.9309 & TST & \\
\hline CHEMBL3957057 & 1642491 & 6.9586 & 7.379 & TST & \\
\hline CHEMBL3644313 & 1642491 & 7.3279 & 7.3281 & TRN & \\
\hline CHEMBL 3644354 & 1642491 & 7.585 & 7.599 & TRN & \\
\hline CHEMBL 3644288 & 1642491 & 7.2924 & 7.7118 & TRN & \\
\hline CHEMBL 3644289 & 1642491 & 7.3665 & 7.36700 & 0000000001 & TRN \\
\hline CHEMBL 3954833 & 1642491 & 6.8539 & 7.1506 & TST & \\
\hline CHEMBL3938651 & 1642491 & 8.0969 & 8.0898 & TST & \\
\hline CHEMBL3644322 & 1642491 & 7.2218 & 7.2101 & TRN & \\
\hline CHEMBL3644300 & 1642491 & 7.7212 & 7.725 & TRN & \\
\hline CHEMBL 3979831 & 1642491 & 6.6696 & 7.7968 & TST & \\
\hline CHEMBL3644297 & 1642491 & 8.3979 & 7.7118 & TRN & \\
\hline CHEMBL3644356 & 1642491 & 9.0 & 9.0083 & TRN & \\
\hline CHEMBL3644336 & 1642491 & 7.4318 & 7.4392 & TRN & \\
\hline CHEMBL3646857 & 1642491 & 8.699 & 8.7065 & TRN & \\
\hline
\end{tabular}


Supplemental Table S2.txt

\begin{tabular}{|c|c|c|c|c|}
\hline Jט & 2491 & 8 & 0438 & 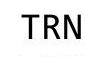 \\
\hline CHEMBL3644279 & 642491 & 6.0 & 5.9973 & \\
\hline HEMBL3644303 & 642491 & 7.4559 & 4595 & \\
\hline HEMBL3955830 & 642491 & 7.1805 & 0072 & \\
\hline HEMBL 3971748 & 642491 & 7.7212 & 7.5465 & \\
\hline HEMBL3644285 & 642491 & 5.5291 & .5003 & \\
\hline HEMBL3893834 & 642491 & 6.7352 & 6.9114 & \\
\hline HEMBL3644290 & 642491 & 7.4815 & 7.4742 & \\
\hline HEMBL3955282 & 1642491 & 9.1549 & 9.2395 & \\
\hline HEMBL3644286 & 1642491 & 5.5203 & 5.5546 & \\
\hline HEMBL3646856 & 1642491 & 9.0 & .9922 & \\
\hline HEMBL3646858 & L642491 & 8.699 & 3.7112 & \\
\hline HEMBL3644327 & L642491 & 7.0655 & 7.2402 & \\
\hline HEMBL36 & 491 & 7.6 & 7.0663 & \\
\hline HEMBL38 & 379 & 605 & 5.7933 & \\
\hline HEMBL 386809 & 379935 & 6.4815 & 6.6039 & \\
\hline HEMBL383920 & 379 & 3.301 & 4.1108 & \\
\hline HEMBL37 & 379 & 86 & 29 & \\
\hline AEMBL21 & 35 & & 99 & \\
\hline HEMBL2: & 35 & 98 & 7.7785 & \\
\hline HEMBL2. & 379 & 7.9208 & 8.0326 & \\
\hline HEMBL386199 & 5 & 86 & 7.5783 & \\
\hline HEMBL 2 & 5 & 6. & 6.8766 & \\
\hline HEMBL 2 & & & 6.1687 & \\
\hline HEMBL & 35 & 39 & 6.8704 & \\
\hline HEMBL441695 & 39 & 65 & 4.2263 & \\
\hline HEMBL 378766 & 79 & 5.5528 & 4.6509 & TST \\
\hline HEMBL 2 & 5 & 7. & 7.5907 & 11 \\
\hline HEMBL2. & 5 & 15 & 7. & NIV \\
\hline HEMBL21 & 375 & $\partial 9$ & 6.3219 & 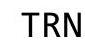 \\
\hline HEMBL 209785 & 79 & 76 & 6.7922 & $\lceil\mathrm{RN}$ \\
\hline HEMBL 386398 & 5 & 7.4 & 5.8129 & ГST \\
\hline IEMBL 21 & & & 38 & $n$ \\
\hline HEMBL 21 & 5 & 32 & 97 & $\lceil\mathrm{RN}$ \\
\hline HEMBL 209541 & 379 & & 5.9658 & $\lceil\mathrm{RN}$ \\
\hline HEMBL 384477 & 79 & 7.5528 & 7.7804 & 「R \\
\hline HEMBL 379732 & 79 & 7.3468 & 7.3918 & $\lceil R$ \\
\hline 377867 & 5 & 76 & 4.7576 & N \\
\hline CHEMB & 5 & 51 & 5.2724 & IST \\
\hline CHEMBL 214090 & 379 & 7.5376 & 7.3155 & TRN \\
\hline CHEMBL214208 & 379935 & 7.3768 & 7.222 & $\Gamma R$ \\
\hline CHEMBL209594 & 379 & 98 & 7.8224 & $\mathrm{~K}$ \\
\hline CHEMBL384829 & 379 & 6.8239 & 7.1632 & \\
\hline CHEMBL379392 & 379935 & 7.3098 & 7.3262 & $\lceil\mathrm{RN}$ \\
\hline HEMBL 209894 & 379935 & 3.301 & 3.2669 & $\lceil\mathrm{RN}$ \\
\hline HEMBL 212495 & 379935 & 7.2596 & 7.278 & 「R \\
\hline LHEMBL 383 & 379 & 6.2924 & 6.2143 & \\
\hline CHEMBL 378066 & 379935 & 7.699 & 7.7495 & \\
\hline
\end{tabular}

Page 24457 


\begin{tabular}{|c|c|c|c|c|c|}
\hline \multicolumn{6}{|c|}{ Supplemental Table S2.txt } \\
\hline CHEMBL385194 & 379935 & 7.1249 & 6.7213 & TRN & \\
\hline CHEMBL378472 & 379935 & 6.6778 & 6.9541 & TRN & \\
\hline CHEMBL214005 & 379935 & 6.585 & 5.7502 & TST & \\
\hline CHEMBL386979 & 379935 & 4.4318 & 3.2985 & TST & \\
\hline CHEMBL213019 & 379935 & 5.7447 & 5.8371 & TRN & \\
\hline CHEMBL212646 & 379935 & 7.2007 & 6.4736 & TST & \\
\hline CHEMBL384293 & 379935 & 4.3979 & 5.0491 & TRN & \\
\hline CHEMBL387078 & 379935 & 5.3979 & 4.769 & TST & \\
\hline CHEMBL379149 & 379935 & 6.7447 & 6.9687 & TRN & \\
\hline CHEMBL209388 & 379935 & 7.2441 & 7.00200 & 0000000001 & TST \\
\hline CHEMBL379975 & 379935 & 7.9586 & 7.9055 & TRN & \\
\hline CHEMBL215900 & 379935 & 7.2291 & 6.2044 & TST & \\
\hline CHEMBL386048 & 379935 & 7.7447 & 7.7322 & TRN & \\
\hline CHEMBL213593 & 379935 & 7.5528 & 7.356 & TRN & \\
\hline CHEMBL 214341 & 379935 & 6.8861 & 5.1232 & TST & \\
\hline CHEMBL209786 & 379935 & 7.3279 & 7.609 & TRN & \\
\hline CHEMBL211626 & 379935 & 6.5086 & 6.00700 & 0000000001 & TRN \\
\hline CHEMBL384103 & 379935 & 6.7959 & 6.4698 & TRN & \\
\hline CHEMBL 212594 & 379935 & 7.2218 & 7.3913 & TRN & \\
\hline CHEMBL379346 & 379935 & 6.2441 & 6.3318 & TRN & \\
\hline CHEMBL211627 & 379935 & 3.301 & 3.7471 & TRN & \\
\hline CHEMBL 211878 & 379935 & 6.1938 & 5.8117 & TRN & \\
\hline CHEMBL215706 & 379935 & 3.301 & 3.3727 & TRN & \\
\hline CHEMBL211157 & 379935 & 5.0132 & 4.4566 & TST & \\
\hline CHEMBL213233 & 379935 & 4.699 & 4.0709 & TST & \\
\hline CHEMBL211140 & 379935 & 7.699 & 7.4603 & TRN & \\
\hline CHEMBL 215470 & 379935 & 6.585 & 6.5435 & TRN & \\
\hline CHEMBL215677 & 379935 & 7.6383 & 7.7325 & TRN & \\
\hline CHEMBL212933 & 379935 & 5.4089 & 3.7409 & TST & \\
\hline CHEMBL378756 & 379935 & 7.1079 & 5.7385 & TST & \\
\hline CHEMBL212494 & 379935 & 6.6576 & 6.2844 & TRN & \\
\hline CHEMBL424888 & 379935 & 6.9586 & 7.1325 & TRN & \\
\hline CHEMBL378921 & 379935 & 3.301 & 3.8438 & TST & \\
\hline CHEMBL 385047 & 379935 & 5.6383 & 4.537 & TST & \\
\hline CHEMBL215815 & 379935 & 7.8861 & 7.5059 & TRN & \\
\hline CHEMBL384369 & 379935 & 5.7959 & 4.6632 & TST & \\
\hline CHEMBL 212659 & 379935 & 6.2366 & 5.6653 & TRN & \\
\hline CHEMBL213346 & 379935 & 6.3098 & 6.3067 & TRN & \\
\hline CHEMBL 379264 & 379935 & 3.301 & 5.0601 & TST & \\
\hline CHEMBL378067 & 379935 & 7.4559 & 7.3371 & TRN & \\
\hline CHEMBL212797 & 379935 & 7.1549 & 6.9868 & TRN & \\
\hline CHEMBL212798 & 379935 & 4.7959 & 5.1839 & TRN & \\
\hline CHEMBL213525 & 379935 & 7.2757 & 7.0973 & TST & \\
\hline CHEMBL 378347 & 379935 & 6.0862 & 6.1072 & TRN & \\
\hline CHEMBL213422 & 379935 & 7.4202 & 7.5378 & TRN & \\
\hline CHEMBL214140 & 379935 & 7.0506 & 6.9046 & TRN & \\
\hline CHEMBL 214172 & 379935 & 6.2366 & 6.3078 & TRN & \\
\hline CHEMBL377456 & 379935 & 5.4437 & 5.3212 & TRN & \\
\hline
\end{tabular}




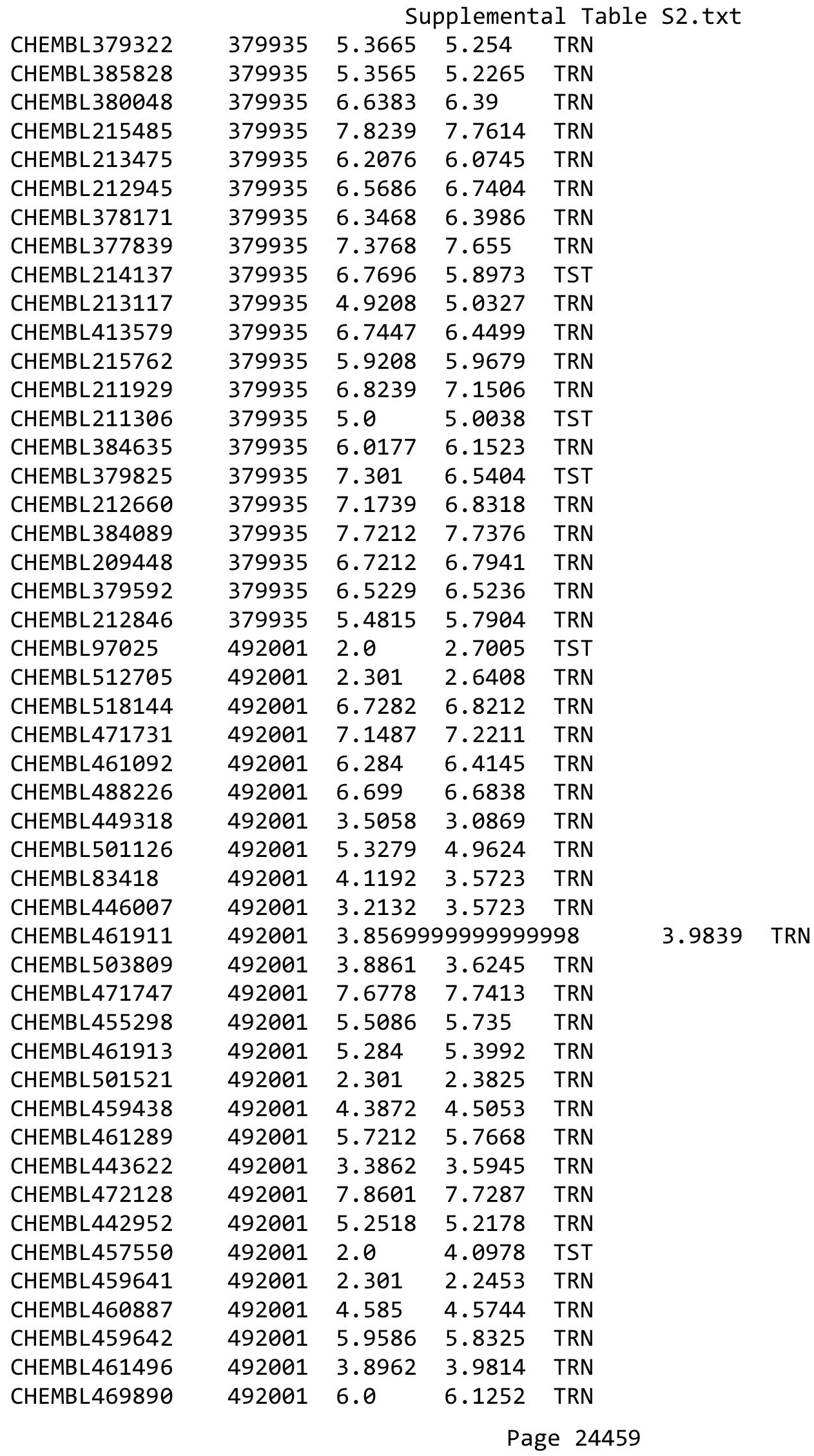


Supplemental Table S2.txt

\begin{tabular}{|c|c|c|c|c|}
\hline CHEMBL510594 & 492001 & 7.2924 & 5.6686 & TST \\
\hline CHEMBL459159 & 492001 & 5.1675 & 5.0926 & TRN \\
\hline CHEMBL460886 & 492001 & 5.4202 & 5.53799 & 7999999999 \\
\hline CHEMBL456298 & 492001 & 4.9031 & 4.9669 & TRN \\
\hline CHEMBL481466 & 492001 & 6.6946 & 6.6916 & TRN \\
\hline CHEMBL459643 & 492001 & 4.7212 & 4.7931 & TRN \\
\hline CHEMBL453574 & 492001 & 4.6383 & 4.7492 & TRN \\
\hline CHEMBL98008 & 492001 & 4.9788 & 4.9666 & TRN \\
\hline CHEMBL511346 & 492001 & 4.0223 & 4.103 & TRN \\
\hline CHEMBL403882 & 492001 & 4.301 & 3.5111 & TST \\
\hline CHEMBL461506 & 492001 & 4.3925 & 4.522 & TRN \\
\hline CHEMBL461912 & 492001 & 6.4685 & 6.1843 & TRN \\
\hline CHEMBL499101 & 492001 & 2.0 & 1.9735 & TRN \\
\hline CHEMBL452029 & 492001 & 3.6162 & 3.56 & TRN \\
\hline CHEMBL98408 & 492001 & 5.2218 & 5.1231 & TRN \\
\hline CHEMBL471544 & 492001 & 6.6198 & 6.7296 & TRN \\
\hline CHEMBL488227 & 492001 & 6.699 & 6.346 & TRN \\
\hline CHEMBL443373 & 492001 & 2.301 & 3.4349 & TST \\
\hline CHEMBL461290 & 492001 & 4.9208 & 4.8265 & TST \\
\hline CHEMBL461291 & 492001 & 4.8539 & 5.0599 & TST \\
\hline CHEMBL452470 & 492001 & 4.6383 & 4.7542 & TST \\
\hline CHEMBL460065 & 492001 & 5.2441 & 5.8759 & TST \\
\hline CHEMBL453918 & 492001 & 3.9393 & 4.409 & TST \\
\hline CHEMBL98869 & 492001 & 3.8477 & 5.2934 & TST \\
\hline CHEMBL460885 & 492001 & 4.9872 & 4.8731 & TST \\
\hline CHEMBL383705 & 492001 & 5.284 & 4.3819 & TST \\
\hline CHEMBL455542 & 492001 & 2.0 & 2.1053 & TST \\
\hline CHEMBL461713 & 1337203 & 5.1726 & 5.1812 & TRN \\
\hline CHEMBL292314 & 1337203 & 3.6021 & 3.5614 & TRN \\
\hline CHEMBL3237355 & 1337203 & 3.5229 & 3.5051 & TRN \\
\hline CHEMBL44789 & 1337203 & 4.8768 & 3.7314 & TST \\
\hline CHEMBL 2153291 & 1337203 & 4.9634 & 4.9707 & TRN \\
\hline CHEMBL3237354 & 1337203 & 3.5229 & 3.5663 & TRN \\
\hline CHEMBL 2153293 & 1337203 & 4.8345 & 4.7261 & TRN \\
\hline CHEMBL1084777 & 1337203 & 3.3979 & 3.4004 & TRN \\
\hline CHEMBL3237352 & 1337203 & 5.3605 & 5.3955 & TRN \\
\hline CHEMBL 2153414 & 1337203 & 4.9718 & 4.9591 & TRN \\
\hline CHEMBL3237345 & 1337203 & 4.8204 & 4.8099 & TRN \\
\hline CHEMBL511319 & 1337203 & 4.8474 & 4.744 & TRN \\
\hline CHEMBL 3237344 & 1337203 & 4.7916 & 4.784 & TRN \\
\hline CHEMBL 2153294 & 1337203 & 4.9662 & 4.9146 & TRN \\
\hline CHEMBL315530 & 1337203 & 5.1656 & 4.3848 & TST \\
\hline CHEMBL471927 & 1337203 & 5.1141 & 4.9504 & TRN \\
\hline CHEMBL471732 & 1337203 & 4.6635 & 4.8911 & TRN \\
\hline CHEMBL1173475 & 1337203 & 4.9385 & 4.2221 & TST \\
\hline CHEMBL3237356 & 1337203 & 3.5229 & 3.6937 & TST \\
\hline CHEMBL3237353 & 1337203 & 4.5036 & 4.4998 & TRN \\
\hline CHEMBL 2153415 & 1337203 & 4.7016 & 4.684 & TRN \\
\hline
\end{tabular}


Supplemental Table S2.txt

\begin{tabular}{|c|c|c|c|c|}
\hline (2) & & 4.8864 & 3 & \\
\hline CHEMPI 2237210 & 337203 & 4.769 & 4.8013 & \\
\hline IEMBL & 7203 & 5.011 & & \\
\hline IEMBL1 & 337203 & 5.1267 & 431 & \\
\hline HEMBL460679 & 337203 & 5.1618 & 237 & \\
\hline HEMBL & 7203 & 4.7212 & 66 & \\
\hline IEMBL: & 37203 & 4.6747 & & \\
\hline 53298 & 337203 & 5.062 & & \\
\hline IEMBL460881 & 337203 & 5.1656 & 493 & \\
\hline AEMBL2153296 & 337203 & 4.8986 & 952 & \\
\hline AEMBL3 & 337203 & 4.8945 & 36 & \\
\hline IEMBL & 337203 & 4.9136 & & \\
\hline 4003 & 337203 & 3.6021 & & \\
\hline 53299 & 337203 & 5.1649 & & \\
\hline AEMBL & 337203 & 5.0487 & 42 & \\
\hline 32 & 203 & 549 & & \\
\hline & 203 & 14 & & \\
\hline 37350 & 203 & 177 & & \\
\hline 2129 & 203 & & & \\
\hline 73 & 03 & 248 & & \\
\hline 13 & 203 & 43 & & \\
\hline D & 803 & & & \\
\hline 3416 & 203 & 854 & & \\
\hline 060 & 203 & 842 & & \\
\hline 3300 & & 36 & & \\
\hline 53295 & 203 & 3. & & \\
\hline 4 & 03 & & & \\
\hline 447 & 03 & & & \\
\hline nב & & 21 & & \\
\hline 200 & 03 & 38 & & \\
\hline & 03 & & & \\
\hline & 23 & 97 & & \\
\hline & & & & \\
\hline 33 & & & & \\
\hline 30 & 337203 & 776 & 73 & \\
\hline & 03 & 509 & & \\
\hline $\mathrm{Cl}$ & & & & \\
\hline 1922 & & 4.7406 & & \\
\hline CHEMBL 3 & 203 & 5.3449 & & TS \\
\hline & 36 & & & \\
\hline $\mathrm{CH}$ & & 3. & & \\
\hline CHEMBL: & & 5.25 & & \\
\hline CHEMBL5 & & 5.6778 & & $\Gamma R$ \\
\hline CHEMBL5 & 36 & 3 . & & TR \\
\hline Cun & 86 & & & \\
\hline CHEMBL603151 & & & & \\
\hline CHEMBL550278 & 612286 & 5.4815 & 5.5807 & \\
\hline CHEMBL599816 & 612286 & 3.301 & 3.4932 & \\
\hline
\end{tabular}

Page 24461 


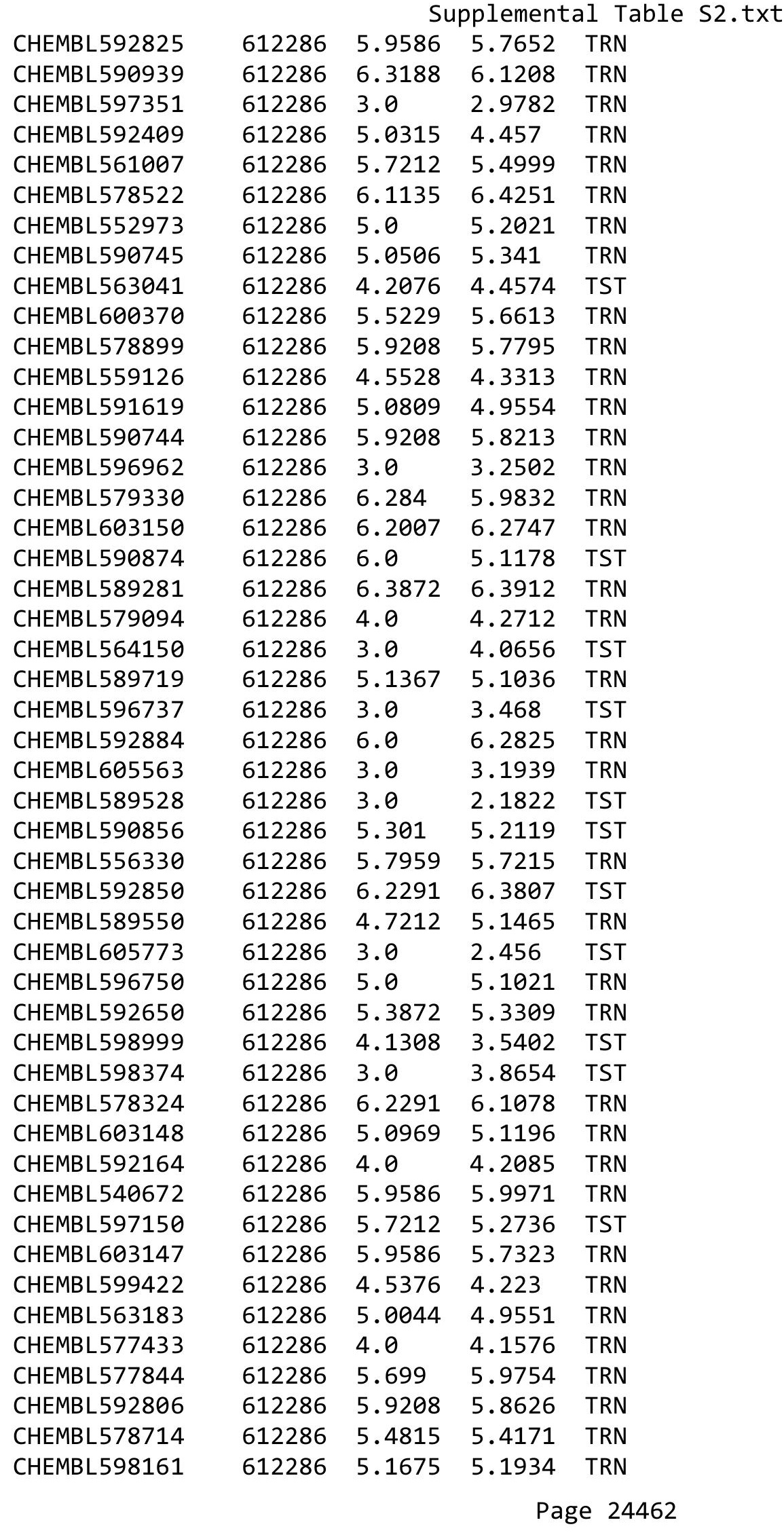


Supplemental Table S2.txt

\begin{tabular}{|c|c|c|c|c|}
\hline CHEMBL592802 & 612286 & 6.6778 & 6.4386 & TRN \\
\hline CHEMBL596769 & 612286 & 4.0915 & 4.2484 & TRN \\
\hline CHEMBL591712 & 612286 & 5.2518 & 5.516 & TST \\
\hline CHEMBL592885 & 612286 & 5.7447 & 5.8432 & TRN \\
\hline CHEMBL589737 & 612286 & 4.9208 & 4.6352 & TRN \\
\hline CHEMBL599005 & 612286 & 4.6778 & 4.7899 & TRN \\
\hline CHEMBL599197 & 612286 & 4.0862 & 4.4928 & TST \\
\hline CHEMBL578335 & 612286 & 5.4318 & 5.3173 & TRN \\
\hline CHEMBL591691 & 612286 & 4.0132 & 4.3158 & TRN \\
\hline CHEMBL561484 & 612286 & 5.2218 & 4.963 & TRN \\
\hline CHEMBL598387 & 612286 & 4.8861 & 4.9115 & TRN \\
\hline CHEMBL578482 & 612286 & 5.2518 & 4.8534 & TRN \\
\hline CHEMBL592410 & 612286 & 5.2366 & 5.6914 & TST \\
\hline CHEMBL597765 & 612286 & 4.6198 & 4.6272 & TRN \\
\hline CHEMBL590742 & 612286 & 5.9586 & 5.7764 & TRN \\
\hline CHEMBL590741 & 612286 & 6.041 & 5.987 & TRN \\
\hline CHEMBL598375 & 612286 & 3.0 & 3.7895 & TST \\
\hline CHEMBL589817 & 612286 & 5.4089 & 5.3571 & TRN \\
\hline CHEMBL599020 & 612286 & 3.0 & 3.1646 & TRN \\
\hline CHEMBL552972 & 612286 & 6.301 & 5.9125 & TRN \\
\hline CHEMBL592678 & 612286 & 6.3279 & 6.4898 & TST \\
\hline CHEMBL592887 & 612286 & 5.3279 & 5.3758 & TRN \\
\hline CHEMBL577854 & 612286 & 4.0 & \multicolumn{2}{|c|}{4.361000000000001} \\
\hline CHEMBL569097 & 612286 & 5.8861 & 5.6652 & TST \\
\hline CHEMBL599991 & 612286 & 3.0 & 3.0798 & TRN \\
\hline CHEMBL592531 & 612286 & 5.6576 & 5.4815 & TRN \\
\hline CHEMBL599604 & 612286 & 3.0 & 3.0192 & TST \\
\hline CHEMBL591185 & 612286 & 5.5086 & 5.1489 & TST \\
\hline CHEMBL597157 & 612286 & 3.0 & 2.7616 & TRN \\
\hline CHEMBL590990 & 612286 & 4.0 & 5.0414 & TST \\
\hline CHEMBL602294 & 612286 & 4.6576 & 4.7083 & TRN \\
\hline CHEMBL600574 & 612286 & 5.3979 & 5.5041 & TRN \\
\hline CHEMBL560009 & 612286 & 4.8239 & \multicolumn{2}{|c|}{4.5280000000000005} \\
\hline CHEMBL590140 & 612286 & 3.0 & 5.6953 & TST \\
\hline CHEMBL579289 & 612286 & 4.9586 & 5.145 & TRN \\
\hline CHEMBL539983 & 612286 & 5.1192 & 5.2136 & TRN \\
\hline CHEMBL590749 & 612286 & 6.4949 & 6.1216 & TRN \\
\hline CHEMBL578271 & 612286 & 6.1612 & 6.2299 & TRN \\
\hline CHEMBL591874 & 612286 & 4.0 & 4.2297 & TRN \\
\hline CHEMBL599825 & 612286 & 5.0555 & 5.1029 & TRN \\
\hline CHEMBL577630 & 612286 & 5.8239 & 5.8734 & TRN \\
\hline CHEMBL598821 & 612286 & 3.0 & 3.0821 & TRN \\
\hline CHEMBL599202 & 612286 & 3.0 & 3.123 & TST \\
\hline CHEMBL586227 & 612286 & 5.7447 & 5.8638 & TRN \\
\hline CHEMBL592570 & 612286 & 6.1938 & 6.0517 & TRN \\
\hline CHEMBL560084 & 612286 & 3.0 & 2.9404 & TST \\
\hline CHEMBL591427 & 612286 & 5.7447 & 5.728 & TRN \\
\hline CHEMBL590673 & 612286 & 5.7212 & 5.7005 & TRN \\
\hline
\end{tabular}

Page 24463 


\begin{tabular}{|c|c|c|c|c|c|}
\hline \multicolumn{6}{|c|}{ Supplemental Table S2.txt } \\
\hline CHEMBL592671 & 612286 & 5.6198 & 5.9125 & TRN & \\
\hline CHEMBL596939 & 612286 & 5.0862 & 5.1718 & TRN & \\
\hline CHEMBL598177 & 612286 & 4.5086 & 4.44600 & 0000000001 & TRN \\
\hline CHEMBL576331 & 612286 & 6.6198 & 6.15799 & 99999999995 & TRN \\
\hline CHEMBL605968 & 612286 & 3.0 & 4.4112 & TST & \\
\hline CHEMBL598388 & 612286 & 3.0 & 2.0614 & TST & \\
\hline CHEMBL578076 & 612286 & 6.0555 & 6.1731 & TRN & \\
\hline CHEMBL557553 & 612286 & 3.0 & 2.9861 & TST & \\
\hline CHEMBL603144 & 612286 & 5.9208 & 5.9991 & TRN & \\
\hline CHEMBL592882 & 612286 & 4.5086 & 4.5221 & TRN & \\
\hline CHEMBL591945 & 612286 & 6.3279 & 6.0845 & TST & \\
\hline CHEMBL598998 & 612286 & 3.0 & 3.3041 & TRN & \\
\hline CHEMBL599605 & 612286 & 4.1487 & 3.8888 & TST & \\
\hline CHEMBL564552 & 612286 & 4.7212 & 4.0656 & TST & \\
\hline CHEMBL592577 & 612286 & 6.0 & 6.0956 & TRN & \\
\hline CHEMBL592886 & 612286 & 5.7696 & 6.019 & TRN & \\
\hline CHEMBL598594 & 612286 & 3.0 & 4.6436 & TST & \\
\hline CHEMBL605847 & 612286 & 4.0969 & 3.7224 & TRN & \\
\hline CHEMBL592165 & 612286 & 4.0 & 4.0953 & TRN & \\
\hline CHEMBL562405 & 612286 & 5.1024 & 5.1268 & TRN & \\
\hline CHEMBL560882 & 612286 & 4.4089 & 4.5455 & TRN & \\
\hline CHEMBL599634 & 612286 & 4.3768 & 4.2574 & TRN & \\
\hline CHEMBL590747 & 612286 & 5.2518 & 5.581 & TST & \\
\hline CHEMBL590748 & 612286 & 6.1487 & 5.9934 & TRN & \\
\hline CHEMBL599399 & 612286 & 3.0 & 4.8774 & TST & \\
\hline CHEMBL590602 & 612286 & 6.3768 & 6.1915 & TRN & \\
\hline CHEMBL590328 & 612286 & 4.7959 & 4.8267 & TRN & \\
\hline CHEMBL590208 & 612286 & 5.6198 & 5.5681 & TRN & \\
\hline CHEMBL599606 & 612286 & 3.0 & 2.7017 & TST & \\
\hline CHEMBL590418 & 612286 & 5.9208 & 6.0111 & TRN & \\
\hline CHEMBL591991 & 612286 & 5.6778 & 5.6572 & TRN & \\
\hline CHEMBL605964 & 612286 & 3.0 & 2.4828 & TST & \\
\hline CHEMBL579081 & 612286 & 5.7447 & 5.6688 & TRN & \\
\hline CHEMBL596961 & 612286 & 4.7696 & 4.9137 & TRN & \\
\hline CHEMBL591367 & 612286 & 5.3468 & 5.4691 & TRN & \\
\hline CHEMBL579334 & 612286 & 5.2757 & 5.3464 & TRN & \\
\hline CHEMBL606209 & 612286 & 4.4437 & 4.4502 & TRN & \\
\hline CHEMBL600056 & 612286 & 6.2366 & 6.5431 & TRN & \\
\hline CHEMBL592535 & 612286 & 5.6383 & 5.6311 & TRN & \\
\hline CHEMBL600576 & 612286 & 5.5229 & 5.57 & TRN & \\
\hline CHEMBL588492 & 612286 & 6.2076 & 6.2952 & TRN & \\
\hline CHEMBL603149 & 612286 & 5.3372 & 5.1666 & TRN & \\
\hline CHEMBL598160 & 612286 & 5.0506 & 4.9801 & TRN & \\
\hline CHEMBL578080 & 612286 & 4.0 & 4.2513 & TRN & \\
\hline CHEMBL551217 & 612286 & 5.1249 & 5.4285 & TRN & \\
\hline CHEMBL599006 & 612286 & 3.0 & 3.0157 & TRN & \\
\hline CHEMBL578094 & 612286 & 4.0 & 4.7661 & TRN & \\
\hline CHEMBL599214 & 612286 & 3.0 & 3.1036 & TRN & \\
\hline
\end{tabular}




\begin{tabular}{|c|c|c|c|c|}
\hline & & & pıemer & \\
\hline CHEMBL589518 & 612286 & 6.041 & 6.0346 & TRN \\
\hline CHEMBL600055 & 612286 & 6.3372 & 6.4423 & TRN \\
\hline CHEMBL589198 & 612286 & 5.7447 & 5.5213 & TRN \\
\hline CHEMBL604497 & 612286 & 4.2518 & 4.4383 & TRN \\
\hline CHEMBL592021 & 612286 & 5.0862 & 5.3051 & TRN \\
\hline CHEMBL597158 & 612286 & 3.0 & 2.9791 & TRN \\
\hline CHEMBL591839 & 612286 & 5.5376 & 5.6109 & TRN \\
\hline CHEMBL590989 & 612286 & 4.0 & 5.4951 & TST \\
\hline CHEMBL597563 & 612286 & 3.0 & 3.7578 & TST \\
\hline CHEMBL592563 & 612286 & 5.585 & 5.7951 & TRN \\
\hline CHEMBL589519 & 612286 & 6.1487 & 6.0075 & TRN \\
\hline CHEMBL596733 & 612286 & 3.0 & 4.6123 & TST \\
\hline CHEMBL592810 & 612286 & 6.3372 & 6.3745 & TRN \\
\hline CHEMBL603333 & 612286 & 3.0 & 3.1447 & TRN \\
\hline CHEMBL592441 & 612286 & 6.1192 & 5.9279 & TRN \\
\hline CHEMBL549724 & 612286 & 4.5528 & 4.5526 & TST \\
\hline CHEMBL592880 & 612286 & 6.0862 & 6.2934 & TRN \\
\hline CHEMBL600369 & 612286 & 6.2596 & 6.1802 & TRN \\
\hline CHEMBL592737 & 612286 & 5.4089 & 5.436 & TRN \\
\hline CHEMBL599637 & 612286 & 5.5376 & 5.4016 & TRN \\
\hline CHEMBL562485 & 612286 & 5.1192 & 4.8576 & TRN \\
\hline CHEMBL603152 & 612286 & 6.041 & 5.7799 & TRN \\
\hline CHEMBL578507 & 612286 & 5.2441 & 5.2567 & TRN \\
\hline CHEMBL590798 & 612286 & 5.4949 & 5.3097 & TST \\
\hline CHEMBL600371 & 612286 & 5.4559 & 5.6364 & TRN \\
\hline CHEMBL605565 & 612286 & 3.301 & 3.2514 & TST \\
\hline CHEMBL589554 & 612286 & 5.7447 & 5.7337 & TRN \\
\hline CHEMBL562344 & 612286 & 5.0458 & 5.0808 & TRN \\
\hline CHEMBL539734 & 612286 & 6.1079 & 6.0014 & TRN \\
\hline CHEMBL600575 & 612286 & 5.1308 & 5.5694 & TRN \\
\hline CHEMBL564981 & 612286 & 4.2518 & 4.0656 & TST \\
\hline CHEMBL592408 & 612286 & 5.3468 & 4.816 & TRN \\
\hline CHEMBL600057 & 612286 & 6.2757 & 6.3068 & TRN \\
\hline CHEMBL552971 & 612286 & 5.3665 & 5.2187 & TRN \\
\hline CHEMBL591536 & 612286 & 3.0 & 2.7232 & TRN \\
\hline CHEMBL598376 & 612286 & 3.0 & 4.6515 & TST \\
\hline CHEMBL589335 & 612286 & 6.0 & 6.0619 & TRN \\
\hline CHEMBL591226 & 612286 & 5.9586 & 5.3657 & TST \\
\hline CHEMBL590746 & 612286 & 6.2366 & 5.9037 & TRN \\
\hline CHEMBL590743 & 612286 & 6.0 & 5.8327 & TRN \\
\hline CHEMBL604288 & 612286 & 5.4949 & 5.5764 & TRN \\
\hline CHEMBL601478 & 612286 & 6.0969 & 5.9649 & TRN \\
\hline CHEMBL577653 & 612286 & 5.0862 & 4.2551 & TST \\
\hline CHEMBL589584 & 612286 & 6.0506 & 6.1161 & TRN \\
\hline CHEMBL592166 & 612286 & 5.4685 & 4.7952 & TST \\
\hline CHEMBL601692 & 612286 & 6.1308 & 5.8919 & TRN \\
\hline CHEMBL589282 & 612286 & 6.4202 & 6.3204 & TRN \\
\hline CHEMBL600573 & 612286 & 5.8239 & 6.086 & TRN \\
\hline
\end{tabular}




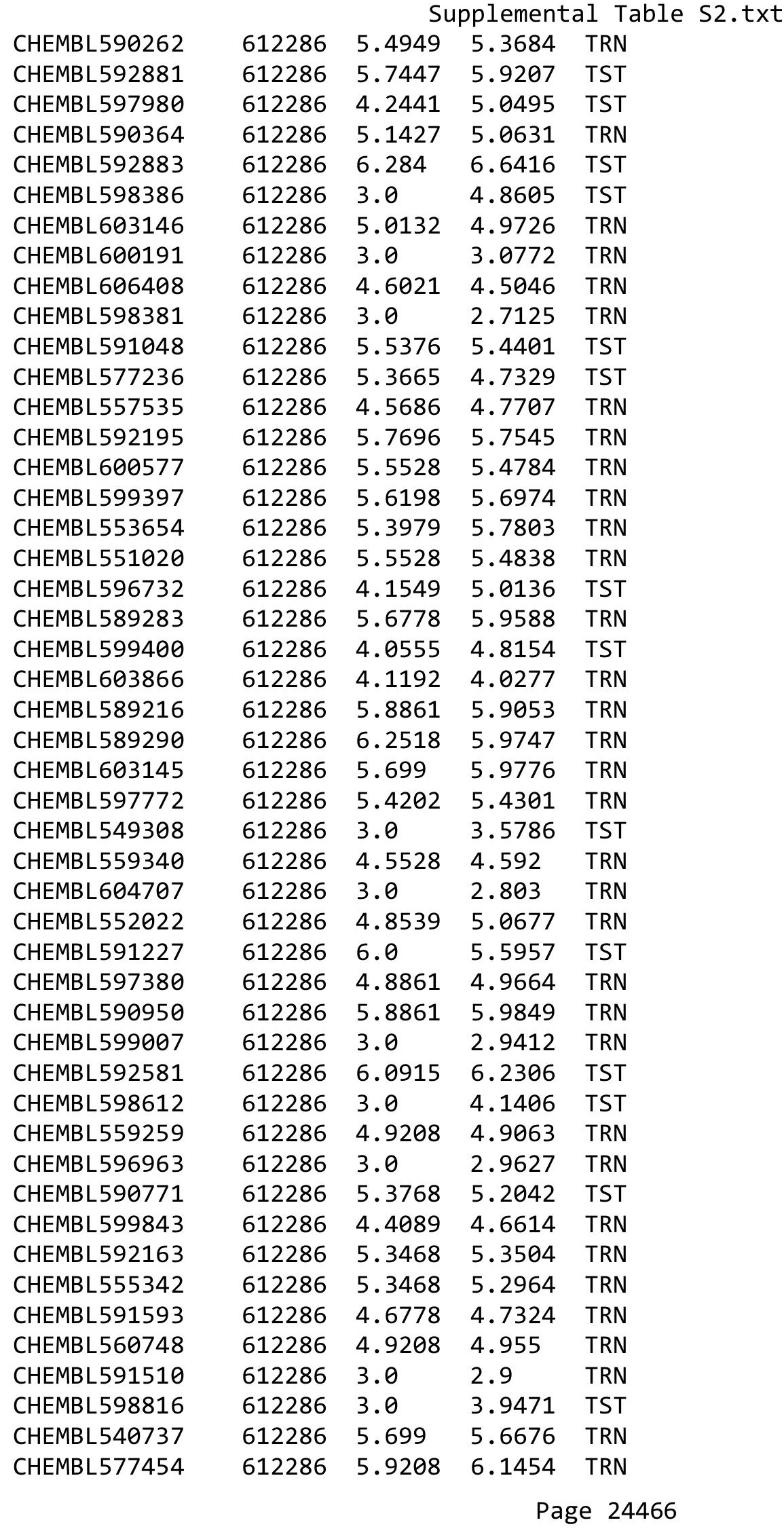




\begin{tabular}{|c|c|c|c|c|c|}
\hline \multirow[b]{2}{*}{ CHEMBL592888 } & \multicolumn{5}{|c|}{ Supplemental Table S2.txt } \\
\hline & 612286 & 6.4815 & 6.0362 & TRN & \\
\hline CHEMBL597976 & 612286 & 3.0 & 3.1831 & TRN & \\
\hline CHEMBL591212 & 612286 & 3.0 & 2.9906 & TRN & \\
\hline CHEMBL598588 & 612286 & 3.0 & 4.5044 & TST & \\
\hline CHEMBL598380 & 612286 & 3.0 & 2.9807 & TRN & \\
\hline CHEMBL550206 & 612286 & 4.4685 & 4.4327 & TRN & \\
\hline CHEMBL556522 & 612286 & 5.6021 & 5.4015 & TRN & \\
\hline CHEMBL3314919 & 1452896 & 4.4711 & 4.8769 & TRN & \\
\hline CHEMBL136689 & 1452896 & 10.3188 & 7.5029 & TST & \\
\hline CHEMBL3314924 & 1452896 & 5.9245 & 5.0839 & TRN & \\
\hline CHEMBL3314929 & 1452896 & 3.0 & 4.238 & TRN & \\
\hline CHEMBL3314905 & 1452896 & 6.4547 & 6.7624 & TST & \\
\hline CHEMBL3314890 & 1452896 & 6.9872 & 7.4424 & TRN & \\
\hline CHEMBL3314897 & 1452896 & 6.8477 & 6.9433 & TRN & \\
\hline CHEMBL3314912 & 1452896 & 3.0 & 3.6605 & TRN & \\
\hline CHEMBL3314908 & 1452896 & 6.5346 & 6.9025 & TRN & \\
\hline CHEMBL3314878 & 1452896 & 5.8182 & 6.0373 & TST & \\
\hline CHEMBL3314899 & 1452896 & 7.1355 & 6.8003 & TRN & \\
\hline CHEMBL3314909 & 1452896 & 5.1884 & 6.1938 & TRN & \\
\hline CHEMBL3314904 & 1452896 & 6.6289 & 6.9117 & TRN & \\
\hline CHEMBL3314903 & 1452896 & 7.5391 & 7.5231 & TRN & \\
\hline CHEMBL3314875 & 1452896 & 7.8239 & 8.1656 & TST & \\
\hline CHEMBL3314882 & 1452896 & 7.5513 & 7.2906 & TRN & \\
\hline CHEMBL3314871 & 1452896 & 6.9355 & 7.2061 & TRN & \\
\hline CHEMBL3314915 & 1452896 & 3.0 & 3.8454 & TRN & \\
\hline CHEMBL3314917 & 1452896 & 4.5702 & 4.6793 & TRN & \\
\hline CHEMBL3314879 & 1452896 & 7.9066 & 7.6175 & TRN & \\
\hline CHEMBL3314887 & 1452896 & 6.983 & 7.1759 & TRN & \\
\hline CHEMBL3314913 & 1452896 & 7.3526 & 7.4204 & TRN & \\
\hline CHEMBL3314926 & 1452896 & 5.1945 & 3.8065 & TRN & \\
\hline CHEMBL3314885 & 1452896 & 4.3696 & 5.1878 & TRN & \\
\hline CHEMBL3314902 & 1452896 & 6.4145 & 6.1771 & TRN & \\
\hline CHEMBL3314873 & 1452896 & 7.5884 & 7.8287 & TRN & \\
\hline CHEMBL3314923 & 1452896 & 5.4365 & 4.9159 & TRN & \\
\hline CHEMBL3314883 & 1452896 & 8.317 & 7.6053 & TRN & \\
\hline CHEMBL3314900 & 1452896 & 6.6799 & 6.5514 & TRN & \\
\hline CHEMBL3314901 & 1452896 & 6.7282 & 6.2788 & TRN & \\
\hline CHEMBL3314914 & 1452896 & 6.6778 & 6.13899 & 9999999999 & TRN \\
\hline CHEMBL3314907 & 1452896 & 5.0872 & 5.0006 & TST & \\
\hline CHEMBL3314881 & 1452896 & 6.1118 & 5.3585 & TRN & \\
\hline CHEMBL324735 & 1452896 & 6.4191 & 8.1829 & TST & \\
\hline CHEMBL 3314872 & 1452896 & 5.2741 & 5.5768 & TRN & \\
\hline CHEMBL3314925 & 1452896 & 4.9066 & 4.8328 & TRN & \\
\hline CHEMBL3314892 & 1452896 & 7.4271 & 7.7453 & TRN & \\
\hline CHEMBL3314896 & 1452896 & 6.9136 & 6.9125 & TRN & \\
\hline CHEMBL3313941 & 1452896 & 7.9547 & 8.3433 & TRN & \\
\hline CHEMBL 3314876 & 1452896 & 8.4789 & 7.3183 & TRN & \\
\hline CHEMBL3314874 & 1452896 & 7.1858 & 7.4846 & TRN & \\
\hline
\end{tabular}

Page 24467 
Supplemental Table S2.txt

\begin{tabular}{|c|c|c|c|c|}
\hline CHEMBL3314884 & 1452896 & 6.7375 & 5.4855 & TST \\
\hline CHEMBL3314928 & 1452896 & 4.7447 & 3.5472 & TRN \\
\hline CHEMBL3314906 & 1452896 & 4.9914 & 4.9648 & TST \\
\hline CHEMBL3314918 & 1452896 & 5.1158 & 4.5978 & TRN \\
\hline CHEMBL3314930 & 1452896 & 3.0 & 4.5345 & TRN \\
\hline CHEMBL3314893 & 1452896 & 7.3625 & 7.6025 & TRN \\
\hline CHEMBL3314921 & 1452896 & 4.4283 & 4.7514 & TST \\
\hline CHEMBL3314911 & 1452896 & 7.2299 & 6.9117 & TRN \\
\hline CHEMBL3314889 & 1452896 & 7.3002 & 6.892 & TRN \\
\hline CHEMBL3314895 & 1452896 & 7.4949 & 7.0818 & TRN \\
\hline CHEMBL3314927 & 1452896 & 3.0 & 3.5305 & TRN \\
\hline CHEMBL3314888 & 1452896 & 7.2984 & 7.4673 & TRN \\
\hline CHEMBL3314916 & 1452896 & 5.4342 & 4.7931 & TRN \\
\hline CHEMBL3314894 & 1452896 & 6.9172 & 6.5967 & TRN \\
\hline CHEMBL3314910 & 1452896 & 4.7545 & 3.5717 & TST \\
\hline CHEMBL3314880 & 1452896 & 7.289 & 7.8707 & TRN \\
\hline CHEMBL3314886 & 1452896 & 4.6073 & 3.44199 & 99999999997 \\
\hline CHEMBL3314920 & 1452896 & 6.2248 & 5.2003 & TST \\
\hline CHEMBL3314877 & 1452896 & 8.2396 & 8.3414 & TRN \\
\hline CHEMBL3314922 & 1452896 & 4.4698 & 4.6453 & TST \\
\hline CHEMBL3314870 & 1452896 & 5.0223 & 5.8661 & TST \\
\hline CHEMBL3314891 & 1452896 & 6.6676 & 6.6654 & TST \\
\hline CHEMBL3314898 & 1452896 & 7.4056 & 6.9593 & TST \\
\hline CHEMBL1613033 & 688816 & 8.0 & 5.1576 & TST \\
\hline CHEMBL1587624 & 688816 & 4.9 & 5.5851 & TRN \\
\hline CHEMBL1566906 & 688816 & 4.7 & 5.0734 & TRN \\
\hline CHEMBL261777 & 688816 & 5.55 & 5.4394 & TRN \\
\hline CHEMBL1545613 & 688816 & 4.45 & 5.1588 & TST \\
\hline CHEMBL1532037 & 688816 & 4.9 & 5.2127 & TRN \\
\hline CHEMBL1525540 & 688816 & 4.95 & 5.2264 & TRN \\
\hline CHEMBL1519155 & 688816 & 7.8996 & 5.7005 & TRN \\
\hline CHEMBL1326967 & 688816 & 6.3 & 5.3973 & TRN \\
\hline CHEMBL1581380 & 688816 & 4.9 & 5.4012 & TRN \\
\hline CHEMBL1456245 & 688816 & 5.25 & 4.8303 & TST \\
\hline CHEMBL3210160 & 688816 & 4.65 & 5.3098 & TRN \\
\hline CHEMBL1588060 & 688816 & 4.8 & 5.142 & TRN \\
\hline CHEMBL1478795 & 688816 & 5.1 & 5.1475 & TRN \\
\hline CHEMBL1501454 & 688816 & 4.85 & 4.7324 & TRN \\
\hline CHEMBL1368977 & 688816 & 7.2503 & 5.1692 & TRN \\
\hline CHEMBL1500320 & 688816 & 5.6 & 5.2834 & TST \\
\hline CHEMBL1447566 & 688816 & 5.0 & 5.1515 & TRN \\
\hline CHEMBL1597166 & 688816 & 4.45 & 5.1979 & TRN \\
\hline CHEMBL1603775 & 688816 & 4.7 & 5.3952 & TRN \\
\hline CHEMBL1604451 & 688816 & 4.6 & 5.1046 & TRN \\
\hline CHEMBL1367872 & 688816 & 5.0 & 5.0055 & TRN \\
\hline CHEMBL1333119 & 688816 & 4.8 & 5.2669 & TST \\
\hline CHEMBL1589526 & 688816 & 4.8 & 4.9996 & TRN \\
\hline CHEMBL1353871 & 688816 & 4.9 & 5.3711 & TRN \\
\hline
\end{tabular}




\begin{tabular}{|c|c|c|c|c|c|}
\hline \multicolumn{6}{|c|}{ Supplemental Table S2.txt } \\
\hline CHEMBL1387553 & 688816 & 6.8 & 5.6752 & TRN & \\
\hline CHEMBL1435969 & 688816 & 4.75 & 5.3894 & TST & \\
\hline CHEMBL 2000338 & 688816 & 5.0 & 4.8737 & TRN & \\
\hline CHEMBL1388387 & 688816 & 6.95 & 5.0681 & TRN & \\
\hline CHEMBL1567019 & 688816 & 4.9 & 5.3718 & TST & \\
\hline CHEMBL1432203 & 688816 & 4.45 & 5.1384 & TST & \\
\hline CHEMBL1580114 & 688816 & 4.85 & 4.9262 & TRN & \\
\hline CHEMBL1392893 & 688816 & 5.3 & 5.4644 & TST & \\
\hline CHEMBL1400378 & 688816 & 4.85 & 5.1757 & TRN & \\
\hline CHEMBL1330991 & 688816 & 5.7 & 5.5097 & TRN & \\
\hline CHEMBL1550125 & 688816 & 4.7 & 4.9988 & TST & \\
\hline CHEMBL1418909 & 688816 & 4.85 & 5.26399 & 9999999999 & TRN \\
\hline CHEMBL1534893 & 688816 & 5.0 & 5.2303 & TRN & \\
\hline CHEMBL1340208 & 688816 & 4.95 & 5.3182 & TRN & \\
\hline CHEMBL1343864 & 688816 & 6.5 & 5.2209 & TRN & \\
\hline CHEMBL3192001 & 688816 & 4.95 & 5.3196 & TRN & \\
\hline CHEMBL1473537 & 688816 & 4.95 & 5.1087 & TRN & \\
\hline CHEMBL1310273 & 688816 & 4.95 & 4.9973 & TST & \\
\hline CHEMBL1546246 & 688816 & 4.75 & 5.1808 & TRN & \\
\hline CHEMBL1577140 & 688816 & 4.9 & 5.0788 & TRN & \\
\hline CHEMBL1335985 & 688816 & 4.75 & 5.2935 & TST & \\
\hline CHEMBL1493743 & 688816 & 5.45 & 5.0254 & TRN & \\
\hline CHEMBL1490562 & 688816 & 5.0 & 5.3514 & TRN & \\
\hline CHEMBL1504000 & 688816 & 5.2 & 5.4604 & TST & \\
\hline CHEMBL1884996 & 688816 & 6.5 & 5.4769 & TRN & \\
\hline CHEMBL604156 & 688816 & 5.5 & 5.4558 & TRN & \\
\hline CHEMBL1517703 & 688816 & 5.5 & 5.1256 & TRN & \\
\hline CHEMBL1372245 & 688816 & 5.55 & 5.33299 & 9999999999 & TRN \\
\hline CHEMBL 3196840 & 688816 & 4.45 & 5.0722 & TRN & \\
\hline CHEMBL1586871 & 688816 & 4.9 & 5.4402 & TST & \\
\hline CHEMBL1465149 & 688816 & 8.3468 & 5.0972 & TST & \\
\hline CHEMBL1326124 & 688816 & 4.95 & 5.6455 & TRN & \\
\hline CHEMBL1455824 & 688816 & 4.9 & 5.3606 & TRN & \\
\hline CHEMBL1537968 & 688816 & 4.7 & 5.3857 & TST & \\
\hline CHEMBL1329073 & 688816 & 4.45 & 5.2175 & TRN & \\
\hline CHEMBL1416631 & 688816 & 5.35 & 5.4965 & TST & \\
\hline CHEMBL1375291 & 688816 & 5.15 & 5.4818 & TRN & \\
\hline CHEMBL1304385 & 688816 & 4.45 & 5.2929 & TRN & \\
\hline CHEMBL1409869 & 688816 & 4.85 & 5.6381 & TST & \\
\hline CHEMBL1560912 & 688816 & 4.45 & 5.3855 & TST & \\
\hline CHEMBL1488610 & 688816 & 4.75 & 5.2521 & TST & \\
\hline CHEMBL1564238 & 688816 & 4.95 & 5.0509 & TRN & \\
\hline CHEMBL1558351 & 688816 & 6.0 & 5.2121 & TRN & \\
\hline CHEMBL1412492 & 688816 & 5.0 & 5.2887 & TRN & \\
\hline CHEMBL1512405 & 688816 & 4.65 & 5.1132 & TRN & \\
\hline CHEMBL1535287 & 688816 & 4.4 & 4.9237 & TRN & \\
\hline CHEMBL1561242 & 688816 & 4.45 & 5.0158 & TRN & \\
\hline CHEMBL1419445 & 688816 & 5.25 & 5.4155 & TRN & \\
\hline
\end{tabular}




\begin{tabular}{|c|c|c|c|c|c|}
\hline \multicolumn{6}{|c|}{ Supplemental Table s2.txt } \\
\hline CHEMBL1510516 & 688816 & 7.0 & 5.39 & TST & \\
\hline CHEMBL1373504 & 688816 & 5.15 & 5.0442 & TRN & \\
\hline CHEMBL1503190 & 688816 & 4.65 & 5.6368 & TST & \\
\hline CHEMBL1477550 & 688816 & 4.9 & 5.1741 & TRN & \\
\hline CHEMBL1386766 & 688816 & 4.85 & 5.2361 & TRN & \\
\hline CHEMBL1521335 & 688816 & 4.9 & 5.0611 & TRN & \\
\hline CHEMBL1571568 & 688816 & 4.55 & 5.2616 & TRN & \\
\hline CHEMBL1413082 & 688816 & 4.95 & 4.9653 & TRN & \\
\hline CHEMBL1414127 & 688816 & 4.95 & 4.86600 & 00000000005 & TST \\
\hline CHEMBL1545968 & 688816 & 4.95 & 5.2222 & TST & \\
\hline CHEMBL1404053 & 688816 & 7.15 & 5.6237 & TRN & \\
\hline CHEMBL1987078 & 688816 & 5.5 & 5.3437 & TRN & \\
\hline CHEMBL1516550 & 688816 & 4.9 & 5.5036 & TRN & \\
\hline CHEMBL1608942 & 688816 & 4.95 & 5.4573 & TRN & \\
\hline CHEMBL1606103 & 688816 & 7.0501 & 5.6873 & TRN & \\
\hline CHEMBL1437979 & 688816 & 4.95 & 4.6745 & TRN & \\
\hline CHEMBL3199557 & 688816 & 5.45 & 5.5398 & TRN & \\
\hline CHEMBL3196499 & 688816 & 5.4 & 5.00899 & 99999999995 & TRN \\
\hline CHEMBL3199152 & 688816 & 4.95 & 5.3861 & TST & \\
\hline CHEMBL1392911 & 688816 & 5.1 & 5.4254 & TRN & \\
\hline CHEMBL1384502 & 688816 & 4.45 & 5.4639 & TRN & \\
\hline CHEMBL1327923 & 688816 & 4.65 & 5.1216 & TRN & \\
\hline CHEMBL 3214241 & 688816 & 4.65 & 5.1687 & TRN & \\
\hline CHEMBL1306242 & 688816 & 5.15 & 5.562 & TRN & \\
\hline CHEMBL1503113 & 688816 & 4.65 & 4.9371 & TRN & \\
\hline CHEMBL1535880 & 688816 & 4.9 & 4.9121 & TRN & \\
\hline CHEMBL1330344 & 688816 & 4.55 & 5.1801 & TRN & \\
\hline CHEMBL1323568 & 688816 & 4.95 & 5.1148 & TRN & \\
\hline CHEMBL1420252 & 688816 & 5.35 & 5.4764 & TRN & \\
\hline CHEMBL1445431 & 688816 & 7.8508 & 4.9514 & TST & \\
\hline CHEMBL1369837 & 688816 & 4.7 & 4.9999 & TRN & \\
\hline CHEMBL1464647 & 688816 & 5.45 & 5.0283 & TRN & \\
\hline CHEMBL1368363 & 688816 & 4.95 & 5.2451 & TRN & \\
\hline CHEMBL1510646 & 688816 & 5.95 & 5.4052 & TRN & \\
\hline CHEMBL1361525 & 688816 & 4.95 & 5.4593 & TRN & \\
\hline CHEMBL1607104 & 688816 & 5.0 & 5.3025 & TRN & \\
\hline CHEMBL1312513 & 688816 & 5.3 & 5.4376 & TRN & \\
\hline CHEMBL3209829 & 688816 & 4.45 & 5.0767 & TST & \\
\hline CHEMBL1320415 & 688816 & 5.55 & 5.7281 & TST & \\
\hline CHEMBL1607673 & 688816 & 6.45 & 5.3216 & TRN & \\
\hline CHEMBL1331475 & 688816 & 4.75 & 5.0938 & TRN & \\
\hline CHEMBL1546343 & 688816 & 5.4 & 4.8184 & TRN & \\
\hline CHEMBL1446967 & 688816 & 4.95 & 5.2198 & TRN & \\
\hline CHEMBL1612536 & 688816 & 5.25 & 5.5516 & TRN & \\
\hline CHEMBL1307028 & 688816 & 5.35 & 5.1468 & TRN & \\
\hline CHEMBL1604650 & 688816 & 5.5 & 5.3021 & TRN & \\
\hline CHEMBL1337984 & 688816 & 5.85 & 5.5047 & TRN & \\
\hline CHEMBL1392709 & 688816 & 4.85 & 5.4993 & TST & \\
\hline
\end{tabular}




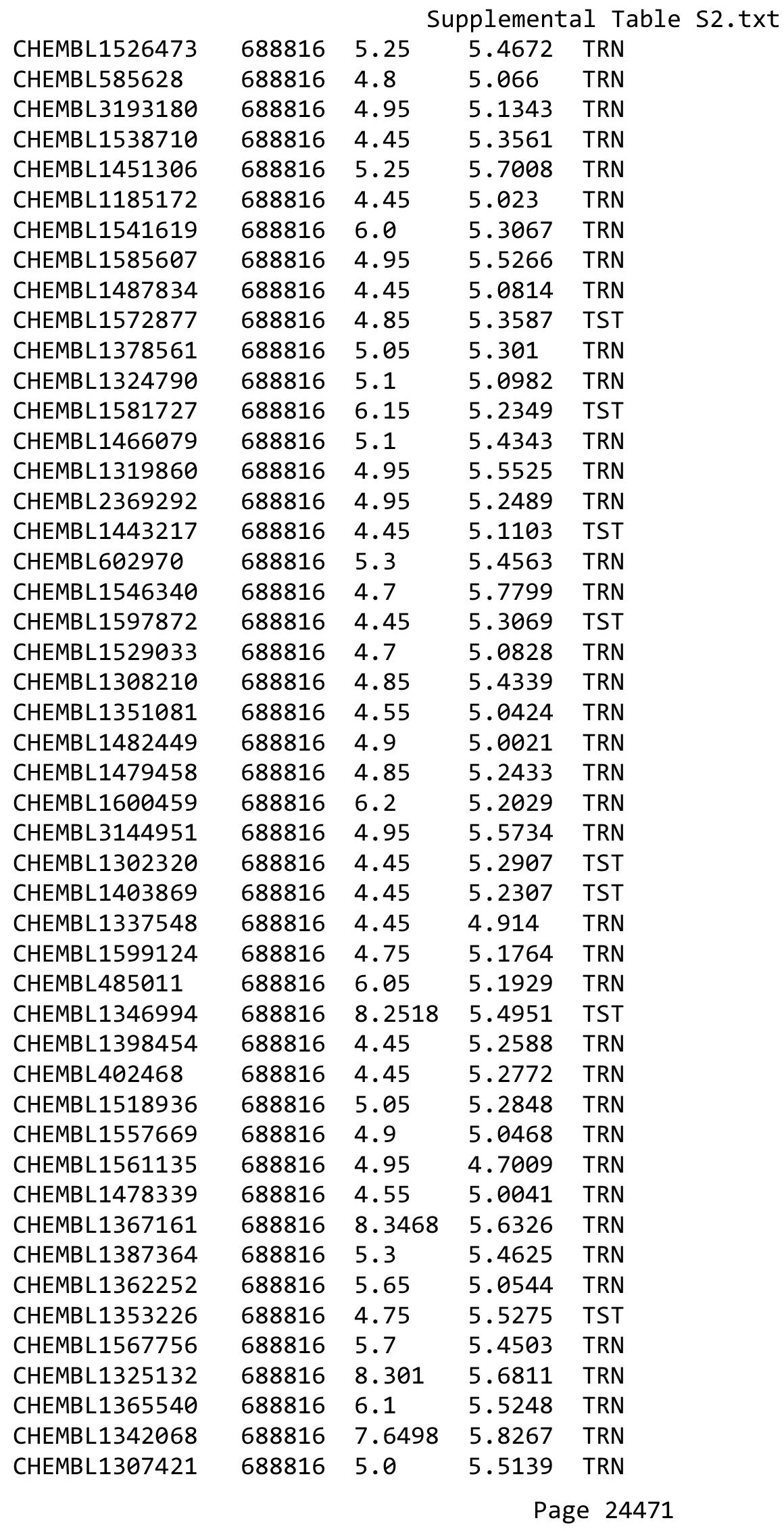




\begin{tabular}{|c|c|c|c|c|}
\hline & & & pplement & al Table S \\
\hline CHEMBL1556156 & 688816 & 7.7496 & 5.2846 & TRN \\
\hline CHEMBL1420639 & 688816 & 5.0 & 5.2561 & TRN \\
\hline CHEMBL1449499 & 688816 & 4.75 & 5.1276 & TRN \\
\hline CHEMBL1546496 & 688816 & 5.5 & 5.4925 & TRN \\
\hline CHEMBL1600941 & 688816 & 4.85 & 5.2177 & TRN \\
\hline CHEMBL1350956 & 688816 & 4.95 & 5.3083 & TRN \\
\hline CHEMBL1563148 & 688816 & 4.9 & 5.5758 & TRN \\
\hline CHEMBL1440528 & 688816 & 5.65 & 5.6564 & TST \\
\hline CHEMBL1368588 & 688816 & 5.7 & 5.1501 & TST \\
\hline CHEMBL3207987 & 688816 & 4.95 & 5.2808 & TST \\
\hline CHEMBL1338941 & 688816 & 5.1 & 5.2015 & TRN \\
\hline CHEMBL1450651 & 688816 & 4.45 & 5.2607 & TRN \\
\hline CHEMBL1527311 & 688816 & 5.15 & 5.237 & TST \\
\hline CHEMBL3191597 & 688816 & 4.45 & 5.4281 & TRN \\
\hline CHEMBL1459016 & 688816 & 5.55 & 5.1887 & TST \\
\hline CHEMBL1585220 & 688816 & 4.45 & 4.76 & TRN \\
\hline CHEMBL1337224 & 688816 & 4.95 & 4.9872 & TRN \\
\hline CHEMBL1350239 & 688816 & 5.25 & 5.0342 & TRN \\
\hline CHEMBL1400514 & 688816 & 5.75 & 5.1119 & TRN \\
\hline CHEMBL1441977 & 688816 & 5.85 & 4.9353 & TRN \\
\hline CHEMBL1323880 & 688816 & 5.15 & 5.4998 & TST \\
\hline CHEMBL1586152 & 688816 & 4.8 & 5.4119 & TST \\
\hline CHEMBL1498545 & 688816 & 4.75 & 5.0883 & TRN \\
\hline CHEMBL1484999 & 688816 & 6.5 & 6.0492 & TRN \\
\hline CHEMBL1441304 & 688816 & 4.75 & 4.7207 & TRN \\
\hline CHEMBL1372828 & 688816 & 4.85 & 5.0866 & TRN \\
\hline CHEMBL1400036 & 688816 & 4.5 & 5.2651 & TRN \\
\hline CHEMBL1422788 & 688816 & 4.9 & 5.4922 & TST \\
\hline CHEMBL1449150 & 688816 & 4.9 & 5.0768 & TRN \\
\hline CHEMBL1522987 & 688816 & 4.95 & 4.8833 & TRN \\
\hline CHEMBL1543948 & 688816 & 5.0 & 5.2455 & TRN \\
\hline CHEMBL1316083 & 688816 & 4.8 & 5.0168 & TRN \\
\hline CHEMBL1519021 & 688816 & 4.45 & 5.4071 & TRN \\
\hline CHEMBL1442507 & 688816 & 4.95 & 5.0007 & TRN \\
\hline CHEMBL1491196 & 688816 & 4.45 & 5.5455 & TRN \\
\hline CHEMBL1592154 & 688816 & 4.55 & 4.9722 & TRN \\
\hline CHEMBL1607184 & 688816 & 5.05 & 4.7111 & TRN \\
\hline CHEMBL1599358 & 688816 & 4.65 & 5.2439 & TRN \\
\hline CHEMBL1313532 & 688816 & 4.9 & 5.0529 & TRN \\
\hline CHEMBL1600851 & 688816 & 4.65 & 5.1675 & TRN \\
\hline CHEMBL1582770 & 688816 & 4.95 & 5.3597 & TRN \\
\hline CHEMBL3192749 & 688816 & 5.0 & 5.1464 & TRN \\
\hline CHEMBL1548929 & 688816 & 5.2 & 5.0536 & TRN \\
\hline CHEMBL 3197870 & 688816 & 4.9 & 5.3084 & TRN \\
\hline CHEMBL1503386 & 688816 & 4.75 & 5.37200 & 0000000001 \\
\hline CHEMBL1337186 & 688816 & 5.0 & 5.5037 & TST \\
\hline CHEMBL1503105 & 688816 & 4.85 & 4.8633 & TRN \\
\hline CHEMBL1578633 & 688816 & 4.95 & 5.1456 & TST \\
\hline
\end{tabular}




\begin{tabular}{|c|c|c|c|c|c|}
\hline \multicolumn{6}{|c|}{ Supplemental Table S2.txt } \\
\hline CHEMBL1559651 & 688816 & 6.45 & 5.6191 & TRN & \\
\hline CHEMBL1416756 & 688816 & 4.45 & 5.0067 & TRN & \\
\hline CHEMBL1501531 & 688816 & 4.45 & 5.6607 & TRN & \\
\hline CHEMBL 7162 & 688816 & 5.35 & 5.5203 & TST & \\
\hline CHEMBL1339049 & 688816 & 7.5003 & 5.5224 & TRN & \\
\hline CHEMBL1494245 & 688816 & 5.95 & 5.425 & TRN & \\
\hline CHEMBL1309463 & 688816 & 4.65 & 5.3518 & TRN & \\
\hline CHEMBL1524085 & 688816 & 4.55 & 5.3099 & TST & \\
\hline CHEMBL1542516 & 688816 & 4.95 & 5.3816 & TRN & \\
\hline CHEMBL 2004417 & 688816 & 5.05 & 5.2395 & TRN & \\
\hline CHEMBL1480424 & 688816 & 4.75 & 5.3053 & TRN & \\
\hline CHEMBL1335628 & 688816 & 4.65 & 5.4144 & TRN & \\
\hline CHEMBL1341711 & 688816 & 4.75 & 5.0256 & TRN & \\
\hline CHEMBL1445828 & 688816 & 5.8 & 5.4542 & TRN & \\
\hline CHEMBL1392067 & 688816 & 5.1 & 5.0945 & TRN & \\
\hline CHEMBL1595759 & 688816 & 4.45 & 5.1287 & TRN & \\
\hline CHEMBL3207331 & 688816 & 8.301 & 5.3344 & TRN & \\
\hline CHEMBL1427730 & 688816 & 4.9 & 5.0077 & TRN & \\
\hline CHEMBL1347359 & 688816 & 5.0 & 5.2091 & TRN & \\
\hline CHEMBL1498419 & 688816 & 5.55 & 5.20799 & 9999999999 & TST \\
\hline CHEMBL1443484 & 688816 & 4.85 & 5.1577 & TRN & \\
\hline CHEMBL1499298 & 688816 & 4.95 & 5.6862 & TST & \\
\hline CHEMBL1424131 & 688816 & 4.9 & 5.1776 & TST & \\
\hline CHEMBL1507922 & 688816 & 6.25 & 5.1556 & TST & \\
\hline CHEMBL1544265 & 688816 & 5.15 & 4.8714 & TST & \\
\hline CHEMBL1535067 & 688816 & 6.4 & 5.1428 & TRN & \\
\hline CHEMBL1599023 & 688816 & 5.05 & 5.4536 & TST & \\
\hline CHEMBL1343951 & 688816 & 4.45 & 5.4745 & TRN & \\
\hline CHEMBL1408519 & 688816 & 4.45 & 5.1792 & TST & \\
\hline CHEMBL1385643 & 688816 & 5.05 & 5.13399 & 99999999995 & TRN \\
\hline CHEMBL1385801 & 688816 & 4.9 & 5.25899 & 99999999995 & TRN \\
\hline CHEMBL1359849 & 688816 & 4.95 & 5.1717 & TRN & \\
\hline CHEMBL1500134 & 688816 & 4.85 & 5.1504 & TRN & \\
\hline CHEMBL1510264 & 688816 & 4.85 & 5.3716 & TRN & \\
\hline CHEMBL465227 & 688816 & 4.95 & 5.1705 & TRN & \\
\hline CHEMBL1580300 & 688816 & 5.0 & 5.2458 & TRN & \\
\hline CHEMBL3198091 & 688816 & 4.45 & 4.9686 & TRN & \\
\hline CHEMBL1494968 & 688816 & 4.65 & 5.0709 & TRN & \\
\hline CHEMBL1386050 & 688816 & 5.5 & 5.1823 & TRN & \\
\hline CHEMBL1409319 & 688816 & 4.5 & 5.2053 & TRN & \\
\hline CHEMBL1493921 & 688816 & 4.95 & 5.1644 & TST & \\
\hline CHEMBL1506506 & 688816 & 5.4 & 4.8131 & TRN & \\
\hline CHEMBL1405339 & 688816 & 4.75 & 5.0228 & TRN & \\
\hline CHEMBL1321646 & 688816 & 4.8 & 5.6224 & TRN & \\
\hline CHEMBL140425 & 688816 & 4.45 & 5.1171 & TRN & \\
\hline CHEMBL1330167 & 688816 & 5.3 & 5.2024 & TRN & \\
\hline CHEMBL1465356 & 688816 & 5.1 & 5.3888 & TRN & \\
\hline CHEMBL1542506 & 688816 & 4.7 & 5.5092 & TST & \\
\hline
\end{tabular}




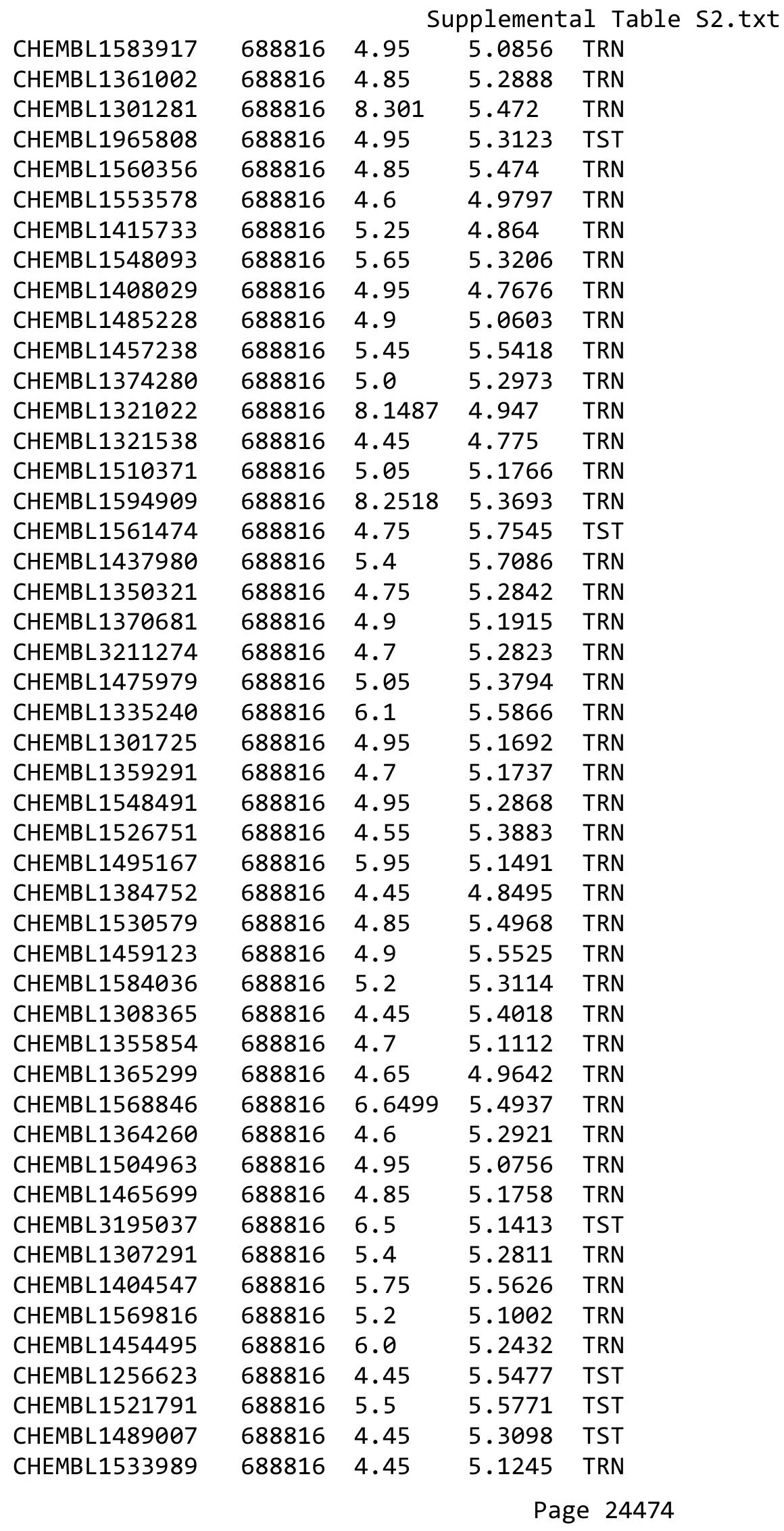




\begin{tabular}{|c|c|c|c|c|}
\hline \multicolumn{5}{|c|}{ Supplemental Table S2.txt } \\
\hline CHEMBL1609324 & 688816 & 5.0 & 5.1701 & TST \\
\hline CHEMBL1403417 & 688816 & 5.5 & 5.129 & TST \\
\hline CHEMBL1596003 & 688816 & 6.5501 & 5.0514 & TST \\
\hline CHEMBL1353865 & 688816 & 5.25 & 5.067 & TRN \\
\hline CHEMBL1377993 & 688816 & 5.45 & 5.5572 & TRN \\
\hline CHEMBL1306003 & 688816 & 5.6 & 5.4094 & TST \\
\hline CHEMBL1538244 & 688816 & 4.8 & 5.4504 & TST \\
\hline CHEMBL1468590 & 688816 & 7.8013 & 5.3502 & TRN \\
\hline CHEMBL1335959 & 688816 & 5.45 & 5.3861 & TRN \\
\hline CHEMBL3194533 & 688816 & 4.65 & 5.4642 & TRN \\
\hline CHEMBL1364191 & 688816 & 8.4949 & 5.4808 & TST \\
\hline CHEMBL1477771 & 688816 & 5.4 & 5.8291 & TRN \\
\hline CHEMBL1595176 & 688816 & 4.85 & 5.2533 & TRN \\
\hline CHEMBL1331587 & 688816 & 4.95 & 5.2163 & TRN \\
\hline CHEMBL1606138 & 688816 & 5.05 & 4.9395 & TRN \\
\hline CHEMBL1391749 & 688816 & 5.4 & 5.2373 & TST \\
\hline CHEMBL3198114 & 688816 & 4.85 & 5.2045 & TRN \\
\hline CHEMBL 3196648 & 688816 & 4.45 & 5.2368 & TRN \\
\hline CHEMBL1363210 & 688816 & 4.95 & 5.433 & TRN \\
\hline CHEMBL1593462 & 688816 & 4.95 & 5.0952 & TST \\
\hline CHEMBL1498599 & 688816 & 4.9 & 5.0715 & TRN \\
\hline CHEMBL1485736 & 688816 & 4.6 & 5.2253 & TRN \\
\hline CHEMBL1370692 & 688816 & 5.4 & 5.6726 & TRN \\
\hline CHEMBL1351279 & 688816 & 8.301 & 5.4459 & TRN \\
\hline CHEMBL1575955 & 688816 & 7.699 & 5.4443 & TST \\
\hline CHEMBL1425868 & 688816 & 4.7 & 5.2602 & TRN \\
\hline CHEMBL1312498 & 688816 & 5.25 & 5.0764 & TRN \\
\hline CHEMBL1445085 & 688816 & 4.6 & 5.4233 & TST \\
\hline CHEMBL1534210 & 688816 & 4.45 & 4.8142 & TRN \\
\hline CHEMBL 3193665 & 688816 & 4.65 & 5.3089 & TRN \\
\hline CHEMBL1427780 & 688816 & 5.35 & 4.9412 & TST \\
\hline CHEMBL1556323 & 688816 & 4.9 & 4.9826 & TRN \\
\hline CHEMBL1515210 & 688816 & 4.45 & 5.2682 & TRN \\
\hline CHEMBL1367596 & 688816 & 4.9 & 5.0472 & TST \\
\hline CHEMBL1611300 & 688816 & 6.0 & 5.1795 & TRN \\
\hline CHEMBL1429196 & 688816 & 4.9 & 5.3328 & TRN \\
\hline CHEMBL1350915 & 688816 & 4.45 & 5.2395 & TRN \\
\hline CHEMBL1416460 & 688816 & 8.3468 & 5.3824 & TRN \\
\hline CHEMBL1479234 & 688816 & 4.9 & 4.8988 & TST \\
\hline CHEMBL1574955 & 688816 & 4.9 & 4.8938 & TRN \\
\hline CHEMBL1371524 & 688816 & 5.2 & 5.6783 & TRN \\
\hline CHEMBL1476100 & 688816 & 4.65 & 5.449 & TRN \\
\hline CHEMBL1560016 & 688816 & 4.95 & 4.8322 & TRN \\
\hline CHEMBL1526136 & 688816 & 4.55 & 5.2174 & TST \\
\hline CHEMBL1309730 & 688816 & 6.7001 & 5.9345 & TRN \\
\hline CHEMBL1439248 & 688816 & 5.05 & 5.2905 & TST \\
\hline CHEMBL1416483 & 688816 & 4.95 & 5.0581 & TRN \\
\hline CHEMBL1323980 & 688816 & 5.85 & 5.4155 & TRN \\
\hline
\end{tabular}




\begin{tabular}{|c|c|c|c|c|}
\hline \multicolumn{5}{|c|}{ Supplemental Table S2.txt } \\
\hline CHEMBL1539612 & 688816 & 5.4 & 5.2503 & TST \\
\hline CHEMBL1383676 & 688816 & 4.65 & 5.3666 & TRN \\
\hline CHEMBL1986284 & 688816 & 5.55 & 5.379 & TST \\
\hline CHEMBL1312636 & 688816 & 5.0 & 4.9167 & TRN \\
\hline CHEMBL1373422 & 688816 & 8.1487 & 5.4033 & TRN \\
\hline CHEMBL1404033 & 688816 & 6.8 & 5.6533 & TST \\
\hline CHEMBL2369183 & 688816 & 6.1 & 5.4583 & TST \\
\hline CHEMBL1377072 & 688816 & 4.95 & 5.6898 & TST \\
\hline CHEMBL1542905 & 688816 & 7.8013 & 5.5787 & TRN \\
\hline CHEMBL1525213 & 688816 & 4.7 & 5.2201 & TRN \\
\hline CHEMBL1490575 & 688816 & 7.6498 & 5.1462 & TRN \\
\hline CHEMBL1368165 & 688816 & 4.45 & 5.3448 & TST \\
\hline CHEMBL1511315 & 688816 & 4.9 & 5.0144 & TRN \\
\hline CHEMBL1476988 & 688816 & 4.75 & 5.45 & TST \\
\hline CHEMBL1486501 & 688816 & 4.8 & 4.8553 & TST \\
\hline CHEMBL1436049 & 688816 & 4.8 & 5.0558 & TRN \\
\hline CHEMBL1334524 & 688816 & 5.2 & 5.4946 & TRN \\
\hline CHEMBL1525468 & 688816 & 4.9 & 5.2611 & TRN \\
\hline CHEMBL603945 & 688816 & 4.8 & 4.9827 & TRN \\
\hline CHEMBL1466817 & 688816 & 6.7501 & 5.6135 & TRN \\
\hline CHEMBL1444794 & 688816 & 8.6021 & 5.9048 & TRN \\
\hline CHEMBL1447880 & 688816 & 8.5528 & 5.6309 & TST \\
\hline CHEMBL1586200 & 688816 & 5.45 & 5.1389 & TRN \\
\hline CHEMBL1331513 & 688816 & 4.9 & 5.1003 & TST \\
\hline CHEMBL1497369 & 688816 & 4.8 & 4.8394 & TST \\
\hline CHEMBL1490212 & 688816 & 5.8 & 5.4121 & TRN \\
\hline CHEMBL1369387 & 688816 & 4.8 & 5.5946 & TST \\
\hline CHEMBL1574149 & 688816 & 5.7 & 5.5242 & TRN \\
\hline CHEMBL1484551 & 688816 & 4.65 & 5.5152 & TST \\
\hline CHEMBL1572811 & 688816 & 4.45 & 5.0373 & TST \\
\hline CHEMBL1356246 & 688816 & 4.95 & 5.1489 & TRN \\
\hline CHEMBL1509674 & 688816 & 4.65 & 5.6509 & TRN \\
\hline CHEMBL1613165 & 688816 & 4.95 & 5.4234 & TST \\
\hline CHEMBL1524678 & 688816 & 5.0 & 5.1113 & TST \\
\hline CHEMBL1307843 & 688816 & 4.65 & 5.3921 & TRN \\
\hline CHEMBL1364205 & 688816 & 5.0 & 4.9925 & TRN \\
\hline CHEMBL1581173 & 688816 & 4.95 & 5.5313 & TRN \\
\hline CHEMBL1452634 & 688816 & 4.9 & 5.3455 & TRN \\
\hline CHEMBL1547983 & 688816 & 4.45 & 5.1813 & TRN \\
\hline CHEMBL1327627 & 688816 & 4.55 & 5.1414 & TRN \\
\hline CHEMBL1316175 & 688816 & 5.3 & 4.8624 & TRN \\
\hline CHEMBL1386412 & 688816 & 4.85 & 5.4474 & TRN \\
\hline CHEMBL1437680 & 688816 & 4.45 & 4.7998 & TRN \\
\hline CHEMBL1419803 & 688816 & 7.5498 & 5.6348 & TRN \\
\hline CHEMBL1314702 & 688816 & 4.8 & 5.4393 & TRN \\
\hline CHEMBL1332139 & 688816 & 5.5 & 4.7703 & TRN \\
\hline CHEMBL1385649 & 688816 & 5.65 & 5.2085 & TRN \\
\hline CHEMBL1304731 & 688816 & 6.9 & 5.8582 & TRN \\
\hline
\end{tabular}




\begin{tabular}{|c|c|c|c|c|c|}
\hline \multicolumn{6}{|c|}{ Supplemental Table s2.txt } \\
\hline CHEMBL1990093 & 688816 & 4.85 & 5.1674 & TRN & \\
\hline CHEMBL1527139 & 688816 & 7.3497 & 5.5545 & TRN & \\
\hline CHEMBL1599408 & 688816 & 4.95 & 4.9513 & TRN & \\
\hline CHEMBL418068 & 688816 & 5.55 & 5.2872 & TST & \\
\hline CHEMBL1574218 & 688816 & 4.45 & 5.3776 & TST & \\
\hline CHEMBL1416644 & 688816 & 4.95 & 5.4175 & TRN & \\
\hline CHEMBL1547349 & 688816 & 4.85 & 5.1226 & TRN & \\
\hline CHEMBL1582819 & 688816 & 4.85 & 5.1602 & TRN & \\
\hline CHEMBL2369311 & 688816 & 4.9 & 5.5522 & TRN & \\
\hline CHEMBL1320446 & 688816 & 4.45 & 4.9268 & TRN & \\
\hline CHEMBL1431883 & 688816 & 6.0 & 5.4942 & TST & \\
\hline CHEMBL1572323 & 688816 & 4.5 & 5.8677 & TST & \\
\hline CHEMBL1558761 & 688816 & 4.95 & 4.9837 & TRN & \\
\hline CHEMBL576317 & 688816 & 4.6 & 5.1542 & TRN & \\
\hline CHEMBL1333766 & 688816 & 4.95 & 5.2321 & TRN & \\
\hline CHEMBL 246447 & 688816 & 7.8996 & 5.36100 & 0000000001 & TST \\
\hline CHEMBL1392106 & 688816 & 5.0 & 5.7743 & TRN & \\
\hline CHEMBL1414577 & 688816 & 4.9 & 5.1937 & TRN & \\
\hline CHEMBL1503960 & 688816 & 4.45 & 5.2646 & TRN & \\
\hline CHEMBL1312561 & 688816 & 6.95 & 5.6177 & TRN & \\
\hline CHEMBL1441833 & 688816 & 4.85 & 5.4287 & TRN & \\
\hline CHEMBL1538084 & 688816 & 4.65 & 5.7351 & TST & \\
\hline CHEMBL1325869 & 688816 & 5.5 & 4.9595 & TRN & \\
\hline CHEMBL1303966 & 688816 & 4.45 & 5.4949 & TRN & \\
\hline CHEMBL1575419 & 688816 & 7.2503 & 5.3665 & TRN & \\
\hline CHEMBL1607675 & 688816 & 5.2 & 5.3072 & TST & \\
\hline CHEMBL1459737 & 688816 & 5.65 & 5.5164 & TRN & \\
\hline CHEMBL1466392 & 688816 & 4.9 & 4.8634 & TRN & \\
\hline CHEMBL1398305 & 688816 & 5.4 & 5.0622 & TST & \\
\hline CHEMBL1506744 & 688816 & 5.55 & 5.3792 & TRN & \\
\hline CHEMBL1474729 & 688816 & 5.5 & 5.2497 & TST & \\
\hline CHEMBL1351392 & 688816 & 5.7 & 5.0216 & TRN & \\
\hline CHEMBL1341929 & 688816 & 4.8 & 5.4045 & TRN & \\
\hline CHEMBL1564517 & 688816 & 4.5 & 5.4781 & TST & \\
\hline CHEMBL235036 & 688816 & 5.5 & 5.189 & TRN & \\
\hline CHEMBL1570626 & 688816 & 7.5003 & 5.2049 & TST & \\
\hline CHEMBL1520694 & 688816 & 4.7 & 4.8604 & TRN & \\
\hline CHEMBL1601116 & 688816 & 4.8 & 5.2638 & TRN & \\
\hline CHEMBL1998984 & 688816 & 5.45 & 5.1065 & TRN & \\
\hline CHEMBL1608832 & 688816 & 4.85 & 5.3171 & TRN & \\
\hline CHEMBL1468261 & 688816 & 4.85 & 5.1922 & TRN & \\
\hline CHEMBL1365095 & 688816 & 4.9 & 4.8273 & TRN & \\
\hline CHEMBL1455766 & 688816 & 5.2 & 5.4884 & TRN & \\
\hline CHEMBL1307129 & 688816 & 4.45 & 5.3235 & TRN & \\
\hline CHEMBL3190276 & 688816 & 7.8996 & 5.5607 & TST & \\
\hline CHEMBL3194711 & 688816 & 4.45 & 5.1386 & TST & \\
\hline CHEMBL1421251 & 688816 & 8.301 & 5.5786 & TST & \\
\hline CHEMBL421088 & 688816 & 4.85 & 5.3785 & TRN & \\
\hline
\end{tabular}




\begin{tabular}{|c|c|c|c|c|c|}
\hline \multicolumn{6}{|c|}{ Supplemental Table s2.txt } \\
\hline CHEMBL296586 & 688816 & 6.0 & 5.1405 & TST & \\
\hline CHEMBL1506345 & 688816 & 4.5 & 5.4995 & TRN & \\
\hline CHEMBL1503124 & 688816 & 5.25 & 5.1753 & TRN & \\
\hline CHEMBL1463069 & 688816 & 4.45 & 4.9918 & TRN & \\
\hline CHEMBL1978424 & 688816 & 4.9 & 5.6392 & TRN & \\
\hline CHEMBL454761 & 688816 & 6.0 & 6.2513 & TST & \\
\hline CHEMBL1462495 & 688816 & 4.9 & 5.1095 & TRN & \\
\hline CHEMBL1468337 & 688816 & 4.9 & 5.0547 & TRN & \\
\hline CHEMBL1504324 & 688816 & 4.45 & 4.7874 & TRN & \\
\hline CHEMBL1488487 & 688816 & 4.95 & 5.6171 & TRN & \\
\hline CHEMBL54716 & 688816 & 4.9 & 5.3065 & TST & \\
\hline CHEMBL1555574 & 688816 & 4.95 & \multicolumn{2}{|c|}{4.8069999999999995} & TRN \\
\hline CHEMBL1422728 & 688816 & 5.4 & 5.6947 & TRN & \\
\hline CHEMBL1461147 & 688816 & 4.9 & 5.2854 & TRN & \\
\hline CHEMBL1336561 & 688816 & 4.65 & 5.1861 & TST & \\
\hline CHEMBL1401707 & 688816 & 5.0 & 5.636 & TRN & \\
\hline CHEMBL1392017 & 688816 & 5.0 & 5.0144 & TRN & \\
\hline CHEMBL1421933 & 688816 & 4.45 & 5.0619 & TRN & \\
\hline CHEMBL1610037 & 688816 & 4.45 & 5.2095 & TRN & \\
\hline CHEMBL1997130 & 688816 & 4.85 & 5.5341 & TRN & \\
\hline CHEMBL1415065 & 688816 & 4.9 & 5.5272 & TRN & \\
\hline CHEMBL1325984 & 688816 & 5.5 & 5.2855 & TRN & \\
\hline CHEMBL1552377 & 688816 & 4.85 & 5.17 & TRN & \\
\hline CHEMBL3196503 & 688816 & 7.5498 & 5.3169 & TST & \\
\hline CHEMBL1548273 & 688816 & 5.1 & 5.0858 & TRN & \\
\hline CHEMBL1366764 & 688816 & 4.85 & 5.0371 & TRN & \\
\hline CHEMBL1543558 & 688816 & 5.1 & 5.7014 & TRN & \\
\hline CHEMBL1407486 & 688816 & 4.95 & 4.9898 & TRN & \\
\hline CHEMBL1430991 & 688816 & 4.9 & 4.6299 & TST & \\
\hline CHEMBL1392801 & 688816 & 4.95 & 5.1908 & TRN & \\
\hline CHEMBL1599302 & 688816 & 4.9 & 5.5305 & TST & \\
\hline CHEMBL1340974 & 688816 & 5.65 & 4.9749 & TRN & \\
\hline CHEMBL1523273 & 688816 & 4.85 & 5.3744 & TRN & \\
\hline CHEMBL1458975 & 688816 & 5.65 & 5.1407 & TRN & \\
\hline CHEMBL1449243 & 688816 & 6.25 & 5.5672 & TRN & \\
\hline CHEMBL1479278 & 688816 & 4.75 & 4.975 & TRN & \\
\hline CHEMBL1400536 & 688816 & 4.75 & 4.8869 & TRN & \\
\hline CHEMBL1416970 & 688816 & 4.9 & 5.1813 & TRN & \\
\hline CHEMBL1427680 & 688816 & 4.45 & 5.0281 & TRN & \\
\hline CHEMBL1420295 & 688816 & 4.75 & 5.407 & TRN & \\
\hline CHEMBL1608477 & 688816 & 4.95 & 5.2874 & TRN & \\
\hline CHEMBL1584508 & 688816 & 4.45 & 5.1441 & TRN & \\
\hline CHEMBL1579138 & 688816 & 5.1 & 5.699 & TST & \\
\hline CHEMBL3211498 & 688816 & 6.6499 & 5.6191 & TST & \\
\hline CHEMBL1424633 & 688816 & 8.1487 & 5.2909 & TST & \\
\hline CHEMBL1471055 & 688816 & 7.699 & 5.4405 & TRN & \\
\hline CHEMBL1549948 & 688816 & 5.4 & 5.96200 & $\partial 000000001$ & TST \\
\hline CHEMBL1409256 & 688816 & 4.45 & 4.7882 & TRN & \\
\hline
\end{tabular}




\begin{tabular}{|c|c|c|c|c|c|}
\hline \multicolumn{6}{|c|}{ Supplemental Table s2.txt } \\
\hline CHEMBL1401103 & 688816 & 4.9 & 5.3186 & TRN & \\
\hline CHEMBL1333369 & 688816 & 4.95 & 5.2835 & TRN & \\
\hline CHEMBL1486235 & 688816 & 4.85 & 5.055 & TST & \\
\hline CHEMBL 3199447 & 688816 & 7.0501 & 4.7756 & TST & \\
\hline CHEMBL1511393 & 688816 & 6.25 & 5.25299 & 9999999999 & TST \\
\hline CHEMBL1348745 & 688816 & 4.95 & 5.0278 & TRN & \\
\hline CHEMBL3211839 & 688816 & 5.15 & 4.9807 & TST & \\
\hline CHEMBL1330969 & 688816 & 9.0969 & 5.1141 & TRN & \\
\hline CHEMBL1585212 & 688816 & 4.95 & 5.334 & TST & \\
\hline CHEMBL1331429 & 688816 & 7.0 & 5.5616 & TRN & \\
\hline CHEMBL1421046 & 688816 & 5.35 & 5.5793 & TRN & \\
\hline CHEMBL1433385 & 688816 & 4.95 & 4.957 & TRN & \\
\hline CHEMBL3197168 & 688816 & 4.45 & 5.1724 & TRN & \\
\hline CHEMBL1371669 & 688816 & 5.15 & 5.5943 & TRN & \\
\hline CHEMBL3199086 & 688816 & 4.5 & 5.7411 & TRN & \\
\hline CHEMBL1409088 & 688816 & 4.8 & 5.3713 & TRN & \\
\hline CHEMBL1559782 & 688816 & 4.45 & 5.5281 & TST & \\
\hline CHEMBL1574858 & 688816 & 5.25 & 5.2043 & TRN & \\
\hline CHEMBL1405285 & 688816 & 6.8 & 5.1958 & TRN & \\
\hline CHEMBL1526966 & 688816 & 4.85 & 4.6724 & TRN & \\
\hline CHEMBL1393395 & 688816 & 4.9 & 5.5145 & TRN & \\
\hline CHEMBL1560062 & 688816 & 5.1 & 4.9919 & TRN & \\
\hline CHEMBL1491456 & 688816 & 7.699 & 5.3984 & TST & \\
\hline CHEMBL1595178 & 688816 & 4.9 & 5.0504 & TRN & \\
\hline CHEMBL1446231 & 688816 & 5.35 & 5.3382 & TST & \\
\hline CHEMBL1547650 & 688816 & 8.301 & 5.9573 & TRN & \\
\hline CHEMBL1340085 & 688816 & 5.25 & 5.2744 & TRN & \\
\hline CHEMBL1452993 & 688816 & 4.9 & 5.1693 & TST & \\
\hline CHEMBL1299751 & 688816 & 4.65 & 5.1806 & TRN & \\
\hline CHEMBL1420272 & 688816 & 7.4498 & 5.4997 & TRN & \\
\hline CHEMBL1499893 & 688816 & 5.3 & 5.1293 & TRN & \\
\hline CHEMBL1361237 & 688816 & 5.6 & 5.0574 & TRN & \\
\hline CHEMBL1548933 & 688816 & 5.6 & 5.2836 & TST & \\
\hline CHEMBL1311597 & 688816 & 7.0 & 5.4348 & TRN & \\
\hline CHEMBL1485847 & 688816 & 5.25 & 5.03100 & 0000000001 & TRN \\
\hline CHEMBL1499308 & 688816 & 4.95 & 5.0829 & TST & \\
\hline CHEMBL1319347 & 688816 & 5.9 & 5.5745 & TRN & \\
\hline CHEMBL1339318 & 688816 & 4.45 & 5.5469 & TRN & \\
\hline CHEMBL 2001887 & 688816 & 5.3 & 5.4351 & TRN & \\
\hline CHEMBL1353306 & 688816 & 5.15 & 5.3299 & TRN & \\
\hline CHEMBL1463167 & 688816 & 6.6499 & 5.3499 & TRN & \\
\hline CHEMBL1406543 & 688816 & 6.8499 & 5.1759 & TRN & \\
\hline CHEMBL1497459 & 688816 & 6.5 & 5.2213 & TRN & \\
\hline CHEMBL1505922 & 688816 & 4.95 & 5.2241 & TRN & \\
\hline CHEMBL1352546 & 688816 & 7.8508 & 5.0205 & TST & \\
\hline CHEMBL1393336 & 688816 & 4.45 & 5.107 & TST & \\
\hline CHEMBL1558210 & 688816 & 4.75 & 4.9895 & TRN & \\
\hline CHEMBL 2001408 & 688816 & 4.95 & 5.1851 & TST & \\
\hline
\end{tabular}




\begin{tabular}{|c|c|c|c|c|c|}
\hline \multicolumn{6}{|c|}{ Supplemental Table S2.txt } \\
\hline CHEMBL 2001139 & 688816 & 5.1 & 5.4861 & TRN & \\
\hline CHEMBL1480042 & 688816 & 5.0 & $5.1610 e$ & 00000000005 & TRN \\
\hline CHEMBL1487212 & 688816 & 4.45 & 5.3317 & TST & \\
\hline CHEMBL1315443 & 688816 & 5.4 & 5.1429 & TRN & \\
\hline CHEMBL1490612 & 688816 & 6.8499 & 5.6306 & TST & \\
\hline CHEMBL1508169 & 688816 & 5.55 & 5.3956 & TRN & \\
\hline CHEMBL1450645 & 688816 & 5.3 & 5.2033 & TRN & \\
\hline CHEMBL1534459 & 688816 & 5.5 & 5.3779 & TST & \\
\hline CHEMBL1514349 & 688816 & 4.6 & 5.776 & TRN & \\
\hline CHEMBL3192183 & 688816 & 4.45 & 5.0351 & TRN & \\
\hline CHEMBL1322094 & 688816 & 4.85 & 5.1888 & TRN & \\
\hline CHEMBL1559426 & 688816 & 4.85 & 5.3663 & TST & \\
\hline CHEMBL1495119 & 688816 & 4.95 & 5.1587 & TRN & \\
\hline CHEMBL1491274 & 688816 & 4.45 & 5.6007 & TRN & \\
\hline CHEMBL602990 & 688816 & 4.95 & 5.1162 & TRN & \\
\hline CHEMBL1370950 & 688816 & 4.5 & 4.9382 & TRN & \\
\hline CHEMBL3208999 & 688816 & 4.85 & 5.7122 & TRN & \\
\hline CHEMBL1598995 & 688816 & 4.45 & 5.6292 & TRN & \\
\hline CHEMBL 3197767 & 688816 & 5.55 & 5.1485 & TRN & \\
\hline CHEMBL1587744 & 688816 & 5.0 & 5.3617 & TRN & \\
\hline CHEMBL1333897 & 688816 & 5.6 & 5.479 & TRN & \\
\hline CHEMBL1571673 & 688816 & 4.75 & 5.4428 & TST & \\
\hline CHEMBL3213335 & 688816 & 4.95 & 5.5252 & TRN & \\
\hline CHEMBL1348126 & 688816 & 4.9 & 5.3579 & TRN & \\
\hline CHEMBL1438117 & 688816 & 4.9 & 4.9736 & TRN & \\
\hline CHEMBL1372909 & 688816 & 4.85 & 5.3634 & TST & \\
\hline CHEMBL1563730 & 688816 & 4.45 & 5.1763 & TRN & \\
\hline CHEMBL1502461 & 688816 & 5.9 & 5.1369 & TRN & \\
\hline CHEMBL1413808 & 688816 & 4.95 & 5.8188 & TRN & \\
\hline CHEMBL1976526 & 688816 & 8.301 & 5.1654 & TRN & \\
\hline CHEMBL1322217 & 688816 & 6.15 & 6.0535 & TRN & \\
\hline CHEMBL1463738 & 688816 & 5.2 & 5.4526 & TRN & \\
\hline CHEMBL1544119 & 688816 & 4.45 & 5.1646 & TRN & \\
\hline CHEMBL1350151 & 688816 & 6.6 & 5.5715 & TRN & \\
\hline CHEMBL600895 & 688816 & 4.9 & 5.147 & TRN & \\
\hline CHEMBL3208557 & 688816 & 4.95 & 5.5832 & TST & \\
\hline CHEMBL 1424742 & 688816 & 6.5501 & 5.4177 & TST & \\
\hline CHEMBL3196495 & 688816 & 5.1 & 5.2468 & TRN & \\
\hline CHEMBL1602931 & 688816 & 4.7 & 4.8659 & TRN & \\
\hline CHEMBL1423849 & 688816 & 4.45 & 4.9596 & TRN & \\
\hline CHEMBL1513594 & 688816 & 4.45 & 5.0789 & TRN & \\
\hline CHEMBL1438265 & 688816 & 4.85 & 5.4261 & TRN & \\
\hline CHEMBL1346783 & 688816 & 4.85 & 5.1436 & TST & \\
\hline CHEMBL1416617 & 688816 & 4.9 & 5.0844 & TRN & \\
\hline CHEMBL1422078 & 688816 & 5.8 & 4.8166 & TRN & \\
\hline CHEMBL1457402 & 688816 & 4.55 & 5.2308 & TRN & \\
\hline CHEMBL1484697 & 688816 & 4.95 & 5.0555 & TRN & \\
\hline CHEMBL1365150 & 688816 & 4.85 & 5.5902 & TRN & \\
\hline
\end{tabular}




\begin{tabular}{|c|c|c|c|c|}
\hline \multicolumn{5}{|c|}{ Supplemental Table S2.txt } \\
\hline CHEMBL1524208 & 688816 & 4.65 & 5.5134 & TRN \\
\hline CHEMBL1437042 & 688816 & 4.6 & 5.3536 & TRN \\
\hline CHEMBL1330961 & 688816 & 5.35 & 5.2384 & TST \\
\hline CHEMBL1517600 & 688816 & 4.7 & 5.1103 & TRN \\
\hline CHEMBL1399241 & 688816 & 4.6 & 4.7281 & TRN \\
\hline CHEMBL251389 & 688816 & 4.55 & 5.1312 & TRN \\
\hline CHEMBL1521833 & 688816 & 5.55 & 5.8651 & TST \\
\hline CHEMBL1597805 & 688816 & 4.8 & 5.0233 & TRN \\
\hline CHEMBL1550685 & 688816 & 4.85 & 4.9763 & TRN \\
\hline CHEMBL1299791 & 688816 & 5.05 & 5.6056 & TRN \\
\hline CHEMBL1554131 & 688816 & 5.75 & 5.6459 & TRN \\
\hline CHEMBL1479528 & 688816 & 6.6 & 5.3352 & TRN \\
\hline CHEMBL1338826 & 688816 & 4.7 & 5.1697 & TRN \\
\hline CHEMBL1506691 & 688816 & 6.05 & 5.3724 & TRN \\
\hline CHEMBL1462983 & 688816 & 4.95 & 5.2815 & TRN \\
\hline CHEMBL1407305 & 688816 & 6.45 & 5.0531 & TST \\
\hline CHEMBL1331908 & 688816 & 5.15 & 5.5121 & TST \\
\hline CHEMBL1517850 & 688816 & 5.35 & 5.1655 & TST \\
\hline CHEMBL1355790 & 688816 & 5.25 & 5.3552 & TRN \\
\hline CHEMBL1355939 & 688816 & 6.1 & 5.5997 & TRN \\
\hline CHEMBL1563920 & 688816 & 5.65 & 5.034 & TRN \\
\hline CHEMBL1504385 & 688816 & 4.45 & 4.9503 & TRN \\
\hline CHEMBL1566161 & 688816 & 5.0 & 5.3181 & TRN \\
\hline CHEMBL1464041 & 688816 & 4.45 & 5.4163 & TST \\
\hline CHEMBL1411088 & 688816 & 5.6 & 5.2352 & TRN \\
\hline CHEMBL1313241 & 688816 & 4.95 & 4.9911 & TRN \\
\hline CHEMBL1533315 & 688816 & 4.85 & 5.0082 & TRN \\
\hline CHEMBL1465021 & 688816 & 4.5 & 5.1123 & TRN \\
\hline CHEMBL 3212977 & 688816 & 4.75 & 5.1172 & TST \\
\hline CHEMBL1303657 & 688816 & 4.95 & 5.1953 & TRN \\
\hline CHEMBL1490447 & 688816 & 6.8 & 5.4151 & TST \\
\hline CHEMBL3199028 & 688816 & 4.5 & 5.3944 & TST \\
\hline CHEMBL1312149 & 688816 & 5.3 & 5.6883 & TRN \\
\hline CHEMBL1493614 & 688816 & 5.5 & 5.0823 & TRN \\
\hline CHEMBL3211285 & 688816 & 6.3 & 5.3011 & TST \\
\hline CHEMBL1212955 & 688816 & 5.2 & 5.4774 & TRN \\
\hline CHEMBL1611713 & 688816 & 6.1 & 5.4238 & TRN \\
\hline CHEMBL1400724 & 688816 & 5.55 & 5.6351 & TRN \\
\hline CHEMBL1379156 & 688816 & 4.9 & 5.5733 & TRN \\
\hline CHEMBL1487166 & 688816 & 5.05 & 5.7993 & TST \\
\hline CHEMBL1609088 & 688816 & 5.2 & 5.3655 & TRN \\
\hline CHEMBL 1487880 & 688816 & 8.4949 & 5.3891 & TRN \\
\hline CHEMBL3213119 & 688816 & 5.05 & 5.4216 & TRN \\
\hline CHEMBL1313784 & 688816 & 4.45 & 5.5197 & TST \\
\hline CHEMBL460515 & 688816 & 4.45 & 5.2614 & TST \\
\hline CHEMBL1541371 & 688816 & 4.9 & 5.4547 & TRN \\
\hline CHEMBL1302351 & 688816 & 4.6 & 5.0584 & TRN \\
\hline CHEMBL1308422 & 688816 & 8.3468 & 5.6251 & TST \\
\hline
\end{tabular}




\begin{tabular}{|c|c|c|c|c|c|}
\hline \multicolumn{6}{|c|}{ able 52.} \\
\hline CHEMBL1481689 & 688816 & 5.6 & 5.1139 & TRN & \\
\hline CHEMBL1422949 & 688816 & 4.9 & 5.154 & TRN & \\
\hline CHEMBL1423811 & 688816 & 4.95 & 5.0547 & TRN & \\
\hline CHEMBL1598791 & 688816 & 4.45 & 5.2892 & TST & \\
\hline CHEMBL1482085 & 688816 & 4.85 & 5.6013 & TST & \\
\hline CHEMBL1370172 & 688816 & 5.6 & 5.171 & TRN & \\
\hline CHEMBL1299919 & 688816 & 4.45 & 5.3979 & TST & \\
\hline CHEMBL1372553 & 688816 & 7.699 & 5.1935 & TST & \\
\hline CHEMBL1412205 & 688816 & 4.85 & 5.3395 & TRN & \\
\hline CHEMBL1490026 & 688816 & 5.25 & 5.3178 & TRN & \\
\hline CHEMBL1574521 & 688816 & 4.9 & 5.5055 & TRN & \\
\hline CHEMBL1471578 & 688816 & 4.95 & 5.435 & TRN & \\
\hline CHEMBL1970896 & 688816 & 5.05 & 5.38700 & 00000000005 & TST \\
\hline CHEMBL1561026 & 688816 & 5.25 & 5.7808 & TRN & \\
\hline CHEMBL1350559 & 688816 & 5.55 & 4.8364 & TRN & \\
\hline CHEMBL1366948 & 688816 & 5.0 & 4.7446 & TRN & \\
\hline CHEMBL579621 & 688816 & 4.8 & 5.3124 & TRN & \\
\hline CHEMBL1446154 & 688816 & 4.9 & 5.5025 & TST & \\
\hline CHEMBL1337614 & 688816 & 4.65 & 5.0943 & TRN & \\
\hline CHEMBL1493090 & 688816 & 6.0 & 5.055 & TRN & \\
\hline CHEMBL1483745 & 688816 & 4.9 & 4.9913 & TRN & \\
\hline CHEMBL1451476 & 688816 & 4.75 & 4.9568 & TRN & \\
\hline CHEMBL1378218 & 688816 & 4.8 & 5.3924 & TST & \\
\hline CHEMBL1582123 & 688816 & 5.9 & 5.0385 & TRN & \\
\hline CHEMBL1604427 & 688816 & 4.85 & 5.3761 & TRN & \\
\hline CHEMBL1334796 & 688816 & 5.4 & 5.565 & TST & \\
\hline CHEMBL 293391 & 688816 & 5.45 & 5.4973 & TST & \\
\hline CHEMBL1424170 & 688816 & 4.95 & 5.5648 & TRN & \\
\hline CHEMBL1351691 & 688816 & 8.301 & 5.2537 & TST & \\
\hline CHEMBL1505192 & 688816 & 4.85 & 5.2932 & TRN & \\
\hline CHEMBL 240333 & 688816 & 4.45 & 4.8674 & TRN & \\
\hline CHEMBL1581491 & 688816 & 4.8 & 4.8242 & TRN & \\
\hline CHEMBL1350656 & 688816 & 4.95 & 5.17200 & 0000000001 & TRN \\
\hline CHEMBL1538705 & 688816 & 7.9508 & 5.29799 & 9999999999 & TRN \\
\hline CHEMBL601192 & 688816 & 4.65 & 5.2823 & TRN & \\
\hline CHEMBL1511113 & 688816 & 4.85 & 5.5564 & TRN & \\
\hline CHEMBL1333069 & 688816 & 4.85 & 5.1244 & TST & \\
\hline CHEMBL1429808 & 688816 & 5.35 & 5.1314 & TRN & \\
\hline CHEMBL1486533 & 688816 & 4.9 & 5.0249 & TRN & \\
\hline CHEMBL1576166 & 688816 & 6.2 & 5.05699 & 99999999995 & TRN \\
\hline CHEMBL1316741 & 688816 & 4.8 & 5.3346 & TRN & \\
\hline CHEMBL1561904 & 688816 & 4.95 & 5.3236 & TRN & \\
\hline CHEMBL1361584 & 688816 & 4.65 & 4.8923 & TST & \\
\hline CHEMBL1539876 & 688816 & 4.85 & 5.00899 & 99999999995 & TST \\
\hline CHEMBL2069121 & 688816 & 5.4 & 5.7243 & TRN & \\
\hline CHEMBL1555834 & 688816 & 5.55 & 5.0979 & TST & \\
\hline CHEMBL1579650 & 688816 & 4.85 & 5.355 & TRN & \\
\hline CHEMBL1546820 & 688816 & 5.45 & 5.3043 & TST & \\
\hline
\end{tabular}




\begin{tabular}{|c|c|c|c|c|}
\hline \multicolumn{5}{|c|}{ Supplemental Table S2.txt } \\
\hline CHEMBL1307784 & 688816 & 4.75 & 5.5428 & TRN \\
\hline CHEMBL1356987 & 688816 & 4.45 & 5.4632 & TRN \\
\hline CHEMBL1503273 & 688816 & 4.95 & 4.9691 & TRN \\
\hline CHEMBL536166 & 688816 & 4.95 & 5.1591 & TRN \\
\hline CHEMBL1531363 & 688816 & 5.25 & 5.3691 & TRN \\
\hline CHEMBL1605349 & 688816 & 5.55 & 5.624 & TST \\
\hline CHEMBL1578384 & 688816 & 5.0 & 5.4686 & TRN \\
\hline CHEMBL1408952 & 688816 & 5.75 & 5.5243 & TRN \\
\hline CHEMBL1375312 & 688816 & 4.9 & 5.2781 & TRN \\
\hline CHEMBL1385260 & 688816 & 4.45 & 5.2274 & TRN \\
\hline CHEMBL1609978 & 688816 & 5.3 & 5.0595 & TRN \\
\hline CHEMBL304069 & 688816 & 4.9 & 5.3484 & TRN \\
\hline CHEMBL1530650 & 688816 & 4.45 & 5.53799 & 9999999999 \\
\hline CHEMBL1382834 & 688816 & 5.6 & 5.3841 & TST \\
\hline CHEMBL1338804 & 688816 & 4.8 & 4.8968 & TRN \\
\hline CHEMBL1302706 & 688816 & 4.45 & 5.0264 & TRN \\
\hline CHEMBL3197544 & 688816 & 4.65 & 5.3031 & TRN \\
\hline CHEMBL1465512 & 688816 & 7.9508 & 5.5348 & TRN \\
\hline CHEMBL1467724 & 688816 & 4.6 & 5.26 & TST \\
\hline CHEMBL1341472 & 688816 & 4.8 & 5.0797 & TRN \\
\hline CHEMBL1431192 & 688816 & 5.6 & 5.2858 & TRN \\
\hline CHEMBL1391325 & 688816 & 4.6 & 4.7638 & TRN \\
\hline CHEMBL1380599 & 688816 & 5.25 & 5.4756 & TRN \\
\hline CHEMBL1401875 & 688816 & 7.1002 & 5.3986 & TRN \\
\hline CHEMBL1330556 & 688816 & 5.45 & 5.0985 & TRN \\
\hline CHEMBL1510123 & 688816 & 4.9 & 5.2801 & TRN \\
\hline CHEMBL1299352 & 688816 & 7.4001 & 5.1324 & TST \\
\hline CHEMBL1544371 & 688816 & 4.85 & 5.0651 & TRN \\
\hline CHEMBL1414472 & 688816 & 4.95 & 5.2382 & TRN \\
\hline CHEMBL 1425794 & 688816 & 4.95 & 5.1954 & TRN \\
\hline CHEMBL1489314 & 688816 & 4.65 & 5.0013 & TRN \\
\hline CHEMBL1472160 & 688816 & 5.45 & 5.4351 & TST \\
\hline CHEMBL1421006 & 688816 & 8.3979 & 5.534 & TRN \\
\hline CHEMBL544348 & 688816 & 4.45 & 5.0146 & TRN \\
\hline CHEMBL1382863 & 688816 & 6.6499 & 5.3385 & TST \\
\hline CHEMBL1445163 & 688816 & 4.75 & 5.1637 & TST \\
\hline CHEMBL1460405 & 688816 & 4.9 & 5.1212 & TRN \\
\hline CHEMBL3213752 & 688816 & 4.45 & 5.5856 & TRN \\
\hline CHEMBL1566224 & 688816 & 7.0501 & 5.5163 & TST \\
\hline CHEMBL1523890 & 688816 & 4.95 & 4.7247 & TRN \\
\hline CHEMBL1540300 & 688816 & 5.6 & 5.2273 & TST \\
\hline CHEMBL1528704 & 688816 & 4.7 & 5.0024 & TST \\
\hline CHEMBL1372421 & 688816 & 4.95 & 5.3921 & TRN \\
\hline CHEMBL1373577 & 688816 & 5.25 & 5.1433 & TST \\
\hline CHEMBL1606419 & 688816 & 5.25 & 5.1367 & TRN \\
\hline CHEMBL3214154 & 688816 & 4.75 & 5.105 & TRN \\
\hline CHEMBL1544831 & 688816 & 4.9 & 5.0523 & TRN \\
\hline CHEMBL1490798 & 688816 & 5.35 & 5.17 & TRN \\
\hline
\end{tabular}




\begin{tabular}{|c|c|c|c|c|}
\hline \multicolumn{5}{|c|}{ Supplemental Table S2.txt } \\
\hline CHEMBL1406660 & 688816 & 4.45 & 5.3253 & TRN \\
\hline CHEMBL1371915 & 688816 & 4.55 & 5.1883 & TRN \\
\hline CHEMBL1303867 & 688816 & 4.45 & 5.505 & TRN \\
\hline CHEMBL1327472 & 688816 & 4.45 & 5.2052 & TRN \\
\hline CHEMBL1441776 & 688816 & 5.65 & 5.0762 & TST \\
\hline CHEMBL1317945 & 688816 & 4.95 & 4.9724 & TRN \\
\hline CHEMBL1256656 & 688816 & 4.9 & 5.0336 & TST \\
\hline CHEMBL1605512 & 688816 & 5.8 & 5.0952 & TRN \\
\hline CHEMBL1506445 & 688816 & 5.95 & 5.3094 & TRN \\
\hline CHEMBL1587862 & 688816 & 5.9 & 5.454 & TRN \\
\hline CHEMBL1311074 & 688816 & 5.3 & 5.2678 & TST \\
\hline CHEMBL1442982 & 688816 & 5.25 & 5.9049 & TST \\
\hline CHEMBL1529250 & 688816 & 5.5 & 5.5819 & TST \\
\hline CHEMBL1444223 & 688816 & 5.55 & 5.1333 & TRN \\
\hline CHEMBL1543168 & 688816 & 4.8 & 5.3628 & TST \\
\hline CHEMBL1377866 & 688816 & 7.5003 & 5.4855 & TST \\
\hline CHEMBL1322222 & 688816 & 5.15 & 5.1382 & TRN \\
\hline CHEMBL1363732 & 688816 & 4.9 & 5.1687 & TRN \\
\hline CHEMBL1365615 & 688816 & 5.4 & 5.155 & TST \\
\hline CHEMBL1595029 & 688816 & 4.45 & 5.3224 & TRN \\
\hline CHEMBL1491000 & 688816 & 4.85 & 5.1642 & TRN \\
\hline CHEMBL1369392 & 688816 & 5.5 & 5.2059 & TRN \\
\hline CHEMBL1306527 & 688816 & 5.5 & 5.3903 & TRN \\
\hline CHEMBL1430142 & 688816 & 4.75 & 5.4964 & TST \\
\hline CHEMBL1445809 & 688816 & 4.95 & 5.4185 & TRN \\
\hline CHEMBL1575440 & 688816 & 4.9 & 5.284 & TRN \\
\hline CHEMBL1461991 & 688816 & 4.95 & 5.1159 & TRN \\
\hline CHEMBL1475857 & 688816 & 5.45 & 5.2011 & TST \\
\hline CHEMBL1543133 & 688816 & 5.3 & 5.0702 & TST \\
\hline CHEMBL1486253 & 688816 & 4.45 & 5.2079 & TST \\
\hline CHEMBL1370742 & 688816 & 5.65 & 5.3224 & TRN \\
\hline CHEMBL1364200 & 688816 & 4.8 & 5.4726 & TRN \\
\hline CHEMBL1587078 & 688816 & 4.6 & 4.9986 & TST \\
\hline CHEMBL1323310 & 688816 & 8.4949 & 5.6239 & TRN \\
\hline CHEMBL1495486 & 688816 & 4.9 & 4.9607 & TRN \\
\hline CHEMBL1522064 & 688816 & 5.0 & 5.1228 & TRN \\
\hline CHEMBL1476095 & 688816 & 4.75 & 4.9957 & TRN \\
\hline CHEMBL1352099 & 688816 & 4.85 & 5.5924 & TRN \\
\hline CHEMBL1596334 & 688816 & 5.0 & 5.1599 & TRN \\
\hline CHEMBL1450574 & 688816 & 4.9 & 5.3262 & TRN \\
\hline CHEMBL1403546 & 688816 & 8.4949 & 5.3134 & TRN \\
\hline CHEMBL1321640 & 688816 & 5.85 & 5.0017 & TRN \\
\hline CHEMBL1333274 & 688816 & 5.45 & 5.5154 & TRN \\
\hline CHEMBL1496791 & 688816 & 4.65 & 5.5388 & TRN \\
\hline CHEMBL1570752 & 688816 & 4.85 & 5.2278 & TRN \\
\hline CHEMBL1515054 & 688816 & 4.7 & 5.3634 & TST \\
\hline CHEMBL474749 & 688816 & 4.85 & 5.3946 & TRN \\
\hline CHEMBL1604413 & 688816 & 4.95 & 5.1827 & TST \\
\hline
\end{tabular}




\begin{tabular}{|c|c|c|c|c|}
\hline \multicolumn{5}{|c|}{ Supplemental Table s2.txt } \\
\hline CHEMBL1409125 & 688816 & 4.85 & 5.5317 & TST \\
\hline CHEMBL1606693 & 688816 & 6.8 & 5.3991 & TST \\
\hline CHEMBL1602550 & 688816 & 6.5 & 4.9312 & TRN \\
\hline CHEMBL1571954 & 688816 & 6.4 & 4.9522 & TRN \\
\hline CHEMBL1343088 & 688816 & 5.25 & 5.0726 & TRN \\
\hline CHEMBL1524805 & 688816 & 4.85 & 5.1034 & TRN \\
\hline CHEMBL1562582 & 688816 & 8.3468 & 5.6569 & TRN \\
\hline CHEMBL1607980 & 688816 & 7.8508 & 5.0682 & TRN \\
\hline CHEMBL1569631 & 688816 & 7.699 & 5.4884 & TST \\
\hline CHEMBL1484304 & 688816 & 4.45 & 5.1852 & TRN \\
\hline CHEMBL1362868 & 688816 & 4.85 & 5.6306 & TST \\
\hline CHEMBL1569654 & 688816 & 4.9 & 5.0184 & TRN \\
\hline CHEMBL1580211 & 688816 & 4.55 & 5.4749 & TST \\
\hline CHEMBL1391774 & 688816 & 4.95 & 5.3188 & TRN \\
\hline CHEMBL1318873 & 688816 & 6.6 & 5.013 & TRN \\
\hline CHEMBL1338613 & 688816 & 4.85 & 5.2364 & TST \\
\hline CHEMBL1509452 & 688816 & 4.9 & 5.0397 & TRN \\
\hline CHEMBL1342181 & 688816 & 8.301 & 5.268 & TRN \\
\hline CHEMBL1392596 & 688816 & 6.15 & 5.4251 & TST \\
\hline CHEMBL1447271 & 688816 & 6.15 & 5.1178 & TRN \\
\hline CHEMBL1380365 & 688816 & 4.95 & 5.1742 & TRN \\
\hline CHEMBL1527585 & 688816 & 5.0 & 4.944 & TST \\
\hline CHEMBL1489024 & 688816 & 4.45 & 5.0128 & TST \\
\hline CHEMBL1305475 & 688816 & 7.5003 & 5.5896 & TRN \\
\hline CHEMBL1985759 & 688816 & 4.9 & 5.3235 & TRN \\
\hline CHEMBL1436324 & 688816 & 5.45 & 4.9332 & TST \\
\hline CHEMBL1320794 & 688816 & 5.05 & 4.7112 & TRN \\
\hline CHEMBL1545088 & 688816 & 5.25 & 5.271 & TST \\
\hline CHEMBL3210262 & 688816 & 4.8 & 5.3551 & TRN \\
\hline CHEMBL1308385 & 688816 & 4.65 & 5.1258 & TST \\
\hline CHEMBL1378902 & 688816 & 5.65 & 5.655 & TRN \\
\hline CHEMBL1483841 & 688816 & 5.6 & 5.2866 & TRN \\
\hline CHEMBL3189725 & 688816 & 6.8499 & 5.1666 & TRN \\
\hline CHEMBL1382724 & 688816 & 4.85 & 5.0695 & TRN \\
\hline CHEMBL1581417 & 688816 & 5.35 & 5.194 & TRN \\
\hline CHEMBL1540190 & 688816 & 6.4 & 5.6199 & TST \\
\hline CHEMBL1423071 & 688816 & 5.6 & 4.9458 & TRN \\
\hline CHEMBL 1386540 & 688816 & 5.45 & 5.1368 & TRN \\
\hline CHEMBL1495166 & 688816 & 6.7001 & 5.5136 & TRN \\
\hline CHEMBL1442624 & 688816 & 4.9 & 5.1001 & TRN \\
\hline CHEMBL1430309 & 688816 & 4.75 & 5.0862 & TST \\
\hline CHEMBL1470676 & 688816 & 6.0 & 5.205 & TRN \\
\hline CHEMBL1387395 & 688816 & 4.9 & 5.0895 & TRN \\
\hline CHEMBL1422182 & 688816 & 5.0 & 4.994 & TRN \\
\hline CHEMBL1457248 & 688816 & 5.75 & 5.2101 & TST \\
\hline CHEMBL1586672 & 688816 & 5.45 & 5.2822 & TST \\
\hline CHEMBL1380702 & 688816 & 4.9 & 5.3021 & TRN \\
\hline CHEMBL1375926 & 688816 & 5.0 & 5.4266 & TRN \\
\hline
\end{tabular}




\begin{tabular}{|c|c|c|c|c|c|}
\hline \multicolumn{6}{|c|}{ Supplemental Table S2.txt } \\
\hline CHEMBL1613266 & 688816 & 5.0 & 4.9637 & TRN & \\
\hline CHEMBL1343095 & 688816 & 4.95 & 5.078 & TRN & \\
\hline CHEMBL3198706 & 688816 & 5.55 & 5.0356 & TST & \\
\hline CHEMBL1419418 & 688816 & 6.3 & 5.2735 & TRN & \\
\hline CHEMBL1387307 & 688816 & 5.05 & 5.1912 & TST & \\
\hline CHEMBL1595632 & 688816 & 5.85 & 5.3197 & TST & \\
\hline CHEMBL1529621 & 688816 & 4.7 & 5.2545 & TRN & \\
\hline CHEMBL1476642 & 688816 & 4.9 & 5.6606 & TRN & \\
\hline CHEMBL1446161 & 688816 & 4.95 & 4.894 & TRN & \\
\hline CHEMBL1318046 & 688816 & 4.45 & 5.2947 & TRN & \\
\hline CHEMBL1345705 & 688816 & 4.8 & 5.5216 & TRN & \\
\hline CHEMBL1462350 & 688816 & 4.45 & $5.5820 e$ & 0000000001 & TRN \\
\hline CHEMBL1549976 & 688816 & 5.2 & 5.9357 & TST & \\
\hline CHEMBL1556968 & 688816 & 5.25 & 4.9368 & TRN & \\
\hline CHEMBL1478415 & 688816 & 5.6 & 5.4955 & TST & \\
\hline CHEMBL3207622 & 688816 & 5.8 & 5.2462 & TST & \\
\hline CHEMBL1469252 & 688816 & 7.6003 & 5.1711 & TST & \\
\hline CHEMBL1570188 & 688816 & 4.45 & 5.3314 & TRN & \\
\hline CHEMBL1333867 & 688816 & 4.65 & 5.3664 & TST & \\
\hline CHEMBL1528047 & 688816 & 5.6 & 5.6394 & TRN & \\
\hline CHEMBL1324600 & 688816 & 4.9 & 5.0972 & TRN & \\
\hline CHEMBL3192050 & 688816 & 4.95 & 5.2112 & TRN & \\
\hline CHEMBL1396252 & 688816 & 4.9 & 5.1974 & TRN & \\
\hline CHEMBL1527175 & 688816 & 4.9 & 5.0094 & TRN & \\
\hline CHEMBL 2003831 & 688816 & 4.65 & 5.3605 & TRN & \\
\hline CHEMBL118009 & 688816 & 4.6 & 5.1902 & TRN & \\
\hline CHEMBL1597693 & 688816 & 4.95 & 5.0883 & TRN & \\
\hline CHEMBL1466625 & 688816 & 4.95 & 4.8147 & TRN & \\
\hline CHEMBL1537300 & 688816 & 8.301 & 5.3986 & TRN & \\
\hline CHEMBL1556646 & 688816 & 4.95 & 5.2974 & TRN & \\
\hline CHEMBL1410491 & 688816 & 4.95 & 5.2979 & TRN & \\
\hline CHEMBL1458782 & 688816 & 5.25 & 5.1016 & TRN & \\
\hline CHEMBL1308079 & 688816 & 4.45 & 5.1088 & TRN & \\
\hline CHEMBL1573208 & 688816 & 4.75 & 5.28799 & 9999999999 & TRN \\
\hline CHEMBL1388853 & 688816 & 4.8 & 5.7179 & TST & \\
\hline CHEMBL1470594 & 688816 & 5.55 & 5.0099 & TRN & \\
\hline CHEMBL1581468 & 688816 & 5.55 & 5.2362 & TRN & \\
\hline CHEMBL1381613 & 688816 & 4.45 & 5.6215 & TRN & \\
\hline CHEMBL1546623 & 688816 & 4.8 & 5.0879 & TRN & \\
\hline CHEMBL1613370 & 688816 & 4.45 & 5.4042 & TRN & \\
\hline CHEMBL1427508 & 688816 & 4.7 & 4.9085 & TRN & \\
\hline CHEMBL1337078 & 688816 & 4.95 & 5.1283 & TST & \\
\hline CHEMBL1437325 & 688816 & 5.0 & 5.2109 & TRN & \\
\hline CHEMBL1612724 & 688816 & 4.9 & 5.5484 & TST & \\
\hline CHEMBL1402142 & 688816 & 5.15 & 5.3258 & TRN & \\
\hline CHEMBL1540914 & 688816 & 4.95 & 5.2144 & TRN & \\
\hline CHEMBL1372889 & 688816 & 6.7001 & 5.6445 & TRN & \\
\hline CHEMBL1544156 & 688816 & 6.25 & 5.0093 & TRN & \\
\hline
\end{tabular}




\begin{tabular}{|c|c|c|c|c|c|}
\hline \multirow[b]{2}{*}{ CHEMBL1352908 } & & \multicolumn{4}{|c|}{ Supplemental Table S2.txt } \\
\hline & 688816 & 4.85 & \multicolumn{2}{|c|}{5.502999999999999} & TRN \\
\hline CHEMBL1462746 & 688816 & 5.7 & \multicolumn{2}{|c|}{5.367000000000001} & TRN \\
\hline CHEMBL1331594 & 688816 & 4.45 & 4.8028 & TRN & \\
\hline CHEMBL1513365 & 688816 & 4.85 & 5.1918 & TRN & \\
\hline CHEMBL1384082 & 688816 & 8.3468 & 5.3439 & TST & \\
\hline CHEMBL1361739 & 688816 & 5.4 & 5.6378 & TST & \\
\hline CHEMBL1584479 & 688816 & 5.0 & 5.0356 & TRN & \\
\hline CHEMBL1331865 & 688816 & 5.35 & 4.8584 & TRN & \\
\hline CHEMBL1376266 & 688816 & 4.85 & 5.3378 & TRN & \\
\hline CHEMBL1438143 & 688816 & 4.95 & \multicolumn{2}{|c|}{5.4270000000000005} & TRN \\
\hline CHEMBL1387480 & 688816 & 4.75 & 5.2776 & TRN & \\
\hline CHEMBL1557821 & 688816 & 5.0 & 5.2693 & TRN & \\
\hline CHEMBL1466913 & 688816 & 4.5 & 5.4712 & TST & \\
\hline CHEMBL1571495 & 688816 & 5.2 & 5.4598 & TST & \\
\hline CHEMBL1370437 & 688816 & 4.5 & 5.0932 & TRN & \\
\hline CHEMBL 3197540 & 688816 & 5.0 & 5.5981 & TRN & \\
\hline CHEMBL1329504 & 688816 & 5.0 & 5.2878 & TST & \\
\hline CHEMBL1346966 & 688816 & 4.45 & 5.1806 & TST & \\
\hline CHEMBL1994034 & 688816 & 4.9 & 4.8726 & TRN & \\
\hline CHEMBL1528463 & 688816 & 4.8 & 5.0843 & TRN & \\
\hline CHEMBL1506464 & 688816 & 7.0501 & 5.2498 & TRN & \\
\hline CHEMBL1602326 & 688816 & 4.7 & 5.4124 & TRN & \\
\hline CHEMBL1588386 & 688816 & 4.65 & 4.9338 & TST & \\
\hline CHEMBL1430959 & 688816 & 4.95 & 5.5496 & TRN & \\
\hline CHEMBL1348395 & 688816 & 6.0 & 4.974 & TRN & \\
\hline CHEMBL1417967 & 688816 & 5.6 & 5.1055 & TRN & \\
\hline CHEMBL1431880 & 688816 & 4.65 & 5.2196 & TRN & \\
\hline CHEMBL1429637 & 688816 & 4.9 & 5.274 & TRN & \\
\hline CHEMBL1401762 & 688816 & 4.6 & 5.3876 & TRN & \\
\hline CHEMBL1459198 & 688816 & 4.45 & 4.901 & TRN & \\
\hline CHEMBL1347156 & 688816 & 5.0 & 5.1681 & TST & \\
\hline CHEMBL1585575 & 688816 & 5.0 & 5.3507 & TRN & \\
\hline CHEMBL1609789 & 688816 & 5.25 & 5.2767 & TST & \\
\hline CHEMBL1607194 & 688816 & 5.0 & 5.0917 & TRN & \\
\hline CHEMBL1589042 & 688816 & 4.9 & 5.3493 & TRN & \\
\hline CHEMBL1367616 & 688816 & 4.8 & 4.923 & TRN & \\
\hline CHEMBL1462003 & 688816 & 5.0 & 5.2653 & TST & \\
\hline CHEMBL1375815 & 688816 & 5.3 & 5.3499 & TST & \\
\hline CHEMBL1326543 & 688816 & 4.65 & 5.0829 & TRN & \\
\hline CHEMBL1375161 & 688816 & 5.3 & 5.2532 & TST & \\
\hline CHEMBL1429192 & 688816 & 4.9 & 5.335 & TRN & \\
\hline CHEMBL1415813 & 688816 & 4.95 & 5.0118 & TST & \\
\hline CHEMBL1540012 & 688816 & 4.75 & 5.5014 & TRN & \\
\hline CHEMBL1546086 & 688816 & 5.45 & 5.643 & TST & \\
\hline CHEMBL1570759 & 688816 & 5.55 & 5.4091 & TST & \\
\hline CHEMBL1371774 & 688816 & 4.8 & 5.1469 & TRN & \\
\hline CHEMBL 3209200 & 688816 & 5.2 & 5.6693 & TRN & \\
\hline CHEMBL1323747 & 688816 & 4.9 & 5.3177 & TRN & \\
\hline
\end{tabular}




\begin{tabular}{|c|c|c|c|c|c|}
\hline \multicolumn{6}{|c|}{ Supplemental Table S2.txt } \\
\hline CHEMBL1329658 & 688816 & 4.85 & 5.2085 & TRN & \\
\hline CHEMBL1507828 & 688816 & 4.45 & 5.107 & TRN & \\
\hline CHEMBL42529 & 688816 & 5.25 & 5.465 & TRN & \\
\hline CHEMBL1355296 & 688816 & 4.65 & 5.0974 & TRN & \\
\hline CHEMBL1306895 & 688816 & 5.45 & 5.13299 & 9999999999 & TRN \\
\hline CHEMBL1302064 & 688816 & 5.0 & 5.2597 & TRN & \\
\hline CHEMBL3213144 & 688816 & 5.5 & 5.2886 & TRN & \\
\hline CHEMBL1500106 & 688816 & 5.5 & 5.37700 & 0000000001 & TRN \\
\hline CHEMBL1347975 & 688816 & 7.4001 & 4.6364 & TST & \\
\hline CHEMBL1448139 & 688816 & 6.7001 & 4.8997 & TRN & \\
\hline CHEMBL1501211 & 688816 & 4.5 & 5.2522 & TRN & \\
\hline CHEMBL1333696 & 688816 & 4.65 & 5.0499 & TRN & \\
\hline CHEMBL1416092 & 688816 & 4.45 & 5.4606 & TRN & \\
\hline CHEMBL1306576 & 688816 & 4.45 & 5.2764 & TRN & \\
\hline CHEMBL598263 & 688816 & 6.0 & 5.80399 & 9999999999 & TST \\
\hline CHEMBL1457964 & 688816 & 4.95 & 5.7041 & TRN & \\
\hline CHEMBL1321262 & 688816 & 4.9 & 5.2372 & TRN & \\
\hline CHEMBL1573186 & 688816 & 5.45 & 4.8653 & TRN & \\
\hline CHEMBL592068 & 688816 & 5.15 & 5.1084 & TRN & \\
\hline CHEMBL1613552 & 688816 & 5.25 & 5.1033 & TST & \\
\hline CHEMBL1479402 & 688816 & 8.3468 & 5.8225 & TRN & \\
\hline CHEMBL1431197 & 688816 & 4.9 & 5.2224 & TRN & \\
\hline CHEMBL3195842 & 688816 & 4.6 & 5.1244 & TST & \\
\hline CHEMBL1449707 & 688816 & 5.25 & 5.1955 & TRN & \\
\hline CHEMBL3194305 & 688816 & 4.95 & 5.2464 & TRN & \\
\hline CHEMBL1506396 & 688816 & 4.65 & 5.1203 & TRN & \\
\hline CHEMBL1420193 & 688816 & 4.9 & 5.0265 & TRN & \\
\hline CHEMBL1391277 & 688816 & 6.15 & 5.0519 & TRN & \\
\hline CHEMBL1579491 & 688816 & 5.5 & 4.933 & TRN & \\
\hline CHEMBL110739 & 688816 & 6.0 & 5.7685 & TST & \\
\hline CHEMBL1522803 & 688816 & 4.95 & 5.1918 & TRN & \\
\hline CHEMBL1603790 & 688816 & 7.5498 & 5.5633 & TRN & \\
\hline CHEMBL1612732 & 688816 & 4.9 & 5.1239 & TRN & \\
\hline CHEMBL1321398 & 688816 & 4.45 & 4.9541 & TST & \\
\hline CHEMBL1468750 & 688816 & 5.4 & 4.9582 & TRN & \\
\hline CHEMBL1483289 & 688816 & 4.65 & 5.3723 & TST & \\
\hline CHEMBL1547102 & 688816 & 4.95 & 5.2155 & TRN & \\
\hline CHEMBL1509143 & 688816 & 4.85 & 5.2031 & TST & \\
\hline CHEMBL1421708 & 688816 & 4.65 & 5.2255 & TRN & \\
\hline CHEMBL1469115 & 688816 & 5.5 & 5.8513 & TST & \\
\hline CHEMBL1356739 & 688816 & 5.55 & 5.2939 & TRN & \\
\hline CHEMBL1463699 & 688816 & 4.45 & 5.2845 & TRN & \\
\hline CHEMBL1530084 & 688816 & 4.8 & 5.1989 & TRN & \\
\hline CHEMBL1993029 & 688816 & 6.2 & 5.153 & TRN & \\
\hline CHEMBL1492665 & 688816 & 4.9 & 5.4674 & TRN & \\
\hline CHEMBL1789996 & 688816 & 6.15 & 5.455 & TST & \\
\hline CHEMBL1481516 & 688816 & 4.9 & 5.0264 & TRN & \\
\hline CHEMBL1378863 & 688816 & 6.7001 & 5.6605 & TRN & \\
\hline
\end{tabular}




\begin{tabular}{|c|c|c|c|c|c|}
\hline \multicolumn{6}{|c|}{ Supplemental Table s2.txt } \\
\hline CHEMBL1500923 & 688816 & 7.0 & 5.6169 & TRN & \\
\hline CHEMBL1536435 & 688816 & 5.0 & 5.1167 & TRN & \\
\hline CHEMBL1541323 & 688816 & 8.3468 & 5.2914 & TST & \\
\hline CHEMBL1422180 & 688816 & 5.0 & 4.9243 & TRN & \\
\hline CHEMBL1418823 & 688816 & 5.35 & $5.2810 e$ & 0000000001 & TRN \\
\hline CHEMBL1386145 & 688816 & 5.1 & 5.0939 & TRN & \\
\hline CHEMBL3211961 & 688816 & 4.8 & 5.2607 & TRN & \\
\hline CHEMBL2006844 & 688816 & 4.95 & 5.2789 & TRN & \\
\hline CHEMBL1331969 & 688816 & 4.95 & 5.1871 & TRN & \\
\hline CHEMBL1599826 & 688816 & 5.0 & 5.3726 & TRN & \\
\hline CHEMBL1490890 & 688816 & 4.45 & 5.474 & TST & \\
\hline CHEMBL1341822 & 688816 & 4.9 & 5.3371 & TRN & \\
\hline CHEMBL592124 & 688816 & 4.45 & 5.2131 & TRN & \\
\hline CHEMBL1496085 & 688816 & 5.4 & 5.3284 & TRN & \\
\hline CHEMBL1358568 & 688816 & 4.45 & 5.5537 & TRN & \\
\hline CHEMBL1416174 & 688816 & 4.95 & 4.9082 & TRN & \\
\hline CHEMBL1302688 & 688816 & 6.2 & 5.4715 & TRN & \\
\hline CHEMBL1568263 & 688816 & 5.5 & 5.6023 & TRN & \\
\hline CHEMBL1324386 & 688816 & 4.45 & 5.2902 & TRN & \\
\hline CHEMBL1484357 & 688816 & 5.6 & 5.42899 & 9999999999 & TRN \\
\hline CHEMBL1336580 & 688816 & 5.35 & 5.3626 & TRN & \\
\hline CHEMBL1334582 & 688816 & 6.45 & 5.1049 & TST & \\
\hline CHEMBL1526367 & 688816 & 5.4 & 5.0861 & TST & \\
\hline CHEMBL1552027 & 688816 & 4.6 & 5.0402 & TRN & \\
\hline CHEMBL1477818 & 688816 & 4.5 & 5.6658 & TRN & \\
\hline CHEMBL1435041 & 688816 & 4.45 & 4.865 & TRN & \\
\hline CHEMBL1440129 & 688816 & 8.301 & 5.2102 & TST & \\
\hline CHEMBL1564533 & 688816 & 6.8 & 5.4413 & TRN & \\
\hline CHEMBL3190853 & 688816 & 4.6 & 5.4864 & TST & \\
\hline CHEMBL1397353 & 688816 & 5.05 & 4.9361 & TRN & \\
\hline CHEMBL1582978 & 688816 & 4.9 & 5.3083 & TRN & \\
\hline CHEMBL1488077 & 688816 & 5.75 & 5.1706 & TRN & \\
\hline CHEMBL1472101 & 688816 & 4.75 & 5.1014 & TRN & \\
\hline CHEMBL1467321 & 688816 & 4.65 & 5.1177 & TRN & \\
\hline CHEMBL3209425 & 688816 & 4.75 & 5.1466 & TST & \\
\hline CHEMBL1404345 & 688816 & 4.8 & 4.9567 & TRN & \\
\hline CHEMBL1387490 & 688816 & 5.6 & 5.6345 & TRN & \\
\hline CHEMBL1606778 & 688816 & 5.55 & 5.1379 & TRN & \\
\hline CHEMBL1372086 & 688816 & 4.45 & 5.2699 & TRN & \\
\hline CHEMBL1561281 & 688816 & 4.8 & 5.2802 & TRN & \\
\hline CHEMBL1407668 & 688816 & 7.5498 & 5.1169 & TRN & \\
\hline CHEMBL3190965 & 688816 & 4.45 & 5.086 & TRN & \\
\hline CHEMBL1562403 & 688816 & 4.65 & 5.1308 & TRN & \\
\hline CHEMBL1433899 & 688816 & 4.45 & 5.5044 & TST & \\
\hline CHEMBL1393476 & 688816 & 4.45 & 5.1332 & TRN & \\
\hline CHEMBL1310808 & 688816 & 5.2 & 5.2669 & TRN & \\
\hline CHEMBL1531825 & 688816 & 4.45 & 5.394 & TST & \\
\hline CHEMBL1430644 & 688816 & 4.9 & 5.471 & TRN & \\
\hline
\end{tabular}




\begin{tabular}{|c|c|c|c|c|c|}
\hline \multicolumn{6}{|c|}{ Supplemental Table S2 } \\
\hline CHEMBL1368084 & 688816 & 8.301 & 5.4307 & TST & \\
\hline CHEMBL1396664 & 688816 & 4.95 & 4.915 & TRN & \\
\hline CHEMBL1338809 & 688816 & 4.9 & 5.3445 & TRN & \\
\hline CHEMBL1369965 & 688816 & 5.05 & 5.3935 & TRN & \\
\hline CHEMBL1349859 & 688816 & 4.9 & 5.1165 & TRN & \\
\hline CHEMBL1385092 & 688816 & 5.0 & 5.2715 & TRN & \\
\hline CHEMBL1536233 & 688816 & 5.55 & 5.0016 & TST & \\
\hline CHEMBL 2003351 & 688816 & 4.65 & 5.2123 & TRN & \\
\hline CHEMBL1471499 & 688816 & 4.45 & 4.9829 & TST & \\
\hline CHEMBL1490064 & 688816 & 5.0 & 5.0527 & TRN & \\
\hline CHEMBL1473874 & 688816 & 5.5 & 5.3727 & TST & \\
\hline CHEMBL3197772 & 688816 & 4.85 & 5.0745 & TST & \\
\hline CHEMBL1502093 & 688816 & 8.3468 & 6.1497 & TST & \\
\hline CHEMBL1498876 & 688816 & 6.95 & 5.4575 & TRN & \\
\hline CHEMBL1428704 & 688816 & 4.8 & 5.3094 & TRN & \\
\hline CHEMBL1558573 & 688816 & 5.3 & 5.6433 & TRN & \\
\hline CHEMBL1483024 & 688816 & 7.7496 & 5.7601 & TRN & \\
\hline CHEMBL1403578 & 688816 & 5.1 & 5.0042 & TRN & \\
\hline CHEMBL1483676 & 688816 & 4.85 & 5.1903 & TRN & \\
\hline CHEMBL1578373 & 688816 & 8.3979 & 5.5942 & TRN & \\
\hline CHEMBL3144830 & 688816 & 4.45 & 5.0351 & TRN & \\
\hline CHEMBL1506287 & 688816 & 8.1487 & 5.6362 & TRN & \\
\hline CHEMBL1534933 & 688816 & 4.95 & 5.3702 & TST & \\
\hline CHEMBL1449051 & 688816 & 7.699 & 5.8478 & TRN & \\
\hline CHEMBL1519276 & 688816 & 4.65 & 5.4786 & TRN & \\
\hline CHEMBL481044 & 688816 & 4.5 & 5.4171 & TST & \\
\hline CHEMBL1360568 & 688816 & 5.05 & 4.9718 & TRN & \\
\hline CHEMBL1506384 & 688816 & 5.0 & $5.0360 e$ & 00000000005 & TRN \\
\hline CHEMBL1442742 & 688816 & 4.45 & 5.1368 & TRN & \\
\hline CHEMBL1495566 & 688816 & 5.0 & 5.4323 & TRN & \\
\hline CHEMBL1978520 & 688816 & 5.2 & 5.2088 & TRN & \\
\hline CHEMBL1301570 & 688816 & 5.05 & 5.284 & TRN & \\
\hline CHEMBL1472308 & 688816 & 4.55 & 5.3896 & TRN & \\
\hline CHEMBL1606592 & 688816 & 4.9 & 5.1447 & TRN & \\
\hline CHEMBL1470714 & 688816 & 4.45 & 5.4534 & TRN & \\
\hline CHEMBL1404372 & 688816 & 4.85 & 5.3461 & TRN & \\
\hline CHEMBL1540706 & 688816 & 8.4559 & 5.2134 & TST & \\
\hline CHEMBL1395961 & 688816 & 4.45 & 5.0372 & TRN & \\
\hline CHEMBL 3214301 & 688816 & 5.35 & 5.7178 & TRN & \\
\hline CHEMBL3195343 & 688816 & 5.5 & 4.8807 & TST & \\
\hline CHEMBL1406504 & 688816 & 4.75 & 4.9228 & TRN & \\
\hline CHEMBL1329127 & 688816 & 4.95 & 5.2041 & TRN & \\
\hline CHEMBL1309451 & 688816 & 4.75 & 5.0758 & TST & \\
\hline CHEMBL1321728 & 688816 & 6.15 & 5.1642 & TRN & \\
\hline CHEMBL1421101 & 688816 & 4.75 & 5.2426 & TRN & \\
\hline CHEMBL1556686 & 688816 & 5.6 & 5.3549 & TRN & \\
\hline CHEMBL1393564 & 688816 & 4.45 & 4.7774 & TST & \\
\hline CHEMBL1585075 & 688816 & 4.95 & 5.0695 & TRN & \\
\hline
\end{tabular}




\begin{tabular}{|c|c|c|c|c|}
\hline \multicolumn{5}{|c|}{ Supplemental Table s2.txt } \\
\hline CHEMBL1527435 & 688816 & 6.0 & 5.1654 & TRN \\
\hline CHEMBL1478228 & 688816 & 4.9 & 5.3138 & TRN \\
\hline CHEMBL1483067 & 688816 & 8.0 & 5.5322 & TST \\
\hline CHEMBL1468693 & 688816 & 4.85 & 5.3549 & TRN \\
\hline CHEMBL1522354 & 688816 & 7.3002 & 5.4829 & TRN \\
\hline CHEMBL1456786 & 688816 & 6.8499 & 5.1543 & TST \\
\hline CHEMBL1558287 & 688816 & 4.95 & 5.2748 & TRN \\
\hline CHEMBL1607191 & 688816 & 4.95 & 5.276 & TRN \\
\hline CHEMBL1448153 & 688816 & 4.9 & 5.0463 & TRN \\
\hline CHEMBL1305241 & 688816 & 4.9 & 5.0339 & TST \\
\hline CHEMBL1538557 & 688816 & 8.301 & 5.3834 & TST \\
\hline CHEMBL1367346 & 688816 & 5.15 & 5.3357 & TRN \\
\hline CHEMBL 3193717 & 688816 & 5.1 & 4.9512 & TRN \\
\hline CHEMBL1412429 & 688816 & 4.65 & 5.3274 & TST \\
\hline CHEMBL1337310 & 688816 & 5.0 & 5.1158 & TRN \\
\hline CHEMBL1301790 & 688816 & 8.301 & 5.8711 & TRN \\
\hline CHEMBL1532616 & 688816 & 5.55 & 5.5197 & TRN \\
\hline CHEMBL1548815 & 688816 & 4.45 & 4.5649 & TRN \\
\hline CHEMBL1522755 & 688816 & 4.9 & 4.87 & TST \\
\hline CHEMBL3196278 & 688816 & 4.9 & 5.3737 & TRN \\
\hline CHEMBL1541549 & 688816 & 4.9 & 5.1753 & TRN \\
\hline CHEMBL3209195 & 688816 & 4.9 & 5.2848 & TST \\
\hline CHEMBL 3189872 & 688816 & 4.5 & 5.2974 & TST \\
\hline CHEMBL1485770 & 688816 & 4.85 & 5.1257 & TRN \\
\hline CHEMBL1358950 & 688816 & 4.95 & 5.0568 & TRN \\
\hline CHEMBL1541425 & 688816 & 4.95 & 5.3494 & TRN \\
\hline CHEMBL1449966 & 688816 & 4.95 & 5.1489 & TST \\
\hline CHEMBL1372932 & 688816 & 4.9 & 5.1586 & TRN \\
\hline CHEMBL1389441 & 688816 & 4.8 & 5.311 & TRN \\
\hline CHEMBL1410447 & 688816 & 4.45 & 5.5876 & TRN \\
\hline CHEMBL1399159 & 688816 & 8.301 & 5.7344 & TRN \\
\hline CHEMBL1606962 & 688816 & 6.8499 & 4.978 & TRN \\
\hline CHEMBL1539609 & 688816 & 5.05 & 5.2931 & TRN \\
\hline CHEMBL1540130 & 688816 & 5.0 & 5.2625 & TRN \\
\hline CHEMBL1222385 & 688816 & 5.2 & 4.993 & TRN \\
\hline CHEMBL1579153 & 688816 & 5.4 & 5.3477 & TST \\
\hline CHEMBL1518079 & 688816 & 5.25 & 5.4704 & TST \\
\hline CHEMBL1566023 & 688816 & 4.7 & 4.9407 & TRN \\
\hline CHEMBL1365417 & 688816 & 4.9 & 5.0932 & TRN \\
\hline CHEMBL1417605 & 688816 & 5.25 & 4.8215 & TRN \\
\hline CHEMBL83552 & 688816 & 4.85 & 5.3605 & TST \\
\hline CHEMBL 3210142 & 688816 & 4.65 & $5.6270 e$ & 0000000001 \\
\hline CHEMBL1606722 & 688816 & 5.15 & 5.5708 & TRN \\
\hline CHEMBL1331269 & 688816 & 7.8508 & 5.1321 & TRN \\
\hline CHEMBL 3196622 & 688816 & 4.85 & 5.3189 & TRN \\
\hline CHEMBL1523593 & 688816 & 8.301 & 5.2656 & TRN \\
\hline CHEMBL1509829 & 688816 & 5.0 & 5.8123 & TRN \\
\hline CHEMBL1345183 & 688816 & 5.0 & 5.305 & TRN \\
\hline
\end{tabular}




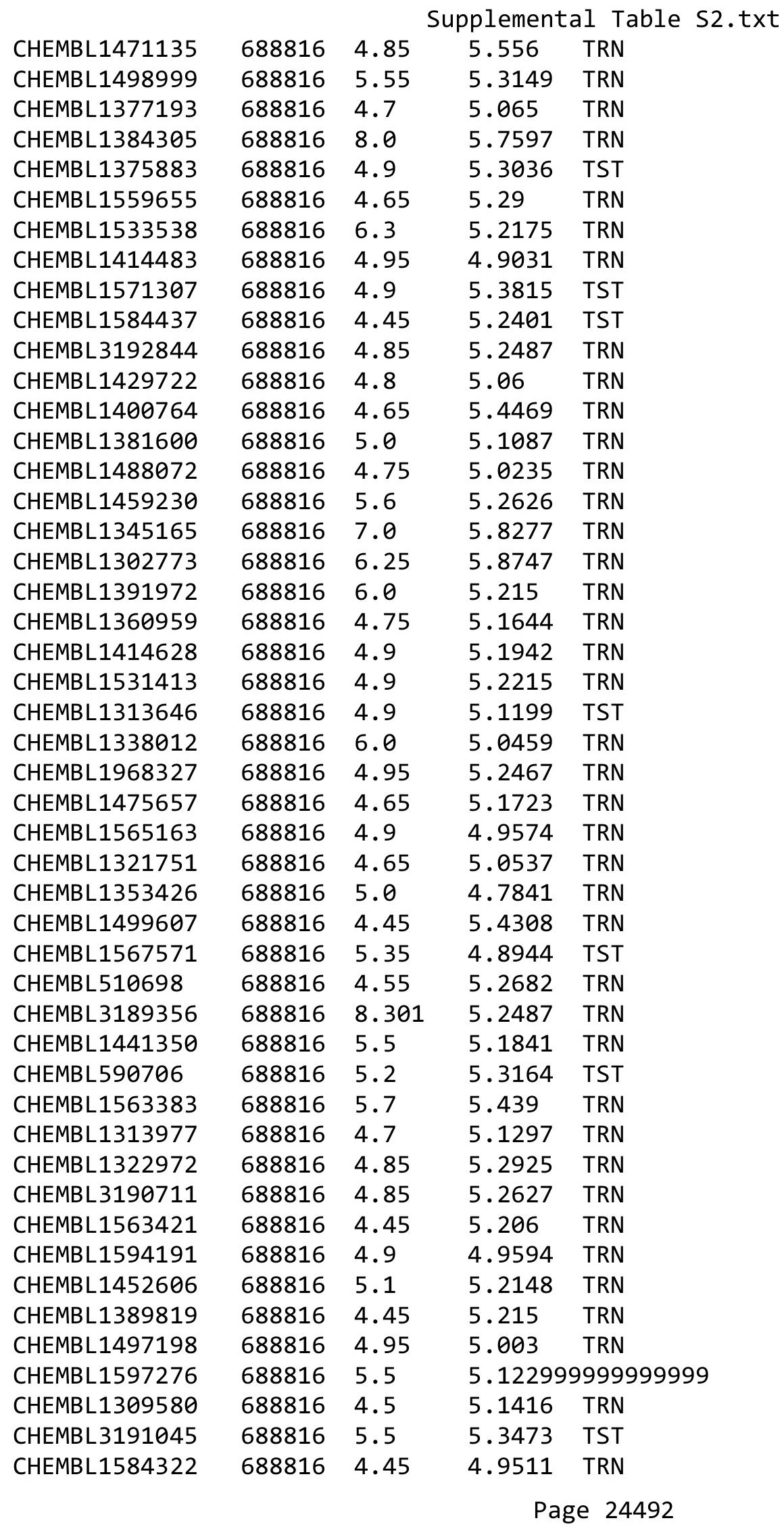

TRN 


\begin{tabular}{|c|c|c|c|c|}
\hline \multicolumn{5}{|c|}{ Supplemental Table S2.txt } \\
\hline CHEMBL1529703 & 688816 & 5.2 & 5.3183 & TRN \\
\hline CHEMBL1406436 & 688816 & 4.6 & 5.0343 & TRN \\
\hline CHEMBL1588018 & 688816 & 4.9 & 5.4801 & TRN \\
\hline CHEMBL1469087 & 688816 & 4.85 & 5.3168 & TRN \\
\hline CHEMBL1541672 & 688816 & 5.0 & 5.1789 & TST \\
\hline CHEMBL1425365 & 688816 & 8.4949 & 5.5914 & TRN \\
\hline CHEMBL1415253 & 688816 & 5.45 & 5.2211 & TRN \\
\hline CHEMBL1487425 & 688816 & 5.45 & 5.7197 & TRN \\
\hline CHEMBL1566989 & 688816 & 4.85 & 5.2476 & TST \\
\hline CHEMBL1341195 & 688816 & 5.5 & 5.0692 & TRN \\
\hline CHEMBL1339339 & 688816 & 4.45 & 5.5563 & TRN \\
\hline CHEMBL1379472 & 688816 & 4.65 & 5.2428 & TST \\
\hline CHEMBL1522060 & 688816 & 5.0 & 5.2948 & TRN \\
\hline CHEMBL1446234 & 688816 & 4.9 & 4.9086 & TRN \\
\hline CHEMBL1466157 & 688816 & 8.2518 & 5.7852 & TRN \\
\hline CHEMBL1349146 & 688816 & 4.95 & 5.2243 & TST \\
\hline CHEMBL1388670 & 688816 & 4.95 & 5.0735 & TRN \\
\hline CHEMBL1408561 & 688816 & 5.35 & 5.1606 & TST \\
\hline CHEMBL1449863 & 688816 & 4.95 & 5.5191 & TRN \\
\hline CHEMBL1418818 & 688816 & 4.85 & 5.2258 & TRN \\
\hline CHEMBL1402807 & 688816 & 4.75 & 5.0379 & TRN \\
\hline CHEMBL1432952 & 688816 & 4.75 & 5.3564 & TST \\
\hline CHEMBL1320092 & 688816 & 4.95 & 4.7201 & TRN \\
\hline CHEMBL1405583 & 688816 & 4.65 & 4.7949 & TRN \\
\hline CHEMBL1502977 & 688816 & 4.85 & 5.3678 & TRN \\
\hline CHEMBL1406374 & 688816 & 4.65 & 5.3508 & TRN \\
\hline CHEMBL1526624 & 688816 & 5.5 & 4.6763 & TRN \\
\hline CHEMBL1472328 & 688816 & 5.2 & 5.5604 & TRN \\
\hline CHEMBL1545284 & 688816 & 4.55 & 5.1162 & TRN \\
\hline CHEMBL1311144 & 688816 & 4.9 & 5.1433 & TRN \\
\hline CHEMBL1548793 & 688816 & 4.45 & 5.4564 & TRN \\
\hline CHEMBL1488264 & 688816 & 6.5 & 5.3732 & TRN \\
\hline CHEMBL1472079 & 688816 & 4.85 & 5.8727 & TRN \\
\hline CHEMBL1574323 & 688816 & 4.45 & 5.1351 & TRN \\
\hline CHEMBL1451875 & 688816 & 4.5 & 5.6088 & TRN \\
\hline CHEMBL3195205 & 688816 & 5.55 & 5.4831 & TRN \\
\hline CHEMBL 1386140 & 688816 & 7.2 & 5.5131 & TRN \\
\hline CHEMBL1419995 & 688816 & 4.9 & 5.085 & TST \\
\hline CHEMBL1360834 & 688816 & 6.8 & 5.3517 & TRN \\
\hline CHEMBL1313954 & 688816 & 4.45 & 4.9948 & TRN \\
\hline CHEMBL1571885 & 688816 & 5.0 & 5.2421 & TRN \\
\hline CHEMBL1334136 & 688816 & 5.45 & 5.1397 & TRN \\
\hline CHEMBL1508134 & 688816 & 6.4 & 5.557 & TRN \\
\hline CHEMBL1507943 & 688816 & 4.45 & 5.645 & TRN \\
\hline CHEMBL1595007 & 688816 & 4.45 & 4.9691 & TRN \\
\hline CHEMBL1434728 & 688816 & 5.55 & 5.0028 & TRN \\
\hline CHEMBL3207903 & 688816 & 4.45 & 5.6384 & TRN \\
\hline CHEMBL1612234 & 688816 & 4.8 & 5.3494 & TST \\
\hline
\end{tabular}




\begin{tabular}{|c|c|c|c|c|}
\hline \multicolumn{5}{|c|}{ Supplemental Table S2.txt } \\
\hline CHEMBL1454433 & 688816 & 5.1 & 5.4718 & TRN \\
\hline CHEMBL1469032 & 688816 & 4.95 & 5.1933 & TRN \\
\hline CHEMBL1403048 & 688816 & 5.65 & 5.3249 & TRN \\
\hline CHEMBL1399453 & 688816 & 4.95 & 5.3872 & TRN \\
\hline CHEMBL1422664 & 688816 & 4.95 & 5.0302 & TRN \\
\hline CHEMBL1503159 & 688816 & 4.6 & 5.6944 & TST \\
\hline CHEMBL1373151 & 688816 & 4.95 & 5.2495 & TRN \\
\hline CHEMBL1564188 & 688816 & 8.301 & 5.4396 & TST \\
\hline CHEMBL1461750 & 688816 & 4.75 & 5.1357 & TRN \\
\hline CHEMBL1353501 & 688816 & 5.25 & 5.2471 & TRN \\
\hline CHEMBL1455027 & 688816 & 4.9 & 5.7056 & TRN \\
\hline CHEMBL1468383 & 688816 & 5.0 & 5.4529 & TRN \\
\hline CHEMBL1373079 & 688816 & 6.2 & 5.4265 & TRN \\
\hline CHEMBL1498475 & 688816 & 5.5 & 5.1752 & TRN \\
\hline CHEMBL1448605 & 688816 & 4.7 & 4.9187 & TST \\
\hline CHEMBL1340080 & 688816 & 4.8 & 5.0549 & TRN \\
\hline CHEMBL1336722 & 688816 & 4.85 & 5.1658 & TST \\
\hline CHEMBL1413781 & 688816 & 4.85 & 5.3122 & TRN \\
\hline CHEMBL1480031 & 688816 & 4.45 & 4.6466 & TRN \\
\hline CHEMBL44 & 688816 & 6.0 & 5.4201 & TRN \\
\hline CHEMBL1490021 & 688816 & 4.5 & 4.9813 & TRN \\
\hline CHEMBL 252403 & 688816 & 6.05 & 5.4771 & TRN \\
\hline CHEMBL1583268 & 688816 & 8.0 & 5.3215 & TRN \\
\hline CHEMBL 3145374 & 688816 & 4.75 & 5.6188 & TRN \\
\hline CHEMBL1592787 & 688816 & 4.75 & 4.9632 & TRN \\
\hline CHEMBL1352627 & 688816 & 4.45 & 5.2958 & TRN \\
\hline CHEMBL1311771 & 688816 & 5.3 & 5.2537 & TRN \\
\hline CHEMBL1335173 & 688816 & 5.25 & 5.1045 & TRN \\
\hline CHEMBL1587645 & 688816 & 4.45 & 5.1325 & TST \\
\hline CHEMBL1382815 & 688816 & 4.45 & 5.4544 & TST \\
\hline CHEMBL1585614 & 688816 & 5.1 & 5.33 & TST \\
\hline CHEMBL1502512 & 688816 & 4.65 & 5.0275 & TST \\
\hline CHEMBL1585236 & 688816 & 4.9 & 5.614 & TST \\
\hline CHEMBL1457665 & 688816 & 5.5 & 5.1041 & TRN \\
\hline CHEMBL1470626 & 688816 & 4.75 & 5.3454 & TRN \\
\hline CHEMBL1413432 & 688816 & 4.6 & 5.2729 & TST \\
\hline CHEMBL1569251 & 688816 & 5.5 & 5.4917 & TST \\
\hline CHEMBL1440813 & 688816 & 4.65 & 5.2128 & TRN \\
\hline CHEMBL1420904 & 688816 & 8.301 & 5.2306 & TST \\
\hline CHEMBL1470451 & 688816 & 4.45 & 4.9812 & TRN \\
\hline CHEMBL1547813 & 688816 & 4.7 & 4.6566 & TRN \\
\hline CHEMBL1487447 & 688816 & 5.0 & 5.3586 & TRN \\
\hline CHEMBL1341351 & 688816 & 4.45 & 4.9222 & TRN \\
\hline CHEMBL1536186 & 688816 & 5.8 & 5.4354 & TRN \\
\hline CHEMBL 3856088 & 688816 & 5.45 & 5.1732 & TRN \\
\hline CHEMBL591370 & 688816 & 6.4 & 5.1485 & TRN \\
\hline CHEMBL1490647 & 688816 & 4.9 & 5.5749 & TRN \\
\hline CHEMBL1499369 & 688816 & 4.45 & 4.9539 & TRN \\
\hline
\end{tabular}




\begin{tabular}{|c|c|c|c|c|c|}
\hline \multicolumn{6}{|c|}{ Supplemental Table S2.txt } \\
\hline CHEMBL1303222 & 688816 & 4.45 & 5.1254 & TRN & \\
\hline CHEMBL1471998 & 688816 & 5.25 & 5.5152 & TRN & \\
\hline CHEMBL1393534 & 688816 & 6.6499 & 5.8214 & TST & \\
\hline CHEMBL1569354 & 688816 & 4.9 & 4.9951 & TRN & \\
\hline CHEMBL1446296 & 688816 & 5.05 & 5.2688 & TST & \\
\hline CHEMBL1452185 & 688816 & 4.75 & 5.7698 & TRN & \\
\hline CHEMBL1574506 & 688816 & 5.25 & 5.2359 & TRN & \\
\hline CHEMBL1337483 & 688816 & 4.85 & 5.4169 & TST & \\
\hline CHEMBL1471305 & 688816 & 4.8 & 4.9926 & TRN & \\
\hline CHEMBL1320208 & 688816 & 5.45 & 5.7232 & TST & \\
\hline CHEMBL1582626 & 688816 & 5.0 & 5.3008 & TRN & \\
\hline CHEMBL1602132 & 688816 & 4.9 & 5.3285 & TRN & \\
\hline CHEMBL1415579 & 688816 & 4.55 & 5.4018 & TRN & \\
\hline CHEMBL1427614 & 688816 & 5.55 & 5.5277 & TRN & \\
\hline CHEMBL1418704 & 688816 & 4.9 & 4.9754 & TST & \\
\hline CHEMBL3198875 & 688816 & 5.7 & 5.4745 & TRN & \\
\hline CHEMBL1429728 & 688816 & 4.65 & 5.1112 & TST & \\
\hline CHEMBL3213117 & 688816 & 5.2 & 5.5213 & TRN & \\
\hline CHEMBL1510830 & 688816 & 6.9 & 5.5827 & TST & \\
\hline CHEMBL1404907 & 688816 & 4.55 & 5.3657 & TRN & \\
\hline CHEMBL1386168 & 688816 & 5.25 & 5.1303 & TRN & \\
\hline CHEMBL1530563 & 688816 & 5.25 & 5.4119 & TRN & \\
\hline CHEMBL1610671 & 688816 & 4.45 & 5.4872 & TRN & \\
\hline CHEMBL1323620 & 688816 & 5.25 & 5.5764 & TRN & \\
\hline CHEMBL1325549 & 688816 & 5.0 & 5.2672 & TRN & \\
\hline CHEMBL1445892 & 688816 & 8.301 & 5.3227 & TRN & \\
\hline CHEMBL1508411 & 688816 & 4.65 & 5.3178 & TRN & \\
\hline CHEMBL1450524 & 688816 & 4.95 & 5.4953 & TST & \\
\hline CHEMBL1374398 & 688816 & 4.45 & 5.3275 & TRN & \\
\hline CHEMBL1338413 & 688816 & 4.95 & 5.1162 & TRN & \\
\hline CHEMBL3209304 & 688816 & 5.0 & 5.2885 & TRN & \\
\hline CHEMBL1445622 & 688816 & 6.15 & 5.3714 & TRN & \\
\hline CHEMBL297784 & 688816 & 5.9 & 5.2229 & TST & \\
\hline CHEMBL1445748 & 688816 & 4.8 & 5.2782 & TRN & \\
\hline CHEMBL1497117 & 688816 & 5.45 & 5.4139 & TST & \\
\hline CHEMBL3198484 & 688816 & 5.1 & 5.2084 & TRN & \\
\hline CHEMBL1482179 & 688816 & 4.8 & 5.16100 & 00000000005 & TRN \\
\hline CHEMBL1566195 & 688816 & 4.45 & 5.2291 & TRN & \\
\hline CHEMBL3195186 & 688816 & 4.95 & 5.5726 & TRN & \\
\hline CHEMBL1492461 & 688816 & 5.15 & 4.9313 & TRN & \\
\hline CHEMBL1570469 & 688816 & 5.6 & 5.3582 & TST & \\
\hline CHEMBL1429882 & 688816 & 4.7 & 5.2356 & TRN & \\
\hline CHEMBL1400453 & 688816 & 5.45 & 5.8199 & TST & \\
\hline CHEMBL1463912 & 688816 & 8.3468 & 5.3932 & TST & \\
\hline CHEMBL1412005 & 688816 & 5.15 & 5.3502 & TRN & \\
\hline CHEMBL1526388 & 688816 & 6.6499 & 5.5612 & TST & \\
\hline CHEMBL3195830 & 688816 & 4.6 & 5.272 & TST & \\
\hline CHEMBL1492396 & 688816 & 6.7001 & 5.1955 & TRN & \\
\hline
\end{tabular}




\begin{tabular}{|c|c|c|c|c|}
\hline \multicolumn{5}{|c|}{ Supplemental Table S2.txt } \\
\hline CHEMBL1380218 & 688816 & 5.8 & 5.5409 & TRN \\
\hline CHEMBL1457134 & 688816 & 4.9 & 5.3181 & TRN \\
\hline CHEMBL1533120 & 688816 & 4.95 & 5.6933 & TRN \\
\hline CHEMBL 1465893 & 688816 & 4.7 & 5.2167 & TRN \\
\hline CHEMBL1573812 & 688816 & 4.45 & 5.2009 & TST \\
\hline CHEMBL1612240 & 688816 & 4.45 & 5.2813 & TST \\
\hline CHEMBL1209962 & 688816 & 5.6 & 5.3337 & TRN \\
\hline CHEMBL1390708 & 688816 & 8.0506 & 5.4678 & TRN \\
\hline CHEMBL1336237 & 688816 & 5.55 & 5.1781 & TRN \\
\hline CHEMBL1513050 & 688816 & 4.5 & 5.4749 & TRN \\
\hline CHEMBL1499028 & 688816 & 5.0 & 5.2439 & TRN \\
\hline CHEMBL1454996 & 688816 & 5.55 & 5.2072 & TRN \\
\hline CHEMBL 3195681 & 688816 & 5.2 & 5.3094 & TST \\
\hline CHEMBL1479409 & 688816 & 4.85 & 5.279 & TRN \\
\hline CHEMBL1541473 & 688816 & 4.45 & 5.1665 & TRN \\
\hline CHEMBL429095 & 688816 & 5.35 & 5.2955 & TST \\
\hline CHEMBL1606385 & 688816 & 5.05 & 5.2951 & TRN \\
\hline CHEMBL1422802 & 688816 & 6.5501 & 5.4722 & TST \\
\hline CHEMBL 302783 & 688816 & 6.95 & 6.31 & TST \\
\hline CHEMBL1503799 & 688816 & 5.45 & 5.2626 & TRN \\
\hline CHEMBL1455667 & 688816 & 4.95 & 5.7249 & TRN \\
\hline CHEMBL1378822 & 688816 & 4.45 & 5.3582 & TRN \\
\hline CHEMBL1520829 & 688816 & 5.45 & 5.1883 & TRN \\
\hline CHEMBL1544180 & 688816 & 5.0 & 5.1239 & TRN \\
\hline CHEMBL1501596 & 688816 & 4.8 & 4.9941 & TRN \\
\hline CHEMBL1609299 & 688816 & 5.3 & 5.4621 & TST \\
\hline CHEMBL1444398 & 688816 & 5.9 & 5.5316 & TRN \\
\hline CHEMBL1383781 & 688816 & 4.8 & 5.3162 & TRN \\
\hline CHEMBL1519727 & 688816 & 4.95 & 5.1021 & TRN \\
\hline CHEMBL1540114 & 688816 & 4.55 & 5.1472 & TRN \\
\hline CHEMBL1360997 & 688816 & 5.5 & 5.6782 & TRN \\
\hline CHEMBL1502643 & 688816 & 5.0 & 5.3933 & TRN \\
\hline CHEMBL 3212246 & 688816 & 5.5 & 5.1481 & TST \\
\hline CHEMBL1442937 & 688816 & 7.0 & 5.5046 & TRN \\
\hline CHEMBL1587375 & 688816 & 5.1 & 4.8774 & TRN \\
\hline CHEMBL3193627 & 688816 & 5.15 & 5.2787 & TRN \\
\hline CHEMBL1457338 & 688816 & 5.25 & 4.9751 & TRN \\
\hline CHEMBL1514311 & 688816 & 4.5 & 5.2739 & TRN \\
\hline CHEMBL1320551 & 688816 & 4.45 & 5.4837 & TST \\
\hline CHEMBL1360916 & 688816 & 5.15 & 5.3081 & TRN \\
\hline CHEMBL1981229 & 688816 & 4.45 & 5.0474 & TRN \\
\hline CHEMBL1363345 & 688816 & 5.15 & 5.6969 & TRN \\
\hline CHEMBL3189738 & 688816 & 6.8 & 5.46399 & 99999999995 \\
\hline CHEMBL1365705 & 688816 & 4.95 & 5.0092 & TRN \\
\hline CHEMBL1392235 & 688816 & 4.95 & 4.9327 & TRN \\
\hline CHEMBL1321292 & 688816 & 4.7 & 5.1724 & TST \\
\hline CHEMBL1574203 & 688816 & 4.45 & 5.0243 & TRN \\
\hline CHEMBL3207941 & 688816 & 5.0 & 5.2194 & TRN \\
\hline
\end{tabular}




\begin{tabular}{|c|c|c|c|c|c|}
\hline \multicolumn{6}{|c|}{ Supplemental Table S2.txt } \\
\hline CHEMBL1376981 & 688816 & 5.35 & 5.1958 & TRN & \\
\hline CHEMBL1369273 & 688816 & 4.55 & 5.2427 & TST & \\
\hline CHEMBL1482930 & 688816 & 4.8 & 5.5369 & TRN & \\
\hline CHEMBL1557584 & 688816 & 5.0 & 5.078 & TRN & \\
\hline CHEMBL1584768 & 688816 & 5.05 & 5.1443 & TST & \\
\hline CHEMBL1426315 & 688816 & 5.25 & 5.5607 & TST & \\
\hline CHEMBL1420808 & 688816 & 4.8 & 5.1312 & TRN & \\
\hline CHEMBL58033 & 688816 & 6.0 & 5.3935 & TRN & \\
\hline CHEMBL1398223 & 688816 & 4.95 & 5.5916 & TST & \\
\hline CHEMBL1583137 & 688816 & 5.25 & 5.1788 & TRN & \\
\hline CHEMBL1304930 & 688816 & 4.8 & 5.2281 & TRN & \\
\hline CHEMBL1537911 & 688816 & 4.65 & 5.3073 & TRN & \\
\hline CHEMBL1587680 & 688816 & 4.45 & 5.3611 & TRN & \\
\hline CHEMBL1601453 & 688816 & 5.35 & 5.3389 & TRN & \\
\hline CHEMBL1527426 & 688816 & 4.85 & 5.2311 & TRN & \\
\hline CHEMBL1305536 & 688816 & 4.65 & 5.0036 & TRN & \\
\hline CHEMBL1442207 & 688816 & 4.8 & 5.2456 & TST & \\
\hline CHEMBL1463056 & 688816 & 4.95 & 5.4891 & TST & \\
\hline CHEMBL1359293 & 688816 & 4.8 & 5.05399 & 9999999999 & TRN \\
\hline CHEMBL1416432 & 688816 & 7.15 & 5.3994 & TST & \\
\hline CHEMBL1513001 & 688816 & 4.45 & 5.5004 & TRN & \\
\hline CHEMBL1583361 & 688816 & 4.85 & 5.4638 & TRN & \\
\hline CHEMBL1601031 & 688816 & 4.95 & 5.4103 & TRN & \\
\hline CHEMBL1483344 & 688816 & 7.0 & 5.18 & TRN & \\
\hline CHEMBL1519140 & 688816 & 5.55 & 5.4276 & TRN & \\
\hline CHEMBL1330941 & 688816 & 6.0 & 5.1854 & TRN & \\
\hline CHEMBL1390279 & 688816 & 4.95 & 5.2771 & TRN & \\
\hline CHEMBL1598581 & 688816 & 5.65 & 5.1463 & TRN & \\
\hline CHEMBL1380604 & 688816 & 4.5 & 5.4047 & TST & \\
\hline CHEMBL1530075 & 688816 & 4.45 & 5.2324 & TRN & \\
\hline CHEMBL1485938 & 688816 & 8.0 & 5.2084 & TST & \\
\hline CHEMBL1470364 & 688816 & 5.95 & 5.919 & TRN & \\
\hline CHEMBL1320065 & 688816 & 7.5498 & 5.6371 & TST & \\
\hline CHEMBL1383226 & 688816 & 8.3979 & 5.5774 & TST & \\
\hline CHEMBL1331263 & 688816 & 5.7 & 5.1404 & TRN & \\
\hline CHEMBL1342951 & 688816 & 4.45 & 5.3612 & TST & \\
\hline CHEMBL1415626 & 688816 & 4.45 & 5.71899 & 9999999999 & TRN \\
\hline CHEMBL1307187 & 688816 & 8.3468 & 5.395 & TRN & \\
\hline CHEMBL1571224 & 688816 & 4.7 & 5.1946 & TRN & \\
\hline CHEMBL1315736 & 688816 & 4.75 & 5.1967 & TRN & \\
\hline CHEMBL1414223 & 688816 & 4.9 & 5.215 & TST & \\
\hline CHEMBL1486993 & 688816 & 4.85 & 5.0935 & TRN & \\
\hline CHEMBL1518817 & 688816 & 4.65 & 5.484 & TRN & \\
\hline CHEMBL1303809 & 688816 & 4.65 & 5.2794 & TRN & \\
\hline CHEMBL1575368 & 688816 & 5.5 & 5.2433 & TRN & \\
\hline CHEMBL1309549 & 688816 & 4.7 & 5.774 & TRN & \\
\hline CHEMBL3189707 & 688816 & 8.4559 & 5.4471 & TRN & \\
\hline CHEMBL1585530 & 688816 & 6.45 & 5.5756 & TST & \\
\hline
\end{tabular}




\begin{tabular}{|c|c|c|c|c|c|}
\hline \multicolumn{6}{|c|}{ Supplemental Table S2.txt } \\
\hline CHEMBL3190201 & 688816 & 4.95 & 5.5514 & TST & \\
\hline CHEMBL1452502 & 688816 & 5.45 & 5.1695 & TRN & \\
\hline CHEMBL1387943 & 688816 & 5.5 & 5.5384 & TST & \\
\hline CHEMBL1606342 & 688816 & 4.9 & 5.1335 & TRN & \\
\hline CHEMBL1523979 & 688816 & 4.65 & 4.8361 & TRN & \\
\hline CHEMBL1500847 & 688816 & 4.95 & 5.4359 & TRN & \\
\hline CHEMBL1420246 & 688816 & 5.85 & 5.3562 & TRN & \\
\hline CHEMBL1385376 & 688816 & 5.05 & 5.1148 & TRN & \\
\hline CHEMBL1507600 & 688816 & 4.45 & 4.9339 & TRN & \\
\hline CHEMBL1574403 & 688816 & 4.7 & 4.9894 & TRN & \\
\hline CHEMBL3197262 & 688816 & 4.9 & 5.1698 & TRN & \\
\hline CHEMBL1377799 & 688816 & 4.95 & 5.2413 & TRN & \\
\hline CHEMBL1451492 & 688816 & 5.85 & 5.0235 & TRN & \\
\hline CHEMBL1558539 & 688816 & 4.95 & 5.37299 & 7999999999 & TRN \\
\hline CHEMBL1348280 & 688816 & 4.95 & 5.3381 & TRN & \\
\hline CHEMBL1539342 & 688816 & 4.45 & 5.3122 & TRN & \\
\hline CHEMBL1566459 & 688816 & 4.75 & 5.4436 & TRN & \\
\hline CHEMBL 3192525 & 688816 & 8.301 & 5.1852 & TRN & \\
\hline CHEMBL1581149 & 688816 & 5.0 & 5.5572 & TRN & \\
\hline CHEMBL1428815 & 688816 & 4.95 & 5.3114 & TRN & \\
\hline CHEMBL1601612 & 688816 & 7.6003 & 5.4282 & TRN & \\
\hline CHEMBL1441505 & 688816 & 5.75 & 5.0319 & TRN & \\
\hline CHEMBL1519195 & 688816 & 5.5 & 5.0394 & TRN & \\
\hline CHEMBL1411878 & 688816 & 4.95 & 5.1316 & TRN & \\
\hline CHEMBL1372127 & 688816 & 4.9 & 5.5384 & TRN & \\
\hline CHEMBL1324703 & 688816 & 4.75 & 5.0367 & TRN & \\
\hline CHEMBL1373709 & 688816 & 7.8013 & 5.1681 & TST & \\
\hline CHEMBL1606581 & 688816 & 4.8 & 4.8677 & TRN & \\
\hline CHEMBL1499327 & 688816 & 4.75 & 5.2838 & TRN & \\
\hline CHEMBL1446335 & 688816 & 5.0 & 5.0887 & TRN & \\
\hline CHEMBL 3194787 & 688816 & 4.95 & 5.693 & TRN & \\
\hline CHEMBL1302263 & 688816 & 4.95 & 5.148 & TRN & \\
\hline CHEMBL1452266 & 688816 & 5.05 & 5.314 & TRN & \\
\hline CHEMBL1372739 & 688816 & 7.8996 & 5.2082 & TRN & \\
\hline CHEMBL1426285 & 688816 & 5.55 & 5.0446 & TST & \\
\hline CHEMBL1512171 & 688816 & 5.5 & 5.0881 & TRN & \\
\hline CHEMBL1521466 & 688816 & 5.85 & 5.1952 & TST & \\
\hline CHEMBL1430526 & 688816 & 5.25 & 5.5482 & TST & \\
\hline CHEMBL1382267 & 688816 & 8.0 & 5.3825 & TST & \\
\hline CHEMBL1521005 & 688816 & 4.8 & 5.0771 & TRN & \\
\hline CHEMBL1608570 & 688816 & 6.7501 & 5.454 & TRN & \\
\hline CHEMBL1462692 & 688816 & 4.95 & 5.0304 & TST & \\
\hline CHEMBL1476287 & 688816 & 6.1 & 5.0372 & TST & \\
\hline CHEMBL1480056 & 688816 & 5.55 & 5.3675 & TRN & \\
\hline CHEMBL578515 & 688816 & 4.9 & 4.971 & TRN & \\
\hline CHEMBL1408543 & 688816 & 5.5 & 5.5072 & TST & \\
\hline CHEMBL1505047 & 688816 & 4.7 & 5.6883 & TRN & \\
\hline CHEMBL1530314 & 688816 & 6.7001 & 5.5127 & TST & \\
\hline
\end{tabular}




\begin{tabular}{|c|c|c|c|c|c|}
\hline \multicolumn{6}{|c|}{ Supplemental Table S2.txt } \\
\hline CHEMBL1460570 & 688816 & 5.05 & 5.5551 & TRN & \\
\hline CHEMBL1437831 & 688816 & 5.25 & 5.5559 & TST & \\
\hline CHEMBL1544874 & 688816 & 4.5 & 5.3944 & TRN & \\
\hline CHEMBL1319677 & 688816 & 5.4 & 5.4124 & TRN & \\
\hline CHEMBL119171 & 688816 & 4.9 & 5.7635 & TRN & \\
\hline CHEMBL1470993 & 688816 & 4.9 & 5.0353 & TRN & \\
\hline CHEMBL119769 & 688816 & 5.65 & 5.3799 & TRN & \\
\hline CHEMBL1331555 & 688816 & 4.95 & 5.0578 & TRN & \\
\hline CHEMBL1360374 & 688816 & 4.45 & 5.3252 & TRN & \\
\hline CHEMBL1541177 & 688816 & 5.1 & 5.1547 & TRN & \\
\hline CHEMBL3192551 & 688816 & 4.65 & 5.3818 & TRN & \\
\hline CHEMBL1542179 & 688816 & 4.95 & 5.3344 & TRN & \\
\hline CHEMBL1494058 & 688816 & 5.65 & 5.2683 & TST & \\
\hline CHEMBL1442735 & 688816 & 8.4949 & 5.5981 & TST & \\
\hline CHEMBL1609018 & 688816 & 4.85 & 5.2155 & TRN & \\
\hline CHEMBL1440077 & 688816 & 4.6 & 5.4914 & TRN & \\
\hline CHEMBL1334813 & 688816 & 4.75 & 5.2581 & TRN & \\
\hline CHEMBL3212001 & 688816 & 8.0 & 5.5794 & TRN & \\
\hline CHEMBL1545267 & 688816 & 5.05 & 5.2564 & TST & \\
\hline CHEMBL1390645 & 688816 & 4.45 & 4.9847 & TRN & \\
\hline CHEMBL1559514 & 688816 & 4.75 & 5.2553 & TST & \\
\hline CHEMBL1392186 & 688816 & 4.95 & 5.2198 & TST & \\
\hline CHEMBL1357946 & 688816 & 4.75 & 5.13399 & 99999999995 & TRN \\
\hline CHEMBL1598895 & 688816 & 4.65 & 4.9239 & TST & \\
\hline CHEMBL1359909 & 688816 & 5.0 & 5.1723 & TST & \\
\hline CHEMBL1491910 & 688816 & 5.4 & 5.3128 & TST & \\
\hline CHEMBL1379653 & 688816 & 4.7 & 5.4587 & TST & \\
\hline CHEMBL1584566 & 688816 & 5.0 & 5.4899 & TRN & \\
\hline CHEMBL1451982 & 688816 & 4.6 & 5.185 & TRN & \\
\hline CHEMBL1351687 & 688816 & 5.0 & 5.3732 & TRN & \\
\hline CHEMBL1521838 & 688816 & 4.45 & 5.0895 & TRN & \\
\hline CHEMBL476190 & 688816 & 4.9 & 5.2608 & TST & \\
\hline CHEMBL1529513 & 688816 & 5.6 & 5.2714 & TRN & \\
\hline CHEMBL1589601 & 688816 & 4.7 & 5.3078 & TRN & \\
\hline CHEMBL1575314 & 688816 & 4.9 & 5.5461 & TST & \\
\hline CHEMBL1352339 & 688816 & 4.95 & 5.3753 & TRN & \\
\hline CHEMBL1353231 & 688816 & 6.1 & 5.1057 & TRN & \\
\hline CHEMBL1502635 & 688816 & 5.1 & 5.4052 & TRN & \\
\hline CHEMBL1423066 & 688816 & 5.35 & 5.3174 & TRN & \\
\hline CHEMBL1441035 & 688816 & 8.301 & 5.7896 & TRN & \\
\hline CHEMBL1301920 & 688816 & 5.2 & 5.1086 & TST & \\
\hline CHEMBL1350057 & 688816 & 5.05 & 5.2892 & TRN & \\
\hline CHEMBL1582891 & 688816 & 4.8 & 5.3351 & TRN & \\
\hline CHEMBL3209382 & 688816 & 6.1 & 5.3356 & TRN & \\
\hline CHEMBL1495590 & 688816 & 4.9 & 5.3854 & TRN & \\
\hline CHEMBL1353533 & 688816 & 6.6 & 5.1557 & TRN & \\
\hline CHEMBL1497391 & 688816 & 5.05 & 5.2408 & TST & \\
\hline CHEMBL1401270 & 688816 & 4.5 & 5.2424 & TRN & \\
\hline
\end{tabular}




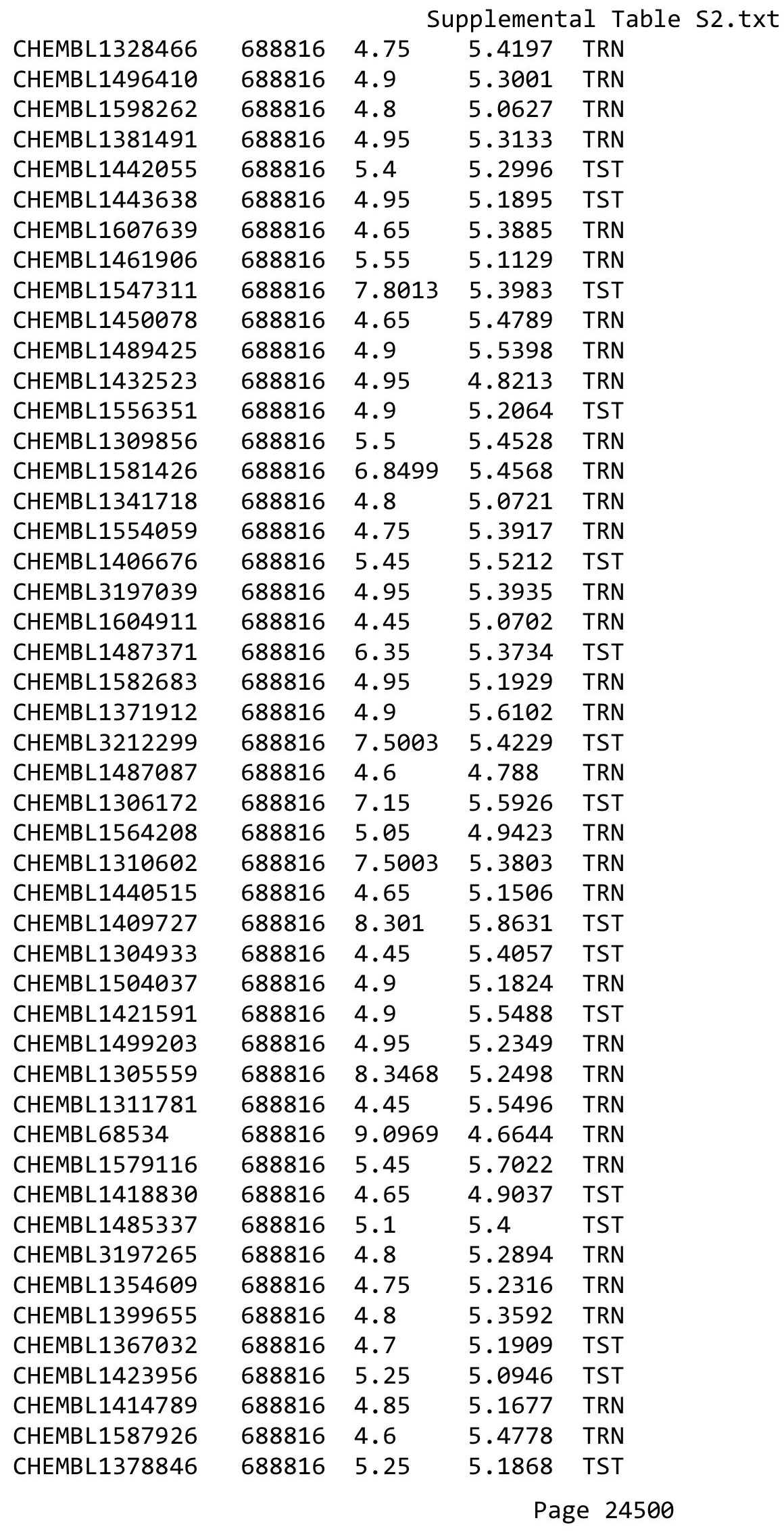




\begin{tabular}{|c|c|c|c|c|c|}
\hline \multicolumn{6}{|c|}{ ptemer } \\
\hline CHEMBL1502796 & 688816 & 6.9 & 5.5058 & TRN & \\
\hline CHEMBL1311838 & 688816 & 4.95 & 5.0736 & TRN & \\
\hline CHEMBL1372044 & 688816 & 7.699 & 5.4788 & TST & \\
\hline CHEMBL1581425 & 688816 & 6.3 & 5.1465 & TRN & \\
\hline CHEMBL1597869 & 688816 & 5.9 & 5.648 & TRN & \\
\hline CHEMBL1561922 & 688816 & 6.0 & 5.4798 & TRN & \\
\hline CHEMBL1583176 & 688816 & 4.9 & 5.3477 & TRN & \\
\hline CHEMBL1308517 & 688816 & 5.5 & 5.6465 & TRN & \\
\hline CHEMBL1465156 & 688816 & 8.3468 & 5.6083 & TRN & \\
\hline CHEMBL1392152 & 688816 & 4.75 & 5.1113 & TRN & \\
\hline CHEMBL1319304 & 688816 & 5.7 & 5.1737 & TRN & \\
\hline CHEMBL3145364 & 688816 & 5.1 & 5.4284 & TST & \\
\hline CHEMBL1331927 & 688816 & 5.0 & 5.1112 & TRN & \\
\hline CHEMBL1456440 & 688816 & 5.2 & 5.4154 & TRN & \\
\hline CHEMBL1443903 & 688816 & 5.15 & 5.148 & TRN & \\
\hline CHEMBL1440340 & 688816 & 4.65 & 5.1667 & TRN & \\
\hline CHEMBL1570720 & 688816 & 4.95 & 5.1547 & TRN & \\
\hline CHEMBL1377924 & 688816 & 4.65 & 5.754 & TRN & \\
\hline CHEMBL1372490 & 688816 & 5.0 & 5.3915 & TST & \\
\hline CHEMBL600896 & 688816 & 6.1 & 5.3686 & TRN & \\
\hline CHEMBL1611227 & 688816 & 5.05 & 4.96899 & 9999999999 & TRN \\
\hline CHEMBL1598049 & 688816 & 4.75 & 5.2063 & TRN & \\
\hline CHEMBL1373256 & 688816 & 4.9 & 5.1893 & TRN & \\
\hline CHEMBL1441918 & 688816 & 4.95 & 5.1854 & TST & \\
\hline CHEMBL1436372 & 688816 & 4.45 & 5.1174 & TRN & \\
\hline CHEMBL1604999 & 688816 & 4.8 & 5.3044 & TRN & \\
\hline CHEMBL3209489 & 688816 & 8.0 & 5.5462 & TRN & \\
\hline CHEMBL1365963 & 688816 & 4.85 & 5.0125 & TRN & \\
\hline CHEMBL1529499 & 688816 & 4.45 & 5.3248 & TRN & \\
\hline CHEMBL1478289 & 688816 & 4.9 & 5.2187 & TRN & \\
\hline CHEMBL1477725 & 688816 & 4.8 & 4.9058 & TRN & \\
\hline CHEMBL1341053 & 688816 & 4.95 & 5.2326 & TRN & \\
\hline CHEMBL540848 & 688816 & 6.0 & 5.061 & TST & \\
\hline CHEMBL1428629 & 688816 & 5.0 & 5.2637 & TRN & \\
\hline CHEMBL1463245 & 688816 & 7.5498 & 5.6035 & TRN & \\
\hline CHEMBL1460373 & 688816 & 6.3 & 5.4619 & TRN & \\
\hline CHEMBL1986418 & 688816 & 5.3 & 4.9748 & TRN & \\
\hline CHEMBL1496695 & 688816 & 4.9 & 4.9984 & TRN & \\
\hline CHEMBL1386834 & 688816 & 4.85 & 4.82600 & 00000000005 & TRN \\
\hline CHEMBL1311188 & 688816 & 4.6 & 5.1624 & TRN & \\
\hline CHEMBL1331895 & 688816 & 5.6 & 4.9473 & TRN & \\
\hline CHEMBL1347245 & 688816 & 5.4 & 5.2235 & TRN & \\
\hline CHEMBL1590707 & 688816 & 4.7 & 5.2289 & TRN & \\
\hline CHEMBL1400018 & 688816 & 4.8 & 5.0091 & TRN & \\
\hline CHEMBL428496 & 688816 & 4.65 & 5.6046 & TST & \\
\hline CHEMBL1488000 & 688816 & 4.45 & 5.039 & TRN & \\
\hline CHEMBL1560799 & 688816 & 4.9 & 5.574 & TRN & \\
\hline CHEMBL1308374 & 688816 & 4.95 & 5.349 & TST & \\
\hline
\end{tabular}




\begin{tabular}{|c|c|c|c|c|c|}
\hline \multicolumn{6}{|c|}{ Supplemental Table s2.txt } \\
\hline CHEMBL1400603 & 688816 & 4.9 & 5.2164 & TRN & \\
\hline CHEMBL3212827 & 688816 & 6.5 & 5.4837 & TRN & \\
\hline CHEMBL1471253 & 688816 & 8.1487 & 5.3053 & TRN & \\
\hline CHEMBL1453296 & 688816 & 6.35 & 5.53299 & 99999999995 & TRN \\
\hline CHEMBL1352335 & 688816 & 4.9 & 5.1725 & TST & \\
\hline CHEMBL1585390 & 688816 & 4.45 & 5.3899 & TST & \\
\hline CHEMBL1545455 & 688816 & 4.65 & 5.3817 & TRN & \\
\hline CHEMBL1402573 & 688816 & 5.6 & 5.46200 & 0000000001 & TST \\
\hline CHEMBL1301851 & 688816 & 4.95 & 5.0541 & TRN & \\
\hline CHEMBL1371852 & 688816 & 8.301 & 5.3874 & TRN & \\
\hline CHEMBL1569850 & 688816 & 5.35 & 5.0187 & TRN & \\
\hline CHEMBL1425720 & 688816 & 4.45 & 5.0192 & TST & \\
\hline CHEMBL1548600 & 688816 & 5.55 & 4.9165 & TRN & \\
\hline CHEMBL1411916 & 688816 & 4.45 & 4.9453 & TST & \\
\hline CHEMBL1493052 & 688816 & 5.25 & 5.1049 & TRN & \\
\hline CHEMBL1400351 & 688816 & 4.9 & 5.1723 & TRN & \\
\hline CHEMBL1545001 & 688816 & 4.9 & 5.4971 & TRN & \\
\hline CHEMBL1567007 & 688816 & 4.85 & 5.0418 & TRN & \\
\hline CHEMBL3196323 & 688816 & 8.3468 & 4.9204 & TRN & \\
\hline CHEMBL16807 & 688816 & 4.5 & 4.9976 & TRN & \\
\hline CHEMBL1340835 & 688816 & 5.1 & 5.2008 & TRN & \\
\hline CHEMBL1466389 & 688816 & 5.25 & 5.6426 & TRN & \\
\hline CHEMBL42288 & 688816 & 7.8013 & 5.4279 & TRN & \\
\hline CHEMBL1374074 & 688816 & 4.95 & 5.5012 & TRN & \\
\hline CHEMBL1542484 & 688816 & 4.75 & 5.0637 & TRN & \\
\hline CHEMBL1339905 & 688816 & 5.4 & 5.3101 & TRN & \\
\hline CHEMBL1598148 & 688816 & 5.9 & 5.2781 & TRN & \\
\hline CHEMBL1301505 & 688816 & 4.45 & 4.8614 & TRN & \\
\hline CHEMBL1343284 & 688816 & 4.9 & 5.4114 & TST & \\
\hline CHEMBL1359579 & 688816 & 4.9 & 5.5232 & TST & \\
\hline CHEMBL1532383 & 688816 & 4.9 & 5.3684 & TRN & \\
\hline CHEMBL1393714 & 688816 & 5.0 & 4.9511 & TRN & \\
\hline CHEMBL1527007 & 688816 & 4.9 & 5.2935 & TRN & \\
\hline CHEMBL1557125 & 688816 & 4.45 & 5.4617 & TST & \\
\hline CHEMBL1432357 & 688816 & 4.85 & 5.1144 & TRN & \\
\hline CHEMBL 2094573 & 688816 & 4.95 & 5.0134 & TRN & \\
\hline CHEMBL1384489 & 688816 & 5.0 & 4.8861 & TRN & \\
\hline CHEMBL1328713 & 688816 & 4.85 & 5.0553 & TST & \\
\hline CHEMBL1424459 & 688816 & 5.2 & 5.4784 & TRN & \\
\hline CHEMBL1380276 & 688816 & 5.7 & 5.4354 & TRN & \\
\hline CHEMBL1580126 & 688816 & 4.45 & 5.1148 & TST & \\
\hline CHEMBL1493857 & 688816 & 7.5003 & 5.4981 & TST & \\
\hline CHEMBL1520599 & 688816 & 5.6 & 5.4581 & TRN & \\
\hline CHEMBL1579211 & 688816 & 8.3468 & 5.624 & TRN & \\
\hline CHEMBL1594244 & 688816 & 4.9 & 5.2596 & TRN & \\
\hline CHEMBL1609735 & 688816 & 8.1024 & 5.3159 & TRN & \\
\hline CHEMBL1310646 & 688816 & 5.45 & 5.4054 & TRN & \\
\hline CHEMBL1308217 & 688816 & 5.15 & 5.3984 & TST & \\
\hline
\end{tabular}




\begin{tabular}{|c|c|c|c|c|}
\hline \multicolumn{5}{|c|}{ Supplemental Table S2.txt } \\
\hline CHEMBL1382751 & 688816 & 4.45 & 5.313 & TST \\
\hline CHEMBL1572552 & 688816 & 6.0 & 5.2262 & TRN \\
\hline CHEMBL1600417 & 688816 & 4.9 & 5.3404 & TRN \\
\hline CHEMBL1448424 & 688816 & 5.0 & 5.306 & TST \\
\hline CHEMBL1438171 & 688816 & 4.9 & 5.2192 & TST \\
\hline CHEMBL1469937 & 688816 & 5.25 & 5.0985 & TST \\
\hline CHEMBL1509967 & 688816 & 4.85 & 5.0955 & TST \\
\hline CHEMBL1488674 & 688816 & 4.65 & 5.2643 & TST \\
\hline CHEMBL1577122 & 688816 & 4.85 & 5.038 & TRN \\
\hline CHEMBL1409554 & 688816 & 5.25 & 5.2 & TST \\
\hline CHEMBL 2374028 & 688816 & 5.05 & 5.9415 & TST \\
\hline CHEMBL1376262 & 688816 & 5.5 & 5.3012 & TRN \\
\hline CHEMBL1439696 & 688816 & 5.2 & 5.3647 & TST \\
\hline CHEMBL1348092 & 688816 & 5.0 & 5.5839 & TRN \\
\hline CHEMBL1451935 & 688816 & 4.6 & 5.1115 & TRN \\
\hline CHEMBL1452652 & 688816 & 4.7 & 5.2197 & TRN \\
\hline CHEMBL1329259 & 688816 & 4.5 & 5.5771 & TST \\
\hline CHEMBL1592591 & 688816 & 4.65 & 5.1918 & TRN \\
\hline CHEMBL1422277 & 688816 & 4.75 & 5.0776 & TRN \\
\hline CHEMBL1602040 & 688816 & 5.5 & 5.2555 & TST \\
\hline CHEMBL1326268 & 688816 & 5.5 & 5.6487 & TST \\
\hline CHEMBL1487897 & 688816 & 4.6 & 5.0758 & TRN \\
\hline CHEMBL1469312 & 688816 & 8.301 & 5.5744 & TST \\
\hline CHEMBL 309016 & 688816 & 4.45 & 5.1466 & TST \\
\hline CHEMBL3191420 & 688816 & 4.95 & 5.2504 & TRN \\
\hline CHEMBL1454660 & 688816 & 4.95 & 5.3131 & TST \\
\hline CHEMBL1595866 & 688816 & 4.85 & 5.2109 & TRN \\
\hline CHEMBL1481243 & 688816 & 5.55 & 6.1034 & TRN \\
\hline CHEMBL1371178 & 688816 & 6.2 & 5.3102 & TRN \\
\hline CHEMBL1606291 & 688816 & 4.95 & 5.0259 & TST \\
\hline CHEMBL1612112 & 688816 & 4.45 & 5.3938 & TRN \\
\hline CHEMBL 1456785 & 688816 & 4.75 & 5.2437 & TRN \\
\hline CHEMBL 3211224 & 688816 & 5.0 & 5.5152 & TST \\
\hline CHEMBL1504131 & 688816 & 4.8 & 5.3662 & TRN \\
\hline CHEMBL1541349 & 688816 & 4.8 & 4.9316 & TRN \\
\hline CHEMBL1379700 & 688816 & 5.0 & 4.9367 & TRN \\
\hline CHEMBL3198801 & 688816 & 5.05 & 5.1502 & TRN \\
\hline CHEMBL1560057 & 688816 & 4.7 & 5.4498 & TRN \\
\hline CHEMBL1440303 & 688816 & 4.45 & 5.2602 & TRN \\
\hline CHEMBL1388817 & 688816 & 4.65 & 4.9614 & TRN \\
\hline CHEMBL1482964 & 688816 & 5.85 & 5.2231 & TRN \\
\hline CHEMBL1409913 & 688816 & 5.2 & 5.5788 & TST \\
\hline CHEMBL1562638 & 688816 & 6.05 & 5.2491 & TRN \\
\hline CHEMBL1489072 & 688816 & 6.3 & 5.199 & TRN \\
\hline CHEMBL1573961 & 688816 & 4.8 & 5.1212 & TRN \\
\hline CHEMBL1384063 & 688816 & 4.95 & 5.2391 & TRN \\
\hline CHEMBL3198412 & 688816 & 5.65 & 5.4833 & TST \\
\hline CHEMBL117813 & 688816 & 4.5 & 5.3201 & TRN \\
\hline
\end{tabular}




\begin{tabular}{|c|c|c|c|c|c|}
\hline \multicolumn{6}{|c|}{ Supplemental Table S2.txt } \\
\hline CHEMBL1420742 & 688816 & 4.6 & 5.1633 & TST & \\
\hline CHEMBL1412695 & 688816 & 5.05 & 5.3216 & TRN & \\
\hline CHEMBL1406911 & 688816 & 4.45 & 4.9977 & TRN & \\
\hline CHEMBL1409909 & 688816 & 4.9 & 5.3261 & TRN & \\
\hline CHEMBL1578356 & 688816 & 4.45 & 5.2254 & TST & \\
\hline CHEMBL1381962 & 688816 & 4.8 & 5.706 & TRN & \\
\hline CHEMBL 3198670 & 688816 & 4.95 & 5.3814 & TST & \\
\hline CHEMBL1403769 & 688816 & 4.95 & 5.0972 & TRN & \\
\hline CHEMBL1565650 & 688816 & 7.7496 & 5.5266 & TST & \\
\hline CHEMBL1494202 & 688816 & 4.9 & 5.1537 & TRN & \\
\hline CHEMBL1603944 & 688816 & 7.0 & 4.8948 & TST & \\
\hline CHEMBL1350897 & 688816 & 4.8 & 5.1416 & TRN & \\
\hline CHEMBL1367137 & 688816 & 8.1024 & 5.8017 & TRN & \\
\hline CHEMBL1541459 & 688816 & 4.85 & 4.9057 & TRN & \\
\hline CHEMBL1331905 & 688816 & 4.45 & 4.9574 & TRN & \\
\hline CHEMBL1483509 & 688816 & 7.699 & 5.6986 & TST & \\
\hline CHEMBL1505738 & 688816 & 4.8 & 5.1758 & TRN & \\
\hline CHEMBL1601318 & 688816 & 5.0 & 5.4 & TRN & \\
\hline CHEMBL1556650 & 688816 & 5.0 & 5.1225 & TRN & \\
\hline CHEMBL1597436 & 688816 & 4.9 & 4.94300 & 00000000005 & TST \\
\hline CHEMBL1377199 & 688816 & 4.75 & 5.4754 & TRN & \\
\hline CHEMBL1368073 & 688816 & 5.4 & 5.1638 & TRN & \\
\hline CHEMBL1509441 & 688816 & 4.9 & 5.3638 & TST & \\
\hline CHEMBL1551628 & 688816 & 5.05 & 4.9782 & TRN & \\
\hline CHEMBL1412970 & 688816 & 4.85 & 5.0792 & TRN & \\
\hline CHEMBL1417654 & 688816 & 4.95 & 5.5224 & TRN & \\
\hline CHEMBL1367260 & 688816 & 4.95 & 5.2895 & TRN & \\
\hline CHEMBL1554156 & 688816 & 4.9 & 5.2634 & TRN & \\
\hline CHEMBL1381595 & 688816 & 5.1 & 5.1648 & TRN & \\
\hline CHEMBL1599585 & 688816 & 4.95 & 5.3671 & TST & \\
\hline CHEMBL 3192271 & 688816 & 5.2 & 5.5319 & TRN & \\
\hline CHEMBL1432025 & 688816 & 6.5 & 5.3442 & TRN & \\
\hline CHEMBL1372377 & 688816 & 4.75 & 5.1022 & TRN & \\
\hline CHEMBL1442022 & 688816 & 5.05 & 5.2639 & TRN & \\
\hline CHEMBL1387923 & 688816 & 4.95 & 4.8576 & TRN & \\
\hline CHEMBL1410937 & 688816 & 4.65 & 5.0308 & TRN & \\
\hline CHEMBL1545435 & 688816 & 4.8 & 5.0689 & TRN & \\
\hline CHEMBL3192854 & 688816 & 8.3468 & 5.4372 & TRN & \\
\hline CHEMBL1423902 & 688816 & 4.95 & 5.2284 & TST & \\
\hline CHEMBL1301402 & 688816 & 4.9 & 5.0061 & TRN & \\
\hline CHEMBL1347577 & 688816 & 4.85 & 4.9782 & TRN & \\
\hline CHEMBL 1317820 & 688816 & 5.25 & 5.1851 & TRN & \\
\hline CHEMBL1299540 & 688816 & 5.2 & 5.3414 & TRN & \\
\hline CHEMBL1598973 & 688816 & 4.9 & 5.0033 & TRN & \\
\hline CHEMBL1446936 & 688816 & 4.9 & 4.8867 & TRN & \\
\hline CHEMBL 3214130 & 688816 & 5.25 & 4.9461 & TRN & \\
\hline CHEMBL3144956 & 688816 & 4.8 & 5.1634 & TST & \\
\hline CHEMBL1309365 & 688816 & 4.45 & 5.2459 & TRN & \\
\hline
\end{tabular}




\begin{tabular}{|c|c|c|c|c|c|}
\hline \multicolumn{6}{|c|}{ Supplemental Table S2.txt } \\
\hline CHEMBL1577362 & 688816 & 5.45 & 5.5977 & TRN & \\
\hline CHEMBL1544028 & 688816 & 5.0 & 5.6187 & TRN & \\
\hline CHEMBL1348091 & 688816 & 4.65 & 5.272 & TRN & \\
\hline CHEMBL1376256 & 688816 & 8.301 & 5.22 & TST & \\
\hline CHEMBL1402982 & 688816 & 4.45 & 5.3883 & TRN & \\
\hline CHEMBL1473167 & 688816 & 4.95 & 5.0145 & TRN & \\
\hline CHEMBL1447960 & 688816 & 6.95 & 5.8749 & TRN & \\
\hline CHEMBL1498537 & 688816 & 5.1 & 5.2998 & TRN & \\
\hline CHEMBL1370087 & 688816 & 5.1 & 5.8313 & TRN & \\
\hline CHEMBL99 & 688816 & 5.85 & 5.3767 & TST & \\
\hline CHEMBL1531042 & 688816 & 4.65 & 4.755 & TRN & \\
\hline CHEMBL1568343 & 688816 & 4.65 & 5.4137 & TRN & \\
\hline CHEMBL1336788 & 688816 & 5.15 & 5.25299 & 7999999999 & TRN \\
\hline CHEMBL1419856 & 688816 & 4.95 & 5.0991 & TRN & \\
\hline CHEMBL251055 & 688816 & 5.5 & 5.4189 & TST & \\
\hline CHEMBL1431624 & 688816 & 4.9 & 5.1508 & TRN & \\
\hline CHEMBL1302326 & 688816 & 4.45 & 4.9745 & TRN & \\
\hline CHEMBL1518032 & 688816 & 4.55 & 5.186 & TRN & \\
\hline CHEMBL1321578 & 688816 & 5.25 & 5.5088 & TRN & \\
\hline CHEMBL3211186 & 688816 & 5.5 & 5.3655 & TST & \\
\hline CHEMBL1437661 & 688816 & 4.95 & 5.1795 & TRN & \\
\hline CHEMBL1317039 & 688816 & 4.95 & 5.1225 & TRN & \\
\hline CHEMBL1389897 & 688816 & 5.5 & 5.2347 & TRN & \\
\hline CHEMBL1447930 & 688816 & 5.75 & 5.8315 & TRN & \\
\hline CHEMBL1382347 & 688816 & 5.7 & 4.8573 & TRN & \\
\hline CHEMBL1447542 & 688816 & 5.0 & 5.2346 & TRN & \\
\hline CHEMBL1609476 & 688816 & 4.95 & 5.012 & TRN & \\
\hline CHEMBL405317 & 688816 & 7.3497 & 5.0293 & TRN & \\
\hline CHEMBL1493461 & 688816 & 4.9 & 5.0254 & TRN & \\
\hline CHEMBL1364620 & 688816 & 5.0 & 5.0778 & TRN & \\
\hline CHEMBL1466932 & 688816 & 4.8 & 5.53799 & 9999999999 & TST \\
\hline CHEMBL1600474 & 688816 & 7.8013 & 5.8897 & TST & \\
\hline CHEMBL1471151 & 688816 & 4.45 & 5.5222 & TST & \\
\hline CHEMBL1334924 & 688816 & 4.95 & 5.2848 & TRN & \\
\hline CHEMBL1575863 & 688816 & 4.9 & 5.0886 & TRN & \\
\hline CHEMBL1365098 & 688816 & 4.95 & 5.3587 & TRN & \\
\hline CHEMBL1542908 & 688816 & 6.8 & 5.565 & TST & \\
\hline CHEMBL3189193 & 688816 & 4.6 & 5.2566 & TRN & \\
\hline CHEMBL1310739 & 688816 & 4.65 & 5.3905 & TRN & \\
\hline CHEMBL1303916 & 688816 & 5.4 & 4.9795 & TRN & \\
\hline CHEMBL1433144 & 688816 & 4.45 & 5.4436 & TST & \\
\hline CHEMBL1455356 & 688816 & 4.9 & 5.5732 & TRN & \\
\hline CHEMBL1509453 & 688816 & 4.9 & 4.9974 & TST & \\
\hline CHEMBL1531833 & 688816 & 7.15 & 5.2255 & TRN & \\
\hline CHEMBL1414610 & 688816 & 4.95 & 5.476 & TRN & \\
\hline CHEMBL1607877 & 688816 & 4.45 & 4.8712 & TRN & \\
\hline CHEMBL1366596 & 688816 & 4.95 & 5.4651 & TRN & \\
\hline CHEMBL1526437 & 688816 & 6.1 & 5.1552 & TRN & \\
\hline
\end{tabular}




\begin{tabular}{|c|c|c|c|c|}
\hline \multicolumn{5}{|c|}{ Supplemental Table S2.txt } \\
\hline CHEMBL1532686 & 688816 & 5.45 & 5.3999 & TRN \\
\hline CHEMBL1591740 & 688816 & 4.75 & 4.9437 & TRN \\
\hline CHEMBL1562581 & 688816 & 5.1 & 5.2867 & TRN \\
\hline CHEMBL1319610 & 688816 & 5.9 & 5.2839 & TRN \\
\hline CHEMBL336467 & 688816 & 4.5 & 4.9764 & TST \\
\hline CHEMBL1418519 & 688816 & 8.1487 & 5.3067 & TRN \\
\hline CHEMBL1348572 & 688816 & 4.95 & 5.2271 & TRN \\
\hline CHEMBL1446226 & 688816 & 5.0 & 5.3583 & TRN \\
\hline CHEMBL1560149 & 688816 & 6.8 & 5.7192 & TST \\
\hline CHEMBL1541805 & 688816 & 4.9 & 5.499 & TRN \\
\hline CHEMBL1464952 & 688816 & 5.15 & 5.3105 & TST \\
\hline CHEMBL1338018 & 688816 & 4.8 & 5.3142 & TRN \\
\hline CHEMBL1349436 & 688816 & 4.45 & 5.3714 & TRN \\
\hline CHEMBL1506855 & 688816 & 4.9 & 5.3577 & TRN \\
\hline CHEMBL1257106 & 688816 & 4.55 & 6.0237 & TST \\
\hline CHEMBL1352420 & 688816 & 4.45 & 5.5367 & TRN \\
\hline CHEMBL1409258 & 688816 & 5.25 & 4.9812 & TRN \\
\hline CHEMBL1271076 & 688816 & 4.95 & 5.2356 & TRN \\
\hline CHEMBL1322190 & 688816 & 4.85 & 5.1527 & TRN \\
\hline CHEMBL1312153 & 688816 & 4.65 & 5.2581 & TRN \\
\hline CHEMBL1313911 & 688816 & 4.9 & 5.4375 & TRN \\
\hline CHEMBL1390000 & 688816 & 4.95 & 5.1401 & TRN \\
\hline CHEMBL 377583 & 688816 & 5.9 & 5.1241 & TRN \\
\hline CHEMBL1469313 & 688816 & 4.45 & 5.484 & TRN \\
\hline CHEMBL1565419 & 688816 & 4.85 & 5.6099 & TRN \\
\hline CHEMBL1556240 & 688816 & 5.5 & 5.0651 & TRN \\
\hline CHEMBL1542203 & 688816 & 4.85 & 5.3022 & TRN \\
\hline CHEMBL1564220 & 688816 & 4.85 & 5.2058 & TRN \\
\hline CHEMBL1447517 & 688816 & 4.9 & 5.0563 & TRN \\
\hline CHEMBL1379003 & 688816 & 4.7 & 5.1987 & TRN \\
\hline CHEMBL1388404 & 688816 & 5.0 & 4.9652 & TRN \\
\hline CHEMBL1376660 & 688816 & 4.5 & 5.269 & TRN \\
\hline CHEMBL3195220 & 688816 & 4.45 & 5.2421 & TRN \\
\hline CHEMBL3197753 & 688816 & 5.05 & 5.1312 & TRN \\
\hline CHEMBL1463693 & 688816 & 4.65 & 5.3403 & TRN \\
\hline CHEMBL1437944 & 688816 & 6.6499 & 5.4566 & TRN \\
\hline CHEMBL1486525 & 688816 & 4.65 & 5.6015 & TST \\
\hline CHEMBL1324108 & 688816 & 4.45 & 5.37 & TST \\
\hline CHEMBL1593686 & 688816 & 5.0 & 4.7069 & TRN \\
\hline CHEMBL1510862 & 688816 & 5.95 & 5.9024 & TRN \\
\hline CHEMBL1349355 & 688816 & 4.9 & 5.0445 & TST \\
\hline CHEMBL1323735 & 688816 & 4.45 & 5.2288 & TRN \\
\hline CHEMBL1337826 & 688816 & 4.95 & $5.3610 e$ & 0000000001 \\
\hline CHEMBL1417716 & 688816 & 4.9 & 5.3974 & TST \\
\hline CHEMBL1508501 & 688816 & 4.8 & 5.5877 & TRN \\
\hline CHEMBL1431800 & 688816 & 4.95 & 5.6017 & TRN \\
\hline CHEMBL1500981 & 688816 & 4.95 & 4.9906 & TRN \\
\hline CHEMBL1389755 & 688816 & 4.95 & 5.1151 & TST \\
\hline
\end{tabular}




\begin{tabular}{|c|c|c|c|c|c|}
\hline & & & & & \\
\hline CHEMBL1591040 & 688816 & 5.1 & 5.2799 & TST & \\
\hline CHEMBL1499803 & 688816 & 4.8 & 5.1088 & TRN & \\
\hline CHEMBL3193595 & 688816 & 4.75 & 5.2979 & TST & \\
\hline CHEMBL1546754 & 688816 & 4.8 & 5.0084 & TST & \\
\hline CHEMBL1506610 & 688816 & 4.7 & 5.1139 & TST & \\
\hline CHEMBL3196282 & 688816 & 4.45 & 5.0169 & TRN & \\
\hline CHEMBL1503806 & 688816 & 7.15 & 5.2999 & TRN & \\
\hline CHEMBL1418559 & 688816 & 4.9 & 5.0815 & TRN & \\
\hline CHEMBL1338750 & 688816 & 4.95 & 5.3495 & TRN & \\
\hline CHEMBL1415249 & 688816 & 4.45 & 5.2728 & TST & \\
\hline CHEMBL1347133 & 688816 & 4.45 & 5.13399 & 99999999995 & TRN \\
\hline CHEMBL1491656 & 688816 & 3.45 & 5.5589 & TRN & \\
\hline CHEMBL1361450 & 688816 & 5.55 & 5.5746 & TST & \\
\hline CHEMBL1430504 & 688816 & 4.7 & 5.1527 & TRN & \\
\hline CHEMBL1445531 & 688816 & 4.65 & 4.9645 & TRN & \\
\hline CHEMBL1332080 & 688816 & 7.4001 & 5.7256 & TST & \\
\hline CHEMBL1429700 & 688816 & 5.0 & 5.478 & TRN & \\
\hline CHEMBL1449788 & 688816 & 5.25 & 5.7803 & TRN & \\
\hline CHEMBL1550664 & 688816 & 6.45 & 5.2767 & TRN & \\
\hline CHEMBL1256737 & 688816 & 6.0 & 5.5094 & TST & \\
\hline CHEMBL3195884 & 688816 & 5.2 & 5.7724 & TST & \\
\hline CHEMBL1357996 & 688816 & 4.9 & 4.9575 & TRN & \\
\hline CHEMBL1464080 & 688816 & 4.45 & 5.1394 & TRN & \\
\hline CHEMBL1536544 & 688816 & 4.45 & 5.1052 & TST & \\
\hline CHEMBL1380651 & 688816 & 4.95 & 5.0174 & TRN & \\
\hline CHEMBL1485313 & 688816 & 4.85 & 5.1098 & TRN & \\
\hline CHEMBL1384904 & 688816 & 5.3 & 4.8022 & TRN & \\
\hline CHEMBL1333049 & 688816 & 5.2 & 5.5093 & TRN & \\
\hline CHEMBL1307168 & 688816 & 4.7 & 5.3994 & TRN & \\
\hline CHEMBL1387744 & 688816 & 4.9 & 5.0916 & TST & \\
\hline CHEMBL3197471 & 688816 & 4.9 & 5.0557 & TRN & \\
\hline CHEMBL1415491 & 688816 & 6.45 & 5.2421 & TRN & \\
\hline CHEMBL3208099 & 688816 & 7.5003 & 5.5359 & TRN & \\
\hline CHEMBL1387617 & 688816 & 4.85 & 5.0968 & TRN & \\
\hline CHEMBL1351896 & 688816 & 7.5003 & 5.3033 & TRN & \\
\hline CHEMBL1503947 & 688816 & 4.8 & 5.4808 & TRN & \\
\hline CHEMBL1391330 & 688816 & 4.95 & 5.4709 & TRN & \\
\hline CHEMBL1534148 & 688816 & 5.25 & 5.3875 & TST & \\
\hline CHEMBL1485165 & 688816 & 4.75 & 5.6995 & TST & \\
\hline CHEMBL3198097 & 688816 & 4.45 & 5.2259 & TRN & \\
\hline CHEMBL1335662 & 688816 & 7.5003 & 5.6685 & TST & \\
\hline CHEMBL1332307 & 688816 & 8.0506 & 4.8516 & TST & \\
\hline CHEMBL1448002 & 688816 & 5.45 & 5.4352 & TRN & \\
\hline CHEMBL1517985 & 688816 & 4.45 & 5.5387 & TRN & \\
\hline CHEMBL1500686 & 688816 & 4.85 & 4.8424 & TRN & \\
\hline CHEMBL1351535 & 688816 & 4.9 & 5.1346 & TRN & \\
\hline CHEMBL1401722 & 688816 & 4.75 & 5.36600 & 00000000005 & TRN \\
\hline CHEMBL1409356 & 688816 & 5.55 & 5.2844 & TRN & \\
\hline & & & & 24507 & \\
\hline
\end{tabular}




\begin{tabular}{|c|c|c|c|c|c|}
\hline \multicolumn{6}{|c|}{ Supplemental Table S2.txt } \\
\hline CHEMBL1344701 & 688816 & 4.45 & 5.1648 & TST & \\
\hline CHEMBL1438962 & 688816 & 4.45 & 5.0769 & TST & \\
\hline CHEMBL1392768 & 688816 & 8.4949 & 5.371 & TRN & \\
\hline CHEMBL1505435 & 688816 & 5.0 & 5.0781 & TRN & \\
\hline CHEMBL1543986 & 688816 & 4.9 & 5.3701 & TRN & \\
\hline CHEMBL1576820 & 688816 & 4.75 & 5.0936 & TRN & \\
\hline CHEMBL1407512 & 688816 & 4.75 & 5.2764 & TRN & \\
\hline CHEMBL1542283 & 688816 & 7.699 & 5.6409 & TRN & \\
\hline CHEMBL1308593 & 688816 & 4.9 & 5.1285 & TRN & \\
\hline CHEMBL1324902 & 688816 & 5.25 & 5.718 & TRN & \\
\hline CHEMBL1371851 & 688816 & 4.7 & 5.2265 & TRN & \\
\hline CHEMBL1558021 & 688816 & 4.55 & 5.0887 & TRN & \\
\hline CHEMBL1499100 & 688816 & 4.85 & 5.2725 & TRN & \\
\hline CHEMBL1482713 & 688816 & 4.9 & 5.4806 & TRN & \\
\hline CHEMBL1412303 & 688816 & 5.5 & 5.3759 & TRN & \\
\hline CHEMBL1461661 & 688816 & 4.75 & 5.2661 & TST & \\
\hline CHEMBL1499811 & 688816 & 4.8 & 5.0956 & TRN & \\
\hline CHEMBL1348658 & 688816 & 5.85 & 5.4553 & TRN & \\
\hline CHEMBL1416307 & 688816 & 4.95 & 5.5803 & TST & \\
\hline CHEMBL1347458 & 688816 & 5.05 & 5.2207 & TRN & \\
\hline CHEMBL1482668 & 688816 & 4.45 & 5.0274 & TST & \\
\hline CHEMBL1597128 & 688816 & 5.5 & 5.1751 & TRN & \\
\hline CHEMBL3212944 & 688816 & 4.95 & 5.2963 & TST & \\
\hline CHEMBL1988708 & 688816 & 4.6 & 5.3455 & TRN & \\
\hline CHEMBL1463543 & 688816 & 4.95 & 4.9939 & TRN & \\
\hline CHEMBL1609104 & 688816 & 5.8 & 5.15799 & 99999999995 & TST \\
\hline CHEMBL1559501 & 688816 & 4.45 & 5.5806 & TST & \\
\hline CHEMBL1349100 & 688816 & 4.7 & 5.2601 & TST & \\
\hline CHEMBL1323902 & 688816 & 4.75 & 5.4285 & TRN & \\
\hline CHEMBL1437886 & 688816 & 8.5528 & 5.1372 & TST & \\
\hline CHEMBL1501402 & 688816 & 4.65 & 5.2907 & TRN & \\
\hline CHEMBL1313447 & 688816 & 4.7 & 5.0466 & TRN & \\
\hline CHEMBL1530118 & 688816 & 5.5 & 5.6245 & TRN & \\
\hline CHEMBL1550841 & 688816 & 4.95 & 5.2706 & TRN & \\
\hline CHEMBL1484105 & 688816 & 4.75 & 5.1401 & TRN & \\
\hline CHEMBL1400056 & 688816 & 4.85 & 4.9078 & TRN & \\
\hline CHEMBL1426412 & 688816 & 4.95 & 5.2366 & TRN & \\
\hline CHEMBL1378654 & 688816 & 4.85 & 4.5133 & TRN & \\
\hline CHEMBL1324899 & 688816 & 5.4 & 5.0094 & TRN & \\
\hline CHEMBL1437827 & 688816 & 5.0 & 5.7614 & TST & \\
\hline CHEMBL1322331 & 688816 & 5.0 & 5.2383 & TRN & \\
\hline CHEMBL578905 & 688816 & 5.0 & 5.4191 & TRN & \\
\hline CHEMBL1334161 & 688816 & 6.0 & 5.0339 & TRN & \\
\hline CHEMBL1372852 & 688816 & 4.5 & 5.584 & TRN & \\
\hline CHEMBL1356114 & 688816 & 4.45 & 5.1928 & TRN & \\
\hline CHEMBL1335718 & 688816 & 4.5 & 4.8348 & TRN & \\
\hline CHEMBL1308947 & 688816 & 4.95 & 4.9959 & TRN & \\
\hline CHEMBL3210131 & 688816 & 5.5 & 5.322 & TRN & \\
\hline
\end{tabular}




\begin{tabular}{|c|c|c|c|c|c|}
\hline \multicolumn{6}{|c|}{ Supplemental Table S2.txt } \\
\hline CHEMBL1587456 & 688816 & 4.45 & 5.0596 & TRN & \\
\hline CHEMBL1452379 & 688816 & 4.8 & 4.962 & TRN & \\
\hline CHEMBL3207376 & 688816 & 4.45 & 5.2302 & TRN & \\
\hline CHEMBL1486651 & 688816 & 4.95 & 5.2763 & TRN & \\
\hline CHEMBL1364557 & 688816 & 8.4949 & 5.439 & TRN & \\
\hline CHEMBL1411438 & 688816 & 4.45 & 5.048 & TRN & \\
\hline CHEMBL1544553 & 688816 & 5.55 & 5.4724 & TST & \\
\hline CHEMBL1577665 & 688816 & 5.0 & 5.5577 & TRN & \\
\hline CHEMBL1299263 & 688816 & 5.6 & 4.928 & TST & \\
\hline CHEMBL1326944 & 688816 & 4.9 & 5.0355 & TRN & \\
\hline CHEMBL1507729 & 688816 & 4.95 & 5.2871 & TRN & \\
\hline CHEMBL448602 & 688816 & 5.7 & 5.5041 & TST & \\
\hline CHEMBL1322434 & 688816 & 4.75 & 5.1426 & TST & \\
\hline CHEMBL1486934 & 688816 & 4.6 & 5.2851 & TST & \\
\hline CHEMBL1454747 & 688816 & 4.95 & 5.082 & TRN & \\
\hline CHEMBL1334852 & 688816 & 4.8 & 5.2802 & TRN & \\
\hline CHEMBL1345242 & 688816 & 4.65 & 5.3795 & TST & \\
\hline CHEMBL1434823 & 688816 & 4.45 & 5.5106 & TRN & \\
\hline CHEMBL1486832 & 688816 & 4.7 & 5.4123 & TRN & \\
\hline CHEMBL1450527 & 688816 & 5.45 & 5.5403 & TRN & \\
\hline CHEMBL1416847 & 688816 & 4.85 & 5.33700 & 0000000001 & TRN \\
\hline CHEMBL1542793 & 688816 & 4.85 & 5.16100 & 00000000005 & TRN \\
\hline CHEMBL1603941 & 688816 & 5.3 & 5.3732 & TRN & \\
\hline CHEMBL1421111 & 688816 & 4.45 & 5.9718 & TRN & \\
\hline CHEMBL1224512 & 688816 & 6.1 & 5.4459 & TRN & \\
\hline CHEMBL1463705 & 688816 & 8.2007 & 5.2607 & TRN & \\
\hline CHEMBL1321811 & 688816 & 4.6 & 5.06800 & 00000000005 & TST \\
\hline CHEMBL1450354 & 688816 & 4.65 & 5.1157 & TRN & \\
\hline CHEMBL1491393 & 688816 & 4.95 & 5.2317 & TRN & \\
\hline CHEMBL1585626 & 688816 & 6.7501 & 4.96899 & 9999999999 & TRN \\
\hline CHEMBL1483254 & 688816 & 7.6003 & 5.5802 & TRN & \\
\hline CHEMBL1424929 & 688816 & 5.85 & 5.3939 & TST & \\
\hline CHEMBL1594747 & 688816 & 4.5 & 4.9575 & TRN & \\
\hline CHEMBL1502862 & 688816 & 4.75 & 5.0187 & TRN & \\
\hline CHEMBL1520130 & 688816 & 4.75 & 5.5346 & TRN & \\
\hline CHEMBL1456428 & 688816 & 4.45 & 5.0092 & TRN & \\
\hline CHEMBL1436644 & 688816 & 4.95 & 5.1007 & TRN & \\
\hline CHEMBL1346935 & 688816 & 4.9 & 5.1648 & TST & \\
\hline CHEMBL1323180 & 688816 & 4.8 & 5.5348 & TRN & \\
\hline CHEMBL1527184 & 688816 & 5.0 & 5.3648 & TRN & \\
\hline CHEMBL1456197 & 688816 & 5.0 & 5.1917 & TST & \\
\hline CHEMBL153036 & 688816 & 5.75 & 5.3704 & TST & \\
\hline CHEMBL1572560 & 688816 & 7.8508 & 5.0071 & TRN & \\
\hline CHEMBL1353252 & 688816 & 4.9 & 4.8383 & TRN & \\
\hline CHEMBL1312178 & 688816 & 4.7 & 5.0301 & TRN & \\
\hline CHEMBL1483955 & 688816 & 6.6 & 5.4752 & TRN & \\
\hline CHEMBL1474597 & 688816 & 4.7 & 4.9559 & TRN & \\
\hline CHEMBL1593589 & 688816 & 5.3 & 5.2023 & TRN & \\
\hline
\end{tabular}




\begin{tabular}{|c|c|c|c|c|}
\hline \multicolumn{5}{|c|}{ Supplemental Table S2.txt } \\
\hline CHEMBL1305169 & 688816 & 5.4 & 5.0491 & TRN \\
\hline CHEMBL1449083 & 688816 & 5.25 & 5.0232 & TRN \\
\hline CHEMBL1503208 & 688816 & 4.65 & 5.4789 & TST \\
\hline CHEMBL1580852 & 688816 & 4.45 & 4.5808 & TST \\
\hline CHEMBL1402051 & 688816 & 4.95 & 5.1294 & TRN \\
\hline CHEMBL1525751 & 688816 & 4.95 & 5.2356 & TRN \\
\hline CHEMBL 3211650 & 688816 & 6.2 & 5.2328 & TRN \\
\hline CHEMBL3198090 & 688816 & 4.8 & 5.3083 & TRN \\
\hline CHEMBL1299962 & 688816 & 4.85 & 4.9344 & TRN \\
\hline CHEMBL1504394 & 688816 & 5.1 & 5.4355 & TRN \\
\hline CHEMBL1448592 & 688816 & 5.3 & 5.376 & TST \\
\hline CHEMBL1410519 & 688816 & 5.9 & 5.2695 & TRN \\
\hline CHEMBL1530807 & 688816 & 4.6 & 5.2487 & TST \\
\hline CHEMBL1356670 & 688816 & 4.65 & 5.3288 & TST \\
\hline CHEMBL1510669 & 688816 & 4.9 & 5.2401 & TRN \\
\hline CHEMBL1334928 & 688816 & 4.45 & 4.9931 & TRN \\
\hline CHEMBL1607862 & 688816 & 4.85 & 4.999 & TRN \\
\hline CHEMBL1345652 & 688816 & 6.1 & 5.5103 & TRN \\
\hline CHEMBL1460832 & 688816 & 4.7 & 5.4325 & TST \\
\hline CHEMBL1445418 & 688816 & 4.45 & 4.9701 & TRN \\
\hline CHEMBL1400927 & 688816 & 6.0 & 5.1993 & TRN \\
\hline CHEMBL1599671 & 688816 & 4.95 & 5.4453 & TST \\
\hline CHEMBL1577110 & 688816 & 4.75 & 5.1399 & TRN \\
\hline CHEMBL1366680 & 688816 & 4.45 & 5.1629 & TST \\
\hline CHEMBL1518446 & 688816 & 5.2 & 5.4481 & TRN \\
\hline CHEMBL1340089 & 688816 & 4.45 & 5.0718 & TRN \\
\hline CHEMBL1313246 & 688816 & 4.95 & 5.5031 & TST \\
\hline CHEMBL1609296 & 688816 & 4.85 & 5.2304 & TRN \\
\hline CHEMBL1567679 & 688816 & 5.45 & 5.4821 & TRN \\
\hline CHEMBL 2095095 & 688816 & 5.3 & 5.2146 & TRN \\
\hline CHEMBL1546383 & 688816 & 5.45 & 5.1262 & TRN \\
\hline CHEMBL1383798 & 688816 & 7.5003 & 5.5381 & TRN \\
\hline CHEMBL1505153 & 688816 & 5.05 & 4.7318 & TRN \\
\hline CHEMBL1323424 & 688816 & 4.85 & 4.812 & TRN \\
\hline CHEMBL1423234 & 688816 & 8.3468 & 5.2401 & TRN \\
\hline CHEMBL1607529 & 688816 & 4.45 & 5.2742 & TRN \\
\hline CHEMBL1402048 & 688816 & 4.85 & 5.1728 & TRN \\
\hline CHEMBL514612 & 688816 & 5.05 & 4.938 & TRN \\
\hline CHEMBL3210692 & 688816 & 4.8 & 5.3163 & TST \\
\hline CHEMBL1415897 & 688816 & 4.45 & 5.3864 & TST \\
\hline CHEMBL1383093 & 688816 & 8.4949 & 5.725 & TST \\
\hline CHEMBL3194613 & 688816 & 4.95 & 5.13899 & 9999999999 \\
\hline CHEMBL1403635 & 688816 & 5.15 & 5.4674 & TRN \\
\hline CHEMBL3196163 & 688816 & 5.0 & 5.1909 & TRN \\
\hline CHEMBL1526232 & 688816 & 4.55 & 5.2987 & TRN \\
\hline CHEMBL1432376 & 688816 & 4.95 & 5.2452 & TRN \\
\hline CHEMBL1369749 & 688816 & 4.5 & 5.0246 & TRN \\
\hline CHEMBL1495474 & 688816 & 4.85 & 4.7851 & TRN \\
\hline
\end{tabular}

TRN 


\begin{tabular}{|c|c|c|c|c|c|}
\hline \multicolumn{6}{|c|}{ splemental } \\
\hline CHEMBL1510485 & 688816 & 5.4 & 5.8887 & TST & \\
\hline CHEMBL1422645 & 688816 & 4.45 & 5.4792 & TST & \\
\hline CHEMBL1544039 & 688816 & 5.45 & 5.5606 & TRN & \\
\hline CHEMBL1584708 & 688816 & 4.9 & 5.388 & TST & \\
\hline CHEMBL1323114 & 688816 & 5.05 & 5.4574 & TRN & \\
\hline CHEMBL1422740 & 688816 & 5.0 & 5.1067 & TRN & \\
\hline CHEMBL1563581 & 688816 & 5.5 & 5.1421 & TRN & \\
\hline CHEMBL1305131 & 688816 & 4.95 & 5.4472 & TST & \\
\hline CHEMBL1573494 & 688816 & 7.6498 & 5.6207 & TST & \\
\hline CHEMBL1502214 & 688816 & 4.8 & 5.2342 & TRN & \\
\hline CHEMBL1300701 & 688816 & 4.85 & 5.0391 & TRN & \\
\hline CHEMBL1325786 & 688816 & 4.95 & 5.2956 & TRN & \\
\hline CHEMBL1579104 & 688816 & 6.3 & 5.8218 & TST & \\
\hline CHEMBL1499978 & 688816 & 5.05 & 5.2545 & TRN & \\
\hline CHEMBL1549840 & 688816 & 4.85 & 5.4997 & TST & \\
\hline CHEMBL1352250 & 688816 & 5.65 & 6.1201 & TRN & \\
\hline CHEMBL1424945 & 688816 & 5.8 & 5.3544 & TRN & \\
\hline CHEMBL1541948 & 688816 & 5.0 & 5.0909 & TRN & \\
\hline CHEMBL1603047 & 688816 & 6.35 & 5.082 & TRN & \\
\hline CHEMBL1366257 & 688816 & 5.4 & 5.5747 & TRN & \\
\hline CHEMBL1595696 & 688816 & 4.9 & 5.1391 & TRN & \\
\hline CHEMBL1522773 & 688816 & 4.7 & 5.3867 & TRN & \\
\hline CHEMBL569750 & 688816 & 5.35 & 5.0854 & TST & \\
\hline CHEMBL1586270 & 688816 & 5.0 & 5.6073 & TST & \\
\hline CHEMBL1329798 & 688816 & 7.4001 & 5.8812 & TRN & \\
\hline CHEMBL1580362 & 688816 & 4.95 & 5.3104 & TRN & \\
\hline CHEMBL1604264 & 688816 & 4.9 & 5.0501 & TRN & \\
\hline CHEMBL1369061 & 688816 & 4.45 & 5.1611 & TRN & \\
\hline CHEMBL1533919 & 688816 & 5.15 & 5.3692 & TRN & \\
\hline CHEMBL1479139 & 688816 & 4.55 & 5.6632 & TST & \\
\hline CHEMBL1504592 & 688816 & 4.85 & 5.3854 & TST & \\
\hline CHEMBL1335485 & 688816 & 8.1487 & 5.3082 & TRN & \\
\hline CHEMBL1348807 & 688816 & 5.15 & 4.8022 & TRN & \\
\hline CHEMBL1459278 & 688816 & 5.15 & 5.375 & TRN & \\
\hline CHEMBL 2003149 & 688816 & 4.9 & 5.271 & TRN & \\
\hline CHEMBL1388083 & 688816 & 4.75 & 5.1789 & TST & \\
\hline CHEMBL1355803 & 688816 & 5.4 & 5.0118 & TRN & \\
\hline CHEMBL1462130 & 688816 & 4.75 & 5.3219 & TST & \\
\hline CHEMBL1467256 & 688816 & 4.9 & 4.8442 & TST & \\
\hline CHEMBL1570431 & 688816 & 4.95 & 5.2631 & TRN & \\
\hline CHEMBL1393727 & 688816 & 5.6 & 5.277 & TRN & \\
\hline CHEMBL1423969 & 688816 & 8.301 & 5.46899 & 9999999999 & TRN \\
\hline CHEMBL1516625 & 688816 & 5.05 & 5.4635 & TRN & \\
\hline CHEMBL2358182 & 688816 & 4.65 & 5.0461 & TRN & \\
\hline CHEMBL1353834 & 688816 & 5.0 & 5.2966 & TRN & \\
\hline CHEMBL 3194474 & 688816 & 5.5 & 5.3872 & TRN & \\
\hline CHEMBL1475879 & 688816 & 8.0 & 5.4064 & TRN & \\
\hline CHEMBL1541182 & 688816 & 5.55 & 5.4709 & TRN & \\
\hline
\end{tabular}




\begin{tabular}{|c|c|c|c|c|c|}
\hline \multicolumn{6}{|c|}{ Supplemental Table S2.txt } \\
\hline CHEMBL1402832 & 688816 & 5.0 & 4.9423 & TRN & \\
\hline CHEMBL1353089 & 688816 & 5.25 & 5.0476 & TST & \\
\hline CHEMBL1532656 & 688816 & 5.25 & 5.0991 & TRN & \\
\hline CHEMBL1998334 & 688816 & 4.8 & 5.2633 & TRN & \\
\hline CHEMBL1605179 & 688816 & 4.75 & 5.4112 & TRN & \\
\hline CHEMBL1432308 & 688816 & 4.9 & 5.0513 & TRN & \\
\hline CHEMBL1545920 & 688816 & 4.65 & \multicolumn{2}{|c|}{5.138999999999999} & TRN \\
\hline CHEMBL1346418 & 688816 & 4.8 & 5.2485 & TRN & \\
\hline CHEMBL1427304 & 688816 & 4.65 & 5.3781 & TRN & \\
\hline CHEMBL1474284 & 688816 & 4.7 & 5.112 & TRN & \\
\hline CHEMBL1566226 & 688816 & 7.9508 & 5.7843 & TRN & \\
\hline CHEMBL1326455 & 688816 & 4.75 & 5.1248 & TRN & \\
\hline CHEMBL1510982 & 688816 & 4.9 & 4.992 & TRN & \\
\hline CHEMBL1550081 & 688816 & 4.6 & 5.0848 & TST & \\
\hline CHEMBL1460367 & 688816 & 4.65 & 5.3373 & TRN & \\
\hline CHEMBL1478729 & 688816 & 4.65 & 5.5558 & TST & \\
\hline CHEMBL1576075 & 688816 & 5.0 & 5.1963 & TRN & \\
\hline CHEMBL1611356 & 688816 & 4.75 & 5.1412 & TST & \\
\hline CHEMBL1416984 & 688816 & 5.6 & \multicolumn{2}{|c|}{5.582999999999999} & TRN \\
\hline CHEMBL1430941 & 688816 & 4.6 & 5.0427 & TRN & \\
\hline CHEMBL1308744 & 688816 & 4.9 & 5.3699 & TRN & \\
\hline CHEMBL1415524 & 688816 & 4.45 & 5.1611 & TST & \\
\hline CHEMBL1301743 & 688816 & 5.0 & 5.1241 & TRN & \\
\hline CHEMBL1323139 & 688816 & 5.15 & 5.1206 & TST & \\
\hline CHEMBL1345630 & 688816 & 4.8 & 5.1054 & TST & \\
\hline CHEMBL1312502 & 688816 & 4.85 & 4.8685 & TRN & \\
\hline CHEMBL1434205 & 688816 & 5.0 & 5.1817 & TRN & \\
\hline CHEMBL1414932 & 688816 & 5.0 & 5.1543 & TRN & \\
\hline CHEMBL1480113 & 688816 & 5.0 & 5.4466 & TST & \\
\hline CHEMBL1449309 & 688816 & 4.75 & 5.5333 & TRN & \\
\hline CHEMBL1324508 & 688816 & 4.9 & 5.1957 & TST & \\
\hline CHEMBL1493402 & 688816 & 4.95 & 5.1933 & TRN & \\
\hline CHEMBL3208533 & 688816 & 4.9 & 5.3114 & TRN & \\
\hline CHEMBL1372292 & 688816 & 6.15 & 5.6105 & TRN & \\
\hline CHEMBL1337986 & 688816 & 5.0 & 5.0565 & TRN & \\
\hline CHEMBL1443091 & 688816 & 4.45 & 5.1913 & TRN & \\
\hline CHEMBL1386783 & 688816 & 4.45 & 5.1692 & TRN & \\
\hline CHEMBL1470674 & 688816 & 5.0 & 5.0463 & TRN & \\
\hline CHEMBL1433289 & 688816 & 4.45 & 5.5542 & TST & \\
\hline CHEMBL1567553 & 688816 & 5.0 & 4.9136 & TST & \\
\hline CHEMBL1588602 & 688816 & 8.3468 & 5.3927 & TST & \\
\hline CHEMBL3197450 & 688816 & 4.45 & 5.135 & TRN & \\
\hline CHEMBL1498241 & 688816 & 4.95 & 5.155 & TRN & \\
\hline CHEMBL1364294 & 688816 & 4.45 & 4.8582 & TRN & \\
\hline CHEMBL1505683 & 688816 & 5.0 & 5.4292 & TRN & \\
\hline CHEMBL1519003 & 688816 & 4.45 & 5.2821 & TRN & \\
\hline CHEMBL1466361 & 688816 & 5.15 & 5.49 & TRN & \\
\hline CHEMBL1348102 & 688816 & 4.45 & 5.0098 & TST & \\
\hline
\end{tabular}




\begin{tabular}{|c|c|c|c|c|c|}
\hline \multicolumn{6}{|c|}{ Supplemental Table S2.txt } \\
\hline CHEMBL1331885 & 688816 & 5.4 & 5.3752 & TST & \\
\hline CHEMBL3199295 & 688816 & 4.85 & 5.3571 & TRN & \\
\hline CHEMBL1460901 & 688816 & 4.45 & 5.2641 & TRN & \\
\hline CHEMBL3198296 & 688816 & 4.85 & 5.2388 & TRN & \\
\hline CHEMBL1535241 & 688816 & 4.65 & 5.2622 & TST & \\
\hline CHEMBL1465638 & 688816 & 4.8 & 5.3906 & TST & \\
\hline CHEMBL3211781 & 688816 & 5.3 & 5.2789 & TRN & \\
\hline CHEMBL1457947 & 688816 & 5.25 & 5.4731 & TST & \\
\hline CHEMBL1382517 & 688816 & 5.6 & 5.0482 & TST & \\
\hline CHEMBL1462847 & 688816 & 4.85 & 5.2069 & TRN & \\
\hline CHEMBL1443124 & 688816 & 5.45 & 5.1571 & TRN & \\
\hline CHEMBL1482853 & 688816 & 8.2518 & 5.4551 & TRN & \\
\hline CHEMBL1442335 & 688816 & 6.7001 & 5.3414 & TST & \\
\hline CHEMBL1596271 & 688816 & 5.35 & 5.1577 & TST & \\
\hline CHEMBL1401880 & 688816 & 5.4 & 5.1013 & TRN & \\
\hline CHEMBL1532343 & 688816 & 6.7501 & 5.3962 & TRN & \\
\hline CHEMBL1432389 & 688816 & 4.75 & 5.4893 & TRN & \\
\hline CHEMBL1371031 & 688816 & 6.1 & 6.022 & TRN & \\
\hline CHEMBL1304777 & 688816 & 8.4949 & 5.6129 & TRN & \\
\hline CHEMBL1407507 & 688816 & 5.0 & 5.1527 & TRN & \\
\hline CHEMBL1322632 & 688816 & 7.1002 & 5.9668 & TRN & \\
\hline CHEMBL1308686 & 688816 & 5.15 & 5.0225 & TST & \\
\hline CHEMBL1486352 & 688816 & 4.75 & 5.2048 & TRN & \\
\hline CHEMBL1334260 & 688816 & 4.45 & 5.4538 & TRN & \\
\hline CHEMBL1492757 & 688816 & 6.95 & 5.5973 & TRN & \\
\hline CHEMBL1586397 & 688816 & 5.3 & 5.6416 & TRN & \\
\hline CHEMBL1497557 & 688816 & 5.4 & 5.2337 & TRN & \\
\hline CHEMBL1353619 & 688816 & 4.85 & 5.0914 & TRN & \\
\hline CHEMBL1558961 & 688816 & 4.9 & 4.9882 & TRN & \\
\hline CHEMBL1499305 & 688816 & 5.0 & 5.2208 & TRN & \\
\hline CHEMBL1387787 & 688816 & 4.9 & 5.0623 & TRN & \\
\hline CHEMBL1477564 & 688816 & 8.0506 & 5.0726 & TRN & \\
\hline CHEMBL1537379 & 688816 & 5.0 & 5.1477 & TRN & \\
\hline CHEMBL3198964 & 688816 & 6.1 & $5.2870 e$ & 0000000001 & TRN \\
\hline CHEMBL3196067 & 688816 & 6.1 & 5.399 & TRN & \\
\hline CHEMBL1510738 & 688816 & 5.0 & 5.3052 & TRN & \\
\hline CHEMBL1395064 & 688816 & 8.301 & 4.947 & TRN & \\
\hline CHEMBL1540150 & 688816 & 4.75 & 5.1313 & TRN & \\
\hline CHEMBL287045 & 688816 & 4.85 & 5.8306 & TRN & \\
\hline CHEMBL1603787 & 688816 & 4.45 & 4.8527 & TST & \\
\hline CHEMBL1416333 & 688816 & 4.95 & 5.0476 & TRN & \\
\hline CHEMBL1371513 & 688816 & 4.65 & 5.5408 & TRN & \\
\hline CHEMBL1533198 & 688816 & 4.95 & 5.2638 & TRN & \\
\hline CHEMBL1557234 & 688816 & 4.95 & 5.0543 & TRN & \\
\hline CHEMBL73711 & 688816 & 4.6 & 5.3985 & TST & \\
\hline CHEMBL3194008 & 688816 & 5.8 & 5.4199 & TRN & \\
\hline CHEMBL1506771 & 688816 & 4.85 & 5.187 & TRN & \\
\hline CHEMBL1352828 & 688816 & 4.95 & 5.2247 & TST & \\
\hline
\end{tabular}




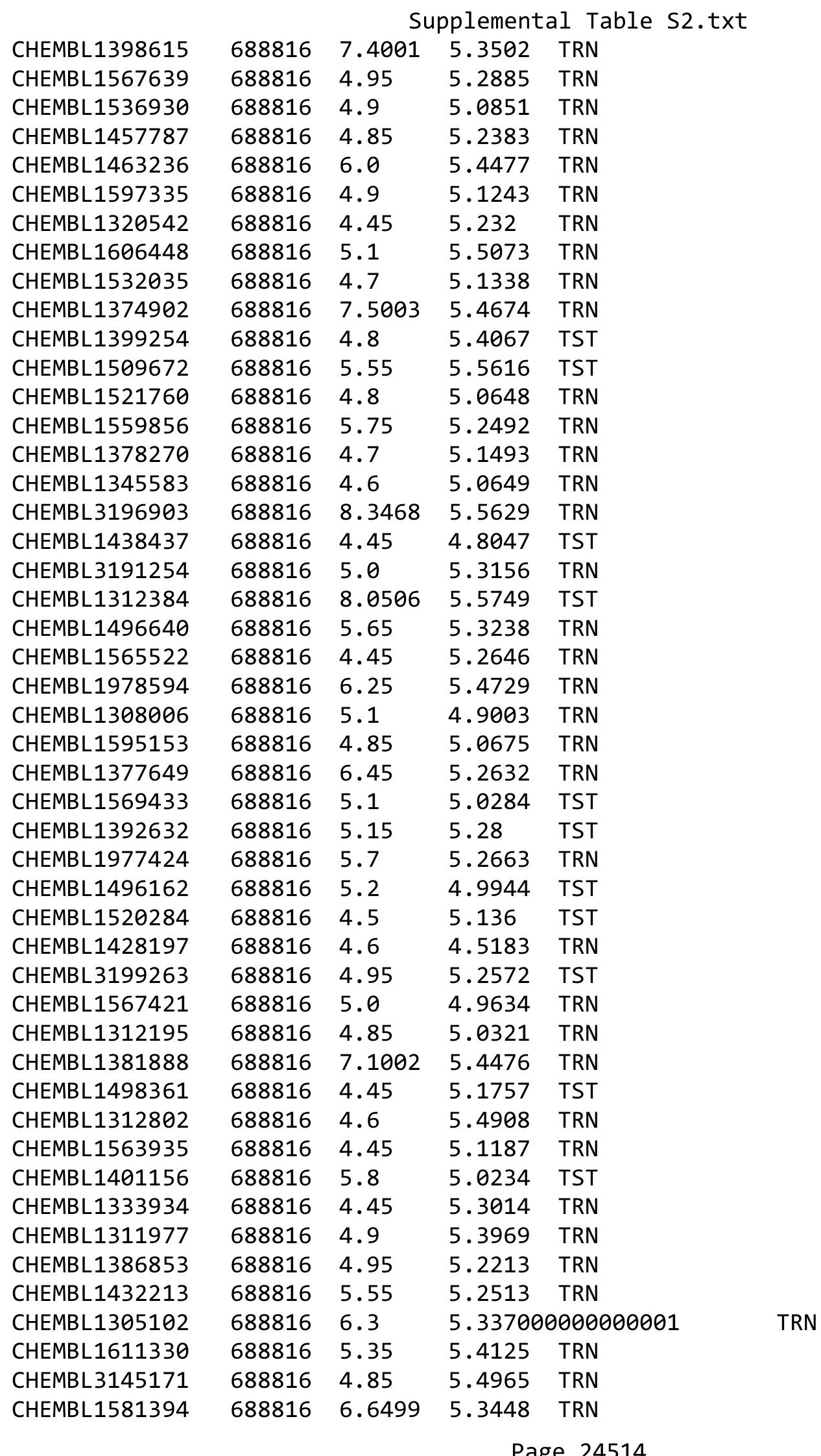




\begin{tabular}{|c|c|c|c|c|}
\hline \multicolumn{5}{|c|}{ Supplemental Table S2.txt } \\
\hline CHEMBL1509194 & 688816 & 8.3468 & 5.5101 & TST \\
\hline CHEMBL1508808 & 688816 & 5.25 & 5.0744 & TRN \\
\hline CHEMBL1453160 & 688816 & 4.65 & 5.0855 & TRN \\
\hline CHEMBL1600935 & 688816 & 4.55 & 5.5202 & TRN \\
\hline CHEMBL1348030 & 688816 & 5.55 & 5.2093 & TRN \\
\hline CHEMBL491981 & 688816 & 4.65 & 5.3169 & TRN \\
\hline CHEMBL1391068 & 688816 & 4.85 & 5.3746 & TST \\
\hline CHEMBL1458485 & 688816 & 8.0506 & 5.3815 & TST \\
\hline CHEMBL3198870 & 688816 & 4.95 & 5.4637 & TRN \\
\hline CHEMBL1612606 & 688816 & 4.95 & 5.1132 & TRN \\
\hline CHEMBL1319978 & 688816 & 6.8 & 5.6931 & TST \\
\hline CHEMBL1461993 & 688816 & 5.0 & 5.4366 & TST \\
\hline CHEMBL1484027 & 688816 & 5.55 & 5.1498 & TRN \\
\hline CHEMBL1492025 & 688816 & 5.95 & 5.4406 & TST \\
\hline CHEMBL1583095 & 688816 & 4.95 & 5.4464 & TRN \\
\hline CHEMBL1584975 & 688816 & 5.0 & 5.4962 & TST \\
\hline CHEMBL1451372 & 688816 & 6.7501 & 5.7857 & TRN \\
\hline CHEMBL1525358 & 688816 & 5.05 & 5.5304 & TST \\
\hline CHEMBL1376472 & 688816 & 5.5 & 5.2582 & TST \\
\hline CHEMBL1352334 & 688816 & 6.5 & 5.6045 & TST \\
\hline CHEMBL1611134 & 688816 & 8.301 & 5.3117 & TRN \\
\hline CHEMBL3198669 & 688816 & 4.45 & 5.3253 & TRN \\
\hline CHEMBL1313679 & 688816 & 4.95 & 5.3348 & TST \\
\hline CHEMBL1549415 & 688816 & 4.45 & 5.4834 & TRN \\
\hline CHEMBL1309645 & 688816 & 4.55 & 5.4292 & TST \\
\hline CHEMBL1505936 & 688816 & 5.05 & 5.2452 & TRN \\
\hline CHEMBL1596211 & 688816 & 4.85 & 5.2933 & TRN \\
\hline CHEMBL1570537 & 688816 & 4.5 & 5.0478 & TRN \\
\hline CHEMBL1578476 & 688816 & 5.05 & 4.7403 & TRN \\
\hline CHEMBL1348501 & 688816 & 4.85 & 4.9563 & TST \\
\hline CHEMBL 1348498 & 688816 & 4.85 & 5.115 & TRN \\
\hline CHEMBL261799 & 688816 & 4.95 & 5.2112 & TRN \\
\hline CHEMBL1467294 & 688816 & 4.85 & 5.4396 & TST \\
\hline CHEMBL1481284 & 688816 & 4.8 & 4.909 & TRN \\
\hline CHEMBL1497932 & 688816 & 4.95 & 5.2686 & TST \\
\hline CHEMBL1327577 & 688816 & 4.75 & 5.0509 & TRN \\
\hline CHEMBL1333772 & 688816 & 4.8 & 5.0697 & TRN \\
\hline CHEMBL 1450884 & 688816 & 4.85 & 5.2723 & TRN \\
\hline CHEMBL1603657 & 688816 & 4.45 & 5.5413 & TRN \\
\hline CHEMBL3209272 & 688816 & 5.15 & 5.3736 & TRN \\
\hline CHEMBL1423525 & 688816 & 6.8 & 5.1509 & TRN \\
\hline CHEMBL1478987 & 688816 & 4.45 & 5.2412 & TRN \\
\hline CHEMBL 71271 & 688816 & 4.45 & 5.0939 & TRN \\
\hline CHEMBL1417368 & 688816 & 4.8 & 5.511 & TRN \\
\hline CHEMBL581452 & 688816 & 4.45 & 5.1783 & TRN \\
\hline CHEMBL 1540792 & 688816 & 5.4 & 5.5042 & TST \\
\hline CHEMBL1520731 & 688816 & 4.85 & 5.1874 & TST \\
\hline CHEMBL1343267 & 688816 & 4.5 & 5.2681 & TRN \\
\hline
\end{tabular}




\begin{tabular}{|c|c|c|c|c|c|}
\hline \multicolumn{6}{|c|}{ Supplemental Table S2.txt } \\
\hline CHEMBL1337592 & 688816 & 4.8 & 4.8438 & TRN & \\
\hline CHEMBL1359387 & 688816 & 4.95 & 5.4171 & TRN & \\
\hline CHEMBL1388892 & 688816 & 4.85 & 5.0013 & TRN & \\
\hline CHEMBL1502665 & 688816 & 5.4 & 5.4061 & TRN & \\
\hline CHEMBL1449408 & 688816 & 4.6 & 5.1514 & TRN & \\
\hline CHEMBL1449627 & 688816 & 5.5 & 4.7863 & TRN & \\
\hline CHEMBL 3212640 & 688816 & 8.0 & 4.9398 & TRN & \\
\hline CHEMBL1344836 & 688816 & 4.75 & 5.354 & TST & \\
\hline CHEMBL1569544 & 688816 & 5.45 & 5.1676 & TRN & \\
\hline CHEMBL1586808 & 688816 & 7.6498 & 5.3063 & TRN & \\
\hline CHEMBL1583505 & 688816 & 4.95 & 5.2994 & TRN & \\
\hline CHEMBL1541440 & 688816 & 4.5 & 4.834 & TRN & \\
\hline CHEMBL1480756 & 688816 & 7.8508 & 5.17899 & 9999999999 & TRN \\
\hline CHEMBL1375729 & 688816 & 4.8 & 5.1948 & TRN & \\
\hline CHEMBL1596825 & 688816 & 4.9 & 5.4362 & TST & \\
\hline CHEMBL1447085 & 688816 & 6.05 & 5.2191 & TST & \\
\hline CHEMBL3190843 & 688816 & 4.95 & 4.957 & TRN & \\
\hline CHEMBL1484725 & 688816 & 6.15 & 5.33200 & 0000000001 & TST \\
\hline CHEMBL1368993 & 688816 & 4.95 & 4.9874 & TRN & \\
\hline CHEMBL1570956 & 688816 & 5.25 & 5.1525 & TRN & \\
\hline CHEMBL1467128 & 688816 & 4.7 & 5.0321 & TRN & \\
\hline CHEMBL1492412 & 688816 & 4.9 & 5.0739 & TRN & \\
\hline CHEMBL1415712 & 688816 & 5.45 & 5.3941 & TRN & \\
\hline CHEMBL1525070 & 688816 & 5.45 & 5.2953 & TRN & \\
\hline CHEMBL1339652 & 688816 & 4.85 & 4.965 & TRN & \\
\hline CHEMBL1303046 & 688816 & 6.5501 & 5.7132 & TRN & \\
\hline CHEMBL1468351 & 688816 & 4.95 & 5.1223 & TRN & \\
\hline CHEMBL1610336 & 688816 & 5.2 & 5.0362 & TRN & \\
\hline CHEMBL1995193 & 688816 & 5.45 & 5.5359 & TRN & \\
\hline CHEMBL1462510 & 688816 & 4.55 & 5.1555 & TRN & \\
\hline CHEMBL1564313 & 688816 & 5.0 & 5.0529 & TST & \\
\hline CHEMBL1501221 & 688816 & 4.95 & 5.0861 & TRN & \\
\hline CHEMBL1513325 & 688816 & 4.95 & 5.1437 & TRN & \\
\hline CHEMBL1558487 & 688816 & 5.25 & 5.4035 & TRN & \\
\hline CHEMBL1522352 & 688816 & 4.8 & 5.4149 & TRN & \\
\hline CHEMBL1518346 & 688816 & 4.85 & 5.0182 & TRN & \\
\hline CHEMBL1406187 & 688816 & 4.8 & 5.3891 & TRN & \\
\hline CHEMBL1545605 & 688816 & 5.85 & 5.3724 & TRN & \\
\hline CHEMBL127757 & 688816 & 5.2 & 5.3914 & TRN & \\
\hline CHEMBL3199624 & 688816 & 8.301 & 5.4507 & TRN & \\
\hline CHEMBL1519625 & 688816 & 8.1487 & 5.3256 & TST & \\
\hline CHEMBL1583226 & 688816 & 4.85 & 5.0333 & TRN & \\
\hline CHEMBL1600570 & 688816 & 8.3468 & 5.7917 & TST & \\
\hline CHEMBL3193166 & 688816 & 4.95 & 5.4971 & TRN & \\
\hline CHEMBL1477140 & 688816 & 4.8 & 4.9801 & TRN & \\
\hline CHEMBL1403993 & 688816 & 6.8 & 5.7253 & TST & \\
\hline CHEMBL1537066 & 688816 & 4.95 & 5.0237 & TRN & \\
\hline CHEMBL 2001582 & 688816 & 4.45 & 5.0974 & TRN & \\
\hline
\end{tabular}




\begin{tabular}{|c|c|c|c|c|c|}
\hline \multicolumn{6}{|c|}{ Supplemental Table S2.txt } \\
\hline CHEMBL1420531 & 688816 & 5.0 & 5.0089 & TRN & \\
\hline CHEMBL3208332 & 688816 & 5.0 & 5.3424 & TRN & \\
\hline CHEMBL3189413 & 688816 & 4.45 & 5.1556 & TRN & \\
\hline CHEMBL1563666 & 688816 & 7.7496 & 5.5092 & TST & \\
\hline CHEMBL309339 & 688816 & 5.4 & 5.1638 & TRN & \\
\hline CHEMBL1611549 & 688816 & 4.8 & 5.5055 & TRN & \\
\hline CHEMBL1504109 & 688816 & 4.9 & 4.8197 & TRN & \\
\hline CHEMBL1369698 & 688816 & 4.75 & 5.0539 & TRN & \\
\hline CHEMBL1445004 & 688816 & 4.9 & 5.0336 & TRN & \\
\hline CHEMBL1449645 & 688816 & 6.1 & 5.2571 & TST & \\
\hline CHEMBL 225230 & 688816 & 6.0 & 5.232 & TRN & \\
\hline CHEMBL1539873 & 688816 & 8.301 & 5.2034 & TRN & \\
\hline CHEMBL533388 & 688816 & 4.9 & 4.7056 & TST & \\
\hline CHEMBL1372307 & 688816 & 5.55 & 5.6117 & TST & \\
\hline CHEMBL1469826 & 688816 & 4.75 & 5.5651 & TRN & \\
\hline CHEMBL1528496 & 688816 & 4.45 & 5.1104 & TRN & \\
\hline CHEMBL1505221 & 688816 & 5.0 & 5.178 & TST & \\
\hline CHEMBL1537319 & 688816 & 4.45 & 5.5711 & TST & \\
\hline CHEMBL1595687 & 688816 & 7.2503 & 5.2618 & TST & \\
\hline CHEMBL1481138 & 688816 & 8.6021 & 5.048 & TRN & \\
\hline CHEMBL1300999 & 688816 & 4.9 & 5.1072 & TRN & \\
\hline CHEMBL1388009 & 688816 & 4.75 & 5.1307 & TST & \\
\hline CHEMBL1320366 & 688816 & 4.65 & 5.2136 & TRN & \\
\hline CHEMBL1414644 & 688816 & 5.25 & 5.381 & TRN & \\
\hline CHEMBL1560460 & 688816 & 4.5 & 5.3375 & TST & \\
\hline CHEMBL585443 & 688816 & 4.9 & 4.9397 & TRN & \\
\hline CHEMBL1526118 & 688816 & 4.8 & 5.7266 & TST & \\
\hline CHEMBL1382067 & 688816 & 4.65 & 5.5183 & TRN & \\
\hline CHEMBL1603752 & 688816 & 6.35 & 5.1417 & TST & \\
\hline CHEMBL1504253 & 688816 & 4.45 & 5.3713 & TRN & \\
\hline CHEMBL1399398 & 688816 & 5.55 & 5.5033 & TRN & \\
\hline CHEMBL1389823 & 688816 & 5.2 & 5.1463 & TST & \\
\hline CHEMBL1580398 & 688816 & 5.85 & 5.1769 & TRN & \\
\hline CHEMBL416657 & 688816 & 4.5 & 4.5861 & TST & \\
\hline CHEMBL3193943 & 688816 & 6.25 & 4.7844 & TRN & \\
\hline CHEMBL1539373 & 688816 & 4.75 & 5.0937 & TRN & \\
\hline CHEMBL1334026 & 688816 & 4.9 & 5.4336 & TRN & \\
\hline CHEMBL1429720 & 688816 & 4.95 & 5.3935 & TST & \\
\hline CHEMBL1448363 & 688816 & 4.95 & 4.9317 & TRN & \\
\hline CHEMBL1350607 & 688816 & 5.55 & 5.8437 & TRN & \\
\hline CHEMBL1519554 & 688816 & 4.95 & 5.2106 & TRN & \\
\hline CHEMBL1346116 & 688816 & 6.15 & 5.1912 & TRN & \\
\hline CHEMBL1506080 & 688816 & 4.45 & 5.3972 & TRN & \\
\hline CHEMBL1501458 & 688816 & 4.65 & 5.25799 & 9999999999 & TRN \\
\hline CHEMBL3190972 & 688816 & 6.2 & 5.6686 & TRN & \\
\hline CHEMBL3208019 & 688816 & 4.9 & 5.0985 & TRN & \\
\hline CHEMBL3192408 & 688816 & 5.75 & 5.0968 & TST & \\
\hline CHEMBL1342789 & 688816 & 4.85 & 5.1559 & TRN & \\
\hline
\end{tabular}




\begin{tabular}{|c|c|c|c|c|c|}
\hline \multicolumn{6}{|c|}{ Supplemental Table S2.txt } \\
\hline CHEMBL1531389 & 688816 & 4.8 & 5.0355 & TRN & \\
\hline CHEMBL1559448 & 688816 & 4.95 & 5.7099 & TST & \\
\hline CHEMBL1399771 & 688816 & 4.85 & 5.2183 & TRN & \\
\hline CHEMBL 3197686 & 688816 & 5.1 & 5.3691 & TRN & \\
\hline CHEMBL1357759 & 688816 & 4.95 & 5.1449 & TRN & \\
\hline CHEMBL1337053 & 688816 & 4.6 & 5.5339 & TST & \\
\hline CHEMBL1366240 & 688816 & 7.8013 & 5.2196 & TST & \\
\hline CHEMBL1427516 & 688816 & 6.5501 & 5.0373 & TST & \\
\hline CHEMBL1498658 & 688816 & 4.7 & 5.0608 & TST & \\
\hline CHEMBL1426611 & 688816 & 4.45 & 5.3751 & TRN & \\
\hline CHEMBL1418744 & 688816 & 4.45 & 4.6159 & TST & \\
\hline CHEMBL1463525 & 688816 & 8.0506 & 4.9595 & TRN & \\
\hline CHEMBL1303626 & 688816 & 4.6 & 4.6924 & TST & \\
\hline CHEMBL3211517 & 688816 & 5.55 & 5.6001 & TRN & \\
\hline CHEMBL1529078 & 688816 & 7.8508 & 5.4739 & TST & \\
\hline CHEMBL1449252 & 688816 & 4.45 & 5.5118 & TST & \\
\hline CHEMBL1599601 & 688816 & 5.05 & 4.9398 & TRN & \\
\hline CHEMBL3199829 & 688816 & 4.7 & 5.3042 & TRN & \\
\hline CHEMBL1470942 & 688816 & 5.25 & 5.2669 & TRN & \\
\hline CHEMBL1599212 & 688816 & 4.8 & 5.2556 & TST & \\
\hline CHEMBL609606 & 688816 & 6.45 & 5.4661 & TRN & \\
\hline CHEMBL1361725 & 688816 & 4.85 & 5.4258 & TRN & \\
\hline CHEMBL1431821 & 688816 & 4.45 & 5.4091 & TRN & \\
\hline CHEMBL1560216 & 688816 & 4.8 & 5.2341 & TRN & \\
\hline CHEMBL1489606 & 688816 & 6.0 & 5.358 & TST & \\
\hline CHEMBL1598711 & 688816 & 6.1 & 5.3933 & TRN & \\
\hline CHEMBL1477735 & 688816 & 5.9 & 4.7288 & TRN & \\
\hline CHEMBL1412602 & 688816 & 5.15 & 5.4968 & TRN & \\
\hline CHEMBL1468497 & 688816 & 4.6 & 5.0734 & TRN & \\
\hline CHEMBL1538360 & 688816 & 4.65 & 4.8493 & TST & \\
\hline CHEMBL1543341 & 688816 & 5.45 & 5.29700 & 0000000001 & TRN \\
\hline CHEMBL1603525 & 688816 & 4.65 & 5.5067 & TRN & \\
\hline CHEMBL1302116 & 688816 & 4.45 & 5.0046 & TRN & \\
\hline CHEMBL1443958 & 688816 & 4.5 & 5.3484 & TRN & \\
\hline CHEMBL1450860 & 688816 & 5.25 & 5.175 & TRN & \\
\hline CHEMBL1548889 & 688816 & 6.5501 & 5.0938 & TRN & \\
\hline CHEMBL1440289 & 688816 & 6.4 & 5.3674 & TST & \\
\hline CHEMBL380184 & 688816 & 6.45 & 5.3332 & TRN & \\
\hline CHEMBL1555862 & 688816 & 5.25 & 5.4944 & TST & \\
\hline CHEMBL1547884 & 688816 & 4.65 & 5.1496 & TRN & \\
\hline CHEMBL1334601 & 688816 & 4.95 & 5.3703 & TRN & \\
\hline CHEMBL1350593 & 688816 & 4.6 & 5.0639 & TST & \\
\hline CHEMBL1423211 & 688816 & 4.75 & 4.955 & TRN & \\
\hline CHEMBL1311028 & 688816 & 4.85 & 4.9093 & TRN & \\
\hline CHEMBL1341628 & 688816 & 4.6 & 5.3699 & TRN & \\
\hline CHEMBL1972573 & 688816 & 4.95 & 5.4284 & TST & \\
\hline CHEMBL610198 & 688816 & 4.45 & 5.319 & TRN & \\
\hline CHEMBL1546020 & 688816 & 4.95 & 5.2506 & TRN & \\
\hline
\end{tabular}




\begin{tabular}{|c|c|c|c|c|c|}
\hline \multicolumn{6}{|c|}{ Supplemental Table S2.txt } \\
\hline CHEMBL1387000 & 688816 & 5.55 & 5.3308 & TST & \\
\hline CHEMBL1580400 & 688816 & 4.9 & 5.325 & TST & \\
\hline CHEMBL1543073 & 688816 & 4.85 & 5.2926 & TST & \\
\hline CHEMBL1429094 & 688816 & 4.7 & 5.4232 & TRN & \\
\hline CHEMBL 3210763 & 688816 & 5.0 & 5.1351 & TRN & \\
\hline CHEMBL1594558 & 688816 & 4.85 & 5.718 & TST & \\
\hline CHEMBL1600869 & 688816 & 5.5 & 5.7157 & TRN & \\
\hline CHEMBL1561218 & 688816 & 5.0 & 5.4081 & TRN & \\
\hline CHEMBL1487496 & 688816 & 8.3468 & 5.581 & TRN & \\
\hline CHEMBL1504976 & 688816 & 4.95 & 5.4221 & TRN & \\
\hline CHEMBL1484399 & 688816 & 7.9508 & 5.584 & TST & \\
\hline CHEMBL1581772 & 688816 & 4.9 & 5.353 & TRN & \\
\hline CHEMBL1330678 & 688816 & 4.55 & 5.1249 & TRN & \\
\hline CHEMBL1531277 & 688816 & 4.75 & 5.1082 & TST & \\
\hline CHEMBL1516381 & 688816 & 4.7 & 4.7563 & TRN & \\
\hline CHEMBL1530893 & 688816 & 4.9 & 4.9737 & TRN & \\
\hline CHEMBL1522315 & 688816 & 4.85 & 5.1478 & TST & \\
\hline CHEMBL1986690 & 688816 & 8.4949 & 5.1315 & TST & \\
\hline CHEMBL1542570 & 688816 & 5.25 & 5.5783 & TRN & \\
\hline CHEMBL1495507 & 688816 & 4.9 & 5.6229 & TST & \\
\hline CHEMBL1364185 & 688816 & 5.0 & 5.5066 & TST & \\
\hline CHEMBL1384705 & 688816 & 5.25 & 5.2431 & TRN & \\
\hline CHEMBL1377247 & 688816 & 4.55 & 5.5131 & TRN & \\
\hline CHEMBL 3210642 & 688816 & 4.8 & 5.1374 & TST & \\
\hline CHEMBL310798 & 688816 & 4.45 & 5.1874 & TRN & \\
\hline CHEMBL1319245 & 688816 & 5.3 & 5.9267 & TRN & \\
\hline CHEMBL1572156 & 688816 & 4.95 & 5.12299 & & TRN \\
\hline CHEMBL1587947 & 688816 & 4.9 & 5.3511 & TRN & \\
\hline CHEMBL1362658 & 688816 & 5.0 & 5.4902 & TRN & \\
\hline CHEMBL1363987 & 688816 & 5.55 & 5.1837 & TRN & \\
\hline CHEMBL1304237 & 688816 & 5.55 & 5.4334 & TRN & \\
\hline CHEMBL1301271 & 688816 & 4.9 & 5.3107 & TRN & \\
\hline CHEMBL1462157 & 688816 & 4.45 & 5.2774 & TRN & \\
\hline CHEMBL 3196467 & 688816 & 4.45 & 4.9621 & TRN & \\
\hline CHEMBL3191310 & 688816 & 5.0 & 5.266 & TRN & \\
\hline CHEMBL1300705 & 688816 & 8.4949 & 5.4042 & TRN & \\
\hline CHEMBL1377820 & 688816 & 4.9 & 5.2471 & TRN & \\
\hline CHEMBL1305478 & 688816 & 4.8 & 4.8984 & TRN & \\
\hline CHEMBL1299250 & 688816 & 7.699 & 5.3275 & TRN & \\
\hline CHEMBL1336922 & 688816 & 4.9 & 5.2316 & TRN & \\
\hline CHEMBL1584825 & 688816 & 8.0506 & 5.1816 & TRN & \\
\hline CHEMBL3190528 & 688816 & 4.9 & 5.1148 & TRN & \\
\hline CHEMBL1570020 & 688816 & 4.95 & 5.1003 & TRN & \\
\hline CHEMBL1350861 & 688816 & 5.35 & 5.1734 & TRN & \\
\hline CHEMBL1495859 & 688816 & 4.85 & 5.0631 & TRN & \\
\hline CHEMBL1455520 & 688816 & 4.9 & 5.1349 & TRN & \\
\hline CHEMBL1561229 & 688816 & 4.9 & 5.2654 & TRN & \\
\hline CHEMBL1603125 & 688816 & 4.85 & 5.3488 & TRN & \\
\hline
\end{tabular}




\begin{tabular}{|c|c|c|c|c|c|}
\hline \multicolumn{6}{|c|}{ Supplemental Table S2.txt } \\
\hline CHEMBL1304390 & 688816 & 7.0 & 5.6371 & TRN & \\
\hline CHEMBL1598564 & 688816 & 4.45 & 5.0257 & TRN & \\
\hline CHEMBL1528726 & 688816 & 4.55 & 4.9167 & TRN & \\
\hline CHEMBL1965472 & 688816 & 4.95 & 5.1051 & TRN & \\
\hline CHEMBL3214231 & 688816 & 4.95 & 5.4306 & TST & \\
\hline CHEMBL1357587 & 688816 & 4.5 & 5.1886 & TRN & \\
\hline CHEMBL1438449 & 688816 & 6.2 & 5.4405 & TRN & \\
\hline CHEMBL1451171 & 688816 & 8.7959 & 5.7638 & TRN & \\
\hline CHEMBL1393409 & 688816 & 7.4498 & 5.5157 & TRN & \\
\hline CHEMBL1546023 & 688816 & 8.4559 & 5.5087 & TRN & \\
\hline CHEMBL1462360 & 688816 & 5.1 & 5.1866 & TRN & \\
\hline CHEMBL1349500 & 688816 & 5.8 & 5.2789 & TRN & \\
\hline CHEMBL1458864 & 688816 & 8.0 & 5.1489 & TRN & \\
\hline CHEMBL1327079 & 688816 & 5.05 & 5.0306 & TRN & \\
\hline CHEMBL1375553 & 688816 & 4.65 & 5.5021 & TRN & \\
\hline CHEMBL1379970 & 688816 & 6.6 & 5.6537 & TRN & \\
\hline CHEMBL1396977 & 688816 & 6.35 & 5.1772 & TRN & \\
\hline CHEMBL1369655 & 688816 & 4.8 & 5.2299 & TRN & \\
\hline CHEMBL1438200 & 688816 & 5.35 & 5.2605 & TRN & \\
\hline CHEMBL1375494 & 688816 & 4.65 & 5.2459 & TRN & \\
\hline CHEMBL3189391 & 688816 & 4.85 & 5.2859 & TRN & \\
\hline CHEMBL1434662 & 688816 & 7.5003 & 5.0032 & TRN & \\
\hline CHEMBL1548321 & 688816 & 5.35 & 5.0994 & TRN & \\
\hline CHEMBL1595073 & 688816 & 5.8 & 5.1509 & TST & \\
\hline CHEMBL3197623 & 688816 & 4.45 & 5.3219 & TST & \\
\hline CHEMBL1491822 & 688816 & 8.3979 & 5.2689 & TRN & \\
\hline CHEMBL1409453 & 688816 & 4.95 & 5.3195 & TRN & \\
\hline CHEMBL1341847 & 688816 & 7.1002 & 5.1195 & TST & \\
\hline CHEMBL1607732 & 688816 & 5.15 & 5.7586 & TRN & \\
\hline CHEMBL1378924 & 688816 & 4.45 & 5.3064 & TST & \\
\hline CHEMBL3197660 & 688816 & 4.45 & 5.51200 & 00000000005 & TST \\
\hline CHEMBL1545815 & 688816 & 4.75 & 5.5007 & TST & \\
\hline CHEMBL3199083 & 688816 & 4.75 & 5.0448 & TRN & \\
\hline CHEMBL1463429 & 688816 & 5.05 & 5.3576 & TST & \\
\hline CHEMBL1485515 & 688816 & 5.15 & 4.9918 & TRN & \\
\hline CHEMBL1329457 & 688816 & 4.6 & 5.2854 & TRN & \\
\hline CHEMBL1581943 & 688816 & 4.5 & 4.9986 & TRN & \\
\hline CHEMBL1591414 & 688816 & 4.65 & 5.0516 & TRN & \\
\hline CHEMBL1334275 & 688816 & 4.6 & 4.9842 & TRN & \\
\hline CHEMBL1458441 & 688816 & 5.4 & 4.8952 & TST & \\
\hline CHEMBL1439391 & 688816 & 4.95 & 5.2428 & TRN & \\
\hline CHEMBL1329414 & 688816 & 4.8 & 5.2684 & TRN & \\
\hline CHEMBL1415385 & 688816 & 4.6 & 5.1252 & TST & \\
\hline CHEMBL1459841 & 688816 & 4.95 & 5.1903 & TRN & \\
\hline CHEMBL1482486 & 688816 & 6.4 & 5.4842 & TRN & \\
\hline CHEMBL1387683 & 688816 & 5.5 & 5.0564 & TST & \\
\hline CHEMBL1413147 & 688816 & 4.85 & 5.5434 & TRN & \\
\hline CHEMBL1492691 & 688816 & 4.65 & 5.307 & TST & \\
\hline
\end{tabular}




\begin{tabular}{|c|c|c|c|c|c|}
\hline \multicolumn{6}{|c|}{ Supplemental Table S2.txt } \\
\hline CHEMBL1455762 & 688816 & 4.8 & 5.2538 & TRN & \\
\hline CHEMBL1367220 & 688816 & 5.35 & 5.4437 & TRN & \\
\hline CHEMBL1441718 & 688816 & 7.15 & 5.2946 & TRN & \\
\hline CHEMBL1553865 & 688816 & 5.15 & 5.2615 & TRN & \\
\hline CHEMBL1490188 & 688816 & 6.8 & 5.1821 & TRN & \\
\hline CHEMBL1440471 & 688816 & 4.95 & 5.2353 & TRN & \\
\hline CHEMBL1503420 & 688816 & 5.0 & 5.13 & TRN & \\
\hline CHEMBL1506264 & 688816 & 5.45 & 5.1483 & TRN & \\
\hline CHEMBL1534994 & 688816 & 4.65 & 5.1672 & TRN & \\
\hline CHEMBL1605454 & 688816 & 4.95 & 5.2516 & TRN & \\
\hline CHEMBL1440445 & 688816 & 7.4001 & 5.5399 & TRN & \\
\hline CHEMBL1315535 & 688816 & 4.95 & 4.8289 & TRN & \\
\hline CHEMBL1372534 & 688816 & 4.9 & 5.6561 & TST & \\
\hline CHEMBL1393183 & 688816 & 4.5 & 5.4646 & TST & \\
\hline CHEMBL1457606 & 688816 & 4.45 & 5.415 & TRN & \\
\hline CHEMBL1991234 & 688816 & 5.0 & 5.0863 & TST & \\
\hline CHEMBL1991441 & 688816 & 4.8 & 5.2126 & TRN & \\
\hline CHEMBL1447799 & 688816 & 5.2 & 5.4287 & TRN & \\
\hline CHEMBL1366800 & 688816 & 5.0 & 5.0602 & TST & \\
\hline CHEMBL1602304 & 688816 & 4.9 & 5.1555 & TRN & \\
\hline CHEMBL1505224 & 688816 & 5.1 & 5.0784 & TRN & \\
\hline CHEMBL1370250 & 688816 & 5.2 & 5.101 & TRN & \\
\hline CHEMBL3189624 & 688816 & 4.5 & 5.3733 & TST & \\
\hline CHEMBL1502645 & 688816 & 7.3002 & 5.1424 & TRN & \\
\hline CHEMBL1442621 & 688816 & 5.25 & 5.4349 & TRN & \\
\hline CHEMBL1445274 & 688816 & 6.05 & 5.1844 & TRN & \\
\hline CHEMBL1486939 & 688816 & 4.9 & 5.1641 & TRN & \\
\hline CHEMBL1544439 & 688816 & 7.0501 & 5.409 & TRN & \\
\hline CHEMBL3197125 & 688816 & 4.9 & 5.0336 & TST & \\
\hline CHEMBL1333819 & 688816 & 5.2 & 5.3731 & TRN & \\
\hline CHEMBL1330269 & 688816 & 4.45 & 5.4418 & TRN & \\
\hline CHEMBL1300800 & 688816 & 5.45 & 5.4058 & TRN & \\
\hline CHEMBL1518282 & 688816 & 4.95 & 5.0523 & TRN & \\
\hline CHEMBL1487287 & 688816 & 4.95 & 5.2375 & TRN & \\
\hline CHEMBL1471845 & 688816 & 4.85 & 5.3034 & TRN & \\
\hline CHEMBL1338965 & 688816 & 4.65 & $5.1670 e$ & 0000000001 & TRN \\
\hline CHEMBL1533706 & 688816 & 4.8 & 5.4539 & TST & \\
\hline CHEMBL3213616 & 688816 & 5.35 & 5.5175 & TST & \\
\hline CHEMBL3195732 & 688816 & 4.85 & 5.1203 & TRN & \\
\hline CHEMBL1543510 & 688816 & 7.9508 & 5.0447 & TRN & \\
\hline CHEMBL3190585 & 688816 & 5.25 & 5.0974 & TRN & \\
\hline CHEMBL1340384 & 688816 & 6.5 & 5.3705 & TRN & \\
\hline CHEMBL1352337 & 688816 & 4.85 & 4.9283 & TRN & \\
\hline CHEMBL1302426 & 688816 & 4.65 & 5.41799 & 9999999999 & TST \\
\hline CHEMBL1593166 & 688816 & 5.5 & 5.1867 & TRN & \\
\hline CHEMBL3195161 & 688816 & 4.9 & 5.3292 & TRN & \\
\hline CHEMBL1429188 & 688816 & 4.95 & 5.6916 & TRN & \\
\hline CHEMBL1387003 & 688816 & 4.45 & 5.4998 & TST & \\
\hline
\end{tabular}




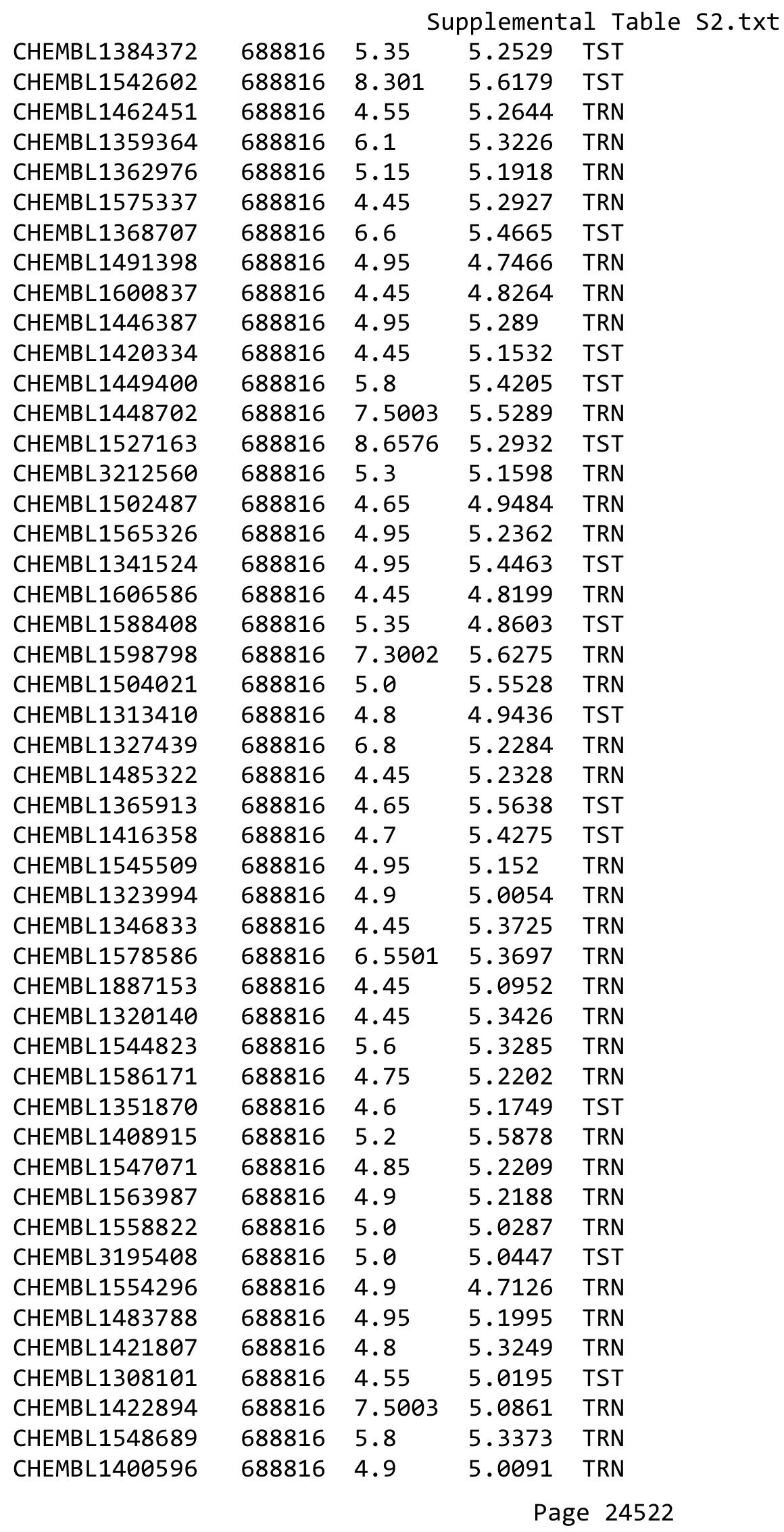




\begin{tabular}{|c|c|c|c|c|c|}
\hline \multicolumn{6}{|c|}{ Supplemental Table S2.txt } \\
\hline CHEMBL1523600 & 688816 & 4.85 & 5.3156 & TRN & \\
\hline CHEMBL1469517 & 688816 & 4.85 & 5.063 & TRN & \\
\hline CHEMBL1302054 & 688816 & 4.45 & 5.0108 & TRN & \\
\hline CHEMBL1463839 & 688816 & 5.85 & 5.7286 & TRN & \\
\hline CHEMBL1544211 & 688816 & 4.85 & 5.5925 & TRN & \\
\hline CHEMBL1361855 & 688816 & 5.3 & 5.3034 & TST & \\
\hline CHEMBL1422280 & 688816 & 4.55 & 5.5276 & TST & \\
\hline CHEMBL1310775 & 688816 & 5.35 & 5.1769 & TRN & \\
\hline CHEMBL1331821 & 688816 & 4.85 & 5.0993 & TST & \\
\hline CHEMBL1336166 & 688816 & 4.45 & 4.9352 & TST & \\
\hline CHEMBL1369229 & 688816 & 4.45 & 5.072 & TRN & \\
\hline CHEMBL1562418 & 688816 & 4.95 & 5.4615 & TRN & \\
\hline CHEMBL1424408 & 688816 & 4.65 & 5.4488 & TRN & \\
\hline CHEMBL1576263 & 688816 & 4.5 & 5.0728 & TRN & \\
\hline CHEMBL1427596 & 688816 & 4.75 & 5.0363 & TRN & \\
\hline CHEMBL1611856 & 688816 & 5.1 & 5.1481 & TRN & \\
\hline CHEMBL1574205 & 688816 & 5.4 & 5.3931 & TRN & \\
\hline CHEMBL1363457 & 688816 & 7.8996 & 5.9086 & TRN & \\
\hline CHEMBL1338045 & 688816 & 4.65 & 5.2106 & TRN & \\
\hline CHEMBL 3193641 & 688816 & 4.95 & 5.1767 & TRN & \\
\hline CHEMBL1562110 & 688816 & 4.75 & 5.0153 & TRN & \\
\hline CHEMBL1320703 & 688816 & 8.3468 & 5.026 & TST & \\
\hline CHEMBL1351458 & 688816 & 4.95 & 4.8029 & TRN & \\
\hline CHEMBL 3212782 & 688816 & 5.0 & 5.5792 & TST & \\
\hline CHEMBL1332508 & 688816 & 5.95 & 5.16 & TRN & \\
\hline CHEMBL1380331 & 688816 & 5.0 & 5.06 & TRN & \\
\hline CHEMBL1350852 & 688816 & 4.7 & 5.6972 & TRN & \\
\hline CHEMBL76904 & 688816 & 6.0 & 5.1034 & TRN & \\
\hline CHEMBL1587185 & 688816 & 4.8 & 5.3305 & TRN & \\
\hline CHEMBL1322941 & 688816 & 4.9 & 5.3131 & TRN & \\
\hline CHEMBL1397627 & 688816 & 4.7 & 5.3069 & TRN & \\
\hline CHEMBL 3192337 & 688816 & 5.1 & 5.41100 & 00000000005 & TRN \\
\hline CHEMBL1567624 & 688816 & 5.5 & 4.8955 & TST & \\
\hline CHEMBL1351957 & 688816 & 6.05 & 5.6713 & TST & \\
\hline CHEMBL1320044 & 688816 & 6.3 & 5.6943 & TRN & \\
\hline CHEMBL1498822 & 688816 & 5.15 & 5.5146 & TRN & \\
\hline CHEMBL1497807 & 688816 & 5.25 & 5.2383 & TST & \\
\hline CHEMBL3199576 & 688816 & 4.8 & 5.4131 & TRN & \\
\hline CHEMBL1461309 & 688816 & 6.4 & 5.376 & TST & \\
\hline CHEMBL1586248 & 688816 & 4.7 & 5.2861 & TRN & \\
\hline CHEMBL3197310 & 688816 & 5.5 & 5.2319 & TRN & \\
\hline CHEMBL1495504 & 688816 & 4.95 & 4.8835 & TRN & \\
\hline CHEMBL1455809 & 688816 & 4.65 & 5.2747 & TRN & \\
\hline CHEMBL1466478 & 688816 & 6.25 & 5.4081 & TRN & \\
\hline CHEMBL1492186 & 688816 & 4.55 & 5.2864 & TRN & \\
\hline CHEMBL1484069 & 688816 & 5.9 & 5.6246 & TRN & \\
\hline CHEMBL1603412 & 688816 & 5.2 & 5.6936 & TRN & \\
\hline CHEMBL1577977 & 688816 & 4.8 & 5.1484 & TRN & \\
\hline
\end{tabular}




\begin{tabular}{|c|c|c|c|c|c|}
\hline \multicolumn{6}{|c|}{ Supplemental Table s2.txt } \\
\hline CHEMBL1428415 & 688816 & 4.45 & 4.9595 & TRN & \\
\hline CHEMBL1491238 & 688816 & 4.5 & 5.0139 & TST & \\
\hline CHEMBL1497715 & 688816 & 7.7496 & 5.9757 & TRN & \\
\hline CHEMBL1492883 & 688816 & 5.65 & 5.7755 & TRN & \\
\hline CHEMBL1576754 & 688816 & 6.15 & 5.1511 & TRN & \\
\hline CHEMBL1362056 & 688816 & 4.55 & 5.3615 & TRN & \\
\hline CHEMBL1507915 & 688816 & 4.85 & 5.5231 & TRN & \\
\hline CHEMBL1488906 & 688816 & 4.85 & 5.4612 & TRN & \\
\hline CHEMBL1309288 & 688816 & 4.95 & 5.3622 & TRN & \\
\hline CHEMBL1452773 & 688816 & 4.45 & 5.7275 & TST & \\
\hline CHEMBL1577902 & 688816 & 5.0 & 5.222 & TRN & \\
\hline CHEMBL1427757 & 688816 & 5.25 & 5.0899 & TRN & \\
\hline CHEMBL1343024 & 688816 & 4.45 & 5.3699 & TRN & \\
\hline CHEMBL1310846 & 688816 & 5.35 & 5.8116 & TRN & \\
\hline CHEMBL1353902 & 688816 & 4.9 & 5.1496 & TRN & \\
\hline CHEMBL1480744 & 688816 & 4.9 & 5.0278 & TRN & \\
\hline CHEMBL1596656 & 688816 & 5.5 & 5.3306 & TRN & \\
\hline CHEMBL1382217 & 688816 & 5.45 & 5.388 & TRN & \\
\hline CHEMBL1453400 & 688816 & 4.65 & 5.4304 & TRN & \\
\hline CHEMBL1303426 & 688816 & 4.85 & 5.5371 & TST & \\
\hline CHEMBL1455566 & 688816 & 4.95 & 5.0178 & TRN & \\
\hline CHEMBL1527581 & 688816 & 4.95 & 5.01699 & 99999999995 & TRN \\
\hline CHEMBL1431705 & 688816 & 4.6 & 5.2884 & TRN & \\
\hline CHEMBL1366625 & 688816 & 5.2 & 6.0057 & TRN & \\
\hline CHEMBL1557762 & 688816 & 4.45 & 5.0994 & TRN & \\
\hline CHEMBL1575219 & 688816 & 5.35 & 5.449 & TRN & \\
\hline CHEMBL1330923 & 688816 & 4.75 & 5.1798 & TRN & \\
\hline CHEMBL1339757 & 688816 & 8.301 & 5.2506 & TRN & \\
\hline CHEMBL1519844 & 688816 & 4.85 & 5.061 & TRN & \\
\hline CHEMBL1575198 & 688816 & 4.95 & 5.0363 & TRN & \\
\hline CHEMBL1506989 & 688816 & 6.05 & 5.2152 & TRN & \\
\hline CHEMBL1504208 & 688816 & 4.45 & 5.1221 & TST & \\
\hline CHEMBL1305665 & 688816 & 4.7 & 5.0486 & TRN & \\
\hline CHEMBL1588401 & 688816 & 5.25 & 5.3247 & TST & \\
\hline CHEMBL1603283 & 688816 & 4.9 & 4.9767 & TRN & \\
\hline CHEMBL1406067 & 688816 & 5.1 & 5.1908 & TRN & \\
\hline CHEMBL1483325 & 688816 & 4.85 & 5.4565 & TRN & \\
\hline CHEMBL1555417 & 688816 & 5.1 & 5.1384 & TRN & \\
\hline CHEMBL1411376 & 688816 & 5.05 & 4.9325 & TRN & \\
\hline CHEMBL1321727 & 688816 & 5.9 & 5.4764 & TRN & \\
\hline CHEMBL1567293 & 688816 & 4.9 & 5.17200 & 0000000001 & TRN \\
\hline CHEMBL1501590 & 688816 & 4.8 & 4.9114 & TST & \\
\hline CHEMBL1994856 & 688816 & 4.8 & 5.3155 & TRN & \\
\hline CHEMBL1509392 & 688816 & 4.95 & 5.0468 & TST & \\
\hline CHEMBL1560379 & 688816 & 4.9 & 5.0722 & TST & \\
\hline CHEMBL1299637 & 688816 & 4.8 & 5.3673 & TRN & \\
\hline CHEMBL1586686 & 688816 & 4.85 & 5.33299 & 9999999999 & TST \\
\hline CHEMBL1310847 & 688816 & 5.4 & 5.4614 & TRN & \\
\hline
\end{tabular}




\begin{tabular}{|c|c|c|c|c|}
\hline \multicolumn{5}{|c|}{ Supplemental Table S2.txt } \\
\hline CHEMBL1386410 & 688816 & 5.4 & 5.5532 & TST \\
\hline CHEMBL1337151 & 688816 & 4.85 & 4.9865 & TRN \\
\hline CHEMBL1337567 & 688816 & 4.7 & 5.4724 & TRN \\
\hline CHEMBL1480116 & 688816 & 5.55 & 4.9173 & TRN \\
\hline CHEMBL1502639 & 688816 & 4.8 & 5.4291 & TRN \\
\hline CHEMBL1547706 & 688816 & 6.1 & 5.3637 & TRN \\
\hline CHEMBL3192110 & 688816 & 6.7501 & 5.4776 & TRN \\
\hline CHEMBL1373517 & 688816 & 5.45 & 5.0769 & TST \\
\hline CHEMBL 294989 & 688816 & 4.9 & 5.6237 & TST \\
\hline CHEMBL1449104 & 688816 & 5.05 & 5.2848 & TRN \\
\hline CHEMBL1507158 & 688816 & 6.0 & 5.7874 & TST \\
\hline CHEMBL1586081 & 688816 & 4.45 & 5.6627 & TRN \\
\hline CHEMBL1411526 & 688816 & 4.95 & 5.0114 & TRN \\
\hline CHEMBL1340838 & 688816 & 5.4 & 5.3239 & TRN \\
\hline CHEMBL1452416 & 688816 & 7.8996 & 5.664 & TRN \\
\hline CHEMBL1300844 & 688816 & 4.7 & 5.059 & TST \\
\hline CHEMBL3198270 & 688816 & 5.4 & 4.7821 & TRN \\
\hline CHEMBL1478755 & 688816 & 5.0 & 5.077 & TRN \\
\hline CHEMBL1411559 & 688816 & 4.65 & 4.9236 & TRN \\
\hline CHEMBL1575524 & 688816 & 6.8 & 5.5275 & TRN \\
\hline CHEMBL1391106 & 688816 & 4.45 & 5.3719 & TST \\
\hline CHEMBL1336197 & 688816 & 5.1 & 5.2619 & TRN \\
\hline CHEMBL1598605 & 688816 & 5.4 & 5.0027 & TRN \\
\hline CHEMBL1434411 & 688816 & 5.05 & 4.967 & TST \\
\hline CHEMBL1508914 & 688816 & 5.1 & 5.025 & TRN \\
\hline CHEMBL1365902 & 688816 & 4.7 & 5.1653 & TRN \\
\hline CHEMBL1587395 & 688816 & 6.15 & 5.274 & TRN \\
\hline CHEMBL1603264 & 688816 & 10.0 & 5.6235 & TST \\
\hline CHEMBL1503563 & 688816 & 4.45 & 4.9993 & TRN \\
\hline CHEMBL1467646 & 688816 & 4.6 & 5.2866 & TRN \\
\hline CHEMBL1543483 & 688816 & 4.45 & 5.078 & TST \\
\hline CHEMBL1323249 & 688816 & 4.75 & 5.267 & TRN \\
\hline CHEMBL1511197 & 688816 & 4.95 & 5.2931 & TRN \\
\hline CHEMBL1457401 & 688816 & 5.0 & 5.1814 & TRN \\
\hline CHEMBL1479908 & 688816 & 8.0506 & 5.3058 & TRN \\
\hline CHEMBL1325297 & 688816 & 6.0 & 5.6988 & TST \\
\hline CHEMBL1440979 & 688816 & 5.35 & 5.2063 & TRN \\
\hline CHEMBL1332979 & 688816 & 4.45 & 4.9385 & TRN \\
\hline CHEMBL1477957 & 688816 & 4.8 & 5.4457 & TRN \\
\hline CHEMBL1482380 & 688816 & 4.8 & 4.9909 & TRN \\
\hline CHEMBL1488602 & 688816 & 4.85 & 5.3469 & TRN \\
\hline CHEMBL1449934 & 688816 & 4.45 & 5.601 & TRN \\
\hline CHEMBL1486369 & 688816 & 4.75 & 5.1097 & TRN \\
\hline CHEMBL1489173 & 688816 & 5.55 & 5.3439 & TRN \\
\hline CHEMBL1494071 & 688816 & 5.25 & 5.4138 & TST \\
\hline CHEMBL1339092 & 688816 & 4.45 & 5.2472 & TRN \\
\hline CHEMBL 1555330 & 688816 & 4.85 & 5.6151 & TST \\
\hline CHEMBL1313565 & 688816 & 4.45 & 4.823 & TRN \\
\hline
\end{tabular}




\begin{tabular}{|c|c|c|c|c|c|}
\hline \multicolumn{6}{|c|}{ Supplemental Table S2.txt } \\
\hline CHEMBL3207320 & 688816 & 4.45 & 5.6123 & TST & \\
\hline CHEMBL1469584 & 688816 & 5.05 & 5.3027 & TST & \\
\hline CHEMBL1337040 & 688816 & 5.25 & 5.4692 & TST & \\
\hline CHEMBL1312226 & 688816 & 4.95 & 5.0851 & TRN & \\
\hline CHEMBL1587965 & 688816 & 5.0 & 5.7371 & TST & \\
\hline CHEMBL1608043 & 688816 & 4.9 & 5.3065 & TST & \\
\hline CHEMBL1482074 & 688816 & 4.45 & 5.2908 & TST & \\
\hline CHEMBL1408619 & 688816 & 4.9 & 5.3483 & TRN & \\
\hline CHEMBL1421168 & 688816 & 7.6003 & 5.24299 & 9999999999 & TRN \\
\hline CHEMBL1565267 & 688816 & 5.35 & 5.1788 & TST & \\
\hline CHEMBL1328319 & 688816 & 6.05 & 5.2911 & TRN & \\
\hline CHEMBL1577386 & 688816 & 4.9 & 5.2407 & TST & \\
\hline CHEMBL1534566 & 688816 & 5.0 & 5.9332 & TST & \\
\hline CHEMBL1336820 & 688816 & 5.85 & 5.3408 & TRN & \\
\hline CHEMBL1370613 & 688816 & 4.45 & 5.621 & TST & \\
\hline CHEMBL1367399 & 688816 & 4.75 & 5.5064 & TRN & \\
\hline CHEMBL1553859 & 688816 & 5.1 & 5.0921 & TRN & \\
\hline CHEMBL3211797 & 688816 & 4.65 & 5.2321 & TRN & \\
\hline CHEMBL1365850 & 688816 & 5.2 & 5.2506 & TRN & \\
\hline CHEMBL1597210 & 688816 & 4.55 & 5.1883 & TRN & \\
\hline CHEMBL1419996 & 688816 & 5.6 & 5.2869 & TST & \\
\hline CHEMBL1497286 & 688816 & 6.1 & 5.2795 & TRN & \\
\hline CHEMBL1541840 & 688816 & 4.45 & 5.0415 & TRN & \\
\hline CHEMBL1376582 & 688816 & 5.95 & 5.2335 & TRN & \\
\hline CHEMBL1593150 & 688816 & 4.9 & 5.3132 & TST & \\
\hline CHEMBL1537481 & 688816 & 4.85 & 4.9755 & TST & \\
\hline CHEMBL1309377 & 688816 & 5.45 & 5.3066 & TRN & \\
\hline CHEMBL1480869 & 688816 & 5.5 & 5.7318 & TST & \\
\hline CHEMBL1577424 & 688816 & 7.8013 & 5.0636 & TRN & \\
\hline CHEMBL1478818 & 688816 & 4.8 & 5.1572 & TRN & \\
\hline CHEMBL1355846 & 688816 & 4.45 & 5.0763 & TRN & \\
\hline CHEMBL1538297 & 688816 & 4.8 & 5.0727 & TST & \\
\hline CHEMBL1520346 & 688816 & 4.75 & 5.2266 & TRN & \\
\hline CHEMBL1307040 & 688816 & 4.8 & 5.0357 & TRN & \\
\hline CHEMBL1304442 & 688816 & 4.85 & 5.4317 & TRN & \\
\hline CHEMBL569958 & 688816 & 4.85 & 5.09399 & 9999999999 & TRN \\
\hline CHEMBL3198070 & 688816 & 4.9 & 5.1403 & TRN & \\
\hline CHEMBL3190146 & 688816 & 6.5 & 5.3407 & TRN & \\
\hline CHEMBL1440223 & 688816 & 4.65 & 5.1128 & TRN & \\
\hline CHEMBL1492684 & 688816 & 5.0 & 5.1466 & TRN & \\
\hline CHEMBL1584570 & 688816 & 4.9 & 5.2264 & TRN & \\
\hline CHEMBL1508467 & 688816 & 4.45 & 5.3431 & TRN & \\
\hline CHEMBL1369258 & 688816 & 7.4498 & 5.2469 & TRN & \\
\hline CHEMBL1389945 & 688816 & 5.65 & 5.5179 & TRN & \\
\hline CHEMBL3209935 & 688816 & 5.55 & 5.4322 & TRN & \\
\hline CHEMBL1342988 & 688816 & 4.7 & 5.404 & TRN & \\
\hline CHEMBL1482365 & 688816 & 4.8 & 5.1092 & TRN & \\
\hline CHEMBL1460591 & 688816 & 4.9 & 5.246 & TRN & \\
\hline
\end{tabular}




\begin{tabular}{|c|c|c|c|c|c|}
\hline \multicolumn{6}{|c|}{ Supplemental Table S2.txt } \\
\hline CHEMBL1520298 & 688816 & 5.75 & 5.4436 & TRN & \\
\hline CHEMBL3190181 & 688816 & 5.45 & 5.2935 & TRN & \\
\hline CHEMBL1611013 & 688816 & 4.6 & 5.11600 & 00000000005 & TST \\
\hline CHEMBL1534553 & 688816 & 5.05 & 5.0627 & TRN & \\
\hline CHEMBL1300249 & 688816 & 5.3 & 5.0399 & TRN & \\
\hline CHEMBL1464469 & 688816 & 4.45 & 5.2157 & TRN & \\
\hline CHEMBL1567179 & 688816 & 4.85 & 5.2177 & TRN & \\
\hline CHEMBL1519261 & 688816 & 4.95 & 4.6398 & TRN & \\
\hline CHEMBL1575634 & 688816 & 4.45 & 5.2412 & TRN & \\
\hline CHEMBL1345889 & 688816 & 5.25 & 5.3642 & TRN & \\
\hline CHEMBL1352202 & 688816 & 5.0 & 5.1319 & TST & \\
\hline CHEMBL1441999 & 688816 & 4.65 & 5.49700 & 0000000001 & TRN \\
\hline CHEMBL1528133 & 688816 & 4.95 & 5.3473 & TRN & \\
\hline CHEMBL3195725 & 688816 & 4.75 & 5.1383 & TRN & \\
\hline CHEMBL1473497 & 688816 & 5.45 & 5.06800 & 00000000005 & TRN \\
\hline CHEMBL1359829 & 688816 & 4.45 & 5.1256 & TRN & \\
\hline CHEMBL1608495 & 688816 & 4.9 & 5.249 & TRN & \\
\hline CHEMBL1515873 & 688816 & 5.05 & 5.192 & TRN & \\
\hline CHEMBL1328660 & 688816 & 4.95 & 5.1474 & TRN & \\
\hline CHEMBL1387760 & 688816 & 4.45 & 5.38899 & 9999999999 & TRN \\
\hline CHEMBL1479786 & 688816 & 4.45 & 5.2004 & TRN & \\
\hline CHEMBL45891 & 688816 & 5.45 & 5.4858 & TRN & \\
\hline CHEMBL1442229 & 688816 & 4.95 & 5.0823 & TRN & \\
\hline CHEMBL1527397 & 688816 & 4.75 & 5.0054 & TRN & \\
\hline CHEMBL1698037 & 688816 & 4.8 & 5.1133 & TRN & \\
\hline CHEMBL1424353 & 688816 & 4.55 & 5.3033 & TRN & \\
\hline CHEMBL1532368 & 688816 & 8.3468 & 5.09 & TRN & \\
\hline CHEMBL1464327 & 688816 & 6.0 & 5.9217 & TRN & \\
\hline CHEMBL1338408 & 688816 & 5.5 & 5.3156 & TST & \\
\hline CHEMBL1497162 & 688816 & 6.0 & 5.4775 & TRN & \\
\hline CHEMBL1443202 & 688816 & 4.45 & 5.5304 & TST & \\
\hline CHEMBL1476754 & 688816 & 4.9 & 5.2738 & TRN & \\
\hline CHEMBL1440061 & 688816 & 5.15 & 5.3112 & TST & \\
\hline CHEMBL1537616 & 688816 & 4.55 & 5.0949 & TRN & \\
\hline CHEMBL1611868 & 688816 & 4.65 & 5.0055 & TRN & \\
\hline CHEMBL1465840 & 688816 & 5.1 & 5.4376 & TRN & \\
\hline CHEMBL1320042 & 688816 & 5.3 & 5.2573 & TST & \\
\hline CHEMBL1542231 & 688816 & 4.65 & 5.2179 & TST & \\
\hline CHEMBL1540286 & 688816 & 4.95 & 5.2672 & TST & \\
\hline CHEMBL1091556 & 688816 & 4.75 & 4.9053 & TRN & \\
\hline CHEMBL1904348 & 688816 & 5.25 & 5.3506 & TRN & \\
\hline CHEMBL1353510 & 688816 & 5.45 & 4.8961 & TRN & \\
\hline CHEMBL1559135 & 688816 & 4.65 & 5.1334 & TRN & \\
\hline CHEMBL1328452 & 688816 & 5.25 & 5.2447 & TRN & \\
\hline CHEMBL1517382 & 688816 & 4.7 & 5.5734 & TRN & \\
\hline CHEMBL1566585 & 688816 & 7.6498 & 5.6347 & TST & \\
\hline CHEMBL1392988 & 688816 & 5.25 & 5.1152 & TRN & \\
\hline CHEMBL1521589 & 688816 & 5.1 & 5.4577 & TRN & \\
\hline
\end{tabular}




\begin{tabular}{|c|c|c|c|c|c|}
\hline \multicolumn{6}{|c|}{ Supplemental Table S2.txt } \\
\hline CHEMBL1432165 & 688816 & 4.85 & 5.3249 & TST & \\
\hline CHEMBL1529368 & 688816 & 5.25 & 4.6478 & TRN & \\
\hline CHEMBL1453956 & 688816 & 5.55 & 5.2629 & TRN & \\
\hline CHEMBL 3191645 & 688816 & 4.45 & 5.3289 & TRN & \\
\hline CHEMBL1442530 & 688816 & 4.65 & 5.2369 & TRN & \\
\hline CHEMBL1418941 & 688816 & 8.301 & 5.4211 & TRN & \\
\hline CHEMBL1420772 & 688816 & 7.0 & 5.4825 & TRN & \\
\hline CHEMBL1448025 & 688816 & 4.75 & 5.5943 & TRN & \\
\hline CHEMBL1414073 & 688816 & 5.35 & 5.3403 & TRN & \\
\hline CHEMBL1318405 & 688816 & 4.8 & 5.1924 & TST & \\
\hline CHEMBL1430559 & 688816 & 5.45 & 5.335 & TST & \\
\hline CHEMBL1402285 & 688816 & 4.45 & 5.26 & TST & \\
\hline CHEMBL1213608 & 688816 & 4.8 & 5.234 & TRN & \\
\hline CHEMBL1352185 & 688816 & 4.85 & 5.3143 & TRN & \\
\hline CHEMBL1333833 & 688816 & 4.85 & 5.2273 & TRN & \\
\hline CHEMBL1368091 & 688816 & 4.5 & 4.9825 & TRN & \\
\hline CHEMBL1973050 & 688816 & 4.9 & 4.9603 & TRN & \\
\hline CHEMBL1433302 & 688816 & 6.2 & 5.8506 & TRN & \\
\hline CHEMBL1409364 & 688816 & 5.95 & 5.1465 & TRN & \\
\hline CHEMBL1527276 & 688816 & 4.95 & 5.2275 & TRN & \\
\hline CHEMBL1319818 & 688816 & 4.45 & 5.2309 & TRN & \\
\hline CHEMBL1329560 & 688816 & 6.8 & 5.2786 & TST & \\
\hline CHEMBL1475707 & 688816 & 4.45 & 5.0808 & TRN & \\
\hline CHEMBL1412835 & 688816 & 4.65 & 5.0849 & TRN & \\
\hline CHEMBL1586062 & 688816 & 4.95 & 4.8148 & TRN & \\
\hline CHEMBL1530756 & 688816 & 4.9 & 5.1383 & TRN & \\
\hline CHEMBL1322878 & 688816 & 5.25 & 5.0055 & TRN & \\
\hline CHEMBL1384411 & 688816 & 4.8 & 5.3018 & TRN & \\
\hline CHEMBL1452944 & 688816 & 5.1 & 5.1289 & TRN & \\
\hline CHEMBL509283 & 688816 & 4.85 & 5.4699 & TRN & \\
\hline CHEMBL1424684 & 688816 & 5.5 & 5.6588 & TRN & \\
\hline CHEMBL1413246 & 688816 & 5.0 & 5.4121 & TRN & \\
\hline CHEMBL1467785 & 688816 & 4.8 & 4.7808 & TRN & \\
\hline CHEMBL1352396 & 688816 & 5.5 & 4.9448 & TRN & \\
\hline CHEMBL1466254 & 688816 & 8.6576 & 5.46200 & 0000000001 & TST \\
\hline CHEMBL1510627 & 688816 & 4.45 & 5.6075 & TRN & \\
\hline CHEMBL1348085 & 688816 & 7.5498 & 5.1227 & TST & \\
\hline CHEMBL1586837 & 688816 & 4.8 & 5.1945 & TRN & \\
\hline CHEMBL1517862 & 688816 & 4.8 & 5.8284 & TST & \\
\hline CHEMBL1344151 & 688816 & 5.25 & 5.6372 & TRN & \\
\hline CHEMBL1607253 & 688816 & 4.95 & 5.0125 & TRN & \\
\hline CHEMBL1469915 & 688816 & 4.95 & 4.9526 & TST & \\
\hline CHEMBL1564822 & 688816 & 4.9 & 5.4624 & TST & \\
\hline CHEMBL1371184 & 688816 & 5.0 & 5.1289 & TRN & \\
\hline CHEMBL1406437 & 688816 & 4.75 & 5.0646 & TST & \\
\hline CHEMBL1305712 & 688816 & 4.8 & 5.5465 & TRN & \\
\hline CHEMBL1451641 & 688816 & 5.0 & 5.032 & TST & \\
\hline CHEMBL1469003 & 688816 & 4.8 & 5.0275 & TRN & \\
\hline
\end{tabular}




\begin{tabular}{|c|c|c|c|c|}
\hline \multicolumn{5}{|c|}{ Supplemental Table S2.txt } \\
\hline CHEMBL1325149 & 688816 & 5.1 & 5.4862 & TRN \\
\hline CHEMBL448515 & 688816 & 4.6 & 5.7568 & TST \\
\hline CHEMBL1499664 & 688816 & 6.35 & 5.3011 & TRN \\
\hline CHEMBL1332844 & 688816 & 5.15 & 5.0713 & TRN \\
\hline CHEMBL1587201 & 688816 & 8.3468 & 5.2837 & TRN \\
\hline CHEMBL1573647 & 688816 & 4.7 & 5.289 & TST \\
\hline CHEMBL1343555 & 688816 & 5.15 & 5.1908 & TRN \\
\hline CHEMBL1538599 & 688816 & 4.45 & 5.8274 & TST \\
\hline CHEMBL1496848 & 688816 & 5.6 & 5.5237 & TRN \\
\hline CHEMBL1524319 & 688816 & 4.85 & 5.6039 & TST \\
\hline CHEMBL1395521 & 688816 & 4.8 & 4.9825 & TST \\
\hline CHEMBL1536628 & 688816 & 4.75 & 5.3581 & TRN \\
\hline CHEMBL1379627 & 688816 & 6.6 & 5.0046 & TRN \\
\hline CHEMBL1309336 & 688816 & 4.9 & 5.4562 & TST \\
\hline CHEMBL1600906 & 688816 & 4.95 & 5.1488 & TRN \\
\hline CHEMBL1561326 & 688816 & 6.95 & 5.331 & TST \\
\hline CHEMBL1505852 & 688816 & 7.6498 & 5.1197 & TST \\
\hline CHEMBL1592926 & 688816 & 4.55 & 5.037 & TRN \\
\hline CHEMBL3211326 & 688816 & 5.15 & 5.2148 & TRN \\
\hline CHEMBL1558211 & 688816 & 4.85 & 5.1454 & TRN \\
\hline CHEMBL1447669 & 688816 & 5.0 & 5.1804 & TRN \\
\hline CHEMBL1505020 & 688816 & 4.95 & 5.101 & TST \\
\hline CHEMBL1400395 & 688816 & 5.2 & 5.2069 & TRN \\
\hline CHEMBL45627 & 688816 & 4.5 & 5.9888 & TST \\
\hline CHEMBL1407154 & 688816 & 4.75 & 5.4289 & TRN \\
\hline CHEMBL1515365 & 688816 & 7.699 & 5.2438 & TRN \\
\hline CHEMBL1491039 & 688816 & 5.6 & 5.2916 & TST \\
\hline CHEMBL1450362 & 688816 & 5.05 & 4.895 & TRN \\
\hline CHEMBL1388717 & 688816 & 4.85 & 5.1766 & TRN \\
\hline CHEMBL3192463 & 688816 & 4.45 & 5.3139 & TRN \\
\hline CHEMBL1601200 & 688816 & 4.8 & 5.4412 & TRN \\
\hline CHEMBL1604016 & 688816 & 4.75 & 5.4635 & TRN \\
\hline CHEMBL3207628 & 688816 & 4.95 & 5.274 & TST \\
\hline CHEMBL1351001 & 688816 & 4.9 & 5.1778 & TRN \\
\hline CHEMBL1320487 & 688816 & 4.8 & 5.0558 & TRN \\
\hline CHEMBL1456452 & 688816 & 5.45 & 5.4011 & TRN \\
\hline CHEMBL1498985 & 688816 & 4.95 & 5.1763 & TRN \\
\hline CHEMBL1427265 & 688816 & 5.95 & 5.0511 & TRN \\
\hline CHEMBL1484574 & 688816 & 4.85 & 5.3238 & TST \\
\hline CHEMBL1546954 & 688816 & 6.05 & 5.3789 & TRN \\
\hline CHEMBL1384330 & 688816 & 4.65 & 5.2368 & TRN \\
\hline CHEMBL1407614 & 688816 & 4.45 & 5.3382 & TRN \\
\hline CHEMBL1349231 & 688816 & 5.65 & 5.1594 & TRN \\
\hline CHEMBL1432761 & 688816 & 4.6 & 5.5617 & TST \\
\hline CHEMBL1346304 & 688816 & 4.95 & 5.4381 & TRN \\
\hline CHEMBL1504500 & 688816 & 6.45 & 5.3259 & TRN \\
\hline CHEMBL1563710 & 688816 & 5.25 & 4.8993 & TRN \\
\hline CHEMBL1319643 & 688816 & 5.5 & 5.0843 & TST \\
\hline
\end{tabular}




\begin{tabular}{|c|c|c|c|c|c|}
\hline \multicolumn{6}{|c|}{ Supplemental Table S2.txt } \\
\hline CHEMBL1303052 & 688816 & 5.0 & 5.0988 & TRN & \\
\hline CHEMBL1608394 & 688816 & 6.0 & 5.5221 & TRN & \\
\hline CHEMBL1588976 & 688816 & 4.55 & 5.2135 & TRN & \\
\hline CHEMBL1469202 & 688816 & 4.75 & 5.6226 & TST & \\
\hline CHEMBL1486168 & 688816 & 4.7 & 5.1275 & TRN & \\
\hline CHEMBL1573621 & 688816 & 5.0 & 5.2578 & TRN & \\
\hline CHEMBL1415363 & 688816 & 4.9 & 4.942 & TRN & \\
\hline CHEMBL1598936 & 688816 & 6.0 & 5.5549 & TRN & \\
\hline CHEMBL 3195787 & 688816 & 5.6 & 5.7155 & TST & \\
\hline CHEMBL1510242 & 688816 & 4.45 & 5.0372 & TRN & \\
\hline CHEMBL1320607 & 688816 & 4.45 & 5.1467 & TRN & \\
\hline CHEMBL1444331 & 688816 & 5.2 & 5.2766 & TRN & \\
\hline CHEMBL1498909 & 688816 & 4.85 & 5.0053 & TRN & \\
\hline CHEMBL1465186 & 688816 & 4.45 & $5.4270 e$ & 00000000005 & TST \\
\hline CHEMBL3207968 & 688816 & 5.55 & 5.3211 & TST & \\
\hline CHEMBL1342527 & 688816 & 4.9 & 5.0141 & TRN & \\
\hline CHEMBL3199536 & 688816 & 5.0 & 5.2575 & TRN & \\
\hline CHEMBL1460983 & 688816 & 6.8499 & 5.2149 & TRN & \\
\hline CHEMBL1439715 & 688816 & 5.5 & 5.3762 & TRN & \\
\hline CHEMBL1430774 & 688816 & 5.45 & 5.9036 & TRN & \\
\hline CHEMBL1340471 & 688816 & 8.0506 & 5.603 & TRN & \\
\hline CHEMBL1562170 & 688816 & 4.9 & 5.0112 & TST & \\
\hline CHEMBL1510059 & 688816 & 5.05 & 5.1568 & TST & \\
\hline CHEMBL53898 & 688816 & 6.0 & 5.3885 & TRN & \\
\hline CHEMBL1569199 & 688816 & 7.1002 & 5.6761 & TRN & \\
\hline CHEMBL 2002444 & 688816 & 4.65 & 5.3924 & TRN & \\
\hline CHEMBL1485246 & 688816 & 4.55 & 5.1325 & TRN & \\
\hline CHEMBL1578786 & 688816 & 5.05 & 5.4595 & TST & \\
\hline CHEMBL1467704 & 688816 & 4.9 & 5.2734 & TRN & \\
\hline CHEMBL1481341 & 688816 & 4.45 & 5.2115 & TRN & \\
\hline CHEMBL1545331 & 688816 & 7.2 & 5.4288 & TRN & \\
\hline CHEMBL1368713 & 688816 & 5.25 & 5.2748 & TRN & \\
\hline CHEMBL1406953 & 688816 & 5.3 & 4.9702 & TRN & \\
\hline CHEMBL1508454 & 688816 & 4.85 & 5.438 & TRN & \\
\hline CHEMBL1336546 & 688816 & 7.5003 & 5.5217 & TRN & \\
\hline CHEMBL8197 & 688816 & 7.699 & 5.3125 & TRN & \\
\hline CHEMBL 241858 & 688816 & 4.75 & 5.3918 & TRN & \\
\hline CHEMBL1467760 & 688816 & 4.95 & 4.8869 & TRN & \\
\hline CHEMBL1429638 & 688816 & 7.5003 & 5.3232 & TRN & \\
\hline CHEMBL1388953 & 688816 & 4.55 & 5.4679 & TST & \\
\hline CHEMBL1442969 & 688816 & 4.8 & 5.403 & TST & \\
\hline CHEMBL1413478 & 688816 & 4.85 & 5.3112 & TRN & \\
\hline CHEMBL1600587 & 688816 & 4.6 & 4.9911 & TST & \\
\hline CHEMBL1322754 & 688816 & 4.9 & 4.9267 & TST & \\
\hline CHEMBL1409234 & 688816 & 5.85 & 5.1457 & TRN & \\
\hline CHEMBL1569892 & 688816 & 4.9 & 5.1389 & TRN & \\
\hline CHEMBL1431247 & 688816 & 5.15 & 5.4041 & TST & \\
\hline CHEMBL1405797 & 688816 & 5.3 & 5.0947 & TRN & \\
\hline
\end{tabular}




\begin{tabular}{|c|c|c|c|c|}
\hline \multicolumn{5}{|c|}{ Supplemental Table s2.txt } \\
\hline CHEMBL1980959 & 688816 & 4.9 & 5.1109 & TRN \\
\hline CHEMBL1373560 & 688816 & 5.2 & 5.2652 & TRN \\
\hline CHEMBL1454725 & 688816 & 4.95 & 5.171 & TST \\
\hline CHEMBL 3191861 & 688816 & 5.45 & 5.2823 & TRN \\
\hline CHEMBL1606905 & 688816 & 5.15 & 5.6488 & TRN \\
\hline CHEMBL1504426 & 688816 & 5.2 & 5.3815 & TRN \\
\hline CHEMBL1604360 & 688816 & 4.45 & 4.9534 & TST \\
\hline CHEMBL1597255 & 688816 & 7.5003 & 5.36600 & 00000000005 \\
\hline CHEMBL1424652 & 688816 & 4.45 & 4.8225 & TRN \\
\hline CHEMBL1545542 & 688816 & 5.65 & 5.2157 & TRN \\
\hline CHEMBL1521654 & 688816 & 8.301 & 5.5259 & TST \\
\hline CHEMBL1308578 & 688816 & 4.8 & 5.1542 & TST \\
\hline CHEMBL1415815 & 688816 & 4.65 & 5.224 & TRN \\
\hline CHEMBL1520373 & 688816 & 4.95 & 5.1439 & TST \\
\hline CHEMBL1989414 & 688816 & 5.3 & 4.9458 & TRN \\
\hline CHEMBL1311783 & 688816 & 4.9 & 5.1609 & TRN \\
\hline CHEMBL1572363 & 688816 & 4.9 & 5.3126 & TRN \\
\hline CHEMBL1433015 & 688816 & 4.7 & 4.6297 & TST \\
\hline CHEMBL1320109 & 688816 & 4.45 & 5.629 & TRN \\
\hline CHEMBL1410993 & 688816 & 6.45 & 5.3215 & TRN \\
\hline CHEMBL1555507 & 688816 & 7.3002 & 5.6828 & TRN \\
\hline CHEMBL1336068 & 688816 & 4.6 & 5.3532 & TRN \\
\hline CHEMBL1977978 & 688816 & 4.5 & 5.0082 & TRN \\
\hline CHEMBL1452118 & 688816 & 7.2503 & 4.9364 & TRN \\
\hline CHEMBL15192 & 688816 & 6.0 & 5.5323 & TST \\
\hline CHEMBL1390396 & 688816 & 7.2 & 4.8712 & TST \\
\hline CHEMBL1306991 & 688816 & 4.45 & 5.079 & TRN \\
\hline CHEMBL1517677 & 688816 & 4.8 & 5.2057 & TRN \\
\hline CHEMBL1440102 & 688816 & 4.9 & 5.0991 & TRN \\
\hline CHEMBL1306640 & 688816 & 5.0 & 5.2269 & TRN \\
\hline CHEMBL1576430 & 688816 & 4.95 & 5.1799 & TRN \\
\hline CHEMBL1459095 & 688816 & 4.45 & 5.1308 & TRN \\
\hline CHEMBL1466588 & 688816 & 7.8996 & 5.3991 & TST \\
\hline CHEMBL1530137 & 688816 & 4.8 & 5.146 & TRN \\
\hline CHEMBL1607190 & 688816 & 6.9 & 5.5318 & TRN \\
\hline CHEMBL1491175 & 688816 & 4.85 & 5.694 & TST \\
\hline CHEMBL1304776 & 688816 & 5.05 & 5.0089 & TST \\
\hline CHEMBL1385747 & 688816 & 4.9 & 5.0658 & TRN \\
\hline CHEMBL1483336 & 688816 & 5.2 & 5.5547 & TST \\
\hline CHEMBL1459096 & 688816 & 4.85 & 5.1514 & TRN \\
\hline CHEMBL1378275 & 688816 & 4.85 & 5.2018 & TRN \\
\hline CHEMBL1543767 & 688816 & 7.2503 & 5.5556 & TRN \\
\hline CHEMBL1344651 & 688816 & 4.45 & 5.4633 & TST \\
\hline CHEMBL1354011 & 688816 & 7.2 & 5.51 & TRN \\
\hline CHEMBL1537554 & 688816 & 4.65 & 4.9026 & TST \\
\hline CHEMBL1352232 & 688816 & 5.4 & 5.1584 & TST \\
\hline CHEMBL1591962 & 688816 & 4.65 & 5.2895 & TRN \\
\hline CHEMBL1510509 & 688816 & 4.95 & 5.3848 & TRN \\
\hline
\end{tabular}




\begin{tabular}{|c|c|c|c|c|}
\hline \multicolumn{5}{|c|}{ Supplemental Table S2.txt } \\
\hline CHEMBL1529064 & 688816 & 5.3 & 5.2479 & TRN \\
\hline CHEMBL1609459 & 688816 & 4.95 & 5.2775 & TST \\
\hline CHEMBL1541162 & 688816 & 5.45 & 4.8936 & TRN \\
\hline CHEMBL1347428 & 688816 & 5.8 & 5.2914 & TRN \\
\hline CHEMBL1350955 & 688816 & 5.3 & 5.46 & TST \\
\hline CHEMBL1409555 & 688816 & 7.8996 & 5.6427 & TRN \\
\hline CHEMBL1599947 & 688816 & 4.7 & 5.1719 & TST \\
\hline CHEMBL1527226 & 688816 & 4.45 & 5.2634 & TRN \\
\hline CHEMBL1427959 & 688816 & 5.45 & 5.2839 & TRN \\
\hline CHEMBL1461809 & 688816 & 4.95 & 4.9971 & TST \\
\hline CHEMBL1573692 & 688816 & 4.95 & 5.3114 & TRN \\
\hline CHEMBL1469424 & 688816 & 5.15 & 5.197 & TRN \\
\hline CHEMBL3193474 & 688816 & 4.65 & 5.2517 & TST \\
\hline CHEMBL1471396 & 688816 & 4.7 & 5.4164 & TRN \\
\hline CHEMBL1482585 & 688816 & 4.85 & 5.1645 & TST \\
\hline CHEMBL1327032 & 688816 & 4.7 & 5.4923 & TRN \\
\hline CHEMBL1495594 & 688816 & 5.55 & 5.0569 & TRN \\
\hline CHEMBL1539173 & 688816 & 4.9 & 5.2138 & TRN \\
\hline CHEMBL1537834 & 688816 & 5.45 & 5.4978 & TST \\
\hline CHEMBL1455024 & 688816 & 4.6 & 4.912 & TRN \\
\hline CHEMBL1541942 & 688816 & 4.6 & 4.8564 & TRN \\
\hline CHEMBL1519393 & 688816 & 4.45 & 5.2208 & TRN \\
\hline CHEMBL1443881 & 688816 & 4.7 & 5.2897 & TRN \\
\hline CHEMBL1498873 & 688816 & 4.75 & 5.4584 & TRN \\
\hline CHEMBL1379580 & 688816 & 4.6 & 4.867 & TRN \\
\hline CHEMBL1488678 & 688816 & 4.7 & 5.2381 & TRN \\
\hline CHEMBL1357813 & 688816 & 4.85 & 4.8364 & TRN \\
\hline CHEMBL1329027 & 688816 & 5.35 & 5.1273 & TRN \\
\hline CHEMBL1371337 & 688816 & 5.05 & 5.0949 & TST \\
\hline CHEMBL1442478 & 688816 & 5.55 & 5.1912 & TST \\
\hline CHEMBL1515925 & 688816 & 5.25 & 5.6569 & TRN \\
\hline CHEMBL1490765 & 688816 & 4.95 & 5.0165 & TRN \\
\hline CHEMBL1330526 & 688816 & 6.3 & 5.5516 & TST \\
\hline CHEMBL1418723 & 688816 & 5.55 & 5.7611 & TST \\
\hline CHEMBL1327860 & 688816 & 5.2 & 5.1689 & TST \\
\hline CHEMBL602069 & 688816 & 4.7 & 5.3027 & TRN \\
\hline CHEMBL 1458767 & 688816 & 6.45 & 5.306 & TRN \\
\hline CHEMBL1517803 & 688816 & 5.5 & 5.3845 & TRN \\
\hline CHEMBL1613182 & 688816 & 4.9 & 5.4385 & TRN \\
\hline CHEMBL1597435 & 688816 & 4.45 & 5.0082 & TRN \\
\hline CHEMBL1429200 & 688816 & 4.8 & 5.5326 & TST \\
\hline CHEMBL1528371 & 688816 & 4.45 & 4.9893 & TRN \\
\hline CHEMBL1558034 & 688816 & 4.95 & 5.4864 & TRN \\
\hline CHEMBL1470550 & 688816 & 6.25 & 5.2883 & TST \\
\hline CHEMBL1323315 & 688816 & 4.85 & 5.3334 & TRN \\
\hline CHEMBL1348852 & 688816 & 4.45 & 5.2357 & TRN \\
\hline CHEMBL1498431 & 688816 & 5.2 & 5.5689 & TRN \\
\hline CHEMBL1594046 & 688816 & 4.65 & 5.3655 & TRN \\
\hline
\end{tabular}




\begin{tabular}{|c|c|c|c|c|c|}
\hline \multicolumn{6}{|c|}{ Supplemental Table S2.txt } \\
\hline CHEMBL1307194 & 688816 & 4.55 & 5.3408 & TRN & \\
\hline CHEMBL1483036 & 688816 & 8.1024 & 5.0949 & TRN & \\
\hline CHEMBL1429646 & 688816 & 5.1 & 5.2445 & TRN & \\
\hline CHEMBL1605017 & 688816 & 4.5 & 5.1122 & TRN & \\
\hline CHEMBL511207 & 688816 & 4.45 & 5.186 & TRN & \\
\hline CHEMBL1311290 & 688816 & 4.6 & 5.575 & TST & \\
\hline CHEMBL1413393 & 688816 & 5.25 & 5.1735 & TRN & \\
\hline CHEMBL1417225 & 688816 & 5.55 & 5.2069 & TST & \\
\hline CHEMBL1376278 & 688816 & 5.45 & 5.7026 & TRN & \\
\hline CHEMBL1472561 & 688816 & 6.6 & 5.8263 & TST & \\
\hline CHEMBL1551836 & 688816 & 5.25 & 5.1468 & TST & \\
\hline CHEMBL1518073 & 688816 & 5.25 & 5.4881 & TST & \\
\hline CHEMBL1461585 & 688816 & 4.6 & 5.0855 & TRN & \\
\hline CHEMBL3213083 & 688816 & 4.8 & 5.3504 & TRN & \\
\hline CHEMBL1480868 & 688816 & 6.0 & 5.4065 & TRN & \\
\hline CHEMBL1319546 & 688816 & 6.5501 & 5.5373 & TST & \\
\hline CHEMBL1324686 & 688816 & 6.1 & 5.2868 & TST & \\
\hline CHEMBL1524487 & 688816 & 4.9 & 5.3333 & TST & \\
\hline CHEMBL1208858 & 688816 & 4.8 & 4.8519 & TST & \\
\hline CHEMBL1572518 & 688816 & 4.7 & 5.3681 & TRN & \\
\hline CHEMBL1484830 & 688816 & 4.75 & 5.3697 & TST & \\
\hline CHEMBL1599803 & 688816 & 4.8 & 5.4233 & TRN & \\
\hline CHEMBL1341938 & 688816 & 5.25 & 5.1744 & TRN & \\
\hline CHEMBL1305023 & 688816 & 5.95 & 5.4806 & TRN & \\
\hline CHEMBL1507437 & 688816 & 4.65 & 5.0453 & TRN & \\
\hline CHEMBL1560707 & 688816 & 5.0 & 5.3961 & TRN & \\
\hline CHEMBL1402384 & 688816 & 5.15 & 5.5957 & TRN & \\
\hline CHEMBL1407627 & 688816 & 4.6 & 4.8939 & TRN & \\
\hline CHEMBL1978103 & 688816 & 4.45 & 5.3555 & TRN & \\
\hline CHEMBL1460225 & 688816 & 5.45 & 5.3239 & TRN & \\
\hline CHEMBL1338889 & 688816 & 4.45 & 5.1524 & TRN & \\
\hline CHEMBL1534430 & 688816 & 4.6 & 5.1803 & TRN & \\
\hline CHEMBL1611768 & 688816 & 5.3 & 5.4866 & TST & \\
\hline CHEMBL3193959 & 688816 & 4.9 & 5.1513 & TRN & \\
\hline CHEMBL1366300 & 688816 & 4.85 & 5.28299 & 99999999995 & TRN \\
\hline CHEMBL1562548 & 688816 & 4.45 & 5.5528 & TRN & \\
\hline CHEMBL1407912 & 688816 & 4.8 & 5.0907 & TRN & \\
\hline CHEMBL1544836 & 688816 & 4.95 & 4.8954 & TRN & \\
\hline CHEMBL1564952 & 688816 & 4.9 & 5.4272 & TRN & \\
\hline CHEMBL1420116 & 688816 & 5.2 & 4.9377 & TST & \\
\hline CHEMBL1561103 & 688816 & 4.45 & 5.1511 & TRN & \\
\hline CHEMBL3211876 & 688816 & 5.85 & 5.7299 & TRN & \\
\hline CHEMBL1426844 & 688816 & 4.45 & 5.2779 & TRN & \\
\hline CHEMBL1383857 & 688816 & 4.9 & 5.3965 & TST & \\
\hline CHEMBL1380552 & 688816 & 4.45 & 5.3867 & TRN & \\
\hline CHEMBL1483026 & 688816 & 4.7 & 5.1805 & TRN & \\
\hline CHEMBL56393 & 688816 & 4.9 & 5.0614 & TRN & \\
\hline CHEMBL1496004 & 688816 & 5.05 & 5.0392 & TST & \\
\hline
\end{tabular}




\begin{tabular}{|c|c|c|c|c|c|}
\hline \multicolumn{6}{|c|}{ Supplemental Table S2.txt } \\
\hline CHEMBL1550616 & 688816 & 5.1 & 5.0239 & TST & \\
\hline CHEMBL1609058 & 688816 & 5.55 & 5.1849 & TRN & \\
\hline CHEMBL1350745 & 688816 & 7.8013 & 5.8451 & TST & \\
\hline CHEMBL484663 & 688816 & 6.0 & 5.2742 & TRN & \\
\hline CHEMBL1335336 & 688816 & 5.0 & 5.2263 & TRN & \\
\hline CHEMBL1366350 & 688816 & 5.1 & 5.0686 & TRN & \\
\hline CHEMBL1307529 & 688816 & 6.95 & 5.4362 & TRN & \\
\hline CHEMBL1567097 & 688816 & 5.5 & 4.8972 & TRN & \\
\hline CHEMBL1465693 & 688816 & 6.15 & 5.206 & TST & \\
\hline CHEMBL1546763 & 688816 & 5.1 & 5.2916 & TRN & \\
\hline CHEMBL1605869 & 688816 & 4.9 & 5.4031 & TRN & \\
\hline CHEMBL1369856 & 688816 & 4.65 & 5.7464 & TRN & \\
\hline CHEMBL1535304 & 688816 & 4.65 & 5.1111 & TRN & \\
\hline CHEMBL1323992 & 688816 & 8.3468 & 5.6778 & TRN & \\
\hline CHEMBL1467407 & 688816 & 4.8 & 5.1063 & TRN & \\
\hline CHEMBL3210188 & 688816 & 4.65 & 5.0651 & TST & \\
\hline CHEMBL1568226 & 688816 & 4.9 & 5.0229 & TRN & \\
\hline CHEMBL1428456 & 688816 & 5.0 & 5.2144 & TRN & \\
\hline CHEMBL1485449 & 688816 & 5.8 & 5.0303 & TRN & \\
\hline CHEMBL1375126 & 688816 & 6.8499 & 5.3871 & TRN & \\
\hline CHEMBL1573293 & 688816 & 4.9 & 5.3205 & TRN & \\
\hline CHEMBL1382739 & 688816 & 4.65 & 5.3619 & TRN & \\
\hline CHEMBL1550507 & 688816 & 4.45 & 5.2448 & TRN & \\
\hline CHEMBL1542702 & 688816 & 5.0 & 5.5866 & TRN & \\
\hline CHEMBL1329082 & 688816 & 5.0 & 4.7985 & TRN & \\
\hline CHEMBL1441206 & 688816 & 4.75 & 5.1635 & TRN & \\
\hline CHEMBL1586972 & 688816 & 4.9 & 5.1508 & TRN & \\
\hline CHEMBL1347861 & 688816 & 4.85 & 4.9689 & TST & \\
\hline CHEMBL1524799 & 688816 & 4.85 & 5.1007 & TST & \\
\hline CHEMBL1412770 & 688816 & 6.7501 & 5.2805 & TST & \\
\hline CHEMBL1407407 & 688816 & 4.95 & 5.0859 & TST & \\
\hline CHEMBL1602622 & 688816 & 5.6 & 5.1023 & TRN & \\
\hline CHEMBL1441851 & 688816 & 4.45 & 5.3635 & TRN & \\
\hline CHEMBL3191903 & 688816 & 4.95 & 5.1688 & TRN & \\
\hline CHEMBL1469991 & 688816 & 4.95 & 5.5349 & TRN & \\
\hline CHEMBL1566410 & 688816 & 5.0 & 5.86700 & 0000000001 & TST \\
\hline CHEMBL1544677 & 688816 & 7.5003 & 5.7404 & TRN & \\
\hline CHEMBL1609798 & 688816 & 5.05 & 5.3128 & TRN & \\
\hline CHEMBL1594576 & 688816 & 4.95 & 5.4028 & TST & \\
\hline CHEMBL1332019 & 688816 & 8.0 & 5.3625 & TRN & \\
\hline CHEMBL1404620 & 688816 & 4.85 & 5.5704 & TRN & \\
\hline CHEMBL1606510 & 688816 & 4.45 & 5.0898 & TRN & \\
\hline CHEMBL1602289 & 688816 & 5.4 & 5.5457 & TST & \\
\hline CHEMBL3196431 & 688816 & 4.9 & 5.2698 & TRN & \\
\hline CHEMBL1416235 & 688816 & 4.45 & 4.9336 & TRN & \\
\hline CHEMBL1404864 & 688816 & 5.35 & 5.4156 & TST & \\
\hline CHEMBL1413839 & 688816 & 4.9 & 5.2221 & TRN & \\
\hline CHEMBL1430650 & 688816 & 4.9 & 5.1997 & TRN & \\
\hline
\end{tabular}




\begin{tabular}{|c|c|c|c|c|c|}
\hline \multicolumn{6}{|c|}{ Supplemental Table S2.txt } \\
\hline CHEMBL1441610 & 688816 & 4.85 & 5.348 & TST & \\
\hline CHEMBL567323 & 688816 & 4.7 & 5.4442 & TST & \\
\hline CHEMBL1371448 & 688816 & 4.45 & 5.1843 & TST & \\
\hline CHEMBL1307716 & 688816 & 4.45 & 5.3735 & TST & \\
\hline CHEMBL1574911 & 688816 & 4.45 & 5.0216 & TRN & \\
\hline CHEMBL1497218 & 688816 & 4.4 & 5.4238 & TST & \\
\hline CHEMBL1318014 & 688816 & 4.45 & 4.9764 & TRN & \\
\hline CHEMBL1593734 & 688816 & 4.9 & 4.9932 & TRN & \\
\hline CHEMBL1569142 & 688816 & 6.5 & 5.4891 & TST & \\
\hline CHEMBL1427170 & 688816 & 8.1487 & 5.6001 & TST & \\
\hline CHEMBL1385555 & 688816 & 5.4 & 5.0826 & TRN & \\
\hline CHEMBL1965956 & 688816 & 5.0 & 5.2645 & TRN & \\
\hline CHEMBL1498761 & 688816 & 5.5 & 5.2373 & TRN & \\
\hline CHEMBL414400 & 688816 & 5.5 & 5.6892 & TST & \\
\hline CHEMBL1524757 & 688816 & 4.45 & 4.98300 & 00000000005 & TRN \\
\hline CHEMBL1568777 & 688816 & 4.8 & 5.2294 & TRN & \\
\hline CHEMBL1467912 & 688816 & 4.85 & 4.8606 & TRN & \\
\hline CHEMBL1482521 & 688816 & 5.45 & 4.9424 & TRN & \\
\hline CHEMBL1546037 & 688816 & 4.95 & 4.8235 & TRN & \\
\hline CHEMBL 3210261 & 688816 & 7.15 & 5.9329 & TRN & \\
\hline CHEMBL1560292 & 688816 & 4.5 & 5.2861 & TRN & \\
\hline CHEMBL1391746 & 688816 & 5.0 & 4.9468 & TRN & \\
\hline CHEMBL1366704 & 688816 & 4.9 & 6.0916 & TRN & \\
\hline CHEMBL1604058 & 688816 & 4.75 & 5.4044 & TRN & \\
\hline CHEMBL1310563 & 688816 & 4.7 & 4.9908 & TRN & \\
\hline CHEMBL3304020 & 688816 & 5.85 & 5.1894 & TRN & \\
\hline CHEMBL1576580 & 688816 & 4.95 & 4.8768 & TRN & \\
\hline CHEMBL1570276 & 688816 & 4.95 & 5.1682 & TST & \\
\hline CHEMBL1526349 & 688816 & 4.45 & 5.4883 & TST & \\
\hline CHEMBL1595842 & 688816 & 5.25 & 5.3308 & TRN & \\
\hline CHEMBL1441328 & 688816 & 4.8 & 5.0933 & TRN & \\
\hline CHEMBL1310338 & 688816 & 6.0 & 5.4048 & TRN & \\
\hline CHEMBL1403377 & 688816 & 4.65 & 5.3648 & TRN & \\
\hline CHEMBL1601910 & 688816 & 6.1 & 5.0615 & TRN & \\
\hline CHEMBL1487451 & 688816 & 5.6 & 5.3666 & TRN & \\
\hline CHEMBL1595685 & 688816 & 4.85 & 5.1172 & TRN & \\
\hline CHEMBL11405 & 688816 & 4.95 & 4.8614 & TRN & \\
\hline CHEMBL1495697 & 688816 & 5.25 & 5.2778 & TRN & \\
\hline CHEMBL1519639 & 688816 & 4.95 & 5.3218 & TST & \\
\hline CHEMBL1450162 & 688816 & 4.7 & 5.2979 & TRN & \\
\hline CHEMBL1499125 & 688816 & 5.35 & 5.1169 & TST & \\
\hline CHEMBL1371188 & 688816 & 4.8 & 4.8787 & TRN & \\
\hline CHEMBL1558371 & 688816 & 5.0 & 5.2479 & TRN & \\
\hline CHEMBL1466479 & 688816 & 5.3 & 5.4506 & TST & \\
\hline CHEMBL1424269 & 688816 & 5.15 & 5.5023 & TRN & \\
\hline CHEMBL1599240 & 688816 & 5.25 & 5.6207 & TRN & \\
\hline CHEMBL1256844 & 688816 & 4.45 & 5.4956 & TST & \\
\hline CHEMBL1607781 & 688816 & 4.95 & 5.4679 & TRN & \\
\hline
\end{tabular}




\begin{tabular}{|c|c|c|c|c|c|}
\hline \multicolumn{6}{|c|}{ Supplemental Table S2.txt } \\
\hline CHEMBL1585489 & 688816 & 4.95 & 5.1104 & TRN & \\
\hline CHEMBL1299584 & 688816 & 4.95 & 5.6004 & TRN & \\
\hline CHEMBL1342703 & 688816 & 5.1 & 5.3581 & TRN & \\
\hline CHEMBL1362734 & 688816 & 4.8 & 5.1303 & TST & \\
\hline CHEMBL3190868 & 688816 & 5.35 & 5.1833 & TRN & \\
\hline CHEMBL1596329 & 688816 & 5.2 & 5.2242 & TRN & \\
\hline CHEMBL1549883 & 688816 & 4.6 & 5.2948 & TRN & \\
\hline CHEMBL1417424 & 688816 & 4.8 & 5.0375 & TRN & \\
\hline CHEMBL1471931 & 688816 & 5.1 & 5.1576 & TRN & \\
\hline CHEMBL1368879 & 688816 & 4.7 & 5.29899 & 99999999995 & TST \\
\hline CHEMBL579224 & 688816 & 5.3 & 5.4985 & TST & \\
\hline CHEMBL1508075 & 688816 & 7.5003 & 5.4825 & TRN & \\
\hline CHEMBL1464376 & 688816 & 4.9 & 5.1263 & TRN & \\
\hline CHEMBL1395999 & 688816 & 5.2 & 5.2432 & TRN & \\
\hline CHEMBL1309274 & 688816 & 5.15 & 5.4343 & TRN & \\
\hline CHEMBL1599663 & 688816 & 4.7 & 4.9359 & TRN & \\
\hline CHEMBL1477924 & 688816 & 5.4 & 5.1385 & TST & \\
\hline CHEMBL1427983 & 688816 & 4.45 & 5.4576 & TRN & \\
\hline CHEMBL1390302 & 688816 & 4.65 & 5.4893 & TRN & \\
\hline CHEMBL1430676 & 688816 & 5.35 & 5.7247 & TST & \\
\hline CHEMBL1347358 & 688816 & 4.45 & 5.1654 & TST & \\
\hline CHEMBL1306028 & 688816 & 4.6 & 5.0457 & TRN & \\
\hline CHEMBL1539698 & 688816 & 5.0 & 5.2167 & TRN & \\
\hline CHEMBL1431829 & 688816 & 4.95 & 5.74200 & 0000000001 & TRN \\
\hline CHEMBL1382516 & 688816 & 4.45 & 5.6592 & TRN & \\
\hline CHEMBL1447846 & 688816 & 7.9508 & 5.4453 & TST & \\
\hline CHEMBL1393450 & 688816 & 4.9 & 5.2992 & TRN & \\
\hline CHEMBL1575223 & 688816 & 5.2 & 5.1576 & TRN & \\
\hline CHEMBL1384675 & 688816 & 7.0501 & 5.5494 & TST & \\
\hline CHEMBL1597898 & 688816 & 4.7 & 5.2152 & TRN & \\
\hline CHEMBL1383681 & 688816 & 5.0 & 5.1501 & TRN & \\
\hline CHEMBL1326188 & 688816 & 5.1 & 5.0278 & TRN & \\
\hline CHEMBL1484006 & 688816 & 4.55 & 5.3642 & TRN & \\
\hline CHEMBL 275224 & 688816 & 5.85 & 5.1418 & TST & \\
\hline CHEMBL1570198 & 688816 & 8.3468 & 5.7693 & TRN & \\
\hline CHEMBL3211818 & 688816 & 4.75 & 4.8805 & TST & \\
\hline CHEMBL1428452 & 688816 & 5.6 & 5.1615 & TRN & \\
\hline CHEMBL1370044 & 688816 & 5.0 & 5.1036 & TRN & \\
\hline CHEMBL1459377 & 688816 & 4.85 & 5.5267 & TRN & \\
\hline CHEMBL3189329 & 688816 & 5.0 & 5.2882 & TRN & \\
\hline CHEMBL1323000 & 688816 & 4.45 & 5.2371 & TRN & \\
\hline CHEMBL1315504 & 688816 & 4.5 & 4.8521 & TRN & \\
\hline CHEMBL1338342 & 688816 & 5.05 & 5.0126 & TRN & \\
\hline CHEMBL1501105 & 688816 & 4.65 & 5.0271 & TRN & \\
\hline CHEMBL1587587 & 688816 & 5.0 & 4.7952 & TRN & \\
\hline CHEMBL1483695 & 688816 & 4.95 & 5.0729 & TRN & \\
\hline CHEMBL1603826 & 688816 & 4.55 & 5.2274 & TRN & \\
\hline CHEMBL1335610 & 688816 & 4.65 & 5.1743 & TRN & \\
\hline
\end{tabular}




\begin{tabular}{|c|c|c|c|c|c|}
\hline \multicolumn{6}{|c|}{ Supplemental Table S2.txt } \\
\hline CHEMBL1445456 & 688816 & 4.45 & 5.1355 & TRN & \\
\hline CHEMBL3208378 & 688816 & 5.2 & 5.1145 & TRN & \\
\hline CHEMBL1540629 & 688816 & 4.9 & 5.2497 & TRN & \\
\hline CHEMBL1579223 & 688816 & 4.95 & 5.0284 & TRN & \\
\hline CHEMBL1977087 & 688816 & 4.95 & 5.1577 & TST & \\
\hline CHEMBL1527043 & 688816 & 4.8 & 5.117 & TRN & \\
\hline CHEMBL1522444 & 688816 & 5.2 & 5.0373 & TRN & \\
\hline CHEMBL1527521 & 688816 & 8.3468 & 5.1769 & TRN & \\
\hline CHEMBL1441178 & 688816 & 4.75 & 5.0692 & TRN & \\
\hline CHEMBL1360165 & 688816 & 4.95 & 4.8073 & TRN & \\
\hline CHEMBL1369549 & 688816 & 4.85 & 5.166 & TRN & \\
\hline CHEMBL1579699 & 688816 & 4.65 & 5.2245 & TST & \\
\hline CHEMBL1582764 & 688816 & 5.4 & 5.2719 & TRN & \\
\hline CHEMBL1460792 & 688816 & 5.55 & 5.6488 & TRN & \\
\hline CHEMBL1312337 & 688816 & 4.45 & 4.7684 & TRN & \\
\hline CHEMBL1569970 & 688816 & 4.9 & 5.334 & TRN & \\
\hline CHEMBL3212758 & 688816 & 4.75 & 5.2613 & TRN & \\
\hline CHEMBL1500271 & 688816 & 5.25 & 5.1613 & TRN & \\
\hline CHEMBL1611059 & 688816 & 7.0 & 5.2555 & TST & \\
\hline CHEMBL1318184 & 688816 & 4.75 & 5.1109 & TRN & \\
\hline CHEMBL1611503 & 688816 & 6.6 & 5.0327 & TRN & \\
\hline CHEMBL1511042 & 688816 & 4.45 & $5.1110 e$ & 0000000001 & TRN \\
\hline CHEMBL3195359 & 688816 & 4.7 & 5.2959 & TRN & \\
\hline CHEMBL1531900 & 688816 & 6.6 & 5.3537 & TRN & \\
\hline CHEMBL1579693 & 688816 & 4.8 & 4.8812 & TRN & \\
\hline CHEMBL1521722 & 688816 & 4.95 & 5.2751 & TRN & \\
\hline CHEMBL1479833 & 688816 & 4.45 & 5.0749 & TRN & \\
\hline CHEMBL1449026 & 688816 & 5.0 & 5.4849 & TRN & \\
\hline CHEMBL1527152 & 688816 & 4.6 & 5.3801 & TRN & \\
\hline CHEMBL 90124 & 688816 & 6.0 & 5.9986 & TRN & \\
\hline CHEMBL1387896 & 688816 & 4.85 & 5.0285 & TRN & \\
\hline CHEMBL1594521 & 688816 & 4.9 & 5.1164 & TRN & \\
\hline CHEMBL1331553 & 688816 & 5.0 & 5.5369 & TRN & \\
\hline CHEMBL1591462 & 688816 & 4.9 & 4.9225 & TRN & \\
\hline CHEMBL1415470 & 688816 & 8.1487 & 5.2484 & TST & \\
\hline CHEMBL1604147 & 688816 & 6.8 & 5.6906 & TST & \\
\hline CHEMBL1334054 & 688816 & 5.0 & 5.2323 & TRN & \\
\hline CHEMBL1442632 & 688816 & 4.6 & 4.867 & TRN & \\
\hline CHEMBL1437815 & 688816 & 6.15 & 5.4311 & TRN & \\
\hline CHEMBL1517032 & 688816 & 4.85 & 5.2505 & TRN & \\
\hline CHEMBL1608799 & 688816 & 6.1 & 5.6101 & TST & \\
\hline CHEMBL1543836 & 688816 & 4.45 & 5.8181 & TST & \\
\hline CHEMBL1400662 & 688816 & 4.85 & 5.3953 & TRN & \\
\hline CHEMBL1503880 & 688816 & 6.05 & 5.695 & TRN & \\
\hline CHEMBL1310930 & 688816 & 4.85 & 5.0178 & TRN & \\
\hline CHEMBL 233302 & 688816 & 4.9 & 5.0376 & TRN & \\
\hline CHEMBL 1377280 & 688816 & 5.25 & 5.2638 & TRN & \\
\hline CHEMBL1550611 & 688816 & 8.301 & 5.2571 & TRN & \\
\hline
\end{tabular}




\begin{tabular}{|c|c|c|c|c|c|}
\hline \multicolumn{6}{|c|}{ plementa } \\
\hline CHEMBL1381270 & 688816 & 6.2 & 5.0831 & TST & \\
\hline CHEMBL1449424 & 688816 & 4.5 & 5.2925 & TRN & \\
\hline CHEMBL1523989 & 688816 & 4.85 & 5.0762 & TST & \\
\hline CHEMBL1611067 & 688816 & 4.45 & 4.8761 & TRN & \\
\hline CHEMBL3196917 & 688816 & 5.45 & 5.2515 & TRN & \\
\hline CHEMBL1564908 & 688816 & 4.85 & 5.3776 & TRN & \\
\hline CHEMBL1342028 & 688816 & 5.5 & 5.0842 & TRN & \\
\hline CHEMBL1432206 & 688816 & 8.301 & 5.6843 & TST & \\
\hline CHEMBL1602452 & 688816 & 4.85 & 5.5242 & TST & \\
\hline CHEMBL1599362 & 688816 & 5.25 & 5.6895 & TRN & \\
\hline CHEMBL1486244 & 688816 & 4.75 & 5.3984 & TRN & \\
\hline CHEMBL1351200 & 688816 & 4.7 & 5.2002 & TST & \\
\hline CHEMBL1547341 & 688816 & 4.95 & 5.0813 & TRN & \\
\hline CHEMBL1587812 & 688816 & 5.4 & 5.5612 & TRN & \\
\hline CHEMBL1602119 & 688816 & 4.75 & 5.6255 & TRN & \\
\hline CHEMBL1345933 & 688816 & 4.9 & 5.1847 & TRN & \\
\hline CHEMBL1482435 & 688816 & 6.7501 & 5.9012 & TRN & \\
\hline CHEMBL1393367 & 688816 & 4.9 & 5.1479 & TST & \\
\hline CHEMBL1600169 & 688816 & 4.7 & 5.2316 & TRN & \\
\hline CHEMBL1410749 & 688816 & 5.5 & 5.2469 & TRN & \\
\hline CHEMBL1478560 & 688816 & 5.15 & 5.0958 & TRN & \\
\hline CHEMBL1489256 & 688816 & 5.45 & 4.938 & TRN & \\
\hline CHEMBL1529062 & 688816 & 5.25 & 5.197 & TST & \\
\hline CHEMBL1536223 & 688816 & 6.9 & 5.2826 & TRN & \\
\hline CHEMBL1493590 & 688816 & 6.6 & 5.4072 & TRN & \\
\hline CHEMBL1528613 & 688816 & 4.45 & 5.5632 & TRN & \\
\hline CHEMBL1394143 & 688816 & 4.45 & 4.9944 & TRN & \\
\hline CHEMBL3196677 & 688816 & 4.9 & 5.0792 & TST & \\
\hline CHEMBL1379132 & 688816 & 5.15 & 5.3829 & TRN & \\
\hline CHEMBL1311684 & 688816 & 5.35 & 5.3641 & TRN & \\
\hline CHEMBL1518000 & 688816 & 7.0501 & 5.0519 & TST & \\
\hline CHEMBL1413571 & 688816 & 4.45 & 5.3845 & TRN & \\
\hline CHEMBL1333929 & 688816 & 4.95 & 5.2088 & TRN & \\
\hline CHEMBL1602151 & 688816 & 4.95 & 5.1344 & TRN & \\
\hline CHEMBL1406332 & 688816 & 8.301 & 5.3941 & TRN & \\
\hline CHEMBL1386609 & 688816 & 4.8 & 4.7714 & TRN & \\
\hline CHEMBL1495910 & 688816 & 4.85 & 5.1868 & TRN & \\
\hline CHEMBL1599602 & 688816 & 4.6 & 5.3979 & TST & \\
\hline CHEMBL1555508 & 688816 & 6.95 & 5.29299 & 9999999999 & TST \\
\hline CHEMBL1584562 & 688816 & 5.2 & 5.2688 & TRN & \\
\hline CHEMBL1505979 & 688816 & 5.35 & 5.4903 & TRN & \\
\hline CHEMBL452954 & 688816 & 4.9 & 5.0177 & TRN & \\
\hline CHEMBL1426739 & 688816 & 4.45 & 5.42299 & 9999999999 & TRN \\
\hline CHEMBL1325217 & 688816 & 4.85 & 5.4921 & TRN & \\
\hline CHEMBL1522672 & 688816 & 5.0 & 5.2545 & TRN & \\
\hline CHEMBL1445168 & 688816 & 4.65 & 4.9131 & TRN & \\
\hline CHEMBL1559377 & 688816 & 4.45 & 5.2129 & TRN & \\
\hline CHEMBL1585557 & 688816 & 4.9 & 5.3207 & TRN & \\
\hline
\end{tabular}




\begin{tabular}{|c|c|c|c|c|c|}
\hline \multicolumn{6}{|c|}{ Supplemental Table s2.txt } \\
\hline CHEMBL1417009 & 688816 & 4.45 & 5.2737 & TRN & \\
\hline CHEMBL 3210244 & 688816 & 5.8 & 5.6439 & TRN & \\
\hline CHEMBL1478163 & 688816 & 4.45 & 5.3457 & TRN & \\
\hline CHEMBL1305235 & 688816 & 4.45 & 5.3778 & TST & \\
\hline CHEMBL1479375 & 688816 & 8.3468 & 5.5557 & TRN & \\
\hline CHEMBL1351951 & 688816 & 4.45 & 5.0939 & TRN & \\
\hline CHEMBL1492779 & 688816 & 5.45 & 5.896 & TST & \\
\hline CHEMBL1339093 & 688816 & 4.9 & 5.5848 & TRN & \\
\hline CHEMBL1576779 & 688816 & 4.5 & 5.3698 & TRN & \\
\hline CHEMBL1549837 & 688816 & 4.95 & 5.3298 & TRN & \\
\hline CHEMBL1568155 & 688816 & 5.85 & 5.4937 & TRN & \\
\hline CHEMBL1468326 & 688816 & 8.4949 & 5.70100 & 00000000005 & TST \\
\hline CHEMBL1572749 & 688816 & 4.8 & 5.0257 & TRN & \\
\hline CHEMBL1372799 & 688816 & 4.7 & 5.2873 & TRN & \\
\hline CHEMBL1314527 & 688816 & 4.95 & 5.0771 & TRN & \\
\hline CHEMBL1481308 & 688816 & 8.301 & 5.6581 & TRN & \\
\hline CHEMBL1344144 & 688816 & 4.5 & 4.9967 & TRN & \\
\hline CHEMBL3193439 & 688816 & 4.65 & 5.0349 & TRN & \\
\hline CHEMBL1365382 & 688816 & 4.45 & 5.1104 & TRN & \\
\hline CHEMBL1403848 & 688816 & 4.95 & 5.1876 & TRN & \\
\hline CHEMBL1382924 & 688816 & 4.85 & 5.0461 & TRN & \\
\hline CHEMBL1422129 & 688816 & 7.8013 & 5.6836 & TRN & \\
\hline CHEMBL1540446 & 688816 & 4.85 & 5.1088 & TRN & \\
\hline CHEMBL1553009 & 688816 & 4.8 & 5.2675 & TRN & \\
\hline CHEMBL1583074 & 688816 & 5.2 & 5.6592 & TST & \\
\hline CHEMBL1307468 & 688816 & 5.25 & 5.0674 & TRN & \\
\hline CHEMBL1401399 & 688816 & 5.05 & 5.3336 & TRN & \\
\hline CHEMBL1336378 & 688816 & 4.75 & 5.1123 & TRN & \\
\hline CHEMBL1516327 & 688816 & 4.85 & 5.1481 & TRN & \\
\hline CHEMBL1484121 & 688816 & 5.1 & 5.6086 & TRN & \\
\hline CHEMBL1440342 & 688816 & 5.25 & 5.5488 & TST & \\
\hline CHEMBL1456743 & 688816 & 5.0 & 5.1082 & TRN & \\
\hline CHEMBL1504299 & 688816 & 4.95 & 4.9925 & TRN & \\
\hline CHEMBL1584333 & 688816 & 4.95 & 5.5251 & TRN & \\
\hline CHEMBL1599295 & 688816 & 4.45 & 5.4211 & TRN & \\
\hline CHEMBL1478825 & 688816 & 4.6 & 5.3289 & TRN & \\
\hline CHEMBL3196713 & 688816 & 7.6498 & 5.1367 & TRN & \\
\hline CHEMBL1428820 & 688816 & 6.25 & 5.3212 & TRN & \\
\hline CHEMBL1520767 & 688816 & 6.2 & 5.4741 & TRN & \\
\hline CHEMBL1469897 & 688816 & 5.0 & 5.5346 & TRN & \\
\hline CHEMBL1377336 & 688816 & 4.95 & 5.0456 & TST & \\
\hline CHEMBL1410427 & 688816 & 5.3 & 5.7727 & TST & \\
\hline CHEMBL1379788 & 688816 & 4.9 & 5.5004 & TRN & \\
\hline CHEMBL1453126 & 688816 & 4.75 & 5.2125 & TRN & \\
\hline CHEMBL1517847 & 688816 & 5.25 & 5.2475 & TRN & \\
\hline CHEMBL1497628 & 688816 & 5.3 & 5.41299 & 9999999999 & TRN \\
\hline CHEMBL3190733 & 688816 & 4.95 & 4.9376 & TRN & \\
\hline CHEMBL1528245 & 688816 & 4.75 & 5.2059 & TRN & \\
\hline
\end{tabular}




\begin{tabular}{|c|c|c|c|c|c|}
\hline \multicolumn{6}{|c|}{ Supplemental Table s2.txt } \\
\hline CHEMBL1530438 & 688816 & 5.2 & 5.2888 & TRN & \\
\hline CHEMBL1415588 & 688816 & 4.8 & 5.067 & TRN & \\
\hline CHEMBL1300262 & 688816 & 4.8 & 5.3621 & TRN & \\
\hline CHEMBL1455816 & 688816 & 6.0 & 4.9366 & TRN & \\
\hline CHEMBL1351384 & 688816 & 5.25 & 5.6789 & TRN & \\
\hline CHEMBL1511384 & 688816 & 4.65 & 5.4653 & TRN & \\
\hline CHEMBL1416366 & 688816 & 6.3 & 5.1561 & TRN & \\
\hline CHEMBL1302670 & 688816 & 4.45 & 5.0714 & TRN & \\
\hline CHEMBL1337650 & 688816 & 7.7496 & 5.6198 & TRN & \\
\hline CHEMBL1576937 & 688816 & 4.9 & 5.1576 & TRN & \\
\hline CHEMBL235658 & 688816 & 4.9 & 5.0749 & TST & \\
\hline CHEMBL1484856 & 688816 & 4.6 & 4.9364 & TRN & \\
\hline CHEMBL1572955 & 688816 & 4.85 & 4.7554 & TRN & \\
\hline CHEMBL1504089 & 688816 & 4.9 & 4.9599 & TRN & \\
\hline CHEMBL1444473 & 688816 & 4.95 & 5.2821 & TRN & \\
\hline CHEMBL1439499 & 688816 & 4.55 & 4.7681 & TRN & \\
\hline CHEMBL1604622 & 688816 & 4.45 & 5.0046 & TRN & \\
\hline CHEMBL1340138 & 688816 & 4.85 & 5.7356 & TRN & \\
\hline CHEMBL1573529 & 688816 & 7.6498 & 5.4624 & TST & \\
\hline CHEMBL1466669 & 688816 & 4.9 & 5.3839 & TRN & \\
\hline CHEMBL3212700 & 688816 & 4.7 & 5.3386 & TRN & \\
\hline CHEMBL1339083 & 688816 & 5.45 & 5.5294 & TRN & \\
\hline CHEMBL1966751 & 688816 & 4.45 & 5.46299 & 9999999999 & TRN \\
\hline CHEMBL1375571 & 688816 & 5.6 & 5.3899 & TRN & \\
\hline CHEMBL1548778 & 688816 & 8.301 & 5.3636 & TRN & \\
\hline CHEMBL1440053 & 688816 & 4.95 & 5.0604 & TRN & \\
\hline CHEMBL1412627 & 688816 & 4.85 & 4.9777 & TRN & \\
\hline CHEMBL1494723 & 688816 & 5.5 & 5.2267 & TRN & \\
\hline CHEMBL1452046 & 688816 & 4.45 & 5.441 & TRN & \\
\hline CHEMBL1483814 & 688816 & 4.95 & 5.2298 & TRN & \\
\hline CHEMBL3189551 & 688816 & 4.85 & 4.9019 & TRN & \\
\hline CHEMBL3212091 & 688816 & 4.45 & 5.3689 & TRN & \\
\hline CHEMBL47940 & 688816 & 5.0 & 5.1015 & TST & \\
\hline CHEMBL1447147 & 688816 & 5.0 & 5.2837 & TST & \\
\hline CHEMBL1541881 & 688816 & 5.3 & 5.0008 & TST & \\
\hline CHEMBL1352616 & 688816 & 4.9 & 5.1045 & TRN & \\
\hline CHEMBL1406822 & 688816 & 5.0 & 5.5834 & TST & \\
\hline CHEMBL3198896 & 688816 & 4.95 & 5.4526 & TST & \\
\hline CHEMBL1333159 & 688816 & 6.7501 & $5.3370 e$ & 0000000001 & TRN \\
\hline CHEMBL1425623 & 688816 & 5.8 & 5.6186 & TRN & \\
\hline CHEMBL1371991 & 688816 & 4.95 & 4.8866 & TRN & \\
\hline CHEMBL1498274 & 688816 & 4.75 & 5.3956 & TRN & \\
\hline CHEMBL1455547 & 688816 & 5.25 & 5.1061 & TRN & \\
\hline CHEMBL1431023 & 688816 & 5.55 & 5.4881 & TRN & \\
\hline CHEMBL1539762 & 688816 & 4.8 & 4.8945 & TRN & \\
\hline CHEMBL1595317 & 688816 & 5.4 & 5.5631 & TST & \\
\hline CHEMBL1409606 & 688816 & 4.45 & 5.3559 & TST & \\
\hline CHEMBL1582936 & 688816 & 7.1002 & 5.2535 & TST & \\
\hline
\end{tabular}




\begin{tabular}{|c|c|c|c|c|c|}
\hline & & \multicolumn{4}{|c|}{ Supplemental Table S2.txt } \\
\hline CHEMBL 3195100 & 688816 & 8.3468 & 5.3439 & TRN & \\
\hline CHEMBL1610205 & 688816 & 5.45 & 5.5649 & TRN & \\
\hline CHEMBL1566726 & 688816 & 4.8 & 5.0482 & TRN & \\
\hline CHEMBL1469328 & 688816 & 5.5 & 5.669 & TRN & \\
\hline CHEMBL1410121 & 688816 & 5.45 & 5.4858 & TRN & \\
\hline CHEMBL1597230 & 688816 & 4.85 & 5.0709 & TRN & \\
\hline CHEMBL1353069 & 688816 & 4.85 & 4.9913 & TRN & \\
\hline CHEMBL1320735 & 688816 & 4.65 & 5.1103 & TRN & \\
\hline CHEMBL1575269 & 688816 & 6.8 & 5.597 & TRN & \\
\hline CHEMBL1484934 & 688816 & 4.95 & 4.878 & TRN & \\
\hline CHEMBL1596260 & 688816 & 4.9 & 5.1303 & TRN & \\
\hline CHEMBL1425853 & 688816 & 4.45 & 4.9117 & TRN & \\
\hline CHEMBL1587823 & 688816 & 7.7496 & 5.5235 & TRN & \\
\hline CHEMBL1549037 & 688816 & 4.85 & 5.3441 & TST & \\
\hline CHEMBL1585912 & 688816 & 4.75 & 5.0113 & TST & \\
\hline CHEMBL1557142 & 688816 & 5.05 & 4.9871 & TST & \\
\hline CHEMBL1605939 & 688816 & 5.2 & 5.0745 & TST & \\
\hline CHEMBL1516587 & 688816 & 6.8 & 5.83 & TRN & \\
\hline CHEMBL1609489 & 688816 & 7.0 & 5.1384 & TST & \\
\hline CHEMBL3197051 & 688816 & 4.9 & 5.3957 & TST & \\
\hline CHEMBL1505071 & 688816 & 5.05 & 4.8139 & TRN & \\
\hline CHEMBL1487466 & 688816 & 4.85 & 4.9566 & TRN & \\
\hline CHEMBL1395100 & 688816 & 4.75 & 4.6368 & TRN & \\
\hline CHEMBL1411203 & 688816 & 4.45 & 4.6706 & TRN & \\
\hline CHEMBL1567419 & 688816 & 4.8 & 5.6216 & TST & \\
\hline CHEMBL1402900 & 688816 & 4.45 & 5.1229 & TST & \\
\hline CHEMBL1390868 & 688816 & 6.3 & 5.3142 & TST & \\
\hline CHEMBL1575261 & 688816 & 4.85 & 4.675 & TRN & \\
\hline CHEMBL3212009 & 688816 & 5.35 & 5.6427 & TRN & \\
\hline CHEMBL1566334 & 688816 & 5.25 & 5.24799 & 9999999999 & TRN \\
\hline CHEMBL1513844 & 688816 & 4.8 & 5.0956 & TRN & \\
\hline CHEMBL1323810 & 688816 & 4.5 & 5.4688 & TRN & \\
\hline CHEMBL1380393 & 688816 & 5.15 & 5.3266 & TST & \\
\hline CHEMBL1479296 & 688816 & 6.2 & 5.1244 & TRN & \\
\hline CHEMBL1366204 & 688816 & 4.9 & 5.357 & TRN & \\
\hline CHEMBL1559566 & 688816 & 4.9 & 4.8546 & TST & \\
\hline CHEMBL1407565 & 688816 & 4.45 & 5.6333 & TRN & \\
\hline CHEMBL1559993 & 688816 & 6.15 & 4.7581 & TRN & \\
\hline CHEMBL1428763 & 688816 & 4.7 & 5.0007 & TRN & \\
\hline CHEMBL1408205 & 688816 & 4.9 & 5.2509 & TRN & \\
\hline CHEMBL1338390 & 688816 & 4.9 & 5.1843 & TRN & \\
\hline CHEMBL1492033 & 688816 & 4.45 & 5.5096 & TRN & \\
\hline CHEMBL1466197 & 688816 & 4.95 & 5.2922 & TRN & \\
\hline CHEMBL1355018 & 688816 & 4.9 & 5.2466 & TRN & \\
\hline CHEMBL1336057 & 688816 & 5.25 & 5.2112 & TRN & \\
\hline CHEMBL 2003452 & 688816 & 6.5501 & 5.4683 & TRN & \\
\hline CHEMBL1465069 & 688816 & 4.6 & 5.3866 & TRN & \\
\hline CHEMBL1403436 & 688816 & 5.05 & 4.8789 & TST & \\
\hline
\end{tabular}




\begin{tabular}{|c|c|c|c|c|c|}
\hline \multicolumn{6}{|c|}{ Supplemental Table s2.txt } \\
\hline CHEMBL1256911 & 688816 & 4.65 & 5.1154 & TST & \\
\hline CHEMBL256202 & 688816 & 5.25 & 5.32 & TRN & \\
\hline CHEMBL1400181 & 688816 & 4.95 & 5.1796 & TST & \\
\hline CHEMBL1985664 & 688816 & 7.699 & 5.329 & TRN & \\
\hline CHEMBL1478035 & 688816 & 5.15 & 5.0552 & TRN & \\
\hline CHEMBL1495506 & 688816 & 5.2 & 5.3852 & TRN & \\
\hline CHEMBL1408904 & 688816 & 4.85 & 5.2584 & TRN & \\
\hline CHEMBL1531593 & 688816 & 4.8 & 5.4685 & TST & \\
\hline CHEMBL1410155 & 688816 & 4.95 & 4.8559 & TRN & \\
\hline CHEMBL1384365 & 688816 & 5.4 & 5.2794 & TST & \\
\hline CHEMBL1309071 & 688816 & 6.4 & 5.3189 & TRN & \\
\hline CHEMBL1602908 & 688816 & 5.4 & 5.2308 & TRN & \\
\hline CHEMBL1467082 & 688816 & 4.45 & 4.9342 & TRN & \\
\hline CHEMBL 2236406 & 688816 & 5.25 & 5.0672 & TRN & \\
\hline CHEMBL1366132 & 688816 & 8.1487 & 6.0652 & TST & \\
\hline CHEMBL1605433 & 688816 & 6.8 & 5.5832 & TRN & \\
\hline CHEMBL1431315 & 688816 & 4.9 & 5.0849 & TRN & \\
\hline CHEMBL1588685 & 688816 & 4.45 & 5.0471 & TST & \\
\hline CHEMBL1447273 & 688816 & 4.85 & 5.4506 & TST & \\
\hline CHEMBL1485911 & 688816 & 4.45 & 5.6586 & TST & \\
\hline CHEMBL1362353 & 688816 & 6.7501 & 5.169 & TRN & \\
\hline CHEMBL1454299 & 688816 & 7.5003 & 5.7391 & TRN & \\
\hline CHEMBL1566972 & 688816 & 4.75 & 5.2991 & TST & \\
\hline CHEMBL1320219 & 688816 & 4.6 & 5.2072 & TRN & \\
\hline CHEMBL1600944 & 688816 & 5.9 & 5.3062 & TRN & \\
\hline CHEMBL1375669 & 688816 & 5.5 & 5.1523 & TRN & \\
\hline CHEMBL1497426 & 688816 & 5.0 & 5.2488 & TRN & \\
\hline CHEMBL1548647 & 688816 & 6.1 & 5.1953 & TRN & \\
\hline CHEMBL1443533 & 688816 & 4.95 & 5.3418 & TRN & \\
\hline CHEMBL1385083 & 688816 & 5.7 & 5.5297 & TRN & \\
\hline CHEMBL1521261 & 688816 & 7.5498 & 4.9791 & TST & \\
\hline CHEMBL3191044 & 688816 & 7.5003 & 5.5809 & TRN & \\
\hline CHEMBL1498265 & 688816 & 4.45 & 5.1084 & TST & \\
\hline CHEMBL1498511 & 688816 & 4.8 & 5.3928 & TRN & \\
\hline CHEMBL1603151 & 688816 & 5.5 & 5.2893 & TRN & \\
\hline CHEMBL1515976 & 688816 & 4.65 & 5.1528 & TRN & \\
\hline CHEMBL1407138 & 688816 & 4.95 & 4.8716 & TRN & \\
\hline CHEMBL1388588 & 688816 & 4.95 & 5.4795 & TRN & \\
\hline CHEMBL1443449 & 688816 & 4.9 & 5.1484 & TRN & \\
\hline CHEMBL1507704 & 688816 & 4.65 & 5.19600 & 0000000001 & TST \\
\hline CHEMBL1557315 & 688816 & 4.9 & 4.9834 & TRN & \\
\hline CHEMBL1303664 & 688816 & 4.9 & 5.1624 & TRN & \\
\hline CHEMBL1576065 & 688816 & 4.6 & 5.12799 & э999999999 & TRN \\
\hline CHEMBL1518278 & 688816 & 4.75 & 5.334 & TRN & \\
\hline CHEMBL2311878 & 688816 & 4.8 & 5.1216 & TRN & \\
\hline CHEMBL1512459 & 688816 & 8.0506 & 5.1709 & TST & \\
\hline CHEMBL1345067 & 688816 & 4.9 & 5.2753 & TRN & \\
\hline CHEMBL1393898 & 688816 & 4.7 & 5.107 & TST & \\
\hline
\end{tabular}




\begin{tabular}{|c|c|c|c|c|c|}
\hline & & \multicolumn{4}{|c|}{ Supplemental Table S2.txt } \\
\hline CHEMBL3192131 & 688816 & 6.8499 & 5.744 & TRN & \\
\hline CHEMBL1568471 & 688816 & 4.8 & 5.09 & TST & \\
\hline CHEMBL491991 & 688816 & 4.85 & 5.2391 & TRN & \\
\hline CHEMBL 225270 & 688816 & 4.8 & 5.0518 & TST & \\
\hline CHEMBL1609323 & 688816 & 4.45 & 5.4503 & TRN & \\
\hline CHEMBL1503058 & 688816 & 6.05 & 5.1898 & TRN & \\
\hline CHEMBL1595194 & 688816 & 4.65 & 5.166 & TRN & \\
\hline CHEMBL1401044 & 688816 & 5.2 & 5.1162 & TRN & \\
\hline CHEMBL1379600 & 688816 & 4.65 & 4.6693 & TRN & \\
\hline CHEMBL1550842 & 688816 & 4.45 & 5.1525 & TRN & \\
\hline CHEMBL1327046 & 688816 & 5.1 & 4.6678 & TRN & \\
\hline CHEMBL1462049 & 688816 & 5.05 & 5.0809 & TRN & \\
\hline CHEMBL1516848 & 688816 & 4.45 & 5.1268 & TRN & \\
\hline CHEMBL1970836 & 688816 & 5.15 & 5.2475 & TRN & \\
\hline CHEMBL1445779 & 688816 & 4.85 & 4.88899 & 9999999999 & TRN \\
\hline CHEMBL1564339 & 688816 & 8.1024 & 5.1558 & TST & \\
\hline CHEMBL1569601 & 688816 & 4.65 & 5.276 & TRN & \\
\hline CHEMBL1431338 & 688816 & 4.5 & 5.0074 & TST & \\
\hline CHEMBL1532901 & 688816 & 8.0 & 5.0496 & TRN & \\
\hline CHEMBL1423970 & 688816 & 5.05 & 5.506 & TRN & \\
\hline CHEMBL252151 & 688816 & 4.95 & 5.3434 & TRN & \\
\hline CHEMBL1348317 & 688816 & 8.3468 & 5.545 & TRN & \\
\hline CHEMBL1459936 & 688816 & 4.9 & 5.3104 & TRN & \\
\hline CHEMBL1399984 & 688816 & 4.65 & 5.1829 & TRN & \\
\hline CHEMBL3198487 & 688816 & 7.5003 & 5.4621 & TST & \\
\hline CHEMBL1596619 & 688816 & 5.0 & 5.5015 & TRN & \\
\hline CHEMBL3190333 & 688816 & 4.45 & 5.50299 & 9999999999 & TST \\
\hline CHEMBL1604081 & 688816 & 5.15 & 5.2374 & TRN & \\
\hline CHEMBL 3145000 & 688816 & 4.9 & 5.0019 & TRN & \\
\hline CHEMBL 1447547 & 688816 & 4.45 & 5.0928 & TRN & \\
\hline CHEMBL1448675 & 688816 & 5.25 & 5.6647 & TST & \\
\hline CHEMBL1373331 & 688816 & 4.75 & 4.8682 & TRN & \\
\hline CHEMBL1451324 & 688816 & 4.45 & 5.0846 & TST & \\
\hline CHEMBL1453813 & 688816 & 4.45 & 5.1087 & TRN & \\
\hline CHEMBL1518145 & 688816 & 4.85 & 5.1813 & TRN & \\
\hline CHEMBL3210025 & 688816 & 5.4 & 4.9482 & TRN & \\
\hline CHEMBL1559003 & 688816 & 8.301 & 5.1881 & TRN & \\
\hline CHEMBL1547630 & 688816 & 4.45 & 5.4549 & TRN & \\
\hline CHEMBL1504264 & 688816 & 5.35 & 5.4515 & TRN & \\
\hline CHEMBL1325324 & 688816 & 4.75 & 5.244 & TRN & \\
\hline CHEMBL1610659 & 688816 & 6.0 & 5.0813 & TRN & \\
\hline CHEMBL1430264 & 688816 & 5.5 & 5.3211 & TST & \\
\hline CHEMBL1564546 & 688816 & 4.9 & 5.2524 & TRN & \\
\hline CHEMBL1312476 & 688816 & 4.45 & 5.2372 & TRN & \\
\hline CHEMBL1560290 & 688816 & 5.1 & 5.2376 & TRN & \\
\hline CHEMBL1423622 & 688816 & 4.8 & 5.1241 & TRN & \\
\hline CHEMBL1403633 & 688816 & 4.8 & 5.1072 & TRN & \\
\hline CHEMBL1544367 & 688816 & 5.2 & 5.3407 & TST & \\
\hline
\end{tabular}




\begin{tabular}{|c|c|c|c|c|c|}
\hline \multicolumn{6}{|c|}{ Supplemental Table S2.txt } \\
\hline CHEMBL1495725 & 688816 & 5.0 & 5.1387 & TRN & \\
\hline CHEMBL1376187 & 688816 & 4.45 & 5.0221 & TRN & \\
\hline CHEMBL1606292 & 688816 & 4.45 & 4.9932 & TRN & \\
\hline CHEMBL1449799 & 688816 & 5.0 & 4.7649 & TRN & \\
\hline CHEMBL1532623 & 688816 & 5.55 & 5.0646 & TRN & \\
\hline CHEMBL1393652 & 688816 & 4.9 & 4.961 & TRN & \\
\hline CHEMBL1489033 & 688816 & 5.0 & 5.1307 & TRN & \\
\hline CHEMBL1416497 & 688816 & 4.9 & 5.0049 & TRN & \\
\hline CHEMBL1585275 & 688816 & 4.45 & 4.6484 & TRN & \\
\hline CHEMBL1601439 & 688816 & 6.15 & 5.4151 & TRN & \\
\hline CHEMBL1583108 & 688816 & 4.9 & 5.4975 & TRN & \\
\hline CHEMBL1575456 & 688816 & 4.85 & 5.5786 & TRN & \\
\hline CHEMBL1432826 & 688816 & 5.45 & 5.4809 & TRN & \\
\hline CHEMBL1566403 & 688816 & 5.25 & 5.4245 & TRN & \\
\hline CHEMBL1410099 & 688816 & 4.7 & 5.0758 & TRN & \\
\hline CHEMBL1487157 & 688816 & 4.65 & 5.1549 & TRN & \\
\hline CHEMBL1427175 & 688816 & 4.85 & 5.58899 & 99999999995 & TRN \\
\hline CHEMBL1518819 & 688816 & 4.85 & 5.5398 & TST & \\
\hline CHEMBL1502209 & 688816 & 4.95 & 5.5275 & TRN & \\
\hline CHEMBL1583698 & 688816 & 4.9 & 5.4729 & TRN & \\
\hline CHEMBL3198615 & 688816 & 5.3 & 5.4056 & TST & \\
\hline CHEMBL1511370 & 688816 & 6.2 & 5.5948 & TRN & \\
\hline CHEMBL1993627 & 688816 & 4.7 & 5.2874 & TRN & \\
\hline CHEMBL1305481 & 688816 & 5.0 & 5.5474 & TRN & \\
\hline CHEMBL1301525 & 688816 & 4.45 & 4.8621 & TRN & \\
\hline CHEMBL1373153 & 688816 & 7.0 & 5.2576 & TRN & \\
\hline CHEMBL3209504 & 688816 & 7.5003 & 5.2785 & TRN & \\
\hline CHEMBL3209385 & 688816 & 4.75 & 5.6889 & TST & \\
\hline CHEMBL1490638 & 688816 & 5.1 & 4.9904 & TRN & \\
\hline CHEMBL1609854 & 688816 & 5.25 & 5.608 & TST & \\
\hline CHEMBL1467533 & 688816 & 5.15 & 5.1182 & TRN & \\
\hline CHEMBL1438861 & 688816 & 5.2 & 5.1752 & TRN & \\
\hline CHEMBL1364051 & 688816 & 4.9 & 4.989 & TRN & \\
\hline CHEMBL1322090 & 688816 & 4.9 & 5.0434 & TRN & \\
\hline CHEMBL1424665 & 688816 & 4.9 & 5.2196 & TRN & \\
\hline CHEMBL3210813 & 688816 & 8.3979 & 5.4127 & TST & \\
\hline CHEMBL 1420229 & 688816 & 4.6 & 5.0379 & TRN & \\
\hline CHEMBL1360238 & 688816 & 4.8 & 5.1041 & TRN & \\
\hline CHEMBL1978186 & 688816 & 7.3002 & 5.1676 & TST & \\
\hline CHEMBL1609730 & 688816 & 5.35 & 5.5672 & TRN & \\
\hline CHEMBL3190592 & 688816 & 5.0 & 5.3917 & TRN & \\
\hline CHEMBL1499094 & 688816 & 8.0 & 5.1105 & TRN & \\
\hline CHEMBL1493183 & 688816 & 5.15 & 5.4157 & TRN & \\
\hline CHEMBL116794 & 688816 & 4.8 & 4.9788 & TST & \\
\hline CHEMBL1527240 & 688816 & 4.7 & 4.9359 & TRN & \\
\hline CHEMBL1541000 & 688816 & 5.45 & 5.3021 & TRN & \\
\hline CHEMBL1434307 & 688816 & 4.9 & 4.9049 & TRN & \\
\hline CHEMBL1443305 & 688816 & 4.95 & 5.1676 & TRN & \\
\hline
\end{tabular}




\begin{tabular}{|c|c|c|c|c|c|}
\hline \multicolumn{6}{|c|}{ Supplemental Table s2.txt } \\
\hline CHEMBL1493222 & 688816 & 4.9 & 5.0659 & TRN & \\
\hline CHEMBL1495053 & 688816 & 4.95 & 5.3137 & TST & \\
\hline CHEMBL1555695 & 688816 & 4.95 & 5.2128 & TST & \\
\hline CHEMBL1476813 & 688816 & 4.8 & 5.1296 & TRN & \\
\hline CHEMBL1311633 & 688816 & 4.95 & 4.8588 & TRN & \\
\hline CHEMBL1439283 & 688816 & 4.75 & 5.3826 & TST & \\
\hline CHEMBL1517132 & 688816 & 5.45 & 5.1616 & TRN & \\
\hline CHEMBL1578858 & 688816 & 6.1 & 5.3289 & TRN & \\
\hline CHEMBL1497631 & 688816 & 5.0 & 5.6042 & TRN & \\
\hline CHEMBL1426819 & 688816 & 5.5 & 5.0133 & TST & \\
\hline CHEMBL1335126 & 688816 & 4.45 & 5.2817 & TRN & \\
\hline CHEMBL1371873 & 688816 & 4.65 & 5.1809 & TST & \\
\hline CHEMBL1448384 & 688816 & 7.6498 & 5.5111 & TST & \\
\hline CHEMBL1577594 & 688816 & 7.699 & 5.6215 & TST & \\
\hline CHEMBL1610051 & 688816 & 4.85 & 4.9399 & TST & \\
\hline CHEMBL1509913 & 688816 & 4.45 & 4.9808 & TST & \\
\hline CHEMBL1376212 & 688816 & 5.4 & 5.085 & TRN & \\
\hline CHEMBL3207461 & 688816 & 5.35 & 5.6035 & TRN & \\
\hline CHEMBL1505207 & 688816 & 4.8 & 5.092 & TRN & \\
\hline CHEMBL1499027 & 688816 & 4.65 & 5.5529 & TRN & \\
\hline CHEMBL1473804 & 688816 & 5.15 & 5.1178 & TRN & \\
\hline CHEMBL3194296 & 688816 & 5.5 & 5.3537 & TRN & \\
\hline CHEMBL1501174 & 688816 & 5.65 & 5.1375 & TRN & \\
\hline CHEMBL1462724 & 688816 & 8.301 & 5.4192 & TRN & \\
\hline CHEMBL1423732 & 688816 & 5.25 & 5.0024 & TRN & \\
\hline CHEMBL1309268 & 688816 & 4.8 & 5.2368 & TST & \\
\hline CHEMBL1506671 & 688816 & 8.301 & 5.5232 & TRN & \\
\hline CHEMBL1390938 & 688816 & 4.7 & 5.2787 & TRN & \\
\hline CHEMBL1457178 & 688816 & 4.8 & 5.5623 & TRN & \\
\hline CHEMBL1328741 & 688816 & 4.65 & 5.0572 & TRN & \\
\hline CHEMBL1542079 & 688816 & 4.45 & 5.3052 & TRN & \\
\hline CHEMBL1556955 & 688816 & 5.05 & 4.8684 & TRN & \\
\hline CHEMBL1348243 & 688816 & 4.9 & 5.1694 & TST & \\
\hline CHEMBL1569357 & 688816 & 4.9 & 4.9114 & TRN & \\
\hline CHEMBL1366102 & 688816 & 8.4949 & 5.4641 & TST & \\
\hline CHEMBL1429057 & 688816 & 4.45 & 5.3391 & TRN & \\
\hline CHEMBL1453942 & 688816 & 4.5 & 4.9365 & TRN & \\
\hline CHEMBL1442981 & 688816 & 5.35 & 5.3093 & TRN & \\
\hline CHEMBL1462585 & 688816 & 4.45 & 5.1439 & TST & \\
\hline CHEMBL1436245 & 688816 & 4.45 & 5.1101 & TRN & \\
\hline CHEMBL1348617 & 688816 & 4.45 & 5.1535 & TRN & \\
\hline CHEMBL1405400 & 688816 & 5.9 & 5.3505 & TST & \\
\hline CHEMBL1469898 & 688816 & 4.75 & 5.0307 & TRN & \\
\hline CHEMBL1409117 & 688816 & 4.85 & 5.1975 & TST & \\
\hline CHEMBL1342337 & 688816 & 4.65 & 4.9985 & TRN & \\
\hline CHEMBL1581897 & 688816 & 5.05 & 5.397 & TST & \\
\hline CHEMBL1465456 & 688816 & 5.45 & 5.3083 & TRN & \\
\hline CHEMBL1588217 & 688816 & 5.45 & $5.1370 e$ & 00000000005 & TRN \\
\hline & & & & 24545 & \\
\hline
\end{tabular}




\begin{tabular}{|c|c|c|c|c|c|}
\hline \multicolumn{6}{|c|}{ Supplemental Table S2.txt } \\
\hline CHEMBL1385443 & 688816 & 4.75 & 4.7115 & TRN & \\
\hline CHEMBL1342243 & 688816 & 4.45 & 5.4415 & TRN & \\
\hline CHEMBL 3210800 & 688816 & 4.8 & 5.062 & TRN & \\
\hline CHEMBL1603612 & 688816 & 6.8 & 5.7413 & TST & \\
\hline CHEMBL1339274 & 688816 & 4.45 & 5.3679 & TST & \\
\hline CHEMBL1451023 & 688816 & 4.8 & 4.7413 & TST & \\
\hline CHEMBL1521854 & 688816 & 4.85 & 5.9232 & TST & \\
\hline CHEMBL1351678 & 688816 & 4.95 & 5.4671 & TST & \\
\hline CHEMBL1415895 & 688816 & 7.7496 & 5.2454 & TST & \\
\hline CHEMBL1337903 & 688816 & 4.9 & 4.8585 & TRN & \\
\hline CHEMBL1359238 & 688816 & 4.45 & 5.3218 & TRN & \\
\hline CHEMBL 3193652 & 688816 & 5.0 & 5.126 & TST & \\
\hline CHEMBL1471779 & 688816 & 5.05 & 4.9592 & TRN & \\
\hline CHEMBL1498990 & 688816 & 4.65 & 4.8128 & TRN & \\
\hline CHEMBL1463780 & 688816 & 4.9 & 5.5732 & TRN & \\
\hline CHEMBL1520357 & 688816 & 4.95 & 5.3532 & TRN & \\
\hline CHEMBL1409193 & 688816 & 4.9 & 5.4497 & TRN & \\
\hline CHEMBL1390647 & 688816 & 5.35 & 4.8787 & TRN & \\
\hline CHEMBL1428303 & 688816 & 7.5003 & 5.4792 & TRN & \\
\hline CHEMBL1335952 & 688816 & 4.8 & 5.3825 & TRN & \\
\hline CHEMBL1382300 & 688816 & 5.4 & 5.1449 & TRN & \\
\hline CHEMBL1605785 & 688816 & 8.3468 & 6.0623 & TRN & \\
\hline CHEMBL1583882 & 688816 & 8.3468 & 5.3561 & TST & \\
\hline CHEMBL1504932 & 688816 & 4.45 & 5.0741 & TRN & \\
\hline CHEMBL1576386 & 688816 & 4.85 & 5.0707 & TST & \\
\hline CHEMBL3213695 & 688816 & 8.301 & 5.2051 & TST & \\
\hline CHEMBL1588575 & 688816 & 5.45 & 5.1672 & TST & \\
\hline CHEMBL1542067 & 688816 & 4.75 & 4.8787 & TRN & \\
\hline CHEMBL 3208873 & 688816 & 4.8 & 5.1581 & TRN & \\
\hline CHEMBL1347161 & 688816 & 6.4 & 5.1726 & TRN & \\
\hline CHEMBL1544103 & 688816 & 5.55 & 5.6614 & TRN & \\
\hline CHEMBL1340837 & 688816 & 4.6 & 5.2516 & TRN & \\
\hline CHEMBL3211960 & 688816 & 4.45 & 5.4739 & TST & \\
\hline CHEMBL1403955 & 688816 & 5.15 & 5.12799 & 7999999999 & TRN \\
\hline CHEMBL1585773 & 688816 & 5.55 & 5.2058 & TRN & \\
\hline CHEMBL1467426 & 688816 & 6.95 & 5.1096 & TRN & \\
\hline CHEMBL1580272 & 688816 & 4.8 & 4.957 & TRN & \\
\hline CHEMBL1378324 & 688816 & 5.85 & 5.3945 & TRN & \\
\hline CHEMBL1447946 & 688816 & 5.45 & 5.1513 & TST & \\
\hline CHEMBL1570650 & 688816 & 4.75 & 5.3664 & TRN & \\
\hline CHEMBL1466959 & 688816 & 4.75 & 4.9261 & TRN & \\
\hline CHEMBL1581574 & 688816 & 4.85 & 5.2526 & TRN & \\
\hline CHEMBL1543885 & 688816 & 5.2 & 5.2699 & TRN & \\
\hline CHEMBL1339787 & 688816 & 5.0 & 5.2498 & TRN & \\
\hline CHEMBL1584099 & 688816 & 5.15 & 5.4793 & TST & \\
\hline CHEMBL1331768 & 688816 & 6.1 & 5.1398 & TST & \\
\hline CHEMBL1602754 & 688816 & 4.95 & 5.2926 & TRN & \\
\hline CHEMBL1301372 & 688816 & 5.05 & 5.2478 & TST & \\
\hline
\end{tabular}




\begin{tabular}{|c|c|c|c|c|}
\hline \multicolumn{5}{|c|}{ Supplemental Table S2.txt } \\
\hline CHEMBL3198389 & 688816 & 4.9 & 5.3205 & TST \\
\hline CHEMBL1499535 & 688816 & 5.0 & 5.3369 & TST \\
\hline CHEMBL1549834 & 688816 & 4.9 & 5.4236 & TST \\
\hline CHEMBL1502451 & 688816 & 7.6003 & 5.2467 & TST \\
\hline CHEMBL1421811 & 688816 & 4.9 & 5.0615 & TRN \\
\hline CHEMBL1314051 & 688816 & 4.9 & 5.8313 & TRN \\
\hline CHEMBL1544834 & 688816 & 4.75 & 5.3417 & TRN \\
\hline CHEMBL1516315 & 688816 & 4.9 & 5.098 & TRN \\
\hline CHEMBL1416433 & 688816 & 4.65 & 5.261 & TST \\
\hline CHEMBL1392683 & 688816 & 4.45 & 5.5903 & TRN \\
\hline CHEMBL1493233 & 688816 & 5.6 & 5.2705 & TST \\
\hline CHEMBL1448074 & 688816 & 5.25 & 5.1289 & TRN \\
\hline CHEMBL1486358 & 688816 & 4.65 & 4.9108 & TRN \\
\hline CHEMBL1588000 & 688816 & 5.3 & 5.3324 & TST \\
\hline CHEMBL 3189242 & 688816 & 6.8499 & 5.6636 & TRN \\
\hline CHEMBL1521886 & 688816 & 4.95 & 5.2817 & TRN \\
\hline CHEMBL1570165 & 688816 & 5.3 & 5.5734 & TRN \\
\hline CHEMBL3208632 & 688816 & 4.9 & 5.5285 & TST \\
\hline CHEMBL1420490 & 688816 & 8.3468 & 5.4665 & TRN \\
\hline CHEMBL1603991 & 688816 & 5.25 & 5.3264 & TRN \\
\hline CHEMBL1317930 & 688816 & 4.45 & 5.1147 & TRN \\
\hline CHEMBL1984179 & 688816 & 7.15 & 5.3909 & TST \\
\hline CHEMBL3145199 & 688816 & 4.75 & 5.4829 & TRN \\
\hline CHEMBL1487567 & 688816 & 4.5 & 5.003 & TRN \\
\hline CHEMBL3196181 & 688816 & 4.65 & 5.0461 & TRN \\
\hline CHEMBL1468616 & 688816 & 7.8013 & 5.2855 & TRN \\
\hline CHEMBL1504891 & 688816 & 4.95 & 4.9581 & TRN \\
\hline CHEMBL1401594 & 688816 & 4.5 & 5.3656 & TRN \\
\hline CHEMBL1373055 & 688816 & 4.9 & 4.9523 & TRN \\
\hline CHEMBL1558563 & 688816 & 6.0 & 5.0767 & TRN \\
\hline CHEMBL1387315 & 688816 & 6.7001 & 5.3539 & TRN \\
\hline CHEMBL 3193888 & 688816 & 5.4 & 5.1207 & TST \\
\hline CHEMBL3211092 & 688816 & 4.65 & 5.29 & TRN \\
\hline CHEMBL1530915 & 688816 & 4.7 & 5.7137 & TRN \\
\hline CHEMBL1531752 & 688816 & 4.9 & 5.1618 & TRN \\
\hline CHEMBL1313879 & 688816 & 4.75 & 5.2806 & TRN \\
\hline CHEMBL1586234 & 688816 & 4.85 & 4.9591 & TRN \\
\hline CHEMBL3212975 & 688816 & 6.45 & 5.1722 & TRN \\
\hline CHEMBL1540526 & 688816 & 6.15 & 5.5408 & TRN \\
\hline CHEMBL1433012 & 688816 & 4.75 & 5.0602 & TRN \\
\hline CHEMBL1465735 & 688816 & 4.65 & 5.2646 & TRN \\
\hline CHEMBL3209769 & 688816 & 5.0 & 5.0009 & TRN \\
\hline CHEMBL84010 & 688816 & 4.9 & 5.7188 & TRN \\
\hline CHEMBL1324699 & 688816 & 4.55 & 5.1512 & TST \\
\hline CHEMBL1375478 & 688816 & 4.75 & 5.3682 & TRN \\
\hline CHEMBL1477453 & 688816 & 4.8 & 4.9631 & TRN \\
\hline CHEMBL1329328 & 688816 & 6.2 & 5.3283 & TRN \\
\hline CHEMBL1557498 & 688816 & 4.9 & 5.2619 & TRN \\
\hline
\end{tabular}




\begin{tabular}{|c|c|c|c|c|c|}
\hline \multicolumn{6}{|c|}{ Supplemental Table S2.txt } \\
\hline CHEMBL1501662 & 688816 & 4.75 & 5.1386 & TRN & \\
\hline CHEMBL1582392 & 688816 & 7.6003 & 5.2212 & TRN & \\
\hline CHEMBL1526167 & 688816 & 4.75 & 5.4039 & TST & \\
\hline CHEMBL1429821 & 688816 & 6.3 & 5.1177 & TRN & \\
\hline CHEMBL1300421 & 688816 & 5.8 & 5.25899 & 99999999995 & TRN \\
\hline CHEMBL1541866 & 688816 & 4.85 & 5.2781 & TRN & \\
\hline CHEMBL1493429 & 688816 & 6.35 & 5.5238 & TRN & \\
\hline CHEMBL1409816 & 688816 & 5.45 & 5.1408 & TST & \\
\hline CHEMBL1347469 & 688816 & 5.85 & 5.0369 & TRN & \\
\hline CHEMBL1580145 & 688816 & 6.25 & 5.665 & TRN & \\
\hline CHEMBL1602445 & 688816 & 4.95 & 4.9509 & TRN & \\
\hline CHEMBL1431254 & 688816 & 4.45 & 5.4275 & TRN & \\
\hline CHEMBL1418247 & 688816 & 4.5 & 5.1963 & TRN & \\
\hline CHEMBL1485774 & 688816 & 4.75 & 5.1184 & TRN & \\
\hline CHEMBL1420265 & 688816 & 5.3 & 5.2199 & TRN & \\
\hline CHEMBL1606266 & 688816 & 5.6 & 5.1485 & TRN & \\
\hline CHEMBL1451756 & 688816 & 4.9 & 5.5089 & TRN & \\
\hline CHEMBL1456099 & 688816 & 5.1 & 5.2867 & TRN & \\
\hline CHEMBL1511114 & 688816 & 4.45 & 5.3436 & TRN & \\
\hline CHEMBL1413204 & 688816 & 7.5498 & 5.8781 & TRN & \\
\hline CHEMBL1536824 & 688816 & 6.6 & 5.2345 & TST & \\
\hline CHEMBL1482400 & 688816 & 4.8 & 5.2665 & TRN & \\
\hline CHEMBL1611482 & 688816 & 4.95 & 5.2883 & TRN & \\
\hline CHEMBL1544136 & 688816 & 7.0501 & 5.0473 & TST & \\
\hline CHEMBL1414377 & 688816 & 5.2 & 5.1422 & TRN & \\
\hline CHEMBL1422368 & 688816 & 4.95 & 4.831 & TRN & \\
\hline CHEMBL1567862 & 688816 & 4.75 & 5.4498 & TRN & \\
\hline CHEMBL1366294 & 688816 & 4.5 & 5.4379 & TRN & \\
\hline CHEMBL1378171 & 688816 & 8.3468 & 5.4403 & TRN & \\
\hline CHEMBL1440606 & 688816 & 6.05 & 5.4683 & TST & \\
\hline CHEMBL1492807 & 688816 & 5.25 & 5.1087 & TST & \\
\hline CHEMBL3195876 & 688816 & 6.35 & 5.5573 & TRN & \\
\hline CHEMBL3197896 & 688816 & 4.75 & 5.2237 & TRN & \\
\hline CHEMBL1435283 & 688816 & 4.65 & 5.0088 & TRN & \\
\hline CHEMBL1393670 & 688816 & 5.2 & 5.3026 & TRN & \\
\hline CHEMBL1576601 & 688816 & 4.85 & 5.0504 & TRN & \\
\hline CHEMBL1611128 & 688816 & 6.2 & 5.2032 & TRN & \\
\hline CHEMBL1468803 & 688816 & 5.0 & 5.7725 & TRN & \\
\hline CHEMBL1438273 & 688816 & 5.25 & 5.2687 & TRN & \\
\hline CHEMBL1319427 & 688816 & 4.95 & 5.3869 & TRN & \\
\hline CHEMBL1472673 & 688816 & 5.55 & 5.5345 & TRN & \\
\hline CHEMBL1460105 & 688816 & 5.2 & 4.8605 & TRN & \\
\hline CHEMBL3213694 & 688816 & 4.9 & 4.9281 & TRN & \\
\hline CHEMBL1333011 & 688816 & 4.7 & 5.269 & TRN & \\
\hline CHEMBL1312885 & 688816 & 4.7 & 4.9354 & TST & \\
\hline CHEMBL1332989 & 688816 & 5.5 & 5.033 & TRN & \\
\hline CHEMBL1429995 & 688816 & 4.95 & 5.4165 & TRN & \\
\hline CHEMBL1541998 & 688816 & 5.8 & 5.4377 & TRN & \\
\hline
\end{tabular}




\begin{tabular}{|c|c|c|c|c|c|}
\hline \multicolumn{6}{|c|}{ Supplemental Table S2.txt } \\
\hline CHEMBL1570919 & 688816 & 4.65 & 5.1939 & TRN & \\
\hline CHEMBL1318984 & 688816 & 5.3 & 5.4482 & TRN & \\
\hline CHEMBL1438250 & 688816 & 4.8 & 5.0742 & TRN & \\
\hline CHEMBL3199496 & 688816 & 6.8 & \multicolumn{2}{|c|}{5.617999999999999} & TRN \\
\hline CHEMBL1444110 & 688816 & 5.45 & 4.9721 & TRN & \\
\hline CHEMBL1443354 & 688816 & 4.9 & 5.6141 & TST & \\
\hline CHEMBL3193348 & 688816 & 4.95 & 5.5409 & TRN & \\
\hline CHEMBL1533212 & 688816 & 4.95 & 4.8241 & TRN & \\
\hline CHEMBL1420155 & 688816 & 4.5 & 5.6082 & TRN & \\
\hline CHEMBL1409430 & 688816 & 5.0 & 4.967 & TRN & \\
\hline CHEMBL1306825 & 688816 & 7.5498 & 5.2984 & TRN & \\
\hline CHEMBL1564972 & 688816 & 5.85 & 5.4796 & TRN & \\
\hline CHEMBL1594603 & 688816 & 4.6 & 5.0844 & TRN & \\
\hline CHEMBL1577282 & 688816 & 7.4498 & 5.2568 & TRN & \\
\hline CHEMBL1312988 & 688816 & 4.45 & 5.3497 & TST & \\
\hline CHEMBL1542439 & 688816 & 6.45 & 4.7539 & TST & \\
\hline CHEMBL1570920 & 688816 & 5.5 & 4.6629 & TST & \\
\hline CHEMBL1473819 & 688816 & 5.4 & 5.2525 & TRN & \\
\hline CHEMBL1540413 & 688816 & 4.85 & 5.16 & TRN & \\
\hline CHEMBL1570119 & 688816 & 7.5498 & 4.9306 & TRN & \\
\hline CHEMBL1504710 & 688816 & 4.95 & 4.8915 & TST & \\
\hline CHEMBL1307918 & 688816 & 5.0 & 5.1306 & TRN & \\
\hline CHEMBL3198460 & 688816 & 5.6 & 5.5021 & TRN & \\
\hline CHEMBL1302285 & 688816 & 4.45 & 5.129 & TRN & \\
\hline CHEMBL3192789 & 688816 & 4.7 & 5.0176 & TRN & \\
\hline CHEMBL1477249 & 688816 & 4.9 & 5.2578 & TRN & \\
\hline CHEMBL1547207 & 688816 & 4.8 & 4.7472 & TRN & \\
\hline CHEMBL1549510 & 688816 & 5.05 & 5.0381 & TRN & \\
\hline CHEMBL1338441 & 688816 & 5.2 & 4.9436 & TRN & \\
\hline CHEMBL1460672 & 688816 & 7.5498 & 5.4016 & TST & \\
\hline CHEMBL1580953 & 688816 & 4.95 & 5.7625 & TRN & \\
\hline CHEMBL1494353 & 688816 & 4.7 & 5.1909 & TRN & \\
\hline CHEMBL1318388 & 688816 & 4.95 & 4.8306 & TST & \\
\hline CHEMBL1492964 & 688816 & 5.05 & 5.254 & TRN & \\
\hline CHEMBL1350392 & 688816 & 4.8 & 5.3838 & TRN & \\
\hline CHEMBL1446596 & 688816 & 4.75 & 5.2644 & TRN & \\
\hline CHEMBL1462946 & 688816 & 5.5 & 5.5535 & TRN & \\
\hline CHEMBL1404201 & 688816 & 5.0 & 5.2366 & TRN & \\
\hline CHEMBL1423285 & 688816 & 5.1 & 5.0776 & TRN & \\
\hline CHEMBL1413519 & 688816 & 4.45 & 4.8278 & TRN & \\
\hline CHEMBL3192108 & 688816 & 7.0501 & 5.6139 & TRN & \\
\hline CHEMBL1563862 & 688816 & 4.45 & 5.1583 & TRN & \\
\hline CHEMBL1547533 & 688816 & 4.8 & 5.2275 & TRN & \\
\hline CHEMBL1584279 & 688816 & 4.6 & 5.0324 & TRN & \\
\hline CHEMBL1520210 & 688816 & 5.25 & 5.4678 & TRN & \\
\hline CHEMBL1496556 & 688816 & 4.45 & 5.4181 & TRN & \\
\hline CHEMBL1330229 & 688816 & 5.6 & 5.4512 & TRN & \\
\hline CHEMBL1370569 & 688816 & 7.2503 & 5.32700 & 2000000001 & TST \\
\hline & & & & 2454 & \\
\hline
\end{tabular}




\begin{tabular}{|c|c|c|c|c|c|}
\hline CHEMBL1383783 & 688816 & 4.9 & \multicolumn{2}{|c|}{5.297000000000001} & TST \\
\hline CHEMBL1547956 & 688816 & 4.85 & 5.2075 & TRN & \\
\hline CHEMBL1576943 & 688816 & 4.95 & 5.4163 & TST & \\
\hline CHEMBL1450032 & 688816 & 4.45 & 5.0869 & TST & \\
\hline CHEMBL1604327 & 688816 & 6.0 & 5.18 & TRN & \\
\hline CHEMBL1986081 & 688816 & 4.45 & 5.559 & TST & \\
\hline CHEMBL590161 & 688816 & 4.8 & 5.5717 & TRN & \\
\hline CHEMBL1545123 & 688816 & 4.95 & 5.2727 & TRN & \\
\hline CHEMBL1308088 & 688816 & 5.1 & 5.1305 & TRN & \\
\hline CHEMBL1491424 & 688816 & 4.55 & 5.7049 & TRN & \\
\hline CHEMBL1612143 & 688816 & 4.45 & 5.2325 & TRN & \\
\hline CHEMBL1344112 & 688816 & 5.0 & 4.9421 & TRN & \\
\hline CHEMBL1538988 & 688816 & 4.65 & 5.4359 & TST & \\
\hline CHEMBL1421339 & 688816 & 4.5 & 5.7004 & TST & \\
\hline CHEMBL1600004 & 688816 & 5.45 & 5.6128 & TST & \\
\hline CHEMBL3214501 & 688816 & 6.5 & 5.5156 & TST & \\
\hline CHEMBL1487208 & 688816 & 4.95 & 5.2688 & TST & \\
\hline CHEMBL1561745 & 688816 & 4.45 & 5.0173 & TRN & \\
\hline CHEMBL1501793 & 688816 & 5.15 & 5.2327 & TST & \\
\hline CHEMBL1311121 & 688816 & 7.6498 & 5.3306 & TRN & \\
\hline CHEMBL3209893 & 688816 & 4.45 & 5.2122 & TRN & \\
\hline CHEMBL1509628 & 688816 & 8.4949 & 5.6675 & TST & \\
\hline CHEMBL1446482 & 688816 & 4.75 & 5.5504 & TST & \\
\hline CHEMBL1558127 & 688816 & 4.75 & 5.2836 & TST & \\
\hline CHEMBL1550581 & 688816 & 5.2 & 5.2377 & TRN & \\
\hline CHEMBL1465263 & 688816 & 7.4001 & 5.8332 & TRN & \\
\hline CHEMBL1536197 & 688816 & 6.1 & 5.1606 & TST & \\
\hline CHEMBL1530295 & 688816 & 4.9 & 5.4936 & TRN & \\
\hline CHEMBL1541868 & 688816 & 4.45 & 5.4905 & TRN & \\
\hline CHEMBL1358990 & 688816 & 5.45 & 5.2121 & TST & \\
\hline CHEMBL1407283 & 688816 & 5.1 & 5.5945 & TST & \\
\hline CHEMBL1414898 & 688816 & 5.45 & 5.1282 & TST & \\
\hline CHEMBL1547164 & 688816 & 4.95 & 4.9955 & TST & \\
\hline CHEMBL1528375 & 688816 & 4.8 & 5.012 & TRN & \\
\hline CHEMBL1408420 & 688816 & 6.1 & 5.4301 & TST & \\
\hline CHEMBL1354474 & 688816 & 4.6 & 5.0301 & TRN & \\
\hline CHEMBL1613607 & 688816 & 5.25 & 5.371 & TST & \\
\hline CHEMBL1498924 & 688816 & 4.45 & 5.0308 & TST & \\
\hline CHEMBL1410495 & 688816 & 4.45 & 5.5345 & TRN & \\
\hline CHEMBL1408303 & 688816 & 4.45 & 4.8799 & TRN & \\
\hline CHEMBL1549328 & 688816 & 8.0506 & 5.4625 & TRN & \\
\hline CHEMBL3193092 & 688816 & 4.7 & 5.1319 & TRN & \\
\hline CHEMBL1482126 & 688816 & 4.6 & 5.3984 & TST & \\
\hline CHEMBL1479746 & 688816 & 4.8 & 5.3177 & TRN & \\
\hline CHEMBL1427492 & 688816 & 4.95 & 5.1072 & TRN & \\
\hline CHEMBL1463931 & 688816 & 4.45 & 5.1609 & TST & \\
\hline CHEMBL1518219 & 688816 & 5.0 & 5.6749 & TST & \\
\hline CHEMBL1491382 & 688816 & 4.45 & 4.9666 & TRN & \\
\hline
\end{tabular}




\begin{tabular}{|c|c|c|c|c|c|}
\hline \multicolumn{6}{|c|}{ Supplemental Table S2.txt } \\
\hline CHEMBL1429705 & 688816 & 4.5 & 5.1754 & TRN & \\
\hline CHEMBL1393647 & 688816 & 4.9 & 5.2171 & TRN & \\
\hline CHEMBL1478902 & 688816 & 7.2 & 5.4975 & TST & \\
\hline CHEMBL1506653 & 688816 & 4.95 & 5.4163 & TST & \\
\hline CHEMBL1368493 & 688816 & 4.95 & 4.9504 & TRN & \\
\hline CHEMBL1375152 & 688816 & 6.8499 & 5.6199 & TRN & \\
\hline CHEMBL1418838 & 688816 & 7.5003 & 5.4196 & TRN & \\
\hline CHEMBL1535587 & 688816 & 4.85 & 5.0095 & TRN & \\
\hline CHEMBL1320688 & 688816 & 6.8 & 5.6238 & TRN & \\
\hline CHEMBL1399415 & 688816 & 6.15 & 5.6144 & TRN & \\
\hline CHEMBL1303634 & 688816 & 6.1 & 5.0233 & TST & \\
\hline CHEMBL1602836 & 688816 & 4.45 & 5.2954 & TRN & \\
\hline CHEMBL1326779 & 688816 & 6.4 & 5.24799 & 9999999999 & TRN \\
\hline CHEMBL1590174 & 688816 & 5.0 & 5.3466 & TRN & \\
\hline CHEMBL1603908 & 688816 & 6.3 & 5.1332 & TRN & \\
\hline CHEMBL1383541 & 688816 & 4.9 & 5.3456 & TRN & \\
\hline CHEMBL1517535 & 688816 & 4.8 & 5.157 & TRN & \\
\hline CHEMBL1533891 & 688816 & 7.699 & 5.1513 & TRN & \\
\hline CHEMBL1611848 & 688816 & 5.2 & 5.6419 & TRN & \\
\hline CHEMBL1545385 & 688816 & 4.8 & 5.0608 & TRN & \\
\hline CHEMBL1579696 & 688816 & 4.95 & 5.0404 & TRN & \\
\hline CHEMBL1457336 & 688816 & 4.95 & 5.1267 & TRN & \\
\hline CHEMBL1365652 & 688816 & 4.9 & 5.0112 & TRN & \\
\hline CHEMBL1489158 & 688816 & 4.95 & 5.386 & TRN & \\
\hline CHEMBL1402174 & 688816 & 4.65 & 4.8972 & TRN & \\
\hline CHEMBL1559707 & 688816 & 4.7 & 5.1677 & TST & \\
\hline CHEMBL1535126 & 688816 & 5.7 & 5.5971 & TRN & \\
\hline CHEMBL1593867 & 688816 & 6.0 & 5.3 & TST & \\
\hline CHEMBL1304382 & 688816 & 4.5 & 5.3118 & TRN & \\
\hline CHEMBL1375845 & 688816 & 8.301 & 5.0471 & TRN & \\
\hline CHEMBL1370818 & 688816 & 5.1 & 5.6165 & TRN & \\
\hline CHEMBL1572107 & 688816 & 4.9 & 4.8102 & TRN & \\
\hline CHEMBL 1345720 & 688816 & 4.45 & 5.3322 & TST & \\
\hline CHEMBL1538399 & 688816 & 4.45 & 5.0942 & TST & \\
\hline CHEMBL3209996 & 688816 & 7.9508 & 5.2824 & TRN & \\
\hline CHEMBL1399631 & 688816 & 5.35 & 5.1263 & TRN & \\
\hline CHEMBL1411746 & 688816 & 6.15 & 5.5599 & TST & \\
\hline CHEMBL1332010 & 688816 & 6.0 & 4.8253 & TRN & \\
\hline CHEMBL1301327 & 688816 & 4.45 & 5.7456 & TRN & \\
\hline CHEMBL1332927 & 688816 & 5.8 & 5.1607 & TRN & \\
\hline CHEMBL1432275 & 688816 & 5.2 & 5.3437 & TRN & \\
\hline CHEMBL1493385 & 688816 & 4.9 & 5.5501 & TRN & \\
\hline CHEMBL1510579 & 688816 & 5.25 & 5.5594 & TRN & \\
\hline CHEMBL1588979 & 688816 & 5.0 & 5.0443 & TST & \\
\hline CHEMBL1459294 & 688816 & 5.65 & 5.3149 & TST & \\
\hline CHEMBL1506477 & 688816 & 4.95 & 5.1168 & TRN & \\
\hline CHEMBL1373959 & 688816 & 5.1 & 4.5925 & TRN & \\
\hline CHEMBL1416824 & 688816 & 4.95 & 5.3958 & TRN & \\
\hline
\end{tabular}




\begin{tabular}{|c|c|c|c|c|c|}
\hline \multicolumn{6}{|c|}{ Supplemental Table S2.txt } \\
\hline CHEMBL1391699 & 688816 & 4.85 & 5.0646 & TRN & \\
\hline CHEMBL1577373 & 688816 & 4.85 & 5.4269 & TRN & \\
\hline CHEMBL1346130 & 688816 & 4.6 & 5.44799 & 99999999995 & TRN \\
\hline CHEMBL1397757 & 688816 & 5.55 & 5.6516 & TST & \\
\hline CHEMBL1341551 & 688816 & 4.5 & 5.7359 & TST & \\
\hline CHEMBL1507645 & 688816 & 5.85 & 5.2502 & TRN & \\
\hline CHEMBL1424942 & 688816 & 5.2 & 5.2131 & TRN & \\
\hline CHEMBL1303810 & 688816 & 4.7 & 4.9831 & TRN & \\
\hline CHEMBL1334438 & 688816 & 5.0 & 5.181 & TRN & \\
\hline CHEMBL1492208 & 688816 & 6.2 & 5.0029 & TRN & \\
\hline CHEMBL1443028 & 688816 & 5.0 & 4.9585 & TRN & \\
\hline CHEMBL1346771 & 688816 & 4.7 & 5.015 & TRN & \\
\hline CHEMBL1320329 & 688816 & 4.65 & 4.8324 & TRN & \\
\hline CHEMBL1415527 & 688816 & 4.6 & 5.2179 & TST & \\
\hline CHEMBL1372627 & 688816 & 5.25 & 5.3326 & TRN & \\
\hline CHEMBL1528806 & 688816 & 5.45 & 5.2851 & TRN & \\
\hline CHEMBL1603384 & 688816 & 4.95 & 5.2916 & TRN & \\
\hline CHEMBL1446151 & 688816 & 4.9 & 5.1259 & TRN & \\
\hline CHEMBL1303316 & 688816 & 4.85 & 5.7109 & TRN & \\
\hline CHEMBL3192307 & 688816 & 6.15 & 5.5131 & TRN & \\
\hline CHEMBL1327688 & 688816 & 5.25 & 5.2478 & TRN & \\
\hline CHEMBL1390403 & 688816 & 7.5498 & 5.2909 & TRN & \\
\hline CHEMBL1482417 & 688816 & 4.75 & 5.1046 & TRN & \\
\hline CHEMBL1604170 & 688816 & 5.5 & 5.2618 & TRN & \\
\hline CHEMBL1563757 & 688816 & 4.95 & 5.4246 & TRN & \\
\hline CHEMBL1441840 & 688816 & 5.1 & 5.45 & TRN & \\
\hline CHEMBL1508147 & 688816 & 5.0 & 5.2677 & TRN & \\
\hline CHEMBL1549188 & 688816 & 4.95 & 5.3374 & TRN & \\
\hline CHEMBL1388625 & 688816 & 4.6 & 5.4932 & TRN & \\
\hline CHEMBL1362537 & 688816 & 4.45 & 5.2785 & TRN & \\
\hline CHEMBL1572579 & 688816 & 4.85 & 5.4409 & TRN & \\
\hline CHEMBL601775 & 688816 & 4.8 & 5.2264 & TRN & \\
\hline CHEMBL1310710 & 688816 & 4.45 & 5.0082 & TRN & \\
\hline CHEMBL1427335 & 688816 & 5.0 & 5.2737 & TRN & \\
\hline CHEMBL1439014 & 688816 & 5.45 & 4.9959 & TRN & \\
\hline CHEMBL1528223 & 688816 & 4.45 & 5.3984 & TRN & \\
\hline CHEMBL1437846 & 688816 & 4.45 & 5.8174 & TST & \\
\hline CHEMBL1380797 & 688816 & 5.05 & 5.13899 & 9999999999 & TRN \\
\hline CHEMBL1559473 & 688816 & 4.9 & 5.0951 & TRN & \\
\hline CHEMBL3193123 & 688816 & 7.5498 & 5.1916 & TRN & \\
\hline CHEMBL1978730 & 688816 & 4.7 & 5.2246 & TRN & \\
\hline CHEMBL1544145 & 688816 & 5.5 & 5.4424 & TST & \\
\hline CHEMBL1402822 & 688816 & 4.75 & 5.3119 & TRN & \\
\hline CHEMBL1982484 & 688816 & 4.45 & 5.3163 & TRN & \\
\hline CHEMBL1990565 & 688816 & 8.3468 & 5.4691 & TRN & \\
\hline CHEMBL1500101 & 688816 & 4.9 & 5.3058 & TRN & \\
\hline CHEMBL1440725 & 688816 & 4.85 & 4.8596 & TRN & \\
\hline CHEMBL3208131 & 688816 & 6.9 & 5.345 & TRN & \\
\hline
\end{tabular}




\begin{tabular}{|c|c|c|c|c|c|}
\hline \multicolumn{6}{|c|}{ Supplemental Table S2.txt } \\
\hline CHEMBL1570543 & 688816 & 4.75 & 5.2047 & TRN & \\
\hline CHEMBL1539742 & 688816 & 4.9 & 5.3565 & TRN & \\
\hline CHEMBL1971901 & 688816 & 5.45 & 4.9059 & TST & \\
\hline CHEMBL 3196037 & 688816 & 6.9 & 5.3582 & TRN & \\
\hline CHEMBL 3207885 & 688816 & 4.5 & 5.1618 & TST & \\
\hline CHEMBL1347392 & 688816 & 4.75 & 4.9878 & TRN & \\
\hline CHEMBL1451735 & 688816 & 5.6 & 5.4681 & TRN & \\
\hline CHEMBL1344664 & 688816 & 4.85 & 5.1256 & TRN & \\
\hline CHEMBL1508507 & 688816 & 5.35 & 5.29899 & 99999999995 & TRN \\
\hline CHEMBL1518144 & 688816 & 5.05 & 4.758 & TRN & \\
\hline CHEMBL1366408 & 688816 & 4.8 & 5.5088 & TST & \\
\hline CHEMBL1517414 & 688816 & 5.7 & 4.8691 & TRN & \\
\hline CHEMBL1542536 & 688816 & 4.9 & 5.5382 & TRN & \\
\hline CHEMBL1408928 & 688816 & 5.05 & 4.798 & TRN & \\
\hline CHEMBL1540162 & 688816 & 4.55 & 5.5859 & TST & \\
\hline CHEMBL1323821 & 688816 & 4.95 & 5.4124 & TST & \\
\hline CHEMBL1457453 & 688816 & 4.95 & 5.1425 & TRN & \\
\hline CHEMBL1566374 & 688816 & 4.5 & 5.5161 & TST & \\
\hline CHEMBL1476520 & 688816 & 4.5 & 5.2222 & TRN & \\
\hline CHEMBL1558598 & 688816 & 4.85 & 5.4511 & TST & \\
\hline CHEMBL1528119 & 688816 & 5.6 & 5.1625 & TRN & \\
\hline CHEMBL1538608 & 688816 & 4.6 & 5.0258 & TST & \\
\hline CHEMBL1413843 & 688816 & 6.9 & 5.3787 & TRN & \\
\hline CHEMBL1607198 & 688816 & 5.65 & 4.9437 & TRN & \\
\hline CHEMBL1482528 & 688816 & 4.75 & 5.5981 & TRN & \\
\hline CHEMBL1366454 & 688816 & 4.9 & 5.1502 & TRN & \\
\hline CHEMBL1467239 & 688816 & 4.9 & 5.3983 & TRN & \\
\hline CHEMBL3199824 & 688816 & 4.75 & 5.3304 & TRN & \\
\hline CHEMBL1497617 & 688816 & 5.45 & 5.0994 & TRN & \\
\hline CHEMBL552439 & 688816 & 5.8 & 5.0236 & TST & \\
\hline CHEMBL1610367 & 688816 & 4.8 & 4.8853 & TRN & \\
\hline CHEMBL1353469 & 688816 & 5.35 & 5.075 & TRN & \\
\hline CHEMBL3213734 & 688816 & 4.7 & 5.4595 & TRN & \\
\hline CHEMBL578539 & 688816 & 4.45 & 5.4991 & TRN & \\
\hline CHEMBL1474500 & 688816 & 4.85 & 5.0032 & TRN & \\
\hline CHEMBL 277498 & 688816 & 6.05 & 5.5026 & TST & \\
\hline CHEMBL1430641 & 688816 & 5.0 & 5.0964 & TRN & \\
\hline CHEMBL1324157 & 688816 & 4.6 & 5.1573 & TRN & \\
\hline CHEMBL1613436 & 688816 & 5.5 & 5.5916 & TRN & \\
\hline CHEMBL1344529 & 688816 & 5.9 & 5.1848 & TRN & \\
\hline CHEMBL1532993 & 688816 & 5.25 & 5.1793 & TRN & \\
\hline CHEMBL1327873 & 688816 & 8.3468 & 5.3705 & TRN & \\
\hline CHEMBL1458133 & 688816 & 6.9 & 5.6547 & TRN & \\
\hline CHEMBL1598000 & 688816 & 4.75 & 5.1371 & TRN & \\
\hline CHEMBL1494284 & 688816 & 5.25 & 5.1831 & TRN & \\
\hline CHEMBL1368610 & 688816 & 6.35 & 5.7258 & TST & \\
\hline CHEMBL1340266 & 688816 & 4.95 & 5.1227 & TRN & \\
\hline CHEMBL1461578 & 688816 & 5.25 & 4.8713 & TRN & \\
\hline
\end{tabular}




\begin{tabular}{|c|c|c|c|c|c|}
\hline \\
\hline CHEMBL1610525 & 688816 & 4.9 & 5.2814 & TST & \\
\hline CHEMBL3198408 & 688816 & 6.95 & 5.4618 & TRN & \\
\hline CHEMBL1497878 & 688816 & 4.85 & 5.1223 & TRN & \\
\hline CHEMBL1607766 & 688816 & 4.95 & 5.1323 & TRN & \\
\hline CHEMBL1419169 & 688816 & 6.1 & 5.4613 & TST & \\
\hline CHEMBL1324188 & 688816 & 6.6499 & 5.2368 & TST & \\
\hline CHEMBL1373914 & 688816 & 4.9 & 5.2126 & TRN & \\
\hline CHEMBL1539114 & 688816 & 5.25 & 5.2622 & TST & \\
\hline CHEMBL1582831 & 688816 & 4.65 & 4.9307 & TRN & \\
\hline CHEMBL1467322 & 688816 & 4.9 & 5.0559 & TRN & \\
\hline CHEMBL1552462 & 688816 & 4.95 & 4.9446 & TRN & \\
\hline CHEMBL1563733 & 688816 & 5.9 & 5.2426 & TRN & \\
\hline CHEMBL1310008 & 688816 & 5.25 & 4.8989 & TRN & \\
\hline CHEMBL1580007 & 688816 & 4.9 & 5.2151 & TRN & \\
\hline CHEMBL1604513 & 688816 & 4.95 & 5.1218 & TRN & \\
\hline CHEMBL373784 & 688816 & 5.05 & 5.3544 & TRN & \\
\hline CHEMBL1383577 & 688816 & 4.95 & 5.5748 & TRN & \\
\hline CHEMBL1333621 & 688816 & 5.9 & 5.684 & TRN & \\
\hline CHEMBL1398702 & 688816 & 5.4 & 4.9005 & TRN & \\
\hline CHEMBL1443324 & 688816 & 7.699 & 5.6051 & TRN & \\
\hline CHEMBL1531955 & 688816 & 4.9 & 5.1968 & TRN & \\
\hline CHEMBL1333268 & 688816 & 4.6 & 5.4204 & TRN & \\
\hline CHEMBL1359482 & 688816 & 5.05 & 5.3173 & TRN & \\
\hline CHEMBL1486789 & 688816 & 6.45 & 5.482 & TST & \\
\hline CHEMBL1425270 & 688816 & 4.85 & 5.1279 & TRN & \\
\hline CHEMBL1440081 & 688816 & 4.9 & 5.3662 & TRN & \\
\hline CHEMBL1417992 & 688816 & 5.95 & 5.1343 & TRN & \\
\hline CHEMBL1569372 & 688816 & 4.95 & 5.6062 & TRN & \\
\hline CHEMBL1410690 & 688816 & 4.8 & 5.0728 & TRN & \\
\hline CHEMBL3198313 & 688816 & 5.75 & $5.1110 e$ & 0000000001 & TRN \\
\hline CHEMBL1483647 & 688816 & 4.8 & 5.00899 & 79999999995 & TRN \\
\hline CHEMBL1505452 & 688816 & 5.0 & 4.952 & TRN & \\
\hline CHEMBL1489383 & 688816 & 5.0 & 5.2594 & TST & \\
\hline CHEMBL1532909 & 688816 & 4.85 & 5.3852 & TST & \\
\hline CHEMBL1576273 & 688816 & 4.85 & 5.2852 & TRN & \\
\hline CHEMBL1463404 & 688816 & 5.15 & 5.2382 & TRN & \\
\hline CHEMBL1469706 & 688816 & 7.699 & 5.5667 & TRN & \\
\hline CHEMBL1305960 & 688816 & 5.45 & 5.2891 & TST & \\
\hline CHEMBL1571315 & 688816 & 5.3 & 5.0449 & TRN & \\
\hline CHEMBL1348761 & 688816 & 4.45 & 5.0213 & TST & \\
\hline CHEMBL1549308 & 688816 & 4.7 & 4.6857 & TRN & \\
\hline CHEMBL1372585 & 688816 & 5.25 & 5.1417 & TRN & \\
\hline CHEMBL3189899 & 688816 & 4.45 & 5.4176 & TRN & \\
\hline CHEMBL1538756 & 688816 & 5.45 & 5.5876 & TRN & \\
\hline CHEMBL1347056 & 688816 & 4.9 & 5.1927 & TRN & \\
\hline CHEMBL1328405 & 688816 & 4.45 & 5.056 & TRN & \\
\hline CHEMBL1559848 & 688816 & 5.1 & 5.3444 & TRN & \\
\hline CHEMBL3199340 & 688816 & 5.05 & 5.2071 & TST & \\
\hline
\end{tabular}




\begin{tabular}{|c|c|c|c|c|c|}
\hline \multirow{3}{*}{$\begin{array}{l}\text { CHEMBL1367626 } \\
\text { CHEMBL1408760 }\end{array}$} & \multirow{3}{*}{$\begin{array}{l}688816 \\
688816\end{array}$} & \multicolumn{4}{|c|}{ Supplemental Table s2.txt } \\
\hline & & 5.0 & \multicolumn{2}{|c|}{4.6530000000000005} & \multirow{2}{*}{ TRN } \\
\hline & & 5.15 & 5.1001 & TRN & \\
\hline CHEMBL1488263 & 688816 & 4.75 & 5.4395 & TRN & \\
\hline CHEMBL1375824 & 688816 & 4.65 & 5.3774 & TRN & \\
\hline CHEMBL1541121 & 688816 & 4.75 & 5.4147 & TRN & \\
\hline CHEMBL1545991 & 688816 & 4.8 & 5.3132 & TST & \\
\hline CHEMBL1322183 & 688816 & 5.0 & 5.0898 & TRN & \\
\hline CHEMBL1471373 & 688816 & 4.8 & 5.0512 & TRN & \\
\hline CHEMBL1537780 & 688816 & 4.75 & 5.443 & TRN & \\
\hline CHEMBL1518646 & 688816 & 5.85 & 5.1223 & TRN & \\
\hline CHEMBL1576652 & 688816 & 5.9 & 5.42 & TRN & \\
\hline CHEMBL1432466 & 688816 & 4.45 & 5.1868 & TRN & \\
\hline CHEMBL1342602 & 688816 & 6.2 & 5.3662 & TRN & \\
\hline CHEMBL1458225 & 688816 & 4.65 & 5.3095 & TST & \\
\hline CHEMBL1340731 & 688816 & 6.5501 & 5.3214 & TRN & \\
\hline CHEMBL1363806 & 688816 & 6.7501 & 5.2925 & TRN & \\
\hline CHEMBL1488393 & 688816 & 4.5 & 5.2328 & TRN & \\
\hline CHEMBL1469152 & 688816 & 4.95 & 5.1737 & TRN & \\
\hline CHEMBL1558832 & 688816 & 5.25 & 5.1725 & TRN & \\
\hline CHEMBL3209078 & 688816 & 4.85 & 5.1082 & TRN & \\
\hline CHEMBL1599945 & 688816 & 4.6 & 4.8976 & TRN & \\
\hline CHEMBL1591556 & 688816 & 6.0 & 5.7388 & TRN & \\
\hline CHEMBL1543931 & 688816 & 4.55 & 4.8691 & TRN & \\
\hline CHEMBL1509216 & 688816 & 5.05 & 4.8008 & TST & \\
\hline CHEMBL1451003 & 688816 & 5.6 & 5.1755 & TRN & \\
\hline CHEMBL1401438 & 688816 & 4.9 & 5.3225 & TST & \\
\hline CHEMBL3191235 & 688816 & 4.45 & 5.3886 & TRN & \\
\hline CHEMBL1547516 & 688816 & 4.7 & 5.3018 & TST & \\
\hline CHEMBL1380236 & 688816 & 5.1 & 5.25200 & 2000000001 & TST \\
\hline CHEMBL1524331 & 688816 & 5.5 & 5.5506 & TST & \\
\hline CHEMBL1346683 & 688816 & 5.2 & 5.244 & TRN & \\
\hline CHEMBL1345400 & 688816 & 4.8 & 5.5045 & TRN & \\
\hline CHEMBL1606065 & 688816 & 5.9 & 5.4447 & TST & \\
\hline CHEMBL3209243 & 688816 & 5.15 & 5.0798 & TRN & \\
\hline CHEMBL1346507 & 688816 & 4.45 & 4.8842 & TRN & \\
\hline CHEMBL3195142 & 688816 & 4.8 & 5.0142 & TST & \\
\hline CHEMBL410484 & 688816 & 4.9 & 5.3396 & TRN & \\
\hline CHEMBL1562917 & 688816 & 4.45 & 4.9931 & TRN & \\
\hline CHEMBL1322825 & 688816 & 5.15 & 5.54299 & 9999999999 & TST \\
\hline CHEMBL1524837 & 688816 & 4.85 & 5.3188 & TRN & \\
\hline CHEMBL1329655 & 688816 & 4.85 & 5.2151 & TRN & \\
\hline CHEMBL1512187 & 688816 & 4.65 & 5.2934 & TST & \\
\hline CHEMBL188225 & 688816 & 5.85 & 5.909 & TST & \\
\hline CHEMBL1390671 & 688816 & 4.85 & 5.0853 & TRN & \\
\hline CHEMBL1571261 & 688816 & 7.699 & 5.3649 & TRN & \\
\hline CHEMBL1505015 & 688816 & 4.45 & 5.4887 & TRN & \\
\hline CHEMBL1453704 & 688816 & 5.2 & 5.5021 & TRN & \\
\hline CHEMBL1510985 & 688816 & 4.45 & 5.2686 & TRN & \\
\hline
\end{tabular}




\begin{tabular}{|c|c|c|c|c|}
\hline \multicolumn{5}{|c|}{ Supplemental Table s2.txt } \\
\hline CHEMBL1424968 & 688816 & 5.0 & 4.7357 & TRN \\
\hline CHEMBL1490171 & 688816 & 6.25 & 5.2213 & TST \\
\hline CHEMBL1373064 & 688816 & 4.8 & 5.3198 & TRN \\
\hline CHEMBL1375123 & 688816 & 7.6003 & 5.4709 & TST \\
\hline CHEMBL1438681 & 688816 & 4.6 & 5.0272 & TRN \\
\hline CHEMBL1373879 & 688816 & 4.9 & 5.0547 & TRN \\
\hline CHEMBL1359384 & 688816 & 6.0 & 5.2332 & TST \\
\hline CHEMBL3192397 & 688816 & 7.6003 & 5.3836 & TRN \\
\hline CHEMBL1605449 & 688816 & 4.45 & 4.8005 & TRN \\
\hline CHEMBL1406088 & 688816 & 4.95 & 5.1683 & TRN \\
\hline CHEMBL1330046 & 688816 & 5.95 & 5.5626 & TST \\
\hline CHEMBL1582859 & 688816 & 5.2 & 5.0741 & TRN \\
\hline CHEMBL1492303 & 688816 & 5.55 & 5.4101 & TST \\
\hline CHEMBL1467354 & 688816 & 5.85 & 5.1164 & TRN \\
\hline CHEMBL1482009 & 688816 & 4.9 & 4.9296 & TRN \\
\hline CHEMBL1306965 & 688816 & 4.95 & 5.1543 & TRN \\
\hline CHEMBL1398770 & 688816 & 4.85 & 4.886 & TRN \\
\hline CHEMBL1406664 & 688816 & 6.05 & 5.4159 & TRN \\
\hline CHEMBL1363022 & 688816 & 5.35 & 5.0248 & TST \\
\hline CHEMBL1544611 & 688816 & 4.95 & 5.4615 & TRN \\
\hline CHEMBL1432234 & 688816 & 4.95 & 5.2675 & TRN \\
\hline CHEMBL1550909 & 688816 & 6.3 & 4.8205 & TST \\
\hline CHEMBL1376784 & 688816 & 4.9 & 5.4313 & TRN \\
\hline CHEMBL1386659 & 688816 & 5.75 & 5.6096 & TST \\
\hline CHEMBL489934 & 688816 & 4.7 & 4.9264 & TRN \\
\hline CHEMBL1579704 & 688816 & 4.9 & 5.2045 & TRN \\
\hline CHEMBL 3207947 & 688816 & 7.4498 & 5.2627 & TRN \\
\hline CHEMBL1540710 & 688816 & 4.45 & 5.3932 & TST \\
\hline CHEMBL1405975 & 688816 & 4.95 & 5.0417 & TST \\
\hline CHEMBL1340519 & 688816 & 5.55 & 4.9329 & TRN \\
\hline CHEMBL1438359 & 688816 & 5.0 & 4.9888 & TRN \\
\hline CHEMBL1407094 & 688816 & 4.9 & 5.2356 & TRN \\
\hline CHEMBL1572783 & 688816 & 5.6 & 5.4464 & TRN \\
\hline CHEMBL1558941 & 688816 & 4.45 & 5.3485 & TRN \\
\hline CHEMBL1444751 & 688816 & 5.45 & 5.5222 & TRN \\
\hline CHEMBL1352409 & 688816 & 5.65 & 5.5102 & TRN \\
\hline CHEMBL1503580 & 688816 & 4.9 & 4.8509 & TRN \\
\hline CHEMBL1449754 & 688816 & 4.75 & 5.0871 & TRN \\
\hline CHEMBL1384519 & 688816 & 4.7 & 4.7905 & TRN \\
\hline CHEMBL1591373 & 688816 & 4.45 & 4.7638 & TRN \\
\hline CHEMBL1381257 & 688816 & 4.65 & 5.6331 & TRN \\
\hline CHEMBL1505542 & 688816 & 4.9 & 5.2131 & TRN \\
\hline CHEMBL1555655 & 688816 & 5.3 & 5.4757 & TST \\
\hline CHEMBL1309056 & 688816 & 4.9 & 5.0966 & TRN \\
\hline CHEMBL1465726 & 688816 & 4.95 & $5.0680 e$ & 00000000005 \\
\hline CHEMBL1470760 & 688816 & 5.05 & 5.4083 & TRN \\
\hline CHEMBL1306995 & 688816 & 4.85 & 5.295 & TRN \\
\hline CHEMBL1501255 & 688816 & 4.95 & 4.774 & TRN \\
\hline
\end{tabular}




\begin{tabular}{|c|c|c|c|c|c|}
\hline \multicolumn{6}{|c|}{ Supplemental Table S2.txt } \\
\hline CHEMBL1343819 & 688816 & 4.9 & 5.4615 & TRN & \\
\hline CHEMBL1556963 & 688816 & 7.0 & 5.1865 & TRN & \\
\hline CHEMBL3192392 & 688816 & 4.8 & 5.008 & TRN & \\
\hline CHEMBL 3210258 & 688816 & 8.5528 & 5.3433 & TRN & \\
\hline CHEMBL1518613 & 688816 & 5.2 & 5.3055 & TRN & \\
\hline CHEMBL1570582 & 688816 & 5.85 & 5.3751 & TRN & \\
\hline CHEMBL1224757 & 688816 & 4.55 & 5.3661 & TRN & \\
\hline CHEMBL1576059 & 688816 & 5.15 & 5.1873 & TST & \\
\hline CHEMBL1498870 & 688816 & 4.95 & 5.4664 & TRN & \\
\hline CHEMBL42219 & 688816 & 5.0 & 5.5796 & TRN & \\
\hline CHEMBL1481132 & 688816 & 6.8 & 5.3306 & TST & \\
\hline CHEMBL1351309 & 688816 & 6.3 & 5.1223 & TRN & \\
\hline CHEMBL1308027 & 688816 & 6.15 & 5.5324 & TRN & \\
\hline CHEMBL1367723 & 688816 & 4.75 & 5.2782 & TRN & \\
\hline CHEMBL1397977 & 688816 & 5.0 & 5.5531 & TRN & \\
\hline CHEMBL 3212446 & 688816 & 4.95 & 5.2719 & TRN & \\
\hline CHEMBL1550088 & 688816 & 6.2 & 5.6469 & TST & \\
\hline CHEMBL1323403 & 688816 & 6.1 & 5.6539 & TRN & \\
\hline CHEMBL1542864 & 688816 & 5.85 & 5.0271 & TRN & \\
\hline CHEMBL1398261 & 688816 & 6.25 & 5.6873 & TRN & \\
\hline CHEMBL1336871 & 688816 & 4.45 & 5.193 & TRN & \\
\hline CHEMBL3211347 & 688816 & 5.9 & 5.1916 & TST & \\
\hline CHEMBL1478769 & 688816 & 5.0 & 5.0813 & TRN & \\
\hline CHEMBL1445924 & 688816 & 4.45 & 5.3597 & TST & \\
\hline CHEMBL1455281 & 688816 & 5.1 & 5.1511 & TRN & \\
\hline CHEMBL1516826 & 688816 & 6.7501 & 4.9302 & TRN & \\
\hline CHEMBL1454611 & 688816 & 5.25 & 5.1003 & TRN & \\
\hline CHEMBL1466004 & 688816 & 4.7 & 5.4344 & TST & \\
\hline CHEMBL1397162 & 688816 & 4.65 & 4.9158 & TRN & \\
\hline CHEMBL1539089 & 688816 & 6.6 & 5.4765 & TRN & \\
\hline CHEMBL1453995 & 688816 & 4.8 & 5.4309 & TRN & \\
\hline CHEMBL1427012 & 688816 & 4.95 & 4.9808 & TRN & \\
\hline CHEMBL1466210 & 688816 & 6.9 & 5.2386 & TRN & \\
\hline CHEMBL1584203 & 688816 & 6.1 & 5.5324 & TST & \\
\hline CHEMBL1472177 & 688816 & 6.5501 & 5.4928 & TRN & \\
\hline CHEMBL1535436 & 688816 & 4.95 & 5.0689 & TRN & \\
\hline CHEMBL1360459 & 688816 & 8.3979 & 5.6887 & TRN & \\
\hline CHEMBL1609361 & 688816 & 8.3468 & 5.78299 & 99999999995 & TRN \\
\hline CHEMBL2369265 & 688816 & 6.15 & 5.4571 & TRN & \\
\hline CHEMBL1492585 & 688816 & 5.9 & 5.2184 & TRN & \\
\hline CHEMBL3195474 & 688816 & 5.3 & 5.1884 & TRN & \\
\hline CHEMBL1337858 & 688816 & 4.8 & 5.0586 & TRN & \\
\hline CHEMBL1449120 & 688816 & 4.95 & 5.1426 & TRN & \\
\hline CHEMBL1384574 & 688816 & 4.7 & 5.5181 & TST & \\
\hline CHEMBL1389690 & 688816 & 4.45 & 5.1325 & TRN & \\
\hline CHEMBL1370675 & 688816 & 5.45 & 5.1605 & TRN & \\
\hline CHEMBL1359596 & 688816 & 4.75 & 5.8243 & TRN & \\
\hline CHEMBL1537935 & 688816 & 4.45 & 5.0184 & TRN & \\
\hline
\end{tabular}




\begin{tabular}{|c|c|c|c|c|}
\hline \multicolumn{5}{|c|}{ Supplemental Table S2.txt } \\
\hline CHEMBL1471669 & 688816 & 6.15 & 5.6515 & TRN \\
\hline CHEMBL1429236 & 688816 & 4.85 & 5.1482 & TST \\
\hline CHEMBL602718 & 688816 & 4.95 & 5.0138 & TRN \\
\hline CHEMBL1529225 & 688816 & 4.8 & 4.9504 & TRN \\
\hline CHEMBL1347593 & 688816 & 5.0 & 5.1987 & TRN \\
\hline CHEMBL1429711 & 688816 & 4.9 & 5.2096 & TRN \\
\hline CHEMBL1547222 & 688816 & 5.25 & 5.0147 & TRN \\
\hline CHEMBL1590581 & 688816 & 4.9 & 5.0584 & TRN \\
\hline CHEMBL1541291 & 688816 & 4.55 & 5.0829 & TRN \\
\hline CHEMBL1368839 & 688816 & 4.8 & 4.9946 & TRN \\
\hline CHEMBL1416841 & 688816 & 4.45 & 4.7847 & TRN \\
\hline CHEMBL1311514 & 688816 & 7.699 & 5.1362 & TRN \\
\hline CHEMBL1485602 & 688816 & 4.45 & 5.4333 & TST \\
\hline CHEMBL1301365 & 688816 & 6.5 & 5.0798 & TRN \\
\hline CHEMBL1573607 & 688816 & 5.45 & 5.4917 & TRN \\
\hline CHEMBL1403538 & 688816 & 4.45 & 5.1074 & TST \\
\hline CHEMBL3196841 & 688816 & 4.95 & 5.2456 & TST \\
\hline CHEMBL1404660 & 688816 & 4.95 & 5.0527 & TRN \\
\hline CHEMBL1504807 & 688816 & 4.45 & 5.0741 & TST \\
\hline CHEMBL1303792 & 688816 & 5.85 & 5.2258 & TRN \\
\hline CHEMBL1568919 & 688816 & 4.5 & 5.391 & TST \\
\hline CHEMBL1611902 & 688816 & 5.6 & 4.8677 & TRN \\
\hline CHEMBL1524115 & 688816 & 4.9 & 5.0522 & TRN \\
\hline CHEMBL1492543 & 688816 & 4.85 & 5.1233 & TRN \\
\hline CHEMBL1428076 & 688816 & 5.35 & 5.2449 & TST \\
\hline CHEMBL1520260 & 688816 & 4.95 & 4.9492 & TRN \\
\hline CHEMBL1566193 & 688816 & 5.45 & 5.0132 & TST \\
\hline CHEMBL1523017 & 688816 & 4.9 & 5.5889 & TRN \\
\hline CHEMBL1409166 & 688816 & 5.0 & 4.971 & TRN \\
\hline CHEMBL1299661 & 688816 & 4.85 & 5.1797 & TRN \\
\hline CHEMBL1529017 & 688816 & 5.05 & 5.3385 & TRN \\
\hline CHEMBL3211620 & 688816 & 5.05 & 5.3517 & TRN \\
\hline CHEMBL1304996 & 688816 & 6.35 & 5.3216 & TRN \\
\hline CHEMBL1303465 & 688816 & 5.15 & 5.3516 & TRN \\
\hline CHEMBL1348043 & 688816 & 4.9 & 5.4684 & TST \\
\hline CHEMBL1340941 & 688816 & 4.45 & 5.7457 & TRN \\
\hline CHEMBL 1324630 & 688816 & 4.8 & 5.2668 & TRN \\
\hline CHEMBL3190770 & 688816 & 4.45 & 5.4155 & TRN \\
\hline CHEMBL1507712 & 688816 & 4.9 & 5.2939 & TST \\
\hline CHEMBL1320589 & 688816 & 4.9 & 5.5081 & TRN \\
\hline CHEMBL1967857 & 688816 & 5.8 & 5.6744 & TRN \\
\hline CHEMBL3212655 & 688816 & 4.5 & 4.8675 & TRN \\
\hline CHEMBL1332378 & 688816 & 5.2 & 5.4015 & TST \\
\hline CHEMBL1303988 & 688816 & 4.85 & 5.3938 & TRN \\
\hline CHEMBL1425679 & 688816 & 4.9 & 5.3262 & TRN \\
\hline CHEMBL1433202 & 688816 & 5.45 & 5.3082 & TRN \\
\hline CHEMBL1466455 & 688816 & 4.85 & 5.1887 & TRN \\
\hline CHEMBL1583011 & 688816 & 5.0 & 5.1431 & TRN \\
\hline
\end{tabular}




\begin{tabular}{|c|c|c|c|c|c|}
\hline \multicolumn{6}{|c|}{ Supplemental Table S2.txt } \\
\hline CHEMBL193627 & 688816 & 5.0 & 5.1672 & TRN & \\
\hline CHEMBL1505303 & 688816 & 4.85 & 5.3022 & TRN & \\
\hline CHEMBL1611316 & 688816 & 6.45 & 5.157 & TST & \\
\hline CHEMBL1426411 & 688816 & 5.5 & 5.5255 & TST & \\
\hline CHEMBL1566965 & 688816 & 4.7 & 5.34200 & 00000000005 & TRN \\
\hline CHEMBL1524617 & 688816 & 4.5 & 5.88700 & 00000000005 & TST \\
\hline CHEMBL1328176 & 688816 & 6.5501 & 5.2561 & TRN & \\
\hline CHEMBL1607212 & 688816 & 5.35 & 5.3459 & TRN & \\
\hline CHEMBL1553682 & 688816 & 4.45 & 5.3178 & TRN & \\
\hline CHEMBL1375390 & 688816 & 4.85 & 5.4206 & TST & \\
\hline CHEMBL1319467 & 688816 & 5.6 & 5.2416 & TST & \\
\hline CHEMBL1538571 & 688816 & 4.9 & 5.0486 & TRN & \\
\hline CHEMBL1525878 & 688816 & 5.35 & 5.0172 & TRN & \\
\hline CHEMBL1605657 & 688816 & 5.05 & 5.8317 & TST & \\
\hline CHEMBL1359565 & 688816 & 4.85 & 5.1202 & TST & \\
\hline CHEMBL1444513 & 688816 & 4.75 & 4.8707 & TRN & \\
\hline CHEMBL1412954 & 688816 & 4.8 & 5.6951 & TRN & \\
\hline CHEMBL1557782 & 688816 & 4.45 & 5.0117 & TST & \\
\hline CHEMBL572346 & 688816 & 4.45 & 5.3425 & TRN & \\
\hline CHEMBL1456011 & 688816 & 4.45 & 5.3315 & TRN & \\
\hline CHEMBL1453609 & 688816 & 4.95 & 4.959 & TRN & \\
\hline CHEMBL3197855 & 688816 & 5.3 & 5.6833 & TRN & \\
\hline CHEMBL1410726 & 688816 & 5.25 & 5.2379 & TST & \\
\hline CHEMBL1613447 & 688816 & 4.95 & 5.3502 & TRN & \\
\hline CHEMBL1402115 & 688816 & 4.8 & 5.7305 & TRN & \\
\hline CHEMBL1518921 & 688816 & 4.45 & 5.2964 & TST & \\
\hline CHEMBL1575102 & 688816 & 5.15 & 4.9027 & TRN & \\
\hline CHEMBL1336100 & 688816 & 5.05 & 5.4708 & TRN & \\
\hline CHEMBL1528718 & 688816 & 5.55 & 5.4216 & TRN & \\
\hline CHEMBL1385294 & 688816 & 8.3468 & 5.1296 & TRN & \\
\hline CHEMBL1464922 & 688816 & 8.1487 & 5.0918 & TRN & \\
\hline CHEMBL1364371 & 688816 & 5.5 & 5.4609 & TRN & \\
\hline CHEMBL1343476 & 688816 & 4.65 & 5.4194 & TRN & \\
\hline CHEMBL1545804 & 688816 & 5.15 & 5.532 & TRN & \\
\hline CHEMBL1599216 & 688816 & 4.7 & 5.6198 & TRN & \\
\hline CHEMBL1452558 & 688816 & 5.8 & 4.7159 & TRN & \\
\hline CHEMBL1968383 & 688816 & 4.95 & 5.0646 & TRN & \\
\hline CHEMBL1522330 & 688816 & 5.25 & 5.1978 & TRN & \\
\hline CHEMBL1983418 & 688816 & 5.55 & 5.4138 & TRN & \\
\hline CHEMBL1420642 & 688816 & 4.75 & 5.6389 & TST & \\
\hline CHEMBL137648 & 688816 & 4.5 & 5.4961 & TST & \\
\hline CHEMBL1502932 & 688816 & 4.95 & 4.9937 & TRN & \\
\hline CHEMBL1455263 & 688816 & 4.5 & 5.0974 & TST & \\
\hline CHEMBL1360562 & 688816 & 5.25 & 4.8315 & TRN & \\
\hline CHEMBL1500208 & 688816 & 4.95 & 5.7244 & TST & \\
\hline CHEMBL1399734 & 688816 & 8.301 & 5.431 & TRN & \\
\hline CHEMBL1349342 & 688816 & 5.05 & 5.6289 & TST & \\
\hline CHEMBL3195763 & 688816 & 5.1 & 5.1026 & TRN & \\
\hline
\end{tabular}




\begin{tabular}{|c|c|c|c|c|}
\hline \multicolumn{5}{|c|}{ Supplemental Table S2.txt } \\
\hline CHEMBL1328285 & 688816 & 4.85 & 5.142 & TRN \\
\hline CHEMBL1530940 & 688816 & 4.45 & 5.3256 & TRN \\
\hline CHEMBL1421164 & 688816 & 4.8 & 4.9851 & TRN \\
\hline CHEMBL1578726 & 688816 & 8.0506 & 4.874 & TST \\
\hline CHEMBL3207292 & 688816 & 4.45 & 5.5421 & TRN \\
\hline CHEMBL1527580 & 688816 & 4.95 & 4.9626 & TRN \\
\hline CHEMBL 2001857 & 688816 & 4.85 & 5.1634 & TST \\
\hline CHEMBL1330326 & 688816 & 4.95 & 5.1012 & TRN \\
\hline CHEMBL1452083 & 688816 & 8.2007 & 5.6178 & TST \\
\hline CHEMBL1535817 & 688816 & 4.45 & 5.0919 & TRN \\
\hline CHEMBL1533378 & 688816 & 8.0 & 5.315 & TRN \\
\hline CHEMBL1307475 & 688816 & 4.5 & 5.2838 & TRN \\
\hline CHEMBL1567308 & 688816 & 6.0 & 5.1399 & TRN \\
\hline CHEMBL1212984 & 688816 & 4.9 & 5.4862 & TRN \\
\hline CHEMBL1410454 & 688816 & 5.55 & 5.666 & TRN \\
\hline CHEMBL3210308 & 688816 & 5.25 & 5.5551 & TRN \\
\hline CHEMBL1301768 & 688816 & 6.25 & 5.2451 & TRN \\
\hline CHEMBL1576055 & 688816 & 4.85 & 5.1614 & TRN \\
\hline CHEMBL1363746 & 688816 & 4.5 & 5.4518 & TRN \\
\hline CHEMBL1448466 & 688816 & 4.9 & 5.0975 & TRN \\
\hline CHEMBL1499806 & 688816 & 4.85 & 5.1039 & TST \\
\hline CHEMBL1363151 & 688816 & 7.5003 & 5.3898 & TST \\
\hline CHEMBL1392107 & 688816 & 8.0 & 5.5047 & TRN \\
\hline CHEMBL1493046 & 688816 & 4.6 & 5.5646 & TRN \\
\hline CHEMBL1571906 & 688816 & 4.45 & 5.4544 & TST \\
\hline CHEMBL1559858 & 688816 & 5.0 & 5.087 & TRN \\
\hline CHEMBL 3212698 & 688816 & 4.65 & 5.5259 & TST \\
\hline CHEMBL3209608 & 688816 & 4.45 & 5.3931 & TST \\
\hline CHEMBL1388094 & 688816 & 5.25 & 5.5109 & TRN \\
\hline CHEMBL1511125 & 688816 & 5.5 & 5.2516 & TRN \\
\hline CHEMBL1376069 & 688816 & 4.95 & 5.3638 & TRN \\
\hline CHEMBL1383608 & 688816 & 5.4 & 5.6086 & TST \\
\hline CHEMBL1299253 & 688816 & 4.55 & 4.896 & TRN \\
\hline CHEMBL1416682 & 688816 & 5.0 & 5.324 & TRN \\
\hline CHEMBL1521700 & 688816 & 4.95 & 5.3942 & TRN \\
\hline CHEMBL1314042 & 688816 & 4.6 & 4.9152 & TRN \\
\hline CHEMBL1500038 & 688816 & 5.25 & 5.7882 & TRN \\
\hline CHEMBL1381833 & 688816 & 5.0 & 5.3127 & TRN \\
\hline CHEMBL 3199560 & 688816 & 4.45 & 5.6122 & TST \\
\hline CHEMBL1508482 & 688816 & 4.85 & 5.1592 & TRN \\
\hline CHEMBL1410654 & 688816 & 5.55 & 5.4193 & TST \\
\hline CHEMBL1535025 & 688816 & 4.9 & 5.0585 & TRN \\
\hline CHEMBL1333498 & 688816 & 4.85 & 5.2268 & TRN \\
\hline CHEMBL1403766 & 688816 & 5.1 & 5.3864 & TST \\
\hline CHEMBL1975583 & 688816 & 6.7501 & 5.3572 & TRN \\
\hline CHEMBL1411716 & 688816 & 6.6 & 5.4146 & TST \\
\hline CHEMBL1547279 & 688816 & 7.4001 & 5.1853 & TRN \\
\hline CHEMBL1300353 & 688816 & 4.85 & 5.4515 & TST \\
\hline
\end{tabular}




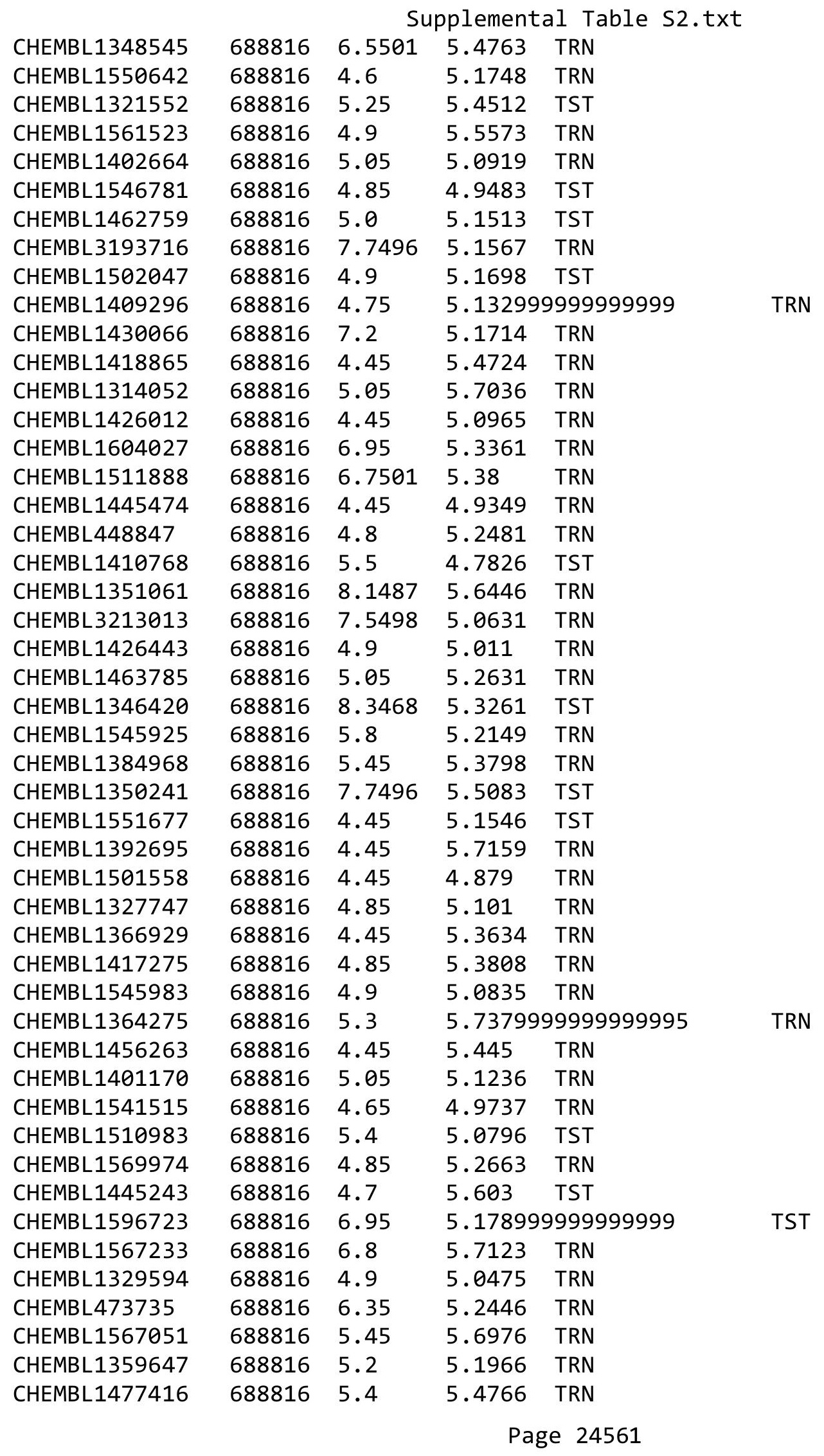




\begin{tabular}{|c|c|c|c|c|c|}
\hline \multicolumn{6}{|c|}{ Supplemental Table S2.txt } \\
\hline CHEMBL1352976 & 688816 & 5.5 & 5.6335 & TRN & \\
\hline CHEMBL1549222 & 688816 & 4.7 & 5.0979 & TRN & \\
\hline CHEMBL1408191 & 688816 & 4.9 & 4.9932 & TRN & \\
\hline CHEMBL1979843 & 688816 & 4.45 & 5.6136 & TRN & \\
\hline CHEMBL1518866 & 688816 & 4.85 & 5.5861 & TRN & \\
\hline CHEMBL1529115 & 688816 & 4.8 & 5.1021 & TST & \\
\hline CHEMBL1552888 & 688816 & 5.25 & 5.2377 & TST & \\
\hline CHEMBL1610972 & 688816 & 5.5 & 5.1531 & TRN & \\
\hline CHEMBL1470150 & 688816 & 6.05 & 5.5875 & TRN & \\
\hline CHEMBL1588753 & 688816 & 4.85 & 5.04899 & 99999999995 & TRN \\
\hline CHEMBL1370100 & 688816 & 5.0 & 4.9556 & TRN & \\
\hline CHEMBL3194602 & 688816 & 5.05 & 5.4613 & TRN & \\
\hline CHEMBL1339427 & 688816 & 4.85 & 5.1232 & TRN & \\
\hline CHEMBL1349938 & 688816 & 4.65 & $5.3210 e$ & 0000000001 & TRN \\
\hline CHEMBL1323660 & 688816 & 4.95 & 5.312 & TST & \\
\hline CHEMBL1601896 & 688816 & 4.8 & 5.1542 & TRN & \\
\hline CHEMBL1430255 & 688816 & 4.95 & 5.3209 & TST & \\
\hline CHEMBL1331543 & 688816 & 4.95 & 5.1174 & TRN & \\
\hline CHEMBL1573485 & 688816 & 4.45 & 5.1111 & TRN & \\
\hline CHEMBL1597854 & 688816 & 5.2 & 5.36 & TRN & \\
\hline CHEMBL1384377 & 688816 & 4.6 & 4.8765 & TRN & \\
\hline CHEMBL1609872 & 688816 & 5.4 & 5.2648 & TRN & \\
\hline CHEMBL3145244 & 688816 & 4.95 & 5.4182 & TST & \\
\hline CHEMBL1471983 & 688816 & 7.6498 & 5.2093 & TST & \\
\hline CHEMBL1325646 & 688816 & 5.85 & 5.5225 & TRN & \\
\hline CHEMBL1441761 & 688816 & 4.7 & 5.2388 & TRN & \\
\hline CHEMBL1330067 & 688816 & 4.65 & 5.1705 & TRN & \\
\hline CHEMBL1411665 & 688816 & 5.45 & 5.3384 & TRN & \\
\hline CHEMBL1337568 & 688816 & 5.2 & 5.3898 & TST & \\
\hline CHEMBL1477320 & 688816 & 4.85 & 5.4049 & TRN & \\
\hline CHEMBL1504310 & 688816 & 4.85 & 5.0003 & TST & \\
\hline CHEMBL1390143 & 688816 & 7.5498 & 5.5483 & TST & \\
\hline CHEMBL1528108 & 688816 & 5.25 & 5.3935 & TRN & \\
\hline CHEMBL1505718 & 688816 & 7.15 & 5.3108 & TST & \\
\hline CHEMBL1422637 & 688816 & 6.0 & 5.2594 & TRN & \\
\hline CHEMBL1530021 & 688816 & 4.85 & 5.4571 & TRN & \\
\hline CHEMBL1438070 & 688816 & 5.4 & 5.6756 & TST & \\
\hline CHEMBL1382135 & 688816 & 4.95 & 5.4803 & TRN & \\
\hline CHEMBL1345573 & 688816 & 4.95 & 5.1966 & TRN & \\
\hline CHEMBL1458510 & 688816 & 5.1 & 5.2925 & TST & \\
\hline CHEMBL1538279 & 688816 & 4.95 & 5.6157 & TRN & \\
\hline CHEMBL1445490 & 688816 & 4.95 & 5.1166 & TRN & \\
\hline CHEMBL1497549 & 688816 & 7.2503 & 5.2688 & TST & \\
\hline CHEMBL16223 & 688816 & 4.95 & $5.2420 e$ & $\partial 000000001$ & TRN \\
\hline CHEMBL1584466 & 688816 & 4.9 & 5.4875 & TRN & \\
\hline CHEMBL1328264 & 688816 & 4.45 & 5.2934 & TRN & \\
\hline CHEMBL 211740 & 688816 & 4.95 & 5.1431 & TRN & \\
\hline CHEMBL1431551 & 688816 & 4.7 & 5.3813 & TRN & \\
\hline
\end{tabular}




\begin{tabular}{|c|c|c|c|c|c|}
\hline \multicolumn{6}{|c|}{ Supplemental Table S2.txt } \\
\hline CHEMBL1575584 & 688816 & 4.45 & 5.3573 & TST & \\
\hline CHEMBL1352758 & 688816 & 4.9 & 5.1535 & TRN & \\
\hline CHEMBL1342062 & 688816 & 4.95 & 4.9709 & TRN & \\
\hline CHEMBL1976099 & 688816 & 4.45 & 4.9593 & TRN & \\
\hline CHEMBL1366812 & 688816 & 6.1 & 5.6175 & TRN & \\
\hline CHEMBL1585706 & 688816 & 5.5 & 5.355 & TRN & \\
\hline CHEMBL1399262 & 688816 & 4.7 & 5.1744 & TST & \\
\hline CHEMBL1469367 & 688816 & 4.95 & 5.5242 & TRN & \\
\hline CHEMBL1428673 & 688816 & 4.95 & 5.2555 & TRN & \\
\hline CHEMBL1576968 & 688816 & 4.45 & 5.0919 & TST & \\
\hline CHEMBL1566269 & 688816 & 4.45 & 5.6816 & TRN & \\
\hline CHEMBL1411209 & 688816 & 4.85 & 5.0854 & TRN & \\
\hline CHEMBL1583650 & 688816 & 5.25 & 5.3125 & TRN & \\
\hline CHEMBL 3192125 & 688816 & 4.85 & 5.2987 & TRN & \\
\hline CHEMBL1427979 & 688816 & 5.5 & 5.5878 & TRN & \\
\hline CHEMBL1432612 & 688816 & 7.5003 & 5.3785 & TRN & \\
\hline CHEMBL1302158 & 688816 & 4.6 & 4.6589 & TRN & \\
\hline CHEMBL1510587 & 688816 & 6.15 & 5.1795 & TRN & \\
\hline CHEMBL1443368 & 688816 & 5.5 & 5.2703 & TRN & \\
\hline CHEMBL1460095 & 688816 & 4.8 & 5.3362 & TRN & \\
\hline CHEMBL1545677 & 688816 & 5.55 & 5.0033 & TRN & \\
\hline CHEMBL1541075 & 688816 & 4.9 & 5.0839 & TST & \\
\hline CHEMBL1421398 & 688816 & 5.6 & 5.3889 & TRN & \\
\hline CHEMBL1375371 & 688816 & 4.75 & 5.6236 & TST & \\
\hline CHEMBL1994221 & 688816 & 4.45 & 5.4525 & TRN & \\
\hline CHEMBL1592291 & 688816 & 4.85 & 4.8821 & TRN & \\
\hline CHEMBL1508190 & 688816 & 4.45 & 5.2409 & TST & \\
\hline CHEMBL1458139 & 688816 & 4.95 & 5.1973 & TRN & \\
\hline CHEMBL265686 & 688816 & 6.3 & 5.1282 & TRN & \\
\hline CHEMBL1310852 & 688816 & 4.7 & 4.99100 & 00000000005 & TRN \\
\hline CHEMBL1304918 & 688816 & 5.7 & 5.0375 & TST & \\
\hline CHEMBL1559863 & 688816 & 5.45 & 5.4317 & TST & \\
\hline CHEMBL1612277 & 688816 & 4.9 & 5.1621 & TRN & \\
\hline CHEMBL1548899 & 688816 & 5.3 & 5.2676 & TST & \\
\hline CHEMBL1528481 & 688816 & 5.35 & 5.1492 & TST & \\
\hline CHEMBL1458792 & 688816 & 4.85 & 5.2606 & TRN & \\
\hline CHEMBL1407077 & 688816 & 5.1 & 5.0743 & TRN & \\
\hline CHEMBL1515132 & 688816 & 4.85 & 5.6148 & TST & \\
\hline CHEMBL56897 & 688816 & 4.95 & 5.4725 & TST & \\
\hline CHEMBL1968356 & 688816 & 4.5 & 5.4681 & TRN & \\
\hline CHEMBL1464753 & 688816 & 4.9 & 5.1443 & TRN & \\
\hline CHEMBL3197486 & 688816 & 7.5003 & 5.2331 & TST & \\
\hline CHEMBL1366550 & 688816 & 7.7496 & 5.2436 & TST & \\
\hline CHEMBL1445852 & 688816 & 6.2 & 5.6804 & TRN & \\
\hline CHEMBL1348388 & 688816 & 7.4001 & 5.4857 & TRN & \\
\hline CHEMBL424581 & 688816 & 4.9 & 5.2145 & TRN & \\
\hline CHEMBL1257003 & 688816 & 4.85 & 5.175 & TRN & \\
\hline CHEMBL1549099 & 688816 & 4.45 & 5.1369 & TRN & \\
\hline
\end{tabular}




\begin{tabular}{|c|c|c|c|c|c|}
\hline \multirow{3}{*}{$\begin{array}{l}\text { CHEMBL1359861 } \\
\text { CHFMRI 1529172 }\end{array}$} & \multirow[b]{2}{*}{688816} & \multicolumn{4}{|c|}{ Supplemental Table S2.txt } \\
\hline & & 5.05 & \multicolumn{2}{|c|}{5.4510000000000005} & TST \\
\hline & 688816 & 4.7 & 5.523 & TRN & \\
\hline CHEMBL1535732 & 688816 & 5.3 & 5.1426 & TST & \\
\hline CHEMBL1343419 & 688816 & 6.05 & 5.3988 & TRN & \\
\hline CHEMBL1414301 & 688816 & 4.8 & 5.0336 & TRN & \\
\hline CHEMBL1569917 & 688816 & 6.6499 & 4.9423 & TRN & \\
\hline CHEMBL1564233 & 688816 & 4.65 & 4.9516 & TRN & \\
\hline CHEMBL1343311 & 688816 & 5.6 & 5.5094 & TRN & \\
\hline CHEMBL1343689 & 688816 & 5.0 & 5.1329 & TRN & \\
\hline CHEMBL3213741 & 688816 & 4.95 & 5.35 & TRN & \\
\hline CHEMBL1482799 & 688816 & 4.9 & \multicolumn{2}{|c|}{4.946000000000001} & TRN \\
\hline CHEMBL1469103 & 688816 & 5.3 & 5.4552 & TST & \\
\hline CHEMBL1333093 & 688816 & 5.35 & 5.4472 & TRN & \\
\hline CHEMBL1352355 & 688816 & 4.95 & 5.3629 & TRN & \\
\hline CHEMBL1612068 & 688816 & 5.5 & 5.4005 & TRN & \\
\hline CHEMBL1408108 & 688816 & 4.95 & 5.2458 & TRN & \\
\hline CHEMBL1490503 & 688816 & 7.1002 & 5.5162 & TRN & \\
\hline CHEMBL1525717 & 688816 & 8.301 & 5.4951 & TST & \\
\hline CHEMBL1311421 & 688816 & 4.95 & 5.3801 & TRN & \\
\hline CHEMBL1535724 & 688816 & 5.45 & 4.9157 & TRN & \\
\hline CHEMBL1322630 & 688816 & 4.9 & 5.3916 & TRN & \\
\hline CHEMBL1457941 & 688816 & 6.3 & 5.1358 & TRN & \\
\hline CHEMBL1440909 & 688816 & 5.5 & 5.6273 & TST & \\
\hline CHEMBL1482542 & 688816 & 6.0 & 5.3723 & TRN & \\
\hline CHEMBL1432258 & 688816 & 4.45 & \multicolumn{2}{|c|}{5.797999999999999} & TST \\
\hline CHEMBL1404098 & 688816 & 4.65 & 4.935 & TRN & \\
\hline CHEMBL1537739 & 688816 & 5.0 & 4.9803 & TRN & \\
\hline CHEMBL1275655 & 688816 & 6.0 & 5.8267 & TST & \\
\hline CHEMBL1346301 & 688816 & 6.5501 & 5.7316 & TRN & \\
\hline CHEMBL576412 & 688816 & 4.8 & 4.8449 & TRN & \\
\hline CHEMBL1489204 & 688816 & 4.95 & 5.3758 & TRN & \\
\hline CHEMBL1582324 & 688816 & 4.45 & 5.0168 & TRN & \\
\hline CHEMBL3196099 & 688816 & 4.85 & 5.4617 & TRN & \\
\hline CHEMBL1391530 & 688816 & 7.699 & 5.2852 & TRN & \\
\hline CHEMBL1534020 & 688816 & 4.8 & 5.3498 & TRN & \\
\hline CHEMBL1310945 & 688816 & 4.7 & 5.8181 & TST & \\
\hline CHEMBL1508596 & 688816 & 5.0 & 5.8117 & TRN & \\
\hline CHEMBL1491927 & 688816 & 4.45 & 4.9597 & TRN & \\
\hline CHEMBL1375481 & 688816 & 4.8 & 5.2279 & TRN & \\
\hline CHEMBL1430437 & 688816 & 4.95 & 5.2125 & TRN & \\
\hline CHEMBL1426614 & 688816 & 4.85 & 5.2158 & TRN & \\
\hline CHEMBL1563513 & 688816 & 4.95 & 5.0619 & TRN & \\
\hline CHEMBL1368889 & 688816 & 4.95 & 5.5546 & TRN & \\
\hline CHEMBL1486404 & 688816 & 8.2518 & 5.6852 & TST & \\
\hline CHEMBL1360792 & 688816 & 5.0 & 5.4366 & TST & \\
\hline CHEMBL1589382 & 688816 & 5.05 & 5.1194 & TST & \\
\hline CHEMBL1365051 & 688816 & 4.45 & 5.1984 & TRN & \\
\hline CHEMBL1497656 & 688816 & 4.8 & 5.0126 & TRN & \\
\hline & & & & & \\
\hline
\end{tabular}




\begin{tabular}{|c|c|c|c|c|}
\hline \multicolumn{5}{|c|}{ Supplemental Table S2.txt } \\
\hline CHEMBL3194936 & 688816 & 5.0 & 5.3646 & TRN \\
\hline CHEMBL1501263 & 688816 & 4.45 & 5.3286 & TRN \\
\hline CHEMBL3195856 & 688816 & 4.85 & 5.407 & TST \\
\hline CHEMBL1386908 & 688816 & 4.9 & 5.2517 & TRN \\
\hline CHEMBL1597673 & 688816 & 4.65 & 5.3647 & TRN \\
\hline CHEMBL1477093 & 688816 & 4.45 & 5.0923 & TRN \\
\hline CHEMBL1538941 & 688816 & 5.5 & 5.5483 & TRN \\
\hline CHEMBL1439171 & 688816 & 4.45 & 5.4997 & TRN \\
\hline CHEMBL1401426 & 688816 & 7.0501 & 5.9077 & TRN \\
\hline CHEMBL3212198 & 688816 & 6.7501 & 5.3999 & TST \\
\hline CHEMBL1342667 & 688816 & 4.8 & 4.9646 & TRN \\
\hline CHEMBL1346468 & 688816 & 4.75 & 4.8381 & TRN \\
\hline CHEMBL1378949 & 688816 & 4.95 & 5.5183 & TST \\
\hline CHEMBL1717301 & 688816 & 4.8 & 5.3787 & TRN \\
\hline CHEMBL1308329 & 688816 & 4.95 & 5.421 & TRN \\
\hline CHEMBL581910 & 688816 & 4.6 & 5.1808 & TRN \\
\hline CHEMBL1366573 & 688816 & 4.7 & 5.4515 & TRN \\
\hline CHEMBL1428472 & 688816 & 4.75 & 5.0001 & TRN \\
\hline CHEMBL227726 & 688816 & 5.0 & 5.1897 & TRN \\
\hline CHEMBL1531038 & 688816 & 5.2 & 5.1891 & TST \\
\hline CHEMBL1308977 & 688816 & 8.3468 & 5.4623 & TRN \\
\hline CHEMBL1403938 & 688816 & 4.95 & 5.2577 & TRN \\
\hline CHEMBL1543163 & 688816 & 5.15 & 5.1561 & TST \\
\hline CHEMBL1393191 & 688816 & 5.0 & 5.4255 & TST \\
\hline CHEMBL1564737 & 688816 & 5.15 & 5.1228 & TRN \\
\hline CHEMBL1373774 & 688816 & 4.85 & 5.3323 & TRN \\
\hline CHEMBL1466445 & 688816 & 5.1 & 5.4122 & TRN \\
\hline CHEMBL1361577 & 688816 & 5.25 & 5.4382 & TRN \\
\hline CHEMBL1426941 & 688816 & 4.85 & 5.2222 & TRN \\
\hline CHEMBL1363629 & 688816 & 4.95 & 5.0493 & TRN \\
\hline CHEMBL3190941 & 688816 & 4.65 & 4.9358 & TRN \\
\hline CHEMBL1355835 & 688816 & 4.45 & 4.8548 & TRN \\
\hline CHEMBL1549782 & 688816 & 4.45 & 5.0555 & TST \\
\hline CHEMBL1324212 & 688816 & 4.5 & 5.1981 & TRN \\
\hline CHEMBL1602145 & 688816 & 4.95 & 5.0553 & TRN \\
\hline CHEMBL1470900 & 688816 & 4.9 & 4.956 & TRN \\
\hline CHEMBL1428709 & 688816 & 8.4949 & 5.4185 & TST \\
\hline CHEMBL1436661 & 688816 & 5.05 & 5.1553 & TRN \\
\hline CHEMBL1402909 & 688816 & 4.45 & 5.176 & TST \\
\hline CHEMBL1453291 & 688816 & 5.15 & 5.4033 & TRN \\
\hline CHEMBL1335354 & 688816 & 6.3 & 5.2635 & TST \\
\hline CHEMBL3196960 & 688816 & 4.5 & 4.8728 & TRN \\
\hline CHEMBL1387320 & 688816 & 4.9 & 5.1347 & TRN \\
\hline CHEMBL3208179 & 688816 & 4.95 & 5.1468 & TRN \\
\hline CHEMBL3214612 & 688816 & 8.301 & 5.0961 & TRN \\
\hline CHEMBL1412473 & 688816 & 5.1 & 5.0545 & TRN \\
\hline CHEMBL1302048 & 688816 & 4.95 & 5.074 & TRN \\
\hline CHEMBL1574404 & 688816 & 4.45 & 4.9558 & TST \\
\hline
\end{tabular}




\begin{tabular}{|c|c|c|c|c|c|}
\hline & & \multicolumn{4}{|c|}{ Supplemental Table s2.txt } \\
\hline CHEMBL1307138 & 688816 & 4.95 & 4.9977 & TRN & \\
\hline CHEMBL1510954 & 688816 & 5.4 & 5.2197 & TRN & \\
\hline CHEMBL1393762 & 688816 & 8.4949 & 5.7134 & TST & \\
\hline CHEMBL1408404 & 688816 & 4.45 & 5.1003 & TRN & \\
\hline CHEMBL1419152 & 688816 & 4.6 & 5.2095 & TRN & \\
\hline CHEMBL1365052 & 688816 & 7.4001 & 5.2893 & TRN & \\
\hline CHEMBL1373964 & 688816 & 7.7496 & 5.2198 & TRN & \\
\hline CHEMBL1414388 & 688816 & 5.0 & 5.2 & TST & \\
\hline CHEMBL3195612 & 688816 & 4.7 & 4.9981 & TST & \\
\hline CHEMBL1352270 & 688816 & 4.8 & 5.2507 & TST & \\
\hline CHEMBL1472201 & 688816 & 5.9 & 4.9799 & TRN & \\
\hline CHEMBL1300136 & 688816 & 5.25 & 4.8427 & TRN & \\
\hline CHEMBL1380760 & 688816 & 4.6 & 5.3869 & TST & \\
\hline CHEMBL1366940 & 688816 & 5.0 & 5.4488 & TRN & \\
\hline CHEMBL1544023 & 688816 & 5.5 & 5.4023 & TST & \\
\hline CHEMBL1549911 & 688816 & 4.85 & 4.8726 & TST & \\
\hline CHEMBL1448984 & 688816 & 4.95 & 5.4748 & TRN & \\
\hline CHEMBL1311863 & 688816 & 5.0 & 5.3504 & TST & \\
\hline CHEMBL1543337 & 688816 & 6.45 & 5.4384 & TRN & \\
\hline CHEMBL1462497 & 688816 & 4.7 & 5.6093 & TST & \\
\hline CHEMBL1309249 & 688816 & 4.55 & 5.4096 & TRN & \\
\hline CHEMBL1502200 & 688816 & 4.7 & 5.0238 & TST & \\
\hline CHEMBL1312683 & 688816 & 4.75 & 5.2767 & TRN & \\
\hline CHEMBL1367629 & 688816 & 7.5498 & 5.5079 & TRN & \\
\hline CHEMBL1336098 & 688816 & 5.45 & 5.1423 & TRN & \\
\hline CHEMBL1470388 & 688816 & 4.6 & 5.479 & TRN & \\
\hline CHEMBL3211707 & 688816 & 4.9 & 5.2493 & TRN & \\
\hline CHEMBL1576946 & 688816 & 4.9 & 5.4551 & TRN & \\
\hline CHEMBL1555976 & 688816 & 4.65 & 5.5149 & TST & \\
\hline CHEMBL1506130 & 688816 & 5.6 & 4.8505 & TRN & \\
\hline CHEMBL1549010 & 688816 & 4.8 & 5.5467 & TRN & \\
\hline CHEMBL1577730 & 688816 & 4.95 & 5.1903 & TST & \\
\hline CHEMBL1386466 & 688816 & 5.4 & 5.4773 & TRN & \\
\hline CHEMBL1439301 & 688816 & 4.95 & 4.9979 & TRN & \\
\hline CHEMBL1342231 & 688816 & 4.9 & 5.1986 & TRN & \\
\hline CHEMBL1451197 & 688816 & 5.4 & 5.1455 & TRN & \\
\hline CHEMBL1526963 & 688816 & 4.55 & 5.1671 & TRN & \\
\hline CHEMBL1534939 & 688816 & 7.6498 & 5.7969 & TRN & \\
\hline CHEMBL1589369 & 688816 & 4.7 & 5.4928 & TST & \\
\hline CHEMBL1514920 & 688816 & 8.6576 & 5.5165 & TRN & \\
\hline CHEMBL1373836 & 688816 & 5.0 & 4.9316 & TRN & \\
\hline CHEMBL1444180 & 688816 & 6.45 & 5.5608 & TRN & \\
\hline CHEMBL1551681 & 688816 & 4.7 & 4.9888 & TRN & \\
\hline CHEMBL527584 & 688816 & 4.45 & 5.16799 & 9999999999 & TRN \\
\hline CHEMBL1447499 & 688816 & 5.55 & $5.3770 e$ & 0000000001 & TRN \\
\hline CHEMBL1464848 & 688816 & 5.0 & 5.4837 & TRN & \\
\hline CHEMBL1381909 & 688816 & 5.0 & 5.1284 & TRN & \\
\hline CHEMBL1567763 & 688816 & 5.3 & 4.9877 & TRN & \\
\hline
\end{tabular}




\begin{tabular}{|c|c|c|c|c|c|}
\hline \multicolumn{6}{|c|}{ Supplemental Table S2.txt } \\
\hline CHEMBL1537112 & 688816 & 4.45 & 5.3117 & TRN & \\
\hline CHEMBL1389556 & 688816 & 4.95 & 5.3795 & TST & \\
\hline CHEMBL1504221 & 688816 & 4.9 & 5.1126 & TST & \\
\hline CHEMBL1398967 & 688816 & 4.95 & 5.3987 & TRN & \\
\hline CHEMBL1435501 & 688816 & 4.45 & 4.9938 & TRN & \\
\hline CHEMBL1437473 & 688816 & 6.0 & 5.3045 & TRN & \\
\hline CHEMBL1578791 & 688816 & 4.8 & 5.2359 & TRN & \\
\hline CHEMBL1304743 & 688816 & 5.05 & 5.0874 & TRN & \\
\hline CHEMBL1364190 & 688816 & 5.2 & 5.1376 & TRN & \\
\hline CHEMBL549321 & 688816 & 4.45 & 5.2697 & TST & \\
\hline CHEMBL1395707 & 688816 & 4.95 & 5.1768 & TRN & \\
\hline CHEMBL1487950 & 688816 & 5.55 & 5.3293 & TRN & \\
\hline CHEMBL1401185 & 688816 & 7.3002 & 5.5655 & TRN & \\
\hline CHEMBL1569724 & 688816 & 5.95 & 5.5079 & TRN & \\
\hline CHEMBL1610604 & 688816 & 4.95 & 5.041 & TRN & \\
\hline CHEMBL1472175 & 688816 & 4.95 & 5.12200 & 0000000001 & TRN \\
\hline CHEMBL1403609 & 688816 & 8.0506 & 5.4419 & TST & \\
\hline CHEMBL1518005 & 688816 & 5.25 & 5.3698 & TST & \\
\hline CHEMBL1527291 & 688816 & 5.0 & 5.319 & TST & \\
\hline CHEMBL1572195 & 688816 & 4.95 & 5.2327 & TRN & \\
\hline CHEMBL1381475 & 688816 & 5.75 & 5.0403 & TST & \\
\hline CHEMBL1409739 & 688816 & 4.95 & 5.1314 & TRN & \\
\hline CHEMBL3208882 & 688816 & 4.9 & 5.63399 & 99999999995 & TST \\
\hline CHEMBL1350122 & 688816 & 5.25 & 5.4768 & TST & \\
\hline CHEMBL3208514 & 688816 & 8.4949 & 5.3795 & TRN & \\
\hline CHEMBL1450615 & 688816 & 4.7 & 5.6283 & TRN & \\
\hline CHEMBL1522917 & 688816 & 4.75 & 5.7581 & TRN & \\
\hline CHEMBL1532898 & 688816 & 4.45 & 5.1245 & TRN & \\
\hline CHEMBL1425227 & 688816 & 4.45 & 5.0124 & TRN & \\
\hline CHEMBL1559427 & 688816 & 6.05 & 5.7171 & TST & \\
\hline CHEMBL3209199 & 688816 & 6.05 & 5.4767 & TRN & \\
\hline CHEMBL1368340 & 688816 & 6.2 & 5.6642 & TST & \\
\hline CHEMBL1518396 & 688816 & 4.45 & 5.0257 & TRN & \\
\hline CHEMBL1558388 & 688816 & 5.3 & 5.136 & TRN & \\
\hline CHEMBL1530526 & 688816 & 6.35 & 5.4148 & TST & \\
\hline CHEMBL1377385 & 688816 & 5.55 & 5.4384 & TRN & \\
\hline CHEMBL1447713 & 688816 & 7.5498 & 5.2836 & TST & \\
\hline CHEMBL1401080 & 688816 & 4.65 & 5.1643 & TRN & \\
\hline CHEMBL1366491 & 688816 & 5.2 & 5.7154 & TRN & \\
\hline CHEMBL3189905 & 688816 & 4.75 & 5.0309 & TST & \\
\hline CHEMBL1477052 & 688816 & 4.9 & 5.2951 & TRN & \\
\hline CHEMBL1966497 & 688816 & 4.45 & 5.433 & TRN & \\
\hline CHEMBL3196143 & 688816 & 8.1024 & 5.3394 & TST & \\
\hline CHEMBL1359139 & 688816 & 6.2 & 6.0209 & TRN & \\
\hline CHEMBL1338033 & 688816 & 8.301 & 5.3381 & TST & \\
\hline CHEMBL 9470 & 688816 & 5.25 & 5.5944 & TST & \\
\hline CHEMBL1323046 & 688816 & 4.95 & 5.5594 & TRN & \\
\hline CHEMBL1591793 & 688816 & 4.95 & 5.4245 & TRN & \\
\hline
\end{tabular}




\begin{tabular}{|c|c|c|c|c|c|}
\hline \multicolumn{6}{|c|}{ Supplemental Table s2.txt } \\
\hline CHEMBL1542825 & 688816 & 5.45 & 5.2937 & TRN & \\
\hline CHEMBL1311267 & 688816 & 5.0 & 5.2105 & TRN & \\
\hline CHEMBL1400742 & 688816 & 4.8 & 5.2462 & TST & \\
\hline CHEMBL1544147 & 688816 & 4.8 & 5.1002 & TST & \\
\hline CHEMBL1612926 & 688816 & 4.45 & 5.4664 & TST & \\
\hline CHEMBL410873 & 688816 & 5.95 & 5.7273 & TST & \\
\hline CHEMBL1998606 & 688816 & 7.5003 & 5.0067 & TRN & \\
\hline CHEMBL1519034 & 688816 & 5.05 & 4.9994 & TRN & \\
\hline CHEMBL1442112 & 688816 & 4.85 & 4.8321 & TRN & \\
\hline CHEMBL1526830 & 688816 & 5.35 & 5.3279 & TRN & \\
\hline CHEMBL 3197522 & 688816 & 4.65 & 5.3857 & TRN & \\
\hline CHEMBL3194956 & 688816 & 4.45 & 5.0481 & TST & \\
\hline CHEMBL1318863 & 688816 & 4.55 & 5.318 & TRN & \\
\hline CHEMBL1458200 & 688816 & 4.65 & 5.2641 & TRN & \\
\hline CHEMBL1364640 & 688816 & 4.8 & 4.9254 & TRN & \\
\hline CHEMBL1479557 & 688816 & 4.8 & 4.9912 & TRN & \\
\hline CHEMBL1391280 & 688816 & 4.45 & 5.1932 & TST & \\
\hline CHEMBL170993 & 688816 & 4.95 & 5.2987 & TRN & \\
\hline CHEMBL1530594 & 688816 & 5.0 & 5.3526 & TRN & \\
\hline CHEMBL3209132 & 688816 & 5.15 & 5.1171 & TRN & \\
\hline CHEMBL1355230 & 688816 & 5.75 & 5.1359 & TRN & \\
\hline CHEMBL 3197141 & 688816 & 5.05 & 5.3185 & TRN & \\
\hline CHEMBL1541329 & 688816 & 4.9 & 5.1557 & TST & \\
\hline CHEMBL1489895 & 688816 & 8.301 & 5.5998 & TRN & \\
\hline CHEMBL1360230 & 688816 & 7.5498 & 5.6084 & TST & \\
\hline CHEMBL1571248 & 688816 & 4.9 & 5.4205 & TRN & \\
\hline CHEMBL1603907 & 688816 & 8.0 & 5.4729 & TRN & \\
\hline CHEMBL1527504 & 688816 & 5.3 & 5.5154 & TRN & \\
\hline CHEMBL1528266 & 688816 & 4.85 & 5.001 & TRN & \\
\hline CHEMBL1364400 & 688816 & 5.2 & 5.5505 & TRN & \\
\hline CHEMBL1417076 & 688816 & 8.3468 & 5.1924 & TRN & \\
\hline CHEMBL1546176 & 688816 & 4.85 & 5.0605 & TRN & \\
\hline CHEMBL1485674 & 688816 & 4.45 & 5.1514 & TRN & \\
\hline CHEMBL1546994 & 688816 & 5.55 & 5.2813 & TST & \\
\hline CHEMBL1350303 & 688816 & 7.0 & 5.5175 & TRN & \\
\hline CHEMBL1455434 & 688816 & 4.45 & 5.4456 & TST & \\
\hline CHEMBL1448997 & 688816 & 4.45 & 5.2121 & TRN & \\
\hline CHEMBL1379666 & 688816 & 4.95 & 5.7834 & TRN & \\
\hline CHEMBL1387159 & 688816 & 5.25 & 5.3895 & TRN & \\
\hline CHEMBL1325980 & 688816 & 4.95 & 5.4969 & TRN & \\
\hline CHEMBL1485713 & 688816 & 5.4 & 5.2721 & TST & \\
\hline CHEMBL1538003 & 688816 & 8.301 & 5.4665 & TST & \\
\hline CHEMBL1506203 & 688816 & 5.15 & 5.2253 & TST & \\
\hline CHEMBL1302928 & 688816 & 4.85 & 5.4448 & TRN & \\
\hline CHEMBL1452399 & 688816 & 4.8 & 5.0905 & TRN & \\
\hline CHEMBL1471965 & 688816 & 5.05 & 5.3661 & TST & \\
\hline CHEMBL1508255 & 688816 & 4.75 & 5.2059 & TRN & \\
\hline CHEMBL1383806 & 688816 & 4.45 & $5.1610 e$ & 00000000005 & TRN \\
\hline & & & & 24568 & \\
\hline
\end{tabular}




\begin{tabular}{|c|c|c|c|c|}
\hline \multicolumn{5}{|c|}{ Supplemental Table s2.txt } \\
\hline CHEMBL1339742 & 688816 & 4.6 & 5.1159 & TRN \\
\hline CHEMBL1434390 & 688816 & 4.9 & 5.3217 & TRN \\
\hline CHEMBL1385411 & 688816 & 4.85 & 4.8582 & TRN \\
\hline CHEMBL1349916 & 688816 & 4.45 & 5.0635 & TRN \\
\hline CHEMBL1549430 & 688816 & 4.9 & 5.0546 & TRN \\
\hline CHEMBL1542192 & 688816 & 4.8 & 5.6031 & TST \\
\hline CHEMBL 3194385 & 688816 & 4.85 & 5.0356 & TRN \\
\hline CHEMBL1344225 & 688816 & 4.95 & 5.2448 & TRN \\
\hline CHEMBL1585205 & 688816 & 7.6498 & 5.1419 & TRN \\
\hline CHEMBL1479097 & 688816 & 4.45 & 5.5096 & TST \\
\hline CHEMBL1530573 & 688816 & 4.45 & 4.8097 & TRN \\
\hline CHEMBL1449638 & 688816 & 4.9 & 5.3383 & TRN \\
\hline CHEMBL 3856093 & 688816 & 5.55 & 5.2267 & TST \\
\hline CHEMBL1520468 & 688816 & 7.2 & 5.4691 & TRN \\
\hline CHEMBL 3213876 & 688816 & 5.5 & 5.0138 & TRN \\
\hline CHEMBL3209263 & 688816 & 4.9 & 5.3808 & TRN \\
\hline CHEMBL1389773 & 688816 & 4.8 & 5.013 & TRN \\
\hline CHEMBL1543827 & 688816 & 4.85 & 5.0968 & TRN \\
\hline CHEMBL1408696 & 688816 & 4.9 & 5.0259 & TRN \\
\hline CHEMBL1466965 & 688816 & 4.75 & 5.1607 & TRN \\
\hline CHEMBL 2369241 & 688816 & 4.95 & 4.9545 & TST \\
\hline CHEMBL1521482 & 688816 & 4.85 & 4.7413 & TRN \\
\hline CHEMBL1377425 & 688816 & 4.45 & 5.3011 & TRN \\
\hline CHEMBL1464860 & 688816 & 6.5501 & 5.1641 & TRN \\
\hline CHEMBL 3197173 & 688816 & 5.05 & 5.0679 & TST \\
\hline CHEMBL1567344 & 688816 & 5.75 & 5.3822 & TRN \\
\hline CHEMBL1507521 & 688816 & 4.95 & 5.2953 & TRN \\
\hline CHEMBL1530943 & 688816 & 5.7 & 5.0688 & TRN \\
\hline CHEMBL1379810 & 688816 & 4.45 & 5.1566 & TRN \\
\hline CHEMBL1302330 & 688816 & 5.95 & 5.2702 & TRN \\
\hline CHEMBL1471421 & 688816 & 4.7 & 5.2168 & TRN \\
\hline CHEMBL1556284 & 688816 & 4.95 & 5.2471 & TRN \\
\hline CHEMBL1383320 & 688816 & 5.0 & 4.8729 & TRN \\
\hline CHEMBL1571034 & 688816 & 5.15 & 5.1053 & TST \\
\hline CHEMBL1373471 & 688816 & 4.6 & 5.8368 & TRN \\
\hline CHEMBL1333909 & 688816 & 5.45 & 5.6632 & TRN \\
\hline CHEMBL1583472 & 688816 & 4.85 & 5.3325 & TST \\
\hline CHEMBL1477884 & 688816 & 4.45 & $5.1270 e$ & 0000000001 \\
\hline CHEMBL1366636 & 688816 & 5.9 & 5.3879 & TRN \\
\hline CHEMBL1333304 & 688816 & 5.0 & 5.1861 & TRN \\
\hline CHEMBL1372453 & 688816 & 5.3 & 5.1611 & TRN \\
\hline CHEMBL1530352 & 688816 & 4.8 & 5.3632 & TRN \\
\hline CHEMBL1316401 & 688816 & 5.7 & 5.6903 & TRN \\
\hline CHEMBL1588993 & 688816 & 5.15 & 5.2186 & TST \\
\hline CHEMBL604311 & 688816 & 4.5 & 4.8633 & TRN \\
\hline CHEMBL1532472 & 688816 & 5.75 & 5.2685 & TRN \\
\hline CHEMBL1444690 & 688816 & 4.6 & 5.2797 & TST \\
\hline CHEMBL1526387 & 688816 & 4.65 & 5.3437 & TRN \\
\hline
\end{tabular}




\begin{tabular}{|c|c|c|c|c|c|}
\hline & & & & & \\
\hline CHEMBL1545060 & 688816 & 4.8 & 5.3632 & TRN & \\
\hline CHEMBL1502940 & 688816 & 4.45 & 5.3187 & TRN & \\
\hline CHEMBL1611569 & 688816 & 4.8 & 5.6751 & TST & \\
\hline CHEMBL1573648 & 688816 & 4.95 & 5.1388 & TRN & \\
\hline CHEMBL1584266 & 688816 & 5.5 & 5.7052 & TRN & \\
\hline CHEMBL1326260 & 688816 & 4.8 & 5.1695 & TRN & \\
\hline CHEMBL1423064 & 688816 & 5.15 & 4.70100 & 00000000005 & TRN \\
\hline CHEMBL1438258 & 688816 & 4.95 & 5.1936 & TRN & \\
\hline CHEMBL3196788 & 688816 & 4.9 & 5.1725 & TRN & \\
\hline CHEMBL1329473 & 688816 & 5.0 & 5.4963 & TST & \\
\hline CHEMBL1484911 & 688816 & 4.6 & 4.9133 & TST & \\
\hline CHEMBL1547038 & 688816 & 8.0 & 5.4575 & TST & \\
\hline CHEMBL1483734 & 688816 & 5.35 & 5.2357 & TST & \\
\hline CHEMBL1990184 & 688816 & 4.6 & 4.9576 & TRN & \\
\hline CHEMBL1469481 & 688816 & 5.0 & 5.1994 & TRN & \\
\hline CHEMBL1606002 & 688816 & 5.25 & 5.2303 & TRN & \\
\hline CHEMBL1375544 & 688816 & 8.5528 & 5.5853 & TRN & \\
\hline CHEMBL3198233 & 688816 & 6.7001 & 5.6334 & TST & \\
\hline CHEMBL1393097 & 688816 & 4.9 & 5.1421 & TRN & \\
\hline CHEMBL1387790 & 688816 & 4.65 & 5.5635 & TRN & \\
\hline CHEMBL1569608 & 688816 & 5.85 & 5.2727 & TRN & \\
\hline CHEMBL1607331 & 688816 & 8.6576 & 5.7099 & TRN & \\
\hline CHEMBL1304735 & 688816 & 8.301 & 5.442 & TRN & \\
\hline CHEMBL1405694 & 688816 & 4.55 & 5.4646 & TST & \\
\hline CHEMBL1307076 & 688816 & 5.0 & 5.3856 & TST & \\
\hline CHEMBL1429941 & 688816 & 4.95 & 5.0544 & TRN & \\
\hline CHEMBL529870 & 688816 & 5.3 & 5.0887 & TRN & \\
\hline CHEMBL1395903 & 688816 & 4.8 & 5.2048 & TST & \\
\hline CHEMBL1574061 & 688816 & 4.9 & 5.3781 & TRN & \\
\hline CHEMBL1455084 & 688816 & 4.85 & 5.0838 & TRN & \\
\hline CHEMBL1333235 & 688816 & 5.0 & 5.0067 & TRN & \\
\hline CHEMBL1468995 & 688816 & 6.4 & 5.5432 & TRN & \\
\hline CHEMBL1300317 & 688816 & 4.85 & 5.041 & TRN & \\
\hline CHEMBL1350575 & 688816 & 4.85 & 5.159 & TRN & \\
\hline CHEMBL1536808 & 688816 & 4.45 & 5.2685 & TST & \\
\hline CHEMBL588804 & 688816 & 4.85 & 4.8217 & TRN & \\
\hline CHEMBL1338261 & 688816 & 4.95 & 5.2402 & TRN & \\
\hline CHEMBL1606839 & 688816 & 4.75 & 5.0998 & TRN & \\
\hline CHEMBL3209462 & 688816 & 4.8 & 5.704 & TST & \\
\hline CHEMBL1513267 & 688816 & 4.9 & 5.2933 & TST & \\
\hline CHEMBL1541343 & 688816 & 4.85 & 4.9246 & TRN & \\
\hline CHEMBL1519764 & 688816 & 4.45 & 5.2896 & TST & \\
\hline CHEMBL1561469 & 688816 & 8.4949 & 5.2751 & TRN & \\
\hline CHEMBL1518861 & 688816 & 5.0 & 5.6185 & TRN & \\
\hline CHEMBL1579113 & 688816 & 8.0 & 5.6622 & TRN & \\
\hline CHEMBL1472841 & 688816 & 4.95 & 5.2013 & TRN & \\
\hline CHEMBL3193135 & 688816 & 4.95 & 5.4099 & TST & \\
\hline CHEMBL1534092 & 688816 & 4.95 & 5.32600 & 20000000005 & TRN \\
\hline & & & & 24570 & \\
\hline
\end{tabular}




\begin{tabular}{|c|c|c|c|c|c|}
\hline \multicolumn{6}{|c|}{ Supplemental Table S2.txt } \\
\hline CHEMBL1511611 & 688816 & 7.2 & 5.1974 & TRN & \\
\hline CHEMBL1359587 & 688816 & 5.05 & 5.1352 & TRN & \\
\hline CHEMBL1584502 & 688816 & 4.9 & 5.4633 & TST & \\
\hline CHEMBL 3198438 & 688816 & 6.8 & 5.4109 & TST & \\
\hline CHEMBL1603152 & 688816 & 8.301 & 5.1923 & TRN & \\
\hline CHEMBL1609841 & 688816 & 4.75 & 5.4649 & TRN & \\
\hline CHEMBL295316 & 688816 & 4.55 & 5.2499 & TST & \\
\hline CHEMBL1372841 & 688816 & 4.85 & 4.8224 & TRN & \\
\hline CHEMBL1511459 & 688816 & 5.0 & 5.4217 & TST & \\
\hline CHEMBL1597701 & 688816 & 7.5498 & 5.3975 & TRN & \\
\hline CHEMBL1467306 & 688816 & 4.45 & 5.5321 & TST & \\
\hline CHEMBL1304595 & 688816 & 4.95 & 4.963 & TRN & \\
\hline CHEMBL 2006817 & 688816 & 4.85 & 5.2644 & TST & \\
\hline CHEMBL1538034 & 688816 & 4.95 & 5.4976 & TRN & \\
\hline CHEMBL3213814 & 688816 & 4.9 & 4.9034 & TST & \\
\hline CHEMBL1374827 & 688816 & 7.2503 & $5.4910 e$ & 00000000005 & TRN \\
\hline CHEMBL1423633 & 688816 & 5.6 & 5.5796 & TRN & \\
\hline CHEMBL1523075 & 688816 & 5.7 & 5.5961 & TST & \\
\hline CHEMBL1428503 & 688816 & 6.4 & 5.5355 & TST & \\
\hline CHEMBL1406072 & 688816 & 8.301 & 5.1618 & TRN & \\
\hline CHEMBL1404734 & 688816 & 5.0 & 5.5832 & TRN & \\
\hline CHEMBL1350614 & 688816 & 5.4 & 5.2505 & TRN & \\
\hline CHEMBL1310435 & 688816 & 5.35 & 5.1387 & TRN & \\
\hline CHEMBL1468858 & 688816 & 5.55 & 5.2899 & TRN & \\
\hline CHEMBL1330525 & 688816 & 5.55 & 5.1982 & TRN & \\
\hline CHEMBL1507370 & 688816 & 4.5 & 5.3922 & TRN & \\
\hline CHEMBL3212343 & 688816 & 4.95 & 5.3968 & TRN & \\
\hline CHEMBL1449007 & 688816 & 4.9 & 5.1121 & TST & \\
\hline CHEMBL 3198131 & 688816 & 4.9 & 5.0557 & TRN & \\
\hline CHEMBL1568652 & 688816 & 5.25 & 5.1714 & TRN & \\
\hline CHEMBL1342889 & 688816 & 5.55 & 5.0534 & TRN & \\
\hline CHEMBL1409903 & 688816 & 5.05 & 5.1236 & TRN & \\
\hline CHEMBL1508837 & 688816 & 5.8 & 4.9767 & TRN & \\
\hline CHEMBL3207596 & 688816 & 6.9 & 5.3837 & TRN & \\
\hline CHEMBL1542169 & 688816 & 5.55 & 5.7394 & TRN & \\
\hline CHEMBL1313498 & 688816 & 7.5498 & 5.4761 & TRN & \\
\hline CHEMBL1434902 & 688816 & 5.3 & 4.8909 & TRN & \\
\hline CHEMBL3213012 & 688816 & 4.85 & 5.2315 & TRN & \\
\hline CHEMBL1337314 & 688816 & 7.5003 & 5.3281 & TRN & \\
\hline CHEMBL1577228 & 688816 & 5.4 & 5.2975 & TRN & \\
\hline CHEMBL1400039 & 688816 & 5.5 & 5.274 & TRN & \\
\hline CHEMBL1458972 & 688816 & 4.95 & 5.0176 & TRN & \\
\hline CHEMBL1605511 & 688816 & 4.95 & 5.2272 & TRN & \\
\hline CHEMBL1611580 & 688816 & 4.85 & 5.5535 & TRN & \\
\hline CHEMBL1339114 & 688816 & 6.0 & 5.3166 & TRN & \\
\hline CHEMBL1388889 & 688816 & 4.85 & 4.9665 & TST & \\
\hline CHEMBL1506731 & 688816 & 5.35 & 5.1841 & TST & \\
\hline CHEMBL1533970 & 688816 & 4.45 & 5.5045 & TRN & \\
\hline
\end{tabular}




\begin{tabular}{|c|c|c|c|c|c|}
\hline \multicolumn{6}{|c|}{ Supplemental Table S2.txt } \\
\hline CHEMBL1341744 & 688816 & 4.65 & 5.2793 & TRN & \\
\hline CHEMBL1603803 & 688816 & 4.45 & 5.0766 & TRN & \\
\hline CHEMBL1434161 & 688816 & 4.45 & 5.1039 & TRN & \\
\hline CHEMBL1347691 & 688816 & 6.7501 & 5.3772 & TRN & \\
\hline CHEMBL1328426 & 688816 & 6.2 & 5.3281 & TST & \\
\hline CHEMBL1525599 & 688816 & 6.0 & 5.205 & TST & \\
\hline CHEMBL1567320 & 688816 & 5.35 & 5.484 & TRN & \\
\hline CHEMBL1508216 & 688816 & 4.95 & 4.9798 & TRN & \\
\hline CHEMBL1328119 & 688816 & 4.95 & 5.2641 & TRN & \\
\hline CHEMBL1340513 & 688816 & 4.65 & 4.8117 & TRN & \\
\hline CHEMBL1520273 & 688816 & 5.05 & 5.13899 & 9999999999 & TRN \\
\hline CHEMBL1578798 & 688816 & 4.9 & 5.4392 & TRN & \\
\hline CHEMBL1429388 & 688816 & 4.65 & 4.9049 & TRN & \\
\hline CHEMBL1347405 & 688816 & 4.45 & 5.1562 & TST & \\
\hline CHEMBL1485060 & 688816 & 5.0 & 5.3886 & TRN & \\
\hline CHEMBL1606636 & 688816 & 4.9 & 5.1364 & TRN & \\
\hline CHEMBL1581391 & 688816 & 5.15 & 5.1151 & TST & \\
\hline CHEMBL1596169 & 688816 & 4.45 & 5.0955 & TRN & \\
\hline CHEMBL3198067 & 688816 & 4.45 & 5.1898 & TRN & \\
\hline CHEMBL1397743 & 688816 & 7.699 & 5.3869 & TST & \\
\hline CHEMBL1566318 & 688816 & 4.65 & 5.6189 & TST & \\
\hline CHEMBL1522965 & 688816 & 4.75 & 5.5513 & TRN & \\
\hline CHEMBL1977568 & 688816 & 4.55 & 4.8387 & TRN & \\
\hline CHEMBL 3194264 & 688816 & 4.95 & 5.1972 & TRN & \\
\hline CHEMBL1571764 & 688816 & 5.0 & 5.6692 & TRN & \\
\hline CHEMBL1353969 & 688816 & 5.8 & 5.3786 & TRN & \\
\hline CHEMBL1432351 & 688816 & 4.85 & 5.152 & TRN & \\
\hline CHEMBL1609172 & 688816 & 4.65 & 4.9819 & TRN & \\
\hline CHEMBL1554763 & 688816 & 5.8 & 5.2628 & TST & \\
\hline CHEMBL1471962 & 688816 & 4.55 & 5.171 & TRN & \\
\hline CHEMBL1574059 & 688816 & 4.85 & 4.9205 & TRN & \\
\hline CHEMBL1448632 & 688816 & 4.9 & 5.3775 & TRN & \\
\hline CHEMBL1354317 & 688816 & 5.55 & 4.8736 & TRN & \\
\hline CHEMBL1323791 & 688816 & 4.95 & 5.239 & TRN & \\
\hline CHEMBL1579592 & 688816 & 4.85 & 4.7046 & TRN & \\
\hline CHEMBL1335510 & 688816 & 4.9 & 5.4694 & TRN & \\
\hline CHEMBL1582872 & 688816 & 4.45 & 5.3186 & TST & \\
\hline CHEMBL1369834 & 688816 & 4.95 & 5.3046 & TRN & \\
\hline CHEMBL1351643 & 688816 & 4.95 & 5.2427 & TRN & \\
\hline CHEMBL1576671 & 688816 & 7.4001 & 5.1946 & TRN & \\
\hline CHEMBL1586617 & 688816 & 4.45 & 5.2728 & TRN & \\
\hline CHEMBL1410888 & 688816 & 5.05 & 5.3882 & TRN & \\
\hline CHEMBL1433895 & 688816 & 5.55 & 5.2295 & TST & \\
\hline CHEMBL1311714 & 688816 & 5.5 & 5.0584 & TST & \\
\hline CHEMBL449690 & 688816 & 4.85 & 5.5441 & TST & \\
\hline CHEMBL1443575 & 688816 & 5.6 & 5.3066 & TRN & \\
\hline CHEMBL1416031 & 688816 & 8.301 & 5.2663 & TRN & \\
\hline CHEMBL1498 & 688816 & 6.0 & 5.7896 & TRN & \\
\hline
\end{tabular}




\begin{tabular}{|c|c|c|c|c|c|}
\hline \multicolumn{6}{|c|}{ Supplemental Table S2.txt } \\
\hline CHEMBL1570780 & 688816 & 4.85 & 5.2867 & TRN & \\
\hline CHEMBL1443420 & 688816 & 4.45 & 5.2745 & TRN & \\
\hline CHEMBL1534619 & 688816 & 8.301 & 5.3737 & TRN & \\
\hline CHEMBL1308988 & 688816 & 4.45 & 5.8285 & TST & \\
\hline CHEMBL1376065 & 688816 & 4.95 & 5.6934 & TST & \\
\hline CHEMBL1584463 & 688816 & 5.05 & 4.8721 & TRN & \\
\hline CHEMBL1384559 & 688816 & 4.9 & 5.521 & TRN & \\
\hline CHEMBL1405319 & 688816 & 4.7 & 5.1434 & TRN & \\
\hline CHEMBL1361883 & 688816 & 4.75 & 5.2899 & TST & \\
\hline CHEMBL1491563 & 688816 & 4.85 & 4.8746 & TRN & \\
\hline CHEMBL1222541 & 688816 & 5.2 & 5.7485 & TRN & \\
\hline CHEMBL1989372 & 688816 & 5.35 & 5.1365 & TRN & \\
\hline CHEMBL1422079 & 688816 & 4.8 & 5.1234 & TRN & \\
\hline CHEMBL1349737 & 688816 & 4.9 & 5.2186 & TRN & \\
\hline CHEMBL3189439 & 688816 & 4.65 & 5.1878 & TRN & \\
\hline CHEMBL1304215 & 688816 & 5.0 & 5.5131 & TRN & \\
\hline CHEMBL1480989 & 688816 & 4.95 & 5.4926 & TRN & \\
\hline CHEMBL1582532 & 688816 & 5.5 & 5.8004 & TST & \\
\hline CHEMBL1343226 & 688816 & 4.75 & 4.8944 & TST & \\
\hline CHEMBL1420705 & 688816 & 5.4 & 5.638 & TRN & \\
\hline CHEMBL1336635 & 688816 & 8.301 & 5.7794 & TRN & \\
\hline CHEMBL1364979 & 688816 & 5.05 & 4.9643 & TRN & \\
\hline CHEMBL1453443 & 688816 & 5.05 & 4.8373 & TRN & \\
\hline CHEMBL1409577 & 688816 & 4.75 & 5.0658 & TRN & \\
\hline CHEMBL1353141 & 688816 & 5.4 & 5.1963 & TRN & \\
\hline CHEMBL1300584 & 688816 & 4.45 & 4.89199 & 99999999995 & TRN \\
\hline CHEMBL1500050 & 688816 & 6.95 & 5.3911 & TRN & \\
\hline CHEMBL1518603 & 688816 & 5.0 & 5.1047 & TRN & \\
\hline CHEMBL1315838 & 688816 & 8.4949 & 5.5219 & TST & \\
\hline CHEMBL1489176 & 688816 & 4.9 & 5.0618 & TRN & \\
\hline CHEMBL1476787 & 688816 & 4.7 & 4.988 & TRN & \\
\hline CHEMBL1542047 & 688816 & 5.15 & 5.4071 & TRN & \\
\hline CHEMBL1601806 & 688816 & 5.0 & 5.1449 & TRN & \\
\hline CHEMBL 393417 & 688816 & 6.25 & 5.5907 & TRN & \\
\hline CHEMBL1587940 & 688816 & 4.95 & 5.3659 & TRN & \\
\hline CHEMBL1508783 & 688816 & 4.85 & 5.6916 & TST & \\
\hline CHEMBL1422672 & 688816 & 5.85 & 5.5811 & TRN & \\
\hline CHEMBL1550545 & 688816 & 4.95 & 5.2256 & TRN & \\
\hline CHEMBL1571464 & 688816 & 4.8 & 5.1937 & TRN & \\
\hline CHEMBL1490123 & 688816 & 6.05 & 5.2389 & TRN & \\
\hline CHEMBL1571703 & 688816 & 4.9 & 5.2581 & TRN & \\
\hline CHEMBL1350733 & 688816 & 4.9 & 4.8792 & TST & \\
\hline CHEMBL1350568 & 688816 & 4.8 & 5.0649 & TRN & \\
\hline CHEMBL1387020 & 688816 & 4.65 & 5.4413 & TRN & \\
\hline CHEMBL600336 & 688816 & 5.0 & 5.1422 & TRN & \\
\hline CHEMBL1548973 & 688816 & 4.45 & 5.6541 & TST & \\
\hline CHEMBL1391127 & 688816 & 4.65 & 5.2607 & TRN & \\
\hline CHEMBL3193434 & 688816 & 4.8 & 5.5205 & TRN & \\
\hline
\end{tabular}




\begin{tabular}{|c|c|c|c|c|}
\hline \multicolumn{5}{|c|}{ Supplemental Table S2.txt } \\
\hline CHEMBL1451899 & 688816 & 5.6 & 5.3913 & TRN \\
\hline CHEMBL1558488 & 688816 & 4.95 & 5.2783 & TRN \\
\hline CHEMBL1612935 & 688816 & 4.9 & 5.3067 & TRN \\
\hline CHEMBL2135351 & 688816 & 4.85 & 5.0165 & TST \\
\hline CHEMBL1544457 & 688816 & 4.8 & 5.1182 & TRN \\
\hline CHEMBL1447922 & 688816 & 4.95 & 5.4675 & TRN \\
\hline CHEMBL1552485 & 688816 & 8.0 & 5.1662 & TRN \\
\hline CHEMBL1611210 & 688816 & 4.65 & 4.7315 & TRN \\
\hline CHEMBL85826 & 688816 & 5.8 & 5.6753 & TRN \\
\hline CHEMBL1349038 & 688816 & 4.45 & 5.2701 & TRN \\
\hline CHEMBL1407438 & 688816 & 5.8 & 4.9606 & TRN \\
\hline CHEMBL1544578 & 688816 & 4.95 & 5.0164 & TRN \\
\hline CHEMBL1588285 & 688816 & 5.0 & 5.3596 & TRN \\
\hline CHEMBL1526213 & 688816 & 4.75 & 5.2508 & TRN \\
\hline CHEMBL1519955 & 688816 & 6.8 & 5.2724 & TST \\
\hline CHEMBL1596040 & 688816 & 4.9 & 4.9485 & TRN \\
\hline CHEMBL1997017 & 688816 & 5.4 & 5.3575 & TST \\
\hline CHEMBL1371864 & 688816 & 5.1 & 4.9583 & TRN \\
\hline CHEMBL1447822 & 688816 & 4.9 & 5.0411 & TRN \\
\hline CHEMBL1520703 & 688816 & 4.9 & 5.3677 & TRN \\
\hline CHEMBL1449759 & 688816 & 4.95 & 4.7299 & TRN \\
\hline CHEMBL1588011 & 688816 & 5.65 & 5.1955 & TRN \\
\hline CHEMBL1602619 & 688816 & 4.45 & 5.5328 & TRN \\
\hline CHEMBL1518259 & 688816 & 5.35 & 5.0215 & TRN \\
\hline CHEMBL1578386 & 688816 & 4.8 & 5.1396 & TRN \\
\hline CHEMBL1574247 & 688816 & 8.301 & 5.3791 & TRN \\
\hline CHEMBL1415792 & 688816 & 4.6 & 5.7319 & TRN \\
\hline CHEMBL1470985 & 688816 & 5.0 & 5.4063 & TRN \\
\hline CHEMBL576349 & 688816 & 5.0 & 5.5712 & TRN \\
\hline CHEMBL1481374 & 688816 & 4.45 & 4.9002 & TRN \\
\hline CHEMBL1346611 & 688816 & 4.75 & 4.97 & TRN \\
\hline CHEMBL1368310 & 688816 & 8.0506 & 5.5299 & TRN \\
\hline CHEMBL1309062 & 688816 & 6.3 & 5.6275 & TST \\
\hline CHEMBL1531815 & 688816 & 5.4 & 5.0341 & TST \\
\hline CHEMBL1481474 & 688816 & 4.75 & 5.5351 & TRN \\
\hline CHEMBL1391144 & 688816 & 7.699 & 5.2399 & TRN \\
\hline CHEMBL3193709 & 688816 & 5.2 & 5.2667 & TRN \\
\hline CHEMBL1572506 & 688816 & 8.5528 & 5.0732 & TST \\
\hline CHEMBL1372035 & 688816 & 8.6021 & 4.8319 & TST \\
\hline CHEMBL1446940 & 688816 & 4.45 & 5.4634 & TRN \\
\hline CHEMBL3195200 & 688816 & 5.85 & 5.3402 & TRN \\
\hline CHEMBL1548446 & 688816 & 7.3002 & 5.4659 & TRN \\
\hline CHEMBL3194192 & 688816 & 6.0 & 5.3578 & TRN \\
\hline CHEMBL3191482 & 688816 & 7.7496 & 5.0846 & TRN \\
\hline CHEMBL259845 & 688816 & 5.45 & 5.9374 & TRN \\
\hline CHEMBL1478299 & 688816 & 5.25 & 5.454 & TST \\
\hline CHEMBL1536968 & 688816 & 4.95 & 5.6323 & TRN \\
\hline CHEMBL1609009 & 688816 & 4.9 & 5.3503 & TST \\
\hline
\end{tabular}




\begin{tabular}{|c|c|c|c|c|}
\hline \multicolumn{5}{|c|}{ Supplemental Table S2.txt } \\
\hline CHEMBL1987516 & 688816 & 4.45 & 5.113 & TST \\
\hline CHEMBL1489599 & 688816 & 5.05 & 5.2987 & TRN \\
\hline CHEMBL1351682 & 688816 & 5.85 & 5.5767 & TRN \\
\hline CHEMBL1471426 & 688816 & 4.95 & 5.0827 & TRN \\
\hline CHEMBL1381882 & 688816 & 6.25 & 5.1606 & TRN \\
\hline CHEMBL1406859 & 688816 & 5.15 & 5.2134 & TRN \\
\hline CHEMBL1510885 & 688816 & 6.3 & 5.5436 & TRN \\
\hline CHEMBL1466980 & 688816 & 5.5 & 5.2832 & TST \\
\hline CHEMBL1409548 & 688816 & 4.6 & 4.7989 & TRN \\
\hline CHEMBL1305944 & 688816 & 4.6 & 5.0845 & TST \\
\hline CHEMBL1530348 & 688816 & 6.25 & 5.1496 & TRN \\
\hline CHEMBL1352549 & 688816 & 7.9508 & 5.4778 & TRN \\
\hline CHEMBL1472021 & 688816 & 6.6499 & 5.1723 & TRN \\
\hline CHEMBL1451471 & 688816 & 7.8996 & 5.5118 & TRN \\
\hline CHEMBL398095 & 688816 & 6.1 & 5.1999 & TRN \\
\hline CHEMBL1470558 & 688816 & 5.0 & 5.1911 & TRN \\
\hline CHEMBL 260213 & 688816 & 5.65 & 5.2463 & TRN \\
\hline CHEMBL1599165 & 688816 & 5.1 & 5.4649 & TRN \\
\hline CHEMBL1431658 & 688816 & 5.0 & 5.1764 & TRN \\
\hline CHEMBL1546800 & 688816 & 4.9 & 5.1171 & TST \\
\hline CHEMBL1314126 & 688816 & 5.1 & 5.2577 & TRN \\
\hline CHEMBL1489183 & 688816 & 5.3 & 5.1707 & TRN \\
\hline CHEMBL1566003 & 688816 & 5.0 & 5.1019 & TRN \\
\hline CHEMBL1339363 & 688816 & 5.0 & 4.9938 & TRN \\
\hline CHEMBL1464978 & 688816 & 4.45 & 4.9002 & TRN \\
\hline CHEMBL1448341 & 688816 & 4.5 & 5.0214 & TRN \\
\hline CHEMBL1599941 & 688816 & 7.5498 & 5.2638 & TRN \\
\hline CHEMBL1468990 & 688816 & 5.3 & 5.2251 & TRN \\
\hline CHEMBL1458316 & 688816 & 5.05 & 5.2118 & TRN \\
\hline CHEMBL1581659 & 688816 & 4.45 & 4.8492 & TRN \\
\hline CHEMBL1343108 & 688816 & 4.9 & 5.2619 & TRN \\
\hline CHEMBL1302741 & 688816 & 5.6 & 5.027 & TRN \\
\hline CHEMBL1386804 & 688816 & 5.0 & 5.3829 & TRN \\
\hline CHEMBL1477333 & 688816 & 4.75 & 5.1623 & TRN \\
\hline CHEMBL1610209 & 688816 & 4.95 & 5.0664 & TRN \\
\hline CHEMBL1306554 & 688816 & 4.85 & 5.0802 & TRN \\
\hline CHEMBL1566731 & 688816 & 4.5 & 5.1207 & TRN \\
\hline CHEMBL1581330 & 688816 & 5.25 & 5.3448 & TRN \\
\hline CHEMBL1422572 & 688816 & 5.2 & 5.4291 & TRN \\
\hline CHEMBL1571220 & 688816 & 4.65 & 5.2854 & TRN \\
\hline CHEMBL1575559 & 688816 & 5.0 & 5.3072 & TRN \\
\hline CHEMBL1579084 & 688816 & 4.55 & 5.3401 & TST \\
\hline CHEMBL1453837 & 688816 & 4.85 & 4.8579 & TRN \\
\hline CHEMBL1522124 & 688816 & 5.65 & 4.8903 & TRN \\
\hline CHEMBL1334308 & 688816 & 5.8 & 5.4278 & TRN \\
\hline CHEMBL1530057 & 688816 & 4.45 & 5.2393 & TRN \\
\hline CHEMBL1541023 & 688816 & 5.2 & 5.4909 & TST \\
\hline CHEMBL1393656 & 688816 & 4.9 & 5.3532 & TRN \\
\hline
\end{tabular}




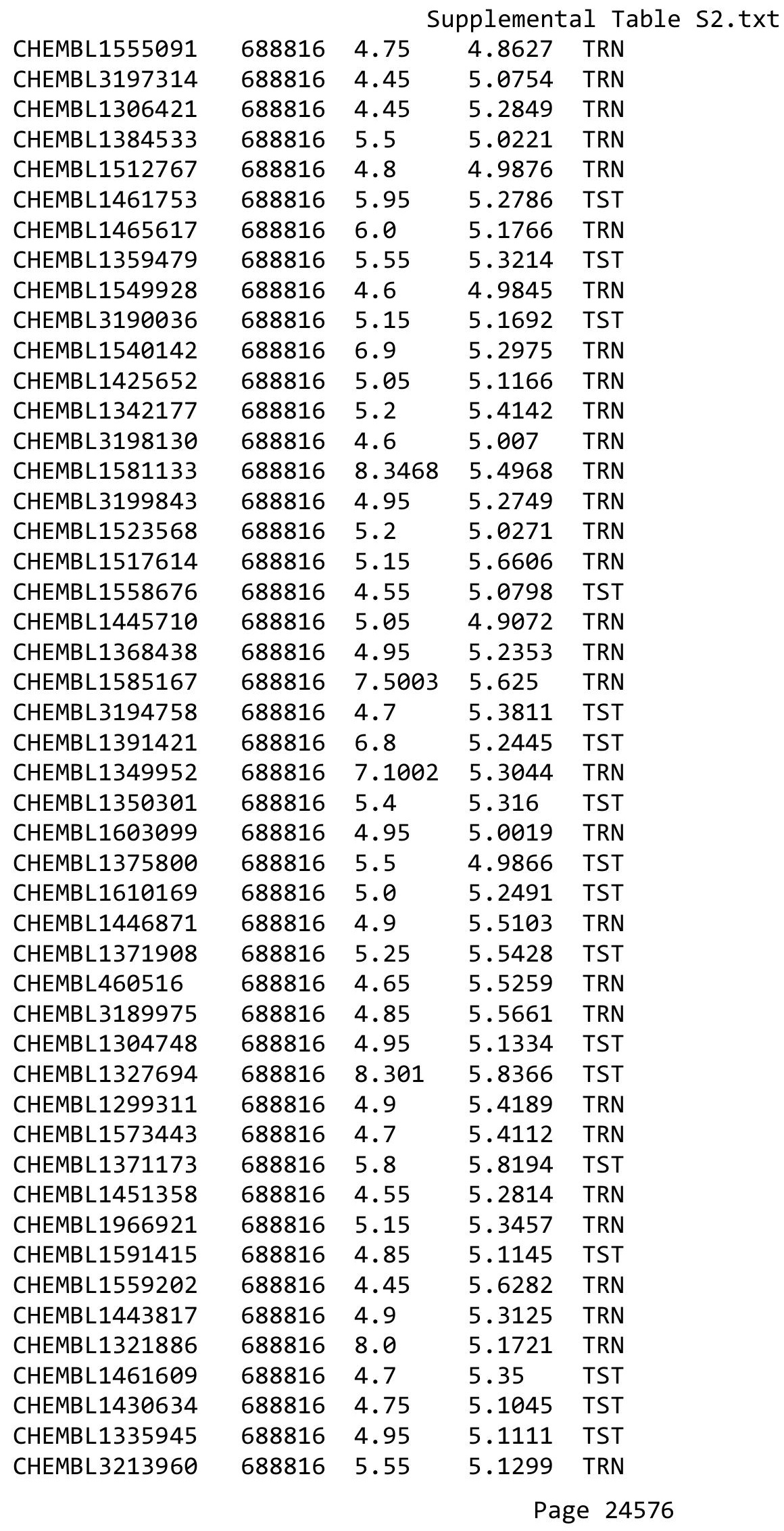




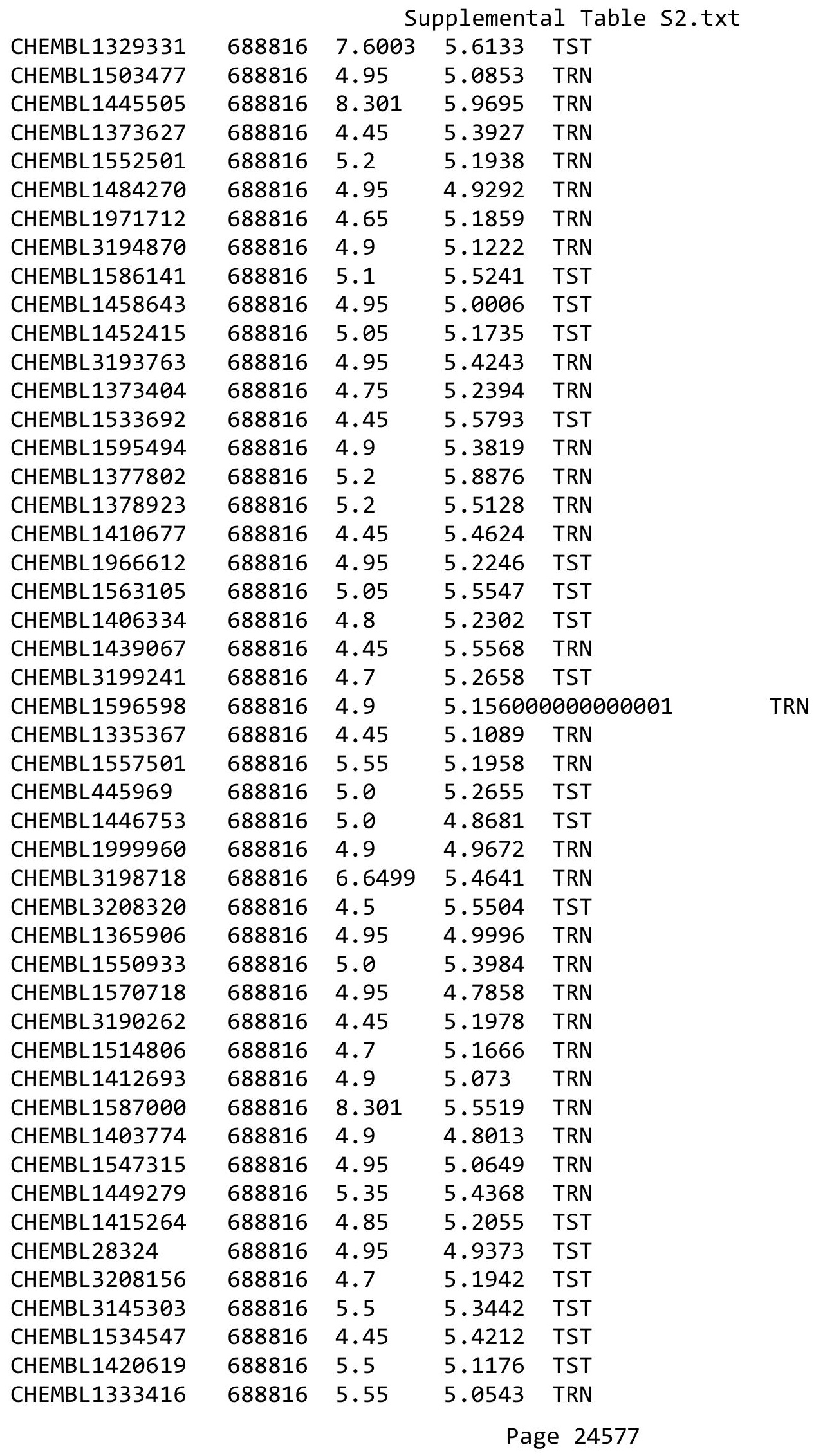




\begin{tabular}{|c|c|c|c|c|c|}
\hline \multicolumn{6}{|c|}{ Supplemental Table S2.txt } \\
\hline CHEMBL1500828 & 688816 & 5.45 & 5.4618 & TRN & \\
\hline CHEMBL1449911 & 688816 & 5.7 & 5.2072 & TRN & \\
\hline CHEMBL1380321 & 688816 & 4.9 & 5.0255 & TRN & \\
\hline CHEMBL1488101 & 688816 & 5.9 & 5.6633 & TRN & \\
\hline CHEMBL1312888 & 688816 & 4.5 & 4.7758 & TRN & \\
\hline CHEMBL1313728 & 688816 & 5.4 & 5.3847 & TRN & \\
\hline CHEMBL3191933 & 688816 & 5.45 & 5.2927 & TRN & \\
\hline CHEMBL1519249 & 688816 & 4.75 & 5.4962 & TRN & \\
\hline CHEMBL1510804 & 688816 & 5.35 & 5.1961 & TRN & \\
\hline CHEMBL1447359 & 688816 & 4.95 & 5.4567 & TRN & \\
\hline CHEMBL1338156 & 688816 & 5.0 & 5.4867 & TST & \\
\hline CHEMBL1334327 & 688816 & 6.0 & 5.3323 & TRN & \\
\hline CHEMBL1511603 & 688816 & 4.45 & 5.1258 & TST & \\
\hline CHEMBL468719 & 688816 & 7.5003 & 5.25299 & 9999999999 & TST \\
\hline CHEMBL1428048 & 688816 & 4.45 & 5.38200 & 0000000001 & TRN \\
\hline CHEMBL1461504 & 688816 & 4.45 & 5.1165 & TRN & \\
\hline CHEMBL1429627 & 688816 & 4.7 & 5.0434 & TRN & \\
\hline CHEMBL430266 & 688816 & 6.5501 & 5.6087 & TST & \\
\hline CHEMBL1363706 & 688816 & 6.1 & 5.5913 & TRN & \\
\hline CHEMBL1479220 & 688816 & 5.65 & 4.93199 & 99999999995 & TRN \\
\hline CHEMBL1442562 & 688816 & 4.9 & 5.2556 & TRN & \\
\hline CHEMBL3193400 & 688816 & 4.95 & 5.2064 & TRN & \\
\hline CHEMBL3198838 & 688816 & 4.8 & 5.4206 & TST & \\
\hline CHEMBL1326968 & 688816 & 4.65 & 5.3166 & TRN & \\
\hline CHEMBL1532750 & 688816 & 5.35 & 5.5933 & TRN & \\
\hline CHEMBL1385217 & 688816 & 5.7 & 5.4195 & TST & \\
\hline CHEMBL1528712 & 688816 & 4.65 & 4.9573 & TST & \\
\hline CHEMBL1407520 & 688816 & 4.95 & 5.2825 & TST & \\
\hline CHEMBL1988731 & 688816 & 5.95 & 5.1928 & TST & \\
\hline CHEMBL1520374 & 688816 & 4.9 & 5.02800 & 00000000005 & TRN \\
\hline CHEMBL1513174 & 688816 & 4.9 & 5.1803 & TRN & \\
\hline CHEMBL3210714 & 688816 & 5.0 & 4.9815 & TST & \\
\hline CHEMBL1436911 & 688816 & 5.35 & 5.1609 & TRN & \\
\hline CHEMBL1583591 & 688816 & 7.8013 & 5.1641 & TST & \\
\hline CHEMBL1504171 & 688816 & 5.85 & 5.24299 & 9999999999 & TRN \\
\hline CHEMBL355280 & 688816 & 4.95 & 5.1563 & TRN & \\
\hline CHEMBL1527106 & 688816 & 8.0506 & 5.5715 & TST & \\
\hline CHEMBL1594420 & 688816 & 5.35 & 4.9271 & TST & \\
\hline CHEMBL32590 & 688816 & 6.25 & 5.1777 & TST & \\
\hline CHEMBL3193693 & 688816 & 4.65 & 5.3132 & TRN & \\
\hline CHEMBL1540622 & 688816 & 5.0 & 5.0064 & TRN & \\
\hline CHEMBL1317750 & 688816 & 5.3 & 5.1718 & TRN & \\
\hline CHEMBL1969992 & 688816 & 4.65 & 4.8016 & TRN & \\
\hline CHEMBL1362813 & 688816 & 4.75 & 5.2527 & TRN & \\
\hline CHEMBL1465791 & 688816 & 5.95 & 5.2385 & TRN & \\
\hline CHEMBL1534441 & 688816 & 5.6 & 5.2897 & TRN & \\
\hline CHEMBL1587338 & 688816 & 5.7 & 5.2151 & TRN & \\
\hline CHEMBL1346677 & 688816 & 4.9 & 4.9904 & TRN & \\
\hline
\end{tabular}




\begin{tabular}{|c|c|c|c|c|}
\hline \multicolumn{5}{|c|}{ Supplemental Table S2.txt } \\
\hline CHEMBL1419880 & 688816 & 5.8 & 4.8126 & TRN \\
\hline CHEMBL1492701 & 688816 & 5.45 & 5.4786 & TRN \\
\hline CHEMBL1306688 & 688816 & 4.9 & 5.4004 & TRN \\
\hline CHEMBL1338212 & 688816 & 4.8 & 5.3497 & TRN \\
\hline CHEMBL1497698 & 688816 & 4.8 & 5.033 & TRN \\
\hline CHEMBL1476184 & 688816 & 5.55 & 5.103 & TRN \\
\hline CHEMBL1379623 & 688816 & 4.7 & 5.2098 & TRN \\
\hline CHEMBL1453125 & 688816 & 5.25 & 4.9877 & TST \\
\hline CHEMBL1432468 & 688816 & 4.45 & 5.2939 & TRN \\
\hline CHEMBL1448024 & 688816 & 4.45 & 5.2126 & TST \\
\hline CHEMBL1481697 & 688816 & 5.05 & 5.0866 & TRN \\
\hline CHEMBL1356147 & 688816 & 5.15 & 4.9264 & TRN \\
\hline CHEMBL1302816 & 688816 & 4.55 & 4.9117 & TRN \\
\hline CHEMBL1407833 & 688816 & 5.35 & 5.1462 & TRN \\
\hline CHEMBL599304 & 688816 & 4.6 & 5.3533 & TST \\
\hline CHEMBL1454086 & 688816 & 4.45 & 5.0849 & TRN \\
\hline CHEMBL3196698 & 688816 & 4.65 & 5.1646 & TST \\
\hline CHEMBL1335146 & 688816 & 4.65 & 5.0277 & TRN \\
\hline CHEMBL1401388 & 688816 & 5.4 & 4.9431 & TRN \\
\hline CHEMBL1982774 & 688816 & 5.0 & 5.3337 & TRN \\
\hline CHEMBL1418371 & 688816 & 5.1 & 5.2149 & TRN \\
\hline CHEMBL1452906 & 688816 & 5.95 & 5.3411 & TRN \\
\hline CHEMBL1425443 & 688816 & 4.95 & 5.642 & TRN \\
\hline CHEMBL1527364 & 688816 & 4.7 & 4.9335 & TRN \\
\hline CHEMBL1360475 & 688816 & 4.9 & 5.4491 & TRN \\
\hline CHEMBL1384401 & 688816 & 4.85 & 5.0714 & TRN \\
\hline CHEMBL3198554 & 688816 & 4.6 & 5.2331 & TRN \\
\hline CHEMBL1379586 & 688816 & 5.5 & 5.3439 & TST \\
\hline CHEMBL1364343 & 688816 & 5.3 & 5.3965 & TRN \\
\hline CHEMBL1548992 & 688816 & 5.1 & 5.2102 & TRN \\
\hline CHEMBL1371110 & 688816 & 5.25 & 5.1673 & TRN \\
\hline CHEMBL1599576 & 688816 & 4.95 & 5.1444 & TRN \\
\hline CHEMBL1420776 & 688816 & 7.6498 & 5.3934 & TRN \\
\hline CHEMBL1309644 & 688816 & 5.1 & 5.4538 & TRN \\
\hline CHEMBL1554267 & 688816 & 4.45 & 5.012 & TRN \\
\hline CHEMBL1383007 & 688816 & 5.35 & 5.2781 & TRN \\
\hline CHEMBL1432873 & 688816 & 4.8 & 4.9596 & TRN \\
\hline CHEMBL1491337 & 688816 & 8.301 & 5.8032 & TST \\
\hline CHEMBL1459393 & 688816 & 4.95 & 5.113 & TRN \\
\hline CHEMBL1499354 & 688816 & 5.15 & 5.1999 & TST \\
\hline CHEMBL1455814 & 688816 & 5.2 & 5.1981 & TRN \\
\hline CHEMBL1341781 & 688816 & 5.0 & 4.9269 & TRN \\
\hline CHEMBL1344054 & 688816 & 5.6 & 5.2061 & TRN \\
\hline CHEMBL1548237 & 688816 & 4.9 & 5.3691 & TRN \\
\hline CHEMBL1555814 & 688816 & 4.5 & 4.9725 & TRN \\
\hline CHEMBL1368196 & 688816 & 5.2 & 4.9053 & TRN \\
\hline CHEMBL1989453 & 688816 & 5.25 & 4.9749 & TRN \\
\hline CHEMBL3199530 & 688816 & 4.8 & 5.0649 & TST \\
\hline
\end{tabular}




\begin{tabular}{|c|c|c|c|c|}
\hline \multicolumn{5}{|c|}{ Supplemental Table S2.txt } \\
\hline CHEMBL1572926 & 688816 & 5.2 & 5.8466 & TRN \\
\hline CHEMBL1416811 & 688816 & 4.4 & 5.3912 & TRN \\
\hline CHEMBL1430569 & 688816 & 5.3 & 5.3636 & TRN \\
\hline CHEMBL1355647 & 688816 & 5.4 & 5.2724 & TRN \\
\hline CHEMBL1495695 & 688816 & 5.4 & 4.8932 & TRN \\
\hline CHEMBL1429463 & 688816 & 4.65 & 5.3103 & TRN \\
\hline CHEMBL1543269 & 688816 & 4.7 & 5.3911 & TRN \\
\hline CHEMBL1488112 & 688816 & 4.9 & 5.4359 & TRN \\
\hline CHEMBL1592789 & 688816 & 4.45 & 5.0258 & TRN \\
\hline CHEMBL1340446 & 688816 & 4.75 & 5.1139 & TRN \\
\hline CHEMBL1506252 & 688816 & 4.9 & 5.4996 & TRN \\
\hline CHEMBL1498680 & 688816 & 5.0 & 4.9377 & TRN \\
\hline CHEMBL1342187 & 688816 & 6.8 & 5.2948 & TST \\
\hline CHEMBL1525015 & 688816 & 4.45 & 5.1433 & TST \\
\hline CHEMBL1376779 & 688816 & 4.95 & 5.1747 & TST \\
\hline CHEMBL1609431 & 688816 & 5.3 & 5.4337 & TRN \\
\hline CHEMBL1405856 & 688816 & 5.75 & 4.9291 & TRN \\
\hline CHEMBL1542070 & 688816 & 4.95 & 5.17200 & 0000000001 \\
\hline CHEMBL1433354 & 688816 & 6.15 & 5.3039 & TRN \\
\hline CHEMBL1326041 & 688816 & 4.95 & 5.1208 & TRN \\
\hline CHEMBL1418549 & 688816 & 4.6 & 5.4467 & TRN \\
\hline CHEMBL1330058 & 688816 & 4.55 & 5.0947 & TRN \\
\hline CHEMBL1479377 & 688816 & 5.2 & 5.5432 & TST \\
\hline CHEMBL1530459 & 688816 & 4.45 & 5.2005 & TRN \\
\hline CHEMBL1570928 & 688816 & 4.45 & 5.3757 & TRN \\
\hline CHEMBL1573017 & 688816 & 4.7 & 5.0711 & TRN \\
\hline CHEMBL1438985 & 688816 & 5.5 & 5.5449 & TST \\
\hline CHEMBL1573840 & 688816 & 5.3 & 5.5956 & TRN \\
\hline CHEMBL1479507 & 688816 & 4.65 & 4.8642 & TRN \\
\hline CHEMBL1568312 & 688816 & 6.5501 & 4.959 & TST \\
\hline CHEMBL255068 & 688816 & 4.6 & 5.3901 & TRN \\
\hline CHEMBL1525293 & 688816 & 4.45 & 4.8637 & TST \\
\hline CHEMBL1599907 & 688816 & 4.45 & 5.7671 & TRN \\
\hline CHEMBL1304494 & 688816 & 4.45 & 5.2437 & TST \\
\hline CHEMBL1478403 & 688816 & 4.95 & 5.425 & TRN \\
\hline CHEMBL1471115 & 688816 & 4.9 & 5.3314 & TRN \\
\hline CHEMBL1592533 & 688816 & 4.8 & 5.227 & TRN \\
\hline CHEMBL1300823 & 688816 & 8.301 & 5.5772 & TRN \\
\hline CHEMBL1572028 & 688816 & 4.45 & 5.1884 & TRN \\
\hline CHEMBL1428180 & 688816 & 4.85 & 5.1454 & TRN \\
\hline CHEMBL1397517 & 688816 & 6.4 & 4.9764 & TRN \\
\hline CHEMBL1345115 & 688816 & 5.0 & 5.2317 & TRN \\
\hline CHEMBL3193417 & 688816 & 5.55 & 5.1009 & TRN \\
\hline CHEMBL1502856 & 688816 & 4.95 & 5.3628 & TRN \\
\hline CHEMBL1567927 & 688816 & 4.85 & 5.1333 & TRN \\
\hline CHEMBL1557668 & 688816 & 5.3 & 5.0696 & TRN \\
\hline CHEMBL1329290 & 688816 & 4.75 & 5.3638 & TST \\
\hline CHEMBL1487533 & 688816 & 5.2 & 5.3137 & TST \\
\hline
\end{tabular}




\begin{tabular}{|c|c|c|c|c|}
\hline \multicolumn{5}{|c|}{ Supplemental Table S2.txt } \\
\hline CHEMBL1400063 & 688816 & 5.0 & 5.6445 & TRN \\
\hline CHEMBL1379749 & 688816 & 5.3 & 5.4461 & TRN \\
\hline CHEMBL1324200 & 688816 & 4.8 & 5.4397 & TRN \\
\hline CHEMBL1349246 & 688816 & 5.2 & 5.4315 & TRN \\
\hline CHEMBL1600927 & 688816 & 5.0 & 5.1562 & TRN \\
\hline CHEMBL1579152 & 688816 & 4.45 & 4.8099 & TRN \\
\hline CHEMBL1362945 & 688816 & 4.95 & 5.3399 & TRN \\
\hline CHEMBL1566838 & 688816 & 5.8 & 4.9311 & TRN \\
\hline CHEMBL1609565 & 688816 & 4.85 & 5.4615 & TRN \\
\hline CHEMBL1526229 & 688816 & 4.85 & 5.36100 & 0000000001 \\
\hline CHEMBL1462959 & 688816 & 4.45 & 5.3851 & TRN \\
\hline CHEMBL1378878 & 688816 & 6.7001 & 5.5814 & TRN \\
\hline CHEMBL1353881 & 688816 & 4.65 & 5.4925 & TST \\
\hline CHEMBL1385320 & 688816 & 5.35 & 5.3067 & TST \\
\hline CHEMBL1578511 & 688816 & 4.85 & 5.0105 & TRN \\
\hline CHEMBL1563642 & 688816 & 4.55 & 5.3796 & TRN \\
\hline CHEMBL1581066 & 688816 & 6.0 & 5.4411 & TRN \\
\hline CHEMBL1376622 & 688816 & 4.65 & 5.3949 & TRN \\
\hline CHEMBL1321558 & 688816 & 8.3468 & 5.3381 & TST \\
\hline CHEMBL1398976 & 688816 & 4.55 & 4.7707 & TRN \\
\hline CHEMBL119247 & 688816 & 4.45 & 5.1259 & TRN \\
\hline CHEMBL1387848 & 688816 & 4.7 & 5.4348 & TRN \\
\hline CHEMBL1364193 & 688816 & 4.6 & 5.2162 & TRN \\
\hline CHEMBL1377849 & 688816 & 4.65 & 5.1151 & TRN \\
\hline CHEMBL1442717 & 688816 & 4.95 & 4.7128 & TRN \\
\hline CHEMBL1335872 & 688816 & 4.5 & 5.0208 & TRN \\
\hline CHEMBL1585843 & 688816 & 5.25 & 4.8035 & TRN \\
\hline CHEMBL1529509 & 688816 & 5.15 & 5.5796 & TRN \\
\hline CHEMBL1370043 & 688816 & 6.05 & 4.9711 & TRN \\
\hline CHEMBL1466023 & 688816 & 4.95 & 5.5845 & TST \\
\hline CHEMBL1344426 & 688816 & 4.8 & 5.2616 & TST \\
\hline CHEMBL1468929 & 688816 & 4.85 & 5.5906 & TST \\
\hline CHEMBL1577776 & 688816 & 4.65 & 4.8228 & TST \\
\hline CHEMBL1324812 & 688816 & 6.0 & 6.0145 & TRN \\
\hline CHEMBL1500577 & 688816 & 4.95 & 4.9892 & TRN \\
\hline CHEMBL1428466 & 688816 & 4.85 & 5.1516 & TRN \\
\hline CHEMBL1409744 & 688816 & 8.301 & 5.8154 & TRN \\
\hline CHEMBL1356051 & 688816 & 6.6 & 5.4056 & TRN \\
\hline CHEMBL1496401 & 688816 & 5.55 & 5.1001 & TRN \\
\hline CHEMBL1605231 & 688816 & 4.9 & 5.2774 & TRN \\
\hline CHEMBL1469107 & 688816 & 4.95 & 4.9934 & TRN \\
\hline CHEMBL1532716 & 688816 & 4.45 & 5.2234 & TST \\
\hline CHEMBL1417546 & 688816 & 4.9 & 5.5844 & TST \\
\hline CHEMBL1472423 & 688816 & 5.3 & 5.4043 & TST \\
\hline CHEMBL1391293 & 688816 & 7.2 & 5.4744 & TRN \\
\hline CHEMBL1575402 & 688816 & 4.9 & 5.1688 & TRN \\
\hline CHEMBL1568475 & 688816 & 4.75 & 4.9922 & TRN \\
\hline CHEMBL1574136 & 688816 & 4.95 & 5.1418 & TRN \\
\hline
\end{tabular}




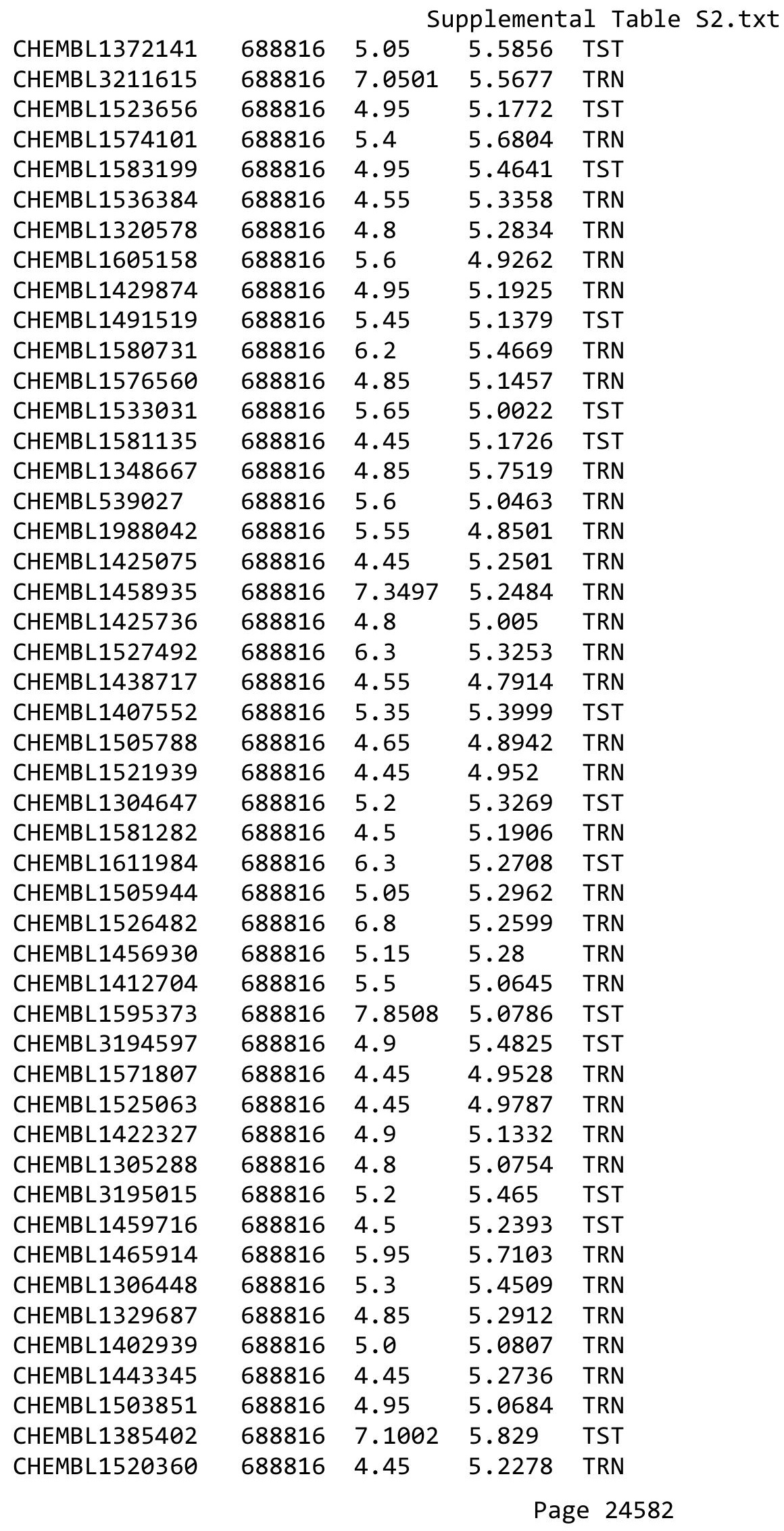




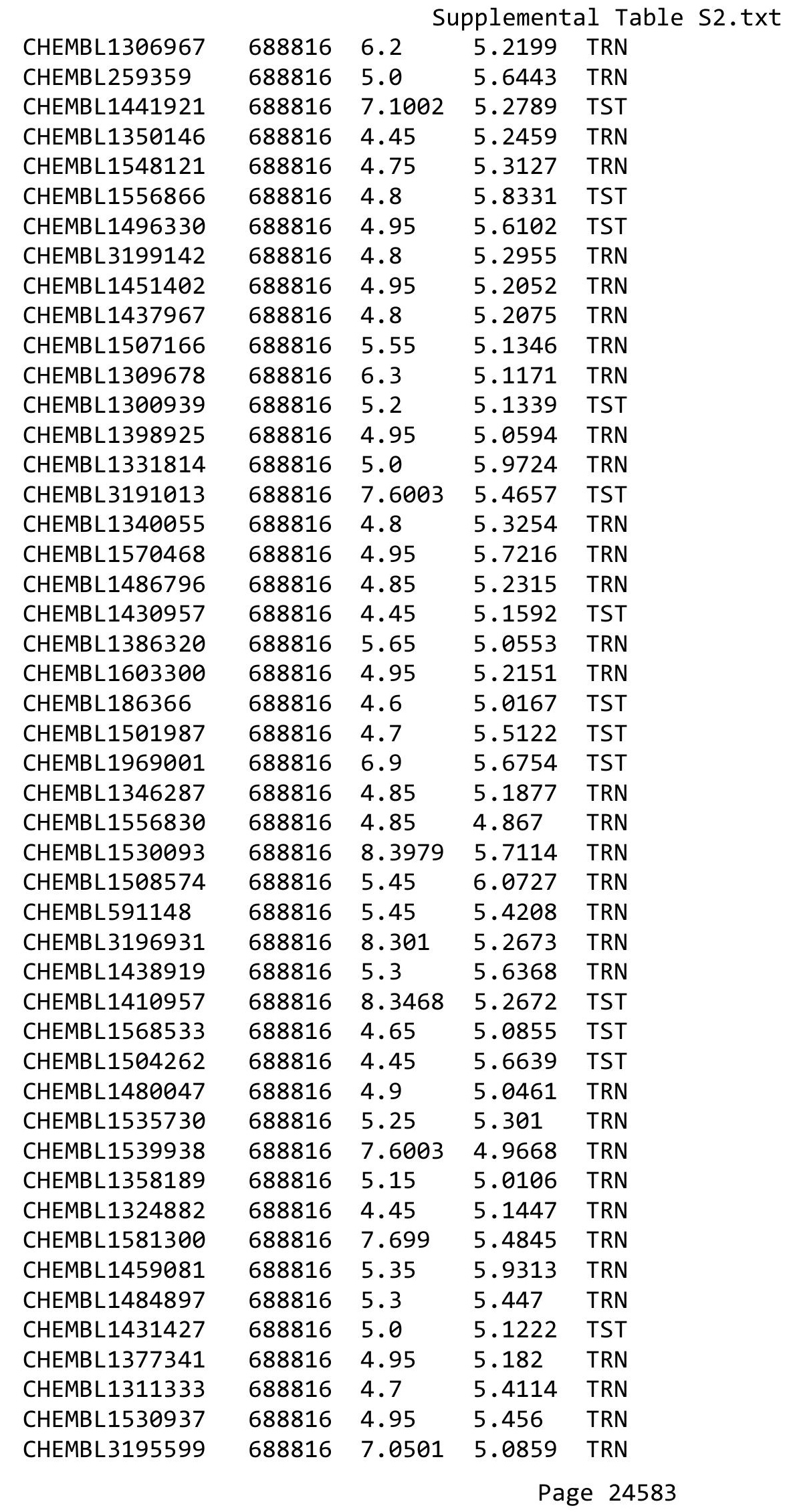




\begin{tabular}{|c|c|c|c|c|c|}
\hline \multicolumn{6}{|c|}{ Supplemental Table S2.txt } \\
\hline CHEMBL1337227 & 688816 & 4.45 & 5.0786 & TRN & \\
\hline CHEMBL 213884 & 688816 & 6.7501 & 5.4844 & TRN & \\
\hline CHEMBL1391798 & 688816 & 4.9 & 5.1948 & TRN & \\
\hline CHEMBL1422620 & 688816 & 4.95 & 5.271 & TRN & \\
\hline CHEMBL1538515 & 688816 & 5.5 & 5.7139 & TRN & \\
\hline CHEMBL1537637 & 688816 & 4.8 & 5.2591 & TRN & \\
\hline CHEMBL37708 & 688816 & 4.75 & 5.3919 & TST & \\
\hline CHEMBL1452498 & 688816 & 5.5 & 5.3079 & TST & \\
\hline CHEMBL1419585 & 688816 & 4.45 & 4.9918 & TST & \\
\hline CHEMBL1582386 & 688816 & 6.2 & 5.3082 & TST & \\
\hline CHEMBL1519379 & 688816 & 5.55 & 5.1723 & TRN & \\
\hline CHEMBL1510779 & 688816 & 5.15 & 5.3482 & TRN & \\
\hline CHEMBL1329733 & 688816 & 6.4 & 5.4045 & TRN & \\
\hline CHEMBL1303263 & 688816 & 4.95 & 5.942 & TST & \\
\hline CHEMBL3194311 & 688816 & 4.95 & 4.9673 & TRN & \\
\hline CHEMBL3197335 & 688816 & 4.45 & 5.1924 & TRN & \\
\hline CHEMBL1411166 & 688816 & 5.55 & 5.0871 & TRN & \\
\hline CHEMBL1563835 & 688816 & 4.85 & 5.12200 & 0000000001 & TRN \\
\hline CHEMBL1413404 & 688816 & 4.75 & 5.2295 & TRN & \\
\hline CHEMBL1588525 & 688816 & 5.3 & 5.3675 & TST & \\
\hline CHEMBL3199377 & 688816 & 4.75 & 5.3591 & TRN & \\
\hline CHEMBL3212799 & 688816 & 5.2 & 4.8893 & TST & \\
\hline CHEMBL1328907 & 688816 & 4.95 & 5.5279 & TST & \\
\hline CHEMBL3197351 & 688816 & 5.65 & 5.3989 & TST & \\
\hline CHEMBL1468097 & 688816 & 8.301 & 5.3152 & TST & \\
\hline CHEMBL1578308 & 688816 & 4.7 & 5.1347 & TRN & \\
\hline CHEMBL1500973 & 688816 & 4.9 & 5.5684 & TST & \\
\hline CHEMBL578504 & 688816 & 5.35 & 5.2861 & TRN & \\
\hline CHEMBL3209203 & 688816 & 4.7 & 5.4052 & TRN & \\
\hline CHEMBL1436429 & 688816 & 4.45 & 5.1386 & TRN & \\
\hline CHEMBL1567335 & 688816 & 4.45 & 5.3306 & TRN & \\
\hline CHEMBL3199755 & 688816 & 5.45 & 5.8462 & TRN & \\
\hline CHEMBL1489422 & 688816 & 5.15 & 5.3581 & TST & \\
\hline CHEMBL1332117 & 688816 & 4.95 & 4.9531 & TRN & \\
\hline CHEMBL1465080 & 688816 & 5.95 & 5.2584 & TRN & \\
\hline CHEMBL1451738 & 688816 & 4.95 & 5.0947 & TRN & \\
\hline CHEMBL3211970 & 688816 & 7.8013 & 5.6744 & TRN & \\
\hline CHEMBL3190594 & 688816 & 5.3 & 5.2534 & TRN & \\
\hline CHEMBL1332346 & 688816 & 5.85 & 5.0145 & TRN & \\
\hline CHEMBL1586230 & 688816 & 4.45 & 4.7193 & TRN & \\
\hline CHEMBL3212897 & 688816 & 4.45 & 5.3702 & TRN & \\
\hline CHEMBL 1367412 & 688816 & 6.5501 & 5.3883 & TRN & \\
\hline CHEMBL1598264 & 688816 & 4.75 & 4.9312 & TRN & \\
\hline CHEMBL3197978 & 688816 & 5.55 & 5.284 & TRN & \\
\hline CHEMBL1313179 & 688816 & 8.3468 & 5.5505 & TST & \\
\hline CHEMBL1457877 & 688816 & 4.7 & 5.2435 & TST & \\
\hline CHEMBL1500492 & 688816 & 6.6 & 5.3307 & TRN & \\
\hline CHEMBL3212843 & 688816 & 5.0 & 5.3844 & TRN & \\
\hline
\end{tabular}




\begin{tabular}{|c|c|c|c|c|c|}
\hline \multicolumn{6}{|c|}{ Supplemental Table S2.txt } \\
\hline CHEMBL1601686 & 688816 & 4.9 & 4.9224 & TRN & \\
\hline CHEMBL3192696 & 688816 & 4.85 & 5.2506 & TST & \\
\hline CHEMBL1335423 & 688816 & 4.9 & 5.3677 & TST & \\
\hline CHEMBL1603431 & 688816 & 8.3468 & 5.521 & TRN & \\
\hline CHEMBL1310642 & 688816 & 7.4498 & 5.4569 & TRN & \\
\hline CHEMBL1546142 & 688816 & 8.0506 & 5.2141 & TRN & \\
\hline CHEMBL1448882 & 688816 & 4.6 & 5.0421 & TRN & \\
\hline CHEMBL1555801 & 688816 & 4.9 & 5.3173 & TST & \\
\hline CHEMBL1597563 & 688816 & 4.65 & 5.3183 & TRN & \\
\hline CHEMBL1422825 & 688816 & 7.6003 & 5.5298 & TRN & \\
\hline CHEMBL1355096 & 688816 & 4.8 & 5.0634 & TRN & \\
\hline CHEMBL1301299 & 688816 & 6.25 & 5.4551 & TRN & \\
\hline CHEMBL1358402 & 688816 & 5.35 & 5.6947 & TST & \\
\hline CHEMBL1446149 & 688816 & 6.0 & 5.7535 & TRN & \\
\hline CHEMBL1370593 & 688816 & 4.45 & 5.1072 & TRN & \\
\hline CHEMBL1585966 & 688816 & 5.3 & 5.3381 & TRN & \\
\hline CHEMBL1596232 & 688816 & 5.0 & 5.01699 & 99999999995 & TRN \\
\hline CHEMBL1369049 & 688816 & 4.45 & 5.2889 & TRN & \\
\hline CHEMBL1417273 & 688816 & 4.8 & 5.5981 & TST & \\
\hline CHEMBL1385532 & 688816 & 4.9 & 5.0401 & TRN & \\
\hline CHEMBL1524212 & 688816 & 4.65 & 5.49200 & 0000000001 & TRN \\
\hline CHEMBL1322295 & 688816 & 4.95 & 5.71200 & 0000000001 & TRN \\
\hline CHEMBL1339928 & 688816 & 4.75 & 5.3423 & TST & \\
\hline CHEMBL1490080 & 688816 & 4.45 & 5.3729 & TRN & \\
\hline CHEMBL1590435 & 688816 & 4.85 & 5.4531 & TRN & \\
\hline CHEMBL1375464 & 688816 & 4.95 & 5.165 & TRN & \\
\hline CHEMBL1549085 & 688816 & 5.5 & 5.3764 & TRN & \\
\hline CHEMBL1503261 & 688816 & 4.45 & 5.142 & TST & \\
\hline CHEMBL1324591 & 688816 & 5.4 & 5.5551 & TRN & \\
\hline CHEMBL1604217 & 688816 & 5.5 & 4.8816 & TRN & \\
\hline CHEMBL1488701 & 688816 & 5.25 & 5.5403 & TST & \\
\hline CHEMBL1530791 & 688816 & 4.85 & 5.1736 & TRN & \\
\hline CHEMBL1591057 & 688816 & 4.95 & 4.9494 & TRN & \\
\hline CHEMBL1426120 & 688816 & 4.65 & 5.3164 & TRN & \\
\hline CHEMBL1413360 & 688816 & 6.6 & 5.5769 & TRN & \\
\hline CHEMBL1341252 & 688816 & 7.5003 & 5.3385 & TST & \\
\hline CHEMBL1411327 & 688816 & 5.1 & 5.4202 & TRN & \\
\hline CHEMBL1340037 & 688816 & 5.0 & 5.03100 & 0000000001 & TRN \\
\hline CHEMBL1464231 & 688816 & 5.25 & 5.8779 & TST & \\
\hline CHEMBL1510185 & 688816 & 4.9 & 5.0957 & TRN & \\
\hline CHEMBL1372439 & 688816 & 4.45 & 5.0632 & TRN & \\
\hline CHEMBL1530978 & 688816 & 4.45 & 5.2373 & TST & \\
\hline CHEMBL1538913 & 688816 & 4.45 & 5.7695 & TST & \\
\hline CHEMBL1396090 & 688816 & 4.8 & 5.2467 & TRN & \\
\hline CHEMBL1530144 & 688816 & 4.9 & 4.7364 & TRN & \\
\hline CHEMBL1476181 & 688816 & 4.9 & 5.2146 & TRN & \\
\hline CHEMBL1371313 & 688816 & 6.6499 & 5.3124 & TRN & \\
\hline CHEMBL1300397 & 688816 & 5.15 & 4.8816 & TRN & \\
\hline
\end{tabular}




\begin{tabular}{|c|c|c|c|c|}
\hline \multicolumn{5}{|c|}{ Supplemental Table S2.txt } \\
\hline CHEMBL1409220 & 688816 & 5.75 & 5.2665 & TRN \\
\hline CHEMBL1398660 & 688816 & 4.45 & 5.5487 & TRN \\
\hline CHEMBL576039 & 688816 & 4.65 & 4.9645 & TRN \\
\hline CHEMBL1537477 & 688816 & 4.9 & 5.528 & TRN \\
\hline CHEMBL1465915 & 688816 & 5.0 & 5.2874 & TRN \\
\hline CHEMBL1606868 & 688816 & 7.2503 & 5.1917 & TRN \\
\hline CHEMBL1359880 & 688816 & 4.95 & 4.9556 & TRN \\
\hline CHEMBL1530280 & 688816 & 5.2 & 5.0197 & TRN \\
\hline CHEMBL3193945 & 688816 & 4.75 & 5.0432 & TRN \\
\hline CHEMBL1327253 & 688816 & 4.9 & 5.4687 & TRN \\
\hline CHEMBL 3211775 & 688816 & 5.35 & 5.0798 & TRN \\
\hline CHEMBL1302655 & 688816 & 4.9 & 5.1242 & TRN \\
\hline CHEMBL1390928 & 688816 & 4.9 & 5.3172 & TRN \\
\hline CHEMBL1442023 & 688816 & 6.25 & 5.5392 & TRN \\
\hline CHEMBL1509511 & 688816 & 4.6 & 4.8806 & TRN \\
\hline CHEMBL1600019 & 688816 & 7.7496 & 5.4633 & TST \\
\hline CHEMBL1482322 & 688816 & 8.5528 & 5.4581 & TRN \\
\hline CHEMBL3189209 & 688816 & 4.9 & 5.5845 & TRN \\
\hline CHEMBL1430931 & 688816 & 4.85 & 5.0108 & TRN \\
\hline CHEMBL1380561 & 688816 & 4.75 & 5.3877 & TRN \\
\hline CHEMBL1456257 & 688816 & 5.25 & 5.5056 & TRN \\
\hline CHEMBL1396761 & 688816 & 4.9 & 5.1037 & TRN \\
\hline CHEMBL1429773 & 688816 & 5.2 & 5.7152 & TST \\
\hline CHEMBL1409173 & 688816 & 5.55 & 5.4299 & TRN \\
\hline CHEMBL1560681 & 688816 & 7.699 & 5.3495 & TRN \\
\hline CHEMBL1570869 & 688816 & 4.75 & 4.9098 & TRN \\
\hline CHEMBL1596217 & 688816 & 7.6003 & 5.3223 & TRN \\
\hline CHEMBL1332578 & 688816 & 5.45 & 5.6686 & TRN \\
\hline CHEMBL1312115 & 688816 & 5.55 & 5.5777 & TST \\
\hline CHEMBL1404945 & 688816 & 4.9 & 4.867 & TRN \\
\hline CHEMBL1365155 & 688816 & 6.8499 & 5.1471 & TST \\
\hline CHEMBL1411912 & 688816 & 6.05 & 5.2454 & TRN \\
\hline CHEMBL1518161 & 688816 & 4.9 & 5.3392 & TRN \\
\hline CHEMBL1332523 & 688816 & 4.95 & 5.0261 & TRN \\
\hline CHEMBL1350257 & 688816 & 4.5 & 4.9491 & TRN \\
\hline CHEMBL1425605 & 688816 & 4.45 & 5.0422 & TRN \\
\hline CHEMBL1511820 & 688816 & 4.45 & 4.94 & TST \\
\hline CHEMBL1482188 & 688816 & 5.4 & 5.3626 & TST \\
\hline CHEMBL3191730 & 688816 & 5.55 & 5.2479 & TRN \\
\hline CHEMBL1441669 & 688816 & 4.45 & 5.1484 & TRN \\
\hline CHEMBL3197611 & 688816 & 4.9 & 5.2407 & TST \\
\hline CHEMBL 260775 & 688816 & 4.85 & 5.0369 & TRN \\
\hline CHEMBL1511259 & 688816 & 4.8 & 5.8775 & TST \\
\hline CHEMBL1610811 & 688816 & 4.75 & 5.8149 & TST \\
\hline CHEMBL1386211 & 688816 & 4.95 & 5.11 & TST \\
\hline CHEMBL1316261 & 688816 & 4.8 & 4.941 & TRN \\
\hline CHEMBL1539279 & 688816 & 8.0506 & 5.0582 & TRN \\
\hline CHEMBL1513416 & 688816 & 4.5 & 4.795 & TRN \\
\hline
\end{tabular}




\begin{tabular}{|c|c|c|c|c|c|}
\hline \multicolumn{6}{|c|}{ Supplemental Table S2.txt } \\
\hline CHEMBL1442028 & 688816 & 5.0 & 4.9843 & TRN & \\
\hline CHEMBL1343352 & 688816 & 6.4 & 5.3187 & TRN & \\
\hline CHEMBL1524932 & 688816 & 8.0 & 5.4107 & TRN & \\
\hline CHEMBL3199671 & 688816 & 5.05 & 5.2941 & TRN & \\
\hline CHEMBL1398616 & 688816 & 4.85 & 5.3765 & TRN & \\
\hline CHEMBL29861 & 688816 & 6.6499 & 5.2912 & TST & \\
\hline CHEMBL1373199 & 688816 & 5.2 & 5.3862 & TRN & \\
\hline CHEMBL1535440 & 688816 & 4.8 & 5.226 & TRN & \\
\hline CHEMBL1319244 & 688816 & 8.3979 & 5.7193 & TST & \\
\hline CHEMBL1600715 & 688816 & 4.85 & 5.6637 & TST & \\
\hline CHEMBL1410034 & 688816 & 6.5501 & 5.4285 & TST & \\
\hline CHEMBL1541991 & 688816 & 5.4 & 5.4921 & TRN & \\
\hline CHEMBL1521591 & 688816 & 4.95 & 5.5088 & TRN & \\
\hline CHEMBL1408650 & 688816 & 4.85 & 5.3392 & TRN & \\
\hline CHEMBL1338548 & 688816 & 4.8 & $5.2070 e$ & 0000000001 & TRN \\
\hline CHEMBL1970527 & 688816 & 4.75 & 5.36299 & 99999999995 & TRN \\
\hline CHEMBL1572968 & 688816 & 5.1 & 5.4859 & TRN & \\
\hline CHEMBL1456420 & 688816 & 4.9 & 5.1 & TRN & \\
\hline CHEMBL1366161 & 688816 & 6.2 & 5.4801 & TRN & \\
\hline CHEMBL1455389 & 688816 & 4.45 & 4.9819 & TRN & \\
\hline CHEMBL1549425 & 688816 & 7.2503 & 5.2297 & TRN & \\
\hline CHEMBL1411706 & 688816 & 8.301 & 5.4229 & TRN & \\
\hline CHEMBL596271 & 688816 & 4.7 & 4.9465 & TST & \\
\hline CHEMBL1557778 & 688816 & 4.65 & 5.1418 & TRN & \\
\hline CHEMBL1421381 & 688816 & 7.6003 & 5.3875 & TRN & \\
\hline CHEMBL1407428 & 688816 & 4.8 & 5.2449 & TRN & \\
\hline CHEMBL1539546 & 688816 & 8.0 & 5.461 & TST & \\
\hline CHEMBL1456946 & 688816 & 4.6 & 5.6083 & TRN & \\
\hline CHEMBL1387470 & 688816 & 5.0 & 5.5224 & TST & \\
\hline CHEMBL1301941 & 688816 & 8.1487 & 5.7075 & TST & \\
\hline CHEMBL1505003 & 688816 & 5.05 & 5.1167 & TRN & \\
\hline CHEMBL1414675 & 688816 & 6.05 & 5.4925 & TRN & \\
\hline CHEMBL1346506 & 688816 & 4.45 & 5.0683 & TRN & \\
\hline CHEMBL1575396 & 688816 & 5.0 & 5.45299 & 9999999999 & TRN \\
\hline CHEMBL1320281 & 688816 & 5.1 & 5.4061 & TST & \\
\hline CHEMBL1371490 & 688816 & 4.6 & 5.3631 & TRN & \\
\hline CHEMBL1575012 & 688816 & 6.45 & 5.8923 & TST & \\
\hline CHEMBL1578499 & 688816 & 5.25 & 5.2446 & TST & \\
\hline CHEMBL3197015 & 688816 & 5.45 & 5.1371 & TST & \\
\hline CHEMBL1352348 & 688816 & 6.5 & 5.2806 & TRN & \\
\hline CHEMBL1438312 & 688816 & 4.75 & 5.0107 & TRN & \\
\hline CHEMBL1322482 & 688816 & 4.8 & 5.2732 & TRN & \\
\hline CHEMBL1604992 & 688816 & 4.45 & 5.5123 & TST & \\
\hline CHEMBL1329175 & 688816 & 8.4949 & 5.3115 & TRN & \\
\hline CHEMBL1509894 & 688816 & 8.301 & 5.6553 & TRN & \\
\hline CHEMBL1460562 & 688816 & 5.55 & 5.4498 & TRN & \\
\hline CHEMBL375530 & 688816 & 5.0 & 5.4097 & TRN & \\
\hline CHEMBL1428789 & 688816 & 4.95 & 5.5847 & TST & \\
\hline
\end{tabular}




\begin{tabular}{|c|c|c|c|c|c|}
\hline \multicolumn{6}{|c|}{ Supplemental Table S2.txt } \\
\hline CHEMBL1499436 & 688816 & 4.95 & 4.6558 & TST & \\
\hline CHEMBL1488556 & 688816 & 5.1 & 5.7299 & TRN & \\
\hline CHEMBL1488901 & 688816 & 5.5 & 5.8465 & TST & \\
\hline CHEMBL1379943 & 688816 & 4.9 & 5.2832 & TRN & \\
\hline CHEMBL1509374 & 688816 & 4.45 & 5.4566 & TST & \\
\hline CHEMBL1502019 & 688816 & 5.15 & 5.5573 & TST & \\
\hline CHEMBL1587801 & 688816 & 4.65 & 5.6053 & TRN & \\
\hline CHEMBL1388583 & 688816 & 8.4949 & 5.3032 & TRN & \\
\hline CHEMBL 3208413 & 688816 & 5.45 & 5.154 & TRN & \\
\hline CHEMBL1524390 & 688816 & 5.05 & 5.2059 & TRN & \\
\hline CHEMBL1504589 & 688816 & 5.0 & 5.4286 & TRN & \\
\hline CHEMBL1460914 & 688816 & 4.95 & 5.2475 & TRN & \\
\hline CHEMBL1334922 & 688816 & 4.95 & 5.4824 & TRN & \\
\hline CHEMBL1390244 & 688816 & 4.45 & 5.4275 & TRN & \\
\hline CHEMBL1480983 & 688816 & 4.75 & 5.1077 & TRN & \\
\hline CHEMBL1446825 & 688816 & 4.45 & 5.2433 & TST & \\
\hline CHEMBL1327326 & 688816 & 4.95 & 4.9874 & TRN & \\
\hline CHEMBL1551318 & 688816 & 4.8 & 5.3164 & TST & \\
\hline CHEMBL1504692 & 688816 & 4.65 & 5.0528 & TRN & \\
\hline CHEMBL1388529 & 688816 & 4.45 & 5.1587 & TRN & \\
\hline CHEMBL1416507 & 688816 & 4.45 & 5.2628 & TRN & \\
\hline CHEMBL1525579 & 688816 & 4.9 & 5.4738 & TRN & \\
\hline CHEMBL1542002 & 688816 & 4.45 & 5.1746 & TRN & \\
\hline CHEMBL1508733 & 688816 & 4.85 & 4.9138 & TRN & \\
\hline CHEMBL1353943 & 688816 & 5.0 & 4.9594 & TRN & \\
\hline CHEMBL1372628 & 688816 & 4.9 & 5.3659 & TRN & \\
\hline CHEMBL1511450 & 688816 & 5.15 & 5.3586 & TRN & \\
\hline CHEMBL3189729 & 688816 & 4.6 & 5.1849 & TRN & \\
\hline CHEMBL1438414 & 688816 & 4.65 & 5.0835 & TRN & \\
\hline CHEMBL1405504 & 688816 & 4.9 & 5.3452 & TRN & \\
\hline CHEMBL1489972 & 688816 & 8.4949 & 5.4523 & TST & \\
\hline CHEMBL1461832 & 688816 & 4.9 & 4.9837 & TRN & \\
\hline CHEMBL1553072 & 688816 & 4.9 & 5.3604 & TST & \\
\hline CHEMBL1327977 & 688816 & 4.85 & 5.3648 & TST & \\
\hline CHEMBL1603924 & 688816 & 4.75 & 5.2802 & TST & \\
\hline CHEMBL1464930 & 688816 & 5.45 & 5.308 & TRN & \\
\hline CHEMBL1536636 & 688816 & 4.85 & 5.08899 & 99999999995 & TRN \\
\hline CHEMBL1478961 & 688816 & 4.9 & 5.4436 & TRN & \\
\hline CHEMBL1601851 & 688816 & 4.45 & 5.2 & TST & \\
\hline CHEMBL1600218 & 688816 & 8.5528 & 5.4568 & TRN & \\
\hline CHEMBL1577814 & 688816 & 4.85 & 5.0324 & TRN & \\
\hline CHEMBL1585701 & 688816 & 4.95 & 5.3609 & TST & \\
\hline CHEMBL1468677 & 688816 & 4.95 & 5.2196 & TRN & \\
\hline CHEMBL1308615 & 688816 & 5.0 & 5.0906 & TRN & \\
\hline CHEMBL1457934 & 688816 & 6.8 & 5.4496 & TRN & \\
\hline CHEMBL1467154 & 688816 & 5.9 & 5.3733 & TRN & \\
\hline CHEMBL1397550 & 688816 & 5.55 & 5.1759 & TRN & \\
\hline CHEMBL1511317 & 688816 & 5.95 & 5.1734 & TST & \\
\hline
\end{tabular}




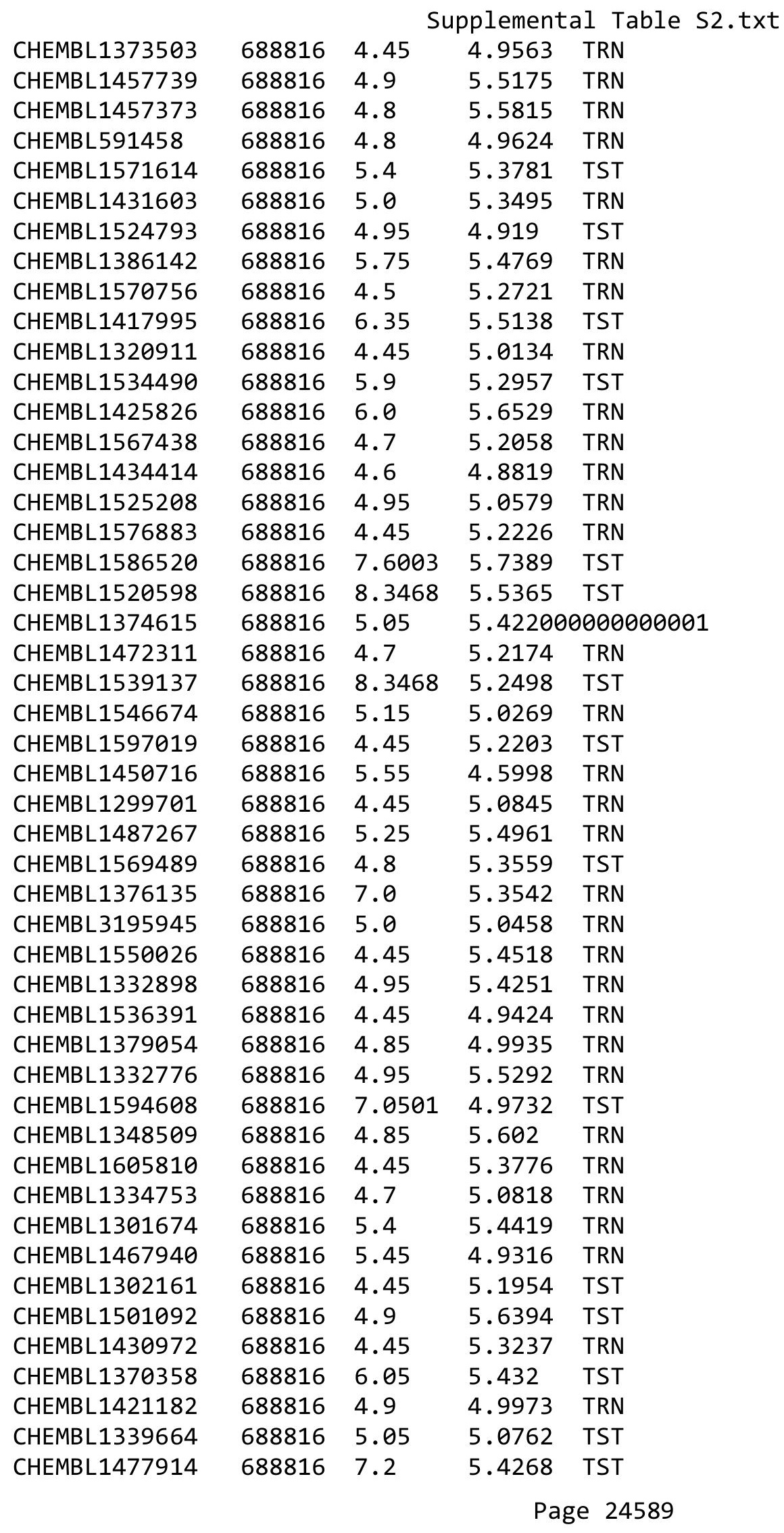

TRN 


\begin{tabular}{|c|c|c|c|c|c|}
\hline \\
\hline CHEMBL1357904 & 688816 & 4.9 & 5.1957 & TRN & \\
\hline CHEMBL1359806 & 688816 & 5.25 & 5.5001 & TRN & \\
\hline CHEMBL1540101 & 688816 & 4.8 & 5.2379 & TST & \\
\hline CHEMBL1550294 & 688816 & 4.45 & 5.1836 & TRN & \\
\hline CHEMBL1521390 & 688816 & 4.45 & 5.3123 & TST & \\
\hline CHEMBL1468257 & 688816 & 4.9 & 5.2412 & TST & \\
\hline CHEMBL1510884 & 688816 & 4.8 & 4.9115 & TRN & \\
\hline CHEMBL1361553 & 688816 & 4.75 & 5.2072 & TST & \\
\hline CHEMBL1587941 & 688816 & 5.0 & 5.1403 & TRN & \\
\hline CHEMBL1428258 & 688816 & 5.45 & 4.9561 & TST & \\
\hline CHEMBL1475230 & 688816 & 5.25 & 5.284 & TRN & \\
\hline CHEMBL1345576 & 688816 & 5.4 & 4.8662 & TRN & \\
\hline CHEMBL3193481 & 688816 & 4.45 & 5.59399 & 9999999999 & TRN \\
\hline CHEMBL1439403 & 688816 & 4.45 & 5.107 & TRN & \\
\hline CHEMBL1450093 & 688816 & 8.3468 & 4.9338 & TST & \\
\hline CHEMBL 2094665 & 688816 & 4.8 & 4.9044 & TRN & \\
\hline CHEMBL1312924 & 688816 & 5.4 & 5.2475 & TST & \\
\hline CHEMBL1328073 & 688816 & 4.95 & 4.9762 & TRN & \\
\hline CHEMBL1543615 & 688816 & 4.75 & 4.9794 & TRN & \\
\hline CHEMBL1459407 & 688816 & 4.65 & 5.2661 & TRN & \\
\hline CHEMBL1451026 & 688816 & 5.9 & 5.171 & TRN & \\
\hline CHEMBL1604453 & 688816 & 5.15 & 5.3532 & TRN & \\
\hline CHEMBL1543853 & 688816 & 4.85 & 5.3227 & TRN & \\
\hline CHEMBL1579408 & 688816 & 4.95 & 5.2488 & TRN & \\
\hline CHEMBL1393448 & 688816 & 5.95 & 5.6192 & TRN & \\
\hline CHEMBL1575590 & 688816 & 4.9 & 5.1233 & TRN & \\
\hline CHEMBL1369099 & 688816 & 5.1 & 5.0898 & TRN & \\
\hline CHEMBL1460215 & 688816 & 5.25 & 4.9166 & TST & \\
\hline CHEMBL1321027 & 688816 & 4.9 & 5.324 & TRN & \\
\hline CHEMBL3195605 & 688816 & 5.25 & 5.614 & TRN & \\
\hline CHEMBL1315850 & 688816 & 4.7 & 5.3211 & TRN & \\
\hline CHEMBL1428054 & 688816 & 4.45 & 5.0761 & TRN & \\
\hline CHEMBL1584493 & 688816 & 5.05 & 5.30200 & 00000000005 & TRN \\
\hline CHEMBL1308075 & 688816 & 5.0 & 5.0889 & TRN & \\
\hline CHEMBL1611434 & 688816 & 4.45 & 4.7828 & TRN & \\
\hline CHEMBL1552178 & 688816 & 4.9 & 5.4222 & TRN & \\
\hline CHEMBL1970160 & 688816 & 4.75 & 5.2303 & TRN & \\
\hline CHEMBL1558470 & 688816 & 4.45 & 5.2465 & TST & \\
\hline CHEMBL1537460 & 688816 & 4.9 & 5.1136 & TRN & \\
\hline CHEMBL1467195 & 688816 & 4.45 & 5.165 & TRN & \\
\hline CHEMBL1450470 & 688816 & 6.45 & 4.9873 & TRN & \\
\hline CHEMBL1337152 & 688816 & 4.75 & 4.9642 & TRN & \\
\hline CHEMBL1533136 & 688816 & 5.0 & 5.3073 & TST & \\
\hline CHEMBL1316255 & 688816 & 5.9 & 4.9796 & TRN & \\
\hline CHEMBL1600758 & 688816 & 4.45 & 5.2067 & TRN & \\
\hline CHEMBL1361016 & 688816 & 5.6 & 5.0348 & TRN & \\
\hline CHEMBL1397779 & 688816 & 4.9 & 5.2809 & TRN & \\
\hline CHEMBL1612746 & 688816 & 5.0 & 5.4226 & TRN & \\
\hline
\end{tabular}




\begin{tabular}{|c|c|c|c|c|c|}
\hline \multicolumn{6}{|c|}{ Supplemental Table S2.txt } \\
\hline CHEMBL1311383 & 688816 & 4.45 & 5.5949 & TST & \\
\hline CHEMBL1510086 & 688816 & 4.95 & 5.2903 & TRN & \\
\hline CHEMBL1302598 & 688816 & 5.0 & 5.296 & TRN & \\
\hline CHEMBL1438270 & 688816 & 4.8 & 5.3137 & TRN & \\
\hline CHEMBL1376120 & 688816 & 4.9 & 4.8047 & TRN & \\
\hline CHEMBL1585290 & 688816 & 5.3 & 5.4672 & TST & \\
\hline CHEMBL1438350 & 688816 & 8.301 & 5.6344 & TST & \\
\hline CHEMBL1495417 & 688816 & 5.5 & 5.2954 & TRN & \\
\hline CHEMBL1467937 & 688816 & 5.2 & 5.0866 & TRN & \\
\hline CHEMBL1566730 & 688816 & 4.95 & 5.5762 & TRN & \\
\hline CHEMBL1300242 & 688816 & 4.45 & 5.3636 & TRN & \\
\hline CHEMBL1375627 & 688816 & 4.85 & 4.9957 & TST & \\
\hline CHEMBL1601580 & 688816 & 4.9 & 5.1537 & TRN & \\
\hline CHEMBL1539250 & 688816 & 6.5 & 5.9685 & TRN & \\
\hline CHEMBL3195746 & 688816 & 4.85 & 5.2804 & TRN & \\
\hline CHEMBL1353349 & 688816 & 6.1 & 4.9796 & TRN & \\
\hline CHEMBL528712 & 688816 & 5.0 & 5.1917 & TRN & \\
\hline CHEMBL1462262 & 688816 & 4.95 & 5.0248 & TRN & \\
\hline CHEMBL1373171 & 688816 & 4.95 & 5.5219 & TST & \\
\hline CHEMBL1595037 & 688816 & 4.85 & 5.16200 & 0000000001 & TST \\
\hline CHEMBL1337695 & 688816 & 4.6 & 5.6754 & TST & \\
\hline CHEMBL1492119 & 688816 & 4.8 & 4.9893 & TRN & \\
\hline CHEMBL1416728 & 688816 & 4.6 & 5.6135 & TST & \\
\hline CHEMBL1432355 & 688816 & 4.95 & 5.4285 & TST & \\
\hline CHEMBL3194170 & 688816 & 5.35 & 5.5613 & TRN & \\
\hline CHEMBL1463115 & 688816 & 6.05 & 5.3658 & TRN & \\
\hline CHEMBL1585117 & 688816 & 4.95 & 5.3777 & TRN & \\
\hline CHEMBL1393581 & 688816 & 4.45 & 4.9986 & TRN & \\
\hline CHEMBL1488923 & 688816 & 5.0 & 5.3271 & TRN & \\
\hline CHEMBL3195498 & 688816 & 4.85 & 5.4457 & TRN & \\
\hline CHEMBL1452163 & 688816 & 4.8 & 5.3642 & TRN & \\
\hline CHEMBL1517940 & 688816 & 4.95 & 5.442 & TRN & \\
\hline CHEMBL1420157 & 688816 & 4.45 & 5.5718 & TRN & \\
\hline CHEMBL3193448 & 688816 & 6.9 & 5.2998 & TRN & \\
\hline CHEMBL1444258 & 688816 & 5.5 & 5.4947 & TRN & \\
\hline CHEMBL1540071 & 688816 & 4.95 & 5.3743 & TRN & \\
\hline CHEMBL 1358840 & 688816 & 5.2 & 5.5633 & TRN & \\
\hline CHEMBL1302444 & 688816 & 4.95 & 5.4373 & TRN & \\
\hline CHEMBL1613550 & 688816 & 4.45 & 5.3261 & TRN & \\
\hline CHEMBL1597655 & 688816 & 4.6 & 5.0014 & TRN & \\
\hline CHEMBL1319593 & 688816 & 4.8 & 5.2999 & TST & \\
\hline CHEMBL1611655 & 688816 & 6.0 & 5.4427 & TRN & \\
\hline CHEMBL3209081 & 688816 & 5.3 & 5.761 & TRN & \\
\hline CHEMBL3192873 & 688816 & 6.4 & 5.8816 & TRN & \\
\hline CHEMBL1522728 & 688816 & 4.7 & 5.2367 & TST & \\
\hline CHEMBL1360431 & 688816 & 4.95 & 4.8673 & TRN & \\
\hline CHEMBL1732085 & 688816 & 5.55 & 5.0717 & TST & \\
\hline CHEMBL1528225 & 688816 & 4.5 & 4.9382 & TRN & \\
\hline
\end{tabular}




\begin{tabular}{|c|c|c|c|c|c|}
\hline \multicolumn{6}{|c|}{ Supplemental Table S2.txt } \\
\hline CHEMBL1323422 & 688816 & 5.25 & 5.0514 & TRN & \\
\hline CHEMBL1326349 & 688816 & 5.4 & 5.1541 & TST & \\
\hline CHEMBL1583447 & 688816 & 6.5501 & 5.2823 & TST & \\
\hline CHEMBL1350514 & 688816 & 4.6 & 5.3061 & TRN & \\
\hline CHEMBL1470448 & 688816 & 6.9 & 4.7552 & TRN & \\
\hline CHEMBL1330435 & 688816 & 4.95 & 4.8823 & TRN & \\
\hline CHEMBL1578584 & 688816 & 5.1 & 5.3768 & TRN & \\
\hline CHEMBL1512156 & 688816 & 5.25 & 5.2549 & TRN & \\
\hline CHEMBL3209151 & 688816 & 4.8 & 5.4291 & TRN & \\
\hline CHEMBL1518550 & 688816 & 5.35 & 5.3791 & TRN & \\
\hline CHEMBL1471701 & 688816 & 5.25 & 5.1444 & TRN & \\
\hline CHEMBL1490792 & 688816 & 4.85 & 5.0165 & TST & \\
\hline CHEMBL1367502 & 688816 & 8.0 & 5.4179 & TRN & \\
\hline CHEMBL1306816 & 688816 & 4.6 & 5.0304 & TRN & \\
\hline CHEMBL3214496 & 688816 & 4.65 & 5.2739 & TRN & \\
\hline CHEMBL1452102 & 688816 & 8.301 & 5.5503 & TST & \\
\hline CHEMBL1484384 & 688816 & 4.45 & 5.2687 & TST & \\
\hline CHEMBL1590580 & 688816 & 4.45 & 4.9641 & TRN & \\
\hline CHEMBL1438855 & 688816 & 4.65 & 4.9706 & TST & \\
\hline CHEMBL1420201 & 688816 & 5.05 & 5.4284 & TRN & \\
\hline CHEMBL1403898 & 688816 & 4.45 & 5.1877 & TST & \\
\hline CHEMBL1501294 & 688816 & 8.2518 & 4.9834 & TRN & \\
\hline CHEMBL1482777 & 688816 & 4.45 & 4.838 & TRN & \\
\hline CHEMBL1323076 & 688816 & 6.6499 & 5.2999 & TRN & \\
\hline CHEMBL1426996 & 688816 & 4.95 & 5.5228 & TRN & \\
\hline CHEMBL1567773 & 688816 & 5.6 & 5.2752 & TRN & \\
\hline CHEMBL1480483 & 688816 & 4.85 & 5.0589 & TRN & \\
\hline CHEMBL1534435 & 688816 & 4.8 & 5.2388 & TRN & \\
\hline CHEMBL1486894 & 688816 & 4.95 & 5.021 & TRN & \\
\hline CHEMBL 1441270 & 688816 & 4.8 & 5.1099 & TRN & \\
\hline CHEMBL1571905 & 688816 & 4.85 & 5.121 & TRN & \\
\hline CHEMBL 3190272 & 688816 & 4.65 & 5.1896 & TRN & \\
\hline CHEMBL1561472 & 688816 & 4.9 & 5.6253 & TRN & \\
\hline CHEMBL1513976 & 688816 & 4.95 & 4.7208 & TRN & \\
\hline CHEMBL1497879 & 688816 & 6.7001 & 5.4988 & TRN & \\
\hline CHEMBL1544435 & 688816 & 4.6 & 5.3199 & TST & \\
\hline CHEMBL3197868 & 688816 & 4.9 & 5.2109 & TRN & \\
\hline CHEMBL1338113 & 688816 & 6.05 & 5.042 & TRN & \\
\hline CHEMBL1322844 & 688816 & 4.9 & 5.3524 & TST & \\
\hline CHEMBL1399944 & 688816 & 4.7 & 5.1954 & TRN & \\
\hline CHEMBL1526496 & 688816 & 4.45 & 5.1815 & TRN & \\
\hline CHEMBL1308508 & 688816 & 5.85 & 5.6038 & TRN & \\
\hline CHEMBL1453849 & 688816 & 6.6 & 5.5261 & TST & \\
\hline CHEMBL1454144 & 688816 & 5.05 & 4.937 & TRN & \\
\hline CHEMBL1533687 & 688816 & 5.55 & 4.9255 & TRN & \\
\hline CHEMBL1580693 & 688816 & 5.25 & 5.215 & TST & \\
\hline CHEMBL1517550 & 688816 & 5.25 & 5.0538 & TRN & \\
\hline CHEMBL1561966 & 688816 & 5.7 & 5.40600 & 0000000001 & TRN \\
\hline & & & & 24592 & \\
\hline
\end{tabular}




\begin{tabular}{|c|c|c|c|c|}
\hline \multicolumn{5}{|c|}{ Supplemental Table S2.txt } \\
\hline CHEMBL1305946 & 688816 & 4.95 & 5.0125 & TST \\
\hline CHEMBL1540848 & 688816 & 5.6 & 4.954 & TRN \\
\hline CHEMBL1562040 & 688816 & 4.65 & 4.9624 & TRN \\
\hline CHEMBL1520039 & 688816 & 5.2 & 5.269 & TRN \\
\hline CHEMBL1447668 & 688816 & 4.45 & 5.3526 & TRN \\
\hline CHEMBL1570213 & 688816 & 5.5 & 5.407 & TRN \\
\hline CHEMBL1368744 & 688816 & 4.6 & 4.9123 & TRN \\
\hline CHEMBL1351918 & 688816 & 5.05 & 5.6334 & TRN \\
\hline CHEMBL1565510 & 688816 & 5.05 & 5.1453 & TRN \\
\hline CHEMBL1575354 & 688816 & 4.85 & 5.5502 & TRN \\
\hline CHEMBL3191212 & 688816 & 4.65 & 5.1484 & TRN \\
\hline CHEMBL1351283 & 688816 & 4.9 & 5.0471 & TRN \\
\hline CHEMBL1561331 & 688816 & 4.95 & 5.2037 & TRN \\
\hline CHEMBL1436966 & 688816 & 4.8 & 5.1551 & TRN \\
\hline CHEMBL1442120 & 688816 & 5.65 & 5.3361 & TST \\
\hline CHEMBL1480939 & 688816 & 4.45 & 5.2222 & TST \\
\hline CHEMBL1530033 & 688816 & 5.7 & 5.0277 & TRN \\
\hline CHEMBL3191227 & 688816 & 4.95 & 5.2804 & TST \\
\hline CHEMBL1527857 & 688816 & 5.1 & 4.9241 & TRN \\
\hline CHEMBL1340187 & 688816 & 5.65 & 5.3963 & TRN \\
\hline CHEMBL1322335 & 688816 & 4.9 & 4.9621 & TST \\
\hline CHEMBL1520558 & 688816 & 4.45 & 5.4005 & TST \\
\hline CHEMBL3144890 & 688816 & 4.45 & 4.9939 & TST \\
\hline CHEMBL1396902 & 688816 & 5.25 & 5.3359 & TST \\
\hline CHEMBL1346495 & 688816 & 6.8499 & 5.5854 & TST \\
\hline CHEMBL1472103 & 688816 & 4.65 & 5.3036 & TST \\
\hline CHEMBL1403555 & 688816 & 4.45 & 5.4482 & TST \\
\hline CHEMBL3211398 & 688816 & 5.5 & 5.4253 & TRN \\
\hline CHEMBL1565686 & 688816 & 5.05 & 5.3775 & TRN \\
\hline CHEMBL1439272 & 688816 & 4.7 & 5.2698 & TRN \\
\hline CHEMBL1607132 & 688816 & 5.5 & 4.9425 & TST \\
\hline CHEMBL1353541 & 688816 & 6.5 & 5.5959 & TRN \\
\hline CHEMBL1504973 & 688816 & 4.6 & 4.9689 & TRN \\
\hline CHEMBL1519626 & 688816 & 4.45 & 5.3799 & TRN \\
\hline CHEMBL1571028 & 688816 & 4.9 & 5.255 & TRN \\
\hline CHEMBL1585164 & 688816 & 4.55 & 5.0003 & TRN \\
\hline CHEMBL1426874 & 688816 & 7.2 & 5.277 & TST \\
\hline CHEMBL3209157 & 688816 & 4.7 & 4.8869 & TRN \\
\hline CHEMBL1346155 & 688816 & 6.7001 & 5.4357 & TST \\
\hline CHEMBL1351340 & 688816 & 4.8 & 5.1141 & TRN \\
\hline CHEMBL1351433 & 688816 & 5.15 & 5.3444 & TST \\
\hline CHEMBL1376975 & 688816 & 4.7 & 5.1795 & TRN \\
\hline CHEMBL1424950 & 688816 & 4.7 & 5.2581 & TST \\
\hline CHEMBL 1477120 & 688816 & 4.45 & 4.6997 & TRN \\
\hline CHEMBL1463789 & 688816 & 4.8 & 4.8605 & TRN \\
\hline CHEMBL1343405 & 688816 & 4.7 & 5.2968 & TST \\
\hline CHEMBL1581124 & 688816 & 5.95 & 5.6944 & TST \\
\hline CHEMBL1992105 & 688816 & 4.9 & 5.5172 & TRN \\
\hline
\end{tabular}




\begin{tabular}{|c|c|c|c|c|c|}
\hline \multicolumn{6}{|c|}{ Supplemental Table S2.txt } \\
\hline CHEMBL1397234 & 688816 & 4.9 & 4.8438 & TRN & \\
\hline CHEMBL1550573 & 688816 & 6.5 & 4.9486 & TRN & \\
\hline CHEMBL582073 & 688816 & 6.0 & 5.3321 & TRN & \\
\hline CHEMBL1492825 & 688816 & 4.95 & 5.0185 & TRN & \\
\hline CHEMBL1502752 & 688816 & 4.9 & 5.0318 & TST & \\
\hline CHEMBL1303824 & 688816 & 5.0 & 5.1032 & TRN & \\
\hline CHEMBL1473776 & 688816 & 4.7 & 5.5113 & TRN & \\
\hline CHEMBL1343333 & 688816 & 4.9 & 5.2198 & TRN & \\
\hline CHEMBL1340617 & 688816 & 4.95 & 4.9703 & TRN & \\
\hline CHEMBL1490111 & 688816 & 4.9 & 4.9736 & TRN & \\
\hline CHEMBL1531311 & 688816 & 6.1 & 5.33700 & 0000000001 & TRN \\
\hline CHEMBL1384746 & 688816 & 4.9 & 5.3732 & TRN & \\
\hline CHEMBL1439247 & 688816 & 5.0 & 5.2008 & TRN & \\
\hline CHEMBL1531619 & 688816 & 4.5 & 5.2953 & TRN & \\
\hline CHEMBL1427896 & 688816 & 7.0501 & 5.2828 & TRN & \\
\hline CHEMBL1410287 & 688816 & 4.7 & 5.1914 & TRN & \\
\hline CHEMBL1563220 & 688816 & 4.75 & 4.8296 & TRN & \\
\hline CHEMBL1576078 & 688816 & 5.4 & 5.2646 & TST & \\
\hline CHEMBL333985 & 688816 & 6.0 & 4.7968 & TST & \\
\hline CHEMBL1532141 & 688816 & 4.65 & 5.2966 & TST & \\
\hline CHEMBL3195487 & 688816 & 4.95 & 5.5091 & TRN & \\
\hline CHEMBL1343252 & 688816 & 8.3468 & 5.266 & TRN & \\
\hline CHEMBL1539536 & 688816 & 4.45 & 5.2594 & TRN & \\
\hline CHEMBL1588628 & 688816 & 4.85 & 4.9272 & TST & \\
\hline CHEMBL1500040 & 688816 & 5.85 & 5.8853 & TRN & \\
\hline CHEMBL1534465 & 688816 & 4.75 & 5.1812 & TRN & \\
\hline CHEMBL1506511 & 688816 & 4.75 & 5.1245 & TRN & \\
\hline CHEMBL1566985 & 688816 & 5.4 & 5.2794 & TRN & \\
\hline CHEMBL3199237 & 688816 & 5.25 & 5.3497 & TRN & \\
\hline CHEMBL1448343 & 688816 & 4.9 & 5.0052 & TST & \\
\hline CHEMBL1439060 & 688816 & 7.1002 & 5.2182 & TRN & \\
\hline CHEMBL1976236 & 688816 & 4.95 & 5.4119 & TST & \\
\hline CHEMBL1587286 & 688816 & 4.65 & 5.1946 & TRN & \\
\hline CHEMBL1343823 & 688816 & 5.35 & 5.2622 & TST & \\
\hline CHEMBL1348765 & 688816 & 8.3468 & 5.5941 & TST & \\
\hline CHEMBL1587629 & 688816 & 5.0 & 5.5479 & TST & \\
\hline CHEMBL1595820 & 688816 & 4.75 & 4.7619 & TRN & \\
\hline CHEMBL1569336 & 688816 & 5.6 & 5.0781 & TRN & \\
\hline CHEMBL1420841 & 688816 & 4.95 & 4.9849 & TST & \\
\hline CHEMBL1312656 & 688816 & 6.0 & 4.9761 & TRN & \\
\hline CHEMBL1571026 & 688816 & 6.5 & 5.2674 & TRN & \\
\hline CHEMBL1583162 & 688816 & 4.45 & 5.4827 & TST & \\
\hline CHEMBL1460316 & 688816 & 5.0 & 5.2437 & TRN & \\
\hline CHEMBL1607067 & 688816 & 5.15 & 5.5162 & TRN & \\
\hline CHEMBL1415138 & 688816 & 7.8508 & 5.3706 & TRN & \\
\hline CHEMBL1345664 & 688816 & 4.45 & 4.9991 & TST & \\
\hline CHEMBL1570492 & 688816 & 4.9 & 5.3243 & TRN & \\
\hline CHEMBL1403202 & 688816 & 4.7 & 5.2024 & TST & \\
\hline
\end{tabular}




\begin{tabular}{|c|c|c|c|c|c|}
\hline \multicolumn{6}{|c|}{ Supplemental Table S2.txt } \\
\hline CHEMBL1321287 & 688816 & 4.45 & 4.6215 & TRN & \\
\hline CHEMBL1471109 & 688816 & 4.85 & 5.3025 & TRN & \\
\hline CHEMBL201221 & 688816 & 4.9 & 5.0831 & TRN & \\
\hline CHEMBL1421029 & 688816 & 4.9 & 4.9241 & TRN & \\
\hline CHEMBL1334764 & 688816 & 5.8 & 5.1264 & TRN & \\
\hline CHEMBL1368256 & 688816 & 4.95 & 4.8442 & TRN & \\
\hline CHEMBL1402502 & 688816 & 5.05 & 5.4533 & TRN & \\
\hline CHEMBL1370977 & 688816 & 4.7 & 5.4491 & TRN & \\
\hline CHEMBL1521880 & 688816 & 5.1 & 5.2418 & TST & \\
\hline CHEMBL1440742 & 688816 & 5.15 & 4.923 & TRN & \\
\hline CHEMBL3199876 & 688816 & 5.3 & 5.1742 & TRN & \\
\hline CHEMBL1390388 & 688816 & 4.95 & 5.1763 & TRN & \\
\hline CHEMBL1310553 & 688816 & 5.95 & 5.4755 & TST & \\
\hline CHEMBL1414854 & 688816 & 8.301 & 5.8932 & TRN & \\
\hline CHEMBL1605515 & 688816 & 5.95 & 5.4553 & TRN & \\
\hline CHEMBL1412167 & 688816 & 4.45 & 4.96899 & 9999999999 & TRN \\
\hline CHEMBL1583740 & 688816 & 4.85 & 4.9399 & TRN & \\
\hline CHEMBL1399545 & 688816 & 4.8 & 5.2924 & TRN & \\
\hline CHEMBL1454470 & 688816 & 5.05 & 5.0268 & TRN & \\
\hline CHEMBL1493761 & 688816 & 4.85 & 5.079 & TRN & \\
\hline CHEMBL3213896 & 688816 & 4.9 & 5.3264 & TRN & \\
\hline CHEMBL1577120 & 688816 & 5.25 & 5.2132 & TRN & \\
\hline CHEMBL1308903 & 688816 & 6.1 & 5.5193 & TRN & \\
\hline CHEMBL3196621 & 688816 & 4.45 & 5.0849 & TRN & \\
\hline CHEMBL 299853 & 688816 & 4.6 & 5.2221 & TRN & \\
\hline CHEMBL1431649 & 688816 & 7.6003 & 5.3915 & TRN & \\
\hline CHEMBL3187659 & 688816 & 5.15 & 5.3083 & TRN & \\
\hline CHEMBL1300450 & 688816 & 4.95 & 5.1184 & TRN & \\
\hline CHEMBL1408115 & 688816 & 5.2 & 5.3383 & TRN & \\
\hline CHEMBL1391868 & 688816 & 7.8996 & 5.4773 & TST & \\
\hline CHEMBL1486297 & 688816 & 4.95 & 5.1193 & TRN & \\
\hline CHEMBL1360977 & 688816 & 5.8 & 5.1897 & TRN & \\
\hline CHEMBL1978383 & 688816 & 4.45 & 5.3494 & TST & \\
\hline CHEMBL1385368 & 688816 & 4.85 & 5.2725 & TRN & \\
\hline CHEMBL1370168 & 688816 & 7.3497 & 5.4159 & TST & \\
\hline CHEMBL1398957 & 688816 & 4.75 & 5.1068 & TST & \\
\hline CHEMBL3214229 & 688816 & 8.3468 & 5.2867 & TRN & \\
\hline CHEMBL19612 & 688816 & 4.9 & 5.841 & TST & \\
\hline CHEMBL1560115 & 688816 & 4.9 & 4.9742 & TRN & \\
\hline CHEMBL1359093 & 688816 & 4.9 & 5.4022 & TRN & \\
\hline CHEMBL1308319 & 688816 & 4.45 & 4.8436 & TST & \\
\hline CHEMBL 1457809 & 688816 & 7.6498 & 5.9773 & TST & \\
\hline CHEMBL1544057 & 688816 & 4.75 & 5.8165 & TRN & \\
\hline CHEMBL1393809 & 688816 & 4.8 & 5.4577 & TRN & \\
\hline CHEMBL119556 & 688816 & 4.6 & 5.6561 & TST & \\
\hline CHEMBL1979383 & 688816 & 4.65 & 5.8513 & TRN & \\
\hline CHEMBL1345928 & 688816 & 4.75 & 5.3607 & TRN & \\
\hline CHEMBL1543857 & 688816 & 4.45 & 4.6933 & TRN & \\
\hline
\end{tabular}




\begin{tabular}{|c|c|c|c|c|c|}
\hline \multicolumn{6}{|c|}{ Supplemental Table S2.txt } \\
\hline CHEMBL1533153 & 688816 & 4.85 & 5.1274 & TRN & \\
\hline CHEMBL1392870 & 688816 & 8.301 & 5.2953 & TRN & \\
\hline CHEMBL3145108 & 688816 & 5.1 & 4.9548 & TRN & \\
\hline CHEMBL605003 & 688816 & 4.95 & 5.3954 & TST & \\
\hline CHEMBL1540328 & 688816 & 4.75 & 5.2239 & TST & \\
\hline CHEMBL1450476 & 688816 & 5.15 & 5.02 & TST & \\
\hline CHEMBL1569378 & 688816 & 4.95 & 5.3648 & TRN & \\
\hline CHEMBL1360199 & 688816 & 4.9 & 5.0587 & TST & \\
\hline CHEMBL1355560 & 688816 & 5.05 & 5.1613 & TRN & \\
\hline CHEMBL1370159 & 688816 & 4.65 & 5.5501 & TRN & \\
\hline CHEMBL1305101 & 688816 & 4.9 & 5.2808 & TRN & \\
\hline CHEMBL1500700 & 688816 & 6.6499 & 4.8445 & TST & \\
\hline CHEMBL1581863 & 688816 & 6.4 & 5.1728 & TRN & \\
\hline CHEMBL1321255 & 688816 & 5.7 & 5.3235 & TRN & \\
\hline CHEMBL1465145 & 688816 & 4.8 & 4.88899 & 9999999999 & TRN \\
\hline CHEMBL1322179 & 688816 & 4.7 & 5.5583 & TRN & \\
\hline CHEMBL1380524 & 688816 & 4.45 & 5.3114 & TRN & \\
\hline CHEMBL1331221 & 688816 & 4.65 & 5.2721 & TRN & \\
\hline CHEMBL1610751 & 688816 & 4.45 & 5.1196 & TRN & \\
\hline CHEMBL3198239 & 688816 & 4.85 & 4.8626 & TST & \\
\hline CHEMBL1519890 & 688816 & 6.8 & 5.731 & TRN & \\
\hline CHEMBL1410541 & 688816 & 4.45 & 5.5456 & TST & \\
\hline CHEMBL1369984 & 688816 & 4.45 & 5.1121 & TRN & \\
\hline CHEMBL1496770 & 688816 & 4.6 & 5.6156 & TRN & \\
\hline CHEMBL1606679 & 688816 & 8.301 & 5.2136 & TRN & \\
\hline CHEMBL1343402 & 688816 & 7.6003 & 5.3004 & TST & \\
\hline CHEMBL1979221 & 688816 & 4.9 & 5.2329 & TST & \\
\hline CHEMBL1526267 & 688816 & 5.0 & 5.6938 & TRN & \\
\hline CHEMBL1521656 & 688816 & 5.25 & 5.1605 & TRN & \\
\hline CHEMBL1366283 & 688816 & 6.05 & 5.2656 & TST & \\
\hline CHEMBL3211268 & 688816 & 6.5501 & 5.3084 & TST & \\
\hline CHEMBL1349464 & 688816 & 4.75 & 5.0063 & TRN & \\
\hline CHEMBL524376 & 688816 & 6.1 & 4.9804 & TST & \\
\hline CHEMBL1493922 & 688816 & 5.25 & 5.5006 & TST & \\
\hline CHEMBL1486715 & 688816 & 4.9 & 4.794 & TRN & \\
\hline CHEMBL1323258 & 688816 & 4.85 & 5.2837 & TRN & \\
\hline CHEMBL1533567 & 688816 & 4.45 & 4.9998 & TRN & \\
\hline CHEMBL1522040 & 688816 & 6.05 & 5.4475 & TRN & \\
\hline CHEMBL1442711 & 688816 & 4.9 & 5.4884 & TST & \\
\hline CHEMBL1489193 & 688816 & 4.85 & 5.3635 & TRN & \\
\hline CHEMBL1548448 & 688816 & 5.75 & 5.6881 & TST & \\
\hline CHEMBL1601042 & 688816 & 5.25 & 5.2934 & TRN & \\
\hline CHEMBL1525619 & 688816 & 4.55 & 4.9945 & TRN & \\
\hline CHEMBL1403119 & 688816 & 5.05 & 5.0734 & TRN & \\
\hline CHEMBL1517007 & 688816 & 4.95 & 5.0467 & TRN & \\
\hline CHEMBL1356824 & 688816 & 4.95 & 5.2477 & TST & \\
\hline CHEMBL1326191 & 688816 & 5.3 & 5.7881 & TRN & \\
\hline CHEMBL1454968 & 688816 & 4.7 & 5.2489 & TRN & \\
\hline
\end{tabular}




\begin{tabular}{|c|c|c|c|c|c|}
\hline \multicolumn{6}{|c|}{ Supplemental Table S2.txt } \\
\hline CHEMBL1391612 & 688816 & 4.75 & 5.0368 & TRN & \\
\hline CHEMBL1406965 & 688816 & 5.25 & 5.2837 & TST & \\
\hline CHEMBL 237253 & 688816 & 4.8 & 5.2899 & TRN & \\
\hline CHEMBL1345878 & 688816 & 4.95 & 5.2897 & TRN & \\
\hline CHEMBL1470886 & 688816 & 4.65 & 5.4589 & TRN & \\
\hline CHEMBL1339047 & 688816 & 4.65 & 5.0853 & TST & \\
\hline CHEMBL1445298 & 688816 & 5.15 & 5.3525 & TRN & \\
\hline CHEMBL1374727 & 688816 & 4.95 & 5.222 & TRN & \\
\hline CHEMBL1497913 & 688816 & 5.05 & 5.07100 & 2000000001 & TRN \\
\hline CHEMBL1494790 & 688816 & 7.2503 & 5.4615 & TST & \\
\hline CHEMBL1305281 & 688816 & 4.6 & 5.3674 & TRN & \\
\hline CHEMBL1608681 & 688816 & 4.9 & 5.3577 & TRN & \\
\hline CHEMBL1987483 & 688816 & 4.45 & 5.2095 & TRN & \\
\hline CHEMBL1541318 & 688816 & 4.75 & 4.9429 & TRN & \\
\hline CHEMBL3216928 & 688816 & 4.45 & 5.3899 & TST & \\
\hline CHEMBL1363042 & 688816 & 4.8 & 5.1447 & TRN & \\
\hline CHEMBL1599549 & 688816 & 4.95 & 5.2141 & TRN & \\
\hline CHEMBL1329677 & 688816 & 5.15 & 5.2595 & TRN & \\
\hline CHEMBL1535660 & 688816 & 4.7 & 4.9349 & TRN & \\
\hline CHEMBL1507542 & 688816 & 4.7 & 5.0485 & TRN & \\
\hline CHEMBL1508816 & 688816 & 5.4 & 5.1617 & TST & \\
\hline CHEMBL1349236 & 688816 & 5.35 & 5.0483 & TST & \\
\hline CHEMBL1478650 & 688816 & 4.9 & 5.7218 & TRN & \\
\hline CHEMBL 238188 & 688816 & 6.0 & 4.9778 & TST & \\
\hline CHEMBL1549192 & 688816 & 5.25 & 5.2811 & TRN & \\
\hline CHEMBL1506175 & 688816 & 5.55 & 5.1118 & TRN & \\
\hline CHEMBL1588329 & 688816 & 5.45 & 5.3369 & TRN & \\
\hline CHEMBL1601582 & 688816 & 4.95 & 5.2459 & TRN & \\
\hline CHEMBL1415961 & 688816 & 7.8508 & 5.2372 & TRN & \\
\hline CHEMBL1372914 & 688816 & 4.65 & 5.2532 & TST & \\
\hline CHEMBL1312811 & 688816 & 4.9 & 5.2434 & TST & \\
\hline CHEMBL1514175 & 688816 & 8.301 & 4.9176 & TRN & \\
\hline CHEMBL1398894 & 688816 & 5.0 & 5.3779 & TRN & \\
\hline CHEMBL1596061 & 688816 & 4.95 & 5.1965 & TRN & \\
\hline CHEMBL1575856 & 688816 & 8.0 & 5.1285 & TRN & \\
\hline CHEMBL1424158 & 688816 & 4.9 & 5.3748 & TRN & \\
\hline CHEMBL1412039 & 688816 & 4.45 & 4.9231 & TRN & \\
\hline CHEMBL1308328 & 688816 & 4.8 & 5.3752 & TRN & \\
\hline CHEMBL1370259 & 688816 & 5.1 & 5.2214 & TRN & \\
\hline CHEMBL 3214434 & 688816 & 5.0 & 5.2823 & TST & \\
\hline CHEMBL1366431 & 688816 & 4.95 & 5.2696 & TRN & \\
\hline CHEMBL 1428288 & 688816 & 5.25 & 5.1945 & TRN & \\
\hline CHEMBL1426379 & 688816 & 4.95 & 5.4042 & TRN & \\
\hline CHEMBL1460406 & 688816 & 5.3 & 5.4369 & TRN & \\
\hline CHEMBL1545761 & 688816 & 4.95 & 5.0204 & TST & \\
\hline CHEMBL1392200 & 688816 & 5.5 & 4.863 & TRN & \\
\hline CHEMBL1402491 & 688816 & 7.5003 & 5.7963 & TRN & \\
\hline CHEMBL1548132 & 688816 & 4.95 & 5.2247 & TRN & \\
\hline
\end{tabular}




\begin{tabular}{|c|c|c|c|c|c|}
\hline \multicolumn{6}{|c|}{ Supplemental Table S2.txt } \\
\hline CHEMBL3195312 & 688816 & 5.45 & 5.2718 & TST & \\
\hline CHEMBL1603695 & 688816 & 4.65 & 5.4074 & TRN & \\
\hline CHEMBL1550565 & 688816 & 4.9 & 5.325 & TRN & \\
\hline CHEMBL3192491 & 688816 & 4.95 & 5.6591 & TRN & \\
\hline CHEMBL1442169 & 688816 & 5.2 & 5.0026 & TRN & \\
\hline CHEMBL1335425 & 688816 & 4.45 & 5.0283 & TRN & \\
\hline CHEMBL1571716 & 688816 & 4.95 & 5.3125 & TRN & \\
\hline CHEMBL1417798 & 688816 & 4.75 & 5.0074 & TRN & \\
\hline CHEMBL1380978 & 688816 & 6.95 & 5.0384 & TRN & \\
\hline CHEMBL1416128 & 688816 & 4.55 & 5.3357 & TRN & \\
\hline CHEMBL1543482 & 688816 & 4.75 & 5.1561 & TST & \\
\hline CHEMBL1531897 & 688816 & 7.3497 & 5.1645 & TST & \\
\hline CHEMBL1556644 & 688816 & 4.65 & 4.6326 & TRN & \\
\hline CHEMBL1465779 & 688816 & 4.95 & 5.0185 & TST & \\
\hline CHEMBL1306522 & 688816 & 5.0 & 5.1397 & TRN & \\
\hline CHEMBL1447106 & 688816 & 5.55 & 5.32100 & 0000000001 & TRN \\
\hline CHEMBL1489723 & 688816 & 4.7 & 5.3208 & TRN & \\
\hline CHEMBL1546295 & 688816 & 5.15 & 5.322 & TST & \\
\hline CHEMBL1544716 & 688816 & 5.2 & 5.6857 & TST & \\
\hline CHEMBL1449118 & 688816 & 4.9 & 5.1312 & TRN & \\
\hline CHEMBL1424769 & 688816 & 5.4 & 5.1227 & TRN & \\
\hline CHEMBL1373238 & 688816 & 6.25 & 5.3647 & TST & \\
\hline CHEMBL 2007180 & 688816 & 6.2 & 4.968 & TRN & \\
\hline CHEMBL1564779 & 688816 & 5.4 & 5.3518 & TRN & \\
\hline CHEMBL1375434 & 688816 & 5.4 & 5.5247 & TRN & \\
\hline CHEMBL1419975 & 688816 & 4.6 & 4.9962 & TRN & \\
\hline CHEMBL1474509 & 688816 & 4.45 & 5.3128 & TRN & \\
\hline CHEMBL1306229 & 688816 & 5.65 & 5.0664 & TST & \\
\hline CHEMBL1579424 & 688816 & 4.45 & 5.4391 & TRN & \\
\hline CHEMBL1466545 & 688816 & 4.45 & 5.2432 & TST & \\
\hline CHEMBL1537867 & 688816 & 4.95 & 5.4319 & TST & \\
\hline CHEMBL1989179 & 688816 & 4.85 & 5.3999 & TRN & \\
\hline CHEMBL1375894 & 688816 & 4.85 & 4.7845 & TRN & \\
\hline CHEMBL1370196 & 688816 & 4.95 & 5.3701 & TRN & \\
\hline CHEMBL1470123 & 688816 & 4.5 & 4.8957 & TST & \\
\hline CHEMBL1328248 & 688816 & 5.55 & 5.3328 & TRN & \\
\hline CHEMBL1493424 & 688816 & 4.95 & 4.8256 & TRN & \\
\hline CHEMBL1417732 & 688816 & 5.3 & 5.5958 & TRN & \\
\hline CHEMBL1391755 & 688816 & 8.301 & 5.4012 & TRN & \\
\hline CHEMBL1413820 & 688816 & 4.8 & 5.2364 & TST & \\
\hline CHEMBL1322579 & 688816 & 5.2 & 5.732 & TST & \\
\hline CHEMBL1478132 & 688816 & 5.15 & 5.1798 & TRN & \\
\hline CHEMBL1323968 & 688816 & 5.9 & 5.2131 & TRN & \\
\hline CHEMBL1451191 & 688816 & 7.8996 & 5.6156 & TRN & \\
\hline CHEMBL1352472 & 688816 & 4.45 & 5.4069 & TST & \\
\hline CHEMBL1418082 & 688816 & 4.6 & 4.9997 & TRN & \\
\hline CHEMBL1570735 & 688816 & 4.95 & 4.9686 & TRN & \\
\hline CHEMBL1500258 & 688816 & 4.9 & 5.5942 & TRN & \\
\hline
\end{tabular}




\begin{tabular}{|c|c|c|c|c|c|}
\hline \multicolumn{6}{|c|}{ Supplemental Table S2.txt } \\
\hline CHEMBL1543260 & 688816 & 4.9 & 5.5744 & TRN & \\
\hline CHEMBL1504662 & 688816 & 5.4 & 5.3825 & TRN & \\
\hline CHEMBL1449786 & 688816 & 4.8 & 5.2529 & TRN & \\
\hline CHEMBL1586354 & 688816 & 4.95 & 5.0051 & TRN & \\
\hline CHEMBL1352434 & 688816 & 5.3 & 5.2442 & TST & \\
\hline CHEMBL1470046 & 688816 & 4.45 & 5.0936 & TST & \\
\hline CHEMBL1333969 & 688816 & 4.4 & 5.4366 & TRN & \\
\hline CHEMBL1482610 & 688816 & 5.25 & 5.3832 & TST & \\
\hline CHEMBL1314682 & 688816 & 5.35 & 4.9033 & TST & \\
\hline CHEMBL1543654 & 688816 & 5.1 & 4.9503 & TRN & \\
\hline CHEMBL1361809 & 688816 & 7.2 & 5.3813 & TRN & \\
\hline CHEMBL1491786 & 688816 & 5.25 & 4.9483 & TRN & \\
\hline CHEMBL1502453 & 688816 & 5.6 & 5.4015 & TST & \\
\hline CHEMBL1339696 & 688816 & 4.9 & 4.8475 & TST & \\
\hline CHEMBL312487 & 688816 & 6.05 & 5.4122 & TST & \\
\hline CHEMBL3199423 & 688816 & 4.65 & 5.2691 & TST & \\
\hline CHEMBL1492702 & 688816 & 4.9 & 5.6672 & TST & \\
\hline CHEMBL1461433 & 688816 & 4.9 & 5.145 & TST & \\
\hline CHEMBL1334340 & 688816 & 5.0 & 5.2218 & TRN & \\
\hline CHEMBL1483625 & 688816 & 4.45 & 5.1407 & TRN & \\
\hline CHEMBL1516388 & 688816 & 6.0 & 5.5991 & TST & \\
\hline CHEMBL 3211278 & 688816 & 5.7 & 5.4005 & TRN & \\
\hline CHEMBL1412989 & 688816 & 8.301 & 5.6849 & TST & \\
\hline CHEMBL1572491 & 688816 & 5.05 & 5.2326 & TRN & \\
\hline CHEMBL1391591 & 688816 & 6.25 & 5.5173 & TRN & \\
\hline CHEMBL1414561 & 688816 & 4.55 & 4.9998 & TRN & \\
\hline CHEMBL1349651 & 688816 & 5.0 & 5.1985 & TRN & \\
\hline CHEMBL1462276 & 688816 & 4.7 & 4.9892 & TRN & \\
\hline CHEMBL1565416 & 688816 & 4.8 & 5.2762 & TRN & \\
\hline CHEMBL1453574 & 688816 & 4.65 & 5.3004 & TST & \\
\hline CHEMBL1427277 & 688816 & 5.55 & 5.0295 & TRN & \\
\hline CHEMBL1389537 & 688816 & 8.0 & 5.2568 & TRN & \\
\hline CHEMBL1537889 & 688816 & 4.95 & 4.8996 & TST & \\
\hline CHEMBL1539796 & 688816 & 4.6 & 5.1945 & TRN & \\
\hline CHEMBL1381574 & 688816 & 4.45 & 5.4748 & TST & \\
\hline CHEMBL3209468 & 688816 & 4.85 & 5.1231 & TST & \\
\hline CHEMBL1470903 & 688816 & 5.45 & 4.8956 & TRN & \\
\hline CHEMBL1477608 & 688816 & 4.6 & 5.314 & TST & \\
\hline CHEMBL1382145 & 688816 & 4.65 & 5.4937 & TST & \\
\hline CHEMBL1370548 & 688816 & 4.7 & 4.9304 & TST & \\
\hline CHEMBL1356779 & 688816 & 6.25 & 5.539 & TRN & \\
\hline CHEMBL1347699 & 688816 & 4.9 & 4.8554 & TRN & \\
\hline CHEMBL1441479 & 688816 & 5.4 & 5.0175 & TRN & \\
\hline CHEMBL1567655 & 688816 & 5.05 & 5.2322 & TRN & \\
\hline CHEMBL1424035 & 688816 & 5.3 & 5.5711 & TRN & \\
\hline CHEMBL1457494 & 688816 & 4.65 & 5.1270 & 0000000001 & TRN \\
\hline CHEMBL1508384 & 688816 & 4.7 & 4.7901 & TRN & \\
\hline CHEMBL1534156 & 688816 & 8.3468 & 5.3315 & TRN & \\
\hline
\end{tabular}

Supplemental Table S2.txt

Page 24599 


\begin{tabular}{|c|c|c|c|c|c|}
\hline \multicolumn{6}{|c|}{ Supplemental Table S2.txt } \\
\hline CHEMBL1520830 & 688816 & 6.5501 & 5.0105 & TRN & \\
\hline CHEMBL1415882 & 688816 & 6.15 & 5.4265 & TRN & \\
\hline CHEMBL1545270 & 688816 & 6.8499 & 5.4791 & TST & \\
\hline CHEMBL1975487 & 688816 & 4.45 & 5.2426 & TST & \\
\hline CHEMBL1561640 & 688816 & 7.699 & 5.5234 & TST & \\
\hline CHEMBL1374129 & 688816 & 4.5 & 5.0011 & TRN & \\
\hline CHEMBL 274847 & 688816 & 4.55 & 5.0663 & TST & \\
\hline CHEMBL1364683 & 688816 & 4.45 & 5.2925 & TRN & \\
\hline CHEMBL1389389 & 688816 & 4.95 & 4.8981 & TRN & \\
\hline CHEMBL1448284 & 688816 & 4.65 & 5.3923 & TRN & \\
\hline CHEMBL1373679 & 688816 & 5.4 & 5.5099 & TST & \\
\hline CHEMBL1421187 & 688816 & 5.0 & 5.1265 & TST & \\
\hline CHEMBL1312565 & 688816 & 4.6 & 5.1386 & TRN & \\
\hline CHEMBL1969692 & 688816 & 4.85 & 5.8026 & TRN & \\
\hline CHEMBL1573859 & 688816 & 4.45 & 5.2538 & TST & \\
\hline CHEMBL1494934 & 688816 & 4.8 & 4.9937 & TRN & \\
\hline CHEMBL1533387 & 688816 & 5.05 & 5.0023 & TRN & \\
\hline CHEMBL1344148 & 688816 & 5.45 & 5.4793 & TST & \\
\hline CHEMBL1329343 & 688816 & 5.1 & 5.3079 & TST & \\
\hline CHEMBL1390539 & 688816 & 4.9 & 5.1761 & TRN & \\
\hline CHEMBL1463300 & 688816 & 5.4 & 5.3423 & TST & \\
\hline CHEMBL1458909 & 688816 & 4.85 & 5.4806 & TRN & \\
\hline CHEMBL 3212094 & 688816 & 5.85 & 5.6133 & TRN & \\
\hline CHEMBL1595361 & 688816 & 4.45 & 5.3977 & TRN & \\
\hline CHEMBL1502876 & 688816 & 4.95 & 5.3534 & TRN & \\
\hline CHEMBL3197533 & 688816 & 6.4 & 5.4688 & TRN & \\
\hline CHEMBL1541756 & 688816 & 7.5498 & 5.7398 & TST & \\
\hline CHEMBL1458962 & 688816 & 5.25 & 5.61799 & 9999999999 & TST \\
\hline CHEMBL1391481 & 688816 & 4.65 & 5.0221 & TRN & \\
\hline CHEMBL1302520 & 688816 & 5.2 & 5.4163 & TST & \\
\hline CHEMBL1299535 & 688816 & 7.8013 & 5.4358 & TRN & \\
\hline CHEMBL 3192374 & 688816 & 4.75 & 5.1619 & TRN & \\
\hline CHEMBL406557 & 688816 & 4.9 & 5.0475 & TRN & \\
\hline CHEMBL1546987 & 688816 & 4.95 & 5.0779 & TRN & \\
\hline CHEMBL1331702 & 688816 & 5.0 & 5.2569 & TRN & \\
\hline CHEMBL1508330 & 688816 & 4.7 & 5.4169 & TRN & \\
\hline CHEMBL1337896 & 688816 & 4.9 & 5.2859 & TRN & \\
\hline CHEMBL1353690 & 688816 & 4.8 & 5.1807 & TST & \\
\hline CHEMBL1525636 & 688816 & 6.25 & 5.4837 & TRN & \\
\hline CHEMBL1347533 & 688816 & 6.1 & 5.3339 & TRN & \\
\hline CHEMBL1342416 & 688816 & 4.55 & 4.8523 & TRN & \\
\hline CHEMBL1435792 & 688816 & 4.7 & 4.9674 & TRN & \\
\hline CHEMBL1301824 & 688816 & 4.9 & 5.8458 & TRN & \\
\hline CHEMBL1547603 & 688816 & 5.1 & 5.3483 & TST & \\
\hline CHEMBL1477459 & 688816 & 4.9 & 5.0822 & TRN & \\
\hline CHEMBL1608474 & 688816 & 5.2 & 5.0459 & TRN & \\
\hline CHEMBL1492207 & 688816 & 4.9 & 5.4834 & TRN & \\
\hline CHEMBL1550557 & 688816 & 4.45 & 5.1676 & TRN & \\
\hline
\end{tabular}




\begin{tabular}{|c|c|c|c|c|c|}
\hline \multicolumn{6}{|c|}{ Supplemental Table S2.txt } \\
\hline CHEMBL1597123 & 688816 & 5.2 & 5.3075 & TRN & \\
\hline CHEMBL1381136 & 688816 & 6.05 & 5.2358 & TST & \\
\hline CHEMBL3199407 & 688816 & 4.85 & 5.0015 & TRN & \\
\hline CHEMBL1540311 & 688816 & 6.8499 & 5.3515 & TRN & \\
\hline CHEMBL1435614 & 688816 & 4.85 & 5.3128 & TRN & \\
\hline CHEMBL1389896 & 688816 & 4.65 & 5.5945 & TST & \\
\hline CHEMBL1588005 & 688816 & 4.5 & 5.0933 & TRN & \\
\hline CHEMBL1445128 & 688816 & 5.4 & 5.4866 & TRN & \\
\hline CHEMBL1407095 & 688816 & 4.85 & 5.2435 & TRN & \\
\hline CHEMBL1445386 & 688816 & 6.1 & 5.9906 & TRN & \\
\hline CHEMBL1503909 & 688816 & 5.55 & 5.3719 & TST & \\
\hline CHEMBL1302225 & 688816 & 4.9 & 5.0985 & TRN & \\
\hline CHEMBL3212380 & 688816 & 4.65 & 5.8689 & TRN & \\
\hline CHEMBL1465567 & 688816 & 5.7 & $5.7520 e$ & 0000000001 & TST \\
\hline CHEMBL1609800 & 688816 & 5.25 & 4.823 & TRN & \\
\hline CHEMBL1351349 & 688816 & 4.95 & 5.0609 & TRN & \\
\hline CHEMBL1534480 & 688816 & 7.0 & 5.6471 & TST & \\
\hline CHEMBL1972298 & 688816 & 7.4498 & 5.7591 & TST & \\
\hline CHEMBL1504316 & 688816 & 4.7 & 5.5892 & TRN & \\
\hline CHEMBL1442987 & 688816 & 4.45 & 5.6181 & TRN & \\
\hline CHEMBL1416853 & 688816 & 6.15 & 5.141 & TRN & \\
\hline CHEMBL1508882 & 688816 & 4.95 & 5.4688 & TRN & \\
\hline CHEMBL3208916 & 688816 & 4.9 & 5.1847 & TRN & \\
\hline CHEMBL1364740 & 688816 & 4.65 & 5.3317 & TRN & \\
\hline CHEMBL1491019 & 688816 & 5.5 & 5.1866 & TST & \\
\hline CHEMBL1531627 & 688816 & 5.05 & 5.2986 & TRN & \\
\hline CHEMBL1368008 & 688816 & 6.7501 & 5.08 & TST & \\
\hline CHEMBL1458766 & 688816 & 5.4 & 5.5376 & TRN & \\
\hline CHEMBL1418611 & 688816 & 4.5 & 5.4554 & TRN & \\
\hline CHEMBL1566136 & 688816 & 4.65 & 4.8442 & TST & \\
\hline CHEMBL1386186 & 688816 & 5.25 & 5.2765 & TRN & \\
\hline CHEMBL1428170 & 688816 & 4.45 & 4.9949 & TRN & \\
\hline CHEMBL1447009 & 688816 & 4.8 & 5.6353 & TRN & \\
\hline CHEMBL1454113 & 688816 & 4.5 & 5.1095 & TST & \\
\hline CHEMBL1466880 & 688816 & 5.0 & 5.2938 & TRN & \\
\hline CHEMBL1578939 & 688816 & 7.0 & 5.2451 & TRN & \\
\hline CHEMBL1304486 & 688816 & 4.75 & 5.7446 & TRN & \\
\hline CHEMBL1382036 & 688816 & 6.5501 & 5.3471 & TRN & \\
\hline CHEMBL1453088 & 688816 & 4.95 & 5.5962 & TRN & \\
\hline CHEMBL601616 & 688816 & 5.75 & 4.9955 & TRN & \\
\hline CHEMBL1535036 & 688816 & 6.45 & 5.5546 & TRN & \\
\hline CHEMBL1530653 & 688816 & 4.45 & 4.8621 & TRN & \\
\hline CHEMBL1388110 & 688816 & 4.9 & 5.1643 & TST & \\
\hline CHEMBL1382731 & 688816 & 4.9 & 4.97 & TST & \\
\hline CHEMBL3210882 & 688816 & 5.1 & 5.3059 & TRN & \\
\hline CHEMBL1411241 & 688816 & 4.45 & 5.2866 & TRN & \\
\hline CHEMBL1545642 & 688816 & 4.85 & 5.4778 & TRN & \\
\hline CHEMBL1561527 & 688816 & 5.0 & 5.1039 & TRN & \\
\hline
\end{tabular}




\begin{tabular}{|c|c|c|c|c|c|}
\hline \multicolumn{6}{|c|}{ Supplemental Table S2.txt } \\
\hline CHEMBL1338183 & 688816 & 6.1 & 5.4076 & TRN & \\
\hline CHEMBL1575854 & 688816 & 4.45 & 5.1472 & TRN & \\
\hline CHEMBL1481621 & 688816 & 8.0506 & 5.6299 & TRN & \\
\hline CHEMBL1589538 & 688816 & 5.0 & 5.2285 & TRN & \\
\hline CHEMBL1358888 & 688816 & 4.45 & 5.5504 & TRN & \\
\hline CHEMBL1388759 & 688816 & 4.9 & 5.2274 & TRN & \\
\hline CHEMBL1460750 & 688816 & 5.5 & 5.3426 & TRN & \\
\hline CHEMBL1403243 & 688816 & 8.0 & 4.7678 & TRN & \\
\hline CHEMBL1397045 & 688816 & 5.7 & 5.1542 & TST & \\
\hline CHEMBL1458755 & 688816 & 5.0 & 5.285 & TRN & \\
\hline CHEMBL1561860 & 688816 & 5.0 & 5.1909 & TRN & \\
\hline CHEMBL1505510 & 688816 & 4.6 & 5.1517 & TRN & \\
\hline CHEMBL3197289 & 688816 & 4.85 & 5.0547 & TRN & \\
\hline CHEMBL1584630 & 688816 & 4.6 & 5.4531 & TRN & \\
\hline CHEMBL1607858 & 688816 & 4.75 & 4.9495 & TRN & \\
\hline CHEMBL1301797 & 688816 & 8.301 & 5.4565 & TRN & \\
\hline CHEMBL1390677 & 688816 & 4.95 & 5.0559 & TRN & \\
\hline CHEMBL1542860 & 688816 & 5.0 & 5.2925 & TRN & \\
\hline CHEMBL1301825 & 688816 & 4.7 & 5.3041 & TST & \\
\hline CHEMBL1321276 & 688816 & 5.0 & 5.1761 & TRN & \\
\hline CHEMBL1469557 & 688816 & 4.85 & 5.1226 & TRN & \\
\hline CHEMBL1555662 & 688816 & 4.6 & 5.6474 & TST & \\
\hline CHEMBL1986898 & 688816 & 5.45 & 5.1364 & TRN & \\
\hline CHEMBL1523403 & 688816 & 8.0506 & 5.5786 & TST & \\
\hline CHEMBL1409472 & 688816 & 4.85 & 5.3279 & TRN & \\
\hline CHEMBL1498695 & 688816 & 4.85 & 4.8337 & TRN & \\
\hline CHEMBL1398665 & 688816 & 4.9 & 5.2196 & TST & \\
\hline CHEMBL1309225 & 688816 & 4.45 & 5.221 & TRN & \\
\hline CHEMBL1444523 & 688816 & 6.0 & 5.0293 & TST & \\
\hline CHEMBL1499536 & 688816 & 6.0 & 5.3924 & TRN & \\
\hline CHEMBL1454472 & 688816 & 4.9 & 5.2892 & TST & \\
\hline CHEMBL1598631 & 688816 & 4.95 & 5.5392 & TRN & \\
\hline CHEMBL1406945 & 688816 & 4.65 & 5.051 & TRN & \\
\hline CHEMBL1597238 & 688816 & 4.8 & 5.1436 & TST & \\
\hline CHEMBL1313512 & 688816 & 5.25 & 5.1279 & TRN & \\
\hline CHEMBL1371168 & 688816 & 5.0 & 5.1813 & TRN & \\
\hline CHEMBL1453002 & 688816 & 4.75 & 5.2248 & TRN & \\
\hline CHEMBL1496341 & 688816 & 5.35 & 5.0926 & TRN & \\
\hline CHEMBL1334162 & 688816 & 4.45 & 5.0824 & TRN & \\
\hline CHEMBL1382105 & 688816 & 6.3 & $5.3320 e$ & 0000000001 & TRN \\
\hline CHEMBL1347123 & 688816 & 6.95 & 5.3886 & TST & \\
\hline CHEMBL1505571 & 688816 & 4.9 & 5.1043 & TRN & \\
\hline CHEMBL1595611 & 688816 & 4.9 & 5.2044 & TRN & \\
\hline CHEMBL1567548 & 688816 & 5.7 & 5.1931 & TRN & \\
\hline CHEMBL1330039 & 688816 & 4.75 & 5.5806 & TST & \\
\hline CHEMBL1576548 & 688816 & 4.95 & 4.7725 & TRN & \\
\hline CHEMBL1318369 & 688816 & 5.2 & 5.5195 & TRN & \\
\hline CHEMBL1328724 & 688816 & 4.85 & 5.7749 & TRN & \\
\hline
\end{tabular}




\begin{tabular}{|c|c|c|c|c|c|}
\hline \multicolumn{6}{|c|}{ Supplemental Table S2.txt } \\
\hline CHEMBL1607699 & 688816 & 4.45 & 5.5359 & TRN & \\
\hline CHEMBL3209249 & 688816 & 4.85 & 5.6047 & TST & \\
\hline CHEMBL1381243 & 688816 & 5.8 & 5.0663 & TRN & \\
\hline CHEMBL1522641 & 688816 & 4.45 & 4.9419 & TRN & \\
\hline CHEMBL1600579 & 688816 & 4.65 & 5.3352 & TRN & \\
\hline CHEMBL1506460 & 688816 & 4.45 & 5.0622 & TRN & \\
\hline CHEMBL1598425 & 688816 & 6.6 & 5.4592 & TST & \\
\hline CHEMBL3193949 & 688816 & 4.7 & 5.5905 & TST & \\
\hline CHEMBL3198648 & 688816 & 5.65 & 5.51200 & 00000000005 & TST \\
\hline CHEMBL1539477 & 688816 & 5.0 & 5.1478 & TRN & \\
\hline CHEMBL1463369 & 688816 & 5.0 & 5.3709 & TRN & \\
\hline CHEMBL1505228 & 688816 & 5.5 & 5.1014 & TRN & \\
\hline CHEMBL1615433 & 688816 & 5.85 & 5.7954 & TRN & \\
\hline CHEMBL1539488 & 688816 & 4.6 & 4.9804 & TST & \\
\hline CHEMBL1606022 & 688816 & 5.0 & 5.4707 & TST & \\
\hline CHEMBL3211803 & 688816 & 4.55 & 5.3587 & TRN & \\
\hline CHEMBL1400837 & 688816 & 4.9 & 5.2934 & TRN & \\
\hline CHEMBL1307991 & 688816 & 5.75 & 5.19600 & 0000000001 & TRN \\
\hline CHEMBL1518421 & 688816 & 5.8 & 5.1545 & TRN & \\
\hline CHEMBL1383255 & 688816 & 4.85 & 5.0776 & TST & \\
\hline CHEMBL1546866 & 688816 & 4.9 & 5.2304 & TRN & \\
\hline CHEMBL 8918 & 688816 & 5.75 & 5.5331 & TRN & \\
\hline CHEMBL1370253 & 688816 & 7.6003 & 5.131 & TRN & \\
\hline CHEMBL1509027 & 688816 & 6.7001 & 5.7415 & TRN & \\
\hline CHEMBL1431324 & 688816 & 4.95 & 5.4279 & TRN & \\
\hline CHEMBL1399339 & 688816 & 4.95 & 5.404 & TRN & \\
\hline CHEMBL1606975 & 688816 & 4.95 & 5.20799 & 9999999999 & TRN \\
\hline CHEMBL1414879 & 688816 & 5.5 & 5.5977 & TRN & \\
\hline CHEMBL1440311 & 688816 & 4.9 & 4.8911 & TRN & \\
\hline CHEMBL1365550 & 688816 & 4.85 & 5.48799 & 99999999995 & TRN \\
\hline CHEMBL1508928 & 688816 & 5.3 & 5.5079 & TRN & \\
\hline CHEMBL1502871 & 688816 & 4.45 & 4.8325 & TRN & \\
\hline CHEMBL1533305 & 688816 & 4.75 & 5.2266 & TRN & \\
\hline CHEMBL1352783 & 688816 & 5.0 & 5.2392 & TRN & \\
\hline CHEMBL1542783 & 688816 & 5.5 & 5.294 & TST & \\
\hline CHEMBL1485914 & 688816 & 4.45 & 5.3725 & TRN & \\
\hline CHEMBL1609025 & 688816 & 4.6 & 5.3954 & TRN & \\
\hline CHEMBL1590185 & 688816 & 4.9 & 5.3309 & TST & \\
\hline CHEMBL1449172 & 688816 & 4.85 & 5.0816 & TRN & \\
\hline CHEMBL1538688 & 688816 & 8.2518 & 5.3325 & TST & \\
\hline CHEMBL1577086 & 688816 & 5.2 & 5.0935 & TST & \\
\hline CHEMBL1521690 & 688816 & 4.95 & 5.1748 & TRN & \\
\hline CHEMBL1539864 & 688816 & 6.5 & 5.1452 & TRN & \\
\hline CHEMBL1433384 & 688816 & 4.95 & 5.4419 & TRN & \\
\hline CHEMBL1342634 & 688816 & 4.7 & 5.33 & TST & \\
\hline CHEMBL1445882 & 688816 & 4.75 & 5.2116 & TRN & \\
\hline CHEMBL1440131 & 688816 & 5.55 & 5.776 & TRN & \\
\hline CHEMBL1527501 & 688816 & 4.85 & 4.716 & TRN & \\
\hline
\end{tabular}




\begin{tabular}{|c|c|c|c|c|c|}
\hline \multicolumn{6}{|c|}{ Supplemental Table S2.txt } \\
\hline CHEMBL1553484 & 688816 & 5.55 & 5.2811 & TRN & \\
\hline CHEMBL1462244 & 688816 & 4.8 & 5.3207 & TRN & \\
\hline CHEMBL1546927 & 688816 & 4.7 & 5.3521 & TST & \\
\hline CHEMBL1540761 & 688816 & 4.95 & 4.947 & TRN & \\
\hline CHEMBL1561083 & 688816 & 4.45 & 5.5369 & TRN & \\
\hline CHEMBL1369408 & 688816 & 5.9 & 5.46299 & 9999999999 & TRN \\
\hline CHEMBL54839 & 688816 & 4.95 & 5.1582 & TST & \\
\hline CHEMBL1598774 & 688816 & 4.6 & 4.905 & TRN & \\
\hline CHEMBL1377414 & 688816 & 4.95 & 4.6578 & TRN & \\
\hline CHEMBL3193269 & 688816 & 7.5498 & 5.3527 & TRN & \\
\hline CHEMBL98350 & 688816 & 6.0 & 5.0369 & TST & \\
\hline CHEMBL1325968 & 688816 & 5.7 & 5.2668 & TRN & \\
\hline CHEMBL1457060 & 688816 & 5.85 & 5.294 & TRN & \\
\hline CHEMBL1438522 & 688816 & 4.85 & 5.5107 & TRN & \\
\hline CHEMBL1415771 & 688816 & 4.9 & 5.3202 & TRN & \\
\hline CHEMBL1589640 & 688816 & 4.45 & 4.7713 & TRN & \\
\hline CHEMBL3192572 & 688816 & 4.45 & 5.2359 & TRN & \\
\hline CHEMBL1352341 & 688816 & 4.45 & 5.0863 & TRN & \\
\hline CHEMBL1338095 & 688816 & 4.95 & 5.0138 & TRN & \\
\hline CHEMBL1309502 & 688816 & 6.2 & 5.0122 & TRN & \\
\hline CHEMBL1345167 & 688816 & 5.35 & 5.2224 & TST & \\
\hline CHEMBL1374746 & 688816 & 5.55 & 5.2868 & TST & \\
\hline CHEMBL1508821 & 688816 & 7.6003 & 5.3474 & TST & \\
\hline CHEMBL1477460 & 688816 & 5.15 & 5.1377 & TRN & \\
\hline CHEMBL1424392 & 688816 & 4.85 & 5.0457 & TRN & \\
\hline CHEMBL1993788 & 688816 & 4.9 & 4.9138 & TRN & \\
\hline CHEMBL1387410 & 688816 & 5.45 & 5.1067 & TRN & \\
\hline CHEMBL1397558 & 688816 & 5.2 & 5.3924 & TRN & \\
\hline CHEMBL1477383 & 688816 & 5.45 & 5.0478 & TST & \\
\hline CHEMBL252901 & 688816 & 4.65 & 4.9779 & TRN & \\
\hline CHEMBL1381308 & 688816 & 4.45 & 5.6414 & TST & \\
\hline CHEMBL1375027 & 688816 & 5.05 & 4.8866 & TRN & \\
\hline CHEMBL1517829 & 688816 & 5.5 & 5.1281 & TRN & \\
\hline CHEMBL1404461 & 688816 & 4.95 & 5.0716 & TRN & \\
\hline CHEMBL1499582 & 688816 & 5.05 & 5.0726 & TRN & \\
\hline CHEMBL1481644 & 688816 & 5.65 & 5.9181 & TRN & \\
\hline CHEMBL1257039 & 688816 & 5.15 & 5.5215 & TST & \\
\hline CHEMBL1412667 & 688816 & 4.9 & 5.3285 & TST & \\
\hline CHEMBL1438256 & 688816 & 4.8 & 5.0442 & TRN & \\
\hline CHEMBL1451916 & 688816 & 4.9 & 4.9142 & TST & \\
\hline CHEMBL1498337 & 688816 & 6.5501 & 5.3156 & TRN & \\
\hline CHEMBL1537425 & 688816 & 4.45 & 4.9726 & TRN & \\
\hline CHEMBL3195663 & 688816 & 7.8996 & 5.2555 & TST & \\
\hline CHEMBL1325782 & 688816 & 5.35 & 5.1128 & TST & \\
\hline CHEMBL1596496 & 688816 & 4.9 & 5.0408 & TRN & \\
\hline CHEMBL1601485 & 688816 & 4.5 & 5.3137 & TRN & \\
\hline CHEMBL1506459 & 688816 & 4.8 & 4.7408 & TRN & \\
\hline CHEMBL1996830 & 688816 & 4.6 & 4.8693 & TRN & \\
\hline
\end{tabular}




\begin{tabular}{|c|c|c|c|c|c|}
\hline \multirow[b]{2}{*}{ CHEMBL3199416 } & \multicolumn{5}{|c|}{ Supplemental Table S2.txt } \\
\hline & 688816 & 7.6498 & 5.2088 & TST & \\
\hline CHEMBL1366367 & 688816 & 4.45 & 5.4542 & TST & \\
\hline CHEMBL1598905 & 688816 & 4.45 & 5.4211 & TRN & \\
\hline CHEMBL1562102 & 688816 & 5.2 & 5.3592 & TRN & \\
\hline CHEMBL1531415 & 688816 & 4.9 & 5.0493 & TRN & \\
\hline CHEMBL1341913 & 688816 & 6.0 & 5.3453 & TST & \\
\hline CHEMBL1565704 & 688816 & 6.2 & 5.3014 & TRN & \\
\hline CHEMBL2004183 & 688816 & 5.0 & 5.6896 & TRN & \\
\hline CHEMBL1345599 & 688816 & 8.301 & 5.609 & TRN & \\
\hline CHEMBL1518326 & 688816 & 4.45 & 5.3022 & TST & \\
\hline CHEMBL1600720 & 688816 & 4.85 & 5.443 & TRN & \\
\hline CHEMBL1347879 & 688816 & 4.8 & 5.1917 & TRN & \\
\hline CHEMBL3191644 & 688816 & 4.95 & 4.8981 & TRN & \\
\hline CHEMBL3195374 & 688816 & 5.2 & 5.11600 & 00000000005 & TRN \\
\hline CHEMBL1329295 & 688816 & 5.25 & 5.3713 & TRN & \\
\hline CHEMBL1334388 & 688816 & 7.8996 & 5.6313 & TST & \\
\hline CHEMBL1573147 & 688816 & 5.05 & 5.2628 & TRN & \\
\hline CHEMBL1418157 & 688816 & 5.0 & 5.1667 & TRN & \\
\hline CHEMBL1601865 & 688816 & 4.95 & 4.8902 & TRN & \\
\hline CHEMBL1537830 & 688816 & 4.55 & 5.0749 & TRN & \\
\hline CHEMBL1563943 & 688816 & 6.05 & 5.1235 & TRN & \\
\hline CHEMBL1319584 & 688816 & 4.95 & 5.1422 & TRN & \\
\hline CHEMBL1307455 & 688816 & 5.25 & 5.2476 & TRN & \\
\hline CHEMBL1367434 & 688816 & 4.45 & 5.5523 & TRN & \\
\hline CHEMBL1424477 & 688816 & 5.0 & 4.7706 & TRN & \\
\hline CHEMBL1468202 & 688816 & 4.95 & 5.4605 & TRN & \\
\hline CHEMBL1495741 & 688816 & 7.5003 & 5.364 & TST & \\
\hline CHEMBL1439730 & 688816 & 4.95 & 5.1584 & TRN & \\
\hline CHEMBL1353630 & 688816 & 5.55 & 5.3985 & TRN & \\
\hline CHEMBL1487728 & 688816 & 4.5 & 5.05699 & 99999999995 & TST \\
\hline CHEMBL1569373 & 688816 & 6.95 & 5.0417 & TST & \\
\hline CHEMBL1556143 & 688816 & 4.7 & 5.088 & TRN & \\
\hline CHEMBL3194824 & 688816 & 4.9 & 5.2963 & TRN & \\
\hline CHEMBL1460296 & 688816 & 5.1 & 5.3888 & TRN & \\
\hline CHEMBL1604004 & 688816 & 4.75 & 4.8271 & TRN & \\
\hline CHEMBL1594762 & 688816 & 6.6 & 5.2177 & TRN & \\
\hline CHEMBL1305344 & 688816 & 4.9 & 5.2067 & TST & \\
\hline CHEMBL1556289 & 688816 & 4.95 & 5.0598 & TRN & \\
\hline CHEMBL1601969 & 688816 & 8.0 & 5.0834 & TRN & \\
\hline CHEMBL 278295 & 688816 & 4.7 & 4.8872 & TST & \\
\hline CHEMBL1391563 & 688816 & 4.8 & 5.1792 & TRN & \\
\hline CHEMBL1308202 & 688816 & 4.95 & 5.4824 & TRN & \\
\hline CHEMBL1588735 & 688816 & 7.4001 & 5.5311 & TST & \\
\hline CHEMBL1427034 & 688816 & 6.25 & 5.2305 & TST & \\
\hline CHEMBL1608784 & 688816 & 4.9 & 5.4759 & TST & \\
\hline CHEMBL1588096 & 688816 & 4.9 & 4.981 & TST & \\
\hline CHEMBL1377892 & 688816 & 4.8 & 5.1221 & TRN & \\
\hline CHEMBL1386169 & 688816 & 5.3 & 5.6629 & TRN & \\
\hline
\end{tabular}




\begin{tabular}{|c|c|c|c|c|c|}
\hline & & \multicolumn{4}{|c|}{ Supplemental Table s2.txt } \\
\hline CHEMBL3207351 & 688816 & 4.45 & 5.1379 & TRN & \\
\hline CHEMBL1341202 & 688816 & 4.65 & 5.3233 & TRN & \\
\hline CHEMBL 3190004 & 688816 & 5.25 & 5.3734 & TRN & \\
\hline CHEMBL1410435 & 688816 & 4.85 & 5.6844 & TST & \\
\hline CHEMBL1431569 & 688816 & 5.45 & 4.9247 & TST & \\
\hline CHEMBL1311214 & 688816 & 5.25 & 5.205 & TST & \\
\hline CHEMBL1502964 & 688816 & 4.85 & 4.9197 & TRN & \\
\hline CHEMBL1533459 & 688816 & 4.6 & 4.9539 & TRN & \\
\hline CHEMBL1519188 & 688816 & 4.45 & 5.4952 & TRN & \\
\hline CHEMBL1415670 & 688816 & 5.8 & 5.3698 & TRN & \\
\hline CHEMBL1426836 & 688816 & 4.95 & 4.86 & TRN & \\
\hline CHEMBL1418716 & 688816 & 4.45 & 4.9204 & TRN & \\
\hline CHEMBL1385193 & 688816 & 4.75 & 4.9577 & TRN & \\
\hline CHEMBL1523129 & 688816 & 5.5 & 5.3055 & TRN & \\
\hline CHEMBL1487869 & 688816 & 4.95 & 4.8525 & TRN & \\
\hline CHEMBL1430101 & 688816 & 4.6 & 5.7068 & TRN & \\
\hline CHEMBL1608986 & 688816 & 5.55 & 5.0268 & TRN & \\
\hline CHEMBL1566332 & 688816 & 4.8 & 4.9821 & TRN & \\
\hline CHEMBL1519521 & 688816 & 4.45 & 5.0094 & TRN & \\
\hline CHEMBL1574349 & 688816 & 5.65 & 5.1968 & TRN & \\
\hline CHEMBL1301940 & 688816 & 4.45 & 5.1917 & TST & \\
\hline CHEMBL1361231 & 688816 & 4.45 & 5.3491 & TRN & \\
\hline CHEMBL1561861 & 688816 & 4.45 & 5.2038 & TST & \\
\hline CHEMBL1509396 & 688816 & 4.45 & 5.2034 & TRN & \\
\hline CHEMBL1345947 & 688816 & 5.0 & 5.2287 & TST & \\
\hline CHEMBL1453508 & 688816 & 4.9 & 5.37 & TRN & \\
\hline CHEMBL1988536 & 688816 & 4.75 & 5.2573 & TST & \\
\hline CHEMBL1599236 & 688816 & 4.9 & 5.2856 & TRN & \\
\hline CHEMBL1527977 & 688816 & 5.25 & 5.5524 & TRN & \\
\hline CHEMBL1338746 & 688816 & 4.95 & 5.3296 & TRN & \\
\hline CHEMBL515248 & 688816 & 4.45 & 5.185 & TRN & \\
\hline CHEMBL1530047 & 688816 & 4.95 & 5.0025 & TST & \\
\hline CHEMBL1491904 & 688816 & 4.9 & 4.9089 & TRN & \\
\hline CHEMBL1517034 & 688816 & 4.95 & 5.2375 & TRN & \\
\hline CHEMBL1546083 & 688816 & 4.95 & 5.0726 & TST & \\
\hline CHEMBL3199168 & 688816 & 4.7 & 5.1313 & TRN & \\
\hline CHEMBL1359525 & 688816 & 4.75 & 5.2105 & TRN & \\
\hline CHEMBL1530272 & 688816 & 4.45 & 5.1119 & TRN & \\
\hline CHEMBL1566808 & 688816 & 4.45 & 5.7272 & TRN & \\
\hline CHEMBL3194522 & 688816 & 4.75 & 5.2522 & TRN & \\
\hline CHEMBL1541339 & 688816 & 6.25 & 5.6474 & TRN & \\
\hline CHEMBL1375712 & 688816 & 5.0 & 5.3786 & TRN & \\
\hline CHEMBL1573079 & 688816 & 4.9 & 5.57600 & 00000000005 & TRN \\
\hline CHEMBL1329626 & 688816 & 4.9 & 5.0851 & TRN & \\
\hline CHEMBL1579902 & 688816 & 5.6 & 5.3675 & TST & \\
\hline CHEMBL1554582 & 688816 & 5.4 & 4.9511 & TRN & \\
\hline CHEMBL1414513 & 688816 & 5.15 & 5.0768 & TRN & \\
\hline CHEMBL1465980 & 688816 & 5.55 & 5.7966 & TRN & \\
\hline
\end{tabular}




\begin{tabular}{|c|c|c|c|c|}
\hline \multicolumn{5}{|c|}{ Supplemental Table S2.txt } \\
\hline CHEMBL1341557 & 688816 & 4.45 & 5.4161 & TRN \\
\hline CHEMBL1461681 & 688816 & 5.2 & 5.1279 & TST \\
\hline CHEMBL1330087 & 688816 & 6.0 & 5.4698 & TRN \\
\hline CHEMBL1516878 & 688816 & 6.4 & 5.7342 & TST \\
\hline CHEMBL1505591 & 688816 & 4.45 & 5.2535 & TRN \\
\hline CHEMBL1345614 & 688816 & 4.85 & 5.2528 & TRN \\
\hline CHEMBL1370438 & 688816 & 4.8 & 5.2713 & TST \\
\hline CHEMBL1412416 & 688816 & 4.9 & 5.2411 & TRN \\
\hline CHEMBL1342103 & 688816 & 4.55 & 5.1197 & TST \\
\hline CHEMBL1566120 & 688816 & 8.3468 & 5.3591 & TST \\
\hline CHEMBL1361800 & 688816 & 4.65 & 5.1142 & TRN \\
\hline CHEMBL1384895 & 688816 & 4.7 & 4.933 & TST \\
\hline CHEMBL1566415 & 688816 & 4.8 & 5.1427 & TST \\
\hline CHEMBL1419929 & 688816 & 6.8 & 5.3161 & TRN \\
\hline CHEMBL1399345 & 688816 & 5.55 & 4.8773 & TRN \\
\hline CHEMBL1585648 & 688816 & 4.8 & 5.4011 & TST \\
\hline CHEMBL1547049 & 688816 & 4.45 & 5.027 & TRN \\
\hline CHEMBL1363509 & 688816 & 5.45 & 5.1307 & TRN \\
\hline CHEMBL1463997 & 688816 & 5.0 & 5.2075 & TST \\
\hline CHEMBL1966944 & 688816 & 8.301 & 5.0001 & TRN \\
\hline CHEMBL1472575 & 688816 & 4.85 & 5.6741 & TST \\
\hline CHEMBL1608126 & 688816 & 7.15 & 5.1031 & TRN \\
\hline CHEMBL1388773 & 688816 & 4.75 & 5.1593 & TRN \\
\hline CHEMBL3196396 & 688816 & 4.8 & $5.1960 e$ & 0000000001 \\
\hline CHEMBL3208086 & 688816 & 5.0 & 5.29 & TRN \\
\hline CHEMBL1557382 & 688816 & 4.8 & 4.9702 & TST \\
\hline CHEMBL1548075 & 688816 & 5.6 & 5.3221 & TRN \\
\hline CHEMBL1361722 & 688816 & 4.75 & 5.0073 & TRN \\
\hline CHEMBL1525682 & 688816 & 7.0 & 5.4568 & TRN \\
\hline CHEMBL1352575 & 688816 & 4.9 & 5.1965 & TRN \\
\hline CHEMBL1327388 & 688816 & 4.65 & 4.9956 & TRN \\
\hline CHEMBL1573046 & 688816 & 4.95 & 4.8215 & TRN \\
\hline CHEMBL1411548 & 688816 & 6.5 & 5.2341 & TRN \\
\hline CHEMBL1491264 & 688816 & 5.5 & 5.6023 & TRN \\
\hline CHEMBL1470605 & 688816 & 4.9 & 5.0925 & TRN \\
\hline CHEMBL3208766 & 688816 & 4.45 & 5.5873 & TRN \\
\hline CHEMBL1446575 & 688816 & 4.95 & 5.4451 & TRN \\
\hline CHEMBL1388530 & 688816 & 4.65 & 5.1529 & TRN \\
\hline CHEMBL1525960 & 688816 & 5.2 & 5.4576 & TRN \\
\hline CHEMBL1353455 & 688816 & 7.7496 & 5.2895 & TST \\
\hline CHEMBL1383149 & 688816 & 5.85 & 5.1778 & TRN \\
\hline CHEMBL1537086 & 688816 & 4.45 & 5.0157 & TRN \\
\hline CHEMBL1339519 & 688816 & 4.9 & 5.2552 & TRN \\
\hline CHEMBL1517360 & 688816 & 5.6 & 5.2559 & TRN \\
\hline CHEMBL1307020 & 688816 & 8.2007 & 4.9931 & TST \\
\hline CHEMBL1343223 & 688816 & 4.9 & 5.4918 & TST \\
\hline CHEMBL1533840 & 688816 & 4.45 & 4.8241 & TRN \\
\hline CHEMBL1388940 & 688816 & 4.8 & 4.953 & TRN \\
\hline
\end{tabular}




\begin{tabular}{|c|c|c|c|c|c|}
\hline \multicolumn{6}{|c|}{ Supplemental Table S2.txt } \\
\hline CHEMBL223453 & 688816 & 4.45 & 4.6993 & TRN & \\
\hline CHEMBL1352679 & 688816 & 4.65 & 5.2265 & TRN & \\
\hline CHEMBL1588029 & 688816 & 5.15 & 5.0704 & TST & \\
\hline CHEMBL600734 & 688816 & 4.7 & 5.1285 & TRN & \\
\hline CHEMBL1518988 & 688816 & 7.0 & 5.8701 & TRN & \\
\hline CHEMBL1471326 & 688816 & 5.4 & 5.6028 & TRN & \\
\hline CHEMBL1314951 & 688816 & 4.6 & 5.2803 & TRN & \\
\hline CHEMBL1439172 & 688816 & 5.0 & 5.4674 & TST & \\
\hline CHEMBL 3208040 & 688816 & 4.45 & 4.9653 & TRN & \\
\hline CHEMBL1440424 & 688816 & 8.301 & 5.54299 & 9999999999 & TST \\
\hline CHEMBL606116 & 688816 & 5.15 & 5.3968 & TST & \\
\hline CHEMBL1994683 & 688816 & 4.8 & 4.8906 & TRN & \\
\hline CHEMBL1444101 & 688816 & 5.5 & 4.8742 & TRN & \\
\hline CHEMBL1462431 & 688816 & 4.65 & 5.3466 & TST & \\
\hline CHEMBL3208586 & 688816 & 4.45 & 5.2129 & TRN & \\
\hline CHEMBL1594953 & 688816 & 4.95 & 5.0731 & TRN & \\
\hline CHEMBL1382097 & 688816 & 5.1 & 5.4663 & TRN & \\
\hline CHEMBL1545999 & 688816 & 4.8 & 4.8178 & TRN & \\
\hline CHEMBL3196226 & 688816 & 4.5 & 5.3346 & TRN & \\
\hline CHEMBL1354339 & 688816 & 8.3468 & 5.4522 & TRN & \\
\hline CHEMBL1582864 & 688816 & 5.65 & 5.5497 & TRN & \\
\hline CHEMBL1488266 & 688816 & 8.3468 & 5.4892 & TRN & \\
\hline CHEMBL1547266 & 688816 & 4.45 & 5.0637 & TRN & \\
\hline CHEMBL1543468 & 688816 & 4.45 & 5.8493 & TRN & \\
\hline CHEMBL3212452 & 688816 & 4.9 & 5.3605 & TRN & \\
\hline CHEMBL1403438 & 688816 & 4.9 & 5.2281 & TRN & \\
\hline CHEMBL1409243 & 688816 & 4.95 & 5.5086 & TRN & \\
\hline CHEMBL1446271 & 688816 & 4.9 & 5.26 & TRN & \\
\hline CHEMBL1381054 & 688816 & 4.45 & 4.9451 & TRN & \\
\hline CHEMBL1588190 & 688816 & 5.35 & 5.6437 & TRN & \\
\hline CHEMBL1418610 & 688816 & 4.75 & 5.2792 & TRN & \\
\hline CHEMBL1450977 & 688816 & 5.25 & 4.9876 & TRN & \\
\hline CHEMBL1505474 & 688816 & 4.95 & 5.1695 & TRN & \\
\hline CHEMBL1303910 & 688816 & 4.95 & 5.2395 & TRN & \\
\hline CHEMBL1309860 & 688816 & 6.35 & 5.1755 & TRN & \\
\hline CHEMBL1501723 & 688816 & 4.95 & 5.2878 & TRN & \\
\hline CHEMBL1549290 & 688816 & 4.45 & 5.1402 & TRN & \\
\hline CHEMBL1519528 & 688816 & 4.45 & 5.1291 & TST & \\
\hline CHEMBL1370223 & 688816 & 4.5 & 5.1855 & TRN & \\
\hline CHEMBL1577227 & 688816 & 4.45 & 4.9926 & TRN & \\
\hline CHEMBL1330960 & 688816 & 5.0 & 5.2111 & TRN & \\
\hline CHEMBL1353571 & 688816 & 5.2 & 5.1433 & TRN & \\
\hline CHEMBL1523072 & 688816 & 6.95 & 5.55 & TRN & \\
\hline CHEMBL1518491 & 688816 & 4.8 & 5.0311 & TRN & \\
\hline CHEMBL236267 & 688816 & 4.7 & 5.5271 & TRN & \\
\hline CHEMBL1413914 & 688816 & 5.0 & 5.71399 & 99999999995 & TRN \\
\hline CHEMBL1413142 & 688816 & 6.6499 & 5.7314 & TRN & \\
\hline CHEMBL1346666 & 688816 & 7.3002 & 5.6273 & TST & \\
\hline
\end{tabular}




\begin{tabular}{|c|c|c|c|c|c|}
\hline \multicolumn{6}{|c|}{ Supplemental Table s2.txt } \\
\hline CHEMBL1533937 & 688816 & 4.6 & 5.3443 & TRN & \\
\hline CHEMBL1583494 & 688816 & 4.85 & 5.1843 & TRN & \\
\hline CHEMBL1508699 & 688816 & 4.95 & 5.206 & TRN & \\
\hline CHEMBL1323774 & 688816 & 5.2 & 5.3445 & TRN & \\
\hline CHEMBL1336346 & 688816 & 4.9 & 5.0617 & TRN & \\
\hline CHEMBL1543843 & 688816 & 4.95 & 5.1758 & TRN & \\
\hline CHEMBL1495014 & 688816 & 4.95 & 5.6618 & TRN & \\
\hline CHEMBL 3145314 & 688816 & 4.65 & 5.2512 & TST & \\
\hline CHEMBL1491976 & 688816 & 4.9 & 4.9104 & TRN & \\
\hline CHEMBL1528083 & 688816 & 4.9 & 5.2622 & TST & \\
\hline CHEMBL1594826 & 688816 & 4.5 & 5.2333 & TST & \\
\hline CHEMBL1301325 & 688816 & 5.45 & 5.3464 & TRN & \\
\hline CHEMBL1488226 & 688816 & 5.35 & 5.2783 & TST & \\
\hline CHEMBL1300945 & 688816 & 4.9 & 5.175 & TRN & \\
\hline CHEMBL1589854 & 688816 & 5.15 & 5.1165 & TRN & \\
\hline CHEMBL1467586 & 688816 & 4.95 & 4.9361 & TRN & \\
\hline CHEMBL193747 & 688816 & 4.75 & 5.1184 & TST & \\
\hline CHEMBL1504497 & 688816 & 4.7 & 5.5269 & TRN & \\
\hline CHEMBL1564593 & 688816 & 4.7 & 5.2187 & TRN & \\
\hline CHEMBL1440040 & 688816 & 5.3 & 5.2507 & TRN & \\
\hline CHEMBL1350293 & 688816 & 4.85 & 5.0683 & TRN & \\
\hline CHEMBL3210562 & 688816 & 4.65 & 5.3598 & TST & \\
\hline CHEMBL581869 & 688816 & 5.6 & 4.9532 & TRN & \\
\hline CHEMBL3211342 & 688816 & 6.7001 & 5.2183 & TST & \\
\hline CHEMBL1543936 & 688816 & 4.9 & 4.9586 & TRN & \\
\hline CHEMBL1558864 & 688816 & 4.65 & 5.8118 & TRN & \\
\hline CHEMBL1457159 & 688816 & 5.1 & 5.3131 & TST & \\
\hline CHEMBL1407064 & 688816 & 4.95 & 5.2808 & TRN & \\
\hline CHEMBL3212107 & 688816 & 6.7001 & 5.3817 & TRN & \\
\hline CHEMBL1568243 & 688816 & 5.3 & 4.9442 & TST & \\
\hline CHEMBL1543451 & 688816 & 5.6 & 5.3985 & TRN & \\
\hline CHEMBL1517012 & 688816 & 5.0 & 5.5271 & TRN & \\
\hline CHEMBL1425723 & 688816 & 8.301 & 5.4602 & TST & \\
\hline CHEMBL1432227 & 688816 & 5.1 & 5.4229 & TRN & \\
\hline CHEMBL1340572 & 688816 & 5.55 & 5.8003 & TRN & \\
\hline CHEMBL1557357 & 688816 & 5.25 & 5.2329 & TST & \\
\hline CHEMBL1563002 & 688816 & 6.9 & 5.28600 & 00000000005 & TRN \\
\hline CHEMBL1572348 & 688816 & 7.3497 & 4.7518 & TRN & \\
\hline CHEMBL1345510 & 688816 & 5.45 & 5.1977 & TRN & \\
\hline CHEMBL1307336 & 688816 & 7.699 & 5.631 & TRN & \\
\hline CHEMBL1402587 & 688816 & 5.65 & 5.6477 & TRN & \\
\hline CHEMBL1467432 & 688816 & 5.0 & 5.4978 & TRN & \\
\hline CHEMBL1307629 & 688816 & 4.9 & 4.88 & TRN & \\
\hline CHEMBL1497957 & 688816 & 8.301 & 5.4102 & TST & \\
\hline CHEMBL1432508 & 688816 & 8.3468 & 5.6724 & TST & \\
\hline CHEMBL1514289 & 688816 & 6.05 & 4.8062 & TRN & \\
\hline CHEMBL1339702 & 688816 & 4.9 & 4.902 & TRN & \\
\hline CHEMBL1416611 & 688816 & 4.45 & 5.1878 & TST & \\
\hline
\end{tabular}




\begin{tabular}{|c|c|c|c|c|}
\hline \multicolumn{5}{|c|}{ Supplemental Table S2.txt } \\
\hline CHEMBL3198851 & 688816 & 4.95 & 5.0092 & TST \\
\hline CHEMBL1585460 & 688816 & 4.95 & 5.3262 & TST \\
\hline CHEMBL1401890 & 688816 & 4.65 & 5.4208 & TST \\
\hline CHEMBL1433097 & 688816 & 4.45 & 4.938 & TRN \\
\hline CHEMBL 1457356 & 688816 & 5.35 & 5.3056 & TRN \\
\hline CHEMBL1344216 & 688816 & 4.9 & 5.0043 & TRN \\
\hline CHEMBL1534273 & 688816 & 5.35 & 5.4289 & TST \\
\hline CHEMBL1447505 & 688816 & 4.75 & 4.949 & TRN \\
\hline CHEMBL1350596 & 688816 & 4.45 & 4.8341 & TRN \\
\hline CHEMBL3192188 & 688816 & 4.8 & 5.4654 & TRN \\
\hline CHEMBL1343224 & 688816 & 5.5 & 4.954 & TRN \\
\hline CHEMBL1543956 & 688816 & 4.9 & 5.1837 & TST \\
\hline CHEMBL1490465 & 688816 & 4.85 & 5.2293 & TRN \\
\hline CHEMBL1349152 & 688816 & 5.15 & 5.3099 & TRN \\
\hline CHEMBL1378449 & 688816 & 4.8 & 5.2352 & TRN \\
\hline CHEMBL1468335 & 688816 & 5.3 & 4.8919 & TRN \\
\hline CHEMBL1328861 & 688816 & 4.5 & 5.5705 & TRN \\
\hline CHEMBL1603530 & 688816 & 4.9 & 5.0877 & TRN \\
\hline CHEMBL1518606 & 688816 & 5.05 & 5.3047 & TRN \\
\hline CHEMBL1440257 & 688816 & 4.45 & 5.4512 & TST \\
\hline CHEMBL1453801 & 688816 & 4.45 & 5.0436 & TRN \\
\hline CHEMBL1403905 & 688816 & 4.65 & 4.8088 & TRN \\
\hline CHEMBL1501236 & 688816 & 4.45 & 5.0487 & TRN \\
\hline CHEMBL1319483 & 688816 & 4.95 & 5.5397 & TST \\
\hline CHEMBL1390791 & 688816 & 6.7001 & 5.3688 & TRN \\
\hline CHEMBL1594924 & 688816 & 4.8 & 5.1684 & TST \\
\hline CHEMBL597035 & 688816 & 4.9 & 5.2993 & TRN \\
\hline CHEMBL1530195 & 688816 & 8.3468 & 5.2695 & TRN \\
\hline CHEMBL1464946 & 688816 & 5.6 & 4.9983 & TST \\
\hline CHEMBL1340530 & 688816 & 4.9 & 5.4104 & TRN \\
\hline CHEMBL1364618 & 688816 & 4.95 & 5.0275 & TRN \\
\hline CHEMBL 71191 & 688816 & 6.0 & 5.1735 & TRN \\
\hline CHEMBL1339873 & 688816 & 5.75 & 5.2786 & TRN \\
\hline CHEMBL1611725 & 688816 & 4.95 & 5.319 & TRN \\
\hline CHEMBL 2005446 & 688816 & 5.4 & 5.3166 & TRN \\
\hline CHEMBL1457094 & 688816 & 4.95 & 4.9325 & TST \\
\hline CHEMBL1503463 & 688816 & 6.05 & 5.0021 & TST \\
\hline CHEMBL1605886 & 688816 & 5.45 & 5.4023 & TST \\
\hline CHEMBL1544693 & 688816 & 4.9 & 5.1086 & TST \\
\hline CHEMBL1425741 & 688816 & 4.65 & 5.1633 & TST \\
\hline CHEMBL1466173 & 688816 & 5.55 & 5.5769 & TST \\
\hline CHEMBL1567990 & 688816 & 4.45 & 5.3959 & TRN \\
\hline CHEMBL1395319 & 688816 & 6.25 & 5.2726 & TRN \\
\hline CHEMBL1977709 & 688816 & 4.6 & 5.3145 & TST \\
\hline CHEMBL1514804 & 688816 & 4.95 & 5.136 & TRN \\
\hline CHEMBL1548527 & 688816 & 4.5 & 5.1557 & TRN \\
\hline CHEMBL 1576282 & 688816 & 5.0 & 4.975 & TRN \\
\hline CHEMBL1545103 & 688816 & 4.85 & 5.0862 & TRN \\
\hline
\end{tabular}




\begin{tabular}{|c|c|c|c|c|c|}
\hline \multicolumn{6}{|c|}{ Supplemental Table S2.txt } \\
\hline CHEMBL1556027 & 688816 & 4.45 & 5.2416 & TRN & \\
\hline CHEMBL1470823 & 688816 & 6.2 & 5.3422 & TST & \\
\hline CHEMBL1421079 & 688816 & 5.45 & 5.1116 & TRN & \\
\hline CHEMBL1572157 & 688816 & 4.8 & 5.2099 & TRN & \\
\hline CHEMBL1485070 & 688816 & 8.3468 & 5.5532 & TRN & \\
\hline CHEMBL1514129 & 688816 & 5.1 & 4.9087 & TST & \\
\hline CHEMBL1365337 & 688816 & 5.5 & 5.5055 & TST & \\
\hline CHEMBL1600932 & 688816 & 4.9 & 5.2002 & TRN & \\
\hline CHEMBL1497150 & 688816 & 6.6 & 5.3668 & TRN & \\
\hline CHEMBL1412283 & 688816 & 5.15 & 5.159 & TRN & \\
\hline CHEMBL1541877 & 688816 & 5.0 & 5.2588 & TST & \\
\hline CHEMBL1548694 & 688816 & 5.7 & 5.4939 & TRN & \\
\hline CHEMBL1402539 & 688816 & 4.6 & 5.2958 & TST & \\
\hline CHEMBL1419343 & 688816 & 6.8 & 5.5231 & TST & \\
\hline CHEMBL 3212249 & 688816 & 4.75 & 5.2697 & TRN & \\
\hline CHEMBL1465410 & 688816 & 4.75 & 5.2918 & TRN & \\
\hline CHEMBL1504422 & 688816 & 5.0 & 5.6434 & TRN & \\
\hline CHEMBL1587219 & 688816 & 4.45 & 5.0713 & TRN & \\
\hline CHEMBL1971420 & 688816 & 4.45 & 5.3628 & TRN & \\
\hline CHEMBL1459087 & 688816 & 4.95 & 5.2318 & TRN & \\
\hline CHEMBL1427103 & 688816 & 4.9 & 5.2972 & TRN & \\
\hline CHEMBL1324256 & 688816 & 4.8 & 5.0122 & TRN & \\
\hline CHEMBL1402639 & 688816 & 4.85 & 4.8911 & TRN & \\
\hline CHEMBL1403914 & 688816 & 5.25 & 5.0316 & TRN & \\
\hline CHEMBL1519843 & 688816 & 4.8 & 4.9985 & TRN & \\
\hline CHEMBL1560633 & 688816 & 4.95 & 5.4509 & TRN & \\
\hline CHEMBL3197907 & 688816 & 5.05 & 5.8969 & TRN & \\
\hline CHEMBL1550676 & 688816 & 4.6 & 5.3328 & TRN & \\
\hline CHEMBL1981538 & 688816 & 4.6 & 4.9218 & TRN & \\
\hline CHEMBL1470598 & 688816 & 4.8 & 5.21899 & 9999999999 & TRN \\
\hline CHEMBL1353025 & 688816 & 4.7 & 5.2421 & TST & \\
\hline CHEMBL1387910 & 688816 & 4.8 & 5.2548 & TRN & \\
\hline CHEMBL1603913 & 688816 & 5.0 & 5.3569 & TRN & \\
\hline CHEMBL1307643 & 688816 & 4.45 & 5.0851 & TRN & \\
\hline CHEMBL1388109 & 688816 & 5.0 & 5.3953 & TRN & \\
\hline CHEMBL1301862 & 688816 & 4.65 & 5.3692 & TRN & \\
\hline CHEMBL1595162 & 688816 & 4.9 & 5.1191 & TRN & \\
\hline CHEMBL1576399 & 688816 & 4.75 & 5.2546 & TRN & \\
\hline CHEMBL1459949 & 688816 & 4.9 & 5.3273 & TRN & \\
\hline CHEMBL1595478 & 688816 & 4.95 & 4.9289 & TRN & \\
\hline CHEMBL1464979 & 688816 & 4.75 & 5.4943 & TRN & \\
\hline CHEMBL1419997 & 688816 & 4.7 & 5.0449 & TRN & \\
\hline CHEMBL1427594 & 688816 & 4.45 & 4.9122 & TRN & \\
\hline CHEMBL3194292 & 688816 & 4.45 & 5.1387 & TRN & \\
\hline CHEMBL1580344 & 688816 & 4.9 & 5.8169 & TRN & \\
\hline CHEMBL1505552 & 688816 & 5.05 & 5.4119 & TST & \\
\hline CHEMBL1347071 & 688816 & 5.7 & 5.223 & TRN & \\
\hline CHEMBL1370165 & 688816 & 5.2 & 5.1852 & TST & \\
\hline
\end{tabular}




\begin{tabular}{|c|c|c|c|c|c|}
\hline \multicolumn{6}{|c|}{ Supplemental Table S2.txt } \\
\hline CHEMBL1327006 & 688816 & 4.65 & 5.0486 & TST & \\
\hline CHEMBL1419176 & 688816 & 4.75 & 4.8168 & TRN & \\
\hline CHEMBL1576303 & 688816 & 4.7 & 5.033 & TRN & \\
\hline CHEMBL1404633 & 688816 & 5.0 & 5.3384 & TST & \\
\hline CHEMBL1524454 & 688816 & 4.8 & 4.7287 & TRN & \\
\hline CHEMBL1609858 & 688816 & 4.75 & 5.3048 & TRN & \\
\hline CHEMBL1455404 & 688816 & 5.25 & 5.46700 & 00000000005 & TST \\
\hline CHEMBL1443073 & 688816 & 5.5 & 5.8731 & TST & \\
\hline CHEMBL1348940 & 688816 & 4.85 & 4.8542 & TRN & \\
\hline CHEMBL1562902 & 688816 & 8.4949 & 5.4298 & TRN & \\
\hline CHEMBL1523920 & 688816 & 4.75 & 5.1429 & TRN & \\
\hline CHEMBL1389692 & 688816 & 5.15 & 5.1273 & TRN & \\
\hline CHEMBL1458044 & 688816 & 4.95 & 5.0922 & TRN & \\
\hline CHEMBL1573697 & 688816 & 4.8 & 4.8744 & TRN & \\
\hline CHEMBL1338677 & 688816 & 5.4 & 4.9633 & TRN & \\
\hline CHEMBL1329189 & 688816 & 4.85 & 5.5123 & TST & \\
\hline CHEMBL1510465 & 688816 & 4.9 & 5.3888 & TRN & \\
\hline CHEMBL1457940 & 688816 & 4.9 & 5.6484 & TRN & \\
\hline CHEMBL1386433 & 688816 & 4.85 & 5.3205 & TRN & \\
\hline CHEMBL1459781 & 688816 & 4.85 & 5.1238 & TRN & \\
\hline CHEMBL1480809 & 688816 & 4.9 & 5.1175 & TRN & \\
\hline CHEMBL1561799 & 688816 & 8.301 & 4.9056 & TRN & \\
\hline CHEMBL1353138 & 688816 & 5.85 & 5.5339 & TRN & \\
\hline CHEMBL1528203 & 688816 & 4.95 & 5.0359 & TRN & \\
\hline CHEMBL1544548 & 688816 & 5.0 & 4.9994 & TRN & \\
\hline CHEMBL3194521 & 688816 & 6.0 & 5.3079 & TRN & \\
\hline CHEMBL1305469 & 688816 & 4.9 & 4.99100 & 00000000005 & TRN \\
\hline CHEMBL3197094 & 688816 & 4.6 & 5.2843 & TST & \\
\hline CHEMBL1514232 & 688816 & 5.55 & 5.1978 & TRN & \\
\hline CHEMBL1336423 & 688816 & 5.7 & 5.3171 & TRN & \\
\hline CHEMBL1534641 & 688816 & 4.45 & 5.0368 & TST & \\
\hline CHEMBL1538072 & 688816 & 6.05 & 5.0661 & TST & \\
\hline CHEMBL1982334 & 688816 & 5.1 & 5.3014 & TRN & \\
\hline CHEMBL1528197 & 688816 & 5.0 & 5.13 & TRN & \\
\hline CHEMBL1570612 & 688816 & 5.1 & 5.2361 & TRN & \\
\hline CHEMBL1362336 & 688816 & 5.35 & 5.1689 & TST & \\
\hline CHEMBL1523096 & 688816 & 4.45 & 5.1443 & TRN & \\
\hline CHEMBL3210678 & 688816 & 4.85 & 5.4224 & TST & \\
\hline CHEMBL1317744 & 688816 & 4.45 & 4.6798 & TST & \\
\hline CHEMBL3190509 & 688816 & 4.45 & 5.4896 & TRN & \\
\hline CHEMBL1305731 & 688816 & 4.9 & 4.7531 & TRN & \\
\hline CHEMBL1304227 & 688816 & 4.6 & 4.9407 & TRN & \\
\hline CHEMBL1501346 & 688816 & 7.699 & 5.5106 & TRN & \\
\hline CHEMBL1598451 & 688816 & 4.85 & 5.319 & TRN & \\
\hline CHEMBL1409468 & 688816 & 5.0 & 5.1662 & TRN & \\
\hline CHEMBL1576833 & 688816 & 8.0506 & 4.9318 & TST & \\
\hline CHEMBL1451648 & 688816 & 4.95 & 5.0579 & TRN & \\
\hline CHEMBL1393225 & 688816 & 5.5 & 5.3307 & TRN & \\
\hline
\end{tabular}




\begin{tabular}{|c|c|c|c|c|c|}
\hline \multicolumn{6}{|c|}{ Supplemental Table S2.txt } \\
\hline CHEMBL1508422 & 688816 & 6.6 & 5.2853 & TRN & \\
\hline CHEMBL3196261 & 688816 & 4.95 & 5.2304 & TST & \\
\hline CHEMBL1350673 & 688816 & 4.45 & 5.2349 & TRN & \\
\hline CHEMBL1552311 & 688816 & 5.45 & 5.1166 & TRN & \\
\hline CHEMBL1484362 & 688816 & 5.05 & 5.3613 & TRN & \\
\hline CHEMBL1385164 & 688816 & 5.5 & 4.9718 & TRN & \\
\hline CHEMBL1417277 & 688816 & 5.0 & 5.2809 & TST & \\
\hline CHEMBL3210414 & 688816 & 6.9 & 5.4597 & TST & \\
\hline CHEMBL1424463 & 688816 & 4.85 & 5.2553 & TRN & \\
\hline CHEMBL1530903 & 688816 & 8.301 & 5.0868 & TST & \\
\hline CHEMBL1519870 & 688816 & 4.65 & 5.1757 & TRN & \\
\hline CHEMBL3199569 & 688816 & 4.8 & 5.2705 & TST & \\
\hline CHEMBL1315725 & 688816 & 5.45 & 5.7736 & TST & \\
\hline CHEMBL1506813 & 688816 & 5.95 & 5.4054 & TST & \\
\hline CHEMBL1468040 & 688816 & 4.95 & 5.3781 & TST & \\
\hline CHEMBL3198047 & 688816 & 4.9 & 5.1778 & TRN & \\
\hline CHEMBL1466715 & 688816 & 4.8 & 5.4962 & TRN & \\
\hline CHEMBL3190936 & 688816 & 4.65 & 5.1776 & TRN & \\
\hline CHEMBL1568512 & 688816 & 4.95 & 5.4608 & TRN & \\
\hline CHEMBL1445628 & 688816 & 4.45 & 4.9813 & TRN & \\
\hline CHEMBL1308743 & 688816 & 5.05 & 5.1752 & TRN & \\
\hline CHEMBL1559869 & 688816 & 5.05 & 5.2525 & TRN & \\
\hline CHEMBL1455742 & 688816 & 7.6003 & 5.2261 & TRN & \\
\hline CHEMBL1412630 & 688816 & 4.8 & 5.4524 & TRN & \\
\hline CHEMBL1444609 & 688816 & 4.95 & 5.33799 & 9999999999 & TRN \\
\hline CHEMBL1331787 & 688816 & 6.0 & 5.2139 & TRN & \\
\hline CHEMBL1472139 & 688816 & 4.95 & 5.4845 & TRN & \\
\hline CHEMBL1609423 & 688816 & 5.0 & 5.2406 & TRN & \\
\hline CHEMBL1391508 & 688816 & 5.3 & 5.6528 & TST & \\
\hline CHEMBL1407672 & 688816 & 5.25 & 5.6233 & TST & \\
\hline CHEMBL1318859 & 688816 & 5.25 & 4.9867 & TST & \\
\hline CHEMBL1446921 & 688816 & 5.15 & 5.3033 & TRN & \\
\hline CHEMBL1340259 & 688816 & 4.45 & 5.4389 & TRN & \\
\hline CHEMBL1527051 & 688816 & 8.301 & 5.1074 & TST & \\
\hline CHEMBL1575869 & 688816 & 4.95 & 5.2235 & TRN & \\
\hline CHEMBL1379474 & 688816 & 5.0 & 5.2742 & TST & \\
\hline CHEMBL1371175 & 688816 & 4.45 & 4.9921 & TRN & \\
\hline CHEMBL1417779 & 688816 & 5.05 & 5.2528 & TST & \\
\hline CHEMBL1712082 & 688816 & 5.45 & 5.82600 & 00000000005 & TRN \\
\hline CHEMBL1521489 & 688816 & 5.5 & 5.4775 & TRN & \\
\hline CHEMBL1405781 & 688816 & 5.05 & 5.4022 & TRN & \\
\hline CHEMBL508779 & 688816 & 5.0 & 5.3633 & TST & \\
\hline CHEMBL3192500 & 688816 & 4.45 & 5.0437 & TRN & \\
\hline CHEMBL1605203 & 688816 & 4.45 & 4.7742 & TRN & \\
\hline CHEMBL3197324 & 688816 & 4.85 & 5.641 & TRN & \\
\hline CHEMBL1503369 & 688816 & 5.4 & 5.7337 & TRN & \\
\hline CHEMBL1386886 & 688816 & 5.55 & 5.1783 & TST & \\
\hline CHEMBL1431818 & 688816 & 5.0 & 5.3057 & TRN & \\
\hline
\end{tabular}




\begin{tabular}{|c|c|c|c|c|c|}
\hline \\
\hline CHEMBL1563355 & 688816 & 5.3 & 4.9048 & TRN & \\
\hline CHEMBL1469317 & 688816 & 5.3 & 5.0849 & TRN & \\
\hline CHEMBL1363418 & 688816 & 6.05 & 5.6356 & TST & \\
\hline CHEMBL1366133 & 688816 & 4.85 & 5.2808 & TRN & \\
\hline CHEMBL1330242 & 688816 & 4.45 & 5.2948 & TRN & \\
\hline CHEMBL1524699 & 688816 & 6.15 & 5.362 & TRN & \\
\hline CHEMBL1385920 & 688816 & 5.25 & 5.6593 & TST & \\
\hline CHEMBL1533909 & 688816 & 4.95 & 5.2578 & TRN & \\
\hline CHEMBL1534204 & 688816 & 5.65 & 5.5645 & TRN & \\
\hline CHEMBL1353704 & 688816 & 4.9 & 5.28100 & 0000000001 & TRN \\
\hline CHEMBL1494678 & 688816 & 4.85 & 5.0339 & TRN & \\
\hline CHEMBL1510861 & 688816 & 7.6498 & 5.45299 & 9999999999 & TRN \\
\hline CHEMBL1540404 & 688816 & 4.45 & 5.2892 & TST & \\
\hline CHEMBL1516772 & 688816 & 4.75 & 4.8353 & TRN & \\
\hline CHEMBL1300901 & 688816 & 7.0501 & 5.4565 & TST & \\
\hline CHEMBL1464812 & 688816 & 4.9 & 5.2722 & TRN & \\
\hline CHEMBL1529489 & 688816 & 6.7501 & 5.3804 & TST & \\
\hline CHEMBL3211130 & 688816 & 5.25 & 5.1034 & TRN & \\
\hline CHEMBL1366311 & 688816 & 5.0 & 5.2301 & TRN & \\
\hline CHEMBL1488360 & 688816 & 4.5 & 5.3836 & TST & \\
\hline CHEMBL1572824 & 688816 & 5.45 & 5.8595 & TRN & \\
\hline CHEMBL1413556 & 688816 & 6.5501 & 5.2796 & TST & \\
\hline CHEMBL1369047 & 688816 & 4.95 & 5.1502 & TRN & \\
\hline CHEMBL1549852 & 688816 & 5.5 & 5.7158 & TRN & \\
\hline CHEMBL1964967 & 688816 & 4.75 & 5.3702 & TRN & \\
\hline CHEMBL1458067 & 688816 & 4.85 & 5.0887 & TRN & \\
\hline CHEMBL1464442 & 688816 & 6.15 & 5.1523 & TRN & \\
\hline CHEMBL1611643 & 688816 & 5.0 & 5.6416 & TRN & \\
\hline CHEMBL1444739 & 688816 & 4.45 & 5.4827 & TRN & \\
\hline CHEMBL1313666 & 688816 & 4.95 & 4.8255 & TRN & \\
\hline CHEMBL1307951 & 688816 & 5.0 & 5.0906 & TRN & \\
\hline CHEMBL1349193 & 688816 & 4.8 & 5.1657 & TRN & \\
\hline CHEMBL1577689 & 688816 & 7.6498 & 5.4437 & TST & \\
\hline CHEMBL1538008 & 688816 & 5.15 & 5.53799 & 9999999999 & TRN \\
\hline CHEMBL1343321 & 688816 & 5.2 & 5.0682 & TRN & \\
\hline CHEMBL91153 & 688816 & 5.0 & 5.1923 & TRN & \\
\hline CHEMBL1486517 & 688816 & 5.0 & 4.855 & TRN & \\
\hline CHEMBL1511471 & 688816 & 4.45 & 5.45 & TRN & \\
\hline CHEMBL1539079 & 688816 & 6.6 & 5.4154 & TRN & \\
\hline CHEMBL1445137 & 688816 & 4.75 & 5.1121 & TRN & \\
\hline CHEMBL1538218 & 688816 & 4.7 & 5.2435 & TRN & \\
\hline CHEMBL1393579 & 688816 & 5.0 & 4.9225 & TRN & \\
\hline CHEMBL1487601 & 688816 & 5.6 & 5.3929 & TRN & \\
\hline CHEMBL1331206 & 688816 & 5.05 & 4.8898 & TRN & \\
\hline CHEMBL1522557 & 688816 & 5.35 & 5.0898 & TRN & \\
\hline CHEMBL1316957 & 688816 & 5.5 & 5.1418 & TRN & \\
\hline CHEMBL1450323 & 688816 & 5.35 & 5.4271 & TRN & \\
\hline CHEMBL1375247 & 688816 & 8.3468 & 5.0907 & TST & \\
\hline
\end{tabular}




\begin{tabular}{|c|c|c|c|c|c|}
\hline \multicolumn{6}{|c|}{ Supplemental Table s2.txt } \\
\hline CHEMBL1386276 & 688816 & 4.6 & 4.9058 & TRN & \\
\hline CHEMBL1414633 & 688816 & 4.45 & 4.8086 & TRN & \\
\hline CHEMBL1320114 & 688816 & 5.45 & 5.4549 & TST & \\
\hline CHEMBL1535215 & 688816 & 5.55 & 5.5209 & TRN & \\
\hline CHEMBL1607837 & 688816 & 7.699 & 5.4102 & TRN & \\
\hline CHEMBL1415935 & 688816 & 4.75 & 5.6134 & TRN & \\
\hline CHEMBL1391887 & 688816 & 4.9 & 5.4021 & TST & \\
\hline CHEMBL1605298 & 688816 & 5.5 & 5.6343 & TRN & \\
\hline CHEMBL1382531 & 688816 & 4.45 & 5.2006 & TST & \\
\hline CHEMBL1377850 & 688816 & 5.65 & 5.0345 & TRN & \\
\hline CHEMBL1594995 & 688816 & 4.45 & 5.1647 & TRN & \\
\hline CHEMBL1441454 & 688816 & 5.6 & 5.2842 & TRN & \\
\hline CHEMBL1423935 & 688816 & 5.55 & 5.0898 & TRN & \\
\hline CHEMBL1547818 & 688816 & 5.0 & 5.2492 & TRN & \\
\hline CHEMBL1331582 & 688816 & 5.6 & 5.3791 & TRN & \\
\hline CHEMBL1494305 & 688816 & 7.5003 & 5.3963 & TRN & \\
\hline CHEMBL1440071 & 688816 & 4.55 & 5.0066 & TRN & \\
\hline CHEMBL1447112 & 688816 & 4.8 & 5.4015 & TRN & \\
\hline CHEMBL1606360 & 688816 & 4.9 & 5.1716 & TRN & \\
\hline CHEMBL1377757 & 688816 & 5.0 & 5.3899 & TRN & \\
\hline CHEMBL1303635 & 688816 & 4.75 & 5.0191 & TRN & \\
\hline CHEMBL1310614 & 688816 & 5.0 & 5.2054 & TRN & \\
\hline CHEMBL1439306 & 688816 & 7.1002 & 6.0235 & TRN & \\
\hline CHEMBL1463063 & 688816 & 4.65 & 5.37700 & 0000000001 & TST \\
\hline CHEMBL1368861 & 688816 & 4.9 & 5.3078 & TRN & \\
\hline CHEMBL1337804 & 688816 & 8.2518 & 5.4227 & TST & \\
\hline CHEMBL1459677 & 688816 & 4.5 & 5.0891 & TRN & \\
\hline CHEMBL1461120 & 688816 & 5.1 & 5.6182 & TRN & \\
\hline CHEMBL1493329 & 688816 & 8.3468 & 5.4791 & TRN & \\
\hline CHEMBL1348753 & 688816 & 8.4949 & 5.064 & TRN & \\
\hline CHEMBL1385182 & 688816 & 4.8 & 5.1469 & TRN & \\
\hline CHEMBL1589073 & 688816 & 6.7501 & 5.599 & TRN & \\
\hline CHEMBL1547904 & 688816 & 4.9 & 5.3242 & TST & \\
\hline CHEMBL1381135 & 688816 & 4.8 & 5.1523 & TRN & \\
\hline CHEMBL1468974 & 688816 & 4.45 & 5.0165 & TRN & \\
\hline CHEMBL1483355 & 688816 & 4.45 & 5.2942 & TRN & \\
\hline CHEMBL1300535 & 688816 & 4.45 & 4.8826 & TRN & \\
\hline CHEMBL1486446 & 688816 & 5.5 & 5.0827 & TRN & \\
\hline CHEMBL1964928 & 688816 & 4.9 & 5.0557 & TST & \\
\hline CHEMBL1352071 & 688816 & 5.0 & 5.16799 & 9999999999 & TRN \\
\hline CHEMBL1489167 & 688816 & 4.45 & 5.1033 & TRN & \\
\hline CHEMBL1310995 & 688816 & 5.25 & 5.1957 & TRN & \\
\hline CHEMBL1604968 & 688816 & 7.699 & 5.4708 & TRN & \\
\hline CHEMBL1335747 & 688816 & 4.45 & 5.3318 & TRN & \\
\hline CHEMBL1503604 & 688816 & 4.95 & 4.8192 & TST & \\
\hline CHEMBL1588757 & 688816 & 5.05 & 5.0767 & TRN & \\
\hline CHEMBL1604609 & 688816 & 4.55 & 5.6562 & TRN & \\
\hline CHEMBL1301307 & 688816 & 5.0 & 5.1572 & TRN & \\
\hline
\end{tabular}




\begin{tabular}{|c|c|c|c|c|c|}
\hline \multicolumn{6}{|c|}{ Supplemental Table s2.txt } \\
\hline CHEMBL1443839 & 688816 & 6.4 & 5.3849 & TST & \\
\hline CHEMBL1420730 & 688816 & 4.45 & 5.0437 & TRN & \\
\hline CHEMBL1496274 & 688816 & 5.0 & 5.4635 & TRN & \\
\hline CHEMBL1509879 & 688816 & 4.85 & 5.5238 & TRN & \\
\hline CHEMBL1582535 & 688816 & 6.15 & 5.2607 & TRN & \\
\hline CHEMBL1339512 & 688816 & 4.95 & 5.4054 & TRN & \\
\hline CHEMBL1387001 & 688816 & 4.95 & 5.3174 & TRN & \\
\hline CHEMBL1444556 & 688816 & 4.75 & 5.24700 & 0000000001 & TST \\
\hline CHEMBL 3210891 & 688816 & 7.3002 & 5.3289 & TST & \\
\hline CHEMBL1307705 & 688816 & 5.05 & 5.4961 & TRN & \\
\hline CHEMBL1405722 & 688816 & 4.9 & 5.0441 & TRN & \\
\hline CHEMBL1520600 & 688816 & 4.95 & 5.2522 & TRN & \\
\hline CHEMBL1332746 & 688816 & 4.8 & 5.0309 & TST & \\
\hline CHEMBL1568200 & 688816 & 6.8 & 5.1843 & TST & \\
\hline CHEMBL1328999 & 688816 & 4.9 & 4.9933 & TRN & \\
\hline CHEMBL1384385 & 688816 & 4.8 & 4.9242 & TRN & \\
\hline CHEMBL3145379 & 688816 & 5.5 & 5.665 & TRN & \\
\hline CHEMBL1368809 & 688816 & 4.8 & 4.9106 & TRN & \\
\hline CHEMBL1388091 & 688816 & 4.9 & 5.2747 & TRN & \\
\hline CHEMBL1555930 & 688816 & 5.5 & 5.1608 & TRN & \\
\hline CHEMBL1462037 & 688816 & 6.1 & 5.523 & TRN & \\
\hline CHEMBL1575787 & 688816 & 5.8 & 5.2741 & TRN & \\
\hline CHEMBL1572468 & 688816 & 5.45 & 5.0508 & TRN & \\
\hline CHEMBL1422590 & 688816 & 5.15 & 5.0672 & TST & \\
\hline CHEMBL1363219 & 688816 & 4.95 & 4.8944 & TRN & \\
\hline CHEMBL1379929 & 688816 & 5.5 & 5.4483 & TRN & \\
\hline CHEMBL1604441 & 688816 & 4.9 & 5.1412 & TST & \\
\hline CHEMBL1471312 & 688816 & 4.65 & 5.0119 & TRN & \\
\hline CHEMBL1974563 & 688816 & 5.05 & 5.1323 & TRN & \\
\hline CHEMBL1499177 & 688816 & 8.4949 & 5.7707 & TST & \\
\hline CHEMBL1302028 & 688816 & 4.7 & 5.2345 & TRN & \\
\hline CHEMBL1517890 & 688816 & 5.35 & 5.9351 & TST & \\
\hline CHEMBL1302557 & 688816 & 4.9 & 5.32799 & & TRN \\
\hline CHEMBL1256914 & 688816 & 4.9 & 4.9156 & TST & \\
\hline CHEMBL1357178 & 688816 & 4.45 & 5.3896 & TRN & \\
\hline CHEMBL 3192265 & 688816 & 4.45 & 5.1845 & TRN & \\
\hline CHEMBL1399408 & 688816 & 4.95 & 5.2684 & TRN & \\
\hline CHEMBL1313499 & 688816 & 5.1 & 4.8084 & TST & \\
\hline CHEMBL1567593 & 688816 & 6.2 & 5.6495 & TRN & \\
\hline CHEMBL3189754 & 688816 & 4.85 & 5.2032 & TRN & \\
\hline CHEMBL1465792 & 688816 & 4.65 & 5.6191 & TRN & \\
\hline CHEMBL1304140 & 688816 & 5.75 & 5.1037 & TST & \\
\hline CHEMBL1372228 & 688816 & 4.95 & 5.379 & TRN & \\
\hline CHEMBL1598210 & 688816 & 6.6 & 5.4074 & TST & \\
\hline CHEMBL1399025 & 688816 & 5.25 & 5.2239 & TRN & \\
\hline CHEMBL1381795 & 688816 & 4.85 & 5.3808 & TRN & \\
\hline CHEMBL1489180 & 688816 & 5.3 & 6.0434 & TRN & \\
\hline CHEMBL1489999 & 688816 & 5.25 & 5.517 & TRN & \\
\hline
\end{tabular}




\begin{tabular}{|c|c|c|c|c|c|}
\hline \multicolumn{6}{|c|}{ plemental lable S2. } \\
\hline CHEMBL1358452 & 688816 & 4.9 & 5.5469 & TRN & \\
\hline CHEMBL1360378 & 688816 & 5.45 & 5.3857 & TRN & \\
\hline CHEMBL1504183 & 688816 & 4.95 & 5.4092 & TRN & \\
\hline CHEMBL3199055 & 688816 & 4.95 & 5.1915 & TST & \\
\hline CHEMBL1598721 & 688816 & 4.95 & 5.375 & TRN & \\
\hline CHEMBL1376048 & 688816 & 4.65 & 4.8843 & TST & \\
\hline CHEMBL1438983 & 688816 & 4.65 & 4.9855 & TST & \\
\hline CHEMBL1577305 & 688816 & 5.6 & 5.1926 & TRN & \\
\hline CHEMBL1517493 & 688816 & 4.85 & 4.8568 & TRN & \\
\hline CHEMBL1409118 & 688816 & 4.9 & 5.176 & TRN & \\
\hline CHEMBL1488932 & 688816 & 4.9 & 4.9804 & TRN & \\
\hline CHEMBL1419303 & 688816 & 4.45 & 4.9125 & TST & \\
\hline CHEMBL1569124 & 688816 & 4.9 & 5.0017 & TRN & \\
\hline CHEMBL1479300 & 688816 & 7.4001 & 5.4343 & TST & \\
\hline CHEMBL1427701 & 688816 & 5.0 & 5.1817 & TRN & \\
\hline CHEMBL1564807 & 688816 & 5.0 & 5.7582 & TRN & \\
\hline CHEMBL1301425 & 688816 & 4.9 & 5.3244 & TRN & \\
\hline CHEMBL1306153 & 688816 & 4.9 & 5.1734 & TST & \\
\hline CHEMBL1605220 & 688816 & 5.85 & 5.2062 & TST & \\
\hline CHEMBL1352896 & 688816 & 4.95 & 5.3468 & TST & \\
\hline CHEMBL53721 & 688816 & 4.45 & 5.4902 & TRN & \\
\hline CHEMBL3213470 & 688816 & 4.7 & 5.2273 & TST & \\
\hline CHEMBL1371633 & 688816 & 7.9508 & 5.2394 & TRN & \\
\hline CHEMBL1599636 & 688816 & 4.7 & 5.0819 & TRN & \\
\hline CHEMBL1537522 & 688816 & 4.95 & 4.9844 & TRN & \\
\hline CHEMBL1373769 & 688816 & 4.65 & 4.9987 & TRN & \\
\hline CHEMBL1576613 & 688816 & 4.65 & 5.0059 & TRN & \\
\hline CHEMBL1364184 & 688816 & 5.05 & 5.3137 & TST & \\
\hline CHEMBL1548142 & 688816 & 4.8 & 5.4325 & TST & \\
\hline CHEMBL3192897 & 688816 & 4.85 & 5.3764 & TST & \\
\hline CHEMBL1580164 & 688816 & 5.1 & 5.0052 & TRN & \\
\hline CHEMBL1500891 & 688816 & 4.75 & 5.3456 & TST & \\
\hline CHEMBL1402732 & 688816 & 4.85 & 5.2338 & TRN & \\
\hline CHEMBL1426402 & 688816 & 4.8 & 5.2275 & TRN & \\
\hline CHEMBL3208249 & 688816 & 4.45 & 5.0136 & TRN & \\
\hline CHEMBL1301096 & 688816 & 6.05 & 5.41799 & 9999999999 & TST \\
\hline CHEMBL1476263 & 688816 & 5.0 & 5.1813 & TRN & \\
\hline CHEMBL1307474 & 688816 & 4.75 & 5.0702 & TRN & \\
\hline CHEMBL1563110 & 688816 & 4.8 & 4.88899 & 9999999999 & TST \\
\hline CHEMBL1304420 & 688816 & 5.45 & 5.2803 & TST & \\
\hline CHEMBL1169930 & 688816 & 5.35 & 5.3007 & TRN & \\
\hline CHEMBL1519504 & 688816 & 7.699 & 5.2831 & TST & \\
\hline CHEMBL1529955 & 688816 & 6.15 & 5.32299 & 99999999995 & TRN \\
\hline CHEMBL 3210660 & 688816 & 4.45 & 5.3758 & TRN & \\
\hline CHEMBL1452190 & 688816 & 7.5003 & 5.3373 & TST & \\
\hline CHEMBL1491542 & 688816 & 4.95 & 5.0119 & TRN & \\
\hline CHEMBL1341742 & 688816 & 4.95 & 5.0701 & TRN & \\
\hline CHEMBL1327409 & 688816 & 5.35 & 5.6205 & TRN & \\
\hline
\end{tabular}




\begin{tabular}{|c|c|c|c|c|c|}
\hline \\
\hline CHEMBL1348430 & 688816 & 4.9 & 5.3869 & TRN & \\
\hline CHEMBL1403015 & 688816 & 5.65 & 4.787 & TRN & \\
\hline CHEMBL1590521 & 688816 & 4.8 & 5.2246 & TST & \\
\hline CHEMBL1556595 & 688816 & 5.5 & 5.6871 & TRN & \\
\hline CHEMBL1342933 & 688816 & 5.05 & 5.1034 & TRN & \\
\hline CHEMBL1485522 & 688816 & 4.5 & 4.8467 & TRN & \\
\hline CHEMBL1586703 & 688816 & 6.05 & 5.1737 & TRN & \\
\hline CHEMBL1455661 & 688816 & 4.8 & 5.21700 & 00000000005 & TRN \\
\hline CHEMBL1561483 & 688816 & 5.65 & 5.3951 & TST & \\
\hline CHEMBL1381564 & 688816 & 4.8 & 4.9996 & TST & \\
\hline CHEMBL1577606 & 688816 & 4.95 & 5.232 & TRN & \\
\hline CHEMBL3194789 & 688816 & 5.0 & 5.2395 & TRN & \\
\hline CHEMBL1994148 & 688816 & 5.15 & 5.178 & TRN & \\
\hline CHEMBL1322400 & 688816 & 4.45 & 4.8355 & TRN & \\
\hline CHEMBL1576167 & 688816 & 7.3497 & 5.5116 & TRN & \\
\hline CHEMBL1450252 & 688816 & 4.45 & 4.8885 & TRN & \\
\hline CHEMBL1429243 & 688816 & 4.5 & 4.9553 & TST & \\
\hline CHEMBL1339080 & 688816 & 5.9 & 5.6633 & TRN & \\
\hline CHEMBL1462363 & 688816 & 4.85 & 5.1985 & TRN & \\
\hline CHEMBL1310862 & 688816 & 4.45 & 5.042 & TRN & \\
\hline CHEMBL1562431 & 688816 & 4.7 & 5.1002 & TRN & \\
\hline CHEMBL1329048 & 688816 & 4.75 & 5.1694 & TRN & \\
\hline CHEMBL1864348 & 688816 & 4.95 & 5.3702 & TST & \\
\hline CHEMBL1396462 & 688816 & 5.2 & 4.8982 & TRN & \\
\hline CHEMBL1580861 & 688816 & 5.45 & 5.3387 & TRN & \\
\hline CHEMBL1317848 & 688816 & 4.45 & 4.9715 & TRN & \\
\hline CHEMBL169143 & 688816 & 5.1 & 5.1801 & TRN & \\
\hline CHEMBL1300338 & 688816 & 5.25 & 4.9909 & TRN & \\
\hline CHEMBL3192936 & 688816 & 4.9 & 5.2967 & TRN & \\
\hline CHEMBL1543955 & 688816 & 7.2 & 5.3946 & TRN & \\
\hline CHEMBL3198668 & 688816 & 4.65 & 5.0373 & TRN & \\
\hline CHEMBL1332895 & 688816 & 4.45 & 5.5994 & TST & \\
\hline CHEMBL1325151 & 688816 & 6.95 & 5.5752 & TRN & \\
\hline CHEMBL1583308 & 688816 & 5.75 & 5.154 & TST & \\
\hline CHEMBL1562734 & 688816 & 4.75 & 4.6941 & TRN & \\
\hline CHEMBL1609033 & 688816 & 5.0 & 4.8232 & TST & \\
\hline CHEMBL1382368 & 688816 & 4.45 & 5.2766 & TRN & \\
\hline CHEMBL1423649 & 688816 & 4.95 & 5.2939 & TRN & \\
\hline CHEMBL1377335 & 688816 & 4.7 & 5.2259 & TRN & \\
\hline CHEMBL1597234 & 688816 & 5.1 & 5.1971 & TRN & \\
\hline CHEMBL1338533 & 688816 & 4.85 & 4.7364 & TRN & \\
\hline CHEMBL1315491 & 688816 & 4.8 & 5.1234 & TST & \\
\hline CHEMBL1388358 & 688816 & 6.1 & 4.9751 & TRN & \\
\hline CHEMBL1385176 & 688816 & 5.05 & 5.3136 & TRN & \\
\hline CHEMBL1442404 & 688816 & 5.3 & 5.1446 & TRN & \\
\hline CHEMBL1361393 & 688816 & 5.1 & 5.2825 & TRN & \\
\hline CHEMBL1577781 & 688816 & 4.5 & 4.922 & TRN & \\
\hline CHEMBL1588205 & 688816 & 4.5 & 5.5139 & TRN & \\
\hline
\end{tabular}




\begin{tabular}{|c|c|c|c|c|}
\hline \multicolumn{5}{|c|}{ Supplemental Table S2.txt } \\
\hline CHEMBL1506482 & 688816 & 5.3 & 4.9017 & TRN \\
\hline CHEMBL1613611 & 688816 & 5.45 & 5.3312 & TST \\
\hline CHEMBL1323581 & 688816 & 5.55 & 5.3419 & TRN \\
\hline CHEMBL1561727 & 688816 & 4.9 & 5.6869 & TST \\
\hline CHEMBL1334669 & 688816 & 4.45 & 5.3222 & TRN \\
\hline CHEMBL1341582 & 688816 & 5.2 & 5.3182 & TRN \\
\hline CHEMBL3196634 & 688816 & 4.85 & 5.2954 & TRN \\
\hline CHEMBL1519868 & 688816 & 6.05 & 5.4968 & TRN \\
\hline CHEMBL1543752 & 688816 & 4.45 & 4.9772 & TST \\
\hline CHEMBL1562630 & 688816 & 4.65 & 5.2547 & TRN \\
\hline CHEMBL1527747 & 688816 & 4.5 & 5.0194 & TRN \\
\hline CHEMBL1303750 & 688816 & 5.25 & 5.2647 & TRN \\
\hline CHEMBL1409928 & 688816 & 4.65 & 5.1065 & TST \\
\hline CHEMBL1522726 & 688816 & 5.55 & 5.218 & TRN \\
\hline CHEMBL3207532 & 688816 & 7.4001 & 5.5805 & TRN \\
\hline CHEMBL1411424 & 688816 & 4.7 & 5.6507 & TST \\
\hline CHEMBL1492469 & 688816 & 4.75 & 5.3297 & TRN \\
\hline CHEMBL1534782 & 688816 & 5.95 & 5.2256 & TRN \\
\hline CHEMBL1468756 & 688816 & 5.35 & 5.3481 & TRN \\
\hline CHEMBL1486121 & 688816 & 4.45 & 5.2329 & TST \\
\hline CHEMBL3191846 & 688816 & 4.75 & 5.1032 & TRN \\
\hline CHEMBL3211661 & 688816 & 4.7 & 5.5193 & TRN \\
\hline CHEMBL 3212424 & 688816 & 4.85 & 5.3428 & TST \\
\hline CHEMBL1595601 & 688816 & 4.75 & 5.3816 & TRN \\
\hline CHEMBL1369033 & 688816 & 4.95 & 5.3918 & TRN \\
\hline CHEMBL1345388 & 688816 & 5.15 & 5.1482 & TRN \\
\hline CHEMBL1541924 & 688816 & 4.45 & 5.0203 & TST \\
\hline CHEMBL1511785 & 688816 & 5.5 & 5.4362 & TST \\
\hline CHEMBL1529295 & 688816 & 4.95 & 4.6601 & TRN \\
\hline CHEMBL1506819 & 688816 & 4.45 & 5.277 & TRN \\
\hline CHEMBL1470651 & 688816 & 6.5501 & 5.7243 & TRN \\
\hline CHEMBL1432768 & 688816 & 4.95 & 5.3242 & TRN \\
\hline CHEMBL153072 & 688816 & 4.45 & 5.0483 & TRN \\
\hline CHEMBL1504441 & 688816 & 4.7 & 5.4121 & TST \\
\hline CHEMBL1405077 & 688816 & 4.7 & 5.6214 & TST \\
\hline CHEMBL1452784 & 688816 & 5.45 & 5.1296 & TRN \\
\hline CHEMBL1305436 & 688816 & 4.9 & 4.8039 & TRN \\
\hline CHEMBL1462784 & 688816 & 4.7 & 4.8178 & TRN \\
\hline CHEMBL1079664 & 688816 & 5.4 & 5.2383 & TRN \\
\hline CHEMBL1506503 & 688816 & 7.5498 & 5.3014 & TRN \\
\hline CHEMBL1393161 & 688816 & 5.0 & 5.4171 & TRN \\
\hline CHEMBL1357307 & 688816 & 4.95 & 5.569 & TRN \\
\hline CHEMBL3145245 & 688816 & 5.0 & 5.6008 & TRN \\
\hline CHEMBL1579317 & 688816 & 4.95 & 5.1887 & TRN \\
\hline CHEMBL1608591 & 688816 & 5.45 & 5.5357 & TRN \\
\hline CHEMBL1566045 & 688816 & 4.45 & 5.1593 & TST \\
\hline CHEMBL3210297 & 688816 & 8.3468 & 5.3689 & TRN \\
\hline CHEMBL1399353 & 688816 & 7.6498 & 5.5618 & TRN \\
\hline
\end{tabular}




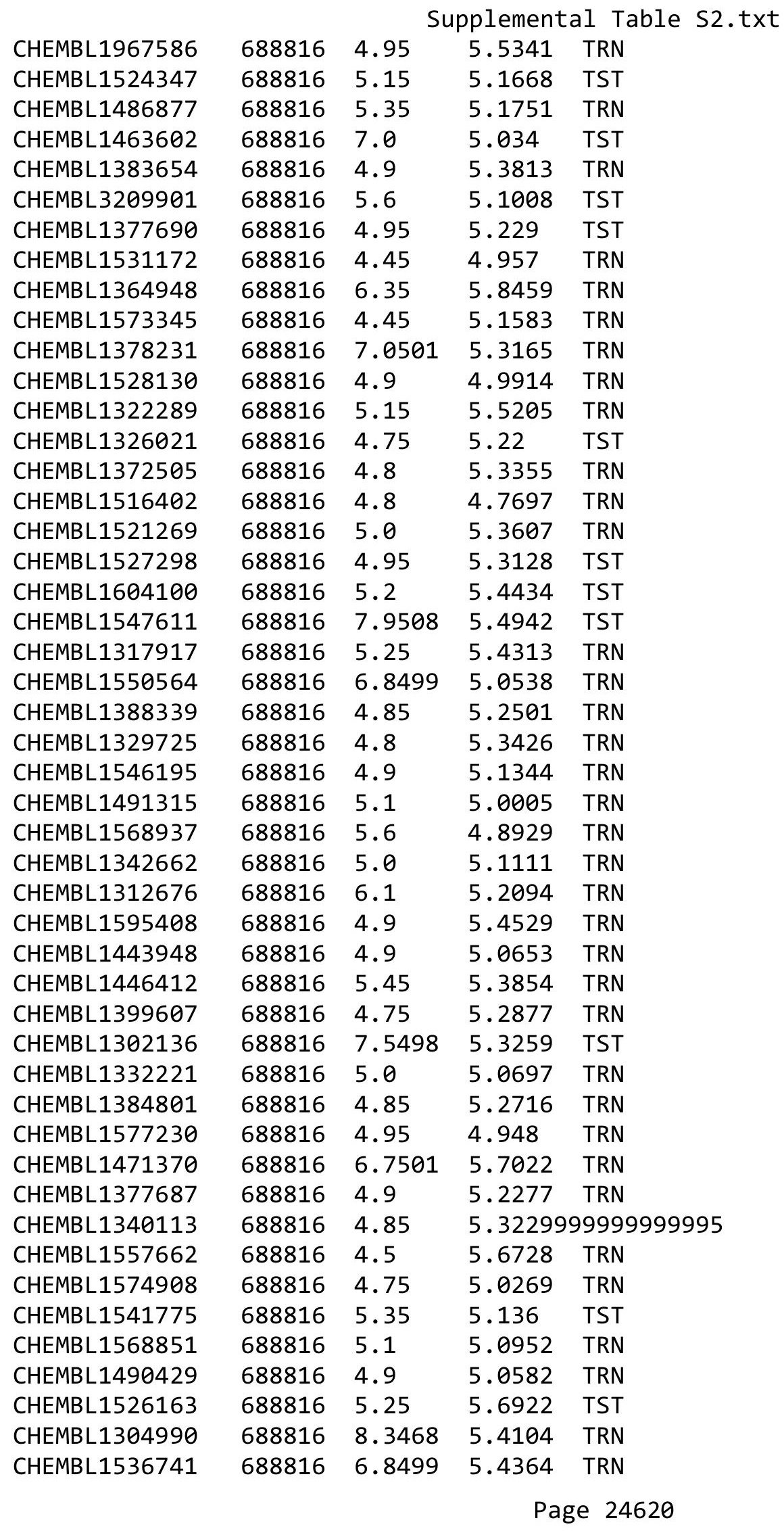




\begin{tabular}{|c|c|c|c|c|c|}
\hline \multicolumn{6}{|c|}{ Supplemental Table S2.txt } \\
\hline CHEMBL1339723 & 688816 & 5.15 & 5.0971 & TRN & \\
\hline CHEMBL1307380 & 688816 & 5.55 & 5.4919 & TRN & \\
\hline CHEMBL1476264 & 688816 & 5.3 & 5.2901 & TRN & \\
\hline CHEMBL1598716 & 688816 & 5.0 & 4.8487 & TRN & \\
\hline CHEMBL1491686 & 688816 & 4.95 & 5.3971 & TRN & \\
\hline CHEMBL1607895 & 688816 & 5.0 & 5.4148 & TRN & \\
\hline CHEMBL1576409 & 688816 & 5.4 & 5.3667 & TRN & \\
\hline CHEMBL1465630 & 688816 & 4.65 & 5.4632 & TST & \\
\hline CHEMBL1526230 & 688816 & 5.85 & 5.3228 & TRN & \\
\hline CHEMBL1329528 & 688816 & 5.05 & 5.113 & TRN & \\
\hline CHEMBL1541186 & 688816 & 5.0 & 5.0001 & TRN & \\
\hline CHEMBL1623028 & 688816 & 4.7 & 5.5164 & TRN & \\
\hline CHEMBL1518561 & 688816 & 4.9 & 5.4114 & TRN & \\
\hline CHEMBL1587531 & 688816 & 4.85 & 5.2139 & TRN & \\
\hline CHEMBL 3189160 & 688816 & 4.75 & 5.4549 & TST & \\
\hline CHEMBL1558858 & 688816 & 4.8 & 5.2725 & TST & \\
\hline CHEMBL1432870 & 688816 & 4.45 & 5.1214 & TRN & \\
\hline CHEMBL1483365 & 688816 & 4.9 & 5.8826 & TST & \\
\hline CHEMBL1335104 & 688816 & 4.9 & 4.9722 & TRN & \\
\hline CHEMBL1574496 & 688816 & 5.05 & 4.9317 & TRN & \\
\hline CHEMBL 254218 & 688816 & 5.05 & 5.0938 & TRN & \\
\hline CHEMBL1327990 & 688816 & 5.3 & 4.8471 & TRN & \\
\hline CHEMBL1558845 & 688816 & 4.9 & 5.5636 & TRN & \\
\hline CHEMBL1599646 & 688816 & 4.75 & 5.3637 & TRN & \\
\hline CHEMBL1505962 & 688816 & 4.45 & 5.3899 & TRN & \\
\hline CHEMBL1348683 & 688816 & 4.9 & 5.4514 & TRN & \\
\hline CHEMBL 2004809 & 688816 & 4.8 & 5.2383 & TST & \\
\hline CHEMBL3212751 & 688816 & 4.9 & 5.2354 & TST & \\
\hline CHEMBL1607987 & 688816 & 4.7 & 5.3078 & TRN & \\
\hline CHEMBL1412271 & 688816 & 5.0 & 5.0684 & TRN & \\
\hline CHEMBL3194214 & 688816 & 4.65 & 5.2227 & TRN & \\
\hline CHEMBL195789 & 688816 & 4.95 & 4.9146 & TRN & \\
\hline CHEMBL1510973 & 688816 & 5.35 & 5.3136 & TRN & \\
\hline CHEMBL1405516 & 688816 & 7.6003 & 4.8755 & TRN & \\
\hline CHEMBL1553281 & 688816 & 5.4 & 5.7459 & TRN & \\
\hline CHEMBL1596381 & 688816 & 6.8499 & 5.4258 & TST & \\
\hline CHEMBL1412831 & 688816 & 4.7 & 4.9133 & TRN & \\
\hline CHEMBL1518774 & 688816 & 5.55 & 5.09699 & 99999999995 & TRN \\
\hline CHEMBL1311621 & 688816 & 6.4 & 5.3474 & TST & \\
\hline CHEMBL1558336 & 688816 & 5.5 & 5.2455 & TRN & \\
\hline CHEMBL1545341 & 688816 & 4.45 & 5.2307 & TRN & \\
\hline CHEMBL1307583 & 688816 & 4.85 & 5.2585 & TRN & \\
\hline CHEMBL3209446 & 688816 & 7.8508 & 5.2173 & TST & \\
\hline CHEMBL1560261 & 688816 & 5.15 & 5.3515 & TRN & \\
\hline CHEMBL1481353 & 688816 & 5.55 & 5.1319 & TRN & \\
\hline CHEMBL1333339 & 688816 & 6.45 & 5.5779 & TRN & \\
\hline CHEMBL1597994 & 688816 & 4.45 & 5.1723 & TRN & \\
\hline CHEMBL1600573 & 688816 & 4.45 & 5.0244 & TRN & \\
\hline
\end{tabular}




\begin{tabular}{|c|c|c|c|c|c|}
\hline \multirow[b]{2}{*}{ CHEMBL1576810 } & \multicolumn{5}{|c|}{ Supplemental Table s2.txt } \\
\hline & 688816 & 4.75 & 5.1104 & TRN & \\
\hline CHEMBL1417800 & 688816 & 4.9 & 5.5729 & TRN & \\
\hline CHEMBL1402714 & 688816 & 4.45 & 4.8742 & TRN & \\
\hline CHEMBL1527872 & 688816 & 5.4 & 5.1777 & TRN & \\
\hline CHEMBL1443784 & 688816 & 4.55 & 5.0672 & TRN & \\
\hline CHEMBL1588056 & 688816 & 4.85 & 5.0385 & TRN & \\
\hline CHEMBL1544947 & 688816 & 4.85 & 5.0507 & TRN & \\
\hline CHEMBL1338275 & 688816 & 5.25 & 5.6107 & TST & \\
\hline CHEMBL1499195 & 688816 & 4.8 & 5.1173 & TRN & \\
\hline CHEMBL1313845 & 688816 & 4.7 & 5.1223 & TRN & \\
\hline CHEMBL1333386 & 688816 & 4.85 & 4.9282 & TST & \\
\hline CHEMBL1584025 & 688816 & 5.25 & 5.4091 & TRN & \\
\hline CHEMBL1581221 & 688816 & 5.15 & 5.306 & TRN & \\
\hline CHEMBL601351 & 688816 & 4.7 & 5.1697 & TST & \\
\hline CHEMBL1558447 & 688816 & 5.45 & 5.4445 & TRN & \\
\hline CHEMBL1496826 & 688816 & 5.75 & 5.46399 & 99999999995 & TRN \\
\hline CHEMBL1373659 & 688816 & 4.75 & 5.1057 & TRN & \\
\hline CHEMBL1336188 & 688816 & 5.2 & 5.5451 & TST & \\
\hline CHEMBL1399058 & 688816 & 5.0 & 5.0634 & TRN & \\
\hline CHEMBL1445780 & 688816 & 8.301 & 5.6597 & TRN & \\
\hline CHEMBL1451548 & 688816 & 4.7 & 5.2065 & TRN & \\
\hline CHEMBL1423166 & 688816 & 4.7 & 4.8384 & TRN & \\
\hline CHEMBL1383029 & 688816 & 5.05 & 5.1185 & TRN & \\
\hline CHEMBL1454221 & 688816 & 5.4 & 5.3173 & TRN & \\
\hline CHEMBL1400811 & 688816 & 4.65 & 4.9697 & TRN & \\
\hline CHEMBL1351105 & 688816 & 5.0 & 5.2407 & TST & \\
\hline CHEMBL1538931 & 688816 & 4.85 & 5.1272 & TRN & \\
\hline CHEMBL1573192 & 688816 & 4.45 & 5.4367 & TRN & \\
\hline CHEMBL1509195 & 688816 & 4.65 & 5.3665 & TRN & \\
\hline CHEMBL1586862 & 688816 & 6.45 & 5.0789 & TRN & \\
\hline CHEMBL1588516 & 688816 & 4.8 & 5.1504 & TRN & \\
\hline CHEMBL1419794 & 688816 & 5.35 & 5.1613 & TRN & \\
\hline CHEMBL1370889 & 688816 & 5.25 & 5.6741 & TRN & \\
\hline CHEMBL3192802 & 688816 & 4.6 & 5.581 & TRN & \\
\hline CHEMBL1599516 & 688816 & 7.2503 & 5.2763 & TRN & \\
\hline CHEMBL1446541 & 688816 & 4.85 & 4.9728 & TRN & \\
\hline CHEMBL1592161 & 688816 & 4.45 & 5.0525 & TRN & \\
\hline CHEMBL1486325 & 688816 & 5.25 & 5.2062 & TRN & \\
\hline CHEMBL1494495 & 688816 & 5.15 & 5.4315 & TRN & \\
\hline CHEMBL2001476 & 688816 & 6.05 & 5.535 & TRN & \\
\hline CHEMBL1478395 & 688816 & 4.45 & 5.5213 & TST & \\
\hline CHEMBL1400975 & 688816 & 4.75 & 4.6231 & TRN & \\
\hline CHEMBL1462213 & 688816 & 4.9 & 5.0276 & TRN & \\
\hline CHEMBL1360653 & 688816 & 4.45 & 5.1812 & TRN & \\
\hline CHEMBL1428727 & 688816 & 6.3 & 5.42899 & 9999999999 & TST \\
\hline CHEMBL1564062 & 688816 & 4.9 & 5.0881 & TRN & \\
\hline CHEMBL1392894 & 688816 & 5.7 & 5.356 & TST & \\
\hline CHEMBL1600014 & 688816 & 4.75 & 5.4059 & TRN & \\
\hline
\end{tabular}




\begin{tabular}{|c|c|c|c|c|c|}
\hline \multicolumn{6}{|c|}{ Supplemental Table S2.txt } \\
\hline CHEMBL1367707 & 688816 & 4.95 & 5.0476 & TRN & \\
\hline CHEMBL1522841 & 688816 & 7.5003 & 5.516 & TRN & \\
\hline CHEMBL1386256 & 688816 & 5.0 & 4.917 & TST & \\
\hline CHEMBL1300991 & 688816 & 5.45 & 5.2233 & TST & \\
\hline CHEMBL1488868 & 688816 & 5.45 & 5.7788 & TRN & \\
\hline CHEMBL1492270 & 688816 & 4.45 & 5.4042 & TRN & \\
\hline CHEMBL1360215 & 688816 & 6.1 & 5.4478 & TRN & \\
\hline CHEMBL3195938 & 688816 & 5.0 & 5.2689 & TST & \\
\hline CHEMBL1537753 & 688816 & 4.8 & 4.9583 & TRN & \\
\hline CHEMBL1526371 & 688816 & 5.65 & 5.7212 & TST & \\
\hline CHEMBL1574778 & 688816 & 4.45 & 5.5799 & TRN & \\
\hline CHEMBL1424038 & 688816 & 4.95 & 5.1976 & TRN & \\
\hline CHEMBL1601967 & 688816 & 4.65 & 5.4353 & TST & \\
\hline CHEMBL1362372 & 688816 & 4.85 & 5.1157 & TRN & \\
\hline CHEMBL1405957 & 688816 & 5.5 & 5.4059 & TST & \\
\hline CHEMBL1447043 & 688816 & 8.301 & 5.2604 & TRN & \\
\hline CHEMBL1602496 & 688816 & 4.75 & 5.2184 & TRN & \\
\hline CHEMBL1316402 & 688816 & 5.0 & 5.0547 & TST & \\
\hline CHEMBL1440062 & 688816 & 4.75 & 5.3168 & TRN & \\
\hline CHEMBL1392405 & 688816 & 4.6 & 5.037 & TST & \\
\hline CHEMBL1533788 & 688816 & 4.95 & 5.5942 & TRN & \\
\hline CHEMBL1596203 & 688816 & 7.0 & 4.6334 & TRN & \\
\hline CHEMBL1365598 & 688816 & 8.3979 & 5.3149 & TRN & \\
\hline CHEMBL1413764 & 688816 & 4.95 & 5.2778 & TRN & \\
\hline CHEMBL1256364 & 688816 & 4.9 & 5.1686 & TRN & \\
\hline CHEMBL1452173 & 688816 & 4.95 & 5.0631 & TRN & \\
\hline CHEMBL1550145 & 688816 & 6.15 & 5.3319 & TST & \\
\hline CHEMBL1540020 & 688816 & 5.55 & 5.4464 & TRN & \\
\hline CHEMBL1538726 & 688816 & 4.7 & 4.7624 & TRN & \\
\hline CHEMBL1328967 & 688816 & 6.7501 & 5.0464 & TST & \\
\hline CHEMBL 2260863 & 688816 & 5.4 & 5.5033 & TRN & \\
\hline CHEMBL1571689 & 688816 & 8.1024 & 5.30200 & 00000000005 & TRN \\
\hline CHEMBL1990214 & 688816 & 4.9 & 4.9365 & TRN & \\
\hline CHEMBL1612318 & 688816 & 5.4 & 5.4202 & TST & \\
\hline CHEMBL1484245 & 688816 & 7.7496 & 5.2233 & TST & \\
\hline CHEMBL1594957 & 688816 & 5.25 & 5.5322 & TST & \\
\hline CHEMBL1349937 & 688816 & 4.85 & 4.921 & TRN & \\
\hline CHEMBL1451454 & 688816 & 6.8 & 5.1609 & TRN & \\
\hline CHEMBL 3193378 & 688816 & 5.55 & 5.2362 & TRN & \\
\hline CHEMBL1580160 & 688816 & 5.65 & 5.2008 & TRN & \\
\hline CHEMBL1359367 & 688816 & 5.3 & 5.767 & TST & \\
\hline CHEMBL1546959 & 688816 & 4.8 & 5.2369 & TST & \\
\hline CHEMBL3189976 & 688816 & 5.0 & 5.2785 & TST & \\
\hline CHEMBL1497135 & 688816 & 5.05 & 5.4481 & TRN & \\
\hline CHEMBL1405491 & 688816 & 4.95 & 5.2811 & TRN & \\
\hline CHEMBL1421762 & 688816 & 7.2 & 4.8009 & TRN & \\
\hline CHEMBL1458398 & 688816 & 5.0 & 5.0493 & TRN & \\
\hline CHEMBL1533190 & 688816 & 4.45 & 5.2475 & TST & \\
\hline
\end{tabular}




\begin{tabular}{|c|c|c|c|c|c|}
\hline \multicolumn{6}{|c|}{ Supplemental Table S2.txt } \\
\hline CHEMBL3208307 & 688816 & 4.45 & 5.4576 & TST & \\
\hline CHEMBL1553449 & 688816 & 5.4 & 4.8402 & TST & \\
\hline CHEMBL1342730 & 688816 & 5.85 & 5.3001 & TST & \\
\hline CHEMBL1526572 & 688816 & 4.45 & 5.1297 & TRN & \\
\hline CHEMBL1306480 & 688816 & 6.6499 & 5.0774 & TRN & \\
\hline CHEMBL1457458 & 688816 & 5.4 & 5.5996 & TRN & \\
\hline CHEMBL1348502 & 688816 & 4.9 & 4.9362 & TRN & \\
\hline CHEMBL1380773 & 688816 & 7.3002 & 5.4431 & TRN & \\
\hline CHEMBL1881714 & 688816 & 4.45 & 4.9381 & TRN & \\
\hline CHEMBL3214051 & 688816 & 4.85 & 5.1516 & TST & \\
\hline CHEMBL1527404 & 688816 & 5.7 & 5.6092 & TRN & \\
\hline CHEMBL1535798 & 688816 & 4.85 & 5.4357 & TRN & \\
\hline CHEMBL1405373 & 688816 & 4.95 & 5.0301 & TRN & \\
\hline CHEMBL1385625 & 688816 & 5.45 & 5.2159 & TST & \\
\hline CHEMBL1609437 & 688816 & 5.6 & 4.8119 & TRN & \\
\hline CHEMBL1588821 & 688816 & 5.3 & 5.3686 & TRN & \\
\hline CHEMBL1325483 & 688816 & 5.6 & 5.7134 & TRN & \\
\hline CHEMBL1603878 & 688816 & 5.0 & 4.9016 & TRN & \\
\hline CHEMBL1386857 & 688816 & 5.2 & 5.3043 & TST & \\
\hline CHEMBL1325554 & 688816 & 4.7 & 5.1811 & TRN & \\
\hline CHEMBL3210387 & 688816 & 5.0 & 5.4831 & TRN & \\
\hline CHEMBL3213337 & 688816 & 4.95 & 5.23799 & 99999999995 & TST \\
\hline CHEMBL1331548 & 688816 & 4.85 & 5.2975 & TST & \\
\hline CHEMBL 3197184 & 688816 & 4.65 & 5.1361 & TST & \\
\hline CHEMBL1368329 & 688816 & 5.15 & 5.1847 & TST & \\
\hline CHEMBL1545558 & 688816 & 4.45 & 5.1479 & TRN & \\
\hline CHEMBL40998 & 688816 & 8.4949 & 5.9654 & TRN & \\
\hline CHEMBL1481830 & 688816 & 5.25 & 5.4164 & TST & \\
\hline CHEMBL1314001 & 688816 & 5.25 & 5.2794 & TRN & \\
\hline CHEMBL1575317 & 688816 & 5.0 & 5.0926 & TST & \\
\hline CHEMBL1536590 & 688816 & 5.85 & 5.2802 & TRN & \\
\hline CHEMBL1351634 & 688816 & 5.0 & 5.1762 & TRN & \\
\hline CHEMBL3194902 & 688816 & 5.35 & 5.3318 & TRN & \\
\hline CHEMBL1347189 & 688816 & 4.5 & 5.4684 & TRN & \\
\hline CHEMBL1510443 & 688816 & 4.8 & 5.5218 & TRN & \\
\hline CHEMBL1445602 & 688816 & 4.45 & 4.7762 & TRN & \\
\hline CHEMBL1567859 & 688816 & 4.7 & 5.2632 & TRN & \\
\hline CHEMBL1412223 & 688816 & 5.05 & 5.1466 & TRN & \\
\hline CHEMBL1488130 & 688816 & 4.45 & 5.1247 & TRN & \\
\hline CHEMBL1422207 & 688816 & 6.1 & 5.6787 & TRN & \\
\hline CHEMBL1410006 & 688816 & 6.05 & 5.4395 & TRN & \\
\hline CHEMBL1556444 & 688816 & 5.45 & 5.5921 & TRN & \\
\hline CHEMBL1391168 & 688816 & 8.0506 & 5.2959 & TST & \\
\hline CHEMBL1453469 & 688816 & 5.05 & 5.1163 & TRN & \\
\hline CHEMBL1310672 & 688816 & 4.8 & 4.9155 & TRN & \\
\hline CHEMBL1489904 & 688816 & 4.45 & 5.0196 & TST & \\
\hline CHEMBL1431539 & 688816 & 6.6499 & 5.5839 & TST & \\
\hline CHEMBL1494345 & 688816 & 4.9 & 5.5566 & TRN & \\
\hline
\end{tabular}




\begin{tabular}{|c|c|c|c|c|c|}
\hline \multicolumn{6}{|c|}{ Supplemental Table S2.txt } \\
\hline CHEMBL3194261 & 688816 & 4.95 & 5.4234 & TRN & \\
\hline CHEMBL1412024 & 688816 & 5.55 & 5.6418 & TRN & \\
\hline CHEMBL1418955 & 688816 & 4.9 & 5.115 & TRN & \\
\hline CHEMBL3209146 & 688816 & 5.3 & 5.4943 & TRN & \\
\hline CHEMBL1480538 & 688816 & 8.301 & 5.4546 & TST & \\
\hline CHEMBL1348057 & 688816 & 4.9 & 4.9872 & TRN & \\
\hline CHEMBL1609273 & 688816 & 4.6 & 5.2228 & TRN & \\
\hline CHEMBL1472062 & 688816 & 4.9 & 4.9479 & TRN & \\
\hline CHEMBL1431245 & 688816 & 5.0 & 5.2332 & TRN & \\
\hline CHEMBL1304752 & 688816 & 4.85 & 5.1785 & TST & \\
\hline CHEMBL3195031 & 688816 & 4.9 & 5.2997 & TRN & \\
\hline CHEMBL1379721 & 688816 & 4.75 & 4.9065 & TRN & \\
\hline CHEMBL1309952 & 688816 & 5.0 & 5.1075 & TRN & \\
\hline CHEMBL1447292 & 688816 & 4.85 & 4.8831 & TRN & \\
\hline CHEMBL1381535 & 688816 & 5.55 & 5.3636 & TRN & \\
\hline CHEMBL1402233 & 688816 & 4.45 & 5.3023 & TRN & \\
\hline CHEMBL1596460 & 688816 & 4.95 & 5.13899 & & TRN \\
\hline CHEMBL1450384 & 688816 & 4.95 & 5.2386 & TRN & \\
\hline CHEMBL1555959 & 688816 & 4.7 & 5.4785 & TRN & \\
\hline CHEMBL3192335 & 688816 & 5.6 & 5.2306 & TRN & \\
\hline CHEMBL1506312 & 688816 & 4.9 & 5.1804 & TRN & \\
\hline CHEMBL1335131 & 688816 & 4.65 & 5.5062 & TRN & \\
\hline CHEMBL1528765 & 688816 & 4.65 & 5.1541 & TST & \\
\hline CHEMBL1348181 & 688816 & 5.0 & 4.7388 & TRN & \\
\hline CHEMBL1346668 & 688816 & 5.55 & 5.6259 & TRN & \\
\hline CHEMBL1576158 & 688816 & 4.8 & 5.1314 & TRN & \\
\hline CHEMBL1351595 & 688816 & 4.5 & 4.8438 & TRN & \\
\hline CHEMBL1514150 & 688816 & 4.85 & 5.2086 & TRN & \\
\hline CHEMBL1521023 & 688816 & 5.35 & 5.28799 & 7999999999 & TRN \\
\hline CHEMBL1364242 & 688816 & 5.0 & 5.1389 & TRN & \\
\hline CHEMBL1380444 & 688816 & 5.9 & 5.0783 & TRN & \\
\hline CHEMBL1562259 & 688816 & 5.4 & 5.3185 & TRN & \\
\hline CHEMBL1389449 & 688816 & 4.95 & 4.9923 & TRN & \\
\hline CHEMBL1407037 & 688816 & 5.1 & 5.1552 & TRN & \\
\hline CHEMBL1507028 & 688816 & 4.95 & 5.4125 & TST & \\
\hline CHEMBL1604664 & 688816 & 4.9 & 5.0507 & TRN & \\
\hline CHEMBL3189611 & 688816 & 6.45 & 5.4451 & TST & \\
\hline CHEMBL1534028 & 688816 & 5.4 & 4.9883 & TRN & \\
\hline CHEMBL1591217 & 688816 & 5.25 & 4.9187 & TST & \\
\hline CHEMBL1478512 & 688816 & 4.65 & 5.3087 & TST & \\
\hline CHEMBL1555800 & 688816 & 4.5 & 5.5157 & TST & \\
\hline CHEMBL1425536 & 688816 & 5.0 & 5.1967 & TRN & \\
\hline CHEMBL1362349 & 688816 & 5.35 & 5.6077 & TST & \\
\hline CHEMBL1414493 & 688816 & 5.2 & 5.4107 & TRN & \\
\hline CHEMBL1345666 & 688816 & 5.0 & 5.5328 & TST & \\
\hline CHEMBL1577831 & 688816 & 4.65 & 5.0759 & TRN & \\
\hline CHEMBL1327498 & 688816 & 5.65 & 5.7268 & TRN & \\
\hline CHEMBL1588432 & 688816 & 4.65 & 5.0559 & TRN & \\
\hline
\end{tabular}




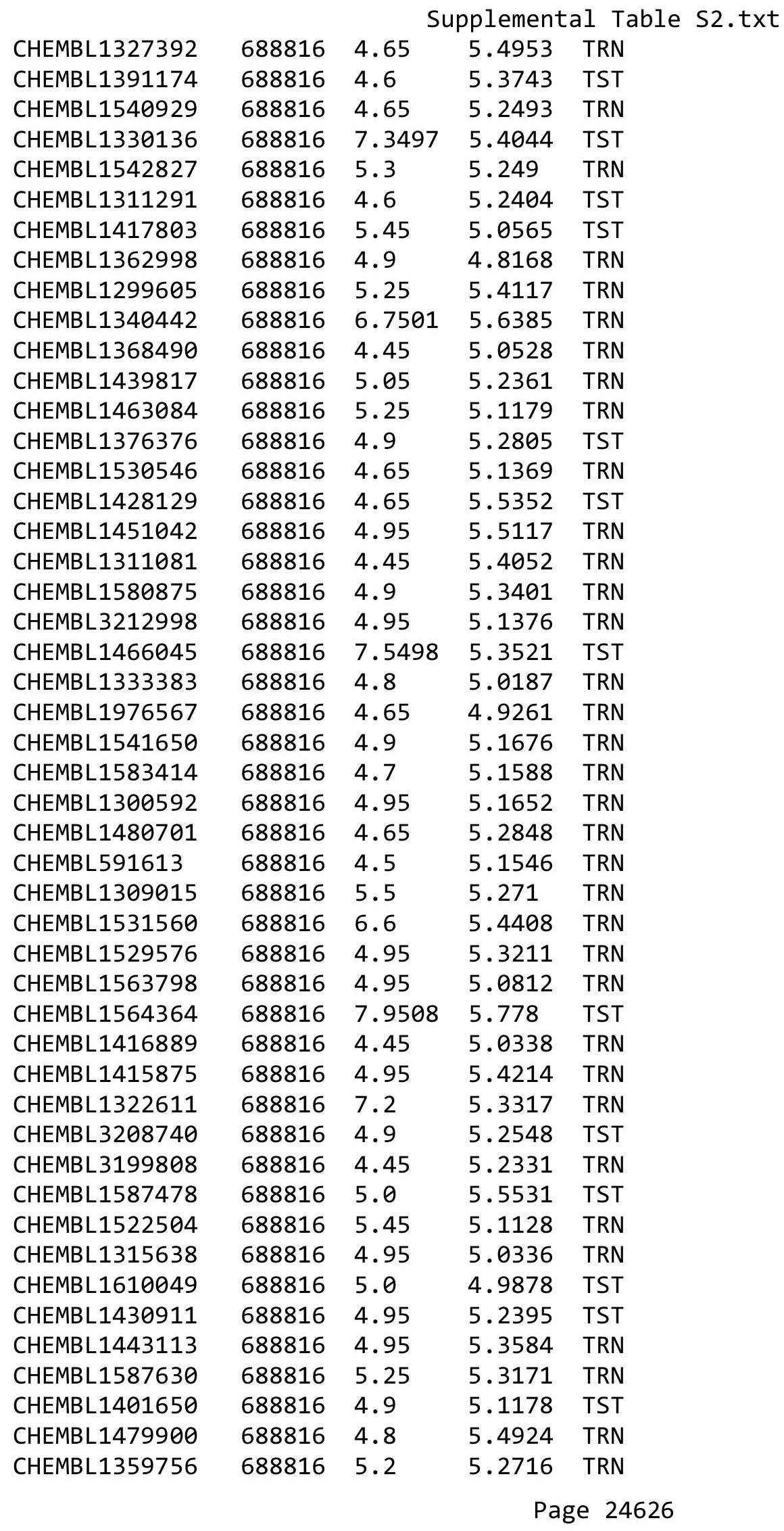




\begin{tabular}{|c|c|c|c|c|}
\hline \multicolumn{5}{|c|}{ Supplemental Table S2.txt } \\
\hline CHEMBL1339050 & 688816 & 4.45 & 5.2977 & TRN \\
\hline CHEMBL1349532 & 688816 & 4.65 & 5.3068 & TST \\
\hline CHEMBL1389955 & 688816 & 8.301 & 5.6029 & TST \\
\hline CHEMBL1484933 & 688816 & 5.5 & 5.2242 & TST \\
\hline CHEMBL1439079 & 688816 & 4.65 & 5.1101 & TRN \\
\hline CHEMBL1495188 & 688816 & 4.8 & 5.2328 & TST \\
\hline CHEMBL1378764 & 688816 & 4.5 & 4.9737 & TRN \\
\hline CHEMBL1496159 & 688816 & 5.65 & 5.6202 & TRN \\
\hline CHEMBL1455594 & 688816 & 5.4 & 5.2003 & TRN \\
\hline CHEMBL1359949 & 688816 & 5.5 & 5.5521 & TRN \\
\hline CHEMBL1347057 & 688816 & 4.9 & 5.0415 & TST \\
\hline CHEMBL1327188 & 688816 & 4.5 & 5.7251 & TRN \\
\hline CHEMBL1304948 & 688816 & 7.3497 & 5.4781 & TST \\
\hline CHEMBL1342556 & 688816 & 5.5 & 5.0995 & TRN \\
\hline CHEMBL1541721 & 688816 & 4.85 & 5.1666 & TRN \\
\hline CHEMBL1412904 & 688816 & 4.95 & 5.3471 & TRN \\
\hline CHEMBL1335623 & 688816 & 7.2 & 5.6196 & TRN \\
\hline CHEMBL1587873 & 688816 & 7.4498 & 5.4015 & TST \\
\hline CHEMBL1602747 & 688816 & 4.7 & 5.3342 & TST \\
\hline CHEMBL1322750 & 688816 & 5.5 & 5.5739 & TRN \\
\hline CHEMBL1478042 & 688816 & 4.95 & 5.4231 & TRN \\
\hline CHEMBL1406601 & 688816 & 8.301 & 5.3476 & TRN \\
\hline CHEMBL1489726 & 688816 & 5.3 & 5.0947 & TRN \\
\hline CHEMBL1565664 & 688816 & 5.6 & 5.007 & TST \\
\hline CHEMBL1341933 & 688816 & 5.15 & 5.4532 & TST \\
\hline CHEMBL1498939 & 688816 & 5.95 & 5.4543 & TST \\
\hline CHEMBL1363228 & 688816 & 4.45 & 5.2269 & TST \\
\hline CHEMBL1535265 & 688816 & 4.95 & 5.0829 & TST \\
\hline CHEMBL1425864 & 688816 & 4.45 & 5.4228 & TST \\
\hline CHEMBL1408983 & 688816 & 4.95 & 5.519 & TRN \\
\hline CHEMBL1535416 & 688816 & 4.45 & 4.8258 & TRN \\
\hline CHEMBL1556271 & 688816 & 4.7 & 5.0742 & TRN \\
\hline CHEMBL1438389 & 688816 & 4.75 & 5.075 & TRN \\
\hline CHEMBL1527256 & 688816 & 4.45 & 5.4204 & TRN \\
\hline CHEMBL1466570 & 688816 & 4.75 & 5.3813 & TST \\
\hline CHEMBL1555674 & 688816 & 4.85 & 5.7172 & TST \\
\hline CHEMBL1485979 & 688816 & 5.1 & 5.5622 & TRN \\
\hline CHEMBL1568150 & 688816 & 4.65 & 5.4086 & TST \\
\hline CHEMBL1498773 & 688816 & 5.15 & 4.6868 & TRN \\
\hline CHEMBL3209187 & 688816 & 4.9 & 5.4003 & TRN \\
\hline CHEMBL1542338 & 688816 & 4.7 & 5.0663 & TST \\
\hline CHEMBL1419205 & 688816 & 5.25 & 5.2902 & TRN \\
\hline CHEMBL1996724 & 688816 & 5.1 & 5.2181 & TRN \\
\hline CHEMBL3196608 & 688816 & 5.0 & 5.4928 & TRN \\
\hline CHEMBL1580941 & 688816 & 5.05 & 5.104 & TRN \\
\hline CHEMBL1367991 & 688816 & 4.9 & 5.1037 & TST \\
\hline CHEMBL1481401 & 688816 & 7.4001 & 4.9733 & TRN \\
\hline CHEMBL1451014 & 688816 & 7.3497 & 5.3373 & TRN \\
\hline
\end{tabular}

Page 24627 


\begin{tabular}{|c|c|c|c|c|}
\hline \multicolumn{5}{|c|}{ Supplemental Table s2.txt } \\
\hline CHEMBL1308451 & 688816 & 6.1 & 5.3578 & TRN \\
\hline CHEMBL1368187 & 688816 & 4.95 & 5.0745 & TRN \\
\hline CHEMBL1300769 & 688816 & 4.9 & 5.0773 & TRN \\
\hline CHEMBL1452229 & 688816 & 4.7 & 4.8061 & TST \\
\hline CHEMBL1505016 & 688816 & 4.45 & 5.0101 & TST \\
\hline CHEMBL1573418 & 688816 & 4.45 & 5.2024 & TRN \\
\hline CHEMBL1445225 & 688816 & 8.4559 & 5.4537 & TST \\
\hline CHEMBL1353528 & 688816 & 4.7 & 4.6014 & TRN \\
\hline CHEMBL1353926 & 688816 & 8.3468 & 5.8029 & TST \\
\hline CHEMBL1541943 & 688816 & 5.05 & 5.3381 & TST \\
\hline CHEMBL584759 & 688816 & 6.0 & 5.4577 & TRN \\
\hline CHEMBL1378418 & 688816 & 4.95 & 5.4086 & TRN \\
\hline CHEMBL1551670 & 688816 & 5.4 & 5.0968 & TST \\
\hline CHEMBL1408451 & 688816 & 5.9 & 5.5067 & TST \\
\hline CHEMBL1491707 & 688816 & 4.8 & 5.1019 & TST \\
\hline CHEMBL1310906 & 688816 & 4.9 & 5.181 & TRN \\
\hline CHEMBL1391167 & 688816 & 5.0 & 5.2969 & TRN \\
\hline CHEMBL1489778 & 688816 & 4.45 & 5.1615 & TST \\
\hline CHEMBL1343817 & 688816 & 5.45 & 5.3723 & TRN \\
\hline CHEMBL1329604 & 688816 & 4.65 & 5.1604 & TST \\
\hline CHEMBL1448969 & 688816 & 4.75 & 5.1309 & TRN \\
\hline CHEMBL1321307 & 688816 & 4.65 & 5.3494 & TST \\
\hline CHEMBL1486724 & 688816 & 8.4559 & 5.5863 & TST \\
\hline CHEMBL1483493 & 688816 & 4.95 & 4.9211 & TST \\
\hline CHEMBL1363796 & 688816 & 4.95 & 5.3723 & TST \\
\hline CHEMBL1496300 & 688816 & 8.0506 & 5.1157 & TRN \\
\hline CHEMBL1571457 & 688816 & 4.9 & 4.9442 & TRN \\
\hline CHEMBL1575206 & 688816 & 8.0 & 5.3038 & TST \\
\hline CHEMBL 1458579 & 688816 & 5.25 & 5.1275 & TRN \\
\hline CHEMBL1445776 & 688816 & 4.9 & 5.1402 & TST \\
\hline CHEMBL1387767 & 688816 & 4.8 & 4.9973 & TST \\
\hline CHEMBL1437287 & 688816 & 4.85 & 4.715 & TRN \\
\hline CHEMBL1584976 & 688816 & 4.5 & 5.3682 & TRN \\
\hline CHEMBL1237212 & 688816 & 5.55 & 5.7598 & TST \\
\hline CHEMBL1461389 & 688816 & 4.9 & 5.2288 & TRN \\
\hline CHEMBL1586331 & 688816 & 6.1 & 5.2289 & TRN \\
\hline CHEMBL3192035 & 688816 & 4.45 & 4.8936 & TRN \\
\hline CHEMBL1727680 & 688816 & 5.35 & 5.3129 & TRN \\
\hline CHEMBL1447833 & 688816 & 4.95 & 5.1702 & TRN \\
\hline CHEMBL1305030 & 688816 & 4.45 & 5.3651 & TST \\
\hline CHEMBL1447804 & 688816 & 6.8 & 5.5969 & TRN \\
\hline CHEMBL1478180 & 688816 & 5.05 & 5.5455 & TRN \\
\hline CHEMBL1423409 & 688816 & 4.95 & 5.3015 & TRN \\
\hline CHEMBL1368708 & 688816 & 4.85 & 5.193 & TRN \\
\hline CHEMBL1425377 & 688816 & 8.0 & 5.5057 & TST \\
\hline CHEMBL1418580 & 688816 & 4.75 & 5.0674 & TRN \\
\hline CHEMBL1329053 & 688816 & 5.25 & 5.8445 & TRN \\
\hline CHEMBL1446306 & 688816 & 6.15 & 5.2563 & TRN \\
\hline
\end{tabular}




\begin{tabular}{|c|c|c|c|c|}
\hline \multicolumn{5}{|c|}{ Supplemental Table S2.txt } \\
\hline CHEMBL1443218 & 688816 & 4.9 & 5.1652 & TRN \\
\hline CHEMBL1447442 & 688816 & 5.2 & 5.1267 & TRN \\
\hline CHEMBL1383593 & 688816 & 4.45 & 4.9629 & TRN \\
\hline CHEMBL1470121 & 688816 & 5.0 & 4.8534 & TRN \\
\hline CHEMBL3198791 & 688816 & 4.9 & 5.2672 & TST \\
\hline CHEMBL1592886 & 688816 & 4.65 & 5.1195 & TRN \\
\hline CHEMBL1309193 & 688816 & 5.0 & 5.1285 & TRN \\
\hline CHEMBL1412945 & 688816 & 5.85 & 5.1933 & TRN \\
\hline CHEMBL1369567 & 688816 & 4.95 & 5.2133 & TST \\
\hline CHEMBL1508642 & 688816 & 4.9 & 5.4577 & TRN \\
\hline CHEMBL1516675 & 688816 & 5.0 & 5.4185 & TST \\
\hline CHEMBL1352408 & 688816 & 4.45 & 5.3038 & TRN \\
\hline CHEMBL1498569 & 688816 & 6.7501 & 5.4586 & TRN \\
\hline CHEMBL1533542 & 688816 & 4.75 & 5.2865 & TST \\
\hline CHEMBL1604871 & 688816 & 4.45 & 5.0339 & TRN \\
\hline CHEMBL1376292 & 688816 & 4.9 & 5.1886 & TRN \\
\hline CHEMBL1498740 & 688816 & 4.95 & 5.2704 & TRN \\
\hline CHEMBL1556864 & 688816 & 4.9 & 5.3224 & TRN \\
\hline CHEMBL1379798 & 688816 & 4.8 & 5.0386 & TRN \\
\hline CHEMBL1368519 & 688816 & 5.15 & 5.141 & TRN \\
\hline CHEMBL1334739 & 688816 & 4.75 & 5.0945 & TST \\
\hline CHEMBL1431698 & 688816 & 4.9 & 5.1859 & TRN \\
\hline CHEMBL1441503 & 688816 & 6.6 & 5.402 & TRN \\
\hline CHEMBL1538140 & 688816 & 5.25 & 5.1976 & TRN \\
\hline CHEMBL1448205 & 688816 & 4.75 & 5.2559 & TST \\
\hline CHEMBL1565520 & 688816 & 4.95 & 5.0758 & TRN \\
\hline CHEMBL1424549 & 688816 & 6.5 & 5.5042 & TST \\
\hline CHEMBL1325500 & 688816 & 4.95 & 5.4557 & TRN \\
\hline CHEMBL1354648 & 688816 & 5.45 & 5.1843 & TST \\
\hline CHEMBL1344274 & 688816 & 4.95 & 5.0976 & TRN \\
\hline CHEMBL1536728 & 688816 & 4.45 & 4.9219 & TRN \\
\hline CHEMBL3209181 & 688816 & 4.95 & 5.2735 & TRN \\
\hline CHEMBL3211553 & 688816 & 4.75 & 5.1235 & TRN \\
\hline CHEMBL1336493 & 688816 & 4.7 & 5.6215 & TST \\
\hline CHEMBL1493078 & 688816 & 4.9 & 5.3941 & TRN \\
\hline CHEMBL1409365 & 688816 & 8.301 & 5.4935 & TST \\
\hline CHEMBL1381262 & 688816 & 4.8 & 5.0784 & TRN \\
\hline CHEMBL1587831 & 688816 & 4.85 & 5.2784 & TST \\
\hline CHEMBL1359603 & 688816 & 5.25 & 5.4236 & TRN \\
\hline CHEMBL1483268 & 688816 & 8.4949 & 5.4129 & TRN \\
\hline CHEMBL1603824 & 688816 & 5.5 & 5.3675 & TST \\
\hline CHEMBL1305968 & 688816 & 5.05 & 5.1207 & TRN \\
\hline CHEMBL1413625 & 688816 & 5.7 & 5.2319 & TRN \\
\hline CHEMBL1562447 & 688816 & 4.85 & 5.1372 & TRN \\
\hline CHEMBL1564924 & 688816 & 4.45 & 5.3483 & TST \\
\hline CHEMBL1312703 & 688816 & 4.6 & 5.2034 & TST \\
\hline CHEMBL1505204 & 688816 & 4.9 & 5.5341 & TRN \\
\hline CHEMBL3198531 & 688816 & 4.95 & 5.4216 & TRN \\
\hline
\end{tabular}




\begin{tabular}{|c|c|c|c|c|c|}
\hline \multicolumn{6}{|c|}{ Supplemental Table S2.txt } \\
\hline CHEMBL1453390 & 688816 & 4.85 & 5.2073 & TRN & \\
\hline CHEMBL1459442 & 688816 & 6.6499 & 5.3674 & TST & \\
\hline CHEMBL1605528 & 688816 & 4.8 & 5.535 & TRN & \\
\hline CHEMBL 2004449 & 688816 & 5.7 & 5.1442 & TRN & \\
\hline CHEMBL1324056 & 688816 & 4.9 & 4.8251 & TRN & \\
\hline CHEMBL1351094 & 688816 & 7.699 & 5.3375 & TST & \\
\hline CHEMBL 3197836 & 688816 & 4.95 & 5.1332 & TRN & \\
\hline CHEMBL1374767 & 688816 & 4.9 & 5.3571 & TRN & \\
\hline CHEMBL1531866 & 688816 & 4.75 & 5.3821 & TRN & \\
\hline CHEMBL1326010 & 688816 & 5.35 & 5.1271 & TST & \\
\hline CHEMBL1543412 & 688816 & 4.45 & 4.8404 & TRN & \\
\hline CHEMBL1343301 & 688816 & 4.45 & 5.2982 & TRN & \\
\hline CHEMBL1464344 & 688816 & 5.0 & 5.2141 & TST & \\
\hline CHEMBL1472192 & 688816 & 8.3468 & 5.7387 & TRN & \\
\hline CHEMBL1563673 & 688816 & 5.4 & 5.2481 & TRN & \\
\hline CHEMBL1382709 & 688816 & 5.65 & 5.4139 & TRN & \\
\hline CHEMBL1437796 & 688816 & 4.9 & 5.0384 & TRN & \\
\hline CHEMBL1365485 & 688816 & 5.25 & 5.3855 & TST & \\
\hline CHEMBL1470269 & 688816 & 4.95 & 5.25200 & 0000000001 & TRN \\
\hline CHEMBL1331798 & 688816 & 4.95 & 5.2419 & TRN & \\
\hline CHEMBL3192886 & 688816 & 5.5 & 5.1788 & TRN & \\
\hline CHEMBL 3210929 & 688816 & 6.7001 & 5.2005 & TST & \\
\hline CHEMBL1597667 & 688816 & 4.45 & 5.5659 & TRN & \\
\hline CHEMBL1583010 & 688816 & 4.8 & 5.2166 & TRN & \\
\hline CHEMBL1464920 & 688816 & 5.25 & 5.0952 & TRN & \\
\hline CHEMBL1334814 & 688816 & 6.7001 & 5.5036 & TST & \\
\hline CHEMBL1508108 & 688816 & 5.15 & 5.2341 & TRN & \\
\hline CHEMBL1467635 & 688816 & 5.9 & 5.5765 & TRN & \\
\hline CHEMBL1608625 & 688816 & 5.3 & 4.9372 & TRN & \\
\hline CHEMBL1459197 & 688816 & 4.45 & 5.0989 & TRN & \\
\hline CHEMBL1303448 & 688816 & 4.7 & 5.4291 & TST & \\
\hline CHEMBL1307459 & 688816 & 4.45 & 5.4996 & TST & \\
\hline CHEMBL1400527 & 688816 & 4.9 & 4.9737 & TRN & \\
\hline CHEMBL1504295 & 688816 & 7.4001 & 5.0758 & TRN & \\
\hline CHEMBL1369533 & 688816 & 5.55 & 5.0671 & TRN & \\
\hline CHEMBL1381473 & 688816 & 5.0 & 5.0321 & TRN & \\
\hline CHEMBL 224869 & 688816 & 5.0 & 5.1746 & TST & \\
\hline CHEMBL1348766 & 688816 & 5.6 & 4.9798 & TRN & \\
\hline CHEMBL1372596 & 688816 & 5.1 & 5.4763 & TRN & \\
\hline CHEMBL596631 & 688816 & 4.6 & 5.4459 & TST & \\
\hline CHEMBL1417946 & 688816 & 7.3002 & 5.6993 & TRN & \\
\hline CHEMBL1420739 & 688816 & 5.35 & 5.4718 & TST & \\
\hline CHEMBL1376145 & 688816 & 4.95 & 5.4343 & TRN & \\
\hline CHEMBL1449116 & 688816 & 5.05 & 5.4285 & TST & \\
\hline CHEMBL1386843 & 688816 & 5.4 & 5.2361 & TRN & \\
\hline CHEMBL1300168 & 688816 & 6.1 & 5.4211 & TST & \\
\hline CHEMBL1542406 & 688816 & 5.0 & 5.3849 & TRN & \\
\hline CHEMBL1339467 & 688816 & 7.3497 & 5.4715 & TRN & \\
\hline
\end{tabular}




\begin{tabular}{|c|c|c|c|c|c|}
\hline \multicolumn{6}{|c|}{ Supplemental Table S2.txt } \\
\hline CHEMBL1360654 & 688816 & 8.3468 & 5.3699 & TRN & \\
\hline CHEMBL1523069 & 688816 & 4.9 & 5.0803 & TRN & \\
\hline CHEMBL1482199 & 688816 & 5.6 & 4.8648 & TRN & \\
\hline CHEMBL1516957 & 688816 & 6.0 & 5.1698 & TST & \\
\hline CHEMBL1342723 & 688816 & 5.0 & 5.4764 & TRN & \\
\hline CHEMBL1428398 & 688816 & 6.7501 & 5.4188 & TRN & \\
\hline CHEMBL1462588 & 688816 & 4.95 & 5.4591 & TRN & \\
\hline CHEMBL1375547 & 688816 & 4.5 & 5.0606 & TRN & \\
\hline CHEMBL1344221 & 688816 & 4.9 & 5.2915 & TRN & \\
\hline CHEMBL 260560 & 688816 & 5.6 & 5.4904 & TRN & \\
\hline CHEMBL1480050 & 688816 & 6.05 & 5.2264 & TRN & \\
\hline CHEMBL1604797 & 688816 & 4.8 & 5.3151 & TRN & \\
\hline CHEMBL1449590 & 688816 & 5.35 & 5.6257 & TST & \\
\hline CHEMBL1612409 & 688816 & 4.8 & 5.6832 & TST & \\
\hline CHEMBL1563897 & 688816 & 5.9 & 5.4248 & TST & \\
\hline CHEMBL1573676 & 688816 & 4.85 & 5.2371 & TRN & \\
\hline CHEMBL1323290 & 688816 & 6.3 & 5.3521 & TRN & \\
\hline CHEMBL1458281 & 688816 & 7.8996 & 5.3137 & TRN & \\
\hline CHEMBL1414246 & 688816 & 4.8 & 5.5536 & TRN & \\
\hline CHEMBL1585269 & 688816 & 5.1 & 5.2091 & TRN & \\
\hline CHEMBL3208852 & 688816 & 5.95 & 5.2114 & TRN & \\
\hline CHEMBL1427924 & 688816 & 5.95 & 5.397 & TRN & \\
\hline CHEMBL1531456 & 688816 & 4.7 & 5.6298 & TRN & \\
\hline CHEMBL1504779 & 688816 & 6.25 & 5.2938 & TRN & \\
\hline CHEMBL1350022 & 688816 & 4.75 & 5.3421 & TRN & \\
\hline CHEMBL1466730 & 688816 & 4.9 & 5.4892 & TST & \\
\hline CHEMBL1429672 & 688816 & 4.45 & 5.7736 & TST & \\
\hline CHEMBL1578404 & 688816 & 4.8 & 4.9278 & TRN & \\
\hline CHEMBL1326541 & 688816 & 5.65 & 5.8672 & TST & \\
\hline CHEMBL1383890 & 688816 & 6.7001 & 5.76399 & 9999999999 & TST \\
\hline CHEMBL3196069 & 688816 & 4.85 & 5.2338 & TRN & \\
\hline CHEMBL1548984 & 688816 & 4.8 & 5.6573 & TRN & \\
\hline CHEMBL1470976 & 688816 & 4.7 & 5.7514 & TST & \\
\hline CHEMBL1405895 & 688816 & 5.0 & 5.5948 & TRN & \\
\hline CHEMBL1570857 & 688816 & 5.0 & 5.0762 & TRN & \\
\hline CHEMBL1576710 & 688816 & 5.0 & 5.1812 & TRN & \\
\hline CHEMBL1563992 & 688816 & 4.95 & 5.1372 & TRN & \\
\hline CHEMBL1576743 & 688816 & 4.8 & 5.1111 & TRN & \\
\hline CHEMBL3209674 & 688816 & 4.75 & 5.2971 & TST & \\
\hline CHEMBL1369836 & 688816 & 5.05 & 5.3649 & TRN & \\
\hline CHEMBL1417577 & 688816 & 4.65 & 5.273 & TRN & \\
\hline CHEMBL1979849 & 688816 & 4.75 & 5.394 & TRN & \\
\hline CHEMBL1599107 & 688816 & 4.6 & 5.1849 & TRN & \\
\hline CHEMBL1497055 & 688816 & 4.5 & 5.4411 & TRN & \\
\hline CHEMBL1600693 & 688816 & 6.95 & 5.4196 & TRN & \\
\hline CHEMBL1401212 & 688816 & 4.95 & 4.9695 & TRN & \\
\hline CHEMBL1579800 & 688816 & 5.05 & 5.0749 & TRN & \\
\hline CHEMBL1530113 & 688816 & 4.45 & 5.3458 & TRN & \\
\hline
\end{tabular}




\begin{tabular}{|c|c|c|c|c|c|}
\hline \multicolumn{6}{|c|}{ Supplemental Table S2.txt } \\
\hline CHEMBL1589651 & 688816 & 4.85 & 5.2336 & TRN & \\
\hline CHEMBL1336959 & 688816 & 4.45 & 5.2581 & TST & \\
\hline CHEMBL1377261 & 688816 & 4.5 & 5.4061 & TRN & \\
\hline CHEMBL1478753 & 688816 & 5.4 & 5.351 & TST & \\
\hline CHEMBL1402489 & 688816 & 4.4 & 5.2609 & TST & \\
\hline CHEMBL1415409 & 688816 & 4.45 & 5.1092 & TRN & \\
\hline CHEMBL1564526 & 688816 & 5.3 & 5.4447 & TRN & \\
\hline CHEMBL1398360 & 688816 & 4.95 & 5.29700 & 3000000001 & TRN \\
\hline CHEMBL273386 & 688816 & 4.95 & 5.3103 & TST & \\
\hline CHEMBL1479120 & 688816 & 5.4 & 4.9008 & TRN & \\
\hline CHEMBL1447973 & 688816 & 4.9 & 5.0242 & TRN & \\
\hline CHEMBL1424625 & 688816 & 7.6003 & 5.4792 & TRN & \\
\hline CHEMBL1329659 & 688816 & 4.55 & 5.1731 & TRN & \\
\hline CHEMBL1410569 & 688816 & 4.95 & 5.1963 & TRN & \\
\hline CHEMBL1483754 & 688816 & 5.4 & 5.4815 & TST & \\
\hline CHEMBL1601286 & 688816 & 4.5 & 5.0649 & TRN & \\
\hline CHEMBL1596567 & 688816 & 5.8 & 5.1556 & TST & \\
\hline CHEMBL1458653 & 688816 & 5.0 & 5.2325 & TRN & \\
\hline CHEMBL1421553 & 688816 & 5.3 & 5.3055 & TRN & \\
\hline CHEMBL1371080 & 688816 & 6.9 & 5.3302 & TRN & \\
\hline CHEMBL1469839 & 688816 & 4.95 & 5.176 & TST & \\
\hline CHEMBL1543123 & 688816 & 4.95 & 4.67 & TRN & \\
\hline CHEMBL1558306 & 688816 & 4.95 & 4.9225 & TRN & \\
\hline CHEMBL1602548 & 688816 & 4.5 & 5.2712 & TRN & \\
\hline CHEMBL1420355 & 688816 & 5.45 & 5.5668 & TST & \\
\hline CHEMBL3211863 & 688816 & 5.25 & 5.4148 & TRN & \\
\hline CHEMBL1603136 & 688816 & 4.9 & 5.5851 & TST & \\
\hline CHEMBL1484451 & 688816 & 4.85 & 5.2406 & TRN & \\
\hline CHEMBL1431744 & 688816 & 5.0 & 5.2551 & TRN & \\
\hline CHEMBL1456373 & 688816 & 4.45 & 4.8827 & TST & \\
\hline CHEMBL1451252 & 688816 & 4.45 & 5.1906 & TRN & \\
\hline CHEMBL1546315 & 688816 & 4.85 & 4.7597 & TST & \\
\hline CHEMBL1441319 & 688816 & 4.9 & 5.0017 & TST & \\
\hline CHEMBL1304065 & 688816 & 4.45 & 5.0937 & TRN & \\
\hline CHEMBL1432327 & 688816 & 4.45 & 5.0162 & TST & \\
\hline CHEMBL1999060 & 688816 & 7.6003 & 5.6744 & TST & \\
\hline CHEMBL1452030 & 688816 & 8.3468 & 5.4066 & TRN & \\
\hline CHEMBL1559379 & 688816 & 4.9 & 5.2219 & TRN & \\
\hline CHEMBL1488771 & 688816 & 5.4 & 5.6715 & TST & \\
\hline CHEMBL1559191 & 688816 & 5.6 & 5.3071 & TRN & \\
\hline CHEMBL1420993 & 688816 & 5.0 & 5.1304 & TRN & \\
\hline CHEMBL1360873 & 688816 & 4.9 & 5.26399 & 9999999999 & TRN \\
\hline CHEMBL1378375 & 688816 & 4.45 & 5.3047 & TRN & \\
\hline CHEMBL1422858 & 688816 & 4.85 & 5.4347 & TRN & \\
\hline CHEMBL1585090 & 688816 & 7.5003 & 5.3726 & TST & \\
\hline CHEMBL3192785 & 688816 & 4.5 & 5.3234 & TRN & \\
\hline CHEMBL1532184 & 688816 & 4.95 & 5.5224 & TRN & \\
\hline CHEMBL1401689 & 688816 & 4.75 & 5.25 & TRN & \\
\hline
\end{tabular}




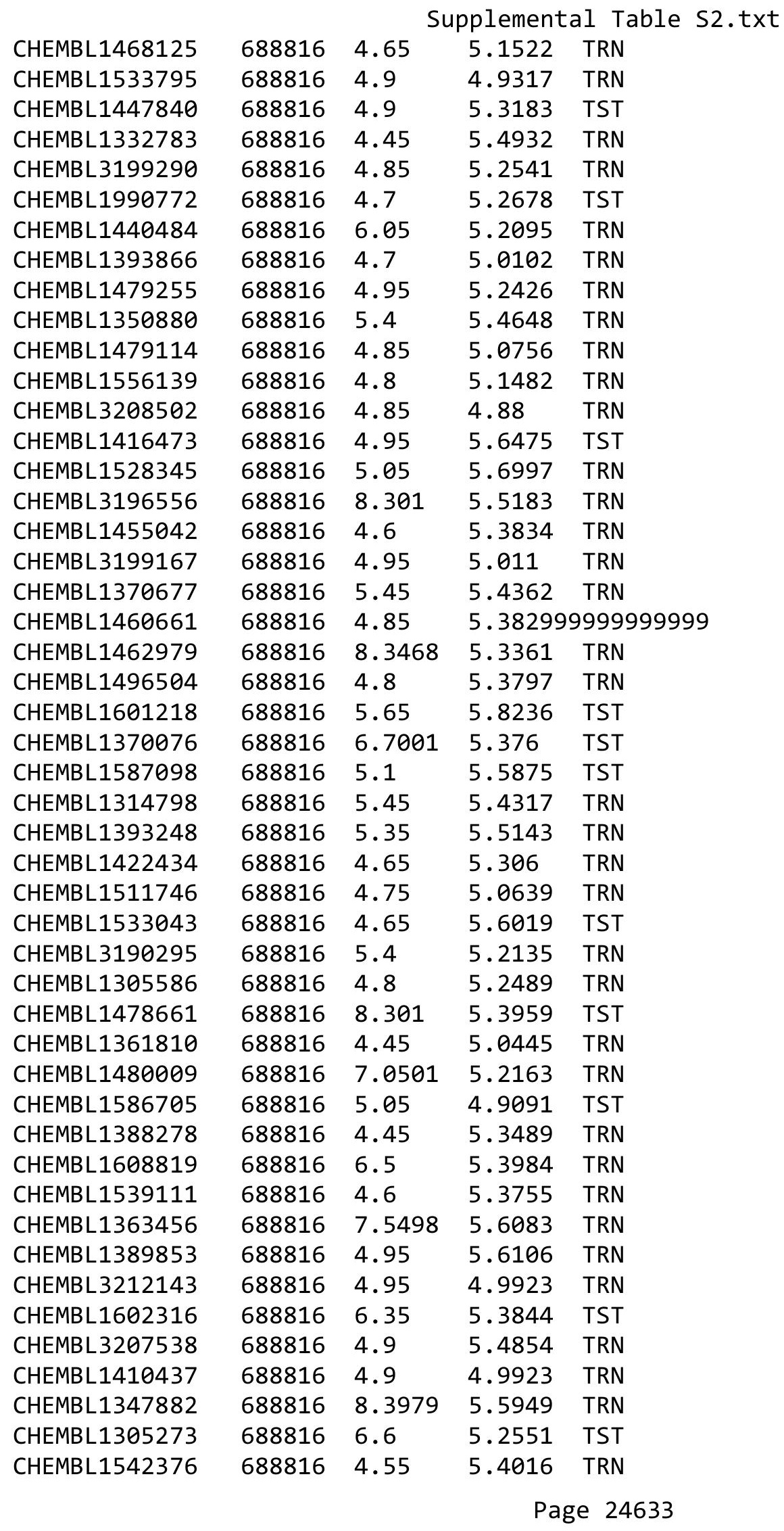




\begin{tabular}{|c|c|c|c|c|}
\hline \multicolumn{5}{|c|}{ Supplemental Table S2.txt } \\
\hline CHEMBL1602800 & 688816 & 5.2 & 5.1752 & TRN \\
\hline CHEMBL1373873 & 688816 & 5.25 & 5.49799 & 9999999999 \\
\hline CHEMBL1477488 & 688816 & 4.8 & 5.1002 & TRN \\
\hline CHEMBL2006568 & 688816 & 5.1 & 4.9158 & TRN \\
\hline CHEMBL1334887 & 688816 & 4.9 & 5.1852 & TRN \\
\hline CHEMBL3351063 & 688816 & 5.55 & 5.3058 & TST \\
\hline CHEMBL1517603 & 688816 & 4.9 & 5.0174 & TRN \\
\hline CHEMBL1565830 & 688816 & 5.55 & 5.3247 & TRN \\
\hline CHEMBL1505240 & 688816 & 5.35 & 5.2726 & TRN \\
\hline CHEMBL1383639 & 688816 & 4.45 & 5.3469 & TRN \\
\hline CHEMBL1411573 & 688816 & 5.55 & 5.0106 & TST \\
\hline CHEMBL1484486 & 688816 & 7.0 & 5.3355 & TRN \\
\hline CHEMBL1427379 & 688816 & 4.95 & 5.4133 & TRN \\
\hline CHEMBL1413208 & 688816 & 4.95 & 5.2428 & TRN \\
\hline CHEMBL1986678 & 688816 & 4.95 & 4.8544 & TRN \\
\hline CHEMBL106265 & 688816 & 4.8 & 5.7261 & TST \\
\hline CHEMBL1493829 & 688816 & 6.5501 & 5.0446 & TRN \\
\hline CHEMBL3195918 & 688816 & 4.45 & 4.9727 & TRN \\
\hline CHEMBL1299956 & 688816 & 5.8 & 4.9412 & TRN \\
\hline CHEMBL1361273 & 688816 & 4.95 & 5.2045 & TST \\
\hline CHEMBL1458614 & 688816 & 8.3979 & 5.5229 & TRN \\
\hline CHEMBL1732228 & 688816 & 4.9 & 5.0646 & TRN \\
\hline CHEMBL1371555 & 688816 & 4.8 & 5.2016 & TRN \\
\hline CHEMBL1493497 & 688816 & 5.3 & 5.3127 & TRN \\
\hline CHEMBL1451989 & 688816 & 8.301 & 5.4715 & TST \\
\hline CHEMBL1352748 & 688816 & 4.85 & 5.4486 & TRN \\
\hline CHEMBL1598707 & 688816 & 4.9 & 5.0319 & TRN \\
\hline CHEMBL1451095 & 688816 & 7.8996 & 5.1264 & TRN \\
\hline CHEMBL1422168 & 688816 & 6.8 & 5.4578 & TRN \\
\hline CHEMBL1578302 & 688816 & 5.0 & 5.2416 & TRN \\
\hline CHEMBL1499899 & 688816 & 5.1 & 5.4462 & TRN \\
\hline CHEMBL1339685 & 688816 & 5.0 & 5.2657 & TRN \\
\hline CHEMBL1337802 & 688816 & 4.8 & 5.358 & TRN \\
\hline CHEMBL1448262 & 688816 & 5.15 & 5.3442 & TRN \\
\hline CHEMBL1525967 & 688816 & 5.3 & 5.3437 & TRN \\
\hline CHEMBL1986443 & 688816 & 4.75 & 5.2342 & TRN \\
\hline CHEMBL1328308 & 688816 & 8.301 & 5.5263 & TRN \\
\hline CHEMBL1969647 & 688816 & 4.9 & 5.0458 & TRN \\
\hline CHEMBL492091 & 688816 & 5.0 & 4.7282 & TST \\
\hline CHEMBL1528143 & 688816 & 8.3468 & 5.5982 & TST \\
\hline CHEMBL1563317 & 688816 & 5.3 & 5.3415 & TST \\
\hline CHEMBL1493560 & 688816 & 4.9 & 5.3601 & TST \\
\hline CHEMBL1403276 & 688816 & 6.1 & 5.4109 & TRN \\
\hline CHEMBL1352528 & 688816 & 5.2 & 5.1536 & TRN \\
\hline CHEMBL1486462 & 688816 & 5.2 & 5.473 & TRN \\
\hline CHEMBL3196108 & 688816 & 5.0 & 5.2985 & TRN \\
\hline CHEMBL1306782 & 688816 & 4.85 & 5.2169 & TST \\
\hline CHEMBL1609640 & 688816 & 5.2 & 5.3321 & TST \\
\hline
\end{tabular}




\begin{tabular}{|c|c|c|c|c|}
\hline \multicolumn{5}{|c|}{ Supplemental Table S2.txt } \\
\hline CHEMBL1451815 & 688816 & 6.5 & 5.2492 & TRN \\
\hline CHEMBL1393777 & 688816 & 5.15 & 5.135 & TST \\
\hline CHEMBL1490323 & 688816 & 4.6 & 5.1424 & TRN \\
\hline CHEMBL1366088 & 688816 & 4.9 & 5.5239 & TRN \\
\hline CHEMBL1972346 & 688816 & 6.0 & 5.4997 & TRN \\
\hline CHEMBL3193962 & 688816 & 4.5 & 5.2755 & TST \\
\hline CHEMBL357389 & 688816 & 5.05 & 5.0322 & TST \\
\hline CHEMBL1408161 & 688816 & 4.55 & 5.1529 & TRN \\
\hline CHEMBL1434738 & 688816 & 4.45 & 5.254 & TRN \\
\hline CHEMBL1575626 & 688816 & 4.9 & 5.1932 & TRN \\
\hline CHEMBL1305756 & 688816 & 4.55 & 5.159 & TRN \\
\hline CHEMBL1386972 & 688816 & 5.15 & 5.2889 & TRN \\
\hline CHEMBL1603512 & 688816 & 4.5 & 5.2428 & TRN \\
\hline CHEMBL1539362 & 688816 & 5.15 & 5.1586 & TRN \\
\hline CHEMBL1578957 & 688816 & 5.75 & 5.5547 & TRN \\
\hline CHEMBL1335616 & 688816 & 4.9 & 5.3865 & TRN \\
\hline CHEMBL1469215 & 688816 & 4.8 & 5.7843 & TRN \\
\hline CHEMBL1424109 & 688816 & 4.45 & 5.3567 & TRN \\
\hline CHEMBL1373541 & 688816 & 4.45 & 5.3827 & TRN \\
\hline CHEMBL1429217 & 688816 & 4.8 & 5.2335 & TRN \\
\hline CHEMBL3208732 & 688816 & 5.2 & 5.4468 & TRN \\
\hline CHEMBL1390735 & 688816 & 5.45 & 5.268 & TRN \\
\hline CHEMBL1407433 & 688816 & 8.6576 & 5.311 & TST \\
\hline CHEMBL1447416 & 688816 & 4.95 & 5.334 & TST \\
\hline CHEMBL1547559 & 688816 & 6.35 & 5.3528 & TST \\
\hline CHEMBL1330989 & 688816 & 4.75 & 5.2067 & TRN \\
\hline CHEMBL1549093 & 688816 & 4.85 & 4.7855 & TRN \\
\hline CHEMBL1411872 & 688816 & 4.85 & 5.0001 & TRN \\
\hline CHEMBL1499599 & 688816 & 7.5003 & 5.3247 & TST \\
\hline CHEMBL1560404 & 688816 & 8.0506 & 5.4607 & TRN \\
\hline CHEMBL1496455 & 688816 & 5.55 & 4.9087 & TRN \\
\hline CHEMBL1465159 & 688816 & 4.7 & 4.9853 & TRN \\
\hline CHEMBL1399393 & 688816 & 5.35 & 5.4178 & TRN \\
\hline CHEMBL1613411 & 688816 & 5.15 & 5.0554 & TRN \\
\hline CHEMBL1351129 & 688816 & 5.8 & 5.3476 & TST \\
\hline CHEMBL1576791 & 688816 & 5.25 & 5.1041 & TRN \\
\hline CHEMBL1555165 & 688816 & 4.75 & 5.1914 & TST \\
\hline CHEMBL1388880 & 688816 & 6.6 & 5.574 & TRN \\
\hline CHEMBL578878 & 688816 & 5.0 & 5.1945 & TRN \\
\hline CHEMBL1434358 & 688816 & 4.95 & 5.0026 & TRN \\
\hline CHEMBL1523124 & 688816 & 5.05 & 5.1551 & TRN \\
\hline CHEMBL1342936 & 688816 & 5.0 & 5.1928 & TRN \\
\hline CHEMBL1347637 & 688816 & 4.65 & 5.2923 & TST \\
\hline CHEMBL1983902 & 688816 & 5.45 & 5.7347 & TRN \\
\hline CHEMBL1591668 & 688816 & 4.45 & 5.2675 & TST \\
\hline CHEMBL1413210 & 688816 & 7.9508 & 5.4358 & TST \\
\hline CHEMBL1495029 & 688816 & 8.3468 & 5.3191 & TRN \\
\hline CHEMBL1978651 & 688816 & 4.95 & 5.2041 & TST \\
\hline
\end{tabular}




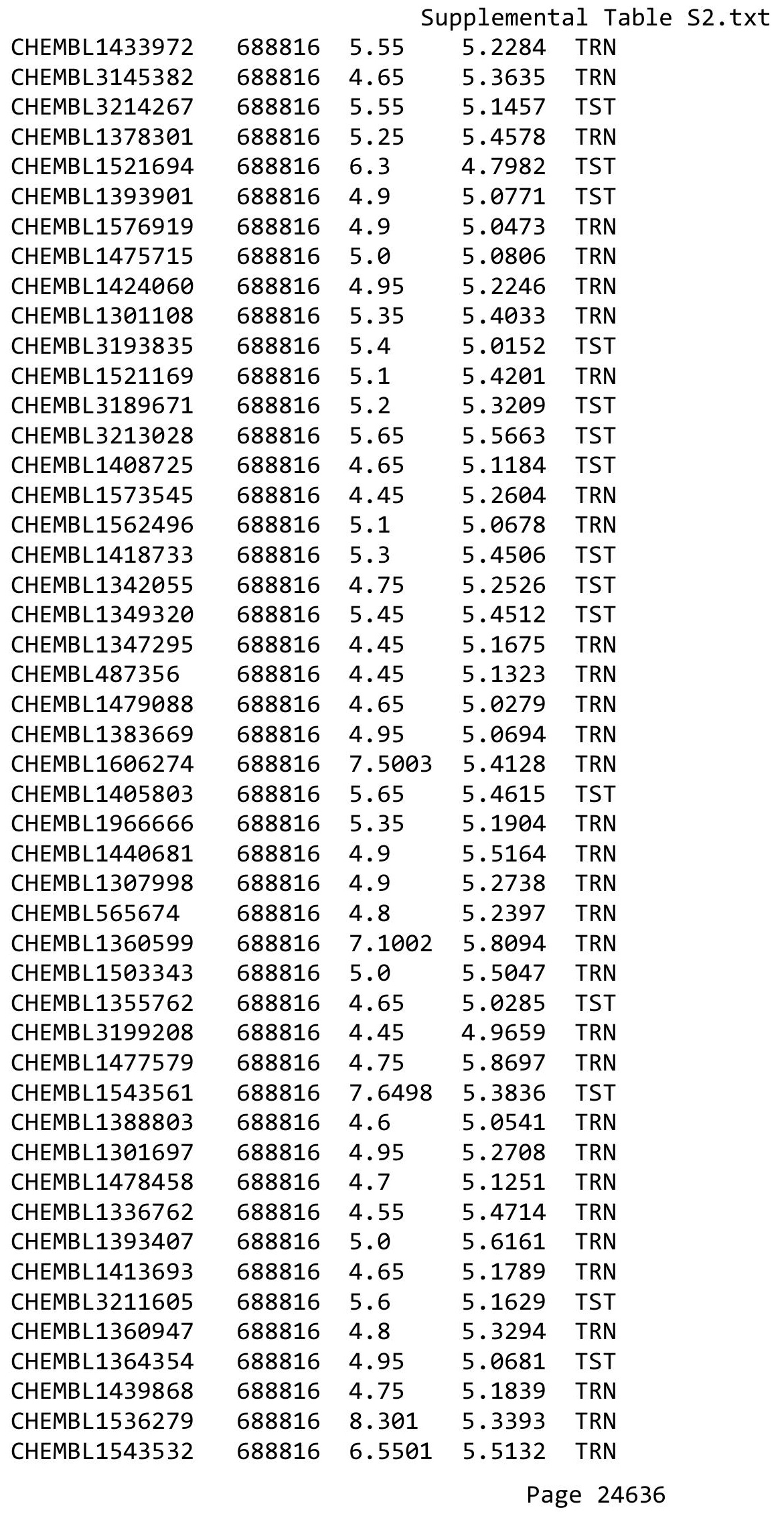




\begin{tabular}{|c|c|c|c|c|c|}
\hline \multicolumn{6}{|c|}{ Supplemental Table S2.txt } \\
\hline CHEMBL1393352 & 688816 & 4.85 & 5.3033 & TRN & \\
\hline CHEMBL1307158 & 688816 & 4.95 & 5.2465 & TRN & \\
\hline CHEMBL1308105 & 688816 & 4.95 & 5.4511 & TST & \\
\hline CHEMBL1594943 & 688816 & 4.9 & 5.5258 & TRN & \\
\hline CHEMBL1605300 & 688816 & 5.65 & 5.0858 & TRN & \\
\hline CHEMBL1338201 & 688816 & 5.25 & 5.3069 & TRN & \\
\hline CHEMBL1345831 & 688816 & 4.8 & 4.9577 & TRN & \\
\hline CHEMBL1597777 & 688816 & 4.95 & 5.0679 & TRN & \\
\hline CHEMBL1559889 & 688816 & 4.9 & 5.4311 & TST & \\
\hline CHEMBL1324559 & 688816 & 5.3 & 5.4504 & TST & \\
\hline CHEMBL1491158 & 688816 & 4.9 & 4.7794 & TRN & \\
\hline CHEMBL1311492 & 688816 & 4.7 & 4.9953 & TRN & \\
\hline CHEMBL1338574 & 688816 & 4.9 & 5.3028 & TST & \\
\hline CHEMBL1477958 & 688816 & 4.8 & 5.0961 & TST & \\
\hline CHEMBL1464644 & 688816 & 4.45 & 4.8554 & TST & \\
\hline CHEMBL1448495 & 688816 & 7.5003 & 5.1407 & TRN & \\
\hline CHEMBL3213916 & 688816 & 5.9 & 5.6761 & TST & \\
\hline CHEMBL3214253 & 688816 & 5.1 & 5.1682 & TST & \\
\hline CHEMBL1484975 & 688816 & 5.25 & 5.3383 & TST & \\
\hline CHEMBL1504879 & 688816 & 5.35 & 5.0291 & TRN & \\
\hline CHEMBL1457780 & 688816 & 4.45 & 5.0061 & TRN & \\
\hline CHEMBL3211215 & 688816 & 4.95 & 5.1165 & TRN & \\
\hline CHEMBL1587874 & 688816 & 4.85 & 5.4887 & TRN & \\
\hline CHEMBL1368268 & 688816 & 4.8 & 5.0629 & TRN & \\
\hline CHEMBL1572929 & 688816 & 4.9 & 5.3146 & TRN & \\
\hline CHEMBL1534744 & 688816 & 5.35 & 5.0025 & TRN & \\
\hline CHEMBL1495189 & 688816 & 6.4 & 5.0395 & TST & \\
\hline CHEMBL1560329 & 688816 & 5.65 & 4.5937 & TRN & \\
\hline CHEMBL1464261 & 688816 & 5.0 & 4.927 & TRN & \\
\hline CHEMBL1441888 & 688816 & 4.95 & 5.1269 & TRN & \\
\hline CHEMBL1505757 & 688816 & 5.1 & 5.3553 & TRN & \\
\hline CHEMBL1505615 & 688816 & 4.45 & 5.23799 & 99999999995 & TRN \\
\hline CHEMBL1457545 & 688816 & 4.8 & 5.4125 & TRN & \\
\hline CHEMBL1535921 & 688816 & 6.0 & 5.3912 & TRN & \\
\hline CHEMBL 3213748 & 688816 & 6.3 & 5.2996 & TST & \\
\hline CHEMBL1215547 & 688816 & 4.5 & 5.2332 & TRN & \\
\hline CHEMBL1394116 & 688816 & 5.05 & 4.9301 & TRN & \\
\hline CHEMBL1309951 & 688816 & 4.8 & 5.3727 & TST & \\
\hline CHEMBL1468662 & 688816 & 5.1 & 5.449 & TRN & \\
\hline CHEMBL1445590 & 688816 & 4.7 & 4.6144 & TRN & \\
\hline CHEMBL1310551 & 688816 & 4.6 & 5.0399 & TRN & \\
\hline CHEMBL3197509 & 688816 & 5.0 & 5.397 & TRN & \\
\hline CHEMBL1327840 & 688816 & 4.45 & 5.1461 & TST & \\
\hline CHEMBL1334261 & 688816 & 6.6499 & 5.7852 & TRN & \\
\hline CHEMBL3210035 & 688816 & 4.7 & 5.2032 & TRN & \\
\hline CHEMBL1587270 & 688816 & 4.9 & 5.0914 & TRN & \\
\hline CHEMBL 3213254 & 688816 & 5.55 & 5.4716 & TST & \\
\hline CHEMBL1498307 & 688816 & 6.1 & 4.965 & TST & \\
\hline
\end{tabular}




\begin{tabular}{|c|c|c|c|c|c|}
\hline \multicolumn{6}{|c|}{ Supplemental Table S2.txt } \\
\hline CHEMBL 3194052 & 688816 & 5.35 & 5.6116 & TRN & \\
\hline CHEMBL1465319 & 688816 & 5.2 & 5.1337 & TRN & \\
\hline CHEMBL1493225 & 688816 & 5.95 & 4.8791 & TRN & \\
\hline CHEMBL1425271 & 688816 & 4.9 & 5.2806 & TRN & \\
\hline CHEMBL1398663 & 688816 & 4.9 & 4.7366 & TRN & \\
\hline CHEMBL3191594 & 688816 & 7.0 & 5.3568 & TRN & \\
\hline CHEMBL1474094 & 688816 & 7.5498 & 5.1315 & TST & \\
\hline CHEMBL1430381 & 688816 & 4.85 & 5.081 & TRN & \\
\hline CHEMBL1385474 & 688816 & 5.15 & 5.6911 & TST & \\
\hline CHEMBL1404669 & 688816 & 8.3468 & 5.2784 & TST & \\
\hline CHEMBL1318943 & 688816 & 4.85 & 5.1436 & TST & \\
\hline CHEMBL1529252 & 688816 & 4.5 & 5.0115 & TRN & \\
\hline CHEMBL1372256 & 688816 & 4.65 & 5.0975 & TRN & \\
\hline CHEMBL1426427 & 688816 & 4.6 & 5.2172 & TRN & \\
\hline CHEMBL1449761 & 688816 & 5.55 & 5.3854 & TRN & \\
\hline CHEMBL1477639 & 688816 & 4.75 & 5.6571 & TRN & \\
\hline CHEMBL1300015 & 688816 & 4.7 & 5.3714 & TRN & \\
\hline CHEMBL17201 & 688816 & 4.45 & 4.8852 & TRN & \\
\hline CHEMBL1384719 & 688816 & 4.85 & 5.3895 & TST & \\
\hline CHEMBL1465380 & 688816 & 4.65 & 5.2497 & TRN & \\
\hline CHEMBL1598261 & 688816 & 4.65 & 5.0244 & TRN & \\
\hline CHEMBL1331875 & 688816 & 6.1 & 5.2673 & TRN & \\
\hline CHEMBL1586346 & 688816 & 4.85 & 5.1752 & TRN & \\
\hline CHEMBL1335727 & 688816 & 8.301 & 5.5407 & TST & \\
\hline CHEMBL1989897 & 688816 & 5.4 & 4.9826 & TST & \\
\hline CHEMBL1539222 & 688816 & 5.0 & 5.3308 & TST & \\
\hline CHEMBL1350550 & 688816 & 5.4 & 5.7296 & TRN & \\
\hline CHEMBL1430037 & 688816 & 4.75 & 5.653 & TRN & \\
\hline CHEMBL1513731 & 688816 & 4.45 & 5.2161 & TRN & \\
\hline CHEMBL1352107 & 688816 & 4.45 & 5.2266 & TST & \\
\hline CHEMBL1591205 & 688816 & 5.45 & 6.16100 & 00000000005 & TRN \\
\hline CHEMBL1345865 & 688816 & 4.95 & 5.2621 & TRN & \\
\hline CHEMBL1495205 & 688816 & 4.95 & 5.0807 & TRN & \\
\hline CHEMBL1545224 & 688816 & 5.95 & 5.8467 & TRN & \\
\hline CHEMBL1510033 & 688816 & 4.45 & 5.2384 & TST & \\
\hline CHEMBL1546398 & 688816 & 5.1 & 5.5455 & TRN & \\
\hline CHEMBL1366850 & 688816 & 4.45 & 5.2676 & TST & \\
\hline CHEMBL1540558 & 688816 & 5.2 & 5.0844 & TST & \\
\hline CHEMBL1405432 & 688816 & 4.85 & 4.8605 & TST & \\
\hline CHEMBL1585940 & 688816 & 4.45 & 4.7942 & TRN & \\
\hline CHEMBL1455054 & 688816 & 4.5 & 5.1076 & TRN & \\
\hline CHEMBL1507781 & 688816 & 5.0 & 5.2541 & TRN & \\
\hline CHEMBL1404186 & 688816 & 6.05 & 5.4529 & TST & \\
\hline CHEMBL1337255 & 688816 & 4.95 & 5.267 & TRN & \\
\hline CHEMBL1375717 & 688816 & 5.1 & 5.7474 & TRN & \\
\hline CHEMBL1360849 & 688816 & 5.25 & 5.2117 & TRN & \\
\hline CHEMBL1307766 & 688816 & 4.95 & 5.3063 & TRN & \\
\hline CHEMBL1300404 & 688816 & 4.95 & 5.6566 & TRN & \\
\hline
\end{tabular}




\begin{tabular}{|c|c|c|c|c|}
\hline \multicolumn{5}{|c|}{ Supplemental Table S2.txt } \\
\hline CHEMBL1401818 & 688816 & 4.85 & 4.9622 & TRN \\
\hline CHEMBL1361072 & 688816 & 4.45 & 5.9437 & TRN \\
\hline CHEMBL1520311 & 688816 & 5.0 & 5.1824 & TRN \\
\hline CHEMBL1541571 & 688816 & 4.95 & 5.1186 & TRN \\
\hline CHEMBL1982658 & 688816 & 4.6 & 5.351 & TRN \\
\hline CHEMBL1402437 & 688816 & 4.85 & 5.1248 & TRN \\
\hline CHEMBL 3194477 & 688816 & 5.4 & 4.9331 & TRN \\
\hline CHEMBL1348933 & 688816 & 4.55 & 4.9109 & TRN \\
\hline CHEMBL1389361 & 688816 & 5.1 & 5.3409 & TRN \\
\hline CHEMBL1470042 & 688816 & 8.301 & 5.7329 & TRN \\
\hline CHEMBL1495788 & 688816 & 5.1 & 5.1786 & TRN \\
\hline CHEMBL1606798 & 688816 & 5.0 & 5.1459 & TRN \\
\hline CHEMBL1407724 & 688816 & 5.5 & 5.5387 & TST \\
\hline CHEMBL1346157 & 688816 & 6.7501 & 5.5764 & TRN \\
\hline CHEMBL1583473 & 688816 & 4.95 & 5.3408 & TRN \\
\hline CHEMBL1376879 & 688816 & 5.1 & 5.3637 & TRN \\
\hline CHEMBL3195720 & 688816 & 4.75 & 5.2587 & TRN \\
\hline CHEMBL1321820 & 688816 & 4.95 & 5.3329 & TRN \\
\hline CHEMBL1417187 & 688816 & 5.55 & 5.5586 & TRN \\
\hline CHEMBL1439249 & 688816 & 7.8996 & 5.3433 & TRN \\
\hline CHEMBL1326028 & 688816 & 5.05 & 5.2643 & TRN \\
\hline CHEMBL1490298 & 688816 & 8.4559 & 5.0668 & TST \\
\hline CHEMBL1426049 & 688816 & 5.3 & 5.3505 & TRN \\
\hline CHEMBL3192170 & 688816 & 5.2 & 5.2649 & TRN \\
\hline CHEMBL1343665 & 688816 & 5.5 & 5.3128 & TRN \\
\hline CHEMBL1538389 & 688816 & 4.45 & 5.0123 & TST \\
\hline CHEMBL1608267 & 688816 & 5.7 & 5.2036 & TRN \\
\hline CHEMBL1557685 & 688816 & 8.301 & 5.263 & TST \\
\hline CHEMBL1562684 & 688816 & 5.45 & 5.2459 & TRN \\
\hline CHEMBL1310530 & 688816 & 7.5003 & 5.3654 & TST \\
\hline CHEMBL1463718 & 688816 & 4.45 & 4.721 & TRN \\
\hline CHEMBL 3189648 & 688816 & 6.3 & 5.5531 & TRN \\
\hline CHEMBL1532668 & 688816 & 4.45 & 5.3857 & TST \\
\hline CHEMBL1562795 & 688816 & 5.4 & 5.2743 & TST \\
\hline CHEMBL1550510 & 688816 & 6.2 & 4.9302 & TRN \\
\hline CHEMBL1411551 & 688816 & 4.65 & 5.0214 & TRN \\
\hline CHEMBL1561158 & 688816 & 5.7 & 5.2743 & TRN \\
\hline CHEMBL1382867 & 688816 & 5.25 & 5.4015 & TRN \\
\hline CHEMBL1412050 & 688816 & 5.2 & 5.2828 & TST \\
\hline CHEMBL1379921 & 688816 & 7.6003 & 5.1574 & TST \\
\hline CHEMBL1360528 & 688816 & 5.25 & 5.13 & TRN \\
\hline CHEMBL1575372 & 688816 & 4.9 & 5.1469 & TRN \\
\hline CHEMBL1506874 & 688816 & 5.5 & 5.4745 & TRN \\
\hline CHEMBL1516891 & 688816 & 4.7 & 5.034 & TRN \\
\hline CHEMBL1460825 & 688816 & 4.7 & 5.5338 & TRN \\
\hline CHEMBL1508300 & 688816 & 5.45 & 5.2643 & TRN \\
\hline CHEMBL1596318 & 688816 & 4.75 & 5.0 & TST \\
\hline CHEMBL1386863 & 688816 & 4.7 & 5.3459 & TRN \\
\hline
\end{tabular}




\begin{tabular}{|c|c|c|c|c|c|}
\hline \multicolumn{6}{|c|}{ pıemental } \\
\hline CHEMBL1571496 & 688816 & 4.85 & 5.8959 & TST & \\
\hline CHEMBL1328500 & 688816 & 4.95 & 4.7161 & TRN & \\
\hline CHEMBL1434727 & 688816 & 5.05 & 4.9938 & TRN & \\
\hline CHEMBL3196941 & 688816 & 6.05 & 5.3441 & TRN & \\
\hline CHEMBL1319704 & 688816 & 4.7 & 4.865 & TRN & \\
\hline CHEMBL462314 & 688816 & 5.4 & 5.4836 & TST & \\
\hline CHEMBL3210360 & 688816 & 4.9 & 5.54700 & 0000000001 & TRN \\
\hline CHEMBL1570464 & 688816 & 4.9 & 5.3231 & TRN & \\
\hline CHEMBL3207823 & 688816 & 4.9 & 5.2909 & TRN & \\
\hline CHEMBL1349570 & 688816 & 4.45 & 5.0678 & TRN & \\
\hline CHEMBL3190606 & 688816 & 5.15 & 4.9075 & TRN & \\
\hline CHEMBL1301945 & 688816 & 5.0 & 5.1853 & TRN & \\
\hline CHEMBL1323854 & 688816 & 5.0 & 5.2703 & TRN & \\
\hline CHEMBL3194256 & 688816 & 5.05 & 5.2615 & TRN & \\
\hline CHEMBL1379927 & 688816 & 4.9 & 5.6183 & TRN & \\
\hline CHEMBL1422008 & 688816 & 4.65 & 5.2841 & TRN & \\
\hline CHEMBL1372113 & 688816 & 5.35 & 5.5773 & TST & \\
\hline CHEMBL1403713 & 688816 & 5.1 & 5.1679 & TRN & \\
\hline CHEMBL1540808 & 688816 & 4.85 & 5.166 & TRN & \\
\hline CHEMBL1087863 & 688816 & 4.7 & 5.0565 & TRN & \\
\hline CHEMBL1545495 & 688816 & 6.5501 & 5.5013 & TRN & \\
\hline CHEMBL1332347 & 688816 & 5.35 & 5.5624 & TRN & \\
\hline CHEMBL3195180 & 688816 & 4.6 & 5.2626 & TRN & \\
\hline CHEMBL1540736 & 688816 & 5.1 & 4.8404 & TRN & \\
\hline CHEMBL601970 & 688816 & 5.0 & 5.4291 & TRN & \\
\hline CHEMBL3196003 & 688816 & 6.5501 & 5.2972 & TRN & \\
\hline CHEMBL571295 & 688816 & 4.95 & 5.6498 & TRN & \\
\hline CHEMBL1580774 & 688816 & 5.6 & 5.29799 & 9999999999 & TRN \\
\hline CHEMBL1383496 & 688816 & 7.6003 & 4.7954 & TST & \\
\hline CHEMBL1415148 & 688816 & 4.85 & 5.2957 & TST & \\
\hline CHEMBL1391819 & 688816 & 4.9 & 5.2725 & TRN & \\
\hline CHEMBL1383514 & 688816 & 4.45 & 5.1217 & TRN & \\
\hline CHEMBL1334336 & 688816 & 4.45 & 5.1205 & TST & \\
\hline CHEMBL1497255 & 688816 & 4.75 & 4.9492 & TRN & \\
\hline CHEMBL1325117 & 688816 & 4.85 & 5.0475 & TST & \\
\hline CHEMBL1334508 & 688816 & 4.95 & 5.67399 & 99999999995 & TRN \\
\hline CHEMBL1442780 & 688816 & 4.55 & 5.4786 & TST & \\
\hline CHEMBL1462373 & 688816 & 5.95 & 5.5706 & TRN & \\
\hline CHEMBL1495892 & 688816 & 4.9 & 5.0804 & TRN & \\
\hline CHEMBL1576054 & 688816 & 4.45 & 5.4711 & TRN & \\
\hline CHEMBL1369478 & 688816 & 4.45 & 5.379 & TST & \\
\hline CHEMBL1542043 & 688816 & 4.95 & 5.1317 & TRN & \\
\hline CHEMBL1362225 & 688816 & 4.9 & 5.3759 & TRN & \\
\hline CHEMBL1400195 & 688816 & 4.75 & 5.0132 & TST & \\
\hline CHEMBL1424048 & 688816 & 5.2 & 5.3856 & TRN & \\
\hline CHEMBL1333047 & 688816 & 5.1 & 5.6929 & TRN & \\
\hline CHEMBL1589416 & 688816 & 4.45 & 5.3134 & TRN & \\
\hline CHEMBL1571454 & 688816 & 5.5 & 5.3521 & TRN & \\
\hline
\end{tabular}




\begin{tabular}{|c|c|c|c|c|c|}
\hline \multicolumn{6}{|c|}{ Supplemental Table S2.txt } \\
\hline CHEMBL1376772 & 688816 & 4.95 & 5.0143 & TST & \\
\hline CHEMBL1332524 & 688816 & 5.3 & 5.1054 & TRN & \\
\hline CHEMBL1412828 & 688816 & 4.8 & 5.0576 & TRN & \\
\hline CHEMBL1494701 & 688816 & 5.75 & 5.4879 & TRN & \\
\hline CHEMBL1425367 & 688816 & 5.25 & 4.9358 & TRN & \\
\hline CHEMBL1360867 & 688816 & 6.9 & 5.3024 & TST & \\
\hline CHEMBL1416310 & 688816 & 4.75 & 5.1928 & TRN & \\
\hline CHEMBL 3199543 & 688816 & 4.65 & 4.7825 & TRN & \\
\hline CHEMBL1302196 & 688816 & 4.8 & 5.6102 & TRN & \\
\hline CHEMBL1588213 & 688816 & 4.95 & 5.0297 & TRN & \\
\hline CHEMBL1444691 & 688816 & 4.45 & 4.6217 & TRN & \\
\hline CHEMBL1598365 & 688816 & 4.45 & 5.1647 & TRN & \\
\hline CHEMBL1450531 & 688816 & 7.1002 & 5.1189 & TRN & \\
\hline CHEMBL1359804 & 688816 & 4.85 & 5.2813 & TRN & \\
\hline CHEMBL3192917 & 688816 & 4.8 & 5.3868 & TRN & \\
\hline CHEMBL1427657 & 688816 & 4.85 & 5.4776 & TST & \\
\hline CHEMBL1360386 & 688816 & 4.9 & 5.3837 & TRN & \\
\hline CHEMBL1525780 & 688816 & 4.95 & 4.9077 & TRN & \\
\hline CHEMBL1481532 & 688816 & 7.6003 & 5.4706 & TRN & \\
\hline CHEMBL1303807 & 688816 & 5.55 & 5.4231 & TRN & \\
\hline CHEMBL3194615 & 688816 & 4.9 & 5.1964 & TRN & \\
\hline CHEMBL1583561 & 688816 & 4.95 & 4.9134 & TRN & \\
\hline CHEMBL1507540 & 688816 & 4.8 & 5.0635 & TRN & \\
\hline CHEMBL1458674 & 688816 & 4.8 & 5.1864 & TRN & \\
\hline CHEMBL3195002 & 688816 & 4.95 & 5.3959 & TRN & \\
\hline CHEMBL3145287 & 688816 & 4.45 & 5.189 & TRN & \\
\hline CHEMBL1604005 & 688816 & 4.95 & 4.8702 & TRN & \\
\hline CHEMBL 75267 & 688816 & 4.45 & 4.8504 & TRN & \\
\hline CHEMBL1388455 & 688816 & 5.95 & 5.20200 & 3000000001 & TRN \\
\hline CHEMBL1392394 & 688816 & 4.95 & 5.1053 & TRN & \\
\hline CHEMBL1599764 & 688816 & 4.95 & 5.496 & TRN & \\
\hline CHEMBL1408676 & 688816 & 4.7 & 5.0409 & TRN & \\
\hline CHEMBL1387110 & 688816 & 5.5 & 5.1302 & TRN & \\
\hline CHEMBL1571239 & 688816 & 4.9 & 5.2452 & TRN & \\
\hline CHEMBL1399833 & 688816 & 5.5 & 5.12799 & э999999999 & TST \\
\hline CHEMBL1601853 & 688816 & 5.0 & 4.8586 & TRN & \\
\hline CHEMBL1471907 & 688816 & 4.95 & 5.419 & TST & \\
\hline CHEMBL1409043 & 688816 & 5.45 & 5.0473 & TRN & \\
\hline CHEMBL1393783 & 688816 & 5.05 & 5.1273 & TRN & \\
\hline CHEMBL1461786 & 688816 & 5.4 & 5.3343 & TRN & \\
\hline CHEMBL1431006 & 688816 & 4.45 & 5.3274 & TRN & \\
\hline CHEMBL1519804 & 688816 & 5.45 & 5.7105 & TRN & \\
\hline CHEMBL1566877 & 688816 & 4.9 & 5.4681 & TRN & \\
\hline CHEMBL1482409 & 688816 & 5.35 & 5.2303 & TRN & \\
\hline CHEMBL1318818 & 688816 & 4.75 & 5.2485 & TST & \\
\hline CHEMBL1398820 & 688816 & 5.05 & 5.4743 & TRN & \\
\hline CHEMBL3208338 & 688816 & 4.95 & 5.2051 & TRN & \\
\hline CHEMBL1579632 & 688816 & 5.7 & 5.2972 & TST & \\
\hline
\end{tabular}




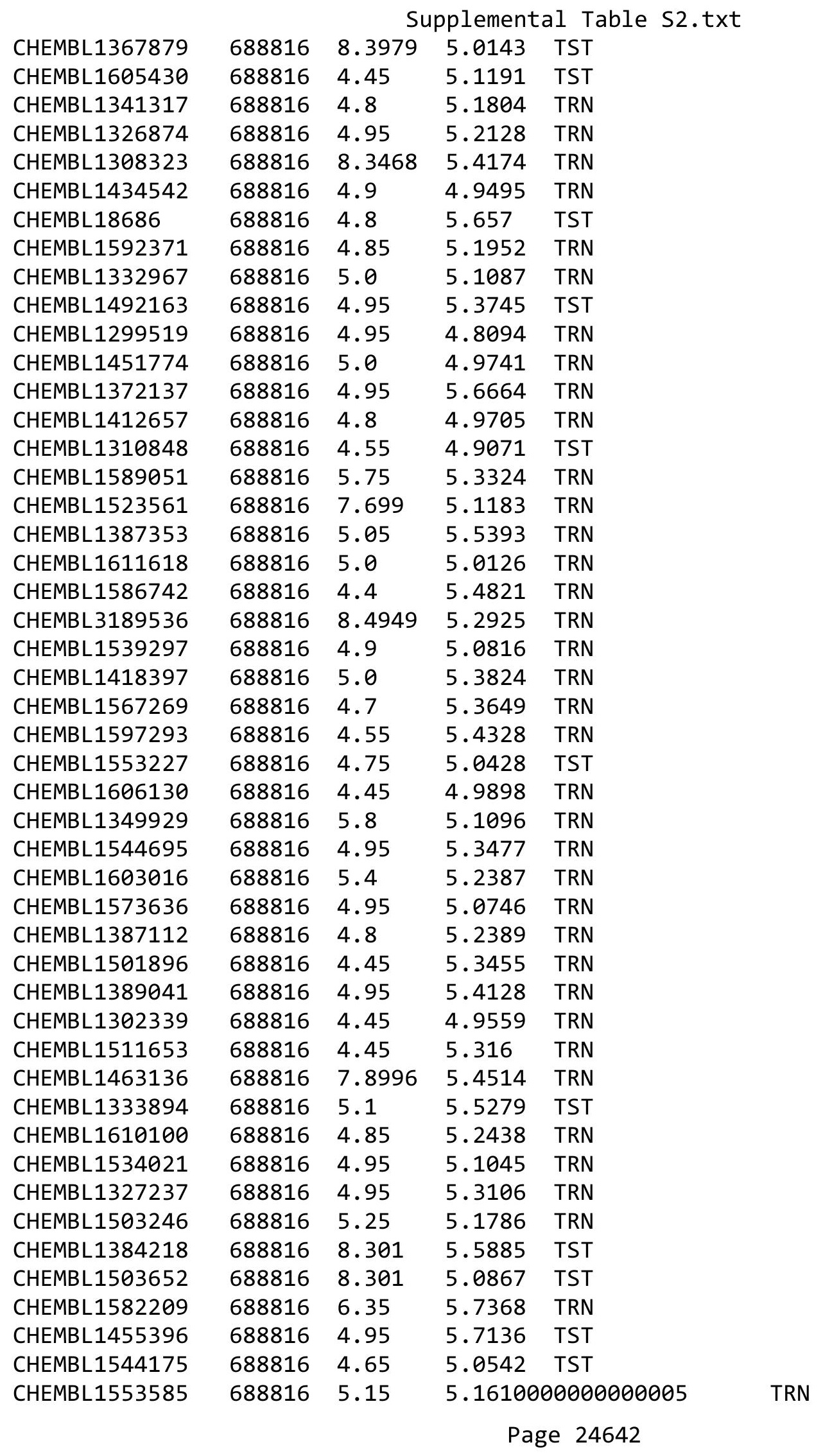




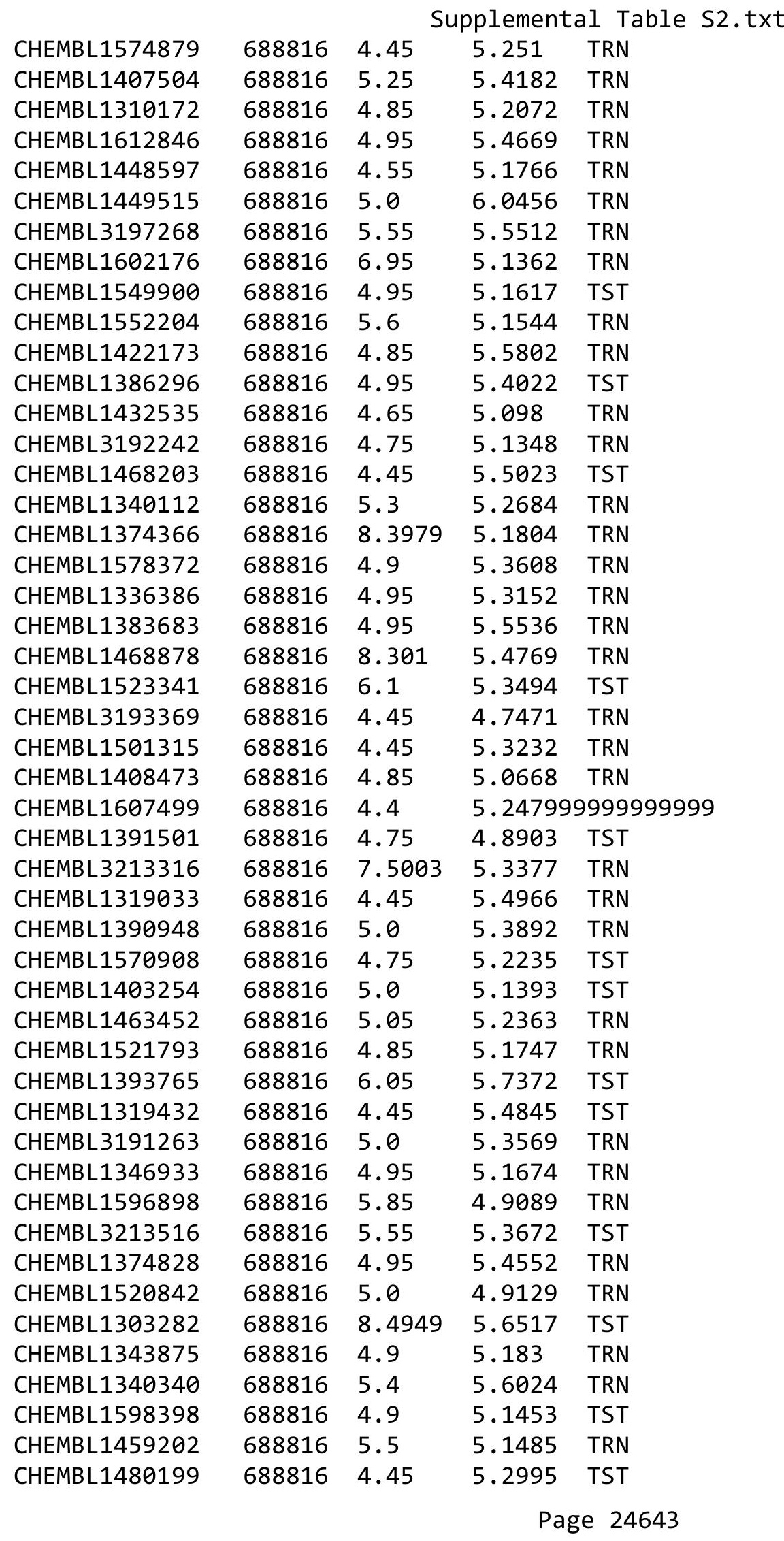




\begin{tabular}{|c|c|c|c|c|}
\hline \multicolumn{5}{|c|}{ Supplemental Table S2.txt } \\
\hline CHEMBL1468142 & 688816 & 5.0 & 5.3035 & TRN \\
\hline CHEMBL1364666 & 688816 & 4.95 & 5.1473 & TST \\
\hline CHEMBL1449326 & 688816 & 4.95 & 5.0524 & TRN \\
\hline CHEMBL1351907 & 688816 & 4.95 & 5.4985 & TST \\
\hline CHEMBL1419555 & 688816 & 5.5 & 5.4716 & TRN \\
\hline CHEMBL1595940 & 688816 & 4.8 & 5.0134 & TRN \\
\hline CHEMBL1529188 & 688816 & 6.6 & 5.0292 & TRN \\
\hline CHEMBL1556612 & 688816 & 4.95 & 4.7258 & TRN \\
\hline CHEMBL1439244 & 688816 & 5.5 & 5.3141 & TRN \\
\hline CHEMBL1539789 & 688816 & 5.0 & 5.4513 & TST \\
\hline CHEMBL1433041 & 688816 & 5.35 & 5.6143 & TRN \\
\hline CHEMBL1521536 & 688816 & 4.45 & 5.2248 & TRN \\
\hline CHEMBL1542918 & 688816 & 6.8499 & 5.1788 & TRN \\
\hline CHEMBL1382022 & 688816 & 4.8 & 4.9001 & TRN \\
\hline CHEMBL1421920 & 688816 & 5.4 & 5.5354 & TRN \\
\hline CHEMBL1325874 & 688816 & 4.65 & 5.1761 & TST \\
\hline CHEMBL1320210 & 688816 & 4.9 & 5.0895 & TRN \\
\hline CHEMBL1558694 & 688816 & 4.45 & 5.3121 & TRN \\
\hline CHEMBL3193010 & 688816 & 4.45 & 5.1374 & TRN \\
\hline CHEMBL1455336 & 688816 & 4.45 & 5.3566 & TRN \\
\hline CHEMBL1488108 & 688816 & 4.9 & 5.3332 & TST \\
\hline CHEMBL3193158 & 688816 & 6.1 & 5.4617 & TRN \\
\hline CHEMBL1595240 & 688816 & 5.6 & 5.1886 & TST \\
\hline CHEMBL1461071 & 688816 & 5.7 & 5.5006 & TRN \\
\hline CHEMBL1345466 & 688816 & 5.15 & 5.1241 & TRN \\
\hline CHEMBL3190668 & 688816 & 4.9 & 5.2061 & TRN \\
\hline CHEMBL1347816 & 688816 & 4.95 & 4.9294 & TRN \\
\hline CHEMBL1303948 & 688816 & 4.6 & 5.4875 & TRN \\
\hline CHEMBL1445962 & 688816 & 5.05 & 5.1604 & TRN \\
\hline CHEMBL1568504 & 688816 & 4.7 & 5.3245 & TST \\
\hline CHEMBL1304162 & 688816 & 4.9 & 5.2364 & TRN \\
\hline CHEMBL1429980 & 688816 & 5.4 & 5.3273 & TRN \\
\hline CHEMBL1417328 & 688816 & 5.0 & 5.6066 & TRN \\
\hline CHEMBL1414090 & 688816 & 5.0 & 5.0157 & TRN \\
\hline CHEMBL1427616 & 688816 & 4.5 & 5.5133 & TST \\
\hline CHEMBL1350313 & 688816 & 4.95 & 5.1882 & TRN \\
\hline CHEMBL1556702 & 688816 & 5.7 & 5.0027 & TRN \\
\hline CHEMBL1342242 & 688816 & 4.95 & 5.2667 & TRN \\
\hline CHEMBL1328072 & 688816 & 4.45 & 5.1315 & TRN \\
\hline CHEMBL1603204 & 688816 & 4.9 & 5.087 & TRN \\
\hline CHEMBL1461772 & 688816 & 4.85 & 5.2472 & TRN \\
\hline CHEMBL1415201 & 688816 & 5.1 & 5.3672 & TST \\
\hline CHEMBL1406709 & 688816 & 6.8499 & 5.3253 & TST \\
\hline CHEMBL1550657 & 688816 & 4.65 & 5.3007 & TRN \\
\hline CHEMBL1391055 & 688816 & 5.0 & 5.1179 & TRN \\
\hline CHEMBL1430012 & 688816 & 8.301 & 5.1504 & TRN \\
\hline CHEMBL1333224 & 688816 & 6.5 & 5.1026 & TRN \\
\hline CHEMBL1581493 & 688816 & 5.0 & 5.3816 & TRN \\
\hline
\end{tabular}




\begin{tabular}{|c|c|c|c|c|}
\hline \multirow[b]{2}{*}{ CHEMBL1966298 } & \multicolumn{4}{|c|}{ Supplemental Table S2.txt } \\
\hline & 688816 & 5.1 & 5.7295 & TST \\
\hline CHEMBL1413351 & 688816 & 7.699 & 5.3243 & TST \\
\hline CHEMBL1533083 & 688816 & 5.65 & 4.8726 & TRN \\
\hline CHEMBL1585332 & 688816 & 5.55 & 4.7911 & TRN \\
\hline CHEMBL1534778 & 688816 & 4.55 & 5.7454 & TST \\
\hline CHEMBL1431577 & 688816 & 4.95 & 5.2012 & TRN \\
\hline CHEMBL1455512 & 688816 & 5.0 & 5.4088 & TRN \\
\hline CHEMBL1371821 & 688816 & 4.9 & 5.4013 & TRN \\
\hline CHEMBL1419436 & 688816 & 7.6003 & 5.1687 & TST \\
\hline CHEMBL1307156 & 688816 & 4.45 & 5.0294 & TRN \\
\hline CHEMBL1422276 & 688816 & 4.5 & 5.432 & TRN \\
\hline CHEMBL1585104 & 688816 & 5.45 & 5.0186 & TST \\
\hline CHEMBL1385824 & 688816 & 4.6 & 5.6426 & TRN \\
\hline CHEMBL1480441 & 688816 & 5.0 & 5.39 & TRN \\
\hline CHEMBL1344762 & 688816 & 6.35 & 5.6908 & TRN \\
\hline CHEMBL1381415 & 688816 & 5.5 & 5.0322 & TRN \\
\hline CHEMBL1366992 & 688816 & 4.8 & 5.0755 & TST \\
\hline CHEMBL1517787 & 688816 & 4.9 & 5.4233 & TRN \\
\hline CHEMBL1534132 & 688816 & 4.8 & 5.1428 & TRN \\
\hline CHEMBL3214176 & 688816 & 5.4 & 5.7763 & TRN \\
\hline CHEMBL1430215 & 688816 & 4.65 & 4.9723 & TRN \\
\hline CHEMBL 3190784 & 688816 & 4.45 & 5.4757 & TRN \\
\hline CHEMBL1340401 & 688816 & 4.45 & 5.0427 & TRN \\
\hline CHEMBL1561628 & 688816 & 5.45 & 5.0688 & TRN \\
\hline CHEMBL1499160 & 688816 & 5.0 & 4.9558 & TRN \\
\hline CHEMBL1431351 & 688816 & 5.25 & 5.7677 & TST \\
\hline CHEMBL1322523 & 688816 & 5.45 & 5.414 & TST \\
\hline CHEMBL1556669 & 688816 & 4.85 & 5.3156 & TRN \\
\hline CHEMBL1459215 & 688816 & 4.95 & 4.9401 & TRN \\
\hline CHEMBL1470502 & 688816 & 6.8 & 5.3697 & TRN \\
\hline CHEMBL1399573 & 688816 & 5.0 & 5.1602 & TRN \\
\hline CHEMBL1521724 & 688816 & 8.3468 & 5.0889 & TRN \\
\hline CHEMBL266459 & 688816 & 5.35 & 5.1409 & TST \\
\hline CHEMBL1410388 & 688816 & 4.85 & 5.3387 & TRN \\
\hline CHEMBL1380072 & 688816 & 4.95 & 5.5168 & TRN \\
\hline CHEMBL1326403 & 688816 & 4.65 & 4.9857 & TRN \\
\hline CHEMBL1569690 & 688816 & 6.0 & 5.0619 & TRN \\
\hline CHEMBL1556193 & 688816 & 8.301 & 5.2674 & TRN \\
\hline CHEMBL1516694 & 688816 & 4.7 & 4.8092 & TRN \\
\hline CHEMBL1471716 & 688816 & 4.6 & 4.9942 & TRN \\
\hline CHEMBL1459332 & 688816 & 4.45 & 4.7728 & TRN \\
\hline CHEMBL1387680 & 688816 & 4.45 & 5.1096 & TRN \\
\hline CHEMBL88326 & 688816 & 5.55 & 5.3268 & TRN \\
\hline CHEMBL1416441 & 688816 & 4.85 & 5.3756 & TST \\
\hline CHEMBL1462938 & 688816 & 7.2 & 5.4478 & TST \\
\hline CHEMBL1561557 & 688816 & 5.15 & 5.5471 & TRN \\
\hline CHEMBL1376792 & 688816 & 5.4 & 5.1704 & TRN \\
\hline CHEMBL1552826 & 688816 & 4.8 & 5.072 & TRN \\
\hline
\end{tabular}




\begin{tabular}{|c|c|c|c|c|c|}
\hline & & & oplement & al Table S & \\
\hline CHEMBL1325909 & 688816 & 4.55 & 4.9071 & TRN & \\
\hline CHEMBL1390860 & 688816 & 6.0 & 5.16700 & 3000000001 & TRN \\
\hline CHEMBL1500007 & 688816 & 4.95 & 5.2046 & TRN & \\
\hline CHEMBL1467492 & 688816 & 5.35 & 5.5728 & TRN & \\
\hline CHEMBL1538259 & 688816 & 5.5 & 4.9131 & TST & \\
\hline CHEMBL1994599 & 688816 & 4.95 & 5.2541 & TRN & \\
\hline CHEMBL1313719 & 688816 & 5.0 & 5.4097 & TRN & \\
\hline CHEMBL1336373 & 688816 & 4.75 & 5.05399 & 9999999999 & TRN \\
\hline CHEMBL 250711 & 688816 & 4.55 & 5.1822 & TST & \\
\hline CHEMBL1607646 & 688816 & 5.15 & 5.1098 & TRN & \\
\hline CHEMBL1305205 & 688816 & 4.65 & 5.2005 & TRN & \\
\hline CHEMBL1503823 & 688816 & 6.5 & 5.1675 & TRN & \\
\hline CHEMBL1607651 & 688816 & 6.6499 & 5.4994 & TST & \\
\hline CHEMBL1483057 & 688816 & 6.7501 & 5.6756 & TRN & \\
\hline CHEMBL1334235 & 688816 & 4.7 & 4.8264 & TRN & \\
\hline CHEMBL1596248 & 688816 & 4.95 & 4.9682 & TRN & \\
\hline CHEMBL1420006 & 688816 & 7.699 & 5.4234 & TRN & \\
\hline CHEMBL1516976 & 688816 & 4.45 & 5.358 & TST & \\
\hline CHEMBL1404569 & 688816 & 4.95 & 5.1807 & TRN & \\
\hline CHEMBL1467750 & 688816 & 4.45 & 5.2427 & TST & \\
\hline CHEMBL1403078 & 688816 & 7.2503 & 5.0067 & TST & \\
\hline CHEMBL1547413 & 688816 & 5.1 & 5.0877 & TRN & \\
\hline CHEMBL1393152 & 688816 & 5.4 & 5.2503 & TRN & \\
\hline CHEMBL1506280 & 688816 & 5.35 & 4.9748 & TST & \\
\hline CHEMBL1507672 & 688816 & 4.95 & 5.2609 & TRN & \\
\hline CHEMBL1607286 & 688816 & 4.85 & 4.7698 & TRN & \\
\hline CHEMBL1602878 & 688816 & 7.5498 & 5.6318 & TST & \\
\hline CHEMBL1386531 & 688816 & 8.301 & 5.3567 & TRN & \\
\hline CHEMBL1505782 & 688816 & 8.4949 & 5.3786 & TRN & \\
\hline CHEMBL1392527 & 688816 & 8.2007 & 5.3193 & TRN & \\
\hline CHEMBL3192674 & 688816 & 6.1 & 5.6024 & TRN & \\
\hline CHEMBL1550800 & 688816 & 5.85 & 5.2943 & TRN & \\
\hline CHEMBL1412504 & 688816 & 4.45 & 4.9725 & TRN & \\
\hline CHEMBL1467693 & 688816 & 7.6498 & 5.7835 & TRN & \\
\hline CHEMBL1444196 & 688816 & 8.301 & 5.4521 & TRN & \\
\hline CHEMBL1594867 & 688816 & 5.7 & 5.3716 & TRN & \\
\hline CHEMBL1374453 & 688816 & 4.75 & 5.2427 & TST & \\
\hline CHEMBL1320203 & 688816 & 5.2 & 5.1841 & TRN & \\
\hline CHEMBL1427001 & 688816 & 6.8 & 5.2701 & TRN & \\
\hline CHEMBL1519587 & 688816 & 4.7 & 5.3402 & TRN & \\
\hline CHEMBL1454502 & 688816 & 5.45 & 5.33299 & 9999999999 & TST \\
\hline CHEMBL1549893 & 688816 & 6.0 & 5.7308 & TST & \\
\hline CHEMBL1518771 & 688816 & 4.45 & 5.6326 & TST & \\
\hline CHEMBL1558335 & 688816 & 8.3468 & 5.6157 & TST & \\
\hline CHEMBL578502 & 688816 & 5.15 & 5.3194 & TST & \\
\hline CHEMBL3195946 & 688816 & 5.35 & 4.9606 & TRN & \\
\hline CHEMBL1468477 & 688816 & 4.95 & 5.0001 & TRN & \\
\hline CHEMBL1397009 & 688816 & 4.75 & 5.2602 & TRN & \\
\hline & & & & 246 & \\
\hline
\end{tabular}




\begin{tabular}{|c|c|c|c|c|}
\hline \multicolumn{5}{|c|}{ Supplemental Table S2.txt } \\
\hline CHEMBL1603485 & 688816 & 4.9 & 5.0323 & TRN \\
\hline CHEMBL1505478 & 688816 & 4.85 & 5.0688 & TRN \\
\hline CHEMBL1531523 & 688816 & 4.85 & 5.0822 & TRN \\
\hline CHEMBL1311879 & 688816 & 4.95 & 5.3679 & TRN \\
\hline CHEMBL3210183 & 688816 & 8.3979 & 5.2686 & TST \\
\hline CHEMBL1582489 & 688816 & 4.9 & 4.9287 & TRN \\
\hline CHEMBL1495386 & 688816 & 5.5 & 5.2477 & TRN \\
\hline CHEMBL1428181 & 688816 & 5.0 & 5.1895 & TRN \\
\hline CHEMBL1478876 & 688816 & 5.0 & 4.9546 & TRN \\
\hline CHEMBL1403305 & 688816 & 5.25 & 4.8254 & TRN \\
\hline CHEMBL1596914 & 688816 & 7.699 & 5.7624 & TRN \\
\hline CHEMBL1378397 & 688816 & 4.85 & 5.2031 & TRN \\
\hline CHEMBL1547537 & 688816 & 4.45 & 5.2243 & TRN \\
\hline CHEMBL1452697 & 688816 & 4.45 & 5.1326 & TRN \\
\hline CHEMBL1409537 & 688816 & 4.45 & 4.921 & TST \\
\hline CHEMBL1464517 & 688816 & 5.7 & 5.3504 & TRN \\
\hline CHEMBL1390452 & 688816 & 4.45 & 5.1588 & TRN \\
\hline CHEMBL1460893 & 688816 & 4.95 & 5.2092 & TRN \\
\hline CHEMBL1366153 & 688816 & 4.95 & 5.5042 & TRN \\
\hline CHEMBL1342162 & 688816 & 6.9 & 4.6979 & TRN \\
\hline CHEMBL1450191 & 688816 & 5.0 & 5.3377 & TRN \\
\hline CHEMBL1335844 & 688816 & 4.65 & 5.2075 & TRN \\
\hline CHEMBL1563006 & 688816 & 7.3497 & 5.3402 & TST \\
\hline CHEMBL1518456 & 688816 & 4.6 & 5.3476 & TRN \\
\hline CHEMBL1390854 & 688816 & 4.75 & 5.1213 & TRN \\
\hline CHEMBL1524396 & 688816 & 5.05 & 5.021 & TRN \\
\hline CHEMBL1588204 & 688816 & 4.9 & 5.1646 & TRN \\
\hline CHEMBL1377415 & 688816 & 7.699 & 5.5812 & TRN \\
\hline CHEMBL1309726 & 688816 & 4.5 & 5.4563 & TRN \\
\hline CHEMBL1586012 & 688816 & 4.45 & 5.3581 & TST \\
\hline CHEMBL1484568 & 688816 & 4.65 & 5.2607 & TRN \\
\hline CHEMBL3210594 & 688816 & 7.5003 & 5.1606 & TRN \\
\hline CHEMBL1346908 & 688816 & 4.75 & 5.3405 & TRN \\
\hline CHEMBL1613213 & 688816 & 4.9 & 4.8737 & TRN \\
\hline CHEMBL1576363 & 688816 & 4.85 & 5.3813 & TRN \\
\hline CHEMBL1567273 & 688816 & 4.5 & 5.3737 & TRN \\
\hline CHEMBL1538175 & 688816 & 6.15 & 5.2549 & TRN \\
\hline CHEMBL1509226 & 688816 & 7.7496 & 5.3309 & TST \\
\hline CHEMBL1486330 & 688816 & 4.6 & $5.1720 e$ & 0000000001 \\
\hline CHEMBL1604548 & 688816 & 4.95 & 5.3649 & TRN \\
\hline CHEMBL3209123 & 688816 & 6.8 & 5.5996 & TST \\
\hline CHEMBL1319522 & 688816 & 4.75 & 5.3925 & TRN \\
\hline CHEMBL1365162 & 688816 & 4.6 & 4.8858 & TRN \\
\hline CHEMBL3199639 & 688816 & 5.85 & 5.0335 & TRN \\
\hline CHEMBL1589374 & 688816 & 5.2 & 5.7524 & TRN \\
\hline CHEMBL1584397 & 688816 & 5.15 & 5.124 & TRN \\
\hline CHEMBL1467183 & 688816 & 4.45 & 5.1743 & TRN \\
\hline CHEMBL1606734 & 688816 & 6.3 & 5.0764 & TST \\
\hline
\end{tabular}




\begin{tabular}{|c|c|c|c|c|}
\hline \multicolumn{5}{|c|}{ Supplemental Table S2.txt } \\
\hline CHEMBL1460307 & 688816 & 4.85 & 5.4218 & TRN \\
\hline CHEMBL1345845 & 688816 & 5.15 & 5.3655 & TRN \\
\hline CHEMBL1406630 & 688816 & 4.45 & 5.0377 & TRN \\
\hline CHEMBL1347356 & 688816 & 4.9 & 5.5438 & TRN \\
\hline CHEMBL 222556 & 688816 & 4.85 & 4.8141 & TRN \\
\hline CHEMBL1607374 & 688816 & 4.85 & 5.1177 & TRN \\
\hline CHEMBL1529106 & 688816 & 4.95 & 4.9113 & TRN \\
\hline CHEMBL1478024 & 688816 & 6.6 & 5.0554 & TRN \\
\hline CHEMBL174588 & 688816 & 4.9 & 5.4668 & TST \\
\hline CHEMBL1330980 & 688816 & 5.35 & 5.3918 & TST \\
\hline CHEMBL1404301 & 688816 & 4.65 & 5.2473 & TRN \\
\hline CHEMBL1520741 & 688816 & 4.45 & 4.9613 & TRN \\
\hline CHEMBL1468238 & 688816 & 4.7 & 5.105 & TRN \\
\hline CHEMBL1489287 & 688816 & 4.95 & 5.2579 & TRN \\
\hline CHEMBL1404855 & 688816 & 4.75 & 5.4823 & TRN \\
\hline CHEMBL1401437 & 688816 & 7.5003 & 5.4068 & TST \\
\hline CHEMBL1319958 & 688816 & 4.8 & 5.2567 & TRN \\
\hline CHEMBL1456644 & 688816 & 5.7 & 5.3722 & TRN \\
\hline CHEMBL1600670 & 688816 & 4.95 & 5.3221 & TRN \\
\hline CHEMBL1455125 & 688816 & 5.85 & 5.216 & TRN \\
\hline CHEMBL1549650 & 688816 & 5.4 & 5.2963 & TRN \\
\hline CHEMBL1345223 & 688816 & 4.5 & 5.2182 & TRN \\
\hline CHEMBL1606306 & 688816 & 4.95 & 5.0351 & TRN \\
\hline CHEMBL1506220 & 688816 & 6.6 & 5.5949 & TST \\
\hline CHEMBL1321361 & 688816 & 4.85 & 5.1886 & TRN \\
\hline CHEMBL1550443 & 688816 & 4.9 & 5.481 & TRN \\
\hline CHEMBL3193616 & 688816 & 4.95 & 4.9031 & TRN \\
\hline CHEMBL1324618 & 688816 & 5.0 & 5.1267 & TRN \\
\hline CHEMBL1585288 & 688816 & 4.85 & 5.275 & TRN \\
\hline CHEMBL3189435 & 688816 & 8.3468 & 5.4474 & TRN \\
\hline CHEMBL1464650 & 688816 & 4.45 & 5.4919 & TRN \\
\hline CHEMBL1455126 & 688816 & 4.95 & 5.6954 & TRN \\
\hline CHEMBL3196139 & 688816 & 6.05 & 5.2805 & TRN \\
\hline CHEMBL1561902 & 688816 & 5.1 & 5.2335 & TRN \\
\hline CHEMBL1500335 & 688816 & 4.8 & 5.3982 & TRN \\
\hline CHEMBL1351260 & 688816 & 4.85 & 5.4183 & TRN \\
\hline CHEMBL1434277 & 688816 & 5.25 & 5.3732 & TST \\
\hline CHEMBL1451002 & 688816 & 5.15 & 5.2932 & TST \\
\hline CHEMBL3190816 & 688816 & 5.55 & 5.98 & TRN \\
\hline CHEMBL1610810 & 688816 & 4.95 & 5.1622 & TRN \\
\hline CHEMBL3192862 & 688816 & 4.6 & 4.9125 & TST \\
\hline CHEMBL1367193 & 688816 & 4.95 & 4.7923 & TRN \\
\hline CHEMBL1480494 & 688816 & 4.9 & 4.8929 & TRN \\
\hline CHEMBL1597773 & 688816 & 4.8 & 5.0213 & TRN \\
\hline CHEMBL1539925 & 688816 & 5.1 & 5.0866 & TRN \\
\hline CHEMBL1461675 & 688816 & 4.8 & 5.188 & TRN \\
\hline CHEMBL1343285 & 688816 & 5.8 & 5.3034 & TRN \\
\hline CHEMBL355496 & 688816 & 4.8 & 4.8743 & TST \\
\hline
\end{tabular}




\begin{tabular}{|c|c|c|c|c|c|}
\hline \multicolumn{6}{|c|}{ Supplemental Table S2.txt } \\
\hline CHEMBL1555575 & 688816 & 6.35 & 5.3917 & TRN & \\
\hline CHEMBL1501852 & 688816 & 6.9 & 5.2008 & TRN & \\
\hline CHEMBL3190259 & 688816 & 4.45 & 5.2877 & TST & \\
\hline CHEMBL1344266 & 688816 & 4.45 & 5.0613 & TRN & \\
\hline CHEMBL1530261 & 688816 & 5.8 & 5.5047 & TRN & \\
\hline CHEMBL1424743 & 688816 & 4.75 & 5.2239 & TRN & \\
\hline CHEMBL1427741 & 688816 & 5.25 & 5.6003 & TRN & \\
\hline CHEMBL1392787 & 688816 & 5.0 & 5.1324 & TRN & \\
\hline CHEMBL1421668 & 688816 & 4.85 & 5.2419 & TRN & \\
\hline CHEMBL1375510 & 688816 & 4.85 & 4.6774 & TRN & \\
\hline CHEMBL1432577 & 688816 & 4.45 & 4.8453 & TRN & \\
\hline CHEMBL1611625 & 688816 & 5.45 & 5.0628 & TRN & \\
\hline CHEMBL1419694 & 688816 & 4.55 & 5.0183 & TST & \\
\hline CHEMBL1511065 & 688816 & 5.2 & 5.4783 & TRN & \\
\hline CHEMBL1564978 & 688816 & 4.6 & 4.9134 & TRN & \\
\hline CHEMBL1582277 & 688816 & 5.5 & 5.2062 & TRN & \\
\hline CHEMBL1306673 & 688816 & 4.9 & 4.9842 & TST & \\
\hline CHEMBL1353461 & 688816 & 5.0 & 5.4502 & TRN & \\
\hline CHEMBL1586135 & 688816 & 4.6 & 4.9876 & TRN & \\
\hline CHEMBL1521958 & 688816 & 5.6 & 5.33299 & 9999999999 & TRN \\
\hline CHEMBL1987427 & 688816 & 4.9 & 4.922 & TRN & \\
\hline CHEMBL1564823 & 688816 & 5.55 & 5.1846 & TRN & \\
\hline CHEMBL1559251 & 688816 & 4.85 & 4.7632 & TRN & \\
\hline CHEMBL1488668 & 688816 & 4.85 & 5.4487 & TST & \\
\hline CHEMBL1424887 & 688816 & 6.1 & 5.1958 & TRN & \\
\hline CHEMBL1465434 & 688816 & 5.45 & 5.3104 & TRN & \\
\hline CHEMBL3392240 & 688816 & 5.5 & 5.1049 & TRN & \\
\hline CHEMBL1374589 & 688816 & 5.55 & 5.3623 & TRN & \\
\hline CHEMBL1422678 & 688816 & 6.0 & 5.5411 & TRN & \\
\hline CHEMBL1566677 & 688816 & 4.8 & 4.9139 & TRN & \\
\hline CHEMBL1498496 & 688816 & 5.45 & 5.1891 & TRN & \\
\hline CHEMBL1256655 & 688816 & 5.45 & 5.4053 & TST & \\
\hline CHEMBL1520399 & 688816 & 4.85 & 5.2313 & TRN & \\
\hline CHEMBL1562280 & 688816 & 5.1 & 5.3058 & TST & \\
\hline CHEMBL1456669 & 688816 & 4.95 & 5.4183 & TRN & \\
\hline CHEMBL1351519 & 688816 & 5.0 & 5.0975 & TRN & \\
\hline CHEMBL1327098 & 688816 & 4.75 & 4.9562 & TRN & \\
\hline CHEMBL1550087 & 688816 & 5.55 & 5.008 & TRN & \\
\hline CHEMBL1344039 & 688816 & 4.95 & 5.0073 & TRN & \\
\hline CHEMBL1353362 & 688816 & 5.3 & 5.2161 & TRN & \\
\hline CHEMBL1576017 & 688816 & 8.3468 & 4.9733 & TST & \\
\hline CHEMBL1549820 & 688816 & 7.5498 & 5.4996 & TRN & \\
\hline CHEMBL1334460 & 688816 & 4.7 & 5.0664 & TST & \\
\hline CHEMBL1602763 & 688816 & 8.301 & 5.4036 & TRN & \\
\hline CHEMBL1589612 & 688816 & 4.95 & 4.9913 & TST & \\
\hline CHEMBL1480394 & 688816 & 4.8 & 5.1598 & TRN & \\
\hline CHEMBL1610307 & 688816 & 8.3468 & 5.1532 & TRN & \\
\hline CHEMBL1303252 & 688816 & 6.1 & 5.3959 & TRN & \\
\hline
\end{tabular}




\begin{tabular}{|c|c|c|c|c|c|}
\hline \multirow{3}{*}{$\begin{array}{l}\text { CHEMBL } 1410200 \\
\text { CHEMBL } 1503392\end{array}$} & \multirow{3}{*}{$\begin{array}{l}688816 \\
688816\end{array}$} & \multicolumn{4}{|c|}{ Supplemental Table S2.txt } \\
\hline & & 4.45 & \multicolumn{2}{|c|}{4.9319999999999995} & TRN \\
\hline & & 4.75 & 5.0878 & TRN & \\
\hline CHEMBL1313174 & 688816 & 4.45 & 5.2331 & TRN & \\
\hline CHEMBL3198939 & 688816 & 7.0 & 5.4707 & TRN & \\
\hline CHEMBL1302762 & 688816 & 4.9 & 5.4002 & TRN & \\
\hline CHEMBL1489218 & 688816 & 4.95 & 5.2735 & TST & \\
\hline CHEMBL1341031 & 688816 & 4.95 & 5.4127 & TRN & \\
\hline CHEMBL1518634 & 688816 & 4.65 & 5.3623 & TRN & \\
\hline CHEMBL1565095 & 688816 & 5.9 & 5.1418 & TRN & \\
\hline CHEMBL3198666 & 688816 & 5.35 & 5.1734 & TRN & \\
\hline CHEMBL1325776 & 688816 & 4.9 & 5.3166 & TRN & \\
\hline CHEMBL 3194160 & 688816 & 6.7001 & 5.5091 & TRN & \\
\hline CHEMBL1584420 & 688816 & 4.6 & 5.1342 & TRN & \\
\hline CHEMBL1461262 & 688816 & 6.45 & 5.2387 & TST & \\
\hline CHEMBL3199393 & 688816 & 4.9 & \multicolumn{2}{|c|}{5.4270000000000005} & TRN \\
\hline CHEMBL1478067 & 688816 & 5.2 & 5.2004 & TRN & \\
\hline CHEMBL1361127 & 688816 & 4.75 & 5.2507 & TRN & \\
\hline CHEMBL1389807 & 688816 & 4.65 & 5.2753 & TRN & \\
\hline CHEMBL1408736 & 688816 & 5.25 & 5.407 & TRN & \\
\hline CHEMBL1604804 & 688816 & 5.45 & 4.8949 & TRN & \\
\hline CHEMBL1350120 & 688816 & 5.05 & 5.0184 & TRN & \\
\hline CHEMBL1483507 & 688816 & 5.15 & 5.2999 & TRN & \\
\hline CHEMBL1790004 & 688816 & 4.45 & 5.5365 & TRN & \\
\hline CHEMBL1483747 & 688816 & 4.45 & 5.6472 & TRN & \\
\hline CHEMBL1485519 & 688816 & 4.9 & 5.2285 & TRN & \\
\hline CHEMBL1361424 & 688816 & 4.95 & 5.2357 & TRN & \\
\hline CHEMBL1369924 & 688816 & 8.4949 & 5.4531 & TRN & \\
\hline CHEMBL 3197571 & 688816 & 4.9 & 5.153 & TST & \\
\hline CHEMBL1525249 & 688816 & 4.65 & 5.1646 & TRN & \\
\hline CHEMBL1426992 & 688816 & 5.45 & 4.8644 & TRN & \\
\hline CHEMBL1517966 & 688816 & 4.95 & 5.1292 & TRN & \\
\hline CHEMBL1600997 & 688816 & 7.6498 & 5.563 & TRN & \\
\hline CHEMBL3189927 & 688816 & 4.8 & 5.1673 & TRN & \\
\hline CHEMBL1447697 & 688816 & 4.45 & 5.5725 & TST & \\
\hline CHEMBL1440404 & 688816 & 4.65 & 5.4679 & TRN & \\
\hline CHEMBL1492397 & 688816 & 7.699 & 5.7127 & TRN & \\
\hline CHEMBL1564261 & 688816 & 5.65 & 5.4928 & TRN & \\
\hline CHEMBL590686 & 688816 & 4.95 & 4.8733 & TRN & \\
\hline CHEMBL1539432 & 688816 & 8.3468 & 5.5181 & TRN & \\
\hline CHEMBL1414563 & 688816 & 4.9 & 5.1997 & TRN & \\
\hline CHEMBL1387710 & 688816 & 4.95 & 4.94 & TST & \\
\hline CHEMBL1610780 & 688816 & 4.9 & 5.1698 & TRN & \\
\hline CHEMBL1411070 & 688816 & 4.75 & 5.12700 & 0000000001 & TST \\
\hline CHEMBL1596442 & 688816 & 4.95 & 5.2352 & TRN & \\
\hline CHEMBL1380717 & 688816 & 5.0 & 5.32799 & 9999999999 & TRN \\
\hline CHEMBL1577389 & 688816 & 6.6 & 5.2695 & TRN & \\
\hline CHEMBL1438967 & 688816 & 4.8 & 5.1425 & TRN & \\
\hline CHEMBL1411450 & 688816 & 5.2 & 5.1371 & TRN & \\
\hline
\end{tabular}




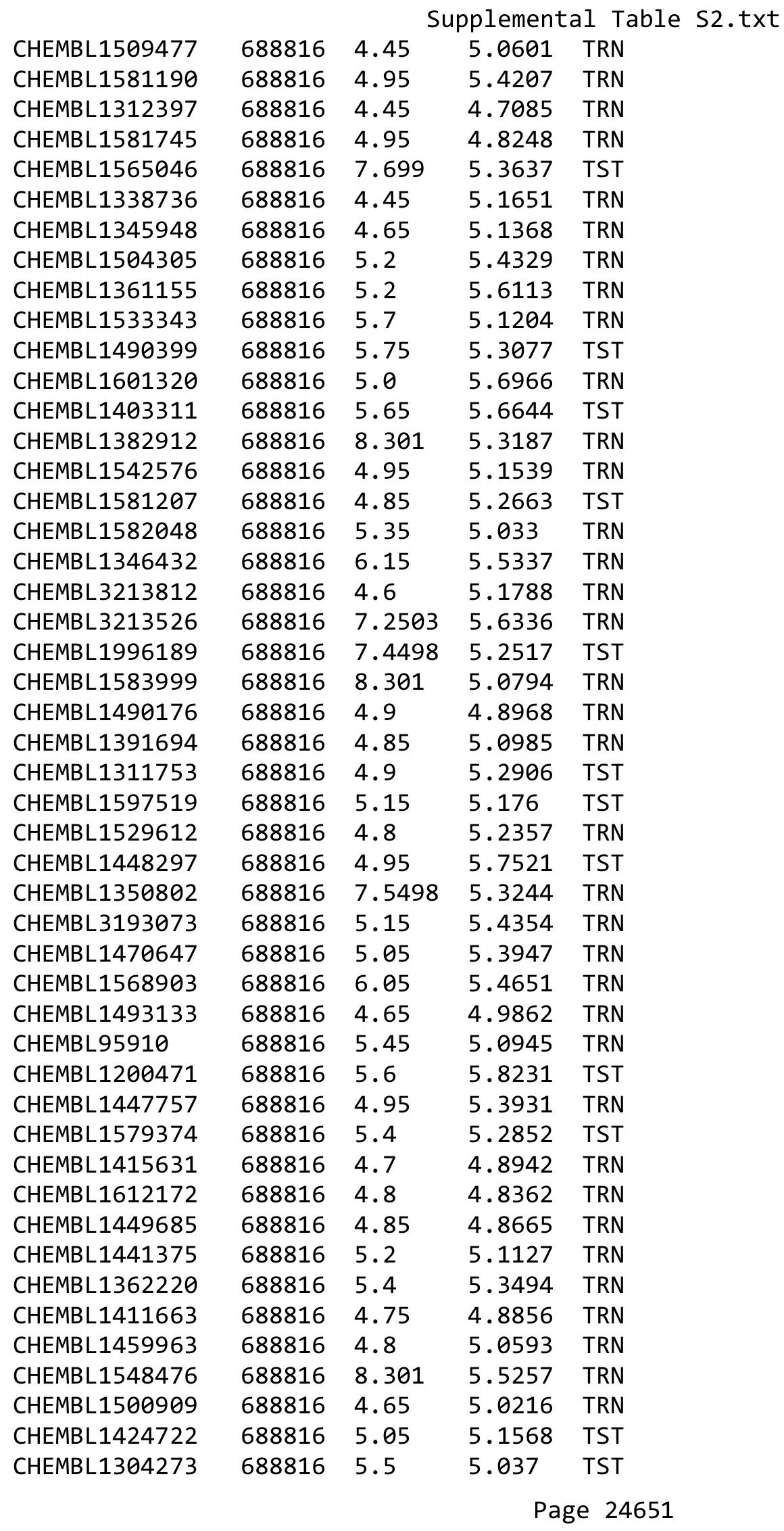




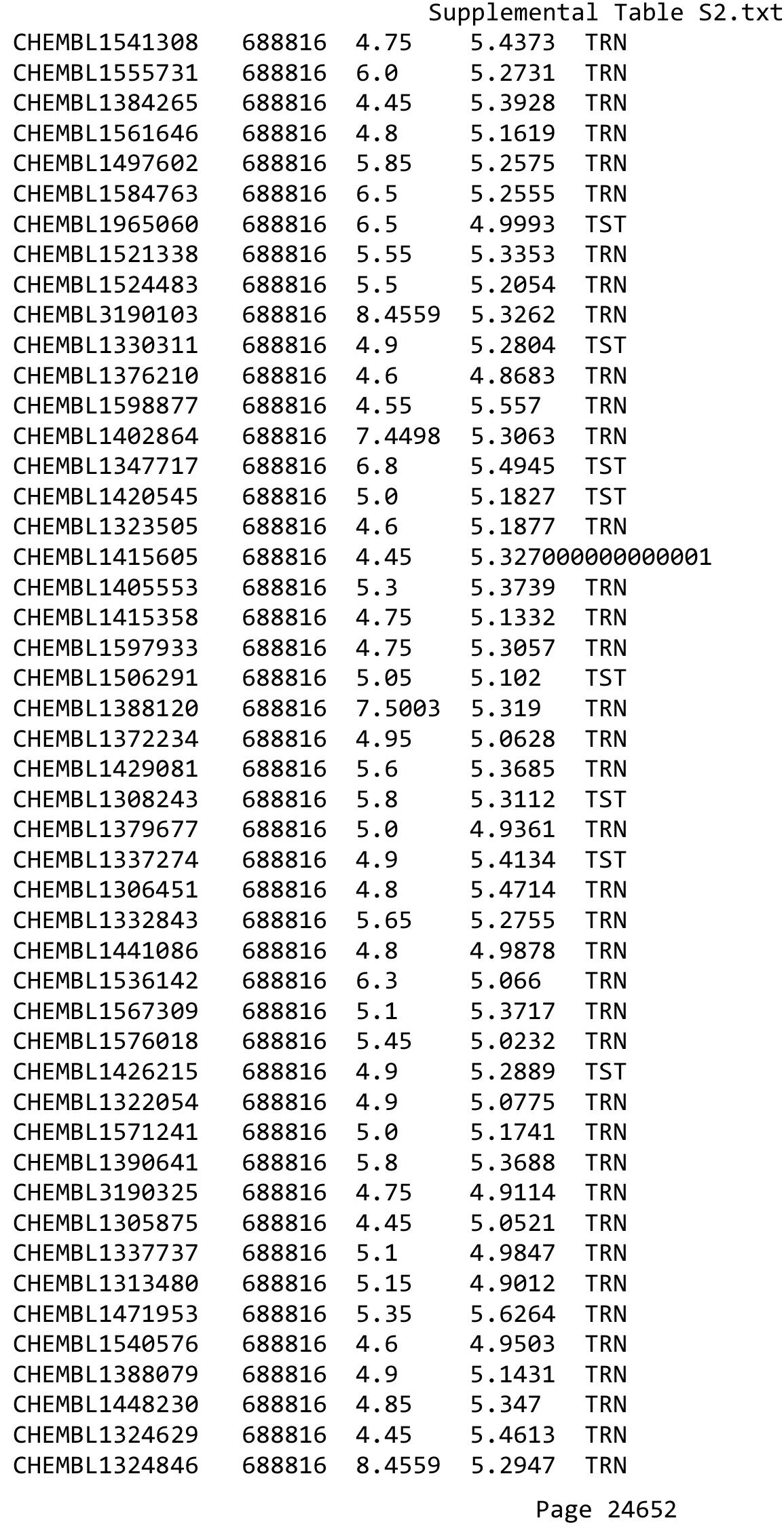




\begin{tabular}{|c|c|c|c|c|c|}
\hline \multicolumn{6}{|c|}{ Supplemental Table S2.txt } \\
\hline CHEMBL1337035 & 688816 & 5.0 & 5.5645 & TST & \\
\hline CHEMBL1387688 & 688816 & 4.75 & 5.0114 & TRN & \\
\hline CHEMBL1459940 & 688816 & 4.9 & 5.5547 & TRN & \\
\hline CHEMBL1428972 & 688816 & 4.65 & 5.2148 & TRN & \\
\hline CHEMBL1519317 & 688816 & 4.45 & 5.7139 & TST & \\
\hline CHEMBL1493311 & 688816 & 5.45 & 5.5455 & TST & \\
\hline CHEMBL 3214129 & 688816 & 7.4498 & 5.2376 & TST & \\
\hline CHEMBL1461037 & 688816 & 4.75 & 5.0651 & TRN & \\
\hline CHEMBL1396635 & 688816 & 5.0 & 5.0708 & TRN & \\
\hline CHEMBL1606429 & 688816 & 4.55 & 5.0036 & TST & \\
\hline CHEMBL1438370 & 688816 & 6.7001 & 5.4915 & TST & \\
\hline CHEMBL1467730 & 688816 & 8.301 & 5.3654 & TRN & \\
\hline CHEMBL1322318 & 688816 & 6.5 & 5.084 & TRN & \\
\hline CHEMBL1319469 & 688816 & 6.8499 & 5.7827 & TRN & \\
\hline CHEMBL1511790 & 688816 & 4.75 & 5.8201 & TST & \\
\hline CHEMBL1352014 & 688816 & 4.8 & 5.1753 & TRN & \\
\hline CHEMBL1442977 & 688816 & 5.1 & 5.3592 & TRN & \\
\hline CHEMBL 1488430 & 688816 & 4.95 & 5.114 & TRN & \\
\hline CHEMBL1410515 & 688816 & 4.9 & 4.9647 & TRN & \\
\hline CHEMBL1584257 & 688816 & 5.2 & 5.4804 & TST & \\
\hline CHEMBL 244857 & 688816 & 4.95 & 5.3978 & TRN & \\
\hline CHEMBL1904396 & 688816 & 6.6 & 5.3186 & TST & \\
\hline CHEMBL3208781 & 688816 & 5.45 & 5.4699 & TST & \\
\hline CHEMBL3207915 & 688816 & 4.95 & 5.4528 & TST & \\
\hline CHEMBL1333600 & 688816 & 6.0 & 5.648 & TST & \\
\hline CHEMBL1327961 & 688816 & 5.15 & 5.9315 & TST & \\
\hline CHEMBL1474625 & 688816 & 5.5 & 5.1097 & TRN & \\
\hline CHEMBL1510215 & 688816 & 4.95 & 5.75899 & 99999999995 & TRN \\
\hline CHEMBL1584429 & 688816 & 4.65 & 5.2291 & TRN & \\
\hline CHEMBL1509620 & 688816 & 5.4 & 5.1008 & TST & \\
\hline CHEMBL1557474 & 688816 & 4.9 & 4.9708 & TRN & \\
\hline CHEMBL1323575 & 688816 & 6.6 & 5.4368 & TST & \\
\hline CHEMBL1974450 & 688816 & 4.65 & 5.2324 & TRN & \\
\hline CHEMBL1437017 & 688816 & 4.8 & 5.5432 & TRN & \\
\hline CHEMBL567132 & 688816 & 5.1 & 4.8277 & TRN & \\
\hline CHEMBL1431189 & 688816 & 4.8 & 5.3925 & TST & \\
\hline CHEMBL3209803 & 688816 & 4.65 & 5.3392 & TRN & \\
\hline CHEMBL1330352 & 688816 & 5.0 & 5.1816 & TRN & \\
\hline CHEMBL1547711 & 688816 & 4.45 & 5.0379 & TRN & \\
\hline CHEMBL1612804 & 688816 & 5.2 & 5.419 & TST & \\
\hline CHEMBL3194397 & 688816 & 4.45 & 4.9358 & TRN & \\
\hline CHEMBL1969300 & 688816 & 4.65 & 5.0925 & TRN & \\
\hline CHEMBL1508871 & 688816 & 5.0 & 5.08 & TRN & \\
\hline CHEMBL1313927 & 688816 & 4.95 & 5.0958 & TST & \\
\hline CHEMBL1969353 & 688816 & 7.0501 & 5.3848 & TRN & \\
\hline CHEMBL1521643 & 688816 & 5.25 & 5.1682 & TRN & \\
\hline CHEMBL1462874 & 688816 & 4.6 & 5.2691 & TRN & \\
\hline CHEMBL1350855 & 688816 & 7.4001 & 5.2571 & TRN & \\
\hline
\end{tabular}




\begin{tabular}{|c|c|c|c|c|}
\hline \multicolumn{5}{|c|}{ Supplemental Table S2.txt } \\
\hline CHEMBL1379483 & 688816 & 4.9 & 5.194 & TRN \\
\hline CHEMBL3197890 & 688816 & 5.15 & 5.6558 & TST \\
\hline CHEMBL1366456 & 688816 & 4.95 & 5.2467 & TRN \\
\hline CHEMBL1517195 & 688816 & 6.0 & 4.8467 & TRN \\
\hline CHEMBL1449365 & 688816 & 5.9 & 5.3396 & TRN \\
\hline CHEMBL1560530 & 688816 & 4.7 & 4.9399 & TRN \\
\hline CHEMBL1577439 & 688816 & 4.5 & 4.8626 & TST \\
\hline CHEMBL1492994 & 688816 & 7.2503 & 4.9602 & TST \\
\hline CHEMBL3191564 & 688816 & 5.65 & 5.1728 & TRN \\
\hline CHEMBL1454738 & 688816 & 4.6 & 4.9011 & TRN \\
\hline CHEMBL3209782 & 688816 & 4.65 & 5.2283 & TRN \\
\hline CHEMBL1376108 & 688816 & 4.9 & 5.5294 & TST \\
\hline CHEMBL1340525 & 688816 & 7.9508 & 5.5809 & TRN \\
\hline CHEMBL1427152 & 688816 & 4.7 & 5.1014 & TRN \\
\hline CHEMBL1339609 & 688816 & 4.8 & 5.0885 & TRN \\
\hline CHEMBL1563532 & 688816 & 4.95 & 5.2719 & TRN \\
\hline CHEMBL1509915 & 688816 & 6.35 & 5.1174 & TST \\
\hline CHEMBL1312613 & 688816 & 4.95 & 5.1333 & TRN \\
\hline CHEMBL1344302 & 688816 & 5.1 & 5.2876 & TRN \\
\hline CHEMBL1469435 & 688816 & 4.95 & 5.0615 & TRN \\
\hline CHEMBL1391171 & 688816 & 4.8 & 5.3138 & TRN \\
\hline CHEMBL1462905 & 688816 & 4.45 & 5.3422 & TRN \\
\hline CHEMBL1508790 & 688816 & 4.9 & 5.093 & TST \\
\hline CHEMBL3212771 & 688816 & 4.9 & 5.2255 & TRN \\
\hline CHEMBL1351829 & 688816 & 5.3 & 5.2538 & TRN \\
\hline CHEMBL1429633 & 688816 & 4.95 & 5.6317 & TRN \\
\hline CHEMBL1369221 & 688816 & 4.9 & 5.1108 & TRN \\
\hline CHEMBL1342408 & 688816 & 4.95 & 5.2048 & TRN \\
\hline CHEMBL1372199 & 688816 & 4.75 & 5.3739 & TRN \\
\hline CHEMBL1417283 & 688816 & 4.95 & 5.4991 & TST \\
\hline CHEMBL1550518 & 688816 & 5.0 & 5.0833 & TRN \\
\hline CHEMBL1400162 & 688816 & 6.05 & 5.2718 & TRN \\
\hline CHEMBL1495750 & 688816 & 5.4 & 4.8687 & TRN \\
\hline CHEMBL1545105 & 688816 & 4.8 & 4.9005 & TRN \\
\hline CHEMBL1556320 & 688816 & 7.2503 & 5.8244 & TST \\
\hline CHEMBL1574148 & 688816 & 4.9 & 4.9561 & TRN \\
\hline CHEMBL1521155 & 688816 & 5.5 & 5.3988 & TRN \\
\hline CHEMBL3194991 & 688816 & 5.15 & 5.5895 & TRN \\
\hline CHEMBL1569537 & 688816 & 5.35 & 5.4859 & TRN \\
\hline CHEMBL1373533 & 688816 & 4.7 & 5.5799 & TRN \\
\hline CHEMBL3192838 & 688816 & 4.95 & 5.0346 & TRN \\
\hline CHEMBL1407141 & 688816 & 4.75 & 5.1367 & TRN \\
\hline CHEMBL3192939 & 688816 & 4.45 & 4.8954 & TRN \\
\hline CHEMBL1506404 & 688816 & 4.45 & 5.4953 & TRN \\
\hline CHEMBL1588595 & 688816 & 7.6498 & 5.3065 & TRN \\
\hline CHEMBL3211831 & 688816 & 4.6 & 4.9977 & TRN \\
\hline CHEMBL1399675 & 688816 & 4.9 & 5.0744 & TRN \\
\hline CHEMBL1373107 & 688816 & 5.1 & 5.4517 & TST \\
\hline
\end{tabular}




\begin{tabular}{|c|c|c|c|c|}
\hline \multicolumn{5}{|c|}{ Supplemental Table S2.txt } \\
\hline CHEMBL1566884 & 688816 & 4.95 & 4.8207 & TRN \\
\hline CHEMBL1499432 & 688816 & 4.45 & 4.9756 & TST \\
\hline CHEMBL1407635 & 688816 & 4.7 & 5.3875 & TRN \\
\hline CHEMBL1357982 & 688816 & 4.45 & 4.9804 & TRN \\
\hline CHEMBL1335722 & 688816 & 4.6 & 5.0286 & TST \\
\hline CHEMBL3194630 & 688816 & 4.5 & 4.8004 & TRN \\
\hline CHEMBL1377521 & 688816 & 6.6499 & 5.9665 & TRN \\
\hline CHEMBL1348277 & 688816 & 4.9 & 5.0195 & TRN \\
\hline CHEMBL1587785 & 688816 & 4.95 & 5.3204 & TRN \\
\hline CHEMBL1331442 & 688816 & 4.8 & 4.9209 & TST \\
\hline CHEMBL1531915 & 688816 & 7.5498 & 5.44600 & 0000000001 \\
\hline CHEMBL1484736 & 688816 & 4.75 & 4.9209 & TRN \\
\hline CHEMBL1569694 & 688816 & 4.9 & 5.1477 & TRN \\
\hline CHEMBL1526929 & 688816 & 4.65 & 5.0662 & TRN \\
\hline CHEMBL1438798 & 688816 & 4.85 & 4.9988 & TRN \\
\hline CHEMBL1495290 & 688816 & 4.85 & 5.3382 & TST \\
\hline CHEMBL1491171 & 688816 & 5.45 & 5.5226 & TRN \\
\hline CHEMBL1400787 & 688816 & 6.5 & 5.2065 & TST \\
\hline CHEMBL1374691 & 688816 & 5.1 & 4.7375 & TRN \\
\hline CHEMBL1331659 & 688816 & 7.699 & 5.4613 & TRN \\
\hline CHEMBL1486191 & 688816 & 5.35 & 4.7985 & TST \\
\hline CHEMBL3193039 & 688816 & 4.45 & 5.5129 & TRN \\
\hline CHEMBL 260283 & 688816 & 5.85 & 5.735 & TRN \\
\hline CHEMBL 3207783 & 688816 & 5.8 & 5.5636 & TRN \\
\hline CHEMBL1311573 & 688816 & 4.45 & 5.2419 & TRN \\
\hline CHEMBL1326434 & 688816 & 4.75 & 5.0974 & TST \\
\hline CHEMBL1332140 & 688816 & 4.85 & 5.2343 & TRN \\
\hline CHEMBL1370664 & 688816 & 4.95 & 5.3021 & TRN \\
\hline CHEMBL1307682 & 688816 & 4.9 & 5.3356 & TST \\
\hline CHEMBL3190009 & 688816 & 4.95 & 4.793 & TST \\
\hline CHEMBL1513689 & 688816 & 7.4001 & 5.0953 & TST \\
\hline CHEMBL1995645 & 688816 & 4.5 & 5.1262 & TRN \\
\hline CHEMBL1431912 & 688816 & 8.301 & 5.9067 & TRN \\
\hline CHEMBL1603450 & 688816 & 6.6 & 5.6 & TST \\
\hline CHEMBL1330565 & 688816 & 4.45 & 5.1972 & TRN \\
\hline CHEMBL1484546 & 688816 & 4.9 & 5.4279 & TST \\
\hline CHEMBL1337623 & 688816 & 8.301 & 5.6711 & TRN \\
\hline CHEMBL1409988 & 688816 & 4.7 & 4.9766 & TRN \\
\hline CHEMBL1412907 & 688816 & 5.65 & 5.3871 & TST \\
\hline CHEMBL1608247 & 688816 & 5.2 & 5.5448 & TRN \\
\hline CHEMBL1595492 & 688816 & 4.45 & 5.4585 & TRN \\
\hline CHEMBL1500701 & 688816 & 4.9 & 5.1842 & TST \\
\hline CHEMBL1394754 & 688816 & 5.25 & 5.6783 & TST \\
\hline CHEMBL1410979 & 688816 & 4.8 & 5.3256 & TRN \\
\hline CHEMBL1470905 & 688816 & 5.25 & 4.6487 & TST \\
\hline CHEMBL1548027 & 688816 & 4.65 & 5.0792 & TRN \\
\hline CHEMBL3212330 & 688816 & 4.45 & 5.2654 & TRN \\
\hline CHEMBL1382030 & 688816 & 4.9 & 5.3403 & TRN \\
\hline
\end{tabular}




\begin{tabular}{|c|c|c|c|c|c|}
\hline \multicolumn{6}{|c|}{ Supplemental Table S2.txt } \\
\hline CHEMBL 3191620 & 688816 & 8.3979 & 5.3276 & TRN & \\
\hline CHEMBL1456922 & 688816 & 4.7 & 5.4607 & TRN & \\
\hline CHEMBL1589219 & 688816 & 6.0 & 5.1472 & TST & \\
\hline CHEMBL1444566 & 688816 & 5.6 & 5.6739 & TST & \\
\hline CHEMBL1464354 & 688816 & 4.7 & 5.3431 & TST & \\
\hline CHEMBL1556970 & 688816 & 4.95 & 5.3285 & TRN & \\
\hline CHEMBL1520322 & 688816 & 4.45 & 4.9905 & TST & \\
\hline CHEMBL1588660 & 688816 & 4.45 & 4.8049 & TRN & \\
\hline CHEMBL1490218 & 688816 & 6.8499 & 5.38 & TRN & \\
\hline CHEMBL1452758 & 688816 & 8.7447 & 5.7063 & TRN & \\
\hline CHEMBL1609946 & 688816 & 5.15 & 5.1933 & TRN & \\
\hline CHEMBL1604696 & 688816 & 5.5 & 5.1903 & TRN & \\
\hline CHEMBL1526319 & 688816 & 4.45 & 5.1942 & TST & \\
\hline CHEMBL1458427 & 688816 & 5.0 & 5.2757 & TST & \\
\hline CHEMBL3189906 & 688816 & 5.05 & 5.4396 & TRN & \\
\hline CHEMBL1569098 & 688816 & 4.9 & 5.28700 & 0000000001 & TRN \\
\hline CHEMBL1365328 & 688816 & 5.0 & 5.4004 & TRN & \\
\hline CHEMBL1460990 & 688816 & 8.0506 & 5.0639 & TST & \\
\hline CHEMBL1409650 & 688816 & 4.9 & 5.5344 & TST & \\
\hline CHEMBL1419680 & 688816 & 4.7 & 5.3111 & TST & \\
\hline CHEMBL1485482 & 688816 & 5.25 & 5.1017 & TRN & \\
\hline CHEMBL1472274 & 688816 & 5.15 & 5.4216 & TRN & \\
\hline CHEMBL1413924 & 688816 & 6.15 & 5.0815 & TRN & \\
\hline CHEMBL1307956 & 688816 & 5.0 & 5.0942 & TRN & \\
\hline CHEMBL1435462 & 688816 & 4.45 & 5.0623 & TST & \\
\hline CHEMBL1438784 & 688816 & 4.85 & 4.9048 & TRN & \\
\hline CHEMBL1431931 & 688816 & 4.95 & 5.8648 & TRN & \\
\hline CHEMBL1443413 & 688816 & 4.45 & 5.7953 & TST & \\
\hline CHEMBL1524586 & 688816 & 5.45 & 5.3944 & TRN & \\
\hline CHEMBL1503952 & 688816 & 4.95 & 5.6056 & TRN & \\
\hline CHEMBL1533464 & 688816 & 4.45 & 5.4255 & TST & \\
\hline CHEMBL1508085 & 688816 & 6.5 & 5.5248 & TRN & \\
\hline CHEMBL1561791 & 688816 & 5.7 & 5.0437 & TRN & \\
\hline CHEMBL3191616 & 688816 & 6.5501 & 5.5344 & TRN & \\
\hline CHEMBL1439438 & 688816 & 6.35 & 5.5267 & TRN & \\
\hline CHEMBL1581582 & 688816 & 5.0 & 5.2023 & TST & \\
\hline CHEMBL1462628 & 688816 & 4.5 & 5.2469 & TST & \\
\hline CHEMBL1422015 & 688816 & 4.8 & 5.25700 & 0000000001 & TRN \\
\hline CHEMBL1970812 & 688816 & 4.9 & 5.4301 & TRN & \\
\hline CHEMBL1423539 & 688816 & 7.4498 & 5.4253 & TRN & \\
\hline CHEMBL1459475 & 688816 & 4.8 & 5.2008 & TST & \\
\hline CHEMBL1595923 & 688816 & 4.45 & 5.4375 & TRN & \\
\hline CHEMBL1541248 & 688816 & 5.35 & 5.7287 & TST & \\
\hline CHEMBL1383297 & 688816 & 5.3 & 4.8993 & TRN & \\
\hline CHEMBL3195051 & 688816 & 4.5 & 5.394 & TRN & \\
\hline CHEMBL 3196334 & 688816 & 8.301 & 5.2025 & TRN & \\
\hline CHEMBL1452187 & 688816 & 4.8 & 5.1793 & TRN & \\
\hline CHEMBL1964998 & 688816 & 4.8 & 5.2326 & TRN & \\
\hline
\end{tabular}




\begin{tabular}{|c|c|c|c|c|}
\hline \multicolumn{5}{|c|}{ Supplemental Table S2.txt } \\
\hline CHEMBL3195688 & 688816 & 5.5 & 5.0657 & TRN \\
\hline CHEMBL1564390 & 688816 & 4.45 & 5.3308 & TRN \\
\hline CHEMBL1501303 & 688816 & 4.9 & 5.5949 & TRN \\
\hline CHEMBL1607399 & 688816 & 6.9 & 5.4376 & TRN \\
\hline CHEMBL1332015 & 688816 & 4.5 & 5.1021 & TRN \\
\hline CHEMBL1585094 & 688816 & 4.75 & 4.9504 & TRN \\
\hline CHEMBL3191783 & 688816 & 4.95 & 5.165 & TST \\
\hline CHEMBL1970117 & 688816 & 4.7 & 5.37 & TRN \\
\hline CHEMBL1502416 & 688816 & 4.85 & 5.0003 & TRN \\
\hline CHEMBL1384020 & 688816 & 4.85 & 5.4424 & TRN \\
\hline CHEMBL1533442 & 688816 & 4.45 & 4.9982 & TRN \\
\hline CHEMBL1410089 & 688816 & 5.0 & 5.1385 & TRN \\
\hline CHEMBL1350664 & 688816 & 5.3 & 5.0827 & TRN \\
\hline CHEMBL1547064 & 688816 & 4.95 & 5.2018 & TRN \\
\hline CHEMBL3211685 & 688816 & 5.05 & 5.3685 & TST \\
\hline CHEMBL1998229 & 688816 & 4.75 & 5.2209 & TRN \\
\hline CHEMBL3197673 & 688816 & 4.95 & 5.525 & TRN \\
\hline CHEMBL1422682 & 688816 & 4.85 & 5.0203 & TRN \\
\hline CHEMBL1532534 & 688816 & 4.85 & 5.0932 & TST \\
\hline CHEMBL1364432 & 688816 & 4.6 & 4.9584 & TRN \\
\hline CHEMBL1596945 & 688816 & 4.45 & 5.0966 & TRN \\
\hline CHEMBL1308972 & 688816 & 4.95 & 5.3099 & TRN \\
\hline CHEMBL1581560 & 688816 & 4.45 & 5.1592 & TRN \\
\hline CHEMBL592842 & 688816 & 5.05 & 5.2465 & TRN \\
\hline CHEMBL1510019 & 688816 & 8.1024 & 5.1966 & TRN \\
\hline CHEMBL1461275 & 688816 & 4.95 & 5.6638 & TRN \\
\hline CHEMBL1453805 & 688816 & 8.4949 & 4.7142 & TRN \\
\hline CHEMBL1418230 & 688816 & 6.0 & 5.0379 & TRN \\
\hline CHEMBL1488608 & 688816 & 5.55 & 5.1448 & TRN \\
\hline CHEMBL1541933 & 688816 & 5.45 & 5.2652 & TRN \\
\hline CHEMBL1478628 & 688816 & 4.95 & 5.0397 & TRN \\
\hline CHEMBL1424243 & 688816 & 4.95 & 4.8849 & TST \\
\hline CHEMBL1324106 & 688816 & 4.95 & 5.2182 & TRN \\
\hline CHEMBL1596681 & 688816 & 5.8 & 5.2009 & TRN \\
\hline CHEMBL1997347 & 688816 & 5.95 & 5.5246 & TRN \\
\hline CHEMBL1386403 & 688816 & 6.05 & 5.3375 & TRN \\
\hline CHEMBL1511444 & 688816 & 5.65 & 5.3017 & TRN \\
\hline CHEMBL1371367 & 688816 & 4.9 & 5.4478 & TRN \\
\hline CHEMBL1571509 & 688816 & 4.65 & 5.3492 & TRN \\
\hline CHEMBL1334745 & 688816 & 8.0 & 5.4089 & TST \\
\hline CHEMBL1344444 & 688816 & 4.75 & 5.5128 & TRN \\
\hline CHEMBL1303968 & 688816 & 4.7 & 4.9684 & TRN \\
\hline CHEMBL1461098 & 688816 & 5.95 & 4.9407 & TST \\
\hline CHEMBL1488150 & 688816 & 4.8 & 5.3615 & TRN \\
\hline CHEMBL1355715 & 688816 & 4.45 & 4.9406 & TRN \\
\hline CHEMBL1455330 & 688816 & 7.2503 & 5.8391 & TST \\
\hline CHEMBL1384688 & 688816 & 5.5 & 5.931 & TRN \\
\hline CHEMBL1482820 & 688816 & 5.5 & 5.2275 & TRN \\
\hline
\end{tabular}




\begin{tabular}{|c|c|c|c|c|}
\hline & & & oplement & \\
\hline CHEMBL1383049 & 688816 & 4.9 & 5.5125 & TRN \\
\hline CHEMBL1331836 & 688816 & 4.95 & 5.2078 & TRN \\
\hline CHEMBL1507686 & 688816 & 6.15 & 5.3872 & TRN \\
\hline CHEMBL1586951 & 688816 & 5.7 & 5.2265 & TRN \\
\hline CHEMBL 1343532 & 688816 & 5.3 & 4.998 & TRN \\
\hline CHEMBL1371170 & 688816 & 6.15 & 5.4268 & TST \\
\hline CHEMBL 2004739 & 688816 & 4.8 & 5.2855 & TRN \\
\hline CHEMBL1299283 & 688816 & 5.9 & 5.2333 & TRN \\
\hline CHEMBL1486982 & 688816 & 5.1 & 5.0589 & TRN \\
\hline CHEMBL1563855 & 688816 & 4.95 & 5.5417 & TRN \\
\hline CHEMBL1508447 & 688816 & 5.3 & 5.4227 & TRN \\
\hline CHEMBL1453819 & 688816 & 5.25 & 5.1082 & TRN \\
\hline CHEMBL1491015 & 688816 & 5.3 & 5.0461 & TST \\
\hline CHEMBL1389805 & 688816 & 4.75 & 5.4352 & TRN \\
\hline CHEMBL1540498 & 688816 & 4.75 & 5.0838 & TRN \\
\hline CHEMBL1595296 & 688816 & 7.3002 & 5.1931 & TST \\
\hline CHEMBL1611444 & 688816 & 5.45 & 5.3375 & TST \\
\hline CHEMBL1523444 & 688816 & 7.5498 & 5.4086 & TST \\
\hline CHEMBL1563754 & 688816 & 4.8 & 5.6568 & TRN \\
\hline CHEMBL1445650 & 688816 & 4.8 & 5.0738 & TRN \\
\hline CHEMBL1525382 & 688816 & 4.7 & 5.1767 & TRN \\
\hline CHEMBL1320694 & 688816 & 5.0 & 4.9472 & TRN \\
\hline CHEMBL1564647 & 688816 & 7.5498 & 5.465 & TST \\
\hline CHEMBL1428926 & 688816 & 4.85 & 5.4826 & TRN \\
\hline CHEMBL1589343 & 688816 & 4.65 & 5.0346 & TST \\
\hline CHEMBL1605488 & 688816 & 4.95 & 5.2521 & TRN \\
\hline CHEMBL3191294 & 688816 & 4.85 & 5.2443 & TST \\
\hline CHEMBL3212619 & 688816 & 4.75 & 5.2968 & TST \\
\hline CHEMBL1487691 & 688816 & 5.0 & 5.3529 & TST \\
\hline CHEMBL1363801 & 688816 & 4.9 & 5.3586 & TRN \\
\hline CHEMBL1490976 & 688816 & 4.7 & 5.1496 & TRN \\
\hline CHEMBL1496658 & 688816 & 5.3 & 5.4673 & TRN \\
\hline CHEMBL1393994 & 688816 & 5.35 & 5.1786 & TRN \\
\hline CHEMBL1526851 & 688816 & 4.7 & 4.8842 & TST \\
\hline CHEMBL1469732 & 688816 & 6.6 & 5.2532 & TRN \\
\hline CHEMBL1402483 & 688816 & 4.8 & 4.9142 & TRN \\
\hline CHEMBL1360254 & 688816 & 6.5 & 5.2956 & TRN \\
\hline CHEMBL1080171 & 688816 & 4.9 & 5.2595 & TRN \\
\hline CHEMBL1430358 & 688816 & 4.85 & 5.2702 & TRN \\
\hline CHEMBL1609651 & 688816 & 4.8 & 5.5256 & TRN \\
\hline CHEMBL1521813 & 688816 & 4.65 & 5.0447 & TRN \\
\hline CHEMBL1531943 & 688816 & 4.95 & 5.178 & TRN \\
\hline CHEMBL1577200 & 688816 & 4.9 & 5.2738 & TST \\
\hline CHEMBL1406428 & 688816 & 5.25 & 5.4467 & TRN \\
\hline CHEMBL1428719 & 688816 & 6.3 & 5.4682 & TST \\
\hline CHEMBL1570977 & 688816 & 4.85 & 5.3416 & TRN \\
\hline CHEMBL1390716 & 688816 & 4.45 & 4.8843 & TRN \\
\hline CHEMBL1444811 & 688816 & 5.25 & 5.1257 & TST \\
\hline
\end{tabular}




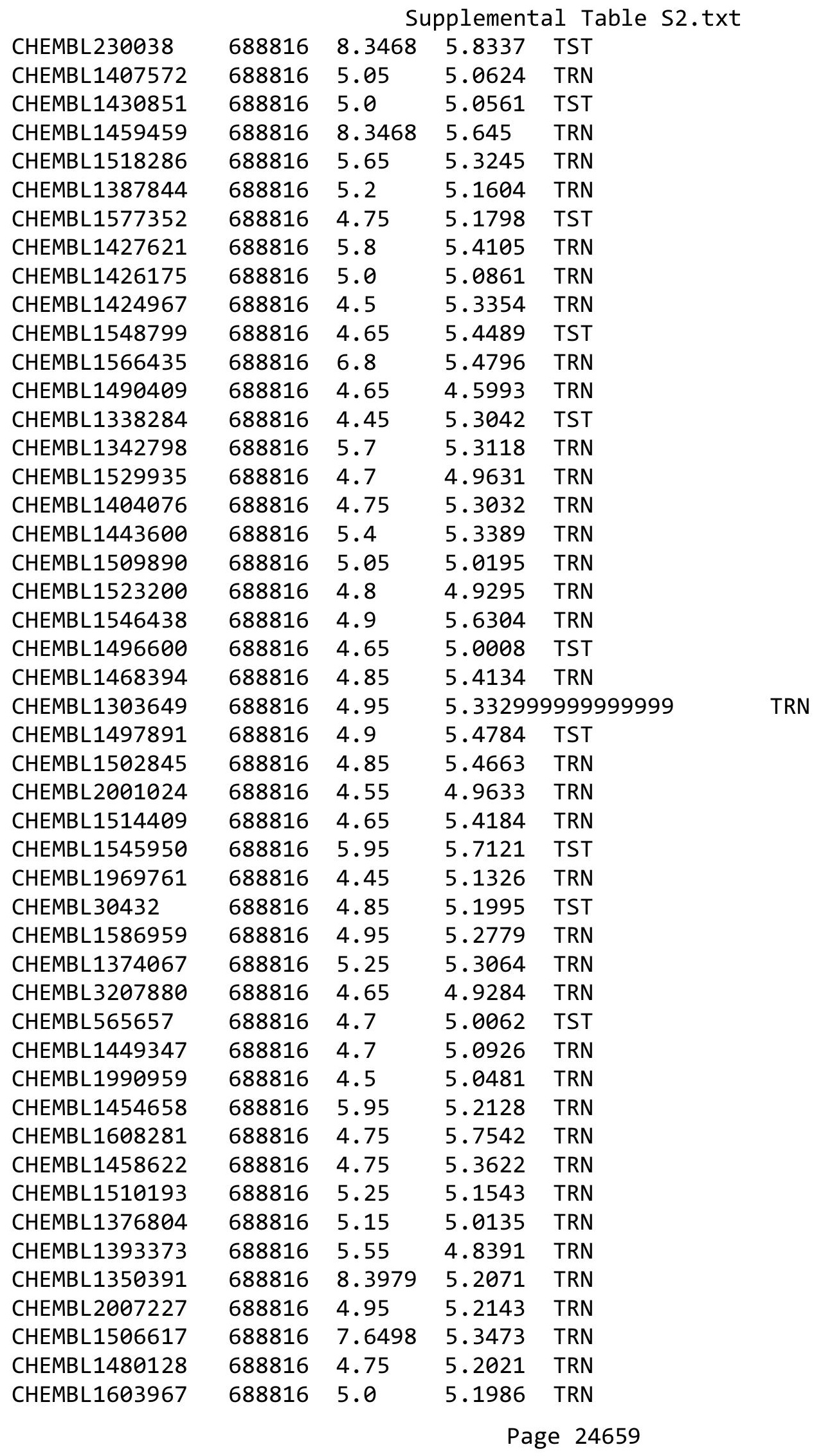




\begin{tabular}{|c|c|c|c|c|c|}
\hline \multicolumn{6}{|c|}{ Supplemental Table S2.txt } \\
\hline CHEMBL1378214 & 688816 & 5.55 & 5.5746 & TRN & \\
\hline CHEMBL1865547 & 688816 & 6.1 & \multicolumn{2}{|c|}{5.446000000000001} & TRN \\
\hline CHEMBL1330318 & 688816 & 5.7 & 5.1414 & TRN & \\
\hline CHEMBL1548515 & 688816 & 4.45 & 5.3781 & TRN & \\
\hline CHEMBL1365325 & 688816 & 5.55 & 5.3723 & TRN & \\
\hline CHEMBL1519807 & 688816 & 4.75 & 4.8169 & TRN & \\
\hline CHEMBL1419744 & 688816 & 5.1 & 5.6904 & TRN & \\
\hline CHEMBL1349657 & 688816 & 4.8 & 5.4976 & TST & \\
\hline CHEMBL1378655 & 688816 & 5.35 & 5.5459 & TST & \\
\hline CHEMBL1413497 & 688816 & 4.95 & 5.1038 & TRN & \\
\hline CHEMBL1560359 & 688816 & 5.1 & 4.9842 & TRN & \\
\hline CHEMBL1522369 & 688816 & 5.9 & 5.5122 & TRN & \\
\hline CHEMBL1419542 & 688816 & 5.0 & 5.5639 & TST & \\
\hline CHEMBL1360457 & 688816 & 4.7 & 5.0086 & TST & \\
\hline CHEMBL1528475 & 688816 & 4.6 & 5.0144 & TRN & \\
\hline CHEMBL1540045 & 688816 & 4.95 & 5.2585 & TRN & \\
\hline CHEMBL1529428 & 688816 & 4.9 & 5.0532 & TRN & \\
\hline CHEMBL1589213 & 688816 & 4.45 & 5.029 & TRN & \\
\hline CHEMBL1493186 & 688816 & 6.05 & 5.5861 & TRN & \\
\hline CHEMBL1418311 & 688816 & 4.9 & 5.5707 & TRN & \\
\hline CHEMBL1469033 & 688816 & 5.5 & 4.9462 & TRN & \\
\hline CHEMBL3191330 & 688816 & 6.8 & 5.355 & TRN & \\
\hline CHEMBL1330591 & 688816 & 5.25 & 5.5637 & TRN & \\
\hline CHEMBL1527634 & 688816 & 4.95 & 5.3636 & TRN & \\
\hline CHEMBL1575312 & 688816 & 5.6 & 5.5625 & TRN & \\
\hline CHEMBL1379823 & 688816 & 6.7501 & 5.5891 & TRN & \\
\hline CHEMBL1578812 & 688816 & 4.6 & 5.7172 & TRN & \\
\hline CHEMBL1391742 & 688816 & 4.95 & 5.4321 & TRN & \\
\hline CHEMBL1402216 & 688816 & 5.3 & 5.3507 & TST & \\
\hline CHEMBL1539718 & 688816 & 4.9 & 5.3793 & TST & \\
\hline CHEMBL1458188 & 688816 & 8.4949 & 5.8856 & TST & \\
\hline CHEMBL3212561 & 688816 & 5.45 & 5.5776 & TST & \\
\hline CHEMBL3195466 & 688816 & 4.9 & 5.4336 & TRN & \\
\hline CHEMBL1510369 & 688816 & 4.75 & 5.619 & TRN & \\
\hline CHEMBL1428157 & 688816 & 5.1 & 5.0713 & TST & \\
\hline CHEMBL1331651 & 688816 & 5.3 & 5.6184 & TRN & \\
\hline CHEMBL1985598 & 688816 & 4.75 & 5.4 & TRN & \\
\hline CHEMBL1543636 & 688816 & 4.45 & 4.9806 & TRN & \\
\hline CHEMBL1533805 & 688816 & 5.15 & 4.9006 & TRN & \\
\hline CHEMBL1561928 & 688816 & 5.5 & 5.145 & TRN & \\
\hline CHEMBL1608077 & 688816 & 4.45 & 4.915 & TRN & \\
\hline CHEMBL463574 & 688816 & 4.45 & 5.0149 & TST & \\
\hline CHEMBL1461714 & 688816 & 4.9 & 4.9194 & TRN & \\
\hline CHEMBL1502185 & 688816 & 4.6 & 4.9641 & TRN & \\
\hline CHEMBL1709970 & 688816 & 7.1002 & 5.0692 & TRN & \\
\hline CHEMBL455284 & 688816 & 6.9 & 5.7728 & TRN & \\
\hline CHEMBL1448826 & 688816 & 4.65 & 5.05699 & 99999999995 & TRN \\
\hline CHEMBL1606973 & 688816 & 4.65 & 5.3404 & TRN & \\
\hline
\end{tabular}




\begin{tabular}{|c|c|c|c|c|c|}
\hline \multicolumn{6}{|c|}{ Supplemental Table S2.txt } \\
\hline CHEMBL1320081 & 688816 & 4.75 & 5.2389 & TRN & \\
\hline CHEMBL1414608 & 688816 & 4.9 & 5.282 & TRN & \\
\hline CHEMBL1449023 & 688816 & 4.7 & 4.9808 & TRN & \\
\hline CHEMBL1352804 & 688816 & 8.4949 & 5.1918 & TST & \\
\hline CHEMBL576208 & 688816 & 4.8 & 5.0892 & TRN & \\
\hline CHEMBL1379046 & 688816 & 4.95 & 5.2793 & TRN & \\
\hline CHEMBL1321273 & 688816 & 4.8 & 5.4122 & TRN & \\
\hline CHEMBL1534410 & 688816 & 4.6 & 5.2409 & TST & \\
\hline CHEMBL1427958 & 688816 & 5.25 & 5.7724 & TRN & \\
\hline CHEMBL1322664 & 688816 & 6.5501 & 5.4112 & TRN & \\
\hline CHEMBL1354829 & 688816 & 4.95 & 5.2668 & TRN & \\
\hline CHEMBL1427237 & 688816 & 4.45 & $5.3820 e$ & 0000000001 & TRN \\
\hline CHEMBL1510925 & 688816 & 4.95 & 5.0686 & TRN & \\
\hline CHEMBL1325342 & 688816 & 4.9 & 5.3602 & TRN & \\
\hline CHEMBL1438925 & 688816 & 5.05 & 5.0684 & TRN & \\
\hline CHEMBL1418573 & 688816 & 5.05 & 5.5032 & TRN & \\
\hline CHEMBL1379426 & 688816 & 4.95 & 5.2273 & TRN & \\
\hline CHEMBL1352100 & 688816 & 4.8 & 5.7132 & TRN & \\
\hline CHEMBL1607208 & 688816 & 4.8 & 4.9584 & TST & \\
\hline CHEMBL602400 & 688816 & 5.9 & 4.9583 & TRN & \\
\hline CHEMBL1320357 & 688816 & 4.75 & 5.1549 & TRN & \\
\hline CHEMBL1534183 & 688816 & 4.45 & 5.3035 & TRN & \\
\hline CHEMBL1451181 & 688816 & 4.95 & 5.3341 & TRN & \\
\hline CHEMBL1572364 & 688816 & 4.45 & 4.9452 & TRN & \\
\hline CHEMBL1530266 & 688816 & 5.25 & 5.3477 & TRN & \\
\hline CHEMBL1416270 & 688816 & 4.85 & 5.0024 & TRN & \\
\hline CHEMBL1353589 & 688816 & 4.65 & 4.9479 & TRN & \\
\hline CHEMBL1437553 & 688816 & 4.45 & 4.6955 & TRN & \\
\hline CHEMBL3194825 & 688816 & 7.6498 & 5.3513 & TRN & \\
\hline CHEMBL1391246 & 688816 & 5.35 & 5.5507 & TST & \\
\hline CHEMBL1303351 & 688816 & 4.45 & 5.532 & TRN & \\
\hline CHEMBL1393328 & 688816 & 5.0 & 5.1629 & TRN & \\
\hline CHEMBL1341318 & 688816 & 8.301 & 5.4439 & TST & \\
\hline CHEMBL1397505 & 688816 & 4.95 & 5.0005 & TRN & \\
\hline CHEMBL1411484 & 688816 & 4.7 & 5.2785 & TRN & \\
\hline CHEMBL1299186 & 688816 & 4.95 & 5.4417 & TRN & \\
\hline CHEMBL467423 & 688816 & 4.9 & 5.2838 & TRN & \\
\hline CHEMBL1589346 & 688816 & 7.7496 & 5.3774 & TST & \\
\hline CHEMBL1419673 & 688816 & 4.9 & 4.9176 & TRN & \\
\hline CHEMBL1524381 & 688816 & 7.699 & 4.8738 & TRN & \\
\hline CHEMBL1382801 & 688816 & 4.9 & 5.404 & TST & \\
\hline CHEMBL 1458726 & 688816 & 5.15 & 5.1482 & TRN & \\
\hline CHEMBL1400568 & 688816 & 4.9 & 5.6435 & TST & \\
\hline CHEMBL1347350 & 688816 & 5.05 & 5.4112 & TRN & \\
\hline CHEMBL1335881 & 688816 & 4.8 & 5.3492 & TST & \\
\hline CHEMBL1540564 & 688816 & 5.3 & 5.8764 & TRN & \\
\hline CHEMBL1313548 & 688816 & 5.6 & 5.4454 & TRN & \\
\hline CHEMBL1556421 & 688816 & 5.6 & 5.0581 & TRN & \\
\hline
\end{tabular}




\begin{tabular}{|c|c|c|c|c|c|}
\hline \multicolumn{6}{|c|}{ Supplemental Table S2.txt } \\
\hline CHEMBL1579951 & 688816 & 6.8 & 5.5975 & TST & \\
\hline CHEMBL1565926 & 688816 & 4.75 & 5.3739 & TST & \\
\hline CHEMBL1573067 & 688816 & 4.9 & 5.0528 & TRN & \\
\hline CHEMBL1585443 & 688816 & 5.4 & 5.4568 & TRN & \\
\hline CHEMBL1526414 & 688816 & 4.8 & 5.4244 & TRN & \\
\hline CHEMBL1400609 & 688816 & 4.9 & 5.0624 & TRN & \\
\hline CHEMBL1582760 & 688816 & 4.65 & 5.3651 & TRN & \\
\hline CHEMBL1543597 & 688816 & 6.35 & 5.7545 & TST & \\
\hline CHEMBL1374919 & 688816 & 4.45 & 5.0527 & TRN & \\
\hline CHEMBL1560010 & 688816 & 4.7 & 5.2388 & TRN & \\
\hline CHEMBL1548633 & 688816 & 4.6 & 5.1045 & TRN & \\
\hline CHEMBL1434773 & 688816 & 4.8 & 4.9465 & TRN & \\
\hline CHEMBL 3207614 & 688816 & 6.8 & 5.0727 & TST & \\
\hline CHEMBL1485349 & 688816 & 4.45 & 5.0206 & TST & \\
\hline CHEMBL1513469 & 688816 & 4.55 & 5.2085 & TRN & \\
\hline CHEMBL1463376 & 688816 & 4.8 & 5.1202 & TRN & \\
\hline CHEMBL1480820 & 688816 & 4.9 & 5.3904 & TRN & \\
\hline CHEMBL1405366 & 688816 & 5.2 & 5.1226 & TST & \\
\hline CHEMBL1586294 & 688816 & 4.55 & 5.1413 & TRN & \\
\hline CHEMBL1547145 & 688816 & 4.8 & 5.1676 & TRN & \\
\hline CHEMBL1523881 & 688816 & 5.0 & 5.1069 & TRN & \\
\hline CHEMBL1588267 & 688816 & 4.45 & 5.1849 & TRN & \\
\hline CHEMBL1306666 & 688816 & 5.25 & 4.7526 & TRN & \\
\hline CHEMBL1342974 & 688816 & 5.25 & 5.0379 & TRN & \\
\hline CHEMBL1459767 & 688816 & 5.25 & 5.4672 & TST & \\
\hline CHEMBL1440876 & 688816 & 5.45 & 5.2533 & TST & \\
\hline CHEMBL1365260 & 688816 & 4.95 & 4.9779 & TRN & \\
\hline CHEMBL1329992 & 688816 & 7.0501 & 5.4917 & TST & \\
\hline CHEMBL1337036 & 688816 & 4.45 & 5.2766 & TRN & \\
\hline CHEMBL1425950 & 688816 & 5.25 & 5.32299 & 99999999995 & TRN \\
\hline CHEMBL1306181 & 688816 & 4.45 & 5.0647 & TRN & \\
\hline CHEMBL1388012 & 688816 & 5.25 & 5.3159 & TST & \\
\hline CHEMBL1599561 & 688816 & 8.0 & 5.7176 & TST & \\
\hline CHEMBL1992154 & 688816 & 5.05 & 5.1184 & TRN & \\
\hline CHEMBL1351395 & 688816 & 4.45 & 5.2868 & TRN & \\
\hline CHEMBL3209623 & 688816 & 4.45 & 5.0094 & TRN & \\
\hline CHEMBL1345170 & 688816 & 7.3002 & 5.3807 & TRN & \\
\hline CHEMBL1449493 & 688816 & 4.85 & 4.9754 & TRN & \\
\hline CHEMBL1611559 & 688816 & 4.95 & 5.2728 & TRN & \\
\hline CHEMBL1459836 & 688816 & 4.45 & 5.691 & TRN & \\
\hline CHEMBL1586716 & 688816 & 4.95 & 5.1593 & TRN & \\
\hline CHEMBL1466181 & 688816 & 4.6 & 5.0613 & TRN & \\
\hline CHEMBL1509254 & 688816 & 5.0 & 4.7605 & TRN & \\
\hline CHEMBL1597389 & 688816 & 5.4 & 5.36700 & $\partial 000000001$ & TST \\
\hline CHEMBL1482321 & 688816 & 7.0 & 4.9849 & TRN & \\
\hline CHEMBL1999900 & 688816 & 4.95 & 5.2054 & TST & \\
\hline CHEMBL1450350 & 688816 & 8.3468 & 5.2221 & TST & \\
\hline CHEMBL1310835 & 688816 & 4.65 & 5.331 & TRN & \\
\hline
\end{tabular}




\begin{tabular}{|c|c|c|c|c|}
\hline \multicolumn{5}{|c|}{ Supplemental Table S2.txt } \\
\hline CHEMBL1386280 & 688816 & 4.45 & 5.1386 & TST \\
\hline CHEMBL1454194 & 688816 & 4.95 & 5.1613 & TRN \\
\hline CHEMBL1337609 & 688816 & 6.05 & 5.4839 & TST \\
\hline CHEMBL1527785 & 688816 & 5.85 & 5.6904 & TST \\
\hline CHEMBL1549923 & 688816 & 5.45 & 5.3294 & TRN \\
\hline CHEMBL1439711 & 688816 & 4.9 & 5.4072 & TST \\
\hline CHEMBL1360854 & 688816 & 5.5 & 5.9659 & TRN \\
\hline CHEMBL1608588 & 688816 & 4.6 & 5.2599 & TRN \\
\hline CHEMBL332898 & 688816 & 5.0 & 5.121 & TST \\
\hline CHEMBL1426367 & 688816 & 5.1 & 5.3986 & TST \\
\hline CHEMBL1413245 & 688816 & 6.05 & 5.2457 & TST \\
\hline CHEMBL582259 & 688816 & 4.65 & 5.3413 & TST \\
\hline CHEMBL1366075 & 688816 & 5.4 & 5.5314 & TST \\
\hline CHEMBL1336520 & 688816 & 5.45 & 5.274 & TRN \\
\hline CHEMBL1981951 & 688816 & 4.9 & 5.3153 & TST \\
\hline CHEMBL1551541 & 688816 & 4.85 & 5.004 & TRN \\
\hline CHEMBL1585774 & 688816 & 4.8 & 5.5547 & TRN \\
\hline CHEMBL1309423 & 688816 & 4.7 & 4.9113 & TST \\
\hline CHEMBL1543544 & 688816 & 8.3468 & 5.6482 & TRN \\
\hline CHEMBL1448671 & 688816 & 4.9 & 5.3384 & TRN \\
\hline CHEMBL1389975 & 688816 & 4.95 & 5.0743 & TRN \\
\hline CHEMBL1319454 & 688816 & 6.2 & 5.44600 & 0000000001 \\
\hline CHEMBL1984523 & 688816 & 4.6 & 5.2919 & TST \\
\hline CHEMBL1414869 & 688816 & 4.9 & 5.1938 & TRN \\
\hline CHEMBL1330663 & 688816 & 4.9 & 5.2196 & TRN \\
\hline CHEMBL1303031 & 688816 & 5.5 & 5.101 & TRN \\
\hline CHEMBL1489481 & 688816 & 4.7 & 5.1778 & TRN \\
\hline CHEMBL1303836 & 688816 & 5.3 & 5.2828 & TRN \\
\hline CHEMBL1401344 & 688816 & 5.1 & 5.1125 & TRN \\
\hline CHEMBL 1408226 & 688816 & 5.25 & 5.5193 & TRN \\
\hline CHEMBL1530714 & 688816 & 4.7 & 5.4322 & TST \\
\hline CHEMBL1355793 & 688816 & 4.7 & 5.518 & TRN \\
\hline CHEMBL1444912 & 688816 & 7.5498 & 5.0268 & TST \\
\hline CHEMBL1485705 & 688816 & 4.95 & 5.3944 & TRN \\
\hline CHEMBL1536532 & 688816 & 8.1024 & 4.9173 & TST \\
\hline CHEMBL1430338 & 688816 & 4.45 & 5.2957 & TST \\
\hline CHEMBL1450215 & 688816 & 4.85 & 5.4004 & TRN \\
\hline CHEMBL1382658 & 688816 & 5.15 & 5.1666 & TRN \\
\hline CHEMBL1402876 & 688816 & 4.65 & 4.9608 & TRN \\
\hline CHEMBL 1471520 & 688816 & 4.9 & 5.518 & TST \\
\hline CHEMBL563919 & 688816 & 4.95 & 5.2554 & TRN \\
\hline CHEMBL1432841 & 688816 & 4.5 & 5.1215 & TRN \\
\hline CHEMBL1531365 & 688816 & 8.5528 & 5.4114 & TST \\
\hline CHEMBL1327239 & 688816 & 8.3468 & 5.6007 & TRN \\
\hline CHEMBL1434704 & 688816 & 4.8 & 5.6036 & TRN \\
\hline CHEMBL1469626 & 688816 & 4.85 & 5.4448 & TST \\
\hline CHEMBL1595197 & 688816 & 4.45 & 5.5333 & TRN \\
\hline CHEMBL1304458 & 688816 & 4.7 & 5.3279 & TST \\
\hline
\end{tabular}

TRN 


\begin{tabular}{|c|c|c|c|c|c|}
\hline \multicolumn{6}{|c|}{ Supplemental Table s2.txt } \\
\hline CHEMBL1507389 & 688816 & 4.95 & 5.1369 & TRN & \\
\hline CHEMBL1398595 & 688816 & 4.45 & 4.814 & TST & \\
\hline CHEMBL1495950 & 688816 & 4.45 & 5.1059 & TST & \\
\hline CHEMBL1421119 & 688816 & 6.7001 & 5.5566 & TST & \\
\hline CHEMBL1533917 & 688816 & 5.35 & 5.2365 & TRN & \\
\hline CHEMBL1367372 & 688816 & 7.6003 & 5.4578 & TRN & \\
\hline CHEMBL1564143 & 688816 & 4.9 & 4.8922 & TRN & \\
\hline CHEMBL1376777 & 688816 & 4.55 & 4.9532 & TRN & \\
\hline CHEMBL 3193445 & 688816 & 4.8 & 5.2007 & TST & \\
\hline CHEMBL1581263 & 688816 & 4.7 & 4.9388 & TRN & \\
\hline CHEMBL1561014 & 688816 & 6.8 & 5.3258 & TST & \\
\hline CHEMBL1351963 & 688816 & 5.65 & 5.5551 & TRN & \\
\hline CHEMBL1465964 & 688816 & 4.95 & 4.8792 & TRN & \\
\hline CHEMBL1577459 & 688816 & 4.95 & 5.26 & TRN & \\
\hline CHEMBL1613467 & 688816 & 4.9 & 5.706 & TST & \\
\hline CHEMBL1303157 & 688816 & 6.6 & 5.2408 & TRN & \\
\hline CHEMBL1317851 & 688816 & 6.9 & 5.36100 & 0000000001 & TRN \\
\hline CHEMBL1409018 & 688816 & 4.95 & 5.0782 & TRN & \\
\hline CHEMBL1556892 & 688816 & 4.95 & 5.2851 & TRN & \\
\hline CHEMBL3213515 & 688816 & 4.95 & 5.1648 & TST & \\
\hline CHEMBL1329000 & 688816 & 4.95 & 5.0018 & TRN & \\
\hline CHEMBL 3214118 & 688816 & 4.45 & 5.2672 & TRN & \\
\hline CHEMBL1499202 & 688816 & 7.5003 & 5.2918 & TRN & \\
\hline CHEMBL1430721 & 688816 & 5.45 & 5.4168 & TST & \\
\hline CHEMBL341910 & 688816 & 6.95 & 5.2778 & TST & \\
\hline CHEMBL1392445 & 688816 & 4.9 & 5.296 & TRN & \\
\hline CHEMBL3195897 & 688816 & 5.1 & 5.4693 & TRN & \\
\hline CHEMBL588038 & 688816 & 5.45 & 5.0793 & TRN & \\
\hline CHEMBL1569085 & 688816 & 5.05 & 4.9478 & TST & \\
\hline CHEMBL1487836 & 688816 & 4.45 & 5.1277 & TRN & \\
\hline CHEMBL1443679 & 688816 & 6.2 & 4.8828 & TRN & \\
\hline CHEMBL1497479 & 688816 & 5.55 & 5.3135 & TST & \\
\hline CHEMBL1517662 & 688816 & 4.65 & 5.2894 & TRN & \\
\hline CHEMBL1454860 & 688816 & 4.45 & 4.8652 & TRN & \\
\hline CHEMBL1497844 & 688816 & 6.0 & 4.9129 & TRN & \\
\hline CHEMBL1342045 & 688816 & 4.45 & 5.2183 & TRN & \\
\hline CHEMBL1588162 & 688816 & 4.45 & 5.1386 & TRN & \\
\hline CHEMBL1499767 & 688816 & 4.4 & 5.2458 & TRN & \\
\hline CHEMBL1326120 & 688816 & 4.9 & 5.4842 & TRN & \\
\hline CHEMBL1453565 & 688816 & 5.65 & 5.4292 & TRN & \\
\hline CHEMBL1477974 & 688816 & 7.6498 & 5.5517 & TRN & \\
\hline CHEMBL1983600 & 688816 & 5.6 & 5.2985 & TRN & \\
\hline CHEMBL1529170 & 688816 & 4.6 & 4.9909 & TRN & \\
\hline CHEMBL429335 & 688816 & 5.6 & 5.1759 & TRN & \\
\hline CHEMBL1518418 & 688816 & 5.6 & 5.4102 & TST & \\
\hline CHEMBL555689 & 688816 & 4.95 & 5.0299 & TRN & \\
\hline CHEMBL1338475 & 688816 & 4.95 & 5.3937 & TRN & \\
\hline CHEMBL1354363 & 688816 & 5.7 & 5.61700 & 2000000001 & TRN \\
\hline & & & & 24664 & \\
\hline
\end{tabular}




\begin{tabular}{|c|c|c|c|c|}
\hline & & & pplement & al $\mathrm{T}$ \\
\hline CHEMBL1344070 & 688816 & 6.0 & 5.5129 & TST \\
\hline CHEMBL1308807 & 688816 & 5.4 & 4.7125 & TRN \\
\hline CHEMBL1495375 & 688816 & 4.95 & 5.3394 & TRN \\
\hline CHEMBL1469912 & 688816 & 4.75 & 5.0591 & TRN \\
\hline CHEMBL1434336 & 688816 & 6.0 & 5.0429 & TST \\
\hline CHEMBL3196102 & 688816 & 4.85 & 4.9198 & TRN \\
\hline CHEMBL1506199 & 688816 & 4.85 & 5.8295 & TRN \\
\hline CHEMBL1531818 & 688816 & 8.0 & 5.5581 & TRN \\
\hline CHEMBL1352140 & 688816 & 8.4949 & 5.7484 & TRN \\
\hline CHEMBL78150 & 688816 & 6.0 & 5.347 & TRN \\
\hline CHEMBL1599425 & 688816 & 4.9 & 5.2756 & TRN \\
\hline CHEMBL1402181 & 688816 & 5.5 & 5.1311 & TRN \\
\hline CHEMBL1301318 & 688816 & 6.05 & 5.6563 & TRN \\
\hline CHEMBL1530730 & 688816 & 4.4 & 5.3694 & TRN \\
\hline CHEMBL 3197575 & 688816 & 4.9 & 5.2329 & TRN \\
\hline CHEMBL1431579 & 688816 & 7.4498 & 5.4516 & TRN \\
\hline CHEMBL1312651 & 688816 & 4.75 & 5.0441 & TRN \\
\hline CHEMBL1393129 & 688816 & 6.3 & 5.2138 & TRN \\
\hline CHEMBL1409227 & 688816 & 4.6 & 5.2651 & TRN \\
\hline CHEMBL1445511 & 688816 & 4.7 & 5.5415 & TRN \\
\hline CHEMBL3193149 & 688816 & 6.8499 & 5.5215 & TST \\
\hline CHEMBL1558625 & 688816 & 7.699 & 5.4007 & TRN \\
\hline CHEMBL1481513 & 688816 & 5.35 & 5.5683 & TST \\
\hline CHEMBL1499877 & 688816 & 4.85 & 5.1876 & TST \\
\hline CHEMBL1504690 & 688816 & 4.6 & 5.2777 & TRN \\
\hline CHEMBL1388788 & 688816 & 5.2 & 4.8335 & TRN \\
\hline CHEMBL 3193510 & 688816 & 5.5 & 5.2218 & TRN \\
\hline CHEMBL1558079 & 688816 & 4.45 & 5.0068 & TRN \\
\hline CHEMBL1481464 & 688816 & 5.95 & 5.2126 & TRN \\
\hline CHEMBL1481264 & 688816 & 4.45 & 5.0413 & TRN \\
\hline CHEMBL1598568 & 688816 & 4.85 & 5.2926 & TRN \\
\hline CHEMBL1384596 & 688816 & 8.4949 & 5.8315 & TRN \\
\hline CHEMBL1517512 & 688816 & 5.05 & 5.4372 & TRN \\
\hline CHEMBL1382365 & 688816 & 5.2 & 5.8424 & TST \\
\hline CHEMBL1371273 & 688816 & 5.85 & 5.2545 & TRN \\
\hline CHEMBL1466867 & 688816 & 7.9508 & 5.3716 & TRN \\
\hline CHEMBL1342085 & 688816 & 4.45 & 5.0143 & TST \\
\hline CHEMBL1443307 & 688816 & 4.45 & 5.3839 & TRN \\
\hline CHEMBL 3194097 & 688816 & 4.55 & 5.1214 & TRN \\
\hline CHEMBL1519630 & 688816 & 4.9 & 4.9174 & TRN \\
\hline CHEMBL1599292 & 688816 & 5.1 & 5.3693 & TRN \\
\hline CHEMBL1331218 & 688816 & 4.9 & 5.2986 & TST \\
\hline CHEMBL1334550 & 688816 & 4.5 & 5.2365 & TRN \\
\hline CHEMBL1520573 & 688816 & 4.9 & 5.2202 & TRN \\
\hline CHEMBL1441291 & 688816 & 4.8 & 4.9777 & TRN \\
\hline CHEMBL3208379 & 688816 & 7.6003 & 5.2384 & TRN \\
\hline CHEMBL1409965 & 688816 & 4.45 & 4.9958 & TST \\
\hline CHEMBL1309629 & 688816 & 7.8508 & 6.0943 & TRN \\
\hline
\end{tabular}




\begin{tabular}{|c|c|c|c|c|}
\hline \multicolumn{5}{|c|}{ Supplemental Table S2.txt } \\
\hline CHEMBL1502802 & 688816 & 4.65 & 5.3553 & TST \\
\hline CHEMBL1331298 & 688816 & 5.6 & 5.3869 & TRN \\
\hline CHEMBL165 & 688816 & 6.0 & 5.50700 & 0000000001 \\
\hline CHEMBL1483791 & 688816 & 4.65 & 5.0967 & TRN \\
\hline CHEMBL1422199 & 688816 & 4.45 & 5.1435 & TST \\
\hline CHEMBL1481541 & 688816 & 5.35 & 5.1414 & TRN \\
\hline CHEMBL3212086 & 688816 & 7.0501 & 5.7339 & TRN \\
\hline CHEMBL1483471 & 688816 & 4.95 & 5.5072 & TRN \\
\hline CHEMBL1400143 & 688816 & 6.05 & 5.3243 & TRN \\
\hline CHEMBL1327664 & 688816 & 4.85 & 5.2706 & TRN \\
\hline CHEMBL1543463 & 688816 & 5.35 & 5.4155 & TST \\
\hline CHEMBL1612183 & 688816 & 4.95 & 4.9333 & TRN \\
\hline CHEMBL1418312 & 688816 & 5.7 & 5.3047 & TRN \\
\hline CHEMBL1544530 & 688816 & 4.65 & 5.0604 & TRN \\
\hline CHEMBL1378461 & 688816 & 4.8 & 5.6546 & TRN \\
\hline CHEMBL1346635 & 688816 & 4.45 & 5.6284 & TRN \\
\hline CHEMBL1422342 & 688816 & 5.05 & 5.397 & TRN \\
\hline CHEMBL1493074 & 688816 & 4.75 & 5.3663 & TST \\
\hline CHEMBL1432287 & 688816 & 5.3 & 5.7001 & TRN \\
\hline CHEMBL1457132 & 688816 & 4.7 & 5.0392 & TRN \\
\hline CHEMBL1339737 & 688816 & 5.0 & 5.3164 & TST \\
\hline CHEMBL1321086 & 688816 & 4.55 & 5.0436 & TRN \\
\hline CHEMBL1518152 & 688816 & 7.8996 & 5.6928 & TRN \\
\hline CHEMBL1340448 & 688816 & 4.85 & 5.4259 & TRN \\
\hline CHEMBL1501419 & 688816 & 6.8 & 5.3624 & TST \\
\hline CHEMBL3195889 & 688816 & 6.35 & 5.2528 & TRN \\
\hline CHEMBL1448117 & 688816 & 7.5498 & 5.6094 & TRN \\
\hline CHEMBL1417264 & 688816 & 4.45 & 5.3476 & TRN \\
\hline CHEMBL1580668 & 688816 & 4.55 & 5.6739 & TST \\
\hline CHEMBL1414859 & 688816 & 5.25 & 4.8864 & TST \\
\hline CHEMBL1448453 & 688816 & 4.9 & 5.3101 & TRN \\
\hline CHEMBL1557582 & 688816 & 5.95 & 5.1964 & TRN \\
\hline CHEMBL1362188 & 688816 & 5.55 & 5.5878 & TRN \\
\hline CHEMBL1526899 & 688816 & 4.85 & 4.8153 & TRN \\
\hline CHEMBL1310861 & 688816 & 6.2 & 5.121 & TST \\
\hline CHEMBL1452503 & 688816 & 5.05 & 5.0988 & TRN \\
\hline CHEMBL 2171381 & 688816 & 4.9 & 5.3929 & TRN \\
\hline CHEMBL1606120 & 688816 & 4.9 & 5.2456 & TRN \\
\hline CHEMBL1333483 & 688816 & 4.45 & 4.9291 & TST \\
\hline CHEMBL426972 & 688816 & 4.75 & 5.2052 & TRN \\
\hline CHEMBL1564134 & 688816 & 4.45 & 4.8331 & TRN \\
\hline CHEMBL1421004 & 688816 & 4.85 & 5.2959 & TRN \\
\hline CHEMBL1377012 & 688816 & 5.25 & 5.3463 & TRN \\
\hline CHEMBL1523107 & 688816 & 5.0 & 5.1489 & TRN \\
\hline CHEMBL1548533 & 688816 & 4.45 & 5.3159 & TRN \\
\hline CHEMBL1405021 & 688816 & 4.95 & 5.4543 & TRN \\
\hline CHEMBL1545325 & 688816 & 8.301 & 5.92 & TRN \\
\hline CHEMBL1600782 & 688816 & 5.0 & 5.2598 & TRN \\
\hline
\end{tabular}

TRN 


\begin{tabular}{|c|c|c|c|c|c|}
\hline \multicolumn{6}{|c|}{ Supplemental Table S2.txt } \\
\hline CHEMBL1530663 & 688816 & 5.25 & 5.1151 & TRN & \\
\hline CHEMBL1421042 & 688816 & 5.15 & 5.5096 & TST & \\
\hline CHEMBL1462500 & 688816 & 5.0 & 4.8947 & TRN & \\
\hline CHEMBL1588339 & 688816 & 4.95 & 4.7891 & TRN & \\
\hline CHEMBL1368952 & 688816 & 5.4 & 5.4365 & TST & \\
\hline CHEMBL1336442 & 688816 & 5.9 & 4.9754 & TST & \\
\hline CHEMBL1390438 & 688816 & 4.9 & 5.2424 & TST & \\
\hline CHEMBL3209766 & 688816 & 4.8 & 5.5169 & TRN & \\
\hline CHEMBL 3194783 & 688816 & 4.45 & 5.2751 & TST & \\
\hline CHEMBL454893 & 688816 & 4.45 & 5.3772 & TST & \\
\hline CHEMBL1570143 & 688816 & 5.25 & 5.2371 & TRN & \\
\hline CHEMBL1428788 & 688816 & 4.9 & 5.2307 & TST & \\
\hline CHEMBL1529775 & 688816 & 6.2 & 5.4193 & TRN & \\
\hline CHEMBL1403922 & 688816 & 4.95 & 4.8745 & TRN & \\
\hline CHEMBL407501 & 688816 & 4.8 & 5.3283 & TRN & \\
\hline CHEMBL1576160 & 688816 & 5.15 & 5.1958 & TRN & \\
\hline CHEMBL1468183 & 688816 & 4.45 & 5.1678 & TST & \\
\hline CHEMBL3197285 & 688816 & 4.95 & 5.2576 & TRN & \\
\hline CHEMBL1510806 & 688816 & 4.8 & 5.1944 & TRN & \\
\hline CHEMBL577635 & 688816 & 6.0 & 5.6298 & TST & \\
\hline CHEMBL1398398 & 688816 & 4.7 & 4.6101 & TRN & \\
\hline CHEMBL1369820 & 688816 & 5.1 & 5.2068 & TRN & \\
\hline CHEMBL1460798 & 688816 & 8.4949 & 5.0057 & TRN & \\
\hline CHEMBL50378 & 688816 & 4.9 & 5.263 & TST & \\
\hline CHEMBL1463309 & 688816 & 4.95 & 5.0654 & TRN & \\
\hline CHEMBL1532928 & 688816 & 4.75 & 4.8611 & TRN & \\
\hline CHEMBL1585724 & 688816 & 5.25 & 5.4214 & TRN & \\
\hline CHEMBL1599610 & 688816 & 5.3 & 4.965 & TRN & \\
\hline CHEMBL1359262 & 688816 & 4.7 & 4.8571 & TRN & \\
\hline CHEMBL3192395 & 688816 & 5.2 & 5.9404 & TRN & \\
\hline CHEMBL1373946 & 688816 & 5.3 & 5.2287 & TRN & \\
\hline CHEMBL1300785 & 688816 & 5.65 & 5.436 & TST & \\
\hline CHEMBL1423377 & 688816 & 6.8499 & 5.3625 & TRN & \\
\hline CHEMBL1372712 & 688816 & 4.8 & 5.3938 & TRN & \\
\hline CHEMBL1448690 & 688816 & 5.0 & 5.17200 & 0000000001 & TRN \\
\hline CHEMBL1460871 & 688816 & 4.6 & 5.3526 & TRN & \\
\hline CHEMBL1599122 & 688816 & 5.3 & 5.5033 & TST & \\
\hline CHEMBL1478570 & 688816 & 5.0 & 5.2297 & TRN & \\
\hline CHEMBL1422602 & 688816 & 5.0 & 5.2251 & TRN & \\
\hline CHEMBL1334743 & 688816 & 5.35 & 5.2684 & TRN & \\
\hline CHEMBL1572342 & 688816 & 5.0 & 5.4273 & TRN & \\
\hline CHEMBL1378621 & 688816 & 4.85 & 5.1848 & TRN & \\
\hline CHEMBL3198000 & 688816 & 4.45 & 5.1364 & TRN & \\
\hline CHEMBL 3211808 & 688816 & 4.7 & 4.9549 & TRN & \\
\hline CHEMBL1451311 & 688816 & 4.85 & 5.2342 & TRN & \\
\hline CHEMBL1404541 & 688816 & 4.45 & 5.1924 & TRN & \\
\hline CHEMBL1438051 & 688816 & 4.9 & 5.0878 & TRN & \\
\hline CHEMBL1422029 & 688816 & 5.45 & 5.1408 & TST & \\
\hline
\end{tabular}




\begin{tabular}{|c|c|c|c|c|c|}
\hline \multicolumn{6}{|c|}{ Supplemental Table S2.txt } \\
\hline CHEMBL3193886 & 688816 & 6.05 & 4.9637 & TST & \\
\hline CHEMBL1310193 & 688816 & 5.3 & 5.2962 & TRN & \\
\hline CHEMBL3194618 & 688816 & 4.8 & 5.3437 & TRN & \\
\hline CHEMBL1577201 & 688816 & 4.9 & 5.6066 & TRN & \\
\hline CHEMBL1434362 & 688816 & 4.95 & 5.4009 & TRN & \\
\hline CHEMBL1544338 & 688816 & 4.45 & 5.222 & TRN & \\
\hline CHEMBL1573754 & 688816 & 5.0 & 5.1772 & TRN & \\
\hline CHEMBL1543316 & 688816 & 4.95 & 4.843 & TST & \\
\hline CHEMBL1500614 & 688816 & 4.7 & 5.2962 & TST & \\
\hline CHEMBL1346886 & 688816 & 7.6498 & 5.6038 & TRN & \\
\hline CHEMBL1386096 & 688816 & 5.3 & 5.2566 & TST & \\
\hline CHEMBL1532960 & 688816 & 5.6 & 5.0799 & TRN & \\
\hline CHEMBL1349308 & 688816 & 4.6 & 5.4228 & TST & \\
\hline CHEMBL1413123 & 688816 & 4.75 & 5.4813 & TST & \\
\hline CHEMBL1452559 & 688816 & 4.85 & 5.2621 & TRN & \\
\hline CHEMBL1527926 & 688816 & 5.25 & 5.5288 & TRN & \\
\hline CHEMBL1613502 & 688816 & 4.45 & 5.3106 & TRN & \\
\hline CHEMBL1429565 & 688816 & 4.7 & 5.1784 & TRN & \\
\hline CHEMBL1479990 & 688816 & 5.45 & 5.0358 & TST & \\
\hline CHEMBL1337380 & 688816 & 4.45 & 5.5169 & TRN & \\
\hline CHEMBL1459537 & 688816 & 7.6003 & 5.6232 & TRN & \\
\hline CHEMBL1458245 & 688816 & 4.9 & 5.1226 & TRN & \\
\hline CHEMBL1564284 & 688816 & 6.7501 & 5.4648 & TRN & \\
\hline CHEMBL1361692 & 688816 & 4.5 & 5.1315 & TRN & \\
\hline CHEMBL1535518 & 688816 & 5.35 & 5.3957 & TRN & \\
\hline CHEMBL1342598 & 688816 & 5.05 & 5.0886 & TRN & \\
\hline CHEMBL1498009 & 688816 & 5.05 & 5.4303 & TRN & \\
\hline CHEMBL1306314 & 688816 & 4.95 & 5.1661 & TRN & \\
\hline CHEMBL1328556 & 688816 & 5.2 & 5.7281 & TST & \\
\hline CHEMBL3196653 & 688816 & 4.8 & 5.5118 & TRN & \\
\hline CHEMBL1425417 & 688816 & 5.0 & 5.2566 & TRN & \\
\hline CHEMBL 3189565 & 688816 & 4.95 & 5.1854 & TRN & \\
\hline CHEMBL1597082 & 688816 & 4.95 & 4.96899 & & TRN \\
\hline CHEMBL1496631 & 688816 & 4.45 & 5.3672 & TRN & \\
\hline CHEMBL1535530 & 688816 & 4.75 & 4.8158 & TRN & \\
\hline CHEMBL1544428 & 688816 & 6.05 & 5.1313 & TRN & \\
\hline CHEMBL1559988 & 688816 & 5.4 & 5.0613 & TRN & \\
\hline CHEMBL1471710 & 688816 & 5.05 & 5.5831 & TRN & \\
\hline CHEMBL1601850 & 688816 & 8.301 & 5.6943 & TST & \\
\hline CHEMBL1511476 & 688816 & 4.45 & 5.088 & TRN & \\
\hline CHEMBL1428264 & 688816 & 4.8 & 4.8883 & TST & \\
\hline CHEMBL1348992 & 688816 & 5.25 & 5.3745 & TRN & \\
\hline CHEMBL1411379 & 688816 & 4.5 & 5.6116 & TST & \\
\hline CHEMBL1434522 & 688816 & 4.45 & 5.5375 & TST & \\
\hline CHEMBL1540359 & 688816 & 5.25 & 5.7437 & TRN & \\
\hline CHEMBL1395440 & 688816 & 5.0 & 5.3116 & TST & \\
\hline CHEMBL1366194 & 688816 & 4.85 & 5.3388 & TST & \\
\hline CHEMBL1366056 & 688816 & 7.15 & 5.1341 & TRN & \\
\hline
\end{tabular}




\begin{tabular}{|c|c|c|c|c|c|}
\hline \multicolumn{6}{|c|}{ Supplemental Table S2.txt } \\
\hline CHEMBL1526719 & 688816 & 4.45 & 5.5412 & TST & \\
\hline CHEMBL1411000 & 688816 & 4.45 & 5.6334 & TRN & \\
\hline CHEMBL1452089 & 688816 & 5.0 & 5.3961 & TRN & \\
\hline CHEMBL1337842 & 688816 & 4.9 & 5.1311 & TRN & \\
\hline CHEMBL193888 & 688816 & 4.95 & 5.1837 & TRN & \\
\hline CHEMBL1570419 & 688816 & 5.1 & 5.3477 & TRN & \\
\hline CHEMBL1494575 & 688816 & 5.3 & 5.4249 & TRN & \\
\hline CHEMBL1445607 & 688816 & 4.8 & 5.1016 & TRN & \\
\hline CHEMBL1450179 & 688816 & 4.75 & 5.1399 & TST & \\
\hline CHEMBL1459310 & 688816 & 4.45 & 4.9584 & TRN & \\
\hline CHEMBL1466868 & 688816 & 4.95 & 5.1218 & TST & \\
\hline CHEMBL1481793 & 688816 & 5.25 & 5.1609 & TST & \\
\hline CHEMBL1532833 & 688816 & 5.35 & 5.2273 & TRN & \\
\hline CHEMBL 3198425 & 688816 & 5.45 & 5.0494 & TRN & \\
\hline CHEMBL1464347 & 688816 & 5.05 & 5.3158 & TST & \\
\hline CHEMBL1414486 & 688816 & 5.5 & 5.1546 & TRN & \\
\hline CHEMBL1978608 & 688816 & 8.3979 & 5.2356 & TRN & \\
\hline CHEMBL1578229 & 688816 & 4.85 & 5.4398 & TRN & \\
\hline CHEMBL1542681 & 688816 & 6.6 & 5.0978 & TST & \\
\hline CHEMBL1334188 & 688816 & 4.45 & 5.3082 & TRN & \\
\hline CHEMBL1360480 & 688816 & 5.3 & 5.4857 & TRN & \\
\hline CHEMBL1534561 & 688816 & 5.1 & 5.0045 & TRN & \\
\hline CHEMBL1420251 & 688816 & 4.95 & 5.59200 & 00000000005 & TRN \\
\hline CHEMBL1528103 & 688816 & 7.9508 & 5.6196 & TST & \\
\hline CHEMBL1585631 & 688816 & 4.75 & 5.4586 & TST & \\
\hline CHEMBL1500770 & 688816 & 5.65 & 5.4906 & TRN & \\
\hline CHEMBL1510119 & 688816 & 5.6 & 5.2129 & TRN & \\
\hline CHEMBL1417496 & 688816 & 4.8 & 4.7915 & TRN & \\
\hline CHEMBL1310385 & 688816 & 4.45 & 5.3597 & TRN & \\
\hline CHEMBL1542321 & 688816 & 5.7 & 4.9965 & TRN & \\
\hline CHEMBL1331497 & 688816 & 4.9 & 5.0821 & TRN & \\
\hline CHEMBL1439216 & 688816 & 6.5501 & 5.5909 & TRN & \\
\hline CHEMBL1359917 & 688816 & 4.5 & 5.2009 & TRN & \\
\hline CHEMBL1528486 & 688816 & 4.45 & 4.9168 & TRN & \\
\hline CHEMBL 3199697 & 688816 & 5.35 & 5.3818 & TST & \\
\hline CHEMBL1568521 & 688816 & 6.9 & 5.1014 & TST & \\
\hline CHEMBL1553477 & 688816 & 4.45 & 5.0077 & TRN & \\
\hline CHEMBL1489923 & 688816 & 5.05 & 5.2563 & TRN & \\
\hline CHEMBL1351019 & 688816 & 4.8 & 5.4815 & TRN & \\
\hline CHEMBL1473136 & 688816 & 5.1 & 4.863 & TRN & \\
\hline CHEMBL1469095 & 688816 & 4.6 & 5.26399 & 9999999999 & TRN \\
\hline CHEMBL3194325 & 688816 & 4.95 & 5.3517 & TRN & \\
\hline CHEMBL1524795 & 688816 & 4.8 & 4.9972 & TRN & \\
\hline CHEMBL1304720 & 688816 & 5.05 & 5.2961 & TRN & \\
\hline CHEMBL 2005423 & 688816 & 5.85 & 5.4403 & TRN & \\
\hline CHEMBL3196847 & 688816 & 5.8 & 5.4649 & TST & \\
\hline CHEMBL1439148 & 688816 & 4.85 & 5.3371 & TST & \\
\hline CHEMBL1391895 & 688816 & 4.6 & 4.8852 & TRN & \\
\hline
\end{tabular}




\begin{tabular}{|c|c|c|c|c|}
\hline \multicolumn{5}{|c|}{ Supplemental Table S2.txt } \\
\hline CHEMBL1415839 & 688816 & 4.55 & 5.1171 & TRN \\
\hline CHEMBL1345023 & 688816 & 5.7 & 5.2114 & TST \\
\hline CHEMBL1506526 & 688816 & 6.8 & 5.6831 & TRN \\
\hline CHEMBL1328216 & 688816 & 6.15 & 5.5712 & TRN \\
\hline CHEMBL1336728 & 688816 & 4.6 & 4.7417 & TST \\
\hline CHEMBL1536493 & 688816 & 5.15 & 5.1341 & TRN \\
\hline CHEMBL1485112 & 688816 & 4.7 & 5.0008 & TST \\
\hline CHEMBL1603691 & 688816 & 5.2 & 5.3681 & TST \\
\hline CHEMBL1509838 & 688816 & 5.2 & 5.8462 & TRN \\
\hline CHEMBL1587302 & 688816 & 5.6 & 5.2906 & TRN \\
\hline CHEMBL1380508 & 688816 & 4.9 & 5.4314 & TRN \\
\hline CHEMBL1369590 & 688816 & 4.45 & 5.2198 & TRN \\
\hline CHEMBL 2369252 & 688816 & 5.65 & 5.5818 & TRN \\
\hline CHEMBL1417614 & 688816 & 4.95 & 5.2951 & TRN \\
\hline CHEMBL1312122 & 688816 & 5.0 & 5.5614 & TST \\
\hline CHEMBL1387937 & 688816 & 4.95 & 5.2054 & TRN \\
\hline CHEMBL1445964 & 688816 & 5.0 & 5.0882 & TRN \\
\hline CHEMBL1464602 & 688816 & 4.85 & 5.4605 & TRN \\
\hline CHEMBL1345769 & 688816 & 5.1 & 5.0453 & TST \\
\hline CHEMBL1509990 & 688816 & 4.8 & 5.4205 & TRN \\
\hline CHEMBL80031 & 688816 & 8.5528 & 5.4467 & TRN \\
\hline CHEMBL1379307 & 688816 & 6.05 & 5.3507 & TRN \\
\hline CHEMBL1613571 & 688816 & 4.8 & 5.2194 & TRN \\
\hline CHEMBL 3207725 & 688816 & 6.05 & 5.5725 & TST \\
\hline CHEMBL1475377 & 688816 & 4.8 & 5.0886 & TRN \\
\hline CHEMBL1454824 & 688816 & 5.05 & 5.2046 & TRN \\
\hline CHEMBL1403897 & 688816 & 7.7496 & 5.2383 & TRN \\
\hline CHEMBL1459195 & 688816 & 4.85 & 5.1324 & TST \\
\hline CHEMBL 602828 & 688816 & 4.85 & 5.0479 & TRN \\
\hline CHEMBL1547259 & 688816 & 4.45 & 5.6048 & TST \\
\hline CHEMBL1605081 & 688816 & 4.65 & 4.925 & TRN \\
\hline CHEMBL1523601 & 688816 & 7.1002 & 5.5414 & TRN \\
\hline CHEMBL1494344 & 688816 & 4.9 & 5.2691 & TRN \\
\hline CHEMBL1306525 & 688816 & 4.9 & 5.6971 & TRN \\
\hline CHEMBL1541931 & 688816 & 5.2 & 5.879 & TST \\
\hline CHEMBL1410836 & 688816 & 4.6 & 5.3239 & TST \\
\hline CHEMBL1529812 & 688816 & 4.45 & 5.3652 & TST \\
\hline CHEMBL1454334 & 688816 & 4.85 & 5.3376 & TRN \\
\hline CHEMBL1583089 & 688816 & 4.8 & 4.8645 & TRN \\
\hline CHEMBL1317831 & 688816 & 4.45 & 5.0341 & TRN \\
\hline CHEMBL3193755 & 688816 & 5.25 & 5.5743 & TST \\
\hline CHEMBL1511248 & 688816 & 6.45 & 5.465 & TRN \\
\hline CHEMBL1414085 & 688816 & 4.75 & 5.3099 & TST \\
\hline CHEMBL1411492 & 688816 & 7.8996 & 5.1111 & TRN \\
\hline CHEMBL1505989 & 688816 & 5.55 & 5.3129 & TRN \\
\hline CHEMBL1568298 & 688816 & 4.45 & 4.8937 & TRN \\
\hline CHEMBL1416713 & 688816 & 4.45 & 5.0884 & TST \\
\hline CHEMBL1489273 & 688816 & 5.05 & 4.9167 & TRN \\
\hline
\end{tabular}




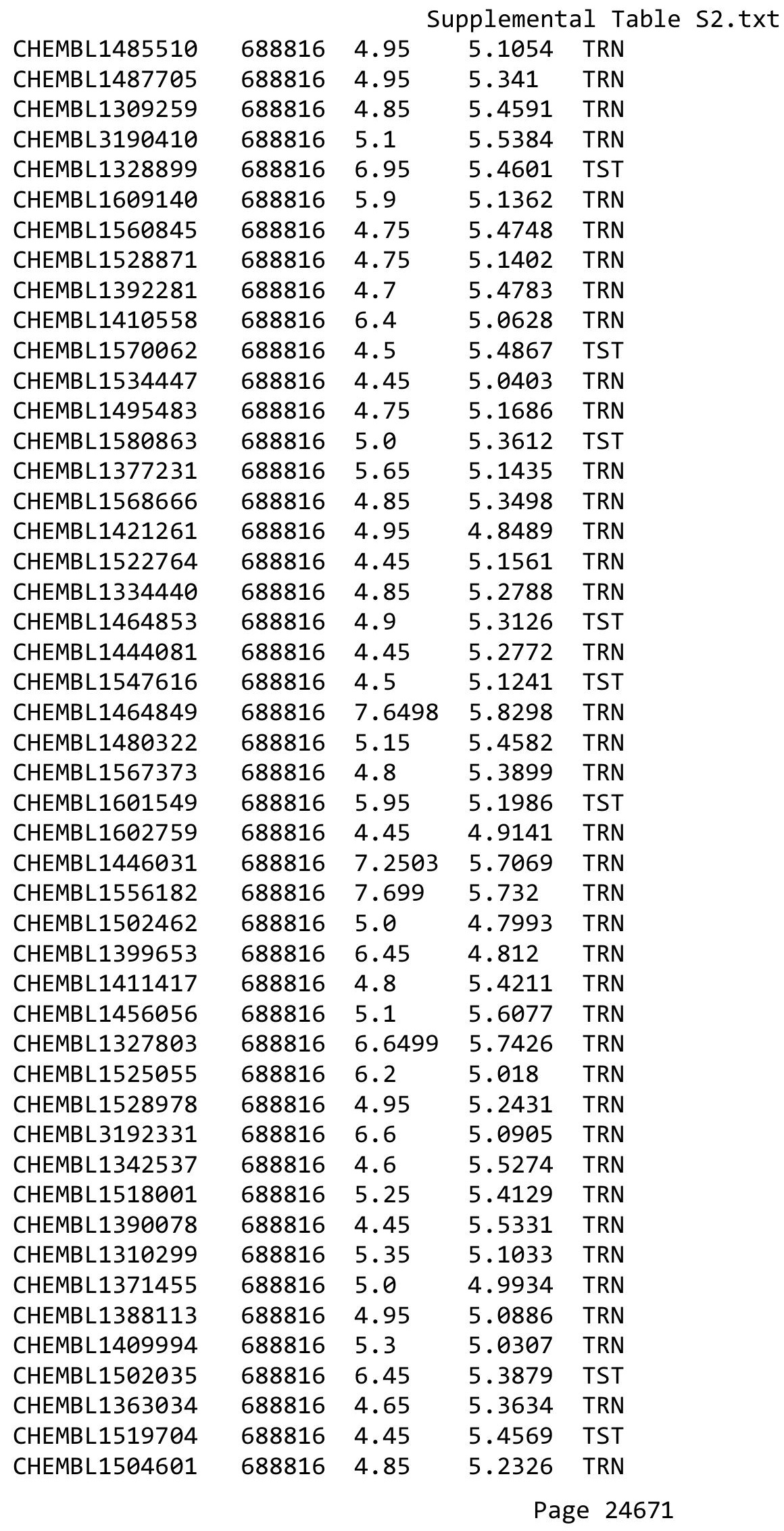




\begin{tabular}{|c|c|c|c|c|c|}
\hline \multicolumn{6}{|c|}{ Supplemental Table S2.txt } \\
\hline CHEMBL1505724 & 688816 & 6.1 & 5.7273 & TST & \\
\hline CHEMBL1595148 & 688816 & 7.3002 & 5.1338 & TRN & \\
\hline CHEMBL1426001 & 688816 & 4.7 & 5.1571 & TRN & \\
\hline CHEMBL1440549 & 688816 & 4.65 & 5.5337 & TRN & \\
\hline CHEMBL1343750 & 688816 & 5.5 & 5.2873 & TRN & \\
\hline CHEMBL1352344 & 688816 & 4.45 & 5.3704 & TRN & \\
\hline CHEMBL1350404 & 688816 & 5.25 & 5.4304 & TRN & \\
\hline CHEMBL1370421 & 688816 & 5.15 & 5.3309 & TRN & \\
\hline CHEMBL1428840 & 688816 & 4.95 & 4.9266 & TRN & \\
\hline CHEMBL1425435 & 688816 & 4.45 & 5.2529 & TRN & \\
\hline CHEMBL1419082 & 688816 & 5.35 & 5.2859 & TST & \\
\hline CHEMBL1522939 & 688816 & 4.7 & 5.4205 & TST & \\
\hline CHEMBL1350445 & 688816 & 7.8508 & 5.1388 & TRN & \\
\hline CHEMBL1446032 & 688816 & 7.5003 & 5.2183 & TRN & \\
\hline CHEMBL1352416 & 688816 & 7.8996 & 5.2015 & TRN & \\
\hline CHEMBL7463 & 688816 & 4.85 & 5.40600 & 0000000001 & TRN \\
\hline CHEMBL3189172 & 688816 & 5.45 & 5.3791 & TST & \\
\hline CHEMBL1520122 & 688816 & 4.9 & 5.2888 & TRN & \\
\hline CHEMBL1371339 & 688816 & 6.25 & 5.074 & TRN & \\
\hline CHEMBL1601650 & 688816 & 5.25 & 5.1252 & TRN & \\
\hline CHEMBL1386638 & 688816 & 4.7 & 5.0854 & TRN & \\
\hline CHEMBL1405479 & 688816 & 6.7001 & 5.6567 & TST & \\
\hline CHEMBL1978330 & 688816 & 4.95 & 5.3874 & TRN & \\
\hline CHEMBL1389555 & 688816 & 5.85 & 5.4054 & TST & \\
\hline CHEMBL1481675 & 688816 & 4.7 & 4.9132 & TRN & \\
\hline CHEMBL1349154 & 688816 & 4.45 & 5.5799 & TST & \\
\hline CHEMBL1458776 & 688816 & 5.7 & 5.1175 & TRN & \\
\hline CHEMBL1362013 & 688816 & 5.4 & 5.4059 & TRN & \\
\hline CHEMBL1547927 & 688816 & 6.05 & 5.244 & TST & \\
\hline CHEMBL1456841 & 688816 & 4.9 & 5.1586 & TRN & \\
\hline CHEMBL1530525 & 688816 & 5.55 & 5.0879 & TST & \\
\hline CHEMBL531401 & 688816 & 8.5528 & 5.1195 & TRN & \\
\hline CHEMBL1429065 & 688816 & 5.1 & 5.3321 & TRN & \\
\hline CHEMBL3190499 & 688816 & 6.1 & 4.9721 & TRN & \\
\hline CHEMBL1603758 & 688816 & 5.25 & 5.3572 & TST & \\
\hline CHEMBL1458697 & 688816 & 4.7 & 5.2036 & TST & \\
\hline CHEMBL1384760 & 688816 & 5.6 & 5.2946 & TST & \\
\hline CHEMBL1306548 & 688816 & 5.2 & 5.1045 & TRN & \\
\hline CHEMBL1448732 & 688816 & 4.75 & 5.0391 & TST & \\
\hline CHEMBL1303418 & 688816 & 5.1 & 5.4535 & TST & \\
\hline CHEMBL1576773 & 688816 & 4.95 & 5.2562 & TST & \\
\hline CHEMBL1310257 & 688816 & 4.9 & 5.0966 & TRN & \\
\hline CHEMBL1437881 & 688816 & 4.9 & 5.4924 & TRN & \\
\hline CHEMBL1386871 & 688816 & 4.9 & 5.1853 & TRN & \\
\hline CHEMBL1575658 & 688816 & 4.9 & 5.49 & TRN & \\
\hline CHEMBL1403530 & 688816 & 5.25 & 5.3521 & TRN & \\
\hline CHEMBL1303094 & 688816 & 5.5 & 5.0785 & TRN & \\
\hline CHEMBL1341735 & 688816 & 4.95 & 5.0035 & TRN & \\
\hline
\end{tabular}




\begin{tabular}{|c|c|c|c|c|}
\hline \multicolumn{5}{|c|}{ Supplemental Table S2.txt } \\
\hline CHEMBL1386894 & 688816 & 4.8 & 5.3533 & TRN \\
\hline CHEMBL1478316 & 688816 & 8.0506 & 5.067 & TRN \\
\hline CHEMBL1565662 & 688816 & 4.45 & 5.431 & TRN \\
\hline CHEMBL1558324 & 688816 & 4.95 & 5.2853 & TST \\
\hline CHEMBL1308887 & 688816 & 4.45 & 4.9018 & TRN \\
\hline CHEMBL1346587 & 688816 & 4.7 & 5.3753 & TRN \\
\hline CHEMBL1415728 & 688816 & 5.0 & 5.043 & TRN \\
\hline CHEMBL1602966 & 688816 & 4.95 & 5.4204 & TST \\
\hline CHEMBL1363160 & 688816 & 5.2 & 5.8013 & TRN \\
\hline CHEMBL1313854 & 688816 & 6.95 & 5.4105 & TRN \\
\hline CHEMBL1332897 & 688816 & 7.0 & 5.4654 & TST \\
\hline CHEMBL1091971 & 688816 & 5.2 & 5.6216 & TST \\
\hline CHEMBL1364519 & 688816 & 4.45 & \multicolumn{2}{|c|}{5.207000000000001} \\
\hline CHEMBL1545247 & 688816 & 5.0 & 5.3894 & TRN \\
\hline CHEMBL1319698 & 688816 & 5.05 & 5.215 & TRN \\
\hline CHEMBL1340091 & 688816 & 6.6 & 5.3288 & TRN \\
\hline CHEMBL1453228 & 688816 & 6.8499 & 5.3122 & TRN \\
\hline CHEMBL1464645 & 688816 & 6.3 & 5.456 & TRN \\
\hline CHEMBL1533609 & 688816 & 4.95 & 5.2967 & TRN \\
\hline CHEMBL472929 & 688816 & 4.9 & 5.0743 & TRN \\
\hline CHEMBL259103 & 688816 & 6.3 & 4.953 & TRN \\
\hline CHEMBL1303714 & 688816 & 6.5 & 5.3495 & TST \\
\hline CHEMBL1454480 & 688816 & 4.65 & 5.1229 & TRN \\
\hline CHEMBL1324642 & 688816 & 5.4 & 5.6798 & TST \\
\hline CHEMBL 3198777 & 688816 & 6.8 & 5.5691 & TRN \\
\hline CHEMBL1445717 & 688816 & 4.6 & 4.9414 & TRN \\
\hline CHEMBL 3190478 & 688816 & 4.8 & 5.0662 & TRN \\
\hline CHEMBL1565826 & 688816 & 7.6003 & 5.4296 & TST \\
\hline CHEMBL1330494 & 688816 & 4.8 & 5.341 & TRN \\
\hline CHEMBL1312355 & 688816 & 4.95 & 5.309 & TRN \\
\hline CHEMBL1576675 & 688816 & 4.9 & 5.1962 & TRN \\
\hline CHEMBL210901 & 688816 & 6.1 & 5.5459 & TRN \\
\hline CHEMBL1324393 & 688816 & 4.65 & 5.3302 & TRN \\
\hline CHEMBL1427065 & 688816 & 5.2 & 5.191 & TRN \\
\hline CHEMBL1366410 & 688816 & 4.45 & 5.5766 & TRN \\
\hline CHEMBL1490377 & 688816 & 5.6 & 5.3616 & TRN \\
\hline CHEMBL1352152 & 688816 & 6.9 & 5.3026 & TRN \\
\hline CHEMBL1333504 & 688816 & 4.75 & 5.2195 & TRN \\
\hline CHEMBL3198754 & 688816 & 4.6 & 5.1026 & TRN \\
\hline CHEMBL1323518 & 688816 & 4.45 & 5.1938 & TRN \\
\hline CHEMBL1313791 & 688816 & 5.25 & 5.349 & TRN \\
\hline CHEMBL1463889 & 688816 & 5.0 & 5.6414 & TST \\
\hline CHEMBL1497323 & 688816 & 4.85 & 5.4814 & TST \\
\hline CHEMBL1377778 & 688816 & 4.75 & 5.4174 & TRN \\
\hline CHEMBL1480490 & 688816 & 5.0 & 5.3294 & TRN \\
\hline CHEMBL1320260 & 688816 & 5.55 & 5.2802 & TRN \\
\hline CHEMBL1505811 & 688816 & 6.8 & 5.0119 & TRN \\
\hline \multirow[t]{2}{*}{ CHEMBL1493997 } & 688816 & 4.9 & 5.3003 & TST \\
\hline & & & \multicolumn{2}{|c|}{ Page 24673} \\
\hline
\end{tabular}




\begin{tabular}{|c|c|c|c|c|c|}
\hline \\
\hline CHEMBL1582298 & 688816 & 4.9 & 5.0978 & TRN & \\
\hline CHEMBL1438458 & 688816 & 6.6 & 5.1751 & TRN & \\
\hline CHEMBL1496045 & 688816 & 4.5 & 4.9196 & TRN & \\
\hline CHEMBL1323966 & 688816 & 4.7 & 5.029 & TST & \\
\hline CHEMBL1321325 & 688816 & 5.25 & 5.3098 & TRN & \\
\hline CHEMBL3190337 & 688816 & 7.2503 & 5.1694 & TRN & \\
\hline CHEMBL368457 & 688816 & 4.65 & 5.0458 & TST & \\
\hline CHEMBL1461783 & 688816 & 4.95 & 5.2658 & TRN & \\
\hline CHEMBL1371028 & 688816 & 4.95 & 5.3801 & TRN & \\
\hline CHEMBL1483686 & 688816 & 4.85 & 5.2386 & TRN & \\
\hline CHEMBL1584545 & 688816 & 5.5 & 5.6453 & TST & \\
\hline CHEMBL1330069 & 688816 & 4.65 & 5.2416 & TRN & \\
\hline CHEMBL1462867 & 688816 & 7.8013 & 5.4799 & TRN & \\
\hline CHEMBL1375966 & 688816 & 4.45 & 5.2091 & TRN & \\
\hline CHEMBL1529175 & 688816 & 6.6 & 5.6154 & TRN & \\
\hline CHEMBL1447865 & 688816 & 4.65 & 5.067 & TRN & \\
\hline CHEMBL1564496 & 688816 & 5.2 & 5.3493 & TRN & \\
\hline CHEMBL1302531 & 688816 & 4.45 & 5.0672 & TRN & \\
\hline CHEMBL1516918 & 688816 & 7.7496 & 5.1355 & TRN & \\
\hline CHEMBL1450173 & 688816 & 5.15 & 5.2143 & TRN & \\
\hline CHEMBL1329129 & 688816 & 4.95 & 5.0917 & TST & \\
\hline CHEMBL1599382 & 688816 & 5.25 & 5.3602 & TRN & \\
\hline CHEMBL1564298 & 688816 & 5.3 & 5.0372 & TRN & \\
\hline CHEMBL60718 & 688816 & 6.0 & 5.436 & TST & \\
\hline CHEMBL1973669 & 688816 & 4.65 & 5.0674 & TRN & \\
\hline CHEMBL1593953 & 688816 & 4.95 & 5.2791 & TRN & \\
\hline CHEMBL1301909 & 688816 & 4.95 & 5.2177 & TRN & \\
\hline CHEMBL1443169 & 688816 & 4.9 & 5.5035 & TRN & \\
\hline CHEMBL1462187 & 688816 & 5.6 & 5.6056 & TRN & \\
\hline CHEMBL1380214 & 688816 & 4.9 & 5.3313 & TRN & \\
\hline CHEMBL1465706 & 688816 & 6.3 & 5.3019 & TRN & \\
\hline CHEMBL1390115 & 688816 & 6.0 & 5.8491 & TST & \\
\hline CHEMBL1362838 & 688816 & 5.55 & 4.9678 & TRN & \\
\hline CHEMBL1578903 & 688816 & 4.45 & 5.6019 & TRN & \\
\hline CHEMBL1339310 & 688816 & 4.9 & 4.8574 & TRN & \\
\hline CHEMBL1518934 & 688816 & 4.45 & 5.4285 & TRN & \\
\hline CHEMBL1382238 & 688816 & 4.45 & 5.1052 & TRN & \\
\hline CHEMBL1331011 & 688816 & 4.9 & 5.0748 & TRN & \\
\hline CHEMBL1393071 & 688816 & 4.45 & 5.1438 & TRN & \\
\hline CHEMBL22996 & 688816 & 7.6498 & 5.6297 & TRN & \\
\hline CHEMBL1554476 & 688816 & 4.85 & 5.5037 & TRN & \\
\hline CHEMBL1555916 & 688816 & 5.0 & 5.25899 & 99999999995 & TRN \\
\hline CHEMBL3196489 & 688816 & 4.85 & 5.5678 & TRN & \\
\hline CHEMBL1569043 & 688816 & 5.0 & 5.0414 & TRN & \\
\hline CHEMBL3191302 & 688816 & 6.05 & 4.8869 & TST & \\
\hline CHEMBL1479290 & 688816 & 5.85 & 5.56 & TRN & \\
\hline CHEMBL1427353 & 688816 & 6.05 & 5.1982 & TRN & \\
\hline CHEMBL1342588 & 688816 & 5.45 & 5.3081 & TRN & \\
\hline
\end{tabular}




\begin{tabular}{|c|c|c|c|c|}
\hline \multicolumn{5}{|c|}{ Supplemental Table S2.txt } \\
\hline CHEMBL1736798 & 688816 & 4.75 & 5.3358 & TRN \\
\hline CHEMBL1508256 & 688816 & 5.5 & 5.4705 & TRN \\
\hline CHEMBL1367217 & 688816 & 5.15 & 5.3295 & TRN \\
\hline CHEMBL1408323 & 688816 & 4.95 & 5.2294 & TRN \\
\hline CHEMBL1483559 & 688816 & 4.9 & 5.0591 & TRN \\
\hline CHEMBL1352200 & 688816 & 7.4001 & 5.2582 & TRN \\
\hline CHEMBL1571186 & 688816 & 4.95 & 5.2908 & TRN \\
\hline CHEMBL1478478 & 688816 & 4.85 & 4.9485 & TRN \\
\hline CHEMBL1595847 & 688816 & 4.95 & 5.3657 & TRN \\
\hline CHEMBL1547768 & 688816 & 5.35 & 5.2143 & TRN \\
\hline CHEMBL1470675 & 688816 & 5.6 & 5.706 & TST \\
\hline CHEMBL1602405 & 688816 & 5.05 & 5.5232 & TRN \\
\hline CHEMBL1576977 & 688816 & 4.45 & 5.067 & TRN \\
\hline CHEMBL1589240 & 688816 & 4.6 & 5.1735 & TRN \\
\hline CHEMBL1341495 & 688816 & 4.65 & 5.2213 & TRN \\
\hline CHEMBL1431130 & 688816 & 4.9 & 5.2265 & TRN \\
\hline CHEMBL1521960 & 688816 & 5.95 & 5.311 & TRN \\
\hline CHEMBL1442927 & 688816 & 5.5 & 5.4055 & TRN \\
\hline CHEMBL1607899 & 688816 & 4.9 & 5.1047 & TST \\
\hline CHEMBL1395921 & 688816 & 4.85 & 5.1861 & TRN \\
\hline CHEMBL1509950 & 688816 & 5.45 & 5.2696 & TST \\
\hline CHEMBL1533563 & 688816 & 4.9 & 5.2883 & TST \\
\hline CHEMBL1558609 & 688816 & 6.5501 & 5.6292 & TST \\
\hline CHEMBL1530686 & 688816 & 5.7 & 4.9346 & TRN \\
\hline CHEMBL1586057 & 688816 & 4.95 & 5.343 & TST \\
\hline CHEMBL1341432 & 688816 & 4.7 & 4.9345 & TRN \\
\hline CHEMBL1304102 & 688816 & 4.45 & 5.2675 & TRN \\
\hline CHEMBL1521818 & 688816 & 8.0 & 5.263 & TRN \\
\hline CHEMBL1348445 & 688816 & 4.45 & 5.1174 & TRN \\
\hline CHEMBL1427457 & 688816 & 5.9 & 5.2804 & TRN \\
\hline CHEMBL1530198 & 688816 & 5.7 & 5.1477 & TST \\
\hline CHEMBL1558607 & 688816 & 4.85 & 5.2388 & TRN \\
\hline CHEMBL1342473 & 688816 & 4.6 & 4.8729 & TST \\
\hline CHEMBL1445389 & 688816 & 4.6 & 5.3577 & TST \\
\hline CHEMBL1351332 & 688816 & 4.9 & 5.1 & TRN \\
\hline CHEMBL1558718 & 688816 & 4.45 & 5.1906 & TRN \\
\hline CHEMBL3208411 & 688816 & 8.0 & 5.4986 & TST \\
\hline CHEMBL 7917 & 688816 & 4.4 & 4.9609 & TRN \\
\hline CHEMBL1441583 & 688816 & 4.95 & 5.2214 & TRN \\
\hline CHEMBL1444031 & 688816 & 4.95 & 4.6735 & TRN \\
\hline CHEMBL1540944 & 688816 & 5.15 & 5.4506 & TST \\
\hline CHEMBL1496871 & 688816 & 4.6 & 5.1791 & TRN \\
\hline CHEMBL1525939 & 688816 & 4.65 & 5.284 & TRN \\
\hline CHEMBL1336054 & 688816 & 4.45 & 5.1748 & TRN \\
\hline CHEMBL1347030 & 688816 & 6.0 & 4.9685 & TRN \\
\hline CHEMBL600715 & 688816 & 5.1 & 5.1803 & TST \\
\hline CHEMBL1489148 & 688816 & 4.85 & 5.0282 & TRN \\
\hline CHEMBL1343946 & 688816 & 4.95 & 5.8195 & TRN \\
\hline
\end{tabular}




\begin{tabular}{|c|c|c|c|c|}
\hline \multicolumn{5}{|c|}{ Supplemental Table S2.txt } \\
\hline CHEMBL1486902 & 688816 & 7.2 & 5.5912 & TRN \\
\hline CHEMBL1580592 & 688816 & 4.95 & 5.1694 & TST \\
\hline CHEMBL1495334 & 688816 & 6.6 & 5.2059 & TRN \\
\hline CHEMBL1550961 & 688816 & 4.95 & 5.8319 & TST \\
\hline CHEMBL1308307 & 688816 & 4.45 & 5.0233 & TRN \\
\hline CHEMBL1384293 & 688816 & 4.65 & 5.1157 & TRN \\
\hline CHEMBL1612772 & 688816 & 4.95 & 5.0738 & TRN \\
\hline CHEMBL1461798 & 688816 & 5.45 & 5.2422 & TRN \\
\hline CHEMBL1509981 & 688816 & 4.95 & 5.1714 & TRN \\
\hline CHEMBL1304604 & 688816 & 4.95 & 5.5999 & TST \\
\hline CHEMBL1346498 & 688816 & 5.35 & 5.2506 & TRN \\
\hline CHEMBL1514305 & 688816 & 4.6 & 5.5444 & TST \\
\hline CHEMBL1405964 & 688816 & 5.0 & 5.3004 & TRN \\
\hline CHEMBL1337395 & 688816 & 4.8 & 5.138 & TRN \\
\hline CHEMBL1418158 & 688816 & 4.45 & 5.0355 & TST \\
\hline CHEMBL1469945 & 688816 & 5.4 & 5.3375 & TST \\
\hline CHEMBL1523781 & 688816 & 8.2007 & 5.0043 & TRN \\
\hline CHEMBL1497555 & 688816 & 4.95 & 5.1385 & TRN \\
\hline CHEMBL1504227 & 688816 & 4.75 & 5.2046 & TST \\
\hline CHEMBL1517881 & 688816 & 4.9 & 5.1788 & TST \\
\hline CHEMBL1580219 & 688816 & 4.45 & 4.9335 & TRN \\
\hline CHEMBL1463349 & 688816 & 4.85 & 4.9937 & TRN \\
\hline CHEMBL1399652 & 688816 & 4.9 & 5.2348 & TRN \\
\hline CHEMBL 3195088 & 688816 & 5.0 & 5.5816 & TRN \\
\hline CHEMBL1576346 & 688816 & 5.15 & 5.26 & TRN \\
\hline CHEMBL1319446 & 688816 & 4.85 & 5.3814 & TRN \\
\hline CHEMBL1428894 & 688816 & 4.85 & 5.0773 & TST \\
\hline CHEMBL602987 & 688816 & 4.9 & 5.2469 & TST \\
\hline CHEMBL1303862 & 688816 & 4.95 & 5.1954 & TRN \\
\hline CHEMBL1095276 & 688816 & 5.7 & 5.6651 & TRN \\
\hline CHEMBL1460232 & 688816 & 5.0 & 5.2856 & TRN \\
\hline CHEMBL1373969 & 688816 & 4.75 & 4.9587 & TRN \\
\hline CHEMBL3213811 & 688816 & 4.55 & 5.3835 & TST \\
\hline CHEMBL1612740 & 688816 & 5.1 & 5.3283 & TST \\
\hline CHEMBL1611840 & 688816 & 4.75 & 5.1947 & TST \\
\hline CHEMBL1560004 & 688816 & 4.75 & 4.7565 & TRN \\
\hline CHEMBL1301093 & 688816 & 7.2503 & 5.1027 & TRN \\
\hline CHEMBL1438442 & 688816 & 4.9 & 5.3486 & TRN \\
\hline CHEMBL1407865 & 688816 & 4.6 & 5.4015 & TRN \\
\hline CHEMBL1438073 & 688816 & 4.8 & 4.7654 & TRN \\
\hline CHEMBL1437468 & 688816 & 4.45 & 5.8009 & TRN \\
\hline CHEMBL1404260 & 688816 & 5.0 & 5.3858 & TRN \\
\hline CHEMBL1527559 & 688816 & 8.4559 & 5.1943 & TRN \\
\hline CHEMBL1505651 & 688816 & 5.3 & 5.0986 & TRN \\
\hline CHEMBL1536469 & 688816 & 4.75 & 5.2514 & TST \\
\hline CHEMBL 2001794 & 688816 & 4.45 & 5.2616 & TRN \\
\hline CHEMBL1571828 & 688816 & 8.4949 & 5.3316 & TRN \\
\hline CHEMBL1388566 & 688816 & 4.75 & 4.8766 & TRN \\
\hline
\end{tabular}




\begin{tabular}{|c|c|c|c|c|}
\hline \multicolumn{5}{|c|}{ Supplemental Table S2.txt } \\
\hline CHEMBL1426946 & 688816 & 5.9 & 5.2419 & TST \\
\hline CHEMBL1426911 & 688816 & 5.4 & 5.3956 & TRN \\
\hline CHEMBL1447942 & 688816 & 4.65 & 5.3168 & TRN \\
\hline CHEMBL1457640 & 688816 & 5.25 & 5.4207 & TST \\
\hline CHEMBL3212610 & 688816 & 4.95 & 5.1017 & TRN \\
\hline CHEMBL1439858 & 688816 & 6.95 & 5.7173 & TRN \\
\hline CHEMBL1449921 & 688816 & 4.85 & 5.0169 & TRN \\
\hline CHEMBL1441216 & 688816 & 4.65 & 5.5258 & TST \\
\hline CHEMBL1456896 & 688816 & 4.45 & 5.2272 & TST \\
\hline CHEMBL1510221 & 688816 & 5.0 & 5.3258 & TRN \\
\hline CHEMBL1365187 & 688816 & 4.9 & 5.3678 & TRN \\
\hline CHEMBL1599860 & 688816 & 4.85 & 5.0555 & TRN \\
\hline CHEMBL1431256 & 688816 & 4.7 & 5.3492 & TST \\
\hline CHEMBL1555617 & 688816 & 6.5501 & 5.1496 & TST \\
\hline CHEMBL1347314 & 688816 & 5.95 & 5.7868 & TRN \\
\hline CHEMBL1313502 & 688816 & 4.9 & 5.4926 & TRN \\
\hline CHEMBL1360622 & 688816 & 4.45 & 5.1735 & TRN \\
\hline CHEMBL3195722 & 688816 & 4.45 & 4.8944 & TRN \\
\hline CHEMBL1974389 & 688816 & 4.45 & 5.4241 & TST \\
\hline CHEMBL1524762 & 688816 & 5.0 & 5.0575 & TRN \\
\hline CHEMBL1432783 & 688816 & 7.5003 & 5.6498 & TRN \\
\hline CHEMBL1519664 & 688816 & 5.05 & 5.1254 & TRN \\
\hline CHEMBL1370293 & 688816 & 4.9 & 5.5741 & TRN \\
\hline CHEMBL1386446 & 688816 & 5.05 & 5.2507 & TRN \\
\hline CHEMBL1450709 & 688816 & 4.95 & 4.9575 & TST \\
\hline CHEMBL3197763 & 688816 & 5.0 & 5.4098 & TST \\
\hline CHEMBL1385212 & 688816 & 8.0506 & 5.2636 & TST \\
\hline CHEMBL1408807 & 688816 & 4.9 & 5.6265 & TRN \\
\hline CHEMBL1591873 & 688816 & 5.55 & 5.1683 & TST \\
\hline CHEMBL3192826 & 688816 & 6.0 & 5.4282 & TST \\
\hline CHEMBL1505161 & 688816 & 8.301 & 5.4544 & TST \\
\hline CHEMBL1386507 & 688816 & 5.95 & 5.3173 & TRN \\
\hline CHEMBL1389418 & 688816 & 4.95 & 5.1772 & TRN \\
\hline CHEMBL1426619 & 688816 & 4.85 & 4.9929 & TRN \\
\hline CHEMBL1602665 & 688816 & 5.5 & 4.8985 & TRN \\
\hline CHEMBL1603596 & 688816 & 8.301 & 5.2217 & TRN \\
\hline CHEMBL1345636 & 688816 & 4.8 & 5.3506 & TST \\
\hline CHEMBL1605780 & 688816 & 5.05 & 4.8156 & TRN \\
\hline CHEMBL1440554 & 688816 & 6.3 & 5.0563 & TRN \\
\hline CHEMBL3198999 & 688816 & 4.6 & 5.4742 & TRN \\
\hline CHEMBL1321713 & 688816 & 4.9 & 4.8873 & TRN \\
\hline CHEMBL1419697 & 688816 & 8.0 & 5.2433 & TRN \\
\hline CHEMBL1301451 & 688816 & 4.95 & 5.6606 & TRN \\
\hline CHEMBL1975051 & 688816 & 7.0501 & 5.4626 & TRN \\
\hline CHEMBL1358862 & 688816 & 4.75 & 5.2243 & TRN \\
\hline CHEMBL1997177 & 688816 & 6.1 & 5.0906 & TST \\
\hline CHEMBL3196599 & 688816 & 4.65 & 5.1856 & TRN \\
\hline CHEMBL1883149 & 688816 & 5.0 & 4.8182 & TRN \\
\hline
\end{tabular}




\begin{tabular}{|c|c|c|c|c|}
\hline \multicolumn{5}{|c|}{ Supplemental Table S2.txt } \\
\hline CHEMBL1585055 & 688816 & 4.95 & 5.2768 & TRN \\
\hline CHEMBL1522985 & 688816 & 6.45 & 5.2034 & TRN \\
\hline CHEMBL1546834 & 688816 & 4.95 & 5.1178 & TRN \\
\hline CHEMBL1602694 & 688816 & 4.8 & 5.0532 & TRN \\
\hline CHEMBL1533738 & 688816 & 5.8 & 5.5126 & TST \\
\hline CHEMBL1503745 & 688816 & 4.75 & 4.9918 & TST \\
\hline CHEMBL1511748 & 688816 & 4.9 & 5.0486 & TRN \\
\hline CHEMBL1559360 & 688816 & 4.45 & 5.0629 & TRN \\
\hline CHEMBL1607827 & 688816 & 6.0 & 5.6917 & TRN \\
\hline CHEMBL1344179 & 688816 & 4.45 & 5.2148 & TST \\
\hline CHEMBL1564348 & 688816 & 4.8 & 5.5209 & TRN \\
\hline CHEMBL1308380 & 688816 & 4.8 & 5.4148 & TRN \\
\hline CHEMBL1499183 & 688816 & 5.35 & 4.8945 & TST \\
\hline CHEMBL1309620 & 688816 & 4.95 & 4.9071 & TRN \\
\hline CHEMBL1556328 & 688816 & 4.8 & 5.4963 & TRN \\
\hline CHEMBL1557179 & 688816 & 5.45 & 5.1607 & TRN \\
\hline CHEMBL1373952 & 688816 & 4.7 & 5.1792 & TRN \\
\hline CHEMBL1532966 & 688816 & 8.0 & 5.4308 & TRN \\
\hline CHEMBL1416717 & 688816 & 4.8 & 5.0185 & TRN \\
\hline CHEMBL1384967 & 688816 & 5.0 & 5.3619 & TRN \\
\hline CHEMBL1377164 & 688816 & 4.9 & 4.6826 & TRN \\
\hline CHEMBL1331249 & 688816 & 5.2 & 5.4535 & TST \\
\hline CHEMBL1374388 & 688816 & 5.9 & 4.6825 & TST \\
\hline CHEMBL1422720 & 688816 & 4.45 & 5.2088 & TST \\
\hline CHEMBL1300992 & 688816 & 4.85 & 5.2809 & TRN \\
\hline CHEMBL1540399 & 688816 & 5.3 & 5.7074 & TRN \\
\hline CHEMBL3198961 & 688816 & 4.45 & 5.2239 & TRN \\
\hline CHEMBL1429330 & 688816 & 5.5 & 5.3502 & TRN \\
\hline CHEMBL1407741 & 688816 & 5.5 & 5.13 & TRN \\
\hline CHEMBL1497815 & 688816 & 4.9 & 5.1507 & TRN \\
\hline CHEMBL1423887 & 688816 & 7.5498 & 5.3936 & TST \\
\hline CHEMBL3191530 & 688816 & 4.9 & 5.1181 & TRN \\
\hline CHEMBL1302891 & 688816 & 4.9 & 4.9566 & TRN \\
\hline CHEMBL1399879 & 688816 & 7.4498 & 5.2035 & TRN \\
\hline CHEMBL1521895 & 688816 & 4.8 & 4.9741 & TRN \\
\hline CHEMBL1602538 & 688816 & 5.0 & 5.4181 & TRN \\
\hline CHEMBL1555120 & 688816 & 4.95 & 5.5187 & TST \\
\hline CHEMBL1497840 & 688816 & 4.7 & 5.4636 & TRN \\
\hline CHEMBL1306277 & 688816 & 5.15 & 5.6942 & TST \\
\hline CHEMBL1383582 & 688816 & 4.8 & 5.4458 & TRN \\
\hline CHEMBL1494038 & 688816 & 4.75 & 4.6137 & TST \\
\hline CHEMBL1366382 & 688816 & 5.2 & 5.1471 & TST \\
\hline CHEMBL1467349 & 688816 & 4.9 & 5.3684 & TRN \\
\hline CHEMBL1596465 & 688816 & 4.6 & 5.3353 & TST \\
\hline CHEMBL1538895 & 688816 & 4.9 & 5.0898 & TRN \\
\hline CHEMBL1542646 & 688816 & 4.85 & 5.2341 & TRN \\
\hline CHEMBL1586946 & 688816 & 6.5 & 5.4616 & TST \\
\hline CHEMBL1421014 & 688816 & 4.9 & 5.2759 & TRN \\
\hline
\end{tabular}




\begin{tabular}{|c|c|c|c|c|c|}
\hline \multicolumn{6}{|c|}{ Supplemental Table S2.txt } \\
\hline CHEMBL1335003 & 688816 & 4.75 & 5.2653 & TST & \\
\hline CHEMBL1447068 & 688816 & 4.95 & 5.4443 & TRN & \\
\hline CHEMBL1331765 & 688816 & 4.8 & 5.2334 & TST & \\
\hline CHEMBL1412478 & 688816 & 4.95 & 5.0056 & TRN & \\
\hline CHEMBL1564491 & 688816 & 4.9 & 5.5867 & TRN & \\
\hline CHEMBL1492915 & 688816 & 8.301 & 5.6616 & TST & \\
\hline CHEMBL1402227 & 688816 & 4.45 & 5.1129 & TRN & \\
\hline CHEMBL1574074 & 688816 & 4.9 & 5.06 & TRN & \\
\hline CHEMBL1429856 & 688816 & 4.95 & 5.25700 & 0000000001 & TRN \\
\hline CHEMBL1407442 & 688816 & 4.95 & 5.3563 & TRN & \\
\hline CHEMBL1309327 & 688816 & 4.45 & 5.4787 & TRN & \\
\hline CHEMBL1335187 & 688816 & 4.9 & 5.4484 & TRN & \\
\hline CHEMBL1415109 & 688816 & 4.65 & 5.0023 & TRN & \\
\hline CHEMBL 2006757 & 688816 & 4.95 & 4.9759 & TRN & \\
\hline CHEMBL1307154 & 688816 & 4.8 & 4.9161 & TRN & \\
\hline CHEMBL1564778 & 688816 & 6.5501 & 5.4974 & TRN & \\
\hline CHEMBL1460815 & 688816 & 5.1 & 5.3578 & TRN & \\
\hline CHEMBL1584016 & 688816 & 4.95 & 5.02 & TRN & \\
\hline CHEMBL1362262 & 688816 & 5.35 & 5.2958 & TST & \\
\hline CHEMBL1452572 & 688816 & 4.75 & 5.2623 & TRN & \\
\hline CHEMBL1332371 & 688816 & 4.65 & 4.7223 & TRN & \\
\hline CHEMBL1306985 & 688816 & 4.8 & 5.6886 & TRN & \\
\hline CHEMBL1518036 & 688816 & 4.8 & 5.1436 & TRN & \\
\hline CHEMBL1538040 & 688816 & 5.55 & 4.9054 & TRN & \\
\hline CHEMBL1466551 & 688816 & 5.65 & 5.0461 & TRN & \\
\hline CHEMBL1318894 & 688816 & 4.8 & 5.0838 & TRN & \\
\hline CHEMBL1445195 & 688816 & 4.95 & 5.1242 & TST & \\
\hline CHEMBL1463686 & 688816 & 4.7 & 5.0068 & TRN & \\
\hline CHEMBL1405215 & 688816 & 5.2 & 5.2334 & TRN & \\
\hline CHEMBL1405114 & 688816 & 5.0 & 5.3108 & TRN & \\
\hline CHEMBL1560212 & 688816 & 4.7 & 5.5463 & TRN & \\
\hline CHEMBL1327406 & 688816 & 4.75 & 5.7591 & TRN & \\
\hline CHEMBL1441485 & 688816 & 7.699 & 4.8757 & TST & \\
\hline CHEMBL 3145200 & 688816 & 5.25 & 5.2981 & TST & \\
\hline CHEMBL1324259 & 688816 & 4.85 & 4.9569 & TRN & \\
\hline CHEMBL1302466 & 688816 & 4.8 & 5.0174 & TRN & \\
\hline CHEMBL1500992 & 688816 & 4.65 & 4.975 & TRN & \\
\hline CHEMBL1503006 & 688816 & 5.0 & 4.6457 & TRN & \\
\hline CHEMBL1237007 & 688816 & 5.0 & 5.2834 & TRN & \\
\hline CHEMBL1327001 & 688816 & 5.0 & 5.2711 & TRN & \\
\hline CHEMBL1347808 & 688816 & 4.85 & 5.4512 & TST & \\
\hline CHEMBL1504116 & 688816 & 4.6 & 5.1435 & TRN & \\
\hline CHEMBL1461248 & 688816 & 5.2 & 6.0657 & TRN & \\
\hline CHEMBL1542108 & 688816 & 5.45 & 5.4468 & TRN & \\
\hline CHEMBL1579968 & 688816 & 7.0 & 4.9964 & TRN & \\
\hline CHEMBL1364828 & 688816 & 4.7 & 5.4217 & TRN & \\
\hline CHEMBL1256191 & 688816 & 4.65 & 5.2252 & TST & \\
\hline CHEMBL1484344 & 688816 & 5.0 & 5.5508 & TRN & \\
\hline
\end{tabular}




\begin{tabular}{|c|c|c|c|c|c|}
\hline \multicolumn{6}{|c|}{ Supplemental Table S2.txt } \\
\hline CHEMBL1579940 & 688816 & 5.05 & 5.6118 & TRN & \\
\hline CHEMBL1393701 & 688816 & 4.95 & 5.2305 & TRN & \\
\hline CHEMBL1452917 & 688816 & 5.2 & 5.2447 & TST & \\
\hline CHEMBL3208977 & 688816 & 4.85 & 4.9312 & TST & \\
\hline CHEMBL1483856 & 688816 & 5.05 & 5.4916 & TST & \\
\hline CHEMBL3209783 & 688816 & 6.5501 & 5.3478 & TRN & \\
\hline CHEMBL1413164 & 688816 & 6.7001 & 5.4394 & TRN & \\
\hline CHEMBL1540513 & 688816 & 4.75 & 4.8302 & TRN & \\
\hline CHEMBL1577590 & 688816 & 5.0 & 5.0621 & TRN & \\
\hline CHEMBL1460627 & 688816 & 5.15 & 5.4449 & TRN & \\
\hline CHEMBL1387424 & 688816 & 4.85 & 5.523 & TRN & \\
\hline CHEMBL1587017 & 688816 & 5.55 & 5.6089 & TST & \\
\hline CHEMBL1582765 & 688816 & 5.5 & 5.6113 & TST & \\
\hline CHEMBL1300726 & 688816 & 5.25 & 5.2444 & TRN & \\
\hline CHEMBL1481985 & 688816 & 7.8013 & 5.3436 & TRN & \\
\hline CHEMBL1336288 & 688816 & 4.85 & 4.9543 & TRN & \\
\hline CHEMBL1543236 & 688816 & 4.5 & 5.4612 & TRN & \\
\hline CHEMBL1493516 & 688816 & 4.45 & 5.0777 & TRN & \\
\hline CHEMBL1424977 & 688816 & 8.301 & 5.1848 & TRN & \\
\hline CHEMBL1338544 & 688816 & 4.9 & 5.3557 & TST & \\
\hline CHEMBL1422986 & 688816 & 5.8 & 5.4647 & TST & \\
\hline CHEMBL1428871 & 688816 & 6.0 & 5.5085 & TST & \\
\hline CHEMBL1334674 & 688816 & 5.8 & 5.7306 & TRN & \\
\hline CHEMBL1312289 & 688816 & 4.6 & 5.3014 & TRN & \\
\hline CHEMBL1534429 & 688816 & 5.25 & 4.8887 & TRN & \\
\hline CHEMBL1498470 & 688816 & 5.6 & 5.28100 & 0000000001 & TRN \\
\hline CHEMBL1521344 & 688816 & 5.85 & 5.4644 & TRN & \\
\hline CHEMBL1512285 & 688816 & 4.85 & 5.0255 & TRN & \\
\hline CHEMBL1367191 & 688816 & 5.4 & 5.2279 & TRN & \\
\hline CHEMBL1162428 & 688816 & 4.45 & 5.2504 & TRN & \\
\hline CHEMBL1403284 & 688816 & 4.7 & 5.2581 & TRN & \\
\hline CHEMBL1438470 & 688816 & 5.25 & 5.5588 & TRN & \\
\hline CHEMBL1523728 & 688816 & 4.85 & 5.0971 & TST & \\
\hline CHEMBL1585738 & 688816 & 4.75 & 5.2256 & TRN & \\
\hline CHEMBL1299269 & 688816 & 4.8 & 5.3239 & TST & \\
\hline CHEMBL 247378 & 688816 & 5.8 & 5.222 & TST & \\
\hline CHEMBL1360403 & 688816 & 7.6498 & 5.7172 & TST & \\
\hline CHEMBL1348110 & 688816 & 4.95 & 5.4312 & TST & \\
\hline CHEMBL1301232 & 688816 & 4.8 & 5.1465 & TRN & \\
\hline CHEMBL1378585 & 688816 & 4.95 & 5.2618 & TRN & \\
\hline CHEMBL1449887 & 688816 & 4.9 & 5.2452 & TRN & \\
\hline CHEMBL1441542 & 688816 & 4.9 & 5.3193 & TRN & \\
\hline CHEMBL3195113 & 688816 & 5.25 & 5.7689 & TST & \\
\hline CHEMBL1391592 & 688816 & 4.45 & 5.4191 & TRN & \\
\hline CHEMBL 3212785 & 688816 & 5.95 & 4.98600 & 0000000001 & TRN \\
\hline CHEMBL1571301 & 688816 & 4.75 & 5.2374 & TRN & \\
\hline CHEMBL1563533 & 688816 & 4.65 & 4.5921 & TRN & \\
\hline CHEMBL1462172 & 688816 & 4.45 & 4.9467 & TRN & \\
\hline
\end{tabular}




\begin{tabular}{|c|c|c|c|c|c|}
\hline \multicolumn{6}{|c|}{ Supplemental Table S2.txt } \\
\hline CHEMBL1409882 & 688816 & 4.75 & 5.0135 & TRN & \\
\hline CHEMBL1403014 & 688816 & 4.85 & 5.125 & TST & \\
\hline CHEMBL1544460 & 688816 & 4.45 & 5.0758 & TRN & \\
\hline CHEMBL1322960 & 688816 & 4.55 & 5.0224 & TRN & \\
\hline CHEMBL1424730 & 688816 & 4.8 & 5.05399 & 9999999999 & TRN \\
\hline CHEMBL3194426 & 688816 & 4.95 & 5.2474 & TRN & \\
\hline CHEMBL1502027 & 688816 & 5.0 & 5.348 & TRN & \\
\hline CHEMBL3192356 & 688816 & 5.0 & 5.3497 & TST & \\
\hline CHEMBL1418340 & 688816 & 5.4 & 4.9099 & TRN & \\
\hline CHEMBL1405002 & 688816 & 4.95 & 5.2837 & TRN & \\
\hline CHEMBL1608818 & 688816 & 7.8508 & 5.0462 & TRN & \\
\hline CHEMBL1562060 & 688816 & 4.55 & 5.1613 & TST & \\
\hline CHEMBL1412015 & 688816 & 4.9 & 5.3943 & TST & \\
\hline CHEMBL1517571 & 688816 & 4.45 & 5.1148 & TRN & \\
\hline CHEMBL1455992 & 688816 & 5.15 & 5.44799 & 99999999995 & TST \\
\hline CHEMBL1393210 & 688816 & 4.45 & 5.1485 & TRN & \\
\hline CHEMBL1458074 & 688816 & 5.0 & 5.1149 & TRN & \\
\hline CHEMBL1242180 & 688816 & 5.4 & 5.1373 & TRN & \\
\hline CHEMBL1498081 & 688816 & 4.45 & 5.2522 & TRN & \\
\hline CHEMBL1504392 & 688816 & 4.45 & 5.2712 & TRN & \\
\hline CHEMBL1331383 & 688816 & 4.45 & 6.0865 & TRN & \\
\hline CHEMBL3213209 & 688816 & 7.9508 & 5.3588 & TST & \\
\hline CHEMBL1498741 & 688816 & 5.2 & 5.4111 & TRN & \\
\hline CHEMBL1385576 & 688816 & 4.9 & 5.1699 & TRN & \\
\hline CHEMBL 2002223 & 688816 & 5.0 & 4.78 & TRN & \\
\hline CHEMBL1427423 & 688816 & 4.95 & 4.9686 & TRN & \\
\hline CHEMBL1447208 & 688816 & 4.95 & 5.1505 & TST & \\
\hline CHEMBL1410156 & 688816 & 4.55 & 5.2112 & TRN & \\
\hline CHEMBL1597934 & 688816 & 4.45 & 5.0093 & TRN & \\
\hline CHEMBL1407618 & 688816 & 5.25 & 5.4223 & TST & \\
\hline CHEMBL1444846 & 688816 & 4.9 & 5.5295 & TRN & \\
\hline CHEMBL565486 & 688816 & 5.05 & 5.2429 & TRN & \\
\hline CHEMBL1468754 & 688816 & 5.25 & 5.3944 & TRN & \\
\hline CHEMBL1352326 & 688816 & 5.4 & 5.2161 & TRN & \\
\hline CHEMBL1440658 & 688816 & 5.2 & 5.4927 & TRN & \\
\hline CHEMBL3193159 & 688816 & 5.2 & 5.4013 & TRN & \\
\hline CHEMBL 1468869 & 688816 & 4.45 & 5.2799 & TRN & \\
\hline CHEMBL1534254 & 688816 & 5.3 & 5.2213 & TRN & \\
\hline CHEMBL1570221 & 688816 & 6.3 & 4.9946 & TST & \\
\hline CHEMBL1579715 & 688816 & 6.1 & 5.1951 & TRN & \\
\hline CHEMBL1480534 & 688816 & 5.0 & 5.0939 & TRN & \\
\hline CHEMBL1307681 & 688816 & 4.5 & 5.3018 & TST & \\
\hline CHEMBL1527784 & 688816 & 4.7 & 5.4994 & TRN & \\
\hline CHEMBL1572983 & 688816 & 8.0 & 5.3912 & TST & \\
\hline CHEMBL1584961 & 688816 & 4.9 & 5.3189 & TRN & \\
\hline CHEMBL1528330 & 688816 & 4.5 & 5.0554 & TRN & \\
\hline CHEMBL1613690 & 688816 & 4.45 & 5.2472 & TRN & \\
\hline CHEMBL1365888 & 688816 & 8.4949 & 5.0791 & TRN & \\
\hline
\end{tabular}




\begin{tabular}{|c|c|c|c|c|c|}
\hline \multicolumn{6}{|c|}{ Supplemental Table S2.txt } \\
\hline CHEMBL1426948 & 688816 & 5.65 & 5.0073 & TST & \\
\hline CHEMBL1587534 & 688816 & 5.35 & 5.1818 & TRN & \\
\hline CHEMBL1380582 & 688816 & 4.5 & 4.9556 & TRN & \\
\hline CHEMBL1387461 & 688816 & 4.55 & 5.5894 & TRN & \\
\hline CHEMBL1522332 & 688816 & 4.65 & 4.7916 & TRN & \\
\hline CHEMBL1481186 & 688816 & 7.0 & 5.4594 & TRN & \\
\hline CHEMBL1429010 & 688816 & 4.9 & 5.3215 & TST & \\
\hline CHEMBL1522729 & 688816 & 5.05 & 5.4318 & TST & \\
\hline CHEMBL1339492 & 688816 & 4.95 & 5.4502 & TRN & \\
\hline CHEMBL3190918 & 688816 & 4.85 & 5.7486 & TST & \\
\hline CHEMBL602234 & 688816 & 4.85 & 4.8 & TRN & \\
\hline CHEMBL1565963 & 688816 & 6.45 & 5.3394 & TRN & \\
\hline CHEMBL1269084 & 688816 & 4.9 & 5.2624 & TST & \\
\hline CHEMBL 3214385 & 688816 & 4.7 & 5.1456 & TRN & \\
\hline CHEMBL1519966 & 688816 & 4.95 & 5.4685 & TRN & \\
\hline CHEMBL1558413 & 688816 & 5.05 & 5.0496 & TST & \\
\hline CHEMBL1459416 & 688816 & 4.95 & 4.905 & TRN & \\
\hline CHEMBL1442534 & 688816 & 5.9 & 5.1414 & TRN & \\
\hline CHEMBL1469603 & 688816 & 5.15 & 4.8245 & TRN & \\
\hline CHEMBL1598520 & 688816 & 4.9 & 5.0706 & TRN & \\
\hline CHEMBL1330819 & 688816 & 4.95 & 5.1515 & TRN & \\
\hline CHEMBL3196537 & 688816 & 5.0 & 5.641 & TRN & \\
\hline CHEMBL1599535 & 688816 & 8.3468 & 5.5457 & TST & \\
\hline CHEMBL1365555 & 688816 & 4.9 & 5.325 & TRN & \\
\hline CHEMBL1519389 & 688816 & 5.4 & 5.438 & TRN & \\
\hline CHEMBL1413278 & 688816 & 4.5 & 4.9793 & TST & \\
\hline CHEMBL1610255 & 688816 & 4.75 & 5.3707 & TRN & \\
\hline CHEMBL1492205 & 688816 & 4.5 & 5.0113 & TRN & \\
\hline CHEMBL1604975 & 688816 & 8.3468 & 5.2323 & TST & \\
\hline CHEMBL1971604 & 688816 & 4.8 & 5.1849 & TRN & \\
\hline CHEMBL1602506 & 688816 & 5.3 & 5.3792 & TRN & \\
\hline CHEMBL1374001 & 688816 & 4.85 & 5.2328 & TRN & \\
\hline CHEMBL1973226 & 688816 & 4.9 & 5.5057 & TRN & \\
\hline CHEMBL1536030 & 688816 & 4.9 & 5.1586 & TST & \\
\hline CHEMBL1518539 & 688816 & 4.95 & 5.223 & TRN & \\
\hline CHEMBL148072 & 688816 & 6.5 & 5.3424 & TST & \\
\hline CHEMBL1504470 & 688816 & 4.65 & 5.4599 & TST & \\
\hline CHEMBL1568750 & 688816 & 7.2 & 5.3844 & TRN & \\
\hline CHEMBL1449103 & 688816 & 5.2 & 5.1218 & TRN & \\
\hline CHEMBL1425778 & 688816 & 5.8 & 4.9965 & TRN & \\
\hline CHEMBL1560473 & 688816 & 4.9 & 5.0016 & TRN & \\
\hline CHEMBL1462417 & 688816 & 4.9 & 5.13899 & 9999999999 & TRN \\
\hline CHEMBL1371069 & 688816 & 4.45 & 5.4253 & TST & \\
\hline CHEMBL1323927 & 688816 & 5.05 & 5.2291 & TST & \\
\hline CHEMBL1539294 & 688816 & 4.95 & 5.3307 & TRN & \\
\hline CHEMBL1586958 & 688816 & 4.95 & 5.2869 & TST & \\
\hline CHEMBL1408542 & 688816 & 7.4498 & 5.8872 & TRN & \\
\hline CHEMBL1560564 & 688816 & 4.7 & 5.2176 & TST & \\
\hline
\end{tabular}




\begin{tabular}{|c|c|c|c|c|c|}
\hline \multicolumn{6}{|c|}{ Supplemental Table S2.txt } \\
\hline CHEMBL1310893 & 688816 & 5.0 & 4.9038 & TRN & \\
\hline CHEMBL1449325 & 688816 & 4.9 & 5.0613 & TRN & \\
\hline CHEMBL333889 & 688816 & 4.9 & 5.8145 & TRN & \\
\hline CHEMBL1303068 & 688816 & 4.45 & 4.7798 & TRN & \\
\hline CHEMBL1321334 & 688816 & 5.35 & 5.1853 & TRN & \\
\hline CHEMBL1518448 & 688816 & 4.9 & \multicolumn{2}{|c|}{5.111000000000001} & TRN \\
\hline CHEMBL1480305 & 688816 & 5.45 & 5.0362 & TRN & \\
\hline CHEMBL1533498 & 688816 & 4.85 & 5.0287 & TRN & \\
\hline CHEMBL1331924 & 688816 & 6.25 & 5.5712 & TRN & \\
\hline CHEMBL1503950 & 688816 & 4.8 & 5.0146 & TST & \\
\hline CHEMBL1427991 & 688816 & 4.65 & 5.3394 & TRN & \\
\hline CHEMBL1516303 & 688816 & 4.9 & \multicolumn{2}{|c|}{5.031000000000001} & TRN \\
\hline CHEMBL1378629 & 688816 & 4.9 & 5.1074 & TRN & \\
\hline CHEMBL3190577 & 688816 & 4.45 & 5.1636 & TST & \\
\hline CHEMBL1335634 & 688816 & 4.95 & 5.7746 & TRN & \\
\hline CHEMBL1493846 & 688816 & 5.35 & 5.3252 & TRN & \\
\hline CHEMBL1447373 & 688816 & 4.5 & \multicolumn{2}{|c|}{5.218999999999999} & TRN \\
\hline CHEMBL1613323 & 688816 & 4.45 & 4.7738 & TRN & \\
\hline CHEMBL1415980 & 688816 & 4.9 & 5.1536 & TRN & \\
\hline CHEMBL1491186 & 688816 & 4.6 & 5.5766 & TST & \\
\hline CHEMBL 3199254 & 688816 & 4.45 & 5.2613 & TRN & \\
\hline CHEMBL1506839 & 688816 & 6.8499 & \multicolumn{2}{|c|}{5.422999999999999} & TRN \\
\hline CHEMBL1301955 & 688816 & 5.25 & 5.2152 & TRN & \\
\hline CHEMBL1588937 & 688816 & 5.15 & 5.651 & TRN & \\
\hline CHEMBL1363156 & 688816 & 5.05 & 5.1429 & TRN & \\
\hline CHEMBL1438294 & 688816 & 4.95 & 5.2788 & TRN & \\
\hline CHEMBL1526684 & 688816 & 8.1487 & 5.4985 & TRN & \\
\hline CHEMBL 3194422 & 688816 & 4.5 & 5.3705 & TRN & \\
\hline CHEMBL1601857 & 688816 & 4.45 & 5.2095 & TST & \\
\hline CHEMBL1479640 & 688816 & 6.25 & 5.4704 & TST & \\
\hline CHEMBL1370929 & 688816 & 4.9 & 4.9629 & TRN & \\
\hline CHEMBL1444213 & 688816 & 4.95 & 5.1649 & TRN & \\
\hline CHEMBL1448939 & 688816 & 4.45 & 5.0135 & TRN & \\
\hline CHEMBL1464787 & 688816 & 4.5 & 5.2831 & TST & \\
\hline CHEMBL1542279 & 688816 & 4.45 & 5.3283 & TST & \\
\hline CHEMBL1526946 & 688816 & 5.75 & 5.3133 & TRN & \\
\hline CHEMBL1407945 & 688816 & 4.45 & 5.0956 & TRN & \\
\hline CHEMBL1447693 & 688816 & 4.85 & 5.1298 & TRN & \\
\hline CHEMBL1505039 & 688816 & 5.1 & 5.3039 & TST & \\
\hline CHEMBL1340116 & 688816 & 6.05 & 5.6005 & TRN & \\
\hline CHEMBL1447529 & 688816 & 4.65 & 5.0484 & TRN & \\
\hline CHEMBL1491587 & 688816 & 4.45 & 4.9796 & TRN & \\
\hline CHEMBL1443086 & 688816 & 6.0 & 5.6444 & TRN & \\
\hline CHEMBL1404743 & 688816 & 8.3979 & 5.4943 & TST & \\
\hline CHEMBL1470712 & 688816 & 4.65 & 5.1492 & TRN & \\
\hline CHEMBL1382773 & 688816 & 4.95 & 5.3531 & TRN & \\
\hline CHEMBL1566101 & 688816 & 4.8 & 5.1509 & TRN & \\
\hline CHEMBL1470588 & 688816 & 5.0 & 4.7548 & TRN & \\
\hline
\end{tabular}




\begin{tabular}{|c|c|c|c|c|}
\hline \multicolumn{5}{|c|}{ Supplemental Table S2.txt } \\
\hline CHEMBL1373002 & 688816 & 5.35 & 5.3338 & TST \\
\hline CHEMBL1337784 & 688816 & 5.35 & 5.2837 & TRN \\
\hline CHEMBL1348803 & 688816 & 4.85 & 5.1561 & TRN \\
\hline CHEMBL1576899 & 688816 & 4.85 & 5.1631 & TRN \\
\hline CHEMBL1322727 & 688816 & 4.95 & 4.9568 & TRN \\
\hline CHEMBL1484588 & 688816 & 6.5501 & 5.5549 & TRN \\
\hline CHEMBL1518794 & 688816 & 4.6 & 4.9993 & TRN \\
\hline CHEMBL1497673 & 688816 & 4.45 & 5.0804 & TRN \\
\hline CHEMBL1596941 & 688816 & 5.2 & 5.54200 & 2000000001 \\
\hline CHEMBL1370480 & 688816 & 4.9 & 5.0929 & TRN \\
\hline CHEMBL1450314 & 688816 & 4.8 & 5.1015 & TRN \\
\hline CHEMBL1335337 & 688816 & 4.7 & 5.1026 & TST \\
\hline CHEMBL1365353 & 688816 & 5.3 & 5.6145 & TRN \\
\hline CHEMBL3213953 & 688816 & 4.95 & 5.6298 & TRN \\
\hline CHEMBL1477081 & 688816 & 5.35 & 5.3671 & TRN \\
\hline CHEMBL1408416 & 688816 & 4.75 & 5.6925 & TST \\
\hline CHEMBL1595681 & 688816 & 4.75 & 5.2723 & TRN \\
\hline CHEMBL1461001 & 688816 & 4.95 & 4.9092 & TRN \\
\hline CHEMBL1583349 & 688816 & 6.8 & 5.4235 & TST \\
\hline CHEMBL1332387 & 688816 & 5.0 & 5.4846 & TRN \\
\hline CHEMBL1528565 & 688816 & 4.45 & 5.1369 & TST \\
\hline CHEMBL1351256 & 688816 & 5.9 & 5.4412 & TRN \\
\hline CHEMBL3193741 & 688816 & 4.8 & 5.3295 & TRN \\
\hline CHEMBL1481789 & 688816 & 4.45 & 5.4935 & TRN \\
\hline CHEMBL1519163 & 688816 & 5.2 & 5.5164 & TRN \\
\hline CHEMBL1460409 & 688816 & 4.65 & 5.3735 & TST \\
\hline CHEMBL412603 & 688816 & 5.1 & 4.8904 & TRN \\
\hline CHEMBL1342344 & 688816 & 7.4001 & 5.5008 & TRN \\
\hline CHEMBL1408140 & 688816 & 5.35 & 5.0646 & TRN \\
\hline CHEMBL1441538 & 688816 & 4.8 & 5.4011 & TRN \\
\hline CHEMBL1529731 & 688816 & 6.45 & 5.4752 & TRN \\
\hline CHEMBL1465701 & 688816 & 4.8 & 5.0156 & TST \\
\hline CHEMBL1527551 & 688816 & 4.8 & 4.9002 & TST \\
\hline CHEMBL1417725 & 688816 & 4.75 & 4.9995 & TRN \\
\hline CHEMBL1528680 & 688816 & 4.95 & 5.5037 & TRN \\
\hline CHEMBL1344996 & 688816 & 8.2518 & 5.8559 & TRN \\
\hline CHEMBL1415504 & 688816 & 5.35 & 5.4494 & TRN \\
\hline CHEMBL1427458 & 688816 & 4.9 & 5.3617 & TRN \\
\hline CHEMBL1572095 & 688816 & 4.8 & 4.6529 & TST \\
\hline CHEMBL1597201 & 688816 & 5.2 & 5.5189 & TRN \\
\hline CHEMBL1422046 & 688816 & 4.85 & 5.0594 & TRN \\
\hline CHEMBL1389677 & 688816 & 4.45 & 5.3636 & TRN \\
\hline CHEMBL1501941 & 688816 & 7.7496 & 5.3476 & TST \\
\hline CHEMBL1463035 & 688816 & 5.25 & 5.2009 & TRN \\
\hline CHEMBL1606194 & 688816 & 5.05 & 5.2297 & TST \\
\hline CHEMBL1341979 & 688816 & 4.7 & 4.9749 & TST \\
\hline CHEMBL1327175 & 688816 & 4.95 & 5.2281 & TRN \\
\hline CHEMBL1447620 & 688816 & 4.45 & 4.9983 & TRN \\
\hline
\end{tabular}




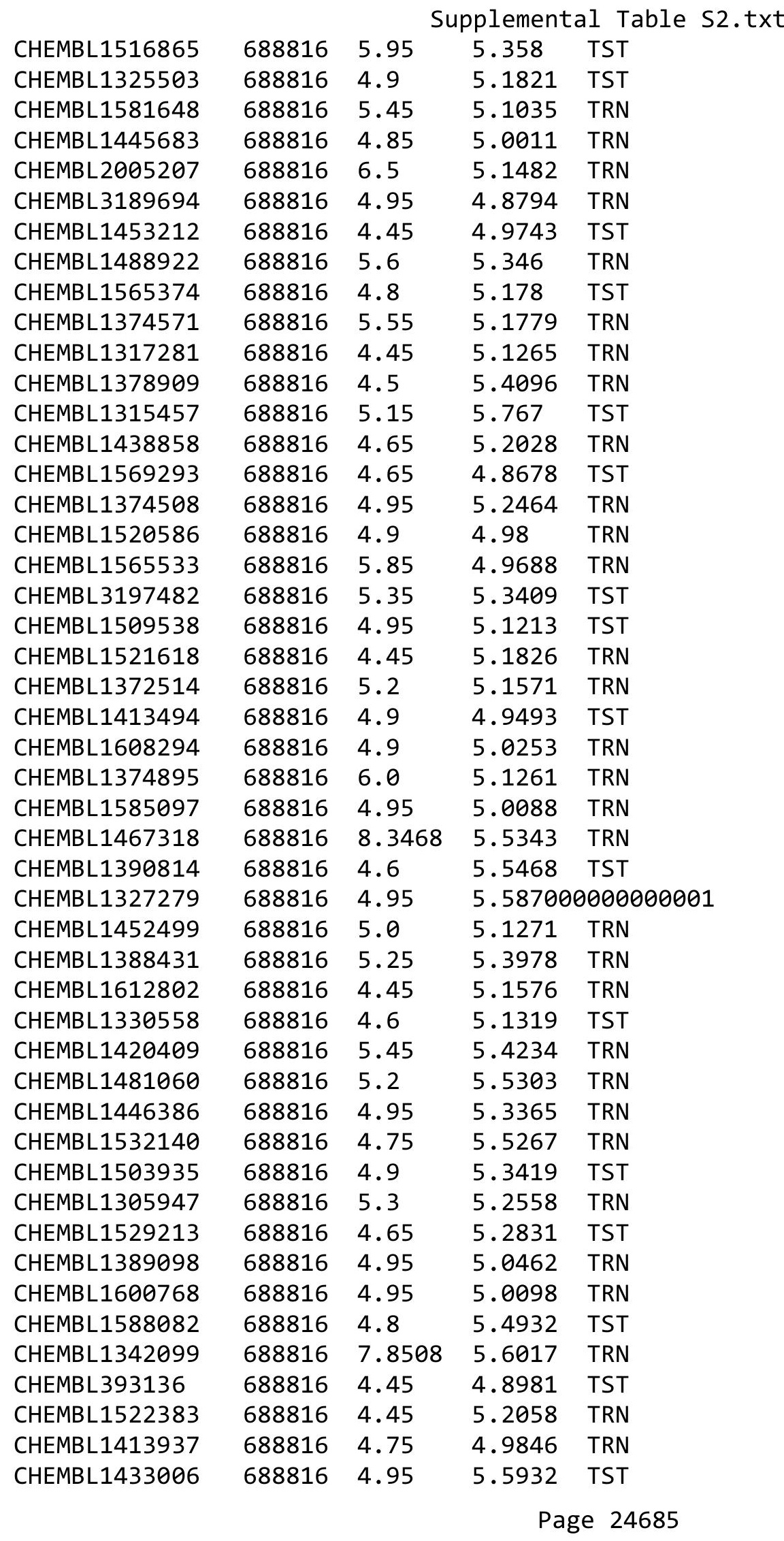




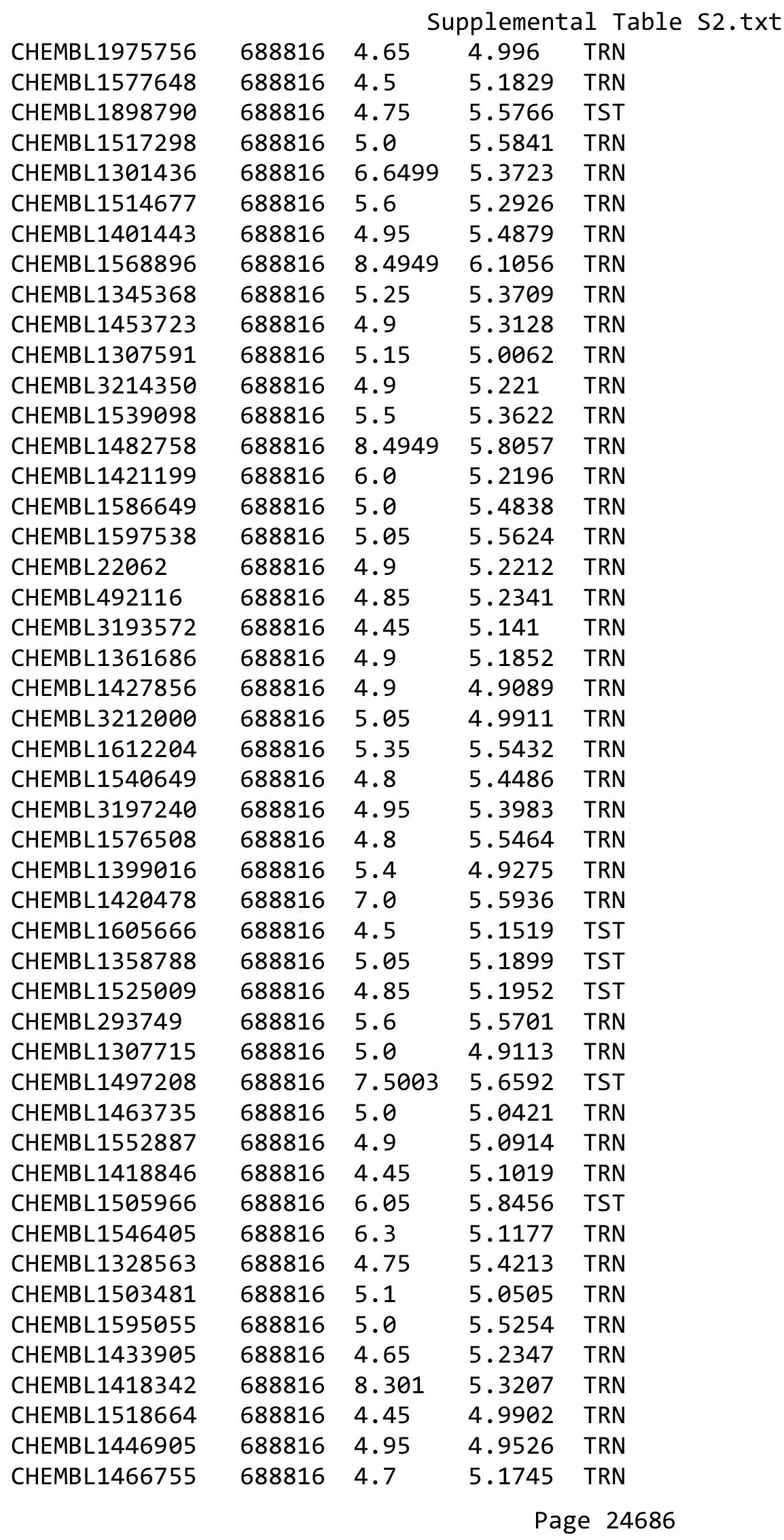




\begin{tabular}{|c|c|c|c|c|c|}
\hline \multicolumn{6}{|c|}{ Supplemental Table S2.txt } \\
\hline CHEMBL3208643 & 688816 & 5.45 & 5.6551 & TST & \\
\hline CHEMBL1333687 & 688816 & 4.75 & 5.4938 & TST & \\
\hline CHEMBL1333177 & 688816 & 5.0 & 4.8764 & TRN & \\
\hline CHEMBL1575088 & 688816 & 5.95 & 5.4605 & TRN & \\
\hline CHEMBL 1452672 & 688816 & 4.95 & 5.3517 & TRN & \\
\hline CHEMBL1304819 & 688816 & 5.9 & 5.4861 & TST & \\
\hline CHEMBL1387663 & 688816 & 5.3 & 5.1735 & TST & \\
\hline CHEMBL1612624 & 688816 & 6.6499 & 5.88200 & 0000000001 & TRN \\
\hline CHEMBL1483863 & 688816 & 5.5 & 5.1696 & TST & \\
\hline CHEMBL1578495 & 688816 & 5.1 & 5.2528 & TRN & \\
\hline CHEMBL3198652 & 688816 & 6.6 & 5.095 & TRN & \\
\hline CHEMBL1458403 & 688816 & 4.45 & 5.4313 & TST & \\
\hline CHEMBL1584073 & 688816 & 5.2 & 5.11 & TRN & \\
\hline CHEMBL3196526 & 688816 & 4.95 & 5.2652 & TRN & \\
\hline CHEMBL1435904 & 688816 & 5.1 & 5.4286 & TRN & \\
\hline CHEMBL1311397 & 688816 & 5.85 & 5.8159 & TRN & \\
\hline CHEMBL1593754 & 688816 & 7.2503 & 5.9856 & TRN & \\
\hline CHEMBL1456984 & 688816 & 4.5 & 5.1745 & TRN & \\
\hline CHEMBL1530860 & 688816 & 7.4498 & 5.2621 & TRN & \\
\hline CHEMBL1549514 & 688816 & 5.4 & 5.2962 & TRN & \\
\hline CHEMBL1430686 & 688816 & 4.6 & 5.0624 & TRN & \\
\hline CHEMBL601146 & 688816 & 6.0 & 5.6194 & TRN & \\
\hline CHEMBL1463057 & 688816 & 4.45 & 5.0239 & TRN & \\
\hline CHEMBL1412105 & 688816 & 5.0 & 5.2042 & TRN & \\
\hline CHEMBL1421426 & 688816 & 6.9 & 5.7146 & TRN & \\
\hline CHEMBL1343944 & 688816 & 5.05 & 4.9578 & TRN & \\
\hline CHEMBL1887938 & 688816 & 5.65 & 5.6708 & TRN & \\
\hline CHEMBL1428260 & 688816 & 5.15 & 5.1079 & TRN & \\
\hline CHEMBL1603708 & 688816 & 4.9 & 5.7713 & TST & \\
\hline CHEMBL1307349 & 688816 & 4.65 & 5.5916 & TST & \\
\hline CHEMBL1310039 & 688816 & 7.2 & 5.874 & TRN & \\
\hline CHEMBL1596709 & 688816 & 4.9 & 5.1764 & TRN & \\
\hline CHEMBL1315050 & 688816 & 4.6 & 5.1425 & TRN & \\
\hline CHEMBL1465750 & 688816 & 7.3002 & 5.5792 & TST & \\
\hline CHEMBL1475990 & 688816 & 4.85 & 4.7197 & TRN & \\
\hline CHEMBL1468479 & 688816 & 4.95 & 5.0056 & TRN & \\
\hline CHEMBL1414657 & 688816 & 5.9 & 5.3019 & TRN & \\
\hline CHEMBL1478234 & 688816 & 6.6 & 5.529 & TRN & \\
\hline CHEMBL1468865 & 688816 & 4.95 & 5.5844 & TRN & \\
\hline CHEMBL1544811 & 688816 & 4.95 & 5.1158 & TRN & \\
\hline CHEMBL1420610 & 688816 & 5.2 & 5.2668 & TRN & \\
\hline CHEMBL 1455362 & 688816 & 4.95 & 5.4148 & TRN & \\
\hline CHEMBL1384509 & 688816 & 4.65 & 5.3079 & TRN & \\
\hline CHEMBL1485058 & 688816 & 4.8 & 5.7127 & TRN & \\
\hline CHEMBL1404689 & 688816 & 6.8499 & 5.3493 & TRN & \\
\hline CHEMBL1342887 & 688816 & 6.8 & 5.4224 & TRN & \\
\hline CHEMBL1324743 & 688816 & 5.55 & 5.7784 & TRN & \\
\hline CHEMBL1366821 & 688816 & 4.85 & 5.4936 & TRN & \\
\hline
\end{tabular}




\begin{tabular}{|c|c|c|c|c|c|}
\hline \multicolumn{6}{|c|}{ Supplemental Table S2.txt } \\
\hline CHEMBL3209622 & 688816 & 5.55 & 5.7556 & TST & \\
\hline CHEMBL1335323 & 688816 & 4.7 & 4.9749 & TRN & \\
\hline CHEMBL1479883 & 688816 & 5.25 & 4.9535 & TST & \\
\hline CHEMBL1415089 & 688816 & 5.45 & 5.2332 & TST & \\
\hline CHEMBL1518678 & 688816 & 4.7 & 5.34200 & 00000000005 & TRN \\
\hline CHEMBL1500162 & 688816 & 5.0 & 5.4363 & TRN & \\
\hline CHEMBL1411784 & 688816 & 5.55 & 5.4397 & TRN & \\
\hline CHEMBL1363938 & 688816 & 4.45 & 5.2072 & TRN & \\
\hline CHEMBL1416536 & 688816 & 4.45 & 5.5558 & TRN & \\
\hline CHEMBL3197638 & 688816 & 4.8 & 5.279 & TRN & \\
\hline CHEMBL1419633 & 688816 & 5.9 & 5.5487 & TRN & \\
\hline CHEMBL1453056 & 688816 & 6.45 & 5.6452 & TRN & \\
\hline CHEMBL1302286 & 688816 & 4.55 & 5.2491 & TST & \\
\hline CHEMBL1475259 & 688816 & 5.1 & 5.1182 & TRN & \\
\hline CHEMBL1585417 & 688816 & 5.0 & 5.7397 & TRN & \\
\hline CHEMBL1559909 & 688816 & 4.5 & 5.0613 & TRN & \\
\hline CHEMBL1431869 & 688816 & 4.45 & 5.3466 & TRN & \\
\hline CHEMBL1438290 & 688816 & 5.8 & 5.0691 & TRN & \\
\hline CHEMBL1521827 & 688816 & 4.7 & 5.052 & TRN & \\
\hline CHEMBL1588468 & 688816 & 8.3468 & 5.2649 & TRN & \\
\hline CHEMBL1523232 & 688816 & 4.85 & $5.2920 e$ & 0000000001 & TRN \\
\hline CHEMBL1374411 & 688816 & 4.65 & 5.0143 & TST & \\
\hline CHEMBL1546524 & 688816 & 4.8 & 4.99 & TST & \\
\hline CHEMBL1331677 & 688816 & 4.45 & 5.2924 & TRN & \\
\hline CHEMBL1450426 & 688816 & 4.9 & 5.2257 & TRN & \\
\hline CHEMBL1547214 & 688816 & 4.85 & 5.1413 & TRN & \\
\hline CHEMBL1355575 & 688816 & 4.8 & 5.3198 & TRN & \\
\hline CHEMBL1411235 & 688816 & 4.6 & 5.1708 & TRN & \\
\hline CHEMBL1597406 & 688816 & 7.699 & 5.6838 & TST & \\
\hline CHEMBL1612401 & 688816 & 6.2 & 5.2431 & TST & \\
\hline CHEMBL1429966 & 688816 & 4.95 & 5.5565 & TRN & \\
\hline CHEMBL1504516 & 688816 & 4.65 & 5.3477 & TRN & \\
\hline CHEMBL1555920 & 688816 & 7.4498 & 5.6296 & TRN & \\
\hline CHEMBL1387347 & 688816 & 7.5498 & 5.2885 & TRN & \\
\hline CHEMBL3199917 & 688816 & 5.9 & 5.3201 & TST & \\
\hline CHEMBL1447733 & 688816 & 5.0 & 5.2952 & TST & \\
\hline CHEMBL1348569 & 688816 & 4.85 & 5.3516 & TRN & \\
\hline CHEMBL1424531 & 688816 & 4.95 & 5.3019 & TRN & \\
\hline CHEMBL1531987 & 688816 & 5.2 & 5.4481 & TST & \\
\hline CHEMBL547483 & 688816 & 4.75 & 5.1074 & TRN & \\
\hline CHEMBL1500769 & 688816 & 4.9 & 5.3307 & TRN & \\
\hline CHEMBL1528309 & 688816 & 4.9 & 5.3386 & TST & \\
\hline CHEMBL1580570 & 688816 & 6.0 & 5.4785 & TRN & \\
\hline CHEMBL1597445 & 688816 & 4.85 & 5.2288 & TST & \\
\hline CHEMBL1565187 & 688816 & 4.9 & 4.8611 & TRN & \\
\hline CHEMBL1479320 & 688816 & 4.95 & 5.3138 & TRN & \\
\hline CHEMBL1333906 & 688816 & 4.55 & 5.0742 & TRN & \\
\hline CHEMBL1586563 & 688816 & 8.3979 & 5.1203 & TRN & \\
\hline
\end{tabular}




\begin{tabular}{|c|c|c|c|c|c|}
\hline \multicolumn{6}{|c|}{ Supplemental Table S2.txt } \\
\hline CHEMBL1521232 & 688816 & 4.95 & 5.5276 & TRN & \\
\hline CHEMBL1416022 & 688816 & 4.45 & 5.2737 & TST & \\
\hline CHEMBL1469613 & 688816 & 5.55 & 5.3674 & TRN & \\
\hline CHEMBL1367874 & 688816 & 4.8 & 4.9597 & TRN & \\
\hline CHEMBL1379345 & 688816 & 5.05 & 5.1151 & TRN & \\
\hline CHEMBL1425921 & 688816 & 4.9 & 4.6909 & TRN & \\
\hline CHEMBL1569002 & 688816 & 6.1 & 5.6166 & TRN & \\
\hline CHEMBL1421422 & 688816 & 4.55 & 5.5188 & TST & \\
\hline CHEMBL1553727 & 688816 & 4.95 & 5.3844 & TST & \\
\hline CHEMBL1307935 & 688816 & 4.7 & 5.754 & TRN & \\
\hline CHEMBL1343047 & 688816 & 4.45 & 5.4759 & TRN & \\
\hline CHEMBL1464941 & 688816 & 7.3002 & 5.3736 & TRN & \\
\hline CHEMBL1404108 & 688816 & 5.3 & 5.6416 & TRN & \\
\hline CHEMBL3197516 & 688816 & 4.85 & 5.2985 & TRN & \\
\hline CHEMBL1508502 & 688816 & 4.85 & 5.3557 & TRN & \\
\hline CHEMBL1305825 & 688816 & 5.15 & 5.0208 & TRN & \\
\hline CHEMBL3195507 & 688816 & 4.55 & 5.0545 & TST & \\
\hline CHEMBL1351942 & 688816 & 4.45 & 4.8376 & TRN & \\
\hline CHEMBL1348612 & 688816 & 6.7501 & 5.521 & TRN & \\
\hline CHEMBL1303141 & 688816 & 5.35 & 5.2335 & TRN & \\
\hline CHEMBL1491745 & 688816 & 5.0 & 5.3879 & TST & \\
\hline CHEMBL1368235 & 688816 & 4.75 & 5.3156 & TRN & \\
\hline CHEMBL1345500 & 688816 & 8.1487 & 5.6124 & TRN & \\
\hline CHEMBL1407272 & 688816 & 5.65 & 5.2908 & TRN & \\
\hline CHEMBL1316355 & 688816 & 5.2 & 5.4338 & TST & \\
\hline CHEMBL1423144 & 688816 & 4.85 & 5.2654 & TRN & \\
\hline CHEMBL3213754 & 688816 & 4.85 & 5.2366 & TRN & \\
\hline CHEMBL1559506 & 688816 & 4.8 & 5.0092 & TRN & \\
\hline CHEMBL1346479 & 688816 & 8.3468 & 5.2313 & TRN & \\
\hline CHEMBL1406568 & 688816 & 5.15 & 5.4584 & TRN & \\
\hline CHEMBL1342466 & 688816 & 5.25 & 5.49100 & 00000000005 & TST \\
\hline CHEMBL1509905 & 688816 & 4.8 & 5.437 & TRN & \\
\hline CHEMBL1372557 & 688816 & 4.9 & 5.3126 & TRN & \\
\hline CHEMBL1365905 & 688816 & 7.6003 & 5.5153 & TRN & \\
\hline CHEMBL1577919 & 688816 & 5.35 & 5.665 & TST & \\
\hline CHEMBL3194103 & 688816 & 5.7 & 5.3559 & TRN & \\
\hline CHEMBL1321384 & 688816 & 5.9 & 6.0015 & TRN & \\
\hline CHEMBL1524981 & 688816 & 4.95 & 5.15600 & 0000000001 & TRN \\
\hline CHEMBL 2001895 & 688816 & 5.5 & 4.9108 & TST & \\
\hline CHEMBL1573994 & 688816 & 6.45 & 5.5197 & TRN & \\
\hline CHEMBL1441560 & 688816 & 4.95 & 4.686 & TRN & \\
\hline CHEMBL1449355 & 688816 & 7.1002 & 5.3853 & TRN & \\
\hline CHEMBL1529037 & 688816 & 4.85 & 5.3399 & TRN & \\
\hline CHEMBL1592569 & 688816 & 4.45 & 4.7998 & TRN & \\
\hline CHEMBL1500629 & 688816 & 4.8 & 5.3529 & TRN & \\
\hline CHEMBL1300383 & 688816 & 6.0 & 5.0784 & TST & \\
\hline CHEMBL 2003172 & 688816 & 4.45 & 5.2933 & TST & \\
\hline CHEMBL1564489 & 688816 & 5.3 & 5.6177 & TST & \\
\hline
\end{tabular}




\begin{tabular}{|c|c|c|c|c|c|}
\hline \multirow{3}{*}{$\begin{array}{l}\text { CHEMBL } 1594760 \\
\text { CHEMBL1558479 }\end{array}$} & \multirow{3}{*}{$\begin{array}{l}688816 \\
688816\end{array}$} & \multicolumn{4}{|c|}{ Supplemental Table S2.txt } \\
\hline & & 4.45 & \multicolumn{2}{|c|}{4.906000000000001} & TRN \\
\hline & & 4.45 & 5.4507 & TRN & \\
\hline CHEMBL1498509 & 688816 & 4.45 & 5.0125 & TRN & \\
\hline CHEMBL1397914 & 688816 & 5.0 & 4.863 & TST & \\
\hline CHEMBL1512449 & 688816 & 5.5 & 5.2748 & TRN & \\
\hline CHEMBL1522351 & 688816 & 5.25 & 5.2176 & TST & \\
\hline CHEMBL1303404 & 688816 & 4.45 & 4.9746 & TRN & \\
\hline CHEMBL1331135 & 688816 & 7.699 & 5.6655 & TST & \\
\hline CHEMBL1432324 & 688816 & 5.55 & 5.1565 & TRN & \\
\hline CHEMBL1441243 & 688816 & 4.95 & 5.2691 & TST & \\
\hline CHEMBL1350450 & 688816 & 6.0 & 5.2214 & TST & \\
\hline CHEMBL1387696 & 688816 & 4.7 & 5.6863 & TRN & \\
\hline CHEMBL3210873 & 688816 & 4.45 & 4.9036 & TRN & \\
\hline CHEMBL1311642 & 688816 & 4.85 & 5.1364 & TRN & \\
\hline CHEMBL1332512 & 688816 & 5.45 & 5.1958 & TRN & \\
\hline CHEMBL1560552 & 688816 & 4.7 & 5.0276 & TRN & \\
\hline CHEMBL3195314 & 688816 & 5.0 & 5.6651 & TRN & \\
\hline CHEMBL1600726 & 688816 & 4.95 & 5.0683 & TRN & \\
\hline CHEMBL1346421 & 688816 & 5.35 & 5.1343 & TST & \\
\hline CHEMBL1496475 & 688816 & 5.25 & 5.6082 & TST & \\
\hline CHEMBL1329524 & 688816 & 5.25 & 5.0193 & TST & \\
\hline CHEMBL1547420 & 688816 & 4.8 & 5.4431 & TRN & \\
\hline CHEMBL1547605 & 688816 & 8.4949 & 5.0434 & TRN & \\
\hline CHEMBL1525233 & 688816 & 4.45 & 5.2793 & TST & \\
\hline CHEMBL1484503 & 688816 & 5.0 & 5.1628 & TST & \\
\hline CHEMBL1458428 & 688816 & 6.7501 & 5.5525 & TST & \\
\hline CHEMBL1503366 & 688816 & 8.0 & 5.1834 & TRN & \\
\hline CHEMBL1400655 & 688816 & 4.7 & 5.0284 & TRN & \\
\hline CHEMBL1428785 & 688816 & 5.5 & 5.2024 & TRN & \\
\hline CHEMBL1478802 & 688816 & 6.8 & 5.3054 & TRN & \\
\hline CHEMBL1430323 & 688816 & 5.3 & 5.5298 & TRN & \\
\hline CHEMBL1514968 & 688816 & 6.05 & 5.6016 & TRN & \\
\hline CHEMBL1423004 & 688816 & 7.0 & 5.6491 & TRN & \\
\hline CHEMBL1396173 & 688816 & 4.45 & 5.3317 & TST & \\
\hline CHEMBL1440011 & 688816 & 5.15 & 5.0151 & TRN & \\
\hline CHEMBL1424916 & 688816 & 4.45 & 4.9753 & TRN & \\
\hline CHEMBL1507474 & 688816 & 5.2 & 5.1057 & TRN & \\
\hline CHEMBL1585470 & 688816 & 4.5 & 5.3758 & TRN & \\
\hline CHEMBL1593037 & 688816 & 5.2 & 5.3095 & TRN & \\
\hline CHEMBL1464390 & 688816 & 6.6499 & 5.2663 & TRN & \\
\hline CHEMBL1581566 & 688816 & 4.45 & 4.9003 & TRN & \\
\hline CHEMBL1588578 & 688816 & 4.85 & 5.1707 & TRN & \\
\hline CHEMBL1446802 & 688816 & 4.6 & 5.0209 & TST & \\
\hline CHEMBL1576976 & 688816 & 6.15 & 5.8325 & TST & \\
\hline CHEMBL1472165 & 688816 & 4.5 & 5.1779 & TRN & \\
\hline CHEMBL1348555 & 688816 & 5.25 & 4.9998 & TRN & \\
\hline CHEMBL1459910 & 688816 & 7.8013 & 5.2909 & TRN & \\
\hline CHEMBL1304661 & 688816 & 5.0 & 5.1663 & TRN & \\
\hline
\end{tabular}




\begin{tabular}{|c|c|c|c|c|}
\hline \multicolumn{5}{|c|}{ Supplemental Table S2.txt } \\
\hline CHEMBL1370274 & 688816 & 4.45 & 4.874 & TRN \\
\hline CHEMBL1327640 & 688816 & 4.95 & 5.1692 & TRN \\
\hline CHEMBL1401099 & 688816 & 4.65 & 4.996 & TRN \\
\hline CHEMBL1576870 & 688816 & 5.65 & 5.3193 & TRN \\
\hline CHEMBL3196244 & 688816 & 7.0 & 5.2832 & TRN \\
\hline CHEMBL1408227 & 688816 & 6.1 & 5.1653 & TRN \\
\hline CHEMBL1451690 & 688816 & 6.8499 & 5.0531 & TRN \\
\hline CHEMBL1349626 & 688816 & 4.85 & 5.8299 & TRN \\
\hline CHEMBL1318302 & 688816 & 4.95 & 5.4076 & TRN \\
\hline CHEMBL1420376 & 688816 & 5.25 & 5.2046 & TRN \\
\hline CHEMBL1543627 & 688816 & 4.95 & 5.0652 & TST \\
\hline CHEMBL580609 & 688816 & 5.05 & 5.1263 & TRN \\
\hline CHEMBL1402333 & 688816 & 5.35 & 5.3804 & TRN \\
\hline CHEMBL1999014 & 688816 & 4.85 & 5.0906 & TST \\
\hline CHEMBL1477090 & 688816 & 4.45 & 4.7659 & TRN \\
\hline CHEMBL1427394 & 688816 & 4.45 & 5.2632 & TRN \\
\hline CHEMBL1382360 & 688816 & 4.45 & 4.9818 & TST \\
\hline CHEMBL1565769 & 688816 & 8.5528 & 5.4566 & TST \\
\hline CHEMBL1405517 & 688816 & 6.8499 & 5.3607 & TST \\
\hline CHEMBL1384880 & 688816 & 4.8 & 5.1192 & TRN \\
\hline CHEMBL1348062 & 688816 & 6.25 & 5.0087 & TRN \\
\hline CHEMBL3209105 & 688816 & 5.95 & 5.3573 & TRN \\
\hline CHEMBL1346801 & 688816 & 4.8 & 5.0332 & TST \\
\hline CHEMBL1390361 & 688816 & 5.0 & 5.1066 & TRN \\
\hline CHEMBL1421559 & 688816 & 4.45 & 4.8608 & TRN \\
\hline CHEMBL1387510 & 688816 & 4.9 & 5.0783 & TST \\
\hline CHEMBL1362973 & 688816 & 4.45 & 5.0986 & TRN \\
\hline CHEMBL1429789 & 688816 & 5.1 & 5.4081 & TRN \\
\hline CHEMBL578177 & 688816 & 5.05 & 5.3407 & TST \\
\hline CHEMBL1393089 & 688816 & 4.45 & 4.9522 & TST \\
\hline CHEMBL1445507 & 688816 & 4.75 & 5.2469 & TRN \\
\hline CHEMBL1412298 & 688816 & 4.9 & 5.6565 & TST \\
\hline CHEMBL1459791 & 688816 & 7.699 & 5.5014 & TST \\
\hline CHEMBL1344775 & 688816 & 5.25 & 4.9634 & TRN \\
\hline CHEMBL1434775 & 688816 & 4.45 & 5.1697 & TST \\
\hline CHEMBL1611002 & 688816 & 4.95 & 5.1324 & TRN \\
\hline CHEMBL1406463 & 688816 & 5.2 & 5.0337 & TRN \\
\hline CHEMBL1362492 & 688816 & 4.9 & 5.1629 & TST \\
\hline CHEMBL1486025 & 688816 & 4.85 & 5.2577 & TRN \\
\hline CHEMBL1460186 & 688816 & 7.4498 & 5.3054 & TST \\
\hline CHEMBL3214405 & 688816 & 4.75 & 5.2618 & TRN \\
\hline CHEMBL1493117 & 688816 & 4.9 & 5.4167 & TST \\
\hline CHEMBL1379888 & 688816 & 4.85 & 5.3085 & TST \\
\hline CHEMBL1469227 & 688816 & 5.05 & 5.3306 & TST \\
\hline CHEMBL1471369 & 688816 & 6.0 & 5.2168 & TRN \\
\hline CHEMBL1588001 & 688816 & 4.95 & 5.6855 & TRN \\
\hline CHEMBL1223587 & 688816 & 4.7 & 5.5934 & TRN \\
\hline CHEMBL1596350 & 688816 & 5.25 & 5.4522 & TRN \\
\hline
\end{tabular}




\begin{tabular}{|c|c|c|c|c|}
\hline & & & oplement & al $\mathrm{T}$ \\
\hline CHEMBL1418671 & 688816 & 7.8508 & 5.4687 & TST \\
\hline CHEMBL1494783 & 688816 & 7.6498 & 5.3648 & TRN \\
\hline CHEMBL1572680 & 688816 & 8.1024 & 5.7817 & TST \\
\hline CHEMBL1398933 & 688816 & 4.9 & 5.1597 & TRN \\
\hline CHEMBL1373194 & 688816 & 5.6 & 5.3708 & TRN \\
\hline CHEMBL1460853 & 688816 & 4.75 & 5.2825 & TRN \\
\hline CHEMBL1348428 & 688816 & 5.25 & 5.5283 & TRN \\
\hline CHEMBL1534598 & 688816 & 5.0 & 4.881 & TRN \\
\hline CHEMBL1511268 & 688816 & 6.15 & 5.5718 & TRN \\
\hline CHEMBL1320220 & 688816 & 5.0 & 5.1378 & TRN \\
\hline CHEMBL1309939 & 688816 & 4.45 & 5.1898 & TRN \\
\hline CHEMBL1571290 & 688816 & 6.0 & 5.2316 & TRN \\
\hline CHEMBL1433072 & 688816 & 4.95 & 5.2045 & TST \\
\hline CHEMBL1599041 & 688816 & 5.2 & 5.9303 & TRN \\
\hline CHEMBL1566244 & 688816 & 4.6 & 5.2701 & TRN \\
\hline CHEMBL1405277 & 688816 & 5.2 & 5.3115 & TRN \\
\hline CHEMBL1341522 & 688816 & 4.8 & 5.3573 & TRN \\
\hline CHEMBL1439631 & 688816 & 4.95 & 5.1614 & TRN \\
\hline CHEMBL1403808 & 688816 & 4.45 & 4.9689 & TRN \\
\hline CHEMBL 3197671 & 688816 & 6.35 & 5.3428 & TRN \\
\hline CHEMBL1459784 & 688816 & 4.85 & 5.2651 & TRN \\
\hline CHEMBL1577071 & 688816 & 5.85 & 5.2997 & TRN \\
\hline CHEMBL1550291 & 688816 & 4.6 & 5.1162 & TRN \\
\hline CHEMBL1450343 & 688816 & 4.65 & 4.9822 & TRN \\
\hline CHEMBL1320641 & 688816 & 5.25 & 5.1715 & TRN \\
\hline CHEMBL1309345 & 688816 & 4.45 & 5.5764 & TST \\
\hline CHEMBL1340965 & 688816 & 4.65 & 5.1197 & TRN \\
\hline CHEMBL1560502 & 688816 & 4.9 & 4.9392 & TRN \\
\hline CHEMBL3212956 & 688816 & 4.9 & 5.2459 & TST \\
\hline CHEMBL3210523 & 688816 & 4.45 & 5.1371 & TST \\
\hline CHEMBL1537961 & 688816 & 4.45 & 5.2356 & TRN \\
\hline CHEMBL1607366 & 688816 & 4.6 & 5.4676 & TRN \\
\hline CHEMBL1583188 & 688816 & 4.6 & 5.2635 & TST \\
\hline CHEMBL64119 & 688816 & 4.75 & 5.3776 & TST \\
\hline CHEMBL1329712 & 688816 & 4.9 & 5.0043 & TST \\
\hline CHEMBL1415199 & 688816 & 4.65 & 5.3318 & TST \\
\hline CHEMBL1383630 & 688816 & 4.65 & 5.3804 & TRN \\
\hline CHEMBL1339776 & 688816 & 4.85 & 5.4637 & TRN \\
\hline CHEMBL1398572 & 688816 & 4.8 & 5.3616 & TRN \\
\hline CHEMBL1465500 & 688816 & 4.8 & 5.2437 & TRN \\
\hline CHEMBL1566548 & 688816 & 4.95 & 5.2228 & TRN \\
\hline CHEMBL1601587 & 688816 & 4.9 & 5.1977 & TRN \\
\hline CHEMBL1326700 & 688816 & 4.45 & 4.9948 & TRN \\
\hline CHEMBL1446084 & 688816 & 6.7001 & 5.2957 & TRN \\
\hline CHEMBL1312936 & 688816 & 5.7 & 5.2362 & TRN \\
\hline CHEMBL3211782 & 688816 & 4.8 & 5.2775 & TRN \\
\hline CHEMBL1601745 & 688816 & 4.8 & 5.1828 & TRN \\
\hline CHEMBL1365746 & 688816 & 5.6 & 4.9978 & TRN \\
\hline
\end{tabular}




\begin{tabular}{|c|c|c|c|c|}
\hline \multicolumn{5}{|c|}{ Supplemental Table S2.txt } \\
\hline CHEMBL1361124 & 688816 & 4.8 & 5.2391 & TRN \\
\hline CHEMBL1602080 & 688816 & 4.95 & 4.9431 & TRN \\
\hline CHEMBL1374025 & 688816 & 5.05 & 5.3062 & TRN \\
\hline CHEMBL1310415 & 688816 & 5.45 & 5.2752 & TRN \\
\hline CHEMBL1587193 & 688816 & 4.8 & 5.0116 & TRN \\
\hline CHEMBL3198187 & 688816 & 5.0 & 5.4236 & TRN \\
\hline CHEMBL1423848 & 688816 & 5.2 & 5.3688 & TRN \\
\hline CHEMBL1276127 & 688816 & 4.7 & 5.2099 & TST \\
\hline CHEMBL1536794 & 688816 & 4.95 & 5.3718 & TRN \\
\hline CHEMBL1439295 & 688816 & 4.9 & 5.2298 & TRN \\
\hline CHEMBL1390551 & 688816 & 4.95 & 5.3219 & TRN \\
\hline CHEMBL1376008 & 688816 & 5.9 & 5.3115 & TRN \\
\hline CHEMBL1438498 & 688816 & 4.9 & 5.215 & TRN \\
\hline CHEMBL1456106 & 688816 & 4.45 & 5.6321 & TRN \\
\hline CHEMBL1570911 & 688816 & 5.2 & 5.6247 & TRN \\
\hline CHEMBL1398721 & 688816 & 4.6 & 4.8456 & TRN \\
\hline CHEMBL1498979 & 688816 & 4.7 & 5.0003 & TRN \\
\hline CHEMBL1391823 & 688816 & 4.45 & 5.1568 & TRN \\
\hline CHEMBL1380399 & 688816 & 5.6 & 5.2063 & TRN \\
\hline CHEMBL1569824 & 688816 & 4.55 & 5.5202 & TRN \\
\hline CHEMBL1570162 & 688816 & 6.0 & 5.1665 & TRN \\
\hline CHEMBL1401945 & 688816 & 4.45 & 4.9677 & TST \\
\hline CHEMBL1499544 & 688816 & 4.45 & 4.8501 & TST \\
\hline CHEMBL1455211 & 688816 & 5.3 & 5.4253 & TST \\
\hline CHEMBL1514084 & 688816 & 4.6 & 5.231 & TRN \\
\hline CHEMBL1300897 & 688816 & 4.45 & 5.4853 & TRN \\
\hline CHEMBL1439790 & 688816 & 5.05 & 5.1861 & TRN \\
\hline CHEMBL1990694 & 688816 & 4.45 & 5.1112 & TRN \\
\hline CHEMBL3213895 & 688816 & 5.45 & 5.4724 & TRN \\
\hline CHEMBL1457538 & 688816 & 5.35 & 5.2666 & TST \\
\hline CHEMBL1457998 & 688816 & 4.8 & 4.7936 & TRN \\
\hline CHEMBL1612927 & 688816 & 5.35 & 5.2801 & TRN \\
\hline CHEMBL1313135 & 688816 & 4.9 & 5.1466 & TRN \\
\hline CHEMBL1611969 & 688816 & 4.9 & 5.2276 & TRN \\
\hline CHEMBL1333361 & 688816 & 6.15 & 5.2384 & TST \\
\hline CHEMBL1510584 & 688816 & 4.45 & 5.2911 & TRN \\
\hline CHEMBL3213863 & 688816 & 5.0 & 5.5954 & TST \\
\hline CHEMBL1339435 & 688816 & 4.85 & 5.3787 & TRN \\
\hline CHEMBL1496153 & 688816 & 4.95 & 5.5148 & TST \\
\hline CHEMBL1413624 & 688816 & 5.55 & 5.044 & TRN \\
\hline CHEMBL1341270 & 688816 & 6.2 & 5.1397 & TRN \\
\hline CHEMBL1530733 & 688816 & 4.8 & 4.9374 & TRN \\
\hline CHEMBL1605463 & 688816 & 4.95 & 5.2124 & TRN \\
\hline CHEMBL1408241 & 688816 & 4.45 & 5.2804 & TRN \\
\hline CHEMBL1517866 & 688816 & 7.1002 & 5.5183 & TST \\
\hline CHEMBL1510089 & 688816 & 7.7496 & 5.3719 & TRN \\
\hline CHEMBL1388553 & 688816 & 5.1 & 5.7605 & TRN \\
\hline CHEMBL1585279 & 688816 & 4.9 & 5.4395 & TST \\
\hline
\end{tabular}




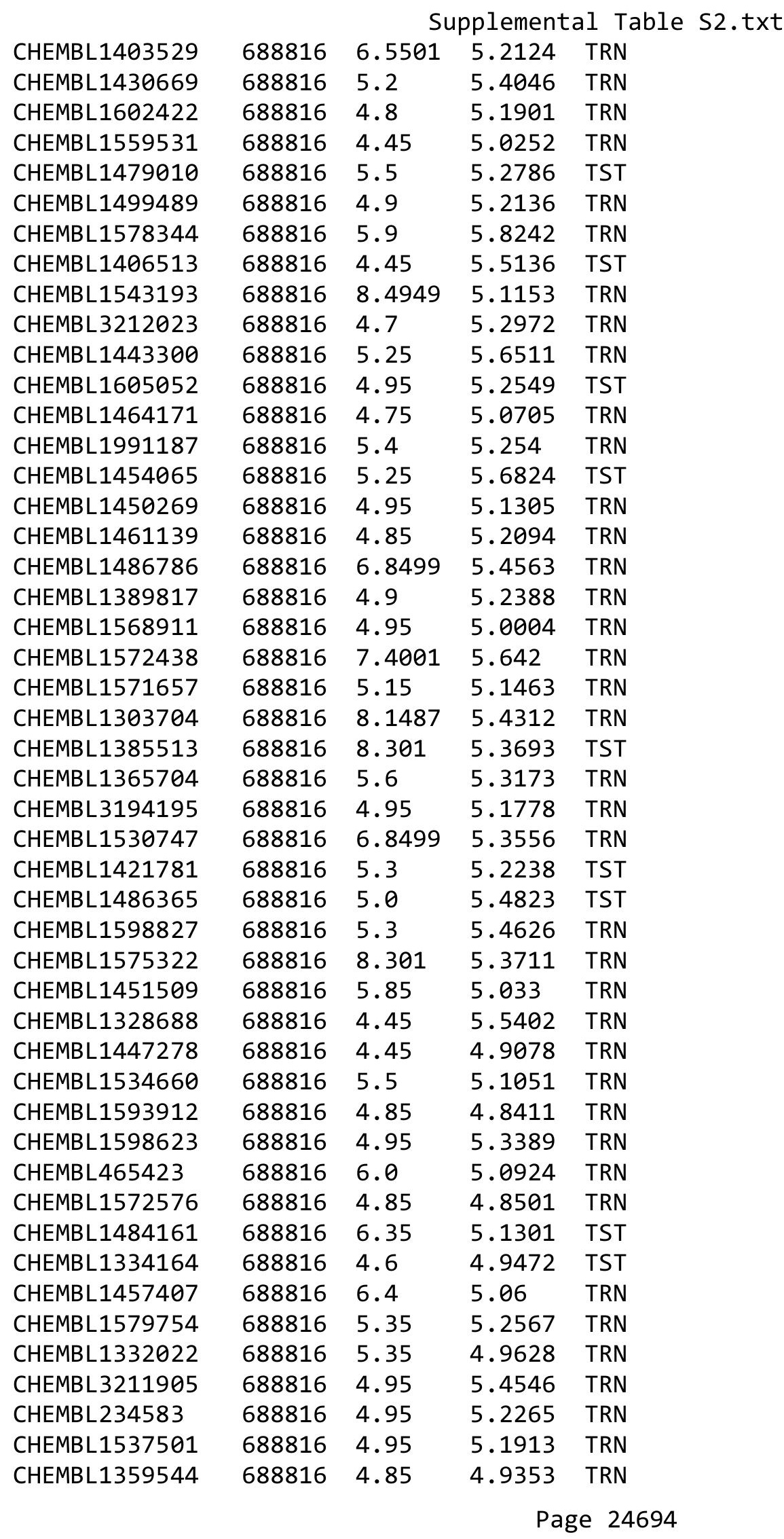




\begin{tabular}{|c|c|c|c|c|c|}
\hline \multirow[b]{2}{*}{ CHEMBL1545058 } & \multicolumn{5}{|c|}{ lemental Table S } \\
\hline & 688816 & 5.5 & 5.0362 & TRN & \multirow{3}{*}{ TST } \\
\hline CHEMBL1428565 & 688816 & 4.75 & \multicolumn{2}{|c|}{5.156000000000001} & \\
\hline CHEMBL1423390 & 688816 & 5.0 & 5.5027 & TRN & \\
\hline CHEMBL1403939 & 688816 & 5.0 & 5.1933 & TRN & \\
\hline CHEMBL1579418 & 688816 & 4.65 & 5.5165 & TRN & \\
\hline CHEMBL1589914 & 688816 & 4.95 & 4.9909 & TRN & \\
\hline CHEMBL1599570 & 688816 & 6.05 & 5.4135 & TRN & \\
\hline CHEMBL1567452 & 688816 & 7.699 & 5.9738 & TRN & \\
\hline CHEMBL1585145 & 688816 & 4.9 & 5.1859 & TST & \\
\hline CHEMBL3191025 & 688816 & 4.8 & 5.1682 & TST & \\
\hline CHEMBL1497298 & 688816 & 4.65 & 5.5546 & TST & \\
\hline CHEMBL 3214237 & 688816 & 4.8 & 5.2187 & TST & \\
\hline CHEMBL1461626 & 688816 & 4.95 & 5.3245 & TST & \\
\hline CHEMBL1306544 & 688816 & 4.45 & 5.7164 & TST & \\
\hline CHEMBL1346591 & 688816 & 5.05 & 5.5203 & TRN & \\
\hline CHEMBL1313733 & 688816 & 4.85 & 5.0278 & TST & \\
\hline CHEMBL1504204 & 688816 & 5.5 & 5.2527 & TRN & \\
\hline CHEMBL1575184 & 688816 & 5.35 & 5.1157 & TST & \\
\hline CHEMBL1429431 & 688816 & 4.9 & 5.7033 & TRN & \\
\hline CHEMBL1496860 & 688816 & 5.25 & 5.0098 & TRN & \\
\hline CHEMBL1478448 & 688816 & 6.05 & 5.5283 & TST & \\
\hline CHEMBL1543167 & 688816 & 5.3 & 4.9307 & TRN & \\
\hline CHEMBL1584621 & 688816 & 4.85 & 5.4734 & TRN & \\
\hline CHEMBL1351103 & 688816 & 4.45 & 5.1374 & TST & \\
\hline CHEMBL1431956 & 688816 & 5.85 & 5.225 & TRN & \\
\hline CHEMBL1575051 & 688816 & 4.9 & 4.8425 & TRN & \\
\hline CHEMBL1439755 & 688816 & 5.1 & 4.9852 & TRN & \\
\hline CHEMBL1572384 & 688816 & 4.45 & 5.3065 & TST & \\
\hline CHEMBL1360559 & 688816 & 5.5 & 5.7098 & TST & \\
\hline CHEMBL3190507 & 688816 & 4.55 & 5.3009 & TRN & \\
\hline CHEMBL1441405 & 688816 & 8.301 & 5.5849 & TST & \\
\hline CHEMBL1441677 & 688816 & 4.45 & 4.9458 & TST & \\
\hline CHEMBL1531142 & 688816 & 4.95 & 5.70799 & 9999999999 & TST \\
\hline CHEMBL1304103 & 688816 & 5.35 & 5.4567 & TST & \\
\hline CHEMBL1600243 & 688816 & 5.6 & 4.7972 & TRN & \\
\hline CHEMBL1326056 & 688816 & 5.25 & 5.5621 & TRN & \\
\hline CHEMBL1303580 & 688816 & 4.9 & 5.2256 & TRN & \\
\hline CHEMBL1531806 & 688816 & 4.8 & 5.4319 & TRN & \\
\hline CHEMBL1537620 & 688816 & 5.0 & 5.316 & TRN & \\
\hline CHEMBL1476692 & 688816 & 4.95 & 5.42899 & 9999999999 & TRN \\
\hline CHEMBL1538011 & 688816 & 6.2 & 5.2193 & TRN & \\
\hline CHEMBL1479626 & 688816 & 5.35 & 5.1076 & TRN & \\
\hline CHEMBL3190473 & 688816 & 8.0 & 5.0288 & TST & \\
\hline CHEMBL1374352 & 688816 & 4.9 & 5.0225 & TRN & \\
\hline CHEMBL1578502 & 688816 & 4.85 & 5.0715 & TST & \\
\hline CHEMBL1483809 & 688816 & 4.65 & 5.1181 & TST & \\
\hline CHEMBL1366073 & 688816 & 4.95 & 5.2769 & TRN & \\
\hline CHEMBL1613066 & 688816 & 4.5 & 4.9993 & TRN & \\
\hline & & & & 24695 & \\
\hline
\end{tabular}




\begin{tabular}{|c|c|c|c|c|c|}
\hline \multicolumn{6}{|c|}{ Supplemental Table S2.txt } \\
\hline CHEMBL1470573 & 688816 & 7.1002 & 5.4997 & TRN & \\
\hline CHEMBL1567976 & 688816 & 7.9508 & 5.0142 & TRN & \\
\hline CHEMBL1575735 & 688816 & 4.75 & 5.1147 & TRN & \\
\hline CHEMBL1546621 & 688816 & 4.95 & 5.1315 & TRN & \\
\hline CHEMBL1438472 & 688816 & 5.6 & 5.3618 & TRN & \\
\hline CHEMBL1430071 & 688816 & 4.9 & 4.8102 & TST & \\
\hline CHEMBL1418563 & 688816 & 4.8 & 5.2915 & TRN & \\
\hline CHEMBL3195258 & 688816 & 4.95 & 5.0148 & TRN & \\
\hline CHEMBL1598986 & 688816 & 5.05 & 5.2159 & TRN & \\
\hline CHEMBL1528539 & 688816 & 4.45 & 5.8293 & TST & \\
\hline CHEMBL1589123 & 688816 & 8.3468 & 5.2754 & TRN & \\
\hline CHEMBL1452159 & 688816 & 4.6 & 5.7267 & TRN & \\
\hline CHEMBL1366293 & 688816 & 4.9 & 5.1883 & TRN & \\
\hline CHEMBL1491524 & 688816 & 4.45 & 5.3436 & TRN & \\
\hline CHEMBL1351628 & 688816 & 4.75 & 5.3514 & TRN & \\
\hline CHEMBL1427180 & 688816 & 4.95 & 5.3822 & TST & \\
\hline CHEMBL1550268 & 688816 & 4.75 & 5.1481 & TRN & \\
\hline CHEMBL1470848 & 688816 & 4.8 & 5.1181 & TRN & \\
\hline CHEMBL1422916 & 688816 & 4.85 & 5.4187 & TRN & \\
\hline CHEMBL3190830 & 688816 & 6.0 & 5.5621 & TRN & \\
\hline CHEMBL1381439 & 688816 & 5.6 & 5.3429 & TST & \\
\hline CHEMBL1328528 & 688816 & 4.8 & 5.2268 & TRN & \\
\hline CHEMBL1303692 & 688816 & 6.1 & 5.1157 & TRN & \\
\hline CHEMBL1473209 & 688816 & 4.8 & 5.5482 & TRN & \\
\hline CHEMBL1563440 & 688816 & 4.85 & 5.5207 & TRN & \\
\hline CHEMBL1426052 & 688816 & 4.45 & 5.209 & TRN & \\
\hline CHEMBL1351617 & 688816 & 4.9 & 5.0823 & TST & \\
\hline CHEMBL1387605 & 688816 & 5.05 & 4.8278 & TRN & \\
\hline CHEMBL1445407 & 688816 & 5.45 & 5.1162 & TRN & \\
\hline CHEMBL1604840 & 688816 & 6.9 & 5.3208 & TRN & \\
\hline CHEMBL1573850 & 688816 & 5.4 & 4.9987 & TRN & \\
\hline CHEMBL1321264 & 688816 & 4.75 & 5.16700 & 0000000001 & TRN \\
\hline CHEMBL1490894 & 688816 & 4.45 & 5.11100 & 0000000001 & TRN \\
\hline CHEMBL1549537 & 688816 & 4.85 & 5.1534 & TST & \\
\hline CHEMBL 281980 & 688816 & 4.95 & 5.385 & TRN & \\
\hline CHEMBL1458700 & 688816 & 5.1 & 5.0194 & TRN & \\
\hline CHEMBL1323801 & 688816 & 5.25 & 5.1513 & TST & \\
\hline CHEMBL3191371 & 688816 & 4.85 & 5.2979 & TRN & \\
\hline CHEMBL1511147 & 688816 & 4.9 & 5.40799 & 99999999995 & TRN \\
\hline CHEMBL1423092 & 688816 & 4.45 & 5.4902 & TRN & \\
\hline CHEMBL1426886 & 688816 & 4.95 & 4.9768 & TST & \\
\hline CHEMBL3194211 & 688816 & 6.5501 & 5.2382 & TRN & \\
\hline CHEMBL3191084 & 688816 & 4.75 & 5.3008 & TRN & \\
\hline CHEMBL1344339 & 688816 & 4.85 & 4.9754 & TST & \\
\hline CHEMBL1327517 & 688816 & 4.95 & 4.992 & TST & \\
\hline CHEMBL1593283 & 688816 & 4.65 & 4.8269 & TRN & \\
\hline CHEMBL1550690 & 688816 & 5.05 & 5.2189 & TRN & \\
\hline CHEMBL1610791 & 688816 & 6.8 & 5.3242 & TRN & \\
\hline
\end{tabular}




\begin{tabular}{|c|c|c|c|c|c|}
\hline \multicolumn{6}{|c|}{ Supplemental Table S2.txt } \\
\hline CHEMBL1405442 & 688816 & 4.8 & 4.9858 & TRN & \\
\hline CHEMBL1401706 & 688816 & 5.05 & 5.1357 & TRN & \\
\hline CHEMBL1575502 & 688816 & 6.3 & 5.6607 & TRN & \\
\hline CHEMBL1362804 & 688816 & 4.75 & 5.2337 & TRN & \\
\hline CHEMBL3195344 & 688816 & 5.85 & 5.2977 & TRN & \\
\hline CHEMBL1448265 & 688816 & 4.7 & 4.8785 & TRN & \\
\hline CHEMBL1325371 & 688816 & 4.45 & 4.7247 & TRN & \\
\hline CHEMBL3211716 & 688816 & 4.95 & 5.1595 & TRN & \\
\hline CHEMBL1336909 & 688816 & 5.4 & 5.0328 & TST & \\
\hline CHEMBL1533274 & 688816 & 5.0 & 5.0852 & TRN & \\
\hline CHEMBL1529647 & 688816 & 4.95 & 5.2958 & TRN & \\
\hline CHEMBL1463660 & 688816 & 4.95 & 5.4777 & TRN & \\
\hline CHEMBL1363762 & 688816 & 4.45 & 5.0241 & TRN & \\
\hline CHEMBL1994877 & 688816 & 5.05 & 4.7467 & TRN & \\
\hline CHEMBL1517387 & 688816 & 5.25 & 5.2509 & TRN & \\
\hline CHEMBL1418134 & 688816 & 4.9 & 5.0453 & TRN & \\
\hline CHEMBL1360821 & 688816 & 4.65 & 5.2058 & TRN & \\
\hline CHEMBL1365448 & 688816 & 4.65 & 5.17299 & 9999999999 & TRN \\
\hline CHEMBL1410796 & 688816 & 4.85 & 5.5035 & TRN & \\
\hline CHEMBL1377712 & 688816 & 4.95 & 5.1863 & TRN & \\
\hline CHEMBL1414225 & 688816 & 4.85 & 5.2853 & TST & \\
\hline CHEMBL1503933 & 688816 & 4.6 & 5.0118 & TRN & \\
\hline CHEMBL1446489 & 688816 & 6.8499 & 5.5332 & TRN & \\
\hline CHEMBL1349634 & 688816 & 4.7 & 5.4921 & TRN & \\
\hline CHEMBL1339563 & 688816 & 4.6 & 5.1035 & TRN & \\
\hline CHEMBL1487964 & 688816 & 4.7 & 5.2779 & TRN & \\
\hline CHEMBL1543541 & 688816 & 5.15 & 5.13899 & 9999999999 & TRN \\
\hline CHEMBL1340267 & 688816 & 4.65 & 5.4435 & TST & \\
\hline CHEMBL 2138014 & 688816 & 4.45 & 4.9416 & TRN & \\
\hline CHEMBL1564434 & 688816 & 5.5 & 5.2425 & TRN & \\
\hline CHEMBL1394916 & 688816 & 4.75 & 4.9079 & TRN & \\
\hline CHEMBL1532782 & 688816 & 5.45 & 5.6645 & TRN & \\
\hline CHEMBL1591017 & 688816 & 5.0 & 5.1922 & TRN & \\
\hline CHEMBL1308894 & 688816 & 4.95 & 5.121 & TRN & \\
\hline CHEMBL528256 & 688816 & 4.8 & 5.164 & TRN & \\
\hline CHEMBL1975289 & 688816 & 5.7 & 5.4548 & TRN & \\
\hline CHEMBL 2000619 & 688816 & 4.9 & 5.2203 & TRN & \\
\hline CHEMBL3192306 & 688816 & 5.35 & 5.3479 & TRN & \\
\hline CHEMBL1580762 & 688816 & 4.85 & 5.1386 & TRN & \\
\hline CHEMBL1565939 & 688816 & 4.7 & 5.3127 & TST & \\
\hline CHEMBL1607763 & 688816 & 6.1 & 5.2476 & TRN & \\
\hline CHEMBL1341634 & 688816 & 4.65 & 5.7157 & TST & \\
\hline CHEMBL1547890 & 688816 & 5.25 & 5.5943 & TRN & \\
\hline CHEMBL1392789 & 688816 & 4.7 & 5.0703 & TRN & \\
\hline CHEMBL 3198821 & 688816 & 5.45 & 5.4065 & TRN & \\
\hline CHEMBL1346533 & 688816 & 4.95 & 5.176 & TRN & \\
\hline CHEMBL1310644 & 688816 & 4.45 & 5.2571 & TRN & \\
\hline CHEMBL1413055 & 688816 & 4.95 & 5.0759 & TRN & \\
\hline
\end{tabular}




\begin{tabular}{|c|c|c|c|c|c|}
\hline \multicolumn{6}{|c|}{ Supplemental Table S2.txt } \\
\hline CHEMBL1605123 & 688816 & 4.45 & 5.5652 & TST & \\
\hline CHEMBL1327221 & 688816 & 8.301 & 5.3055 & TRN & \\
\hline CHEMBL1301877 & 688816 & 4.85 & 5.1195 & TRN & \\
\hline CHEMBL1789998 & 688816 & 5.05 & 5.22 & TRN & \\
\hline CHEMBL1509787 & 688816 & 5.4 & 5.9485 & TRN & \\
\hline CHEMBL1485687 & 688816 & 5.95 & 5.1243 & TST & \\
\hline CHEMBL1472809 & 688816 & 5.0 & 5.4642 & TRN & \\
\hline CHEMBL1478994 & 688816 & 4.45 & 5.2541 & TRN & \\
\hline CHEMBL3194460 & 688816 & 4.65 & 5.1101 & TRN & \\
\hline CHEMBL1586173 & 688816 & 4.8 & 4.9727 & TRN & \\
\hline CHEMBL1581141 & 688816 & 5.2 & 5.2648 & TRN & \\
\hline CHEMBL1489219 & 688816 & 4.45 & 5.1222 & TRN & \\
\hline CHEMBL1495806 & 688816 & 5.2 & 5.6312 & TST & \\
\hline CHEMBL3192443 & 688816 & 5.4 & 5.5585 & TST & \\
\hline CHEMBL1383484 & 688816 & 4.5 & 5.5458 & TST & \\
\hline CHEMBL1340152 & 688816 & 5.4 & 4.8798 & TRN & \\
\hline CHEMBL1386684 & 688816 & 5.15 & 5.2369 & TRN & \\
\hline CHEMBL1612006 & 688816 & 5.25 & 5.28799 & э999999999 & TRN \\
\hline CHEMBL1413675 & 688816 & 4.55 & 4.8961 & TRN & \\
\hline CHEMBL3189334 & 688816 & 4.85 & 5.2159 & TRN & \\
\hline CHEMBL1448584 & 688816 & 5.0 & 4.5619 & TRN & \\
\hline CHEMBL1424441 & 688816 & 5.05 & 5.2682 & TRN & \\
\hline CHEMBL1606485 & 688816 & 6.15 & 5.76399 & 7999999999 & TST \\
\hline CHEMBL1421948 & 688816 & 4.95 & 5.7837 & TRN & \\
\hline CHEMBL1547165 & 688816 & 6.7501 & 5.2405 & TRN & \\
\hline CHEMBL1360022 & 688816 & 4.45 & 5.3029 & TRN & \\
\hline CHEMBL1315287 & 688816 & 5.05 & 4.9933 & TRN & \\
\hline CHEMBL1323117 & 688816 & 4.9 & 5.2958 & TRN & \\
\hline CHEMBL1415578 & 688816 & 4.9 & 5.2106 & TRN & \\
\hline CHEMBL1559811 & 688816 & 5.35 & 5.2382 & TRN & \\
\hline CHEMBL1330342 & 688816 & 4.45 & 5.0947 & TRN & \\
\hline CHEMBL1526645 & 688816 & 5.0 & 5.2499 & TST & \\
\hline CHEMBL1564813 & 688816 & 5.15 & 5.4691 & TRN & \\
\hline CHEMBL1440056 & 688816 & 4.9 & 5.2396 & TRN & \\
\hline CHEMBL1374456 & 688816 & 4.75 & 5.1757 & TRN & \\
\hline CHEMBL1320525 & 688816 & 4.7 & 5.3695 & TRN & \\
\hline CHEMBL1386851 & 688816 & 4.45 & 4.9832 & TST & \\
\hline CHEMBL1307919 & 688816 & 4.95 & 5.5042 & TRN & \\
\hline CHEMBL1390519 & 688816 & 4.65 & 5.3118 & TRN & \\
\hline CHEMBL1587031 & 688816 & 4.45 & 4.6949 & TST & \\
\hline CHEMBL1457150 & 688816 & 4.65 & 5.1468 & TRN & \\
\hline CHEMBL1486546 & 688816 & 4.45 & 5.0631 & TRN & \\
\hline CHEMBL1420768 & 688816 & 4.5 & 5.1418 & TST & \\
\hline CHEMBL1558655 & 688816 & 8.301 & 5.5465 & TST & \\
\hline CHEMBL1507490 & 688816 & 5.45 & 5.3092 & TRN & \\
\hline CHEMBL1310093 & 688816 & 6.0 & 5.3622 & TRN & \\
\hline CHEMBL1350332 & 688816 & 5.05 & 5.3023 & TRN & \\
\hline CHEMBL1608460 & 688816 & 8.0 & 5.7741 & TRN & \\
\hline
\end{tabular}




\begin{tabular}{|c|c|c|c|c|c|}
\hline \\
\hline CHEMBL1343309 & 688816 & 4.5 & 5.0904 & TRN & \\
\hline CHEMBL1304120 & 688816 & 5.95 & 5.506 & TRN & \\
\hline CHEMBL1342795 & 688816 & 5.75 & 5.2675 & TRN & \\
\hline CHEMBL1459264 & 688816 & 8.301 & 5.775 & TST & \\
\hline CHEMBL1528536 & 688816 & 4.7 & 4.7934 & TRN & \\
\hline CHEMBL1327408 & 688816 & 4.9 & 5.2024 & TRN & \\
\hline CHEMBL1340053 & 688816 & 4.5 & 5.2864 & TRN & \\
\hline CHEMBL1579029 & 688816 & 4.95 & 5.0745 & TRN & \\
\hline CHEMBL1449793 & 688816 & 4.9 & 5.3098 & TRN & \\
\hline CHEMBL3196661 & 688816 & 4.7 & 4.8777 & TRN & \\
\hline CHEMBL1494697 & 688816 & 4.6 & 5.3236 & TRN & \\
\hline CHEMBL1482052 & 688816 & 4.9 & 5.3731 & TRN & \\
\hline CHEMBL3192997 & 688816 & 4.7 & 5.4802 & TRN & \\
\hline CHEMBL1308354 & 688816 & 4.95 & 5.1483 & TST & \\
\hline CHEMBL1393918 & 688816 & 5.25 & 5.54700 & 0000000001 & TST \\
\hline CHEMBL1348002 & 688816 & 5.45 & 5.1441 & TRN & \\
\hline CHEMBL1323268 & 688816 & 4.45 & 5.2056 & TRN & \\
\hline CHEMBL2140539 & 688816 & 5.15 & 5.5541 & TST & \\
\hline CHEMBL1546789 & 688816 & 4.9 & 4.9354 & TRN & \\
\hline CHEMBL1480352 & 688816 & 4.8 & 5.24100 & 00000000005 & TRN \\
\hline CHEMBL1376176 & 688816 & 4.75 & 5.1578 & TRN & \\
\hline CHEMBL1435790 & 688816 & 4.9 & 4.9706 & TRN & \\
\hline CHEMBL1500422 & 688816 & 4.65 & 5.0535 & TRN & \\
\hline CHEMBL1572194 & 688816 & 4.45 & 5.1508 & TRN & \\
\hline CHEMBL3196245 & 688816 & 6.05 & 5.2321 & TRN & \\
\hline CHEMBL1329020 & 688816 & 4.95 & 5.1372 & TST & \\
\hline CHEMBL1481231 & 688816 & 6.5 & 5.2505 & TRN & \\
\hline CHEMBL1455545 & 688816 & 4.95 & 5.1286 & TRN & \\
\hline CHEMBL1347706 & 688816 & 4.85 & 5.1984 & TRN & \\
\hline CHEMBL1449173 & 688816 & 4.85 & 5.2092 & TST & \\
\hline CHEMBL3190537 & 688816 & 4.45 & 5.0758 & TRN & \\
\hline CHEMBL1965384 & 688816 & 7.5003 & 5.5998 & TRN & \\
\hline CHEMBL1393635 & 688816 & 5.25 & 5.1648 & TRN & \\
\hline CHEMBL1404096 & 688816 & 4.45 & 5.4914 & TRN & \\
\hline CHEMBL1590533 & 688816 & 4.95 & 5.1188 & TRN & \\
\hline CHEMBL1977747 & 688816 & 4.95 & 5.0893 & TRN & \\
\hline CHEMBL1334484 & 688816 & 4.45 & 5.1383 & TST & \\
\hline CHEMBL1456696 & 688816 & 4.65 & 5.2432 & TRN & \\
\hline CHEMBL1511861 & 688816 & 4.9 & 5.1177 & TRN & \\
\hline CHEMBL1417840 & 688816 & 5.1 & 5.0433 & TRN & \\
\hline CHEMBL1311284 & 688816 & 7.6498 & 5.3297 & TRN & \\
\hline CHEMBL1609479 & 688816 & 7.4498 & 5.3992 & TRN & \\
\hline CHEMBL1443319 & 688816 & 6.5 & 5.4774 & TRN & \\
\hline CHEMBL1415045 & 688816 & 8.301 & 5.5041 & TST & \\
\hline CHEMBL3208334 & 688816 & 4.85 & 5.23 & TRN & \\
\hline CHEMBL1582302 & 688816 & 5.15 & 5.1813 & TST & \\
\hline CHEMBL1481452 & 688816 & 4.45 & 4.7972 & TRN & \\
\hline CHEMBL1402026 & 688816 & 4.85 & 5.0891 & TST & \\
\hline
\end{tabular}




\begin{tabular}{|c|c|c|c|c|c|}
\hline \multicolumn{6}{|c|}{ Supplemental Table S2.txt } \\
\hline CHEMBL1300822 & 688816 & 4.7 & 4.9997 & TRN & \\
\hline CHEMBL1334574 & 688816 & 7.2503 & 5.2011 & TRN & \\
\hline CHEMBL1523251 & 688816 & 4.5 & 5.5105 & TST & \\
\hline CHEMBL1598541 & 688816 & 7.6003 & 5.1853 & TST & \\
\hline CHEMBL1608905 & 688816 & 4.65 & 5.3023 & TRN & \\
\hline CHEMBL1458524 & 688816 & 6.05 & 5.1138 & TRN & \\
\hline CHEMBL1452090 & 688816 & 4.85 & 5.3015 & TRN & \\
\hline CHEMBL1509048 & 688816 & 5.75 & 5.3261 & TRN & \\
\hline CHEMBL1469928 & 688816 & 6.2 & 5.4592 & TST & \\
\hline CHEMBL3199351 & 688816 & 4.9 & 5.0858 & TRN & \\
\hline CHEMBL1415035 & 688816 & 4.8 & 5.3386 & TRN & \\
\hline CHEMBL1539904 & 688816 & 4.6 & 5.6674 & TRN & \\
\hline CHEMBL1605970 & 688816 & 4.7 & 5.24 & TRN & \\
\hline CHEMBL1461541 & 688816 & 4.95 & 5.2077 & TST & \\
\hline CHEMBL1458764 & 688816 & 6.6 & 5.5879 & TRN & \\
\hline CHEMBL1583889 & 688816 & 4.95 & 5.5343 & TRN & \\
\hline CHEMBL1332088 & 688816 & 4.45 & 5.2721 & TRN & \\
\hline CHEMBL1397639 & 688816 & 5.0 & 5.364 & TRN & \\
\hline CHEMBL1559481 & 688816 & 4.95 & 5.0877 & TST & \\
\hline CHEMBL1334503 & 688816 & 5.1 & 5.3605 & TRN & \\
\hline CHEMBL1350827 & 688816 & 4.45 & 5.3872 & TRN & \\
\hline CHEMBL1313016 & 688816 & 4.45 & 5.1157 & TRN & \\
\hline CHEMBL1437970 & 688816 & 5.9 & 5.3124 & TRN & \\
\hline CHEMBL1594800 & 688816 & 4.7 & 5.1583 & TST & \\
\hline CHEMBL1437337 & 688816 & 6.8499 & 5.4232 & TST & \\
\hline CHEMBL1506611 & 688816 & 4.7 & 5.3379 & TRN & \\
\hline CHEMBL1613264 & 688816 & 4.95 & 5.146 & TST & \\
\hline CHEMBL1306925 & 688816 & 5.5 & 5.125 & TRN & \\
\hline CHEMBL1603345 & 688816 & 4.45 & 5.1956 & TST & \\
\hline CHEMBL1477252 & 688816 & 7.7496 & 5.1273 & TRN & \\
\hline CHEMBL1507825 & 688816 & 4.5 & 5.4643 & TST & \\
\hline CHEMBL1526016 & 688816 & 4.75 & 5.206 & TRN & \\
\hline CHEMBL3198362 & 688816 & 6.25 & 5.3104 & TRN & \\
\hline CHEMBL1508544 & 688816 & 8.0 & 5.3315 & TST & \\
\hline CHEMBL1372304 & 688816 & 4.45 & 5.3892 & TST & \\
\hline CHEMBL1356253 & 688816 & 4.85 & 5.3122 & TRN & \\
\hline CHEMBL1583625 & 688816 & 4.95 & 5.5203 & TRN & \\
\hline CHEMBL1384108 & 688816 & 4.8 & 5.3466 & TRN & \\
\hline CHEMBL1542099 & 688816 & 6.5 & 5.5215 & TRN & \\
\hline CHEMBL1378100 & 688816 & 4.45 & 5.2565 & TST & \\
\hline CHEMBL1390771 & 688816 & 4.45 & 5.4075 & TST & \\
\hline CHEMBL1394535 & 688816 & 4.85 & 4.94600 & 0000000001 & TRN \\
\hline CHEMBL1496852 & 688816 & 7.3002 & 5.2138 & TST & \\
\hline CHEMBL1489933 & 688816 & 4.95 & 5.3643 & TST & \\
\hline CHEMBL1458607 & 688816 & 7.0 & 5.5702 & TRN & \\
\hline CHEMBL1535700 & 688816 & 4.95 & 4.8925 & TRN & \\
\hline CHEMBL1368402 & 688816 & 4.7 & 5.195 & TRN & \\
\hline CHEMBL1427266 & 688816 & 4.75 & 4.9464 & TRN & \\
\hline
\end{tabular}




\begin{tabular}{|c|c|c|c|c|c|}
\hline \\
\hline CHEMBL1538461 & 688816 & 4.8 & 4.9951 & TST & \\
\hline CHEMBL1490952 & 688816 & 5.0 & 5.114 & TST & \\
\hline CHEMBL1324408 & 688816 & 4.95 & 5.8037 & TRN & \\
\hline CHEMBL1359561 & 688816 & 6.1 & 5.4076 & TST & \\
\hline CHEMBL1556930 & 688816 & 4.85 & 5.2107 & TRN & \\
\hline CHEMBL3192894 & 688816 & 6.05 & 5.0892 & TRN & \\
\hline CHEMBL1583997 & 688816 & 4.95 & 4.8896 & TST & \\
\hline CHEMBL1374363 & 688816 & 5.25 & 5.3543 & TST & \\
\hline CHEMBL1564558 & 688816 & 4.6 & 5.1932 & TRN & \\
\hline CHEMBL1500646 & 688816 & 4.65 & 5.3584 & TST & \\
\hline CHEMBL1518900 & 688816 & 4.5 & 5.1568 & TRN & \\
\hline CHEMBL1571069 & 688816 & 5.1 & 5.8102 & TRN & \\
\hline CHEMBL3195432 & 688816 & 5.1 & 5.2355 & TRN & \\
\hline CHEMBL1387918 & 688816 & 4.95 & 5.2811 & TRN & \\
\hline CHEMBL1459747 & 688816 & 5.4 & 5.6913 & TST & \\
\hline CHEMBL1301784 & 688816 & 4.65 & 5.245 & TST & \\
\hline CHEMBL1590306 & 688816 & 8.3468 & 5.1351 & TRN & \\
\hline CHEMBL1449217 & 688816 & 4.45 & 5.4559 & TST & \\
\hline CHEMBL1575708 & 688816 & 5.55 & 5.4978 & TRN & \\
\hline CHEMBL 3198743 & 688816 & 4.6 & 5.4185 & TRN & \\
\hline CHEMBL1424685 & 688816 & 4.9 & 4.9445 & TRN & \\
\hline CHEMBL3191671 & 688816 & 4.5 & 4.8436 & TRN & \\
\hline CHEMBL1467839 & 688816 & 4.95 & 5.2866 & TRN & \\
\hline CHEMBL1388135 & 688816 & 4.95 & 4.9769 & TRN & \\
\hline CHEMBL1533942 & 688816 & 4.95 & 5.1403 & TRN & \\
\hline CHEMBL1587128 & 688816 & 4.9 & 5.0266 & TRN & \\
\hline CHEMBL3199253 & 688816 & 4.5 & 5.2456 & TRN & \\
\hline CHEMBL1573798 & 688816 & 7.8508 & 5.2278 & TRN & \\
\hline CHEMBL1501694 & 688816 & 5.75 & 5.3122 & TRN & \\
\hline CHEMBL1233274 & 688816 & 5.95 & 5.6442 & TRN & \\
\hline CHEMBL1385933 & 688816 & 4.45 & 5.0793 & TRN & \\
\hline CHEMBL1569375 & 688816 & 5.0 & 4.9135 & TRN & \\
\hline CHEMBL1359243 & 688816 & 4.9 & 5.1277 & TRN & \\
\hline CHEMBL1529111 & 688816 & 4.85 & 5.1933 & TRN & \\
\hline CHEMBL1373491 & 688816 & 6.8 & 5.4879 & TST & \\
\hline CHEMBL1610353 & 688816 & 4.85 & 5.2021 & TRN & \\
\hline CHEMBL1451720 & 688816 & 5.0 & 5.1022 & TRN & \\
\hline CHEMBL1412392 & 688816 & 4.45 & 5.2057 & TRN & \\
\hline CHEMBL1461593 & 688816 & 4.8 & 5.16299 & 9999999999 & TRN \\
\hline CHEMBL1585791 & 688816 & 5.2 & 5.3807 & TST & \\
\hline CHEMBL1335162 & 688816 & 4.85 & 5.0666 & TRN & \\
\hline CHEMBL1333878 & 688816 & 4.95 & 5.3218 & TRN & \\
\hline CHEMBL1482670 & 688816 & 6.1 & 5.1387 & TRN & \\
\hline CHEMBL1348652 & 688816 & 4.95 & 4.8801 & TRN & \\
\hline CHEMBL3199077 & 688816 & 5.85 & 5.0139 & TRN & \\
\hline CHEMBL1302550 & 688816 & 5.9 & 5.4301 & TRN & \\
\hline CHEMBL3195752 & 688816 & 4.55 & 5.0926 & TRN & \\
\hline CHEMBL1305233 & 688816 & 6.15 & 5.1912 & TRN & \\
\hline
\end{tabular}




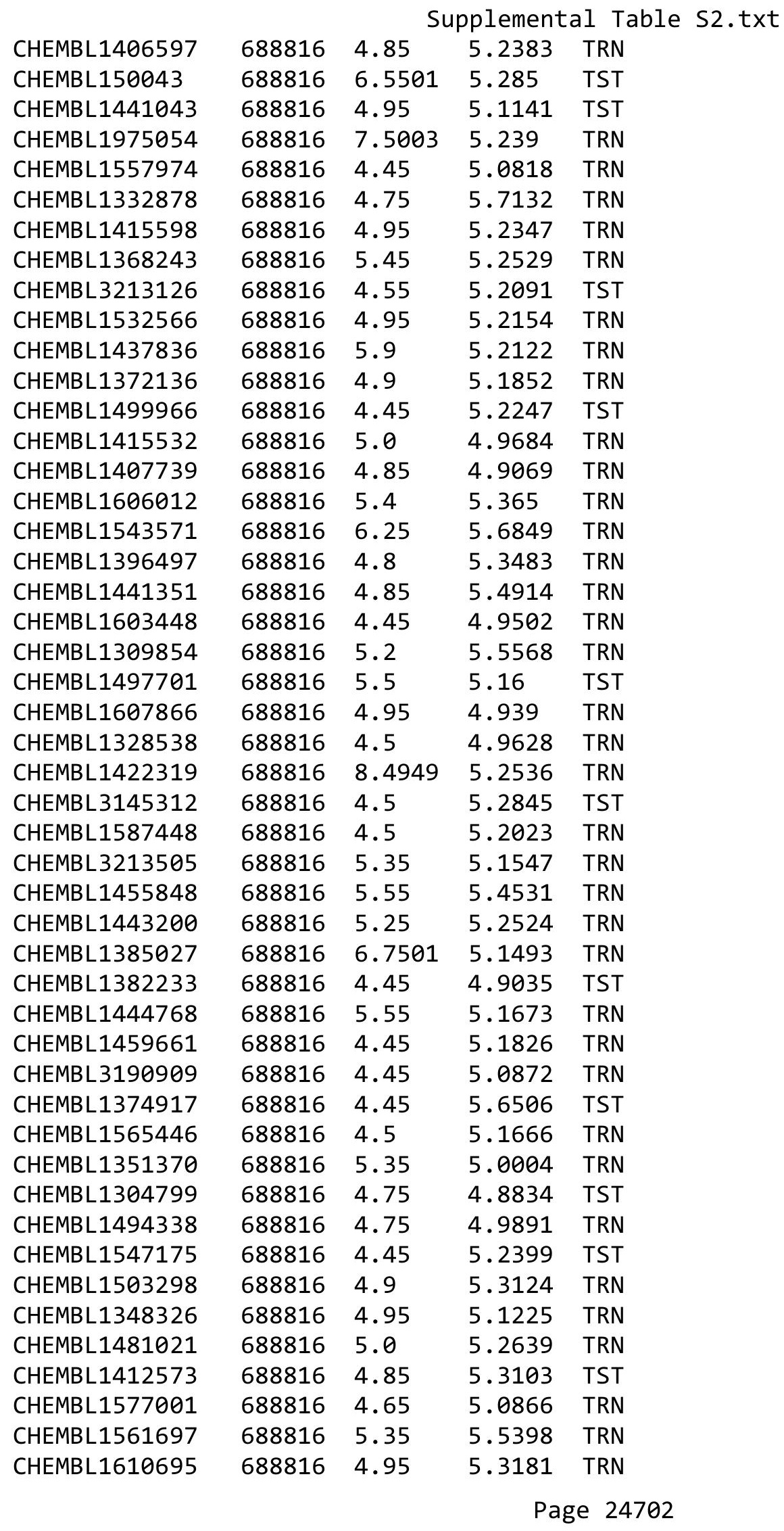




\begin{tabular}{|c|c|c|c|c|c|}
\hline \multicolumn{6}{|c|}{ Supplemental Table s2.txt } \\
\hline CHEMBL1316953 & 688816 & 5.05 & 6.096 & TST & \\
\hline CHEMBL1310168 & 688816 & 5.1 & 4.9993 & TRN & \\
\hline CHEMBL1464208 & 688816 & 5.0 & 5.3932 & TST & \\
\hline CHEMBL1573311 & 688816 & 6.15 & 5.0466 & TRN & \\
\hline CHEMBL1964464 & 688816 & 5.25 & 5.1657 & TRN & \\
\hline CHEMBL1534315 & 688816 & 4.95 & 5.4245 & TRN & \\
\hline CHEMBL1575060 & 688816 & 7.4001 & 5.3629 & TST & \\
\hline CHEMBL1544331 & 688816 & 4.85 & 5.0469 & TST & \\
\hline CHEMBL1310031 & 688816 & 4.8 & 5.1259 & TST & \\
\hline CHEMBL1568028 & 688816 & 5.0 & 5.0271 & TRN & \\
\hline CHEMBL1300411 & 688816 & 5.6 & 5.0814 & TRN & \\
\hline CHEMBL1366104 & 688816 & 4.45 & 5.0115 & TRN & \\
\hline CHEMBL1575581 & 688816 & 7.8996 & 5.2776 & TST & \\
\hline CHEMBL1529127 & 688816 & 4.8 & 5.2797 & TRN & \\
\hline CHEMBL1368333 & 688816 & 4.95 & 5.4424 & TRN & \\
\hline CHEMBL1429432 & 688816 & 5.7 & 5.0807 & TST & \\
\hline CHEMBL3209479 & 688816 & 4.45 & 5.003 & TRN & \\
\hline CHEMBL1479831 & 688816 & 4.45 & 5.2111 & TRN & \\
\hline CHEMBL1320769 & 688816 & 4.95 & 6.2385 & TRN & \\
\hline CHEMBL1560701 & 688816 & 4.45 & 5.2338 & TST & \\
\hline CHEMBL492886 & 688816 & 7.6003 & 5.3701 & TST & \\
\hline CHEMBL1493646 & 688816 & 5.9 & 5.4314 & TRN & \\
\hline CHEMBL1344518 & 688816 & 7.3497 & 5.1932 & TRN & \\
\hline CHEMBL1362841 & 688816 & 5.15 & 5.45100 & 00000000005 & TRN \\
\hline CHEMBL1546975 & 688816 & 5.55 & 5.6785 & TST & \\
\hline CHEMBL395808 & 688816 & 4.45 & 4.9202 & TRN & \\
\hline CHEMBL1503930 & 688816 & 5.2 & 5.1684 & TRN & \\
\hline CHEMBL3192960 & 688816 & 4.95 & 5.2983 & TRN & \\
\hline CHEMBL1500819 & 688816 & 4.9 & 5.2992 & TRN & \\
\hline CHEMBL1584252 & 688816 & 5.9 & 5.3304 & TST & \\
\hline CHEMBL1464006 & 688816 & 6.45 & 5.4984 & TRN & \\
\hline CHEMBL1462914 & 688816 & 4.8 & 5.1082 & TRN & \\
\hline CHEMBL1493886 & 688816 & 5.6 & 5.2175 & TRN & \\
\hline CHEMBL1406720 & 688816 & 4.45 & 5.1419 & TRN & \\
\hline CHEMBL3194087 & 688816 & 4.95 & 4.938 & TST & \\
\hline CHEMBL1372850 & 688816 & 5.25 & 5.2049 & TRN & \\
\hline CHEMBL1399507 & 688816 & 4.5 & 5.0701 & TST & \\
\hline CHEMBL1514071 & 688816 & 5.0 & 5.0396 & TRN & \\
\hline CHEMBL1311605 & 688816 & 4.8 & 5.3194 & TRN & \\
\hline CHEMBL1405370 & 688816 & 4.45 & 5.2907 & TST & \\
\hline CHEMBL1452157 & 688816 & 4.85 & 4.864 & TRN & \\
\hline CHEMBL1437035 & 688816 & 6.2 & 5.3339 & TRN & \\
\hline CHEMBL1352511 & 688816 & 4.9 & 5.1349 & TRN & \\
\hline CHEMBL1408438 & 688816 & 5.3 & 5.2538 & TRN & \\
\hline CHEMBL1403917 & 688816 & 4.95 & 4.9663 & TRN & \\
\hline CHEMBL1323376 & 688816 & 4.45 & 4.6645 & TRN & \\
\hline CHEMBL1333484 & 688816 & 4.95 & 5.1072 & TRN & \\
\hline CHEMBL1409019 & 688816 & 5.4 & 5.6485 & TST & \\
\hline
\end{tabular}




\begin{tabular}{|c|c|c|c|c|}
\hline \multicolumn{5}{|c|}{ Supplemental Table S2.txt } \\
\hline CHEMBL1411660 & 688816 & 5.05 & 5.4098 & TRN \\
\hline CHEMBL1470666 & 688816 & 5.3 & 5.3291 & TRN \\
\hline CHEMBL1612392 & 688816 & 6.5 & 4.6752 & TRN \\
\hline CHEMBL1587728 & 688816 & 4.65 & 5.1458 & TRN \\
\hline CHEMBL1609124 & 688816 & 5.2 & 5.2785 & TRN \\
\hline CHEMBL1337997 & 688816 & 4.45 & 5.0227 & TRN \\
\hline CHEMBL1491655 & 688816 & 4.95 & 5.4407 & TST \\
\hline CHEMBL1411446 & 688816 & 7.6003 & 5.7204 & TRN \\
\hline CHEMBL1312826 & 688816 & 5.35 & 5.5682 & TST \\
\hline CHEMBL587728 & 688816 & 4.85 & 5.1078 & TRN \\
\hline CHEMBL1443659 & 688816 & 5.65 & 4.9603 & TRN \\
\hline CHEMBL1392313 & 688816 & 4.45 & 5.4996 & TST \\
\hline CHEMBL1589169 & 688816 & 6.7501 & 5.4962 & TRN \\
\hline CHEMBL1361413 & 688816 & 5.6 & 5.2095 & TST \\
\hline CHEMBL1328862 & 688816 & 4.8 & 5.1591 & TRN \\
\hline CHEMBL1459372 & 688816 & 4.7 & 5.2983 & TST \\
\hline CHEMBL1497760 & 688816 & 5.25 & 5.4332 & TST \\
\hline CHEMBL1386157 & 688816 & 5.05 & 5.4943 & TRN \\
\hline CHEMBL3191729 & 688816 & 4.55 & 4.8521 & TRN \\
\hline CHEMBL1498517 & 688816 & 4.5 & 5.4326 & TRN \\
\hline CHEMBL3209015 & 688816 & 4.75 & 5.4842 & TRN \\
\hline CHEMBL1567742 & 688816 & 4.9 & 5.1808 & TRN \\
\hline CHEMBL1538806 & 688816 & 5.1 & 5.2533 & TRN \\
\hline CHEMBL1495521 & 688816 & 4.6 & 5.1955 & TRN \\
\hline CHEMBL1566174 & 688816 & 4.9 & 5.2534 & TRN \\
\hline CHEMBL1977384 & 688816 & 4.9 & 5.2012 & TRN \\
\hline CHEMBL1359361 & 688816 & 5.25 & 5.1846 & TST \\
\hline CHEMBL1373016 & 688816 & 6.05 & 5.2419 & TRN \\
\hline CHEMBL1586735 & 688816 & 4.9 & 5.0849 & TRN \\
\hline CHEMBL1563580 & 688816 & 4.9 & 5.3587 & TRN \\
\hline CHEMBL1521862 & 688816 & 5.55 & 5.5955 & TRN \\
\hline CHEMBL1402713 & 688816 & 6.1 & 5.3812 & TRN \\
\hline CHEMBL3196774 & 688816 & 6.15 & 5.6449 & TRN \\
\hline CHEMBL1536379 & 688816 & 4.45 & 5.1775 & TRN \\
\hline CHEMBL1406208 & 688816 & 6.0 & 5.2806 & TRN \\
\hline CHEMBL1609165 & 688816 & 6.8 & 5.3978 & TRN \\
\hline CHEMBL3195525 & 688816 & 4.75 & 5.0263 & TRN \\
\hline CHEMBL1331271 & 688816 & 5.2 & 5.5483 & TRN \\
\hline CHEMBL1482446 & 688816 & 5.05 & 5.5421 & TST \\
\hline CHEMBL1327342 & 688816 & 4.75 & 5.2042 & TRN \\
\hline CHEMBL1412825 & 688816 & 5.4 & 5.3052 & TRN \\
\hline CHEMBL1389179 & 688816 & 4.95 & 5.237 & TST \\
\hline CHEMBL1585715 & 688816 & 5.15 & 4.9867 & TRN \\
\hline CHEMBL1565816 & 688816 & 6.8499 & 5.4134 & TRN \\
\hline CHEMBL1928491 & 688816 & 5.35 & 5.1419 & TST \\
\hline CHEMBL1257002 & 688816 & 4.4 & 5.249 & TST \\
\hline CHEMBL1584269 & 688816 & 5.1 & 5.4434 & TRN \\
\hline CHEMBL1299534 & 688816 & 5.55 & 5.3695 & TST \\
\hline
\end{tabular}




\begin{tabular}{|c|c|c|c|c|c|}
\hline \multicolumn{6}{|c|}{ Supplemental Table S2.txt } \\
\hline CHEMBL1539150 & 688816 & 5.15 & 5.0698 & TST & \\
\hline CHEMBL1312040 & 688816 & 5.25 & 5.115 & TRN & \\
\hline CHEMBL1426306 & 688816 & 5.0 & 4.9521 & TST & \\
\hline CHEMBL1600241 & 688816 & 5.2 & 5.2563 & TRN & \\
\hline CHEMBL1321411 & 688816 & 6.6499 & 5.6709 & TST & \\
\hline CHEMBL1505611 & 688816 & 5.25 & 5.0733 & TRN & \\
\hline CHEMBL1329107 & 688816 & 5.4 & 5.805 & TRN & \\
\hline CHEMBL1392177 & 688816 & 5.25 & 5.6166 & TRN & \\
\hline CHEMBL1496056 & 688816 & 4.85 & 5.0052 & TRN & \\
\hline CHEMBL3193795 & 688816 & 5.85 & 5.8291 & TRN & \\
\hline CHEMBL1534019 & 688816 & 5.25 & 5.1506 & TST & \\
\hline CHEMBL1555053 & 688816 & 4.5 & 5.2481 & TRN & \\
\hline CHEMBL1511546 & 688816 & 4.7 & 5.1756 & TRN & \\
\hline CHEMBL1339999 & 688816 & 7.7496 & 5.20799 & 9999999999 & TST \\
\hline CHEMBL1582088 & 688816 & 4.95 & 5.2855 & TRN & \\
\hline CHEMBL1310154 & 688816 & 5.05 & 5.4747 & TRN & \\
\hline CHEMBL1502550 & 688816 & 5.05 & 4.9145 & TRN & \\
\hline CHEMBL1398981 & 688816 & 5.5 & 5.2801 & TRN & \\
\hline CHEMBL1327089 & 688816 & 4.65 & 5.0879 & TRN & \\
\hline CHEMBL1454211 & 688816 & 4.9 & 5.2044 & TRN & \\
\hline CHEMBL1498476 & 688816 & 4.95 & 4.8004 & TRN & \\
\hline CHEMBL1334604 & 688816 & 5.1 & 5.0709 & TRN & \\
\hline CHEMBL1555435 & 688816 & 4.45 & 4.8597 & TST & \\
\hline CHEMBL1343676 & 688816 & 6.0 & 5.3989 & TST & \\
\hline CHEMBL1559130 & 688816 & 4.7 & 5.0548 & TST & \\
\hline CHEMBL1574120 & 688816 & 4.9 & 5.1179 & TRN & \\
\hline CHEMBL1493905 & 688816 & 5.0 & 5.2171 & TRN & \\
\hline CHEMBL1506250 & 688816 & 5.85 & 4.9713 & TRN & \\
\hline CHEMBL1540607 & 688816 & 5.25 & 5.2572 & TRN & \\
\hline CHEMBL1367297 & 688816 & 4.5 & 5.5527 & TST & \\
\hline CHEMBL1426795 & 688816 & 5.45 & 5.1805 & TST & \\
\hline CHEMBL1496344 & 688816 & 5.2 & 4.9847 & TRN & \\
\hline CHEMBL 3214190 & 688816 & 4.65 & 5.2131 & TRN & \\
\hline CHEMBL1560478 & 688816 & 4.45 & 5.0852 & TRN & \\
\hline CHEMBL1306507 & 688816 & 6.5 & 5.0192 & TRN & \\
\hline CHEMBL1426005 & 688816 & 4.6 & 5.118 & TST & \\
\hline CHEMBL1570615 & 688816 & 7.4498 & 5.2707 & TRN & \\
\hline CHEMBL1507647 & 688816 & 4.95 & 5.8484 & TRN & \\
\hline CHEMBL1527114 & 688816 & 4.85 & 5.2885 & TRN & \\
\hline CHEMBL1548774 & 688816 & 4.65 & 5.4033 & TRN & \\
\hline CHEMBL1549305 & 688816 & 4.75 & 4.9646 & TRN & \\
\hline CHEMBL1463336 & 688816 & 4.85 & 4.984 & TRN & \\
\hline CHEMBL1491838 & 688816 & 4.85 & 5.0766 & TRN & \\
\hline CHEMBL1381206 & 688816 & 4.6 & 5.153 & TST & \\
\hline CHEMBL1360605 & 688816 & 5.15 & 5.2094 & TST & \\
\hline CHEMBL1558378 & 688816 & 5.8 & 5.3247 & TST & \\
\hline CHEMBL1540089 & 688816 & 5.5 & 5.3984 & TRN & \\
\hline CHEMBL1611120 & 688816 & 7.5003 & 5.043 & TRN & \\
\hline
\end{tabular}




\begin{tabular}{|c|c|c|c|c|c|}
\hline \multicolumn{6}{|c|}{ Supplemental Table s2.txt } \\
\hline CHEMBL1350185 & 688816 & 6.35 & 5.2644 & TST & \\
\hline CHEMBL1439325 & 688816 & 4.6 & 4.9082 & TRN & \\
\hline CHEMBL95606 & 688816 & 5.8 & 5.7752 & TRN & \\
\hline CHEMBL 2007601 & 688816 & 4.45 & 4.9557 & TRN & \\
\hline CHEMBL1341936 & 688816 & 4.45 & 5.2204 & TST & \\
\hline CHEMBL1518405 & 688816 & 4.45 & 5.1997 & TRN & \\
\hline CHEMBL1472769 & 688816 & 4.9 & 5.1789 & TRN & \\
\hline CHEMBL1529232 & 688816 & 6.2 & 5.2474 & TRN & \\
\hline CHEMBL1600293 & 688816 & 4.85 & 5.1716 & TRN & \\
\hline CHEMBL3194550 & 688816 & 4.95 & 4.8391 & TRN & \\
\hline CHEMBL1486673 & 688816 & 5.5 & 5.4822 & TRN & \\
\hline CHEMBL1335155 & 688816 & 4.8 & 5.0904 & TRN & \\
\hline CHEMBL1538919 & 688816 & 4.85 & 4.9862 & TRN & \\
\hline CHEMBL1464485 & 688816 & 4.85 & 5.5499 & TST & \\
\hline CHEMBL1348205 & 688816 & 4.85 & 5.2977 & TRN & \\
\hline CHEMBL1570863 & 688816 & 4.55 & 4.5789 & TRN & \\
\hline CHEMBL1348917 & 688816 & 6.05 & 5.2227 & TST & \\
\hline CHEMBL1389757 & 688816 & 4.65 & 5.2772 & TRN & \\
\hline CHEMBL3193098 & 688816 & 4.9 & 5.13200 & $\partial 000000001$ & TRN \\
\hline CHEMBL1385794 & 688816 & 4.95 & 4.8467 & TRN & \\
\hline CHEMBL1341770 & 688816 & 4.4 & 5.5418 & TST & \\
\hline CHEMBL1559025 & 688816 & 5.0 & 5.3715 & TRN & \\
\hline CHEMBL1588531 & 688816 & 4.45 & 5.2581 & TRN & \\
\hline CHEMBL1398321 & 688816 & 4.9 & 5.224 & TST & \\
\hline CHEMBL1532659 & 688816 & 5.5 & 5.2923 & TRN & \\
\hline CHEMBL1309763 & 688816 & 5.0 & 5.105 & TST & \\
\hline CHEMBL1504121 & 688816 & 5.05 & 5.105 & TRN & \\
\hline CHEMBL1327780 & 688816 & 5.3 & 5.024 & TRN & \\
\hline CHEMBL1328682 & 688816 & 8.1024 & 5.6002 & TST & \\
\hline CHEMBL1462290 & 688816 & 7.8508 & 5.2313 & TRN & \\
\hline CHEMBL1366613 & 688816 & 7.15 & 5.6739 & TRN & \\
\hline CHEMBL1472336 & 688816 & 6.15 & 5.6589 & TRN & \\
\hline CHEMBL1601768 & 688816 & 4.6 & 5.6201 & TRN & \\
\hline CHEMBL1360931 & 688816 & 5.25 & 5.1679 & TRN & \\
\hline CHEMBL1464666 & 688816 & 4.65 & 5.103 & TRN & \\
\hline CHEMBL1579162 & 688816 & 7.0501 & 5.4979 & TRN & \\
\hline CHEMBL1351997 & 688816 & 4.45 & 5.1737 & TRN & \\
\hline CHEMBL1332576 & 688816 & 4.45 & 5.2641 & TST & \\
\hline CHEMBL1306775 & 688816 & 4.95 & 5.2062 & TRN & \\
\hline CHEMBL1571624 & 688816 & 4.95 & 5.5256 & TRN & \\
\hline CHEMBL1581737 & 688816 & 4.45 & 5.5404 & TST & \\
\hline CHEMBL3195656 & 688816 & 4.45 & 5.0311 & TST & \\
\hline CHEMBL482116 & 688816 & 4.8 & 5.1193 & TRN & \\
\hline CHEMBL1384524 & 688816 & 5.0 & 4.7262 & TRN & \\
\hline CHEMBL1545701 & 688816 & 4.95 & 5.19799 & 99999999995 & TST \\
\hline CHEMBL1386745 & 688816 & 4.95 & 4.9334 & TRN & \\
\hline CHEMBL1511071 & 688816 & 5.15 & 5.2672 & TRN & \\
\hline CHEMBL1372800 & 688816 & 7.0501 & 5.75 & TST & \\
\hline
\end{tabular}




\begin{tabular}{|c|c|c|c|c|c|}
\hline \multicolumn{6}{|c|}{ Supplemental Table S2.txt } \\
\hline CHEMBL1432524 & 688816 & 4.45 & 5.164 & TRN & \\
\hline CHEMBL 3209218 & 688816 & 5.65 & 5.2214 & TRN & \\
\hline CHEMBL1339459 & 688816 & 4.45 & 5.5242 & TRN & \\
\hline CHEMBL1384582 & 688816 & 4.95 & 5.0498 & TRN & \\
\hline CHEMBL1440086 & 688816 & 4.45 & 5.3812 & TRN & \\
\hline CHEMBL1343743 & 688816 & 5.15 & 5.5707 & TRN & \\
\hline CHEMBL 3195046 & 688816 & 4.8 & 5.2969 & TRN & \\
\hline CHEMBL1603287 & 688816 & 5.15 & 5.0938 & TRN & \\
\hline CHEMBL 3193267 & 688816 & 4.85 & 5.4113 & TST & \\
\hline CHEMBL1387807 & 688816 & 4.95 & 5.1913 & TRN & \\
\hline CHEMBL1424738 & 688816 & 5.2 & 5.921 & TRN & \\
\hline CHEMBL1442383 & 688816 & 5.4 & 4.9658 & TST & \\
\hline CHEMBL1518946 & 688816 & 5.55 & 5.2563 & TRN & \\
\hline CHEMBL1505391 & 688816 & 4.85 & 5.0891 & TRN & \\
\hline CHEMBL1596470 & 688816 & 7.5003 & 5.704 & TST & \\
\hline CHEMBL1322599 & 688816 & 4.75 & 5.5786 & TRN & \\
\hline CHEMBL1496625 & 688816 & 4.95 & 4.9103 & TRN & \\
\hline CHEMBL1376974 & 688816 & 6.0 & 6.0053 & TST & \\
\hline CHEMBL1370078 & 688816 & 4.75 & 5.2549 & TRN & \\
\hline CHEMBL1561605 & 688816 & 4.9 & 5.0283 & TRN & \\
\hline CHEMBL1419983 & 688816 & 4.95 & 5.45100 & 00000000005 & TST \\
\hline CHEMBL1356166 & 688816 & 4.95 & 5.1728 & TRN & \\
\hline CHEMBL1603199 & 688816 & 4.45 & 5.4831 & TST & \\
\hline CHEMBL1345529 & 688816 & 4.6 & 5.0578 & TRN & \\
\hline CHEMBL1322182 & 688816 & 4.45 & 5.4419 & TRN & \\
\hline CHEMBL1391463 & 688816 & 4.45 & 5.5355 & TRN & \\
\hline CHEMBL1371568 & 688816 & 5.05 & 5.0871 & TRN & \\
\hline CHEMBL3214595 & 688816 & 4.45 & 5.4591 & TRN & \\
\hline CHEMBL1594336 & 688816 & 5.0 & 5.1976 & TRN & \\
\hline CHEMBL1306433 & 688816 & 4.95 & 4.9805 & TRN & \\
\hline CHEMBL1461577 & 688816 & 6.7501 & 5.3104 & TST & \\
\hline CHEMBL1506607 & 688816 & 4.6 & 4.9172 & TRN & \\
\hline CHEMBL1438768 & 688816 & 4.95 & 5.1135 & TRN & \\
\hline CHEMBL1486910 & 688816 & 4.6 & 5.2977 & TRN & \\
\hline CHEMBL1966798 & 688816 & 4.45 & 4.9385 & TRN & \\
\hline CHEMBL1344755 & 688816 & 4.45 & 5.0214 & TRN & \\
\hline CHEMBL1372860 & 688816 & 6.95 & 5.5616 & TST & \\
\hline CHEMBL589469 & 688816 & 8.0506 & 5.1885 & TRN & \\
\hline CHEMBL1361930 & 688816 & 4.5 & 5.4447 & TRN & \\
\hline CHEMBL1337641 & 688816 & 5.0 & 4.9437 & TRN & \\
\hline CHEMBL1602085 & 688816 & 6.05 & 5.4326 & TRN & \\
\hline CHEMBL1572074 & 688816 & 4.8 & 5.5648 & TRN & \\
\hline CHEMBL1599870 & 688816 & 5.55 & 5.3323 & TRN & \\
\hline CHEMBL1548134 & 688816 & 4.6 & 5.5425 & TRN & \\
\hline CHEMBL1574559 & 688816 & 5.1 & 5.0511 & TST & \\
\hline CHEMBL1353921 & 688816 & 4.95 & 5.0428 & TRN & \\
\hline CHEMBL1568864 & 688816 & 8.3979 & 5.5851 & TRN & \\
\hline CHEMBL1419647 & 688816 & 6.25 & 5.1943 & TRN & \\
\hline
\end{tabular}




\begin{tabular}{|c|c|c|c|c|}
\hline \multicolumn{5}{|c|}{ Supplemental Table S2.txt } \\
\hline CHEMBL1353454 & 688816 & 4.95 & 5.1635 & TRN \\
\hline CHEMBL1531630 & 688816 & 5.65 & 5.2946 & TRN \\
\hline CHEMBL1579365 & 688816 & 8.301 & 5.5395 & TST \\
\hline CHEMBL 310310 & 688816 & 4.45 & 5.4066 & TST \\
\hline CHEMBL1388002 & 688816 & 4.8 & 5.1693 & TST \\
\hline CHEMBL1328635 & 688816 & 5.8 & 5.2215 & TRN \\
\hline CHEMBL1600947 & 688816 & 4.8 & 5.2816 & TRN \\
\hline CHEMBL1470953 & 688816 & 4.75 & 5.1909 & TRN \\
\hline CHEMBL1470829 & 688816 & 4.85 & 5.3724 & TRN \\
\hline CHEMBL1389654 & 688816 & 6.05 & 5.0754 & TRN \\
\hline CHEMBL1578291 & 688816 & 5.0 & 5.5649 & TST \\
\hline CHEMBL3211290 & 688816 & 4.7 & 4.9524 & TRN \\
\hline CHEMBL1573769 & 688816 & 7.5498 & 5.6329 & TRN \\
\hline CHEMBL323356 & 688816 & 5.0 & 4.7045 & TST \\
\hline CHEMBL1381489 & 688816 & 4.9 & 5.4266 & TRN \\
\hline CHEMBL1487859 & 688816 & 4.95 & 5.4332 & TRN \\
\hline CHEMBL1508579 & 688816 & 5.0 & 5.2948 & TRN \\
\hline CHEMBL1544177 & 688816 & 5.2 & 5.5933 & TST \\
\hline CHEMBL1536135 & 688816 & 4.85 & 5.1357 & TRN \\
\hline CHEMBL1498210 & 688816 & 6.1 & 5.5817 & TST \\
\hline CHEMBL1462879 & 688816 & 5.5 & 5.6217 & TST \\
\hline CHEMBL1540434 & 688816 & 4.7 & 5.4374 & TST \\
\hline CHEMBL1596448 & 688816 & 5.0 & 5.5824 & TRN \\
\hline CHEMBL1309029 & 688816 & 6.7501 & 5.5047 & TRN \\
\hline CHEMBL1376360 & 688816 & 4.85 & 5.2141 & TRN \\
\hline CHEMBL1436195 & 688816 & 4.45 & 5.0218 & TRN \\
\hline CHEMBL1441148 & 688816 & 5.0 & 5.0572 & TRN \\
\hline CHEMBL1472197 & 688816 & 5.5 & 5.5151 & TRN \\
\hline CHEMBL1453017 & 688816 & 4.45 & 5.1469 & TRN \\
\hline CHEMBL1536488 & 688816 & 6.7501 & 4.9443 & TST \\
\hline CHEMBL1482427 & 688816 & 4.95 & 5.1181 & TRN \\
\hline CHEMBL1353157 & 688816 & 7.5003 & 5.0307 & TRN \\
\hline CHEMBL1550302 & 688816 & 4.95 & 5.4226 & TRN \\
\hline CHEMBL1563145 & 688816 & 5.35 & 5.2746 & TST \\
\hline CHEMBL1477881 & 688816 & 5.45 & 5.3235 & TRN \\
\hline CHEMBL3190070 & 688816 & 7.7496 & 5.3457 & TRN \\
\hline CHEMBL1372417 & 688816 & 8.1487 & 5.2002 & TRN \\
\hline CHEMBL1419104 & 688816 & 4.9 & 5.6074 & TST \\
\hline CHEMBL1502531 & 688816 & 4.8 & 5.3283 & TRN \\
\hline CHEMBL1525127 & 688816 & 4.8 & 5.2637 & TRN \\
\hline CHEMBL1429696 & 688816 & 4.55 & 5.2528 & TRN \\
\hline CHEMBL1597084 & 688816 & 5.15 & 5.5353 & TRN \\
\hline CHEMBL1544478 & 688816 & 4.9 & 5.2195 & TRN \\
\hline CHEMBL1536785 & 688816 & 4.9 & 5.4719 & TRN \\
\hline CHEMBL1382562 & 688816 & 4.95 & 5.3817 & TRN \\
\hline CHEMBL1409770 & 688816 & 4.9 & 5.1086 & TRN \\
\hline CHEMBL3210537 & 688816 & 6.0 & 5.1401 & TST \\
\hline CHEMBL3191492 & 688816 & 5.25 & 5.5196 & TST \\
\hline
\end{tabular}




\begin{tabular}{|c|c|c|c|c|c|}
\hline CHEMBL1388639 & 688816 & 4.5 & \multicolumn{2}{|c|}{5.236000000000001} & TST \\
\hline CHEMBL1485778 & 688816 & 4.5 & 5.4418 & TST & \\
\hline CHEMBL3197065 & 688816 & 5.15 & 5.2532 & TRN & \\
\hline CHEMBL1996730 & 688816 & 5.55 & 5.3275 & TRN & \\
\hline CHEMBL1527692 & 688816 & 4.65 & 4.9483 & TRN & \\
\hline CHEMBL1305641 & 688816 & 4.8 & 5.2745 & TRN & \\
\hline CHEMBL1497396 & 688816 & 5.1 & 5.2179 & TRN & \\
\hline CHEMBL1523869 & 688816 & 5.45 & 5.2587 & TRN & \\
\hline CHEMBL1584982 & 688816 & 6.7001 & 5.5426 & TST & \\
\hline CHEMBL1567830 & 688816 & 6.5 & 5.3251 & TST & \\
\hline CHEMBL1314724 & 688816 & 4.45 & 5.0149 & TRN & \\
\hline CHEMBL1412529 & 688816 & 5.55 & 4.9612 & TRN & \\
\hline CHEMBL1522230 & 688816 & 4.7 & 5.555 & TST & \\
\hline CHEMBL1598732 & 688816 & 4.85 & 4.7261 & TRN & \\
\hline CHEMBL1406577 & 688816 & 5.1 & 5.1901 & TRN & \\
\hline CHEMBL1599174 & 688816 & 5.25 & 5.0718 & TRN & \\
\hline CHEMBL1433026 & 688816 & 8.0 & 5.3411 & TRN & \\
\hline CHEMBL1605673 & 688816 & 5.2 & 5.388 & TRN & \\
\hline CHEMBL1509493 & 688816 & 5.75 & 5.6632 & TRN & \\
\hline CHEMBL3211512 & 688816 & 5.55 & 5.2616 & TRN & \\
\hline CHEMBL3211427 & 688816 & 5.2 & 5.3602 & TRN & \\
\hline CHEMBL1449322 & 688816 & 7.3497 & 5.5896 & TST & \\
\hline CHEMBL1309573 & 688816 & 5.3 & 5.1532 & TRN & \\
\hline CHEMBL1556068 & 688816 & 4.8 & 5.3072 & TRN & \\
\hline CHEMBL1484462 & 688816 & 5.45 & 5.1845 & TST & \\
\hline CHEMBL1373098 & 688816 & 4.9 & 5.1129 & TRN & \\
\hline CHEMBL1384368 & 688816 & 4.9 & 4.7416 & TRN & \\
\hline CHEMBL3209206 & 688816 & 5.35 & 5.1126 & TRN & \\
\hline CHEMBL1412487 & 688816 & 5.6 & 5.5889 & TRN & \\
\hline CHEMBL3196704 & 688816 & 4.8 & 5.23799 & 99999999995 & TRN \\
\hline CHEMBL222838 & 688816 & 5.25 & 5.5882 & TST & \\
\hline CHEMBL1544122 & 688816 & 6.25 & 5.4157 & TRN & \\
\hline CHEMBL1516357 & 688816 & 4.75 & 5.4713 & TRN & \\
\hline CHEMBL1434456 & 688816 & 4.9 & 4.8387 & TST & \\
\hline CHEMBL1302199 & 688816 & 4.95 & 5.6765 & TRN & \\
\hline CHEMBL1545429 & 688816 & 5.05 & 5.1448 & TRN & \\
\hline CHEMBL1364865 & 688816 & 6.5501 & 5.1907 & TRN & \\
\hline CHEMBL1382812 & 688816 & 8.301 & 5.6151 & TRN & \\
\hline CHEMBL1606088 & 688816 & 4.8 & 5.1874 & TRN & \\
\hline CHEMBL1424864 & 688816 & 4.8 & 5.4007 & TRN & \\
\hline CHEMBL1348393 & 688816 & 4.9 & 5.3376 & TRN & \\
\hline CHEMBL1364203 & 688816 & 4.65 & 5.4456 & TST & \\
\hline CHEMBL1500455 & 688816 & 5.25 & 5.4457 & TST & \\
\hline CHEMBL1427969 & 688816 & 5.4 & 5.3303 & TRN & \\
\hline CHEMBL1377568 & 688816 & 5.35 & 5.5901 & TRN & \\
\hline CHEMBL1610061 & 688816 & 5.0 & 5.1408 & TRN & \\
\hline CHEMBL1598065 & 688816 & 4.7 & 4.8625 & TRN & \\
\hline CHEMBL1563157 & 688816 & 4.8 & 5.1799 & TRN & \\
\hline
\end{tabular}




\begin{tabular}{|c|c|c|c|c|c|}
\hline & & \multicolumn{4}{|c|}{ Supplemental Table S2.txt } \\
\hline CHEMBL1302170 & 688816 & 4.95 & 5.106 & TST & \\
\hline CHEMBL1423438 & 688816 & 4.75 & 5.4271 & TRN & \\
\hline CHEMBL1567686 & 688816 & 6.0 & 5.2394 & TRN & \\
\hline CHEMBL1346869 & 688816 & 5.5 & 5.1877 & TST & \\
\hline CHEMBL1532917 & 688816 & 4.95 & 5.227 & TRN & \\
\hline CHEMBL1461896 & 688816 & 4.85 & 5.2177 & TRN & \\
\hline CHEMBL1519059 & 688816 & 4.65 & 5.489 & TRN & \\
\hline CHEMBL1419413 & 688816 & 4.5 & 5.1552 & TRN & \\
\hline CHEMBL1379255 & 688816 & 4.9 & 4.923 & TST & \\
\hline CHEMBL3209509 & 688816 & 5.4 & 5.4335 & TST & \\
\hline CHEMBL1501377 & 688816 & 4.8 & 4.8885 & TRN & \\
\hline CHEMBL1537553 & 688816 & 4.6 & 5.294 & TST & \\
\hline CHEMBL1573448 & 688816 & 4.75 & 5.1093 & TRN & \\
\hline CHEMBL1555037 & 688816 & 4.7 & 5.048 & TRN & \\
\hline CHEMBL1487162 & 688816 & 4.65 & 5.2785 & TRN & \\
\hline CHEMBL1379423 & 688816 & 6.6 & 5.6586 & TRN & \\
\hline CHEMBL1470754 & 688816 & 4.9 & 5.1895 & TRN & \\
\hline CHEMBL1487259 & 688816 & 7.0 & 4.7407 & TST & \\
\hline CHEMBL1369571 & 688816 & 4.6 & 4.9257 & TRN & \\
\hline CHEMBL 3190911 & 688816 & 5.0 & 5.2355 & TST & \\
\hline CHEMBL1492304 & 688816 & 4.45 & 5.1819 & TST & \\
\hline CHEMBL1408894 & 688816 & 4.45 & 5.3506 & TST & \\
\hline CHEMBL1424479 & 688816 & 5.1 & 4.8079 & TRN & \\
\hline CHEMBL1581503 & 688816 & 4.45 & 4.8202 & TST & \\
\hline CHEMBL 3211005 & 688816 & 5.2 & 5.0342 & TRN & \\
\hline CHEMBL1481417 & 688816 & 4.5 & 5.2204 & TST & \\
\hline CHEMBL1529889 & 688816 & 4.8 & 5.0412 & TRN & \\
\hline CHEMBL1450725 & 688816 & 5.1 & 5.2747 & TRN & \\
\hline CHEMBL1430321 & 688816 & 4.45 & 5.2614 & TRN & \\
\hline CHEMBL1361974 & 688816 & 4.8 & 5.0605 & TRN & \\
\hline CHEMBL1316122 & 688816 & 4.95 & 5.0188 & TRN & \\
\hline CHEMBL1446363 & 688816 & 5.35 & 5.24299 & 9999999999 & TRN \\
\hline CHEMBL1429954 & 688816 & 5.2 & 5.3478 & TRN & \\
\hline CHEMBL1525611 & 688816 & 4.45 & 5.4979 & TST & \\
\hline CHEMBL1458899 & 688816 & 4.85 & 5.4166 & TST & \\
\hline CHEMBL1572007 & 688816 & 4.45 & 5.0409 & TST & \\
\hline CHEMBL1377921 & 688816 & 4.8 & 5.1605 & TST & \\
\hline CHEMBL1500105 & 688816 & 4.95 & 5.56 & TRN & \\
\hline CHEMBL1374594 & 688816 & 4.85 & 4.9451 & TRN & \\
\hline CHEMBL 3207864 & 688816 & 6.8 & 5.2327 & TRN & \\
\hline CHEMBL365342 & 688816 & 4.9 & 5.2453 & TRN & \\
\hline CHEMBL1325301 & 688816 & 4.5 & 5.2444 & TST & \\
\hline CHEMBL3189442 & 688816 & 5.35 & 5.2834 & TRN & \\
\hline CHEMBL1431070 & 688816 & 4.95 & 5.2301 & TRN & \\
\hline CHEMBL1301857 & 688816 & 6.15 & 5.3971 & TST & \\
\hline CHEMBL1417981 & 688816 & 4.65 & 4.6139 & TRN & \\
\hline CHEMBL1586535 & 688816 & 5.3 & 5.6446 & TRN & \\
\hline CHEMBL1336246 & 688816 & 6.25 & 5.8005 & TRN & \\
\hline
\end{tabular}




\begin{tabular}{|c|c|c|c|c|}
\hline \multicolumn{5}{|c|}{ Supplemental Table S2.tx } \\
\hline CHEMBL1452151 & 688816 & 5.4 & 5.1673 & TST \\
\hline CHEMBL1350141 & 688816 & 5.25 & 5.2011 & TRN \\
\hline CHEMBL1321350 & 688816 & 4.95 & 5.1816 & TRN \\
\hline CHEMBL1495537 & 688816 & 4.7 & 5.1182 & TRN \\
\hline CHEMBL603020 & 688816 & 4.95 & 4.9717 & TRN \\
\hline CHEMBL1482597 & 688816 & 4.45 & 5.2514 & TRN \\
\hline CHEMBL1983530 & 688816 & 5.55 & 5.4215 & TST \\
\hline CHEMBL1569989 & 688816 & 4.8 & 5.2345 & TRN \\
\hline CHEMBL1611513 & 688816 & 4.65 & 4.7312 & TRN \\
\hline CHEMBL1464468 & 688816 & 5.05 & 5.33 & TRN \\
\hline CHEMBL1433192 & 688816 & 6.6 & 5.54799 & 9999999999 \\
\hline CHEMBL1412213 & 688816 & 4.65 & 5.2379 & TRN \\
\hline CHEMBL3196412 & 688816 & 6.45 & 5.3195 & TRN \\
\hline CHEMBL1500190 & 688816 & 4.65 & 5.0767 & TRN \\
\hline CHEMBL1560080 & 688816 & 8.301 & 5.593 & TRN \\
\hline CHEMBL1415155 & 688816 & 4.9 & 5.1032 & TRN \\
\hline CHEMBL3192148 & 688816 & 4.65 & 5.3724 & TST \\
\hline CHEMBL1503678 & 688816 & 4.45 & 5.3534 & TST \\
\hline CHEMBL1538354 & 688816 & 4.75 & 5.4602 & TST \\
\hline CHEMBL1351651 & 688816 & 4.85 & 5.2945 & TRN \\
\hline CHEMBL1349959 & 688816 & 6.2 & 5.5682 & TRN \\
\hline CHEMBL1338034 & 688816 & 4.9 & 5.1313 & TRN \\
\hline CHEMBL1325978 & 688816 & 5.85 & 5.4551 & TST \\
\hline CHEMBL1374837 & 688816 & 5.7 & 4.8516 & TRN \\
\hline CHEMBL1520146 & 688816 & 5.35 & 5.1202 & TRN \\
\hline CHEMBL1425143 & 688816 & 4.45 & 5.0961 & TRN \\
\hline CHEMBL1341296 & 688816 & 5.0 & 5.2021 & TRN \\
\hline CHEMBL1584991 & 688816 & 5.0 & 5.4228 & TST \\
\hline CHEMBL1547498 & 688816 & 7.3002 & 5.8547 & TST \\
\hline CHEMBL 1461586 & 688816 & 5.25 & 6.2173 & TRN \\
\hline CHEMBL1527382 & 688816 & 4.95 & 5.1944 & TRN \\
\hline CHEMBL1398738 & 688816 & 4.45 & 5.5471 & TRN \\
\hline CHEMBL1493477 & 688816 & 5.8 & 5.3922 & TRN \\
\hline CHEMBL1594052 & 688816 & 5.05 & 5.0022 & TRN \\
\hline CHEMBL1320633 & 688816 & 4.45 & 5.4299 & TST \\
\hline CHEMBL1526324 & 688816 & 4.9 & 5.029 & TRN \\
\hline CHEMBL1594512 & 688816 & 4.8 & 5.0341 & TRN \\
\hline CHEMBL1465865 & 688816 & 8.301 & 5.5181 & TST \\
\hline CHEMBL320295 & 688816 & 6.35 & 5.4823 & TRN \\
\hline CHEMBL1364712 & 688816 & 7.3002 & 5.2118 & TRN \\
\hline CHEMBL1381247 & 688816 & 5.85 & 5.3092 & TRN \\
\hline CHEMBL1489449 & 688816 & 4.95 & 5.0736 & TRN \\
\hline CHEMBL1329863 & 688816 & 4.65 & 5.0447 & TRN \\
\hline CHEMBL1378769 & 688816 & 6.5 & 5.5989 & TST \\
\hline CHEMBL1526775 & 688816 & 8.301 & 5.346 & TST \\
\hline CHEMBL1366945 & 688816 & 5.1 & 5.1507 & TRN \\
\hline CHEMBL528186 & 688816 & 4.45 & 5.3371 & TRN \\
\hline CHEMBL1310615 & 688816 & 8.3468 & 5.3833 & TRN \\
\hline
\end{tabular}




\begin{tabular}{|c|c|c|c|c|c|}
\hline \multicolumn{6}{|c|}{ plemental Table } \\
\hline CHEMBL1570747 & 688816 & 4.85 & 5.2909 & TST & \\
\hline CHEMBL1456147 & 688816 & 5.6 & 5.4111 & TRN & \\
\hline CHEMBL1557691 & 688816 & 4.9 & 5.1463 & TST & \\
\hline CHEMBL1529350 & 688816 & 4.65 & 4.9276 & TRN & \\
\hline CHEMBL1322521 & 688816 & 4.9 & 5.17 & TRN & \\
\hline CHEMBL1581497 & 688816 & 4.9 & 4.9428 & TRN & \\
\hline CHEMBL1465709 & 688816 & 4.9 & 4.9865 & TRN & \\
\hline CHEMBL1519862 & 688816 & 4.95 & 5.1836 & TRN & \\
\hline CHEMBL1483395 & 688816 & 4.75 & 5.0992 & TST & \\
\hline CHEMBL1495685 & 688816 & 5.35 & 4.7893 & TST & \\
\hline CHEMBL1444387 & 688816 & 4.65 & 4.9593 & TST & \\
\hline CHEMBL1307702 & 688816 & 7.0 & 5.3542 & TRN & \\
\hline CHEMBL1577562 & 688816 & 6.4 & 5.3275 & TRN & \\
\hline CHEMBL1499649 & 688816 & 4.45 & 5.2486 & TRN & \\
\hline CHEMBL1534913 & 688816 & 8.0506 & 5.4289 & TRN & \\
\hline CHEMBL1426490 & 688816 & 4.9 & 5.0916 & TRN & \\
\hline CHEMBL1359452 & 688816 & 7.0501 & 5.5453 & TRN & \\
\hline CHEMBL1446131 & 688816 & 5.25 & 5.392 & TRN & \\
\hline CHEMBL1324638 & 688816 & 4.85 & 5.1077 & TRN & \\
\hline CHEMBL1979550 & 688816 & 4.45 & 5.3518 & TST & \\
\hline CHEMBL1369262 & 688816 & 5.4 & 4.8235 & TRN & \\
\hline CHEMBL1380758 & 688816 & 5.45 & 5.0745 & TRN & \\
\hline CHEMBL1497353 & 688816 & 4.65 & $5.1720 e$ & 0000000001 & TRN \\
\hline CHEMBL155563 & 688816 & 4.45 & 4.9577 & TRN & \\
\hline CHEMBL1375037 & 688816 & 5.5 & 5.7092 & TRN & \\
\hline CHEMBL1572558 & 688816 & 4.75 & 5.306 & TST & \\
\hline CHEMBL1465128 & 688816 & 7.15 & 4.8006 & TST & \\
\hline CHEMBL1545068 & 688816 & 4.8 & 5.3024 & TRN & \\
\hline CHEMBL1577213 & 688816 & 4.7 & 5.1832 & TRN & \\
\hline CHEMBL1348191 & 688816 & 5.0 & 5.1845 & TRN & \\
\hline CHEMBL1493693 & 688816 & 6.5 & 5.1742 & TRN & \\
\hline CHEMBL1414061 & 688816 & 5.3 & 5.041 & TST & \\
\hline CHEMBL1331081 & 688816 & 5.55 & 5.50299 & 9999999999 & TST \\
\hline CHEMBL1428504 & 688816 & 4.45 & 5.2109 & TRN & \\
\hline CHEMBL1446172 & 688816 & 5.3 & 5.1544 & TRN & \\
\hline CHEMBL1439841 & 688816 & 4.7 & 4.8763 & TRN & \\
\hline CHEMBL1350256 & 688816 & 4.65 & 5.1315 & TRN & \\
\hline CHEMBL1382050 & 688816 & 4.45 & 5.7827 & TST & \\
\hline CHEMBL1464152 & 688816 & 8.3468 & 5.6678 & TRN & \\
\hline CHEMBL1599630 & 688816 & 4.95 & 4.9341 & TRN & \\
\hline CHEMBL1609127 & 688816 & 5.1 & 5.2995 & TRN & \\
\hline CHEMBL1353676 & 688816 & 4.75 & 5.1796 & TST & \\
\hline CHEMBL1484439 & 688816 & 4.45 & 5.4813 & TRN & \\
\hline CHEMBL1420020 & 688816 & 4.9 & 5.6552 & TRN & \\
\hline CHEMBL1315691 & 688816 & 4.75 & 4.9993 & TRN & \\
\hline CHEMBL1358610 & 688816 & 4.95 & 4.8606 & TST & \\
\hline CHEMBL1477864 & 688816 & 4.45 & 5.5089 & TRN & \\
\hline CHEMBL1414841 & 688816 & 4.45 & 5.2339 & TRN & \\
\hline
\end{tabular}




\begin{tabular}{|c|c|c|c|c|}
\hline \multicolumn{5}{|c|}{ Supplemental Table S2.txt } \\
\hline CHEMBL1304037 & 688816 & 6.5 & 5.2886 & TRN \\
\hline CHEMBL1455446 & 688816 & 4.7 & 4.996 & TRN \\
\hline CHEMBL1611362 & 688816 & 4.45 & 5.2057 & TST \\
\hline CHEMBL1502022 & 688816 & 5.55 & 5.3204 & TRN \\
\hline CHEMBL1587285 & 688816 & 5.25 & 5.3923 & TST \\
\hline CHEMBL1339678 & 688816 & 5.45 & 5.138 & TRN \\
\hline CHEMBL1455830 & 688816 & 5.55 & 5.1366 & TRN \\
\hline CHEMBL1377208 & 688816 & 4.95 & 5.3833 & TRN \\
\hline CHEMBL1323757 & 688816 & 4.9 & 5.3018 & TRN \\
\hline CHEMBL1449532 & 688816 & 4.8 & 5.7029 & TRN \\
\hline CHEMBL1542072 & 688816 & 4.6 & 5.4907 & TRN \\
\hline CHEMBL1361074 & 688816 & 7.3497 & 5.1878 & TST \\
\hline CHEMBL1337767 & 688816 & 5.4 & 5.1643 & TRN \\
\hline CHEMBL1530122 & 688816 & 4.85 & 5.0056 & TRN \\
\hline CHEMBL1444020 & 688816 & 4.85 & 5.0503 & TRN \\
\hline CHEMBL1372094 & 688816 & 5.1 & 5.0432 & TRN \\
\hline CHEMBL1574931 & 688816 & 5.25 & 4.9971 & TRN \\
\hline CHEMBL1498006 & 688816 & 4.45 & 5.0627 & TRN \\
\hline CHEMBL 3209112 & 688816 & 4.45 & 5.3866 & TRN \\
\hline CHEMBL1415508 & 688816 & 4.8 & 5.0045 & TRN \\
\hline CHEMBL1602650 & 688816 & 5.0 & 5.521 & TST \\
\hline CHEMBL1477674 & 688816 & 5.0 & 5.1512 & TRN \\
\hline CHEMBL1566311 & 688816 & 4.9 & 4.9955 & TRN \\
\hline CHEMBL1365304 & 688816 & 4.9 & 5.2267 & TST \\
\hline CHEMBL1342957 & 688816 & 5.3 & 4.9508 & TRN \\
\hline CHEMBL1439482 & 688816 & 5.35 & 5.4133 & TRN \\
\hline CHEMBL1340433 & 688816 & 4.6 & 5.2061 & TRN \\
\hline CHEMBL1396475 & 688816 & 4.9 & 5.0936 & TRN \\
\hline CHEMBL1368106 & 688816 & 5.2 & 5.0017 & TRN \\
\hline CHEMBL1510649 & 688816 & 4.9 & 4.9164 & TST \\
\hline CHEMBL1336415 & 688816 & 5.5 & 5.3788 & TST \\
\hline CHEMBL1324011 & 688816 & 4.95 & 4.8449 & TRN \\
\hline CHEMBL1530935 & 688816 & 4.8 & 4.8911 & TRN \\
\hline CHEMBL1307984 & 688816 & 4.5 & 5.2755 & TRN \\
\hline CHEMBL1532095 & 688816 & 4.65 & 5.3526 & TRN \\
\hline CHEMBL1412795 & 688816 & 5.35 & 5.3162 & TRN \\
\hline CHEMBL1572842 & 688816 & 4.9 & 5.4252 & TST \\
\hline CHEMBL603129 & 688816 & 4.8 & 4.9008 & TRN \\
\hline CHEMBL1372441 & 688816 & 7.2503 & 5.5946 & TRN \\
\hline CHEMBL1493625 & 688816 & 4.5 & 5.8621 & TRN \\
\hline CHEMBL1333785 & 688816 & 4.95 & 5.3565 & TRN \\
\hline CHEMBL3211761 & 688816 & 4.95 & 5.2913 & TRN \\
\hline CHEMBL3191746 & 688816 & 4.45 & 5.6341 & TST \\
\hline CHEMBL1478871 & 688816 & 4.9 & 5.2752 & TRN \\
\hline CHEMBL1353432 & 688816 & 4.9 & 5.1041 & TRN \\
\hline CHEMBL1507620 & 688816 & 5.0 & 5.5299 & TRN \\
\hline CHEMBL1507560 & 688816 & 4.85 & 5.1896 & TRN \\
\hline CHEMBL1343740 & 688816 & 4.45 & 4.8501 & TRN \\
\hline
\end{tabular}




\begin{tabular}{|c|c|c|c|c|}
\hline \multicolumn{5}{|c|}{ Supplemental Table S2.txt } \\
\hline CHEMBL1334370 & 688816 & 5.55 & 5.2785 & TRN \\
\hline CHEMBL1549721 & 688816 & 4.95 & 5.2871 & TRN \\
\hline CHEMBL1565082 & 688816 & 4.45 & 5.3935 & TRN \\
\hline CHEMBL1425788 & 688816 & 4.5 & 5.0615 & TRN \\
\hline CHEMBL1557023 & 688816 & 5.05 & 5.216 & TRN \\
\hline CHEMBL1321990 & 688816 & 4.65 & 5.2908 & TRN \\
\hline CHEMBL3191887 & 688816 & 4.85 & 5.4193 & TRN \\
\hline CHEMBL1572507 & 688816 & 4.95 & 5.2591 & TRN \\
\hline CHEMBL1581326 & 688816 & 6.0 & 5.3669 & TST \\
\hline CHEMBL1407889 & 688816 & 4.45 & 5.1705 & TRN \\
\hline CHEMBL1538524 & 688816 & 4.6 & 5.521 & TST \\
\hline CHEMBL1303864 & 688816 & 5.0 & 5.1082 & TRN \\
\hline CHEMBL1456558 & 688816 & 8.3468 & 5.7993 & TRN \\
\hline CHEMBL566064 & 688816 & 4.95 & 5.0296 & TRN \\
\hline CHEMBL533602 & 688816 & 5.8 & 5.0885 & TRN \\
\hline CHEMBL1549092 & 688816 & 4.85 & 5.4915 & TRN \\
\hline CHEMBL1448422 & 688816 & 4.85 & 5.3582 & TRN \\
\hline CHEMBL1442886 & 688816 & 6.4 & 5.1857 & TRN \\
\hline CHEMBL1560671 & 688816 & 6.6 & 5.6695 & TRN \\
\hline CHEMBL1367362 & 688816 & 8.301 & 5.3088 & TRN \\
\hline CHEMBL1595181 & 688816 & 6.8 & 5.5257 & TRN \\
\hline CHEMBL1611867 & 688816 & 7.0 & 5.3728 & TST \\
\hline CHEMBL1309498 & 688816 & 5.25 & 5.2207 & TRN \\
\hline CHEMBL1459112 & 688816 & 4.9 & 5.1022 & TST \\
\hline CHEMBL1574230 & 688816 & 4.95 & 5.1699 & TRN \\
\hline CHEMBL1348442 & 688816 & 4.8 & 5.3731 & TRN \\
\hline CHEMBL1509112 & 688816 & 4.45 & 5.0987 & TRN \\
\hline CHEMBL1303367 & 688816 & 4.8 & 5.0857 & TRN \\
\hline CHEMBL1586739 & 688816 & 4.45 & 5.0557 & TRN \\
\hline CHEMBL1314122 & 688816 & 4.85 & 5.3955 & TRN \\
\hline CHEMBL1382849 & 688816 & 4.95 & 5.2568 & TST \\
\hline CHEMBL1459659 & 688816 & 7.0 & 5.7216 & TST \\
\hline CHEMBL1600828 & 688816 & 4.6 & 5.1666 & TRN \\
\hline CHEMBL1497438 & 688816 & 4.95 & 5.2656 & TRN \\
\hline CHEMBL1401174 & 688816 & 4.6 & 5.3672 & TRN \\
\hline CHEMBL1453844 & 688816 & 4.45 & 4.938 & TRN \\
\hline CHEMBL591618 & 688816 & 4.65 & 5.0774 & TRN \\
\hline CHEMBL1530707 & 688816 & 4.95 & 5.4915 & TST \\
\hline CHEMBL3197083 & 688816 & 4.95 & 5.6062 & TRN \\
\hline CHEMBL1481462 & 688816 & 4.65 & 5.5988 & TRN \\
\hline CHEMBL1992801 & 688816 & 4.75 & 5.121 & TRN \\
\hline CHEMBL1608471 & 688816 & 4.7 & 5.1243 & TRN \\
\hline CHEMBL1309820 & 688816 & 7.5498 & 5.1405 & TST \\
\hline CHEMBL1542131 & 688816 & 4.65 & 5.5087 & TST \\
\hline CHEMBL1463150 & 688816 & 4.95 & $5.2520 e$ & 0000000001 \\
\hline CHEMBL1305918 & 688816 & 4.55 & 5.4987 & TRN \\
\hline CHEMBL1585747 & 688816 & 4.95 & 5.4102 & TST \\
\hline CHEMBL1539910 & 688816 & 4.95 & 5.1928 & TRN \\
\hline
\end{tabular}

TRN 


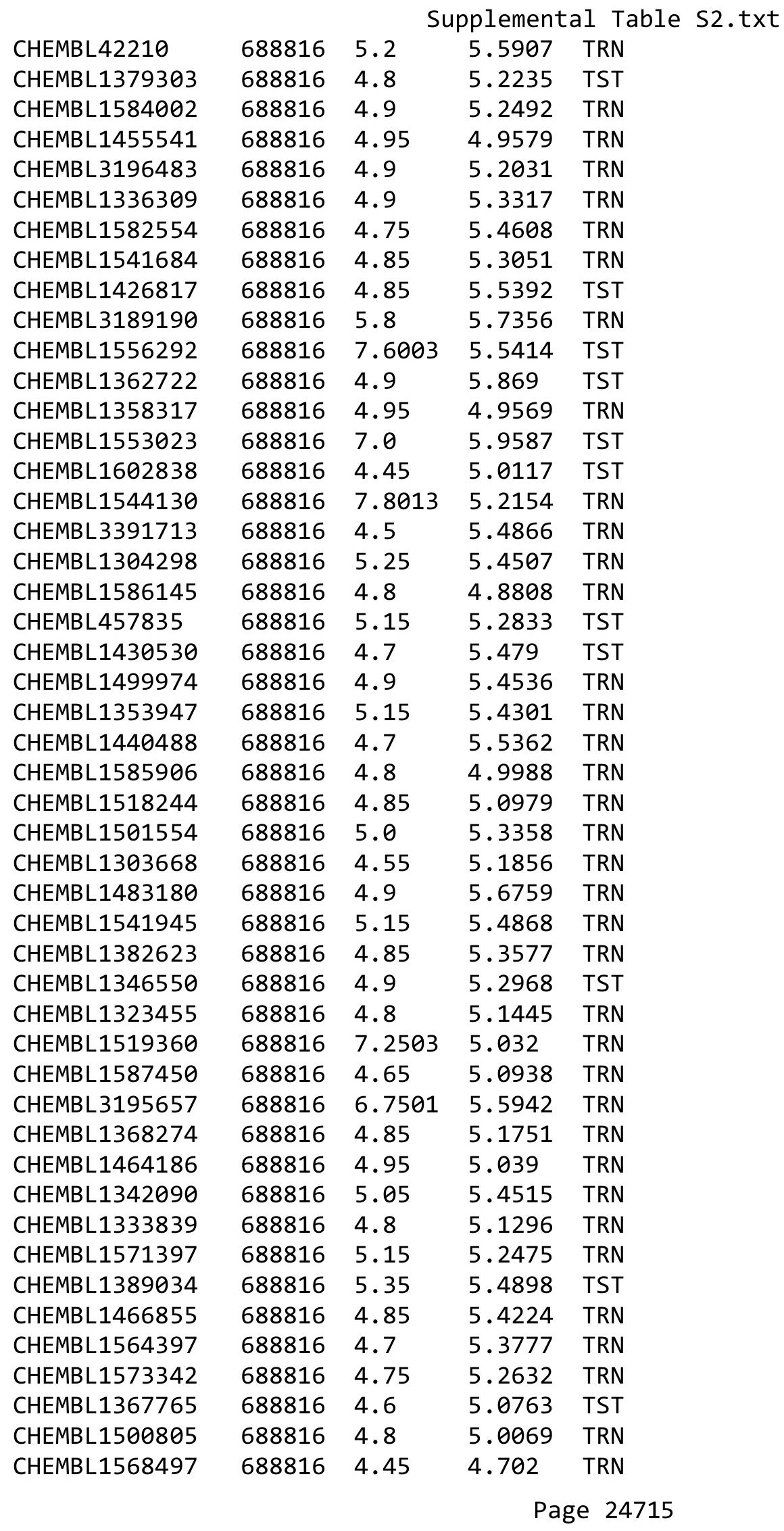




\begin{tabular}{|c|c|c|c|c|c|}
\hline \multicolumn{6}{|c|}{ Supplemental Table S2.txt } \\
\hline CHEMBL1424043 & 688816 & 6.25 & 5.4561 & TRN & \\
\hline CHEMBL1458192 & 688816 & 4.8 & 5.0602 & TRN & \\
\hline CHEMBL1605956 & 688816 & 4.45 & 5.1976 & TRN & \\
\hline CHEMBL1372214 & 688816 & 4.9 & 5.2154 & TRN & \\
\hline CHEMBL1430306 & 688816 & 5.75 & 5.4131 & TRN & \\
\hline CHEMBL1422644 & 688816 & 4.65 & 5.1795 & TRN & \\
\hline CHEMBL1490272 & 688816 & 4.7 & 5.6204 & TRN & \\
\hline CHEMBL1340195 & 688816 & 6.0 & 5.5457 & TRN & \\
\hline CHEMBL1491137 & 688816 & 4.85 & 5.6525 & TRN & \\
\hline CHEMBL1401717 & 688816 & 4.85 & 5.3138 & TST & \\
\hline CHEMBL530361 & 688816 & 4.9 & 4.9193 & TRN & \\
\hline CHEMBL1540442 & 688816 & 8.301 & 5.6358 & TRN & \\
\hline CHEMBL1529656 & 688816 & 5.5 & 5.3073 & TRN & \\
\hline CHEMBL1339320 & 688816 & 5.0 & 5.2133 & TST & \\
\hline CHEMBL1548641 & 688816 & 4.95 & 4.9921 & TRN & \\
\hline CHEMBL1597697 & 688816 & 5.15 & 5.1895 & TRN & \\
\hline CHEMBL1564305 & 688816 & 5.55 & 5.2399 & TRN & \\
\hline CHEMBL468341 & 688816 & 5.25 & 5.1135 & TRN & \\
\hline CHEMBL1363335 & 688816 & 4.9 & 5.4291 & TRN & \\
\hline CHEMBL1559423 & 688816 & 4.8 & 5.3854 & TRN & \\
\hline CHEMBL1440188 & 688816 & 5.4 & 5.0603 & TRN & \\
\hline CHEMBL1372734 & 688816 & 4.45 & 4.9326 & TRN & \\
\hline CHEMBL1526991 & 688816 & 5.6 & 5.3866 & TRN & \\
\hline CHEMBL1583595 & 688816 & 8.0506 & 5.1123 & TRN & \\
\hline CHEMBL 3212933 & 688816 & 5.9 & 5.1727 & TRN & \\
\hline CHEMBL118481 & 688816 & 4.9 & 5.0885 & TRN & \\
\hline CHEMBL1440996 & 688816 & 7.5498 & 5.37700 & 0000000001 & TRN \\
\hline CHEMBL1491094 & 688816 & 4.85 & 5.3311 & TRN & \\
\hline CHEMBL1443752 & 688816 & 4.85 & 5.2384 & TST & \\
\hline CHEMBL1443953 & 688816 & 7.8996 & 5.6887 & TRN & \\
\hline CHEMBL 3214400 & 688816 & 7.8996 & 5.1165 & TST & \\
\hline CHEMBL1604306 & 688816 & 5.75 & 5.3075 & TRN & \\
\hline CHEMBL3190071 & 688816 & 4.75 & 5.4988 & TRN & \\
\hline CHEMBL1480652 & 688816 & 4.95 & 5.5964 & TRN & \\
\hline CHEMBL1334576 & 688816 & 4.75 & 5.2246 & TRN & \\
\hline CHEMBL1566106 & 688816 & 5.7 & 5.4417 & TRN & \\
\hline CHEMBL1491929 & 688816 & 6.6 & 5.3057 & TRN & \\
\hline CHEMBL1547935 & 688816 & 4.95 & 5.1043 & TST & \\
\hline CHEMBL1454143 & 688816 & 4.95 & 4.9833 & TST & \\
\hline CHEMBL1458448 & 688816 & 4.5 & 5.5009 & TST & \\
\hline CHEMBL536375 & 688816 & 4.95 & 5.1256 & TRN & \\
\hline CHEMBL3208190 & 688816 & 4.9 & 5.1731 & TRN & \\
\hline CHEMBL1368218 & 688816 & 4.45 & 5.1911 & TRN & \\
\hline CHEMBL1539012 & 688816 & 4.85 & 5.1471 & TRN & \\
\hline CHEMBL1561596 & 688816 & 6.0 & 5.6544 & TRN & \\
\hline CHEMBL1470255 & 688816 & 6.1 & 5.2599 & TRN & \\
\hline CHEMBL1489593 & 688816 & 5.0 & 4.9695 & TST & \\
\hline CHEMBL1575294 & 688816 & 4.95 & 5.2496 & TRN & \\
\hline
\end{tabular}




\begin{tabular}{|c|c|c|c|c|c|}
\hline \multicolumn{6}{|c|}{ Supplemental Table S2.txt } \\
\hline CHEMBL1482284 & 688816 & 4.45 & 4.7475 & TRN & \\
\hline CHEMBL1555482 & 688816 & 5.5 & 5.2947 & TST & \\
\hline CHEMBL1430200 & 688816 & 4.75 & 5.2613 & TRN & \\
\hline CHEMBL194594 & 688816 & 5.9 & 5.3041 & TST & \\
\hline CHEMBL 3190384 & 688816 & 4.7 & 5.0311 & TST & \\
\hline CHEMBL1508470 & 688816 & 4.95 & 5.2616 & TRN & \\
\hline CHEMBL1604945 & 688816 & 5.35 & 5.2548 & TRN & \\
\hline CHEMBL1528249 & 688816 & 7.2503 & 5.3858 & TRN & \\
\hline CHEMBL1339171 & 688816 & 4.95 & 4.8688 & TRN & \\
\hline CHEMBL1426371 & 688816 & 5.4 & 5.2547 & TST & \\
\hline CHEMBL1514151 & 688816 & 4.5 & 5.0318 & TRN & \\
\hline CHEMBL1609015 & 688816 & 4.85 & 5.2738 & TST & \\
\hline CHEMBL1330907 & 688816 & 5.0 & 4.7809 & TRN & \\
\hline CHEMBL1594302 & 688816 & 5.25 & 5.2748 & TRN & \\
\hline CHEMBL1523513 & 688816 & 6.05 & 4.81 & TST & \\
\hline CHEMBL1524677 & 688816 & 7.8013 & 5.5945 & TST & \\
\hline CHEMBL1534949 & 688816 & 5.05 & 5.5033 & TRN & \\
\hline CHEMBL1301170 & 688816 & 5.45 & 5.3737 & TST & \\
\hline CHEMBL1540158 & 688816 & 4.8 & 4.8935 & TRN & \\
\hline CHEMBL1500379 & 688816 & 5.85 & 5.1771 & TRN & \\
\hline CHEMBL 3194878 & 688816 & 5.0 & 5.2794 & TRN & \\
\hline CHEMBL1427823 & 688816 & 4.85 & 5.0678 & TRN & \\
\hline CHEMBL1335620 & 688816 & 4.85 & 5.3715 & TRN & \\
\hline CHEMBL1446466 & 688816 & 5.35 & 5.0488 & TRN & \\
\hline CHEMBL1488194 & 688816 & 4.85 & 5.5113 & TST & \\
\hline CHEMBL1502164 & 688816 & 5.1 & 5.1616 & TRN & \\
\hline CHEMBL1495481 & 688816 & 8.3468 & 4.9817 & TST & \\
\hline CHEMBL1500404 & 688816 & 5.0 & 5.1254 & TRN & \\
\hline CHEMBL1547670 & 688816 & 4.5 & 5.25899 & 99999999995 & TRN \\
\hline CHEMBL1523556 & 688816 & 5.55 & 5.2389 & TRN & \\
\hline CHEMBL1393834 & 688816 & 4.8 & 5.3938 & TRN & \\
\hline CHEMBL1594058 & 688816 & 4.7 & 5.1106 & TRN & \\
\hline CHEMBL1466696 & 688816 & 5.95 & 5.1488 & TRN & \\
\hline CHEMBL1399698 & 688816 & 5.05 & 5.0777 & TRN & \\
\hline CHEMBL1374564 & 688816 & 8.4949 & 5.4526 & TRN & \\
\hline CHEMBL1383644 & 688816 & 5.25 & 5.6235 & TST & \\
\hline CHEMBL1387239 & 688816 & 6.05 & 5.3316 & TRN & \\
\hline CHEMBL1301796 & 688816 & 4.75 & 5.0639 & TRN & \\
\hline CHEMBL1475270 & 688816 & 5.55 & 5.1504 & TRN & \\
\hline CHEMBL1304467 & 688816 & 8.3468 & 5.4739 & TST & \\
\hline CHEMBL1423731 & 688816 & 5.65 & 5.4524 & TRN & \\
\hline CHEMBL1572006 & 688816 & 4.45 & 5.2032 & TRN & \\
\hline CHEMBL1580723 & 688816 & 4.85 & 5.2953 & TRN & \\
\hline CHEMBL1556235 & 688816 & 4.45 & 5.0181 & TRN & \\
\hline CHEMBL1586516 & 688816 & 8.301 & 5.4233 & TRN & \\
\hline CHEMBL1467789 & 688816 & 4.45 & 5.1544 & TRN & \\
\hline CHEMBL1418225 & 688816 & 5.25 & 5.3181 & TST & \\
\hline CHEMBL1314582 & 688816 & 4.9 & 5.902 & TRN & \\
\hline
\end{tabular}




\begin{tabular}{|c|c|c|c|c|}
\hline \multicolumn{5}{|c|}{ Supplemental Table S2.txt } \\
\hline CHEMBL1528168 & 688816 & 4.95 & 4.9519 & TRN \\
\hline CHEMBL1424137 & 688816 & 4.45 & 5.1909 & TRN \\
\hline CHEMBL1558310 & 688816 & 4.9 & 4.9 & TRN \\
\hline CHEMBL 3207394 & 688816 & 5.65 & 5.3996 & TRN \\
\hline CHEMBL1585209 & 688816 & 5.1 & 5.5928 & TRN \\
\hline CHEMBL1465338 & 688816 & 4.75 & 4.9107 & TRN \\
\hline CHEMBL1424180 & 688816 & 5.3 & 5.5762 & TRN \\
\hline CHEMBL1372163 & 688816 & 6.6 & 5.2208 & TRN \\
\hline CHEMBL1326623 & 688816 & 4.85 & 5.0423 & TRN \\
\hline CHEMBL1328533 & 688816 & 4.5 & 5.2133 & TRN \\
\hline CHEMBL 3197044 & 688816 & 5.0 & 5.6328 & TRN \\
\hline CHEMBL1580377 & 688816 & 4.9 & 5.0388 & TRN \\
\hline CHEMBL1325846 & 688816 & 5.05 & 5.0117 & TRN \\
\hline CHEMBL1456351 & 688816 & 7.0 & 5.3416 & TRN \\
\hline CHEMBL1495977 & 688816 & 6.3 & 5.3599 & TRN \\
\hline CHEMBL1516493 & 688816 & 7.699 & 5.5688 & TST \\
\hline CHEMBL1415767 & 688816 & 6.4 & 5.5337 & TST \\
\hline CHEMBL1549756 & 688816 & 5.0 & 5.13 & TRN \\
\hline CHEMBL1344717 & 688816 & 8.301 & 5.6058 & TRN \\
\hline CHEMBL1554915 & 688816 & 5.4 & 5.4713 & TRN \\
\hline CHEMBL1306243 & 688816 & 4.95 & 5.2729 & TRN \\
\hline CHEMBL1980826 & 688816 & 4.65 & 5.0982 & TRN \\
\hline CHEMBL1542427 & 688816 & 4.7 & 5.5844 & TRN \\
\hline CHEMBL1463435 & 688816 & 5.15 & 4.9947 & TRN \\
\hline CHEMBL1541987 & 688816 & 4.65 & 5.4745 & TST \\
\hline CHEMBL1349841 & 688816 & 6.8 & 5.6851 & TRN \\
\hline CHEMBL1537925 & 688816 & 6.5501 & 5.7012 & TST \\
\hline CHEMBL1450954 & 688816 & 5.0 & 5.2198 & TRN \\
\hline CHEMBL1604880 & 688816 & 4.9 & 5.3057 & TRN \\
\hline CHEMBL1327716 & 688816 & 4.65 & 5.1596 & TRN \\
\hline CHEMBL1528283 & 688816 & 8.301 & 5.0231 & TST \\
\hline CHEMBL1546932 & 688816 & 4.95 & 4.961 & TRN \\
\hline CHEMBL589715 & 688816 & 4.65 & 4.9773 & TRN \\
\hline CHEMBL1386457 & 688816 & 4.95 & 5.3501 & TRN \\
\hline CHEMBL1425890 & 688816 & 4.95 & 4.801 & TRN \\
\hline CHEMBL1582488 & 688816 & 4.95 & 5.4558 & TRN \\
\hline CHEMBL1506533 & 688816 & 7.0 & 5.1509 & TRN \\
\hline CHEMBL1404398 & 688816 & 4.95 & 5.6108 & TRN \\
\hline CHEMBL1527814 & 688816 & 4.9 & 5.3934 & TRN \\
\hline CHEMBL1521122 & 688816 & 5.95 & 5.2576 & TST \\
\hline CHEMBL1525187 & 688816 & 5.1 & 5.192 & TST \\
\hline CHEMBL1417661 & 688816 & 8.0506 & 5.2317 & TRN \\
\hline CHEMBL1580616 & 688816 & 5.0 & 5.1606 & TST \\
\hline CHEMBL1430362 & 688816 & 4.95 & 4.9603 & TRN \\
\hline CHEMBL1501462 & 688816 & 4.75 & 5.3972 & TST \\
\hline CHEMBL1309247 & 688816 & 4.9 & 5.3847 & TRN \\
\hline CHEMBL 1452277 & 688816 & 4.65 & 5.1229 & TRN \\
\hline CHEMBL1541973 & 688816 & 4.6 & 5.2221 & TRN \\
\hline
\end{tabular}




\begin{tabular}{|c|c|c|c|c|c|}
\hline \multicolumn{6}{|c|}{ Supplemental Table S2.txt } \\
\hline CHEMBL567422 & 688816 & 4.65 & 5.6326 & TST & \\
\hline CHEMBL1542483 & 688816 & 5.4 & 5.7236 & TRN & \\
\hline CHEMBL1363196 & 688816 & 4.6 & 5.2896 & TRN & \\
\hline CHEMBL1605266 & 688816 & 4.45 & 5.3436 & TRN & \\
\hline CHEMBL1438622 & 688816 & 7.0 & 5.3556 & TRN & \\
\hline CHEMBL 3145378 & 688816 & 5.5 & 5.3208 & TRN & \\
\hline CHEMBL1597195 & 688816 & 4.8 & 5.2308 & TST & \\
\hline CHEMBL1509253 & 688816 & 4.85 & 4.9212 & TRN & \\
\hline CHEMBL1300278 & 688816 & 7.0 & 5.1792 & TRN & \\
\hline CHEMBL1539980 & 688816 & 5.25 & 5.119 & TST & \\
\hline CHEMBL1351926 & 688816 & 4.8 & 5.6461 & TRN & \\
\hline CHEMBL 244743 & 688816 & 4.95 & 5.1733 & TST & \\
\hline CHEMBL1586964 & 688816 & 4.9 & 4.9151 & TRN & \\
\hline CHEMBL1554913 & 688816 & 4.65 & 4.9289 & TRN & \\
\hline CHEMBL 3192743 & 688816 & 4.95 & 5.4867 & TST & \\
\hline CHEMBL1507978 & 688816 & 4.65 & 5.095 & TRN & \\
\hline CHEMBL1516249 & 688816 & 4.6 & 5.3975 & TRN & \\
\hline CHEMBL1399208 & 688816 & 5.0 & 5.1742 & TRN & \\
\hline CHEMBL1307792 & 688816 & 5.15 & 4.7997 & TST & \\
\hline CHEMBL1486531 & 688816 & 4.8 & 5.3232 & TRN & \\
\hline CHEMBL1441238 & 688816 & 5.1 & 5.4841 & TRN & \\
\hline CHEMBL1575814 & 688816 & 7.5498 & 5.434 & TRN & \\
\hline CHEMBL365939 & 688816 & 5.1 & 5.0052 & TRN & \\
\hline CHEMBL479368 & 688816 & 4.65 & 5.2863 & TRN & \\
\hline CHEMBL1543567 & 688816 & 4.75 & 5.499 & TST & \\
\hline CHEMBL1441082 & 688816 & 6.0 & 5.5578 & TRN & \\
\hline CHEMBL1408931 & 688816 & 7.5498 & 5.8523 & TST & \\
\hline CHEMBL1347782 & 688816 & 4.9 & 4.9986 & TRN & \\
\hline CHEMBL1383088 & 688816 & 4.95 & 5.2491 & TST & \\
\hline CHEMBL1472293 & 688816 & 4.8 & 5.2559 & TRN & \\
\hline CHEMBL1345531 & 688816 & 5.0 & 5.5467 & TRN & \\
\hline CHEMBL1455191 & 688816 & 4.75 & 5.3979 & TRN & \\
\hline CHEMBL1317795 & 688816 & 4.9 & 5.0346 & TRN & \\
\hline CHEMBL1607915 & 688816 & 4.6 & 5.2057 & TST & \\
\hline CHEMBL1256693 & 688816 & 4.55 & 5.2344 & TST & \\
\hline CHEMBL1456547 & 688816 & 4.9 & 5.166 & TRN & \\
\hline CHEMBL1329228 & 688816 & 4.85 & 5.2748 & TRN & \\
\hline CHEMBL1589462 & 688816 & 4.45 & 5.6141 & TRN & \\
\hline CHEMBL1575565 & 688816 & 4.8 & 4.84699 & 99999999995 & TRN \\
\hline CHEMBL1522545 & 688816 & 6.8 & 4.9984 & TST & \\
\hline CHEMBL1452080 & 688816 & 4.9 & 5.325 & TST & \\
\hline CHEMBL1417949 & 688816 & 4.45 & 5.0048 & TRN & \\
\hline CHEMBL1393058 & 688816 & 4.75 & 5.0185 & TRN & \\
\hline CHEMBL1345938 & 688816 & 5.05 & 5.048 & TRN & \\
\hline CHEMBL1423600 & 688816 & 7.6498 & 5.5298 & TST & \\
\hline CHEMBL1320653 & 688816 & 5.45 & 5.2248 & TRN & \\
\hline CHEMBL1971015 & 688816 & 4.65 & 5.2918 & TRN & \\
\hline CHEMBL1568925 & 688816 & 4.95 & 5.0903 & TRN & \\
\hline
\end{tabular}




\begin{tabular}{|c|c|c|c|c|c|}
\hline \\
\hline CHEMBL1493668 & 688816 & 4.7 & 5.2084 & TST & \\
\hline CHEMBL1481181 & 688816 & 6.8 & 5.3325 & TRN & \\
\hline CHEMBL1432704 & 688816 & 6.0 & 5.5557 & TST & \\
\hline CHEMBL1578232 & 688816 & 5.35 & 5.395 & TRN & \\
\hline CHEMBL1470284 & 688816 & 4.7 & 5.7439 & TRN & \\
\hline CHEMBL1503312 & 688816 & 5.0 & 4.9413 & TRN & \\
\hline CHEMBL1483199 & 688816 & 6.8 & 5.2921 & TST & \\
\hline CHEMBL1499350 & 688816 & 4.8 & 5.0434 & TRN & \\
\hline CHEMBL1485010 & 688816 & 4.5 & 5.1991 & TRN & \\
\hline CHEMBL1564229 & 688816 & 5.1 & 5.1422 & TST & \\
\hline CHEMBL1579477 & 688816 & 4.45 & 5.3813 & TRN & \\
\hline CHEMBL1604011 & 688816 & 5.0 & 4.6607 & TRN & \\
\hline CHEMBL1420206 & 688816 & 5.35 & 4.8283 & TST & \\
\hline CHEMBL3213102 & 688816 & 5.95 & 5.6909 & TRN & \\
\hline CHEMBL1520048 & 688816 & 4.9 & 4.9583 & TRN & \\
\hline CHEMBL1561933 & 688816 & 5.0 & 5.1181 & TST & \\
\hline CHEMBL1412086 & 688816 & 5.8 & 4.8727 & TST & \\
\hline CHEMBL1532480 & 688816 & 6.95 & 5.2763 & TRN & \\
\hline CHEMBL1609599 & 688816 & 6.05 & 5.0183 & TRN & \\
\hline CHEMBL1537548 & 688816 & 6.4 & 5.3492 & TST & \\
\hline CHEMBL1546494 & 688816 & 8.0 & 5.4234 & TRN & \\
\hline CHEMBL1451113 & 688816 & 6.0 & 5.4755 & TRN & \\
\hline CHEMBL1343635 & 688816 & 4.9 & 4.7454 & TRN & \\
\hline CHEMBL1456491 & 688816 & 5.75 & 4.83 & TRN & \\
\hline CHEMBL3189573 & 688816 & 4.45 & 5.4002 & TRN & \\
\hline CHEMBL1359573 & 688816 & 5.0 & 5.1353 & TRN & \\
\hline CHEMBL1361837 & 688816 & 5.25 & 5.6213 & TRN & \\
\hline CHEMBL1327298 & 688816 & 6.35 & 5.5116 & TRN & \\
\hline CHEMBL1373239 & 688816 & 5.3 & 5.7218 & TRN & \\
\hline CHEMBL1435819 & 688816 & 6.5 & 4.9819 & TST & \\
\hline CHEMBL3210861 & 688816 & 5.2 & 5.5668 & TRN & \\
\hline CHEMBL1370810 & 688816 & 4.6 & 4.9201 & TRN & \\
\hline CHEMBL1445889 & 688816 & 5.85 & 5.5325 & TRN & \\
\hline CHEMBL1446286 & 688816 & 4.65 & 4.9637 & TRN & \\
\hline CHEMBL1558952 & 688816 & 4.9 & 4.7916 & TRN & \\
\hline CHEMBL1574112 & 688816 & 4.65 & 5.4317 & TRN & \\
\hline CHEMBL1576634 & 688816 & 4.9 & 5.3353 & TRN & \\
\hline CHEMBL1446426 & 688816 & 5.45 & 5.4787 & TRN & \\
\hline CHEMBL1403940 & 688816 & 4.55 & 5.2437 & TST & \\
\hline CHEMBL 1443740 & 688816 & 4.45 & 5.2104 & TRN & \\
\hline CHEMBL539947 & 688816 & 6.0 & 5.3508 & TRN & \\
\hline CHEMBL1333985 & 688816 & 4.6 & 4.9986 & TRN & \\
\hline CHEMBL3199091 & 688816 & 4.75 & 5.01699 & 99999999995 & TRN \\
\hline CHEMBL1373906 & 688816 & 5.15 & 5.067 & TRN & \\
\hline CHEMBL1384007 & 688816 & 4.45 & 5.2526 & TRN & \\
\hline CHEMBL1320504 & 688816 & 5.75 & 5.3749 & TRN & \\
\hline CHEMBL1545180 & 688816 & 4.65 & 5.059 & TRN & \\
\hline CHEMBL1470773 & 688816 & 6.45 & 5.3878 & TRN & \\
\hline
\end{tabular}




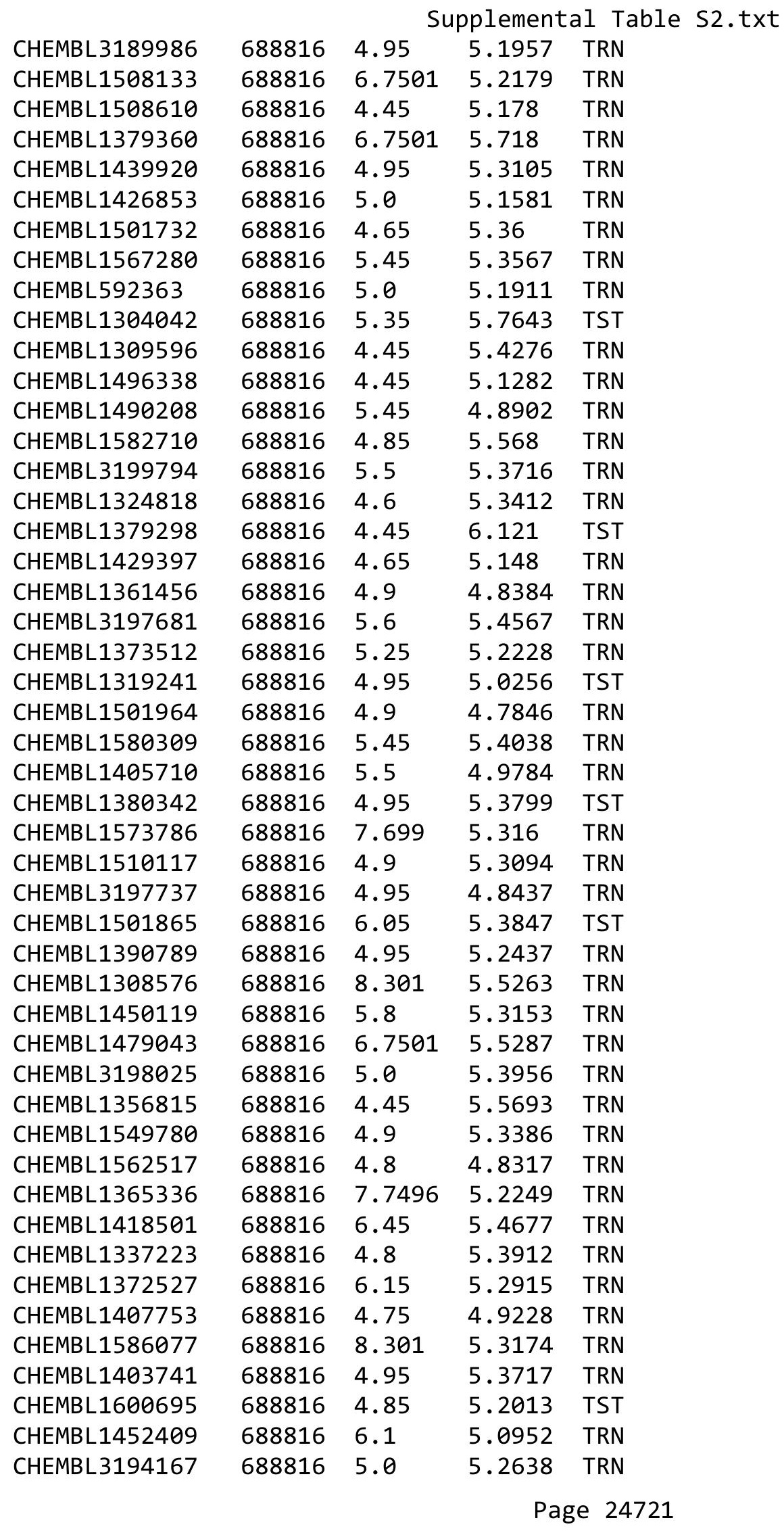




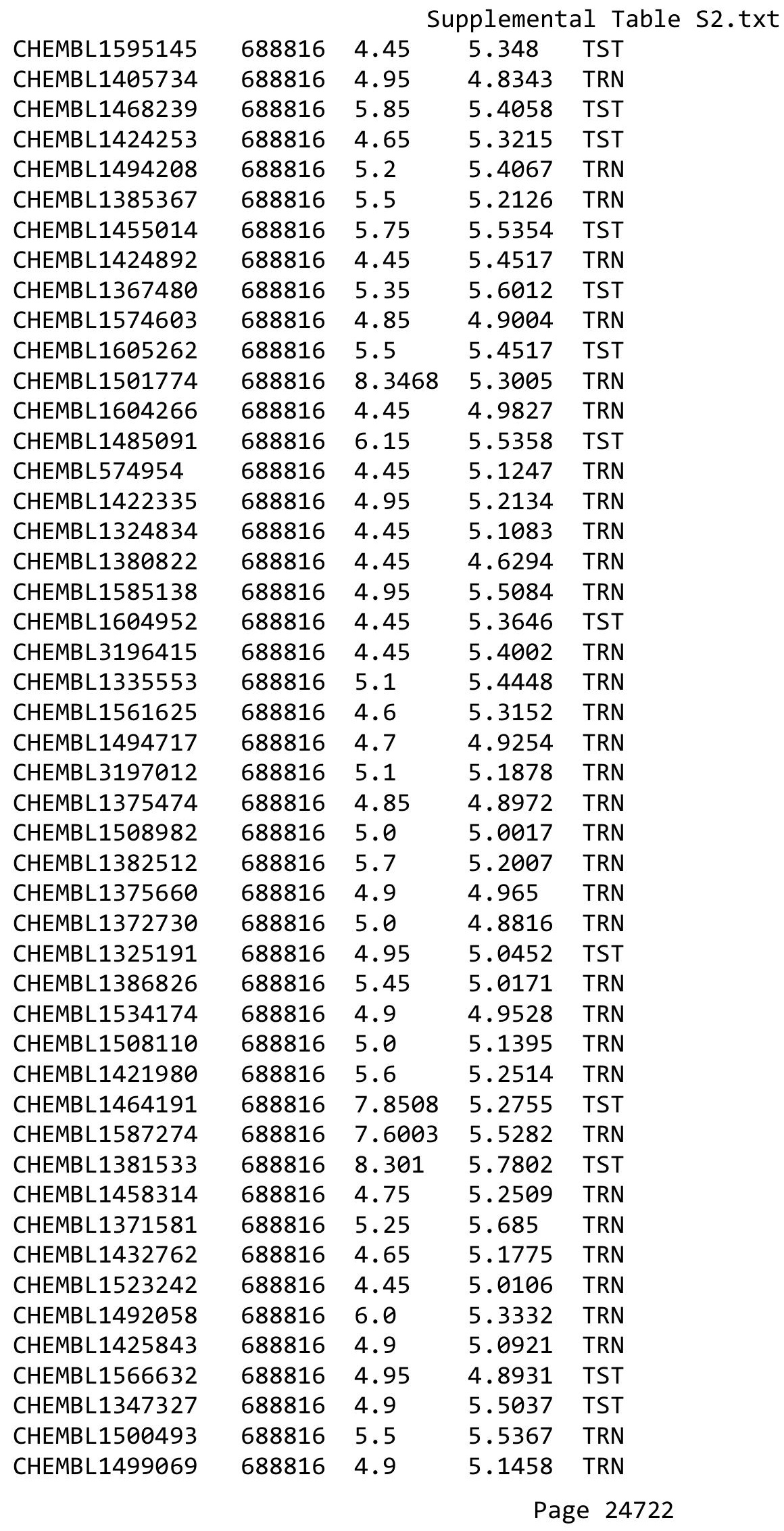




\begin{tabular}{|c|c|c|c|c|c|}
\hline \multicolumn{6}{|c|}{ Supplemental Table S2.txt } \\
\hline CHEMBL3211119 & 688816 & 5.8 & 5.5129 & TRN & \\
\hline CHEMBL3211955 & 688816 & 6.8 & 5.6493 & TST & \\
\hline CHEMBL1360566 & 688816 & 4.85 & 5.3576 & TRN & \\
\hline CHEMBL1469982 & 688816 & 4.95 & 5.2075 & TRN & \\
\hline CHEMBL1599391 & 688816 & 4.95 & 5.1231 & TRN & \\
\hline CHEMBL1360365 & 688816 & 7.6498 & 5.5861 & TST & \\
\hline CHEMBL1572883 & 688816 & 5.1 & 4.8168 & TST & \\
\hline CHEMBL1455026 & 688816 & 7.5498 & 5.6579 & TRN & \\
\hline CHEMBL1306533 & 688816 & 7.2 & 5.3202 & TRN & \\
\hline CHEMBL1531688 & 688816 & 5.25 & 5.53299 & 99999999995 & TRN \\
\hline CHEMBL1567184 & 688816 & 4.95 & 4.9204 & TRN & \\
\hline CHEMBL1359417 & 688816 & 4.65 & 5.1943 & TST & \\
\hline CHEMBL1531626 & 688816 & 4.45 & 5.1722 & TST & \\
\hline CHEMBL1611110 & 688816 & 4.85 & 5.3145 & TRN & \\
\hline CHEMBL1502014 & 688816 & 4.9 & 4.8555 & TST & \\
\hline CHEMBL1352613 & 688816 & 4.75 & 5.6123 & TST & \\
\hline CHEMBL1542726 & 688816 & 4.9 & 5.0703 & TRN & \\
\hline CHEMBL1577165 & 688816 & 7.699 & 5.1632 & TRN & \\
\hline CHEMBL1341704 & 688816 & 4.45 & 5.249 & TST & \\
\hline CHEMBL1398418 & 688816 & 4.75 & 4.5836 & TRN & \\
\hline CHEMBL1520368 & 688816 & 5.0 & 5.5514 & TST & \\
\hline CHEMBL1462662 & 688816 & 5.25 & 5.0822 & TST & \\
\hline CHEMBL1404060 & 688816 & 4.45 & 5.1738 & TRN & \\
\hline CHEMBL1572131 & 688816 & 8.3979 & 5.6401 & TRN & \\
\hline CHEMBL1580776 & 688816 & 4.8 & 5.3249 & TRN & \\
\hline CHEMBL1508173 & 688816 & 4.7 & 5.7165 & TRN & \\
\hline CHEMBL1379776 & 688816 & 5.0 & 4.9958 & TRN & \\
\hline CHEMBL1580679 & 688816 & 4.95 & 5.3607 & TST & \\
\hline CHEMBL1344072 & 688816 & 5.1 & 5.4151 & TRN & \\
\hline CHEMBL1552810 & 688816 & 6.15 & 5.4353 & TRN & \\
\hline CHEMBL1383973 & 688816 & 4.95 & 5.1657 & TRN & \\
\hline CHEMBL1368385 & 688816 & 4.9 & 5.2802 & TRN & \\
\hline CHEMBL1563164 & 688816 & 4.75 & 5.2516 & TRN & \\
\hline CHEMBL1606312 & 688816 & 4.85 & 5.2754 & TST & \\
\hline CHEMBL1481776 & 688816 & 4.85 & 5.216 & TRN & \\
\hline CHEMBL3144931 & 688816 & 4.45 & 5.2012 & TRN & \\
\hline CHEMBL1561660 & 688816 & 5.2 & 5.6659 & TRN & \\
\hline CHEMBL1400761 & 688816 & 6.4 & 4.9191 & TRN & \\
\hline CHEMBL1306232 & 688816 & 4.8 & 5.2221 & TRN & \\
\hline CHEMBL1510856 & 688816 & 5.55 & 5.1565 & TRN & \\
\hline CHEMBL1390939 & 688816 & 5.95 & 5.4852 & TRN & \\
\hline CHEMBL1453272 & 688816 & 5.05 & 5.4249 & TRN & \\
\hline CHEMBL1453953 & 688816 & 4.85 & 4.9128 & TRN & \\
\hline CHEMBL1327858 & 688816 & 5.55 & 5.5828 & TRN & \\
\hline CHEMBL1382766 & 688816 & 4.65 & 5.5615 & TRN & \\
\hline CHEMBL1974529 & 688816 & 4.9 & 5.1627 & TRN & \\
\hline CHEMBL1505059 & 688816 & 7.6003 & 5.5885 & TRN & \\
\hline CHEMBL1418686 & 688816 & 4.65 & 4.7435 & TRN & \\
\hline
\end{tabular}




\begin{tabular}{|c|c|c|c|c|c|}
\hline & & \multicolumn{4}{|c|}{ Supplemental Table S2.txt } \\
\hline CHEMBL1587422 & 688816 & 8.4559 & 5.3225 & TST & \\
\hline CHEMBL1450132 & 688816 & 4.45 & 5.2794 & TST & \\
\hline CHEMBL1518926 & 688816 & 4.45 & 5.1922 & TRN & \\
\hline CHEMBL 3214227 & 688816 & 7.7496 & 5.5187 & TRN & \\
\hline CHEMBL1364267 & 688816 & 5.9 & 5.0064 & TRN & \\
\hline CHEMBL1465463 & 688816 & 4.75 & 5.2565 & TST & \\
\hline CHEMBL1428527 & 688816 & 7.699 & 5.4599 & TST & \\
\hline CHEMBL1305924 & 688816 & 4.9 & 5.0987 & TRN & \\
\hline CHEMBL1604961 & 688816 & 8.3468 & 5.5326 & TST & \\
\hline CHEMBL1578294 & 688816 & 4.95 & 4.8943 & TRN & \\
\hline CHEMBL1485372 & 688816 & 5.15 & 5.0768 & TRN & \\
\hline CHEMBL1572512 & 688816 & 6.6499 & 4.9814 & TRN & \\
\hline CHEMBL1338556 & 688816 & 5.5 & 5.5347 & TRN & \\
\hline CHEMBL1530805 & 688816 & 5.15 & 5.2351 & TST & \\
\hline CHEMBL1967436 & 688816 & 4.45 & 5.2543 & TRN & \\
\hline CHEMBL3209651 & 688816 & 5.5 & 5.2172 & TRN & \\
\hline CHEMBL1427014 & 688816 & 4.7 & 5.16700 & $\partial 000000001$ & TRN \\
\hline CHEMBL1403205 & 688816 & 5.65 & 4.9188 & TRN & \\
\hline CHEMBL1471633 & 688816 & 4.8 & 5.4446 & TRN & \\
\hline CHEMBL1341157 & 688816 & 4.65 & 5.0928 & TRN & \\
\hline CHEMBL1527427 & 688816 & 5.5 & 5.1635 & TRN & \\
\hline CHEMBL1523172 & 688816 & 5.15 & 5.0384 & TRN & \\
\hline CHEMBL18115 & 688816 & 4.6 & 5.5184 & TRN & \\
\hline CHEMBL1369420 & 688816 & 4.6 & 4.9742 & TRN & \\
\hline CHEMBL1395301 & 688816 & 5.8 & 5.4571 & TST & \\
\hline CHEMBL1534495 & 688816 & 5.85 & 5.7078 & TRN & \\
\hline CHEMBL1470636 & 688816 & 4.65 & 5.2671 & TRN & \\
\hline CHEMBL1538398 & 688816 & 4.9 & 4.9242 & TRN & \\
\hline CHEMBL1478389 & 688816 & 4.7 & 5.226 & TRN & \\
\hline CHEMBL1351489 & 688816 & 6.8499 & 5.5039 & TRN & \\
\hline CHEMBL1538653 & 688816 & 4.45 & 5.6152 & TRN & \\
\hline CHEMBL1390470 & 688816 & 4.7 & 5.0651 & TST & \\
\hline CHEMBL3195423 & 688816 & 7.699 & 5.5356 & TRN & \\
\hline CHEMBL1511385 & 688816 & 4.9 & 5.0254 & TRN & \\
\hline CHEMBL1564542 & 688816 & 4.8 & 5.0154 & TRN & \\
\hline CHEMBL1542333 & 688816 & 5.05 & 5.2088 & TRN & \\
\hline CHEMBL1510755 & 688816 & 6.8499 & 5.6846 & TRN & \\
\hline CHEMBL3192620 & 688816 & 8.301 & 5.6777 & TRN & \\
\hline CHEMBL3193515 & 688816 & 4.6 & 5.0951 & TRN & \\
\hline CHEMBL1488713 & 688816 & 5.35 & 5.5648 & TST & \\
\hline CHEMBL1470839 & 688816 & 4.45 & 5.1391 & TRN & \\
\hline CHEMBL1469644 & 688816 & 4.45 & 4.9723 & TRN & \\
\hline CHEMBL3196853 & 688816 & 5.1 & 5.4713 & TRN & \\
\hline CHEMBL1580202 & 688816 & 5.4 & 5.3251 & TRN & \\
\hline CHEMBL1269508 & 688816 & 5.15 & 5.152 & TRN & \\
\hline CHEMBL1609019 & 688816 & 5.25 & 4.9427 & TRN & \\
\hline CHEMBL1548366 & 688816 & 6.6 & 5.9608 & TST & \\
\hline CHEMBL1420204 & 688816 & 4.5 & 5.4033 & TRN & \\
\hline
\end{tabular}




\begin{tabular}{|c|c|c|c|c|c|}
\hline \multicolumn{6}{|c|}{ Supplemental Table S2.txt } \\
\hline CHEMBL1372293 & 688816 & 5.0 & 4.7892 & TRN & \\
\hline CHEMBL564708 & 688816 & 4.95 & $5.0680 e$ & 00000000005 & TRN \\
\hline CHEMBL 3197474 & 688816 & 4.9 & 5.4236 & TRN & \\
\hline CHEMBL1399643 & 688816 & 4.8 & 5.3045 & TRN & \\
\hline CHEMBL536950 & 688816 & 4.85 & 5.1108 & TST & \\
\hline CHEMBL1370269 & 688816 & 8.3468 & 5.3498 & TRN & \\
\hline CHEMBL1572578 & 688816 & 4.75 & 5.2343 & TRN & \\
\hline CHEMBL1565450 & 688816 & 4.65 & 5.3658 & TRN & \\
\hline CHEMBL1573700 & 688816 & 5.45 & 5.2637 & TST & \\
\hline CHEMBL1409445 & 688816 & 5.4 & 5.3554 & TST & \\
\hline CHEMBL1509850 & 688816 & 4.9 & 5.4848 & TST & \\
\hline CHEMBL1540335 & 688816 & 7.699 & 5.0807 & TST & \\
\hline CHEMBL3194752 & 688816 & 4.65 & 4.9825 & TRN & \\
\hline CHEMBL1608868 & 688816 & 4.95 & 4.9741 & TRN & \\
\hline CHEMBL1304407 & 688816 & 4.6 & 5.0481 & TRN & \\
\hline CHEMBL1377860 & 688816 & 4.9 & 5.4374 & TRN & \\
\hline CHEMBL1532403 & 688816 & 7.0501 & 5.4019 & TRN & \\
\hline CHEMBL1301037 & 688816 & 7.2503 & 5.1288 & TRN & \\
\hline CHEMBL1579548 & 688816 & 4.6 & 4.7131 & TST & \\
\hline CHEMBL1537623 & 688816 & 4.85 & 5.1725 & TRN & \\
\hline CHEMBL1324074 & 688816 & 4.95 & 5.2243 & TRN & \\
\hline CHEMBL1981200 & 688816 & 5.05 & 5.2114 & TRN & \\
\hline CHEMBL1450517 & 688816 & 5.55 & 5.1749 & TST & \\
\hline CHEMBL1445891 & 688816 & 6.05 & 5.8144 & TST & \\
\hline CHEMBL3213329 & 688816 & 4.45 & 5.2809 & TRN & \\
\hline CHEMBL1572158 & 688816 & 4.9 & 5.4562 & TRN & \\
\hline CHEMBL1415560 & 688816 & 5.25 & 5.3206 & TRN & \\
\hline CHEMBL1378174 & 688816 & 8.4949 & 5.2101 & TRN & \\
\hline CHEMBL1603969 & 688816 & 5.15 & 5.3874 & TRN & \\
\hline CHEMBL1395477 & 688816 & 4.95 & 5.0996 & TRN & \\
\hline CHEMBL1459565 & 688816 & 6.8499 & 5.8097 & TRN & \\
\hline CHEMBL1393786 & 688816 & 4.45 & 5.7052 & TRN & \\
\hline CHEMBL1531214 & 688816 & 4.8 & 5.2147 & TST & \\
\hline CHEMBL1547777 & 688816 & 4.6 & 4.7147 & TRN & \\
\hline CHEMBL1981398 & 688816 & 5.25 & 5.1267 & TRN & \\
\hline CHEMBL1549509 & 688816 & 5.5 & 5.391 & TRN & \\
\hline CHEMBL1567359 & 688816 & 4.9 & 5.2284 & TRN & \\
\hline CHEMBL1531426 & 688816 & 5.7 & 5.6196 & TST & \\
\hline CHEMBL1591741 & 688816 & 5.0 & 5.4772 & TRN & \\
\hline CHEMBL3192555 & 688816 & 5.4 & 5.2916 & TRN & \\
\hline CHEMBL1468740 & 688816 & 4.8 & 5.0313 & TRN & \\
\hline CHEMBL1484108 & 688816 & 4.8 & 5.1244 & TRN & \\
\hline CHEMBL1338234 & 688816 & 8.1487 & 5.4401 & TRN & \\
\hline CHEMBL1507150 & 688816 & 4.85 & 5.3231 & TST & \\
\hline CHEMBL1492185 & 688816 & 5.2 & 5.6027 & TRN & \\
\hline CHEMBL1335349 & 688816 & 4.45 & 5.0477 & TRN & \\
\hline CHEMBL 84472 & 688816 & 4.85 & 5.5495 & TST & \\
\hline CHEMBL1440973 & 688816 & 5.35 & 5.0789 & TRN & \\
\hline
\end{tabular}




\begin{tabular}{|c|c|c|c|c|c|}
\hline \multicolumn{6}{|c|}{ Supplemental Table S2.txt } \\
\hline CHEMBL1501189 & 688816 & 5.1 & 5.1206 & TRN & \\
\hline CHEMBL1569531 & 688816 & 6.0 & 5.513 & TRN & \\
\hline CHEMBL1300195 & 688816 & 8.301 & 5.381 & TRN & \\
\hline CHEMBL1380326 & 688816 & 4.9 & 5.0591 & TRN & \\
\hline CHEMBL1588816 & 688816 & 5.2 & 5.4744 & TRN & \\
\hline CHEMBL1334684 & 688816 & 4.8 & 5.0983 & TST & \\
\hline CHEMBL1468561 & 688816 & 5.15 & 5.1075 & TST & \\
\hline CHEMBL1605575 & 688816 & 4.8 & 5.0409 & TRN & \\
\hline CHEMBL3213336 & 688816 & 8.301 & 5.7743 & TRN & \\
\hline CHEMBL1389874 & 688816 & 5.25 & 5.2873 & TST & \\
\hline CHEMBL1450251 & 688816 & 4.9 & 5.4268 & TST & \\
\hline CHEMBL 2003564 & 688816 & 6.6 & 5.6441 & TRN & \\
\hline CHEMBL1342513 & 688816 & 4.75 & 4.9961 & TRN & \\
\hline CHEMBL1367897 & 688816 & 5.0 & 5.0307 & TRN & \\
\hline CHEMBL1333310 & 688816 & 4.95 & 4.9344 & TST & \\
\hline CHEMBL261118 & 688816 & 5.4 & 5.4526 & TRN & \\
\hline CHEMBL1569222 & 688816 & 5.0 & 5.1552 & TRN & \\
\hline CHEMBL1547700 & 688816 & 5.35 & 5.5427 & TRN & \\
\hline CHEMBL1535745 & 688816 & 5.45 & 5.2105 & TST & \\
\hline CHEMBL1610333 & 688816 & 6.9 & 5.3519 & TST & \\
\hline CHEMBL1453502 & 688816 & 4.45 & 5.1304 & TRN & \\
\hline CHEMBL1970872 & 688816 & 4.45 & 5.1384 & TRN & \\
\hline CHEMBL1566587 & 688816 & 5.45 & 5.5843 & TRN & \\
\hline CHEMBL1410628 & 688816 & 6.05 & 5.5461 & TRN & \\
\hline CHEMBL1317796 & 688816 & 5.55 & 5.2545 & TRN & \\
\hline CHEMBL1521423 & 688816 & 5.05 & 5.1555 & TRN & \\
\hline CHEMBL1405015 & 688816 & 7.3002 & 4.9829 & TRN & \\
\hline CHEMBL1449212 & 688816 & 5.4 & 5.2229 & TRN & \\
\hline CHEMBL1547431 & 688816 & 4.75 & 5.5785 & TST & \\
\hline CHEMBL1314699 & 688816 & 4.6 & 4.7029 & TRN & \\
\hline CHEMBL1444326 & 688816 & 6.7501 & 5.471 & TST & \\
\hline CHEMBL1478726 & 688816 & 4.5 & 5.4409 & TST & \\
\hline CHEMBL1351757 & 688816 & 7.4498 & 5.84399 & 9999999999 & TRN \\
\hline CHEMBL1606014 & 688816 & 4.95 & 5.3939 & TST & \\
\hline CHEMBL1455508 & 688816 & 4.5 & 5.1569 & TRN & \\
\hline CHEMBL1340590 & 688816 & 7.8508 & 5.7731 & TRN & \\
\hline CHEMBL1584928 & 688816 & 5.2 & 5.402 & TRN & \\
\hline CHEMBL1555153 & 688816 & 4.7 & 5.6568 & TST & \\
\hline CHEMBL1507523 & 688816 & 4.85 & 5.1354 & TRN & \\
\hline CHEMBL1472478 & 688816 & 4.45 & 5.0387 & TRN & \\
\hline CHEMBL1567985 & 688816 & 6.3 & 5.1227 & TRN & \\
\hline CHEMBL1524357 & 688816 & 4.45 & 4.6962 & TRN & \\
\hline CHEMBL1378830 & 688816 & 5.65 & 5.2989 & TRN & \\
\hline CHEMBL1545419 & 688816 & 4.85 & 5.4209 & TRN & \\
\hline CHEMBL1364032 & 688816 & 6.5 & 5.2805 & TRN & \\
\hline CHEMBL3191091 & 688816 & 4.9 & 5.0209 & TRN & \\
\hline CHEMBL1321297 & 688816 & 5.5 & 5.0346 & TRN & \\
\hline CHEMBL1536260 & 688816 & 4.7 & 5.0202 & TST & \\
\hline
\end{tabular}




\begin{tabular}{|c|c|c|c|c|}
\hline \multicolumn{5}{|c|}{ Supplemental Table S2.txt } \\
\hline CHEMBL1608208 & 688816 & 5.35 & 5.0104 & TRN \\
\hline CHEMBL1603278 & 688816 & 4.95 & 5.0994 & TRN \\
\hline CHEMBL1339307 & 688816 & 4.85 & 5.4716 & TRN \\
\hline CHEMBL1985582 & 688816 & 5.4 & 5.1774 & TRN \\
\hline CHEMBL1325327 & 688816 & 4.8 & 5.3766 & TRN \\
\hline CHEMBL1506833 & 688816 & 5.45 & 5.3998 & TRN \\
\hline CHEMBL3193873 & 688816 & 6.5 & 5.2666 & TRN \\
\hline CHEMBL1336102 & 688816 & 4.45 & 5.1695 & TRN \\
\hline CHEMBL1499842 & 688816 & 6.05 & 4.9677 & TST \\
\hline CHEMBL1367222 & 688816 & 6.0 & 4.9607 & TRN \\
\hline CHEMBL1428992 & 688816 & 4.75 & 5.3663 & TST \\
\hline CHEMBL1466337 & 688816 & 5.5 & 5.9836 & TST \\
\hline CHEMBL1353909 & 688816 & 4.8 & 5.1242 & TRN \\
\hline CHEMBL1368484 & 688816 & 4.45 & 4.8958 & TRN \\
\hline CHEMBL1427430 & 688816 & 4.9 & 5.2485 & TRN \\
\hline CHEMBL1984604 & 688816 & 4.55 & 4.8625 & TRN \\
\hline CHEMBL1418775 & 688816 & 6.15 & 5.4171 & TRN \\
\hline CHEMBL1483981 & 688816 & 4.7 & 5.4693 & TST \\
\hline CHEMBL1528526 & 688816 & 4.9 & 5.4615 & TRN \\
\hline CHEMBL1304008 & 688816 & 4.95 & 5.0853 & TRN \\
\hline CHEMBL1610067 & 688816 & 7.4001 & 4.9603 & TRN \\
\hline CHEMBL1561532 & 688816 & 4.75 & 4.7931 & TRN \\
\hline CHEMBL1424992 & 688816 & 5.6 & 5.2143 & TRN \\
\hline CHEMBL1396949 & 688816 & 4.45 & 5.2196 & TRN \\
\hline CHEMBL1371815 & 688816 & 5.35 & 5.4443 & TRN \\
\hline CHEMBL 2369327 & 688816 & 6.3 & 5.4202 & TRN \\
\hline CHEMBL460518 & 688816 & 4.9 & 5.2365 & TRN \\
\hline CHEMBL1420513 & 688816 & 4.5 & 5.2772 & TRN \\
\hline CHEMBL1517623 & 688816 & 4.45 & 5.1252 & TRN \\
\hline CHEMBL1578760 & 688816 & 4.7 & 5.4063 & TRN \\
\hline CHEMBL1468680 & 688816 & 4.8 & 5.0521 & TRN \\
\hline CHEMBL1443282 & 688816 & 4.9 & 5.0829 & TRN \\
\hline CHEMBL1339496 & 688816 & 4.9 & 5.0754 & TRN \\
\hline CHEMBL1538632 & 688816 & 5.35 & 5.2656 & TST \\
\hline CHEMBL1608401 & 688816 & 4.45 & 5.021 & TRN \\
\hline CHEMBL1432476 & 688816 & 4.75 & 5.4525 & TRN \\
\hline CHEMBL3192482 & 688816 & 5.3 & 5.1766 & TST \\
\hline CHEMBL1422454 & 688816 & 6.7001 & 5.7778 & TST \\
\hline CHEMBL1476463 & 688816 & 5.3 & 5.0067 & TST \\
\hline CHEMBL935 & 688816 & 6.0 & 5.5961 & TST \\
\hline CHEMBL1383415 & 688816 & 4.8 & 4.8006 & TRN \\
\hline CHEMBL1472342 & 688816 & 4.95 & 5.775 & TRN \\
\hline CHEMBL1365340 & 688816 & 5.0 & $5.1110 e$ & 0000000001 \\
\hline CHEMBL1307972 & 688816 & 4.5 & 5.0159 & TST \\
\hline CHEMBL1605295 & 688816 & 4.65 & 5.2333 & TST \\
\hline CHEMBL1597292 & 688816 & 4.7 & 5.2934 & TST \\
\hline CHEMBL1336368 & 688816 & 4.9 & 5.3561 & TRN \\
\hline CHEMBL3210383 & 688816 & 4.9 & 5.5899 & TRN \\
\hline
\end{tabular}




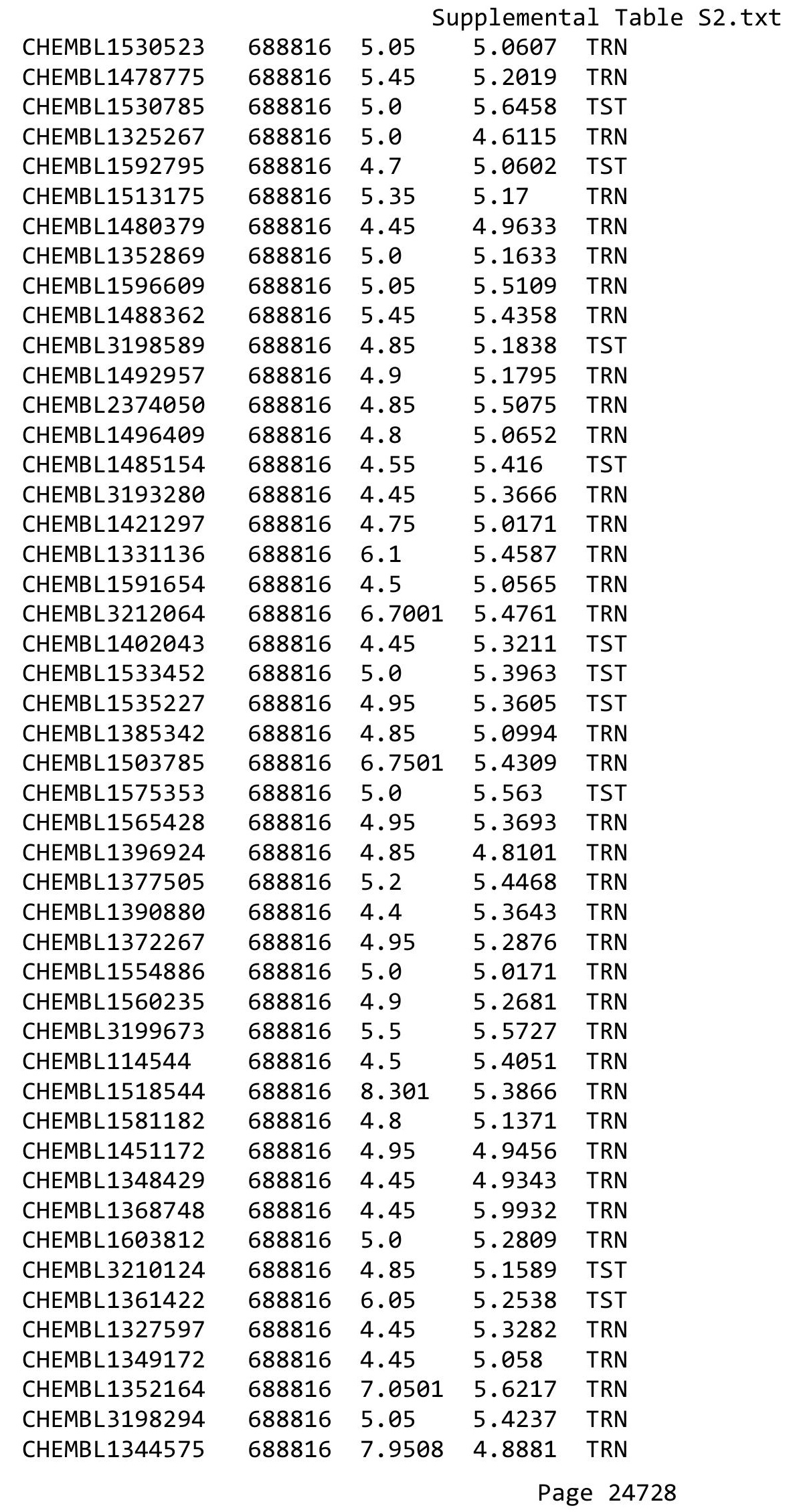




\begin{tabular}{|c|c|c|c|c|}
\hline \multicolumn{5}{|c|}{ Supplemental Table S2.txt } \\
\hline CHEMBL1323183 & 688816 & 6.5501 & 4.9548 & TST \\
\hline CHEMBL1415546 & 688816 & 4.85 & 4.7625 & TRN \\
\hline CHEMBL1411684 & 688816 & 5.55 & 5.3835 & TRN \\
\hline CHEMBL 3213503 & 688816 & 5.9 & 5.5929 & TRN \\
\hline CHEMBL1337529 & 688816 & 6.5 & 5.4472 & TRN \\
\hline CHEMBL1443795 & 688816 & 4.95 & 5.3422 & TRN \\
\hline CHEMBL1385055 & 688816 & 4.65 & 5.3868 & TRN \\
\hline CHEMBL1454233 & 688816 & 4.45 & 5.1725 & TRN \\
\hline CHEMBL1494056 & 688816 & 4.45 & 5.0899 & TRN \\
\hline CHEMBL1541283 & 688816 & 5.35 & 5.1208 & TRN \\
\hline CHEMBL1421592 & 688816 & 5.25 & 4.8282 & TRN \\
\hline CHEMBL1582073 & 688816 & 4.8 & 5.4121 & TST \\
\hline CHEMBL1481317 & 688816 & 4.55 & 5.2386 & TST \\
\hline CHEMBL1333496 & 688816 & 7.0 & 5.2933 & TRN \\
\hline CHEMBL3193566 & 688816 & 5.05 & 4.7187 & TRN \\
\hline CHEMBL1556606 & 688816 & 5.65 & 5.2287 & TRN \\
\hline CHEMBL1557676 & 688816 & 6.0 & 5.4774 & TRN \\
\hline CHEMBL1447445 & 688816 & 5.5 & 5.1279 & TRN \\
\hline CHEMBL1580641 & 688816 & 5.0 & 4.7484 & TRN \\
\hline CHEMBL573319 & 688816 & 5.4 & 5.1978 & TRN \\
\hline CHEMBL1337709 & 688816 & 8.0 & 5.5011 & TRN \\
\hline CHEMBL1532722 & 688816 & 5.9 & 5.0365 & TRN \\
\hline CHEMBL3210914 & 688816 & 5.0 & 5.2981 & TRN \\
\hline CHEMBL1520135 & 688816 & 4.45 & 5.1868 & TRN \\
\hline CHEMBL501711 & 688816 & 4.9 & 5.5986 & TST \\
\hline CHEMBL3207842 & 688816 & 5.25 & 5.6899 & TRN \\
\hline CHEMBL1343899 & 688816 & 6.7501 & 5.4895 & TRN \\
\hline CHEMBL1442136 & 688816 & 4.75 & 4.791 & TST \\
\hline CHEMBL1529950 & 688816 & 5.3 & 5.25 & TRN \\
\hline CHEMBL1450483 & 688816 & 4.9 & 5.0475 & TRN \\
\hline CHEMBL1500581 & 688816 & 4.45 & 5.2966 & TRN \\
\hline CHEMBL1484565 & 688816 & 4.75 & 5.0216 & TRN \\
\hline CHEMBL1375693 & 688816 & 7.9508 & 5.2873 & TST \\
\hline CHEMBL3189568 & 688816 & 5.0 & 4.9482 & TRN \\
\hline CHEMBL1304603 & 688816 & 4.9 & 5.2049 & TRN \\
\hline CHEMBL1367866 & 688816 & 4.7 & 4.9401 & TRN \\
\hline CHEMBL1444181 & 688816 & 4.45 & 5.0075 & TRN \\
\hline CHEMBL1418330 & 688816 & 5.2 & 5.2215 & TRN \\
\hline CHEMBL1530537 & 688816 & 4.9 & 4.8061 & TRN \\
\hline CHEMBL1533848 & 688816 & 5.15 & 5.4565 & TST \\
\hline CHEMBL1390112 & 688816 & 4.95 & 5.0286 & TRN \\
\hline CHEMBL1479996 & 688816 & 5.0 & 5.3411 & TRN \\
\hline CHEMBL1495847 & 688816 & 4.95 & 4.6614 & TRN \\
\hline CHEMBL1521641 & 688816 & 4.45 & 5.2473 & TRN \\
\hline CHEMBL1548916 & 688816 & 4.95 & 5.6567 & TST \\
\hline CHEMBL1582518 & 688816 & 4.9 & 4.9789 & TST \\
\hline CHEMBL1338243 & 688816 & 4.45 & 5.2544 & TRN \\
\hline CHEMBL1344403 & 688816 & 6.1 & 5.5194 & TRN \\
\hline
\end{tabular}




\begin{tabular}{|c|c|c|c|c|}
\hline \multicolumn{5}{|c|}{ Supplemental Table S2.txt } \\
\hline CHEMBL1382211 & 688816 & 4.9 & 5.5927 & TRN \\
\hline CHEMBL1303439 & 688816 & 5.5 & 5.2855 & TST \\
\hline CHEMBL1420835 & 688816 & 4.65 & 5.2801 & TRN \\
\hline CHEMBL1462788 & 688816 & 4.95 & 5.2305 & TRN \\
\hline CHEMBL1532575 & 688816 & 4.95 & 4.7573 & TRN \\
\hline CHEMBL1363728 & 688816 & 5.55 & 5.3777 & TST \\
\hline CHEMBL1427178 & 688816 & 4.95 & 5.1545 & TRN \\
\hline CHEMBL1562620 & 688816 & 4.9 & 5.2497 & TST \\
\hline CHEMBL3210013 & 688816 & 4.95 & 5.2817 & TRN \\
\hline CHEMBL1596903 & 688816 & 4.8 & 4.6931 & TST \\
\hline CHEMBL1256698 & 688816 & 5.25 & 5.2779 & TST \\
\hline CHEMBL1580509 & 688816 & 6.1 & 5.3717 & TRN \\
\hline CHEMBL1405112 & 688816 & 4.85 & 6.0594 & TRN \\
\hline CHEMBL1589112 & 688816 & 6.25 & 5.652 & TRN \\
\hline CHEMBL1464383 & 688816 & 4.75 & 5.1728 & TRN \\
\hline CHEMBL1391597 & 688816 & 5.8 & 5.2116 & TRN \\
\hline CHEMBL1309599 & 688816 & 5.25 & 5.3964 & TRN \\
\hline CHEMBL1523742 & 688816 & 5.45 & 5.2609 & TRN \\
\hline CHEMBL1345198 & 688816 & 6.8 & 5.1707 & TRN \\
\hline CHEMBL1310876 & 688816 & 4.9 & 5.9084 & TRN \\
\hline CHEMBL1567942 & 688816 & 4.65 & 5.4419 & TRN \\
\hline CHEMBL1538424 & 688816 & 5.95 & 5.2553 & TRN \\
\hline CHEMBL1598614 & 688816 & 5.8 & 5.5329 & TRN \\
\hline CHEMBL1487155 & 688816 & 4.95 & 4.9894 & TRN \\
\hline CHEMBL1556895 & 688816 & 7.0 & 5.6664 & TRN \\
\hline CHEMBL1581650 & 688816 & 5.85 & 5.1096 & TRN \\
\hline CHEMBL3212885 & 688816 & 4.75 & 5.1215 & TRN \\
\hline CHEMBL1411212 & 688816 & 5.0 & 5.2224 & TRN \\
\hline CHEMBL1397050 & 688816 & 4.45 & 5.6338 & TST \\
\hline CHEMBL1464140 & 688816 & 5.75 & 5.0329 & TRN \\
\hline CHEMBL1383468 & 688816 & 4.6 & 5.0116 & TRN \\
\hline CHEMBL1417602 & 688816 & 5.25 & 5.2815 & TRN \\
\hline CHEMBL1508377 & 688816 & 5.4 & 5.2783 & TRN \\
\hline CHEMBL225354 & 688816 & 5.2 & 5.3151 & TRN \\
\hline CHEMBL1561456 & 688816 & 5.15 & 5.0963 & TRN \\
\hline CHEMBL1373476 & 688816 & 6.8499 & 5.1832 & TRN \\
\hline CHEMBL1610802 & 688816 & 4.95 & 5.6023 & TST \\
\hline CHEMBL1575333 & 688816 & 5.05 & 5.3399 & TRN \\
\hline CHEMBL1575905 & 688816 & 5.55 & 5.0601 & TRN \\
\hline CHEMBL1390863 & 688816 & 5.0 & 4.9751 & TRN \\
\hline CHEMBL1370581 & 688816 & 4.45 & 5.4925 & TRN \\
\hline CHEMBL1525361 & 688816 & 4.75 & 5.4226 & TRN \\
\hline CHEMBL1424943 & 688816 & 5.75 & 5.6953 & TRN \\
\hline CHEMBL3195194 & 688816 & 8.301 & 4.9138 & TST \\
\hline CHEMBL1368254 & 688816 & 8.301 & 5.2313 & TRN \\
\hline CHEMBL1569806 & 688816 & 4.7 & 4.8334 & TRN \\
\hline CHEMBL1530520 & 688816 & 6.5501 & 5.3711 & TRN \\
\hline CHEMBL1432279 & 688816 & 4.85 & 5.0945 & TRN \\
\hline
\end{tabular}




\begin{tabular}{|c|c|c|c|c|c|}
\hline \multirow[b]{2}{*}{ CHEMBL1581440 } & \multirow[b]{2}{*}{688816} & \multicolumn{4}{|c|}{ Supplemental Table S2.txt } \\
\hline & & 4.65 & 5.3138 & TRN & \\
\hline CHEMBL1480192 & 688816 & 4.85 & 4.9786 & TRN & \\
\hline CHEMBL1331356 & 688816 & 4.75 & 5.5762 & TRN & \\
\hline CHEMBL1541116 & 688816 & 4.9 & 5.1747 & TST & \\
\hline CHEMBL1489418 & 688816 & 5.0 & 4.9957 & TRN & \\
\hline CHEMBL1564386 & 688816 & 4.9 & 4.61600 & 00000000005 & TST \\
\hline CHEMBL1222382 & 688816 & 4.95 & 4.9114 & TRN & \\
\hline CHEMBL1305180 & 688816 & 4.45 & 5.5265 & TST & \\
\hline CHEMBL1308861 & 688816 & 4.7 & 5.4398 & TRN & \\
\hline CHEMBL1420181 & 688816 & 4.95 & 5.2849 & TRN & \\
\hline CHEMBL1481252 & 688816 & 5.15 & 5.4165 & TRN & \\
\hline CHEMBL1453006 & 688816 & 5.0 & 5.2433 & TRN & \\
\hline CHEMBL1330020 & 688816 & 5.35 & 4.9961 & TRN & \\
\hline CHEMBL1490332 & 688816 & 5.5 & 5.438 & TST & \\
\hline CHEMBL1532276 & 688816 & 5.5 & 5.5532 & TST & \\
\hline CHEMBL1490481 & 688816 & 4.95 & 4.9481 & TRN & \\
\hline CHEMBL3212365 & 688816 & 4.95 & 5.4897 & TST & \\
\hline CHEMBL1721226 & 688816 & 5.55 & 5.6742 & TRN & \\
\hline CHEMBL1408864 & 688816 & 4.45 & 5.2133 & TRN & \\
\hline CHEMBL1463529 & 688816 & 5.95 & 5.1051 & TRN & \\
\hline CHEMBL1603615 & 688816 & 5.75 & 4.79899 & 99999999995 & TRN \\
\hline CHEMBL1433291 & 688816 & 5.55 & 5.0411 & TRN & \\
\hline CHEMBL1572948 & 688816 & 4.95 & 5.1872 & TST & \\
\hline CHEMBL1997062 & 688816 & 4.6 & 5.3768 & TRN & \\
\hline CHEMBL1352521 & 688816 & 4.85 & 5.4196 & TST & \\
\hline CHEMBL1369366 & 688816 & 4.8 & 5.0012 & TST & \\
\hline CHEMBL1539476 & 688816 & 4.45 & 5.2759 & TRN & \\
\hline CHEMBL1327069 & 688816 & 5.0 & 5.2383 & TRN & \\
\hline CHEMBL1413536 & 688816 & 6.95 & 5.5796 & TST & \\
\hline CHEMBL1384676 & 688816 & 5.25 & 5.23600 & 0000000001 & TRN \\
\hline CHEMBL1393197 & 688816 & 4.8 & 5.4294 & TRN & \\
\hline CHEMBL1587299 & 688816 & 4.65 & 5.04 & TRN & \\
\hline CHEMBL1368838 & 688816 & 4.6 & 5.50799 & 9999999999 & TRN \\
\hline CHEMBL1391037 & 688816 & 4.45 & 4.8335 & TRN & \\
\hline CHEMBL1404976 & 688816 & 5.5 & 5.2972 & TST & \\
\hline CHEMBL1454877 & 688816 & 4.8 & 5.1502 & TST & \\
\hline CHEMBL1555583 & 688816 & 4.75 & 5.40600 & 0000000001 & TRN \\
\hline CHEMBL3194563 & 688816 & 5.45 & 4.88 & TRN & \\
\hline CHEMBL1612830 & 688816 & 4.9 & 5.2978 & TRN & \\
\hline CHEMBL1524184 & 688816 & 4.95 & 5.1949 & TRN & \\
\hline CHEMBL1432034 & 688816 & 4.85 & 5.3715 & TRN & \\
\hline CHEMBL1341696 & 688816 & 4.95 & 5.1451 & TRN & \\
\hline CHEMBL1389083 & 688816 & 4.7 & 5.4549 & TRN & \\
\hline CHEMBL1309376 & 688816 & 8.3468 & 5.0239 & TRN & \\
\hline CHEMBL1452785 & 688816 & 4.45 & 5.0609 & TST & \\
\hline CHEMBL3198629 & 688816 & 4.45 & 5.4758 & TRN & \\
\hline CHEMBL1375509 & 688816 & 5.0 & 5.0667 & TRN & \\
\hline CHEMBL1324619 & 688816 & 8.3979 & 5.0345 & TST & \\
\hline
\end{tabular}




\begin{tabular}{|c|c|c|c|c|c|}
\hline \multicolumn{6}{|c|}{ splemental la } \\
\hline CHEMBL1602928 & 688816 & 4.9 & 5.5384 & TST & \\
\hline CHEMBL1308837 & 688816 & 4.95 & 5.074 & TRN & \\
\hline CHEMBL1543858 & 688816 & 5.35 & 5.2754 & TRN & \\
\hline CHEMBL1511479 & 688816 & 4.65 & 5.4062 & TRN & \\
\hline CHEMBL1332862 & 688816 & 5.5 & 4.854 & TRN & \\
\hline CHEMBL1417929 & 688816 & 5.3 & 5.0527 & TRN & \\
\hline CHEMBL1485820 & 688816 & 5.1 & 4.8328 & TRN & \\
\hline CHEMBL1490423 & 688816 & 4.95 & 5.0322 & TRN & \\
\hline CHEMBL1518472 & 688816 & 4.95 & 5.5235 & TST & \\
\hline CHEMBL1771411 & 688816 & 4.85 & 5.1361 & TRN & \\
\hline CHEMBL1582709 & 688816 & 4.85 & 5.336 & TST & \\
\hline CHEMBL3210723 & 688816 & 4.45 & 4.9115 & TRN & \\
\hline CHEMBL1592972 & 688816 & 4.65 & 4.79899 & 99999999995 & TST \\
\hline CHEMBL1986459 & 688816 & 4.9 & 5.0756 & TRN & \\
\hline CHEMBL1424464 & 688816 & 4.95 & 5.4705 & TRN & \\
\hline CHEMBL1427820 & 688816 & 4.45 & 5.7125 & TST & \\
\hline CHEMBL3213317 & 688816 & 4.75 & 5.2169 & TST & \\
\hline CHEMBL1567232 & 688816 & 4.95 & 4.8634 & TRN & \\
\hline CHEMBL159895 & 688816 & 5.45 & 5.3636 & TRN & \\
\hline CHEMBL1431694 & 688816 & 4.9 & 5.0905 & TRN & \\
\hline CHEMBL1461819 & 688816 & 5.5 & 5.3773 & TST & \\
\hline CHEMBL1342907 & 688816 & 4.45 & 4.9656 & TST & \\
\hline CHEMBL1405968 & 688816 & 4.95 & 5.2343 & TRN & \\
\hline CHEMBL1438547 & 688816 & 4.45 & 5.3997 & TRN & \\
\hline CHEMBL1537036 & 688816 & 4.95 & 5.2208 & TRN & \\
\hline CHEMBL1309171 & 688816 & 4.65 & 5.1363 & TRN & \\
\hline CHEMBL1597131 & 688816 & 5.1 & 5.3939 & TRN & \\
\hline CHEMBL1467984 & 688816 & 4.7 & 5.0065 & TRN & \\
\hline CHEMBL1490351 & 688816 & 4.55 & 5.1969 & TRN & \\
\hline CHEMBL1344570 & 688816 & 10.2 & 5.4343 & TRN & \\
\hline CHEMBL1493138 & 688816 & 4.6 & 5.1354 & TRN & \\
\hline CHEMBL1984120 & 688816 & 4.45 & 5.1837 & TRN & \\
\hline CHEMBL1477568 & 688816 & 7.3002 & 5.1909 & TRN & \\
\hline CHEMBL1401364 & 688816 & 4.45 & 5.15600 & 0000000001 & TRN \\
\hline CHEMBL1493983 & 688816 & 4.6 & 5.0722 & TST & \\
\hline CHEMBL1375546 & 688816 & 4.7 & 5.0716 & TRN & \\
\hline CHEMBL1531378 & 688816 & 5.25 & 5.529 & TST & \\
\hline CHEMBL1421124 & 688816 & 8.301 & 5.721 & TRN & \\
\hline CHEMBL1582722 & 688816 & 6.35 & 5.6785 & TRN & \\
\hline CHEMBL1469693 & 688816 & 4.9 & 5.3496 & TRN & \\
\hline CHEMBL 3190671 & 688816 & 4.5 & 5.5928 & TRN & \\
\hline CHEMBL1504503 & 688816 & 4.95 & 5.2044 & TST & \\
\hline CHEMBL1459981 & 688816 & 4.95 & 5.572 & TRN & \\
\hline CHEMBL1500380 & 688816 & 4.65 & 5.2755 & TRN & \\
\hline CHEMBL1987798 & 688816 & 5.55 & 5.1047 & TRN & \\
\hline CHEMBL1510034 & 688816 & 4.95 & 5.1429 & TRN & \\
\hline CHEMBL1428267 & 688816 & 5.1 & 5.5798 & TRN & \\
\hline CHEMBL1595752 & 688816 & 6.5 & 5.4215 & TST & \\
\hline
\end{tabular}




\begin{tabular}{|c|c|c|c|c|c|}
\hline \multirow{3}{*}{$\begin{array}{l}\text { CHEMBL1520347 } \\
\text { CHEMBL1510989 }\end{array}$} & \multicolumn{5}{|c|}{ Supplemental Table S2.txt } \\
\hline & 688816 & 4.95 & 5.1729 & 9999999999 & TRN \\
\hline & 688816 & 4.95 & 5.4896 & TRN & \\
\hline CHEMBL1564349 & 688816 & 8.1024 & 5.6432 & TRN & \\
\hline CHEMBL3189930 & 688816 & 4.95 & 5.1535 & TRN & \\
\hline CHEMBL1386018 & 688816 & 5.4 & 5.6492 & TST & \\
\hline CHEMBL1570567 & 688816 & 5.65 & 4.92 & TST & \\
\hline CHEMBL1563597 & 688816 & 4.95 & 5.0921 & TRN & \\
\hline CHEMBL1308891 & 688816 & 7.0 & 5.2416 & TRN & \\
\hline CHEMBL1427796 & 688816 & 6.7501 & 5.5247 & TST & \\
\hline CHEMBL1416016 & 688816 & 5.75 & 5.3862 & TRN & \\
\hline CHEMBL1519944 & 688816 & 4.9 & 5.5115 & TRN & \\
\hline CHEMBL1336180 & 688816 & 4.85 & 5.303 & TRN & \\
\hline CHEMBL1417240 & 688816 & 7.7496 & 5.2516 & TRN & \\
\hline CHEMBL1596342 & 688816 & 4.45 & 4.8943 & TRN & \\
\hline CHEMBL1388409 & 688816 & 8.2007 & 5.1157 & TRN & \\
\hline CHEMBL1445589 & 688816 & 7.4498 & 4.9553 & TRN & \\
\hline CHEMBL598663 & 688816 & 4.8 & 5.085 & TST & \\
\hline CHEMBL1445800 & 688816 & 4.65 & 4.6123 & TRN & \\
\hline CHEMBL1321253 & 688816 & 4.9 & 5.1589 & TRN & \\
\hline CHEMBL1468826 & 688816 & 4.45 & 5.3317 & TRN & \\
\hline CHEMBL1377670 & 688816 & 8.0 & 5.2564 & TST & \\
\hline CHEMBL1344081 & 688816 & 4.9 & 5.35 & TRN & \\
\hline CHEMBL1483538 & 688816 & 5.15 & 5.3904 & TRN & \\
\hline CHEMBL3199779 & 688816 & 5.2 & 5.2641 & TRN & \\
\hline CHEMBL1414033 & 688816 & 4.85 & 5.0983 & TRN & \\
\hline CHEMBL1504716 & 688816 & 4.95 & 5.1336 & TRN & \\
\hline CHEMBL3209668 & 688816 & 5.5 & 5.3091 & TST & \\
\hline CHEMBL1304013 & 688816 & 4.45 & 5.5554 & TST & \\
\hline CHEMBL3189149 & 688816 & 5.15 & 5.3673 & TST & \\
\hline CHEMBL 2000847 & 688816 & 4.95 & 5.3246 & TRN & \\
\hline CHEMBL3210076 & 688816 & 4.5 & 5.3002 & TRN & \\
\hline CHEMBL1584401 & 688816 & 4.8 & 5.1354 & TRN & \\
\hline CHEMBL1453038 & 688816 & 4.45 & 5.1878 & TRN & \\
\hline CHEMBL3196659 & 688816 & 5.5 & 5.3868 & TST & \\
\hline CHEMBL1438971 & 688816 & 4.6 & 4.9706 & TRN & \\
\hline CHEMBL1342404 & 688816 & 6.8499 & 5.4288 & TRN & \\
\hline CHEMBL1408390 & 688816 & 4.95 & 5.596 & TRN & \\
\hline CHEMBL1534269 & 688816 & 6.2 & 5.4423 & TRN & \\
\hline CHEMBL1303953 & 688816 & 4.8 & 4.8397 & TRN & \\
\hline CHEMBL1334930 & 688816 & 4.9 & 4.8654 & TRN & \\
\hline CHEMBL1486229 & 688816 & 6.35 & 5.2005 & TST & \\
\hline CHEMBL1420027 & 688816 & 5.25 & 5.1335 & TRN & \\
\hline CHEMBL3196230 & 688816 & 4.45 & 5.1792 & TST & \\
\hline CHEMBL1505332 & 688816 & 5.4 & 5.5037 & TRN & \\
\hline CHEMBL1445251 & 688816 & 4.95 & 5.2502 & TRN & \\
\hline CHEMBL1517268 & 688816 & 5.55 & 5.3213 & TRN & \\
\hline CHEMBL1442857 & 688816 & 8.301 & 5.4483 & TRN & \\
\hline CHEMBL1585540 & 688816 & 7.699 & 5.5679 & TST & \\
\hline
\end{tabular}




\begin{tabular}{|c|c|c|c|c|c|}
\hline \multirow{3}{*}{$\begin{array}{l}\text { CHEMBL1980667 } \\
\text { CHEMBL } 1504431\end{array}$} & & \multicolumn{4}{|c|}{ Supplemental Table S2.txt } \\
\hline & 688816 & 5.35 & 5.20299 & 9999999999 & TRN \\
\hline & 688816 & 5.6 & 5.3961 & TST & \\
\hline CHEMBL1573594 & 688816 & 5.7 & 4.8229 & TRN & \\
\hline CHEMBL1422230 & 688816 & 4.6 & 4.8922 & TRN & \\
\hline CHEMBL1527400 & 688816 & 6.3 & 5.026 & TRN & \\
\hline CHEMBL1321734 & 688816 & 4.95 & 5.0745 & TST & \\
\hline CHEMBL1390760 & 688816 & 5.0 & 5.7454 & TRN & \\
\hline CHEMBL1346634 & 688816 & 4.65 & 4.7048 & TST & \\
\hline CHEMBL1528991 & 688816 & 4.85 & 5.2605 & TST & \\
\hline CHEMBL1299670 & 688816 & 4.95 & 5.7216 & TST & \\
\hline CHEMBL3197801 & 688816 & 4.95 & 5.3929 & TRN & \\
\hline CHEMBL1445314 & 688816 & 5.1 & 4.7197 & TRN & \\
\hline CHEMBL1572901 & 688816 & 5.0 & 5.2856 & TRN & \\
\hline CHEMBL1416931 & 688816 & 4.45 & 5.4461 & TST & \\
\hline CHEMBL1965298 & 688816 & 6.0 & 5.1121 & TRN & \\
\hline CHEMBL1478421 & 688816 & 5.8 & 4.9271 & TRN & \\
\hline CHEMBL3211073 & 688816 & 6.2 & 5.3249 & TST & \\
\hline CHEMBL1480464 & 688816 & 4.6 & 5.129 & TRN & \\
\hline CHEMBL1576788 & 688816 & 4.8 & 5.1344 & TRN & \\
\hline CHEMBL1517843 & 688816 & 5.35 & 5.0612 & TRN & \\
\hline CHEMBL1533990 & 688816 & 5.15 & 5.6486 & TRN & \\
\hline CHEMBL1544205 & 688816 & 4.75 & 5.4115 & TRN & \\
\hline CHEMBL1440679 & 688816 & 5.2 & 5.2961 & TRN & \\
\hline CHEMBL1325456 & 688816 & 7.0501 & 5.7578 & TST & \\
\hline CHEMBL1511730 & 688816 & 4.5 & 5.4672 & TRN & \\
\hline CHEMBL1541889 & 688816 & 4.95 & 5.2579 & TRN & \\
\hline CHEMBL1329722 & 688816 & 4.95 & 5.2026 & TRN & \\
\hline CHEMBL1407968 & 688816 & 4.9 & 5.16299 & 9999999999 & TRN \\
\hline CHEMBL1576499 & 688816 & 5.25 & 5.3213 & TST & \\
\hline CHEMBL1533370 & 688816 & 4.85 & 5.1052 & TST & \\
\hline CHEMBL1524563 & 688816 & 8.301 & 5.749 & TRN & \\
\hline CHEMBL1477399 & 688816 & 5.85 & 5.2859 & TRN & \\
\hline CHEMBL1421488 & 688816 & 4.7 & 5.0302 & TST & \\
\hline CHEMBL3207722 & 688816 & 5.0 & 5.2547 & TST & \\
\hline CHEMBL1490121 & 688816 & 4.95 & 5.3656 & TRN & \\
\hline CHEMBL607253 & 688816 & 4.45 & 5.2341 & TRN & \\
\hline CHEMBL3207839 & 688816 & 4.75 & 5.3781 & TRN & \\
\hline CHEMBL1328882 & 688816 & 6.7001 & 5.3615 & TRN & \\
\hline CHEMBL1414312 & 688816 & 5.0 & 5.2446 & TRN & \\
\hline CHEMBL1495206 & 688816 & 5.85 & 5.431 & TRN & \\
\hline CHEMBL1529147 & 688816 & 6.0 & 5.6754 & TST & \\
\hline CHEMBL1454358 & 688816 & 4.45 & 5.2677 & TRN & \\
\hline CHEMBL600060 & 688816 & 4.95 & 5.3122 & TRN & \\
\hline CHEMBL1360178 & 688816 & 4.75 & 5.5464 & TST & \\
\hline CHEMBL1371059 & 688816 & 4.9 & 5.36 & TRN & \\
\hline CHEMBL1987472 & 688816 & 5.45 & 4.8423 & TST & \\
\hline CHEMBL1544425 & 688816 & 4.8 & 5.6026 & TST & \\
\hline CHEMBL1543965 & 688816 & 4.8 & 5.006 & TRN & \\
\hline
\end{tabular}




\begin{tabular}{|c|c|c|c|c|}
\hline & & & pplement & al $\mathrm{T}$ \\
\hline CHEMBL1489937 & 688816 & 5.3 & 5.1906 & TST \\
\hline CHEMBL1431012 & 688816 & 6.2 & 5.6099 & TRN \\
\hline CHEMBL1610388 & 688816 & 5.4 & 5.2584 & TRN \\
\hline CHEMBL1378803 & 688816 & 5.85 & 5.0959 & TST \\
\hline CHEMBL1507774 & 688816 & 8.3468 & 5.5518 & TRN \\
\hline CHEMBL1388036 & 688816 & 4.95 & 4.9904 & TRN \\
\hline CHEMBL1466191 & 688816 & 5.0 & 4.8113 & TRN \\
\hline CHEMBL 3214175 & 688816 & 7.5003 & 5.7369 & TST \\
\hline CHEMBL 3190834 & 688816 & 4.95 & 5.5345 & TST \\
\hline CHEMBL1497918 & 688816 & 4.85 & 5.3106 & TRN \\
\hline CHEMBL1428447 & 688816 & 4.8 & 5.2074 & TST \\
\hline CHEMBL1381540 & 688816 & 4.45 & 5.3287 & TRN \\
\hline CHEMBL1361189 & 688816 & 4.8 & 5.3576 & TRN \\
\hline CHEMBL1350882 & 688816 & 4.45 & 5.0096 & TRN \\
\hline CHEMBL1490617 & 688816 & 4.6 & 5.0706 & TRN \\
\hline CHEMBL1488943 & 688816 & 5.25 & 5.614 & TST \\
\hline CHEMBL1433253 & 688816 & 6.5 & 5.2218 & TRN \\
\hline CHEMBL1527470 & 688816 & 7.1002 & 5.5871 & TST \\
\hline CHEMBL1342076 & 688816 & 4.9 & 5.3961 & TRN \\
\hline CHEMBL507112 & 688816 & 5.75 & 5.4944 & TRN \\
\hline CHEMBL1581882 & 688816 & 4.85 & 5.2858 & TST \\
\hline CHEMBL1468908 & 688816 & 5.0 & 5.0891 & TST \\
\hline CHEMBL1608104 & 688816 & 5.2 & 5.129 & TRN \\
\hline CHEMBL1452963 & 688816 & 4.9 & 5.3225 & TST \\
\hline CHEMBL1532870 & 688816 & 5.05 & 4.7904 & TRN \\
\hline CHEMBL1450341 & 688816 & 4.95 & 5.6057 & TRN \\
\hline CHEMBL1361741 & 688816 & 4.85 & 4.9558 & TRN \\
\hline CHEMBL1466147 & 688816 & 5.85 & 5.0858 & TST \\
\hline CHEMBL1502475 & 688816 & 5.3 & 5.3087 & TST \\
\hline CHEMBL 1456353 & 688816 & 4.95 & 5.0678 & TRN \\
\hline CHEMBL1534106 & 688816 & 4.95 & 5.2562 & TRN \\
\hline CHEMBL3194959 & 688816 & 5.0 & 5.5613 & TRN \\
\hline CHEMBL1498726 & 688816 & 7.3002 & 5.3882 & TRN \\
\hline CHEMBL1498874 & 688816 & 5.25 & 5.5935 & TRN \\
\hline CHEMBL1581188 & 688816 & 4.5 & 4.8007 & TRN \\
\hline CHEMBL1508326 & 688816 & 8.0506 & 5.5009 & TRN \\
\hline CHEMBL 3212722 & 688816 & 5.6 & 5.6116 & TST \\
\hline CHEMBL1601378 & 688816 & 8.301 & 5.2643 & TRN \\
\hline CHEMBL1588598 & 688816 & 5.4 & 5.3409 & TRN \\
\hline CHEMBL1610286 & 688816 & 4.9 & 5.3374 & TRN \\
\hline CHEMBL1496570 & 688816 & 5.05 & 5.1391 & TRN \\
\hline CHEMBL1374510 & 688816 & 7.2503 & 5.3521 & TRN \\
\hline CHEMBL1433150 & 688816 & 8.3468 & 5.4035 & TST \\
\hline CHEMBL1413243 & 688816 & 4.45 & 4.7905 & TRN \\
\hline CHEMBL 1451044 & 688816 & 8.301 & 5.4305 & TRN \\
\hline CHEMBL1586930 & 688816 & 4.85 & 5.0794 & TRN \\
\hline CHEMBL1346612 & 688816 & 5.25 & 5.4335 & TST \\
\hline CHEMBL1306329 & 688816 & 4.75 & 5.2639 & TST \\
\hline
\end{tabular}




\begin{tabular}{|c|c|c|c|c|c|}
\hline \\
\hline CHEMBL1504598 & 688816 & 4.7 & 5.5037 & TRN & \\
\hline CHEMBL1375704 & 688816 & 4.75 & 5.4458 & TRN & \\
\hline CHEMBL3213395 & 688816 & 5.25 & 5.2859 & TRN & \\
\hline CHEMBL1321817 & 688816 & 4.45 & 5.104 & TRN & \\
\hline CHEMBL1443671 & 688816 & 4.9 & 5.3648 & TRN & \\
\hline CHEMBL1385926 & 688816 & 4.75 & 5.0535 & TRN & \\
\hline CHEMBL1306459 & 688816 & 4.45 & 5.2462 & TRN & \\
\hline CHEMBL1418110 & 688816 & 5.4 & 5.2325 & TST & \\
\hline CHEMBL1462043 & 688816 & 4.45 & 5.1431 & TRN & \\
\hline CHEMBL1355552 & 688816 & 5.35 & 5.3738 & TRN & \\
\hline CHEMBL1490009 & 688816 & 4.6 & 5.20700 & 0000000001 & TRN \\
\hline CHEMBL1441024 & 688816 & 4.65 & 4.9551 & TRN & \\
\hline CHEMBL1468714 & 688816 & 4.45 & 4.9775 & TST & \\
\hline CHEMBL1315021 & 688816 & 4.45 & 5.095 & TRN & \\
\hline CHEMBL1453055 & 688816 & 6.35 & 5.3086 & TRN & \\
\hline CHEMBL1290249 & 688816 & 4.85 & 5.3209 & TRN & \\
\hline CHEMBL1347204 & 688816 & 4.6 & 4.5331 & TRN & \\
\hline CHEMBL1389932 & 688816 & 4.9 & 5.3475 & TRN & \\
\hline CHEMBL1483368 & 688816 & 6.05 & 5.4903 & TST & \\
\hline CHEMBL1989750 & 688816 & 4.65 & 5.3305 & TRN & \\
\hline CHEMBL1413339 & 688816 & 5.0 & 5.5584 & TRN & \\
\hline CHEMBL1536048 & 688816 & 5.0 & 5.1301 & TRN & \\
\hline CHEMBL1464497 & 688816 & 5.65 & 5.3997 & TRN & \\
\hline CHEMBL1359079 & 688816 & 7.8508 & 5.4305 & TRN & \\
\hline CHEMBL1502528 & 688816 & 5.05 & 4.8267 & TRN & \\
\hline CHEMBL1557896 & 688816 & 4.5 & 5.1103 & TRN & \\
\hline CHEMBL1490620 & 688816 & 5.8 & 5.2337 & TRN & \\
\hline CHEMBL1377608 & 688816 & 6.5 & 5.2078 & TRN & \\
\hline CHEMBL1980322 & 688816 & 4.85 & 5.155 & TRN & \\
\hline CHEMBL1429922 & 688816 & 4.7 & 5.30399 & 9999999999 & TRN \\
\hline CHEMBL1431928 & 688816 & 4.8 & 5.0678 & TRN & \\
\hline CHEMBL1331193 & 688816 & 4.75 & 5.1711 & TRN & \\
\hline CHEMBL1584229 & 688816 & 4.8 & 5.2971 & TST & \\
\hline CHEMBL1444290 & 688816 & 6.1 & 5.6567 & TST & \\
\hline CHEMBL1586245 & 688816 & 5.35 & 5.4067 & TST & \\
\hline CHEMBL1501432 & 688816 & 4.95 & 5.5683 & TRN & \\
\hline CHEMBL1510367 & 688816 & 4.95 & 5.0835 & TRN & \\
\hline CHEMBL1479184 & 688816 & 5.25 & 5.2374 & TST & \\
\hline CHEMBL1309162 & 688816 & 5.2 & 5.1907 & TRN & \\
\hline CHEMBL1404817 & 688816 & 4.8 & 5.4297 & TST & \\
\hline CHEMBL1404259 & 688816 & 4.95 & 5.2694 & TST & \\
\hline CHEMBL1390196 & 688816 & 4.95 & 5.7251 & TRN & \\
\hline CHEMBL1500218 & 688816 & 5.2 & 5.4004 & TRN & \\
\hline CHEMBL1483076 & 688816 & 5.6 & 5.309 & TRN & \\
\hline CHEMBL1418891 & 688816 & 5.8 & 5.4028 & TST & \\
\hline CHEMBL1447673 & 688816 & 5.7 & 5.1686 & TST & \\
\hline CHEMBL1458376 & 688816 & 4.9 & 5.0079 & TRN & \\
\hline CHEMBL1447267 & 688816 & 5.35 & 5.2107 & TRN & \\
\hline
\end{tabular}




\begin{tabular}{|c|c|c|c|c|}
\hline \multicolumn{5}{|c|}{ Supplemental Table S2.txt } \\
\hline CHEMBL1439277 & 688816 & 4.55 & 5.0479 & TRN \\
\hline CHEMBL1451147 & 688816 & 7.6498 & 5.1287 & TRN \\
\hline CHEMBL1400824 & 688816 & 4.9 & 5.0608 & TRN \\
\hline CHEMBL3211451 & 688816 & 4.95 & 5.2811 & TRN \\
\hline CHEMBL1430411 & 688816 & 5.25 & 5.2899 & TRN \\
\hline CHEMBL1588216 & 688816 & 4.55 & 5.3295 & TRN \\
\hline CHEMBL1488703 & 688816 & 4.95 & 5.2049 & TRN \\
\hline CHEMBL3195103 & 688816 & 4.45 & 5.4103 & TST \\
\hline CHEMBL1381328 & 688816 & 7.6498 & 5.5463 & TRN \\
\hline CHEMBL1352181 & 688816 & 4.9 & 4.8482 & TRN \\
\hline CHEMBL1362856 & 688816 & 4.45 & 4.8497 & TRN \\
\hline CHEMBL1319158 & 688816 & 6.1 & 5.511 & TRN \\
\hline CHEMBL1426908 & 688816 & 6.1 & 5.0304 & TST \\
\hline CHEMBL1340514 & 688816 & 4.95 & 4.6762 & TST \\
\hline CHEMBL1313251 & 688816 & 4.55 & 5.2575 & TRN \\
\hline CHEMBL1594182 & 688816 & 4.85 & 5.17 & TST \\
\hline CHEMBL1580066 & 688816 & 4.9 & 5.1632 & TRN \\
\hline CHEMBL1420172 & 688816 & 4.8 & 5.0313 & TRN \\
\hline CHEMBL1401475 & 688816 & 4.75 & 4.9172 & TRN \\
\hline CHEMBL1464836 & 688816 & 4.85 & 5.0626 & TRN \\
\hline CHEMBL1432562 & 688816 & 4.45 & 5.5882 & TRN \\
\hline CHEMBL1547394 & 688816 & 8.4949 & 5.3247 & TST \\
\hline CHEMBL1332282 & 688816 & 4.45 & 5.0165 & TRN \\
\hline CHEMBL1498042 & 688816 & 4.45 & 5.2685 & TRN \\
\hline CHEMBL3208952 & 688816 & 6.7001 & 5.2307 & TRN \\
\hline CHEMBL1505895 & 688816 & 8.0506 & 5.2782 & TRN \\
\hline CHEMBL1317858 & 688816 & 4.45 & 5.32 & TRN \\
\hline CHEMBL1372286 & 688816 & 4.45 & 4.6907 & TRN \\
\hline CHEMBL1324944 & 688816 & 4.65 & 4.8694 & TRN \\
\hline CHEMBL1612026 & 688816 & 4.45 & 5.1285 & TRN \\
\hline CHEMBL1438160 & 688816 & 5.6 & 5.8241 & TST \\
\hline CHEMBL1496543 & 688816 & 5.45 & 5.5662 & TRN \\
\hline CHEMBL1401804 & 688816 & 4.6 & 5.4545 & TRN \\
\hline CHEMBL1342278 & 688816 & 4.8 & 5.086 & TRN \\
\hline CHEMBL1304631 & 688816 & 4.8 & 5.1282 & TRN \\
\hline CHEMBL1303208 & 688816 & 4.45 & 5.3799 & TRN \\
\hline CHEMBL1440945 & 688816 & 6.5 & 5.2229 & TRN \\
\hline CHEMBL3196616 & 688816 & 4.95 & 5.1062 & TRN \\
\hline CHEMBL2385797 & 688816 & 8.2518 & 5.3963 & TRN \\
\hline CHEMBL1589096 & 688816 & 6.05 & 5.2574 & TST \\
\hline CHEMBL1612629 & 688816 & 4.6 & 5.0786 & TST \\
\hline CHEMBL1380013 & 688816 & 6.4 & 5.6789 & TRN \\
\hline CHEMBL1333571 & 688816 & 4.5 & 5.5728 & TRN \\
\hline CHEMBL564201 & 688816 & 5.7 & 5.83200 & 0000000001 \\
\hline CHEMBL1530614 & 688816 & 7.8508 & 5.7067 & TST \\
\hline CHEMBL1561827 & 688816 & 5.3 & 5.371 & TRN \\
\hline CHEMBL1387849 & 688816 & 4.85 & 4.9275 & TRN \\
\hline CHEMBL1510228 & 688816 & 4.85 & 5.3219 & TST \\
\hline
\end{tabular}




\begin{tabular}{|c|c|c|c|c|c|}
\hline \multicolumn{6}{|c|}{ Supplemental Table S2.txt } \\
\hline CHEMBL1305145 & 688816 & 4.95 & 4.9449 & TRN & \\
\hline CHEMBL1451659 & 688816 & 4.6 & 5.4477 & TST & \\
\hline CHEMBL1372102 & 688816 & 4.5 & 5.3759 & TST & \\
\hline CHEMBL 3199545 & 688816 & 5.35 & 4.9878 & TST & \\
\hline CHEMBL1299707 & 688816 & 4.45 & 4.8336 & TST & \\
\hline CHEMBL1595722 & 688816 & 7.9508 & 5.4487 & TST & \\
\hline CHEMBL1562381 & 688816 & 6.0 & 4.9037 & TST & \\
\hline CHEMBL1315282 & 688816 & 4.9 & 5.0227 & TRN & \\
\hline CHEMBL1346969 & 688816 & 5.3 & 4.9819 & TRN & \\
\hline CHEMBL1349631 & 688816 & 4.95 & 4.8525 & TRN & \\
\hline CHEMBL1975620 & 688816 & 4.65 & 5.5343 & TRN & \\
\hline CHEMBL1361017 & 688816 & 5.0 & 5.1576 & TRN & \\
\hline CHEMBL1416594 & 688816 & 4.45 & 5.2645 & TRN & \\
\hline CHEMBL1389176 & 688816 & 4.9 & 5.2351 & TRN & \\
\hline CHEMBL1439498 & 688816 & 4.65 & 5.1317 & TST & \\
\hline CHEMBL1430322 & 688816 & 5.45 & 5.3865 & TRN & \\
\hline CHEMBL1968326 & 688816 & 4.45 & 5.1761 & TRN & \\
\hline CHEMBL1521430 & 688816 & 8.4559 & 5.3075 & TST & \\
\hline CHEMBL1362149 & 688816 & 5.95 & 5.1717 & TRN & \\
\hline CHEMBL1437179 & 688816 & 4.45 & 5.4673 & TRN & \\
\hline CHEMBL3197076 & 688816 & 4.8 & 5.6256 & TST & \\
\hline CHEMBL1389829 & 688816 & 4.85 & 5.1005 & TRN & \\
\hline CHEMBL1256775 & 688816 & 6.0 & 5.5739 & TST & \\
\hline CHEMBL1462279 & 688816 & 5.0 & 5.12200 & 0000000001 & TST \\
\hline CHEMBL1532976 & 688816 & 4.45 & 5.2174 & TRN & \\
\hline CHEMBL1442326 & 688816 & 6.1 & 5.2513 & TRN & \\
\hline CHEMBL1421901 & 688816 & 8.3468 & 5.0266 & TST & \\
\hline CHEMBL1328473 & 688816 & 4.55 & 4.7816 & TRN & \\
\hline CHEMBL1377728 & 688816 & 4.7 & 5.3107 & TRN & \\
\hline CHEMBL1394510 & 688816 & 4.65 & 4.7053 & TRN & \\
\hline CHEMBL1430119 & 688816 & 5.0 & 5.092 & TRN & \\
\hline CHEMBL1425565 & 688816 & 5.75 & 5.0565 & TRN & \\
\hline CHEMBL1553055 & 688816 & 4.6 & 4.8739 & TRN & \\
\hline CHEMBL1558556 & 688816 & 4.95 & 5.2008 & TRN & \\
\hline CHEMBL3193534 & 688816 & 4.45 & 5.2507 & TRN & \\
\hline CHEMBL1305610 & 688816 & 4.8 & 5.3271 & TRN & \\
\hline CHEMBL1384607 & 688816 & 7.15 & 5.59399 & 9999999999 & TST \\
\hline CHEMBL1400207 & 688816 & 4.95 & 5.5427 & TST & \\
\hline CHEMBL1439261 & 688816 & 5.55 & 5.8664 & TST & \\
\hline CHEMBL1501483 & 688816 & 5.1 & 5.1407 & TRN & \\
\hline CHEMBL1452578 & 688816 & 5.55 & 5.3432 & TST & \\
\hline CHEMBL1321240 & 688816 & 4.75 & 4.8393 & TRN & \\
\hline CHEMBL1461558 & 688816 & 4.8 & 5.1069 & TRN & \\
\hline CHEMBL1607158 & 688816 & 4.85 & 5.2398 & TST & \\
\hline CHEMBL1380174 & 688816 & 4.9 & 5.317 & TRN & \\
\hline CHEMBL1307075 & 688816 & 6.8 & 5.5899 & TST & \\
\hline CHEMBL1466185 & 688816 & 6.8 & 5.2694 & TRN & \\
\hline CHEMBL1462459 & 688816 & 4.45 & 5.1132 & TRN & \\
\hline
\end{tabular}




\begin{tabular}{|c|c|c|c|c|}
\hline \multicolumn{5}{|c|}{ Supplemental Table S2.txt } \\
\hline CHEMBL1998652 & 688816 & 5.55 & 5.4057 & TRN \\
\hline CHEMBL408129 & 688816 & 5.5 & 5.7227 & TST \\
\hline CHEMBL1431479 & 688816 & 7.6498 & 5.6505 & TST \\
\hline CHEMBL1311510 & 688816 & 4.95 & 5.5688 & TRN \\
\hline CHEMBL1531754 & 688816 & 5.0 & 5.8165 & TST \\
\hline CHEMBL1301287 & 688816 & 5.5 & 5.3217 & TRN \\
\hline CHEMBL 2436520 & 688816 & 4.9 & 5.25 & TRN \\
\hline CHEMBL 3208288 & 688816 & 4.9 & 5.4833 & TRN \\
\hline CHEMBL1523828 & 688816 & 4.95 & 4.6725 & TST \\
\hline CHEMBL1317703 & 688816 & 4.9 & 5.2734 & TRN \\
\hline CHEMBL1413340 & 688816 & 4.65 & 4.9293 & TRN \\
\hline CHEMBL1331088 & 688816 & 4.7 & 5.5639 & TRN \\
\hline CHEMBL1405480 & 688816 & 5.8 & 5.362 & TRN \\
\hline CHEMBL1600827 & 688816 & 6.15 & 4.9112 & TRN \\
\hline CHEMBL1350727 & 688816 & 5.4 & 4.9476 & TST \\
\hline CHEMBL1500336 & 688816 & 4.45 & 5.1627 & TST \\
\hline CHEMBL1568419 & 688816 & 4.8 & 5.4406 & TRN \\
\hline CHEMBL1369038 & 688816 & 6.45 & 5.6092 & TRN \\
\hline CHEMBL1352023 & 688816 & 4.95 & 5.2672 & TRN \\
\hline CHEMBL1462467 & 688816 & 8.0506 & 5.4859 & TRN \\
\hline CHEMBL1580316 & 688816 & 4.7 & 5.1188 & TRN \\
\hline CHEMBL1346999 & 688816 & 4.85 & 5.1499 & TRN \\
\hline CHEMBL1300217 & 688816 & 5.25 & 5.4114 & TRN \\
\hline CHEMBL1443559 & 688816 & 4.95 & 5.28 & TRN \\
\hline CHEMBL1488090 & 688816 & 4.95 & 5.3532 & TRN \\
\hline CHEMBL1559131 & 688816 & 4.45 & 5.3564 & TRN \\
\hline CHEMBL50175 & 688816 & 4.6 & 5.2974 & TRN \\
\hline CHEMBL1382875 & 688816 & 4.45 & 5.0943 & TST \\
\hline CHEMBL1340260 & 688816 & 4.9 & 5.4986 & TRN \\
\hline CHEMBL 266540 & 688816 & 5.95 & 5.4359 & TST \\
\hline CHEMBL1430706 & 688816 & 4.5 & 5.9468 & TST \\
\hline CHEMBL1448639 & 688816 & 4.95 & 5.0063 & TRN \\
\hline CHEMBL1601552 & 688816 & 8.301 & 5.3186 & TST \\
\hline CHEMBL1582050 & 688816 & 4.8 & 5.2443 & TST \\
\hline CHEMBL1301055 & 688816 & 4.95 & 5.008 & TRN \\
\hline CHEMBL1511251 & 688816 & 4.9 & 5.3517 & TST \\
\hline CHEMBL1548385 & 688816 & 4.9 & 5.4269 & TST \\
\hline CHEMBL1388653 & 688816 & 4.65 & 5.0265 & TRN \\
\hline CHEMBL1433271 & 688816 & 6.15 & 5.5429 & TRN \\
\hline CHEMBL1214407 & 688816 & 4.45 & 5.136 & TRN \\
\hline CHEMBL1463989 & 688816 & 5.45 & 5.2784 & TRN \\
\hline CHEMBL1606351 & 688816 & 5.8 & 5.6588 & TRN \\
\hline CHEMBL1581434 & 688816 & 4.9 & 5.6322 & TRN \\
\hline CHEMBL1491084 & 688816 & 5.55 & 5.8238 & TST \\
\hline CHEMBL1398070 & 688816 & 5.25 & 5.6905 & TRN \\
\hline CHEMBL1529462 & 688816 & 5.2 & 4.8054 & TRN \\
\hline CHEMBL1493367 & 688816 & 4.85 & 5.3275 & TRN \\
\hline CHEMBL1415063 & 688816 & 6.4 & 5.3315 & TRN \\
\hline
\end{tabular}




\begin{tabular}{|c|c|c|c|c|c|}
\hline \multicolumn{6}{|c|}{ Supplemental Table S2.txt } \\
\hline CHEMBL1444899 & 688816 & 4.65 & 5.234 & TST & \\
\hline CHEMBL3189409 & 688816 & 6.2 & 4.8545 & TRN & \\
\hline CHEMBL1465465 & 688816 & 4.95 & 5.0701 & TRN & \\
\hline CHEMBL1330303 & 688816 & 4.95 & 5.4185 & TST & \\
\hline CHEMBL1461090 & 688816 & 4.95 & 5.1714 & TRN & \\
\hline CHEMBL1586573 & 688816 & 7.5498 & 5.6384 & TRN & \\
\hline CHEMBL1479951 & 688816 & 4.75 & 5.0735 & TRN & \\
\hline CHEMBL1471095 & 688816 & 4.8 & 5.4072 & TRN & \\
\hline CHEMBL1368766 & 688816 & 5.15 & 5.3277 & TRN & \\
\hline CHEMBL1544656 & 688816 & 6.7501 & 5.0077 & TRN & \\
\hline CHEMBL1371966 & 688816 & 4.9 & 5.226 & TRN & \\
\hline CHEMBL1492168 & 688816 & 4.45 & 5.1014 & TST & \\
\hline CHEMBL1346522 & 688816 & 5.3 & 4.9247 & TRN & \\
\hline CHEMBL1488020 & 688816 & 5.9 & 5.4296 & TRN & \\
\hline CHEMBL1336306 & 688816 & 4.9 & 5.28799 & 9999999999 & TRN \\
\hline CHEMBL1560887 & 688816 & 6.5501 & 5.2859 & TRN & \\
\hline CHEMBL1480193 & 688816 & 4.75 & 5.1053 & TRN & \\
\hline CHEMBL1346200 & 688816 & 7.5498 & 5.4238 & TRN & \\
\hline CHEMBL1541584 & 688816 & 4.8 & 5.2294 & TRN & \\
\hline CHEMBL1386768 & 688816 & 4.85 & 4.9451 & TRN & \\
\hline CHEMBL1443561 & 688816 & 5.0 & 5.024 & TRN & \\
\hline CHEMBL1342298 & 688816 & 4.95 & 5.2591 & TRN & \\
\hline CHEMBL1163763 & 688816 & 4.6 & 5.2075 & TRN & \\
\hline CHEMBL 3193844 & 688816 & 4.65 & 5.2985 & TST & \\
\hline CHEMBL1507506 & 688816 & 5.25 & 5.3317 & TRN & \\
\hline CHEMBL1477216 & 688816 & 5.0 & 5.574 & TST & \\
\hline CHEMBL1381396 & 688816 & 4.95 & 5.1219 & TRN & \\
\hline CHEMBL1521937 & 688816 & 4.95 & 5.0019 & TST & \\
\hline CHEMBL1967987 & 688816 & 4.45 & 5.1006 & TRN & \\
\hline CHEMBL1999166 & 688816 & 4.85 & 5.2531 & TST & \\
\hline CHEMBL1418864 & 688816 & 5.95 & 5.0473 & TRN & \\
\hline CHEMBL1419739 & 688816 & 5.05 & 5.63700 & 00000000005 & TRN \\
\hline CHEMBL1380056 & 688816 & 5.0 & 5.4221 & TST & \\
\hline CHEMBL1575970 & 688816 & 6.0 & 5.1146 & TRN & \\
\hline CHEMBL1372279 & 688816 & 4.95 & 5.0758 & TRN & \\
\hline CHEMBL1612335 & 688816 & 8.0506 & 5.6075 & TST & \\
\hline CHEMBL1463222 & 688816 & 6.05 & 5.1831 & TST & \\
\hline CHEMBL1409344 & 688816 & 4.65 & 5.3537 & TRN & \\
\hline CHEMBL1414464 & 688816 & 6.8499 & 5.2213 & TRN & \\
\hline CHEMBL1589298 & 688816 & 4.95 & 5.2508 & TST & \\
\hline CHEMBL1438836 & 688816 & 4.95 & 5.289 & TST & \\
\hline CHEMBL1498729 & 688816 & 4.95 & 5.3661 & TST & \\
\hline CHEMBL1478340 & 688816 & 6.45 & 5.1048 & TST & \\
\hline CHEMBL3199114 & 688816 & 4.9 & 5.2325 & TRN & \\
\hline CHEMBL1472240 & 688816 & 4.75 & 4.9098 & TRN & \\
\hline CHEMBL1496993 & 688816 & 5.25 & 4.79 & TRN & \\
\hline CHEMBL1567769 & 688816 & 4.45 & 5.7243 & TST & \\
\hline CHEMBL1496760 & 688816 & 4.95 & 5.4721 & TRN & \\
\hline
\end{tabular}




\begin{tabular}{|c|c|c|c|c|c|}
\hline \multicolumn{6}{|c|}{ Supplemental Table S2.txt } \\
\hline CHEMBL1314701 & 688816 & 5.35 & 4.883 & TRN & \\
\hline CHEMBL1400965 & 688816 & 5.95 & 5.223 & TRN & \\
\hline CHEMBL1496635 & 688816 & 4.8 & 5.0936 & TST & \\
\hline CHEMBL1370451 & 688816 & 4.8 & 4.9219 & TST & \\
\hline CHEMBL1520424 & 688816 & 5.05 & 5.2654 & TRN & \\
\hline CHEMBL1610792 & 688816 & 4.95 & 5.0895 & TRN & \\
\hline CHEMBL1539339 & 688816 & 4.6 & 5.3065 & TRN & \\
\hline CHEMBL1497597 & 688816 & 4.9 & 4.8051 & TRN & \\
\hline CHEMBL1333638 & 688816 & 4.55 & 5.4592 & TRN & \\
\hline CHEMBL1407822 & 688816 & 4.5 & 4.9358 & TST & \\
\hline CHEMBL1301776 & 688816 & 4.9 & 4.9939 & TRN & \\
\hline CHEMBL1350007 & 688816 & 6.25 & 5.4521 & TRN & \\
\hline CHEMBL1349063 & 688816 & 5.35 & 5.5017 & TRN & \\
\hline CHEMBL1327022 & 688816 & 4.9 & 5.2735 & TRN & \\
\hline CHEMBL1372032 & 688816 & 5.45 & 5.1833 & TRN & \\
\hline CHEMBL1390654 & 688816 & 4.75 & 5.0952 & TRN & \\
\hline CHEMBL1326389 & 688816 & 4.75 & 5.2857 & TST & \\
\hline CHEMBL1344802 & 688816 & 4.65 & 5.3099 & TRN & \\
\hline CHEMBL1334430 & 688816 & 4.85 & 5.5615 & TRN & \\
\hline CHEMBL1502052 & 688816 & 5.0 & 5.3553 & TRN & \\
\hline CHEMBL1487658 & 688816 & 5.15 & 5.2653 & TST & \\
\hline CHEMBL1462524 & 688816 & 4.7 & 5.1608 & TST & \\
\hline CHEMBL3212303 & 688816 & 8.301 & 5.5229 & TST & \\
\hline CHEMBL1475048 & 688816 & 4.45 & 5.0238 & TST & \\
\hline CHEMBL1506241 & 688816 & 4.45 & 5.1352 & TRN & \\
\hline CHEMBL3191291 & 688816 & 4.45 & 5.0684 & TST & \\
\hline CHEMBL 1385158 & 688816 & 4.8 & 5.2519 & TRN & \\
\hline CHEMBL1356505 & 688816 & 4.95 & 4.7564 & TST & \\
\hline CHEMBL1429064 & 688816 & 5.0 & 5.1567 & TRN & \\
\hline CHEMBL261508 & 688816 & 4.55 & 5.2329 & TRN & \\
\hline CHEMBL3199177 & 688816 & 4.45 & 5.12200 & 0000000001 & TRN \\
\hline CHEMBL1508555 & 688816 & 4.45 & 5.1551 & TRN & \\
\hline CHEMBL1352844 & 688816 & 6.6499 & 4.7076 & TRN & \\
\hline CHEMBL 260311 & 688816 & 4.95 & 5.3311 & TRN & \\
\hline CHEMBL3189867 & 688816 & 5.45 & 5.6264 & TST & \\
\hline CHEMBL1391607 & 688816 & 4.45 & 5.0439 & TRN & \\
\hline CHEMBL1342998 & 688816 & 4.65 & 5.064 & TST & \\
\hline CHEMBL1320000 & 688816 & 4.75 & 5.2493 & TRN & \\
\hline CHEMBL1301087 & 688816 & 6.6499 & 5.50200 & 3000000001 & TRN \\
\hline CHEMBL1491435 & 688816 & 4.45 & 5.3722 & TRN & \\
\hline CHEMBL1429891 & 688816 & 5.25 & 5.3111 & TST & \\
\hline CHEMBL1434606 & 688816 & 4.95 & 4.8146 & TRN & \\
\hline CHEMBL1380816 & 688816 & 4.75 & 4.981 & TRN & \\
\hline CHEMBL3194199 & 688816 & 6.1 & 5.2452 & TRN & \\
\hline CHEMBL1528690 & 688816 & 4.95 & 5.0884 & TRN & \\
\hline CHEMBL1587747 & 688816 & 4.95 & 5.1264 & TRN & \\
\hline CHEMBL1357943 & 688816 & 4.65 & 5.1758 & TST & \\
\hline CHEMBL1419913 & 688816 & 4.85 & 5.5439 & TRN & \\
\hline
\end{tabular}




\begin{tabular}{|c|c|c|c|c|}
\hline \multicolumn{5}{|c|}{ Supplemental Table S2.txt } \\
\hline CHEMBL1385089 & 688816 & 4.85 & 4.8894 & TRN \\
\hline CHEMBL3210203 & 688816 & 5.5 & 5.7771 & TRN \\
\hline CHEMBL1516990 & 688816 & 5.35 & 5.4765 & TRN \\
\hline CHEMBL1462109 & 688816 & 4.9 & 5.0107 & TRN \\
\hline CHEMBL1565167 & 688816 & 5.3 & 5.5031 & TRN \\
\hline CHEMBL1187074 & 688816 & 5.5 & 5.043 & TRN \\
\hline CHEMBL1321438 & 688816 & 5.2 & 5.5486 & TRN \\
\hline CHEMBL1351197 & 688816 & 4.5 & 5.5385 & TST \\
\hline CHEMBL3208850 & 688816 & 5.85 & 5.5412 & TST \\
\hline CHEMBL1439309 & 688816 & 4.7 & 5.3409 & TST \\
\hline CHEMBL1598771 & 688816 & 6.8 & 5.0881 & TRN \\
\hline CHEMBL1313042 & 688816 & 5.95 & 5.5573 & TRN \\
\hline CHEMBL1538109 & 688816 & 4.8 & 4.7114 & TRN \\
\hline CHEMBL3212136 & 688816 & 5.2 & 5.4 & TRN \\
\hline CHEMBL1391259 & 688816 & 4.6 & 5.3966 & TRN \\
\hline CHEMBL1430509 & 688816 & 5.5 & 5.4985 & TRN \\
\hline CHEMBL1607360 & 688816 & 5.35 & 5.6278 & TRN \\
\hline CHEMBL579380 & 688816 & 4.9 & 5.2892 & TST \\
\hline CHEMBL1564201 & 688816 & 4.9 & 5.2308 & TST \\
\hline CHEMBL1335540 & 688816 & 4.6 & 5.0318 & TRN \\
\hline CHEMBL1361051 & 688816 & 4.55 & 5.4642 & TRN \\
\hline CHEMBL1438466 & 688816 & 5.15 & 5.5293 & TST \\
\hline CHEMBL1438903 & 688816 & 5.2 & 5.4579 & TRN \\
\hline CHEMBL1348336 & 688816 & 4.65 & 4.8737 & TRN \\
\hline CHEMBL1382121 & 688816 & 4.85 & 5.3286 & TRN \\
\hline CHEMBL1524276 & 688816 & 4.8 & 5.3396 & TRN \\
\hline CHEMBL1410061 & 688816 & 5.0 & 5.3974 & TRN \\
\hline CHEMBL1384598 & 688816 & 4.9 & 5.4859 & TRN \\
\hline CHEMBL1537276 & 688816 & 4.85 & 4.7708 & TRN \\
\hline CHEMBL1416890 & 688816 & 6.6499 & 5.1295 & TRN \\
\hline CHEMBL1321135 & 688816 & 5.25 & 5.8424 & TRN \\
\hline CHEMBL123 & 688816 & 6.0 & 5.1918 & TRN \\
\hline CHEMBL1600217 & 688816 & 4.65 & 5.3562 & TST \\
\hline CHEMBL1428328 & 688816 & 7.5498 & 5.2779 & TRN \\
\hline CHEMBL3208905 & 688816 & 4.7 & 5.5236 & TRN \\
\hline CHEMBL1560539 & 688816 & 5.35 & 4.9163 & TRN \\
\hline CHEMBL1348874 & 688816 & 4.9 & 4.8859 & TRN \\
\hline CHEMBL1453505 & 688816 & 5.7 & 5.0849 & TST \\
\hline CHEMBL1556303 & 688816 & 4.9 & 5.3792 & TRN \\
\hline CHEMBL3211634 & 688816 & 5.25 & 5.2657 & TRN \\
\hline CHEMBL1546392 & 688816 & 4.85 & 4.7734 & TRN \\
\hline CHEMBL1456135 & 688816 & 4.65 & 5.4195 & TRN \\
\hline CHEMBL1387773 & 688816 & 4.9 & 5.1753 & TST \\
\hline CHEMBL1446331 & 688816 & 4.9 & 5.1411 & TRN \\
\hline CHEMBL1378608 & 688816 & 4.45 & 5.6405 & TRN \\
\hline CHEMBL1532111 & 688816 & 4.45 & 5.4237 & TST \\
\hline CHEMBL1379881 & 688816 & 5.0 & 5.1849 & TST \\
\hline CHEMBL1528997 & 688816 & 6.6499 & 5.1964 & TRN \\
\hline
\end{tabular}




\begin{tabular}{|c|c|c|c|c|c|}
\hline \\
\hline CHEMBL1580218 & 688816 & 6.5 & 5.2779 & TRN & \\
\hline CHEMBL485012 & 688816 & 5.8 & 5.1305 & TRN & \\
\hline CHEMBL1561206 & 688816 & 5.45 & 5.3262 & TRN & \\
\hline CHEMBL1427738 & 688816 & 6.0 & 5.2035 & TST & \\
\hline CHEMBL1601391 & 688816 & 5.6 & 5.2373 & TRN & \\
\hline CHEMBL1540976 & 688816 & 4.8 & 5.5349 & TRN & \\
\hline CHEMBL1385489 & 688816 & 4.45 & 5.1718 & TST & \\
\hline CHEMBL1492574 & 688816 & 7.5498 & 5.5658 & TRN & \\
\hline CHEMBL1518291 & 688816 & 5.05 & 5.4614 & TST & \\
\hline CHEMBL589235 & 688816 & 4.75 & 5.1728 & TST & \\
\hline CHEMBL1406600 & 688816 & 4.65 & 4.8129 & TRN & \\
\hline CHEMBL1363396 & 688816 & 4.9 & 5.1301 & TST & \\
\hline CHEMBL1303681 & 688816 & 4.95 & 5.29700 & 3000000001 & TRN \\
\hline CHEMBL1546223 & 688816 & 4.6 & 5.5622 & TST & \\
\hline CHEMBL1974501 & 688816 & 5.05 & 4.893 & TRN & \\
\hline CHEMBL1399260 & 688816 & 7.6498 & 5.4017 & TST & \\
\hline CHEMBL1300625 & 688816 & 4.75 & 5.3514 & TRN & \\
\hline CHEMBL1423661 & 688816 & 4.7 & 5.4382 & TRN & \\
\hline CHEMBL1408854 & 688816 & 4.85 & 5.2172 & TRN & \\
\hline CHEMBL1535297 & 688816 & 4.95 & 5.1811 & TRN & \\
\hline CHEMBL1580298 & 688816 & 5.2 & 5.67700 & 20000000005 & TRN \\
\hline CHEMBL1379985 & 688816 & 4.7 & 5.4262 & TST & \\
\hline CHEMBL1531735 & 688816 & 5.45 & 5.2046 & TRN & \\
\hline CHEMBL1471444 & 688816 & 4.9 & 4.9494 & TRN & \\
\hline CHEMBL1507423 & 688816 & 4.5 & 5.0902 & TRN & \\
\hline CHEMBL1399134 & 688816 & 5.55 & 5.5824 & TRN & \\
\hline CHEMBL1578145 & 688816 & 5.05 & 5.0185 & TRN & \\
\hline CHEMBL1578077 & 688816 & 4.75 & 5.141 & TRN & \\
\hline CHEMBL1331097 & 688816 & 4.95 & 5.107 & TRN & \\
\hline CHEMBL1482007 & 688816 & 4.9 & 5.1526 & TRN & \\
\hline CHEMBL1549015 & 688816 & 5.35 & 5.3836 & TST & \\
\hline CHEMBL1444434 & 688816 & 7.6498 & 5.6359 & TST & \\
\hline CHEMBL1378839 & 688816 & 4.45 & 5.3595 & TRN & \\
\hline CHEMBL1388351 & 688816 & 5.7 & 5.1602 & TST & \\
\hline CHEMBL1427049 & 688816 & 5.15 & 5.55 & TST & \\
\hline CHEMBL1338899 & 688816 & 5.55 & 5.3235 & TST & \\
\hline CHEMBL1363390 & 688816 & 4.45 & 4.9359 & TRN & \\
\hline CHEMBL1416561 & 688816 & 4.6 & 4.8259 & TRN & \\
\hline CHEMBL1417108 & 688816 & 5.9 & 5.4121 & TRN & \\
\hline CHEMBL1547957 & 688816 & 6.8499 & 5.561 & TST & \\
\hline CHEMBL1350628 & 688816 & 4.95 & 5.3845 & TST & \\
\hline CHEMBL1333149 & 688816 & 4.95 & 5.5517 & TRN & \\
\hline CHEMBL1302511 & 688816 & 5.5 & 6.0113 & TRN & \\
\hline CHEMBL1391692 & 688816 & 4.45 & 5.1259 & TRN & \\
\hline CHEMBL1383622 & 688816 & 4.45 & 4.9909 & TST & \\
\hline CHEMBL1594709 & 688816 & 4.65 & 5.6348 & TRN & \\
\hline CHEMBL1521145 & 688816 & 4.95 & 5.1628 & TRN & \\
\hline CHEMBL1566479 & 688816 & 5.05 & 5.0794 & TST & \\
\hline
\end{tabular}




\begin{tabular}{|c|c|c|c|c|}
\hline \multicolumn{5}{|c|}{ Supplemental Table S2.txt } \\
\hline CHEMBL1432789 & 688816 & 7.2 & 5.2542 & TST \\
\hline CHEMBL321747 & 688816 & 6.0 & 5.6459 & TRN \\
\hline CHEMBL1580438 & 688816 & 5.2 & 5.5044 & TRN \\
\hline CHEMBL1599132 & 688816 & 4.9 & 5.1136 & TRN \\
\hline CHEMBL1478999 & 688816 & 8.301 & 5.725 & TRN \\
\hline CHEMBL1300613 & 688816 & 4.95 & 5.2744 & TRN \\
\hline CHEMBL1402912 & 688816 & 4.95 & 5.1717 & TRN \\
\hline CHEMBL1319679 & 688816 & 5.65 & 5.2138 & TRN \\
\hline CHEMBL1612381 & 688816 & 5.15 & 5.026 & TRN \\
\hline CHEMBL1462070 & 688816 & 4.9 & 4.651 & TRN \\
\hline CHEMBL1305183 & 688816 & 4.9 & 5.2974 & TRN \\
\hline CHEMBL1505359 & 688816 & 4.65 & 5.5055 & TST \\
\hline CHEMBL1445305 & 688816 & 6.7001 & 5.4124 & TRN \\
\hline CHEMBL1469540 & 688816 & 5.0 & 4.8929 & TRN \\
\hline CHEMBL1567100 & 688816 & 4.95 & 4.9843 & TRN \\
\hline CHEMBL1389264 & 688816 & 6.6499 & 5.5213 & TRN \\
\hline CHEMBL1367325 & 688816 & 6.3 & 5.165 & TRN \\
\hline CHEMBL1339232 & 688816 & 8.0506 & 5.5021 & TRN \\
\hline CHEMBL1612236 & 688816 & 4.8 & 4.9612 & TST \\
\hline CHEMBL1306402 & 688816 & 4.8 & 5.3295 & TRN \\
\hline CHEMBL1457776 & 688816 & 4.9 & 5.0813 & TRN \\
\hline CHEMBL1363891 & 688816 & 8.3468 & 5.6331 & TRN \\
\hline CHEMBL1541811 & 688816 & 7.8508 & 5.5623 & TST \\
\hline CHEMBL1448047 & 688816 & 4.7 & 5.4403 & TST \\
\hline CHEMBL1451836 & 688816 & 5.2 & 5.0966 & TRN \\
\hline CHEMBL1978773 & 688816 & 5.15 & 5.059 & TST \\
\hline CHEMBL1409064 & 688816 & 8.301 & 4.9962 & TST \\
\hline CHEMBL1465381 & 688816 & 7.5498 & 5.6466 & TST \\
\hline CHEMBL1507990 & 688816 & 4.8 & 4.5351 & TRN \\
\hline CHEMBL1471225 & 688816 & 6.0 & 5.1696 & TRN \\
\hline CHEMBL1461215 & 688816 & 4.45 & 5.4319 & TST \\
\hline CHEMBL1390899 & 688816 & 4.7 & 5.3873 & TRN \\
\hline CHEMBL1466720 & 688816 & 5.45 & 5.4422 & TRN \\
\hline CHEMBL1428721 & 688816 & 4.8 & 5.1829 & TST \\
\hline CHEMBL1572772 & 688816 & 5.2 & 5.5508 & TRN \\
\hline CHEMBL3197429 & 688816 & 4.9 & 5.5025 & TST \\
\hline CHEMBL 1307940 & 688816 & 4.85 & 5.5751 & TST \\
\hline CHEMBL1300295 & 688816 & 4.95 & 5.231 & TRN \\
\hline CHEMBL1309607 & 688816 & 4.85 & 5.0696 & TRN \\
\hline CHEMBL1570368 & 688816 & 8.4949 & 5.2518 & TRN \\
\hline CHEMBL1332448 & 688816 & 4.95 & 5.2512 & TRN \\
\hline CHEMBL1338436 & 688816 & 4.8 & 4.9413 & TRN \\
\hline CHEMBL1448029 & 688816 & 4.9 & 5.3006 & TRN \\
\hline CHEMBL1580015 & 688816 & 7.6498 & 5.5098 & TST \\
\hline CHEMBL1331707 & 688816 & 5.3 & 5.2058 & TRN \\
\hline CHEMBL1404058 & 688816 & 6.3 & 5.0625 & TRN \\
\hline CHEMBL1345494 & 688816 & 4.95 & 5.1567 & TRN \\
\hline CHEMBL1608991 & 688816 & 4.9 & 5.2894 & TRN \\
\hline
\end{tabular}




\begin{tabular}{|c|c|c|c|c|c|}
\hline \multicolumn{6}{|c|}{ Supplemental Table S2.txt } \\
\hline CHEMBL1453421 & 688816 & 5.15 & 4.9223 & TRN & \\
\hline CHEMBL1300864 & 688816 & 5.3 & 4.9649 & TRN & \\
\hline CHEMBL3192890 & 688816 & 5.4 & 5.2223 & TRN & \\
\hline CHEMBL1504881 & 688816 & 5.7 & 5.5233 & TRN & \\
\hline CHEMBL1389330 & 688816 & 4.7 & 5.3743 & TST & \\
\hline CHEMBL1577887 & 688816 & 4.45 & 5.4899 & TRN & \\
\hline CHEMBL1475142 & 688816 & 4.9 & 5.2102 & TRN & \\
\hline CHEMBL1387717 & 688816 & 4.95 & 5.2884 & TRN & \\
\hline CHEMBL1420361 & 688816 & 4.85 & 5.2429 & TRN & \\
\hline CHEMBL1352525 & 688816 & 5.2 & 4.7251 & TRN & \\
\hline CHEMBL1376001 & 688816 & 4.9 & 5.1141 & TST & \\
\hline CHEMBL1512859 & 688816 & 5.3 & 4.7969 & TST & \\
\hline CHEMBL1493550 & 688816 & 4.85 & 5.4853 & TST & \\
\hline CHEMBL1477875 & 688816 & 6.4 & 5.3089 & TRN & \\
\hline CHEMBL1529835 & 688816 & 5.8 & 4.9838 & TRN & \\
\hline CHEMBL405616 & 688816 & 4.45 & 5.0782 & TRN & \\
\hline CHEMBL1504626 & 688816 & 4.65 & 5.6117 & TRN & \\
\hline CHEMBL1560296 & 688816 & 4.85 & 4.7028 & TRN & \\
\hline CHEMBL1360015 & 688816 & 4.75 & 5.49299 & 9999999999 & TRN \\
\hline CHEMBL1459777 & 688816 & 4.45 & 5.6062 & TRN & \\
\hline CHEMBL1601808 & 688816 & 4.85 & 5.272 & TRN & \\
\hline CHEMBL1440205 & 688816 & 4.7 & 5.6651 & TST & \\
\hline CHEMBL1431300 & 688816 & 5.2 & 5.4542 & TST & \\
\hline CHEMBL1520512 & 688816 & 4.9 & 5.1813 & TST & \\
\hline CHEMBL1561768 & 688816 & 4.95 & 4.9087 & TRN & \\
\hline CHEMBL1437197 & 688816 & 5.0 & 5.013 & TST & \\
\hline CHEMBL1349248 & 688816 & 4.95 & 5.4011 & TST & \\
\hline CHEMBL1567855 & 688816 & 4.75 & 4.9988 & TST & \\
\hline CHEMBL1366942 & 688816 & 5.6 & 5.1926 & TST & \\
\hline CHEMBL1438001 & 688816 & 8.0 & 5.5922 & TRN & \\
\hline CHEMBL1373114 & 688816 & 6.0 & 5.5382 & TRN & \\
\hline CHEMBL1437139 & 688816 & 6.0 & 5.5713 & TRN & \\
\hline CHEMBL1577173 & 688816 & 5.35 & 5.0762 & TRN & \\
\hline CHEMBL1524866 & 688816 & 4.85 & 5.5131 & TST & \\
\hline CHEMBL1305645 & 688816 & 4.65 & 5.2119 & TRN & \\
\hline CHEMBL1336255 & 688816 & 4.9 & 5.436 & TST & \\
\hline CHEMBL1472067 & 688816 & 7.7496 & 5.2951 & TRN & \\
\hline CHEMBL1376675 & 688816 & 6.8499 & 5.7858 & TRN & \\
\hline CHEMBL1378059 & 688816 & 4.45 & 5.1817 & TST & \\
\hline CHEMBL1508340 & 688816 & 8.301 & 5.7358 & TST & \\
\hline CHEMBL1975032 & 688816 & 4.85 & 5.1544 & TST & \\
\hline CHEMBL 1600760 & 688816 & 4.95 & 5.7752 & TRN & \\
\hline CHEMBL504977 & 688816 & 4.45 & 5.0434 & TRN & \\
\hline CHEMBL1381834 & 688816 & 4.85 & 5.0752 & TRN & \\
\hline CHEMBL1604884 & 688816 & 4.45 & 5.1208 & TRN & \\
\hline CHEMBL1577306 & 688816 & 4.45 & 5.295 & TRN & \\
\hline CHEMBL1530022 & 688816 & 6.1 & 5.5066 & TST & \\
\hline CHEMBL1361461 & 688816 & 5.55 & 5.0637 & TRN & \\
\hline
\end{tabular}




\begin{tabular}{|c|c|c|c|c|c|}
\hline \multicolumn{6}{|c|}{ Supplemental Table s2.txt } \\
\hline CHEMBL1423841 & 688816 & 6.5 & 5.2369 & TRN & \\
\hline CHEMBL585408 & 688816 & 5.35 & 5.4306 & TRN & \\
\hline CHEMBL1388178 & 688816 & 6.3 & 5.2149 & TST & \\
\hline CHEMBL1376349 & 688816 & 5.95 & 5.419 & TST & \\
\hline CHEMBL1377743 & 688816 & 5.15 & 5.0623 & TRN & \\
\hline CHEMBL1573641 & 688816 & 4.85 & 5.7106 & TRN & \\
\hline CHEMBL1328705 & 688816 & 8.301 & 4.8843 & TRN & \\
\hline CHEMBL1481094 & 688816 & 4.75 & 5.2102 & TRN & \\
\hline CHEMBL1341320 & 688816 & 4.45 & 5.4385 & TST & \\
\hline CHEMBL1302721 & 688816 & 5.45 & 5.6745 & TRN & \\
\hline CHEMBL1484332 & 688816 & 4.45 & 5.3219 & TST & \\
\hline CHEMBL1476689 & 688816 & 5.25 & 5.2851 & TRN & \\
\hline CHEMBL1509080 & 688816 & 5.05 & 4.9907 & TRN & \\
\hline CHEMBL3210893 & 688816 & 4.85 & 5.2644 & TST & \\
\hline CHEMBL1544132 & 688816 & 4.9 & 4.8039 & TRN & \\
\hline CHEMBL1506683 & 688816 & 4.45 & 5.3369 & TST & \\
\hline CHEMBL1347499 & 688816 & 4.45 & 5.3908 & TRN & \\
\hline CHEMBL1536272 & 688816 & 4.8 & 5.1044 & TRN & \\
\hline CHEMBL1408414 & 688816 & 4.95 & 5.4336 & TRN & \\
\hline CHEMBL1443064 & 688816 & 4.75 & 5.166 & TRN & \\
\hline CHEMBL1421520 & 688816 & 4.95 & 4.7596 & TRN & \\
\hline CHEMBL1496395 & 688816 & 5.05 & 5.0082 & TRN & \\
\hline CHEMBL1375321 & 688816 & 4.9 & 5.2293 & TST & \\
\hline CHEMBL1508058 & 688816 & 4.8 & 5.1348 & TST & \\
\hline CHEMBL1303876 & 688816 & 5.45 & 4.8448 & TRN & \\
\hline CHEMBL3194494 & 688816 & 4.95 & 5.4195 & TST & \\
\hline CHEMBL1574288 & 688816 & 4.95 & 5.3876 & TRN & \\
\hline CHEMBL1598230 & 688816 & 4.8 & 5.268 & TRN & \\
\hline CHEMBL460433 & 688816 & 4.8 & 5.4072 & TST & \\
\hline CHEMBL1452808 & 688816 & 4.8 & 4.9344 & TRN & \\
\hline CHEMBL1472005 & 688816 & 5.7 & 5.1411 & TRN & \\
\hline CHEMBL560919 & 688816 & 4.45 & 5.0264 & TRN & \\
\hline CHEMBL1548498 & 688816 & 4.45 & 5.5943 & TST & \\
\hline CHEMBL1432011 & 688816 & 5.0 & 5.1954 & TST & \\
\hline CHEMBL1601779 & 688816 & 4.95 & 5.2002 & TST & \\
\hline CHEMBL1535032 & 688816 & 5.1 & 5.0928 & TST & \\
\hline CHEMBL1404129 & 688816 & 5.2 & 5.3403 & TST & \\
\hline CHEMBL1470952 & 688816 & 4.95 & 5.4202 & TRN & \\
\hline CHEMBL1318965 & 688816 & 5.1 & 5.0347 & TRN & \\
\hline CHEMBL1372401 & 688816 & 4.45 & 5.2652 & TRN & \\
\hline CHEMBL587433 & 688816 & 5.6 & 4.7972 & TRN & \\
\hline CHEMBL1330079 & 688816 & 4.95 & 5.249 & TRN & \\
\hline CHEMBL1573044 & 688816 & 7.699 & 5.3436 & TRN & \\
\hline CHEMBL1490834 & 688816 & 4.45 & 5.3197 & TST & \\
\hline CHEMBL3212689 & 688816 & 4.65 & 5.16700 & 0000000001 & TRN \\
\hline CHEMBL3199870 & 688816 & 4.45 & 5.3981 & TRN & \\
\hline CHEMBL3213422 & 688816 & 4.85 & 4.9918 & TRN & \\
\hline CHEMBL1305079 & 688816 & 4.9 & 5.1513 & TRN & \\
\hline
\end{tabular}




\begin{tabular}{|c|c|c|c|c|}
\hline \multicolumn{5}{|c|}{ Supplemental Table S2.txt } \\
\hline CHEMBL1480371 & 688816 & 5.3 & 5.2125 & TRN \\
\hline CHEMBL1355470 & 688816 & 4.45 & 4.78 & TRN \\
\hline CHEMBL1378942 & 688816 & 4.6 & 5.3213 & TRN \\
\hline CHEMBL1449299 & 688816 & 4.55 & 5.4253 & TRN \\
\hline CHEMBL352865 & 688816 & 5.45 & 5.3262 & TST \\
\hline CHEMBL1449608 & 688816 & 8.301 & 5.6031 & TRN \\
\hline CHEMBL1480325 & 688816 & 4.7 & 5.1773 & TRN \\
\hline CHEMBL1596675 & 688816 & 4.45 & 5.2105 & TST \\
\hline CHEMBL1411305 & 688816 & 5.05 & 5.2164 & TRN \\
\hline CHEMBL1327978 & 688816 & 8.0506 & 5.4177 & TRN \\
\hline CHEMBL1518971 & 688816 & 5.45 & 5.3589 & TRN \\
\hline CHEMBL1480039 & 688816 & 5.5 & 5.1696 & TRN \\
\hline CHEMBL1450888 & 688816 & 6.15 & 5.3648 & TST \\
\hline CHEMBL1311378 & 688816 & 5.25 & 5.117 & TRN \\
\hline CHEMBL1482689 & 688816 & 5.25 & 4.6545 & TRN \\
\hline CHEMBL1375043 & 688816 & 8.4949 & 5.4907 & TRN \\
\hline CHEMBL1517771 & 688816 & 4.45 & 5.2922 & TST \\
\hline CHEMBL1487402 & 688816 & 4.95 & 5.1815 & TRN \\
\hline CHEMBL1347374 & 688816 & 4.65 & 5.5348 & TRN \\
\hline CHEMBL1333044 & 688816 & 4.85 & 5.1374 & TRN \\
\hline CHEMBL1406747 & 688816 & 5.2 & 5.1481 & TST \\
\hline CHEMBL1537686 & 688816 & 4.5 & 5.4909 & TRN \\
\hline CHEMBL1485735 & 688816 & 4.55 & 5.4825 & TRN \\
\hline CHEMBL1308432 & 688816 & 4.45 & 5.0717 & TRN \\
\hline CHEMBL1566498 & 688816 & 6.8499 & 5.7767 & TRN \\
\hline CHEMBL1343396 & 688816 & 5.2 & 5.3242 & TST \\
\hline CHEMBL1356314 & 688816 & 4.8 & 5.2731 & TST \\
\hline CHEMBL1487109 & 688816 & 8.3468 & 5.2719 & TRN \\
\hline CHEMBL465339 & 688816 & 6.5 & 5.2214 & TST \\
\hline CHEMBL1976225 & 688816 & 4.45 & 5.2562 & TRN \\
\hline CHEMBL1577426 & 688816 & 5.0 & 5.2004 & TRN \\
\hline CHEMBL1584536 & 688816 & 4.8 & 5.2419 & TRN \\
\hline CHEMBL1321860 & 688816 & 4.9 & 5.3991 & TRN \\
\hline CHEMBL1417986 & 688816 & 4.45 & 4.9104 & TRN \\
\hline CHEMBL1400336 & 688816 & 4.9 & 5.0562 & TST \\
\hline CHEMBL1482510 & 688816 & 4.95 & 4.668 & TRN \\
\hline CHEMBL1548890 & 688816 & 4.65 & 4.9136 & TRN \\
\hline CHEMBL1412096 & 688816 & 6.5 & 5.183 & TST \\
\hline CHEMBL1469904 & 688816 & 4.5 & 4.6287 & TRN \\
\hline CHEMBL1548518 & 688816 & 5.3 & 5.3361 & TST \\
\hline CHEMBL1393496 & 688816 & 4.9 & 5.5085 & TRN \\
\hline CHEMBL1487953 & 688816 & 4.45 & 5.2949 & TRN \\
\hline CHEMBL1321046 & 688816 & 5.05 & 5.5209 & TRN \\
\hline CHEMBL1378975 & 688816 & 5.45 & 5.3578 & TST \\
\hline CHEMBL1575728 & 688816 & 4.45 & 5.642 & TRN \\
\hline CHEMBL1521903 & 688816 & 4.8 & 5.2124 & TRN \\
\hline CHEMBL1426679 & 688816 & 6.6499 & 5.1248 & TRN \\
\hline CHEMBL1613035 & 688816 & 4.75 & 5.2707 & TRN \\
\hline
\end{tabular}




\begin{tabular}{|c|c|c|c|c|}
\hline \multicolumn{5}{|c|}{ Supplemental Table S2.txt } \\
\hline CHEMBL1510303 & 688816 & 4.95 & 5.4409 & TST \\
\hline CHEMBL1361709 & 688816 & 4.6 & 4.9596 & TST \\
\hline CHEMBL1561009 & 688816 & 5.5 & 5.0598 & TST \\
\hline CHEMBL1300389 & 688816 & 4.9 & 4.9766 & TRN \\
\hline CHEMBL1498512 & 688816 & 4.65 & 5.0012 & TRN \\
\hline CHEMBL1391520 & 688816 & 4.45 & 4.8799 & TRN \\
\hline CHEMBL1386982 & 688816 & 6.0 & 6.0161 & TRN \\
\hline CHEMBL1431767 & 688816 & 5.85 & 5.2351 & TRN \\
\hline CHEMBL1437965 & 688816 & 5.4 & 4.9589 & TRN \\
\hline CHEMBL1460766 & 688816 & 7.699 & 5.6113 & TRN \\
\hline CHEMBL1520381 & 688816 & 5.0 & 5.1093 & TRN \\
\hline CHEMBL1516907 & 688816 & 4.9 & 5.364 & TRN \\
\hline CHEMBL1475307 & 688816 & 5.0 & 5.3809 & TRN \\
\hline CHEMBL1374356 & 688816 & 4.45 & 4.9374 & TRN \\
\hline CHEMBL1316854 & 688816 & 5.45 & 5.5254 & TRN \\
\hline CHEMBL1364878 & 688816 & 4.9 & 4.8881 & TRN \\
\hline CHEMBL1458285 & 688816 & 4.5 & 5.7351 & TST \\
\hline CHEMBL2003942 & 688816 & 7.3002 & 5.3779 & TRN \\
\hline CHEMBL1369376 & 688816 & 4.45 & 4.9898 & TST \\
\hline CHEMBL1572984 & 688816 & 4.85 & 5.8752 & TST \\
\hline CHEMBL1363376 & 688816 & 5.45 & 4.942 & TRN \\
\hline CHEMBL1545971 & 688816 & 4.8 & 4.8269 & TRN \\
\hline CHEMBL1386512 & 688816 & 5.0 & 5.2431 & TRN \\
\hline CHEMBL1419695 & 688816 & 5.1 & 5.2249 & TST \\
\hline CHEMBL1544877 & 688816 & 5.25 & 5.1274 & TRN \\
\hline CHEMBL1459866 & 688816 & 4.85 & 5.6285 & TRN \\
\hline CHEMBL1594554 & 688816 & 4.95 & 5.3506 & TRN \\
\hline CHEMBL1598673 & 688816 & 6.5501 & 5.5659 & TRN \\
\hline CHEMBL 3190781 & 688816 & 4.95 & 5.0012 & TRN \\
\hline CHEMBL1425856 & 688816 & 4.85 & 5.3683 & TRN \\
\hline CHEMBL1484014 & 688816 & 7.5003 & 5.2815 & TRN \\
\hline CHEMBL1506574 & 688816 & 7.1002 & 5.4573 & TRN \\
\hline CHEMBL1335712 & 688816 & 4.6 & 4.8052 & TRN \\
\hline CHEMBL1494739 & 688816 & 8.301 & 5.425 & TRN \\
\hline CHEMBL1466566 & 688816 & 4.55 & 5.3068 & TST \\
\hline CHEMBL1968859 & 688816 & 4.95 & 5.3208 & TRN \\
\hline CHEMBL1500713 & 688816 & 5.15 & 5.2898 & TRN \\
\hline CHEMBL1476591 & 688816 & 4.85 & 4.8974 & TRN \\
\hline CHEMBL 3190479 & 688816 & 4.6 & 5.3701 & TRN \\
\hline CHEMBL1455486 & 688816 & 5.2 & 5.4093 & TRN \\
\hline CHEMBL1313522 & 688816 & 5.0 & 5.2368 & TRN \\
\hline CHEMBL1599438 & 688816 & 4.95 & 5.0592 & TST \\
\hline CHEMBL1344555 & 688816 & 5.65 & 5.0801 & TRN \\
\hline CHEMBL1310306 & 688816 & 4.45 & 5.4297 & TST \\
\hline CHEMBL1584313 & 688816 & 8.301 & 5.5997 & TRN \\
\hline CHEMBL1588312 & 688816 & 4.9 & 5.0238 & TRN \\
\hline CHEMBL1407530 & 688816 & 5.7 & 5.4159 & TRN \\
\hline CHEMBL1355406 & 688816 & 4.85 & 5.4496 & TRN \\
\hline
\end{tabular}




\begin{tabular}{|c|c|c|c|c|c|}
\hline & & & & & \\
\hline CHEMBL1366369 & 688816 & 4.8 & 5.1274 & TRN & \\
\hline CHEMBL1600077 & 688816 & 5.6 & 5.4358 & TRN & \\
\hline CHEMBL1346600 & 688816 & 6.9 & 5.3357 & TST & \\
\hline CHEMBL1417848 & 688816 & 5.0 & 5.2036 & TRN & \\
\hline CHEMBL1353421 & 688816 & 5.1 & 5.2623 & TRN & \\
\hline CHEMBL1370037 & 688816 & 7.2503 & 4.9246 & TRN & \\
\hline CHEMBL1609181 & 688816 & 4.8 & 5.3186 & TRN & \\
\hline CHEMBL1587218 & 688816 & 5.95 & 5.3427 & TST & \\
\hline CHEMBL1359492 & 688816 & 4.75 & 5.233 & TRN & \\
\hline CHEMBL1499050 & 688816 & 4.45 & 5.2805 & TST & \\
\hline CHEMBL1441578 & 688816 & 4.45 & 5.7888 & TST & \\
\hline CHEMBL1533589 & 688816 & 8.301 & 5.4396 & TRN & \\
\hline CHEMBL1376242 & 688816 & 4.95 & 5.314 & TRN & \\
\hline CHEMBL1596690 & 688816 & 4.8 & 5.083 & TRN & \\
\hline CHEMBL1506430 & 688816 & 6.95 & 5.2517 & TST & \\
\hline CHEMBL1508806 & 688816 & 4.6 & 5.8286 & TRN & \\
\hline CHEMBL1440390 & 688816 & 6.8499 & 5.2927 & TST & \\
\hline CHEMBL1349822 & 688816 & 5.25 & 5.336 & TRN & \\
\hline CHEMBL1411698 & 688816 & 4.85 & 5.0025 & TRN & \\
\hline CHEMBL148296 & 688816 & 6.0 & 5.0227 & TST & \\
\hline CHEMBL1442788 & 688816 & 4.55 & 5.2255 & TST & \\
\hline CHEMBL1496318 & 688816 & 5.2 & 5.3927 & TRN & \\
\hline CHEMBL1536963 & 688816 & 4.8 & 5.0297 & TRN & \\
\hline CHEMBL1395275 & 688816 & 4.85 & 5.1693 & TST & \\
\hline CHEMBL1545411 & 688816 & 8.301 & 5.5244 & TRN & \\
\hline CHEMBL1577023 & 688816 & 4.45 & 5.4997 & TRN & \\
\hline CHEMBL1450563 & 688816 & 4.95 & 4.9666 & TRN & \\
\hline CHEMBL1538267 & 688816 & 5.15 & 5.0568 & TRN & \\
\hline CHEMBL1523697 & 688816 & 5.35 & 4.9854 & TRN & \\
\hline CHEMBL1570045 & 688816 & 4.95 & 5.4169 & TST & \\
\hline CHEMBL1392980 & 688816 & 5.85 & 5.4895 & TST & \\
\hline CHEMBL1256667 & 688816 & 5.55 & 5.3064 & TST & \\
\hline CHEMBL1453461 & 688816 & 5.4 & 5.0779 & TRN & \\
\hline CHEMBL3191831 & 688816 & 4.65 & 5.0143 & TRN & \\
\hline CHEMBL1612374 & 688816 & 5.25 & 5.688 & TRN & \\
\hline CHEMBL1578113 & 688816 & 4.9 & 5.3748 & TRN & \\
\hline CHEMBL1432556 & 688816 & 4.95 & 5.1409 & TST & \\
\hline CHEMBL3190832 & 688816 & 4.45 & 5.3569 & TRN & \\
\hline CHEMBL1428002 & 688816 & 8.4949 & 5.2949 & TRN & \\
\hline CHEMBL1343390 & 688816 & 4.95 & 5.2802 & TRN & \\
\hline CHEMBL1445871 & 688816 & 6.3 & 5.3377 & TRN & \\
\hline CHEMBL1503853 & 688816 & 5.25 & 5.1035 & TRN & \\
\hline CHEMBL1365154 & 688816 & 4.8 & 5.0725 & TRN & \\
\hline CHEMBL1468315 & 688816 & 4.9 & 5.1656 & TRN & \\
\hline CHEMBL1447073 & 688816 & 5.05 & 4.9919 & TRN & \\
\hline CHEMBL1462545 & 688816 & 6.05 & 5.4822 & TRN & \\
\hline CHEMBL1579878 & 688816 & 5.0 & 5.13899 & 9999999999 & TRN \\
\hline CHEMBL1544634 & 688816 & 7.7496 & 5.2892 & TST & \\
\hline & & & & 24749 & \\
\hline
\end{tabular}




\begin{tabular}{|c|c|c|c|c|}
\hline & & & oplement & al Table S \\
\hline CHEMBL1480448 & 688816 & 7.699 & 5.2774 & TRN \\
\hline CHEMBL1348696 & 688816 & 5.2 & 5.3947 & TST \\
\hline CHEMBL1578449 & 688816 & 5.5 & 5.3531 & TRN \\
\hline CHEMBL1501314 & 688816 & 8.301 & 5.1933 & TST \\
\hline CHEMBL1441915 & 688816 & 5.05 & 5.3305 & TRN \\
\hline CHEMBL3196033 & 688816 & 8.301 & 5.5287 & TST \\
\hline CHEMBL1346970 & 688816 & 4.9 & 5.1552 & TRN \\
\hline CHEMBL1349908 & 688816 & 4.8 & 4.817 & TRN \\
\hline CHEMBL1367043 & 688816 & 5.0 & 5.1306 & TRN \\
\hline CHEMBL1381671 & 688816 & 4.45 & 5.191 & TRN \\
\hline CHEMBL1407323 & 688816 & 6.8 & 5.4568 & TRN \\
\hline CHEMBL1977007 & 688816 & 4.85 & 4.927 & TRN \\
\hline CHEMBL1365618 & 688816 & 5.5 & 5.6143 & TST \\
\hline CHEMBL1520344 & 688816 & 4.45 & 5.6621 & TRN \\
\hline CHEMBL1302243 & 688816 & 4.45 & 6.1177 & TST \\
\hline CHEMBL1577649 & 688816 & 4.65 & 4.9579 & TRN \\
\hline CHEMBL1460071 & 688816 & 5.35 & 5.6473 & TRN \\
\hline CHEMBL1363043 & 688816 & 5.1 & 5.3885 & TRN \\
\hline CHEMBL1438560 & 688816 & 6.5 & 5.1969 & TST \\
\hline CHEMBL1999906 & 688816 & 5.0 & 5.1603 & TST \\
\hline CHEMBL1332714 & 688816 & 7.6498 & 4.8597 & TST \\
\hline CHEMBL502315 & 688816 & 4.95 & 5.1108 & TRN \\
\hline CHEMBL1453858 & 688816 & 5.2 & 5.2218 & TRN \\
\hline CHEMBL1600963 & 688816 & 4.9 & 5.7564 & TST \\
\hline CHEMBL1541647 & 688816 & 5.0 & 5.1336 & TST \\
\hline CHEMBL1487345 & 688816 & 6.05 & 4.9676 & TRN \\
\hline CHEMBL1340698 & 688816 & 4.65 & 5.2396 & TRN \\
\hline CHEMBL1539604 & 688816 & 5.0 & 5.4476 & TRN \\
\hline CHEMBL1521977 & 688816 & 4.9 & 4.6715 & TRN \\
\hline CHEMBL1443309 & 688816 & 7.699 & 5.6703 & TRN \\
\hline CHEMBL1611998 & 688816 & 4.75 & 4.9661 & TRN \\
\hline CHEMBL1473040 & 688816 & 4.7 & 5.0163 & TRN \\
\hline CHEMBL1320937 & 688816 & 4.7 & 5.5135 & TST \\
\hline CHEMBL1371615 & 688816 & 6.45 & 5.3359 & TST \\
\hline CHEMBL477139 & 688816 & 4.95 & 5.2174 & TRN \\
\hline CHEMBL1496487 & 688816 & 5.05 & 5.1243 & TRN \\
\hline CHEMBL3191271 & 688816 & 4.85 & 5.24700 & 0000000001 \\
\hline CHEMBL1328814 & 688816 & 5.65 & 5.4512 & TRN \\
\hline CHEMBL1341629 & 688816 & 5.6 & 5.0115 & TRN \\
\hline CHEMBL1790009 & 688816 & 5.25 & 5.56 & TRN \\
\hline CHEMBL67212 & 688816 & 4.45 & 5.3566 & TRN \\
\hline CHEMBL1411907 & 688816 & 4.85 & 5.0631 & TST \\
\hline CHEMBL1419698 & 688816 & 6.0 & 5.5178 & TRN \\
\hline CHEMBL1340864 & 688816 & 5.8 & 5.3745 & TST \\
\hline CHEMBL1382310 & 688816 & 5.0 & 5.0045 & TRN \\
\hline CHEMBL1485445 & 688816 & 4.7 & 5.2915 & TRN \\
\hline CHEMBL1419157 & 688816 & 4.45 & 5.1019 & TRN \\
\hline CHEMBL116569 & 688816 & 6.0 & 5.2416 & TRN \\
\hline
\end{tabular}




\begin{tabular}{|c|c|c|c|c|c|}
\hline \multicolumn{6}{|c|}{ Supplemental Table s2.txt } \\
\hline CHEMBL1379071 & 688816 & 5.15 & 5.1466 & TRN & \\
\hline CHEMBL1544633 & 688816 & 5.25 & 4.9584 & TRN & \\
\hline CHEMBL600773 & 688816 & 4.85 & 5.2263 & TRN & \\
\hline CHEMBL1374015 & 688816 & 4.45 & 4.9895 & TRN & \\
\hline CHEMBL1448386 & 688816 & 5.35 & 5.7845 & TRN & \\
\hline CHEMBL1325279 & 688816 & 5.25 & 5.2038 & TRN & \\
\hline CHEMBL1366443 & 688816 & 4.95 & 5.0939 & TST & \\
\hline CHEMBL1547141 & 688816 & 4.55 & 5.3713 & TST & \\
\hline CHEMBL1421605 & 688816 & 5.6 & 5.0463 & TST & \\
\hline CHEMBL1581333 & 688816 & 4.85 & 5.2795 & TST & \\
\hline CHEMBL1446959 & 688816 & 4.7 & 5.0911 & TRN & \\
\hline CHEMBL1415600 & 688816 & 4.85 & 5.1579 & TRN & \\
\hline CHEMBL1576462 & 688816 & 4.95 & 5.305 & TRN & \\
\hline CHEMBL 3192656 & 688816 & 4.6 & 5.2328 & TRN & \\
\hline CHEMBL1396203 & 688816 & 4.45 & 4.8366 & TRN & \\
\hline CHEMBL1382120 & 688816 & 5.65 & 5.0907 & TRN & \\
\hline CHEMBL 3207847 & 688816 & 4.8 & 5.4389 & TRN & \\
\hline CHEMBL1540809 & 688816 & 4.95 & 5.4696 & TST & \\
\hline CHEMBL1537041 & 688816 & 5.0 & 5.4103 & TRN & \\
\hline CHEMBL3194104 & 688816 & 4.95 & 5.40799 & 99999999995 & TRN \\
\hline CHEMBL1546137 & 688816 & 4.95 & 5.2992 & TRN & \\
\hline CHEMBL1443475 & 688816 & 4.6 & 5.2732 & TRN & \\
\hline CHEMBL1538325 & 688816 & 4.45 & 4.9672 & TRN & \\
\hline CHEMBL1400683 & 688816 & 5.65 & 5.1281 & TRN & \\
\hline CHEMBL1495628 & 688816 & 8.301 & 5.5647 & TRN & \\
\hline CHEMBL1450487 & 688816 & 6.45 & 5.5126 & TST & \\
\hline CHEMBL1532205 & 688816 & 5.7 & 5.3374 & TRN & \\
\hline CHEMBL3198230 & 688816 & 4.75 & 5.0957 & TST & \\
\hline CHEMBL 3193739 & 688816 & 4.85 & 5.0757 & TRN & \\
\hline CHEMBL1389641 & 688816 & 4.5 & 5.185 & TST & \\
\hline CHEMBL1565992 & 688816 & 5.35 & 5.2874 & TRN & \\
\hline CHEMBL1432106 & 688816 & 4.45 & 5.4627 & TST & \\
\hline CHEMBL1400909 & 688816 & 4.8 & 5.2456 & TRN & \\
\hline CHEMBL1491181 & 688816 & 6.5 & 5.0278 & TRN & \\
\hline CHEMBL1395876 & 688816 & 5.0 & 5.1328 & TRN & \\
\hline CHEMBL 3209982 & 688816 & 5.65 & 5.0398 & TST & \\
\hline CHEMBL460601 & 688816 & 4.55 & 5.5262 & TST & \\
\hline CHEMBL1424910 & 688816 & 4.75 & 5.2161 & TRN & \\
\hline CHEMBL1599303 & 688816 & 8.3468 & 5.478 & TRN & \\
\hline CHEMBL1555853 & 688816 & 4.55 & 5.1614 & TRN & \\
\hline CHEMBL1550486 & 688816 & 5.6 & 5.4704 & TRN & \\
\hline CHEMBL1311906 & 688816 & 5.0 & 5.2873 & TST & \\
\hline CHEMBL1402400 & 688816 & 4.7 & 5.1306 & TRN & \\
\hline CHEMBL1384757 & 688816 & 4.65 & 5.4334 & TST & \\
\hline CHEMBL1504938 & 688816 & 4.45 & 5.205 & TRN & \\
\hline CHEMBL1594351 & 688816 & 4.85 & 5.3394 & TRN & \\
\hline CHEMBL1598442 & 688816 & 4.6 & 5.0699 & TRN & \\
\hline CHEMBL1326305 & 688816 & 4.45 & 5.4692 & TRN & \\
\hline
\end{tabular}




\begin{tabular}{|c|c|c|c|c|c|}
\hline \multicolumn{6}{|c|}{ Supplemental Table S2.txt } \\
\hline CHEMBL1332292 & 688816 & 4.85 & 4.9756 & TRN & \\
\hline CHEMBL1518154 & 688816 & 7.5003 & 5.9894 & TRN & \\
\hline CHEMBL1376330 & 688816 & 8.0 & 4.9906 & TST & \\
\hline CHEMBL1418014 & 688816 & 4.45 & 5.1283 & TRN & \\
\hline CHEMBL1417302 & 688816 & 4.85 & 4.9758 & TST & \\
\hline CHEMBL1447467 & 688816 & 4.8 & 5.3953 & TST & \\
\hline CHEMBL1330157 & 688816 & 4.65 & 5.1162 & TRN & \\
\hline CHEMBL1574687 & 688816 & 4.45 & 5.3475 & TST & \\
\hline CHEMBL1565402 & 688816 & 4.45 & 5.4065 & TST & \\
\hline CHEMBL1604106 & 688816 & 5.0 & 5.0279 & TRN & \\
\hline CHEMBL1483822 & 688816 & 7.5498 & 5.6575 & TST & \\
\hline CHEMBL1404538 & 688816 & 5.4 & 4.9121 & TST & \\
\hline CHEMBL1358939 & 688816 & 4.75 & 5.2247 & TRN & \\
\hline CHEMBL1367313 & 688816 & 4.85 & 5.1712 & TST & \\
\hline CHEMBL1455689 & 688816 & 4.85 & 5.1538 & TRN & \\
\hline CHEMBL1311497 & 688816 & 4.95 & 5.1564 & TRN & \\
\hline CHEMBL1448415 & 688816 & 5.95 & 4.8787 & TRN & \\
\hline CHEMBL1556100 & 688816 & 5.5 & 5.4674 & TRN & \\
\hline CHEMBL1478490 & 688816 & 4.8 & 4.7754 & TST & \\
\hline CHEMBL1457342 & 688816 & 4.6 & 4.8248 & TRN & \\
\hline CHEMBL1586427 & 688816 & 4.6 & 5.234 & TST & \\
\hline CHEMBL1493226 & 688816 & 4.7 & 5.204 & TRN & \\
\hline CHEMBL1436489 & 688816 & 4.95 & 5.0378 & TRN & \\
\hline CHEMBL1447716 & 688816 & 4.45 & 5.3596 & TRN & \\
\hline CHEMBL1454222 & 688816 & 4.9 & 5.2033 & TRN & \\
\hline CHEMBL1333306 & 688816 & 4.45 & 5.3037 & TRN & \\
\hline CHEMBL1372449 & 688816 & 4.95 & 5.1755 & TRN & \\
\hline CHEMBL1299881 & 688816 & 5.2 & 5.46399 & 99999999995 & TST \\
\hline CHEMBL1533643 & 688816 & 6.1 & 5.2941 & TST & \\
\hline CHEMBL 3213415 & 688816 & 4.9 & 5.532 & TRN & \\
\hline CHEMBL1446342 & 688816 & 4.9 & 5.3511 & TRN & \\
\hline CHEMBL1487557 & 688816 & 5.25 & 5.3218 & TST & \\
\hline CHEMBL1305574 & 688816 & 4.45 & 5.5062 & TST & \\
\hline CHEMBL1370217 & 688816 & 4.45 & 5.2035 & TRN & \\
\hline CHEMBL1550085 & 688816 & 4.65 & 5.3565 & TST & \\
\hline CHEMBL1307515 & 688816 & 4.5 & 5.3937 & TRN & \\
\hline CHEMBL1408017 & 688816 & 5.0 & 4.9113 & TRN & \\
\hline CHEMBL1983549 & 688816 & 5.1 & 5.3957 & TST & \\
\hline CHEMBL1409316 & 688816 & 4.9 & 5.4207 & TRN & \\
\hline CHEMBL1544735 & 688816 & 4.5 & 5.2014 & TRN & \\
\hline CHEMBL604321 & 688816 & 4.7 & 4.9963 & TRN & \\
\hline CHEMBL1477076 & 688816 & 6.0 & 5.3937 & TRN & \\
\hline CHEMBL1365280 & 688816 & 4.7 & 5.8292 & TRN & \\
\hline CHEMBL1427981 & 688816 & 5.35 & 5.0669 & TRN & \\
\hline CHEMBL1383603 & 688816 & 4.75 & 5.09 & TRN & \\
\hline CHEMBL1610142 & 688816 & 5.3 & 5.0518 & TRN & \\
\hline CHEMBL1466497 & 688816 & 4.9 & 5.0745 & TRN & \\
\hline CHEMBL1365638 & 688816 & 6.15 & 5.1632 & TRN & \\
\hline
\end{tabular}




\begin{tabular}{|c|c|c|c|c|c|}
\hline \multicolumn{6}{|c|}{ Supplemental Table S2.txt } \\
\hline CHEMBL1389044 & 688816 & 6.8 & 6.09 & TRN & \\
\hline CHEMBL1486819 & 688816 & 4.85 & 5.2102 & TRN & \\
\hline CHEMBL1419855 & 688816 & 4.55 & 5.5687 & TRN & \\
\hline CHEMBL1508582 & 688816 & 5.05 & 5.1044 & TST & \\
\hline CHEMBL1430469 & 688816 & 4.45 & 5.0094 & TRN & \\
\hline CHEMBL1500290 & 688816 & 4.7 & 4.9953 & TRN & \\
\hline CHEMBL1544221 & 688816 & 4.95 & 5.2261 & TRN & \\
\hline CHEMBL1399925 & 688816 & 5.75 & 5.19799 & 99999999995 & TRN \\
\hline CHEMBL1487756 & 688816 & 5.3 & 5.2073 & TRN & \\
\hline CHEMBL1571459 & 688816 & 4.9 & 5.1002 & TRN & \\
\hline CHEMBL1311143 & 688816 & 7.699 & 5.2442 & TRN & \\
\hline CHEMBL1320532 & 688816 & 7.8508 & 5.0859 & TST & \\
\hline CHEMBL1585356 & 688816 & 4.85 & 5.2816 & TRN & \\
\hline CHEMBL1549241 & 688816 & 5.25 & 5.4923 & TRN & \\
\hline CHEMBL1604707 & 688816 & 4.45 & 5.1898 & TRN & \\
\hline CHEMBL1365206 & 688816 & 8.0 & 5.37200 & 0000000001 & TRN \\
\hline CHEMBL1600127 & 688816 & 4.95 & 5.4566 & TST & \\
\hline CHEMBL 3190495 & 688816 & 5.45 & 5.4683 & TST & \\
\hline CHEMBL1416773 & 688816 & 5.6 & 5.1146 & TRN & \\
\hline CHEMBL1344549 & 688816 & 4.75 & 5.3881 & TRN & \\
\hline CHEMBL1312956 & 688816 & 5.5 & 5.4741 & TST & \\
\hline CHEMBL1455579 & 688816 & 5.15 & 5.3359 & TRN & \\
\hline CHEMBL3190423 & 688816 & 4.45 & 5.4955 & TST & \\
\hline CHEMBL1562996 & 688816 & 5.0 & 5.1315 & TRN & \\
\hline CHEMBL1506397 & 688816 & 4.8 & 5.6943 & TRN & \\
\hline CHEMBL1604071 & 688816 & 4.45 & 5.1847 & TRN & \\
\hline CHEMBL1360754 & 688816 & 4.95 & 5.3013 & TST & \\
\hline CHEMBL1497265 & 688816 & 5.0 & 5.3123 & TRN & \\
\hline CHEMBL1535209 & 688816 & 4.95 & 5.2724 & TRN & \\
\hline CHEMBL1384897 & 688816 & 5.2 & 5.6649 & TRN & \\
\hline CHEMBL1517459 & 688816 & 4.8 & 5.2682 & TRN & \\
\hline CHEMBL1597265 & 688816 & 5.15 & 5.3065 & TRN & \\
\hline CHEMBL1348241 & 688816 & 4.45 & 5.2217 & TRN & \\
\hline CHEMBL1431611 & 688816 & 5.05 & 5.2171 & TRN & \\
\hline CHEMBL1604090 & 688816 & 4.45 & 5.095 & TST & \\
\hline CHEMBL1573600 & 688816 & 4.45 & 5.4498 & TRN & \\
\hline CHEMBL1565349 & 688816 & 4.8 & 5.1236 & TRN & \\
\hline CHEMBL1459714 & 688816 & 4.8 & 5.1164 & TRN & \\
\hline CHEMBL1474157 & 688816 & 4.95 & 4.9715 & TST & \\
\hline CHEMBL3197847 & 688816 & 4.65 & 4.9796 & TRN & \\
\hline CHEMBL1448138 & 688816 & 5.0 & 5.0319 & TRN & \\
\hline CHEMBL1384414 & 688816 & 4.95 & 4.8768 & TST & \\
\hline CHEMBL3208843 & 688816 & 4.9 & 5.3631 & TRN & \\
\hline CHEMBL1302153 & 688816 & 5.2 & 5.4835 & TRN & \\
\hline CHEMBL1412151 & 688816 & 7.7496 & 5.3887 & TST & \\
\hline CHEMBL1516527 & 688816 & 4.9 & 5.4437 & TRN & \\
\hline CHEMBL1416076 & 688816 & 6.8 & 5.3978 & TRN & \\
\hline CHEMBL1345747 & 688816 & 4.65 & 5.1758 & TRN & \\
\hline
\end{tabular}




\begin{tabular}{|c|c|c|c|c|}
\hline \multicolumn{5}{|c|}{ Supplemental Table S2.txt } \\
\hline CHEMBL1487321 & 688816 & 4.95 & 5.3133 & TRN \\
\hline CHEMBL1513797 & 688816 & 4.7 & 5.3752 & TRN \\
\hline CHEMBL1378441 & 688816 & 4.9 & 4.8919 & TRN \\
\hline CHEMBL1383111 & 688816 & 5.05 & 5.2194 & TRN \\
\hline CHEMBL1393502 & 688816 & 6.1 & 4.9193 & TRN \\
\hline CHEMBL1308359 & 688816 & 6.8 & 5.0835 & TRN \\
\hline CHEMBL1432721 & 688816 & 5.95 & 5.3093 & TRN \\
\hline CHEMBL1582505 & 688816 & 4.45 & 5.3708 & TST \\
\hline CHEMBL1606433 & 688816 & 4.65 & 5.2763 & TST \\
\hline CHEMBL1609034 & 688816 & 4.9 & 5.1422 & TRN \\
\hline CHEMBL1566938 & 688816 & 4.45 & 5.1253 & TRN \\
\hline CHEMBL1392800 & 688816 & 4.45 & 5.2477 & TRN \\
\hline CHEMBL1322448 & 688816 & 4.95 & 5.0025 & TRN \\
\hline CHEMBL1584363 & 688816 & 4.9 & 5.2978 & TRN \\
\hline CHEMBL1382461 & 688816 & 4.5 & 4.9969 & TRN \\
\hline CHEMBL1362366 & 688816 & 4.45 & 5.5877 & TRN \\
\hline CHEMBL1330233 & 688816 & 5.35 & 4.7729 & TRN \\
\hline CHEMBL1547179 & 688816 & 4.9 & 4.8663 & TRN \\
\hline CHEMBL1333092 & 688816 & 8.0506 & 5.2425 & TRN \\
\hline CHEMBL1586082 & 688816 & 4.8 & 5.581 & TRN \\
\hline CHEMBL1501400 & 688816 & 5.0 & 5.011 & TRN \\
\hline CHEMBL1412174 & 688816 & 5.35 & 5.2921 & TRN \\
\hline CHEMBL1323152 & 688816 & 4.75 & 5.1638 & TRN \\
\hline CHEMBL1300952 & 688816 & 4.45 & 5.7119 & TRN \\
\hline CHEMBL1422574 & 688816 & 7.15 & 5.2198 & TST \\
\hline CHEMBL1472299 & 688816 & 4.9 & 5.0445 & TRN \\
\hline CHEMBL1463412 & 688816 & 6.9 & 5.2966 & TST \\
\hline CHEMBL1560507 & 688816 & 4.45 & 5.0635 & TRN \\
\hline CHEMBL1323419 & 688816 & 5.55 & 5.9412 & TST \\
\hline CHEMBL1499077 & 688816 & 4.45 & 4.8975 & TST \\
\hline CHEMBL1394002 & 688816 & 4.45 & 5.0418 & TRN \\
\hline CHEMBL1410615 & 688816 & 4.45 & 5.4714 & TST \\
\hline CHEMBL1529573 & 688816 & 4.7 & 5.5319 & TRN \\
\hline CHEMBL1557747 & 688816 & 4.85 & 5.1903 & TRN \\
\hline CHEMBL3194762 & 688816 & 4.45 & 5.0702 & TRN \\
\hline CHEMBL1459556 & 688816 & 4.95 & 5.506 & TRN \\
\hline CHEMBL1526539 & 688816 & 4.9 & 5.3069 & TRN \\
\hline CHEMBL1497344 & 688816 & 4.7 & 5.4628 & TST \\
\hline CHEMBL1474836 & 688816 & 5.75 & 5.2247 & TST \\
\hline CHEMBL1592567 & 688816 & 5.25 & 5.2745 & TRN \\
\hline CHEMBL1468306 & 688816 & 4.45 & 4.9876 & TRN \\
\hline CHEMBL1548893 & 688816 & 4.95 & 4.9422 & TRN \\
\hline CHEMBL1362576 & 688816 & 4.9 & 4.9458 & TRN \\
\hline CHEMBL1352510 & 688816 & 8.1024 & 5.6646 & TRN \\
\hline CHEMBL1323174 & 688816 & 5.15 & 5.1235 & TRN \\
\hline CHEMBL1570696 & 688816 & 4.9 & 5.2041 & TRN \\
\hline CHEMBL1380402 & 688816 & 5.45 & 4.863 & TRN \\
\hline CHEMBL1412930 & 688816 & 5.45 & 5.2972 & TRN \\
\hline
\end{tabular}




\begin{tabular}{|c|c|c|c|c|}
\hline \multicolumn{5}{|c|}{ Supplemental Table S2.txt } \\
\hline CHEMBL1989823 & 688816 & 4.45 & 5.2295 & TST \\
\hline CHEMBL1405170 & 688816 & 5.9 & 5.1613 & TST \\
\hline CHEMBL1400385 & 688816 & 5.65 & 5.1465 & TRN \\
\hline CHEMBL1607497 & 688816 & 4.95 & 5.3931 & TRN \\
\hline CHEMBL1415042 & 688816 & 6.8499 & 5.0768 & TRN \\
\hline CHEMBL1370256 & 688816 & 4.8 & 5.0582 & TRN \\
\hline CHEMBL1498792 & 688816 & 5.7 & 5.6072 & TRN \\
\hline CHEMBL1431645 & 688816 & 4.8 & 4.937 & TRN \\
\hline CHEMBL 3213240 & 688816 & 5.0 & 5.3066 & TRN \\
\hline CHEMBL1384654 & 688816 & 6.3 & 5.1442 & TRN \\
\hline CHEMBL1308219 & 688816 & 4.45 & 5.282 & TST \\
\hline CHEMBL1698464 & 688816 & 4.95 & 5.0665 & TST \\
\hline CHEMBL1319461 & 688816 & 4.45 & 5.5216 & TST \\
\hline CHEMBL1487256 & 688816 & 4.45 & 5.0231 & TRN \\
\hline CHEMBL1605299 & 688816 & 5.15 & 5.0622 & TRN \\
\hline CHEMBL1395128 & 688816 & 5.2 & 5.4374 & TST \\
\hline CHEMBL1417852 & 688816 & 5.45 & 5.5941 & TST \\
\hline CHEMBL1465074 & 688816 & 4.95 & 4.9297 & TRN \\
\hline CHEMBL1964690 & 688816 & 4.6 & 5.0309 & TST \\
\hline CHEMBL1538759 & 688816 & 4.85 & 5.1162 & TRN \\
\hline CHEMBL1322196 & 688816 & 4.45 & 5.0756 & TST \\
\hline CHEMBL1328827 & 688816 & 4.65 & 4.8407 & TRN \\
\hline CHEMBL1392383 & 688816 & 6.7001 & 5.6109 & TRN \\
\hline CHEMBL1531239 & 688816 & 4.85 & 5.4105 & TRN \\
\hline CHEMBL1518753 & 688816 & 4.95 & 5.0726 & TST \\
\hline CHEMBL1496984 & 688816 & 5.15 & 5.8025 & TRN \\
\hline CHEMBL1323077 & 688816 & 5.55 & 5.9522 & TRN \\
\hline CHEMBL1447745 & 688816 & 4.65 & 5.1213 & TRN \\
\hline CHEMBL272682 & 688816 & 4.45 & 4.9227 & TRN \\
\hline CHEMBL1354119 & 688816 & 4.8 & 5.1962 & TRN \\
\hline CHEMBL1340407 & 688816 & 4.95 & 4.8392 & TRN \\
\hline CHEMBL3194537 & 688816 & 4.9 & 5.4026 & TRN \\
\hline CHEMBL1362348 & 688816 & 8.4949 & 5.5726 & TRN \\
\hline CHEMBL1419131 & 688816 & 5.05 & 5.4923 & TST \\
\hline CHEMBL1428644 & 688816 & 5.2 & 5.2051 & TRN \\
\hline CHEMBL3209794 & 688816 & 7.0 & 5.3985 & TRN \\
\hline CHEMBL1561085 & 688816 & 4.8 & 5.5183 & TST \\
\hline CHEMBL1520338 & 688816 & 8.0 & 5.4346 & TRN \\
\hline CHEMBL1411211 & 688816 & 4.95 & 5.3365 & TRN \\
\hline CHEMBL1511480 & 688816 & 5.25 & 4.9866 & TRN \\
\hline CHEMBL1443541 & 688816 & 7.8508 & 5.5126 & TST \\
\hline CHEMBL1413184 & 688816 & 4.95 & 5.1419 & TRN \\
\hline CHEMBL1610478 & 688816 & 4.7 & 5.4413 & TRN \\
\hline CHEMBL549216 & 688816 & 5.0 & 5.0044 & TRN \\
\hline CHEMBL1535582 & 688816 & 8.3468 & 5.2811 & TST \\
\hline CHEMBL1310041 & 688816 & 4.95 & 5.1326 & TRN \\
\hline CHEMBL1538893 & 688816 & 4.95 & 4.9996 & TRN \\
\hline CHEMBL1570184 & 688816 & 4.8 & 5.4795 & TRN \\
\hline
\end{tabular}




\begin{tabular}{|c|c|c|c|c|c|}
\hline \multicolumn{6}{|c|}{ Supplemental Table S2.txt } \\
\hline CHEMBL1372890 & 688816 & 5.2 & 5.3194 & TRN & \\
\hline CHEMBL1565794 & 688816 & 4.55 & 5.2602 & TRN & \\
\hline CHEMBL1997644 & 688816 & 5.5 & 5.2036 & TRN & \\
\hline CHEMBL1482468 & 688816 & 5.35 & 5.0528 & TRN & \\
\hline CHEMBL1325762 & 688816 & 4.95 & 5.1509 & TRN & \\
\hline CHEMBL1568316 & 688816 & 5.2 & 5.0782 & TRN & \\
\hline CHEMBL1508215 & 688816 & 7.8996 & 5.3665 & TST & \\
\hline CHEMBL1305287 & 688816 & 5.0 & 5.5123 & TRN & \\
\hline CHEMBL1562057 & 688816 & 4.45 & 5.1933 & TRN & \\
\hline CHEMBL1537297 & 688816 & 5.05 & 5.1501 & TRN & \\
\hline CHEMBL1397302 & 688816 & 4.45 & 5.2702 & TRN & \\
\hline CHEMBL1366756 & 688816 & 5.7 & 5.6019 & TST & \\
\hline CHEMBL1608965 & 688816 & 4.95 & 4.939 & TRN & \\
\hline CHEMBL1531041 & 688816 & 5.15 & 4.9436 & TRN & \\
\hline CHEMBL1457196 & 688816 & 5.0 & 4.98 & TRN & \\
\hline CHEMBL1365114 & 688816 & 6.8 & 5.4913 & TRN & \\
\hline CHEMBL1489760 & 688816 & 4.9 & 4.9118 & TRN & \\
\hline CHEMBL1340925 & 688816 & 5.5 & 5.4956 & TRN & \\
\hline CHEMBL1416398 & 688816 & 5.3 & 5.0865 & TRN & \\
\hline CHEMBL1489401 & 688816 & 5.25 & 5.0202 & TRN & \\
\hline CHEMBL530049 & 688816 & 4.6 & 4.94300 & 00000000005 & TST \\
\hline CHEMBL1342751 & 688816 & 4.55 & 5.3644 & TST & \\
\hline CHEMBL1382100 & 688816 & 6.8 & 5.5141 & TRN & \\
\hline CHEMBL1455400 & 688816 & 5.1 & 5.2606 & TRN & \\
\hline CHEMBL1344163 & 688816 & 5.35 & 5.255 & TRN & \\
\hline CHEMBL1550646 & 688816 & 5.55 & 5.6508 & TST & \\
\hline CHEMBL1303805 & 688816 & 4.45 & 5.1366 & TRN & \\
\hline CHEMBL1392042 & 688816 & 5.0 & 4.7703 & TRN & \\
\hline CHEMBL1544761 & 688816 & 4.95 & 5.4084 & TST & \\
\hline CHEMBL1386750 & 688816 & 4.95 & 5.016 & TRN & \\
\hline CHEMBL1366374 & 688816 & 4.95 & 5.5749 & TST & \\
\hline CHEMBL 3190075 & 688816 & 4.8 & 5.9194 & TRN & \\
\hline CHEMBL1478565 & 688816 & 4.45 & 5.2234 & TST & \\
\hline CHEMBL1361326 & 688816 & 5.15 & 5.0474 & TRN & \\
\hline CHEMBL1443308 & 688816 & 4.95 & 5.4224 & TRN & \\
\hline CHEMBL1353698 & 688816 & 4.9 & 5.1586 & TRN & \\
\hline CHEMBL1337232 & 688816 & 7.8013 & 5.6875 & TRN & \\
\hline CHEMBL1380062 & 688816 & 4.45 & 5.2917 & TRN & \\
\hline CHEMBL1340058 & 688816 & 4.45 & 5.3884 & TRN & \\
\hline CHEMBL1428313 & 688816 & 4.45 & 5.204 & TRN & \\
\hline CHEMBL1333300 & 688816 & 7.5003 & 5.4359 & TST & \\
\hline CHEMBL1495010 & 688816 & 4.45 & 4.7769 & TRN & \\
\hline CHEMBL1495539 & 688816 & 4.45 & 5.1601 & TRN & \\
\hline CHEMBL1610894 & 688816 & 5.65 & 5.3036 & TRN & \\
\hline CHEMBL1540570 & 688816 & 4.95 & 5.5286 & TST & \\
\hline CHEMBL1463318 & 688816 & 6.6 & 5.2537 & TRN & \\
\hline CHEMBL1464748 & 688816 & 5.4 & 5.2431 & TRN & \\
\hline CHEMBL1423861 & 688816 & 6.5 & 5.7518 & TST & \\
\hline
\end{tabular}




\begin{tabular}{|c|c|c|c|c|c|}
\hline \multicolumn{6}{|c|}{ Supplemental Table S2.txt } \\
\hline CHEMBL1544159 & 688816 & 5.55 & 5.5836 & TRN & \\
\hline CHEMBL1488187 & 688816 & 4.8 & 5.5647 & TRN & \\
\hline CHEMBL1502859 & 688816 & 4.6 & 5.4481 & TRN & \\
\hline CHEMBL1528904 & 688816 & 4.65 & 4.7517 & TRN & \\
\hline CHEMBL1585720 & 688816 & 5.0 & 5.4933 & TRN & \\
\hline CHEMBL1445752 & 688816 & 4.45 & 5.0538 & TRN & \\
\hline CHEMBL1450586 & 688816 & 5.35 & 5.4209 & TST & \\
\hline CHEMBL1509105 & 688816 & 5.2 & 5.5051 & TRN & \\
\hline CHEMBL1466418 & 688816 & 5.35 & 5.4303 & TRN & \\
\hline CHEMBL1346316 & 688816 & 4.65 & 5.0155 & TRN & \\
\hline CHEMBL1529688 & 688816 & 5.0 & 5.2895 & TST & \\
\hline CHEMBL1479781 & 688816 & 4.8 & 5.447 & TRN & \\
\hline CHEMBL1998302 & 688816 & 4.95 & 5.3008 & TRN & \\
\hline CHEMBL1439072 & 688816 & 5.0 & 5.5262 & TST & \\
\hline CHEMBL1458380 & 688816 & 5.15 & 5.2306 & TRN & \\
\hline CHEMBL1324123 & 688816 & 5.4 & 5.19799 & 99999999995 & TRN \\
\hline CHEMBL1377067 & 688816 & 4.95 & 5.0602 & TRN & \\
\hline CHEMBL1450420 & 688816 & 4.95 & 5.1172 & TRN & \\
\hline CHEMBL1418605 & 688816 & 5.55 & 5.439 & TRN & \\
\hline CHEMBL1301964 & 688816 & 4.9 & 5.3688 & TST & \\
\hline CHEMBL1537642 & 688816 & 4.95 & 4.9308 & TST & \\
\hline CHEMBL1494153 & 688816 & 4.45 & 5.2246 & TST & \\
\hline CHEMBL1390676 & 688816 & 4.95 & 5.1075 & TRN & \\
\hline CHEMBL1302784 & 688816 & 4.95 & 5.1133 & TRN & \\
\hline CHEMBL1596661 & 688816 & 5.25 & 5.2295 & TRN & \\
\hline CHEMBL1568124 & 688816 & 4.45 & 5.1071 & TRN & \\
\hline CHEMBL1505283 & 688816 & 4.9 & 4.8786 & TRN & \\
\hline CHEMBL1610118 & 688816 & 5.3 & 5.289 & TRN & \\
\hline CHEMBL1497727 & 688816 & 4.95 & 5.428 & TST & \\
\hline CHEMBL1602029 & 688816 & 8.3979 & 5.2333 & TRN & \\
\hline CHEMBL1442537 & 688816 & 5.2 & 5.0559 & TRN & \\
\hline CHEMBL1539934 & 688816 & 4.45 & 5.3574 & TRN & \\
\hline CHEMBL1355236 & 688816 & 5.4 & 5.436 & TRN & \\
\hline CHEMBL1892270 & 688816 & 4.9 & 5.1077 & TRN & \\
\hline CHEMBL1302436 & 688816 & 8.0506 & 5.77 & TST & \\
\hline CHEMBL1593453 & 688816 & 5.55 & 4.9117 & TRN & \\
\hline CHEMBL1320785 & 688816 & 4.95 & 5.0534 & TRN & \\
\hline CHEMBL584442 & 688816 & 5.65 & 5.4844 & TRN & \\
\hline CHEMBL1371706 & 688816 & 5.55 & 5.34 & TRN & \\
\hline CHEMBL1608518 & 688816 & 6.5 & 5.4207 & TST & \\
\hline CHEMBL1342229 & 688816 & 7.8508 & 5.439 & TRN & \\
\hline CHEMBL1549469 & 688816 & 4.85 & 5.0362 & TRN & \\
\hline CHEMBL1503742 & 688816 & 5.95 & 5.1357 & TRN & \\
\hline CHEMBL1303345 & 688816 & 4.85 & 5.2934 & TRN & \\
\hline CHEMBL1375232 & 688816 & 4.45 & 5.5808 & TRN & \\
\hline CHEMBL1300717 & 688816 & 4.95 & 4.9943 & TRN & \\
\hline CHEMBL1333399 & 688816 & 4.65 & 5.3097 & TRN & \\
\hline CHEMBL1541239 & 688816 & 4.9 & 5.2222 & TST & \\
\hline
\end{tabular}




\begin{tabular}{|c|c|c|c|c|}
\hline \multicolumn{5}{|c|}{ Supplemental Table S2.txt } \\
\hline CHEMBL1302988 & 688816 & 4.95 & 5.3306 & TRN \\
\hline CHEMBL1607948 & 688816 & 4.95 & 4.6906 & TST \\
\hline CHEMBL1345760 & 688816 & 5.45 & 5.5365 & TRN \\
\hline CHEMBL1374328 & 688816 & 5.45 & 5.6191 & TST \\
\hline CHEMBL1551151 & 688816 & 4.85 & 5.5867 & TRN \\
\hline CHEMBL1561348 & 688816 & 4.9 & 4.9286 & TRN \\
\hline CHEMBL1524509 & 688816 & 4.45 & 5.2696 & TRN \\
\hline CHEMBL1550200 & 688816 & 5.25 & 5.5307 & TST \\
\hline CHEMBL1507468 & 688816 & 4.5 & 5.1449 & TST \\
\hline CHEMBL1458147 & 688816 & 4.9 & 5.2383 & TRN \\
\hline CHEMBL1585064 & 688816 & 6.95 & 4.9873 & TRN \\
\hline CHEMBL1582641 & 688816 & 8.301 & 5.0013 & TST \\
\hline CHEMBL 236388 & 688816 & 4.95 & 5.3037 & TRN \\
\hline CHEMBL1309101 & 688816 & 6.3 & 5.4011 & TRN \\
\hline CHEMBL1345448 & 688816 & 4.75 & 5.0803 & TRN \\
\hline CHEMBL3210896 & 688816 & 4.45 & 5.3588 & TRN \\
\hline CHEMBL3213453 & 688816 & 5.5 & 5.8681 & TST \\
\hline CHEMBL1451434 & 688816 & 4.6 & 5.0442 & TST \\
\hline CHEMBL1520407 & 688816 & 4.75 & 5.2988 & TRN \\
\hline CHEMBL1502254 & 688816 & 5.0 & 5.4565 & TRN \\
\hline CHEMBL1488614 & 688816 & 4.85 & 5.1595 & TRN \\
\hline CHEMBL 221721 & 688816 & 5.4 & 5.1152 & TRN \\
\hline CHEMBL294878 & 688816 & 4.45 & 5.1744 & TRN \\
\hline CHEMBL1560925 & 688816 & 5.9 & 5.5378 & TST \\
\hline CHEMBL1433109 & 688816 & 4.9 & 5.2798 & TST \\
\hline CHEMBL1342858 & 688816 & 4.45 & 5.0333 & TST \\
\hline CHEMBL1570792 & 688816 & 4.8 & 5.2518 & TRN \\
\hline CHEMBL 3144873 & 688816 & 7.699 & 5.3358 & TST \\
\hline CHEMBL1562842 & 688816 & 4.9 & 5.3192 & TRN \\
\hline CHEMBL1337098 & 688816 & 4.95 & 5.3796 & TRN \\
\hline CHEMBL1545291 & 688816 & 6.25 & 5.2888 & TRN \\
\hline CHEMBL1442444 & 688816 & 4.95 & 5.2606 & TRN \\
\hline CHEMBL3191151 & 688816 & 5.5 & 5.2426 & TST \\
\hline CHEMBL1583611 & 688816 & 4.9 & 5.3324 & TRN \\
\hline CHEMBL1580610 & 688816 & 4.85 & 5.5491 & TST \\
\hline CHEMBL1534289 & 688816 & 4.95 & 4.9725 & TRN \\
\hline CHEMBL1554449 & 688816 & 4.95 & 4.7031 & TRN \\
\hline CHEMBL1610565 & 688816 & 4.8 & 4.5196 & TRN \\
\hline CHEMBL1393678 & 688816 & 8.0506 & 5.2471 & TRN \\
\hline CHEMBL1214519 & 688816 & 4.95 & 5.356 & TRN \\
\hline CHEMBL1419741 & 688816 & 5.05 & 5.4784 & TST \\
\hline CHEMBL1554034 & 688816 & 5.35 & 5.5981 & TRN \\
\hline CHEMBL1473368 & 688816 & 4.8 & 4.9087 & TRN \\
\hline CHEMBL1608347 & 688816 & 4.75 & 5.3946 & TRN \\
\hline CHEMBL1390781 & 688816 & 4.45 & 5.1734 & TRN \\
\hline CHEMBL3208285 & 688816 & 4.7 & 5.4716 & TRN \\
\hline CHEMBL1096706 & 688816 & 4.95 & 4.9997 & TRN \\
\hline CHEMBL1576741 & 688816 & 4.6 & 5.4774 & TST \\
\hline
\end{tabular}




\begin{tabular}{|c|c|c|c|c|}
\hline \multicolumn{5}{|c|}{ Supplemental Table S2.txt } \\
\hline CHEMBL1522868 & 688816 & 5.3 & 5.3604 & TRN \\
\hline CHEMBL1531925 & 688816 & 4.9 & 5.2692 & TRN \\
\hline CHEMBL39763 & 688816 & 4.6 & 5.2949 & TST \\
\hline CHEMBL1987441 & 688816 & 4.75 & 5.2248 & TRN \\
\hline CHEMBL1409400 & 688816 & 5.85 & 5.2542 & TRN \\
\hline CHEMBL1469995 & 688816 & 4.75 & 5.2207 & TRN \\
\hline CHEMBL1373447 & 688816 & 7.6003 & 5.4818 & TRN \\
\hline CHEMBL582081 & 688816 & 5.0 & 5.2028 & TST \\
\hline CHEMBL577595 & 688816 & 6.7501 & 5.4017 & TST \\
\hline CHEMBL1376795 & 688816 & 4.9 & 5.0944 & TRN \\
\hline CHEMBL3192911 & 688816 & 5.35 & 5.1344 & TRN \\
\hline CHEMBL1386660 & 688816 & 7.699 & 5.4283 & TRN \\
\hline CHEMBL1438803 & 688816 & 5.35 & 5.1609 & TRN \\
\hline CHEMBL1346891 & 688816 & 4.9 & 5.1367 & TRN \\
\hline CHEMBL1578348 & 688816 & 5.0 & 5.3151 & TRN \\
\hline CHEMBL1324999 & 688816 & 4.95 & 4.9052 & TRN \\
\hline CHEMBL1519390 & 688816 & 5.6 & 5.2422 & TRN \\
\hline CHEMBL1492539 & 688816 & 4.45 & 5.0263 & TRN \\
\hline CHEMBL1470958 & 688816 & 5.2 & 5.063 & TRN \\
\hline CHEMBL3197431 & 688816 & 4.6 & 5.3249 & TRN \\
\hline CHEMBL1319368 & 688816 & 4.45 & 5.0262 & TRN \\
\hline CHEMBL1494557 & 688816 & 6.2 & 5.7322 & TRN \\
\hline CHEMBL1529086 & 688816 & 5.7 & 5.0175 & TRN \\
\hline CHEMBL1452986 & 688816 & 5.55 & 5.4843 & TST \\
\hline CHEMBL1544113 & 688816 & 8.301 & 5.6446 & TST \\
\hline CHEMBL1429843 & 688816 & 4.95 & 5.0823 & TRN \\
\hline CHEMBL3210576 & 688816 & 4.9 & 5.285 & TRN \\
\hline CHEMBL1358883 & 688816 & 4.8 & 5.0927 & TRN \\
\hline CHEMBL1391159 & 688816 & 4.85 & 4.8715 & TRN \\
\hline CHEMBL1481234 & 688816 & 4.6 & 5.143 & TST \\
\hline CHEMBL1345341 & 688816 & 4.85 & 5.1662 & TRN \\
\hline CHEMBL1365959 & 688816 & 4.45 & 4.9812 & TRN \\
\hline CHEMBL3189230 & 688816 & 4.95 & 5.2665 & TRN \\
\hline CHEMBL1423628 & 688816 & 4.8 & 5.0668 & TRN \\
\hline CHEMBL1310691 & 688816 & 5.0 & 5.3201 & TRN \\
\hline CHEMBL1516027 & 688816 & 4.95 & 5.5577 & TRN \\
\hline CHEMBL1510300 & 688816 & 5.0 & 5.1729 & TRN \\
\hline CHEMBL1579184 & 688816 & 4.85 & 5.8137 & TRN \\
\hline CHEMBL134871 & 688816 & 4.9 & 5.4613 & TST \\
\hline CHEMBL1465006 & 688816 & 5.4 & 5.2779 & TST \\
\hline CHEMBL1337725 & 688816 & 4.75 & 5.1435 & TST \\
\hline CHEMBL1375070 & 688816 & 5.2 & 5.5091 & TST \\
\hline CHEMBL1382374 & 688816 & 4.85 & 5.4638 & TRN \\
\hline CHEMBL1445725 & 688816 & 4.95 & 5.3962 & TRN \\
\hline CHEMBL1587014 & 688816 & 4.7 & 5.034 & TRN \\
\hline CHEMBL3192101 & 688816 & 4.45 & 5.3426 & TRN \\
\hline CHEMBL1543268 & 688816 & 4.9 & 5.1034 & TST \\
\hline CHEMBL1492368 & 688816 & 4.9 & 5.4718 & TRN \\
\hline
\end{tabular}




\begin{tabular}{|c|c|c|c|c|}
\hline \multicolumn{5}{|c|}{ Supplemental Table S2.txt } \\
\hline CHEMBL1361926 & 688816 & 4.65 & 5.3049 & TRN \\
\hline CHEMBL1562527 & 688816 & 7.4001 & 5.4554 & TRN \\
\hline CHEMBL1575621 & 688816 & 5.65 & 5.2512 & TRN \\
\hline CHEMBL1375985 & 688816 & 4.75 & 5.3302 & TRN \\
\hline CHEMBL1492780 & 688816 & 4.9 & 5.4571 & TRN \\
\hline CHEMBL1519160 & 688816 & 5.35 & 5.2156 & TRN \\
\hline CHEMBL1467010 & 688816 & 5.25 & 5.3141 & TRN \\
\hline CHEMBL1510301 & 688816 & 6.4 & 5.2906 & TRN \\
\hline CHEMBL1426792 & 688816 & 4.45 & 5.1497 & TRN \\
\hline CHEMBL1421353 & 688816 & 4.45 & 4.8904 & TRN \\
\hline CHEMBL1419015 & 688816 & 4.65 & 5.0936 & TRN \\
\hline CHEMBL1989294 & 688816 & 5.2 & 5.0737 & TRN \\
\hline CHEMBL1336660 & 688816 & 4.85 & 5.2474 & TST \\
\hline CHEMBL1484158 & 688816 & 5.5 & 6.059 & TRN \\
\hline CHEMBL1733957 & 688816 & 4.85 & 5.3491 & TST \\
\hline CHEMBL1447882 & 688816 & 4.95 & 5.0136 & TRN \\
\hline CHEMBL1309164 & 688816 & 4.75 & 5.2021 & TRN \\
\hline CHEMBL1565541 & 688816 & 6.15 & 5.1801 & TRN \\
\hline CHEMBL1531383 & 688816 & 4.45 & 4.8683 & TRN \\
\hline CHEMBL1390367 & 688816 & 5.0 & 5.5631 & TRN \\
\hline CHEMBL1342553 & 688816 & 4.85 & 5.477 & TST \\
\hline CHEMBL1420677 & 688816 & 4.85 & 5.1962 & TRN \\
\hline CHEMBL1383987 & 688816 & 4.6 & 4.7646 & TST \\
\hline CHEMBL1224310 & 688816 & 4.5 & 5.2746 & TST \\
\hline CHEMBL1541113 & 688816 & 4.95 & 5.4307 & TRN \\
\hline CHEMBL1588412 & 688816 & 4.85 & 5.5483 & TRN \\
\hline CHEMBL1386310 & 688816 & 4.95 & 4.7581 & TRN \\
\hline CHEMBL1453896 & 688816 & 5.2 & 5.135 & TRN \\
\hline CHEMBL1441219 & 688816 & 4.95 & 5.0766 & TRN \\
\hline CHEMBL1375507 & 688816 & 4.65 & 5.3289 & TST \\
\hline CHEMBL1596216 & 688816 & 4.7 & 5.4313 & TST \\
\hline CHEMBL1488368 & 688816 & 4.85 & 5.3579 & TST \\
\hline CHEMBL1463601 & 688816 & 4.95 & 5.0854 & TRN \\
\hline CHEMBL1598091 & 688816 & 4.45 & 4.6352 & TRN \\
\hline CHEMBL1511879 & 688816 & 4.45 & 4.8063 & TRN \\
\hline CHEMBL1313028 & 688816 & 4.95 & 5.3983 & TST \\
\hline CHEMBL 1433776 & 688816 & 4.75 & 5.0174 & TRN \\
\hline CHEMBL1431742 & 688816 & 5.35 & 5.1096 & TRN \\
\hline CHEMBL1457303 & 688816 & 5.0 & 5.4353 & TRN \\
\hline CHEMBL1086026 & 688816 & 5.8 & 5.1013 & TST \\
\hline CHEMBL1579518 & 688816 & 4.85 & 5.4236 & TRN \\
\hline CHEMBL1382393 & 688816 & 4.85 & 5.0537 & TRN \\
\hline CHEMBL1347274 & 688816 & 6.1 & 5.0889 & TRN \\
\hline CHEMBL3190891 & 688816 & 5.5 & 5.51 & TST \\
\hline CHEMBL1600395 & 688816 & 4.6 & 5.2682 & TRN \\
\hline CHEMBL1606809 & 688816 & 4.55 & 5.0561 & TST \\
\hline CHEMBL1393334 & 688816 & 8.3468 & 5.8043 & TRN \\
\hline CHEMBL1545371 & 688816 & 8.4949 & 5.4758 & TRN \\
\hline
\end{tabular}




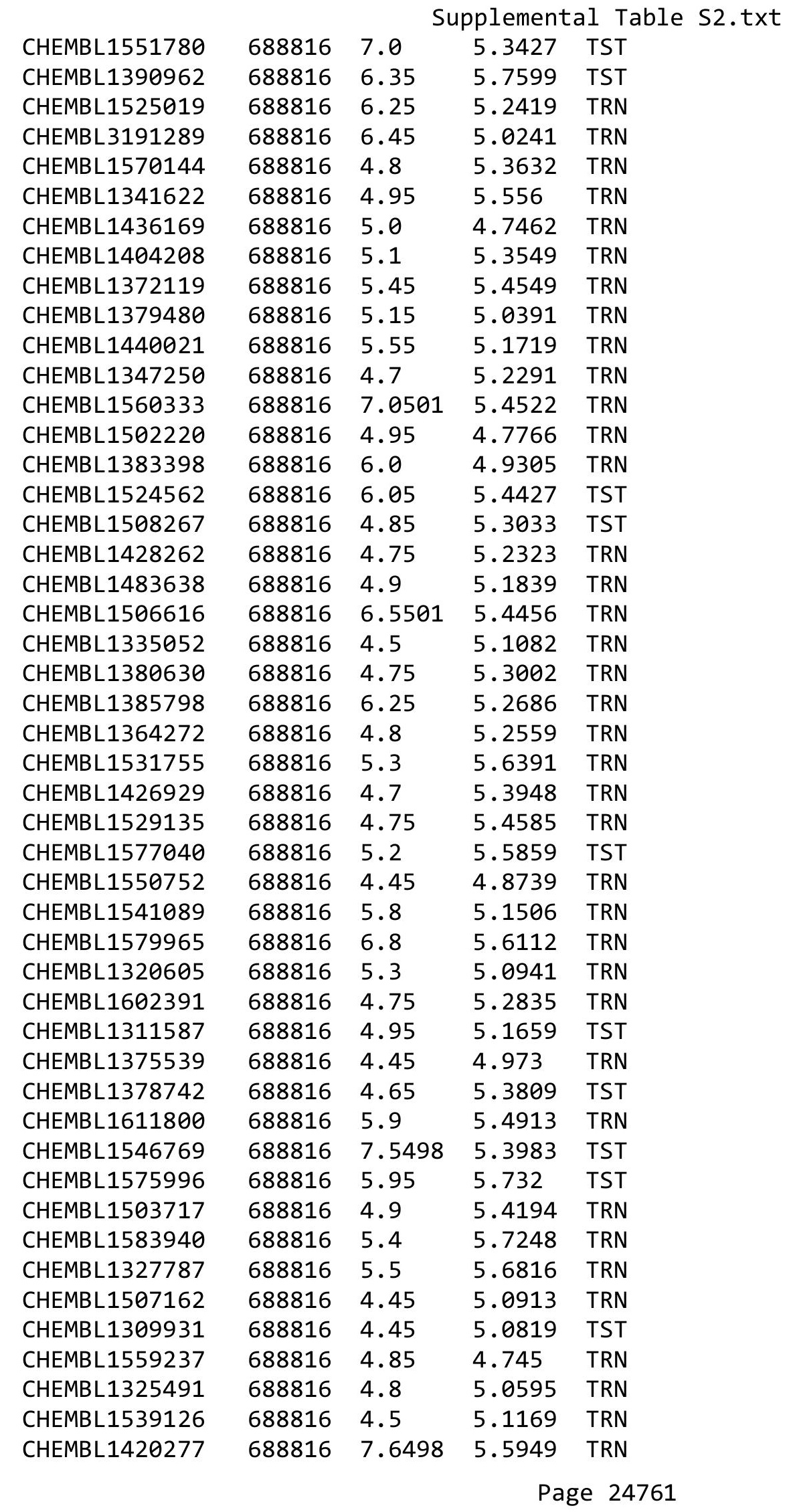




\begin{tabular}{|c|c|c|c|c|c|}
\hline \multicolumn{6}{|c|}{ Supplemental Table s2.txt } \\
\hline CHEMBL1465613 & 688816 & 4.7 & 5.3097 & TST & \\
\hline CHEMBL3192940 & 688816 & 7.699 & 5.2492 & TRN & \\
\hline CHEMBL1530049 & 688816 & 4.85 & 5.3694 & TRN & \\
\hline CHEMBL1504346 & 688816 & 4.95 & 5.2253 & TRN & \\
\hline CHEMBL1305441 & 688816 & 8.301 & 5.4966 & TST & \\
\hline CHEMBL1431385 & 688816 & 4.9 & 5.3363 & TRN & \\
\hline CHEMBL1601129 & 688816 & 4.6 & 4.9385 & TRN & \\
\hline CHEMBL1462511 & 688816 & 7.9508 & 5.0623 & TRN & \\
\hline CHEMBL1451719 & 688816 & 4.7 & 5.2865 & TRN & \\
\hline CHEMBL3196161 & 688816 & 4.95 & 5.2704 & TRN & \\
\hline CHEMBL1489506 & 688816 & 5.1 & 5.3174 & TRN & \\
\hline CHEMBL1406440 & 688816 & 5.1 & 4.9869 & TST & \\
\hline CHEMBL1434796 & 688816 & 5.5 & 5.7105 & TST & \\
\hline CHEMBL1394640 & 688816 & 4.45 & 5.1031 & TRN & \\
\hline CHEMBL1431827 & 688816 & 8.3468 & 5.1457 & TRN & \\
\hline CHEMBL1302746 & 688816 & 4.8 & 5.2885 & TRN & \\
\hline CHEMBL1463825 & 688816 & 4.5 & 5.0752 & TRN & \\
\hline CHEMBL1309210 & 688816 & 4.95 & 5.4329 & TRN & \\
\hline CHEMBL1320454 & 688816 & 4.95 & 5.42399 & 99999999995 & TRN \\
\hline CHEMBL3196688 & 688816 & 4.45 & 5.285 & TRN & \\
\hline CHEMBL1416325 & 688816 & 5.1 & 5.3076 & TST & \\
\hline CHEMBL483633 & 688816 & 4.9 & 5.0868 & TRN & \\
\hline CHEMBL1603340 & 688816 & 5.3 & 5.4738 & TRN & \\
\hline CHEMBL3199558 & 688816 & 4.8 & 5.4457 & TRN & \\
\hline CHEMBL1325250 & 688816 & 4.9 & 4.7607 & TRN & \\
\hline CHEMBL3212796 & 688816 & 5.15 & 4.9151 & TRN & \\
\hline CHEMBL1572001 & 688816 & 5.55 & 4.9435 & TRN & \\
\hline CHEMBL1466248 & 688816 & 5.5 & 5.2548 & TRN & \\
\hline CHEMBL1529860 & 688816 & 4.45 & 5.1681 & TRN & \\
\hline CHEMBL1389565 & 688816 & 4.85 & 5.0582 & TRN & \\
\hline CHEMBL1600038 & 688816 & 4.95 & 5.2724 & TRN & \\
\hline CHEMBL1477397 & 688816 & 6.1 & 5.1091 & TRN & \\
\hline CHEMBL1468698 & 688816 & 5.0 & 5.4225 & TRN & \\
\hline CHEMBL1337987 & 688816 & 4.45 & 5.0803 & TRN & \\
\hline CHEMBL1465527 & 688816 & 4.45 & 5.4205 & TST & \\
\hline CHEMBL1597484 & 688816 & 4.45 & 5.1935 & TRN & \\
\hline CHEMBL1511467 & 688816 & 4.95 & 5.4382 & TRN & \\
\hline CHEMBL1377656 & 688816 & 4.95 & 5.0989 & TRN & \\
\hline CHEMBL1411188 & 688816 & 5.5 & 5.567 & TRN & \\
\hline CHEMBL1491210 & 688816 & 4.85 & 5.2787 & TRN & \\
\hline CHEMBL1330131 & 688816 & 7.5003 & 5.2767 & TST & \\
\hline CHEMBL1582179 & 688816 & 5.15 & 5.0252 & TRN & \\
\hline CHEMBL3196515 & 688816 & 5.4 & 5.239 & TST & \\
\hline CHEMBL1544664 & 688816 & 4.45 & 4.7143 & TST & \\
\hline CHEMBL1318117 & 688816 & 5.65 & 5.4055 & TST & \\
\hline CHEMBL1504424 & 688816 & 5.1 & 4.9926 & TRN & \\
\hline CHEMBL1366951 & 688816 & 6.0 & 5.2585 & TRN & \\
\hline CHEMBL1464136 & 688816 & 6.3 & 5.7846 & TRN & \\
\hline
\end{tabular}




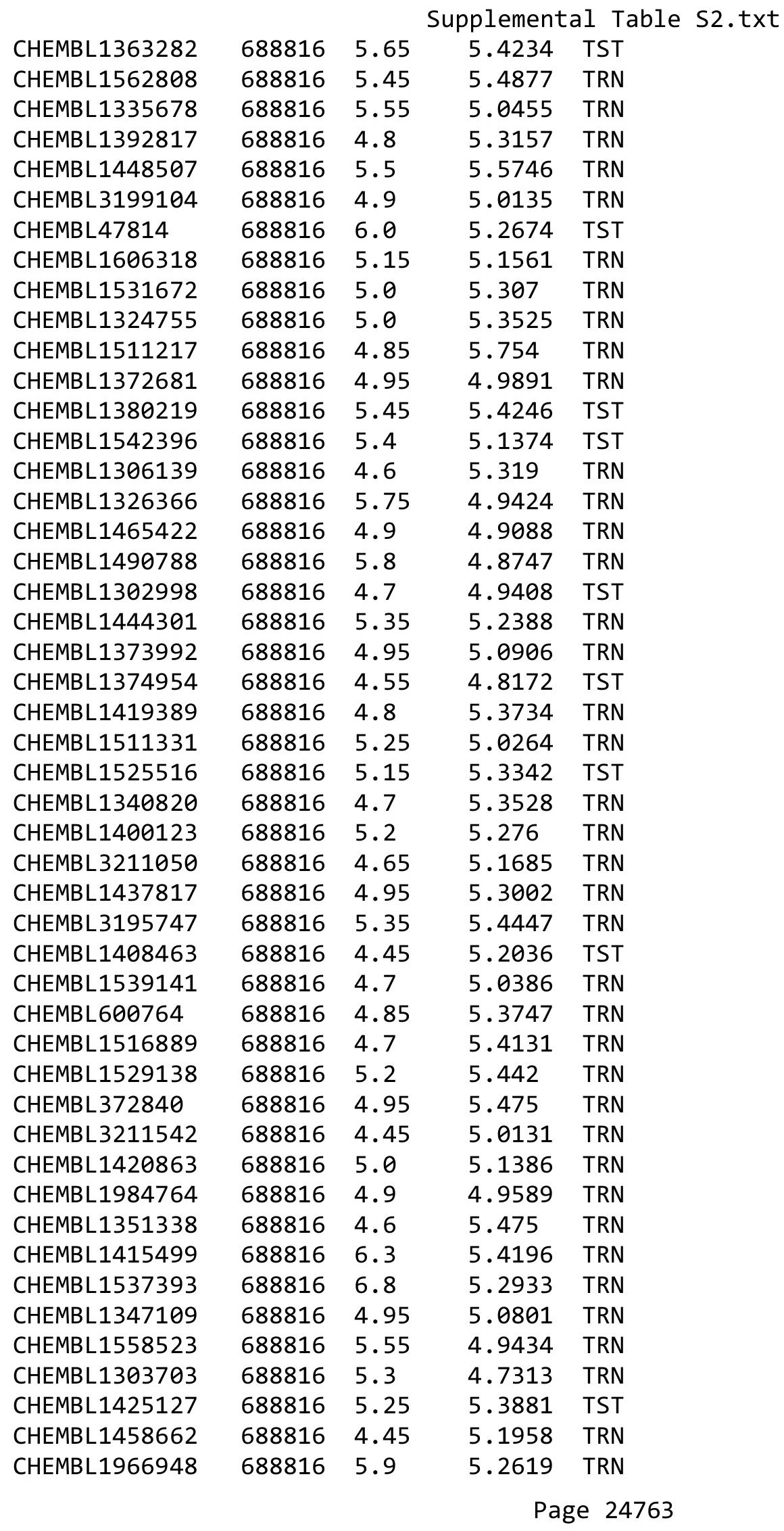




\begin{tabular}{|c|c|c|c|c|c|}
\hline \multicolumn{6}{|c|}{ Supplemental Table s2.txt } \\
\hline CHEMBL1407400 & 688816 & 4.95 & 5.5189 & TST & \\
\hline CHEMBL3189960 & 688816 & 4.75 & 5.0366 & TRN & \\
\hline CHEMBL1430923 & 688816 & 4.95 & 5.3987 & TRN & \\
\hline CHEMBL1605375 & 688816 & 4.65 & 5.3021 & TRN & \\
\hline CHEMBL1970014 & 688816 & 4.45 & 4.812 & TRN & \\
\hline CHEMBL1399835 & 688816 & 4.75 & 5.4 & TRN & \\
\hline CHEMBL1473832 & 688816 & 5.3 & 5.0135 & TST & \\
\hline CHEMBL1462064 & 688816 & 4.85 & 5.2475 & TRN & \\
\hline CHEMBL1445633 & 688816 & 6.5 & 5.3301 & TRN & \\
\hline CHEMBL1424034 & 688816 & 4.7 & 5.2818 & TRN & \\
\hline CHEMBL1394041 & 688816 & 5.95 & 5.2103 & TRN & \\
\hline CHEMBL1599262 & 688816 & 7.5498 & 5.2332 & TRN & \\
\hline CHEMBL1521702 & 688816 & 5.15 & 5.0822 & TST & \\
\hline CHEMBL1480368 & 688816 & 7.6003 & 5.4571 & TRN & \\
\hline CHEMBL1544694 & 688816 & 4.45 & 5.4465 & TST & \\
\hline CHEMBL1384397 & 688816 & 5.35 & 5.2083 & TRN & \\
\hline CHEMBL1390081 & 688816 & 4.95 & 5.2244 & TRN & \\
\hline CHEMBL1504256 & 688816 & 4.95 & 5.4675 & TST & \\
\hline CHEMBL1551639 & 688816 & 4.95 & 5.4179 & TRN & \\
\hline CHEMBL1429464 & 688816 & 4.5 & 5.1905 & TRN & \\
\hline CHEMBL1598222 & 688816 & 4.9 & 5.0572 & TRN & \\
\hline CHEMBL1499688 & 688816 & 5.4 & 5.4094 & TST & \\
\hline CHEMBL1557356 & 688816 & 4.45 & 4.8996 & TRN & \\
\hline CHEMBL1422359 & 688816 & 4.75 & 5.2111 & TRN & \\
\hline CHEMBL1409619 & 688816 & 5.0 & 4.8329 & TRN & \\
\hline CHEMBL1608157 & 688816 & 8.0506 & 5.466 & TRN & \\
\hline CHEMBL1573917 & 688816 & 8.2007 & 5.289 & TRN & \\
\hline CHEMBL1585656 & 688816 & 8.301 & 4.9613 & TRN & \\
\hline CHEMBL1383194 & 688816 & 5.5 & 5.1997 & TRN & \\
\hline CHEMBL1559624 & 688816 & 4.95 & 5.2852 & TRN & \\
\hline CHEMBL 2000750 & 688816 & 4.9 & 5.0215 & TST & \\
\hline CHEMBL1971760 & 688816 & 7.5498 & 5.1215 & TST & \\
\hline CHEMBL1566011 & 688816 & 4.85 & 5.0106 & TRN & \\
\hline CHEMBL1545380 & 688816 & 5.0 & 5.0854 & TST & \\
\hline CHEMBL265177 & 688816 & 5.55 & 5.42399 & 99999999995 & TST \\
\hline CHEMBL1438237 & 688816 & 4.9 & 5.4878 & TRN & \\
\hline CHEMBL1540747 & 688816 & 6.0 & 5.3731 & TRN & \\
\hline CHEMBL1531592 & 688816 & 7.3002 & 5.4134 & TRN & \\
\hline CHEMBL1319873 & 688816 & 4.85 & 5.0663 & TRN & \\
\hline CHEMBL1395958 & 688816 & 4.7 & 5.2363 & TRN & \\
\hline CHEMBL1389618 & 688816 & 5.5 & 5.4736 & TST & \\
\hline CHEMBL1340247 & 688816 & 5.25 & 5.4206 & TRN & \\
\hline CHEMBL1384515 & 688816 & 4.95 & 5.0674 & TRN & \\
\hline CHEMBL1344667 & 688816 & 4.9 & 5.1325 & TST & \\
\hline CHEMBL1460190 & 688816 & 5.15 & 5.0626 & TRN & \\
\hline CHEMBL1480530 & 688816 & 8.4559 & 5.5506 & TST & \\
\hline CHEMBL1389974 & 688816 & 7.7496 & 5.3475 & TRN & \\
\hline CHEMBL1432833 & 688816 & 4.45 & 5.4816 & TRN & \\
\hline
\end{tabular}




\begin{tabular}{|c|c|c|c|c|}
\hline \multicolumn{5}{|c|}{ Supplemental Table S2.txt } \\
\hline CHEMBL1378733 & 688816 & 4.85 & 5.2744 & TRN \\
\hline CHEMBL1391071 & 688816 & 4.65 & 5.2033 & TRN \\
\hline CHEMBL1319492 & 688816 & 5.9 & 5.1784 & TST \\
\hline CHEMBL1430943 & 688816 & 4.9 & 5.3106 & TRN \\
\hline CHEMBL1442316 & 688816 & 4.65 & 5.0517 & TRN \\
\hline CHEMBL1490818 & 688816 & 4.75 & 5.1233 & TRN \\
\hline CHEMBL1464845 & 688816 & 5.4 & 5.3178 & TST \\
\hline CHEMBL1518745 & 688816 & 7.4001 & 5.3984 & TRN \\
\hline CHEMBL1520855 & 688816 & 7.6498 & 5.4457 & TST \\
\hline CHEMBL1446778 & 688816 & 4.45 & 5.2548 & TRN \\
\hline CHEMBL1367569 & 688816 & 4.45 & 4.984 & TRN \\
\hline CHEMBL3193971 & 688816 & 4.7 & 5.4516 & TRN \\
\hline CHEMBL1420203 & 688816 & 4.95 & 5.1639 & TRN \\
\hline CHEMBL1524187 & 688816 & 5.35 & 5.1041 & TRN \\
\hline CHEMBL1343382 & 688816 & 8.1024 & 5.278 & TRN \\
\hline CHEMBL1484963 & 688816 & 4.65 & 5.0073 & TRN \\
\hline CHEMBL1312057 & 688816 & 4.95 & 4.9777 & TRN \\
\hline CHEMBL1563595 & 688816 & 4.5 & 5.1888 & TRN \\
\hline CHEMBL1327925 & 688816 & 5.2 & 6.0184 & TRN \\
\hline CHEMBL1456227 & 688816 & 4.9 & 5.1737 & TST \\
\hline CHEMBL1440158 & 688816 & 4.45 & 5.2655 & TST \\
\hline CHEMBL1587581 & 688816 & 4.7 & 5.0765 & TRN \\
\hline CHEMBL1519718 & 688816 & 4.55 & $5.2970 e$ & 0000000001 \\
\hline CHEMBL1386786 & 688816 & 4.45 & 4.7527 & TRN \\
\hline CHEMBL1505809 & 688816 & 5.5 & 5.2265 & TST \\
\hline CHEMBL1388007 & 688816 & 4.85 & 5.5237 & TST \\
\hline CHEMBL1392776 & 688816 & 4.95 & 5.4725 & TRN \\
\hline CHEMBL1477920 & 688816 & 4.45 & 5.1849 & TRN \\
\hline CHEMBL1317124 & 688816 & 4.9 & 5.2397 & TST \\
\hline CHEMBL1992276 & 688816 & 4.9 & 5.3976 & TRN \\
\hline CHEMBL1382551 & 688816 & 5.0 & 4.9475 & TRN \\
\hline CHEMBL1406696 & 688816 & 4.7 & 4.5933 & TST \\
\hline CHEMBL1452463 & 688816 & 4.8 & 5.2832 & TRN \\
\hline CHEMBL1399679 & 688816 & 4.75 & 5.2478 & TRN \\
\hline CHEMBL1351223 & 688816 & 4.95 & 5.6419 & TRN \\
\hline CHEMBL1517200 & 688816 & 4.45 & 4.9384 & TRN \\
\hline CHEMBL1413203 & 688816 & 5.0 & 5.2072 & TRN \\
\hline CHEMBL1302268 & 688816 & 4.5 & 5.3517 & TST \\
\hline CHEMBL1362715 & 688816 & 4.95 & 5.1359 & TRN \\
\hline CHEMBL1571157 & 688816 & 5.35 & 5.1344 & TRN \\
\hline CHEMBL1549243 & 688816 & 4.95 & 5.2886 & TRN \\
\hline CHEMBL3194654 & 688816 & 4.95 & 4.9866 & TRN \\
\hline CHEMBL1371385 & 688816 & 6.1 & 5.3094 & TST \\
\hline CHEMBL1454026 & 688816 & 8.301 & 5.5519 & TRN \\
\hline CHEMBL3195706 & 688816 & 6.7501 & 5.4237 & TRN \\
\hline CHEMBL1414123 & 688816 & 4.6 & 4.9776 & TRN \\
\hline CHEMBL1489639 & 688816 & 4.85 & 5.1884 & TRN \\
\hline CHEMBL1419375 & 688816 & 4.45 & 5.2304 & TST \\
\hline
\end{tabular}




\begin{tabular}{|c|c|c|c|c|}
\hline \multicolumn{5}{|c|}{ Supplemental Table S2.txt } \\
\hline CHEMBL1475311 & 688816 & 4.45 & 4.9866 & TRN \\
\hline CHEMBL1608180 & 688816 & 5.0 & 5.0043 & TRN \\
\hline CHEMBL1584523 & 688816 & 4.75 & 5.0334 & TRN \\
\hline CHEMBL1390565 & 688816 & 4.45 & 4.9345 & TRN \\
\hline CHEMBL1299642 & 688816 & 4.75 & 4.9104 & TRN \\
\hline CHEMBL1340694 & 688816 & 5.0 & 4.904 & TRN \\
\hline CHEMBL1558024 & 688816 & 5.5 & 4.9979 & TRN \\
\hline CHEMBL1447344 & 688816 & 5.0 & 5.41 & TST \\
\hline CHEMBL1579114 & 688816 & 5.05 & 5.471 & TRN \\
\hline CHEMBL1457653 & 688816 & 4.65 & 5.0859 & TRN \\
\hline CHEMBL1404144 & 688816 & 4.8 & 5.3514 & TST \\
\hline CHEMBL3196777 & 688816 & 4.75 & 5.317 & TRN \\
\hline CHEMBL1378076 & 688816 & 4.95 & 4.8894 & TRN \\
\hline CHEMBL1435875 & 688816 & 4.45 & 5.1015 & TRN \\
\hline CHEMBL1433084 & 688816 & 4.4 & 5.0412 & TRN \\
\hline CHEMBL1401596 & 688816 & 4.45 & 5.0989 & TST \\
\hline CHEMBL1327060 & 688816 & 5.3 & 5.0907 & TRN \\
\hline CHEMBL1322969 & 688816 & 5.05 & 5.2134 & TRN \\
\hline CHEMBL1304946 & 688816 & 4.65 & 5.0605 & TRN \\
\hline CHEMBL1546765 & 688816 & 4.85 & 5.5393 & TRN \\
\hline CHEMBL1605723 & 688816 & 6.05 & 5.0515 & TRN \\
\hline CHEMBL1475851 & 688816 & 4.95 & 5.0012 & TRN \\
\hline CHEMBL1468087 & 688816 & 7.1002 & 4.8868 & TST \\
\hline CHEMBL1479098 & 688816 & 5.65 & 5.0734 & TRN \\
\hline CHEMBL1522414 & 688816 & 4.65 & 4.7593 & TRN \\
\hline CHEMBL1373727 & 688816 & 4.95 & 4.8296 & TRN \\
\hline CHEMBL1431863 & 688816 & 7.3002 & 5.4778 & TST \\
\hline CHEMBL1358515 & 688816 & 4.9 & 5.1079 & TRN \\
\hline CHEMBL1446191 & 688816 & 6.05 & 5.4624 & TRN \\
\hline CHEMBL1404459 & 688816 & 4.75 & 5.0204 & TRN \\
\hline CHEMBL1342419 & 688816 & 6.95 & 5.0898 & TRN \\
\hline CHEMBL1378294 & 688816 & 4.45 & 4.9374 & TST \\
\hline CHEMBL1443174 & 688816 & 5.35 & 5.3852 & TRN \\
\hline CHEMBL1422847 & 688816 & 5.25 & 5.1669 & TRN \\
\hline CHEMBL417727 & 688816 & 5.15 & 5.3123 & TRN \\
\hline CHEMBL1456683 & 688816 & 5.2 & 5.4484 & TRN \\
\hline CHEMBL3213103 & 688816 & 4.95 & 5.6407 & TST \\
\hline CHEMBL1403616 & 688816 & 4.95 & 5.15 & TRN \\
\hline CHEMBL1526876 & 688816 & 4.45 & 5.1032 & TRN \\
\hline CHEMBL1303623 & 688816 & 5.4 & 5.2818 & TRN \\
\hline CHEMBL1344918 & 688816 & 4.45 & 4.8336 & TRN \\
\hline CHEMBL1547356 & 688816 & 5.45 & 4.8064 & TRN \\
\hline CHEMBL1339060 & 688816 & 7.5003 & 5.4409 & TRN \\
\hline CHEMBL1497448 & 688816 & 4.85 & 5.3502 & TRN \\
\hline CHEMBL1552526 & 688816 & 4.5 & 5.099 & TST \\
\hline CHEMBL1543875 & 688816 & 4.6 & 4.8646 & TRN \\
\hline CHEMBL1329382 & 688816 & 4.7 & 5.0902 & TRN \\
\hline CHEMBL1562391 & 688816 & 5.1 & 5.087 & TRN \\
\hline
\end{tabular}




\begin{tabular}{|c|c|c|c|c|}
\hline & & & oplement & al $\mathrm{T}$ \\
\hline CHEMBL1339111 & 688816 & 4.95 & 5.14 & TRN \\
\hline CHEMBL1347638 & 688816 & 4.9 & 5.0044 & TRN \\
\hline CHEMBL3193310 & 688816 & 4.85 & 5.2165 & TRN \\
\hline CHEMBL1405325 & 688816 & 5.45 & 5.0089 & TRN \\
\hline CHEMBL407232 & 688816 & 4.8 & 5.1644 & TST \\
\hline CHEMBL1537144 & 688816 & 4.95 & 5.0419 & TRN \\
\hline CHEMBL1309497 & 688816 & 4.95 & 4.9961 & TRN \\
\hline CHEMBL1559803 & 688816 & 5.65 & 5.5925 & TRN \\
\hline CHEMBL1545683 & 688816 & 6.6499 & 5.3911 & TRN \\
\hline CHEMBL1318915 & 688816 & 4.8 & 5.2174 & TRN \\
\hline CHEMBL1332310 & 688816 & 8.301 & 5.6385 & TRN \\
\hline CHEMBL1595564 & 688816 & 4.8 & 5.3051 & TRN \\
\hline CHEMBL1313277 & 688816 & 8.301 & 5.3071 & TRN \\
\hline CHEMBL513436 & 688816 & 4.95 & 5.376 & TRN \\
\hline CHEMBL1550164 & 688816 & 4.95 & 4.6345 & TRN \\
\hline CHEMBL1491817 & 688816 & 4.95 & 5.2746 & TST \\
\hline CHEMBL1312619 & 688816 & 4.95 & 5.3187 & TRN \\
\hline CHEMBL1550175 & 688816 & 4.4 & 5.9052 & TST \\
\hline CHEMBL1479577 & 688816 & 4.85 & 5.5021 & TRN \\
\hline CHEMBL1603043 & 688816 & 7.0501 & 5.3415 & TST \\
\hline CHEMBL1304354 & 688816 & 4.45 & 5.1791 & TRN \\
\hline CHEMBL1481836 & 688816 & 4.75 & 4.9836 & TST \\
\hline CHEMBL1968080 & 688816 & 5.8 & 5.2715 & TRN \\
\hline CHEMBL1502319 & 688816 & 4.8 & 5.4555 & TST \\
\hline CHEMBL1516740 & 688816 & 6.3 & 5.4546 & TRN \\
\hline CHEMBL1493321 & 688816 & 8.3468 & 5.5036 & TRN \\
\hline CHEMBL1507565 & 688816 & 4.7 & 5.3969 & TRN \\
\hline CHEMBL1514773 & 688816 & 4.45 & 5.1336 & TRN \\
\hline CHEMBL1425314 & 688816 & 5.1 & 5.1695 & TST \\
\hline CHEMBL1414012 & 688816 & 4.45 & 4.7813 & TST \\
\hline CHEMBL1500719 & 688816 & 4.45 & 5.045 & TRN \\
\hline CHEMBL1978643 & 688816 & 5.8 & 5.245 & TRN \\
\hline CHEMBL1416280 & 688816 & 7.15 & 5.4113 & TRN \\
\hline CHEMBL1347781 & 688816 & 5.5 & 5.2762 & TST \\
\hline CHEMBL1368374 & 688816 & 5.55 & 5.3631 & TRN \\
\hline CHEMBL1584449 & 688816 & 4.95 & 5.2172 & TRN \\
\hline CHEMBL1329684 & 688816 & 4.45 & 5.1651 & TRN \\
\hline CHEMBL1303884 & 688816 & 5.2 & 4.7804 & TRN \\
\hline CHEMBL3214459 & 688816 & 5.55 & 5.734 & TST \\
\hline CHEMBL1573605 & 688816 & 4.45 & 5.4995 & TRN \\
\hline CHEMBL3190255 & 688816 & 4.9 & 5.1296 & TRN \\
\hline CHEMBL1306326 & 688816 & 8.3468 & 5.479 & TST \\
\hline CHEMBL1568694 & 688816 & 8.301 & 5.5065 & TRN \\
\hline CHEMBL1371241 & 688816 & 4.45 & 5.1939 & TRN \\
\hline CHEMBL1607077 & 688816 & 5.05 & 5.2963 & TRN \\
\hline CHEMBL1505505 & 688816 & 5.1 & 5.4517 & TRN \\
\hline CHEMBL1483803 & 688816 & 4.55 & 5.0369 & TST \\
\hline CHEMBL1527302 & 688816 & 4.8 & 5.2932 & TRN \\
\hline
\end{tabular}




\begin{tabular}{|c|c|c|c|c|}
\hline \multicolumn{5}{|c|}{ Supplemental Table S2.txt } \\
\hline CHEMBL1482356 & 688816 & 5.55 & 5.2794 & TST \\
\hline CHEMBL1587675 & 688816 & 5.6 & 4.9484 & TRN \\
\hline CHEMBL1348131 & 688816 & 4.75 & 4.8944 & TRN \\
\hline CHEMBL1451857 & 688816 & 7.0 & 5.3928 & TRN \\
\hline CHEMBL3213359 & 688816 & 4.45 & 5.1502 & TST \\
\hline CHEMBL1613560 & 688816 & 4.95 & 5.0263 & TRN \\
\hline CHEMBL1572388 & 688816 & 6.3 & 5.7668 & TRN \\
\hline CHEMBL1535593 & 688816 & 8.3468 & 5.5914 & TST \\
\hline CHEMBL1452256 & 688816 & 4.95 & 5.1354 & TRN \\
\hline CHEMBL1417632 & 688816 & 8.2518 & 5.709 & TST \\
\hline CHEMBL1427943 & 688816 & 5.1 & 5.1407 & TRN \\
\hline CHEMBL1594610 & 688816 & 4.95 & 5.2694 & TST \\
\hline CHEMBL3208665 & 688816 & 5.35 & 5.1562 & TST \\
\hline CHEMBL1376657 & 688816 & 5.9 & 5.5485 & TRN \\
\hline CHEMBL1421569 & 688816 & 5.55 & 5.6769 & TST \\
\hline CHEMBL1511409 & 688816 & 4.8 & 5.2854 & TST \\
\hline CHEMBL1518533 & 688816 & 4.6 & 5.4365 & TRN \\
\hline CHEMBL1416329 & 688816 & 4.8 & 4.9684 & TST \\
\hline CHEMBL1600540 & 688816 & 4.75 & 5.3675 & TRN \\
\hline CHEMBL1362294 & 688816 & 4.75 & 4.9076 & TRN \\
\hline CHEMBL1399767 & 688816 & 4.9 & 4.8615 & TRN \\
\hline CHEMBL1372204 & 688816 & 5.0 & 5.2492 & TRN \\
\hline CHEMBL1484256 & 688816 & 4.45 & 5.2934 & TRN \\
\hline CHEMBL1443398 & 688816 & 8.4949 & 5.4918 & TST \\
\hline CHEMBL1599643 & 688816 & 4.5 & 5.0603 & TRN \\
\hline CHEMBL1361999 & 688816 & 4.45 & 5.3781 & TRN \\
\hline CHEMBL1429586 & 688816 & 4.95 & 5.5975 & TRN \\
\hline CHEMBL1556990 & 688816 & 4.85 & 5.3022 & TRN \\
\hline CHEMBL1423304 & 688816 & 4.95 & 5.1999 & TRN \\
\hline CHEMBL1310058 & 688816 & 6.8 & 5.5018 & TRN \\
\hline CHEMBL1566780 & 688816 & 4.6 & 5.042 & TRN \\
\hline CHEMBL1339592 & 688816 & 4.9 & 5.0699 & TRN \\
\hline CHEMBL1390670 & 688816 & 5.25 & 5.2327 & TRN \\
\hline CHEMBL 3197388 & 688816 & 7.5498 & 5.5348 & TST \\
\hline CHEMBL1409486 & 688816 & 4.9 & 5.1359 & TRN \\
\hline CHEMBL1486055 & 688816 & 6.8 & 5.4353 & TST \\
\hline CHEMBL1466305 & 688816 & 5.5 & 5.3126 & TST \\
\hline CHEMBL1452981 & 688816 & 4.9 & 4.8421 & TRN \\
\hline CHEMBL1600296 & 688816 & 5.75 & 5.2194 & TRN \\
\hline CHEMBL3194619 & 688816 & 6.05 & 5.3255 & TST \\
\hline CHEMBL1439852 & 688816 & 4.9 & 5.3186 & TRN \\
\hline CHEMBL 1577570 & 688816 & 4.45 & 5.3577 & TRN \\
\hline CHEMBL1466678 & 688816 & 4.95 & 4.8324 & TRN \\
\hline CHEMBL1555831 & 688816 & 5.95 & 5.0249 & TRN \\
\hline CHEMBL1541791 & 688816 & 5.15 & 5.3798 & TRN \\
\hline CHEMBL1322201 & 688816 & 4.5 & 5.3566 & TRN \\
\hline CHEMBL1524059 & 688816 & 4.45 & 5.2227 & TRN \\
\hline CHEMBL1384846 & 688816 & 5.25 & 5.5944 & TRN \\
\hline
\end{tabular}




\begin{tabular}{|c|c|c|c|c|c|}
\hline \multicolumn{6}{|c|}{ Supplemental Table S2.txt } \\
\hline CHEMBL3198584 & 688816 & 4.45 & 5.5389 & TRN & \\
\hline CHEMBL3193349 & 688816 & 4.95 & 5.3266 & TST & \\
\hline CHEMBL1324155 & 688816 & 4.8 & 5.2285 & TRN & \\
\hline CHEMBL1455688 & 688816 & 5.3 & 5.4268 & TST & \\
\hline CHEMBL3192270 & 688816 & 4.8 & 4.8535 & TRN & \\
\hline CHEMBL1508252 & 688816 & 4.5 & 4.9839 & TRN & \\
\hline CHEMBL1547688 & 688816 & 4.7 & 5.335 & TST & \\
\hline CHEMBL1459891 & 688816 & 4.65 & 5.0078 & TST & \\
\hline CHEMBL1583471 & 688816 & 5.45 & 4.8657 & TRN & \\
\hline CHEMBL1412585 & 688816 & 4.9 & 5.0426 & TRN & \\
\hline CHEMBL1417085 & 688816 & 6.05 & 5.0978 & TRN & \\
\hline CHEMBL1598550 & 688816 & 8.4949 & 5.4429 & TRN & \\
\hline CHEMBL1377108 & 688816 & 4.8 & 5.1605 & TRN & \\
\hline CHEMBL1320854 & 688816 & 8.3468 & 5.6237 & TST & \\
\hline CHEMBL1523528 & 688816 & 4.8 & 5.121 & TST & \\
\hline CHEMBL1481739 & 688816 & 5.05 & 5.223 & TRN & \\
\hline CHEMBL1490203 & 688816 & 5.15 & 5.5752 & TRN & \\
\hline CHEMBL1462556 & 688816 & 4.9 & 5.239 & TRN & \\
\hline CHEMBL1326704 & 688816 & 4.45 & 5.5106 & TRN & \\
\hline CHEMBL1576368 & 688816 & 4.9 & 5.5053 & TST & \\
\hline CHEMBL1380457 & 688816 & 7.6003 & 5.2635 & TST & \\
\hline CHEMBL3191635 & 688816 & 5.7 & 5.416 & TST & \\
\hline CHEMBL1401198 & 688816 & 5.55 & 5.6196 & TST & \\
\hline CHEMBL1445361 & 688816 & 4.45 & 5.4283 & TST & \\
\hline CHEMBL1421407 & 688816 & 5.85 & 5.3424 & TRN & \\
\hline CHEMBL1592602 & 688816 & 4.95 & 5.0339 & TST & \\
\hline CHEMBL1487625 & 688816 & 5.3 & 4.9736 & TST & \\
\hline CHEMBL1588387 & 688816 & 4.95 & 5.2206 & TRN & \\
\hline CHEMBL1446960 & 688816 & 4.45 & 5.3532 & TRN & \\
\hline CHEMBL1407026 & 688816 & 4.45 & 5.0927 & TST & \\
\hline CHEMBL3190324 & 688816 & 4.85 & 5.2591 & TRN & \\
\hline CHEMBL1996013 & 688816 & 4.8 & 5.0218 & TRN & \\
\hline CHEMBL1601093 & 688816 & 8.0506 & 5.3158 & TST & \\
\hline CHEMBL1465063 & 688816 & 6.0 & 5.0379 & TRN & \\
\hline CHEMBL1452881 & 688816 & 4.85 & 6.0749 & TST & \\
\hline CHEMBL1425620 & 688816 & 4.9 & 5.1151 & TRN & \\
\hline CHEMBL1318762 & 688816 & 4.45 & 5.24799 & 9999999999 & TRN \\
\hline CHEMBL1371383 & 688816 & 4.85 & 5.1933 & TRN & \\
\hline CHEMBL1564678 & 688816 & 6.25 & 5.30399 & 7999999999 & TST \\
\hline CHEMBL1314157 & 688816 & 5.0 & 5.5916 & TRN & \\
\hline CHEMBL1609578 & 688816 & 4.95 & 5.4474 & TRN & \\
\hline CHEMBL1422158 & 688816 & 4.45 & 5.1596 & TRN & \\
\hline CHEMBL1524881 & 688816 & 4.45 & 5.0347 & TRN & \\
\hline CHEMBL1369893 & 688816 & 4.8 & 5.3663 & TRN & \\
\hline CHEMBL1426922 & 688816 & 4.95 & 5.2297 & TRN & \\
\hline CHEMBL1333561 & 688816 & 4.7 & 5.4781 & TRN & \\
\hline CHEMBL1386570 & 688816 & 5.85 & 5.1518 & TRN & \\
\hline CHEMBL1305409 & 688816 & 5.25 & 4.8885 & TRN & \\
\hline
\end{tabular}




\begin{tabular}{|c|c|c|c|c|c|}
\hline \multicolumn{6}{|c|}{ Supplemental Table S2.txt } \\
\hline CHEMBL1431894 & 688816 & 5.3 & 5.3924 & TRN & \\
\hline CHEMBL1540099 & 688816 & 4.85 & 5.6106 & TRN & \\
\hline CHEMBL1509257 & 688816 & 5.9 & 5.5168 & TRN & \\
\hline CHEMBL1413504 & 688816 & 4.7 & 4.9053 & TRN & \\
\hline CHEMBL1612383 & 688816 & 5.35 & 5.105 & TRN & \\
\hline CHEMBL1341251 & 688816 & 5.35 & 5.6208 & TST & \\
\hline CHEMBL1319973 & 688816 & 4.9 & 4.9322 & TRN & \\
\hline CHEMBL1545245 & 688816 & 4.75 & 5.461 & TRN & \\
\hline CHEMBL1413597 & 688816 & 4.85 & 5.1557 & TRN & \\
\hline CHEMBL1339235 & 688816 & 4.45 & 5.24200 & 0000000001 & TRN \\
\hline CHEMBL1437014 & 688816 & 5.85 & 5.1453 & TRN & \\
\hline CHEMBL1471717 & 688816 & 5.05 & 5.4636 & TRN & \\
\hline CHEMBL24759 & 688816 & 4.85 & 5.1866 & TRN & \\
\hline CHEMBL1300736 & 688816 & 4.9 & 4.4813 & TRN & \\
\hline CHEMBL1336704 & 688816 & 5.2 & 5.0065 & TRN & \\
\hline CHEMBL1486324 & 688816 & 8.0 & 5.813 & TRN & \\
\hline CHEMBL1596590 & 688816 & 4.9 & 5.2896 & TRN & \\
\hline CHEMBL1410125 & 688816 & 4.45 & 4.9976 & TRN & \\
\hline CHEMBL1509974 & 688816 & 5.6 & 5.6543 & TST & \\
\hline CHEMBL1584543 & 688816 & 7.5003 & 5.4479 & TST & \\
\hline CHEMBL1500299 & 688816 & 4.45 & 5.2896 & TRN & \\
\hline CHEMBL1500150 & 688816 & 4.8 & 5.1433 & TST & \\
\hline CHEMBL1433222 & 688816 & 5.25 & 5.6521 & TRN & \\
\hline CHEMBL1606412 & 688816 & 4.75 & 4.9226 & TRN & \\
\hline CHEMBL1320149 & 688816 & 4.65 & 5.2373 & TRN & \\
\hline CHEMBL1315150 & 688816 & 4.9 & 5.4007 & TRN & \\
\hline CHEMBL1446705 & 688816 & 5.15 & 5.1424 & TRN & \\
\hline CHEMBL1398931 & 688816 & 5.45 & 4.9774 & TRN & \\
\hline CHEMBL3192925 & 688816 & 4.9 & 5.4223 & TRN & \\
\hline CHEMBL1369254 & 688816 & 4.45 & 5.26 & TST & \\
\hline CHEMBL3192217 & 688816 & 4.45 & 4.8693 & TRN & \\
\hline CHEMBL1456293 & 688816 & 4.45 & 5.1405 & TRN & \\
\hline CHEMBL 2136569 & 688816 & 5.55 & 4.9856 & TRN & \\
\hline CHEMBL1557636 & 688816 & 5.3 & 5.9892 & TRN & \\
\hline CHEMBL1526488 & 688816 & 5.45 & 5.1212 & TRN & \\
\hline CHEMBL1311979 & 688816 & 4.6 & 5.0637 & TST & \\
\hline CHEMBL3189415 & 688816 & 4.9 & 5.3483 & TRN & \\
\hline CHEMBL1593511 & 688816 & 5.0 & 5.0013 & TRN & \\
\hline CHEMBL1462518 & 688816 & 4.65 & 5.2497 & TST & \\
\hline CHEMBL1605540 & 688816 & 5.45 & 5.1062 & TST & \\
\hline CHEMBL1304779 & 688816 & 4.95 & 5.4913 & TRN & \\
\hline CHEMBL3196042 & 688816 & 6.0 & 5.5451 & TRN & \\
\hline CHEMBL1567165 & 688816 & 4.45 & 5.2088 & TRN & \\
\hline CHEMBL1385349 & 688816 & 4.85 & 5.3889 & TST & \\
\hline CHEMBL1581228 & 688816 & 5.5 & 5.1262 & TRN & \\
\hline CHEMBL1383587 & 688816 & 5.4 & 5.3993 & TRN & \\
\hline CHEMBL141110 & 688816 & 4.45 & 5.4162 & TRN & \\
\hline CHEMBL606532 & 688816 & 4.9 & 5.2084 & TRN & \\
\hline
\end{tabular}




\begin{tabular}{|c|c|c|c|c|c|}
\hline \multicolumn{6}{|c|}{ splemental labıe s } \\
\hline CHEMBL1562079 & 688816 & 4.8 & 5.2302 & TRN & \\
\hline CHEMBL1478820 & 688816 & 4.45 & 4.9526 & TRN & \\
\hline CHEMBL1477663 & 688816 & 5.5 & 5.0901 & TST & \\
\hline CHEMBL1358996 & 688816 & 8.1487 & 5.3242 & TRN & \\
\hline CHEMBL1407768 & 688816 & 6.05 & 5.2401 & TST & \\
\hline CHEMBL1412140 & 688816 & 4.45 & 5.3232 & TST & \\
\hline CHEMBL1505813 & 688816 & 4.65 & 5.1436 & TRN & \\
\hline CHEMBL1432564 & 688816 & 4.9 & 5.1408 & TRN & \\
\hline CHEMBL2028176 & 688816 & 5.7 & 5.7644 & TST & \\
\hline CHEMBL1411317 & 688816 & 4.95 & 5.2423 & TRN & \\
\hline CHEMBL1474989 & 688816 & 5.45 & 5.0104 & TRN & \\
\hline CHEMBL1576672 & 688816 & 4.8 & 5.5524 & TRN & \\
\hline CHEMBL1320538 & 688816 & 5.3 & 5.3785 & TRN & \\
\hline CHEMBL1588780 & 688816 & 5.55 & 5.2304 & TRN & \\
\hline CHEMBL1377959 & 688816 & 5.9 & 5.1956 & TRN & \\
\hline CHEMBL1572873 & 688816 & 4.45 & 5.1899 & TST & \\
\hline CHEMBL1541086 & 688816 & 6.6499 & 5.2665 & TRN & \\
\hline CHEMBL1521327 & 688816 & 4.8 & 5.0529 & TRN & \\
\hline CHEMBL1446966 & 688816 & 5.9 & 5.4079 & TRN & \\
\hline CHEMBL1572788 & 688816 & 4.95 & 5.2132 & TRN & \\
\hline CHEMBL1421976 & 688816 & 5.0 & 5.5319 & TRN & \\
\hline CHEMBL1584637 & 688816 & 4.45 & 4.7895 & TRN & \\
\hline CHEMBL1353085 & 688816 & 4.9 & 5.2189 & TST & \\
\hline CHEMBL1569436 & 688816 & 6.95 & 5.66799 & 9999999999 & TRN \\
\hline CHEMBL1303998 & 688816 & 8.5528 & 5.56 & TRN & \\
\hline CHEMBL1370166 & 688816 & 4.9 & 5.0464 & TRN & \\
\hline CHEMBL1305412 & 688816 & 4.85 & 5.5473 & TRN & \\
\hline CHEMBL1408982 & 688816 & 4.45 & 4.9874 & TRN & \\
\hline CHEMBL1420144 & 688816 & 7.8996 & 5.1968 & TST & \\
\hline CHEMBL1422028 & 688816 & 4.85 & 5.1432 & TRN & \\
\hline CHEMBL1546043 & 688816 & 4.85 & 5.2026 & TRN & \\
\hline CHEMBL1549777 & 688816 & 4.8 & 4.9158 & TRN & \\
\hline CHEMBL1317495 & 688816 & 4.95 & 4.7299 & TRN & \\
\hline CHEMBL1464502 & 688816 & 5.45 & 4.9096 & TRN & \\
\hline CHEMBL1300023 & 688816 & 4.9 & 5.1672 & TRN & \\
\hline CHEMBL1455610 & 688816 & 4.65 & 5.4424 & TRN & \\
\hline CHEMBL1575397 & 688816 & 5.1 & 5.6614 & TRN & \\
\hline CHEMBL431525 & 688816 & 4.8 & 5.3224 & TST & \\
\hline CHEMBL1303564 & 688816 & 8.4949 & 5.4048 & TRN & \\
\hline CHEMBL1405952 & 688816 & 6.15 & 5.4626 & TRN & \\
\hline CHEMBL1974521 & 688816 & 4.5 & 5.1763 & TRN & \\
\hline CHEMBL1535192 & 688816 & 5.2 & 5.237 & TRN & \\
\hline CHEMBL1499164 & 688816 & 7.0 & 5.0148 & TRN & \\
\hline CHEMBL1429408 & 688816 & 4.9 & 5.192 & TRN & \\
\hline CHEMBL1443895 & 688816 & 5.9 & 5.4384 & TST & \\
\hline CHEMBL1340938 & 688816 & 6.4 & 5.7539 & TST & \\
\hline CHEMBL3191575 & 688816 & 4.95 & 5.1934 & TRN & \\
\hline CHEMBL3192308 & 688816 & 4.75 & 5.1368 & TRN & \\
\hline
\end{tabular}




\begin{tabular}{|c|c|c|c|c|c|}
\hline & & \multicolumn{4}{|c|}{ Supplemental Table S2.txt } \\
\hline CHEMBL1558222 & 688816 & 7.3002 & 5.3982 & TST & \\
\hline CHEMBL1459796 & 688816 & 4.55 & 5.2441 & TRN & \\
\hline CHEMBL1519445 & 688816 & 5.3 & 5.0277 & TRN & \\
\hline CHEMBL530038 & 688816 & 4.75 & 5.4558 & TRN & \\
\hline CHEMBL1430772 & 688816 & 5.0 & 5.1433 & TST & \\
\hline CHEMBL1526331 & 688816 & 7.6498 & 5.4008 & TST & \\
\hline CHEMBL1483469 & 688816 & 4.65 & 5.1698 & TST & \\
\hline CHEMBL1571565 & 688816 & 4.7 & 5.4262 & TRN & \\
\hline CHEMBL1588939 & 688816 & 4.8 & 5.4105 & TRN & \\
\hline CHEMBL16671 & 688816 & 6.0 & 6.023 & TRN & \\
\hline CHEMBL1517045 & 688816 & 5.3 & 5.0151 & TST & \\
\hline CHEMBL1379729 & 688816 & 4.85 & 5.1367 & TRN & \\
\hline CHEMBL1309877 & 688816 & 4.8 & 5.2293 & TRN & \\
\hline CHEMBL1367915 & 688816 & 4.45 & 5.2501 & TRN & \\
\hline CHEMBL1487720 & 688816 & 6.05 & 5.2064 & TRN & \\
\hline CHEMBL 3198521 & 688816 & 4.95 & 4.9689 & TRN & \\
\hline CHEMBL1369483 & 688816 & 5.0 & 5.0318 & TRN & \\
\hline CHEMBL1389400 & 688816 & 4.6 & 5.2684 & TRN & \\
\hline CHEMBL1374292 & 688816 & 5.45 & 5.6597 & TST & \\
\hline CHEMBL1362100 & 688816 & 5.15 & 4.783 & TST & \\
\hline CHEMBL1301404 & 688816 & 7.5498 & 5.4769 & TRN & \\
\hline CHEMBL3190431 & 688816 & 4.9 & 5.0037 & TST & \\
\hline CHEMBL1562521 & 688816 & 8.3468 & 5.033 & TRN & \\
\hline CHEMBL1559780 & 688816 & 4.45 & 5.4286 & TRN & \\
\hline CHEMBL1408827 & 688816 & 6.1 & 5.3711 & TRN & \\
\hline CHEMBL1424268 & 688816 & 5.3 & 5.1961 & TRN & \\
\hline CHEMBL1429472 & 688816 & 4.95 & 5.2114 & TRN & \\
\hline CHEMBL1471476 & 688816 & 4.95 & 4.8613 & TRN & \\
\hline CHEMBL1486650 & 688816 & 4.95 & 5.8043 & TRN & \\
\hline CHEMBL486078 & 688816 & 8.3468 & 5.2475 & TST & \\
\hline CHEMBL1412185 & 688816 & 6.1 & 4.9658 & TRN & \\
\hline CHEMBL1353535 & 688816 & 4.95 & 5.3075 & TRN & \\
\hline CHEMBL1423054 & 688816 & 4.9 & 5.49700 & 0000000001 & TRN \\
\hline CHEMBL1563287 & 688816 & 4.45 & 5.2394 & TRN & \\
\hline CHEMBL1321271 & 688816 & 5.25 & 5.2205 & TST & \\
\hline CHEMBL1557521 & 688816 & 4.6 & 5.2337 & TRN & \\
\hline CHEMBL1308630 & 688816 & 4.9 & 5.4151 & TST & \\
\hline CHEMBL 1405030 & 688816 & 7.5003 & 5.4573 & TST & \\
\hline CHEMBL1576456 & 688816 & 4.85 & 5.7051 & TST & \\
\hline CHEMBL1444124 & 688816 & 6.4 & 5.1848 & TRN & \\
\hline CHEMBL1335557 & 688816 & 5.0 & 5.1767 & TRN & \\
\hline CHEMBL1549798 & 688816 & 5.0 & 5.3285 & TRN & \\
\hline CHEMBL1303246 & 688816 & 4.75 & 5.005 & TRN & \\
\hline CHEMBL1504067 & 688816 & 4.9 & 5.3876 & TST & \\
\hline CHEMBL1477044 & 688816 & 4.65 & 5.6239 & TRN & \\
\hline CHEMBL1330016 & 688816 & 5.85 & 5.5089 & TST & \\
\hline CHEMBL1307243 & 688816 & 5.5 & 5.0395 & TRN & \\
\hline CHEMBL 3208840 & 688816 & 4.45 & 5.1639 & TRN & \\
\hline
\end{tabular}




\begin{tabular}{|c|c|c|c|c|c|}
\hline \multicolumn{6}{|c|}{ Supplemental Table S2.txt } \\
\hline CHEMBL1587153 & 688816 & 4.45 & 5.6317 & TRN & \\
\hline CHEMBL1500402 & 688816 & 7.699 & 5.6804 & TRN & \\
\hline CHEMBL1583083 & 688816 & 7.2503 & 5.5789 & TRN & \\
\hline CHEMBL1513347 & 688816 & 4.8 & 5.1308 & TRN & \\
\hline CHEMBL1339536 & 688816 & 4.95 & 5.07 & TRN & \\
\hline CHEMBL1432996 & 688816 & 6.35 & 5.5179 & TRN & \\
\hline CHEMBL1427876 & 688816 & 4.9 & 5.2744 & TRN & \\
\hline CHEMBL1422539 & 688816 & 5.15 & 4.7291 & TRN & \\
\hline CHEMBL1563700 & 688816 & 5.1 & 5.1016 & TRN & \\
\hline CHEMBL1311887 & 688816 & 4.8 & 5.1729 & TRN & \\
\hline CHEMBL589912 & 688816 & 4.45 & 5.1455 & TRN & \\
\hline CHEMBL1582997 & 688816 & 4.75 & 5.1298 & TRN & \\
\hline CHEMBL1404339 & 688816 & 5.75 & 5.7289 & TST & \\
\hline CHEMBL3198678 & 688816 & 4.8 & 5.1544 & TRN & \\
\hline CHEMBL1335302 & 688816 & 5.9 & 5.0653 & TRN & \\
\hline CHEMBL1519210 & 688816 & 4.45 & 5.1632 & TRN & \\
\hline CHEMBL1383439 & 688816 & 4.45 & 4.824 & TRN & \\
\hline CHEMBL1328527 & 688816 & 5.5 & 5.2053 & TRN & \\
\hline CHEMBL1439000 & 688816 & 4.95 & 5.3024 & TRN & \\
\hline CHEMBL1370676 & 688816 & 5.0 & 5.2489 & TRN & \\
\hline CHEMBL3208784 & 688816 & 4.95 & 5.2249 & TST & \\
\hline CHEMBL3213630 & 688816 & 4.95 & 5.0462 & TST & \\
\hline CHEMBL1306267 & 688816 & 5.1 & 4.8508 & TRN & \\
\hline CHEMBL1426152 & 688816 & 4.6 & 5.615 & TRN & \\
\hline CHEMBL1520991 & 688816 & 4.45 & 5.4089 & TRN & \\
\hline CHEMBL1567172 & 688816 & 5.25 & 5.15799 & 99999999995 & TRN \\
\hline CHEMBL1312969 & 688816 & 4.65 & 5.2037 & TRN & \\
\hline CHEMBL1443084 & 688816 & 5.45 & 5.4533 & TRN & \\
\hline CHEMBL1336183 & 688816 & 5.15 & 5.1808 & TST & \\
\hline CHEMBL1445349 & 688816 & 8.301 & 5.46700 & 30000000005 & TRN \\
\hline CHEMBL1404744 & 688816 & 7.0501 & 5.4852 & TRN & \\
\hline CHEMBL1407587 & 688816 & 4.9 & 5.1167 & TST & \\
\hline CHEMBL1597236 & 688816 & 6.15 & 5.607 & TRN & \\
\hline CHEMBL1533740 & 688816 & 4.85 & 4.8862 & TRN & \\
\hline CHEMBL3191012 & 688816 & 4.75 & 5.1801 & TRN & \\
\hline CHEMBL 2373279 & 688816 & 6.0 & 5.3025 & TST & \\
\hline CHEMBL1370787 & 688816 & 4.75 & 5.3007 & TRN & \\
\hline CHEMBL1580401 & 688816 & 5.25 & 5.54799 & э999999999 & TRN \\
\hline CHEMBL1313011 & 688816 & 5.25 & 5.5195 & TST & \\
\hline CHEMBL1468368 & 688816 & 5.15 & 5.1578 & TST & \\
\hline CHEMBL1565519 & 688816 & 4.95 & 4.888 & TRN & \\
\hline CHEMBL1467518 & 688816 & 7.7496 & 5.2672 & TST & \\
\hline CHEMBL1611360 & 688816 & 4.75 & 5.1068 & TRN & \\
\hline CHEMBL1366832 & 688816 & 4.45 & 4.9876 & TRN & \\
\hline CHEMBL1479214 & 688816 & 4.95 & 5.2358 & TRN & \\
\hline CHEMBL1444397 & 688816 & 4.65 & 5.2291 & TST & \\
\hline CHEMBL1256719 & 688816 & 9.0458 & 5.4441 & TST & \\
\hline CHEMBL1337181 & 688816 & 4.45 & 5.3867 & TRN & \\
\hline
\end{tabular}




\begin{tabular}{|c|c|c|c|c|c|}
\hline \multicolumn{6}{|c|}{ Supplemental Table S2.txt } \\
\hline CHEMBL1492126 & 688816 & 5.3 & 4.8855 & TRN & \\
\hline CHEMBL1479629 & 688816 & 4.95 & 5.0644 & TRN & \\
\hline CHEMBL1476186 & 688816 & 4.95 & 5.1474 & TRN & \\
\hline CHEMBL1608565 & 688816 & 6.5 & 5.3812 & TRN & \\
\hline CHEMBL1329909 & 688816 & 5.05 & 5.2667 & TST & \\
\hline CHEMBL1519067 & 688816 & 4.65 & 5.6732 & TRN & \\
\hline CHEMBL1429325 & 688816 & 6.05 & 5.5623 & TRN & \\
\hline CHEMBL1401610 & 688816 & 4.9 & 4.9596 & TRN & \\
\hline CHEMBL1312250 & 688816 & 4.95 & 5.1343 & TRN & \\
\hline CHEMBL3192589 & 688816 & 4.45 & 4.9789 & TRN & \\
\hline CHEMBL1964467 & 688816 & 5.3 & 5.3569 & TRN & \\
\hline CHEMBL1451556 & 688816 & 4.45 & 5.2006 & TRN & \\
\hline CHEMBL1449156 & 688816 & 5.95 & 5.263 & TRN & \\
\hline CHEMBL1486183 & 688816 & 5.1 & 5.4146 & TST & \\
\hline CHEMBL1571328 & 688816 & 4.8 & 5.1323 & TST & \\
\hline CHEMBL1418391 & 688816 & 8.301 & 5.1907 & TST & \\
\hline CHEMBL1970918 & 688816 & 4.7 & 5.1262 & TRN & \\
\hline CHEMBL1529009 & 688816 & 6.0 & 5.0241 & TST & \\
\hline CHEMBL1322812 & 688816 & 4.8 & 4.9831 & TRN & \\
\hline CHEMBL1566639 & 688816 & 4.9 & 5.1822 & TRN & \\
\hline CHEMBL1538536 & 688816 & 5.7 & 5.2526 & TRN & \\
\hline CHEMBL1401306 & 688816 & 4.95 & 5.09699 & 99999999995 & TRN \\
\hline CHEMBL1506281 & 688816 & 4.45 & 5.4991 & TRN & \\
\hline CHEMBL80155 & 688816 & 4.9 & 5.2433 & TRN & \\
\hline CHEMBL1322976 & 688816 & 5.95 & 5.3255 & TRN & \\
\hline CHEMBL1546940 & 688816 & 4.75 & 5.1647 & TST & \\
\hline CHEMBL1384973 & 688816 & 7.2 & 5.4414 & TRN & \\
\hline CHEMBL1475049 & 688816 & 4.9 & 5.0489 & TRN & \\
\hline CHEMBL1432398 & 688816 & 4.95 & 5.2764 & TST & \\
\hline CHEMBL1549711 & 688816 & 5.65 & 5.0748 & TRN & \\
\hline CHEMBL1461937 & 688816 & 4.95 & 5.1958 & TRN & \\
\hline CHEMBL246957 & 688816 & 5.1 & 5.1464 & TST & \\
\hline CHEMBL1435115 & 688816 & 4.95 & 5.136 & TRN & \\
\hline CHEMBL1583277 & 688816 & 5.0 & 5.3114 & TRN & \\
\hline CHEMBL1571597 & 688816 & 4.45 & 5.553 & TRN & \\
\hline CHEMBL1421210 & 688816 & 4.8 & 5.206 & TRN & \\
\hline CHEMBL1313699 & 688816 & 5.5 & 5.0972 & TRN & \\
\hline CHEMBL1392500 & 688816 & 4.45 & 5.048 & TRN & \\
\hline CHEMBL1609204 & 688816 & 5.9 & 5.0419 & TRN & \\
\hline CHEMBL1996360 & 688816 & 4.45 & 5.3919 & TRN & \\
\hline CHEMBL1420469 & 688816 & 4.45 & 5.0643 & TRN & \\
\hline CHEMBL1325561 & 688816 & 5.8 & 5.4229 & TST & \\
\hline CHEMBL1600295 & 688816 & 4.8 & 4.7274 & TRN & \\
\hline CHEMBL1607084 & 688816 & 4.85 & 5.4399 & TRN & \\
\hline CHEMBL1370337 & 688816 & 5.2 & 4.9811 & TRN & \\
\hline CHEMBL1348190 & 688816 & 4.6 & 4.7953 & TRN & \\
\hline CHEMBL1303279 & 688816 & 6.0 & 5.2536 & TRN & \\
\hline CHEMBL1494059 & 688816 & 5.25 & 5.2656 & TRN & \\
\hline
\end{tabular}




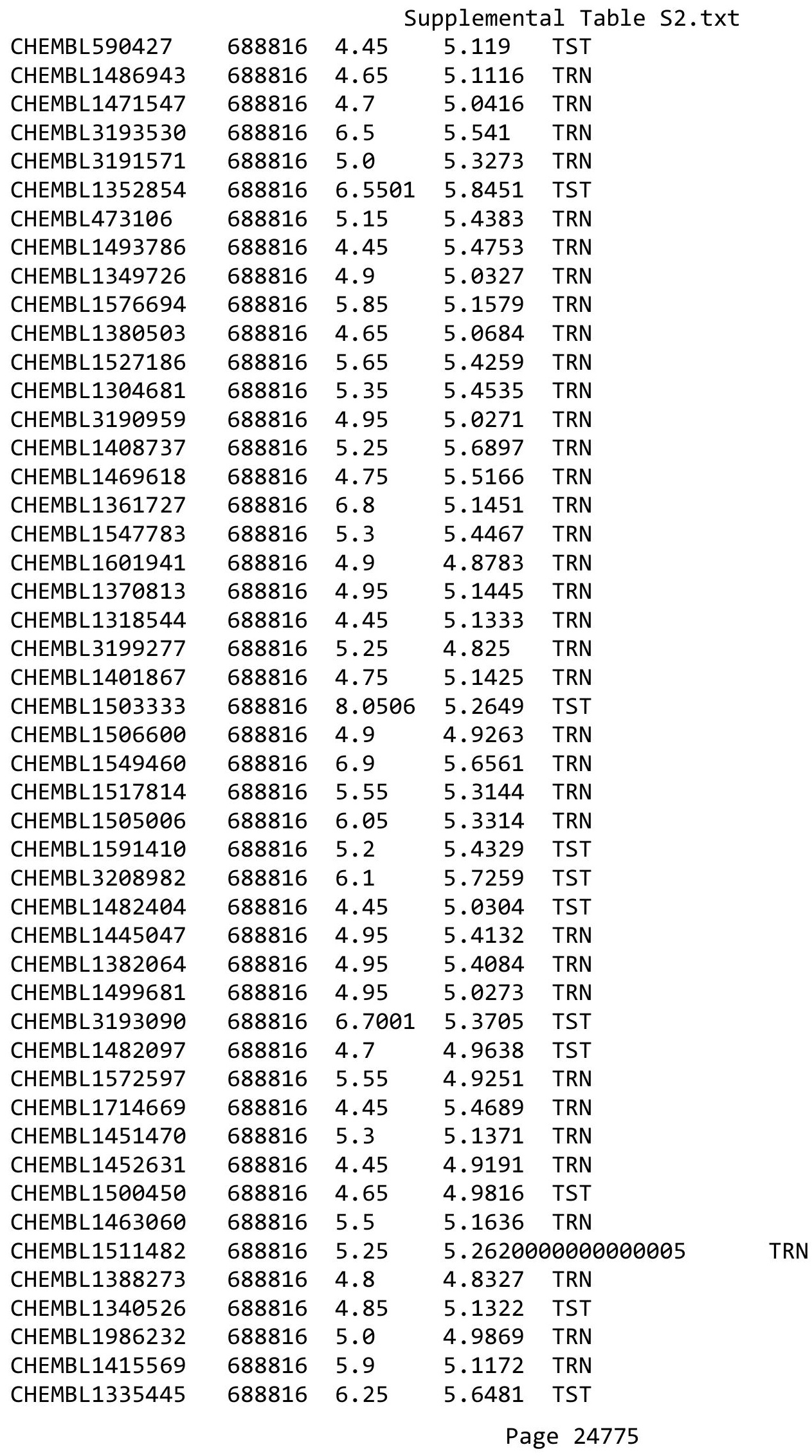




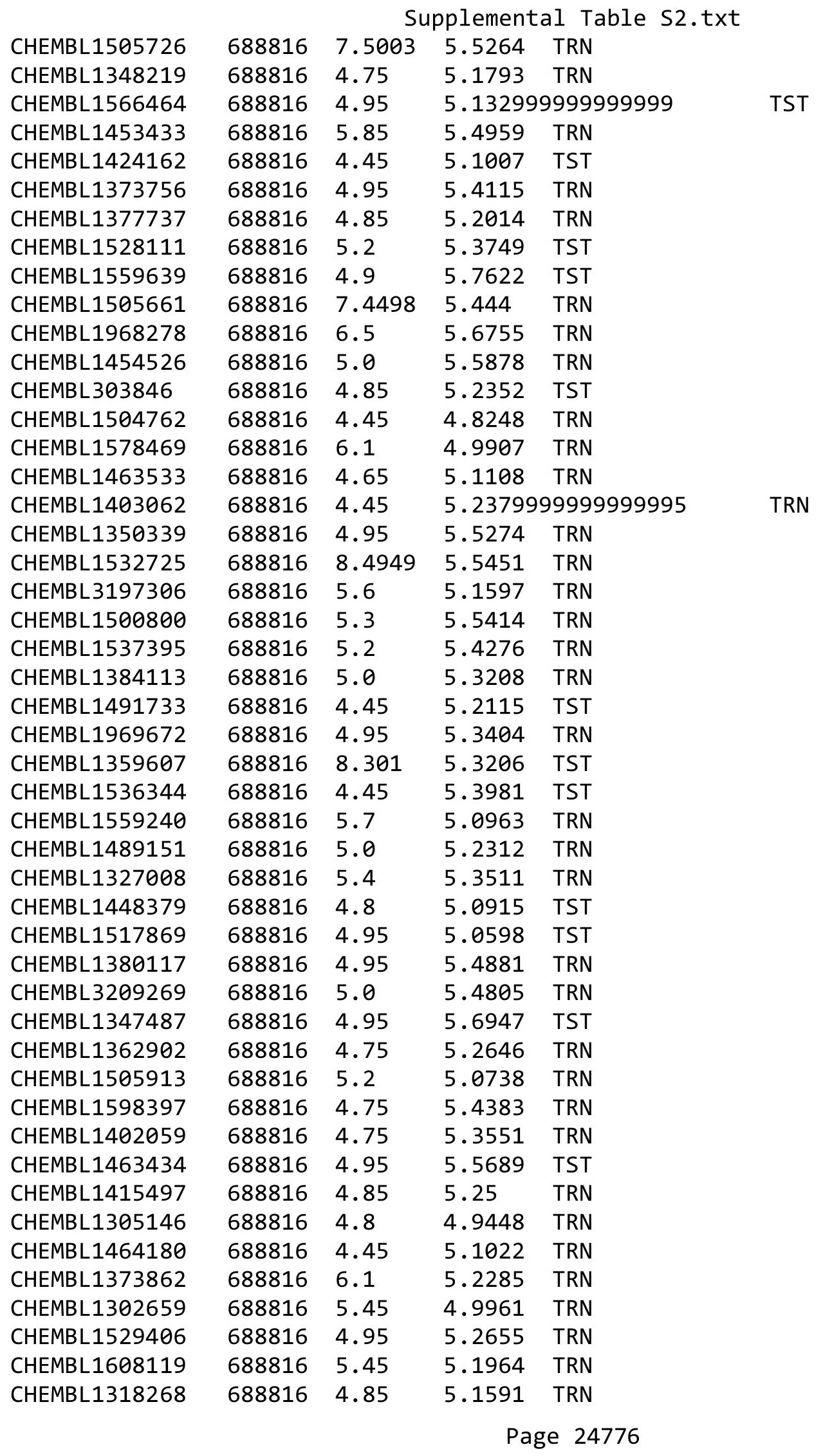




\begin{tabular}{|c|c|c|c|c|}
\hline \multicolumn{5}{|c|}{ Supplemental Table S2.txt } \\
\hline CHEMBL3197123 & 688816 & 4.9 & 5.3452 & TST \\
\hline CHEMBL1505588 & 688816 & 8.301 & 5.6256 & TRN \\
\hline CHEMBL2369217 & 688816 & 5.4 & 5.5482 & TRN \\
\hline CHEMBL1401264 & 688816 & 4.95 & 5.2231 & TST \\
\hline CHEMBL 1451348 & 688816 & 4.8 & 4.5234 & TST \\
\hline CHEMBL1299777 & 688816 & 4.75 & 5.1127 & TRN \\
\hline CHEMBL1429999 & 688816 & 4.75 & 5.3875 & TRN \\
\hline CHEMBL1562870 & 688816 & 4.9 & 5.2307 & TRN \\
\hline CHEMBL1551498 & 688816 & 4.75 & 5.2433 & TST \\
\hline CHEMBL1388695 & 688816 & 4.75 & 5.0928 & TST \\
\hline CHEMBL1608068 & 688816 & 4.45 & 5.4808 & TRN \\
\hline CHEMBL1459166 & 688816 & 5.35 & 5.3184 & TRN \\
\hline CHEMBL1566069 & 688816 & 8.3468 & 4.9371 & TRN \\
\hline CHEMBL 3190445 & 688816 & 8.3468 & 5.4882 & TST \\
\hline CHEMBL1438194 & 688816 & 5.7 & 5.0819 & TRN \\
\hline CHEMBL1450293 & 688816 & 4.9 & 5.2463 & TRN \\
\hline CHEMBL1465135 & 688816 & 4.65 & 4.973 & TST \\
\hline CHEMBL1301558 & 688816 & 4.8 & 5.2317 & TST \\
\hline CHEMBL1309909 & 688816 & 4.9 & 5.2336 & TRN \\
\hline CHEMBL1377127 & 688816 & 5.2 & 5.648 & TRN \\
\hline CHEMBL1531091 & 688816 & 5.35 & 5.4745 & TRN \\
\hline CHEMBL1432492 & 688816 & 4.45 & 5.1464 & TRN \\
\hline CHEMBL1410599 & 688816 & 4.45 & 5.2204 & TRN \\
\hline CHEMBL1534508 & 688816 & 4.95 & 5.5894 & TRN \\
\hline CHEMBL1559713 & 688816 & 4.7 & 4.8761 & TRN \\
\hline CHEMBL1301364 & 688816 & 5.0 & 4.9638 & TST \\
\hline CHEMBL1372823 & 688816 & 6.05 & 5.6022 & TST \\
\hline CHEMBL1361185 & 688816 & 4.5 & 5.4892 & TRN \\
\hline CHEMBL1389029 & 688816 & 4.75 & 5.481 & TRN \\
\hline CHEMBL1398501 & 688816 & 5.0 & 5.1895 & TRN \\
\hline CHEMBL1362599 & 688816 & 4.45 & 5.3913 & TRN \\
\hline CHEMBL1299525 & 688816 & 4.85 & 5.151 & TRN \\
\hline CHEMBL1403796 & 688816 & 4.8 & 5.4393 & TST \\
\hline CHEMBL1324003 & 688816 & 5.2 & 5.358 & TRN \\
\hline CHEMBL1579743 & 688816 & 5.15 & 5.4538 & TRN \\
\hline CHEMBL1546836 & 688816 & 4.95 & 5.0408 & TRN \\
\hline CHEMBL1340673 & 688816 & 4.9 & 5.0676 & TRN \\
\hline CHEMBL1462299 & 688816 & 4.85 & 5.2502 & TRN \\
\hline CHEMBL1412428 & 688816 & 5.1 & 5.3518 & TST \\
\hline CHEMBL1335008 & 688816 & 5.05 & 4.9415 & TRN \\
\hline CHEMBL1454326 & 688816 & 5.2 & 5.2831 & TRN \\
\hline CHEMBL1603017 & 688816 & 7.1002 & 5.4058 & TRN \\
\hline CHEMBL1563528 & 688816 & 4.9 & 4.9728 & TRN \\
\hline CHEMBL1413093 & 688816 & 5.2 & 5.5595 & TRN \\
\hline CHEMBL1490654 & 688816 & 4.7 & 5.2953 & TST \\
\hline CHEMBL1464904 & 688816 & 4.8 & 5.0066 & TRN \\
\hline CHEMBL1352347 & 688816 & 5.65 & 5.4673 & TST \\
\hline CHEMBL1566540 & 688816 & 7.5003 & 5.5316 & TST \\
\hline
\end{tabular}




\begin{tabular}{|c|c|c|c|c|}
\hline \multicolumn{5}{|c|}{ Supplemental Table S2.txt } \\
\hline CHEMBL 2002248 & 688816 & 5.45 & 5.0454 & TRN \\
\hline CHEMBL1596324 & 688816 & 4.75 & 5.0376 & TRN \\
\hline CHEMBL1481651 & 688816 & 4.9 & 5.607 & TRN \\
\hline CHEMBL3193933 & 688816 & 7.6498 & 5.1888 & TST \\
\hline CHEMBL1422641 & 688816 & 4.95 & 5.4296 & TST \\
\hline CHEMBL1547126 & 688816 & 5.15 & 5.5118 & TRN \\
\hline CHEMBL1586316 & 688816 & 6.8499 & 5.5323 & TRN \\
\hline CHEMBL1498891 & 688816 & 6.2 & 5.3812 & TRN \\
\hline CHEMBL1438512 & 688816 & 6.05 & 5.2581 & TRN \\
\hline CHEMBL1302020 & 688816 & 4.6 & 5.2736 & TRN \\
\hline CHEMBL1392298 & 688816 & 4.75 & 5.0554 & TRN \\
\hline CHEMBL1313121 & 688816 & 4.95 & 5.0145 & TRN \\
\hline CHEMBL3191348 & 688816 & 4.9 & 5.4655 & TRN \\
\hline CHEMBL1602888 & 688816 & 5.55 & 5.2014 & TRN \\
\hline CHEMBL1541001 & 688816 & 4.95 & 5.3455 & TRN \\
\hline CHEMBL1451268 & 688816 & 7.7496 & 4.7795 & TRN \\
\hline CHEMBL1533611 & 688816 & 4.75 & 5.224 & TST \\
\hline CHEMBL1382488 & 688816 & 7.6003 & 4.9931 & TRN \\
\hline CHEMBL1379319 & 688816 & 8.3468 & 5.1357 & TRN \\
\hline CHEMBL1607115 & 688816 & 4.95 & 5.4458 & TRN \\
\hline CHEMBL1508748 & 688816 & 4.45 & 5.3542 & TST \\
\hline CHEMBL1311799 & 688816 & 8.0506 & 5.4536 & TRN \\
\hline CHEMBL1467769 & 688816 & 4.9 & 5.2434 & TRN \\
\hline CHEMBL1589649 & 688816 & 5.65 & 5.0324 & TRN \\
\hline CHEMBL3191278 & 688816 & 5.4 & 5.2857 & TST \\
\hline CHEMBL1530879 & 688816 & 6.5501 & 5.0708 & TRN \\
\hline CHEMBL1326961 & 688816 & 6.25 & 5.2022 & TRN \\
\hline CHEMBL1348800 & 688816 & 4.9 & 5.5918 & TST \\
\hline CHEMBL1602307 & 688816 & 4.45 & 5.2267 & TRN \\
\hline CHEMBL1479034 & 688816 & 4.7 & 5.6015 & TRN \\
\hline CHEMBL1340926 & 688816 & 4.4 & 5.3119 & TRN \\
\hline CHEMBL1547039 & 688816 & 5.0 & 5.4254 & TRN \\
\hline CHEMBL1518925 & 688816 & 8.301 & 5.3939 & TRN \\
\hline CHEMBL1326225 & 688816 & 4.8 & 5.1956 & TRN \\
\hline CHEMBL1309149 & 688816 & 4.75 & 5.6706 & TST \\
\hline CHEMBL3144868 & 688816 & 4.95 & 5.4387 & TRN \\
\hline CHEMBL1483479 & 688816 & 4.45 & 4.9686 & TRN \\
\hline CHEMBL1459545 & 688816 & 5.3 & 5.0466 & TRN \\
\hline CHEMBL512372 & 688816 & 5.25 & 5.3244 & TST \\
\hline CHEMBL1437133 & 688816 & 4.65 & 5.1012 & TRN \\
\hline CHEMBL1604296 & 688816 & 4.45 & 5.4131 & TST \\
\hline CHEMBL1311443 & 688816 & 5.45 & 5.0333 & TST \\
\hline CHEMBL1300307 & 688816 & 5.0 & 4.8939 & TRN \\
\hline CHEMBL1406316 & 688816 & 5.25 & 5.6102 & TRN \\
\hline CHEMBL1431186 & 688816 & 6.95 & 5.2415 & TST \\
\hline CHEMBL1433308 & 688816 & 4.65 & 5.3653 & TRN \\
\hline CHEMBL1310778 & 688816 & 4.85 & 5.5068 & TRN \\
\hline CHEMBL1528784 & 688816 & 4.9 & 5.4717 & TRN \\
\hline
\end{tabular}




\begin{tabular}{|c|c|c|c|c|c|}
\hline \multicolumn{6}{|c|}{ Supplemental Table S2.txt } \\
\hline CHEMBL1444483 & 688816 & 4.85 & 5.1635 & TRN & \\
\hline CHEMBL1311754 & 688816 & 4.9 & 5.1127 & TRN & \\
\hline CHEMBL1613732 & 688816 & 4.85 & 5.0252 & TRN & \\
\hline CHEMBL1307618 & 688816 & 4.8 & 5.0137 & TRN & \\
\hline CHEMBL1371377 & 688816 & 4.85 & 5.221 & TRN & \\
\hline CHEMBL1562877 & 688816 & 4.9 & 4.9861 & TRN & \\
\hline CHEMBL1600780 & 688816 & 4.6 & 5.1688 & TST & \\
\hline CHEMBL1363717 & 688816 & 8.0 & 5.6444 & TST & \\
\hline CHEMBL1461287 & 688816 & 4.75 & 5.444 & TRN & \\
\hline CHEMBL1603142 & 688816 & 7.699 & 5.2445 & TRN & \\
\hline CHEMBL1371384 & 688816 & 4.9 & 5.5118 & TRN & \\
\hline CHEMBL1412156 & 688816 & 5.35 & 5.3084 & TST & \\
\hline CHEMBL1574942 & 688816 & 7.6498 & 4.9765 & TRN & \\
\hline CHEMBL1410798 & 688816 & 4.75 & 5.1788 & TRN & \\
\hline CHEMBL1576722 & 688816 & 4.45 & 5.0467 & TST & \\
\hline CHEMBL3199355 & 688816 & 4.85 & 5.2051 & TRN & \\
\hline CHEMBL3191958 & 688816 & 4.5 & 5.0495 & TRN & \\
\hline CHEMBL1304587 & 688816 & 6.2 & 5.50200 & 0000000001 & TST \\
\hline CHEMBL3209494 & 688816 & 4.85 & 4.9804 & TRN & \\
\hline CHEMBL1480366 & 688816 & 8.3468 & 5.5042 & TST & \\
\hline CHEMBL1536981 & 688816 & 4.85 & 5.4533 & TRN & \\
\hline CHEMBL1480522 & 688816 & 4.9 & 5.0552 & TRN & \\
\hline CHEMBL1574409 & 688816 & 5.1 & 5.5657 & TST & \\
\hline CHEMBL1500912 & 688816 & 4.45 & 4.9381 & TRN & \\
\hline CHEMBL1349632 & 688816 & 4.9 & 5.4115 & TRN & \\
\hline CHEMBL1540987 & 688816 & 5.0 & 5.2355 & TRN & \\
\hline CHEMBL1572197 & 688816 & 4.95 & 5.7213 & TRN & \\
\hline CHEMBL1563210 & 688816 & 4.9 & 5.2948 & TRN & \\
\hline CHEMBL1345181 & 688816 & 6.7001 & 5.7855 & TST & \\
\hline CHEMBL1389262 & 688816 & 4.75 & 4.9793 & TST & \\
\hline CHEMBL1426581 & 688816 & 4.8 & 5.3424 & TST & \\
\hline CHEMBL1323019 & 688816 & 4.55 & 5.4202 & TRN & \\
\hline CHEMBL1386623 & 688816 & 4.65 & 5.0045 & TRN & \\
\hline CHEMBL1331363 & 688816 & 4.55 & 5.0279 & TST & \\
\hline CHEMBL1529419 & 688816 & 7.8013 & 5.0983 & TST & \\
\hline CHEMBL1441858 & 688816 & 4.9 & 5.3006 & TRN & \\
\hline CHEMBL1411256 & 688816 & 6.45 & 5.2639 & TST & \\
\hline CHEMBL452241 & 688816 & 5.0 & 5.2409 & TRN & \\
\hline CHEMBL1591817 & 688816 & 4.6 & 5.0523 & TRN & \\
\hline CHEMBL1453054 & 688816 & 6.5 & 4.9679 & TRN & \\
\hline CHEMBL1517370 & 688816 & 6.6 & 5.1613 & TST & \\
\hline CHEMBL1309610 & 688816 & 6.8 & 5.4026 & TRN & \\
\hline CHEMBL1577401 & 688816 & 5.65 & 5.15600 & 0000000001 & TRN \\
\hline CHEMBL1486361 & 688816 & 5.25 & 5.7514 & TST & \\
\hline CHEMBL1309276 & 688816 & 5.2 & 5.3217 & TST & \\
\hline CHEMBL1326813 & 688816 & 4.6 & 5.3389 & TST & \\
\hline CHEMBL1439672 & 688816 & 4.95 & 4.9634 & TST & \\
\hline CHEMBL3210112 & 688816 & 5.25 & 5.2976 & TST & \\
\hline
\end{tabular}




\begin{tabular}{|c|c|c|c|c|}
\hline \multirow[b]{2}{*}{ CHEMBL1578785 } & \multicolumn{4}{|c|}{ Supplementa } \\
\hline & 688816 & 4.45 & 5.0261 & TRN \\
\hline CHEMBL1530926 & 688816 & 5.6 & 5.1232 & TRN \\
\hline CHEMBL1380268 & 688816 & 4.85 & 5.3464 & TRN \\
\hline CHEMBL1454677 & 688816 & 4.65 & 4.9669 & TRN \\
\hline CHEMBL1576585 & 688816 & 4.8 & 5.1094 & TRN \\
\hline CHEMBL1416655 & 688816 & 4.95 & 5.308 & TRN \\
\hline CHEMBL3211670 & 688816 & 4.9 & 5.2371 & TST \\
\hline CHEMBL1480650 & 688816 & 5.05 & 5.3301 & TRN \\
\hline CHEMBL1564969 & 688816 & 4.8 & 5.2075 & TRN \\
\hline CHEMBL1488267 & 688816 & 5.0 & 5.4181 & TRN \\
\hline CHEMBL1365456 & 688816 & 4.45 & 5.284 & TRN \\
\hline CHEMBL1565214 & 688816 & 4.9 & 5.2528 & TST \\
\hline CHEMBL1359483 & 688816 & 5.05 & 5.454 & TRN \\
\hline CHEMBL1344296 & 688816 & 4.65 & 5.0623 & TST \\
\hline CHEMBL1369212 & 688816 & 4.45 & 5.5001 & TRN \\
\hline CHEMBL1380762 & 688816 & 4.75 & 5.0316 & TST \\
\hline CHEMBL1418207 & 688816 & 5.25 & 5.125 & TRN \\
\hline CHEMBL1332191 & 688816 & 6.8 & 5.2789 & TRN \\
\hline CHEMBL1550055 & 688816 & 4.9 & 4.8853 & TRN \\
\hline CHEMBL1969293 & 688816 & 5.05 & 5.1755 & TRN \\
\hline CHEMBL1307523 & 688816 & 5.25 & 5.8043 & TST \\
\hline CHEMBL1414254 & 688816 & 4.45 & 5.1569 & TST \\
\hline CHEMBL1332675 & 688816 & 5.45 & 5.5526 & TRN \\
\hline CHEMBL1385338 & 688816 & 4.6 & 5.1954 & TRN \\
\hline CHEMBL1330038 & 688816 & 5.05 & 5.3039 & TRN \\
\hline CHEMBL1426866 & 688816 & 4.65 & 5.2158 & TST \\
\hline CHEMBL1545463 & 688816 & 4.95 & 5.1758 & TRN \\
\hline CHEMBL1601341 & 688816 & 8.3468 & 5.7618 & TRN \\
\hline CHEMBL1451087 & 688816 & 4.85 & 5.6017 & TRN \\
\hline CHEMBL1568366 & 688816 & 4.85 & 5.5755 & TRN \\
\hline CHEMBL1455151 & 688816 & 5.35 & 5.3544 & TST \\
\hline CHEMBL1442866 & 688816 & 8.0 & 5.6073 & TRN \\
\hline CHEMBL 3208726 & 688816 & 5.35 & 5.1244 & TRN \\
\hline CHEMBL1488740 & 688816 & 6.35 & 5.6308 & TRN \\
\hline CHEMBL1315730 & 688816 & 4.55 & 5.1092 & TRN \\
\hline CHEMBL1402356 & 688816 & 8.1024 & 5.1703 & TRN \\
\hline CHEMBL1313588 & 688816 & 4.95 & 4.7729 & TRN \\
\hline CHEMBL1433241 & 688816 & 5.05 & 5.1491 & TRN \\
\hline CHEMBL1341239 & 688816 & 4.65 & 5.526 & TRN \\
\hline CHEMBL3198842 & 688816 & 5.25 & 5.2988 & TRN \\
\hline CHEMBL1359368 & 688816 & 5.0 & 4.9948 & TRN \\
\hline CHEMBL1973429 & 688816 & 4.45 & 5.2175 & TST \\
\hline CHEMBL1546487 & 688816 & 8.4949 & 5.4011 & TST \\
\hline CHEMBL1545965 & 688816 & 4.9 & 5.2574 & TRN \\
\hline CHEMBL1413505 & 688816 & 4.95 & 5.2487 & TRN \\
\hline CHEMBL1329907 & 688816 & 4.45 & 4.9901 & TRN \\
\hline CHEMBL1560646 & 688816 & 4.85 & 5.0067 & TRN \\
\hline CHEMBL1580876 & 688816 & 8.3468 & 5.1298 & TRN \\
\hline
\end{tabular}

Page 24780 


\begin{tabular}{|c|c|c|c|c|c|}
\hline \multicolumn{6}{|c|}{ Supplemental Table S2.txt } \\
\hline CHEMBL1379462 & 688816 & 4.45 & 5.5275 & TRN & \\
\hline CHEMBL1496611 & 688816 & 5.1 & 5.17 & TRN & \\
\hline CHEMBL1438901 & 688816 & 4.8 & 5.6367 & TST & \\
\hline CHEMBL1325640 & 688816 & 4.45 & 4.8795 & TST & \\
\hline CHEMBL1340353 & 688816 & 4.45 & 5.48799 & 99999999995 & TRN \\
\hline CHEMBL1589110 & 688816 & 4.6 & 5.0561 & TRN & \\
\hline CHEMBL1507042 & 688816 & 4.95 & 5.2752 & TRN & \\
\hline CHEMBL1457974 & 688816 & 4.95 & 5.3477 & TRN & \\
\hline CHEMBL1401234 & 688816 & 5.95 & 5.5115 & TRN & \\
\hline CHEMBL1452139 & 688816 & 5.45 & 5.2463 & TRN & \\
\hline CHEMBL 3191540 & 688816 & 4.45 & 5.5234 & TST & \\
\hline CHEMBL1325383 & 688816 & 5.45 & 5.1956 & TRN & \\
\hline CHEMBL1489769 & 688816 & 4.9 & 5.2575 & TST & \\
\hline CHEMBL1449219 & 688816 & 4.8 & 5.0029 & TRN & \\
\hline CHEMBL1400275 & 688816 & 4.8 & 5.0872 & TRN & \\
\hline CHEMBL 2142883 & 688816 & 5.9 & 5.4908 & TST & \\
\hline CHEMBL1540772 & 688816 & 5.8 & 5.5368 & TRN & \\
\hline CHEMBL1581644 & 688816 & 5.0 & 5.1793 & TRN & \\
\hline CHEMBL1594144 & 688816 & 4.9 & 5.3172 & TRN & \\
\hline CHEMBL 3212873 & 688816 & 6.6499 & 5.4039 & TRN & \\
\hline CHEMBL3192486 & 688816 & 4.95 & 5.4764 & TRN & \\
\hline CHEMBL1407914 & 688816 & 5.1 & 5.1372 & TRN & \\
\hline CHEMBL1977478 & 688816 & 5.25 & 5.6792 & TRN & \\
\hline CHEMBL1319789 & 688816 & 5.95 & 4.9484 & TST & \\
\hline CHEMBL1401241 & 688816 & 4.45 & 5.1844 & TRN & \\
\hline CHEMBL 280998 & 688816 & 4.9 & 5.13399 & 99999999995 & TRN \\
\hline CHEMBL1971698 & 688816 & 4.75 & 4.9003 & TRN & \\
\hline CHEMBL1399594 & 688816 & 5.15 & 5.6525 & TRN & \\
\hline CHEMBL1538669 & 688816 & 5.5 & 5.4255 & TST & \\
\hline CHEMBL1592136 & 688816 & 5.85 & 5.2988 & TRN & \\
\hline CHEMBL 3189257 & 688816 & 8.301 & 5.4872 & TRN & \\
\hline CHEMBL1408964 & 688816 & 4.95 & 5.1777 & TST & \\
\hline CHEMBL1413540 & 688816 & 6.3 & 5.8208 & TRN & \\
\hline CHEMBL1415866 & 688816 & 5.05 & 5.1471 & TRN & \\
\hline CHEMBL1523156 & 688816 & 8.301 & 5.3642 & TRN & \\
\hline CHEMBL1405708 & 688816 & 4.9 & 5.1691 & TRN & \\
\hline CHEMBL 3189326 & 688816 & 5.6 & 5.2234 & TRN & \\
\hline CHEMBL1493620 & 688816 & 5.6 & 4.8304 & TRN & \\
\hline CHEMBL1414685 & 688816 & 4.95 & 5.6866 & TST & \\
\hline CHEMBL1347002 & 688816 & 5.25 & 5.0615 & TRN & \\
\hline CHEMBL1330033 & 688816 & 4.85 & 5.183 & TRN & \\
\hline CHEMBL3209958 & 688816 & 4.85 & 5.6056 & TRN & \\
\hline CHEMBL1421083 & 688816 & 5.8 & 5.6744 & TRN & \\
\hline CHEMBL1376682 & 688816 & 4.7 & 5.3324 & TRN & \\
\hline CHEMBL1362588 & 688816 & 4.95 & 5.2444 & TRN & \\
\hline CHEMBL1563149 & 688816 & 5.7 & 5.7434 & TRN & \\
\hline CHEMBL1612794 & 688816 & 4.45 & 5.3873 & TST & \\
\hline CHEMBL3196612 & 688816 & 8.4949 & 5.5052 & TRN & \\
\hline
\end{tabular}




\begin{tabular}{|c|c|c|c|c|c|}
\hline \multicolumn{6}{|c|}{ Supplemental Table S2.txt } \\
\hline CHEMBL1313128 & 688816 & 5.0 & 4.9279 & TST & \\
\hline CHEMBL1331514 & 688816 & 7.2503 & 5.3756 & TRN & \\
\hline CHEMBL3197922 & 688816 & 4.95 & 5.7604 & TRN & \\
\hline CHEMBL1499725 & 688816 & 4.45 & 5.3061 & TRN & \\
\hline CHEMBL1483147 & 688816 & 4.95 & 5.1966 & TRN & \\
\hline CHEMBL1499236 & 688816 & 5.35 & 5.3467 & TRN & \\
\hline CHEMBL3212116 & 688816 & 5.2 & 5.5127 & TST & \\
\hline CHEMBL1381858 & 688816 & 5.0 & 5.6923 & TRN & \\
\hline CHEMBL1488999 & 688816 & 5.4 & 5.4566 & TRN & \\
\hline CHEMBL1578464 & 688816 & 4.95 & 5.3935 & TRN & \\
\hline CHEMBL1451868 & 688816 & 4.65 & 5.6782 & TRN & \\
\hline CHEMBL355318 & 688816 & 4.9 & 5.176 & TRN & \\
\hline CHEMBL1341833 & 688816 & 5.3 & 5.3191 & TRN & \\
\hline CHEMBL1431106 & 688816 & 5.3 & 5.3092 & TRN & \\
\hline CHEMBL1421461 & 688816 & 7.8508 & 5.7849 & TST & \\
\hline CHEMBL1425131 & 688816 & 5.55 & 5.256 & TRN & \\
\hline CHEMBL1455676 & 688816 & 5.0 & 5.2076 & TRN & \\
\hline CHEMBL1499855 & 688816 & 4.8 & 5.5062 & TRN & \\
\hline CHEMBL1429921 & 688816 & 5.25 & 5.1245 & TRN & \\
\hline CHEMBL1484670 & 688816 & 7.4001 & 5.9873 & TRN & \\
\hline CHEMBL1432615 & 688816 & 5.0 & 5.1614 & TRN & \\
\hline CHEMBL1605565 & 688816 & 4.95 & 5.169 & TRN & \\
\hline CHEMBL1433682 & 688816 & 4.45 & 5.2751 & TRN & \\
\hline CHEMBL1460179 & 688816 & 5.3 & 4.5499 & TRN & \\
\hline CHEMBL1576545 & 688816 & 4.95 & 4.9318 & TRN & \\
\hline CHEMBL1543271 & 688816 & 4.95 & $5.2170 e$ & 00000000005 & TRN \\
\hline CHEMBL1610284 & 688816 & 4.85 & 5.4984 & TRN & \\
\hline CHEMBL1501197 & 688816 & 5.65 & 5.3551 & TRN & \\
\hline CHEMBL1310912 & 688816 & 8.0506 & 5.3768 & TRN & \\
\hline CHEMBL1507208 & 688816 & 5.25 & 5.4798 & TRN & \\
\hline CHEMBL1362507 & 688816 & 6.0 & 5.303 & TRN & \\
\hline CHEMBL1513610 & 688816 & 4.7 & 5.1965 & TRN & \\
\hline CHEMBL1367947 & 688816 & 4.55 & 5.775 & TRN & \\
\hline CHEMBL1462474 & 688816 & 5.35 & 5.1895 & TST & \\
\hline CHEMBL1341978 & 688816 & 4.95 & 4.7606 & TRN & \\
\hline CHEMBL1491654 & 688816 & 5.15 & 5.0782 & TRN & \\
\hline CHEMBL1385990 & 688816 & 5.55 & 5.053 & TRN & \\
\hline CHEMBL1322980 & 688816 & 5.55 & $5.2520 e$ & 0000000001 & TRN \\
\hline CHEMBL1428139 & 688816 & 5.0 & 5.1013 & TRN & \\
\hline CHEMBL1575766 & 688816 & 4.75 & 4.9937 & TST & \\
\hline CHEMBL3212545 & 688816 & 5.45 & 5.8147 & TST & \\
\hline CHEMBL1372907 & 688816 & 4.85 & 5.0966 & TRN & \\
\hline CHEMBL1391243 & 688816 & 8.0506 & 5.1977 & TRN & \\
\hline CHEMBL1402099 & 688816 & 8.0506 & 5.4184 & TST & \\
\hline CHEMBL1545712 & 688816 & 8.3468 & 5.1143 & TST & \\
\hline CHEMBL3198998 & 688816 & 4.8 & 5.3597 & TST & \\
\hline CHEMBL1406565 & 688816 & 4.95 & 5.3418 & TST & \\
\hline CHEMBL1488205 & 688816 & 5.45 & 5.6378 & TST & \\
\hline
\end{tabular}




\begin{tabular}{|c|c|c|c|c|}
\hline \multicolumn{5}{|c|}{ Supplemental Table S2.txt } \\
\hline CHEMBL1497435 & 688816 & 5.2 & 5.256 & TRN \\
\hline CHEMBL1508196 & 688816 & 4.9 & 4.9812 & TRN \\
\hline CHEMBL1470398 & 688816 & 4.45 & 5.1996 & TRN \\
\hline CHEMBL 3194800 & 688816 & 4.8 & 5.0283 & TRN \\
\hline CHEMBL1542479 & 688816 & 4.45 & 5.2577 & TRN \\
\hline CHEMBL1348507 & 688816 & 4.5 & 4.9192 & TRN \\
\hline CHEMBL573226 & 688816 & 4.45 & 5.1409 & TRN \\
\hline CHEMBL1543011 & 688816 & 5.25 & 5.5497 & TRN \\
\hline CHEMBL3199093 & 688816 & 4.45 & 5.0575 & TRN \\
\hline CHEMBL1597676 & 688816 & 5.2 & 5.3897 & TST \\
\hline CHEMBL1364515 & 688816 & 4.65 & 5.5028 & TST \\
\hline CHEMBL1411391 & 688816 & 4.8 & 5.1734 & TRN \\
\hline CHEMBL1498146 & 688816 & 4.75 & 5.1473 & TRN \\
\hline CHEMBL1367776 & 688816 & 4.6 & 5.0726 & TRN \\
\hline CHEMBL1524482 & 688816 & 5.75 & 5.0778 & TRN \\
\hline CHEMBL1351571 & 688816 & 4.9 & 5.3328 & TRN \\
\hline CHEMBL1593799 & 688816 & 4.65 & 5.3529 & TRN \\
\hline CHEMBL1307543 & 688816 & 4.7 & 5.2548 & TRN \\
\hline CHEMBL1489212 & 688816 & 4.45 & 5.4381 & TST \\
\hline CHEMBL1415686 & 688816 & 4.45 & 5.3965 & TRN \\
\hline CHEMBL1442237 & 688816 & 5.15 & 5.1103 & TRN \\
\hline CHEMBL1586654 & 688816 & 8.301 & 5.0948 & TRN \\
\hline CHEMBL1571462 & 688816 & 4.75 & 5.371 & TST \\
\hline CHEMBL1444829 & 688816 & 4.75 & 5.0762 & TRN \\
\hline CHEMBL1532649 & 688816 & 4.45 & 5.1805 & TRN \\
\hline CHEMBL1481825 & 688816 & 4.55 & 5.50200 & 0000000001 \\
\hline CHEMBL1336056 & 688816 & 4.75 & 5.1186 & TST \\
\hline CHEMBL1358420 & 688816 & 4.7 & 4.9772 & TRN \\
\hline CHEMBL1321064 & 688816 & 4.95 & 5.4889 & TRN \\
\hline CHEMBL1313087 & 688816 & 4.45 & 5.0851 & TRN \\
\hline CHEMBL1789988 & 688816 & 5.7 & 5.437 & TRN \\
\hline CHEMBL1582875 & 688816 & 4.5 & 5.4027 & TST \\
\hline CHEMBL1410897 & 688816 & 4.75 & 5.1963 & TRN \\
\hline CHEMBL1302822 & 688816 & 4.8 & 5.4635 & TRN \\
\hline CHEMBL1358464 & 688816 & 4.45 & 5.4627 & TST \\
\hline CHEMBL3199873 & 688816 & 5.55 & 5.2843 & TRN \\
\hline CHEMBL1595161 & 688816 & 4.95 & 5.2469 & TST \\
\hline CHEMBL1586103 & 688816 & 4.5 & 4.8498 & TRN \\
\hline CHEMBL1343616 & 688816 & 5.4 & 5.9514 & TRN \\
\hline CHEMBL1584663 & 688816 & 4.95 & 5.3513 & TRN \\
\hline CHEMBL1419520 & 688816 & 7.15 & 5.2876 & TST \\
\hline CHEMBL1479060 & 688816 & 7.5003 & 5.1804 & TRN \\
\hline CHEMBL1506350 & 688816 & 4.9 & 5.3791 & TRN \\
\hline CHEMBL1360618 & 688816 & 6.3 & 5.4593 & TRN \\
\hline CHEMBL1526021 & 688816 & 4.65 & 5.3271 & TST \\
\hline CHEMBL1352310 & 688816 & 4.75 & 5.6836 & TST \\
\hline CHEMBL3195459 & 688816 & 5.35 & 5.0397 & TRN \\
\hline CHEMBL1570501 & 688816 & 5.1 & 5.0874 & TST \\
\hline
\end{tabular}




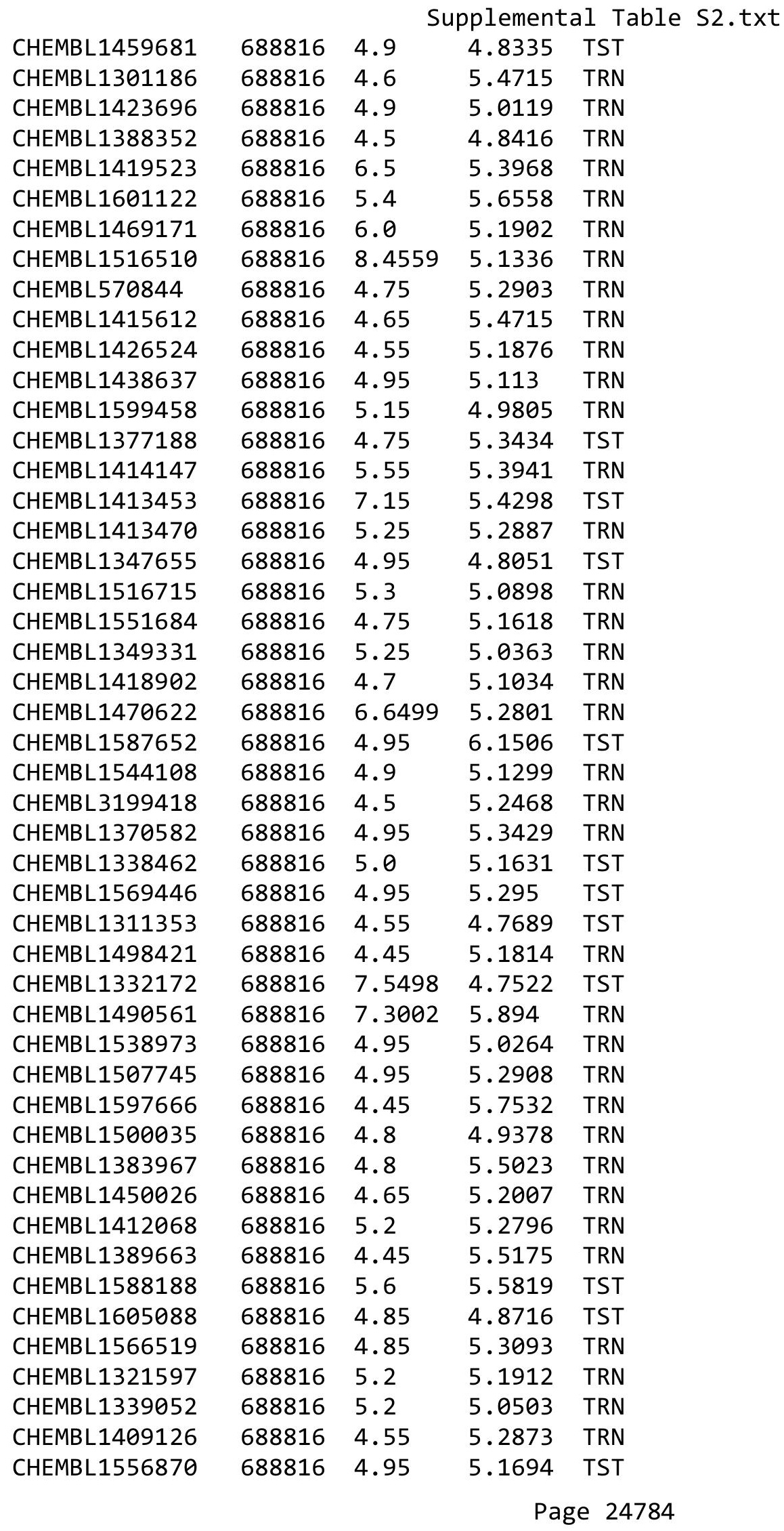




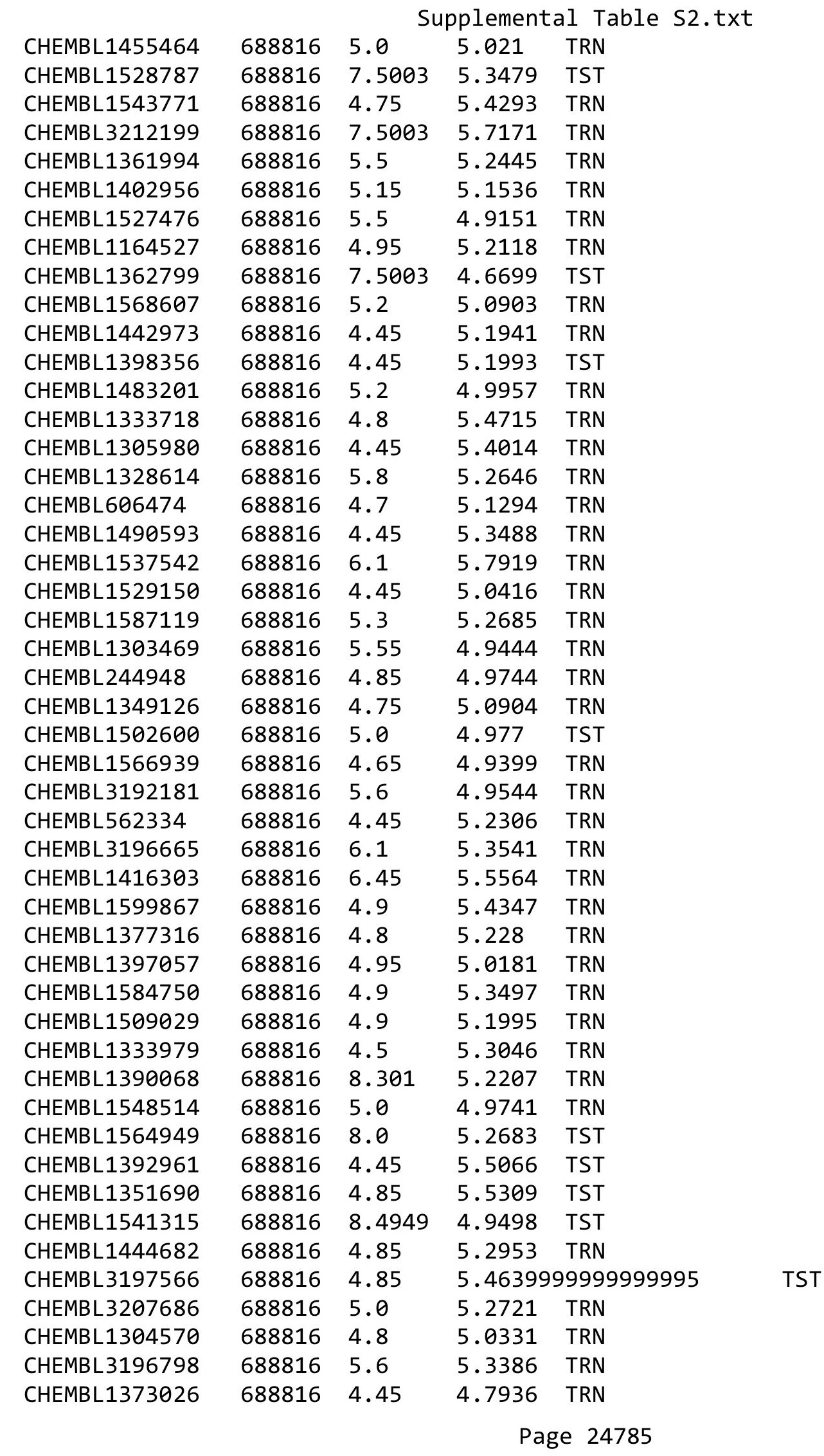




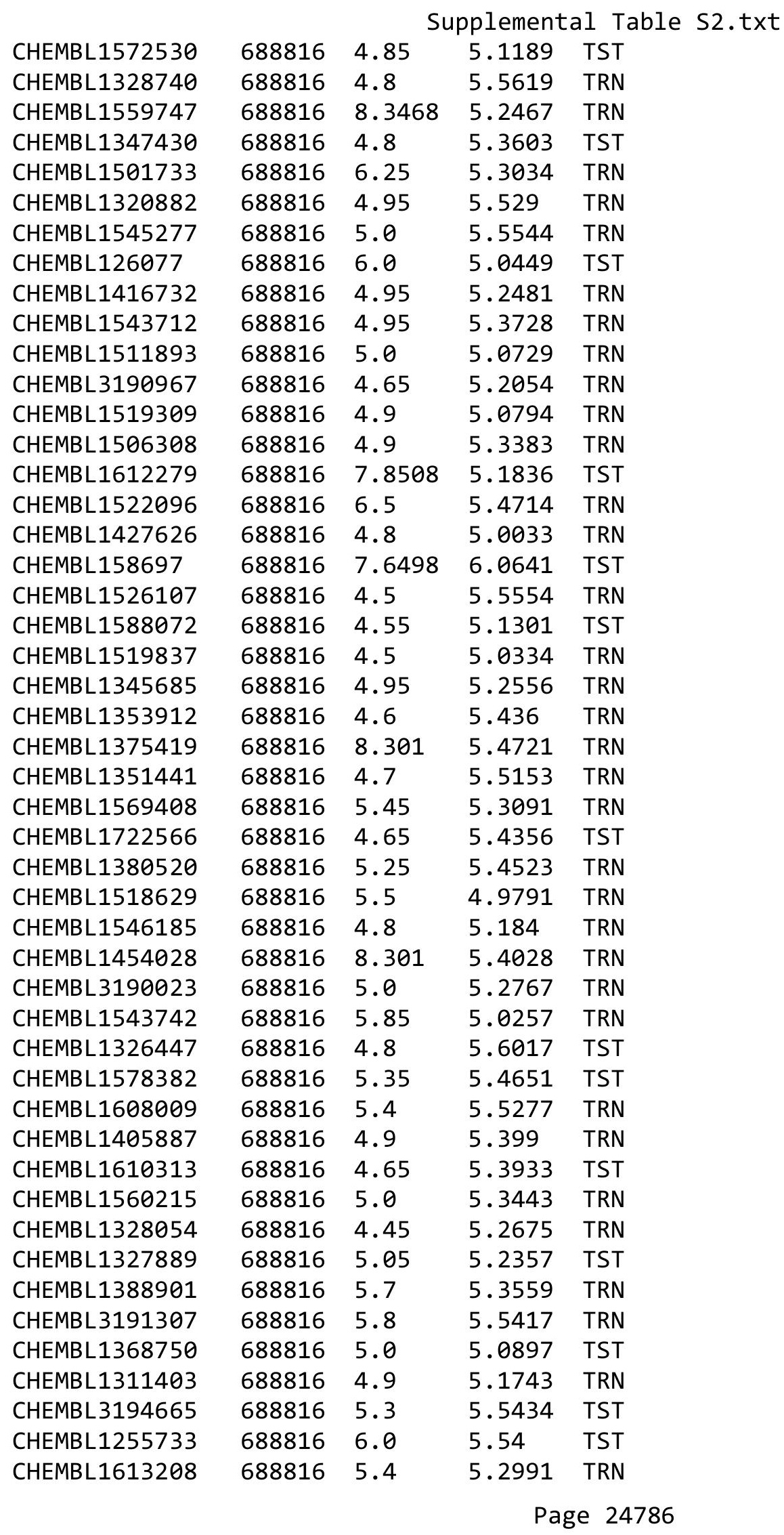




\begin{tabular}{|c|c|c|c|c|c|}
\hline \multicolumn{6}{|c|}{ Supplemental Table S2.txt } \\
\hline CHEMBL1427391 & 688816 & 4.85 & 5.2528 & TRN & \\
\hline CHEMBL1486203 & 688816 & 4.95 & 5.2511 & TRN & \\
\hline CHEMBL1587416 & 688816 & 5.35 & 5.2288 & TRN & \\
\hline CHEMBL 262347 & 688816 & 4.7 & 4.9701 & TRN & \\
\hline CHEMBL1585277 & 688816 & 4.85 & 5.1322 & TST & \\
\hline CHEMBL1571426 & 688816 & 4.85 & 5.3683 & TRN & \\
\hline CHEMBL1477697 & 688816 & 4.9 & 5.0291 & TRN & \\
\hline CHEMBL1301342 & 688816 & 5.85 & 5.6649 & TRN & \\
\hline CHEMBL1320376 & 688816 & 4.6 & 5.2128 & TST & \\
\hline CHEMBL3191469 & 688816 & 5.7 & 5.2565 & TST & \\
\hline CHEMBL 3212188 & 688816 & 4.6 & 5.1482 & TRN & \\
\hline CHEMBL1528533 & 688816 & 4.85 & 5.3317 & TRN & \\
\hline CHEMBL1514379 & 688816 & 4.45 & 5.25799 & 9999999999 & TRN \\
\hline CHEMBL1463088 & 688816 & 5.4 & 5.5202 & TST & \\
\hline CHEMBL1565189 & 688816 & 4.9 & 5.2588 & TST & \\
\hline CHEMBL1401034 & 688816 & 5.0 & 5.1449 & TRN & \\
\hline CHEMBL1509536 & 688816 & 6.8499 & 5.3974 & TRN & \\
\hline CHEMBL1613591 & 688816 & 4.85 & 5.3717 & TST & \\
\hline CHEMBL1390366 & 688816 & 4.45 & 5.1244 & TRN & \\
\hline CHEMBL1451037 & 688816 & 5.25 & 5.329 & TRN & \\
\hline CHEMBL1610481 & 688816 & 7.15 & 5.2985 & TST & \\
\hline CHEMBL1479168 & 688816 & 4.95 & 5.0747 & TRN & \\
\hline CHEMBL1569267 & 688816 & 4.55 & 5.2151 & TRN & \\
\hline CHEMBL1562706 & 688816 & 4.7 & 4.9569 & TST & \\
\hline CHEMBL1475166 & 688816 & 4.85 & 5.4773 & TST & \\
\hline CHEMBL1429336 & 688816 & 4.95 & 5.0748 & TRN & \\
\hline CHEMBL1457111 & 688816 & 5.6 & 5.2667 & TRN & \\
\hline CHEMBL1310884 & 688816 & 4.55 & 5.352 & TRN & \\
\hline CHEMBL1328106 & 688816 & 4.45 & 5.0026 & TRN & \\
\hline CHEMBL1451915 & 688816 & 4.85 & 5.3701 & TRN & \\
\hline CHEMBL1538406 & 688816 & 4.65 & 5.5518 & TST & \\
\hline CHEMBL1604690 & 688816 & 4.6 & 4.7987 & TRN & \\
\hline CHEMBL1524033 & 688816 & 5.15 & 5.2222 & TRN & \\
\hline CHEMBL1545927 & 688816 & 4.85 & 5.2363 & TRN & \\
\hline CHEMBL1479567 & 688816 & 4.95 & 5.1367 & TRN & \\
\hline CHEMBL1346079 & 688816 & 4.65 & 5.0932 & TRN & \\
\hline CHEMBL1577404 & 688816 & 5.1 & 5.1706 & TRN & \\
\hline CHEMBL1497825 & 688816 & 4.45 & 5.5165 & TRN & \\
\hline CHEMBL1332355 & 688816 & 5.85 & 5.3978 & TRN & \\
\hline CHEMBL1345199 & 688816 & 8.4949 & 5.0161 & TRN & \\
\hline CHEMBL1983104 & 688816 & 4.85 & 5.0187 & TRN & \\
\hline CHEMBL1493754 & 688816 & 5.25 & 5.4394 & TRN & \\
\hline CHEMBL1326090 & 688816 & 5.25 & 5.117 & TRN & \\
\hline CHEMBL1478350 & 688816 & 4.95 & 4.782 & TRN & \\
\hline CHEMBL334707 & 688816 & 4.65 & 5.1822 & TRN & \\
\hline CHEMBL1430719 & 688816 & 4.95 & 5.2747 & TRN & \\
\hline CHEMBL1350685 & 688816 & 6.6499 & 5.2231 & TRN & \\
\hline CHEMBL1471415 & 688816 & 5.5 & 5.3626 & TRN & \\
\hline
\end{tabular}




\begin{tabular}{|c|c|c|c|c|c|}
\hline \multicolumn{6}{|c|}{ Supplemental Table S2.txt } \\
\hline CHEMBL1449968 & 688816 & 4.75 & 5.0345 & TRN & \\
\hline CHEMBL1545169 & 688816 & 5.2 & 5.3271 & TST & \\
\hline CHEMBL1361859 & 688816 & 4.95 & 5.0652 & TRN & \\
\hline CHEMBL1530543 & 688816 & 5.4 & 5.2458 & TRN & \\
\hline CHEMBL1588864 & 688816 & 5.25 & 5.4936 & TRN & \\
\hline CHEMBL1569394 & 688816 & 5.2 & 4.9485 & TRN & \\
\hline CHEMBL1599691 & 688816 & 6.5501 & 5.6703 & TRN & \\
\hline CHEMBL1450815 & 688816 & 6.1 & 5.9555 & TST & \\
\hline CHEMBL1421463 & 688816 & 6.5 & 5.1178 & TST & \\
\hline CHEMBL1353319 & 688816 & 4.9 & 5.409 & TST & \\
\hline CHEMBL1572445 & 688816 & 4.9 & 5.0158 & TRN & \\
\hline CHEMBL1534862 & 688816 & 4.5 & 5.3484 & TRN & \\
\hline CHEMBL 3198633 & 688816 & 5.55 & 5.1203 & TRN & \\
\hline CHEMBL1418016 & 688816 & 7.5003 & 5.5044 & TST & \\
\hline CHEMBL1582739 & 688816 & 4.75 & 5.1923 & TRN & \\
\hline CHEMBL1366816 & 688816 & 5.2 & 5.2615 & TRN & \\
\hline CHEMBL1562025 & 688816 & 5.65 & 5.1108 & TRN & \\
\hline CHEMBL3195749 & 688816 & 4.45 & 5.3331 & TRN & \\
\hline CHEMBL1536647 & 688816 & 5.0 & 5.22 & TRN & \\
\hline CHEMBL1507967 & 688816 & 5.0 & 5.2357 & TRN & \\
\hline CHEMBL1405899 & 688816 & 4.9 & 5.2846 & TRN & \\
\hline CHEMBL1468329 & 688816 & 4.85 & 5.1325 & TRN & \\
\hline CHEMBL1408206 & 688816 & 5.15 & 5.5171 & TRN & \\
\hline CHEMBL 3194782 & 688816 & 4.45 & 5.23600 & 0000000001 & TRN \\
\hline CHEMBL1460214 & 688816 & 6.2 & 5.5901 & TST & \\
\hline CHEMBL1567133 & 688816 & 4.45 & 5.9613 & TRN & \\
\hline CHEMBL3210853 & 688816 & 6.6499 & 5.1839 & TRN & \\
\hline CHEMBL1485587 & 688816 & 4.45 & 5.1716 & TST & \\
\hline CHEMBL1535233 & 688816 & 4.95 & 5.5398 & TRN & \\
\hline CHEMBL1418105 & 688816 & 4.45 & 5.3659 & TST & \\
\hline CHEMBL1453086 & 688816 & 4.4 & 4.8966 & TRN & \\
\hline CHEMBL1594395 & 688816 & 4.8 & 5.1188 & TRN & \\
\hline CHEMBL1492849 & 688816 & 7.3497 & 5.5134 & TST & \\
\hline CHEMBL 3190400 & 688816 & 5.15 & 5.6695 & TRN & \\
\hline CHEMBL1500683 & 688816 & 5.3 & 5.2223 & TST & \\
\hline CHEMBL1537615 & 688816 & 4.95 & 5.1437 & TRN & \\
\hline CHEMBL1338622 & 688816 & 5.5 & 5.3912 & TST & \\
\hline CHEMBL1452391 & 688816 & 4.75 & 5.1725 & TRN & \\
\hline CHEMBL1460642 & 688816 & 4.95 & 5.2799 & TST & \\
\hline CHEMBL1582440 & 688816 & 4.8 & 5.2509 & TST & \\
\hline CHEMBL1412289 & 688816 & 4.45 & 5.1933 & TRN & \\
\hline CHEMBL1309603 & 688816 & 4.8 & 5.0129 & TST & \\
\hline CHEMBL1507513 & 688816 & 4.9 & 5.3815 & TRN & \\
\hline CHEMBL1541111 & 688816 & 4.95 & 5.7396 & TST & \\
\hline CHEMBL1302071 & 688816 & 4.9 & 4.6913 & TRN & \\
\hline CHEMBL1314978 & 688816 & 5.5 & 5.2426 & TRN & \\
\hline CHEMBL1529330 & 688816 & 4.9 & 5.2445 & TRN & \\
\hline CHEMBL1325627 & 688816 & 4.95 & 5.1033 & TRN & \\
\hline
\end{tabular}




\begin{tabular}{|c|c|c|c|c|c|}
\hline \multicolumn{6}{|c|}{ Supplemental Table S2.txt } \\
\hline CHEMBL1500924 & 688816 & 4.45 & 5.0795 & TST & \\
\hline CHEMBL1322589 & 688816 & 4.9 & 4.7864 & TRN & \\
\hline CHEMBL1500420 & 688816 & 4.9 & 5.0978 & TST & \\
\hline CHEMBL1454807 & 688816 & 4.95 & 5.2859 & TRN & \\
\hline CHEMBL1396826 & 688816 & 4.6 & 4.5615 & TRN & \\
\hline CHEMBL3199587 & 688816 & 5.05 & 5.5011 & TST & \\
\hline CHEMBL1458275 & 688816 & 4.85 & 5.504 & TST & \\
\hline CHEMBL1411820 & 688816 & 4.7 & 4.9228 & TRN & \\
\hline CHEMBL1359581 & 688816 & 4.95 & 5.3425 & TST & \\
\hline CHEMBL1376248 & 688816 & 4.85 & 5.1716 & TST & \\
\hline CHEMBL1509467 & 688816 & 5.15 & 5.4742 & TRN & \\
\hline CHEMBL1369593 & 688816 & 4.45 & 4.734 & TRN & \\
\hline CHEMBL1497843 & 688816 & 4.45 & 5.2543 & TRN & \\
\hline CHEMBL1465172 & 688816 & 4.8 & 5.1598 & TRN & \\
\hline CHEMBL1462686 & 688816 & 4.85 & 5.3596 & TST & \\
\hline CHEMBL1598664 & 688816 & 4.45 & 5.2252 & TRN & \\
\hline CHEMBL1380741 & 688816 & 5.25 & 5.2139 & TRN & \\
\hline CHEMBL1547589 & 688816 & 4.45 & 5.0266 & TRN & \\
\hline CHEMBL 3210521 & 688816 & 8.301 & 5.6216 & TRN & \\
\hline CHEMBL1611604 & 688816 & 5.25 & 5.4661 & TRN & \\
\hline CHEMBL3199431 & 688816 & 4.45 & 5.0754 & TRN & \\
\hline CHEMBL1302696 & 688816 & 4.85 & 5.0201 & TRN & \\
\hline CHEMBL1538442 & 688816 & 4.95 & 5.1482 & TRN & \\
\hline CHEMBL1448477 & 688816 & 4.75 & 5.3803 & TRN & \\
\hline CHEMBL1544377 & 688816 & 4.95 & 5.25200 & 0000000001 & TRN \\
\hline CHEMBL1556998 & 688816 & 4.8 & 5.3833 & TRN & \\
\hline CHEMBL1541779 & 688816 & 5.0 & 5.3951 & TRN & \\
\hline CHEMBL1343700 & 688816 & 5.9 & 5.2404 & TRN & \\
\hline CHEMBL1469136 & 688816 & 4.9 & 5.2813 & TRN & \\
\hline CHEMBL1401556 & 688816 & 4.95 & 5.2339 & TRN & \\
\hline CHEMBL3209779 & 688816 & 4.9 & 4.89 & TRN & \\
\hline CHEMBL1576663 & 688816 & 4.8 & 5.3687 & TRN & \\
\hline CHEMBL1580124 & 688816 & 4.95 & 5.2262 & TRN & \\
\hline CHEMBL1594527 & 688816 & 4.45 & 5.3717 & TST & \\
\hline CHEMBL1601628 & 688816 & 4.9 & 4.9469 & TRN & \\
\hline CHEMBL1529873 & 688816 & 4.85 & 5.1295 & TRN & \\
\hline CHEMBL1418959 & 688816 & 4.7 & 5.126 & TRN & \\
\hline CHEMBL1389481 & 688816 & 7.6498 & 5.3241 & TRN & \\
\hline CHEMBL1582363 & 688816 & 4.45 & 5.1578 & TRN & \\
\hline CHEMBL1324975 & 688816 & 5.15 & 5.53100 & 2000000001 & TST \\
\hline CHEMBL1370573 & 688816 & 5.0 & 5.3742 & TRN & \\
\hline CHEMBL1488499 & 688816 & 4.85 & 5.1748 & TRN & \\
\hline CHEMBL1586991 & 688816 & 4.9 & 5.3428 & TST & \\
\hline CHEMBL1599168 & 688816 & 5.25 & 5.1882 & TRN & \\
\hline CHEMBL1478783 & 688816 & 5.45 & 5.1674 & TRN & \\
\hline CHEMBL3212038 & 688816 & 4.9 & 5.2621 & TRN & \\
\hline CHEMBL1604680 & 688816 & 4.8 & 4.9842 & TRN & \\
\hline CHEMBL1353266 & 688816 & 4.85 & 5.4626 & TRN & \\
\hline
\end{tabular}




\begin{tabular}{|c|c|c|c|c|c|}
\hline \multicolumn{6}{|c|}{ Supplemental Table S2.txt } \\
\hline CHEMBL1329161 & 688816 & 4.95 & 5.2226 & TRN & \\
\hline CHEMBL1333619 & 688816 & 4.6 & 5.4472 & TST & \\
\hline CHEMBL1309616 & 688816 & 5.55 & 5.8229 & TRN & \\
\hline CHEMBL1385123 & 688816 & 5.45 & 5.282 & TRN & \\
\hline CHEMBL1328553 & 688816 & 4.8 & 5.1581 & TST & \\
\hline CHEMBL1461698 & 688816 & 5.0 & 5.0153 & TST & \\
\hline CHEMBL1337343 & 688816 & 5.25 & 5.4238 & TRN & \\
\hline CHEMBL1327545 & 688816 & 5.0 & 5.1286 & TRN & \\
\hline CHEMBL1447453 & 688816 & 4.9 & 5.0612 & TRN & \\
\hline CHEMBL1382967 & 688816 & 4.75 & 5.1345 & TRN & \\
\hline CHEMBL1506389 & 688816 & 6.1 & 5.3235 & TST & \\
\hline CHEMBL1527875 & 688816 & 4.8 & 5.0629 & TRN & \\
\hline CHEMBL 294018 & 688816 & 4.75 & 5.5749 & TST & \\
\hline CHEMBL 2000440 & 688816 & 7.5498 & 5.316 & TRN & \\
\hline CHEMBL1603925 & 688816 & 5.1 & 5.17899 & 9999999999 & TRN \\
\hline CHEMBL1516928 & 688816 & 5.05 & 5.1883 & TRN & \\
\hline CHEMBL1457898 & 688816 & 4.95 & 5.1384 & TRN & \\
\hline CHEMBL1520849 & 688816 & 4.9 & 5.0147 & TRN & \\
\hline CHEMBL1592589 & 688816 & 4.45 & 5.0138 & TST & \\
\hline CHEMBL1592352 & 688816 & 5.3 & 5.9253 & TST & \\
\hline CHEMBL1351847 & 688816 & 4.45 & 5.2739 & TST & \\
\hline CHEMBL1406761 & 688816 & 4.45 & 5.1994 & TRN & \\
\hline CHEMBL1612903 & 688816 & 4.45 & 4.9499 & TRN & \\
\hline CHEMBL1500474 & 688816 & 4.9 & 5.3771 & TRN & \\
\hline CHEMBL1342888 & 688816 & 5.3 & 5.3493 & TST & \\
\hline CHEMBL1382854 & 688816 & 4.85 & 5.6587 & TST & \\
\hline CHEMBL1498324 & 688816 & 5.95 & 5.2217 & TRN & \\
\hline CHEMBL1449047 & 688816 & 4.9 & 5.0022 & TRN & \\
\hline CHEMBL1454205 & 688816 & 8.301 & 5.2062 & TRN & \\
\hline CHEMBL 1454840 & 688816 & 6.25 & 5.4436 & TRN & \\
\hline CHEMBL1347466 & 688816 & 4.9 & 4.9919 & TRN & \\
\hline CHEMBL1479041 & 688816 & 4.7 & 5.4169 & TRN & \\
\hline CHEMBL1173823 & 688816 & 4.8 & 4.9244 & TRN & \\
\hline CHEMBL1335797 & 688816 & 8.3468 & 5.7333 & TST & \\
\hline CHEMBL1550106 & 688816 & 8.2518 & 5.1808 & TST & \\
\hline CHEMBL1580434 & 688816 & 4.5 & 4.962 & TRN & \\
\hline CHEMBL1372415 & 688816 & 4.95 & 5.0765 & TRN & \\
\hline CHEMBL1421358 & 688816 & 5.1 & 4.931 & TRN & \\
\hline CHEMBL1568018 & 688816 & 4.75 & 5.291 & TRN & \\
\hline CHEMBL521970 & 688816 & 4.45 & 4.8625 & TRN & \\
\hline CHEMBL1431003 & 688816 & 4.45 & 4.9747 & TRN & \\
\hline CHEMBL1472066 & 688816 & 4.95 & 5.4768 & TRN & \\
\hline CHEMBL1511432 & 688816 & 5.0 & 5.3742 & TRN & \\
\hline CHEMBL1453237 & 688816 & 4.8 & 4.699 & TRN & \\
\hline CHEMBL1384857 & 688816 & 4.85 & 5.612 & TRN & \\
\hline CHEMBL1484188 & 688816 & 5.05 & 5.4407 & TRN & \\
\hline CHEMBL1491837 & 688816 & 4.45 & 5.5684 & TRN & \\
\hline CHEMBL1311047 & 688816 & 4.95 & 5.3863 & TRN & \\
\hline
\end{tabular}




\begin{tabular}{|c|c|c|c|c|}
\hline \multicolumn{5}{|c|}{ Supplemental Table S2.txt } \\
\hline CHEMBL1581309 & 688816 & 4.95 & 5.2558 & TST \\
\hline CHEMBL1336651 & 688816 & 4.7 & 4.902 & TRN \\
\hline CHEMBL1558471 & 688816 & 4.5 & 5.0914 & TST \\
\hline CHEMBL1568709 & 688816 & 6.7001 & 5.6125 & TRN \\
\hline CHEMBL1583894 & 688816 & 5.6 & 5.1956 & TST \\
\hline CHEMBL1600689 & 688816 & 4.9 & 5.1725 & TRN \\
\hline CHEMBL1386869 & 688816 & 4.7 & 5.5498 & TST \\
\hline CHEMBL1380081 & 688816 & 6.2 & 5.6282 & TRN \\
\hline CHEMBL1451103 & 688816 & 5.05 & 5.3068 & TRN \\
\hline CHEMBL1384800 & 688816 & 4.5 & 5.495 & TRN \\
\hline CHEMBL1325945 & 688816 & 4.45 & 5.3211 & TRN \\
\hline CHEMBL1501014 & 688816 & 5.5 & 5.3019 & TRN \\
\hline CHEMBL1405190 & 688816 & 4.8 & 5.2534 & TST \\
\hline CHEMBL3197709 & 688816 & 5.35 & 5.1768 & TRN \\
\hline CHEMBL1470330 & 688816 & 5.0 & 5.2123 & TRN \\
\hline CHEMBL3208961 & 688816 & 8.0 & 5.7518 & TST \\
\hline CHEMBL1305077 & 688816 & 4.9 & 5.2399 & TST \\
\hline CHEMBL1536977 & 688816 & 4.85 & 5.3287 & TST \\
\hline CHEMBL1392034 & 688816 & 8.301 & 6.0253 & TRN \\
\hline CHEMBL1318850 & 688816 & 5.4 & 5.2817 & TRN \\
\hline CHEMBL589458 & 688816 & 4.95 & 5.6676 & TRN \\
\hline CHEMBL3190778 & 688816 & 6.05 & 5.4382 & TST \\
\hline CHEMBL1357429 & 688816 & 5.0 & 5.0098 & TRN \\
\hline CHEMBL1342568 & 688816 & 4.85 & 5.3978 & TRN \\
\hline CHEMBL1988679 & 688816 & 5.0 & 5.205 & TRN \\
\hline CHEMBL1356913 & 688816 & 4.65 & 5.0853 & TRN \\
\hline CHEMBL3195397 & 688816 & 4.95 & 5.5604 & TRN \\
\hline CHEMBL1490470 & 688816 & 5.4 & 5.2027 & TRN \\
\hline CHEMBL1307328 & 688816 & 4.95 & 5.1101 & TRN \\
\hline CHEMBL1564081 & 688816 & 5.95 & 5.2813 & TST \\
\hline CHEMBL1403787 & 688816 & 5.55 & 5.1831 & TRN \\
\hline CHEMBL1312037 & 688816 & 4.8 & 5.2929 & TST \\
\hline CHEMBL3199841 & 688816 & 4.75 & 5.37 & TRN \\
\hline CHEMBL1549800 & 688816 & 5.0 & 5.1676 & TRN \\
\hline CHEMBL1455137 & 688816 & 4.65 & 5.3051 & TRN \\
\hline CHEMBL1461835 & 688816 & 5.2 & 5.505 & TRN \\
\hline CHEMBL1507611 & 688816 & 4.8 & 5.4308 & TRN \\
\hline CHEMBL1542217 & 688816 & 5.6 & 5.5257 & TST \\
\hline CHEMBL1964439 & 688816 & 5.3 & 5.1132 & TRN \\
\hline CHEMBL1611029 & 688816 & 4.8 & 6.1334 & TST \\
\hline CHEMBL1419839 & 688816 & 4.95 & 5.0169 & TRN \\
\hline CHEMBL1304520 & 688816 & 6.9 & 5.5568 & TRN \\
\hline CHEMBL1404553 & 688816 & 7.0501 & 5.5878 & TRN \\
\hline CHEMBL1408173 & 688816 & 5.25 & 5.2666 & TRN \\
\hline CHEMBL1395838 & 688816 & 4.95 & 5.1063 & TRN \\
\hline CHEMBL1452653 & 688816 & 5.95 & 5.4929 & TST \\
\hline CHEMBL1972651 & 688816 & 4.75 & 5.3217 & TRN \\
\hline CHEMBL1484577 & 688816 & 5.45 & 5.4804 & TST \\
\hline
\end{tabular}




\begin{tabular}{|c|c|c|c|c|c|}
\hline \multicolumn{6}{|c|}{ Supplemental Table S2.txt } \\
\hline CHEMBL1319064 & 688816 & 5.55 & 5.2743 & TRN & \\
\hline CHEMBL1359059 & 688816 & 4.7 & 5.051 & TST & \\
\hline CHEMBL1559605 & 688816 & 4.9 & 5.0607 & TRN & \\
\hline CHEMBL1332602 & 688816 & 5.9 & 5.3034 & TRN & \\
\hline CHEMBL1488133 & 688816 & 5.1 & 5.24700 & 0000000001 & TRN \\
\hline CHEMBL1499216 & 688816 & 5.0 & 5.311 & TRN & \\
\hline CHEMBL1504225 & 688816 & 4.95 & 5.4818 & TRN & \\
\hline CHEMBL1383735 & 688816 & 5.05 & 5.0041 & TRN & \\
\hline CHEMBL1312754 & 688816 & 6.3 & 5.3825 & TRN & \\
\hline CHEMBL1345140 & 688816 & 4.75 & 4.9175 & TRN & \\
\hline CHEMBL1426754 & 688816 & 4.9 & 5.0658 & TST & \\
\hline CHEMBL1306638 & 688816 & 6.2 & 5.2015 & TRN & \\
\hline CHEMBL3199242 & 688816 & 4.95 & 5.348 & TRN & \\
\hline CHEMBL1430893 & 688816 & 4.75 & 5.1106 & TRN & \\
\hline CHEMBL1480275 & 688816 & 6.1 & 4.9241 & TST & \\
\hline CHEMBL1558739 & 688816 & 4.45 & 5.2677 & TRN & \\
\hline CHEMBL1421135 & 688816 & 4.95 & 5.2039 & TRN & \\
\hline CHEMBL583378 & 688816 & 5.2 & 5.5846 & TRN & \\
\hline CHEMBL1517348 & 688816 & 5.5 & 5.3561 & TRN & \\
\hline CHEMBL1213834 & 688816 & 4.95 & 5.3642 & TRN & \\
\hline CHEMBL1581028 & 688816 & 4.9 & 5.4901 & TRN & \\
\hline CHEMBL1424024 & 688816 & 5.0 & 4.9314 & TRN & \\
\hline CHEMBL1554658 & 688816 & 4.65 & 5.1012 & TRN & \\
\hline CHEMBL1588042 & 688816 & 4.9 & 5.113 & TRN & \\
\hline CHEMBL1467524 & 688816 & 5.35 & 5.2849 & TRN & \\
\hline CHEMBL1381226 & 688816 & 5.2 & 5.6475 & TRN & \\
\hline CHEMBL1481162 & 688816 & 5.6 & 5.2193 & TRN & \\
\hline CHEMBL1502170 & 688816 & 6.1 & 5.3341 & TRN & \\
\hline CHEMBL411481 & 688816 & 5.0 & 4.9972 & TST & \\
\hline CHEMBL1562190 & 688816 & 4.45 & 5.6152 & TRN & \\
\hline CHEMBL1570531 & 688816 & 4.6 & 5.7847 & TRN & \\
\hline CHEMBL1568529 & 688816 & 5.25 & 5.3541 & TRN & \\
\hline CHEMBL1432837 & 688816 & 4.85 & 5.224 & TST & \\
\hline CHEMBL1345321 & 688816 & 4.95 & 5.0984 & TRN & \\
\hline CHEMBL1594333 & 688816 & 5.0 & 5.08 & TRN & \\
\hline CHEMBL1608935 & 688816 & 4.45 & 5.1614 & TRN & \\
\hline CHEMBL1557200 & 688816 & 4.8 & 4.7823 & TRN & \\
\hline CHEMBL1419801 & 688816 & 4.6 & 5.0934 & TRN & \\
\hline CHEMBL1469287 & 688816 & 5.2 & 5.1988 & TRN & \\
\hline CHEMBL1410784 & 688816 & 8.3468 & 5.1066 & TRN & \\
\hline CHEMBL1518885 & 688816 & 8.6021 & 5.21899 & 9999999999 & TRN \\
\hline CHEMBL1487713 & 688816 & 4.65 & 4.9482 & TRN & \\
\hline CHEMBL1383334 & 688816 & 5.15 & 5.4406 & TRN & \\
\hline CHEMBL1437037 & 688816 & 4.45 & 5.2382 & TRN & \\
\hline CHEMBL1329883 & 688816 & 7.3497 & 5.2117 & TRN & \\
\hline CHEMBL1459473 & 688816 & 5.0 & 4.6949 & TRN & \\
\hline CHEMBL1316654 & 688816 & 4.75 & 4.8617 & TRN & \\
\hline CHEMBL3196364 & 688816 & 5.6 & 5.2662 & TRN & \\
\hline
\end{tabular}




\begin{tabular}{|c|c|c|c|c|c|}
\hline \multicolumn{6}{|c|}{ Supplemental Table S2.txt } \\
\hline CHEMBL1372016 & 688816 & 7.6498 & 5.3967 & TRN & \\
\hline CHEMBL1448382 & 688816 & 5.0 & 5.1787 & TRN & \\
\hline CHEMBL1465501 & 688816 & 5.25 & 5.5937 & TST & \\
\hline CHEMBL1341145 & 688816 & 4.95 & 5.66 & TRN & \\
\hline CHEMBL3192203 & 688816 & 4.6 & 5.37700 & 0000000001 & TRN \\
\hline CHEMBL1519138 & 688816 & 5.35 & 5.6912 & TST & \\
\hline CHEMBL 2003688 & 688816 & 4.45 & 5.0186 & TRN & \\
\hline CHEMBL1352195 & 688816 & 4.95 & 5.505 & TRN & \\
\hline CHEMBL1573586 & 688816 & 6.25 & 5.2914 & TST & \\
\hline CHEMBL1516972 & 688816 & 5.5 & 5.1853 & TRN & \\
\hline CHEMBL1331120 & 688816 & 8.0506 & 5.1063 & TRN & \\
\hline CHEMBL3189237 & 688816 & 4.75 & 4.9468 & TRN & \\
\hline CHEMBL1341159 & 688816 & 8.0 & 5.2207 & TST & \\
\hline CHEMBL1472393 & 688816 & 5.35 & 5.0405 & TRN & \\
\hline CHEMBL1447768 & 688816 & 5.0 & 4.9904 & TRN & \\
\hline CHEMBL1546347 & 688816 & 5.95 & 5.3994 & TRN & \\
\hline CHEMBL1392242 & 688816 & 5.3 & 5.6125 & TRN & \\
\hline CHEMBL1523465 & 688816 & 5.3 & 5.3565 & TRN & \\
\hline CHEMBL1413136 & 688816 & 4.6 & 5.42 & TRN & \\
\hline CHEMBL1431035 & 688816 & 4.8 & 5.501 & TRN & \\
\hline CHEMBL1404335 & 688816 & 8.4949 & 5.1446 & TST & \\
\hline CHEMBL1381253 & 688816 & 6.45 & 5.0689 & TRN & \\
\hline CHEMBL1508227 & 688816 & 6.3 & 5.3089 & TRN & \\
\hline CHEMBL1492020 & 688816 & 6.7001 & 5.0715 & TRN & \\
\hline CHEMBL1362843 & 688816 & 4.45 & 5.4261 & TRN & \\
\hline CHEMBL1416660 & 688816 & 5.0 & 4.9893 & TRN & \\
\hline CHEMBL1527170 & 688816 & 4.45 & 5.0845 & TRN & \\
\hline CHEMBL 2006390 & 688816 & 5.0 & 5.1323 & TRN & \\
\hline CHEMBL1373361 & 688816 & 4.45 & 5.0003 & TST & \\
\hline CHEMBL1430916 & 688816 & 6.8499 & 5.3283 & TST & \\
\hline CHEMBL1442280 & 688816 & 5.3 & 4.9519 & TRN & \\
\hline CHEMBL1404519 & 688816 & 5.0 & 5.3768 & TST & \\
\hline CHEMBL1488377 & 688816 & 5.45 & 4.8954 & TRN & \\
\hline CHEMBL1534523 & 688816 & 4.45 & 5.2151 & TST & \\
\hline CHEMBL1376494 & 688816 & 6.6499 & 4.8651 & TRN & \\
\hline CHEMBL1452255 & 688816 & 5.1 & 5.6751 & TRN & \\
\hline CHEMBL1453320 & 688816 & 5.5 & 4.9545 & TRN & \\
\hline CHEMBL1532487 & 688816 & 5.65 & 5.6491 & TRN & \\
\hline CHEMBL3195172 & 688816 & 5.5 & 5.2962 & TRN & \\
\hline CHEMBL1573242 & 688816 & 4.45 & 5.3302 & TRN & \\
\hline CHEMBL3197903 & 688816 & 4.9 & 5.1337 & TST & \\
\hline CHEMBL1483828 & 688816 & 8.7959 & 5.819 & TRN & \\
\hline CHEMBL1429395 & 688816 & 6.1 & 5.3618 & TST & \\
\hline CHEMBL1409552 & 688816 & 4.45 & 5.5616 & TRN & \\
\hline CHEMBL1375759 & 688816 & 4.7 & 5.3916 & TRN & \\
\hline CHEMBL1578871 & 688816 & 4.85 & 5.23799 & 99999999995 & TRN \\
\hline CHEMBL1353317 & 688816 & 4.9 & 4.9751 & TRN & \\
\hline CHEMBL1330607 & 688816 & 8.301 & 5.2986 & TRN & \\
\hline
\end{tabular}




\begin{tabular}{|c|c|c|c|c|c|}
\hline \multicolumn{6}{|c|}{ Supplemental Table S2.txt } \\
\hline CHEMBL1387571 & 688816 & 4.45 & 5.2336 & TRN & \\
\hline CHEMBL1461487 & 688816 & 5.1 & 5.2712 & TRN & \\
\hline CHEMBL1408740 & 688816 & 5.3 & 5.0523 & TRN & \\
\hline CHEMBL1461545 & 688816 & 5.7 & 5.942 & TST & \\
\hline CHEMBL1330934 & 688816 & 4.95 & 4.7743 & TRN & \\
\hline CHEMBL1543409 & 688816 & 6.5 & 5.4384 & TRN & \\
\hline CHEMBL1579882 & 688816 & 8.3468 & 5.1279 & TST & \\
\hline CHEMBL1338815 & 688816 & 5.0 & 5.2186 & TRN & \\
\hline CHEMBL1534870 & 688816 & 4.95 & 5.1423 & TRN & \\
\hline CHEMBL1348630 & 688816 & 4.95 & 5.1769 & TRN & \\
\hline CHEMBL504598 & 688816 & 5.35 & 5.0671 & TRN & \\
\hline CHEMBL1572423 & 688816 & 4.6 & 5.3441 & TRN & \\
\hline CHEMBL3194568 & 688816 & 6.05 & 5.392 & TRN & \\
\hline CHEMBL 3213883 & 688816 & 4.45 & 5.4438 & TST & \\
\hline CHEMBL1486831 & 688816 & 4.8 & 5.0309 & TST & \\
\hline CHEMBL1388370 & 688816 & 5.3 & 5.0847 & TST & \\
\hline CHEMBL1370769 & 688816 & 5.8 & 4.6695 & TRN & \\
\hline CHEMBL 3198641 & 688816 & 4.45 & 5.13399 & 99999999995 & TRN \\
\hline CHEMBL1431557 & 688816 & 8.0 & 5.5518 & TST & \\
\hline CHEMBL1601181 & 688816 & 5.4 & 5.102 & TRN & \\
\hline CHEMBL1570624 & 688816 & 5.9 & 5.7477 & TST & \\
\hline CHEMBL3189519 & 688816 & 5.45 & 4.952 & TRN & \\
\hline CHEMBL1386939 & 688816 & 4.5 & 5.074 & TST & \\
\hline CHEMBL1528079 & 688816 & 5.6 & 5.2905 & TRN & \\
\hline CHEMBL1397156 & 688816 & 4.9 & 5.1519 & TRN & \\
\hline CHEMBL1492961 & 688816 & 4.8 & 4.9073 & TRN & \\
\hline CHEMBL1340541 & 688816 & 5.55 & 5.3142 & TRN & \\
\hline CHEMBL1346516 & 688816 & 5.55 & 4.9645 & TRN & \\
\hline CHEMBL1548953 & 688816 & 4.9 & 5.6233 & TRN & \\
\hline CHEMBL1571647 & 688816 & 5.75 & 4.9306 & TRN & \\
\hline CHEMBL1381047 & 688816 & 4.9 & 4.9589 & TRN & \\
\hline CHEMBL1331313 & 688816 & 4.9 & 4.9619 & TRN & \\
\hline CHEMBL1541289 & 688816 & 7.8508 & 5.4834 & TRN & \\
\hline CHEMBL1504859 & 688816 & 5.45 & 5.1792 & TST & \\
\hline CHEMBL1465085 & 688816 & 5.3 & 5.1721 & TRN & \\
\hline CHEMBL1564641 & 688816 & 5.05 & 4.9737 & TRN & \\
\hline CHEMBL1412672 & 688816 & 4.6 & 5.0621 & TRN & \\
\hline CHEMBL1502279 & 688816 & 5.0 & 5.4865 & TRN & \\
\hline CHEMBL1604546 & 688816 & 4.45 & 5.3452 & TST & \\
\hline CHEMBL1552795 & 688816 & 4.45 & 5.1463 & TRN & \\
\hline CHEMBL1333650 & 688816 & 4.9 & 5.2114 & TRN & \\
\hline CHEMBL1601979 & 688816 & 4.9 & 5.1975 & TRN & \\
\hline CHEMBL1473600 & 688816 & 5.9 & 5.4648 & TST & \\
\hline CHEMBL1391644 & 688816 & 4.85 & 5.3587 & TRN & \\
\hline CHEMBL1594961 & 688816 & 6.4 & 5.3713 & TRN & \\
\hline CHEMBL1393045 & 688816 & 5.25 & 5.2989 & TRN & \\
\hline CHEMBL573524 & 688816 & 4.65 & 5.3181 & TRN & \\
\hline CHEMBL1371067 & 688816 & 6.6499 & 4.934 & TRN & \\
\hline
\end{tabular}




\begin{tabular}{|c|c|c|c|c|}
\hline \multicolumn{5}{|c|}{ Supplemental Table S2.txt } \\
\hline CHEMBL1348808 & 688816 & 5.0 & 5.3395 & TRN \\
\hline CHEMBL1331007 & 688816 & 4.95 & 5.1552 & TRN \\
\hline CHEMBL1531764 & 688816 & 4.6 & 5.1063 & TST \\
\hline CHEMBL1464102 & 688816 & 4.65 & 5.3397 & TRN \\
\hline CHEMBL1548147 & 688816 & 7.4498 & 5.058 & TRN \\
\hline CHEMBL1492846 & 688816 & 4.95 & 5.1287 & TRN \\
\hline CHEMBL1583880 & 688816 & 7.1002 & 5.4239 & TST \\
\hline CHEMBL1495763 & 688816 & 4.6 & 5.4023 & TST \\
\hline CHEMBL1345327 & 688816 & 4.95 & 5.5181 & TRN \\
\hline CHEMBL1354307 & 688816 & 5.15 & 5.2826 & TRN \\
\hline CHEMBL1412669 & 688816 & 4.85 & 5.0693 & TRN \\
\hline CHEMBL1502049 & 688816 & 4.45 & 5.0205 & TRN \\
\hline CHEMBL1378644 & 688816 & 4.45 & 4.8417 & TRN \\
\hline CHEMBL1362510 & 688816 & 6.4 & 5.5719 & TRN \\
\hline CHEMBL3199730 & 688816 & 4.65 & 5.2143 & TRN \\
\hline CHEMBL1550687 & 688816 & 5.0 & 5.0113 & TRN \\
\hline CHEMBL1451001 & 688816 & 6.5501 & 5.6227 & TST \\
\hline CHEMBL1565613 & 688816 & 4.65 & 5.29 & TRN \\
\hline CHEMBL1539863 & 688816 & 4.95 & 5.5832 & TRN \\
\hline CHEMBL1543347 & 688816 & 4.45 & 5.215 & TST \\
\hline CHEMBL1328778 & 688816 & 4.65 & 5.0012 & TRN \\
\hline CHEMBL1342119 & 688816 & 4.95 & 5.1999 & TRN \\
\hline CHEMBL 297508 & 688816 & 4.6 & 5.1498 & TST \\
\hline CHEMBL1599566 & 688816 & 4.75 & 5.4103 & TRN \\
\hline CHEMBL1560655 & 688816 & 4.75 & 5.37299 & 9999999999 \\
\hline CHEMBL1579245 & 688816 & 4.95 & 5.3421 & TRN \\
\hline CHEMBL1422210 & 688816 & 4.85 & 5.1872 & TRN \\
\hline CHEMBL1607290 & 688816 & 5.55 & 5.0432 & TRN \\
\hline CHEMBL3211458 & 688816 & 4.65 & 5.171 & TST \\
\hline CHEMBL1523565 & 688816 & 4.45 & 4.7753 & TRN \\
\hline CHEMBL1521540 & 688816 & 4.45 & 5.0406 & TRN \\
\hline CHEMBL3195483 & 688816 & 4.8 & 5.1612 & TRN \\
\hline CHEMBL570400 & 688816 & 4.45 & 4.801 & TRN \\
\hline CHEMBL1454894 & 688816 & 5.5 & 5.2611 & TRN \\
\hline CHEMBL1596737 & 688816 & 5.5 & 5.3104 & TRN \\
\hline CHEMBL1301787 & 688816 & 7.3002 & 5.8978 & TRN \\
\hline CHEMBL1477947 & 688816 & 5.1 & 5.7881 & TRN \\
\hline CHEMBL1539706 & 688816 & 4.9 & 5.7629 & TRN \\
\hline CHEMBL1570871 & 688816 & 4.45 & 4.8225 & TST \\
\hline CHEMBL1392570 & 688816 & 5.6 & 5.2987 & TRN \\
\hline CHEMBL3190273 & 688816 & 4.95 & 5.1704 & TST \\
\hline CHEMBL1343080 & 688816 & 4.95 & 5.2137 & TRN \\
\hline CHEMBL1610816 & 688816 & 4.85 & 5.3055 & TRN \\
\hline CHEMBL1449145 & 688816 & 7.5003 & 5.4235 & TST \\
\hline CHEMBL1334238 & 688816 & 5.7 & 5.3198 & TRN \\
\hline CHEMBL1462626 & 688816 & 5.4 & 5.5294 & TST \\
\hline CHEMBL1596185 & 688816 & 7.3002 & 5.6416 & TRN \\
\hline CHEMBL1305870 & 688816 & 7.4498 & 5.2851 & TRN \\
\hline
\end{tabular}




\begin{tabular}{|c|c|c|c|c|c|}
\hline \multicolumn{6}{|c|}{ Supplemental Table S2.txt } \\
\hline CHEMBL1468169 & 688816 & 5.05 & 5.4589 & TRN & \\
\hline CHEMBL1595525 & 688816 & 4.65 & 4.9349 & TST & \\
\hline CHEMBL1465342 & 688816 & 5.05 & 4.96899 & 9999999999 & TRN \\
\hline CHEMBL1438089 & 688816 & 4.7 & 5.8345 & TRN & \\
\hline CHEMBL1361264 & 688816 & 8.4559 & 5.1454 & TST & \\
\hline CHEMBL3209007 & 688816 & 4.85 & 5.3828 & TRN & \\
\hline CHEMBL3212167 & 688816 & 4.75 & 5.1799 & TST & \\
\hline CHEMBL3194980 & 688816 & 6.7501 & 5.3997 & TRN & \\
\hline CHEMBL1331065 & 688816 & 4.95 & 5.0469 & TRN & \\
\hline CHEMBL1551331 & 688816 & 4.85 & 5.2644 & TRN & \\
\hline CHEMBL1366328 & 688816 & 5.55 & 5.3413 & TST & \\
\hline CHEMBL1524443 & 688816 & 4.5 & 5.1065 & TRN & \\
\hline CHEMBL1597549 & 688816 & 4.95 & 5.2414 & TRN & \\
\hline CHEMBL1496363 & 688816 & 5.45 & 5.6287 & TST & \\
\hline CHEMBL1312665 & 688816 & 5.2 & 4.8606 & TRN & \\
\hline CHEMBL1579258 & 688816 & 6.0 & 5.3973 & TRN & \\
\hline CHEMBL1478528 & 688816 & 8.4949 & 5.1467 & TRN & \\
\hline CHEMBL1391435 & 688816 & 5.5 & 5.631 & TRN & \\
\hline CHEMBL1507046 & 688816 & 5.15 & 5.05399 & 9999999999 & TRN \\
\hline CHEMBL3197783 & 688816 & 4.6 & 5.1107 & TRN & \\
\hline CHEMBL1440589 & 688816 & 6.8499 & 5.0341 & TRN & \\
\hline CHEMBL1507898 & 688816 & 4.6 & 5.2425 & TRN & \\
\hline CHEMBL1440097 & 688816 & 5.85 & 5.3208 & TST & \\
\hline CHEMBL1306646 & 688816 & 4.45 & 5.426 & TRN & \\
\hline CHEMBL1479373 & 688816 & 4.8 & 5.3422 & TRN & \\
\hline CHEMBL1442219 & 688816 & 4.95 & 5.145 & TST & \\
\hline CHEMBL1358184 & 688816 & 5.05 & 5.2264 & TRN & \\
\hline CHEMBL1472136 & 688816 & 7.7496 & 5.1001 & TRN & \\
\hline CHEMBL1484824 & 688816 & 5.2 & 5.0187 & TST & \\
\hline CHEMBL3211529 & 688816 & 5.0 & 5.4343 & TRN & \\
\hline CHEMBL1603577 & 688816 & 5.45 & 5.3614 & TRN & \\
\hline CHEMBL1328498 & 688816 & 5.15 & 5.1448 & TRN & \\
\hline CHEMBL1330459 & 688816 & 6.0 & 5.5297 & TST & \\
\hline CHEMBL1310135 & 688816 & 5.3 & 5.5662 & TRN & \\
\hline CHEMBL1379632 & 688816 & 4.95 & 5.3174 & TRN & \\
\hline CHEMBL1488806 & 688816 & 4.85 & 5.4059 & TST & \\
\hline CHEMBL1599392 & 688816 & 7.9508 & 5.3731 & TST & \\
\hline CHEMBL1467291 & 688816 & 5.15 & 4.9771 & TRN & \\
\hline CHEMBL1571628 & 688816 & 4.8 & 5.05699 & 99999999995 & TST \\
\hline CHEMBL1540269 & 688816 & 7.8508 & 5.5295 & TST & \\
\hline CHEMBL1400188 & 688816 & 5.45 & 5.2135 & TST & \\
\hline CHEMBL1300292 & 688816 & 5.45 & 5.1296 & TST & \\
\hline CHEMBL1516825 & 688816 & 7.7496 & 5.5672 & TRN & \\
\hline CHEMBL1575576 & 688816 & 4.8 & 5.016 & TRN & \\
\hline CHEMBL1572280 & 688816 & 5.1 & 5.2411 & TST & \\
\hline CHEMBL1386911 & 688816 & 4.7 & 5.0521 & TRN & \\
\hline CHEMBL1442928 & 688816 & 4.9 & 5.2086 & TRN & \\
\hline CHEMBL1417993 & 688816 & 5.5 & 5.5243 & TRN & \\
\hline
\end{tabular}




\begin{tabular}{|c|c|c|c|c|c|}
\hline \multicolumn{6}{|c|}{ Supplemental Table S2.txt } \\
\hline CHEMBL1528337 & 688816 & 4.8 & 5.1702 & TRN & \\
\hline CHEMBL1393059 & 688816 & 5.1 & 5.2984 & TST & \\
\hline CHEMBL1580359 & 688816 & 4.85 & 5.0992 & TRN & \\
\hline CHEMBL3189397 & 688816 & 4.75 & 4.9933 & TRN & \\
\hline CHEMBL1301717 & 688816 & 4.45 & 5.0261 & TST & \\
\hline CHEMBL1431252 & 688816 & 4.75 & 5.145 & TRN & \\
\hline CHEMBL1528126 & 688816 & 8.3468 & 5.3852 & TST & \\
\hline CHEMBL1405774 & 688816 & 8.2518 & 5.18 & TRN & \\
\hline CHEMBL1516818 & 688816 & 5.0 & 5.6761 & TRN & \\
\hline CHEMBL1471449 & 688816 & 4.9 & 5.4949 & TRN & \\
\hline CHEMBL1379526 & 688816 & 4.75 & 5.4281 & TRN & \\
\hline CHEMBL1486687 & 688816 & 4.9 & 5.4794 & TRN & \\
\hline CHEMBL1467481 & 688816 & 5.0 & 5.0248 & TRN & \\
\hline CHEMBL1546470 & 688816 & 8.3468 & 5.24 & TRN & \\
\hline CHEMBL1382595 & 688816 & 8.301 & 5.282 & TRN & \\
\hline CHEMBL1517172 & 688816 & 4.9 & 5.115 & TRN & \\
\hline CHEMBL1422429 & 688816 & 5.7 & 5.5245 & TRN & \\
\hline CHEMBL1317031 & 688816 & 4.85 & 5.2939 & TST & \\
\hline CHEMBL1160544 & 688816 & 5.85 & 5.59399 & 9999999999 & TST \\
\hline CHEMBL1582193 & 688816 & 5.0 & 5.0868 & TRN & \\
\hline CHEMBL1488661 & 688816 & 4.45 & 5.147 & TRN & \\
\hline CHEMBL102714 & 688816 & 5.25 & 5.2223 & TRN & \\
\hline CHEMBL1344650 & 688816 & 5.4 & 5.3577 & TRN & \\
\hline CHEMBL1546074 & 688816 & 7.0 & 5.584 & TRN & \\
\hline CHEMBL1349622 & 688816 & 4.5 & 5.3471 & TST & \\
\hline CHEMBL1501859 & 688816 & 5.55 & 4.8869 & TRN & \\
\hline CHEMBL1510327 & 688816 & 6.05 & 5.5813 & TRN & \\
\hline CHEMBL1535176 & 688816 & 4.7 & 5.1958 & TST & \\
\hline CHEMBL1326229 & 688816 & 4.8 & 5.0852 & TST & \\
\hline CHEMBL1386420 & 688816 & 5.35 & 5.74799 & 9999999999 & TST \\
\hline CHEMBL1538820 & 688816 & 4.45 & 5.2515 & TRN & \\
\hline CHEMBL1485469 & 688816 & 4.6 & 5.2894 & TST & \\
\hline CHEMBL1611779 & 688816 & 4.7 & 4.7668 & TRN & \\
\hline CHEMBL1397276 & 688816 & 5.2 & 5.3638 & TRN & \\
\hline CHEMBL1550612 & 688816 & 6.3 & 5.2896 & TRN & \\
\hline CHEMBL1599863 & 688816 & 4.9 & 5.4156 & TRN & \\
\hline CHEMBL1431326 & 688816 & 5.45 & 5.3996 & TRN & \\
\hline CHEMBL1594821 & 688816 & 4.95 & 5.2197 & TRN & \\
\hline CHEMBL1575438 & 688816 & 6.8 & 5.4417 & TRN & \\
\hline CHEMBL1491946 & 688816 & 4.95 & 5.0527 & TRN & \\
\hline CHEMBL1972029 & 688816 & 5.6 & 5.1881 & TRN & \\
\hline CHEMBL1429832 & 688816 & 4.45 & 5.3081 & TRN & \\
\hline CHEMBL1418530 & 688816 & 5.75 & 5.4922 & TRN & \\
\hline CHEMBL1406950 & 688816 & 5.0 & 5.5059 & TST & \\
\hline CHEMBL1472422 & 688816 & 4.9 & 5.3175 & TRN & \\
\hline CHEMBL1313275 & 688816 & 5.45 & 5.6171 & TRN & \\
\hline CHEMBL3190491 & 688816 & 5.15 & 5.1154 & TRN & \\
\hline CHEMBL1375393 & 688816 & 8.301 & 4.9626 & TST & \\
\hline
\end{tabular}




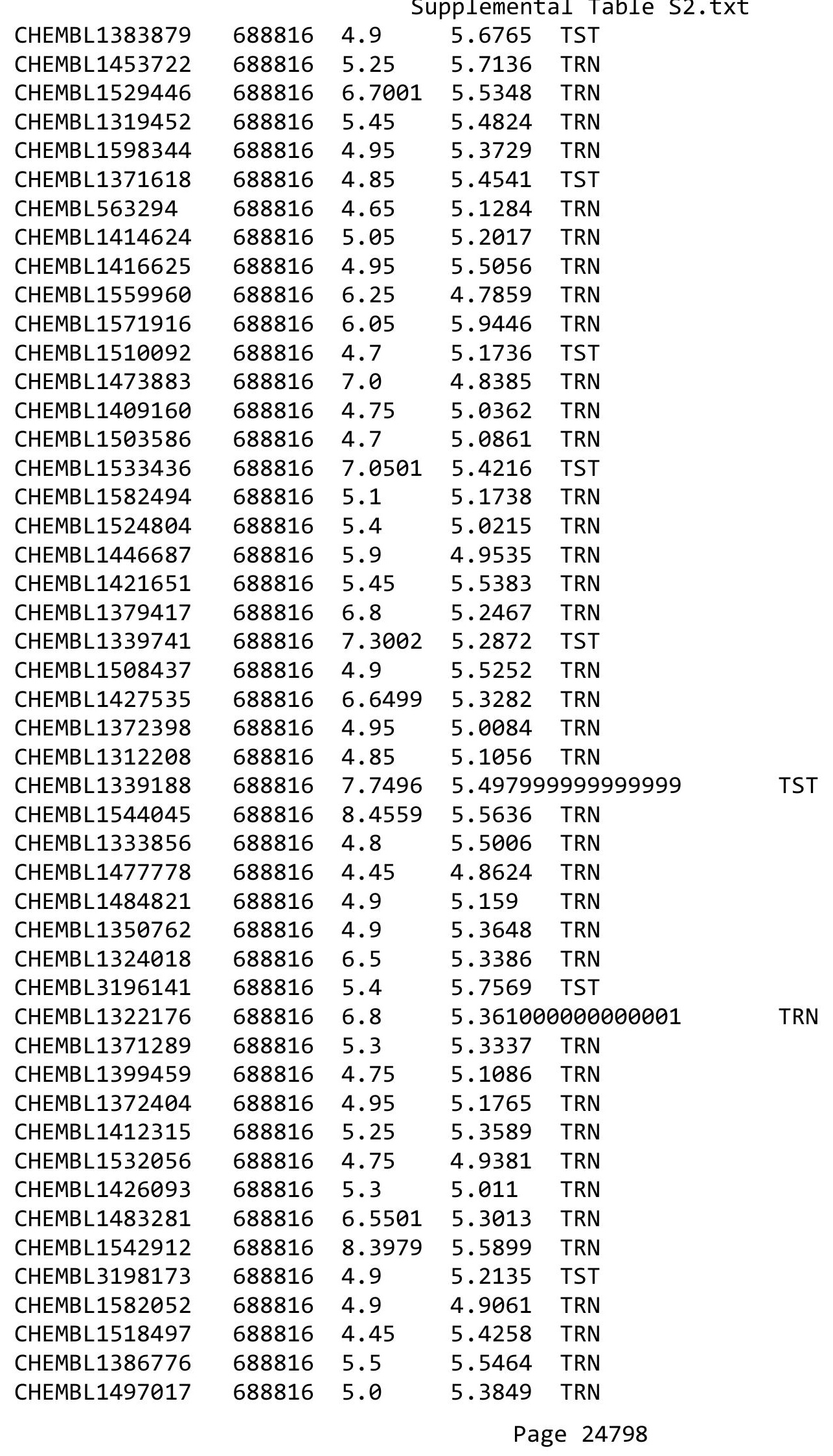




\begin{tabular}{|c|c|c|c|c|}
\hline \multicolumn{5}{|c|}{ Supplemental Table S2.txt } \\
\hline CHEMBL1403147 & 688816 & 4.95 & 5.4826 & TRN \\
\hline CHEMBL1347919 & 688816 & 4.9 & 5.6055 & TRN \\
\hline CHEMBL1389704 & 688816 & 4.8 & 5.4174 & TRN \\
\hline CHEMBL1576777 & 688816 & 4.95 & 4.7781 & TRN \\
\hline CHEMBL 1405855 & 688816 & 4.7 & 5.4313 & TST \\
\hline CHEMBL1356773 & 688816 & 4.75 & 4.9006 & TRN \\
\hline CHEMBL1414380 & 688816 & 4.6 & 5.6262 & TST \\
\hline CHEMBL1604591 & 688816 & 4.85 & 5.3123 & TRN \\
\hline CHEMBL1436888 & 688816 & 4.45 & 5.2897 & TRN \\
\hline CHEMBL1404107 & 688816 & 4.85 & 5.1679 & TRN \\
\hline CHEMBL1383376 & 688816 & 4.7 & 5.3164 & TRN \\
\hline CHEMBL1470609 & 688816 & 4.9 & 5.3431 & TRN \\
\hline CHEMBL1301968 & 688816 & 4.75 & 4.9755 & TRN \\
\hline CHEMBL1445372 & 688816 & 4.45 & 4.9339 & TRN \\
\hline CHEMBL3195077 & 688816 & 4.45 & 5.1807 & TRN \\
\hline CHEMBL 2369280 & 688816 & 4.6 & 4.8433 & TST \\
\hline CHEMBL1302112 & 688816 & 5.45 & 5.131 & TST \\
\hline CHEMBL1543588 & 688816 & 8.3979 & 5.1578 & TST \\
\hline CHEMBL1970265 & 688816 & 4.75 & 5.4483 & TRN \\
\hline CHEMBL1346293 & 688816 & 4.8 & 5.3854 & TST \\
\hline CHEMBL1405653 & 688816 & 5.55 & 5.4221 & TRN \\
\hline CHEMBL1523093 & 688816 & 5.65 & 5.3009 & TRN \\
\hline CHEMBL1558756 & 688816 & 4.8 & 4.7987 & TRN \\
\hline CHEMBL1321295 & 688816 & 4.45 & 5.1926 & TRN \\
\hline CHEMBL1304251 & 688816 & 4.45 & 5.4432 & TRN \\
\hline CHEMBL1543589 & 688816 & 5.0 & 5.2145 & TRN \\
\hline CHEMBL1560390 & 688816 & 5.85 & 5.1317 & TST \\
\hline CHEMBL1426831 & 688816 & 4.95 & 5.5985 & TRN \\
\hline CHEMBL1327085 & 688816 & 5.0 & 5.3078 & TST \\
\hline CHEMBL1492244 & 688816 & 4.95 & 5.2603 & TST \\
\hline CHEMBL1575690 & 688816 & 5.2 & 5.226 & TST \\
\hline CHEMBL1466102 & 688816 & 5.95 & 5.3326 & TRN \\
\hline CHEMBL1545885 & 688816 & 5.25 & 5.4499 & TRN \\
\hline CHEMBL1497853 & 688816 & 4.95 & 4.6052 & TRN \\
\hline CHEMBL1485948 & 688816 & 4.65 & 5.4471 & TRN \\
\hline CHEMBL1326496 & 688816 & 7.9508 & 5.4739 & TRN \\
\hline CHEMBL1520152 & 688816 & 4.7 & 5.0165 & TRN \\
\hline CHEMBL1330924 & 688816 & 4.45 & 5.5041 & TRN \\
\hline CHEMBL1465137 & 688816 & 4.9 & 5.1324 & TRN \\
\hline CHEMBL1996867 & 688816 & 4.6 & 4.931 & TST \\
\hline CHEMBL1588201 & 688816 & 5.45 & 5.6354 & TRN \\
\hline CHEMBL3197300 & 688816 & 5.2 & 4.8396 & TRN \\
\hline CHEMBL1438722 & 688816 & 6.0 & 5.2466 & TRN \\
\hline CHEMBL1569820 & 688816 & 5.55 & 5.4515 & TRN \\
\hline CHEMBL1559420 & 688816 & 8.301 & 5.5259 & TRN \\
\hline CHEMBL1350099 & 688816 & 8.0 & 5.4779 & TRN \\
\hline CHEMBL1454351 & 688816 & 8.0506 & 5.5181 & TRN \\
\hline CHEMBL1589188 & 688816 & 7.0 & 5.3675 & TRN \\
\hline
\end{tabular}




\begin{tabular}{|c|c|c|c|c|}
\hline & & & oplement & al $\mathrm{Tc}$ \\
\hline CHEMBL1426425 & 688816 & 7.7496 & 5.3131 & TRN \\
\hline CHEMBL1403495 & 688816 & 4.9 & 5.1783 & TRN \\
\hline CHEMBL1367777 & 688816 & 4.45 & 4.7904 & TRN \\
\hline CHEMBL1408781 & 688816 & 4.5 & 4.8618 & TRN \\
\hline CHEMBL3194145 & 688816 & 5.5 & 5.0007 & TRN \\
\hline CHEMBL1486925 & 688816 & 4.9 & 5.3023 & TRN \\
\hline CHEMBL1583424 & 688816 & 4.8 & 5.6241 & TRN \\
\hline CHEMBL3197550 & 688816 & 4.75 & 4.7312 & TRN \\
\hline CHEMBL1417597 & 688816 & 6.15 & 5.2168 & TRN \\
\hline CHEMBL1411121 & 688816 & 5.55 & 5.4191 & TST \\
\hline CHEMBL1303510 & 688816 & 5.45 & 5.2362 & TST \\
\hline CHEMBL1489612 & 688816 & 8.301 & 5.671 & TST \\
\hline CHEMBL1458228 & 688816 & 4.5 & 5.211 & TRN \\
\hline CHEMBL1438566 & 688816 & 6.0 & 5.6263 & TRN \\
\hline CHEMBL1461271 & 688816 & 5.1 & 5.0714 & TRN \\
\hline CHEMBL355159 & 688816 & 5.45 & 5.3257 & TRN \\
\hline CHEMBL1471088 & 688816 & 4.85 & 5.2904 & TRN \\
\hline CHEMBL1309284 & 688816 & 8.0506 & 5.4547 & TRN \\
\hline CHEMBL1586531 & 688816 & 4.6 & 4.9563 & TST \\
\hline CHEMBL 2004978 & 688816 & 4.8 & 5.2188 & TST \\
\hline CHEMBL1607143 & 688816 & 4.8 & 5.2634 & TRN \\
\hline CHEMBL1400240 & 688816 & 4.9 & 5.3705 & TRN \\
\hline CHEMBL1430041 & 688816 & 4.95 & 5.4139 & TRN \\
\hline CHEMBL1354002 & 688816 & 5.2 & 5.393 & TST \\
\hline CHEMBL1459889 & 688816 & 4.8 & 5.1215 & TST \\
\hline CHEMBL1508965 & 688816 & 5.15 & 5.06 & TRN \\
\hline CHEMBL1480121 & 688816 & 4.85 & 4.5101 & TRN \\
\hline CHEMBL1586674 & 688816 & 5.2 & 5.199 & TRN \\
\hline CHEMBL1363917 & 688816 & 5.1 & 5.074 & TRN \\
\hline CHEMBL1511811 & 688816 & 4.45 & 5.1969 & TRN \\
\hline CHEMBL1438383 & 688816 & 4.9 & 5.1935 & TST \\
\hline CHEMBL1509460 & 688816 & 5.25 & 5.4664 & TRN \\
\hline CHEMBL1462220 & 688816 & 4.95 & 5.1964 & TRN \\
\hline CHEMBL1599778 & 688816 & 4.95 & 5.1644 & TRN \\
\hline CHEMBL1538328 & 688816 & 4.7 & 5.5366 & TST \\
\hline CHEMBL1581950 & 688816 & 4.45 & 5.1632 & TRN \\
\hline CHEMBL3194108 & 688816 & 4.45 & 5.4164 & TST \\
\hline CHEMBL1325665 & 688816 & 4.45 & 5.3059 & TST \\
\hline CHEMBL1570607 & 688816 & 4.95 & 5.2607 & TRN \\
\hline CHEMBL1413662 & 688816 & 4.95 & 5.405 & TRN \\
\hline CHEMBL1613374 & 688816 & 5.05 & 5.3044 & TRN \\
\hline CHEMBL1357128 & 688816 & 4.8 & 4.5208 & TRN \\
\hline CHEMBL1562771 & 688816 & 4.85 & 5.3536 & TRN \\
\hline CHEMBL1511420 & 688816 & 5.25 & 5.3819 & TRN \\
\hline CHEMBL1425216 & 688816 & 4.8 & 5.4725 & TRN \\
\hline CHEMBL1379011 & 688816 & 4.8 & 5.1767 & TRN \\
\hline CHEMBL1579394 & 688816 & 4.75 & 5.3771 & TRN \\
\hline CHEMBL1572752 & 688816 & 4.9 & 4.978 & TRN \\
\hline
\end{tabular}




\begin{tabular}{|c|c|c|c|c|c|}
\hline \multicolumn{6}{|c|}{ Supplemental Table S2.txt } \\
\hline CHEMBL1412811 & 688816 & 5.2 & 5.4921 & TRN & \\
\hline CHEMBL1566887 & 688816 & 6.3 & 5.4012 & TRN & \\
\hline CHEMBL1523180 & 688816 & 5.05 & 5.2781 & TRN & \\
\hline CHEMBL1493936 & 688816 & 5.05 & 4.7964 & TRN & \\
\hline CHEMBL1349809 & 688816 & 5.15 & 5.4606 & TST & \\
\hline CHEMBL3194091 & 688816 & 4.45 & 5.4309 & TRN & \\
\hline CHEMBL1322519 & 688816 & 4.65 & 5.8299 & TST & \\
\hline CHEMBL1577858 & 688816 & 8.5528 & 5.4425 & TRN & \\
\hline CHEMBL1377174 & 688816 & 4.55 & 5.3305 & TST & \\
\hline CHEMBL1328024 & 688816 & 4.95 & 5.3595 & TRN & \\
\hline CHEMBL1510331 & 688816 & 4.8 & 5.1426 & TRN & \\
\hline CHEMBL1511762 & 688816 & 4.95 & 5.2768 & TRN & \\
\hline CHEMBL1345248 & 688816 & 5.85 & 5.3899 & TST & \\
\hline CHEMBL1447496 & 688816 & 5.55 & 5.2637 & TRN & \\
\hline CHEMBL1580532 & 688816 & 4.45 & 5.38700 & 00000000005 & TRN \\
\hline CHEMBL1494751 & 688816 & 4.8 & 5.4914 & TST & \\
\hline CHEMBL1555267 & 688816 & 4.95 & 5.2661 & TRN & \\
\hline CHEMBL1519116 & 688816 & 6.6499 & 4.8956 & TRN & \\
\hline CHEMBL1467384 & 688816 & 4.95 & 4.7183 & TRN & \\
\hline CHEMBL3190662 & 688816 & 4.95 & 5.1383 & TST & \\
\hline CHEMBL1323587 & 688816 & 5.1 & 5.2517 & TRN & \\
\hline CHEMBL1402525 & 688816 & 5.1 & 5.5884 & TST & \\
\hline CHEMBL1421583 & 688816 & 4.8 & 4.6326 & TRN & \\
\hline CHEMBL1507568 & 688816 & 4.7 & 4.9594 & TRN & \\
\hline CHEMBL1461377 & 688816 & 5.0 & 5.51399 & 9999999999 & TRN \\
\hline CHEMBL1500808 & 688816 & 5.7 & 5.4283 & TST & \\
\hline CHEMBL1564738 & 688816 & 4.8 & 5.3796 & TST & \\
\hline CHEMBL1455694 & 688816 & 5.1 & 5.4616 & TRN & \\
\hline CHEMBL1421436 & 688816 & 6.0 & 4.8242 & TST & \\
\hline CHEMBL1439396 & 688816 & 4.65 & 5.4513 & TRN & \\
\hline CHEMBL1518344 & 688816 & 4.7 & 5.2294 & TRN & \\
\hline CHEMBL1517410 & 688816 & 4.85 & 5.5434 & TST & \\
\hline CHEMBL1468020 & 688816 & 8.301 & 5.6846 & TST & \\
\hline CHEMBL1577044 & 688816 & 4.6 & 5.1836 & TRN & \\
\hline CHEMBL1312743 & 688816 & 4.9 & 5.4212 & TRN & \\
\hline CHEMBL1510254 & 688816 & 5.9 & 5.1526 & TRN & \\
\hline CHEMBL1464550 & 688816 & 4.8 & 5.0763 & TRN & \\
\hline CHEMBL1391087 & 688816 & 5.3 & 4.7407 & TST & \\
\hline CHEMBL1400587 & 688816 & 4.9 & 5.1899 & TRN & \\
\hline CHEMBL1581176 & 688816 & 8.301 & 4.9027 & TRN & \\
\hline CHEMBL1489456 & 688816 & 4.85 & 5.2227 & TRN & \\
\hline CHEMBL1352836 & 688816 & 5.4 & 5.0934 & TRN & \\
\hline CHEMBL1379416 & 688816 & 4.9 & 5.4133 & TRN & \\
\hline CHEMBL 1604350 & 688816 & 4.45 & 4.9977 & TRN & \\
\hline CHEMBL 3209778 & 688816 & 6.7001 & 5.4505 & TRN & \\
\hline CHEMBL1399869 & 688816 & 5.0 & 5.4624 & TRN & \\
\hline CHEMBL3198603 & 688816 & 5.15 & 5.2177 & TRN & \\
\hline CHEMBL1303565 & 688816 & 4.95 & 5.2873 & TRN & \\
\hline
\end{tabular}




\begin{tabular}{|c|c|c|c|c|c|}
\hline \multicolumn{6}{|c|}{ Supplemental Table s2.txt } \\
\hline CHEMBL1328388 & 688816 & 4.85 & 5.3621 & TRN & \\
\hline CHEMBL1381310 & 688816 & 5.25 & 5.0257 & TRN & \\
\hline CHEMBL1570319 & 688816 & 4.85 & 5.0428 & TST & \\
\hline CHEMBL3199275 & 688816 & 4.95 & 5.3803 & TRN & \\
\hline CHEMBL1574905 & 688816 & 4.7 & 5.2638 & TRN & \\
\hline CHEMBL1334106 & 688816 & 5.0 & 5.5883 & TRN & \\
\hline CHEMBL1353693 & 688816 & 5.0 & 5.2849 & TRN & \\
\hline CHEMBL1508143 & 688816 & 5.3 & 5.4023 & TRN & \\
\hline CHEMBL1495849 & 688816 & 5.4 & 5.1431 & TRN & \\
\hline CHEMBL1390057 & 688816 & 4.9 & 5.2784 & TST & \\
\hline CHEMBL1303155 & 688816 & 4.95 & 5.1485 & TRN & \\
\hline CHEMBL3189917 & 688816 & 5.8 & 5.1946 & TRN & \\
\hline CHEMBL1463306 & 688816 & 4.9 & 5.1429 & TRN & \\
\hline CHEMBL1354538 & 688816 & 5.55 & 5.1534 & TRN & \\
\hline CHEMBL1425513 & 688816 & 5.45 & 5.70799 & 9999999999 & TRN \\
\hline CHEMBL1585127 & 688816 & 5.1 & 5.0263 & TRN & \\
\hline CHEMBL3199198 & 688816 & 5.55 & 5.2944 & TRN & \\
\hline CHEMBL1377777 & 688816 & 4.45 & 5.0204 & TST & \\
\hline CHEMBL1414651 & 688816 & 7.15 & 5.2674 & TST & \\
\hline CHEMBL1331367 & 688816 & 6.8499 & 5.5528 & TST & \\
\hline CHEMBL 3211828 & 688816 & 6.8499 & 5.6915 & TRN & \\
\hline CHEMBL1470074 & 688816 & 4.45 & 5.4203 & TRN & \\
\hline CHEMBL1427716 & 688816 & 4.9 & 5.0722 & TST & \\
\hline CHEMBL1590348 & 688816 & 4.95 & 5.13299 & 9999999999 & TRN \\
\hline CHEMBL1305206 & 688816 & 5.0 & 5.4611 & TRN & \\
\hline CHEMBL1538128 & 688816 & 4.95 & 4.8773 & TRN & \\
\hline CHEMBL1610717 & 688816 & 4.65 & 5.2864 & TRN & \\
\hline CHEMBL1423787 & 688816 & 5.4 & 5.7082 & TST & \\
\hline CHEMBL1362549 & 688816 & 4.95 & 5.5102 & TST & \\
\hline CHEMBL1479146 & 688816 & 4.7 & 5.3584 & TRN & \\
\hline CHEMBL1343498 & 688816 & 6.45 & 5.6871 & TRN & \\
\hline CHEMBL1529007 & 688816 & 4.65 & 5.3273 & TRN & \\
\hline CHEMBL1394829 & 688816 & 5.0 & 5.1177 & TRN & \\
\hline CHEMBL1456923 & 688816 & 4.8 & 5.2888 & TRN & \\
\hline CHEMBL1586822 & 688816 & 4.8 & 5.2842 & TRN & \\
\hline CHEMBL131921 & 688816 & 6.0 & 5.2742 & TRN & \\
\hline CHEMBL1367086 & 688816 & 4.95 & 5.3795 & TRN & \\
\hline CHEMBL3199580 & 688816 & 4.65 & 4.9141 & TRN & \\
\hline CHEMBL1531488 & 688816 & 6.5501 & 5.4956 & TST & \\
\hline CHEMBL1391266 & 688816 & 5.25 & 5.1164 & TRN & \\
\hline CHEMBL1447018 & 688816 & 5.2 & 6.0773 & TRN & \\
\hline CHEMBL 3145042 & 688816 & 4.45 & 5.2772 & TRN & \\
\hline CHEMBL1401288 & 688816 & 4.85 & 5.3188 & TRN & \\
\hline CHEMBL3213501 & 688816 & 5.55 & 5.3477 & TRN & \\
\hline CHEMBL1589746 & 688816 & 5.5 & 4.994 & TST & \\
\hline CHEMBL1305698 & 688816 & 4.9 & 5.1379 & TRN & \\
\hline CHEMBL1370572 & 688816 & 5.25 & 5.4509 & TST & \\
\hline CHEMBL1440005 & 688816 & 4.95 & 5.45200 & 2000000001 & TRN \\
\hline & & & & 24802 & \\
\hline
\end{tabular}




\begin{tabular}{|c|c|c|c|c|c|}
\hline \multicolumn{6}{|c|}{ Supplemental Table s2.txt } \\
\hline CHEMBL1463075 & 688816 & 6.25 & 5.2699 & TST & \\
\hline CHEMBL1304398 & 688816 & 5.2 & 5.3374 & TRN & \\
\hline CHEMBL1444752 & 688816 & 5.25 & 5.5594 & TRN & \\
\hline CHEMBL1461285 & 688816 & 4.95 & 5.3398 & TRN & \\
\hline CHEMBL1350047 & 688816 & 5.05 & 4.8988 & TRN & \\
\hline CHEMBL1542421 & 688816 & 4.65 & 4.9862 & TST & \\
\hline CHEMBL1459111 & 688816 & 4.85 & 4.9788 & TRN & \\
\hline CHEMBL1421464 & 688816 & 7.3002 & 5.3598 & TRN & \\
\hline CHEMBL1487395 & 688816 & 5.2 & 5.3744 & TST & \\
\hline CHEMBL1300711 & 688816 & 4.9 & 5.6119 & TRN & \\
\hline CHEMBL1470195 & 688816 & 5.15 & 5.38 & TRN & \\
\hline CHEMBL1607129 & 688816 & 4.95 & 5.4532 & TRN & \\
\hline CHEMBL1271881 & 688816 & 6.3 & 5.5078 & TRN & \\
\hline CHEMBL1326812 & 688816 & 8.0 & 4.7884 & TRN & \\
\hline CHEMBL1536696 & 688816 & 4.75 & 5.319 & TRN & \\
\hline CHEMBL1502048 & 688816 & 5.35 & 4.9687 & TRN & \\
\hline CHEMBL1601252 & 688816 & 4.95 & 5.1389 & TRN & \\
\hline CHEMBL1513452 & 688816 & 4.95 & 5.4411 & TRN & \\
\hline CHEMBL1375023 & 688816 & 5.5 & 5.7532 & TRN & \\
\hline CHEMBL1404984 & 688816 & 4.95 & 5.1739 & TRN & \\
\hline CHEMBL1373580 & 688816 & 4.9 & 5.1871 & TRN & \\
\hline CHEMBL1367185 & 688816 & 7.4001 & 5.5468 & TRN & \\
\hline CHEMBL1404239 & 688816 & 6.2 & 5.1143 & TRN & \\
\hline CHEMBL3211293 & 688816 & 8.301 & 5.26399 & 9999999999 & TRN \\
\hline CHEMBL1611857 & 688816 & 7.2503 & 5.3223 & TRN & \\
\hline CHEMBL1596683 & 688816 & 4.95 & 5.7503 & TRN & \\
\hline CHEMBL1537781 & 688816 & 6.05 & 5.0817 & TRN & \\
\hline CHEMBL1965669 & 688816 & 5.05 & 5.119 & TRN & \\
\hline CHEMBL610 & 688816 & 4.85 & $5.2870 e$ & 0000000001 & TST \\
\hline CHEMBL1352829 & 688816 & 5.35 & 4.9698 & TRN & \\
\hline CHEMBL1392364 & 688816 & 5.1 & 5.4265 & TRN & \\
\hline CHEMBL1319037 & 688816 & 5.3 & 5.4479 & TRN & \\
\hline CHEMBL1585051 & 688816 & 4.95 & 5.3417 & TRN & \\
\hline CHEMBL1333930 & 688816 & 5.8 & 5.3163 & TRN & \\
\hline CHEMBL1602896 & 688816 & 4.85 & 5.4157 & TRN & \\
\hline CHEMBL1541720 & 688816 & 4.9 & 5.2145 & TRN & \\
\hline CHEMBL1521905 & 688816 & 4.95 & 5.0484 & TST & \\
\hline CHEMBL1608149 & 688816 & 6.05 & 5.03 & TRN & \\
\hline CHEMBL1562934 & 688816 & 5.25 & 5.688 & TST & \\
\hline CHEMBL1496970 & 688816 & 4.75 & 5.2483 & TRN & \\
\hline CHEMBL1311791 & 688816 & 4.9 & 5.3936 & TRN & \\
\hline CHEMBL1509005 & 688816 & 4.5 & 5.5451 & TST & \\
\hline CHEMBL1390556 & 688816 & 4.45 & 4.8812 & TST & \\
\hline CHEMBL1609062 & 688816 & 4.9 & 5.0783 & TRN & \\
\hline CHEMBL1427801 & 688816 & 6.4 & 5.5424 & TRN & \\
\hline CHEMBL1454245 & 688816 & 4.95 & 5.1669 & TST & \\
\hline CHEMBL1488300 & 688816 & 4.9 & 5.2635 & TRN & \\
\hline CHEMBL 2006780 & 688816 & 5.9 & 5.4331 & TST & \\
\hline
\end{tabular}




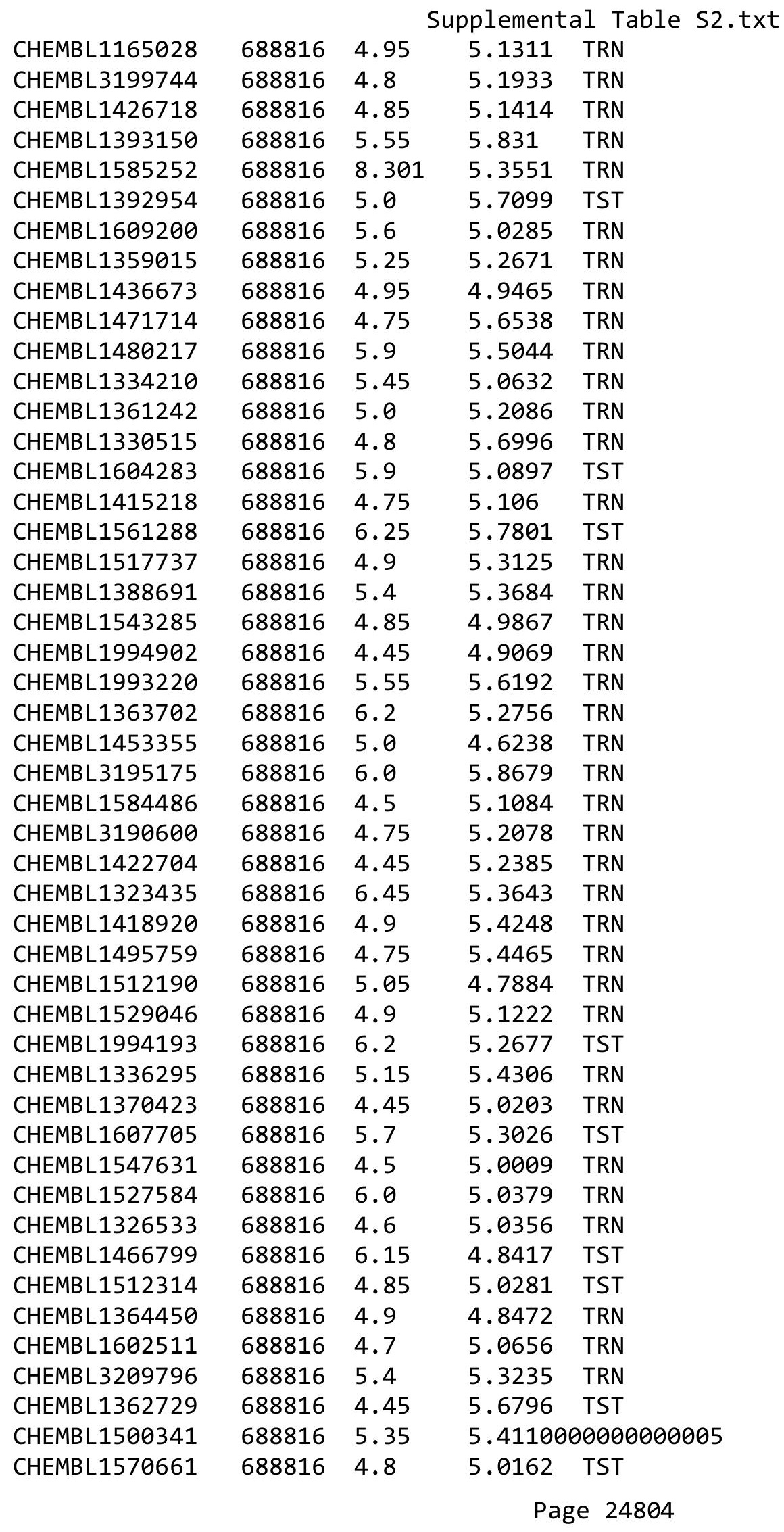




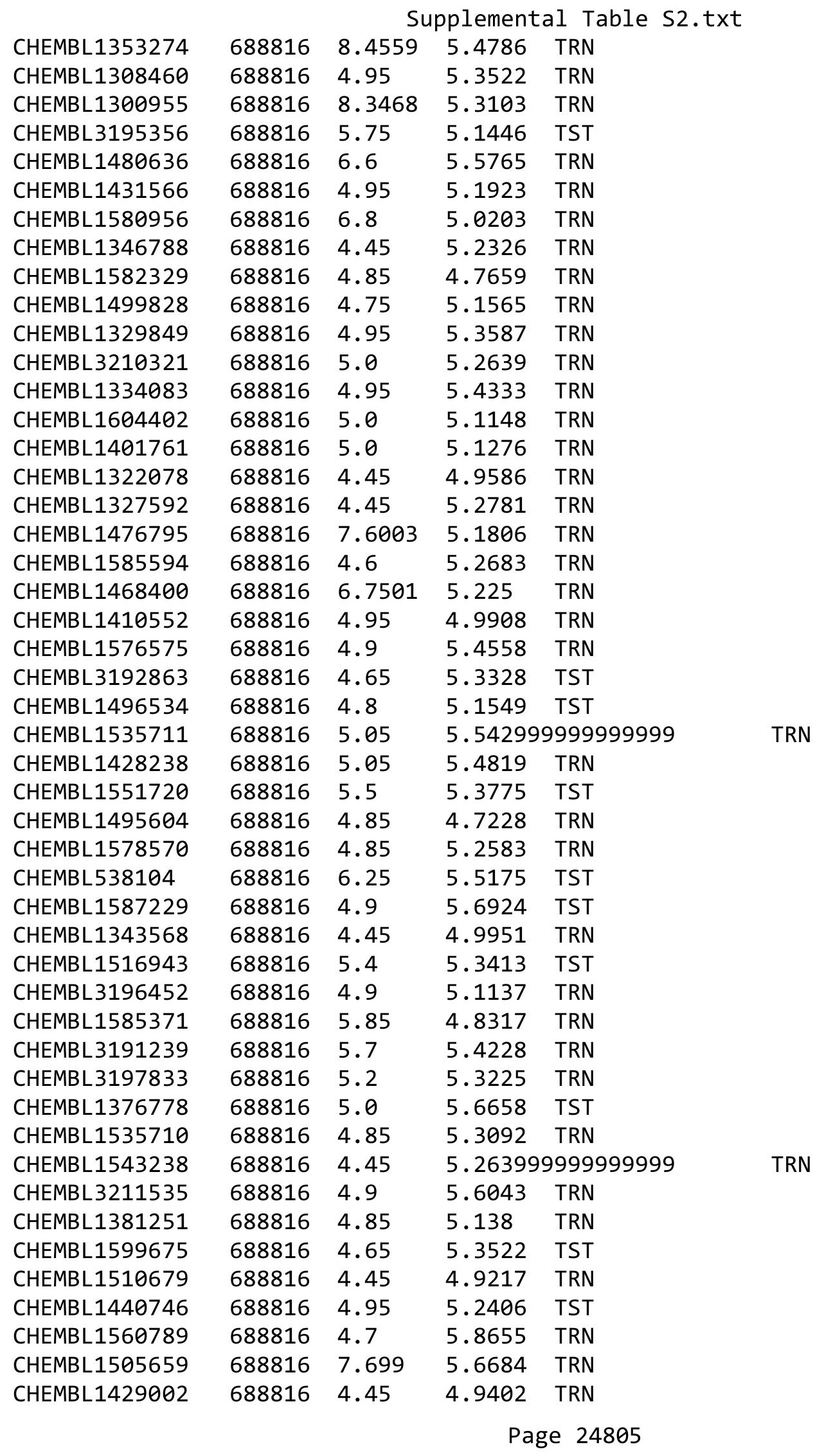




\begin{tabular}{|c|c|c|c|c|c|}
\hline \multicolumn{6}{|c|}{ Supplemental Table S2.txt } \\
\hline CHEMBL1384873 & 688816 & 5.4 & 5.4157 & TRN & \\
\hline CHEMBL1559640 & 688816 & 6.4 & 5.5611 & TST & \\
\hline CHEMBL1561718 & 688816 & 5.55 & 5.0723 & TST & \\
\hline CHEMBL1407896 & 688816 & 7.5003 & 5.4 & TRN & \\
\hline CHEMBL1476521 & 688816 & 5.1 & 5.3194 & TRN & \\
\hline CHEMBL1506068 & 688816 & 4.9 & 5.3016 & TRN & \\
\hline CHEMBL1350405 & 688816 & 4.95 & 5.3024 & TRN & \\
\hline CHEMBL 202380 & 688816 & 5.2 & 5.7661 & TRN & \\
\hline CHEMBL1421779 & 688816 & 4.95 & 4.925 & TST & \\
\hline CHEMBL1459004 & 688816 & 5.25 & 5.3835 & TRN & \\
\hline CHEMBL1598201 & 688816 & 8.0506 & 5.3416 & TRN & \\
\hline CHEMBL203108 & 688816 & 6.5501 & 5.2059 & TST & \\
\hline CHEMBL1487951 & 688816 & 4.7 & 5.2403 & TRN & \\
\hline CHEMBL1534531 & 688816 & 5.65 & 5.6279 & TST & \\
\hline CHEMBL1305642 & 688816 & 4.55 & 5.0453 & TRN & \\
\hline CHEMBL3196498 & 688816 & 6.5 & 5.0568 & TST & \\
\hline CHEMBL1533123 & 688816 & 5.45 & 5.0963 & TST & \\
\hline CHEMBL3192666 & 688816 & 5.15 & 4.8486 & TRN & \\
\hline CHEMBL1511575 & 688816 & 6.15 & 5.5338 & TRN & \\
\hline CHEMBL602158 & 688816 & 4.85 & 5.2634 & TRN & \\
\hline CHEMBL1576565 & 688816 & 4.7 & 5.5754 & TRN & \\
\hline CHEMBL470671 & 688816 & 5.0 & 5.34 & TST & \\
\hline CHEMBL1392037 & 688816 & 5.35 & 5.0078 & TRN & \\
\hline CHEMBL1361862 & 688816 & 4.45 & 5.4137 & TRN & \\
\hline CHEMBL1610636 & 688816 & 6.25 & 5.1048 & TRN & \\
\hline CHEMBL1608261 & 688816 & 4.8 & 5.2397 & TRN & \\
\hline CHEMBL1535643 & 688816 & 6.15 & 5.3754 & TST & \\
\hline CHEMBL3195551 & 688816 & 4.6 & 5.1027 & TRN & \\
\hline CHEMBL1415333 & 688816 & 4.45 & 5.4409 & TRN & \\
\hline CHEMBL1498466 & 688816 & 4.55 & 4.982 & TRN & \\
\hline CHEMBL1429944 & 688816 & 4.75 & 5.4407 & TRN & \\
\hline CHEMBL494891 & 688816 & 4.95 & 5.3885 & TST & \\
\hline CHEMBL1533117 & 688816 & 6.25 & 5.126 & TRN & \\
\hline CHEMBL1457314 & 688816 & 4.9 & 5.3436 & TRN & \\
\hline CHEMBL1556692 & 688816 & 4.9 & 5.3138 & TRN & \\
\hline CHEMBL3145373 & 688816 & 5.0 & 5.5335 & TRN & \\
\hline CHEMBL1408423 & 688816 & 4.85 & 4.8582 & TRN & \\
\hline CHEMBL1377358 & 688816 & 6.6499 & 5.0245 & TRN & \\
\hline CHEMBL 3208700 & 688816 & 8.2007 & 5.3896 & TST & \\
\hline CHEMBL1600357 & 688816 & 5.0 & 5.5176 & TRN & \\
\hline CHEMBL1441119 & 688816 & 5.2 & 5.0305 & TRN & \\
\hline CHEMBL1456823 & 688816 & 4.65 & 5.479 & TRN & \\
\hline CHEMBL1568340 & 688816 & 4.95 & 5.081 & TRN & \\
\hline CHEMBL1493673 & 688816 & 4.85 & $5.1770 e$ & 00000000005 & TRN \\
\hline CHEMBL 228792 & 688816 & 5.0 & 5.4585 & TRN & \\
\hline CHEMBL1332220 & 688816 & 4.7 & 4.9415 & TRN & \\
\hline CHEMBL1557844 & 688816 & 4.65 & 5.2554 & TRN & \\
\hline CHEMBL1256740 & 688816 & 4.45 & 5.2916 & TST & \\
\hline
\end{tabular}




\begin{tabular}{|c|c|c|c|c|c|}
\hline \\
\hline CHEMBL1588880 & 688816 & 5.0 & 5.1339 & TRN & \\
\hline CHEMBL1584206 & 688816 & 8.301 & 5.5216 & TRN & \\
\hline CHEMBL1576720 & 688816 & 5.9 & 5.5077 & TST & \\
\hline CHEMBL1560069 & 688816 & 4.95 & 4.9949 & TRN & \\
\hline CHEMBL1481085 & 688816 & 4.6 & 4.8772 & TRN & \\
\hline CHEMBL1495505 & 688816 & 4.95 & 5.1926 & TRN & \\
\hline CHEMBL1439229 & 688816 & 4.9 & 5.2092 & TST & \\
\hline CHEMBL1439867 & 688816 & 5.05 & 4.989 & TRN & \\
\hline CHEMBL1392377 & 688816 & 8.301 & 5.1246 & TRN & \\
\hline CHEMBL1324894 & 688816 & 5.55 & 5.41700 & 0000000001 & TRN \\
\hline CHEMBL1604123 & 688816 & 4.9 & 5.1878 & TRN & \\
\hline CHEMBL1536608 & 688816 & 5.15 & 5.223 & TRN & \\
\hline CHEMBL1606158 & 688816 & 4.45 & 5.1761 & TRN & \\
\hline CHEMBL1510946 & 688816 & 4.95 & 4.9538 & TRN & \\
\hline CHEMBL1585194 & 688816 & 4.65 & 5.3624 & TST & \\
\hline CHEMBL1432760 & 688816 & 4.85 & 5.1519 & TRN & \\
\hline CHEMBL1388018 & 688816 & 4.65 & 5.1067 & TRN & \\
\hline CHEMBL1548462 & 688816 & 6.35 & 5.5057 & TRN & \\
\hline CHEMBL1538783 & 688816 & 4.45 & 5.3846 & TST & \\
\hline CHEMBL1449473 & 688816 & 4.9 & 5.5496 & TRN & \\
\hline CHEMBL1588857 & 688816 & 5.0 & 5.4421 & TRN & \\
\hline CHEMBL1469467 & 688816 & 5.1 & 5.1503 & TST & \\
\hline CHEMBL1532441 & 688816 & 5.35 & 5.1498 & TRN & \\
\hline CHEMBL 2373582 & 688816 & 5.7 & 5.9228 & TST & \\
\hline CHEMBL1387024 & 688816 & 4.95 & 4.82100 & 0000000001 & TRN \\
\hline CHEMBL1447657 & 688816 & 8.3979 & 5.454 & TST & \\
\hline CHEMBL446315 & 688816 & 5.95 & 5.4456 & TRN & \\
\hline CHEMBL1965415 & 688816 & 4.45 & 5.0251 & TRN & \\
\hline CHEMBL1532506 & 688816 & 4.9 & 5.1123 & TRN & \\
\hline CHEMBL1502381 & 688816 & 5.35 & 5.3163 & TST & \\
\hline CHEMBL1989723 & 688816 & 4.55 & 5.112 & TRN & \\
\hline CHEMBL1431659 & 688816 & 4.8 & 5.1169 & TRN & \\
\hline CHEMBL1574671 & 688816 & 4.95 & 4.9861 & TST & \\
\hline CHEMBL1320057 & 688816 & 6.3 & 5.5908 & TST & \\
\hline CHEMBL1547865 & 688816 & 4.95 & 5.2143 & TST & \\
\hline CHEMBL1365119 & 688816 & 5.2 & 5.4787 & TST & \\
\hline CHEMBL1448277 & 688816 & 4.65 & 5.0295 & TRN & \\
\hline CHEMBL1427898 & 688816 & 4.95 & 5.1726 & TRN & \\
\hline CHEMBL1599873 & 688816 & 7.4001 & 5.7331 & TST & \\
\hline CHEMBL1352677 & 688816 & 5.35 & 5.5977 & TRN & \\
\hline CHEMBL3189150 & 688816 & 6.1 & 5.4815 & TST & \\
\hline CHEMBL1389764 & 688816 & 5.5 & 5.1938 & TRN & \\
\hline CHEMBL1547000 & 688816 & 4.65 & 5.1019 & TRN & \\
\hline CHEMBL1566542 & 688816 & 6.0 & 5.3663 & TRN & \\
\hline CHEMBL1334699 & 688816 & 4.45 & 5.282 & TST & \\
\hline CHEMBL1561843 & 688816 & 4.95 & 5.2504 & TRN & \\
\hline CHEMBL1395340 & 688816 & 4.95 & 5.1598 & TRN & \\
\hline CHEMBL1459387 & 688816 & 4.8 & 5.3665 & TRN & \\
\hline
\end{tabular}




\begin{tabular}{|c|c|c|c|c|}
\hline \multicolumn{5}{|c|}{ Supplemental Table S2.txt } \\
\hline CHEMBL1299705 & 688816 & 5.2 & 5.1229 & TST \\
\hline CHEMBL 3197622 & 688816 & 4.45 & 5.2256 & TRN \\
\hline CHEMBL1327913 & 688816 & 8.3468 & 5.6489 & TRN \\
\hline CHEMBL1524738 & 688816 & 7.5003 & 5.1705 & TST \\
\hline CHEMBL 1418980 & 688816 & 4.95 & 5.3178 & TRN \\
\hline CHEMBL1556277 & 688816 & 4.45 & 4.9476 & TRN \\
\hline CHEMBL1461857 & 688816 & 4.55 & 5.1441 & TRN \\
\hline CHEMBL1376498 & 688816 & 6.0 & 5.1868 & TST \\
\hline CHEMBL1594185 & 688816 & 4.95 & 5.5918 & TRN \\
\hline CHEMBL1505879 & 688816 & 4.65 & 5.7463 & TRN \\
\hline CHEMBL1468931 & 688816 & 4.75 & 4.9301 & TRN \\
\hline CHEMBL1501055 & 688816 & 8.4949 & 5.3921 & TRN \\
\hline CHEMBL1471696 & 688816 & 6.7501 & 5.3854 & TST \\
\hline CHEMBL1453757 & 688816 & 5.6 & 4.922 & TRN \\
\hline CHEMBL1790016 & 688816 & 4.45 & 5.0893 & TRN \\
\hline CHEMBL1332932 & 688816 & 4.85 & 4.7734 & TRN \\
\hline CHEMBL1604702 & 688816 & 6.8 & 5.4742 & TRN \\
\hline CHEMBL1572226 & 688816 & 6.25 & 5.4656 & TRN \\
\hline CHEMBL1481043 & 688816 & 4.65 & 5.2367 & TRN \\
\hline CHEMBL3192729 & 688816 & 4.8 & 5.2982 & TRN \\
\hline CHEMBL1388233 & 688816 & 4.85 & 5.06 & TRN \\
\hline CHEMBL1457690 & 688816 & 4.9 & 5.1511 & TRN \\
\hline CHEMBL1484048 & 688816 & 4.45 & 4.8449 & TST \\
\hline CHEMBL542493 & 688816 & 4.6 & 5.1879 & TRN \\
\hline CHEMBL1409057 & 688816 & 4.9 & 5.648 & TRN \\
\hline CHEMBL3199292 & 688816 & 7.2 & 5.6058 & TST \\
\hline CHEMBL 89671 & 688816 & 4.75 & 5.0596 & TRN \\
\hline CHEMBL1472072 & 688816 & 5.35 & 5.2251 & TST \\
\hline CHEMBL1422523 & 688816 & 4.7 & 5.5113 & TRN \\
\hline CHEMBL1347518 & 688816 & 4.95 & 5.2686 & TRN \\
\hline CHEMBL1386558 & 688816 & 4.7 & 5.4488 & TRN \\
\hline CHEMBL1365442 & 688816 & 8.1024 & 5.1297 & TRN \\
\hline CHEMBL1579452 & 688816 & 5.45 & 5.1353 & TRN \\
\hline CHEMBL1382633 & 688816 & 7.5498 & 5.1326 & TST \\
\hline CHEMBL1321159 & 688816 & 5.7 & 5.1271 & TRN \\
\hline CHEMBL1599069 & 688816 & 5.25 & 5.2313 & TRN \\
\hline CHEMBL1568205 & 688816 & 6.05 & 5.5809 & TST \\
\hline CHEMBL1374043 & 688816 & 4.8 & 5.4019 & TRN \\
\hline CHEMBL1410373 & 688816 & 7.5003 & 5.4885 & TRN \\
\hline CHEMBL1302925 & 688816 & 5.05 & 5.4338 & TRN \\
\hline CHEMBL1509727 & 688816 & 4.95 & 5.2152 & TRN \\
\hline CHEMBL1563864 & 688816 & 4.45 & 5.4181 & TRN \\
\hline CHEMBL1366032 & 688816 & 4.45 & 5.296 & TRN \\
\hline CHEMBL1329696 & 688816 & 6.5 & 5.5779 & TRN \\
\hline CHEMBL1471057 & 688816 & 5.2 & 5.3099 & TRN \\
\hline CHEMBL1398830 & 688816 & 5.5 & 5.2346 & TST \\
\hline CHEMBL1388951 & 688816 & 4.95 & 5.2878 & TRN \\
\hline CHEMBL1498130 & 688816 & 4.9 & 5.0387 & TST \\
\hline
\end{tabular}




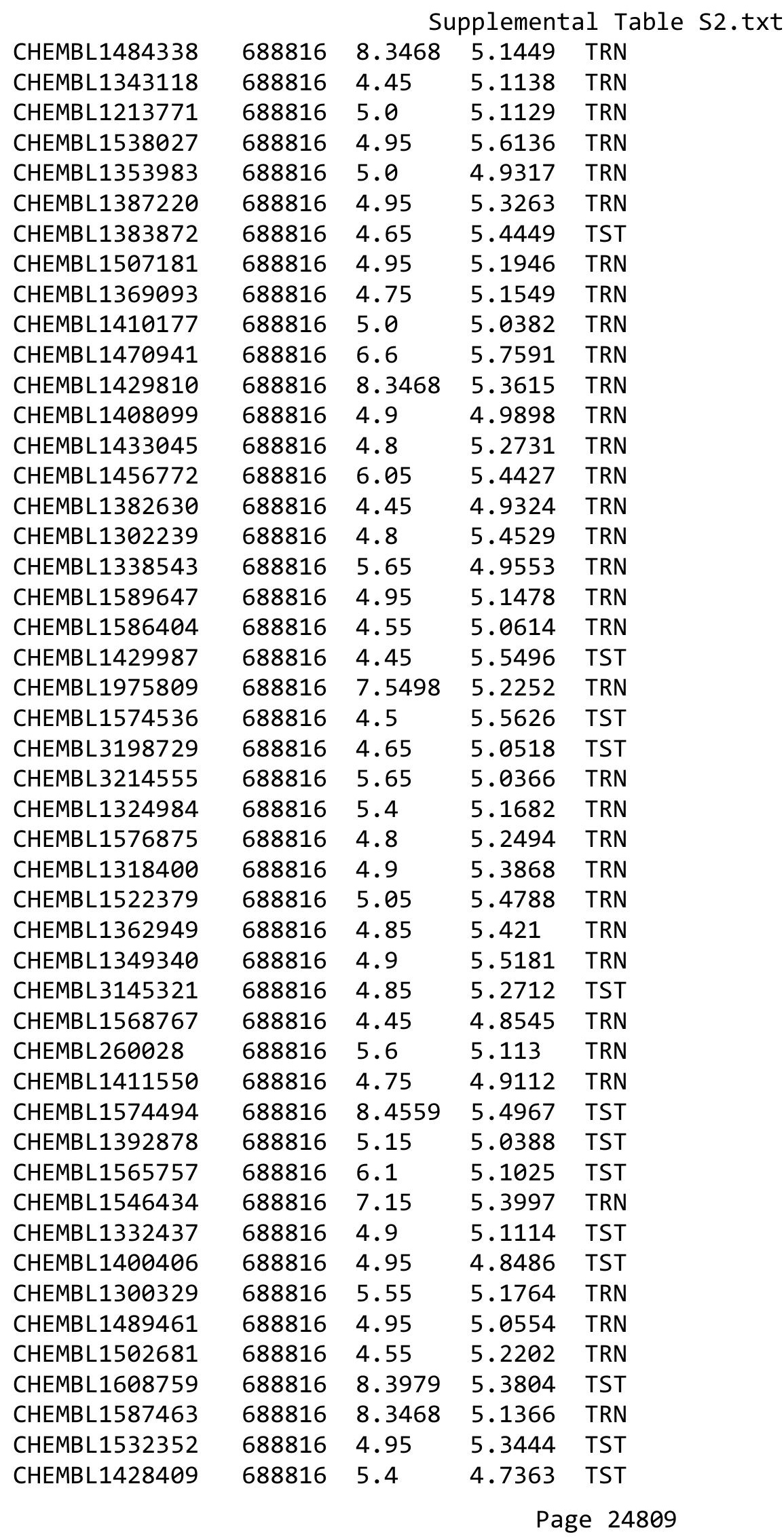




\begin{tabular}{|c|c|c|c|c|c|}
\hline \multirow[b]{2}{*}{ CHEMBL1597066 } & \multicolumn{5}{|c|}{ olemental Table S2 } \\
\hline & 688816 & 4.6 & 4.8726 & TRN & \\
\hline CHEMBL1255941 & 688816 & 4.7 & 5.8602 & TST & \\
\hline CHEMBL1605568 & 688816 & 5.0 & 5.05399 & 9999999999 & TRN \\
\hline CHEMBL1549022 & 688816 & 4.45 & 5.1147 & TRN & \\
\hline CHEMBL1380456 & 688816 & 8.0 & 5.9568 & TRN & \\
\hline CHEMBL1392409 & 688816 & 5.4 & 5.4095 & TST & \\
\hline CHEMBL1498228 & 688816 & 4.8 & 5.1683 & TRN & \\
\hline CHEMBL1461634 & 688816 & 5.05 & 4.9502 & TRN & \\
\hline CHEMBL1372319 & 688816 & 5.0 & 5.4646 & TRN & \\
\hline CHEMBL1460164 & 688816 & 5.05 & 5.813 & TRN & \\
\hline CHEMBL1416980 & 688816 & 5.0 & 5.5081 & TRN & \\
\hline CHEMBL 285480 & 688816 & 4.85 & 5.077 & TST & \\
\hline CHEMBL1529298 & 688816 & 4.6 & 5.204 & TRN & \\
\hline CHEMBL1586729 & 688816 & 4.75 & 5.7645 & TST & \\
\hline CHEMBL1569091 & 688816 & 4.45 & 5.6265 & TST & \\
\hline CHEMBL1432694 & 688816 & 5.0 & 5.36 & TRN & \\
\hline CHEMBL1608108 & 688816 & 4.65 & 5.3863 & TRN & \\
\hline CHEMBL1355970 & 688816 & 7.8013 & 5.4223 & TRN & \\
\hline CHEMBL1379990 & 688816 & 6.25 & 5.3304 & TRN & \\
\hline CHEMBL1515599 & 688816 & 4.95 & 4.6842 & TRN & \\
\hline CHEMBL1465557 & 688816 & 5.5 & 5.5011 & TRN & \\
\hline CHEMBL1404579 & 688816 & 4.9 & 5.4335 & TRN & \\
\hline CHEMBL1557231 & 688816 & 5.5 & 4.9273 & TRN & \\
\hline CHEMBL3189284 & 688816 & 4.8 & 5.2947 & TRN & \\
\hline CHEMBL1365585 & 688816 & 5.35 & 5.0698 & TRN & \\
\hline CHEMBL1374800 & 688816 & 4.9 & 5.7694 & TRN & \\
\hline CHEMBL1343447 & 688816 & 5.45 & 5.5019 & TRN & \\
\hline CHEMBL1438813 & 688816 & 4.45 & 5.4694 & TRN & \\
\hline CHEMBL1613275 & 688816 & 4.8 & 5.2822 & TRN & \\
\hline CHEMBL1461196 & 688816 & 5.45 & 5.0166 & TRN & \\
\hline CHEMBL1381433 & 688816 & 6.5 & 5.5885 & TST & \\
\hline CHEMBL1598517 & 688816 & 4.45 & 5.1417 & TRN & \\
\hline CHEMBL1345015 & 688816 & 4.95 & 5.2657 & TRN & \\
\hline CHEMBL1403112 & 688816 & 4.95 & 5.2948 & TRN & \\
\hline CHEMBL1599234 & 688816 & 4.8 & 4.92399 & 99999999995 & TRN \\
\hline CHEMBL1477047 & 688816 & 4.5 & 5.2699 & TST & \\
\hline CHEMBL1471016 & 688816 & 5.0 & 5.7189 & TRN & \\
\hline CHEMBL1530294 & 688816 & 5.25 & 5.0207 & TRN & \\
\hline CHEMBL1366570 & 688816 & 4.95 & 4.9158 & TRN & \\
\hline CHEMBL1559795 & 688816 & 4.7 & 5.3488 & TST & \\
\hline CHEMBL1302701 & 688816 & 4.7 & 5.2779 & TST & \\
\hline CHEMBL1419714 & 688816 & 4.9 & 5.1019 & TRN & \\
\hline CHEMBL1531483 & 688816 & 4.45 & 5.3042 & TRN & \\
\hline CHEMBL1483423 & 688816 & 5.05 & 5.4432 & TRN & \\
\hline CHEMBL1332165 & 688816 & 4.45 & 5.0291 & TRN & \\
\hline CHEMBL1384388 & 688816 & 4.95 & 5.0294 & TRN & \\
\hline CHEMBL1351610 & 688816 & 4.95 & 5.2455 & TST & \\
\hline CHEMBL1451721 & 688816 & 5.05 & 4.9012 & TST & \\
\hline & & & & 24810 & \\
\hline
\end{tabular}




\begin{tabular}{|c|c|c|c|c|}
\hline \multicolumn{5}{|c|}{ Supplemental Table S2.txt } \\
\hline CHEMBL1387948 & 688816 & 4.7 & 5.0901 & TRN \\
\hline CHEMBL1354598 & 688816 & 5.25 & 4.6814 & TST \\
\hline CHEMBL1422144 & 688816 & 4.9 & 5.4498 & TST \\
\hline CHEMBL 3198860 & 688816 & 5.4 & 5.2462 & TRN \\
\hline CHEMBL1535245 & 688816 & 4.9 & 5.0775 & TRN \\
\hline CHEMBL1596744 & 688816 & 4.8 & 5.3225 & TRN \\
\hline CHEMBL1483331 & 688816 & 4.45 & 5.2896 & TRN \\
\hline CHEMBL1517542 & 688816 & 4.85 & 5.2413 & TRN \\
\hline CHEMBL1600048 & 688816 & 8.3979 & 5.2522 & TST \\
\hline CHEMBL1378399 & 688816 & 4.8 & 5.1887 & TRN \\
\hline CHEMBL1302921 & 688816 & 5.25 & 5.4811 & TST \\
\hline CHEMBL1536478 & 688816 & 5.1 & 5.2662 & TRN \\
\hline CHEMBL1455975 & 688816 & 4.95 & 5.2345 & TST \\
\hline CHEMBL1446252 & 688816 & 8.301 & 5.8396 & TST \\
\hline CHEMBL1441254 & 688816 & 4.65 & 5.1985 & TRN \\
\hline CHEMBL1452795 & 688816 & 5.9 & 5.5097 & TST \\
\hline CHEMBL3198788 & 688816 & 5.0 & 5.4551 & TRN \\
\hline CHEMBL99408 & 688816 & 6.45 & 5.4417 & TST \\
\hline CHEMBL1414589 & 688816 & 4.55 & 5.3149 & TRN \\
\hline CHEMBL1566716 & 688816 & 6.8499 & 5.4054 & TRN \\
\hline CHEMBL1328930 & 688816 & 4.95 & 5.1653 & TRN \\
\hline CHEMBL1492000 & 688816 & 5.05 & 5.3155 & TST \\
\hline CHEMBL1394612 & 688816 & 4.45 & 5.0484 & TRN \\
\hline CHEMBL1524053 & 688816 & 4.95 & 5.3303 & TRN \\
\hline CHEMBL1580587 & 688816 & 5.2 & 5.0851 & TRN \\
\hline CHEMBL1517431 & 688816 & 4.9 & 5.2931 & TST \\
\hline CHEMBL1347185 & 688816 & 4.45 & 5.4454 & TRN \\
\hline CHEMBL1543818 & 688816 & 5.6 & 5.2261 & TRN \\
\hline CHEMBL1601148 & 688816 & 4.95 & 5.3997 & TST \\
\hline CHEMBL1428502 & 688816 & 5.0 & 5.1397 & TRN \\
\hline CHEMBL1568733 & 688816 & 4.9 & 5.818 & TRN \\
\hline CHEMBL1462522 & 688816 & 4.9 & 5.2568 & TRN \\
\hline CHEMBL1304837 & 688816 & 4.95 & 4.8172 & TRN \\
\hline CHEMBL1346555 & 688816 & 4.85 & 5.2195 & TRN \\
\hline CHEMBL1321877 & 688816 & 5.75 & 5.5085 & TRN \\
\hline CHEMBL1427039 & 688816 & 5.05 & 5.2299 & TRN \\
\hline CHEMBL1337445 & 688816 & 4.65 & 4.9544 & TST \\
\hline CHEMBL1534496 & 688816 & 4.95 & 5.3766 & TRN \\
\hline CHEMBL1382331 & 688816 & 5.25 & 5.2784 & TST \\
\hline CHEMBL1316087 & 688816 & 4.9 & 4.9242 & TRN \\
\hline CHEMBL3192296 & 688816 & 4.95 & 5.4082 & TRN \\
\hline CHEMBL1479449 & 688816 & 4.95 & 5.1887 & TRN \\
\hline CHEMBL1532105 & 688816 & 5.0 & 5.0557 & TRN \\
\hline CHEMBL1512157 & 688816 & 4.8 & 4.9973 & TRN \\
\hline CHEMBL1430921 & 688816 & 5.25 & 5.2927 & TRN \\
\hline CHEMBL1569625 & 688816 & 4.45 & 5.0283 & TST \\
\hline CHEMBL1339711 & 688816 & 5.35 & 5.4193 & TRN \\
\hline CHEMBL1540134 & 688816 & 4.9 & 5.3286 & TRN \\
\hline
\end{tabular}




\begin{tabular}{|c|c|c|c|c|c|}
\hline \multicolumn{6}{|c|}{ Supplemental Table S2.txt } \\
\hline CHEMBL1484452 & 688816 & 4.6 & 5.4546 & TST & \\
\hline CHEMBL1348074 & 688816 & 4.8 & 5.3585 & TST & \\
\hline CHEMBL1309211 & 688816 & 8.3468 & 5.3968 & TST & \\
\hline CHEMBL1446282 & 688816 & 4.45 & 5.1173 & TRN & \\
\hline CHEMBL1391488 & 688816 & 4.6 & 5.1158 & TRN & \\
\hline CHEMBL1486390 & 688816 & 4.95 & 5.1267 & TRN & \\
\hline CHEMBL1322899 & 688816 & 4.8 & 5.5258 & TRN & \\
\hline CHEMBL1415890 & 688816 & 5.2 & 5.1685 & TRN & \\
\hline CHEMBL1516211 & 688816 & 5.0 & 4.9284 & TRN & \\
\hline CHEMBL1511055 & 688816 & 8.6021 & 5.5951 & TST & \\
\hline CHEMBL1419031 & 688816 & 4.45 & 5.4152 & TRN & \\
\hline CHEMBL1408204 & 688816 & 4.7 & 5.0434 & TST & \\
\hline CHEMBL3207466 & 688816 & 4.9 & 5.0623 & TRN & \\
\hline CHEMBL1988416 & 688816 & 4.45 & 4.9987 & TST & \\
\hline CHEMBL1416992 & 688816 & 4.45 & 5.2237 & TRN & \\
\hline CHEMBL1409512 & 688816 & 5.5 & 5.6134 & TST & \\
\hline CHEMBL1311534 & 688816 & 5.25 & 5.5331 & TRN & \\
\hline CHEMBL3198492 & 688816 & 5.05 & 5.1484 & TRN & \\
\hline CHEMBL1525583 & 688816 & 7.6003 & 5.2147 & TST & \\
\hline CHEMBL1377784 & 688816 & 5.55 & 5.0798 & TRN & \\
\hline CHEMBL1532478 & 688816 & 6.7001 & 5.2903 & TRN & \\
\hline CHEMBL1458022 & 688816 & 5.55 & 5.6979 & TST & \\
\hline CHEMBL1309672 & 688816 & 7.0501 & 5.1384 & TRN & \\
\hline CHEMBL1347459 & 688816 & 4.75 & 5.237 & TRN & \\
\hline CHEMBL464433 & 688816 & 4.9 & 5.3216 & TRN & \\
\hline CHEMBL1401309 & 688816 & 4.9 & 5.0338 & TRN & \\
\hline CHEMBL1413291 & 688816 & 5.2 & 4.9082 & TRN & \\
\hline CHEMBL1400938 & 688816 & 5.0 & 5.5834 & TRN & \\
\hline CHEMBL1535737 & 688816 & 5.05 & 5.2338 & TRN & \\
\hline CHEMBL1489074 & 688816 & 4.9 & 5.2209 & TRN & \\
\hline CHEMBL1982290 & 688816 & 4.9 & 5.3942 & TST & \\
\hline CHEMBL1554592 & 688816 & 4.9 & 5.3507 & TRN & \\
\hline CHEMBL1461043 & 688816 & 4.7 & 4.9711 & TRN & \\
\hline CHEMBL1532391 & 688816 & 8.3468 & 5.581 & TRN & \\
\hline CHEMBL3211959 & 688816 & 5.15 & 5.5692 & TST & \\
\hline CHEMBL1606695 & 688816 & 4.55 & 5.3212 & TRN & \\
\hline CHEMBL1555494 & 688816 & 5.25 & 4.995 & TRN & \\
\hline CHEMBL1607516 & 688816 & 4.45 & 4.9749 & TRN & \\
\hline CHEMBL1569096 & 688816 & 4.45 & 5.20299 & 9999999999 & TRN \\
\hline CHEMBL1490406 & 688816 & 4.55 & 5.2581 & TRN & \\
\hline CHEMBL1387618 & 688816 & 6.7501 & 5.4056 & TST & \\
\hline CHEMBL3209652 & 688816 & 4.95 & 5.2253 & TRN & \\
\hline CHEMBL1418789 & 688816 & 4.95 & 5.1844 & TRN & \\
\hline CHEMBL1579923 & 688816 & 6.0 & 5.2006 & TRN & \\
\hline CHEMBL1454802 & 688816 & 7.8508 & 5.0931 & TRN & \\
\hline CHEMBL1395944 & 688816 & 5.25 & 4.8102 & TRN & \\
\hline CHEMBL1348144 & 688816 & 6.0 & 5.2996 & TRN & \\
\hline CHEMBL1361088 & 688816 & 5.15 & 5.1419 & TRN & \\
\hline
\end{tabular}




\begin{tabular}{|c|c|c|c|c|c|}
\hline \multicolumn{6}{|c|}{ Supplemental Table S2.txt } \\
\hline CHEMBL1533030 & 688816 & 4.45 & 5.0824 & TRN & \\
\hline CHEMBL1526812 & 688816 & 4.45 & 5.4073 & TST & \\
\hline CHEMBL1422053 & 688816 & 5.0 & 4.9679 & TRN & \\
\hline CHEMBL1347778 & 688816 & 4.95 & 5.2439 & TRN & \\
\hline CHEMBL3211024 & 688816 & 7.2503 & 5.5696 & TRN & \\
\hline CHEMBL1563187 & 688816 & 4.85 & 5.0627 & TRN & \\
\hline CHEMBL3213935 & 688816 & 7.6498 & 5.5608 & TRN & \\
\hline CHEMBL1412855 & 688816 & 5.3 & 5.4255 & TRN & \\
\hline CHEMBL1462215 & 688816 & 6.25 & 5.1308 & TST & \\
\hline CHEMBL 233895 & 688816 & 4.45 & 5.1348 & TRN & \\
\hline CHEMBL1425730 & 688816 & 5.2 & 5.49700 & 2000000001 & TRN \\
\hline CHEMBL1321054 & 688816 & 5.2 & 5.2633 & TRN & \\
\hline CHEMBL1477153 & 688816 & 4.95 & 5.0245 & TRN & \\
\hline CHEMBL1348875 & 688816 & 5.3 & 5.4657 & TRN & \\
\hline CHEMBL1532449 & 688816 & 7.1002 & 5.3545 & TST & \\
\hline CHEMBL1458083 & 688816 & 4.8 & 5.2564 & TRN & \\
\hline CHEMBL1471008 & 688816 & 4.9 & 5.2736 & TRN & \\
\hline CHEMBL1493204 & 688816 & 4.8 & 5.1402 & TST & \\
\hline CHEMBL1336924 & 688816 & 4.9 & 5.25200 & 0000000001 & TRN \\
\hline CHEMBL1518562 & 688816 & 4.65 & 5.1086 & TRN & \\
\hline CHEMBL340416 & 688816 & 5.2 & 5.3867 & TST & \\
\hline CHEMBL1484417 & 688816 & 5.6 & 5.0392 & TRN & \\
\hline CHEMBL1571570 & 688816 & 5.3 & 4.9599 & TRN & \\
\hline CHEMBL1498301 & 688816 & 4.75 & 4.7679 & TRN & \\
\hline CHEMBL3211193 & 688816 & 4.6 & 5.1291 & TRN & \\
\hline CHEMBL1332869 & 688816 & 4.45 & 5.7534 & TRN & \\
\hline CHEMBL1607407 & 688816 & 5.4 & 5.2435 & TRN & \\
\hline CHEMBL1411171 & 688816 & 7.6498 & 5.7249 & TRN & \\
\hline CHEMBL1351986 & 688816 & 4.7 & 5.3361 & TRN & \\
\hline CHEMBL1364417 & 688816 & 4.75 & 4.9799 & TRN & \\
\hline CHEMBL1378158 & 688816 & 4.45 & 4.8871 & TRN & \\
\hline CHEMBL1584622 & 688816 & 5.45 & 5.2185 & TST & \\
\hline CHEMBL1404376 & 688816 & 4.95 & 4.9491 & TST & \\
\hline CHEMBL1558490 & 688816 & 5.55 & 5.6304 & TRN & \\
\hline CHEMBL1550570 & 688816 & 4.95 & 5.5781 & TRN & \\
\hline CHEMBL1592095 & 688816 & 4.75 & 5.9911 & TST & \\
\hline CHEMBL1409944 & 688816 & 4.8 & 5.33 & TST & \\
\hline CHEMBL1303278 & 688816 & 8.2007 & 5.441 & TRN & \\
\hline CHEMBL1391852 & 688816 & 7.4001 & 5.2868 & TRN & \\
\hline CHEMBL1438725 & 688816 & 5.7 & 5.1641 & TRN & \\
\hline CHEMBL1487794 & 688816 & 7.7496 & 5.4312 & TRN & \\
\hline CHEMBL1497197 & 688816 & 4.75 & 5.403 & TST & \\
\hline CHEMBL1310690 & 688816 & 5.6 & 4.9045 & TRN & \\
\hline CHEMBL1341999 & 688816 & 4.85 & 5.032 & TRN & \\
\hline CHEMBL1526316 & 688816 & 4.7 & 5.3159 & TRN & \\
\hline CHEMBL1987417 & 688816 & 4.65 & 4.9439 & TRN & \\
\hline CHEMBL1611758 & 688816 & 5.0 & 5.1362 & TRN & \\
\hline CHEMBL1338882 & 688816 & 4.45 & 5.1196 & TST & \\
\hline
\end{tabular}




\begin{tabular}{|c|c|c|c|c|c|}
\hline \multicolumn{6}{|c|}{ Supplemental Table S2.txt } \\
\hline CHEMBL1419250 & 688816 & 5.6 & 4.9419 & TST & \\
\hline CHEMBL1606583 & 688816 & 5.15 & 4.9607 & TRN & \\
\hline CHEMBL1409622 & 688816 & 4.95 & 5.0994 & TRN & \\
\hline CHEMBL1306971 & 688816 & 4.85 & 5.1005 & TRN & \\
\hline CHEMBL1483568 & 688816 & 4.7 & 5.357 & TRN & \\
\hline CHEMBL1498276 & 688816 & 5.5 & 5.1229 & TRN & \\
\hline CHEMBL1580915 & 688816 & 5.1 & 5.6194 & TRN & \\
\hline CHEMBL1441108 & 688816 & 8.3468 & 5.2614 & TST & \\
\hline CHEMBL1370834 & 688816 & 4.95 & 5.3248 & TRN & \\
\hline CHEMBL1531369 & 688816 & 8.4949 & 5.3539 & TRN & \\
\hline CHEMBL1421547 & 688816 & 4.9 & 4.9272 & TRN & \\
\hline CHEMBL3195298 & 688816 & 4.65 & 5.1516 & TST & \\
\hline CHEMBL1304206 & 688816 & 4.65 & 5.0835 & TRN & \\
\hline CHEMBL1381653 & 688816 & 4.95 & 5.4893 & TRN & \\
\hline CHEMBL1382944 & 688816 & 4.95 & 5.2806 & TST & \\
\hline CHEMBL1490582 & 688816 & 4.85 & 5.2073 & TRN & \\
\hline CHEMBL1450690 & 688816 & 5.35 & 4.8657 & TRN & \\
\hline CHEMBL1580773 & 688816 & 4.45 & 5.0086 & TRN & \\
\hline CHEMBL1510852 & 688816 & 5.55 & 5.096 & TRN & \\
\hline CHEMBL1510792 & 688816 & 5.6 & 5.1688 & TRN & \\
\hline CHEMBL1374156 & 688816 & 5.6 & 5.3327 & TRN & \\
\hline CHEMBL1322396 & 688816 & 6.8 & 5.3983 & TRN & \\
\hline CHEMBL1611453 & 688816 & 4.95 & 5.0282 & TRN & \\
\hline CHEMBL1335513 & 688816 & 7.2 & 5.3588 & TRN & \\
\hline CHEMBL1557041 & 688816 & 8.3468 & 5.5572 & TRN & \\
\hline CHEMBL1588873 & 688816 & 4.95 & 5.0195 & TRN & \\
\hline CHEMBL1467157 & 688816 & 4.7 & 5.279 & TRN & \\
\hline CHEMBL1513373 & 688816 & 4.45 & 5.0628 & TRN & \\
\hline CHEMBL3199125 & 688816 & 4.9 & 5.0783 & TRN & \\
\hline CHEMBL3209305 & 688816 & 4.7 & 5.2326 & TRN & \\
\hline CHEMBL3207922 & 688816 & 4.65 & 5.2317 & TRN & \\
\hline CHEMBL1600229 & 688816 & 4.85 & 5.2325 & TRN & \\
\hline CHEMBL1485437 & 688816 & 6.6 & 5.4486 & TRN & \\
\hline CHEMBL1396707 & 688816 & 4.7 & 5.0519 & TRN & \\
\hline CHEMBL1580050 & 688816 & 4.8 & 5.21700 & 00000000005 & TRN \\
\hline CHEMBL1509116 & 688816 & 5.25 & 5.306 & TRN & \\
\hline CHEMBL1411505 & 688816 & 5.3 & 5.3488 & TRN & \\
\hline CHEMBL1325063 & 688816 & 4.45 & 5.0795 & TST & \\
\hline CHEMBL1507805 & 688816 & 4.5 & 5.6576 & TST & \\
\hline CHEMBL1362605 & 688816 & 4.4 & 5.28100 & $\partial 000000001$ & TRN \\
\hline CHEMBL1590379 & 688816 & 5.55 & 5.3624 & TRN & \\
\hline CHEMBL1381780 & 688816 & 4.45 & 5.1328 & TRN & \\
\hline CHEMBL1428652 & 688816 & 5.0 & 5.5284 & TST & \\
\hline CHEMBL1349677 & 688816 & 8.1487 & 5.2624 & TRN & \\
\hline CHEMBL1500772 & 688816 & 4.95 & 5.2198 & TRN & \\
\hline CHEMBL1488260 & 688816 & 4.9 & 5.1422 & TRN & \\
\hline CHEMBL1443546 & 688816 & 7.6498 & 4.9112 & TST & \\
\hline CHEMBL1495508 & 688816 & 5.45 & 5.6328 & TRN & \\
\hline
\end{tabular}




\begin{tabular}{|c|c|c|c|c|}
\hline & & & pplement & al $\mathrm{T}$ \\
\hline CHEMBL1325178 & 688816 & 4.6 & 5.2339 & TRN \\
\hline CHEMBL1452424 & 688816 & 5.0 & 5.3554 & TRN \\
\hline CHEMBL1582938 & 688816 & 4.8 & 4.9069 & TRN \\
\hline CHEMBL1333661 & 688816 & 4.9 & 5.2489 & TST \\
\hline CHEMBL1405644 & 688816 & 4.5 & 5.3881 & TRN \\
\hline CHEMBL1425419 & 688816 & 4.65 & 4.9569 & TRN \\
\hline CHEMBL1412531 & 688816 & 5.5 & 5.2525 & TRN \\
\hline CHEMBL1505091 & 688816 & 5.05 & 5.2196 & TRN \\
\hline CHEMBL1509590 & 688816 & 4.95 & 5.0182 & TST \\
\hline CHEMBL1507821 & 688816 & 5.3 & 5.2385 & TRN \\
\hline CHEMBL1456516 & 688816 & 8.3468 & 5.6223 & TRN \\
\hline CHEMBL1495184 & 688816 & 4.65 & 5.1013 & TRN \\
\hline CHEMBL600554 & 688816 & 4.9 & 5.2229 & TRN \\
\hline CHEMBL1347610 & 688816 & 4.85 & 5.4322 & TRN \\
\hline CHEMBL1413364 & 688816 & 6.0 & 5.3191 & TST \\
\hline CHEMBL1330106 & 688816 & 4.9 & 5.2472 & TST \\
\hline CHEMBL1499925 & 688816 & 4.8 & 5.0604 & TRN \\
\hline CHEMBL1422361 & 688816 & 4.85 & 5.0492 & TRN \\
\hline CHEMBL1567428 & 688816 & 5.6 & 5.5145 & TRN \\
\hline CHEMBL1496023 & 688816 & 5.5 & 5.4797 & TRN \\
\hline CHEMBL1490903 & 688816 & 4.95 & 5.5665 & TRN \\
\hline CHEMBL1330735 & 688816 & 4.6 & 5.1521 & TRN \\
\hline CHEMBL54727 & 688816 & 4.75 & 5.206 & TST \\
\hline CHEMBL1572320 & 688816 & 5.55 & 5.4684 & TST \\
\hline CHEMBL1372905 & 688816 & 5.5 & 5.334 & TRN \\
\hline CHEMBL1422138 & 688816 & 5.8 & 5.0992 & TRN \\
\hline CHEMBL1351713 & 688816 & 5.85 & 5.2278 & TRN \\
\hline CHEMBL1392265 & 688816 & 4.85 & 5.1282 & TRN \\
\hline CHEMBL1462760 & 688816 & 4.95 & 5.4711 & TRN \\
\hline CHEMBL1387072 & 688816 & 5.45 & 5.3261 & TRN \\
\hline CHEMBL1588173 & 688816 & 5.45 & 4.7248 & TST \\
\hline CHEMBL1499015 & 688816 & 4.75 & 5.2843 & TRN \\
\hline CHEMBL1480087 & 688816 & 5.55 & 5.3061 & TRN \\
\hline CHEMBL 3190343 & 688816 & 4.45 & 5.1588 & TST \\
\hline CHEMBL1375163 & 688816 & 7.0501 & 5.1885 & TST \\
\hline CHEMBL1510486 & 688816 & 4.45 & 5.2834 & TRN \\
\hline CHEMBL1516259 & 688816 & 5.15 & 5.2773 & TRN \\
\hline CHEMBL1332670 & 688816 & 4.95 & 5.3803 & TST \\
\hline CHEMBL1571231 & 688816 & 5.55 & 5.8895 & TRN \\
\hline CHEMBL1311916 & 688816 & 4.8 & 5.2962 & TRN \\
\hline CHEMBL1507548 & 688816 & 4.45 & 5.1623 & TRN \\
\hline CHEMBL1342710 & 688816 & 5.05 & 5.4548 & TRN \\
\hline CHEMBL3198186 & 688816 & 5.0 & 5.0365 & TRN \\
\hline CHEMBL1300125 & 688816 & 5.65 & 5.2244 & TST \\
\hline CHEMBL1481597 & 688816 & 4.45 & 4.9 & TRN \\
\hline CHEMBL1501828 & 688816 & 4.6 & 4.9253 & TRN \\
\hline CHEMBL1352041 & 688816 & 4.45 & 5.2797 & TST \\
\hline CHEMBL1438075 & 688816 & 5.0 & 5.4613 & TST \\
\hline
\end{tabular}




\begin{tabular}{|c|c|c|c|c|c|}
\hline \multicolumn{6}{|c|}{ Supplemental Table S2.txt } \\
\hline CHEMBL1487872 & 688816 & 5.5 & 5.2138 & TRN & \\
\hline CHEMBL1408530 & 688816 & 4.65 & 5.3761 & TST & \\
\hline CHEMBL1557658 & 688816 & 4.9 & 5.2763 & TRN & \\
\hline CHEMBL1314369 & 688816 & 4.9 & 5.1733 & TST & \\
\hline CHEMBL1374211 & 688816 & 4.95 & 5.0028 & TRN & \\
\hline CHEMBL3193678 & 688816 & 5.4 & 5.562 & TST & \\
\hline CHEMBL1335277 & 688816 & 6.8 & 5.1726 & TRN & \\
\hline CHEMBL1495299 & 688816 & 4.45 & 5.0692 & TRN & \\
\hline CHEMBL1609199 & 688816 & 4.8 & 5.1521 & TRN & \\
\hline CHEMBL1516459 & 688816 & 4.9 & 5.6737 & TST & \\
\hline CHEMBL1303757 & 688816 & 8.0506 & 5.6448 & TST & \\
\hline CHEMBL1545205 & 688816 & 5.3 & 4.9158 & TST & \\
\hline CHEMBL1993662 & 688816 & 5.4 & 5.1095 & TRN & \\
\hline CHEMBL1433269 & 688816 & 4.85 & 5.4463 & TST & \\
\hline CHEMBL 2004950 & 688816 & 5.45 & 5.3451 & TRN & \\
\hline CHEMBL1383945 & 688816 & 6.45 & 5.2532 & TRN & \\
\hline CHEMBL1388710 & 688816 & 4.5 & 5.2504 & TRN & \\
\hline CHEMBL1503249 & 688816 & 5.5 & 5.4282 & TRN & \\
\hline CHEMBL1414053 & 688816 & 6.7001 & 5.1397 & TRN & \\
\hline CHEMBL1424882 & 688816 & 6.5 & 5.3364 & TRN & \\
\hline CHEMBL1547182 & 688816 & 4.8 & 5.2991 & TRN & \\
\hline CHEMBL1303283 & 688816 & 4.9 & 5.5606 & TRN & \\
\hline CHEMBL1500876 & 688816 & 4.95 & 5.1197 & TRN & \\
\hline CHEMBL1351239 & 688816 & 4.65 & 5.2759 & TRN & \\
\hline CHEMBL1496895 & 688816 & 5.75 & 5.1636 & TRN & \\
\hline CHEMBL1310207 & 688816 & 5.4 & 5.5035 & TST & \\
\hline CHEMBL1457013 & 688816 & 4.65 & 5.4158 & TST & \\
\hline CHEMBL1548408 & 688816 & 4.95 & 5.2142 & TRN & \\
\hline CHEMBL1566138 & 688816 & 4.45 & 5.4548 & TST & \\
\hline CHEMBL1400851 & 688816 & 4.7 & 5.2529 & TRN & \\
\hline CHEMBL1580795 & 688816 & 4.65 & 5.9386 & TST & \\
\hline CHEMBL1973921 & 688816 & 5.7 & 5.3282 & TRN & \\
\hline CHEMBL3196224 & 688816 & 4.75 & 5.2958 & TRN & \\
\hline CHEMBL1329474 & 688816 & 4.4 & 4.9574 & TST & \\
\hline CHEMBL3197555 & 688816 & 4.8 & 5.2105 & TRN & \\
\hline CHEMBL1330201 & 688816 & 4.9 & 4.9441 & TRN & \\
\hline CHEMBL1366347 & 688816 & 6.15 & 5.1905 & TRN & \\
\hline CHEMBL3193392 & 688816 & 5.7 & 5.3035 & TRN & \\
\hline CHEMBL1547657 & 688816 & 7.6003 & 5.8047 & TRN & \\
\hline CHEMBL1410130 & 688816 & 4.45 & 5.4667 & TRN & \\
\hline CHEMBL3197371 & 688816 & 4.65 & 5.1347 & TST & \\
\hline CHEMBL1498712 & 688816 & 5.2 & 5.3706 & TRN & \\
\hline CHEMBL1527530 & 688816 & 5.1 & 4.945 & TRN & \\
\hline CHEMBL3211421 & 688816 & 5.45 & 5.32600 & 00000000005 & TRN \\
\hline CHEMBL1542892 & 688816 & 7.3497 & 5.3488 & TRN & \\
\hline CHEMBL1311676 & 688816 & 5.0 & 5.2413 & TRN & \\
\hline CHEMBL1503377 & 688816 & 4.95 & 5.3009 & TST & \\
\hline CHEMBL3194734 & 688816 & 6.1 & 5.1731 & TRN & \\
\hline
\end{tabular}




\begin{tabular}{|c|c|c|c|c|c|}
\hline \multicolumn{6}{|c|}{ Supplemental Table S2.txt } \\
\hline CHEMBL1417505 & 688816 & 4.95 & 5.3752 & TRN & \\
\hline CHEMBL1328931 & 688816 & 4.75 & 5.396 & TRN & \\
\hline CHEMBL1328117 & 688816 & 4.9 & 5.0405 & TRN & \\
\hline CHEMBL1407648 & 688816 & 4.95 & 5.0295 & TRN & \\
\hline CHEMBL1586759 & 688816 & 5.25 & 5.143 & TRN & \\
\hline CHEMBL1494654 & 688816 & 4.75 & 5.0566 & TRN & \\
\hline CHEMBL1389540 & 688816 & 4.95 & 5.1431 & TRN & \\
\hline CHEMBL1422980 & 688816 & 5.4 & 4.9921 & TRN & \\
\hline CHEMBL1534277 & 688816 & 4.9 & 5.35 & TRN & \\
\hline CHEMBL1540098 & 688816 & 4.9 & 5.2379 & TST & \\
\hline CHEMBL1416501 & 688816 & 4.85 & 5.2847 & TRN & \\
\hline CHEMBL1500851 & 688816 & 5.0 & 5.0644 & TRN & \\
\hline CHEMBL1462987 & 688816 & 5.6 & 5.3154 & TRN & \\
\hline CHEMBL1450461 & 688816 & 4.45 & 4.9297 & TRN & \\
\hline CHEMBL1592678 & 688816 & 4.45 & 5.0817 & TRN & \\
\hline CHEMBL1311724 & 688816 & 4.95 & 5.2626 & TRN & \\
\hline CHEMBL3212721 & 688816 & 6.4 & 5.5009 & TRN & \\
\hline CHEMBL1418888 & 688816 & 5.45 & 5.2076 & TST & \\
\hline CHEMBL1370510 & 688816 & 5.1 & 5.5176 & TST & \\
\hline CHEMBL1522482 & 688816 & 4.55 & 5.1699 & TRN & \\
\hline CHEMBL1515438 & 688816 & 6.1 & 5.5851 & TRN & \\
\hline CHEMBL1565632 & 688816 & 5.0 & 5.4555 & TST & \\
\hline CHEMBL1589738 & 688816 & 5.6 & 5.2624 & TRN & \\
\hline CHEMBL1413104 & 688816 & 5.1 & 5.1764 & TRN & \\
\hline CHEMBL1464097 & 688816 & 5.75 & 5.4163 & TST & \\
\hline CHEMBL1580472 & 688816 & 4.6 & 5.1104 & TRN & \\
\hline CHEMBL1432463 & 688816 & 7.3497 & 5.2515 & TRN & \\
\hline CHEMBL1348563 & 688816 & 8.3468 & 5.6321 & TRN & \\
\hline CHEMBL1317167 & 688816 & 4.45 & 5.4813 & TRN & \\
\hline CHEMBL1362958 & 688816 & 7.5003 & 5.4891 & TST & \\
\hline CHEMBL1438817 & 688816 & 6.8 & 5.1368 & TST & \\
\hline CHEMBL1517259 & 688816 & 4.45 & 5.04899 & 99999999995 & TRN \\
\hline CHEMBL1333390 & 688816 & 4.85 & 4.9304 & TRN & \\
\hline CHEMBL1307025 & 688816 & 4.45 & 5.1516 & TRN & \\
\hline CHEMBL1605552 & 688816 & 4.6 & 4.8242 & TRN & \\
\hline CHEMBL1466963 & 688816 & 5.5 & 4.8562 & TRN & \\
\hline CHEMBL1465154 & 688816 & 4.45 & 4.94600 & 0000000001 & TRN \\
\hline CHEMBL3197290 & 688816 & 4.45 & 5.5544 & TRN & \\
\hline CHEMBL1601731 & 688816 & 4.8 & 5.1283 & TRN & \\
\hline CHEMBL1303766 & 688816 & 5.5 & 5.3361 & TRN & \\
\hline CHEMBL1523636 & 688816 & 4.45 & 5.1237 & TRN & \\
\hline CHEMBL1345927 & 688816 & 5.45 & 5.5788 & TRN & \\
\hline CHEMBL1352966 & 688816 & 8.3468 & 5.5515 & TRN & \\
\hline CHEMBL1305054 & 688816 & 4.45 & 5.4198 & TRN & \\
\hline CHEMBL1454991 & 688816 & 5.3 & 5.3344 & TRN & \\
\hline CHEMBL1459263 & 688816 & 4.65 & 4.8155 & TRN & \\
\hline CHEMBL1588416 & 688816 & 4.45 & 4.9898 & TRN & \\
\hline CHEMBL1577592 & 688816 & 4.45 & 5.4592 & TRN & \\
\hline
\end{tabular}




\begin{tabular}{|c|c|c|c|c|c|}
\hline \multicolumn{6}{|c|}{ Supplemental Table s2.txt } \\
\hline CHEMBL1390385 & 688816 & 5.1 & 5.5625 & TRN & \\
\hline CHEMBL1589672 & 688816 & 5.25 & 5.4951 & TST & \\
\hline CHEMBL1468050 & 688816 & 5.3 & 5.4251 & TST & \\
\hline CHEMBL1394736 & 688816 & 4.9 & 5.4289 & TST & \\
\hline CHEMBL1455877 & 688816 & 4.9 & 5.223 & TRN & \\
\hline CHEMBL1422352 & 688816 & 4.9 & 4.8654 & TRN & \\
\hline CHEMBL1307185 & 688816 & 4.85 & 4.9463 & TST & \\
\hline CHEMBL1516833 & 688816 & 4.9 & 5.4032 & TST & \\
\hline CHEMBL1567643 & 688816 & 5.05 & 5.2042 & TRN & \\
\hline CHEMBL1426359 & 688816 & 4.75 & 5.6907 & TRN & \\
\hline CHEMBL1325426 & 688816 & 4.45 & 5.2749 & TRN & \\
\hline CHEMBL1385762 & 688816 & 6.9 & 5.1735 & TST & \\
\hline CHEMBL1388163 & 688816 & 4.9 & 5.2467 & TRN & \\
\hline CHEMBL1388364 & 688816 & 4.45 & 5.1586 & TRN & \\
\hline CHEMBL3196546 & 688816 & 4.95 & 5.2696 & TRN & \\
\hline CHEMBL1595765 & 688816 & 4.9 & 5.2258 & TRN & \\
\hline CHEMBL1346168 & 688816 & 5.05 & 5.1436 & TRN & \\
\hline CHEMBL 3207447 & 688816 & 4.95 & 5.782 & TRN & \\
\hline CHEMBL1363708 & 688816 & 5.15 & 5.5968 & TRN & \\
\hline CHEMBL3199524 & 688816 & 6.8 & 5.3731 & TST & \\
\hline CHEMBL1495165 & 688816 & 5.45 & 5.2967 & TRN & \\
\hline CHEMBL1383475 & 688816 & 4.9 & 5.1391 & TRN & \\
\hline CHEMBL1585541 & 688816 & 4.6 & 5.3655 & TRN & \\
\hline CHEMBL1353108 & 688816 & 4.45 & 5.0411 & TST & \\
\hline CHEMBL1410358 & 688816 & 4.45 & 5.534 & TST & \\
\hline CHEMBL1437413 & 688816 & 4.95 & 5.1529 & TRN & \\
\hline CHEMBL1547946 & 688816 & 4.45 & 5.3003 & TST & \\
\hline CHEMBL1363582 & 688816 & 4.9 & 5.2479 & TST & \\
\hline CHEMBL1541522 & 688816 & 4.9 & 5.2918 & TRN & \\
\hline CHEMBL1980889 & 688816 & 4.8 & $5.1320 e$ & 0000000001 & TRN \\
\hline CHEMBL1542533 & 688816 & 4.95 & 5.121 & TST & \\
\hline CHEMBL1516552 & 688816 & 4.65 & 5.2313 & TRN & \\
\hline CHEMBL1575693 & 688816 & 5.05 & 6.1182 & TST & \\
\hline CHEMBL1460795 & 688816 & 5.4 & 5.2009 & TST & \\
\hline CHEMBL1346466 & 688816 & 4.45 & 5.2466 & TRN & \\
\hline CHEMBL1490510 & 688816 & 5.45 & 5.5359 & TRN & \\
\hline CHEMBL1316178 & 688816 & 5.0 & 5.4393 & TRN & \\
\hline CHEMBL1357890 & 688816 & 4.85 & 4.9875 & TRN & \\
\hline CHEMBL1417554 & 688816 & 4.9 & 5.1285 & TRN & \\
\hline CHEMBL1362712 & 688816 & 4.45 & 5.0154 & TRN & \\
\hline CHEMBL1373978 & 688816 & 4.9 & 5.1281 & TRN & \\
\hline CHEMBL1417953 & 688816 & 4.45 & 5.2829 & TRN & \\
\hline CHEMBL1312395 & 688816 & 6.8 & 5.4669 & TST & \\
\hline CHEMBL408653 & 688816 & 6.15 & 5.0316 & TRN & \\
\hline CHEMBL1389668 & 688816 & 4.75 & 5.2582 & TRN & \\
\hline CHEMBL1477013 & 688816 & 5.3 & 5.2772 & TST & \\
\hline CHEMBL3194031 & 688816 & 4.85 & 5.2308 & TRN & \\
\hline CHEMBL1373805 & 688816 & 8.3468 & 5.71899 & 9999999999 & TRN \\
\hline & & & & 2481 & \\
\hline
\end{tabular}




\begin{tabular}{|c|c|c|c|c|c|}
\hline \multicolumn{6}{|c|}{ Supplemental Table S2.txt } \\
\hline CHEMBL1378914 & 688816 & 4.9 & 5.1927 & TRN & \\
\hline CHEMBL1562275 & 688816 & 7.5498 & 5.6574 & TRN & \\
\hline CHEMBL1409214 & 688816 & 7.699 & 5.3463 & TST & \\
\hline CHEMBL1309808 & 688816 & 4.65 & 5.2572 & TRN & \\
\hline CHEMBL1329235 & 688816 & 5.2 & 5.2362 & TRN & \\
\hline CHEMBL1311924 & 688816 & 6.7501 & 5.6907 & TST & \\
\hline CHEMBL1489205 & 688816 & 4.85 & 5.0144 & TRN & \\
\hline CHEMBL1540904 & 688816 & 4.4 & 5.5058 & TRN & \\
\hline CHEMBL1383855 & 688816 & 4.85 & 5.3368 & TRN & \\
\hline CHEMBL1561979 & 688816 & 4.85 & 4.904 & TRN & \\
\hline CHEMBL3196340 & 688816 & 5.25 & 5.309 & TRN & \\
\hline CHEMBL1608334 & 688816 & 5.85 & 4.7191 & TRN & \\
\hline CHEMBL3210630 & 688816 & 4.75 & 5.4048 & TRN & \\
\hline CHEMBL1548802 & 688816 & 5.45 & 5.4624 & TST & \\
\hline CHEMBL1304579 & 688816 & 4.75 & 4.9998 & TRN & \\
\hline CHEMBL1384862 & 688816 & 4.65 & 5.0366 & TRN & \\
\hline CHEMBL1353544 & 688816 & 4.9 & 5.0699 & TRN & \\
\hline CHEMBL435539 & 688816 & 4.6 & 5.494 & TST & \\
\hline CHEMBL1412950 & 688816 & 5.0 & 5.4423 & TRN & \\
\hline CHEMBL1524921 & 688816 & 5.45 & 5.0572 & TRN & \\
\hline CHEMBL3211339 & 688816 & 4.8 & 5.3575 & TST & \\
\hline CHEMBL1505295 & 688816 & 4.9 & 5.4251 & TRN & \\
\hline CHEMBL3190736 & 688816 & 4.8 & 5.6212 & TST & \\
\hline CHEMBL1501282 & 688816 & 4.95 & 5.0259 & TRN & \\
\hline CHEMBL1465892 & 688816 & 7.6003 & 5.434 & TRN & \\
\hline CHEMBL1549875 & 688816 & 4.8 & 5.2319 & TRN & \\
\hline CHEMBL1600506 & 688816 & 5.2 & 5.2403 & TRN & \\
\hline CHEMBL1307207 & 688816 & 6.7001 & 5.2264 & TST & \\
\hline CHEMBL1326299 & 688816 & 4.9 & 5.3325 & TRN & \\
\hline CHEMBL1454427 & 688816 & 4.8 & 4.8336 & TRN & \\
\hline CHEMBL1467194 & 688816 & 4.7 & 5.3174 & TST & \\
\hline CHEMBL1548942 & 688816 & 4.95 & 5.1868 & TST & \\
\hline CHEMBL1581035 & 688816 & 5.2 & 4.9316 & TRN & \\
\hline CHEMBL1491079 & 688816 & 5.6 & 4.8288 & TRN & \\
\hline CHEMBL1360613 & 688816 & 5.2 & 5.2105 & TRN & \\
\hline CHEMBL1496488 & 688816 & 5.0 & 5.0486 & TST & \\
\hline CHEMBL399761 & 688816 & 9.0458 & 5.2394 & TRN & \\
\hline CHEMBL3213659 & 688816 & 4.45 & 4.7181 & TRN & \\
\hline CHEMBL1425166 & 688816 & 4.7 & 5.1719 & TRN & \\
\hline CHEMBL1464618 & 688816 & 4.45 & 5.0905 & TRN & \\
\hline CHEMBL1441265 & 688816 & 5.45 & 5.0368 & TRN & \\
\hline CHEMBL1330781 & 688816 & 4.45 & 5.3066 & TRN & \\
\hline CHEMBL1366819 & 688816 & 4.7 & 5.0668 & TRN & \\
\hline CHEMBL1561836 & 688816 & 4.9 & 5.25899 & 99999999995 & TRN \\
\hline CHEMBL1307635 & 688816 & 4.9 & 5.2242 & TRN & \\
\hline CHEMBL1391358 & 688816 & 4.95 & 5.3509 & TRN & \\
\hline CHEMBL1530710 & 688816 & 5.55 & 5.9015 & TRN & \\
\hline CHEMBL1611026 & 688816 & 4.7 & 5.3748 & TRN & \\
\hline
\end{tabular}




\begin{tabular}{|c|c|c|c|c|}
\hline & & & pplement & al $\mathrm{Tc}$ \\
\hline CHEMBL1538520 & 688816 & 8.301 & 5.6162 & TRN \\
\hline CHEMBL1581766 & 688816 & 4.75 & 5.4043 & TRN \\
\hline CHEMBL3189962 & 688816 & 5.9 & 5.4479 & TST \\
\hline CHEMBL1569257 & 688816 & 6.1 & 5.0728 & TST \\
\hline CHEMBL1313621 & 688816 & 6.15 & 5.6103 & TST \\
\hline CHEMBL1409389 & 688816 & 5.8 & 4.7873 & TST \\
\hline CHEMBL1307646 & 688816 & 7.0501 & 5.3326 & TRN \\
\hline CHEMBL1536891 & 688816 & 4.45 & 5.5002 & TST \\
\hline CHEMBL1378331 & 688816 & 5.0 & 5.1132 & TRN \\
\hline CHEMBL1371531 & 688816 & 4.9 & 5.0544 & TRN \\
\hline CHEMBL 300797 & 688816 & 6.05 & 5.7724 & TST \\
\hline CHEMBL1322789 & 688816 & 4.45 & 5.3597 & TST \\
\hline CHEMBL1587526 & 688816 & 4.85 & 5.4639 & TRN \\
\hline CHEMBL1084643 & 688816 & 4.45 & 6.0332 & TST \\
\hline CHEMBL1486465 & 688816 & 6.0 & 5.6583 & TRN \\
\hline CHEMBL1410577 & 688816 & 5.0 & 4.8295 & TRN \\
\hline CHEMBL1384870 & 688816 & 4.95 & 5.815 & TST \\
\hline CHEMBL1596813 & 688816 & 4.9 & 5.2084 & TRN \\
\hline CHEMBL1403481 & 688816 & 4.45 & 5.2531 & TRN \\
\hline CHEMBL1336509 & 688816 & 4.45 & 5.0736 & TRN \\
\hline CHEMBL1581871 & 688816 & 4.75 & 5.2056 & TST \\
\hline CHEMBL1981449 & 688816 & 5.0 & 5.3527 & TRN \\
\hline CHEMBL1592544 & 688816 & 4.8 & 4.8959 & TRN \\
\hline CHEMBL1415843 & 688816 & 5.55 & 5.7486 & TRN \\
\hline CHEMBL1313110 & 688816 & 5.9 & 5.4068 & TRN \\
\hline CHEMBL1531728 & 688816 & 5.0 & 5.1925 & TRN \\
\hline CHEMBL1440700 & 688816 & 4.95 & 5.2381 & TST \\
\hline CHEMBL 3213622 & 688816 & 4.5 & 5.3609 & TRN \\
\hline CHEMBL1387085 & 688816 & 5.65 & 5.3759 & TRN \\
\hline CHEMBL1580609 & 688816 & 4.85 & 5.4312 & TST \\
\hline CHEMBL1533959 & 688816 & 4.45 & 4.928 & TRN \\
\hline CHEMBL1572502 & 688816 & 7.5498 & 5.3605 & TRN \\
\hline CHEMBL1374635 & 688816 & 4.45 & 5.3244 & TRN \\
\hline CHEMBL1333230 & 688816 & 4.85 & 5.1759 & TRN \\
\hline CHEMBL1594897 & 688816 & 4.8 & 5.1726 & TRN \\
\hline CHEMBL1412073 & 688816 & 5.6 & 5.6503 & TST \\
\hline CHEMBL1540542 & 688816 & 4.65 & 5.4172 & TRN \\
\hline CHEMBL1373252 & 688816 & 4.7 & 5.5152 & TRN \\
\hline CHEMBL149322 & 688816 & 4.5 & 5.1069 & TRN \\
\hline CHEMBL1520121 & 688816 & 4.9 & 5.3154 & TRN \\
\hline CHEMBL1541819 & 688816 & 5.0 & 5.2424 & TRN \\
\hline CHEMBL1452706 & 688816 & 4.8 & 5.0606 & TRN \\
\hline CHEMBL1334040 & 688816 & 4.45 & 4.9028 & TST \\
\hline CHEMBL1402883 & 688816 & 4.75 & 5.2097 & TRN \\
\hline CHEMBL1530742 & 688816 & 4.75 & 4.8889 & TST \\
\hline CHEMBL1346338 & 688816 & 4.8 & 5.1545 & TRN \\
\hline CHEMBL1543937 & 688816 & 4.95 & 5.2897 & TRN \\
\hline CHEMBL3196563 & 688816 & 4.9 & 5.3518 & TRN \\
\hline
\end{tabular}




\begin{tabular}{|c|c|c|c|c|c|}
\hline \multicolumn{6}{|c|}{ Supplemental Table S2.txt } \\
\hline CHEMBL1451802 & 688816 & 4.8 & 5.4601 & TRN & \\
\hline CHEMBL1469462 & 688816 & 4.45 & 5.4209 & TRN & \\
\hline CHEMBL1535100 & 688816 & 4.95 & 5.3583 & TRN & \\
\hline CHEMBL1415798 & 688816 & 5.2 & 4.7501 & TRN & \\
\hline CHEMBL1531914 & 688816 & 6.05 & 5.335 & TRN & \\
\hline CHEMBL1544495 & 688816 & 4.9 & 5.2615 & TRN & \\
\hline CHEMBL1541839 & 688816 & 4.45 & 5.3389 & TRN & \\
\hline CHEMBL1376451 & 688816 & 4.45 & 5.1855 & TRN & \\
\hline CHEMBL1358032 & 688816 & 4.45 & 5.044 & TRN & \\
\hline CHEMBL1608398 & 688816 & 7.6003 & 5.7586 & TRN & \\
\hline CHEMBL1447724 & 688816 & 5.7 & 4.86 & TRN & \\
\hline CHEMBL1487699 & 688816 & 4.45 & 5.5487 & TRN & \\
\hline CHEMBL258767 & 688816 & 6.0 & 5.1966 & TRN & \\
\hline CHEMBL1461235 & 688816 & 8.3468 & 5.54299 & 9999999999 & TRN \\
\hline CHEMBL1441788 & 688816 & 4.95 & 5.6003 & TST & \\
\hline CHEMBL1368699 & 688816 & 4.85 & 5.2831 & TRN & \\
\hline CHEMBL1497478 & 688816 & 4.9 & 5.2972 & TST & \\
\hline CHEMBL3212393 & 688816 & 6.7501 & 5.6702 & TST & \\
\hline CHEMBL444376 & 688816 & 4.95 & 5.0589 & TRN & \\
\hline CHEMBL1546981 & 688816 & 4.6 & 5.7576 & TRN & \\
\hline CHEMBL1407472 & 688816 & 5.25 & 5.4525 & TRN & \\
\hline CHEMBL1977034 & 688816 & 4.45 & 5.1098 & TRN & \\
\hline CHEMBL1567345 & 688816 & 4.8 & 5.1397 & TRN & \\
\hline CHEMBL1599721 & 688816 & 5.25 & 5.3294 & TST & \\
\hline CHEMBL1579849 & 688816 & 7.7496 & 5.2953 & TRN & \\
\hline CHEMBL1404247 & 688816 & 4.7 & 5.2639 & TRN & \\
\hline CHEMBL1463216 & 688816 & 5.4 & 5.284 & TRN & \\
\hline CHEMBL1573259 & 688816 & 4.9 & 5.4434 & TRN & \\
\hline CHEMBL1321644 & 688816 & 5.2 & 5.2541 & TRN & \\
\hline CHEMBL1406593 & 688816 & 5.0 & 4.8494 & TRN & \\
\hline CHEMBL1372396 & 688816 & 5.65 & 5.4128 & TRN & \\
\hline CHEMBL1409333 & 688816 & 4.45 & 5.4044 & TST & \\
\hline CHEMBL3212574 & 688816 & 4.8 & 5.1973 & TST & \\
\hline CHEMBL546475 & 688816 & 4.7 & 5.3814 & TRN & \\
\hline CHEMBL1460608 & 688816 & 4.85 & 5.3416 & TRN & \\
\hline CHEMBL1442213 & 688816 & 6.7501 & 5.4616 & TRN & \\
\hline CHEMBL1301175 & 688816 & 4.9 & 5.3188 & TRN & \\
\hline CHEMBL3191171 & 688816 & 6.35 & 5.4734 & TRN & \\
\hline CHEMBL1382165 & 688816 & 5.05 & 5.2992 & TST & \\
\hline CHEMBL1559611 & 688816 & 5.05 & 5.1658 & TRN & \\
\hline CHEMBL1490786 & 688816 & 6.0 & 5.0736 & TRN & \\
\hline CHEMBL1491369 & 688816 & 5.2 & 5.2317 & TST & \\
\hline CHEMBL1360091 & 688816 & 5.45 & 5.136 & TRN & \\
\hline CHEMBL1461522 & 688816 & 4.85 & 5.1086 & TRN & \\
\hline CHEMBL1301802 & 688816 & 6.5501 & 5.4653 & TRN & \\
\hline CHEMBL1422100 & 688816 & 5.45 & 5.2981 & TRN & \\
\hline CHEMBL1571536 & 688816 & 6.35 & 5.2704 & TRN & \\
\hline CHEMBL1429379 & 688816 & 4.85 & 5.1188 & TST & \\
\hline
\end{tabular}




\begin{tabular}{|c|c|c|c|c|c|}
\hline \multicolumn{6}{|c|}{ Supplemental Table S2.txt } \\
\hline CHEMBL1411044 & 688816 & 4.75 & 5.4018 & TRN & \\
\hline CHEMBL1335890 & 688816 & 6.0 & 5.0419 & TRN & \\
\hline CHEMBL1360994 & 688816 & 4.45 & 5.0962 & TRN & \\
\hline CHEMBL1348831 & 688816 & 5.15 & 5.2206 & TST & \\
\hline CHEMBL3191771 & 688816 & 4.9 & 5.1466 & TRN & \\
\hline CHEMBL1593860 & 688816 & 4.85 & 5.1143 & TRN & \\
\hline CHEMBL1487890 & 688816 & 4.95 & 5.3235 & TST & \\
\hline CHEMBL1567221 & 688816 & 4.8 & 5.2508 & TRN & \\
\hline CHEMBL1527899 & 688816 & 5.0 & 5.3274 & TRN & \\
\hline CHEMBL1545890 & 688816 & 4.8 & 5.0287 & TST & \\
\hline CHEMBL1400485 & 688816 & 4.95 & 4.9997 & TRN & \\
\hline CHEMBL1309445 & 688816 & 5.0 & 5.2478 & TRN & \\
\hline CHEMBL1558550 & 688816 & 4.9 & 5.093 & TRN & \\
\hline CHEMBL1613717 & 688816 & 4.65 & 5.0973 & TRN & \\
\hline CHEMBL1378852 & 688816 & 5.3 & 5.3792 & TRN & \\
\hline CHEMBL1342516 & 688816 & 4.7 & 5.4615 & TRN & \\
\hline CHEMBL1313256 & 688816 & 5.4 & 5.9084 & TST & \\
\hline CHEMBL1448213 & 688816 & 5.7 & 5.1487 & TRN & \\
\hline CHEMBL1481570 & 688816 & 4.95 & 4.9929 & TRN & \\
\hline CHEMBL1530498 & 688816 & 5.0 & 5.0037 & TRN & \\
\hline CHEMBL1377637 & 688816 & 4.45 & 5.1519 & TRN & \\
\hline CHEMBL3208946 & 688816 & 7.6498 & 5.3352 & TST & \\
\hline CHEMBL1346484 & 688816 & 8.3468 & 5.7013 & TRN & \\
\hline CHEMBL1372312 & 688816 & 4.85 & 5.2356 & TRN & \\
\hline CHEMBL1455894 & 688816 & 5.0 & 5.17200 & 0000000001 & TRN \\
\hline CHEMBL1534185 & 688816 & 6.7501 & 5.7171 & TST & \\
\hline CHEMBL1571413 & 688816 & 4.85 & 5.4307 & TRN & \\
\hline CHEMBL1547470 & 688816 & 4.45 & 4.9123 & TRN & \\
\hline CHEMBL1520349 & 688816 & 4.95 & 5.4746 & TRN & \\
\hline CHEMBL1409060 & 688816 & 4.95 & 4.9011 & TST & \\
\hline CHEMBL1507220 & 688816 & 4.65 & 5.2739 & TST & \\
\hline CHEMBL1582281 & 688816 & 5.45 & 5.7959 & TRN & \\
\hline CHEMBL1367673 & 688816 & 4.45 & 5.2383 & TRN & \\
\hline CHEMBL1460723 & 688816 & 4.95 & 5.067 & TST & \\
\hline CHEMBL1527502 & 688816 & 4.85 & 5.4099 & TRN & \\
\hline CHEMBL1504959 & 688816 & 4.9 & 5.50200 & 0000000001 & TRN \\
\hline CHEMBL1306564 & 688816 & 4.6 & 5.3341 & TRN & \\
\hline CHEMBL1380337 & 688816 & 4.65 & 5.2612 & TRN & \\
\hline CHEMBL1555040 & 688816 & 4.45 & 5.1021 & TRN & \\
\hline CHEMBL3145369 & 688816 & 5.9 & 5.5099 & TRN & \\
\hline CHEMBL1555898 & 688816 & 4.75 & 4.9382 & TRN & \\
\hline CHEMBL1435324 & 688816 & 4.9 & 5.0864 & TRN & \\
\hline CHEMBL1406503 & 688816 & 6.3 & 5.6685 & TRN & \\
\hline CHEMBL1506690 & 688816 & 4.9 & 5.1825 & TRN & \\
\hline CHEMBL3195878 & 688816 & 4.75 & 5.2687 & TRN & \\
\hline CHEMBL1377446 & 688816 & 4.75 & 5.3598 & TRN & \\
\hline CHEMBL1481525 & 688816 & 4.8 & 5.2316 & TST & \\
\hline CHEMBL1560802 & 688816 & 5.05 & 5.6042 & TRN & \\
\hline
\end{tabular}




\begin{tabular}{|c|c|c|c|c|c|}
\hline \multicolumn{6}{|c|}{ Supplemental Table S2.txt } \\
\hline CHEMBL1373160 & 688816 & 4.75 & 5.136 & TRN & \\
\hline CHEMBL1308051 & 688816 & 8.0 & 4.775 & TST & \\
\hline CHEMBL1609743 & 688816 & 5.55 & 4.8168 & TRN & \\
\hline CHEMBL1564375 & 688816 & 5.0 & 5.1156 & TRN & \\
\hline CHEMBL1457201 & 688816 & 4.45 & 4.7738 & TRN & \\
\hline CHEMBL3198419 & 688816 & 5.0 & 5.0009 & TRN & \\
\hline CHEMBL1405453 & 688816 & 6.7001 & 5.4227 & TRN & \\
\hline CHEMBL1311237 & 688816 & 4.95 & 5.3458 & TST & \\
\hline CHEMBL1523157 & 688816 & 4.7 & 5.2906 & TRN & \\
\hline CHEMBL1447437 & 688816 & 5.05 & 5.6472 & TST & \\
\hline CHEMBL1315700 & 688816 & 5.0 & 5.2966 & TRN & \\
\hline CHEMBL1339814 & 688816 & 4.85 & 5.0725 & TRN & \\
\hline CHEMBL1489087 & 688816 & 5.35 & 5.1033 & TRN & \\
\hline CHEMBL1579833 & 688816 & 4.65 & 5.0698 & TST & \\
\hline CHEMBL1530216 & 688816 & 4.9 & 4.7149 & TRN & \\
\hline CHEMBL1438881 & 688816 & 5.1 & 5.2189 & TRN & \\
\hline CHEMBL1467677 & 688816 & 4.95 & 5.42700 & 00000000005 & TST \\
\hline CHEMBL1534436 & 688816 & 4.95 & 5.1328 & TRN & \\
\hline CHEMBL1483153 & 688816 & 5.25 & 5.2831 & TST & \\
\hline CHEMBL1328190 & 688816 & 4.95 & 5.3369 & TRN & \\
\hline CHEMBL1338133 & 688816 & 4.95 & 5.2084 & TST & \\
\hline CHEMBL1385314 & 688816 & 5.45 & 5.1038 & TST & \\
\hline CHEMBL1595331 & 688816 & 4.45 & 4.961 & TRN & \\
\hline CHEMBL1510211 & 688816 & 4.95 & 5.1742 & TRN & \\
\hline CHEMBL1364002 & 688816 & 4.8 & 5.1825 & TRN & \\
\hline CHEMBL1543776 & 688816 & 4.55 & 5.0599 & TRN & \\
\hline CHEMBL1511860 & 688816 & 8.301 & 5.2641 & TRN & \\
\hline CHEMBL1365427 & 688816 & 4.95 & 5.2642 & TST & \\
\hline CHEMBL1353950 & 688816 & 4.7 & 5.6935 & TST & \\
\hline CHEMBL327209 & 688816 & 4.9 & 5.0692 & TRN & \\
\hline CHEMBL1465298 & 688816 & 8.3468 & 5.0487 & TRN & \\
\hline CHEMBL1355871 & 688816 & 4.6 & 5.475 & TRN & \\
\hline CHEMBL1600694 & 688816 & 4.65 & 4.9903 & TRN & \\
\hline CHEMBL1505730 & 688816 & 5.85 & 5.5796 & TRN & \\
\hline CHEMBL1463023 & 688816 & 4.85 & 5.3139 & TRN & \\
\hline CHEMBL1414244 & 688816 & 4.9 & 5.5054 & TRN & \\
\hline CHEMBL3192045 & 688816 & 4.85 & 5.4684 & TRN & \\
\hline CHEMBL1456433 & 688816 & 5.9 & 4.9952 & TRN & \\
\hline CHEMBL1579992 & 688816 & 6.7001 & 4.9158 & TRN & \\
\hline CHEMBL1549219 & 688816 & 5.2 & 5.2186 & TST & \\
\hline CHEMBL1402884 & 688816 & 4.9 & 5.2611 & TRN & \\
\hline CHEMBL1606858 & 688816 & 4.9 & 5.4021 & TRN & \\
\hline CHEMBL3189998 & 688816 & 4.45 & 5.0396 & TRN & \\
\hline CHEMBL1522438 & 688816 & 5.55 & 5.2981 & TRN & \\
\hline CHEMBL1323129 & 688816 & 5.5 & 5.2571 & TRN & \\
\hline CHEMBL1355262 & 688816 & 5.0 & 5.0145 & TRN & \\
\hline CHEMBL1463885 & 688816 & 4.5 & 4.6648 & TRN & \\
\hline CHEMBL1355119 & 688816 & 4.55 & 4.6962 & TRN & \\
\hline
\end{tabular}




\begin{tabular}{|c|c|c|c|c|c|}
\hline \multicolumn{6}{|c|}{ Supplemental Table S2.txt } \\
\hline CHEMBL1367237 & 688816 & 5.6 & 5.7091 & TRN & \\
\hline CHEMBL1381633 & 688816 & 4.9 & 5.1079 & TRN & \\
\hline CHEMBL578741 & 688816 & 4.75 & 5.2116 & TRN & \\
\hline CHEMBL1275790 & 688816 & 6.05 & 5.1409 & TRN & \\
\hline CHEMBL1550895 & 688816 & 5.65 & 5.0777 & TRN & \\
\hline CHEMBL1366891 & 688816 & 5.15 & 5.2312 & TST & \\
\hline CHEMBL1366331 & 688816 & 7.5003 & 5.3445 & TRN & \\
\hline CHEMBL1305110 & 688816 & 4.45 & 5.3717 & TST & \\
\hline CHEMBL1319884 & 688816 & 4.95 & 5.1389 & TRN & \\
\hline CHEMBL1326937 & 688816 & 5.35 & 4.9148 & TRN & \\
\hline CHEMBL243664 & 688816 & 6.0 & 5.1727 & TRN & \\
\hline CHEMBL1518906 & 688816 & 5.45 & 5.0672 & TRN & \\
\hline CHEMBL1557680 & 688816 & 6.0 & 5.3703 & TRN & \\
\hline CHEMBL1500352 & 688816 & 4.8 & 5.0328 & TRN & \\
\hline CHEMBL1426595 & 688816 & 4.8 & 5.1424 & TRN & \\
\hline CHEMBL1255870 & 688816 & 5.8 & 5.6958 & TST & \\
\hline CHEMBL1566871 & 688816 & 4.45 & 5.2752 & TST & \\
\hline CHEMBL 3194640 & 688816 & 5.5 & 5.1077 & TRN & \\
\hline CHEMBL1474869 & 688816 & 4.45 & 5.2616 & TST & \\
\hline CHEMBL1492918 & 688816 & 4.95 & 5.1564 & TRN & \\
\hline CHEMBL2000525 & 688816 & 5.0 & 5.0789 & TRN & \\
\hline CHEMBL1501995 & 688816 & 4.8 & 4.9677 & TRN & \\
\hline CHEMBL1991311 & 688816 & 4.45 & 5.0465 & TRN & \\
\hline CHEMBL1403752 & 688816 & 4.95 & 5.2291 & TRN & \\
\hline CHEMBL3191576 & 688816 & 7.5003 & 5.5846 & TRN & \\
\hline CHEMBL1392025 & 688816 & 4.45 & 5.496 & TRN & \\
\hline CHEMBL1308315 & 688816 & 4.7 & 5.5219 & TRN & \\
\hline CHEMBL1368819 & 688816 & 4.8 & 5.2721 & TST & \\
\hline CHEMBL1564015 & 688816 & 4.45 & 4.8945 & TRN & \\
\hline CHEMBL1540048 & 688816 & 4.95 & 4.9605 & TRN & \\
\hline CHEMBL1416057 & 688816 & 4.75 & 5.6606 & TRN & \\
\hline CHEMBL1326112 & 688816 & 4.45 & 5.7054 & TST & \\
\hline CHEMBL1567437 & 688816 & 5.0 & $5.1220 e$ & $\partial 000000001$ & TRN \\
\hline CHEMBL1481805 & 688816 & 4.85 & 5.2298 & TST & \\
\hline CHEMBL3196267 & 688816 & 5.0 & 5.1442 & TRN & \\
\hline CHEMBL1561138 & 688816 & 4.65 & 5.1828 & TRN & \\
\hline CHEMBL1448447 & 688816 & 5.0 & 5.4578 & TRN & \\
\hline CHEMBL1530114 & 688816 & 7.3002 & 5.2042 & TRN & \\
\hline CHEMBL1346237 & 688816 & 5.4 & 5.0725 & TRN & \\
\hline CHEMBL1335647 & 688816 & 4.95 & 5.349 & TRN & \\
\hline CHEMBL1986805 & 688816 & 4.85 & 5.3877 & TRN & \\
\hline CHEMBL1528465 & 688816 & 6.5 & 5.0756 & TRN & \\
\hline CHEMBL1300301 & 688816 & 4.7 & 5.2006 & TRN & \\
\hline CHEMBL1559029 & 688816 & 4.95 & 4.8088 & TST & \\
\hline CHEMBL1545695 & 688816 & 4.45 & 5.0581 & TRN & \\
\hline CHEMBL1301770 & 688816 & 4.9 & 5.2372 & TRN & \\
\hline CHEMBL1408325 & 688816 & 4.95 & 5.0472 & TRN & \\
\hline CHEMBL1370901 & 688816 & 5.5 & 5.3131 & TRN & \\
\hline
\end{tabular}




\begin{tabular}{|c|c|c|c|c|c|}
\hline \multicolumn{6}{|c|}{ Supplemental Table S2.txt } \\
\hline CHEMBL1367180 & 688816 & 4.9 & 5.0678 & TRN & \\
\hline CHEMBL1603458 & 688816 & 7.7496 & 5.3767 & TRN & \\
\hline CHEMBL1599791 & 688816 & 6.6499 & 5.4383 & TRN & \\
\hline CHEMBL1518696 & 688816 & 4.45 & 5.227 & TRN & \\
\hline CHEMBL1540669 & 688816 & 5.0 & 4.6157 & TST & \\
\hline CHEMBL1423474 & 688816 & 4.7 & 4.8717 & TRN & \\
\hline CHEMBL1568944 & 688816 & 4.85 & 5.2032 & TST & \\
\hline CHEMBL1311172 & 688816 & 4.45 & 5.7835 & TRN & \\
\hline CHEMBL1390074 & 688816 & 4.6 & 5.2748 & TRN & \\
\hline CHEMBL1305462 & 688816 & 5.05 & 5.0065 & TRN & \\
\hline CHEMBL1609707 & 688816 & 5.2 & 5.8655 & TST & \\
\hline CHEMBL1430225 & 688816 & 4.9 & 5.4456 & TST & \\
\hline CHEMBL1447448 & 688816 & 4.95 & 5.07 & TRN & \\
\hline CHEMBL1539535 & 688816 & 4.95 & 5.5998 & TST & \\
\hline CHEMBL1607739 & 688816 & 5.4 & 5.61799 & 7999999999 & TST \\
\hline CHEMBL1505482 & 688816 & 4.9 & 5.0075 & TRN & \\
\hline CHEMBL1332931 & 688816 & 4.5 & 5.1746 & TRN & \\
\hline CHEMBL1375117 & 688816 & 6.6499 & 5.2898 & TST & \\
\hline CHEMBL548615 & 688816 & 4.75 & 4.7379 & TRN & \\
\hline CHEMBL1437540 & 688816 & 4.65 & 5.1716 & TRN & \\
\hline CHEMBL1326449 & 688816 & 4.9 & 4.9671 & TRN & \\
\hline CHEMBL1403095 & 688816 & 5.3 & 5.2018 & TRN & \\
\hline CHEMBL1387692 & 688816 & 4.9 & 5.0341 & TRN & \\
\hline CHEMBL1341337 & 688816 & 7.4498 & 5.3896 & TRN & \\
\hline CHEMBL1345453 & 688816 & 5.5 & 5.0098 & TST & \\
\hline CHEMBL1606890 & 688816 & 5.5 & 5.0805 & TRN & \\
\hline CHEMBL1390986 & 688816 & 5.2 & 5.154 & TRN & \\
\hline CHEMBL507369 & 688816 & 5.15 & 5.5497 & TST & \\
\hline CHEMBL1515334 & 688816 & 5.15 & 5.4136 & TST & \\
\hline CHEMBL41794 & 688816 & 4.45 & 5.2634 & TRN & \\
\hline CHEMBL1434001 & 688816 & 4.85 & 5.153 & TRN & \\
\hline CHEMBL151937 & 688816 & 4.45 & 5.6762 & TST & \\
\hline CHEMBL1405692 & 688816 & 5.9 & 5.4481 & TRN & \\
\hline CHEMBL1338570 & 688816 & 4.55 & 5.4407 & TRN & \\
\hline CHEMBL1494457 & 688816 & 8.3468 & 5.5304 & TRN & \\
\hline CHEMBL1411726 & 688816 & 4.9 & 4.8114 & TRN & \\
\hline CHEMBL1386178 & 688816 & 5.2 & 5.1384 & TRN & \\
\hline CHEMBL1435100 & 688816 & 6.15 & 5.285 & TRN & \\
\hline CHEMBL1464718 & 688816 & 4.65 & 4.9552 & TST & \\
\hline CHEMBL1481756 & 688816 & 6.0 & 5.2192 & TST & \\
\hline CHEMBL1419289 & 688816 & 4.6 & 5.4331 & TRN & \\
\hline CHEMBL1312228 & 688816 & 8.301 & 5.4098 & TST & \\
\hline CHEMBL1542198 & 688816 & 8.3979 & 5.5981 & TRN & \\
\hline CHEMBL1336686 & 688816 & 4.45 & 5.0856 & TRN & \\
\hline CHEMBL1360045 & 688816 & 8.0 & 5.2388 & TST & \\
\hline CHEMBL1584232 & 688816 & 5.25 & 5.4406 & TRN & \\
\hline CHEMBL1451727 & 688816 & 4.45 & 5.5076 & TRN & \\
\hline CHEMBL1486211 & 688816 & 4.5 & 5.4873 & TST & \\
\hline
\end{tabular}




\begin{tabular}{|c|c|c|c|c|c|}
\hline \multicolumn{6}{|c|}{ 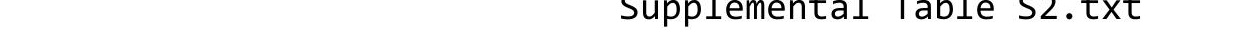 } \\
\hline CHEMBL1456884 & 688816 & 8.301 & 5.3254 & TST & \\
\hline CHEMBL1499116 & 688816 & 4.9 & 5.3225 & TRN & \\
\hline CHEMBL1364085 & 688816 & 5.3 & 5.0958 & TST & \\
\hline CHEMBL1463984 & 688816 & 4.85 & 5.315 & TRN & \\
\hline CHEMBL1493273 & 688816 & 4.6 & 5.0424 & TRN & \\
\hline CHEMBL1452541 & 688816 & 5.15 & 5.8802 & TST & \\
\hline CHEMBL1495117 & 688816 & 5.55 & 5.3459 & TRN & \\
\hline CHEMBL1543484 & 688816 & 6.45 & 5.3011 & TRN & \\
\hline CHEMBL1450344 & 688816 & 4.95 & 5.0343 & TST & \\
\hline CHEMBL1323726 & 688816 & 5.9 & 5.7093 & TRN & \\
\hline CHEMBL1519558 & 688816 & 5.15 & 5.1109 & TRN & \\
\hline CHEMBL17127 & 688816 & 5.65 & 4.881 & TST & \\
\hline CHEMBL1405992 & 688816 & 6.9 & 5.2639 & TRN & \\
\hline CHEMBL1468328 & 688816 & 4.95 & 5.0164 & TRN & \\
\hline CHEMBL1345626 & 688816 & 6.25 & 5.2878 & TRN & \\
\hline CHEMBL1389453 & 688816 & 4.65 & 4.9253 & TRN & \\
\hline CHEMBL1595804 & 688816 & 4.65 & 5.2319 & TRN & \\
\hline CHEMBL1567824 & 688816 & 4.45 & 5.2029 & TRN & \\
\hline CHEMBL1468628 & 688816 & 6.05 & 5.38200 & 0000000001 & TRN \\
\hline CHEMBL1342754 & 688816 & 5.55 & 5.2387 & TRN & \\
\hline CHEMBL1466034 & 688816 & 8.0 & 5.3621 & TST & \\
\hline CHEMBL1573272 & 688816 & 4.5 & 5.1819 & TRN & \\
\hline CHEMBL1596719 & 688816 & 5.7 & 5.5728 & TRN & \\
\hline CHEMBL1974640 & 688816 & 5.2 & 5.0664 & TRN & \\
\hline CHEMBL1550525 & 688816 & 4.55 & 5.1671 & TRN & \\
\hline CHEMBL1380805 & 688816 & 5.45 & 5.2146 & TRN & \\
\hline CHEMBL1571443 & 688816 & 4.65 & 5.3706 & TST & \\
\hline CHEMBL1587777 & 688816 & 6.7001 & 5.9624 & TRN & \\
\hline CHEMBL3214454 & 688816 & 7.3002 & 5.3736 & TST & \\
\hline CHEMBL1372076 & 688816 & 4.85 & 4.9858 & TST & \\
\hline CHEMBL1331152 & 688816 & 5.6 & 5.0706 & TST & \\
\hline CHEMBL1488309 & 688816 & 5.25 & 5.8436 & TRN & \\
\hline CHEMBL1345893 & 688816 & 5.95 & 5.468 & TRN & \\
\hline CHEMBL1569154 & 688816 & 4.6 & 5.3987 & TRN & \\
\hline CHEMBL1365911 & 688816 & 5.35 & 5.5645 & TRN & \\
\hline CHEMBL1485407 & 688816 & 5.25 & 5.2022 & TRN & \\
\hline CHEMBL1386816 & 688816 & 5.8 & 5.5827 & TST & \\
\hline CHEMBL1548051 & 688816 & 5.05 & 5.0158 & TRN & \\
\hline CHEMBL1304523 & 688816 & 8.301 & 5.3786 & TRN & \\
\hline CHEMBL1534804 & 688816 & 4.75 & 5.6395 & TRN & \\
\hline CHEMBL1341720 & 688816 & 5.2 & 5.2907 & TST & \\
\hline CHEMBL1550609 & 688816 & 4.75 & 5.1752 & TRN & \\
\hline CHEMBL1395804 & 688816 & 4.65 & 5.1433 & TRN & \\
\hline CHEMBL1381551 & 688816 & 4.75 & 5.0445 & TRN & \\
\hline CHEMBL1404493 & 688816 & 5.65 & 5.5034 & TRN & \\
\hline CHEMBL1414933 & 688816 & 4.85 & 4.9925 & TRN & \\
\hline CHEMBL1534828 & 688816 & 5.4 & 5.4215 & TRN & \\
\hline CHEMBL1442915 & 688816 & 4.9 & 5.5318 & TRN & \\
\hline
\end{tabular}




\begin{tabular}{|c|c|c|c|c|}
\hline \multicolumn{5}{|c|}{ Supplemental Table S2.txt } \\
\hline CHEMBL1406060 & 688816 & 6.0 & 5.2825 & TRN \\
\hline CHEMBL1350352 & 688816 & 4.5 & 5.142 & TRN \\
\hline CHEMBL1484799 & 688816 & 4.95 & 5.1421 & TRN \\
\hline CHEMBL 3209645 & 688816 & 5.0 & 4.9452 & TST \\
\hline CHEMBL1322308 & 688816 & 5.65 & 5.2893 & TRN \\
\hline CHEMBL 3194186 & 688816 & 5.55 & 5.0214 & TRN \\
\hline CHEMBL3207390 & 688816 & 5.45 & 5.5054 & TRN \\
\hline CHEMBL1570760 & 688816 & 5.5 & 5.1203 & TRN \\
\hline CHEMBL1610687 & 688816 & 4.95 & 5.0786 & TRN \\
\hline CHEMBL1428588 & 688816 & 4.8 & 5.0253 & TRN \\
\hline CHEMBL 3195400 & 688816 & 4.45 & 4.9277 & TRN \\
\hline CHEMBL1307850 & 688816 & 4.9 & 5.3176 & TRN \\
\hline CHEMBL1568984 & 688816 & 4.95 & 5.2456 & TST \\
\hline CHEMBL1382485 & 688816 & 4.45 & 5.0121 & TST \\
\hline CHEMBL1608011 & 688816 & 4.7 & 4.9034 & TRN \\
\hline CHEMBL1571580 & 688816 & 4.45 & 5.3087 & TRN \\
\hline CHEMBL1412523 & 688816 & 5.0 & 5.1111 & TRN \\
\hline CHEMBL1518776 & 688816 & 4.6 & 5.2639 & TRN \\
\hline CHEMBL1535991 & 688816 & 4.7 & 5.2931 & TRN \\
\hline CHEMBL1549366 & 688816 & 4.65 & 5.3277 & TST \\
\hline CHEMBL1454473 & 688816 & 4.9 & 5.3603 & TRN \\
\hline CHEMBL1537872 & 688816 & 5.15 & 5.3356 & TST \\
\hline CHEMBL1569126 & 688816 & 4.95 & 4.9521 & TRN \\
\hline CHEMBL1428617 & 688816 & 7.699 & 5.3843 & TRN \\
\hline CHEMBL1300808 & 688816 & 4.55 & 5.5326 & TRN \\
\hline CHEMBL 3210528 & 688816 & 5.1 & 5.6444 & TRN \\
\hline CHEMBL1588196 & 688816 & 4.9 & 5.335 & TST \\
\hline CHEMBL1323748 & 688816 & 4.9 & 5.5068 & TRN \\
\hline CHEMBL1430370 & 688816 & 4.9 & 5.6757 & TRN \\
\hline CHEMBL1517161 & 688816 & 4.8 & 5.1622 & TRN \\
\hline CHEMBL1332827 & 688816 & 5.0 & 5.1977 & TRN \\
\hline CHEMBL1350119 & 688816 & 4.95 & 5.2846 & TRN \\
\hline CHEMBL1559362 & 688816 & 5.8 & 4.8799 & TRN \\
\hline CHEMBL1364919 & 688816 & 6.0 & 5.5969 & TST \\
\hline CHEMBL1481384 & 688816 & 4.6 & 5.0911 & TRN \\
\hline CHEMBL1721986 & 688816 & 4.8 & 5.2262 & TRN \\
\hline CHEMBL3194473 & 688816 & 4.95 & 5.1284 & TRN \\
\hline CHEMBL1312068 & 688816 & 6.7001 & 5.1453 & TRN \\
\hline CHEMBL1371356 & 688816 & 4.9 & 5.4809 & TRN \\
\hline CHEMBL1329321 & 688816 & 4.9 & 4.9425 & TRN \\
\hline CHEMBL1400945 & 688816 & 5.9 & 5.511 & TST \\
\hline CHEMBL1557428 & 688816 & 4.85 & 4.9493 & TST \\
\hline CHEMBL3197010 & 688816 & 5.3 & 5.2019 & TRN \\
\hline CHEMBL1331001 & 688816 & 4.95 & 5.4231 & TRN \\
\hline CHEMBL1499676 & 688816 & 4.65 & 5.5759 & TRN \\
\hline CHEMBL1534646 & 688816 & 4.4 & 5.3127 & TRN \\
\hline CHEMBL1560305 & 688816 & 5.0 & 4.95 & TRN \\
\hline CHEMBL468018 & 688816 & 5.0 & 5.1172 & TRN \\
\hline
\end{tabular}




\begin{tabular}{|c|c|c|c|c|c|}
\hline \multicolumn{6}{|c|}{ Supplemental Table S2.txt } \\
\hline CHEMBL1608433 & 688816 & 4.8 & 5.0501 & TST & \\
\hline CHEMBL3209904 & 688816 & 4.65 & 5.164 & TST & \\
\hline CHEMBL1611380 & 688816 & 5.1 & 5.5145 & TRN & \\
\hline CHEMBL1605178 & 688816 & 4.55 & 5.5337 & TRN & \\
\hline CHEMBL1528916 & 688816 & 5.95 & 5.4634 & TST & \\
\hline CHEMBL1348385 & 688816 & 4.75 & 5.1286 & TRN & \\
\hline CHEMBL1307726 & 688816 & 6.45 & 5.62700 & 0000000001 & TRN \\
\hline CHEMBL1337581 & 688816 & 4.9 & 5.3538 & TRN & \\
\hline CHEMBL1540010 & 688816 & 5.1 & 5.082 & TRN & \\
\hline CHEMBL1506515 & 688816 & 4.45 & 5.5078 & TRN & \\
\hline CHEMBL1969707 & 688816 & 4.7 & 5.1232 & TRN & \\
\hline CHEMBL1492833 & 688816 & 4.9 & 5.1702 & TST & \\
\hline CHEMBL1610586 & 688816 & 4.45 & 4.6692 & TRN & \\
\hline CHEMBL1370553 & 688816 & 4.45 & 5.2487 & TRN & \\
\hline CHEMBL3211008 & 688816 & 4.75 & 5.0622 & TRN & \\
\hline CHEMBL1522885 & 688816 & 4.95 & 5.0711 & TRN & \\
\hline CHEMBL3212461 & 688816 & 5.3 & 5.4281 & TST & \\
\hline CHEMBL1998184 & 688816 & 5.65 & 5.2413 & TRN & \\
\hline CHEMBL1329102 & 688816 & 5.45 & 4.9984 & TST & \\
\hline CHEMBL1565401 & 688816 & 5.0 & 5.1198 & TRN & \\
\hline CHEMBL3192756 & 688816 & 4.9 & 5.1716 & TRN & \\
\hline CHEMBL1408513 & 688816 & 4.75 & 5.1089 & TRN & \\
\hline CHEMBL1596738 & 688816 & 4.45 & 5.2337 & TRN & \\
\hline CHEMBL1588969 & 688816 & 4.9 & 5.4924 & TRN & \\
\hline CHEMBL1557157 & 688816 & 4.8 & 5.4706 & TST & \\
\hline CHEMBL1311185 & 688816 & 4.8 & 5.222 & TST & \\
\hline CHEMBL1492868 & 688816 & 4.95 & 5.0334 & TRN & \\
\hline CHEMBL1302128 & 688816 & 5.0 & 5.4125 & TRN & \\
\hline CHEMBL1601595 & 688816 & 4.85 & 5.0918 & TRN & \\
\hline CHEMBL1349399 & 688816 & 4.8 & 5.2559 & TRN & \\
\hline CHEMBL1318141 & 688816 & 5.15 & 5.3205 & TRN & \\
\hline CHEMBL1312586 & 688816 & 4.65 & 4.9356 & TRN & \\
\hline CHEMBL1475976 & 688816 & 4.85 & 5.255 & TRN & \\
\hline CHEMBL1448929 & 688816 & 4.85 & 4.9036 & TRN & \\
\hline CHEMBL1402623 & 688816 & 4.95 & 5.2958 & TST & \\
\hline CHEMBL1596486 & 688816 & 5.55 & 5.1035 & TRN & \\
\hline CHEMBL1508525 & 688816 & 4.45 & 5.2708 & TRN & \\
\hline CHEMBL1574540 & 688816 & 5.0 & 5.3216 & TRN & \\
\hline CHEMBL1428108 & 688816 & 5.55 & 5.0825 & TRN & \\
\hline CHEMBL1400434 & 688816 & 7.699 & 5.2407 & TRN & \\
\hline CHEMBL1425060 & 688816 & 4.75 & 5.6843 & TRN & \\
\hline CHEMBL1513061 & 688816 & 4.85 & 5.1294 & TRN & \\
\hline CHEMBL84685 & 688816 & 4.8 & 5.4007 & TRN & \\
\hline CHEMBL1523967 & 688816 & 4.9 & 5.3224 & TRN & \\
\hline CHEMBL1496298 & 688816 & 4.6 & 5.3362 & TST & \\
\hline CHEMBL1408141 & 688816 & 4.95 & 5.4553 & TRN & \\
\hline CHEMBL3208296 & 688816 & 4.8 & 5.2718 & TRN & \\
\hline CHEMBL1381096 & 688816 & 7.0501 & 5.3184 & TST & \\
\hline
\end{tabular}




\begin{tabular}{|c|c|c|c|c|}
\hline \multicolumn{5}{|c|}{ Supplemental Table S2.txt } \\
\hline CHEMBL1462620 & 688816 & 5.4 & 5.5327 & TST \\
\hline CHEMBL1326637 & 688816 & 4.85 & 5.2012 & TRN \\
\hline CHEMBL1420816 & 688816 & 5.85 & 5.0871 & TRN \\
\hline CHEMBL1602614 & 688816 & 5.15 & 5.0957 & TRN \\
\hline CHEMBL1508669 & 688816 & 5.0 & 5.5785 & TRN \\
\hline CHEMBL1384233 & 688816 & 4.6 & 5.0557 & TST \\
\hline CHEMBL1586438 & 688816 & 4.95 & 4.9229 & TRN \\
\hline CHEMBL1587756 & 688816 & 4.45 & 5.1841 & TRN \\
\hline CHEMBL1462118 & 688816 & 5.7 & 5.4171 & TST \\
\hline CHEMBL1462280 & 688816 & 4.45 & 4.9463 & TRN \\
\hline CHEMBL1338747 & 688816 & 5.5 & 5.2213 & TST \\
\hline CHEMBL1982913 & 688816 & 6.05 & 5.1389 & TRN \\
\hline CHEMBL1427972 & 688816 & 4.7 & 4.9546 & TRN \\
\hline CHEMBL1444538 & 688816 & 5.1 & 5.2154 & TRN \\
\hline CHEMBL1578366 & 688816 & 4.7 & 5.3441 & TRN \\
\hline CHEMBL3199337 & 688816 & 4.8 & 5.1662 & TRN \\
\hline CHEMBL1501891 & 688816 & 5.0 & 4.8335 & TRN \\
\hline CHEMBL1466707 & 688816 & 5.5 & 5.4219 & TRN \\
\hline CHEMBL1570784 & 688816 & 4.75 & 5.4368 & TRN \\
\hline CHEMBL1338885 & 688816 & 4.75 & 5.3138 & TRN \\
\hline CHEMBL1401699 & 688816 & 5.1 & 4.8764 & TRN \\
\hline CHEMBL1331612 & 688816 & 7.0 & 5.4835 & TST \\
\hline CHEMBL1305793 & 688816 & 4.75 & 5.1357 & TRN \\
\hline CHEMBL1424009 & 688816 & 4.65 & 5.032 & TST \\
\hline CHEMBL1387593 & 688816 & 4.7 & 4.6976 & TRN \\
\hline CHEMBL1352342 & 688816 & 4.85 & 5.4051 & TRN \\
\hline CHEMBL1441879 & 688816 & 4.75 & 5.5682 & TST \\
\hline CHEMBL1493717 & 688816 & 4.95 & 5.6678 & TST \\
\hline CHEMBL1504357 & 688816 & 5.5 & 5.1972 & TST \\
\hline CHEMBL1329291 & 688816 & 4.95 & 5.2094 & TST \\
\hline CHEMBL3213759 & 688816 & 4.95 & 5.29 & TST \\
\hline CHEMBL1736254 & 688816 & 5.3 & 5.2985 & TST \\
\hline CHEMBL1376253 & 688816 & 4.75 & 5.0228 & TRN \\
\hline CHEMBL1570120 & 688816 & 5.2 & 5.1735 & TRN \\
\hline CHEMBL1441181 & 688816 & 4.45 & 5.4 & TRN \\
\hline CHEMBL1556013 & 688816 & 4.9 & 5.4218 & TRN \\
\hline CHEMBL1511314 & 688816 & 5.15 & 5.0878 & TRN \\
\hline CHEMBL3190837 & 688816 & 4.7 & 5.3003 & TRN \\
\hline CHEMBL 3210377 & 688816 & 5.0 & 5.421 & TRN \\
\hline CHEMBL1479201 & 688816 & 4.85 & 4.9908 & TRN \\
\hline CHEMBL1547051 & 688816 & 4.95 & 5.0984 & TRN \\
\hline CHEMBL1440703 & 688816 & 4.45 & 5.2714 & TST \\
\hline CHEMBL1545931 & 688816 & 8.3468 & 5.6852 & TST \\
\hline CHEMBL1412266 & 688816 & 4.95 & 5.8388 & TRN \\
\hline CHEMBL1303501 & 688816 & 5.5 & 5.1202 & TRN \\
\hline CHEMBL1326459 & 688816 & 4.8 & 5.4591 & TRN \\
\hline CHEMBL1385613 & 688816 & 8.3468 & 5.5738 & TRN \\
\hline CHEMBL1487593 & 688816 & 4.65 & 4.8486 & TRN \\
\hline
\end{tabular}




\begin{tabular}{|c|c|c|c|c|}
\hline \multicolumn{5}{|c|}{ Supplemental Table S2.txt } \\
\hline CHEMBL1409399 & 688816 & 5.5 & 5.3282 & TRN \\
\hline CHEMBL1527002 & 688816 & 4.8 & 5.81 & TRN \\
\hline CHEMBL1345625 & 688816 & 5.0 & 5.3105 & TST \\
\hline CHEMBL1392056 & 688816 & 4.85 & 5.7022 & TRN \\
\hline CHEMBL1447872 & 688816 & 4.95 & 4.9897 & TRN \\
\hline CHEMBL1539285 & 688816 & 4.9 & 5.2034 & TST \\
\hline CHEMBL 1424490 & 688816 & 5.35 & 5.3379 & TRN \\
\hline CHEMBL1339521 & 688816 & 4.75 & 5.6526 & TRN \\
\hline CHEMBL1537589 & 688816 & 4.8 & 5.4746 & TRN \\
\hline CHEMBL3209511 & 688816 & 4.85 & 5.1272 & TST \\
\hline CHEMBL1494366 & 688816 & 5.0 & 5.0645 & TRN \\
\hline CHEMBL1301361 & 688816 & 4.7 & 5.3949 & TRN \\
\hline CHEMBL 3144995 & 688816 & 5.2 & 5.4468 & TST \\
\hline CHEMBL1440833 & 688816 & 4.45 & 4.9625 & TRN \\
\hline CHEMBL 1424340 & 688816 & 4.45 & 5.0034 & TRN \\
\hline CHEMBL1321657 & 688816 & 4.65 & 5.1988 & TRN \\
\hline CHEMBL1313043 & 688816 & 4.9 & 5.1296 & TRN \\
\hline CHEMBL1521406 & 688816 & 6.1 & 5.7255 & TST \\
\hline CHEMBL1537613 & 688816 & 5.45 & 5.6876 & TST \\
\hline CHEMBL1558944 & 688816 & 5.0 & 4.9137 & TRN \\
\hline CHEMBL1411145 & 688816 & 4.8 & 5.4049 & TRN \\
\hline CHEMBL1432054 & 688816 & 5.4 & 5.4337 & TRN \\
\hline CHEMBL 3197234 & 688816 & 5.0 & 5.2311 & TRN \\
\hline CHEMBL1488583 & 688816 & 5.05 & 5.0016 & TRN \\
\hline CHEMBL1428373 & 688816 & 4.45 & 5.6562 & TST \\
\hline CHEMBL1454726 & 688816 & 4.6 & 5.0281 & TST \\
\hline CHEMBL1466652 & 688816 & 4.85 & 5.195 & TST \\
\hline CHEMBL1453846 & 688816 & 5.05 & 5.2785 & TRN \\
\hline CHEMBL1588420 & 688816 & 5.55 & 5.2444 & TRN \\
\hline CHEMBL 1416700 & 688816 & 5.0 & 5.4252 & TRN \\
\hline CHEMBL3189672 & 688816 & 4.9 & 5.1892 & TRN \\
\hline CHEMBL1435310 & 688816 & 5.05 & 5.1402 & TRN \\
\hline CHEMBL1393549 & 688816 & 7.6003 & 5.1774 & TRN \\
\hline CHEMBL 263972 & 688816 & 5.05 & 5.4468 & TST \\
\hline CHEMBL1446759 & 688816 & 4.8 & 5.322 & TRN \\
\hline CHEMBL567861 & 688816 & 4.45 & 5.0522 & TRN \\
\hline CHEMBL1432908 & 688816 & 4.45 & 5.92899 & 9999999999 \\
\hline CHEMBL1376741 & 688816 & 5.0 & 4.9563 & TRN \\
\hline CHEMBL1462162 & 688816 & 5.7 & 5.1518 & TRN \\
\hline CHEMBL1520736 & 688816 & 4.65 & 5.3192 & TRN \\
\hline CHEMBL 2359072 & 688816 & 4.95 & 5.2123 & TRN \\
\hline CHEMBL1496916 & 688816 & 4.85 & 5.5772 & TRN \\
\hline CHEMBL1348715 & 688816 & 5.7 & 5.8116 & TRN \\
\hline CHEMBL1608782 & 688816 & 4.6 & 5.2679 & TRN \\
\hline CHEMBL1445829 & 688816 & 4.9 & 4.9673 & TST \\
\hline CHEMBL1457913 & 688816 & 4.9 & 5.1735 & TRN \\
\hline CHEMBL1502524 & 688816 & 5.45 & 5.9046 & TRN \\
\hline CHEMBL452861 & 688816 & 4.55 & 5.2163 & TST \\
\hline
\end{tabular}




\begin{tabular}{|c|c|c|c|c|c|}
\hline \multicolumn{6}{|c|}{ Supplemental Table S2.txt } \\
\hline CHEMBL1462610 & 688816 & 4.75 & 4.9289 & TRN & \\
\hline CHEMBL3208662 & 688816 & 5.25 & 5.2721 & TRN & \\
\hline CHEMBL1429303 & 688816 & 5.05 & 5.1511 & TRN & \\
\hline CHEMBL1551610 & 688816 & 5.4 & 5.6096 & TST & \\
\hline CHEMBL1332007 & 688816 & 4.9 & 5.2026 & TST & \\
\hline CHEMBL1508811 & 688816 & 4.45 & 5.3779 & TRN & \\
\hline CHEMBL1369506 & 688816 & 4.8 & 5.2317 & TRN & \\
\hline CHEMBL1385640 & 688816 & 7.5498 & 5.3023 & TRN & \\
\hline CHEMBL1401877 & 688816 & 4.95 & 4.8798 & TRN & \\
\hline CHEMBL1363583 & 688816 & 4.85 & 5.3618 & TRN & \\
\hline CHEMBL1382599 & 688816 & 6.25 & 5.001 & TRN & \\
\hline CHEMBL1534932 & 688816 & 4.5 & 5.6346 & TST & \\
\hline CHEMBL1370292 & 688816 & 4.7 & 5.0993 & TRN & \\
\hline CHEMBL1536898 & 688816 & 5.2 & 5.41799 & 9999999999 & TRN \\
\hline CHEMBL 3212556 & 688816 & 4.8 & 5.0417 & TRN & \\
\hline CHEMBL1363964 & 688816 & 5.4 & 5.4851 & TRN & \\
\hline CHEMBL1440441 & 688816 & 4.75 & 5.2657 & TRN & \\
\hline CHEMBL1521742 & 688816 & 6.8 & 5.5106 & TST & \\
\hline CHEMBL1322708 & 688816 & 5.5 & 5.5141 & TRN & \\
\hline CHEMBL1578064 & 688816 & 4.8 & 4.9177 & TST & \\
\hline CHEMBL1593141 & 688816 & 4.5 & 5.1494 & TRN & \\
\hline CHEMBL1467461 & 688816 & 5.4 & 5.5493 & TRN & \\
\hline CHEMBL1477793 & 688816 & 4.95 & 5.0224 & TRN & \\
\hline CHEMBL1427061 & 688816 & 4.45 & 4.9927 & TRN & \\
\hline CHEMBL1605539 & 688816 & 8.4949 & 5.49100 & 00000000005 & TRN \\
\hline CHEMBL1595727 & 688816 & 5.7 & 5.4041 & TRN & \\
\hline CHEMBL3190251 & 688816 & 4.45 & 5.0153 & TRN & \\
\hline CHEMBL1485420 & 688816 & 4.95 & 4.9632 & TRN & \\
\hline CHEMBL1573813 & 688816 & 4.65 & 5.1854 & TRN & \\
\hline CHEMBL1551294 & 688816 & 5.05 & 5.1999 & TRN & \\
\hline CHEMBL1330516 & 688816 & 4.45 & 5.2636 & TRN & \\
\hline CHEMBL1476900 & 688816 & 4.85 & 4.9975 & TRN & \\
\hline CHEMBL1389232 & 688816 & 4.95 & 5.1316 & TRN & \\
\hline CHEMBL1448387 & 688816 & 4.95 & 5.1319 & TST & \\
\hline CHEMBL 38576 & 688816 & 4.55 & 5.4943 & TRN & \\
\hline CHEMBL1418201 & 688816 & 5.2 & 5.2252 & TRN & \\
\hline CHEMBL1390155 & 688816 & 4.95 & 5.3677 & TRN & \\
\hline CHEMBL1444884 & 688816 & 4.75 & 5.3739 & TRN & \\
\hline CHEMBL1305719 & 688816 & 7.4498 & 5.5389 & TST & \\
\hline CHEMBL1500461 & 688816 & 5.0 & 5.3684 & TRN & \\
\hline CHEMBL1341563 & 688816 & 5.25 & 5.0658 & TST & \\
\hline CHEMBL1500961 & 688816 & 4.8 & 5.5164 & TRN & \\
\hline CHEMBL590397 & 688816 & 4.65 & 5.31 & TST & \\
\hline CHEMBL1567377 & 688816 & 8.3468 & 5.1085 & TST & \\
\hline CHEMBL1390166 & 688816 & 4.8 & 5.2806 & TRN & \\
\hline CHEMBL1605977 & 688816 & 5.1 & 5.1442 & TRN & \\
\hline CHEMBL1339270 & 688816 & 5.55 & 4.9068 & TRN & \\
\hline CHEMBL1489291 & 688816 & 4.95 & 5.1848 & TRN & \\
\hline
\end{tabular}




\begin{tabular}{|c|c|c|c|c|c|}
\hline \multicolumn{6}{|c|}{ Supplemental Table S2.txt } \\
\hline CHEMBL1431944 & 688816 & 4.45 & 5.1057 & TST & \\
\hline CHEMBL1347600 & 688816 & 4.65 & 5.1802 & TRN & \\
\hline CHEMBL1569933 & 688816 & 6.8 & 5.2373 & TRN & \\
\hline CHEMBL1610043 & 688816 & 4.45 & 5.4977 & TRN & \\
\hline CHEMBL3198693 & 688816 & 7.7496 & 5.1089 & TST & \\
\hline CHEMBL1462174 & 688816 & 4.45 & 5.2127 & TRN & \\
\hline CHEMBL3195091 & 688816 & 5.3 & 5.2295 & TST & \\
\hline CHEMBL1519109 & 688816 & 6.7501 & 5.6059 & TRN & \\
\hline CHEMBL1548078 & 688816 & 5.55 & 5.443 & TRN & \\
\hline CHEMBL1533828 & 688816 & 8.3468 & 5.6049 & TRN & \\
\hline CHEMBL1497166 & 688816 & 4.8 & 5.21299 & 9999999999 & TRN \\
\hline CHEMBL1329398 & 688816 & 4.45 & 5.0494 & TST & \\
\hline CHEMBL1393426 & 688816 & 7.4498 & 5.5727 & TRN & \\
\hline CHEMBL1311453 & 688816 & 4.7 & 4.732 & TST & \\
\hline CHEMBL1349530 & 688816 & 4.9 & 5.4869 & TRN & \\
\hline CHEMBL3197208 & 688816 & 5.25 & 5.4265 & TRN & \\
\hline CHEMBL1312108 & 688816 & 7.6498 & 5.4999 & TRN & \\
\hline CHEMBL1390643 & 688816 & 7.6003 & 5.3891 & TRN & \\
\hline CHEMBL1315146 & 688816 & 4.85 & 5.37700 & 0000000001 & TST \\
\hline CHEMBL1457070 & 688816 & 4.95 & 5.4257 & TRN & \\
\hline CHEMBL1333088 & 688816 & 5.15 & 5.4045 & TST & \\
\hline CHEMBL1305570 & 688816 & 5.4 & 5.3634 & TRN & \\
\hline CHEMBL1481659 & 688816 & 4.85 & 5.499 & TRN & \\
\hline CHEMBL1359648 & 688816 & 6.3 & 5.0395 & TRN & \\
\hline CHEMBL1535221 & 688816 & 4.95 & 5.0271 & TRN & \\
\hline CHEMBL1392608 & 688816 & 5.05 & 5.5801 & TRN & \\
\hline CHEMBL3190824 & 688816 & 5.8 & 5.369 & TRN & \\
\hline CHEMBL3210422 & 688816 & 6.8 & 5.6399 & TST & \\
\hline CHEMBL1449698 & 688816 & 7.0 & 5.2379 & TRN & \\
\hline CHEMBL1604597 & 688816 & 6.35 & 5.2101 & TST & \\
\hline CHEMBL1427911 & 688816 & 4.45 & 5.8365 & TST & \\
\hline CHEMBL1567154 & 688816 & 5.3 & 5.1995 & TST & \\
\hline CHEMBL1356041 & 688816 & 4.6 & 4.5577 & TST & \\
\hline CHEMBL 259358 & 688816 & 4.45 & 5.5891 & TRN & \\
\hline CHEMBL1457966 & 688816 & 5.15 & 5.4104 & TST & \\
\hline CHEMBL1510213 & 688816 & 4.45 & 5.0529 & TRN & \\
\hline CHEMBL1536349 & 688816 & 4.75 & 5.3506 & TST & \\
\hline CHEMBL1561802 & 688816 & 4.95 & 5.1513 & TRN & \\
\hline CHEMBL1491253 & 688816 & 5.25 & 5.20299 & 9999999999 & TRN \\
\hline CHEMBL1543952 & 688816 & 4.65 & 5.5665 & TRN & \\
\hline CHEMBL1491118 & 688816 & 4.95 & 5.1597 & TST & \\
\hline CHEMBL1403453 & 688816 & 6.0 & 5.3851 & TRN & \\
\hline CHEMBL1529203 & 688816 & 4.45 & 5.1871 & TRN & \\
\hline CHEMBL1347493 & 688816 & 4.8 & 5.0633 & TRN & \\
\hline CHEMBL1520366 & 688816 & 5.15 & 5.5427 & TRN & \\
\hline CHEMBL1501703 & 688816 & 4.65 & 5.0218 & TST & \\
\hline CHEMBL1341408 & 688816 & 4.45 & 5.1214 & TRN & \\
\hline CHEMBL1461517 & 688816 & 7.6003 & 5.6033 & TRN & \\
\hline
\end{tabular}




\begin{tabular}{|c|c|c|c|c|}
\hline \multicolumn{5}{|c|}{ Supplemental Table S2.txt } \\
\hline CHEMBL1365692 & 688816 & 5.6 & 5.4225 & TRN \\
\hline CHEMBL3195471 & 688816 & 4.85 & 4.9283 & TRN \\
\hline CHEMBL1585637 & 688816 & 5.0 & 5.1796 & TRN \\
\hline CHEMBL1968462 & 688816 & 4.45 & 5.5045 & TST \\
\hline CHEMBL1351932 & 688816 & 4.7 & 5.21 & TST \\
\hline CHEMBL3197122 & 688816 & 4.45 & 5.5408 & TRN \\
\hline CHEMBL1605809 & 688816 & 4.8 & 5.4816 & TRN \\
\hline CHEMBL3194739 & 688816 & 6.7001 & 5.4384 & TRN \\
\hline CHEMBL1380160 & 688816 & 5.8 & 5.4214 & TRN \\
\hline CHEMBL3189584 & 688816 & 9.0969 & 5.6583 & TST \\
\hline CHEMBL1485983 & 688816 & 6.1 & 5.4047 & TST \\
\hline CHEMBL1464256 & 688816 & 4.5 & 5.0254 & TRN \\
\hline CHEMBL1527033 & 688816 & 5.25 & 5.3773 & TRN \\
\hline CHEMBL1512121 & 688816 & 5.0 & 5.291 & TRN \\
\hline CHEMBL1374369 & 688816 & 8.301 & 5.5873 & TRN \\
\hline CHEMBL584015 & 688816 & 4.95 & 5.1538 & TST \\
\hline CHEMBL1555101 & 688816 & 4.65 & 5.2398 & TRN \\
\hline CHEMBL1496449 & 688816 & 4.9 & 5.2112 & TRN \\
\hline CHEMBL1325703 & 688816 & 8.4949 & 5.5126 & TRN \\
\hline CHEMBL1457702 & 688816 & 4.9 & 5.3286 & TST \\
\hline CHEMBL1429707 & 688816 & 7.0 & 5.4919 & TRN \\
\hline CHEMBL1400688 & 688816 & 4.9 & 5.3364 & TST \\
\hline CHEMBL3190436 & 688816 & 6.6 & 5.3359 & TST \\
\hline CHEMBL1583692 & 688816 & 4.9 & 5.345 & TRN \\
\hline CHEMBL1583180 & 688816 & 4.65 & 4.952 & TRN \\
\hline CHEMBL1562405 & 688816 & 4.95 & 5.007 & TRN \\
\hline CHEMBL1428072 & 688816 & 4.85 & 5.4241 & TRN \\
\hline CHEMBL1341788 & 688816 & 4.7 & 5.3513 & TRN \\
\hline CHEMBL1452208 & 688816 & 4.9 & 5.0196 & TRN \\
\hline CHEMBL1393983 & 688816 & 5.2 & 5.6184 & TRN \\
\hline CHEMBL1391347 & 688816 & 4.45 & 5.2141 & TRN \\
\hline CHEMBL1413026 & 688816 & 5.25 & 5.2654 & TRN \\
\hline CHEMBL1481664 & 688816 & 5.3 & 5.4273 & TST \\
\hline CHEMBL1589224 & 688816 & 5.6 & 5.5793 & TRN \\
\hline CHEMBL1334048 & 688816 & 8.301 & 5.5415 & TST \\
\hline CHEMBL1559414 & 688816 & 5.2 & 5.3616 & TRN \\
\hline CHEMBL1497245 & 688816 & 4.45 & 5.1013 & TRN \\
\hline CHEMBL1468078 & 688816 & 4.45 & 4.9576 & TRN \\
\hline CHEMBL1598713 & 688816 & 4.9 & 4.9349 & TRN \\
\hline CHEMBL1567522 & 688816 & 8.3468 & 5.0809 & TRN \\
\hline CHEMBL1597728 & 688816 & 5.0 & 5.0843 & TRN \\
\hline CHEMBL1505569 & 688816 & 4.75 & 5.0603 & TRN \\
\hline CHEMBL1452671 & 688816 & 5.05 & 4.8724 & TRN \\
\hline CHEMBL1379989 & 688816 & 4.9 & 5.5079 & TST \\
\hline CHEMBL1530458 & 688816 & 5.0 & 5.095 & TRN \\
\hline CHEMBL1547261 & 688816 & 4.85 & 5.1616 & TRN \\
\hline CHEMBL1474935 & 688816 & 4.85 & 5.092 & TRN \\
\hline CHEMBL1585651 & 688816 & 4.75 & 4.9317 & TRN \\
\hline
\end{tabular}




\begin{tabular}{|c|c|c|c|c|c|}
\hline \multicolumn{6}{|c|}{ Supplemental Table s2.txt } \\
\hline CHEMBL1427212 & 688816 & 4.65 & 5.1749 & TRN & \\
\hline CHEMBL1404673 & 688816 & 4.5 & 5.34 & TST & \\
\hline CHEMBL1515137 & 688816 & 4.85 & 5.4171 & TST & \\
\hline CHEMBL1330308 & 688816 & 4.9 & 5.6729 & TRN & \\
\hline CHEMBL1496874 & 688816 & 4.45 & 5.2858 & TRN & \\
\hline CHEMBL1369010 & 688816 & 6.1 & 5.5714 & TRN & \\
\hline CHEMBL1382656 & 688816 & 5.05 & 5.3795 & TRN & \\
\hline CHEMBL1371825 & 688816 & 5.25 & 5.2226 & TRN & \\
\hline CHEMBL1606810 & 688816 & 4.75 & 4.9239 & TST & \\
\hline CHEMBL1530789 & 688816 & 5.65 & 5.1764 & TRN & \\
\hline CHEMBL1390831 & 688816 & 5.45 & 5.1373 & TRN & \\
\hline CHEMBL1335995 & 688816 & 4.45 & 5.1851 & TRN & \\
\hline CHEMBL3199117 & 688816 & 4.65 & 5.0235 & TST & \\
\hline CHEMBL1358676 & 688816 & 4.7 & 5.055 & TRN & \\
\hline CHEMBL1371354 & 688816 & 6.0 & 5.4108 & TRN & \\
\hline CHEMBL1459626 & 688816 & 4.45 & 5.2332 & TST & \\
\hline CHEMBL1539721 & 688816 & 5.35 & 5.4664 & TRN & \\
\hline CHEMBL1577538 & 688816 & 5.0 & 5.272 & TRN & \\
\hline CHEMBL1392156 & 688816 & 4.45 & 5.5349 & TRN & \\
\hline CHEMBL1582865 & 688816 & 4.85 & 5.7309 & TRN & \\
\hline CHEMBL1440037 & 688816 & 6.0 & 5.1147 & TRN & \\
\hline CHEMBL1425287 & 688816 & 5.7 & 5.6554 & TRN & \\
\hline CHEMBL1454524 & 688816 & 8.301 & 5.33700 & 0000000001 & TRN \\
\hline CHEMBL1440416 & 688816 & 5.0 & 4.7565 & TRN & \\
\hline CHEMBL1490632 & 688816 & 6.05 & 4.8489 & TST & \\
\hline CHEMBL1372688 & 688816 & 5.35 & 5.6028 & TST & \\
\hline CHEMBL1441394 & 688816 & 4.95 & 5.1298 & TRN & \\
\hline CHEMBL1565275 & 688816 & 7.4001 & 5.5585 & TRN & \\
\hline CHEMBL1420529 & 688816 & 4.45 & 5.0551 & TRN & \\
\hline CHEMBL1563246 & 688816 & 5.75 & 5.7175 & TRN & \\
\hline CHEMBL1517177 & 688816 & 4.95 & 5.355 & TST & \\
\hline CHEMBL1325585 & 688816 & 5.0 & 5.6408 & TST & \\
\hline CHEMBL1478800 & 688816 & 8.4559 & 5.70700 & 0000000001 & TST \\
\hline CHEMBL1483312 & 688816 & 4.9 & 5.0654 & TRN & \\
\hline CHEMBL1401030 & 688816 & 5.6 & 5.3113 & TRN & \\
\hline CHEMBL1390507 & 688816 & 4.45 & 5.4596 & TRN & \\
\hline CHEMBL1309656 & 688816 & 4.45 & 5.1566 & TRN & \\
\hline CHEMBL1350181 & 688816 & 4.75 & 5.1149 & TRN & \\
\hline CHEMBL1430574 & 688816 & 4.45 & 5.6335 & TRN & \\
\hline CHEMBL1402494 & 688816 & 5.1 & 5.4792 & TRN & \\
\hline CHEMBL1351355 & 688816 & 4.75 & 4.9333 & TRN & \\
\hline CHEMBL1523311 & 688816 & 4.45 & 5.3205 & TRN & \\
\hline CHEMBL1308917 & 688816 & 4.8 & 5.7033 & TST & \\
\hline CHEMBL1448182 & 688816 & 4.8 & 5.1935 & TRN & \\
\hline CHEMBL3207736 & 688816 & 4.7 & 5.4093 & TRN & \\
\hline CHEMBL1526051 & 688816 & 6.25 & 5.30399 & 9999999999 & TRN \\
\hline CHEMBL1415303 & 688816 & 4.9 & 5.5114 & TRN & \\
\hline CHEMBL1562926 & 688816 & 5.0 & 5.138 & TRN & \\
\hline
\end{tabular}




\begin{tabular}{|c|c|c|c|c|}
\hline \multicolumn{5}{|c|}{ Supplemental Table S2.txt } \\
\hline CHEMBL1506680 & 688816 & 4.95 & 5.4816 & TST \\
\hline CHEMBL1529191 & 688816 & 6.9 & 5.2799 & TRN \\
\hline CHEMBL1350361 & 688816 & 4.9 & 5.4253 & TRN \\
\hline CHEMBL1577395 & 688816 & 4.65 & 5.0902 & TRN \\
\hline CHEMBL3197127 & 688816 & 4.75 & 5.0007 & TRN \\
\hline CHEMBL1312088 & 688816 & 5.05 & 5.2538 & TRN \\
\hline CHEMBL1485970 & 688816 & 4.9 & 5.0239 & TRN \\
\hline CHEMBL1498231 & 688816 & 5.15 & 5.2991 & TRN \\
\hline CHEMBL1319046 & 688816 & 4.7 & 5.0147 & TRN \\
\hline CHEMBL1458900 & 688816 & 4.85 & 5.4915 & TRN \\
\hline CHEMBL1581374 & 688816 & 5.0 & 5.2958 & TRN \\
\hline CHEMBL1544075 & 688816 & 4.45 & 5.1834 & TRN \\
\hline CHEMBL3195910 & 688816 & 4.95 & 5.6614 & TST \\
\hline CHEMBL1301788 & 688816 & 7.5003 & 5.2957 & TST \\
\hline CHEMBL1413743 & 688816 & 5.0 & 4.843 & TRN \\
\hline CHEMBL3210546 & 688816 & 4.8 & 5.1162 & TRN \\
\hline CHEMBL1422253 & 688816 & 5.15 & 5.782 & TRN \\
\hline CHEMBL1313691 & 688816 & 4.85 & 5.1886 & TRN \\
\hline CHEMBL1392355 & 688816 & 4.85 & 5.3599 & TST \\
\hline CHEMBL1352752 & 688816 & 5.0 & 4.9749 & TRN \\
\hline CHEMBL1441370 & 688816 & 4.8 & 5.3305 & TRN \\
\hline CHEMBL1473254 & 688816 & 4.45 & 5.0734 & TRN \\
\hline CHEMBL1384651 & 688816 & 4.95 & 5.1784 & TRN \\
\hline CHEMBL1352590 & 688816 & 4.95 & 5.3693 & TRN \\
\hline CHEMBL1500140 & 688816 & 4.7 & 5.4898 & TRN \\
\hline CHEMBL1331753 & 688816 & 6.05 & 5.2807 & TST \\
\hline CHEMBL1592793 & 688816 & 4.7 & 5.598 & TRN \\
\hline CHEMBL1572019 & 688816 & 4.65 & 5.6047 & TRN \\
\hline CHEMBL1337583 & 688816 & 6.05 & 5.2451 & TRN \\
\hline CHEMBL1545553 & 688816 & 4.7 & 5.103 & TST \\
\hline CHEMBL1572688 & 688816 & 5.5 & 5.2718 & TRN \\
\hline CHEMBL1407653 & 688816 & 4.65 & 5.0397 & TRN \\
\hline CHEMBL3191966 & 688816 & 5.0 & 4.9726 & TRN \\
\hline CHEMBL1537588 & 688816 & 4.5 & 5.2212 & TST \\
\hline CHEMBL1447831 & 688816 & 4.95 & 4.9343 & TRN \\
\hline CHEMBL1456286 & 688816 & 4.65 & 5.5657 & TRN \\
\hline CHEMBL 2003304 & 688816 & 5.0 & 5.2097 & TRN \\
\hline CHEMBL3192704 & 688816 & 4.45 & 5.385 & TST \\
\hline CHEMBL1466372 & 688816 & 4.45 & 5.2226 & TRN \\
\hline CHEMBL1309266 & 688816 & 4.9 & 5.4478 & TRN \\
\hline CHEMBL1381979 & 688816 & 4.75 & 4.9929 & TRN \\
\hline CHEMBL1360035 & 688816 & 5.45 & 5.6428 & TRN \\
\hline CHEMBL1378999 & 688816 & 8.301 & 5.4062 & TST \\
\hline CHEMBL1605804 & 688816 & 5.15 & 5.4665 & TRN \\
\hline CHEMBL1329222 & 688816 & 4.65 & 5.3239 & TST \\
\hline CHEMBL1479817 & 688816 & 4.9 & 5.2328 & TRN \\
\hline CHEMBL1581561 & 688816 & 8.3468 & 5.4451 & TRN \\
\hline CHEMBL1487468 & 688816 & 4.45 & 5.021 & TRN \\
\hline
\end{tabular}




\begin{tabular}{|c|c|c|c|c|c|}
\hline \multicolumn{6}{|c|}{ Supplemental Table S2.txt } \\
\hline CHEMBL1561813 & 688816 & 4.85 & 4.9358 & TRN & \\
\hline CHEMBL3199347 & 688816 & 5.0 & 5.0746 & TRN & \\
\hline CHEMBL1411089 & 688816 & 5.5 & 5.1524 & TST & \\
\hline CHEMBL1406081 & 688816 & 5.15 & 5.0937 & TRN & \\
\hline CHEMBL1989853 & 688816 & 5.0 & 5.2311 & TST & \\
\hline CHEMBL1349003 & 688816 & 6.8499 & 5.3061 & TRN & \\
\hline CHEMBL1553839 & 688816 & 4.9 & 5.0526 & TRN & \\
\hline CHEMBL1574894 & 688816 & 6.15 & 4.9851 & TRN & \\
\hline CHEMBL1376729 & 688816 & 4.95 & 5.086 & TRN & \\
\hline CHEMBL1393105 & 688816 & 5.5 & 5.1783 & TRN & \\
\hline CHEMBL1548717 & 688816 & 4.45 & 5.4059 & TRN & \\
\hline CHEMBL1332154 & 688816 & 4.95 & 5.1168 & TRN & \\
\hline CHEMBL1373867 & 688816 & 5.8 & 5.2637 & TRN & \\
\hline CHEMBL1478298 & 688816 & 5.25 & 5.4113 & TRN & \\
\hline CHEMBL1489698 & 688816 & 4.75 & 5.6692 & TRN & \\
\hline CHEMBL1484167 & 688816 & 4.95 & 5.1134 & TST & \\
\hline CHEMBL3194973 & 688816 & 4.9 & 5.2777 & TRN & \\
\hline CHEMBL1583513 & 688816 & 4.75 & 4.89199 & 99999999995 & TRN \\
\hline CHEMBL1427408 & 688816 & 4.9 & 4.9043 & TRN & \\
\hline CHEMBL1328159 & 688816 & 5.7 & 5.0065 & TRN & \\
\hline CHEMBL1510389 & 688816 & 7.15 & 5.2297 & TRN & \\
\hline CHEMBL1591263 & 688816 & 5.0 & 5.3396 & TRN & \\
\hline CHEMBL1531371 & 688816 & 4.95 & 5.1355 & TRN & \\
\hline CHEMBL590947 & 688816 & 4.85 & 4.9569 & TRN & \\
\hline CHEMBL1311769 & 688816 & 5.05 & 5.1247 & TRN & \\
\hline CHEMBL1529960 & 688816 & 4.85 & 5.1377 & TRN & \\
\hline CHEMBL1564121 & 688816 & 4.95 & 5.2883 & TRN & \\
\hline CHEMBL1463644 & 688816 & 7.699 & 5.3699 & TST & \\
\hline CHEMBL1431910 & 688816 & 5.05 & 5.0804 & TRN & \\
\hline CHEMBL3193623 & 688816 & 5.1 & 5.2741 & TRN & \\
\hline CHEMBL1364157 & 688816 & 5.55 & 5.4363 & TRN & \\
\hline CHEMBL1598747 & 688816 & 7.699 & 5.1835 & TRN & \\
\hline CHEMBL1426720 & 688816 & 4.95 & 5.4878 & TRN & \\
\hline CHEMBL1447816 & 688816 & 5.2 & 4.9287 & TRN & \\
\hline CHEMBL1379948 & 688816 & 4.9 & 4.8811 & TRN & \\
\hline CHEMBL1464966 & 688816 & 4.85 & 4.8174 & TST & \\
\hline CHEMBL1582999 & 688816 & 4.45 & 5.1609 & TST & \\
\hline CHEMBL1453551 & 688816 & 5.7 & 5.1717 & TRN & \\
\hline CHEMBL1334567 & 688816 & 4.8 & 5.1086 & TRN & \\
\hline CHEMBL1348014 & 688816 & 4.85 & 5.2746 & TRN & \\
\hline CHEMBL607299 & 688816 & 4.8 & 5.1391 & TRN & \\
\hline CHEMBL 1325826 & 688816 & 4.9 & 5.0049 & TRN & \\
\hline CHEMBL1560908 & 688816 & 5.35 & 5.4276 & TST & \\
\hline CHEMBL1429159 & 688816 & 4.6 & 5.0582 & TST & \\
\hline CHEMBL1439821 & 688816 & 5.55 & 5.047 & TRN & \\
\hline CHEMBL1529928 & 688816 & 5.3 & 4.7866 & TRN & \\
\hline CHEMBL1421500 & 688816 & 5.55 & 5.0867 & TRN & \\
\hline CHEMBL1610066 & 688816 & 4.85 & 5.2465 & TRN & \\
\hline
\end{tabular}




\begin{tabular}{|c|c|c|c|c|c|}
\hline \multicolumn{6}{|c|}{ Supplemental Table s2.txt } \\
\hline CHEMBL1352117 & 688816 & 4.9 & 5.3077 & TRN & \\
\hline CHEMBL1365228 & 688816 & 8.301 & 5.3401 & TRN & \\
\hline CHEMBL1336039 & 688816 & 4.9 & 5.124 & TRN & \\
\hline CHEMBL1359886 & 688816 & 5.8 & 5.5418 & TRN & \\
\hline CHEMBL1391658 & 688816 & 7.6498 & 5.4793 & TRN & \\
\hline CHEMBL1401847 & 688816 & 4.7 & 5.3682 & TST & \\
\hline CHEMBL1364431 & 688816 & 4.9 & 5.485 & TRN & \\
\hline CHEMBL1575897 & 688816 & 4.85 & 5.3755 & TST & \\
\hline CHEMBL1524758 & 688816 & 4.9 & 5.3122 & TRN & \\
\hline CHEMBL1554707 & 688816 & 4.8 & 5.1242 & TRN & \\
\hline CHEMBL1586340 & 688816 & 6.4 & 5.3677 & TRN & \\
\hline CHEMBL1502374 & 688816 & 6.7501 & 5.3732 & TRN & \\
\hline CHEMBL428064 & 688816 & 5.0 & 5.0374 & TST & \\
\hline CHEMBL1349840 & 688816 & 5.0 & 5.2312 & TRN & \\
\hline CHEMBL1459140 & 688816 & 6.0 & 5.1993 & TRN & \\
\hline CHEMBL1559263 & 688816 & 4.45 & 4.9428 & TST & \\
\hline CHEMBL1528049 & 688816 & 4.95 & 5.3096 & TRN & \\
\hline CHEMBL1455316 & 688816 & 4.95 & 5.0277 & TRN & \\
\hline CHEMBL1491327 & 688816 & 5.55 & 5.072 & TRN & \\
\hline CHEMBL 258893 & 688816 & 6.0 & 5.3201 & TST & \\
\hline CHEMBL1581349 & 688816 & 5.25 & 5.705 & TST & \\
\hline CHEMBL1434157 & 688816 & 5.6 & 5.0834 & TST & \\
\hline CHEMBL1333720 & 688816 & 4.6 & 5.1324 & TST & \\
\hline CHEMBL1586113 & 688816 & 4.95 & 4.9883 & TRN & \\
\hline CHEMBL1337488 & 688816 & 5.8 & 5.2646 & TST & \\
\hline CHEMBL1365201 & 688816 & 4.45 & 5.0641 & TRN & \\
\hline CHEMBL1313215 & 688816 & 6.05 & 5.3639 & TRN & \\
\hline CHEMBL1374933 & 688816 & 5.5 & 5.3232 & TRN & \\
\hline CHEMBL1519065 & 688816 & 4.45 & 5.5619 & TST & \\
\hline CHEMBL1438448 & 688816 & 4.55 & 5.5857 & TST & \\
\hline CHEMBL1422781 & 688816 & 4.95 & 5.143 & TST & \\
\hline CHEMBL1372064 & 688816 & 4.45 & 4.9008 & TRN & \\
\hline CHEMBL1349898 & 688816 & 5.1 & 5.3523 & TST & \\
\hline CHEMBL1344920 & 688816 & 4.95 & 5.36700 & 3000000001 & TRN \\
\hline CHEMBL1431995 & 688816 & 5.7 & 5.2316 & TRN & \\
\hline CHEMBL1332547 & 688816 & 4.95 & 5.1375 & TRN & \\
\hline CHEMBL1491580 & 688816 & 5.2 & 5.4173 & TST & \\
\hline CHEMBL1306412 & 688816 & 4.9 & 5.1904 & TST & \\
\hline CHEMBL1398576 & 688816 & 4.7 & 5.5428 & TRN & \\
\hline CHEMBL1562876 & 688816 & 4.45 & 5.3599 & TST & \\
\hline CHEMBL1301119 & 688816 & 4.85 & 5.6144 & TRN & \\
\hline CHEMBL1364685 & 688816 & 4.95 & 5.6317 & TRN & \\
\hline CHEMBL1575166 & 688816 & 5.25 & 5.2806 & TRN & \\
\hline CHEMBL1371147 & 688816 & 5.25 & 4.8028 & TRN & \\
\hline CHEMBL1577016 & 688816 & 5.2 & 5.3618 & TRN & \\
\hline CHEMBL1372609 & 688816 & 4.45 & 5.1353 & TRN & \\
\hline CHEMBL1524355 & 688816 & 5.1 & 5.1173 & TRN & \\
\hline CHEMBL3210489 & 688816 & 5.3 & 5.6012 & TST & \\
\hline
\end{tabular}




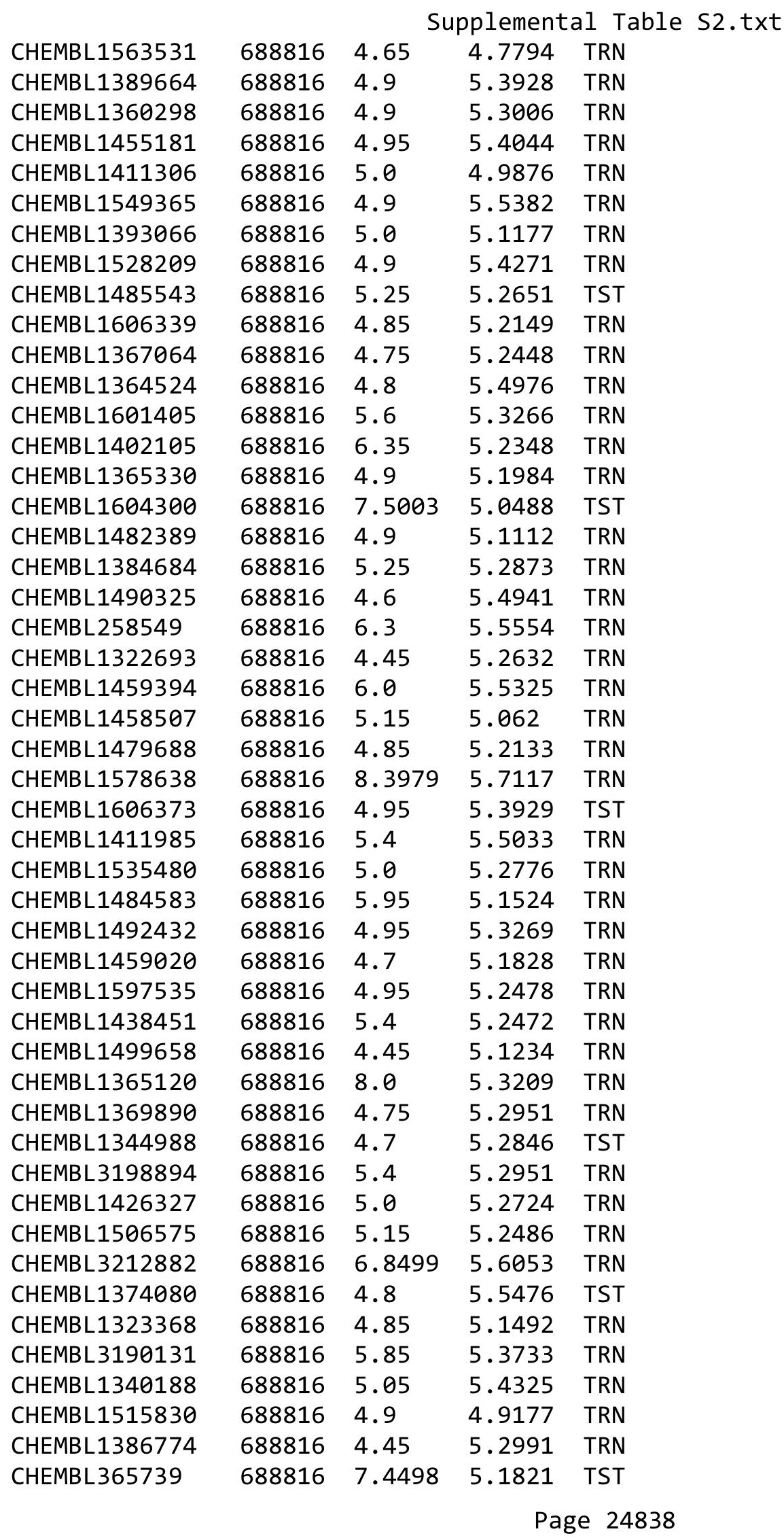




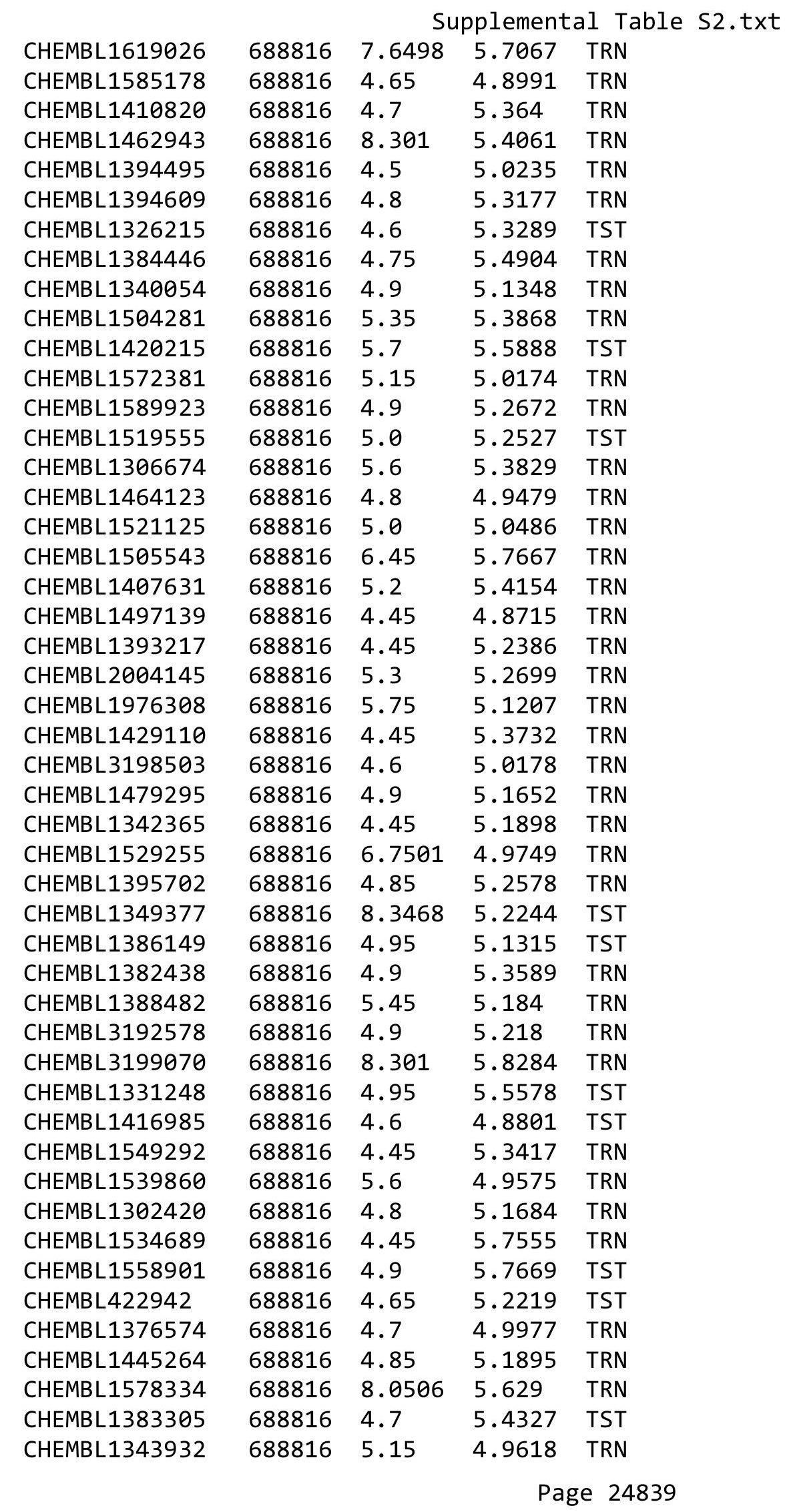




\begin{tabular}{|c|c|c|c|c|c|}
\hline \multicolumn{6}{|c|}{ Supplemental Table S2.txt } \\
\hline CHEMBL1565806 & 688816 & 4.55 & 5.1807 & TRN & \\
\hline CHEMBL1386399 & 688816 & 5.3 & 4.8902 & TRN & \\
\hline CHEMBL1389814 & 688816 & 7.7496 & 5.6951 & TRN & \\
\hline CHEMBL1450348 & 688816 & 5.7 & 5.2573 & TRN & \\
\hline CHEMBL3207979 & 688816 & 4.95 & 5.5158 & TST & \\
\hline CHEMBL1557708 & 688816 & 7.6003 & 4.7994 & TST & \\
\hline CHEMBL1448512 & 688816 & 5.45 & 5.6833 & TRN & \\
\hline CHEMBL1599964 & 688816 & 4.95 & 5.2383 & TRN & \\
\hline CHEMBL1510634 & 688816 & 5.5 & 4.9316 & TST & \\
\hline CHEMBL1383537 & 688816 & 6.0 & 5.3267 & TRN & \\
\hline CHEMBL1540484 & 688816 & 4.45 & 5.2753 & TST & \\
\hline CHEMBL1467621 & 688816 & 6.45 & 5.5917 & TST & \\
\hline CHEMBL1545478 & 688816 & 5.1 & 5.3572 & TRN & \\
\hline CHEMBL1340021 & 688816 & 4.6 & 5.1753 & TST & \\
\hline CHEMBL1448503 & 688816 & 4.85 & 5.5525 & TRN & \\
\hline CHEMBL1498147 & 688816 & 4.45 & 5.3177 & TST & \\
\hline CHEMBL1557605 & 688816 & 5.1 & 5.4136 & TRN & \\
\hline CHEMBL1419208 & 688816 & 4.7 & 5.204 & TRN & \\
\hline CHEMBL1368418 & 688816 & 5.5 & 4.8183 & TRN & \\
\hline CHEMBL1610829 & 688816 & 5.4 & 5.8087 & TRN & \\
\hline CHEMBL3214179 & 688816 & 5.55 & 5.3184 & TRN & \\
\hline CHEMBL1556621 & 688816 & 5.25 & 5.1994 & TRN & \\
\hline CHEMBL1361905 & 688816 & 4.95 & 5.2299 & TRN & \\
\hline CHEMBL583594 & 688816 & 5.95 & 5.3825 & TRN & \\
\hline CHEMBL1525329 & 688816 & 5.25 & 5.476 & TST & \\
\hline CHEMBL1572570 & 688816 & 4.6 & 5.1646 & TRN & \\
\hline CHEMBL1372314 & 688816 & 4.75 & 5.0032 & TRN & \\
\hline CHEMBL1609251 & 688816 & 5.2 & 4.9526 & TRN & \\
\hline CHEMBL1303720 & 688816 & 4.95 & 5.506 & TRN & \\
\hline CHEMBL1501584 & 688816 & 4.9 & 5.1152 & TRN & \\
\hline CHEMBL1494263 & 688816 & 4.75 & 5.0244 & TRN & \\
\hline CHEMBL1301598 & 688816 & 4.45 & 5.2489 & TRN & \\
\hline CHEMBL1568805 & 688816 & 4.45 & 5.1175 & TST & \\
\hline CHEMBL1560709 & 688816 & 4.85 & 5.30200 & 00000000005 & TRN \\
\hline CHEMBL1425297 & 688816 & 4.85 & 5.3016 & TRN & \\
\hline CHEMBL1579339 & 688816 & 4.85 & 5.056 & TRN & \\
\hline CHEMBL1482219 & 688816 & 7.6003 & 4.9246 & TST & \\
\hline CHEMBL1348452 & 688816 & 4.75 & 5.3299 & TRN & \\
\hline CHEMBL1456080 & 688816 & 4.45 & 5.4248 & TRN & \\
\hline CHEMBL1417399 & 688816 & 4.5 & 5.1579 & TRN & \\
\hline CHEMBL1580254 & 688816 & 5.4 & 5.2585 & TRN & \\
\hline CHEMBL1564494 & 688816 & 4.9 & 5.2365 & TRN & \\
\hline CHEMBL1466265 & 688816 & 4.45 & 5.5133 & TRN & \\
\hline CHEMBL1532382 & 688816 & 4.45 & 5.7321 & TST & \\
\hline CHEMBL1566810 & 688816 & 4.45 & 5.1019 & TRN & \\
\hline CHEMBL1520296 & 688816 & 5.0 & 5.6976 & TRN & \\
\hline CHEMBL1601425 & 688816 & 6.05 & 5.3087 & TRN & \\
\hline CHEMBL1967859 & 688816 & 5.45 & 4.9796 & TST & \\
\hline
\end{tabular}




\begin{tabular}{|c|c|c|c|c|}
\hline \multicolumn{5}{|c|}{ Supplemental Table S2.txt } \\
\hline CHEMBL1539498 & 688816 & 4.8 & 5.022 & TRN \\
\hline CHEMBL1407088 & 688816 & 4.9 & 4.9658 & TRN \\
\hline CHEMBL3197874 & 688816 & 5.25 & 5.6198 & TST \\
\hline CHEMBL1329383 & 688816 & 4.9 & 5.0607 & TRN \\
\hline CHEMBL1979455 & 688816 & 5.5 & 5.0586 & TRN \\
\hline CHEMBL1454247 & 688816 & 4.45 & 5.3858 & TRN \\
\hline CHEMBL1373003 & 688816 & 4.45 & 5.6344 & TRN \\
\hline CHEMBL1376681 & 688816 & 4.95 & 5.4491 & TRN \\
\hline CHEMBL1396311 & 688816 & 4.85 & 5.0798 & TRN \\
\hline CHEMBL1411164 & 688816 & 6.0 & 5.1476 & TRN \\
\hline CHEMBL1530061 & 688816 & 4.9 & 4.8584 & TST \\
\hline CHEMBL1444824 & 688816 & 5.6 & 5.2244 & TST \\
\hline CHEMBL1426362 & 688816 & 4.8 & 5.3871 & TST \\
\hline CHEMBL1361141 & 688816 & 6.35 & 5.5517 & TRN \\
\hline CHEMBL1594307 & 688816 & 5.0 & 5.3974 & TST \\
\hline CHEMBL1462034 & 688816 & 4.75 & 5.3278 & TRN \\
\hline CHEMBL1550184 & 688816 & 5.4 & 5.8256 & TRN \\
\hline CHEMBL1606486 & 688816 & 4.95 & 5.1862 & TRN \\
\hline CHEMBL229907 & 688816 & 6.1 & 5.0212 & TRN \\
\hline CHEMBL1471886 & 688816 & 8.301 & 5.7072 & TRN \\
\hline CHEMBL1340596 & 688816 & 6.1 & 5.3564 & TRN \\
\hline CHEMBL1583788 & 688816 & 4.85 & 5.0816 & TRN \\
\hline CHEMBL1375977 & 688816 & 5.15 & 5.039 & TRN \\
\hline CHEMBL1505658 & 688816 & 4.8 & 5.0662 & TST \\
\hline CHEMBL1337149 & 688816 & 6.4 & 5.3851 & TRN \\
\hline CHEMBL1456567 & 688816 & 4.45 & 5.7581 & TRN \\
\hline CHEMBL1453831 & 688816 & 4.85 & 5.2633 & TST \\
\hline CHEMBL1390889 & 688816 & 4.65 & 4.9249 & TRN \\
\hline CHEMBL602575 & 688816 & 6.0 & 5.6205 & TST \\
\hline CHEMBL1452115 & 688816 & 5.0 & 5.2678 & TRN \\
\hline CHEMBL1520340 & 688816 & 5.25 & 5.1034 & TRN \\
\hline CHEMBL1345379 & 688816 & 5.1 & 5.3579 & TRN \\
\hline CHEMBL3195083 & 688816 & 4.65 & 5.2092 & TRN \\
\hline CHEMBL1555497 & 688816 & 4.75 & 5.0502 & TRN \\
\hline CHEMBL 2005317 & 688816 & 5.1 & 4.8825 & TRN \\
\hline CHEMBL1578422 & 688816 & 5.25 & 5.4413 & TST \\
\hline CHEMBL1341237 & 688816 & 5.2 & 5.0511 & TRN \\
\hline CHEMBL1440329 & 688816 & 5.05 & 5.0562 & TRN \\
\hline CHEMBL1340738 & 688816 & 5.0 & 5.5243 & TRN \\
\hline CHEMBL 3212478 & 688816 & 4.95 & 5.3441 & TRN \\
\hline CHEMBL1371171 & 688816 & 4.95 & 5.3434 & TRN \\
\hline CHEMBL1425795 & 688816 & 4.9 & 4.8642 & TST \\
\hline CHEMBL1385946 & 688816 & 4.9 & 5.4163 & TRN \\
\hline CHEMBL1602775 & 688816 & 5.65 & 5.4458 & TRN \\
\hline CHEMBL1345620 & 688816 & 5.0 & 4.9602 & TRN \\
\hline CHEMBL1349866 & 688816 & 5.65 & 5.8466 & TRN \\
\hline CHEMBL1459129 & 688816 & 4.9 & 5.1405 & TRN \\
\hline CHEMBL1371606 & 688816 & 5.2 & 5.4411 & TST \\
\hline
\end{tabular}




\begin{tabular}{|c|c|c|c|c|c|}
\hline \multicolumn{6}{|c|}{ Supplemental Table S2.txt } \\
\hline CHEMBL1460935 & 688816 & 5.0 & 5.0197 & TRN & \\
\hline CHEMBL1613578 & 688816 & 5.7 & 5.4358 & TST & \\
\hline CHEMBL3190706 & 688816 & 5.35 & 5.5274 & TST & \\
\hline CHEMBL1395277 & 688816 & 5.15 & 4.9901 & TRN & \\
\hline CHEMBL1571990 & 688816 & 5.2 & 5.0544 & TRN & \\
\hline CHEMBL328710 & 688816 & 6.0 & 5.1594 & TRN & \\
\hline CHEMBL1600648 & 688816 & 7.5498 & 5.3833 & TST & \\
\hline CHEMBL1965784 & 688816 & 5.25 & \multicolumn{2}{|c|}{5.667999999999999} & TRN \\
\hline CHEMBL1404583 & 688816 & 5.3 & 5.3731 & TST & \\
\hline CHEMBL1530253 & 688816 & 7.5003 & 5.2273 & TST & \\
\hline CHEMBL1380999 & 688816 & 5.4 & 5.3868 & TRN & \\
\hline CHEMBL1321047 & 688816 & 6.5 & 5.5557 & TRN & \\
\hline CHEMBL1469857 & 688816 & 4.45 & 5.1143 & TRN & \\
\hline CHEMBL1495394 & 688816 & 5.1 & 5.0475 & TRN & \\
\hline CHEMBL1988339 & 688816 & 5.1 & 5.4986 & TRN & \\
\hline CHEMBL1304979 & 688816 & 4.45 & 5.4928 & TRN & \\
\hline CHEMBL1605477 & 688816 & 4.45 & 5.7944 & TST & \\
\hline CHEMBL1468192 & 688816 & 4.45 & \multicolumn{2}{|c|}{5.212000000000001} & TRN \\
\hline CHEMBL1600136 & 688816 & 4.95 & 5.1648 & TRN & \\
\hline CHEMBL1328894 & 688816 & 4.8 & 5.0065 & TRN & \\
\hline CHEMBL1369747 & 688816 & 6.5 & 5.3454 & TRN & \\
\hline CHEMBL1413072 & 688816 & 4.7 & 5.0178 & TRN & \\
\hline CHEMBL1550490 & 688816 & 4.45 & 5.2086 & TRN & \\
\hline CHEMBL1510848 & 688816 & 5.1 & 5.1641 & TST & \\
\hline CHEMBL1422346 & 688816 & 5.65 & 5.3828 & TRN & \\
\hline CHEMBL1403629 & 688816 & 5.1 & 5.2945 & TST & \\
\hline CHEMBL1342873 & 688816 & 4.95 & 5.1762 & TST & \\
\hline CHEMBL1366292 & 688816 & 8.4949 & 5.7007 & TST & \\
\hline CHEMBL1462020 & 688816 & 8.0 & 5.3256 & TST & \\
\hline CHEMBL1497582 & 688816 & 5.2 & 5.5929 & TRN & \\
\hline CHEMBL1425537 & 688816 & 4.95 & 5.3134 & TRN & \\
\hline CHEMBL1312265 & 688816 & 5.0 & 5.0557 & TRN & \\
\hline CHEMBL1390653 & 688816 & 6.4 & 5.5429 & TRN & \\
\hline CHEMBL1502863 & 688816 & 4.9 & 4.9626 & TRN & \\
\hline CHEMBL1429875 & 688816 & 4.95 & \multicolumn{2}{|c|}{5.707999999999999} & TST \\
\hline CHEMBL1408978 & 688816 & 4.95 & 5.5045 & TRN & \\
\hline CHEMBL1565528 & 688816 & 5.05 & 5.2529 & TST & \\
\hline CHEMBL1431578 & 688816 & 4.45 & 5.0602 & TST & \\
\hline CHEMBL1335148 & 688816 & 8.3468 & 5.4628 & TST & \\
\hline CHEMBL1594890 & 688816 & 5.6 & 5.2744 & TRN & \\
\hline CHEMBL1506468 & 688816 & 8.0506 & 5.9043 & TRN & \\
\hline CHEMBL1604833 & 688816 & 4.75 & 4.9585 & TRN & \\
\hline CHEMBL1565396 & 688816 & 8.3979 & 5.4718 & TRN & \\
\hline CHEMBL1583836 & 688816 & 5.5 & \multicolumn{2}{|c|}{5.327999999999999} & TST \\
\hline CHEMBL1377593 & 688816 & 4.9 & 5.2153 & TRN & \\
\hline CHEMBL1541685 & 688816 & 5.4 & 5.4054 & TST & \\
\hline CHEMBL1557468 & 688816 & 4.8 & 5.1906 & TRN & \\
\hline CHEMBL1501466 & 688816 & 4.9 & 5.4946 & TST & \\
\hline
\end{tabular}




\begin{tabular}{|c|c|c|c|c|}
\hline & & & oplement & al $\mathrm{Tc}$ \\
\hline CHEMBL1362074 & 688816 & 7.8508 & 5.2106 & TRN \\
\hline CHEMBL1536613 & 688816 & 5.0 & 5.1674 & TST \\
\hline CHEMBL1343460 & 688816 & 4.6 & 4.9676 & TST \\
\hline CHEMBL1372696 & 688816 & 5.8 & 5.3956 & TRN \\
\hline CHEMBL1351731 & 688816 & 5.45 & 5.3787 & TRN \\
\hline CHEMBL1529476 & 688816 & 4.95 & 5.5278 & TRN \\
\hline CHEMBL1346628 & 688816 & 4.6 & 4.9177 & TRN \\
\hline CHEMBL1536625 & 688816 & 4.9 & 5.1896 & TRN \\
\hline CHEMBL1581345 & 688816 & 5.05 & 5.4256 & TST \\
\hline CHEMBL1559341 & 688816 & 4.9 & 4.9276 & TST \\
\hline CHEMBL 3190467 & 688816 & 4.45 & 5.3145 & TST \\
\hline CHEMBL1585001 & 688816 & 5.35 & 5.3035 & TST \\
\hline CHEMBL1431564 & 688816 & 5.1 & 5.0794 & TRN \\
\hline CHEMBL1518716 & 688816 & 6.05 & 5.3725 & TRN \\
\hline CHEMBL1511245 & 688816 & 4.9 & 5.1462 & TRN \\
\hline CHEMBL1466886 & 688816 & 5.05 & 5.046 & TRN \\
\hline CHEMBL1551190 & 688816 & 5.05 & 5.3484 & TRN \\
\hline CHEMBL1526717 & 688816 & 4.95 & 5.5588 & TRN \\
\hline CHEMBL1452967 & 688816 & 4.95 & 5.3511 & TRN \\
\hline CHEMBL1324649 & 688816 & 7.9508 & 5.3754 & TRN \\
\hline CHEMBL3197259 & 688816 & 5.35 & 5.1871 & TRN \\
\hline CHEMBL1398104 & 688816 & 4.9 & 5.1528 & TRN \\
\hline CHEMBL1531270 & 688816 & 4.65 & 5.1411 & TRN \\
\hline CHEMBL1387277 & 688816 & 4.95 & 5.2233 & TRN \\
\hline CHEMBL1428592 & 688816 & 6.0 & 5.0666 & TST \\
\hline CHEMBL1391767 & 688816 & 4.85 & 5.3328 & TST \\
\hline CHEMBL1608747 & 688816 & 7.9508 & 5.8121 & TRN \\
\hline CHEMBL3189277 & 688816 & 7.5498 & 5.5664 & TRN \\
\hline CHEMBL1611497 & 688816 & 4.5 & 5.1638 & TRN \\
\hline CHEMBL1468890 & 688816 & 5.45 & 5.4044 & TST \\
\hline CHEMBL1512794 & 688816 & 4.6 & 5.0447 & TRN \\
\hline CHEMBL1452098 & 688816 & 5.45 & 5.0866 & TRN \\
\hline CHEMBL1582720 & 688816 & 4.45 & 5.693 & TRN \\
\hline CHEMBL1559056 & 688816 & 5.25 & 5.0657 & TRN \\
\hline CHEMBL1494985 & 688816 & 4.45 & 5.4004 & TRN \\
\hline CHEMBL1490577 & 688816 & 4.95 & 4.9971 & TRN \\
\hline CHEMBL1520312 & 688816 & 4.55 & 4.9924 & TRN \\
\hline CHEMBL1370978 & 688816 & 4.45 & 5.1896 & TST \\
\hline CHEMBL1487401 & 688816 & 4.65 & 4.961 & TRN \\
\hline CHEMBL405110 & 688816 & 5.0 & 5.1512 & TST \\
\hline CHEMBL1417719 & 688816 & 4.55 & 5.4188 & TRN \\
\hline CHEMBL1416855 & 688816 & 5.15 & 5.1518 & TRN \\
\hline CHEMBL1325039 & 688816 & 4.45 & 5.1902 & TRN \\
\hline CHEMBL1491781 & 688816 & 5.0 & 5.1753 & TRN \\
\hline CHEMBL1452430 & 688816 & 5.3 & 5.2844 & TRN \\
\hline CHEMBL1598419 & 688816 & 5.25 & 5.4138 & TRN \\
\hline CHEMBL1311362 & 688816 & 8.5528 & 5.5107 & TRN \\
\hline CHEMBL1311350 & 688816 & 4.6 & 5.2086 & TST \\
\hline
\end{tabular}




\begin{tabular}{|c|c|c|c|c|c|}
\hline \multicolumn{6}{|c|}{ Supplemental Table S2.txt } \\
\hline CHEMBL1418238 & 688816 & 5.2 & 5.2557 & TRN & \\
\hline CHEMBL1468432 & 688816 & 4.65 & 5.2493 & TRN & \\
\hline CHEMBL1341112 & 688816 & 4.75 & 5.44799 & 99999999995 & TRN \\
\hline CHEMBL1508141 & 688816 & 5.05 & 5.0438 & TRN & \\
\hline CHEMBL1565106 & 688816 & 4.85 & 5.3867 & TST & \\
\hline CHEMBL3196987 & 688816 & 4.85 & 5.2409 & TST & \\
\hline CHEMBL 2359467 & 688816 & 5.5 & 5.1574 & TRN & \\
\hline CHEMBL1580408 & 688816 & 4.45 & 5.1599 & TRN & \\
\hline CHEMBL1468106 & 688816 & 5.55 & 5.2731 & TRN & \\
\hline CHEMBL3192570 & 688816 & 7.3002 & 5.5832 & TST & \\
\hline CHEMBL3191619 & 688816 & 4.95 & 5.2755 & TRN & \\
\hline CHEMBL1400844 & 688816 & 5.4 & 5.2907 & TRN & \\
\hline CHEMBL1982575 & 688816 & 5.6 & 5.4066 & TRN & \\
\hline CHEMBL1569915 & 688816 & 6.6499 & 5.2671 & TST & \\
\hline CHEMBL1453423 & 688816 & 5.25 & 5.4663 & TRN & \\
\hline CHEMBL1441608 & 688816 & 5.05 & 5.5214 & TST & \\
\hline CHEMBL3197603 & 688816 & 4.95 & 5.2296 & TST & \\
\hline CHEMBL1432131 & 688816 & 5.8 & 5.2698 & TRN & \\
\hline CHEMBL339561 & 688816 & 5.5 & 5.3345 & TRN & \\
\hline CHEMBL1472469 & 688816 & 5.15 & 5.2967 & TST & \\
\hline CHEMBL1342410 & 688816 & 4.85 & 5.0206 & TST & \\
\hline CHEMBL1576321 & 688816 & 4.6 & 5.42299 & 9999999999 & TRN \\
\hline CHEMBL1430566 & 688816 & 4.85 & 5.2373 & TRN & \\
\hline CHEMBL1324113 & 688816 & 4.95 & 5.24700 & 0000000001 & TRN \\
\hline CHEMBL3189394 & 688816 & 4.95 & 5.3964 & TRN & \\
\hline CHEMBL1523940 & 688816 & 6.05 & 5.2563 & TRN & \\
\hline CHEMBL279335 & 688816 & 4.95 & 5.1777 & TRN & \\
\hline CHEMBL1380459 & 688816 & 4.9 & 5.0443 & TRN & \\
\hline CHEMBL1483904 & 688816 & 4.45 & 4.9878 & TRN & \\
\hline CHEMBL1403178 & 688816 & 4.85 & 5.2333 & TRN & \\
\hline CHEMBL1364348 & 688816 & 4.9 & 5.042 & TRN & \\
\hline CHEMBL56543 & 688816 & 6.0 & 5.3154 & TRN & \\
\hline CHEMBL1306233 & 688816 & 5.25 & 5.4853 & TRN & \\
\hline CHEMBL1400404 & 688816 & 5.05 & 5.2759 & TRN & \\
\hline CHEMBL1430319 & 688816 & 4.9 & 4.8987 & TRN & \\
\hline CHEMBL1575611 & 688816 & 8.301 & 5.2292 & TRN & \\
\hline CHEMBL1440644 & 688816 & 6.6499 & 5.3743 & TRN & \\
\hline CHEMBL1410567 & 688816 & 4.45 & 4.8174 & TRN & \\
\hline CHEMBL1426392 & 688816 & 4.95 & 5.1627 & TRN & \\
\hline CHEMBL1444565 & 688816 & 4.85 & 5.1402 & TRN & \\
\hline CHEMBL1304885 & 688816 & 4.65 & 5.5964 & TRN & \\
\hline CHEMBL239275 & 688816 & 4.95 & 5.37700 & 0000000001 & TRN \\
\hline CHEMBL 2369261 & 688816 & 4.7 & 5.4228 & TRN & \\
\hline CHEMBL1443697 & 688816 & 8.0506 & 5.4897 & TRN & \\
\hline CHEMBL1515106 & 688816 & 4.95 & 5.3461 & TRN & \\
\hline CHEMBL1340374 & 688816 & 4.8 & 4.9201 & TRN & \\
\hline CHEMBL1451498 & 688816 & 5.0 & 5.2417 & TST & \\
\hline CHEMBL1413333 & 688816 & 4.45 & 5.433 & TRN & \\
\hline
\end{tabular}




\begin{tabular}{|c|c|c|c|c|c|}
\hline \multicolumn{6}{|c|}{ Supplemental Table S2.txt } \\
\hline CHEMBL1331329 & 688816 & 4.9 & 4.6019 & TRN & \\
\hline CHEMBL1576333 & 688816 & 4.8 & 4.9334 & TRN & \\
\hline CHEMBL1522372 & 688816 & 4.75 & 4.879 & TST & \\
\hline CHEMBL1527843 & 688816 & 5.3 & 5.3571 & TRN & \\
\hline CHEMBL1586540 & 688816 & 6.05 & 5.6495 & TST & \\
\hline CHEMBL3196124 & 688816 & 5.55 & 5.1878 & TRN & \\
\hline CHEMBL1444568 & 688816 & 4.8 & 5.3646 & TRN & \\
\hline CHEMBL1303653 & 688816 & 4.65 & 5.204 & TRN & \\
\hline CHEMBL1338065 & 688816 & 6.6 & 5.2946 & TRN & \\
\hline CHEMBL1511490 & 688816 & 4.45 & 5.4488 & TRN & \\
\hline CHEMBL 2001433 & 688816 & 4.6 & 5.0081 & TRN & \\
\hline CHEMBL 3198450 & 688816 & 4.95 & 5.3358 & TRN & \\
\hline CHEMBL1359536 & 688816 & 6.95 & 4.9112 & TRN & \\
\hline CHEMBL1502481 & 688816 & 4.9 & 5.6675 & TRN & \\
\hline CHEMBL1365063 & 688816 & 4.65 & 5.1397 & TRN & \\
\hline CHEMBL1309982 & 688816 & 4.95 & 5.7747 & TRN & \\
\hline CHEMBL1582333 & 688816 & 4.45 & 5.2858 & TRN & \\
\hline CHEMBL1466241 & 688816 & 6.7001 & 5.3194 & TST & \\
\hline CHEMBL 3145137 & 688816 & 4.85 & 5.1105 & TST & \\
\hline CHEMBL1423891 & 688816 & 6.45 & 5.2208 & TRN & \\
\hline CHEMBL1519922 & 688816 & 4.85 & 5.1872 & TRN & \\
\hline CHEMBL1367546 & 688816 & 8.0 & 5.7534 & TRN & \\
\hline CHEMBL1451256 & 688816 & 4.9 & 5.2084 & TRN & \\
\hline CHEMBL1547028 & 688816 & 4.9 & 5.077 & TRN & \\
\hline CHEMBL1528393 & 688816 & 5.25 & 5.3092 & TRN & \\
\hline CHEMBL1599611 & 688816 & 4.85 & 5.4539 & TRN & \\
\hline CHEMBL1416344 & 688816 & 4.9 & 5.1745 & TRN & \\
\hline CHEMBL1408367 & 688816 & 8.3468 & 5.6027 & TST & \\
\hline CHEMBL1482795 & 688816 & 4.65 & 5.0478 & TRN & \\
\hline CHEMBL1369125 & 688816 & 4.6 & 5.0871 & TRN & \\
\hline CHEMBL1484299 & 688816 & 4.45 & 5.1244 & TRN & \\
\hline CHEMBL1362401 & 688816 & 4.9 & 5.2346 & TRN & \\
\hline CHEMBL1305002 & 688816 & 4.9 & 4.9353 & TRN & \\
\hline CHEMBL1539237 & 688816 & 4.95 & 5.25899 & 99999999995 & TRN \\
\hline CHEMBL1516548 & 688816 & 4.5 & 5.3716 & TRN & \\
\hline CHEMBL1505715 & 688816 & 4.6 & 5.1722 & TST & \\
\hline CHEMBL 1344388 & 688816 & 4.45 & 5.0034 & TRN & \\
\hline CHEMBL1478933 & 688816 & 5.55 & 5.6736 & TRN & \\
\hline CHEMBL1425438 & 688816 & 6.5 & 5.0418 & TRN & \\
\hline CHEMBL1577171 & 688816 & 4.95 & 5.2475 & TRN & \\
\hline CHEMBL1394146 & 688816 & 4.85 & 4.9241 & TRN & \\
\hline CHEMBL1372025 & 688816 & 4.45 & 5.3141 & TST & \\
\hline CHEMBL1379951 & 688816 & 4.45 & 5.0731 & TRN & \\
\hline CHEMBL1302881 & 688816 & 8.3468 & 5.3107 & TRN & \\
\hline CHEMBL1352987 & 688816 & 4.75 & 5.0388 & TRN & \\
\hline CHEMBL1518652 & 688816 & 4.75 & 5.2064 & TRN & \\
\hline CHEMBL1508167 & 688816 & 7.1002 & 5.4838 & TRN & \\
\hline CHEMBL1532732 & 688816 & 5.5 & 5.2926 & TRN & \\
\hline
\end{tabular}




\begin{tabular}{|c|c|c|c|c|c|}
\hline \multicolumn{6}{|c|}{ Supplemental Table S2.txt } \\
\hline CHEMBL1542557 & 688816 & 4.65 & 5.3354 & TRN & \\
\hline CHEMBL3199886 & 688816 & 4.95 & 5.1762 & TRN & \\
\hline CHEMBL1485573 & 688816 & 4.45 & 5.3041 & TRN & \\
\hline CHEMBL1706577 & 688816 & 4.5 & 5.3491 & TRN & \\
\hline CHEMBL1483096 & 688816 & 5.35 & 4.9775 & TRN & \\
\hline CHEMBL1993612 & 688816 & 7.6498 & 5.3333 & TRN & \\
\hline CHEMBL1470555 & 688816 & 4.95 & 5.4018 & TST & \\
\hline CHEMBL1441409 & 688816 & 5.45 & 5.32799 & 9999999999 & TRN \\
\hline CHEMBL1524134 & 688816 & 5.15 & 5.4111 & TRN & \\
\hline CHEMBL1400338 & 688816 & 4.5 & 5.2768 & TRN & \\
\hline CHEMBL1351905 & 688816 & 4.9 & 4.9787 & TRN & \\
\hline CHEMBL1424022 & 688816 & 4.45 & 4.8467 & TRN & \\
\hline CHEMBL1351261 & 688816 & 4.95 & 5.2905 & TRN & \\
\hline CHEMBL1350917 & 688816 & 5.35 & 5.58899 & 99999999995 & TST \\
\hline CHEMBL1518104 & 688816 & 5.4 & 5.204 & TST & \\
\hline CHEMBL1337908 & 688816 & 4.9 & 4.9578 & TRN & \\
\hline CHEMBL3193816 & 688816 & 4.9 & 5.2443 & TST & \\
\hline CHEMBL1503780 & 688816 & 5.4 & 5.0636 & TRN & \\
\hline CHEMBL1498753 & 688816 & 8.301 & 5.3315 & TRN & \\
\hline CHEMBL1522698 & 688816 & 4.8 & 5.7653 & TRN & \\
\hline CHEMBL1613499 & 688816 & 4.55 & 4.7409 & TRN & \\
\hline CHEMBL585769 & 688816 & 4.9 & 5.3393 & TRN & \\
\hline CHEMBL1441256 & 688816 & 4.7 & 5.3978 & TRN & \\
\hline CHEMBL1563561 & 688816 & 4.85 & 5.2281 & TRN & \\
\hline CHEMBL1566310 & 688816 & 6.7501 & 5.4178 & TST & \\
\hline CHEMBL1315588 & 688816 & 4.9 & 5.2002 & TRN & \\
\hline CHEMBL1329046 & 688816 & 4.75 & 4.9925 & TRN & \\
\hline CHEMBL1406753 & 688816 & 5.0 & 5.1617 & TRN & \\
\hline CHEMBL1517000 & 688816 & 5.15 & 4.9052 & TRN & \\
\hline CHEMBL3197115 & 688816 & 4.9 & 5.2107 & TST & \\
\hline CHEMBL1305152 & 688816 & 4.65 & 5.3709 & TST & \\
\hline CHEMBL1457165 & 688816 & 4.9 & 5.1452 & TST & \\
\hline CHEMBL1422878 & 688816 & 7.3002 & 5.3527 & TST & \\
\hline CHEMBL3199110 & 688816 & 4.45 & 5.4066 & TRN & \\
\hline CHEMBL1312198 & 688816 & 4.75 & 5.3532 & TRN & \\
\hline CHEMBL1425184 & 688816 & 5.15 & 4.9695 & TST & \\
\hline CHEMBL1572205 & 688816 & 5.4 & 5.2894 & TST & \\
\hline CHEMBL1342605 & 688816 & 8.2518 & 5.9594 & TRN & \\
\hline CHEMBL1609884 & 688816 & 4.45 & 5.1013 & TRN & \\
\hline CHEMBL1502133 & 688816 & 6.0 & 5.671 & TRN & \\
\hline CHEMBL1503693 & 688816 & 8.3468 & 5.3474 & TRN & \\
\hline CHEMBL1461939 & 688816 & 6.8 & 5.1866 & TST & \\
\hline CHEMBL1469307 & 688816 & 4.95 & 4.8837 & TRN & \\
\hline CHEMBL1452567 & 688816 & 6.8499 & 5.1691 & TST & \\
\hline CHEMBL1424628 & 688816 & 5.3 & 5.1995 & TRN & \\
\hline CHEMBL1409379 & 688816 & 7.4498 & 5.5185 & TRN & \\
\hline CHEMBL1442271 & 688816 & 4.75 & 5.1606 & TST & \\
\hline CHEMBL1408231 & 688816 & 7.0 & 5.4256 & TST & \\
\hline
\end{tabular}




\begin{tabular}{|c|c|c|c|c|c|}
\hline \\
\hline CHEMBL1350152 & 688816 & 5.5 & 5.2286 & TRN & \\
\hline CHEMBL1559104 & 688816 & 4.65 & 5.2258 & TRN & \\
\hline CHEMBL1309542 & 688816 & 5.0 & 5.3317 & TRN & \\
\hline CHEMBL1453359 & 688816 & 4.8 & 5.2366 & TRN & \\
\hline CHEMBL1497507 & 688816 & 5.0 & 5.4186 & TRN & \\
\hline CHEMBL1320643 & 688816 & 4.95 & 5.3691 & TRN & \\
\hline CHEMBL1466494 & 688816 & 4.65 & 4.7761 & TST & \\
\hline CHEMBL1350055 & 688816 & 8.1024 & 5.595 & TRN & \\
\hline CHEMBL1442885 & 688816 & 7.0501 & 4.9703 & TRN & \\
\hline CHEMBL1363304 & 688816 & 5.0 & 5.2571 & TST & \\
\hline CHEMBL1567706 & 688816 & 4.8 & 5.1725 & TRN & \\
\hline CHEMBL1535022 & 688816 & 4.95 & 5.08899 & 99999999995 & TRN \\
\hline CHEMBL1303918 & 688816 & 4.6 & 5.06 & TST & \\
\hline CHEMBL1323843 & 688816 & 7.9508 & 5.5305 & TST & \\
\hline CHEMBL3212915 & 688816 & 6.1 & 5.1275 & TRN & \\
\hline CHEMBL1417158 & 688816 & 5.75 & 5.5901 & TST & \\
\hline CHEMBL1361420 & 688816 & 4.45 & 5.5405 & TRN & \\
\hline CHEMBL1299565 & 688816 & 5.45 & 5.5639 & TRN & \\
\hline CHEMBL1335417 & 688816 & 4.45 & 5.2049 & TRN & \\
\hline CHEMBL1469738 & 688816 & 8.4949 & 5.205 & TRN & \\
\hline CHEMBL1300069 & 688816 & 4.85 & 4.8697 & TST & \\
\hline CHEMBL1528468 & 688816 & 6.0 & 5.3717 & TRN & \\
\hline CHEMBL1490872 & 688816 & 4.8 & 5.4366 & TRN & \\
\hline CHEMBL1447536 & 688816 & 5.35 & 5.5312 & TRN & \\
\hline CHEMBL3195212 & 688816 & 5.25 & 5.5045 & TRN & \\
\hline CHEMBL1375135 & 688816 & 4.45 & 5.2236 & TRN & \\
\hline CHEMBL1605832 & 688816 & 5.05 & 5.606 & TST & \\
\hline CHEMBL1504962 & 688816 & 7.6003 & 5.6873 & TST & \\
\hline CHEMBL1579060 & 688816 & 4.6 & 4.9424 & TRN & \\
\hline CHEMBL1570942 & 688816 & 4.85 & 5.3332 & TRN & \\
\hline CHEMBL1401888 & 688816 & 4.95 & 5.0279 & TRN & \\
\hline CHEMBL1581456 & 688816 & 4.9 & 5.4128 & TRN & \\
\hline CHEMBL1424333 & 688816 & 4.9 & 5.1724 & TRN & \\
\hline CHEMBL1384103 & 688816 & 4.95 & 4.6601 & TRN & \\
\hline CHEMBL1347580 & 688816 & 4.8 & 4.7664 & TRN & \\
\hline CHEMBL1345128 & 688816 & 4.95 & 5.2735 & TRN & \\
\hline CHEMBL1383990 & 688816 & 4.45 & 4.9923 & TST & \\
\hline CHEMBL3145026 & 688816 & 5.5 & 5.6876 & TST & \\
\hline CHEMBL1363038 & 688816 & 5.35 & 5.0146 & TRN & \\
\hline CHEMBL1552547 & 688816 & 5.75 & 5.3135 & TST & \\
\hline CHEMBL1470373 & 688816 & 5.05 & 5.1862 & TST & \\
\hline CHEMBL1567340 & 688816 & 5.6 & 5.2776 & TRN & \\
\hline CHEMBL1430757 & 688816 & 4.95 & 5.4191 & TRN & \\
\hline CHEMBL1320194 & 688816 & 6.5 & 5.7037 & TRN & \\
\hline CHEMBL1388107 & 688816 & 6.0 & 5.3206 & TRN & \\
\hline CHEMBL3191809 & 688816 & 4.85 & 5.0836 & TRN & \\
\hline CHEMBL3199547 & 688816 & 4.85 & 5.3214 & TST & \\
\hline CHEMBL1383899 & 688816 & 5.25 & 5.6635 & TST & \\
\hline
\end{tabular}




\begin{tabular}{|c|c|c|c|c|c|}
\hline \multicolumn{6}{|c|}{ Supplemental Table S2.txt } \\
\hline CHEMBL1509816 & 688816 & 4.8 & 5.2547 & TRN & \\
\hline CHEMBL1457019 & 688816 & 8.4559 & 5.5094 & TRN & \\
\hline CHEMBL 2000339 & 688816 & 6.45 & 5.2732 & TRN & \\
\hline CHEMBL1486655 & 688816 & 7.15 & 5.1976 & TRN & \\
\hline CHEMBL3192157 & 688816 & 5.3 & 5.4101 & TRN & \\
\hline CHEMBL1570216 & 688816 & 7.5003 & 5.439 & TRN & \\
\hline CHEMBL1424928 & 688816 & 5.6 & 5.4786 & TRN & \\
\hline CHEMBL1398620 & 688816 & 4.45 & 5.2191 & TST & \\
\hline CHEMBL1341497 & 688816 & 5.2 & 5.1328 & TST & \\
\hline CHEMBL1329484 & 688816 & 5.0 & 5.0356 & TRN & \\
\hline CHEMBL1425919 & 688816 & 5.5 & 5.0407 & TRN & \\
\hline CHEMBL1350903 & 688816 & 4.75 & 5.2719 & TRN & \\
\hline CHEMBL1471861 & 688816 & 5.0 & 5.1875 & TRN & \\
\hline CHEMBL1522023 & 688816 & 5.45 & 5.6896 & TST & \\
\hline CHEMBL106437 & 688816 & 4.7 & 5.17200 & 0000000001 & TRN \\
\hline CHEMBL1458757 & 688816 & 4.45 & 4.8662 & TRN & \\
\hline CHEMBL3196968 & 688816 & 4.75 & 4.8253 & TRN & \\
\hline CHEMBL1455378 & 688816 & 4.8 & 5.0865 & TRN & \\
\hline CHEMBL1381290 & 688816 & 4.8 & 5.1514 & TRN & \\
\hline CHEMBL1539689 & 688816 & 4.45 & 5.2566 & TRN & \\
\hline CHEMBL1348920 & 688816 & 6.6499 & 5.3157 & TST & \\
\hline CHEMBL1612642 & 688816 & 4.6 & 5.1872 & TRN & \\
\hline CHEMBL1324347 & 688816 & 4.95 & 5.1958 & TRN & \\
\hline CHEMBL1599866 & 688816 & 5.25 & 5.5081 & TRN & \\
\hline CHEMBL1609811 & 688816 & 4.7 & 5.0874 & TRN & \\
\hline CHEMBL1432868 & 688816 & 4.5 & 5.5585 & TST & \\
\hline CHEMBL1505604 & 688816 & 5.55 & 5.1226 & TRN & \\
\hline CHEMBL1437895 & 688816 & 4.75 & 5.3479 & TRN & \\
\hline CHEMBL1332366 & 688816 & 4.85 & 5.2421 & TRN & \\
\hline CHEMBL1312219 & 688816 & 4.9 & 5.3038 & TST & \\
\hline CHEMBL1556882 & 688816 & 5.9 & 5.1512 & TRN & \\
\hline CHEMBL3193133 & 688816 & 4.85 & 5.1705 & TRN & \\
\hline CHEMBL1568611 & 688816 & 4.45 & 4.9132 & TRN & \\
\hline CHEMBL1595934 & 688816 & 4.95 & 5.2187 & TRN & \\
\hline CHEMBL1307963 & 688816 & 5.25 & 5.6808 & TRN & \\
\hline CHEMBL1428058 & 688816 & 7.8013 & 5.7527 & TRN & \\
\hline CHEMBL 1488743 & 688816 & 4.65 & 5.0439 & TRN & \\
\hline CHEMBL1420889 & 688816 & 4.75 & 5.2915 & TRN & \\
\hline CHEMBL1525688 & 688816 & 8.301 & 6.1638 & TRN & \\
\hline CHEMBL1433186 & 688816 & 6.45 & 5.1183 & TST & \\
\hline CHEMBL1346409 & 688816 & 5.15 & 4.9814 & TRN & \\
\hline CHEMBL1369888 & 688816 & 7.6003 & 5.3849 & TST & \\
\hline CHEMBL1546467 & 688816 & 5.35 & 5.3163 & TRN & \\
\hline CHEMBL1339562 & 688816 & 4.45 & 5.1274 & TRN & \\
\hline CHEMBL1470919 & 688816 & 4.95 & 5.3269 & TST & \\
\hline CHEMBL1556365 & 688816 & 4.85 & 5.0538 & TRN & \\
\hline CHEMBL1399692 & 688816 & 5.25 & 5.3054 & TST & \\
\hline CHEMBL1303788 & 688816 & 5.9 & 5.0372 & TRN & \\
\hline
\end{tabular}




\begin{tabular}{|c|c|c|c|c|c|}
\hline \multicolumn{6}{|c|}{ Supplemental Table S2.txt } \\
\hline CHEMBL1362006 & 688816 & 4.9 & 4.6576 & TRN & \\
\hline CHEMBL1579841 & 688816 & 4.9 & 5.0916 & TRN & \\
\hline CHEMBL1560939 & 688816 & 7.8996 & 5.0774 & TRN & \\
\hline CHEMBL1549011 & 688816 & 5.05 & 5.3354 & TRN & \\
\hline CHEMBL1372017 & 688816 & 4.95 & 4.9638 & TRN & \\
\hline CHEMBL1545838 & 688816 & 4.7 & 5.7128 & TST & \\
\hline CHEMBL1468631 & 688816 & 5.0 & 5.1036 & TRN & \\
\hline CHEMBL1610706 & 688816 & 5.0 & 4.9791 & TRN & \\
\hline CHEMBL1322328 & 688816 & 4.95 & 5.4498 & TRN & \\
\hline CHEMBL1455904 & 688816 & 6.7501 & 5.0025 & TST & \\
\hline CHEMBL1345540 & 688816 & 4.6 & 4.746 & TST & \\
\hline CHEMBL1484482 & 688816 & 5.0 & 5.4778 & TRN & \\
\hline CHEMBL1526621 & 688816 & 4.85 & 5.0362 & TRN & \\
\hline CHEMBL1328875 & 688816 & 4.45 & 5.2387 & TRN & \\
\hline CHEMBL1425872 & 688816 & 5.6 & 5.1633 & TRN & \\
\hline CHEMBL1518094 & 688816 & 4.45 & 5.2986 & TRN & \\
\hline CHEMBL1578927 & 688816 & 8.4949 & 5.3059 & TST & \\
\hline CHEMBL1460410 & 688816 & 5.25 & 5.6081 & TRN & \\
\hline CHEMBL1493166 & 688816 & 4.45 & 4.9272 & TRN & \\
\hline CHEMBL1547550 & 688816 & 6.2 & 5.3888 & TRN & \\
\hline CHEMBL1463850 & 688816 & 4.95 & 5.2981 & TRN & \\
\hline CHEMBL1450318 & 688816 & 4.45 & 4.8716 & TRN & \\
\hline CHEMBL1497433 & 688816 & 4.85 & 5.4192 & TRN & \\
\hline CHEMBL1566901 & 688816 & 6.0 & 4.888 & TRN & \\
\hline CHEMBL1525271 & 688816 & 4.9 & 5.2992 & TRN & \\
\hline CHEMBL1562012 & 688816 & 4.9 & 5.0581 & TRN & \\
\hline CHEMBL1371114 & 688816 & 4.65 & 4.9664 & TRN & \\
\hline CHEMBL 3198496 & 688816 & 4.9 & 4.9838 & TRN & \\
\hline CHEMBL1569505 & 688816 & 8.3468 & $5.2620 e$ & 00000000005 & TRN \\
\hline CHEMBL1461521 & 688816 & 4.45 & 5.2855 & TST & \\
\hline CHEMBL1370297 & 688816 & 4.8 & 5.5255 & TRN & \\
\hline CHEMBL1566633 & 688816 & 4.75 & 5.3002 & TRN & \\
\hline CHEMBL1579885 & 688816 & 7.6498 & 5.5239 & TRN & \\
\hline CHEMBL1403077 & 688816 & 5.5 & 5.4297 & TRN & \\
\hline CHEMBL1578888 & 688816 & 4.75 & 5.2083 & TRN & \\
\hline CHEMBL1487005 & 688816 & 5.4 & 5.3907 & TST & \\
\hline CHEMBL3199380 & 688816 & 5.7 & 5.0884 & TST & \\
\hline CHEMBL1543685 & 688816 & 4.9 & 5.2621 & TST & \\
\hline CHEMBL1505567 & 688816 & 4.45 & 5.0388 & TRN & \\
\hline CHEMBL1309482 & 688816 & 6.4 & 5.3442 & TRN & \\
\hline CHEMBL1531362 & 688816 & 4.9 & 5.1433 & TRN & \\
\hline CHEMBL3209603 & 688816 & 8.0 & 5.2185 & TST & \\
\hline CHEMBL1392845 & 688816 & 4.9 & 5.1582 & TRN & \\
\hline CHEMBL1323072 & 688816 & 4.65 & 4.9656 & TST & \\
\hline CHEMBL1453944 & 688816 & 4.45 & 5.2734 & TRN & \\
\hline CHEMBL1547198 & 688816 & 5.2 & 5.0092 & TRN & \\
\hline CHEMBL3197453 & 688816 & 4.9 & 5.0839 & TRN & \\
\hline CHEMBL1352919 & 688816 & 8.3468 & 5.4714 & TRN & \\
\hline
\end{tabular}




\begin{tabular}{|c|c|c|c|c|}
\hline \multicolumn{5}{|c|}{ Supplemental Table S2.txt } \\
\hline CHEMBL1529511 & 688816 & 4.85 & 5.3619 & TRN \\
\hline CHEMBL1434344 & 688816 & 4.45 & 4.9874 & TRN \\
\hline CHEMBL1310104 & 688816 & 4.6 & 5.1204 & TRN \\
\hline CHEMBL1544506 & 688816 & 8.301 & 5.8192 & TST \\
\hline CHEMBL1542346 & 688816 & 5.05 & 5.3577 & TRN \\
\hline CHEMBL1443783 & 688816 & 4.7 & 4.974 & TRN \\
\hline CHEMBL1429703 & 688816 & 4.95 & 5.2545 & TST \\
\hline CHEMBL1468618 & 688816 & 4.45 & 5.3114 & TRN \\
\hline CHEMBL1493426 & 688816 & 5.0 & 5.0426 & TST \\
\hline CHEMBL1436339 & 688816 & 4.95 & 5.2727 & TRN \\
\hline CHEMBL1567692 & 688816 & 4.9 & 4.9095 & TRN \\
\hline CHEMBL1407390 & 688816 & 4.75 & 4.9495 & TRN \\
\hline CHEMBL1559226 & 688816 & 4.9 & 5.1033 & TRN \\
\hline CHEMBL1559946 & 688816 & 4.45 & 4.9883 & TRN \\
\hline CHEMBL1491081 & 688816 & 6.7501 & 5.4913 & TRN \\
\hline CHEMBL1399783 & 688816 & 6.5501 & 5.4272 & TRN \\
\hline CHEMBL1490914 & 688816 & 6.9 & 5.5166 & TRN \\
\hline CHEMBL1307513 & 688816 & 5.1 & 5.3109 & TRN \\
\hline CHEMBL1469247 & 688816 & 6.8499 & 5.3248 & TST \\
\hline CHEMBL578675 & 688816 & 4.95 & 5.1638 & TRN \\
\hline CHEMBL3199256 & 688816 & 4.85 & 5.553 & TRN \\
\hline CHEMBL1424036 & 688816 & 4.45 & 5.1949 & TRN \\
\hline CHEMBL1329887 & 688816 & 7.699 & 5.7148 & TRN \\
\hline CHEMBL1491031 & 688816 & 5.25 & 5.5632 & TRN \\
\hline CHEMBL1534720 & 688816 & 5.25 & 5.1515 & TRN \\
\hline CHEMBL1387575 & 688816 & 4.95 & 5.2807 & TRN \\
\hline CHEMBL1497095 & 688816 & 4.65 & 5.096 & TRN \\
\hline CHEMBL1485566 & 688816 & 4.85 & 4.8632 & TRN \\
\hline CHEMBL1472362 & 688816 & 4.9 & 5.2246 & TRN \\
\hline CHEMBL1392483 & 688816 & 4.45 & 5.2797 & TRN \\
\hline CHEMBL1465934 & 688816 & 5.3 & 5.4903 & TRN \\
\hline CHEMBL1300502 & 688816 & 5.3 & 5.0448 & TRN \\
\hline CHEMBL1361998 & 688816 & 7.3002 & 5.5393 & TRN \\
\hline CHEMBL1460864 & 688816 & 5.95 & 5.4916 & TRN \\
\hline CHEMBL1505490 & 688816 & 4.75 & 5.0884 & TRN \\
\hline CHEMBL1502803 & 688816 & 4.75 & 5.4168 & TRN \\
\hline CHEMBL1516355 & 688816 & 5.0 & 5.0781 & TST \\
\hline CHEMBL1533356 & 688816 & 5.2 & $5.4170 e$ & 0000000001 \\
\hline CHEMBL1476424 & 688816 & 4.85 & 5.5799 & TRN \\
\hline CHEMBL1362146 & 688816 & 4.75 & 4.9728 & TRN \\
\hline CHEMBL1597516 & 688816 & 5.55 & 5.2375 & TRN \\
\hline CHEMBL1558893 & 688816 & 4.95 & 5.2309 & TST \\
\hline CHEMBL1372751 & 688816 & 4.7 & 5.0042 & TRN \\
\hline CHEMBL1450983 & 688816 & 5.55 & 5.1807 & TRN \\
\hline CHEMBL1467966 & 688816 & 4.85 & 4.9951 & TRN \\
\hline CHEMBL1380153 & 688816 & 4.95 & 5.5057 & TRN \\
\hline CHEMBL3191956 & 688816 & 5.25 & 5.3947 & TST \\
\hline CHEMBL1471525 & 688816 & 5.5 & 5.2283 & TST \\
\hline
\end{tabular}




\begin{tabular}{|c|c|c|c|c|c|}
\hline \multirow[b]{2}{*}{ CHEMBL1359398 } & \multicolumn{5}{|c|}{ Supplemental Table S2.txt } \\
\hline & 688816 & 8.301 & 5.7756 & TRN & \\
\hline CHEMBL1520705 & 688816 & 4.8 & 4.9415 & TRN & \\
\hline CHEMBL1442026 & 688816 & 4.85 & 5.3162 & TRN & \\
\hline CHEMBL1322330 & 688816 & 5.2 & 5.2554 & TRN & \\
\hline CHEMBL1480705 & 688816 & 4.85 & 4.6102 & TRN & \\
\hline CHEMBL1348954 & 688816 & 4.7 & 5.226 & TRN & \\
\hline CHEMBL1463449 & 688816 & 4.95 & 5.2394 & TRN & \\
\hline CHEMBL1450943 & 688816 & 4.7 & 5.1441 & TRN & \\
\hline CHEMBL 3192225 & 688816 & 4.45 & 5.4796 & TST & \\
\hline CHEMBL1583587 & 688816 & 4.95 & 5.2234 & TRN & \\
\hline CHEMBL1556279 & 688816 & 4.7 & 5.1979 & TST & \\
\hline CHEMBL1562712 & 688816 & 5.9 & 5.6892 & TRN & \\
\hline CHEMBL1374457 & 688816 & 4.9 & 5.3482 & TRN & \\
\hline CHEMBL1538317 & 688816 & 4.45 & 5.093 & TRN & \\
\hline CHEMBL1485721 & 688816 & 4.7 & 5.3211 & TRN & \\
\hline CHEMBL1300880 & 688816 & 6.6 & 5.5479 & TST & \\
\hline CHEMBL1609971 & 688816 & 4.9 & 5.274 & TRN & \\
\hline CHEMBL1374795 & 688816 & 4.8 & 5.6525 & TRN & \\
\hline CHEMBL 2001712 & 688816 & 4.95 & 5.0848 & TRN & \\
\hline CHEMBL1453731 & 688816 & 4.95 & 5.23600 & 0000000001 & TRN \\
\hline CHEMBL1519347 & 688816 & 4.55 & 5.3147 & TST & \\
\hline CHEMBL1442190 & 688816 & 6.3 & 5.1265 & TRN & \\
\hline CHEMBL1498608 & 688816 & 4.95 & 5.0716 & TRN & \\
\hline CHEMBL1585320 & 688816 & 4.85 & 5.4299 & TRN & \\
\hline CHEMBL1384493 & 688816 & 4.9 & 5.3867 & TST & \\
\hline CHEMBL1570969 & 688816 & 5.05 & 5.1518 & TRN & \\
\hline CHEMBL1612607 & 688816 & 5.3 & 5.8552 & TST & \\
\hline CHEMBL1372556 & 688816 & 4.8 & 5.0917 & TRN & \\
\hline CHEMBL1613480 & 688816 & 6.8 & 5.5084 & TRN & \\
\hline CHEMBL1548458 & 688816 & 5.0 & 5.2961 & TRN & \\
\hline CHEMBL1383699 & 688816 & 6.9 & 5.25 & TRN & \\
\hline CHEMBL1608546 & 688816 & 8.4949 & 5.71899 & 9999999999 & TST \\
\hline CHEMBL1521754 & 688816 & 4.95 & 4.9759 & TRN & \\
\hline CHEMBL1530139 & 688816 & 4.95 & 4.9604 & TRN & \\
\hline CHEMBL1554715 & 688816 & 5.15 & 4.691 & TRN & \\
\hline CHEMBL1586982 & 688816 & 4.95 & 4.9007 & TRN & \\
\hline CHEMBL 1450858 & 688816 & 4.65 & 5.3033 & TRN & \\
\hline CHEMBL1407079 & 688816 & 4.45 & 5.0964 & TRN & \\
\hline CHEMBL1455111 & 688816 & 4.7 & 4.9726 & TRN & \\
\hline CHEMBL1340950 & 688816 & 4.55 & 5.2543 & TST & \\
\hline CHEMBL1583995 & 688816 & 4.8 & 5.0374 & TST & \\
\hline CHEMBL1350534 & 688816 & 4.95 & 5.0927 & TRN & \\
\hline CHEMBL1375022 & 688816 & 4.45 & 5.3375 & TRN & \\
\hline CHEMBL1555367 & 688816 & 4.95 & 4.8376 & TRN & \\
\hline CHEMBL1364803 & 688816 & 5.1 & 4.8389 & TRN & \\
\hline CHEMBL1419335 & 688816 & 4.75 & 4.8762 & TRN & \\
\hline CHEMBL1520992 & 688816 & 5.25 & 5.3722 & TRN & \\
\hline CHEMBL1573284 & 688816 & 4.85 & 5.437 & TST & \\
\hline
\end{tabular}




\begin{tabular}{|c|c|c|c|c|}
\hline & & & pplement & al $\mathrm{Ta}$ \\
\hline CHEMBL1596925 & 688816 & 4.9 & 5.2938 & TST \\
\hline CHEMBL1536395 & 688816 & 4.95 & 5.565 & TRN \\
\hline CHEMBL1413510 & 688816 & 5.45 & 5.4058 & TST \\
\hline CHEMBL1429925 & 688816 & 4.75 & 5.3111 & TRN \\
\hline CHEMBL1351088 & 688816 & 6.7001 & 5.3553 & TST \\
\hline CHEMBL1391484 & 688816 & 4.8 & 4.7158 & TRN \\
\hline CHEMBL1568758 & 688816 & 5.0 & 5.0977 & TRN \\
\hline CHEMBL1516925 & 688816 & 5.2 & 5.0898 & TRN \\
\hline CHEMBL1407886 & 688816 & 6.7501 & 5.0749 & TST \\
\hline CHEMBL1435961 & 688816 & 5.6 & 5.0504 & TRN \\
\hline CHEMBL1303969 & 688816 & 4.45 & 5.2936 & TST \\
\hline CHEMBL1454332 & 688816 & 4.75 & 5.0516 & TRN \\
\hline CHEMBL1502046 & 688816 & 4.6 & 5.2605 & TRN \\
\hline CHEMBL1520808 & 688816 & 5.05 & 5.0117 & TST \\
\hline CHEMBL1503839 & 688816 & 4.9 & 5.4583 & TRN \\
\hline CHEMBL1393594 & 688816 & 4.95 & 5.1984 & TST \\
\hline CHEMBL1324810 & 688816 & 4.85 & 5.2351 & TRN \\
\hline CHEMBL1163879 & 688816 & 4.75 & 5.3186 & TRN \\
\hline CHEMBL1333568 & 688816 & 5.0 & 5.1925 & TRN \\
\hline CHEMBL1575914 & 688816 & 4.6 & 5.1234 & TRN \\
\hline CHEMBL 3212858 & 688816 & 4.9 & 5.1562 & TST \\
\hline CHEMBL3197534 & 688816 & 5.4 & 5.5578 & TRN \\
\hline CHEMBL1383763 & 688816 & 6.6 & 5.5398 & TRN \\
\hline CHEMBL1392427 & 688816 & 4.9 & 5.2952 & TRN \\
\hline CHEMBL1506563 & 688816 & 8.3979 & 5.2687 & TRN \\
\hline CHEMBL1571742 & 688816 & 4.45 & 5.1882 & TRN \\
\hline CHEMBL 3193405 & 688816 & 7.15 & 5.5752 & TRN \\
\hline CHEMBL3211059 & 688816 & 5.85 & 5.1269 & TRN \\
\hline CHEMBL1568783 & 688816 & 4.45 & 5.0999 & TST \\
\hline CHEMBL1382561 & 688816 & 4.5 & 5.4403 & TST \\
\hline CHEMBL1450551 & 688816 & 4.45 & 4.8691 & TRN \\
\hline CHEMBL1365141 & 688816 & 5.05 & 5.4077 & TST \\
\hline CHEMBL1366264 & 688816 & 7.3002 & 5.4949 & TRN \\
\hline CHEMBL1443523 & 688816 & 5.65 & 5.1516 & TRN \\
\hline CHEMBL1472244 & 688816 & 4.85 & 5.0419 & TRN \\
\hline CHEMBL3208496 & 688816 & 5.0 & 5.1205 & TST \\
\hline CHEMBL1320425 & 688816 & 4.95 & 5.0233 & TRN \\
\hline CHEMBL1336017 & 688816 & 5.55 & 5.5376 & TRN \\
\hline CHEMBL1425552 & 688816 & 5.6 & 5.4531 & TRN \\
\hline CHEMBL1345717 & 688816 & 4.6 & 5.1522 & TRN \\
\hline CHEMBL1997171 & 688816 & 4.45 & 5.4841 & TRN \\
\hline CHEMBL1431996 & 688816 & 5.1 & 5.5642 & TST \\
\hline CHEMBL1353806 & 688816 & 4.7 & 5.4201 & TST \\
\hline CHEMBL1566948 & 688816 & 5.9 & 5.1639 & TRN \\
\hline CHEMBL1562713 & 688816 & 4.95 & 5.2857 & TRN \\
\hline CHEMBL1511201 & 688816 & 5.25 & 5.3607 & TRN \\
\hline CHEMBL1361205 & 688816 & 4.45 & 5.7088 & TST \\
\hline CHEMBL1570209 & 688816 & 5.0 & 5.2293 & TST \\
\hline
\end{tabular}




\begin{tabular}{|c|c|c|c|c|c|}
\hline \multirow[b]{2}{*}{ CHEMBL3190849 } & \multicolumn{5}{|c|}{ splemental Table S } \\
\hline & 688816 & 4.6 & 5.0727 & TRN & \\
\hline CHEMBL1510984 & 688816 & 4.85 & 5.1717 & TRN & \\
\hline CHEMBL1313133 & 688816 & 5.0 & 5.46899 & 9999999999 & TST \\
\hline CHEMBL1448469 & 688816 & 4.6 & 5.0177 & TRN & \\
\hline CHEMBL1482470 & 688816 & 5.0 & 5.0794 & TRN & \\
\hline CHEMBL1602701 & 688816 & 4.5 & 5.4987 & TRN & \\
\hline CHEMBL3191430 & 688816 & 4.65 & 5.6964 & TRN & \\
\hline CHEMBL1564460 & 688816 & 4.65 & 5.4547 & TRN & \\
\hline CHEMBL1369801 & 688816 & 5.3 & 5.2777 & TST & \\
\hline CHEMBL1557437 & 688816 & 4.95 & 5.2347 & TRN & \\
\hline CHEMBL1433135 & 688816 & 4.9 & 5.4128 & TRN & \\
\hline CHEMBL1471808 & 688816 & 4.45 & 5.5346 & TRN & \\
\hline CHEMBL1319194 & 688816 & 4.85 & 5.215 & TRN & \\
\hline CHEMBL1574375 & 688816 & 4.5 & 5.3923 & TRN & \\
\hline CHEMBL1584139 & 688816 & 4.95 & 5.16799 & 9999999999 & TRN \\
\hline CHEMBL1457503 & 688816 & 4.95 & 4.8452 & TST & \\
\hline CHEMBL1596886 & 688816 & 5.0 & 5.1552 & TST & \\
\hline CHEMBL1338551 & 688816 & 4.45 & 5.499 & TRN & \\
\hline CHEMBL1335518 & 688816 & 4.75 & 5.2418 & TRN & \\
\hline CHEMBL1449742 & 688816 & 4.45 & 5.3556 & TRN & \\
\hline CHEMBL3192362 & 688816 & 5.55 & 5.29200 & 0000000001 & TST \\
\hline CHEMBL1565801 & 688816 & 4.8 & 5.1253 & TRN & \\
\hline CHEMBL459715 & 688816 & 5.5 & 5.4027 & TRN & \\
\hline CHEMBL1528841 & 688816 & 5.25 & 5.4545 & TST & \\
\hline CHEMBL 3211478 & 688816 & 4.45 & 5.1924 & TRN & \\
\hline CHEMBL581194 & 688816 & 4.45 & 4.9807 & TRN & \\
\hline CHEMBL1350226 & 688816 & 6.95 & 5.3429 & TRN & \\
\hline CHEMBL92708 & 688816 & 4.5 & 5.3745 & TRN & \\
\hline CHEMBL3190922 & 688816 & 4.85 & 5.4642 & TRN & \\
\hline CHEMBL1551013 & 688816 & 4.7 & 5.4392 & TST & \\
\hline CHEMBL1429300 & 688816 & 4.95 & 5.3593 & TRN & \\
\hline CHEMBL1510344 & 688816 & 4.95 & 5.3705 & TRN & \\
\hline CHEMBL1484973 & 688816 & 5.75 & 5.0404 & TRN & \\
\hline CHEMBL1415028 & 688816 & 4.9 & 5.0762 & TRN & \\
\hline CHEMBL1608407 & 688816 & 4.45 & 5.4445 & TRN & \\
\hline CHEMBL1428760 & 688816 & 4.45 & 4.9657 & TRN & \\
\hline CHEMBL1605293 & 688816 & 5.35 & 4.8619 & TRN & \\
\hline CHEMBL1390601 & 688816 & 5.4 & 5.6908 & TRN & \\
\hline CHEMBL1392977 & 688816 & 6.25 & 5.079 & TST & \\
\hline CHEMBL1337511 & 688816 & 8.301 & 5.8163 & TRN & \\
\hline CHEMBL1304770 & 688816 & 4.6 & 5.2454 & TRN & \\
\hline CHEMBL1429927 & 688816 & 5.0 & 5.5488 & TRN & \\
\hline CHEMBL1459918 & 688816 & 4.85 & 4.8508 & TRN & \\
\hline CHEMBL1481381 & 688816 & 5.0 & 5.4727 & TRN & \\
\hline CHEMBL 3208028 & 688816 & 4.75 & 5.2567 & TST & \\
\hline CHEMBL1585261 & 688816 & 7.9508 & 5.3185 & TST & \\
\hline CHEMBL1541596 & 688816 & 4.65 & 4.8672 & TRN & \\
\hline CHEMBL1378023 & 688816 & 5.5 & 5.2389 & TRN & \\
\hline
\end{tabular}




\begin{tabular}{|c|c|c|c|c|c|}
\hline & & & & & \\
\hline CHEMBL1533660 & 688816 & 8.301 & 5.8397 & TST & \\
\hline CHEMBL1347775 & 688816 & 8.301 & 5.3676 & TRN & \\
\hline CHEMBL1510156 & 688816 & 4.45 & 5.5527 & TRN & \\
\hline CHEMBL1372361 & 688816 & 5.25 & 5.2962 & TST & \\
\hline CHEMBL1391251 & 688816 & 4.45 & 5.2472 & TRN & \\
\hline CHEMBL1595789 & 688816 & 4.5 & 5.1169 & TRN & \\
\hline CHEMBL450288 & 688816 & 6.05 & 5.42700 & 00000000005 & TST \\
\hline CHEMBL1524186 & 688816 & 4.9 & 5.316 & TRN & \\
\hline CHEMBL1425952 & 688816 & 5.0 & 5.1625 & TST & \\
\hline CHEMBL3193173 & 688816 & 4.45 & 5.5452 & TST & \\
\hline CHEMBL1412040 & 688816 & 4.85 & 5.1223 & TRN & \\
\hline CHEMBL1519202 & 688816 & 6.6 & 5.5971 & TRN & \\
\hline CHEMBL3194357 & 688816 & 5.4 & 5.4682 & TRN & \\
\hline CHEMBL1566015 & 688816 & 5.6 & 5.1179 & TRN & \\
\hline CHEMBL1542110 & 688816 & 4.75 & 5.1262 & TRN & \\
\hline CHEMBL3210049 & 688816 & 5.0 & 5.2786 & TRN & \\
\hline CHEMBL1338728 & 688816 & 6.95 & 5.38299 & 9999999999 & TRN \\
\hline CHEMBL1423250 & 688816 & 4.45 & 5.2957 & TRN & \\
\hline CHEMBL1382367 & 688816 & 4.95 & 5.3291 & TRN & \\
\hline CHEMBL1564115 & 688816 & 4.8 & 4.9438 & TST & \\
\hline CHEMBL1344344 & 688816 & 4.95 & 5.585 & TRN & \\
\hline CHEMBL 3212850 & 688816 & 5.3 & 5.5386 & TRN & \\
\hline CHEMBL1426008 & 688816 & 5.85 & 5.3634 & TRN & \\
\hline CHEMBL1445427 & 688816 & 4.75 & 5.3996 & TRN & \\
\hline CHEMBL1613489 & 688816 & 5.05 & 5.2558 & TST & \\
\hline CHEMBL1537418 & 688816 & 4.95 & 5.1621 & TST & \\
\hline CHEMBL1497238 & 688816 & 5.2 & 5.1069 & TST & \\
\hline CHEMBL1320908 & 688816 & 7.0501 & 5.2453 & TRN & \\
\hline CHEMBL1377911 & 688816 & 4.45 & 5.2636 & TST & \\
\hline CHEMBL1365133 & 688816 & 4.45 & 5.1688 & TST & \\
\hline CHEMBL1533013 & 688816 & 6.6499 & 5.6188 & TRN & \\
\hline CHEMBL530291 & 688816 & 5.85 & 5.2009 & TRN & \\
\hline CHEMBL1329007 & 688816 & 4.4 & 5.6671 & TST & \\
\hline CHEMBL1608597 & 688816 & 4.85 & 5.3255 & TRN & \\
\hline CHEMBL1308702 & 688816 & 5.4 & 5.0029 & TRN & \\
\hline CHEMBL1348139 & 688816 & 5.45 & 5.0654 & TRN & \\
\hline CHEMBL1463025 & 688816 & 4.95 & 5.3233 & TRN & \\
\hline CHEMBL1965791 & 688816 & 5.45 & 5.4019 & TST & \\
\hline CHEMBL1393304 & 688816 & 4.95 & 5.3093 & TRN & \\
\hline CHEMBL1499296 & 688816 & 5.1 & 5.0489 & TRN & \\
\hline CHEMBL1336537 & 688816 & 5.1 & 5.0817 & TRN & \\
\hline CHEMBL1340878 & 688816 & 4.8 & 5.025 & TST & \\
\hline CHEMBL1453327 & 688816 & 5.25 & 4.8097 & TRN & \\
\hline CHEMBL1394238 & 688816 & 4.5 & 5.1124 & TRN & \\
\hline CHEMBL1442027 & 688816 & 5.0 & 4.9251 & TRN & \\
\hline CHEMBL1597789 & 688816 & 5.0 & 5.3161 & TRN & \\
\hline CHEMBL552741 & 688816 & 5.15 & 5.2876 & TRN & \\
\hline CHEMBL1518922 & 688816 & 4.5 & 5.364 & TRN & \\
\hline
\end{tabular}




\begin{tabular}{|c|c|c|c|c|}
\hline & & & pplement & al Table S \\
\hline CHEMBL1385436 & 688816 & 7.699 & 5.0821 & TRN \\
\hline CHEMBL1321017 & 688816 & 4.9 & 5.0175 & TRN \\
\hline CHEMBL1430853 & 688816 & 4.45 & 5.2606 & TRN \\
\hline CHEMBL1548270 & 688816 & 6.1 & 5.3075 & TRN \\
\hline CHEMBL3190626 & 688816 & 4.85 & 5.6836 & TST \\
\hline CHEMBL1534143 & 688816 & 5.0 & 4.9565 & TRN \\
\hline CHEMBL1352208 & 688816 & 4.95 & 5.2558 & TRN \\
\hline CHEMBL1442633 & 688816 & 5.25 & 5.7836 & TRN \\
\hline CHEMBL1595903 & 688816 & 7.0501 & 5.3114 & TST \\
\hline CHEMBL1427225 & 688816 & 4.45 & 5.0196 & TRN \\
\hline CHEMBL1560232 & 688816 & 5.2 & 5.4075 & TRN \\
\hline CHEMBL1384417 & 688816 & 5.0 & 5.3457 & TRN \\
\hline CHEMBL1597924 & 688816 & 4.9 & 5.092 & TRN \\
\hline CHEMBL1447183 & 688816 & 6.05 & 5.5366 & TRN \\
\hline CHEMBL1449038 & 688816 & 4.45 & 4.9442 & TRN \\
\hline CHEMBL535307 & 688816 & 6.15 & 6.0752 & TRN \\
\hline CHEMBL1472345 & 688816 & 4.95 & 5.0962 & TRN \\
\hline CHEMBL1515022 & 688816 & 4.85 & 5.17 & TST \\
\hline CHEMBL1368897 & 688816 & 4.6 & 5.0886 & TRN \\
\hline CHEMBL1411002 & 688816 & 5.0 & 5.2296 & TRN \\
\hline CHEMBL1375429 & 688816 & 7.6498 & 5.395 & TRN \\
\hline CHEMBL1328088 & 688816 & 4.45 & 5.483 & TST \\
\hline CHEMBL1505177 & 688816 & 5.95 & 5.0965 & TRN \\
\hline CHEMBL1341403 & 688816 & 6.2 & 5.2099 & TRN \\
\hline CHEMBL1352368 & 688816 & 4.45 & 5.2507 & TRN \\
\hline CHEMBL1566667 & 688816 & 4.45 & 5.2874 & TST \\
\hline CHEMBL1526722 & 688816 & 5.15 & 5.0235 & TRN \\
\hline CHEMBL1613574 & 688816 & 4.65 & 5.3701 & TRN \\
\hline CHEMBL1349075 & 688816 & 5.0 & 5.2887 & TRN \\
\hline CHEMBL1456092 & 688816 & 4.75 & 4.8656 & TRN \\
\hline CHEMBL1518056 & 688816 & 4.95 & 5.1153 & TRN \\
\hline CHEMBL1417652 & 688816 & 5.45 & 5.3456 & TRN \\
\hline CHEMBL1576076 & 688816 & 4.95 & 5.3157 & TRN \\
\hline CHEMBL1349059 & 688816 & 4.95 & 5.2057 & TRN \\
\hline CHEMBL1573240 & 688816 & 4.8 & 5.0695 & TRN \\
\hline CHEMBL1554253 & 688816 & 6.1 & 5.1731 & TRN \\
\hline CHEMBL1491104 & 688816 & 4.75 & 5.1316 & TRN \\
\hline CHEMBL1442281 & 688816 & 5.55 & 5.2723 & TRN \\
\hline CHEMBL3193432 & 688816 & 5.4 & 5.692 & TRN \\
\hline CHEMBL1534326 & 688816 & 7.6003 & 5.3465 & TRN \\
\hline CHEMBL1557367 & 688816 & 7.0 & 5.34399 & 9999999999 \\
\hline CHEMBL1352585 & 688816 & 4.45 & 5.3565 & TST \\
\hline CHEMBL480626 & 688816 & 4.95 & 5.1762 & TST \\
\hline CHEMBL1520180 & 688816 & 5.05 & 5.2077 & TRN \\
\hline CHEMBL3198308 & 688816 & 4.8 & 5.671 & TRN \\
\hline CHEMBL 3208442 & 688816 & 4.45 & 5.0479 & TST \\
\hline CHEMBL1310634 & 688816 & 4.9 & 5.2446 & TRN \\
\hline CHEMBL1522280 & 688816 & 4.95 & 5.3434 & TRN \\
\hline
\end{tabular}




\begin{tabular}{|c|c|c|c|c|c|}
\hline \multicolumn{6}{|c|}{ Supplemental Table S2.txt } \\
\hline CHEMBL1351033 & 688816 & 5.8 & 5.2802 & TST & \\
\hline CHEMBL1308384 & 688816 & 4.9 & 5.4794 & TST & \\
\hline CHEMBL1487064 & 688816 & 4.95 & 5.1369 & TRN & \\
\hline CHEMBL1456595 & 688816 & 4.95 & 5.152 & TRN & \\
\hline CHEMBL2134693 & 688816 & 5.2 & 5.5446 & TRN & \\
\hline CHEMBL1510043 & 688816 & 4.45 & 5.2313 & TST & \\
\hline CHEMBL1330509 & 688816 & 4.75 & 5.3118 & TRN & \\
\hline CHEMBL1450538 & 688816 & 5.0 & 4.9524 & TRN & \\
\hline CHEMBL1460497 & 688816 & 4.45 & 5.0283 & TRN & \\
\hline CHEMBL1498673 & 688816 & 5.2 & 5.5565 & TRN & \\
\hline CHEMBL1569186 & 688816 & 4.75 & 5.1325 & TRN & \\
\hline CHEMBL1428877 & 688816 & 4.95 & 5.1117 & TRN & \\
\hline CHEMBL1458102 & 688816 & 5.3 & 5.3345 & TST & \\
\hline CHEMBL1418036 & 688816 & 5.4 & 5.5118 & TRN & \\
\hline CHEMBL1501217 & 688816 & 8.3468 & 5.0769 & TST & \\
\hline CHEMBL1466843 & 688816 & 4.95 & 5.5725 & TRN & \\
\hline CHEMBL1388708 & 688816 & 4.45 & 4.8696 & TRN & \\
\hline CHEMBL1595996 & 688816 & 5.0 & $5.1620 e$ & 0000000001 & TRN \\
\hline CHEMBL1559071 & 688816 & 4.9 & 5.4158 & TRN & \\
\hline CHEMBL1450974 & 688816 & 5.3 & 5.0781 & TST & \\
\hline CHEMBL1363295 & 688816 & 6.7501 & 4.9481 & TRN & \\
\hline CHEMBL1528443 & 688816 & 4.45 & 5.1896 & TST & \\
\hline CHEMBL1299766 & 688816 & 4.8 & 5.1482 & TRN & \\
\hline CHEMBL1589330 & 688816 & 7.5003 & 4.9863 & TRN & \\
\hline CHEMBL1415166 & 688816 & 4.6 & 5.2044 & TRN & \\
\hline CHEMBL1534895 & 688816 & 7.4498 & 5.3083 & TRN & \\
\hline CHEMBL1580603 & 688816 & 4.95 & 5.3443 & TRN & \\
\hline CHEMBL1426332 & 688816 & 4.95 & 4.8957 & TRN & \\
\hline CHEMBL1576046 & 688816 & 7.5003 & 5.4361 & TST & \\
\hline CHEMBL1465179 & 688816 & 5.6 & 5.42899 & 9999999999 & TST \\
\hline CHEMBL1431340 & 688816 & 6.25 & 5.5235 & TRN & \\
\hline CHEMBL1388769 & 688816 & 4.8 & 4.9763 & TRN & \\
\hline CHEMBL1522743 & 688816 & 6.4 & 5.2034 & TRN & \\
\hline CHEMBL1464448 & 688816 & 5.9 & 5.2674 & TRN & \\
\hline CHEMBL1255755 & 688816 & 5.5 & 5.3774 & TRN & \\
\hline CHEMBL1564863 & 688816 & 4.9 & 5.3595 & TST & \\
\hline CHEMBL1459757 & 688816 & 6.35 & 5.3196 & TRN & \\
\hline CHEMBL1524534 & 688816 & 8.3468 & 5.2338 & TRN & \\
\hline CHEMBL66654 & 688816 & 6.0 & 6.0775 & TST & \\
\hline CHEMBL1586593 & 688816 & 5.2 & 4.9473 & TRN & \\
\hline CHEMBL1461281 & 688816 & 4.85 & 5.2003 & TRN & \\
\hline CHEMBL1382302 & 688816 & 8.3468 & 5.4708 & TRN & \\
\hline CHEMBL1383911 & 688816 & 4.5 & 5.1386 & TRN & \\
\hline CHEMBL1587685 & 688816 & 4.85 & 5.284 & TRN & \\
\hline CHEMBL1394905 & 688816 & 5.2 & 5.1883 & TRN & \\
\hline CHEMBL1536775 & 688816 & 4.9 & 5.3638 & TRN & \\
\hline CHEMBL1474054 & 688816 & 4.75 & 5.3121 & TRN & \\
\hline CHEMBL1575872 & 688816 & 5.4 & 5.3286 & TST & \\
\hline
\end{tabular}




\begin{tabular}{|c|c|c|c|c|c|}
\hline \multicolumn{6}{|c|}{ Supplemental Table S2.txt } \\
\hline CHEMBL1488584 & 688816 & 5.8 & 5.2838 & TRN & \\
\hline CHEMBL1440875 & 688816 & 5.8 & 5.9432 & TST & \\
\hline CHEMBL1350832 & 688816 & 4.85 & 5.0357 & TRN & \\
\hline CHEMBL1433143 & 688816 & 4.65 & 5.5645 & TRN & \\
\hline CHEMBL1310090 & 688816 & 4.45 & 5.2172 & TRN & \\
\hline CHEMBL3213742 & 688816 & 5.1 & 5.229 & TST & \\
\hline CHEMBL1352777 & 688816 & 4.85 & 5.3888 & TRN & \\
\hline CHEMBL1998263 & 688816 & 5.05 & 5.3384 & TST & \\
\hline CHEMBL1342524 & 688816 & 4.9 & 5.566 & TST & \\
\hline CHEMBL1350777 & 688816 & 4.85 & 5.029 & TRN & \\
\hline CHEMBL1534666 & 688816 & 6.15 & 5.5675 & TRN & \\
\hline CHEMBL1389630 & 688816 & 4.95 & 5.2296 & TRN & \\
\hline CHEMBL1485925 & 688816 & 8.4949 & 5.1785 & TST & \\
\hline CHEMBL1383407 & 688816 & 4.95 & 5.4271 & TRN & \\
\hline CHEMBL1375878 & 688816 & 4.45 & 5.3946 & TRN & \\
\hline CHEMBL1313197 & 688816 & 4.45 & 5.0856 & TRN & \\
\hline CHEMBL1536314 & 688816 & 5.25 & 5.5167 & TST & \\
\hline CHEMBL1528110 & 688816 & 4.5 & 5.265 & TRN & \\
\hline CHEMBL1380485 & 688816 & 5.2 & 5.4375 & TRN & \\
\hline CHEMBL1462803 & 688816 & 6.0 & 5.0451 & TRN & \\
\hline CHEMBL1380303 & 688816 & 5.5 & 5.3295 & TRN & \\
\hline CHEMBL1368807 & 688816 & 5.35 & 5.6879 & TST & \\
\hline CHEMBL1349748 & 688816 & 4.7 & $5.2860 e$ & 00000000005 & TRN \\
\hline CHEMBL1375094 & 688816 & 5.25 & 5.5382 & TRN & \\
\hline CHEMBL 228078 & 688816 & 7.8508 & $5.9570 e$ & 0000000001 & TRN \\
\hline CHEMBL1333430 & 688816 & 4.95 & 5.3081 & TRN & \\
\hline CHEMBL1600749 & 688816 & 4.85 & 5.1487 & TRN & \\
\hline CHEMBL1320334 & 688816 & 7.5498 & 5.1705 & TST & \\
\hline CHEMBL1600913 & 688816 & 4.95 & 5.2786 & TRN & \\
\hline CHEMBL1409268 & 688816 & 4.6 & 5.2799 & TRN & \\
\hline CHEMBL1305455 & 688816 & 5.35 & 5.1931 & TRN & \\
\hline CHEMBL1363098 & 688816 & 5.25 & 5.6666 & TRN & \\
\hline CHEMBL1415354 & 688816 & 5.2 & 5.1635 & TST & \\
\hline CHEMBL1301913 & 688816 & 4.45 & 5.0796 & TRN & \\
\hline CHEMBL3193377 & 688816 & 5.05 & 5.4195 & TRN & \\
\hline CHEMBL338474 & 688816 & 8.2518 & 5.735 & TST & \\
\hline CHEMBL1475562 & 688816 & 4.45 & 5.0769 & TRN & \\
\hline CHEMBL117966 & 688816 & 4.7 & 5.0193 & TRN & \\
\hline CHEMBL1304144 & 688816 & 7.4498 & 5.2796 & TST & \\
\hline CHEMBL1412987 & 688816 & 5.85 & 5.2478 & TRN & \\
\hline CHEMBL1521340 & 688816 & 4.9 & 5.2035 & TRN & \\
\hline CHEMBL1400204 & 688816 & 5.25 & 5.5536 & TST & \\
\hline CHEMBL1369612 & 688816 & 4.95 & 5.0398 & TRN & \\
\hline CHEMBL1462564 & 688816 & 5.8 & $5.2360 e$ & $\partial 000000001$ & TRN \\
\hline CHEMBL1447921 & 688816 & 5.7 & 5.0345 & TRN & \\
\hline CHEMBL1337230 & 688816 & 4.9 & 5.2532 & TST & \\
\hline CHEMBL1447392 & 688816 & 4.8 & 4.9931 & TRN & \\
\hline CHEMBL1345334 & 688816 & 4.6 & 4.8499 & TRN & \\
\hline
\end{tabular}




\begin{tabular}{|c|c|c|c|c|}
\hline \multicolumn{5}{|c|}{ Supplemental Table S2.txt } \\
\hline CHEMBL584883 & 688816 & 4.95 & 5.0878 & TRN \\
\hline CHEMBL1361043 & 688816 & 6.5 & 5.4674 & TST \\
\hline CHEMBL1386925 & 688816 & 5.7 & 5.6989 & TST \\
\hline CHEMBL1408962 & 688816 & 5.0 & 4.9726 & TST \\
\hline CHEMBL1586301 & 688816 & 4.55 & 5.1079 & TRN \\
\hline CHEMBL1431352 & 688816 & 5.45 & 4.9988 & TRN \\
\hline CHEMBL1424062 & 688816 & 4.9 & 5.2366 & TRN \\
\hline CHEMBL1601104 & 688816 & 5.5 & 5.3625 & TST \\
\hline CHEMBL1545432 & 688816 & 4.95 & 5.2945 & TRN \\
\hline CHEMBL1520219 & 688816 & 4.9 & 5.4221 & TRN \\
\hline CHEMBL1446369 & 688816 & 4.7 & 5.0536 & TRN \\
\hline CHEMBL1345974 & 688816 & 5.0 & 5.5437 & TST \\
\hline CHEMBL3191965 & 688816 & 4.45 & 5.6855 & TRN \\
\hline CHEMBL1484031 & 688816 & 4.45 & 5.3989 & TRN \\
\hline CHEMBL1349216 & 688816 & 4.65 & 4.8941 & TRN \\
\hline CHEMBL1503485 & 688816 & 4.85 & 5.6198 & TST \\
\hline CHEMBL1339725 & 688816 & 4.85 & 4.9523 & TRN \\
\hline CHEMBL1444417 & 688816 & 4.85 & 5.2424 & TRN \\
\hline CHEMBL1427062 & 688816 & 5.0 & 5.0383 & TRN \\
\hline CHEMBL1494861 & 688816 & 7.2503 & 5.1372 & TRN \\
\hline CHEMBL1524484 & 688816 & 6.8 & 5.1727 & TRN \\
\hline CHEMBL1530948 & 688816 & 4.45 & 5.4817 & TRN \\
\hline CHEMBL1454711 & 688816 & 4.45 & 5.3592 & TST \\
\hline CHEMBL1502516 & 688816 & 6.05 & 5.6526 & TRN \\
\hline CHEMBL1373387 & 688816 & 6.25 & 5.3619 & TRN \\
\hline CHEMBL1469470 & 688816 & 4.65 & 5.5308 & TRN \\
\hline CHEMBL3207559 & 688816 & 7.3002 & 5.3277 & TST \\
\hline CHEMBL1340481 & 688816 & 5.35 & 5.0801 & TST \\
\hline CHEMBL1582510 & 688816 & 4.95 & 5.1586 & TRN \\
\hline CHEMBL1398391 & 688816 & 4.9 & 4.9126 & TRN \\
\hline CHEMBL1525701 & 688816 & 5.0 & 5.023 & TST \\
\hline CHEMBL1306289 & 688816 & 5.05 & 5.5006 & TRN \\
\hline CHEMBL3392393 & 688816 & 4.95 & 5.3781 & TRN \\
\hline CHEMBL1571129 & 688816 & 6.5501 & 5.5596 & TST \\
\hline CHEMBL1597190 & 688816 & 5.05 & 5.3156 & TRN \\
\hline CHEMBL1459389 & 688816 & 5.5 & 5.4471 & TST \\
\hline CHEMBL1398960 & 688816 & 4.95 & 5.1566 & TRN \\
\hline CHEMBL1425828 & 688816 & 5.25 & 5.0368 & TRN \\
\hline CHEMBL1543779 & 688816 & 4.95 & 5.2143 & TST \\
\hline CHEMBL1485577 & 688816 & 4.75 & 5.1903 & TRN \\
\hline CHEMBL1409320 & 688816 & 4.45 & 4.9709 & TRN \\
\hline CHEMBL3192618 & 688816 & 5.05 & $5.4060 e$ & 0000000001 \\
\hline CHEMBL1355197 & 688816 & 4.9 & 5.2838 & TRN \\
\hline CHEMBL579859 & 688816 & 4.95 & 4.6559 & TRN \\
\hline CHEMBL1500641 & 688816 & 4.85 & 5.4703 & TRN \\
\hline CHEMBL1412546 & 688816 & 4.8 & 5.4608 & TRN \\
\hline CHEMBL1599015 & 688816 & 5.1 & 5.4854 & TST \\
\hline CHEMBL1568248 & 688816 & 4.9 & 4.9986 & TRN \\
\hline
\end{tabular}

TRN 


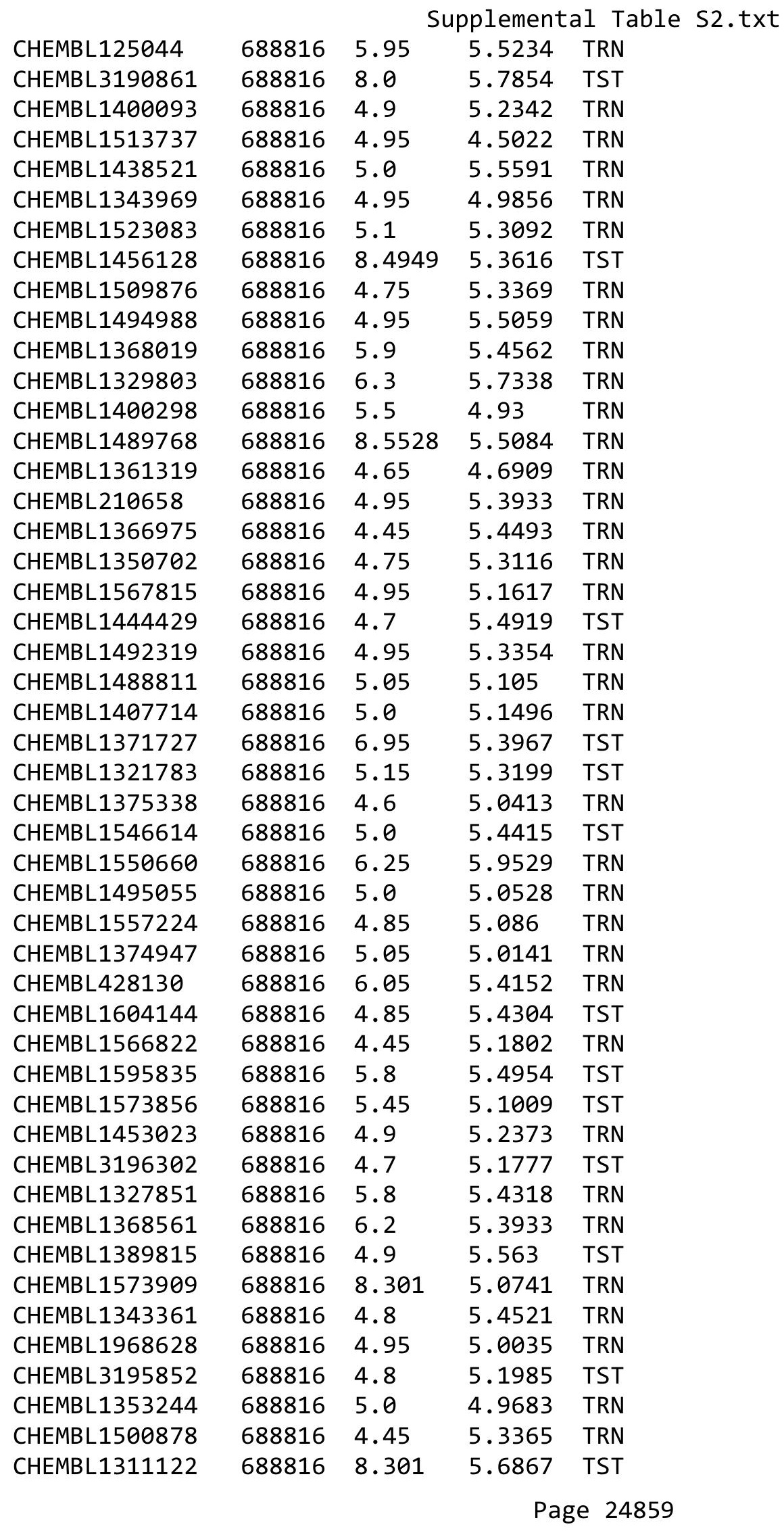




\begin{tabular}{|c|c|c|c|c|}
\hline \multicolumn{5}{|c|}{ Supplemental Table S2.txt } \\
\hline CHEMBL1493996 & 688816 & 5.0 & 5.2632 & TRN \\
\hline CHEMBL1398171 & 688816 & 5.7 & 4.9831 & TRN \\
\hline CHEMBL1450813 & 688816 & 5.0 & 5.4709 & TRN \\
\hline CHEMBL1596618 & 688816 & 8.3979 & 5.4064 & TRN \\
\hline CHEMBL1409784 & 688816 & 4.45 & 5.3244 & TST \\
\hline CHEMBL1461785 & 688816 & 4.65 & 5.7432 & TRN \\
\hline CHEMBL1507273 & 688816 & 4.7 & 5.3458 & TRN \\
\hline CHEMBL1524342 & 688816 & 7.5498 & 4.9656 & TRN \\
\hline CHEMBL1307710 & 688816 & 4.9 & 5.1812 & TST \\
\hline CHEMBL1508851 & 688816 & 8.3468 & 5.4033 & TRN \\
\hline CHEMBL72135 & 688816 & 8.4949 & 5.3324 & TST \\
\hline CHEMBL1377073 & 688816 & 6.25 & 5.7104 & TRN \\
\hline CHEMBL1537436 & 688816 & 5.05 & 5.1601 & TRN \\
\hline CHEMBL1440191 & 688816 & 5.2 & 4.931 & TRN \\
\hline CHEMBL1602056 & 688816 & 8.301 & 5.1786 & TRN \\
\hline CHEMBL1584686 & 688816 & 4.45 & 5.1181 & TST \\
\hline CHEMBL1555470 & 688816 & 5.8 & 5.8906 & TST \\
\hline CHEMBL1442475 & 688816 & 4.95 & 5.0861 & TRN \\
\hline CHEMBL1343065 & 688816 & 7.5498 & 5.1175 & TST \\
\hline CHEMBL1492346 & 688816 & 4.8 & 5.3046 & TRN \\
\hline CHEMBL1413331 & 688816 & 4.9 & 5.6445 & TRN \\
\hline CHEMBL1345839 & 688816 & 8.301 & 5.2593 & TRN \\
\hline CHEMBL1489380 & 688816 & 4.7 & 5.038 & TRN \\
\hline CHEMBL1307261 & 688816 & 6.8 & 5.2555 & TST \\
\hline CHEMBL1497695 & 688816 & 4.95 & 5.4585 & TRN \\
\hline CHEMBL1472110 & 688816 & 5.5 & 5.042 & TRN \\
\hline CHEMBL1401231 & 688816 & 4.95 & 5.1264 & TST \\
\hline CHEMBL1507579 & 688816 & 7.699 & 6.1869 & TST \\
\hline CHEMBL1530130 & 688816 & 6.05 & 5.6881 & TRN \\
\hline CHEMBL1361790 & 688816 & 7.6498 & 5.3639 & TST \\
\hline CHEMBL1557816 & 688816 & 5.7 & 5.3112 & TST \\
\hline CHEMBL3207988 & 688816 & 4.75 & 5.2322 & TRN \\
\hline CHEMBL3191909 & 688816 & 4.45 & 5.0732 & TST \\
\hline CHEMBL1544685 & 688816 & 6.2 & 4.9647 & TST \\
\hline CHEMBL1369610 & 688816 & 5.4 & 5.4912 & TST \\
\hline CHEMBL1439546 & 688816 & 8.301 & 5.5585 & TST \\
\hline CHEMBL1423027 & 688816 & 4.95 & 5.646 & TST \\
\hline CHEMBL1344875 & 688816 & 5.0 & 4.7836 & TRN \\
\hline CHEMBL1610429 & 688816 & 4.45 & 5.0108 & TST \\
\hline CHEMBL1367786 & 688816 & 4.85 & 5.3128 & TST \\
\hline CHEMBL1326176 & 688816 & 4.95 & 5.2444 & TRN \\
\hline CHEMBL1477767 & 688816 & 4.75 & 5.893 & TRN \\
\hline CHEMBL1328055 & 688816 & 5.95 & 5.1928 & TRN \\
\hline CHEMBL1490017 & 688816 & 6.0 & 5.1496 & TRN \\
\hline CHEMBL468167 & 688816 & 5.3 & 5.7416 & TST \\
\hline CHEMBL3198453 & 688816 & 4.85 & 5.2694 & TRN \\
\hline CHEMBL1578438 & 688816 & 5.25 & 5.7397 & TRN \\
\hline CHEMBL1530644 & 688816 & 4.45 & 5.0554 & TRN \\
\hline
\end{tabular}




\begin{tabular}{|c|c|c|c|c|c|}
\hline & & & & & \\
\hline CHEMBL1974810 & 688816 & 5.1 & 5.1398 & TST & \\
\hline CHEMBL3192236 & 688816 & 5.7 & 5.7609 & TST & \\
\hline CHEMBL1509411 & 688816 & 6.0 & 5.7562 & TRN & \\
\hline CHEMBL1337704 & 688816 & 5.2 & 5.4679 & TRN & \\
\hline CHEMBL1446716 & 688816 & 5.55 & 5.4341 & TST & \\
\hline CHEMBL1569074 & 688816 & 5.35 & 5.2823 & TRN & \\
\hline CHEMBL 7724 & 688816 & 5.3 & 5.1271 & TRN & \\
\hline CHEMBL1427447 & 688816 & 4.9 & 5.249 & TRN & \\
\hline CHEMBL3189652 & 688816 & 4.5 & 5.3733 & TST & \\
\hline CHEMBL1365552 & 688816 & 4.9 & 5.1508 & TST & \\
\hline CHEMBL1424280 & 688816 & 4.65 & 5.3324 & TST & \\
\hline CHEMBL1336564 & 688816 & 7.699 & 5.3306 & TST & \\
\hline CHEMBL1494593 & 688816 & 4.8 & 4.9216 & TRN & \\
\hline CHEMBL1561851 & 688816 & 4.55 & 5.1059 & TRN & \\
\hline CHEMBL1575951 & 688816 & 5.35 & 5.2434 & TST & \\
\hline CHEMBL1577058 & 688816 & 4.8 & 5.2949 & TST & \\
\hline CHEMBL1405419 & 688816 & 5.2 & 5.1908 & TRN & \\
\hline CHEMBL1552874 & 688816 & 4.45 & 4.8347 & TRN & \\
\hline CHEMBL1396585 & 688816 & 4.9 & 5.11 & TRN & \\
\hline CHEMBL1403215 & 688816 & 4.9 & 5.4829 & TRN & \\
\hline CHEMBL1463807 & 688816 & 5.0 & 5.3347 & TRN & \\
\hline CHEMBL445420 & 688816 & 4.9 & 5.1927 & TRN & \\
\hline CHEMBL1375292 & 688816 & 4.65 & 4.6872 & TRN & \\
\hline CHEMBL3189634 & 688816 & 4.45 & 5.4025 & TRN & \\
\hline CHEMBL81215 & 688816 & 4.45 & 5.1357 & TST & \\
\hline CHEMBL1376099 & 688816 & 5.8 & 5.46700 & 00000000005 & TRN \\
\hline CHEMBL1574303 & 688816 & 4.9 & 5.1683 & TRN & \\
\hline CHEMBL1610005 & 688816 & 5.2 & 5.2313 & TRN & \\
\hline CHEMBL1312486 & 688816 & 4.9 & 4.6917 & TRN & \\
\hline CHEMBL1342840 & 688816 & 5.0 & 5.0905 & TRN & \\
\hline CHEMBL1517849 & 688816 & 4.45 & 5.1834 & TRN & \\
\hline CHEMBL1490895 & 688816 & 5.8 & 5.5695 & TRN & \\
\hline CHEMBL3198532 & 688816 & 4.85 & 5.2703 & TST & \\
\hline CHEMBL1500274 & 688816 & 4.95 & 5.1896 & TRN & \\
\hline CHEMBL1483624 & 688816 & 6.05 & 4.9501 & TRN & \\
\hline CHEMBL1544317 & 688816 & 4.85 & 5.12200 & 0000000001 & TST \\
\hline CHEMBL1475818 & 688816 & 5.25 & 5.1323 & TRN & \\
\hline CHEMBL1302681 & 688816 & 4.95 & 5.5793 & TRN & \\
\hline CHEMBL1352134 & 688816 & 6.15 & 5.5897 & TST & \\
\hline CHEMBL1511091 & 688816 & 4.95 & 5.6402 & TRN & \\
\hline CHEMBL1488272 & 688816 & 7.5003 & 5.6183 & TST & \\
\hline CHEMBL1599370 & 688816 & 4.95 & 5.1123 & TRN & \\
\hline CHEMBL1303150 & 688816 & 4.85 & 5.38299 & 9999999999 & TRN \\
\hline CHEMBL1365290 & 688816 & 4.65 & 5.0192 & TRN & \\
\hline CHEMBL1377744 & 688816 & 4.9 & 4.9289 & TST & \\
\hline CHEMBL1613268 & 688816 & 5.15 & 5.0524 & TRN & \\
\hline CHEMBL1382858 & 688816 & 5.05 & 5.17299 & 9999999999 & TRN \\
\hline CHEMBL1474175 & 688816 & 5.35 & 5.4069 & TRN & \\
\hline
\end{tabular}




\begin{tabular}{|c|c|c|c|c|}
\hline \multicolumn{5}{|c|}{ Supplemental Table S2.txt } \\
\hline CHEMBL1499611 & 688816 & 6.1 & 5.2362 & TST \\
\hline CHEMBL1529092 & 688816 & 5.0 & 5.0469 & TRN \\
\hline CHEMBL1523794 & 688816 & 5.5 & 5.4768 & TRN \\
\hline CHEMBL1555803 & 688816 & 5.5 & 5.4342 & TRN \\
\hline CHEMBL1427085 & 688816 & 6.5501 & 5.5482 & TST \\
\hline CHEMBL1580550 & 688816 & 4.85 & 5.5719 & TRN \\
\hline CHEMBL1333464 & 688816 & 4.85 & 5.2185 & TRN \\
\hline CHEMBL1544250 & 688816 & 4.75 & 4.9328 & TRN \\
\hline CHEMBL1399730 & 688816 & 4.9 & 5.0303 & TRN \\
\hline CHEMBL1321672 & 688816 & 4.95 & 4.9717 & TRN \\
\hline CHEMBL1423038 & 688816 & 4.95 & 5.7183 & TRN \\
\hline CHEMBL1335387 & 688816 & 4.8 & 5.0659 & TRN \\
\hline CHEMBL1410179 & 688816 & 4.8 & 5.1965 & TRN \\
\hline CHEMBL1351680 & 688816 & 4.85 & 5.2272 & TRN \\
\hline CHEMBL1527817 & 688816 & 5.0 & 5.0094 & TST \\
\hline CHEMBL1334234 & 688816 & 5.25 & 5.0554 & TRN \\
\hline CHEMBL1538586 & 688816 & 4.75 & 4.9705 & TST \\
\hline CHEMBL1383057 & 688816 & 4.45 & 5.3542 & TST \\
\hline CHEMBL1404052 & 688816 & 5.05 & 5.1653 & TRN \\
\hline CHEMBL1524495 & 688816 & 6.8499 & 5.3205 & TRN \\
\hline CHEMBL1402375 & 688816 & 4.75 & 5.1586 & TST \\
\hline CHEMBL3199249 & 688816 & 5.3 & 5.0237 & TST \\
\hline CHEMBL1576347 & 688816 & 4.8 & 5.4452 & TRN \\
\hline CHEMBL1544770 & 688816 & 4.6 & 4.94 & TRN \\
\hline CHEMBL1301334 & 688816 & 4.85 & 5.3496 & TRN \\
\hline CHEMBL1362574 & 688816 & 4.5 & 4.8821 & TRN \\
\hline CHEMBL1320403 & 688816 & 8.301 & 6.0718 & TRN \\
\hline CHEMBL1520647 & 688816 & 4.9 & 5.6778 & TRN \\
\hline CHEMBL1519667 & 688816 & 4.45 & 5.474 & TST \\
\hline CHEMBL1309290 & 688816 & 4.8 & 4.6833 & TRN \\
\hline CHEMBL1348302 & 688816 & 4.45 & 5.6904 & TRN \\
\hline CHEMBL1450612 & 688816 & 4.8 & 5.169 & TRN \\
\hline CHEMBL3199825 & 688816 & 4.85 & 5.2388 & TRN \\
\hline CHEMBL1331856 & 688816 & 4.95 & 4.6773 & TRN \\
\hline CHEMBL1386396 & 688816 & 4.9 & 5.3028 & TRN \\
\hline CHEMBL3191350 & 688816 & 5.3 & 5.211 & TST \\
\hline CHEMBL1545132 & 688816 & 4.45 & 5.481 & TRN \\
\hline CHEMBL1550008 & 688816 & 4.6 & 5.034 & TRN \\
\hline CHEMBL1430117 & 688816 & 4.9 & 5.8925 & TST \\
\hline CHEMBL1337193 & 688816 & 4.7 & 5.0692 & TRN \\
\hline CHEMBL1608618 & 688816 & 4.45 & 5.3633 & TRN \\
\hline CHEMBL1413841 & 688816 & 4.9 & 5.3786 & TRN \\
\hline CHEMBL1462547 & 688816 & 5.0 & 5.1086 & TRN \\
\hline CHEMBL3210445 & 688816 & 5.25 & 5.5484 & TST \\
\hline CHEMBL1321836 & 688816 & 5.5 & 5.1608 & TRN \\
\hline CHEMBL1410706 & 688816 & 4.7 & 5.6106 & TRN \\
\hline CHEMBL3199796 & 688816 & 6.0 & 5.1383 & TRN \\
\hline CHEMBL1456255 & 688816 & 4.45 & 4.8187 & TRN \\
\hline
\end{tabular}




\begin{tabular}{|c|c|c|c|c|}
\hline & & & pplement & al $\mathrm{T}$ \\
\hline CHEMBL1469894 & 688816 & 6.8499 & 5.1062 & TST \\
\hline CHEMBL1398633 & 688816 & 5.4 & 5.1881 & TRN \\
\hline CHEMBL1569176 & 688816 & 4.9 & 5.1262 & TST \\
\hline CHEMBL1576449 & 688816 & 8.0 & 5.4391 & TST \\
\hline CHEMBL1492835 & 688816 & 5.0 & 5.2207 & TRN \\
\hline CHEMBL1449477 & 688816 & 5.65 & 5.5666 & TST \\
\hline CHEMBL1426124 & 688816 & 4.85 & 4.9418 & TRN \\
\hline CHEMBL1374664 & 688816 & 5.2 & 5.024 & TRN \\
\hline CHEMBL1516902 & 688816 & 4.8 & 4.9976 & TRN \\
\hline CHEMBL1586370 & 688816 & 5.65 & 5.3888 & TRN \\
\hline CHEMBL1344810 & 688816 & 4.95 & 5.0103 & TRN \\
\hline CHEMBL1510845 & 688816 & 5.25 & 5.4918 & TST \\
\hline CHEMBL3194037 & 688816 & 4.6 & 5.1221 & TRN \\
\hline CHEMBL1429719 & 688816 & 5.2 & 5.4279 & TRN \\
\hline CHEMBL1579309 & 688816 & 8.301 & 5.6394 & TST \\
\hline CHEMBL1387468 & 688816 & 4.65 & 5.2611 & TRN \\
\hline CHEMBL1463447 & 688816 & 4.95 & 5.4608 & TRN \\
\hline CHEMBL1404463 & 688816 & 4.85 & 5.4123 & TST \\
\hline CHEMBL3208910 & 688816 & 5.2 & 5.5577 & TRN \\
\hline CHEMBL1580031 & 688816 & 4.9 & 5.1928 & TRN \\
\hline CHEMBL1407250 & 688816 & 6.6 & 5.0831 & TST \\
\hline CHEMBL589692 & 688816 & 4.45 & 5.517 & TRN \\
\hline CHEMBL1486372 & 688816 & 4.75 & 5.5193 & TST \\
\hline CHEMBL1583558 & 688816 & 4.95 & 5.2424 & TRN \\
\hline CHEMBL1497024 & 688816 & 4.9 & 5.0941 & TRN \\
\hline CHEMBL1369552 & 688816 & 5.25 & 5.4362 & TRN \\
\hline CHEMBL1389210 & 688816 & 6.3 & 4.9005 & TRN \\
\hline CHEMBL1522807 & 688816 & 4.95 & 5.0905 & TRN \\
\hline CHEMBL3196314 & 688816 & 5.0 & 5.794 & TST \\
\hline CHEMBL193872 & 688816 & 6.05 & 5.3212 & TRN \\
\hline CHEMBL1579256 & 688816 & 4.9 & 5.1463 & TRN \\
\hline CHEMBL1428566 & 688816 & 6.2 & 5.0889 & TRN \\
\hline CHEMBL1450118 & 688816 & 5.2 & 5.7133 & TRN \\
\hline CHEMBL1372902 & 688816 & 4.9 & 5.1227 & TRN \\
\hline CHEMBL1414665 & 688816 & 4.95 & 5.4239 & TRN \\
\hline CHEMBL1488243 & 688816 & 5.9 & 5.4697 & TRN \\
\hline CHEMBL1455428 & 688816 & 4.85 & 5.6594 & TRN \\
\hline CHEMBL1529338 & 688816 & 5.2 & 5.5943 & TRN \\
\hline CHEMBL1322199 & 688816 & 5.7 & 5.0614 & TST \\
\hline CHEMBL1550330 & 688816 & 4.8 & 5.4664 & TRN \\
\hline CHEMBL1380563 & 688816 & 4.45 & 5.3644 & TRN \\
\hline CHEMBL273094 & 688816 & 7.5003 & 5.4441 & TST \\
\hline CHEMBL2369177 & 688816 & 4.8 & 5.4307 & TST \\
\hline CHEMBL1605408 & 688816 & 4.95 & 5.2536 & TST \\
\hline CHEMBL1378398 & 688816 & 4.85 & 5.1246 & TRN \\
\hline CHEMBL1345841 & 688816 & 4.45 & 4.9143 & TRN \\
\hline CHEMBL 3194187 & 688816 & 4.75 & 5.1684 & TRN \\
\hline CHEMBL1587116 & 688816 & 4.9 & 5.1811 & TRN \\
\hline
\end{tabular}




\begin{tabular}{|c|c|c|c|c|c|}
\hline \multicolumn{6}{|c|}{ Supplemental Table S2.txt } \\
\hline CHEMBL1330227 & 688816 & 4.95 & 5.3093 & TRN & \\
\hline CHEMBL1613593 & 688816 & 6.6 & 5.3848 & TRN & \\
\hline CHEMBL1427452 & 688816 & 4.45 & 5.1836 & TRN & \\
\hline CHEMBL1509793 & 688816 & 4.8 & 5.2609 & TST & \\
\hline CHEMBL1585318 & 688816 & 4.9 & 4.9504 & TRN & \\
\hline CHEMBL1578375 & 688816 & 5.8 & 5.3631 & TRN & \\
\hline CHEMBL1489276 & 688816 & 7.699 & 5.4557 & TST & \\
\hline CHEMBL1587637 & 688816 & 5.0 & 5.1938 & TRN & \\
\hline CHEMBL1452003 & 688816 & 4.95 & 5.0748 & TRN & \\
\hline CHEMBL1336499 & 688816 & 8.4559 & 5.5399 & TRN & \\
\hline CHEMBL1378421 & 688816 & 4.8 & 5.37700 & 0000000001 & TRN \\
\hline CHEMBL1402345 & 688816 & 4.7 & 5.3455 & TST & \\
\hline CHEMBL1433260 & 688816 & 6.4 & 5.4189 & TRN & \\
\hline CHEMBL1411383 & 688816 & 4.6 & 5.6961 & TRN & \\
\hline CHEMBL1340069 & 688816 & 8.1487 & 5.3338 & TRN & \\
\hline CHEMBL1527300 & 688816 & 4.85 & 4.873 & TRN & \\
\hline CHEMBL1509617 & 688816 & 4.6 & 5.37700 & 0000000001 & TST \\
\hline CHEMBL1556354 & 688816 & 4.85 & 5.4377 & TRN & \\
\hline CHEMBL518292 & 688816 & 5.6 & 5.2961 & TST & \\
\hline CHEMBL1360514 & 688816 & 4.6 & 5.1414 & TRN & \\
\hline CHEMBL1304741 & 688816 & 4.45 & 5.5482 & TST & \\
\hline CHEMBL1524766 & 688816 & 4.8 & 4.9935 & TRN & \\
\hline CHEMBL1538944 & 688816 & 5.4 & 5.5381 & TST & \\
\hline CHEMBL1393271 & 688816 & 7.0501 & 5.4246 & TRN & \\
\hline CHEMBL1501382 & 688816 & 5.25 & 5.7057 & TRN & \\
\hline CHEMBL1974180 & 688816 & 4.85 & 5.2926 & TST & \\
\hline CHEMBL1535064 & 688816 & 4.85 & 5.4315 & TST & \\
\hline CHEMBL1404931 & 688816 & 4.95 & 5.193 & TRN & \\
\hline CHEMBL1516900 & 688816 & 4.9 & 5.2784 & TRN & \\
\hline CHEMBL1582602 & 688816 & 4.7 & 5.1925 & TST & \\
\hline CHEMBL1505267 & 688816 & 5.5 & 4.9118 & TRN & \\
\hline CHEMBL1568772 & 688816 & 5.15 & 5.2617 & TRN & \\
\hline CHEMBL1441180 & 688816 & 4.85 & 5.4498 & TST & \\
\hline CHEMBL3195334 & 688816 & 4.65 & 5.4281 & TST & \\
\hline CHEMBL1573230 & 688816 & 5.1 & 5.1714 & TRN & \\
\hline CHEMBL1451128 & 688816 & 5.6 & 5.2759 & TRN & \\
\hline CHEMBL1570525 & 688816 & 5.25 & 5.5823 & TST & \\
\hline CHEMBL1427138 & 688816 & 4.85 & 5.0365 & TST & \\
\hline CHEMBL1562632 & 688816 & 7.699 & 5.5314 & TRN & \\
\hline CHEMBL3191415 & 688816 & 6.9 & 5.5439 & TRN & \\
\hline CHEMBL1319619 & 688816 & 4.8 & 5.1557 & TRN & \\
\hline CHEMBL1602086 & 688816 & 6.7001 & 5.5504 & TRN & \\
\hline CHEMBL1370467 & 688816 & 4.8 & 5.4717 & TRN & \\
\hline CHEMBL1564991 & 688816 & 4.45 & 4.9103 & TST & \\
\hline CHEMBL3193601 & 688816 & 4.95 & 5.4645 & TST & \\
\hline CHEMBL3196361 & 688816 & 5.05 & 5.3518 & TRN & \\
\hline CHEMBL 1338676 & 688816 & 7.0 & 5.5151 & TST & \\
\hline CHEMBL1521302 & 688816 & 5.15 & 5.4719 & TRN & \\
\hline
\end{tabular}




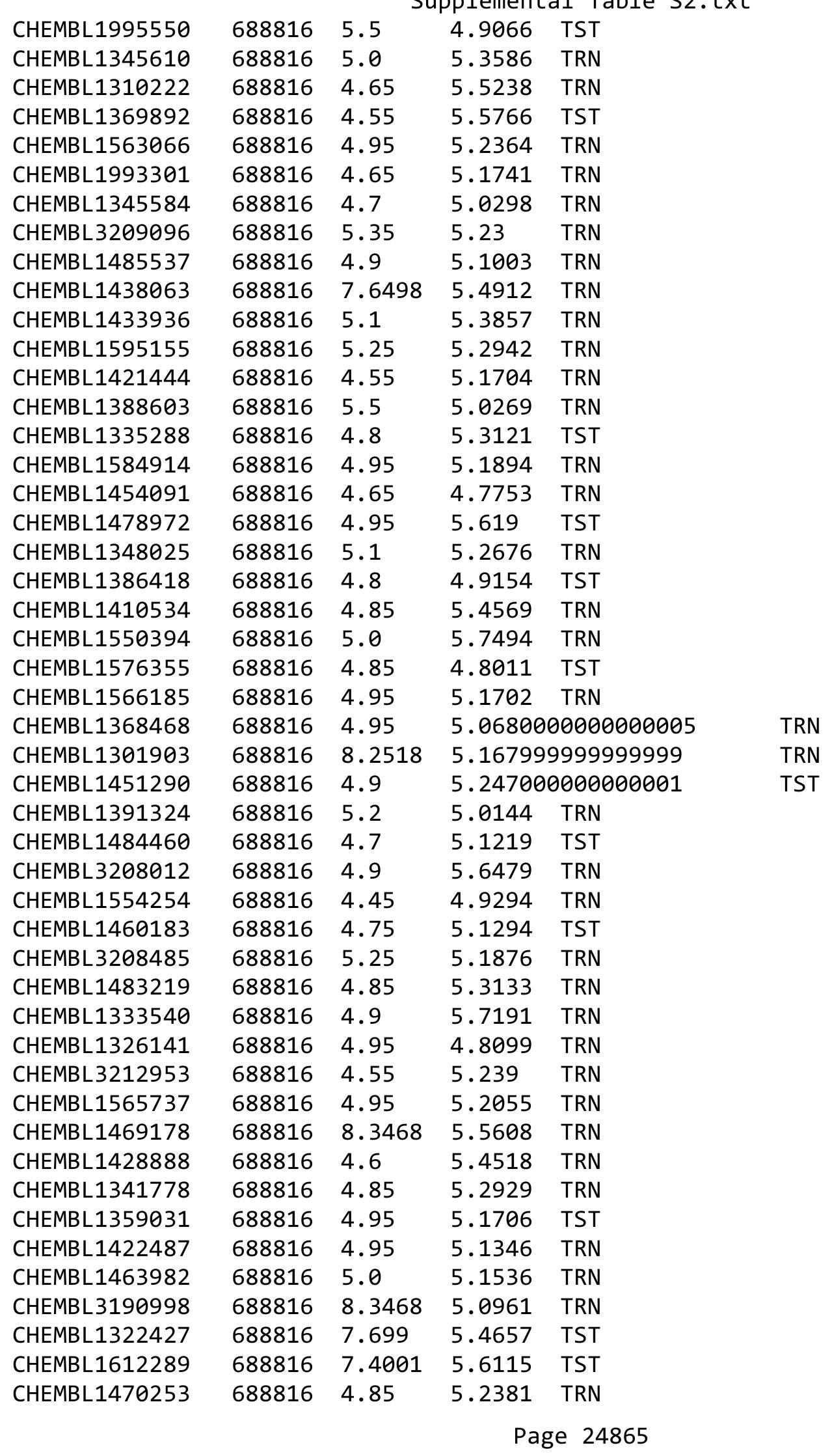




\begin{tabular}{|c|c|c|c|c|c|}
\hline \multicolumn{6}{|c|}{ Supplemental Table S2.txt } \\
\hline CHEMBL1450462 & 688816 & 5.05 & 5.2925 & TRN & \\
\hline CHEMBL1433100 & 688816 & 5.4 & 5.3159 & TST & \\
\hline CHEMBL1477355 & 688816 & 5.15 & 5.13700 & 00000000005 & TRN \\
\hline CHEMBL1570217 & 688816 & 4.95 & 5.1182 & TRN & \\
\hline CHEMBL1456985 & 688816 & 4.9 & 4.957 & TST & \\
\hline CHEMBL1430803 & 688816 & 4.7 & 5.3995 & TRN & \\
\hline CHEMBL3189939 & 688816 & 5.15 & 5.1751 & TRN & \\
\hline CHEMBL1567943 & 688816 & 4.65 & 5.4764 & TST & \\
\hline CHEMBL1407496 & 688816 & 6.05 & 5.5314 & TRN & \\
\hline CHEMBL3193160 & 688816 & 5.2 & 5.4618 & TRN & \\
\hline CHEMBL1335471 & 688816 & 4.6 & 5.4787 & TST & \\
\hline CHEMBL1606685 & 688816 & 4.45 & 4.9944 & TST & \\
\hline CHEMBL1546290 & 688816 & 4.65 & 4.9257 & TRN & \\
\hline CHEMBL 3212046 & 688816 & 4.65 & 5.1085 & TRN & \\
\hline CHEMBL1425315 & 688816 & 5.0 & 5.2972 & TRN & \\
\hline CHEMBL1464391 & 688816 & 5.0 & 5.1833 & TST & \\
\hline CHEMBL1401455 & 688816 & 5.55 & 5.5202 & TRN & \\
\hline CHEMBL1570488 & 688816 & 7.4498 & 5.3233 & TRN & \\
\hline CHEMBL1488839 & 688816 & 5.4 & 4.9339 & TRN & \\
\hline CHEMBL1348534 & 688816 & 4.9 & 5.1348 & TRN & \\
\hline CHEMBL1313756 & 688816 & 5.75 & 5.5219 & TRN & \\
\hline CHEMBL1374022 & 688816 & 6.2 & 5.6922 & TRN & \\
\hline CHEMBL1415950 & 688816 & 5.05 & 5.5057 & TRN & \\
\hline CHEMBL1459901 & 688816 & 6.0 & 5.391 & TRN & \\
\hline CHEMBL1478916 & 688816 & 4.65 & 5.1841 & TRN & \\
\hline CHEMBL502257 & 688816 & 5.2 & 5.5547 & TST & \\
\hline CHEMBL3189751 & 688816 & 6.05 & 5.1529 & TRN & \\
\hline CHEMBL451574 & 688816 & 4.45 & 5.3871 & TST & \\
\hline CHEMBL1420142 & 688816 & 4.45 & 5.3212 & TRN & \\
\hline CHEMBL1466462 & 688816 & 4.85 & 5.4229 & TRN & \\
\hline CHEMBL1373676 & 688816 & 4.95 & 5.4163 & TRN & \\
\hline CHEMBL1372573 & 688816 & 4.9 & 5.2505 & TRN & \\
\hline CHEMBL1374414 & 688816 & 7.8508 & 5.5462 & TRN & \\
\hline CHEMBL1342977 & 688816 & 4.75 & 5.4708 & TRN & \\
\hline CHEMBL1363834 & 688816 & 4.6 & 5.53299 & 99999999995 & TRN \\
\hline CHEMBL1488258 & 688816 & 4.8 & 4.9002 & TRN & \\
\hline CHEMBL1357934 & 688816 & 4.45 & 4.7573 & TST & \\
\hline CHEMBL516040 & 688816 & 5.45 & 4.8124 & TRN & \\
\hline CHEMBL1383713 & 688816 & 4.9 & 4.9691 & TST & \\
\hline CHEMBL3192388 & 688816 & 7.5003 & 5.4282 & TRN & \\
\hline CHEMBL1528905 & 688816 & 4.95 & 5.1538 & TRN & \\
\hline CHEMBL1548861 & 688816 & 8.301 & 5.2264 & TST & \\
\hline CHEMBL1450406 & 688816 & 5.0 & 5.0883 & TRN & \\
\hline CHEMBL1420595 & 688816 & 4.8 & 5.205 & TRN & \\
\hline CHEMBL1380341 & 688816 & 4.75 & 5.05 & TRN & \\
\hline CHEMBL1429351 & 688816 & 8.1487 & 5.0839 & TRN & \\
\hline CHEMBL1432427 & 688816 & 4.45 & 5.0163 & TRN & \\
\hline CHEMBL1540392 & 688816 & 6.0 & 4.9023 & TRN & \\
\hline
\end{tabular}




\begin{tabular}{|c|c|c|c|c|c|}
\hline \multicolumn{6}{|c|}{ Supplemental Table S2.txt } \\
\hline CHEMBL1432319 & 688816 & 4.95 & 5.1888 & TRN & \\
\hline CHEMBL1611574 & 688816 & 4.45 & 5.3202 & TST & \\
\hline CHEMBL1342967 & 688816 & 4.85 & 5.3373 & TST & \\
\hline CHEMBL1309419 & 688816 & 5.5 & 5.1731 & TST & \\
\hline CHEMBL1580908 & 688816 & 5.15 & 5.0707 & TST & \\
\hline CHEMBL1344390 & 688816 & 4.95 & 5.1972 & TRN & \\
\hline CHEMBL1364646 & 688816 & 5.0 & 5.1804 & TST & \\
\hline CHEMBL1383097 & 688816 & 8.3468 & 5.2748 & TRN & \\
\hline CHEMBL1441325 & 688816 & 6.3 & 5.3344 & TRN & \\
\hline CHEMBL1472108 & 688816 & 4.6 & 4.82600 & 00000000005 & TRN \\
\hline CHEMBL1502695 & 688816 & 4.85 & 5.3137 & TST & \\
\hline CHEMBL1508066 & 688816 & 5.4 & 5.6363 & TST & \\
\hline CHEMBL1448573 & 688816 & 4.95 & 5.0995 & TST & \\
\hline CHEMBL1453168 & 688816 & 4.95 & 5.1261 & TRN & \\
\hline CHEMBL1500249 & 688816 & 4.45 & 5.1988 & TST & \\
\hline CHEMBL1540781 & 688816 & 6.8 & 5.379 & TRN & \\
\hline CHEMBL1542790 & 688816 & 4.95 & 5.2673 & TRN & \\
\hline CHEMBL1423457 & 688816 & 4.45 & 5.6655 & TST & \\
\hline CHEMBL1344031 & 688816 & 8.4559 & 5.2915 & TST & \\
\hline CHEMBL1413319 & 688816 & 6.8 & 5.5942 & TRN & \\
\hline CHEMBL1509707 & 688816 & 6.05 & 5.0436 & TRN & \\
\hline CHEMBL1529427 & 688816 & 4.8 & 4.9214 & TRN & \\
\hline CHEMBL1539364 & 688816 & 4.75 & 5.0897 & TRN & \\
\hline CHEMBL1340299 & 688816 & 6.8499 & 5.30399 & 9999999999 & TST \\
\hline CHEMBL1454889 & 688816 & 6.7501 & 5.6441 & TST & \\
\hline CHEMBL1514008 & 688816 & 4.45 & 4.8773 & TRN & \\
\hline CHEMBL1462543 & 688816 & 5.65 & 5.3584 & TST & \\
\hline CHEMBL1387991 & 688816 & 4.85 & 5.0839 & TRN & \\
\hline CHEMBL1529158 & 688816 & 5.05 & 5.0715 & TRN & \\
\hline CHEMBL3190053 & 688816 & 6.2 & 5.2796 & TRN & \\
\hline CHEMBL1547325 & 688816 & 5.05 & 4.9985 & TRN & \\
\hline CHEMBL1311367 & 688816 & 4.85 & 5.2629 & TST & \\
\hline CHEMBL1478082 & 688816 & 5.05 & 5.2854 & TRN & \\
\hline CHEMBL1583778 & 688816 & 7.0501 & 5.1757 & TST & \\
\hline CHEMBL1421092 & 688816 & 4.95 & 5.4918 & TRN & \\
\hline CHEMBL3195360 & 688816 & 4.9 & 5.6362 & TRN & \\
\hline CHEMBL1546778 & 688816 & 4.7 & 5.1561 & TRN & \\
\hline CHEMBL1340675 & 688816 & 4.45 & 5.2976 & TRN & \\
\hline CHEMBL1383807 & 688816 & 4.8 & 5.3817 & TRN & \\
\hline CHEMBL1489856 & 688816 & 5.6 & 5.3623 & TST & \\
\hline CHEMBL1432530 & 688816 & 5.5 & 5.2792 & TST & \\
\hline CHEMBL1510906 & 688816 & 4.6 & 5.4047 & TRN & \\
\hline CHEMBL1440827 & 688816 & 5.9 & 5.1068 & TRN & \\
\hline CHEMBL1409990 & 688816 & 4.95 & 5.0488 & TRN & \\
\hline CHEMBL1454341 & 688816 & 4.6 & 5.6105 & TRN & \\
\hline CHEMBL1452119 & 688816 & 4.75 & 5.0006 & TRN & \\
\hline CHEMBL1399466 & 688816 & 5.7 & 5.081 & TRN & \\
\hline CHEMBL1546266 & 688816 & 4.9 & 5.556 & TRN & \\
\hline
\end{tabular}




\begin{tabular}{|c|c|c|c|c|}
\hline \multicolumn{5}{|c|}{ Supplemental Table S2.txt } \\
\hline CHEMBL1554098 & 688816 & 4.95 & 5.8623 & TST \\
\hline CHEMBL1310407 & 688816 & 4.8 & 4.9973 & TRN \\
\hline CHEMBL1561980 & 688816 & 5.25 & 5.1624 & TST \\
\hline CHEMBL1320033 & 688816 & 4.8 & 6.0739 & TST \\
\hline CHEMBL1510916 & 688816 & 5.5 & 5.6114 & TST \\
\hline CHEMBL1376554 & 688816 & 4.8 & 5.1416 & TRN \\
\hline CHEMBL1365173 & 688816 & 6.6499 & 5.145 & TST \\
\hline CHEMBL1353367 & 688816 & 4.95 & 4.9433 & TST \\
\hline CHEMBL1412778 & 688816 & 4.9 & 5.4114 & TRN \\
\hline CHEMBL3198109 & 688816 & 4.85 & 5.0418 & TRN \\
\hline CHEMBL1435724 & 688816 & 4.9 & 5.0378 & TRN \\
\hline CHEMBL1582537 & 688816 & 4.9 & 5.2046 & TST \\
\hline CHEMBL1547448 & 688816 & 4.45 & 5.6952 & TST \\
\hline CHEMBL 3208084 & 688816 & 7.7496 & 5.2955 & TRN \\
\hline CHEMBL1414209 & 688816 & 8.301 & 4.9946 & TRN \\
\hline CHEMBL1321899 & 688816 & 4.85 & 5.1328 & TRN \\
\hline CHEMBL1503993 & 688816 & 6.5 & 5.4377 & TRN \\
\hline CHEMBL1311535 & 688816 & 4.85 & 5.105 & TRN \\
\hline CHEMBL1485078 & 688816 & 4.9 & 4.8477 & TRN \\
\hline CHEMBL1539031 & 688816 & 8.5528 & 5.5114 & TRN \\
\hline CHEMBL1328281 & 688816 & 4.45 & 5.2425 & TRN \\
\hline CHEMBL1438517 & 688816 & 4.9 & 4.8339 & TST \\
\hline CHEMBL1567660 & 688816 & 8.3468 & 5.3655 & TST \\
\hline CHEMBL1419089 & 688816 & 4.85 & 4.8738 & TRN \\
\hline CHEMBL1521776 & 688816 & 8.0 & 4.7375 & TST \\
\hline CHEMBL1466981 & 688816 & 4.95 & 5.1198 & TRN \\
\hline CHEMBL3196240 & 688816 & 4.45 & 5.1643 & TRN \\
\hline CHEMBL1466151 & 688816 & 4.9 & 5.0626 & TRN \\
\hline CHEMBL 3194528 & 688816 & 4.95 & 4.9212 & TRN \\
\hline CHEMBL1595336 & 688816 & 6.0 & 5.1708 & TRN \\
\hline CHEMBL1496875 & 688816 & 4.95 & 5.4335 & TRN \\
\hline CHEMBL1480238 & 688816 & 6.05 & 5.4778 & TRN \\
\hline CHEMBL1588945 & 688816 & 4.55 & 5.2362 & TRN \\
\hline CHEMBL1532305 & 688816 & 4.8 & 5.272 & TRN \\
\hline CHEMBL1581396 & 688816 & 4.45 & 4.7586 & TRN \\
\hline CHEMBL1564471 & 688816 & 6.2 & 5.3806 & TRN \\
\hline CHEMBL1451617 & 688816 & 5.35 & 5.3111 & TRN \\
\hline CHEMBL1527882 & 688816 & 4.7 & 5.1209 & TST \\
\hline CHEMBL1440308 & 688816 & 4.75 & 5.0511 & TRN \\
\hline CHEMBL1565626 & 688816 & 5.0 & 5.0851 & TRN \\
\hline CHEMBL1373340 & 688816 & 5.05 & 4.9246 & TRN \\
\hline CHEMBL1370381 & 688816 & 5.4 & 5.1057 & TRN \\
\hline CHEMBL1351247 & 688816 & 4.45 & 5.3906 & TRN \\
\hline CHEMBL1600493 & 688816 & 7.15 & 5.3103 & TST \\
\hline CHEMBL1574596 & 688816 & 5.25 & 5.8198 & TRN \\
\hline CHEMBL1596347 & 688816 & 4.9 & 5.0759 & TST \\
\hline CHEMBL1346972 & 688816 & 5.25 & 4.7456 & TRN \\
\hline CHEMBL1390773 & 688816 & 5.2 & 5.2394 & TRN \\
\hline
\end{tabular}




\begin{tabular}{|c|c|c|c|c|c|}
\hline \multicolumn{6}{|c|}{ Supplemental Table s2.txt } \\
\hline CHEMBL1319488 & 688816 & 4.45 & 5.0402 & TRN & \\
\hline CHEMBL1540153 & 688816 & 8.7447 & 5.2152 & TRN & \\
\hline CHEMBL1315978 & 688816 & 5.55 & 5.2155 & TRN & \\
\hline CHEMBL3209842 & 688816 & 5.75 & \multicolumn{2}{|c|}{5.553999999999999} & TRN \\
\hline CHEMBL1476737 & 688816 & 4.45 & 4.6184 & TRN & \\
\hline CHEMBL1390487 & 688816 & 5.4 & 5.1695 & TST & \\
\hline CHEMBL1497326 & 688816 & 4.5 & 5.2386 & TRN & \\
\hline CHEMBL1308212 & 688816 & 4.65 & 5.4286 & TRN & \\
\hline CHEMBL1494586 & 688816 & 4.65 & 5.0974 & TRN & \\
\hline CHEMBL1495154 & 688816 & 5.55 & 5.3403 & TRN & \\
\hline CHEMBL1321224 & 688816 & 4.95 & 5.414 & TRN & \\
\hline CHEMBL1303982 & 688816 & 4.95 & 5.3492 & TST & \\
\hline CHEMBL3197561 & 688816 & 5.25 & 5.1689 & TRN & \\
\hline CHEMBL1595095 & 688816 & 4.95 & 5.4481 & TRN & \\
\hline CHEMBL1431692 & 688816 & 5.25 & 5.4729 & TRN & \\
\hline CHEMBL1609751 & 688816 & 4.85 & 5.3902 & TRN & \\
\hline CHEMBL1580432 & 688816 & 4.85 & 5.1545 & TRN & \\
\hline CHEMBL1511024 & 688816 & 4.9 & 5.1336 & TRN & \\
\hline CHEMBL1470808 & 688816 & 7.6498 & \multicolumn{2}{|c|}{5.5329999999999995} & TRN \\
\hline CHEMBL1523928 & 688816 & 4.95 & 5.5155 & TRN & \\
\hline CHEMBL1581992 & 688816 & 5.35 & 5.2012 & TRN & \\
\hline CHEMBL304621 & 688816 & 4.8 & 5.2406 & TST & \\
\hline CHEMBL1516589 & 688816 & 4.95 & 5.2245 & TRN & \\
\hline CHEMBL1336101 & 688816 & 8.1487 & 4.9902 & TRN & \\
\hline CHEMBL1408808 & 688816 & 4.9 & 5.391 & TST & \\
\hline CHEMBL1505013 & 688816 & 8.301 & 5.3803 & TRN & \\
\hline CHEMBL1391475 & 688816 & 4.9 & 5.1432 & TST & \\
\hline CHEMBL1310637 & 688816 & 4.9 & 5.0795 & TRN & \\
\hline CHEMBL270299 & 688816 & 4.45 & 5.1938 & TST & \\
\hline CHEMBL1535074 & 688816 & 4.9 & 5.2376 & TRN & \\
\hline CHEMBL3192920 & 688816 & 5.0 & 5.2512 & TRN & \\
\hline CHEMBL1533450 & 688816 & 4.9 & 5.0939 & TRN & \\
\hline CHEMBL3209700 & 688816 & 4.5 & 5.1537 & TRN & \\
\hline CHEMBL1595876 & 688816 & 5.85 & 5.3532 & TST & \\
\hline CHEMBL1391098 & 688816 & 6.45 & 5.6609 & TRN & \\
\hline CHEMBL1353324 & 688816 & 4.65 & 5.154 & TRN & \\
\hline CHEMBL1487021 & 688816 & 4.95 & 5.5726 & TRN & \\
\hline CHEMBL1370271 & 688816 & 4.45 & 5.2816 & TRN & \\
\hline CHEMBL224343 & 688816 & 5.35 & 5.314 & TRN & \\
\hline CHEMBL1363506 & 688816 & 5.1 & 5.3401 & TRN & \\
\hline CHEMBL1536133 & 688816 & 5.0 & 4.8643 & TRN & \\
\hline CHEMBL1480051 & 688816 & 6.5501 & 5.2857 & TRN & \\
\hline CHEMBL1577773 & 688816 & 5.35 & 5.0315 & TRN & \\
\hline CHEMBL1351009 & 688816 & 6.5 & 5.4614 & TRN & \\
\hline CHEMBL1192110 & 688816 & 8.3468 & 5.5351 & TRN & \\
\hline CHEMBL1402138 & 688816 & 4.45 & 5.105 & TRN & \\
\hline CHEMBL1377895 & 688816 & 4.45 & 5.16299 & 9999999999 & TST \\
\hline CHEMBL1381413 & 688816 & 6.7501 & 5.3806 & TST & \\
\hline
\end{tabular}




\begin{tabular}{|c|c|c|c|c|c|}
\hline \\
\hline CHEMBL1373473 & 688816 & 6.9 & 5.2255 & TST & \\
\hline CHEMBL1437258 & 688816 & 5.15 & 5.2404 & TRN & \\
\hline CHEMBL1424480 & 688816 & 5.3 & 5.1084 & TRN & \\
\hline CHEMBL1393358 & 688816 & 5.75 & 5.1212 & TRN & \\
\hline CHEMBL1558074 & 688816 & 4.9 & 5.7478 & TST & \\
\hline CHEMBL1597124 & 688816 & 4.45 & 5.6202 & TRN & \\
\hline CHEMBL1301696 & 688816 & 4.45 & 5.2752 & TRN & \\
\hline CHEMBL1489460 & 688816 & 4.45 & 5.1549 & TRN & \\
\hline CHEMBL1446233 & 688816 & 4.85 & 5.1667 & TRN & \\
\hline CHEMBL1306357 & 688816 & 4.85 & 4.9184 & TRN & \\
\hline CHEMBL1530638 & 688816 & 4.95 & 5.0728 & TRN & \\
\hline CHEMBL1307447 & 688816 & 4.45 & 5.2184 & TRN & \\
\hline CHEMBL1387309 & 688816 & 4.85 & 4.9894 & TST & \\
\hline CHEMBL1557441 & 688816 & 4.6 & 5.481 & TRN & \\
\hline CHEMBL1330251 & 688816 & 4.75 & 5.4401 & TST & \\
\hline CHEMBL1310468 & 688816 & 4.6 & 5.7051 & TRN & \\
\hline CHEMBL1323824 & 688816 & 4.45 & 4.9875 & TRN & \\
\hline CHEMBL1567078 & 688816 & 4.8 & $5.4520 e$ & 0000000001 & TRN \\
\hline CHEMBL1524710 & 688816 & 4.9 & 5.1093 & TRN & \\
\hline CHEMBL1477565 & 688816 & 5.2 & 5.0311 & TRN & \\
\hline CHEMBL1530398 & 688816 & 4.65 & 5.0698 & TST & \\
\hline CHEMBL3193818 & 688816 & 4.45 & 5.5076 & TRN & \\
\hline CHEMBL1329814 & 688816 & 4.65 & 4.7397 & TRN & \\
\hline CHEMBL1388601 & 688816 & 4.45 & 5.4937 & TRN & \\
\hline CHEMBL1575493 & 688816 & 5.0 & 5.2886 & TRN & \\
\hline CHEMBL3193443 & 688816 & 4.95 & 5.3611 & TST & \\
\hline CHEMBL458328 & 688816 & 4.9 & 5.9021 & TST & \\
\hline CHEMBL1447683 & 688816 & 4.9 & 5.1889 & TRN & \\
\hline CHEMBL1424169 & 688816 & 4.45 & 5.391 & TRN & \\
\hline CHEMBL3192892 & 688816 & 5.05 & 5.0639 & TRN & \\
\hline CHEMBL1442564 & 688816 & 4.8 & 5.3325 & TRN & \\
\hline CHEMBL1310543 & 688816 & 4.85 & 5.4842 & TRN & \\
\hline CHEMBL1555815 & 688816 & 4.65 & 5.125 & TST & \\
\hline CHEMBL1361870 & 688816 & 5.55 & 5.1886 & TST & \\
\hline CHEMBL1495559 & 688816 & 5.55 & 5.1559 & TRN & \\
\hline CHEMBL1499127 & 688816 & 4.75 & 5.2524 & TRN & \\
\hline CHEMBL1319420 & 688816 & 4.45 & 5.0501 & TRN & \\
\hline CHEMBL1326385 & 688816 & 9.699 & 5.3279 & TRN & \\
\hline CHEMBL1506970 & 688816 & 4.5 & 5.4885 & TRN & \\
\hline CHEMBL1352563 & 688816 & 5.6 & 5.2296 & TRN & \\
\hline CHEMBL1308926 & 688816 & 6.25 & 5.1055 & TST & \\
\hline CHEMBL402063 & 688816 & 6.0 & 5.6644 & TRN & \\
\hline CHEMBL1483527 & 688816 & 5.55 & 5.2809 & TRN & \\
\hline CHEMBL1515852 & 688816 & 4.8 & 5.4865 & TRN & \\
\hline CHEMBL1581321 & 688816 & 6.15 & 5.4519 & TRN & \\
\hline CHEMBL1306488 & 688816 & 4.9 & 4.9962 & TRN & \\
\hline CHEMBL3214196 & 688816 & 5.4 & 5.86299 & 99999999995 & TST \\
\hline CHEMBL1489638 & 688816 & 6.5 & 5.2286 & TRN & \\
\hline & & & & 4870 & \\
\hline
\end{tabular}




\begin{tabular}{|c|c|c|c|c|}
\hline \multicolumn{5}{|c|}{ Supplemental Table S2.txt } \\
\hline CHEMBL1424326 & 688816 & 5.25 & 5.2498 & TST \\
\hline CHEMBL1307416 & 688816 & 5.05 & 5.1943 & TST \\
\hline CHEMBL1399709 & 688816 & 4.65 & 5.225 & TRN \\
\hline CHEMBL1458559 & 688816 & 4.45 & 5.1885 & TRN \\
\hline CHEMBL1325240 & 688816 & 6.5501 & 5.3226 & TRN \\
\hline CHEMBL1418087 & 688816 & 5.05 & 5.3889 & TRN \\
\hline CHEMBL1407677 & 688816 & 4.85 & 5.2191 & TRN \\
\hline CHEMBL1546285 & 688816 & 4.7 & 4.8797 & TRN \\
\hline CHEMBL1540979 & 688816 & 4.75 & 5.7294 & TST \\
\hline CHEMBL1469797 & 688816 & 4.75 & 5.5568 & TRN \\
\hline CHEMBL3208113 & 688816 & 8.3468 & 5.0773 & TRN \\
\hline CHEMBL1409629 & 688816 & 4.95 & 5.525 & TRN \\
\hline CHEMBL1599443 & 688816 & 6.95 & 5.4131 & TRN \\
\hline CHEMBL1509104 & 688816 & 4.9 & 5.3397 & TRN \\
\hline CHEMBL1486922 & 688816 & 5.7 & 5.2241 & TRN \\
\hline CHEMBL578915 & 688816 & 4.45 & 5.2289 & TRN \\
\hline CHEMBL1438193 & 688816 & 4.45 & 5.4958 & TRN \\
\hline CHEMBL1606703 & 688816 & 4.95 & 5.2218 & TST \\
\hline CHEMBL1306573 & 688816 & 5.45 & 5.0698 & TRN \\
\hline CHEMBL59026 & 688816 & 4.9 & 4.8918 & TRN \\
\hline CHEMBL1420312 & 688816 & 8.4559 & 5.3432 & TRN \\
\hline CHEMBL1501773 & 688816 & 5.15 & 4.9406 & TST \\
\hline CHEMBL1334367 & 688816 & 6.7501 & 5.4236 & TRN \\
\hline CHEMBL1560551 & 688816 & 4.45 & 5.2907 & TRN \\
\hline CHEMBL1321138 & 688816 & 4.9 & 5.8162 & TRN \\
\hline CHEMBL1414611 & 688816 & 6.2 & 5.5036 & TRN \\
\hline CHEMBL1466442 & 688816 & 4.55 & 4.8457 & TRN \\
\hline CHEMBL1605210 & 688816 & 5.0 & 5.0289 & TRN \\
\hline CHEMBL1378495 & 688816 & 4.85 & 5.0685 & TRN \\
\hline CHEMBL1467002 & 688816 & 4.95 & 5.0532 & TRN \\
\hline CHEMBL1360505 & 688816 & 4.85 & 4.909 & TRN \\
\hline CHEMBL1451654 & 688816 & 6.7501 & 5.5344 & TRN \\
\hline CHEMBL1605394 & 688816 & 4.45 & 5.6495 & TRN \\
\hline CHEMBL1502227 & 688816 & 5.0 & 5.0122 & TST \\
\hline CHEMBL1304798 & 688816 & 5.05 & 5.2588 & TRN \\
\hline CHEMBL1457506 & 688816 & 7.9508 & 5.6343 & TRN \\
\hline CHEMBL3193569 & 688816 & 4.45 & 5.3461 & TRN \\
\hline CHEMBL1613592 & 688816 & 4.45 & 5.6992 & TRN \\
\hline CHEMBL1331084 & 688816 & 5.6 & 5.0439 & TST \\
\hline CHEMBL1569541 & 688816 & 4.9 & 4.9249 & TRN \\
\hline CHEMBL1477075 & 688816 & 4.7 & 4.8909 & TRN \\
\hline CHEMBL1487899 & 688816 & 6.05 & 5.7873 & TST \\
\hline CHEMBL1322508 & 688816 & 8.0506 & 5.4507 & TRN \\
\hline CHEMBL1492403 & 688816 & 4.7 & 5.1248 & TST \\
\hline CHEMBL1324947 & 688816 & 4.9 & 4.8181 & TRN \\
\hline CHEMBL1424094 & 688816 & 6.15 & 5.4081 & TRN \\
\hline CHEMBL1308147 & 688816 & 4.95 & 5.2577 & TRN \\
\hline CHEMBL1554058 & 688816 & 4.9 & 4.5665 & TRN \\
\hline
\end{tabular}




\begin{tabular}{|c|c|c|c|c|c|}
\hline \multicolumn{6}{|c|}{ Supplemental Table S2.txt } \\
\hline CHEMBL1429632 & 688816 & 4.9 & 5.2143 & TST & \\
\hline CHEMBL1364965 & 688816 & 5.25 & 5.36299 & 99999999995 & TST \\
\hline CHEMBL1214410 & 688816 & 4.85 & 5.2265 & TRN & \\
\hline CHEMBL452409 & 688816 & 4.9 & 5.1869 & TRN & \\
\hline CHEMBL1421715 & 688816 & 5.0 & 5.4998 & TRN & \\
\hline CHEMBL1337494 & 688816 & 8.0 & 5.5778 & TST & \\
\hline CHEMBL1412052 & 688816 & 4.95 & 5.0105 & TRN & \\
\hline CHEMBL1492594 & 688816 & 5.6 & 5.106 & TRN & \\
\hline CHEMBL543876 & 688816 & 4.85 & 5.4216 & TRN & \\
\hline CHEMBL3210494 & 688816 & 5.0 & 5.211 & TST & \\
\hline CHEMBL1544907 & 688816 & 5.8 & 4.9812 & TRN & \\
\hline CHEMBL1528425 & 688816 & 4.45 & 5.0501 & TRN & \\
\hline CHEMBL1572967 & 688816 & 4.65 & 5.188 & TRN & \\
\hline CHEMBL1527600 & 688816 & 4.7 & 5.4883 & TRN & \\
\hline CHEMBL1340314 & 688816 & 5.0 & 5.2683 & TST & \\
\hline CHEMBL1553592 & 688816 & 5.05 & 5.654 & TST & \\
\hline CHEMBL1542330 & 688816 & 4.6 & 5.1111 & TRN & \\
\hline CHEMBL1464223 & 688816 & 4.55 & 5.3232 & TRN & \\
\hline CHEMBL1596095 & 688816 & 5.0 & 5.1741 & TRN & \\
\hline CHEMBL1449640 & 688816 & 4.65 & 5.3062 & TRN & \\
\hline CHEMBL1480202 & 688816 & 4.9 & 5.1324 & TRN & \\
\hline CHEMBL1341969 & 688816 & 5.25 & 5.57600 & 00000000005 & TRN \\
\hline CHEMBL1526738 & 688816 & 5.55 & 5.285 & TRN & \\
\hline CHEMBL1387008 & 688816 & 5.0 & 5.2647 & TRN & \\
\hline CHEMBL1596241 & 688816 & 5.0 & 4.6304 & TRN & \\
\hline CHEMBL1414781 & 688816 & 5.65 & 5.2567 & TRN & \\
\hline CHEMBL566531 & 688816 & 4.45 & 5.1871 & TRN & \\
\hline CHEMBL1359188 & 688816 & 4.5 & 5.2674 & TRN & \\
\hline CHEMBL1330130 & 688816 & 4.6 & 5.6003 & TRN & \\
\hline CHEMBL1426934 & 688816 & 4.45 & 5.0413 & TRN & \\
\hline CHEMBL3189207 & 688816 & 4.95 & 5.0244 & TST & \\
\hline CHEMBL1452852 & 688816 & 4.9 & 4.8574 & TRN & \\
\hline CHEMBL3198775 & 688816 & 5.9 & 5.42200 & 2000000001 & TRN \\
\hline CHEMBL3197817 & 688816 & 5.2 & 5.5203 & TST & \\
\hline CHEMBL1559439 & 688816 & 4.7 & 5.3039 & TRN & \\
\hline CHEMBL1486463 & 688816 & 5.55 & 5.7706 & TRN & \\
\hline CHEMBL1359521 & 688816 & 6.05 & 5.4213 & TRN & \\
\hline CHEMBL3195647 & 688816 & 5.0 & 5.2813 & TRN & \\
\hline CHEMBL1326475 & 688816 & 5.0 & 4.9937 & TRN & \\
\hline CHEMBL1461302 & 688816 & 5.0 & 5.2411 & TRN & \\
\hline CHEMBL1392231 & 688816 & 4.75 & 4.9996 & TRN & \\
\hline CHEMBL1495194 & 688816 & 4.7 & 4.9997 & TRN & \\
\hline CHEMBL3195827 & 688816 & 4.85 & 5.1463 & TRN & \\
\hline CHEMBL1452378 & 688816 & 7.3002 & 5.8199 & TST & \\
\hline CHEMBL1508457 & 688816 & 6.15 & 5.0832 & TRN & \\
\hline CHEMBL1461353 & 688816 & 4.95 & 5.2894 & TRN & \\
\hline CHEMBL1460705 & 688816 & 6.0 & 4.7826 & TRN & \\
\hline CHEMBL1407484 & 688816 & 4.95 & 4.9628 & TST & \\
\hline
\end{tabular}




\begin{tabular}{|c|c|c|c|c|c|}
\hline \multicolumn{6}{|c|}{ Supplemental Table s2.txt } \\
\hline CHEMBL1371686 & 688816 & 4.95 & 5.7407 & TRN & \\
\hline CHEMBL1335130 & 688816 & 4.95 & 5.0803 & TRN & \\
\hline CHEMBL1524150 & 688816 & 5.35 & 5.5236 & TRN & \\
\hline CHEMBL1342495 & 688816 & 4.95 & 5.3699 & TST & \\
\hline CHEMBL1606995 & 688816 & 4.95 & 5.3228 & TST & \\
\hline CHEMBL1457397 & 688816 & 4.45 & 5.7202 & TRN & \\
\hline CHEMBL1373698 & 688816 & 4.65 & 5.3855 & TST & \\
\hline CHEMBL1463766 & 688816 & 6.15 & 5.20299 & 9999999999 & TRN \\
\hline CHEMBL1313243 & 688816 & 5.15 & 5.2175 & TST & \\
\hline CHEMBL1304553 & 688816 & 4.9 & 4.9788 & TRN & \\
\hline CHEMBL1536605 & 688816 & 4.45 & 5.3682 & TRN & \\
\hline CHEMBL1496372 & 688816 & 6.6 & 5.2953 & TRN & \\
\hline CHEMBL3212830 & 688816 & 5.4 & 5.2956 & TRN & \\
\hline CHEMBL1316216 & 688816 & 5.1 & 4.9945 & TRN & \\
\hline CHEMBL1519696 & 688816 & 4.95 & 4.7932 & TRN & \\
\hline CHEMBL1422559 & 688816 & 5.4 & 5.6603 & TST & \\
\hline CHEMBL1523164 & 688816 & 4.75 & 5.13 & TRN & \\
\hline CHEMBL1332130 & 688816 & 5.05 & 5.5097 & TRN & \\
\hline CHEMBL 2000888 & 688816 & 6.5501 & 5.5333 & TST & \\
\hline CHEMBL1582789 & 688816 & 6.35 & 5.7377 & TRN & \\
\hline CHEMBL1442043 & 688816 & 5.0 & 5.2229 & TRN & \\
\hline CHEMBL1393857 & 688816 & 4.95 & 5.3907 & TRN & \\
\hline CHEMBL1530735 & 688816 & 4.9 & 5.3238 & TRN & \\
\hline CHEMBL1524206 & 688816 & 5.4 & 5.1937 & TRN & \\
\hline CHEMBL3194766 & 688816 & 6.35 & 5.0699 & TRN & \\
\hline CHEMBL1509160 & 688816 & 4.8 & 4.8846 & TRN & \\
\hline CHEMBL1596244 & 688816 & 4.65 & 5.33899 & 99999999995 & TRN \\
\hline CHEMBL1355340 & 688816 & 5.25 & 5.5679 & TRN & \\
\hline CHEMBL1582519 & 688816 & 4.8 & 5.3231 & TRN & \\
\hline CHEMBL1410518 & 688816 & 6.7001 & 5.5772 & TRN & \\
\hline CHEMBL500996 & 688816 & 4.5 & 5.8547 & TST & \\
\hline CHEMBL3209853 & 688816 & 4.8 & 5.0454 & TRN & \\
\hline CHEMBL1977078 & 688816 & 4.5 & 5.1194 & TRN & \\
\hline CHEMBL1301234 & 688816 & 4.95 & 5.3895 & TRN & \\
\hline CHEMBL1582900 & 688816 & 4.9 & 5.4532 & TRN & \\
\hline CHEMBL1312658 & 688816 & 4.95 & 5.2975 & TST & \\
\hline CHEMBL1540905 & 688816 & 4.45 & 4.9666 & TST & \\
\hline CHEMBL1306407 & 688816 & 4.6 & 5.519 & TRN & \\
\hline CHEMBL1364848 & 688816 & 4.45 & 5.1309 & TST & \\
\hline CHEMBL1489641 & 688816 & 5.85 & 5.2577 & TRN & \\
\hline CHEMBL1455913 & 688816 & 4.45 & 5.114 & TRN & \\
\hline CHEMBL1608078 & 688816 & 4.8 & 5.2444 & TST & \\
\hline CHEMBL1577491 & 688816 & 4.95 & 4.7926 & TRN & \\
\hline CHEMBL3213175 & 688816 & 4.65 & 5.1691 & TRN & \\
\hline CHEMBL1308224 & 688816 & 4.65 & 5.36799 & 9999999999 & TST \\
\hline CHEMBL1328375 & 688816 & 4.8 & 5.4431 & TRN & \\
\hline CHEMBL1565610 & 688816 & 5.0 & 5.4965 & TRN & \\
\hline CHEMBL1410689 & 688816 & 4.45 & 5.0526 & TRN & \\
\hline
\end{tabular}




\begin{tabular}{|c|c|c|c|c|c|}
\hline \multicolumn{6}{|c|}{ Supplemental Table S2.txt } \\
\hline CHEMBL1324312 & 688816 & 7.15 & 4.8386 & TRN & \\
\hline CHEMBL1406850 & 688816 & 4.45 & 5.6958 & TRN & \\
\hline CHEMBL 3191626 & 688816 & 4.9 & 5.225 & TRN & \\
\hline CHEMBL1586847 & 688816 & 4.45 & 5.0175 & TRN & \\
\hline CHEMBL1305967 & 688816 & 4.65 & 5.52 & TST & \\
\hline CHEMBL1377975 & 688816 & 5.9 & 5.6346 & TRN & \\
\hline CHEMBL1370549 & 688816 & 4.85 & 5.03600 & 00000000005 & TRN \\
\hline CHEMBL1463541 & 688816 & 5.1 & 4.9844 & TRN & \\
\hline CHEMBL1588856 & 688816 & 4.85 & 5.2265 & TRN & \\
\hline CHEMBL1338800 & 688816 & 5.3 & 5.1387 & TRN & \\
\hline CHEMBL1303735 & 688816 & 4.95 & 5.6195 & TRN & \\
\hline CHEMBL1568578 & 688816 & 4.85 & 5.1805 & TRN & \\
\hline CHEMBL1371355 & 688816 & 6.2 & 5.3666 & TST & \\
\hline CHEMBL1473218 & 688816 & 4.55 & 4.974 & TRN & \\
\hline CHEMBL3194726 & 688816 & 4.75 & 5.5065 & TRN & \\
\hline CHEMBL1590571 & 688816 & 4.6 & 5.1219 & TRN & \\
\hline CHEMBL571065 & 688816 & 5.95 & 5.4021 & TST & \\
\hline CHEMBL1456813 & 688816 & 6.45 & 5.2911 & TRN & \\
\hline CHEMBL1374662 & 688816 & 4.85 & 5.6431 & TST & \\
\hline CHEMBL1443246 & 688816 & 4.8 & 5.2579 & TRN & \\
\hline CHEMBL1339520 & 688816 & 4.45 & 4.8967 & TST & \\
\hline CHEMBL1392447 & 688816 & 5.05 & 5.3393 & TST & \\
\hline CHEMBL1498011 & 688816 & 5.8 & 5.3521 & TRN & \\
\hline CHEMBL1507036 & 688816 & 7.699 & 5.6317 & TRN & \\
\hline CHEMBL1453236 & 688816 & 4.95 & 5.1169 & TRN & \\
\hline CHEMBL1459189 & 688816 & 4.75 & 4.9481 & TRN & \\
\hline CHEMBL3195228 & 688816 & 4.7 & 5.3141 & TRN & \\
\hline CHEMBL1430260 & 688816 & 4.75 & 4.9814 & TRN & \\
\hline CHEMBL1526056 & 688816 & 4.95 & 5.1151 & TRN & \\
\hline CHEMBL 3214157 & 688816 & 6.5 & 5.2559 & TST & \\
\hline CHEMBL1412556 & 688816 & 5.0 & 5.2084 & TRN & \\
\hline CHEMBL1395466 & 688816 & 4.85 & 4.8791 & TRN & \\
\hline CHEMBL1370175 & 688816 & 5.0 & 5.1625 & TST & \\
\hline CHEMBL1401841 & 688816 & 4.7 & 5.2597 & TST & \\
\hline CHEMBL1363032 & 688816 & 4.95 & 4.9984 & TRN & \\
\hline CHEMBL1461612 & 688816 & 4.45 & 5.4119 & TST & \\
\hline CHEMBL1599897 & 688816 & 5.1 & 5.2077 & TRN & \\
\hline CHEMBL1392206 & 688816 & 6.6 & 5.4293 & TRN & \\
\hline CHEMBL1580548 & 688816 & 4.95 & 5.2451 & TRN & \\
\hline CHEMBL1481837 & 688816 & 5.5 & 5.4646 & TRN & \\
\hline CHEMBL1490621 & 688816 & 4.9 & 5.4478 & TRN & \\
\hline CHEMBL1374298 & 688816 & 4.45 & 5.1673 & TRN & \\
\hline CHEMBL1389625 & 688816 & 6.7501 & 5.027 & TST & \\
\hline CHEMBL1420924 & 688816 & 4.45 & 5.0671 & TRN & \\
\hline CHEMBL1431097 & 688816 & 4.45 & 5.4628 & TST & \\
\hline CHEMBL1565996 & 688816 & 7.699 & 5.6367 & TST & \\
\hline CHEMBL 1548474 & 688816 & 5.2 & 5.6059 & TRN & \\
\hline CHEMBL1338375 & 688816 & 5.5 & 5.4145 & TRN & \\
\hline
\end{tabular}




\begin{tabular}{|c|c|c|c|c|c|}
\hline & & & & & \\
\hline CHEMBL1544272 & 688816 & 4.7 & 5.1774 & TRN & \\
\hline CHEMBL1341996 & 688816 & 4.8 & 4.9963 & TRN & \\
\hline CHEMBL3189835 & 688816 & 4.45 & 5.4567 & TST & \\
\hline CHEMBL1589029 & 688816 & 4.95 & \multicolumn{2}{|c|}{4.986000000000001} & TRN \\
\hline CHEMBL1309509 & 688816 & 4.7 & 5.4883 & TRN & \\
\hline CHEMBL1558956 & 688816 & 4.45 & 5.2565 & TRN & \\
\hline CHEMBL1312299 & 688816 & 4.9 & 4.9471 & TRN & \\
\hline CHEMBL346258 & 688816 & 5.3 & 5.3994 & TRN & \\
\hline CHEMBL3192210 & 688816 & 5.0 & 5.5807 & TRN & \\
\hline CHEMBL1558198 & 688816 & 4.75 & 5.3937 & TRN & \\
\hline CHEMBL3212533 & 688816 & 4.65 & 5.261 & TRN & \\
\hline CHEMBL1546458 & 688816 & 4.95 & 5.274 & TRN & \\
\hline CHEMBL1596653 & 688816 & 5.0 & 5.4097 & TST & \\
\hline CHEMBL1520559 & 688816 & 4.9 & 5.0831 & TRN & \\
\hline CHEMBL1585185 & 688816 & 4.95 & 5.0348 & TRN & \\
\hline CHEMBL1523894 & 688816 & 4.6 & 5.3746 & TST & \\
\hline CHEMBL1301164 & 688816 & 4.95 & 5.0448 & TST & \\
\hline CHEMBL1314202 & 688816 & 4.95 & 5.0046 & TRN & \\
\hline CHEMBL1489874 & 688816 & 6.8499 & 5.0156 & TRN & \\
\hline CHEMBL1518223 & 688816 & 5.55 & 4.904 & TRN & \\
\hline CHEMBL1451664 & 688816 & 4.9 & 5.1886 & TRN & \\
\hline CHEMBL1606371 & 688816 & 5.0 & \multicolumn{2}{|c|}{5.207000000000001} & TRN \\
\hline CHEMBL1340224 & 688816 & 7.5498 & 5.846 & TST & \\
\hline CHEMBL1406297 & 688816 & 4.45 & \multicolumn{2}{|c|}{5.1610000000000005} & TRN \\
\hline CHEMBL1612720 & 688816 & 4.95 & 4.9801 & TRN & \\
\hline CHEMBL1443119 & 688816 & 4.75 & 5.4655 & TRN & \\
\hline CHEMBL1477336 & 688816 & 4.45 & 5.1631 & TST & \\
\hline CHEMBL1450672 & 688816 & 4.45 & 5.5116 & TRN & \\
\hline CHEMBL1527714 & 688816 & 4.9 & 5.558 & TRN & \\
\hline CHEMBL 3214510 & 688816 & 4.95 & 4.9504 & TRN & \\
\hline CHEMBL1304283 & 688816 & 5.35 & 5.1125 & TRN & \\
\hline CHEMBL1606829 & 688816 & 8.3468 & 5.3829 & TST & \\
\hline CHEMBL1557564 & 688816 & 5.15 & 5.2847 & TRN & \\
\hline CHEMBL1585527 & 688816 & 4.7 & 5.1004 & TRN & \\
\hline CHEMBL1485362 & 688816 & 4.45 & 5.2163 & TRN & \\
\hline CHEMBL1408861 & 688816 & 4.95 & 4.9884 & TRN & \\
\hline CHEMBL1322748 & 688816 & 5.2 & 5.4556 & TRN & \\
\hline CHEMBL1577882 & 688816 & 5.0 & 5.5913 & TRN & \\
\hline CHEMBL1337288 & 688816 & 4.95 & 4.7413 & TRN & \\
\hline CHEMBL1557815 & 688816 & 6.15 & 5.4458 & TRN & \\
\hline CHEMBL1342080 & 688816 & 4.85 & 5.2307 & TST & \\
\hline CHEMBL1413222 & 688816 & 5.55 & 5.1197 & TRN & \\
\hline CHEMBL1453996 & 688816 & 5.8 & 5.2217 & TRN & \\
\hline CHEMBL1531634 & 688816 & 4.9 & 5.0898 & TRN & \\
\hline CHEMBL1565636 & 688816 & 5.9 & 5.416 & TRN & \\
\hline CHEMBL1559500 & 688816 & 5.5 & 5.2316 & TRN & \\
\hline CHEMBL1480179 & 688816 & 5.35 & 5.0756 & TST & \\
\hline \multirow[t]{2}{*}{ CHEMBL1373730 } & 688816 & 6.4 & \multicolumn{2}{|c|}{5.5120000000000005} & TST \\
\hline & & & & 24875 & \\
\hline
\end{tabular}




\begin{tabular}{|c|c|c|c|c|c|}
\hline \multicolumn{6}{|c|}{ Supplemental Table S2.txt } \\
\hline CHEMBL1409618 & 688816 & 4.6 & 5.0941 & TRN & \\
\hline CHEMBL1360484 & 688816 & 4.95 & 5.4012 & TRN & \\
\hline CHEMBL1389904 & 688816 & 4.45 & 5.3048 & TRN & \\
\hline CHEMBL1317461 & 688816 & 5.05 & 5.0468 & TRN & \\
\hline CHEMBL1471592 & 688816 & 4.9 & 5.4624 & TRN & \\
\hline CHEMBL1392136 & 688816 & 5.0 & 5.3499 & TRN & \\
\hline CHEMBL1333761 & 688816 & 4.45 & 5.2333 & TST & \\
\hline CHEMBL1470144 & 688816 & 6.6 & 5.2566 & TST & \\
\hline CHEMBL1355328 & 688816 & 4.5 & 5.0507 & TRN & \\
\hline CHEMBL1585251 & 688816 & 5.3 & 5.1879 & TST & \\
\hline CHEMBL 3190496 & 688816 & 8.3468 & 5.3643 & TST & \\
\hline CHEMBL1565955 & 688816 & 4.85 & 5.0151 & TRN & \\
\hline CHEMBL1553014 & 688816 & 5.05 & 5.0244 & TRN & \\
\hline CHEMBL1319504 & 688816 & 4.9 & 5.3347 & TRN & \\
\hline CHEMBL1469503 & 688816 & 6.6499 & 5.2551 & TST & \\
\hline CHEMBL1308604 & 688816 & 4.45 & 5.3377 & TRN & \\
\hline CHEMBL1775009 & 688816 & 5.45 & 5.495 & TRN & \\
\hline CHEMBL1361160 & 688816 & 6.25 & 5.316 & TST & \\
\hline CHEMBL1440819 & 688816 & 5.5 & 5.4838 & TRN & \\
\hline CHEMBL1350019 & 688816 & 4.8 & 5.0344 & TRN & \\
\hline CHEMBL1341895 & 688816 & 4.7 & 5.0385 & TRN & \\
\hline CHEMBL1416854 & 688816 & 4.45 & 5.3309 & TRN & \\
\hline CHEMBL1574106 & 688816 & 4.95 & 5.0664 & TRN & \\
\hline CHEMBL 3214479 & 688816 & 5.5 & 5.8457 & TST & \\
\hline CHEMBL1446909 & 688816 & 4.85 & 4.8284 & TRN & \\
\hline CHEMBL1311499 & 688816 & 5.95 & 5.3402 & TRN & \\
\hline CHEMBL1381534 & 688816 & 5.25 & 5.6343 & TST & \\
\hline CHEMBL1322336 & 688816 & 4.75 & 5.2004 & TRN & \\
\hline CHEMBL1600575 & 688816 & 4.45 & 5.4945 & TRN & \\
\hline CHEMBL1494936 & 688816 & 4.95 & 5.1747 & TRN & \\
\hline CHEMBL1547434 & 688816 & 4.9 & 5.1661 & TRN & \\
\hline CHEMBL1345010 & 688816 & 8.0 & 5.5285 & TRN & \\
\hline CHEMBL1256686 & 688816 & 6.0 & 5.1539 & TST & \\
\hline CHEMBL1403442 & 688816 & 5.75 & 4.8149 & TST & \\
\hline CHEMBL1442299 & 688816 & 4.9 & 5.1659 & TRN & \\
\hline CHEMBL1545329 & 688816 & 7.5498 & 5.5898 & TST & \\
\hline CHEMBL1582010 & 688816 & 4.95 & 5.28799 & 9999999999 & TRN \\
\hline CHEMBL1325876 & 688816 & 4.55 & 5.5381 & TST & \\
\hline CHEMBL1301967 & 688816 & 4.85 & 5.1813 & TRN & \\
\hline CHEMBL1546948 & 688816 & 8.4559 & 5.53100 & 0000000001 & TRN \\
\hline CHEMBL1503536 & 688816 & 6.25 & 5.5842 & TRN & \\
\hline CHEMBL1382728 & 688816 & 5.2 & 5.4542 & TST & \\
\hline CHEMBL1354013 & 688816 & 5.5 & 5.6576 & TRN & \\
\hline CHEMBL1523960 & 688816 & 4.9 & 5.0944 & TRN & \\
\hline CHEMBL1359842 & 688816 & 5.65 & 5.3118 & TST & \\
\hline CHEMBL1466250 & 688816 & 4.45 & 5.0157 & TRN & \\
\hline CHEMBL1409943 & 688816 & 4.9 & 5.3707 & TST & \\
\hline CHEMBL1302403 & 688816 & 4.45 & 5.5684 & TST & \\
\hline
\end{tabular}




\begin{tabular}{|c|c|c|c|c|c|}
\hline \multirow[b]{2}{*}{ CHEMBL3212775 } & \multicolumn{5}{|c|}{ Supplemental Table S2.txt } \\
\hline & 688816 & 4.45 & 5.4167 & TST & \\
\hline CHEMBL1484081 & 688816 & 4.7 & 4.80399 & 9999999999 & TRN \\
\hline CHEMBL1442570 & 688816 & 4.9 & 5.4643 & TRN & \\
\hline CHEMBL1368552 & 688816 & 4.8 & 5.1921 & TST & \\
\hline CHEMBL1524664 & 688816 & 4.95 & 5.6258 & TRN & \\
\hline CHEMBL1347390 & 688816 & 4.85 & 5.227 & TST & \\
\hline CHEMBL1603489 & 688816 & 5.4 & 5.7216 & TST & \\
\hline CHEMBL1556484 & 688816 & 4.45 & 5.4864 & TRN & \\
\hline CHEMBL1336558 & 688816 & 8.3468 & 5.3033 & TRN & \\
\hline CHEMBL1398137 & 688816 & 5.0 & 4.9467 & TRN & \\
\hline CHEMBL1488918 & 688816 & 4.95 & 4.9648 & TRN & \\
\hline CHEMBL601385 & 688816 & 4.85 & 4.9672 & TST & \\
\hline CHEMBL1578699 & 688816 & 6.15 & 5.3663 & TRN & \\
\hline CHEMBL1529334 & 688816 & 4.95 & 5.461 & TRN & \\
\hline CHEMBL 1457149 & 688816 & 5.55 & 5.0062 & TRN & \\
\hline CHEMBL1494069 & 688816 & 5.0 & 5.349 & TRN & \\
\hline CHEMBL1521301 & 688816 & 4.85 & 5.1104 & TRN & \\
\hline CHEMBL1534239 & 688816 & 4.95 & 5.2845 & TST & \\
\hline CHEMBL1487947 & 688816 & 4.95 & 4.9577 & TRN & \\
\hline CHEMBL1370512 & 688816 & 4.9 & 5.0521 & TRN & \\
\hline CHEMBL1589567 & 688816 & 4.85 & 4.9925 & TRN & \\
\hline CHEMBL1455127 & 688816 & 4.7 & 5.2742 & TRN & \\
\hline CHEMBL1607638 & 688816 & 4.6 & 5.0407 & TRN & \\
\hline CHEMBL1441412 & 688816 & 6.8499 & 5.729 & TRN & \\
\hline CHEMBL1372785 & 688816 & 5.2 & 5.1251 & TRN & \\
\hline CHEMBL1344937 & 688816 & 4.5 & 5.2344 & TRN & \\
\hline CHEMBL1367526 & 688816 & 4.45 & 5.3011 & TST & \\
\hline CHEMBL1512257 & 688816 & 4.95 & 5.1924 & TRN & \\
\hline CHEMBL1517852 & 688816 & 5.45 & 4.9712 & TRN & \\
\hline CHEMBL1426394 & 688816 & 5.3 & 5.2194 & TRN & \\
\hline CHEMBL1389953 & 688816 & 4.55 & 5.3072 & TRN & \\
\hline CHEMBL1500773 & 688816 & 4.65 & 5.0114 & TRN & \\
\hline CHEMBL1358205 & 688816 & 4.95 & 5.3795 & TRN & \\
\hline CHEMBL1342739 & 688816 & 5.5 & 5.4082 & TRN & \\
\hline CHEMBL1986151 & 688816 & 4.55 & 5.1569 & TRN & \\
\hline CHEMBL1583697 & 688816 & 4.9 & 5.0056 & TRN & \\
\hline CHEMBL1536591 & 688816 & 5.0 & 5.3429 & TRN & \\
\hline CHEMBL1430096 & 688816 & 6.7001 & 5.6985 & TRN & \\
\hline CHEMBL1409441 & 688816 & 4.45 & 5.5293 & TRN & \\
\hline CHEMBL1497445 & 688816 & 4.5 & 5.3179 & TST & \\
\hline CHEMBL1497305 & 688816 & 4.9 & 5.0259 & TRN & \\
\hline CHEMBL1479727 & 688816 & 4.7 & 5.1621 & TST & \\
\hline CHEMBL1371081 & 688816 & 4.9 & 5.2629 & TRN & \\
\hline CHEMBL1533799 & 688816 & 4.8 & 5.3413 & TRN & \\
\hline CHEMBL1384153 & 688816 & 4.9 & 5.117 & TRN & \\
\hline CHEMBL1399806 & 688816 & 5.85 & 4.7301 & TRN & \\
\hline CHEMBL1390453 & 688816 & 4.45 & 5.2005 & TST & \\
\hline CHEMBL1481424 & 688816 & 4.45 & 5.3301 & TRN & \\
\hline
\end{tabular}




\begin{tabular}{|c|c|c|c|c|c|}
\hline \multicolumn{6}{|c|}{ Supplemental Table s2.txt } \\
\hline CHEMBL1357326 & 688816 & 5.9 & 5.3416 & TRN & \\
\hline CHEMBL3197031 & 688816 & 4.8 & 5.0956 & TRN & \\
\hline CHEMBL1458921 & 688816 & 7.4001 & 5.6016 & TST & \\
\hline CHEMBL1335333 & 688816 & 4.65 & 5.3447 & TRN & \\
\hline CHEMBL1509671 & 688816 & 4.85 & 5.3907 & TST & \\
\hline CHEMBL1522373 & 688816 & 4.45 & 5.1835 & TRN & \\
\hline CHEMBL1577390 & 688816 & 4.7 & 5.2597 & TRN & \\
\hline CHEMBL 322970 & 688816 & 6.0 & 5.2062 & TST & \\
\hline CHEMBL1548099 & 688816 & 5.15 & 5.7348 & TRN & \\
\hline CHEMBL1594066 & 688816 & 4.85 & 4.944 & TST & \\
\hline CHEMBL1503002 & 688816 & 5.1 & 5.3698 & TRN & \\
\hline CHEMBL1497667 & 688816 & 4.45 & 5.5145 & TST & \\
\hline CHEMBL1381367 & 688816 & 4.8 & 5.2455 & TRN & \\
\hline CHEMBL1451065 & 688816 & 4.9 & 5.3747 & TST & \\
\hline CHEMBL1566163 & 688816 & 5.65 & 5.6352 & TST & \\
\hline CHEMBL1349329 & 688816 & 4.9 & 5.2017 & TRN & \\
\hline CHEMBL1376485 & 688816 & 5.3 & 4.9869 & TRN & \\
\hline CHEMBL1443852 & 688816 & 5.05 & 4.9795 & TRN & \\
\hline CHEMBL1418168 & 688816 & 4.55 & 5.268 & TST & \\
\hline CHEMBL1492096 & 688816 & 5.1 & 5.2483 & TRN & \\
\hline CHEMBL1469600 & 688816 & 4.65 & 5.034 & TST & \\
\hline CHEMBL1352637 & 688816 & 4.45 & 5.5311 & TRN & \\
\hline CHEMBL1469929 & 688816 & 4.95 & 5.3026 & TRN & \\
\hline CHEMBL1607304 & 688816 & 5.15 & 5.13700 & 00000000005 & TRN \\
\hline CHEMBL1517226 & 688816 & 5.0 & 5.5592 & TST & \\
\hline CHEMBL1447302 & 688816 & 6.05 & 5.3231 & TRN & \\
\hline CHEMBL1571270 & 688816 & 4.75 & 5.3421 & TST & \\
\hline CHEMBL1576867 & 688816 & 4.65 & 5.1575 & TRN & \\
\hline CHEMBL1523026 & 688816 & 4.9 & 5.4191 & TRN & \\
\hline CHEMBL 1501748 & 688816 & 4.45 & 4.9046 & TRN & \\
\hline CHEMBL1568572 & 688816 & 4.45 & 4.9593 & TRN & \\
\hline CHEMBL1532299 & 688816 & 4.45 & 4.7308 & TRN & \\
\hline CHEMBL1459083 & 688816 & 4.65 & 5.2172 & TST & \\
\hline CHEMBL1550401 & 688816 & 4.45 & 5.7388 & TRN & \\
\hline CHEMBL1446886 & 688816 & 4.45 & 5.4558 & TRN & \\
\hline CHEMBL1306270 & 688816 & 7.5003 & 5.4906 & TRN & \\
\hline CHEMBL1493139 & 688816 & 4.45 & 5.183 & TRN & \\
\hline CHEMBL1346112 & 688816 & 4.65 & 4.8954 & TRN & \\
\hline CHEMBL1419786 & 688816 & 4.85 & 5.1745 & TST & \\
\hline CHEMBL1375064 & 688816 & 4.95 & 5.5908 & TRN & \\
\hline CHEMBL1319255 & 688816 & 6.6499 & 5.5378 & TRN & \\
\hline CHEMBL1584594 & 688816 & 4.9 & 4.8646 & TRN & \\
\hline CHEMBL1466481 & 688816 & 4.8 & 5.151 & TRN & \\
\hline CHEMBL1543820 & 688816 & 4.9 & 5.3304 & TRN & \\
\hline CHEMBL1476953 & 688816 & 4.7 & 4.8865 & TRN & \\
\hline CHEMBL1495905 & 688816 & 4.85 & 4.9957 & TRN & \\
\hline CHEMBL 3212690 & 688816 & 4.5 & 5.5087 & TST & \\
\hline CHEMBL 3145049 & 688816 & 4.75 & 5.0283 & TST & \\
\hline
\end{tabular}




\begin{tabular}{|c|c|c|c|c|}
\hline \multicolumn{5}{|c|}{ Supplemental Table S2.txt } \\
\hline CHEMBL1382518 & 688816 & 4.45 & 4.8733 & TRN \\
\hline CHEMBL1348406 & 688816 & 5.4 & 5.1899 & TRN \\
\hline CHEMBL1606721 & 688816 & 5.75 & 5.6329 & TST \\
\hline CHEMBL1538921 & 688816 & 8.3979 & 5.4604 & TST \\
\hline CHEMBL1392702 & 688816 & 4.45 & 5.1144 & TRN \\
\hline CHEMBL1424900 & 688816 & 4.95 & 5.1429 & TRN \\
\hline CHEMBL1511795 & 688816 & 4.6 & 5.5034 & TRN \\
\hline CHEMBL1301630 & 688816 & 4.9 & 5.1265 & TRN \\
\hline CHEMBL1313116 & 688816 & 4.9 & 5.1118 & TRN \\
\hline CHEMBL1485681 & 688816 & 6.4 & 5.5116 & TRN \\
\hline CHEMBL1526810 & 688816 & 4.9 & 5.0317 & TRN \\
\hline CHEMBL1605612 & 688816 & 5.75 & 5.2415 & TST \\
\hline CHEMBL1531778 & 688816 & 4.75 & 4.9382 & TRN \\
\hline CHEMBL1313882 & 688816 & 5.6 & 5.5606 & TRN \\
\hline CHEMBL1376941 & 688816 & 7.9508 & 5.2589 & TST \\
\hline CHEMBL3198031 & 688816 & 4.6 & 5.2055 & TRN \\
\hline CHEMBL1393172 & 688816 & 4.45 & 4.953 & TRN \\
\hline CHEMBL1499839 & 688816 & 4.95 & 5.0486 & TST \\
\hline CHEMBL1607134 & 688816 & 8.3468 & 5.3614 & TST \\
\hline CHEMBL1448548 & 688816 & 4.95 & 5.4506 & TRN \\
\hline CHEMBL1477215 & 688816 & 5.5 & 5.345 & TRN \\
\hline CHEMBL1393266 & 688816 & 4.95 & 5.1774 & TRN \\
\hline CHEMBL1574087 & 688816 & 8.0506 & 5.6897 & TRN \\
\hline CHEMBL1409287 & 688816 & 4.6 & 5.4089 & TRN \\
\hline CHEMBL1525425 & 688816 & 4.95 & 5.3618 & TRN \\
\hline CHEMBL1334189 & 688816 & 4.8 & 4.9322 & TRN \\
\hline CHEMBL1469144 & 688816 & 4.45 & 5.0462 & TRN \\
\hline CHEMBL1404000 & 688816 & 8.3468 & 5.6353 & TST \\
\hline CHEMBL1587127 & 688816 & 7.699 & 5.4079 & TRN \\
\hline CHEMBL1307014 & 688816 & 5.25 & 5.4956 & TRN \\
\hline CHEMBL1433240 & 688816 & 8.301 & 5.3942 & TST \\
\hline CHEMBL1367788 & 688816 & 4.45 & 5.039 & TRN \\
\hline CHEMBL1393408 & 688816 & 4.45 & 5.6359 & TRN \\
\hline CHEMBL1337569 & 688816 & 4.45 & 5.1825 & TRN \\
\hline CHEMBL1518412 & 688816 & 5.15 & 5.3477 & TRN \\
\hline CHEMBL1577865 & 688816 & 7.0501 & 5.2594 & TRN \\
\hline CHEMBL1437902 & 688816 & 6.0 & 5.7244 & TST \\
\hline CHEMBL1439231 & 688816 & 6.5501 & 5.4556 & TRN \\
\hline CHEMBL1593699 & 688816 & 4.95 & 4.9764 & TRN \\
\hline CHEMBL3198499 & 688816 & 4.45 & 5.3215 & TRN \\
\hline CHEMBL1359739 & 688816 & 4.45 & 5.4742 & TRN \\
\hline CHEMBL1305292 & 688816 & 4.45 & 5.0599 & TRN \\
\hline CHEMBL1501550 & 688816 & 5.1 & 5.0205 & TRN \\
\hline CHEMBL1432416 & 688816 & 4.95 & 5.0245 & TRN \\
\hline CHEMBL1323781 & 688816 & 4.45 & 5.4464 & TRN \\
\hline CHEMBL1521860 & 688816 & 6.7501 & 5.0167 & TRN \\
\hline CHEMBL1440967 & 688816 & 4.7 & 5.3207 & TST \\
\hline CHEMBL1567897 & 688816 & 4.9 & 4.8739 & TRN \\
\hline
\end{tabular}




\begin{tabular}{|c|c|c|c|c|c|}
\hline \multicolumn{6}{|c|}{ Supplemental Table S2.txt } \\
\hline CHEMBL1532008 & 688816 & 4.45 & 5.0343 & TRN & \\
\hline CHEMBL1528947 & 688816 & 7.4001 & 5.6293 & TST & \\
\hline CHEMBL600976 & 688816 & 4.9 & 5.3177 & TRN & \\
\hline CHEMBL598903 & 688816 & 4.45 & 5.0824 & TRN & \\
\hline CHEMBL1548970 & 688816 & 5.0 & 4.6971 & TRN & \\
\hline CHEMBL1488141 & 688816 & 5.25 & 5.2548 & TRN & \\
\hline CHEMBL1527616 & 688816 & 4.95 & 5.2456 & TST & \\
\hline CHEMBL1334638 & 688816 & 5.5 & 4.9536 & TRN & \\
\hline CHEMBL 3193297 & 688816 & 5.0 & 5.6787 & TST & \\
\hline CHEMBL1346932 & 688816 & 4.45 & 5.1421 & TRN & \\
\hline CHEMBL1348232 & 688816 & 4.85 & 5.3345 & TRN & \\
\hline CHEMBL1526659 & 688816 & 4.8 & 5.5866 & TST & \\
\hline CHEMBL1354521 & 688816 & 4.45 & 4.8883 & TRN & \\
\hline CHEMBL1346657 & 688816 & 6.7501 & 5.2389 & TST & \\
\hline CHEMBL1496925 & 688816 & 4.9 & 5.3783 & TST & \\
\hline CHEMBL1612860 & 688816 & 4.9 & 5.2274 & TST & \\
\hline CHEMBL1470009 & 688816 & 5.9 & 5.0225 & TST & \\
\hline CHEMBL1530426 & 688816 & 4.95 & 5.2542 & TST & \\
\hline CHEMBL1307737 & 688816 & 4.5 & 5.266 & TRN & \\
\hline CHEMBL1561017 & 688816 & 4.85 & 4.9639 & TRN & \\
\hline CHEMBL1489194 & 688816 & 4.9 & 5.1198 & TRN & \\
\hline CHEMBL1401648 & 688816 & 4.7 & 5.2281 & TRN & \\
\hline CHEMBL1461283 & 688816 & 4.45 & 5.1374 & TRN & \\
\hline CHEMBL1375009 & 688816 & 4.45 & 5.1655 & TST & \\
\hline CHEMBL1611515 & 688816 & 4.9 & 5.2392 & TRN & \\
\hline CHEMBL1347449 & 688816 & 4.65 & 5.2322 & TRN & \\
\hline CHEMBL1446805 & 688816 & 4.95 & 5.1045 & TRN & \\
\hline CHEMBL1570711 & 688816 & 4.65 & 5.1998 & TRN & \\
\hline CHEMBL1534042 & 688816 & 6.1 & 5.3232 & TRN & \\
\hline CHEMBL1301369 & 688816 & 5.8 & 5.36600 & 00000000005 & TRN \\
\hline CHEMBL1523293 & 688816 & 4.45 & 5.2397 & TRN & \\
\hline CHEMBL1488718 & 688816 & 5.35 & 5.2487 & TRN & \\
\hline CHEMBL1546629 & 688816 & 5.25 & 5.5152 & TRN & \\
\hline CHEMBL1611061 & 688816 & 4.85 & 5.0167 & TRN & \\
\hline CHEMBL1986111 & 688816 & 5.1 & 4.9251 & TRN & \\
\hline CHEMBL1524109 & 688816 & 4.9 & 5.1918 & TRN & \\
\hline CHEMBL1483910 & 688816 & 5.0 & 5.3737 & TRN & \\
\hline CHEMBL1466923 & 688816 & 5.2 & 5.1831 & TRN & \\
\hline CHEMBL3195389 & 688816 & 6.2 & 5.2796 & TRN & \\
\hline CHEMBL1359531 & 688816 & 6.8499 & 5.19799 & 99999999995 & TST \\
\hline CHEMBL1555137 & 688816 & 5.2 & 5.2568 & TRN & \\
\hline CHEMBL1562480 & 688816 & 4.8 & 4.8908 & TRN & \\
\hline CHEMBL1446012 & 688816 & 4.95 & 5.3151 & TRN & \\
\hline CHEMBL1385054 & 688816 & 5.45 & 5.4467 & TRN & \\
\hline CHEMBL 2004776 & 688816 & 5.0 & 5.3554 & TST & \\
\hline CHEMBL1991908 & 688816 & 8.4949 & 5.2132 & TRN & \\
\hline CHEMBL1439578 & 688816 & 6.05 & 5.3677 & TRN & \\
\hline CHEMBL1611341 & 688816 & 6.1 & 5.7149 & TST & \\
\hline
\end{tabular}




\begin{tabular}{|c|c|c|c|c|c|}
\hline \\
\hline CHEMBL1313576 & 688816 & 5.2 & 5.2904 & TST & \\
\hline CHEMBL3212098 & 688816 & 4.85 & 5.1965 & TRN & \\
\hline CHEMBL1532524 & 688816 & 4.95 & 5.3417 & TRN & \\
\hline CHEMBL1478675 & 688816 & 4.6 & 5.1545 & TRN & \\
\hline CHEMBL1342141 & 688816 & 5.0 & 5.1032 & TST & \\
\hline CHEMBL1589407 & 688816 & 4.95 & 5.3034 & TST & \\
\hline CHEMBL3191320 & 688816 & 4.45 & 5.0977 & TRN & \\
\hline CHEMBL1462936 & 688816 & 4.8 & 5.3598 & TRN & \\
\hline CHEMBL1565386 & 688816 & 4.9 & 5.4115 & TST & \\
\hline CHEMBL1341676 & 688816 & 4.45 & 4.9092 & TRN & \\
\hline CHEMBL1570773 & 688816 & 4.45 & 5.29700 & 0000000001 & TRN \\
\hline CHEMBL1505823 & 688816 & 4.7 & 5.1541 & TRN & \\
\hline CHEMBL1605855 & 688816 & 4.45 & 5.2711 & TRN & \\
\hline CHEMBL1466844 & 688816 & 5.2 & 4.9507 & TRN & \\
\hline CHEMBL1609851 & 688816 & 5.5 & 5.2267 & TRN & \\
\hline CHEMBL1416511 & 688816 & 4.45 & 5.5758 & TRN & \\
\hline CHEMBL1428950 & 688816 & 4.5 & 4.9806 & TRN & \\
\hline CHEMBL1361416 & 688816 & 5.1 & 5.7371 & TRN & \\
\hline CHEMBL1467405 & 688816 & 6.4 & 5.3665 & TRN & \\
\hline CHEMBL1529039 & 688816 & 4.95 & 5.0959 & TRN & \\
\hline CHEMBL1312443 & 688816 & 4.85 & 5.2517 & TRN & \\
\hline CHEMBL1600854 & 688816 & 5.1 & 5.3899 & TRN & \\
\hline CHEMBL1362687 & 688816 & 4.45 & 4.8431 & TST & \\
\hline CHEMBL1548843 & 688816 & 4.75 & 5.4078 & TST & \\
\hline CHEMBL1537508 & 688816 & 4.8 & 5.409 & TRN & \\
\hline CHEMBL1505299 & 688816 & 4.55 & 5.2285 & TRN & \\
\hline CHEMBL1400845 & 688816 & 4.45 & 5.5504 & TRN & \\
\hline CHEMBL1516879 & 688816 & 5.85 & 5.2499 & TRN & \\
\hline CHEMBL1301555 & 688816 & 4.85 & 5.526 & TST & \\
\hline CHEMBL1392667 & 688816 & 5.1 & 5.6501 & TRN & \\
\hline CHEMBL1379173 & 688816 & 4.7 & 4.9964 & TRN & \\
\hline CHEMBL3190314 & 688816 & 5.35 & 5.2923 & TRN & \\
\hline CHEMBL1422422 & 688816 & 6.5501 & 5.41799 & 9999999999 & TRN \\
\hline CHEMBL1423346 & 688816 & 5.6 & 5.5182 & TRN & \\
\hline CHEMBL1481444 & 688816 & 4.45 & 4.8256 & TRN & \\
\hline CHEMBL1349200 & 688816 & 5.7 & 5.3467 & TST & \\
\hline CHEMBL1499408 & 688816 & 5.25 & 5.5688 & TRN & \\
\hline CHEMBL1458453 & 688816 & 4.6 & 5.2694 & TRN & \\
\hline CHEMBL1387564 & 688816 & 4.95 & 5.3862 & TRN & \\
\hline CHEMBL1504120 & 688816 & 5.2 & 5.5618 & TRN & \\
\hline CHEMBL1457636 & 688816 & 5.0 & 5.25299 & 9999999999 & TRN \\
\hline CHEMBL1451563 & 688816 & 8.5528 & 5.1863 & TRN & \\
\hline CHEMBL1425987 & 688816 & 5.2 & 4.935 & TRN & \\
\hline CHEMBL1565563 & 688816 & 5.05 & 4.7206 & TRN & \\
\hline CHEMBL1469054 & 688816 & 4.9 & 5.106 & TST & \\
\hline CHEMBL1335863 & 688816 & 5.45 & 5.1971 & TRN & \\
\hline CHEMBL1331090 & 688816 & 5.35 & 5.083 & TRN & \\
\hline CHEMBL1539956 & 688816 & 4.85 & 5.1996 & TRN & \\
\hline
\end{tabular}




\begin{tabular}{|c|c|c|c|c|c|}
\hline \multicolumn{6}{|c|}{ Supplemental Table S2.txt } \\
\hline CHEMBL1316314 & 688816 & 4.45 & 5.1721 & TST & \\
\hline CHEMBL1327458 & 688816 & 8.301 & 5.9597 & TRN & \\
\hline CHEMBL1367586 & 688816 & 4.8 & 5.4943 & TRN & \\
\hline CHEMBL1457388 & 688816 & 4.45 & 5.6412 & TRN & \\
\hline CHEMBL1528882 & 688816 & 4.95 & 5.1018 & TRN & \\
\hline CHEMBL1547386 & 688816 & 5.4 & 5.5006 & TRN & \\
\hline CHEMBL1570149 & 688816 & 4.9 & 5.3073 & TRN & \\
\hline CHEMBL3198899 & 688816 & 5.45 & 5.9498 & TRN & \\
\hline CHEMBL1389011 & 688816 & 5.4 & 5.3633 & TST & \\
\hline CHEMBL1436508 & 688816 & 4.9 & 5.1335 & TRN & \\
\hline CHEMBL1364405 & 688816 & 6.35 & 5.58899 & 99999999995 & TRN \\
\hline CHEMBL1408368 & 688816 & 4.65 & 5.3255 & TST & \\
\hline CHEMBL1339798 & 688816 & 5.65 & 5.1768 & TRN & \\
\hline CHEMBL1402151 & 688816 & 8.301 & 5.7834 & TST & \\
\hline CHEMBL1353353 & 688816 & 4.75 & 5.5167 & TRN & \\
\hline CHEMBL1488494 & 688816 & 4.8 & 5.2611 & TRN & \\
\hline CHEMBL1896260 & 688816 & 4.8 & 5.341 & TRN & \\
\hline CHEMBL1578487 & 688816 & 5.35 & 5.2237 & TRN & \\
\hline CHEMBL1450652 & 688816 & 4.45 & 4.8069 & TRN & \\
\hline CHEMBL3189512 & 688816 & 5.45 & 5.3086 & TST & \\
\hline CHEMBL1422176 & 688816 & 4.65 & 5.0358 & TRN & \\
\hline CHEMBL1517699 & 688816 & 4.65 & 5.2475 & TST & \\
\hline CHEMBL1369358 & 688816 & 4.8 & 5.2931 & TST & \\
\hline CHEMBL3198303 & 688816 & 4.7 & 5.2099 & TRN & \\
\hline CHEMBL1599113 & 688816 & 4.85 & 5.2084 & TRN & \\
\hline CHEMBL1406951 & 688816 & 6.2 & 5.8765 & TRN & \\
\hline CHEMBL1577214 & 688816 & 7.0501 & 5.4791 & TST & \\
\hline CHEMBL 1603040 & 688816 & 6.4 & 5.0756 & TST & \\
\hline CHEMBL1549665 & 688816 & 4.9 & 4.9649 & TST & \\
\hline CHEMBL1588738 & 688816 & 4.85 & 5.3937 & TST & \\
\hline CHEMBL1301887 & 688816 & 5.0 & 5.2225 & TRN & \\
\hline CHEMBL1504969 & 688816 & 4.65 & 5.1224 & TRN & \\
\hline CHEMBL1607821 & 688816 & 7.7496 & 5.4658 & TST & \\
\hline CHEMBL1409224 & 688816 & 4.75 & 5.0115 & TST & \\
\hline CHEMBL3212856 & 688816 & 5.0 & 5.2471 & TRN & \\
\hline CHEMBL1343481 & 688816 & 5.0 & 5.0056 & TRN & \\
\hline CHEMBL1999810 & 688816 & 5.35 & 5.4233 & TRN & \\
\hline CHEMBL1442642 & 688816 & 5.25 & 5.4691 & TRN & \\
\hline CHEMBL1469487 & 688816 & 4.9 & 5.0799 & TRN & \\
\hline CHEMBL1409939 & 688816 & 4.8 & 5.5253 & TRN & \\
\hline CHEMBL1335492 & 688816 & 4.95 & 4.8548 & TRN & \\
\hline CHEMBL1563695 & 688816 & 5.05 & 4.846 & TRN & \\
\hline CHEMBL1547169 & 688816 & 4.95 & 5.0713 & TRN & \\
\hline CHEMBL1574984 & 688816 & 4.95 & 5.405 & TRN & \\
\hline CHEMBL1605749 & 688816 & 5.2 & 5.4157 & TST & \\
\hline CHEMBL 3195883 & 688816 & 4.75 & 5.6216 & TRN & \\
\hline CHEMBL1305704 & 688816 & 5.0 & 4.9867 & TRN & \\
\hline CHEMBL3194188 & 688816 & 4.45 & 5.5335 & TST & \\
\hline
\end{tabular}




\begin{tabular}{|c|c|c|c|c|}
\hline \multicolumn{5}{|c|}{ Supplemental Table S2.txt } \\
\hline CHEMBL1568022 & 688816 & 4.5 & 5.0777 & TRN \\
\hline CHEMBL1998425 & 688816 & 4.95 & 5.1532 & TST \\
\hline CHEMBL1465282 & 688816 & 4.8 & 5.2379 & TRN \\
\hline CHEMBL1501186 & 688816 & 4.9 & 5.4824 & TST \\
\hline CHEMBL3192211 & 688816 & 7.699 & 5.4926 & TST \\
\hline CHEMBL1497747 & 688816 & 5.9 & 5.2746 & TRN \\
\hline CHEMBL1324332 & 688816 & 4.9 & 5.1579 & TRN \\
\hline CHEMBL1422329 & 688816 & 5.1 & 5.2745 & TRN \\
\hline CHEMBL601547 & 688816 & 4.9 & 4.8965 & TRN \\
\hline CHEMBL3198736 & 688816 & 4.6 & 5.3827 & TRN \\
\hline CHEMBL1326322 & 688816 & 4.6 & 5.0002 & TST \\
\hline CHEMBL1594388 & 688816 & 4.45 & 5.535 & TST \\
\hline CHEMBL1509605 & 688816 & 5.55 & 5.1986 & TRN \\
\hline CHEMBL1561797 & 688816 & 5.5 & 5.1379 & TRN \\
\hline CHEMBL1422658 & 688816 & 5.4 & 5.211 & TST \\
\hline CHEMBL1382087 & 688816 & 8.0506 & 5.3787 & TRN \\
\hline CHEMBL1527383 & 688816 & 4.55 & 5.1483 & TRN \\
\hline CHEMBL289356 & 688816 & 4.85 & 5.2968 & TST \\
\hline CHEMBL1549700 & 688816 & 4.9 & 5.3323 & TST \\
\hline CHEMBL1606110 & 688816 & 5.0 & 4.7043 & TRN \\
\hline CHEMBL1528173 & 688816 & 5.5 & 5.5321 & TST \\
\hline CHEMBL1398946 & 688816 & 4.8 & 5.4326 & TRN \\
\hline CHEMBL1413608 & 688816 & 4.45 & 5.853 & TRN \\
\hline CHEMBL1583898 & 688816 & 4.95 & 5.3825 & TRN \\
\hline CHEMBL1570935 & 688816 & 5.0 & 5.2325 & TRN \\
\hline CHEMBL1332684 & 688816 & 5.0 & 5.4068 & TST \\
\hline CHEMBL3209919 & 688816 & 6.6 & 5.4338 & TST \\
\hline CHEMBL1376367 & 688816 & 4.95 & 5.2475 & TRN \\
\hline CHEMBL1451015 & 688816 & 5.0 & 5.409 & TRN \\
\hline CHEMBL1304521 & 688816 & 5.45 & 5.6169 & TRN \\
\hline CHEMBL2369190 & 688816 & 4.45 & 5.3796 & TST \\
\hline CHEMBL1539915 & 688816 & 4.75 & 5.1684 & TRN \\
\hline CHEMBL1357894 & 688816 & 6.95 & 5.1899 & TST \\
\hline CHEMBL3195129 & 688816 & 4.65 & 5.0215 & TRN \\
\hline CHEMBL1442840 & 688816 & 4.95 & 5.1692 & TRN \\
\hline CHEMBL1516021 & 688816 & 4.95 & 4.9519 & TRN \\
\hline CHEMBL1484980 & 688816 & 5.65 & 5.1432 & TRN \\
\hline CHEMBL1581112 & 688816 & 4.45 & 5.6024 & TST \\
\hline CHEMBL1300899 & 688816 & 5.0 & 5.047 & TRN \\
\hline CHEMBL1478639 & 688816 & 5.9 & 5.5056 & TRN \\
\hline CHEMBL1464175 & 688816 & 4.9 & 5.1113 & TRN \\
\hline CHEMBL1990027 & 688816 & 8.301 & 5.4089 & TRN \\
\hline CHEMBL1584228 & 688816 & 4.7 & 5.4901 & TRN \\
\hline CHEMBL1462124 & 688816 & 5.4 & 5.0359 & TRN \\
\hline CHEMBL3193391 & 688816 & 4.7 & 5.1977 & TST \\
\hline CHEMBL448245 & 688816 & 4.65 & 5.2073 & TST \\
\hline CHEMBL1393625 & 688816 & 4.7 & 4.9952 & TRN \\
\hline CHEMBL1574354 & 688816 & 4.7 & 5.2795 & TRN \\
\hline
\end{tabular}




\begin{tabular}{|c|c|c|c|c|}
\hline \multicolumn{5}{|c|}{ Supplemental Table S2.txt } \\
\hline CHEMBL3193315 & 688816 & 5.15 & 4.8739 & TRN \\
\hline CHEMBL528373 & 688816 & 4.85 & 4.8428 & TRN \\
\hline CHEMBL1366055 & 688816 & 4.55 & 4.7839 & TRN \\
\hline CHEMBL1468063 & 688816 & 7.699 & 5.5079 & TRN \\
\hline CHEMBL1376258 & 688816 & 4.95 & 4.8825 & TRN \\
\hline CHEMBL1386302 & 688816 & 4.85 & 5.2157 & TRN \\
\hline CHEMBL1360208 & 688816 & 5.5 & 4.8454 & TRN \\
\hline CHEMBL1478480 & 688816 & 5.35 & 4.8942 & TRN \\
\hline CHEMBL1362222 & 688816 & 4.95 & 5.2945 & TRN \\
\hline CHEMBL1600374 & 688816 & 5.4 & 5.654 & TRN \\
\hline CHEMBL1458054 & 688816 & 4.9 & 4.9676 & TRN \\
\hline CHEMBL1424970 & 688816 & 4.45 & 5.3428 & TST \\
\hline CHEMBL1383554 & 688816 & 4.85 & 5.0786 & TRN \\
\hline CHEMBL1319561 & 688816 & 4.7 & 4.9613 & TRN \\
\hline CHEMBL1469984 & 688816 & 4.45 & 5.0855 & TRN \\
\hline CHEMBL1299757 & 688816 & 4.55 & 4.9899 & TRN \\
\hline CHEMBL1300792 & 688816 & 4.85 & 5.0075 & TRN \\
\hline CHEMBL1446428 & 688816 & 4.45 & 5.9706 & TRN \\
\hline CHEMBL144626 & 688816 & 4.9 & 4.9424 & TRN \\
\hline CHEMBL1350448 & 688816 & 4.65 & 5.2347 & TST \\
\hline CHEMBL1458016 & 688816 & 5.0 & 5.3444 & TRN \\
\hline CHEMBL1486765 & 688816 & 5.0 & 4.9799 & TRN \\
\hline CHEMBL1598005 & 688816 & 5.25 & 5.1917 & TRN \\
\hline CHEMBL1393877 & 688816 & 5.6 & 5.2463 & TRN \\
\hline CHEMBL1386441 & 688816 & 5.3 & 5.9302 & TST \\
\hline CHEMBL1437992 & 688816 & 5.15 & 5.3338 & TRN \\
\hline CHEMBL1524972 & 688816 & 6.2 & 5.3237 & TRN \\
\hline CHEMBL1582238 & 688816 & 5.2 & 5.4464 & TST \\
\hline CHEMBL1402422 & 688816 & 4.45 & 5.2796 & TRN \\
\hline CHEMBL3189696 & 688816 & 6.5 & 4.9113 & TRN \\
\hline CHEMBL3212696 & 688816 & 4.6 & 5.4076 & TRN \\
\hline CHEMBL1490527 & 688816 & 4.8 & 5.6151 & TRN \\
\hline CHEMBL1609724 & 688816 & 4.5 & 4.8749 & TRN \\
\hline CHEMBL1488410 & 688816 & 7.7496 & 5.6551 & TRN \\
\hline CHEMBL1502787 & 688816 & 4.95 & 5.069 & TRN \\
\hline CHEMBL1310596 & 688816 & 4.9 & 5.0336 & TRN \\
\hline CHEMBL1376666 & 688816 & 4.9 & 5.1638 & TRN \\
\hline CHEMBL1457516 & 688816 & 4.5 & 5.2899 & TRN \\
\hline CHEMBL1449525 & 688816 & 5.2 & 5.4183 & TRN \\
\hline CHEMBL1340479 & 688816 & 4.95 & 5.1353 & TST \\
\hline CHEMBL1445850 & 688816 & 5.25 & 5.1373 & TRN \\
\hline CHEMBL379179 & 688816 & 5.6 & 5.2893 & TRN \\
\hline CHEMBL1582654 & 688816 & 5.2 & 5.0071 & TRN \\
\hline CHEMBL1511816 & 688816 & 5.4 & 5.175 & TRN \\
\hline CHEMBL1407226 & 688816 & 4.45 & 5.0214 & TRN \\
\hline CHEMBL3213499 & 688816 & 4.75 & 5.1445 & TRN \\
\hline CHEMBL1570616 & 688816 & 4.95 & 5.1049 & TRN \\
\hline CHEMBL1490104 & 688816 & 5.15 & 5.0573 & TRN \\
\hline
\end{tabular}




\begin{tabular}{|c|c|c|c|c|c|}
\hline \multicolumn{6}{|c|}{ Supplemental Table S2.txt } \\
\hline CHEMBL1589415 & 688816 & 5.0 & 4.952 & TRN & \\
\hline CHEMBL1536427 & 688816 & 4.65 & 5.24 & TRN & \\
\hline CHEMBL1351347 & 688816 & 5.1 & 5.2061 & TRN & \\
\hline CHEMBL1382847 & 688816 & 5.1 & 5.3044 & TST & \\
\hline CHEMBL3195808 & 688816 & 4.95 & 5.2598 & TRN & \\
\hline CHEMBL1508906 & 688816 & 4.9 & 5.2517 & TRN & \\
\hline CHEMBL1333795 & 688816 & 5.0 & 5.4525 & TRN & \\
\hline CHEMBL1545183 & 688816 & 4.85 & 4.8818 & TRN & \\
\hline CHEMBL1463446 & 688816 & 4.65 & 5.1702 & TRN & \\
\hline CHEMBL1532268 & 688816 & 4.8 & 5.1516 & TRN & \\
\hline CHEMBL1427245 & 688816 & 5.5 & 5.2383 & TRN & \\
\hline CHEMBL1501021 & 688816 & 7.6498 & 5.6263 & TST & \\
\hline CHEMBL1470358 & 688816 & 4.45 & 5.2146 & TRN & \\
\hline CHEMBL1550809 & 688816 & 4.85 & 5.2642 & TRN & \\
\hline CHEMBL1555840 & 688816 & 4.85 & 5.5887 & TRN & \\
\hline CHEMBL1505030 & 688816 & 4.7 & 4.9129 & TRN & \\
\hline CHEMBL1363773 & 688816 & 5.2 & 5.0588 & TRN & \\
\hline CHEMBL1541648 & 688816 & 4.8 & 5.2132 & TRN & \\
\hline CHEMBL1575878 & 688816 & 4.85 & 5.0494 & TRN & \\
\hline CHEMBL1509102 & 688816 & 7.8013 & 5.9139 & TRN & \\
\hline CHEMBL1419730 & 688816 & 5.05 & 5.3488 & TRN & \\
\hline CHEMBL1576023 & 688816 & 4.45 & 5.1369 & TRN & \\
\hline CHEMBL1407577 & 688816 & 5.2 & 5.3918 & TRN & \\
\hline CHEMBL1308152 & 688816 & 4.65 & 5.1051 & TRN & \\
\hline CHEMBL1305736 & 688816 & 5.0 & 5.1229 & 9999999999 & TRN \\
\hline CHEMBL1511679 & 688816 & 4.8 & 4.9468 & TRN & \\
\hline CHEMBL1323490 & 688816 & 5.05 & 5.7301 & TRN & \\
\hline CHEMBL1349906 & 688816 & 4.75 & 5.4438 & TRN & \\
\hline CHEMBL1437942 & 688816 & 7.4001 & 5.1319 & TST & \\
\hline CHEMBL3189974 & 688816 & 4.8 & 5.2192 & TRN & \\
\hline CHEMBL3189642 & 688816 & 4.95 & 5.0310 & 0000000001 & TRN \\
\hline CHEMBL1325865 & 688816 & 6.8499 & 5.0952 & TRN & \\
\hline CHEMBL1424690 & 688816 & 5.25 & 5.4197 & TRN & \\
\hline CHEMBL1504815 & 688816 & 4.65 & 5.2421 & TRN & \\
\hline CHEMBL1451528 & 688816 & 4.9 & 4.9756 & TST & \\
\hline CHEMBL1586486 & 688816 & 4.6 & 4.9368 & TRN & \\
\hline CHEMBL 229012 & 688816 & 4.9 & 5.1882 & TRN & \\
\hline CHEMBL1537312 & 688816 & 8.301 & 5.3185 & TST & \\
\hline CHEMBL1446815 & 688816 & 4.5 & 5.0588 & TRN & \\
\hline CHEMBL1330983 & 688816 & 4.7 & 5.1611 & TRN & \\
\hline CHEMBL1550325 & 688816 & 5.0 & 5.1991 & TRN & \\
\hline CHEMBL1411190 & 688816 & 4.9 & 5.1766 & TRN & \\
\hline CHEMBL3208787 & 688816 & 4.95 & 5.1306 & TRN & \\
\hline CHEMBL1983243 & 688816 & 4.95 & 5.496 & TRN & \\
\hline CHEMBL1341396 & 688816 & 4.65 & 5.1711 & TRN & \\
\hline CHEMBL1509917 & 688816 & 7.8996 & 5.392 & TST & \\
\hline CHEMBL1546378 & 688816 & 6.45 & 5.3145 & TRN & \\
\hline CHEMBL1425588 & 688816 & 8.301 & 5.1654 & TRN & \\
\hline
\end{tabular}




\begin{tabular}{|c|c|c|c|c|c|}
\hline \multicolumn{6}{|c|}{ Supplemental Table S2.txt } \\
\hline CHEMBL3193989 & 688816 & 4.75 & 5.4645 & TRN & \\
\hline CHEMBL1410112 & 688816 & 4.75 & 5.1657 & TRN & \\
\hline CHEMBL1468313 & 688816 & 4.45 & 5.3626 & TRN & \\
\hline CHEMBL1477200 & 688816 & 8.3468 & 5.6537 & TRN & \\
\hline CHEMBL1542383 & 688816 & 6.3 & 5.4472 & TRN & \\
\hline CHEMBL1569404 & 688816 & 4.6 & 5.0309 & TRN & \\
\hline CHEMBL1342038 & 688816 & 6.2 & 4.8346 & TRN & \\
\hline CHEMBL1352317 & 688816 & 4.65 & 5.2235 & TST & \\
\hline CHEMBL1488036 & 688816 & 4.85 & 5.04899 & 99999999995 & TRN \\
\hline CHEMBL1546463 & 688816 & 5.25 & 5.0842 & TST & \\
\hline CHEMBL1557802 & 688816 & 4.85 & 5.46700 & 00000000005 & TST \\
\hline CHEMBL3198165 & 688816 & 7.5003 & 5.3661 & TST & \\
\hline CHEMBL1510072 & 688816 & 4.45 & 5.0102 & TRN & \\
\hline CHEMBL1510564 & 688816 & 8.6576 & 5.5437 & TST & \\
\hline CHEMBL1582120 & 688816 & 7.6498 & 5.454 & TST & \\
\hline CHEMBL1557094 & 688816 & 4.55 & 5.0184 & TRN & \\
\hline CHEMBL1397215 & 688816 & 4.85 & 5.0856 & TRN & \\
\hline CHEMBL1597632 & 688816 & 7.9508 & 5.3915 & TRN & \\
\hline CHEMBL1605355 & 688816 & 5.05 & 5.1507 & TRN & \\
\hline CHEMBL1579636 & 688816 & 5.8 & 5.2206 & TRN & \\
\hline CHEMBL1370130 & 688816 & 5.5 & 5.4157 & TRN & \\
\hline CHEMBL1569136 & 688816 & 4.75 & 5.2766 & TRN & \\
\hline CHEMBL1359366 & 688816 & 4.45 & 5.237 & TRN & \\
\hline CHEMBL1527582 & 688816 & 7.0501 & 5.2922 & TRN & \\
\hline CHEMBL1353883 & 688816 & 4.45 & 5.6471 & TST & \\
\hline CHEMBL1352968 & 688816 & 4.85 & 4.9203 & TRN & \\
\hline CHEMBL1500037 & 688816 & 4.9 & 5.1619 & TRN & \\
\hline CHEMBL1173693 & 688816 & 7.6003 & 5.8099 & TST & \\
\hline CHEMBL 3189204 & 688816 & 7.5498 & 5.4731 & TST & \\
\hline CHEMBL1450979 & 688816 & 4.8 & 5.1497 & TRN & \\
\hline CHEMBL1504753 & 688816 & 4.45 & 5.3243 & TRN & \\
\hline CHEMBL 1447382 & 688816 & 4.8 & 5.3304 & TRN & \\
\hline CHEMBL1566487 & 688816 & 5.35 & 5.2395 & TRN & \\
\hline CHEMBL1604041 & 688816 & 4.9 & 4.9444 & TST & \\
\hline CHEMBL1482103 & 688816 & 4.6 & 5.0177 & TRN & \\
\hline CHEMBL354676 & 688816 & 6.0 & 4.9526 & TRN & \\
\hline CHEMBL1505937 & 688816 & 5.65 & 5.4906 & TST & \\
\hline CHEMBL1343826 & 688816 & 4.85 & 5.0819 & TRN & \\
\hline CHEMBL1442455 & 688816 & 8.4949 & 5.6933 & TRN & \\
\hline CHEMBL1523385 & 688816 & 4.45 & 4.9514 & TRN & \\
\hline CHEMBL1380946 & 688816 & 5.8 & 5.4816 & TRN & \\
\hline CHEMBL1367384 & 688816 & 5.0 & 5.6207 & TRN & \\
\hline CHEMBL1329642 & 688816 & 4.5 & 5.3706 & TRN & \\
\hline CHEMBL1544022 & 688816 & 4.65 & 5.2732 & TRN & \\
\hline CHEMBL1511371 & 688816 & 4.85 & 5.0587 & TRN & \\
\hline CHEMBL1613229 & 688816 & 4.95 & 5.1923 & TRN & \\
\hline CHEMBL1572026 & 688816 & 4.65 & 5.1957 & TRN & \\
\hline CHEMBL1555980 & 688816 & 4.45 & 4.9949 & TRN & \\
\hline
\end{tabular}




\begin{tabular}{|c|c|c|c|c|}
\hline \multicolumn{5}{|c|}{ Supplemental Table S2.txt } \\
\hline CHEMBL1453109 & 688816 & 4.45 & 5.1474 & TRN \\
\hline CHEMBL1425943 & 688816 & 4.45 & 4.9925 & TRN \\
\hline CHEMBL1353527 & 688816 & 5.1 & 5.1058 & TST \\
\hline CHEMBL1485918 & 688816 & 5.25 & 5.4312 & TRN \\
\hline CHEMBL569020 & 688816 & 5.05 & 5.2046 & TRN \\
\hline CHEMBL3189995 & 688816 & 4.9 & 5.3322 & TRN \\
\hline CHEMBL1562193 & 688816 & 4.95 & 4.8862 & TRN \\
\hline CHEMBL1391807 & 688816 & 5.75 & 5.7096 & TST \\
\hline CHEMBL1391864 & 688816 & 4.8 & 5.1509 & TRN \\
\hline CHEMBL1443976 & 688816 & 4.95 & 5.0713 & TST \\
\hline CHEMBL1303599 & 688816 & 4.9 & 5.8795 & TST \\
\hline CHEMBL1537337 & 688816 & 5.0 & 5.4761 & TRN \\
\hline CHEMBL1996757 & 688816 & 4.65 & 4.9912 & TRN \\
\hline CHEMBL1369200 & 688816 & 5.35 & 5.1886 & TRN \\
\hline CHEMBL1372109 & 688816 & 4.5 & 5.2107 & TRN \\
\hline CHEMBL1419009 & 688816 & 4.65 & 4.9694 & TRN \\
\hline CHEMBL1364650 & 688816 & 6.2 & 5.3412 & TRN \\
\hline CHEMBL1455962 & 688816 & 6.0 & 5.4387 & TRN \\
\hline CHEMBL1462337 & 688816 & 4.45 & 5.0418 & TRN \\
\hline CHEMBL1466838 & 688816 & 4.45 & 5.3677 & TST \\
\hline CHEMBL1472265 & 688816 & 4.45 & 5.5417 & TRN \\
\hline CHEMBL3195375 & 688816 & 4.9 & 5.0649 & TRN \\
\hline CHEMBL3189333 & 688816 & 4.9 & 5.2423 & TRN \\
\hline CHEMBL1458727 & 688816 & 7.3002 & 5.4295 & TRN \\
\hline CHEMBL1397471 & 688816 & 4.6 & 5.144 & TST \\
\hline CHEMBL1573251 & 688816 & 5.0 & 4.9641 & TRN \\
\hline CHEMBL1413056 & 688816 & 4.75 & 5.2323 & TRN \\
\hline CHEMBL1551181 & 688816 & 4.95 & 5.2754 & TRN \\
\hline CHEMBL1547157 & 688816 & 4.45 & 5.3682 & TST \\
\hline CHEMBL1348311 & 688816 & 5.25 & 5.55 & TRN \\
\hline CHEMBL1493697 & 688816 & 5.2 & 5.3748 & TST \\
\hline CHEMBL1331520 & 688816 & 4.9 & 5.2506 & TST \\
\hline CHEMBL1339963 & 688816 & 4.85 & 5.5246 & TST \\
\hline CHEMBL1472141 & 688816 & 4.85 & 5.4158 & TRN \\
\hline CHEMBL1428482 & 688816 & 4.9 & 5.1721 & TST \\
\hline CHEMBL408850 & 688816 & 5.7 & 5.2514 & TRN \\
\hline CHEMBL3190012 & 688816 & 5.05 & 5.3071 & TRN \\
\hline CHEMBL1390560 & 688816 & 5.35 & 5.5146 & TST \\
\hline CHEMBL1992104 & 688816 & 4.95 & 5.4855 & TRN \\
\hline CHEMBL1371237 & 688816 & 4.95 & 5.3416 & TRN \\
\hline CHEMBL1467280 & 688816 & 6.1 & 5.535 & TST \\
\hline CHEMBL1477794 & 688816 & 4.8 & 5.3676 & TRN \\
\hline CHEMBL1993522 & 688816 & 5.25 & 4.977 & TRN \\
\hline CHEMBL1466122 & 688816 & 4.9 & 5.8072 & TRN \\
\hline CHEMBL1468516 & 688816 & 8.2007 & 5.2647 & TRN \\
\hline CHEMBL1541373 & 688816 & 8.301 & 5.7174 & TST \\
\hline CHEMBL1418940 & 688816 & 5.35 & 5.6075 & TRN \\
\hline CHEMBL3211060 & 688816 & 5.45 & 5.3086 & TRN \\
\hline
\end{tabular}




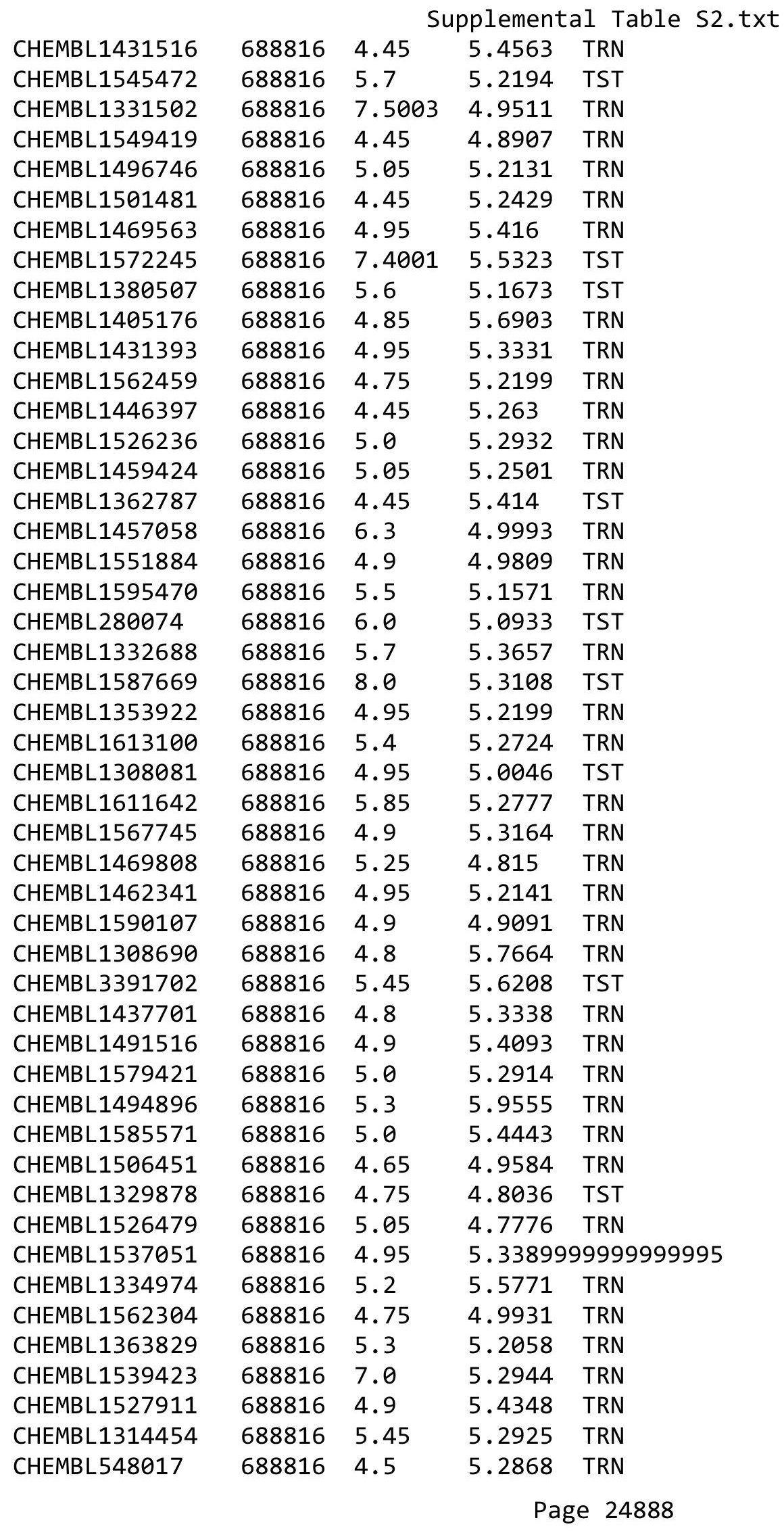




\begin{tabular}{|c|c|c|c|c|}
\hline \multicolumn{5}{|c|}{ Supplemental Table S2.txt } \\
\hline CHEMBL1495248 & 688816 & 4.6 & 5.8097 & TRN \\
\hline CHEMBL1315549 & 688816 & 4.75 & 5.3278 & TST \\
\hline CHEMBL1562858 & 688816 & 6.6 & 5.2264 & TRN \\
\hline CHEMBL1510218 & 688816 & 7.6003 & 5.4125 & TRN \\
\hline CHEMBL1360343 & 688816 & 4.95 & 5.0833 & TST \\
\hline CHEMBL1560223 & 688816 & 4.85 & 5.2303 & TRN \\
\hline CHEMBL1508320 & 688816 & 5.15 & 5.1981 & TST \\
\hline CHEMBL472839 & 688816 & 4.95 & 4.9949 & TRN \\
\hline CHEMBL1343023 & 688816 & 4.9 & 5.2715 & TRN \\
\hline CHEMBL1548421 & 688816 & 5.45 & 5.9864 & TRN \\
\hline CHEMBL1571834 & 688816 & 6.5501 & 5.4981 & TRN \\
\hline CHEMBL1329596 & 688816 & 5.65 & 4.9858 & TST \\
\hline CHEMBL1359143 & 688816 & 4.95 & 5.1936 & TRN \\
\hline CHEMBL1413773 & 688816 & 5.55 & 5.3059 & TRN \\
\hline CHEMBL1364404 & 688816 & 6.3 & 5.3142 & TRN \\
\hline CHEMBL1330905 & 688816 & 4.85 & 5.2891 & TRN \\
\hline CHEMBL1441920 & 688816 & 4.85 & 5.2261 & TST \\
\hline CHEMBL1452077 & 688816 & 4.65 & 5.3922 & TRN \\
\hline CHEMBL 3210984 & 688816 & 4.45 & 5.2961 & TRN \\
\hline CHEMBL1393820 & 688816 & 4.75 & 5.2056 & TRN \\
\hline CHEMBL1540003 & 688816 & 8.3468 & 5.6592 & TST \\
\hline CHEMBL1371974 & 688816 & 5.6 & 5.5973 & TRN \\
\hline CHEMBL1586511 & 688816 & 4.5 & 5.1963 & TRN \\
\hline CHEMBL1300659 & 688816 & 8.301 & 5.5972 & TRN \\
\hline CHEMBL1575677 & 688816 & 4.9 & 5.1674 & TRN \\
\hline CHEMBL1313644 & 688816 & 4.8 & 5.2349 & TRN \\
\hline CHEMBL1577662 & 688816 & 4.85 & 5.5482 & TST \\
\hline CHEMBL1328097 & 688816 & 5.3 & 5.4356 & TRN \\
\hline CHEMBL1499996 & 688816 & 4.45 & 5.9063 & TST \\
\hline CHEMBL 3212558 & 688816 & 4.7 & 5.2353 & TRN \\
\hline CHEMBL1372654 & 688816 & 4.95 & 5.0171 & TRN \\
\hline CHEMBL581880 & 688816 & 5.0 & 5.3363 & TRN \\
\hline CHEMBL1347494 & 688816 & 5.25 & 4.888 & TRN \\
\hline CHEMBL1375545 & 688816 & 4.75 & 4.9839 & TRN \\
\hline CHEMBL1516103 & 688816 & 4.9 & 4.8981 & TRN \\
\hline CHEMBL1526667 & 688816 & 5.3 & 5.4648 & TST \\
\hline CHEMBL1383598 & 688816 & 4.45 & 4.9981 & TRN \\
\hline CHEMBL3199076 & 688816 & 5.55 & 5.1135 & TST \\
\hline CHEMBL1422301 & 688816 & 4.95 & 5.58299 & 9999999999 \\
\hline CHEMBL1551416 & 688816 & 4.7 & 4.9907 & TRN \\
\hline CHEMBL1338496 & 688816 & 8.3468 & 5.3766 & TST \\
\hline CHEMBL1330772 & 688816 & 4.95 & 5.3135 & TRN \\
\hline CHEMBL1575578 & 688816 & 4.85 & 5.1597 & TST \\
\hline CHEMBL1414067 & 688816 & 4.9 & 5.1701 & TRN \\
\hline CHEMBL 1387448 & 688816 & 5.15 & 5.197 & TRN \\
\hline CHEMBL1598743 & 688816 & 5.95 & 5.0743 & TRN \\
\hline CHEMBL1511306 & 688816 & 5.15 & 5.2092 & TRN \\
\hline CHEMBL3195616 & 688816 & 4.85 & 5.256 & TRN \\
\hline
\end{tabular}




\begin{tabular}{|c|c|c|c|c|c|}
\hline \multicolumn{6}{|c|}{ Supplemental Table S2.txt } \\
\hline CHEMBL1418231 & 688816 & 5.8 & 5.5032 & TST & \\
\hline CHEMBL1484257 & 688816 & 4.85 & \multicolumn{2}{|c|}{5.053999999999999} & TRN \\
\hline CHEMBL1511557 & 688816 & 4.85 & 5.3363 & TRN & \\
\hline CHEMBL1382563 & 688816 & 6.2 & 5.0192 & TRN & \\
\hline CHEMBL1347890 & 688816 & 5.6 & 5.032 & TRN & \\
\hline CHEMBL1576283 & 688816 & 5.05 & 5.2003 & TRN & \\
\hline CHEMBL1577278 & 688816 & 8.301 & 5.415 & TRN & \\
\hline CHEMBL1418893 & 688816 & 4.85 & 5.2283 & TRN & \\
\hline CHEMBL1593998 & 688816 & 4.85 & 5.5085 & TRN & \\
\hline CHEMBL1388718 & 688816 & 7.2503 & 5.2379 & TRN & \\
\hline CHEMBL1422220 & 688816 & 5.65 & 5.5018 & TST & \\
\hline CHEMBL1528008 & 688816 & 4.5 & 5.3283 & TRN & \\
\hline CHEMBL1602833 & 688816 & 4.45 & 4.9262 & TRN & \\
\hline CHEMBL1547468 & 688816 & 4.8 & 5.2028 & TST & \\
\hline CHEMBL1558936 & 688816 & 5.3 & 5.2381 & TST & \\
\hline CHEMBL1589463 & 688816 & 4.9 & 4.9087 & TST & \\
\hline CHEMBL1405979 & 688816 & 4.85 & 5.2359 & TRN & \\
\hline CHEMBL1359157 & 688816 & 4.45 & 5.2215 & TST & \\
\hline CHEMBL1331689 & 688816 & 4.45 & 5.6156 & TRN & \\
\hline CHEMBL1587780 & 688816 & 4.85 & 5.1324 & TST & \\
\hline CHEMBL1462804 & 688816 & 5.1 & 4.6914 & TRN & \\
\hline CHEMBL1414439 & 688816 & 4.95 & 5.2133 & TRN & \\
\hline CHEMBL1571483 & 688816 & 4.95 & 5.3838 & TRN & \\
\hline CHEMBL1501789 & 688816 & 6.3 & 5.8709 & TST & \\
\hline CHEMBL1609151 & 688816 & 5.15 & 5.9348 & TRN & \\
\hline CHEMBL1563381 & 688816 & 4.95 & 5.2446 & TST & \\
\hline CHEMBL1606513 & 688816 & 4.8 & 5.4196 & TRN & \\
\hline CHEMBL1587453 & 688816 & 5.55 & 5.1748 & TRN & \\
\hline CHEMBL1313620 & 688816 & 4.75 & 4.8831 & TRN & \\
\hline CHEMBL1432656 & 688816 & 5.25 & 5.1339 & TRN & \\
\hline CHEMBL1379313 & 688816 & 4.95 & 5.2321 & TRN & \\
\hline CHEMBL1584978 & 688816 & 5.45 & 5.562 & TST & \\
\hline CHEMBL1575839 & 688816 & 6.8499 & 5.4245 & TRN & \\
\hline CHEMBL1345855 & 688816 & 6.5 & 5.0555 & TRN & \\
\hline CHEMBL1369853 & 688816 & 4.85 & \multicolumn{2}{|c|}{5.4079999999999995} & TRN \\
\hline CHEMBL 285843 & 688816 & 5.45 & 6.2503 & TST & \\
\hline CHEMBL1412712 & 688816 & 4.45 & 4.8777 & TRN & \\
\hline CHEMBL1384052 & 688816 & 8.3468 & 5.7519 & TRN & \\
\hline CHEMBL1524324 & 688816 & 4.45 & 4.9889 & TRN & \\
\hline CHEMBL1974916 & 688816 & 6.0 & 5.2118 & TRN & \\
\hline CHEMBL1565967 & 688816 & 4.45 & \multicolumn{2}{|c|}{5.582000000000001} & TST \\
\hline CHEMBL1543949 & 688816 & 4.7 & 5.1528 & TST & \\
\hline CHEMBL1468733 & 688816 & 4.95 & 5.3305 & TRN & \\
\hline CHEMBL1584467 & 688816 & 4.45 & 4.9521 & TRN & \\
\hline CHEMBL1472363 & 688816 & 5.65 & 5.2146 & TRN & \\
\hline CHEMBL1577172 & 688816 & 6.15 & 5.557 & TST & \\
\hline CHEMBL1361468 & 688816 & 4.8 & \multicolumn{2}{|c|}{5.122000000000001} & TRN \\
\hline CHEMBL1392693 & 688816 & 6.2 & 5.2187 & TRN & \\
\hline
\end{tabular}




\begin{tabular}{|c|c|c|c|c|c|}
\hline \multicolumn{6}{|c|}{ Supplemental Table S2.txt } \\
\hline CHEMBL245962 & 688816 & 5.45 & 4.7486 & TRN & \\
\hline CHEMBL1364171 & 688816 & 5.45 & 5.2236 & TRN & \\
\hline CHEMBL1418212 & 688816 & 4.95 & 5.3925 & TRN & \\
\hline CHEMBL1307895 & 688816 & 4.9 & 5.0508 & TRN & \\
\hline CHEMBL1307720 & 688816 & 5.35 & 5.1459 & TRN & \\
\hline CHEMBL1310986 & 688816 & 5.0 & 5.3477 & TRN & \\
\hline CHEMBL1452979 & 688816 & 6.35 & 5.3456 & TRN & \\
\hline CHEMBL1312006 & 688816 & 4.9 & 5.2673 & TRN & \\
\hline CHEMBL1571631 & 688816 & 4.95 & 5.1928 & TRN & \\
\hline CHEMBL1370636 & 688816 & 4.9 & 4.9158 & TRN & \\
\hline CHEMBL1411740 & 688816 & 6.7501 & 5.3701 & TRN & \\
\hline CHEMBL1381147 & 688816 & 7.6498 & 5.1778 & TRN & \\
\hline CHEMBL1404510 & 688816 & 4.6 & 5.3159 & TRN & \\
\hline CHEMBL1419498 & 688816 & 4.45 & 5.3727 & TRN & \\
\hline CHEMBL1331200 & 688816 & 4.85 & 5.3147 & TRN & \\
\hline CHEMBL1493336 & 688816 & 4.9 & 5.2651 & TST & \\
\hline CHEMBL1460290 & 688816 & 4.7 & 4.85800 & 00000000005 & TST \\
\hline CHEMBL1335317 & 688816 & 7.15 & 5.4516 & TST & \\
\hline CHEMBL1410374 & 688816 & 4.65 & 5.1877 & TRN & \\
\hline CHEMBL1496441 & 688816 & 5.55 & 5.1668 & TRN & \\
\hline CHEMBL1469102 & 688816 & 5.45 & 5.1699 & TRN & \\
\hline CHEMBL1359616 & 688816 & 5.25 & 5.5378 & TRN & \\
\hline CHEMBL1439100 & 688816 & 4.65 & 5.2963 & TRN & \\
\hline CHEMBL1523321 & 688816 & 4.45 & 5.2624 & TRN & \\
\hline CHEMBL1382794 & 688816 & 5.45 & 5.1668 & TST & \\
\hline CHEMBL1508245 & 688816 & 4.6 & 5.1271 & TST & \\
\hline CHEMBL1588051 & 688816 & 4.45 & 5.0804 & TRN & \\
\hline CHEMBL1351608 & 688816 & 4.7 & 5.2777 & TRN & \\
\hline CHEMBL1367044 & 688816 & 5.45 & 5.2524 & TRN & \\
\hline CHEMBL1392908 & 688816 & 5.0 & 5.7244 & TRN & \\
\hline CHEMBL1568054 & 688816 & 4.7 & 5.3314 & TRN & \\
\hline CHEMBL1585628 & 688816 & 4.45 & 5.1556 & TRN & \\
\hline CHEMBL1478310 & 688816 & 5.5 & 5.2501 & TST & \\
\hline CHEMBL1607728 & 688816 & 4.75 & 5.1228 & TRN & \\
\hline CHEMBL1550390 & 688816 & 5.35 & 5.5618 & TRN & \\
\hline CHEMBL65 & 688816 & 6.0 & 6.1263 & TRN & \\
\hline CHEMBL1597875 & 688816 & 5.25 & 5.8606 & TRN & \\
\hline CHEMBL1312116 & 688816 & 5.45 & 5.2649 & TRN & \\
\hline CHEMBL1335083 & 688816 & 4.9 & 5.2097 & TRN & \\
\hline CHEMBL1492912 & 688816 & 5.0 & 5.267 & TRN & \\
\hline CHEMBL1462256 & 688816 & 4.5 & 5.2039 & TST & \\
\hline CHEMBL1426737 & 688816 & 7.2503 & 5.2707 & TRN & \\
\hline CHEMBL1374907 & 688816 & 4.55 & 5.0102 & TRN & \\
\hline CHEMBL1300807 & 688816 & 4.45 & 5.3833 & TST & \\
\hline CHEMBL1381380 & 688816 & 5.05 & 4.9432 & TRN & \\
\hline CHEMBL3198630 & 688816 & 4.75 & 5.2066 & TRN & \\
\hline CHEMBL1481912 & 688816 & 5.2 & 5.107 & TRN & \\
\hline CHEMBL1532062 & 688816 & 4.45 & 5.1055 & TRN & \\
\hline
\end{tabular}




\begin{tabular}{|c|c|c|c|c|c|}
\hline \multicolumn{6}{|c|}{ Supplemental Table S2.txt } \\
\hline CHEMBL1508560 & 688816 & 4.95 & 5.2084 & TRN & \\
\hline CHEMBL3214412 & 688816 & 4.95 & 5.3277 & TRN & \\
\hline CHEMBL1712384 & 688816 & 4.75 & 5.1012 & TST & \\
\hline CHEMBL1452486 & 688816 & 5.9 & 5.6655 & TST & \\
\hline CHEMBL1320499 & 688816 & 6.45 & 5.1898 & TST & \\
\hline CHEMBL1438750 & 688816 & 4.65 & 5.2182 & TRN & \\
\hline CHEMBL1344541 & 688816 & 5.1 & 5.1056 & TST & \\
\hline CHEMBL1508793 & 688816 & 4.8 & 5.5892 & TRN & \\
\hline CHEMBL1589719 & 688816 & 8.301 & 5.4143 & TRN & \\
\hline CHEMBL1536768 & 688816 & 4.8 & 5.1509 & TRN & \\
\hline CHEMBL1415501 & 688816 & 4.45 & 5.4129 & TRN & \\
\hline CHEMBL1401314 & 688816 & 4.45 & 5.227 & TRN & \\
\hline CHEMBL1328395 & 688816 & 5.05 & 4.9309 & TRN & \\
\hline CHEMBL1333180 & 688816 & 4.85 & 5.38 & TST & \\
\hline CHEMBL1607986 & 688816 & 4.95 & 5.2705 & TRN & \\
\hline CHEMBL1608194 & 688816 & 5.45 & 5.1259 & TRN & \\
\hline CHEMBL1492662 & 688816 & 5.0 & 4.9209 & TRN & \\
\hline CHEMBL1309526 & 688816 & 4.9 & 5.1602 & TST & \\
\hline CHEMBL1550351 & 688816 & 6.1 & 5.0596 & TRN & \\
\hline CHEMBL1389289 & 688816 & 6.45 & 4.9491 & TRN & \\
\hline CHEMBL1364704 & 688816 & 4.95 & 5.4244 & TRN & \\
\hline CHEMBL1427084 & 688816 & 6.7501 & 5.5027 & TRN & \\
\hline CHEMBL1550123 & 688816 & 4.9 & 4.8718 & TRN & \\
\hline CHEMBL1478690 & 688816 & 4.45 & 5.2354 & TRN & \\
\hline CHEMBL1378617 & 688816 & 5.85 & 5.1066 & TRN & \\
\hline CHEMBL1309483 & 688816 & 4.45 & 5.0523 & TST & \\
\hline CHEMBL1998281 & 688816 & 4.7 & 5.3784 & TST & \\
\hline CHEMBL1580096 & 688816 & 5.45 & 5.0563 & TRN & \\
\hline CHEMBL1318811 & 688816 & 4.6 & 5.1333 & TRN & \\
\hline CHEMBL1546974 & 688816 & 4.7 & 5.3483 & TRN & \\
\hline CHEMBL1466753 & 688816 & 4.9 & 5.181 & TRN & \\
\hline CHEMBL1370905 & 688816 & 4.95 & 5.11100 & 0000000001 & TRN \\
\hline CHEMBL1520976 & 688816 & 5.85 & 5.8325 & TST & \\
\hline CHEMBL1477451 & 688816 & 4.95 & 5.0053 & TRN & \\
\hline CHEMBL1357265 & 688816 & 5.0 & 5.1928 & TST & \\
\hline CHEMBL1312266 & 688816 & 5.5 & 5.409 & TRN & \\
\hline CHEMBL1562615 & 688816 & 4.8 & 5.3241 & TST & \\
\hline CHEMBL 26320 & 688816 & 6.0 & 5.4072 & TRN & \\
\hline CHEMBL1399006 & 688816 & 4.8 & 5.3001 & TST & \\
\hline CHEMBL1454070 & 688816 & 4.45 & 5.3791 & TRN & \\
\hline CHEMBL1340447 & 688816 & 4.95 & 5.5721 & TRN & \\
\hline CHEMBL454173 & 688816 & 6.0 & 5.5002 & TRN & \\
\hline CHEMBL1549179 & 688816 & 5.05 & 5.4043 & TRN & \\
\hline CHEMBL1577941 & 688816 & 4.9 & 5.1096 & TST & \\
\hline CHEMBL1485871 & 688816 & 5.2 & 5.1764 & TRN & \\
\hline CHEMBL1581890 & 688816 & 4.5 & 5.0972 & TRN & \\
\hline CHEMBL1525066 & 688816 & 5.1 & 5.3035 & TRN & \\
\hline CHEMBL1347362 & 688816 & 4.9 & 5.3526 & TST & \\
\hline
\end{tabular}




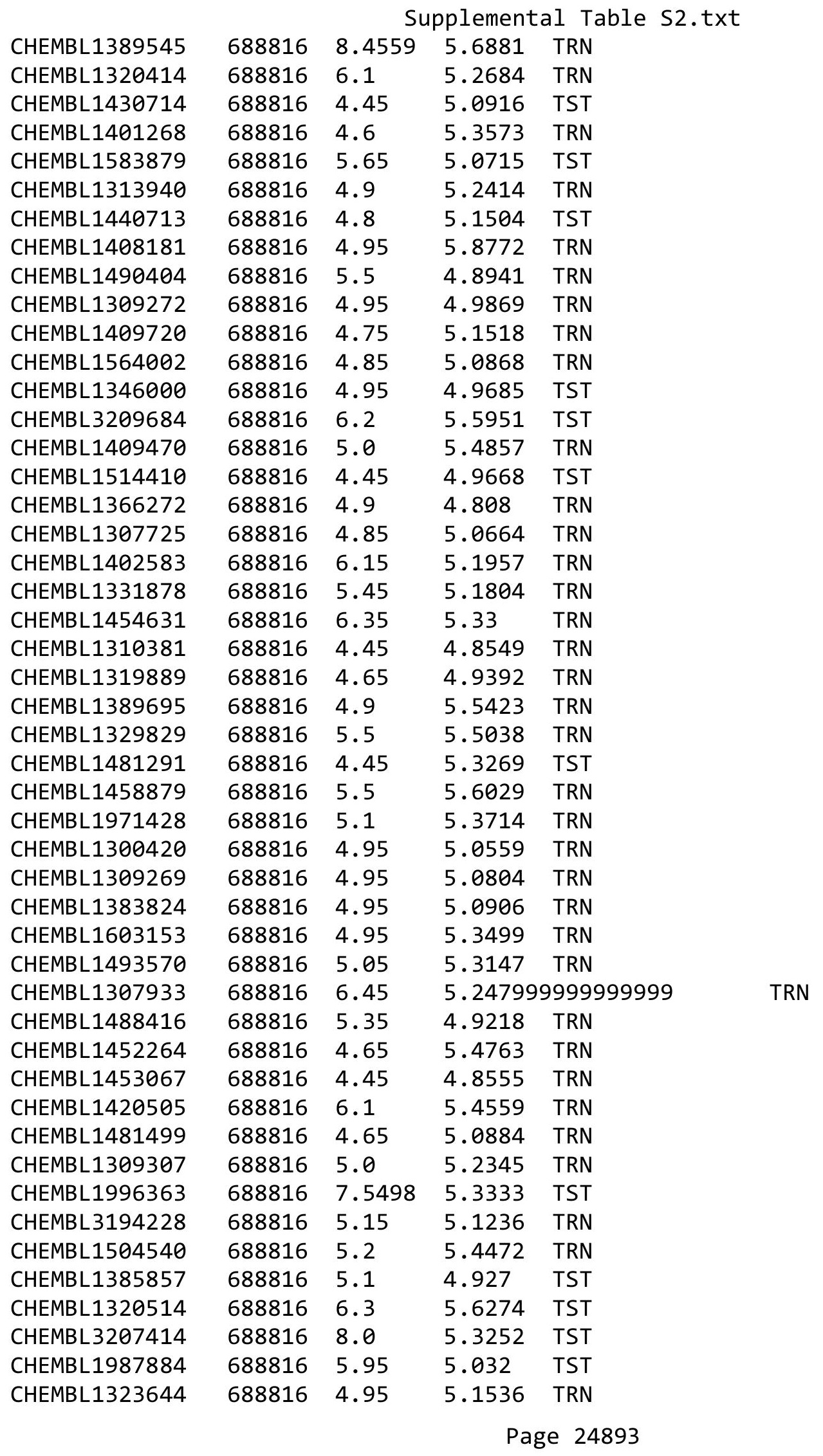




\begin{tabular}{|c|c|c|c|c|}
\hline \multicolumn{5}{|c|}{ Supplemental Table S2.txt } \\
\hline CHEMBL1588236 & 688816 & 4.45 & 5.5215 & TST \\
\hline CHEMBL 1457783 & 688816 & 4.45 & 5.1641 & TRN \\
\hline CHEMBL1351555 & 688816 & 4.65 & 5.4412 & TST \\
\hline CHEMBL1415059 & 688816 & 4.55 & 5.0242 & TRN \\
\hline CHEMBL1334264 & 688816 & 5.25 & 5.4323 & TRN \\
\hline CHEMBL1310290 & 688816 & 4.7 & 5.2117 & TRN \\
\hline CHEMBL1598299 & 688816 & 5.85 & 5.0721 & TST \\
\hline CHEMBL 3189416 & 688816 & 4.9 & 4.7581 & TST \\
\hline CHEMBL 1444705 & 688816 & 4.95 & 5.5064 & TRN \\
\hline CHEMBL1510572 & 688816 & 4.9 & 5.1658 & TRN \\
\hline CHEMBL1559401 & 688816 & 4.85 & 5.5329 & TRN \\
\hline CHEMBL 1412940 & 688816 & 4.85 & 5.0305 & TRN \\
\hline CHEMBL1486726 & 688816 & 5.9 & 5.3434 & TRN \\
\hline CHEMBL1523438 & 688816 & 5.45 & 4.9503 & TRN \\
\hline CHEMBL3193177 & 688816 & 5.4 & 5.182 & TST \\
\hline CHEMBL1597569 & 688816 & 4.5 & 5.1684 & TRN \\
\hline CHEMBL1300063 & 688816 & 5.75 & 4.9872 & TRN \\
\hline CHEMBL1422748 & 688816 & 4.95 & 4.9199 & TRN \\
\hline CHEMBL1515861 & 688816 & 5.4 & 5.3057 & TRN \\
\hline CHEMBL1461738 & 688816 & 4.65 & 5.0018 & TST \\
\hline CHEMBL1372087 & 688816 & 4.95 & 5.2349 & TRN \\
\hline CHEMBL3212055 & 688816 & 7.6003 & 5.1032 & TST \\
\hline CHEMBL1322716 & 688816 & 4.95 & 5.2557 & TRN \\
\hline CHEMBL182461 & 688816 & 5.35 & 5.9738 & TST \\
\hline CHEMBL1379814 & 688816 & 5.0 & 5.4202 & TRN \\
\hline CHEMBL1400969 & 688816 & 7.4498 & 5.0418 & TRN \\
\hline CHEMBL1546345 & 688816 & 4.8 & 5.3891 & TRN \\
\hline CHEMBL1544202 & 688816 & 5.3 & 5.4156 & TRN \\
\hline CHEMBL1374566 & 688816 & 4.45 & 5.4483 & TRN \\
\hline CHEMBL1299319 & 688816 & 5.2 & 5.065 & TRN \\
\hline CHEMBL1566031 & 688816 & 5.25 & 5.2349 & TST \\
\hline CHEMBL1464148 & 688816 & 4.55 & 5.0118 & TRN \\
\hline CHEMBL1360965 & 688816 & 4.8 & 4.8949 & TST \\
\hline CHEMBL1309913 & 688816 & 4.95 & 5.0564 & TRN \\
\hline CHEMBL1372072 & 688816 & 4.55 & 5.1809 & TRN \\
\hline CHEMBL1358556 & 688816 & 4.45 & 4.9606 & TRN \\
\hline CHEMBL1510835 & 688816 & 5.9 & $5.2020 e$ & 0000000001 \\
\hline CHEMBL1308314 & 688816 & 4.7 & 5.2227 & TRN \\
\hline CHEMBL1427426 & 688816 & 5.45 & 5.1301 & TRN \\
\hline CHEMBL1560623 & 688816 & 5.3 & 5.2608 & TRN \\
\hline CHEMBL1498141 & 688816 & 5.35 & 5.4575 & TST \\
\hline CHEMBL1321156 & 688816 & 4.45 & 5.1478 & TRN \\
\hline CHEMBL3209020 & 688816 & 7.6498 & 5.474 & TRN \\
\hline CHEMBL1311009 & 688816 & 5.5 & 5.629 & TRN \\
\hline CHEMBL1362669 & 688816 & 4.75 & 5.2059 & TRN \\
\hline CHEMBL1419798 & 688816 & 6.5501 & 5.5025 & TRN \\
\hline CHEMBL1599784 & 688816 & 4.6 & 4.7279 & TRN \\
\hline CHEMBL1431210 & 688816 & 4.95 & 5.3084 & TRN \\
\hline
\end{tabular}




\begin{tabular}{|c|c|c|c|c|c|}
\hline \multicolumn{6}{|c|}{ Supplemental Table S2.txt } \\
\hline CHEMBL1463888 & 688816 & 5.25 & 5.3205 & TRN & \\
\hline CHEMBL1455775 & 688816 & 6.5501 & 5.5516 & TRN & \\
\hline CHEMBL1506208 & 688816 & 6.3 & 5.4849 & TST & \\
\hline CHEMBL1392551 & 688816 & 4.95 & 5.3111 & TST & \\
\hline CHEMBL1401690 & 688816 & 6.3 & 5.5562 & TRN & \\
\hline CHEMBL1341782 & 688816 & 4.6 & 4.9017 & TRN & \\
\hline CHEMBL1377303 & 688816 & 5.0 & 5.3058 & TRN & \\
\hline CHEMBL3194388 & 688816 & 6.5 & 5.3925 & TRN & \\
\hline CHEMBL1532879 & 688816 & 4.95 & 5.3695 & TRN & \\
\hline CHEMBL1445826 & 688816 & 5.6 & 5.5918 & TRN & \\
\hline CHEMBL1487986 & 688816 & 4.45 & 5.5406 & TRN & \\
\hline CHEMBL1607779 & 688816 & 8.3468 & 5.605 & TRN & \\
\hline CHEMBL1558321 & 688816 & 4.85 & 5.3327 & TRN & \\
\hline CHEMBL 3211725 & 688816 & 5.35 & 5.3547 & TRN & \\
\hline CHEMBL1483875 & 688816 & 4.95 & 5.1224 & TRN & \\
\hline CHEMBL1306039 & 688816 & 4.85 & 5.261 & TRN & \\
\hline CHEMBL1546267 & 688816 & 4.95 & 5.3578 & TRN & \\
\hline CHEMBL1559419 & 688816 & 5.5 & 5.7267 & TRN & \\
\hline CHEMBL1530387 & 688816 & 4.9 & 5.32299 & 99999999995 & TST \\
\hline CHEMBL1521587 & 688816 & 5.6 & 5.3781 & TRN & \\
\hline CHEMBL3856090 & 688816 & 5.15 & 5.3049 & TRN & \\
\hline CHEMBL1446827 & 688816 & 6.15 & 5.3369 & TRN & \\
\hline CHEMBL1551786 & 688816 & 4.65 & 5.3855 & TRN & \\
\hline CHEMBL1969332 & 688816 & 5.95 & 5.3465 & TRN & \\
\hline CHEMBL3192150 & 688816 & 4.55 & 5.0124 & TRN & \\
\hline CHEMBL3212680 & 688816 & 5.0 & 5.3319 & TST & \\
\hline CHEMBL1393674 & 688816 & 4.9 & 5.316 & TST & \\
\hline CHEMBL1533774 & 688816 & 4.6 & 5.0762 & TRN & \\
\hline CHEMBL1382945 & 688816 & 6.8 & 5.3847 & TST & \\
\hline CHEMBL3196478 & 688816 & 4.9 & 5.0411 & TRN & \\
\hline CHEMBL1511588 & 688816 & 6.6 & 5.6086 & TRN & \\
\hline CHEMBL 308688 & 688816 & 4.95 & 5.2364 & TRN & \\
\hline CHEMBL1520320 & 688816 & 6.8499 & 5.4936 & TST & \\
\hline CHEMBL1384221 & 688816 & 5.15 & 5.3803 & TST & \\
\hline CHEMBL1320490 & 688816 & 6.05 & 5.5787 & TRN & \\
\hline CHEMBL1488004 & 688816 & 5.25 & 5.5977 & TRN & \\
\hline CHEMBL1535919 & 688816 & 4.55 & 4.8297 & TRN & \\
\hline CHEMBL1409532 & 688816 & 4.9 & 5.271 & TRN & \\
\hline CHEMBL1322290 & 688816 & 7.6498 & 5.2875 & TST & \\
\hline CHEMBL1462478 & 688816 & 4.45 & 5.1104 & TST & \\
\hline CHEMBL1606582 & 688816 & 4.95 & 5.5852 & TRN & \\
\hline CHEMBL1340034 & 688816 & 4.85 & 5.5424 & TST & \\
\hline CHEMBL538430 & 688816 & 4.5 & 5.1171 & TRN & \\
\hline CHEMBL1481925 & 688816 & 4.9 & 4.9431 & TRN & \\
\hline CHEMBL1452240 & 688816 & 5.5 & 5.2837 & TRN & \\
\hline CHEMBL1390237 & 688816 & 6.6499 & 5.1714 & TST & \\
\hline CHEMBL1413172 & 688816 & 4.9 & 5.129 & TRN & \\
\hline CHEMBL1408162 & 688816 & 5.55 & 5.2247 & TST & \\
\hline
\end{tabular}




\begin{tabular}{|c|c|c|c|c|c|}
\hline \multicolumn{6}{|c|}{ Supplemental Table S2.txt } \\
\hline CHEMBL1475727 & 688816 & 6.05 & 5.1296 & TRN & \\
\hline CHEMBL1360000 & 688816 & 4.95 & 5.3107 & TRN & \\
\hline CHEMBL242341 & 688816 & 4.95 & 5.4564 & TRN & \\
\hline CHEMBL3191056 & 688816 & 5.45 & 5.1772 & TRN & \\
\hline CHEMBL1389082 & 688816 & 4.7 & 5.5012 & TST & \\
\hline CHEMBL1371415 & 688816 & 4.45 & 5.3039 & TRN & \\
\hline CHEMBL1562688 & 688816 & 4.85 & 5.2645 & TST & \\
\hline CHEMBL1495310 & 688816 & 5.05 & 5.3904 & TRN & \\
\hline CHEMBL3194374 & 688816 & 5.1 & 5.19 & TRN & \\
\hline CHEMBL 1422950 & 688816 & 7.0 & 5.4894 & TRN & \\
\hline CHEMBL1439772 & 688816 & 6.6 & 5.1112 & TRN & \\
\hline CHEMBL1481294 & 688816 & 4.45 & 5.3971 & TRN & \\
\hline CHEMBL1441164 & 688816 & 5.05 & 5.0683 & TRN & \\
\hline CHEMBL 2002008 & 688816 & 5.3 & 4.8428 & TRN & \\
\hline CHEMBL1400731 & 688816 & 4.45 & 4.94300 & 00000000005 & TRN \\
\hline CHEMBL1561133 & 688816 & 4.45 & 5.0903 & TRN & \\
\hline CHEMBL1524792 & 688816 & 4.95 & 5.0432 & TRN & \\
\hline CHEMBL1973332 & 688816 & 4.45 & 5.1882 & TRN & \\
\hline CHEMBL1464555 & 688816 & 6.3 & 5.3883 & TRN & \\
\hline CHEMBL1365560 & 688816 & 4.85 & 5.2773 & TRN & \\
\hline CHEMBL1367600 & 688816 & 4.7 & 5.1289 & TRN & \\
\hline CHEMBL1341400 & 688816 & 4.8 & 5.1132 & TRN & \\
\hline CHEMBL3211221 & 688816 & 4.85 & 5.1647 & TRN & \\
\hline CHEMBL1502546 & 688816 & 5.1 & 5.027 & TRN & \\
\hline CHEMBL1310680 & 688816 & 4.95 & 5.2383 & TST & \\
\hline CHEMBL1597278 & 688816 & 5.0 & 4.7985 & TRN & \\
\hline CHEMBL1612263 & 688816 & 4.8 & 5.4419 & TRN & \\
\hline CHEMBL1498886 & 688816 & 4.95 & 5.1742 & TST & \\
\hline CHEMBL1416450 & 688816 & 4.8 & 5.6234 & TRN & \\
\hline CHEMBL1462775 & 688816 & 4.8 & 5.2124 & TRN & \\
\hline CHEMBL599503 & 688816 & 4.75 & 5.1617 & TRN & \\
\hline CHEMBL1368212 & 688816 & 5.4 & 5.2516 & TRN & \\
\hline CHEMBL1396167 & 688816 & 5.95 & 5.4111 & TRN & \\
\hline CHEMBL1595480 & 688816 & 5.0 & 5.6954 & TST & \\
\hline CHEMBL1497122 & 688816 & 8.0 & 5.8739 & TST & \\
\hline CHEMBL1382491 & 688816 & 4.8 & 5.0064 & TST & \\
\hline CHEMBL 1377696 & 688816 & 5.15 & 5.2367 & TRN & \\
\hline CHEMBL1556381 & 688816 & 4.6 & 5.1305 & TRN & \\
\hline CHEMBL1362635 & 688816 & 4.85 & 5.1958 & TRN & \\
\hline CHEMBL1349707 & 688816 & 7.6003 & 5.4924 & TRN & \\
\hline CHEMBL1525466 & 688816 & 5.45 & 5.2971 & TST & \\
\hline CHEMBL1491864 & 688816 & 8.301 & 5.022 & TRN & \\
\hline CHEMBL1578310 & 688816 & 7.6498 & 5.3109 & TRN & \\
\hline CHEMBL1443266 & 688816 & 4.95 & 5.1624 & TRN & \\
\hline CHEMBL1506770 & 688816 & 4.9 & 4.9674 & TRN & \\
\hline CHEMBL1523966 & 688816 & 4.65 & 5.6547 & TRN & \\
\hline CHEMBL1399635 & 688816 & 4.45 & 4.9793 & TRN & \\
\hline CHEMBL1425381 & 688816 & 4.9 & 4.9266 & TRN & \\
\hline
\end{tabular}




\begin{tabular}{|c|c|c|c|c|}
\hline \multicolumn{5}{|c|}{ Supplemental Table S2.txt } \\
\hline CHEMBL1557777 & 688816 & 5.5 & 5.4146 & TST \\
\hline CHEMBL1360631 & 688816 & 4.6 & 5.1814 & TRN \\
\hline CHEMBL1491744 & 688816 & 4.75 & 5.3417 & TRN \\
\hline CHEMBL1502086 & 688816 & 5.5 & 5.6145 & TRN \\
\hline CHEMBL1464730 & 688816 & 5.25 & 5.4212 & TRN \\
\hline CHEMBL3199204 & 688816 & 4.55 & 4.9952 & TRN \\
\hline CHEMBL1335878 & 688816 & 6.3 & 5.3893 & TRN \\
\hline CHEMBL1411465 & 688816 & 4.45 & 5.0108 & TRN \\
\hline CHEMBL1582289 & 688816 & 5.25 & 5.3048 & TRN \\
\hline CHEMBL1377580 & 688816 & 5.05 & 5.3488 & TST \\
\hline CHEMBL1585997 & 688816 & 4.85 & 4.9875 & TRN \\
\hline CHEMBL1529473 & 688816 & 4.9 & 5.6068 & TST \\
\hline CHEMBL1349263 & 688816 & 4.45 & 5.1727 & TST \\
\hline CHEMBL1606964 & 688816 & 5.1 & 5.2278 & TRN \\
\hline CHEMBL1534503 & 688816 & 4.6 & 4.9585 & TRN \\
\hline CHEMBL1366175 & 688816 & 4.45 & 5.6098 & TRN \\
\hline CHEMBL1388554 & 688816 & 4.95 & 5.0449 & TRN \\
\hline CHEMBL3392439 & 688816 & 4.45 & 5.2638 & TRN \\
\hline CHEMBL1321333 & 688816 & 4.95 & 5.1346 & TRN \\
\hline CHEMBL1456446 & 688816 & 6.2 & 5.0919 & TRN \\
\hline CHEMBL1595973 & 688816 & 6.05 & 5.3321 & TRN \\
\hline CHEMBL1541975 & 688816 & 4.75 & 5.0893 & TST \\
\hline CHEMBL1353696 & 688816 & 5.3 & 5.2158 & TRN \\
\hline CHEMBL1347752 & 688816 & 4.85 & 5.2488 & TRN \\
\hline CHEMBL1581280 & 688816 & 5.2 & 5.1351 & TRN \\
\hline CHEMBL1597783 & 688816 & 5.3 & 5.352 & TRN \\
\hline CHEMBL1575335 & 688816 & 5.1 & 5.4435 & TST \\
\hline CHEMBL1421171 & 688816 & 4.9 & 5.2952 & TRN \\
\hline CHEMBL1381590 & 688816 & 5.15 & 5.2491 & TRN \\
\hline CHEMBL1334298 & 688816 & 6.7001 & 5.2474 & TST \\
\hline CHEMBL1477456 & 688816 & 4.45 & 5.2406 & TRN \\
\hline CHEMBL1322618 & 688816 & 4.45 & 5.1305 & TRN \\
\hline CHEMBL507237 & 688816 & 4.95 & 5.6202 & TST \\
\hline CHEMBL1384748 & 688816 & 6.15 & 5.0938 & TRN \\
\hline CHEMBL3197990 & 688816 & 4.85 & 5.3086 & TRN \\
\hline CHEMBL1382628 & 688816 & 4.95 & 5.1674 & TRN \\
\hline CHEMBL1490683 & 688816 & 4.45 & 4.8853 & TRN \\
\hline CHEMBL1410412 & 688816 & 4.85 & 5.007 & TRN \\
\hline CHEMBL1503513 & 688816 & 5.55 & 5.275 & TST \\
\hline CHEMBL3190082 & 688816 & 4.9 & 5.1422 & TRN \\
\hline CHEMBL1575221 & 688816 & 4.9 & 4.8242 & TRN \\
\hline CHEMBL1444450 & 688816 & 5.4 & 5.3165 & TST \\
\hline CHEMBL1598670 & 688816 & 4.7 & 5.1554 & TRN \\
\hline CHEMBL1504300 & 688816 & 5.25 & 5.1656 & TRN \\
\hline CHEMBL1545566 & 688816 & 4.85 & 5.3717 & TRN \\
\hline CHEMBL1561471 & 688816 & 7.9508 & 5.2806 & TST \\
\hline CHEMBL1494423 & 688816 & 4.65 & 5.3241 & TRN \\
\hline CHEMBL1565015 & 688816 & 4.95 & 5.3881 & TRN \\
\hline
\end{tabular}




\begin{tabular}{|c|c|c|c|c|c|}
\hline \multicolumn{6}{|c|}{ plemental } \\
\hline CHEMBL1568401 & 688816 & 6.5 & 5.3056 & TST & \\
\hline CHEMBL1333767 & 688816 & 4.95 & 5.1329 & TRN & \\
\hline CHEMBL1315586 & 688816 & 4.95 & 4.98 & TRN & \\
\hline CHEMBL1583537 & 688816 & 4.95 & 4.9979 & TST & \\
\hline CHEMBL1586587 & 688816 & 4.9 & 5.7478 & TST & \\
\hline CHEMBL1395495 & 688816 & 4.65 & 5.3434 & TRN & \\
\hline CHEMBL1374843 & 688816 & 4.45 & 5.6167 & TST & \\
\hline CHEMBL126804 & 688816 & 5.5 & 4.9718 & TRN & \\
\hline CHEMBL1440120 & 688816 & 4.9 & 4.9969 & TRN & \\
\hline CHEMBL1377695 & 688816 & 4.45 & 5.5438 & TRN & \\
\hline CHEMBL1587730 & 688816 & 4.95 & 5.1166 & TRN & \\
\hline CHEMBL1336347 & 688816 & 5.45 & 4.9505 & TRN & \\
\hline CHEMBL1546355 & 688816 & 5.4 & 5.3091 & TRN & \\
\hline CHEMBL1486374 & 688816 & 4.8 & 5.3202 & TRN & \\
\hline CHEMBL 3211743 & 688816 & 4.65 & 5.1272 & TRN & \\
\hline CHEMBL1397174 & 688816 & 4.5 & 5.2981 & TRN & \\
\hline CHEMBL1309035 & 688816 & 6.0 & 5.3617 & TRN & \\
\hline CHEMBL1421775 & 688816 & 4.9 & 5.4252 & TRN & \\
\hline CHEMBL1491556 & 688816 & 4.45 & 5.0729 & TRN & \\
\hline CHEMBL1541007 & 688816 & 7.6003 & 5.3773 & TST & \\
\hline CHEMBL578943 & 688816 & 4.45 & 5.3957 & TST & \\
\hline CHEMBL1525334 & 688816 & 5.8 & 5.2582 & TRN & \\
\hline CHEMBL1439641 & 688816 & 4.45 & 5.2693 & TRN & \\
\hline CHEMBL1537638 & 688816 & 4.65 & 5.8995 & TRN & \\
\hline CHEMBL1486569 & 688816 & 5.0 & 4.9584 & TRN & \\
\hline CHEMBL1452106 & 688816 & 4.5 & 5.279 & TRN & \\
\hline CHEMBL1395456 & 688816 & 4.75 & 5.2729 & TRN & \\
\hline CHEMBL1393771 & 688816 & 4.85 & 5.2244 & TRN & \\
\hline CHEMBL1484063 & 688816 & 5.25 & 5.442 & TRN & \\
\hline CHEMBL1579074 & 688816 & 6.8499 & 5.2019 & TRN & \\
\hline CHEMBL1395862 & 688816 & 4.9 & 5.3748 & TRN & \\
\hline CHEMBL579624 & 688816 & 4.9 & 5.385 & TRN & \\
\hline CHEMBL1478995 & 688816 & 4.8 & 5.0764 & TRN & \\
\hline CHEMBL3193435 & 688816 & 4.9 & 5.3417 & TRN & \\
\hline CHEMBL1344478 & 688816 & 4.85 & 5.1333 & TRN & \\
\hline CHEMBL1303945 & 688816 & 4.75 & 5.1634 & TRN & \\
\hline CHEMBL1434762 & 688816 & 4.6 & 5.3341 & TRN & \\
\hline CHEMBL1585241 & 688816 & 7.0 & 5.33899 & 99999999995 & TST \\
\hline CHEMBL1548220 & 688816 & 4.9 & 5.1841 & TRN & \\
\hline CHEMBL1527685 & 688816 & 5.45 & 5.5007 & TRN & \\
\hline CHEMBL3211789 & 688816 & 7.2 & 5.32700 & 0000000001 & TRN \\
\hline CHEMBL1503213 & 688816 & 5.3 & 5.6738 & TRN & \\
\hline CHEMBL1583106 & 688816 & 6.5 & 4.9547 & TRN & \\
\hline CHEMBL1581738 & 688816 & 4.9 & 5.0105 & TRN & \\
\hline CHEMBL1385743 & 688816 & 4.8 & 5.2364 & TRN & \\
\hline CHEMBL 384759 & 688816 & 4.85 & 6.0686 & TST & \\
\hline CHEMBL2369211 & 688816 & 5.45 & 5.4729 & TRN & \\
\hline CHEMBL1550533 & 688816 & 5.4 & 5.012 & TRN & \\
\hline
\end{tabular}




\begin{tabular}{|c|c|c|c|c|c|}
\hline \multicolumn{6}{|c|}{ Supplemental Table S2.txt } \\
\hline CHEMBL1492716 & 688816 & 5.5 & 5.3855 & TST & \\
\hline CHEMBL1410211 & 688816 & 5.05 & 5.8328 & TRN & \\
\hline CHEMBL1573110 & 688816 & 4.8 & 5.4873 & TRN & \\
\hline CHEMBL 3212968 & 688816 & 8.301 & 5.6379 & TST & \\
\hline CHEMBL1478585 & 688816 & 5.5 & 5.3454 & TRN & \\
\hline CHEMBL1526805 & 688816 & 5.6 & 5.6937 & TRN & \\
\hline CHEMBL1450138 & 688816 & 6.05 & 5.3158 & TRN & \\
\hline CHEMBL3193809 & 688816 & 4.8 & 5.4006 & TST & \\
\hline CHEMBL1466964 & 688816 & 4.95 & 5.5345 & TRN & \\
\hline CHEMBL1447370 & 688816 & 4.65 & 5.2877 & TRN & \\
\hline CHEMBL1369228 & 688816 & 4.95 & 5.1079 & TRN & \\
\hline CHEMBL1352538 & 688816 & 4.95 & 5.5933 & TRN & \\
\hline CHEMBL1454039 & 688816 & 4.85 & 5.1296 & TRN & \\
\hline CHEMBL1303315 & 688816 & 4.85 & 5.0624 & TRN & \\
\hline CHEMBL1585523 & 688816 & 5.25 & 5.8522 & TST & \\
\hline CHEMBL1468098 & 688816 & 5.5 & 5.3945 & TST & \\
\hline CHEMBL1433331 & 688816 & 4.85 & 5.33200 & 0000000001 & TRN \\
\hline CHEMBL1478232 & 688816 & 4.8 & 4.9427 & TRN & \\
\hline CHEMBL1419762 & 688816 & 4.5 & 5.1262 & TRN & \\
\hline CHEMBL1475378 & 688816 & 4.95 & 5.2394 & TRN & \\
\hline CHEMBL1309471 & 688816 & 5.35 & 5.8174 & TRN & \\
\hline CHEMBL1417847 & 688816 & 5.7 & 5.2318 & TST & \\
\hline CHEMBL1539969 & 688816 & 4.8 & 5.0871 & TRN & \\
\hline CHEMBL1401041 & 688816 & 4.7 & 5.6334 & TST & \\
\hline CHEMBL1335529 & 688816 & 4.95 & 4.9779 & TST & \\
\hline CHEMBL1371479 & 688816 & 5.4 & 5.3763 & TRN & \\
\hline CHEMBL3197831 & 688816 & 4.95 & 5.2176 & TRN & \\
\hline CHEMBL1365670 & 688816 & 4.9 & 5.1076 & TRN & \\
\hline CHEMBL1581994 & 688816 & 4.9 & 5.4483 & TRN & \\
\hline CHEMBL3210338 & 688816 & 4.9 & 5.8518 & TRN & \\
\hline CHEMBL1375823 & 688816 & 4.85 & 5.5493 & TRN & \\
\hline CHEMBL1559159 & 688816 & 5.0 & 5.0794 & TST & \\
\hline CHEMBL1418912 & 688816 & 4.45 & 4.8647 & TRN & \\
\hline CHEMBL1339432 & 688816 & 5.0 & 4.9489 & TRN & \\
\hline CHEMBL1402615 & 688816 & 6.0 & 4.9879 & TRN & \\
\hline CHEMBL1452817 & 688816 & 4.45 & 5.0423 & TRN & \\
\hline CHEMBL1349282 & 688816 & 4.65 & 4.8836 & TRN & \\
\hline CHEMBL1380199 & 688816 & 5.95 & 5.1332 & TRN & \\
\hline CHEMBL1576330 & 688816 & 4.95 & 4.73 & TST & \\
\hline CHEMBL1989847 & 688816 & 4.85 & 5.1307 & TST & \\
\hline CHEMBL1496801 & 688816 & 5.4 & 5.3072 & TST & \\
\hline CHEMBL1508791 & 688816 & 4.55 & 5.0489 & TST & \\
\hline CHEMBL1372244 & 688816 & 5.85 & 5.4277 & TRN & \\
\hline CHEMBL1512069 & 688816 & 4.9 & 5.0766 & TRN & \\
\hline CHEMBL1597878 & 688816 & 4.75 & 5.1647 & TRN & \\
\hline CHEMBL1555747 & 688816 & 4.9 & 5.4792 & TRN & \\
\hline CHEMBL1303211 & 688816 & 6.7501 & 5.529 & TRN & \\
\hline CHEMBL1351769 & 688816 & 4.85 & 5.0507 & TRN & \\
\hline
\end{tabular}




\begin{tabular}{|c|c|c|c|c|c|}
\hline \multicolumn{6}{|c|}{ Supplemental Table S2.txt } \\
\hline CHEMBL1300793 & 688816 & 5.2 & 5.3542 & TRN & \\
\hline CHEMBL1328639 & 688816 & 4.45 & 5.6387 & TRN & \\
\hline CHEMBL1531399 & 688816 & 7.0 & 5.0526 & TST & \\
\hline CHEMBL1549472 & 688816 & 4.5 & 5.1928 & TRN & \\
\hline CHEMBL1574127 & 688816 & 4.8 & 5.3689 & TRN & \\
\hline CHEMBL1302432 & 688816 & 5.35 & 5.4598 & TRN & \\
\hline CHEMBL1993173 & 688816 & 4.95 & 5.1604 & TRN & \\
\hline CHEMBL1508138 & 688816 & 4.85 & 5.0158 & TRN & \\
\hline CHEMBL3192051 & 688816 & 5.6 & 5.348 & TRN & \\
\hline CHEMBL1504403 & 688816 & 5.15 & 5.42899 & 9999999999 & TRN \\
\hline CHEMBL1515077 & 688816 & 4.45 & 4.9542 & TRN & \\
\hline CHEMBL1500256 & 688816 & 4.45 & 5.0424 & TRN & \\
\hline CHEMBL1574843 & 688816 & 5.7 & 5.9526 & TST & \\
\hline CHEMBL1425861 & 688816 & 4.45 & 5.4283 & TRN & \\
\hline CHEMBL1539591 & 688816 & 4.45 & 5.2234 & TRN & \\
\hline CHEMBL1303320 & 688816 & 5.55 & 5.4186 & TRN & \\
\hline CHEMBL1310555 & 688816 & 5.95 & 5.5275 & TRN & \\
\hline CHEMBL1469710 & 688816 & 4.75 & 5.1669 & TRN & \\
\hline CHEMBL1335494 & 688816 & 4.95 & 5.0082 & TST & \\
\hline CHEMBL1509175 & 688816 & 4.45 & 5.7567 & TRN & \\
\hline CHEMBL1483112 & 688816 & 5.7 & 4.8497 & TRN & \\
\hline CHEMBL1491053 & 688816 & 5.05 & 5.1544 & TRN & \\
\hline CHEMBL1420628 & 688816 & 4.75 & 5.2217 & TRN & \\
\hline CHEMBL1522185 & 688816 & 5.0 & 5.1626 & TRN & \\
\hline CHEMBL1507441 & 688816 & 4.45 & 4.8783 & TRN & \\
\hline CHEMBL1417191 & 688816 & 4.75 & 4.9154 & TRN & \\
\hline CHEMBL1452716 & 688816 & 5.85 & 5.5394 & TST & \\
\hline CHEMBL1562618 & 688816 & 4.45 & 5.2886 & TRN & \\
\hline CHEMBL1435576 & 688816 & 4.7 & 4.8421 & TRN & \\
\hline CHEMBL 388931 & 688816 & 5.6 & 5.7573 & TRN & \\
\hline CHEMBL1567835 & 688816 & 4.9 & 5.3903 & TRN & \\
\hline CHEMBL1432218 & 688816 & 4.9 & 4.7523 & TRN & \\
\hline CHEMBL 3198786 & 688816 & 5.45 & 5.358 & TRN & \\
\hline CHEMBL1567103 & 688816 & 4.85 & 4.8158 & TST & \\
\hline CHEMBL1507324 & 688816 & 5.2 & 4.7722 & TRN & \\
\hline CHEMBL1510734 & 688816 & 4.45 & 5.4239 & TRN & \\
\hline CHEMBL1527372 & 688816 & 4.95 & 5.1006 & TRN & \\
\hline CHEMBL1546812 & 688816 & 4.65 & 5.5615 & TRN & \\
\hline CHEMBL1301609 & 688816 & 5.25 & 5.118 & TRN & \\
\hline CHEMBL1469228 & 688816 & 4.5 & 5.2403 & TST & \\
\hline CHEMBL1338492 & 688816 & 4.95 & 5.3875 & TRN & \\
\hline CHEMBL1554608 & 688816 & 6.5501 & 5.3759 & TRN & \\
\hline CHEMBL1609329 & 688816 & 5.35 & 5.5316 & TRN & \\
\hline CHEMBL1383299 & 688816 & 5.25 & 5.6844 & TST & \\
\hline CHEMBL1366462 & 688816 & 8.3468 & 5.7571 & TRN & \\
\hline CHEMBL1362871 & 688816 & 6.7501 & 5.3318 & TST & \\
\hline CHEMBL1467893 & 688816 & 4.95 & 5.2679 & TRN & \\
\hline CHEMBL1390242 & 688816 & 5.05 & 5.1711 & TRN & \\
\hline
\end{tabular}




\begin{tabular}{|c|c|c|c|c|c|}
\hline & & \multicolumn{4}{|c|}{ Supplemental Table s2.txt } \\
\hline CHEMBL1352153 & 688816 & 4.55 & 4.9055 & TRN & \\
\hline CHEMBL1485424 & 688816 & 5.2 & 5.4424 & TST & \\
\hline CHEMBL1492474 & 688816 & 4.95 & 5.0817 & TST & \\
\hline CHEMBL1461715 & 688816 & 4.85 & 5.263 & TRN & \\
\hline CHEMBL1540841 & 688816 & 5.15 & 5.0809 & TRN & \\
\hline CHEMBL1363351 & 688816 & 4.9 & 5.228 & TRN & \\
\hline CHEMBL1468577 & 688816 & 5.25 & 4.8282 & TRN & \\
\hline CHEMBL1593766 & 688816 & 4.45 & 5.042 & TRN & \\
\hline CHEMBL1331213 & 688816 & 4.9 & 5.15 & TST & \\
\hline CHEMBL1499406 & 688816 & 4.7 & 5.435 & TRN & \\
\hline CHEMBL1499209 & 688816 & 4.9 & 5.1968 & TRN & \\
\hline CHEMBL1401953 & 688816 & 4.7 & 5.0344 & TRN & \\
\hline CHEMBL1390593 & 688816 & 4.7 & 5.1521 & TRN & \\
\hline CHEMBL1536066 & 688816 & 5.45 & 5.2655 & TST & \\
\hline CHEMBL1461080 & 688816 & 5.25 & 4.6888 & TRN & \\
\hline CHEMBL1473491 & 688816 & 4.65 & 5.3031 & TRN & \\
\hline CHEMBL1573874 & 688816 & 4.8 & 4.9561 & TRN & \\
\hline CHEMBL1466554 & 688816 & 4.95 & 5.1526 & TRN & \\
\hline CHEMBL1308092 & 688816 & 5.75 & 5.3799 & TRN & \\
\hline CHEMBL1302314 & 688816 & 5.1 & 5.1424 & TRN & \\
\hline CHEMBL1458410 & 688816 & 5.25 & 5.4275 & TRN & \\
\hline CHEMBL1427254 & 688816 & 4.45 & 5.5427 & TRN & \\
\hline CHEMBL1608945 & 688816 & 4.8 & 5.3615 & TRN & \\
\hline CHEMBL1572378 & 688816 & 4.75 & 5.17700 & 00000000005 & TRN \\
\hline CHEMBL1412344 & 688816 & 4.95 & 5.0576 & TRN & \\
\hline CHEMBL1341575 & 688816 & 5.0 & 4.7882 & TRN & \\
\hline CHEMBL1587301 & 688816 & 4.65 & 4.917 & TRN & \\
\hline CHEMBL1472249 & 688816 & 4.85 & 5.3539 & TRN & \\
\hline CHEMBL1404710 & 688816 & 4.7 & 5.3061 & TST & \\
\hline CHEMBL1559239 & 688816 & 4.95 & 4.7078 & TRN & \\
\hline CHEMBL1341995 & 688816 & 4.75 & 5.1496 & TRN & \\
\hline CHEMBL1429589 & 688816 & 4.7 & 5.21299 & 9999999999 & TRN \\
\hline CHEMBL1494181 & 688816 & 5.15 & 5.1514 & TRN & \\
\hline CHEMBL1409398 & 688816 & 4.9 & 5.2672 & TST & \\
\hline CHEMBL1565594 & 688816 & 5.9 & 5.5146 & TRN & \\
\hline CHEMBL575073 & 688816 & 4.9 & 5.2451 & TRN & \\
\hline CHEMBL3212589 & 688816 & 6.5 & 5.1904 & TRN & \\
\hline CHEMBL1455345 & 688816 & 4.45 & 5.3174 & TRN & \\
\hline CHEMBL1607629 & 688816 & 4.85 & 5.2548 & TRN & \\
\hline CHEMBL1414036 & 688816 & 5.1 & 4.9834 & TRN & \\
\hline CHEMBL70582 & 688816 & 4.95 & 5.4833 & TST & \\
\hline CHEMBL1323165 & 688816 & 4.95 & 5.3078 & TRN & \\
\hline CHEMBL1606706 & 688816 & 4.8 & 5.3131 & TST & \\
\hline CHEMBL1583585 & 688816 & 5.6 & 5.3225 & TRN & \\
\hline CHEMBL1413150 & 688816 & 4.75 & 5.4526 & TRN & \\
\hline CHEMBL1307707 & 688816 & 4.9 & 5.0164 & TRN & \\
\hline CHEMBL1543066 & 688816 & 6.2 & 5.1524 & TST & \\
\hline CHEMBL1488927 & 688816 & 4.65 & 5.5245 & TST & \\
\hline
\end{tabular}




\begin{tabular}{|c|c|c|c|c|}
\hline \multicolumn{5}{|c|}{ Supplemental Table s2.txt } \\
\hline CHEMBL1334877 & 688816 & 4.6 & 4.9646 & TRN \\
\hline CHEMBL1548714 & 688816 & 4.9 & 5.191 & TRN \\
\hline CHEMBL1373944 & 688816 & 4.9 & 5.4852 & TRN \\
\hline CHEMBL1464561 & 688816 & 4.9 & 5.2383 & TRN \\
\hline CHEMBL1355364 & 688816 & 4.45 & 5.2956 & TRN \\
\hline CHEMBL1378671 & 688816 & 6.1 & 5.8217 & TRN \\
\hline CHEMBL1603033 & 688816 & 6.7501 & 5.0325 & TST \\
\hline CHEMBL1505665 & 688816 & 4.75 & 5.7842 & TRN \\
\hline CHEMBL1425981 & 688816 & 4.7 & 4.8271 & TRN \\
\hline CHEMBL1462991 & 688816 & 5.75 & 5.3016 & TRN \\
\hline CHEMBL1456451 & 688816 & 5.0 & 5.4484 & TRN \\
\hline CHEMBL 3212258 & 688816 & 4.5 & 5.3861 & TST \\
\hline CHEMBL1409082 & 688816 & 4.8 & 5.1972 & TRN \\
\hline CHEMBL1518348 & 688816 & 5.15 & 4.9947 & TRN \\
\hline CHEMBL1342546 & 688816 & 5.0 & 5.2462 & TRN \\
\hline CHEMBL1438625 & 688816 & 4.95 & 5.0502 & TST \\
\hline CHEMBL1570227 & 688816 & 5.2 & 5.1531 & TRN \\
\hline CHEMBL1984924 & 688816 & 4.6 & 4.883 & TRN \\
\hline CHEMBL1534171 & 688816 & 4.9 & 5.3423 & TRN \\
\hline CHEMBL1317810 & 688816 & 4.9 & 5.28700 & 0000000001 \\
\hline CHEMBL3208459 & 688816 & 4.85 & 5.3377 & TST \\
\hline CHEMBL1553821 & 688816 & 4.5 & 4.9597 & TRN \\
\hline CHEMBL1496161 & 688816 & 4.75 & 5.4408 & TRN \\
\hline CHEMBL1371573 & 688816 & 4.7 & 5.5035 & TRN \\
\hline CHEMBL1413322 & 688816 & 4.45 & 5.1489 & TST \\
\hline CHEMBL1385138 & 688816 & 4.9 & 5.0352 & TRN \\
\hline CHEMBL1417249 & 688816 & 5.05 & 5.1515 & TRN \\
\hline CHEMBL1459113 & 688816 & 4.7 & 4.9986 & TRN \\
\hline CHEMBL1366037 & 688816 & 4.95 & 5.3229 & TRN \\
\hline CHEMBL1967837 & 688816 & 8.4949 & 5.1926 & TRN \\
\hline CHEMBL1466104 & 688816 & 4.95 & 5.3953 & TRN \\
\hline CHEMBL1359570 & 688816 & 7.0 & 5.48 & TST \\
\hline CHEMBL1399543 & 688816 & 4.55 & 5.099 & TRN \\
\hline CHEMBL1488735 & 688816 & 4.8 & 5.0851 & TRN \\
\hline CHEMBL1420656 & 688816 & 7.5003 & 5.2206 & TRN \\
\hline CHEMBL3195873 & 688816 & 5.7 & 5.438 & TRN \\
\hline CHEMBL1485264 & 688816 & 4.95 & 4.9781 & TRN \\
\hline CHEMBL1570716 & 688816 & 4.45 & 5.025 & TRN \\
\hline CHEMBL1539893 & 688816 & 4.65 & 5.1658 & TST \\
\hline CHEMBL1303987 & 688816 & 5.5 & 5.6288 & TRN \\
\hline CHEMBL485683 & 688816 & 5.9 & 5.7675 & TRN \\
\hline CHEMBL1469579 & 688816 & 5.2 & 4.8135 & TRN \\
\hline CHEMBL1364598 & 688816 & 4.9 & 5.2328 & TRN \\
\hline CHEMBL1584855 & 688816 & 4.8 & 5.1908 & TRN \\
\hline CHEMBL1588627 & 688816 & 4.95 & 5.5245 & TRN \\
\hline CHEMBL1329269 & 688816 & 4.95 & 5.3038 & TRN \\
\hline CHEMBL1548871 & 688816 & 4.45 & 5.1593 & TRN \\
\hline CHEMBL1449575 & 688816 & 4.55 & 5.4123 & TST \\
\hline
\end{tabular}

TRN 


\begin{tabular}{|c|c|c|c|c|c|}
\hline & & & & & \\
\hline CHEMBL1372488 & 688816 & 5.3 & 5.1361 & TRN & \\
\hline CHEMBL1525080 & 688816 & 4.45 & 5.3112 & TST & \\
\hline CHEMBL1304106 & 688816 & 4.75 & 5.6616 & TRN & \\
\hline CHEMBL1062 & 688816 & 5.65 & 5.7469 & TRN & \\
\hline CHEMBL1600887 & 688816 & 6.0 & 5.3068 & TRN & \\
\hline CHEMBL1583096 & 688816 & 5.15 & 5.3329 & TST & \\
\hline CHEMBL1434787 & 688816 & 4.45 & 5.0841 & TRN & \\
\hline CHEMBL1318092 & 688816 & 5.55 & 5.0247 & TRN & \\
\hline CHEMBL1304397 & 688816 & 4.95 & 4.8912 & TRN & \\
\hline CHEMBL1374135 & 688816 & 6.3 & 5.2103 & TRN & \\
\hline CHEMBL1401498 & 688816 & 4.95 & 4.9146 & TRN & \\
\hline CHEMBL1470997 & 688816 & 4.75 & 5.0896 & TRN & \\
\hline CHEMBL1982308 & 688816 & 4.65 & 4.9074 & TST & \\
\hline CHEMBL1568793 & 688816 & 4.95 & 5.1323 & TRN & \\
\hline CHEMBL3190250 & 688816 & 4.95 & 5.1362 & TRN & \\
\hline CHEMBL1428196 & 688816 & 5.5 & 5.5059 & TRN & \\
\hline CHEMBL1348171 & 688816 & 4.85 & 5.42399 & 99999999995 & TRN \\
\hline CHEMBL1609819 & 688816 & 4.85 & 5.3053 & TST & \\
\hline CHEMBL1310726 & 688816 & 4.95 & 5.251 & TRN & \\
\hline CHEMBL1446248 & 688816 & 4.95 & 5.6714 & TRN & \\
\hline CHEMBL1329638 & 688816 & 4.45 & 5.2521 & TRN & \\
\hline CHEMBL1494135 & 688816 & 4.65 & 5.3395 & TST & \\
\hline CHEMBL1310397 & 688816 & 6.9 & 5.4877 & TRN & \\
\hline CHEMBL1335226 & 688816 & 4.75 & 5.3372 & TRN & \\
\hline CHEMBL1376163 & 688816 & 4.95 & 5.2157 & TRN & \\
\hline CHEMBL1484097 & 688816 & 4.9 & 5.273 & TRN & \\
\hline CHEMBL1308455 & 688816 & 4.45 & 4.9277 & TST & \\
\hline CHEMBL1382723 & 688816 & 4.95 & 5.2008 & TRN & \\
\hline CHEMBL1524294 & 688816 & 5.0 & 5.2238 & TST & \\
\hline CHEMBL1301322 & 688816 & 4.8 & 5.4359 & TRN & \\
\hline CHEMBL553503 & 688816 & 4.45 & 5.2607 & TST & \\
\hline CHEMBL1581944 & 688816 & 4.7 & 5.0017 & TST & \\
\hline CHEMBL1487513 & 688816 & 4.9 & 4.9574 & TRN & \\
\hline CHEMBL1441548 & 688816 & 4.8 & 5.1539 & TRN & \\
\hline CHEMBL1399924 & 688816 & 5.0 & 5.5466 & TRN & \\
\hline CHEMBL1352898 & 688816 & 4.65 & 5.19 & TRN & \\
\hline CHEMBL1383378 & 688816 & 4.95 & 5.2052 & TRN & \\
\hline CHEMBL1488820 & 688816 & 5.65 & 5.0794 & TRN & \\
\hline CHEMBL1337645 & 688816 & 5.25 & 5.1522 & TRN & \\
\hline CHEMBL1336113 & 688816 & 4.8 & 5.1457 & TST & \\
\hline CHEMBL1506167 & 688816 & 9.1549 & 5.09399 & 9999999999 & TRN \\
\hline CHEMBL1609109 & 688816 & 4.65 & 5.0318 & TRN & \\
\hline CHEMBL1569585 & 688816 & 6.0 & 5.5745 & TRN & \\
\hline CHEMBL3196686 & 688816 & 4.8 & 5.0387 & TST & \\
\hline CHEMBL1499121 & 688816 & 5.0 & 5.36600 & 00000000005 & TRN \\
\hline CHEMBL1366997 & 688816 & 4.65 & 5.46700 & 00000000005 & TST \\
\hline CHEMBL1605099 & 688816 & 4.9 & 5.3538 & TRN & \\
\hline CHEMBL1481796 & 688816 & 6.5 & 5.3195 & TRN & \\
\hline & & & & 24903 & \\
\hline
\end{tabular}




\begin{tabular}{|c|c|c|c|c|c|}
\hline \multicolumn{6}{|c|}{ Supplemental Table S2.txt } \\
\hline CHEMBL1464157 & 688816 & 4.75 & 5.1523 & TRN & \\
\hline CHEMBL1594208 & 688816 & 8.301 & 5.3279 & TST & \\
\hline CHEMBL1595697 & 688816 & 4.8 & 5.4614 & TRN & \\
\hline CHEMBL1462691 & 688816 & 6.15 & 5.2998 & TST & \\
\hline CHEMBL1412100 & 688816 & 7.5498 & 5.7063 & TRN & \\
\hline CHEMBL1588123 & 688816 & 4.9 & 5.0884 & TST & \\
\hline CHEMBL1400525 & 688816 & 5.25 & 5.5219 & TRN & \\
\hline CHEMBL1609492 & 688816 & 4.9 & 5.3948 & TRN & \\
\hline CHEMBL1336952 & 688816 & 6.9 & 5.5159 & TRN & \\
\hline CHEMBL1455963 & 688816 & 4.5 & 5.2183 & TRN & \\
\hline CHEMBL1369569 & 688816 & 5.05 & 5.1892 & TRN & \\
\hline CHEMBL1563743 & 688816 & 5.0 & 4.9628 & TRN & \\
\hline CHEMBL1987579 & 688816 & 4.6 & 5.1547 & TRN & \\
\hline CHEMBL1501307 & 688816 & 4.45 & 5.3759 & TST & \\
\hline CHEMBL1419737 & 688816 & 5.15 & 5.0217 & TRN & \\
\hline CHEMBL1349575 & 688816 & 5.05 & 4.8365 & TRN & \\
\hline CHEMBL1349572 & 688816 & 4.8 & 5.2297 & TRN & \\
\hline CHEMBL1586237 & 688816 & 4.9 & 5.2989 & TRN & \\
\hline CHEMBL 3198839 & 688816 & 4.4 & 5.3268 & TRN & \\
\hline CHEMBL1473734 & 688816 & 4.95 & 5.6108 & TST & \\
\hline CHEMBL1309378 & 688816 & 4.85 & 5.3831 & TRN & \\
\hline CHEMBL1335298 & 688816 & 4.6 & 5.3983 & TST & \\
\hline CHEMBL1996030 & 688816 & 4.45 & 5.4943 & TRN & \\
\hline CHEMBL 3189325 & 688816 & 5.45 & 5.29700 & 0000000001 & TRN \\
\hline CHEMBL1319128 & 688816 & 5.35 & 5.3988 & TST & \\
\hline CHEMBL1525858 & 688816 & 4.45 & 4.8016 & TST & \\
\hline CHEMBL1534577 & 688816 & 4.7 & 5.1145 & TRN & \\
\hline CHEMBL1716494 & 688816 & 4.75 & 5.1928 & TST & \\
\hline CHEMBL1417200 & 688816 & 4.45 & 5.1484 & TRN & \\
\hline CHEMBL1382040 & 688816 & 5.9 & 4.9709 & TST & \\
\hline CHEMBL1386092 & 688816 & 4.5 & 5.3458 & TST & \\
\hline CHEMBL1465529 & 688816 & 5.2 & 5.7666 & TRN & \\
\hline CHEMBL1464247 & 688816 & 7.7496 & 5.265 & TRN & \\
\hline CHEMBL1500543 & 688816 & 5.3 & 5.3567 & TRN & \\
\hline CHEMBL1386564 & 688816 & 4.85 & 5.1221 & TRN & \\
\hline CHEMBL1564150 & 688816 & 7.3497 & 5.0725 & TRN & \\
\hline CHEMBL1525769 & 688816 & 5.15 & 4.9924 & TRN & \\
\hline CHEMBL1562005 & 688816 & 4.65 & 5.0125 & TRN & \\
\hline CHEMBL1602259 & 688816 & 6.45 & 5.2921 & TRN & \\
\hline CHEMBL1388864 & 688816 & 6.0 & 5.0931 & TRN & \\
\hline CHEMBL1364141 & 688816 & 6.1 & 5.5036 & TRN & \\
\hline CHEMBL3189686 & 688816 & 4.95 & 5.4159 & TRN & \\
\hline CHEMBL1577413 & 688816 & 5.05 & 5.2875 & TRN & \\
\hline CHEMBL1367157 & 688816 & 6.7001 & 5.6777 & TRN & \\
\hline CHEMBL1570111 & 688816 & 4.45 & 5.1357 & TRN & \\
\hline CHEMBL1603315 & 688816 & 5.4 & 5.3375 & TRN & \\
\hline CHEMBL1334265 & 688816 & 4.45 & 5.2049 & TRN & \\
\hline CHEMBL1339780 & 688816 & 4.95 & 5.0939 & TRN & \\
\hline
\end{tabular}




\begin{tabular}{|c|c|c|c|c|}
\hline & & & pplement & al $\mathrm{T}$ \\
\hline CHEMBL1332600 & 688816 & 5.3 & 5.4329 & TST \\
\hline CHEMBL1427478 & 688816 & 5.7 & 5.3361 & TST \\
\hline CHEMBL1460449 & 688816 & 5.7 & 5.2201 & TRN \\
\hline CHEMBL1575244 & 688816 & 7.0501 & 5.3879 & TST \\
\hline CHEMBL1535361 & 688816 & 4.45 & 5.0404 & TRN \\
\hline CHEMBL1540371 & 688816 & 4.7 & 5.4445 & TST \\
\hline CHEMBL1398123 & 688816 & 4.45 & 5.2603 & TRN \\
\hline CHEMBL1422096 & 688816 & 4.8 & 5.0508 & TST \\
\hline CHEMBL1557083 & 688816 & 5.2 & 5.2898 & TRN \\
\hline CHEMBL1548966 & 688816 & 4.95 & 5.3077 & TRN \\
\hline CHEMBL1412995 & 688816 & 7.8508 & 5.7113 & TRN \\
\hline CHEMBL1406145 & 688816 & 5.5 & 5.0896 & TST \\
\hline CHEMBL1343157 & 688816 & 5.45 & 5.1389 & TRN \\
\hline CHEMBL1392412 & 688816 & 4.95 & 5.3119 & TRN \\
\hline CHEMBL1492241 & 688816 & 5.5 & 5.0277 & TRN \\
\hline CHEMBL1418314 & 688816 & 6.0 & 5.2346 & TRN \\
\hline CHEMBL1305254 & 688816 & 5.0 & 5.1861 & TST \\
\hline CHEMBL1548862 & 688816 & 4.55 & 5.0902 & TRN \\
\hline CHEMBL1313505 & 688816 & 4.45 & 4.9302 & TST \\
\hline CHEMBL1508450 & 688816 & 4.45 & 5.001 & TRN \\
\hline CHEMBL1489005 & 688816 & 5.1 & 5.0494 & TST \\
\hline CHEMBL1351345 & 688816 & 5.6 & 5.4452 & TRN \\
\hline CHEMBL1535204 & 688816 & 4.6 & 5.0968 & TST \\
\hline CHEMBL 1484622 & 688816 & 5.95 & 5.4317 & TRN \\
\hline CHEMBL1546180 & 688816 & 4.85 & 5.2972 & TRN \\
\hline CHEMBL1454850 & 688816 & 4.65 & 5.336 & TRN \\
\hline CHEMBL1353606 & 688816 & 5.25 & 5.3955 & TRN \\
\hline CHEMBL1575351 & 688816 & 4.9 & 5.443 & TRN \\
\hline CHEMBL1535757 & 688816 & 4.75 & 5.2622 & TRN \\
\hline CHEMBL1339117 & 688816 & 4.95 & 5.3389 & TRN \\
\hline CHEMBL1500516 & 688816 & 8.3468 & 5.4796 & TST \\
\hline CHEMBL1535638 & 688816 & 4.45 & 5.8616 & TST \\
\hline CHEMBL1567331 & 688816 & 5.3 & 5.1139 & TRN \\
\hline CHEMBL1609175 & 688816 & 5.0 & 5.2819 & TST \\
\hline CHEMBL1326357 & 688816 & 4.95 & 5.2564 & TRN \\
\hline CHEMBL1486638 & 688816 & 4.65 & 5.3127 & TST \\
\hline CHEMBL1443834 & 688816 & 4.7 & 5.1401 & TRN \\
\hline CHEMBL1410645 & 688816 & 7.6498 & 6.1377 & TST \\
\hline CHEMBL 3189801 & 688816 & 4.85 & 5.1798 & TRN \\
\hline CHEMBL1544832 & 688816 & 4.95 & 5.2308 & TST \\
\hline CHEMBL3211454 & 688816 & 5.9 & 5.4561 & TST \\
\hline CHEMBL1424915 & 688816 & 4.9 & 5.1392 & TRN \\
\hline CHEMBL1362194 & 688816 & 4.9 & 5.0347 & TRN \\
\hline CHEMBL 1478644 & 688816 & 5.15 & 5.3991 & TRN \\
\hline CHEMBL1517566 & 688816 & 6.7501 & 5.3957 & TST \\
\hline CHEMBL1574311 & 688816 & 4.95 & 5.6685 & TRN \\
\hline CHEMBL1445979 & 688816 & 4.8 & 5.4027 & TRN \\
\hline CHEMBL1085765 & 688816 & 4.45 & 5.085 & TST \\
\hline
\end{tabular}




\begin{tabular}{|c|c|c|c|c|}
\hline \multicolumn{5}{|c|}{ Supplemental Table S2.txt } \\
\hline CHEMBL1300729 & 688816 & 4.45 & 4.6034 & TRN \\
\hline CHEMBL1444275 & 688816 & 4.45 & 5.29200 & 0000000001 \\
\hline CHEMBL1610557 & 688816 & 4.95 & 5.3004 & TRN \\
\hline CHEMBL1540073 & 688816 & 5.25 & 5.3862 & TRN \\
\hline CHEMBL1605061 & 688816 & 5.2 & 5.1889 & TRN \\
\hline CHEMBL1511867 & 688816 & 5.0 & 5.1945 & TRN \\
\hline CHEMBL1368496 & 688816 & 4.8 & 4.9844 & TRN \\
\hline CHEMBL1449391 & 688816 & 4.45 & 5.2604 & TRN \\
\hline CHEMBL1340200 & 688816 & 6.9 & 5.5245 & TST \\
\hline CHEMBL1466948 & 688816 & 5.85 & 5.1311 & TRN \\
\hline CHEMBL1531258 & 688816 & 4.5 & 4.752 & TRN \\
\hline CHEMBL1413846 & 688816 & 4.6 & 5.0238 & TRN \\
\hline CHEMBL1333901 & 688816 & 5.2 & 5.5083 & TRN \\
\hline CHEMBL1552771 & 688816 & 4.8 & 5.0895 & TRN \\
\hline CHEMBL1361562 & 688816 & 5.0 & 5.331 & TST \\
\hline CHEMBL1312654 & 688816 & 5.0 & 4.5754 & TRN \\
\hline CHEMBL1408986 & 688816 & 8.3468 & 5.2778 & TRN \\
\hline CHEMBL1432254 & 688816 & 4.7 & 5.6422 & TRN \\
\hline CHEMBL1580980 & 688816 & 4.9 & 5.426 & TRN \\
\hline CHEMBL3213042 & 688816 & 4.5 & 5.5956 & TRN \\
\hline CHEMBL1408557 & 688816 & 7.6498 & 5.5357 & TST \\
\hline CHEMBL3195833 & 688816 & 6.9 & 5.1521 & TST \\
\hline CHEMBL1398919 & 688816 & 4.8 & 5.3392 & TRN \\
\hline CHEMBL1536287 & 688816 & 4.75 & 5.2604 & TST \\
\hline CHEMBL2374027 & 688816 & 4.5 & 5.2316 & TST \\
\hline CHEMBL1332625 & 688816 & 4.85 & 4.9539 & TST \\
\hline CHEMBL3199232 & 688816 & 5.25 & 5.3794 & TRN \\
\hline CHEMBL1330716 & 688816 & 5.15 & 5.2395 & TRN \\
\hline CHEMBL1347504 & 688816 & 5.0 & 5.3404 & TRN \\
\hline CHEMBL1567017 & 688816 & 4.85 & 4.9825 & TRN \\
\hline CHEMBL1374653 & 688816 & 4.95 & 5.1444 & TRN \\
\hline CHEMBL1299633 & 688816 & 7.3497 & 5.3057 & TST \\
\hline CHEMBL1584509 & 688816 & 4.45 & 5.6147 & TST \\
\hline CHEMBL1341601 & 688816 & 4.85 & 4.835 & TST \\
\hline CHEMBL1591111 & 688816 & 4.65 & 5.1321 & TRN \\
\hline CHEMBL1579321 & 688816 & 8.1024 & 5.2587 & TRN \\
\hline CHEMBL1311207 & 688816 & 8.0506 & 5.5478 & TST \\
\hline CHEMBL1520608 & 688816 & 4.75 & 4.9677 & TRN \\
\hline CHEMBL1346147 & 688816 & 5.85 & 5.1678 & TRN \\
\hline CHEMBL1439422 & 688816 & 4.65 & 4.8886 & TRN \\
\hline CHEMBL1402192 & 688816 & 4.65 & 4.5081 & TRN \\
\hline CHEMBL1610002 & 688816 & 4.45 & 5.0132 & TST \\
\hline CHEMBL1585395 & 688816 & 5.2 & 5.6169 & TST \\
\hline CHEMBL1478754 & 688816 & 4.85 & 5.3067 & TST \\
\hline CHEMBL1415836 & 688816 & 7.5498 & 5.7566 & TRN \\
\hline CHEMBL1379159 & 688816 & 8.3468 & 5.0926 & TRN \\
\hline CHEMBL1496428 & 688816 & 4.45 & 5.033 & TRN \\
\hline CHEMBL1468256 & 688816 & 4.9 & 5.2807 & TRN \\
\hline
\end{tabular}

TRN 


\begin{tabular}{|c|c|c|c|c|c|}
\hline \multicolumn{6}{|c|}{ Supplemental Table S2.txt } \\
\hline CHEMBL1587726 & 688816 & 8.301 & 5.2251 & TRN & \\
\hline CHEMBL1399840 & 688816 & 7.15 & 5.5676 & TRN & \\
\hline CHEMBL1536507 & 688816 & 4.9 & 5.1737 & TRN & \\
\hline CHEMBL1426944 & 688816 & 5.35 & 5.2552 & TRN & \\
\hline CHEMBL1412637 & 688816 & 5.05 & 5.2128 & TRN & \\
\hline CHEMBL1332841 & 688816 & 6.7501 & 5.1168 & TRN & \\
\hline CHEMBL1428071 & 688816 & 4.45 & 5.1061 & TRN & \\
\hline CHEMBL3199765 & 688816 & 4.95 & 4.9289 & TRN & \\
\hline CHEMBL1319118 & 688816 & 4.45 & 5.41799 & 9999999999 & TST \\
\hline CHEMBL1510281 & 688816 & 4.9 & 5.3848 & TRN & \\
\hline CHEMBL1570559 & 688816 & 5.25 & 5.1913 & TRN & \\
\hline CHEMBL3193416 & 688816 & 4.95 & 5.2215 & TRN & \\
\hline CHEMBL1525532 & 688816 & 5.2 & 5.3984 & TST & \\
\hline CHEMBL1490373 & 688816 & 4.95 & 5.1664 & TST & \\
\hline CHEMBL1375376 & 688816 & 4.6 & 4.8896 & TRN & \\
\hline CHEMBL1541214 & 688816 & 6.8 & 5.0944 & TST & \\
\hline CHEMBL1586026 & 688816 & 4.95 & 5.7129 & TRN & \\
\hline CHEMBL1364090 & 688816 & 6.05 & 5.5647 & TRN & \\
\hline CHEMBL72683 & 688816 & 5.5 & 5.6107 & TRN & \\
\hline CHEMBL1313766 & 688816 & 5.2 & 5.3451 & TRN & \\
\hline CHEMBL1353759 & 688816 & 6.15 & 5.2883 & TRN & \\
\hline CHEMBL1482163 & 688816 & 7.5003 & 5.3545 & TST & \\
\hline CHEMBL1418985 & 688816 & 8.3468 & 5.8507 & TST & \\
\hline CHEMBL1602810 & 688816 & 7.2503 & 5.4115 & TST & \\
\hline CHEMBL1342771 & 688816 & 7.3497 & 5.1854 & TRN & \\
\hline CHEMBL1308437 & 688816 & 4.9 & 5.5729 & TRN & \\
\hline CHEMBL 3192214 & 688816 & 4.8 & 5.3543 & TST & \\
\hline CHEMBL154580 & 688816 & 4.65 & 5.0833 & TST & \\
\hline CHEMBL 1484278 & 688816 & 4.85 & 4.9669 & TRN & \\
\hline CHEMBL1379493 & 688816 & 4.45 & 5.3186 & TRN & \\
\hline CHEMBL1528633 & 688816 & 4.65 & 4.8474 & TST & \\
\hline CHEMBL1484509 & 688816 & 5.25 & 5.4756 & TRN & \\
\hline CHEMBL253989 & 688816 & 6.15 & 5.945 & TRN & \\
\hline CHEMBL1424541 & 688816 & 5.0 & 5.4845 & TRN & \\
\hline CHEMBL1300243 & 688816 & 4.85 & 5.7635 & TST & \\
\hline CHEMBL1323360 & 688816 & 4.9 & 5.2149 & TRN & \\
\hline CHEMBL1716038 & 688816 & 4.7 & 5.3154 & TRN & \\
\hline CHEMBL1529779 & 688816 & 4.95 & 5.2058 & TRN & \\
\hline CHEMBL1609235 & 688816 & 5.95 & 5.3315 & TRN & \\
\hline CHEMBL1465339 & 688816 & 4.45 & 4.9976 & TRN & \\
\hline CHEMBL1335760 & 688816 & 4.6 & 5.1752 & TRN & \\
\hline CHEMBL1555192 & 688816 & 4.65 & 5.2219 & TRN & \\
\hline CHEMBL1402745 & 688816 & 4.45 & 5.5714 & TRN & \\
\hline CHEMBL1604685 & 688816 & 4.85 & 5.103 & TRN & \\
\hline CHEMBL1463326 & 688816 & 5.3 & 4.8946 & TRN & \\
\hline CHEMBL1595690 & 688816 & 4.45 & 5.0736 & TRN & \\
\hline CHEMBL1470934 & 688816 & 5.1 & 5.205 & TRN & \\
\hline CHEMBL1369691 & 688816 & 6.0 & 5.1964 & TRN & \\
\hline
\end{tabular}




\begin{tabular}{|c|c|c|c|c|c|}
\hline \multicolumn{6}{|c|}{ Supplemental Table S2.txt } \\
\hline CHEMBL1466362 & 688816 & 4.65 & 5.1176 & TRN & \\
\hline CHEMBL 2006909 & 688816 & 5.95 & 5.2035 & TRN & \\
\hline CHEMBL1348463 & 688816 & 5.2 & 5.4932 & TST & \\
\hline CHEMBL3209003 & 688816 & 8.2007 & 5.4636 & TST & \\
\hline CHEMBL1531860 & 688816 & 5.35 & 5.4269 & TST & \\
\hline CHEMBL1612220 & 688816 & 4.8 & 5.2938 & TRN & \\
\hline CHEMBL1522531 & 688816 & 8.0 & 5.5734 & TRN & \\
\hline CHEMBL1497999 & 688816 & 5.35 & 4.9926 & TRN & \\
\hline CHEMBL1429739 & 688816 & 4.9 & 4.9181 & TRN & \\
\hline CHEMBL1393562 & 688816 & 4.45 & 5.4593 & TST & \\
\hline CHEMBL1301791 & 688816 & 4.65 & 4.9307 & TRN & \\
\hline CHEMBL1507274 & 688816 & 5.2 & 5.6836 & TRN & \\
\hline CHEMBL1406086 & 688816 & 5.05 & 5.3442 & TRN & \\
\hline CHEMBL1545976 & 688816 & 4.85 & 5.0651 & TRN & \\
\hline CHEMBL1446402 & 688816 & 5.15 & 5.4091 & TST & \\
\hline CHEMBL1531037 & 688816 & 5.0 & 5.3257 & TRN & \\
\hline CHEMBL1425916 & 688816 & 5.0 & 4.9061 & TRN & \\
\hline CHEMBL1997140 & 688816 & 8.3468 & 5.4936 & TRN & \\
\hline CHEMBL178531 & 688816 & 4.45 & 5.32799 & 9999999999 & TRN \\
\hline CHEMBL1526864 & 688816 & 4.75 & 4.9662 & TST & \\
\hline CHEMBL1595001 & 688816 & 6.2 & 5.2745 & TRN & \\
\hline CHEMBL1612208 & 688816 & 4.85 & 5.1371 & TRN & \\
\hline CHEMBL1378913 & 688816 & 5.2 & 4.9898 & TRN & \\
\hline CHEMBL1476099 & 688816 & 5.95 & 5.4873 & TRN & \\
\hline CHEMBL1558163 & 688816 & 4.95 & 5.0061 & TRN & \\
\hline CHEMBL1585214 & 688816 & 5.8 & 5.0755 & TRN & \\
\hline CHEMBL1561093 & 688816 & 4.45 & 5.371 & TRN & \\
\hline CHEMBL1607713 & 688816 & 4.9 & 5.0821 & TRN & \\
\hline CHEMBL1404611 & 688816 & 5.0 & 5.0659 & TRN & \\
\hline CHEMBL1364863 & 688816 & 7.7496 & 5.4362 & TST & \\
\hline CHEMBL1385235 & 688816 & 4.85 & 5.2493 & TRN & \\
\hline CHEMBL1532892 & 688816 & 4.65 & 5.3461 & TRN & \\
\hline CHEMBL1567220 & 688816 & 5.0 & 5.5678 & TRN & \\
\hline CHEMBL1391783 & 688816 & 5.65 & 5.7902 & TST & \\
\hline CHEMBL1321884 & 688816 & 4.95 & 5.5957 & TRN & \\
\hline CHEMBL1453572 & 688816 & 5.1 & 4.9027 & TRN & \\
\hline CHEMBL 1343389 & 688816 & 5.55 & 5.1816 & TRN & \\
\hline CHEMBL1420467 & 688816 & 5.2 & 5.09699 & 99999999995 & TRN \\
\hline CHEMBL3208173 & 688816 & 4.7 & 5.1503 & TRN & \\
\hline CHEMBL1556570 & 688816 & 5.35 & 5.1828 & TRN & \\
\hline CHEMBL1580310 & 688816 & 4.9 & 5.3771 & TRN & \\
\hline CHEMBL1319768 & 688816 & 4.85 & 4.8268 & TRN & \\
\hline CHEMBL1522572 & 688816 & 8.301 & 5.0438 & TST & \\
\hline CHEMBL1440535 & 688816 & 5.15 & 5.3148 & TST & \\
\hline CHEMBL1411847 & 688816 & 4.95 & 5.2633 & TRN & \\
\hline CHEMBL1358743 & 688816 & 6.0 & 5.5215 & TST & \\
\hline CHEMBL1560721 & 688816 & 4.45 & 5.1267 & TST & \\
\hline CHEMBL1546553 & 688816 & 7.9508 & 5.4093 & TRN & \\
\hline
\end{tabular}




\begin{tabular}{|c|c|c|c|c|c|}
\hline \multicolumn{6}{|c|}{ Supplemental Table S2.txt } \\
\hline CHEMBL1381567 & 688816 & 4.5 & 5.1231 & TRN & \\
\hline CHEMBL1479547 & 688816 & 4.45 & 5.4183 & TRN & \\
\hline CHEMBL1361821 & 688816 & 4.65 & 5.0891 & TST & \\
\hline CHEMBL 2373660 & 688816 & 8.0 & 6.0943 & TRN & \\
\hline CHEMBL1611888 & 688816 & 4.9 & 5.221 & TRN & \\
\hline CHEMBL1385355 & 688816 & 5.0 & 4.8061 & TRN & \\
\hline CHEMBL1557211 & 688816 & 5.35 & 5.0809 & TRN & \\
\hline CHEMBL1339069 & 688816 & 4.95 & 5.1142 & TRN & \\
\hline CHEMBL1583149 & 688816 & 4.55 & 5.445 & TST & \\
\hline CHEMBL1432204 & 688816 & 4.7 & 5.3415 & TRN & \\
\hline CHEMBL1382920 & 688816 & 5.2 & 5.4795 & TRN & \\
\hline CHEMBL1374633 & 688816 & 4.95 & 4.9914 & TRN & \\
\hline CHEMBL1528962 & 688816 & 4.95 & 5.362 & TRN & \\
\hline CHEMBL1527466 & 688816 & 5.7 & 5.3001 & TRN & \\
\hline CHEMBL1527851 & 688816 & 4.95 & 5.4674 & TRN & \\
\hline CHEMBL1341290 & 688816 & 4.45 & 5.3864 & TST & \\
\hline CHEMBL1373043 & 688816 & 4.9 & 5.223 & TRN & \\
\hline CHEMBL1588626 & 688816 & 5.35 & 5.2424 & TRN & \\
\hline CHEMBL1597996 & 688816 & 7.0 & 5.1423 & TRN & \\
\hline CHEMBL1513241 & 688816 & 4.95 & 5.1472 & TST & \\
\hline CHEMBL1347982 & 688816 & 5.1 & 5.1418 & TRN & \\
\hline CHEMBL1515135 & 688816 & 4.9 & 4.678 & TRN & \\
\hline CHEMBL1407183 & 688816 & 7.699 & 5.2243 & TRN & \\
\hline CHEMBL1611930 & 688816 & 4.85 & 5.5877 & TRN & \\
\hline CHEMBL1368125 & 688816 & 5.25 & 5.5259 & TST & \\
\hline CHEMBL1461546 & 688816 & 4.9 & 5.146 & TST & \\
\hline CHEMBL1536035 & 688816 & 8.301 & 5.54700 & 0000000001 & TST \\
\hline CHEMBL1417994 & 688816 & 4.85 & 5.4383 & TRN & \\
\hline CHEMBL1506508 & 688816 & 4.45 & 5.4309 & TRN & \\
\hline CHEMBL1256923 & 688816 & 8.5528 & 5.3913 & TST & \\
\hline CHEMBL1587062 & 688816 & 5.0 & 5.8072 & TRN & \\
\hline CHEMBL391351 & 688816 & 4.8 & 5.0678 & TRN & \\
\hline CHEMBL1565418 & 688816 & 5.25 & 5.3244 & TST & \\
\hline CHEMBL1349012 & 688816 & 4.8 & 5.3897 & TRN & \\
\hline CHEMBL3189987 & 688816 & 4.6 & 5.6913 & TRN & \\
\hline CHEMBL1469976 & 688816 & 4.65 & 5.3628 & TRN & \\
\hline CHEMBL3194761 & 688816 & 4.85 & 5.5477 & TRN & \\
\hline CHEMBL1356497 & 688816 & 4.9 & 5.0945 & TST & \\
\hline CHEMBL1507697 & 688816 & 8.0 & 5.5863 & TRN & \\
\hline CHEMBL1322673 & 688816 & 4.45 & 5.16799 & 9999999999 & TRN \\
\hline CHEMBL1343919 & 688816 & 5.25 & 5.5503 & TRN & \\
\hline CHEMBL1471725 & 688816 & 5.55 & 5.546 & TRN & \\
\hline CHEMBL3191158 & 688816 & 4.85 & 4.8768 & TRN & \\
\hline CHEMBL1420247 & 688816 & 4.9 & 5.0571 & TST & \\
\hline CHEMBL1566853 & 688816 & 4.95 & 5.1515 & TRN & \\
\hline CHEMBL3189270 & 688816 & 7.4498 & 5.3129 & TST & \\
\hline CHEMBL1422615 & 688816 & 8.4559 & 5.5115 & TST & \\
\hline CHEMBL1428056 & 688816 & 4.45 & 5.5048 & TRN & \\
\hline
\end{tabular}




\begin{tabular}{|c|c|c|c|c|c|}
\hline \multicolumn{6}{|c|}{ Supplemental Table S2.txt } \\
\hline CHEMBL1602508 & 688816 & 5.25 & 5.2973 & TRN & \\
\hline CHEMBL1456921 & 688816 & 4.95 & 5.4261 & TRN & \\
\hline CHEMBL1589162 & 688816 & 4.45 & 5.3959 & TRN & \\
\hline CHEMBL1548081 & 688816 & 5.85 & 5.5904 & TRN & \\
\hline CHEMBL1482602 & 688816 & 4.7 & 5.6035 & TRN & \\
\hline CHEMBL1492763 & 688816 & 4.9 & 5.1888 & TRN & \\
\hline CHEMBL1448296 & 688816 & 4.45 & 5.3245 & TRN & \\
\hline CHEMBL1564717 & 688816 & 5.05 & 5.1928 & TRN & \\
\hline CHEMBL1401831 & 688816 & 4.95 & 5.0917 & TRN & \\
\hline CHEMBL1581490 & 688816 & 8.301 & 5.1925 & TRN & \\
\hline CHEMBL1438708 & 688816 & 4.45 & 5.1485 & TRN & \\
\hline CHEMBL1442698 & 688816 & 4.65 & 5.1331 & TRN & \\
\hline CHEMBL1379105 & 688816 & 6.35 & 4.9994 & TRN & \\
\hline CHEMBL1469026 & 688816 & 5.25 & 5.6852 & TST & \\
\hline CHEMBL1480731 & 688816 & 5.0 & 5.1349 & TRN & \\
\hline CHEMBL1356766 & 688816 & 4.9 & 5.0317 & TRN & \\
\hline CHEMBL1579490 & 688816 & 4.8 & 5.1016 & TRN & \\
\hline CHEMBL1606246 & 688816 & 4.6 & 5.61299 & 99999999995 & TRN \\
\hline CHEMBL1556273 & 688816 & 4.55 & 5.1954 & TRN & \\
\hline CHEMBL1214345 & 688816 & 4.75 & 5.3172 & TRN & \\
\hline CHEMBL1418206 & 688816 & 4.95 & 5.07100 & 0000000001 & TRN \\
\hline CHEMBL42355 & 688816 & 4.8 & 5.0977 & TST & \\
\hline CHEMBL1317882 & 688816 & 4.4 & 5.4028 & TST & \\
\hline CHEMBL1609380 & 688816 & 7.6498 & 5.3234 & TRN & \\
\hline CHEMBL3207698 & 688816 & 4.8 & 5.1195 & TRN & \\
\hline CHEMBL1397626 & 688816 & 4.8 & 4.95100 & 00000000005 & TST \\
\hline CHEMBL1300171 & 688816 & 4.9 & 5.565 & TST & \\
\hline CHEMBL1501707 & 688816 & 4.45 & 5.2355 & TRN & \\
\hline CHEMBL1309310 & 688816 & 4.8 & 4.9831 & TRN & \\
\hline CHEMBL1461263 & 688816 & 5.6 & 5.3486 & TRN & \\
\hline CHEMBL1412578 & 688816 & 5.4 & 5.2836 & TRN & \\
\hline CHEMBL1490178 & 688816 & 6.6 & 5.5692 & TRN & \\
\hline CHEMBL1508037 & 688816 & 4.95 & 5.2751 & TRN & \\
\hline CHEMBL3194213 & 688816 & 4.85 & 5.29799 & 9999999999 & TRN \\
\hline CHEMBL1384990 & 688816 & 4.7 & 5.0914 & TRN & \\
\hline CHEMBL1468909 & 688816 & 4.95 & 5.1511 & TRN & \\
\hline CHEMBL 1307370 & 688816 & 8.301 & 5.4721 & TST & \\
\hline CHEMBL1465571 & 688816 & 8.301 & 5.5248 & TST & \\
\hline CHEMBL1531705 & 688816 & 5.1 & 5.184 & TRN & \\
\hline CHEMBL1521312 & 688816 & 5.65 & 5.5254 & TRN & \\
\hline CHEMBL1324690 & 688816 & 5.3 & 5.2254 & TRN & \\
\hline CHEMBL1490718 & 688816 & 4.95 & 5.6737 & TRN & \\
\hline CHEMBL1576874 & 688816 & 4.65 & 5.2976 & TST & \\
\hline CHEMBL1543919 & 688816 & 5.0 & 5.0365 & TRN & \\
\hline CHEMBL3189570 & 688816 & 4.95 & 5.2671 & TRN & \\
\hline CHEMBL1309436 & 688816 & 4.75 & 5.4171 & TRN & \\
\hline CHEMBL1308070 & 688816 & 5.75 & 5.022 & TRN & \\
\hline CHEMBL1385001 & 688816 & 7.5003 & 5.2036 & TRN & \\
\hline
\end{tabular}




\begin{tabular}{|c|c|c|c|c|}
\hline \multicolumn{5}{|c|}{ Supplemental Table S2.txt } \\
\hline CHEMBL3199869 & 688816 & 6.8 & 5.2746 & TST \\
\hline CHEMBL1544830 & 688816 & 4.9 & 5.1254 & TRN \\
\hline CHEMBL1411500 & 688816 & 5.2 & 5.3895 & TRN \\
\hline CHEMBL1504241 & 688816 & 5.65 & 5.7341 & TRN \\
\hline CHEMBL1602636 & 688816 & 4.45 & 5.7229 & TRN \\
\hline CHEMBL1582340 & 688816 & 7.3497 & 5.2584 & TRN \\
\hline CHEMBL1533351 & 688816 & 4.65 & 5.2059 & TRN \\
\hline CHEMBL131199 & 688816 & 4.8 & 5.2403 & TRN \\
\hline CHEMBL1478054 & 688816 & 4.85 & 5.3384 & TRN \\
\hline CHEMBL1571110 & 688816 & 5.15 & 5.216 & TST \\
\hline CHEMBL1490600 & 688816 & 4.6 & 5.4001 & TST \\
\hline CHEMBL1351513 & 688816 & 4.65 & 5.4181 & TRN \\
\hline CHEMBL1424555 & 688816 & 4.9 & 5.4934 & TRN \\
\hline CHEMBL1583945 & 688816 & 4.9 & 5.3752 & TST \\
\hline CHEMBL1465325 & 688816 & 6.25 & 5.6425 & TRN \\
\hline CHEMBL1605104 & 688816 & 4.95 & 4.9046 & TRN \\
\hline CHEMBL1445102 & 688816 & 4.9 & 5.4574 & TRN \\
\hline CHEMBL1401765 & 688816 & 4.85 & 5.1655 & TRN \\
\hline CHEMBL1569645 & 688816 & 4.7 & 5.3547 & TRN \\
\hline CHEMBL1491765 & 688816 & 4.95 & 4.8216 & TRN \\
\hline CHEMBL1503437 & 688816 & 4.8 & 5.5715 & TST \\
\hline CHEMBL1455565 & 688816 & 5.5 & 5.5693 & TRN \\
\hline CHEMBL3198029 & 688816 & 5.55 & 5.3173 & TRN \\
\hline CHEMBL1432872 & 688816 & 7.7496 & 5.5084 & TRN \\
\hline CHEMBL1342915 & 688816 & 4.75 & 5.211 & TST \\
\hline CHEMBL1437950 & 688816 & 4.8 & 4.9258 & TST \\
\hline CHEMBL3195074 & 688816 & 4.8 & 5.2515 & TRN \\
\hline CHEMBL262083 & 688816 & 6.0 & 5.4071 & TRN \\
\hline CHEMBL1460356 & 688816 & 4.95 & 4.9605 & TRN \\
\hline CHEMBL1375177 & 688816 & 5.75 & 5.0837 & TRN \\
\hline CHEMBL1311772 & 688816 & 5.1 & 5.0623 & TST \\
\hline CHEMBL1313436 & 688816 & 4.9 & 5.0825 & TRN \\
\hline CHEMBL1401907 & 688816 & 5.2 & 5.268 & TRN \\
\hline CHEMBL1312140 & 688816 & 4.9 & 4.8067 & TST \\
\hline CHEMBL1310554 & 688816 & 5.9 & 4.9687 & TRN \\
\hline CHEMBL1565155 & 688816 & 4.8 & 5.4218 & TRN \\
\hline CHEMBL 1358722 & 688816 & 6.0 & 6.1562 & TST \\
\hline CHEMBL1350986 & 688816 & 5.25 & 5.0307 & TRN \\
\hline CHEMBL1426254 & 688816 & 5.85 & 5.2455 & TRN \\
\hline CHEMBL1468119 & 688816 & 4.85 & 5.3078 & TRN \\
\hline CHEMBL1489260 & 688816 & 5.15 & 5.2722 & TRN \\
\hline CHEMBL1579395 & 688816 & 4.9 & 5.3623 & TST \\
\hline CHEMBL1399478 & 688816 & 5.35 & 4.8996 & TRN \\
\hline CHEMBL1365939 & 688816 & 4.8 & 5.1423 & TST \\
\hline CHEMBL1605632 & 688816 & 4.85 & 5.1924 & TRN \\
\hline CHEMBL3198285 & 688816 & 5.6 & 5.3971 & TRN \\
\hline CHEMBL1380379 & 688816 & 6.35 & 5.1666 & TST \\
\hline CHEMBL1352911 & 688816 & 4.85 & 5.0762 & TST \\
\hline
\end{tabular}




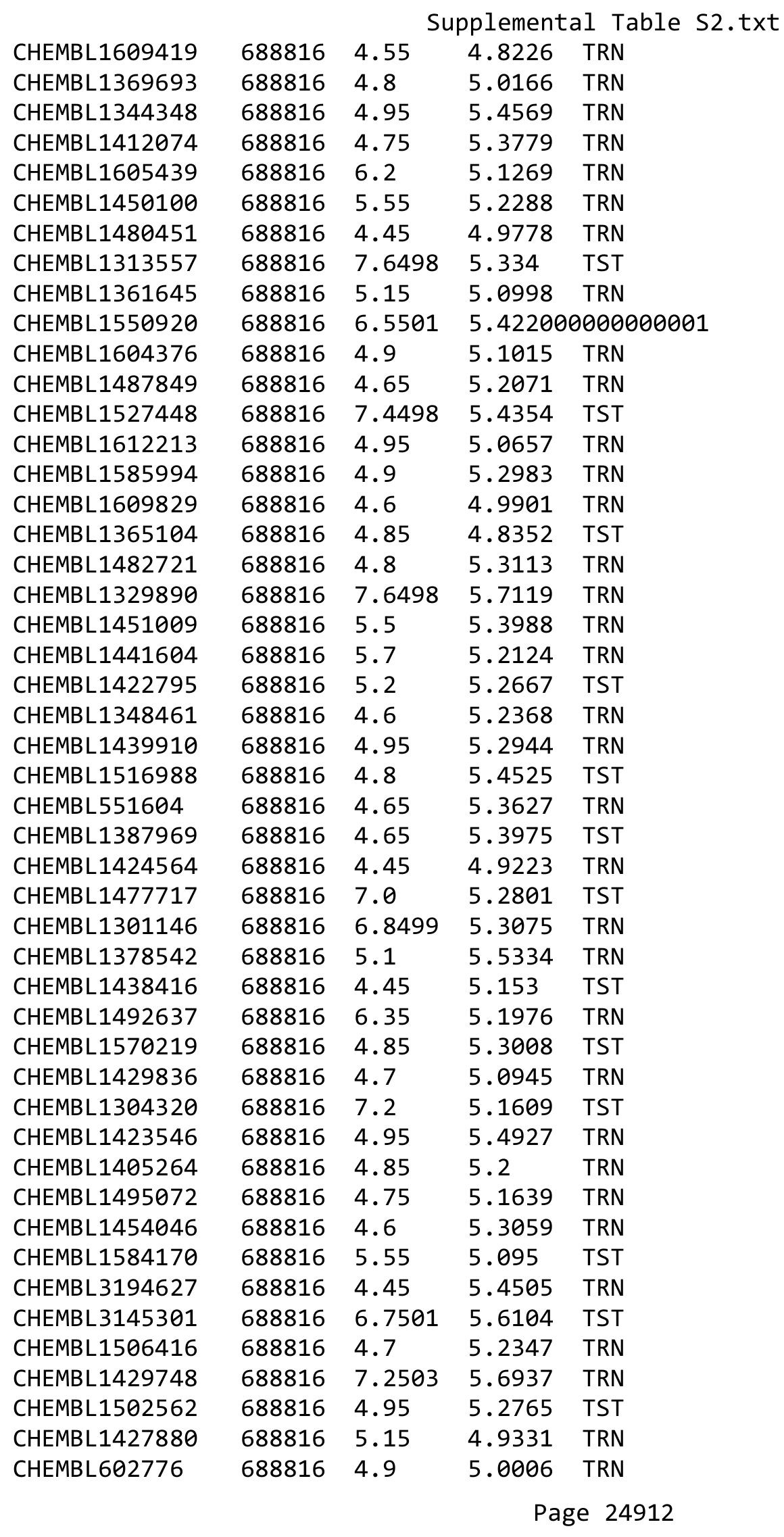




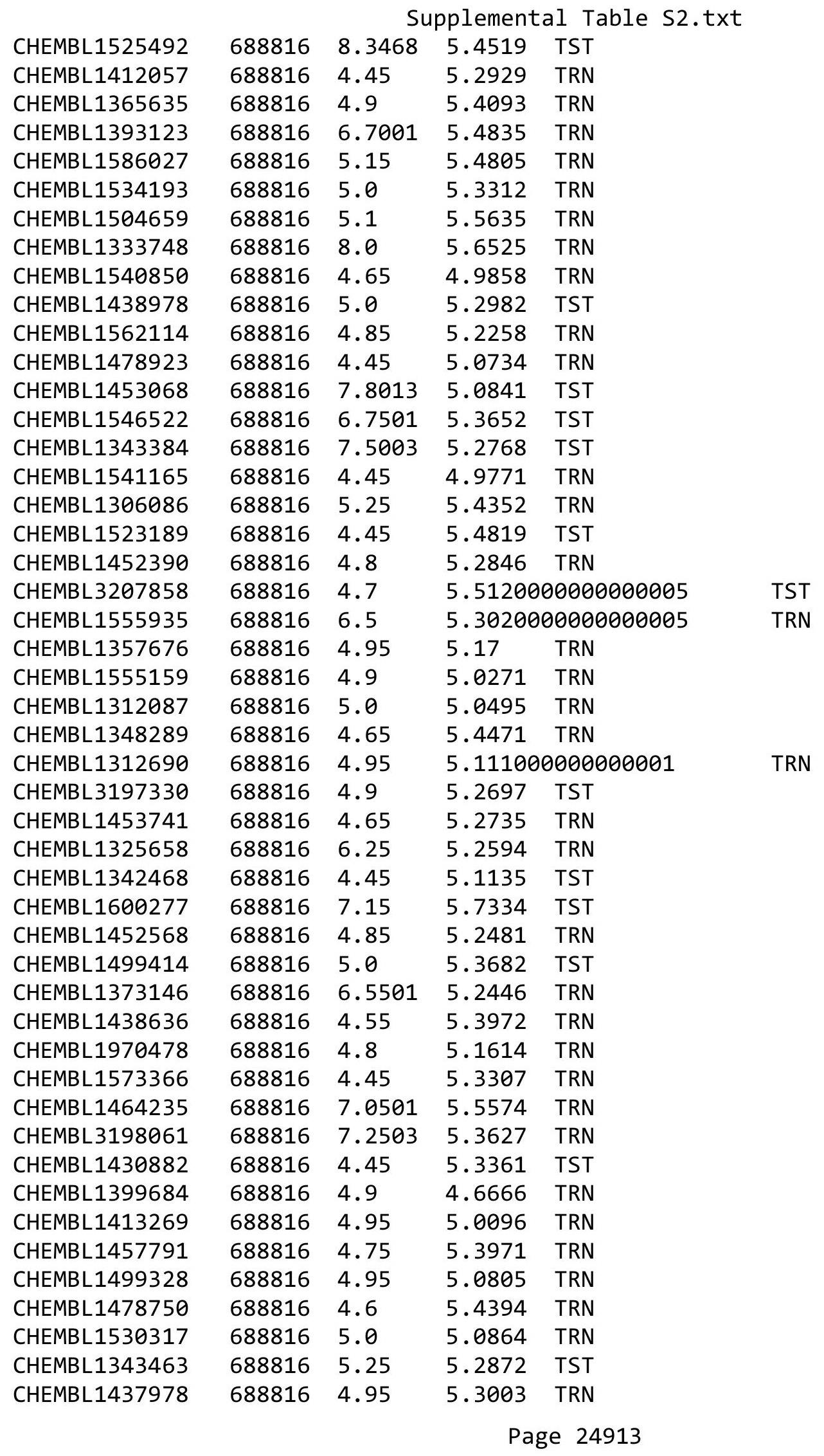




\begin{tabular}{|c|c|c|c|c|c|}
\hline \multicolumn{6}{|c|}{ Supplemental Table S2.txt } \\
\hline CHEMBL1429262 & 688816 & 6.45 & 5.3033 & TST & \\
\hline CHEMBL1503256 & 688816 & 5.5 & 5.3132 & TRN & \\
\hline CHEMBL3195990 & 688816 & 4.7 & 5.4351 & TRN & \\
\hline CHEMBL1516689 & 688816 & 4.45 & 4.9211 & TRN & \\
\hline CHEMBL1541093 & 688816 & 7.6498 & 5.0963 & TST & \\
\hline CHEMBL1348792 & 688816 & 4.5 & 5.5496 & TRN & \\
\hline CHEMBL1500469 & 688816 & 4.9 & 4.9224 & TRN & \\
\hline CHEMBL1335464 & 688816 & 5.0 & 4.9577 & TRN & \\
\hline CHEMBL1400331 & 688816 & 4.85 & 5.1852 & TST & \\
\hline CHEMBL3211065 & 688816 & 5.0 & 5.2707 & TRN & \\
\hline CHEMBL1605404 & 688816 & 8.3979 & 5.3938 & TRN & \\
\hline CHEMBL1556847 & 688816 & 4.9 & 5.1013 & TRN & \\
\hline CHEMBL1388295 & 688816 & 4.9 & 5.2218 & TRN & \\
\hline CHEMBL1502354 & 688816 & 5.1 & 5.3498 & TRN & \\
\hline CHEMBL1544502 & 688816 & 4.75 & 5.1661 & TRN & \\
\hline CHEMBL1337403 & 688816 & 6.35 & 5.57 & TRN & \\
\hline CHEMBL1452574 & 688816 & 4.7 & 5.3343 & TRN & \\
\hline CHEMBL1604396 & 688816 & 4.95 & 5.2014 & TST & \\
\hline CHEMBL 1455720 & 688816 & 4.9 & 5.3662 & TST & \\
\hline CHEMBL 1446010 & 688816 & 4.45 & 5.0895 & TRN & \\
\hline CHEMBL1415770 & 688816 & 5.05 & 5.3636 & TST & \\
\hline CHEMBL3207534 & 688816 & 5.4 & 5.3861 & TRN & \\
\hline CHEMBL1582268 & 688816 & 4.45 & 4.9995 & TRN & \\
\hline CHEMBL1299526 & 688816 & 4.45 & 5.5744 & TRN & \\
\hline CHEMBL1465138 & 688816 & 4.95 & 5.2214 & TRN & \\
\hline CHEMBL1423442 & 688816 & 4.9 & 5.474 & TST & \\
\hline CHEMBL1330034 & 688816 & 4.85 & 5.1654 & TRN & \\
\hline CHEMBL1525495 & 688816 & 4.7 & 4.8418 & TRN & \\
\hline CHEMBL1488481 & 688816 & 5.5 & 5.13299 & 9999999999 & TRN \\
\hline CHEMBL1582152 & 688816 & 5.65 & 5.5965 & TRN & \\
\hline CHEMBL1600901 & 688816 & 5.65 & 5.1151 & TRN & \\
\hline CHEMBL1597432 & 688816 & 5.05 & 5.1726 & TRN & \\
\hline CHEMBL1347404 & 688816 & 4.8 & 5.4453 & TRN & \\
\hline CHEMBL1523355 & 688816 & 5.6 & 5.2812 & TRN & \\
\hline CHEMBL1413610 & 688816 & 4.7 & 4.9676 & TRN & \\
\hline CHEMBL1578794 & 688816 & 4.5 & 5.2242 & TRN & \\
\hline CHEMBL1538772 & 688816 & 4.45 & 5.0787 & TRN & \\
\hline CHEMBL1541787 & 688816 & 5.9 & 5.4433 & TRN & \\
\hline CHEMBL1311319 & 688816 & 4.9 & 4.8524 & TRN & \\
\hline CHEMBL1583236 & 688816 & 5.05 & 5.0692 & TRN & \\
\hline CHEMBL1565562 & 688816 & 4.7 & 5.4954 & TRN & \\
\hline CHEMBL1502527 & 688816 & 4.85 & 5.2617 & TRN & \\
\hline CHEMBL1397533 & 688816 & 5.85 & 4.7737 & TRN & \\
\hline CHEMBL1470120 & 688816 & 4.9 & 5.0619 & TRN & \\
\hline CHEMBL1377200 & 688816 & 5.8 & 5.4732 & TST & \\
\hline CHEMBL1354023 & 688816 & 4.85 & 5.44799 & 99999999995 & TRN \\
\hline CHEMBL1455060 & 688816 & 5.0 & 5.6179 & TRN & \\
\hline CHEMBL1306061 & 688816 & 6.7001 & 5.3856 & TRN & \\
\hline
\end{tabular}

Page 24914 


\begin{tabular}{|c|c|c|c|c|c|}
\hline \multicolumn{6}{|c|}{ able S2. } \\
\hline CHEMBL1313479 & 688816 & 4.9 & 5.3364 & TRN & \\
\hline CHEMBL3194948 & 688816 & 6.7501 & 5.4133 & TRN & \\
\hline CHEMBL1364763 & 688816 & 4.85 & 5.4115 & TRN & \\
\hline CHEMBL1555517 & 688816 & 5.95 & 4.8346 & TST & \\
\hline CHEMBL1087460 & 688816 & 7.6498 & 5.3845 & TST & \\
\hline CHEMBL1403099 & 688816 & 5.6 & 5.2255 & TRN & \\
\hline CHEMBL1609765 & 688816 & 4.7 & 5.3871 & TRN & \\
\hline CHEMBL1452447 & 688816 & 7.5003 & 5.5087 & TST & \\
\hline CHEMBL1371489 & 688816 & 4.95 & 5.3579 & TST & \\
\hline CHEMBL1482822 & 688816 & 5.15 & 5.5894 & TST & \\
\hline CHEMBL1451845 & 688816 & 5.1 & 5.3604 & TRN & \\
\hline CHEMBL1400060 & 688816 & 4.85 & 5.0313 & TST & \\
\hline CHEMBL1461841 & 688816 & 4.45 & 5.3248 & TST & \\
\hline CHEMBL1595100 & 688816 & 4.95 & 5.1735 & TRN & \\
\hline CHEMBL1429409 & 688816 & 4.45 & 5.1132 & TRN & \\
\hline CHEMBL1463283 & 688816 & 5.1 & 5.0946 & TRN & \\
\hline CHEMBL1546497 & 688816 & 4.9 & 5.206 & TRN & \\
\hline CHEMBL1404230 & 688816 & 4.9 & 5.7091 & TRN & \\
\hline CHEMBL1405704 & 688816 & 4.8 & 5.1044 & TRN & \\
\hline CHEMBL1545179 & 688816 & 5.3 & 5.05699 & 99999999995 & TRN \\
\hline CHEMBL1600804 & 688816 & 4.45 & 5.4011 & TRN & \\
\hline CHEMBL1381043 & 688816 & 4.45 & 5.3049 & TST & \\
\hline CHEMBL1335100 & 688816 & 4.9 & 5.4164 & TRN & \\
\hline CHEMBL1367550 & 688816 & 5.4 & 5.2303 & TRN & \\
\hline CHEMBL 21260 & 688816 & 5.2 & 5.9181 & TRN & \\
\hline CHEMBL1425746 & 688816 & 5.5 & 5.1817 & TRN & \\
\hline CHEMBL1321380 & 688816 & 4.75 & 5.2291 & TRN & \\
\hline CHEMBL1327534 & 688816 & 4.45 & 4.8243 & TRN & \\
\hline CHEMBL1316223 & 688816 & 5.2 & 4.9992 & TRN & \\
\hline CHEMBL1341932 & 688816 & 4.45 & 5.129 & TST & \\
\hline CHEMBL3189317 & 688816 & 4.45 & 5.2822 & TRN & \\
\hline CHEMBL1310721 & 688816 & 4.65 & 5.1622 & TRN & \\
\hline CHEMBL1609093 & 688816 & 4.95 & 5.1895 & TRN & \\
\hline CHEMBL1408745 & 688816 & 4.95 & 5.2815 & TRN & \\
\hline CHEMBL1563685 & 688816 & 4.75 & 5.2421 & TRN & \\
\hline CHEMBL1373057 & 688816 & 4.75 & 5.6827 & TRN & \\
\hline CHEMBL1346780 & 688816 & 8.3468 & 5.5345 & TRN & \\
\hline CHEMBL1526778 & 688816 & 4.95 & 4.8195 & TRN & \\
\hline CHEMBL1441194 & 688816 & 5.3 & 5.5028 & TRN & \\
\hline CHEMBL1491445 & 688816 & 5.25 & 5.7335 & TRN & \\
\hline CHEMBL1584745 & 688816 & 4.45 & 5.41700 & 0000000001 & TRN \\
\hline CHEMBL1501562 & 688816 & 6.6 & 5.5076 & TRN & \\
\hline CHEMBL3207735 & 688816 & 6.8 & 5.2441 & TRN & \\
\hline CHEMBL1330095 & 688816 & 4.45 & 4.981 & TRN & \\
\hline CHEMBL3191208 & 688816 & 5.55 & 5.432 & TRN & \\
\hline CHEMBL1379302 & 688816 & 8.0 & 5.5037 & TRN & \\
\hline CHEMBL1532190 & 688816 & 5.45 & 5.1496 & TRN & \\
\hline CHEMBL1466712 & 688816 & 5.35 & 5.0631 & TRN & \\
\hline
\end{tabular}




\begin{tabular}{|c|c|c|c|c|c|}
\hline \multicolumn{6}{|c|}{ Supplemental Table s2.txt } \\
\hline CHEMBL1340031 & 688816 & 4.9 & 4.9827 & TRN & \\
\hline CHEMBL1416351 & 688816 & 5.15 & 5.3085 & TRN & \\
\hline CHEMBL1376803 & 688816 & 8.3468 & 5.4187 & TRN & \\
\hline CHEMBL1502732 & 688816 & 5.0 & 5.0335 & TST & \\
\hline CHEMBL1507020 & 688816 & 4.45 & 5.0481 & TRN & \\
\hline CHEMBL1382876 & 688816 & 5.2 & 5.7415 & TRN & \\
\hline CHEMBL1980982 & 688816 & 8.3468 & 5.0309 & TST & \\
\hline CHEMBL2003595 & 688816 & 4.65 & 5.2977 & TRN & \\
\hline CHEMBL1385419 & 688816 & 7.2503 & 5.0387 & TST & \\
\hline CHEMBL1304356 & 688816 & 5.0 & 5.0458 & TRN & \\
\hline CHEMBL1327845 & 688816 & 4.9 & 4.9253 & TRN & \\
\hline CHEMBL1444628 & 688816 & 5.5 & 5.2644 & TRN & \\
\hline CHEMBL1438478 & 688816 & 4.55 & 5.2705 & TRN & \\
\hline CHEMBL1425422 & 688816 & 4.9 & 5.439 & TST & \\
\hline CHEMBL1391842 & 688816 & 6.5501 & 5.2363 & TRN & \\
\hline CHEMBL1549229 & 688816 & 7.1002 & 5.3318 & TST & \\
\hline CHEMBL3195947 & 688816 & 4.45 & 5.3594 & TST & \\
\hline CHEMBL1562710 & 688816 & 5.05 & 5.231 & TRN & \\
\hline CHEMBL1608505 & 688816 & 4.85 & 5.8559 & TRN & \\
\hline CHEMBL1377785 & 688816 & 6.1 & 5.1666 & TRN & \\
\hline CHEMBL1311425 & 688816 & 4.9 & 5.1928 & TST & \\
\hline CHEMBL1320669 & 688816 & 6.8 & 5.7128 & TRN & \\
\hline CHEMBL1497781 & 688816 & 5.8 & 5.0871 & TST & \\
\hline CHEMBL1490743 & 688816 & 4.9 & 5.1662 & TRN & \\
\hline CHEMBL1383461 & 688816 & 4.9 & 5.4266 & TST & \\
\hline CHEMBL1338593 & 688816 & 4.9 & 5.2222 & TRN & \\
\hline CHEMBL3208642 & 688816 & 5.35 & 5.557 & TRN & \\
\hline CHEMBL1563293 & 688816 & 4.45 & 5.1175 & TST & \\
\hline CHEMBL1368700 & 688816 & 4.45 & 5.1278 & TST & \\
\hline CHEMBL1563483 & 688816 & 5.2 & 5.6318 & TST & \\
\hline CHEMBL1371918 & 688816 & 4.95 & 5.121 & TRN & \\
\hline CHEMBL1500454 & 688816 & 5.0 & 4.9559 & TRN & \\
\hline CHEMBL1419590 & 688816 & 6.0 & 5.1396 & TST & \\
\hline CHEMBL1542218 & 688816 & 8.3468 & 5.5531 & TRN & \\
\hline CHEMBL1585904 & 688816 & 5.95 & 5.3279 & TST & \\
\hline CHEMBL1331699 & 688816 & 5.25 & 5.5342 & TRN & \\
\hline CHEMBL1438627 & 688816 & 4.75 & 5.1277 & TRN & \\
\hline CHEMBL1465476 & 688816 & 4.6 & 5.1251 & TRN & \\
\hline CHEMBL1447896 & 688816 & 4.8 & 5.6386 & TRN & \\
\hline CHEMBL1336445 & 688816 & 4.95 & 5.8269 & TST & \\
\hline CHEMBL1547058 & 688816 & 4.9 & 4.9685 & TRN & \\
\hline CHEMBL1492972 & 688816 & 4.7 & 5.0206 & TRN & \\
\hline CHEMBL1562105 & 688816 & 4.95 & 5.07100 & 0000000001 & TRN \\
\hline CHEMBL3192582 & 688816 & 4.65 & 5.5751 & TRN & \\
\hline CHEMBL1523569 & 688816 & 4.85 & 5.4264 & TST & \\
\hline CHEMBL1557374 & 688816 & 4.6 & 5.3571 & TRN & \\
\hline CHEMBL1604951 & 688816 & 4.65 & 5.1939 & TRN & \\
\hline CHEMBL1489471 & 688816 & 4.65 & 5.4598 & TRN & \\
\hline
\end{tabular}




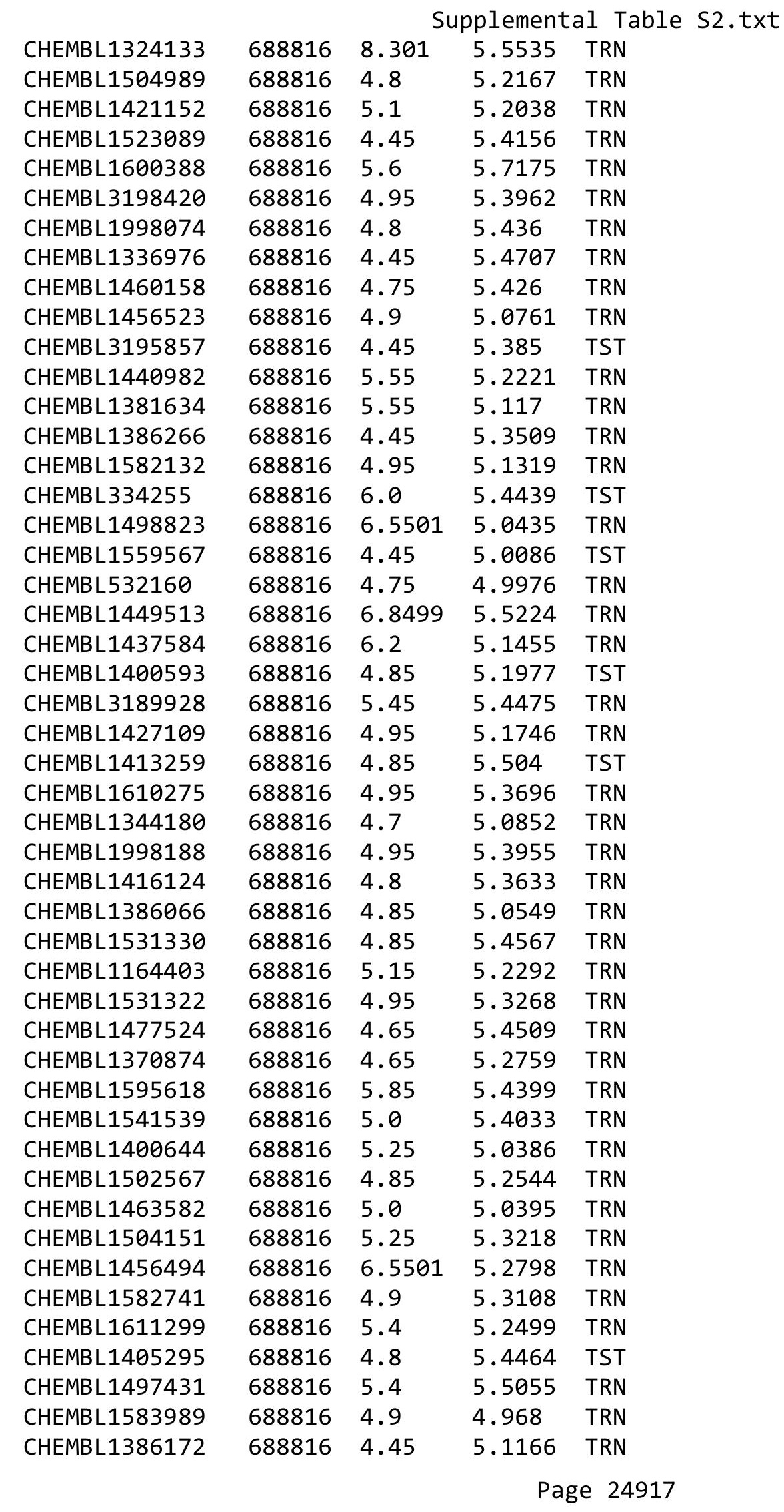




\begin{tabular}{|c|c|c|c|c|}
\hline \multicolumn{5}{|c|}{ Supplemental Table S2.txt } \\
\hline CHEMBL1313386 & 688816 & 4.7 & 5.2602 & TRN \\
\hline CHEMBL1340426 & 688816 & 8.301 & 5.2043 & TRN \\
\hline CHEMBL1312004 & 688816 & 4.45 & 5.182 & TRN \\
\hline CHEMBL1432372 & 688816 & 4.95 & 5.6311 & TRN \\
\hline CHEMBL1371535 & 688816 & 6.1 & 5.6287 & TST \\
\hline CHEMBL1404473 & 688816 & 4.45 & 5.1534 & TST \\
\hline CHEMBL1407580 & 688816 & 5.55 & 5.2136 & TRN \\
\hline CHEMBL1352380 & 688816 & 4.5 & 5.3038 & TRN \\
\hline CHEMBL1439363 & 688816 & 4.95 & 5.2143 & TRN \\
\hline CHEMBL1339340 & 688816 & 4.85 & 5.1499 & TRN \\
\hline CHEMBL1536842 & 688816 & 5.0 & 5.058 & TRN \\
\hline CHEMBL1409382 & 688816 & 6.7501 & 5.726 & TRN \\
\hline CHEMBL1493931 & 688816 & 5.25 & 5.5267 & TRN \\
\hline CHEMBL1337282 & 688816 & 5.0 & 5.3585 & TRN \\
\hline CHEMBL1369345 & 688816 & 4.85 & 5.2498 & TRN \\
\hline CHEMBL1505185 & 688816 & 4.45 & 5.0553 & TST \\
\hline CHEMBL1361251 & 688816 & 4.9 & 5.2609 & TRN \\
\hline CHEMBL1383545 & 688816 & 5.4 & 5.0077 & TRN \\
\hline CHEMBL1314885 & 688816 & 5.35 & 5.4586 & TRN \\
\hline CHEMBL1301995 & 688816 & 5.55 & 5.2544 & TRN \\
\hline CHEMBL1346485 & 688816 & 5.5 & 5.2218 & TST \\
\hline CHEMBL1305892 & 688816 & 4.8 & 5.1253 & TRN \\
\hline CHEMBL1429659 & 688816 & 5.45 & 5.5455 & TRN \\
\hline CHEMBL1440860 & 688816 & 4.75 & 5.1965 & TRN \\
\hline CHEMBL1439227 & 688816 & 4.45 & 5.0988 & TRN \\
\hline CHEMBL1575428 & 688816 & 4.45 & 5.2764 & TRN \\
\hline CHEMBL1423216 & 688816 & 8.0 & 5.4554 & TST \\
\hline CHEMBL1502716 & 688816 & 5.0 & 4.7315 & TRN \\
\hline CHEMBL1463842 & 688816 & 7.5498 & 5.3859 & TRN \\
\hline CHEMBL1528986 & 688816 & 4.75 & 4.7385 & TRN \\
\hline CHEMBL1329630 & 688816 & 4.8 & 5.4266 & TRN \\
\hline CHEMBL1575557 & 688816 & 4.9 & 5.3281 & TRN \\
\hline CHEMBL1578091 & 688816 & 4.75 & 5.4633 & TRN \\
\hline CHEMBL1604783 & 688816 & 5.6 & 5.2899 & TRN \\
\hline CHEMBL1307359 & 688816 & 7.8013 & 5.3942 & TRN \\
\hline CHEMBL1317034 & 688816 & 4.6 & 5.1095 & TRN \\
\hline CHEMBL1479967 & 688816 & 7.7496 & 5.3677 & TST \\
\hline CHEMBL1550511 & 688816 & 4.85 & 5.1521 & TST \\
\hline CHEMBL1586034 & 688816 & 4.9 & 5.2438 & TRN \\
\hline CHEMBL1329532 & 688816 & 4.8 & 5.1974 & TST \\
\hline CHEMBL1526831 & 688816 & 4.6 & 5.5525 & TST \\
\hline CHEMBL1500471 & 688816 & 8.301 & 5.1474 & TRN \\
\hline CHEMBL3198547 & 688816 & 4.65 & 5.5784 & TST \\
\hline CHEMBL1608954 & 688816 & 4.45 & 4.9611 & TRN \\
\hline CHEMBL1495974 & 688816 & 4.75 & 5.2365 & TST \\
\hline CHEMBL1595747 & 688816 & 5.45 & 5.3078 & TST \\
\hline CHEMBL1342790 & 688816 & 5.2 & 5.6614 & TRN \\
\hline CHEMBL3197567 & 688816 & 4.45 & 5.3795 & TRN \\
\hline
\end{tabular}




\begin{tabular}{|c|c|c|c|c|c|}
\hline \multicolumn{6}{|c|}{ Supplemental Table S2.txt } \\
\hline CHEMBL1409100 & 688816 & 4.6 & 5.095 & TRN & \\
\hline CHEMBL1328601 & 688816 & 5.45 & 5.0571 & TST & \\
\hline CHEMBL1421478 & 688816 & 4.45 & 5.2532 & TRN & \\
\hline CHEMBL1368409 & 688816 & 5.95 & 5.4922 & TST & \\
\hline CHEMBL1377523 & 688816 & 6.8499 & 5.9173 & TST & \\
\hline CHEMBL1371655 & 688816 & 4.85 & 5.1716 & TRN & \\
\hline CHEMBL1301482 & 688816 & 5.0 & 5.2467 & TRN & \\
\hline CHEMBL1462041 & 688816 & 4.45 & 5.2339 & TRN & \\
\hline CHEMBL1569037 & 688816 & 5.0 & 5.4831 & TRN & \\
\hline CHEMBL1406181 & 688816 & 8.0506 & 5.7172 & TST & \\
\hline CHEMBL1380008 & 688816 & 4.65 & 4.9247 & TRN & \\
\hline CHEMBL1338487 & 688816 & 4.85 & 5.0645 & TRN & \\
\hline CHEMBL1518129 & 688816 & 8.3468 & 5.3462 & TST & \\
\hline CHEMBL1308335 & 688816 & 5.2 & 5.1681 & TRN & \\
\hline CHEMBL1326428 & 688816 & 4.85 & 5.2994 & TRN & \\
\hline CHEMBL1533634 & 688816 & 4.9 & 5.2732 & TRN & \\
\hline CHEMBL1340133 & 688816 & 4.75 & 5.0789 & TRN & \\
\hline CHEMBL1492029 & 688816 & 4.9 & 5.5488 & TRN & \\
\hline CHEMBL1371111 & 688816 & 5.0 & 5.4928 & TRN & \\
\hline CHEMBL1406997 & 688816 & 4.8 & 5.0517 & TRN & \\
\hline CHEMBL1570995 & 688816 & 5.2 & 5.3869 & TRN & \\
\hline CHEMBL1368375 & 688816 & 4.55 & 4.9234 & TST & \\
\hline CHEMBL1331422 & 688816 & 4.95 & 5.25299 & 9999999999 & TST \\
\hline CHEMBL1606911 & 688816 & 4.45 & 5.0214 & TRN & \\
\hline CHEMBL1539865 & 688816 & 4.45 & 4.9861 & TRN & \\
\hline CHEMBL1550074 & 688816 & 4.85 & 5.4514 & TRN & \\
\hline CHEMBL1601322 & 688816 & 8.301 & 5.3588 & TRN & \\
\hline CHEMBL1305934 & 688816 & 8.4559 & 5.2492 & TST & \\
\hline CHEMBL1194310 & 688816 & 4.85 & 5.9013 & TST & \\
\hline CHEMBL1569169 & 688816 & 5.2 & 5.5155 & TST & \\
\hline CHEMBL1318220 & 688816 & 4.95 & 5.1802 & TST & \\
\hline CHEMBL1322317 & 688816 & 4.85 & 5.2363 & TRN & \\
\hline CHEMBL3199705 & 688816 & 5.05 & 5.2075 & TRN & \\
\hline CHEMBL3197447 & 688816 & 5.25 & 5.7766 & TRN & \\
\hline CHEMBL1485561 & 688816 & 4.9 & 4.8886 & TRN & \\
\hline CHEMBL1321387 & 688816 & 5.0 & 5.3338 & TRN & \\
\hline CHEMBL1430846 & 688816 & 5.5 & 5.1981 & TST & \\
\hline CHEMBL1371124 & 688816 & 5.0 & 5.0747 & TRN & \\
\hline CHEMBL1355323 & 688816 & 6.3 & 5.4212 & TRN & \\
\hline CHEMBL1613540 & 688816 & 4.45 & 5.3776 & TST & \\
\hline CHEMBL1549166 & 688816 & 4.45 & 5.0837 & TRN & \\
\hline CHEMBL1499951 & 688816 & 4.45 & 5.16299 & 9999999999 & TST \\
\hline CHEMBL3192231 & 688816 & 4.95 & 5.5097 & TRN & \\
\hline CHEMBL1457395 & 688816 & 7.15 & 5.2592 & TST & \\
\hline CHEMBL1549437 & 688816 & 5.4 & 5.4466 & TRN & \\
\hline CHEMBL1567016 & 688816 & 4.6 & 5.2797 & TRN & \\
\hline CHEMBL1499501 & 688816 & 5.8 & 5.0694 & TRN & \\
\hline CHEMBL1383968 & 688816 & 4.85 & 5.2351 & TST & \\
\hline
\end{tabular}




\begin{tabular}{|c|c|c|c|c|c|}
\hline \multicolumn{6}{|c|}{ Supplemental Table S2.txt } \\
\hline CHEMBL1357093 & 688816 & 4.5 & 5.746 & TRN & \\
\hline CHEMBL1442285 & 688816 & 5.4 & 5.3339 & TST & \\
\hline CHEMBL1508612 & 688816 & 4.65 & 5.472 & TRN & \\
\hline CHEMBL 3192017 & 688816 & 4.8 & 4.9422 & TRN & \\
\hline CHEMBL1364592 & 688816 & 4.9 & 4.8943 & TRN & \\
\hline CHEMBL1568145 & 688816 & 4.5 & 5.1985 & TST & \\
\hline CHEMBL1448090 & 688816 & 5.0 & 5.0939 & TRN & \\
\hline CHEMBL1322368 & 688816 & 5.95 & 5.1053 & TST & \\
\hline CHEMBL1423529 & 688816 & 5.4 & 5.0808 & TRN & \\
\hline CHEMBL3194985 & 688816 & 4.8 & 5.3026 & TRN & \\
\hline CHEMBL1463642 & 688816 & 5.0 & 5.96 & TRN & \\
\hline CHEMBL1367601 & 688816 & 4.9 & 5.0289 & TST & \\
\hline CHEMBL1537258 & 688816 & 5.05 & 5.2294 & TRN & \\
\hline CHEMBL1564250 & 688816 & 4.65 & 5.0515 & TST & \\
\hline CHEMBL1596707 & 688816 & 4.95 & 5.2042 & TRN & \\
\hline CHEMBL546257 & 688816 & 6.0 & 5.6719 & TST & \\
\hline CHEMBL1350793 & 688816 & 6.8499 & 5.2008 & TST & \\
\hline CHEMBL1331458 & 688816 & 8.3979 & 5.2888 & TST & \\
\hline CHEMBL1407388 & 688816 & 5.5 & 5.0201 & TRN & \\
\hline CHEMBL3213419 & 688816 & 5.6 & 5.5094 & TRN & \\
\hline CHEMBL1556363 & 688816 & 4.95 & 5.70200 & 0000000001 & TST \\
\hline CHEMBL 380370 & 688816 & 5.05 & 5.3201 & TRN & \\
\hline CHEMBL1317276 & 688816 & 4.75 & 5.042 & TST & \\
\hline CHEMBL1433739 & 688816 & 4.95 & 5.113 & TRN & \\
\hline CHEMBL1498458 & 688816 & 4.45 & 5.2314 & TRN & \\
\hline CHEMBL1345564 & 688816 & 5.0 & 5.2356 & TRN & \\
\hline CHEMBL1509739 & 688816 & 5.0 & 5.2005 & TRN & \\
\hline CHEMBL3208475 & 688816 & 6.05 & 5.5786 & TRN & \\
\hline CHEMBL1587743 & 688816 & 5.35 & 5.3752 & TRN & \\
\hline CHEMBL1459766 & 688816 & 8.301 & 5.3964 & TRN & \\
\hline CHEMBL1314072 & 688816 & 7.15 & 5.5354 & TST & \\
\hline CHEMBL1431242 & 688816 & 4.5 & 5.1009 & TRN & \\
\hline CHEMBL1332883 & 688816 & 4.8 & 5.6345 & TST & \\
\hline CHEMBL 3213057 & 688816 & 4.9 & 5.4228 & TRN & \\
\hline CHEMBL1460226 & 688816 & 5.1 & 5.4451 & TRN & \\
\hline CHEMBL1526083 & 688816 & 7.3497 & 5.3734 & TRN & \\
\hline CHEMBL1420313 & 688816 & 4.45 & 5.274 & TRN & \\
\hline CHEMBL1492486 & 688816 & 4.75 & 5.7613 & TRN & \\
\hline CHEMBL 3195248 & 688816 & 4.9 & 5.3245 & TST & \\
\hline CHEMBL3213442 & 688816 & 4.8 & 5.5325 & TRN & \\
\hline CHEMBL1387162 & 688816 & 5.1 & 5.0295 & TRN & \\
\hline CHEMBL1439008 & 688816 & 4.6 & 5.1367 & TRN & \\
\hline CHEMBL1408752 & 688816 & 4.45 & 5.2275 & TRN & \\
\hline CHEMBL1575463 & 688816 & 4.8 & 5.3805 & TST & \\
\hline CHEMBL1484041 & 688816 & 5.1 & 5.2206 & TRN & \\
\hline CHEMBL1496476 & 688816 & 4.85 & 5.4201 & TRN & \\
\hline CHEMBL1612190 & 688816 & 4.75 & 5.1527 & TRN & \\
\hline CHEMBL1464931 & 688816 & 4.45 & 5.2399 & TRN & \\
\hline
\end{tabular}




\begin{tabular}{|c|c|c|c|c|}
\hline \multicolumn{5}{|c|}{ Supplemental Table S2.txt } \\
\hline CHEMBL1457301 & 688816 & 5.0 & 5.2583 & TST \\
\hline CHEMBL1402802 & 688816 & 5.4 & 5.6579 & TST \\
\hline CHEMBL1527766 & 688816 & 4.65 & 5.2813 & TRN \\
\hline CHEMBL 239883 & 688816 & 4.8 & 4.9345 & TRN \\
\hline CHEMBL1304919 & 688816 & 5.45 & 4.8396 & TRN \\
\hline CHEMBL1464951 & 688816 & 4.45 & 5.0777 & TRN \\
\hline CHEMBL1426729 & 688816 & 4.55 & 4.8773 & TRN \\
\hline CHEMBL1510263 & 688816 & 4.75 & 5.0022 & TRN \\
\hline CHEMBL1311077 & 688816 & 4.65 & 5.2024 & TRN \\
\hline CHEMBL1580353 & 688816 & 4.95 & 5.3254 & TST \\
\hline CHEMBL1522989 & 688816 & 4.95 & 5.1993 & TRN \\
\hline CHEMBL1491925 & 688816 & 5.2 & 5.612 & TRN \\
\hline CHEMBL1497677 & 688816 & 4.75 & 5.1918 & TRN \\
\hline CHEMBL1571004 & 688816 & 4.9 & 5.2541 & TRN \\
\hline CHEMBL1511778 & 688816 & 8.1487 & 5.3902 & TRN \\
\hline CHEMBL1572119 & 688816 & 4.65 & 5.0326 & TRN \\
\hline CHEMBL1413346 & 688816 & 6.7501 & 5.4842 & TRN \\
\hline CHEMBL1464742 & 688816 & 4.45 & 5.0666 & TRN \\
\hline CHEMBL1971120 & 688816 & 4.6 & 5.5336 & TRN \\
\hline CHEMBL1312967 & 688816 & 5.85 & 5.3673 & TRN \\
\hline CHEMBL1403123 & 688816 & 5.15 & 5.0707 & TRN \\
\hline CHEMBL1523873 & 688816 & 6.25 & 5.4894 & TRN \\
\hline CHEMBL1555913 & 688816 & 4.65 & 5.2387 & TRN \\
\hline CHEMBL1399553 & 688816 & 4.65 & 5.7642 & TST \\
\hline CHEMBL1456371 & 688816 & 4.9 & 4.9986 & TST \\
\hline CHEMBL1312064 & 688816 & 4.55 & 4.8955 & TRN \\
\hline CHEMBL1310025 & 688816 & 6.35 & 5.2275 & TRN \\
\hline CHEMBL1414265 & 688816 & 4.95 & 5.2164 & TRN \\
\hline CHEMBL1502936 & 688816 & 5.1 & 5.1653 & TRN \\
\hline CHEMBL1494200 & 688816 & 4.45 & 5.2502 & TRN \\
\hline CHEMBL1439528 & 688816 & 6.15 & 5.3691 & TRN \\
\hline CHEMBL1570719 & 688816 & 5.25 & 5.6123 & TST \\
\hline CHEMBL1536472 & 688816 & 4.45 & 5.0019 & TST \\
\hline CHEMBL1371014 & 688816 & 4.55 & 5.6342 & TRN \\
\hline CHEMBL1454617 & 688816 & 4.95 & 5.6818 & TRN \\
\hline CHEMBL1576415 & 688816 & 4.5 & 5.2403 & TRN \\
\hline CHEMBL1491222 & 688816 & 4.95 & 4.8632 & TRN \\
\hline CHEMBL1389107 & 688816 & 4.65 & 5.2506 & TRN \\
\hline CHEMBL1526938 & 688816 & 4.6 & 4.8925 & TRN \\
\hline CHEMBL1508463 & 688816 & 5.0 & 5.3816 & TRN \\
\hline CHEMBL1976917 & 688816 & 4.9 & 5.2845 & TRN \\
\hline CHEMBL1353383 & 688816 & 6.5501 & 5.3808 & TRN \\
\hline CHEMBL1343949 & 688816 & 4.95 & 5.205 & TST \\
\hline CHEMBL3213837 & 688816 & 5.5 & 5.4544 & TRN \\
\hline CHEMBL1505429 & 688816 & 4.9 & 5.3134 & TRN \\
\hline CHEMBL1341971 & 688816 & 5.3 & 5.3136 & TRN \\
\hline CHEMBL3194159 & 688816 & 5.3 & 5.4996 & TRN \\
\hline CHEMBL1560297 & 688816 & 4.45 & 5.5593 & TRN \\
\hline
\end{tabular}




\begin{tabular}{|c|c|c|c|c|c|}
\hline \multirow[b]{2}{*}{ CHEMBL1401460 } & & \multicolumn{4}{|c|}{ Supplemental Table S2.txt } \\
\hline & 688816 & 6.05 & \multicolumn{2}{|c|}{5.196000000000001} & TST \\
\hline CHEMBL1450063 & 688816 & 4.7 & \multicolumn{2}{|c|}{5.127999999999999} & TST \\
\hline CHEMBL1309857 & 688816 & 4.8 & 5.3419 & TRN & \\
\hline CHEMBL1383939 & 688816 & 5.0 & 5.6343 & TRN & \\
\hline CHEMBL1498063 & 688816 & 4.45 & 5.3327 & TRN & \\
\hline CHEMBL1346499 & 688816 & 5.2 & 5.3395 & TRN & \\
\hline CHEMBL1608330 & 688816 & 4.95 & 5.5074 & TRN & \\
\hline CHEMBL1545142 & 688816 & 4.65 & 5.4395 & TST & \\
\hline CHEMBL1353798 & 688816 & 4.95 & 5.7356 & TRN & \\
\hline CHEMBL1545674 & 688816 & 5.25 & 5.4157 & TRN & \\
\hline CHEMBL1374672 & 688816 & 6.15 & 5.7814 & TRN & \\
\hline CHEMBL1560147 & 688816 & 4.95 & 4.9797 & TST & \\
\hline CHEMBL1346136 & 688816 & 7.4001 & 5.4412 & TST & \\
\hline CHEMBL1501996 & 688816 & 4.45 & 5.3744 & TST & \\
\hline CHEMBL1598391 & 688816 & 4.7 & 4.9999 & TRN & \\
\hline CHEMBL3199613 & 688816 & 5.5 & 5.4104 & TRN & \\
\hline CHEMBL1548582 & 688816 & 4.7 & 5.3038 & TST & \\
\hline CHEMBL1521989 & 688816 & 4.6 & 5.3637 & TST & \\
\hline CHEMBL1317135 & 688816 & 6.45 & 5.8083 & TST & \\
\hline CHEMBL1342627 & 688816 & 4.95 & 5.3365 & TRN & \\
\hline CHEMBL1334701 & 688816 & 4.45 & 5.2822 & TST & \\
\hline CHEMBL1350693 & 688816 & 4.7 & 5.1605 & TST & \\
\hline CHEMBL 3199360 & 688816 & 5.4 & 5.36799 & 9999999999 & TRN \\
\hline CHEMBL1350935 & 688816 & 4.45 & 5.274 & TRN & \\
\hline CHEMBL1479974 & 688816 & 4.95 & 5.3359 & TRN & \\
\hline CHEMBL1364312 & 688816 & 4.45 & 5.5678 & TRN & \\
\hline CHEMBL1422189 & 688816 & 4.65 & 5.3785 & TST & \\
\hline CHEMBL1498547 & 688816 & 4.95 & 5.0785 & TRN & \\
\hline CHEMBL1503206 & 688816 & 5.0 & 5.2029 & TRN & \\
\hline CHEMBL1407401 & 688816 & 4.45 & 4.9872 & TST & \\
\hline CHEMBL1511802 & 688816 & 5.55 & 5.3284 & TRN & \\
\hline CHEMBL1306879 & 688816 & 5.9 & 4.9755 & TRN & \\
\hline CHEMBL 1435770 & 688816 & 5.05 & 5.3324 & TST & \\
\hline CHEMBL1868277 & 688816 & 4.6 & 5.2217 & TST & \\
\hline CHEMBL1492452 & 688816 & 4.9 & 5.5623 & TRN & \\
\hline CHEMBL1372678 & 688816 & 4.95 & 5.1174 & TRN & \\
\hline CHEMBL1556680 & 688816 & 7.6003 & 5.0651 & TST & \\
\hline CHEMBL1596066 & 688816 & 4.45 & 5.4802 & TRN & \\
\hline CHEMBL 3196573 & 688816 & 5.2 & 5.1778 & TRN & \\
\hline CHEMBL3214509 & 688816 & 5.2 & 5.6618 & TRN & \\
\hline CHEMBL1344010 & 688816 & 4.65 & 5.2813 & TRN & \\
\hline CHEMBL1335798 & 688816 & 6.6499 & 5.3356 & TRN & \\
\hline CHEMBL1457262 & 688816 & 4.9 & 5.2101 & TRN & \\
\hline CHEMBL1440857 & 688816 & 5.9 & 5.36299 & 99999999995 & TRN \\
\hline CHEMBL 3196517 & 688816 & 4.95 & 5.4843 & TRN & \\
\hline CHEMBL1363415 & 688816 & 5.1 & 5.215 & TRN & \\
\hline CHEMBL1538037 & 688816 & 5.55 & 5.1605 & TRN & \\
\hline CHEMBL1391470 & 688816 & 4.9 & 5.7282 & TRN & \\
\hline
\end{tabular}




\begin{tabular}{|c|c|c|c|c|c|}
\hline \multicolumn{6}{|c|}{ Supplemental Table S2.txt } \\
\hline CHEMBL1330929 & 688816 & 5.5 & 5.0877 & TRN & \\
\hline CHEMBL1577933 & 688816 & 4.9 & 5.3536 & TRN & \\
\hline CHEMBL1353113 & 688816 & 5.25 & 5.3382 & TRN & \\
\hline CHEMBL1331415 & 688816 & 4.85 & 5.1526 & TRN & \\
\hline CHEMBL 3189165 & 688816 & 4.75 & 5.0449 & TST & \\
\hline CHEMBL1410625 & 688816 & 5.85 & 5.2985 & TRN & \\
\hline CHEMBL1333387 & 688816 & 6.0 & 4.9659 & TRN & \\
\hline CHEMBL1578078 & 688816 & 4.45 & 5.5429 & TRN & \\
\hline CHEMBL1970082 & 688816 & 4.95 & 5.2734 & TRN & \\
\hline CHEMBL1322961 & 688816 & 5.0 & 5.5917 & TRN & \\
\hline CHEMBL1524117 & 688816 & 4.95 & 5.1907 & TST & \\
\hline CHEMBL1494635 & 688816 & 5.55 & 5.3457 & TRN & \\
\hline CHEMBL1341513 & 688816 & 4.85 & 5.2518 & TST & \\
\hline CHEMBL1520414 & 688816 & 4.95 & 4.9619 & TRN & \\
\hline CHEMBL1414129 & 688816 & 4.95 & 5.2106 & TRN & \\
\hline CHEMBL1328633 & 688816 & 6.1 & 5.5901 & TRN & \\
\hline CHEMBL1373823 & 688816 & 4.45 & 5.8899 & TRN & \\
\hline CHEMBL1499956 & 688816 & 4.65 & 4.9049 & TRN & \\
\hline CHEMBL 3213584 & 688816 & 4.6 & 5.2629 & TRN & \\
\hline CHEMBL1613548 & 688816 & 7.6003 & 5.7572 & TRN & \\
\hline CHEMBL1447010 & 688816 & 5.25 & 5.1735 & TST & \\
\hline CHEMBL1527176 & 688816 & 5.15 & 5.0419 & TRN & \\
\hline CHEMBL1533067 & 688816 & 4.9 & 5.2302 & TST & \\
\hline CHEMBL1375563 & 688816 & 5.0 & 5.276 & TRN & \\
\hline CHEMBL3209036 & 688816 & 4.7 & 4.896 & TRN & \\
\hline CHEMBL1606216 & 688816 & 5.35 & 5.9635 & TRN & \\
\hline CHEMBL1417144 & 688816 & 4.9 & 5.4517 & TRN & \\
\hline CHEMBL238624 & 688816 & 5.2 & 5.3683 & TST & \\
\hline CHEMBL1486041 & 688816 & 4.45 & 5.1856 & TST & \\
\hline CHEMBL1517036 & 688816 & 4.45 & 5.0209 & TST & \\
\hline CHEMBL8883 & 688816 & 4.85 & 5.2773 & TRN & \\
\hline CHEMBL1329458 & 688816 & 4.65 & 5.4165 & TST & \\
\hline CHEMBL1379149 & 688816 & 5.3 & 5.1049 & TST & \\
\hline CHEMBL3199612 & 688816 & 4.75 & 5.3344 & TRN & \\
\hline CHEMBL3209471 & 688816 & 5.5 & 5.7779 & TRN & \\
\hline CHEMBL1996804 & 688816 & 4.7 & 5.5327 & TRN & \\
\hline CHEMBL1443926 & 688816 & 5.25 & 5.4638 & TRN & \\
\hline CHEMBL1441041 & 688816 & 4.95 & 5.159 & TRN & \\
\hline CHEMBL1565809 & 688816 & 4.8 & 5.1683 & TRN & \\
\hline CHEMBL1541090 & 688816 & 5.45 & 5.2157 & TST & \\
\hline CHEMBL1509113 & 688816 & 4.95 & 5.2837 & TRN & \\
\hline CHEMBL3195943 & 688816 & 4.55 & 5.2589 & TRN & \\
\hline CHEMBL1316245 & 688816 & 4.65 & 5.06800 & 00000000005 & TRN \\
\hline CHEMBL1299213 & 688816 & 5.85 & 4.995 & TRN & \\
\hline CHEMBL1602286 & 688816 & 4.45 & 5.401 & TST & \\
\hline CHEMBL1571941 & 688816 & 4.45 & 5.1882 & TRN & \\
\hline CHEMBL1492031 & 688816 & 4.6 & 5.5111 & TRN & \\
\hline CHEMBL1549788 & 688816 & 5.3 & 5.3986 & TRN & \\
\hline
\end{tabular}




\begin{tabular}{|c|c|c|c|c|c|}
\hline \multicolumn{6}{|c|}{ Supplemental Table S2.txt } \\
\hline CHEMBL1420794 & 688816 & 4.8 & 5.2304 & TRN & \\
\hline CHEMBL1548167 & 688816 & 4.95 & 4.9856 & TRN & \\
\hline CHEMBL1409626 & 688816 & 5.0 & 5.1171 & TRN & \\
\hline CHEMBL1427857 & 688816 & 5.1 & 5.0202 & TRN & \\
\hline CHEMBL1593815 & 688816 & 6.0 & 5.4927 & TST & \\
\hline CHEMBL 3196448 & 688816 & 5.05 & 5.3119 & TRN & \\
\hline CHEMBL1572145 & 688816 & 4.95 & 4.8406 & TRN & \\
\hline CHEMBL1487007 & 688816 & 6.95 & 5.0514 & TST & \\
\hline CHEMBL1439717 & 688816 & 4.8 & 5.1858 & TRN & \\
\hline CHEMBL1483327 & 688816 & 6.1 & 5.2528 & TRN & \\
\hline CHEMBL1453063 & 688816 & 7.699 & 5.1017 & TRN & \\
\hline CHEMBL 3197849 & 688816 & 4.45 & 5.4191 & TRN & \\
\hline CHEMBL1330357 & 688816 & 4.8 & 5.7026 & TST & \\
\hline CHEMBL1608582 & 688816 & 4.7 & 5.0966 & TRN & \\
\hline CHEMBL1509209 & 688816 & 5.9 & 5.3424 & TRN & \\
\hline CHEMBL1487706 & 688816 & 7.699 & 5.3683 & TST & \\
\hline CHEMBL1557842 & 688816 & 4.85 & 5.1659 & TST & \\
\hline CHEMBL1467655 & 688816 & 4.8 & 4.8629 & TRN & \\
\hline CHEMBL1580743 & 688816 & 4.85 & 5.5823 & TRN & \\
\hline CHEMBL3197058 & 688816 & 4.45 & 5.3764 & TRN & \\
\hline CHEMBL1522834 & 688816 & 5.2 & 5.3533 & TRN & \\
\hline CHEMBL1430195 & 688816 & 4.8 & 4.9314 & TRN & \\
\hline CHEMBL1467260 & 688816 & 5.45 & 5.30399 & 9999999999 & TRN \\
\hline CHEMBL1540205 & 688816 & 4.45 & 5.1333 & TRN & \\
\hline CHEMBL1335386 & 688816 & 4.45 & 5.3115 & TST & \\
\hline CHEMBL1498332 & 688816 & 7.5003 & 5.5406 & TRN & \\
\hline CHEMBL1985744 & 688816 & 4.9 & 5.3653 & TST & \\
\hline CHEMBL1368116 & 688816 & 4.95 & 5.2609 & TRN & \\
\hline CHEMBL1536571 & 688816 & 5.4 & 5.648 & TST & \\
\hline CHEMBL1557101 & 688816 & 4.95 & 5.2416 & TRN & \\
\hline CHEMBL1549553 & 688816 & 7.5498 & 4.9541 & TST & \\
\hline CHEMBL1486759 & 688816 & 4.65 & 4.9384 & TST & \\
\hline CHEMBL1325568 & 688816 & 4.45 & 5.801 & TST & \\
\hline CHEMBL1417871 & 688816 & 4.75 & 5.2003 & TRN & \\
\hline CHEMBL1522277 & 688816 & 4.9 & 5.3287 & TRN & \\
\hline CHEMBL1547598 & 688816 & 7.7496 & 5.4185 & TRN & \\
\hline CHEMBL1608423 & 688816 & 5.0 & 5.6115 & TST & \\
\hline CHEMBL1374663 & 688816 & 4.95 & 5.7662 & TRN & \\
\hline CHEMBL1587393 & 688816 & 5.9 & 5.0288 & TRN & \\
\hline CHEMBL1419072 & 688816 & 4.75 & 5.0083 & TRN & \\
\hline CHEMBL1307497 & 688816 & 8.3468 & 5.2155 & TRN & \\
\hline CHEMBL1992517 & 688816 & 8.301 & 5.3807 & TST & \\
\hline CHEMBL3214380 & 688816 & 6.25 & 5.1685 & TRN & \\
\hline CHEMBL1584736 & 688816 & 6.7501 & 5.7786 & TST & \\
\hline CHEMBL3189810 & 688816 & 4.9 & 5.1551 & TRN & \\
\hline CHEMBL 3194420 & 688816 & 4.95 & 5.5377 & TST & \\
\hline CHEMBL 1431830 & 688816 & 7.4001 & 5.3612 & TRN & \\
\hline CHEMBL1608486 & 688816 & 4.85 & 5.2919 & TRN & \\
\hline
\end{tabular}




\begin{tabular}{|c|c|c|c|c|}
\hline \multicolumn{5}{|c|}{ Supplemental Table S2.txt } \\
\hline CHEMBL1556135 & 688816 & 7.6003 & 5.2292 & TRN \\
\hline CHEMBL1347971 & 688816 & 8.3468 & 5.3883 & TRN \\
\hline CHEMBL1444270 & 688816 & 6.15 & 5.3043 & TRN \\
\hline CHEMBL1529932 & 688816 & 4.9 & 5.2748 & TRN \\
\hline CHEMBL 1465176 & 688816 & 4.95 & 5.6481 & TST \\
\hline CHEMBL1449686 & 688816 & 4.45 & 5.3277 & TRN \\
\hline CHEMBL1608454 & 688816 & 5.2 & 5.6667 & TRN \\
\hline CHEMBL1348582 & 688816 & 4.45 & 5.2291 & TRN \\
\hline CHEMBL1610643 & 688816 & 4.45 & 5.3599 & TRN \\
\hline CHEMBL1505279 & 688816 & 4.9 & 4.7481 & TRN \\
\hline CHEMBL1382306 & 688816 & 8.3468 & 5.1847 & TST \\
\hline CHEMBL1345152 & 688816 & 5.15 & 5.8597 & TST \\
\hline CHEMBL1582334 & 688816 & 7.7496 & 5.5882 & TRN \\
\hline CHEMBL1437166 & 688816 & 5.05 & 5.1589 & TRN \\
\hline CHEMBL1475100 & 688816 & 6.9 & 5.2659 & TRN \\
\hline CHEMBL1367711 & 688816 & 4.75 & 4.5826 & TRN \\
\hline CHEMBL1380995 & 688816 & 4.7 & 5.2801 & TRN \\
\hline CHEMBL1489382 & 688816 & 5.1 & 5.5226 & TST \\
\hline CHEMBL1474468 & 688816 & 4.5 & 5.0353 & TRN \\
\hline CHEMBL1578017 & 688816 & 5.05 & 5.3794 & TRN \\
\hline CHEMBL1549450 & 688816 & 5.9 & 5.3044 & TRN \\
\hline CHEMBL1538009 & 688816 & 8.3468 & 5.409 & TRN \\
\hline CHEMBL1400357 & 688816 & 4.95 & 5.1791 & TRN \\
\hline CHEMBL1535096 & 688816 & 4.8 & 5.4041 & TRN \\
\hline CHEMBL1490799 & 688816 & 4.9 & 5.1511 & TRN \\
\hline CHEMBL1999667 & 688816 & 6.9 & 5.343 & TST \\
\hline CHEMBL1337579 & 688816 & 4.85 & 5.3051 & TRN \\
\hline CHEMBL1600026 & 688816 & 5.25 & 5.4505 & TRN \\
\hline CHEMBL1492526 & 688816 & 4.75 & 5.1454 & TRN \\
\hline CHEMBL1434514 & 688816 & 4.45 & 4.9992 & TRN \\
\hline CHEMBL1475125 & 688816 & 5.4 & 5.5153 & TRN \\
\hline CHEMBL1391677 & 688816 & 5.0 & 4.9937 & TRN \\
\hline CHEMBL1528265 & 688816 & 4.85 & 5.2782 & TST \\
\hline CHEMBL3194631 & 688816 & 4.75 & 5.7948 & TST \\
\hline CHEMBL1479912 & 688816 & 7.8508 & 5.3134 & TRN \\
\hline CHEMBL1599026 & 688816 & 4.95 & 5.0165 & TRN \\
\hline CHEMBL1341169 & 688816 & 4.9 & 5.3226 & TRN \\
\hline CHEMBL1352093 & 688816 & 8.301 & 5.3384 & TRN \\
\hline CHEMBL1580920 & 688816 & 5.15 & 4.9991 & TST \\
\hline CHEMBL1392755 & 688816 & 4.65 & 4.9425 & TRN \\
\hline CHEMBL1603820 & 688816 & 4.75 & 6.3506 & TRN \\
\hline CHEMBL1359770 & 688816 & 4.75 & 5.1319 & TRN \\
\hline CHEMBL1542362 & 688816 & 5.0 & 5.0292 & TRN \\
\hline CHEMBL1421446 & 688816 & 4.85 & 5.0498 & TRN \\
\hline CHEMBL1610391 & 688816 & 5.0 & 5.1705 & TRN \\
\hline CHEMBL1548664 & 688816 & 6.15 & 5.1028 & TST \\
\hline CHEMBL1309986 & 688816 & 4.85 & 4.9584 & TRN \\
\hline CHEMBL1556122 & 688816 & 4.7 & 5.5805 & TRN \\
\hline
\end{tabular}




\begin{tabular}{|c|c|c|c|c|}
\hline \multicolumn{5}{|c|}{ Supplemental Table S2.txt } \\
\hline CHEMBL1965976 & 688816 & 5.0 & 5.4891 & TRN \\
\hline CHEMBL1347534 & 688816 & 5.45 & 5.1933 & TRN \\
\hline CHEMBL1301544 & 688816 & 5.05 & 5.2594 & TRN \\
\hline CHEMBL1987145 & 688816 & 5.0 & 5.1463 & TRN \\
\hline CHEMBL1505212 & 688816 & 4.9 & 5.1365 & TRN \\
\hline CHEMBL1574187 & 688816 & 4.45 & 5.2605 & TRN \\
\hline CHEMBL1332656 & 688816 & 7.3497 & 5.1633 & TRN \\
\hline CHEMBL585656 & 688816 & 4.65 & 4.8248 & TRN \\
\hline CHEMBL1341404 & 688816 & 7.6498 & 5.4067 & TRN \\
\hline CHEMBL1323437 & 688816 & 6.7501 & 5.4177 & TRN \\
\hline CHEMBL1460075 & 688816 & 4.7 & 5.3032 & TRN \\
\hline CHEMBL1561911 & 688816 & 4.8 & 5.3822 & TRN \\
\hline CHEMBL1376693 & 688816 & 5.2 & 5.3715 & TRN \\
\hline CHEMBL1455189 & 688816 & 5.0 & 5.3986 & TST \\
\hline CHEMBL1455655 & 688816 & 4.95 & 5.141 & TRN \\
\hline CHEMBL1449750 & 688816 & 4.95 & 4.9936 & TRN \\
\hline CHEMBL1374838 & 688816 & 7.15 & 4.9523 & TRN \\
\hline CHEMBL1608692 & 688816 & 4.45 & 5.2637 & TRN \\
\hline CHEMBL3194970 & 688816 & 4.8 & 5.2745 & TRN \\
\hline CHEMBL106780 & 688816 & 5.9 & 5.141 & TRN \\
\hline CHEMBL1333087 & 688816 & 5.45 & 5.2989 & TRN \\
\hline CHEMBL1488712 & 688816 & 5.55 & 4.9761 & TRN \\
\hline CHEMBL3198951 & 688816 & 4.95 & 5.0213 & TRN \\
\hline CHEMBL1612125 & 688816 & 4.9 & 5.1837 & TRN \\
\hline CHEMBL1535551 & 688816 & 5.5 & 5.2801 & TRN \\
\hline CHEMBL1344803 & 688816 & 4.9 & 5.4626 & TRN \\
\hline CHEMBL1329251 & 688816 & 5.4 & 5.5524 & TRN \\
\hline CHEMBL1323278 & 688816 & 4.7 & 5.0266 & TRN \\
\hline CHEMBL408982 & 688816 & 4.45 & 5.4306 & TRN \\
\hline CHEMBL1472810 & 688816 & 5.95 & 5.1491 & TST \\
\hline CHEMBL1968580 & 688816 & 6.6499 & 5.1831 & TRN \\
\hline CHEMBL1584941 & 688816 & 5.8 & 5.5637 & TRN \\
\hline CHEMBL1611188 & 688816 & 4.7 & 5.2069 & TRN \\
\hline CHEMBL1302310 & 688816 & 4.45 & 5.3676 & TRN \\
\hline CHEMBL1351763 & 688816 & 4.95 & 5.3432 & TRN \\
\hline CHEMBL1392842 & 688816 & 4.75 & 5.1118 & TRN \\
\hline CHEMBL1322923 & 688816 & 4.95 & 5.3194 & TST \\
\hline CHEMBL1504701 & 688816 & 5.9 & 5.4136 & TRN \\
\hline CHEMBL1579691 & 688816 & 5.55 & 5.1239 & TST \\
\hline CHEMBL1585777 & 688816 & 4.75 & 4.6419 & TRN \\
\hline CHEMBL1441292 & 688816 & 4.6 & 5.1634 & TRN \\
\hline CHEMBL1611048 & 688816 & 5.0 & 5.1034 & TST \\
\hline CHEMBL518923 & 688816 & 4.8 & 4.8634 & TRN \\
\hline CHEMBL3192095 & 688816 & 5.5 & 5.2677 & TRN \\
\hline CHEMBL1584091 & 688816 & 4.95 & 5.2227 & TST \\
\hline CHEMBL1537341 & 688816 & 4.95 & 5.4381 & TRN \\
\hline CHEMBL1507205 & 688816 & 4.8 & 5.1891 & TRN \\
\hline CHEMBL1546370 & 688816 & 5.65 & 5.2324 & TRN \\
\hline
\end{tabular}




\begin{tabular}{|c|c|c|c|c|}
\hline \multicolumn{5}{|c|}{ Supplemental Table s2.txt } \\
\hline CHEMBL1539841 & 688816 & 5.5 & 5.36 & TRN \\
\hline CHEMBL1584067 & 688816 & 5.9 & 5.1977 & TRN \\
\hline CHEMBL1575549 & 688816 & 4.85 & 5.1972 & TRN \\
\hline CHEMBL1562715 & 688816 & 5.25 & 5.4631 & TST \\
\hline CHEMBL1531019 & 688816 & 4.85 & 5.313 & TRN \\
\hline CHEMBL1611066 & 688816 & 5.0 & 5.0717 & TRN \\
\hline CHEMBL3198423 & 688816 & 4.85 & 5.4685 & TST \\
\hline CHEMBL 3191874 & 688816 & 6.0 & 5.1895 & TRN \\
\hline CHEMBL1331109 & 688816 & 4.9 & 5.2983 & TRN \\
\hline CHEMBL236615 & 688816 & 5.25 & 5.1493 & TRN \\
\hline CHEMBL1573723 & 688816 & 6.7501 & 5.5924 & TRN \\
\hline CHEMBL1468635 & 688816 & 5.0 & 5.3164 & TRN \\
\hline CHEMBL1329340 & 688816 & 6.6499 & 5.6029 & TRN \\
\hline CHEMBL1423358 & 688816 & 5.65 & 5.165 & TRN \\
\hline CHEMBL1406699 & 688816 & 4.45 & 5.1476 & TRN \\
\hline CHEMBL1445486 & 688816 & 5.55 & 5.3947 & TRN \\
\hline CHEMBL1469802 & 688816 & 4.9 & 5.276 & TRN \\
\hline CHEMBL586031 & 688816 & 4.95 & 5.3308 & TST \\
\hline CHEMBL1482041 & 688816 & 5.55 & 5.4485 & TRN \\
\hline CHEMBL1461881 & 688816 & 5.9 & 5.234 & TRN \\
\hline CHEMBL1533438 & 688816 & 4.85 & 4.9537 & TST \\
\hline CHEMBL1508221 & 688816 & 4.45 & 5.3045 & TRN \\
\hline CHEMBL1304582 & 688816 & 5.15 & 5.0814 & TRN \\
\hline CHEMBL1596508 & 688816 & 4.7 & 5.1468 & TRN \\
\hline CHEMBL1583356 & 688816 & 4.9 & 5.1822 & TRN \\
\hline CHEMBL1491777 & 688816 & 4.8 & 4.8567 & TRN \\
\hline CHEMBL1560476 & 688816 & 4.65 & 4.9699 & TST \\
\hline CHEMBL1547292 & 688816 & 8.4949 & 5.4212 & TRN \\
\hline CHEMBL1352196 & 688816 & 8.301 & 5.37299 & 9999999999 \\
\hline CHEMBL1472135 & 688816 & 4.95 & 5.24 & TST \\
\hline CHEMBL1361296 & 688816 & 5.4 & 5.4692 & TRN \\
\hline CHEMBL1592493 & 688816 & 6.3 & 5.2957 & TRN \\
\hline CHEMBL1410012 & 688816 & 4.95 & 4.9929 & TST \\
\hline CHEMBL1567977 & 688816 & 4.8 & 5.2564 & TRN \\
\hline CHEMBL1353803 & 688816 & 4.45 & 5.1194 & TRN \\
\hline CHEMBL1384194 & 688816 & 4.9 & 4.8721 & TRN \\
\hline CHEMBL1491665 & 688816 & 4.95 & 5.4239 & TRN \\
\hline CHEMBL1384689 & 688816 & 4.5 & 5.0629 & TRN \\
\hline CHEMBL1602150 & 688816 & 4.9 & 5.0525 & TRN \\
\hline CHEMBL1359379 & 688816 & 4.95 & 5.2876 & TRN \\
\hline CHEMBL1482245 & 688816 & 4.75 & 5.0785 & TRN \\
\hline CHEMBL1388375 & 688816 & 5.2 & 5.5237 & TRN \\
\hline CHEMBL1342198 & 688816 & 4.85 & 5.055 & TST \\
\hline CHEMBL1379542 & 688816 & 4.45 & 5.1797 & TRN \\
\hline CHEMBL1312568 & 688816 & 6.0 & 4.999 & TRN \\
\hline CHEMBL1596599 & 688816 & 4.95 & 4.6937 & TRN \\
\hline CHEMBL1333254 & 688816 & 4.8 & 5.206 & TRN \\
\hline CHEMBL1489253 & 688816 & 5.0 & 5.5966 & TST \\
\hline
\end{tabular}




\begin{tabular}{|c|c|c|c|c|c|}
\hline \multicolumn{6}{|c|}{ Supplemental Table S2.txt } \\
\hline CHEMBL262103 & 688816 & 4.45 & 5.9351 & TST & \\
\hline CHEMBL1580974 & 688816 & 4.45 & 5.09399 & 9999999999 & TRN \\
\hline CHEMBL327902 & 688816 & 8.0506 & 5.4409 & TRN & \\
\hline CHEMBL1575073 & 688816 & 4.95 & 4.9801 & TRN & \\
\hline CHEMBL1359097 & 688816 & 8.3468 & 5.1538 & TRN & \\
\hline CHEMBL1508614 & 688816 & 4.7 & 5.7504 & TRN & \\
\hline CHEMBL1344643 & 688816 & 4.95 & 5.1684 & TRN & \\
\hline CHEMBL1530182 & 688816 & 4.45 & 5.1921 & TST & \\
\hline CHEMBL1400654 & 688816 & 5.05 & 5.6541 & TRN & \\
\hline CHEMBL1341812 & 688816 & 8.301 & 5.3664 & TRN & \\
\hline CHEMBL1381720 & 688816 & 4.95 & 5.2237 & TST & \\
\hline CHEMBL1348564 & 688816 & 5.25 & 5.2599 & TRN & \\
\hline CHEMBL1332626 & 688816 & 5.85 & 5.7494 & TRN & \\
\hline CHEMBL1306974 & 688816 & 7.5498 & 5.2303 & TRN & \\
\hline CHEMBL1328355 & 688816 & 5.35 & 5.8306 & TST & \\
\hline CHEMBL1478927 & 688816 & 5.65 & 5.4779 & TRN & \\
\hline CHEMBL1580758 & 688816 & 5.85 & 5.2317 & TST & \\
\hline CHEMBL1364949 & 688816 & 5.0 & 5.4266 & TRN & \\
\hline CHEMBL1600525 & 688816 & 8.4949 & 5.4437 & TST & \\
\hline CHEMBL1339240 & 688816 & 4.8 & 5.1353 & TRN & \\
\hline CHEMBL1595444 & 688816 & 4.85 & 5.49200 & 0000000001 & TRN \\
\hline CHEMBL1403159 & 688816 & 8.4559 & 5.7101 & TRN & \\
\hline CHEMBL1407451 & 688816 & 7.6003 & 5.3271 & TRN & \\
\hline CHEMBL1320049 & 688816 & 4.65 & 5.44799 & 99999999995 & TRN \\
\hline CHEMBL1487803 & 688816 & 4.45 & 5.3514 & TST & \\
\hline CHEMBL1335501 & 688816 & 4.65 & 5.3803 & TRN & \\
\hline CHEMBL1586817 & 688816 & 4.45 & 4.9767 & TST & \\
\hline CHEMBL1506937 & 688816 & 8.3468 & 5.555 & TRN & \\
\hline CHEMBL1334642 & 688816 & 5.6 & 5.6339 & TRN & \\
\hline CHEMBL1580793 & 688816 & 5.05 & 5.235 & TST & \\
\hline CHEMBL3197209 & 688816 & 5.0 & 5.3294 & TRN & \\
\hline CHEMBL1306790 & 688816 & 7.4001 & 5.1466 & TRN & \\
\hline CHEMBL1448087 & 688816 & 6.7001 & 5.5926 & TRN & \\
\hline CHEMBL1416940 & 688816 & 4.95 & 5.4491 & TRN & \\
\hline CHEMBL1350125 & 688816 & 5.4 & 5.3169 & TRN & \\
\hline CHEMBL1360502 & 688816 & 5.0 & 5.3638 & TST & \\
\hline CHEMBL1492321 & 688816 & 4.9 & 5.3781 & TRN & \\
\hline CHEMBL1505307 & 688816 & 4.95 & 5.1523 & TRN & \\
\hline CHEMBL1496061 & 688816 & 4.45 & 5.282 & TRN & \\
\hline CHEMBL1544658 & 688816 & 4.45 & 5.358 & TRN & \\
\hline CHEMBL1347677 & 688816 & 4.7 & 5.28700 & 0000000001 & TRN \\
\hline CHEMBL1446987 & 688816 & 4.95 & 5.6291 & TRN & \\
\hline CHEMBL1588487 & 688816 & 4.45 & 5.0261 & TRN & \\
\hline CHEMBL1423254 & 688816 & 4.45 & 5.6281 & TRN & \\
\hline CHEMBL1572935 & 688816 & 5.15 & 5.3329 & TRN & \\
\hline CHEMBL1389982 & 688816 & 4.5 & 5.0137 & TST & \\
\hline CHEMBL1594254 & 688816 & 4.95 & 5.0669 & TRN & \\
\hline CHEMBL1468417 & 688816 & 8.301 & 5.4515 & TRN & \\
\hline
\end{tabular}




\begin{tabular}{|c|c|c|c|c|c|}
\hline \multicolumn{6}{|c|}{ Supplemental Table S2.txt } \\
\hline CHEMBL1374818 & 688816 & 7.8013 & 5.3179 & TRN & \\
\hline CHEMBL1304729 & 688816 & 7.0501 & 5.0513 & TST & \\
\hline CHEMBL1322151 & 688816 & 4.7 & 5.007 & TRN & \\
\hline CHEMBL1509119 & 688816 & 8.2007 & 5.3739 & TST & \\
\hline CHEMBL1451237 & 688816 & 4.95 & 5.1799 & TRN & \\
\hline CHEMBL1353255 & 688816 & 7.9508 & 5.5004 & TRN & \\
\hline CHEMBL1392331 & 688816 & 4.75 & 5.1837 & TRN & \\
\hline CHEMBL1471475 & 688816 & 5.9 & 5.2526 & TRN & \\
\hline CHEMBL1325890 & 688816 & 5.15 & 5.12299 & 9999999999 & TST \\
\hline CHEMBL1300860 & 688816 & 5.0 & 5.2575 & TST & \\
\hline CHEMBL1390816 & 688816 & 4.75 & 5.6757 & TRN & \\
\hline CHEMBL1391032 & 688816 & 4.45 & 5.284 & TST & \\
\hline CHEMBL1576451 & 688816 & 8.0506 & 5.1853 & TRN & \\
\hline CHEMBL3194518 & 688816 & 5.5 & 5.3647 & TRN & \\
\hline CHEMBL191750 & 688816 & 4.95 & 5.1242 & TRN & \\
\hline CHEMBL1451964 & 688816 & 5.25 & 5.4803 & TST & \\
\hline CHEMBL1454708 & 688816 & 8.3468 & 4.9513 & TRN & \\
\hline CHEMBL1380911 & 688816 & 4.95 & 5.0904 & TRN & \\
\hline CHEMBL3207845 & 688816 & 4.85 & 5.3386 & TRN & \\
\hline CHEMBL1389810 & 688816 & 4.9 & 5.1471 & TRN & \\
\hline CHEMBL1432780 & 688816 & 4.75 & 4.9913 & TRN & \\
\hline CHEMBL 3193814 & 688816 & 5.05 & 5.2461 & TRN & \\
\hline CHEMBL1343527 & 688816 & 4.75 & 5.1137 & TRN & \\
\hline CHEMBL1511401 & 688816 & 4.65 & 5.5553 & TRN & \\
\hline CHEMBL1346787 & 688816 & 6.5 & 5.4959 & TRN & \\
\hline CHEMBL1597005 & 688816 & 5.85 & 5.1283 & TRN & \\
\hline CHEMBL1349408 & 688816 & 5.1 & 5.3842 & TST & \\
\hline CHEMBL1541010 & 688816 & 4.6 & 5.2293 & TST & \\
\hline CHEMBL1229712 & 688816 & 5.0 & 5.3404 & TRN & \\
\hline CHEMBL1545361 & 688816 & 4.95 & 4.7522 & TRN & \\
\hline CHEMBL3199221 & 688816 & 5.0 & 5.2262 & TST & \\
\hline CHEMBL1369045 & 688816 & 4.95 & 5.1537 & TRN & \\
\hline CHEMBL1339283 & 688816 & 5.35 & 5.4339 & TRN & \\
\hline CHEMBL3196930 & 688816 & 4.8 & 4.9237 & TST & \\
\hline CHEMBL1449631 & 688816 & 5.55 & 5.3803 & TRN & \\
\hline CHEMBL1605458 & 688816 & 4.65 & 5.5316 & TST & \\
\hline CHEMBL1548944 & 688816 & 4.9 & 5.3488 & TST & \\
\hline CHEMBL1381148 & 688816 & 4.95 & 4.9894 & TRN & \\
\hline CHEMBL1445986 & 688816 & 4.8 & 5.1225 & TRN & \\
\hline CHEMBL1566407 & 688816 & 6.5 & 4.9858 & TRN & \\
\hline CHEMBL1567082 & 688816 & 4.95 & 5.4849 & TRN & \\
\hline CHEMBL1531186 & 688816 & 4.75 & 5.098 & TRN & \\
\hline CHEMBL1389302 & 688816 & 4.85 & 4.9059 & TST & \\
\hline CHEMBL1449551 & 688816 & 4.95 & 5.1342 & TRN & \\
\hline CHEMBL1334730 & 688816 & 5.0 & 5.1883 & TST & \\
\hline CHEMBL3189992 & 688816 & 5.1 & 5.4125 & TRN & \\
\hline CHEMBL1319292 & 688816 & 4.7 & 5.0357 & TRN & \\
\hline CHEMBL1411222 & 688816 & 7.4498 & 5.2368 & TRN & \\
\hline
\end{tabular}




\begin{tabular}{|c|c|c|c|c|}
\hline \multicolumn{5}{|c|}{ Supplemental Table S2.txt } \\
\hline CHEMBL 2000380 & 688816 & 4.45 & 5.289 & TRN \\
\hline CHEMBL1575411 & 688816 & 5.2 & 5.0834 & TRN \\
\hline CHEMBL3191640 & 688816 & 6.05 & 5.3773 & TRN \\
\hline CHEMBL1304596 & 688816 & 6.6 & 5.3596 & TST \\
\hline CHEMBL1499914 & 688816 & 5.3 & 5.1854 & TRN \\
\hline CHEMBL1506677 & 688816 & 4.85 & 4.9734 & TRN \\
\hline CHEMBL1360005 & 688816 & 7.5003 & 5.4031 & TRN \\
\hline CHEMBL1341393 & 688816 & 4.55 & 4.9111 & TRN \\
\hline CHEMBL1413563 & 688816 & 4.9 & 5.4211 & TRN \\
\hline CHEMBL1373933 & 688816 & 5.55 & 5.2416 & TRN \\
\hline CHEMBL1589221 & 688816 & 4.65 & 5.2385 & TRN \\
\hline CHEMBL1406937 & 688816 & 7.8996 & 5.2747 & TRN \\
\hline CHEMBL1594201 & 688816 & 5.15 & 5.0749 & TRN \\
\hline CHEMBL48449 & 688816 & 6.0 & 5.79 & TST \\
\hline CHEMBL1488502 & 688816 & 4.75 & 5.5124 & TRN \\
\hline CHEMBL1443435 & 688816 & 4.95 & 5.5235 & TRN \\
\hline CHEMBL1449615 & 688816 & 4.5 & 5.1203 & TRN \\
\hline CHEMBL1524363 & 688816 & 4.7 & 5.3507 & TST \\
\hline CHEMBL3193579 & 688816 & 4.8 & 4.7145 & TRN \\
\hline CHEMBL3197889 & 688816 & 4.9 & 5.2749 & TST \\
\hline CHEMBL1606236 & 688816 & 5.55 & 5.5529 & TRN \\
\hline CHEMBL1508715 & 688816 & 5.35 & 5.1949 & TRN \\
\hline CHEMBL1563333 & 688816 & 5.3 & 5.3345 & TRN \\
\hline CHEMBL1576414 & 688816 & 7.5498 & 5.5949 & TST \\
\hline CHEMBL1526672 & 688816 & 4.45 & 5.3419 & TRN \\
\hline CHEMBL1483253 & 688816 & 4.9 & 5.3221 & TRN \\
\hline CHEMBL3211375 & 688816 & 4.9 & 5.1892 & TRN \\
\hline CHEMBL3189938 & 688816 & 4.95 & 5.473 & TRN \\
\hline CHEMBL1406755 & 688816 & 7.0 & 5.0529 & TST \\
\hline CHEMBL1346059 & 688816 & 5.25 & 5.3712 & TRN \\
\hline CHEMBL1501724 & 688816 & 4.85 & 5.5348 & TRN \\
\hline CHEMBL1597204 & 688816 & 6.05 & 5.4979 & TRN \\
\hline CHEMBL1352332 & 688816 & 5.3 & 5.0883 & TRN \\
\hline CHEMBL1429963 & 688816 & 5.55 & 5.3382 & TRN \\
\hline CHEMBL1606512 & 688816 & 5.05 & 5.3053 & TRN \\
\hline CHEMBL1500306 & 688816 & 4.65 & 4.8195 & TRN \\
\hline CHEMBL1399420 & 688816 & 6.2 & 5.3154 & TRN \\
\hline CHEMBL1478962 & 688816 & 6.3 & 5.3255 & TRN \\
\hline CHEMBL1425702 & 688816 & 4.75 & 5.4995 & TST \\
\hline CHEMBL3196868 & 688816 & 4.9 & 5.4368 & TST \\
\hline CHEMBL1369595 & 688816 & 5.8 & 5.1733 & TRN \\
\hline CHEMBL1402526 & 688816 & 4.65 & 4.9442 & TRN \\
\hline CHEMBL1599543 & 688816 & 4.65 & 5.1167 & TRN \\
\hline CHEMBL1419509 & 688816 & 5.5 & 5.8883 & TRN \\
\hline CHEMBL1579333 & 688816 & 5.35 & 5.5084 & TST \\
\hline CHEMBL1417862 & 688816 & 5.4 & 5.5761 & TRN \\
\hline CHEMBL1302894 & 688816 & 5.7 & 4.984 & TST \\
\hline CHEMBL1507108 & 688816 & 4.45 & 5.4011 & TST \\
\hline
\end{tabular}




\begin{tabular}{|c|c|c|c|c|c|}
\hline \multicolumn{6}{|c|}{ Supplemental Table S2.txt } \\
\hline CHEMBL1569243 & 688816 & 4.95 & 5.2825 & TRN & \\
\hline CHEMBL1603547 & 688816 & 4.85 & 5.3613 & TST & \\
\hline CHEMBL1552346 & 688816 & 5.05 & 5.4839 & TRN & \\
\hline CHEMBL472646 & 688816 & 5.3 & 5.6108 & TST & \\
\hline CHEMBL1491404 & 688816 & 7.6498 & 5.3891 & TRN & \\
\hline CHEMBL1596484 & 688816 & 5.15 & 5.3041 & TST & \\
\hline CHEMBL1307764 & 688816 & 4.7 & 5.3146 & TRN & \\
\hline CHEMBL1500584 & 688816 & 4.9 & 5.2878 & TRN & \\
\hline CHEMBL1314507 & 688816 & 4.6 & 5.1887 & TST & \\
\hline CHEMBL1460018 & 688816 & 4.45 & 5.2205 & TRN & \\
\hline CHEMBL1359401 & 688816 & 7.9508 & 5.1897 & TRN & \\
\hline CHEMBL1537967 & 688816 & 4.8 & 5.24799 & 9999999999 & TRN \\
\hline CHEMBL1527662 & 688816 & 8.0 & 5.3721 & TRN & \\
\hline CHEMBL1456592 & 688816 & 7.6498 & 5.7251 & TST & \\
\hline CHEMBL1409985 & 688816 & 4.45 & 5.6394 & TST & \\
\hline CHEMBL1401052 & 688816 & 4.9 & 5.2275 & TRN & \\
\hline CHEMBL1331418 & 688816 & 4.75 & 4.9708 & TRN & \\
\hline CHEMBL1489960 & 688816 & 5.2 & 5.2209 & TRN & \\
\hline CHEMBL1301885 & 688816 & 4.75 & 4.9012 & TRN & \\
\hline CHEMBL1583789 & 688816 & 7.9508 & 4.9353 & TRN & \\
\hline CHEMBL1491625 & 688816 & 4.75 & 5.0715 & TRN & \\
\hline CHEMBL1526746 & 688816 & 5.45 & 5.2642 & TRN & \\
\hline CHEMBL1599705 & 688816 & 7.6498 & 5.1796 & TRN & \\
\hline CHEMBL1359427 & 688816 & 6.15 & 4.9917 & TRN & \\
\hline CHEMBL1420184 & 688816 & 4.9 & 4.8669 & TRN & \\
\hline CHEMBL1525546 & 688816 & 4.95 & 5.3159 & TRN & \\
\hline CHEMBL1320971 & 688816 & 4.95 & 5.0049 & TRN & \\
\hline CHEMBL1336860 & 688816 & 5.1 & 5.37299 & 9999999999 & TRN \\
\hline CHEMBL1419471 & 688816 & 4.45 & 5.1427 & TRN & \\
\hline CHEMBL1368887 & 688816 & 6.0 & 5.3516 & TRN & \\
\hline CHEMBL1313232 & 688816 & 4.9 & 5.4336 & TRN & \\
\hline CHEMBL1368718 & 688816 & 5.25 & 5.2587 & TRN & \\
\hline CHEMBL1303706 & 688816 & 7.6498 & 5.636 & TRN & \\
\hline CHEMBL1416520 & 688816 & 4.95 & 5.0974 & TRN & \\
\hline CHEMBL1515707 & 688816 & 5.25 & 5.325 & TST & \\
\hline CHEMBL1342150 & 688816 & 5.2 & 5.1621 & TRN & \\
\hline CHEMBL1537891 & 688816 & 5.7 & 5.0744 & TRN & \\
\hline CHEMBL1511000 & 688816 & 5.0 & 5.1954 & TRN & \\
\hline CHEMBL1408587 & 688816 & 5.15 & 5.2364 & TRN & \\
\hline CHEMBL1413766 & 688816 & 6.05 & 5.796 & TRN & \\
\hline CHEMBL1424069 & 688816 & 4.85 & 5.2507 & TST & \\
\hline CHEMBL 1558433 & 688816 & 5.7 & 5.0596 & TRN & \\
\hline CHEMBL1612295 & 688816 & 4.45 & 5.0627 & TRN & \\
\hline CHEMBL1466563 & 688816 & 4.45 & 5.336 & TRN & \\
\hline CHEMBL1501016 & 688816 & 6.4 & 5.3902 & TRN & \\
\hline CHEMBL 3213234 & 688816 & 7.7496 & 5.3132 & TRN & \\
\hline CHEMBL1498716 & 688816 & 4.45 & 5.3944 & TST & \\
\hline CHEMBL1406860 & 688816 & 4.85 & 5.5779 & TRN & \\
\hline
\end{tabular}




\begin{tabular}{|c|c|c|c|c|c|}
\hline \multicolumn{6}{|c|}{ Supplemental Table S2.txt } \\
\hline CHEMBL1420323 & 688816 & 4.65 & 5.6099 & TRN & \\
\hline CHEMBL1602472 & 688816 & 4.95 & 5.3255 & TRN & \\
\hline CHEMBL1381134 & 688816 & 4.45 & 5.0976 & TRN & \\
\hline CHEMBL1540438 & 688816 & 5.45 & 5.2155 & TRN & \\
\hline CHEMBL1540577 & 688816 & 4.5 & 5.1095 & TRN & \\
\hline CHEMBL1411363 & 688816 & 4.85 & 4.9373 & TRN & \\
\hline CHEMBL1455321 & 688816 & 4.9 & 5.581 & TST & \\
\hline CHEMBL1409329 & 688816 & 5.45 & 5.2685 & TRN & \\
\hline CHEMBL1587097 & 688816 & 6.15 & 5.314 & TRN & \\
\hline CHEMBL1352375 & 688816 & 4.45 & 5.0676 & TRN & \\
\hline CHEMBL 2007163 & 688816 & 4.75 & 5.0677 & TST & \\
\hline CHEMBL 3212718 & 688816 & 5.55 & 5.3413 & TST & \\
\hline CHEMBL1431591 & 688816 & 5.35 & 5.2815 & TRN & \\
\hline CHEMBL1365810 & 688816 & 4.75 & 5.0785 & TRN & \\
\hline CHEMBL1997543 & 688816 & 4.45 & 5.9984 & TST & \\
\hline CHEMBL1580071 & 688816 & 4.7 & 5.1179 & TRN & \\
\hline CHEMBL1402205 & 688816 & 8.3979 & 5.3764 & TST & \\
\hline CHEMBL1310221 & 688816 & 5.45 & 5.0886 & TRN & \\
\hline CHEMBL1304674 & 688816 & 4.85 & 5.4153 & TST & \\
\hline CHEMBL1453857 & 688816 & 5.4 & 4.9122 & TST & \\
\hline CHEMBL1563604 & 688816 & 4.45 & 5.3952 & TRN & \\
\hline CHEMBL1332988 & 688816 & 5.15 & 5.5982 & TRN & \\
\hline CHEMBL1334872 & 688816 & 4.75 & 4.9352 & TRN & \\
\hline CHEMBL1368337 & 688816 & 5.75 & 4.9642 & TRN & \\
\hline CHEMBL1334710 & 688816 & 4.75 & 4.8052 & TRN & \\
\hline CHEMBL1426079 & 688816 & 4.8 & 5.0899 & TRN & \\
\hline CHEMBL1366820 & 688816 & 5.0 & 5.2517 & TRN & \\
\hline CHEMBL1491767 & 688816 & 4.45 & 5.2802 & TRN & \\
\hline CHEMBL1451443 & 688816 & 5.4 & 5.5127 & TST & \\
\hline CHEMBL1325377 & 688816 & 4.75 & 5.2999 & TRN & \\
\hline CHEMBL1467647 & 688816 & 4.65 & 4.9229 & TRN & \\
\hline CHEMBL1500265 & 688816 & 4.5 & 4.8147 & TRN & \\
\hline CHEMBL1597458 & 688816 & 4.55 & 5.1149 & TST & \\
\hline CHEMBL1492365 & 688816 & 4.8 & 5.261 & TRN & \\
\hline CHEMBL1605613 & 688816 & 4.95 & 5.3017 & TRN & \\
\hline CHEMBL1498987 & 688816 & 4.85 & 5.3854 & TRN & \\
\hline CHEMBL1481061 & 688816 & 5.3 & 5.481 & TRN & \\
\hline CHEMBL1411609 & 688816 & 5.45 & 5.1754 & TST & \\
\hline CHEMBL 3189198 & 688816 & 7.4498 & 5.20799 & & TRN \\
\hline CHEMBL1589030 & 688816 & 4.45 & 5.4625 & TRN & \\
\hline CHEMBL1311222 & 688816 & 4.55 & 5.4018 & TST & \\
\hline CHEMBL1520225 & 688816 & 4.95 & 5.3105 & TRN & \\
\hline CHEMBL1381974 & 688816 & 4.85 & 4.9589 & TST & \\
\hline CHEMBL1560310 & 688816 & 6.6 & 5.1828 & TRN & \\
\hline CHEMBL1326733 & 688816 & 5.3 & 5.5335 & TST & \\
\hline CHEMBL1538731 & 688816 & 6.6 & 5.1765 & TRN & \\
\hline CHEMBL1587922 & 688816 & 4.7 & 5.2606 & TST & \\
\hline CHEMBL1605435 & 688816 & 4.75 & 5.3523 & TRN & \\
\hline
\end{tabular}




\begin{tabular}{|c|c|c|c|c|c|}
\hline \multirow[b]{2}{*}{ CHEMBL1541680 } & \multicolumn{5}{|c|}{ } \\
\hline & 688816 & 8.301 & 5.4169 & TST & \\
\hline CHEMBL1993037 & 688816 & 5.05 & 5.3783 & TRN & \\
\hline CHEMBL1473362 & 688816 & 4.75 & 5.04899 & 99999999995 & TST \\
\hline CHEMBL1448736 & 688816 & 7.699 & 5.6693 & TRN & \\
\hline CHEMBL1456530 & 688816 & 5.5 & 5.1975 & TST & \\
\hline CHEMBL1351857 & 688816 & 4.85 & 5.3905 & TRN & \\
\hline CHEMBL3212927 & 688816 & 5.3 & 5.1095 & TST & \\
\hline CHEMBL1519372 & 688816 & 5.25 & 5.4718 & TRN & \\
\hline CHEMBL1382293 & 688816 & 4.95 & 5.0358 & TRN & \\
\hline CHEMBL1513003 & 688816 & 6.45 & 5.6199 & TST & \\
\hline CHEMBL3193733 & 688816 & 5.0 & 5.4867 & TRN & \\
\hline CHEMBL1347282 & 688816 & 4.45 & 5.1057 & TRN & \\
\hline CHEMBL1443757 & 688816 & 4.95 & 5.2572 & TRN & \\
\hline CHEMBL1525796 & 688816 & 5.6 & 5.0996 & TST & \\
\hline CHEMBL3194329 & 688816 & 5.25 & 5.2831 & TST & \\
\hline CHEMBL1448705 & 688816 & 5.1 & 5.1148 & TRN & \\
\hline CHEMBL1583985 & 688816 & 5.5 & 5.096 & TST & \\
\hline CHEMBL1423123 & 688816 & 4.95 & 5.2873 & TST & \\
\hline CHEMBL1427568 & 688816 & 4.85 & 5.1864 & TRN & \\
\hline CHEMBL1586758 & 688816 & 5.25 & 6.0295 & TRN & \\
\hline CHEMBL1443586 & 688816 & 4.7 & 5.2672 & TRN & \\
\hline CHEMBL1538755 & 688816 & 4.85 & 5.5395 & TRN & \\
\hline CHEMBL1417078 & 688816 & 6.4 & 5.4887 & TRN & \\
\hline CHEMBL1444854 & 688816 & 4.45 & 5.2493 & TRN & \\
\hline CHEMBL1493566 & 688816 & 4.95 & 5.3127 & TST & \\
\hline CHEMBL1481260 & 688816 & 8.301 & 5.3737 & TST & \\
\hline CHEMBL3195823 & 688816 & 4.8 & 5.33 & TRN & \\
\hline CHEMBL1540666 & 688816 & 6.05 & 5.25200 & 0000000001 & TRN \\
\hline CHEMBL3189853 & 688816 & 4.85 & 5.3088 & TRN & \\
\hline CHEMBL1433079 & 688816 & 4.95 & 5.284 & TRN & \\
\hline CHEMBL1468928 & 688816 & 5.0 & 4.8651 & TRN & \\
\hline CHEMBL1501480 & 688816 & 4.9 & 5.3475 & TRN & \\
\hline CHEMBL1595111 & 688816 & 4.95 & 4.9649 & TRN & \\
\hline CHEMBL1430765 & 688816 & 5.55 & 5.2179 & TRN & \\
\hline CHEMBL1345642 & 688816 & 4.65 & 4.8704 & TRN & \\
\hline CHEMBL1585585 & 688816 & 8.301 & 5.5967 & TRN & \\
\hline CHEMBL1537169 & 688816 & 5.55 & 5.15799 & 99999999995 & TRN \\
\hline CHEMBL1585187 & 688816 & 5.3 & 5.0862 & TRN & \\
\hline CHEMBL1326689 & 688816 & 4.6 & 5.3365 & TRN & \\
\hline CHEMBL1345525 & 688816 & 4.9 & 5.055 & TRN & \\
\hline CHEMBL1370177 & 688816 & 4.85 & 5.5256 & TRN & \\
\hline CHEMBL1510563 & 688816 & 4.85 & 5.1987 & TRN & \\
\hline CHEMBL1458536 & 688816 & 5.0 & 5.136 & TRN & \\
\hline CHEMBL1383094 & 688816 & 4.9 & 5.17200 & $\partial 000000001$ & TRN \\
\hline CHEMBL1413562 & 688816 & 4.5 & 5.5253 & TST & \\
\hline CHEMBL1545955 & 688816 & 6.8 & 5.093 & TRN & \\
\hline CHEMBL3195326 & 688816 & 5.2 & 5.5704 & TST & \\
\hline CHEMBL1309127 & 688816 & 5.6 & 5.0809 & TRN & \\
\hline & & & & 24933 & \\
\hline
\end{tabular}




\begin{tabular}{|c|c|c|c|c|c|}
\hline \multicolumn{6}{|c|}{ Supplemental Table S2.txt } \\
\hline CHEMBL1603662 & 688816 & 5.55 & 5.6438 & TRN & \\
\hline CHEMBL1318796 & 688816 & 4.45 & 5.0337 & TRN & \\
\hline CHEMBL1404071 & 688816 & 4.7 & 5.0968 & TST & \\
\hline CHEMBL3191951 & 688816 & 5.5 & 5.176 & TRN & \\
\hline CHEMBL1521258 & 688816 & 4.9 & 5.3686 & TRN & \\
\hline CHEMBL1408121 & 688816 & 4.85 & 5.2889 & TST & \\
\hline CHEMBL1586337 & 688816 & 5.0 & 5.2946 & TRN & \\
\hline CHEMBL1524817 & 688816 & 4.95 & 5.0803 & TRN & \\
\hline CHEMBL3391864 & 688816 & 4.9 & 5.3595 & TRN & \\
\hline CHEMBL3192197 & 688816 & 4.45 & 5.3714 & TRN & \\
\hline CHEMBL1364069 & 688816 & 4.5 & 5.4478 & TST & \\
\hline CHEMBL1612673 & 688816 & 4.95 & 5.7357 & TRN & \\
\hline CHEMBL1487415 & 688816 & 4.95 & 5.0377 & TRN & \\
\hline CHEMBL1362768 & 688816 & 5.1 & 5.63399 & 99999999995 & TST \\
\hline CHEMBL1400463 & 688816 & 4.7 & 5.2172 & TRN & \\
\hline CHEMBL1990675 & 688816 & 4.8 & 5.317 & TRN & \\
\hline CHEMBL1416089 & 688816 & 4.8 & 4.7448 & TRN & \\
\hline CHEMBL1523375 & 688816 & 4.6 & 5.1199 & TRN & \\
\hline CHEMBL1542803 & 688816 & 4.45 & 6.0225 & TRN & \\
\hline CHEMBL1302411 & 688816 & 7.0 & 5.5716 & TRN & \\
\hline CHEMBL1519489 & 688816 & 7.3497 & 5.2908 & TRN & \\
\hline CHEMBL1416946 & 688816 & 4.75 & 4.8324 & TRN & \\
\hline CHEMBL1200792 & 688816 & 5.75 & 5.2376 & TRN & \\
\hline CHEMBL1540897 & 688816 & 4.45 & 5.1543 & TRN & \\
\hline CHEMBL1495438 & 688816 & 4.45 & 5.3816 & TRN & \\
\hline CHEMBL1551433 & 688816 & 4.45 & 4.8434 & TRN & \\
\hline CHEMBL3199665 & 688816 & 5.35 & 5.0618 & TST & \\
\hline CHEMBL1443660 & 688816 & 4.55 & 5.2311 & TST & \\
\hline CHEMBL1343306 & 688816 & 4.9 & 5.1183 & TRN & \\
\hline CHEMBL1564354 & 688816 & 4.8 & 5.045 & TRN & \\
\hline CHEMBL1312488 & 688816 & 5.0 & 5.3043 & TRN & \\
\hline CHEMBL1565635 & 688816 & 4.45 & 5.23 & TRN & \\
\hline CHEMBL1502184 & 688816 & 4.85 & 4.8301 & TRN & \\
\hline CHEMBL1433022 & 688816 & 4.95 & 5.22 & TRN & \\
\hline CHEMBL1406557 & 688816 & 4.45 & 5.4657 & TRN & \\
\hline CHEMBL1456496 & 688816 & 4.95 & 5.1581 & TRN & \\
\hline CHEMBL3199737 & 688816 & 5.45 & 5.2823 & TRN & \\
\hline CHEMBL1321294 & 688816 & 4.45 & 5.3634 & TST & \\
\hline CHEMBL1525419 & 688816 & 4.9 & 5.215 & TST & \\
\hline CHEMBL1423028 & 688816 & 4.7 & 5.084 & TST & \\
\hline CHEMBL3198707 & 688816 & 4.95 & 5.3168 & TST & \\
\hline CHEMBL1320353 & 688816 & 5.35 & 5.4971 & TRN & \\
\hline CHEMBL1509077 & 688816 & 5.25 & 5.0816 & TRN & \\
\hline CHEMBL1546901 & 688816 & 8.3979 & 5.6592 & TRN & \\
\hline CHEMBL1570745 & 688816 & 4.85 & 5.1434 & TRN & \\
\hline CHEMBL1450386 & 688816 & 6.2 & 5.0965 & TRN & \\
\hline CHEMBL1423024 & 688816 & 7.2503 & 5.3379 & TST & \\
\hline CHEMBL1376404 & 688816 & 4.65 & 5.2531 & TRN & \\
\hline
\end{tabular}




\begin{tabular}{|c|c|c|c|c|c|}
\hline \\
\hline CHEMBL1597932 & 688816 & 4.9 & 5.2267 & TRN & \\
\hline CHEMBL1417819 & 688816 & 4.55 & 5.1907 & TST & \\
\hline CHEMBL1525890 & 688816 & 6.1 & 5.2363 & TRN & \\
\hline CHEMBL1577297 & 688816 & 4.65 & 5.3309 & TRN & \\
\hline CHEMBL1550323 & 688816 & 4.85 & 5.6372 & TRN & \\
\hline CHEMBL1520043 & 688816 & 4.85 & 5.5891 & TRN & \\
\hline CHEMBL1606856 & 688816 & 4.45 & 5.2511 & TRN & \\
\hline CHEMBL1440566 & 688816 & 4.45 & 5.33299 & 9999999999 & TRN \\
\hline CHEMBL1337331 & 688816 & 4.9 & 5.1044 & TRN & \\
\hline CHEMBL1430035 & 688816 & 4.9 & 5.388 & TRN & \\
\hline CHEMBL1477262 & 688816 & 4.45 & 5.4304 & TRN & \\
\hline CHEMBL1304589 & 688816 & 4.55 & 4.8853 & TRN & \\
\hline CHEMBL1390836 & 688816 & 5.7 & 5.2921 & TRN & \\
\hline CHEMBL1322677 & 688816 & 4.45 & 5.0544 & TST & \\
\hline CHEMBL1462207 & 688816 & 4.95 & 4.6308 & TRN & \\
\hline CHEMBL1341471 & 688816 & 4.8 & 5.3814 & TRN & \\
\hline CHEMBL1350427 & 688816 & 5.0 & 5.0779 & TRN & \\
\hline CHEMBL1385179 & 688816 & 4.9 & 5.3889 & TST & \\
\hline CHEMBL1333157 & 688816 & 4.65 & 5.3815 & TRN & \\
\hline CHEMBL1488055 & 688816 & 4.75 & 5.3254 & TRN & \\
\hline CHEMBL1431377 & 688816 & 5.0 & 5.3688 & TST & \\
\hline CHEMBL1521374 & 688816 & 4.65 & 4.8974 & TRN & \\
\hline CHEMBL1339768 & 688816 & 5.0 & 5.0363 & TRN & \\
\hline CHEMBL1606476 & 688816 & 7.3497 & 5.4738 & TRN & \\
\hline CHEMBL1574420 & 688816 & 5.15 & 5.5034 & TRN & \\
\hline CHEMBL1446495 & 688816 & 5.45 & 5.4365 & TRN & \\
\hline CHEMBL1603857 & 688816 & 4.95 & 4.8024 & TRN & \\
\hline CHEMBL1498736 & 688816 & 5.5 & 5.1226 & TST & \\
\hline CHEMBL1326818 & 688816 & 5.0 & 5.3941 & TRN & \\
\hline CHEMBL1307755 & 688816 & 8.301 & 5.4275 & TRN & \\
\hline CHEMBL1554403 & 688816 & 4.45 & 5.0967 & TST & \\
\hline CHEMBL1610845 & 688816 & 4.9 & 5.2074 & TRN & \\
\hline CHEMBL1599171 & 688816 & 6.5 & 6.0377 & TRN & \\
\hline CHEMBL1464886 & 688816 & 5.15 & 5.2991 & TRN & \\
\hline CHEMBL1345147 & 688816 & 4.65 & 4.822 & TST & \\
\hline CHEMBL1383742 & 688816 & 5.2 & 5.0493 & TRN & \\
\hline CHEMBL1577087 & 688816 & 5.35 & 5.3966 & TST & \\
\hline CHEMBL1487634 & 688816 & 4.5 & 5.2092 & TRN & \\
\hline CHEMBL1555320 & 688816 & 4.9 & 5.2214 & TRN & \\
\hline CHEMBL3196606 & 688816 & 4.95 & 4.949 & TRN & \\
\hline CHEMBL1338658 & 688816 & 4.95 & 5.1146 & TRN & \\
\hline CHEMBL1494829 & 688816 & 4.45 & 5.095 & TST & \\
\hline CHEMBL1531295 & 688816 & 4.85 & 4.9324 & TRN & \\
\hline CHEMBL1528736 & 688816 & 4.85 & 5.1578 & TRN & \\
\hline CHEMBL1478341 & 688816 & 4.45 & 5.855 & TST & \\
\hline CHEMBL1320386 & 688816 & 4.95 & 5.4398 & TRN & \\
\hline CHEMBL1325806 & 688816 & 5.2 & 5.6231 & TST & \\
\hline CHEMBL3189405 & 688816 & 5.45 & 5.4049 & TRN & \\
\hline
\end{tabular}




\begin{tabular}{|c|c|c|c|c|c|}
\hline \multicolumn{6}{|c|}{ Supplemental Table S2.txt } \\
\hline CHEMBL1518543 & 688816 & 4.45 & 5.5781 & TRN & \\
\hline CHEMBL1351826 & 688816 & 4.75 & 5.0302 & TST & \\
\hline CHEMBL1495008 & 688816 & 8.5528 & 4.9564 & TRN & \\
\hline CHEMBL1364298 & 688816 & 5.0 & 4.9201 & TRN & \\
\hline CHEMBL1533076 & 688816 & 5.1 & 5.4352 & TRN & \\
\hline CHEMBL1359675 & 688816 & 6.3 & 5.188 & TRN & \\
\hline CHEMBL1311124 & 688816 & 4.9 & 4.9309 & TRN & \\
\hline CHEMBL1585833 & 688816 & 4.75 & 5.2518 & TST & \\
\hline CHEMBL1450434 & 688816 & 4.95 & 5.4124 & TRN & \\
\hline CHEMBL1442725 & 688816 & 6.25 & 5.0866 & TRN & \\
\hline CHEMBL1350254 & 688816 & 6.45 & 5.28600 & 00000000005 & TRN \\
\hline CHEMBL1352912 & 688816 & 4.8 & 5.4079 & TRN & \\
\hline CHEMBL1602468 & 688816 & 6.5 & 5.1419 & TRN & \\
\hline CHEMBL1449735 & 688816 & 5.75 & 4.9388 & TRN & \\
\hline CHEMBL1495896 & 688816 & 7.3497 & 5.651 & TRN & \\
\hline CHEMBL1439781 & 688816 & 4.8 & 5.2539 & TRN & \\
\hline CHEMBL1387927 & 688816 & 4.65 & 4.9906 & TRN & \\
\hline CHEMBL1335515 & 688816 & 4.8 & 5.2279 & TRN & \\
\hline CHEMBL1608071 & 688816 & 6.1 & 4.9963 & TRN & \\
\hline CHEMBL1471259 & 688816 & 4.45 & 5.3184 & TRN & \\
\hline CHEMBL1328901 & 688816 & 5.4 & 5.1675 & TRN & \\
\hline CHEMBL3193482 & 688816 & 5.25 & 5.6974 & TST & \\
\hline CHEMBL1303389 & 688816 & 5.05 & 5.3206 & TRN & \\
\hline CHEMBL408563 & 688816 & 6.0 & 5.2603 & TRN & \\
\hline CHEMBL1530181 & 688816 & 4.95 & 5.2351 & TRN & \\
\hline CHEMBL1338435 & 688816 & 6.6499 & 5.0816 & TRN & \\
\hline CHEMBL1410009 & 688816 & 4.45 & 4.9029 & TRN & \\
\hline CHEMBL1308648 & 688816 & 5.25 & 5.3841 & TRN & \\
\hline CHEMBL1449328 & 688816 & 4.95 & 5.067 & TRN & \\
\hline CHEMBL1396540 & 688816 & 4.65 & 4.9035 & TRN & \\
\hline CHEMBL1568017 & 688816 & 8.301 & 5.3705 & TRN & \\
\hline CHEMBL1352621 & 688816 & 4.45 & 5.42200 & 0000000001 & TRN \\
\hline CHEMBL1467018 & 688816 & 4.65 & 5.3746 & TRN & \\
\hline CHEMBL1419372 & 688816 & 5.35 & 5.0355 & TRN & \\
\hline CHEMBL1339116 & 688816 & 4.8 & 5.2041 & TST & \\
\hline CHEMBL1531695 & 688816 & 4.95 & 5.4784 & TRN & \\
\hline CHEMBL1584684 & 688816 & 6.1 & 5.1038 & TRN & \\
\hline CHEMBL1381885 & 688816 & 4.9 & 5.2886 & TRN & \\
\hline CHEMBL 3198578 & 688816 & 6.7501 & 5.3953 & TST & \\
\hline CHEMBL 3199549 & 688816 & 5.0 & 5.3701 & TST & \\
\hline CHEMBL1450643 & 688816 & 5.3 & 5.2191 & TRN & \\
\hline CHEMBL1511676 & 688816 & 4.65 & 5.7094 & TST & \\
\hline CHEMBL1412076 & 688816 & 5.4 & 5.6292 & TRN & \\
\hline CHEMBL1995692 & 688816 & 5.0 & 5.0144 & TRN & \\
\hline CHEMBL1530993 & 688816 & 4.85 & 5.6047 & TRN & \\
\hline CHEMBL1545160 & 688816 & 4.95 & 4.7347 & TRN & \\
\hline CHEMBL1534035 & 688816 & 4.8 & 5.003 & TST & \\
\hline CHEMBL1550269 & 688816 & 4.85 & 5.008 & TRN & \\
\hline
\end{tabular}




\begin{tabular}{|c|c|c|c|c|}
\hline \multicolumn{5}{|c|}{ Supplemental Table S2.txt } \\
\hline CHEMBL1556335 & 688816 & 6.4 & 5.7944 & TST \\
\hline CHEMBL 2094789 & 688816 & 5.4 & 5.115 & TRN \\
\hline CHEMBL1311351 & 688816 & 5.2 & 5.2323 & TRN \\
\hline CHEMBL1588959 & 688816 & 5.05 & 5.2341 & TRN \\
\hline CHEMBL 1480872 & 688816 & 4.45 & 5.1805 & TST \\
\hline CHEMBL1582450 & 688816 & 4.85 & 5.0583 & TRN \\
\hline CHEMBL1601133 & 688816 & 4.7 & 5.0596 & TRN \\
\hline CHEMBL1588363 & 688816 & 4.45 & 5.1663 & TRN \\
\hline CHEMBL1558955 & 688816 & 5.25 & 5.1525 & TRN \\
\hline CHEMBL1574677 & 688816 & 4.65 & 5.1088 & TRN \\
\hline CHEMBL3198094 & 688816 & 5.1 & 5.2872 & TRN \\
\hline CHEMBL1347477 & 688816 & 4.85 & 5.3479 & TRN \\
\hline CHEMBL1528861 & 688816 & 4.95 & 5.4366 & TRN \\
\hline CHEMBL1499205 & 688816 & 5.6 & 5.0014 & TRN \\
\hline CHEMBL1568835 & 688816 & 4.95 & 5.0509 & TRN \\
\hline CHEMBL1457601 & 688816 & 4.45 & 5.1264 & TRN \\
\hline CHEMBL1438753 & 688816 & 6.4 & 5.2117 & TRN \\
\hline CHEMBL1489716 & 688816 & 4.45 & 5.3242 & TRN \\
\hline CHEMBL1479966 & 688816 & 4.9 & 5.3598 & TRN \\
\hline CHEMBL1608727 & 688816 & 5.45 & 5.4344 & TRN \\
\hline CHEMBL1506673 & 688816 & 4.45 & 4.8829 & TRN \\
\hline CHEMBL1541906 & 688816 & 4.7 & 5.2147 & TRN \\
\hline CHEMBL1377317 & 688816 & 4.45 & 5.1185 & TRN \\
\hline CHEMBL1477182 & 688816 & 6.0 & 6.0471 & TRN \\
\hline CHEMBL1343187 & 688816 & 4.8 & 5.3254 & TST \\
\hline CHEMBL1417912 & 688816 & 6.1 & 5.2965 & TST \\
\hline CHEMBL1438988 & 688816 & 5.55 & 5.2203 & TRN \\
\hline CHEMBL1380944 & 688816 & 6.5 & 5.4338 & TRN \\
\hline CHEMBL592712 & 688816 & 4.95 & 5.0824 & TST \\
\hline CHEMBL1328161 & 688816 & 4.6 & 5.1884 & TST \\
\hline CHEMBL1510582 & 688816 & 4.85 & 5.2191 & TRN \\
\hline CHEMBL1387990 & 688816 & 4.8 & 5.2029 & TRN \\
\hline CHEMBL1491534 & 688816 & 4.45 & 5.2554 & TRN \\
\hline CHEMBL582507 & 688816 & 4.95 & 5.1162 & TRN \\
\hline CHEMBL1540906 & 688816 & 4.9 & 5.2529 & TRN \\
\hline CHEMBL1404264 & 688816 & 4.55 & 5.0976 & TRN \\
\hline CHEMBL1380221 & 688816 & 7.5003 & 5.2071 & TST \\
\hline CHEMBL1514579 & 688816 & 4.7 & 5.2803 & TRN \\
\hline CHEMBL1309484 & 688816 & 8.3468 & 5.2255 & TST \\
\hline CHEMBL1488460 & 688816 & 5.0 & 5.0217 & TRN \\
\hline CHEMBL1607346 & 688816 & 5.45 & 5.3565 & TRN \\
\hline CHEMBL 1467557 & 688816 & 4.9 & 5.2091 & TST \\
\hline CHEMBL1488030 & 688816 & 5.15 & 5.184 & TRN \\
\hline CHEMBL3196435 & 688816 & 5.05 & 5.2791 & TRN \\
\hline CHEMBL1456165 & 688816 & 5.3 & 5.8115 & TRN \\
\hline CHEMBL1361173 & 688816 & 4.45 & 5.2676 & TRN \\
\hline CHEMBL1329747 & 688816 & 5.4 & 5.0761 & TRN \\
\hline CHEMBL1531555 & 688816 & 4.95 & 5.0926 & TRN \\
\hline
\end{tabular}




\begin{tabular}{|c|c|c|c|c|}
\hline \multicolumn{5}{|c|}{ Supplemental Table S2.txt } \\
\hline CHEMBL1369402 & 688816 & 6.05 & 5.4492 & TRN \\
\hline CHEMBL1304445 & 688816 & 5.0 & 5.0754 & TRN \\
\hline CHEMBL3193422 & 688816 & 5.0 & 5.3204 & TRN \\
\hline CHEMBL1373897 & 688816 & 5.2 & 5.0937 & TRN \\
\hline CHEMBL 1375320 & 688816 & 4.45 & 4.9496 & TRN \\
\hline CHEMBL1332491 & 688816 & 5.45 & 5.3558 & TRN \\
\hline CHEMBL1608253 & 688816 & 6.3 & 5.7408 & TRN \\
\hline CHEMBL1553089 & 688816 & 4.8 & 5.2596 & TST \\
\hline CHEMBL1444261 & 688816 & 4.95 & 4.8336 & TRN \\
\hline CHEMBL1565180 & 688816 & 4.8 & 5.0114 & TRN \\
\hline CHEMBL1594707 & 688816 & 5.6 & 4.9741 & TRN \\
\hline CHEMBL1300959 & 688816 & 4.8 & 4.9487 & TRN \\
\hline CHEMBL1400003 & 688816 & 4.45 & 4.867 & TRN \\
\hline CHEMBL3212224 & 688816 & 4.95 & 5.3753 & TRN \\
\hline CHEMBL1335729 & 688816 & 5.55 & 5.5756 & TST \\
\hline CHEMBL1461638 & 688816 & 5.4 & 5.2462 & TST \\
\hline CHEMBL1360609 & 688816 & 5.35 & 5.1643 & TRN \\
\hline CHEMBL1320533 & 688816 & 4.6 & 4.9225 & TRN \\
\hline CHEMBL3194268 & 688816 & 6.25 & 5.2025 & TRN \\
\hline CHEMBL1443235 & 688816 & 5.5 & 5.0784 & TST \\
\hline CHEMBL1527316 & 688816 & 4.9 & 5.4603 & TRN \\
\hline CHEMBL1537470 & 688816 & 4.45 & 5.5542 & TRN \\
\hline CHEMBL1541861 & 688816 & 5.45 & 5.0837 & TRN \\
\hline CHEMBL3190125 & 688816 & 4.6 & 5.0012 & TRN \\
\hline CHEMBL491499 & 688816 & 5.5 & 5.3586 & TRN \\
\hline CHEMBL1999513 & 688816 & 4.9 & 5.0836 & TRN \\
\hline CHEMBL1586303 & 688816 & 4.9 & 5.045 & TRN \\
\hline CHEMBL475244 & 688816 & 8.5528 & 5.2852 & TRN \\
\hline CHEMBL1572728 & 688816 & 5.0 & 5.8268 & TST \\
\hline CHEMBL1386536 & 688816 & 4.8 & 5.3227 & TRN \\
\hline CHEMBL1551338 & 688816 & 4.85 & 5.0256 & TRN \\
\hline CHEMBL1462749 & 688816 & 8.301 & 5.7814 & TRN \\
\hline CHEMBL3193208 & 688816 & 4.85 & 5.3934 & TRN \\
\hline CHEMBL1455117 & 688816 & 5.25 & 5.2415 & TRN \\
\hline CHEMBL1344301 & 688816 & 4.45 & 5.4009 & TRN \\
\hline CHEMBL1338440 & 688816 & 7.0501 & 5.4122 & TST \\
\hline CHEMBL1326833 & 688816 & 4.9 & 4.9842 & TST \\
\hline CHEMBL1425424 & 688816 & 5.4 & 5.3566 & TST \\
\hline CHEMBL1596468 & 688816 & 4.45 & 5.2348 & TRN \\
\hline CHEMBL1495161 & 688816 & 4.8 & 4.99 & TRN \\
\hline CHEMBL1413986 & 688816 & 4.85 & 5.3516 & TRN \\
\hline CHEMBL1501547 & 688816 & 5.7 & 5.301 & TRN \\
\hline CHEMBL1601128 & 688816 & 4.95 & 4.9426 & TRN \\
\hline CHEMBL1507840 & 688816 & 4.6 & 5.3318 & TRN \\
\hline CHEMBL1569287 & 688816 & 4.95 & 5.3148 & TRN \\
\hline CHEMBL1544554 & 688816 & 5.2 & 5.4082 & TRN \\
\hline CHEMBL3210725 & 688816 & 5.25 & 5.2984 & TRN \\
\hline CHEMBL1505717 & 688816 & 4.95 & 5.3451 & TRN \\
\hline
\end{tabular}




\begin{tabular}{|c|c|c|c|c|c|}
\hline \multicolumn{6}{|c|}{ Supplemental Table s2.txt } \\
\hline CHEMBL1336829 & 688816 & 5.05 & 5.2054 & TRN & \\
\hline CHEMBL1409674 & 688816 & 8.3468 & 5.1174 & TST & \\
\hline CHEMBL1535652 & 688816 & 4.7 & 5.0168 & TRN & \\
\hline CHEMBL1384326 & 688816 & 5.0 & 5.2283 & TRN & \\
\hline CHEMBL1484542 & 688816 & 5.4 & 5.3114 & TRN & \\
\hline CHEMBL1381436 & 688816 & 4.65 & 5.1284 & TST & \\
\hline CHEMBL3195439 & 688816 & 4.85 & 5.5062 & TRN & \\
\hline CHEMBL1400762 & 688816 & 8.3468 & 5.6503 & TRN & \\
\hline CHEMBL1515743 & 688816 & 4.7 & 4.751 & TRN & \\
\hline CHEMBL1575273 & 688816 & 5.75 & 5.4406 & TST & \\
\hline CHEMBL1513329 & 688816 & 6.6 & 5.2015 & TRN & \\
\hline CHEMBL1581212 & 688816 & 4.95 & 5.5558 & TRN & \\
\hline CHEMBL1338938 & 688816 & 5.4 & 5.9968 & TRN & \\
\hline CHEMBL1374922 & 688816 & 5.55 & \multicolumn{2}{|c|}{5.502999999999999} & TRN \\
\hline CHEMBL1428263 & 688816 & 4.95 & 5.4085 & TRN & \\
\hline CHEMBL3198967 & 688816 & 4.9 & 5.064 & TRN & \\
\hline CHEMBL3211348 & 688816 & 6.25 & 5.4883 & TRN & \\
\hline CHEMBL1601781 & 688816 & 4.45 & 4.8633 & TST & \\
\hline CHEMBL1525697 & 688816 & 4.45 & 4.8724 & TRN & \\
\hline CHEMBL371523 & 688816 & 4.9 & 5.4278 & TRN & \\
\hline CHEMBL1428396 & 688816 & 4.45 & 5.0548 & TRN & \\
\hline CHEMBL1501872 & 688816 & 4.85 & 5.2733 & TRN & \\
\hline CHEMBL1549272 & 688816 & 5.65 & 5.0394 & TRN & \\
\hline CHEMBL1367880 & 688816 & 5.85 & 5.1504 & TRN & \\
\hline CHEMBL1352545 & 688816 & 4.5 & 5.0287 & TST & \\
\hline CHEMBL1506271 & 688816 & 4.95 & 5.425 & TRN & \\
\hline CHEMBL1531836 & 688816 & 5.6 & 5.4316 & TRN & \\
\hline CHEMBL1345643 & 688816 & 4.9 & 5.0949 & TRN & \\
\hline CHEMBL1565716 & 688816 & 5.8 & 5.5943 & TRN & \\
\hline CHEMBL1526653 & 688816 & 5.5 & 5.3505 & TRN & \\
\hline CHEMBL1536685 & 688816 & 5.95 & 5.0507 & TST & \\
\hline CHEMBL 2005042 & 688816 & 4.75 & 5.1286 & TRN & \\
\hline CHEMBL486422 & 688816 & 4.6 & 5.3571 & TRN & \\
\hline CHEMBL1595205 & 688816 & 4.75 & 5.3141 & TRN & \\
\hline CHEMBL1487131 & 688816 & 5.25 & 4.803 & TST & \\
\hline CHEMBL1429292 & 688816 & 4.85 & 5.3817 & TRN & \\
\hline CHEMBL1988072 & 688816 & 4.75 & 4.9638 & TST & \\
\hline CHEMBL1331509 & 688816 & 5.1 & 5.3623 & TRN & \\
\hline CHEMBL1540692 & 688816 & 4.85 & 5.8549 & TST & \\
\hline CHEMBL1374893 & 688816 & 4.75 & 5.6338 & TRN & \\
\hline CHEMBL1448854 & 688816 & 5.4 & 5.2578 & TRN & \\
\hline CHEMBL1598471 & 688816 & 5.0 & 5.4298 & TRN & \\
\hline CHEMBL1603517 & 688816 & 5.25 & 5.483 & TRN & \\
\hline CHEMBL1572129 & 688816 & 4.65 & 5.3415 & TST & \\
\hline CHEMBL1461181 & 688816 & 4.95 & 4.9361 & TRN & \\
\hline CHEMBL1363614 & 688816 & 4.8 & 4.6931 & TST & \\
\hline CHEMBL1522328 & 688816 & 4.85 & 5.32100 & 0000000001 & TRN \\
\hline \multirow[t]{2}{*}{ CHEMBL1418877 } & 688816 & 4.45 & 5.0207 & TRN & \\
\hline & & \multicolumn{4}{|c|}{ Page 24939} \\
\hline
\end{tabular}




\begin{tabular}{|c|c|c|c|c|}
\hline \multicolumn{5}{|c|}{ Supplemental Table S2.txt } \\
\hline CHEMBL1595858 & 688816 & 4.95 & 4.8862 & TRN \\
\hline CHEMBL1989852 & 688816 & 7.5498 & 5.2721 & TST \\
\hline CHEMBL1419935 & 688816 & 4.95 & 5.3408 & TRN \\
\hline CHEMBL1406353 & 688816 & 8.4559 & 5.7186 & TRN \\
\hline CHEMBL1520220 & 688816 & 4.5 & 5.0547 & TRN \\
\hline CHEMBL1582368 & 688816 & 4.8 & 5.1533 & TRN \\
\hline CHEMBL1460755 & 688816 & 5.05 & 5.3439 & TRN \\
\hline CHEMBL 3189222 & 688816 & 5.3 & 5.5806 & TRN \\
\hline CHEMBL1379675 & 688816 & 4.95 & 4.87 & TRN \\
\hline CHEMBL1548378 & 688816 & 5.0 & 5.3663 & TRN \\
\hline CHEMBL1561032 & 688816 & 4.8 & 5.1194 & TRN \\
\hline CHEMBL1464103 & 688816 & 4.95 & 5.2425 & TST \\
\hline CHEMBL1406399 & 688816 & 7.3002 & 5.4828 & TRN \\
\hline CHEMBL1437732 & 688816 & 6.05 & 5.4803 & TST \\
\hline CHEMBL1538429 & 688816 & 6.1 & 5.2964 & TRN \\
\hline CHEMBL1383267 & 688816 & 4.7 & 4.7124 & TRN \\
\hline CHEMBL475908 & 688816 & 4.6 & 4.9282 & TRN \\
\hline CHEMBL1521642 & 688816 & 6.8499 & 5.5822 & TST \\
\hline CHEMBL1467221 & 688816 & 8.4949 & 5.6167 & TST \\
\hline CHEMBL1479020 & 688816 & 5.5 & 5.2516 & TST \\
\hline CHEMBL3194828 & 688816 & 4.9 & 5.2106 & TRN \\
\hline CHEMBL1365218 & 688816 & 7.0501 & 5.5087 & TRN \\
\hline CHEMBL1353719 & 688816 & 4.9 & 5.2781 & TST \\
\hline CHEMBL1305912 & 688816 & 4.9 & 4.9016 & TRN \\
\hline CHEMBL1328018 & 688816 & 5.15 & 5.3226 & TRN \\
\hline CHEMBL1303799 & 688816 & 5.05 & 5.2044 & TRN \\
\hline CHEMBL1336084 & 688816 & 5.3 & 5.5055 & TRN \\
\hline CHEMBL1606790 & 688816 & 4.5 & 5.3503 & TRN \\
\hline CHEMBL1501355 & 688816 & 8.3468 & 5.6236 & TST \\
\hline CHEMBL1315721 & 688816 & 7.9508 & 5.3564 & TRN \\
\hline CHEMBL1318900 & 688816 & 4.45 & 4.8817 & TRN \\
\hline CHEMBL 3212028 & 688816 & 4.8 & 5.2454 & TRN \\
\hline CHEMBL405912 & 688816 & 4.9 & 4.8931 & TST \\
\hline CHEMBL1519874 & 688816 & 4.85 & 5.1377 & TRN \\
\hline CHEMBL1478485 & 688816 & 4.85 & 5.0112 & TRN \\
\hline CHEMBL1305250 & 688816 & 5.5 & 5.4119 & TRN \\
\hline CHEMBL1599625 & 688816 & 4.9 & 5.1374 & TRN \\
\hline CHEMBL1555816 & 688816 & 4.75 & 5.2065 & TRN \\
\hline CHEMBL1459071 & 688816 & 5.0 & 5.6963 & TRN \\
\hline CHEMBL1573287 & 688816 & 4.85 & 5.0331 & TRN \\
\hline CHEMBL1525315 & 688816 & 4.85 & 4.9968 & TRN \\
\hline CHEMBL1548844 & 688816 & 4.85 & 5.0265 & TRN \\
\hline CHEMBL1321591 & 688816 & 5.8 & 4.8804 & TRN \\
\hline CHEMBL1350199 & 688816 & 4.7 & 5.0771 & TRN \\
\hline CHEMBL1613147 & 688816 & 5.7 & 5.3796 & TRN \\
\hline CHEMBL1604779 & 688816 & 4.8 & 5.2654 & TRN \\
\hline CHEMBL1304290 & 688816 & 5.0 & 5.1998 & TRN \\
\hline CHEMBL1456775 & 688816 & 6.4 & 4.8721 & TRN \\
\hline
\end{tabular}




\begin{tabular}{|c|c|c|c|c|c|}
\hline \multicolumn{6}{|c|}{ Supplemental Table S2.txt } \\
\hline CHEMBL1363083 & 688816 & 4.65 & 4.97 & TRN & \\
\hline CHEMBL1498275 & 688816 & 4.45 & 5.303 & TRN & \\
\hline CHEMBL1441508 & 688816 & 4.9 & 4.9447 & TST & \\
\hline CHEMBL1496776 & 688816 & 4.85 & 5.6214 & TRN & \\
\hline CHEMBL3195420 & 688816 & 5.65 & 5.40799 & 99999999995 & TST \\
\hline CHEMBL3213349 & 688816 & 6.1 & 5.3369 & TRN & \\
\hline CHEMBL1542760 & 688816 & 4.8 & 5.2497 & TRN & \\
\hline CHEMBL394287 & 688816 & 5.0 & 5.5506 & TRN & \\
\hline CHEMBL3197296 & 688816 & 4.95 & 5.2382 & TRN & \\
\hline CHEMBL3197921 & 688816 & 4.95 & 4.9243 & TRN & \\
\hline CHEMBL1582976 & 688816 & 4.45 & 5.1485 & TRN & \\
\hline CHEMBL1605044 & 688816 & 4.65 & 4.7408 & TRN & \\
\hline CHEMBL1310373 & 688816 & 5.7 & 5.3884 & TST & \\
\hline CHEMBL1561182 & 688816 & 4.75 & 5.2439 & TST & \\
\hline CHEMBL1578026 & 688816 & 5.95 & 5.4551 & TRN & \\
\hline CHEMBL1299783 & 688816 & 4.45 & 4.9693 & TRN & \\
\hline CHEMBL1443396 & 688816 & 4.45 & 5.6823 & TRN & \\
\hline CHEMBL1366974 & 688816 & 5.6 & 5.1475 & TRN & \\
\hline CHEMBL1425675 & 688816 & 4.45 & 4.8939 & TRN & \\
\hline CHEMBL1545240 & 688816 & 6.3 & 5.2088 & TRN & \\
\hline CHEMBL1470923 & 688816 & 5.25 & 5.8122 & TRN & \\
\hline CHEMBL1496787 & 688816 & 5.25 & 5.3794 & TST & \\
\hline CHEMBL1587063 & 688816 & 4.45 & 5.46899 & 9999999999 & TST \\
\hline CHEMBL1386099 & 688816 & 5.25 & 5.1526 & TRN & \\
\hline CHEMBL1544531 & 688816 & 5.1 & 5.3687 & TRN & \\
\hline CHEMBL1533547 & 688816 & 4.95 & 5.15600 & 0000000001 & TST \\
\hline CHEMBL1339809 & 688816 & 5.25 & 5.6808 & TRN & \\
\hline CHEMBL1599562 & 688816 & 5.45 & 5.41200 & 0000000001 & TRN \\
\hline CHEMBL1401754 & 688816 & 4.45 & 5.2436 & TST & \\
\hline CHEMBL1385880 & 688816 & 5.25 & 5.3688 & TRN & \\
\hline CHEMBL3213939 & 688816 & 4.95 & 5.5793 & TST & \\
\hline CHEMBL3193644 & 688816 & 7.1002 & 5.38 & TST & \\
\hline CHEMBL1461686 & 688816 & 5.6 & 5.4224 & TRN & \\
\hline CHEMBL1578763 & 688816 & 5.1 & 5.2924 & TST & \\
\hline CHEMBL3192714 & 688816 & 5.9 & 5.6111 & TRN & \\
\hline CHEMBL1600079 & 688816 & 4.45 & 5.2241 & TRN & \\
\hline CHEMBL1365291 & 688816 & 4.45 & 5.2545 & TRN & \\
\hline CHEMBL1563821 & 688816 & 5.1 & 4.9023 & TRN & \\
\hline CHEMBL1327260 & 688816 & 4.95 & 5.1522 & TRN & \\
\hline CHEMBL1416592 & 688816 & 5.55 & 5.0438 & TRN & \\
\hline CHEMBL1339466 & 688816 & 4.9 & 5.2174 & TRN & \\
\hline CHEMBL1418026 & 688816 & 6.6499 & 5.3697 & TRN & \\
\hline CHEMBL1341789 & 688816 & 5.5 & 5.4606 & TST & \\
\hline CHEMBL1459069 & 688816 & 4.45 & 5.1152 & TRN & \\
\hline CHEMBL1520502 & 688816 & 4.75 & 5.0967 & TRN & \\
\hline CHEMBL1254201 & 688816 & 4.7 & 5.3358 & TRN & \\
\hline CHEMBL1378452 & 688816 & 4.45 & 4.9674 & TST & \\
\hline CHEMBL1339953 & 688816 & 4.95 & 5.9166 & TST & \\
\hline
\end{tabular}




\begin{tabular}{|c|c|c|c|c|c|}
\hline \multicolumn{6}{|c|}{ Supplemental Table S2.txt } \\
\hline CHEMBL1338853 & 688816 & 4.9 & 5.114 & TRN & \\
\hline CHEMBL1550498 & 688816 & 5.4 & 5.4421 & TRN & \\
\hline CHEMBL1583288 & 688816 & 4.45 & 4.894 & TRN & \\
\hline CHEMBL1388911 & 688816 & 4.45 & 5.6655 & TRN & \\
\hline CHEMBL3195322 & 688816 & 5.8 & 5.2004 & TRN & \\
\hline CHEMBL585213 & 688816 & 5.2 & 5.2006 & TST & \\
\hline CHEMBL1606999 & 688816 & 6.05 & 5.3487 & TRN & \\
\hline CHEMBL1540741 & 688816 & 5.0 & 4.9589 & TRN & \\
\hline CHEMBL1578394 & 688816 & 8.3468 & 5.4112 & TST & \\
\hline CHEMBL3195265 & 688816 & 4.45 & 5.3706 & TST & \\
\hline CHEMBL1444859 & 688816 & 4.8 & 5.0717 & TST & \\
\hline CHEMBL1564625 & 688816 & 4.85 & 5.1424 & TRN & \\
\hline CHEMBL1366707 & 688816 & 4.5 & 5.2571 & TRN & \\
\hline CHEMBL1992359 & 688816 & 4.85 & 5.3102 & TRN & \\
\hline CHEMBL1375184 & 688816 & 4.45 & 5.0283 & TRN & \\
\hline CHEMBL1372821 & 688816 & 6.0 & 5.0543 & TST & \\
\hline CHEMBL1302070 & 688816 & 8.3468 & 5.5917 & TRN & \\
\hline CHEMBL1585273 & 688816 & 5.6 & 5.0666 & TST & \\
\hline CHEMBL1380591 & 688816 & 4.45 & 5.216 & TRN & \\
\hline CHEMBL1485518 & 688816 & 5.25 & 5.2566 & TST & \\
\hline CHEMBL1569348 & 688816 & 5.45 & 5.50799 & 9999999999 & TRN \\
\hline CHEMBL1354976 & 688816 & 4.95 & 4.9207 & TRN & \\
\hline CHEMBL1392771 & 688816 & 4.7 & 5.1669 & TST & \\
\hline CHEMBL1400667 & 688816 & 4.5 & 5.1047 & TST & \\
\hline CHEMBL1422611 & 688816 & 4.5 & 5.4892 & TST & \\
\hline CHEMBL1331419 & 688816 & 4.9 & 5.0489 & TST & \\
\hline CHEMBL1385780 & 688816 & 4.8 & 5.3832 & TST & \\
\hline CHEMBL 201325 & 688816 & 5.15 & 5.0838 & TRN & \\
\hline CHEMBL1538240 & 688816 & 4.85 & 5.1453 & TRN & \\
\hline CHEMBL1488225 & 688816 & 5.95 & 5.6233 & TRN & \\
\hline CHEMBL1430227 & 688816 & 5.0 & 5.3436 & TRN & \\
\hline CHEMBL1372066 & 688816 & 5.05 & 5.2202 & TRN & \\
\hline CHEMBL1318259 & 688816 & 4.9 & 5.6062 & TST & \\
\hline CHEMBL1404525 & 688816 & 5.1 & 5.1376 & TRN & \\
\hline CHEMBL1413514 & 688816 & 6.8499 & 5.6126 & TRN & \\
\hline CHEMBL1426505 & 688816 & 4.95 & 5.1247 & TST & \\
\hline CHEMBL1397425 & 688816 & 5.3 & 5.4228 & TRN & \\
\hline CHEMBL1336358 & 688816 & 8.3468 & 5.1742 & TST & \\
\hline CHEMBL1427051 & 688816 & 4.95 & 4.96399 & 99999999995 & TRN \\
\hline CHEMBL1403669 & 688816 & 4.85 & 5.2938 & TST & \\
\hline CHEMBL1501505 & 688816 & 4.45 & 5.0129 & TRN & \\
\hline CHEMBL1420544 & 688816 & 7.4498 & 5.3889 & TRN & \\
\hline CHEMBL1335358 & 688816 & 4.85 & 5.131 & TRN & \\
\hline CHEMBL1477833 & 688816 & 4.9 & 5.4714 & TRN & \\
\hline CHEMBL1407693 & 688816 & 5.5 & 4.9086 & TRN & \\
\hline CHEMBL3195733 & 688816 & 7.699 & 5.2252 & TRN & \\
\hline CHEMBL1380687 & 688816 & 4.9 & 5.3648 & TRN & \\
\hline CHEMBL1992745 & 688816 & 4.95 & 5.1823 & TRN & \\
\hline
\end{tabular}




\begin{tabular}{|c|c|c|c|c|c|}
\hline \multicolumn{6}{|c|}{ Supplemental Table S2.txt } \\
\hline CHEMBL1422146 & 688816 & 4.85 & 5.1224 & TRN & \\
\hline CHEMBL1580157 & 688816 & 4.85 & 5.1681 & TRN & \\
\hline CHEMBL1382807 & 688816 & 4.95 & 5.2084 & TRN & \\
\hline CHEMBL1972996 & 688816 & 4.7 & 5.3557 & TST & \\
\hline CHEMBL1531512 & 688816 & 4.45 & 5.0977 & TRN & \\
\hline CHEMBL1351525 & 688816 & 4.9 & 5.0123 & TRN & \\
\hline CHEMBL1542974 & 688816 & 4.9 & 5.1771 & TRN & \\
\hline CHEMBL1527604 & 688816 & 4.8 & 5.2097 & TRN & \\
\hline CHEMBL1409148 & 688816 & 4.45 & 4.8439 & TRN & \\
\hline CHEMBL1996426 & 688816 & 4.45 & 5.6623 & TST & \\
\hline CHEMBL1445165 & 688816 & 4.8 & 5.2022 & TST & \\
\hline CHEMBL1347831 & 688816 & 4.9 & 5.2459 & TRN & \\
\hline CHEMBL1429539 & 688816 & 5.55 & 5.0513 & TRN & \\
\hline CHEMBL1347976 & 688816 & 5.3 & 5.4044 & TST & \\
\hline CHEMBL3208739 & 688816 & 5.25 & 5.3952 & TST & \\
\hline CHEMBL1967744 & 688816 & 5.6 & 5.015 & TRN & \\
\hline CHEMBL1415793 & 688816 & 4.45 & 4.8639 & TST & \\
\hline CHEMBL1256661 & 688816 & 4.45 & 5.2561 & TST & \\
\hline CHEMBL1305074 & 688816 & 5.45 & 5.0214 & TRN & \\
\hline CHEMBL1571968 & 688816 & 5.6 & 5.3796 & TRN & \\
\hline CHEMBL1436623 & 688816 & 6.7001 & 5.104 & TRN & \\
\hline CHEMBL1481473 & 688816 & 4.95 & 5.3433 & TRN & \\
\hline CHEMBL1319663 & 688816 & 7.5003 & 5.7508 & TRN & \\
\hline CHEMBL1425391 & 688816 & 4.9 & 5.2581 & TRN & \\
\hline CHEMBL1456468 & 688816 & 4.95 & 5.4793 & TRN & \\
\hline CHEMBL3189712 & 688816 & 5.0 & 4.9309 & TRN & \\
\hline CHEMBL1472819 & 688816 & 5.45 & 5.1291 & TST & \\
\hline CHEMBL1499666 & 688816 & 4.9 & 5.4573 & TRN & \\
\hline CHEMBL1339317 & 688816 & 6.8499 & 5.3234 & TST & \\
\hline CHEMBL1597579 & 688816 & 5.25 & 5.3696 & TRN & \\
\hline CHEMBL1466502 & 688816 & 4.45 & 5.3792 & TRN & \\
\hline CHEMBL1589805 & 688816 & 4.45 & 5.9492 & TRN & \\
\hline CHEMBL1600085 & 688816 & 5.2 & 5.6269 & TRN & \\
\hline CHEMBL 3196262 & 688816 & 4.45 & 5.0281 & TST & \\
\hline CHEMBL1605590 & 688816 & 8.301 & 5.4657 & TRN & \\
\hline CHEMBL1461748 & 688816 & 4.6 & 4.9673 & TRN & \\
\hline CHEMBL1324853 & 688816 & 5.05 & 5.3357 & TRN & \\
\hline CHEMBL1611583 & 688816 & 4.7 & 4.7864 & TRN & \\
\hline CHEMBL1537619 & 688816 & 6.25 & 5.4411 & TRN & \\
\hline CHEMBL1513687 & 688816 & 4.8 & 5.46399 & 99999999995 & TRN \\
\hline CHEMBL1602974 & 688816 & 4.85 & 5.5496 & TRN & \\
\hline CHEMBL1329721 & 688816 & 4.8 & 5.0053 & TRN & \\
\hline CHEMBL1411028 & 688816 & 4.85 & 5.1186 & TRN & \\
\hline CHEMBL1380108 & 688816 & 4.6 & 5.4744 & TST & \\
\hline CHEMBL1345176 & 688816 & 5.5 & 5.4062 & TST & \\
\hline CHEMBL1324658 & 688816 & 4.45 & 5.2225 & TRN & \\
\hline CHEMBL1310005 & 688816 & 4.65 & 4.8153 & TRN & \\
\hline CHEMBL1554693 & 688816 & 5.7 & 5.3661 & TRN & \\
\hline
\end{tabular}




\begin{tabular}{|c|c|c|c|c|c|}
\hline \multicolumn{6}{|c|}{ Supplemental Table s2.txt } \\
\hline CHEMBL1302615 & 688816 & 4.75 & 5.2434 & TST & \\
\hline CHEMBL1565133 & 688816 & 4.95 & 5.2127 & TST & \\
\hline CHEMBL1396334 & 688816 & 5.45 & 5.3432 & TRN & \\
\hline CHEMBL1382819 & 688816 & 4.9 & 5.678 & TST & \\
\hline CHEMBL1344582 & 688816 & 6.4 & 5.5884 & TRN & \\
\hline CHEMBL1379364 & 688816 & 6.0 & 4.9503 & TRN & \\
\hline CHEMBL1457068 & 688816 & 6.25 & 5.1984 & TRN & \\
\hline CHEMBL1499770 & 688816 & 5.55 & 5.3388 & TRN & \\
\hline CHEMBL1383597 & 688816 & 5.35 & 5.322 & TRN & \\
\hline CHEMBL1448785 & 688816 & 4.55 & 5.5402 & TST & \\
\hline CHEMBL1562130 & 688816 & 5.2 & 5.432 & TRN & \\
\hline CHEMBL1518824 & 688816 & 4.8 & 5.4006 & TRN & \\
\hline CHEMBL1461256 & 688816 & 6.25 & 5.6215 & TRN & \\
\hline CHEMBL1348931 & 688816 & 5.25 & 5.3434 & TRN & \\
\hline CHEMBL1568465 & 688816 & 5.25 & 5.32799 & 9999999999 & TRN \\
\hline CHEMBL1568190 & 688816 & 4.85 & 4.96899 & 9999999999 & TRN \\
\hline CHEMBL1569554 & 688816 & 4.45 & 5.345 & TRN & \\
\hline CHEMBL1487405 & 688816 & 5.25 & 5.1732 & TRN & \\
\hline CHEMBL1564080 & 688816 & 5.9 & 5.3966 & TRN & \\
\hline CHEMBL1603638 & 688816 & 6.35 & 5.5157 & TRN & \\
\hline CHEMBL1496854 & 688816 & 5.75 & 5.2437 & TRN & \\
\hline CHEMBL1312788 & 688816 & 4.45 & 5.1149 & TRN & \\
\hline CHEMBL1463900 & 688816 & 4.9 & 5.2168 & TRN & \\
\hline CHEMBL1580065 & 688816 & 4.6 & 5.5438 & TRN & \\
\hline CHEMBL3197045 & 688816 & 4.65 & 5.6072 & TST & \\
\hline CHEMBL1517892 & 688816 & 4.45 & 5.3892 & TRN & \\
\hline CHEMBL1336439 & 688816 & 5.0 & 5.0154 & TRN & \\
\hline CHEMBL1586732 & 688816 & 5.15 & 5.38899 & 9999999999 & TRN \\
\hline CHEMBL1400382 & 688816 & 5.55 & 5.0228 & TST & \\
\hline CHEMBL1409282 & 688816 & 6.6 & 5.2082 & TST & \\
\hline CHEMBL1507124 & 688816 & 8.3468 & 5.5023 & TRN & \\
\hline CHEMBL1488595 & 688816 & 4.65 & 5.3558 & TRN & \\
\hline CHEMBL1573690 & 688816 & 4.95 & 5.3986 & TST & \\
\hline CHEMBL1523751 & 688816 & 5.1 & 5.3051 & TRN & \\
\hline CHEMBL1331851 & 688816 & 4.95 & 4.9604 & TRN & \\
\hline CHEMBL1569910 & 688816 & 5.3 & 5.1393 & TRN & \\
\hline CHEMBL1459118 & 688816 & 7.3497 & 5.4785 & TRN & \\
\hline CHEMBL1583455 & 688816 & 7.3497 & 5.6958 & TRN & \\
\hline CHEMBL1489459 & 688816 & 4.75 & 5.0868 & TRN & \\
\hline CHEMBL491940 & 688816 & 4.65 & 4.6078 & TRN & \\
\hline CHEMBL1574242 & 688816 & 4.5 & 5.3762 & TRN & \\
\hline CHEMBL1500948 & 688816 & 5.25 & 5.4441 & TST & \\
\hline CHEMBL1580571 & 688816 & 4.95 & 5.0883 & TRN & \\
\hline CHEMBL1504348 & 688816 & 4.95 & 5.0123 & TRN & \\
\hline CHEMBL1348475 & 688816 & 5.85 & 5.2235 & TRN & \\
\hline CHEMBL1394012 & 688816 & 6.1 & 5.2142 & TST & \\
\hline CHEMBL1402581 & 688816 & 4.6 & 5.0033 & TRN & \\
\hline CHEMBL1450777 & 688816 & 4.7 & 5.25700 & 0000000001 & TRN \\
\hline & & & & 24944 & \\
\hline
\end{tabular}




\begin{tabular}{|c|c|c|c|c|c|}
\hline \multicolumn{6}{|c|}{ Supplemental Table S2.txt } \\
\hline CHEMBL1579646 & 688816 & 8.1024 & 5.5816 & TST & \\
\hline CHEMBL1412195 & 688816 & 4.65 & 5.2004 & TST & \\
\hline CHEMBL1506268 & 688816 & 4.7 & 5.1244 & TRN & \\
\hline CHEMBL1384268 & 688816 & 5.25 & 5.6794 & TRN & \\
\hline CHEMBL1338662 & 688816 & 4.9 & 4.8677 & TRN & \\
\hline CHEMBL1524045 & 688816 & 6.8 & 4.9303 & TRN & \\
\hline CHEMBL285819 & 688816 & 4.45 & 5.7598 & TRN & \\
\hline CHEMBL1501110 & 688816 & 4.85 & 5.1088 & TRN & \\
\hline CHEMBL1488035 & 688816 & 5.15 & 5.0389 & TRN & \\
\hline CHEMBL1607928 & 688816 & 4.7 & 5.3624 & TRN & \\
\hline CHEMBL3193770 & 688816 & 5.6 & 5.2927 & TST & \\
\hline CHEMBL1546162 & 688816 & 4.45 & 4.9101 & TRN & \\
\hline CHEMBL1461615 & 688816 & 4.9 & 5.1604 & TRN & \\
\hline CHEMBL607805 & 688816 & 5.4 & 5.6201 & TST & \\
\hline CHEMBL1569407 & 688816 & 4.9 & 5.055 & TRN & \\
\hline CHEMBL1420103 & 688816 & 5.0 & 5.1665 & TRN & \\
\hline CHEMBL1323133 & 688816 & 4.95 & 5.42700 & 00000000005 & TRN \\
\hline CHEMBL1410429 & 688816 & 5.0 & 5.41 & TRN & \\
\hline CHEMBL1984155 & 688816 & 4.95 & 5.3928 & TRN & \\
\hline CHEMBL1319041 & 688816 & 4.45 & 5.5409 & TRN & \\
\hline CHEMBL1588972 & 688816 & 4.45 & 5.3978 & TST & \\
\hline CHEMBL1314172 & 688816 & 5.05 & 5.1981 & TRN & \\
\hline CHEMBL1308104 & 688816 & 8.3468 & 5.4099 & TST & \\
\hline CHEMBL1513076 & 688816 & 8.4949 & 5.5447 & TST & \\
\hline CHEMBL1323332 & 688816 & 5.15 & 5.399 & TRN & \\
\hline CHEMBL1346148 & 688816 & 4.55 & 4.9429 & TRN & \\
\hline CHEMBL1538989 & 688816 & 5.75 & 5.7558 & TRN & \\
\hline CHEMBL1494792 & 688816 & 4.8 & 5.3194 & TRN & \\
\hline CHEMBL1577714 & 688816 & 4.45 & 4.793 & TRN & \\
\hline CHEMBL1572931 & 688816 & 6.0 & 5.16799 & э999999999 & TST \\
\hline CHEMBL1465211 & 688816 & 4.9 & 5.2226 & TST & \\
\hline CHEMBL1413425 & 688816 & 8.0506 & 5.0795 & TST & \\
\hline CHEMBL1480310 & 688816 & 4.95 & 5.465 & TRN & \\
\hline CHEMBL1379942 & 688816 & 7.5003 & 5.5516 & TST & \\
\hline CHEMBL1559691 & 688816 & 4.45 & 5.0088 & TRN & \\
\hline CHEMBL1339249 & 688816 & 5.25 & 5.2808 & TRN & \\
\hline CHEMBL1584468 & 688816 & 4.9 & 5.1474 & TRN & \\
\hline CHEMBL1429795 & 688816 & 5.2 & 5.2857 & TST & \\
\hline CHEMBL1381447 & 688816 & 6.05 & 5.5105 & TST & \\
\hline CHEMBL1537900 & 688816 & 5.3 & 5.008 & TRN & \\
\hline CHEMBL1367263 & 688816 & 5.3 & 5.2124 & TST & \\
\hline CHEMBL1401588 & 688816 & 5.65 & 5.0245 & TRN & \\
\hline CHEMBL3197272 & 688816 & 4.9 & 5.311 & TRN & \\
\hline CHEMBL3197079 & 688816 & 4.85 & 5.2545 & TRN & \\
\hline CHEMBL260774 & 688816 & 4.45 & 5.2435 & TRN & \\
\hline CHEMBL1309584 & 688816 & 5.85 & 5.7706 & TRN & \\
\hline CHEMBL1546603 & 688816 & 5.0 & 5.0274 & TRN & \\
\hline CHEMBL1343439 & 688816 & 4.9 & 5.2951 & TRN & \\
\hline
\end{tabular}




\begin{tabular}{|c|c|c|c|c|c|}
\hline \multicolumn{6}{|c|}{ Supplemental Table S2.txt } \\
\hline CHEMBL1337912 & 688816 & 4.8 & 5.103 & TRN & \\
\hline CHEMBL1461935 & 688816 & 4.95 & 5.1637 & TST & \\
\hline CHEMBL1610004 & 688816 & 4.9 & 5.0564 & TRN & \\
\hline CHEMBL1360620 & 688816 & 6.0 & 5.6683 & TRN & \\
\hline CHEMBL1347901 & 688816 & 5.0 & 5.0528 & TRN & \\
\hline CHEMBL1379391 & 688816 & 4.85 & 4.9298 & TRN & \\
\hline CHEMBL1573799 & 688816 & 4.9 & 5.5146 & TRN & \\
\hline CHEMBL1472117 & 688816 & 4.85 & 5.1064 & TST & \\
\hline CHEMBL1499306 & 688816 & 4.45 & 5.1553 & TRN & \\
\hline CHEMBL1542804 & 688816 & 4.65 & 4.94 & TST & \\
\hline CHEMBL1310965 & 688816 & 5.35 & 5.2042 & TRN & \\
\hline CHEMBL1429218 & 688816 & 5.1 & 5.3238 & TRN & \\
\hline CHEMBL1497473 & 688816 & 5.7 & 5.3772 & TST & \\
\hline CHEMBL1507963 & 688816 & 6.05 & 5.0738 & TRN & \\
\hline CHEMBL1452037 & 688816 & 7.699 & 5.0405 & TRN & \\
\hline CHEMBL1479116 & 688816 & 5.0 & 4.8164 & TRN & \\
\hline CHEMBL1606309 & 688816 & 5.45 & 4.9853 & TRN & \\
\hline CHEMBL1532922 & 688816 & 7.8508 & 5.4919 & TST & \\
\hline CHEMBL1414438 & 688816 & 4.9 & 5.3458 & TRN & \\
\hline CHEMBL1426736 & 688816 & 5.05 & 5.228 & TRN & \\
\hline CHEMBL1324562 & 688816 & 4.75 & 4.9033 & TRN & \\
\hline CHEMBL1438232 & 688816 & 4.9 & 5.0871 & TRN & \\
\hline CHEMBL1439347 & 688816 & 5.15 & 5.5987 & TRN & \\
\hline CHEMBL1422426 & 688816 & 4.75 & 5.2563 & TRN & \\
\hline CHEMBL1452426 & 688816 & 6.8499 & 4.9876 & TRN & \\
\hline CHEMBL1533923 & 688816 & 6.0 & 5.2137 & TRN & \\
\hline CHEMBL1232313 & 688816 & 6.05 & 5.8702 & TST & \\
\hline CHEMBL1364726 & 688816 & 4.65 & 5.0887 & TRN & \\
\hline CHEMBL1559586 & 688816 & 5.0 & 5.33299 & 9999999999 & TRN \\
\hline CHEMBL1377552 & 688816 & 4.95 & 4.6297 & TRN & \\
\hline CHEMBL1565422 & 688816 & 4.65 & 5.2349 & TRN & \\
\hline CHEMBL1556111 & 688816 & 4.75 & 5.26399 & 9999999999 & TRN \\
\hline CHEMBL611661 & 688816 & 4.75 & 5.2324 & TST & \\
\hline CHEMBL1607362 & 688816 & 5.0 & 4.8131 & TRN & \\
\hline CHEMBL1485290 & 688816 & 4.9 & 5.4698 & TST & \\
\hline CHEMBL1415853 & 688816 & 4.85 & 5.5717 & TRN & \\
\hline CHEMBL66 & 688816 & 4.45 & 5.2889 & TST & \\
\hline CHEMBL1361774 & 688816 & 7.6003 & 5.4208 & TRN & \\
\hline CHEMBL1418095 & 688816 & 6.05 & 5.1104 & TRN & \\
\hline CHEMBL1369796 & 688816 & 5.45 & 4.9465 & TST & \\
\hline CHEMBL1545474 & 688816 & 4.45 & 5.5385 & TRN & \\
\hline CHEMBL1408040 & 688816 & 8.2518 & 5.6859 & TST & \\
\hline CHEMBL1507719 & 688816 & 4.65 & 5.1073 & TRN & \\
\hline CHEMBL1352651 & 688816 & 4.45 & 5.4149 & TST & \\
\hline CHEMBL3198175 & 688816 & 4.85 & 5.4122 & TRN & \\
\hline CHEMBL1422234 & 688816 & 4.55 & 5.5749 & TRN & \\
\hline CHEMBL1574710 & 688816 & 5.25 & 5.5891 & TRN & \\
\hline CHEMBL1590279 & 688816 & 4.65 & 5.0327 & TST & \\
\hline
\end{tabular}




\begin{tabular}{|c|c|c|c|c|}
\hline & & & oplement & al Ta \\
\hline CHEMBL1310509 & 688816 & 7.8013 & 5.1076 & TST \\
\hline CHEMBL3191336 & 688816 & 4.95 & 5.4703 & TRN \\
\hline CHEMBL3194857 & 688816 & 4.8 & 5.3075 & TRN \\
\hline CHEMBL1319900 & 688816 & 4.95 & 5.1715 & TRN \\
\hline CHEMBL1484624 & 688816 & 4.95 & 4.864 & TRN \\
\hline CHEMBL1424944 & 688816 & 4.7 & 5.2829 & TRN \\
\hline CHEMBL1543053 & 688816 & 5.6 & 5.5 & TRN \\
\hline CHEMBL1420801 & 688816 & 7.8508 & 6.0628 & TST \\
\hline CHEMBL1605885 & 688816 & 4.65 & 4.8114 & TRN \\
\hline CHEMBL1572999 & 688816 & 7.0501 & 5.5244 & TST \\
\hline CHEMBL1386922 & 688816 & 5.85 & 4.9001 & TST \\
\hline CHEMBL1525587 & 688816 & 5.4 & 5.324 & TST \\
\hline CHEMBL3195451 & 688816 & 5.4 & 5.4538 & TRN \\
\hline CHEMBL 3197844 & 688816 & 5.95 & 5.3854 & TRN \\
\hline CHEMBL1535563 & 688816 & 4.85 & 5.3623 & TRN \\
\hline CHEMBL1331199 & 688816 & 5.7 & 5.3318 & TRN \\
\hline CHEMBL1567923 & 688816 & 5.2 & 5.2024 & TST \\
\hline CHEMBL1561978 & 688816 & 5.4 & 4.9875 & TRN \\
\hline CHEMBL1544535 & 688816 & 4.45 & 5.6547 & TST \\
\hline CHEMBL1439006 & 688816 & 4.85 & 5.0665 & TRN \\
\hline CHEMBL1382357 & 688816 & 6.7001 & 5.0675 & TRN \\
\hline CHEMBL1467762 & 688816 & 4.65 & 5.9808 & TST \\
\hline CHEMBL1557272 & 688816 & 4.55 & 5.1414 & TRN \\
\hline CHEMBL1322082 & 688816 & 5.4 & 5.5257 & TRN \\
\hline CHEMBL1608744 & 688816 & 4.7 & 4.992 & TST \\
\hline CHEMBL1362660 & 688816 & 4.75 & 5.5454 & TRN \\
\hline CHEMBL1428004 & 688816 & 4.85 & 4.8924 & TRN \\
\hline CHEMBL1501527 & 688816 & 5.2 & 4.9241 & TRN \\
\hline CHEMBL1528127 & 688816 & 7.5498 & 5.1777 & TRN \\
\hline CHEMBL1516456 & 688816 & 4.85 & 4.731 & TRN \\
\hline CHEMBL1605595 & 688816 & 4.45 & 4.8551 & TRN \\
\hline CHEMBL1341417 & 688816 & 7.1002 & 5.2583 & TRN \\
\hline CHEMBL1418394 & 688816 & 6.7001 & 5.876 & TRN \\
\hline CHEMBL1306800 & 688816 & 5.6 & 5.1798 & TRN \\
\hline CHEMBL1326050 & 688816 & 4.8 & 4.9619 & TRN \\
\hline CHEMBL1533353 & 688816 & 5.5 & 5.3201 & TRN \\
\hline CHEMBL1542356 & 688816 & 4.9 & 5.5622 & TRN \\
\hline CHEMBL1383419 & 688816 & 4.75 & 5.0977 & TST \\
\hline CHEMBL1363475 & 688816 & 4.8 & 5.322 & TRN \\
\hline CHEMBL1378564 & 688816 & 4.9 & 5.231 & TRN \\
\hline CHEMBL1431169 & 688816 & 4.65 & 5.8256 & TRN \\
\hline CHEMBL1454434 & 688816 & 6.05 & 5.2741 & TRN \\
\hline CHEMBL1440235 & 688816 & 4.45 & 4.7025 & TRN \\
\hline CHEMBL1380164 & 688816 & 6.45 & 5.6317 & TRN \\
\hline CHEMBL3189161 & 688816 & 5.4 & 5.3261 & TRN \\
\hline CHEMBL1345505 & 688816 & 4.85 & 5.5005 & TRN \\
\hline CHEMBL1478806 & 688816 & 4.85 & 5.3859 & TRN \\
\hline CHEMBL3213834 & 688816 & 4.75 & 5.3259 & TRN \\
\hline
\end{tabular}




\begin{tabular}{|c|c|c|c|c|c|}
\hline & & & & & \\
\hline CHEMBL1482669 & 688816 & 4.8 & 4.9105 & TRN & \\
\hline CHEMBL3212879 & 688816 & 5.25 & 5.0789 & TRN & \\
\hline CHEMBL1533208 & 688816 & 4.75 & 5.2356 & TRN & \\
\hline CHEMBL3195278 & 688816 & 4.95 & 5.015 & TRN & \\
\hline CHEMBL1504381 & 688816 & 5.5 & 5.6666 & TST & \\
\hline CHEMBL1508613 & 688816 & 4.95 & 5.1476 & TRN & \\
\hline CHEMBL1570947 & 688816 & 4.65 & 5.1147 & TRN & \\
\hline CHEMBL1373435 & 688816 & 7.6003 & 4.7815 & TRN & \\
\hline CHEMBL1485223 & 688816 & 4.9 & 5.10800 & 00000000005 & TRN \\
\hline CHEMBL1523623 & 688816 & 5.1 & 4.8796 & TRN & \\
\hline CHEMBL1578993 & 688816 & 4.45 & 5.5239 & TRN & \\
\hline CHEMBL1583099 & 688816 & 4.45 & 4.8407 & TRN & \\
\hline CHEMBL1565457 & 688816 & 4.45 & 5.3029 & TST & \\
\hline CHEMBL1534248 & 688816 & 6.0 & 5.4579 & TST & \\
\hline CHEMBL1569612 & 688816 & 6.1 & 5.4939 & TRN & \\
\hline CHEMBL1382245 & 688816 & 5.75 & 5.2076 & TRN & \\
\hline CHEMBL1527177 & 688816 & 6.6 & 5.2141 & TRN & \\
\hline CHEMBL1409330 & 688816 & 4.95 & 5.09399 & 9999999999 & TRN \\
\hline CHEMBL1573144 & 688816 & 4.65 & 5.2213 & TRN & \\
\hline CHEMBL1499532 & 688816 & 6.9 & 5.3821 & TST & \\
\hline CHEMBL1405996 & 688816 & 7.5003 & 5.5312 & TRN & \\
\hline CHEMBL1301814 & 688816 & 4.85 & 5.1202 & TRN & \\
\hline CHEMBL1524734 & 688816 & 6.5501 & 5.4916 & TRN & \\
\hline CHEMBL1574052 & 688816 & 7.4001 & 5.0639 & TST & \\
\hline CHEMBL1478146 & 688816 & 5.8 & 5.3164 & TRN & \\
\hline CHEMBL84532 & 688816 & 4.7 & 5.4735 & TRN & \\
\hline CHEMBL325681 & 688816 & 5.35 & 5.081 & TRN & \\
\hline CHEMBL1435774 & 688816 & 5.45 & 5.2539 & TST & \\
\hline CHEMBL1418885 & 688816 & 4.7 & 4.5441 & TRN & \\
\hline CHEMBL99203 & 688816 & 6.0 & 5.6629 & TRN & \\
\hline CHEMBL1362398 & 688816 & 5.1 & 4.8395 & TRN & \\
\hline CHEMBL1482338 & 688816 & 4.75 & 5.2212 & TRN & \\
\hline CHEMBL1312573 & 688816 & 5.7 & 5.5983 & TRN & \\
\hline CHEMBL1200512 & 688816 & 5.2 & 5.7337 & TRN & \\
\hline CHEMBL1510550 & 688816 & 4.45 & 5.3434 & TRN & \\
\hline CHEMBL1447159 & 688816 & 4.95 & 5.3485 & TRN & \\
\hline CHEMBL1541438 & 688816 & 4.65 & 5.072 & TST & \\
\hline CHEMBL1299775 & 688816 & 4.7 & 5.1803 & TST & \\
\hline CHEMBL1571494 & 688816 & 6.1 & 5.1549 & TRN & \\
\hline CHEMBL1337527 & 688816 & 5.65 & 5.4123 & TRN & \\
\hline CHEMBL1433155 & 688816 & 5.7 & 4.9592 & TRN & \\
\hline CHEMBL1523140 & 688816 & 5.15 & 5.4043 & TRN & \\
\hline CHEMBL1544015 & 688816 & 4.9 & 5.19799 & 99999999995 & TRN \\
\hline CHEMBL1334746 & 688816 & 5.55 & 5.4271 & TRN & \\
\hline CHEMBL 3195082 & 688816 & 5.05 & 5.4187 & TRN & \\
\hline CHEMBL586135 & 688816 & 5.2 & 5.1131 & TRN & \\
\hline CHEMBL1308149 & 688816 & 4.65 & 5.2209 & TST & \\
\hline CHEMBL1598339 & 688816 & 4.9 & 5.3073 & TST & \\
\hline & & & & 24948 & \\
\hline
\end{tabular}




\begin{tabular}{|c|c|c|c|c|c|}
\hline \multicolumn{6}{|c|}{ Supplemental Table S2.txt } \\
\hline CHEMBL1973773 & 688816 & 5.45 & 5.6352 & TRN & \\
\hline CHEMBL1559110 & 688816 & 4.45 & 5.2814 & TRN & \\
\hline CHEMBL1458347 & 688816 & 5.25 & 5.3204 & TRN & \\
\hline CHEMBL1528089 & 688816 & 7.7496 & 5.5168 & TST & \\
\hline CHEMBL3192055 & 688816 & 4.95 & 5.2346 & TRN & \\
\hline CHEMBL1567300 & 688816 & 4.85 & 5.4797 & TRN & \\
\hline CHEMBL1306079 & 688816 & 5.25 & 5.1735 & TRN & \\
\hline CHEMBL1308188 & 688816 & 7.15 & 5.0509 & TRN & \\
\hline CHEMBL1371660 & 688816 & 4.95 & 5.3884 & TRN & \\
\hline CHEMBL1599996 & 688816 & 7.1002 & 5.5196 & TRN & \\
\hline CHEMBL1309435 & 688816 & 4.6 & 4.8747 & TRN & \\
\hline CHEMBL1392643 & 688816 & 4.95 & 5.4377 & TRN & \\
\hline CHEMBL95431 & 688816 & 5.35 & 5.2829 & TST & \\
\hline CHEMBL1457532 & 688816 & 4.9 & 4.845 & TRN & \\
\hline CHEMBL1493254 & 688816 & 4.8 & 4.70100 & 00000000005 & TRN \\
\hline CHEMBL1492524 & 688816 & 5.25 & 5.1881 & TRN & \\
\hline CHEMBL1502945 & 688816 & 4.9 & 5.1529 & TRN & \\
\hline CHEMBL1486499 & 688816 & 7.8013 & 5.6877 & TST & \\
\hline CHEMBL1441614 & 688816 & 5.0 & 4.9777 & TRN & \\
\hline CHEMBL1579897 & 688816 & 5.0 & 5.205 & TST & \\
\hline CHEMBL1398260 & 688816 & 5.0 & 5.9497 & TRN & \\
\hline CHEMBL1324223 & 688816 & 4.95 & 5.0236 & TRN & \\
\hline CHEMBL1360466 & 688816 & 7.6003 & 5.5916 & TRN & \\
\hline CHEMBL1342147 & 688816 & 6.3 & 5.2096 & TRN & \\
\hline CHEMBL1589594 & 688816 & 4.85 & 5.5663 & TRN & \\
\hline CHEMBL1392828 & 688816 & 5.15 & 5.3799 & TRN & \\
\hline CHEMBL1586846 & 688816 & 4.9 & 5.3333 & TRN & \\
\hline CHEMBL1306797 & 688816 & 7.4498 & 5.3277 & TST & \\
\hline CHEMBL1306322 & 688816 & 6.7501 & 5.4204 & TRN & \\
\hline CHEMBL1510635 & 688816 & 4.65 & 5.4426 & TRN & \\
\hline CHEMBL1389194 & 688816 & 4.45 & 5.1729 & TST & \\
\hline CHEMBL1316440 & 688816 & 4.95 & 5.3326 & TST & \\
\hline CHEMBL1426610 & 688816 & 5.55 & 5.4405 & TRN & \\
\hline CHEMBL1607086 & 688816 & 4.55 & 5.4665 & TST & \\
\hline CHEMBL1351068 & 688816 & 4.55 & 5.3207 & TRN & \\
\hline CHEMBL1518002 & 688816 & 6.95 & 4.9649 & TRN & \\
\hline CHEMBL1311123 & 688816 & 5.25 & 5.2578 & TRN & \\
\hline CHEMBL1465989 & 688816 & 5.0 & 5.164 & TRN & \\
\hline CHEMBL1382740 & 688816 & 5.45 & 5.4519 & TRN & \\
\hline CHEMBL1545631 & 688816 & 5.05 & 4.9181 & TRN & \\
\hline CHEMBL1493757 & 688816 & 6.2 & 5.6069 & TST & \\
\hline CHEMBL 1353188 & 688816 & 4.45 & 4.9 & TRN & \\
\hline CHEMBL1327537 & 688816 & 5.0 & 5.175 & TRN & \\
\hline CHEMBL3197898 & 688816 & 6.9 & 5.2059 & TRN & \\
\hline CHEMBL1427650 & 688816 & 4.75 & 5.3365 & TRN & \\
\hline CHEMBL1439526 & 688816 & 5.9 & 5.239 & TRN & \\
\hline CHEMBL 1304270 & 688816 & 5.25 & 5.4501 & TRN & \\
\hline CHEMBL1385133 & 688816 & 5.25 & 5.3227 & TST & \\
\hline
\end{tabular}




\begin{tabular}{|c|c|c|c|c|c|}
\hline \multicolumn{6}{|c|}{ Supplemental Table S2.txt } \\
\hline CHEMBL1402923 & 688816 & 6.45 & 5.3764 & TST & \\
\hline CHEMBL1447203 & 688816 & 4.45 & 5.4131 & TST & \\
\hline CHEMBL1325798 & 688816 & 4.85 & 5.0663 & TRN & \\
\hline CHEMBL1231847 & 688816 & 4.8 & 5.4281 & TRN & \\
\hline CHEMBL1469541 & 688816 & 4.9 & 5.191 & TRN & \\
\hline CHEMBL1290401 & 688816 & 4.9 & 5.0534 & TST & \\
\hline CHEMBL1534812 & 688816 & 5.3 & 5.5468 & TRN & \\
\hline CHEMBL1560590 & 688816 & 5.45 & 5.1616 & TRN & \\
\hline CHEMBL1300068 & 688816 & 4.65 & 5.4854 & TRN & \\
\hline CHEMBL1554627 & 688816 & 4.75 & 5.4379 & TRN & \\
\hline CHEMBL1425718 & 688816 & 5.25 & 5.3756 & TRN & \\
\hline CHEMBL1522730 & 688816 & 4.95 & 5.4733 & TST & \\
\hline CHEMBL1611142 & 688816 & 4.95 & 5.1934 & TRN & \\
\hline CHEMBL1577388 & 688816 & 6.6499 & 5.4608 & TST & \\
\hline CHEMBL1541009 & 688816 & 5.05 & 4.9691 & TRN & \\
\hline CHEMBL1389542 & 688816 & 4.95 & 4.9269 & TRN & \\
\hline CHEMBL1448914 & 688816 & 4.95 & 5.3201 & TRN & \\
\hline CHEMBL1381994 & 688816 & 8.4559 & 5.4109 & TRN & \\
\hline CHEMBL1318854 & 688816 & 4.8 & 5.3286 & TRN & \\
\hline CHEMBL1530010 & 688816 & 5.25 & 5.5642 & TST & \\
\hline CHEMBL1503697 & 688816 & 4.65 & 5.3998 & TRN & \\
\hline CHEMBL1585946 & 688816 & 5.05 & 5.7127 & TRN & \\
\hline CHEMBL1318766 & 688816 & 5.55 & 5.2512 & TST & \\
\hline CHEMBL1485964 & 688816 & 5.1 & 5.0726 & TRN & \\
\hline CHEMBL1347384 & 688816 & 4.45 & 5.0015 & TRN & \\
\hline CHEMBL1397819 & 688816 & 6.4 & 5.2505 & TRN & \\
\hline CHEMBL1334903 & 688816 & 5.15 & 5.2348 & TRN & \\
\hline CHEMBL1611993 & 688816 & 4.45 & 5.2506 & TST & \\
\hline CHEMBL1578679 & 688816 & 4.85 & 5.3342 & TRN & \\
\hline CHEMBL1334256 & 688816 & 5.45 & 5.8315 & TST & \\
\hline CHEMBL1468793 & 688816 & 5.6 & 5.1519 & TST & \\
\hline CHEMBL1369575 & 688816 & 4.8 & 5.1362 & TRN & \\
\hline CHEMBL1501288 & 688816 & 4.95 & 5.404 & TST & \\
\hline CHEMBL1366030 & 688816 & 5.65 & 5.07 & TRN & \\
\hline CHEMBL1531422 & 688816 & 8.301 & 5.7357 & TRN & \\
\hline CHEMBL1548314 & 688816 & 7.5498 & 5.1915 & TST & \\
\hline CHEMBL1392939 & 688816 & 8.3468 & 5.8515 & TST & \\
\hline CHEMBL1406998 & 688816 & 6.1 & 5.3606 & TRN & \\
\hline CHEMBL210730 & 688816 & 5.4 & 5.33799 & 9999999999 & TRN \\
\hline CHEMBL3193843 & 688816 & 4.95 & 5.3227 & TRN & \\
\hline CHEMBL1331684 & 688816 & 5.75 & 5.4906 & TRN & \\
\hline CHEMBL1300311 & 688816 & 5.05 & 5.0952 & TRN & \\
\hline CHEMBL1425838 & 688816 & 5.7 & 5.454 & TRN & \\
\hline CHEMBL1313771 & 688816 & 4.95 & 5.1144 & TRN & \\
\hline CHEMBL1573579 & 688816 & 6.7001 & 5.5362 & TRN & \\
\hline CHEMBL1519507 & 688816 & 4.45 & 5.0623 & TST & \\
\hline CHEMBL1390864 & 688816 & 8.301 & $5.7620 e$ & 00000000005 & TRN \\
\hline CHEMBL1439130 & 688816 & 8.0506 & 5.4641 & TST & \\
\hline
\end{tabular}




\begin{tabular}{|c|c|c|c|c|c|}
\hline \multirow{3}{*}{$\begin{array}{l}\text { CHEMBL591137 } \\
\text { CHEMBL1336634 }\end{array}$} & \multirow{3}{*}{$\begin{array}{l}688816 \\
688816\end{array}$} & \multicolumn{4}{|c|}{ Supplemental Table S2.txt } \\
\hline & & 5.2 & 5.16200 & 0000000001 & TST \\
\hline & & 7.5498 & 5.8239 & TRN & \\
\hline CHEMBL1544679 & 688816 & 4.45 & 5.1943 & TRN & \\
\hline CHEMBL 381518 & 688816 & 4.9 & 4.99 & TST & \\
\hline CHEMBL1329396 & 688816 & 5.05 & 4.8191 & TRN & \\
\hline CHEMBL1364056 & 688816 & 4.45 & 5.2417 & TST & \\
\hline CHEMBL1306180 & 688816 & 5.25 & 5.2229 & TRN & \\
\hline CHEMBL1489988 & 688816 & 4.9 & 4.9892 & TST & \\
\hline CHEMBL1467697 & 688816 & 5.3 & 5.4083 & TRN & \\
\hline CHEMBL1531260 & 688816 & 4.8 & 5.4309 & TRN & \\
\hline CHEMBL1435654 & 688816 & 4.9 & 5.265 & TRN & \\
\hline CHEMBL1455542 & 688816 & 5.3 & 5.2278 & TST & \\
\hline CHEMBL1531162 & 688816 & 5.25 & 5.1638 & TRN & \\
\hline CHEMBL1554981 & 688816 & 4.45 & 4.8129 & TRN & \\
\hline CHEMBL1547256 & 688816 & 7.3002 & 5.3235 & TRN & \\
\hline CHEMBL1613672 & 688816 & 4.45 & 5.0364 & TRN & \\
\hline CHEMBL1565242 & 688816 & 4.85 & 5.0238 & TRN & \\
\hline CHEMBL1490130 & 688816 & 4.95 & 5.0274 & TRN & \\
\hline CHEMBL1302862 & 688816 & 5.55 & 5.5807 & TRN & \\
\hline CHEMBL1392074 & 688816 & 7.2503 & 5.4938 & TRN & \\
\hline CHEMBL1577342 & 688816 & 4.95 & 5.2628 & TRN & \\
\hline CHEMBL1307790 & 688816 & 4.55 & 5.1583 & TST & \\
\hline CHEMBL 2003794 & 688816 & 4.7 & 4.953 & TRN & \\
\hline CHEMBL1334888 & 688816 & 4.65 & 5.2308 & TRN & \\
\hline CHEMBL1490515 & 688816 & 5.15 & 5.2006 & TRN & \\
\hline CHEMBL3212802 & 688816 & 4.85 & 5.2614 & TRN & \\
\hline CHEMBL1319858 & 688816 & 4.6 & 5.3278 & TRN & \\
\hline CHEMBL1442814 & 688816 & 6.35 & 5.6196 & TST & \\
\hline CHEMBL1584691 & 688816 & 6.15 & 5.7547 & TRN & \\
\hline CHEMBL1342930 & 688816 & 5.15 & 5.0983 & TRN & \\
\hline CHEMBL1489565 & 688816 & 4.95 & 4.975 & TRN & \\
\hline CHEMBL1418494 & 688816 & 5.05 & 4.9254 & TRN & \\
\hline CHEMBL1568599 & 688816 & 6.1 & 5.3005 & TST & \\
\hline CHEMBL1421739 & 688816 & 6.5 & 5.2355 & TRN & \\
\hline CHEMBL1507408 & 688816 & 4.6 & 5.5046 & TRN & \\
\hline CHEMBL1567795 & 688816 & 5.05 & 5.2427 & TRN & \\
\hline CHEMBL 1517818 & 688816 & 4.95 & 5.4645 & TRN & \\
\hline CHEMBL1434576 & 688816 & 4.7 & 5.2237 & TRN & \\
\hline CHEMBL1459968 & 688816 & 4.8 & 5.1441 & TRN & \\
\hline CHEMBL1299989 & 688816 & 8.5528 & 5.7909 & TST & \\
\hline CHEMBL1520012 & 688816 & 4.85 & 5.2916 & TRN & \\
\hline CHEMBL1559070 & 688816 & 4.45 & 5.0837 & TST & \\
\hline CHEMBL1540337 & 688816 & 5.25 & 5.3486 & TRN & \\
\hline CHEMBL1586606 & 688816 & 4.6 & 5.7659 & TRN & \\
\hline CHEMBL1605879 & 688816 & 4.75 & 5.2058 & TRN & \\
\hline CHEMBL3207859 & 688816 & 5.75 & 5.9994 & TST & \\
\hline CHEMBL1343004 & 688816 & 4.65 & 5.5958 & TST & \\
\hline CHEMBL1445627 & 688816 & 4.9 & 5.6346 & TRN & \\
\hline
\end{tabular}




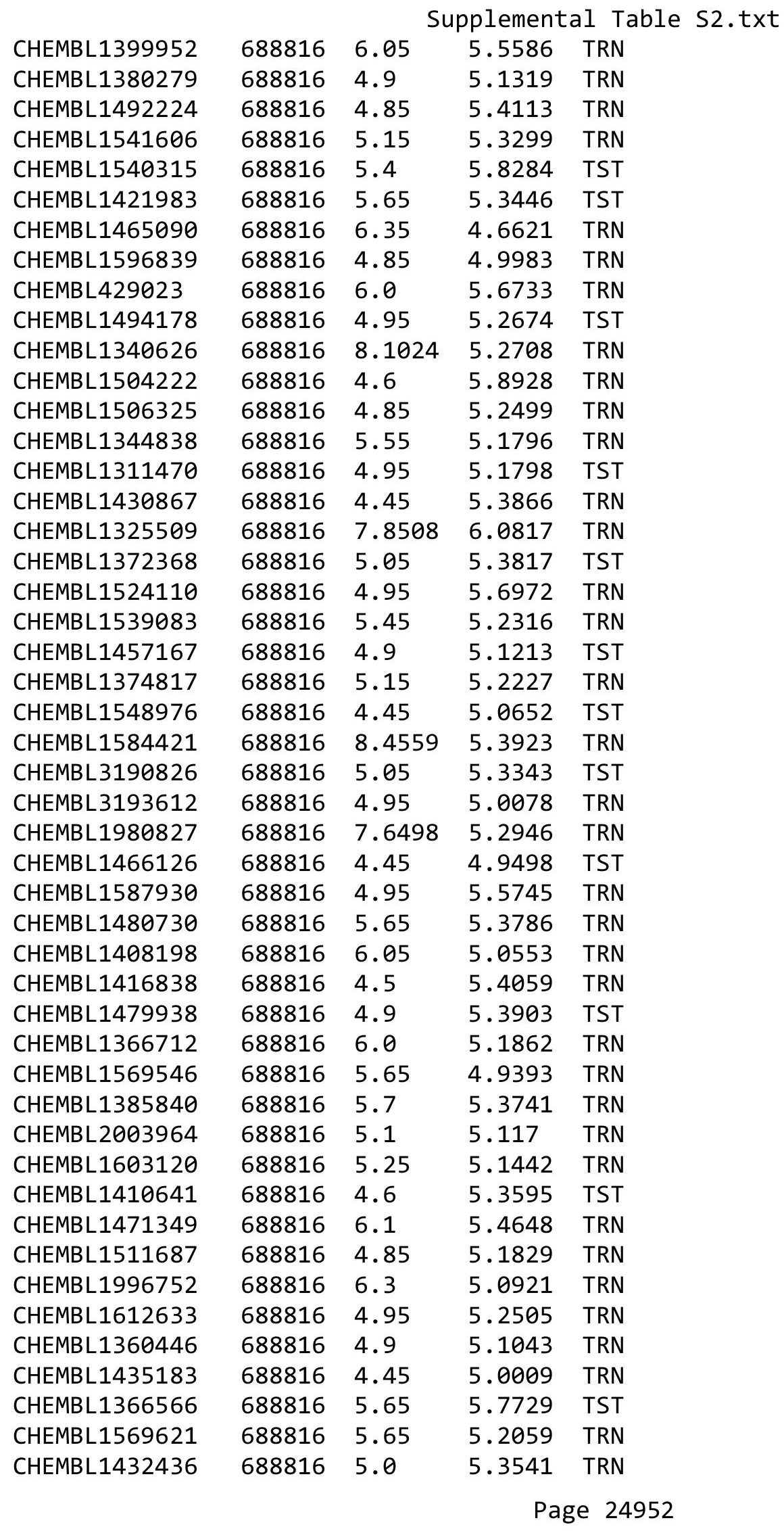




\begin{tabular}{|c|c|c|c|c|}
\hline \multicolumn{5}{|c|}{ Supplemental Table S2.txt } \\
\hline CHEMBL1372863 & 688816 & 5.45 & 5.15 & TRN \\
\hline CHEMBL1342778 & 688816 & 4.8 & 5.2083 & TRN \\
\hline CHEMBL1374704 & 688816 & 4.95 & 5.4429 & TST \\
\hline CHEMBL1563949 & 688816 & 4.75 & 5.0234 & TRN \\
\hline CHEMBL3190118 & 688816 & 4.9 & 5.2621 & TRN \\
\hline CHEMBL1383333 & 688816 & 4.6 & 4.9462 & TRN \\
\hline CHEMBL1418436 & 688816 & 8.3468 & 5.24200 & 0000000001 \\
\hline CHEMBL609628 & 688816 & 4.85 & 4.7761 & TST \\
\hline CHEMBL1421556 & 688816 & 5.05 & 5.3175 & TRN \\
\hline CHEMBL1526740 & 688816 & 4.85 & 4.9852 & TRN \\
\hline CHEMBL1328326 & 688816 & 4.45 & 5.3094 & TRN \\
\hline CHEMBL1537168 & 688816 & 5.3 & 5.4664 & TRN \\
\hline CHEMBL1433282 & 688816 & 5.1 & 5.6798 & TRN \\
\hline CHEMBL1568689 & 688816 & 4.45 & 4.9444 & TRN \\
\hline CHEMBL1304261 & 688816 & 4.95 & 5.3773 & TRN \\
\hline CHEMBL1466068 & 688816 & 4.6 & 5.2289 & TRN \\
\hline CHEMBL1446238 & 688816 & 5.1 & 5.1246 & TRN \\
\hline CHEMBL1470479 & 688816 & 8.301 & 5.4088 & TST \\
\hline CHEMBL1564711 & 688816 & 4.7 & 5.2579 & TRN \\
\hline CHEMBL1519103 & 688816 & 5.2 & 4.9441 & TRN \\
\hline CHEMBL1338499 & 688816 & 4.5 & 5.315 & TRN \\
\hline CHEMBL1477918 & 688816 & 5.0 & 5.1358 & TRN \\
\hline CHEMBL1427968 & 688816 & 7.2503 & 5.362 & TRN \\
\hline CHEMBL1384565 & 688816 & 5.15 & 4.9172 & TRN \\
\hline CHEMBL1501825 & 688816 & 4.7 & 5.4665 & TRN \\
\hline CHEMBL1396641 & 688816 & 5.25 & 5.3606 & TRN \\
\hline CHEMBL1418362 & 688816 & 6.7001 & 5.7079 & TRN \\
\hline CHEMBL1455544 & 688816 & 4.75 & 5.0764 & TRN \\
\hline CHEMBL1529777 & 688816 & 4.45 & 5.1767 & TST \\
\hline CHEMBL1349727 & 688816 & 5.45 & 5.0682 & TST \\
\hline CHEMBL1569530 & 688816 & 7.0501 & 5.6358 & TRN \\
\hline CHEMBL1469777 & 688816 & 5.0 & 5.43 & TRN \\
\hline CHEMBL1454064 & 688816 & 4.85 & 5.6326 & TRN \\
\hline CHEMBL1345062 & 688816 & 5.2 & 5.4384 & TRN \\
\hline CHEMBL1545819 & 688816 & 5.0 & 5.0008 & TRN \\
\hline CHEMBL 3214498 & 688816 & 5.25 & 5.5407 & TRN \\
\hline CHEMBL3192679 & 688816 & 4.7 & 5.0119 & TRN \\
\hline CHEMBL1352280 & 688816 & 5.1 & 4.9679 & TRN \\
\hline CHEMBL1314817 & 688816 & 4.6 & 5.2005 & TRN \\
\hline CHEMBL1596068 & 688816 & 5.0 & 5.4879 & TRN \\
\hline CHEMBL1476712 & 688816 & 5.9 & 4.7792 & TRN \\
\hline CHEMBL1384697 & 688816 & 4.85 & 5.4197 & TRN \\
\hline CHEMBL1336808 & 688816 & 4.95 & 5.5406 & TRN \\
\hline CHEMBL1447051 & 688816 & 6.8499 & 5.2451 & TRN \\
\hline CHEMBL1413999 & 688816 & 4.95 & 5.2356 & TRN \\
\hline CHEMBL1433017 & 688816 & 4.45 & 5.3451 & TRN \\
\hline CHEMBL1405341 & 688816 & 4.95 & 5.1508 & TRN \\
\hline CHEMBL1413611 & 688816 & 4.55 & 5.0564 & TST \\
\hline
\end{tabular}




\begin{tabular}{|c|c|c|c|c|}
\hline \multicolumn{5}{|c|}{ Supplemental Table s2.txt } \\
\hline CHEMBL1586415 & 688816 & 5.4 & 5.5364 & TRN \\
\hline CHEMBL1444023 & 688816 & 5.5 & 5.1241 & TRN \\
\hline CHEMBL1460211 & 688816 & 4.8 & 5.3329 & TRN \\
\hline CHEMBL1301534 & 688816 & 4.95 & 5.3296 & TRN \\
\hline CHEMBL1527546 & 688816 & 4.7 & 5.2468 & TRN \\
\hline CHEMBL1461513 & 688816 & 7.2503 & 5.0689 & TRN \\
\hline CHEMBL1399314 & 688816 & 5.4 & 5.527 & TRN \\
\hline CHEMBL1486572 & 688816 & 4.8 & 4.9805 & TRN \\
\hline CHEMBL1552379 & 688816 & 4.9 & 5.4312 & TRN \\
\hline CHEMBL1453802 & 688816 & 4.65 & 5.0943 & TRN \\
\hline CHEMBL1979295 & 688816 & 5.75 & 5.505 & TRN \\
\hline CHEMBL1541938 & 688816 & 7.9508 & 5.274 & TRN \\
\hline CHEMBL1430269 & 688816 & 4.8 & 5.1449 & TRN \\
\hline CHEMBL1546590 & 688816 & 5.0 & 5.2521 & TRN \\
\hline CHEMBL1373110 & 688816 & 4.75 & 5.1486 & TRN \\
\hline CHEMBL1497880 & 688816 & 4.45 & 5.5117 & TRN \\
\hline CHEMBL1384512 & 688816 & 5.8 & 5.3206 & TST \\
\hline CHEMBL1328951 & 688816 & 5.1 & 5.3767 & TRN \\
\hline CHEMBL1441491 & 688816 & 4.8 & 5.3543 & TST \\
\hline CHEMBL1610955 & 688816 & 4.85 & 5.3016 & TRN \\
\hline CHEMBL1464649 & 688816 & 8.2518 & 5.4863 & TRN \\
\hline CHEMBL3195849 & 688816 & 4.5 & 5.0567 & TST \\
\hline CHEMBL 3198887 & 688816 & 5.2 & 5.983 & TST \\
\hline CHEMBL1456801 & 688816 & 4.45 & 5.3937 & TST \\
\hline CHEMBL1405731 & 688816 & 6.45 & 5.1555 & TST \\
\hline CHEMBL1356040 & 688816 & 4.95 & 5.1974 & TRN \\
\hline CHEMBL1356105 & 688816 & 4.45 & 4.8665 & TST \\
\hline CHEMBL1444255 & 688816 & 4.45 & 5.3791 & TRN \\
\hline CHEMBL1545442 & 688816 & 4.9 & 5.224 & TRN \\
\hline CHEMBL1491255 & 688816 & 4.65 & 5.3977 & TST \\
\hline CHEMBL1580214 & 688816 & 4.45 & 4.999 & TRN \\
\hline CHEMBL1448932 & 688816 & 4.85 & 5.3494 & TRN \\
\hline CHEMBL1583209 & 688816 & 4.8 & 4.9496 & TRN \\
\hline CHEMBL1510945 & 688816 & 5.1 & 5.2354 & TRN \\
\hline CHEMBL1467428 & 688816 & 7.8013 & 5.5834 & TRN \\
\hline CHEMBL1519958 & 688816 & 4.7 & 5.4543 & TRN \\
\hline CHEMBL1476215 & 688816 & 6.6 & 5.2392 & TRN \\
\hline CHEMBL1306570 & 688816 & 4.65 & 5.5846 & TRN \\
\hline CHEMBL1490411 & 688816 & 5.3 & 5.043 & TRN \\
\hline CHEMBL1604642 & 688816 & 4.95 & 5.5447 & TRN \\
\hline CHEMBL1342758 & 688816 & 4.45 & 5.55399 & 9999999999 \\
\hline CHEMBL1501927 & 688816 & 5.35 & 5.4593 & TRN \\
\hline CHEMBL1397621 & 688816 & 5.6 & 5.3982 & TRN \\
\hline CHEMBL1411696 & 688816 & 4.6 & 5.4164 & TRN \\
\hline CHEMBL 3207378 & 688816 & 4.9 & 5.1854 & TST \\
\hline CHEMBL1343178 & 688816 & 5.1 & 4.8234 & TRN \\
\hline CHEMBL254576 & 688816 & 5.65 & 4.9677 & TST \\
\hline CHEMBL1421568 & 688816 & 4.9 & 5.2246 & TRN \\
\hline
\end{tabular}




\begin{tabular}{|c|c|c|c|c|}
\hline \multicolumn{5}{|c|}{ Supplemental Table S2.txt } \\
\hline CHEMBL1535788 & 688816 & 6.8 & 5.1354 & TRN \\
\hline CHEMBL1325932 & 688816 & 4.95 & 5.3117 & TRN \\
\hline CHEMBL1590010 & 688816 & 4.7 & 5.1598 & TRN \\
\hline CHEMBL1410279 & 688816 & 6.0 & 5.2694 & TRN \\
\hline CHEMBL1334616 & 688816 & 5.25 & 5.1188 & TST \\
\hline CHEMBL1333282 & 688816 & 4.95 & 5.1598 & TRN \\
\hline CHEMBL1365246 & 688816 & 4.9 & 5.0918 & TRN \\
\hline CHEMBL1339722 & 688816 & 4.9 & 5.0649 & TRN \\
\hline CHEMBL391123 & 688816 & 4.9 & 4.9426 & TRN \\
\hline CHEMBL1522464 & 688816 & 4.85 & 5.082 & TRN \\
\hline CHEMBL1495908 & 688816 & 4.85 & 5.2443 & TRN \\
\hline CHEMBL1458493 & 688816 & 4.85 & 5.1847 & TST \\
\hline CHEMBL1526483 & 688816 & 4.7 & 5.4848 & TST \\
\hline CHEMBL1315314 & 688816 & 4.75 & 4.8483 & TRN \\
\hline CHEMBL1388826 & 688816 & 5.2 & 5.3495 & TRN \\
\hline CHEMBL1453082 & 688816 & 6.15 & 5.6449 & TRN \\
\hline CHEMBL1449254 & 688816 & 4.45 & 5.2472 & TST \\
\hline CHEMBL1598561 & 688816 & 4.65 & 4.9359 & TRN \\
\hline CHEMBL1414689 & 688816 & 4.75 & 4.935 & TRN \\
\hline CHEMBL3191786 & 688816 & 6.8 & 5.2232 & TST \\
\hline CHEMBL1301723 & 688816 & 4.75 & 5.1216 & TRN \\
\hline CHEMBL1525640 & 688816 & 4.9 & 4.9336 & TRN \\
\hline CHEMBL1459660 & 688816 & 4.45 & 4.6645 & TRN \\
\hline CHEMBL1411570 & 688816 & 4.9 & 5.2514 & TRN \\
\hline CHEMBL1508471 & 688816 & 4.95 & 5.4875 & TRN \\
\hline CHEMBL3193923 & 688816 & 4.45 & 5.3098 & TRN \\
\hline CHEMBL1307022 & 688816 & 4.45 & 4.9251 & TRN \\
\hline CHEMBL1459274 & 688816 & 7.5003 & 5.4194 & TRN \\
\hline CHEMBL1422320 & 688816 & 4.95 & 5.1808 & TRN \\
\hline CHEMBL1540957 & 688816 & 4.45 & 5.2584 & TRN \\
\hline CHEMBL1450900 & 688816 & 5.45 & 5.5714 & TST \\
\hline CHEMBL1603388 & 688816 & 4.9 & 5.1599 & TRN \\
\hline CHEMBL1434689 & 688816 & 8.3979 & 5.4262 & TRN \\
\hline CHEMBL1580190 & 688816 & 7.8996 & 5.5612 & TRN \\
\hline CHEMBL3211870 & 688816 & 5.0 & 5.2401 & TRN \\
\hline CHEMBL1522937 & 688816 & 4.95 & 4.9664 & TRN \\
\hline CHEMBL1517059 & 688816 & 5.0 & 5.1382 & TRN \\
\hline CHEMBL1373063 & 688816 & 5.25 & 5.4676 & TRN \\
\hline CHEMBL1541526 & 688816 & 4.8 & 5.4152 & TRN \\
\hline CHEMBL1507091 & 688816 & 5.15 & 5.1379 & TRN \\
\hline CHEMBL1335937 & 688816 & 6.2 & 5.3869 & TRN \\
\hline CHEMBL1341192 & 688816 & 6.2 & 5.1914 & TRN \\
\hline CHEMBL1319647 & 688816 & 4.9 & 4.9676 & TST \\
\hline CHEMBL1583133 & 688816 & 4.95 & 5.2706 & TRN \\
\hline CHEMBL1500517 & 688816 & 4.85 & 5.5422 & TRN \\
\hline CHEMBL1566654 & 688816 & 6.2 & 5.3831 & TST \\
\hline CHEMBL1376998 & 688816 & 4.8 & 5.4842 & TST \\
\hline CHEMBL1375202 & 688816 & 4.95 & 5.0067 & TRN \\
\hline
\end{tabular}




\begin{tabular}{|c|c|c|c|c|c|}
\hline \multicolumn{6}{|c|}{ Supplemental Table s2.txt } \\
\hline CHEMBL1562186 & 688816 & 8.301 & 5.5537 & TRN & \\
\hline CHEMBL1535003 & 688816 & 4.45 & 5.0412 & TRN & \\
\hline CHEMBL1380152 & 688816 & 5.3 & 5.4854 & TRN & \\
\hline CHEMBL1527656 & 688816 & 5.0 & 5.7005 & TRN & \\
\hline CHEMBL1572356 & 688816 & 4.45 & 5.1057 & TST & \\
\hline CHEMBL1347626 & 688816 & 5.15 & 5.2825 & TRN & \\
\hline CHEMBL1577749 & 688816 & 6.5 & 4.726 & TRN & \\
\hline CHEMBL1603647 & 688816 & 4.85 & 5.898 & TRN & \\
\hline CHEMBL1485748 & 688816 & 5.5 & 5.0511 & TRN & \\
\hline CHEMBL1417167 & 688816 & 5.25 & 5.0828 & TST & \\
\hline CHEMBL1500475 & 688816 & 7.0 & 5.5494 & TRN & \\
\hline CHEMBL1330858 & 688816 & 4.9 & 5.3398 & TST & \\
\hline CHEMBL1573167 & 688816 & 4.45 & 5.0548 & TST & \\
\hline CHEMBL1525657 & 688816 & 5.6 & 5.5762 & TST & \\
\hline CHEMBL1400495 & 688816 & 7.5498 & 5.6525 & TRN & \\
\hline CHEMBL3207626 & 688816 & 5.45 & 5.4303 & TRN & \\
\hline CHEMBL1376409 & 688816 & 8.3468 & 5.1733 & TST & \\
\hline CHEMBL1331499 & 688816 & 4.95 & 5.0861 & TRN & \\
\hline CHEMBL1300386 & 688816 & 5.15 & 5.4485 & TRN & \\
\hline CHEMBL1373904 & 688816 & 4.45 & 4.99 & TRN & \\
\hline CHEMBL1523414 & 688816 & 5.05 & 5.3108 & TST & \\
\hline CHEMBL1372229 & 688816 & 4.8 & 5.1556 & TRN & \\
\hline CHEMBL1460017 & 688816 & 5.95 & 5.5722 & TRN & \\
\hline CHEMBL1489939 & 688816 & 5.05 & 5.2165 & TRN & \\
\hline CHEMBL473721 & 688816 & 6.5501 & 5.3733 & TRN & \\
\hline CHEMBL1968361 & 688816 & 4.9 & 5.4528 & TRN & \\
\hline CHEMBL3198038 & 688816 & 4.45 & 5.2278 & TRN & \\
\hline CHEMBL1550574 & 688816 & 5.45 & 5.5446 & TRN & \\
\hline CHEMBL1409077 & 688816 & 6.05 & 5.449 & TRN & \\
\hline CHEMBL1431475 & 688816 & 4.8 & 5.21200 & 0000000001 & TST \\
\hline CHEMBL1420996 & 688816 & 5.1 & 5.0038 & TST & \\
\hline CHEMBL1546412 & 688816 & 5.0 & 4.6965 & TRN & \\
\hline CHEMBL3195553 & 688816 & 5.8 & 5.3807 & TST & \\
\hline CHEMBL1518393 & 688816 & 4.95 & 4.9827 & TRN & \\
\hline CHEMBL1505952 & 688816 & 5.1 & 5.2388 & TRN & \\
\hline CHEMBL1588763 & 688816 & 5.9 & 4.9738 & TRN & \\
\hline CHEMBL1552375 & 688816 & 4.45 & 5.4892 & TST & \\
\hline CHEMBL1306250 & 688816 & 5.3 & 5.2055 & TRN & \\
\hline CHEMBL1466440 & 688816 & 7.5498 & 5.5629 & TRN & \\
\hline CHEMBL1372903 & 688816 & 4.8 & 5.3475 & TRN & \\
\hline CHEMBL1460807 & 688816 & 4.65 & 5.3856 & TST & \\
\hline CHEMBL1474369 & 688816 & 4.75 & 5.2315 & TRN & \\
\hline CHEMBL472931 & 688816 & 4.75 & 5.1579 & TRN & \\
\hline CHEMBL1343523 & 688816 & 5.0 & 5.1505 & TRN & \\
\hline CHEMBL1452065 & 688816 & 5.15 & 5.0262 & TRN & \\
\hline CHEMBL1597594 & 688816 & 4.95 & 5.3321 & TRN & \\
\hline CHEMBL1501630 & 688816 & 5.3 & 5.6143 & TRN & \\
\hline CHEMBL1439751 & 688816 & 4.8 & 5.0481 & TRN & \\
\hline
\end{tabular}




\begin{tabular}{|c|c|c|c|c|}
\hline \multicolumn{5}{|c|}{ Supplemental Table S2.txt } \\
\hline CHEMBL1352186 & 688816 & 4.95 & 5.8448 & TRN \\
\hline CHEMBL1561338 & 688816 & 4.6 & 5.0488 & TRN \\
\hline CHEMBL1384333 & 688816 & 5.75 & 5.3605 & TST \\
\hline CHEMBL1535444 & 688816 & 5.25 & 5.2882 & TRN \\
\hline CHEMBL1592150 & 688816 & 4.45 & 5.3195 & TRN \\
\hline CHEMBL1531329 & 688816 & 5.8 & 5.1458 & TRN \\
\hline CHEMBL1411594 & 688816 & 5.0 & 5.0605 & TRN \\
\hline CHEMBL1480332 & 688816 & 4.95 & 4.7546 & TRN \\
\hline CHEMBL1330359 & 688816 & 6.1 & 5.5171 & TRN \\
\hline CHEMBL522504 & 688816 & 4.85 & 5.2347 & TRN \\
\hline CHEMBL1523209 & 688816 & 6.9 & 5.2773 & TST \\
\hline CHEMBL1341853 & 688816 & 4.8 & 5.4704 & TST \\
\hline CHEMBL1413216 & 688816 & 4.65 & 5.1897 & TRN \\
\hline CHEMBL1589246 & 688816 & 4.9 & 5.1229 & TRN \\
\hline CHEMBL1503147 & 688816 & 5.05 & 5.4788 & TRN \\
\hline CHEMBL1452783 & 688816 & 4.85 & 5.3013 & TRN \\
\hline CHEMBL1576304 & 688816 & 7.699 & $5.4060 e$ & 0000000001 \\
\hline CHEMBL1567136 & 688816 & 5.55 & 5.4083 & TRN \\
\hline CHEMBL1327926 & 688816 & 5.4 & 5.5105 & TST \\
\hline CHEMBL1506784 & 688816 & 4.95 & 5.2358 & TST \\
\hline CHEMBL1425376 & 688816 & 5.25 & 5.7538 & TRN \\
\hline CHEMBL1424065 & 688816 & 7.8013 & 5.5413 & TRN \\
\hline CHEMBL3211046 & 688816 & 4.85 & 5.4379 & TRN \\
\hline CHEMBL1589395 & 688816 & 6.7501 & 5.4779 & TST \\
\hline CHEMBL1549599 & 688816 & 4.95 & 5.2134 & TRN \\
\hline CHEMBL1504344 & 688816 & 8.4559 & 5.4032 & TST \\
\hline CHEMBL1312907 & 688816 & 4.65 & 5.1991 & TRN \\
\hline CHEMBL1435525 & 688816 & 4.8 & 5.3042 & TRN \\
\hline CHEMBL1448178 & 688816 & 4.95 & 5.0682 & TRN \\
\hline CHEMBL1361716 & 688816 & 5.35 & 5.5948 & TRN \\
\hline CHEMBL1454879 & 688816 & 5.15 & 5.1521 & TRN \\
\hline CHEMBL1320536 & 688816 & 5.5 & 5.5474 & TRN \\
\hline CHEMBL1376365 & 688816 & 4.45 & 5.0682 & TST \\
\hline CHEMBL1375970 & 688816 & 4.6 & 5.0918 & TRN \\
\hline CHEMBL1519385 & 688816 & 4.75 & 5.3102 & TRN \\
\hline CHEMBL462861 & 688816 & 5.85 & 5.2312 & TST \\
\hline CHEMBL1335874 & 688816 & 5.7 & 5.4226 & TRN \\
\hline CHEMBL1447309 & 688816 & 5.4 & 4.577 & TST \\
\hline CHEMBL1336933 & 688816 & 4.7 & 5.2749 & TRN \\
\hline CHEMBL1535537 & 688816 & 5.0 & 5.6037 & TRN \\
\hline CHEMBL1342035 & 688816 & 6.7001 & 5.2464 & TRN \\
\hline CHEMBL1577983 & 688816 & 5.35 & 5.0107 & TRN \\
\hline CHEMBL1307228 & 688816 & 4.95 & 5.1701 & TRN \\
\hline CHEMBL1596277 & 688816 & 4.9 & 5.282 & TST \\
\hline CHEMBL1489002 & 688816 & 8.0 & 5.3112 & TRN \\
\hline CHEMBL1415010 & 688816 & 4.5 & 5.2717 & TST \\
\hline CHEMBL1557704 & 688816 & 4.45 & 5.1977 & TRN \\
\hline CHEMBL3209710 & 688816 & 7.5498 & 5.4518 & TRN \\
\hline
\end{tabular}




\begin{tabular}{|c|c|c|c|c|c|}
\hline \multicolumn{6}{|c|}{ Supplemental Table S2.txt } \\
\hline CHEMBL1457533 & 688816 & 4.45 & 5.1806 & TRN & \\
\hline CHEMBL1546224 & 688816 & 5.45 & 5.3497 & TST & \\
\hline CHEMBL1567215 & 688816 & 4.45 & 5.1467 & TRN & \\
\hline CHEMBL1446404 & 688816 & 5.15 & 5.1843 & TRN & \\
\hline CHEMBL1461184 & 688816 & 4.8 & 5.3847 & TRN & \\
\hline CHEMBL 3211946 & 688816 & 5.25 & 5.1019 & TST & \\
\hline CHEMBL1421190 & 688816 & 4.45 & 5.4022 & TRN & \\
\hline CHEMBL1492392 & 688816 & 4.95 & 5.7976 & TST & \\
\hline CHEMBL581929 & 688816 & 5.3 & 5.3032 & TRN & \\
\hline CHEMBL1531997 & 688816 & 4.95 & 5.4969 & TRN & \\
\hline CHEMBL1556373 & 688816 & 4.45 & 5.42299 & 9999999999 & TST \\
\hline CHEMBL1538448 & 688816 & 4.9 & 5.5773 & TST & \\
\hline CHEMBL1342451 & 688816 & 4.45 & 5.2955 & TRN & \\
\hline CHEMBL1597769 & 688816 & 4.7 & 5.7426 & TST & \\
\hline CHEMBL1417381 & 688816 & 5.3 & 5.0972 & TRN & \\
\hline CHEMBL1341038 & 688816 & 4.9 & 4.9098 & TRN & \\
\hline CHEMBL1480802 & 688816 & 4.6 & 5.5826 & TST & \\
\hline CHEMBL1587927 & 688816 & 5.2 & 4.9513 & TRN & \\
\hline CHEMBL1382284 & 688816 & 5.5 & 5.2098 & TST & \\
\hline CHEMBL1470256 & 688816 & 5.5 & 5.3183 & TRN & \\
\hline CHEMBL1496864 & 688816 & 5.4 & 4.9524 & TRN & \\
\hline CHEMBL1577241 & 688816 & 4.8 & 4.9294 & TRN & \\
\hline CHEMBL1465355 & 688816 & 5.15 & 4.8743 & TST & \\
\hline CHEMBL1386224 & 688816 & 4.9 & 5.2963 & TRN & \\
\hline CHEMBL1607035 & 688816 & 6.05 & 5.2224 & TRN & \\
\hline CHEMBL1535336 & 688816 & 5.25 & 5.8107 & TST & \\
\hline CHEMBL1503155 & 688816 & 4.8 & 5.24299 & 9999999999 & TRN \\
\hline CHEMBL1361785 & 688816 & 4.65 & 5.1851 & TRN & \\
\hline CHEMBL1538789 & 688816 & 4.95 & 5.0394 & TRN & \\
\hline CHEMBL1457476 & 688816 & 4.45 & 5.077 & TRN & \\
\hline CHEMBL1341644 & 688816 & 4.45 & 5.0002 & TRN & \\
\hline CHEMBL1584290 & 688816 & 4.45 & 5.1755 & TST & \\
\hline CHEMBL1579046 & 688816 & 4.85 & 5.2224 & TRN & \\
\hline CHEMBL3197761 & 688816 & 5.35 & 5.1487 & TRN & \\
\hline CHEMBL1394596 & 688816 & 4.9 & 5.2274 & TRN & \\
\hline CHEMBL3197504 & 688816 & 5.05 & 5.5045 & TRN & \\
\hline CHEMBL1562036 & 688816 & 4.95 & 5.1714 & TRN & \\
\hline CHEMBL1320577 & 688816 & 4.65 & 5.5077 & TRN & \\
\hline CHEMBL1965698 & 688816 & 4.9 & 5.5128 & TST & \\
\hline CHEMBL1339419 & 688816 & 4.45 & 5.4971 & TST & \\
\hline CHEMBL1477507 & 688816 & 4.9 & 5.0578 & TST & \\
\hline CHEMBL1428759 & 688816 & 4.55 & 5.3032 & TRN & \\
\hline CHEMBL3193041 & 688816 & 4.8 & 5.2214 & TRN & \\
\hline CHEMBL1470386 & 688816 & 5.25 & 4.8835 & TRN & \\
\hline CHEMBL 3194476 & 688816 & 6.2 & 5.2812 & TRN & \\
\hline CHEMBL1569739 & 688816 & 5.0 & 5.1499 & TRN & \\
\hline CHEMBL1420098 & 688816 & 4.85 & 5.2721 & TRN & \\
\hline CHEMBL1445702 & 688816 & 4.95 & 5.2578 & TRN & \\
\hline
\end{tabular}




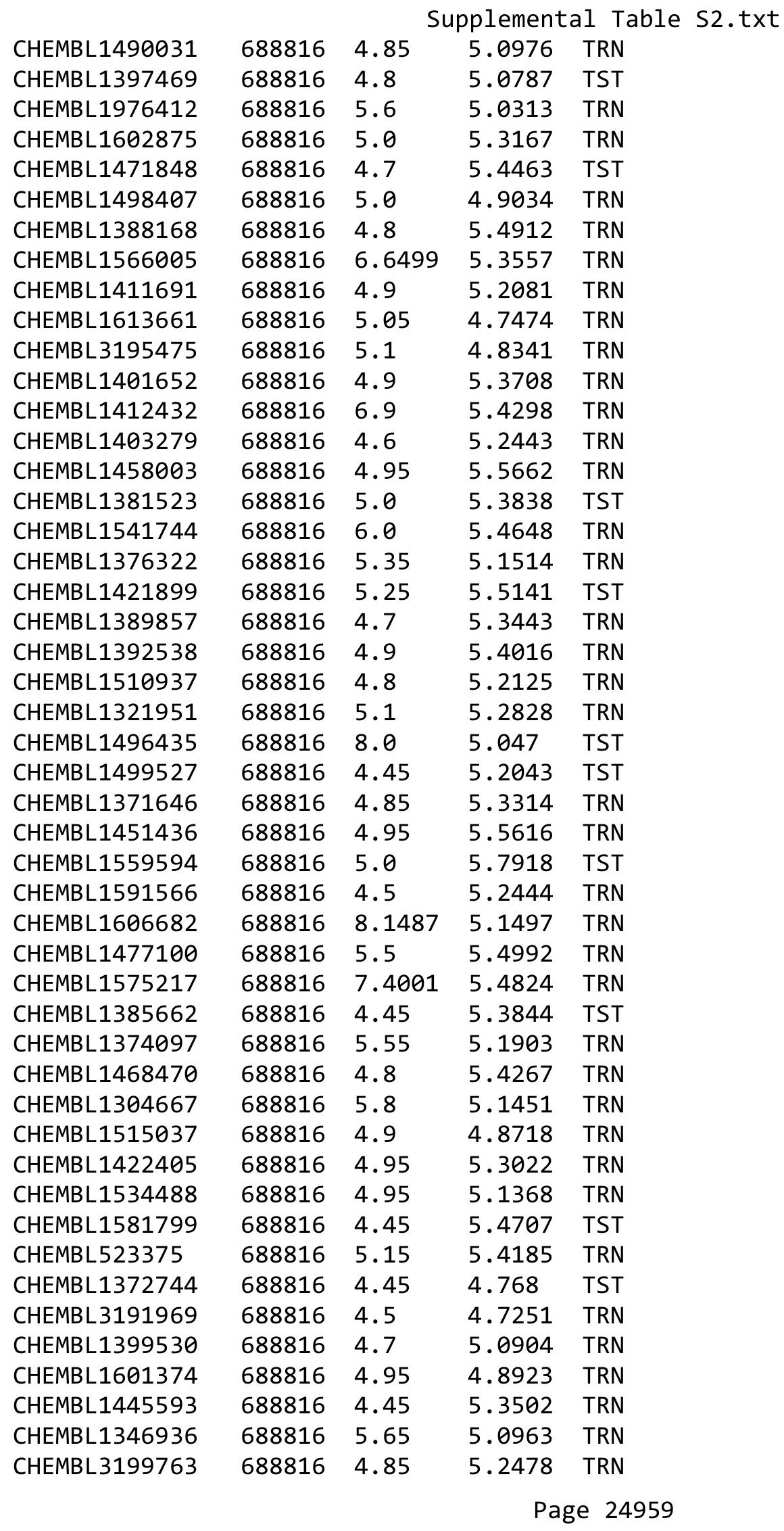




\begin{tabular}{|c|c|c|c|c|c|}
\hline \multicolumn{6}{|c|}{ Supplemental Table S2.txt } \\
\hline CHEMBL3209513 & 688816 & 4.45 & 5.4766 & TST & \\
\hline CHEMBL1563587 & 688816 & 5.0 & 5.3709 & TRN & \\
\hline CHEMBL1399191 & 688816 & 4.55 & 5.3241 & TST & \\
\hline CHEMBL1333225 & 688816 & 4.85 & 5.1635 & TST & \\
\hline CHEMBL1400703 & 688816 & 5.0 & 4.8849 & TRN & \\
\hline CHEMBL1609632 & 688816 & 5.25 & 5.2246 & TRN & \\
\hline CHEMBL1501495 & 688816 & 5.0 & 5.3658 & TRN & \\
\hline CHEMBL1613021 & 688816 & 5.25 & 5.40799 & 99999999995 & TST \\
\hline CHEMBL1422701 & 688816 & 8.301 & 5.5792 & TST & \\
\hline CHEMBL1419308 & 688816 & 6.1 & 5.4204 & TRN & \\
\hline CHEMBL1404648 & 688816 & 4.45 & 5.2792 & TRN & \\
\hline CHEMBL1371963 & 688816 & 4.45 & 4.8676 & TRN & \\
\hline CHEMBL1518540 & 688816 & 5.0 & 5.2547 & TST & \\
\hline CHEMBL1524890 & 688816 & 5.95 & 4.9809 & TRN & \\
\hline CHEMBL1619901 & 688816 & 5.35 & 5.1808 & TRN & \\
\hline CHEMBL1472038 & 688816 & 4.9 & 5.3475 & TST & \\
\hline CHEMBL3190983 & 688816 & 4.65 & 5.1977 & TRN & \\
\hline CHEMBL1430479 & 688816 & 5.45 & 4.933 & TRN & \\
\hline CHEMBL1461706 & 688816 & 5.35 & 5.2203 & TRN & \\
\hline CHEMBL1431727 & 688816 & 6.5501 & 5.2465 & TRN & \\
\hline CHEMBL1467073 & 688816 & 4.75 & 5.1322 & TST & \\
\hline CHEMBL1404086 & 688816 & 4.9 & 4.9603 & TRN & \\
\hline CHEMBL3216654 & 688816 & 4.45 & 5.1543 & TST & \\
\hline CHEMBL1477057 & 688816 & 4.9 & 5.1411 & TRN & \\
\hline CHEMBL1389726 & 688816 & 4.95 & 4.8767 & TRN & \\
\hline CHEMBL1443170 & 688816 & 4.9 & 5.0203 & TRN & \\
\hline CHEMBL1345939 & 688816 & 4.7 & 4.52800 & 00000000005 & TRN \\
\hline CHEMBL1450042 & 688816 & 4.6 & 5.0874 & TRN & \\
\hline CHEMBL1511301 & 688816 & 4.95 & 5.25799 & 9999999999 & TRN \\
\hline CHEMBL1605478 & 688816 & 4.95 & 5.0756 & TRN & \\
\hline CHEMBL56731 & 688816 & 4.65 & 5.1038 & TRN & \\
\hline CHEMBL1375830 & 688816 & 4.95 & 5.5248 & TRN & \\
\hline CHEMBL3198912 & 688816 & 5.5 & 5.4165 & TST & \\
\hline CHEMBL1511624 & 688816 & 5.2 & 5.2609 & TST & \\
\hline CHEMBL1566737 & 688816 & 5.1 & 5.2125 & TRN & \\
\hline CHEMBL1582677 & 688816 & 4.9 & 5.5134 & TRN & \\
\hline CHEMBL1335350 & 688816 & 5.35 & 5.13399 & 99999999995 & TRN \\
\hline CHEMBL3192909 & 688816 & 8.0506 & 5.664 & TRN & \\
\hline CHEMBL1517189 & 688816 & 4.55 & 5.5064 & TRN & \\
\hline CHEMBL1462921 & 688816 & 4.95 & 5.1271 & TRN & \\
\hline CHEMBL1480246 & 688816 & 4.75 & 4.9791 & TRN & \\
\hline CHEMBL1410281 & 688816 & 8.3468 & 5.3343 & TRN & \\
\hline CHEMBL1468638 & 688816 & 4.45 & 5.4068 & TRN & \\
\hline CHEMBL1463463 & 688816 & 4.8 & 5.1642 & TRN & \\
\hline CHEMBL3213569 & 688816 & 8.301 & 5.9429 & TRN & \\
\hline CHEMBL1546114 & 688816 & 6.0 & 5.4113 & TST & \\
\hline CHEMBL1399252 & 688816 & 4.95 & 5.1939 & TRN & \\
\hline CHEMBL1595473 & 688816 & 4.65 & 5.0989 & TST & \\
\hline
\end{tabular}




\begin{tabular}{|c|c|c|c|c|c|}
\hline \multicolumn{6}{|c|}{ Supplemental Table s2.txt } \\
\hline CHEMBL1505273 & 688816 & 4.45 & 5.3194 & TST & \\
\hline CHEMBL1461468 & 688816 & 5.5 & 5.2729 & TST & \\
\hline CHEMBL1330527 & 688816 & 7.8013 & 5.0008 & TRN & \\
\hline CHEMBL1540621 & 688816 & 4.75 & 5.2387 & TRN & \\
\hline CHEMBL1423037 & 688816 & 4.45 & 5.3324 & TRN & \\
\hline CHEMBL1509668 & 688816 & 4.65 & 5.6006 & TST & \\
\hline CHEMBL1384217 & 688816 & 5.25 & 5.4463 & TRN & \\
\hline CHEMBL1521346 & 688816 & 5.2 & 5.1501 & TST & \\
\hline CHEMBL1309915 & 688816 & 5.35 & 5.2761 & TST & \\
\hline CHEMBL1535312 & 688816 & 5.8 & 5.255 & TRN & \\
\hline CHEMBL3213665 & 688816 & 4.85 & 5.0638 & TRN & \\
\hline CHEMBL1343901 & 688816 & 4.7 & 5.0709 & TRN & \\
\hline CHEMBL3197629 & 688816 & 5.15 & 5.5243 & TST & \\
\hline CHEMBL1309183 & 688816 & 4.65 & 5.3593 & TST & \\
\hline CHEMBL1573048 & 688816 & 4.45 & 5.1983 & TRN & \\
\hline CHEMBL1303547 & 688816 & 5.25 & 5.794 & TST & \\
\hline CHEMBL1444612 & 688816 & 4.45 & 5.3102 & TRN & \\
\hline CHEMBL1440529 & 688816 & 4.85 & 5.4137 & TRN & \\
\hline CHEMBL1380907 & 688816 & 5.0 & 5.0708 & TRN & \\
\hline CHEMBL3145322 & 688816 & 4.95 & 5.3832 & TST & \\
\hline CHEMBL3144912 & 688816 & 7.0 & 5.6252 & TST & \\
\hline CHEMBL3196090 & 688816 & 5.0 & 5.4436 & TST & \\
\hline CHEMBL1356030 & 688816 & 4.7 & 4.9706 & TRN & \\
\hline CHEMBL1488177 & 688816 & 4.45 & 5.3537 & TRN & \\
\hline CHEMBL1598482 & 688816 & 4.9 & 5.2399 & TRN & \\
\hline CHEMBL1504558 & 688816 & 5.2 & 5.0924 & TST & \\
\hline CHEMBL428789 & 688816 & 5.55 & 5.0007 & TRN & \\
\hline CHEMBL1400501 & 688816 & 6.5501 & 5.356 & TRN & \\
\hline CHEMBL1393431 & 688816 & 5.0 & 5.2462 & TRN & \\
\hline CHEMBL1445108 & 688816 & 7.8996 & 5.1421 & TST & \\
\hline CHEMBL1505861 & 688816 & 5.5 & 5.4368 & TRN & \\
\hline CHEMBL1313145 & 688816 & 4.65 & 5.4176 & TRN & \\
\hline CHEMBL1352875 & 688816 & 8.3468 & 5.5911 & TRN & \\
\hline CHEMBL1424940 & 688816 & 5.9 & 5.5295 & TRN & \\
\hline CHEMBL1398975 & 688816 & 6.45 & 5.1739 & TRN & \\
\hline CHEMBL1508223 & 688816 & 6.0 & 5.0361 & TST & \\
\hline CHEMBL1333454 & 688816 & 5.25 & 5.2689 & TRN & \\
\hline CHEMBL1402279 & 688816 & 6.9 & 5.6387 & TRN & \\
\hline CHEMBL1411405 & 688816 & 4.5 & 5.6661 & TST & \\
\hline CHEMBL1613622 & 688816 & 6.25 & 5.8979 & TRN & \\
\hline CHEMBL1415107 & 688816 & 5.25 & 5.6126 & TRN & \\
\hline CHEMBL1450246 & 688816 & 4.8 & 5.102 & TRN & \\
\hline CHEMBL1504776 & 688816 & 5.0 & 4.9682 & TRN & \\
\hline CHEMBL3214441 & 688816 & 5.0 & 5.1818 & TST & \\
\hline CHEMBL1278181 & 688816 & 4.95 & 5.25799 & 9999999999 & TRN \\
\hline CHEMBL1390616 & 688816 & 5.0 & 5.25799 & 9999999999 & TRN \\
\hline CHEMBL1569409 & 688816 & 5.2 & 5.5614 & TRN & \\
\hline CHEMBL1462008 & 688816 & 4.95 & 5.4625 & TRN & \\
\hline
\end{tabular}




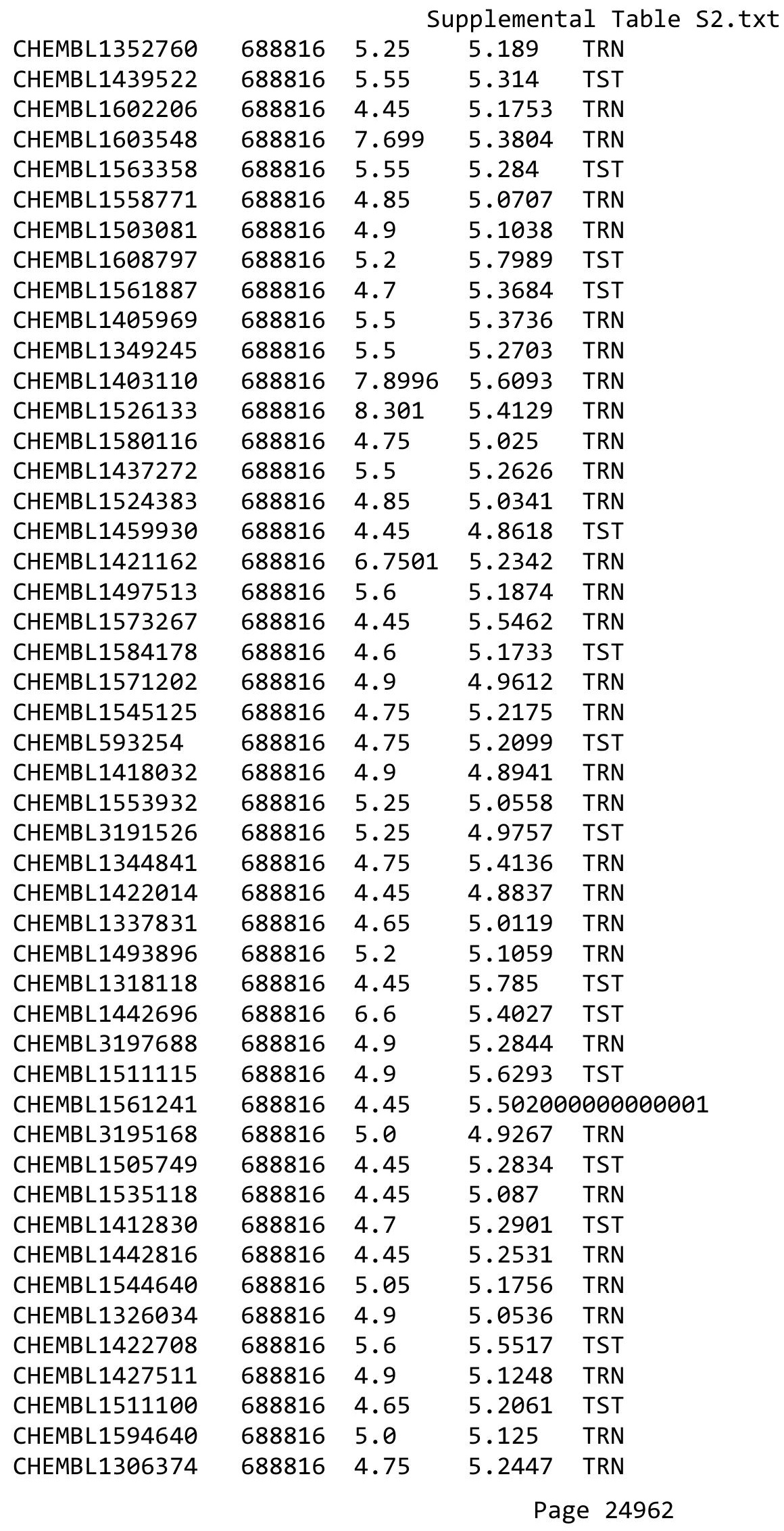




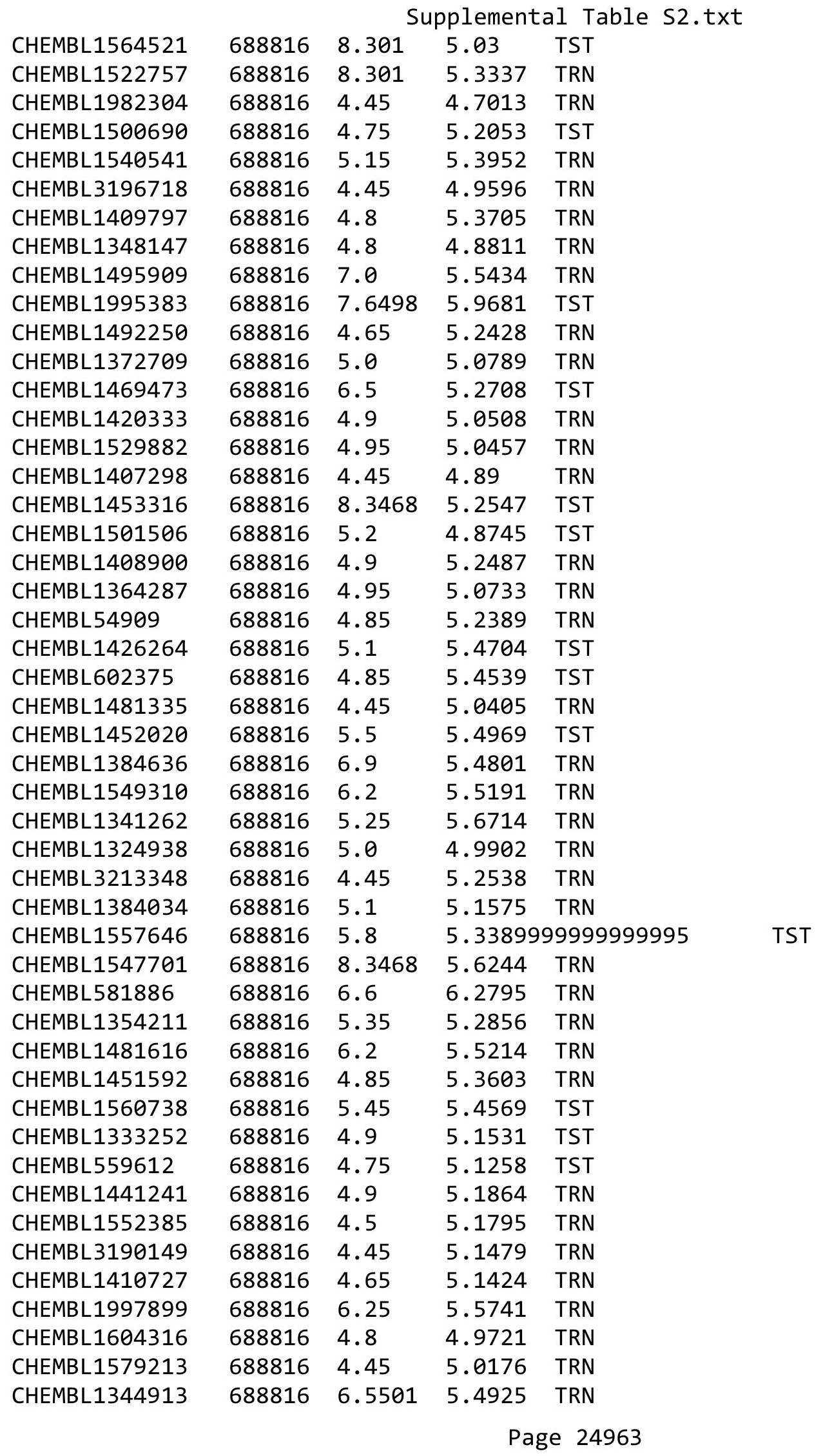




\begin{tabular}{|c|c|c|c|c|c|}
\hline \multicolumn{6}{|c|}{ Supplemental Table S2.txt } \\
\hline CHEMBL1329274 & 688816 & 4.95 & 4.9978 & TRN & \\
\hline CHEMBL1497736 & 688816 & 4.9 & 5.25 & TRN & \\
\hline CHEMBL1348263 & 688816 & 4.85 & 5.0354 & TRN & \\
\hline CHEMBL1527845 & 688816 & 4.95 & 5.33299 & 9999999999 & TRN \\
\hline CHEMBL1539582 & 688816 & 4.8 & $5.5120 e$ & 00000000005 & TRN \\
\hline CHEMBL1327105 & 688816 & 5.8 & 5.9796 & TRN & \\
\hline CHEMBL693 & 688816 & 6.3 & 5.0722 & TST & \\
\hline CHEMBL3212392 & 688816 & 4.9 & 5.3239 & TRN & \\
\hline CHEMBL 2007021 & 688816 & 5.55 & 5.2619 & TRN & \\
\hline CHEMBL1427027 & 688816 & 5.4 & 5.3358 & TRN & \\
\hline CHEMBL1516617 & 688816 & 4.8 & 5.0844 & TRN & \\
\hline CHEMBL1464307 & 688816 & 4.7 & 5.0102 & TRN & \\
\hline CHEMBL1432356 & 688816 & 4.9 & 5.2943 & TST & \\
\hline CHEMBL1343180 & 688816 & 4.45 & 5.0221 & TRN & \\
\hline CHEMBL1321310 & 688816 & 5.2 & 5.08 & TRN & \\
\hline CHEMBL1409750 & 688816 & 4.45 & 5.1403 & TST & \\
\hline CHEMBL1413264 & 688816 & 4.9 & 5.2536 & TRN & \\
\hline CHEMBL1441992 & 688816 & 5.4 & 4.9545 & TRN & \\
\hline CHEMBL1607187 & 688816 & 6.05 & 5.2865 & TRN & \\
\hline CHEMBL1494167 & 688816 & 5.0 & 5.2672 & TRN & \\
\hline CHEMBL1545002 & 688816 & 4.9 & 5.0396 & TRN & \\
\hline CHEMBL1584315 & 688816 & 5.0 & 5.2689 & TST & \\
\hline CHEMBL1407454 & 688816 & 5.05 & 5.6674 & TST & \\
\hline CHEMBL1489045 & 688816 & 5.0 & 5.1674 & TRN & \\
\hline CHEMBL1558748 & 688816 & 4.85 & 5.4926 & TST & \\
\hline CHEMBL1414988 & 688816 & 4.65 & 5.3376 & TRN & \\
\hline CHEMBL1485959 & 688816 & 5.4 & 5.6068 & TST & \\
\hline CHEMBL1368311 & 688816 & 4.95 & 4.8005 & TRN & \\
\hline CHEMBL1420612 & 688816 & 4.45 & 5.7506 & TST & \\
\hline CHEMBL 8260 & 688816 & 4.9 & 5.0373 & TRN & \\
\hline CHEMBL1599620 & 688816 & 4.45 & 5.3365 & TRN & \\
\hline CHEMBL1339679 & 688816 & 4.95 & 4.8089 & TRN & \\
\hline CHEMBL1497780 & 688816 & 4.95 & 5.3578 & TRN & \\
\hline CHEMBL1339862 & 688816 & 4.5 & 5.4989 & TRN & \\
\hline CHEMBL1363949 & 688816 & 4.85 & 4.9248 & TRN & \\
\hline CHEMBL1471762 & 688816 & 4.85 & 5.49299 & 9999999999 & TRN \\
\hline CHEMBL1448223 & 688816 & 4.95 & 5.2868 & TST & \\
\hline CHEMBL1537206 & 688816 & 4.45 & 5.3346 & TST & \\
\hline CHEMBL1343061 & 688816 & 7.5003 & 5.3787 & TST & \\
\hline CHEMBL1511650 & 688816 & 4.5 & 5.0861 & TST & \\
\hline CHEMBL1511951 & 688816 & 5.85 & 5.2825 & TRN & \\
\hline CHEMBL3191879 & 688816 & 4.45 & 5.0547 & TRN & \\
\hline CHEMBL1565991 & 688816 & 4.45 & 5.2271 & TST & \\
\hline CHEMBL1526189 & 688816 & 5.45 & 4.7684 & TRN & \\
\hline CHEMBL1332415 & 688816 & 4.7 & 5.8707 & TRN & \\
\hline CHEMBL1504368 & 688816 & 4.45 & 5.2313 & TRN & \\
\hline CHEMBL1325488 & 688816 & 6.15 & 5.3142 & TRN & \\
\hline CHEMBL1571654 & 688816 & 7.3002 & 5.0559 & TRN & \\
\hline
\end{tabular}




\begin{tabular}{|c|c|c|c|c|c|}
\hline \multicolumn{6}{|c|}{ Supplemental Table s2.txt } \\
\hline CHEMBL1466968 & 688816 & 4.45 & 5.4437 & TST & \\
\hline CHEMBL1466452 & 688816 & 4.45 & 5.024 & TRN & \\
\hline CHEMBL3212376 & 688816 & 4.9 & 5.3306 & TRN & \\
\hline CHEMBL3193851 & 688816 & 5.55 & 5.1919 & TRN & \\
\hline CHEMBL1417893 & 688816 & 6.15 & 5.0502 & TRN & \\
\hline CHEMBL1499276 & 688816 & 4.95 & 5.0839 & TRN & \\
\hline CHEMBL1607896 & 688816 & 4.9 & 5.1467 & TRN & \\
\hline CHEMBL1996281 & 688816 & 4.65 & 4.8472 & TRN & \\
\hline CHEMBL1523984 & 688816 & 4.9 & 5.3769 & TST & \\
\hline CHEMBL1359978 & 688816 & 4.65 & 5.4511 & TRN & \\
\hline CHEMBL1374258 & 688816 & 5.9 & 5.2106 & TRN & \\
\hline CHEMBL1339352 & 688816 & 5.25 & 5.5911 & TST & \\
\hline CHEMBL3208651 & 688816 & 7.5003 & 5.0201 & TRN & \\
\hline CHEMBL1470237 & 688816 & 4.9 & 5.4589 & TRN & \\
\hline CHEMBL1322476 & 688816 & 4.8 & 5.6012 & TRN & \\
\hline CHEMBL1346689 & 688816 & 4.9 & 5.3001 & TST & \\
\hline CHEMBL1348585 & 688816 & 4.85 & 5.0516 & TRN & \\
\hline CHEMBL1429370 & 688816 & 4.95 & 5.4503 & TRN & \\
\hline CHEMBL1343703 & 688816 & 8.0506 & 5.4218 & TRN & \\
\hline CHEMBL1511361 & 688816 & 5.55 & 5.5723 & TST & \\
\hline CHEMBL1380614 & 688816 & 4.55 & 5.4768 & TRN & \\
\hline CHEMBL1505968 & 688816 & 4.65 & 5.1413 & TRN & \\
\hline CHEMBL1350778 & 688816 & 4.75 & 5.0152 & TRN & \\
\hline CHEMBL3213705 & 688816 & 4.85 & 5.5778 & TRN & \\
\hline CHEMBL1482872 & 688816 & 4.9 & 5.2839 & TRN & \\
\hline CHEMBL1342791 & 688816 & 4.95 & 5.2352 & TRN & \\
\hline CHEMBL1323829 & 688816 & 4.5 & 4.7181 & TRN & \\
\hline CHEMBL1445184 & 688816 & 4.9 & 5.4771 & TST & \\
\hline CHEMBL 217926 & 688816 & 4.9 & 5.4961 & TRN & \\
\hline CHEMBL1481146 & 688816 & 5.0 & 5.7554 & TST & \\
\hline CHEMBL1467404 & 688816 & 5.45 & 5.4201 & TRN & \\
\hline CHEMBL1343759 & 688816 & 4.95 & 5.1427 & TRN & \\
\hline CHEMBL1411921 & 688816 & 4.9 & 5.1597 & TRN & \\
\hline CHEMBL1336245 & 688816 & 5.3 & 5.0796 & TST & \\
\hline CHEMBL1445772 & 688816 & 4.7 & 5.4619 & TRN & \\
\hline CHEMBL1324093 & 688816 & 6.05 & 5.1477 & TRN & \\
\hline CHEMBL1467999 & 688816 & 4.85 & 5.439 & TRN & \\
\hline CHEMBL1499515 & 688816 & 5.0 & 5.3657 & TRN & \\
\hline CHEMBL1970925 & 688816 & 4.95 & 5.0603 & TRN & \\
\hline CHEMBL1541197 & 688816 & 5.15 & 5.3547 & TRN & \\
\hline CHEMBL1326876 & 688816 & 6.0 & 5.1411 & TRN & \\
\hline CHEMBL1486125 & 688816 & 5.25 & 5.2384 & TRN & \\
\hline CHEMBL1460085 & 688816 & 4.9 & 5.1019 & TRN & \\
\hline CHEMBL1531944 & 688816 & 4.65 & 4.9788 & TRN & \\
\hline CHEMBL3207660 & 688816 & 7.7496 & 5.12799 & 9999999999 & TRN \\
\hline CHEMBL1402021 & 688816 & 7.2503 & 5.33299 & 9999999999 & TRN \\
\hline CHEMBL1361026 & 688816 & 5.05 & 5.7932 & TRN & \\
\hline CHEMBL3198021 & 688816 & 5.45 & 5.5931 & TST & \\
\hline
\end{tabular}




\begin{tabular}{|c|c|c|c|c|c|}
\hline \multicolumn{6}{|c|}{ Supplemental Table S2.txt } \\
\hline CHEMBL1565855 & 688816 & 4.8 & 5.2337 & TRN & \\
\hline CHEMBL1377506 & 688816 & 8.3979 & 5.6835 & TRN & \\
\hline CHEMBL1558119 & 688816 & 4.85 & 4.8911 & TRN & \\
\hline CHEMBL1384348 & 688816 & 4.9 & 4.86 & TRN & \\
\hline CHEMBL1567878 & 688816 & 8.3979 & 5.2996 & TRN & \\
\hline CHEMBL1372483 & 688816 & 5.85 & 5.59 & TST & \\
\hline CHEMBL1429312 & 688816 & 4.55 & 4.9252 & TST & \\
\hline CHEMBL1477244 & 688816 & 4.6 & 5.2824 & TRN & \\
\hline CHEMBL1489858 & 688816 & 4.8 & 5.1531 & TRN & \\
\hline CHEMBL1536994 & 688816 & 4.95 & 5.4134 & TRN & \\
\hline CHEMBL1429913 & 688816 & 8.4949 & 5.8969 & TRN & \\
\hline CHEMBL1326316 & 688816 & 4.65 & 5.4805 & TST & \\
\hline CHEMBL 3199448 & 688816 & 4.65 & 5.2637 & TRN & \\
\hline CHEMBL1467870 & 688816 & 6.7001 & 5.5383 & TST & \\
\hline CHEMBL1604403 & 688816 & 8.4949 & 5.1166 & TRN & \\
\hline CHEMBL1472233 & 688816 & 4.8 & 5.1103 & TRN & \\
\hline CHEMBL3213851 & 688816 & 7.5003 & 5.6408 & TRN & \\
\hline CHEMBL1504670 & 688816 & 4.85 & 5.1282 & TRN & \\
\hline CHEMBL1420139 & 688816 & 5.0 & 5.1872 & TRN & \\
\hline CHEMBL1423447 & 688816 & 8.3468 & 5.4613 & TRN & \\
\hline CHEMBL1346036 & 688816 & 5.9 & 5.7198 & TST & \\
\hline CHEMBL1469940 & 688816 & 7.699 & 5.0911 & TRN & \\
\hline CHEMBL1308462 & 688816 & 7.6498 & 5.0633 & TRN & \\
\hline CHEMBL1275611 & 688816 & 5.85 & 5.7616 & TRN & \\
\hline CHEMBL1523801 & 688816 & 5.05 & 5.3352 & TRN & \\
\hline CHEMBL1605247 & 688816 & 4.75 & 5.2212 & TRN & \\
\hline CHEMBL1323541 & 688816 & 5.6 & 5.38899 & 9999999999 & TST \\
\hline CHEMBL1311768 & 688816 & 4.95 & 5.1107 & TST & \\
\hline CHEMBL1411616 & 688816 & 5.05 & 5.54899 & 99999999995 & TRN \\
\hline CHEMBL1544445 & 688816 & 5.05 & 5.5025 & TRN & \\
\hline CHEMBL3191027 & 688816 & 4.95 & 5.3176 & TRN & \\
\hline CHEMBL1328302 & 688816 & 5.9 & 5.2319 & TRN & \\
\hline CHEMBL1373558 & 688816 & 5.8 & 5.2153 & TRN & \\
\hline CHEMBL1469632 & 688816 & 4.75 & 5.2777 & TRN & \\
\hline CHEMBL1525243 & 688816 & 4.85 & 4.9445 & TRN & \\
\hline CHEMBL1409514 & 688816 & 4.45 & 5.2904 & TST & \\
\hline CHEMBL1383048 & 688816 & 4.45 & 4.9424 & TST & \\
\hline CHEMBL1573956 & 688816 & 6.7501 & 4.878 & TRN & \\
\hline CHEMBL1507034 & 688816 & 4.8 & 5.1206 & TRN & \\
\hline CHEMBL1471351 & 688816 & 5.05 & 4.8761 & TRN & \\
\hline CHEMBL1364829 & 688816 & 4.45 & 5.0728 & TRN & \\
\hline CHEMBL1365927 & 688816 & 4.95 & 4.9082 & TST & \\
\hline CHEMBL1451926 & 688816 & 4.95 & 5.1931 & TRN & \\
\hline CHEMBL1378735 & 688816 & 4.95 & 5.7804 & TRN & \\
\hline CHEMBL1594699 & 688816 & 4.85 & 4.934 & TRN & \\
\hline CHEMBL1439989 & 688816 & 4.7 & 5.2112 & TST & \\
\hline CHEMBL1346560 & 688816 & 7.699 & 5.5519 & TST & \\
\hline CHEMBL1351466 & 688816 & 6.9 & 5.1793 & TST & \\
\hline
\end{tabular}




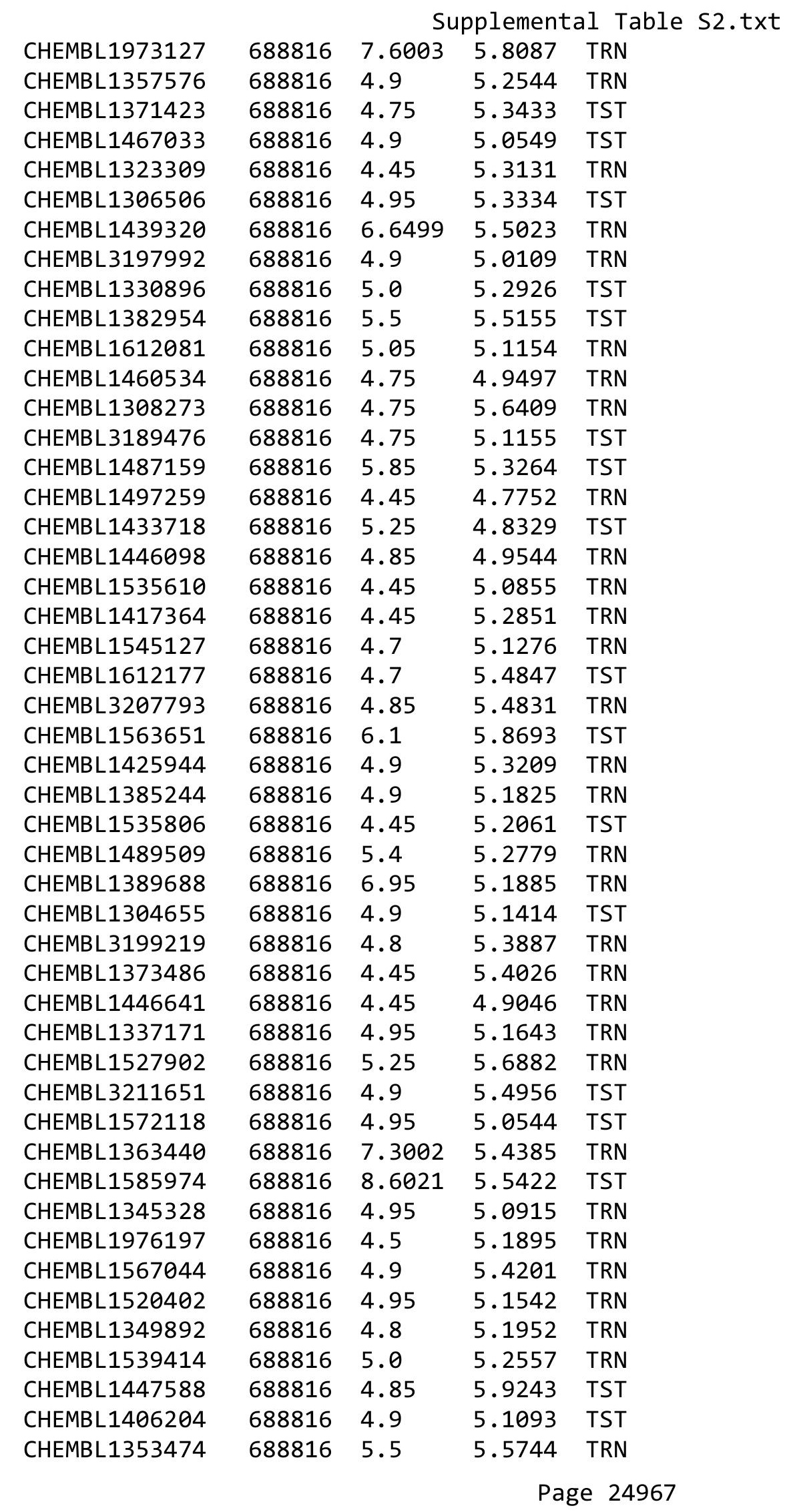




\begin{tabular}{|c|c|c|c|c|c|}
\hline \\
\hline CHEMBL1408059 & 688816 & 5.2 & 5.3519 & TST & \\
\hline CHEMBL1309803 & 688816 & 5.9 & 4.9283 & TRN & \\
\hline CHEMBL1335835 & 688816 & 5.95 & 5.4947 & TRN & \\
\hline CHEMBL1536520 & 688816 & 7.3497 & 5.4843 & TRN & \\
\hline CHEMBL1522881 & 688816 & 5.35 & 5.6018 & TRN & \\
\hline CHEMBL1524828 & 688816 & 4.6 & 5.2954 & TRN & \\
\hline CHEMBL1501202 & 688816 & 4.95 & 5.28299 & 99999999995 & TRN \\
\hline CHEMBL1379069 & 688816 & 4.65 & 5.2907 & TRN & \\
\hline CHEMBL1428003 & 688816 & 4.9 & 4.9312 & TRN & \\
\hline CHEMBL1588219 & 688816 & 5.0 & 5.4547 & TRN & \\
\hline CHEMBL1489325 & 688816 & 5.25 & 5.1755 & TST & \\
\hline CHEMBL1433043 & 688816 & 8.2518 & 5.1534 & TRN & \\
\hline CHEMBL1365985 & 688816 & 4.95 & 4.8767 & TRN & \\
\hline CHEMBL1383736 & 688816 & 4.95 & 5.157 & TST & \\
\hline CHEMBL1528452 & 688816 & 4.9 & 5.354 & TRN & \\
\hline CHEMBL1612481 & 688816 & 4.7 & 5.4137 & TRN & \\
\hline CHEMBL1320019 & 688816 & 7.2503 & 5.0898 & TST & \\
\hline CHEMBL1426502 & 688816 & 4.45 & 5.5925 & TRN & \\
\hline CHEMBL1484672 & 688816 & 5.05 & 5.0909 & TRN & \\
\hline CHEMBL1511360 & 688816 & 7.4001 & 5.6581 & TRN & \\
\hline CHEMBL3193502 & 688816 & 4.5 & 5.455 & TRN & \\
\hline CHEMBL1469044 & 688816 & 4.85 & 5.1766 & TRN & \\
\hline CHEMBL1603731 & 688816 & 5.5 & 5.436 & TRN & \\
\hline CHEMBL1501397 & 688816 & 5.4 & 5.4768 & TST & \\
\hline CHEMBL1363246 & 688816 & 5.0 & 5.49700 & 0000000001 & TRN \\
\hline CHEMBL1561025 & 688816 & 5.95 & 5.5037 & TRN & \\
\hline CHEMBL1415386 & 688816 & 7.5003 & 5.4874 & TST & \\
\hline CHEMBL1495454 & 688816 & 6.6499 & 5.2858 & TRN & \\
\hline CHEMBL1370907 & 688816 & 4.95 & 4.8968 & TRN & \\
\hline CHEMBL1326803 & 688816 & 4.45 & 5.4331 & TRN & \\
\hline CHEMBL1319938 & 688816 & 4.65 & 5.3858 & TRN & \\
\hline CHEMBL1424572 & 688816 & 6.7001 & 5.152 & TRN & \\
\hline CHEMBL1585509 & 688816 & 8.301 & 5.4642 & TRN & \\
\hline CHEMBL1341736 & 688816 & 5.75 & 4.8649 & TRN & \\
\hline CHEMBL1474052 & 688816 & 4.9 & 4.8322 & TRN & \\
\hline CHEMBL1585905 & 688816 & 4.85 & 5.2081 & TRN & \\
\hline CHEMBL1381418 & 688816 & 5.85 & 5.2595 & TRN & \\
\hline CHEMBL1524966 & 688816 & 4.85 & 5.2564 & TRN & \\
\hline CHEMBL1489337 & 688816 & 5.3 & 5.1574 & TRN & \\
\hline CHEMBL1365439 & 688816 & 4.95 & 5.5745 & TRN & \\
\hline CHEMBL1311505 & 688816 & 4.9 & 4.9086 & TRN & \\
\hline CHEMBL1309238 & 688816 & 8.1024 & 5.3383 & TST & \\
\hline CHEMBL1468872 & 688816 & 4.9 & 5.805 & TST & \\
\hline CHEMBL1479955 & 688816 & 4.45 & 5.3884 & TRN & \\
\hline CHEMBL1485494 & 688816 & 5.1 & 4.9439 & TST & \\
\hline CHEMBL1301997 & 688816 & 5.2 & 5.2602 & TRN & \\
\hline CHEMBL1462175 & 688816 & 4.7 & 5.1095 & TRN & \\
\hline CHEMBL1305081 & 688816 & 4.45 & 5.1258 & TRN & \\
\hline
\end{tabular}




\begin{tabular}{|c|c|c|c|c|}
\hline & & & oplement & al $\mathrm{Ta}$ \\
\hline CHEMBL1983745 & 688816 & 5.7 & 5.4017 & TST \\
\hline CHEMBL1366988 & 688816 & 4.95 & 5.529 & TRN \\
\hline CHEMBL1521766 & 688816 & 5.0 & 4.846 & TST \\
\hline CHEMBL1533813 & 688816 & 5.0 & 4.9069 & TRN \\
\hline CHEMBL1543876 & 688816 & 4.45 & 5.4919 & TRN \\
\hline CHEMBL1429483 & 688816 & 5.45 & 4.7593 & TST \\
\hline CHEMBL1464030 & 688816 & 7.6498 & 5.2913 & TRN \\
\hline CHEMBL1537002 & 688816 & 4.45 & 4.9947 & TRN \\
\hline CHEMBL1360203 & 688816 & 5.4 & 5.114 & TRN \\
\hline CHEMBL1337672 & 688816 & 4.8 & 4.9927 & TRN \\
\hline CHEMBL1415756 & 688816 & 5.15 & 5.0305 & TRN \\
\hline CHEMBL1300493 & 688816 & 5.8 & 5.232 & TRN \\
\hline CHEMBL1494097 & 688816 & 4.45 & 5.4137 & TRN \\
\hline CHEMBL1414578 & 688816 & 5.6 & 5.8321 & TST \\
\hline CHEMBL1368495 & 688816 & 5.65 & 5.5144 & TRN \\
\hline CHEMBL1337268 & 688816 & 4.45 & 5.5442 & TST \\
\hline CHEMBL1444532 & 688816 & 5.25 & 5.1516 & TST \\
\hline CHEMBL3193688 & 688816 & 4.8 & 5.044 & TRN \\
\hline CHEMBL1612542 & 688816 & 5.0 & 5.3122 & TRN \\
\hline CHEMBL1545173 & 688816 & 5.2 & 5.3656 & TRN \\
\hline CHEMBL1545212 & 688816 & 4.45 & 5.1425 & TRN \\
\hline CHEMBL1596911 & 688816 & 6.5 & 5.3709 & TST \\
\hline CHEMBL1546773 & 688816 & 5.4 & 5.2049 & TRN \\
\hline CHEMBL1580320 & 688816 & 4.95 & 5.0188 & TRN \\
\hline CHEMBL1463624 & 688816 & 5.2 & 5.2452 & TRN \\
\hline CHEMBL1609392 & 688816 & 4.45 & 5.2976 & TRN \\
\hline CHEMBL1445358 & 688816 & 5.55 & 4.925 & TRN \\
\hline CHEMBL1465164 & 688816 & 4.45 & 5.1837 & TST \\
\hline CHEMBL1300524 & 688816 & 4.6 & 5.2092 & TRN \\
\hline CHEMBL3194151 & 688816 & 4.85 & 4.8685 & TRN \\
\hline CHEMBL1555495 & 688816 & 4.45 & 4.7117 & TRN \\
\hline CHEMBL1571059 & 688816 & 4.95 & 5.746 & TST \\
\hline CHEMBL1408917 & 688816 & 4.8 & 5.6555 & TRN \\
\hline CHEMBL1571934 & 688816 & 5.0 & 5.4515 & TRN \\
\hline CHEMBL1352379 & 688816 & 6.8 & 5.2784 & TRN \\
\hline CHEMBL1585864 & 688816 & 4.65 & 5.1008 & TRN \\
\hline CHEMBL1300205 & 688816 & 4.55 & 5.5509 & TRN \\
\hline CHEMBL1448336 & 688816 & 6.0 & 5.2103 & TRN \\
\hline CHEMBL1523011 & 688816 & 4.65 & 5.4053 & TRN \\
\hline CHEMBL1580565 & 688816 & 4.9 & 5.7952 & TRN \\
\hline CHEMBL1462208 & 688816 & 4.9 & 5.1737 & TRN \\
\hline CHEMBL1573277 & 688816 & 4.9 & 5.5076 & TRN \\
\hline CHEMBL1309079 & 688816 & 4.95 & 5.4424 & TST \\
\hline CHEMBL1509619 & 688816 & 8.301 & 5.1052 & TST \\
\hline CHEMBL1391927 & 688816 & 4.45 & 5.3389 & TST \\
\hline CHEMBL1528874 & 688816 & 5.6 & 5.0755 & TRN \\
\hline CHEMBL1415805 & 688816 & 6.5501 & 5.2997 & TST \\
\hline CHEMBL1393469 & 688816 & 4.75 & 5.2069 & TRN \\
\hline
\end{tabular}




\begin{tabular}{|c|c|c|c|c|c|}
\hline & & \multicolumn{4}{|c|}{ Supplemental Table S2.txt } \\
\hline CHEMBL1306331 & 688816 & 7.699 & 5.4589 & TRN & \\
\hline CHEMBL1567961 & 688816 & 4.85 & 5.3786 & TRN & \\
\hline CHEMBL3196509 & 688816 & 4.8 & 5.12700 & 0000000001 & TST \\
\hline CHEMBL566096 & 688816 & 4.7 & 5.1699 & TRN & \\
\hline CHEMBL1460126 & 688816 & 5.65 & 5.19600 & 3000000001 & TRN \\
\hline CHEMBL1518438 & 688816 & 5.35 & 4.8942 & TRN & \\
\hline CHEMBL1383876 & 688816 & 5.1 & 5.3144 & TRN & \\
\hline CHEMBL1475685 & 688816 & 7.4001 & 5.2265 & TST & \\
\hline CHEMBL1596918 & 688816 & 5.35 & 5.3804 & TRN & \\
\hline CHEMBL1511020 & 688816 & 7.0 & 5.2894 & TRN & \\
\hline CHEMBL1527860 & 688816 & 4.45 & 5.4709 & TST & \\
\hline CHEMBL1537106 & 688816 & 4.9 & 4.9377 & TST & \\
\hline CHEMBL1471516 & 688816 & 7.7496 & 5.1766 & TRN & \\
\hline CHEMBL1376888 & 688816 & 4.9 & 4.8942 & TRN & \\
\hline CHEMBL1307524 & 688816 & 8.3468 & 5.2881 & TST & \\
\hline CHEMBL1407509 & 688816 & 4.95 & 5.0579 & TRN & \\
\hline CHEMBL3193782 & 688816 & 4.9 & 5.3451 & TST & \\
\hline CHEMBL 3192262 & 688816 & 4.45 & 5.3888 & TRN & \\
\hline CHEMBL1520005 & 688816 & 5.25 & 5.3636 & TRN & \\
\hline CHEMBL3193638 & 688816 & 7.4001 & 5.3054 & TST & \\
\hline CHEMBL1389253 & 688816 & 5.35 & 5.6528 & TST & \\
\hline CHEMBL1453649 & 688816 & 4.45 & 4.9586 & TRN & \\
\hline CHEMBL1566148 & 688816 & 4.9 & 5.431 & TRN & \\
\hline CHEMBL 1483226 & 688816 & 5.0 & 5.2963 & TRN & \\
\hline CHEMBL1320018 & 688816 & 5.5 & 5.419 & TST & \\
\hline CHEMBL1566536 & 688816 & 4.85 & 5.2846 & TRN & \\
\hline CHEMBL3196620 & 688816 & 4.45 & 5.2985 & TRN & \\
\hline CHEMBL1456650 & 688816 & 4.95 & 5.2767 & TRN & \\
\hline CHEMBL1527407 & 688816 & 4.85 & 5.0245 & TRN & \\
\hline CHEMBL1441096 & 688816 & 4.9 & 5.3032 & TRN & \\
\hline CHEMBL1463480 & 688816 & 4.65 & 4.8951 & TRN & \\
\hline CHEMBL1550485 & 688816 & 8.3468 & 5.1272 & TRN & \\
\hline CHEMBL1326500 & 688816 & 5.0 & 5.5132 & TRN & \\
\hline CHEMBL1522020 & 688816 & 4.9 & 5.4731 & TST & \\
\hline CHEMBL1611409 & 688816 & 7.2 & 5.1049 & TST & \\
\hline CHEMBL1466523 & 688816 & 4.95 & 5.5008 & TRN & \\
\hline CHEMBL3196936 & 688816 & 4.8 & 5.5655 & TRN & \\
\hline CHEMBL1343058 & 688816 & 5.0 & 5.0402 & TRN & \\
\hline CHEMBL1379634 & 688816 & 5.45 & 5.2659 & TRN & \\
\hline CHEMBL1456328 & 688816 & 4.95 & 5.1065 & TRN & \\
\hline CHEMBL1478691 & 688816 & 5.15 & 5.2986 & TRN & \\
\hline CHEMBL1311910 & 688816 & 4.75 & 5.263 & TST & \\
\hline CHEMBL1378743 & 688816 & 5.5 & 5.3838 & TST & \\
\hline CHEMBL1569734 & 688816 & 4.7 & 5.0146 & TRN & \\
\hline CHEMBL1498953 & 688816 & 4.8 & 5.0652 & TRN & \\
\hline CHEMBL3190024 & 688816 & 5.15 & 5.4319 & TST & \\
\hline CHEMBL1381375 & 688816 & 6.7501 & 5.4248 & TRN & \\
\hline CHEMBL1521669 & 688816 & 4.7 & 5.6478 & TRN & \\
\hline
\end{tabular}




\begin{tabular}{|c|c|c|c|c|}
\hline \multicolumn{5}{|c|}{ Supplemental Table S2.txt } \\
\hline CHEMBL1541303 & 688816 & 5.0 & 4.7857 & TST \\
\hline CHEMBL1531390 & 688816 & 6.2 & 5.835 & TST \\
\hline CHEMBL1504629 & 688816 & 6.3 & 5.5574 & TRN \\
\hline CHEMBL209101 & 688816 & 4.45 & 5.3409 & TRN \\
\hline CHEMBL1353220 & 688816 & 4.8 & 5.0809 & TRN \\
\hline CHEMBL1379592 & 688816 & 6.0 & 5.2982 & TST \\
\hline CHEMBL1428891 & 688816 & 5.4 & 5.052 & TST \\
\hline CHEMBL 3209143 & 688816 & 5.0 & 5.4309 & TRN \\
\hline CHEMBL1510332 & 688816 & 4.6 & 4.8929 & TRN \\
\hline CHEMBL1602879 & 688816 & 5.25 & 5.3373 & TRN \\
\hline CHEMBL1568591 & 688816 & 7.6003 & 5.3989 & TRN \\
\hline CHEMBL1605074 & 688816 & 5.65 & 4.7549 & TRN \\
\hline CHEMBL1451995 & 688816 & 4.45 & 5.0766 & TRN \\
\hline CHEMBL579088 & 688816 & 4.85 & 5.3782 & TST \\
\hline CHEMBL494326 & 688816 & 4.45 & 4.8507 & TRN \\
\hline CHEMBL3211998 & 688816 & 5.25 & 5.0628 & TRN \\
\hline CHEMBL1557648 & 688816 & 4.45 & 4.6528 & TRN \\
\hline CHEMBL1492352 & 688816 & 4.6 & 5.1386 & TRN \\
\hline CHEMBL1304009 & 688816 & 5.2 & 5.2377 & TRN \\
\hline CHEMBL1546719 & 688816 & 4.9 & 5.2692 & TRN \\
\hline CHEMBL1458475 & 688816 & 4.95 & 5.4638 & TRN \\
\hline CHEMBL1423596 & 688816 & 4.45 & 5.2644 & TRN \\
\hline CHEMBL1502432 & 688816 & 5.25 & 5.3395 & TST \\
\hline CHEMBL1971234 & 688816 & 5.1 & 4.9853 & TST \\
\hline CHEMBL1523016 & 688816 & 7.6498 & 5.3157 & TRN \\
\hline CHEMBL1330143 & 688816 & 4.65 & 5.317 & TRN \\
\hline CHEMBL1542560 & 688816 & 4.95 & 5.0612 & TRN \\
\hline CHEMBL1359154 & 688816 & 4.8 & 5.0657 & TRN \\
\hline CHEMBL1345888 & 688816 & 4.9 & 4.7589 & TRN \\
\hline CHEMBL1404213 & 688816 & 6.8499 & 5.636 & TRN \\
\hline CHEMBL1352983 & 688816 & 4.75 & 5.1478 & TRN \\
\hline CHEMBL1347425 & 688816 & 5.2 & 5.3489 & TST \\
\hline CHEMBL1384150 & 688816 & 4.85 & 5.4872 & TRN \\
\hline CHEMBL1550005 & 688816 & 5.0 & 5.4463 & TRN \\
\hline CHEMBL1582803 & 688816 & 4.95 & 5.1707 & TST \\
\hline CHEMBL1528872 & 688816 & 4.9 & 5.2409 & TRN \\
\hline CHEMBL1384734 & 688816 & 4.7 & 5.0675 & TRN \\
\hline CHEMBL1500962 & 688816 & 5.35 & 5.8434 & TST \\
\hline CHEMBL 3208298 & 688816 & 4.55 & 5.0944 & TRN \\
\hline CHEMBL1358946 & 688816 & 4.45 & 5.3046 & TRN \\
\hline CHEMBL1443046 & 688816 & 5.55 & 5.6812 & TST \\
\hline CHEMBL1572251 & 688816 & 4.9 & 5.4034 & TST \\
\hline CHEMBL1526269 & 688816 & 5.0 & 5.1243 & TST \\
\hline CHEMBL1300197 & 688816 & 5.05 & 4.9543 & TRN \\
\hline CHEMBL1372646 & 688816 & 4.9 & 5.0412 & TST \\
\hline CHEMBL1325008 & 688816 & 4.9 & 5.2684 & TST \\
\hline CHEMBL1517986 & 688816 & 5.0 & 5.1645 & TST \\
\hline CHEMBL1597211 & 688816 & 5.0 & 5.0379 & TRN \\
\hline
\end{tabular}




\begin{tabular}{|c|c|c|c|c|c|}
\hline & & \multicolumn{4}{|c|}{ Supplemental Table S2.txt } \\
\hline CHEMBL1375672 & 688816 & 8.2007 & 5.075 & TRN & \\
\hline CHEMBL1561754 & 688816 & 4.95 & 5.4418 & TRN & \\
\hline CHEMBL1330723 & 688816 & 4.9 & 5.1345 & TRN & \\
\hline CHEMBL1452488 & 688816 & 4.75 & 5.09399 & 9999999999 & TRN \\
\hline CHEMBL1375473 & 688816 & 5.55 & 4.9689 & TRN & \\
\hline CHEMBL1472078 & 688816 & 7.5498 & 5.388 & TRN & \\
\hline CHEMBL3190986 & 688816 & 5.0 & 4.7913 & TRN & \\
\hline CHEMBL1470069 & 688816 & 5.5 & 5.2418 & TRN & \\
\hline CHEMBL1501771 & 688816 & 4.45 & 5.1961 & TRN & \\
\hline CHEMBL1582189 & 688816 & 4.45 & 5.2126 & TST & \\
\hline CHEMBL1328462 & 688816 & 4.6 & 5.2857 & TRN & \\
\hline CHEMBL1399417 & 688816 & 8.4559 & 5.0818 & TST & \\
\hline CHEMBL1428401 & 688816 & 5.2 & 5.2445 & TRN & \\
\hline CHEMBL1567703 & 688816 & 4.45 & 5.2533 & TRN & \\
\hline CHEMBL1336281 & 688816 & 6.1 & 5.6769 & TRN & \\
\hline CHEMBL1571674 & 688816 & 4.45 & 5.00899 & 99999999995 & TRN \\
\hline CHEMBL125150 & 688816 & 5.95 & 5.5914 & TST & \\
\hline CHEMBL1399331 & 688816 & 8.4949 & 5.4362 & TST & \\
\hline CHEMBL1512319 & 688816 & 4.45 & 4.9688 & TRN & \\
\hline CHEMBL1343599 & 688816 & 5.5 & 5.2638 & TRN & \\
\hline CHEMBL3191434 & 688816 & 4.85 & 5.5034 & TRN & \\
\hline CHEMBL1429841 & 688816 & 4.7 & 5.2574 & TRN & \\
\hline CHEMBL1521136 & 688816 & 5.45 & 5.3361 & TRN & \\
\hline CHEMBL1302976 & 688816 & 5.25 & 5.3798 & TRN & \\
\hline CHEMBL1523844 & 688816 & 4.95 & 4.9544 & TRN & \\
\hline CHEMBL1331116 & 688816 & 5.95 & 5.313 & TRN & \\
\hline CHEMBL3212794 & 688816 & 4.8 & 5.0106 & TRN & \\
\hline CHEMBL1334082 & 688816 & 6.4 & 5.6877 & TST & \\
\hline CHEMBL1599396 & 688816 & 4.9 & 5.1108 & TRN & \\
\hline CHEMBL1371084 & 688816 & 4.75 & 5.2124 & TRN & \\
\hline CHEMBL1329389 & 688816 & 4.9 & 5.1149 & TRN & \\
\hline CHEMBL1357084 & 688816 & 5.0 & 5.1453 & TRN & \\
\hline CHEMBL410533 & 688816 & 4.45 & 4.8338 & TRN & \\
\hline CHEMBL1388917 & 688816 & 5.5 & 5.4115 & TRN & \\
\hline CHEMBL1503075 & 688816 & 4.9 & 5.2785 & TRN & \\
\hline CHEMBL1389732 & 688816 & 6.2 & 5.4946 & TRN & \\
\hline CHEMBL1566592 & 688816 & 6.7001 & 5.4473 & TRN & \\
\hline CHEMBL1471162 & 688816 & 4.75 & 5.2696 & TRN & \\
\hline CHEMBL1611247 & 688816 & 4.95 & 4.968 & TRN & \\
\hline CHEMBL1443211 & 688816 & 5.25 & 5.4687 & TRN & \\
\hline CHEMBL1360260 & 688816 & 4.7 & 5.2456 & TRN & \\
\hline CHEMBL1535018 & 688816 & 4.65 & 5.2595 & TRN & \\
\hline CHEMBL1497073 & 688816 & 6.05 & 5.6278 & TST & \\
\hline CHEMBL48310 & 688816 & 5.05 & 5.2669 & TST & \\
\hline CHEMBL1331316 & 688816 & 4.9 & 5.6439 & TST & \\
\hline CHEMBL1602231 & 688816 & 5.5 & 4.9766 & TRN & \\
\hline CHEMBL1320276 & 688816 & 5.35 & 5.1335 & TRN & \\
\hline CHEMBL1462076 & 688816 & 5.15 & 5.4774 & TRN & \\
\hline
\end{tabular}




\begin{tabular}{|c|c|c|c|c|}
\hline \multicolumn{5}{|c|}{ Supplemental Table s2.txt } \\
\hline CHEMBL1453108 & 688816 & 6.0 & 5.3399 & TRN \\
\hline CHEMBL1536874 & 688816 & 4.8 & 5.3168 & TRN \\
\hline CHEMBL1356506 & 688816 & 4.45 & 4.9197 & TRN \\
\hline CHEMBL1582984 & 688816 & 4.95 & 5.6336 & TRN \\
\hline CHEMBL1310121 & 688816 & 4.9 & 5.645 & TRN \\
\hline CHEMBL1565209 & 688816 & 5.05 & 5.4045 & TST \\
\hline CHEMBL1336630 & 688816 & 5.0 & 5.0673 & TRN \\
\hline CHEMBL1495381 & 688816 & 5.0 & 5.5769 & TST \\
\hline CHEMBL 244023 & 688816 & 4.95 & 5.9161 & TRN \\
\hline CHEMBL1383856 & 688816 & 5.5 & 5.227 & TRN \\
\hline CHEMBL1583290 & 688816 & 4.85 & 5.2902 & TST \\
\hline CHEMBL1595782 & 688816 & 6.9 & 5.5799 & TRN \\
\hline CHEMBL1455268 & 688816 & 4.85 & 4.9337 & TRN \\
\hline CHEMBL1609836 & 688816 & 4.45 & 5.0376 & TST \\
\hline CHEMBL1445232 & 688816 & 4.75 & 5.2111 & TRN \\
\hline CHEMBL1492491 & 688816 & 4.6 & 5.2279 & TRN \\
\hline CHEMBL1395912 & 688816 & 4.9 & 5.0516 & TRN \\
\hline CHEMBL1386452 & 688816 & 6.6 & 5.5134 & TRN \\
\hline CHEMBL1499545 & 688816 & 5.1 & 5.5574 & TRN \\
\hline CHEMBL1509780 & 688816 & 8.0 & 5.848 & TRN \\
\hline CHEMBL3191117 & 688816 & 4.8 & 5.3246 & TRN \\
\hline CHEMBL1593518 & 688816 & 4.45 & 5.2755 & TRN \\
\hline CHEMBL1531190 & 688816 & 4.45 & 5.2855 & TRN \\
\hline CHEMBL1445472 & 688816 & 8.301 & 5.3953 & TRN \\
\hline CHEMBL 1486608 & 688816 & 4.45 & 5.3888 & TRN \\
\hline CHEMBL1386337 & 688816 & 5.0 & 5.272 & TRN \\
\hline CHEMBL1465124 & 688816 & 4.9 & 5.3879 & TRN \\
\hline CHEMBL1563797 & 688816 & 4.65 & 5.1088 & TRN \\
\hline CHEMBL1312652 & 688816 & 4.75 & 4.9716 & TRN \\
\hline CHEMBL1515375 & 688816 & 4.8 & 5.2879 & TRN \\
\hline CHEMBL1557619 & 688816 & 4.95 & 4.9373 & TRN \\
\hline CHEMBL1301633 & 688816 & 4.5 & 4.9783 & TST \\
\hline CHEMBL1467396 & 688816 & 6.5 & 5.2822 & TST \\
\hline CHEMBL1611429 & 688816 & 4.45 & 5.305 & TRN \\
\hline CHEMBL1417733 & 688816 & 4.8 & 5.1005 & TRN \\
\hline CHEMBL1605073 & 688816 & 4.9 & 4.9594 & TRN \\
\hline CHEMBL1403248 & 688816 & 4.45 & 5.0396 & TRN \\
\hline CHEMBL3192166 & 688816 & 7.2503 & 5.4978 & TRN \\
\hline CHEMBL1470506 & 688816 & 4.65 & 5.4435 & TST \\
\hline CHEMBL1560487 & 688816 & 5.75 & 5.3183 & TRN \\
\hline CHEMBL1517361 & 688816 & 4.45 & 5.2585 & TRN \\
\hline CHEMBL1418839 & 688816 & 4.85 & 5.0999 & TRN \\
\hline CHEMBL1486172 & 688816 & 5.15 & 5.1196 & TRN \\
\hline CHEMBL1583690 & 688816 & 4.8 & 5.2164 & TRN \\
\hline CHEMBL1373093 & 688816 & 4.9 & 5.2495 & TRN \\
\hline CHEMBL1401242 & 688816 & 6.3 & 5.0868 & TRN \\
\hline CHEMBL1349645 & 688816 & 5.35 & $5.4570 e$ & 0000000001 \\
\hline CHEMBL1512914 & 688816 & 4.95 & 5.3054 & TST \\
\hline
\end{tabular}

TRN 


\begin{tabular}{|c|c|c|c|c|c|}
\hline \multirow[b]{2}{*}{ CHEMBL1491099 } & \multicolumn{5}{|c|}{ Supplemental Table S2.txt } \\
\hline & 688816 & 4.45 & 5.4011 & TST & \\
\hline CHEMBL1499948 & 688816 & 4.45 & 5.0279 & TRN & \\
\hline CHEMBL1382919 & 688816 & 7.8996 & 5.50299 & 9999999999 & TST \\
\hline CHEMBL1333395 & 688816 & 5.3 & 5.2059 & TRN & \\
\hline CHEMBL1609905 & 688816 & 8.301 & 5.5356 & TST & \\
\hline CHEMBL1452515 & 688816 & 5.45 & 5.2153 & TRN & \\
\hline CHEMBL1303589 & 688816 & 5.0 & 5.2603 & TRN & \\
\hline CHEMBL1312320 & 688816 & 5.6 & 4.7683 & TRN & \\
\hline CHEMBL1323331 & 688816 & 4.8 & 4.9339 & TRN & \\
\hline CHEMBL1460654 & 688816 & 5.3 & 5.0177 & TST & \\
\hline CHEMBL1586994 & 688816 & 4.45 & 4.8848 & TST & \\
\hline CHEMBL1335850 & 688816 & 5.2 & 5.6803 & TRN & \\
\hline CHEMBL1410523 & 688816 & 5.1 & 5.1834 & TRN & \\
\hline CHEMBL1330586 & 688816 & 4.45 & 5.0951 & TRN & \\
\hline CHEMBL1557394 & 688816 & 5.9 & 5.0015 & TRN & \\
\hline CHEMBL1338870 & 688816 & 6.9 & 5.2959 & TST & \\
\hline CHEMBL1595853 & 688816 & 4.9 & 5.3196 & TST & \\
\hline CHEMBL1302772 & 688816 & 4.45 & 5.0823 & TRN & \\
\hline CHEMBL1430860 & 688816 & 4.9 & 5.5377 & TRN & \\
\hline CHEMBL3199324 & 688816 & 5.65 & 5.2416 & TRN & \\
\hline CHEMBL1387529 & 688816 & 5.65 & 5.2999 & TRN & \\
\hline CHEMBL1457473 & 688816 & 5.0 & 5.1602 & TRN & \\
\hline CHEMBL1347099 & 688816 & 6.05 & 4.9876 & TRN & \\
\hline CHEMBL1310643 & 688816 & 4.95 & 5.4295 & TRN & \\
\hline CHEMBL1333962 & 688816 & 5.2 & 5.04899 & 99999999995 & TRN \\
\hline CHEMBL6291 & 688816 & 4.45 & 5.472 & TRN & \\
\hline CHEMBL1544818 & 688816 & 4.9 & 5.416 & TST & \\
\hline CHEMBL1431235 & 688816 & 4.45 & 5.0708 & TRN & \\
\hline CHEMBL3197279 & 688816 & 7.4498 & 5.4779 & TRN & \\
\hline CHEMBL1409280 & 688816 & 4.95 & 5.2156 & TRN & \\
\hline CHEMBL1565953 & 688816 & 4.9 & 5.5049 & TRN & \\
\hline CHEMBL1386957 & 688816 & 8.301 & 4.9388 & TRN & \\
\hline CHEMBL1440420 & 688816 & 4.45 & 5.1925 & TST & \\
\hline CHEMBL1483025 & 688816 & 4.6 & 5.86799 & 9999999999 & TRN \\
\hline CHEMBL1418013 & 688816 & 6.1 & 5.5295 & TRN & \\
\hline CHEMBL1562195 & 688816 & 4.5 & 4.8191 & TRN & \\
\hline CHEMBL1565485 & 688816 & 4.95 & 4.9903 & TST & \\
\hline CHEMBL1404111 & 688816 & 4.9 & 5.2004 & TRN & \\
\hline CHEMBL1406191 & 688816 & 5.25 & 5.1083 & TST & \\
\hline CHEMBL1571160 & 688816 & 4.95 & 5.4691 & TRN & \\
\hline CHEMBL1370988 & 688816 & 5.45 & 4.9251 & TRN & \\
\hline CHEMBL1563370 & 688816 & 4.45 & 5.5582 & TST & \\
\hline CHEMBL3194401 & 688816 & 4.6 & 5.181 & TST & \\
\hline CHEMBL1410367 & 688816 & 7.8013 & 5.3663 & TST & \\
\hline CHEMBL1352569 & 688816 & 4.8 & 4.8494 & TRN & \\
\hline CHEMBL1408449 & 688816 & 4.9 & 4.9966 & TRN & \\
\hline CHEMBL1406449 & 688816 & 4.45 & 4.9336 & TRN & \\
\hline CHEMBL1583895 & 688816 & 4.6 & 5.4086 & TRN & \\
\hline
\end{tabular}




\begin{tabular}{|c|c|c|c|c|c|}
\hline \multicolumn{6}{|c|}{ Supplemental Table S2.txt } \\
\hline CHEMBL1606886 & 688816 & 5.0 & 5.3517 & TRN & \\
\hline CHEMBL1378090 & 688816 & 4.9 & 5.6971 & TST & \\
\hline CHEMBL1302785 & 688816 & 5.15 & 5.0127 & TRN & \\
\hline CHEMBL1597290 & 688816 & 4.9 & 5.4923 & TRN & \\
\hline CHEMBL1592173 & 688816 & 5.4 & 5.6134 & TRN & \\
\hline CHEMBL1356624 & 688816 & 5.65 & 5.3023 & TRN & \\
\hline CHEMBL1301394 & 688816 & 5.4 & 5.5207 & TST & \\
\hline CHEMBL1511292 & 688816 & 6.0 & 5.5484 & TRN & \\
\hline CHEMBL1418203 & 688816 & 5.5 & 5.0567 & TRN & \\
\hline CHEMBL1366296 & 688816 & 4.45 & 5.0894 & TRN & \\
\hline CHEMBL1347881 & 688816 & 4.85 & 5.3729 & TRN & \\
\hline CHEMBL104264 & 688816 & 6.0 & 4.8716 & TST & \\
\hline CHEMBL1608635 & 688816 & 7.6498 & 5.403 & TRN & \\
\hline CHEMBL1544798 & 688816 & 4.45 & 4.8709 & TST & \\
\hline CHEMBL234978 & 688816 & 4.65 & 4.9966 & TRN & \\
\hline CHEMBL1999571 & 688816 & 4.5 & 5.36600 & 00000000005 & TRN \\
\hline CHEMBL1516908 & 688816 & 4.95 & 5.2603 & TRN & \\
\hline CHEMBL1322466 & 688816 & 7.6498 & 5.6503 & TST & \\
\hline CHEMBL1559996 & 688816 & 4.9 & 5.2701 & TRN & \\
\hline CHEMBL1350245 & 688816 & 6.0 & 5.4212 & TRN & \\
\hline CHEMBL1302096 & 688816 & 4.6 & 5.5455 & TRN & \\
\hline CHEMBL583578 & 688816 & 6.0 & 5.2058 & TRN & \\
\hline CHEMBL1320489 & 688816 & 4.95 & 4.9326 & TRN & \\
\hline CHEMBL1439020 & 688816 & 4.7 & 5.1561 & TRN & \\
\hline CHEMBL1554244 & 688816 & 4.45 & 4.7692 & TRN & \\
\hline CHEMBL1523198 & 688816 & 4.85 & 4.9991 & TRN & \\
\hline CHEMBL1590020 & 688816 & 5.15 & 5.3332 & TST & \\
\hline CHEMBL1386681 & 688816 & 7.3002 & 5.1332 & TST & \\
\hline CHEMBL1611777 & 688816 & 7.5498 & 5.11100 & 3000000001 & TRN \\
\hline CHEMBL 203606 & 688816 & 4.85 & 5.5732 & TST & \\
\hline CHEMBL1407168 & 688816 & 4.9 & 5.3205 & TRN & \\
\hline CHEMBL3194248 & 688816 & 7.0 & 5.5328 & TRN & \\
\hline CHEMBL1991055 & 688816 & 4.95 & 5.0143 & TRN & \\
\hline CHEMBL1327879 & 688816 & 5.0 & 4.9597 & TRN & \\
\hline CHEMBL1351158 & 688816 & 4.8 & 4.9167 & TRN & \\
\hline CHEMBL3198185 & 688816 & 4.95 & 5.0297 & TRN & \\
\hline CHEMBL1599025 & 688816 & 4.85 & 5.2574 & TRN & \\
\hline CHEMBL1603156 & 688816 & 5.3 & 5.54700 & 0000000001 & TRN \\
\hline CHEMBL1346096 & 688816 & 4.95 & 5.2258 & TST & \\
\hline CHEMBL1337298 & 688816 & 5.1 & 5.568 & TRN & \\
\hline CHEMBL1467245 & 688816 & 5.4 & 5.125 & TRN & \\
\hline CHEMBL1369876 & 688816 & 4.95 & 5.3312 & TRN & \\
\hline CHEMBL1586518 & 688816 & 4.65 & 5.0013 & TST & \\
\hline CHEMBL1335397 & 688816 & 5.4 & 5.3192 & TST & \\
\hline CHEMBL 309848 & 688816 & 4.85 & 5.1584 & TRN & \\
\hline CHEMBL1345069 & 688816 & 7.9508 & 5.6856 & TRN & \\
\hline CHEMBL1319409 & 688816 & 4.6 & 5.5791 & TRN & \\
\hline CHEMBL1447121 & 688816 & 4.75 & 5.4082 & TRN & \\
\hline
\end{tabular}




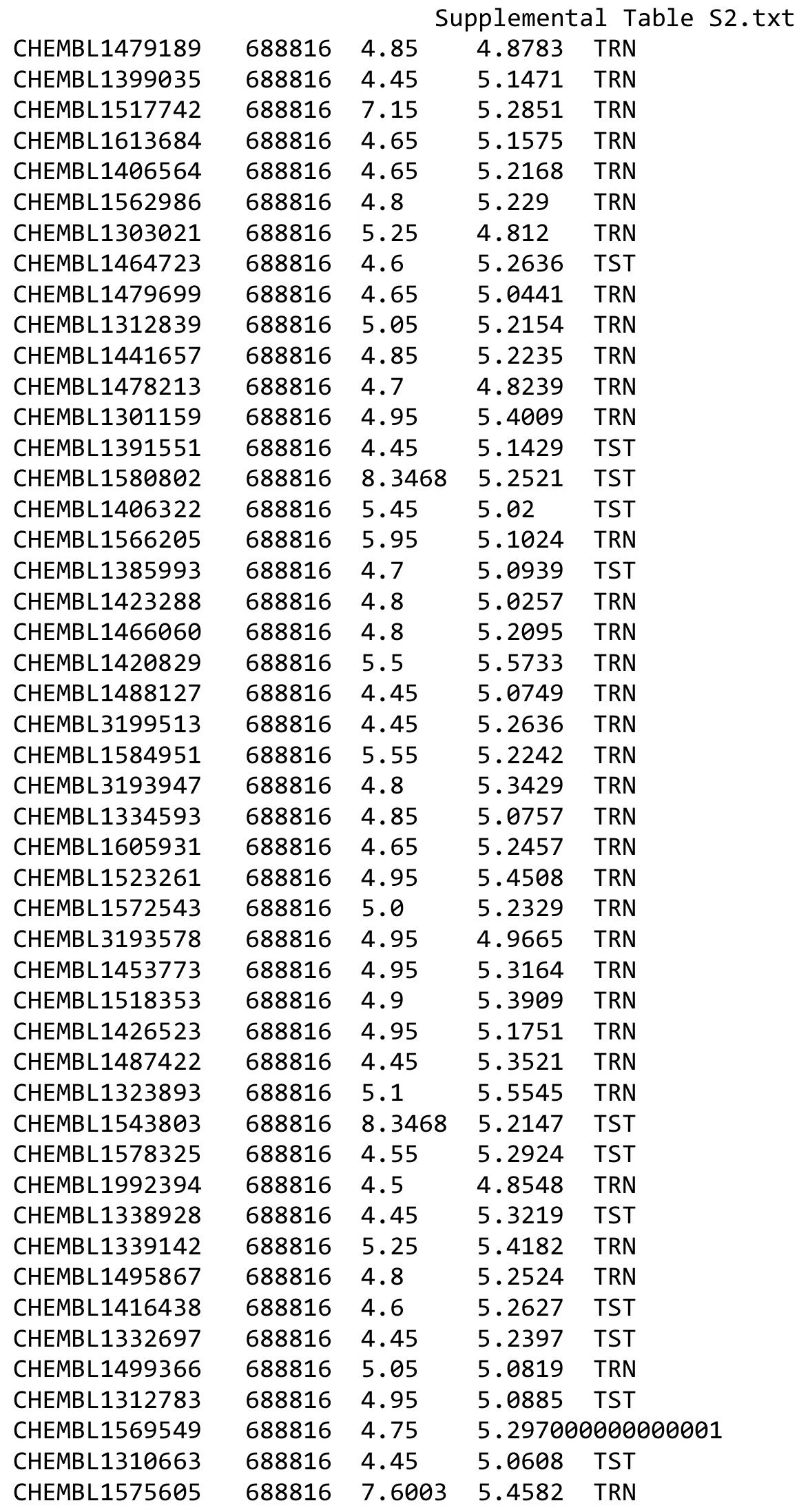




\begin{tabular}{|c|c|c|c|c|c|}
\hline \multicolumn{6}{|c|}{ Supplemental Table S2.txt } \\
\hline CHEMBL1465250 & 688816 & 4.6 & 5.3578 & TRN & \\
\hline CHEMBL1323969 & 688816 & 4.9 & 5.0622 & TST & \\
\hline CHEMBL1330531 & 688816 & 5.0 & 5.5617 & TST & \\
\hline CHEMBL1417809 & 688816 & 5.05 & 5.3068 & TRN & \\
\hline CHEMBL1581810 & 688816 & 5.0 & 5.1872 & TRN & \\
\hline CHEMBL598885 & 688816 & 6.25 & 5.6147 & TRN & \\
\hline CHEMBL568419 & 688816 & 4.95 & 5.4799 & TRN & \\
\hline CHEMBL1389547 & 688816 & 4.65 & 5.1391 & TRN & \\
\hline CHEMBL1328609 & 688816 & 7.8996 & 5.4249 & TRN & \\
\hline CHEMBL1416338 & 688816 & 5.0 & 5.3057 & TRN & \\
\hline CHEMBL1521021 & 688816 & 6.4 & 5.1963 & TRN & \\
\hline CHEMBL3211390 & 688816 & 4.45 & 5.4006 & TRN & \\
\hline CHEMBL1328386 & 688816 & 5.0 & 5.374 & TST & \\
\hline CHEMBL1465368 & 688816 & 7.2503 & 5.4073 & TRN & \\
\hline CHEMBL1471493 & 688816 & 5.55 & 5.6429 & TRN & \\
\hline CHEMBL1509745 & 688816 & 7.6498 & 5.6748 & TST & \\
\hline CHEMBL1336801 & 688816 & 4.75 & 5.4556 & TRN & \\
\hline CHEMBL1406464 & 688816 & 4.6 & 5.5052 & TRN & \\
\hline CHEMBL1602376 & 688816 & 5.05 & 5.251 & TST & \\
\hline CHEMBL1501489 & 688816 & 4.45 & 5.0448 & TRN & \\
\hline CHEMBL1481522 & 688816 & 5.0 & 5.8043 & TRN & \\
\hline CHEMBL1444355 & 688816 & 4.8 & 5.4112 & TRN & \\
\hline CHEMBL1466399 & 688816 & 4.45 & 5.3616 & TRN & \\
\hline CHEMBL1327547 & 688816 & 4.85 & 4.9294 & TST & \\
\hline CHEMBL1446049 & 688816 & 5.15 & 4.7936 & TRN & \\
\hline CHEMBL1532004 & 688816 & 6.1 & 5.2081 & TRN & \\
\hline CHEMBL1580342 & 688816 & 6.25 & 4.9484 & TRN & \\
\hline CHEMBL1381330 & 688816 & 5.35 & 5.1859 & TRN & \\
\hline CHEMBL3198616 & 688816 & 4.9 & 5.4461 & TST & \\
\hline CHEMBL1594593 & 688816 & 7.7496 & 5.6678 & TRN & \\
\hline CHEMBL1580715 & 688816 & 4.45 & 5.3482 & TST & \\
\hline CHEMBL1305429 & 688816 & 4.5 & 5.20700 & 0000000001 & TRN \\
\hline CHEMBL1547003 & 688816 & 4.7 & 5.5433 & TST & \\
\hline CHEMBL1494432 & 688816 & 4.45 & 5.233 & TRN & \\
\hline CHEMBL1574067 & 688816 & 8.301 & 5.5409 & TRN & \\
\hline CHEMBL1322541 & 688816 & 4.8 & 5.3191 & TRN & \\
\hline CHEMBL1337904 & 688816 & 4.65 & 5.5462 & TRN & \\
\hline CHEMBL1449907 & 688816 & 7.0 & 5.6953 & TST & \\
\hline CHEMBL1367406 & 688816 & 8.3468 & 5.2071 & TRN & \\
\hline CHEMBL3189331 & 688816 & 5.0 & 5.1609 & TST & \\
\hline CHEMBL1371186 & 688816 & 5.9 & 5.3351 & TST & \\
\hline CHEMBL1430872 & 688816 & 4.9 & 4.9052 & TRN & \\
\hline CHEMBL1576204 & 688816 & 5.55 & 5.6113 & TRN & \\
\hline CHEMBL1602860 & 688816 & 6.05 & 5.2752 & TST & \\
\hline CHEMBL1466458 & 688816 & 4.6 & 5.315 & TRN & \\
\hline CHEMBL1403372 & 688816 & 5.7 & 4.777 & TRN & \\
\hline CHEMBL1391518 & 688816 & 4.95 & 4.9218 & TRN & \\
\hline CHEMBL1510923 & 688816 & 4.45 & 5.4252 & TRN & \\
\hline
\end{tabular}




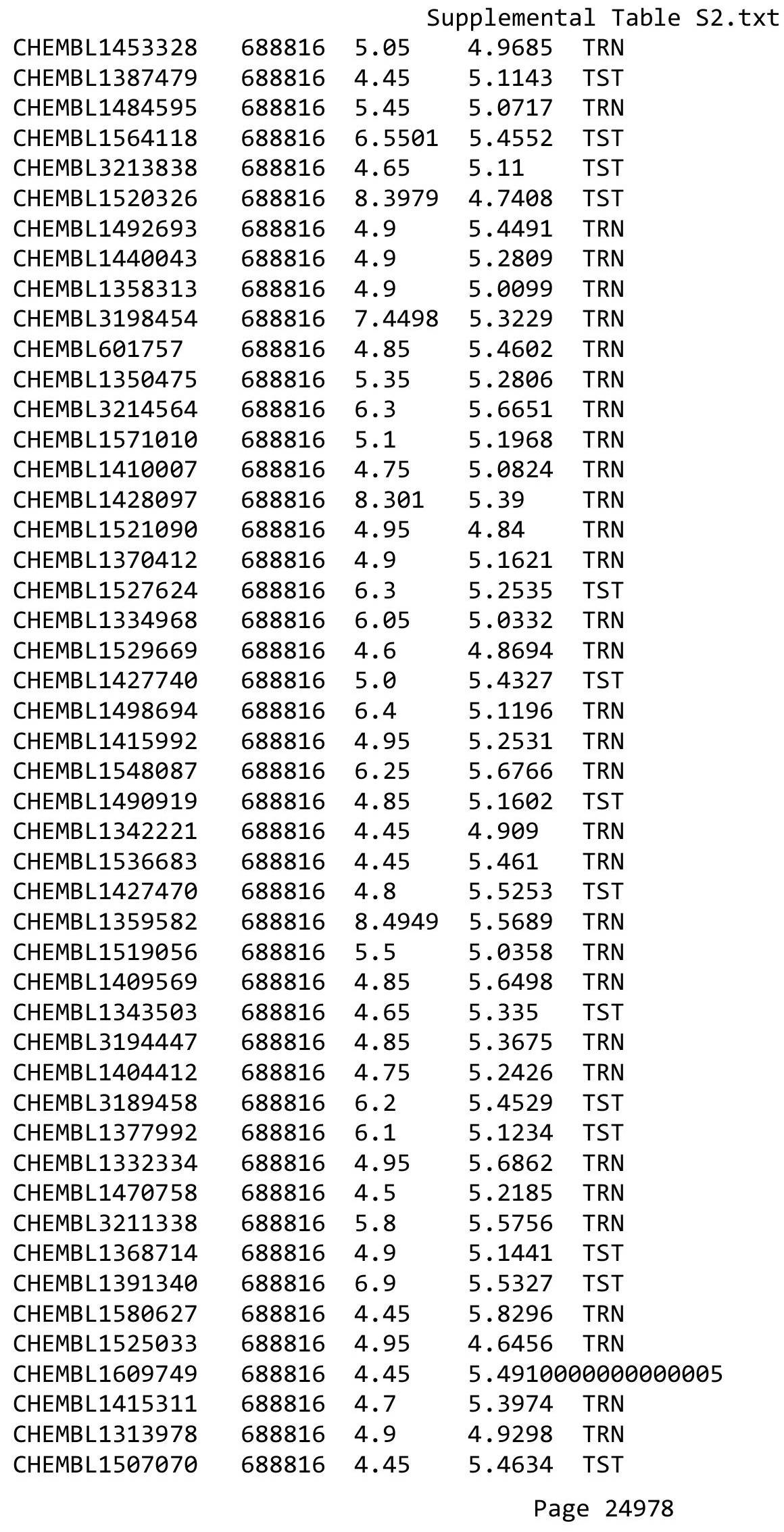




\begin{tabular}{|c|c|c|c|c|}
\hline \multicolumn{5}{|c|}{ Supplemental Table S2.txt } \\
\hline CHEMBL1309684 & 688816 & 6.45 & 5.2716 & TRN \\
\hline CHEMBL1383424 & 688816 & 5.8 & 5.4273 & TST \\
\hline CHEMBL1414892 & 688816 & 4.7 & 5.6606 & TRN \\
\hline CHEMBL1391448 & 688816 & 4.95 & 5.0659 & TRN \\
\hline CHEMBL1316831 & 688816 & 6.2 & 5.3277 & TRN \\
\hline CHEMBL1527947 & 688816 & 5.95 & 5.15 & TST \\
\hline CHEMBL1443863 & 688816 & 4.9 & 5.0336 & TRN \\
\hline CHEMBL1377471 & 688816 & 8.4949 & 5.891 & TST \\
\hline CHEMBL1585221 & 688816 & 4.8 & 5.2287 & TST \\
\hline CHEMBL1402173 & 688816 & 4.45 & 5.2832 & TRN \\
\hline CHEMBL1378337 & 688816 & 8.0 & 5.3167 & TRN \\
\hline CHEMBL1602214 & 688816 & 4.85 & 5.2294 & TST \\
\hline CHEMBL1328836 & 688816 & 4.95 & 4.8941 & TST \\
\hline CHEMBL3210595 & 688816 & 4.5 & 5.6977 & TST \\
\hline CHEMBL 3211450 & 688816 & 5.05 & 5.1855 & TST \\
\hline CHEMBL1529791 & 688816 & 5.95 & 5.499 & TRN \\
\hline CHEMBL1455297 & 688816 & 5.0 & 5.1654 & TST \\
\hline CHEMBL1596245 & 688816 & 4.45 & 5.4717 & TST \\
\hline CHEMBL1571695 & 688816 & 4.95 & 5.3028 & TST \\
\hline CHEMBL1552904 & 688816 & 4.85 & 5.2731 & TRN \\
\hline CHEMBL1999475 & 688816 & 4.95 & 5.3641 & TRN \\
\hline CHEMBL1347277 & 688816 & 4.8 & 5.3768 & TRN \\
\hline CHEMBL1410678 & 688816 & 6.5501 & 5.3674 & TST \\
\hline CHEMBL1519352 & 688816 & 4.9 & 5.4251 & TRN \\
\hline CHEMBL1382927 & 688816 & 4.95 & 4.9033 & TST \\
\hline CHEMBL1499235 & 688816 & 4.95 & 5.2116 & TRN \\
\hline CHEMBL1348314 & 688816 & 5.65 & 5.0801 & TRN \\
\hline CHEMBL1412094 & 688816 & 4.85 & 4.9125 & TRN \\
\hline CHEMBL1373982 & 688816 & 4.8 & 5.5179 & TST \\
\hline CHEMBL1546956 & 688816 & 4.7 & 5.3553 & TRN \\
\hline CHEMBL1593169 & 688816 & 5.65 & 5.1246 & TRN \\
\hline CHEMBL1429304 & 688816 & 4.45 & 5.32 & TST \\
\hline CHEMBL1448751 & 688816 & 4.65 & 5.222 & TRN \\
\hline CHEMBL1446951 & 688816 & 4.95 & 5.113 & TRN \\
\hline CHEMBL1304199 & 688816 & 5.4 & 5.103 & TRN \\
\hline CHEMBL3192850 & 688816 & 5.95 & 5.0582 & TRN \\
\hline CHEMBL1401348 & 688816 & 5.9 & 6.3501 & TST \\
\hline CHEMBL1508760 & 688816 & 4.95 & 5.5277 & TRN \\
\hline CHEMBL1548481 & 688816 & 4.45 & 5.55 & TRN \\
\hline CHEMBL 3190884 & 688816 & 5.2 & 5.4193 & TRN \\
\hline CHEMBL1311826 & 688816 & 5.2 & 5.0137 & TRN \\
\hline CHEMBL1535149 & 688816 & 4.8 & 5.8206 & TST \\
\hline CHEMBL1439532 & 688816 & 5.5 & 4.9176 & TRN \\
\hline CHEMBL1299457 & 688816 & 4.6 & 5.109 & TRN \\
\hline CHEMBL1318989 & 688816 & 5.55 & 5.1241 & TRN \\
\hline CHEMBL1587790 & 688816 & 5.65 & 5.0582 & TRN \\
\hline CHEMBL1364300 & 688816 & 6.4 & 5.6611 & TRN \\
\hline CHEMBL1448611 & 688816 & 4.9 & 5.2486 & TST \\
\hline
\end{tabular}




\begin{tabular}{|c|c|c|c|c|c|}
\hline \multicolumn{6}{|c|}{ Supplemental Table S2.txt } \\
\hline CHEMBL1504223 & 688816 & 4.9 & 5.435 & TRN & \\
\hline CHEMBL1322477 & 688816 & 4.45 & 5.3546 & TRN & \\
\hline CHEMBL1527672 & 688816 & 6.2 & 4.8556 & TRN & \\
\hline CHEMBL1309004 & 688816 & 4.45 & 5.3299 & TRN & \\
\hline CHEMBL1590554 & 688816 & 4.45 & 4.6865 & TRN & \\
\hline CHEMBL1562845 & 688816 & 8.301 & 5.6176 & TST & \\
\hline CHEMBL1417590 & 688816 & 4.95 & 5.2892 & TRN & \\
\hline CHEMBL1418632 & 688816 & 4.9 & 4.9763 & TRN & \\
\hline CHEMBL1331226 & 688816 & 4.85 & 5.522 & TRN & \\
\hline CHEMBL1383569 & 688816 & 5.1 & 5.2654 & TRN & \\
\hline CHEMBL1409802 & 688816 & 5.6 & 4.8785 & TRN & \\
\hline CHEMBL1601103 & 688816 & 4.7 & 5.095 & TRN & \\
\hline CHEMBL1471919 & 688816 & 4.45 & 5.2044 & TRN & \\
\hline CHEMBL1353216 & 688816 & 4.95 & 5.0948 & TRN & \\
\hline CHEMBL1454071 & 688816 & 6.95 & 5.5111 & TST & \\
\hline CHEMBL1469969 & 688816 & 4.85 & 5.2429 & TRN & \\
\hline CHEMBL1460869 & 688816 & 5.55 & 5.3798 & TRN & \\
\hline CHEMBL1346307 & 688816 & 7.6003 & 5.1279 & TRN & \\
\hline CHEMBL1538843 & 688816 & 4.45 & 5.0769 & TST & \\
\hline CHEMBL1995020 & 688816 & 5.0 & 5.2223 & TRN & \\
\hline CHEMBL1606031 & 688816 & 5.4 & 5.1653 & TRN & \\
\hline CHEMBL1486652 & 688816 & 4.8 & 5.322 & TRN & \\
\hline CHEMBL1559578 & 688816 & 5.55 & $5.3210 e$ & $\partial 000000001$ & TRN \\
\hline CHEMBL1459270 & 688816 & 4.9 & 5.1251 & TRN & \\
\hline CHEMBL486706 & 688816 & 5.05 & 4.816 & TST & \\
\hline CHEMBL1420047 & 688816 & 5.55 & 5.2002 & TRN & \\
\hline CHEMBL1490706 & 688816 & 4.45 & 5.4942 & TST & \\
\hline CHEMBL1489817 & 688816 & 4.95 & 5.348 & TRN & \\
\hline CHEMBL 3213844 & 688816 & 4.55 & 5.2014 & TRN & \\
\hline CHEMBL505019 & 688816 & 4.45 & 5.4461 & TST & \\
\hline CHEMBL1535477 & 688816 & 8.301 & 5.7878 & TRN & \\
\hline CHEMBL1582428 & 688816 & 4.6 & 5.5009 & TRN & \\
\hline CHEMBL1967273 & 688816 & 4.95 & 5.3523 & TRN & \\
\hline CHEMBL1445196 & 688816 & 4.7 & 5.1135 & TRN & \\
\hline CHEMBL1543909 & 688816 & 5.3 & 5.3809 & TST & \\
\hline CHEMBL1493293 & 688816 & 4.45 & 5.2681 & TRN & \\
\hline CHEMBL1454148 & 688816 & 4.95 & 5.21 & TRN & \\
\hline CHEMBL1602192 & 688816 & 4.45 & 5.0362 & TRN & \\
\hline CHEMBL 388978 & 688816 & 6.1 & 5.7645 & TST & \\
\hline CHEMBL3196948 & 688816 & 5.05 & 5.4695 & TRN & \\
\hline CHEMBL3190634 & 688816 & 4.75 & 5.00899 & 99999999995 & TRN \\
\hline CHEMBL1564133 & 688816 & 4.9 & 5.3371 & TRN & \\
\hline CHEMBL1361988 & 688816 & 4.9 & 5.1913 & TST & \\
\hline CHEMBL1326481 & 688816 & 4.9 & 5.0622 & TRN & \\
\hline CHEMBL1373822 & 688816 & 4.85 & 4.9168 & TRN & \\
\hline CHEMBL1427967 & 688816 & 5.0 & 5.6662 & TRN & \\
\hline CHEMBL1546767 & 688816 & 4.45 & 5.4161 & TRN & \\
\hline CHEMBL1423218 & 688816 & 6.8499 & 5.4698 & TRN & \\
\hline
\end{tabular}




\begin{tabular}{|c|c|c|c|c|c|}
\hline \\
\hline CHEMBL1480005 & 688816 & 4.8 & 5.6006 & TRN & \\
\hline CHEMBL1490152 & 688816 & 4.95 & 5.2543 & TRN & \\
\hline CHEMBL1594854 & 688816 & 4.9 & 5.0773 & TRN & \\
\hline CHEMBL1402715 & 688816 & 4.85 & 4.7504 & TRN & \\
\hline CHEMBL1477311 & 688816 & 5.2 & 5.1045 & TRN & \\
\hline CHEMBL1583449 & 688816 & 6.35 & 5.2476 & TST & \\
\hline CHEMBL1341775 & 688816 & 5.0 & 5.6605 & TRN & \\
\hline CHEMBL1384423 & 688816 & 6.1 & 5.07600 & 00000000005 & TRN \\
\hline CHEMBL1990057 & 688816 & 4.6 & 5.2827 & TRN & \\
\hline CHEMBL1362403 & 688816 & 6.05 & 5.1918 & TRN & \\
\hline CHEMBL1555486 & 688816 & 5.25 & 5.3272 & TRN & \\
\hline CHEMBL3197479 & 688816 & 4.95 & 5.0514 & TRN & \\
\hline CHEMBL 3194073 & 688816 & 4.65 & 5.1022 & TRN & \\
\hline CHEMBL1300618 & 688816 & 4.9 & 4.9377 & TRN & \\
\hline CHEMBL1492655 & 688816 & 4.55 & 5.092 & TRN & \\
\hline CHEMBL1467359 & 688816 & 4.95 & 5.0725 & TRN & \\
\hline CHEMBL1549398 & 688816 & 6.25 & 4.8496 & TRN & \\
\hline CHEMBL1589357 & 688816 & 4.85 & 5.311 & TRN & \\
\hline CHEMBL3193528 & 688816 & 4.5 & 5.3105 & TRN & \\
\hline CHEMBL1383793 & 688816 & 5.8 & 5.5896 & TRN & \\
\hline CHEMBL1582906 & 688816 & 5.25 & 4.9518 & TRN & \\
\hline CHEMBL1451375 & 688816 & 4.95 & 5.5443 & TRN & \\
\hline CHEMBL3190774 & 688816 & 5.15 & 5.0007 & TRN & \\
\hline CHEMBL1519770 & 688816 & 5.65 & 5.3933 & TST & \\
\hline CHEMBL1972090 & 688816 & 6.25 & 5.5478 & TRN & \\
\hline CHEMBL3199262 & 688816 & 5.05 & 4.9723 & TST & \\
\hline CHEMBL1534854 & 688816 & 5.35 & 5.3915 & TRN & \\
\hline CHEMBL3210088 & 688816 & 6.9 & 5.4999 & TRN & \\
\hline CHEMBL1427009 & 688816 & 6.5 & 5.1583 & TRN & \\
\hline CHEMBL1409809 & 688816 & 5.0 & 5.0553 & TRN & \\
\hline CHEMBL1464464 & 688816 & 5.1 & 5.4735 & TST & \\
\hline CHEMBL1555093 & 688816 & 4.95 & 5.4532 & TST & \\
\hline CHEMBL1463189 & 688816 & 5.25 & 5.2822 & TRN & \\
\hline CHEMBL1544381 & 688816 & 4.5 & 5.5266 & TST & \\
\hline CHEMBL1468711 & 688816 & 7.5498 & 5.3333 & TRN & \\
\hline CHEMBL1332208 & 688816 & 5.4 & 5.3717 & TST & \\
\hline CHEMBL1371751 & 688816 & 4.9 & 5.2491 & TST & \\
\hline CHEMBL1428961 & 688816 & 5.85 & 4.8876 & TRN & \\
\hline CHEMBL1546972 & 688816 & 6.8 & 5.6224 & TRN & \\
\hline CHEMBL1546332 & 688816 & 5.1 & 5.1012 & TRN & \\
\hline CHEMBL1453336 & 688816 & 5.35 & 5.2735 & TRN & \\
\hline CHEMBL3197750 & 688816 & 4.9 & 5.3205 & TRN & \\
\hline CHEMBL1363734 & 688816 & 5.45 & 5.2355 & TST & \\
\hline CHEMBL1600994 & 688816 & 5.85 & 5.3082 & TRN & \\
\hline CHEMBL1537077 & 688816 & 5.45 & 5.3879 & TST & \\
\hline CHEMBL6567 & 688816 & 4.95 & 5.9035 & TST & \\
\hline CHEMBL1431728 & 688816 & 4.8 & 5.1718 & TRN & \\
\hline CHEMBL3192314 & 688816 & 4.75 & 5.1347 & TRN & \\
\hline
\end{tabular}




\begin{tabular}{|c|c|c|c|c|}
\hline \multicolumn{5}{|c|}{ Supplemental Table S2.txt } \\
\hline CHEMBL1503816 & 688816 & 5.05 & 5.3956 & TST \\
\hline CHEMBL1312268 & 688816 & 5.05 & 5.2266 & TST \\
\hline CHEMBL3210323 & 688816 & 5.85 & 5.2343 & TRN \\
\hline CHEMBL1303431 & 688816 & 7.0 & 5.3024 & TRN \\
\hline CHEMBL1453514 & 688816 & 7.5003 & 5.0488 & TRN \\
\hline CHEMBL1470693 & 688816 & 6.05 & 5.7657 & TRN \\
\hline CHEMBL1467636 & 688816 & 4.45 & 4.7911 & TRN \\
\hline CHEMBL1458742 & 688816 & 4.45 & 5.1223 & TRN \\
\hline CHEMBL1412810 & 688816 & 4.85 & 5.0071 & TRN \\
\hline CHEMBL1571094 & 688816 & 5.0 & 5.32 & TRN \\
\hline CHEMBL1444851 & 688816 & 4.8 & 5.4855 & TRN \\
\hline CHEMBL1419247 & 688816 & 5.45 & 5.2457 & TRN \\
\hline CHEMBL1379737 & 688816 & 4.8 & 5.1262 & TST \\
\hline CHEMBL1417669 & 688816 & 4.6 & 5.2049 & TRN \\
\hline CHEMBL1440525 & 688816 & 5.2 & 5.3146 & TRN \\
\hline CHEMBL1470813 & 688816 & 7.5498 & 5.244 & TST \\
\hline CHEMBL1360034 & 688816 & 4.8 & 5.3436 & TST \\
\hline CHEMBL3191023 & 688816 & 5.35 & 5.4175 & TRN \\
\hline CHEMBL1538462 & 688816 & 8.3468 & 4.8525 & TST \\
\hline CHEMBL1456390 & 688816 & 5.9 & 5.4836 & TST \\
\hline CHEMBL1459538 & 688816 & 4.45 & 5.0735 & TRN \\
\hline CHEMBL1534016 & 688816 & 6.7501 & 5.4574 & TRN \\
\hline CHEMBL1525004 & 688816 & 4.6 & 4.9665 & TRN \\
\hline CHEMBL1536829 & 688816 & 5.0 & 5.1293 & TRN \\
\hline CHEMBL1565441 & 688816 & 6.2 & 5.2792 & TRN \\
\hline CHEMBL1560938 & 688816 & 5.0 & 4.6973 & TRN \\
\hline CHEMBL1492409 & 688816 & 4.9 & 5.7279 & TRN \\
\hline CHEMBL1335193 & 688816 & 5.55 & 5.3257 & TST \\
\hline CHEMBL1413286 & 688816 & 5.95 & 5.3883 & TRN \\
\hline CHEMBL1302253 & 688816 & 5.7 & 5.2145 & TRN \\
\hline CHEMBL1347011 & 688816 & 5.55 & 5.2189 & TRN \\
\hline CHEMBL1426950 & 688816 & 7.4001 & 5.3514 & TRN \\
\hline CHEMBL1355650 & 688816 & 4.65 & 4.8903 & TRN \\
\hline CHEMBL1546535 & 688816 & 4.75 & 5.0071 & TRN \\
\hline CHEMBL1367525 & 688816 & 5.0 & 5.0427 & TRN \\
\hline CHEMBL1604836 & 688816 & 5.15 & 4.9272 & TST \\
\hline CHEMBL1488898 & 688816 & 4.75 & 4.5826 & TRN \\
\hline CHEMBL1428546 & 688816 & 4.95 & 5.072 & TRN \\
\hline CHEMBL1572474 & 688816 & 5.2 & 5.1876 & TRN \\
\hline CHEMBL1560597 & 688816 & 4.45 & 5.1654 & TRN \\
\hline CHEMBL1563204 & 688816 & 4.75 & 5.0435 & TST \\
\hline CHEMBL1318458 & 688816 & 5.0 & 5.5853 & TRN \\
\hline CHEMBL1349652 & 688816 & 4.45 & 4.852 & TRN \\
\hline CHEMBL1439239 & 688816 & 5.7 & 5.1521 & TRN \\
\hline CHEMBL1306555 & 688816 & 7.7496 & 5.2676 & TRN \\
\hline CHEMBL1436804 & 688816 & 4.7 & 5.1849 & TRN \\
\hline CHEMBL1360645 & 688816 & 5.1 & 5.1204 & TRN \\
\hline CHEMBL1469806 & 688816 & 4.85 & 4.9699 & TST \\
\hline
\end{tabular}




\begin{tabular}{|c|c|c|c|c|}
\hline \multicolumn{5}{|c|}{ Supplemental Table s2.txt } \\
\hline CHEMBL1360295 & 688816 & 6.15 & 5.3672 & TRN \\
\hline CHEMBL1576332 & 688816 & 8.3468 & 5.591 & TST \\
\hline CHEMBL3210234 & 688816 & 5.9 & 5.4175 & TRN \\
\hline CHEMBL1580072 & 688816 & 8.1487 & 5.5197 & TST \\
\hline CHEMBL1408989 & 688816 & 4.9 & 5.1885 & TRN \\
\hline CHEMBL1463860 & 688816 & 5.05 & 5.5943 & TRN \\
\hline CHEMBL1463363 & 688816 & 5.15 & 5.0919 & TRN \\
\hline CHEMBL1315392 & 688816 & 4.75 & 5.2292 & TRN \\
\hline CHEMBL1510975 & 688816 & 8.301 & 5.0291 & TRN \\
\hline CHEMBL1560378 & 688816 & 6.3 & 5.409 & TRN \\
\hline CHEMBL1538813 & 688816 & 6.7501 & 5.4381 & TST \\
\hline CHEMBL1328145 & 688816 & 5.8 & 5.1708 & TRN \\
\hline CHEMBL1389500 & 688816 & 7.4498 & 5.2034 & TST \\
\hline CHEMBL1394215 & 688816 & 4.75 & 4.8132 & TRN \\
\hline CHEMBL1454088 & 688816 & 6.95 & 5.1143 & TRN \\
\hline CHEMBL1411542 & 688816 & 5.0 & 4.9097 & TRN \\
\hline CHEMBL1588888 & 688816 & 4.95 & 5.7729 & TRN \\
\hline CHEMBL1585749 & 688816 & 5.4 & 5.5041 & TRN \\
\hline CHEMBL1528485 & 688816 & 4.95 & 5.6403 & TST \\
\hline CHEMBL1375425 & 688816 & 5.4 & 5.1348 & TRN \\
\hline CHEMBL1419233 & 688816 & 4.95 & 5.1683 & TRN \\
\hline CHEMBL1429403 & 688816 & 4.6 & 5.6244 & TST \\
\hline CHEMBL1571932 & 688816 & 4.8 & 5.4098 & TST \\
\hline CHEMBL1409339 & 688816 & 5.1 & 5.3197 & TST \\
\hline CHEMBL1528094 & 688816 & 4.7 & 5.0095 & TRN \\
\hline CHEMBL1301213 & 688816 & 4.7 & 4.8685 & TRN \\
\hline CHEMBL1540664 & 688816 & 5.6 & 5.2971 & TST \\
\hline CHEMBL1429823 & 688816 & 4.65 & 4.9076 & TRN \\
\hline CHEMBL1442361 & 688816 & 4.85 & 4.8819 & TRN \\
\hline CHEMBL1256024 & 688816 & 4.75 & 5.9106 & TST \\
\hline CHEMBL1360156 & 688816 & 8.3979 & 5.9967 & TRN \\
\hline CHEMBL1585921 & 688816 & 4.75 & 5.1231 & TRN \\
\hline CHEMBL 2000877 & 688816 & 4.85 & 4.8132 & TST \\
\hline CHEMBL1323156 & 688816 & 4.95 & 5.357 & TST \\
\hline CHEMBL1402035 & 688816 & 4.55 & 4.8614 & TRN \\
\hline CHEMBL3199161 & 688816 & 5.0 & 5.3085 & TRN \\
\hline CHEMBL1485865 & 688816 & 4.9 & 5.4116 & TST \\
\hline CHEMBL1383892 & 688816 & 5.5 & 5.1908 & TRN \\
\hline CHEMBL1388144 & 688816 & 5.5 & 5.0788 & TST \\
\hline CHEMBL1507448 & 688816 & 4.45 & 5.0588 & TST \\
\hline CHEMBL3199594 & 688816 & 4.45 & 5.077 & TRN \\
\hline CHEMBL1577613 & 688816 & 4.9 & 5.6822 & TRN \\
\hline CHEMBL1378357 & 688816 & 4.85 & 5.2647 & TRN \\
\hline CHEMBL3208696 & 688816 & 4.9 & 5.1393 & TRN \\
\hline CHEMBL1599437 & 688816 & 4.45 & 5.4189 & TRN \\
\hline CHEMBL 3210044 & 688816 & 4.65 & 5.1246 & TRN \\
\hline CHEMBL1411764 & 688816 & 5.6 & 5.2188 & TRN \\
\hline CHEMBL1352489 & 688816 & 5.0 & 5.2967 & TST \\
\hline
\end{tabular}




\begin{tabular}{|c|c|c|c|c|c|}
\hline \multicolumn{6}{|c|}{ Supplemental Table S2.txt } \\
\hline CHEMBL1342112 & 688816 & 4.45 & 5.0722 & TRN & \\
\hline CHEMBL1578324 & 688816 & 5.75 & 5.1397 & TRN & \\
\hline CHEMBL1200958 & 688816 & 5.85 & 5.6851 & TST & \\
\hline CHEMBL 300814 & 688816 & 4.5 & $5.0280 e$ & 00000000005 & TRN \\
\hline CHEMBL1309700 & 688816 & 4.45 & 5.0696 & TRN & \\
\hline CHEMBL1458591 & 688816 & 4.45 & 4.6102 & TRN & \\
\hline CHEMBL1540891 & 688816 & 5.55 & 5.2693 & TRN & \\
\hline CHEMBL1526866 & 688816 & 4.95 & 5.1364 & TRN & \\
\hline CHEMBL1415917 & 688816 & 5.25 & 5.5 & TRN & \\
\hline CHEMBL1542693 & 688816 & 4.45 & 5.0938 & TRN & \\
\hline CHEMBL1511191 & 688816 & 4.85 & 5.0001 & TRN & \\
\hline CHEMBL1566664 & 688816 & 4.95 & 4.7313 & TRN & \\
\hline CHEMBL1474584 & 688816 & 4.45 & 5.1253 & TRN & \\
\hline CHEMBL1363908 & 688816 & 5.35 & 5.6991 & TST & \\
\hline CHEMBL1453607 & 688816 & 4.9 & 5.3421 & TRN & \\
\hline CHEMBL1552405 & 688816 & 5.5 & 5.3305 & TRN & \\
\hline CHEMBL1503138 & 688816 & 4.9 & 5.2968 & TRN & \\
\hline CHEMBL1384874 & 688816 & 4.65 & 4.9832 & TRN & \\
\hline CHEMBL1544803 & 688816 & 4.9 & 5.0617 & TRN & \\
\hline CHEMBL1442201 & 688816 & 5.1 & 5.0552 & TRN & \\
\hline CHEMBL1477417 & 688816 & 4.45 & 5.0256 & TRN & \\
\hline CHEMBL1483455 & 688816 & 6.5 & 5.7871 & TRN & \\
\hline CHEMBL1310360 & 688816 & 4.75 & 5.2287 & TST & \\
\hline CHEMBL1610783 & 688816 & 6.2 & 5.2573 & TRN & \\
\hline CHEMBL1340489 & 688816 & 5.3 & 5.13399 & 99999999995 & TRN \\
\hline CHEMBL1425542 & 688816 & 4.9 & 5.01399 & 9999999999 & TRN \\
\hline CHEMBL1577442 & 688816 & 7.4001 & 5.9683 & TST & \\
\hline CHEMBL1427661 & 688816 & 5.6 & 4.8079 & TRN & \\
\hline CHEMBL1327193 & 688816 & 8.4949 & 4.8658 & TRN & \\
\hline CHEMBL1323989 & 688816 & 5.5 & 4.9878 & TRN & \\
\hline CHEMBL1600246 & 688816 & 5.2 & 5.2515 & TRN & \\
\hline CHEMBL3199537 & 688816 & 4.9 & 5.4399 & TRN & \\
\hline CHEMBL1538920 & 688816 & 5.5 & 5.2907 & TRN & \\
\hline CHEMBL1456854 & 688816 & 5.3 & 5.5821 & TST & \\
\hline CHEMBL1596959 & 688816 & 6.6 & 5.303 & TRN & \\
\hline CHEMBL1322263 & 688816 & 6.6499 & 5.1016 & TRN & \\
\hline CHEMBL1526559 & 688816 & 4.8 & 5.2017 & TRN & \\
\hline CHEMBL1972470 & 688816 & 4.85 & 5.4528 & TRN & \\
\hline CHEMBL1403468 & 688816 & 4.85 & 5.086 & TRN & \\
\hline CHEMBL1567508 & 688816 & 4.45 & 5.6836 & TRN & \\
\hline CHEMBL1502686 & 688816 & 4.95 & 5.1069 & TRN & \\
\hline CHEMBL1302390 & 688816 & 6.2 & 5.5857 & TRN & \\
\hline CHEMBL1387187 & 688816 & 4.8 & 5.1443 & TST & \\
\hline CHEMBL1413025 & 688816 & 5.05 & 5.5854 & TST & \\
\hline CHEMBL1365881 & 688816 & 5.45 & 5.2285 & TRN & \\
\hline CHEMBL408994 & 688816 & 4.45 & 5.5857 & TRN & \\
\hline CHEMBL1502428 & 688816 & 4.7 & 5.1661 & TST & \\
\hline CHEMBL1376788 & 688816 & 5.3 & 5.3179 & TRN & \\
\hline
\end{tabular}




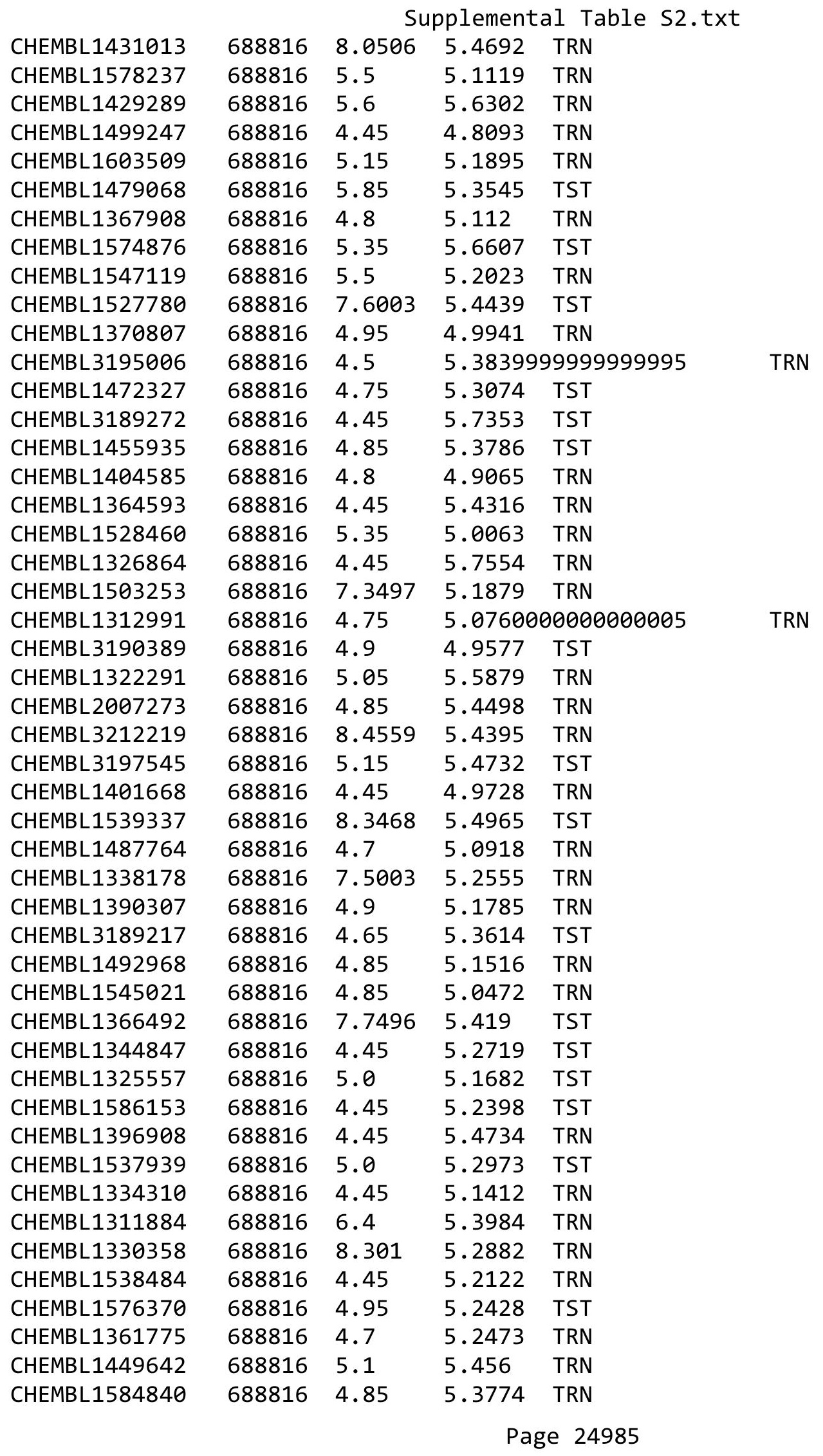




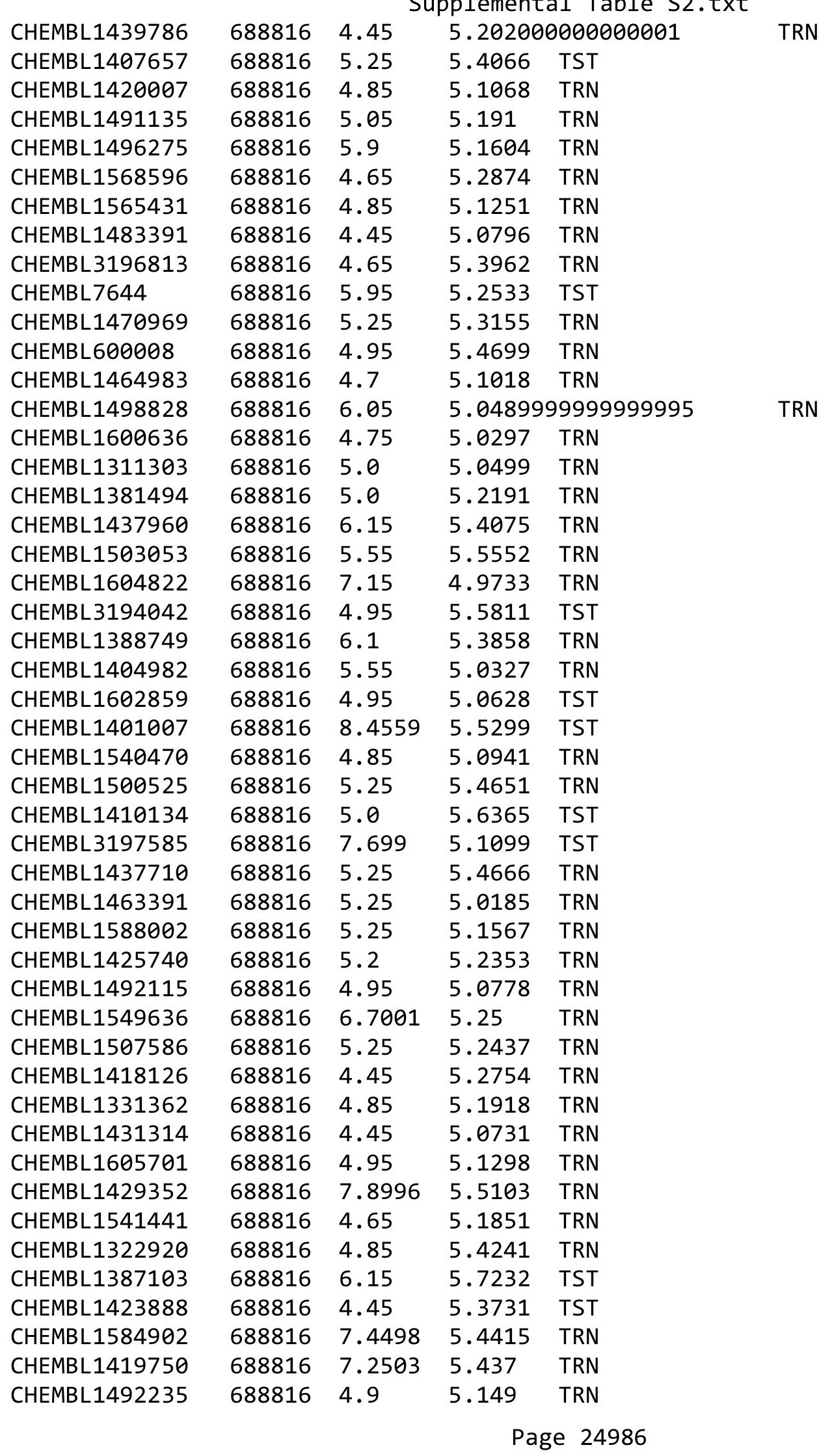




\begin{tabular}{|c|c|c|c|c|c|}
\hline \multicolumn{6}{|c|}{ Supplemental Table S2.txt } \\
\hline CHEMBL1482011 & 688816 & 4.8 & 5.6453 & TRN & \\
\hline CHEMBL19980 & 688816 & 6.0 & 5.7938 & TST & \\
\hline CHEMBL1450294 & 688816 & 4.95 & 5.2662 & TRN & \\
\hline CHEMBL1343371 & 688816 & 5.1 & 5.0475 & TRN & \\
\hline CHEMBL1447107 & 688816 & 4.95 & 5.4906 & TRN & \\
\hline CHEMBL1300522 & 688816 & 5.25 & 5.244 & TRN & \\
\hline CHEMBL1438598 & 688816 & 4.7 & 5.1573 & TRN & \\
\hline CHEMBL1341238 & 688816 & 4.5 & 5.6515 & TRN & \\
\hline CHEMBL1371198 & 688816 & 4.9 & 5.3879 & TRN & \\
\hline CHEMBL339304 & 688816 & 5.55 & 5.1685 & TRN & \\
\hline CHEMBL1386547 & 688816 & 4.6 & 5.1605 & TRN & \\
\hline CHEMBL1500738 & 688816 & 6.15 & 5.2138 & TRN & \\
\hline CHEMBL1497000 & 688816 & 4.45 & 5.3256 & TST & \\
\hline CHEMBL1410557 & 688816 & 4.45 & 5.405 & TRN & \\
\hline CHEMBL1305122 & 688816 & 5.25 & 4.7266 & TST & \\
\hline CHEMBL1411743 & 688816 & 4.5 & 5.0655 & TRN & \\
\hline CHEMBL1532045 & 688816 & 4.45 & 5.2188 & TRN & \\
\hline CHEMBL 3198440 & 688816 & 4.45 & 4.836 & TRN & \\
\hline CHEMBL3208177 & 688816 & 4.95 & 5.1448 & TST & \\
\hline CHEMBL1586256 & 688816 & 4.95 & 5.1649 & TRN & \\
\hline CHEMBL3190963 & 688816 & 4.95 & 5.4392 & TRN & \\
\hline CHEMBL1521560 & 688816 & 5.7 & 5.8154 & TST & \\
\hline CHEMBL1580327 & 688816 & 5.3 & 5.561 & TRN & \\
\hline CHEMBL1522326 & 688816 & 5.25 & 5.3281 & TRN & \\
\hline CHEMBL3194910 & 688816 & 4.95 & 5.5641 & TRN & \\
\hline CHEMBL1385239 & 688816 & 8.301 & 4.7703 & TRN & \\
\hline CHEMBL1362928 & 688816 & 4.8 & 5.645 & TRN & \\
\hline CHEMBL1548212 & 688816 & 4.45 & 5.5311 & TRN & \\
\hline CHEMBL1533725 & 688816 & 5.25 & 5.3392 & TRN & \\
\hline CHEMBL3211699 & 688816 & 8.0 & 5.4621 & TST & \\
\hline CHEMBL1392169 & 688816 & 5.15 & 4.9561 & TRN & \\
\hline CHEMBL1404623 & 688816 & 5.65 & 5.3364 & TRN & \\
\hline CHEMBL1599782 & 688816 & 4.45 & 5.2284 & TRN & \\
\hline CHEMBL1525749 & 688816 & 5.45 & 5.2588 & TRN & \\
\hline CHEMBL1496239 & 688816 & 5.65 & 5.7514 & TRN & \\
\hline CHEMBL1608240 & 688816 & 6.15 & 5.2543 & TST & \\
\hline CHEMBL1401959 & 688816 & 4.9 & 5.1655 & TRN & \\
\hline CHEMBL1474261 & 688816 & 4.5 & 5.3399 & TRN & \\
\hline CHEMBL1996376 & 688816 & 4.6 & 5.24100 & 00000000005 & TST \\
\hline CHEMBL3189378 & 688816 & 5.35 & 5.1091 & TST & \\
\hline CHEMBL1491942 & 688816 & 4.45 & 5.191 & TRN & \\
\hline CHEMBL3193066 & 688816 & 4.95 & 5.1554 & TRN & \\
\hline CHEMBL1494120 & 688816 & 4.95 & 5.1398 & TRN & \\
\hline CHEMBL10284 & 688816 & 4.6 & 5.2152 & TST & \\
\hline CHEMBL3208894 & 688816 & 4.8 & 5.1458 & TRN & \\
\hline CHEMBL98572 & 688816 & 4.6 & 5.2167 & TST & \\
\hline CHEMBL1439237 & 688816 & 7.5498 & 5.4834 & TST & \\
\hline CHEMBL 2018847 & 688816 & 4.75 & 4.9728 & TRN & \\
\hline
\end{tabular}




\begin{tabular}{|c|c|c|c|c|c|}
\hline \multicolumn{6}{|c|}{ Supplemental Table S2.txt } \\
\hline CHEMBL1334445 & 688816 & 4.6 & 5.1649 & TRN & \\
\hline CHEMBL1441694 & 688816 & 6.35 & 5.3496 & TRN & \\
\hline CHEMBL1429929 & 688816 & 4.45 & 5.058 & TRN & \\
\hline CHEMBL1426797 & 688816 & 5.45 & 5.3701 & TRN & \\
\hline CHEMBL1426651 & 688816 & 6.3 & 5.092 & TRN & \\
\hline CHEMBL1369373 & 688816 & 4.65 & 5.16799 & 9999999999 & TRN \\
\hline CHEMBL1333443 & 688816 & 5.0 & 5.2161 & TRN & \\
\hline CHEMBL1542990 & 688816 & 5.85 & 5.1735 & TRN & \\
\hline CHEMBL1335899 & 688816 & 5.0 & 5.2213 & TRN & \\
\hline CHEMBL1507578 & 688816 & 4.8 & 5.1484 & TRN & \\
\hline CHEMBL1344904 & 688816 & 5.3 & 5.0204 & TRN & \\
\hline CHEMBL1349112 & 688816 & 4.75 & 5.581 & TST & \\
\hline CHEMBL1381249 & 688816 & 4.45 & 5.2243 & TRN & \\
\hline CHEMBL1418957 & 688816 & 8.301 & 5.5331 & TST & \\
\hline CHEMBL1605211 & 688816 & 7.699 & 5.3491 & TST & \\
\hline CHEMBL1574325 & 688816 & 4.9 & 4.9185 & TRN & \\
\hline CHEMBL1411036 & 688816 & 5.5 & 4.9267 & TST & \\
\hline CHEMBL1374294 & 688816 & 4.9 & 5.3468 & TRN & \\
\hline CHEMBL1319015 & 688816 & 4.45 & 4.6733 & TRN & \\
\hline CHEMBL1404792 & 688816 & 5.8 & 5.3986 & TRN & \\
\hline CHEMBL1508151 & 688816 & 6.4 & 5.0054 & TRN & \\
\hline CHEMBL1407161 & 688816 & 4.5 & 5.032 & TRN & \\
\hline CHEMBL1595229 & 688816 & 5.15 & 4.9909 & TRN & \\
\hline CHEMBL1354417 & 688816 & 4.45 & 5.2775 & TRN & \\
\hline CHEMBL1608566 & 688816 & 5.35 & 5.7042 & TST & \\
\hline CHEMBL1387850 & 688816 & 4.9 & 5.5268 & TST & \\
\hline CHEMBL1310318 & 688816 & 4.95 & 5.072 & TST & \\
\hline CHEMBL1481158 & 688816 & 4.45 & 5.0906 & TRN & \\
\hline CHEMBL1339656 & 688816 & 4.5 & 5.0908 & TST & \\
\hline CHEMBL1471945 & 688816 & 4.45 & 5.444 & TST & \\
\hline CHEMBL1301789 & 688816 & 6.5501 & 5.2293 & TST & \\
\hline CHEMBL1440422 & 688816 & 5.3 & 5.5264 & TRN & \\
\hline CHEMBL3199619 & 688816 & 4.95 & 5.545 & TST & \\
\hline CHEMBL1494815 & 688816 & 4.45 & 6.034 & TST & \\
\hline CHEMBL1465056 & 688816 & 7.0 & 5.5918 & TRN & \\
\hline CHEMBL1525487 & 688816 & 4.9 & 5.0997 & TRN & \\
\hline CHEMBL1447306 & 688816 & 4.8 & 5.0575 & TRN & \\
\hline CHEMBL1508750 & 688816 & 5.25 & 5.4648 & TRN & \\
\hline CHEMBL3192514 & 688816 & 4.75 & 5.49100 & 00000000005 & TRN \\
\hline CHEMBL1521131 & 688816 & 8.3468 & 5.465 & TRN & \\
\hline CHEMBL1598769 & 688816 & 6.3 & 5.3557 & TRN & \\
\hline CHEMBL1304673 & 688816 & 7.5003 & 5.2662 & TST & \\
\hline CHEMBL3210669 & 688816 & 4.9 & 5.3043 & TRN & \\
\hline CHEMBL1350251 & 688816 & 4.85 & 5.5652 & TRN & \\
\hline CHEMBL1471304 & 688816 & 4.6 & 5.2807 & TRN & \\
\hline CHEMBL1420457 & 688816 & 4.85 & 5.4258 & TRN & \\
\hline CHEMBL1511379 & 688816 & 5.1 & 5.6784 & TRN & \\
\hline CHEMBL1533641 & 688816 & 4.95 & 4.9553 & TRN & \\
\hline
\end{tabular}




\begin{tabular}{|c|c|c|c|c|c|}
\hline \multirow[b]{2}{*}{ CHEMBL1364596 } & \multicolumn{5}{|c|}{ Supplemental Table S2.txt } \\
\hline & 688816 & 4.65 & 5.33 & TRN & \\
\hline CHEMBL1368234 & 688816 & 6.0 & 5.6301 & TST & \\
\hline CHEMBL1378018 & 688816 & 4.65 & 5.3986 & TRN & \\
\hline CHEMBL1303986 & 688816 & 5.3 & 5.2978 & TRN & \\
\hline CHEMBL1392119 & 688816 & 4.65 & 5.396 & TST & \\
\hline CHEMBL1557566 & 688816 & 7.8508 & 5.0192 & TRN & \\
\hline CHEMBL1381182 & 688816 & 8.0 & 6.1426 & TST & \\
\hline CHEMBL1332800 & 688816 & 4.45 & 5.32600 & 00000000005 & TRN \\
\hline CHEMBL1555208 & 688816 & 4.45 & 5.4573 & TST & \\
\hline CHEMBL1403065 & 688816 & 5.8 & 5.0452 & TRN & \\
\hline CHEMBL1710 & 688816 & 4.85 & 5.3524 & TRN & \\
\hline CHEMBL1352129 & 688816 & 4.9 & 5.0563 & TRN & \\
\hline CHEMBL1451142 & 688816 & 7.5498 & 5.6306 & TRN & \\
\hline CHEMBL1577208 & 688816 & 5.25 & 4.9603 & TRN & \\
\hline CHEMBL1302377 & 688816 & 7.3002 & 5.8223 & TRN & \\
\hline CHEMBL1343203 & 688816 & 4.85 & 5.2852 & TRN & \\
\hline CHEMBL1422232 & 688816 & 5.25 & 5.5967 & TST & \\
\hline CHEMBL1577505 & 688816 & 4.9 & 5.4131 & TRN & \\
\hline CHEMBL3194911 & 688816 & 4.7 & 5.1029 & TST & \\
\hline CHEMBL1340068 & 688816 & 4.85 & 4.92899 & 9999999999 & TST \\
\hline CHEMBL1388433 & 688816 & 5.05 & 5.3675 & TST & \\
\hline CHEMBL 2002510 & 688816 & 4.95 & 5.6734 & TRN & \\
\hline CHEMBL1514885 & 688816 & 4.95 & 5.3685 & TRN & \\
\hline CHEMBL1430895 & 688816 & 4.55 & 4.9126 & TRN & \\
\hline CHEMBL1528930 & 688816 & 4.9 & 5.44 & TRN & \\
\hline CHEMBL1374642 & 688816 & 5.0 & 5.2358 & TRN & \\
\hline CHEMBL1335880 & 688816 & 5.25 & 4.8616 & TRN & \\
\hline CHEMBL1556534 & 688816 & 4.9 & 5.2673 & TRN & \\
\hline CHEMBL1577187 & 688816 & 4.65 & 5.0958 & TRN & \\
\hline CHEMBL1374158 & 688816 & 4.85 & 5.7043 & TRN & \\
\hline CHEMBL1555967 & 688816 & 4.45 & 5.1504 & TRN & \\
\hline CHEMBL1528677 & 688816 & 4.45 & 5.2408 & TRN & \\
\hline CHEMBL1599486 & 688816 & 4.9 & 5.13399 & 99999999995 & TRN \\
\hline CHEMBL1521278 & 688816 & 4.95 & 5.3689 & TST & \\
\hline CHEMBL1418424 & 688816 & 8.301 & 5.5807 & TRN & \\
\hline CHEMBL1389236 & 688816 & 5.0 & 5.3964 & TRN & \\
\hline CHEMBL1408629 & 688816 & 4.55 & 5.296 & TRN & \\
\hline CHEMBL1565742 & 688816 & 5.55 & 5.2811 & TRN & \\
\hline CHEMBL1406814 & 688816 & 7.3497 & 5.4149 & TRN & \\
\hline CHEMBL575494 & 688816 & 6.6499 & 5.42899 & 9999999999 & TST \\
\hline CHEMBL1487967 & 688816 & 4.75 & 5.0647 & TRN & \\
\hline CHEMBL1341073 & 688816 & 4.95 & 5.0336 & TST & \\
\hline CHEMBL1459374 & 688816 & 4.65 & 5.4405 & TRN & \\
\hline CHEMBL1511390 & 688816 & 4.8 & 5.1356 & TRN & \\
\hline CHEMBL1966241 & 688816 & 5.0 & 5.391 & TRN & \\
\hline CHEMBL1344404 & 688816 & 5.55 & 5.4845 & TRN & \\
\hline CHEMBL1511560 & 688816 & 7.699 & 5.4871 & TST & \\
\hline CHEMBL3208669 & 688816 & 6.7501 & 5.3642 & TRN & \\
\hline
\end{tabular}




\begin{tabular}{|c|c|c|c|c|c|}
\hline \multicolumn{6}{|c|}{ Supplemental Table S2.txt } \\
\hline CHEMBL1541054 & 688816 & 6.8 & 5.3625 & TST & \\
\hline CHEMBL 3190720 & 688816 & 4.95 & 5.1228 & TRN & \\
\hline CHEMBL1463234 & 688816 & 4.45 & 4.9826 & TRN & \\
\hline CHEMBL1335491 & 688816 & 4.95 & 4.8298 & TRN & \\
\hline CHEMBL1565387 & 688816 & 8.2007 & 5.6048 & TST & \\
\hline CHEMBL1413814 & 688816 & 4.95 & 5.2766 & TRN & \\
\hline CHEMBL1504289 & 688816 & 5.55 & 5.5535 & TRN & \\
\hline CHEMBL1499214 & 688816 & 4.6 & 5.2913 & TRN & \\
\hline CHEMBL1439504 & 688816 & 4.5 & 5.7004 & TRN & \\
\hline CHEMBL1449434 & 688816 & 7.9508 & 5.0656 & TRN & \\
\hline CHEMBL1480059 & 688816 & 4.6 & 5.2727 & TRN & \\
\hline CHEMBL1384749 & 688816 & 4.9 & 5.3741 & TRN & \\
\hline CHEMBL1452998 & 688816 & 4.85 & 5.2763 & TRN & \\
\hline CHEMBL1487833 & 688816 & 4.9 & 5.2749 & TRN & \\
\hline CHEMBL1328771 & 688816 & 5.3 & 5.2885 & TRN & \\
\hline CHEMBL1407925 & 688816 & 4.85 & 5.1167 & TRN & \\
\hline CHEMBL1339367 & 688816 & 4.45 & 5.1418 & TRN & \\
\hline CHEMBL1404112 & 688816 & 4.45 & 4.9675 & TRN & \\
\hline CHEMBL1315690 & 688816 & 4.75 & 5.1921 & TRN & \\
\hline CHEMBL1359798 & 688816 & 4.8 & 4.9954 & TST & \\
\hline CHEMBL1532756 & 688816 & 4.75 & 5.0903 & TST & \\
\hline CHEMBL1452827 & 688816 & 5.15 & 5.2238 & TRN & \\
\hline CHEMBL1477186 & 688816 & 5.0 & 5.5205 & TST & \\
\hline CHEMBL1562800 & 688816 & 4.7 & 4.9949 & TRN & \\
\hline CHEMBL1403101 & 688816 & 5.2 & 4.9677 & TRN & \\
\hline CHEMBL1580197 & 688816 & 5.7 & 5.2509 & TST & \\
\hline CHEMBL1451533 & 688816 & 5.15 & 5.7205 & TRN & \\
\hline CHEMBL1605677 & 688816 & 4.45 & 5.6679 & TST & \\
\hline CHEMBL1508036 & 688816 & 4.45 & 5.2751 & TST & \\
\hline CHEMBL1502445 & 688816 & 4.9 & 5.6339 & TST & \\
\hline CHEMBL1364982 & 688816 & 4.45 & 5.1297 & TRN & \\
\hline CHEMBL1448066 & 688816 & 5.35 & 5.0549 & TRN & \\
\hline CHEMBL1410766 & 688816 & 4.45 & 5.0609 & TRN & \\
\hline CHEMBL14284 & 688816 & 5.6 & 5.2854 & TRN & \\
\hline CHEMBL1605124 & 688816 & 5.5 & 5.2419 & TST & \\
\hline CHEMBL1385850 & 688816 & 7.5003 & 5.55399 & 9999999999 & TST \\
\hline CHEMBL1420922 & 688816 & 4.8 & 5.2615 & TRN & \\
\hline CHEMBL1967031 & 688816 & 6.4 & 5.3869 & TRN & \\
\hline CHEMBL1523783 & 688816 & 7.0501 & 5.6466 & TRN & \\
\hline CHEMBL1380024 & 688816 & 4.95 & 5.4129 & TRN & \\
\hline CHEMBL1589248 & 688816 & 4.45 & 4.752 & TST & \\
\hline CHEMBL1547901 & 688816 & 4.45 & 4.9837 & TRN & \\
\hline CHEMBL1359056 & 688816 & 6.5 & 5.5036 & TRN & \\
\hline CHEMBL1439666 & 688816 & 4.9 & 5.1742 & TRN & \\
\hline CHEMBL1503828 & 688816 & 4.95 & 5.1514 & TRN & \\
\hline CHEMBL1355746 & 688816 & 7.699 & 5.4528 & TRN & \\
\hline CHEMBL1425260 & 688816 & 4.9 & 5.2792 & TRN & \\
\hline CHEMBL1319150 & 688816 & 5.4 & 5.2409 & TRN & \\
\hline
\end{tabular}




\begin{tabular}{|c|c|c|c|c|c|}
\hline \multicolumn{6}{|c|}{ Supplemental Table S2.txt } \\
\hline CHEMBL1476939 & 688816 & 5.55 & 5.3667 & TRN & \\
\hline CHEMBL1599139 & 688816 & 4.75 & 5.0596 & TRN & \\
\hline CHEMBL1448784 & 688816 & 5.25 & 5.3687 & TRN & \\
\hline CHEMBL1387035 & 688816 & 5.35 & 5.58700 & 0000000001 & TRN \\
\hline CHEMBL1490856 & 688816 & 4.8 & 5.088 & TRN & \\
\hline CHEMBL1412137 & 688816 & 5.8 & 5.3775 & TRN & \\
\hline CHEMBL 3197909 & 688816 & 5.55 & 5.4395 & TST & \\
\hline CHEMBL1516565 & 688816 & 8.1024 & 4.9674 & TRN & \\
\hline CHEMBL1506697 & 688816 & 4.9 & 5.1378 & TRN & \\
\hline CHEMBL1508593 & 688816 & 4.45 & 5.3432 & TST & \\
\hline CHEMBL1471728 & 688816 & 4.6 & 5.2036 & TRN & \\
\hline CHEMBL1439808 & 688816 & 4.95 & 5.3115 & TRN & \\
\hline CHEMBL1407336 & 688816 & 4.85 & 5.0197 & TRN & \\
\hline CHEMBL1444127 & 688816 & 5.75 & 5.6051 & TST & \\
\hline CHEMBL1417610 & 688816 & 5.0 & 4.9129 & TRN & \\
\hline CHEMBL1376930 & 688816 & 4.45 & 5.465 & TRN & \\
\hline CHEMBL 3199849 & 688816 & 5.5 & 5.6599 & TRN & \\
\hline CHEMBL1520801 & 688816 & 8.0506 & 5.2756 & TST & \\
\hline CHEMBL1509086 & 688816 & 4.95 & 4.9886 & TRN & \\
\hline CHEMBL1511045 & 688816 & 4.65 & 4.6974 & TRN & \\
\hline CHEMBL1495112 & 688816 & 4.45 & 5.1082 & TRN & \\
\hline CHEMBL1380544 & 688816 & 4.95 & 5.6182 & TRN & \\
\hline CHEMBL1557790 & 688816 & 4.75 & 4.8827 & TRN & \\
\hline CHEMBL1534392 & 688816 & 4.85 & 5.4413 & TRN & \\
\hline CHEMBL 3189814 & 688816 & 5.0 & 5.0089 & TRN & \\
\hline CHEMBL1320125 & 688816 & 5.1 & 5.2714 & TRN & \\
\hline CHEMBL1515837 & 688816 & 4.9 & 5.3638 & TST & \\
\hline CHEMBL1428041 & 688816 & 7.8508 & 5.7851 & TRN & \\
\hline CHEMBL1611695 & 688816 & 4.45 & 5.2333 & TRN & \\
\hline CHEMBL1588771 & 688816 & 5.5 & 5.2 & TRN & \\
\hline CHEMBL1414102 & 688816 & 4.85 & 5.45799 & 9999999999 & TRN \\
\hline CHEMBL1381126 & 688816 & 5.3 & 5.2637 & TST & \\
\hline CHEMBL1586625 & 688816 & 4.45 & 5.3414 & TRN & \\
\hline CHEMBL1468699 & 688816 & 4.95 & 4.8024 & TRN & \\
\hline CHEMBL 24983 & 688816 & 4.55 & 5.2805 & TST & \\
\hline CHEMBL 3208680 & 688816 & 6.25 & 5.7538 & TST & \\
\hline CHEMBL1482495 & 688816 & 4.95 & 5.1217 & TRN & \\
\hline CHEMBL1469035 & 688816 & 4.6 & 5.0659 & TRN & \\
\hline CHEMBL1418606 & 688816 & 5.1 & 5.3308 & TRN & \\
\hline CHEMBL1362880 & 688816 & 5.05 & 5.1595 & TRN & \\
\hline CHEMBL1463093 & 688816 & 4.85 & 5.353 & TRN & \\
\hline CHEMBL1465686 & 688816 & 5.75 & 5.1161 & TRN & \\
\hline CHEMBL1361229 & 688816 & 4.9 & 4.8009 & TRN & \\
\hline CHEMBL1501102 & 688816 & 4.8 & 5.3369 & TST & \\
\hline CHEMBL1327749 & 688816 & 4.95 & 5.4442 & TRN & \\
\hline CHEMBL1410042 & 688816 & 5.4 & 5.1116 & TRN & \\
\hline CHEMBL1313342 & 688816 & 4.45 & 5.1781 & TRN & \\
\hline CHEMBL1338489 & 688816 & 4.65 & 5.2136 & TRN & \\
\hline
\end{tabular}




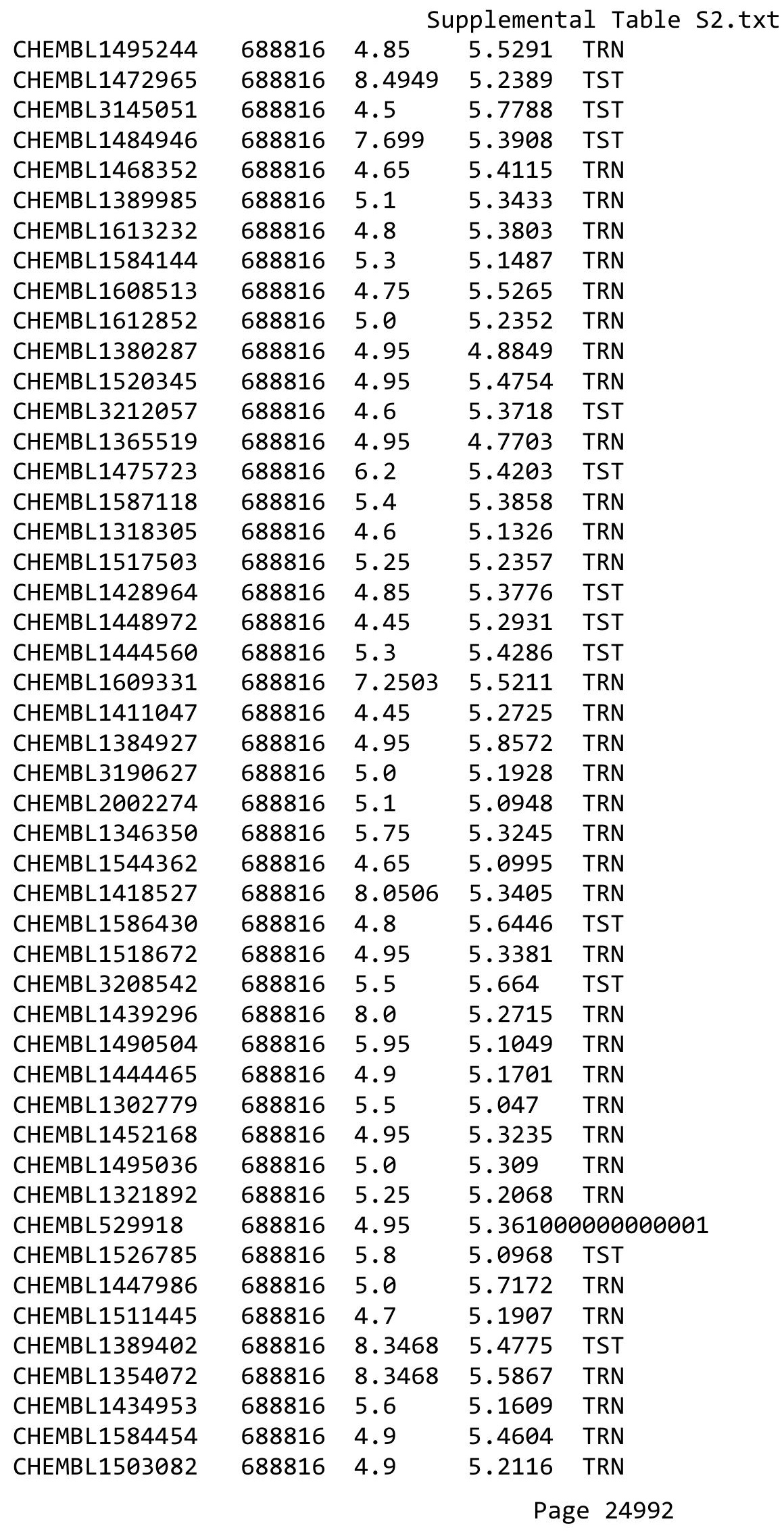




\begin{tabular}{|c|c|c|c|c|c|}
\hline \multicolumn{6}{|c|}{ Supplemental Table S2.txt } \\
\hline CHEMBL1407112 & 688816 & 4.45 & 5.2842 & TRN & \\
\hline CHEMBL1463473 & 688816 & 4.95 & 5.4365 & TRN & \\
\hline CHEMBL1349364 & 688816 & 4.95 & 5.2806 & TRN & \\
\hline CHEMBL1566646 & 688816 & 7.8996 & 5.3507 & TRN & \\
\hline CHEMBL340701 & 688816 & 5.6 & 5.38200 & 0000000001 & TRN \\
\hline CHEMBL3197319 & 688816 & 4.75 & 5.6497 & TRN & \\
\hline CHEMBL1568633 & 688816 & 4.45 & 5.1717 & TRN & \\
\hline CHEMBL1333405 & 688816 & 4.45 & 5.3441 & TRN & \\
\hline CHEMBL1386551 & 688816 & 4.8 & 4.8505 & TRN & \\
\hline CHEMBL447876 & 688816 & 5.3 & 5.3977 & TST & \\
\hline CHEMBL1421223 & 688816 & 4.95 & 5.0467 & TRN & \\
\hline CHEMBL3197360 & 688816 & 4.75 & 5.2932 & TRN & \\
\hline CHEMBL1305069 & 688816 & 5.0 & 5.3253 & TRN & \\
\hline CHEMBL1600439 & 688816 & 5.25 & 5.1118 & TRN & \\
\hline CHEMBL1582826 & 688816 & 4.65 & 5.1965 & TRN & \\
\hline CHEMBL1493863 & 688816 & 7.0501 & 5.6663 & TST & \\
\hline CHEMBL1494473 & 688816 & 4.75 & 4.9059 & TRN & \\
\hline CHEMBL1302146 & 688816 & 5.6 & 5.0945 & TRN & \\
\hline CHEMBL1324130 & 688816 & 4.65 & 4.9587 & TRN & \\
\hline CHEMBL1470135 & 688816 & 4.45 & 4.9446 & TRN & \\
\hline CHEMBL1600752 & 688816 & 8.0 & 4.878 & TRN & \\
\hline CHEMBL1421705 & 688816 & 4.95 & 5.4351 & TRN & \\
\hline CHEMBL1389701 & 688816 & 4.75 & 4.94600 & 0000000001 & TRN \\
\hline CHEMBL52884 & 688816 & 4.9 & 5.2914 & TRN & \\
\hline CHEMBL1485824 & 688816 & 4.65 & 5.17399 & 99999999995 & TRN \\
\hline CHEMBL1319667 & 688816 & 5.3 & 5.3564 & TRN & \\
\hline CHEMBL1455455 & 688816 & 7.6003 & 4.9042 & TRN & \\
\hline CHEMBL1573389 & 688816 & 5.0 & 5.2779 & TRN & \\
\hline CHEMBL1330884 & 688816 & 8.3979 & 5.5836 & TRN & \\
\hline CHEMBL1423374 & 688816 & 5.15 & 5.2307 & TRN & \\
\hline CHEMBL1502020 & 688816 & 5.55 & 4.9137 & TRN & \\
\hline CHEMBL1998531 & 688816 & 6.0 & 5.2618 & TST & \\
\hline CHEMBL1406980 & 688816 & 4.65 & 5.5244 & TRN & \\
\hline CHEMBL1413096 & 688816 & 8.4559 & 5.0033 & TRN & \\
\hline CHEMBL1372939 & 688816 & 4.65 & 4.8533 & TST & \\
\hline CHEMBL1546240 & 688816 & 4.8 & 5.0015 & TRN & \\
\hline CHEMBL1334396 & 688816 & 6.8499 & 5.1975 & TRN & \\
\hline CHEMBL1519329 & 688816 & 4.45 & 5.3437 & TRN & \\
\hline CHEMBL3210502 & 688816 & 4.6 & 5.526 & TST & \\
\hline CHEMBL1460357 & 688816 & 4.9 & 5.28 & TRN & \\
\hline CHEMBL1427186 & 688816 & 4.95 & 5.0637 & TRN & \\
\hline CHEMBL1418742 & 688816 & 4.45 & 5.0525 & TRN & \\
\hline CHEMBL1302392 & 688816 & 4.7 & 5.0705 & TRN & \\
\hline CHEMBL1362840 & 688816 & 4.45 & 5.0886 & TRN & \\
\hline CHEMBL1393312 & 688816 & 4.45 & 5.4054 & TRN & \\
\hline CHEMBL405343 & 688816 & 4.45 & 5.1672 & TRN & \\
\hline CHEMBL1472406 & 688816 & 4.85 & 5.4072 & TST & \\
\hline CHEMBL3192027 & 688816 & 4.95 & 5.2545 & TST & \\
\hline
\end{tabular}




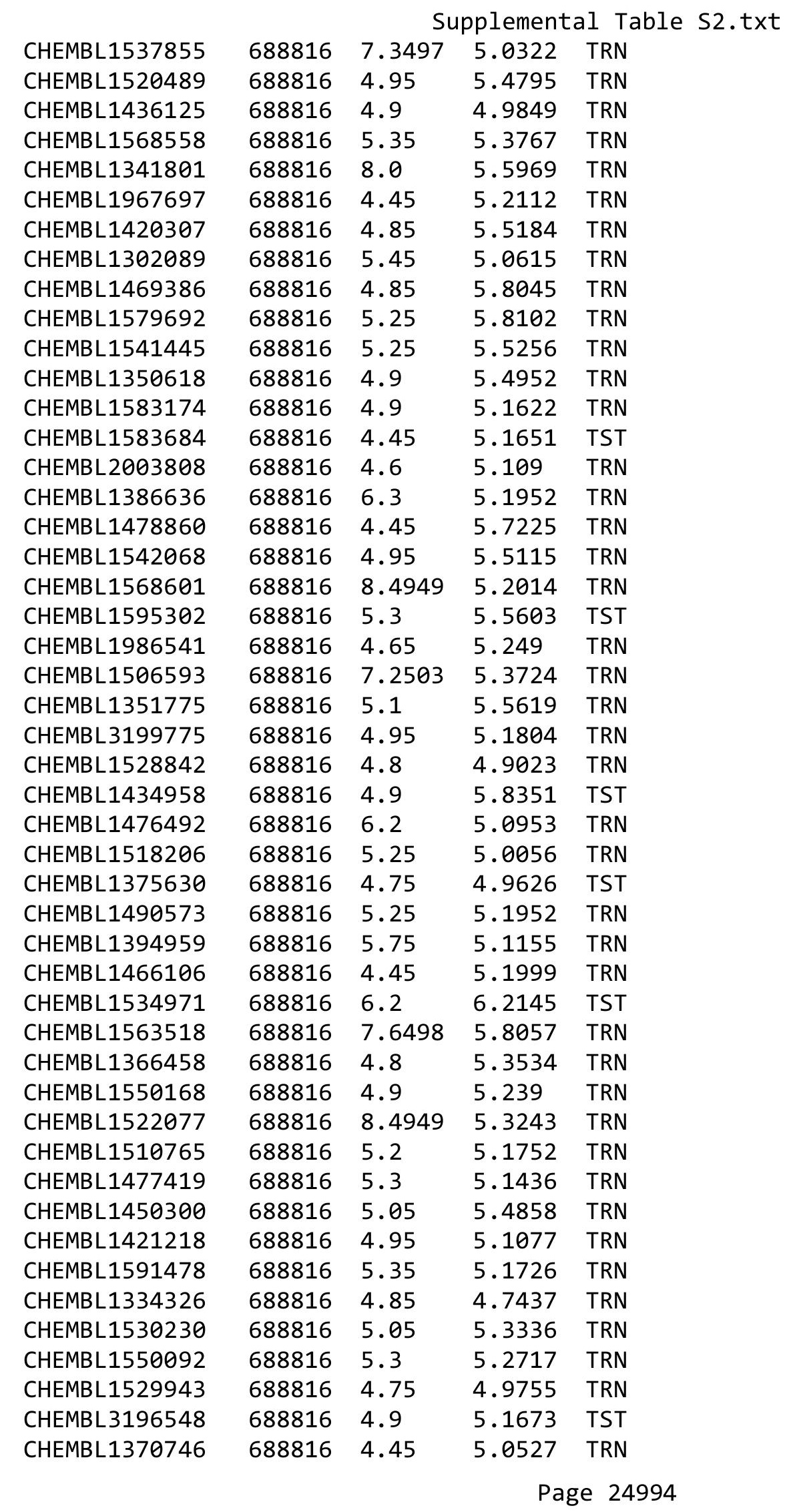




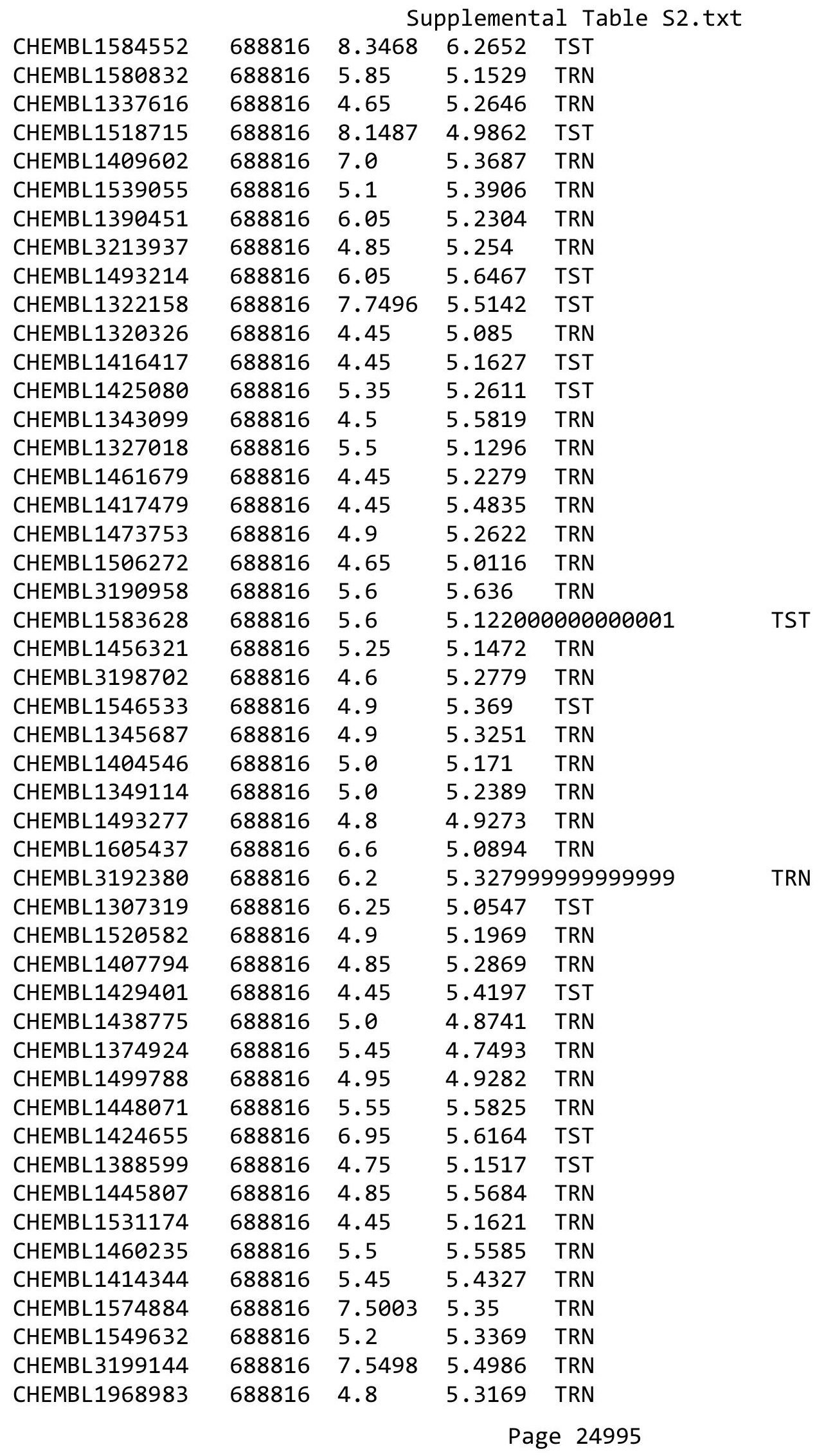




\begin{tabular}{|c|c|c|c|c|c|}
\hline \multicolumn{6}{|c|}{ Supplemental Table S2.txt } \\
\hline CHEMBL1408266 & 688816 & 4.45 & 5.1043 & TST & \\
\hline CHEMBL1369639 & 688816 & 5.4 & 4.9733 & TRN & \\
\hline CHEMBL1505997 & 688816 & 4.9 & 5.0175 & TRN & \\
\hline CHEMBL1605130 & 688816 & 5.0 & 5.2255 & TRN & \\
\hline CHEMBL1536136 & 688816 & 5.6 & 4.9788 & TRN & \\
\hline CHEMBL1527187 & 688816 & 5.15 & 5.1587 & TRN & \\
\hline CHEMBL1370627 & 688816 & 4.75 & 5.0048 & TRN & \\
\hline CHEMBL1611046 & 688816 & 5.45 & 5.2389 & TRN & \\
\hline CHEMBL1464873 & 688816 & 8.3468 & 5.6442 & TST & \\
\hline CHEMBL3195548 & 688816 & 4.9 & 5.5175 & TST & \\
\hline CHEMBL1364582 & 688816 & 7.8508 & 5.2148 & TRN & \\
\hline CHEMBL1387578 & 688816 & 4.85 & 5.0872 & TRN & \\
\hline CHEMBL1458455 & 688816 & 5.65 & 4.8433 & TRN & \\
\hline CHEMBL1454061 & 688816 & 4.9 & 5.28600 & 00000000005 & TRN \\
\hline CHEMBL1379503 & 688816 & 8.4949 & 5.3475 & TRN & \\
\hline CHEMBL1338083 & 688816 & 4.45 & 5.4749 & TRN & \\
\hline CHEMBL1590419 & 688816 & 4.8 & 5.1391 & TRN & \\
\hline CHEMBL1449337 & 688816 & 4.75 & 5.5741 & TRN & \\
\hline CHEMBL1431587 & 688816 & 5.45 & 5.1445 & TRN & \\
\hline CHEMBL1360191 & 688816 & 4.9 & 5.0267 & TRN & \\
\hline CHEMBL1377010 & 688816 & 4.45 & 5.1624 & TRN & \\
\hline CHEMBL3196538 & 688816 & 4.85 & 5.0539 & TST & \\
\hline CHEMBL3199583 & 688816 & 8.301 & 5.1332 & TRN & \\
\hline CHEMBL1540483 & 688816 & 4.85 & 5.1338 & TST & \\
\hline CHEMBL1304064 & 688816 & 4.45 & 4.7715 & TRN & \\
\hline CHEMBL1609096 & 688816 & 4.9 & 5.2988 & TST & \\
\hline CHEMBL1390713 & 688816 & 5.25 & 5.3811 & TRN & \\
\hline CHEMBL1506256 & 688816 & 4.7 & 5.6297 & TST & \\
\hline CHEMBL1578945 & 688816 & 4.45 & 5.1862 & TRN & \\
\hline CHEMBL1493765 & 688816 & 4.9 & 5.4339 & TRN & \\
\hline CHEMBL1589288 & 688816 & 4.95 & 5.2118 & TRN & \\
\hline CHEMBL1538299 & 688816 & 6.7501 & 5.0781 & TRN & \\
\hline CHEMBL3189189 & 688816 & 4.6 & 5.2978 & TRN & \\
\hline CHEMBL1538068 & 688816 & 7.699 & 5.4545 & TST & \\
\hline CHEMBL1426047 & 688816 & 4.85 & 5.117 & TRN & \\
\hline CHEMBL1437358 & 688816 & 4.7 & 5.2631 & TRN & \\
\hline CHEMBL1461154 & 688816 & 4.8 & 5.6628 & TST & \\
\hline CHEMBL1463327 & 688816 & 8.301 & 5.62799 & 9999999999 & TRN \\
\hline CHEMBL1310733 & 688816 & 4.6 & 5.37 & TRN & \\
\hline CHEMBL1530597 & 688816 & 4.9 & 5.2924 & TRN & \\
\hline CHEMBL1400778 & 688816 & 4.85 & 5.2628 & TRN & \\
\hline CHEMBL1549103 & 688816 & 4.65 & 5.1457 & TRN & \\
\hline CHEMBL1353499 & 688816 & 4.6 & 5.7256 & TRN & \\
\hline CHEMBL3213919 & 688816 & 8.301 & 5.2423 & TRN & \\
\hline CHEMBL1410688 & 688816 & 4.45 & 5.191 & TRN & \\
\hline CHEMBL1379547 & 688816 & 5.0 & 5.2967 & TRN & \\
\hline CHEMBL1603623 & 688816 & 6.2 & 4.7757 & TRN & \\
\hline CHEMBL1600961 & 688816 & 4.95 & 5.523 & TRN & \\
\hline
\end{tabular}




\begin{tabular}{|c|c|c|c|c|c|}
\hline \multicolumn{6}{|c|}{ Supplemental Table S2.txt } \\
\hline CHEMBL1574562 & 688816 & 4.85 & 5.235 & TRN & \\
\hline CHEMBL1383954 & 688816 & 4.6 & 5.267 & TRN & \\
\hline CHEMBL1313356 & 688816 & 4.45 & 4.9744 & TRN & \\
\hline CHEMBL1612698 & 688816 & 4.65 & 5.6421 & TST & \\
\hline CHEMBL1392507 & 688816 & 7.699 & 5.4654 & TRN & \\
\hline CHEMBL340807 & 688816 & 4.9 & 5.2466 & TST & \\
\hline CHEMBL1520674 & 688816 & 4.9 & 5.2802 & TRN & \\
\hline CHEMBL1966867 & 688816 & 5.3 & 5.3783 & TST & \\
\hline CHEMBL1444764 & 688816 & 5.05 & 4.9953 & TRN & \\
\hline CHEMBL1547896 & 688816 & 5.15 & 5.3291 & TRN & \\
\hline CHEMBL1350985 & 688816 & 5.0 & 5.57799 & 9999999999 & TST \\
\hline CHEMBL1457803 & 688816 & 5.15 & 5.5326 & TRN & \\
\hline CHEMBL471397 & 688816 & 5.25 & 5.0056 & TST & \\
\hline CHEMBL1381710 & 688816 & 5.5 & 5.0412 & TST & \\
\hline CHEMBL1376794 & 688816 & 4.45 & 5.2151 & TRN & \\
\hline CHEMBL 3208047 & 688816 & 4.45 & 4.9824 & TRN & \\
\hline CHEMBL3195232 & 688816 & 4.75 & 5.2148 & TRN & \\
\hline CHEMBL1307043 & 688816 & 5.0 & 5.1356 & TRN & \\
\hline CHEMBL1511950 & 688816 & 5.0 & 5.3475 & TRN & \\
\hline CHEMBL1445578 & 688816 & 4.95 & 5.0786 & TRN & \\
\hline CHEMBL1302338 & 688816 & 4.65 & 5.4506 & TRN & \\
\hline CHEMBL1466562 & 688816 & 4.9 & 5.0026 & TST & \\
\hline CHEMBL1523501 & 688816 & 5.9 & 5.4208 & TRN & \\
\hline CHEMBL1331796 & 688816 & 5.3 & 5.4118 & TST & \\
\hline CHEMBL 3211300 & 688816 & 5.2 & 5.1283 & TST & \\
\hline CHEMBL1450951 & 688816 & 6.1 & 5.3707 & TST & \\
\hline CHEMBL1966952 & 688816 & 6.8 & 5.2173 & TST & \\
\hline CHEMBL1404733 & 688816 & 4.9 & 5.6097 & TRN & \\
\hline CHEMBL1423437 & 688816 & 5.9 & 5.355 & TST & \\
\hline CHEMBL1558884 & 688816 & 4.8 & 5.4016 & TST & \\
\hline CHEMBL1492922 & 688816 & 4.5 & 5.3522 & TST & \\
\hline CHEMBL1603321 & 688816 & 4.65 & 5.496 & TRN & \\
\hline CHEMBL1483446 & 688816 & 4.65 & 4.9897 & TRN & \\
\hline CHEMBL1448332 & 688816 & 6.35 & 5.1614 & TRN & \\
\hline CHEMBL1548832 & 688816 & 4.75 & 4.8389 & TST & \\
\hline CHEMBL1313956 & 688816 & 4.45 & 5.1106 & TRN & \\
\hline CHEMBL1389153 & 688816 & 4.85 & 5.25899 & 99999999995 & TRN \\
\hline CHEMBL1496259 & 688816 & 7.5003 & 5.4799 & TRN & \\
\hline CHEMBL1414655 & 688816 & 4.75 & 4.7986 & TRN & \\
\hline CHEMBL1526829 & 688816 & 4.9 & 5.0391 & TRN & \\
\hline CHEMBL3182281 & 688816 & 4.65 & 5.5248 & TRN & \\
\hline CHEMBL1582404 & 688816 & 8.301 & 5.775 & TRN & \\
\hline CHEMBL1406583 & 688816 & 5.95 & 4.8319 & TRN & \\
\hline CHEMBL1306802 & 688816 & 4.95 & 4.9691 & TST & \\
\hline CHEMBL1605335 & 688816 & 6.5501 & 5.6575 & TST & \\
\hline CHEMBL1505284 & 688816 & 7.8996 & 5.5048 & TRN & \\
\hline CHEMBL1561248 & 688816 & 5.2 & 5.376 & TRN & \\
\hline CHEMBL1603446 & 688816 & 4.65 & 5.2694 & TRN & \\
\hline
\end{tabular}




\begin{tabular}{|c|c|c|c|c|c|}
\hline & & & \multirow{2}{*}{\multicolumn{2}{|c|}{5.422000000000001}} & \\
\hline CHEMBL1599426 & 688816 & 8.3468 & & & TRN \\
\hline CHEMBL1400339 & 688816 & 5.1 & 5.4022 & TRN & \\
\hline CHEMBL1323486 & 688816 & 4.95 & 5.3498 & TRN & \\
\hline CHEMBL1491324 & 688816 & 4.6 & \multicolumn{2}{|c|}{5.093999999999999} & TRN \\
\hline CHEMBL1447424 & 688816 & 5.45 & 5.5836 & TST & \\
\hline CHEMBL1383066 & 688816 & 4.75 & 4.9038 & TRN & \\
\hline CHEMBL1540051 & 688816 & 5.6 & 5.3014 & TRN & \\
\hline CHEMBL319931 & 688816 & 6.0 & 5.675 & TRN & \\
\hline CHEMBL1427860 & 688816 & 4.45 & 4.7095 & TRN & \\
\hline CHEMBL1406438 & 688816 & 4.45 & 5.1542 & TRN & \\
\hline CHEMBL3194088 & 688816 & 4.75 & 5.2987 & TST & \\
\hline CHEMBL1311739 & 688816 & 4.85 & 5.39 & TRN & \\
\hline CHEMBL1324768 & 688816 & 5.25 & 5.4398 & TRN & \\
\hline CHEMBL1367285 & 688816 & 7.8996 & 5.4051 & TRN & \\
\hline CHEMBL1576091 & 688816 & 5.25 & 5.274 & TRN & \\
\hline CHEMBL1466446 & 688816 & 5.25 & \multicolumn{2}{|c|}{5.1160000000000005} & TST \\
\hline CHEMBL1334062 & 688816 & 4.45 & \multicolumn{2}{|c|}{4.8580000000000005} & TRN \\
\hline CHEMBL1488539 & 688816 & 5.05 & 5.2266 & TRN & \\
\hline CHEMBL3196521 & 688816 & 4.85 & 5.1655 & TRN & \\
\hline CHEMBL1370062 & 688816 & 4.45 & 5.129 & TRN & \\
\hline CHEMBL1568610 & 688816 & 7.2 & 5.2192 & TRN & \\
\hline CHEMBL1537736 & 688816 & 5.95 & 5.1552 & TRN & \\
\hline CHEMBL1467873 & 688816 & 4.45 & 4.9526 & TST & \\
\hline CHEMBL1430482 & 688816 & 4.9 & 5.1073 & TRN & \\
\hline CHEMBL1543804 & 688816 & 5.7 & 5.3371 & TRN & \\
\hline CHEMBL3196297 & 688816 & 7.4498 & 5.1677 & TRN & \\
\hline CHEMBL1330341 & 688816 & 4.95 & 5.4116 & TRN & \\
\hline CHEMBL1611014 & 688816 & 6.1 & \multicolumn{2}{|c|}{5.3229999999999995} & TRN \\
\hline CHEMBL21708 & 688816 & 7.0 & 5.6781 & TRN & \\
\hline CHEMBL1429108 & 688816 & 4.95 & 4.948 & TRN & \\
\hline CHEMBL1343554 & 688816 & 4.95 & 5.2127 & TRN & \\
\hline CHEMBL1587524 & 688816 & 4.5 & 5.1683 & TRN & \\
\hline CHEMBL1545709 & 688816 & 5.15 & 5.2724 & TRN & \\
\hline CHEMBL1364909 & 688816 & 5.7 & 5.4252 & TST & \\
\hline CHEMBL1345779 & 688816 & 8.3468 & 5.4327 & TRN & \\
\hline CHEMBL1528160 & 688816 & 4.55 & 4.8496 & TRN & \\
\hline CHEMBL1516070 & 688816 & 5.55 & 5.3519 & TRN & \\
\hline CHEMBL1573687 & 688816 & 5.45 & 5.7101 & TRN & \\
\hline CHEMBL1424762 & 688816 & 4.65 & 5.4145 & TRN & \\
\hline CHEMBL1432345 & 688816 & 4.75 & 5.0481 & TRN & \\
\hline CHEMBL1302109 & 688816 & 5.5 & 5.0648 & TRN & \\
\hline CHEMBL1528926 & 688816 & 4.45 & 4.7958 & TRN & \\
\hline CHEMBL3190552 & 688816 & 4.95 & 5.0054 & TRN & \\
\hline CHEMBL1518990 & 688816 & 4.85 & 5.1195 & TRN & \\
\hline CHEMBL1572963 & 688816 & 4.9 & 5.1761 & TRN & \\
\hline CHEMBL1372756 & 688816 & 4.45 & 5.3041 & TST & \\
\hline CHEMBL1313273 & 688816 & 5.0 & 5.5519 & TRN & \\
\hline CHEMBL1588726 & 688816 & 4.85 & 5.3171 & TRN & \\
\hline & & & & 4998 & \\
\hline
\end{tabular}




\begin{tabular}{|c|c|c|c|c|}
\hline & & & pplement & al $\mathrm{T}$ \\
\hline CHEMBL1511029 & 688816 & 5.2 & 5.4016 & TRN \\
\hline CHEMBL1347210 & 688816 & 8.0 & 5.3995 & TRN \\
\hline CHEMBL1447972 & 688816 & 5.3 & 5.6305 & TST \\
\hline CHEMBL1594268 & 688816 & 4.45 & 5.4198 & TST \\
\hline CHEMBL1376366 & 688816 & 4.5 & 5.2405 & TRN \\
\hline CHEMBL1425650 & 688816 & 6.05 & 5.7231 & TRN \\
\hline CHEMBL1415878 & 688816 & 4.75 & 4.9574 & TRN \\
\hline CHEMBL1401346 & 688816 & 5.25 & 5.2426 & TRN \\
\hline CHEMBL1611765 & 688816 & 5.2 & 4.6792 & TRN \\
\hline CHEMBL1597399 & 688816 & 8.3468 & 5.4934 & TRN \\
\hline CHEMBL1465762 & 688816 & 4.7 & 5.3099 & TRN \\
\hline CHEMBL1558469 & 688816 & 4.65 & 5.2961 & TRN \\
\hline CHEMBL1366941 & 688816 & 4.95 & 5.3761 & TRN \\
\hline CHEMBL1419905 & 688816 & 5.35 & 5.6578 & TRN \\
\hline CHEMBL1594735 & 688816 & 7.3002 & 6.0198 & TST \\
\hline CHEMBL3209746 & 688816 & 6.6 & 5.5461 & TRN \\
\hline CHEMBL3208114 & 688816 & 4.75 & 5.3468 & TRN \\
\hline CHEMBL1410837 & 688816 & 4.9 & 5.3019 & TRN \\
\hline CHEMBL1544326 & 688816 & 5.0 & 5.8162 & TRN \\
\hline CHEMBL1480370 & 688816 & 4.65 & 5.6398 & TRN \\
\hline CHEMBL1460324 & 688816 & 4.85 & 5.3936 & TRN \\
\hline CHEMBL1565372 & 688816 & 4.95 & 5.2749 & TST \\
\hline CHEMBL1448354 & 688816 & 4.45 & 5.5727 & TRN \\
\hline CHEMBL1493281 & 688816 & 4.75 & 5.138 & TST \\
\hline CHEMBL1342760 & 688816 & 5.05 & 5.2366 & TRN \\
\hline CHEMBL1571128 & 688816 & 5.3 & 5.7826 & TRN \\
\hline CHEMBL1508918 & 688816 & 4.5 & 5.2147 & TRN \\
\hline CHEMBL1496126 & 688816 & 4.9 & 5.1334 & TST \\
\hline CHEMBL1519642 & 688816 & 6.5501 & 5.349 & TRN \\
\hline CHEMBL1492272 & 688816 & 4.95 & 5.0746 & TRN \\
\hline CHEMBL1458528 & 688816 & 6.8 & 5.32 & TRN \\
\hline CHEMBL1607209 & 688816 & 4.65 & 5.3058 & TRN \\
\hline CHEMBL1422188 & 688816 & 4.9 & 5.4387 & TST \\
\hline CHEMBL1575050 & 688816 & 4.45 & 5.2018 & TRN \\
\hline CHEMBL3145060 & 688816 & 4.75 & 5.5107 & TRN \\
\hline CHEMBL1439770 & 688816 & 4.45 & 5.0226 & TRN \\
\hline CHEMBL1538482 & 688816 & 5.15 & 5.7006 & TRN \\
\hline CHEMBL1496123 & 688816 & 5.05 & 5.9363 & TRN \\
\hline CHEMBL1524441 & 688816 & 5.0 & 4.8525 & TRN \\
\hline CHEMBL1420563 & 688816 & 4.45 & 5.2783 & TRN \\
\hline CHEMBL1509877 & 688816 & 5.15 & 4.8345 & TRN \\
\hline CHEMBL1325897 & 688816 & 8.4949 & 5.2592 & TRN \\
\hline CHEMBL1409866 & 688816 & 5.05 & 4.9111 & TST \\
\hline CHEMBL1560769 & 688816 & 5.3 & 5.3325 & TST \\
\hline CHEMBL1481309 & 688816 & 6.8 & 5.3408 & TRN \\
\hline CHEMBL3191590 & 688816 & 4.45 & 4.8898 & TRN \\
\hline CHEMBL1539834 & 688816 & 4.85 & 5.0772 & TRN \\
\hline CHEMBL1590820 & 688816 & 4.45 & 5.33 & TRN \\
\hline
\end{tabular}




\begin{tabular}{|c|c|c|c|c|c|}
\hline \multicolumn{6}{|c|}{ Supplemental Table s2.txt } \\
\hline CHEMBL1362256 & 688816 & 4.85 & 4.8024 & TST & \\
\hline CHEMBL1580791 & 688816 & 4.5 & 5.187 & TRN & \\
\hline CHEMBL1524731 & 688816 & 4.6 & 4.8294 & TRN & \\
\hline CHEMBL1300077 & 688816 & 7.8508 & 5.2812 & TRN & \\
\hline CHEMBL252909 & 688816 & 4.45 & 5.6728 & TST & \\
\hline CHEMBL1471612 & 688816 & 4.7 & 4.8267 & TRN & \\
\hline CHEMBL1427609 & 688816 & 5.05 & 5.1806 & TRN & \\
\hline CHEMBL1411257 & 688816 & 6.3 & 5.3196 & TRN & \\
\hline CHEMBL1527906 & 688816 & 7.6003 & 5.4823 & TST & \\
\hline CHEMBL1430824 & 688816 & 4.75 & 5.2023 & TRN & \\
\hline CHEMBL1305319 & 688816 & 5.85 & 4.9515 & TRN & \\
\hline CHEMBL1380844 & 688816 & 4.45 & 5.4085 & TRN & \\
\hline CHEMBL1545598 & 688816 & 5.35 & 5.0204 & TST & \\
\hline CHEMBL1994362 & 688816 & 6.1 & 5.2123 & TRN & \\
\hline CHEMBL1391825 & 688816 & 4.45 & 5.2329 & TST & \\
\hline CHEMBL1325708 & 688816 & 6.7501 & 5.955 & TST & \\
\hline CHEMBL1587244 & 688816 & 4.95 & 5.4712 & TST & \\
\hline CHEMBL1420568 & 688816 & 4.85 & 5.34399 & 9999999999 & TST \\
\hline CHEMBL1323387 & 688816 & 4.95 & 5.2089 & TRN & \\
\hline CHEMBL1509470 & 688816 & 4.9 & 5.4862 & TST & \\
\hline CHEMBL1305452 & 688816 & 7.15 & 5.2841 & TRN & \\
\hline CHEMBL1424504 & 688816 & 4.95 & 5.2808 & TRN & \\
\hline CHEMBL1603888 & 688816 & 4.65 & 5.6001 & TST & \\
\hline CHEMBL3197632 & 688816 & 4.85 & 5.394 & TRN & \\
\hline CHEMBL1494711 & 688816 & 4.5 & 5.17299 & 9999999999 & TRN \\
\hline CHEMBL1397338 & 688816 & 4.7 & 5.2595 & TRN & \\
\hline CHEMBL1568554 & 688816 & 4.95 & 5.0874 & TRN & \\
\hline CHEMBL1321353 & 688816 & 5.0 & 5.16799 & 9999999999 & TST \\
\hline CHEMBL1511532 & 688816 & 5.05 & 5.4322 & TRN & \\
\hline CHEMBL1308545 & 688816 & 6.2 & 5.6561 & TRN & \\
\hline CHEMBL1352587 & 688816 & 4.75 & 5.3797 & TRN & \\
\hline CHEMBL1605693 & 688816 & 4.45 & 4.5596 & TRN & \\
\hline CHEMBL1461006 & 688816 & 5.25 & 5.4687 & TRN & \\
\hline CHEMBL1354458 & 688816 & 4.95 & 5.3112 & TRN & \\
\hline CHEMBL1359381 & 688816 & 5.45 & 5.6377 & TRN & \\
\hline CHEMBL1594296 & 688816 & 5.2 & 5.7322 & TRN & \\
\hline CHEMBL1360443 & 688816 & 5.05 & 5.5319 & TST & \\
\hline CHEMBL3192032 & 688816 & 7.8996 & 5.6467 & TST & \\
\hline CHEMBL1559957 & 688816 & 4.95 & 5.0532 & TRN & \\
\hline CHEMBL1603053 & 688816 & 5.5 & 5.3506 & TRN & \\
\hline CHEMBL1452996 & 688816 & 4.8 & 5.2131 & TRN & \\
\hline CHEMBL1490738 & 688816 & 4.55 & 5.294 & TRN & \\
\hline CHEMBL1563496 & 688816 & 4.95 & 5.4458 & TRN & \\
\hline CHEMBL1417506 & 688816 & 5.55 & 5.3504 & TRN & \\
\hline CHEMBL1376530 & 688816 & 5.3 & 5.6546 & TRN & \\
\hline CHEMBL1404835 & 688816 & 4.75 & 5.3106 & TRN & \\
\hline CHEMBL1430213 & 688816 & 5.25 & 5.4768 & TRN & \\
\hline CHEMBL1611447 & 688816 & 8.0506 & 5.4068 & TRN & \\
\hline
\end{tabular}




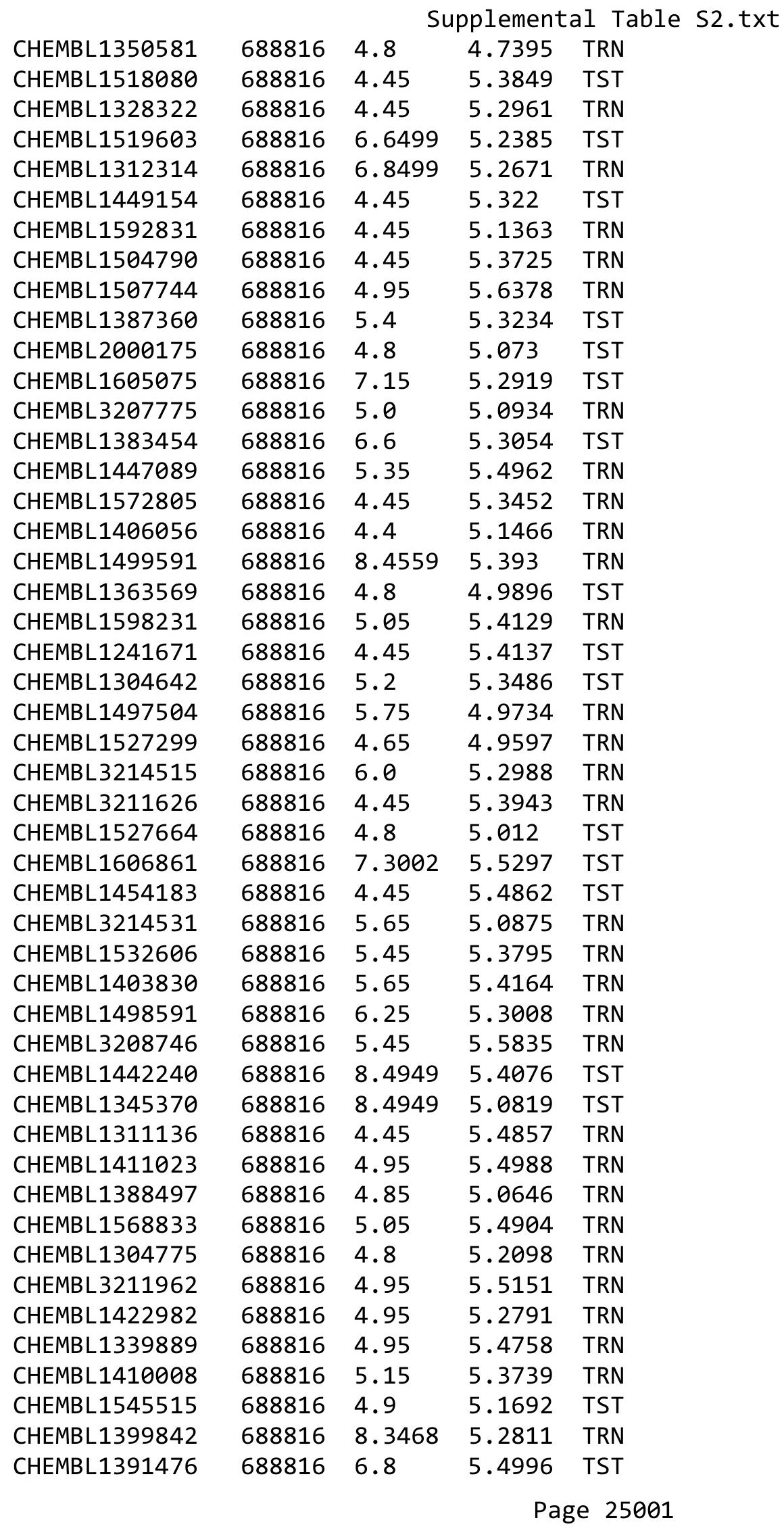




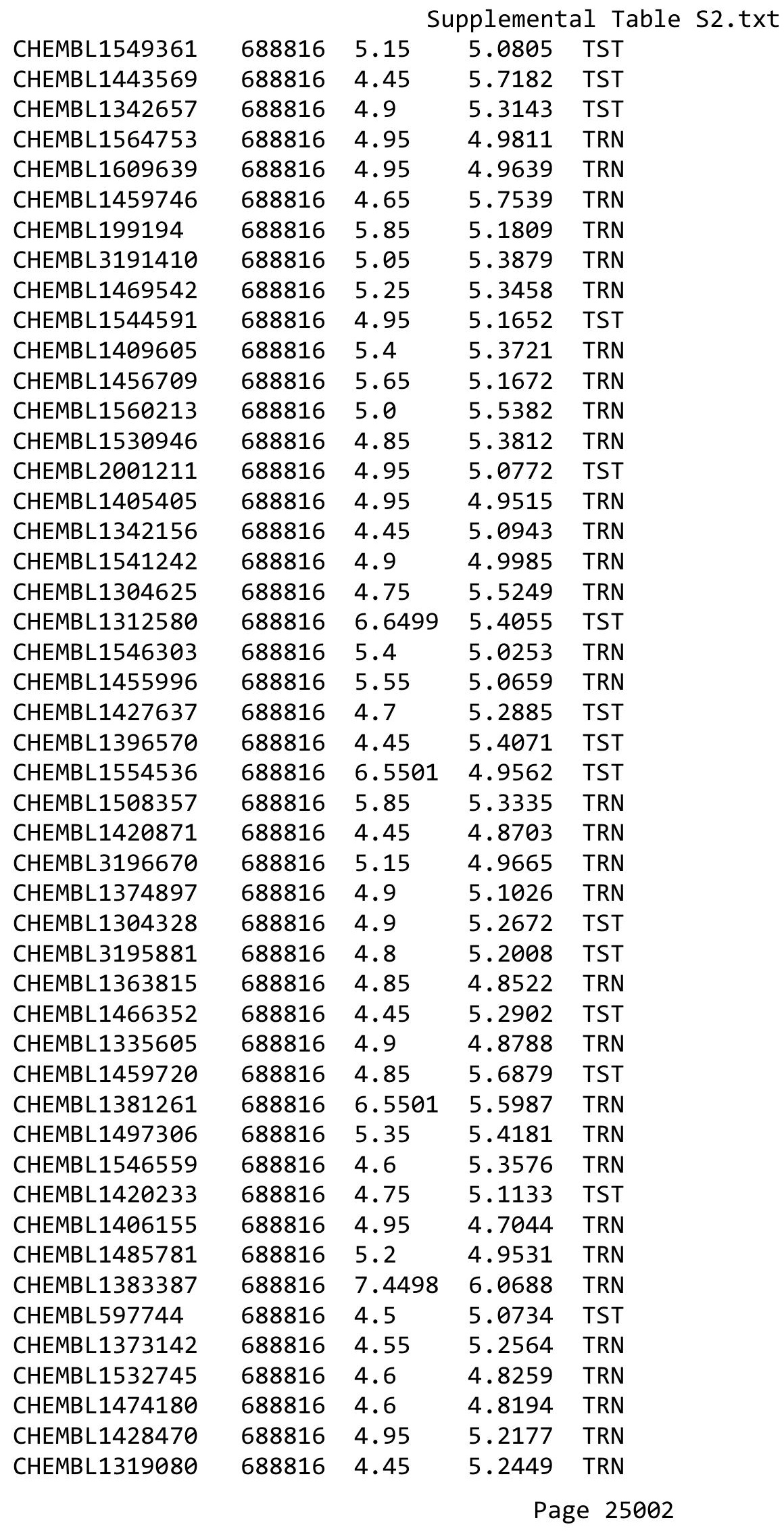




\begin{tabular}{|c|c|c|c|c|c|}
\hline \\
\hline CHEMBL1549660 & 688816 & 4.95 & 5.0959 & TST & \\
\hline CHEMBL1599874 & 688816 & 4.65 & 5.3392 & TRN & \\
\hline CHEMBL3213965 & 688816 & 5.15 & 5.4464 & TRN & \\
\hline CHEMBL1608989 & 688816 & 4.45 & 4.6875 & TRN & \\
\hline CHEMBL1545206 & 688816 & 7.1002 & 5.4874 & TRN & \\
\hline CHEMBL1477555 & 688816 & 4.9 & 5.2614 & TRN & \\
\hline CHEMBL1389005 & 688816 & 7.699 & 5.4299 & TRN & \\
\hline CHEMBL1351457 & 688816 & 4.45 & 5.33 & TRN & \\
\hline CHEMBL1542387 & 688816 & 4.95 & 5.5327 & TRN & \\
\hline CHEMBL1542767 & 688816 & 6.5501 & 5.8498 & TRN & \\
\hline CHEMBL1575719 & 688816 & 6.0 & 5.6297 & TST & \\
\hline CHEMBL 1452756 & 688816 & 4.8 & 5.8266 & TRN & \\
\hline CHEMBL1567738 & 688816 & 5.5 & 5.2768 & TRN & \\
\hline CHEMBL1311812 & 688816 & 4.45 & 4.7468 & TRN & \\
\hline CHEMBL1602581 & 688816 & 4.45 & 5.10800 & 00000000005 & TST \\
\hline CHEMBL1564162 & 688816 & 4.45 & 5.6896 & TRN & \\
\hline CHEMBL1565768 & 688816 & 5.15 & 5.2281 & TRN & \\
\hline CHEMBL1581310 & 688816 & 4.95 & 5.0791 & TRN & \\
\hline CHEMBL1493785 & 688816 & 4.9 & 5.1867 & TRN & \\
\hline CHEMBL1324524 & 688816 & 5.25 & 4.8155 & TRN & \\
\hline CHEMBL598680 & 688816 & 4.8 & 5.0785 & TRN & \\
\hline CHEMBL1527242 & 688816 & 5.0 & 4.9719 & TRN & \\
\hline CHEMBL1423031 & 688816 & 4.45 & 5.21200 & 0000000001 & TRN \\
\hline CHEMBL1598440 & 688816 & 4.5 & 5.216 & TST & \\
\hline CHEMBL319381 & 688816 & 4.7 & 5.2308 & TRN & \\
\hline CHEMBL1452357 & 688816 & 5.5 & 5.6267 & TRN & \\
\hline CHEMBL 1487520 & 688816 & 4.6 & 5.0705 & TRN & \\
\hline CHEMBL1608984 & 688816 & 5.05 & 5.187 & TRN & \\
\hline CHEMBL1517727 & 688816 & 5.0 & 5.1087 & TRN & \\
\hline CHEMBL1424013 & 688816 & 5.4 & 6.0582 & TST & \\
\hline CHEMBL1302162 & 688816 & 8.3468 & 5.5249 & TST & \\
\hline CHEMBL1520970 & 688816 & 4.7 & 5.3007 & TRN & \\
\hline CHEMBL1438733 & 688816 & 4.45 & 4.85800 & 30000000005 & TRN \\
\hline CHEMBL1584746 & 688816 & 5.2 & 5.2103 & TST & \\
\hline CHEMBL1300373 & 688816 & 4.85 & 5.5411 & TRN & \\
\hline CHEMBL3196374 & 688816 & 4.9 & 5.2905 & TRN & \\
\hline CHEMBL 275516 & 688816 & 4.9 & 5.5698 & TST & \\
\hline CHEMBL1455255 & 688816 & 4.8 & 5.2731 & TRN & \\
\hline CHEMBL1355444 & 688816 & 4.45 & 5.1204 & TRN & \\
\hline CHEMBL3190038 & 688816 & 4.95 & 5.4815 & TRN & \\
\hline CHEMBL1440412 & 688816 & 5.95 & 5.0888 & TRN & \\
\hline CHEMBL1464013 & 688816 & 7.8013 & 5.6409 & TRN & \\
\hline CHEMBL3193130 & 688816 & 4.6 & 5.1622 & TST & \\
\hline CHEMBL1306978 & 688816 & 4.95 & 4.8951 & TRN & \\
\hline CHEMBL1436860 & 688816 & 5.8 & 5.4437 & TRN & \\
\hline CHEMBL1580452 & 688816 & 5.35 & 5.2733 & TRN & \\
\hline CHEMBL 1334570 & 688816 & 5.2 & 5.4076 & TRN & \\
\hline CHEMBL1365364 & 688816 & 4.95 & 5.0061 & TRN & \\
\hline
\end{tabular}




\begin{tabular}{|c|c|c|c|c|c|}
\hline \multicolumn{6}{|c|}{ Supplemental Table S2.txt } \\
\hline CHEMBL1307546 & 688816 & 5.2 & 5.2636 & TRN & \\
\hline CHEMBL1381242 & 688816 & 5.05 & 5.2224 & TRN & \\
\hline CHEMBL1365301 & 688816 & 6.8 & 5.1358 & TRN & \\
\hline CHEMBL1545868 & 688816 & 5.0 & 5.6908 & TRN & \\
\hline CHEMBL1415368 & 688816 & 5.25 & 5.3813 & TRN & \\
\hline CHEMBL1331240 & 688816 & 4.75 & 5.1533 & TRN & \\
\hline CHEMBL1542288 & 688816 & 8.4949 & 5.4769 & TRN & \\
\hline CHEMBL1408016 & 688816 & 4.85 & 5.2724 & TRN & \\
\hline CHEMBL1394148 & 688816 & 4.45 & 5.4507 & TST & \\
\hline CHEMBL1588919 & 688816 & 5.5 & 5.0097 & TRN & \\
\hline CHEMBL1444402 & 688816 & 4.55 & 5.1246 & TRN & \\
\hline CHEMBL1535257 & 688816 & 4.9 & 5.2937 & TRN & \\
\hline CHEMBL1536491 & 688816 & 4.7 & 4.6329 & TRN & \\
\hline CHEMBL1499190 & 688816 & 5.25 & 5.1598 & TRN & \\
\hline CHEMBL1479679 & 688816 & 5.05 & 5.0784 & TRN & \\
\hline CHEMBL1546695 & 688816 & 4.7 & 5.2033 & TRN & \\
\hline CHEMBL1518386 & 688816 & 4.75 & 5.1076 & TRN & \\
\hline CHEMBL3190497 & 688816 & 8.4949 & 5.2109 & TST & \\
\hline CHEMBL1488974 & 688816 & 6.5 & 5.3802 & TST & \\
\hline CHEMBL1533593 & 688816 & 4.9 & 5.1787 & TRN & \\
\hline CHEMBL1448901 & 688816 & 5.0 & 5.15600 & 0000000001 & TRN \\
\hline CHEMBL1383015 & 688816 & 4.8 & 5.5157 & TST & \\
\hline CHEMBL1431034 & 688816 & 4.95 & 5.2604 & TRN & \\
\hline CHEMBL1563839 & 688816 & 4.95 & 5.1372 & TRN & \\
\hline CHEMBL1314384 & 688816 & 4.55 & 5.5778 & TST & \\
\hline CHEMBL1533107 & 688816 & 5.15 & 4.9398 & TRN & \\
\hline CHEMBL1490169 & 688816 & 4.85 & 5.2817 & TRN & \\
\hline CHEMBL3193804 & 688816 & 4.85 & 5.5041 & TRN & \\
\hline CHEMBL1535532 & 688816 & 4.6 & 4.9748 & TST & \\
\hline CHEMBL1506436 & 688816 & 4.65 & 5.1749 & TRN & \\
\hline CHEMBL3214525 & 688816 & 5.4 & 5.3756 & TRN & \\
\hline CHEMBL1595859 & 688816 & 4.7 & 5.034 & TRN & \\
\hline CHEMBL1563549 & 688816 & 4.9 & 5.5785 & TRN & \\
\hline CHEMBL3199839 & 688816 & 6.2 & 5.1836 & TRN & \\
\hline CHEMBL1607932 & 688816 & 4.75 & 5.047 & TRN & \\
\hline CHEMBL1433719 & 688816 & 4.8 & 5.3964 & TRN & \\
\hline CHEMBL1564189 & 688816 & 4.95 & 5.3052 & TST & \\
\hline CHEMBL1489757 & 688816 & 4.55 & 5.2267 & TST & \\
\hline CHEMBL1322538 & 688816 & 4.95 & 5.0569 & TRN & \\
\hline CHEMBL 3145114 & 688816 & 5.65 & 5.5849 & TRN & \\
\hline CHEMBL1383565 & 688816 & 8.0506 & 5.2198 & TST & \\
\hline CHEMBL1446566 & 688816 & 5.35 & 5.0464 & TRN & \\
\hline CHEMBL1604460 & 688816 & 6.95 & 5.5383 & TRN & \\
\hline CHEMBL1510662 & 688816 & 4.7 & 5.2753 & TRN & \\
\hline CHEMBL1349072 & 688816 & 4.5 & 5.135 & TRN & \\
\hline CHEMBL1370390 & 688816 & 4.45 & 5.2885 & TRN & \\
\hline CHEMBL1412199 & 688816 & 4.9 & 5.21899 & 9999999999 & TRN \\
\hline CHEMBL1497930 & 688816 & 4.95 & 4.9377 & TRN & \\
\hline
\end{tabular}




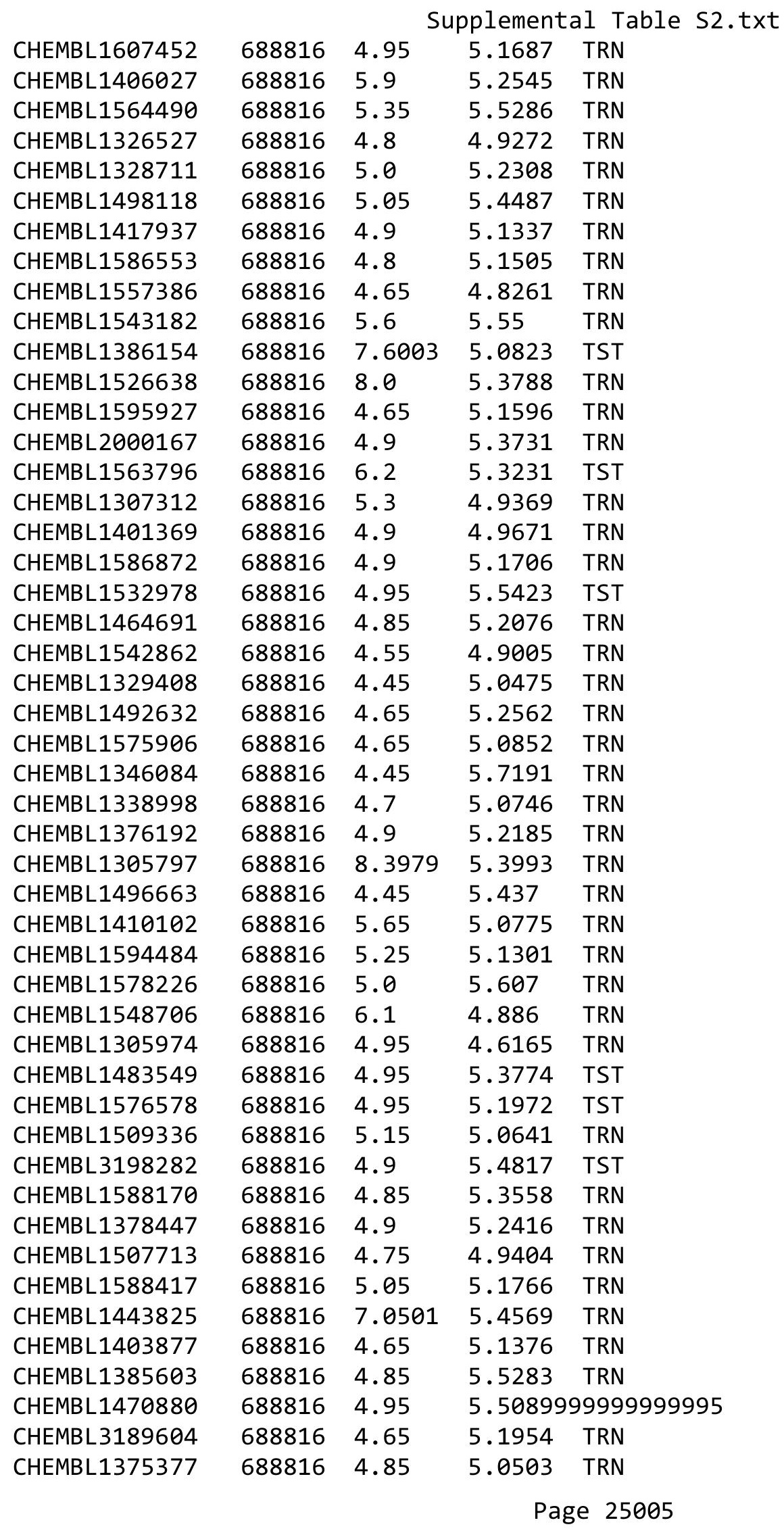




\begin{tabular}{|c|c|c|c|c|}
\hline \multicolumn{5}{|c|}{ Supplemental Table S2.txt } \\
\hline CHEMBL1400061 & 688816 & 5.0 & 5.4974 & TST \\
\hline CHEMBL1460740 & 688816 & 4.9 & 5.3221 & TRN \\
\hline CHEMBL1588263 & 688816 & 7.2503 & 5.2821 & TST \\
\hline CHEMBL1319894 & 688816 & 8.5528 & 5.4951 & TRN \\
\hline CHEMBL1565486 & 688816 & 4.7 & 4.9934 & TST \\
\hline CHEMBL1593567 & 688816 & 8.3468 & 5.0407 & TRN \\
\hline CHEMBL1302265 & 688816 & 5.25 & 5.5727 & TST \\
\hline CHEMBL1522232 & 688816 & 7.7496 & 5.2646 & TST \\
\hline CHEMBL1471201 & 688816 & 4.7 & 5.1297 & TRN \\
\hline CHEMBL1341111 & 688816 & 6.7001 & 5.4072 & TST \\
\hline CHEMBL1601726 & 688816 & 8.3468 & 4.982 & TST \\
\hline CHEMBL1594377 & 688816 & 5.6 & 5.4204 & TRN \\
\hline CHEMBL1607568 & 688816 & 5.6 & 5.1301 & TRN \\
\hline CHEMBL1491728 & 688816 & 4.95 & 5.0303 & TRN \\
\hline CHEMBL1389045 & 688816 & 4.7 & 5.2205 & TST \\
\hline CHEMBL1537630 & 688816 & 6.1 & 5.211 & TRN \\
\hline CHEMBL3211795 & 688816 & 5.25 & 5.3234 & TRN \\
\hline CHEMBL1337852 & 688816 & 8.301 & 5.5433 & TST \\
\hline CHEMBL97407 & 688816 & 4.9 & 5.2786 & TRN \\
\hline CHEMBL1527645 & 688816 & 4.65 & 5.145 & TRN \\
\hline CHEMBL1577742 & 688816 & 4.75 & 4.9318 & TRN \\
\hline CHEMBL1522967 & 688816 & 7.4498 & 5.2085 & TST \\
\hline CHEMBL1386065 & 688816 & 5.1 & 5.232 & TST \\
\hline CHEMBL1309277 & 688816 & 5.65 & 5.7322 & TRN \\
\hline CHEMBL1577737 & 688816 & 5.2 & 5.4106 & TRN \\
\hline CHEMBL1370091 & 688816 & 5.75 & 5.3581 & TST \\
\hline CHEMBL1347467 & 688816 & 7.8508 & 5.5491 & TRN \\
\hline CHEMBL1426300 & 688816 & 4.95 & 5.2104 & TRN \\
\hline CHEMBL1360485 & 688816 & 5.0 & 5.0952 & TRN \\
\hline CHEMBL1306649 & 688816 & 4.45 & 5.4912 & TRN \\
\hline CHEMBL1457290 & 688816 & 4.9 & 5.047 & TRN \\
\hline CHEMBL404613 & 688816 & 6.7001 & 5.3629 & TST \\
\hline CHEMBL1449547 & 688816 & 4.9 & 5.1106 & TRN \\
\hline CHEMBL1518516 & 688816 & 7.4498 & 5.0936 & TRN \\
\hline CHEMBL1446690 & 688816 & 5.3 & 5.0512 & TRN \\
\hline CHEMBL1598610 & 688816 & 8.4949 & 5.5235 & TRN \\
\hline CHEMBL3208652 & 688816 & 8.0 & 5.2158 & TRN \\
\hline CHEMBL1423466 & 688816 & 4.9 & 5.2768 & TRN \\
\hline CHEMBL1374813 & 688816 & 4.95 & 5.1874 & TRN \\
\hline CHEMBL1355396 & 688816 & 4.9 & 5.2875 & TRN \\
\hline CHEMBL1417620 & 688816 & 4.65 & 4.9075 & TST \\
\hline CHEMBL1426825 & 688816 & 5.25 & 5.1977 & TRN \\
\hline CHEMBL1402185 & 688816 & 4.45 & 4.7247 & TRN \\
\hline CHEMBL1595691 & 688816 & 4.45 & 5.3105 & TRN \\
\hline CHEMBL1576464 & 688816 & 5.35 & 5.7656 & TRN \\
\hline CHEMBL1567389 & 688816 & 4.95 & 5.2204 & TRN \\
\hline CHEMBL1536993 & 688816 & 4.7 & 5.2311 & TRN \\
\hline CHEMBL3208117 & 688816 & 8.301 & 5.6722 & TST \\
\hline
\end{tabular}




\begin{tabular}{|c|c|c|c|c|}
\hline \multicolumn{5}{|c|}{ Supplemental Table S2.txt } \\
\hline CHEMBL1580426 & 688816 & 5.2 & 5.3713 & TRN \\
\hline CHEMBL1555835 & 688816 & 5.95 & 5.3453 & TRN \\
\hline CHEMBL1493903 & 688816 & 4.65 & 5.4034 & TRN \\
\hline CHEMBL1452840 & 688816 & 5.95 & 5.76 & TRN \\
\hline CHEMBL1325295 & 688816 & 4.6 & 5.2486 & TST \\
\hline CHEMBL1458036 & 688816 & 4.95 & 5.5982 & TRN \\
\hline CHEMBL1513458 & 688816 & 4.9 & 5.0493 & TRN \\
\hline CHEMBL1507613 & 688816 & 4.85 & 5.135 & TRN \\
\hline CHEMBL1485763 & 688816 & 4.85 & 5.1953 & TRN \\
\hline CHEMBL1566650 & 688816 & 4.45 & 5.1179 & TRN \\
\hline CHEMBL1607661 & 688816 & 5.05 & 4.8125 & TRN \\
\hline CHEMBL1385440 & 688816 & 4.8 & 5.2738 & TRN \\
\hline CHEMBL1484854 & 688816 & 4.85 & 5.1518 & TRN \\
\hline CHEMBL1347964 & 688816 & 5.2 & 5.3244 & TST \\
\hline CHEMBL1429732 & 688816 & 4.95 & 5.3064 & TRN \\
\hline CHEMBL1426323 & 688816 & 6.9 & 5.5981 & TRN \\
\hline CHEMBL1582131 & 688816 & 6.1 & 4.8519 & TST \\
\hline CHEMBL1349446 & 688816 & 5.45 & 5.4048 & TRN \\
\hline CHEMBL1515872 & 688816 & 4.75 & 5.3215 & TRN \\
\hline CHEMBL1507638 & 688816 & 4.8 & 5.4303 & TRN \\
\hline CHEMBL1359186 & 688816 & 6.35 & 5.2011 & TST \\
\hline CHEMBL3193394 & 688816 & 4.5 & 4.7605 & TRN \\
\hline CHEMBL1413787 & 688816 & 4.9 & 5.2336 & TRN \\
\hline CHEMBL1387868 & 688816 & 5.0 & 5.1531 & TRN \\
\hline CHEMBL1354761 & 688816 & 5.25 & 5.2048 & TRN \\
\hline CHEMBL1391254 & 688816 & 4.8 & 5.3771 & TRN \\
\hline CHEMBL1347960 & 688816 & 6.7501 & 5.8146 & TRN \\
\hline CHEMBL3210695 & 688816 & 4.95 & 5.3777 & TRN \\
\hline CHEMBL1445171 & 688816 & 4.95 & 5.3382 & TRN \\
\hline CHEMBL1520790 & 688816 & 5.2 & 5.1703 & TRN \\
\hline CHEMBL1546727 & 688816 & 4.8 & 5.4779 & TRN \\
\hline CHEMBL1361268 & 688816 & 4.95 & 4.9906 & TRN \\
\hline CHEMBL1581778 & 688816 & 5.95 & 4.7587 & TRN \\
\hline CHEMBL1420667 & 688816 & 5.15 & 5.1064 & TRN \\
\hline CHEMBL1563193 & 688816 & 5.4 & 5.2141 & TRN \\
\hline CHEMBL1363308 & 688816 & 4.95 & 5.3704 & TRN \\
\hline CHEMBL1421315 & 688816 & 4.9 & 5.1389 & TRN \\
\hline CHEMBL1465314 & 688816 & 5.1 & 4.7854 & TRN \\
\hline CHEMBL1340607 & 688816 & 5.0 & 5.5113 & TRN \\
\hline CHEMBL1526609 & 688816 & 5.85 & 5.2666 & TST \\
\hline CHEMBL1369544 & 688816 & 4.5 & 5.1246 & TST \\
\hline CHEMBL1312363 & 688816 & 5.15 & 5.1077 & TST \\
\hline CHEMBL1405334 & 688816 & 5.25 & 5.3789 & TRN \\
\hline CHEMBL1453211 & 688816 & 5.0 & 5.2001 & TRN \\
\hline CHEMBL1402377 & 688816 & 8.4559 & 5.5795 & TRN \\
\hline CHEMBL1477923 & 688816 & 4.45 & 5.1196 & TRN \\
\hline CHEMBL1527690 & 688816 & 4.95 & 5.4117 & TRN \\
\hline CHEMBL3197815 & 688816 & 4.95 & 4.779 & TRN \\
\hline
\end{tabular}




\begin{tabular}{|c|c|c|c|c|c|}
\hline \multicolumn{6}{|c|}{ Supplemental Table S2.txt } \\
\hline CHEMBL1578890 & 688816 & 5.45 & 5.1668 & TRN & \\
\hline CHEMBL1485151 & 688816 & 4.85 & 5.3765 & TRN & \\
\hline CHEMBL1173475 & 688816 & 4.45 & 5.0579 & TST & \\
\hline CHEMBL1561439 & 688816 & 4.6 & 5.2035 & TRN & \\
\hline CHEMBL1391743 & 688816 & 8.2518 & 5.5007 & TRN & \\
\hline CHEMBL1484879 & 688816 & 7.6003 & 5.3226 & TST & \\
\hline CHEMBL1301377 & 688816 & 4.45 & 5.0386 & TRN & \\
\hline CHEMBL1548156 & 688816 & 4.7 & 5.3316 & TRN & \\
\hline CHEMBL1589137 & 688816 & 4.8 & 5.1789 & TRN & \\
\hline CHEMBL1599710 & 688816 & 5.15 & 5.1047 & TRN & \\
\hline CHEMBL1346942 & 688816 & 7.5003 & 5.8642 & TST & \\
\hline CHEMBL1421574 & 688816 & 4.45 & 5.0057 & TRN & \\
\hline CHEMBL1449995 & 688816 & 4.95 & 5.1012 & TRN & \\
\hline CHEMBL1317999 & 688816 & 5.0 & 5.1146 & TRN & \\
\hline CHEMBL1494359 & 688816 & 5.25 & 5.2805 & TRN & \\
\hline CHEMBL1420238 & 688816 & 4.45 & 5.2639 & TST & \\
\hline CHEMBL1341952 & 688816 & 4.75 & 5.2923 & TST & \\
\hline CHEMBL1498045 & 688816 & 4.6 & 5.1947 & TRN & \\
\hline CHEMBL1399486 & 688816 & 4.8 & 5.1349 & TRN & \\
\hline CHEMBL3197893 & 688816 & 4.9 & 5.3492 & TST & \\
\hline CHEMBL1352671 & 688816 & 4.95 & 5.3568 & TRN & \\
\hline CHEMBL1576390 & 688816 & 5.1 & 4.8609 & TRN & \\
\hline CHEMBL3213364 & 688816 & 6.6 & 5.551 & TST & \\
\hline CHEMBL1538322 & 688816 & 4.95 & 5.2256 & TRN & \\
\hline CHEMBL3199602 & 688816 & 8.301 & 5.3256 & TST & \\
\hline CHEMBL112597 & 688816 & 4.7 & 5.3773 & TRN & \\
\hline CHEMBL1452449 & 688816 & 4.95 & 4.8701 & TRN & \\
\hline CHEMBL1564088 & 688816 & 4.45 & 5.4042 & TST & \\
\hline CHEMBL1608621 & 688816 & 8.1024 & 5.7304 & TRN & \\
\hline CHEMBL1429071 & 688816 & 4.95 & 5.6798 & TRN & \\
\hline CHEMBL1480700 & 688816 & 5.5 & 5.1636 & TRN & \\
\hline CHEMBL1388540 & 688816 & 5.4 & 5.8894 & TRN & \\
\hline CHEMBL1413962 & 688816 & 5.6 & 5.1001 & TRN & \\
\hline CHEMBL1316828 & 688816 & 4.8 & 5.23600 & 0000000001 & TST \\
\hline CHEMBL1450387 & 688816 & 4.45 & 5.2609 & TRN & \\
\hline CHEMBL1480093 & 688816 & 4.95 & 5.4597 & TRN & \\
\hline CHEMBL1347289 & 688816 & 5.5 & 5.3502 & TRN & \\
\hline CHEMBL1595634 & 688816 & 5.55 & 5.7877 & TRN & \\
\hline CHEMBL1509949 & 688816 & 4.9 & 5.0978 & TRN & \\
\hline CHEMBL29711 & 688816 & 6.0 & 5.5951 & TST & \\
\hline CHEMBL1996163 & 688816 & 4.5 & 5.1117 & TRN & \\
\hline CHEMBL1608798 & 688816 & 4.9 & 5.449 & TRN & \\
\hline CHEMBL1374554 & 688816 & 5.0 & 5.5637 & TRN & \\
\hline CHEMBL1461346 & 688816 & 4.75 & 4.8643 & TRN & \\
\hline CHEMBL1506738 & 688816 & 5.4 & 5.2579 & TRN & \\
\hline CHEMBL1412184 & 688816 & 4.45 & 4.98600 & 0000000001 & TRN \\
\hline CHEMBL1462044 & 688816 & 5.05 & 5.4017 & TRN & \\
\hline CHEMBL1506830 & 688816 & 4.95 & 5.1376 & TST & \\
\hline
\end{tabular}




\begin{tabular}{|c|c|c|c|c|c|}
\hline & & \multicolumn{4}{|c|}{ Supplemental Table S2.txt } \\
\hline CHEMBL 3189840 & 688816 & 7.5498 & 5.2545 & TST & \\
\hline CHEMBL1504529 & 688816 & 4.95 & 4.9099 & TRN & \\
\hline CHEMBL1351318 & 688816 & 4.75 & 4.9994 & TRN & \\
\hline CHEMBL1425680 & 688816 & 5.35 & 5.4998 & TST & \\
\hline CHEMBL1430953 & 688816 & 5.0 & 5.1248 & TRN & \\
\hline CHEMBL1308223 & 688816 & 5.7 & 5.4908 & TRN & \\
\hline CHEMBL1369117 & 688816 & 4.6 & 5.3356 & TST & \\
\hline CHEMBL1580718 & 688816 & 5.25 & 5.4518 & TRN & \\
\hline CHEMBL1313680 & 688816 & 6.5 & 5.612 & TRN & \\
\hline CHEMBL1418197 & 688816 & 5.95 & 5.1405 & TRN & \\
\hline CHEMBL3190207 & 688816 & 4.9 & 5.3045 & TRN & \\
\hline CHEMBL1533019 & 688816 & 5.45 & 5.4596 & TRN & \\
\hline CHEMBL1585255 & 688816 & 5.2 & 5.7057 & TRN & \\
\hline CHEMBL1361130 & 688816 & 4.8 & 5.104 & TRN & \\
\hline CHEMBL1532227 & 688816 & 5.4 & 5.4032 & TRN & \\
\hline CHEMBL1360370 & 688816 & 8.0 & 5.5177 & TST & \\
\hline CHEMBL1430695 & 688816 & 4.9 & 5.1419 & TST & \\
\hline CHEMBL1439788 & 688816 & 5.45 & 5.4908 & TST & \\
\hline CHEMBL1560982 & 688816 & 4.75 & 5.232 & TRN & \\
\hline CHEMBL1374845 & 688816 & 5.1 & 5.1239 & TRN & \\
\hline CHEMBL1487590 & 688816 & 4.55 & 5.4039 & TRN & \\
\hline CHEMBL1538992 & 688816 & 5.95 & 5.0498 & TRN & \\
\hline CHEMBL1414188 & 688816 & 4.6 & 4.7766 & TRN & \\
\hline CHEMBL1504829 & 688816 & 4.45 & 5.1701 & TRN & \\
\hline CHEMBL1450872 & 688816 & 4.7 & 5.19600 & 0000000001 & TST \\
\hline CHEMBL1592093 & 688816 & 4.95 & 5.0483 & TRN & \\
\hline CHEMBL1533113 & 688816 & 4.45 & 5.0101 & TRN & \\
\hline CHEMBL1427719 & 688816 & 8.4949 & 5.2632 & TRN & \\
\hline CHEMBL 3189254 & 688816 & 4.6 & 5.3732 & TST & \\
\hline CHEMBL1464827 & 688816 & 4.95 & 5.0438 & TRN & \\
\hline CHEMBL1426634 & 688816 & 4.85 & 5.2241 & TRN & \\
\hline CHEMBL1405533 & 688816 & 4.75 & 5.421 & TRN & \\
\hline CHEMBL1528069 & 688816 & 8.5528 & 5.6253 & TRN & \\
\hline CHEMBL1413793 & 688816 & 4.75 & 5.1848 & TRN & \\
\hline CHEMBL1582303 & 688816 & 4.7 & 5.2486 & TST & \\
\hline CHEMBL1544734 & 688816 & 4.95 & 5.0807 & TRN & \\
\hline CHEMBL1578377 & 688816 & 4.75 & 5.251 & TST & \\
\hline CHEMBL1404458 & 688816 & 5.0 & 5.0957 & TRN & \\
\hline CHEMBL1480605 & 688816 & 5.4 & 5.5889 & TRN & \\
\hline CHEMBL1362470 & 688816 & 7.699 & 5.2005 & TST & \\
\hline CHEMBL1383640 & 688816 & 8.301 & 5.3167 & TST & \\
\hline CHEMBL1394707 & 688816 & 4.45 & 5.1264 & TRN & \\
\hline CHEMBL1573261 & 688816 & 4.8 & 5.16700 & 0000000001 & TRN \\
\hline CHEMBL1445282 & 688816 & 4.85 & 5.1972 & TRN & \\
\hline CHEMBL1338713 & 688816 & 4.9 & 5.5716 & TRN & \\
\hline CHEMBL1404016 & 688816 & 7.4498 & 5.4521 & TRN & \\
\hline CHEMBL1425407 & 688816 & 4.95 & 4.8779 & TRN & \\
\hline CHEMBL1432403 & 688816 & 7.7496 & 5.3551 & TRN & \\
\hline
\end{tabular}




\begin{tabular}{|c|c|c|c|c|c|}
\hline \multirow[b]{2}{*}{ CHEMBL1558972 } & & \multicolumn{4}{|c|}{ Supplemental Table S2.txt } \\
\hline & 688816 & 4.65 & 4.9155 & TRN & \\
\hline CHEMBL1462243 & 688816 & 5.05 & 4.9637 & TST & \\
\hline CHEMBL1442737 & 688816 & 6.9 & 5.1544 & TST & \\
\hline CHEMBL1494390 & 688816 & 4.7 & 4.7876 & TRN & \\
\hline CHEMBL1413054 & 688816 & 5.25 & 4.8338 & TRN & \\
\hline CHEMBL1980018 & 688816 & 4.9 & 5.1902 & TRN & \\
\hline CHEMBL 2004185 & 688816 & 5.45 & 5.1327 & TRN & \\
\hline CHEMBL1332073 & 688816 & 4.45 & 5.2015 & TRN & \\
\hline CHEMBL1361279 & 688816 & 4.9 & 5.2167 & TRN & \\
\hline CHEMBL1515797 & 688816 & 5.0 & 5.2761 & TRN & \\
\hline CHEMBL1612797 & 688816 & 5.15 & 5.4534 & TRN & \\
\hline CHEMBL365327 & 688816 & 5.1 & 5.3836 & TRN & \\
\hline CHEMBL1477327 & 688816 & 4.6 & 5.2212 & TST & \\
\hline CHEMBL1441190 & 688816 & 4.85 & \multicolumn{2}{|c|}{5.492000000000001} & TRN \\
\hline CHEMBL1527532 & 688816 & 4.9 & 5.3877 & TRN & \\
\hline CHEMBL 3208392 & 688816 & 5.2 & 5.265 & TRN & \\
\hline CHEMBL1335062 & 688816 & 5.1 & 5.4454 & TST & \\
\hline CHEMBL1997928 & 688816 & 4.65 & 5.3934 & TST & \\
\hline CHEMBL1540596 & 688816 & 5.35 & 5.07 & TST & \\
\hline CHEMBL1383645 & 688816 & 5.1 & 5.1777 & TRN & \\
\hline CHEMBL1558094 & 688816 & 5.55 & 5.1551 & TRN & \\
\hline CHEMBL1594414 & 688816 & 6.8 & 5.9896 & TRN & \\
\hline CHEMBL1554969 & 688816 & 5.5 & 5.5255 & TRN & \\
\hline CHEMBL1484989 & 688816 & 4.95 & 5.063 & TRN & \\
\hline CHEMBL1493011 & 688816 & 6.0 & 5.7491 & TST & \\
\hline CHEMBL1348239 & 688816 & 5.4 & 5.1162 & TRN & \\
\hline CHEMBL1412890 & 688816 & 7.8508 & 5.7175 & TRN & \\
\hline CHEMBL1448741 & 688816 & 4.75 & 4.7512 & TRN & \\
\hline CHEMBL1384790 & 688816 & 5.7 & 5.6647 & TRN & \\
\hline CHEMBL3145329 & 688816 & 4.45 & 5.5324 & TST & \\
\hline CHEMBL1425932 & 688816 & 4.9 & 5.0322 & TRN & \\
\hline CHEMBL1391066 & 688816 & 4.85 & 5.2589 & TST & \\
\hline CHEMBL3191634 & 688816 & 8.3468 & 5.1424 & TST & \\
\hline CHEMBL1299414 & 688816 & 6.25 & 5.7786 & TRN & \\
\hline CHEMBL1550963 & 688816 & 4.9 & 5.2899 & TRN & \\
\hline CHEMBL1309673 & 688816 & 5.0 & 5.5471 & TST & \\
\hline CHEMBL1586403 & 688816 & 8.301 & 5.3706 & TRN & \\
\hline CHEMBL1416324 & 688816 & 4.95 & 5.4034 & TRN & \\
\hline CHEMBL1501078 & 688816 & 4.75 & 5.1025 & TRN & \\
\hline CHEMBL1486838 & 688816 & 7.6498 & 5.3737 & TRN & \\
\hline CHEMBL3195756 & 688816 & 5.3 & 5.2529 & TRN & \\
\hline CHEMBL1569708 & 688816 & 4.45 & 5.4659 & TST & \\
\hline CHEMBL1548343 & 688816 & 8.301 & 5.3408 & TRN & \\
\hline CHEMBL1345104 & 688816 & 4.75 & 5.065 & TST & \\
\hline CHEMBL3196193 & 688816 & 5.65 & 5.1958 & TRN & \\
\hline CHEMBL1581546 & 688816 & 4.95 & 5.249 & TRN & \\
\hline CHEMBL1486315 & 688816 & 4.45 & 5.0212 & TRN & \\
\hline \multirow[t]{2}{*}{ CHEMBL1548349 } & 688816 & 4.65 & \multicolumn{2}{|c|}{5.156000000000001} & TRN \\
\hline & & & & 25010 & \\
\hline
\end{tabular}




\begin{tabular}{|c|c|c|c|c|c|}
\hline & & & & & \\
\hline CHEMBL1375365 & 688816 & 4.85 & 5.0069 & TRN & \\
\hline CHEMBL1399395 & 688816 & 7.699 & 5.7863 & TRN & \\
\hline CHEMBL1556256 & 688816 & 7.699 & 5.1567 & TRN & \\
\hline CHEMBL 3207520 & 688816 & 4.75 & 4.9673 & TST & \\
\hline CHEMBL1555344 & 688816 & 4.65 & 5.2003 & TRN & \\
\hline CHEMBL1299741 & 688816 & 4.85 & 5.4311 & TST & \\
\hline CHEMBL1451343 & 688816 & 8.301 & 5.0659 & TRN & \\
\hline CHEMBL1322012 & 688816 & 6.05 & 4.9677 & TRN & \\
\hline CHEMBL1328760 & 688816 & 4.95 & 5.3854 & TRN & \\
\hline CHEMBL1334953 & 688816 & 8.3468 & 5.76399 & 9999999999 & TST \\
\hline CHEMBL1415300 & 688816 & 4.45 & 4.9987 & TST & \\
\hline CHEMBL1369511 & 688816 & 7.4498 & 5.7589 & TRN & \\
\hline CHEMBL 3195351 & 688816 & 6.7501 & 5.4687 & TRN & \\
\hline CHEMBL1359668 & 688816 & 5.0 & 5.3667 & TST & \\
\hline CHEMBL1587892 & 688816 & 6.8 & 5.5082 & TRN & \\
\hline CHEMBL 2005518 & 688816 & 4.9 & 5.0613 & TRN & \\
\hline CHEMBL1864436 & 688816 & 4.9 & 5.3129 & TRN & \\
\hline CHEMBL1413641 & 688816 & 5.1 & 5.1309 & TRN & \\
\hline CHEMBL1507191 & 688816 & 7.5498 & 5.4469 & TST & \\
\hline CHEMBL1372768 & 688816 & 4.95 & 5.5415 & TRN & \\
\hline CHEMBL1349905 & 688816 & 4.45 & 5.33799 & 9999999999 & TRN \\
\hline CHEMBL1364528 & 688816 & 4.65 & 5.2362 & TRN & \\
\hline CHEMBL1412869 & 688816 & 6.5501 & 5.7233 & TRN & \\
\hline CHEMBL 2007091 & 688816 & 4.45 & 5.0135 & TRN & \\
\hline CHEMBL1467457 & 688816 & 4.55 & 5.3008 & TST & \\
\hline CHEMBL1349361 & 688816 & 5.35 & 5.6721 & TRN & \\
\hline CHEMBL518575 & 688816 & 4.85 & 5.3847 & TRN & \\
\hline CHEMBL1325900 & 688816 & 4.7 & 5.4182 & TRN & \\
\hline CHEMBL1453299 & 688816 & 4.75 & 4.9894 & TRN & \\
\hline CHEMBL1582039 & 688816 & 4.8 & 5.1891 & TRN & \\
\hline CHEMBL3195652 & 688816 & 5.55 & 5.0014 & TRN & \\
\hline CHEMBL1410647 & 688816 & 5.45 & 5.3089 & TRN & \\
\hline CHEMBL1438621 & 688816 & 4.45 & 5.0301 & TRN & \\
\hline CHEMBL1323090 & 688816 & 5.4 & 5.5251 & TST & \\
\hline CHEMBL1375877 & 688816 & 4.95 & 5.6074 & TRN & \\
\hline CHEMBL1300763 & 688816 & 4.45 & 5.2115 & TRN & \\
\hline CHEMBL1326613 & 688816 & 5.5 & 5.237 & TRN & \\
\hline CHEMBL1405922 & 688816 & 6.0 & 5.08899 & 99999999995 & TST \\
\hline CHEMBL1428483 & 688816 & 5.5 & 5.3491 & TST & \\
\hline CHEMBL1333559 & 688816 & 4.45 & 4.7974 & TRN & \\
\hline CHEMBL1372629 & 688816 & 4.45 & 5.3037 & TRN & \\
\hline CHEMBL1580673 & 688816 & 6.4 & 5.6751 & TRN & \\
\hline CHEMBL1372191 & 688816 & 5.0 & 5.4558 & TRN & \\
\hline CHEMBL1369023 & 688816 & 4.7 & 5.2511 & TST & \\
\hline CHEMBL1521676 & 688816 & 4.45 & 5.3783 & TRN & \\
\hline CHEMBL1502260 & 688816 & 4.5 & 4.9631 & TRN & \\
\hline CHEMBL1549209 & 688816 & 4.75 & 4.9296 & TRN & \\
\hline CHEMBL1364602 & 688816 & 4.95 & 5.4955 & TRN & \\
\hline
\end{tabular}




\begin{tabular}{|c|c|c|c|c|c|}
\hline \multicolumn{6}{|c|}{ Supplemental Table S2.txt } \\
\hline CHEMBL1437644 & 688816 & 4.45 & 5.4035 & TST & \\
\hline CHEMBL1521204 & 688816 & 4.85 & 4.8135 & TRN & \\
\hline CHEMBL1334330 & 688816 & 4.9 & 4.9031 & TRN & \\
\hline CHEMBL1483666 & 688816 & 8.4559 & 5.6221 & TST & \\
\hline CHEMBL3198579 & 688816 & 4.8 & 5.088 & TST & \\
\hline CHEMBL3195924 & 688816 & 4.95 & 4.989 & TST & \\
\hline CHEMBL1391443 & 688816 & 4.95 & 5.1215 & TRN & \\
\hline CHEMBL 3191488 & 688816 & 4.9 & 5.2138 & TRN & \\
\hline CHEMBL1407235 & 688816 & 4.95 & 5.2067 & TST & \\
\hline CHEMBL1446957 & 688816 & 4.9 & 5.2558 & TST & \\
\hline CHEMBL1546062 & 688816 & 4.7 & 5.4338 & TRN & \\
\hline CHEMBL1497109 & 688816 & 5.2 & 5.4274 & TRN & \\
\hline CHEMBL1549115 & 688816 & 8.301 & 5.3397 & TRN & \\
\hline CHEMBL1420649 & 688816 & 5.2 & 5.1077 & TST & \\
\hline CHEMBL1339717 & 688816 & 4.9 & 5.0676 & TST & \\
\hline CHEMBL1534753 & 688816 & 8.301 & 5.1855 & TST & \\
\hline CHEMBL1522299 & 688816 & 6.7001 & 5.7902 & TRN & \\
\hline CHEMBL3194298 & 688816 & 8.3468 & 5.1428 & TRN & \\
\hline CHEMBL1504719 & 688816 & 4.45 & 5.2469 & TRN & \\
\hline CHEMBL1544606 & 688816 & 4.9 & 5.1981 & TRN & \\
\hline CHEMBL 2000008 & 688816 & 5.45 & 5.3549 & TRN & \\
\hline CHEMBL1332461 & 688816 & 5.8 & 5.2543 & TRN & \\
\hline CHEMBL1545268 & 688816 & 4.7 & 5.232 & TRN & \\
\hline CHEMBL1346410 & 688816 & 5.35 & 5.391 & TRN & \\
\hline CHEMBL1501846 & 688816 & 4.85 & 4.8943 & TRN & \\
\hline CHEMBL1380158 & 688816 & 5.0 & 5.2269 & TRN & \\
\hline CHEMBL1549018 & 688816 & 4.65 & 5.2567 & TRN & \\
\hline CHEMBL 1480640 & 688816 & 5.05 & 5.6199 & TRN & \\
\hline CHEMBL1587317 & 688816 & 8.0 & 5.6935 & TST & \\
\hline CHEMBL1457427 & 688816 & 4.9 & 5.0309 & TRN & \\
\hline CHEMBL 295344 & 688816 & 4.6 & 5.3238 & TST & \\
\hline CHEMBL1336006 & 688816 & 4.8 & 5.3712 & TRN & \\
\hline CHEMBL1502883 & 688816 & 4.95 & 5.0249 & TRN & \\
\hline CHEMBL1508723 & 688816 & 4.45 & 5.13399 & 99999999995 & TRN \\
\hline CHEMBL1423291 & 688816 & 5.0 & 4.8253 & TRN & \\
\hline CHEMBL1397888 & 688816 & 4.45 & 5.246 & TRN & \\
\hline CHEMBL1485278 & 688816 & 5.3 & 5.5564 & TRN & \\
\hline CHEMBL1345598 & 688816 & 4.85 & 5.3403 & TST & \\
\hline CHEMBL1363982 & 688816 & 4.45 & 4.9804 & TRN & \\
\hline CHEMBL199925 & 688816 & 4.8 & 5.3649 & TRN & \\
\hline CHEMBL1336025 & 688816 & 5.0 & 5.4735 & TST & \\
\hline CHEMBL1425351 & 688816 & 5.85 & 5.6692 & TRN & \\
\hline CHEMBL3210205 & 688816 & 6.4 & 5.7145 & TST & \\
\hline CHEMBL1556513 & 688816 & 5.1 & 5.143 & TRN & \\
\hline CHEMBL3195387 & 688816 & 4.6 & 5.3089 & TRN & \\
\hline CHEMBL1597699 & 688816 & 4.95 & 5.4008 & TST & \\
\hline CHEMBL1358986 & 688816 & 5.2 & 5.2368 & TRN & \\
\hline CHEMBL1578460 & 688816 & 4.95 & 5.2079 & TRN & \\
\hline
\end{tabular}




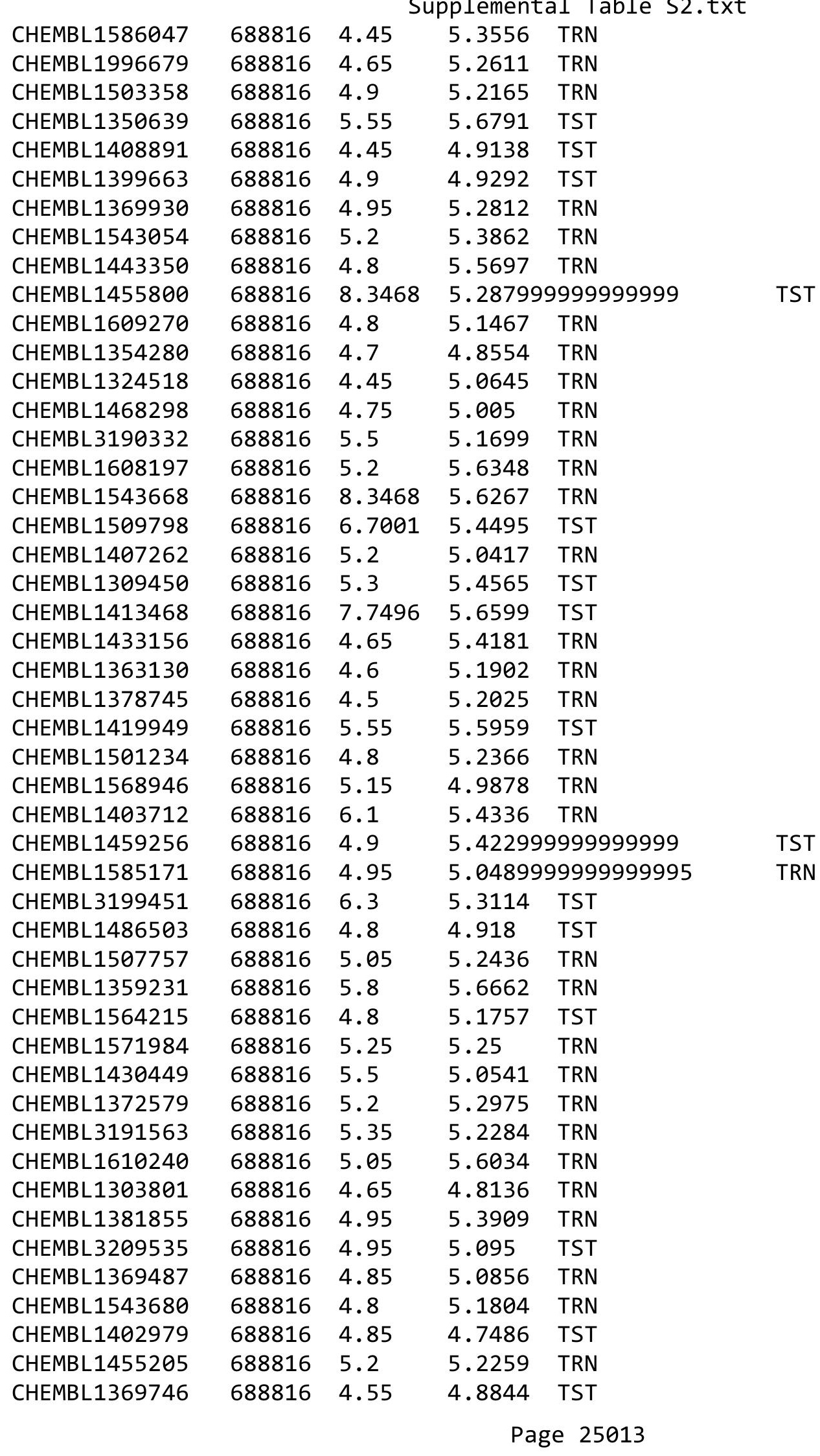




\begin{tabular}{|c|c|c|c|c|c|}
\hline \\
\hline CHEMBL1561564 & 688816 & 4.7 & 5.3874 & TRN & \\
\hline CHEMBL1604382 & 688816 & 5.4 & 5.8719 & TRN & \\
\hline CHEMBL1486095 & 688816 & 5.5 & 4.9322 & TRN & \\
\hline CHEMBL1420018 & 688816 & 5.0 & 5.6341 & TST & \\
\hline CHEMBL1609314 & 688816 & 8.301 & 5.2028 & TRN & \\
\hline CHEMBL1486150 & 688816 & 5.4 & 5.1988 & TRN & \\
\hline CHEMBL1599821 & 688816 & 4.95 & 5.0234 & TRN & \\
\hline CHEMBL1351676 & 688816 & 5.15 & 5.318 & TRN & \\
\hline CHEMBL3210006 & 688816 & 7.8996 & 5.53299 & 99999999995 & TRN \\
\hline CHEMBL1409871 & 688816 & 5.25 & 5.6749 & TRN & \\
\hline CHEMBL1269779 & 688816 & 4.5 & 4.9951 & TST & \\
\hline CHEMBL1528816 & 688816 & 4.8 & 5.1411 & TRN & \\
\hline CHEMBL1412319 & 688816 & 4.95 & 5.385 & TRN & \\
\hline CHEMBL1462944 & 688816 & 6.5 & 5.4593 & TRN & \\
\hline CHEMBL1561578 & 688816 & 5.2 & 5.6921 & TST & \\
\hline CHEMBL1337492 & 688816 & 4.45 & 4.9601 & TRN & \\
\hline CHEMBL1545203 & 688816 & 6.1 & 5.2213 & TRN & \\
\hline CHEMBL1449336 & 688816 & 5.9 & 5.2874 & TST & \\
\hline CHEMBL1596490 & 688816 & 5.0 & 5.405 & TRN & \\
\hline CHEMBL1301125 & 688816 & 4.8 & 5.3902 & TRN & \\
\hline CHEMBL1403854 & 688816 & 4.45 & 5.1949 & TST & \\
\hline CHEMBL1550083 & 688816 & 4.85 & 5.1358 & TST & \\
\hline CHEMBL1506339 & 688816 & 4.75 & 5.1138 & TRN & \\
\hline CHEMBL1608332 & 688816 & 4.45 & 5.1149 & TST & \\
\hline CHEMBL1500748 & 688816 & 7.6498 & 5.4675 & TRN & \\
\hline CHEMBL1462192 & 688816 & 4.85 & 4.8923 & TST & \\
\hline CHEMBL1529299 & 688816 & 4.9 & 4.9844 & TRN & \\
\hline CHEMBL1523671 & 688816 & 8.0 & 5.5487 & TST & \\
\hline CHEMBL1569671 & 688816 & 5.05 & 5.2254 & TRN & \\
\hline CHEMBL1578568 & 688816 & 4.9 & 5.1156 & TRN & \\
\hline CHEMBL1426556 & 688816 & 5.05 & 5.1113 & TRN & \\
\hline CHEMBL1501374 & 688816 & 5.35 & 5.407 & TRN & \\
\hline CHEMBL1579301 & 688816 & 4.95 & 5.4026 & TRN & \\
\hline CHEMBL1516465 & 688816 & 5.25 & 5.40600 & 0000000001 & TST \\
\hline CHEMBL1558065 & 688816 & 4.8 & 4.8307 & TRN & \\
\hline CHEMBL1528007 & 688816 & 5.45 & 4.9791 & TRN & \\
\hline CHEMBL1324863 & 688816 & 4.65 & 5.2618 & TRN & \\
\hline CHEMBL1519118 & 688816 & 4.85 & 5.3463 & TRN & \\
\hline CHEMBL1611222 & 688816 & 5.0 & 5.1154 & TRN & \\
\hline CHEMBL1405946 & 688816 & 4.9 & 4.9491 & TRN & \\
\hline CHEMBL1300434 & 688816 & 5.65 & 5.7455 & TST & \\
\hline CHEMBL1563969 & 688816 & 4.45 & 5.7129 & TST & \\
\hline CHEMBL1453884 & 688816 & 4.45 & 5.1502 & TRN & \\
\hline CHEMBL1325049 & 688816 & 4.95 & 5.2823 & TRN & \\
\hline CHEMBL1584127 & 688816 & 4.6 & 5.3366 & TRN & \\
\hline CHEMBL1500521 & 688816 & 4.95 & 5.3927 & TRN & \\
\hline CHEMBL1378967 & 688816 & 6.05 & 5.2051 & TRN & \\
\hline CHEMBL1988457 & 688816 & 4.85 & 5.1415 & TRN & \\
\hline
\end{tabular}




\begin{tabular}{|c|c|c|c|c|c|}
\hline \multicolumn{6}{|c|}{ Supplemental Table S2.txt } \\
\hline CHEMBL1350084 & 688816 & 4.95 & 5.0321 & TST & \\
\hline CHEMBL1444774 & 688816 & 4.95 & 4.9636 & TRN & \\
\hline CHEMBL1300575 & 688816 & 5.75 & 5.1476 & TRN & \\
\hline CHEMBL1302991 & 688816 & 4.9 & 5.5675 & TRN & \\
\hline CHEMBL1575686 & 688816 & 4.65 & 5.1994 & TRN & \\
\hline CHEMBL1418012 & 688816 & 4.9 & 5.4218 & TRN & \\
\hline CHEMBL1309640 & 688816 & 4.95 & 5.0773 & TRN & \\
\hline CHEMBL1492533 & 688816 & 5.05 & 5.2113 & TRN & \\
\hline CHEMBL1519404 & 688816 & 4.8 & 5.1091 & TRN & \\
\hline CHEMBL1468458 & 688816 & 4.65 & 4.9091 & TRN & \\
\hline CHEMBL1549595 & 688816 & 4.45 & 5.4323 & TRN & \\
\hline CHEMBL1375231 & 688816 & 4.95 & 5.2972 & TRN & \\
\hline CHEMBL1375793 & 688816 & 4.45 & 4.8929 & TRN & \\
\hline CHEMBL1354320 & 688816 & 4.95 & 5.4484 & TRN & \\
\hline CHEMBL609030 & 688816 & 4.8 & 5.3071 & TST & \\
\hline CHEMBL1989225 & 688816 & 6.45 & 5.3511 & TRN & \\
\hline CHEMBL3189518 & 688816 & 4.6 & 5.5423 & TRN & \\
\hline CHEMBL1541594 & 688816 & 6.8 & 4.8905 & TRN & \\
\hline CHEMBL1402926 & 688816 & 8.0 & 5.1817 & TRN & \\
\hline CHEMBL1585652 & 688816 & 4.9 & 4.882 & TRN & \\
\hline CHEMBL1349509 & 688816 & 7.4001 & 5.4491 & TST & \\
\hline CHEMBL491716 & 688816 & 5.3 & 5.4656 & TRN & \\
\hline CHEMBL1436424 & 688816 & 4.95 & 5.1459 & TRN & \\
\hline CHEMBL1429373 & 688816 & 4.85 & 5.3598 & TRN & \\
\hline CHEMBL1603928 & 688816 & 4.95 & 5.4185 & TRN & \\
\hline CHEMBL3194962 & 688816 & 5.4 & 5.38399 & 99999999995 & TRN \\
\hline CHEMBL1413263 & 688816 & 8.301 & 5.4603 & TRN & \\
\hline CHEMBL1389939 & 688816 & 4.8 & 5.348 & TRN & \\
\hline CHEMBL1458306 & 688816 & 4.8 & 5.0173 & TRN & \\
\hline CHEMBL1325852 & 688816 & 4.45 & 5.2889 & TRN & \\
\hline CHEMBL1375289 & 688816 & 5.05 & 5.4996 & TRN & \\
\hline CHEMBL1349067 & 688816 & 4.95 & 5.1949 & TRN & \\
\hline CHEMBL1565535 & 688816 & 7.699 & 5.3512 & TST & \\
\hline CHEMBL1586361 & 688816 & 4.9 & 5.3046 & TST & \\
\hline CHEMBL1385570 & 688816 & 4.75 & 5.1692 & TRN & \\
\hline CHEMBL1387421 & 688816 & 5.65 & 4.9392 & TRN & \\
\hline CHEMBL1524554 & 688816 & 4.75 & 4.8649 & TRN & \\
\hline CHEMBL1509992 & 688816 & 4.75 & 5.1012 & TRN & \\
\hline CHEMBL1449011 & 688816 & 4.9 & 5.0793 & TRN & \\
\hline CHEMBL1529029 & 688816 & 4.9 & 4.8251 & TRN & \\
\hline CHEMBL1594604 & 688816 & 6.0 & 4.7602 & TST & \\
\hline CHEMBL1411420 & 688816 & 6.8 & 5.4364 & TRN & \\
\hline CHEMBL1407353 & 688816 & 6.05 & 5.184 & TRN & \\
\hline CHEMBL1307358 & 688816 & 4.8 & 5.3295 & TRN & \\
\hline CHEMBL3198544 & 688816 & 5.65 & 5.3495 & TRN & \\
\hline CHEMBL1448330 & 688816 & 5.3 & 5.5023 & TST & \\
\hline CHEMBL1576748 & 688816 & 5.3 & 5.49100 & 00000000005 & TRN \\
\hline CHEMBL1420552 & 688816 & 4.7 & 5.1783 & TRN & \\
\hline
\end{tabular}




\begin{tabular}{|c|c|c|c|c|c|}
\hline \multirow{3}{*}{$\begin{array}{l}\text { CHEMBL1532931 } \\
\text { CHEMBL } 1581581\end{array}$} & & \multicolumn{4}{|c|}{ Supplemental Table S2.txt } \\
\hline & 688816 & 4.95 & \multicolumn{2}{|c|}{5.2989999999999995} & TRN \\
\hline & 688816 & 4.75 & 4.8344 & TRN & \\
\hline CHEMBL1515577 & 688816 & 5.45 & 5.2965 & TRN & \\
\hline CHEMBL3198976 & 688816 & 4.95 & 5.0266 & TST & \\
\hline CHEMBL1380904 & 688816 & 5.5 & 5.5204 & TST & \\
\hline CHEMBL1516768 & 688816 & 4.45 & 5.1399 & TRN & \\
\hline CHEMBL1569490 & 688816 & 6.8 & 5.63 & TRN & \\
\hline CHEMBL1302591 & 688816 & 6.7501 & 5.2444 & TRN & \\
\hline CHEMBL1419139 & 688816 & 4.45 & 5.4324 & TRN & \\
\hline CHEMBL1331222 & 688816 & 5.05 & 5.0692 & TRN & \\
\hline CHEMBL1518828 & 688816 & 6.1 & 5.1169 & TST & \\
\hline CHEMBL3213263 & 688816 & 5.25 & 5.1813 & TRN & \\
\hline CHEMBL1471529 & 688816 & 4.95 & 5.1843 & TST & \\
\hline CHEMBL1399286 & 688816 & 5.4 & 5.8443 & TST & \\
\hline CHEMBL1376055 & 688816 & 6.3 & 5.3713 & TRN & \\
\hline CHEMBL1589782 & 688816 & 4.7 & 4.7647 & TRN & \\
\hline CHEMBL20730 & 688816 & 6.0 & 5.3681 & TRN & \\
\hline CHEMBL1402756 & 688816 & 4.9 & 4.9177 & TRN & \\
\hline CHEMBL1560244 & 688816 & 4.6 & 5.2612 & TRN & \\
\hline CHEMBL1428935 & 688816 & 4.8 & 4.9926 & TRN & \\
\hline CHEMBL1534849 & 688816 & 5.15 & 5.2612 & TRN & \\
\hline CHEMBL1370244 & 688816 & 5.1 & 5.2028 & TRN & \\
\hline CHEMBL1487269 & 688816 & 5.0 & 5.2537 & TRN & \\
\hline CHEMBL1319100 & 688816 & 5.25 & 5.3148 & TRN & \\
\hline CHEMBL1303115 & 688816 & 4.45 & 4.9439 & TRN & \\
\hline CHEMBL1357369 & 688816 & 6.4 & 6.0368 & TRN & \\
\hline CHEMBL1340454 & 688816 & 4.8 & 5.0705 & TRN & \\
\hline CHEMBL1353904 & 688816 & 4.45 & 5.0626 & TST & \\
\hline CHEMBL1421735 & 688816 & 4.65 & 5.4672 & TRN & \\
\hline CHEMBL1602699 & 688816 & 4.55 & 5.8695 & TST & \\
\hline CHEMBL1534578 & 688816 & 4.95 & 5.6583 & TST & \\
\hline CHEMBL1570713 & 688816 & 4.45 & 5.6372 & TRN & \\
\hline CHEMBL3194074 & 688816 & 5.25 & 5.66799 & 9999999999 & TRN \\
\hline CHEMBL1367682 & 688816 & 4.45 & 5.3125 & TRN & \\
\hline CHEMBL1330928 & 688816 & 4.45 & 5.3366 & TRN & \\
\hline CHEMBL1532486 & 688816 & 5.05 & 5.2912 & TST & \\
\hline CHEMBL1990598 & 688816 & 5.2 & 5.7712 & TRN & \\
\hline CHEMBL1364859 & 688816 & 5.9 & 5.3879 & TRN & \\
\hline CHEMBL1330417 & 688816 & 6.4 & 5.1787 & TST & \\
\hline CHEMBL1450038 & 688816 & 4.55 & 5.4001 & TRN & \\
\hline CHEMBL1998061 & 688816 & 5.0 & 5.2462 & TST & \\
\hline CHEMBL1334966 & 688816 & 7.5003 & 5.2899 & TRN & \\
\hline CHEMBL1532453 & 688816 & 4.75 & 5.4778 & TRN & \\
\hline CHEMBL1469876 & 688816 & 4.85 & 5.077 & TRN & \\
\hline CHEMBL1557513 & 688816 & 5.8 & 5.5474 & TRN & \\
\hline CHEMBL1463950 & 688816 & 4.85 & 5.3179 & TST & \\
\hline CHEMBL1320728 & 688816 & 7.5498 & 5.5548 & TST & \\
\hline CHEMBL1500025 & 688816 & 4.45 & 5.0712 & TRN & \\
\hline
\end{tabular}




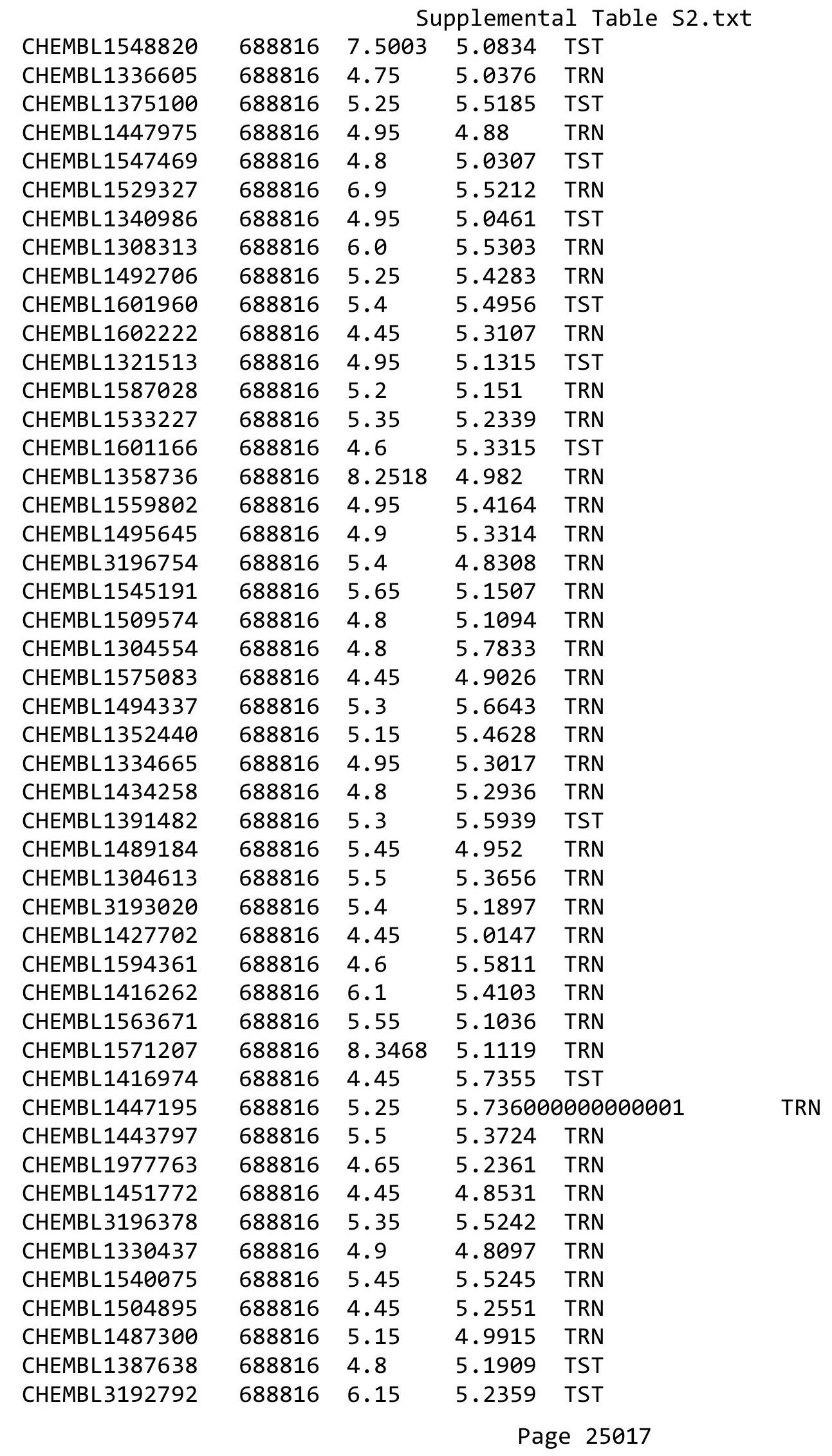




\begin{tabular}{|c|c|c|c|c|}
\hline \multicolumn{5}{|c|}{ Supplemental Table S2.txt } \\
\hline CHEMBL1413316 & 688816 & 5.55 & 4.9851 & TRN \\
\hline CHEMBL1520019 & 688816 & 4.7 & 5.3891 & TST \\
\hline CHEMBL1401162 & 688816 & 4.9 & 5.0567 & TRN \\
\hline CHEMBL1454268 & 688816 & 5.4 & 5.6892 & TST \\
\hline CHEMBL1582564 & 688816 & 4.65 & 5.1876 & TRN \\
\hline CHEMBL1581094 & 688816 & 4.9 & 5.7776 & TST \\
\hline CHEMBL1347497 & 688816 & 4.45 & 5.175 & TST \\
\hline CHEMBL1481348 & 688816 & 4.45 & 5.6537 & TST \\
\hline CHEMBL1565508 & 688816 & 4.45 & 5.2979 & TRN \\
\hline CHEMBL1381816 & 688816 & 4.8 & 5.2321 & TRN \\
\hline CHEMBL1432842 & 688816 & 4.85 & 4.6433 & TST \\
\hline CHEMBL1430455 & 688816 & 5.05 & 5.2603 & TRN \\
\hline CHEMBL1440842 & 688816 & 6.05 & 5.4531 & TST \\
\hline CHEMBL1608248 & 688816 & 4.95 & 4.9414 & TRN \\
\hline CHEMBL1380598 & 688816 & 5.45 & 5.2916 & TRN \\
\hline CHEMBL1533086 & 688816 & 5.1 & 5.1579 & TRN \\
\hline CHEMBL1575926 & 688816 & 5.2 & 5.5613 & TRN \\
\hline CHEMBL1494467 & 688816 & 4.95 & 5.4863 & TRN \\
\hline CHEMBL1403437 & 688816 & 5.0 & 5.3138 & TRN \\
\hline CHEMBL1319624 & 688816 & 4.65 & 5.4726 & TRN \\
\hline CHEMBL1380359 & 688816 & 4.95 & 4.9661 & TRN \\
\hline CHEMBL1306594 & 688816 & 4.6 & 5.6383 & TRN \\
\hline CHEMBL1589808 & 688816 & 4.9 & 4.734 & TRN \\
\hline CHEMBL1347636 & 688816 & 5.25 & 5.2168 & TST \\
\hline CHEMBL1570526 & 688816 & 5.5 & 5.1867 & TRN \\
\hline CHEMBL1576998 & 688816 & 5.25 & 4.8938 & TRN \\
\hline CHEMBL1566290 & 688816 & 8.3468 & 5.7495 & TRN \\
\hline CHEMBL1306877 & 688816 & 7.5003 & 5.28 & TST \\
\hline CHEMBL1519919 & 688816 & 5.0 & 5.4404 & TRN \\
\hline CHEMBL1567907 & 688816 & 4.65 & 5.3713 & TST \\
\hline CHEMBL1465932 & 688816 & 4.5 & 4.9856 & TRN \\
\hline CHEMBL3189607 & 688816 & 4.95 & 5.0455 & TRN \\
\hline CHEMBL579150 & 688816 & 4.7 & 5.2295 & TST \\
\hline CHEMBL1326728 & 688816 & 5.1 & 5.0124 & TRN \\
\hline CHEMBL567850 & 688816 & 6.8 & 5.1107 & TRN \\
\hline CHEMBL1495889 & 688816 & 4.95 & 5.2891 & TRN \\
\hline CHEMBL1573112 & 688816 & 5.2 & 5.5659 & TRN \\
\hline CHEMBL1465748 & 688816 & 4.45 & 5.3704 & TRN \\
\hline CHEMBL1319186 & 688816 & 5.15 & 5.1793 & TRN \\
\hline CHEMBL1528382 & 688816 & 4.8 & 5.3187 & TST \\
\hline CHEMBL454487 & 688816 & 4.95 & 5.2052 & TRN \\
\hline CHEMBL1461408 & 688816 & 4.8 & 5.2317 & TRN \\
\hline CHEMBL1392327 & 688816 & 4.45 & 5.6217 & TRN \\
\hline CHEMBL1517525 & 688816 & 5.2 & 5.1665 & TST \\
\hline CHEMBL1474093 & 688816 & 4.65 & 4.9952 & TRN \\
\hline CHEMBL3197200 & 688816 & 6.6499 & 5.5924 & TRN \\
\hline CHEMBL1387048 & 688816 & 4.8 & 5.535 & TST \\
\hline CHEMBL1335741 & 688816 & 4.55 & 5.468 & TRN \\
\hline
\end{tabular}




\begin{tabular}{|c|c|c|c|c|c|}
\hline \multicolumn{6}{|c|}{ Supplemental Table S2.txt } \\
\hline CHEMBL1342281 & 688816 & 5.0 & 5.0665 & TRN & \\
\hline CHEMBL1464368 & 688816 & 4.65 & 5.6542 & TRN & \\
\hline CHEMBL1449569 & 688816 & 4.85 & 4.6373 & TRN & \\
\hline CHEMBL1331409 & 688816 & 6.0 & 5.0828 & TRN & \\
\hline CHEMBL1349717 & 688816 & 5.85 & 5.3869 & TST & \\
\hline CHEMBL1568982 & 688816 & 4.9 & 5.0795 & TST & \\
\hline CHEMBL1494769 & 688816 & 4.45 & 5.3053 & TRN & \\
\hline CHEMBL1470561 & 688816 & 4.45 & 5.0764 & TRN & \\
\hline CHEMBL1424204 & 688816 & 4.9 & 5.2441 & TRN & \\
\hline CHEMBL1528072 & 688816 & 5.0 & 5.3889 & TRN & \\
\hline CHEMBL1981856 & 688816 & 4.9 & 5.1569 & TST & \\
\hline CHEMBL1384253 & 688816 & 5.25 & 5.3012 & TRN & \\
\hline CHEMBL71936 & 688816 & 4.9 & 5.191 & TRN & \\
\hline CHEMBL1433140 & 688816 & 7.6498 & 5.4491 & TRN & \\
\hline CHEMBL1367066 & 688816 & 5.5 & 5.6661 & TRN & \\
\hline CHEMBL1501676 & 688816 & 5.95 & 5.5387 & TRN & \\
\hline CHEMBL1463365 & 688816 & 4.85 & 5.1111 & TRN & \\
\hline CHEMBL1370673 & 688816 & 7.4001 & 5.3666 & TRN & \\
\hline CHEMBL1424691 & 688816 & 4.5 & 5.3451 & TST & \\
\hline CHEMBL1386967 & 688816 & 4.8 & 5.3672 & TRN & \\
\hline CHEMBL1364663 & 688816 & 8.3468 & 5.374 & TST & \\
\hline CHEMBL1585388 & 688816 & 4.8 & 5.138 & TRN & \\
\hline CHEMBL1573534 & 688816 & 6.7501 & 5.3068 & TRN & \\
\hline CHEMBL1299740 & 688816 & 5.55 & 5.3415 & TST & \\
\hline CHEMBL1443454 & 688816 & 4.95 & 5.2654 & TRN & \\
\hline CHEMBL1459969 & 688816 & 7.3002 & 5.4343 & TST & \\
\hline CHEMBL1329090 & 688816 & 4.45 & 4.7865 & TRN & \\
\hline CHEMBL1590304 & 688816 & 4.95 & 5.0414 & TRN & \\
\hline CHEMBL1386032 & 688816 & 4.7 & 5.0744 & TST & \\
\hline CHEMBL1507501 & 688816 & 8.4949 & 5.8508 & TRN & \\
\hline CHEMBL40004 & 688816 & 5.0 & 5.05399 & 9999999999 & TRN \\
\hline CHEMBL1978415 & 688816 & 5.0 & 5.29299 & 9999999999 & TST \\
\hline CHEMBL1576301 & 688816 & 4.95 & 5.1332 & TRN & \\
\hline CHEMBL1486883 & 688816 & 4.9 & 5.3536 & TRN & \\
\hline CHEMBL1531691 & 688816 & 6.25 & 5.4712 & TRN & \\
\hline CHEMBL1332127 & 688816 & 5.3 & 5.224 & TRN & \\
\hline CHEMBL1416583 & 688816 & 4.95 & 5.2304 & TRN & \\
\hline CHEMBL1412433 & 688816 & 4.7 & 5.309 & TST & \\
\hline CHEMBL1346532 & 688816 & 8.0 & 5.1882 & TRN & \\
\hline CHEMBL1543899 & 688816 & 4.6 & 5.1523 & TST & \\
\hline CHEMBL1301914 & 688816 & 8.4949 & 5.1954 & TRN & \\
\hline CHEMBL1434220 & 688816 & 4.9 & 5.1837 & TRN & \\
\hline CHEMBL1557961 & 688816 & 7.4498 & 5.1305 & TST & \\
\hline CHEMBL1442312 & 688816 & 4.95 & 4.9403 & TRN & \\
\hline CHEMBL3190227 & 688816 & 6.25 & 5.2292 & TST & \\
\hline CHEMBL1501265 & 688816 & 4.85 & 4.8049 & TRN & \\
\hline CHEMBL1512783 & 688816 & 4.85 & 5.0285 & TST & \\
\hline CHEMBL1455585 & 688816 & 5.2 & 5.5304 & TRN & \\
\hline
\end{tabular}




\begin{tabular}{|c|c|c|c|c|}
\hline \multicolumn{5}{|c|}{ Supplemental Table s2.txt } \\
\hline CHEMBL1576457 & 688816 & 5.4 & 5.1846 & TRN \\
\hline CHEMBL1596589 & 688816 & 5.1 & 5.4928 & TRN \\
\hline CHEMBL1466477 & 688816 & 6.25 & 5.6287 & TRN \\
\hline CHEMBL1442884 & 688816 & 5.45 & 4.8225 & TST \\
\hline CHEMBL1448420 & 688816 & 5.8 & 5.256 & TST \\
\hline CHEMBL1305025 & 688816 & 4.45 & 5.317 & TRN \\
\hline CHEMBL1429016 & 688816 & 5.0 & 5.3326 & TST \\
\hline CHEMBL1609635 & 688816 & 4.45 & 5.2837 & TRN \\
\hline CHEMBL1487914 & 688816 & 4.95 & 5.1474 & TRN \\
\hline CHEMBL1597147 & 688816 & 5.0 & 5.2969 & TRN \\
\hline CHEMBL1499871 & 688816 & 4.45 & 5.2146 & TRN \\
\hline CHEMBL1478344 & 688816 & 6.35 & 5.1246 & TRN \\
\hline CHEMBL1454464 & 688816 & 5.85 & 5.2525 & TRN \\
\hline CHEMBL1537857 & 688816 & 4.65 & 5.109 & TRN \\
\hline CHEMBL1335293 & 688816 & 4.45 & 5.8978 & TRN \\
\hline CHEMBL1538517 & 688816 & 4.9 & 5.1806 & TRN \\
\hline CHEMBL1461234 & 688816 & 4.45 & 5.2968 & TRN \\
\hline CHEMBL1584799 & 688816 & 5.4 & 5.1858 & TRN \\
\hline CHEMBL1595675 & 688816 & 4.95 & 5.4047 & TST \\
\hline CHEMBL1494625 & 688816 & 5.4 & 5.5447 & TRN \\
\hline CHEMBL1473470 & 688816 & 4.95 & 5.2094 & TRN \\
\hline CHEMBL1388808 & 688816 & 4.75 & 5.3619 & TRN \\
\hline CHEMBL1352918 & 688816 & 7.7496 & 5.2989 & TRN \\
\hline CHEMBL1359019 & 688816 & 5.3 & 5.3361 & TRN \\
\hline CHEMBL1534071 & 688816 & 4.95 & 5.4492 & TST \\
\hline CHEMBL1299268 & 688816 & 4.9 & 4.8944 & TRN \\
\hline CHEMBL1483321 & 688816 & 5.0 & 5.0146 & TRN \\
\hline CHEMBL1569183 & 688816 & 4.6 & 5.0248 & TRN \\
\hline CHEMBL1537385 & 688816 & 4.9 & 5.1134 & TRN \\
\hline CHEMBL1355825 & 688816 & 4.95 & 5.3201 & TRN \\
\hline CHEMBL1607003 & 688816 & 8.301 & 5.1212 & TRN \\
\hline CHEMBL1501755 & 688816 & 4.5 & 5.1807 & TRN \\
\hline CHEMBL1340845 & 688816 & 5.5 & 5.1947 & TRN \\
\hline CHEMBL1527277 & 688816 & 7.5003 & 5.176 & TST \\
\hline CHEMBL1605766 & 688816 & 5.25 & 5.2283 & TRN \\
\hline CHEMBL3213535 & 688816 & 4.45 & $5.5070 e$ & 0000000001 \\
\hline CHEMBL1487761 & 688816 & 4.95 & 5.0159 & TRN \\
\hline CHEMBL1401090 & 688816 & 4.9 & 5.2033 & TRN \\
\hline CHEMBL1547092 & 688816 & 4.45 & 4.9236 & TST \\
\hline CHEMBL1300882 & 688816 & 4.45 & 5.346 & TRN \\
\hline CHEMBL1518107 & 688816 & 4.7 & 5.2437 & TRN \\
\hline CHEMBL1402284 & 688816 & 6.35 & 5.5915 & TRN \\
\hline CHEMBL1559487 & 688816 & 4.95 & 5.5146 & TST \\
\hline CHEMBL1578697 & 688816 & 8.301 & 5.3321 & TST \\
\hline CHEMBL1327169 & 688816 & 4.85 & 5.2408 & TRN \\
\hline CHEMBL1540208 & 688816 & 4.9 & 4.9248 & TRN \\
\hline CHEMBL1318630 & 688816 & 4.95 & 5.2958 & TST \\
\hline CHEMBL1603032 & 688816 & 4.85 & 5.3544 & TST \\
\hline
\end{tabular}




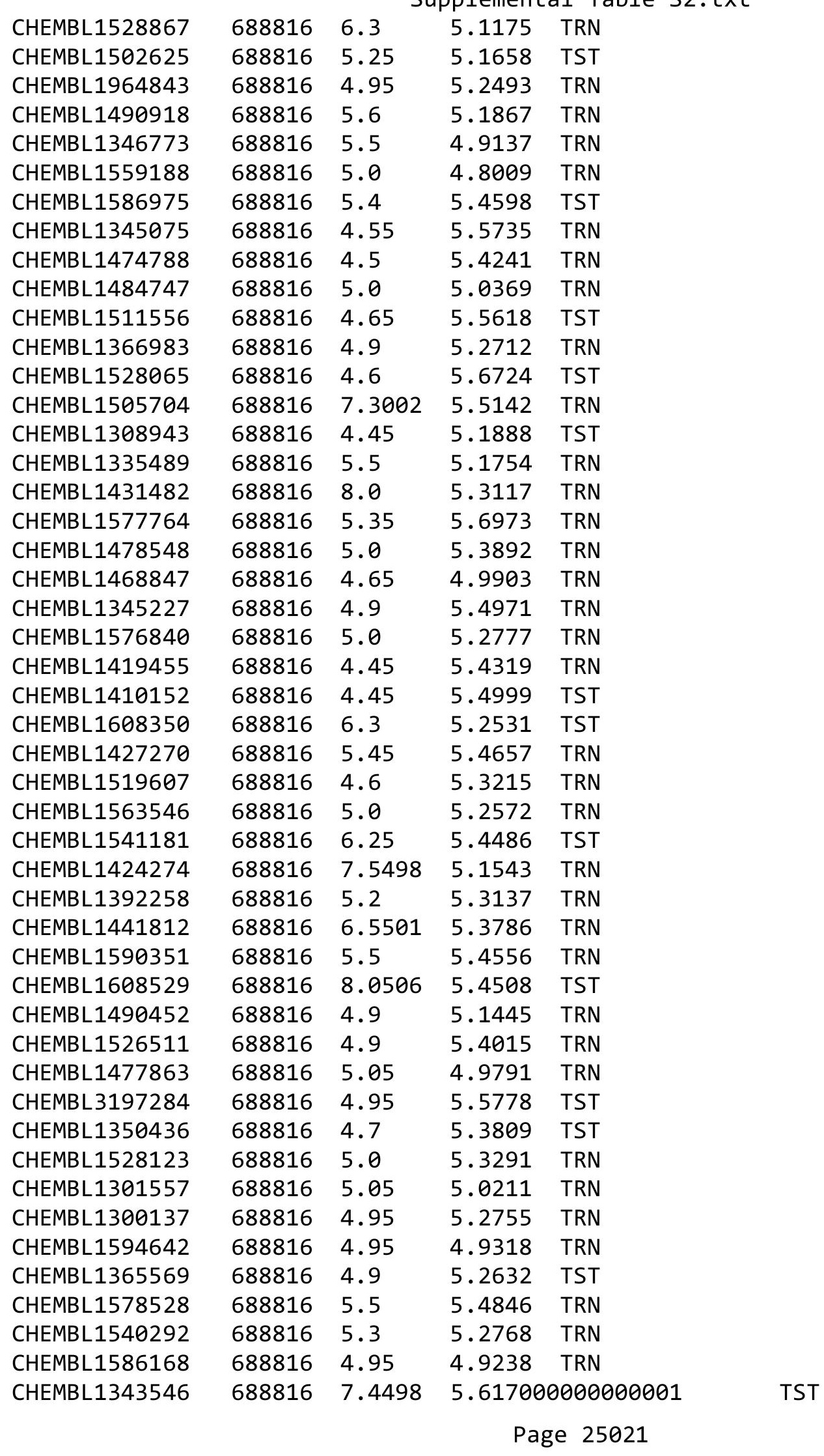




\begin{tabular}{|c|c|c|c|c|c|}
\hline \multicolumn{6}{|c|}{ Supplemental Table S2.txt } \\
\hline CHEMBL1374270 & 688816 & 4.85 & 5.3279 & TRN & \\
\hline CHEMBL1303224 & 688816 & 4.85 & 5.2414 & TRN & \\
\hline CHEMBL3209607 & 688816 & 6.7001 & 5.3086 & TST & \\
\hline CHEMBL1477953 & 688816 & 4.9 & 5.343 & TRN & \\
\hline CHEMBL1372535 & 688816 & 5.9 & 5.1424 & TRN & \\
\hline CHEMBL1411576 & 688816 & 5.0 & 5.4764 & TST & \\
\hline CHEMBL1314142 & 688816 & 5.25 & 5.5172 & TST & \\
\hline CHEMBL1312046 & 688816 & 5.35 & 5.3313 & TRN & \\
\hline CHEMBL1530872 & 688816 & 5.35 & 5.1531 & TST & \\
\hline CHEMBL1450990 & 688816 & 5.75 & 5.2995 & TST & \\
\hline CHEMBL1363533 & 688816 & 5.6 & 5.6219 & TRN & \\
\hline CHEMBL1382355 & 688816 & 4.95 & 5.3263 & TRN & \\
\hline CHEMBL1409370 & 688816 & 4.75 & 5.3685 & TRN & \\
\hline CHEMBL1399702 & 688816 & 4.5 & 5.4859 & TRN & \\
\hline CHEMBL1510042 & 688816 & 4.5 & 5.2993 & TRN & \\
\hline CHEMBL1594672 & 688816 & 4.45 & 5.4583 & TRN & \\
\hline CHEMBL1591619 & 688816 & 5.7 & 5.3122 & TST & \\
\hline CHEMBL1404382 & 688816 & 6.3 & 5.2954 & TRN & \\
\hline CHEMBL1304331 & 688816 & 4.7 & 5.1856 & TRN & \\
\hline CHEMBL1486773 & 688816 & 5.55 & 5.5197 & TST & \\
\hline CHEMBL3196136 & 688816 & 7.4001 & 5.4875 & TRN & \\
\hline CHEMBL1431983 & 688816 & 4.85 & 4.895 & TRN & \\
\hline CHEMBL502774 & 688816 & 4.9 & 5.2957 & TRN & \\
\hline CHEMBL1461096 & 688816 & 5.05 & 5.70200 & 0000000001 & TRN \\
\hline CHEMBL1487028 & 688816 & 4.95 & 5.2452 & TRN & \\
\hline CHEMBL1488504 & 688816 & 4.9 & 5.01699 & 99999999995 & TST \\
\hline CHEMBL1418213 & 688816 & 8.1024 & 5.1356 & TST & \\
\hline CHEMBL1604776 & 688816 & 5.25 & 5.8358 & TRN & \\
\hline CHEMBL1431063 & 688816 & 4.95 & 5.3255 & TRN & \\
\hline CHEMBL1583161 & 688816 & 4.45 & 5.0427 & TRN & \\
\hline CHEMBL1461437 & 688816 & 5.5 & 5.504 & TRN & \\
\hline CHEMBL1494587 & 688816 & 4.9 & 5.3905 & TST & \\
\hline CHEMBL1486286 & 688816 & 5.4 & 5.0682 & TRN & \\
\hline CHEMBL1329153 & 688816 & 6.15 & 5.4389 & TST & \\
\hline CHEMBL1444873 & 688816 & 4.65 & 4.9188 & TRN & \\
\hline CHEMBL1605893 & 688816 & 4.7 & 5.2748 & TRN & \\
\hline CHEMBL1571156 & 688816 & 4.45 & 5.3562 & TRN & \\
\hline CHEMBL1483975 & 688816 & 4.95 & 4.9375 & TRN & \\
\hline CHEMBL1446080 & 688816 & 5.2 & 5.3613 & TST & \\
\hline CHEMBL1600173 & 688816 & 5.2 & 5.3156 & TRN & \\
\hline CHEMBL1436368 & 688816 & 4.55 & 4.8661 & TRN & \\
\hline CHEMBL1331145 & 688816 & 5.65 & 5.0037 & TRN & \\
\hline CHEMBL1367076 & 688816 & 4.95 & 5.0336 & TRN & \\
\hline CHEMBL1442342 & 688816 & 4.5 & 4.881 & TST & \\
\hline CHEMBL1377588 & 688816 & 5.4 & 5.331 & TRN & \\
\hline CHEMBL1408523 & 688816 & 4.95 & 5.2396 & TRN & \\
\hline CHEMBL1433255 & 688816 & 4.7 & 5.2255 & TRN & \\
\hline CHEMBL1601532 & 688816 & 5.0 & 5.0421 & TRN & \\
\hline
\end{tabular}




\begin{tabular}{|c|c|c|c|c|}
\hline \multicolumn{5}{|c|}{ Supplemental Table S2.txt } \\
\hline CHEMBL1424276 & 688816 & 5.25 & 5.1466 & TST \\
\hline CHEMBL1598969 & 688816 & 5.3 & 5.2901 & TRN \\
\hline CHEMBL1337134 & 688816 & 4.85 & 5.5339 & TRN \\
\hline CHEMBL1563054 & 688816 & 5.4 & 5.3319 & TRN \\
\hline CHEMBL1330065 & 688816 & 8.1024 & 5.2581 & TRN \\
\hline CHEMBL1363558 & 688816 & 4.6 & 5.3898 & TST \\
\hline CHEMBL1461902 & 688816 & 4.45 & 5.045 & TRN \\
\hline CHEMBL1494464 & 688816 & 4.95 & 5.7071 & TST \\
\hline CHEMBL1579464 & 688816 & 6.15 & 5.0938 & TRN \\
\hline CHEMBL1505864 & 688816 & 4.9 & 5.2995 & TST \\
\hline CHEMBL1344324 & 688816 & 5.15 & 5.4168 & TRN \\
\hline CHEMBL1465522 & 688816 & 5.6 & 5.0639 & TST \\
\hline CHEMBL1450867 & 688816 & 5.4 & 5.1228 & TST \\
\hline CHEMBL1256924 & 688816 & 4.75 & 5.3355 & TST \\
\hline CHEMBL1478788 & 688816 & 4.45 & 5.4354 & TRN \\
\hline CHEMBL3213991 & 688816 & 5.0 & 5.2983 & TRN \\
\hline CHEMBL1521116 & 688816 & 5.4 & 5.1684 & TRN \\
\hline CHEMBL1539847 & 688816 & 4.8 & 5.6257 & TRN \\
\hline CHEMBL1563449 & 688816 & 5.25 & 5.3284 & TRN \\
\hline CHEMBL1429979 & 688816 & 5.25 & 5.7381 & TRN \\
\hline CHEMBL1449655 & 688816 & 4.9 & 5.5574 & TST \\
\hline CHEMBL1411547 & 688816 & 5.05 & 5.0891 & TRN \\
\hline CHEMBL1327789 & 688816 & 4.9 & 5.1193 & TRN \\
\hline CHEMBL1485168 & 688816 & 4.95 & 4.9299 & TST \\
\hline CHEMBL1354578 & 688816 & 4.95 & 5.1811 & TRN \\
\hline CHEMBL1588099 & 688816 & 8.301 & 5.4475 & TRN \\
\hline CHEMBL1347695 & 688816 & 8.3468 & 5.0491 & TRN \\
\hline CHEMBL3211414 & 688816 & 4.5 & 5.0442 & TRN \\
\hline CHEMBL523052 & 688816 & 4.45 & 5.2818 & TRN \\
\hline CHEMBL1519247 & 688816 & 5.35 & 5.4507 & TRN \\
\hline CHEMBL1585086 & 688816 & 5.15 & 4.9226 & TRN \\
\hline CHEMBL1309330 & 688816 & 5.35 & 5.2946 & TST \\
\hline CHEMBL1362057 & 688816 & 4.95 & 5.2308 & TRN \\
\hline CHEMBL1555035 & 688816 & 4.75 & 5.0174 & TRN \\
\hline CHEMBL1359230 & 688816 & 5.0 & 5.386 & TST \\
\hline CHEMBL1309246 & 688816 & 7.3497 & 5.0885 & TRN \\
\hline CHEMBL1385481 & 688816 & 4.45 & 5.5625 & TRN \\
\hline CHEMBL1505994 & 688816 & 4.45 & 5.1581 & TST \\
\hline CHEMBL601335 & 688816 & 6.0 & 5.3449 & TRN \\
\hline CHEMBL1554720 & 688816 & 4.95 & 4.6821 & TRN \\
\hline CHEMBL1335493 & 688816 & 4.85 & 5.2547 & TRN \\
\hline CHEMBL1408709 & 688816 & 8.301 & 5.0749 & TST \\
\hline CHEMBL1433149 & 688816 & 4.45 & 5.3214 & TRN \\
\hline CHEMBL1589244 & 688816 & 4.9 & 5.3944 & TRN \\
\hline CHEMBL1521691 & 688816 & 4.45 & 5.3344 & TRN \\
\hline CHEMBL1467705 & 688816 & 4.95 & 5.1364 & TRN \\
\hline CHEMBL1432272 & 688816 & 4.45 & 5.2644 & TST \\
\hline CHEMBL3190091 & 688816 & 4.85 & 5.2245 & TRN \\
\hline
\end{tabular}




\begin{tabular}{|c|c|c|c|c|}
\hline \multicolumn{5}{|c|}{ Supplemental Table S2.txt } \\
\hline CHEMBL1364655 & 688816 & 4.75 & 5.0997 & TRN \\
\hline CHEMBL1489221 & 688816 & 4.9 & 5.1194 & TST \\
\hline CHEMBL1405194 & 688816 & 6.0 & 5.3312 & TRN \\
\hline CHEMBL1458446 & 688816 & 5.8 & 5.3236 & TRN \\
\hline CHEMBL1484561 & 688816 & 4.9 & 5.6773 & TRN \\
\hline CHEMBL1517276 & 688816 & 5.0 & 5.1788 & TRN \\
\hline CHEMBL1528922 & 688816 & 5.25 & 5.7006 & TRN \\
\hline CHEMBL1329566 & 688816 & 4.75 & 4.7946 & TRN \\
\hline CHEMBL1421576 & 688816 & 4.95 & 5.3424 & TST \\
\hline CHEMBL1595262 & 688816 & 5.4 & 5.3991 & TRN \\
\hline CHEMBL3195978 & 688816 & 5.0 & 5.3353 & TRN \\
\hline CHEMBL1391672 & 688816 & 4.45 & 4.9962 & TRN \\
\hline CHEMBL1455874 & 688816 & 6.9 & 5.3733 & TST \\
\hline CHEMBL1607670 & 688816 & 6.05 & 4.9004 & TST \\
\hline CHEMBL3189943 & 688816 & 5.6 & 5.4302 & TRN \\
\hline CHEMBL1699206 & 688816 & 4.75 & 5.05 & TST \\
\hline CHEMBL1373521 & 688816 & 4.95 & 5.2557 & TRN \\
\hline CHEMBL1561762 & 688816 & 8.3468 & 5.4292 & TRN \\
\hline CHEMBL 3194300 & 688816 & 4.95 & 5.4644 & TRN \\
\hline CHEMBL1577857 & 688816 & 6.3 & 5.4686 & TRN \\
\hline CHEMBL198759 & 688816 & 6.3 & 5.1175 & TST \\
\hline CHEMBL1468941 & 688816 & 6.0 & 5.3806 & TST \\
\hline CHEMBL1456780 & 688816 & 4.45 & 4.5853 & TRN \\
\hline CHEMBL1315519 & 688816 & 6.7501 & 5.2213 & TRN \\
\hline CHEMBL1580138 & 688816 & 7.8996 & 5.4581 & TRN \\
\hline CHEMBL3196933 & 688816 & 4.7 & 5.352 & TRN \\
\hline CHEMBL1606399 & 688816 & 6.05 & 5.4203 & TRN \\
\hline CHEMBL1441222 & 688816 & 5.9 & 5.1395 & TST \\
\hline CHEMBL1566301 & 688816 & 6.7501 & 5.0865 & TRN \\
\hline CHEMBL1450911 & 688816 & 5.6 & 5.2557 & TRN \\
\hline CHEMBL147514 & 688816 & 4.9 & 5.3638 & TRN \\
\hline CHEMBL1410792 & 688816 & 5.45 & 5.3417 & TRN \\
\hline CHEMBL1980031 & 688816 & 4.75 & 5.6432 & TRN \\
\hline CHEMBL1439741 & 688816 & 4.45 & 5.3569 & TST \\
\hline CHEMBL1531450 & 688816 & 4.9 & 5.1386 & TRN \\
\hline CHEMBL1504575 & 688816 & 4.85 & 5.2109 & TRN \\
\hline CHEMBL1490289 & 688816 & 4.8 & 5.4962 & TRN \\
\hline CHEMBL1408398 & 688816 & 4.9 & 5.1547 & TRN \\
\hline CHEMBL1426487 & 688816 & 4.95 & 5.2616 & TST \\
\hline CHEMBL1545972 & 688816 & 4.45 & 5.0817 & TRN \\
\hline CHEMBL1541693 & 688816 & 4.45 & 4.9353 & TRN \\
\hline CHEMBL1604272 & 688816 & 4.6 & 4.9967 & TRN \\
\hline CHEMBL1304058 & 688816 & 4.45 & 5.3066 & TRN \\
\hline CHEMBL1496462 & 688816 & 4.8 & 5.3388 & TRN \\
\hline CHEMBL1414314 & 688816 & 6.8 & 5.6608 & TRN \\
\hline CHEMBL1572416 & 688816 & 4.95 & 5.2424 & TRN \\
\hline CHEMBL1574587 & 688816 & 5.45 & 5.2453 & TST \\
\hline CHEMBL1584692 & 688816 & 5.25 & 5.4647 & TST \\
\hline
\end{tabular}




\begin{tabular}{|c|c|c|c|c|c|}
\hline \\
\hline CHEMBL3209890 & 688816 & 4.8 & 5.5368 & TST & \\
\hline CHEMBL1507127 & 688816 & 4.6 & 5.1349 & TRN & \\
\hline CHEMBL1347444 & 688816 & 4.95 & 5.0395 & TRN & \\
\hline CHEMBL1994815 & 688816 & 4.45 & 4.74100 & 00000000005 & TRN \\
\hline CHEMBL1597322 & 688816 & 5.6 & 5.3399 & TRN & \\
\hline CHEMBL1421231 & 688816 & 5.25 & 5.433 & TRN & \\
\hline CHEMBL 3197410 & 688816 & 4.9 & 5.3102 & TRN & \\
\hline CHEMBL1415516 & 688816 & 4.95 & 5.072 & TRN & \\
\hline CHEMBL1430036 & 688816 & 6.5501 & 5.2476 & TRN & \\
\hline CHEMBL1462104 & 688816 & 7.2503 & 5.8191 & TST & \\
\hline CHEMBL1477574 & 688816 & 4.9 & 5.426 & TST & \\
\hline CHEMBL1361719 & 688816 & 5.65 & 5.2812 & TRN & \\
\hline CHEMBL1336900 & 688816 & 6.6 & 5.3563 & TST & \\
\hline CHEMBL1575214 & 688816 & 5.0 & 5.477 & TST & \\
\hline CHEMBL1982539 & 688816 & 4.45 & 4.6961 & TST & \\
\hline CHEMBL1411654 & 688816 & 8.301 & 5.2561 & TRN & \\
\hline CHEMBL1338774 & 688816 & 6.2 & 5.4202 & TRN & \\
\hline CHEMBL1561506 & 688816 & 5.25 & 5.1864 & TRN & \\
\hline CHEMBL1492933 & 688816 & 4.95 & 5.1554 & TRN & \\
\hline CHEMBL 3211733 & 688816 & 4.9 & 4.9316 & TRN & \\
\hline CHEMBL1352969 & 688816 & 6.35 & 5.3203 & TRN & \\
\hline CHEMBL1498574 & 688816 & 5.0 & 5.2534 & TST & \\
\hline CHEMBL1376395 & 688816 & 5.85 & 5.3972 & TRN & \\
\hline CHEMBL1603373 & 688816 & 4.95 & 4.9064 & TRN & \\
\hline CHEMBL1323700 & 688816 & 8.4949 & 5.7514 & TRN & \\
\hline CHEMBL1521823 & 688816 & 5.55 & 5.2829 & TRN & \\
\hline CHEMBL1587699 & 688816 & 5.2 & 5.3663 & TRN & \\
\hline CHEMBL1549802 & 688816 & 7.5498 & 5.2382 & TST & \\
\hline CHEMBL1515842 & 688816 & 4.9 & 5.2093 & TRN & \\
\hline CHEMBL 1459929 & 688816 & 4.9 & 5.5672 & TRN & \\
\hline CHEMBL1491322 & 688816 & 5.0 & 5.1306 & TST & \\
\hline CHEMBL1601297 & 688816 & 5.25 & 5.2109 & TRN & \\
\hline CHEMBL1373600 & 688816 & 8.1024 & 5.4416 & TRN & \\
\hline CHEMBL 3195606 & 688816 & 4.85 & 5.0568 & TRN & \\
\hline CHEMBL1371119 & 688816 & 4.65 & 4.9345 & TRN & \\
\hline CHEMBL1312285 & 688816 & 4.9 & 5.7552 & TRN & \\
\hline CHEMBL1406599 & 688816 & 7.6003 & 5.3103 & TST & \\
\hline CHEMBL1402600 & 688816 & 5.35 & 5.4993 & TST & \\
\hline CHEMBL1446651 & 688816 & 4.75 & 5.2194 & TRN & \\
\hline CHEMBL 1378826 & 688816 & 4.65 & 5.2883 & TRN & \\
\hline CHEMBL1542091 & 688816 & 5.5 & 5.1565 & TRN & \\
\hline CHEMBL 1588394 & 688816 & 4.45 & 5.0928 & TRN & \\
\hline CHEMBL1558124 & 688816 & 8.0506 & 5.4239 & TRN & \\
\hline CHEMBL1587709 & 688816 & 4.95 & 5.5272 & TRN & \\
\hline CHEMBL1362825 & 688816 & 4.6 & 5.169 & TRN & \\
\hline CHEMBL1472490 & 688816 & 8.0 & 5.5096 & TRN & \\
\hline CHEMBL1561543 & 688816 & 4.95 & 5.1717 & TRN & \\
\hline CHEMBL3197355 & 688816 & 5.65 & 5.2489 & TRN & \\
\hline
\end{tabular}




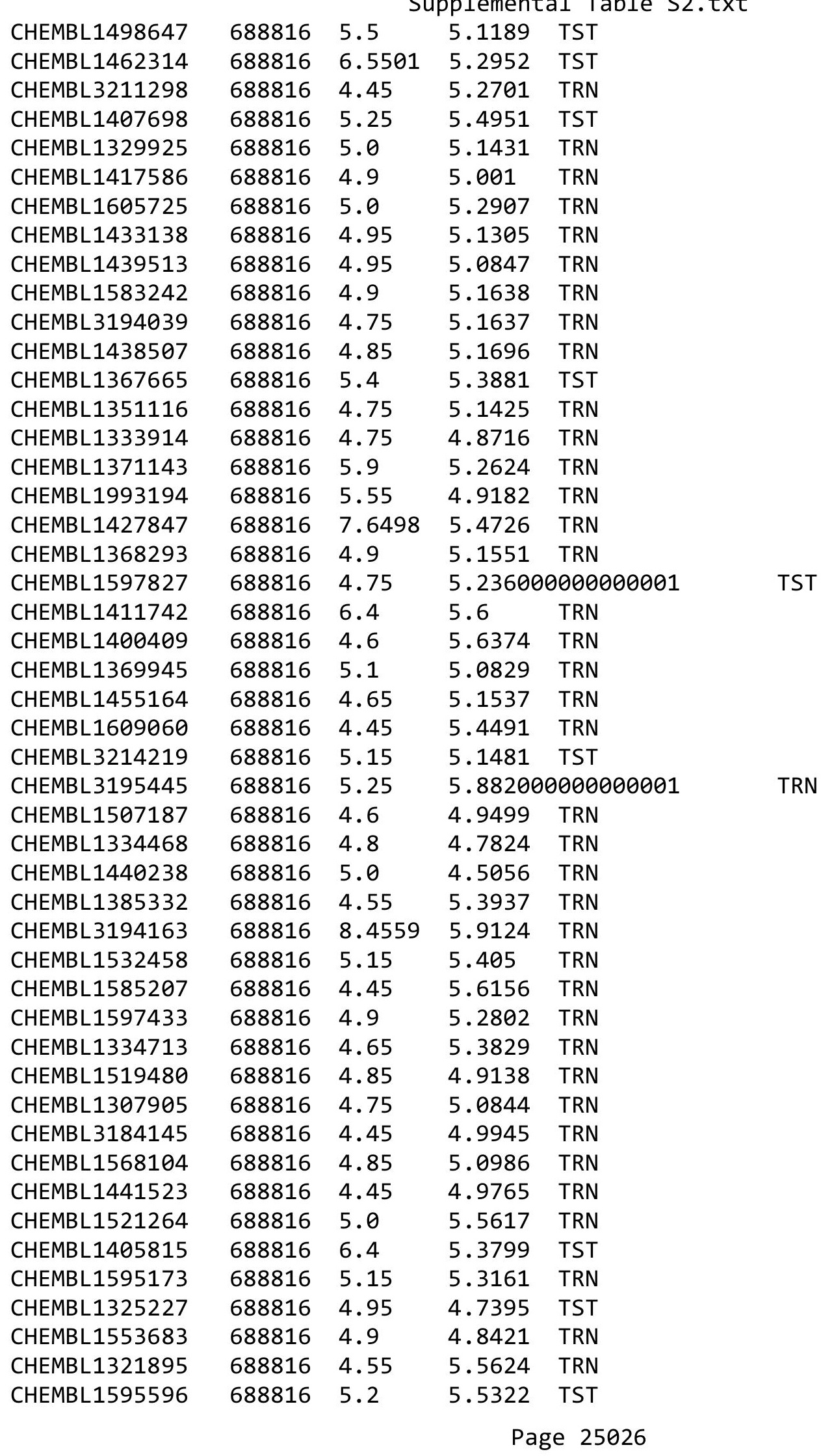




\begin{tabular}{|c|c|c|c|c|c|}
\hline & & & & & \\
\hline CHEMBL1569072 & 688816 & 4.9 & 5.2823 & TRN & \\
\hline CHEMBL1526240 & 688816 & 5.65 & 5.3596 & TRN & \\
\hline CHEMBL1328997 & 688816 & 7.15 & 5.4869 & TRN & \\
\hline CHEMBL1484241 & 688816 & 6.8499 & 5.4179 & TRN & \\
\hline CHEMBL1509514 & 688816 & 4.7 & 5.3823 & TRN & \\
\hline CHEMBL1566396 & 688816 & 4.8 & 5.1332 & TRN & \\
\hline CHEMBL1562494 & 688816 & 4.9 & 5.3212 & TRN & \\
\hline CHEMBL1346294 & 688816 & 4.9 & 5.2756 & TRN & \\
\hline CHEMBL1478870 & 688816 & 4.45 & 5.188 & TRN & \\
\hline CHEMBL1528329 & 688816 & 4.95 & 5.48 & TRN & \\
\hline CHEMBL1508230 & 688816 & 4.85 & 5.7364 & TRN & \\
\hline CHEMBL 3210474 & 688816 & 4.9 & 5.1169 & TRN & \\
\hline CHEMBL1477167 & 688816 & 6.8 & 5.4408 & TST & \\
\hline CHEMBL1535572 & 688816 & 4.65 & 5.2621 & TRN & \\
\hline CHEMBL1320917 & 688816 & 5.15 & 5.1147 & TST & \\
\hline CHEMBL1391103 & 688816 & 4.95 & 4.9391 & TRN & \\
\hline CHEMBL388823 & 688816 & 4.95 & 5.03100 & 0000000001 & TRN \\
\hline CHEMBL1368216 & 688816 & 5.4 & 5.3863 & TRN & \\
\hline CHEMBL1510764 & 688816 & 4.45 & 5.1495 & TST & \\
\hline CHEMBL1598968 & 688816 & 4.6 & 5.029 & TRN & \\
\hline CHEMBL1428924 & 688816 & 5.35 & 5.5322 & TRN & \\
\hline CHEMBL1385668 & 688816 & 5.0 & 5.124 & TRN & \\
\hline CHEMBL1385094 & 688816 & 4.8 & 5.2745 & TRN & \\
\hline CHEMBL1449500 & 688816 & 4.7 & 5.4756 & TST & \\
\hline CHEMBL1478032 & 688816 & 5.8 & 5.49799 & 9999999999 & TRN \\
\hline CHEMBL1329550 & 688816 & 4.45 & 5.6019 & TST & \\
\hline CHEMBL1501851 & 688816 & 4.9 & 5.26200 & 00000000005 & TRN \\
\hline CHEMBL1342148 & 688816 & 4.6 & 4.928 & TRN & \\
\hline CHEMBL1335918 & 688816 & 5.1 & 5.2882 & TST & \\
\hline CHEMBL 3190508 & 688816 & 4.75 & 5.152 & TRN & \\
\hline CHEMBL1318248 & 688816 & 5.05 & 4.8391 & TRN & \\
\hline CHEMBL1442317 & 688816 & 4.9 & 5.0501 & TRN & \\
\hline CHEMBL1368806 & 688816 & 6.0 & 5.5079 & TRN & \\
\hline CHEMBL1387598 & 688816 & 4.45 & 5.3195 & TST & \\
\hline CHEMBL1501091 & 688816 & 5.15 & 4.8196 & TRN & \\
\hline CHEMBL1431216 & 688816 & 7.6498 & 5.9477 & TST & \\
\hline CHEMBL1445436 & 688816 & 4.9 & 4.9296 & TRN & \\
\hline CHEMBL1981454 & 688816 & 5.0 & 5.7306 & TRN & \\
\hline CHEMBL1581949 & 688816 & 5.45 & 5.2216 & TRN & \\
\hline CHEMBL1304876 & 688816 & 4.95 & 5.3339 & TRN & \\
\hline CHEMBL1339029 & 688816 & 4.45 & 5.0893 & TST & \\
\hline CHEMBL1603354 & 688816 & 6.7001 & 5.7052 & TRN & \\
\hline CHEMBL1578932 & 688816 & 6.05 & 5.1799 & TRN & \\
\hline CHEMBL1581273 & 688816 & 5.55 & 5.1659 & TRN & \\
\hline CHEMBL1519193 & 688816 & 6.3 & 5.5329 & TRN & \\
\hline CHEMBL1583826 & 688816 & 4.45 & 5.4434 & TST & \\
\hline CHEMBL1548838 & 688816 & 7.0501 & 5.4708 & TRN & \\
\hline CHEMBL 2374058 & 688816 & 7.8013 & 5.6195 & TST & \\
\hline
\end{tabular}




\begin{tabular}{|c|c|c|c|c|c|}
\hline \multicolumn{6}{|c|}{ Supplemental Table S2.txt } \\
\hline CHEMBL1343458 & 688816 & 5.85 & 5.5156 & TRN & \\
\hline CHEMBL1505519 & 688816 & 5.7 & 5.2542 & TRN & \\
\hline CHEMBL1541551 & 688816 & 8.0 & 5.6276 & TRN & \\
\hline CHEMBL1464805 & 688816 & 8.301 & 5.3176 & TRN & \\
\hline CHEMBL1442469 & 688816 & 7.699 & 5.4186 & TRN & \\
\hline CHEMBL1390083 & 688816 & 4.9 & 5.3758 & TRN & \\
\hline CHEMBL1325278 & 688816 & 4.55 & 5.8264 & TRN & \\
\hline CHEMBL1591714 & 688816 & 4.45 & 5.3154 & TST & \\
\hline CHEMBL510773 & 688816 & 4.75 & 5.2698 & TST & \\
\hline CHEMBL1471500 & 688816 & 8.3468 & 5.825 & TRN & \\
\hline CHEMBL1609518 & 688816 & 4.9 & 5.2217 & TRN & \\
\hline CHEMBL1612840 & 688816 & 5.65 & 5.4023 & TRN & \\
\hline CHEMBL1533412 & 688816 & 4.6 & 5.4125 & TRN & \\
\hline CHEMBL1566813 & 688816 & 5.45 & 5.067 & TRN & \\
\hline CHEMBL1557932 & 688816 & 5.4 & 5.2803 & TRN & \\
\hline CHEMBL1452182 & 688816 & 7.15 & 5.67899 & 9999999999 & TRN \\
\hline CHEMBL1311641 & 688816 & 4.95 & 4.835 & TRN & \\
\hline CHEMBL1423338 & 688816 & 4.45 & 5.1373 & TRN & \\
\hline CHEMBL1557445 & 688816 & 4.75 & 5.1143 & TRN & \\
\hline CHEMBL1577145 & 688816 & 4.6 & 4.8609 & TRN & \\
\hline CHEMBL1499792 & 688816 & 4.9 & 5.2471 & TST & \\
\hline CHEMBL1416690 & 688816 & 5.4 & 5.4198 & TST & \\
\hline CHEMBL1548851 & 688816 & 4.8 & 5.3463 & TST & \\
\hline CHEMBL1485880 & 688816 & 5.2 & 5.4024 & TRN & \\
\hline CHEMBL34241 & 688816 & 6.0 & 4.8541 & TST & \\
\hline CHEMBL1420638 & 688816 & 5.4 & 4.8181 & TST & \\
\hline CHEMBL1478645 & 688816 & 4.7 & 5.0899 & TRN & \\
\hline CHEMBL1327810 & 688816 & 4.45 & 5.1285 & TRN & \\
\hline CHEMBL1567235 & 688816 & 4.95 & 5.2872 & TRN & \\
\hline CHEMBL1500898 & 688816 & 8.1024 & 5.354 & TRN & \\
\hline CHEMBL1525404 & 688816 & 4.9 & 4.5707 & TRN & \\
\hline CHEMBL1403194 & 688816 & 5.25 & 5.2063 & TRN & \\
\hline CHEMBL1309878 & 688816 & 5.0 & 5.2945 & TRN & \\
\hline CHEMBL1382492 & 688816 & 4.2 & 4.9241 & TRN & \\
\hline CHEMBL1485296 & 688816 & 5.45 & 5.0288 & TRN & \\
\hline CHEMBL3192839 & 688816 & 5.0 & 5.8412 & TRN & \\
\hline CHEMBL1379659 & 688816 & 4.65 & 4.9313 & TRN & \\
\hline CHEMBL1319964 & 688816 & 5.0 & 5.2094 & TRN & \\
\hline CHEMBL1494369 & 688816 & 4.65 & 5.4884 & TRN & \\
\hline CHEMBL1491438 & 688816 & 4.8 & 4.8414 & TRN & \\
\hline CHEMBL1513762 & 688816 & 4.95 & 5.2464 & TRN & \\
\hline CHEMBL1531301 & 688816 & 8.301 & 5.2982 & TRN & \\
\hline CHEMBL1611137 & 688816 & 4.9 & 4.9773 & TRN & \\
\hline CHEMBL3194638 & 688816 & 4.95 & 5.20200 & 0000000001 & TST \\
\hline CHEMBL3194361 & 688816 & 5.3 & 5.4678 & TRN & \\
\hline CHEMBL1484317 & 688816 & 4.45 & 5.0463 & TRN & \\
\hline CHEMBL1375345 & 688816 & 6.6 & 5.4731 & TRN & \\
\hline CHEMBL3199616 & 688816 & 4.5 & 5.3972 & TRN & \\
\hline
\end{tabular}




\begin{tabular}{|c|c|c|c|c|c|}
\hline \multicolumn{6}{|c|}{ Supplemental Table S2.txt } \\
\hline CHEMBL1290347 & 688816 & 5.8 & 5.0284 & TRN & \\
\hline CHEMBL1378332 & 688816 & 6.6 & 5.2028 & TRN & \\
\hline CHEMBL1537137 & 688816 & 7.3497 & 5.5613 & TRN & \\
\hline CHEMBL1598907 & 688816 & 4.7 & 5.4214 & TRN & \\
\hline CHEMBL1585457 & 688816 & 4.75 & 5.0451 & TRN & \\
\hline CHEMBL1482289 & 688816 & 4.5 & 5.4262 & TRN & \\
\hline CHEMBL1363096 & 688816 & 4.45 & 5.4133 & TRN & \\
\hline CHEMBL1370532 & 688816 & 8.301 & 5.2719 & TST & \\
\hline CHEMBL 286494 & 688816 & 4.75 & 5.4832 & TST & \\
\hline CHEMBL1383732 & 688816 & 4.8 & 5.3365 & TST & \\
\hline CHEMBL1978817 & 688816 & 6.5 & 5.4292 & TRN & \\
\hline CHEMBL1561653 & 688816 & 8.301 & 5.4742 & TST & \\
\hline CHEMBL1448275 & 688816 & 5.5 & 5.0048 & TRN & \\
\hline CHEMBL1323755 & 688816 & 4.95 & 5.1975 & TST & \\
\hline CHEMBL1380733 & 688816 & 4.75 & 5.21899 & 9999999999 & TRN \\
\hline CHEMBL1521872 & 688816 & 4.8 & 5.0066 & TST & \\
\hline CHEMBL1390913 & 688816 & 4.95 & 5.2652 & TRN & \\
\hline CHEMBL1986380 & 688816 & 4.9 & 5.2537 & TRN & \\
\hline CHEMBL1349291 & 688816 & 5.05 & 5.5297 & TST & \\
\hline CHEMBL1579932 & 688816 & 4.9 & 5.4063 & TRN & \\
\hline CHEMBL1350322 & 688816 & 8.301 & 5.4189 & TST & \\
\hline CHEMBL1542055 & 688816 & 6.25 & 5.2296 & TST & \\
\hline CHEMBL1319876 & 688816 & 4.65 & 5.8266 & TRN & \\
\hline CHEMBL1519513 & 688816 & 4.7 & 5.1596 & TRN & \\
\hline CHEMBL1349022 & 688816 & 4.45 & 5.2084 & TST & \\
\hline CHEMBL1376387 & 688816 & 4.8 & 5.0595 & TRN & \\
\hline CHEMBL1390386 & 688816 & 4.9 & 5.0321 & TRN & \\
\hline CHEMBL1334620 & 688816 & 5.65 & 5.4158 & TRN & \\
\hline CHEMBL1321410 & 688816 & 5.0 & 5.0738 & TRN & \\
\hline CHEMBL1556792 & 688816 & 4.8 & 4.8491 & TST & \\
\hline CHEMBL3207401 & 688816 & 5.4 & 5.3043 & TST & \\
\hline CHEMBL 3196746 & 688816 & 4.85 & 5.4298 & TST & \\
\hline CHEMBL1444606 & 688816 & 7.7496 & 5.2562 & TST & \\
\hline CHEMBL1526581 & 688816 & 5.55 & 5.7632 & TST & \\
\hline CHEMBL1402312 & 688816 & 5.35 & 5.5429 & TRN & \\
\hline CHEMBL1428659 & 688816 & 5.6 & 5.0226 & TRN & \\
\hline CHEMBL1367405 & 688816 & 6.7501 & 5.9564 & TST & \\
\hline CHEMBL1532281 & 688816 & 5.05 & 5.3411 & TRN & \\
\hline CHEMBL252966 & 688816 & 5.0 & 5.4045 & TRN & \\
\hline CHEMBL1503843 & 688816 & 4.9 & 5.3676 & TST & \\
\hline CHEMBL1415305 & 688816 & 4.8 & 5.0802 & TRN & \\
\hline CHEMBL1322517 & 688816 & 7.0501 & 5.2123 & TST & \\
\hline CHEMBL1452688 & 688816 & 4.95 & 5.3471 & TST & \\
\hline CHEMBL3197270 & 688816 & 5.4 & 5.3738 & TRN & \\
\hline CHEMBL1580053 & 688816 & 4.9 & 5.1269 & TRN & \\
\hline CHEMBL1573183 & 688816 & 4.45 & 4.9976 & TRN & \\
\hline CHEMBL1420448 & 688816 & 4.8 & 5.3563 & TST & \\
\hline CHEMBL1411881 & 688816 & 5.0 & 5.2905 & TST & \\
\hline
\end{tabular}




\begin{tabular}{|c|c|c|c|c|}
\hline \multicolumn{5}{|c|}{ Supplemental Table S2.txt } \\
\hline CHEMBL3193555 & 688816 & 4.45 & 4.8979 & TRN \\
\hline CHEMBL1331593 & 688816 & 4.8 & 5.0703 & TRN \\
\hline CHEMBL3194277 & 688816 & 4.9 & 5.1659 & TRN \\
\hline CHEMBL1300949 & 688816 & 5.3 & 5.5004 & TRN \\
\hline CHEMBL1557273 & 688816 & 4.45 & 5.2859 & TRN \\
\hline CHEMBL1332646 & 688816 & 4.45 & 5.2573 & TST \\
\hline CHEMBL1465806 & 688816 & 4.45 & 5.2916 & TRN \\
\hline CHEMBL1366972 & 688816 & 5.45 & 5.5414 & TRN \\
\hline CHEMBL1409641 & 688816 & 5.35 & 5.4502 & TRN \\
\hline CHEMBL3191538 & 688816 & 8.301 & 5.4 & TRN \\
\hline CHEMBL1363681 & 688816 & 6.9 & 5.2324 & TRN \\
\hline CHEMBL1536953 & 688816 & 4.45 & 5.4665 & TRN \\
\hline CHEMBL1592061 & 688816 & 6.6499 & 4.9624 & TRN \\
\hline CHEMBL1376769 & 688816 & 4.45 & 5.3561 & TRN \\
\hline CHEMBL1462657 & 688816 & 5.1 & 5.0961 & TRN \\
\hline CHEMBL1195425 & 688816 & 4.9 & 5.4605 & TRN \\
\hline CHEMBL1582067 & 688816 & 5.4 & 5.3743 & TRN \\
\hline CHEMBL1529520 & 688816 & 5.3 & 5.1841 & TST \\
\hline CHEMBL1324885 & 688816 & 5.55 & 5.282 & TRN \\
\hline CHEMBL1548959 & 688816 & 7.2 & 5.7065 & TRN \\
\hline CHEMBL 260370 & 688816 & 4.95 & 4.7537 & TRN \\
\hline CHEMBL1412123 & 688816 & 5.0 & 5.2902 & TRN \\
\hline CHEMBL3198809 & 688816 & 4.45 & 5.1659 & TRN \\
\hline CHEMBL1547659 & 688816 & 4.9 & 5.6816 & TST \\
\hline CHEMBL1360718 & 688816 & 4.95 & 4.9759 & TRN \\
\hline CHEMBL1460868 & 688816 & 4.9 & 5.3743 & TRN \\
\hline CHEMBL1464088 & 688816 & 4.85 & 5.0988 & TRN \\
\hline CHEMBL1409748 & 688816 & 6.8 & 5.1312 & TRN \\
\hline CHEMBL1363492 & 688816 & 5.0 & 5.0525 & TST \\
\hline CHEMBL1545590 & 688816 & 4.95 & 5.6301 & TRN \\
\hline CHEMBL1994838 & 688816 & 4.65 & 5.7055 & TST \\
\hline CHEMBL87791 & 688816 & 7.8508 & 5.7506 & TRN \\
\hline CHEMBL3198576 & 688816 & 5.45 & 5.4137 & TRN \\
\hline CHEMBL1546005 & 688816 & 4.65 & 5.4875 & TRN \\
\hline CHEMBL1483739 & 688816 & 4.45 & 5.1563 & TRN \\
\hline CHEMBL1493748 & 688816 & 5.45 & 5.1398 & TRN \\
\hline CHEMBL1459532 & 688816 & 4.8 & 5.0774 & TRN \\
\hline CHEMBL1365128 & 688816 & 4.75 & 5.1641 & TRN \\
\hline CHEMBL1423879 & 688816 & 5.5 & 5.2591 & TRN \\
\hline CHEMBL1360735 & 688816 & 4.95 & 4.9445 & TST \\
\hline CHEMBL1336277 & 688816 & 6.4 & 5.3619 & TST \\
\hline CHEMBL1612893 & 688816 & 4.95 & 5.3029 & TRN \\
\hline CHEMBL1571768 & 688816 & 6.5 & 5.3297 & TRN \\
\hline CHEMBL1503882 & 688816 & 4.55 & 4.9615 & TRN \\
\hline CHEMBL1346123 & 688816 & 7.5498 & 5.0505 & TST \\
\hline CHEMBL1442187 & 688816 & 5.25 & 5.3727 & TRN \\
\hline CHEMBL3392062 & 688816 & 5.25 & 5.2081 & TST \\
\hline CHEMBL1564760 & 688816 & 4.9 & 5.0778 & TST \\
\hline
\end{tabular}




\begin{tabular}{|c|c|c|c|c|c|}
\hline \multicolumn{6}{|c|}{ Supplemental Table S2.txt } \\
\hline CHEMBL1448220 & 688816 & 4.45 & 4.9537 & TRN & \\
\hline CHEMBL1605348 & 688816 & 4.8 & 5.2758 & TRN & \\
\hline CHEMBL1527544 & 688816 & 5.4 & 5.5343 & TST & \\
\hline CHEMBL1320080 & 688816 & 4.95 & 5.2179 & TRN & \\
\hline CHEMBL1478343 & 688816 & 4.9 & 5.7304 & TST & \\
\hline CHEMBL1438778 & 688816 & 8.301 & 5.2229 & TRN & \\
\hline CHEMBL1420437 & 688816 & 5.0 & 5.1658 & TRN & \\
\hline CHEMBL1440829 & 688816 & 4.85 & 5.1641 & TRN & \\
\hline CHEMBL1532203 & 688816 & 4.75 & 5.2966 & TRN & \\
\hline CHEMBL1324770 & 688816 & 4.85 & 5.1517 & TRN & \\
\hline CHEMBL1378837 & 688816 & 4.45 & 5.3253 & TST & \\
\hline CHEMBL1519422 & 688816 & 4.85 & 5.0981 & TRN & \\
\hline CHEMBL1971154 & 688816 & 4.95 & 4.915 & TRN & \\
\hline CHEMBL465843 & 688816 & 6.0 & 5.4594 & TRN & \\
\hline CHEMBL1564617 & 688816 & 4.95 & 5.1816 & TRN & \\
\hline CHEMBL 3208877 & 688816 & 5.2 & 5.3387 & TRN & \\
\hline CHEMBL1579670 & 688816 & 4.85 & 5.3528 & TRN & \\
\hline CHEMBL1339547 & 688816 & 4.45 & 5.1672 & TRN & \\
\hline CHEMBL1325701 & 688816 & 6.9 & 5.157 & TRN & \\
\hline CHEMBL 3198834 & 688816 & 5.85 & 5.5441 & TRN & \\
\hline CHEMBL3196880 & 688816 & 4.9 & 5.5897 & TRN & \\
\hline CHEMBL1385627 & 688816 & 8.301 & 5.7616 & TRN & \\
\hline CHEMBL1610454 & 688816 & 4.45 & 5.615 & TRN & \\
\hline CHEMBL1507539 & 688816 & 5.1 & 5.235 & TST & \\
\hline CHEMBL1372665 & 688816 & 4.95 & 5.1556 & TRN & \\
\hline CHEMBL1317673 & 688816 & 4.75 & 5.13200 & 0000000001 & TRN \\
\hline CHEMBL1545616 & 688816 & 5.2 & 5.5387 & TRN & \\
\hline CHEMBL1503039 & 688816 & 5.0 & 5.3611 & TRN & \\
\hline CHEMBL1535689 & 688816 & 4.8 & 5.5429 & TST & \\
\hline CHEMBL1484798 & 688816 & 5.3 & 5.3859 & TRN & \\
\hline CHEMBL1453167 & 688816 & 4.75 & 5.1207 & TRN & \\
\hline CHEMBL1339088 & 688816 & 5.15 & 5.3003 & TRN & \\
\hline CHEMBL1449838 & 688816 & 5.35 & 5.0473 & TST & \\
\hline CHEMBL1415226 & 688816 & 4.85 & 4.7831 & TRN & \\
\hline CHEMBL1364355 & 688816 & 5.0 & 5.1207 & TST & \\
\hline CHEMBL1528869 & 688816 & 4.45 & 5.0029 & TRN & \\
\hline CHEMBL1349450 & 688816 & 7.15 & 4.8384 & TRN & \\
\hline CHEMBL1503890 & 688816 & 5.1 & 5.3505 & TST & \\
\hline CHEMBL1990481 & 688816 & 5.4 & 5.21299 & 9999999999 & TRN \\
\hline CHEMBL1424316 & 688816 & 5.3 & 5.2411 & TRN & \\
\hline CHEMBL1359257 & 688816 & 8.0506 & 5.7128 & TRN & \\
\hline CHEMBL1346385 & 688816 & 5.0 & 5.2293 & TRN & \\
\hline CHEMBL1359715 & 688816 & 5.7 & 5.2235 & TRN & \\
\hline CHEMBL1583400 & 688816 & 4.85 & 5.2716 & TRN & \\
\hline CHEMBL1409423 & 688816 & 4.8 & 5.3254 & TRN & \\
\hline CHEMBL1407506 & 688816 & 4.95 & 5.3929 & TRN & \\
\hline CHEMBL1362964 & 688816 & 5.7 & 5.2239 & TRN & \\
\hline CHEMBL1323955 & 688816 & 5.05 & 5.2776 & TRN & \\
\hline
\end{tabular}




\begin{tabular}{|c|c|c|c|c|c|}
\hline \multicolumn{6}{|c|}{ Supplemental Table S2.txt } \\
\hline CHEMBL 3214090 & 688816 & 8.3979 & 5.0919 & TST & \\
\hline CHEMBL1502322 & 688816 & 5.3 & 5.1713 & TRN & \\
\hline CHEMBL1612194 & 688816 & 4.85 & 5.1944 & TRN & \\
\hline CHEMBL1986025 & 688816 & 4.65 & 5.1702 & TRN & \\
\hline CHEMBL1369054 & 688816 & 4.65 & 4.7743 & TRN & \\
\hline CHEMBL3212666 & 688816 & 5.25 & 5.5521 & TST & \\
\hline CHEMBL 3196241 & 688816 & 4.9 & 5.0943 & TRN & \\
\hline CHEMBL1531727 & 688816 & 5.25 & 5.2502 & TST & \\
\hline CHEMBL1369425 & 688816 & 5.0 & 5.1517 & TRN & \\
\hline CHEMBL1547376 & 688816 & 8.0 & 5.5197 & TRN & \\
\hline CHEMBL1406702 & 688816 & 5.15 & 5.0834 & TRN & \\
\hline CHEMBL1451110 & 688816 & 4.85 & 4.8576 & TRN & \\
\hline CHEMBL1423060 & 688816 & 5.7 & 5.7909 & TRN & \\
\hline CHEMBL3196726 & 688816 & 4.95 & 5.0715 & TRN & \\
\hline CHEMBL1552066 & 688816 & 4.45 & 5.2223 & TRN & \\
\hline CHEMBL1494670 & 688816 & 4.45 & 5.0999 & TRN & \\
\hline CHEMBL1334514 & 688816 & 6.1 & 5.6158 & TRN & \\
\hline CHEMBL1362404 & 688816 & 5.55 & 5.7272 & TRN & \\
\hline CHEMBL1498639 & 688816 & 5.35 & 5.5797 & TRN & \\
\hline CHEMBL1404591 & 688816 & 6.8 & 5.4972 & TRN & \\
\hline CHEMBL1414703 & 688816 & 4.75 & 5.0141 & TRN & \\
\hline CHEMBL1467921 & 688816 & 4.9 & 5.1483 & TST & \\
\hline CHEMBL1580709 & 688816 & 4.9 & 5.0874 & TRN & \\
\hline CHEMBL1533494 & 688816 & 4.75 & 4.9514 & TRN & \\
\hline CHEMBL1379629 & 688816 & 6.8499 & 5.6024 & TRN & \\
\hline CHEMBL1417221 & 688816 & 4.95 & 5.3709 & TRN & \\
\hline CHEMBL1330754 & 688816 & 4.95 & 5.3805 & TRN & \\
\hline CHEMBL1344965 & 688816 & 5.25 & 5.4465 & TRN & \\
\hline CHEMBL1303819 & 688816 & 5.5 & 5.1307 & TRN & \\
\hline CHEMBL1420596 & 688816 & 4.7 & 5.0122 & TRN & \\
\hline CHEMBL1496813 & 688816 & 8.301 & 5.3477 & TRN & \\
\hline CHEMBL1564728 & 688816 & 4.8 & 5.2446 & TRN & \\
\hline CHEMBL1439199 & 688816 & 4.8 & 5.2423 & TRN & \\
\hline CHEMBL1443994 & 688816 & 4.8 & 5.2468 & TRN & \\
\hline CHEMBL1520874 & 688816 & 4.85 & 5.5719 & TRN & \\
\hline CHEMBL1429611 & 688816 & 4.95 & 5.3654 & TRN & \\
\hline CHEMBL1522337 & 688816 & 4.8 & 4.9705 & TRN & \\
\hline CHEMBL1386874 & 688816 & 8.0 & 5.1077 & TST & \\
\hline CHEMBL1601155 & 688816 & 8.301 & 5.5868 & TST & \\
\hline CHEMBL1484335 & 688816 & 4.65 & 5.5854 & TRN & \\
\hline CHEMBL1543675 & 688816 & 4.95 & 5.1024 & TRN & \\
\hline CHEMBL1558549 & 688816 & 4.45 & 5.0729 & TRN & \\
\hline CHEMBL1494005 & 688816 & 5.8 & 5.36299 & 99999999995 & TST \\
\hline CHEMBL1438516 & 688816 & 8.4949 & 5.2144 & TST & \\
\hline CHEMBL1381893 & 688816 & 4.95 & 5.3033 & TRN & \\
\hline CHEMBL1375428 & 688816 & 4.75 & 4.9706 & TRN & \\
\hline CHEMBL1508893 & 688816 & 8.301 & 5.0528 & TRN & \\
\hline CHEMBL1580044 & 688816 & 4.7 & 5.7221 & TRN & \\
\hline
\end{tabular}




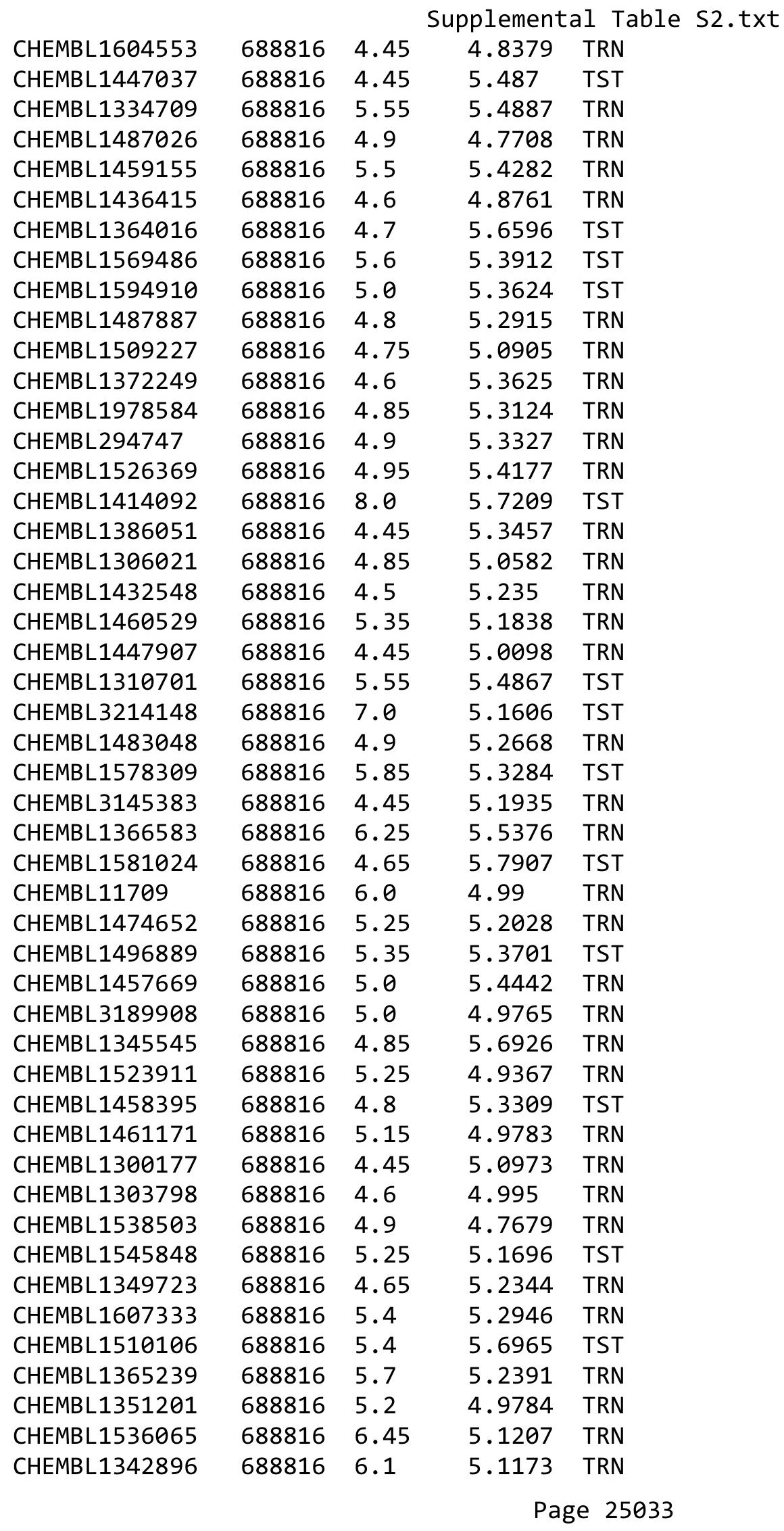




\begin{tabular}{|c|c|c|c|c|c|}
\hline \multirow[b]{2}{*}{ CHEMBL1344968 } & \multicolumn{5}{|c|}{ Supplemental Table S2.txt } \\
\hline & 688816 & 8.0506 & 5.0133 & TRN & \\
\hline CHEMBL1441688 & 688816 & 4.45 & 5.1538 & TRN & \\
\hline CHEMBL576404 & 688816 & 5.4 & 5.21399 & 99999999995 & TRN \\
\hline CHEMBL1411056 & 688816 & 5.15 & 5.0861 & TRN & \\
\hline CHEMBL1585499 & 688816 & 4.9 & 5.0621 & TRN & \\
\hline CHEMBL1572569 & 688816 & 8.3468 & 5.6747 & TRN & \\
\hline CHEMBL1391546 & 688816 & 5.55 & 5.5456 & TRN & \\
\hline CHEMBL1505425 & 688816 & 5.75 & 5.5971 & TST & \\
\hline CHEMBL1565158 & 688816 & 4.95 & 4.9417 & TRN & \\
\hline CHEMBL1390210 & 688816 & 4.45 & 5.01 & TRN & \\
\hline CHEMBL1458161 & 688816 & 8.3979 & 5.6459 & TST & \\
\hline CHEMBL1483326 & 688816 & 5.25 & 5.5126 & TRN & \\
\hline CHEMBL1409036 & 688816 & 7.4498 & 5.20100 & 00000000005 & TRN \\
\hline CHEMBL1480572 & 688816 & 4.45 & 5.1159 & TST & \\
\hline CHEMBL1556141 & 688816 & 6.3 & 5.4776 & TST & \\
\hline CHEMBL1392086 & 688816 & 8.301 & 5.3144 & TRN & \\
\hline CHEMBL1506225 & 688816 & 5.6 & 6.0071 & TRN & \\
\hline CHEMBL1596603 & 688816 & 4.7 & 5.6417 & TST & \\
\hline CHEMBL1390515 & 688816 & 6.0 & 5.5022 & TST & \\
\hline CHEMBL1299674 & 688816 & 4.85 & 5.2588 & TRN & \\
\hline CHEMBL1343119 & 688816 & 5.15 & 5.1671 & TRN & \\
\hline CHEMBL1429227 & 688816 & 7.699 & 5.4352 & TRN & \\
\hline CHEMBL1303930 & 688816 & 8.3979 & 5.4294 & TST & \\
\hline CHEMBL1569415 & 688816 & 4.85 & 5.5538 & TRN & \\
\hline CHEMBL1453612 & 688816 & 4.6 & 5.4234 & TST & \\
\hline CHEMBL1456058 & 688816 & 4.9 & 5.308 & TRN & \\
\hline CHEMBL1324981 & 688816 & 4.85 & 5.0466 & TRN & \\
\hline CHEMBL1323110 & 688816 & 4.9 & 5.3158 & TRN & \\
\hline CHEMBL1534875 & 688816 & 5.6 & 4.9813 & TRN & \\
\hline CHEMBL589694 & 688816 & 5.0 & 5.2519 & TRN & \\
\hline CHEMBL1362858 & 688816 & 4.95 & 5.396 & TRN & \\
\hline CHEMBL1327682 & 688816 & 5.75 & 5.3987 & TRN & \\
\hline CHEMBL1425585 & 688816 & 4.85 & 5.1706 & TRN & \\
\hline CHEMBL1418552 & 688816 & 4.7 & 5.6175 & TRN & \\
\hline CHEMBL1497072 & 688816 & 4.5 & 5.0723 & TST & \\
\hline CHEMBL1570553 & 688816 & 5.85 & 5.0234 & TRN & \\
\hline CHEMBL1422699 & 688816 & 4.95 & 5.0014 & TRN & \\
\hline CHEMBL1481029 & 688816 & 5.25 & 5.1066 & TST & \\
\hline CHEMBL1575262 & 688816 & 5.45 & 5.6611 & TRN & \\
\hline CHEMBL1498211 & 688816 & 4.95 & 5.46200 & 0000000001 & TRN \\
\hline CHEMBL1488143 & 688816 & 6.1 & 5.8192 & TRN & \\
\hline CHEMBL1430790 & 688816 & 5.25 & 5.2388 & TRN & \\
\hline CHEMBL1465209 & 688816 & 5.15 & 5.2441 & TRN & \\
\hline CHEMBL1405468 & 688816 & 7.15 & 5.5768 & TRN & \\
\hline CHEMBL1430611 & 688816 & 5.9 & 5.5504 & TST & \\
\hline CHEMBL1986725 & 688816 & 4.65 & 5.4742 & TRN & \\
\hline CHEMBL1503342 & 688816 & 4.95 & 5.2615 & TST & \\
\hline CHEMBL1462560 & 688816 & 8.0 & 5.7501 & TRN & \\
\hline
\end{tabular}




\begin{tabular}{|c|c|c|c|c|c|}
\hline \multicolumn{6}{|c|}{ Supplemental Table S2.txt } \\
\hline CHEMBL1326394 & 688816 & 4.85 & 5.2406 & TRN & \\
\hline CHEMBL1531349 & 688816 & 4.85 & 5.013 & TRN & \\
\hline CHEMBL1484741 & 688816 & 5.15 & 5.5297 & TRN & \\
\hline CHEMBL1510399 & 688816 & 5.85 & 5.0639 & TRN & \\
\hline CHEMBL1439992 & 688816 & 4.95 & 5.1015 & TST & \\
\hline CHEMBL1493661 & 688816 & 5.05 & 5.35 & TRN & \\
\hline CHEMBL1450746 & 688816 & 5.3 & 5.6077 & TRN & \\
\hline CHEMBL1332548 & 688816 & 5.6 & 5.30399 & 9999999999 & TST \\
\hline CHEMBL1453835 & 688816 & 4.7 & 5.1097 & TRN & \\
\hline CHEMBL1441685 & 688816 & 6.4 & 5.8944 & TRN & \\
\hline CHEMBL1490005 & 688816 & 4.5 & 5.0226 & TRN & \\
\hline CHEMBL1389439 & 688816 & 5.65 & 5.8131 & TRN & \\
\hline CHEMBL1372813 & 688816 & 4.7 & 4.9619 & TRN & \\
\hline CHEMBL1479977 & 688816 & 5.05 & 5.0326 & TRN & \\
\hline CHEMBL1487065 & 688816 & 4.45 & 5.2153 & TST & \\
\hline CHEMBL1585019 & 688816 & 5.6 & 5.039 & TRN & \\
\hline CHEMBL1456417 & 688816 & 8.699 & 5.1875 & TRN & \\
\hline CHEMBL1408341 & 688816 & 4.65 & 5.2381 & TRN & \\
\hline CHEMBL1389646 & 688816 & 4.95 & 5.2131 & TRN & \\
\hline CHEMBL1391549 & 688816 & 6.45 & 5.3398 & TRN & \\
\hline CHEMBL1376611 & 688816 & 4.75 & 5.2483 & TRN & \\
\hline CHEMBL1501006 & 688816 & 5.95 & 5.1854 & TRN & \\
\hline CHEMBL1325877 & 688816 & 4.65 & 4.9021 & TST & \\
\hline CHEMBL1325779 & 688816 & 4.9 & 4.9674 & TRN & \\
\hline CHEMBL1576677 & 688816 & 6.0 & 5.5636 & TRN & \\
\hline CHEMBL1502842 & 688816 & 4.95 & 5.5073 & TRN & \\
\hline CHEMBL3207491 & 688816 & 4.8 & 4.9385 & TRN & \\
\hline CHEMBL1501998 & 688816 & 4.8 & 4.9138 & TRN & \\
\hline CHEMBL192566 & 688816 & 4.75 & 5.8077 & TST & \\
\hline CHEMBL1368826 & 688816 & 7.4498 & 5.6918 & TRN & \\
\hline CHEMBL1384620 & 688816 & 4.95 & 5.2536 & TRN & \\
\hline CHEMBL1439651 & 688816 & 4.45 & 5.3353 & TST & \\
\hline CHEMBL1559772 & 688816 & 4.95 & 5.3434 & TRN & \\
\hline CHEMBL1504413 & 688816 & 7.5498 & 5.6224 & TRN & \\
\hline CHEMBL3191835 & 688816 & 5.0 & 5.2498 & TRN & \\
\hline CHEMBL1334012 & 688816 & 4.95 & 5.3261 & TRN & \\
\hline CHEMBL 1306748 & 688816 & 5.0 & 5.3927 & TRN & \\
\hline CHEMBL1603982 & 688816 & 4.9 & 5.2439 & TRN & \\
\hline CHEMBL1301760 & 688816 & 5.1 & 4.8924 & TRN & \\
\hline CHEMBL1403122 & 688816 & 4.85 & 4.9399 & TRN & \\
\hline CHEMBL1439719 & 688816 & 4.7 & 5.5466 & TST & \\
\hline CHEMBL1416928 & 688816 & 5.45 & 5.1616 & TST & \\
\hline CHEMBL1603963 & 688816 & 4.95 & 5.38700 & 00000000005 & TRN \\
\hline CHEMBL1477318 & 688816 & 4.45 & 4.9805 & TRN & \\
\hline CHEMBL1391017 & 688816 & 4.9 & 4.9804 & TRN & \\
\hline CHEMBL264931 & 688816 & 5.9 & 5.6964 & TRN & \\
\hline CHEMBL1356104 & 688816 & 4.75 & 5.5931 & TRN & \\
\hline CHEMBL1493953 & 688816 & 7.4001 & 4.9345 & TRN & \\
\hline
\end{tabular}




\begin{tabular}{|c|c|c|c|c|c|}
\hline \multicolumn{6}{|c|}{ Supplemental Table S2.txt } \\
\hline CHEMBL1528157 & 688816 & 5.1 & 5.1882 & TRN & \\
\hline CHEMBL1469924 & 688816 & 4.95 & 5.2557 & TST & \\
\hline CHEMBL111951 & 688816 & 5.35 & 5.1978 & TRN & \\
\hline CHEMBL1479782 & 688816 & 6.95 & 5.2837 & TRN & \\
\hline CHEMBL460517 & 688816 & 4.85 & 5.1562 & TRN & \\
\hline CHEMBL3198761 & 688816 & 8.4949 & 5.3866 & TRN & \\
\hline CHEMBL1482316 & 688816 & 5.5 & 5.0469 & TRN & \\
\hline CHEMBL3193022 & 688816 & 4.45 & 5.0245 & TRN & \\
\hline CHEMBL1576031 & 688816 & 4.8 & 5.0698 & TST & \\
\hline CHEMBL1341531 & 688816 & 4.7 & 5.3165 & TRN & \\
\hline CHEMBL1463396 & 688816 & 4.45 & \multicolumn{2}{|c|}{4.9830000000000005} & TRN \\
\hline CHEMBL1584009 & 688816 & 4.45 & 5.3729 & TRN & \\
\hline CHEMBL1421045 & 688816 & 5.0 & 5.0721 & TRN & \\
\hline CHEMBL1506955 & 688816 & 6.1 & 5.8993 & TRN & \\
\hline CHEMBL1307453 & 688816 & 4.95 & 4.9482 & TRN & \\
\hline CHEMBL1546134 & 688816 & 4.45 & 4.8766 & TRN & \\
\hline CHEMBL1332598 & 688816 & 5.1 & 5.0683 & TRN & \\
\hline CHEMBL 3209882 & 688816 & 4.5 & 5.2656 & TRN & \\
\hline CHEMBL1976586 & 688816 & 4.45 & 5.3077 & TRN & \\
\hline CHEMBL1422677 & 688816 & 6.5 & 5.1882 & TST & \\
\hline CHEMBL1461897 & 688816 & 4.5 & 4.9418 & TRN & \\
\hline CHEMBL1345997 & 688816 & 4.95 & 5.6111 & TST & \\
\hline CHEMBL1416521 & 688816 & 5.2 & 5.3253 & TRN & \\
\hline CHEMBL1426838 & 688816 & 5.15 & 5.7236 & TRN & \\
\hline CHEMBL1581308 & 688816 & 4.9 & \multicolumn{2}{|c|}{5.0360000000000005} & TRN \\
\hline CHEMBL1970221 & 688816 & 4.7 & \multicolumn{2}{|c|}{5.167000000000001} & TRN \\
\hline CHEMBL1600630 & 688816 & 4.45 & 5.1096 & TRN & \\
\hline CHEMBL1587023 & 688816 & 4.95 & 5.2334 & TRN & \\
\hline CHEMBL1550493 & 688816 & 5.3 & \multicolumn{2}{|c|}{5.406000000000001} & TST \\
\hline CHEMBL1414552 & 688816 & 5.95 & 5.2509 & TRN & \\
\hline CHEMBL1421544 & 688816 & 4.85 & 5.2104 & TST & \\
\hline CHEMBL1346171 & 688816 & 5.1 & 5.2448 & TST & \\
\hline CHEMBL1568147 & 688816 & 4.65 & \multicolumn{2}{|c|}{5.2170000000000005} & TRN \\
\hline CHEMBL1425046 & 688816 & 5.35 & 4.7723 & TRN & \\
\hline CHEMBL1599856 & 688816 & 4.45 & 4.9462 & TRN & \\
\hline CHEMBL1603074 & 688816 & 4.8 & 5.052 & TRN & \\
\hline CHEMBL1544094 & 688816 & 5.55 & 5.1434 & TRN & \\
\hline CHEMBL1535609 & 688816 & 4.75 & 5.0614 & TRN & \\
\hline CHEMBL1491154 & 688816 & 4.65 & 4.9945 & TRN & \\
\hline CHEMBL1589786 & 688816 & 5.4 & 5.5668 & TST & \\
\hline CHEMBL1552561 & 688816 & 4.95 & 5.0835 & TRN & \\
\hline CHEMBL3211886 & 688816 & 7.699 & 5.2973 & TST & \\
\hline CHEMBL1379224 & 688816 & 4.8 & 5.1149 & TRN & \\
\hline CHEMBL1411463 & 688816 & 4.45 & 5.6787 & TRN & \\
\hline CHEMBL1381466 & 688816 & 4.9 & 4.9503 & TRN & \\
\hline CHEMBL1471829 & 688816 & 4.95 & 5.1199 & TRN & \\
\hline CHEMBL1542512 & 688816 & 5.15 & 5.2263 & TRN & \\
\hline CHEMBL1481987 & 688816 & 5.0 & 5.4304 & TRN & \\
\hline
\end{tabular}




\begin{tabular}{|c|c|c|c|c|}
\hline \multicolumn{5}{|c|}{ Supplemental Table } \\
\hline CHEMBL1348641 & 688816 & 5.05 & 5.3337 & TST \\
\hline CHEMBL1312463 & 688816 & 4.9 & 5.2496 & TRN \\
\hline CHEMBL1458849 & 688816 & 4.95 & 5.316 & TRN \\
\hline CHEMBL1341123 & 688816 & 4.9 & 5.2387 & TRN \\
\hline CHEMBL1333831 & 688816 & 5.3 & 5.3526 & TRN \\
\hline CHEMBL1403057 & 688816 & 5.0 & 5.7238 & TRN \\
\hline CHEMBL1582681 & 688816 & 4.85 & 5.402 & TRN \\
\hline CHEMBL1370265 & 688816 & 4.85 & 5.2039 & TRN \\
\hline CHEMBL1518470 & 688816 & 4.8 & 5.1817 & TST \\
\hline CHEMBL1479917 & 688816 & 8.4559 & 5.6202 & TST \\
\hline CHEMBL1582933 & 688816 & 4.8 & 4.7744 & TST \\
\hline CHEMBL1494572 & 688816 & 4.9 & 5.1427 & TRN \\
\hline CHEMBL 259421 & 688816 & 4.95 & 5.3259 & TRN \\
\hline CHEMBL1362680 & 688816 & 4.85 & 5.0184 & TRN \\
\hline CHEMBL512749 & 688816 & 5.95 & 5.1517 & TRN \\
\hline CHEMBL498373 & 688816 & 4.95 & 5.5858 & TRN \\
\hline CHEMBL1421459 & 688816 & 4.8 & 5.3827 & TRN \\
\hline CHEMBL3210249 & 688816 & 4.4 & 5.0056 & TRN \\
\hline CHEMBL1581244 & 688816 & 4.95 & 4.82 & TST \\
\hline CHEMBL1577466 & 688816 & 4.95 & 5.3392 & TRN \\
\hline CHEMBL1335845 & 688816 & 5.4 & 5.2846 & TST \\
\hline CHEMBL1548988 & 688816 & 5.35 & 5.2803 & TRN \\
\hline CHEMBL1482171 & 688816 & 6.7501 & 5.2621 & TRN \\
\hline CHEMBL3212351 & 688816 & 4.45 & 5.2397 & TRN \\
\hline CHEMBL1308181 & 688816 & 5.05 & 5.473 & TRN \\
\hline CHEMBL1567827 & 688816 & 5.0 & 4.8832 & TRN \\
\hline CHEMBL1562314 & 688816 & 4.9 & 5.1721 & TRN \\
\hline CHEMBL1370991 & 688816 & 5.0 & 5.3904 & TRN \\
\hline CHEMBL1580736 & 688816 & 4.95 & 5.437 & TST \\
\hline CHEMBL3213891 & 688816 & 5.05 & 5.7101 & TRN \\
\hline CHEMBL1414511 & 688816 & 5.35 & 5.2807 & TST \\
\hline CHEMBL1560522 & 688816 & 4.95 & 5.2416 & TRN \\
\hline CHEMBL 3208540 & 688816 & 4.75 & 5.0607 & TST \\
\hline CHEMBL1487242 & 688816 & 5.25 & 5.152 & TRN \\
\hline CHEMBL1582448 & 688816 & 6.5501 & 5.3632 & TRN \\
\hline CHEMBL1316434 & 688816 & 4.95 & 4.5872 & TRN \\
\hline CHEMBL1425204 & 688816 & 5.25 & 5.5938 & TRN \\
\hline CHEMBL1438100 & 688816 & 4.95 & 5.4171 & TRN \\
\hline CHEMBL578928 & 688816 & 5.0 & 4.9491 & TRN \\
\hline CHEMBL14568 & 688816 & 5.3 & 5.7258 & TST \\
\hline CHEMBL1501515 & 688816 & 4.95 & 5.1296 & TRN \\
\hline CHEMBL1590663 & 688816 & 4.8 & 4.9692 & TRN \\
\hline CHEMBL1309323 & 688816 & 4.9 & 5.2174 & TRN \\
\hline CHEMBL1376345 & 688816 & 4.95 & 5.2121 & TRN \\
\hline CHEMBL1503222 & 688816 & 4.5 & 5.2894 & TRN \\
\hline CHEMBL1404699 & 688816 & 4.9 & 4.7916 & TST \\
\hline CHEMBL1504759 & 688816 & 4.75 & 5.8117 & TST \\
\hline CHEMBL1568468 & 688816 & 5.0 & 5.2379 & TRN \\
\hline
\end{tabular}




\begin{tabular}{|c|c|c|c|c|c|}
\hline & & \\
\hline CHEMBL3197662 & 688816 & 4.5 & 4.9553 & TRN & \\
\hline CHEMBL1483908 & 688816 & 4.6 & 4.9785 & TRN & \\
\hline CHEMBL1558180 & 688816 & 4.45 & 5.1566 & TRN & \\
\hline CHEMBL1569860 & 688816 & 4.95 & 5.2053 & TRN & \\
\hline CHEMBL1596198 & 688816 & 5.25 & 5.2591 & TST & \\
\hline CHEMBL1419591 & 688816 & 6.5 & 5.3545 & TRN & \\
\hline CHEMBL1370277 & 688816 & 4.9 & 5.018 & TRN & \\
\hline CHEMBL1425521 & 688816 & 5.15 & 5.2492 & TRN & \\
\hline CHEMBL1538766 & 688816 & 5.5 & 5.4533 & TRN & \\
\hline CHEMBL1321812 & 688816 & 4.65 & 5.4284 & TRN & \\
\hline CHEMBL1388618 & 688816 & 5.0 & 5.3312 & TRN & \\
\hline CHEMBL3197002 & 688816 & 4.95 & 5.3463 & TRN & \\
\hline CHEMBL1384642 & 688816 & 7.6498 & 5.1305 & TRN & \\
\hline CHEMBL3190726 & 688816 & 5.85 & 5.1842 & TRN & \\
\hline CHEMBL586029 & 688816 & 4.45 & 5.405 & TRN & \\
\hline CHEMBL1513747 & 688816 & 4.85 & 5.4283 & TRN & \\
\hline CHEMBL1332901 & 688816 & 6.6499 & 5.2848 & TRN & \\
\hline CHEMBL1344040 & 688816 & 5.4 & 5.4155 & TST & \\
\hline CHEMBL3212606 & 688816 & 4.45 & 5.5912 & TRN & \\
\hline CHEMBL1417400 & 688816 & 4.9 & 5.5085 & TST & \\
\hline CHEMBL1595508 & 688816 & 5.0 & 5.5736 & TRN & \\
\hline CHEMBL1440551 & 688816 & 5.25 & 5.1476 & TRN & \\
\hline CHEMBL1426292 & 688816 & 4.8 & 5.1946 & TRN & \\
\hline CHEMBL1571626 & 688816 & 4.9 & 5.2206 & TRN & \\
\hline CHEMBL1343537 & 688816 & 4.9 & 4.7128 & TRN & \\
\hline CHEMBL1566891 & 688816 & 4.65 & 5.0811 & TRN & \\
\hline CHEMBL1511093 & 688816 & 8.4559 & 5.5503 & TST & \\
\hline CHEMBL1371266 & 688816 & 6.1 & 5.4195 & TST & \\
\hline CHEMBL1390918 & 688816 & 5.6 & 5.37799 & 9999999999 & TRN \\
\hline CHEMBL1389724 & 688816 & 6.4 & 5.5346 & TRN & \\
\hline CHEMBL3193509 & 688816 & 7.5003 & 5.3617 & TRN & \\
\hline CHEMBL1349604 & 688816 & 4.95 & 5.1859 & TRN & \\
\hline CHEMBL1312263 & 688816 & 5.95 & 5.0483 & TST & \\
\hline CHEMBL1379599 & 688816 & 4.9 & 5.1296 & TRN & \\
\hline CHEMBL1450996 & 688816 & 6.5 & 5.5635 & TST & \\
\hline CHEMBL1366544 & 688816 & 5.05 & 5.7111 & TRN & \\
\hline CHEMBL1584284 & 688816 & 4.9 & 5.1154 & TST & \\
\hline CHEMBL1304993 & 688816 & 4.8 & 5.2937 & TRN & \\
\hline CHEMBL1401911 & 688816 & 5.55 & 5.3568 & TRN & \\
\hline CHEMBL1586650 & 688816 & 4.45 & 5.5613 & TST & \\
\hline CHEMBL3208621 & 688816 & 4.9 & 5.499 & TRN & \\
\hline CHEMBL1336136 & 688816 & 4.95 & 5.2834 & TRN & \\
\hline CHEMBL1581259 & 688816 & 4.85 & 4.7848 & TRN & \\
\hline CHEMBL1371005 & 688816 & 5.25 & 5.1873 & TRN & \\
\hline CHEMBL1491637 & 688816 & 5.25 & 5.24799 & 9999999999 & TRN \\
\hline CHEMBL1400483 & 688816 & 4.7 & 5.7354 & TRN & \\
\hline CHEMBL1582030 & 688816 & 5.0 & 5.4387 & TST & \\
\hline CHEMBL3195241 & 688816 & 4.7 & 5.0327 & TRN & \\
\hline & & & & 25038 & \\
\hline
\end{tabular}




\begin{tabular}{|c|c|c|c|c|c|}
\hline \multicolumn{6}{|c|}{ Supplemental Table s2.txt } \\
\hline CHEMBL1513145 & 688816 & 4.95 & 5.1788 & TRN & \\
\hline CHEMBL1599901 & 688816 & 4.45 & 5.1626 & TRN & \\
\hline CHEMBL1301832 & 688816 & 4.75 & 5.1489 & TRN & \\
\hline CHEMBL1495409 & 688816 & 5.0 & 5.16 & TRN & \\
\hline CHEMBL1552870 & 688816 & 5.0 & 5.4308 & TST & \\
\hline CHEMBL567332 & 688816 & 5.25 & 4.7728 & TRN & \\
\hline CHEMBL1583248 & 688816 & 4.45 & 5.1625 & TST & \\
\hline CHEMBL1565736 & 688816 & 5.05 & 5.3885 & TRN & \\
\hline CHEMBL1348741 & 688816 & 4.9 & 5.3387 & TRN & \\
\hline CHEMBL1604679 & 688816 & 4.95 & 5.0548 & TRN & \\
\hline CHEMBL1363790 & 688816 & 5.25 & 5.5837 & TRN & \\
\hline CHEMBL1406991 & 688816 & 5.25 & 5.0626 & TST & \\
\hline CHEMBL3199095 & 688816 & 4.65 & 5.6927 & TST & \\
\hline CHEMBL1613092 & 688816 & 4.5 & 5.0515 & TRN & \\
\hline CHEMBL1613288 & 688816 & 5.45 & 5.2681 & TRN & \\
\hline CHEMBL472930 & 688816 & 4.7 & 4.9968 & TRN & \\
\hline CHEMBL1393069 & 688816 & 4.75 & 5.2304 & TRN & \\
\hline CHEMBL1364928 & 688816 & 4.9 & 4.9419 & TRN & \\
\hline CHEMBL1596531 & 688816 & 5.55 & 5.155 & TRN & \\
\hline CHEMBL3211726 & 688816 & 5.35 & 5.5661 & TRN & \\
\hline CHEMBL1309874 & 688816 & 5.35 & 4.7267 & TRN & \\
\hline CHEMBL1490793 & 688816 & 4.45 & 5.2277 & TST & \\
\hline CHEMBL1610124 & 688816 & 5.15 & 5.5742 & TRN & \\
\hline CHEMBL1369467 & 688816 & 4.45 & 5.3108 & TRN & \\
\hline CHEMBL1299628 & 688816 & 5.05 & 5.2779 & TRN & \\
\hline CHEMBL1511215 & 688816 & 4.65 & 5.3113 & TST & \\
\hline CHEMBL1299293 & 688816 & 8.301 & 5.5601 & TRN & \\
\hline CHEMBL1571688 & 688816 & 4.45 & 5.2584 & TRN & \\
\hline CHEMBL1404832 & 688816 & 4.9 & 5.16100 & 00000000005 & TRN \\
\hline CHEMBL3195417 & 688816 & 4.7 & 5.3874 & TST & \\
\hline CHEMBL1325104 & 688816 & 4.45 & 5.4343 & TRN & \\
\hline CHEMBL1600311 & 688816 & 4.85 & 5.1682 & TRN & \\
\hline CHEMBL1371282 & 688816 & 4.65 & 5.2796 & TRN & \\
\hline CHEMBL1502631 & 688816 & 4.55 & 5.6497 & TRN & \\
\hline CHEMBL1425773 & 688816 & 4.9 & 4.9404 & TRN & \\
\hline CHEMBL3192249 & 688816 & 5.2 & 5.4934 & TRN & \\
\hline CHEMBL1388694 & 688816 & 5.45 & 5.1008 & TRN & \\
\hline CHEMBL1419398 & 688816 & 4.9 & 5.0196 & TRN & \\
\hline CHEMBL1566600 & 688816 & 4.7 & 5.0736 & TRN & \\
\hline CHEMBL1386184 & 688816 & 5.2 & 5.289 & TRN & \\
\hline CHEMBL1570233 & 688816 & 4.45 & 5.2164 & TRN & \\
\hline CHEMBL1462998 & 688816 & 4.85 & 5.0405 & TRN & \\
\hline CHEMBL1511067 & 688816 & 5.05 & 5.2733 & TRN & \\
\hline CHEMBL1469763 & 688816 & 4.8 & 5.4392 & TRN & \\
\hline CHEMBL224214 & 688816 & 5.1 & 5.4207 & TST & \\
\hline CHEMBL1348198 & 688816 & 5.65 & 5.48600 & 0000000001 & TST \\
\hline CHEMBL1548234 & 688816 & 4.95 & 4.9347 & TRN & \\
\hline CHEMBL1310374 & 688816 & 4.9 & 5.0747 & TRN & \\
\hline
\end{tabular}




\begin{tabular}{|c|c|c|c|c|c|}
\hline \multicolumn{6}{|c|}{ Supplemental Table s2.txt } \\
\hline CHEMBL1330191 & 688816 & 4.45 & 5.5133 & TRN & \\
\hline CHEMBL1500362 & 688816 & 4.7 & 5.3418 & TRN & \\
\hline CHEMBL1588028 & 688816 & 5.95 & 5.0724 & TST & \\
\hline CHEMBL1384167 & 688816 & 5.1 & 5.1735 & TRN & \\
\hline CHEMBL1393740 & 688816 & 4.45 & 5.314 & TRN & \\
\hline CHEMBL1420234 & 688816 & 4.65 & 5.2882 & TST & \\
\hline CHEMBL1313968 & 688816 & 4.8 & 5.2111 & TRN & \\
\hline CHEMBL1510212 & 688816 & 4.45 & 5.0765 & TRN & \\
\hline CHEMBL1482664 & 688816 & 5.4 & 5.1 & TST & \\
\hline CHEMBL1340832 & 688816 & 5.25 & 5.2678 & TRN & \\
\hline CHEMBL1570807 & 688816 & 4.6 & 5.6086 & TRN & \\
\hline CHEMBL 1418800 & 688816 & 8.301 & 5.83899 & 99999999995 & TRN \\
\hline CHEMBL1578123 & 688816 & 4.9 & 5.2985 & TRN & \\
\hline CHEMBL1505995 & 688816 & 5.35 & 5.3039 & TRN & \\
\hline CHEMBL1964614 & 688816 & 5.25 & 5.1595 & TRN & \\
\hline CHEMBL1393333 & 688816 & 4.5 & 5.0966 & TRN & \\
\hline CHEMBL1341040 & 688816 & 4.85 & 4.8187 & TST & \\
\hline CHEMBL1429684 & 688816 & 4.95 & 5.3842 & TRN & \\
\hline CHEMBL1318261 & 688816 & 4.9 & 5.153 & TRN & \\
\hline CHEMBL1454969 & 688816 & 5.4 & 5.6306 & TST & \\
\hline CHEMBL1366006 & 688816 & 4.75 & 5.529 & TRN & \\
\hline CHEMBL1387630 & 688816 & 6.5501 & 5.6195 & TST & \\
\hline CHEMBL1482831 & 688816 & 5.8 & 5.7945 & TST & \\
\hline CHEMBL1312853 & 688816 & 5.2 & 5.3298 & TRN & \\
\hline CHEMBL1536204 & 688816 & 5.6 & 5.3369 & TRN & \\
\hline CHEMBL3187596 & 688816 & 4.7 & 4.9096 & TST & \\
\hline CHEMBL1479454 & 688816 & 4.85 & 5.5809 & TRN & \\
\hline CHEMBL1466075 & 688816 & 4.95 & 5.1416 & TRN & \\
\hline CHEMBL1564023 & 688816 & 4.95 & 4.6707 & TRN & \\
\hline CHEMBL1484418 & 688816 & 4.5 & 5.1434 & TRN & \\
\hline CHEMBL1461047 & 688816 & 5.25 & 5.3816 & TRN & \\
\hline CHEMBL1349639 & 688816 & 5.85 & 5.4218 & TRN & \\
\hline CHEMBL1332047 & 688816 & 5.8 & 5.1016 & TRN & \\
\hline CHEMBL 239673 & 688816 & 5.15 & 4.9743 & TRN & \\
\hline CHEMBL1405502 & 688816 & 6.5501 & 5.4843 & TRN & \\
\hline CHEMBL1388947 & 688816 & 4.9 & 5.05399 & 9999999999 & TRN \\
\hline CHEMBL1522033 & 688816 & 4.65 & 5.1315 & TRN & \\
\hline CHEMBL1606782 & 688816 & 4.45 & 5.4031 & TRN & \\
\hline CHEMBL1482241 & 688816 & 5.2 & 5.6829 & TRN & \\
\hline CHEMBL1470904 & 688816 & 6.3 & 5.1827 & TRN & \\
\hline CHEMBL1540682 & 688816 & 4.8 & 5.2467 & TRN & \\
\hline CHEMBL1510104 & 688816 & 4.95 & 5.4574 & TRN & \\
\hline CHEMBL1498649 & 688816 & 4.45 & 5.2894 & TRN & \\
\hline CHEMBL1481000 & 688816 & 4.9 & 4.9035 & TRN & \\
\hline CHEMBL1472464 & 688816 & 4.95 & 5.0321 & TRN & \\
\hline CHEMBL509531 & 688816 & 4.35 & 5.42200 & 0000000001 & TST \\
\hline CHEMBL 3194355 & 688816 & 4.55 & 5.2923 & TRN & \\
\hline CHEMBL3190653 & 688816 & 8.0 & 5.9268 & TRN & \\
\hline
\end{tabular}




\begin{tabular}{|c|c|c|c|c|c|}
\hline \multirow{2}{*}{\multicolumn{2}{|c|}{ CHEMBL1525077 }} & \\
\hline & & 4.9 & 5.0904 & TRN & \\
\hline CHEMBL1398378 & 688816 & 6.15 & 5.4795 & TST & \\
\hline CHEMBL1598921 & 688816 & 5.7 & 5.0053 & TRN & \\
\hline CHEMBL1307065 & 688816 & 4.95 & 5.1447 & TRN & \\
\hline CHEMBL1548532 & 688816 & 5.25 & 5.0581 & TST & \\
\hline CHEMBL1608392 & 688816 & 4.45 & 5.1422 & TST & \\
\hline CHEMBL1604735 & 688816 & 5.9 & 4.8061 & TRN & \\
\hline CHEMBL1426002 & 688816 & 7.4498 & 5.346 & TRN & \\
\hline CHEMBL1526438 & 688816 & 5.25 & 5.3929 & TRN & \\
\hline CHEMBL1444902 & 688816 & 4.95 & 5.6383 & TST & \\
\hline CHEMBL1600740 & 688816 & 4.5 & 5.0865 & TRN & \\
\hline CHEMBL3195664 & 688816 & 5.5 & 5.0323 & TRN & \\
\hline CHEMBL1405531 & 688816 & 5.0 & 5.74200 & 2000000001 & TRN \\
\hline CHEMBL1491844 & 688816 & 4.9 & 5.0352 & TRN & \\
\hline CHEMBL1422019 & 688816 & 4.6 & 5.1615 & TRN & \\
\hline CHEMBL1363661 & 688816 & 8.301 & 5.4151 & TRN & \\
\hline CHEMBL3212034 & 688816 & 4.65 & 5.3971 & TRN & \\
\hline CHEMBL1541930 & 688816 & 5.7 & 5.4246 & TRN & \\
\hline CHEMBL1350820 & 688816 & 4.45 & 5.0015 & TST & \\
\hline CHEMBL1340321 & 688816 & 4.9 & 4.805 & TRN & \\
\hline CHEMBL3194168 & 688816 & 4.95 & 5.2869 & TRN & \\
\hline CHEMBL1413739 & 688816 & 4.45 & 5.0566 & TRN & \\
\hline CHEMBL1512312 & 688816 & 6.1 & 4.9512 & TST & \\
\hline CHEMBL1524254 & 688816 & 4.8 & 5.062 & TRN & \\
\hline CHEMBL601968 & 688816 & 4.7 & 5.0889 & TST & \\
\hline CHEMBL1576762 & 688816 & 4.95 & 5.1817 & TRN & \\
\hline CHEMBL1367869 & 688816 & 4.85 & 4.9766 & TRN & \\
\hline CHEMBL1606862 & 688816 & 5.05 & 5.3418 & TRN & \\
\hline CHEMBL1392266 & 688816 & 5.05 & 5.3451 & TRN & \\
\hline CHEMBL1585105 & 688816 & 4.95 & 5.0657 & TRN & \\
\hline CHEMBL 280317 & 688816 & 4.55 & 5.3366 & TST & \\
\hline CHEMBL1360758 & 688816 & 4.6 & 5.2848 & TRN & \\
\hline CHEMBL1570371 & 688816 & 5.95 & 5.2585 & TRN & \\
\hline CHEMBL3214609 & 688816 & 4.65 & 5.3205 & TRN & \\
\hline CHEMBL 2000122 & 688816 & 5.45 & 5.3967 & TRN & \\
\hline CHEMBL1609354 & 688816 & 5.15 & 5.0405 & TRN & \\
\hline CHEMBL1452437 & 688816 & 5.25 & 5.57100 & 3000000001 & TRN \\
\hline CHEMBL1413941 & 688816 & 4.65 & 5.1244 & TRN & \\
\hline CHEMBL3190596 & 688816 & 4.65 & 5.1256 & TRN & \\
\hline CHEMBL1541328 & 688816 & 4.65 & 5.0013 & TRN & \\
\hline CHEMBL1376590 & 688816 & 4.45 & 5.3109 & TST & \\
\hline CHEMBL1571093 & 688816 & 4.45 & 5.5854 & TRN & \\
\hline CHEMBL1447185 & 688816 & 4.9 & 5.5223 & TST & \\
\hline CHEMBL1501469 & 688816 & 4.7 & 5.3196 & TRN & \\
\hline CHEMBL1352924 & 688816 & 5.05 & 5.1626 & TRN & \\
\hline CHEMBL1561044 & 688816 & 5.1 & 5.1565 & TRN & \\
\hline CHEMBL1481033 & 688816 & 6.25 & 5.59399 & 9999999999 & TRN \\
\hline CHEMBL1471744 & 688816 & 6.6 & 5.284 & TRN & \\
\hline & & & & 25041 & \\
\hline
\end{tabular}




\begin{tabular}{|c|c|c|c|c|c|}
\hline \multicolumn{6}{|c|}{ Supplemental Table S2.txt } \\
\hline CHEMBL1527737 & 688816 & 5.4 & 4.8704 & TRN & \\
\hline CHEMBL1493465 & 688816 & 4.7 & 5.1352 & TRN & \\
\hline CHEMBL3199410 & 688816 & 4.95 & 5.2633 & TRN & \\
\hline CHEMBL1965236 & 688816 & 4.8 & 5.3082 & TST & \\
\hline CHEMBL1612106 & 688816 & 6.3 & 5.3359 & TRN & \\
\hline CHEMBL1364105 & 688816 & 4.85 & 4.9712 & TRN & \\
\hline CHEMBL1541530 & 688816 & 4.7 & 4.9324 & TRN & \\
\hline CHEMBL1538764 & 688816 & 5.6 & 5.0348 & TRN & \\
\hline CHEMBL1323262 & 688816 & 5.35 & 5.6231 & TRN & \\
\hline CHEMBL1542748 & 688816 & 6.2 & 5.5187 & TRN & \\
\hline CHEMBL1567825 & 688816 & 8.3979 & 5.4542 & TST & \\
\hline CHEMBL1426304 & 688816 & 5.25 & 4.9944 & TRN & \\
\hline CHEMBL1548574 & 688816 & 8.4949 & 5.4845 & TRN & \\
\hline CHEMBL1495231 & 688816 & 7.5498 & 5.4502 & TRN & \\
\hline CHEMBL1312231 & 688816 & 4.65 & 5.0109 & TRN & \\
\hline CHEMBL1587724 & 688816 & 4.45 & 5.4216 & TRN & \\
\hline CHEMBL1608662 & 688816 & 4.45 & 5.3241 & TST & \\
\hline CHEMBL1454685 & 688816 & 4.9 & 5.2226 & TST & \\
\hline CHEMBL1360526 & 688816 & 5.35 & 5.0464 & TRN & \\
\hline CHEMBL1606193 & 688816 & 4.65 & 5.0293 & TST & \\
\hline CHEMBL1550065 & 688816 & 6.15 & 5.3582 & TST & \\
\hline CHEMBL1501198 & 688816 & 6.0 & 5.0943 & TRN & \\
\hline CHEMBL3191648 & 688816 & 5.2 & 5.2094 & TRN & \\
\hline CHEMBL1519341 & 688816 & 4.7 & 5.1952 & TRN & \\
\hline CHEMBL1376933 & 688816 & 4.95 & 4.8898 & TST & \\
\hline CHEMBL1497019 & 688816 & 6.4 & 5.0521 & TRN & \\
\hline CHEMBL1399361 & 688816 & 4.7 & 5.2378 & TRN & \\
\hline CHEMBL1537956 & 688816 & 8.301 & 5.9728 & TST & \\
\hline CHEMBL1411621 & 688816 & 5.05 & 4.8517 & TRN & \\
\hline CHEMBL1443059 & 688816 & 4.95 & 5.21399 & 99999999995 & TRN \\
\hline CHEMBL1517270 & 688816 & 7.1002 & 5.438 & TRN & \\
\hline CHEMBL1376127 & 688816 & 4.95 & 5.2529 & TRN & \\
\hline CHEMBL1584101 & 688816 & 4.95 & 5.2636 & TRN & \\
\hline CHEMBL1464150 & 688816 & 5.4 & 5.0731 & TRN & \\
\hline CHEMBL1393843 & 688816 & 4.75 & 5.3418 & TRN & \\
\hline CHEMBL1611612 & 688816 & 4.85 & 5.0831 & TRN & \\
\hline CHEMBL1361726 & 688816 & 4.45 & 5.6607 & TST & \\
\hline CHEMBL1554717 & 688816 & 4.8 & 5.3477 & TST & \\
\hline CHEMBL3189297 & 688816 & 5.2 & 5.2698 & TST & \\
\hline CHEMBL1416923 & 688816 & 4.95 & 5.46 & TRN & \\
\hline CHEMBL1585439 & 688816 & 8.3468 & 5.7714 & TST & \\
\hline CHEMBL1582063 & 688816 & 4.65 & 5.3142 & TRN & \\
\hline CHEMBL1367143 & 688816 & 4.95 & 5.046 & TRN & \\
\hline CHEMBL1358872 & 688816 & 4.9 & 5.0339 & TRN & \\
\hline CHEMBL1323663 & 688816 & 4.45 & 5.1256 & TST & \\
\hline CHEMBL1402848 & 688816 & 4.85 & 5.1043 & TRN & \\
\hline CHEMBL1350905 & 688816 & 4.45 & 5.1183 & TRN & \\
\hline CHEMBL1518765 & 688816 & 4.45 & 5.1733 & TRN & \\
\hline
\end{tabular}




\begin{tabular}{|c|c|c|c|c|c|}
\hline \multicolumn{6}{|c|}{ Supplemental Table S2.txt } \\
\hline CHEMBL1510057 & 688816 & 5.75 & 5.6246 & TRN & \\
\hline CHEMBL1383315 & 688816 & 4.95 & 5.3255 & TRN & \\
\hline CHEMBL1373225 & 688816 & 4.95 & 5.2551 & TRN & \\
\hline CHEMBL1392055 & 688816 & 4.95 & 5.45700 & 0000000001 & TRN \\
\hline CHEMBL1544597 & 688816 & 5.15 & 5.3978 & TRN & \\
\hline CHEMBL1304004 & 688816 & 5.9 & 4.8052 & TRN & \\
\hline CHEMBL3189714 & 688816 & 5.35 & 5.2493 & TRN & \\
\hline CHEMBL1589282 & 688816 & 4.85 & 5.3415 & TST & \\
\hline CHEMBL1989858 & 688816 & 4.45 & 5.1358 & TRN & \\
\hline CHEMBL1313579 & 688816 & 4.45 & 4.9832 & TST & \\
\hline CHEMBL1321507 & 688816 & 4.7 & 5.3596 & TRN & \\
\hline CHEMBL1391307 & 688816 & 5.05 & 5.2968 & TRN & \\
\hline CHEMBL1474763 & 688816 & 4.5 & 4.7987 & TRN & \\
\hline CHEMBL1386522 & 688816 & 4.85 & 5.0634 & TRN & \\
\hline CHEMBL225012 & 688816 & 6.15 & 5.6492 & TRN & \\
\hline CHEMBL1453623 & 688816 & 4.75 & 5.059 & TRN & \\
\hline CHEMBL1429353 & 688816 & 7.0 & 5.7037 & TRN & \\
\hline CHEMBL1336513 & 688816 & 4.9 & 5.062 & TRN & \\
\hline CHEMBL1463450 & 688816 & 5.2 & 5.569 & TRN & \\
\hline CHEMBL1498903 & 688816 & 4.9 & 5.2292 & TRN & \\
\hline CHEMBL1369100 & 688816 & 5.25 & 4.9035 & TRN & \\
\hline CHEMBL1301844 & 688816 & 4.45 & 4.7132 & TRN & \\
\hline CHEMBL1407089 & 688816 & 4.45 & 5.2756 & TRN & \\
\hline CHEMBL1433176 & 688816 & 4.95 & 5.0942 & TRN & \\
\hline CHEMBL1447059 & 688816 & 4.8 & 5.13200 & 0000000001 & TRN \\
\hline CHEMBL1389685 & 688816 & 5.2 & 4.9526 & TRN & \\
\hline CHEMBL1558220 & 688816 & 4.95 & 5.2982 & TST & \\
\hline CHEMBL1404229 & 688816 & 4.8 & 5.0622 & TRN & \\
\hline CHEMBL1443781 & 688816 & 6.95 & 5.2873 & TST & \\
\hline CHEMBL1404498 & 688816 & 5.4 & 5.2048 & TST & \\
\hline CHEMBL1499266 & 688816 & 4.9 & 5.4317 & TRN & \\
\hline CHEMBL3199567 & 688816 & 5.4 & 5.2171 & TRN & \\
\hline CHEMBL1574262 & 688816 & 5.5 & 5.3073 & TRN & \\
\hline CHEMBL1531336 & 688816 & 4.9 & 5.3632 & TRN & \\
\hline CHEMBL1347505 & 688816 & 4.95 & 4.8541 & TST & \\
\hline CHEMBL1582269 & 688816 & 4.85 & 5.16700 & 2000000001 & TRN \\
\hline CHEMBL1567747 & 688816 & 4.45 & 5.246 & TRN & \\
\hline CHEMBL1542809 & 688816 & 5.9 & 5.1749 & TRN & \\
\hline CHEMBL1408144 & 688816 & 7.4498 & 5.642 & TRN & \\
\hline CHEMBL1550817 & 688816 & 4.95 & 5.5127 & TST & \\
\hline CHEMBL1518742 & 688816 & 5.2 & 5.1424 & TST & \\
\hline CHEMBL1312376 & 688816 & 4.5 & 5.4818 & TRN & \\
\hline CHEMBL1364243 & 688816 & 7.5003 & 5.7391 & TRN & \\
\hline CHEMBL1356488 & 688816 & 4.45 & 4.9583 & TRN & \\
\hline CHEMBL1533166 & 688816 & 5.5 & 5.4103 & TRN & \\
\hline CHEMBL1530885 & 688816 & 4.55 & 5.3548 & TRN & \\
\hline CHEMBL1579812 & 688816 & 4.7 & 4.9752 & TRN & \\
\hline CHEMBL1610601 & 688816 & 4.65 & 5.0098 & TRN & \\
\hline
\end{tabular}




\begin{tabular}{|c|c|c|c|c|c|}
\hline \multicolumn{6}{|c|}{ Supplemental Table S2.txt } \\
\hline CHEMBL1399673 & 688816 & 5.3 & 5.1382 & TRN & \\
\hline CHEMBL1590378 & 688816 & 4.8 & 5.5745 & TST & \\
\hline CHEMBL1516472 & 688816 & 4.45 & 5.1385 & TST & \\
\hline CHEMBL104728 & 688816 & 5.0 & 5.1935 & TRN & \\
\hline CHEMBL1523053 & 688816 & 4.9 & 5.2975 & TRN & \\
\hline CHEMBL1494030 & 688816 & 4.45 & 5.2269 & TRN & \\
\hline CHEMBL1532152 & 688816 & 5.0 & 5.7996 & TST & \\
\hline CHEMBL1303995 & 688816 & 4.65 & 5.0257 & TRN & \\
\hline CHEMBL3197786 & 688816 & 4.45 & 5.1845 & TST & \\
\hline CHEMBL1488733 & 688816 & 4.85 & 5.2716 & TRN & \\
\hline CHEMBL1595937 & 688816 & 5.3 & 5.3698 & TRN & \\
\hline CHEMBL1339990 & 688816 & 5.05 & 5.2412 & TRN & \\
\hline CHEMBL1439035 & 688816 & 4.45 & 4.9819 & TRN & \\
\hline CHEMBL3196580 & 688816 & 8.301 & 5.5289 & TST & \\
\hline CHEMBL1534136 & 688816 & 5.0 & 5.348 & TRN & \\
\hline CHEMBL1336496 & 688816 & 5.25 & 5.0892 & TRN & \\
\hline CHEMBL1525126 & 688816 & 4.45 & 4.9734 & TRN & \\
\hline CHEMBL1601502 & 688816 & 5.05 & 5.2336 & TRN & \\
\hline CHEMBL1341289 & 688816 & 4.9 & 5.3399 & TRN & \\
\hline CHEMBL 3196200 & 688816 & 8.301 & 5.0022 & TRN & \\
\hline CHEMBL1493383 & 688816 & 4.95 & 5.6058 & TRN & \\
\hline CHEMBL 3207894 & 688816 & 4.9 & 5.1469 & TRN & \\
\hline CHEMBL1389285 & 688816 & 4.8 & 5.13299 & 9999999999 & TRN \\
\hline CHEMBL1594844 & 688816 & 4.45 & 5.1248 & TRN & \\
\hline CHEMBL1462462 & 688816 & 4.9 & 5.1968 & TRN & \\
\hline CHEMBL1345250 & 688816 & 6.3 & 5.6461 & TST & \\
\hline CHEMBL1600472 & 688816 & 5.3 & 5.2271 & TRN & \\
\hline CHEMBL1556579 & 688816 & 5.5 & 5.32 & TRN & \\
\hline CHEMBL1345082 & 688816 & 5.5 & 5.4012 & TRN & \\
\hline CHEMBL1343768 & 688816 & 4.9 & 5.5695 & TRN & \\
\hline CHEMBL1367453 & 688816 & 5.05 & 5.352 & TRN & \\
\hline CHEMBL1369927 & 688816 & 4.8 & 5.1534 & TRN & \\
\hline CHEMBL1558727 & 688816 & 5.35 & 5.4221 & TRN & \\
\hline CHEMBL1544131 & 688816 & 4.55 & 5.3044 & TRN & \\
\hline CHEMBL580340 & 688816 & 5.25 & 5.1762 & TRN & \\
\hline CHEMBL1389827 & 688816 & 4.85 & 5.4905 & TRN & \\
\hline CHEMBL1345273 & 688816 & 4.8 & 5.3162 & TRN & \\
\hline CHEMBL1488204 & 688816 & 5.05 & 5.2159 & TRN & \\
\hline CHEMBL1458938 & 688816 & 7.1002 & 5.5255 & TRN & \\
\hline CHEMBL1335597 & 688816 & 5.3 & 4.9161 & TRN & \\
\hline CHEMBL1507644 & 688816 & 4.8 & 5.2815 & TST & \\
\hline CHEMBL1450973 & 688816 & 4.7 & 5.3391 & TRN & \\
\hline CHEMBL 2003567 & 688816 & 5.45 & 4.8705 & TST & \\
\hline CHEMBL1381742 & 688816 & 4.95 & 5.5061 & TRN & \\
\hline CHEMBL1580001 & 688816 & 4.95 & 5.0213 & TRN & \\
\hline CHEMBL1613155 & 688816 & 5.25 & 5.7977 & TRN & \\
\hline CHEMBL1408779 & 688816 & 5.05 & 4.8618 & TRN & \\
\hline CHEMBL1457162 & 688816 & 5.2 & 5.5263 & TRN & \\
\hline
\end{tabular}




\begin{tabular}{|c|c|c|c|c|c|}
\hline \multicolumn{6}{|c|}{ Supplemental Table S2.txt } \\
\hline CHEMBL3193241 & 688816 & 4.85 & 5.3489 & TST & \\
\hline CHEMBL1432420 & 688816 & 4.45 & 5.4027 & TRN & \\
\hline CHEMBL1390118 & 688816 & 5.05 & 5.4823 & TRN & \\
\hline CHEMBL1482648 & 688816 & 5.35 & 5.6327 & TST & \\
\hline CHEMBL1610385 & 688816 & 5.0 & 5.3237 & TRN & \\
\hline CHEMBL1468023 & 688816 & 4.45 & 5.157 & TRN & \\
\hline CHEMBL1445846 & 688816 & 6.0 & 5.4069 & TST & \\
\hline CHEMBL1332770 & 688816 & 4.85 & 5.2942 & TRN & \\
\hline CHEMBL1439769 & 688816 & 4.45 & 5.1126 & TRN & \\
\hline CHEMBL1375410 & 688816 & 8.301 & 5.4984 & TST & \\
\hline CHEMBL1607863 & 688816 & 4.45 & 5.7204 & TST & \\
\hline CHEMBL1537487 & 688816 & 4.95 & 5.0084 & TST & \\
\hline CHEMBL1548737 & 688816 & 5.55 & 5.5042 & TRN & \\
\hline CHEMBL1581780 & 688816 & 6.5 & 5.4199 & TST & \\
\hline CHEMBL456446 & 688816 & 5.1 & 5.2554 & TRN & \\
\hline CHEMBL1580060 & 688816 & 4.75 & 5.5262 & TST & \\
\hline CHEMBL1399667 & 688816 & 4.65 & 5.1266 & TRN & \\
\hline CHEMBL1448931 & 688816 & 4.65 & 5.0372 & TRN & \\
\hline CHEMBL 89445 & 688816 & 6.0 & 5.3182 & TRN & \\
\hline CHEMBL1596629 & 688816 & 8.0506 & 5.4354 & TRN & \\
\hline CHEMBL1577174 & 688816 & 6.4 & 5.2176 & TRN & \\
\hline CHEMBL1456623 & 688816 & 4.45 & 5.2173 & TRN & \\
\hline CHEMBL1565909 & 688816 & 4.6 & 5.2507 & TRN & \\
\hline CHEMBL1439459 & 688816 & 4.8 & 5.2124 & TRN & \\
\hline CHEMBL1557859 & 688816 & 4.85 & 4.9213 & TRN & \\
\hline CHEMBL1384702 & 688816 & 4.45 & 5.0358 & TRN & \\
\hline CHEMBL515505 & 688816 & 5.45 & 5.4365 & TST & \\
\hline CHEMBL1418027 & 688816 & 4.9 & 5.2561 & TRN & \\
\hline CHEMBL1547908 & 688816 & 5.5 & 5.2137 & TRN & \\
\hline CHEMBL1518886 & 688816 & 4.45 & 5.6396 & TST & \\
\hline CHEMBL1467391 & 688816 & 4.9 & 5.2792 & TRN & \\
\hline CHEMBL1582165 & 688816 & 4.8 & 5.6045 & TRN & \\
\hline CHEMBL3195811 & 688816 & 4.45 & 5.2613 & TRN & \\
\hline CHEMBL1582579 & 688816 & 5.45 & 5.3551 & TRN & \\
\hline CHEMBL1410353 & 688816 & 5.25 & 5.1775 & TRN & \\
\hline CHEMBL1545406 & 688816 & 4.85 & 4.9777 & TRN & \\
\hline CHEMBL1359872 & 688816 & 4.9 & 5.4479 & TRN & \\
\hline CHEMBL1448642 & 688816 & 5.6 & 5.229 & TRN & \\
\hline CHEMBL1555721 & 688816 & 4.8 & 5.0277 & TST & \\
\hline CHEMBL1338683 & 688816 & 4.7 & 5.3841 & TRN & \\
\hline CHEMBL1388179 & 688816 & 5.25 & 5.42899 & 9999999999 & TRN \\
\hline CHEMBL1445153 & 688816 & 5.1 & 5.0087 & TRN & \\
\hline CHEMBL1497430 & 688816 & 4.45 & 5.1803 & TST & \\
\hline CHEMBL1574488 & 688816 & 6.1 & 5.2766 & TRN & \\
\hline CHEMBL1979784 & 688816 & 5.55 & 5.0603 & TRN & \\
\hline CHEMBL3196468 & 688816 & 5.0 & 4.9032 & TRN & \\
\hline CHEMBL3194854 & 688816 & 4.6 & 5.0927 & TRN & \\
\hline CHEMBL8145 & 688816 & 6.0 & 5.7293 & TRN & \\
\hline
\end{tabular}




\begin{tabular}{|c|c|c|c|c|}
\hline \multicolumn{5}{|c|}{ Supplemental Table S2.txt } \\
\hline CHEMBL1605795 & 688816 & 5.35 & 5.6031 & TRN \\
\hline CHEMBL1544424 & 688816 & 7.6003 & 5.2506 & TST \\
\hline CHEMBL1317147 & 688816 & 5.15 & 5.2538 & TRN \\
\hline CHEMBL1336541 & 688816 & 4.6 & 5.2772 & TRN \\
\hline CHEMBL1381755 & 688816 & 4.9 & 5.0547 & TRN \\
\hline CHEMBL1403041 & 688816 & 5.2 & 5.083 & TRN \\
\hline CHEMBL1444221 & 688816 & 4.45 & 4.9721 & TRN \\
\hline CHEMBL1375020 & 688816 & 6.6499 & 5.3691 & TST \\
\hline CHEMBL1990783 & 688816 & 5.3 & 5.2866 & TRN \\
\hline CHEMBL1585778 & 688816 & 4.95 & 5.4966 & TST \\
\hline CHEMBL1343122 & 688816 & 8.301 & 5.5527 & TRN \\
\hline CHEMBL1318033 & 688816 & 4.45 & 4.6895 & TRN \\
\hline CHEMBL1535667 & 688816 & 4.85 & 5.1548 & TST \\
\hline CHEMBL1570806 & 688816 & 4.75 & 5.3134 & TRN \\
\hline CHEMBL1308839 & 688816 & 4.75 & 5.267 & TRN \\
\hline CHEMBL1579487 & 688816 & 4.95 & 5.2856 & TST \\
\hline CHEMBL1312817 & 688816 & 5.0 & 5.2064 & TRN \\
\hline CHEMBL1360765 & 688816 & 4.45 & 5.2884 & TRN \\
\hline CHEMBL1392329 & 688816 & 4.95 & 5.2574 & TST \\
\hline CHEMBL1413584 & 688816 & 4.65 & 5.039 & TRN \\
\hline CHEMBL1444703 & 688816 & 4.95 & 5.23 & TRN \\
\hline CHEMBL1409908 & 688816 & 6.1 & 4.9513 & TRN \\
\hline CHEMBL1331237 & 688816 & 4.75 & 5.244 & TRN \\
\hline CHEMBL1567363 & 688816 & 4.9 & 5.3037 & TST \\
\hline CHEMBL1444421 & 688816 & 6.45 & 5.6304 & TST \\
\hline CHEMBL1391490 & 688816 & 4.7 & 5.0011 & TRN \\
\hline CHEMBL1422136 & 688816 & 7.6003 & 5.6768 & TRN \\
\hline CHEMBL1346165 & 688816 & 5.0 & 5.6452 & TRN \\
\hline CHEMBL1327618 & 688816 & 5.7 & 5.4811 & TRN \\
\hline CHEMBL1551271 & 688816 & 4.85 & 5.3239 & TST \\
\hline CHEMBL 225903 & 688816 & 6.5 & 4.9849 & TRN \\
\hline CHEMBL1364461 & 688816 & 5.9 & 5.426 & TST \\
\hline CHEMBL1988883 & 688816 & 5.3 & 5.4183 & TRN \\
\hline CHEMBL1303927 & 688816 & 4.45 & 5.0193 & TST \\
\hline CHEMBL1409509 & 688816 & 5.0 & 5.3202 & TRN \\
\hline CHEMBL1489579 & 688816 & 5.2 & 5.4357 & TRN \\
\hline CHEMBL1514761 & 688816 & 5.7 & 5.2609 & TRN \\
\hline CHEMBL1418367 & 688816 & 4.75 & 5.1422 & TRN \\
\hline CHEMBL1612197 & 688816 & 4.9 & 5.3029 & TRN \\
\hline CHEMBL1462498 & 688816 & 4.65 & 5.3249 & TRN \\
\hline CHEMBL1329966 & 688816 & 4.45 & 5.7162 & TRN \\
\hline CHEMBL1502433 & 688816 & 8.3468 & 5.4094 & TST \\
\hline CHEMBL1429259 & 688816 & 5.3 & 5.115 & TST \\
\hline CHEMBL1415574 & 688816 & 5.4 & 5.416 & TRN \\
\hline CHEMBL1483468 & 688816 & 4.85 & 5.0784 & TRN \\
\hline CHEMBL1413765 & 688816 & 4.7 & 5.1366 & TST \\
\hline CHEMBL1543605 & 688816 & 5.45 & 5.1333 & TST \\
\hline CHEMBL1413963 & 688816 & 4.95 & 4.7775 & TST \\
\hline
\end{tabular}




\begin{tabular}{|c|c|c|c|c|}
\hline \multicolumn{5}{|c|}{ Supplemental Table S2.txt } \\
\hline CHEMBL1355214 & 688816 & 4.85 & 5.2267 & TRN \\
\hline CHEMBL1458413 & 688816 & 6.45 & 5.2805 & TRN \\
\hline CHEMBL1348188 & 688816 & 4.95 & 5.4728 & TRN \\
\hline CHEMBL1549128 & 688816 & 5.0 & 5.1463 & TST \\
\hline CHEMBL1541996 & 688816 & 4.8 & 5.3748 & TRN \\
\hline CHEMBL1431286 & 688816 & 4.9 & 5.6153 & TRN \\
\hline CHEMBL1417737 & 688816 & 4.6 & 5.0656 & TRN \\
\hline CHEMBL1561168 & 688816 & 5.15 & 4.7209 & TRN \\
\hline CHEMBL1542058 & 688816 & 4.8 & 5.4009 & TST \\
\hline CHEMBL1560295 & 688816 & 5.35 & 5.0349 & TRN \\
\hline CHEMBL1313788 & 688816 & 4.9 & 5.265 & TRN \\
\hline CHEMBL484385 & 688816 & 4.9 & 5.2892 & TRN \\
\hline CHEMBL1606091 & 688816 & 4.65 & 5.3578 & TRN \\
\hline CHEMBL1565161 & 688816 & 5.5 & 5.4776 & TST \\
\hline CHEMBL1487152 & 688816 & 4.9 & 5.0867 & TRN \\
\hline CHEMBL413800 & 688816 & 8.3468 & 5.5273 & TRN \\
\hline CHEMBL1499605 & 688816 & 5.55 & 5.3531 & TST \\
\hline CHEMBL3199298 & 688816 & 4.45 & 5.2551 & TRN \\
\hline CHEMBL1304395 & 688816 & 5.15 & 5.3855 & TRN \\
\hline CHEMBL1417917 & 688816 & 4.9 & 5.0541 & TRN \\
\hline CHEMBL1605551 & 688816 & 6.5 & 5.5024 & TRN \\
\hline CHEMBL1354093 & 688816 & 4.95 & 5.1906 & TST \\
\hline CHEMBL1401350 & 688816 & 4.9 & 5.6371 & TRN \\
\hline CHEMBL1299537 & 688816 & 4.95 & 5.0406 & TST \\
\hline CHEMBL1536497 & 688816 & 4.95 & 5.305 & TRN \\
\hline CHEMBL1596870 & 688816 & 5.2 & 5.5214 & TST \\
\hline CHEMBL1404602 & 688816 & 4.45 & 5.2026 & TST \\
\hline CHEMBL1529895 & 688816 & 4.8 & 5.276 & TRN \\
\hline CHEMBL1497158 & 688816 & 4.95 & 5.3689 & TRN \\
\hline CHEMBL1426131 & 688816 & 4.85 & 5.4102 & TST \\
\hline CHEMBL592369 & 688816 & 5.0 & 5.0587 & TRN \\
\hline CHEMBL1548894 & 688816 & 4.45 & 5.1776 & TRN \\
\hline CHEMBL3193700 & 688816 & 4.65 & 5.119 & TRN \\
\hline CHEMBL1455631 & 688816 & 5.0 & 5.1295 & TRN \\
\hline CHEMBL1518823 & 688816 & 4.75 & 4.9052 & TRN \\
\hline CHEMBL1318397 & 688816 & 4.95 & 4.8306 & TRN \\
\hline CHEMBL1323641 & 688816 & 4.45 & 5.4118 & TRN \\
\hline CHEMBL1870697 & 688816 & 6.9 & 5.1038 & TST \\
\hline CHEMBL1601379 & 688816 & 4.5 & 5.2622 & TRN \\
\hline CHEMBL1522123 & 688816 & 4.85 & 5.0463 & TRN \\
\hline CHEMBL1480026 & 688816 & 5.75 & 5.3576 & TST \\
\hline CHEMBL 1421410 & 688816 & 5.55 & 5.5215 & TRN \\
\hline CHEMBL1417064 & 688816 & 6.0 & 5.4003 & TRN \\
\hline CHEMBL1368428 & 688816 & 4.95 & 5.2478 & TRN \\
\hline CHEMBL1331048 & 688816 & 8.0506 & 5.4873 & TST \\
\hline CHEMBL51931 & 688816 & 4.75 & 5.2529 & TRN \\
\hline CHEMBL1612271 & 688816 & 8.4949 & 5.3636 & TRN \\
\hline CHEMBL1470792 & 688816 & 4.85 & 5.3414 & TRN \\
\hline
\end{tabular}




\begin{tabular}{|c|c|c|c|c|}
\hline & & & pplement & al $\mathrm{T}$ \\
\hline CHEMBL1490071 & 688816 & 5.3 & 5.2001 & TST \\
\hline CHEMBL1581915 & 688816 & 4.95 & 5.0526 & TRN \\
\hline CHEMBL3196959 & 688816 & 4.9 & 5.2864 & TRN \\
\hline CHEMBL1471515 & 688816 & 4.45 & 5.3105 & TRN \\
\hline CHEMBL1564801 & 688816 & 5.1 & 5.0955 & TST \\
\hline CHEMBL1596097 & 688816 & 6.35 & 5.0883 & TRN \\
\hline CHEMBL1439954 & 688816 & 4.8 & 5.1825 & TRN \\
\hline CHEMBL1352759 & 688816 & 5.1 & 5.4212 & TRN \\
\hline CHEMBL1498925 & 688816 & 4.95 & 5.4378 & TRN \\
\hline CHEMBL1471727 & 688816 & 7.7496 & 5.1789 & TRN \\
\hline CHEMBL1328085 & 688816 & 5.7 & 5.2812 & TRN \\
\hline CHEMBL1457688 & 688816 & 4.7 & 5.3004 & TRN \\
\hline CHEMBL1380103 & 688816 & 4.65 & 4.8757 & TRN \\
\hline CHEMBL1425337 & 688816 & 4.75 & 5.3228 & TST \\
\hline CHEMBL1522716 & 688816 & 4.95 & 5.1067 & TRN \\
\hline CHEMBL1334271 & 688816 & 5.25 & 5.2184 & TRN \\
\hline CHEMBL1339697 & 688816 & 4.65 & 5.1833 & TRN \\
\hline CHEMBL3197399 & 688816 & 8.0 & 5.2427 & TST \\
\hline CHEMBL1404549 & 688816 & 8.3468 & 5.4216 & TRN \\
\hline CHEMBL1575663 & 688816 & 4.95 & 5.3045 & TRN \\
\hline CHEMBL1339106 & 688816 & 4.85 & 5.0955 & TRN \\
\hline CHEMBL1376738 & 688816 & 4.9 & 5.7853 & TST \\
\hline CHEMBL1314857 & 688816 & 4.9 & 5.2736 & TRN \\
\hline CHEMBL1559704 & 688816 & 5.15 & 5.4655 & TRN \\
\hline CHEMBL1313491 & 688816 & 4.95 & 5.3428 & TRN \\
\hline CHEMBL1581626 & 688816 & 4.65 & 5.2623 & TRN \\
\hline CHEMBL1507682 & 688816 & 4.95 & 5.0284 & TST \\
\hline CHEMBL1464765 & 688816 & 5.5 & 5.2346 & TRN \\
\hline CHEMBL1421194 & 688816 & 4.9 & 5.591 & TRN \\
\hline CHEMBL1386815 & 688816 & 4.7 & 4.9015 & TRN \\
\hline CHEMBL1402826 & 688816 & 8.301 & 5.1598 & TRN \\
\hline CHEMBL1381184 & 688816 & 4.85 & 4.9673 & TRN \\
\hline CHEMBL1543323 & 688816 & 4.95 & 5.0792 & TST \\
\hline CHEMBL1446569 & 688816 & 4.45 & 5.1116 & TRN \\
\hline CHEMBL1499865 & 688816 & 6.05 & 5.4303 & TRN \\
\hline CHEMBL1495025 & 688816 & 5.0 & 5.145 & TST \\
\hline CHEMBL1465485 & 688816 & 5.05 & 5.2154 & TRN \\
\hline CHEMBL1583951 & 688816 & 4.9 & 5.3955 & TRN \\
\hline CHEMBL1441891 & 688816 & 5.05 & 4.9145 & TST \\
\hline CHEMBL1299536 & 688816 & 4.45 & 4.7707 & TRN \\
\hline CHEMBL1606431 & 688816 & 4.95 & 5.0384 & TRN \\
\hline CHEMBL1533581 & 688816 & 7.6003 & 5.6228 & TRN \\
\hline CHEMBL1470229 & 688816 & 4.9 & 5.2516 & TST \\
\hline CHEMBL1311161 & 688816 & 4.95 & 5.3459 & TRN \\
\hline CHEMBL1453905 & 688816 & 4.85 & 4.7752 & TRN \\
\hline CHEMBL1546191 & 688816 & 5.5 & 5.6999 & TST \\
\hline CHEMBL1509487 & 688816 & 4.75 & 4.9662 & TRN \\
\hline CHEMBL1443320 & 688816 & 4.85 & 5.5817 & TRN \\
\hline
\end{tabular}




\begin{tabular}{|c|c|c|c|c|c|}
\hline \multicolumn{6}{|c|}{ splemental } \\
\hline CHEMBL1516515 & 688816 & 4.9 & 5.4132 & TST & \\
\hline CHEMBL1489514 & 688816 & 4.7 & 5.2744 & TRN & \\
\hline CHEMBL1539905 & 688816 & 4.45 & 5.0935 & TRN & \\
\hline CHEMBL1587713 & 688816 & 4.45 & 5.445 & TST & \\
\hline CHEMBL1521748 & 688816 & 8.301 & 5.7282 & TRN & \\
\hline CHEMBL1416679 & 688816 & 7.8508 & 5.0151 & TRN & \\
\hline CHEMBL1447689 & 688816 & 4.6 & 5.3048 & TRN & \\
\hline CHEMBL1611690 & 688816 & 5.2 & 5.6137 & TRN & \\
\hline CHEMBL1465346 & 688816 & 5.35 & 5.6349 & TST & \\
\hline CHEMBL1458688 & 688816 & 5.75 & 5.1675 & TRN & \\
\hline CHEMBL1573511 & 688816 & 5.3 & 5.1888 & TRN & \\
\hline CHEMBL1585924 & 688816 & 6.0 & 5.2614 & TRN & \\
\hline CHEMBL1496928 & 688816 & 5.4 & 5.5539 & TRN & \\
\hline CHEMBL1612547 & 688816 & 4.8 & 5.5095 & TRN & \\
\hline CHEMBL1415594 & 688816 & 4.6 & 5.0642 & TRN & \\
\hline CHEMBL1444970 & 688816 & 4.55 & 5.2168 & TST & \\
\hline CHEMBL1451019 & 688816 & 8.0 & 5.2852 & TRN & \\
\hline CHEMBL 329872 & 688816 & 4.6 & 5.3009 & TRN & \\
\hline CHEMBL1560192 & 688816 & 5.1 & 4.9442 & TRN & \\
\hline CHEMBL1545469 & 688816 & 5.35 & 5.2383 & TST & \\
\hline CHEMBL1527913 & 688816 & 5.35 & 5.6099 & TRN & \\
\hline CHEMBL1431609 & 688816 & 8.3468 & 5.2075 & TRN & \\
\hline CHEMBL1324563 & 688816 & 4.9 & 5.038 & TRN & \\
\hline CHEMBL1421040 & 688816 & 4.6 & 5.2049 & TRN & \\
\hline CHEMBL1343394 & 688816 & 4.95 & 5.2192 & TRN & \\
\hline CHEMBL1326664 & 688816 & 5.0 & 5.4675 & TRN & \\
\hline CHEMBL1449070 & 688816 & 4.65 & 4.6321 & TRN & \\
\hline CHEMBL1425095 & 688816 & 4.45 & 5.2606 & TRN & \\
\hline CHEMBL1607309 & 688816 & 4.6 & 5.2635 & TST & \\
\hline CHEMBL1546106 & 688816 & 4.9 & 5.2206 & TST & \\
\hline CHEMBL1557151 & 688816 & 4.4 & 5.5863 & TRN & \\
\hline CHEMBL1370514 & 688816 & 5.2 & 5.6755 & TRN & \\
\hline CHEMBL1407475 & 688816 & 5.05 & 5.4943 & TRN & \\
\hline CHEMBL1583021 & 688816 & 4.85 & 5.2048 & TRN & \\
\hline CHEMBL1341114 & 688816 & 4.65 & 5.2059 & TRN & \\
\hline CHEMBL1321129 & 688816 & 4.55 & 5.1635 & TST & \\
\hline CHEMBL1408338 & 688816 & 5.4 & 5.4007 & TST & \\
\hline CHEMBL1465002 & 688816 & 5.05 & 5.7819 & TST & \\
\hline CHEMBL67535 & 688816 & 4.45 & 5.3577 & TRN & \\
\hline CHEMBL1330219 & 688816 & 4.7 & 5.1656 & TRN & \\
\hline CHEMBL1601423 & 688816 & 6.7501 & 5.0516 & TST & \\
\hline CHEMBL1416632 & 688816 & 4.45 & 5.63899 & 9999999999 & TRN \\
\hline CHEMBL1463973 & 688816 & 5.45 & 5.1981 & TRN & \\
\hline CHEMBL1380530 & 688816 & 4.85 & 4.9026 & TRN & \\
\hline CHEMBL1299995 & 688816 & 4.8 & 5.1414 & TST & \\
\hline CHEMBL1388388 & 688816 & 6.7001 & 5.3773 & TRN & \\
\hline CHEMBL1309184 & 688816 & 4.45 & 5.4764 & TRN & \\
\hline CHEMBL1332667 & 688816 & 4.45 & 5.1013 & TRN & \\
\hline
\end{tabular}




\begin{tabular}{|c|c|c|c|c|c|}
\hline \multicolumn{6}{|c|}{ Supplemental Table S2.txt } \\
\hline CHEMBL1440258 & 688816 & 4.95 & 4.9036 & TRN & \\
\hline CHEMBL3192625 & 688816 & 4.65 & 5.3004 & TRN & \\
\hline CHEMBL1560988 & 688816 & 4.9 & 5.2154 & TRN & \\
\hline CHEMBL1589156 & 688816 & 4.65 & 5.2941 & TRN & \\
\hline CHEMBL1408389 & 688816 & 4.8 & 5.3915 & TRN & \\
\hline CHEMBL1600625 & 688816 & 8.301 & 5.3775 & TRN & \\
\hline CHEMBL1526826 & 688816 & 5.65 & 5.2695 & TRN & \\
\hline CHEMBL1312985 & 688816 & 5.05 & 5.5691 & TRN & \\
\hline CHEMBL1427465 & 688816 & 5.4 & 5.3902 & TRN & \\
\hline CHEMBL1573807 & 688816 & 5.05 & 5.336 & TRN & \\
\hline CHEMBL1508567 & 688816 & 4.95 & 5.1225 & TRN & \\
\hline CHEMBL1375863 & 688816 & 4.45 & 5.4787 & TRN & \\
\hline CHEMBL1536876 & 688816 & 5.5 & 5.09699 & 99999999995 & TRN \\
\hline CHEMBL1311219 & 688816 & 4.9 & 4.8384 & TRN & \\
\hline CHEMBL1310681 & 688816 & 5.45 & 5.3002 & TST & \\
\hline CHEMBL1318843 & 688816 & 5.0 & 5.5909 & TRN & \\
\hline CHEMBL1305588 & 688816 & 6.7001 & 5.1722 & TRN & \\
\hline CHEMBL1418010 & 688816 & 4.8 & 5.1536 & TST & \\
\hline CHEMBL1494420 & 688816 & 4.7 & 5.2982 & TRN & \\
\hline CHEMBL1361193 & 688816 & 4.6 & 5.1793 & TST & \\
\hline CHEMBL1458167 & 688816 & 4.85 & 5.5984 & TRN & \\
\hline CHEMBL1329652 & 688816 & 4.6 & 5.146 & TRN & \\
\hline CHEMBL3189845 & 688816 & 8.301 & 5.0972 & TST & \\
\hline CHEMBL1305581 & 688816 & 6.05 & 5.7681 & TRN & \\
\hline CHEMBL1460464 & 688816 & 4.45 & 5.2509 & TRN & \\
\hline CHEMBL1462962 & 688816 & 5.4 & 5.5484 & TST & \\
\hline CHEMBL1567944 & 688816 & 6.0 & 6.2678 & TRN & \\
\hline CHEMBL1307101 & 688816 & 5.4 & 5.3971 & TRN & \\
\hline CHEMBL458768 & 688816 & 8.301 & 5.3499 & TST & \\
\hline CHEMBL1995825 & 688816 & 5.6 & 5.435 & TST & \\
\hline CHEMBL1347551 & 688816 & 5.0 & 5.4165 & TRN & \\
\hline CHEMBL1429544 & 688816 & 4.8 & 5.25799 & 9999999999 & TRN \\
\hline CHEMBL1352557 & 688816 & 4.6 & 4.9701 & TRN & \\
\hline CHEMBL1490318 & 688816 & 4.85 & 5.3196 & TRN & \\
\hline CHEMBL3198058 & 688816 & 4.85 & 5.3079 & TRN & \\
\hline CHEMBL1542259 & 688816 & 4.45 & 5.41299 & 9999999999 & TST \\
\hline CHEMBL1345447 & 688816 & 4.45 & 4.9668 & TST & \\
\hline CHEMBL1489356 & 688816 & 4.85 & 5.2158 & TRN & \\
\hline CHEMBL1603351 & 688816 & 4.75 & 4.8796 & TRN & \\
\hline CHEMBL1525704 & 688816 & 4.8 & 5.1977 & TRN & \\
\hline CHEMBL1342620 & 688816 & 4.95 & 5.2557 & TRN & \\
\hline CHEMBL1492011 & 688816 & 5.05 & 5.5045 & TRN & \\
\hline CHEMBL1587810 & 688816 & 5.0 & 5.1849 & TST & \\
\hline CHEMBL1611181 & 688816 & 8.1024 & 5.4839 & TRN & \\
\hline CHEMBL1990971 & 688816 & 6.0 & 5.3756 & TST & \\
\hline CHEMBL533293 & 688816 & 5.05 & 5.0672 & TST & \\
\hline CHEMBL1386326 & 688816 & 4.8 & 4.9428 & TRN & \\
\hline CHEMBL1373722 & 688816 & 4.8 & 5.2553 & TRN & \\
\hline
\end{tabular}




\begin{tabular}{|c|c|c|c|c|c|}
\hline \multicolumn{6}{|c|}{ Supplemental Table S2.txt } \\
\hline CHEMBL1370479 & 688816 & 4.75 & 5.2403 & TRN & \\
\hline CHEMBL1522796 & 688816 & 5.45 & 5.1853 & TST & \\
\hline CHEMBL1468487 & 688816 & 5.0 & 5.45100 & 00000000005 & TRN \\
\hline CHEMBL1489556 & 688816 & 4.5 & 5.5506 & TRN & \\
\hline CHEMBL1412583 & 688816 & 4.75 & 4.9255 & TST & \\
\hline CHEMBL1468774 & 688816 & 4.9 & 5.2619 & TRN & \\
\hline CHEMBL1398771 & 688816 & 4.9 & 5.3989 & TRN & \\
\hline CHEMBL1550420 & 688816 & 4.45 & 5.069 & TRN & \\
\hline CHEMBL1520077 & 688816 & 4.95 & 5.6018 & TRN & \\
\hline CHEMBL1442954 & 688816 & 5.65 & 5.39 & TST & \\
\hline CHEMBL1339433 & 688816 & 4.95 & 4.9431 & TRN & \\
\hline CHEMBL1574509 & 688816 & 4.9 & 5.004 & TRN & \\
\hline CHEMBL1499456 & 688816 & 5.05 & 5.4124 & TRN & \\
\hline CHEMBL3191996 & 688816 & 6.3 & 5.3027 & TRN & \\
\hline CHEMBL1581006 & 688816 & 8.4559 & 5.7866 & TST & \\
\hline CHEMBL475742 & 688816 & 4.8 & 5.6022 & TST & \\
\hline CHEMBL1256869 & 688816 & 4.5 & 5.10800 & 00000000005 & TST \\
\hline CHEMBL1321970 & 688816 & 5.5 & 5.3531 & TRN & \\
\hline CHEMBL1486050 & 688816 & 7.0 & 5.4089 & TRN & \\
\hline CHEMBL3191706 & 688816 & 4.9 & 5.17700 & 00000000005 & TRN \\
\hline CHEMBL1405397 & 688816 & 6.7501 & 5.5053 & TST & \\
\hline CHEMBL1592213 & 688816 & 4.45 & 4.8783 & TRN & \\
\hline CHEMBL1580082 & 688816 & 5.3 & 5.1134 & TRN & \\
\hline CHEMBL1381284 & 688816 & 5.5 & 5.4201 & TRN & \\
\hline CHEMBL3197475 & 688816 & 4.95 & 5.0039 & TRN & \\
\hline CHEMBL1734063 & 688816 & 4.85 & 5.1356 & TRN & \\
\hline CHEMBL1348675 & 688816 & 5.45 & 5.5016 & TRN & \\
\hline CHEMBL1547414 & 688816 & 6.8 & 5.1188 & TRN & \\
\hline CHEMBL1577720 & 688816 & 5.8 & 5.7725 & TRN & \\
\hline CHEMBL1429974 & 688816 & 6.8499 & 5.7222 & TRN & \\
\hline CHEMBL1365774 & 688816 & 5.0 & 5.4399 & TST & \\
\hline CHEMBL1392599 & 688816 & 4.95 & 5.6021 & TST & \\
\hline CHEMBL1601724 & 688816 & 4.8 & 4.9086 & TRN & \\
\hline CHEMBL3191102 & 688816 & 6.1 & 5.2556 & TRN & \\
\hline CHEMBL1556113 & 688816 & 4.45 & 5.0481 & TRN & \\
\hline CHEMBL1603307 & 688816 & 5.4 & 5.808 & TST & \\
\hline CHEMBL1378138 & 688816 & 4.65 & 4.8913 & TRN & \\
\hline CHEMBL1533607 & 688816 & 4.95 & 5.0315 & TST & \\
\hline CHEMBL233194 & 688816 & 4.9 & 5.0886 & TRN & \\
\hline CHEMBL3192010 & 688816 & 4.95 & 5.3115 & TRN & \\
\hline CHEMBL1464835 & 688816 & 8.0 & 5.2852 & TRN & \\
\hline CHEMBL1326273 & 688816 & 4.6 & 5.6618 & TST & \\
\hline CHEMBL1471820 & 688816 & 5.25 & 5.5825 & TRN & \\
\hline CHEMBL1408797 & 688816 & 4.6 & 4.7979 & TST & \\
\hline CHEMBL1603399 & 688816 & 4.75 & 4.9685 & TRN & \\
\hline CHEMBL1368702 & 688816 & 5.55 & 5.0245 & TRN & \\
\hline CHEMBL1532512 & 688816 & 4.95 & 5.2068 & TRN & \\
\hline CHEMBL1333373 & 688816 & 5.4 & 5.4117 & TRN & \\
\hline
\end{tabular}




\begin{tabular}{|c|c|c|c|c|c|}
\hline \multicolumn{6}{|c|}{ Supplemental Table S2.txt } \\
\hline CHEMBL1508929 & 688816 & 5.65 & 5.3366 & TRN & \\
\hline CHEMBL1381908 & 688816 & 4.45 & 5.4783 & TRN & \\
\hline CHEMBL1333616 & 688816 & 4.95 & 4.872 & TRN & \\
\hline CHEMBL 3208611 & 688816 & 4.9 & 5.4826 & TRN & \\
\hline CHEMBL1484274 & 688816 & 5.55 & 5.4376 & TRN & \\
\hline CHEMBL1548229 & 688816 & 6.35 & 5.5789 & TRN & \\
\hline CHEMBL1301053 & 688816 & 5.0 & 5.4684 & TRN & \\
\hline CHEMBL1421384 & 688816 & 5.0 & 5.1891 & TRN & \\
\hline CHEMBL1595774 & 688816 & 5.4 & 5.1609 & TRN & \\
\hline CHEMBL1325601 & 688816 & 4.9 & 5.2627 & TRN & \\
\hline CHEMBL1378790 & 688816 & 4.95 & 5.4259 & TRN & \\
\hline CHEMBL1584440 & 688816 & 4.85 & 5.3806 & TRN & \\
\hline CHEMBL1445746 & 688816 & 4.95 & 5.6412 & TRN & \\
\hline CHEMBL1469947 & 688816 & 4.75 & 5.7799 & TRN & \\
\hline CHEMBL1606319 & 688816 & 5.05 & 5.0477 & TRN & \\
\hline CHEMBL504791 & 688816 & 6.0 & 5.2227 & TST & \\
\hline CHEMBL3195488 & 688816 & 5.0 & 5.29700 & 0000000001 & TST \\
\hline CHEMBL1508810 & 688816 & 4.45 & 5.3479 & TST & \\
\hline CHEMBL1570475 & 688816 & 4.9 & 4.9092 & TRN & \\
\hline CHEMBL1311287 & 688816 & 5.25 & 5.4278 & TRN & \\
\hline CHEMBL1460848 & 688816 & 4.75 & 4.8036 & TRN & \\
\hline CHEMBL1456474 & 688816 & 8.301 & 5.6187 & TST & \\
\hline CHEMBL1528087 & 688816 & 4.45 & 5.1047 & TRN & \\
\hline CHEMBL1441696 & 688816 & 7.0501 & 5.7485 & TST & \\
\hline CHEMBL1570047 & 688816 & 4.65 & 5.1936 & TST & \\
\hline CHEMBL3192022 & 688816 & 4.85 & 4.7855 & TRN & \\
\hline CHEMBL1334185 & 688816 & 4.45 & 5.0775 & TRN & \\
\hline CHEMBL3213249 & 688816 & 4.8 & 5.2711 & TRN & \\
\hline CHEMBL1305090 & 688816 & 4.45 & 5.4132 & TRN & \\
\hline CHEMBL1467399 & 688816 & 8.2007 & 5.4258 & TST & \\
\hline CHEMBL1371903 & 688816 & 4.45 & 5.3917 & TRN & \\
\hline CHEMBL1335571 & 688816 & 4.45 & 4.8702 & TRN & \\
\hline CHEMBL1326099 & 688816 & 5.05 & 5.4574 & TRN & \\
\hline CHEMBL1441885 & 688816 & 5.15 & 5.29799 & 9999999999 & TRN \\
\hline CHEMBL1336164 & 688816 & 4.8 & 5.5257 & TRN & \\
\hline CHEMBL1599808 & 688816 & 6.7001 & 5.3872 & TST & \\
\hline CHEMBL1369199 & 688816 & 4.95 & 4.9404 & TRN & \\
\hline CHEMBL1333505 & 688816 & 4.95 & 4.9898 & TST & \\
\hline CHEMBL1487311 & 688816 & 4.85 & 5.2129 & TRN & \\
\hline CHEMBL1556750 & 688816 & 5.4 & 5.3675 & TST & \\
\hline CHEMBL1424127 & 688816 & 5.2 & 5.3628 & TRN & \\
\hline CHEMBL1411902 & 688816 & 6.4 & 5.3914 & TST & \\
\hline CHEMBL1566264 & 688816 & 4.45 & 5.2753 & TRN & \\
\hline CHEMBL85139 & 688816 & 5.1 & 5.6714 & TRN & \\
\hline CHEMBL1594286 & 688816 & 6.05 & 5.1973 & TRN & \\
\hline CHEMBL1533407 & 688816 & 5.45 & 5.4002 & TRN & \\
\hline CHEMBL1365367 & 688816 & 4.7 & 5.1643 & TRN & \\
\hline CHEMBL1389379 & 688816 & 4.45 & 5.3543 & TRN & \\
\hline
\end{tabular}




\begin{tabular}{|c|c|c|c|c|c|}
\hline \multicolumn{6}{|c|}{ Supplemental Table s2.txt } \\
\hline CHEMBL1403626 & 688816 & 4.65 & 5.3639 & TRN & \\
\hline CHEMBL1463220 & 688816 & 5.2 & 5.1436 & TRN & \\
\hline CHEMBL1454476 & 688816 & 4.9 & 5.2795 & TRN & \\
\hline CHEMBL1610045 & 688816 & 4.95 & 5.4267 & TRN & \\
\hline CHEMBL3211875 & 688816 & 4.85 & 5.44 & TRN & \\
\hline CHEMBL1565394 & 688816 & 4.8 & 5.0619 & TRN & \\
\hline CHEMBL1534683 & 688816 & 5.05 & 5.1634 & TST & \\
\hline CHEMBL1497574 & 688816 & 5.55 & 5.3173 & TRN & \\
\hline CHEMBL1386989 & 688816 & 4.95 & 5.5879 & TRN & \\
\hline CHEMBL1494197 & 688816 & 4.55 & 5.2391 & TRN & \\
\hline CHEMBL1532707 & 688816 & 4.45 & 5.1092 & TST & \\
\hline CHEMBL1470246 & 688816 & 7.8013 & 5.4722 & TRN & \\
\hline CHEMBL1503512 & 688816 & 4.95 & 5.3716 & TRN & \\
\hline CHEMBL1522508 & 688816 & 4.85 & 4.7241 & TRN & \\
\hline CHEMBL1353980 & 688816 & 5.1 & 5.106 & TST & \\
\hline CHEMBL1502874 & 688816 & 4.8 & 5.1239 & TRN & \\
\hline CHEMBL1317551 & 688816 & 5.2 & 4.8361 & TRN & \\
\hline CHEMBL1347628 & 688816 & 4.6 & 5.2259 & TRN & \\
\hline CHEMBL1371579 & 688816 & 4.5 & 5.0036 & TRN & \\
\hline CHEMBL1548608 & 688816 & 5.6 & 5.0017 & TST & \\
\hline CHEMBL1338442 & 688816 & 8.5528 & 5.6228 & TST & \\
\hline CHEMBL1381179 & 688816 & 5.0 & 5.0497 & TRN & \\
\hline CHEMBL1357087 & 688816 & 4.9 & 4.98 & TRN & \\
\hline CHEMBL589924 & 688816 & 4.65 & 5.10800 & 00000000005 & TRN \\
\hline CHEMBL1418018 & 688816 & 6.15 & 5.3639 & TRN & \\
\hline CHEMBL1454099 & 688816 & 5.5 & 5.1953 & TST & \\
\hline CHEMBL3198613 & 688816 & 4.95 & 5.2142 & TST & \\
\hline CHEMBL1470446 & 688816 & 5.45 & 5.2157 & TST & \\
\hline CHEMBL1609391 & 688816 & 5.0 & 5.0784 & TRN & \\
\hline CHEMBL1517733 & 688816 & 5.45 & 5.5825 & TST & \\
\hline CHEMBL184074 & 688816 & 4.45 & 5.2579 & TST & \\
\hline CHEMBL 3211166 & 688816 & 7.5003 & 5.2261 & TRN & \\
\hline CHEMBL1446926 & 688816 & 4.45 & 4.9866 & TRN & \\
\hline CHEMBL1464078 & 688816 & 5.05 & 5.5697 & TRN & \\
\hline CHEMBL1339570 & 688816 & 4.45 & 5.3423 & TRN & \\
\hline CHEMBL1510879 & 688816 & 7.3497 & 4.9997 & TST & \\
\hline CHEMBL1504855 & 688816 & 5.7 & 4.9849 & TRN & \\
\hline CHEMBL1368654 & 688816 & 5.35 & 5.2382 & TRN & \\
\hline CHEMBL1537999 & 688816 & 4.85 & 5.3644 & TST & \\
\hline CHEMBL1451523 & 688816 & 5.25 & 5.2338 & TST & \\
\hline CHEMBL1584180 & 688816 & 4.45 & 5.1475 & TRN & \\
\hline CHEMBL1536054 & 688816 & 8.4559 & 4.8659 & TRN & \\
\hline CHEMBL1356666 & 688816 & 4.8 & 5.1588 & TRN & \\
\hline CHEMBL1583314 & 688816 & 4.8 & 5.6651 & TRN & \\
\hline CHEMBL1255655 & 688816 & 5.5 & 5.6131 & TST & \\
\hline CHEMBL1515851 & 688816 & 4.9 & 5.4973 & TRN & \\
\hline CHEMBL1320274 & 688816 & 4.6 & 4.7876 & TST & \\
\hline CHEMBL1608383 & 688816 & 6.3 & 5.4154 & TRN & \\
\hline
\end{tabular}




\begin{tabular}{|c|c|c|c|c|c|}
\hline \multicolumn{6}{|c|}{ Supplemental Table S2.txt } \\
\hline CHEMBL1545121 & 688816 & 4.45 & 5.0957 & TRN & \\
\hline CHEMBL1599977 & 688816 & 7.4498 & 5.4617 & TRN & \\
\hline CHEMBL1488449 & 688816 & 4.85 & 5.2729 & TRN & \\
\hline CHEMBL1578966 & 688816 & 4.7 & 5.1169 & TRN & \\
\hline CHEMBL1411535 & 688816 & 7.6498 & 4.9293 & TRN & \\
\hline CHEMBL1464553 & 688816 & 4.7 & 5.0723 & TRN & \\
\hline CHEMBL3189866 & 688816 & 8.301 & 5.1121 & TRN & \\
\hline CHEMBL1197556 & 688816 & 5.8 & 5.3966 & TRN & \\
\hline CHEMBL1501300 & 688816 & 8.3468 & 4.9308 & TRN & \\
\hline CHEMBL1324493 & 688816 & 5.95 & 5.5942 & TRN & \\
\hline CHEMBL1359774 & 688816 & 7.2 & 5.4255 & TRN & \\
\hline CHEMBL1303173 & 688816 & 7.2503 & 5.1691 & TRN & \\
\hline CHEMBL578257 & 688816 & 5.1 & 5.1857 & TRN & \\
\hline CHEMBL1321097 & 688816 & 4.6 & 4.8173 & TST & \\
\hline CHEMBL1459479 & 688816 & 5.45 & 5.2546 & TRN & \\
\hline CHEMBL1439346 & 688816 & 4.65 & 5.1827 & TRN & \\
\hline CHEMBL1977589 & 688816 & 5.05 & 5.034 & TRN & \\
\hline CHEMBL1355522 & 688816 & 5.8 & 6.1973 & TRN & \\
\hline CHEMBL1510273 & 688816 & 5.6 & 5.1213 & TST & \\
\hline CHEMBL1718568 & 688816 & 5.55 & 4.8273 & TRN & \\
\hline CHEMBL1306709 & 688816 & 4.6 & 5.5785 & TRN & \\
\hline CHEMBL1555396 & 688816 & 7.8508 & 5.2633 & TST & \\
\hline CHEMBL1601903 & 688816 & 4.8 & 5.0664 & TRN & \\
\hline CHEMBL1342746 & 688816 & 4.85 & 5.4021 & TRN & \\
\hline CHEMBL1559819 & 688816 & 7.5498 & 5.3999 & TST & \\
\hline CHEMBL1344696 & 688816 & 5.25 & 5.0736 & TST & \\
\hline CHEMBL3191175 & 688816 & 4.7 & 5.1928 & TRN & \\
\hline CHEMBL1340508 & 688816 & 4.7 & 5.2341 & TRN & \\
\hline CHEMBL1419499 & 688816 & 4.9 & 4.9771 & TRN & \\
\hline CHEMBL1537926 & 688816 & 4.55 & 5.2588 & TRN & \\
\hline CHEMBL1480142 & 688816 & 7.6498 & 5.1303 & TST & \\
\hline CHEMBL1353794 & 688816 & 4.5 & 5.1905 & TST & \\
\hline CHEMBL399121 & 688816 & 4.5 & 5.5966 & TST & \\
\hline CHEMBL1515400 & 688816 & 4.95 & 5.32299 & 99999999995 & TRN \\
\hline CHEMBL1579918 & 688816 & 4.85 & 5.2449 & TRN & \\
\hline CHEMBL1343219 & 688816 & 5.0 & 5.0065 & TST & \\
\hline CHEMBL1560830 & 688816 & 4.45 & 5.0851 & TRN & \\
\hline CHEMBL1341366 & 688816 & 5.15 & 5.4144 & TRN & \\
\hline CHEMBL1353194 & 688816 & 4.8 & 5.2897 & TRN & \\
\hline CHEMBL1397973 & 688816 & 4.45 & 5.0578 & TRN & \\
\hline CHEMBL1306923 & 688816 & 4.6 & 5.0162 & TST & \\
\hline CHEMBL577660 & 688816 & 5.55 & 5.3961 & TRN & \\
\hline CHEMBL1341802 & 688816 & 4.9 & 5.1444 & TRN & \\
\hline CHEMBL1535377 & 688816 & 4.45 & 5.1594 & TST & \\
\hline CHEMBL1497571 & 688816 & 5.75 & 5.3248 & TRN & \\
\hline CHEMBL1539870 & 688816 & 5.35 & 5.2429 & TRN & \\
\hline CHEMBL1575894 & 688816 & 4.75 & 4.9895 & TRN & \\
\hline CHEMBL1481630 & 688816 & 5.15 & 5.1924 & TRN & \\
\hline
\end{tabular}




\begin{tabular}{|c|c|c|c|c|}
\hline \multicolumn{5}{|c|}{ Supplemental Table S2.txt } \\
\hline CHEMBL1334763 & 688816 & 4.95 & 5.2181 & TRN \\
\hline CHEMBL1385609 & 688816 & 5.35 & 5.2071 & TST \\
\hline CHEMBL1350073 & 688816 & 5.0 & 5.2103 & TRN \\
\hline CHEMBL1575415 & 688816 & 5.1 & 5.1804 & TRN \\
\hline CHEMBL1560895 & 688816 & 6.1 & 5.6183 & TRN \\
\hline CHEMBL1458773 & 688816 & 8.3468 & 4.9077 & TRN \\
\hline CHEMBL1510336 & 688816 & 7.5003 & 5.2195 & TRN \\
\hline CHEMBL1362749 & 688816 & 4.55 & 5.49700 & 0000000001 \\
\hline CHEMBL1439253 & 688816 & 4.85 & 5.6346 & TRN \\
\hline CHEMBL1365988 & 688816 & 4.45 & 5.4285 & TRN \\
\hline CHEMBL1393005 & 688816 & 4.9 & 5.2554 & TRN \\
\hline CHEMBL1380848 & 688816 & 4.95 & 5.1869 & TRN \\
\hline CHEMBL1304688 & 688816 & 5.0 & 5.3801 & TRN \\
\hline CHEMBL1401057 & 688816 & 6.3 & 5.1103 & TRN \\
\hline CHEMBL1371405 & 688816 & 6.15 & 5.3048 & TRN \\
\hline CHEMBL1463028 & 688816 & 4.85 & 5.4574 & TST \\
\hline CHEMBL1325062 & 688816 & 4.85 & 4.6482 & TRN \\
\hline CHEMBL1604506 & 688816 & 4.95 & 5.2901 & TRN \\
\hline CHEMBL1556717 & 688816 & 5.2 & 5.2756 & TST \\
\hline CHEMBL1545149 & 688816 & 4.9 & 5.1932 & TRN \\
\hline CHEMBL1468942 & 688816 & 4.95 & 5.1563 & TRN \\
\hline CHEMBL1578197 & 688816 & 5.25 & 5.1506 & TRN \\
\hline CHEMBL1407150 & 688816 & 4.45 & 5.1076 & TRN \\
\hline CHEMBL1564884 & 688816 & 6.8 & 5.2566 & TST \\
\hline CHEMBL1510257 & 688816 & 4.95 & 5.2413 & TRN \\
\hline CHEMBL1515025 & 688816 & 4.95 & 5.0275 & TRN \\
\hline CHEMBL3144884 & 688816 & 4.7 & 4.9598 & TST \\
\hline CHEMBL1452226 & 688816 & 5.25 & 5.0682 & TRN \\
\hline CHEMBL1447750 & 688816 & 4.9 & 5.3178 & TRN \\
\hline CHEMBL1423122 & 688816 & 5.25 & 5.2887 & TRN \\
\hline CHEMBL1320977 & 688816 & 4.95 & 5.3078 & TRN \\
\hline CHEMBL1565578 & 688816 & 6.0 & 5.6138 & TST \\
\hline CHEMBL1589625 & 688816 & 4.9 & 5.0054 & TRN \\
\hline CHEMBL1482757 & 688816 & 4.45 & 5.0231 & TRN \\
\hline CHEMBL1487485 & 688816 & 4.45 & 5.8963 & TRN \\
\hline CHEMBL1386123 & 688816 & 4.75 & 5.2393 & TRN \\
\hline CHEMBL1328925 & 688816 & 4.9 & 5.477 & TRN \\
\hline CHEMBL1449795 & 688816 & 7.0501 & 5.5961 & TST \\
\hline CHEMBL1415061 & 688816 & 5.25 & 5.3972 & TRN \\
\hline CHEMBL1299725 & 688816 & 5.85 & 5.3011 & TRN \\
\hline CHEMBL1563106 & 688816 & 5.25 & 4.9381 & TST \\
\hline CHEMBL1304767 & 688816 & 7.7496 & 5.4018 & TST \\
\hline CHEMBL1526703 & 688816 & 4.95 & 5.2598 & TRN \\
\hline CHEMBL1401244 & 688816 & 4.75 & 4.9728 & TRN \\
\hline CHEMBL1444953 & 688816 & 6.1 & 5.3597 & TRN \\
\hline CHEMBL3209992 & 688816 & 4.95 & 5.3143 & TST \\
\hline CHEMBL1479891 & 688816 & 7.4498 & 5.352 & TST \\
\hline CHEMBL1438614 & 688816 & 5.5 & 5.4438 & TRN \\
\hline
\end{tabular}




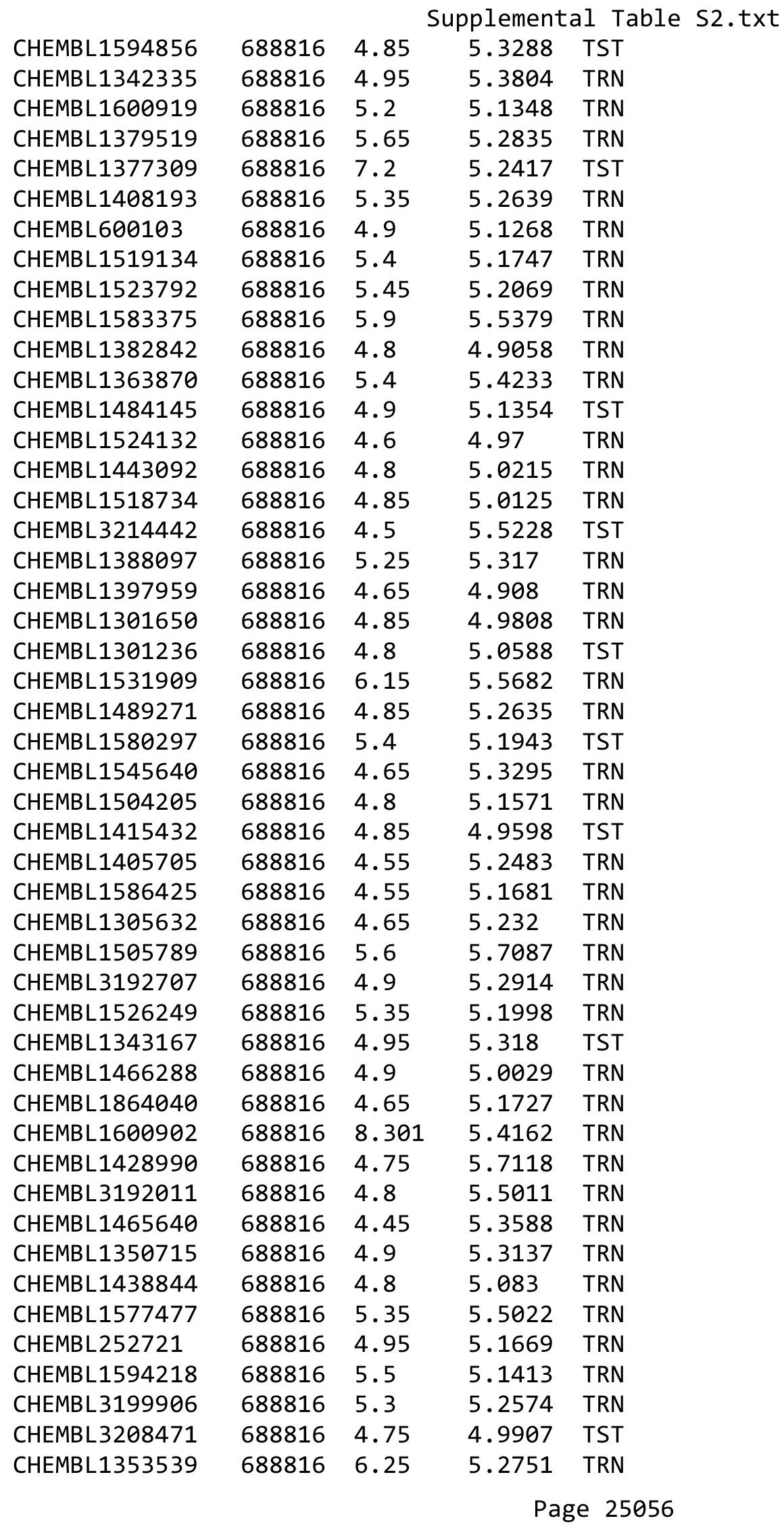




\begin{tabular}{|c|c|c|c|c|}
\hline \multicolumn{5}{|c|}{ Supplemental Table S2.txt } \\
\hline CHEMBL1363514 & 688816 & 5.0 & 5.1833 & TRN \\
\hline CHEMBL1313102 & 688816 & 4.8 & 5.9691 & TST \\
\hline CHEMBL1460592 & 688816 & 4.45 & 5.3322 & TRN \\
\hline CHEMBL1315803 & 688816 & 4.95 & 5.1306 & TRN \\
\hline CHEMBL1592338 & 688816 & 4.75 & 5.0236 & TRN \\
\hline CHEMBL3213945 & 688816 & 4.45 & 4.9646 & TRN \\
\hline CHEMBL1528153 & 688816 & 5.25 & 4.8895 & TRN \\
\hline CHEMBL1393911 & 688816 & 4.45 & 4.7856 & TRN \\
\hline CHEMBL1335843 & 688816 & 4.9 & 5.2353 & TRN \\
\hline CHEMBL1492459 & 688816 & 7.2503 & 5.4569 & TST \\
\hline CHEMBL1565523 & 688816 & 4.8 & 5.3023 & TRN \\
\hline CHEMBL1343627 & 688816 & 4.95 & 5.3199 & TRN \\
\hline CHEMBL1464503 & 688816 & 5.15 & 5.3332 & TST \\
\hline CHEMBL1390920 & 688816 & 7.8508 & 5.3301 & TST \\
\hline CHEMBL1318799 & 688816 & 4.85 & 5.0862 & TRN \\
\hline CHEMBL1329033 & 688816 & 4.95 & 5.0921 & TST \\
\hline CHEMBL1451974 & 688816 & 5.05 & 5.1176 & TST \\
\hline CHEMBL1417613 & 688816 & 7.3002 & 5.2772 & TST \\
\hline CHEMBL1421039 & 688816 & 5.0 & 5.3514 & TRN \\
\hline CHEMBL1429768 & 688816 & 4.95 & 5.2927 & TRN \\
\hline CHEMBL1520169 & 688816 & 4.45 & 5.4354 & TST \\
\hline CHEMBL1595663 & 688816 & 4.9 & 4.8825 & TRN \\
\hline CHEMBL1441782 & 688816 & 4.85 & 5.0819 & TRN \\
\hline CHEMBL1431082 & 688816 & 5.65 & 5.2683 & TRN \\
\hline CHEMBL1387929 & 688816 & 5.45 & 5.4164 & TRN \\
\hline CHEMBL1358179 & 688816 & 4.7 & 5.0894 & TST \\
\hline CHEMBL1461075 & 688816 & 7.3497 & 5.5396 & TRN \\
\hline CHEMBL1542463 & 688816 & 7.15 & 5.4207 & TST \\
\hline CHEMBL1544670 & 688816 & 7.5003 & 5.7867 & TRN \\
\hline CHEMBL93353 & 688816 & 5.0 & 5.5295 & TST \\
\hline CHEMBL1535109 & 688816 & 5.05 & 5.0154 & TRN \\
\hline CHEMBL1524101 & 688816 & 4.7 & 4.8711 & TRN \\
\hline CHEMBL1394013 & 688816 & 5.75 & 5.4754 & TRN \\
\hline CHEMBL1432063 & 688816 & 4.45 & 5.0595 & TRN \\
\hline CHEMBL603024 & 688816 & 4.9 & 5.0074 & TST \\
\hline CHEMBL1364304 & 688816 & 4.75 & 5.5318 & TRN \\
\hline CHEMBL 1305380 & 688816 & 5.05 & 5.3155 & TRN \\
\hline CHEMBL1413518 & 688816 & 6.15 & 5.5079 & TRN \\
\hline CHEMBL1488034 & 688816 & 4.95 & 4.9393 & TRN \\
\hline CHEMBL1354014 & 688816 & 4.95 & 5.6145 & TRN \\
\hline CHEMBL1343103 & 688816 & 4.85 & 5.2593 & TST \\
\hline CHEMBL1347216 & 688816 & 5.3 & 5.4662 & TST \\
\hline CHEMBL1425019 & 688816 & 5.35 & 5.1488 & TRN \\
\hline CHEMBL1500398 & 688816 & 4.45 & 4.9624 & TST \\
\hline CHEMBL1500027 & 688816 & 4.6 & 4.8914 & TST \\
\hline CHEMBL1519762 & 688816 & 4.95 & 5.3816 & TRN \\
\hline CHEMBL1456699 & 688816 & 5.15 & 5.1312 & TST \\
\hline CHEMBL1477131 & 688816 & 5.15 & 5.1674 & TRN \\
\hline
\end{tabular}




\begin{tabular}{|c|c|c|c|c|c|}
\hline \multicolumn{6}{|c|}{ Supplemental Table S2.txt } \\
\hline CHEMBL1602608 & 688816 & 4.45 & 5.0934 & TST & \\
\hline CHEMBL1353934 & 688816 & 4.65 & 5.3042 & TRN & \\
\hline CHEMBL1489384 & 688816 & 8.1024 & 5.6473 & TST & \\
\hline CHEMBL1424996 & 688816 & 6.0 & 5.2585 & TRN & \\
\hline CHEMBL1343313 & 688816 & 4.45 & 5.1026 & TRN & \\
\hline CHEMBL1493362 & 688816 & 4.75 & 4.8597 & TRN & \\
\hline CHEMBL1500160 & 688816 & 5.95 & 5.6831 & TST & \\
\hline CHEMBL1449248 & 688816 & 8.301 & 5.4967 & TRN & \\
\hline CHEMBL1547543 & 688816 & 4.5 & 5.4454 & TST & \\
\hline CHEMBL1372056 & 688816 & 4.9 & 5.2276 & TRN & \\
\hline CHEMBL1303416 & 688816 & 4.45 & 4.9746 & TST & \\
\hline CHEMBL1392070 & 688816 & 4.9 & 5.3272 & TRN & \\
\hline CHEMBL3196867 & 688816 & 6.3 & 5.4513 & TRN & \\
\hline CHEMBL1454132 & 688816 & 4.5 & 5.6185 & TST & \\
\hline CHEMBL1548377 & 688816 & 4.9 & 4.8495 & TST & \\
\hline CHEMBL1601858 & 688816 & 4.55 & 5.2004 & TRN & \\
\hline CHEMBL1426492 & 688816 & 5.0 & 5.7058 & TRN & \\
\hline CHEMBL 3214497 & 688816 & 5.3 & 5.3596 & TRN & \\
\hline CHEMBL1449875 & 688816 & 4.9 & 4.8449 & TST & \\
\hline CHEMBL1414585 & 688816 & 4.85 & 5.4805 & TRN & \\
\hline CHEMBL1493427 & 688816 & 4.8 & 5.5367 & TRN & \\
\hline CHEMBL1543181 & 688816 & 4.65 & 5.1572 & TRN & \\
\hline CHEMBL1554371 & 688816 & 5.0 & 5.5767 & TRN & \\
\hline CHEMBL1367996 & 688816 & 4.45 & 5.2307 & TST & \\
\hline CHEMBL1385137 & 688816 & 4.45 & 5.2153 & TST & \\
\hline CHEMBL1578578 & 688816 & 4.6 & 4.9856 & TRN & \\
\hline CHEMBL1536914 & 688816 & 4.8 & 5.2377 & TRN & \\
\hline CHEMBL1593367 & 688816 & 4.55 & 5.3705 & TRN & \\
\hline CHEMBL1468307 & 688816 & 4.95 & 5.234 & TRN & \\
\hline CHEMBL1379133 & 688816 & 5.55 & 5.4434 & TRN & \\
\hline CHEMBL 3194418 & 688816 & 4.75 & 5.33299 & 9999999999 & TRN \\
\hline CHEMBL1421785 & 688816 & 4.9 & 5.2034 & TST & \\
\hline CHEMBL1346848 & 688816 & 5.45 & 5.1065 & TRN & \\
\hline CHEMBL1343006 & 688816 & 4.45 & 5.7913 & TRN & \\
\hline CHEMBL1500630 & 688816 & 5.8 & 5.3206 & TST & \\
\hline CHEMBL1324385 & 688816 & 5.25 & 5.5967 & TRN & \\
\hline CHEMBL1306838 & 688816 & 5.05 & 4.7591 & TRN & \\
\hline CHEMBL1451119 & 688816 & 5.55 & 5.3073 & TRN & \\
\hline CHEMBL1426127 & 688816 & 4.8 & 5.3167 & TST & \\
\hline CHEMBL1535167 & 688816 & 4.45 & 5.1444 & TRN & \\
\hline CHEMBL1533697 & 688816 & 5.55 & 5.4411 & TRN & \\
\hline CHEMBL3207582 & 688816 & 4.45 & 5.0902 & TRN & \\
\hline CHEMBL1375326 & 688816 & 4.9 & 5.0522 & TRN & \\
\hline CHEMBL1344929 & 688816 & 4.85 & 5.0561 & TRN & \\
\hline CHEMBL1345310 & 688816 & 4.45 & 5.1122 & TRN & \\
\hline CHEMBL1330876 & 688816 & 4.85 & 5.6787 & TRN & \\
\hline CHEMBL1386270 & 688816 & 4.95 & 5.0876 & TRN & \\
\hline CHEMBL1510802 & 688816 & 5.05 & 5.1696 & TRN & \\
\hline
\end{tabular}




\begin{tabular}{|c|c|c|c|c|c|}
\hline \multicolumn{6}{|c|}{ Supplemental Table S2.txt } \\
\hline CHEMBL1546760 & 688816 & 5.35 & 5.3963 & TRN & \\
\hline CHEMBL1427239 & 688816 & 6.0 & 5.0692 & TST & \\
\hline CHEMBL3193902 & 688816 & 8.301 & 5.1575 & TST & \\
\hline CHEMBL1387428 & 688816 & 4.6 & 5.6958 & TST & \\
\hline CHEMBL1468114 & 688816 & 7.0 & 5.3997 & TRN & \\
\hline CHEMBL1467311 & 688816 & 5.75 & 4.8347 & TST & \\
\hline CHEMBL1432388 & 688816 & 6.9 & 5.6399 & TRN & \\
\hline CHEMBL1467435 & 688816 & 5.0 & 5.5995 & TRN & \\
\hline CHEMBL1463769 & 688816 & 4.45 & 5.0513 & TRN & \\
\hline CHEMBL1488145 & 688816 & 6.2 & 5.7318 & TRN & \\
\hline CHEMBL1344622 & 688816 & 7.7496 & 5.2198 & TRN & \\
\hline CHEMBL1587981 & 688816 & 4.9 & 5.3902 & TST & \\
\hline CHEMBL1470281 & 688816 & 4.7 & 5.5037 & TST & \\
\hline CHEMBL1452892 & 688816 & 4.7 & 5.6598 & TRN & \\
\hline CHEMBL1405702 & 688816 & 7.2 & 5.4702 & TRN & \\
\hline CHEMBL1540065 & 688816 & 4.45 & 5.6262 & TRN & \\
\hline CHEMBL3192422 & 688816 & 5.0 & 5.2419 & TST & \\
\hline CHEMBL1549201 & 688816 & 5.6 & 5.5 & TRN & \\
\hline CHEMBL1483621 & 688816 & 5.5 & 5.3464 & TRN & \\
\hline CHEMBL1452914 & 688816 & 4.85 & 5.5648 & TRN & \\
\hline CHEMBL1374152 & 688816 & 5.2 & 5.4968 & TRN & \\
\hline CHEMBL1589677 & 688816 & 5.5 & 5.1925 & TRN & \\
\hline CHEMBL1339535 & 688816 & 7.2503 & 5.2233 & TRN & \\
\hline CHEMBL1415015 & 688816 & 4.85 & 4.9674 & TRN & \\
\hline CHEMBL1976754 & 688816 & 5.2 & 5.442 & TRN & \\
\hline CHEMBL1304061 & 688816 & 7.1002 & 5.66200 & 0000000001 & TST \\
\hline CHEMBL1967081 & 688816 & 5.0 & 4.9774 & TRN & \\
\hline CHEMBL1575805 & 688816 & 4.95 & 4.9409 & TRN & \\
\hline CHEMBL1360487 & 688816 & 4.7 & 5.4966 & TST & \\
\hline CHEMBL1598194 & 688816 & 6.5501 & 5.3089 & TST & \\
\hline CHEMBL1465287 & 688816 & 4.45 & 4.9845 & TRN & \\
\hline CHEMBL3190306 & 688816 & 5.9 & 5.3431 & TRN & \\
\hline CHEMBL1561809 & 688816 & 5.0 & 4.8033 & TRN & \\
\hline CHEMBL3192364 & 688816 & 4.9 & 5.0521 & TRN & \\
\hline CHEMBL3211142 & 688816 & 4.95 & 5.2347 & TRN & \\
\hline CHEMBL1601809 & 688816 & 4.6 & 4.90300 & 00000000005 & TRN \\
\hline CHEMBL1345169 & 688816 & 7.5003 & 5.2548 & TRN & \\
\hline CHEMBL1540237 & 688816 & 4.8 & 5.0348 & TRN & \\
\hline CHEMBL1313648 & 688816 & 5.4 & 5.3191 & TRN & \\
\hline CHEMBL1300536 & 688816 & 5.05 & 4.86600 & 00000000005 & TRN \\
\hline CHEMBL1409289 & 688816 & 4.8 & 5.3255 & TRN & \\
\hline CHEMBL1455538 & 688816 & 4.8 & 4.9068 & TRN & \\
\hline CHEMBL1539945 & 688816 & 5.5 & 5.9924 & TRN & \\
\hline CHEMBL1497967 & 688816 & 4.8 & 5.3902 & TST & \\
\hline CHEMBL1608218 & 688816 & 4.9 & 5.1788 & TRN & \\
\hline CHEMBL1370357 & 688816 & 5.45 & 5.0541 & TRN & \\
\hline CHEMBL1343485 & 688816 & 4.9 & 5.1021 & TRN & \\
\hline CHEMBL3192856 & 688816 & 4.65 & 4.6758 & TRN & \\
\hline
\end{tabular}




\begin{tabular}{|c|c|c|c|c|}
\hline \multicolumn{5}{|c|}{ Supplemental Table S2.txt } \\
\hline CHEMBL1329986 & 688816 & 5.65 & 5.0831 & TRN \\
\hline CHEMBL3199098 & 688816 & 4.8 & 5.3925 & TRN \\
\hline CHEMBL1498887 & 688816 & 4.95 & 5.2617 & TRN \\
\hline CHEMBL1575439 & 688816 & 6.6 & 5.5567 & TRN \\
\hline CHEMBL1323622 & 688816 & 4.85 & 5.0514 & TRN \\
\hline CHEMBL1327643 & 688816 & 4.9 & 5.0853 & TST \\
\hline CHEMBL1431151 & 688816 & 6.2 & 4.9849 & TRN \\
\hline CHEMBL3198931 & 688816 & 4.95 & 5.3764 & TRN \\
\hline CHEMBL1428261 & 688816 & 4.8 & 4.9468 & TRN \\
\hline CHEMBL210465 & 688816 & 6.5 & 5.6691 & TRN \\
\hline CHEMBL1531697 & 688816 & 4.85 & 5.055 & TST \\
\hline CHEMBL1574638 & 688816 & 4.45 & 5.1301 & TRN \\
\hline CHEMBL1470789 & 688816 & 6.8 & 5.2329 & TRN \\
\hline CHEMBL1558810 & 688816 & 4.7 & 5.0848 & TRN \\
\hline CHEMBL1558425 & 688816 & 5.05 & 5.0705 & TRN \\
\hline CHEMBL1545079 & 688816 & 5.65 & 5.7169 & TRN \\
\hline CHEMBL1578930 & 688816 & 4.7 & 5.0574 & TRN \\
\hline CHEMBL1989636 & 688816 & 4.9 & 5.4257 & TRN \\
\hline CHEMBL1429560 & 688816 & 7.699 & 4.9995 & TST \\
\hline CHEMBL1604508 & 688816 & 5.4 & 5.5428 & TRN \\
\hline CHEMBL1485300 & 688816 & 4.75 & 5.2857 & TRN \\
\hline CHEMBL1526446 & 688816 & 5.05 & 5.4723 & TRN \\
\hline CHEMBL3208316 & 688816 & 5.05 & 5.322 & TST \\
\hline CHEMBL1421632 & 688816 & 4.45 & 5.2272 & TRN \\
\hline CHEMBL3213755 & 688816 & 4.85 & 5.3888 & TST \\
\hline CHEMBL3194360 & 688816 & 4.5 & 4.875 & TRN \\
\hline CHEMBL443127 & 688816 & 4.45 & 5.7462 & TST \\
\hline CHEMBL1557176 & 688816 & 6.8 & 5.6825 & TRN \\
\hline CHEMBL1444277 & 688816 & 5.5 & 5.1972 & TRN \\
\hline CHEMBL1404526 & 688816 & 4.65 & 5.5022 & TST \\
\hline CHEMBL1546211 & 688816 & 4.65 & 5.034 & TRN \\
\hline CHEMBL1341641 & 688816 & 7.5003 & 5.6699 & TRN \\
\hline CHEMBL1363615 & 688816 & 4.9 & 4.9847 & TRN \\
\hline CHEMBL1344355 & 688816 & 4.95 & 5.2938 & TRN \\
\hline CHEMBL1379567 & 688816 & 4.85 & 5.3643 & TST \\
\hline CHEMBL1604614 & 688816 & 4.9 & 4.7203 & TRN \\
\hline CHEMBL1347924 & 688816 & 4.95 & $5.4860 e$ & 0000000001 \\
\hline CHEMBL1484116 & 688816 & 4.75 & 5.0779 & TST \\
\hline CHEMBL1345262 & 688816 & 4.45 & 4.8957 & TRN \\
\hline CHEMBL1306780 & 688816 & 5.05 & 5.3456 & TST \\
\hline CHEMBL1503764 & 688816 & 5.4 & 5.2087 & TRN \\
\hline CHEMBL1413087 & 688816 & 6.5 & 5.3673 & TRN \\
\hline CHEMBL1453563 & 688816 & 8.301 & 5.0214 & TST \\
\hline CHEMBL1432026 & 688816 & 4.9 & 5.2422 & TST \\
\hline CHEMBL1384273 & 688816 & 4.45 & 5.1014 & TRN \\
\hline CHEMBL1530562 & 688816 & 6.9 & 5.6076 & TRN \\
\hline CHEMBL1547301 & 688816 & 4.65 & 5.0665 & TRN \\
\hline CHEMBL589507 & 688816 & 5.65 & 5.3036 & TRN \\
\hline
\end{tabular}




\begin{tabular}{|c|c|c|c|c|c|}
\hline \multicolumn{6}{|c|}{ Supplemental Table S2.txt } \\
\hline CHEMBL1552868 & 688816 & 4.95 & 5.0899 & TRN & \\
\hline CHEMBL3208216 & 688816 & 4.45 & 5.0525 & TRN & \\
\hline CHEMBL1359126 & 688816 & 4.65 & 5.4286 & TRN & \\
\hline CHEMBL1498272 & 688816 & 5.0 & 5.2714 & TRN & \\
\hline CHEMBL1349341 & 688816 & 4.45 & 5.2191 & TRN & \\
\hline CHEMBL1513169 & 688816 & 5.0 & 5.0073 & TRN & \\
\hline CHEMBL1326897 & 688816 & 4.65 & 5.3436 & TST & \\
\hline CHEMBL1511039 & 688816 & 4.95 & 5.4946 & TRN & \\
\hline CHEMBL 3197814 & 688816 & 4.9 & 5.5893 & TRN & \\
\hline CHEMBL1527195 & 688816 & 6.3 & 5.6174 & TRN & \\
\hline CHEMBL1445561 & 688816 & 7.15 & 5.4602 & TRN & \\
\hline CHEMBL1334476 & 688816 & 5.3 & 5.7978 & TRN & \\
\hline CHEMBL1477926 & 688816 & 4.85 & 5.0807 & TRN & \\
\hline CHEMBL1522550 & 688816 & 4.95 & 5.0416 & TST & \\
\hline CHEMBL1439783 & 688816 & 4.7 & 5.2009 & TST & \\
\hline CHEMBL1409599 & 688816 & 4.9 & 5.1991 & TRN & \\
\hline CHEMBL1523413 & 688816 & 5.4 & 5.399 & TST & \\
\hline CHEMBL1341666 & 688816 & 4.65 & 5.256 & TRN & \\
\hline CHEMBL1589405 & 688816 & 4.7 & 5.5029 & TST & \\
\hline CHEMBL1375268 & 688816 & 4.45 & 4.9254 & TST & \\
\hline CHEMBL1307978 & 688816 & 4.95 & 4.8237 & TST & \\
\hline CHEMBL1531086 & 688816 & 4.45 & 5.4896 & TRN & \\
\hline CHEMBL1558805 & 688816 & 4.85 & 4.9587 & TRN & \\
\hline CHEMBL1387409 & 688816 & 8.3468 & 5.6017 & TST & \\
\hline CHEMBL1577030 & 688816 & 6.9 & 5.0995 & TRN & \\
\hline CHEMBL1306199 & 688816 & 4.6 & 5.3262 & TRN & \\
\hline CHEMBL1597622 & 688816 & 4.6 & 4.9734 & TRN & \\
\hline CHEMBL55814 & 688816 & 4.65 & 5.052 & TRN & \\
\hline CHEMBL1336286 & 688816 & 4.45 & 5.002 & TRN & \\
\hline CHEMBL1447475 & 688816 & 4.45 & 5.7673 & TRN & \\
\hline CHEMBL1498707 & 688816 & 5.1 & 5.3029 & TRN & \\
\hline CHEMBL1444097 & 688816 & 4.45 & 5.08899 & 99999999995 & TRN \\
\hline CHEMBL1456621 & 688816 & 4.95 & 5.4601 & TRN & \\
\hline CHEMBL1372192 & 688816 & 5.25 & 5.5675 & TRN & \\
\hline CHEMBL 2003521 & 688816 & 4.9 & 5.1874 & TRN & \\
\hline CHEMBL1543127 & 688816 & 4.9 & 5.1876 & TRN & \\
\hline CHEMBL1490742 & 688816 & 4.85 & 5.2871 & TRN & \\
\hline CHEMBL 3195222 & 688816 & 4.55 & 5.244 & TRN & \\
\hline CHEMBL2003973 & 688816 & 4.65 & 5.2828 & TST & \\
\hline CHEMBL1369518 & 688816 & 5.0 & 5.2578 & TRN & \\
\hline CHEMBL1573190 & 688816 & 4.55 & 5.37799 & 7999999999 & TST \\
\hline CHEMBL1330844 & 688816 & 4.65 & 5.4462 & TRN & \\
\hline CHEMBL1400829 & 688816 & 5.95 & 5.3681 & TRN & \\
\hline CHEMBL1552341 & 688816 & 4.8 & 5.1291 & TST & \\
\hline CHEMBL1585002 & 688816 & 4.95 & 5.4313 & TRN & \\
\hline CHEMBL1557987 & 688816 & 8.3468 & 5.3315 & TRN & \\
\hline CHEMBL1982381 & 688816 & 5.4 & 5.08 & TRN & \\
\hline CHEMBL1503093 & 688816 & 8.301 & 5.3013 & TRN & \\
\hline
\end{tabular}




\begin{tabular}{|c|c|c|c|c|c|}
\hline \multicolumn{6}{|c|}{ Supplemental Table s2.txt } \\
\hline CHEMBL1396907 & 688816 & 4.85 & 5.3551 & TRN & \\
\hline CHEMBL1521681 & 688816 & 6.5501 & 5.7031 & TST & \\
\hline CHEMBL1514132 & 688816 & 5.0 & 4.9963 & TRN & \\
\hline CHEMBL1311844 & 688816 & 4.85 & 4.9536 & TRN & \\
\hline CHEMBL1975447 & 688816 & 5.6 & 5.4007 & TST & \\
\hline CHEMBL1339424 & 688816 & 5.0 & 5.7621 & TRN & \\
\hline CHEMBL1410662 & 688816 & 8.0 & 5.4378 & TST & \\
\hline CHEMBL1507152 & 688816 & 4.65 & 4.9776 & TRN & \\
\hline CHEMBL1425181 & 688816 & 6.7001 & 5.6881 & TST & \\
\hline CHEMBL1407998 & 688816 & 5.7 & 5.3356 & TRN & \\
\hline CHEMBL 248654 & 688816 & 5.55 & 5.3507 & TRN & \\
\hline CHEMBL489940 & 688816 & 4.6 & 5.1734 & TST & \\
\hline CHEMBL3207313 & 688816 & 4.7 & 5.4447 & TST & \\
\hline CHEMBL 3199720 & 688816 & 4.7 & 5.1396 & TRN & \\
\hline CHEMBL1481223 & 688816 & 7.8996 & 5.4 & TRN & \\
\hline CHEMBL1319104 & 688816 & 4.5 & 4.9212 & TST & \\
\hline CHEMBL1569304 & 688816 & 5.1 & 5.612 & TRN & \\
\hline CHEMBL1439170 & 688816 & 4.9 & 5.2772 & TST & \\
\hline CHEMBL1393317 & 688816 & 4.75 & 5.8794 & TRN & \\
\hline CHEMBL1594242 & 688816 & 5.35 & 5.0608 & TRN & \\
\hline CHEMBL1401772 & 688816 & 4.45 & 5.4567 & TST & \\
\hline CHEMBL3191397 & 688816 & 4.8 & 5.38200 & 0000000001 & TST \\
\hline CHEMBL1501444 & 688816 & 4.8 & 5.2008 & TRN & \\
\hline CHEMBL 3189537 & 688816 & 4.45 & 5.2364 & TRN & \\
\hline CHEMBL3213197 & 688816 & 4.7 & 5.3258 & TST & \\
\hline CHEMBL1447803 & 688816 & 7.5498 & 5.3409 & TST & \\
\hline CHEMBL1470450 & 688816 & 4.95 & 4.9333 & TST & \\
\hline CHEMBL1570135 & 688816 & 4.9 & 4.81 & TRN & \\
\hline CHEMBL1323216 & 688816 & 7.5498 & 5.1817 & TRN & \\
\hline CHEMBL1470538 & 688816 & 5.35 & 5.2971 & TRN & \\
\hline CHEMBL1613636 & 688816 & 5.8 & 5.2463 & TRN & \\
\hline CHEMBL1574463 & 688816 & 4.95 & 5.2793 & TST & \\
\hline CHEMBL1443763 & 688816 & 5.95 & 5.3053 & TRN & \\
\hline CHEMBL1329507 & 688816 & 4.7 & 5.2337 & TRN & \\
\hline CHEMBL1323899 & 688816 & 6.0 & 5.5388 & TRN & \\
\hline CHEMBL1405532 & 688816 & 5.65 & 4.9935 & TRN & \\
\hline CHEMBL1350736 & 688816 & 8.0506 & 5.3562 & TRN & \\
\hline CHEMBL268868 & 688816 & 5.0 & 5.4806 & TST & \\
\hline CHEMBL1508706 & 688816 & 4.9 & 5.0556 & TRN & \\
\hline CHEMBL157710 & 688816 & 6.6499 & 5.1402 & TST & \\
\hline CHEMBL167869 & 688816 & 4.9 & 4.9993 & TRN & \\
\hline CHEMBL3213600 & 688816 & 5.4 & 5.2225 & TRN & \\
\hline CHEMBL1352313 & 688816 & 4.95 & 5.1596 & TST & \\
\hline CHEMBL1530949 & 688816 & 8.301 & 5.5279 & TRN & \\
\hline CHEMBL3199860 & 688816 & 5.1 & 4.9956 & TRN & \\
\hline CHEMBL1608168 & 688816 & 4.8 & 4.9538 & TRN & \\
\hline CHEMBL3195070 & 688816 & 8.3468 & 5.6521 & TRN & \\
\hline CHEMBL1467156 & 688816 & 5.65 & 5.1688 & TST & \\
\hline
\end{tabular}




\begin{tabular}{|c|c|c|c|c|c|}
\hline \\
\hline CHEMBL1412479 & 688816 & 4.7 & 5.0214 & TRN & \\
\hline CHEMBL1521240 & 688816 & 6.95 & 5.5619 & TRN & \\
\hline CHEMBL1463175 & 688816 & 5.0 & 5.2391 & TRN & \\
\hline CHEMBL1449871 & 688816 & 4.45 & 4.8002 & TRN & \\
\hline CHEMBL1455612 & 688816 & 4.45 & 5.313 & TRN & \\
\hline CHEMBL1387938 & 688816 & 7.3002 & 5.2936 & TRN & \\
\hline CHEMBL1505031 & 688816 & 4.7 & 5.0059 & TRN & \\
\hline CHEMBL1570159 & 688816 & 4.45 & 5.2444 & TST & \\
\hline CHEMBL1305267 & 688816 & 5.95 & 5.1759 & TRN & \\
\hline CHEMBL1380684 & 688816 & 6.0 & 5.4228 & TRN & \\
\hline CHEMBL1468327 & 688816 & 4.9 & 5.1246 & TRN & \\
\hline CHEMBL1499999 & 688816 & 4.95 & 5.7793 & TRN & \\
\hline CHEMBL1310980 & 688816 & 4.85 & 5.0618 & TRN & \\
\hline CHEMBL1565371 & 688816 & 4.75 & 5.13399 & 99999999995 & TRN \\
\hline CHEMBL1549871 & 688816 & 5.1 & 5.2743 & TRN & \\
\hline CHEMBL1509364 & 688816 & 4.65 & 5.2451 & TRN & \\
\hline CHEMBL1309589 & 688816 & 8.301 & 5.8489 & TRN & \\
\hline CHEMBL1410098 & 688816 & 4.95 & 5.3276 & TRN & \\
\hline CHEMBL1489733 & 688816 & 4.95 & 5.2322 & TRN & \\
\hline CHEMBL1607970 & 688816 & 5.25 & 5.4999 & TRN & \\
\hline CHEMBL1327703 & 688816 & 4.95 & 5.335 & TRN & \\
\hline CHEMBL1610219 & 688816 & 5.4 & 5.7145 & TST & \\
\hline CHEMBL1430074 & 688816 & 4.9 & 5.07600 & 00000000005 & TST \\
\hline CHEMBL1328184 & 688816 & 4.45 & 5.4294 & TRN & \\
\hline CHEMBL1380091 & 688816 & 6.0 & 4.9524 & TRN & \\
\hline CHEMBL1389886 & 688816 & 4.4 & 5.0588 & TRN & \\
\hline CHEMBL3193017 & 688816 & 4.8 & 5.1984 & TRN & \\
\hline CHEMBL535331 & 688816 & 4.45 & 4.8953 & TRN & \\
\hline CHEMBL1429958 & 688816 & 5.1 & 5.3035 & TRN & \\
\hline CHEMBL1342523 & 688816 & 4.95 & 5.5066 & TRN & \\
\hline CHEMBL1586935 & 688816 & 4.8 & 5.3432 & TRN & \\
\hline CHEMBL1528512 & 688816 & 4.9 & 5.3201 & TRN & \\
\hline CHEMBL1409488 & 688816 & 5.45 & 5.6215 & TRN & \\
\hline CHEMBL1310781 & 688816 & 4.95 & 5.3575 & TRN & \\
\hline CHEMBL1450898 & 688816 & 7.1002 & 5.3005 & TRN & \\
\hline CHEMBL1304887 & 688816 & 4.9 & 5.6248 & TRN & \\
\hline CHEMBL 2003939 & 688816 & 5.0 & 5.7722 & TST & \\
\hline CHEMBL1562741 & 688816 & 4.85 & 5.5745 & TRN & \\
\hline CHEMBL1337730 & 688816 & 6.3 & 5.2305 & TRN & \\
\hline CHEMBL1466313 & 688816 & 4.95 & 5.1629 & TRN & \\
\hline CHEMBL1498364 & 688816 & 4.95 & 5.388 & TRN & \\
\hline CHEMBL1353679 & 688816 & 4.9 & 5.4796 & TRN & \\
\hline CHEMBL1612394 & 688816 & 5.7 & 5.5022 & TRN & \\
\hline CHEMBL1978180 & 688816 & 4.7 & 5.2102 & TRN & \\
\hline CHEMBL1485101 & 688816 & 6.25 & 5.0577 & TRN & \\
\hline CHEMBL1380188 & 688816 & 5.25 & 5.5951 & TST & \\
\hline CHEMBL1483347 & 688816 & 4.8 & 4.8202 & TRN & \\
\hline CHEMBL1484987 & 688816 & 5.95 & 5.3369 & TST & \\
\hline
\end{tabular}




\begin{tabular}{|c|c|c|c|c|c|}
\hline \multicolumn{6}{|c|}{ Supplemental Table S2.txt } \\
\hline CHEMBL1308052 & 688816 & 4.45 & 5.1608 & TST & \\
\hline CHEMBL1551768 & 688816 & 4.85 & 4.9883 & TST & \\
\hline CHEMBL1350749 & 688816 & 5.05 & 5.2828 & TRN & \\
\hline CHEMBL1598149 & 688816 & 4.45 & 5.0436 & TRN & \\
\hline CHEMBL1542955 & 688816 & 5.9 & 5.2686 & TRN & \\
\hline CHEMBL582722 & 688816 & 4.75 & 5.0425 & TST & \\
\hline CHEMBL1350923 & 688816 & 6.8 & 5.3906 & TRN & \\
\hline CHEMBL1425571 & 688816 & 4.85 & 5.3205 & TRN & \\
\hline CHEMBL1527993 & 688816 & 4.9 & 5.144 & TRN & \\
\hline CHEMBL1484743 & 688816 & 5.0 & 5.9273 & TRN & \\
\hline CHEMBL1387256 & 688816 & 4.8 & 5.3285 & TRN & \\
\hline CHEMBL1512253 & 688816 & 4.75 & 5.13899 & 9999999999 & TST \\
\hline CHEMBL1446401 & 688816 & 5.4 & 5.4162 & TRN & \\
\hline CHEMBL1342444 & 688816 & 4.95 & 5.1576 & TRN & \\
\hline CHEMBL1556035 & 688816 & 5.45 & 5.6327 & TRN & \\
\hline CHEMBL1568981 & 688816 & 4.9 & 5.3507 & TST & \\
\hline CHEMBL1382239 & 688816 & 4.85 & 4.9179 & TRN & \\
\hline CHEMBL1380514 & 688816 & 5.55 & 5.1205 & TRN & \\
\hline CHEMBL1571054 & 688816 & 4.5 & 4.98600 & 0000000001 & TRN \\
\hline CHEMBL1421768 & 688816 & 7.6498 & 5.2209 & TRN & \\
\hline CHEMBL1379930 & 688816 & 5.2 & 5.7889 & TRN & \\
\hline CHEMBL1506388 & 688816 & 8.1024 & 5.612 & TRN & \\
\hline CHEMBL1521617 & 688816 & 4.8 & 5.2611 & TRN & \\
\hline CHEMBL1355390 & 688816 & 4.95 & 5.1913 & TRN & \\
\hline CHEMBL1306826 & 688816 & 4.45 & 5.0992 & TRN & \\
\hline CHEMBL1531080 & 688816 & 4.8 & 5.3324 & TRN & \\
\hline CHEMBL1538995 & 688816 & 5.65 & 5.3704 & TST & \\
\hline CHEMBL1454714 & 688816 & 4.8 & 5.4012 & TST & \\
\hline CHEMBL1558637 & 688816 & 4.95 & 5.2046 & TRN & \\
\hline CHEMBL1311424 & 688816 & 4.5 & 5.2499 & TRN & \\
\hline CHEMBL1551166 & 688816 & 4.75 & 5.1348 & TRN & \\
\hline CHEMBL1379093 & 688816 & 4.45 & 5.1084 & TRN & \\
\hline CHEMBL1491054 & 688816 & 4.8 & 5.0436 & TRN & \\
\hline CHEMBL1609117 & 688816 & 4.45 & 4.681 & TRN & \\
\hline CHEMBL1536779 & 688816 & 7.699 & 5.1956 & TST & \\
\hline CHEMBL1492214 & 688816 & 4.9 & 5.3199 & TST & \\
\hline CHEMBL1309489 & 688816 & 4.9 & 5.28 & TST & \\
\hline CHEMBL1603952 & 688816 & 4.6 & 5.1308 & TRN & \\
\hline CHEMBL1557873 & 688816 & 8.0506 & 5.4019 & TRN & \\
\hline CHEMBL 3213480 & 688816 & 5.4 & 5.3088 & TRN & \\
\hline CHEMBL259615 & 688816 & 5.4 & 5.0415 & TRN & \\
\hline CHEMBL1341018 & 688816 & 7.1002 & 5.2674 & TRN & \\
\hline CHEMBL1307559 & 688816 & 4.6 & 5.0139 & TRN & \\
\hline CHEMBL1423818 & 688816 & 7.5003 & 5.2412 & TRN & \\
\hline CHEMBL3196747 & 688816 & 4.6 & 5.0023 & TRN & \\
\hline CHEMBL1568597 & 688816 & 4.9 & 4.9935 & TST & \\
\hline CHEMBL 1332780 & 688816 & 5.4 & 5.5143 & TRN & \\
\hline CHEMBL1470470 & 688816 & 4.95 & 5.1622 & TRN & \\
\hline
\end{tabular}




\begin{tabular}{|c|c|c|c|c|c|}
\hline \multirow[b]{2}{*}{ CHEMBL465226 } & \multicolumn{5}{|c|}{ Supplemental Table S2.txt } \\
\hline & 688816 & 6.0 & 5.0825 & TRN & \\
\hline CHEMBL1377980 & 688816 & 5.35 & 5.20700 & 0000000001 & TRN \\
\hline CHEMBL1494309 & 688816 & 4.85 & 5.3002 & TRN & \\
\hline CHEMBL1346225 & 688816 & 4.7 & 5.0062 & TRN & \\
\hline CHEMBL1360109 & 688816 & 4.9 & 5.3448 & TRN & \\
\hline CHEMBL1451846 & 688816 & 4.7 & 4.8551 & TRN & \\
\hline CHEMBL1429671 & 688816 & 5.2 & 5.5957 & TST & \\
\hline CHEMBL1449506 & 688816 & 4.5 & 5.2884 & TRN & \\
\hline CHEMBL1593872 & 688816 & 6.0 & 5.2219 & TRN & \\
\hline CHEMBL1529631 & 688816 & 4.9 & 5.26399 & 9999999999 & TRN \\
\hline CHEMBL1362253 & 688816 & 4.95 & 5.0291 & TRN & \\
\hline CHEMBL3210132 & 688816 & 4.9 & 5.5045 & TST & \\
\hline CHEMBL1377323 & 688816 & 5.0 & 5.2954 & TST & \\
\hline CHEMBL1400290 & 688816 & 4.8 & 5.3232 & TRN & \\
\hline CHEMBL1532244 & 688816 & 7.8013 & 5.36100 & 0000000001 & TRN \\
\hline CHEMBL1341367 & 688816 & 5.15 & 5.5083 & TRN & \\
\hline CHEMBL1333993 & 688816 & 4.85 & 5.1971 & TRN & \\
\hline CHEMBL1534474 & 688816 & 4.45 & 5.1495 & TRN & \\
\hline CHEMBL1603387 & 688816 & 4.95 & 5.0764 & TRN & \\
\hline CHEMBL1425992 & 688816 & 4.9 & 5.2211 & TRN & \\
\hline CHEMBL1549525 & 688816 & 4.75 & 5.2169 & TRN & \\
\hline CHEMBL1505088 & 688816 & 5.0 & 5.3221 & TRN & \\
\hline CHEMBL1967821 & 688816 & 4.9 & 5.4281 & TRN & \\
\hline CHEMBL 2006154 & 688816 & 4.65 & 5.2153 & TRN & \\
\hline CHEMBL1495105 & 688816 & 5.55 & 5.6423 & TST & \\
\hline CHEMBL1601377 & 688816 & 5.2 & 5.2412 & TST & \\
\hline CHEMBL1353128 & 688816 & 4.85 & 5.3403 & TRN & \\
\hline CHEMBL1431604 & 688816 & 4.45 & 5.2144 & TST & \\
\hline CHEMBL1369134 & 688816 & 5.45 & 5.2848 & TRN & \\
\hline CHEMBL1586519 & 688816 & 4.5 & 5.7219 & TRN & \\
\hline CHEMBL1509244 & 688816 & 4.95 & 5.40799 & 99999999995 & TRN \\
\hline CHEMBL1575476 & 688816 & 4.9 & 5.3398 & TST & \\
\hline CHEMBL1581238 & 688816 & 6.2 & 5.5159 & TST & \\
\hline CHEMBL1527109 & 688816 & 5.0 & 5.7639 & TST & \\
\hline CHEMBL1557590 & 688816 & 4.65 & 4.9281 & TRN & \\
\hline CHEMBL494668 & 688816 & 5.05 & 4.9281 & TRN & \\
\hline CHEMBL1510442 & 688816 & 5.6 & 5.4818 & TST & \\
\hline CHEMBL1506301 & 688816 & 4.9 & 5.2295 & TRN & \\
\hline CHEMBL1566495 & 688816 & 6.7501 & 5.4521 & TST & \\
\hline CHEMBL1520058 & 688816 & 4.45 & 5.0293 & TRN & \\
\hline CHEMBL1601263 & 688816 & 4.9 & 5.4168 & TST & \\
\hline CHEMBL1422695 & 688816 & 4.85 & 4.803 & TST & \\
\hline CHEMBL1491246 & 688816 & 4.6 & 5.3702 & TRN & \\
\hline CHEMBL1509998 & 688816 & 4.9 & 5.06 & TRN & \\
\hline CHEMBL1451869 & 688816 & 5.0 & 5.3002 & TST & \\
\hline CHEMBL1479574 & 688816 & 4.65 & 4.8749 & TRN & \\
\hline CHEMBL1434051 & 688816 & 4.85 & 5.0648 & TRN & \\
\hline CHEMBL1352253 & 688816 & 4.8 & 5.3805 & TRN & \\
\hline
\end{tabular}




\begin{tabular}{|c|c|c|c|c|c|}
\hline \multicolumn{6}{|c|}{ Supplemental Table s2.txt } \\
\hline CHEMBL1412114 & 688816 & 4.65 & 5.0965 & TST & \\
\hline CHEMBL1305886 & 688816 & 4.95 & 5.3943 & TRN & \\
\hline CHEMBL1465084 & 688816 & 5.0 & 4.9403 & TRN & \\
\hline CHEMBL1577179 & 688816 & 4.6 & 5.1868 & TRN & \\
\hline CHEMBL1522105 & 688816 & 5.0 & 5.1394 & TST & \\
\hline CHEMBL1354263 & 688816 & 4.6 & 5.1834 & TRN & \\
\hline CHEMBL1557962 & 688816 & 5.55 & 5.3659 & TRN & \\
\hline CHEMBL1594363 & 688816 & 8.2518 & 5.6148 & TST & \\
\hline CHEMBL1479639 & 688816 & 4.45 & 5.6587 & TST & \\
\hline CHEMBL1589488 & 688816 & 5.45 & 5.1954 & TRN & \\
\hline CHEMBL1300212 & 688816 & 5.0 & 5.2844 & TRN & \\
\hline CHEMBL3190212 & 688816 & 5.1 & 5.4104 & TRN & \\
\hline CHEMBL1404908 & 688816 & 4.9 & 5.1305 & TRN & \\
\hline CHEMBL1474158 & 688816 & 5.55 & 5.1653 & TST & \\
\hline CHEMBL1306518 & 688816 & 5.5 & 5.4788 & TST & \\
\hline CHEMBL1605917 & 688816 & 4.65 & 4.7935 & TRN & \\
\hline CHEMBL1556247 & 688816 & 5.35 & 5.2546 & TST & \\
\hline CHEMBL1224755 & 688816 & 4.45 & 5.5819 & TRN & \\
\hline CHEMBL1520776 & 688816 & 6.4 & 5.2814 & TRN & \\
\hline CHEMBL1345993 & 688816 & 4.85 & 4.6939 & TRN & \\
\hline CHEMBL1468992 & 688816 & 8.0506 & 5.2391 & TST & \\
\hline CHEMBL1359315 & 688816 & 4.95 & 5.0514 & TRN & \\
\hline CHEMBL1352146 & 688816 & 4.45 & 5.6567 & TRN & \\
\hline CHEMBL1324688 & 688816 & 4.85 & 5.4375 & TRN & \\
\hline CHEMBL1321602 & 688816 & 4.9 & 5.267 & TRN & \\
\hline CHEMBL1446971 & 688816 & 4.9 & 5.36 & TST & \\
\hline CHEMBL1303045 & 688816 & 5.25 & 5.1416 & TRN & \\
\hline CHEMBL1601416 & 688816 & 4.95 & 4.9846 & TRN & \\
\hline CHEMBL1402455 & 688816 & 4.95 & 5.0947 & TST & \\
\hline CHEMBL1451376 & 688816 & 6.5 & 5.437 & TST & \\
\hline CHEMBL3196249 & 688816 & 5.0 & 5.4552 & TRN & \\
\hline CHEMBL1577207 & 688816 & 4.7 & 5.2608 & TST & \\
\hline CHEMBL1530101 & 688816 & 5.4 & 5.0561 & TST & \\
\hline CHEMBL1491816 & 688816 & 8.301 & 5.5399 & TRN & \\
\hline CHEMBL1410512 & 688816 & 7.1002 & 5.62700 & 0000000001 & TRN \\
\hline CHEMBL1466111 & 688816 & 4.9 & 5.5301 & TST & \\
\hline CHEMBL1534492 & 688816 & 4.65 & 5.0566 & TRN & \\
\hline CHEMBL1320154 & 688816 & 6.7501 & 5.3702 & TST & \\
\hline CHEMBL3213178 & 688816 & 5.2 & 5.609 & TRN & \\
\hline CHEMBL1303203 & 688816 & 4.7 & 5.2659 & TRN & \\
\hline CHEMBL1335357 & 688816 & 4.65 & 5.3596 & TRN & \\
\hline CHEMBL1487662 & 688816 & 4.65 & 5.5108 & TRN & \\
\hline CHEMBL3209335 & 688816 & 4.95 & 5.0406 & TST & \\
\hline CHEMBL1575556 & 688816 & 5.05 & 5.315 & TST & \\
\hline CHEMBL107251 & 688816 & 8.4559 & 5.62299 & 9999999999 & TST \\
\hline CHEMBL1334008 & 688816 & 5.5 & 5.2401 & TRN & \\
\hline CHEMBL1313683 & 688816 & 5.15 & 5.0991 & TRN & \\
\hline CHEMBL1501381 & 688816 & 5.05 & 5.1863 & TRN & \\
\hline
\end{tabular}




\begin{tabular}{|c|c|c|c|c|c|}
\hline \multicolumn{6}{|c|}{ Supplemental Table S2.txt } \\
\hline CHEMBL 3198245 & 688816 & 4.6 & 5.0774 & TST & \\
\hline CHEMBL1598445 & 688816 & 6.7001 & 5.5086 & TRN & \\
\hline CHEMBL1388701 & 688816 & 4.65 & 5.1407 & TRN & \\
\hline CHEMBL1454530 & 688816 & 7.0 & 5.2871 & TST & \\
\hline CHEMBL3189455 & 688816 & 5.0 & 5.1837 & TST & \\
\hline CHEMBL1349824 & 688816 & 8.0 & 5.3588 & TRN & \\
\hline CHEMBL1611383 & 688816 & 4.95 & 5.1911 & TRN & \\
\hline CHEMBL1374200 & 688816 & 6.25 & 5.2171 & TRN & \\
\hline CHEMBL600971 & 688816 & 7.9508 & 5.0828 & TRN & \\
\hline CHEMBL1314144 & 688816 & 4.7 & 5.0025 & TRN & \\
\hline CHEMBL1426243 & 688816 & 7.8508 & 5.1984 & TRN & \\
\hline CHEMBL1604534 & 688816 & 6.0 & 5.2583 & TRN & \\
\hline CHEMBL3196440 & 688816 & 5.25 & 5.0206 & TRN & \\
\hline CHEMBL1611597 & 688816 & 8.301 & 5.29200 & 0000000001 & TRN \\
\hline CHEMBL1452847 & 688816 & 4.65 & 5.3195 & TRN & \\
\hline CHEMBL1517088 & 688816 & 4.95 & 4.9487 & TRN & \\
\hline CHEMBL1400589 & 688816 & 5.6 & 5.0214 & TRN & \\
\hline CHEMBL1490596 & 688816 & 5.55 & 5.1556 & TRN & \\
\hline CHEMBL507264 & 688816 & 4.9 & 5.2737 & TST & \\
\hline CHEMBL1454139 & 688816 & 4.95 & 5.13 & TRN & \\
\hline CHEMBL3211325 & 688816 & 4.8 & 5.4564 & TRN & \\
\hline CHEMBL1534924 & 688816 & 4.85 & 5.1678 & TST & \\
\hline CHEMBL3197912 & 688816 & 4.6 & 5.1139 & TRN & \\
\hline CHEMBL3196961 & 688816 & 4.65 & 5.0737 & TRN & \\
\hline CHEMBL1324032 & 688816 & 5.2 & 5.2828 & TST & \\
\hline CHEMBL1426961 & 688816 & 4.95 & 5.2321 & TST & \\
\hline CHEMBL1364447 & 688816 & 5.0 & 5.5366 & TST & \\
\hline CHEMBL1500264 & 688816 & 4.85 & 5.6901 & TST & \\
\hline CHEMBL589479 & 688816 & 4.75 & 5.1594 & TRN & \\
\hline CHEMBL1466041 & 688816 & 4.8 & 5.2433 & TRN & \\
\hline CHEMBL1364055 & 688816 & 8.301 & 5.237 & TRN & \\
\hline CHEMBL1440677 & 688816 & 4.45 & 5.1004 & TRN & \\
\hline CHEMBL1331657 & 688816 & 4.8 & 5.0117 & TRN & \\
\hline CHEMBL1604705 & 688816 & 4.55 & 5.4768 & TRN & \\
\hline CHEMBL1380674 & 688816 & 5.25 & 5.1545 & TRN & \\
\hline CHEMBL1401573 & 688816 & 7.5498 & 4.9954 & TRN & \\
\hline CHEMBL1412422 & 688816 & 4.45 & 5.2801 & TRN & \\
\hline CHEMBL1508526 & 688816 & 4.65 & 5.2578 & TST & \\
\hline CHEMBL3196523 & 688816 & 5.05 & 5.1424 & TRN & \\
\hline CHEMBL1338786 & 688816 & 4.95 & 5.4188 & TRN & \\
\hline CHEMBL1523761 & 688816 & 4.65 & 4.948 & TST & \\
\hline CHEMBL1439577 & 688816 & 4.7 & 5.6242 & TRN & \\
\hline CHEMBL1542797 & 688816 & 4.6 & 4.7782 & TRN & \\
\hline CHEMBL3209097 & 688816 & 4.7 & 5.275 & TRN & \\
\hline CHEMBL1550442 & 688816 & 4.8 & 5.2967 & TRN & \\
\hline CHEMBL1600513 & 688816 & 4.7 & 4.988 & TRN & \\
\hline CHEMBL1496021 & 688816 & 5.0 & 5.3809 & TST & \\
\hline CHEMBL1537092 & 688816 & 5.05 & 5.4405 & TRN & \\
\hline
\end{tabular}




\begin{tabular}{|c|c|c|c|c|c|}
\hline \multicolumn{6}{|c|}{ Supplemental Table S2.txt } \\
\hline CHEMBL 2006503 & 688816 & 5.5 & 5.0697 & TRN & \\
\hline CHEMBL606167 & 688816 & 4.7 & 5.1333 & TST & \\
\hline CHEMBL1361946 & 688816 & 4.9 & 5.4158 & TRN & \\
\hline CHEMBL1561466 & 688816 & 7.5003 & 5.1871 & TRN & \\
\hline CHEMBL1367465 & 688816 & 4.45 & 5.1434 & TRN & \\
\hline CHEMBL1311815 & 688816 & 5.25 & 5.2436 & TRN & \\
\hline CHEMBL594385 & 688816 & 4.55 & 5.4773 & TRN & \\
\hline CHEMBL276168 & 688816 & 5.9 & 5.6317 & TRN & \\
\hline CHEMBL1582776 & 688816 & 4.9 & 5.6053 & TRN & \\
\hline CHEMBL1547229 & 688816 & 4.75 & 5.2371 & TRN & \\
\hline CHEMBL1503484 & 688816 & 4.9 & 5.0065 & TRN & \\
\hline CHEMBL3199891 & 688816 & 5.5 & 5.4542 & TST & \\
\hline CHEMBL1327295 & 688816 & 7.4498 & 5.0792 & TRN & \\
\hline CHEMBL1472916 & 688816 & 5.55 & 5.2189 & TRN & \\
\hline CHEMBL1529597 & 688816 & 5.65 & 5.3047 & TRN & \\
\hline CHEMBL1421437 & 688816 & 5.2 & 5.3423 & TRN & \\
\hline CHEMBL1464091 & 688816 & 5.9 & 5.2815 & TRN & \\
\hline CHEMBL1546726 & 688816 & 4.9 & 5.2922 & TRN & \\
\hline CHEMBL1420826 & 688816 & 4.65 & 4.8015 & TRN & \\
\hline CHEMBL1428126 & 688816 & 8.301 & 5.4808 & TRN & \\
\hline CHEMBL1973328 & 688816 & 6.05 & 5.335 & TRN & \\
\hline CHEMBL582070 & 688816 & 4.95 & 5.1841 & TRN & \\
\hline CHEMBL1412351 & 688816 & 6.05 & 5.5837 & TST & \\
\hline CHEMBL1488223 & 688816 & 4.85 & 5.441 & TRN & \\
\hline CHEMBL1373664 & 688816 & 5.45 & 5.2952 & TRN & \\
\hline CHEMBL1385147 & 688816 & 5.6 & 5.0288 & TRN & \\
\hline CHEMBL1567227 & 688816 & 4.95 & 5.3865 & TRN & \\
\hline CHEMBL3191437 & 688816 & 5.35 & 5.3559 & TRN & \\
\hline CHEMBL1308750 & 688816 & 4.45 & 5.3264 & TRN & \\
\hline CHEMBL600313 & 688816 & 4.45 & 5.1894 & TST & \\
\hline CHEMBL1589840 & 688816 & 4.85 & 5.3262 & TRN & \\
\hline CHEMBL1439266 & 688816 & 5.2 & 4.947 & TRN & \\
\hline CHEMBL1570025 & 688816 & 4.75 & 5.1864 & TRN & \\
\hline CHEMBL1467152 & 688816 & 6.5501 & 5.2832 & TST & \\
\hline CHEMBL1550430 & 688816 & 4.5 & 4.7541 & TRN & \\
\hline CHEMBL1508952 & 688816 & 4.6 & 5.5935 & TST & \\
\hline CHEMBL1570389 & 688816 & 4.85 & 5.48600 & 0000000001 & TRN \\
\hline CHEMBL1546440 & 688816 & 8.3468 & 5.3177 & TST & \\
\hline CHEMBL1332685 & 688816 & 5.45 & 5.1739 & TRN & \\
\hline CHEMBL1371688 & 688816 & 4.65 & 4.8864 & TRN & \\
\hline CHEMBL1380186 & 688816 & 4.95 & 5.586 & TRN & \\
\hline CHEMBL1309825 & 688816 & 8.0 & 5.0492 & TRN & \\
\hline CHEMBL1609569 & 688816 & 4.45 & 5.0788 & TRN & \\
\hline CHEMBL1379079 & 688816 & 5.0 & 5.2497 & TRN & \\
\hline CHEMBL1537279 & 688816 & 4.45 & 5.5108 & TST & \\
\hline CHEMBL3197612 & 688816 & 4.45 & 4.6935 & TRN & \\
\hline CHEMBL1299470 & 688816 & 4.95 & 5.0336 & TRN & \\
\hline CHEMBL1493246 & 688816 & 4.65 & 5.5823 & TRN & \\
\hline
\end{tabular}




\begin{tabular}{|c|c|c|c|c|c|}
\hline \\
\hline CHEMBL1600668 & 688816 & 5.3 & 5.2006 & TRN & \\
\hline CHEMBL1303449 & 688816 & 5.0 & 5.2716 & TRN & \\
\hline CHEMBL1302157 & 688816 & 5.05 & 5.3174 & TST & \\
\hline CHEMBL1576307 & 688816 & 4.65 & 5.2129 & TST & \\
\hline CHEMBL1331597 & 688816 & 4.8 & 5.4015 & TRN & \\
\hline CHEMBL1393060 & 688816 & 5.25 & 5.3731 & TST & \\
\hline CHEMBL 28 & 688816 & 6.0 & 5.2866 & TRN & \\
\hline CHEMBL1471010 & 688816 & 4.65 & 5.2476 & TRN & \\
\hline CHEMBL262627 & 688816 & 5.3 & 5.0111 & TRN & \\
\hline CHEMBL1529622 & 688816 & 4.6 & 5.2226 & TRN & \\
\hline CHEMBL1461202 & 688816 & 6.3 & 5.077 & TRN & \\
\hline CHEMBL1379796 & 688816 & 8.0506 & 5.2391 & TRN & \\
\hline CHEMBL1213905 & 688816 & 4.75 & 5.2743 & TRN & \\
\hline CHEMBL1366271 & 688816 & 4.95 & 5.0757 & TRN & \\
\hline CHEMBL1324273 & 688816 & 4.6 & 5.4366 & TRN & \\
\hline CHEMBL1430717 & 688816 & 5.5 & 5.4924 & TST & \\
\hline CHEMBL3196345 & 688816 & 4.85 & 5.3604 & TRN & \\
\hline CHEMBL1483619 & 688816 & 4.65 & 5.0351 & TST & \\
\hline CHEMBL402477 & 688816 & 5.65 & 5.3212 & TRN & \\
\hline CHEMBL1314458 & 688816 & 6.0 & 5.6687 & TRN & \\
\hline CHEMBL1520496 & 688816 & 4.95 & 5.1382 & TRN & \\
\hline CHEMBL 3192174 & 688816 & 5.0 & 5.1323 & TRN & \\
\hline CHEMBL1381158 & 688816 & 4.75 & 5.4438 & TRN & \\
\hline CHEMBL1988657 & 688816 & 4.65 & 5.1323 & TRN & \\
\hline CHEMBL 1452510 & 688816 & 4.85 & 5.2747 & TRN & \\
\hline CHEMBL1387472 & 688816 & 4.8 & 4.8552 & TST & \\
\hline CHEMBL1603978 & 688816 & 4.9 & 5.3038 & TRN & \\
\hline CHEMBL1419452 & 688816 & 8.3468 & 5.6026 & TRN & \\
\hline CHEMBL1417112 & 688816 & 5.9 & 5.0919 & TRN & \\
\hline CHEMBL3210625 & 688816 & 7.5498 & 5.25299 & 9999999999 & TRN \\
\hline CHEMBL1410093 & 688816 & 4.85 & 4.9191 & TRN & \\
\hline CHEMBL1399495 & 688816 & 4.95 & 4.8553 & TRN & \\
\hline CHEMBL1382470 & 688816 & 5.25 & 5.33299 & 9999999999 & TRN \\
\hline CHEMBL3196932 & 688816 & 5.4 & 5.4659 & TRN & \\
\hline CHEMBL1346427 & 688816 & 5.0 & 5.2822 & TRN & \\
\hline CHEMBL1309260 & 688816 & 5.45 & 5.3808 & TRN & \\
\hline CHEMBL1493701 & 688816 & 4.65 & 5.141 & TST & \\
\hline CHEMBL 1610180 & 688816 & 4.65 & 5.3632 & TRN & \\
\hline CHEMBL1424231 & 688816 & 6.0 & 5.5214 & TRN & \\
\hline CHEMBL 1555702 & 688816 & 5.7 & 5.2693 & TRN & \\
\hline CHEMBL1559727 & 688816 & 4.9 & 5.1874 & TRN & \\
\hline CHEMBL1583647 & 688816 & 4.95 & 5.3097 & TRN & \\
\hline CHEMBL1499108 & 688816 & 6.3 & 5.3706 & TRN & \\
\hline CHEMBL3209485 & 688816 & 8.0 & 5.3331 & TST & \\
\hline CHEMBL1588058 & 688816 & 4.95 & 5.3077 & TST & \\
\hline CHEMBL3196182 & 688816 & 4.7 & 5.2977 & TST & \\
\hline CHEMBL1496662 & 688816 & 4.9 & 4.8646 & TRN & \\
\hline CHEMBL1452851 & 688816 & 4.9 & 5.1016 & TST & \\
\hline
\end{tabular}




\begin{tabular}{|c|c|c|c|c|c|}
\hline \multicolumn{6}{|c|}{ Supplemental Table s2.txt } \\
\hline CHEMBL3198379 & 688816 & 5.25 & 5.4354 & TRN & \\
\hline CHEMBL1371624 & 688816 & 4.9 & 4.8333 & TRN & \\
\hline CHEMBL1308487 & 688816 & 4.75 & 5.0482 & TRN & \\
\hline CHEMBL1373869 & 688816 & 4.9 & 5.2015 & TRN & \\
\hline CHEMBL1433229 & 688816 & 8.301 & 5.3075 & TRN & \\
\hline CHEMBL1605845 & 688816 & 4.7 & 5.3776 & TRN & \\
\hline CHEMBL1607660 & 688816 & 5.95 & 5.1817 & TRN & \\
\hline CHEMBL1498085 & 688816 & 4.9 & 5.524 & TRN & \\
\hline CHEMBL1422287 & 688816 & 8.301 & 5.4924 & TST & \\
\hline CHEMBL1423997 & 688816 & 4.9 & 5.3318 & TRN & \\
\hline CHEMBL1413435 & 688816 & 5.85 & 5.329 & TRN & \\
\hline CHEMBL1536388 & 688816 & 5.9 & 5.3946 & TRN & \\
\hline CHEMBL1416188 & 688816 & 5.75 & 5.6691 & TRN & \\
\hline CHEMBL1402278 & 688816 & 4.95 & 5.3964 & TRN & \\
\hline CHEMBL1534834 & 688816 & 7.3002 & \multicolumn{2}{|c|}{5.196000000000001} & TRN \\
\hline CHEMBL1487487 & 688816 & 5.9 & 5.6353 & TRN & \\
\hline CHEMBL1371364 & 688816 & 4.6 & 5.2456 & TRN & \\
\hline CHEMBL1348248 & 688816 & 5.2 & 5.05 & TST & \\
\hline CHEMBL1594328 & 688816 & 4.7 & 5.5022 & TRN & \\
\hline CHEMBL3189959 & 688816 & 5.05 & 5.496 & TST & \\
\hline CHEMBL1339268 & 688816 & 5.15 & 5.0716 & TRN & \\
\hline CHEMBL1349745 & 688816 & 4.95 & 5.4661 & TRN & \\
\hline CHEMBL1470607 & 688816 & 7.3497 & 5.2983 & TRN & \\
\hline CHEMBL1402226 & 688816 & 4.85 & 5.2444 & TRN & \\
\hline CHEMBL1324389 & 688816 & 5.15 & 5.4491 & TST & \\
\hline CHEMBL1588246 & 688816 & 4.9 & 5.1302 & TRN & \\
\hline CHEMBL1565286 & 688816 & 4.6 & 4.9232 & TRN & \\
\hline CHEMBL1543404 & 688816 & 5.0 & \multicolumn{2}{|c|}{5.252000000000001} & TST \\
\hline CHEMBL1613363 & 688816 & 4.95 & 4.9468 & TRN & \\
\hline CHEMBL1588962 & 688816 & 4.75 & 5.1531 & TST & \\
\hline CHEMBL1372701 & 688816 & 4.95 & 5.1828 & TRN & \\
\hline CHEMBL1506327 & 688816 & 4.65 & 5.2804 & TRN & \\
\hline CHEMBL1333530 & 688816 & 4.85 & 5.4328 & TST & \\
\hline CHEMBL1411555 & 688816 & 4.8 & 4.9654 & TRN & \\
\hline CHEMBL3193128 & 688816 & 4.5 & 5.3094 & TRN & \\
\hline CHEMBL3199789 & 688816 & 4.8 & 5.0752 & TST & \\
\hline CHEMBL1459920 & 688816 & 5.3 & 5.7145 & TRN & \\
\hline CHEMBL3195159 & 688816 & 4.9 & 5.53 & TRN & \\
\hline CHEMBL1368420 & 688816 & 5.0 & 4.9491 & TRN & \\
\hline CHEMBL1408969 & 688816 & 6.05 & 4.9738 & TST & \\
\hline CHEMBL1256739 & 688816 & 6.0 & 5.4716 & TST & \\
\hline CHEMBL1450889 & 688816 & 5.25 & 4.7555 & TRN & \\
\hline CHEMBL1461972 & 688816 & 5.4 & 4.9445 & TRN & \\
\hline CHEMBL1969934 & 688816 & 4.45 & 5.1488 & TRN & \\
\hline CHEMBL1492984 & 688816 & 5.4 & 5.7006 & TST & \\
\hline CHEMBL1484204 & 688816 & 5.65 & 5.6639 & TRN & \\
\hline CHEMBL1441655 & 688816 & 5.45 & 5.0537 & TRN & \\
\hline \multirow[t]{2}{*}{ CHEMBL1425956 } & 688816 & 4.45 & \multicolumn{2}{|c|}{4.9430000000000005} & TRN \\
\hline & & & & 25070 & \\
\hline
\end{tabular}




\begin{tabular}{|c|c|c|c|c|c|}
\hline \multicolumn{6}{|c|}{ Supplemental Table s2.txt } \\
\hline CHEMBL1375105 & 688816 & 4.7 & 5.1475 & TRN & \\
\hline CHEMBL1432649 & 688816 & 4.75 & 5.2626 & TST & \\
\hline CHEMBL1529863 & 688816 & 6.7501 & 5.1739 & TRN & \\
\hline CHEMBL1333732 & 688816 & 4.65 & 4.8985 & TRN & \\
\hline CHEMBL1370490 & 688816 & 5.5 & 5.3371 & TRN & \\
\hline CHEMBL2001739 & 688816 & 4.6 & 5.5079 & TRN & \\
\hline CHEMBL1372826 & 688816 & 5.0 & 5.0611 & TRN & \\
\hline CHEMBL1499521 & 688816 & 5.4 & 5.7673 & TRN & \\
\hline CHEMBL 2003332 & 688816 & 4.6 & 5.0331 & TRN & \\
\hline CHEMBL1458132 & 688816 & 5.0 & 5.4691 & TST & \\
\hline CHEMBL1341697 & 688816 & 4.65 & 5.0591 & TST & \\
\hline CHEMBL1351248 & 688816 & 5.15 & 4.9995 & TRN & \\
\hline CHEMBL1424401 & 688816 & 6.25 & 5.4863 & TRN & \\
\hline CHEMBL1501423 & 688816 & 5.7 & 5.32600 & 00000000005 & TST \\
\hline CHEMBL1414853 & 688816 & 4.9 & 5.1821 & TST & \\
\hline CHEMBL1494786 & 688816 & 7.8508 & 5.7087 & TRN & \\
\hline CHEMBL1458567 & 688816 & 5.35 & 5.3216 & TRN & \\
\hline CHEMBL1424935 & 688816 & 4.65 & 5.0741 & TRN & \\
\hline CHEMBL1344249 & 688816 & 5.0 & 5.0216 & TRN & \\
\hline CHEMBL1539619 & 688816 & 4.75 & 5.1457 & TRN & \\
\hline CHEMBL1349358 & 688816 & 4.95 & 5.3644 & TRN & \\
\hline CHEMBL1601617 & 688816 & 5.3 & 5.4263 & TST & \\
\hline CHEMBL1595098 & 688816 & 4.9 & 5.1524 & TRN & \\
\hline CHEMBL1586660 & 688816 & 4.9 & 5.1226 & TRN & \\
\hline CHEMBL1603994 & 688816 & 5.25 & 5.1473 & TST & \\
\hline CHEMBL1454972 & 688816 & 7.8508 & 5.475 & TST & \\
\hline CHEMBL1353787 & 688816 & 4.45 & 5.4329 & TRN & \\
\hline CHEMBL1478025 & 688816 & 8.3979 & 5.44 & TRN & \\
\hline CHEMBL1346072 & 688816 & 5.45 & 5.1508 & TRN & \\
\hline CHEMBL1590048 & 688816 & 4.55 & 5.3011 & TST & \\
\hline CHEMBL1347429 & 688816 & 7.9508 & 5.7218 & TST & \\
\hline CHEMBL1389900 & 688816 & 5.35 & 5.5245 & TRN & \\
\hline CHEMBL1328832 & 688816 & 4.85 & 5.0844 & TRN & \\
\hline CHEMBL1424339 & 688816 & 4.45 & 5.308 & TST & \\
\hline CHEMBL1544993 & 688816 & 4.9 & 5.0839 & TRN & \\
\hline CHEMBL1567635 & 688816 & 4.65 & 5.1727 & TRN & \\
\hline CHEMBL1387610 & 688816 & 6.3 & 5.1711 & TRN & \\
\hline CHEMBL1443587 & 688816 & 5.45 & 5.3866 & TST & \\
\hline CHEMBL1521974 & 688816 & 4.5 & 5.3702 & TRN & \\
\hline CHEMBL1574132 & 688816 & 4.55 & 4.7902 & TRN & \\
\hline CHEMBL1384998 & 688816 & 4.45 & 4.8192 & TRN & \\
\hline CHEMBL1420658 & 688816 & 4.45 & 5.37799 & 9999999999 & TRN \\
\hline CHEMBL1326156 & 688816 & 5.3 & 5.1372 & TRN & \\
\hline CHEMBL1444080 & 688816 & 4.95 & 5.6639 & TRN & \\
\hline CHEMBL3191249 & 688816 & 8.3468 & 5.3443 & TST & \\
\hline CHEMBL1508930 & 688816 & 4.6 & 5.3101 & TST & \\
\hline CHEMBL151946 & 688816 & 4.7 & 5.5497 & TST & \\
\hline CHEMBL1489709 & 688816 & 5.0 & 4.9907 & TRN & \\
\hline
\end{tabular}




\begin{tabular}{|c|c|c|c|c|}
\hline \multicolumn{5}{|c|}{ Supplemental Table S2.txt } \\
\hline CHEMBL1464035 & 688816 & 4.9 & 5.3389 & TRN \\
\hline CHEMBL1344261 & 688816 & 5.1 & 5.2766 & TRN \\
\hline CHEMBL1325451 & 688816 & 4.9 & 5.15600 & 0000000001 \\
\hline CHEMBL1421546 & 688816 & 4.7 & 5.1448 & TRN \\
\hline CHEMBL1321837 & 688816 & 4.9 & 5.3248 & TST \\
\hline CHEMBL1448015 & 688816 & 4.8 & 5.3166 & TRN \\
\hline CHEMBL1427440 & 688816 & 7.8996 & 5.6698 & TST \\
\hline CHEMBL1491697 & 688816 & 4.45 & 5.3708 & TRN \\
\hline CHEMBL3207561 & 688816 & 4.45 & 5.2509 & TRN \\
\hline CHEMBL547977 & 688816 & 4.6 & 5.3777 & TRN \\
\hline CHEMBL1403324 & 688816 & 4.9 & 5.7263 & TST \\
\hline CHEMBL1498801 & 688816 & 6.0 & 5.3323 & TRN \\
\hline CHEMBL1337183 & 688816 & 4.8 & 4.8682 & TRN \\
\hline CHEMBL1343279 & 688816 & 4.95 & 5.1515 & TRN \\
\hline CHEMBL1361633 & 688816 & 4.5 & 5.5877 & TRN \\
\hline CHEMBL1361474 & 688816 & 4.55 & 5.1888 & TRN \\
\hline CHEMBL1481622 & 688816 & 4.45 & 4.7585 & TRN \\
\hline CHEMBL1301168 & 688816 & 4.9 & 4.9072 & TRN \\
\hline CHEMBL3211801 & 688816 & 4.6 & 5.0305 & TRN \\
\hline CHEMBL1418216 & 688816 & 4.55 & 4.8387 & TRN \\
\hline CHEMBL3189492 & 688816 & 4.9 & 5.4791 & TRN \\
\hline CHEMBL1422308 & 688816 & 4.45 & 4.8712 & TST \\
\hline CHEMBL1527393 & 688816 & 5.15 & 4.9298 & TRN \\
\hline CHEMBL1351533 & 688816 & 4.45 & 4.8094 & TRN \\
\hline CHEMBL1317596 & 688816 & 4.9 & 5.169 & TRN \\
\hline CHEMBL1585589 & 688816 & 4.65 & 5.2553 & TRN \\
\hline CHEMBL1540894 & 688816 & 5.7 & 5.2167 & TRN \\
\hline CHEMBL1406625 & 688816 & 5.4 & 5.0223 & TRN \\
\hline CHEMBL1353790 & 688816 & 4.8 & 5.2195 & TRN \\
\hline CHEMBL1559717 & 688816 & 6.0 & 5.3524 & TST \\
\hline CHEMBL1533161 & 688816 & 4.45 & 5.3323 & TRN \\
\hline CHEMBL1557465 & 688816 & 5.25 & 5.3676 & TRN \\
\hline CHEMBL1485176 & 688816 & 8.3468 & 5.2992 & TST \\
\hline CHEMBL1603476 & 688816 & 4.9 & 5.0478 & TRN \\
\hline CHEMBL1391609 & 688816 & 4.5 & 5.1932 & TRN \\
\hline CHEMBL1547350 & 688816 & 5.55 & 4.9443 & TRN \\
\hline CHEMBL1306009 & 688816 & 5.0 & 5.1341 & TRN \\
\hline CHEMBL3195032 & 688816 & 4.45 & 5.0134 & TRN \\
\hline CHEMBL1424249 & 688816 & 4.9 & 5.2802 & TRN \\
\hline CHEMBL1528391 & 688816 & 4.9 & 4.7675 & TRN \\
\hline CHEMBL1419563 & 688816 & 5.1 & 5.0498 & TRN \\
\hline CHEMBL3195968 & 688816 & 4.75 & 5.1574 & TST \\
\hline CHEMBL1543257 & 688816 & 5.35 & 5.3453 & TRN \\
\hline CHEMBL1450259 & 688816 & 4.85 & 5.2872 & TRN \\
\hline CHEMBL1350077 & 688816 & 4.85 & 5.4856 & TST \\
\hline CHEMBL1537645 & 688816 & 8.3468 & 5.5934 & TRN \\
\hline CHEMBL1603961 & 688816 & 5.45 & 5.3444 & TRN \\
\hline CHEMBL1464657 & 688816 & 4.5 & 5.3252 & TRN \\
\hline
\end{tabular}

TRN 


\begin{tabular}{|c|c|c|c|c|c|}
\hline \multicolumn{6}{|c|}{ Supplemental Table S2.txt } \\
\hline CHEMBL1547645 & 688816 & 4.6 & 5.1443 & TRN & \\
\hline CHEMBL1508563 & 688816 & 8.301 & 5.3354 & TST & \\
\hline CHEMBL1330568 & 688816 & 5.0 & 5.0987 & TST & \\
\hline CHEMBL1596591 & 688816 & 7.5498 & 5.4499 & TST & \\
\hline CHEMBL1571527 & 688816 & 5.45 & 5.483 & TRN & \\
\hline CHEMBL3189667 & 688816 & 4.85 & 5.5329 & TRN & \\
\hline CHEMBL1393615 & 688816 & 5.0 & 5.0731 & TRN & \\
\hline CHEMBL1578479 & 688816 & 4.65 & 4.9721 & TRN & \\
\hline CHEMBL436589 & 688816 & 4.55 & 5.3622 & TRN & \\
\hline CHEMBL1406820 & 688816 & 4.55 & 5.1755 & TRN & \\
\hline CHEMBL3183210 & 688816 & 4.45 & 5.038 & TRN & \\
\hline CHEMBL1310600 & 688816 & 8.301 & 5.4897 & TRN & \\
\hline CHEMBL1525113 & 688816 & 4.85 & 5.2808 & TRN & \\
\hline CHEMBL1585308 & 688816 & 5.05 & 5.24200 & 3000000001 & TRN \\
\hline CHEMBL1502683 & 688816 & 6.5 & 5.1945 & TST & \\
\hline CHEMBL1323655 & 688816 & 4.45 & 5.1688 & TRN & \\
\hline CHEMBL1556157 & 688816 & 4.45 & 5.2245 & TRN & \\
\hline CHEMBL1336066 & 688816 & 5.5 & 5.3683 & TRN & \\
\hline CHEMBL1563286 & 688816 & 8.3979 & 5.8028 & TST & \\
\hline CHEMBL1597595 & 688816 & 4.75 & 5.2435 & TRN & \\
\hline CHEMBL1527441 & 688816 & 5.25 & 5.4197 & TST & \\
\hline CHEMBL1508462 & 688816 & 4.9 & 5.1329 & TST & \\
\hline CHEMBL1567631 & 688816 & 8.3468 & 5.1611 & TRN & \\
\hline CHEMBL1413321 & 688816 & 6.1 & 5.1747 & TRN & \\
\hline CHEMBL1392647 & 688816 & 4.75 & 5.9155 & TST & \\
\hline CHEMBL1530910 & 688816 & 5.6 & 5.4706 & TRN & \\
\hline CHEMBL3189577 & 688816 & 4.8 & 5.2597 & TRN & \\
\hline CHEMBL1363765 & 688816 & 4.45 & 5.2671 & TRN & \\
\hline CHEMBL1540611 & 688816 & 4.95 & 5.4043 & TRN & \\
\hline CHEMBL3189688 & 688816 & 5.75 & 5.2491 & TRN & \\
\hline CHEMBL1373611 & 688816 & 6.95 & 5.2975 & TST & \\
\hline CHEMBL1515999 & 688816 & 5.3 & 4.8873 & TRN & \\
\hline CHEMBL1345217 & 688816 & 4.45 & 5.6521 & TRN & \\
\hline CHEMBL1383480 & 688816 & 4.5 & 5.3875 & TST & \\
\hline CHEMBL1406607 & 688816 & 4.45 & 5.2242 & TST & \\
\hline CHEMBL1322123 & 688816 & 4.75 & 5.472 & TST & \\
\hline CHEMBL1479886 & 688816 & 5.15 & 5.3388 & TRN & \\
\hline CHEMBL1599881 & 688816 & 4.95 & 5.3476 & TST & \\
\hline CHEMBL1320883 & 688816 & 4.8 & 4.9589 & TRN & \\
\hline CHEMBL475627 & 688816 & 6.15 & 5.0946 & TRN & \\
\hline CHEMBL1535851 & 688816 & 5.4 & 5.4576 & TST & \\
\hline CHEMBL1455009 & 688816 & 4.75 & 5.4482 & TRN & \\
\hline CHEMBL1387367 & 688816 & 5.0 & 4.815 & TRN & \\
\hline CHEMBL191015 & 688816 & 4.9 & 4.9628 & TRN & \\
\hline CHEMBL1611594 & 688816 & 4.45 & 4.9995 & TRN & \\
\hline CHEMBL1562707 & 688816 & 5.0 & 5.3155 & TRN & \\
\hline CHEMBL1491750 & 688816 & 4.45 & 4.9064 & TST & \\
\hline CHEMBL1465951 & 688816 & 6.5 & 5.647 & TST & \\
\hline
\end{tabular}




\begin{tabular}{|c|c|c|c|c|}
\hline \multicolumn{5}{|c|}{ Supplemental Table S2.txt } \\
\hline CHEMBL1458023 & 688816 & 5.55 & 5.1746 & TST \\
\hline CHEMBL1398350 & 688816 & 5.5 & 5.1601 & TRN \\
\hline CHEMBL1495514 & 688816 & 5.4 & 5.6905 & TST \\
\hline CHEMBL1369594 & 688816 & 4.8 & 5.0408 & TRN \\
\hline CHEMBL1430788 & 688816 & 4.8 & 5.019 & TRN \\
\hline CHEMBL1408559 & 688816 & 5.0 & 5.4262 & TST \\
\hline CHEMBL1502852 & 688816 & 5.0 & 5.1713 & TRN \\
\hline CHEMBL1449334 & 688816 & 4.45 & 5.1363 & TST \\
\hline CHEMBL1489587 & 688816 & 6.5 & 5.0652 & TRN \\
\hline CHEMBL1504625 & 688816 & 4.6 & 5.1501 & TRN \\
\hline CHEMBL1522947 & 688816 & 4.45 & 4.915 & TRN \\
\hline CHEMBL1305329 & 688816 & 4.95 & 4.9839 & TST \\
\hline CHEMBL3194320 & 688816 & 7.8013 & 5.8001 & TRN \\
\hline CHEMBL1501632 & 688816 & 5.55 & 5.0487 & TRN \\
\hline CHEMBL1611843 & 688816 & 5.9 & 5.2508 & TRN \\
\hline CHEMBL76144 & 688816 & 4.9 & 4.909 & TRN \\
\hline CHEMBL1420271 & 688816 & 4.75 & 5.3556 & TRN \\
\hline CHEMBL1530196 & 688816 & 4.75 & 5.5022 & TST \\
\hline CHEMBL1306283 & 688816 & 4.95 & 4.8159 & TRN \\
\hline CHEMBL1587962 & 688816 & 4.45 & 5.4106 & TST \\
\hline CHEMBL1348292 & 688816 & 5.45 & 5.2818 & TRN \\
\hline CHEMBL1371155 & 688816 & 5.1 & 5.4881 & TST \\
\hline CHEMBL1574121 & 688816 & 4.65 & 4.6496 & TRN \\
\hline CHEMBL1406791 & 688816 & 4.95 & 4.9858 & TRN \\
\hline CHEMBL1410477 & 688816 & 4.45 & 5.2393 & TST \\
\hline CHEMBL1312321 & 688816 & 4.5 & 5.0257 & TST \\
\hline CHEMBL1351750 & 688816 & 4.45 & 4.8273 & TRN \\
\hline CHEMBL1428648 & 688816 & 4.6 & 5.1283 & TRN \\
\hline CHEMBL1988782 & 688816 & 4.85 & 5.2962 & TRN \\
\hline CHEMBL1344635 & 688816 & 6.45 & 5.6434 & TRN \\
\hline CHEMBL1602715 & 688816 & 4.95 & 5.4276 & TRN \\
\hline CHEMBL1438864 & 688816 & 4.9 & 5.5306 & TRN \\
\hline CHEMBL1595919 & 688816 & 5.25 & 5.0478 & TRN \\
\hline CHEMBL3190842 & 688816 & 4.95 & 5.3665 & TRN \\
\hline CHEMBL1602564 & 688816 & 4.5 & 4.8712 & TRN \\
\hline CHEMBL1317158 & 688816 & 4.95 & 4.7601 & TRN \\
\hline CHEMBL1310574 & 688816 & 4.45 & 5.1034 & TST \\
\hline CHEMBL1312918 & 688816 & 8.3468 & 5.4456 & TRN \\
\hline CHEMBL1384111 & 688816 & 5.1 & 5.30399 & 9999999999 \\
\hline CHEMBL1585270 & 688816 & 8.301 & 5.3834 & TRN \\
\hline CHEMBL1408744 & 688816 & 5.25 & 5.4273 & TRN \\
\hline CHEMBL1596663 & 688816 & 5.25 & 5.5455 & TRN \\
\hline CHEMBL3196268 & 688816 & 7.699 & 5.1425 & TRN \\
\hline CHEMBL1465376 & 688816 & 5.25 & 5.3921 & TRN \\
\hline CHEMBL1364270 & 688816 & 5.1 & 5.3334 & TRN \\
\hline CHEMBL73188 & 688816 & 5.25 & 5.6788 & TST \\
\hline CHEMBL1312886 & 688816 & 8.4949 & 5.8226 & TST \\
\hline CHEMBL3189681 & 688816 & 4.65 & 5.4315 & TST \\
\hline
\end{tabular}




\begin{tabular}{|c|c|c|c|c|c|}
\hline \multicolumn{6}{|c|}{ Supplemental Table S2.txt } \\
\hline CHEMBL1397952 & 688816 & 5.8 & 5.3424 & TRN & \\
\hline CHEMBL1549784 & 688816 & 4.45 & 5.0834 & TRN & \\
\hline CHEMBL1489928 & 688816 & 4.9 & 5.40799 & 99999999995 & TRN \\
\hline CHEMBL1316301 & 688816 & 5.85 & 5.2644 & TRN & \\
\hline CHEMBL1587473 & 688816 & 4.45 & 5.0495 & TST & \\
\hline CHEMBL1365949 & 688816 & 4.9 & 5.3118 & TRN & \\
\hline CHEMBL3193591 & 688816 & 5.35 & 5.2328 & TST & \\
\hline CHEMBL1307804 & 688816 & 5.6 & 5.0898 & TRN & \\
\hline CHEMBL1306690 & 688816 & 4.75 & 5.3477 & TST & \\
\hline CHEMBL1344501 & 688816 & 5.3 & 5.1143 & TRN & \\
\hline CHEMBL1511858 & 688816 & 4.65 & 5.388 & TRN & \\
\hline CHEMBL1301519 & 688816 & 4.7 & 5.4922 & TRN & \\
\hline CHEMBL1371556 & 688816 & 4.45 & 5.0534 & TST & \\
\hline CHEMBL1347792 & 688816 & 4.45 & 5.3124 & TRN & \\
\hline CHEMBL1315014 & 688816 & 6.15 & 5.2107 & TST & \\
\hline CHEMBL1426909 & 688816 & 7.5498 & 5.4651 & TRN & \\
\hline CHEMBL1456645 & 688816 & 4.95 & 4.8704 & TST & \\
\hline CHEMBL1374777 & 688816 & 4.95 & 5.7616 & TRN & \\
\hline CHEMBL1422242 & 688816 & 4.45 & 5.0137 & TRN & \\
\hline CHEMBL1550335 & 688816 & 4.95 & 5.1321 & TST & \\
\hline CHEMBL1986274 & 688816 & 5.0 & 5.1472 & TRN & \\
\hline CHEMBL63154 & 688816 & 4.7 & 5.3214 & TST & \\
\hline CHEMBL1548357 & 688816 & 4.95 & 5.5088 & TST & \\
\hline CHEMBL1344207 & 688816 & 5.35 & 5.49799 & 9999999999 & TRN \\
\hline CHEMBL1410185 & 688816 & 8.4949 & 5.6355 & TST & \\
\hline CHEMBL1583714 & 688816 & 4.6 & 5.3279 & TRN & \\
\hline CHEMBL1350449 & 688816 & 4.95 & 5.0009 & TST & \\
\hline CHEMBL1398585 & 688816 & 4.9 & 5.7022 & TRN & \\
\hline CHEMBL1393031 & 688816 & 6.2 & 5.4884 & TRN & \\
\hline CHEMBL1395778 & 688816 & 5.9 & 5.2149 & TRN & \\
\hline CHEMBL 2004505 & 688816 & 6.0 & 5.6449 & TST & \\
\hline CHEMBL1375246 & 688816 & 4.45 & 5.2207 & TRN & \\
\hline CHEMBL1329268 & 688816 & 4.9 & 5.4985 & TRN & \\
\hline CHEMBL1526853 & 688816 & 4.9 & 4.9631 & TRN & \\
\hline CHEMBL1429297 & 688816 & 4.95 & 4.9217 & TRN & \\
\hline CHEMBL1510809 & 688816 & 4.9 & 5.1085 & TRN & \\
\hline CHEMBL1446501 & 688816 & 5.25 & 5.2748 & TST & \\
\hline CHEMBL1498380 & 688816 & 4.8 & 5.3532 & TRN & \\
\hline CHEMBL1455629 & 688816 & 7.1002 & 5.4117 & TRN & \\
\hline CHEMBL1453473 & 688816 & 4.85 & 5.2215 & TRN & \\
\hline CHEMBL1499 & 688816 & 5.9 & 5.7694 & TRN & \\
\hline CHEMBL2369296 & 688816 & 4.95 & 5.147 & TST & \\
\hline CHEMBL1502169 & 688816 & 5.65 & 5.5864 & TST & \\
\hline CHEMBL1406971 & 688816 & 7.5498 & 5.4807 & TST & \\
\hline CHEMBL1991779 & 688816 & 5.3 & 5.3466 & TRN & \\
\hline CHEMBL1450966 & 688816 & 5.6 & 5.513 & TST & \\
\hline CHEMBL1609328 & 688816 & 4.95 & 5.6311 & TRN & \\
\hline CHEMBL1532479 & 688816 & 4.75 & 4.8932 & TRN & \\
\hline
\end{tabular}




\begin{tabular}{|c|c|c|c|c|c|}
\hline \multicolumn{6}{|c|}{ Supplemental Table S2.txt } \\
\hline CHEMBL 3195523 & 688816 & 4.65 & 5.6019 & TRN & \\
\hline CHEMBL 2007448 & 688816 & 4.95 & 5.2107 & TRN & \\
\hline CHEMBL1504945 & 688816 & 6.35 & 5.1135 & TRN & \\
\hline CHEMBL1300013 & 688816 & 4.8 & 5.1087 & TRN & \\
\hline CHEMBL1360419 & 688816 & 4.9 & 5.0357 & TRN & \\
\hline CHEMBL319244 & 688816 & 6.0 & 5.0402 & TST & \\
\hline CHEMBL1389572 & 688816 & 5.05 & 5.4509 & TRN & \\
\hline CHEMBL1462713 & 688816 & 5.0 & 5.4799 & TRN & \\
\hline CHEMBL1545357 & 688816 & 7.3497 & 5.7391 & TST & \\
\hline CHEMBL1483627 & 688816 & 6.1 & 5.0141 & TRN & \\
\hline CHEMBL1443698 & 688816 & 4.45 & 5.3975 & TRN & \\
\hline CHEMBL1351106 & 688816 & 4.95 & 5.4136 & TRN & \\
\hline CHEMBL1451515 & 688816 & 5.6 & 5.5548 & TRN & \\
\hline CHEMBL1303748 & 688816 & 4.9 & 5.29799 & 9999999999 & TRN \\
\hline CHEMBL1305316 & 688816 & 4.45 & 5.2796 & TRN & \\
\hline CHEMBL1078244 & 688816 & 6.45 & 5.2752 & TST & \\
\hline CHEMBL1404713 & 688816 & 4.45 & 5.2971 & TRN & \\
\hline CHEMBL1301480 & 688816 & 5.0 & 5.0613 & TRN & \\
\hline CHEMBL 3208401 & 688816 & 5.0 & 5.1456 & TRN & \\
\hline CHEMBL1255866 & 688816 & 4.75 & 5.3201 & TST & \\
\hline CHEMBL1606690 & 688816 & 4.45 & 5.0674 & TST & \\
\hline CHEMBL1518905 & 688816 & 6.35 & 5.4304 & TST & \\
\hline CHEMBL600334 & 688816 & 5.65 & 5.055 & TRN & \\
\hline CHEMBL1323347 & 688816 & 4.45 & 5.0338 & TRN & \\
\hline CHEMBL1375468 & 688816 & 5.25 & 5.4123 & TST & \\
\hline CHEMBL1322593 & 688816 & 5.25 & 5.4436 & TST & \\
\hline CHEMBL1341581 & 688816 & 4.6 & 5.3428 & TST & \\
\hline CHEMBL1501678 & 688816 & 5.65 & 5.2017 & TRN & \\
\hline CHEMBL1521190 & 688816 & 4.9 & 5.2152 & TRN & \\
\hline CHEMBL1549972 & 688816 & 8.2518 & 5.6073 & TRN & \\
\hline CHEMBL1576502 & 688816 & 4.65 & 5.3184 & TRN & \\
\hline CHEMBL1446779 & 688816 & 4.8 & 4.9608 & TRN & \\
\hline CHEMBL1385257 & 688816 & 8.3468 & 5.2683 & TRN & \\
\hline CHEMBL117 & 688816 & 6.0 & 5.0335 & TRN & \\
\hline CHEMBL1476045 & 688816 & 4.85 & 5.1568 & TRN & \\
\hline CHEMBL1523432 & 688816 & 4.45 & 4.7344 & TRN & \\
\hline CHEMBL1555375 & 688816 & 4.8 & 5.3247 & TRN & \\
\hline CHEMBL1423577 & 688816 & 5.05 & 5.4625 & TST & \\
\hline CHEMBL1558555 & 688816 & 4.95 & 5.2761 & TRN & \\
\hline CHEMBL1378391 & 688816 & 5.8 & 5.1313 & TRN & \\
\hline CHEMBL1535794 & 688816 & 6.6499 & 5.5767 & TST & \\
\hline CHEMBL1574669 & 688816 & 4.8 & 5.4354 & TRN & \\
\hline CHEMBL1586590 & 688816 & 4.45 & 4.8378 & TRN & \\
\hline CHEMBL 3207340 & 688816 & 4.95 & 5.3099 & TRN & \\
\hline CHEMBL1539878 & 688816 & 5.5 & 5.4627 & TRN & \\
\hline CHEMBL1314082 & 688816 & 5.2 & 6.0436 & TST & \\
\hline CHEMBL 1589790 & 688816 & 4.7 & 5.2052 & TRN & \\
\hline CHEMBL1423463 & 688816 & 4.8 & 5.2962 & TRN & \\
\hline
\end{tabular}




\begin{tabular}{|c|c|c|c|c|c|}
\hline \multicolumn{6}{|c|}{ Supplemental Table S2.txt } \\
\hline CHEMBL584225 & 688816 & 6.1 & 5.431 & TST & \\
\hline CHEMBL1364122 & 688816 & 7.699 & 5.46899 & 9999999999 & TRN \\
\hline CHEMBL3199217 & 688816 & 4.75 & 5.2874 & TST & \\
\hline CHEMBL1415809 & 688816 & 7.4498 & 5.6263 & TST & \\
\hline CHEMBL1320356 & 688816 & 5.0 & 5.635 & TRN & \\
\hline CHEMBL3214362 & 688816 & 4.7 & 5.3076 & TRN & \\
\hline CHEMBL1539288 & 688816 & 5.15 & 5.1896 & TRN & \\
\hline CHEMBL1372264 & 688816 & 5.45 & 5.6121 & TRN & \\
\hline CHEMBL1526521 & 688816 & 7.8996 & 5.2672 & TST & \\
\hline CHEMBL1480377 & 688816 & 6.5 & 5.4364 & TRN & \\
\hline CHEMBL1320874 & 688816 & 5.65 & 5.1593 & TRN & \\
\hline CHEMBL1312387 & 688816 & 4.95 & 4.7812 & TRN & \\
\hline CHEMBL1367219 & 688816 & 4.9 & 5.4533 & TRN & \\
\hline CHEMBL1335575 & 688816 & 8.4949 & 5.5711 & TST & \\
\hline CHEMBL1561863 & 688816 & 4.8 & 5.1347 & TST & \\
\hline CHEMBL1611871 & 688816 & 5.2 & 5.4593 & TRN & \\
\hline CHEMBL1455948 & 688816 & 4.95 & 5.1106 & TRN & \\
\hline CHEMBL1576923 & 688816 & 4.9 & 5.5342 & TRN & \\
\hline CHEMBL1484500 & 688816 & 4.5 & 5.5183 & TRN & \\
\hline CHEMBL1493633 & 688816 & 5.3 & 4.855 & TRN & \\
\hline CHEMBL1976304 & 688816 & 4.65 & 5.1254 & TST & \\
\hline CHEMBL1360939 & 688816 & 5.1 & 5.4214 & TST & \\
\hline CHEMBL1484429 & 688816 & 5.95 & 5.4339 & TRN & \\
\hline CHEMBL1484661 & 688816 & 5.1 & 5.4858 & TRN & \\
\hline CHEMBL1421615 & 688816 & 4.9 & 5.1093 & TRN & \\
\hline CHEMBL1440902 & 688816 & 4.65 & 4.8635 & TST & \\
\hline CHEMBL1460305 & 688816 & 6.0 & 5.3428 & TST & \\
\hline CHEMBL1505926 & 688816 & 6.5 & 5.6145 & TRN & \\
\hline CHEMBL1412291 & 688816 & 5.3 & 4.9206 & TRN & \\
\hline CHEMBL1402034 & 688816 & 6.8499 & 5.025 & TST & \\
\hline CHEMBL1974063 & 688816 & 4.8 & 5.1296 & TST & \\
\hline CHEMBL1454278 & 688816 & 5.0 & 5.1081 & TRN & \\
\hline CHEMBL1444771 & 688816 & 5.55 & 5.2009 & TRN & \\
\hline CHEMBL1521433 & 688816 & 4.45 & 5.4728 & TRN & \\
\hline CHEMBL1343474 & 688816 & 8.301 & 5.1195 & TRN & \\
\hline CHEMBL1610422 & 688816 & 5.35 & 5.2015 & TRN & \\
\hline CHEMBL1451622 & 688816 & 4.95 & 5.2586 & TRN & \\
\hline CHEMBL1565011 & 688816 & 5.65 & 5.357 & TST & \\
\hline CHEMBL1405690 & 688816 & 5.5 & 5.0783 & TST & \\
\hline CHEMBL2005117 & 688816 & 4.45 & 5.42 & TRN & \\
\hline CHEMBL1341691 & 688816 & 4.65 & 4.9972 & TRN & \\
\hline CHEMBL1388753 & 688816 & 4.45 & 5.3863 & TRN & \\
\hline CHEMBL1481585 & 688816 & 4.8 & 5.0427 & TRN & \\
\hline CHEMBL1598105 & 688816 & 4.85 & 4.9612 & TRN & \\
\hline CHEMBL1438945 & 688816 & 4.8 & 5.1373 & TST & \\
\hline CHEMBL1339172 & 688816 & 5.3 & 5.3723 & TRN & \\
\hline CHEMBL1485127 & 688816 & 4.45 & 5.0477 & TRN & \\
\hline CHEMBL1406932 & 688816 & 4.45 & 5.6105 & TST & \\
\hline
\end{tabular}




\begin{tabular}{|c|c|c|c|c|}
\hline \multicolumn{5}{|c|}{ Supplemental Table S2.txt } \\
\hline CHEMBL1308725 & 688816 & 4.65 & 4.9555 & TRN \\
\hline CHEMBL1397089 & 688816 & 6.5 & 5.7741 & TRN \\
\hline CHEMBL1378442 & 688816 & 5.35 & 4.9955 & TRN \\
\hline CHEMBL3199845 & 688816 & 5.0 & 5.0353 & TRN \\
\hline CHEMBL1403860 & 688816 & 5.3 & 5.7084 & TRN \\
\hline CHEMBL1342842 & 688816 & 4.8 & 5.2024 & TST \\
\hline CHEMBL1600081 & 688816 & 4.95 & 4.7912 & TRN \\
\hline CHEMBL1500196 & 688816 & 7.699 & 5.3073 & TST \\
\hline CHEMBL358546 & 688816 & 4.8 & 4.7163 & TST \\
\hline CHEMBL1388490 & 688816 & 4.85 & 4.9946 & TRN \\
\hline CHEMBL1345088 & 688816 & 4.45 & 5.5721 & TRN \\
\hline CHEMBL1557069 & 688816 & 4.45 & 4.7709 & TRN \\
\hline CHEMBL1584280 & 688816 & 4.45 & 5.0516 & TRN \\
\hline CHEMBL1606786 & 688816 & 4.45 & 5.317 & TRN \\
\hline CHEMBL1367165 & 688816 & 5.0 & 5.4267 & TRN \\
\hline CHEMBL1533854 & 688816 & 6.6 & 5.3083 & TRN \\
\hline CHEMBL1488215 & 688816 & 7.699 & 5.2892 & TST \\
\hline CHEMBL1374686 & 688816 & 4.45 & 5.1186 & TRN \\
\hline CHEMBL1407085 & 688816 & 4.8 & 5.2387 & TRN \\
\hline CHEMBL1414465 & 688816 & 5.15 & 5.1344 & TRN \\
\hline CHEMBL1361494 & 688816 & 5.0 & 5.6182 & TST \\
\hline CHEMBL1393954 & 688816 & 4.65 & 5.5039 & TRN \\
\hline CHEMBL1413592 & 688816 & 4.85 & 5.0069 & TRN \\
\hline CHEMBL1571145 & 688816 & 5.6 & 5.6616 & TRN \\
\hline CHEMBL1475922 & 688816 & 5.35 & 5.2779 & TRN \\
\hline CHEMBL1468734 & 688816 & 5.0 & 4.9958 & TRN \\
\hline CHEMBL1420984 & 688816 & 8.3468 & 5.4328 & TRN \\
\hline CHEMBL66620 & 688816 & 5.45 & 4.8028 & TRN \\
\hline CHEMBL1568277 & 688816 & 4.45 & 4.7602 & TRN \\
\hline CHEMBL1402772 & 688816 & 4.45 & 5.5216 & TRN \\
\hline CHEMBL1545723 & 688816 & 5.0 & 5.1185 & TRN \\
\hline CHEMBL1339208 & 688816 & 4.75 & 5.4814 & TRN \\
\hline CHEMBL1329074 & 688816 & 4.45 & 4.8489 & TRN \\
\hline CHEMBL3213790 & 688816 & 8.301 & 5.4164 & TST \\
\hline CHEMBL1351052 & 688816 & 4.65 & 5.1593 & TRN \\
\hline CHEMBL1568996 & 688816 & 5.2 & 4.7832 & TST \\
\hline CHEMBL1338079 & 688816 & 5.05 & 5.3792 & TRN \\
\hline CHEMBL1421288 & 688816 & 4.45 & 5.0001 & TRN \\
\hline CHEMBL1517473 & 688816 & 4.65 & 4.9073 & TRN \\
\hline CHEMBL1323555 & 688816 & 5.0 & 5.4984 & TRN \\
\hline CHEMBL1389720 & 688816 & 7.2503 & 5.3997 & TRN \\
\hline CHEMBL1965174 & 688816 & 6.3 & 5.3605 & TST \\
\hline CHEMBL1588926 & 688816 & 5.6 & 5.3296 & TRN \\
\hline CHEMBL1313072 & 688816 & 5.55 & 5.3181 & TRN \\
\hline CHEMBL1342609 & 688816 & 4.7 & 5.0139 & TRN \\
\hline CHEMBL1419224 & 688816 & 5.85 & 5.2026 & TRN \\
\hline CHEMBL1312733 & 688816 & 8.301 & 5.4335 & TST \\
\hline CHEMBL3195008 & 688816 & 5.2 & 5.5032 & TST \\
\hline
\end{tabular}




\begin{tabular}{|c|c|c|c|c|c|}
\hline \multicolumn{6}{|c|}{ Supplemental Table S2.txt } \\
\hline CHEMBL1565304 & 688816 & 5.0 & 5.0592 & TRN & \\
\hline CHEMBL133576 & 688816 & 4.95 & 5.3373 & TST & \\
\hline CHEMBL1605598 & 688816 & 5.0 & 5.4173 & TRN & \\
\hline CHEMBL1346443 & 688816 & 4.95 & 5.2182 & TRN & \\
\hline CHEMBL1432729 & 688816 & 4.75 & 5.8039 & TRN & \\
\hline CHEMBL1407617 & 688816 & 7.8508 & 5.2045 & TRN & \\
\hline CHEMBL 3212126 & 688816 & 4.95 & 5.2427 & TRN & \\
\hline CHEMBL1524648 & 688816 & 4.45 & 5.3105 & TRN & \\
\hline CHEMBL1490338 & 688816 & 6.3 & 5.48600 & $\partial 000000001$ & TRN \\
\hline CHEMBL1426297 & 688816 & 5.25 & 5.4551 & TST & \\
\hline CHEMBL1459435 & 688816 & 6.1 & 5.2733 & TST & \\
\hline CHEMBL1384017 & 688816 & 7.6003 & 4.9723 & TRN & \\
\hline CHEMBL1543240 & 688816 & 4.95 & 5.0209 & TRN & \\
\hline CHEMBL1341605 & 688816 & 5.0 & 5.1295 & TRN & \\
\hline CHEMBL1550144 & 688816 & 8.6576 & 5.4762 & TST & \\
\hline CHEMBL1508177 & 688816 & 5.05 & 5.3231 & TRN & \\
\hline CHEMBL1381180 & 688816 & 4.95 & 5.1904 & TRN & \\
\hline CHEMBL1310517 & 688816 & 4.8 & 5.0793 & TRN & \\
\hline CHEMBL1312478 & 688816 & 4.7 & 5.1165 & TRN & \\
\hline CHEMBL1342276 & 688816 & 5.55 & 5.7427 & TST & \\
\hline CHEMBL1391275 & 688816 & 4.65 & 5.1405 & TRN & \\
\hline CHEMBL1574209 & 688816 & 4.45 & 4.8566 & TRN & \\
\hline CHEMBL1529219 & 688816 & 4.9 & 5.3106 & TRN & \\
\hline CHEMBL1304449 & 688816 & 4.9 & 5.1447 & TRN & \\
\hline CHEMBL1610238 & 688816 & 4.85 & 5.2535 & TST & \\
\hline CHEMBL1524564 & 688816 & 4.65 & 5.1221 & TRN & \\
\hline CHEMBL591126 & 688816 & 4.8 & 5.3514 & TRN & \\
\hline CHEMBL1548867 & 688816 & 4.95 & 5.2766 & TRN & \\
\hline CHEMBL3190684 & 688816 & 5.25 & 5.3182 & TRN & \\
\hline CHEMBL1389615 & 688816 & 5.2 & 5.5214 & TRN & \\
\hline CHEMBL1392167 & 688816 & 4.9 & 5.1234 & TRN & \\
\hline CHEMBL3209005 & 688816 & 4.8 & 5.3435 & TRN & \\
\hline CHEMBL1594926 & 688816 & 4.65 & 5.1838 & TRN & \\
\hline CHEMBL1378390 & 688816 & 5.35 & 5.3093 & TRN & \\
\hline CHEMBL1509840 & 688816 & 4.8 & 5.4127 & TRN & \\
\hline CHEMBL1610551 & 688816 & 4.9 & 5.3393 & TST & \\
\hline CHEMBL1423262 & 688816 & 6.0 & 5.3305 & TST & \\
\hline CHEMBL1374512 & 688816 & 4.7 & 5.7869 & TRN & \\
\hline CHEMBL1350518 & 688816 & 4.9 & 5.1646 & TST & \\
\hline CHEMBL1432434 & 688816 & 5.65 & 5.1133 & TST & \\
\hline CHEMBL1319623 & 688816 & 4.45 & 4.8949 & TRN & \\
\hline CHEMBL1322916 & 688816 & 5.1 & 5.1714 & TST & \\
\hline CHEMBL1366836 & 688816 & 4.85 & 5.1211 & TST & \\
\hline CHEMBL1483386 & 688816 & 5.1 & 5.6905 & TRN & \\
\hline CHEMBL1429939 & 688816 & 7.0501 & 5.2154 & TRN & \\
\hline CHEMBL 3197340 & 688816 & 4.45 & 5.3313 & TRN & \\
\hline CHEMBL1458004 & 688816 & 4.65 & 5.4843 & TRN & \\
\hline CHEMBL1388928 & 688816 & 5.6 & 5.1692 & TRN & \\
\hline
\end{tabular}




\begin{tabular}{|c|c|c|c|c|c|}
\hline \multicolumn{6}{|c|}{ Supplemental Table S2.txt } \\
\hline CHEMBL1532523 & 688816 & 4.5 & 5.1953 & TRN & \\
\hline CHEMBL1320111 & 688816 & 7.5003 & 5.5127 & TRN & \\
\hline CHEMBL1542038 & 688816 & 4.8 & 5.1534 & TRN & \\
\hline CHEMBL1453647 & 688816 & 5.25 & 5.3589 & TST & \\
\hline CHEMBL1466448 & 688816 & 5.35 & 5.5151 & TRN & \\
\hline CHEMBL1506275 & 688816 & 4.7 & 5.4935 & TST & \\
\hline CHEMBL1518661 & 688816 & 4.9 & 5.2588 & TRN & \\
\hline CHEMBL1338674 & 688816 & 4.9 & 4.6521 & TRN & \\
\hline CHEMBL1400375 & 688816 & 5.5 & 5.5065 & TRN & \\
\hline CHEMBL1600554 & 688816 & 6.05 & 5.3383 & TRN & \\
\hline CHEMBL1470638 & 688816 & 5.9 & 4.8998 & TRN & \\
\hline CHEMBL1337995 & 688816 & 4.45 & 5.4585 & TST & \\
\hline CHEMBL1505764 & 688816 & 4.45 & 5.8139 & TRN & \\
\hline CHEMBL 2004884 & 688816 & 4.45 & 5.0591 & TRN & \\
\hline CHEMBL1465257 & 688816 & 6.0 & 5.7214 & TRN & \\
\hline CHEMBL1548996 & 688816 & 5.3 & 5.058 & TST & \\
\hline CHEMBL1494571 & 688816 & 5.2 & 5.2087 & TRN & \\
\hline CHEMBL343002 & 688816 & 5.4 & 5.1103 & TRN & \\
\hline CHEMBL1388526 & 688816 & 4.8 & 5.2573 & TST & \\
\hline CHEMBL1448694 & 688816 & 4.75 & 5.1462 & TRN & \\
\hline CHEMBL3213557 & 688816 & 4.45 & 5.2818 & TST & \\
\hline CHEMBL1596777 & 688816 & 4.75 & 5.7198 & TRN & \\
\hline CHEMBL1328454 & 688816 & 4.75 & 5.186 & TRN & \\
\hline CHEMBL1479749 & 688816 & 4.95 & 5.4641 & TST & \\
\hline CHEMBL1421270 & 688816 & 5.05 & 5.0667 & TST & \\
\hline CHEMBL1323044 & 688816 & 4.9 & 5.80399 & 9999999999 & TRN \\
\hline CHEMBL1567403 & 688816 & 4.55 & 5.1684 & TRN & \\
\hline CHEMBL3209990 & 688816 & 4.65 & 5.2389 & TRN & \\
\hline CHEMBL1402931 & 688816 & 4.8 & 5.0037 & TST & \\
\hline CHEMBL1349609 & 688816 & 4.95 & 5.0171 & TRN & \\
\hline CHEMBL1515918 & 688816 & 4.45 & 4.9664 & TRN & \\
\hline CHEMBL1304330 & 688816 & 5.25 & 5.4312 & TST & \\
\hline CHEMBL1401115 & 688816 & 4.95 & 4.9682 & TRN & \\
\hline CHEMBL1536786 & 688816 & 5.15 & 5.6736 & TRN & \\
\hline CHEMBL1503814 & 688816 & 4.85 & 5.0091 & TRN & \\
\hline CHEMBL 2005364 & 688816 & 4.95 & 5.2859 & TRN & \\
\hline CHEMBL1549074 & 688816 & 4.45 & 5.4756 & TRN & \\
\hline CHEMBL1527206 & 688816 & 5.15 & 5.2709 & TRN & \\
\hline CHEMBL1517061 & 688816 & 4.95 & 4.9011 & TRN & \\
\hline CHEMBL1496587 & 688816 & 5.2 & 5.4457 & TRN & \\
\hline CHEMBL1561192 & 688816 & 8.4559 & 5.2019 & TRN & \\
\hline CHEMBL1530900 & 688816 & 5.0 & 5.6138 & TST & \\
\hline CHEMBL1442522 & 688816 & 4.95 & 5.3345 & TST & \\
\hline CHEMBL1325273 & 688816 & 5.6 & 4.9078 & TST & \\
\hline CHEMBL1337156 & 688816 & 4.95 & 5.5514 & TST & \\
\hline CHEMBL1437977 & 688816 & 4.85 & 5.2048 & TST & \\
\hline CHEMBL1492581 & 688816 & 4.8 & 4.8924 & TRN & \\
\hline CHEMBL1480721 & 688816 & 4.95 & 5.2512 & TRN & \\
\hline
\end{tabular}




\begin{tabular}{|c|c|c|c|c|c|}
\hline \multirow[b]{2}{*}{ CHEMBL1490040 } & \multicolumn{5}{|c|}{ Supplemental Table S2.txt } \\
\hline & 688816 & 4.85 & 5.3401 & TRN & \\
\hline CHEMBL1506829 & 688816 & 7.8013 & 5.4627 & TST & \\
\hline CHEMBL1351353 & 688816 & 4.85 & 5.12299 & 9999999999 & TST \\
\hline CHEMBL1500070 & 688816 & 4.9 & 4.8437 & TRN & \\
\hline CHEMBL1490873 & 688816 & 7.0 & 5.5656 & TRN & \\
\hline CHEMBL1557922 & 688816 & 4.45 & 5.2127 & TRN & \\
\hline CHEMBL1481069 & 688816 & 4.8 & 5.2708 & TST & \\
\hline CHEMBL1329311 & 688816 & 4.45 & 5.1565 & TRN & \\
\hline CHEMBL1559843 & 688816 & 5.5 & 5.1135 & TRN & \\
\hline CHEMBL394242 & 688816 & 5.2 & 4.9813 & TRN & \\
\hline CHEMBL1488909 & 688816 & 4.9 & 5.3273 & TRN & \\
\hline CHEMBL3195027 & 688816 & 6.15 & 5.6719 & TRN & \\
\hline CHEMBL1435946 & 688816 & 4.9 & 5.4327 & TRN & \\
\hline CHEMBL1550628 & 688816 & 4.45 & 4.8144 & TRN & \\
\hline CHEMBL1412106 & 688816 & 5.1 & 5.193 & TST & \\
\hline CHEMBL1450098 & 688816 & 5.0 & 5.136 & TRN & \\
\hline CHEMBL1443965 & 688816 & 4.95 & 5.1359 & TRN & \\
\hline CHEMBL1446073 & 688816 & 4.45 & 4.7834 & TRN & \\
\hline CHEMBL3190687 & 688816 & 4.8 & 5.2307 & TRN & \\
\hline CHEMBL1556190 & 688816 & 5.7 & 5.1677 & TST & \\
\hline CHEMBL3196281 & 688816 & 7.5498 & 5.1989 & TRN & \\
\hline CHEMBL1471685 & 688816 & 4.85 & 5.4854 & TST & \\
\hline CHEMBL1442870 & 688816 & 8.4949 & 5.6095 & TRN & \\
\hline CHEMBL1453047 & 688816 & 5.5 & 5.22 & TRN & \\
\hline CHEMBL1576561 & 688816 & 6.4 & 5.3336 & TRN & \\
\hline CHEMBL1321656 & 688816 & 8.3468 & 5.2267 & TRN & \\
\hline CHEMBL3191226 & 688816 & 4.95 & 5.3933 & TRN & \\
\hline CHEMBL1400840 & 688816 & 4.95 & 5.17200 & 0000000001 & TRN \\
\hline CHEMBL1453691 & 688816 & 4.9 & 5.2932 & TRN & \\
\hline CHEMBL1401837 & 688816 & 4.95 & 5.0539 & TRN & \\
\hline CHEMBL1550863 & 688816 & 4.95 & 5.2526 & TRN & \\
\hline CHEMBL1423370 & 688816 & 4.65 & 5.3571 & TRN & \\
\hline CHEMBL1404590 & 688816 & 4.75 & 5.175 & TRN & \\
\hline CHEMBL456295 & 688816 & 4.45 & 5.5443 & TST & \\
\hline CHEMBL1578423 & 688816 & 4.45 & 5.2318 & TST & \\
\hline CHEMBL1346236 & 688816 & 5.1 & 5.3263 & TRN & \\
\hline CHEMBL1425034 & 688816 & 7.0 & 5.2269 & TRN & \\
\hline CHEMBL1504648 & 688816 & 4.45 & 5.5447 & TRN & \\
\hline CHEMBL1496902 & 688816 & 5.2 & 5.5073 & TST & \\
\hline CHEMBL1490334 & 688816 & 4.9 & 5.1865 & TRN & \\
\hline CHEMBL1466160 & 688816 & 4.7 & 4.8581 & TRN & \\
\hline CHEMBL1324830 & 688816 & 5.45 & 5.4401 & TRN & \\
\hline CHEMBL1312914 & 688816 & 4.65 & 5.1511 & TST & \\
\hline CHEMBL1299329 & 688816 & 4.45 & 5.0022 & TST & \\
\hline CHEMBL1498877 & 688816 & 5.0 & 5.0748 & TRN & \\
\hline CHEMBL1417569 & 688816 & 7.6498 & 5.0788 & TRN & \\
\hline CHEMBL1385922 & 688816 & 6.5501 & 5.4474 & TRN & \\
\hline CHEMBL1533225 & 688816 & 5.2 & 5.1297 & TST & \\
\hline
\end{tabular}




\begin{tabular}{|c|c|c|c|c|c|}
\hline \multicolumn{6}{|c|}{ Supplemental Table S2.txt } \\
\hline CHEMBL3212677 & 688816 & 4.95 & 5.2384 & TST & \\
\hline CHEMBL3191913 & 688816 & 4.6 & 5.2268 & TRN & \\
\hline CHEMBL1579718 & 688816 & 4.95 & 5.6377 & TST & \\
\hline CHEMBL303579 & 688816 & 4.55 & 5.36799 & 9999999999 & TRN \\
\hline CHEMBL 1607616 & 688816 & 5.4 & 5.5324 & TST & \\
\hline CHEMBL1340495 & 688816 & 4.95 & 5.2835 & TRN & \\
\hline CHEMBL3195837 & 688816 & 4.75 & 5.3119 & TRN & \\
\hline CHEMBL1475193 & 688816 & 4.45 & 4.8353 & TRN & \\
\hline CHEMBL1557948 & 688816 & 4.95 & 5.314 & TRN & \\
\hline CHEMBL1511535 & 688816 & 5.5 & 5.8865 & TRN & \\
\hline CHEMBL1440093 & 688816 & 4.95 & 4.9119 & TRN & \\
\hline CHEMBL1313823 & 688816 & 4.55 & 4.988 & TRN & \\
\hline CHEMBL1444191 & 688816 & 4.6 & 5.3751 & TRN & \\
\hline CHEMBL1438876 & 688816 & 7.0501 & 5.0618 & TST & \\
\hline CHEMBL1399557 & 688816 & 4.45 & 5.5758 & TRN & \\
\hline CHEMBL1299914 & 688816 & 4.75 & 4.9906 & TRN & \\
\hline CHEMBL1545229 & 688816 & 4.45 & 5.3338 & TRN & \\
\hline CHEMBL1332059 & 688816 & 5.25 & 5.379 & TRN & \\
\hline CHEMBL1304355 & 688816 & 5.15 & 5.0181 & TRN & \\
\hline CHEMBL1602693 & 688816 & 4.6 & 4.9445 & TST & \\
\hline CHEMBL1975615 & 688816 & 4.85 & 5.4291 & TRN & \\
\hline CHEMBL3194933 & 688816 & 4.75 & 5.1666 & TRN & \\
\hline CHEMBL1332657 & 688816 & 5.25 & 5.24299 & 9999999999 & TST \\
\hline CHEMBL1342406 & 688816 & 4.95 & 5.3296 & TST & \\
\hline CHEMBL3197756 & 688816 & 4.9 & 5.40799 & 99999999995 & TRN \\
\hline CHEMBL1437954 & 688816 & 4.45 & 4.9862 & TRN & \\
\hline CHEMBL1579839 & 688816 & 4.85 & 4.7745 & TRN & \\
\hline CHEMBL 254255 & 688816 & 4.45 & 4.8531 & TRN & \\
\hline CHEMBL1531126 & 688816 & 6.95 & 5.3316 & TRN & \\
\hline CHEMBL1561778 & 688816 & 5.35 & 5.54899 & 99999999995 & TRN \\
\hline CHEMBL1559144 & 688816 & 4.45 & 5.4031 & TRN & \\
\hline CHEMBL1420375 & 688816 & 7.8508 & 5.3884 & TRN & \\
\hline CHEMBL3193972 & 688816 & 8.301 & 5.315 & TST & \\
\hline CHEMBL 2095128 & 688816 & 4.55 & 5.0576 & TST & \\
\hline CHEMBL1477172 & 688816 & 4.55 & 5.1447 & TRN & \\
\hline CHEMBL1455796 & 688816 & 5.25 & 5.4263 & TST & \\
\hline CHEMBL3189422 & 688816 & 5.9 & 5.4384 & TST & \\
\hline CHEMBL1400989 & 688816 & 5.0 & 4.9336 & TRN & \\
\hline CHEMBL1347000 & 688816 & 5.35 & 5.6852 & TRN & \\
\hline CHEMBL1391986 & 688816 & 5.45 & 5.3535 & TST & \\
\hline CHEMBL1310132 & 688816 & 6.0 & 4.8816 & TRN & \\
\hline CHEMBL1469340 & 688816 & 4.75 & 5.1265 & TRN & \\
\hline CHEMBL1440489 & 688816 & 4.8 & 4.9568 & TRN & \\
\hline CHEMBL1459547 & 688816 & 4.6 & 5.2432 & TRN & \\
\hline CHEMBL1368314 & 688816 & 5.35 & 5.6818 & TRN & \\
\hline CHEMBL1421259 & 688816 & 4.65 & 4.9833 & TRN & \\
\hline CHEMBL1590646 & 688816 & 4.95 & 5.021 & TRN & \\
\hline CHEMBL1326738 & 688816 & 6.8499 & 5.3902 & TRN & \\
\hline
\end{tabular}




\begin{tabular}{|c|c|c|c|c|c|}
\hline \multicolumn{6}{|c|}{ Supplemental Table s2.txt } \\
\hline CHEMBL1383636 & 688816 & 5.25 & 5.1202 & TRN & \\
\hline CHEMBL1532471 & 688816 & 6.5 & 5.3613 & TST & \\
\hline CHEMBL1451423 & 688816 & 4.45 & 5.5182 & TRN & \\
\hline CHEMBL1437883 & 688816 & 4.85 & 5.0178 & TST & \\
\hline CHEMBL1482191 & 688816 & 4.85 & 5.0686 & TRN & \\
\hline CHEMBL1464168 & 688816 & 4.75 & 5.221 & TRN & \\
\hline CHEMBL1299787 & 688816 & 4.45 & 5.2633 & TRN & \\
\hline CHEMBL1362309 & 688816 & 4.9 & 5.1525 & TRN & \\
\hline CHEMBL1575466 & 688816 & 4.95 & 5.1616 & TRN & \\
\hline CHEMBL1611739 & 688816 & 4.8 & 5.0946 & TRN & \\
\hline CHEMBL1569274 & 688816 & 5.1 & 5.1478 & TST & \\
\hline CHEMBL1554888 & 688816 & 4.95 & 4.734 & TRN & \\
\hline CHEMBL3192393 & 688816 & 4.9 & 4.6311 & TRN & \\
\hline CHEMBL1463648 & 688816 & 4.45 & 5.4093 & TST & \\
\hline CHEMBL1377119 & 688816 & 4.45 & 4.9729 & TRN & \\
\hline CHEMBL1469216 & 688816 & 4.9 & 5.2639 & TRN & \\
\hline CHEMBL1318836 & 688816 & 4.85 & 5.2461 & TRN & \\
\hline CHEMBL1425122 & 688816 & 4.95 & 5.0855 & TRN & \\
\hline CHEMBL1470619 & 688816 & 4.45 & 4.9773 & TRN & \\
\hline CHEMBL1323818 & 688816 & 5.55 & 5.2179 & TRN & \\
\hline CHEMBL1538234 & 688816 & 4.65 & 4.8718 & TRN & \\
\hline CHEMBL1539962 & 688816 & 4.45 & 5.24100 & 00000000005 & TST \\
\hline CHEMBL1417039 & 688816 & 4.9 & 5.2276 & TRN & \\
\hline CHEMBL1371954 & 688816 & 4.7 & 5.2115 & TST & \\
\hline CHEMBL1517284 & 688816 & 5.5 & 5.2301 & TRN & \\
\hline CHEMBL3199379 & 688816 & 5.35 & 5.2683 & TST & \\
\hline CHEMBL1519567 & 688816 & 5.2 & 5.3425 & TRN & \\
\hline CHEMBL1406396 & 688816 & 5.25 & 5.1285 & TST & \\
\hline CHEMBL1498207 & 688816 & 5.4 & 5.0851 & TST & \\
\hline CHEMBL1414744 & 688816 & 4.85 & 5.4922 & TST & \\
\hline CHEMBL1559192 & 688816 & 4.9 & 5.0015 & TRN & \\
\hline CHEMBL1505251 & 688816 & 4.85 & 5.5574 & TRN & \\
\hline CHEMBL1496964 & 688816 & 4.9 & 5.0797 & TRN & \\
\hline CHEMBL1424567 & 688816 & 5.1 & 5.4056 & TRN & \\
\hline CHEMBL1381918 & 688816 & 4.95 & 4.8714 & TRN & \\
\hline CHEMBL1322281 & 688816 & 6.05 & 5.3711 & TRN & \\
\hline CHEMBL375270 & 688816 & 4.9 & 5.1549 & TRN & \\
\hline CHEMBL1323536 & 688816 & 4.9 & 4.9729 & TRN & \\
\hline CHEMBL1307616 & 688816 & 4.85 & 5.8149 & TRN & \\
\hline CHEMBL1610116 & 688816 & 7.6498 & 5.9325 & TRN & \\
\hline CHEMBL1485571 & 688816 & 4.7 & 5.3709 & TRN & \\
\hline CHEMBL1324156 & 688816 & 5.0 & 5.3905 & TRN & \\
\hline CHEMBL1426942 & 688816 & 4.95 & 5.1171 & TRN & \\
\hline CHEMBL1612831 & 688816 & 5.05 & 5.1837 & TRN & \\
\hline CHEMBL1527200 & 688816 & 4.45 & 5.1505 & TST & \\
\hline CHEMBL3198447 & 688816 & 4.45 & 5.8108 & TST & \\
\hline CHEMBL1333515 & 688816 & 5.2 & 5.0236 & TRN & \\
\hline CHEMBL1464070 & 688816 & 4.75 & 5.0759 & TRN & \\
\hline
\end{tabular}




\begin{tabular}{|c|c|c|c|c|c|}
\hline \multicolumn{6}{|c|}{ Supplemental Table S2.txt } \\
\hline CHEMBL1313625 & 688816 & 4.45 & 5.206 & TST & \\
\hline CHEMBL3211058 & 688816 & 6.7501 & 5.4152 & TRN & \\
\hline CHEMBL1406809 & 688816 & 5.0 & 5.2218 & TRN & \\
\hline CHEMBL1432857 & 688816 & 4.45 & 5.0657 & TRN & \\
\hline CHEMBL 2000196 & 688816 & 4.9 & 5.3 & TRN & \\
\hline CHEMBL1535986 & 688816 & 4.65 & 5.0819 & TRN & \\
\hline CHEMBL3209428 & 688816 & 4.95 & 5.2566 & TST & \\
\hline CHEMBL1540525 & 688816 & 4.45 & 5.4596 & TRN & \\
\hline CHEMBL1401670 & 688816 & 4.95 & 5.4802 & TRN & \\
\hline CHEMBL1605811 & 688816 & 4.9 & 5.1056 & TST & \\
\hline CHEMBL1311255 & 688816 & 4.8 & 5.1965 & TRN & \\
\hline CHEMBL1613054 & 688816 & 4.9 & 4.8241 & TRN & \\
\hline CHEMBL1594696 & 688816 & 5.05 & 5.1731 & TRN & \\
\hline CHEMBL1329031 & 688816 & 4.45 & 5.19 & TRN & \\
\hline CHEMBL1470349 & 688816 & 4.95 & 5.3283 & TRN & \\
\hline CHEMBL1538113 & 688816 & 5.65 & 5.2892 & TRN & \\
\hline CHEMBL1399002 & 688816 & 8.3468 & 5.3402 & TST & \\
\hline CHEMBL1425715 & 688816 & 5.85 & 5.0163 & TRN & \\
\hline CHEMBL1481190 & 688816 & 4.75 & 5.11600 & 20000000005 & TRN \\
\hline CHEMBL1495180 & 688816 & 4.9 & 5.081 & TST & \\
\hline CHEMBL1300843 & 688816 & 5.6 & 5.0332 & TRN & \\
\hline CHEMBL1475937 & 688816 & 4.55 & 5.2003 & TRN & \\
\hline CHEMBL1388200 & 688816 & 6.7501 & 5.6869 & TST & \\
\hline CHEMBL 250450 & 688816 & 6.35 & 5.101 & TRN & \\
\hline CHEMBL1602421 & 688816 & 4.85 & 5.45200 & 2000000001 & TRN \\
\hline CHEMBL1510275 & 688816 & 5.0 & 5.5556 & TRN & \\
\hline CHEMBL1364577 & 688816 & 5.95 & 5.4273 & TRN & \\
\hline CHEMBL1545089 & 688816 & 8.0506 & 5.3528 & TST & \\
\hline CHEMBL1565734 & 688816 & 4.65 & 4.8866 & TRN & \\
\hline CHEMBL3209997 & 688816 & 4.7 & 5.3135 & TRN & \\
\hline CHEMBL1319980 & 688816 & 4.8 & 5.3564 & TRN & \\
\hline CHEMBL1517308 & 688816 & 6.3 & 5.49799 & 9999999999 & TRN \\
\hline CHEMBL1444536 & 688816 & 4.9 & 5.0818 & TRN & \\
\hline CHEMBL1538271 & 688816 & 4.9 & 5.3796 & TST & \\
\hline CHEMBL3196997 & 688816 & 4.95 & 5.0131 & TRN & \\
\hline CHEMBL1431735 & 688816 & 4.45 & 5.5569 & TRN & \\
\hline CHEMBL1579458 & 688816 & 7.4498 & 5.5367 & TST & \\
\hline CHEMBL1415534 & 688816 & 4.8 & 5.3856 & TRN & \\
\hline CHEMBL 1400090 & 688816 & 5.0 & 4.9517 & TRN & \\
\hline CHEMBL1546958 & 688816 & 4.6 & 5.3933 & TST & \\
\hline CHEMBL1599896 & 688816 & 6.8 & 5.7567 & TRN & \\
\hline CHEMBL1508278 & 688816 & 4.7 & 5.0577 & TST & \\
\hline CHEMBL1610090 & 688816 & 4.85 & 5.0328 & TRN & \\
\hline CHEMBL1341284 & 688816 & 4.9 & 5.3946 & TRN & \\
\hline CHEMBL1611106 & 688816 & 4.8 & 5.1296 & TRN & \\
\hline CHEMBL1506578 & 688816 & 5.25 & 5.8628 & TRN & \\
\hline CHEMBL1586489 & 688816 & 5.0 & 4.9556 & TRN & \\
\hline CHEMBL1325673 & 688816 & 5.55 & 4.9212 & TRN & \\
\hline
\end{tabular}




\begin{tabular}{|c|c|c|c|c|c|}
\hline \multicolumn{6}{|c|}{ Supplemental Table S2.txt } \\
\hline CHEMBL1366817 & 688816 & 5.85 & 5.5637 & TST & \\
\hline CHEMBL1539802 & 688816 & 7.2 & 5.3725 & TRN & \\
\hline CHEMBL1569013 & 688816 & 5.0 & 5.4031 & TRN & \\
\hline CHEMBL1574141 & 688816 & 4.9 & 5.1445 & TST & \\
\hline CHEMBL1586581 & 688816 & 5.15 & 5.4761 & TST & \\
\hline CHEMBL1302078 & 688816 & 5.0 & 5.1369 & TST & \\
\hline CHEMBL1383758 & 688816 & 4.9 & 5.0351 & TRN & \\
\hline CHEMBL1563747 & 688816 & 5.6 & 5.1799 & TRN & \\
\hline CHEMBL1441317 & 688816 & 4.95 & 5.3754 & TRN & \\
\hline CHEMBL1992834 & 688816 & 5.4 & 5.4461 & TRN & \\
\hline CHEMBL1379136 & 688816 & 4.8 & 4.8272 & TRN & \\
\hline CHEMBL1594205 & 688816 & 4.75 & 5.3381 & TRN & \\
\hline CHEMBL1569027 & 688816 & 4.9 & 5.3967 & TRN & \\
\hline CHEMBL 2002465 & 688816 & 4.7 & 4.9921 & TRN & \\
\hline CHEMBL1449781 & 688816 & 4.9 & 5.0325 & TRN & \\
\hline CHEMBL1606344 & 688816 & 6.25 & 4.8521 & TRN & \\
\hline CHEMBL1442411 & 688816 & 4.9 & 4.9448 & TRN & \\
\hline CHEMBL1406519 & 688816 & 7.8013 & 6.1136 & TRN & \\
\hline CHEMBL1337345 & 688816 & 4.95 & 5.0534 & TRN & \\
\hline CHEMBL1440341 & 688816 & 4.8 & 5.2975 & TRN & \\
\hline CHEMBL1307769 & 688816 & 5.05 & 4.9847 & TRN & \\
\hline CHEMBL1498167 & 688816 & 5.6 & 5.2277 & TRN & \\
\hline CHEMBL1379816 & 688816 & 4.45 & 4.928 & TRN & \\
\hline CHEMBL1493778 & 688816 & 4.9 & 5.0451 & TRN & \\
\hline CHEMBL1524500 & 688816 & 4.95 & 5.1142 & TRN & \\
\hline CHEMBL1595810 & 688816 & 6.25 & 4.8698 & TRN & \\
\hline CHEMBL1586805 & 688816 & 4.9 & 4.9444 & TST & \\
\hline CHEMBL1365852 & 688816 & 8.4949 & 5.74299 & 9999999999 & TRN \\
\hline CHEMBL1588013 & 688816 & 5.4 & 5.4376 & TRN & \\
\hline CHEMBL1438613 & 688816 & 5.6 & 5.1204 & TRN & \\
\hline CHEMBL1552562 & 688816 & 4.85 & 5.2167 & TRN & \\
\hline CHEMBL1321101 & 688816 & 4.8 & 5.3435 & TRN & \\
\hline CHEMBL3197275 & 688816 & 4.65 & 5.5826 & TRN & \\
\hline CHEMBL1449484 & 688816 & 4.9 & 4.8709 & TRN & \\
\hline CHEMBL1536710 & 688816 & 4.9 & 5.1816 & TRN & \\
\hline CHEMBL1379840 & 688816 & 4.9 & 5.1023 & TRN & \\
\hline CHEMBL1469293 & 688816 & 4.8 & 5.2206 & TRN & \\
\hline CHEMBL1472845 & 688816 & 5.15 & 5.1613 & TRN & \\
\hline CHEMBL460508 & 688816 & 5.5 & 5.1745 & TRN & \\
\hline CHEMBL1980684 & 688816 & 4.45 & 5.4449 & TRN & \\
\hline CHEMBL1450152 & 688816 & 4.9 & 5.4864 & TRN & \\
\hline CHEMBL1426426 & 688816 & 4.45 & 5.5161 & TRN & \\
\hline CHEMBL1469864 & 688816 & 4.75 & 4.9866 & TRN & \\
\hline CHEMBL1353363 & 688816 & 7.8013 & 5.3934 & TRN & \\
\hline CHEMBL3194690 & 688816 & 5.4 & 5.2437 & TRN & \\
\hline CHEMBL1436822 & 688816 & 4.6 & 5.1834 & TST & \\
\hline CHEMBL1432043 & 688816 & 4.45 & 5.0747 & TRN & \\
\hline CHEMBL1503191 & 688816 & 4.55 & 5.2559 & TRN & \\
\hline
\end{tabular}




\begin{tabular}{|c|c|c|c|c|c|}
\hline \multicolumn{6}{|c|}{ Supplemental Table S2.txt } \\
\hline CHEMBL1448956 & 688816 & 5.05 & 5.2114 & TRN & \\
\hline CHEMBL1506065 & 688816 & 5.55 & 5.5073 & TRN & \\
\hline CHEMBL1529126 & 688816 & 4.8 & 5.0007 & TRN & \\
\hline CHEMBL1544552 & 688816 & 5.2 & 5.5754 & TST & \\
\hline CHEMBL1311707 & 688816 & 4.95 & 4.8714 & TST & \\
\hline CHEMBL1452287 & 688816 & 4.45 & 4.7335 & TRN & \\
\hline CHEMBL1353427 & 688816 & 4.95 & 5.0131 & TST & \\
\hline CHEMBL1334407 & 688816 & 5.4 & 5.0275 & TRN & \\
\hline CHEMBL1576514 & 688816 & 4.6 & 4.9631 & TRN & \\
\hline CHEMBL1408002 & 688816 & 4.85 & 4.98600 & 0000000001 & TRN \\
\hline CHEMBL1544192 & 688816 & 4.9 & 4.713 & TRN & \\
\hline CHEMBL3191378 & 688816 & 4.65 & 5.5144 & TRN & \\
\hline CHEMBL1337347 & 688816 & 5.1 & 5.5328 & TRN & \\
\hline CHEMBL1388669 & 688816 & 8.301 & 5.63899 & 9999999999 & TST \\
\hline CHEMBL1375769 & 688816 & 4.95 & 5.039 & TRN & \\
\hline CHEMBL1428580 & 688816 & 5.2 & 5.4253 & TRN & \\
\hline CHEMBL1303038 & 688816 & 4.7 & 5.2097 & TST & \\
\hline CHEMBL1478319 & 688816 & 5.75 & 5.1641 & TRN & \\
\hline CHEMBL1579204 & 688816 & 8.301 & 5.6162 & TST & \\
\hline CHEMBL1518779 & 688816 & 5.25 & 5.7748 & TST & \\
\hline CHEMBL1509790 & 688816 & 4.45 & 5.2031 & TRN & \\
\hline CHEMBL1531935 & 688816 & 4.8 & 5.2425 & TRN & \\
\hline CHEMBL1419766 & 688816 & 4.9 & 5.2417 & TST & \\
\hline CHEMBL1351979 & 688816 & 4.6 & 5.1108 & TRN & \\
\hline CHEMBL1405871 & 688816 & 4.95 & 5.4065 & TRN & \\
\hline CHEMBL1429642 & 688816 & 4.95 & 5.4904 & TRN & \\
\hline CHEMBL1501649 & 688816 & 4.45 & 5.2749 & TRN & \\
\hline CHEMBL1444853 & 688816 & 4.95 & 4.9128 & TRN & \\
\hline CHEMBL1364462 & 688816 & 8.4949 & 5.6298 & TST & \\
\hline CHEMBL1563799 & 688816 & 5.35 & 5.1876 & TRN & \\
\hline CHEMBL1471737 & 688816 & 4.6 & 4.8755 & TRN & \\
\hline CHEMBL1593989 & 688816 & 5.15 & 4.9367 & TRN & \\
\hline CHEMBL1411937 & 688816 & 4.95 & 5.3308 & TRN & \\
\hline CHEMBL1522402 & 688816 & 8.3979 & 5.6555 & TST & \\
\hline CHEMBL3210553 & 688816 & 4.65 & 5.3374 & TST & \\
\hline CHEMBL3856095 & 688816 & 5.35 & 5.2322 & TRN & \\
\hline CHEMBL1517695 & 688816 & 5.35 & 5.1485 & TRN & \\
\hline CHEMBL3209204 & 688816 & 4.75 & 5.3078 & TST & \\
\hline CHEMBL1328677 & 688816 & 4.85 & 5.3789 & TRN & \\
\hline CHEMBL1327373 & 688816 & 4.9 & 5.3506 & TRN & \\
\hline CHEMBL1339038 & 688816 & 4.45 & 5.4438 & TST & \\
\hline CHEMBL1607974 & 688816 & 4.9 & 5.151 & TRN & \\
\hline CHEMBL1484893 & 688816 & 5.15 & 5.4698 & TRN & \\
\hline CHEMBL1365602 & 688816 & 4.65 & 5.2455 & TRN & \\
\hline CHEMBL3213105 & 688816 & 5.4 & 5.3484 & TRN & \\
\hline CHEMBL1471371 & 688816 & 4.45 & 5.0915 & TRN & \\
\hline CHEMBL3194588 & 688816 & 6.5501 & 5.3862 & TRN & \\
\hline CHEMBL1580886 & 688816 & 5.5 & 5.3875 & TRN & \\
\hline
\end{tabular}




\begin{tabular}{|c|c|c|c|c|}
\hline \multicolumn{5}{|c|}{ Supplemental Table S2.txt } \\
\hline CHEMBL1411779 & 688816 & 4.85 & 5.1736 & TRN \\
\hline CHEMBL1458379 & 688816 & 5.25 & 5.1745 & TST \\
\hline CHEMBL1365634 & 688816 & 4.7 & 5.1858 & TST \\
\hline CHEMBL1409926 & 688816 & 5.2 & 5.4986 & TST \\
\hline CHEMBL1587306 & 688816 & 5.25 & 5.6293 & TST \\
\hline CHEMBL1345354 & 688816 & 4.85 & 5.0101 & TRN \\
\hline CHEMBL1503085 & 688816 & 4.45 & 5.1795 & TST \\
\hline CHEMBL1463265 & 688816 & 5.4 & 5.5599 & TRN \\
\hline CHEMBL1328147 & 688816 & 4.85 & 5.249 & TRN \\
\hline CHEMBL1582550 & 688816 & 4.85 & 5.2153 & TRN \\
\hline CHEMBL1322828 & 688816 & 5.1 & 5.0088 & TRN \\
\hline CHEMBL1969851 & 688816 & 4.95 & 5.2487 & TRN \\
\hline CHEMBL1466166 & 688816 & 4.6 & 4.9727 & TRN \\
\hline CHEMBL1343685 & 688816 & 4.9 & 5.4201 & TRN \\
\hline CHEMBL1346055 & 688816 & 7.0 & 5.4221 & TST \\
\hline CHEMBL1361550 & 688816 & 4.8 & 5.0453 & TRN \\
\hline CHEMBL1441868 & 688816 & 4.95 & 5.1511 & TRN \\
\hline CHEMBL1460431 & 688816 & 5.4 & 5.5972 & TST \\
\hline CHEMBL1491467 & 688816 & 4.85 & 5.5185 & TRN \\
\hline CHEMBL1495815 & 688816 & 4.8 & 5.3613 & TRN \\
\hline CHEMBL1423866 & 688816 & 4.85 & 5.0398 & TST \\
\hline CHEMBL1323214 & 688816 & 6.0 & 5.0295 & TRN \\
\hline CHEMBL1604007 & 688816 & 4.55 & 5.1674 & TRN \\
\hline CHEMBL1407195 & 688816 & 4.8 & 5.4253 & TRN \\
\hline CHEMBL1308391 & 688816 & 4.9 & 4.8903 & TRN \\
\hline CHEMBL1580558 & 688816 & 5.05 & 5.2908 & TST \\
\hline CHEMBL1412192 & 688816 & 4.45 & 5.4985 & TRN \\
\hline CHEMBL1610287 & 688816 & 7.6003 & 5.2676 & TST \\
\hline CHEMBL1567814 & 688816 & 4.45 & 5.1408 & TST \\
\hline CHEMBL1576555 & 688816 & 5.0 & 4.6908 & TRN \\
\hline CHEMBL1581602 & 688816 & 8.4949 & 5.4646 & TRN \\
\hline CHEMBL1504572 & 688816 & 4.7 & 5.1381 & TRN \\
\hline CHEMBL567959 & 688816 & 4.85 & 5.0064 & TRN \\
\hline CHEMBL3198433 & 688816 & 4.8 & 5.511 & TST \\
\hline CHEMBL1969893 & 688816 & 4.95 & 5.2261 & TRN \\
\hline CHEMBL1347107 & 688816 & 6.5 & 5.0569 & TST \\
\hline CHEMBL1576175 & 688816 & 4.45 & 5.2753 & TRN \\
\hline CHEMBL1505698 & 688816 & 4.85 & 5.2361 & TST \\
\hline CHEMBL1458819 & 688816 & 4.95 & 5.2353 & TST \\
\hline CHEMBL1419977 & 688816 & 5.25 & 4.7505 & TRN \\
\hline CHEMBL1976834 & 688816 & 4.45 & 5.2578 & TRN \\
\hline CHEMBL1546919 & 688816 & 4.45 & 5.9223 & TRN \\
\hline CHEMBL1460730 & 688816 & 5.3 & 5.6784 & TRN \\
\hline CHEMBL1376674 & 688816 & 6.0 & 5.2465 & TST \\
\hline CHEMBL1500986 & 688816 & 5.7 & 5.5528 & TRN \\
\hline CHEMBL1474015 & 688816 & 5.0 & 5.2677 & TRN \\
\hline CHEMBL1339529 & 688816 & 4.85 & 5.4518 & TST \\
\hline CHEMBL1353392 & 688816 & 5.4 & 5.1231 & TRN \\
\hline
\end{tabular}




\begin{tabular}{|c|c|c|c|c|}
\hline \multicolumn{5}{|c|}{ Supplemental Table S2.txt } \\
\hline CHEMBL 3214164 & 688816 & 5.15 & 5.4871 & TRN \\
\hline CHEMBL1465040 & 688816 & 4.45 & 5.3638 & TRN \\
\hline CHEMBL1334103 & 688816 & 4.85 & 5.1101 & TRN \\
\hline CHEMBL1438515 & 688816 & 4.45 & 5.084 & TRN \\
\hline CHEMBL1460134 & 688816 & 5.6 & 5.1241 & TST \\
\hline CHEMBL1299332 & 688816 & 6.8499 & 5.5989 & TST \\
\hline CHEMBL1571840 & 688816 & 5.95 & 5.2734 & TST \\
\hline CHEMBL1432018 & 688816 & 5.0 & 5.3166 & TRN \\
\hline CHEMBL547924 & 688816 & 4.75 & 4.9718 & TRN \\
\hline CHEMBL1603258 & 688816 & 5.55 & 5.5095 & TST \\
\hline CHEMBL1402596 & 688816 & 4.45 & 5.2496 & TRN \\
\hline CHEMBL1559383 & 688816 & 5.5 & 5.2009 & TST \\
\hline CHEMBL1510118 & 688816 & 4.65 & 5.2342 & TRN \\
\hline CHEMBL1359529 & 688816 & 4.5 & 5.0308 & TRN \\
\hline CHEMBL3195395 & 688816 & 6.6 & 5.2768 & TRN \\
\hline CHEMBL1562679 & 688816 & 6.05 & 5.3287 & TRN \\
\hline CHEMBL1452585 & 688816 & 4.45 & 5.0232 & TST \\
\hline CHEMBL1325065 & 688816 & 4.65 & 5.1378 & TST \\
\hline CHEMBL1517511 & 688816 & 4.45 & 5.3109 & TRN \\
\hline CHEMBL1346440 & 688816 & 7.0501 & 5.2159 & TRN \\
\hline CHEMBL1581627 & 688816 & 5.95 & 5.3072 & TST \\
\hline CHEMBL1484293 & 688816 & 4.9 & 5.3774 & TRN \\
\hline CHEMBL1478525 & 688816 & 5.25 & 4.9323 & TRN \\
\hline CHEMBL1366606 & 688816 & 4.75 & 5.2743 & TRN \\
\hline CHEMBL1421232 & 688816 & 4.95 & 5.1911 & TRN \\
\hline CHEMBL1579602 & 688816 & 4.95 & 5.4916 & TST \\
\hline CHEMBL1529425 & 688816 & 4.7 & 4.8909 & TRN \\
\hline CHEMBL1395953 & 688816 & 4.8 & 4.7674 & TRN \\
\hline CHEMBL1338888 & 688816 & 4.85 & 5.1404 & TRN \\
\hline CHEMBL1329497 & 688816 & 4.8 & 5.1679 & TRN \\
\hline CHEMBL1556239 & 688816 & 5.0 & 5.2681 & TST \\
\hline CHEMBL1612024 & 688816 & 5.5 & 5.4534 & TRN \\
\hline CHEMBL1458061 & 688816 & 5.5 & 5.3867 & TRN \\
\hline CHEMBL1386036 & 688816 & 4.9 & 5.1992 & TRN \\
\hline CHEMBL1595645 & 688816 & 7.699 & 5.1513 & TST \\
\hline CHEMBL1463869 & 688816 & 4.95 & 5.0948 & TRN \\
\hline CHEMBL3207874 & 688816 & 4.8 & 5.4279 & TST \\
\hline CHEMBL1350768 & 688816 & 5.0 & 4.883 & TST \\
\hline CHEMBL1411444 & 688816 & 4.95 & 5.0042 & TRN \\
\hline CHEMBL1449188 & 688816 & 4.9 & 5.3543 & TRN \\
\hline CHEMBL1331045 & 688816 & 4.7 & 5.4365 & TST \\
\hline CHEMBL1409101 & 688816 & 6.0 & 5.2316 & TRN \\
\hline CHEMBL1551012 & 688816 & 4.95 & 5.3911 & TRN \\
\hline CHEMBL1536118 & 688816 & 4.85 & 5.2111 & TRN \\
\hline CHEMBL1438584 & 688816 & 4.75 & 5.5172 & TRN \\
\hline CHEMBL1344944 & 688816 & 5.6 & 5.3276 & TST \\
\hline CHEMBL1510345 & 688816 & 8.0506 & 5.4212 & TRN \\
\hline CHEMBL1408585 & 688816 & 6.8 & 5.3109 & TST \\
\hline
\end{tabular}




\begin{tabular}{|c|c|c|c|c|c|}
\hline \multicolumn{6}{|c|}{ Supplemental Table S2.txt } \\
\hline CHEMBL1460531 & 688816 & 4.9 & 5.1477 & TST & \\
\hline CHEMBL1570017 & 688816 & 4.9 & 5.1708 & TRN & \\
\hline CHEMBL3197649 & 688816 & 4.9 & 5.2078 & TST & \\
\hline CHEMBL1463045 & 688816 & 5.8 & 5.6061 & TST & \\
\hline CHEMBL1570824 & 688816 & 4.65 & 5.0478 & TRN & \\
\hline CHEMBL1605111 & 688816 & 7.1002 & 5.0891 & TRN & \\
\hline CHEMBL1407682 & 688816 & 6.05 & 5.1653 & TRN & \\
\hline CHEMBL1309265 & 688816 & 4.6 & 5.5291 & TRN & \\
\hline CHEMBL1372911 & 688816 & 5.3 & 5.3885 & TRN & \\
\hline CHEMBL1370475 & 688816 & 5.0 & 5.0512 & TRN & \\
\hline CHEMBL1497589 & 688816 & 4.8 & 5.1987 & TRN & \\
\hline CHEMBL1309328 & 688816 & 5.9 & 5.2606 & TST & \\
\hline CHEMBL1438252 & 688816 & 5.0 & 5.7386 & TRN & \\
\hline CHEMBL 3211545 & 688816 & 7.2503 & 5.2897 & TRN & \\
\hline CHEMBL1350014 & 688816 & 6.35 & 5.2324 & TST & \\
\hline CHEMBL1313258 & 688816 & 4.9 & 5.2605 & TRN & \\
\hline CHEMBL1349921 & 688816 & 5.0 & 5.5557 & TRN & \\
\hline CHEMBL1361479 & 688816 & 6.5501 & 5.6324 & TST & \\
\hline CHEMBL1492949 & 688816 & 5.6 & $5.2020 e$ & 0000000001 & TRN \\
\hline CHEMBL 2003806 & 688816 & 4.6 & 5.1597 & TRN & \\
\hline CHEMBL1344958 & 688816 & 4.9 & 5.4127 & TRN & \\
\hline CHEMBL3199520 & 688816 & 5.6 & 5.2815 & TRN & \\
\hline CHEMBL1384832 & 688816 & 4.95 & 5.3159 & TRN & \\
\hline CHEMBL1498271 & 688816 & 5.95 & 5.6115 & TST & \\
\hline CHEMBL1335626 & 688816 & 6.25 & 5.3155 & TST & \\
\hline CHEMBL1590140 & 688816 & 5.5 & 5.3103 & TRN & \\
\hline CHEMBL1337578 & 688816 & 5.25 & 5.4401 & TRN & \\
\hline CHEMBL1418123 & 688816 & 5.35 & 5.8946 & TRN & \\
\hline CHEMBL1385846 & 688816 & 4.8 & 5.5225 & TRN & \\
\hline CHEMBL3212312 & 688816 & 4.85 & 4.8055 & TRN & \\
\hline CHEMBL1364818 & 688816 & 5.3 & 5.2326 & TST & \\
\hline CHEMBL34704 & 688816 & 6.0 & 5.8343 & TST & \\
\hline CHEMBL1468464 & 688816 & 5.25 & 5.0195 & TRN & \\
\hline CHEMBL1533434 & 688816 & 7.2 & 5.541 & TRN & \\
\hline CHEMBL1585513 & 688816 & 4.5 & 5.0398 & TRN & \\
\hline CHEMBL1339245 & 688816 & 4.55 & 5.0957 & TRN & \\
\hline CHEMBL579105 & 688816 & 4.85 & 5.1609 & TRN & \\
\hline CHEMBL1505690 & 688816 & 6.45 & 5.2076 & TRN & \\
\hline CHEMBL1383070 & 688816 & 7.2503 & 5.3084 & TRN & \\
\hline CHEMBL1363473 & 688816 & 4.7 & 5.5351 & TST & \\
\hline CHEMBL1584010 & 688816 & 7.4001 & 5.126 & TRN & \\
\hline CHEMBL3193790 & 688816 & 4.9 & 5.0506 & TRN & \\
\hline CHEMBL1328723 & 688816 & 4.9 & 5.664 & TRN & \\
\hline CHEMBL1463564 & 688816 & 4.8 & 4.7827 & TST & \\
\hline CHEMBL1415528 & 688816 & 5.15 & 5.4691 & TRN & \\
\hline CHEMBL1449651 & 688816 & 4.85 & 5.9806 & TST & \\
\hline CHEMBL1562136 & 688816 & 5.35 & 5.2856 & TRN & \\
\hline CHEMBL580727 & 688816 & 4.9 & 5.2375 & TRN & \\
\hline
\end{tabular}




\begin{tabular}{|c|c|c|c|c|}
\hline \multicolumn{5}{|c|}{ Supplemental Table S2.txt } \\
\hline CHEMBL1575703 & 688816 & 7.5003 & 5.519 & TST \\
\hline CHEMBL1472214 & 688816 & 5.35 & 5.3675 & TST \\
\hline CHEMBL1561235 & 688816 & 4.9 & 5.3708 & TRN \\
\hline CHEMBL1526596 & 688816 & 4.45 & 4.9403 & TRN \\
\hline CHEMBL1599884 & 688816 & 5.0 & 5.9459 & TST \\
\hline CHEMBL1326724 & 688816 & 4.65 & 4.9583 & TRN \\
\hline CHEMBL1535258 & 688816 & 5.45 & 5.4478 & TST \\
\hline CHEMBL3196123 & 688816 & 4.45 & 5.5833 & TRN \\
\hline CHEMBL3196039 & 688816 & 4.65 & 5.0494 & TRN \\
\hline CHEMBL1577816 & 688816 & 7.6003 & 5.0094 & TST \\
\hline CHEMBL 3193425 & 688816 & 4.9 & 5.3662 & TRN \\
\hline CHEMBL1580335 & 688816 & 5.5 & 5.136 & TRN \\
\hline CHEMBL3197463 & 688816 & 4.65 & 5.3774 & TRN \\
\hline CHEMBL3199633 & 688816 & 4.8 & 5.2113 & TRN \\
\hline CHEMBL1608893 & 688816 & 4.8 & 5.2763 & TRN \\
\hline CHEMBL1505083 & 688816 & 4.85 & 5.0403 & TRN \\
\hline CHEMBL1532806 & 688816 & 5.15 & 5.2018 & TRN \\
\hline CHEMBL1405535 & 688816 & 4.65 & 5.579 & TRN \\
\hline CHEMBL1487762 & 688816 & 4.65 & 5.1452 & TRN \\
\hline CHEMBL416984 & 688816 & 7.5498 & 5.8037 & TRN \\
\hline CHEMBL1325529 & 688816 & 5.35 & 5.671 & TRN \\
\hline CHEMBL1569652 & 688816 & 4.95 & 5.2734 & TRN \\
\hline CHEMBL3189498 & 688816 & 5.25 & 5.277 & TRN \\
\hline CHEMBL1391471 & 688816 & 4.9 & 5.4056 & TRN \\
\hline CHEMBL1376325 & 688816 & 5.0 & 5.1231 & TRN \\
\hline CHEMBL1407091 & 688816 & 4.95 & 5.0862 & TRN \\
\hline CHEMBL1985343 & 688816 & 4.65 & 4.9862 & TRN \\
\hline CHEMBL1966108 & 688816 & 4.65 & 5.2543 & TRN \\
\hline CHEMBL1563668 & 688816 & 4.95 & 5.4561 & TRN \\
\hline CHEMBL1372231 & 688816 & 4.75 & 5.0809 & TRN \\
\hline CHEMBL1603092 & 688816 & 4.45 & 5.1568 & TRN \\
\hline CHEMBL1319676 & 688816 & 4.9 & 5.51 & TRN \\
\hline CHEMBL1443552 & 688816 & 4.9 & 5.1084 & TRN \\
\hline CHEMBL1320946 & 688816 & 6.0 & 5.072 & TST \\
\hline CHEMBL1511528 & 688816 & 4.45 & 5.1672 & TST \\
\hline CHEMBL1349863 & 688816 & 5.9 & 5.2127 & TRN \\
\hline CHEMBL1508375 & 688816 & 6.0 & 5.8045 & TRN \\
\hline CHEMBL1601139 & 688816 & 8.3468 & 5.4542 & TRN \\
\hline CHEMBL1399776 & 688816 & 4.75 & 5.3553 & TRN \\
\hline CHEMBL1349088 & 688816 & 5.25 & 5.0374 & TRN \\
\hline CHEMBL1504877 & 688816 & 5.05 & 5.6532 & TRN \\
\hline CHEMBL1461987 & 688816 & 7.3002 & 5.5616 & TRN \\
\hline CHEMBL1402010 & 688816 & 5.55 & 5.415 & TRN \\
\hline CHEMBL1568313 & 688816 & 5.95 & 5.2262 & TRN \\
\hline CHEMBL1371726 & 688816 & 8.3468 & 5.8068 & TRN \\
\hline CHEMBL1528413 & 688816 & 4.8 & 5.1705 & TST \\
\hline CHEMBL1431307 & 688816 & 4.95 & 5.3702 & TST \\
\hline CHEMBL1342220 & 688816 & 8.4559 & 5.6959 & TST \\
\hline
\end{tabular}




\begin{tabular}{|c|c|c|c|c|c|}
\hline \multicolumn{6}{|c|}{ plemental } \\
\hline CHEMBL1559310 & 688816 & 4.8 & 5.0113 & TRN & \\
\hline CHEMBL590422 & 688816 & 5.0 & 5.08 & TRN & \\
\hline CHEMBL1444012 & 688816 & 5.0 & 5.1918 & TRN & \\
\hline CHEMBL1559480 & 688816 & 8.3468 & 5.6042 & TRN & \\
\hline CHEMBL1493490 & 688816 & 5.25 & 5.295 & TRN & \\
\hline CHEMBL1370936 & 688816 & 8.301 & 5.0831 & TST & \\
\hline CHEMBL1609271 & 688816 & 4.9 & 4.9852 & TRN & \\
\hline CHEMBL1372934 & 688816 & 6.45 & 5.4191 & TRN & \\
\hline CHEMBL1332218 & 688816 & 5.25 & 5.3666 & TRN & \\
\hline CHEMBL1595318 & 688816 & 7.6498 & 5.3063 & TST & \\
\hline CHEMBL1569172 & 688816 & 4.9 & 5.2348 & TST & \\
\hline CHEMBL1482957 & 688816 & 4.65 & 5.5542 & TST & \\
\hline CHEMBL1347151 & 688816 & 4.7 & 5.1677 & TRN & \\
\hline CHEMBL1358562 & 688816 & 4.95 & 5.1395 & TRN & \\
\hline CHEMBL1406433 & 688816 & 4.85 & 5.5373 & TRN & \\
\hline CHEMBL1414008 & 688816 & 4.85 & 5.251 & TRN & \\
\hline CHEMBL1358989 & 688816 & 5.1 & 5.0479 & TRN & \\
\hline CHEMBL1299590 & 688816 & 5.4 & 5.6472 & TRN & \\
\hline CHEMBL1323554 & 688816 & 4.6 & 5.4585 & TRN & \\
\hline CHEMBL2359911 & 688816 & 5.3 & 4.8977 & TST & \\
\hline CHEMBL1299760 & 688816 & 4.8 & 5.1259 & TRN & \\
\hline CHEMBL3197338 & 688816 & 4.95 & 5.54799 & 9999999999 & TST \\
\hline CHEMBL1561548 & 688816 & 4.95 & 5.4909 & TRN & \\
\hline CHEMBL235891 & 688816 & 4.8 & 5.0467 & TRN & \\
\hline CHEMBL1425642 & 688816 & 7.4498 & 5.3498 & TST & \\
\hline CHEMBL1471622 & 688816 & 5.45 & 5.2179 & TRN & \\
\hline CHEMBL1430278 & 688816 & 4.6 & 5.3406 & TRN & \\
\hline CHEMBL1980658 & 688816 & 4.7 & 5.2577 & TST & \\
\hline CHEMBL1330965 & 688816 & 4.9 & 5.3805 & TRN & \\
\hline CHEMBL1520833 & 688816 & 4.7 & 4.9049 & TRN & \\
\hline CHEMBL1365756 & 688816 & 8.4949 & 5.5172 & TRN & \\
\hline CHEMBL1367252 & 688816 & 4.95 & 4.7997 & TRN & \\
\hline CHEMBL1387450 & 688816 & 4.95 & 5.2702 & TRN & \\
\hline CHEMBL1469018 & 688816 & 4.9 & 5.3016 & TRN & \\
\hline CHEMBL1439913 & 688816 & 4.75 & 5.3231 & TRN & \\
\hline CHEMBL1516545 & 688816 & 4.65 & 5.345 & TRN & \\
\hline CHEMBL1549253 & 688816 & 5.95 & 5.4024 & TST & \\
\hline CHEMBL1424373 & 688816 & 4.9 & 5.0725 & TRN & \\
\hline CHEMBL1420843 & 688816 & 4.65 & 5.3009 & TRN & \\
\hline CHEMBL1390291 & 688816 & 8.1487 & 5.4462 & TRN & \\
\hline CHEMBL1439294 & 688816 & 4.6 & 5.2195 & TRN & \\
\hline CHEMBL1353075 & 688816 & 4.9 & 5.2103 & TRN & \\
\hline CHEMBL1430076 & 688816 & 5.35 & 5.3793 & TST & \\
\hline CHEMBL1301129 & 688816 & 4.85 & 5.0119 & TRN & \\
\hline CHEMBL1418081 & 688816 & 4.95 & 5.0625 & TRN & \\
\hline CHEMBL1408509 & 688816 & 6.6 & 5.49100 & 00000000005 & TST \\
\hline CHEMBL1400948 & 688816 & 4.85 & 5.1576 & TRN & \\
\hline CHEMBL1348536 & 688816 & 5.45 & 5.092 & TST & \\
\hline
\end{tabular}




\begin{tabular}{|c|c|c|c|c|c|}
\hline \multicolumn{6}{|c|}{ Supplemental Table S2.txt } \\
\hline CHEMBL1430221 & 688816 & 4.75 & 5.2063 & TRN & \\
\hline CHEMBL1463756 & 688816 & 5.15 & 5.9098 & TST & \\
\hline CHEMBL1453959 & 688816 & 4.8 & 5.0583 & TRN & \\
\hline CHEMBL1428664 & 688816 & 5.0 & 5.0736 & TST & \\
\hline CHEMBL1464153 & 688816 & 4.95 & 5.2607 & TRN & \\
\hline CHEMBL1417174 & 688816 & 4.85 & 5.4357 & TRN & \\
\hline CHEMBL1607041 & 688816 & 6.8 & 5.4178 & TRN & \\
\hline CHEMBL1495691 & 688816 & 4.45 & 5.1012 & TRN & \\
\hline CHEMBL1383324 & 688816 & 4.9 & 5.2093 & TRN & \\
\hline CHEMBL1457192 & 688816 & 4.9 & 5.0213 & TRN & \\
\hline CHEMBL1432008 & 688816 & 4.95 & 4.8403 & TRN & \\
\hline CHEMBL3207939 & 688816 & 4.7 & 5.2021 & TRN & \\
\hline CHEMBL1549440 & 688816 & 6.25 & 5.5356 & TST & \\
\hline CHEMBL 2007318 & 688816 & 4.45 & 5.1212 & TRN & \\
\hline CHEMBL1603884 & 688816 & 5.5 & 5.4926 & TST & \\
\hline CHEMBL1505696 & 688816 & 5.8 & 5.5631 & TST & \\
\hline CHEMBL1557359 & 688816 & 5.25 & 5.7575 & TRN & \\
\hline CHEMBL1335916 & 688816 & 5.3 & 5.0613 & TRN & \\
\hline CHEMBL1469733 & 688816 & 4.9 & 5.2419 & TRN & \\
\hline CHEMBL1500910 & 688816 & 4.85 & 5.3612 & TRN & \\
\hline CHEMBL1515953 & 688816 & 4.45 & 5.2321 & TRN & \\
\hline CHEMBL1542554 & 688816 & 7.5003 & 5.2568 & TRN & \\
\hline CHEMBL1327510 & 688816 & 5.15 & 5.4115 & TRN & \\
\hline CHEMBL1382028 & 688816 & 5.75 & 5.2352 & TRN & \\
\hline CHEMBL1606172 & 688816 & 5.0 & 5.0944 & TRN & \\
\hline CHEMBL1426187 & 688816 & 4.8 & 5.2896 & TST & \\
\hline CHEMBL1611715 & 688816 & 4.65 & 5.4992 & TST & \\
\hline CHEMBL1523400 & 688816 & 4.95 & 5.4059 & TRN & \\
\hline CHEMBL1481289 & 688816 & 6.7501 & 5.3283 & TRN & \\
\hline CHEMBL1595047 & 688816 & 4.95 & 5.0129 & TRN & \\
\hline CHEMBL1531059 & 688816 & 4.65 & 5.4491 & TRN & \\
\hline CHEMBL1566824 & 688816 & 5.95 & 5.6533 & TRN & \\
\hline CHEMBL1992346 & 688816 & 5.25 & 5.3136 & TRN & \\
\hline CHEMBL1569227 & 688816 & 5.35 & 5.4012 & TRN & \\
\hline CHEMBL1362720 & 688816 & 5.0 & 5.2384 & TRN & \\
\hline CHEMBL1565369 & 688816 & 4.9 & 4.901 & TRN & \\
\hline CHEMBL1404152 & 688816 & 5.25 & 5.4714 & TRN & \\
\hline CHEMBL1329592 & 688816 & 8.4559 & 5.37299 & э999999999 & TRN \\
\hline CHEMBL1600546 & 688816 & 4.8 & 5.1762 & TRN & \\
\hline CHEMBL1410712 & 688816 & 4.7 & 5.0134 & TRN & \\
\hline CHEMBL1597416 & 688816 & 4.65 & 5.3323 & TRN & \\
\hline CHEMBL3190576 & 688816 & 8.301 & 5.3563 & TST & \\
\hline CHEMBL1588024 & 688816 & 4.85 & 4.9596 & TRN & \\
\hline CHEMBL1353771 & 688816 & 4.6 & 4.8952 & TRN & \\
\hline CHEMBL1478930 & 688816 & 4.85 & 4.9474 & TRN & \\
\hline CHEMBL1546310 & 688816 & 5.3 & 5.0172 & TST & \\
\hline CHEMBL1302365 & 688816 & 4.9 & 5.3109 & TST & \\
\hline CHEMBL1442010 & 688816 & 4.85 & 5.0952 & TRN & \\
\hline
\end{tabular}




\begin{tabular}{|c|c|c|c|c|}
\hline \multicolumn{5}{|c|}{ Supplemental Table S2.txt } \\
\hline CHEMBL1487582 & 688816 & 4.9 & 4.8726 & TRN \\
\hline CHEMBL1513639 & 688816 & 4.95 & 5.4762 & TRN \\
\hline CHEMBL1461318 & 688816 & 4.7 & 5.1271 & TRN \\
\hline CHEMBL1525949 & 688816 & 8.301 & 5.3414 & TST \\
\hline CHEMBL1350573 & 688816 & 6.05 & 5.3153 & TST \\
\hline CHEMBL1488905 & 688816 & 4.7 & 5.6044 & TST \\
\hline CHEMBL1348405 & 688816 & 7.5003 & 5.0341 & TRN \\
\hline CHEMBL1575613 & 688816 & 4.45 & 5.0683 & TRN \\
\hline CHEMBL1425409 & 688816 & 4.95 & 5.3081 & TST \\
\hline CHEMBL1530090 & 688816 & 5.55 & 5.2505 & TRN \\
\hline CHEMBL1467996 & 688816 & 7.6498 & 5.6385 & TRN \\
\hline CHEMBL1600820 & 688816 & 5.1 & 6.0557 & TST \\
\hline CHEMBL1485014 & 688816 & 4.95 & 5.1592 & TST \\
\hline CHEMBL1479662 & 688816 & 6.8 & 5.6024 & TST \\
\hline CHEMBL3194330 & 688816 & 4.6 & 5.5226 & TST \\
\hline CHEMBL1433068 & 688816 & 5.8 & 5.3595 & TRN \\
\hline CHEMBL1499843 & 688816 & 4.95 & 5.2737 & TRN \\
\hline CHEMBL1412108 & 688816 & 4.8 & 5.0173 & TRN \\
\hline CHEMBL1304031 & 688816 & 5.0 & 4.9207 & TRN \\
\hline CHEMBL1401384 & 688816 & 5.1 & 5.2297 & TRN \\
\hline CHEMBL1432223 & 688816 & 4.9 & 5.2273 & TST \\
\hline CHEMBL1332377 & 688816 & 4.95 & 5.3804 & TRN \\
\hline CHEMBL1344025 & 688816 & 5.1 & 4.9021 & TRN \\
\hline CHEMBL170458 & 688816 & 4.85 & 5.6061 & TST \\
\hline CHEMBL1582895 & 688816 & 5.55 & 5.6485 & TRN \\
\hline CHEMBL1536459 & 688816 & 5.05 & 5.2927 & TRN \\
\hline CHEMBL1455421 & 688816 & 5.15 & 5.1089 & TRN \\
\hline CHEMBL1300080 & 688816 & 4.45 & 4.9095 & TRN \\
\hline CHEMBL1508158 & 688816 & 4.55 & 5.0762 & TRN \\
\hline CHEMBL1566875 & 688816 & 6.25 & 5.4358 & TRN \\
\hline CHEMBL1310213 & 688816 & 4.45 & 5.6502 & TRN \\
\hline CHEMBL1460414 & 688816 & 5.05 & 5.3083 & TRN \\
\hline CHEMBL1363291 & 688816 & 4.8 & 4.8065 & TRN \\
\hline CHEMBL1472147 & 688816 & 4.45 & 5.2568 & TRN \\
\hline CHEMBL1448016 & 688816 & 8.301 & 5.4332 & TRN \\
\hline CHEMBL1600755 & 688816 & 6.3 & 5.3821 & TRN \\
\hline CHEMBL1213769 & 688816 & 5.55 & 5.1334 & TRN \\
\hline CHEMBL 3212280 & 688816 & 5.2 & 5.4917 & TRN \\
\hline CHEMBL1375169 & 688816 & 4.9 & 5.3649 & TRN \\
\hline CHEMBL1312377 & 688816 & 8.3468 & 5.1396 & TST \\
\hline CHEMBL1545518 & 688816 & 4.45 & 5.391 & TRN \\
\hline CHEMBL1344814 & 688816 & 4.65 & 4.9407 & TRN \\
\hline CHEMBL1349899 & 688816 & 4.95 & 4.9925 & TRN \\
\hline CHEMBL1331867 & 688816 & 6.95 & 5.3529 & TST \\
\hline CHEMBL1493141 & 688816 & 5.25 & 4.9946 & TRN \\
\hline CHEMBL1467982 & 688816 & 4.9 & 5.6173 & TST \\
\hline CHEMBL1324496 & 688816 & 5.15 & 5.2179 & TRN \\
\hline CHEMBL1410115 & 688816 & 5.15 & 5.6157 & TRN \\
\hline
\end{tabular}




\begin{tabular}{|c|c|c|c|c|c|}
\hline & & \multicolumn{4}{|c|}{ Supplemental Table S2.txt } \\
\hline CHEMBL1605584 & 688816 & 7.6003 & 5.6794 & TRN & \\
\hline CHEMBL1301654 & 688816 & 8.5528 & 5.5269 & TST & \\
\hline CHEMBL1329672 & 688816 & 5.0 & 5.28100 & 0000000001 & TRN \\
\hline CHEMBL1417099 & 688816 & 5.65 & 5.1272 & TST & \\
\hline CHEMBL1482951 & 688816 & 5.55 & 5.3077 & TRN & \\
\hline CHEMBL1526597 & 688816 & 4.8 & 5.3031 & TRN & \\
\hline CHEMBL1417999 & 688816 & 5.15 & 4.9854 & TRN & \\
\hline CHEMBL1604166 & 688816 & 5.0 & 5.4218 & TRN & \\
\hline CHEMBL1511035 & 688816 & 5.0 & 5.7632 & TRN & \\
\hline CHEMBL1569483 & 688816 & 5.25 & 5.3235 & TRN & \\
\hline CHEMBL1436059 & 688816 & 4.8 & 5.0815 & TRN & \\
\hline CHEMBL1522664 & 688816 & 5.25 & 5.7905 & TRN & \\
\hline CHEMBL1373513 & 688816 & 6.5501 & 5.718 & TRN & \\
\hline CHEMBL1579599 & 688816 & 5.7 & 5.1165 & TRN & \\
\hline CHEMBL1324181 & 688816 & 4.45 & 5.8115 & TST & \\
\hline CHEMBL3196156 & 688816 & 6.1 & 5.5673 & TRN & \\
\hline CHEMBL602997 & 688816 & 4.45 & 5.3956 & TRN & \\
\hline CHEMBL1516442 & 688816 & 5.25 & 5.3455 & TST & \\
\hline CHEMBL1562871 & 688816 & 5.15 & 5.1312 & TRN & \\
\hline CHEMBL1440937 & 688816 & 4.95 & 5.4705 & TST & \\
\hline CHEMBL1432918 & 688816 & 5.45 & 5.315 & TRN & \\
\hline CHEMBL1342894 & 688816 & 5.9 & 5.2005 & TST & \\
\hline CHEMBL1509409 & 688816 & 4.9 & 5.311 & TRN & \\
\hline CHEMBL1552300 & 688816 & 4.9 & 4.9603 & TRN & \\
\hline CHEMBL1324727 & 688816 & 5.45 & 4.8804 & TST & \\
\hline CHEMBL398765 & 688816 & 4.6 & 4.9366 & TRN & \\
\hline CHEMBL533226 & 688816 & 5.5 & 5.1609 & TRN & \\
\hline CHEMBL1367627 & 688816 & 6.35 & 5.3816 & TST & \\
\hline CHEMBL1510974 & 688816 & 4.95 & 5.2188 & TRN & \\
\hline CHEMBL1517458 & 688816 & 8.0506 & 5.4745 & TST & \\
\hline CHEMBL1391158 & 688816 & 6.45 & 5.4599 & TRN & \\
\hline CHEMBL1990825 & 688816 & 4.95 & 5.1611 & TRN & \\
\hline CHEMBL1466438 & 688816 & 6.5501 & 5.5886 & TRN & \\
\hline CHEMBL1567776 & 688816 & 4.5 & 5.4857 & TRN & \\
\hline CHEMBL3194964 & 688816 & 5.45 & 5.0457 & TRN & \\
\hline CHEMBL1367316 & 688816 & 4.8 & 5.2134 & TST & \\
\hline CHEMBL1314849 & 688816 & 5.25 & 5.4347 & TRN & \\
\hline CHEMBL3196441 & 688816 & 4.5 & 5.5133 & TRN & \\
\hline CHEMBL 1457410 & 688816 & 4.9 & 4.7842 & TRN & \\
\hline CHEMBL1299744 & 688816 & 5.05 & 5.6977 & TRN & \\
\hline CHEMBL1583900 & 688816 & 4.8 & 5.7337 & TST & \\
\hline CHEMBL1527570 & 688816 & 4.95 & 5.3613 & TRN & \\
\hline CHEMBL1474458 & 688816 & 4.5 & 4.7856 & TRN & \\
\hline CHEMBL1541016 & 688816 & 4.45 & 4.9615 & TRN & \\
\hline CHEMBL1585564 & 688816 & 4.45 & 5.5311 & TST & \\
\hline CHEMBL1425027 & 688816 & 5.0 & 5.3638 & TRN & \\
\hline CHEMBL1299883 & 688816 & 4.95 & 5.5785 & TRN & \\
\hline CHEMBL1439833 & 688816 & 5.0 & 5.079 & TRN & \\
\hline
\end{tabular}




\begin{tabular}{|c|c|c|c|c|c|}
\hline \multicolumn{6}{|c|}{ Supplemental Table S2.txt } \\
\hline CHEMBL1492652 & 688816 & 5.05 & 5.1576 & TRN & \\
\hline CHEMBL1316106 & 688816 & 4.5 & 5.2927 & TRN & \\
\hline CHEMBL3192922 & 688816 & 4.8 & 5.3752 & TRN & \\
\hline CHEMBL1570521 & 688816 & 5.5 & 5.2002 & TRN & \\
\hline CHEMBL1471345 & 688816 & 5.8 & 5.2724 & TRN & \\
\hline CHEMBL1494996 & 688816 & 4.85 & 4.9725 & TST & \\
\hline CHEMBL1331549 & 688816 & 5.0 & 5.25799 & 9999999999 & TRN \\
\hline CHEMBL1419053 & 688816 & 5.3 & 5.206 & TRN & \\
\hline CHEMBL1572746 & 688816 & 4.45 & 5.4773 & TRN & \\
\hline CHEMBL1331024 & 688816 & 8.1487 & 5.6169 & TRN & \\
\hline CHEMBL1393899 & 688816 & 4.95 & 5.3549 & TRN & \\
\hline CHEMBL600968 & 688816 & 4.95 & 5.0247 & TRN & \\
\hline CHEMBL1573279 & 688816 & 4.45 & 5.1273 & TRN & \\
\hline CHEMBL1601449 & 688816 & 4.9 & 5.1594 & TRN & \\
\hline CHEMBL1531166 & 688816 & 6.95 & 5.3621 & TRN & \\
\hline CHEMBL1515929 & 688816 & 5.15 & 5.3122 & TRN & \\
\hline CHEMBL1440699 & 688816 & 4.9 & 5.1733 & TRN & \\
\hline CHEMBL1486974 & 688816 & 4.95 & 5.2674 & TRN & \\
\hline CHEMBL1368012 & 688816 & 6.25 & 5.6147 & TRN & \\
\hline CHEMBL1514089 & 688816 & 5.8 & 5.0541 & TRN & \\
\hline CHEMBL1482764 & 688816 & 4.55 & 5.0528 & TRN & \\
\hline CHEMBL1985629 & 688816 & 4.95 & 5.2465 & TST & \\
\hline CHEMBL1352938 & 688816 & 8.301 & 5.0326 & TST & \\
\hline CHEMBL1613234 & 688816 & 5.55 & 4.9807 & TRN & \\
\hline CHEMBL1467977 & 688816 & 5.05 & 5.1667 & TRN & \\
\hline CHEMBL3189357 & 688816 & 4.95 & 5.4684 & TRN & \\
\hline CHEMBL1587162 & 688816 & 4.95 & 5.4781 & TRN & \\
\hline CHEMBL1307407 & 688816 & 4.85 & 5.38299 & 9999999999 & TRN \\
\hline CHEMBL1320821 & 688816 & 7.6498 & 5.9169 & TST & \\
\hline CHEMBL1422349 & 688816 & 4.6 & 4.9433 & TRN & \\
\hline CHEMBL1401522 & 688816 & 5.5 & 5.0341 & TST & \\
\hline CHEMBL1534915 & 688816 & 5.15 & 5.4625 & TRN & \\
\hline CHEMBL1401808 & 688816 & 4.65 & 5.5832 & TRN & \\
\hline CHEMBL1581364 & 688816 & 4.8 & 5.3019 & TRN & \\
\hline CHEMBL1385983 & 688816 & 4.45 & 4.9386 & TRN & \\
\hline CHEMBL1393739 & 688816 & 5.05 & 5.2781 & TRN & \\
\hline CHEMBL1542384 & 688816 & 4.95 & 5.3524 & TST & \\
\hline CHEMBL1565792 & 688816 & 4.55 & 5.0951 & TRN & \\
\hline CHEMBL1385251 & 688816 & 4.45 & 5.1422 & TRN & \\
\hline CHEMBL 1481195 & 688816 & 8.3468 & 6.0302 & TRN & \\
\hline CHEMBL1561521 & 688816 & 7.5003 & 5.16 & TST & \\
\hline CHEMBL1510390 & 688816 & 6.25 & 5.1481 & TRN & \\
\hline CHEMBL 1485549 & 688816 & 4.9 & 5.0951 & TRN & \\
\hline CHEMBL1098658 & 688816 & 4.85 & 5.2673 & TRN & \\
\hline CHEMBL1597352 & 688816 & 4.55 & 5.0812 & TRN & \\
\hline CHEMBL1526670 & 688816 & 4.9 & 5.2546 & TRN & \\
\hline CHEMBL1518592 & 688816 & 5.1 & 5.2268 & TRN & \\
\hline CHEMBL3191201 & 688816 & 7.5498 & 5.5936 & TRN & \\
\hline
\end{tabular}

Page 25095 


\begin{tabular}{|c|c|c|c|c|c|}
\hline \multirow[b]{2}{*}{ CHEMBL1309999 } & \multicolumn{5}{|c|}{ Supplemental Table S2.txt } \\
\hline & 688816 & 7.3002 & 5.2526 & TRN & \\
\hline CHEMBL1471916 & 688816 & 4.9 & 5.1207 & TRN & \\
\hline CHEMBL1393189 & 688816 & 4.6 & 5.1704 & TRN & \\
\hline CHEMBL1531521 & 688816 & 4.9 & 4.7744 & TRN & \\
\hline CHEMBL1539680 & 688816 & 5.95 & 5.1874 & TRN & \\
\hline CHEMBL1600351 & 688816 & 4.5 & 5.3105 & TRN & \\
\hline CHEMBL1370897 & 688816 & 4.95 & 5.1917 & TRN & \\
\hline CHEMBL1551341 & 688816 & 4.8 & 5.1334 & TRN & \\
\hline CHEMBL1560747 & 688816 & 5.35 & 4.982 & TRN & \\
\hline CHEMBL1430573 & 688816 & 5.05 & 5.2762 & TRN & \\
\hline CHEMBL1563900 & 688816 & 4.9 & 5.2478 & TST & \\
\hline CHEMBL1428695 & 688816 & 4.45 & 5.3474 & TST & \\
\hline CHEMBL1309731 & 688816 & 4.9 & 5.1574 & TST & \\
\hline CHEMBL1529108 & 688816 & 5.45 & 5.4489 & TRN & \\
\hline CHEMBL1589667 & 688816 & 4.95 & 5.4071 & TST & \\
\hline CHEMBL1460194 & 688816 & 4.9 & 4.9721 & TRN & \\
\hline CHEMBL1524207 & 688816 & 5.95 & 5.2563 & TRN & \\
\hline CHEMBL1443732 & 688816 & 7.0501 & 5.1423 & TST & \\
\hline CHEMBL1612219 & 688816 & 4.45 & 5.0333 & TRN & \\
\hline CHEMBL600908 & 688816 & 4.85 & 5.0655 & TRN & \\
\hline CHEMBL1408789 & 688816 & 4.95 & 5.2843 & TRN & \\
\hline CHEMBL1415244 & 688816 & 5.7 & 5.3784 & TST & \\
\hline CHEMBL1415437 & 688816 & 5.1 & 5.313 & TST & \\
\hline CHEMBL1446096 & 688816 & 4.45 & 5.1013 & TRN & \\
\hline CHEMBL1500987 & 688816 & 4.5 & 5.641 & TST & \\
\hline CHEMBL113142 & 688816 & 5.0 & 4.996 & TST & \\
\hline CHEMBL1438102 & 688816 & 5.9 & 5.4118 & TRN & \\
\hline CHEMBL1408926 & 688816 & 6.05 & 5.2124 & TRN & \\
\hline CHEMBL1370317 & 688816 & 4.9 & 5.4093 & TST & \\
\hline CHEMBL1581174 & 688816 & 4.95 & 5.7079 & TRN & \\
\hline CHEMBL1360891 & 688816 & 5.0 & 5.51399 & 9999999999 & TRN \\
\hline CHEMBL1603566 & 688816 & 5.25 & 5.1624 & TRN & \\
\hline CHEMBL1972129 & 688816 & 7.699 & 5.2479 & TRN & \\
\hline CHEMBL 2004144 & 688816 & 4.45 & 5.1372 & TRN & \\
\hline CHEMBL1399432 & 688816 & 4.95 & 5.3129 & TRN & \\
\hline CHEMBL1447186 & 688816 & 4.9 & 4.9154 & TRN & \\
\hline CHEMBL123810 & 688816 & 5.0 & 5.4194 & TST & \\
\hline CHEMBL1511894 & 688816 & 8.0 & 5.2915 & TRN & \\
\hline CHEMBL1353847 & 688816 & 5.6 & 5.3197 & TRN & \\
\hline CHEMBL1530018 & 688816 & 5.05 & 4.8745 & TRN & \\
\hline CHEMBL3193056 & 688816 & 5.0 & 5.3765 & TST & \\
\hline CHEMBL1416948 & 688816 & 5.1 & 5.6017 & TRN & \\
\hline CHEMBL1380894 & 688816 & 4.95 & 5.2064 & TRN & \\
\hline CHEMBL1613469 & 688816 & 4.75 & 5.0397 & TRN & \\
\hline CHEMBL3213436 & 688816 & 4.9 & 5.1814 & TRN & \\
\hline CHEMBL1343552 & 688816 & 4.7 & 5.2004 & TRN & \\
\hline CHEMBL1365395 & 688816 & 4.95 & 5.2045 & TRN & \\
\hline CHEMBL1583939 & 688816 & 8.301 & 5.1051 & TST & \\
\hline
\end{tabular}




\begin{tabular}{|c|c|c|c|c|}
\hline \multicolumn{5}{|c|}{ Supplemental Table S2.txt } \\
\hline CHEMBL1338744 & 688816 & 5.0 & 5.1544 & TRN \\
\hline CHEMBL 394171 & 688816 & 6.9 & 5.7259 & TRN \\
\hline CHEMBL1503325 & 688816 & 4.6 & 4.9373 & TST \\
\hline CHEMBL1604351 & 688816 & 7.0 & 5.56 & TST \\
\hline CHEMBL1348663 & 688816 & 4.5 & 5.3611 & TRN \\
\hline CHEMBL1518557 & 688816 & 4.45 & 5.2654 & TST \\
\hline CHEMBL1306383 & 688816 & 4.45 & 5.1743 & TRN \\
\hline CHEMBL1588639 & 688816 & 5.25 & 5.2625 & TRN \\
\hline CHEMBL1458940 & 688816 & 4.95 & 5.2338 & TRN \\
\hline CHEMBL1479133 & 688816 & 4.7 & 5.2176 & TRN \\
\hline CHEMBL1544703 & 688816 & 5.05 & 4.8574 & TRN \\
\hline CHEMBL1375207 & 688816 & 4.45 & 5.279 & TST \\
\hline CHEMBL1587117 & 688816 & 7.5003 & 5.8647 & TRN \\
\hline CHEMBL1508182 & 688816 & 5.55 & 5.0066 & TST \\
\hline CHEMBL1475164 & 688816 & 4.45 & 5.1557 & TRN \\
\hline CHEMBL1372765 & 688816 & 6.35 & 5.4065 & TRN \\
\hline CHEMBL1472334 & 688816 & 4.55 & 5.4625 & TRN \\
\hline CHEMBL1529539 & 688816 & 5.55 & 5.715 & TST \\
\hline CHEMBL1538545 & 688816 & 5.55 & 5.5549 & TRN \\
\hline CHEMBL1446095 & 688816 & 4.65 & 5.1131 & TST \\
\hline CHEMBL1422803 & 688816 & 4.9 & 5.4359 & TST \\
\hline CHEMBL1449266 & 688816 & 4.95 & 5.0411 & TRN \\
\hline CHEMBL1566034 & 688816 & 4.85 & 5.421 & TST \\
\hline CHEMBL1505328 & 688816 & 4.95 & 5.2524 & TRN \\
\hline CHEMBL 1607780 & 688816 & 4.55 & 5.4294 & TRN \\
\hline CHEMBL1472168 & 688816 & 4.45 & 4.8861 & TRN \\
\hline CHEMBL1525590 & 688816 & 4.95 & 5.0689 & TST \\
\hline CHEMBL1601032 & 688816 & 4.85 & 5.1854 & TRN \\
\hline CHEMBL1349344 & 688816 & 4.9 & 5.1889 & TST \\
\hline CHEMBL 3197060 & 688816 & 4.7 & 5.775 & TST \\
\hline CHEMBL1437726 & 688816 & 5.75 & 5.2158 & TRN \\
\hline CHEMBL1971634 & 688816 & 5.05 & 5.234 & TRN \\
\hline CHEMBL1445640 & 688816 & 7.5003 & 5.104 & TRN \\
\hline CHEMBL509256 & 688816 & 4.7 & 4.904 & TRN \\
\hline CHEMBL1479506 & 688816 & 4.95 & 5.0749 & TRN \\
\hline CHEMBL1497004 & 688816 & 4.45 & 4.8859 & TRN \\
\hline CHEMBL1449333 & 688816 & 4.85 & 5.0372 & TRN \\
\hline CHEMBL1547139 & 688816 & 4.85 & 5.4869 & TST \\
\hline CHEMBL1581431 & 688816 & 4.95 & 5.2393 & TRN \\
\hline CHEMBL1343776 & 688816 & 4.45 & 5.7878 & TRN \\
\hline CHEMBL1539216 & 688816 & 4.95 & 5.586 & TRN \\
\hline CHEMBL1333605 & 688816 & 6.5 & 5.6206 & TST \\
\hline CHEMBL1359102 & 688816 & 5.05 & 5.2181 & TRN \\
\hline CHEMBL1366058 & 688816 & 4.45 & 4.831 & TRN \\
\hline CHEMBL1481212 & 688816 & 6.0 & 5.8253 & TRN \\
\hline CHEMBL1567682 & 688816 & 4.8 & 5.0923 & TRN \\
\hline CHEMBL 1577420 & 688816 & 4.95 & 5.2151 & TRN \\
\hline CHEMBL1457902 & 688816 & 5.3 & 4.9577 & TRN \\
\hline
\end{tabular}




\begin{tabular}{|c|c|c|c|c|}
\hline \multicolumn{5}{|c|}{ Supplemental Table S2.txt } \\
\hline CHEMBL1426203 & 688816 & 5.3 & 5.5391 & TRN \\
\hline CHEMBL 3194247 & 688816 & 4.65 & 5.3433 & TRN \\
\hline CHEMBL1459157 & 688816 & 4.8 & 5.0133 & TRN \\
\hline CHEMBL1535988 & 688816 & 4.95 & 5.3645 & TRN \\
\hline CHEMBL1337495 & 688816 & 4.95 & 5.4981 & TRN \\
\hline CHEMBL1531805 & 688816 & 4.9 & 4.9072 & TRN \\
\hline CHEMBL1534466 & 688816 & 4.85 & 5.2596 & TRN \\
\hline CHEMBL1344481 & 688816 & 4.45 & 5.3022 & TRN \\
\hline CHEMBL1565863 & 688816 & 4.9 & 5.2299 & TRN \\
\hline CHEMBL1405122 & 688816 & 6.6 & 5.8359 & TST \\
\hline CHEMBL1588806 & 688816 & 5.0 & 5.2554 & TRN \\
\hline CHEMBL1992631 & 688816 & 4.45 & 5.2267 & TST \\
\hline CHEMBL1505921 & 688816 & 4.8 & 5.0103 & TRN \\
\hline CHEMBL1315394 & 688816 & 4.5 & 5.3016 & TRN \\
\hline CHEMBL1397552 & 688816 & 4.7 & 5.4161 & TRN \\
\hline CHEMBL1505014 & 688816 & 5.5 & 5.2484 & TST \\
\hline CHEMBL1299363 & 688816 & 4.9 & 5.0682 & TST \\
\hline CHEMBL1550119 & 688816 & 5.4 & 5.5506 & TST \\
\hline CHEMBL1532208 & 688816 & 4.8 & 5.3263 & TST \\
\hline CHEMBL1367503 & 688816 & 8.301 & 5.7571 & TRN \\
\hline CHEMBL1580933 & 688816 & 6.5 & 5.4601 & TST \\
\hline CHEMBL1508248 & 688816 & 4.95 & 5.5422 & TST \\
\hline CHEMBL1491944 & 688816 & 5.35 & 5.2003 & TRN \\
\hline CHEMBL1350496 & 688816 & 4.85 & 5.1264 & TRN \\
\hline CHEMBL1344407 & 688816 & 6.95 & 5.5794 & TST \\
\hline CHEMBL1384060 & 688816 & 4.75 & 5.2213 & TST \\
\hline CHEMBL1350128 & 688816 & 5.25 & 5.2552 & TRN \\
\hline CHEMBL1438333 & 688816 & 4.8 & 5.3415 & TRN \\
\hline CHEMBL1556088 & 688816 & 5.35 & 5.4601 & TRN \\
\hline CHEMBL1471561 & 688816 & 4.8 & 5.3698 & TST \\
\hline CHEMBL1367385 & 688816 & 5.0 & 5.4214 & TST \\
\hline CHEMBL585081 & 688816 & 4.7 & 4.9238 & TRN \\
\hline CHEMBL490592 & 688816 & 4.9 & 5.2457 & TRN \\
\hline CHEMBL1469709 & 688816 & 5.1 & 5.3433 & TRN \\
\hline CHEMBL1384484 & 688816 & 4.45 & 5.4553 & TRN \\
\hline CHEMBL1502264 & 688816 & 4.75 & 5.5328 & TST \\
\hline CHEMBL1302726 & 688816 & 4.8 & 5.5579 & TRN \\
\hline CHEMBL1312460 & 688816 & 4.8 & 5.5977 & TRN \\
\hline CHEMBL1538754 & 688816 & 5.95 & 5.2497 & TRN \\
\hline CHEMBL1379100 & 688816 & 5.0 & 5.2096 & TRN \\
\hline CHEMBL3209869 & 688816 & 6.95 & 5.2836 & TST \\
\hline CHEMBL 1605720 & 688816 & 5.2 & 5.7005 & TST \\
\hline CHEMBL1610927 & 688816 & 6.25 & 5.9776 & TRN \\
\hline CHEMBL1409253 & 688816 & 5.15 & 5.499 & TRN \\
\hline CHEMBL1452937 & 688816 & 5.0 & 5.2156 & TRN \\
\hline CHEMBL1431440 & 688816 & 4.5 & 5.0525 & TRN \\
\hline CHEMBL1374958 & 688816 & 5.75 & 4.9987 & TRN \\
\hline CHEMBL1332390 & 688816 & 4.45 & 5.1496 & TST \\
\hline
\end{tabular}




\begin{tabular}{|c|c|c|c|c|}
\hline \multicolumn{5}{|c|}{ Supplemental Table S2.txt } \\
\hline CHEMBL1425035 & 688816 & 4.45 & 4.7038 & TRN \\
\hline CHEMBL1327831 & 688816 & 4.45 & 5.4038 & TRN \\
\hline CHEMBL1439768 & 688816 & 4.85 & 5.4041 & TRN \\
\hline CHEMBL2369304 & 688816 & 4.95 & 5.4922 & TRN \\
\hline CHEMBL1497808 & 688816 & 5.45 & 5.2959 & TRN \\
\hline CHEMBL1343671 & 688816 & 4.9 & 5.352 & TRN \\
\hline CHEMBL1613713 & 688816 & 4.8 & 5.2787 & TST \\
\hline CHEMBL1341614 & 688816 & 7.3002 & 5.6307 & TRN \\
\hline CHEMBL 2000517 & 688816 & 4.9 & 5.2427 & TRN \\
\hline CHEMBL1502703 & 688816 & 6.7501 & 5.3496 & TST \\
\hline CHEMBL1977877 & 688816 & 5.5 & 5.3079 & TST \\
\hline CHEMBL1582794 & 688816 & 5.55 & 4.9519 & TRN \\
\hline CHEMBL1597544 & 688816 & 4.9 & 5.465 & TRN \\
\hline CHEMBL1387819 & 688816 & 6.8 & 5.2508 & TRN \\
\hline CHEMBL1545554 & 688816 & 5.05 & 5.2407 & TST \\
\hline CHEMBL1482113 & 688816 & 8.1024 & 5.3487 & TRN \\
\hline CHEMBL201039 & 688816 & 6.15 & 5.641 & TRN \\
\hline CHEMBL1482341 & 688816 & 4.95 & 5.5538 & TRN \\
\hline CHEMBL1557514 & 688816 & 4.6 & 5.1254 & TRN \\
\hline CHEMBL1451112 & 688816 & 4.95 & 5.1961 & TRN \\
\hline CHEMBL1504983 & 688816 & 4.7 & 5.3887 & TRN \\
\hline CHEMBL1468354 & 688816 & 5.45 & 5.1964 & TRN \\
\hline CHEMBL3194382 & 688816 & 6.8 & 5.5501 & TRN \\
\hline CHEMBL1353081 & 688816 & 4.65 & 5.1339 & TRN \\
\hline CHEMBL1325328 & 688816 & 4.65 & 5.6639 & TST \\
\hline CHEMBL3212500 & 688816 & 5.9 & 5.4437 & TRN \\
\hline CHEMBL1356402 & 688816 & 5.9 & 5.7499 & TRN \\
\hline CHEMBL1465191 & 688816 & 5.4 & 4.7609 & TRN \\
\hline CHEMBL1365982 & 688816 & 4.85 & 5.3836 & TRN \\
\hline CHEMBL1428859 & 688816 & 4.95 & 5.1177 & TRN \\
\hline CHEMBL1499849 & 688816 & 5.45 & 5.4371 & TRN \\
\hline CHEMBL1567720 & 688816 & 5.1 & 5.2873 & TST \\
\hline CHEMBL1443649 & 688816 & 4.8 & 4.8934 & TRN \\
\hline CHEMBL3199470 & 688816 & 4.45 & 5.4519 & TRN \\
\hline CHEMBL1470146 & 688816 & 4.85 & 4.8677 & TRN \\
\hline CHEMBL1573642 & 688816 & 5.45 & 5.0896 & TST \\
\hline CHEMBL 1585082 & 688816 & 5.25 & 5.3563 & TST \\
\hline CHEMBL1536406 & 688816 & 4.75 & 4.901 & TRN \\
\hline CHEMBL1370379 & 688816 & 4.8 & 5.4721 & TST \\
\hline CHEMBL1471258 & 688816 & 4.95 & 5.3503 & TRN \\
\hline CHEMBL302449 & 688816 & 5.3 & 5.3846 & TST \\
\hline CHEMBL1481775 & 688816 & 4.45 & 5.2525 & TRN \\
\hline CHEMBL1478439 & 688816 & 4.85 & 5.2002 & TRN \\
\hline CHEMBL1526045 & 688816 & 4.45 & 5.4159 & TRN \\
\hline CHEMBL1499671 & 688816 & 4.5 & 4.8318 & TRN \\
\hline CHEMBL1409352 & 688816 & 4.75 & 5.1268 & TRN \\
\hline CHEMBL1390775 & 688816 & 4.95 & 5.3664 & TRN \\
\hline CHEMBL1367811 & 688816 & 5.25 & 5.0601 & TRN \\
\hline
\end{tabular}




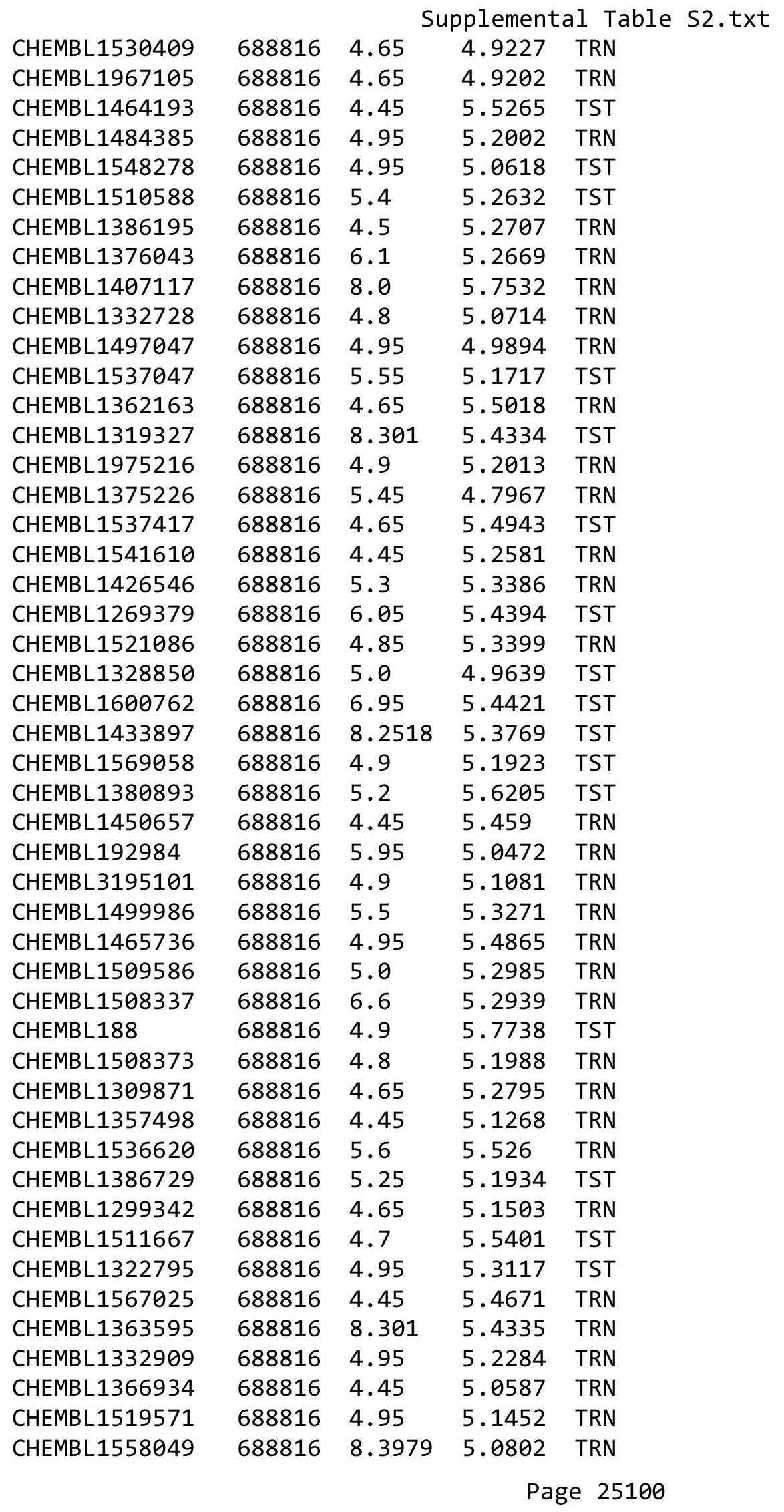




\begin{tabular}{|c|c|c|c|c|c|}
\hline \multicolumn{6}{|c|}{ Supplemental Table S2.txt } \\
\hline CHEMBL1332111 & 688816 & 5.1 & 4.8944 & TRN & \\
\hline CHEMBL1450935 & 688816 & 4.45 & 5.5443 & TRN & \\
\hline CHEMBL1464424 & 688816 & 5.8 & 5.3424 & TRN & \\
\hline CHEMBL1385759 & 688816 & 4.55 & 5.6226 & TRN & \\
\hline CHEMBL3191691 & 688816 & 5.1 & 4.9962 & TST & \\
\hline CHEMBL1331076 & 688816 & 5.6 & 5.0907 & TRN & \\
\hline CHEMBL1301860 & 688816 & 7.6498 & 5.6826 & TRN & \\
\hline CHEMBL1372039 & 688816 & 5.9 & 5.2356 & TRN & \\
\hline CHEMBL1532181 & 688816 & 4.45 & 5.2328 & TRN & \\
\hline CHEMBL1607807 & 688816 & 8.4559 & 5.3162 & TRN & \\
\hline CHEMBL 3213770 & 688816 & 5.05 & 5.0726 & TRN & \\
\hline CHEMBL1455593 & 688816 & 7.3497 & 5.4218 & TST & \\
\hline CHEMBL1424857 & 688816 & 4.55 & 5.5704 & TST & \\
\hline CHEMBL1972519 & 688816 & 5.45 & 5.3507 & TRN & \\
\hline CHEMBL1482782 & 688816 & 8.3468 & 4.973 & TRN & \\
\hline CHEMBL1566191 & 688816 & 4.95 & 5.2381 & TRN & \\
\hline CHEMBL1304256 & 688816 & 5.15 & 5.1208 & TRN & \\
\hline CHEMBL 3213180 & 688816 & 5.25 & 5.3163 & TST & \\
\hline CHEMBL1317435 & 688816 & 4.6 & 5.2902 & TRN & \\
\hline CHEMBL1231644 & 688816 & 4.65 & 5.8685 & TST & \\
\hline CHEMBL1376426 & 688816 & 5.0 & 5.2444 & TRN & \\
\hline CHEMBL1468171 & 688816 & 5.0 & 5.3858 & TRN & \\
\hline CHEMBL1341869 & 688816 & 4.95 & 5.2477 & TRN & \\
\hline CHEMBL1506665 & 688816 & 5.05 & 5.2521 & TRN & \\
\hline CHEMBL1556924 & 688816 & 5.0 & 5.5554 & TST & \\
\hline CHEMBL1417974 & 688816 & 4.75 & 5.3234 & TRN & \\
\hline CHEMBL1530705 & 688816 & 4.65 & 5.1076 & TRN & \\
\hline CHEMBL1595193 & 688816 & 4.6 & 5.2429 & TRN & \\
\hline CHEMBL1565819 & 688816 & 4.85 & 5.0322 & TST & \\
\hline CHEMBL1466205 & 688816 & 5.55 & 5.4966 & TST & \\
\hline CHEMBL1595352 & 688816 & 4.9 & 5.2399 & TRN & \\
\hline CHEMBL16312 & 688816 & 5.0 & 5.1236 & TRN & \\
\hline CHEMBL1410988 & 688816 & 4.6 & 5.2494 & TRN & \\
\hline CHEMBL1502956 & 688816 & 4.8 & 4.9505 & TRN & \\
\hline CHEMBL1444064 & 688816 & 4.8 & 5.3066 & TRN & \\
\hline CHEMBL8747 & 688816 & 4.65 & 5.3369 & TST & \\
\hline CHEMBL3207361 & 688816 & 4.45 & 6.1041 & TRN & \\
\hline CHEMBL1410733 & 688816 & 4.95 & 5.0583 & TST & \\
\hline CHEMBL1480560 & 688816 & 4.6 & 4.9811 & TRN & \\
\hline CHEMBL3195983 & 688816 & 4.45 & 4.9538 & TRN & \\
\hline CHEMBL1605238 & 688816 & 4.9 & 5.1303 & TRN & \\
\hline CHEMBL1392812 & 688816 & 4.9 & 5.2918 & TRN & \\
\hline CHEMBL1317923 & 688816 & 6.8 & 5.1264 & TRN & \\
\hline CHEMBL1596341 & 688816 & 5.25 & 5.5228 & TST & \\
\hline CHEMBL1312727 & 688816 & 4.75 & $5.1620 e$ & 0000000001 & TRN \\
\hline CHEMBL1490268 & 688816 & 4.75 & 5.3717 & TRN & \\
\hline CHEMBL1304478 & 688816 & 5.0 & 4.8451 & TRN & \\
\hline CHEMBL1527076 & 688816 & 4.9 & 5.4495 & TRN & \\
\hline
\end{tabular}




\begin{tabular}{|c|c|c|c|c|c|}
\hline \multicolumn{6}{|c|}{ Supplemental Table S2.txt } \\
\hline CHEMBL1411997 & 688816 & 5.1 & 5.3851 & TRN & \\
\hline CHEMBL3192415 & 688816 & 6.25 & 5.278 & TRN & \\
\hline CHEMBL3213663 & 688816 & 4.8 & 5.3336 & TRN & \\
\hline CHEMBL3209405 & 688816 & 5.45 & 5.3525 & TST & \\
\hline CHEMBL1524798 & 688816 & 5.8 & 5.2885 & TST & \\
\hline CHEMBL1583293 & 688816 & 4.8 & 4.9435 & TST & \\
\hline CHEMBL1464631 & 688816 & 4.8 & 5.3747 & TRN & \\
\hline CHEMBL 3189377 & 688816 & 6.5501 & 5.3535 & TRN & \\
\hline CHEMBL1366818 & 688816 & 4.9 & 5.0284 & TRN & \\
\hline CHEMBL1495966 & 688816 & 4.7 & 5.0047 & TRN & \\
\hline CHEMBL1479550 & 688816 & 4.95 & 5.1935 & TST & \\
\hline CHEMBL1550290 & 688816 & 5.05 & 5.0446 & TRN & \\
\hline CHEMBL1382966 & 688816 & 7.6003 & 5.2385 & TRN & \\
\hline CHEMBL1427421 & 688816 & 4.75 & 5.0675 & TRN & \\
\hline CHEMBL 3198034 & 688816 & 5.05 & 5.2655 & TRN & \\
\hline CHEMBL1490081 & 688816 & 4.8 & 5.5561 & TST & \\
\hline CHEMBL1339823 & 688816 & 5.5 & 5.6854 & TST & \\
\hline CHEMBL3211613 & 688816 & 4.75 & 5.5561 & TRN & \\
\hline CHEMBL3210983 & 688816 & 6.5 & 5.5167 & TRN & \\
\hline CHEMBL1538859 & 688816 & 8.301 & 5.4131 & TRN & \\
\hline CHEMBL1544989 & 688816 & 5.05 & 4.7801 & TRN & \\
\hline CHEMBL1405911 & 688816 & 8.2518 & 5.1698 & TST & \\
\hline CHEMBL 3192670 & 688816 & 4.75 & 4.9637 & TRN & \\
\hline CHEMBL1418786 & 688816 & 4.8 & 5.1695 & TRN & \\
\hline CHEMBL1604526 & 688816 & 6.2 & 5.72 & TRN & \\
\hline CHEMBL3191763 & 688816 & 4.45 & 5.36299 & 99999999995 & TRN \\
\hline CHEMBL3210540 & 688816 & 5.3 & 5.3886 & TRN & \\
\hline CHEMBL1506096 & 688816 & 4.7 & 5.1159 & TST & \\
\hline CHEMBL1307371 & 688816 & 4.45 & 5.0327 & TRN & \\
\hline CHEMBL1321885 & 688816 & 4.8 & 5.0438 & TRN & \\
\hline CHEMBL1508068 & 688816 & 5.3 & 5.2919 & TRN & \\
\hline CHEMBL1576787 & 688816 & 4.8 & 4.8882 & TRN & \\
\hline CHEMBL1971324 & 688816 & 5.4 & 5.2069 & TRN & \\
\hline CHEMBL3199401 & 688816 & 5.1 & 5.0253 & TRN & \\
\hline CHEMBL1471958 & 688816 & 7.3497 & 5.3719 & TRN & \\
\hline CHEMBL1388127 & 688816 & 4.95 & 5.4518 & TST & \\
\hline CHEMBL1454798 & 688816 & 5.1 & 5.0873 & TRN & \\
\hline CHEMBL1559930 & 688816 & 5.15 & 5.0367 & TRN & \\
\hline CHEMBL1553346 & 688816 & 5.2 & 4.6015 & TRN & \\
\hline CHEMBL3198581 & 688816 & 4.45 & 4.9084 & TRN & \\
\hline CHEMBL1302493 & 688816 & 4.9 & 5.4786 & TST & \\
\hline CHEMBL1373167 & 688816 & 4.9 & 4.7371 & TRN & \\
\hline CHEMBL1429893 & 688816 & 4.7 & 5.6795 & TRN & \\
\hline CHEMBL1310822 & 688816 & 4.75 & 5.345 & TRN & \\
\hline CHEMBL1339883 & 688816 & 4.95 & 5.4976 & TRN & \\
\hline CHEMBL1369899 & 688816 & 5.1 & 5.0335 & TRN & \\
\hline CHEMBL1487784 & 688816 & 4.45 & 5.1154 & TRN & \\
\hline CHEMBL1479386 & 688816 & 4.9 & 5.4314 & TRN & \\
\hline
\end{tabular}




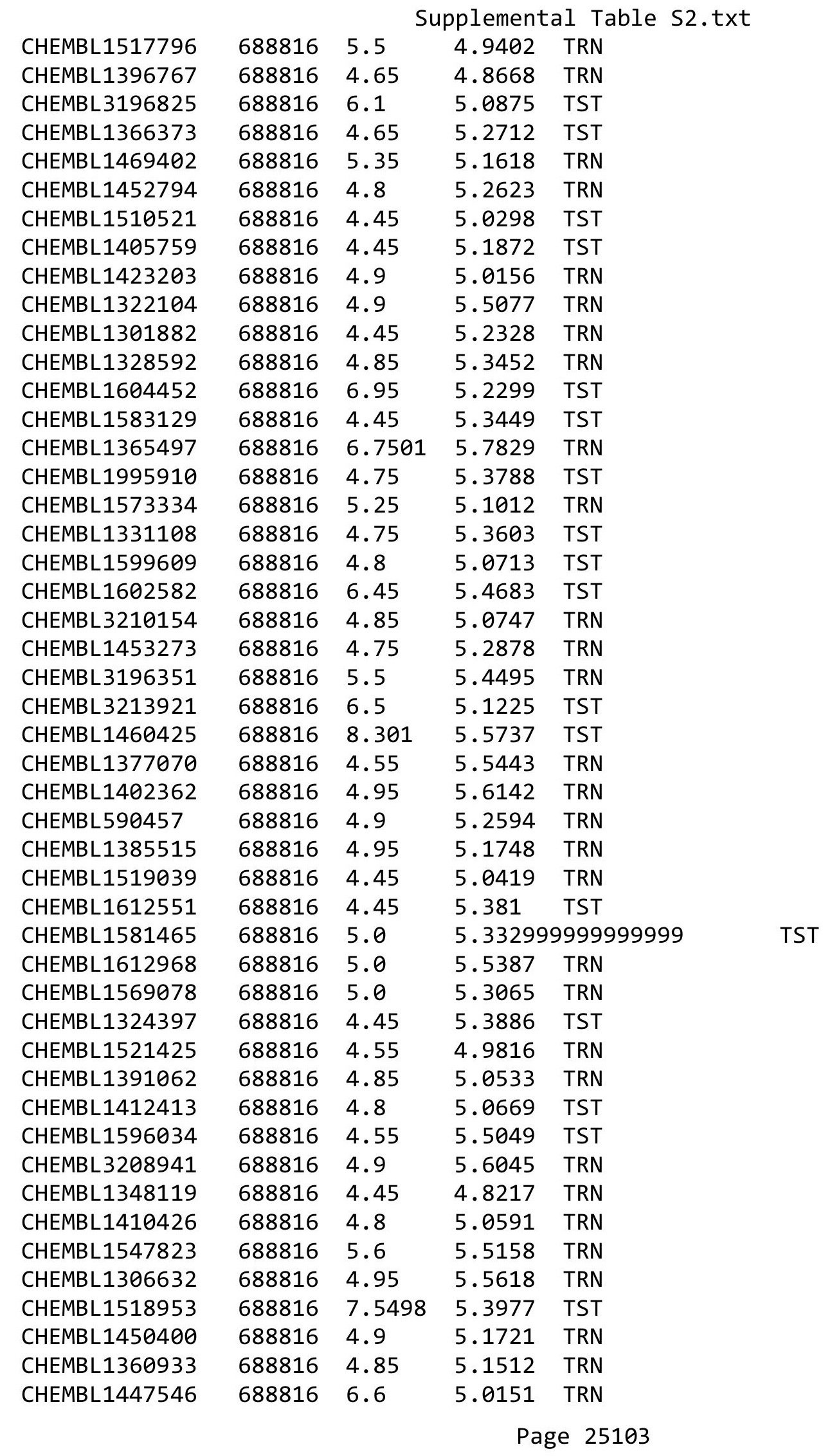




\begin{tabular}{|c|c|c|c|c|c|}
\hline \multicolumn{6}{|c|}{ Supplemental Table S2.txt } \\
\hline CHEMBL1410919 & 688816 & 5.25 & 5.5253 & TRN & \\
\hline CHEMBL1556254 & 688816 & 4.9 & 5.0877 & TRN & \\
\hline CHEMBL1335250 & 688816 & 5.0 & 5.1605 & TRN & \\
\hline CHEMBL1544137 & 688816 & 6.0 & 5.0128 & TRN & \\
\hline CHEMBL1525530 & 688816 & 4.8 & 4.83899 & 99999999995 & TRN \\
\hline CHEMBL1575558 & 688816 & 4.6 & 5.6044 & TRN & \\
\hline CHEMBL1507328 & 688816 & 4.95 & 5.1044 & TRN & \\
\hline CHEMBL1425678 & 688816 & 4.95 & 5.2965 & TRN & \\
\hline CHEMBL1363915 & 688816 & 4.95 & 4.9996 & TRN & \\
\hline CHEMBL1588982 & 688816 & 5.0 & 5.1988 & TRN & \\
\hline CHEMBL1310458 & 688816 & 4.95 & 5.2133 & TRN & \\
\hline CHEMBL3192954 & 688816 & 4.8 & 5.0964 & TRN & \\
\hline CHEMBL1519425 & 688816 & 4.55 & 5.6184 & TRN & \\
\hline CHEMBL1404393 & 688816 & 5.1 & 5.1842 & TRN & \\
\hline CHEMBL1310857 & 688816 & 4.9 & 4.6269 & TST & \\
\hline CHEMBL1352766 & 688816 & 4.45 & 5.4216 & TRN & \\
\hline CHEMBL1380763 & 688816 & 4.9 & 5.0939 & TRN & \\
\hline CHEMBL1409915 & 688816 & 5.0 & 5.5579 & TRN & \\
\hline CHEMBL1570736 & 688816 & 6.45 & 4.9062 & TRN & \\
\hline CHEMBL1583459 & 688816 & 4.9 & 5.4131 & TRN & \\
\hline CHEMBL1531165 & 688816 & 4.45 & 5.2141 & TST & \\
\hline CHEMBL1571273 & 688816 & 6.6 & 5.1569 & TRN & \\
\hline CHEMBL1458762 & 688816 & 5.3 & 5.4778 & TST & \\
\hline CHEMBL1537659 & 688816 & 4.95 & 4.7843 & TRN & \\
\hline CHEMBL1406051 & 688816 & 8.1024 & 5.2408 & TST & \\
\hline CHEMBL1526755 & 688816 & 4.5 & 5.0246 & TST & \\
\hline CHEMBL1440781 & 688816 & 5.8 & 5.4217 & TRN & \\
\hline CHEMBL 1600056 & 688816 & 4.85 & 5.4634 & TRN & \\
\hline CHEMBL1367980 & 688816 & 4.95 & 5.2855 & TRN & \\
\hline CHEMBL1314856 & 688816 & 5.7 & 5.6599 & TRN & \\
\hline CHEMBL1542928 & 688816 & 4.9 & 5.2988 & TRN & \\
\hline CHEMBL1529534 & 688816 & 4.45 & 5.36 & TRN & \\
\hline CHEMBL1364651 & 688816 & 4.95 & 5.851 & TRN & \\
\hline CHEMBL1452049 & 688816 & 5.4 & 4.8829 & TRN & \\
\hline CHEMBL1374291 & 688816 & 4.9 & 5.3809 & TST & \\
\hline CHEMBL1507655 & 688816 & 4.9 & 4.8507 & TRN & \\
\hline CHEMBL1308547 & 688816 & 5.65 & 5.4407 & TRN & \\
\hline CHEMBL1346383 & 688816 & 4.9 & 5.3735 & TRN & \\
\hline CHEMBL1514122 & 688816 & 4.75 & 5.7863 & TRN & \\
\hline CHEMBL1344409 & 688816 & 4.5 & 5.2535 & TRN & \\
\hline CHEMBL1462582 & 688816 & 4.45 & 5.0924 & TST & \\
\hline CHEMBL 1507410 & 688816 & 4.75 & 4.9745 & TRN & \\
\hline CHEMBL1464273 & 688816 & 5.0 & 5.4489 & TST & \\
\hline CHEMBL1303553 & 688816 & 5.6 & 5.4127 & TRN & \\
\hline CHEMBL1342916 & 688816 & 4.45 & 5.0319 & TRN & \\
\hline CHEMBL1613465 & 688816 & 5.6 & 5.3868 & TRN & \\
\hline CHEMBL 1385323 & 688816 & 4.95 & 5.4366 & TST & \\
\hline CHEMBL1481665 & 688816 & 6.5 & 5.2635 & TST & \\
\hline
\end{tabular}




\begin{tabular}{|c|c|c|c|c|c|}
\hline \multicolumn{6}{|c|}{ Supplemental Table S2.txt } \\
\hline CHEMBL1523955 & 688816 & 5.7 & 5.4939 & TRN & \\
\hline CHEMBL1340715 & 688816 & 5.6 & 5.657 & TRN & \\
\hline CHEMBL1256624 & 688816 & 4.45 & 5.6254 & TST & \\
\hline CHEMBL1996068 & 688816 & 5.65 & 5.1157 & TST & \\
\hline CHEMBL1385132 & 688816 & 5.35 & 5.0483 & TRN & \\
\hline CHEMBL3207627 & 688816 & 4.9 & 5.355 & TRN & \\
\hline CHEMBL1583165 & 688816 & 5.4 & 5.2094 & TRN & \\
\hline CHEMBL1548043 & 688816 & 4.95 & 5.2977 & TST & \\
\hline CHEMBL1556184 & 688816 & 4.9 & 4.7809 & TRN & \\
\hline CHEMBL1569653 & 688816 & 5.0 & 5.1623 & TRN & \\
\hline CHEMBL1417724 & 688816 & 4.95 & 5.0269 & TST & \\
\hline CHEMBL1556615 & 688816 & 4.95 & 5.24799 & 9999999999 & TRN \\
\hline CHEMBL1379163 & 688816 & 8.301 & 4.9201 & TRN & \\
\hline CHEMBL1506496 & 688816 & 4.7 & 5.0762 & TRN & \\
\hline CHEMBL1442546 & 688816 & 4.95 & 5.0754 & TRN & \\
\hline CHEMBL1389634 & 688816 & 4.95 & 5.6123 & TRN & \\
\hline CHEMBL1330474 & 688816 & 4.85 & 5.478 & TST & \\
\hline CHEMBL1528776 & 688816 & 4.75 & 5.5136 & TRN & \\
\hline CHEMBL1318310 & 688816 & 4.95 & 5.0 & TRN & \\
\hline CHEMBL1381673 & 688816 & 4.45 & 5.1629 & TRN & \\
\hline CHEMBL1509314 & 688816 & 4.75 & 4.7704 & TRN & \\
\hline CHEMBL1484186 & 688816 & 5.25 & 5.3291 & TST & \\
\hline CHEMBL1431428 & 688816 & 8.3468 & 5.8609 & TRN & \\
\hline CHEMBL1378446 & 688816 & 4.45 & 5.341 & TRN & \\
\hline CHEMBL591836 & 688816 & 4.9 & 5.8568 & TRN & \\
\hline CHEMBL1558379 & 688816 & 5.0 & 5.1663 & TRN & \\
\hline CHEMBL1497588 & 688816 & 4.65 & 4.9359 & TRN & \\
\hline CHEMBL1562198 & 688816 & 6.7501 & 5.6617 & TRN & \\
\hline CHEMBL1584480 & 688816 & 4.65 & 5.4197 & TST & \\
\hline CHEMBL1301479 & 688816 & 4.8 & 5.2513 & TST & \\
\hline CHEMBL1403568 & 688816 & 4.45 & 5.1959 & TRN & \\
\hline CHEMBL1599290 & 688816 & 5.8 & 5.794 & TRN & \\
\hline CHEMBL1466429 & 688816 & 5.05 & 5.6039 & TRN & \\
\hline CHEMBL1497856 & 688816 & 4.45 & 5.2507 & TST & \\
\hline CHEMBL1400481 & 688816 & 4.9 & 5.2474 & TST & \\
\hline CHEMBL1310814 & 688816 & 4.8 & 5.7521 & TST & \\
\hline CHEMBL1721937 & 688816 & 4.45 & 5.0816 & TRN & \\
\hline CHEMBL1359326 & 688816 & 5.3 & 4.8969 & TRN & \\
\hline CHEMBL1376922 & 688816 & 4.85 & 5.2115 & TRN & \\
\hline CHEMBL1607691 & 688816 & 4.85 & 5.5217 & TST & \\
\hline CHEMBL1345300 & 688816 & 4.9 & 5.3105 & TRN & \\
\hline CHEMBL1331006 & 688816 & 4.45 & 5.4064 & TRN & \\
\hline CHEMBL1414078 & 688816 & 4.95 & 5.1638 & TRN & \\
\hline CHEMBL1359652 & 688816 & 5.8 & 5.37299 & 9999999999 & TRN \\
\hline CHEMBL1432305 & 688816 & 5.85 & 5.3542 & TRN & \\
\hline CHEMBL1417341 & 688816 & 4.9 & 5.0369 & TRN & \\
\hline CHEMBL1415361 & 688816 & 5.0 & 5.5911 & TST & \\
\hline CHEMBL1467225 & 688816 & 5.0 & 5.1243 & TRN & \\
\hline
\end{tabular}




\begin{tabular}{|c|c|c|c|c|}
\hline \multicolumn{5}{|c|}{ Supplemental Table S2.txt } \\
\hline CHEMBL1350195 & 688816 & 4.9 & 5.3139 & TRN \\
\hline CHEMBL1361685 & 688816 & 5.0 & 5.2161 & TRN \\
\hline CHEMBL1330405 & 688816 & 4.65 & 5.3701 & TRN \\
\hline CHEMBL1367493 & 688816 & 4.75 & 5.4194 & TRN \\
\hline CHEMBL1552344 & 688816 & 4.95 & 5.218 & TST \\
\hline CHEMBL1342441 & 688816 & 5.1 & 5.2671 & TRN \\
\hline CHEMBL1415430 & 688816 & 4.45 & 5.4483 & TST \\
\hline CHEMBL1383022 & 688816 & 5.15 & 5.4078 & TRN \\
\hline CHEMBL581225 & 688816 & 4.95 & 5.6258 & TST \\
\hline CHEMBL1383992 & 688816 & 5.05 & 5.051 & TRN \\
\hline CHEMBL1478021 & 688816 & 5.15 & 5.2584 & TRN \\
\hline CHEMBL1344863 & 688816 & 6.1 & 5.1501 & TST \\
\hline CHEMBL1574031 & 688816 & 8.0 & 4.8309 & TST \\
\hline CHEMBL1440510 & 688816 & 4.5 & 5.6348 & TRN \\
\hline CHEMBL1486310 & 688816 & 5.9 & 5.6816 & TST \\
\hline CHEMBL1376596 & 688816 & 4.55 & 5.3418 & TRN \\
\hline CHEMBL1351117 & 688816 & 5.45 & 5.0419 & TRN \\
\hline CHEMBL1603319 & 688816 & 4.45 & 5.3225 & TST \\
\hline CHEMBL1517141 & 688816 & 5.15 & 5.2948 & TRN \\
\hline CHEMBL1461878 & 688816 & 4.5 & 5.0772 & TRN \\
\hline CHEMBL1964573 & 688816 & 4.75 & 5.2411 & TRN \\
\hline CHEMBL1304499 & 688816 & 5.05 & 4.9503 & TRN \\
\hline CHEMBL1607973 & 688816 & 4.95 & 5.0972 & TRN \\
\hline CHEMBL1352810 & 688816 & 4.95 & 5.1898 & TRN \\
\hline CHEMBL1360667 & 688816 & 4.6 & 5.5084 & TRN \\
\hline CHEMBL 2007403 & 688816 & 4.9 & 5.2631 & TRN \\
\hline CHEMBL1504758 & 688816 & 4.85 & 5.246 & TRN \\
\hline CHEMBL1339230 & 688816 & 4.9 & 4.8485 & TRN \\
\hline CHEMBL1418821 & 688816 & 4.95 & 5.278 & TRN \\
\hline CHEMBL1337624 & 688816 & 4.95 & 5.3052 & TRN \\
\hline CHEMBL1567121 & 688816 & 5.45 & 5.4832 & TST \\
\hline CHEMBL1327494 & 688816 & 4.9 & 5.0354 & TRN \\
\hline CHEMBL1492896 & 688816 & 4.9 & 5.0632 & TRN \\
\hline CHEMBL1611858 & 688816 & 5.3 & 4.8391 & TRN \\
\hline CHEMBL3193941 & 688816 & 4.95 & 5.1843 & TRN \\
\hline CHEMBL1519165 & 688816 & 5.0 & 5.0414 & TST \\
\hline CHEMBL1488364 & 688816 & 4.8 & 5.4717 & TST \\
\hline CHEMBL1501720 & 688816 & 5.2 & 5.4335 & TRN \\
\hline CHEMBL1392992 & 688816 & 4.7 & 5.0394 & TST \\
\hline CHEMBL1443977 & 688816 & 4.95 & 5.2872 & TRN \\
\hline CHEMBL143703 & 688816 & 4.85 & 5.1119 & TRN \\
\hline CHEMBL1462318 & 688816 & 4.85 & 5.3098 & TRN \\
\hline CHEMBL1607708 & 688816 & 5.6 & 5.4456 & TST \\
\hline CHEMBL1468355 & 688816 & 6.3 & 5.5056 & TRN \\
\hline CHEMBL1603779 & 688816 & 4.65 & 5.0688 & TRN \\
\hline CHEMBL1455739 & 688816 & 7.5498 & 5.3242 & TST \\
\hline CHEMBL1312852 & 688816 & 5.25 & 5.5276 & TST \\
\hline CHEMBL1382229 & 688816 & 4.95 & 5.0175 & TRN \\
\hline
\end{tabular}




\begin{tabular}{|c|c|c|c|c|c|}
\hline \multicolumn{6}{|c|}{ Supplemental Table S2.txt } \\
\hline CHEMBL1586472 & 688816 & 4.7 & 4.8315 & TRN & \\
\hline CHEMBL1404783 & 688816 & 7.4001 & 5.4521 & TST & \\
\hline CHEMBL1398809 & 688816 & 4.45 & 5.0701 & TRN & \\
\hline CHEMBL1382564 & 688816 & 4.75 & 5.1932 & TRN & \\
\hline CHEMBL1508938 & 688816 & 4.8 & 5.3943 & TRN & \\
\hline CHEMBL1587591 & 688816 & 6.5 & 5.519 & TRN & \\
\hline CHEMBL1532425 & 688816 & 5.5 & 5.0771 & TRN & \\
\hline CHEMBL1503282 & 688816 & 7.6498 & 5.0662 & TRN & \\
\hline CHEMBL1580757 & 688816 & 4.85 & 4.996 & TRN & \\
\hline CHEMBL1493981 & 688816 & 4.6 & 5.1956 & TRN & \\
\hline CHEMBL1344374 & 688816 & 4.45 & 5.148 & TRN & \\
\hline CHEMBL3208352 & 688816 & 5.25 & 5.0957 & TRN & \\
\hline CHEMBL3210543 & 688816 & 7.15 & 5.4653 & TRN & \\
\hline CHEMBL1368754 & 688816 & 6.0 & 5.2253 & TRN & \\
\hline CHEMBL3212157 & 688816 & 6.4 & 5.4613 & TRN & \\
\hline CHEMBL3856094 & 688816 & 4.85 & 5.7176 & TRN & \\
\hline CHEMBL1450731 & 688816 & 4.95 & 5.1512 & TRN & \\
\hline CHEMBL1382278 & 688816 & 4.95 & 5.0887 & TRN & \\
\hline CHEMBL1534170 & 688816 & 5.25 & 4.8986 & TST & \\
\hline CHEMBL1385370 & 688816 & 6.9 & 5.3532 & TST & \\
\hline CHEMBL1604444 & 688816 & 5.15 & 5.1998 & TRN & \\
\hline CHEMBL3208161 & 688816 & 5.0 & 5.3226 & TST & \\
\hline CHEMBL1325533 & 688816 & 4.6 & 5.3786 & TRN & \\
\hline CHEMBL1391909 & 688816 & 4.9 & 5.3251 & TRN & \\
\hline CHEMBL1986392 & 688816 & 4.95 & 5.1932 & TRN & \\
\hline CHEMBL1422415 & 688816 & 4.6 & 4.7993 & TST & \\
\hline CHEMBL1401543 & 688816 & 8.4559 & 5.38899 & 9999999999 & TRN \\
\hline CHEMBL1574261 & 688816 & 4.95 & 5.1006 & TRN & \\
\hline CHEMBL3145282 & 688816 & 4.45 & 5.3688 & TST & \\
\hline CHEMBL1320424 & 688816 & 4.9 & 5.2692 & TRN & \\
\hline CHEMBL1484885 & 688816 & 4.9 & 5.0286 & TRN & \\
\hline CHEMBL1520417 & 688816 & 4.5 & 4.8703 & TRN & \\
\hline CHEMBL1483261 & 688816 & 4.95 & 4.8383 & TRN & \\
\hline CHEMBL1540740 & 688816 & 4.8 & 5.3642 & TST & \\
\hline CHEMBL528724 & 688816 & 4.9 & 5.4007 & TST & \\
\hline CHEMBL1557232 & 688816 & 4.9 & 5.4981 & TRN & \\
\hline CHEMBL1358331 & 688816 & 5.15 & 4.9788 & TRN & \\
\hline CHEMBL1492530 & 688816 & 4.85 & 5.4915 & TRN & \\
\hline CHEMBL1523817 & 688816 & 8.1024 & 5.5019 & TST & \\
\hline CHEMBL1329200 & 688816 & 5.45 & 5.107 & TRN & \\
\hline CHEMBL1325354 & 688816 & 4.95 & 4.6142 & TST & \\
\hline CHEMBL1501923 & 688816 & 5.05 & 5.1792 & TRN & \\
\hline CHEMBL582644 & 688816 & 5.8 & 5.443 & TRN & \\
\hline CHEMBL1327477 & 688816 & 5.35 & 5.4479 & TRN & \\
\hline CHEMBL1376959 & 688816 & 4.85 & 5.6617 & TRN & \\
\hline CHEMBL1508477 & 688816 & 5.1 & 5.0837 & TRN & \\
\hline CHEMBL3193168 & 688816 & 4.8 & 5.0184 & TRN & \\
\hline CHEMBL3213351 & 688816 & 7.6498 & 5.2145 & TRN & \\
\hline
\end{tabular}




\begin{tabular}{|c|c|c|c|c|c|}
\hline \multicolumn{6}{|c|}{ Supplemental Table S2.txt } \\
\hline CHEMBL1368425 & 688816 & 5.25 & 5.3179 & TST & \\
\hline CHEMBL1492059 & 688816 & 4.75 & 5.4489 & TRN & \\
\hline CHEMBL1456354 & 688816 & 5.15 & 5.1417 & TRN & \\
\hline CHEMBL1332928 & 688816 & 5.4 & 5.3125 & TST & \\
\hline CHEMBL1528027 & 688816 & 5.0 & 5.2514 & TRN & \\
\hline CHEMBL1414737 & 688816 & 4.6 & 5.1785 & TRN & \\
\hline CHEMBL1560831 & 688816 & 4.45 & 5.4693 & TST & \\
\hline CHEMBL1542340 & 688816 & 5.05 & 5.3402 & TRN & \\
\hline CHEMBL1576246 & 688816 & 5.25 & 4.7878 & TST & \\
\hline CHEMBL1348868 & 688816 & 5.15 & 5.6469 & TRN & \\
\hline CHEMBL1391038 & 688816 & 4.9 & 5.4642 & TRN & \\
\hline CHEMBL1308716 & 688816 & 4.7 & 5.4935 & TST & \\
\hline CHEMBL1400508 & 688816 & 5.05 & 5.4577 & TRN & \\
\hline CHEMBL1381517 & 688816 & 4.85 & 4.8301 & TRN & \\
\hline CHEMBL1385084 & 688816 & 5.1 & 4.9301 & TRN & \\
\hline CHEMBL1299940 & 688816 & 4.9 & 5.0778 & TRN & \\
\hline CHEMBL1564202 & 688816 & 4.95 & 5.6177 & TRN & \\
\hline CHEMBL1350207 & 688816 & 4.9 & 5.2827 & TST & \\
\hline CHEMBL1455016 & 688816 & 6.1 & 5.5249 & TRN & \\
\hline CHEMBL1408238 & 688816 & 5.8 & 5.2451 & TRN & \\
\hline CHEMBL1362857 & 688816 & 4.45 & 5.2669 & TRN & \\
\hline CHEMBL1562832 & 688816 & 4.65 & 5.4487 & TST & \\
\hline CHEMBL1546374 & 688816 & 5.25 & 4.9802 & TRN & \\
\hline CHEMBL1426209 & 688816 & 7.4001 & 5.9177 & TRN & \\
\hline CHEMBL1390109 & 688816 & 4.95 & 5.6871 & TRN & \\
\hline CHEMBL1312917 & 688816 & 4.45 & 5.5717 & TRN & \\
\hline CHEMBL1332861 & 688816 & 7.2503 & 5.5314 & TST & \\
\hline CHEMBL3199467 & 688816 & 4.95 & 5.2141 & TRN & \\
\hline CHEMBL1467355 & 688816 & 5.95 & 5.4991 & TST & \\
\hline CHEMBL1370744 & 688816 & 5.0 & 5.2449 & TRN & \\
\hline CHEMBL1416516 & 688816 & 4.8 & 5.4674 & TST & \\
\hline CHEMBL1390546 & 688816 & 5.0 & 4.9279 & TST & \\
\hline CHEMBL1483163 & 688816 & 5.0 & 5.1381 & TRN & \\
\hline CHEMBL1336351 & 688816 & 4.95 & 5.2608 & TRN & \\
\hline CHEMBL1578825 & 688816 & 4.85 & 5.3421 & TRN & \\
\hline CHEMBL1302618 & 688816 & 4.9 & 5.0795 & TRN & \\
\hline CHEMBL1492576 & 688816 & 4.5 & 5.6379 & TST & \\
\hline CHEMBL1608540 & 688816 & 5.55 & 5.21899 & 9999999999 & TRN \\
\hline CHEMBL1548173 & 688816 & 6.0 & 5.2117 & TRN & \\
\hline CHEMBL1554756 & 688816 & 4.7 & 4.8037 & TRN & \\
\hline CHEMBL1539525 & 688816 & 4.7 & 5.1342 & TST & \\
\hline CHEMBL1542546 & 688816 & 4.95 & 5.1536 & TST & \\
\hline CHEMBL3198304 & 688816 & 4.95 & 5.4446 & TRN & \\
\hline CHEMBL1393872 & 688816 & 4.5 & 4.9729 & TRN & \\
\hline CHEMBL1394209 & 688816 & 4.95 & 4.8373 & TRN & \\
\hline CHEMBL1464995 & 688816 & 8.0506 & 5.2049 & TRN & \\
\hline CHEMBL 3190602 & 688816 & 5.25 & 5.1267 & TRN & \\
\hline CHEMBL1910223 & 688816 & 4.85 & 5.3091 & TST & \\
\hline
\end{tabular}




\begin{tabular}{|c|c|c|c|c|}
\hline \multicolumn{5}{|c|}{ Supplemental Table S2.txt } \\
\hline CHEMBL1347224 & 688816 & 4.8 & 5.6132 & TST \\
\hline CHEMBL1394464 & 688816 & 4.65 & 5.1975 & TST \\
\hline CHEMBL1567083 & 688816 & 4.45 & 5.5398 & TST \\
\hline CHEMBL 3199278 & 688816 & 4.7 & 5.5268 & TRN \\
\hline CHEMBL1421825 & 688816 & 8.3468 & 5.5706 & TST \\
\hline CHEMBL1529604 & 688816 & 8.4949 & 5.6434 & TRN \\
\hline CHEMBL1477410 & 688816 & 7.1002 & 5.291 & TRN \\
\hline CHEMBL1451141 & 688816 & 5.55 & 5.091 & TRN \\
\hline CHEMBL3198915 & 688816 & 4.6 & 5.4683 & TRN \\
\hline CHEMBL1541834 & 688816 & 4.9 & 5.06 & TRN \\
\hline CHEMBL1390079 & 688816 & 7.8996 & 5.0452 & TRN \\
\hline CHEMBL1587563 & 688816 & 6.0 & 5.7415 & TRN \\
\hline CHEMBL1553121 & 688816 & 4.85 & 5.033 & TRN \\
\hline CHEMBL1600739 & 688816 & 4.8 & 4.9494 & TST \\
\hline CHEMBL1499819 & 688816 & 5.45 & 5.2189 & TRN \\
\hline CHEMBL1375643 & 688816 & 4.75 & 5.4182 & TST \\
\hline CHEMBL582717 & 688816 & 5.0 & 5.1101 & TRN \\
\hline CHEMBL3190559 & 688816 & 4.75 & 5.2007 & TRN \\
\hline CHEMBL1345932 & 688816 & 5.6 & 5.2787 & TRN \\
\hline CHEMBL1371801 & 688816 & 7.8508 & 5.0246 & TRN \\
\hline CHEMBL1461826 & 688816 & 4.95 & 5.5109 & TRN \\
\hline CHEMBL3197525 & 688816 & 5.25 & 5.3662 & TST \\
\hline CHEMBL601941 & 688816 & 6.6 & 5.6173 & TRN \\
\hline CHEMBL1547696 & 688816 & 4.9 & 5.0019 & TRN \\
\hline CHEMBL1314163 & 688816 & 6.15 & 5.5251 & TST \\
\hline CHEMBL3207796 & 688816 & 4.45 & 5.2754 & TRN \\
\hline CHEMBL1573422 & 688816 & 6.4 & 5.3664 & TST \\
\hline CHEMBL1388942 & 688816 & 4.95 & 5.3079 & TRN \\
\hline CHEMBL1493366 & 688816 & 5.2 & 5.0862 & TRN \\
\hline CHEMBL1487337 & 688816 & 4.45 & 5.2154 & TRN \\
\hline CHEMBL1326528 & 688816 & 5.55 & 6.0876 & TRN \\
\hline CHEMBL1371536 & 688816 & 4.95 & 5.1741 & TRN \\
\hline CHEMBL1369635 & 688816 & 4.9 & 5.7105 & TST \\
\hline CHEMBL1440653 & 688816 & 4.6 & 5.4248 & TRN \\
\hline CHEMBL1418863 & 688816 & 6.25 & 5.3458 & TST \\
\hline CHEMBL1452597 & 688816 & 4.45 & 5.6321 & TST \\
\hline CHEMBL1608441 & 688816 & 5.35 & 5.1378 & TRN \\
\hline CHEMBL1312644 & 688816 & 5.05 & 5.1874 & TRN \\
\hline CHEMBL202366 & 688816 & 5.9 & 5.5894 & TRN \\
\hline CHEMBL1372194 & 688816 & 4.8 & 5.4831 & TRN \\
\hline CHEMBL1602186 & 688816 & 4.65 & 5.2621 & TRN \\
\hline CHEMBL3212742 & 688816 & 4.45 & 5.5179 & TST \\
\hline CHEMBL1415135 & 688816 & 6.5 & 4.9328 & TST \\
\hline CHEMBL1386083 & 688816 & 4.75 & 5.0077 & TRN \\
\hline CHEMBL3191866 & 688816 & 4.45 & 5.3537 & TRN \\
\hline CHEMBL1573168 & 688816 & 4.95 & 5.733 & TRN \\
\hline CHEMBL1396810 & 688816 & 4.45 & 5.2766 & TRN \\
\hline CHEMBL1405800 & 688816 & 4.8 & 5.6719 & TRN \\
\hline
\end{tabular}




\begin{tabular}{|c|c|c|c|c|c|}
\hline \multicolumn{6}{|c|}{ Supplemental Table S2.txt } \\
\hline CHEMBL1377682 & 688816 & 4.6 & 5.2881 & TRN & \\
\hline CHEMBL1476419 & 688816 & 4.45 & 4.9031 & TRN & \\
\hline CHEMBL1531500 & 688816 & 4.9 & 5.1309 & TST & \\
\hline CHEMBL1547246 & 688816 & 4.8 & 5.1747 & TST & \\
\hline CHEMBL1425004 & 688816 & 5.25 & 5.3703 & TST & \\
\hline CHEMBL1468180 & 688816 & 5.45 & 5.4507 & TRN & \\
\hline CHEMBL3189736 & 688816 & 4.65 & 5.2309 & TST & \\
\hline CHEMBL1383189 & 688816 & 4.9 & 5.4536 & TRN & \\
\hline CHEMBL1486711 & 688816 & 5.25 & 5.2556 & TRN & \\
\hline CHEMBL1375193 & 688816 & 5.2 & 5.1502 & TST & \\
\hline CHEMBL1503016 & 688816 & 4.75 & 5.1308 & TRN & \\
\hline CHEMBL1438407 & 688816 & 4.9 & 4.8574 & TRN & \\
\hline CHEMBL1536782 & 688816 & 4.9 & 4.9953 & TRN & \\
\hline CHEMBL1450998 & 688816 & 5.05 & 5.0857 & TRN & \\
\hline CHEMBL3197348 & 688816 & 4.7 & 5.0136 & TRN & \\
\hline CHEMBL1522331 & 688816 & 4.8 & 5.5192 & TST & \\
\hline CHEMBL1518284 & 688816 & 4.95 & 5.2327 & TRN & \\
\hline CHEMBL1308441 & 688816 & 4.65 & 5.0651 & TRN & \\
\hline CHEMBL1456009 & 688816 & 4.65 & 5.29899 & 99999999995 & TRN \\
\hline CHEMBL1609788 & 688816 & 4.85 & 5.3701 & TRN & \\
\hline CHEMBL1383866 & 688816 & 4.45 & 5.0705 & TRN & \\
\hline CHEMBL1550249 & 688816 & 5.2 & 5.188 & TST & \\
\hline CHEMBL1425183 & 688816 & 4.85 & 5.1578 & TRN & \\
\hline CHEMBL1303003 & 688816 & 5.25 & 5.1108 & TRN & \\
\hline CHEMBL1363243 & 688816 & 4.7 & 5.8002 & TST & \\
\hline CHEMBL1508781 & 688816 & 5.25 & 4.9834 & TRN & \\
\hline CHEMBL1430052 & 688816 & 4.9 & 5.2744 & TRN & \\
\hline CHEMBL3192833 & 688816 & 4.9 & 5.0879 & TRN & \\
\hline CHEMBL1353928 & 688816 & 4.45 & 5.4417 & TST & \\
\hline CHEMBL1579560 & 688816 & 5.5 & 5.3604 & TST & \\
\hline CHEMBL1378551 & 688816 & 4.9 & 5.7047 & TST & \\
\hline CHEMBL1461103 & 688816 & 4.75 & 5.3981 & TRN & \\
\hline CHEMBL454549 & 688816 & 5.2 & 5.1917 & TRN & \\
\hline CHEMBL1415308 & 688816 & 5.0 & 5.2579 & TRN & \\
\hline CHEMBL1325077 & 688816 & 4.7 & 5.0892 & TRN & \\
\hline CHEMBL1439324 & 688816 & 5.3 & 5.2945 & TRN & \\
\hline CHEMBL1384451 & 688816 & 5.0 & 5.2483 & TRN & \\
\hline CHEMBL1350893 & 688816 & 4.55 & 5.0886 & TRN & \\
\hline CHEMBL1477014 & 688816 & 4.65 & 5.131 & TRN & \\
\hline CHEMBL1399306 & 688816 & 4.95 & 5.0741 & TST & \\
\hline CHEMBL3195145 & 688816 & 5.0 & 5.3712 & TRN & \\
\hline CHEMBL1419188 & 688816 & 4.6 & 5.0141 & TRN & \\
\hline CHEMBL1455588 & 688816 & 4.95 & 5.4673 & TST & \\
\hline CHEMBL1461351 & 688816 & 4.45 & 5.0811 & TRN & \\
\hline CHEMBL1375036 & 688816 & 5.8 & 5.1907 & TST & \\
\hline CHEMBL1567032 & 688816 & 4.9 & 5.4892 & TRN & \\
\hline CHEMBL1305166 & 688816 & 4.45 & 5.2139 & TRN & \\
\hline CHEMBL1548144 & 688816 & 4.85 & 5.1154 & TST & \\
\hline
\end{tabular}




\begin{tabular}{|c|c|c|c|c|}
\hline \multicolumn{5}{|c|}{ Supplemental Table S2.txt } \\
\hline CHEMBL1334216 & 688816 & 4.55 & 5.3479 & TST \\
\hline CHEMBL1332278 & 688816 & 4.7 & 5.5548 & TRN \\
\hline CHEMBL1380195 & 688816 & 6.2 & 5.1945 & TST \\
\hline CHEMBL1500185 & 688816 & 5.0 & 5.2582 & TST \\
\hline CHEMBL1974800 & 688816 & 4.45 & 5.3555 & TRN \\
\hline CHEMBL1423187 & 688816 & 4.65 & 5.2896 & TST \\
\hline CHEMBL1412501 & 688816 & 4.85 & 5.2473 & TRN \\
\hline CHEMBL1579950 & 688816 & 4.45 & 5.3845 & TST \\
\hline CHEMBL1414522 & 688816 & 4.8 & 5.2247 & TRN \\
\hline CHEMBL3214024 & 688816 & 8.301 & 5.2818 & TST \\
\hline CHEMBL1391583 & 688816 & 4.85 & 5.1547 & TRN \\
\hline CHEMBL1380220 & 688816 & 6.4 & 5.5329 & TRN \\
\hline CHEMBL1405806 & 688816 & 4.45 & 5.1591 & TRN \\
\hline CHEMBL1550115 & 688816 & 4.95 & 4.9837 & TRN \\
\hline CHEMBL1485551 & 688816 & 4.45 & 5.0483 & TRN \\
\hline CHEMBL1561349 & 688816 & 4.45 & 5.5668 & TRN \\
\hline CHEMBL1529822 & 688816 & 5.2 & 5.4595 & TRN \\
\hline CHEMBL1506379 & 688816 & 5.25 & 5.3204 & TRN \\
\hline CHEMBL1424405 & 688816 & 7.4498 & 5.5036 & TRN \\
\hline CHEMBL1421654 & 688816 & 4.5 & 5.2663 & TRN \\
\hline CHEMBL1331634 & 688816 & 5.8 & 5.1258 & TRN \\
\hline CHEMBL1539526 & 688816 & 4.65 & 4.8639 & TST \\
\hline CHEMBL1596985 & 688816 & 5.0 & 4.9321 & TRN \\
\hline CHEMBL1598141 & 688816 & 5.7 & 5.4482 & TST \\
\hline CHEMBL1482924 & 688816 & 4.95 & 5.3504 & TRN \\
\hline CHEMBL1481261 & 688816 & 5.55 & 5.2705 & TRN \\
\hline CHEMBL1419011 & 688816 & 5.7 & 5.0146 & TRN \\
\hline CHEMBL1337500 & 688816 & 4.75 & 5.1751 & TST \\
\hline CHEMBL1425986 & 688816 & 8.301 & 5.3658 & TRN \\
\hline CHEMBL1455113 & 688816 & 5.2 & 5.3027 & TRN \\
\hline CHEMBL1526203 & 688816 & 5.0 & 5.1331 & TRN \\
\hline CHEMBL1494713 & 688816 & 5.0 & 4.9141 & TRN \\
\hline CHEMBL1464998 & 688816 & 5.05 & 5.1458 & TRN \\
\hline CHEMBL1304736 & 688816 & 4.7 & 5.2635 & TST \\
\hline CHEMBL1515061 & 688816 & 4.5 & 4.7182 & TRN \\
\hline CHEMBL602573 & 688816 & 6.45 & 5.2735 & TST \\
\hline CHEMBL1483562 & 688816 & 4.9 & 4.9122 & TRN \\
\hline CHEMBL1465487 & 688816 & 5.15 & 5.5694 & TRN \\
\hline CHEMBL1380119 & 688816 & 6.0 & 4.8489 & TRN \\
\hline CHEMBL1480264 & 688816 & 4.8 & 5.077 & TRN \\
\hline CHEMBL1549529 & 688816 & 6.0 & 4.9173 & TRN \\
\hline CHEMBL1478384 & 688816 & 5.25 & 5.2532 & TRN \\
\hline CHEMBL3193762 & 688816 & 4.85 & 5.3866 & TST \\
\hline CHEMBL1495873 & 688816 & 4.9 & 5.2044 & TRN \\
\hline CHEMBL1387100 & 688816 & 4.9 & 5.3014 & TRN \\
\hline CHEMBL1312806 & 688816 & 7.15 & 5.5136 & TRN \\
\hline CHEMBL1509841 & 688816 & 4.55 & 5.0997 & TST \\
\hline CHEMBL1502351 & 688816 & 4.6 & 4.9626 & TRN \\
\hline
\end{tabular}




\begin{tabular}{|c|c|c|c|c|c|}
\hline \multicolumn{6}{|c|}{ Supplemental Table S2.txt } \\
\hline CHEMBL1574990 & 688816 & 4.95 & 5.2569 & TRN & \\
\hline CHEMBL1550768 & 688816 & 4.8 & 5.3221 & TRN & \\
\hline CHEMBL1563973 & 688816 & 5.5 & 5.1974 & TRN & \\
\hline CHEMBL1465555 & 688816 & 4.95 & 5.5165 & TRN & \\
\hline CHEMBL1554006 & 688816 & 5.6 & 4.7914 & TRN & \\
\hline CHEMBL1474185 & 688816 & 4.75 & 5.0487 & TRN & \\
\hline CHEMBL1501051 & 688816 & 4.8 & 4.9182 & TST & \\
\hline CHEMBL1084955 & 688816 & 4.85 & 5.1873 & TRN & \\
\hline CHEMBL1308302 & 688816 & 8.4559 & 5.6835 & TRN & \\
\hline CHEMBL1549744 & 688816 & 4.95 & 4.9633 & TRN & \\
\hline CHEMBL1485819 & 688816 & 5.1 & 5.19600 & 0000000001 & TRN \\
\hline CHEMBL1319525 & 688816 & 4.9 & 5.17299 & 9999999999 & TST \\
\hline CHEMBL1498329 & 688816 & 5.65 & 5.1358 & TRN & \\
\hline CHEMBL1379380 & 688816 & 4.85 & 4.99 & TST & \\
\hline CHEMBL1563557 & 688816 & 4.95 & 5.4624 & TRN & \\
\hline CHEMBL1596026 & 688816 & 5.6 & 5.4395 & TST & \\
\hline CHEMBL1447662 & 688816 & 4.9 & 5.7053 & TRN & \\
\hline CHEMBL260342 & 688816 & 5.6 & 5.2427 & TRN & \\
\hline CHEMBL1379520 & 688816 & 5.25 & 4.8341 & TRN & \\
\hline CHEMBL3198502 & 688816 & 4.95 & 4.958 & TRN & \\
\hline CHEMBL1350790 & 688816 & 4.9 & 5.045 & TRN & \\
\hline CHEMBL1516729 & 688816 & 6.0 & 5.1867 & TRN & \\
\hline CHEMBL1329586 & 688816 & 4.9 & 5.4304 & TRN & \\
\hline CHEMBL1440541 & 688816 & 5.25 & 5.0931 & TRN & \\
\hline CHEMBL1522582 & 688816 & 4.75 & 5.0469 & TST & \\
\hline CHEMBL1543004 & 688816 & 4.45 & 5.5999 & TST & \\
\hline CHEMBL1613630 & 688816 & 5.3 & 5.7325 & TRN & \\
\hline CHEMBL1328783 & 688816 & 4.95 & 5.124 & TRN & \\
\hline CHEMBL1596412 & 688816 & 4.7 & 5.3248 & TRN & \\
\hline CHEMBL1564465 & 688816 & 4.5 & 5.1232 & TRN & \\
\hline CHEMBL1448181 & 688816 & 4.95 & 4.7333 & TST & \\
\hline CHEMBL1401915 & 688816 & 5.05 & 5.1724 & TRN & \\
\hline CHEMBL1541120 & 688816 & 4.45 & 4.7643 & TRN & \\
\hline CHEMBL1457234 & 688816 & 4.85 & 5.3366 & TRN & \\
\hline CHEMBL3196536 & 688816 & 6.3 & 5.1151 & TST & \\
\hline CHEMBL1415808 & 688816 & 4.35 & 5.3888 & TRN & \\
\hline CHEMBL 1342216 & 688816 & 4.45 & 5.3587 & TST & \\
\hline CHEMBL1373269 & 688816 & 5.0 & 5.5499 & TRN & \\
\hline CHEMBL1415927 & 688816 & 4.95 & 4.9696 & TST & \\
\hline CHEMBL595700 & 688816 & 5.0 & 5.0781 & TRN & \\
\hline CHEMBL1605514 & 688816 & 4.9 & 5.0656 & TRN & \\
\hline CHEMBL 1503772 & 688816 & 4.95 & 5.2969 & TST & \\
\hline CHEMBL1504473 & 688816 & 4.9 & 5.3819 & TRN & \\
\hline CHEMBL1445932 & 688816 & 4.8 & 5.1906 & TRN & \\
\hline CHEMBL1372208 & 688816 & 5.25 & 5.5701 & TRN & \\
\hline CHEMBL1511881 & 688816 & 4.9 & 5.6437 & TRN & \\
\hline CHEMBL1326239 & 688816 & 4.85 & 4.9365 & TRN & \\
\hline CHEMBL1597661 & 688816 & 7.8508 & 5.4371 & TRN & \\
\hline
\end{tabular}




\begin{tabular}{|c|c|c|c|c|c|}
\hline \multicolumn{6}{|c|}{ Supplemental Table S2.txt } \\
\hline CHEMBL1352436 & 688816 & 4.95 & 5.1171 & TRN & \\
\hline CHEMBL1358595 & 688816 & 5.65 & 5.3491 & TRN & \\
\hline CHEMBL1333410 & 688816 & 4.95 & 5.2398 & TRN & \\
\hline CHEMBL3195409 & 688816 & 4.45 & 4.9522 & TRN & \\
\hline CHEMBL1408945 & 688816 & 7.4498 & 5.6039 & TST & \\
\hline CHEMBL1392849 & 688816 & 6.35 & 5.6517 & TST & \\
\hline CHEMBL1606984 & 688816 & 4.9 & 5.1845 & TRN & \\
\hline CHEMBL1477332 & 688816 & 5.25 & 4.9015 & TRN & \\
\hline CHEMBL1415411 & 688816 & 5.0 & 5.2732 & TRN & \\
\hline CHEMBL1527802 & 688816 & 4.95 & 5.1559 & TRN & \\
\hline CHEMBL1320721 & 688816 & 4.95 & 5.2953 & TRN & \\
\hline CHEMBL1573265 & 688816 & 4.9 & 5.1501 & TST & \\
\hline CHEMBL1495625 & 688816 & 4.9 & 4.7938 & TRN & \\
\hline CHEMBL1375519 & 688816 & 5.25 & 5.4716 & TRN & \\
\hline CHEMBL 3210600 & 688816 & 5.25 & 5.2306 & TRN & \\
\hline CHEMBL1389294 & 688816 & 8.3979 & 5.1746 & TRN & \\
\hline CHEMBL1400376 & 688816 & 5.35 & 5.2068 & TRN & \\
\hline CHEMBL1447004 & 688816 & 4.85 & 5.1269 & TRN & \\
\hline CHEMBL1544101 & 688816 & 5.4 & 5.5294 & TRN & \\
\hline CHEMBL284028 & 688816 & 4.95 & 5.5513 & TST & \\
\hline CHEMBL1603038 & 688816 & 4.65 & 4.9275 & TRN & \\
\hline CHEMBL1448625 & 688816 & 4.8 & 5.1398 & TRN & \\
\hline CHEMBL1401783 & 688816 & 5.4 & 5.0737 & TRN & \\
\hline CHEMBL1457311 & 688816 & 4.65 & 5.0586 & TRN & \\
\hline CHEMBL1422500 & 688816 & 4.45 & 5.2507 & TRN & \\
\hline CHEMBL1319505 & 688816 & 5.2 & 5.199 & TRN & \\
\hline CHEMBL1347491 & 688816 & 6.1 & 5.40799 & 99999999995 & TRN \\
\hline CHEMBL1539400 & 688816 & 6.4 & 5.6147 & TRN & \\
\hline CHEMBL3195828 & 688816 & 5.0 & 5.4354 & TRN & \\
\hline CHEMBL1559853 & 688816 & 4.95 & 5.2998 & TST & \\
\hline CHEMBL1562972 & 688816 & 5.05 & 5.3421 & TRN & \\
\hline CHEMBL1474766 & 688816 & 4.8 & 4.6398 & TRN & \\
\hline CHEMBL1307866 & 688816 & 4.85 & 5.2497 & TRN & \\
\hline CHEMBL587856 & 688816 & 4.8 & 5.2689 & TRN & \\
\hline CHEMBL1373529 & 688816 & 5.0 & 4.7725 & TRN & \\
\hline CHEMBL1493815 & 688816 & 5.0 & 5.1825 & TRN & \\
\hline CHEMBL1367684 & 688816 & 6.3 & 5.7379 & TST & \\
\hline CHEMBL1423013 & 688816 & 4.9 & 5.1178 & TRN & \\
\hline CHEMBL1986889 & 688816 & 4.85 & 4.8775 & TRN & \\
\hline CHEMBL1527590 & 688816 & 4.6 & 5.191 & TST & \\
\hline CHEMBL1330307 & 688816 & 4.65 & 5.0438 & TRN & \\
\hline CHEMBL1468876 & 688816 & 5.0 & 5.513 & TRN & \\
\hline CHEMBL1439118 & 688816 & 4.8 & 4.8659 & TRN & \\
\hline CHEMBL1595694 & 688816 & 8.4949 & 5.4985 & TST & \\
\hline CHEMBL1578720 & 688816 & 5.4 & 5.6017 & TRN & \\
\hline CHEMBL1441386 & 688816 & 7.699 & 5.2432 & TST & \\
\hline CHEMBL1569501 & 688816 & 4.9 & 4.8906 & TRN & \\
\hline CHEMBL1572872 & 688816 & 7.0 & 5.1853 & TST & \\
\hline
\end{tabular}




\begin{tabular}{|c|c|c|c|c|c|}
\hline \multicolumn{6}{|c|}{ Supplemental Table S2.txt } \\
\hline CHEMBL1585012 & 688816 & 7.3002 & 5.1249 & TST & \\
\hline CHEMBL1585681 & 688816 & 4.9 & 5.138 & TRN & \\
\hline CHEMBL1520939 & 688816 & 4.75 & 5.1208 & TRN & \\
\hline CHEMBL1453777 & 688816 & 4.45 & 4.9318 & TRN & \\
\hline CHEMBL1573864 & 688816 & 4.85 & 5.1518 & TRN & \\
\hline CHEMBL3189623 & 688816 & 4.9 & 5.15799 & 99999999995 & TST \\
\hline CHEMBL1487122 & 688816 & 4.45 & 5.3253 & TRN & \\
\hline CHEMBL1573937 & 688816 & 7.4498 & 5.5746 & TRN & \\
\hline CHEMBL1508735 & 688816 & 5.55 & 5.2028 & TRN & \\
\hline CHEMBL2006221 & 688816 & 4.6 & 5.1006 & TST & \\
\hline CHEMBL1397735 & 688816 & 4.95 & 5.1998 & TRN & \\
\hline CHEMBL1313346 & 688816 & 5.2 & 5.0312 & TRN & \\
\hline CHEMBL1394388 & 688816 & 6.15 & 5.2136 & TRN & \\
\hline CHEMBL3213830 & 688816 & 4.45 & 5.3064 & TRN & \\
\hline CHEMBL1559297 & 688816 & 7.5498 & 5.1507 & TRN & \\
\hline CHEMBL1356263 & 688816 & 4.9 & 5.0934 & TRN & \\
\hline CHEMBL226664 & 688816 & 4.85 & 5.227 & TRN & \\
\hline CHEMBL1519574 & 688816 & 4.5 & 5.0308 & TRN & \\
\hline CHEMBL1320841 & 688816 & 4.9 & 5.0265 & TRN & \\
\hline CHEMBL1428896 & 688816 & 6.6499 & 5.6669 & TRN & \\
\hline CHEMBL1450671 & 688816 & 6.7001 & 5.2461 & TST & \\
\hline CHEMBL1555401 & 688816 & 6.3 & 5.7378 & TRN & \\
\hline CHEMBL1466749 & 688816 & 4.45 & 5.2455 & TRN & \\
\hline CHEMBL1365132 & 688816 & 5.2 & 5.4191 & TRN & \\
\hline CHEMBL1453853 & 688816 & 5.95 & 5.3194 & TST & \\
\hline CHEMBL1323858 & 688816 & 5.15 & 4.99 & TRN & \\
\hline CHEMBL1334818 & 688816 & 4.9 & 5.3165 & TRN & \\
\hline CHEMBL1453960 & 688816 & 5.9 & 5.3467 & TRN & \\
\hline CHEMBL1415585 & 688816 & 5.1 & 4.7758 & TST & \\
\hline CHEMBL1340220 & 688816 & 4.9 & 5.1224 & TRN & \\
\hline CHEMBL1440581 & 688816 & 4.95 & 4.8557 & TRN & \\
\hline CHEMBL1481668 & 688816 & 5.35 & 5.6095 & TST & \\
\hline CHEMBL1326065 & 688816 & 4.55 & 5.2012 & TST & \\
\hline CHEMBL1351290 & 688816 & 4.8 & 5.4364 & TRN & \\
\hline CHEMBL1560274 & 688816 & 5.4 & 5.6189 & TST & \\
\hline CHEMBL1430401 & 688816 & 8.301 & 5.2664 & TRN & \\
\hline CHEMBL1339940 & 688816 & 7.6498 & 5.3713 & TST & \\
\hline CHEMBL1344220 & 688816 & 4.95 & 5.1362 & TRN & \\
\hline CHEMBL3213075 & 688816 & 4.45 & 4.9709 & TRN & \\
\hline CHEMBL1543601 & 688816 & 5.0 & 5.1478 & TRN & \\
\hline CHEMBL3199742 & 688816 & 6.0 & 5.5486 & TRN & \\
\hline CHEMBL578689 & 688816 & 4.75 & 5.1976 & TRN & \\
\hline CHEMBL1331713 & 688816 & 4.95 & 5.1846 & TRN & \\
\hline CHEMBL1571182 & 688816 & 4.5 & 5.0794 & TST & \\
\hline CHEMBL1469668 & 688816 & 4.85 & 5.1996 & TRN & \\
\hline CHEMBL3199921 & 688816 & 4.8 & 5.4355 & TRN & \\
\hline CHEMBL1505219 & 688816 & 4.75 & 5.1658 & TRN & \\
\hline CHEMBL1527757 & 688816 & 5.4 & 5.0947 & TRN & \\
\hline
\end{tabular}




\begin{tabular}{|c|c|c|c|c|c|}
\hline \multicolumn{6}{|c|}{ Supplemental Table S2.txt } \\
\hline CHEMBL1570680 & 688816 & 4.45 & 5.2701 & TRN & \\
\hline CHEMBL1461180 & 688816 & 4.85 & 5.1239 & TRN & \\
\hline CHEMBL1417242 & 688816 & 5.65 & 4.9812 & TRN & \\
\hline CHEMBL1574158 & 688816 & 5.85 & 5.0661 & TRN & \\
\hline CHEMBL1362589 & 688816 & 4.45 & 4.8127 & TRN & \\
\hline CHEMBL1562169 & 688816 & 4.75 & 5.2785 & TRN & \\
\hline CHEMBL1312898 & 688816 & 5.4 & 5.4154 & TRN & \\
\hline CHEMBL1589897 & 688816 & 4.85 & 5.0303 & TRN & \\
\hline CHEMBL1386631 & 688816 & 5.0 & 4.9215 & TRN & \\
\hline CHEMBL1447912 & 688816 & 4.45 & 5.3362 & TRN & \\
\hline CHEMBL1339736 & 688816 & 4.9 & 5.6687 & TRN & \\
\hline CHEMBL1561947 & 688816 & 4.85 & 4.8666 & TRN & \\
\hline CHEMBL1561748 & 688816 & 5.2 & 5.1949 & TRN & \\
\hline CHEMBL1456689 & 688816 & 4.8 & 5.3913 & TRN & \\
\hline CHEMBL1585424 & 688816 & 4.45 & 5.2814 & TRN & \\
\hline CHEMBL1465199 & 688816 & 8.0 & 5.2645 & TST & \\
\hline CHEMBL1480544 & 688816 & 4.85 & 5.4119 & TRN & \\
\hline CHEMBL1367282 & 688816 & 6.2 & 5.4168 & TST & \\
\hline CHEMBL1521914 & 688816 & 6.3 & 5.1252 & TRN & \\
\hline CHEMBL3191752 & 688816 & 5.4 & 5.1822 & TRN & \\
\hline CHEMBL1483231 & 688816 & 4.45 & 5.3273 & TRN & \\
\hline CHEMBL494474 & 688816 & 5.1 & 5.3652 & TRN & \\
\hline CHEMBL1498229 & 688816 & 5.05 & 5.33700 & 0000000001 & TRN \\
\hline CHEMBL3197642 & 688816 & 5.45 & 5.0754 & TRN & \\
\hline CHEMBL1332873 & 688816 & 5.25 & 4.8978 & TRN & \\
\hline CHEMBL1496744 & 688816 & 5.65 & 5.3088 & TRN & \\
\hline CHEMBL1523537 & 688816 & 4.9 & 5.1356 & TST & \\
\hline CHEMBL1422892 & 688816 & 5.35 & 5.4086 & TRN & \\
\hline CHEMBL1966853 & 688816 & 4.9 & 5.1742 & TRN & \\
\hline CHEMBL1553491 & 688816 & 4.7 & 5.3603 & TRN & \\
\hline CHEMBL1327766 & 688816 & 5.15 & 5.1945 & TRN & \\
\hline CHEMBL1335318 & 688816 & 4.45 & 5.3517 & TST & \\
\hline CHEMBL1379775 & 688816 & 5.25 & 5.7648 & TRN & \\
\hline CHEMBL1366360 & 688816 & 4.8 & 5.28299 & 99999999995 & TRN \\
\hline CHEMBL1519387 & 688816 & 4.9 & 5.095 & TRN & \\
\hline CHEMBL1306404 & 688816 & 7.5003 & 5.1755 & TST & \\
\hline CHEMBL1377709 & 688816 & 4.75 & 5.2975 & TST & \\
\hline CHEMBL1354079 & 688816 & 4.7 & 5.4295 & TRN & \\
\hline CHEMBL 3109023 & 688816 & 4.65 & 5.0013 & TRN & \\
\hline CHEMBL1605714 & 688816 & 4.9 & 5.4209 & TRN & \\
\hline CHEMBL1414729 & 688816 & 5.45 & 5.1818 & TRN & \\
\hline CHEMBL1308222 & 688816 & 4.5 & 5.1628 & TRN & \\
\hline CHEMBL1457747 & 688816 & 4.75 & 5.6694 & TRN & \\
\hline CHEMBL1364335 & 688816 & 4.4 & 5.4159 & TRN & \\
\hline CHEMBL1557628 & 688816 & 4.75 & 5.1867 & TRN & \\
\hline CHEMBL1369582 & 688816 & 5.0 & 5.2123 & TRN & \\
\hline CHEMBL1382624 & 688816 & 6.05 & 4.9785 & TRN & \\
\hline CHEMBL1409241 & 688816 & 4.8 & 5.0418 & TRN & \\
\hline
\end{tabular}




\begin{tabular}{|c|c|c|c|c|c|}
\hline \multicolumn{6}{|c|}{ Supplemental Table S2.txt } \\
\hline CHEMBL1388436 & 688816 & 4.6 & 5.2457 & TRN & \\
\hline CHEMBL1399198 & 688816 & 4.8 & 5.4313 & TRN & \\
\hline CHEMBL1340213 & 688816 & 4.85 & 5.1792 & TST & \\
\hline CHEMBL1545760 & 688816 & 4.6 & 5.2352 & TRN & \\
\hline CHEMBL1354749 & 688816 & 4.9 & 5.3757 & TST & \\
\hline CHEMBL1606763 & 688816 & 4.6 & 5.0406 & TRN & \\
\hline CHEMBL1366729 & 688816 & 4.7 & 4.9282 & TRN & \\
\hline CHEMBL1328481 & 688816 & 5.35 & 5.6288 & TRN & \\
\hline CHEMBL1583444 & 688816 & 4.75 & 5.7028 & TRN & \\
\hline CHEMBL1421919 & 688816 & 4.85 & 5.2218 & TRN & \\
\hline CHEMBL 3189855 & 688816 & 4.8 & 5.0081 & TRN & \\
\hline CHEMBL1428965 & 688816 & 4.45 & 5.0438 & TRN & \\
\hline CHEMBL1539405 & 688816 & 4.45 & 5.29299 & 9999999999 & TRN \\
\hline CHEMBL1577266 & 688816 & 4.9 & 5.0167 & TRN & \\
\hline CHEMBL1530341 & 688816 & 4.95 & 5.0989 & TRN & \\
\hline CHEMBL1566929 & 688816 & 4.8 & 5.1159 & TRN & \\
\hline CHEMBL1332178 & 688816 & 4.75 & 5.2913 & TST & \\
\hline CHEMBL1380778 & 688816 & 7.3002 & 5.1509 & TRN & \\
\hline CHEMBL1424510 & 688816 & 8.3468 & 5.7414 & TRN & \\
\hline CHEMBL1402343 & 688816 & 5.85 & 4.9889 & TST & \\
\hline CHEMBL1400744 & 688816 & 4.7 & 4.7526 & TST & \\
\hline CHEMBL1339359 & 688816 & 4.95 & 5.1788 & TRN & \\
\hline CHEMBL1442302 & 688816 & 6.05 & 5.5143 & TRN & \\
\hline CHEMBL1430138 & 688816 & 4.45 & 5.0142 & TRN & \\
\hline CHEMBL1503170 & 688816 & 6.05 & 5.2796 & TST & \\
\hline CHEMBL1494578 & 688816 & 6.9 & 5.0773 & TST & \\
\hline CHEMBL1576129 & 688816 & 4.45 & 5.5277 & TRN & \\
\hline CHEMBL1553697 & 688816 & 4.65 & 4.8176 & TRN & \\
\hline CHEMBL1351569 & 688816 & 8.3468 & 6.1542 & TST & \\
\hline CHEMBL1434098 & 688816 & 5.4 & 4.9195 & TRN & \\
\hline CHEMBL1477485 & 688816 & 4.85 & 5.2101 & TRN & \\
\hline CHEMBL314639 & 688816 & 4.55 & 5.2005 & TST & \\
\hline CHEMBL1390460 & 688816 & 6.15 & 5.2351 & TRN & \\
\hline CHEMBL1313409 & 688816 & 5.25 & 5.4599 & TST & \\
\hline CHEMBL1369677 & 688816 & 4.45 & 5.2174 & TRN & \\
\hline CHEMBL1353561 & 688816 & 4.95 & 5.42899 & 9999999999 & TRN \\
\hline CHEMBL1332404 & 688816 & 5.15 & 5.2773 & TRN & \\
\hline CHEMBL1310409 & 688816 & 4.95 & 5.2911 & TRN & \\
\hline CHEMBL1528655 & 688816 & 4.45 & 4.8418 & TRN & \\
\hline CHEMBL1352167 & 688816 & 5.25 & 5.3449 & TRN & \\
\hline CHEMBL1326309 & 688816 & 4.8 & 5.0897 & TRN & \\
\hline CHEMBL1335257 & 688816 & 4.45 & 5.1613 & TRN & \\
\hline CHEMBL565856 & 688816 & 4.5 & 4.773 & TST & \\
\hline CHEMBL1310101 & 688816 & 4.95 & 5.3503 & TRN & \\
\hline CHEMBL1439775 & 688816 & 4.5 & 5.1387 & TRN & \\
\hline CHEMBL1488805 & 688816 & 6.5 & 5.517 & TRN & \\
\hline CHEMBL1412980 & 688816 & 4.5 & 5.2832 & TST & \\
\hline CHEMBL3195658 & 688816 & 4.7 & 4.9619 & TRN & \\
\hline
\end{tabular}




\begin{tabular}{|c|c|c|c|c|c|}
\hline \multicolumn{6}{|c|}{ Supplemental Table S2.txt } \\
\hline CHEMBL1432673 & 688816 & 4.95 & 5.0332 & TRN & \\
\hline CHEMBL1337923 & 688816 & 4.95 & 5.256 & TRN & \\
\hline CHEMBL1351663 & 688816 & 4.6 & 5.0012 & TRN & \\
\hline CHEMBL1509754 & 688816 & 4.45 & 4.6117 & TST & \\
\hline CHEMBL1450959 & 688816 & 4.45 & 4.7829 & TST & \\
\hline CHEMBL3199844 & 688816 & 4.9 & 5.4428 & TRN & \\
\hline CHEMBL1504704 & 688816 & 4.6 & 5.4502 & TST & \\
\hline CHEMBL3192389 & 688816 & 4.95 & 5.1649 & TRN & \\
\hline CHEMBL1500654 & 688816 & 5.2 & 5.6123 & TRN & \\
\hline CHEMBL592316 & 688816 & 4.45 & 5.4449 & TST & \\
\hline CHEMBL1597614 & 688816 & 4.45 & 5.1459 & TRN & \\
\hline CHEMBL1366713 & 688816 & 4.65 & 5.1578 & TRN & \\
\hline CHEMBL1482579 & 688816 & 4.9 & 5.6452 & TRN & \\
\hline CHEMBL1522247 & 688816 & 4.8 & 5.2104 & TST & \\
\hline CHEMBL1527088 & 688816 & 4.6 & 5.2289 & TRN & \\
\hline CHEMBL1596764 & 688816 & 5.0 & 4.7749 & TRN & \\
\hline CHEMBL1451549 & 688816 & 8.0 & 5.5677 & TRN & \\
\hline CHEMBL1538400 & 688816 & 5.0 & 5.33799 & э999999999 & TRN \\
\hline CHEMBL1509896 & 688816 & 5.8 & 5.2749 & TRN & \\
\hline CHEMBL1339008 & 688816 & 4.95 & 5.565 & TST & \\
\hline CHEMBL1480321 & 688816 & 4.95 & 4.9061 & TST & \\
\hline CHEMBL1454500 & 688816 & 4.8 & 4.9537 & TRN & \\
\hline CHEMBL1505044 & 688816 & 4.45 & 4.8003 & TST & \\
\hline CHEMBL1344524 & 688816 & 6.8499 & 5.5978 & TRN & \\
\hline CHEMBL1536850 & 688816 & 5.5 & 5.5638 & TRN & \\
\hline CHEMBL1429254 & 688816 & 4.55 & 5.4238 & TRN & \\
\hline CHEMBL105310 & 688816 & 4.55 & 4.8873 & TRN & \\
\hline CHEMBL1486170 & 688816 & 4.95 & 5.2555 & TST & \\
\hline CHEMBL1364010 & 688816 & 4.45 & 5.0455 & TRN & \\
\hline CHEMBL1413859 & 688816 & 4.45 & 5.1848 & TRN & \\
\hline CHEMBL1567913 & 688816 & 5.4 & 5.2417 & TST & \\
\hline CHEMBL1527462 & 688816 & 7.5003 & 5.7891 & TST & \\
\hline CHEMBL1525289 & 688816 & 4.55 & 5.3875 & TRN & \\
\hline CHEMBL1456499 & 688816 & 5.0 & 5.1025 & TRN & \\
\hline CHEMBL1403657 & 688816 & 4.95 & 5.2306 & TRN & \\
\hline CHEMBL1413506 & 688816 & 4.45 & 5.4716 & TRN & \\
\hline CHEMBL1441415 & 688816 & 4.95 & 5.0195 & TRN & \\
\hline CHEMBL3193476 & 688816 & 4.55 & 5.205 & TRN & \\
\hline CHEMBL1470301 & 688816 & 5.85 & 5.6134 & TRN & \\
\hline CHEMBL602561 & 688816 & 4.65 & 5.0528 & TRN & \\
\hline CHEMBL1445719 & 688816 & 5.45 & 5.5016 & TRN & \\
\hline CHEMBL1495270 & 688816 & 4.95 & 5.3088 & TRN & \\
\hline CHEMBL1378502 & 688816 & 4.95 & 5.2655 & TST & \\
\hline CHEMBL1475574 & 688816 & 4.8 & 5.3491 & TRN & \\
\hline CHEMBL1327563 & 688816 & 5.15 & 5.6973 & TRN & \\
\hline CHEMBL1556540 & 688816 & 4.7 & 5.4623 & TRN & \\
\hline CHEMBL1973427 & 688816 & 5.2 & 5.1382 & TST & \\
\hline CHEMBL1340787 & 688816 & 5.15 & 5.034 & TRN & \\
\hline
\end{tabular}




\begin{tabular}{|c|c|c|c|c|c|}
\hline \multirow[b]{2}{*}{ CHEMBL3212409 } & \multicolumn{5}{|c|}{ Supplemental Table s2.txt } \\
\hline & 688816 & 4.8 & 5.3515 & TRN & \\
\hline CHEMBL1328955 & 688816 & 5.0 & 5.7107 & TRN & \\
\hline CHEMBL1370224 & 688816 & 5.4 & 5.20700 & 0000000001 & TRN \\
\hline CHEMBL 3193084 & 688816 & 4.45 & 4.8248 & TRN & \\
\hline CHEMBL492267 & 688816 & 4.45 & 5.3569 & TST & \\
\hline CHEMBL225986 & 688816 & 5.9 & 5.9519 & TST & \\
\hline CHEMBL1488371 & 688816 & 4.9 & 4.81 & TRN & \\
\hline CHEMBL1584200 & 688816 & 4.95 & 5.2578 & TRN & \\
\hline CHEMBL1303089 & 688816 & 4.65 & 4.9652 & TST & \\
\hline CHEMBL1397092 & 688816 & 4.7 & 4.8753 & TRN & \\
\hline CHEMBL1604894 & 688816 & 5.7 & 5.233 & TST & \\
\hline CHEMBL1432727 & 688816 & 5.55 & 5.0757 & TRN & \\
\hline CHEMBL 1471700 & 688816 & 4.65 & 4.9258 & TST & \\
\hline CHEMBL 1454300 & 688816 & 5.8 & 5.5295 & TRN & \\
\hline CHEMBL1314999 & 688816 & 4.9 & 5.2891 & TRN & \\
\hline CHEMBL1327351 & 688816 & 4.95 & 5.0027 & TST & \\
\hline CHEMBL1452028 & 688816 & 4.8 & 5.0518 & TST & \\
\hline CHEMBL1541771 & 688816 & 4.6 & 4.9401 & TRN & \\
\hline CHEMBL476513 & 688816 & 4.85 & 5.0865 & TRN & \\
\hline CHEMBL1588295 & 688816 & 4.45 & 5.1079 & TRN & \\
\hline CHEMBL1398645 & 688816 & 5.55 & 5.398 & TST & \\
\hline CHEMBL1606843 & 688816 & 4.75 & 5.4583 & TRN & \\
\hline CHEMBL1598974 & 688816 & 5.4 & 5.2837 & TRN & \\
\hline CHEMBL1512598 & 688816 & 4.8 & 5.3313 & TRN & \\
\hline CHEMBL1497455 & 688816 & 5.15 & 5.3394 & TRN & \\
\hline CHEMBL1348505 & 688816 & 5.0 & 5.4423 & TRN & \\
\hline CHEMBL1538689 & 688816 & 4.95 & 5.3386 & TRN & \\
\hline CHEMBL1543997 & 688816 & 4.45 & 5.2803 & TST & \\
\hline CHEMBL1480124 & 688816 & 4.95 & 5.63899 & 9999999999 & TST \\
\hline CHEMBL1433142 & 688816 & 6.45 & 5.6577 & TST & \\
\hline CHEMBL1530739 & 688816 & 4.75 & 5.0544 & TRN & \\
\hline CHEMBL1365726 & 688816 & 4.75 & 5.1435 & TRN & \\
\hline CHEMBL1563725 & 688816 & 5.75 & 5.3495 & TRN & \\
\hline CHEMBL1348943 & 688816 & 4.9 & 5.1109 & TRN & \\
\hline CHEMBL1451679 & 688816 & 4.65 & 4.9566 & TRN & \\
\hline CHEMBL1466630 & 688816 & 5.0 & 5.24200 & 0000000001 & TRN \\
\hline CHEMBL1411813 & 688816 & 4.45 & 5.1655 & TRN & \\
\hline CHEMBL1572755 & 688816 & 4.7 & 5.1242 & TRN & \\
\hline CHEMBL1401882 & 688816 & 5.0 & 5.3939 & TST & \\
\hline CHEMBL1336425 & 688816 & 4.45 & 5.3971 & TST & \\
\hline CHEMBL 2374449 & 688816 & 4.55 & 5.1976 & TST & \\
\hline CHEMBL1539487 & 688816 & 5.25 & 5.4398 & TST & \\
\hline CHEMBL1584460 & 688816 & 4.9 & 5.4856 & TRN & \\
\hline CHEMBL1507129 & 688816 & 4.95 & 4.9094 & TRN & \\
\hline CHEMBL 1454230 & 688816 & 5.0 & 5.1187 & TRN & \\
\hline CHEMBL1500193 & 688816 & 5.05 & 5.1445 & TRN & \\
\hline CHEMBL1349053 & 688816 & 7.699 & 5.5182 & TST & \\
\hline CHEMBL1441056 & 688816 & 5.5 & 5.0489 & TRN & \\
\hline & & & & 25118 & \\
\hline
\end{tabular}




\begin{tabular}{|c|c|c|c|c|}
\hline \multicolumn{5}{|c|}{ Supplemental Table S2.txt } \\
\hline CHEMBL328834 & 688816 & 6.0 & 5.6958 & TRN \\
\hline CHEMBL1455429 & 688816 & 5.0 & 5.6898 & TRN \\
\hline CHEMBL1606097 & 688816 & 4.8 & 5.0191 & TRN \\
\hline CHEMBL1369680 & 688816 & 5.7 & 5.4441 & TST \\
\hline CHEMBL1388470 & 688816 & 4.8 & 5.2139 & TST \\
\hline CHEMBL1407950 & 688816 & 5.0 & 4.9237 & TST \\
\hline CHEMBL1363507 & 688816 & 7.2503 & 5.4616 & TRN \\
\hline CHEMBL1419035 & 688816 & 8.301 & 5.0946 & TRN \\
\hline CHEMBL1343733 & 688816 & 5.1 & 5.402 & TRN \\
\hline CHEMBL1424630 & 688816 & 4.85 & 5.0889 & TRN \\
\hline CHEMBL1300250 & 688816 & 5.6 & 5.8274 & TRN \\
\hline CHEMBL1489149 & 688816 & 6.05 & 5.1369 & TRN \\
\hline CHEMBL1576836 & 688816 & 4.45 & 5.1816 & TRN \\
\hline CHEMBL1564271 & 688816 & 6.4 & 5.2893 & TRN \\
\hline CHEMBL1333349 & 688816 & 4.95 & 5.2637 & TRN \\
\hline CHEMBL1388494 & 688816 & 5.2 & 5.2087 & TST \\
\hline CHEMBL1311796 & 688816 & 4.45 & 5.4234 & TST \\
\hline CHEMBL1453826 & 688816 & 5.05 & 5.1462 & TST \\
\hline CHEMBL1333360 & 688816 & 4.7 & 5.3146 & TRN \\
\hline CHEMBL1419780 & 688816 & 4.9 & 5.391 & TRN \\
\hline CHEMBL1568695 & 688816 & 4.85 & 5.2828 & TRN \\
\hline CHEMBL1461119 & 688816 & 4.6 & 5.1228 & TRN \\
\hline CHEMBL1587104 & 688816 & 5.1 & 5.5704 & TRN \\
\hline CHEMBL1302207 & 688816 & 6.95 & 5.5694 & TRN \\
\hline CHEMBL1422097 & 688816 & 4.9 & 5.2431 & TRN \\
\hline CHEMBL1608237 & 688816 & 5.8 & 5.2143 & TRN \\
\hline CHEMBL1455756 & 688816 & 5.8 & 5.4617 & TRN \\
\hline CHEMBL1352145 & 688816 & 4.85 & 5.4943 & TRN \\
\hline CHEMBL1468573 & 688816 & 6.7501 & 5.6133 & TST \\
\hline CHEMBL1345243 & 688816 & 7.3002 & 5.2902 & TST \\
\hline CHEMBL1442702 & 688816 & 4.8 & 4.9802 & TRN \\
\hline CHEMBL3197633 & 688816 & 5.9 & 4.9619 & TST \\
\hline CHEMBL3212844 & 688816 & 4.85 & 5.3474 & TST \\
\hline CHEMBL1382411 & 688816 & 4.95 & 4.6237 & TRN \\
\hline CHEMBL1301526 & 688816 & 4.5 & 5.0543 & TRN \\
\hline CHEMBL1414490 & 688816 & 4.7 & 5.2841 & TRN \\
\hline CHEMBL1393182 & 688816 & 5.15 & 5.0994 & TRN \\
\hline CHEMBL1558547 & 688816 & 5.35 & 5.4443 & TST \\
\hline CHEMBL1498973 & 688816 & 5.1 & 4.8635 & TRN \\
\hline CHEMBL1544282 & 688816 & 5.4 & 4.8851 & TRN \\
\hline CHEMBL1442243 & 688816 & 4.65 & 5.2226 & TRN \\
\hline CHEMBL1581962 & 688816 & 5.0 & 5.4112 & TRN \\
\hline CHEMBL1385756 & 688816 & 5.25 & 5.7302 & TST \\
\hline CHEMBL1374755 & 688816 & 4.95 & 5.3191 & TRN \\
\hline CHEMBL1562033 & 688816 & 4.95 & 4.9691 & TRN \\
\hline CHEMBL1310570 & 688816 & 4.55 & 4.9961 & TRN \\
\hline CHEMBL1367081 & 688816 & 7.5003 & 5.3983 & TRN \\
\hline CHEMBL1524533 & 688816 & 4.9 & 5.1733 & TRN \\
\hline
\end{tabular}




\begin{tabular}{|c|c|c|c|c|c|}
\hline \multicolumn{6}{|c|}{ Supplemental Table S2.txt } \\
\hline CHEMBL1528030 & 688816 & 4.45 & 5.0174 & TRN & \\
\hline CHEMBL1422813 & 688816 & 7.699 & 5.3996 & TRN & \\
\hline CHEMBL1573665 & 688816 & 4.8 & 5.2878 & TRN & \\
\hline CHEMBL1493488 & 688816 & 5.1 & 5.4727 & TST & \\
\hline CHEMBL1594568 & 688816 & 8.301 & 4.9642 & TST & \\
\hline CHEMBL1481415 & 688816 & 5.45 & 5.0015 & TRN & \\
\hline CHEMBL1311206 & 688816 & 4.45 & 5.50299 & 9999999999 & TRN \\
\hline CHEMBL1594342 & 688816 & 5.05 & 5.2289 & TST & \\
\hline CHEMBL1570262 & 688816 & 7.0 & 5.5469 & TRN & \\
\hline CHEMBL1463272 & 688816 & 4.8 & 5.1968 & TRN & \\
\hline CHEMBL1370909 & 688816 & 5.05 & 4.8113 & TRN & \\
\hline CHEMBL1391966 & 688816 & 4.45 & 5.2234 & TRN & \\
\hline CHEMBL1542791 & 688816 & 4.95 & 5.1328 & TRN & \\
\hline CHEMBL1436230 & 688816 & 5.0 & 5.2492 & TRN & \\
\hline CHEMBL1288106 & 688816 & 5.5 & 4.9046 & TST & \\
\hline CHEMBL1401734 & 688816 & 5.3 & 5.1154 & TRN & \\
\hline CHEMBL1479641 & 688816 & 6.5501 & 5.809 & TRN & \\
\hline CHEMBL1299759 & 688816 & 5.5 & 5.3303 & TRN & \\
\hline CHEMBL3195128 & 688816 & 4.95 & 5.0656 & TRN & \\
\hline CHEMBL1438308 & 688816 & 4.9 & 5.1615 & TRN & \\
\hline CHEMBL1567495 & 688816 & 5.55 & 5.2637 & TRN & \\
\hline CHEMBL1387940 & 688816 & 4.65 & 5.49100 & 00000000005 & TRN \\
\hline CHEMBL1579535 & 688816 & 4.45 & 5.24 & TST & \\
\hline CHEMBL1405099 & 688816 & 5.05 & 5.3794 & TST & \\
\hline CHEMBL1348775 & 688816 & 4.8 & 5.3094 & TST & \\
\hline CHEMBL1542660 & 688816 & 4.85 & 5.1424 & TRN & \\
\hline CHEMBL1430023 & 688816 & 6.5 & 5.2948 & TRN & \\
\hline CHEMBL1404882 & 688816 & 4.95 & 5.0449 & TRN & \\
\hline CHEMBL1571804 & 688816 & 4.9 & 4.947 & TRN & \\
\hline CHEMBL1513053 & 688816 & 5.5 & 5.3962 & TRN & \\
\hline CHEMBL1241420 & 688816 & 4.45 & 4.9771 & TST & \\
\hline CHEMBL112060 & 688816 & 4.7 & 4.9052 & TRN & \\
\hline CHEMBL1414183 & 688816 & 4.9 & 5.0936 & TRN & \\
\hline CHEMBL1426936 & 688816 & 4.95 & 5.5816 & TRN & \\
\hline CHEMBL1432672 & 688816 & 4.45 & 5.02800 & 00000000005 & TRN \\
\hline CHEMBL1503034 & 688816 & 4.7 & 5.0016 & TRN & \\
\hline CHEMBL1375958 & 688816 & 4.6 & 5.0336 & TRN & \\
\hline CHEMBL1328408 & 688816 & 5.8 & 5.3447 & TRN & \\
\hline CHEMBL1443564 & 688816 & 4.95 & 5.1691 & TRN & \\
\hline CHEMBL1430742 & 688816 & 4.45 & 5.5017 & TST & \\
\hline CHEMBL1435313 & 688816 & 5.95 & 6.4033 & TST & \\
\hline CHEMBL1587179 & 688816 & 4.9 & 4.8056 & TST & \\
\hline CHEMBL1610733 & 688816 & 4.45 & 4.9151 & TRN & \\
\hline CHEMBL1532372 & 688816 & 4.75 & 5.1707 & TST & \\
\hline CHEMBL69003 & 688816 & 5.0 & 5.4057 & TRN & \\
\hline CHEMBL579550 & 688816 & 5.05 & 4.9168 & TRN & \\
\hline CHEMBL1431072 & 688816 & 4.45 & 5.369 & TRN & \\
\hline CHEMBL1468409 & 688816 & 6.25 & 5.6205 & TRN & \\
\hline
\end{tabular}




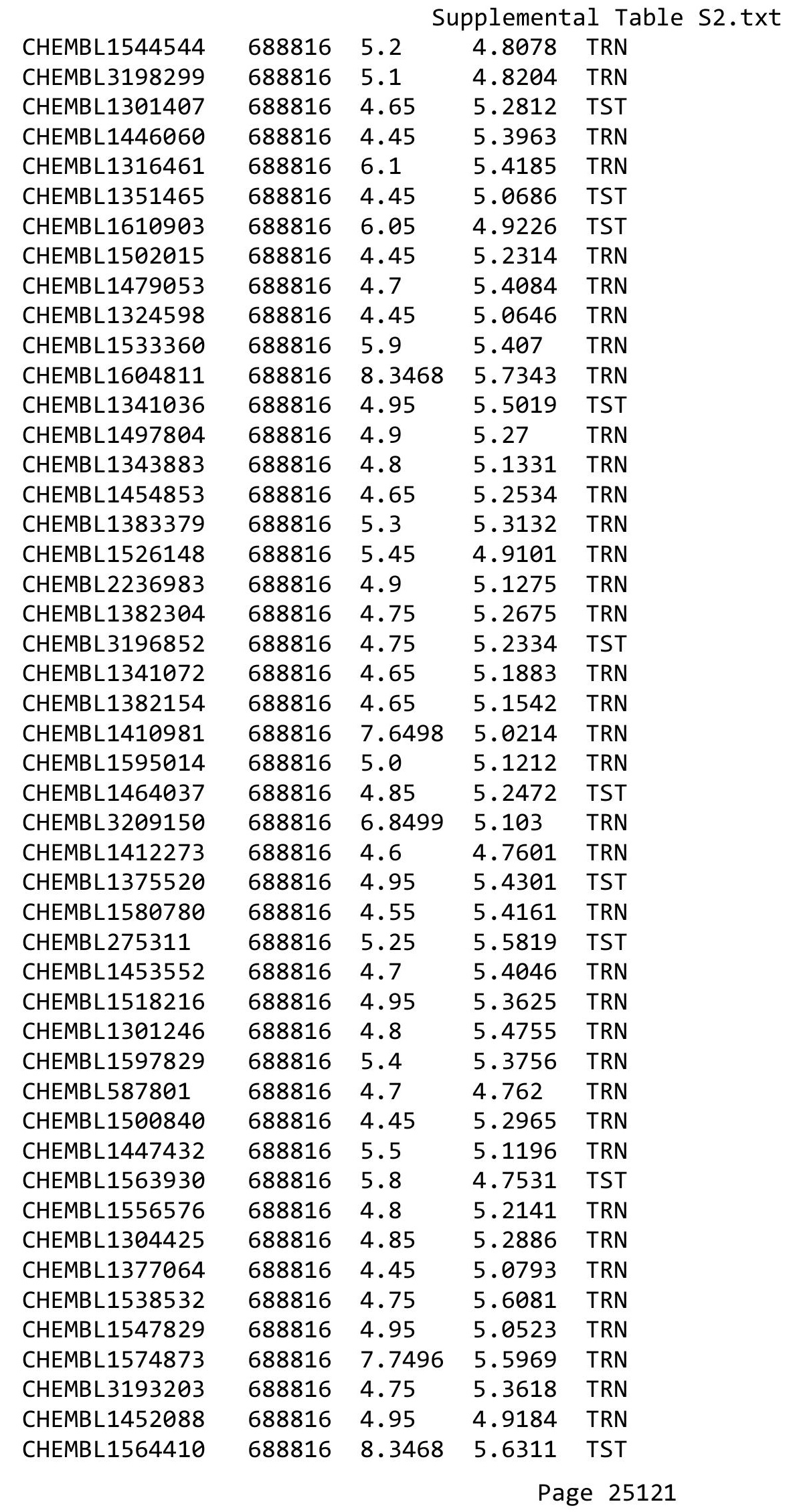




\begin{tabular}{|c|c|c|c|c|c|}
\hline \multicolumn{6}{|c|}{ Supplemental Table S2.txt } \\
\hline CHEMBL1322698 & 688816 & 4.75 & 5.1704 & TRN & \\
\hline CHEMBL1396485 & 688816 & 5.6 & 5.2248 & TRN & \\
\hline CHEMBL1504143 & 688816 & 8.2518 & 5.6627 & TST & \\
\hline CHEMBL1580667 & 688816 & 6.7501 & 5.1109 & TST & \\
\hline CHEMBL1444006 & 688816 & 5.15 & 5.2883 & TRN & \\
\hline CHEMBL1729277 & 688816 & 4.85 & 5.4286 & TST & \\
\hline CHEMBL3195869 & 688816 & 5.0 & 5.5027 & TRN & \\
\hline CHEMBL195008 & 688816 & 4.9 & 5.2783 & TST & \\
\hline CHEMBL 3210228 & 688816 & 4.45 & 5.0145 & TRN & \\
\hline CHEMBL1353015 & 688816 & 4.45 & 5.3324 & TRN & \\
\hline CHEMBL1605875 & 688816 & 5.1 & 4.9534 & TRN & \\
\hline CHEMBL1547847 & 688816 & 4.8 & 4.8056 & TRN & \\
\hline CHEMBL1380683 & 688816 & 4.65 & 5.4193 & TRN & \\
\hline CHEMBL1588349 & 688816 & 4.8 & 5.0828 & TRN & \\
\hline CHEMBL1399429 & 688816 & 6.0 & 5.2409 & TRN & \\
\hline CHEMBL1484902 & 688816 & 4.75 & 5.1599 & TRN & \\
\hline CHEMBL1443775 & 688816 & 4.45 & 5.0811 & TRN & \\
\hline CHEMBL1357827 & 688816 & 4.75 & 5.034 & TRN & \\
\hline CHEMBL1479953 & 688816 & 5.3 & 5.3395 & TRN & \\
\hline CHEMBL1470523 & 688816 & 4.5 & 5.6065 & TRN & \\
\hline CHEMBL1520777 & 688816 & 5.25 & 5.0464 & TST & \\
\hline CHEMBL1463307 & 688816 & 5.4 & 5.6021 & TRN & \\
\hline CHEMBL1485512 & 688816 & 6.3 & 5.695 & TRN & \\
\hline CHEMBL1419363 & 688816 & 4.95 & 5.0227 & TRN & \\
\hline CHEMBL1419608 & 688816 & 4.95 & 5.1476 & TRN & \\
\hline CHEMBL1606927 & 688816 & 4.65 & 5.1675 & TST & \\
\hline CHEMBL1544497 & 688816 & 4.8 & 5.3932 & TRN & \\
\hline CHEMBL1379828 & 688816 & 5.1 & 5.15 & TRN & \\
\hline CHEMBL1399332 & 688816 & 4.45 & 5.2225 & TRN & \\
\hline CHEMBL1526257 & 688816 & 4.7 & 5.3913 & TST & \\
\hline CHEMBL1329715 & 688816 & 4.85 & 5.1938 & TRN & \\
\hline CHEMBL1492633 & 688816 & 5.0 & 5.1268 & TRN & \\
\hline CHEMBL1507537 & 688816 & 4.85 & 5.4273 & TRN & \\
\hline CHEMBL1569094 & 688816 & 4.9 & 5.3188 & TST & \\
\hline CHEMBL1486228 & 688816 & 8.3468 & 5.15600 & 0000000001 & TRN \\
\hline CHEMBL1499310 & 688816 & 4.75 & 5.2968 & TRN & \\
\hline CHEMBL1578021 & 688816 & 4.75 & 5.1485 & TRN & \\
\hline CHEMBL1383476 & 688816 & 5.0 & 4.9553 & TRN & \\
\hline CHEMBL1418755 & 688816 & 4.45 & 4.931 & TST & \\
\hline CHEMBL1499374 & 688816 & 8.301 & 5.6073 & TRN & \\
\hline CHEMBL1518248 & 688816 & 4.45 & 5.36100 & 0000000001 & TRN \\
\hline CHEMBL1403852 & 688816 & 5.25 & 5.4941 & TRN & \\
\hline CHEMBL1389229 & 688816 & 5.6 & 5.1653 & TST & \\
\hline CHEMBL1325888 & 688816 & 5.0 & 5.1958 & TRN & \\
\hline CHEMBL1483860 & 688816 & 5.95 & 5.08 & TST & \\
\hline CHEMBL3194487 & 688816 & 4.9 & 4.9719 & TRN & \\
\hline CHEMBL1492122 & 688816 & 4.85 & 5.171 & TRN & \\
\hline CHEMBL1507845 & 688816 & 4.45 & 5.0517 & TRN & \\
\hline
\end{tabular}




\begin{tabular}{|c|c|c|c|c|c|}
\hline \multicolumn{6}{|c|}{ Supplemental Table s2.txt } \\
\hline CHEMBL1395018 & 688816 & 4.45 & 5.1159 & TRN & \\
\hline CHEMBL1373362 & 688816 & 5.25 & 5.4963 & TRN & \\
\hline CHEMBL1584645 & 688816 & 7.6003 & 5.5413 & TRN & \\
\hline CHEMBL1610366 & 688816 & 8.4949 & 5.3763 & TRN & \\
\hline CHEMBL1419684 & 688816 & 4.95 & 5.3703 & TRN & \\
\hline CHEMBL1575002 & 688816 & 4.95 & 4.9646 & TST & \\
\hline CHEMBL1575604 & 688816 & 8.301 & 5.3715 & TST & \\
\hline CHEMBL1394271 & 688816 & 4.95 & 4.9392 & TRN & \\
\hline CHEMBL1306439 & 688816 & 4.9 & 5.4419 & TRN & \\
\hline CHEMBL1350660 & 688816 & 5.4 & 5.1907 & TST & \\
\hline CHEMBL1581590 & 688816 & 4.95 & 5.2838 & TRN & \\
\hline CHEMBL1589520 & 688816 & 7.2503 & 5.1397 & TST & \\
\hline CHEMBL1387681 & 688816 & 4.75 & 5.0884 & TRN & \\
\hline CHEMBL1399193 & 688816 & 5.55 & 5.2097 & TRN & \\
\hline CHEMBL1505469 & 688816 & 4.85 & 4.8648 & TRN & \\
\hline CHEMBL15193 & 688816 & 6.0 & 5.2159 & TST & \\
\hline CHEMBL3198008 & 688816 & 4.45 & 5.0388 & TRN & \\
\hline CHEMBL1601220 & 688816 & 4.85 & 5.4079 & TRN & \\
\hline CHEMBL1535150 & 688816 & 5.45 & 5.0854 & TRN & \\
\hline CHEMBL1390065 & 688816 & 5.1 & 5.3808 & TRN & \\
\hline CHEMBL1572503 & 688816 & 4.9 & 5.0236 & TRN & \\
\hline CHEMBL1490089 & 688816 & 7.9508 & 5.2047 & TRN & \\
\hline CHEMBL1499152 & 688816 & 5.55 & 5.1914 & TRN & \\
\hline CHEMBL3193831 & 688816 & 4.65 & 5.2442 & TRN & \\
\hline CHEMBL1585059 & 688816 & 4.75 & 5.4757 & TST & \\
\hline CHEMBL1475620 & 688816 & 4.6 & 5.1284 & TST & \\
\hline CHEMBL1555019 & 688816 & 4.6 & 5.3371 & TST & \\
\hline CHEMBL1496825 & 688816 & 8.3979 & 5.61799 & 9999999999 & TRN \\
\hline CHEMBL1363016 & 688816 & 5.7 & 5.2988 & TRN & \\
\hline CHEMBL1364725 & 688816 & 5.1 & 5.0514 & TST & \\
\hline CHEMBL3195772 & 688816 & 4.95 & 5.3783 & TST & \\
\hline CHEMBL1400177 & 688816 & 5.25 & 5.2713 & TRN & \\
\hline CHEMBL1510261 & 688816 & 4.95 & 5.0696 & TRN & \\
\hline CHEMBL3210467 & 688816 & 6.6 & 5.2952 & TST & \\
\hline CHEMBL1596319 & 688816 & 5.25 & 5.093 & TRN & \\
\hline CHEMBL1579025 & 688816 & 7.6498 & 5.3986 & TST & \\
\hline CHEMBL1452420 & 688816 & 5.05 & 5.8084 & TRN & \\
\hline CHEMBL1530831 & 688816 & 5.45 & 5.1154 & TRN & \\
\hline CHEMBL3210690 & 688816 & 8.301 & 5.5152 & TST & \\
\hline CHEMBL1536738 & 688816 & 5.35 & 5.4515 & TST & \\
\hline CHEMBL1507139 & 688816 & 5.35 & 5.3338 & TRN & \\
\hline CHEMBL1462302 & 688816 & 5.0 & 5.1784 & TRN & \\
\hline CHEMBL1502706 & 688816 & 4.9 & 5.2532 & TRN & \\
\hline CHEMBL1528207 & 688816 & 4.85 & 5.1433 & TRN & \\
\hline CHEMBL1425684 & 688816 & 4.9 & 4.9078 & TRN & \\
\hline CHEMBL3192885 & 688816 & 5.0 & 5.3708 & TRN & \\
\hline CHEMBL1410494 & 688816 & 5.1 & 5.11600 & 00000000005 & TST \\
\hline CHEMBL1495959 & 688816 & 6.3 & 5.5112 & TRN & \\
\hline & & & & 25123 & \\
\hline
\end{tabular}




\begin{tabular}{|c|c|c|c|c|c|}
\hline & & \multicolumn{4}{|c|}{ Supplemental Table S2.txt } \\
\hline CHEMBL1394349 & 688816 & 4.45 & 5.45299 & 9999999999 & TRN \\
\hline CHEMBL1392033 & 688816 & 5.3 & 5.1389 & TRN & \\
\hline CHEMBL1476684 & 688816 & 4.75 & 5.4019 & TST & \\
\hline CHEMBL1308584 & 688816 & 7.15 & 5.3797 & TRN & \\
\hline CHEMBL1380737 & 688816 & 8.2518 & 5.606 & TRN & \\
\hline CHEMBL3193629 & 688816 & 4.75 & 5.1886 & TRN & \\
\hline CHEMBL1343517 & 688816 & 5.45 & 5.4057 & TRN & \\
\hline CHEMBL1326110 & 688816 & 5.45 & 5.2298 & TRN & \\
\hline CHEMBL1416387 & 688816 & 4.95 & 5.2333 & TRN & \\
\hline CHEMBL1456899 & 688816 & 4.45 & 4.8685 & TRN & \\
\hline CHEMBL1999481 & 688816 & 5.75 & 5.3853 & TRN & \\
\hline CHEMBL1341474 & 688816 & 4.8 & 5.1335 & TRN & \\
\hline CHEMBL1452153 & 688816 & 4.95 & 5.136 & TRN & \\
\hline CHEMBL1502330 & 688816 & 4.45 & 5.6386 & TRN & \\
\hline CHEMBL1307425 & 688816 & 4.95 & 5.5481 & TST & \\
\hline CHEMBL3208242 & 688816 & 7.699 & 5.66100 & 00000000005 & TST \\
\hline CHEMBL1539205 & 688816 & 4.45 & 5.2974 & TRN & \\
\hline CHEMBL1518575 & 688816 & 5.25 & 5.3765 & TRN & \\
\hline CHEMBL1386656 & 688816 & 4.95 & 5.2315 & TRN & \\
\hline CHEMBL1356196 & 688816 & 4.75 & 5.3654 & TRN & \\
\hline CHEMBL1607620 & 688816 & 4.7 & 5.2769 & TST & \\
\hline CHEMBL1439722 & 688816 & 4.9 & 5.2147 & TRN & \\
\hline CHEMBL1388015 & 688816 & 4.5 & 5.1141 & TRN & \\
\hline CHEMBL1475880 & 688816 & 4.8 & 5.1894 & TRN & \\
\hline CHEMBL1418298 & 688816 & 8.301 & 4.9762 & TRN & \\
\hline CHEMBL1524133 & 688816 & 4.95 & 5.2795 & TRN & \\
\hline CHEMBL1587070 & 688816 & 4.95 & 5.1824 & TST & \\
\hline CHEMBL1597187 & 688816 & 4.7 & 5.3629 & TRN & \\
\hline CHEMBL1574813 & 688816 & 4.9 & 5.0866 & TRN & \\
\hline CHEMBL1554639 & 688816 & 5.2 & 4.7509 & TRN & \\
\hline CHEMBL3209936 & 688816 & 4.65 & 5.2112 & TRN & \\
\hline CHEMBL1443819 & 688816 & 5.85 & 5.6657 & TRN & \\
\hline CHEMBL1498249 & 688816 & 5.1 & 5.4791 & TRN & \\
\hline CHEMBL3190293 & 688816 & 4.75 & 4.8037 & TRN & \\
\hline CHEMBL1445652 & 688816 & 4.55 & 4.9659 & TRN & \\
\hline CHEMBL1428244 & 688816 & 4.95 & 5.2211 & TRN & \\
\hline CHEMBL1581252 & 688816 & 4.8 & 5.8456 & TRN & \\
\hline CHEMBL1343248 & 688816 & 6.0 & 5.4755 & TRN & \\
\hline CHEMBL1428813 & 688816 & 5.25 & 5.1405 & TRN & \\
\hline CHEMBL1492188 & 688816 & 5.0 & 5.1719 & TRN & \\
\hline CHEMBL492010 & 688816 & 4.95 & 5.2384 & TRN & \\
\hline CHEMBL1480147 & 688816 & 5.2 & 5.2348 & TRN & \\
\hline CHEMBL1310561 & 688816 & 8.3468 & 5.5259 & TST & \\
\hline CHEMBL1370720 & 688816 & 5.15 & 5.3382 & TRN & \\
\hline CHEMBL1433340 & 688816 & 4.95 & 5.0373 & TST & \\
\hline CHEMBL1378821 & 688816 & 4.95 & 5.477 & TST & \\
\hline CHEMBL1545634 & 688816 & 5.65 & 5.2503 & TST & \\
\hline CHEMBL1496347 & 688816 & 4.9 & 4.8205 & TRN & \\
\hline
\end{tabular}




\begin{tabular}{|c|c|c|c|c|c|}
\hline \multirow[b]{2}{*}{ CHEMBL1536361 } & \multicolumn{5}{|c|}{ Supplemental Table S2.txt } \\
\hline & 688816 & 4.85 & 5.159 & TRN & \\
\hline CHEMBL1396899 & 688816 & 4.95 & 4.9799 & TRN & \\
\hline CHEMBL1495457 & 688816 & 5.25 & 5.189 & TRN & \\
\hline CHEMBL1975109 & 688816 & 4.85 & 5.3176 & TRN & \\
\hline CHEMBL1373658 & 688816 & 4.75 & 5.57600 & 00000000005 & TST \\
\hline CHEMBL1504798 & 688816 & 4.8 & 4.9383 & TRN & \\
\hline CHEMBL1403598 & 688816 & 4.45 & 5.1861 & TRN & \\
\hline CHEMBL3193406 & 688816 & 4.6 & 5.4289 & TRN & \\
\hline CHEMBL1346595 & 688816 & 5.0 & 4.7121 & TST & \\
\hline CHEMBL3212798 & 688816 & 4.95 & 5.5509 & TRN & \\
\hline CHEMBL1575435 & 688816 & 4.65 & 4.9833 & TRN & \\
\hline CHEMBL1358857 & 688816 & 4.85 & 4.8885 & TRN & \\
\hline CHEMBL1542915 & 688816 & 4.85 & 5.1773 & TST & \\
\hline CHEMBL1339319 & 688816 & 4.95 & 5.2818 & TST & \\
\hline CHEMBL1476170 & 688816 & 6.0 & 5.4981 & TRN & \\
\hline CHEMBL1362753 & 688816 & 4.9 & 5.4773 & TST & \\
\hline CHEMBL1429744 & 688816 & 4.95 & 5.0374 & TRN & \\
\hline CHEMBL1464671 & 688816 & 4.45 & 5.0395 & TRN & \\
\hline CHEMBL1548773 & 688816 & 7.0 & 5.3429 & TRN & \\
\hline CHEMBL1522932 & 688816 & 7.8013 & 5.3653 & TRN & \\
\hline CHEMBL1500966 & 688816 & 4.85 & 5.2234 & TRN & \\
\hline CHEMBL1594615 & 688816 & 4.45 & 5.1041 & TRN & \\
\hline CHEMBL1570881 & 688816 & 4.6 & 4.9228 & TRN & \\
\hline CHEMBL1492738 & 688816 & 5.95 & 5.2522 & TRN & \\
\hline CHEMBL1361689 & 688816 & 5.0 & 4.9604 & TRN & \\
\hline CHEMBL3213438 & 688816 & 6.8 & 5.6427 & TRN & \\
\hline CHEMBL1432344 & 688816 & 6.5 & 5.4137 & TRN & \\
\hline CHEMBL1506811 & 688816 & 4.9 & 5.1577 & TRN & \\
\hline CHEMBL1427595 & 688816 & 4.8 & 5.0101 & TRN & \\
\hline CHEMBL1490615 & 688816 & 4.7 & 4.815 & TRN & \\
\hline CHEMBL1581798 & 688816 & 4.65 & 4.8044 & TRN & \\
\hline CHEMBL1556061 & 688816 & 7.4498 & 5.4405 & TRN & \\
\hline CHEMBL1534942 & 688816 & 4.95 & 5.2236 & TRN & \\
\hline CHEMBL1389747 & 688816 & 5.05 & 5.4165 & TRN & \\
\hline CHEMBL1334636 & 688816 & 4.9 & 4.6902 & TRN & \\
\hline CHEMBL1570474 & 688816 & 4.95 & 5.2931 & TRN & \\
\hline CHEMBL1594282 & 688816 & 5.5 & 5.0855 & TRN & \\
\hline CHEMBL1390411 & 688816 & 7.699 & 5.487 & TST & \\
\hline CHEMBL1367717 & 688816 & 7.2503 & 5.0655 & TRN & \\
\hline CHEMBL3192977 & 688816 & 4.45 & 5.3628 & TRN & \\
\hline CHEMBL1528263 & 688816 & 5.65 & 5.4109 & TRN & \\
\hline CHEMBL1534654 & 688816 & 4.65 & 5.2729 & TST & \\
\hline CHEMBL1360539 & 688816 & 4.8 & 5.1614 & TRN & \\
\hline CHEMBL1575120 & 688816 & 5.5 & 5.2183 & TRN & \\
\hline CHEMBL1385088 & 688816 & 5.0 & 4.9889 & TRN & \\
\hline CHEMBL1510601 & 688816 & 4.5 & 5.3995 & TRN & \\
\hline CHEMBL1371856 & 688816 & 7.699 & 5.4745 & TRN & \\
\hline CHEMBL1600310 & 688816 & 8.2007 & 5.1969 & TRN & \\
\hline
\end{tabular}




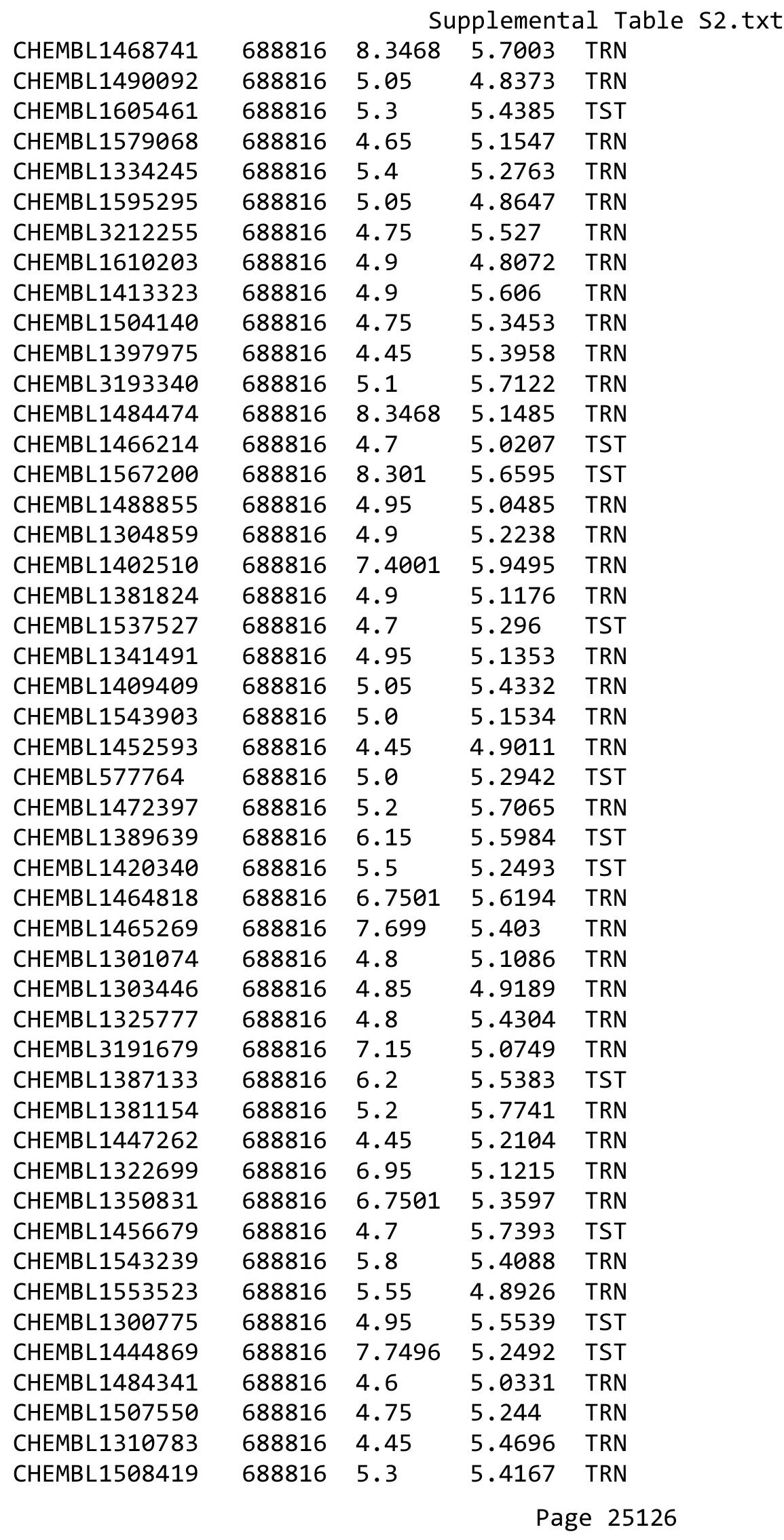




\begin{tabular}{|c|c|c|c|c|c|}
\hline \multicolumn{6}{|c|}{ Supplemental Table s2.txt } \\
\hline CHEMBL1517627 & 688816 & 6.95 & 4.9568 & TRN & \\
\hline CHEMBL1539239 & 688816 & 4.45 & 5.2366 & TRN & \\
\hline CHEMBL3192212 & 688816 & 4.8 & 5.3979 & TRN & \\
\hline CHEMBL3195603 & 688816 & 4.9 & 5.1911 & TST & \\
\hline CHEMBL1515344 & 688816 & 4.95 & 5.4024 & TRN & \\
\hline CHEMBL1508400 & 688816 & 6.0 & 6.0314 & TRN & \\
\hline CHEMBL1387098 & 688816 & 6.1 & 5.3082 & TRN & \\
\hline CHEMBL1567125 & 688816 & 4.95 & 5.2755 & TRN & \\
\hline CHEMBL1414384 & 688816 & 5.0 & 5.2124 & TRN & \\
\hline CHEMBL1351040 & 688816 & 4.6 & 5.4816 & TRN & \\
\hline CHEMBL1379751 & 688816 & 4.8 & 5.0988 & TRN & \\
\hline CHEMBL1612486 & 688816 & 5.0 & 5.3714 & TRN & \\
\hline CHEMBL1495183 & 688816 & 4.9 & 5.0992 & TRN & \\
\hline CHEMBL1503301 & 688816 & 5.55 & 5.164 & TST & \\
\hline CHEMBL1420838 & 688816 & 5.05 & 5.2823 & TRN & \\
\hline CHEMBL1442502 & 688816 & 4.95 & 5.2311 & TRN & \\
\hline CHEMBL1429787 & 688816 & 7.8013 & 5.1808 & TRN & \\
\hline CHEMBL1335031 & 688816 & 6.7501 & 5.3918 & TST & \\
\hline CHEMBL1558557 & 688816 & 4.45 & 5.5535 & TRN & \\
\hline CHEMBL1511497 & 688816 & 4.45 & 5.0741 & TRN & \\
\hline CHEMBL3198442 & 688816 & 5.85 & 5.8288 & TST & \\
\hline CHEMBL1603209 & 688816 & 4.5 & 5.1739 & TRN & \\
\hline CHEMBL1489444 & 688816 & 5.55 & 5.1161 & TRN & \\
\hline CHEMBL1500357 & 688816 & 6.7001 & 5.95200 & 3000000001 & TST \\
\hline CHEMBL1540230 & 688816 & 5.0 & 5.0408 & TRN & \\
\hline CHEMBL1402917 & 688816 & 4.7 & 5.2499 & TST & \\
\hline CHEMBL1407659 & 688816 & 5.15 & 5.2048 & TRN & \\
\hline CHEMBL1479486 & 688816 & 4.85 & 4.9722 & TRN & \\
\hline CHEMBL1585927 & 688816 & 4.9 & 5.5313 & TRN & \\
\hline CHEMBL1467411 & 688816 & 5.0 & 5.2249 & TRN & \\
\hline CHEMBL1423660 & 688816 & 6.3 & 5.4174 & TRN & \\
\hline CHEMBL1612983 & 688816 & 4.75 & 5.3588 & TRN & \\
\hline CHEMBL1377607 & 688816 & 5.85 & 5.444 & TRN & \\
\hline CHEMBL1428626 & 688816 & 4.75 & 5.2054 & TST & \\
\hline CHEMBL1419992 & 688816 & 8.3468 & 5.3556 & TRN & \\
\hline CHEMBL1387964 & 688816 & 5.35 & 5.3665 & TRN & \\
\hline CHEMBL1508453 & 688816 & 4.6 & 5.5736 & TST & \\
\hline CHEMBL1494650 & 688816 & 5.15 & 5.0939 & TRN & \\
\hline CHEMBL1350110 & 688816 & 5.35 & 5.5049 & TST & \\
\hline CHEMBL1561198 & 688816 & 6.0 & 5.29700 & 0000000001 & TRN \\
\hline CHEMBL3199057 & 688816 & 4.6 & 5.0737 & TST & \\
\hline CHEMBL1302750 & 688816 & 4.65 & 5.5434 & TST & \\
\hline CHEMBL1362562 & 688816 & 4.45 & 5.0356 & TRN & \\
\hline CHEMBL1361887 & 688816 & 4.5 & 5.1465 & TST & \\
\hline CHEMBL1409954 & 688816 & 4.85 & 5.11600 & 00000000005 & TRN \\
\hline CHEMBL1571615 & 688816 & 5.1 & 5.0275 & TRN & \\
\hline CHEMBL1566952 & 688816 & 4.45 & 4.945 & TRN & \\
\hline CHEMBL1393007 & 688816 & 4.95 & 5.2717 & TST & \\
\hline
\end{tabular}




\begin{tabular}{|c|c|c|c|c|c|}
\hline \multirow[b]{2}{*}{ CHEMBL1578946 } & \multicolumn{5}{|c|}{ Supplemental Table s2.txt } \\
\hline & 688816 & 4.75 & 4.9962 & TRN & \\
\hline CHEMBL1504620 & 688816 & 5.05 & 5.2725 & TRN & \\
\hline CHEMBL1971935 & 688816 & 5.35 & 5.2319 & TRN & \\
\hline CHEMBL1560125 & 688816 & 7.5003 & 5.0505 & TST & \\
\hline CHEMBL1893861 & 688816 & 4.8 & 5.11100 & 0000000001 & TRN \\
\hline CHEMBL1573963 & 688816 & 6.15 & 5.6003 & TRN & \\
\hline CHEMBL1506407 & 688816 & 5.6 & 4.9839 & TRN & \\
\hline CHEMBL1540271 & 688816 & 5.85 & 5.4681 & TRN & \\
\hline CHEMBL261692 & 688816 & 4.5 & 5.2471 & TRN & \\
\hline CHEMBL1312170 & 688816 & 5.0 & 5.3202 & TRN & \\
\hline CHEMBL1450197 & 688816 & 7.15 & 5.6925 & TRN & \\
\hline CHEMBL3209375 & 688816 & 8.3468 & 5.5453 & TRN & \\
\hline CHEMBL1403985 & 688816 & 4.6 & 5.0122 & TRN & \\
\hline CHEMBL1971267 & 688816 & 5.8 & 5.5651 & TRN & \\
\hline CHEMBL1442133 & 688816 & 5.4 & 5.8124 & TRN & \\
\hline CHEMBL1515501 & 688816 & 4.95 & 5.0961 & TRN & \\
\hline CHEMBL1327924 & 688816 & 5.0 & 4.9861 & TRN & \\
\hline CHEMBL1338865 & 688816 & 4.95 & 5.0126 & TRN & \\
\hline CHEMBL1609953 & 688816 & 6.7001 & 5.3761 & TRN & \\
\hline CHEMBL1491026 & 688816 & 4.85 & 4.9795 & TRN & \\
\hline CHEMBL1518706 & 688816 & 4.45 & 5.3022 & TST & \\
\hline CHEMBL1502745 & 688816 & 4.9 & 4.8826 & TRN & \\
\hline CHEMBL1378104 & 688816 & 7.6498 & 5.4513 & TST & \\
\hline CHEMBL1525320 & 688816 & 5.25 & 5.358 & TRN & \\
\hline CHEMBL1336400 & 688816 & 4.45 & 5.4818 & TRN & \\
\hline CHEMBL1337016 & 688816 & 4.7 & 5.1975 & TRN & \\
\hline CHEMBL1299495 & 688816 & 4.7 & 5.1094 & TST & \\
\hline CHEMBL1347552 & 688816 & 6.25 & 5.0898 & TST & \\
\hline CHEMBL1421602 & 688816 & 4.85 & 5.3104 & TRN & \\
\hline CHEMBL1315699 & 688816 & 4.85 & 4.9651 & TRN & \\
\hline CHEMBL1576234 & 688816 & 6.05 & 5.2987 & TST & \\
\hline CHEMBL3189985 & 688816 & 6.0 & 5.2078 & TST & \\
\hline CHEMBL1606956 & 688816 & 5.15 & 5.0294 & TRN & \\
\hline CHEMBL1419748 & 688816 & 8.4949 & 5.2721 & TRN & \\
\hline CHEMBL1531236 & 688816 & 5.3 & 5.3398 & TRN & \\
\hline CHEMBL1573243 & 688816 & 4.9 & 5.1309 & TRN & \\
\hline CHEMBL1608066 & 688816 & 4.95 & 5.52 & TRN & \\
\hline CHEMBL1410239 & 688816 & 6.15 & 5.3898 & TRN & \\
\hline CHEMBL1581102 & 688816 & 4.75 & 5.3063 & TRN & \\
\hline CHEMBL1540779 & 688816 & 4.6 & 5.0359 & TRN & \\
\hline CHEMBL1355172 & 688816 & 4.95 & 4.90600 & 0000000001 & TRN \\
\hline CHEMBL1442997 & 688816 & 4.95 & 4.9275 & TRN & \\
\hline CHEMBL1527596 & 688816 & 6.0 & 5.5192 & TST & \\
\hline CHEMBL1488285 & 688816 & 4.75 & 5.1345 & TST & \\
\hline CHEMBL186784 & 688816 & 4.9 & 5.2875 & TRN & \\
\hline CHEMBL1485450 & 688816 & 5.0 & 5.10800 & 00000000005 & TST \\
\hline CHEMBL1402122 & 688816 & 7.8996 & 5.2304 & TST & \\
\hline CHEMBL1464833 & 688816 & 4.95 & 5.17399 & 99999999995 & TRN \\
\hline & & & & $2512 \varepsilon$ & \\
\hline
\end{tabular}




\begin{tabular}{|c|c|c|c|c|c|}
\hline \multicolumn{6}{|c|}{ Supplemental Table S2.txt } \\
\hline CHEMBL1307390 & 688816 & 4.45 & 5.4835 & TRN & \\
\hline CHEMBL1365070 & 688816 & 4.9 & 4.9929 & TST & \\
\hline CHEMBL1331686 & 688816 & 5.05 & 5.2494 & TRN & \\
\hline CHEMBL1584343 & 688816 & 4.45 & 5.4426 & TRN & \\
\hline CHEMBL1509958 & 688816 & 4.95 & 4.959 & TRN & \\
\hline CHEMBL1573699 & 688816 & 5.5 & 5.3839 & TRN & \\
\hline CHEMBL1575687 & 688816 & 5.25 & 5.3237 & TST & \\
\hline CHEMBL1453442 & 688816 & 5.45 & 5.6904 & TST & \\
\hline CHEMBL1315914 & 688816 & 4.45 & 5.1192 & TST & \\
\hline CHEMBL1302516 & 688816 & 4.95 & 4.9921 & TRN & \\
\hline CHEMBL1377223 & 688816 & 5.25 & 5.3817 & TRN & \\
\hline CHEMBL1380498 & 688816 & 4.4 & 5.3383 & TRN & \\
\hline CHEMBL1506622 & 688816 & 4.75 & 4.6219 & TST & \\
\hline CHEMBL1416253 & 688816 & 4.95 & 5.3974 & TRN & \\
\hline CHEMBL1501787 & 688816 & 5.05 & 5.1692 & TRN & \\
\hline CHEMBL1527586 & 688816 & 4.45 & 5.0683 & TRN & \\
\hline CHEMBL1355134 & 688816 & 4.75 & 5.2221 & TST & \\
\hline CHEMBL1328169 & 688816 & 4.65 & 5.2739 & TRN & \\
\hline CHEMBL1546598 & 688816 & 7.5498 & 5.0769 & TRN & \\
\hline CHEMBL1354188 & 688816 & 4.45 & 5.3377 & TST & \\
\hline CHEMBL1461357 & 688816 & 5.35 & 5.5874 & TST & \\
\hline CHEMBL1556312 & 688816 & 4.85 & 5.5822 & TST & \\
\hline CHEMBL1349389 & 688816 & 4.5 & 5.1498 & TRN & \\
\hline CHEMBL1425105 & 688816 & 5.5 & 5.3314 & TRN & \\
\hline CHEMBL1339806 & 688816 & 4.9 & 4.9696 & TRN & \\
\hline CHEMBL1526147 & 688816 & 4.8 & 5.54200 & 0000000001 & TRN \\
\hline CHEMBL1544714 & 688816 & 7.5498 & 5.1925 & TRN & \\
\hline CHEMBL1427464 & 688816 & 6.25 & 5.0168 & TRN & \\
\hline CHEMBL1521747 & 688816 & 4.7 & 5.2973 & TRN & \\
\hline CHEMBL1571018 & 688816 & 5.85 & 5.0365 & TRN & \\
\hline CHEMBL1384867 & 688816 & 5.25 & 5.3387 & TRN & \\
\hline CHEMBL1382410 & 688816 & 4.7 & 5.01399 & 9999999999 & TRN \\
\hline CHEMBL1305523 & 688816 & 4.65 & 5.3467 & TST & \\
\hline CHEMBL1380985 & 688816 & 4.6 & 5.3727 & TRN & \\
\hline CHEMBL1566379 & 688816 & 5.0 & 5.1869 & TST & \\
\hline CHEMBL1500459 & 688816 & 4.45 & 5.3596 & TRN & \\
\hline CHEMBL1600515 & 688816 & 4.75 & 5.3654 & TRN & \\
\hline CHEMBL1461276 & 688816 & 5.5 & 5.6411 & TRN & \\
\hline CHEMBL1564696 & 688816 & 4.65 & 5.0728 & TRN & \\
\hline CHEMBL1316551 & 688816 & 4.45 & 4.746 & TST & \\
\hline CHEMBL1469391 & 688816 & 6.9 & 5.4264 & TST & \\
\hline CHEMBL1313214 & 688816 & 8.301 & 5.5812 & TST & \\
\hline CHEMBL1609264 & 688816 & 4.95 & 4.6729 & TRN & \\
\hline CHEMBL 302420 & 688816 & 7.1002 & 5.5179 & TST & \\
\hline CHEMBL 3214232 & 688816 & 5.0 & 5.5848 & TRN & \\
\hline CHEMBL1541872 & 688816 & 7.5003 & 5.1272 & TRN & \\
\hline CHEMBL3211934 & 688816 & 4.9 & 5.3723 & TRN & \\
\hline CHEMBL1464137 & 688816 & 5.0 & 5.3539 & TST & \\
\hline
\end{tabular}




\begin{tabular}{|c|c|c|c|c|c|}
\hline \multirow[b]{2}{*}{ CHEMBL1540365 } & \multicolumn{5}{|c|}{ Supplemental Table S2.txt } \\
\hline & 688816 & 5.0 & 5.154 & TRN & \\
\hline CHEMBL1560937 & 688816 & 6.5501 & 5.0424 & TST & \\
\hline CHEMBL1530518 & 688816 & 5.6 & 5.3742 & TRN & \\
\hline CHEMBL1610471 & 688816 & 5.55 & 5.96299 & 9999999999 & TRN \\
\hline CHEMBL1577936 & 688816 & 5.35 & 5.78299 & 99999999995 & TRN \\
\hline CHEMBL1350147 & 688816 & 4.6 & 5.4473 & TRN & \\
\hline CHEMBL1413671 & 688816 & 5.4 & 5.2367 & TRN & \\
\hline CHEMBL3209591 & 688816 & 6.0 & 5.4216 & TST & \\
\hline CHEMBL1442426 & 688816 & 8.301 & 5.2975 & TST & \\
\hline CHEMBL1519311 & 688816 & 4.65 & 5.151 & TRN & \\
\hline CHEMBL1300476 & 688816 & 8.0 & 5.2039 & TRN & \\
\hline CHEMBL1371811 & 688816 & 4.5 & 5.2708 & TRN & \\
\hline CHEMBL1577378 & 688816 & 4.65 & 5.3223 & TRN & \\
\hline CHEMBL2003214 & 688816 & 8.301 & 5.2675 & TRN & \\
\hline CHEMBL1452517 & 688816 & 4.65 & 4.9915 & TRN & \\
\hline CHEMBL1321213 & 688816 & 4.65 & 5.2112 & TRN & \\
\hline CHEMBL1359040 & 688816 & 4.75 & 5.3743 & TRN & \\
\hline CHEMBL1975101 & 688816 & 4.45 & 5.0381 & TST & \\
\hline CHEMBL1382419 & 688816 & 8.301 & 5.5909 & TRN & \\
\hline CHEMBL1403521 & 688816 & 8.301 & 5.1754 & TRN & \\
\hline CHEMBL1299977 & 688816 & 5.5 & 5.19 & TRN & \\
\hline CHEMBL1447722 & 688816 & 5.25 & 5.3587 & TRN & \\
\hline CHEMBL1527534 & 688816 & 4.9 & 5.8739 & TST & \\
\hline CHEMBL1596181 & 688816 & 4.75 & 5.4118 & TRN & \\
\hline CHEMBL1505455 & 688816 & 5.35 & 5.2392 & TRN & \\
\hline CHEMBL1528808 & 688816 & 5.25 & 5.5429 & TRN & \\
\hline CHEMBL1529216 & 688816 & 7.5003 & 5.2228 & TRN & \\
\hline CHEMBL1568288 & 688816 & 4.7 & 5.0445 & TRN & \\
\hline CHEMBL1584434 & 688816 & 7.5498 & 5.2963 & TST & \\
\hline CHEMBL1214525 & 688816 & 4.95 & 5.1783 & TRN & \\
\hline CHEMBL1447771 & 688816 & 4.9 & 5.4026 & TRN & \\
\hline CHEMBL1972750 & 688816 & 4.9 & 5.1431 & TST & \\
\hline CHEMBL1349811 & 688816 & 7.2 & 5.0265 & TST & \\
\hline CHEMBL1482271 & 688816 & 5.05 & 5.0879 & TRN & \\
\hline CHEMBL1502606 & 688816 & 5.35 & 5.524 & TST & \\
\hline CHEMBL1580519 & 688816 & 4.95 & 5.3285 & TRN & \\
\hline CHEMBL1320672 & 688816 & 5.6 & 5.4637 & TRN & \\
\hline CHEMBL1373470 & 688816 & 4.45 & 5.1122 & TRN & \\
\hline CHEMBL1386322 & 688816 & 5.0 & 5.2023 & TRN & \\
\hline CHEMBL1455791 & 688816 & 4.45 & 5.3648 & TRN & \\
\hline CHEMBL1350491 & 688816 & 4.45 & 5.4686 & TRN & \\
\hline CHEMBL1350043 & 688816 & 4.95 & 4.8754 & TRN & \\
\hline CHEMBL3213265 & 688816 & 4.45 & 5.2447 & TRN & \\
\hline CHEMBL1469682 & 688816 & 5.7 & 5.8421 & TRN & \\
\hline CHEMBL1400923 & 688816 & 7.4498 & 5.6921 & TRN & \\
\hline CHEMBL535166 & 688816 & 5.7 & 5.4281 & TST & \\
\hline CHEMBL1600946 & 688816 & 4.8 & 5.4036 & TST & \\
\hline CHEMBL1445658 & 688816 & 4.45 & 5.1807 & TST & \\
\hline
\end{tabular}




\begin{tabular}{|c|c|c|c|c|c|}
\hline \multirow[b]{2}{*}{ CHEMBL1994133 } & \multicolumn{5}{|c|}{ Supplemental Table S2.txt } \\
\hline & 688816 & 8.3979 & 5.8538 & TRN & \\
\hline CHEMBL1450881 & 688816 & 4.9 & 5.1158 & TST & \\
\hline CHEMBL1458338 & 688816 & 4.9 & 5.24700 & 0000000001 & TRN \\
\hline CHEMBL1438037 & 688816 & 5.05 & 5.7308 & TST & \\
\hline CHEMBL405358 & 688816 & 6.0 & 4.9708 & TST & \\
\hline CHEMBL1430822 & 688816 & 4.6 & 4.8951 & TRN & \\
\hline CHEMBL1349225 & 688816 & 4.45 & 5.31 & TST & \\
\hline CHEMBL1393221 & 688816 & 4.9 & 5.5058 & TRN & \\
\hline CHEMBL1487418 & 688816 & 5.0 & 4.9814 & TRN & \\
\hline CHEMBL1531352 & 688816 & 5.65 & 5.54 & TRN & \\
\hline CHEMBL 1562740 & 688816 & 4.45 & 5.4508 & TRN & \\
\hline CHEMBL1319307 & 688816 & 4.45 & 5.0337 & TRN & \\
\hline CHEMBL1384594 & 688816 & 4.9 & 4.9828 & TRN & \\
\hline CHEMBL1419536 & 688816 & 5.25 & 4.8135 & TRN & \\
\hline CHEMBL1608282 & 688816 & 5.4 & 5.8001 & TRN & \\
\hline CHEMBL1344211 & 688816 & 5.25 & 5.0454 & TRN & \\
\hline CHEMBL210868 & 688816 & 4.45 & 5.4863 & TST & \\
\hline CHEMBL1435723 & 688816 & 4.85 & 5.1433 & TST & \\
\hline CHEMBL1405315 & 688816 & 4.45 & 5.1629 & TRN & \\
\hline CHEMBL1402578 & 688816 & 5.25 & 5.5681 & TRN & \\
\hline CHEMBL1333344 & 688816 & 4.85 & 5.1887 & TRN & \\
\hline CHEMBL1197976 & 688816 & 4.65 & 4.9805 & TRN & \\
\hline CHEMBL1358695 & 688816 & 5.45 & 5.0663 & TRN & \\
\hline CHEMBL1409633 & 688816 & 4.8 & 5.1758 & TRN & \\
\hline CHEMBL1325833 & 688816 & 4.8 & 5.1731 & TRN & \\
\hline CHEMBL1420321 & 688816 & 4.45 & 4.8632 & TRN & \\
\hline CHEMBL1453941 & 688816 & 8.2518 & 5.4707 & TST & \\
\hline CHEMBL1589079 & 688816 & 4.85 & 5.2306 & TST & \\
\hline CHEMBL1446788 & 688816 & 4.95 & 5.6043 & TRN & \\
\hline CHEMBL1479475 & 688816 & 4.65 & 5.0781 & TRN & \\
\hline CHEMBL1572993 & 688816 & 5.5 & 5.3024 & TRN & \\
\hline CHEMBL1372446 & 688816 & 6.0 & 5.544 & TRN & \\
\hline CHEMBL1352063 & 688816 & 5.9 & 5.1567 & TRN & \\
\hline CHEMBL1429863 & 688816 & 4.8 & 4.9993 & TRN & \\
\hline CHEMBL1432964 & 688816 & 4.85 & 5.2608 & TRN & \\
\hline CHEMBL1450223 & 688816 & 5.4 & 5.0147 & TST & \\
\hline CHEMBL1349894 & 688816 & 5.0 & 5.7351 & TRN & \\
\hline CHEMBL1562824 & 688816 & 4.9 & 5.4205 & TRN & \\
\hline CHEMBL1503948 & 688816 & 5.2 & 5.3932 & TRN & \\
\hline CHEMBL1993070 & 688816 & 4.8 & 4.9299 & TRN & \\
\hline CHEMBL1494000 & 688816 & 4.9 & 5.4497 & TRN & \\
\hline CHEMBL1345214 & 688816 & 5.45 & 5.5654 & TST & \\
\hline CHEMBL1494979 & 688816 & 4.7 & 5.5256 & TRN & \\
\hline CHEMBL1428254 & 688816 & 4.95 & 5.3296 & TRN & \\
\hline CHEMBL1579352 & 688816 & 8.3468 & 5.3629 & TST & \\
\hline CHEMBL3197105 & 688816 & 4.95 & 5.1624 & TST & \\
\hline CHEMBL 3211087 & 688816 & 7.5498 & 5.3807 & TST & \\
\hline CHEMBL1460830 & 688816 & 5.45 & 5.2814 & TST & \\
\hline
\end{tabular}




\begin{tabular}{|c|c|c|c|c|c|}
\hline \multicolumn{6}{|c|}{ Supplemental Table s2.txt } \\
\hline CHEMBL1541686 & 688816 & 4.95 & 5.3378 & TRN & \\
\hline CHEMBL1461994 & 688816 & 5.45 & 5.5051 & TRN & \\
\hline CHEMBL1470391 & 688816 & 4.95 & 5.4642 & TRN & \\
\hline CHEMBL1353416 & 688816 & 5.6 & 5.0875 & TRN & \\
\hline CHEMBL1543422 & 688816 & 4.85 & 5.2115 & TRN & \\
\hline CHEMBL1438615 & 688816 & 4.6 & 5.1458 & TRN & \\
\hline CHEMBL1501305 & 688816 & 4.95 & 5.607 & TRN & \\
\hline CHEMBL1447711 & 688816 & 4.95 & 5.0862 & TRN & \\
\hline CHEMBL1438871 & 688816 & 4.45 & 5.4665 & TRN & \\
\hline CHEMBL1510726 & 688816 & 8.0506 & 5.53100 & 0000000001 & TST \\
\hline CHEMBL1337963 & 688816 & 5.0 & 5.1172 & TRN & \\
\hline CHEMBL1506078 & 688816 & 4.8 & 5.5879 & TST & \\
\hline CHEMBL1330008 & 688816 & 4.5 & 5.2317 & TRN & \\
\hline CHEMBL1452128 & 688816 & 4.95 & 5.0601 & TRN & \\
\hline CHEMBL3197514 & 688816 & 6.5501 & 5.5204 & TST & \\
\hline CHEMBL3192004 & 688816 & 4.8 & 5.5973 & TRN & \\
\hline CHEMBL1359029 & 688816 & 5.55 & 5.275 & TRN & \\
\hline CHEMBL1491170 & 688816 & 4.9 & 5.5464 & TRN & \\
\hline CHEMBL1468583 & 688816 & 4.95 & 5.1594 & TRN & \\
\hline CHEMBL1403180 & 688816 & 4.95 & 5.5326 & TRN & \\
\hline CHEMBL1095796 & 688816 & 8.3468 & 5.4729 & TRN & \\
\hline CHEMBL1334369 & 688816 & 6.8499 & 5.4478 & TRN & \\
\hline CHEMBL598952 & 688816 & 4.65 & 5.1311 & TST & \\
\hline CHEMBL1430134 & 688816 & 5.45 & 5.1491 & TRN & \\
\hline CHEMBL1479499 & 688816 & 4.45 & 5.2599 & TRN & \\
\hline CHEMBL1376678 & 688816 & 7.0 & 5.395 & TRN & \\
\hline CHEMBL1508535 & 688816 & 4.95 & 5.2284 & TST & \\
\hline CHEMBL1484231 & 688816 & 4.85 & 4.9886 & TRN & \\
\hline CHEMBL1578481 & 688816 & 5.9 & 5.4366 & TRN & \\
\hline CHEMBL1588181 & 688816 & 4.95 & 5.2464 & TRN & \\
\hline CHEMBL1460581 & 688816 & 6.7501 & 5.5884 & TRN & \\
\hline CHEMBL1470332 & 688816 & 4.9 & 5.3645 & TST & \\
\hline CHEMBL1322114 & 688816 & 4.95 & 5.1635 & TST & \\
\hline CHEMBL1311612 & 688816 & 4.8 & 5.2884 & TST & \\
\hline CHEMBL1320692 & 688816 & 6.45 & 5.7179 & TST & \\
\hline CHEMBL1410462 & 688816 & 7.7496 & 4.9799 & TRN & \\
\hline CHEMBL151176 & 688816 & 6.05 & 5.33700 & 0000000001 & TRN \\
\hline CHEMBL1521772 & 688816 & 5.75 & 5.015 & TRN & \\
\hline CHEMBL 3197873 & 688816 & 4.45 & 5.4802 & TRN & \\
\hline CHEMBL1477584 & 688816 & 4.45 & 5.2609 & TST & \\
\hline CHEMBL1583504 & 688816 & 4.6 & 5.3931 & TRN & \\
\hline CHEMBL1435450 & 688816 & 4.45 & 5.0356 & TRN & \\
\hline CHEMBL1372359 & 688816 & 4.9 & 5.0173 & TST & \\
\hline CHEMBL1417359 & 688816 & 5.2 & 5.4621 & TRN & \\
\hline CHEMBL1505991 & 688816 & 5.6 & 5.2606 & TRN & \\
\hline CHEMBL1500842 & 688816 & 5.05 & 5.3638 & TRN & \\
\hline CHEMBL1560399 & 688816 & 4.5 & 4.8237 & TRN & \\
\hline CHEMBL1401194 & 688816 & 4.85 & 5.5642 & TRN & \\
\hline
\end{tabular}




\begin{tabular}{|c|c|c|c|c|c|}
\hline \multicolumn{6}{|c|}{ Supplemental Table S2.txt } \\
\hline CHEMBL1531957 & 688816 & 4.45 & 5.1462 & TRN & \\
\hline CHEMBL1350380 & 688816 & 5.0 & 5.4165 & TRN & \\
\hline CHEMBL1732967 & 688816 & 5.2 & 4.7033 & TRN & \\
\hline CHEMBL1453005 & 688816 & 4.45 & 5.2009 & TRN & \\
\hline CHEMBL1360031 & 688816 & 5.5 & 5.2143 & TST & \\
\hline CHEMBL1373773 & 688816 & 5.0 & 5.048 & TRN & \\
\hline CHEMBL1367591 & 688816 & 8.3468 & 5.4194 & TRN & \\
\hline CHEMBL3210855 & 688816 & 4.9 & 5.2584 & TRN & \\
\hline CHEMBL1477727 & 688816 & 4.85 & 5.3586 & TST & \\
\hline CHEMBL1424589 & 688816 & 4.85 & 5.1031 & TRN & \\
\hline CHEMBL1461975 & 688816 & 8.3468 & 5.5554 & TRN & \\
\hline CHEMBL1320775 & 688816 & 6.6499 & 5.4461 & TRN & \\
\hline CHEMBL1549584 & 688816 & 8.3468 & 5.2372 & TRN & \\
\hline CHEMBL1524149 & 688816 & 6.6499 & 5.5818 & TRN & \\
\hline CHEMBL1326452 & 688816 & 5.2 & 4.6958 & TRN & \\
\hline CHEMBL1540119 & 688816 & 4.7 & 5.3782 & TRN & \\
\hline CHEMBL1364445 & 688816 & 4.95 & 5.0673 & TST & \\
\hline CHEMBL3190414 & 688816 & 4.9 & 4.9794 & TRN & \\
\hline CHEMBL1606145 & 688816 & 4.65 & 4.867 & TRN & \\
\hline CHEMBL 3210532 & 688816 & 4.75 & 5.1074 & TRN & \\
\hline CHEMBL1360998 & 688816 & 4.8 & 5.1263 & TST & \\
\hline CHEMBL1592272 & 688816 & 5.25 & 5.5858 & TST & \\
\hline CHEMBL1582627 & 688816 & 5.45 & 5.529 & TRN & \\
\hline CHEMBL3199429 & 688816 & 4.45 & 5.1296 & TRN & \\
\hline CHEMBL1387644 & 688816 & 4.95 & 5.6375 & TRN & \\
\hline CHEMBL1386546 & 688816 & 5.55 & 5.4449 & TRN & \\
\hline CHEMBL1588104 & 688816 & 5.15 & 5.3003 & TST & \\
\hline CHEMBL1508562 & 688816 & 5.25 & 5.58299 & 9999999999 & TRN \\
\hline CHEMBL1572494 & 688816 & 5.5 & 5.3657 & TRN & \\
\hline CHEMBL1551068 & 688816 & 4.7 & 5.1897 & TRN & \\
\hline CHEMBL1371275 & 688816 & 4.9 & 5.1129 & TST & \\
\hline CHEMBL1608480 & 688816 & 4.6 & 4.7772 & TRN & \\
\hline CHEMBL3211445 & 688816 & 5.55 & 5.0108 & TRN & \\
\hline CHEMBL1431865 & 688816 & 7.699 & 5.3601 & TRN & \\
\hline CHEMBL1389794 & 688816 & 4.95 & 5.4667 & TRN & \\
\hline CHEMBL1573866 & 688816 & 4.75 & 4.9304 & TST & \\
\hline CHEMBL1560061 & 688816 & 6.35 & 5.1333 & TRN & \\
\hline CHEMBL1583205 & 688816 & 5.85 & 5.0133 & TRN & \\
\hline CHEMBL1566940 & 688816 & 5.4 & 4.9959 & TRN & \\
\hline CHEMBL 3192223 & 688816 & 8.3468 & 5.102 & TRN & \\
\hline CHEMBL1597157 & 688816 & 4.8 & 4.9109 & TRN & \\
\hline CHEMBL1455664 & 688816 & 4.5 & 5.4082 & TRN & \\
\hline CHEMBL1306958 & 688816 & 7.0501 & 5.4153 & TRN & \\
\hline CHEMBL1402024 & 688816 & 4.75 & 5.3452 & TST & \\
\hline CHEMBL1513710 & 688816 & 4.45 & 5.1129 & TRN & \\
\hline CHEMBL1442585 & 688816 & 5.05 & 5.0723 & TRN & \\
\hline CHEMBL1539862 & 688816 & 4.45 & 5.3884 & TRN & \\
\hline CHEMBL1385545 & 688816 & 4.95 & 5.3224 & TST & \\
\hline
\end{tabular}




\begin{tabular}{|c|c|c|c|c|}
\hline & & & oplement & al $\mathrm{Ta}$ \\
\hline CHEMBL1560348 & 688816 & 6.6 & 5.6522 & TRN \\
\hline CHEMBL1495598 & 688816 & 6.4 & 5.0439 & TST \\
\hline CHEMBL1567050 & 688816 & 5.25 & 5.6562 & TST \\
\hline CHEMBL1409587 & 688816 & 5.1 & 5.5425 & TST \\
\hline CHEMBL1591234 & 688816 & 4.45 & 4.9397 & TRN \\
\hline CHEMBL1477847 & 688816 & 4.85 & 5.1398 & TRN \\
\hline CHEMBL1507947 & 688816 & 5.0 & 5.0195 & TST \\
\hline CHEMBL1549270 & 688816 & 4.45 & 5.2865 & TST \\
\hline CHEMBL1531357 & 688816 & 5.0 & 5.1883 & TRN \\
\hline CHEMBL1363142 & 688816 & 4.45 & 5.2697 & TRN \\
\hline CHEMBL1487444 & 688816 & 4.65 & 5.5463 & TRN \\
\hline CHEMBL 3211774 & 688816 & 4.7 & 4.8922 & TRN \\
\hline CHEMBL1532412 & 688816 & 4.95 & 5.3651 & TRN \\
\hline CHEMBL1333681 & 688816 & 6.4 & 5.557 & TRN \\
\hline CHEMBL1587160 & 688816 & 6.7501 & 5.4014 & TRN \\
\hline CHEMBL1364757 & 688816 & 7.6498 & 5.6977 & TRN \\
\hline CHEMBL1362370 & 688816 & 5.1 & 5.1393 & TRN \\
\hline CHEMBL1493816 & 688816 & 4.45 & 5.4777 & TRN \\
\hline CHEMBL1538428 & 688816 & 7.0501 & 5.358 & TST \\
\hline CHEMBL1305872 & 688816 & 4.45 & 5.4403 & TRN \\
\hline CHEMBL1299420 & 688816 & 5.5 & 5.4242 & TRN \\
\hline CHEMBL1465017 & 688816 & 6.8 & 5.2321 & TRN \\
\hline CHEMBL1576649 & 688816 & 4.75 & 5.1516 & TRN \\
\hline CHEMBL1539502 & 688816 & 6.1 & 5.227 & TRN \\
\hline CHEMBL1310341 & 688816 & 5.5 & 5.3134 & TRN \\
\hline CHEMBL1490789 & 688816 & 5.0 & 5.2742 & TRN \\
\hline CHEMBL3195233 & 688816 & 5.45 & 5.1119 & TST \\
\hline CHEMBL1545803 & 688816 & 7.0 & 5.3374 & TRN \\
\hline CHEMBL1301828 & 688816 & 5.0 & 5.2727 & TRN \\
\hline CHEMBL1551537 & 688816 & 4.75 & 5.4089 & TRN \\
\hline CHEMBL3210960 & 688816 & 7.5498 & 5.5549 & TST \\
\hline CHEMBL1397042 & 688816 & 4.5 & 5.6444 & TRN \\
\hline CHEMBL1310979 & 688816 & 4.75 & 5.2662 & TRN \\
\hline CHEMBL1401598 & 688816 & 4.95 & 5.2912 & TRN \\
\hline CHEMBL1351428 & 688816 & 6.7001 & 5.7818 & TST \\
\hline CHEMBL1986214 & 688816 & 6.15 & 5.3653 & TRN \\
\hline CHEMBL1534349 & 688816 & 4.9 & 5.1946 & TRN \\
\hline CHEMBL1310923 & 688816 & 5.4 & 5.3057 & TRN \\
\hline CHEMBL1372862 & 688816 & 4.9 & 5.1719 & TRN \\
\hline CHEMBL1535714 & 688816 & 5.25 & 5.6925 & TST \\
\hline CHEMBL1312107 & 688816 & 5.15 & 5.0895 & TRN \\
\hline CHEMBL1500421 & 688816 & 4.8 & 5.215 & TRN \\
\hline CHEMBL1350669 & 688816 & 7.2 & 5.7776 & TRN \\
\hline CHEMBL1484604 & 688816 & 4.75 & 5.0582 & TRN \\
\hline CHEMBL1389496 & 688816 & 5.25 & 5.1297 & TST \\
\hline CHEMBL1386467 & 688816 & 4.95 & 4.9926 & TRN \\
\hline CHEMBL 3197902 & 688816 & 4.45 & 5.0996 & TRN \\
\hline CHEMBL1419847 & 688816 & 4.95 & 5.166 & TRN \\
\hline
\end{tabular}




\begin{tabular}{|c|c|c|c|c|}
\hline \multicolumn{5}{|c|}{ Supplemental Table S2.txt } \\
\hline CHEMBL1412539 & 688816 & 5.1 & 5.4178 & TRN \\
\hline CHEMBL1490000 & 688816 & 8.301 & 5.5233 & TRN \\
\hline CHEMBL1484487 & 688816 & 5.25 & 5.6592 & TRN \\
\hline CHEMBL3197489 & 688816 & 4.7 & 4.8384 & TST \\
\hline CHEMBL1304900 & 688816 & 4.95 & 5.2525 & TRN \\
\hline CHEMBL1383279 & 688816 & 4.45 & 5.1872 & TST \\
\hline CHEMBL3214169 & 688816 & 4.85 & 5.7748 & TRN \\
\hline CHEMBL1423597 & 688816 & 4.45 & 5.0974 & TRN \\
\hline CHEMBL1424526 & 688816 & 5.35 & 5.2155 & TRN \\
\hline CHEMBL1445141 & 688816 & 4.8 & 5.4487 & TST \\
\hline CHEMBL1391035 & 688816 & 5.3 & 5.1792 & TRN \\
\hline CHEMBL1389304 & 688816 & 5.45 & 5.2189 & TRN \\
\hline CHEMBL1479210 & 688816 & 4.65 & 5.0633 & TRN \\
\hline CHEMBL1347227 & 688816 & 5.1 & 5.4151 & TRN \\
\hline CHEMBL1520757 & 688816 & 4.9 & 5.2239 & TRN \\
\hline CHEMBL1401683 & 688816 & 4.55 & 5.2421 & TRN \\
\hline CHEMBL1478354 & 688816 & 8.301 & 5.3448 & TRN \\
\hline CHEMBL1494290 & 688816 & 4.45 & 4.9467 & TRN \\
\hline CHEMBL1535173 & 688816 & 4.95 & 5.1565 & TRN \\
\hline CHEMBL1382144 & 688816 & 4.5 & 5.4092 & TRN \\
\hline CHEMBL1311348 & 688816 & 4.9 & 4.935 & TRN \\
\hline CHEMBL1606610 & 688816 & 8.4949 & 5.376 & TST \\
\hline CHEMBL1376490 & 688816 & 6.8 & 5.2678 & TST \\
\hline CHEMBL1537203 & 688816 & 5.25 & 5.7917 & TRN \\
\hline CHEMBL1544171 & 688816 & 4.95 & 5.1999 & TRN \\
\hline CHEMBL1464563 & 688816 & 5.05 & 5.3889 & TST \\
\hline CHEMBL1341454 & 688816 & 5.35 & 5.4627 & TRN \\
\hline CHEMBL3198829 & 688816 & 4.95 & 5.6372 & TRN \\
\hline CHEMBL 3198941 & 688816 & 5.05 & 4.9492 & TRN \\
\hline CHEMBL1477846 & 688816 & 5.85 & 5.1075 & TRN \\
\hline CHEMBL1493171 & 688816 & 4.85 & 5.148 & TST \\
\hline CHEMBL1460315 & 688816 & 4.95 & 4.9591 & TRN \\
\hline CHEMBL1510618 & 688816 & 4.8 & 5.0673 & TRN \\
\hline CHEMBL1531043 & 688816 & 4.6 & 5.2427 & TRN \\
\hline CHEMBL1470559 & 688816 & 4.45 & 5.1598 & TRN \\
\hline CHEMBL1590957 & 688816 & 4.65 & 5.2049 & TRN \\
\hline CHEMBL1568570 & 688816 & 8.2518 & 5.3606 & TRN \\
\hline CHEMBL1349814 & 688816 & 4.65 & 5.0087 & TST \\
\hline CHEMBL1367204 & 688816 & 5.4 & 5.3484 & TRN \\
\hline CHEMBL1421780 & 688816 & 4.45 & 5.1355 & TST \\
\hline CHEMBL1439269 & 688816 & 4.45 & 5.0994 & TST \\
\hline CHEMBL1555931 & 688816 & 4.8 & 5.407 & TRN \\
\hline CHEMBL1527251 & 688816 & 4.95 & 5.3718 & TRN \\
\hline CHEMBL1905960 & 688816 & 5.3 & 5.3145 & TRN \\
\hline CHEMBL1345220 & 688816 & 4.7 & 5.2283 & TRN \\
\hline CHEMBL1521283 & 688816 & 8.1487 & 5.7167 & TST \\
\hline CHEMBL1526476 & 688816 & 5.25 & 5.1318 & TRN \\
\hline CHEMBL3189883 & 688816 & 5.0 & 5.1831 & TRN \\
\hline
\end{tabular}




\begin{tabular}{|c|c|c|c|c|c|}
\hline \multicolumn{6}{|c|}{ Supplemental Table S2.txt } \\
\hline CHEMBL1488667 & 688816 & 4.85 & 5.3149 & TRN & \\
\hline CHEMBL3145366 & 688816 & 4.6 & 5.4404 & TRN & \\
\hline CHEMBL1424472 & 688816 & 4.8 & 5.272 & TST & \\
\hline CHEMBL1608403 & 688816 & 4.95 & 5.5419 & TRN & \\
\hline CHEMBL1506888 & 688816 & 4.8 & 5.235 & TRN & \\
\hline CHEMBL1606451 & 688816 & 4.95 & 5.1151 & TRN & \\
\hline CHEMBL1349947 & 688816 & 4.9 & 5.2894 & TRN & \\
\hline CHEMBL1508692 & 688816 & 6.7001 & 5.3919 & TST & \\
\hline CHEMBL1440039 & 688816 & 4.85 & 5.3029 & TRN & \\
\hline CHEMBL1563955 & 688816 & 5.05 & 5.7841 & TRN & \\
\hline CHEMBL1497676 & 688816 & 8.4559 & 5.7848 & TST & \\
\hline CHEMBL1449821 & 688816 & 5.4 & 5.29 & TRN & \\
\hline CHEMBL1327866 & 688816 & 4.7 & 5.1647 & TST & \\
\hline CHEMBL1345721 & 688816 & 5.0 & 5.2527 & TRN & \\
\hline CHEMBL1462878 & 688816 & 6.25 & 4.9546 & TST & \\
\hline CHEMBL1412538 & 688816 & 4.45 & 4.8741 & TST & \\
\hline CHEMBL1307945 & 688816 & 6.8 & 5.4583 & TST & \\
\hline CHEMBL1324878 & 688816 & 6.0 & 5.0351 & TRN & \\
\hline CHEMBL1418548 & 688816 & 4.45 & 5.1946 & TRN & \\
\hline CHEMBL1341584 & 688816 & 4.75 & 5.505 & TRN & \\
\hline CHEMBL1314442 & 688816 & 4.45 & 5.0981 & TRN & \\
\hline CHEMBL1578840 & 688816 & 5.2 & 5.4099 & TRN & \\
\hline CHEMBL1479719 & 688816 & 4.75 & 5.1942 & TRN & \\
\hline CHEMBL1310682 & 688816 & 4.5 & 5.1598 & TRN & \\
\hline CHEMBL1304136 & 688816 & 4.7 & 5.3936 & TRN & \\
\hline CHEMBL1370884 & 688816 & 4.7 & 4.8302 & TRN & \\
\hline CHEMBL1550862 & 688816 & 4.45 & 5.0331 & TRN & \\
\hline CHEMBL1491320 & 688816 & 5.25 & 4.6721 & TRN & \\
\hline CHEMBL1528847 & 688816 & 4.9 & 4.8158 & TRN & \\
\hline CHEMBL1313578 & 688816 & 4.7 & 5.46899 & 9999999999 & TRN \\
\hline CHEMBL1315216 & 688816 & 4.95 & 4.9024 & TRN & \\
\hline CHEMBL1470531 & 688816 & 8.301 & 5.6251 & TRN & \\
\hline CHEMBL1332301 & 688816 & 6.1 & 5.6813 & TRN & \\
\hline CHEMBL1588226 & 688816 & 4.65 & 5.153 & TST & \\
\hline CHEMBL1444918 & 688816 & 5.25 & 5.34399 & 9999999999 & TST \\
\hline CHEMBL3196376 & 688816 & 7.0501 & 5.3063 & TRN & \\
\hline CHEMBL1365720 & 688816 & 5.25 & 5.3595 & TRN & \\
\hline CHEMBL1566079 & 688816 & 4.85 & 5.61799 & 9999999999 & TRN \\
\hline CHEMBL1353169 & 688816 & 4.9 & 5.305 & TRN & \\
\hline CHEMBL1079460 & 688816 & 4.45 & 5.4264 & TST & \\
\hline CHEMBL1991516 & 688816 & 4.45 & 5.4124 & TRN & \\
\hline CHEMBL1439584 & 688816 & 4.45 & 5.442 & TRN & \\
\hline CHEMBL1304363 & 688816 & 5.1 & 4.7557 & TRN & \\
\hline CHEMBL1328876 & 688816 & 6.8 & 5.6775 & TRN & \\
\hline CHEMBL1392259 & 688816 & 4.6 & 5.2296 & TRN & \\
\hline CHEMBL1583501 & 688816 & 6.7501 & 5.6558 & TST & \\
\hline CHEMBL1334459 & 688816 & 5.5 & 5.1081 & TRN & \\
\hline CHEMBL1320713 & 688816 & 6.5 & 5.4575 & TRN & \\
\hline
\end{tabular}




\begin{tabular}{|c|c|c|c|c|c|}
\hline \multirow[b]{2}{*}{ CHEMBL1372480 } & \multicolumn{5}{|c|}{ plemental lable S2. } \\
\hline & 688816 & 5.0 & 5.3821 & TRN & \\
\hline CHEMBL1346919 & 688816 & 4.75 & 5.1557 & TRN & \\
\hline CHEMBL3191520 & 688816 & 4.45 & 5.0635 & TST & \\
\hline CHEMBL 3197264 & 688816 & 5.0 & 5.1546 & TRN & \\
\hline CHEMBL1413274 & 688816 & 6.5501 & 5.3298 & TRN & \\
\hline CHEMBL1349962 & 688816 & 4.95 & 5.63399 & 99999999995 & TST \\
\hline CHEMBL1303593 & 688816 & 5.3 & 5.6918 & TRN & \\
\hline CHEMBL1406889 & 688816 & 4.45 & 5.7147 & TRN & \\
\hline CHEMBL1450912 & 688816 & 4.95 & 4.9994 & TRN & \\
\hline CHEMBL1180 & 688816 & 5.55 & 5.0744 & TST & \\
\hline CHEMBL1401361 & 688816 & 4.95 & 5.0665 & TST & \\
\hline CHEMBL1353508 & 688816 & 4.65 & 5.114 & TRN & \\
\hline CHEMBL1322503 & 688816 & 4.85 & 5.18 & TRN & \\
\hline CHEMBL1725507 & 688816 & 5.3 & 5.6365 & TST & \\
\hline CHEMBL1548037 & 688816 & 4.95 & 5.3497 & TRN & \\
\hline CHEMBL3190712 & 688816 & 5.05 & 5.0203 & TRN & \\
\hline CHEMBL1367725 & 688816 & 5.35 & 5.3835 & TRN & \\
\hline CHEMBL1483902 & 688816 & 5.65 & 5.2711 & TST & \\
\hline CHEMBL1479154 & 688816 & 5.4 & 5.2601 & TST & \\
\hline CHEMBL1344297 & 688816 & 4.95 & 5.0555 & TRN & \\
\hline CHEMBL1388814 & 688816 & 5.25 & 5.5744 & TST & \\
\hline CHEMBL1529284 & 688816 & 6.4 & 5.2853 & TRN & \\
\hline CHEMBL3207517 & 688816 & 4.45 & 5.3733 & TRN & \\
\hline CHEMBL1504623 & 688816 & 4.95 & 5.1501 & TRN & \\
\hline CHEMBL1534313 & 688816 & 4.85 & 5.379 & TRN & \\
\hline CHEMBL1308010 & 688816 & 4.6 & 4.8932 & TRN & \\
\hline CHEMBL3195894 & 688816 & 5.4 & 5.6257 & TRN & \\
\hline CHEMBL1550635 & 688816 & 4.45 & 5.3513 & TRN & \\
\hline CHEMBL1594647 & 688816 & 5.05 & 5.42899 & 9999999999 & TRN \\
\hline CHEMBL1346423 & 688816 & 4.75 & 5.3812 & TRN & \\
\hline CHEMBL1420897 & 688816 & 4.85 & 5.2729 & TRN & \\
\hline CHEMBL1535949 & 688816 & 5.35 & 5.1125 & TRN & \\
\hline CHEMBL1399775 & 688816 & 7.8996 & 5.5246 & TRN & \\
\hline CHEMBL1418359 & 688816 & 4.6 & 5.2181 & TST & \\
\hline CHEMBL1386425 & 688816 & 4.55 & 5.5043 & TST & \\
\hline CHEMBL1445811 & 688816 & 4.5 & 5.5279 & TRN & \\
\hline CHEMBL3210908 & 688816 & 4.7 & 5.05399 & 9999999999 & TRN \\
\hline CHEMBL1305951 & 688816 & 4.95 & 4.8803 & TST & \\
\hline CHEMBL1516542 & 688816 & 5.15 & 4.7839 & TRN & \\
\hline CHEMBL1367426 & 688816 & 4.8 & 4.7128 & TRN & \\
\hline CHEMBL1477878 & 688816 & 4.6 & 5.3614 & TRN & \\
\hline CHEMBL1369469 & 688816 & 4.45 & 5.2981 & TRN & \\
\hline CHEMBL1569676 & 688816 & 7.4001 & 5.4175 & TST & \\
\hline CHEMBL1388093 & 688816 & 7.9508 & 5.2911 & TST & \\
\hline CHEMBL1572827 & 688816 & 4.45 & 5.1555 & TST & \\
\hline CHEMBL1401137 & 688816 & 5.1 & 5.0822 & TRN & \\
\hline CHEMBL1399758 & 688816 & 5.15 & 5.1236 & TST & \\
\hline CHEMBL1562310 & 688816 & 5.35 & 5.2811 & TRN & \\
\hline & & & & 25137 & \\
\hline
\end{tabular}




\begin{tabular}{|c|c|c|c|c|c|}
\hline \multicolumn{6}{|c|}{ Supplemental Table S2.txt } \\
\hline CHEMBL1597376 & 688816 & 5.35 & 5.1494 & TRN & \\
\hline CHEMBL1379178 & 688816 & 4.95 & 4.8409 & TRN & \\
\hline CHEMBL1585099 & 688816 & 4.85 & 5.0249 & TRN & \\
\hline CHEMBL1479411 & 688816 & 6.0 & 5.1945 & TST & \\
\hline CHEMBL1299728 & 688816 & 5.05 & 5.0962 & TRN & \\
\hline CHEMBL442925 & 688816 & 4.65 & 5.0386 & TRN & \\
\hline CHEMBL1426340 & 688816 & 4.7 & 4.8474 & TRN & \\
\hline CHEMBL1517192 & 688816 & 5.3 & 5.0285 & TRN & \\
\hline CHEMBL1366987 & 688816 & 4.65 & 5.0817 & TST & \\
\hline CHEMBL1439330 & 688816 & 5.05 & 5.1034 & TRN & \\
\hline CHEMBL1346281 & 688816 & 4.95 & 5.0641 & TST & \\
\hline CHEMBL1524030 & 688816 & 5.55 & 5.2456 & TST & \\
\hline CHEMBL1444339 & 688816 & 4.95 & 4.9355 & TRN & \\
\hline CHEMBL1472111 & 688816 & 8.301 & 5.3317 & TST & \\
\hline CHEMBL1527686 & 688816 & 4.95 & 5.5749 & TST & \\
\hline CHEMBL1487366 & 688816 & 7.3497 & 5.4192 & TRN & \\
\hline CHEMBL1403707 & 688816 & 5.75 & 5.1723 & TST & \\
\hline CHEMBL1396086 & 688816 & 4.8 & 4.9575 & TRN & \\
\hline CHEMBL1333052 & 688816 & 4.45 & 4.7601 & TRN & \\
\hline CHEMBL1334912 & 688816 & 5.25 & 5.1159 & TRN & \\
\hline CHEMBL1478404 & 688816 & 5.95 & 4.9604 & TRN & \\
\hline CHEMBL 3194558 & 688816 & 4.45 & 5.1468 & TST & \\
\hline CHEMBL 3213690 & 688816 & 5.8 & 5.1303 & TRN & \\
\hline CHEMBL1371323 & 688816 & 4.45 & 5.0074 & TRN & \\
\hline CHEMBL1480526 & 688816 & 4.95 & 5.1284 & TRN & \\
\hline CHEMBL1438153 & 688816 & 7.8996 & 5.4681 & TRN & \\
\hline CHEMBL1535810 & 688816 & 5.5 & 5.3657 & TST & \\
\hline CHEMBL1313283 & 688816 & 5.1 & 5.0162 & TRN & \\
\hline CHEMBL1371507 & 688816 & 5.8 & 5.7567 & TRN & \\
\hline CHEMBL1482541 & 688816 & 4.95 & 5.1046 & TRN & \\
\hline CHEMBL1496972 & 688816 & 4.45 & 4.9509 & TRN & \\
\hline CHEMBL1213045 & 688816 & 5.25 & 5.21200 & 0000000001 & TRN \\
\hline CHEMBL1493472 & 688816 & 5.55 & 5.1992 & TRN & \\
\hline CHEMBL1359106 & 688816 & 4.45 & 5.602 & TST & \\
\hline CHEMBL1513260 & 688816 & 4.95 & 5.1309 & TRN & \\
\hline CHEMBL1426241 & 688816 & 8.0 & 5.879 & TRN & \\
\hline CHEMBL1460352 & 688816 & 5.45 & 4.7565 & TST & \\
\hline CHEMBL1427996 & 688816 & 5.8 & 5.1482 & TRN & \\
\hline CHEMBL1299662 & 688816 & 6.0 & 5.6327 & TRN & \\
\hline CHEMBL1532011 & 688816 & 6.3 & 5.1962 & TRN & \\
\hline CHEMBL1375741 & 688816 & 4.8 & 5.1305 & TRN & \\
\hline CHEMBL 1495002 & 688816 & 4.9 & 5.355 & TRN & \\
\hline CHEMBL1431131 & 688816 & 4.95 & 4.9976 & TRN & \\
\hline CHEMBL1376710 & 688816 & 4.8 & 4.9683 & TRN & \\
\hline CHEMBL1093246 & 688816 & 4.45 & 5.2651 & TRN & \\
\hline CHEMBL1358225 & 688816 & 6.2 & 5.4635 & TRN & \\
\hline CHEMBL 1555884 & 688816 & 6.0 & 5.5141 & TST & \\
\hline CHEMBL1587121 & 688816 & 5.95 & 5.5111 & TRN & \\
\hline
\end{tabular}




\begin{tabular}{|c|c|c|c|c|c|}
\hline \multicolumn{6}{|c|}{ Supplemental Table s2.txt } \\
\hline CHEMBL1414196 & 688816 & 4.45 & 5.0737 & TRN & \\
\hline CHEMBL1583496 & 688816 & 4.8 & 5.2847 & TRN & \\
\hline CHEMBL1531392 & 688816 & 5.3 & 4.975 & TRN & \\
\hline CHEMBL1496647 & 688816 & 5.6 & 4.7441 & TRN & \\
\hline CHEMBL1328040 & 688816 & 4.45 & \multicolumn{2}{|c|}{5.742999999999999} & TST \\
\hline CHEMBL1539062 & 688816 & 4.45 & 5.3104 & TRN & \\
\hline CHEMBL1525390 & 688816 & 5.55 & 4.9504 & TRN & \\
\hline CHEMBL1482053 & 688816 & 4.65 & 5.3751 & TRN & \\
\hline CHEMBL1470437 & 688816 & 8.0 & 5.1893 & TST & \\
\hline CHEMBL1419320 & 688816 & 4.75 & 5.055 & TRN & \\
\hline CHEMBL2354668 & 688816 & 5.0 & 5.1927 & TRN & \\
\hline CHEMBL1525901 & 688816 & 4.85 & 5.2623 & TRN & \\
\hline CHEMBL1524341 & 688816 & 4.9 & 5.1063 & TST & \\
\hline CHEMBL1559685 & 688816 & 5.1 & 5.5761 & TRN & \\
\hline CHEMBL1587883 & 688816 & 5.5 & 4.7992 & TRN & \\
\hline CHEMBL1308955 & 688816 & 5.05 & 5.2401 & TRN & \\
\hline CHEMBL1326918 & 688816 & 4.65 & 5.1877 & TRN & \\
\hline CHEMBL1514449 & 688816 & 4.7 & 4.896 & TRN & \\
\hline CHEMBL1561725 & 688816 & 6.45 & 5.6035 & TRN & \\
\hline CHEMBL1412520 & 688816 & 5.0 & 5.0943 & TRN & \\
\hline CHEMBL1306343 & 688816 & 5.1 & 5.3279 & TRN & \\
\hline CHEMBL1462519 & 688816 & 5.4 & 5.4589 & TST & \\
\hline CHEMBL1417731 & 688816 & 5.65 & 4.9416 & TST & \\
\hline CHEMBL1321144 & 688816 & 4.95 & 5.2844 & TST & \\
\hline CHEMBL1460108 & 688816 & 4.8 & 4.9993 & TRN & \\
\hline CHEMBL 2003909 & 688816 & 4.45 & 5.119 & TRN & \\
\hline CHEMBL1547217 & 688816 & 5.3 & 5.3326 & TRN & \\
\hline CHEMBL1378707 & 688816 & 6.0 & 4.9551 & TRN & \\
\hline CHEMBL1557627 & 688816 & 5.25 & 5.4124 & TRN & \\
\hline CHEMBL1306395 & 688816 & 4.45 & 5.2487 & TRN & \\
\hline CHEMBL1429269 & 688816 & 4.8 & 5.3145 & TRN & \\
\hline CHEMBL1501096 & 688816 & 4.45 & 5.4662 & TRN & \\
\hline CHEMBL1493878 & 688816 & 6.1 & 5.3571 & TST & \\
\hline CHEMBL1585161 & 688816 & 8.301 & 5.7672 & TRN & \\
\hline CHEMBL1492153 & 688816 & 4.75 & 4.9529 & TST & \\
\hline CHEMBL1365716 & 688816 & 4.95 & 5.4447 & TRN & \\
\hline CHEMBL1598186 & 688816 & 5.0 & 5.4778 & TRN & \\
\hline CHEMBL1529335 & 688816 & 4.9 & 5.3161 & TRN & \\
\hline CHEMBL1322039 & 688816 & 4.9 & 5.306 & TRN & \\
\hline CHEMBL1563059 & 688816 & 4.65 & 4.9994 & TRN & \\
\hline CHEMBL1402073 & 688816 & 6.1 & 5.5919 & TST & \\
\hline CHEMBL3211480 & 688816 & 4.85 & 5.4885 & TRN & \\
\hline CHEMBL1368562 & 688816 & 4.65 & 5.0763 & TST & \\
\hline CHEMBL1417134 & 688816 & 5.85 & 5.6265 & TRN & \\
\hline CHEMBL1498966 & 688816 & 5.1 & 5.2087 & TRN & \\
\hline CHEMBL1581929 & 688816 & 5.25 & 5.3538 & TST & \\
\hline CHEMBL1470191 & 688816 & 8.4949 & 5.5434 & TRN & \\
\hline \multirow[t]{2}{*}{ CHEMBL1478975 } & 688816 & 5.0 & 4.79899 & 99999999995 & TRN \\
\hline & & \multicolumn{4}{|c|}{ Page 25139} \\
\hline
\end{tabular}




\begin{tabular}{|c|c|c|c|c|}
\hline \multicolumn{5}{|c|}{ Supplemental Table S2.txt } \\
\hline CHEMBL1329650 & 688816 & 5.65 & 5.2393 & TRN \\
\hline CHEMBL1411498 & 688816 & 4.8 & 5.6102 & TST \\
\hline CHEMBL1343490 & 688816 & 5.05 & 4.8852 & TRN \\
\hline CHEMBL1607020 & 688816 & 8.4949 & 5.2219 & TRN \\
\hline CHEMBL406845 & 688816 & 6.0 & 5.0602 & TST \\
\hline CHEMBL1447012 & 688816 & 7.5498 & 5.3447 & TST \\
\hline CHEMBL1530192 & 688816 & 4.9 & 5.2396 & TRN \\
\hline CHEMBL1302814 & 688816 & 6.7501 & 5.1535 & TST \\
\hline CHEMBL1339591 & 688816 & 5.8 & 5.0832 & TST \\
\hline CHEMBL1305811 & 688816 & 4.45 & 5.3447 & TRN \\
\hline CHEMBL1340639 & 688816 & 4.75 & 5.4672 & TRN \\
\hline CHEMBL1601947 & 688816 & 5.5 & 5.3742 & TRN \\
\hline CHEMBL1598303 & 688816 & 4.65 & 5.2664 & TST \\
\hline CHEMBL1374625 & 688816 & 8.301 & 5.7537 & TRN \\
\hline CHEMBL1317294 & 688816 & 4.65 & 5.3688 & TRN \\
\hline CHEMBL1495282 & 688816 & 4.45 & 5.2891 & TST \\
\hline CHEMBL1589858 & 688816 & 4.7 & 5.2126 & TST \\
\hline CHEMBL1487979 & 688816 & 4.8 & 5.0567 & TRN \\
\hline CHEMBL1302274 & 688816 & 6.05 & 4.9192 & TRN \\
\hline CHEMBL1496822 & 688816 & 6.2 & 5.528 & TRN \\
\hline CHEMBL1488791 & 688816 & 7.0 & 5.404 & TRN \\
\hline CHEMBL1346494 & 688816 & 4.95 & 5.4571 & TRN \\
\hline CHEMBL1542237 & 688816 & 4.7 & 5.1527 & TRN \\
\hline CHEMBL1464667 & 688816 & 4.45 & 5.2401 & TST \\
\hline CHEMBL1371999 & 688816 & 4.7 & 5.4194 & TRN \\
\hline CHEMBL10050 & 688816 & 5.0 & 5.3842 & TST \\
\hline CHEMBL1337683 & 688816 & 4.45 & 5.0457 & TST \\
\hline CHEMBL1578433 & 688816 & 4.55 & 5.1693 & TRN \\
\hline CHEMBL1393260 & 688816 & 5.45 & 5.0679 & TST \\
\hline CHEMBL1420682 & 688816 & 5.0 & 5.2038 & TST \\
\hline CHEMBL1543577 & 688816 & 4.9 & 5.0805 & TRN \\
\hline CHEMBL1347211 & 688816 & 4.9 & 5.0484 & TRN \\
\hline CHEMBL1336917 & 688816 & 4.45 & 5.0738 & TST \\
\hline CHEMBL1410497 & 688816 & 4.8 & 5.3151 & TRN \\
\hline CHEMBL1546279 & 688816 & 4.75 & 5.75 & TRN \\
\hline CHEMBL1503585 & 688816 & 5.05 & 5.5882 & TRN \\
\hline CHEMBL1355005 & 688816 & 4.95 & 5.3404 & TRN \\
\hline CHEMBL1354507 & 688816 & 5.05 & 4.9208 & TRN \\
\hline CHEMBL1488160 & 688816 & 5.0 & 5.4999 & TRN \\
\hline CHEMBL478960 & 688816 & 4.6 & 4.9414 & TST \\
\hline CHEMBL1557254 & 688816 & 5.0 & 4.9536 & TRN \\
\hline CHEMBL 2369223 & 688816 & 4.95 & 5.5184 & TRN \\
\hline CHEMBL1406740 & 688816 & 4.6 & 5.4599 & TRN \\
\hline CHEMBL411307 & 688816 & 4.85 & 4.9171 & TRN \\
\hline CHEMBL3197789 & 688816 & 4.95 & 5.4768 & TRN \\
\hline CHEMBL1565895 & 688816 & 4.95 & 5.4886 & TST \\
\hline CHEMBL 1536377 & 688816 & 5.2 & 5.4133 & TRN \\
\hline CHEMBL1545565 & 688816 & 4.7 & 5.6094 & TRN \\
\hline
\end{tabular}




\begin{tabular}{|c|c|c|c|c|}
\hline \multicolumn{5}{|c|}{ Supplemental Table S2.txt } \\
\hline CHEMBL1406441 & 688816 & 4.85 & 4.9119 & TRN \\
\hline CHEMBL1308610 & 688816 & 4.85 & 5.0348 & TRN \\
\hline CHEMBL1329123 & 688816 & 4.95 & 5.2766 & TRN \\
\hline CHEMBL1421192 & 688816 & 4.6 & 4.7961 & TRN \\
\hline CHEMBL1566714 & 688816 & 5.05 & 5.0507 & TRN \\
\hline CHEMBL1383897 & 688816 & 4.85 & 5.6687 & TST \\
\hline CHEMBL1414133 & 688816 & 4.85 & 5.2334 & TRN \\
\hline CHEMBL1451519 & 688816 & 5.45 & 5.1938 & TST \\
\hline CHEMBL1565496 & 688816 & 6.1 & 5.1007 & TST \\
\hline CHEMBL1603561 & 688816 & 4.6 & 4.9567 & TST \\
\hline CHEMBL1481267 & 688816 & 4.85 & 5.4396 & TST \\
\hline CHEMBL1527607 & 688816 & 8.301 & 5.8043 & TRN \\
\hline CHEMBL1256243 & 688816 & 5.85 & 5.7157 & TST \\
\hline CHEMBL1347686 & 688816 & 4.85 & 5.2248 & TRN \\
\hline CHEMBL1389366 & 688816 & 5.9 & 5.4636 & TRN \\
\hline CHEMBL1572547 & 688816 & 6.15 & 5.2516 & TRN \\
\hline CHEMBL1502115 & 688816 & 7.5003 & 5.29 & TRN \\
\hline CHEMBL1407944 & 688816 & 5.35 & 5.3111 & TRN \\
\hline CHEMBL1560924 & 688816 & 7.4498 & 5.4148 & TST \\
\hline CHEMBL1313564 & 688816 & 4.7 & 4.9808 & TRN \\
\hline CHEMBL3189514 & 688816 & 4.95 & 4.9249 & TRN \\
\hline CHEMBL 3210364 & 688816 & 5.05 & 4.8932 & TRN \\
\hline CHEMBL1515997 & 688816 & 5.5 & 5.6987 & TST \\
\hline CHEMBL1389300 & 688816 & 5.2 & 5.4441 & TRN \\
\hline CHEMBL1398099 & 688816 & 4.9 & 5.013 & TRN \\
\hline CHEMBL1354189 & 688816 & 5.6 & 5.6898 & TST \\
\hline CHEMBL1452868 & 688816 & 6.0 & 5.2431 & TRN \\
\hline CHEMBL 294590 & 688816 & 6.6499 & 5.5034 & TST \\
\hline CHEMBL1576528 & 688816 & 4.8 & 4.9123 & TST \\
\hline CHEMBL1495592 & 688816 & 4.95 & 5.0608 & TST \\
\hline CHEMBL1430987 & 688816 & 4.75 & 5.1326 & TST \\
\hline CHEMBL3209430 & 688816 & 4.85 & 5.4686 & TST \\
\hline CHEMBL3207825 & 688816 & 5.75 & 5.7614 & TRN \\
\hline CHEMBL 3145304 & 688816 & 4.45 & 5.356 & TRN \\
\hline CHEMBL1360081 & 688816 & 4.65 & 4.8755 & TRN \\
\hline CHEMBL1609667 & 688816 & 4.95 & 4.8298 & TRN \\
\hline CHEMBL1356683 & 688816 & 4.55 & 5.1922 & TRN \\
\hline CHEMBL3195162 & 688816 & 4.9 & 5.1499 & TRN \\
\hline CHEMBL1337806 & 688816 & 4.75 & 5.2295 & TRN \\
\hline CHEMBL1612281 & 688816 & 5.25 & 5.5163 & TST \\
\hline CHEMBL1421853 & 688816 & 5.5 & 5.8177 & TST \\
\hline CHEMBL1448691 & 688816 & 4.45 & 5.306 & TRN \\
\hline CHEMBL576607 & 688816 & 5.05 & 5.2774 & TRN \\
\hline CHEMBL1490760 & 688816 & 4.45 & 5.5707 & TRN \\
\hline CHEMBL1561943 & 688816 & 4.95 & 5.3113 & TRN \\
\hline CHEMBL1379279 & 688816 & 7.2503 & 5.5056 & TST \\
\hline CHEMBL1509037 & 688816 & 4.65 & 5.5257 & TST \\
\hline CHEMBL1408857 & 688816 & 4.95 & 5.6599 & TRN \\
\hline
\end{tabular}




\begin{tabular}{|c|c|c|c|c|c|}
\hline \multicolumn{6}{|c|}{ Supplemental Table S2.txt } \\
\hline CHEMBL1303189 & 688816 & 4.95 & 5.0578 & TST & \\
\hline CHEMBL3195123 & 688816 & 5.25 & 5.3855 & TST & \\
\hline CHEMBL1481347 & 688816 & 5.5 & 5.2009 & TRN & \\
\hline CHEMBL1409128 & 688816 & 8.0 & 5.4382 & TRN & \\
\hline CHEMBL1564332 & 688816 & 4.9 & 5.188 & TRN & \\
\hline CHEMBL1527452 & 688816 & 4.9 & 5.3731 & TRN & \\
\hline CHEMBL1320665 & 688816 & 5.05 & 5.1323 & TST & \\
\hline CHEMBL1565798 & 688816 & 5.7 & 5.726 & TST & \\
\hline CHEMBL1498192 & 688816 & 5.05 & 5.4068 & TST & \\
\hline CHEMBL1545313 & 688816 & 4.9 & 5.1584 & TST & \\
\hline CHEMBL1379978 & 688816 & 6.1 & 5.3894 & TRN & \\
\hline CHEMBL1345314 & 688816 & 6.7001 & 5.5013 & TST & \\
\hline CHEMBL1444472 & 688816 & 5.25 & 5.2677 & TRN & \\
\hline CHEMBL1537419 & 688816 & 5.55 & 5.4202 & TRN & \\
\hline CHEMBL3190648 & 688816 & 5.45 & 5.2559 & TRN & \\
\hline CHEMBL1498923 & 688816 & 5.5 & 5.6892 & TRN & \\
\hline CHEMBL1488910 & 688816 & 6.0 & 5.6175 & TRN & \\
\hline CHEMBL1499433 & 688816 & 4.95 & 5.2445 & TRN & \\
\hline CHEMBL1455302 & 688816 & 8.0 & 5.3681 & TRN & \\
\hline CHEMBL1432545 & 688816 & 4.75 & 5.2013 & TRN & \\
\hline CHEMBL1399826 & 688816 & 4.95 & 4.9055 & TRN & \\
\hline CHEMBL1613198 & 688816 & 4.8 & 5.3297 & TRN & \\
\hline CHEMBL1589324 & 688816 & 4.9 & 5.2918 & TRN & \\
\hline CHEMBL3209125 & 688816 & 7.5003 & 5.1007 & TRN & \\
\hline CHEMBL1256484 & 688816 & 4.45 & 4.8792 & TST & \\
\hline CHEMBL1364668 & 688816 & 6.5501 & 5.1031 & TRN & \\
\hline CHEMBL1300572 & 688816 & 8.3468 & 5.6875 & TST & \\
\hline CHEMBL1361350 & 688816 & 4.5 & 5.33899 & 99999999995 & TST \\
\hline CHEMBL1565774 & 688816 & 5.85 & 5.4689 & TRN & \\
\hline CHEMBL1582569 & 688816 & 4.95 & 4.9561 & TST & \\
\hline CHEMBL1522486 & 688816 & 6.0 & 5.3006 & TST & \\
\hline CHEMBL1410376 & 688816 & 4.95 & 5.6168 & TST & \\
\hline CHEMBL1566873 & 688816 & 4.45 & 5.5109 & TRN & \\
\hline CHEMBL1598767 & 688816 & 8.301 & 5.6847 & TRN & \\
\hline CHEMBL1361904 & 688816 & 4.45 & 5.3816 & TST & \\
\hline CHEMBL1575331 & 688816 & 4.9 & 5.1685 & TRN & \\
\hline CHEMBL1440676 & 688816 & 4.55 & 4.9626 & TRN & \\
\hline CHEMBL1557660 & 688816 & 5.5 & 5.2102 & TRN & \\
\hline CHEMBL1608430 & 688816 & 5.65 & 5.1393 & TRN & \\
\hline CHEMBL1419863 & 688816 & 6.7001 & 5.1555 & TRN & \\
\hline CHEMBL1519852 & 688816 & 5.3 & 5.1617 & TRN & \\
\hline CHEMBL3207755 & 688816 & 5.25 & 5.4953 & TRN & \\
\hline CHEMBL1526908 & 688816 & 4.65 & 5.4216 & TRN & \\
\hline CHEMBL1332463 & 688816 & 4.9 & 4.8788 & TRN & \\
\hline CHEMBL1498140 & 688816 & 7.2 & 5.166 & TST & \\
\hline CHEMBL1412008 & 688816 & 4.8 & 5.0821 & TRN & \\
\hline CHEMBL1445008 & 688816 & 6.1 & 5.3408 & TST & \\
\hline CHEMBL1413888 & 688816 & 6.4 & 5.3918 & TRN & \\
\hline
\end{tabular}




\begin{tabular}{|c|c|c|c|c|c|}
\hline \\
\hline CHEMBL1585225 & 688816 & 6.3 & 5.4112 & TRN & \\
\hline CHEMBL1567272 & 688816 & 4.9 & 5.1737 & TRN & \\
\hline CHEMBL1536762 & 688816 & 4.5 & 5.2081 & TRN & \\
\hline CHEMBL35482 & 688816 & 6.0 & 5.1531 & TRN & \\
\hline CHEMBL1383594 & 688816 & 4.9 & 4.9582 & TRN & \\
\hline CHEMBL1593187 & 688816 & 5.55 & 5.3582 & TRN & \\
\hline CHEMBL1301574 & 688816 & 8.3468 & 5.6602 & TRN & \\
\hline CHEMBL3189188 & 688816 & 4.5 & 5.5131 & TRN & \\
\hline CHEMBL1427087 & 688816 & 4.8 & 5.0375 & TRN & \\
\hline CHEMBL301735 & 688816 & 5.35 & 5.1413 & TRN & \\
\hline CHEMBL3214055 & 688816 & 5.25 & 5.6442 & TRN & \\
\hline CHEMBL1464060 & 688816 & 4.9 & 5.2944 & TRN & \\
\hline CHEMBL1471856 & 688816 & 5.5 & 5.3824 & TRN & \\
\hline CHEMBL1591080 & 688816 & 4.95 & 5.0298 & TRN & \\
\hline CHEMBL1984816 & 688816 & 4.9 & 5.4371 & TRN & \\
\hline CHEMBL1346995 & 688816 & 4.75 & 5.0985 & TRN & \\
\hline CHEMBL3209435 & 688816 & 4.7 & 5.4007 & TST & \\
\hline CHEMBL1605100 & 688816 & 4.65 & 5.0232 & TRN & \\
\hline CHEMBL1391965 & 688816 & 4.9 & 5.0175 & TRN & \\
\hline CHEMBL1533936 & 688816 & 5.55 & 5.3988 & TRN & \\
\hline CHEMBL1351018 & 688816 & 4.5 & 5.0812 & TRN & \\
\hline CHEMBL1341540 & 688816 & 4.7 & 5.153 & TRN & \\
\hline CHEMBL 275638 & 688816 & 4.85 & 5.1251 & TRN & \\
\hline CHEMBL1340571 & 688816 & 6.0 & 5.1925 & TRN & \\
\hline CHEMBL1592065 & 688816 & 4.45 & 5.7985 & TST & \\
\hline CHEMBL1527024 & 688816 & 5.65 & 5.23799 & 99999999995 & TRN \\
\hline CHEMBL1610188 & 688816 & 5.6 & 5.5459 & TST & \\
\hline CHEMBL1417770 & 688816 & 4.6 & 4.9152 & TRN & \\
\hline CHEMBL1539922 & 688816 & 4.55 & 4.8125 & TRN & \\
\hline CHEMBL1558223 & 688816 & 5.2 & 5.2275 & TST & \\
\hline CHEMBL1513637 & 688816 & 5.15 & 5.435 & TRN & \\
\hline CHEMBL1426196 & 688816 & 4.85 & 5.6297 & TRN & \\
\hline CHEMBL1322852 & 688816 & 6.0 & 5.4604 & TRN & \\
\hline CHEMBL1470359 & 688816 & 5.0 & 4.9984 & TST & \\
\hline CHEMBL3199184 & 688816 & 5.25 & 5.4061 & TST & \\
\hline CHEMBL1573946 & 688816 & 4.45 & 4.9753 & TRN & \\
\hline CHEMBL3196189 & 688816 & 6.0 & 5.3058 & TRN & \\
\hline CHEMBL1524733 & 688816 & 4.9 & 5.3118 & TST & \\
\hline CHEMBL1598379 & 688816 & 4.45 & 5.3235 & TST & \\
\hline CHEMBL1470242 & 688816 & 5.65 & 5.2074 & TRN & \\
\hline CHEMBL1565412 & 688816 & 6.15 & 5.0905 & TRN & \\
\hline CHEMBL3208944 & 688816 & 4.45 & 5.3426 & TRN & \\
\hline CHEMBL63349 & 688816 & 7.6003 & 5.3616 & TRN & \\
\hline CHEMBL1510137 & 688816 & 4.45 & 5.2789 & TRN & \\
\hline CHEMBL1559053 & 688816 & 5.25 & 5.3389 & TRN & \\
\hline CHEMBL3198366 & 688816 & 4.9 & 5.3241 & TST & \\
\hline CHEMBL1332561 & 688816 & 4.8 & 5.5043 & TRN & \\
\hline CHEMBL3196046 & 688816 & 4.85 & 5.3841 & TST & \\
\hline
\end{tabular}




\begin{tabular}{|c|c|c|c|c|}
\hline \multicolumn{5}{|c|}{ Supplemental Table S2.txt } \\
\hline CHEMBL1414773 & 688816 & 4.95 & 5.1982 & TRN \\
\hline CHEMBL 3210635 & 688816 & 5.35 & 4.9229 & TST \\
\hline CHEMBL1374582 & 688816 & 5.0 & 5.1193 & TRN \\
\hline CHEMBL 3190685 & 688816 & 4.6 & 5.2355 & TRN \\
\hline CHEMBL1480267 & 688816 & 4.65 & 5.0415 & TST \\
\hline CHEMBL3195531 & 688816 & 4.45 & 5.0577 & TRN \\
\hline CHEMBL472437 & 688816 & 4.8 & 5.4177 & TRN \\
\hline CHEMBL1604389 & 688816 & 5.25 & 5.3335 & TRN \\
\hline CHEMBL1373082 & 688816 & 4.45 & 5.1401 & TRN \\
\hline CHEMBL1587583 & 688816 & 4.85 & 5.0482 & TRN \\
\hline CHEMBL1564070 & 688816 & 6.1 & 5.7507 & TRN \\
\hline CHEMBL 3193230 & 688816 & 7.6498 & 5.7795 & TRN \\
\hline CHEMBL1368039 & 688816 & 5.0 & 5.0396 & TRN \\
\hline CHEMBL1351128 & 688816 & 4.75 & 5.1041 & TRN \\
\hline CHEMBL1567527 & 688816 & 4.7 & 5.428 & TST \\
\hline CHEMBL1471227 & 688816 & 7.6003 & 5.4332 & TRN \\
\hline CHEMBL1532212 & 688816 & 5.55 & 5.3851 & TRN \\
\hline CHEMBL1415803 & 688816 & 4.45 & 5.271 & TRN \\
\hline CHEMBL1980737 & 688816 & 4.45 & 4.9148 & TRN \\
\hline CHEMBL1527377 & 688816 & 4.9 & 5.3865 & TRN \\
\hline CHEMBL1598224 & 688816 & 5.5 & 5.5855 & TRN \\
\hline CHEMBL1465704 & 688816 & 5.05 & 5.0011 & TRN \\
\hline CHEMBL 3211423 & 688816 & 4.85 & 5.1603 & TRN \\
\hline CHEMBL1320024 & 688816 & 4.95 & 5.104 & TRN \\
\hline CHEMBL1503962 & 688816 & 4.45 & 5.152 & TST \\
\hline CHEMBL1438022 & 688816 & 5.0 & 5.6634 & TRN \\
\hline CHEMBL1410479 & 688816 & 4.45 & 5.0067 & TRN \\
\hline CHEMBL1452665 & 688816 & 6.35 & 5.7383 & TRN \\
\hline CHEMBL1322185 & 688816 & 4.95 & 5.2123 & TRN \\
\hline CHEMBL1517971 & 688816 & 5.0 & 5.3175 & TRN \\
\hline CHEMBL1543453 & 688816 & 4.95 & 5.034 & TRN \\
\hline CHEMBL1523066 & 688816 & 5.25 & 5.6505 & TRN \\
\hline CHEMBL1577531 & 688816 & 6.5501 & 5.4628 & TST \\
\hline CHEMBL1311883 & 688816 & 5.35 & 5.1031 & TRN \\
\hline CHEMBL1540677 & 688816 & 4.55 & 5.1667 & TST \\
\hline CHEMBL1356728 & 688816 & 5.35 & 5.1773 & TRN \\
\hline CHEMBL1335212 & 688816 & 4.75 & 5.0948 & TRN \\
\hline CHEMBL1349839 & 688816 & 5.2 & 4.9333 & TRN \\
\hline CHEMBL1387474 & 688816 & 5.9 & 4.9762 & TST \\
\hline CHEMBL1334787 & 688816 & 4.9 & 4.8604 & TRN \\
\hline CHEMBL1498946 & 688816 & 4.95 & 5.4146 & TRN \\
\hline CHEMBL 1582888 & 688816 & 5.0 & 5.2872 & TST \\
\hline CHEMBL1382951 & 688816 & 4.7 & 5.1769 & TRN \\
\hline CHEMBL1599792 & 688816 & 4.65 & 5.8267 & TRN \\
\hline CHEMBL1308461 & 688816 & 4.8 & 4.9972 & TRN \\
\hline CHEMBL1338690 & 688816 & 4.95 & 4.9703 & TRN \\
\hline CHEMBL 1425380 & 688816 & 4.9 & 5.0707 & TRN \\
\hline CHEMBL1380071 & 688816 & 5.3 & 5.4536 & TST \\
\hline
\end{tabular}




\begin{tabular}{|c|c|c|c|c|c|}
\hline \multicolumn{6}{|c|}{ splemental } \\
\hline CHEMBL1403579 & 688816 & 4.9 & 5.5093 & TST & \\
\hline CHEMBL1339952 & 688816 & 4.45 & 5.3095 & TRN & \\
\hline CHEMBL1336484 & 688816 & 5.55 & 5.3134 & TRN & \\
\hline CHEMBL1427766 & 688816 & 5.0 & 5.3879 & TRN & \\
\hline CHEMBL1338986 & 688816 & 5.45 & 5.1968 & TRN & \\
\hline CHEMBL1579795 & 688816 & 4.75 & 5.0259 & TST & \\
\hline CHEMBL1308129 & 688816 & 4.75 & 5.5096 & TRN & \\
\hline CHEMBL1406878 & 688816 & 6.5501 & 5.6977 & TRN & \\
\hline CHEMBL1437927 & 688816 & 4.5 & 5.1054 & TRN & \\
\hline CHEMBL1541218 & 688816 & 4.9 & 5.1687 & TRN & \\
\hline CHEMBL1373439 & 688816 & 4.85 & 5.2928 & TRN & \\
\hline CHEMBL1418285 & 688816 & 7.15 & 5.4656 & TST & \\
\hline CHEMBL1468130 & 688816 & 4.9 & 4.8597 & TST & \\
\hline CHEMBL1578648 & 688816 & 5.25 & 5.3674 & TST & \\
\hline CHEMBL1300779 & 688816 & 4.8 & 5.1061 & TRN & \\
\hline CHEMBL2369186 & 688816 & 5.5 & 5.6611 & TRN & \\
\hline CHEMBL1516543 & 688816 & 4.95 & 5.5363 & TRN & \\
\hline CHEMBL1542394 & 688816 & 5.05 & 5.1956 & TST & \\
\hline CHEMBL1410266 & 688816 & 4.9 & 5.1208 & TST & \\
\hline CHEMBL1332669 & 688816 & 5.0 & 4.9655 & TRN & \\
\hline CHEMBL1380750 & 688816 & 4.65 & 5.4016 & TST & \\
\hline CHEMBL1568082 & 688816 & 4.7 & 5.0262 & TRN & \\
\hline CHEMBL1331573 & 688816 & 4.85 & 5.1373 & TST & \\
\hline CHEMBL1601158 & 688816 & 4.45 & 5.092 & TRN & \\
\hline CHEMBL1441182 & 688816 & 4.75 & 5.2274 & TRN & \\
\hline CHEMBL1551874 & 688816 & 4.45 & 4.881 & TRN & \\
\hline CHEMBL3193628 & 688816 & 4.6 & 5.3982 & TRN & \\
\hline CHEMBL1597855 & 688816 & 7.6498 & 5.2326 & TST & \\
\hline CHEMBL1498951 & 688816 & 5.3 & 5.602 & TST & \\
\hline CHEMBL1974432 & 688816 & 5.45 & 5.3249 & TRN & \\
\hline CHEMBL1394126 & 688816 & 5.55 & 5.2747 & TRN & \\
\hline CHEMBL1587589 & 688816 & 5.4 & 5.3023 & TST & \\
\hline CHEMBL1334132 & 688816 & 6.4 & 5.112 & TRN & \\
\hline CHEMBL1370095 & 688816 & 6.7001 & 5.4192 & TST & \\
\hline CHEMBL1302391 & 688816 & 4.95 & 5.0626 & TRN & \\
\hline CHEMBL1425457 & 688816 & 7.9508 & 5.6337 & TST & \\
\hline CHEMBL1998118 & 688816 & 5.1 & 5.28799 & 9999999999 & TRN \\
\hline CHEMBL1309060 & 688816 & 4.95 & 5.05699 & 99999999995 & TRN \\
\hline CHEMBL1431970 & 688816 & 5.2 & 5.4487 & TST & \\
\hline CHEMBL1609187 & 688816 & 4.95 & 5.5415 & TRN & \\
\hline CHEMBL1540120 & 688816 & 4.85 & 5.36799 & 9999999999 & TRN \\
\hline CHEMBL1458012 & 688816 & 4.75 & 5.3433 & TRN & \\
\hline CHEMBL1613309 & 688816 & 4.9 & 4.8698 & TRN & \\
\hline CHEMBL1337367 & 688816 & 5.25 & 5.2415 & TRN & \\
\hline CHEMBL1508452 & 688816 & 5.05 & 5.3315 & TRN & \\
\hline CHEMBL1425688 & 688816 & 5.8 & 5.1397 & TRN & \\
\hline CHEMBL1340399 & 688816 & 4.7 & 5.0748 & TST & \\
\hline CHEMBL1427736 & 688816 & 4.7 & 5.1526 & TRN & \\
\hline
\end{tabular}




\begin{tabular}{|c|c|c|c|c|}
\hline \multicolumn{5}{|c|}{ Supplemental Table S2.txt } \\
\hline CHEMBL1416749 & 688816 & 5.8 & 5.3981 & TRN \\
\hline CHEMBL3214251 & 688816 & 5.3 & 5.5632 & TRN \\
\hline CHEMBL1499288 & 688816 & 7.0501 & 5.6387 & TRN \\
\hline CHEMBL1584661 & 688816 & 4.9 & 5.5076 & TST \\
\hline CHEMBL1530979 & 688816 & 7.9508 & 5.4666 & TRN \\
\hline CHEMBL1567399 & 688816 & 5.05 & 5.3161 & TRN \\
\hline CHEMBL1417899 & 688816 & 4.85 & 5.0652 & TST \\
\hline CHEMBL 3210428 & 688816 & 4.8 & 5.0835 & TST \\
\hline CHEMBL1557755 & 688816 & 8.301 & 5.5942 & TST \\
\hline CHEMBL1595879 & 688816 & 4.95 & 5.1428 & TRN \\
\hline CHEMBL1501848 & 688816 & 4.8 & 5.1212 & TST \\
\hline CHEMBL3191329 & 688816 & 4.95 & 5.0854 & TRN \\
\hline CHEMBL1400676 & 688816 & 4.45 & 5.1873 & TRN \\
\hline CHEMBL1501238 & 688816 & 6.25 & 5.4793 & TRN \\
\hline CHEMBL1575588 & 688816 & 4.85 & 5.1173 & TRN \\
\hline CHEMBL1431232 & 688816 & 4.95 & 5.3134 & TRN \\
\hline CHEMBL1382054 & 688816 & 4.8 & 5.4247 & TRN \\
\hline CHEMBL 3207560 & 688816 & 8.3468 & 5.6033 & TRN \\
\hline CHEMBL1385616 & 688816 & 8.3468 & 5.6304 & TST \\
\hline CHEMBL1570546 & 688816 & 4.6 & 5.1739 & TRN \\
\hline CHEMBL1455387 & 688816 & 4.95 & 5.1652 & TRN \\
\hline CHEMBL1328050 & 688816 & 7.7496 & 5.1624 & TRN \\
\hline CHEMBL1416130 & 688816 & 4.55 & 5.3451 & TRN \\
\hline CHEMBL1466840 & 688816 & 4.9 & 5.2358 & TRN \\
\hline CHEMBL1612259 & 688816 & 4.95 & 5.4466 & TRN \\
\hline CHEMBL1384425 & 688816 & 8.301 & 5.4043 & TST \\
\hline CHEMBL1428697 & 688816 & 4.95 & 5.6763 & TRN \\
\hline CHEMBL1326139 & 688816 & 5.3 & 5.9804 & TRN \\
\hline CHEMBL3192957 & 688816 & 5.8 & 5.2705 & TRN \\
\hline CHEMBL1498144 & 688816 & 4.45 & 5.1816 & TRN \\
\hline CHEMBL1379892 & 688816 & 4.95 & 5.2864 & TRN \\
\hline CHEMBL1561853 & 688816 & 4.95 & 5.1643 & TRN \\
\hline CHEMBL1335115 & 688816 & 4.7 & 5.1289 & TRN \\
\hline CHEMBL1429914 & 688816 & 5.7 & 5.255 & TST \\
\hline CHEMBL1519438 & 688816 & 4.95 & 5.5212 & TST \\
\hline CHEMBL1303513 & 688816 & 4.7 & 5.4977 & TST \\
\hline CHEMBL1594251 & 688816 & 4.95 & 5.0846 & TRN \\
\hline CHEMBL1403339 & 688816 & 5.05 & 5.3353 & TRN \\
\hline CHEMBL1532964 & 688816 & 8.1024 & 5.555 & TRN \\
\hline CHEMBL1342532 & 688816 & 5.55 & 5.5257 & TRN \\
\hline CHEMBL3212894 & 688816 & 5.0 & 5.4839 & TRN \\
\hline CHEMBL1450621 & 688816 & 4.45 & 5.3498 & TRN \\
\hline CHEMBL1411010 & 688816 & 5.15 & 5.7874 & TRN \\
\hline CHEMBL1367761 & 688816 & 5.15 & 5.1506 & TRN \\
\hline CHEMBL1599411 & 688816 & 4.8 & 5.2618 & TRN \\
\hline CHEMBL1430704 & 688816 & 8.1487 & 5.1753 & TRN \\
\hline CHEMBL3189303 & 688816 & 5.1 & 5.4283 & TRN \\
\hline CHEMBL1360537 & 688816 & 4.5 & 5.527 & TRN \\
\hline
\end{tabular}




\begin{tabular}{|c|c|c|c|c|c|}
\hline \multicolumn{6}{|c|}{ Supplemental Table S2.txt } \\
\hline CHEMBL1997293 & 688816 & 4.95 & 5.2888 & TRN & \\
\hline CHEMBL1499003 & 688816 & 5.25 & 5.4255 & TST & \\
\hline CHEMBL1392749 & 688816 & 6.7001 & 5.244 & TRN & \\
\hline CHEMBL1401667 & 688816 & 5.6 & 5.087 & TRN & \\
\hline CHEMBL1601822 & 688816 & 4.65 & 5.142 & TST & \\
\hline CHEMBL1423624 & 688816 & 6.25 & 5.7217 & TST & \\
\hline CHEMBL 3189860 & 688816 & 5.4 & 5.2802 & TRN & \\
\hline CHEMBL1381360 & 688816 & 5.0 & 4.9386 & TRN & \\
\hline CHEMBL 3190825 & 688816 & 4.65 & 5.3187 & TRN & \\
\hline CHEMBL1538486 & 688816 & 4.8 & 5.3176 & TRN & \\
\hline CHEMBL1346474 & 688816 & 5.0 & 5.1714 & TST & \\
\hline CHEMBL1494925 & 688816 & 7.3002 & 4.8023 & TRN & \\
\hline CHEMBL1362518 & 688816 & 5.2 & 5.0683 & TST & \\
\hline CHEMBL1299799 & 688816 & 5.75 & 5.4518 & TST & \\
\hline CHEMBL1545840 & 688816 & 6.35 & 5.6132 & TRN & \\
\hline CHEMBL1503468 & 688816 & 4.85 & 5.0812 & TRN & \\
\hline CHEMBL1501661 & 688816 & 5.25 & 5.3056 & TST & \\
\hline CHEMBL1489209 & 688816 & 4.95 & 5.1167 & TRN & \\
\hline CHEMBL1509337 & 688816 & 5.2 & 5.5637 & TRN & \\
\hline CHEMBL69151 & 688816 & 4.45 & 5.0736 & TRN & \\
\hline CHEMBL1331907 & 688816 & 4.8 & 5.1794 & TRN & \\
\hline CHEMBL1427146 & 688816 & 5.05 & 5.2573 & TST & \\
\hline CHEMBL1418614 & 688816 & 5.2 & 4.9924 & TRN & \\
\hline CHEMBL1347065 & 688816 & 4.85 & 5.4273 & TST & \\
\hline CHEMBL1324875 & 688816 & 8.0506 & 5.3864 & TST & \\
\hline CHEMBL3208815 & 688816 & 5.2 & 5.3389 & TRN & \\
\hline CHEMBL1446542 & 688816 & 4.95 & 5.0748 & TRN & \\
\hline CHEMBL1461816 & 688816 & 6.0 & 4.9896 & TRN & \\
\hline CHEMBL1442374 & 688816 & 8.301 & 5.5017 & TRN & \\
\hline CHEMBL1557760 & 688816 & 5.05 & 5.2956 & TST & \\
\hline CHEMBL1578388 & 688816 & 6.8 & 5.3118 & TRN & \\
\hline CHEMBL1423814 & 688816 & 5.25 & 5.0297 & TST & \\
\hline CHEMBL1608017 & 688816 & 4.65 & 5.2358 & TRN & \\
\hline CHEMBL1561067 & 688816 & 5.05 & 5.3648 & TRN & \\
\hline CHEMBL1358873 & 688816 & 4.65 & 4.8544 & TRN & \\
\hline CHEMBL1546028 & 688816 & 4.95 & 5.1123 & TRN & \\
\hline CHEMBL1348645 & 688816 & 7.6498 & 5.3648 & TRN & \\
\hline CHEMBL1511502 & 688816 & 5.65 & 5.2505 & TRN & \\
\hline CHEMBL1436656 & 688816 & 5.25 & 5.1982 & TST & \\
\hline CHEMBL1389268 & 688816 & 4.45 & 4.8858 & TRN & \\
\hline CHEMBL1566604 & 688816 & 5.05 & 5.4022 & TRN & \\
\hline CHEMBL1595487 & 688816 & 4.75 & 4.993 & TRN & \\
\hline CHEMBL1333847 & 688816 & 6.0 & 5.4611 & TRN & \\
\hline CHEMBL1471587 & 688816 & 4.9 & 5.29799 & 9999999999 & TRN \\
\hline CHEMBL1332962 & 688816 & 5.15 & 5.1324 & TRN & \\
\hline CHEMBL3191681 & 688816 & 4.45 & 5.5794 & TRN & \\
\hline CHEMBL1327812 & 688816 & 4.7 & 5.2206 & TRN & \\
\hline CHEMBL3211420 & 688816 & 4.85 & 5.7546 & TRN & \\
\hline
\end{tabular}




\begin{tabular}{|c|c|c|c|c|}
\hline & & & oplement & al Ta \\
\hline CHEMBL1577969 & 688816 & 7.8013 & 5.0349 & TST \\
\hline CHEMBL1394302 & 688816 & 4.5 & 5.0317 & TST \\
\hline CHEMBL 3213344 & 688816 & 4.45 & 5.5015 & TST \\
\hline CHEMBL1974112 & 688816 & 4.45 & 5.3246 & TRN \\
\hline CHEMBL1343012 & 688816 & 5.35 & 5.5573 & TRN \\
\hline CHEMBL1456048 & 688816 & 4.95 & 5.1439 & TST \\
\hline CHEMBL1362096 & 688816 & 4.9 & 4.9589 & TST \\
\hline CHEMBL1985061 & 688816 & 4.9 & 5.1966 & TRN \\
\hline CHEMBL1580658 & 688816 & 4.95 & 5.226 & TRN \\
\hline CHEMBL1569345 & 688816 & 4.65 & 5.2391 & TRN \\
\hline CHEMBL1564066 & 688816 & 4.45 & 4.6589 & TST \\
\hline CHEMBL1329781 & 688816 & 5.0 & 4.9614 & TRN \\
\hline CHEMBL1432188 & 688816 & 6.8 & 5.4786 & TRN \\
\hline CHEMBL1546491 & 688816 & 4.95 & 5.285 & TRN \\
\hline CHEMBL1532729 & 688816 & 5.35 & 5.0126 & TST \\
\hline CHEMBL3193916 & 688816 & 4.75 & 5.4361 & TRN \\
\hline CHEMBL1469088 & 688816 & 5.2 & 5.6404 & TRN \\
\hline CHEMBL1502443 & 688816 & 4.45 & 5.3012 & TRN \\
\hline CHEMBL1310885 & 688816 & 4.75 & 5.6119 & TRN \\
\hline CHEMBL1350789 & 688816 & 5.35 & 5.4875 & TRN \\
\hline CHEMBL1317346 & 688816 & 4.6 & 4.957 & TRN \\
\hline CHEMBL1333902 & 688816 & 7.4498 & 5.4944 & TRN \\
\hline CHEMBL1596331 & 688816 & 4.45 & 5.5456 & TRN \\
\hline CHEMBL1571630 & 688816 & 6.4 & 5.4817 & TRN \\
\hline CHEMBL3193761 & 688816 & 4.45 & 5.2704 & TST \\
\hline CHEMBL3197819 & 688816 & 4.65 & 5.5185 & TST \\
\hline CHEMBL1493322 & 688816 & 7.0 & 5.4105 & TRN \\
\hline CHEMBL1303685 & 688816 & 5.65 & 5.1614 & TRN \\
\hline CHEMBL 3208847 & 688816 & 5.75 & 5.4131 & TST \\
\hline CHEMBL1419600 & 688816 & 4.45 & 5.436 & TRN \\
\hline CHEMBL1556395 & 688816 & 4.45 & 5.1286 & TRN \\
\hline CHEMBL1364838 & 688816 & 4.55 & 5.2625 & TRN \\
\hline CHEMBL1478030 & 688816 & 4.7 & 5.3599 & TST \\
\hline CHEMBL1522617 & 688816 & 5.0 & 5.0194 & TRN \\
\hline CHEMBL1492065 & 688816 & 7.2503 & 5.5863 & TRN \\
\hline CHEMBL1309979 & 688816 & 5.05 & 5.2086 & TRN \\
\hline CHEMBL1466226 & 688816 & 7.0 & 5.3994 & TST \\
\hline CHEMBL3193151 & 688816 & 7.0 & 5.0985 & TRN \\
\hline CHEMBL602424 & 688816 & 4.45 & 5.1007 & TRN \\
\hline CHEMBL1558602 & 688816 & 5.3 & 4.8945 & TRN \\
\hline CHEMBL1606053 & 688816 & 4.75 & 5.3626 & TRN \\
\hline CHEMBL1453432 & 688816 & 4.9 & 5.545 & TRN \\
\hline CHEMBL1372263 & 688816 & 5.5 & 5.546 & TRN \\
\hline CHEMBL1554801 & 688816 & 4.5 & 4.9553 & TST \\
\hline CHEMBL1452108 & 688816 & 4.9 & 5.2843 & TRN \\
\hline CHEMBL1383307 & 688816 & 4.95 & 5.3255 & TRN \\
\hline CHEMBL1350641 & 688816 & 4.95 & 5.0188 & TRN \\
\hline CHEMBL1444615 & 688816 & 5.35 & 5.6502 & TRN \\
\hline
\end{tabular}




\begin{tabular}{|c|c|c|c|c|c|}
\hline & & & & & \\
\hline CHEMBL1380769 & 688816 & 6.8 & 5.4127 & TRN & \\
\hline CHEMBL1312009 & 688816 & 6.15 & 5.3542 & TRN & \\
\hline CHEMBL1585829 & 688816 & 4.85 & 5.4073 & TRN & \\
\hline CHEMBL1594171 & 688816 & 5.25 & 4.7574 & TRN & \\
\hline CHEMBL1491573 & 688816 & 5.55 & 5.4938 & TRN & \\
\hline CHEMBL1530583 & 688816 & 4.85 & 4.9033 & TRN & \\
\hline CHEMBL1365738 & 688816 & 5.0 & 5.1181 & TST & \\
\hline CHEMBL1521215 & 688816 & 5.5 & 5.2973 & TRN & \\
\hline CHEMBL1492105 & 688816 & 4.9 & 5.3303 & TST & \\
\hline CHEMBL1502879 & 688816 & 4.9 & 4.8533 & TRN & \\
\hline CHEMBL1344282 & 688816 & 6.15 & 5.4795 & TST & \\
\hline CHEMBL1540581 & 688816 & 4.85 & 5.0959 & TRN & \\
\hline CHEMBL1423440 & 688816 & 4.75 & 5.2896 & TST & \\
\hline CHEMBL1541696 & 688816 & 5.35 & 5.5275 & TRN & \\
\hline CHEMBL1430219 & 688816 & 4.85 & 5.4359 & TRN & \\
\hline CHEMBL1465794 & 688816 & 4.45 & 5.4929 & TRN & \\
\hline CHEMBL3145030 & 688816 & 4.45 & 5.3361 & TRN & \\
\hline CHEMBL1338521 & 688816 & 5.25 & 5.7134 & TRN & \\
\hline CHEMBL1581270 & 688816 & 5.65 & 5.3262 & TRN & \\
\hline CHEMBL1563318 & 688816 & 4.85 & 5.4324 & TRN & \\
\hline CHEMBL1429195 & 688816 & 8.3468 & 5.4841 & TRN & \\
\hline CHEMBL1536674 & 688816 & 4.45 & 5.2408 & TST & \\
\hline CHEMBL3213273 & 688816 & 7.699 & 5.41299 & 9999999999 & TST \\
\hline CHEMBL1528077 & 688816 & 5.1 & 5.1858 & TRN & \\
\hline CHEMBL1372613 & 688816 & 5.8 & 5.1943 & TRN & \\
\hline CHEMBL1581754 & 688816 & 4.45 & 5.1968 & TRN & \\
\hline CHEMBL 3212708 & 688816 & 4.45 & 5.1923 & TRN & \\
\hline CHEMBL3197901 & 688816 & 4.95 & 5.2265 & TRN & \\
\hline CHEMBL1356155 & 688816 & 4.9 & 5.065 & TST & \\
\hline CHEMBL1572265 & 688816 & 4.9 & 5.1989 & TRN & \\
\hline CHEMBL1411280 & 688816 & 4.6 & 5.2299 & TRN & \\
\hline CHEMBL1601364 & 688816 & 4.9 & 4.9532 & TRN & \\
\hline CHEMBL1500619 & 688816 & 5.0 & 5.1218 & TRN & \\
\hline CHEMBL1482584 & 688816 & 8.3468 & 5.2903 & TST & \\
\hline CHEMBL1434332 & 688816 & 5.0 & 5.2388 & TRN & \\
\hline CHEMBL1608301 & 688816 & 6.0 & 5.0903 & TRN & \\
\hline CHEMBL1468167 & 688816 & 4.45 & 4.7927 & TRN & \\
\hline CHEMBL1509595 & 688816 & 5.3 & 5.1368 & TRN & \\
\hline CHEMBL1472595 & 688816 & 5.5 & 5.9844 & TST & \\
\hline CHEMBL1407854 & 688816 & 4.95 & 5.2198 & TRN & \\
\hline CHEMBL1586616 & 688816 & 4.9 & 5.0258 & TRN & \\
\hline CHEMBL1530215 & 688816 & 4.8 & 5.2517 & TRN & \\
\hline CHEMBL1422356 & 688816 & 4.65 & 5.5902 & TRN & \\
\hline CHEMBL1385195 & 688816 & 4.8 & 4.9849 & TRN & \\
\hline CHEMBL1312763 & 688816 & 5.6 & 5.3064 & TRN & \\
\hline CHEMBL1513443 & 688816 & 5.8 & 5.0892 & TST & \\
\hline CHEMBL1501967 & 688816 & 5.2 & 5.6672 & TRN & \\
\hline CHEMBL1359062 & 688816 & 4.85 & 4.68199 & 99999999995 & TRN \\
\hline & & & & 25149 & \\
\hline
\end{tabular}




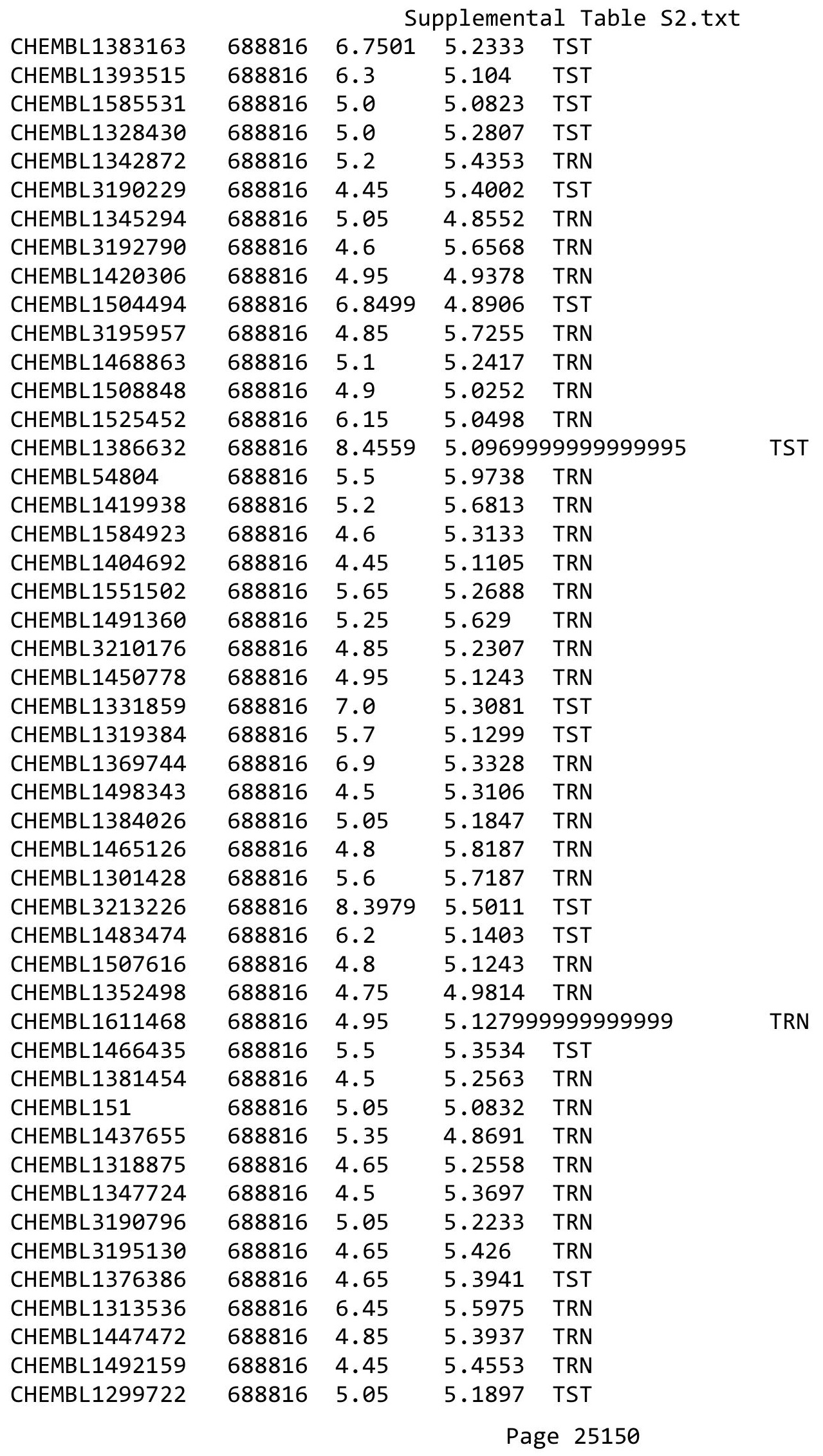




\begin{tabular}{|c|c|c|c|c|c|}
\hline & & & & & \\
\hline CHEMBL1500979 & 688816 & 5.0 & 5.2072 & TST & \\
\hline CHEMBL1377511 & 688816 & 4.45 & 4.8138 & TRN & \\
\hline CHEMBL1569938 & 688816 & 4.9 & 5.059 & TRN & \\
\hline CHEMBL1480952 & 688816 & 4.85 & 5.2225 & TRN & \\
\hline CHEMBL1437146 & 688816 & 4.95 & 5.3106 & TRN & \\
\hline CHEMBL1407918 & 688816 & 5.0 & 5.3203 & TRN & \\
\hline CHEMBL1432712 & 688816 & 5.0 & 4.927 & TRN & \\
\hline CHEMBL1538796 & 688816 & 4.45 & 4.9796 & TST & \\
\hline CHEMBL1377290 & 688816 & 5.0 & 5.2986 & TRN & \\
\hline CHEMBL1521148 & 688816 & 4.9 & 4.9034 & TRN & \\
\hline CHEMBL1309430 & 688816 & 4.85 & 5.3452 & TST & \\
\hline CHEMBL1481276 & 688816 & 4.45 & 5.1224 & TRN & \\
\hline CHEMBL1301813 & 688816 & 4.65 & 4.8961 & TRN & \\
\hline CHEMBL1438303 & 688816 & 4.5 & 5.4963 & TRN & \\
\hline CHEMBL1468981 & 688816 & 4.45 & 5.0973 & TST & \\
\hline CHEMBL1863606 & 688816 & 4.8 & 5.0989 & TRN & \\
\hline CHEMBL1367738 & 688816 & 5.65 & 5.3488 & TST & \\
\hline CHEMBL1583033 & 688816 & 8.0506 & 5.239 & TRN & \\
\hline CHEMBL1326164 & 688816 & 4.95 & 5.24700 & 0000000001 & TRN \\
\hline CHEMBL1583974 & 688816 & 5.25 & 5.5736 & TST & \\
\hline CHEMBL1595251 & 688816 & 4.95 & 5.3311 & TRN & \\
\hline CHEMBL1530156 & 688816 & 5.55 & 5.3503 & TRN & \\
\hline CHEMBL1333810 & 688816 & 4.45 & 5.1881 & TRN & \\
\hline CHEMBL1454651 & 688816 & 4.85 & 5.0087 & TRN & \\
\hline CHEMBL584841 & 688816 & 4.9 & 5.1103 & TRN & \\
\hline CHEMBL1534634 & 688816 & 4.45 & 5.5816 & TST & \\
\hline CHEMBL1386278 & 688816 & 5.25 & 5.2956 & TRN & \\
\hline CHEMBL1506234 & 688816 & 5.35 & 5.7133 & TRN & \\
\hline CHEMBL1334705 & 688816 & 4.7 & 5.2753 & TRN & \\
\hline CHEMBL1485329 & 688816 & 7.2503 & 5.3083 & TST & \\
\hline CHEMBL1441856 & 688816 & 5.5 & 4.933 & TST & \\
\hline CHEMBL1558159 & 688816 & 4.9 & 5.3977 & TRN & \\
\hline CHEMBL1541620 & 688816 & 4.65 & 5.3496 & TST & \\
\hline CHEMBL1463731 & 688816 & 4.9 & 5.2196 & TST & \\
\hline CHEMBL1341412 & 688816 & 5.35 & 5.4573 & TRN & \\
\hline CHEMBL1363803 & 688816 & 4.65 & 5.0277 & TRN & \\
\hline CHEMBL1498052 & 688816 & 4.6 & 4.9647 & TRN & \\
\hline CHEMBL1462597 & 688816 & 7.0 & 5.4629 & TST & \\
\hline CHEMBL1300057 & 688816 & 4.85 & 5.6441 & TRN & \\
\hline CHEMBL1355585 & 688816 & 5.25 & 5.2757 & TRN & \\
\hline CHEMBL1579996 & 688816 & 5.45 & 5.5278 & TRN & \\
\hline CHEMBL1304934 & 688816 & 4.65 & 5.206 & TRN & \\
\hline CHEMBL1501061 & 688816 & 4.9 & 4.9714 & TRN & \\
\hline CHEMBL1337416 & 688816 & 5.9 & 5.223 & TRN & \\
\hline CHEMBL1343215 & 688816 & 6.5501 & 5.1049 & TST & \\
\hline CHEMBL1465845 & 688816 & 5.1 & 4.9645 & TRN & \\
\hline CHEMBL1392341 & 688816 & 5.05 & 4.6856 & TRN & \\
\hline CHEMBL1402896 & 688816 & 5.0 & 5.29899 & 99999999995 & TRN \\
\hline & & & & 25151 & \\
\hline
\end{tabular}




\begin{tabular}{|c|c|c|c|c|}
\hline \multicolumn{5}{|c|}{ Supplemental Table S2.txt } \\
\hline CHEMBL1312714 & 688816 & 4.8 & 5.2443 & TST \\
\hline CHEMBL1439930 & 688816 & 4.95 & 4.8675 & TST \\
\hline CHEMBL1582479 & 688816 & 5.05 & 4.9884 & TRN \\
\hline CHEMBL1300695 & 688816 & 4.8 & 5.3054 & TRN \\
\hline CHEMBL1308871 & 688816 & 4.5 & 4.5369 & TRN \\
\hline CHEMBL1375329 & 688816 & 4.7 & 5.3659 & TRN \\
\hline CHEMBL488803 & 688816 & 5.4 & 5.2234 & TST \\
\hline CHEMBL1440237 & 688816 & 4.45 & 4.9303 & TST \\
\hline CHEMBL1455985 & 688816 & 4.8 & 5.1981 & TRN \\
\hline CHEMBL1422439 & 688816 & 6.15 & 5.0109 & TST \\
\hline CHEMBL1442362 & 688816 & 8.0506 & 5.4867 & TST \\
\hline CHEMBL1375223 & 688816 & 4.8 & 5.4545 & TRN \\
\hline CHEMBL1306787 & 688816 & 4.45 & 5.0841 & TST \\
\hline CHEMBL1319022 & 688816 & 7.7496 & 5.688 & TRN \\
\hline CHEMBL1582125 & 688816 & 4.6 & 4.7908 & TRN \\
\hline CHEMBL1451347 & 688816 & 4.8 & 5.1103 & TRN \\
\hline CHEMBL1351387 & 688816 & 4.9 & 5.4797 & TST \\
\hline CHEMBL1579790 & 688816 & 4.65 & 5.0549 & TST \\
\hline CHEMBL1577056 & 688816 & 4.95 & 5.35 & TST \\
\hline CHEMBL346516 & 688816 & 4.45 & 5.5332 & TST \\
\hline CHEMBL1476319 & 688816 & 6.0 & 5.022 & TRN \\
\hline CHEMBL1338960 & 688816 & 4.8 & 5.0999 & TST \\
\hline CHEMBL1562181 & 688816 & 5.1 & 5.2341 & TRN \\
\hline CHEMBL1580858 & 688816 & 8.301 & 5.7283 & TRN \\
\hline CHEMBL1344537 & 688816 & 5.25 & 5.4472 & TST \\
\hline CHEMBL1412133 & 688816 & 5.0 & 5.4149 & TRN \\
\hline CHEMBL1496470 & 688816 & 5.0 & 5.1548 & TRN \\
\hline CHEMBL1526304 & 688816 & 4.95 & 4.9286 & TST \\
\hline CHEMBL1536680 & 688816 & 4.95 & 4.9535 & TST \\
\hline CHEMBL1300497 & 688816 & 4.95 & 5.0005 & TRN \\
\hline CHEMBL1424458 & 688816 & 4.9 & 5.0905 & TRN \\
\hline CHEMBL1368219 & 688816 & 4.95 & 5.3837 & TRN \\
\hline CHEMBL1494039 & 688816 & 4.65 & 5.0344 & TRN \\
\hline CHEMBL1314745 & 688816 & 4.45 & 5.2913 & TRN \\
\hline CHEMBL1371452 & 688816 & 4.75 & 5.0369 & TRN \\
\hline CHEMBL1524471 & 688816 & 4.85 & 5.3649 & TRN \\
\hline CHEMBL1361452 & 688816 & 5.45 & 5.0288 & TRN \\
\hline CHEMBL600090 & 688816 & 4.6 & 5.3584 & TRN \\
\hline CHEMBL1533439 & 688816 & 4.9 & 5.3564 & TRN \\
\hline CHEMBL1601285 & 688816 & 4.65 & 4.8282 & TRN \\
\hline CHEMBL1418140 & 688816 & 7.5003 & 5.4296 & TRN \\
\hline CHEMBL1560102 & 688816 & 5.0 & 5.2295 & TRN \\
\hline CHEMBL1504141 & 688816 & 5.0 & 5.1892 & TRN \\
\hline CHEMBL1093074 & 688816 & 5.0 & 5.4184 & TRN \\
\hline CHEMBL1368138 & 688816 & 5.0 & 5.2387 & TRN \\
\hline CHEMBL3210649 & 688816 & 6.15 & 5.3188 & TRN \\
\hline CHEMBL1353415 & 688816 & 4.75 & 5.393 & TRN \\
\hline CHEMBL1570812 & 688816 & 4.7 & 5.4772 & TRN \\
\hline
\end{tabular}




\begin{tabular}{|c|c|c|c|c|c|}
\hline \multicolumn{6}{|c|}{ Supplemental Table S2.txt } \\
\hline CHEMBL1423147 & 688816 & 5.15 & 5.4364 & TRN & \\
\hline CHEMBL 3208102 & 688816 & 6.0 & 6.1187 & TRN & \\
\hline CHEMBL1393595 & 688816 & 4.85 & 5.4846 & TST & \\
\hline CHEMBL1330747 & 688816 & 4.9 & 5.1957 & TRN & \\
\hline CHEMBL1308060 & 688816 & 6.1 & 5.9334 & TRN & \\
\hline CHEMBL3199731 & 688816 & 5.0 & 5.4164 & TST & \\
\hline CHEMBL3392043 & 688816 & 4.8 & 5.3415 & TRN & \\
\hline CHEMBL1542257 & 688816 & 4.85 & 5.5038 & TST & \\
\hline CHEMBL1965068 & 688816 & 4.8 & 5.5863 & TRN & \\
\hline CHEMBL1536150 & 688816 & 5.0 & 5.7097 & TST & \\
\hline CHEMBL1414277 & 688816 & 5.95 & 4.8253 & TRN & \\
\hline CHEMBL1400203 & 688816 & 4.6 & 5.1986 & TST & \\
\hline CHEMBL1492305 & 688816 & 4.75 & 5.4615 & TST & \\
\hline CHEMBL1305304 & 688816 & 4.85 & 5.2919 & TRN & \\
\hline CHEMBL1339113 & 688816 & 5.35 & 5.0493 & TRN & \\
\hline CHEMBL3210895 & 688816 & 5.05 & 5.1337 & TST & \\
\hline CHEMBL1426951 & 688816 & 5.4 & 5.0678 & TST & \\
\hline CHEMBL1466346 & 688816 & 4.95 & 5.7091 & TRN & \\
\hline CHEMBL1564640 & 688816 & 4.45 & 5.0862 & TRN & \\
\hline CHEMBL1387904 & 688816 & 5.45 & 5.4521 & TRN & \\
\hline CHEMBL1494955 & 688816 & 4.8 & 4.9718 & TST & \\
\hline CHEMBL1488039 & 688816 & 8.0506 & 5.1097 & TRN & \\
\hline CHEMBL1577483 & 688816 & 4.9 & 5.2159 & TRN & \\
\hline CHEMBL1381446 & 688816 & 4.95 & 5.0845 & TRN & \\
\hline CHEMBL1506713 & 688816 & 4.9 & 4.8941 & TST & \\
\hline CHEMBL1321669 & 688816 & 5.25 & 5.2144 & TRN & \\
\hline CHEMBL1982896 & 688816 & 4.45 & 4.8349 & TRN & \\
\hline CHEMBL1329152 & 688816 & 4.45 & 4.9809 & TRN & \\
\hline CHEMBL1306836 & 688816 & 4.45 & 5.2993 & TST & \\
\hline CHEMBL 3197771 & 688816 & 5.1 & 5.20799 & 9999999999 & TRN \\
\hline CHEMBL1565648 & 688816 & 4.95 & 5.4569 & TRN & \\
\hline CHEMBL1345724 & 688816 & 4.9 & 5.3289 & TST & \\
\hline CHEMBL1352955 & 688816 & 5.2 & 5.0958 & TRN & \\
\hline CHEMBL1318988 & 688816 & 5.2 & 5.0612 & TRN & \\
\hline CHEMBL1324266 & 688816 & 6.5501 & 5.0194 & TST & \\
\hline CHEMBL1544923 & 688816 & 4.6 & 5.4411 & TRN & \\
\hline CHEMBL1440300 & 688816 & 4.8 & 5.3693 & TST & \\
\hline CHEMBL1427687 & 688816 & 4.7 & 5.2093 & TRN & \\
\hline CHEMBL1533921 & 688816 & 4.7 & 5.2956 & TRN & \\
\hline CHEMBL1575015 & 688816 & 4.9 & 5.5552 & TRN & \\
\hline CHEMBL1332636 & 688816 & 4.45 & 5.5509 & TRN & \\
\hline CHEMBL1464809 & 688816 & 4.7 & 5.3048 & TST & \\
\hline CHEMBL1351990 & 688816 & 5.05 & 5.5191 & TST & \\
\hline CHEMBL1539755 & 688816 & 4.95 & 5.6731 & TRN & \\
\hline CHEMBL1571897 & 688816 & 4.85 & 5.0773 & TRN & \\
\hline CHEMBL1484030 & 688816 & 4.8 & 5.5239 & TRN & \\
\hline CHEMBL337173 & 688816 & 4.95 & 5.3457 & TRN & \\
\hline CHEMBL1569696 & 688816 & 8.301 & 5.0608 & TST & \\
\hline
\end{tabular}




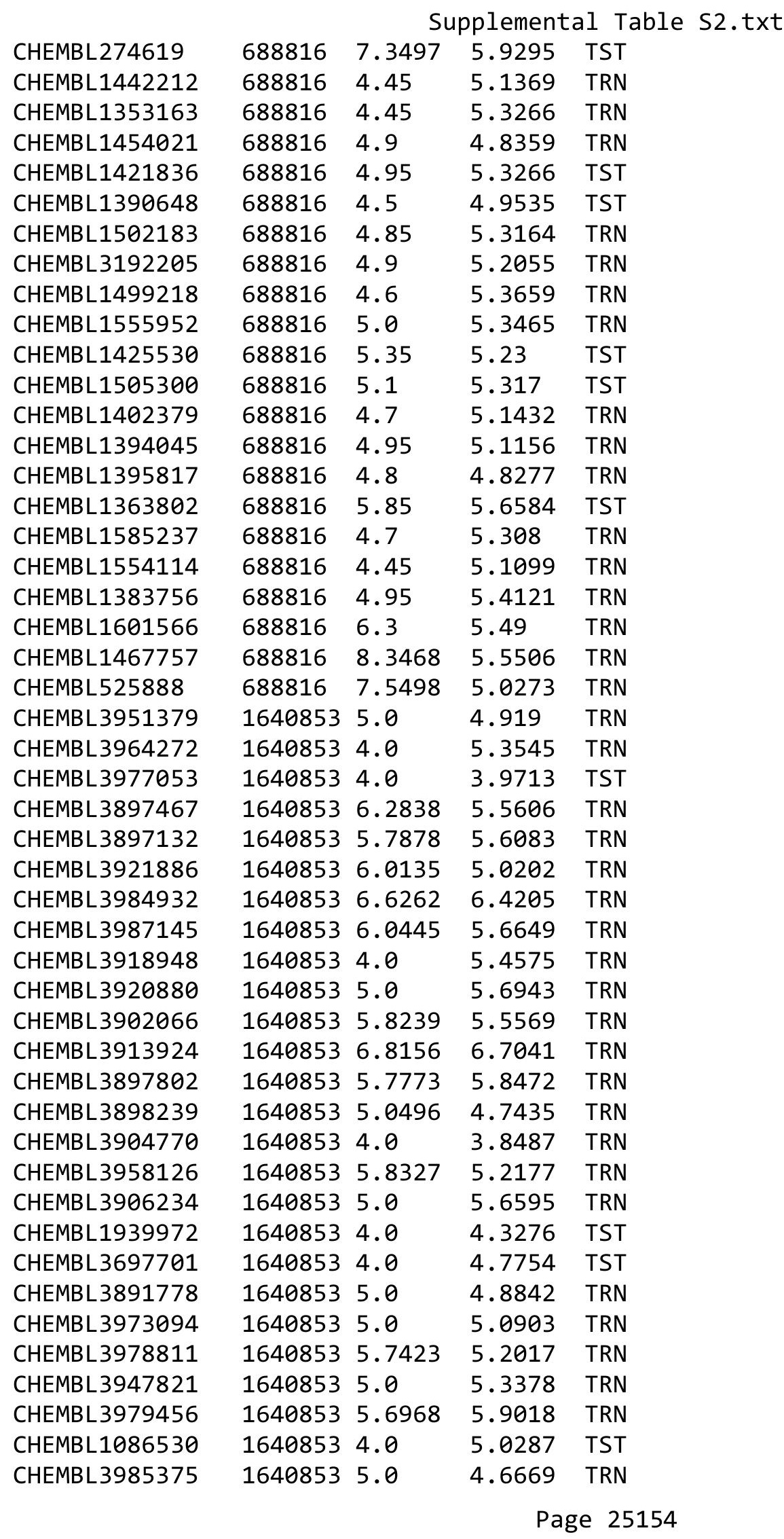


Supplemental Table S2.txt

\begin{tabular}{|c|c|c|c|c|c|}
\hline CHEMBL3896592 & 1640853 & 5.0 & 4.5861 & TST & \\
\hline CHEMBL 3894760 & 1640853 & 5.0 & 5.5236 & TRN & \\
\hline CHEMBL 3977240 & 1640853 & 4.0 & 4.444 & TRN & \\
\hline CHEMBL3939180 & 1640853 & 5.5528 & 5.1686 & TRN & \\
\hline CHEMBL 3944172 & 1640853 & 6.0831 & 6.6468 & TRN & \\
\hline CHEMBL3976535 & 1640853 & 5.0 & 5.0357 & TRN & \\
\hline CHEMBL3905460 & 1640853 & 4.0 & 4.3729 & TRN & \\
\hline CHEMBL3945471 & 1640853 & 6.8798 & 6.7187 & TRN & \\
\hline CHEMBL3968269 & 1640853 & 5.0 & 4.9414 & TRN & \\
\hline CHEMBL3914798 & 1640853 & 4.0 & 4.7528 & TST & \\
\hline CHEMBL 3949747 & 1640853 & 5.0 & 5.0215 & TRN & \\
\hline CHEMBL3939505 & 1640853 & 5.8697 & 4.873 & TRN & \\
\hline CHEMBL 3947801 & 1640853 & 6.8002 & 5.7595 & TRN & \\
\hline CHEMBL 3981620 & 1640853 & 5.0 & 4.8196 & TRN & \\
\hline CHEMBL 3968210 & 1640853 & 4.0 & 4.474 & TRN & \\
\hline CHEMBL 3932546 & 1640853 & 4.0 & 4.3007 & TRN & \\
\hline CHEMBL 3896060 & 1640853 & 5.0 & 4.8111 & TRN & \\
\hline CHEMBL3956560 & 1640853 & 4.0 & 4.5571 & TRN & \\
\hline CHEMBL3976217 & 1640853 & 5.5482 & \multicolumn{2}{|c|}{5.593999999999999} & TRN \\
\hline CHEMBL 3935604 & 1640853 & 4.0 & 5.3602 & TST & \\
\hline CHEMBL 3904928 & 1640853 & 5.0 & 4.3908 & TRN & \\
\hline CHEMBL3929233 & 1640853 & 5.0 & 4.9677 & TRN & \\
\hline CHEMBL3906012 & 1640853 & 5.0 & 5.0884 & TRN & \\
\hline CHEMBL3953065 & 1640853 & 5.0 & 4.9309 & TRN & \\
\hline CHEMBL 3948438 & 1640853 & 5.0 & 4.9107 & TRN & \\
\hline CHEMBL 3927494 & 1640853 & 4.0 & 4.5752 & TRN & \\
\hline CHEMBL3944579 & 1640853 & 4.0 & 4.6613 & TRN & \\
\hline CHEMBL3931425 & 1640853 & 4.0 & 5.3732 & TST & \\
\hline CHEMBL3930651 & 1640853 & 4.0 & 4.8431 & TRN & \\
\hline CHEMBL 3947368 & 1640853 & 7.0 & 5.3468 & TRN & \\
\hline CHEMBL 3945044 & 1640853 & 5.3958 & 4.9223 & TRN & \\
\hline CHEMBL3956711 & 1640853 & 5.7282 & 5.6183 & TRN & \\
\hline CHEMBL3936454 & 1640853 & 5.0 & 4.8509 & TRN & \\
\hline CHEMBL3904057 & 1640853 & 4.0 & 4.8056 & TRN & \\
\hline CHEMBL 3908909 & 1640853 & 5.0 & 4.7968 & TRN & \\
\hline CHEMBL3958453 & 1640853 & 4.0 & 5.0002 & TRN & \\
\hline CHEMBL 3894821 & 1640853 & 5.4157 & 5.4394 & TST & \\
\hline CHEMBL3894956 & 1640853 & 5.0511 & \multicolumn{2}{|c|}{5.428999999999999} & TRN \\
\hline CHEMBL3922771 & 1640853 & 4.0 & 4.2164 & TRN & \\
\hline CHEMBL3935137 & 1640853 & 5.8794 & 5.7211 & TRN & \\
\hline CHEMBL 3911625 & 1640853 & 4.0 & 4.7687 & TRN & \\
\hline CHEMBL 3981050 & 1640853 & 5.0 & 4.9594 & TRN & \\
\hline CHEMBL3953123 & 1640853 & 4.0 & 5.1912 & TST & \\
\hline CHEMBL3987098 & 1640853 & 5.6289 & 4.2221 & TST & \\
\hline CHEMBL3924373 & 1640853 & 4.0 & 4.4405 & TRN & \\
\hline CHEMBL 3899453 & 1640853 & 5.0 & 4.2981 & TRN & \\
\hline CHEMBL3920106 & 1640853 & 5.0 & 4.6563 & TRN & \\
\hline CHEMBL3892326 & 1640853 & 6.5549 & 6.2893 & TRN & \\
\hline
\end{tabular}

Page 25155 
Supplemental Table S2.txt

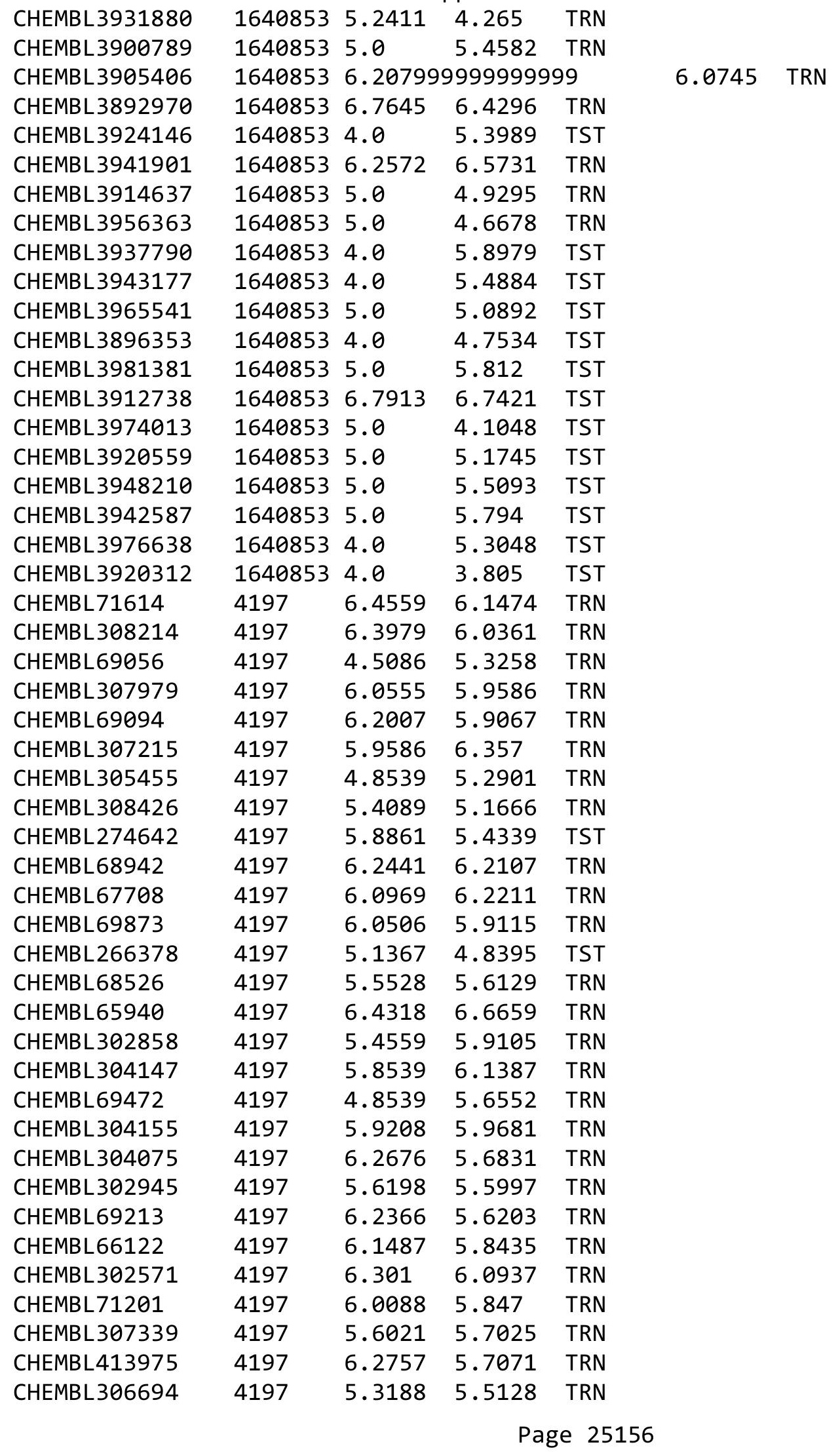




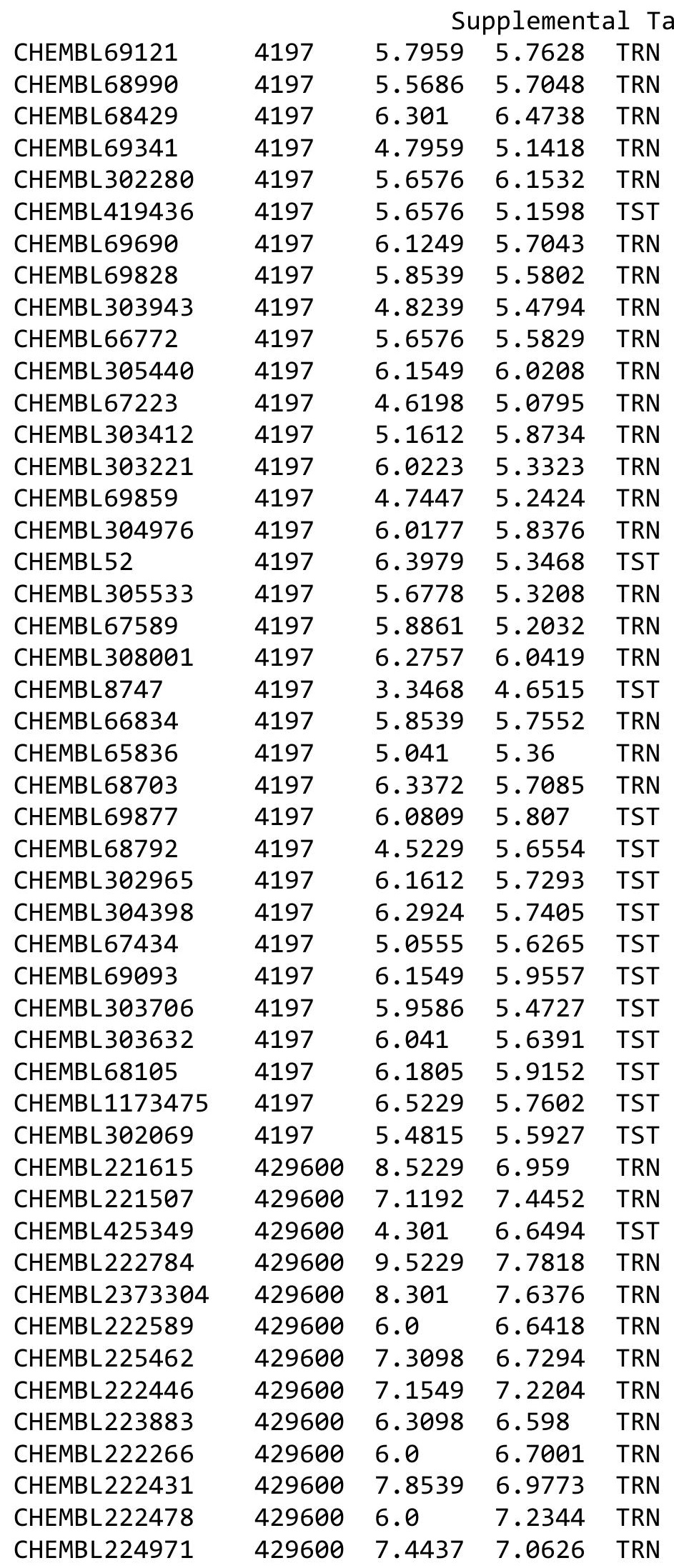

Page 25157 


\begin{tabular}{|c|c|c|c|c|c|}
\hline \multicolumn{6}{|c|}{ Supplemental Table s2.txt } \\
\hline CHEMBL223321 & 429600 & 5.301 & 6.8708 & TST & \\
\hline CHEMBL 375772 & 429600 & 6.0 & 6.3072 & TRN & \\
\hline CHEMBL17127 & 429600 & 7.4318 & 6.6159 & TST & \\
\hline CHEMBL222901 & 429600 & 6.8861 & 6.4994 & TRN & \\
\hline CHEMBL374881 & 429600 & 9.2218 & 7.7927 & TRN & \\
\hline CHEMBL 373941 & 429600 & 8.0458 & 7.2033 & TRN & \\
\hline CHEMBL374276 & 429600 & 6.7447 & 7.0223 & TRN & \\
\hline CHEMBL221896 & 429600 & 6.0 & 7.5693 & TRN & \\
\hline CHEMBL 223745 & 429600 & 8.3979 & 7.4781 & TRN & \\
\hline CHEMBL375436 & 429600 & 7.3468 & 6.9892 & TRN & \\
\hline CHEMBL 222374 & 429600 & 6.7696 & 6.1452 & TRN & \\
\hline CHEMBL386501 & 429600 & 6.0 & 6.3655 & TRN & \\
\hline CHEMBL376346 & 429600 & 7.8861 & 7.4145 & TRN & \\
\hline CHEMBL 222481 & 429600 & 7.3279 & 6.7929 & TRN & \\
\hline CHEMBL221573 & 429600 & 8.5229 & 7.1055 & TRN & \\
\hline CHEMBL 222532 & 429600 & 7.0969 & 7.5373 & TRN & \\
\hline CHEMBL222783 & 429600 & 6.0 & 7.3514 & TRN & \\
\hline CHEMBL 222530 & 429600 & 8.1549 & 7.5011 & TRN & \\
\hline CHEMBL 223035 & 429600 & 6.0 & 6.9282 & TRN & \\
\hline CHEMBL 221772 & 429600 & 6.0 & 7.2648 & TRN & \\
\hline CHEMBL221359 & 429600 & 6.0 & 7.04299 & 9999999999 & TRN \\
\hline CHEMBL221352 & 429600 & 6.0 & 6.4441 & TRN & \\
\hline CHEMBL222131 & 429600 & 6.0 & 7.3134 & TRN & \\
\hline CHEMBL 222914 & 429600 & 5.301 & 6.6983 & TRN & \\
\hline CHEMBL446621 & 429600 & 7.5229 & 7.0195 & TRN & \\
\hline CHEMBL 221561 & 429600 & 8.3979 & 7.138 & TRN & \\
\hline CHEMBL221947 & 429600 & 6.6383 & 6.4033 & TRN & \\
\hline CHEMBL 387327 & 429600 & 6.0 & 7.4239 & TRN & \\
\hline CHEMBL426906 & 429600 & 7.2518 & 6.3648 & TRN & \\
\hline CHEMBL2096851 & 429600 & 6.0 & 6.1653 & TRN & \\
\hline CHEMBL223419 & 429600 & 9.0458 & 7.3681 & TRN & \\
\hline CHEMBL387318 & 429600 & 6.0 & 7.3888 & TRN & \\
\hline CHEMBL189192 & 429600 & 7.8539 & 6.9479 & TST & \\
\hline CHEMBL221613 & 429600 & 7.3279 & 6.7815 & TRN & \\
\hline CHEMBL222731 & 429600 & 6.0 & 7.6173 & TRN & \\
\hline CHEMBL 222641 & 429600 & 6.9586 & 6.6776 & TST & \\
\hline CHEMBL375846 & 429600 & 7.4202 & 6.1833 & TST & \\
\hline CHEMBL222855 & 429600 & 6.8539 & 6.2344 & TST & \\
\hline CHEMBL223976 & 429600 & 7.4685 & 7.0702 & TST & \\
\hline CHEMBL373560 & 429600 & 9.5229 & 7.1003 & TST & \\
\hline CHEMBL 222097 & 429600 & 8.699 & 6.6817 & TST & \\
\hline CHEMBL390976 & 429600 & 7.2924 & 7.1831 & TST & \\
\hline CHEMBL387319 & 429600 & 6.2147 & 6.6211 & TST & \\
\hline CHEMBL173672 & 429600 & 8.4437 & 6.45700 & 0000000001 & TST \\
\hline CHEMBL439141 & 429600 & 7.9208 & 6.5158 & TST & \\
\hline CHEMBL222086 & 429600 & 6.0809 & 7.5944 & TST & \\
\hline CHEMBL3891299 & 1640506 & 6.5229 & 7.4393 & TRN & \\
\hline CHEMBL3928273 & 1640506 & 5.0 & 6.6155 & TST & \\
\hline
\end{tabular}




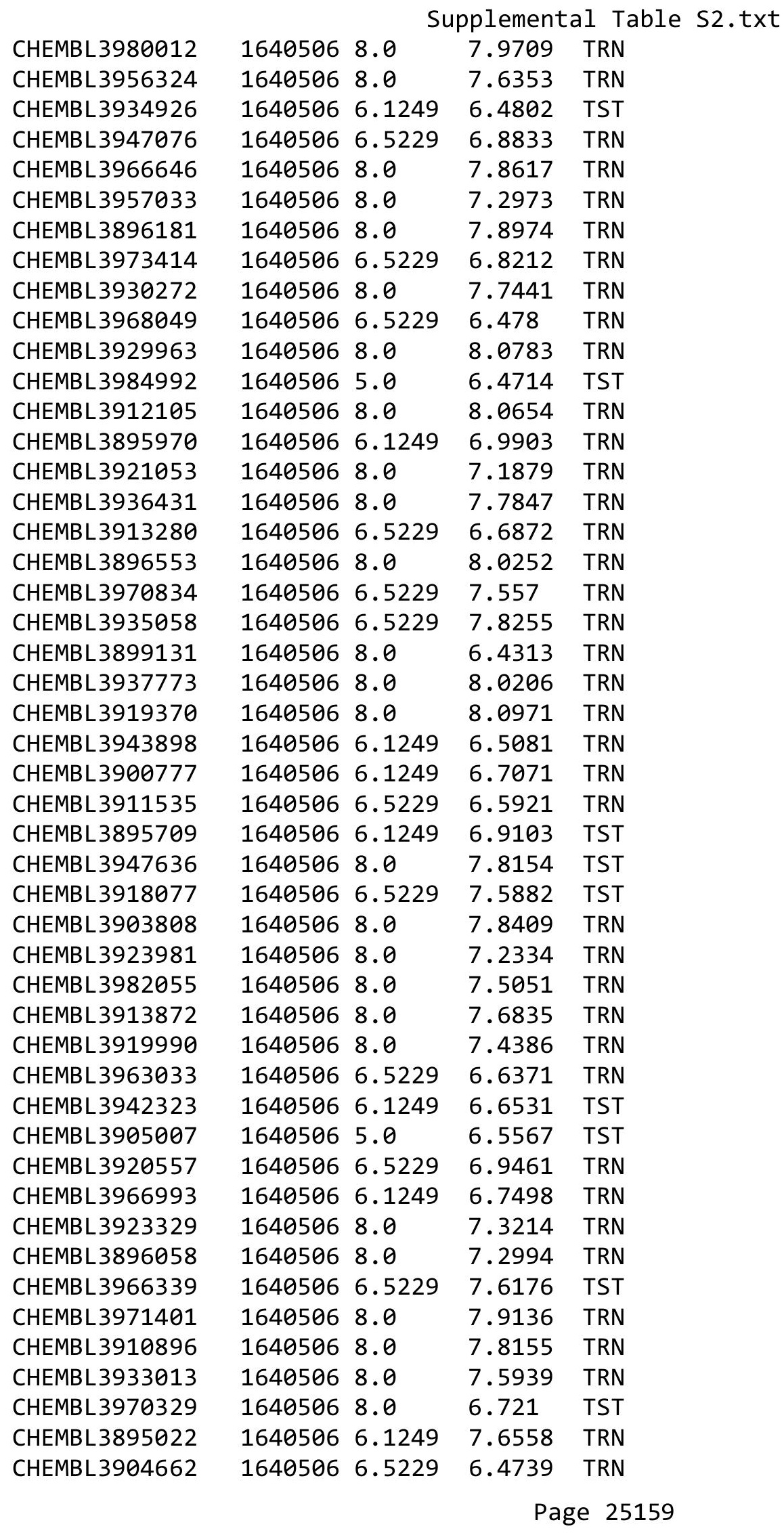


Supplemental Table S2.txt

\begin{tabular}{|c|c|c|c|c|}
\hline 779 & 1640506 & 6.12 & 6.9494 & $=$ \\
\hline CHEMBL3925819 & 1640506 & 8.0 & 7.9551 & \\
\hline HEMBL3971930 & 640506 & 6.5229 & & \\
\hline 03220 & 640506 & 8.0 & 256 & \\
\hline IEMBL 3972300 & 640506 & 6.5229 & 6.4313 & \\
\hline AEMBL3914860 & 640506 & 8.0 & 7.2682 & \\
\hline HEMBL3929457 & 1640506 & 8.0 & 7.131 & \\
\hline CHEMBL3958133 & 640506 & 6.5229 & 6.8615 & \\
\hline AEMBL3 & 640506 & 6.5229 & 7.6045 & \\
\hline AEMBL3 & 1640506 & 6.5229 & 7.0608 & \\
\hline HEMBL3941003 & 1640506 & 6.5229 & 7.6321 & \\
\hline AEMBL573477 & 588710 & 7.0362 & 6.9387 & \\
\hline LHEMBL573929 & 88710 & 7.3665 & 7.5197 & \\
\hline HEMBL5 & 588710 & 8.699 & 8.7125 & \\
\hline HEMBL5 & 588710 & 6.5287 & 6.5842 & \\
\hline HEMBL572781 & 88710 & 8.5229 & 9.0088 & \\
\hline AEMBL5 & 588710 & $6 . \varepsilon$ & 136 & \\
\hline CHEMBL5 & 10 & 7. & 705 & \\
\hline AEMBLS & 588710 & 8. & 21 & \\
\hline HEMBL5 & 588710 & 7. & 51 & \\
\hline AEMBL5 & 588710 & 7. & 813 & \\
\hline AEMBL 5 & 588 & & 469 & \\
\hline CHEMBL: & 588710 & 6. & 17 & \\
\hline CHEMBI & 10 & & 49 & \\
\hline HEMBL: & 588710 & 7. & 997 & \\
\hline AEMBL5 & 10 & 7. & 356 & \\
\hline CHEMBL 5 & 588710 & 9.2 & 568 & \\
\hline CHEMBL: & 10 & 8.6 & & \\
\hline CHEMI & 10 & 7. & 74 & \\
\hline CHEMBL: & 588 & 7. & 281 & \\
\hline CHEMBL 57 & 588 & 7.4 & 991 & \\
\hline CHEMBL 5 & 588710 & 7.4202 & 111 & \\
\hline & 10 & & 37 & \\
\hline $\mathrm{CHE}$ & 10 & 6. & 81 & \\
\hline CHEMBL 5 & 588710 & 7.6 & 7.5451 & \\
\hline CHEMBL585182 & 588710 & 8.699 & 8.6011 & TR \\
\hline CHEMBL584161 & 588710 & 9.0969 & 243 & . \\
\hline CHEME & 588710 & 8.5 & 53 & \\
\hline $\mathrm{CHE}$ & 588 & 6.4 & 97 & \\
\hline CHEMBL583947 & 588710 & 7.3098 & 7.7678 & TR \\
\hline CHEMBL572783 & 588710 & 8.0969 & 8.1297 & TR \\
\hline CHEMBL 5 & 588710 & 49 & 103 & II \\
\hline CHEMBL 5 & 588710 & 8.0 & 451 & \\
\hline CHEMBL572815 & 588710 & 7.8539 & 7.7012 & \\
\hline CHEMBL573036 & 588710 & 7.5376 & 7.8843 & TR \\
\hline CHEMBL572550 & 588710 & 8.301 & 8.0505 & TR \\
\hline $\mathrm{CH}$ & 588 & 7.95 & 7.7836 & \\
\hline CHEMBL572743 & 588710 & 7.7696 & 7.8308 & \\
\hline
\end{tabular}

Page 25160 


\begin{tabular}{|c|c|c|c|c|c|c|}
\hline & & \multicolumn{5}{|c|}{ Supplemental Table S2.txt } \\
\hline CHEMBL573037 & 588710 & 7.9586 & 8.0621 & TRN & & \\
\hline CHEMBL575470 & 588710 & 8.301 & 8.3047 & TRN & & \\
\hline CHEMBL583187 & 588710 & 9.1549 & 9.21 & TST & & \\
\hline CHEMBL573011 & 588710 & 8.699 & 8.709 & TRN & & \\
\hline CHEMBL573478 & 588710 & 7.7959 & 8.0552 & TRN & & \\
\hline CHEMBL573957 & 588710 & 8.3979 & 8.3193 & TST & & \\
\hline CHEMBL573470 & 588710 & 8.0458 & 8.0457 & TRN & & \\
\hline CHEMBL583273 & 588710 & 8.3979 & 8.2778 & TRN & & \\
\hline CHEMBL576734 & 588710 & 8.5229 & 8.9064 & TST & & \\
\hline CHEMBL573463 & 588710 & 9.0969 & 9.2604 & TST & & \\
\hline CHEMBL572514 & 588710 & 9.0 & 8.7062 & TRN & & \\
\hline CHEMBL573702 & 588710 & 8.301 & 8.4715 & TRN & & \\
\hline CHEMBL582844 & 588710 & 8.5229 & 8.8397 & TRN & & \\
\hline CHEMBL573475 & 588710 & 7.3768 & 8.2781 & TST & & \\
\hline CHEMBL573696 & 588710 & 7.0362 & 7.0935 & TRN & & \\
\hline CHEMBL575460 & 588710 & 7.7447 & 7.5062 & TRN & & \\
\hline CHEMBL584159 & 588710 & 6.4789 & 8.256 & TST & & \\
\hline CHEMBL573462 & 588710 & 7.9586 & 8.1667 & TST & & \\
\hline CHEMBL575471 & 588710 & 8.3979 & 8.2541 & TRN & & \\
\hline CHEMBL574169 & 588710 & 8.699 & 8.6132 & TRN & & \\
\hline CHEMBL583913 & 588710 & 9.0 & 8.9215 & TRN & & \\
\hline CHEMBL575263 & 588710 & 8.3979 & 8.4133 & TRN & & \\
\hline CHEMBL576387 & 588710 & 9.0 & 8.9411 & TRN & & \\
\hline CHEMBL573476 & 588710 & 9.0458 & 8.3372 & TRN & & \\
\hline CHEMBL573044 & 588710 & 7.1871 & 7.1621 & TRN & & \\
\hline CHEMBL574168 & 588710 & 8.301 & 8.1012 & TRN & & \\
\hline CHEMBL572810 & 588710 & 7.3979 & 7.6699 & TRN & & \\
\hline CHEMBL573012 & 588710 & 8.301 & 9.0645 & TST & & \\
\hline CHEMBL573705 & 588710 & 8.2218 & 8.6199 & TRN & & \\
\hline CHEMBL575255 & 588710 & 8.3979 & 8.4608 & TRN & & \\
\hline CHEMBL575463 & 588710 & 9.0 & 9.0566 & TST & & \\
\hline CHEMBL202116 & 331630 & 7.2218 & 7.0577 & TRN & & \\
\hline CHEMBL382491 & 331630 & 6.279 & 5.7662 & TRN & & \\
\hline CHEMBL370453 & 331630 & 6.8539 & 5.5438 & TST & & \\
\hline CHEMBL202436 & 331630 & 7.5969 & 6.8531 & TRN & & \\
\hline CHEMBL201857 & 331630 & 6.1561 & 5.0708 & TST & & \\
\hline CHEMBL383771 & 331630 & 7.34200 & 00000000 & 005 & 5.1184 & TST \\
\hline CHEMBL371884 & 331630 & 5.7375 & 5.7678 & TRN & & \\
\hline CHEMBL202277 & 331630 & 5.9055 & 4.9684 & TST & & \\
\hline CHEMBL382527 & 331630 & 5.51 & 5.0939 & TST & & \\
\hline CHEMBL 202203 & 331630 & 5.9614 & 6.004 & TRN & & \\
\hline CHEMBL182950 & 331630 & 7.08299 & 99999999 & 99 & 7.0031 & TRN \\
\hline CHEMBL373017 & 331630 & 5.5302 & 5.8533 & TRN & & \\
\hline CHEMBL370559 & 331630 & 7.1046 & 5.7407 & TRN & & \\
\hline CHEMBL440220 & 331630 & 7.3098 & 7.2435 & TRN & & \\
\hline CHEMBL201787 & 331630 & 6.7905 & 6.7608 & TRN & & \\
\hline CHEMBL202125 & 331630 & 5.5278 & 6.4663 & TRN & & \\
\hline CHEMBL202523 & 331630 & 4.0 & 4.735 & TST & & \\
\hline
\end{tabular}




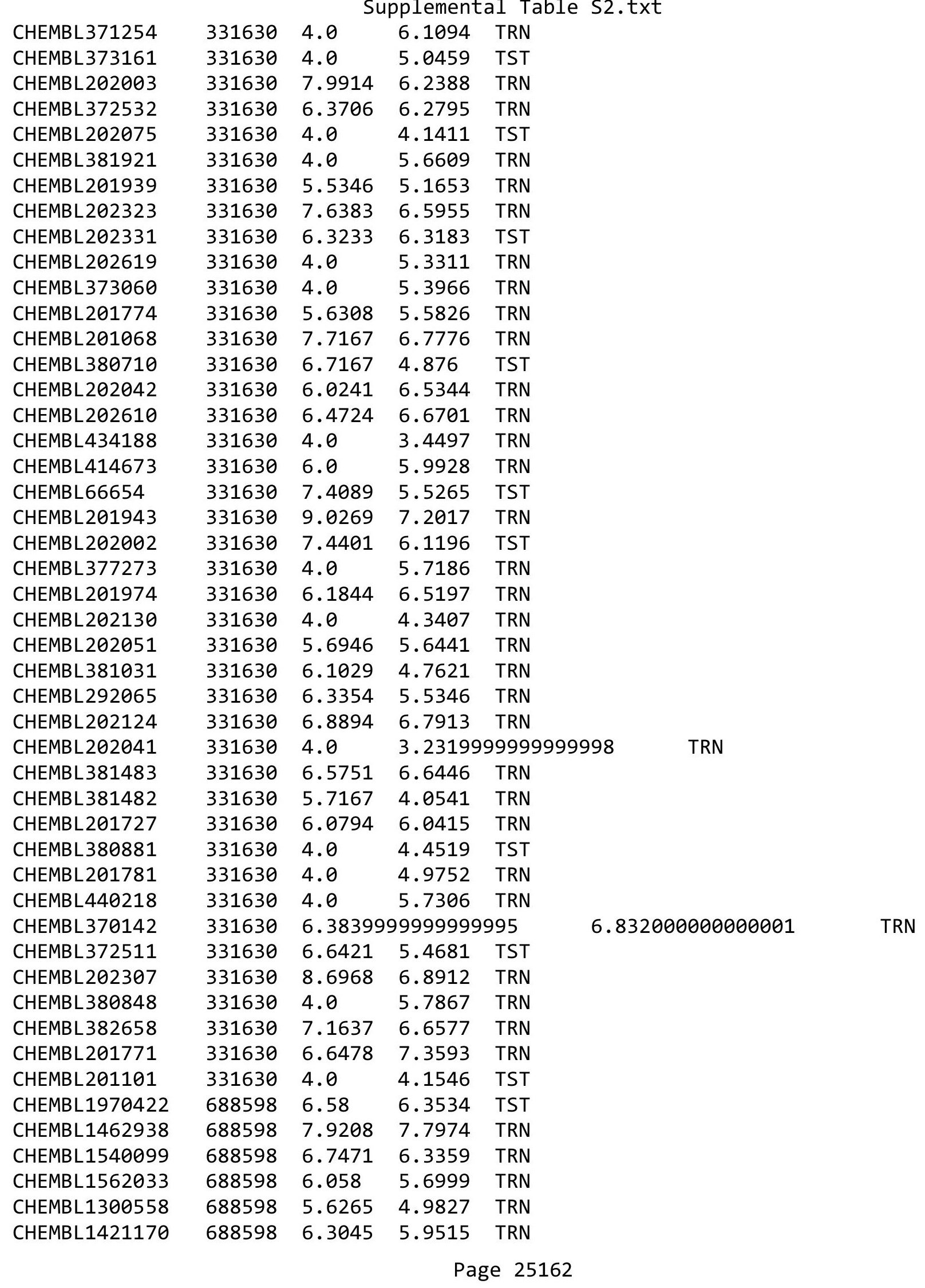


Supplemental Table S2.txt

\begin{tabular}{|c|c|c|c|c|c|}
\hline CHEMBL1405749 & 688598 & 6.6402 & 6.3445 & TRN & \\
\hline CHEMBL1500190 & 688598 & 5.6747 & 5.2813 & TRN & \\
\hline CHEMBL1451935 & 688598 & 6.3316 & 5.7061 & TRN & \\
\hline CHEMBL 251785 & 688598 & 6.3063 & 6.1311 & TRN & \\
\hline CHEMBL222409 & 688598 & 6.6326 & 6.2873 & TRN & \\
\hline CHEMBL1415899 & 688598 & 3.9208 & 4.7208 & TRN & \\
\hline CHEMBL1447284 & 688598 & 5.7817 & 4.6393 & TRN & \\
\hline CHEMBL1537098 & 688598 & 6.4634 & 6.5309 & TRN & \\
\hline CHEMBL3199311 & 688598 & 5.6605 & 4.5741 & TRN & \\
\hline CHEMBL1606583 & 688598 & 3.9208 & 4.837 & TRN & \\
\hline CHEMBL1602385 & 688598 & 6.9957 & 6.386 & TRN & \\
\hline CHEMBL1332878 & 688598 & 6.1574 & 5.9161 & TRN & \\
\hline CHEMBL1567568 & 688598 & 5.1396 & 5.8679 & TRN & \\
\hline CHEMBL1316831 & 688598 & 6.6383 & 6.4652 & TST & \\
\hline CHEMBL1379970 & 688598 & 6.4989 & 6.3724 & TRN & \\
\hline CHEMBL1324061 & 688598 & 3.9208 & 5.0477 & TRN & \\
\hline CHEMBL1371507 & 688598 & 6.1397 & 6.1173 & TRN & \\
\hline CHEMBL1567269 & 688598 & 5.7557 & 5.4976 & TRN & \\
\hline CHEMBL1472681 & 688598 & 6.1002 & 6.04899 & 99999999995 & TR \\
\hline CHEMBL1386228 & 688598 & 5.9927 & 5.2526 & TRN & \\
\hline CHEMBL1976786 & 688598 & 5.8536 & 5.6194 & TRN & \\
\hline CHEMBL304291 & 688598 & 6.6536 & 6.3906 & TST & \\
\hline CHEMBL1374715 & 688598 & 5.6273 & 5.4721 & TRN & \\
\hline CHEMBL1576870 & 688598 & 6.2865 & 6.1625 & TRN & \\
\hline CHEMBL1605021 & 688598 & 3.9208 & 6.0077 & TST & \\
\hline CHEMBL1428735 & 688598 & 6.5017 & 6.2083 & TRN & \\
\hline CHEMBL517645 & 688598 & 6.2161 & 6.1943 & TRN & \\
\hline CHEMBL1572139 & 688598 & 5.5553 & 5.7986 & TRN & \\
\hline CHEMBL1307091 & 688598 & 6.7496 & 6.6103 & TRN & \\
\hline CHEMBL 3185655 & 688598 & 7.1249 & 6.7758 & TRN & \\
\hline CHEMBL 300389 & 688598 & 7.1192 & 6.4179 & TST & \\
\hline CHEMBL1432507 & 688598 & 6.5935 & 6.1618 & TRN & \\
\hline CHEMBL1530673 & 688598 & 5.9062 & 5.2144 & TST & \\
\hline CHEMBL1408486 & 688598 & 5.9129 & 5.8374 & TRN & \\
\hline CHEMBL3198912 & 688598 & \multicolumn{3}{|c|}{6.162999999999999} & TRN \\
\hline CHEMBL1333449 & 688598 & \multicolumn{4}{|c|}{5.827999999999999} \\
\hline CHEMBL 3195389 & 688598 & 7.4437 & 6.5001 & TRN & \\
\hline CHEMBL1500581 & 688598 & 5.8072 & 5.1888 & TRN & \\
\hline CHEMBL1307769 & 688598 & 6.4609 & 6.4179 & TRN & \\
\hline CHEMBL1329237 & 688598 & 6.066 & 5.8466 & TRN & \\
\hline CHEMBL1368103 & 688598 & 7.2218 & 6.539 & TRN & \\
\hline CHEMBL1384292 & 688598 & 6.5003 & 6.3077 & TRN & \\
\hline CHEMBL1595169 & 688598 & 6.983 & 6.4409 & TRN & \\
\hline CHEMBL1327496 & 688598 & 6.0665 & 5.17899 & 9999999999 & $10 \mathrm{n}$ \\
\hline CHEMBL1349428 & 688598 & 5.9539 & 5.5913 & TRN & \\
\hline CHEMBL1333930 & 688598 & 5.311 & 6.4431 & TRN & \\
\hline CHEMBL 3192138 & 688598 & 7.585 & 7.0665 & TRN & \\
\hline CHEMBL1376974 & 688598 & 7.1079 & 6.8347 & TST & \\
\hline
\end{tabular}




\begin{tabular}{|c|c|c|c|c|c|}
\hline \multirow[b]{2}{*}{ CHEMBL1562712 } & \multirow[b]{2}{*}{688598} & \multicolumn{4}{|c|}{ Supplemental Table S2.txt } \\
\hline & & 3.9208 & 5.9551 & TRN & \\
\hline CHEMBL1313520 & 688598 & 6.4935 & 5.9358 & TRN & \\
\hline CHEMBL1440954 & 688598 & 6.3215 & 6.2401 & TRN & \\
\hline CHEMBL1389580 & 688598 & 3.9208 & 5.7287 & TRN & \\
\hline CHEMBL1521023 & 688598 & 6.58 & 6.5115 & TRN & \\
\hline CHEMBL1586862 & 688598 & 5.9788 & 5.0422 & TRN & \\
\hline CHEMBL1560237 & 688598 & 5.7501 & 5.9964 & TST & \\
\hline CHEMBL1603960 & 688598 & 3.9208 & 4.6736 & TST & \\
\hline CHEMBL1479301 & 688598 & 6.5969 & 6.4006 & TST & \\
\hline CHEMBL1321427 & 688598 & 6.4622 & 5.9879 & TRN & \\
\hline CHEMBL1998521 & 688598 & 6.3261 & 6.1769 & TRN & \\
\hline CHEMBL193627 & 688598 & 3.9208 & 5.2303 & TST & \\
\hline CHEMBL1503006 & 688598 & 3.9208 & 4.5224 & TRN & \\
\hline CHEMBL1381392 & 688598 & 3.9208 & 5.7614 & TRN & \\
\hline CHEMBL3189712 & 688598 & 5.9133 & 5.8429 & TRN & \\
\hline CHEMBL1513325 & 688598 & 5.3725 & 5.5264 & TRN & \\
\hline CHEMBL1543238 & 688598 & 3.9208 & 5.9831 & TRN & \\
\hline CHEMBL1525789 & 688598 & 3.9208 & 5.8432 & TRN & \\
\hline CHEMBL1359872 & 688598 & 5.8894 & 5.9833 & TRN & \\
\hline CHEMBL1476215 & 688598 & 6.0947 & 5.8235 & TRN & \\
\hline CHEMBL1572214 & 688598 & 6.0904 & 5.8787 & TST & \\
\hline CHEMBL1518647 & 688598 & 5.8732 & 6.0595 & TRN & \\
\hline CHEMBL3191808 & 688598 & 6.0079 & 5.1194 & TRN & \\
\hline CHEMBL373137 & 688598 & 6.9355 & 6.5269 & TRN & \\
\hline CHEMBL1455468 & 688598 & 6.4306 & 6.1006 & TRN & \\
\hline CHEMBL1402510 & 688598 & 6.5129 & 6.3738 & TRN & \\
\hline CHEMBL1537452 & 688598 & 6.3401 & 6.1094 & TRN & \\
\hline CHEMBL486504 & 688598 & 7.0 & 6.4281 & TRN & \\
\hline CHEMBL1355541 & 688598 & 7.0969 & 6.629 & TST & \\
\hline CHEMBL1524034 & 688598 & 6.5361 & 6.2455 & TRN & \\
\hline CHEMBL1476264 & 688598 & 6.1085 & 5.8242 & TRN & \\
\hline CHEMBL1362507 & 688598 & 6.1331 & 5.1023 & TRN & \\
\hline CHEMBL1358782 & 688598 & 6.1068 & 5.6535 & TRN & \\
\hline CHEMBL19980 & 688598 & 7.1079 & 6.6339 & TST & \\
\hline CHEMBL1572278 & 688598 & 5.7082 & 5.8781 & TRN & \\
\hline CHEMBL1357620 & 688598 & 6.5129 & 6.8644 & TST & \\
\hline CHEMBL1584985 & 688598 & 6.0066 & 5.8584 & TRN & \\
\hline CHEMBL1312738 & 688598 & 7.0809 & 6.3348 & TST & \\
\hline CHEMBL1984876 & 688598 & 6.015 & 5.7557 & TRN & \\
\hline CHEMBL3211308 & 688598 & 6.0482 & 6.1184 & TRN & \\
\hline CHEMBL3193098 & 688598 & 5.8979 & 5.2768 & TRN & \\
\hline CHEMBL1423927 & 688598 & 3.9208 & 5.8816 & TST & \\
\hline CHEMBL1339289 & 688598 & 3.9208 & 5.3425 & TRN & \\
\hline CHEMBL1423192 & 688598 & 3.9208 & 6.4344 & TRN & \\
\hline CHEMBL1493731 & 688598 & 5.6972 & 5.1914 & TRN & \\
\hline CHEMBL1451921 & 688598 & 6.38200 & 30000000 & $\partial 1$ & 6.0797 \\
\hline CHEMBL1447219 & 688598 & 5.9846 & 4.8145 & TST & \\
\hline CHEMBL460601 & 688598 & 6.9508 & 6.4237 & TRN & \\
\hline
\end{tabular}

Page 25164 


\begin{tabular}{|c|c|c|c|c|c|}
\hline & & & & & \\
\hline CHEMBL1473676 & 688598 & 6.7212 & 6.5999 & TST & \\
\hline CHEMBL1305304 & 688598 & 6.2941 & 6.2684 & TRN & \\
\hline CHEMBL1527380 & 688598 & 6.0762 & 5.8967 & TRN & \\
\hline CHEMBL1453996 & 688598 & 6.9101 & 6.5414 & TRN & \\
\hline CHEMBL1580848 & 688598 & 6.0164 & 5.8534 & TRN & \\
\hline CHEMBL1342336 & 688598 & 7.3372 & 6.5188 & TRN & \\
\hline CHEMBL1422161 & 688598 & 4.9299 & 5.7623 & TRN & \\
\hline CHEMBL1414112 & 688598 & 3.9208 & 5.8799 & TRN & \\
\hline CHEMBL1495092 & 688598 & 6.7122 & 6.4792 & TST & \\
\hline CHEMBL1406361 & 688598 & 5.845 & 6.3568 & TRN & \\
\hline CHEMBL563577 & 688598 & 5.3379 & 5.1802 & TRN & \\
\hline CHEMBL1391313 & 688598 & 5.7272 & 5.8336 & TRN & \\
\hline CHEMBL1372163 & 688598 & 5.9255 & 5.8643 & TRN & \\
\hline CHEMBL1431151 & 688598 & 3.9208 & 5.7174 & TRN & \\
\hline CHEMBL600060 & 688598 & 6.0137 & 6.0344 & TRN & \\
\hline CHEMBL1340058 & 688598 & 6.0367 & 5.21899 & 9999999999 & TRN \\
\hline CHEMBL261115 & 688598 & 5.7778 & 4.4886 & TRN & \\
\hline CHEMBL1331904 & 688598 & 6.0531 & 6.0107 & TRN & \\
\hline CHEMBL1347346 & 688598 & 6.9431 & 6.7136 & TRN & \\
\hline CHEMBL1372889 & 688598 & 6.8697 & 6.4972 & TRN & \\
\hline CHEMBL1587117 & 688598 & 6.9957 & 6.7375 & TRN & \\
\hline CHEMBL1459109 & 688598 & 6.2882 & 6.0453 & TRN & \\
\hline CHEMBL259103 & 688598 & 6.1586 & 5.9777 & TRN & \\
\hline CHEMBL1459841 & 688598 & 3.9208 & 5.104 & TRN & \\
\hline CHEMBL1994623 & 688598 & 6.2993 & 5.2476 & TRN & \\
\hline CHEMBL1392228 & 688598 & 6.1746 & 6.1086 & TRN & \\
\hline CHEMBL1321290 & 688598 & 6.0391 & 6.1068 & TRN & \\
\hline CHEMBL290077 & 688598 & 7.0757 & 6.4404 & TST & \\
\hline CHEMBL1586489 & 688598 & 3.9208 & 5.1048 & TRN & \\
\hline CHEMBL585591 & 688598 & 6.064 & 5.8206 & TST & \\
\hline CHEMBL3191453 & 688598 & 6.0186 & 5.7126 & TRN & \\
\hline CHEMBL1360484 & 688598 & 6.4802 & 6.25200 & 0000000001 & TRN \\
\hline CHEMBL1537509 & 688598 & 6.6421 & 6.5825 & TST & \\
\hline CHEMBL1306460 & 688598 & 3.9208 & 5.2129 & TST & \\
\hline CHEMBL1536981 & 688598 & 7.5686 & 6.9817 & TRN & \\
\hline CHEMBL1324197 & 688598 & 6.5575 & 6.1368 & TST & \\
\hline CHEMBL1563201 & 688598 & 5.9718 & 5.8836 & TRN & \\
\hline CHEMBL1332139 & 688598 & 6.4498 & 6.0025 & TRN & \\
\hline CHEMBL598263 & 688598 & 6.9172 & 6.44600 & 2000000001 & TRN \\
\hline CHEMBL1567841 & 688598 & 3.9208 & 5.1889 & TRN & \\
\hline CHEMBL1322272 & 688598 & 3.9208 & 5.6509 & TRN & \\
\hline CHEMBL1585825 & 688598 & 3.9208 & 4.9581 & TRN & \\
\hline CHEMBL1541017 & 688598 & 5.5572 & 5.9847 & TRN & \\
\hline CHEMBL1996189 & 688598 & 5.8867 & 5.3454 & TRN & \\
\hline CHEMBL1305287 & 688598 & 5.4814 & 6.0846 & TRN & \\
\hline CHEMBL1396209 & 688598 & 5.4614 & 5.8392 & TRN & \\
\hline CHEMBL1528660 & 688598 & 6.6676 & 6.4003 & TRN & \\
\hline CHEMBL1579258 & 688598 & 3.9208 & 5.9402 & TRN & \\
\hline
\end{tabular}




\begin{tabular}{|c|c|c|c|c|}
\hline & & & oplement & al Ta \\
\hline CHEMBL1327749 & 688598 & 3.9208 & 5.8925 & TRN \\
\hline CHEMBL1505209 & 688598 & 5.5267 & 5.7838 & TRN \\
\hline CHEMBL1884996 & 688598 & 7.1192 & 6.435 & TRN \\
\hline CHEMBL1324125 & 688598 & 6.317 & 6.2148 & TRN \\
\hline CHEMBL1331514 & 688598 & 6.0762 & 4.5804 & TRN \\
\hline CHEMBL1467877 & 688598 & 5.2647 & 5.0538 & TRN \\
\hline CHEMBL267099 & 688598 & 6.6517 & 6.3032 & TST \\
\hline CHEMBL3192855 & 688598 & 6.0453 & 5.3305 & TST \\
\hline CHEMBL1555935 & 688598 & 7.7959 & 7.2974 & TST \\
\hline CHEMBL1323774 & 688598 & 6.7878 & 6.7309 & TST \\
\hline CHEMBL1392142 & 688598 & 6.8356 & 6.3702 & TST \\
\hline CHEMBL1597778 & 688598 & 5.5436 & 5.8419 & TST \\
\hline CHEMBL1483593 & 688598 & 6.5376 & 6.4807 & TST \\
\hline CHEMBL1567944 & 688598 & 6.9957 & 6.7128 & TST \\
\hline CHEMBL1488760 & 688598 & 6.3526 & 6.0176 & TST \\
\hline CHEMBL1576251 & 688598 & 6.3449 & 6.2188 & TST \\
\hline CHEMBL1323668 & 688598 & 6.0297 & 5.8573 & TST \\
\hline CHEMBL1329221 & 688598 & 6.2388 & 5.7972 & TST \\
\hline CHEMBL1371056 & 688598 & 5.8033 & 5.7113 & TST \\
\hline CHEMBL579318 & 688598 & 6.6345 & 6.3198 & TST \\
\hline CHEMBL1376166 & 688598 & 6.0182 & 5.9601 & TST \\
\hline CHEMBL1490293 & 688598 & 6.4724 & 6.0822 & TST \\
\hline CHEMBL1468323 & 688598 & 6.2692 & 6.3951 & TST \\
\hline CHEMBL1420319 & 688598 & 5.5599 & 5.9878 & TST \\
\hline CHEMBL1562575 & 688598 & 7.6778 & 6.9421 & TST \\
\hline CHEMBL215063 & 404277 & 7.1871 & 6.9209 & TRN \\
\hline CHEMBL 214590 & 404277 & 4.3979 & 3.8725 & TRN \\
\hline CHEMBL 212072 & 404277 & 7.041 & 6.6561 & TST \\
\hline CHEMBL 214563 & 404277 & 6.7905 & 6.6067 & TRN \\
\hline CHEMBL 214274 & 404277 & 7.2076 & 6.9435 & TRN \\
\hline CHEMBL215751 & 404277 & 4.3979 & 4.6737 & TRN \\
\hline CHEMBL 385966 & 404277 & 6.3799 & 6.4821 & TRN \\
\hline CHEMBL425258 & 404277 & 6.9101 & 6.522 & TRN \\
\hline CHEMBL 384700 & 404277 & 6.4067 & 6.7924 & TRN \\
\hline CHEMBL 213718 & 404277 & 6.7212 & 6.8273 & TRN \\
\hline CHEMBL386251 & 404277 & 7.3098 & 7.7271 & TRN \\
\hline CHEMBL180138 & 404277 & 7.9586 & 7.4118 & TRN \\
\hline CHEMBL 385241 & 404277 & 6.2048 & 6.1039 & TRN \\
\hline CHEMBL 214852 & 404277 & 6.6326 & 6.4217 & TRN \\
\hline CHEMBL214331 & 404277 & 8.5229 & 8.5654 & TRN \\
\hline CHEMBL 215015 & 404277 & 5.5875 & 4.7201 & TRN \\
\hline CHEMBL 386040 & 404277 & 7.5229 & 7.6623 & TRN \\
\hline CHEMBL215650 & 404277 & 6.5867 & 5.8277 & TST \\
\hline CHEMBL 213660 & 404277 & 5.7498 & 5.9077 & TRN \\
\hline CHEMBL 387433 & 404277 & 6.7235 & 6.2969 & TRN \\
\hline CHEMBL214989 & 404277 & 9.0969 & 8.5122 & TRN \\
\hline CHEMBL 214880 & 404277 & 7.041 & 6.4425 & TRN \\
\hline CHEMBL378563 & 404277 & 7.8539 & 7.9886 & TRN \\
\hline
\end{tabular}




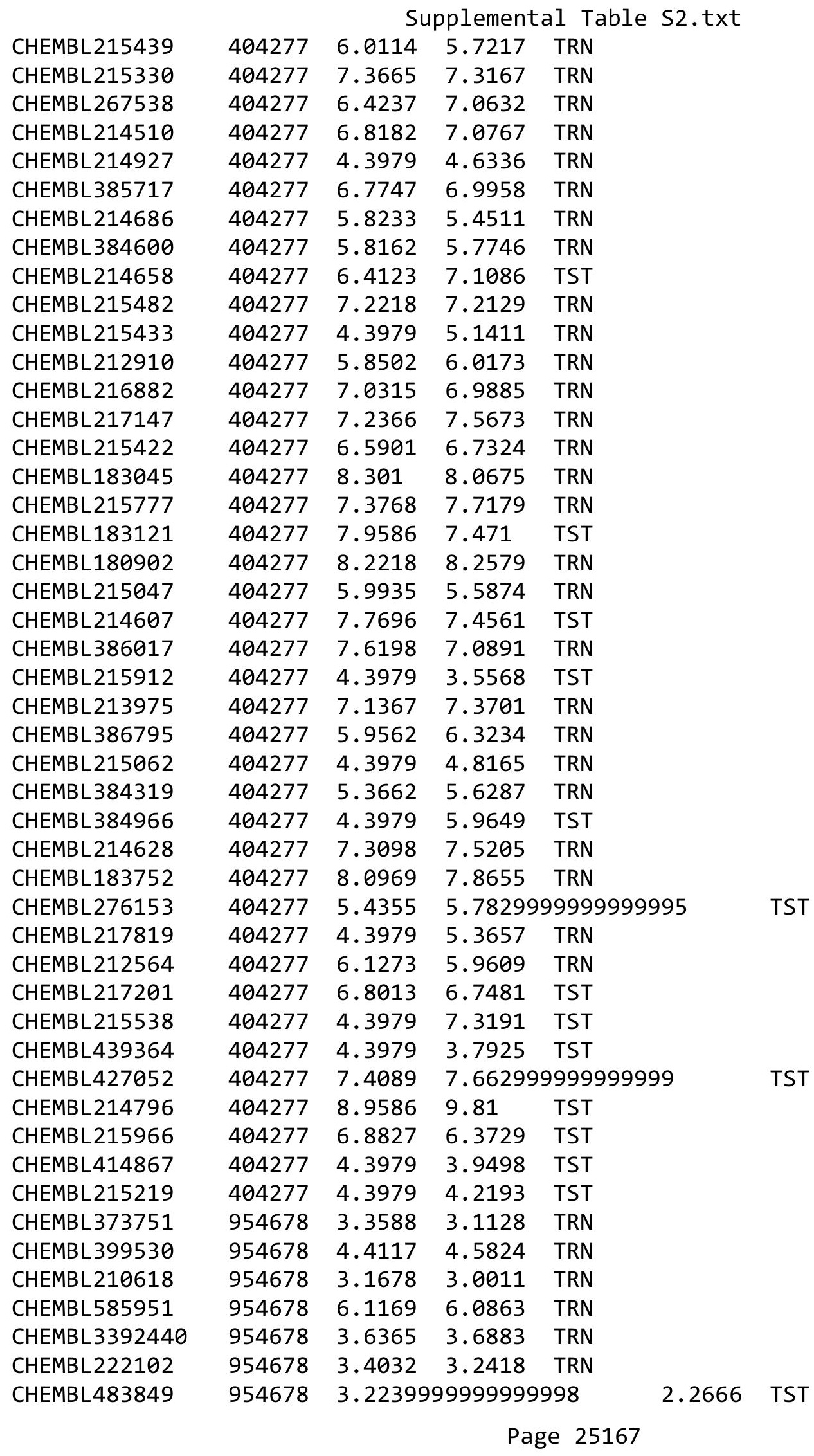




\begin{tabular}{|c|c|c|c|c|c|c|}
\hline & & \multicolumn{5}{|c|}{ Supplemental Table S2.txt } \\
\hline CHEMBL3349342 & 954678 & 6.2528 & 6.2298 & TRN & & \\
\hline CHEMBL514499 & 954678 & 5.4732 & 5.5128 & TRN & & \\
\hline CHEMBL1242367 & 954678 & 3.4002 & 3.3923 & TRN & & \\
\hline CHEMBL1186585 & 954678 & 4.8847 & 4.7711 & TRN & & \\
\hline CHEMBL 258844 & 954678 & 4.8643 & 4.8406 & TRN & & \\
\hline CHEMBL188678 & 954678 & 3.8469 & 3.8327 & TRN & & \\
\hline CHEMBL1788116 & 954678 & 4.4009 & 4.3116 & TRN & & \\
\hline CHEMBL135561 & 954678 & \multicolumn{3}{|c|}{3.9610000000000003} & 4.0032 & TRN \\
\hline CHEMBL449158 & 954678 & 5.7804 & 6.6537 & TST & & \\
\hline CHEMBL209148 & 954678 & 3.9368 & 3.9805 & TRN & & \\
\hline CHEMBL512504 & 954678 & 3.9808 & 3.9655 & TRN & & \\
\hline CHEMBL1404918 & 954678 & 3.5424 & 3.6734 & TRN & & \\
\hline CHEMBL515416 & 954678 & 5.5629 & 5.6384 & TRN & & \\
\hline CHEMBL65 & 954678 & 8.613 & 8.6145 & TRN & & \\
\hline CHEMBL180127 & 954678 & 3.3052 & 3.4038 & TRN & & \\
\hline CHEMBL1590308 & 954678 & 3.1017 & 2.9175 & TST & & \\
\hline CHEMBL1643959 & 954678 & 3.0516 & 3.0821 & TRN & & \\
\hline CHEMBL221137 & 954678 & 4.8559 & 4.9341 & TST & & \\
\hline CHEMBL577784 & 954678 & 4.9649 & 4.8732 & TRN & & \\
\hline CHEMBL392695 & 954678 & 4.198 & 4.3726 & TRN & & \\
\hline CHEMBL 2134202 & 954678 & 4.2498 & 4.3047 & TRN & & \\
\hline CHEMBL379300 & 954678 & 5.6834 & 5.7886 & TRN & & \\
\hline CHEMBL300389 & 954678 & 6.8125 & 6.7533 & TRN & & \\
\hline CHEMBL3199475 & 954678 & 5.1758 & 5.1337 & TRN & & \\
\hline CHEMBL 2137530 & 954678 & 4.7549 & 4.8549 & TRN & & \\
\hline CHEMBL573107 & 954678 & 5.006 & 4.9513 & TRN & & \\
\hline CHEMBL213100 & 954678 & 5.2377 & 5.2457 & TRN & & \\
\hline CHEMBL189584 & 954678 & 4.181 & 4.1372 & TRN & & \\
\hline CHEMBL1970879 & 954678 & 6.121 & 6.2574 & TRN & & \\
\hline CHEMBL255342 & 954678 & 3.3437 & 3.3577 & TRN & & \\
\hline CHEMBL1190711 & 954678 & 4.6849 & 4.8242 & TRN & & \\
\hline CHEMBL1256459 & 954678 & 6.8618 & 6.7874 & TRN & & \\
\hline CHEMBL3186408 & 954678 & 4.6014 & \multicolumn{3}{|c|}{3.6430000000000002} & T \\
\hline CHEMBL220241 & 954678 & 3.6649 & 3.6254 & TRN & & \\
\hline CHEMBL483847 & 954678 & 4.1896 & 4.2078 & TRN & & \\
\hline CHEMBL509032 & 954678 & \multicolumn{3}{|c|}{5.888999999999999} & 5.603 & TRN \\
\hline CHEMBL202721 & 954678 & 4.3251 & 4.4828 & TRN & & \\
\hline CHEMBL472940 & 954678 & 4.2864 & 4.3155 & TRN & & \\
\hline CHEMBL1673039 & 954678 & 3.3166 & 3.6285 & TRN & & \\
\hline CHEMBL558642 & 954678 & 4.0786 & 3.9261 & TRN & & \\
\hline CHEMBL1909414 & 954678 & 5.7082 & 5.6232 & TRN & & \\
\hline CHEMBL412142 & 954678 & 3.5219 & 3.4541 & TRN & & \\
\hline CHEMBL259181 & 954678 & 4.5012 & 4.836 & TRN & & \\
\hline CHEMBL 2005886 & 954678 & 5.2903 & 5.1908 & TRN & & \\
\hline CHEMBL240954 & 954678 & 4.1873 & 4.0737 & TST & & \\
\hline CHEMBL192566 & 954678 & 7.5327 & 8.1432 & TST & & \\
\hline CHEMBL2363137 & 954678 & 4.5946 & 4.4423 & TRN & & \\
\hline CHEMBL379975 & 954678 & 5.4028 & 5.2734 & TRN & & \\
\hline
\end{tabular}




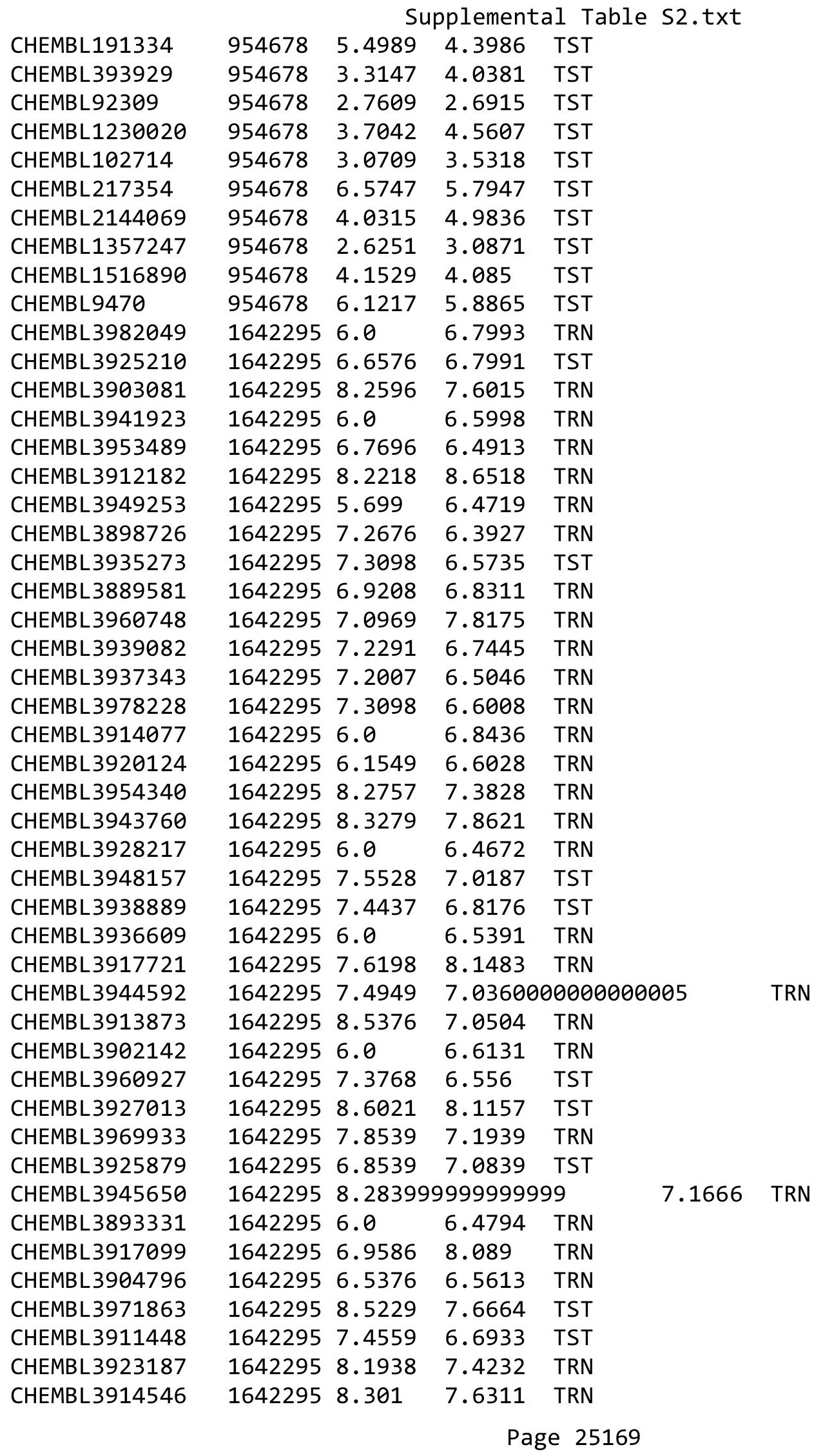


Supplemental Table S2.txt

\begin{tabular}{|c|c|c|c|c|}
\hline CHEMBL3936815 & 1642295 & 7.7696 & 8.2197 & TRN \\
\hline CHEMBL3956855 & 1642295 & 7.3979 & 6.9243 & TST \\
\hline CHEMBL3932549 & 1642295 & 6.1367 & 6.5966 & TRN \\
\hline CHEMBL3956938 & 1642295 & 6.3665 & 6.6541 & TST \\
\hline CHEMBL 3898838 & 1642295 & 8.3665 & 7.8531 & TRN \\
\hline CHEMBL3984687 & 1642295 & 7.9586 & 7.029 & TRN \\
\hline CHEMBL3889716 & 1642295 & 8.4559 & 8.1133 & TRN \\
\hline CHEMBL3980964 & 1642295 & 8.1675 & 8.3031 & TST \\
\hline CHEMBL3956193 & 1642295 & 6.0 & 6.8722 & TRN \\
\hline CHEMBL3983013 & 1642295 & 8.4089 & 8.6603 & TRN \\
\hline CHEMBL3956975 & 1642295 & 7.3098 & 7.8013 & TRN \\
\hline CHEMBL3923066 & 1642295 & 6.0 & 6.6922 & TRN \\
\hline CHEMBL3982121 & 1642295 & 5.9586 & 7.216 & TRN \\
\hline CHEMBL3957637 & 1642295 & 7.7212 & 8.1067 & TRN \\
\hline CHEMBL3922280 & 1642295 & 8.1675 & 8.2691 & TST \\
\hline CHEMBL3959649 & 1642295 & 7.5086 & 7.0673 & TRN \\
\hline CHEMBL3954079 & 1642295 & 8.4089 & 7.3719 & TRN \\
\hline CHEMBL3930238 & 1642295 & 6.0 & 6.6416 & TRN \\
\hline CHEMBL3917439 & 1642295 & 7.4815 & 6.8047 & TST \\
\hline CHEMBL3927359 & 1642295 & 6.0 & 7.6381 & TRN \\
\hline CHEMBL3969604 & 1642295 & 7.6576 & 7.8697 & TRN \\
\hline CHEMBL3946990 & 1642295 & 6.0 & 6.6516 & TRN \\
\hline CHEMBL3897730 & 1642295 & 7.5528 & 8.4636 & TRN \\
\hline CHEMBL3908276 & 1642295 & 6.0 & 6.5953 & TRN \\
\hline CHEMBL3962192 & 1642295 & 7.0862 & 6.9879 & TST \\
\hline CHEMBL3924673 & 1642295 & 6.0 & 6.8946 & TRN \\
\hline CHEMBL3973428 & 1642295 & 6.0 & 6.8202 & TRN \\
\hline CHEMBL3928186 & 1642295 & 5.7696 & 6.6443 & TST \\
\hline CHEMBL3949941 & 1642295 & 6.9586 & 6.7335 & TST \\
\hline CHEMBL3956935 & 1642295 & 6.7696 & 6.8437 & TRN \\
\hline CHEMBL3900766 & 1642295 & 8.0 & 6.9804 & TRN \\
\hline CHEMBL3900572 & 1642295 & 6.6198 & 6.6451 & TST \\
\hline CHEMBL3985414 & 1642295 & 6.301 & 6.6738 & TRN \\
\hline CHEMBL 3924876 & 1642295 & 7.9208 & 7.735 & TRN \\
\hline CHEMBL3923079 & 1642295 & 6.3565 & 6.5874 & TST \\
\hline CHEMBL3926677 & 1642295 & 7.4685 & 7.8824 & TRN \\
\hline CHEMBL3982518 & 1642295 & 8.3979 & 7.3221 & TRN \\
\hline CHEMBL3897517 & 1642295 & 7.3665 & 6.6493 & TRN \\
\hline CHEMBL3983295 & 1642295 & 6.2007 & 6.61299 & 99999999995 \\
\hline CHEMBL3898409 & 1642295 & 7.7447 & 8.1678 & TRN \\
\hline CHEMBL3984852 & 1642295 & 7.0915 & 6.6743 & TRN \\
\hline CHEMBL3974049 & 1642295 & 8.0 & 7.1837 & TRN \\
\hline CHEMBL3921152 & 1642295 & 8.7212 & 7.8677 & TRN \\
\hline CHEMBL3936311 & 1642295 & 8.3188 & 7.5462 & TRN \\
\hline CHEMBL3948414 & 1642295 & 7.7696 & 8.2163 & TST \\
\hline CHEMBL3971719 & 1642295 & 6.3665 & 6.6471 & TST \\
\hline CHEMBL 3897554 & 1642295 & 8.3468 & 7.9021 & TST \\
\hline CHEMBL3979869 & 1642295 & 6.0 & 6.5777 & TRN \\
\hline
\end{tabular}


Supplemental Table S2.txt

\begin{tabular}{|c|c|c|c|c|c|}
\hline CHEMBL3923234 & 1642295 & 6.4815 & 6.6361 & TST & \\
\hline CHEMBL3943692 & 1642295 & 6.0 & 7.1827 & TST & \\
\hline CHEMBL3910039 & 1642295 & 5.4559 & 6.5555 & TRN & \\
\hline CHEMBL 3944243 & 1642295 & 8.585 & 7.6938 & TST & \\
\hline CHEMBL3963222 & 1642295 & 6.2218 & 6.4926 & TRN & \\
\hline CHEMBL 3908498 & 1642295 & 6.1249 & 6.5806 & TRN & \\
\hline CHEMBL3935849 & 1642295 & 5.9586 & 6.4754 & TRN & \\
\hline CHEMBL3903612 & 1642295 & 7.1805 & 7.6446 & TRN & \\
\hline CHEMBL3892107 & 1642295 & 6.301 & 6.6769 & TRN & \\
\hline CHEMBL3917739 & 1642295 & 8.6383 & 7.558 & TRN & \\
\hline CHEMBL3919700 & 1642295 & 8.1487 & 7.2879 & TRN & \\
\hline CHEMBL3908025 & 1642295 & 8.2076 & 8.0189 & TRN & \\
\hline CHEMBL3964607 & 1642295 & 8.1192 & 7.2869 & TST & \\
\hline CHEMBL3934484 & 1642295 & 7.3768 & 6.5707 & TRN & \\
\hline CHEMBL3934031 & 1642295 & 6.041 & 6.4888 & TRN & \\
\hline CHEMBL3945321 & 1642295 & 7.1308 & 6.7131 & TRN & \\
\hline CHEMBL3938292 & 1642295 & 6.0177 & 6.7673 & TST & \\
\hline CHEMBL3960241 & 1642295 & 6.0 & 6.54299 & 9999999999 & TRN \\
\hline CHEMBL3962972 & 1642295 & 7.284 & 6.63399 & 99999999995 & TRN \\
\hline CHEMBL3893545 & 1642295 & 6.6198 & 6.6223 & TST & \\
\hline CHEMBL 3940320 & 1642295 & 8.585 & 7.4926 & TRN & \\
\hline CHEMBL3928954 & 1642295 & 7.6198 & 6.7242 & TRN & \\
\hline CHEMBL3921560 & 1642295 & 6.8239 & 6.8246 & TST & \\
\hline CHEMBL 3900078 & 1642295 & 7.3372 & 6.8015 & TRN & \\
\hline CHEMBL3936037 & 1642295 & 6.0 & 6.4839 & TRN & \\
\hline CHEMBL3974117 & 1642295 & 8.6576 & 8.8205 & TRN & \\
\hline CHEMBL3903278 & 1642295 & 6.0 & 6.6956 & TRN & \\
\hline CHEMBL3952128 & 1642295 & 6.8239 & 7.7634 & TRN & \\
\hline CHEMBL3970697 & 1642295 & 7.301 & 6.449 & TRN & \\
\hline CHEMBL3970695 & 1642295 & 7.4685 & 7.0696 & TRN & \\
\hline CHEMBL3945139 & 1642295 & 6.0 & 6.6655 & TRN & \\
\hline CHEMBL3933633 & 1642295 & 7.8239 & 8.22 & TRN & \\
\hline CHEMBL3902216 & 1642295 & 7.4949 & 8.173 & TRN & \\
\hline CHEMBL3952719 & 1642295 & 6.0 & 6.6446 & TRN & \\
\hline CHEMBL3932136 & 1642295 & 8.0362 & 7.3216 & TRN & \\
\hline CHEMBL3948974 & 1642295 & 7.2757 & 6.9849 & TRN & \\
\hline CHEMBL3968424 & 1642295 & 6.0 & 6.4405 & TST & \\
\hline CHEMBL3908677 & 1642295 & 8.3468 & 7.3992 & TRN & \\
\hline CHEMBL3953103 & 1642295 & 7.2757 & 6.6502 & TST & \\
\hline CHEMBL3935534 & 1642295 & 7.7696 & 6.9578 & TRN & \\
\hline CHEMBL3979068 & 1642295 & 6.0 & 6.5462 & TRN & \\
\hline CHEMBL3929038 & 1642295 & 6.3279 & 6.5478 & TRN & \\
\hline CHEMBL3934838 & 1642295 & 6.0757 & 6.7579 & TST & \\
\hline CHEMBL3915797 & 1642295 & 7.8539 & 7.4435 & TRN & \\
\hline CHEMBL3969859 & 1642295 & 7.6778 & 6.8565 & TRN & \\
\hline CHEMBL3975553 & 1642295 & 6.585 & 6.5069 & TST & \\
\hline CHEMBL 3957607 & 1642295 & 8.6383 & 7.8611 & TRN & \\
\hline CHEMBL3913190 & 1642295 & 6.8239 & 6.8014 & TST & \\
\hline
\end{tabular}


Supplemental Table S2.txt

\begin{tabular}{|c|c|c|c|c|}
\hline CHEMBL 3953597 & 1642295 & 6.6383 & 6.629 & TRN \\
\hline CHEMBL 3950326 & 1642295 & 7.9586 & 8.4556 & TRN \\
\hline CHEMBL3954349 & 1642295 & 6.7959 & 7.7524 & TST \\
\hline CHEMBL1904071 & 1301583 & 4.0834 & 4.4111 & TST \\
\hline CHEMBL 2358863 & 1301583 & 4.2501 & 3.5635 & TRN \\
\hline CHEMBL1530866 & 1301583 & 5.065 & 4.9515 & TRN \\
\hline CHEMBL 2359612 & 1301583 & 4.6605 & 4.6224 & TRN \\
\hline CHEMBL1711200 & 1301583 & 3.0 & 4.2862 & TRN \\
\hline CHEMBL 3188935 & 1301583 & 4.4088 & 4.1331 & TRN \\
\hline CHEMBL2359502 & 1301583 & 4.4726 & 4.1324 & TRN \\
\hline CHEMBL 2354539 & 1301583 & 4.3236 & 4.968999 & э999999999 \\
\hline CHEMBL 2354712 & 1301583 & 6.0 & 4.6373 & TRN \\
\hline CHEMBL 2356549 & 1301583 & 3.1549 & 3.7803 & TRN \\
\hline CHEMBL 2359622 & 1301583 & 4.6419 & 4.9206 & TRN \\
\hline CHEMBL2359406 & 1301583 & 4.8398 & 4.5289 & TRN \\
\hline CHEMBL 2356442 & 1301583 & 4.6276 & 4.1324 & TRN \\
\hline CHEMBL1519285 & 1301583 & 4.2008 & 4.2014 & TST \\
\hline CHEMBL1378851 & 1301583 & 4.3511 & 4.5888 & TST \\
\hline CHEMBL1602637 & 1301583 & 5.585 & 5.0663 & TST \\
\hline CHEMBL1580784 & 1301583 & 4.0898 & 4.2622 & TST \\
\hline CHEMBL 2358729 & 1301583 & 4.838 & 4.9332 & TRN \\
\hline CHEMBL3185444 & 1301583 & 4.5766 & 4.2337 & TRN \\
\hline CHEMBL1420472 & 1301583 & 4.4451 & 4.6698 & TRN \\
\hline CHEMBL1344930 & 1301583 & 4.0618 & 3.9329 & TRN \\
\hline CHEMBL1452421 & 1301583 & 4.9694 & 5.395 & TRN \\
\hline CHEMBL2359110 & 1301583 & 3.1549 & 3.8548 & TRN \\
\hline CHEMBL1321754 & 1301583 & 5.24799 & 99999999 & 4.8798 \\
\hline CHEMBL1543417 & 1301583 & 4.5812 & 4.6596 & TRN \\
\hline CHEMBL1500469 & 1301583 & 4.6813 & 4.8212 & TRN \\
\hline CHEMBL1451348 & 1301583 & 3.0 & 3.324 & TRN \\
\hline CHEMBL1390112 & 1301583 & 5.0004 & 4.7474 & TRN \\
\hline CHEMBL1617452 & 1301583 & 4.763 & 4.8051 & TRN \\
\hline CHEMBL1582221 & 1301583 & 3.0 & 3.5694 & TRN \\
\hline CHEMBL3186226 & 1301583 & 3.1549 & 3.9317 & TRN \\
\hline CHEMBL 2354788 & 1301583 & 3.1549 & 3.4726 & TRN \\
\hline CHEMBL1625031 & 1301583 & 4.8824 & 4.4043 & TRN \\
\hline CHEMBL257286 & 1301583 & 4.8147 & 4.8982 & TRN \\
\hline CHEMBL 2138714 & 1301583 & 5.0376 & 4.8807 & TRN \\
\hline CHEMBL 2356271 & 1301583 & 4.1836 & 4.8893 & TRN \\
\hline CHEMBL1350915 & 1301583 & 4.3281 & 3.9903 & TRN \\
\hline CHEMBL1487099 & 1301583 & 5.7878 & 5.346 & TST \\
\hline CHEMBL 2362650 & 1301583 & 5.1319 & 4.8559 & TRN \\
\hline CHEMBL 3182041 & 1301583 & 3.0 & 3.57 & TRN \\
\hline CHEMBL 2360014 & 1301583 & 4.537 & 4.0728 & TRN \\
\hline CHEMBL1574530 & 1301583 & 4.6356 & 4.4588 & TST \\
\hline CHEMBL1597245 & 1301583 & 3.0 & 3.3341 & TRN \\
\hline CHEMBL 3182281 & 1301583 & 4.4345 & 4.2159 & TRN \\
\hline CHEMBL1584985 & 1301583 & 5.8665 & 4.8105 & TST \\
\hline
\end{tabular}


Supplemental Table S2.txt

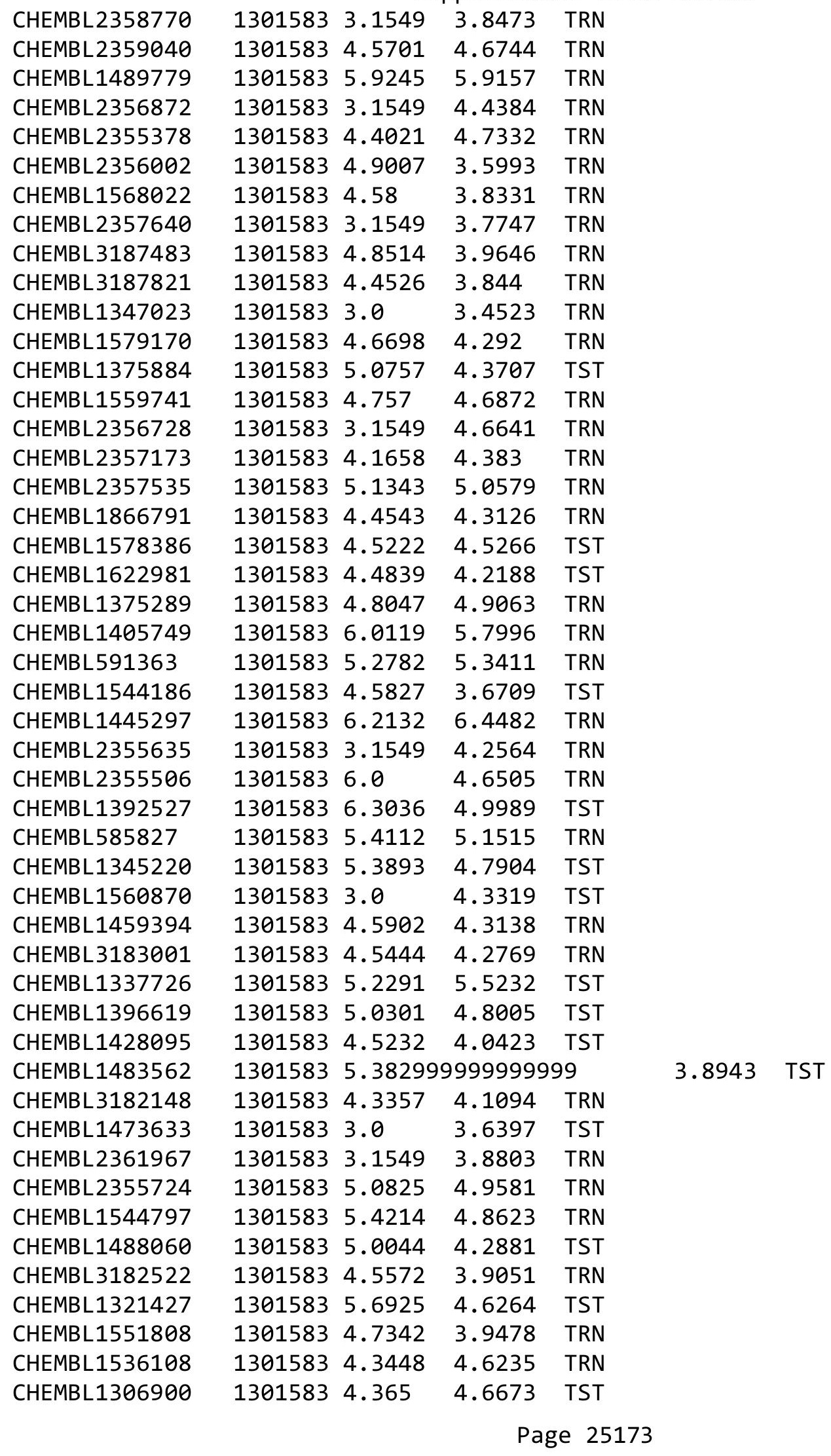


Supplemental Table S2.txt

\begin{tabular}{|c|c|c|c|c|}
\hline HEM & & & 5063 & \\
\hline & & 4.7518 & 4.4461 & \\
\hline & & & & \\
\hline IEMBL 23 & & 7181 & 5656 & \\
\hline AEMBL1242476 & 54924 & 957 & $\partial 817$ & \\
\hline HEMBL1241145 & 54924 & 4.8239 & 1558 & \\
\hline HEMBL12 & & 665 & 507 & \\
\hline IEMBL12 & & & 807 & RN \\
\hline AEMBL1242204 & 24 & & 6524 & \\
\hline HEMBL1241859 & 54924 & 153 & 6689 & \\
\hline HEMBL1241680 & 24 & 59 & 1833 & \\
\hline IEMBL12 & 24 & & 636 & \\
\hline AEMBL12 & & 5 & & \\
\hline HEMBL12 & 24 & & 5663 & \\
\hline AEMBL 12 & 24 & & 276 & \\
\hline AEMBL1 & 24 & 21 & 3551 & \\
\hline AEMBL12 & 4 & & 601 & \\
\hline HEMBL12 & & & & \\
\hline HEMBL124 & & & 2629 & \\
\hline AEMBL124 & & & & \\
\hline HEMBLI & 4 & & 89 & Niv \\
\hline AEMBL12 & & & 958 & 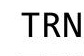 \\
\hline AEMBL12 & & & & \\
\hline AEMBL12 & & & 9405 & \\
\hline HEMBL124 & & 1 & & \\
\hline HEMBL1 & & 2 & 008 & 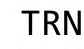 \\
\hline HEMBL12 & & & 097 & 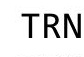 \\
\hline HFMBI 1 & & & 598 & \\
\hline AEMBL12 & & & 3824 & iv \\
\hline HEMBL1231371 & & & 676 & iv \\
\hline HEMBL1 & & & 727 & RN \\
\hline HEMBL1 & & & 289 & RN \\
\hline HEMBL1 & & & 474 & RN \\
\hline HEMBL1242203 & & & 9998 & IRN \\
\hline HEMBL1241391 & & & $\partial 807$ & TRN \\
\hline HEMBL1 & & & 275 & RN \\
\hline HEMRI 1 & & & 935 & IRIN \\
\hline HEMBL12 & & & 17 & ST \\
\hline HEMBL1242664 & 24 & & 7134 & $\Gamma \mathrm{RN}$ \\
\hline AEMBL12 & & - & 5073 & TRN \\
\hline HEMBL12 & 4 & & 1337 & - \\
\hline HEMBL 124 & & & 2079 & TRN \\
\hline HEMBL124 & & 24 & 2637 & RN \\
\hline HEMBL124 & 24 & 3979 & 916 & TST \\
\hline MBL1 & & & 681 & RN \\
\hline HEMBL12 & & & 5404 & \\
\hline CHEMBL 124 & & 5.699 & .9487 & \\
\hline CHEMBL1242376 & 654924 & 7.2676 & 7.0023 & RN \\
\hline
\end{tabular}

Page 25174 


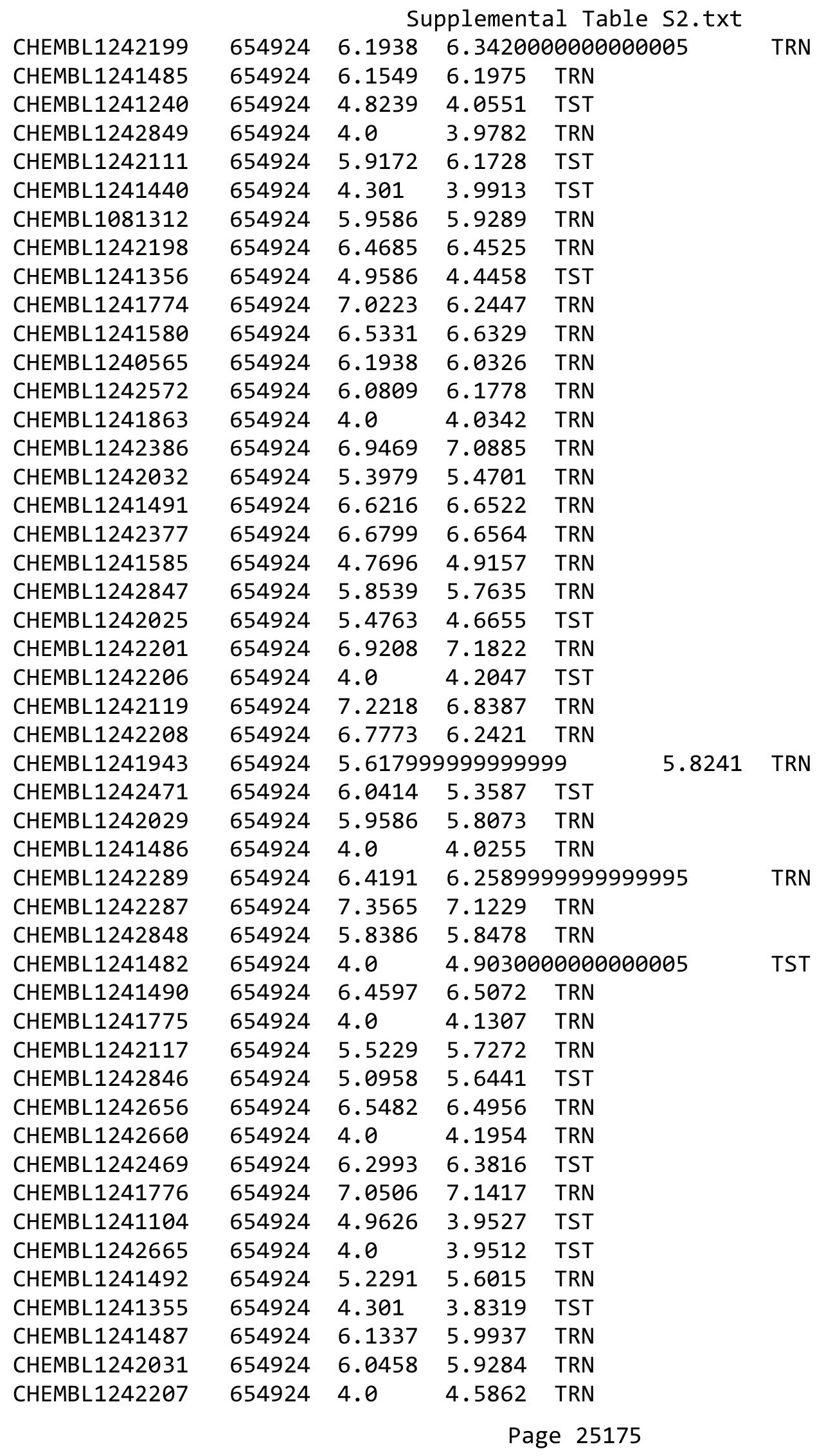


Supplemental Table S2.txt

\begin{tabular}{|c|c|c|c|c|c|}
\hline CHEMBL1242568 & 654924 & 6.5901 & 6.3229 & TRN & \\
\hline CHEMBL1240594 & 654924 & 5.7959 & 5.8271 & TST & \\
\hline CHEMBL1241439 & 654924 & 6.0269 & 5.4655 & TST & \\
\hline CHEMBL1242662 & 654924 & 6.2314 & 6.268 & TRN & \\
\hline CHEMBL1242034 & 654924 & 5.1612 & 5.0158 & TRN & \\
\hline CHEMBL1241586 & 654924 & 4.6576 & 4.9288 & TRN & \\
\hline CHEMBL1241242 & 654924 & 5.7696 & 4.8533 & TST & \\
\hline CHEMBL1241860 & 654924 & 5.6198 & 5.8272 & TRN & \\
\hline CHEMBL1241679 & 654924 & 5.6198 & 5.6372 & TRN & \\
\hline CHEMBL1241773 & 654924 & 6.0655 & 5.6909 & TRN & \\
\hline CHEMBL1241684 & 654924 & 5.6198 & 5.525 & TST & \\
\hline CHEMBL1242209 & 654924 & 6.6421 & 6.482 & TRN & \\
\hline CHEMBL1241142 & 654924 & 5.1135 & \multicolumn{2}{|c|}{4.486000000000001} & TST \\
\hline CHEMBL1242024 & 654924 & 5.8239 & 6.0029 & TRN & \\
\hline CHEMBL1241269 & 654924 & 5.1938 & 5.1683 & TST & \\
\hline CHEMBL1241583 & 654924 & 5.8861 & 5.8341 & TRN & \\
\hline CHEMBL1242755 & 654924 & 5.8861 & 5.8315 & TRN & \\
\hline CHEMBL1241484 & 654924 & 6.8539 & 6.9437 & TRN & \\
\hline CHEMBL1242567 & 654924 & 6.1986 & 6.2533 & TRN & \\
\hline CHEMBL1241864 & 654924 & 4.0 & 3.8572 & TRN & \\
\hline CHEMBL1242852 & 654924 & 6.0975 & 6.0982 & TRN & \\
\hline CHEMBL1242292 & 654924 & 4.0 & 3.8116 & TST & \\
\hline CHEMBL1241676 & 654924 & 6.8327 & 6.8606 & TRN & \\
\hline CHEMBL1242027 & 654924 & 6.0857 & 6.126 & TRN & \\
\hline CHEMBL1241588 & 654924 & 5.9586 & 5.3528 & TST & \\
\hline CHEMBL1242384 & 654924 & 6.2027 & 5.4737 & TRN & \\
\hline CHEMBL1242115 & 654924 & 6.0044 & 5.8004 & TST & \\
\hline CHEMBL1241358 & 654924 & 4.0 & 4.2338 & TST & \\
\hline CHEMBL1240553 & 654924 & 7.0605 & 7.0794 & TRN & \\
\hline CHEMBL1242663 & 654924 & 4.0 & 5.5275 & TST & \\
\hline CHEMBL1242290 & 654924 & 6.699 & 6.6829 & TRN & \\
\hline CHEMBL1241578 & 654924 & 7.0 & 7.1436 & TRN & \\
\hline CHEMBL1241682 & 654924 & 6.3363 & 6.8346 & TRN & \\
\hline CHEMBL1242113 & 654924 & 6.4498 & 6.4071 & TRN & \\
\hline CHEMBL1241582 & 654924 & 6.0506 & 6.055 & TRN & \\
\hline CHEMBL1241677 & 654924 & 6.4365 & 6.5888 & TRN & \\
\hline CHEMBL1242666 & 654924 & 6.8539 & 6.9082 & TRN & \\
\hline CHEMBL1242573 & 654924 & 6.2041 & 6.0338 & TRN & \\
\hline CHEMBL1242286 & 654924 & 5.1024 & 5.1689 & TRN & \\
\hline CHEMBL1242758 & 654924 & 5.9431 & 5.8312 & TST & \\
\hline CHEMBL1242844 & 654924 & 4.7852 & 5.147 & TRN & \\
\hline CHEMBL1242205 & 654924 & 4.0 & 3.5871 & TST & \\
\hline CHEMBL1241945 & 654924 & 6.7282 & 6.6745 & TRN & \\
\hline CHEMBL1241488 & 654924 & 5.4437 & 5.5954 & TRN & \\
\hline CHEMBL1240566 & 654924 & 5.7447 & 5.8689 & TRN & \\
\hline CHEMBL1242285 & 654924 & 6.5686 & 6.3852 & TRN & \\
\hline CHEMBL1242657 & 654924 & 6.0 & 6.0192 & TRN & \\
\hline CHEMBL1241950 & 654924 & 6.2321 & 6.25799 & & TRN \\
\hline
\end{tabular}

Page 25176 
Supplemental Table S2.txt

\begin{tabular}{|c|c|c|c|c|c|}
\hline CHEMBL1242569 & 654924 & 6.5072 & 6.3752 & TRN & \\
\hline CHEMBL1241681 & 654924 & 6.2291 & 6.5559 & TRN & \\
\hline CHEMBL1242378 & 654924 & 6.0 & 5.9792 & TRN & \\
\hline CHEMBL1241581 & 654924 & 6.567 & 6.7358 & TRN & \\
\hline CHEMBL1242030 & 654924 & 5.1427 & 5.1599 & TRN & \\
\hline CHEMBL1242109 & 654924 & 6.1124 & 6.0283 & TRN & \\
\hline CHEMBL1241675 & 654924 & 5.6198 & 4.9331 & TST & \\
\hline CHEMBL1241300 & 654924 & 6.2815 & 5.7961 & TST & \\
\hline CHEMBL1240554 & 654924 & 6.9355 & 6.8693 & TRN & \\
\hline CHEMBL1242659 & 654924 & 6.4522 & 6.3797 & TRN & \\
\hline CHEMBL1241489 & 654924 & 5.3468 & 5.489 & TRN & \\
\hline CHEMBL1242751 & 654924 & 4.0 & 3.8898 & TRN & \\
\hline CHEMBL1242566 & 654924 & 5.9706 & 6.0079 & TRN & \\
\hline CHEMBL1242661 & 654924 & 5.5686 & \multicolumn{2}{|c|}{5.3660000000000005} & TRN \\
\hline CHEMBL1241771 & 654924 & 5.2076 & 5.2977 & TRN & \\
\hline CHEMBL1242757 & 654924 & 5.9905 & 5.4315 & TST & \\
\hline CHEMBL1242028 & 654924 & 6.9281 & 7.1041 & TRN & \\
\hline CHEMBL1242748 & 654924 & 6.0 & 5.8642 & TRN & \\
\hline CHEMBL1242026 & 654924 & 6.3615 & 6.4501 & TRN & \\
\hline CHEMBL1230790 & 654924 & 5.8239 & 5.7363 & TRN & \\
\hline CHEMBL1241389 & 654924 & 5.5229 & 5.1868 & TST & \\
\hline CHEMBL1241858 & 654924 & 4.9031 & 4.9463 & TRN & \\
\hline CHEMBL1242118 & 654924 & 5.5229 & 5.7919 & TRN & \\
\hline CHEMBL1241241 & 654924 & 6.1675 & 6.1863 & TRN & \\
\hline CHEMBL1241143 & 654924 & 5.6198 & 5.1463 & TST & \\
\hline CHEMBL1241947 & 654924 & 5.8539 & 5.6092 & TST & \\
\hline CHEMBL1242112 & 654924 & 6.7212 & 6.7541 & TRN & \\
\hline CHEMBL1242845 & 654924 & 5.9706 & 5.9531 & TST & \\
\hline CHEMBL1242293 & 654924 & 5.8861 & 6.0677 & TRN & \\
\hline CHEMBL1241483 & 654924 & 6.2588 & 6.024 & TRN & \\
\hline CHEMBL1241271 & 654924 & 6.2596 & 6.3662 & TRN & \\
\hline CHEMBL1241270 & 654924 & 6.0696 & \multicolumn{2}{|c|}{5.593999999999999} & TST \\
\hline CHEMBL1242752 & 654924 & 6.1409 & 6.2739 & TRN & \\
\hline CHEMBL1241942 & 654924 & 4.0 & 3.6283 & TRN & \\
\hline CHEMBL1242033 & 654924 & 5.1367 & 5.2385 & TRN & \\
\hline CHEMBL1242474 & 654924 & 4.7959 & 4.752 & TRN & \\
\hline CHEMBL1241481 & 654924 & 5.7447 & 5.7615 & TRN & \\
\hline CHEMBL1242385 & 654924 & 4.5086 & 5.0372 & TRN & \\
\hline CHEMBL1242754 & 654924 & 5.5686 & 5.6934 & TRN & \\
\hline CHEMBL1242200 & 654924 & 5.3716 & 5.1252 & TRN & \\
\hline CHEMBL1242472 & 654924 & 5.2874 & 6.1444 & TRN & \\
\hline CHEMBL1241674 & 654924 & 5.8861 & 6.0467 & TST & \\
\hline CHEMBL1242756 & 654924 & 6.6576 & 6.8105 & TRN & \\
\hline CHEMBL1234815 & 654924 & 6.2441 & 5.8486 & TRN & \\
\hline CHEMBL1242753 & 654924 & 5.6968 & 5.5242 & TRN & \\
\hline CHEMBL1241441 & 654924 & 6.0132 & 5.3415 & TST & \\
\hline CHEMBL1242295 & 654924 & 6.3615 & 6.5319 & TRN & \\
\hline CHEMBL1242288 & 654924 & 5.8962 & 5.9988 & TRN & \\
\hline
\end{tabular}

Page 25177 


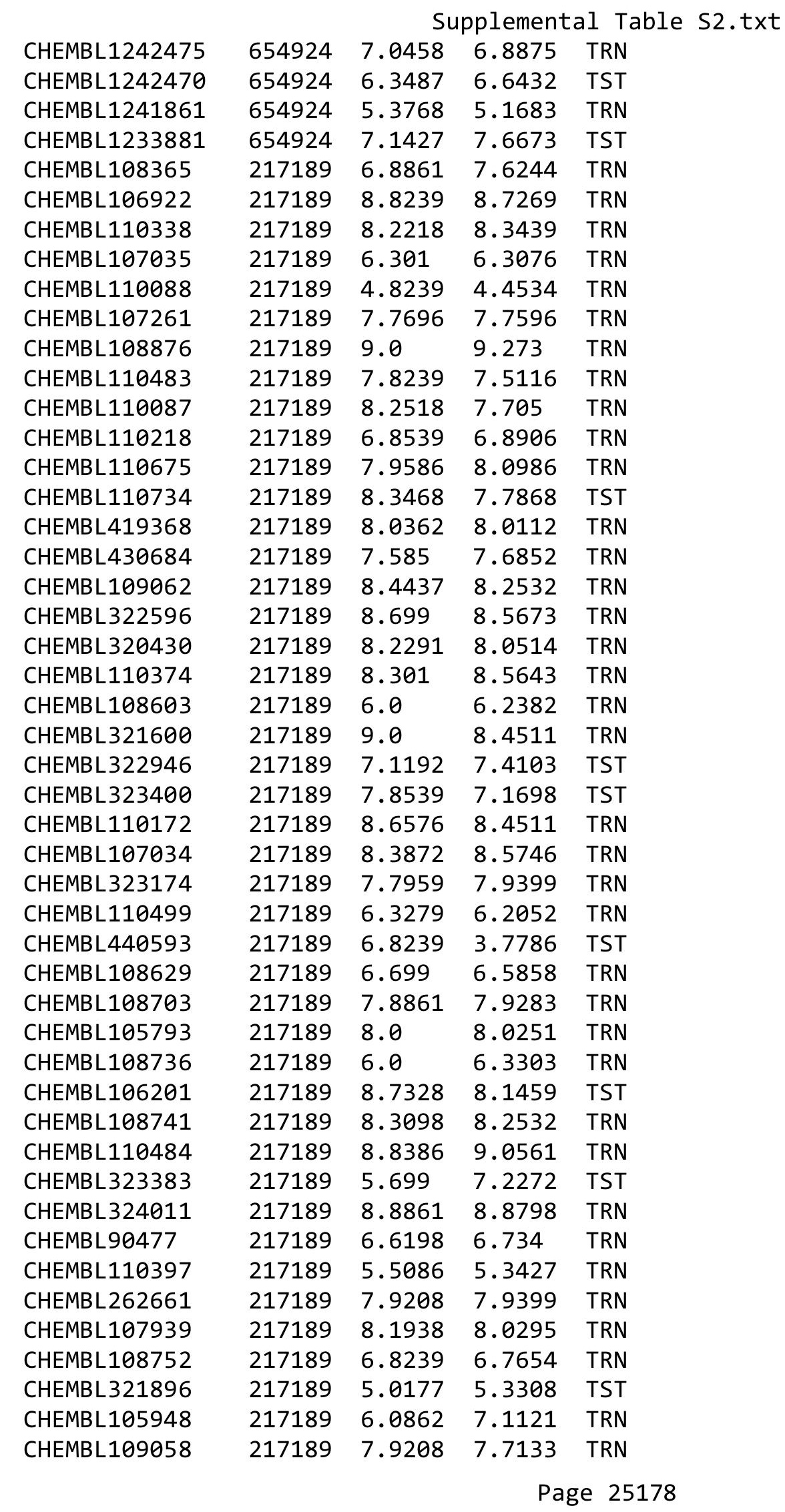




\begin{tabular}{|c|c|c|c|c|c|}
\hline \multicolumn{6}{|c|}{ oplemental Table S } \\
\hline CHEMBL323494 & 217189 & 7.1427 & 7.2111 & TRN & \\
\hline CHEMBL108973 & 217189 & 4.5686 & 4.5944 & TRN & \\
\hline CHEMBL110450 & 217189 & 7.8697 & 7.5375 & TRN & \\
\hline CHEMBL320180 & 217189 & 7.9031 & 8.289 & TRN & \\
\hline CHEMBL110350 & 217189 & 8.5686 & 7.8856 & TRN & \\
\hline CHEMBL320296 & 217189 & 6.7447 & 6.5642 & TST & \\
\hline CHEMBL313609 & 217189 & 6.5528 & 6.4813 & TRN & \\
\hline CHEMBL109057 & 217189 & 6.9208 & 7.29799 & 9999999999 & TRN \\
\hline CHEMBL108641 & 217189 & 5.7959 & 5.7929 & TRN & \\
\hline CHEMBL108913 & 217189 & 7.585 & 7.5609 & TRN & \\
\hline CHEMBL108414 & 217189 & 5.2676 & 7.7912 & TST & \\
\hline CHEMBL108413 & 217189 & 4.6021 & 5.7567 & TST & \\
\hline CHEMBL326891 & 217189 & 9.0269 & 9.1464 & TRN & \\
\hline CHEMBL109149 & 217189 & 8.9586 & 8.829 & TRN & \\
\hline CHEMBL109096 & 217189 & 8.3372 & 7.9759 & TRN & \\
\hline CHEMBL109043 & 217189 & 4.1192 & 4.4556 & TRN & \\
\hline CHEMBL326867 & 217189 & 5.7696 & 5.6722 & TRN & \\
\hline CHEMBL110173 & 217189 & 6.0 & 6.1412 & TRN & \\
\hline CHEMBL106053 & 217189 & 5.9208 & 5.6872 & TRN & \\
\hline CHEMBL110620 & 217189 & 5.3565 & 5.3259 & TRN & \\
\hline CHEMBL108152 & 217189 & 7.7447 & 7.7382 & TST & \\
\hline CHEMBL432398 & 217189 & 7.3188 & 7.9897 & TST & \\
\hline CHEMBL107651 & 217189 & 8.8386 & 8.596 & TST & \\
\hline CHEMBL109052 & 217189 & 6.1612 & 5.9186 & TST & \\
\hline CHEMBL321435 & 217189 & 6.585 & 6.066 & TST & \\
\hline CHEMBL110593 & 217189 & 6.1192 & 6.0933 & TST & \\
\hline CHEMBL106979 & 217189 & 6.4685 & 5.7713 & TST & \\
\hline CHEMBL108914 & 217189 & 8.4949 & 8.4749 & TST & \\
\hline CHEMBL106923 & 217189 & 5.7959 & 6.1851 & TST & \\
\hline CHEMBL 240954 & 955055 & 3.1768 & 3.611 & TST & \\
\hline CHEMBL1404918 & 955055 & 3.1224 & 3.0786 & TRN & \\
\hline CHEMBL9470 & 955055 & 6.1238 & 5.1527 & TST & \\
\hline CHEMBL1516890 & 955055 & 4.2648 & 4.1648 & TRN & \\
\hline CHEMBL1357247 & 955055 & 3.7801 & 3.7756 & TRN & \\
\hline CHEMBL 220241 & 955055 & 4.3006 & 4.1944 & TRN & \\
\hline CHEMBL573107 & 955055 & 4.2712 & 4.2656 & TRN & \\
\hline CHEMBL 217354 & 955055 & 5.5025 & 5.4408 & TRN & \\
\hline CHEMBL 259181 & 955055 & 4.7652 & 4.7082 & TRN & \\
\hline CHEMBL412142 & 955055 & 3.583 & 3.4921 & TRN & \\
\hline CHEMBL92309 & 955055 & 3.0551 & 3.3246 & TST & \\
\hline CHEMBL3199475 & 955055 & 4.2414 & 4.1962 & TRN & \\
\hline CHEMBL1788116 & 955055 & 3.2686 & 3.276999 & 99999999997 & TRN \\
\hline CHEMBL192566 & 955055 & 7.5488 & 7.4874 & TST & \\
\hline CHEMBL 3186408 & 955055 & 4.0245 & 3.7306 & TST & \\
\hline CHEMBL1190711 & 955055 & 4.4419 & 4.3972 & TRN & \\
\hline CHEMBL 2005886 & 955055 & 6.3007 & 6.3406 & TRN & \\
\hline CHEMBL577784 & 955055 & 3.5866 & 3.6759 & TRN & \\
\hline CHEMBL 213100 & 955055 & 3.83 & 3.8277 & TRN & \\
\hline
\end{tabular}




\begin{tabular}{|c|c|c|c|c|}
\hline & & & & \\
\hline CHEMBL188678 & 955055 & 4.0716 & 4.1598 & TRN \\
\hline CHEMBL135561 & 955055 & 4.1518 & 4.13899 & 9999999999 \\
\hline CHEMBL1590308 & 955055 & 2.6882 & 3.0373 & TST \\
\hline CHEMBL449158 & 955055 & 6.3 & 6.0108 & TST \\
\hline CHEMBL1230020 & 955055 & 6.1636 & 6.1927 & TRN \\
\hline CHEMBL379975 & 955055 & 3.862 & 3.8544 & TRN \\
\hline CHEMBL1643959 & 955055 & 3.415 & 3.4291 & TRN \\
\hline CHEMBL191334 & 955055 & 4.9831 & 5.0159 & TRN \\
\hline CHEMBL 255342 & 955055 & 4.0657 & 3.983 & TRN \\
\hline CHEMBL393929 & 955055 & 4.388 & 4.4707 & TRN \\
\hline CHEMBL512504 & 955055 & 4.1174 & 4.1515 & TRN \\
\hline CHEMBL202721 & 955055 & 4.6383 & 4.543 & TRN \\
\hline CHEMBL221137 & 955055 & 4.5714 & 4.7188 & TST \\
\hline CHEMBL210618 & 955055 & 3.9972 & 4.0748 & TRN \\
\hline CHEMBL585951 & 955055 & 5.6061 & 5.657 & TRN \\
\hline CHEMBL189584 & 955055 & 4.8711 & 4.8862 & TRN \\
\hline CHEMBL 300389 & 955055 & 6.4514 & 6.4845 & TRN \\
\hline CHEMBL483849 & 955055 & 1.5041 & 1.4272 & TRN \\
\hline CHEMBL399530 & 955055 & 4.1042 & 4.151 & TRN \\
\hline CHEMBL222102 & 955055 & 3.9957 & 3.8561 & TRN \\
\hline CHEMBL514499 & 955055 & 6.2876 & 6.1923 & TRN \\
\hline CHEMBL2137530 & 955055 & 4.4063 & 4.4587 & TRN \\
\hline CHEMBL1186585 & 955055 & 4.0251 & 4.0264 & TRN \\
\hline CHEMBL65 & 955055 & 7.4157 & 7.4118 & TRN \\
\hline CHEMBL102714 & 955055 & 2.9497 & 3.1358 & TRN \\
\hline CHEMBL 2144069 & 955055 & 7.3972 & 7.4047 & TRN \\
\hline CHEMBL 2134202 & 955055 & 4.7601 & 4.6158 & TRN \\
\hline CHEMBL1673039 & 955055 & 3.7255 & 3.8463 & TRN \\
\hline CHEMBL180127 & 955055 & 3.9552 & 4.0186 & TRN \\
\hline CHEMBL483847 & 955055 & 4.4827 & 4.5034 & TRN \\
\hline CHEMBL1242367 & 955055 & 3.8662 & 3.8848 & TRN \\
\hline CHEMBL509032 & 955055 & 5.1509 & 5.1266 & TRN \\
\hline CHEMBL373751 & 955055 & 3.4031 & 3.491 & TRN \\
\hline CHEMBL379300 & 955055 & 5.2837 & 5.3079 & TRN \\
\hline CHEMBL 2363137 & 955055 & 5.407 & 5.4122 & TRN \\
\hline CHEMBL558642 & 955055 & 4.3762 & 4.3905 & TRN \\
\hline CHEMBL1256459 & 955055 & 7.5795 & 6.7844 & TST \\
\hline CHEMBL209148 & 955055 & 4.6125 & 4.7848 & TST \\
\hline CHEMBL1970879 & 955055 & 4.7868 & 4.2897 & TST \\
\hline CHEMBL3392440 & 955055 & 3.8908 & 4.0715 & TST \\
\hline CHEMBL472940 & 955055 & 2.8418 & 3.1507 & TST \\
\hline CHEMBL515416 & 955055 & 5.2193 & 4.7422 & TST \\
\hline CHEMBL258844 & 955055 & 4.0188 & 4.1085 & TST \\
\hline CHEMBL392695 & 955055 & 5.5708 & 4.8025 & TST \\
\hline CHEMBL3216702 & 647228 & 6.4012 & 6.8296 & TRN \\
\hline CHEMBL1214045 & 647228 & 6.5467 & 6.5132 & TRN \\
\hline CHEMBL1213931 & 647228 & 6.6478 & 6.722 & TRN \\
\hline CHEMBL1088163 & 647228 & 7.1192 & 6.5907 & TRN \\
\hline
\end{tabular}

TRN 


\begin{tabular}{|c|c|c|c|c|c|}
\hline \multirow[b]{2}{*}{ CHEMBL1080522 } & \multicolumn{5}{|c|}{ Supplemental Table S2.txt } \\
\hline & 647228 & 7.0605 & 7.4061 & TRN & \\
\hline CHEMBL1214427 & 647228 & 7.2518 & 7.454 & TRN & \\
\hline CHEMBL1214047 & 647228 & 5.965 & 5.7748 & TRN & \\
\hline CHEMBL1214304 & 647228 & 7.1079 & 6.2414 & TST & \\
\hline CHEMBL1080728 & 647228 & 7.0315 & 7.0205 & TRN & \\
\hline CHEMBL1214546 & 647228 & 6.8761 & 7.2906 & TRN & \\
\hline CHEMBL1214113 & 647228 & 6.4921 & 5.8957 & TRN & \\
\hline CHEMBL1214594 & 647228 & 7.1079 & 6.7974 & TRN & \\
\hline CHEMBL1081035 & 647228 & 7.4949 & 6.8443 & TRN & \\
\hline CHEMBL1213673 & 647228 & 6.0655 & 6.6333 & TRN & \\
\hline CHEMBL1214597 & 647228 & 7.3468 & 6.0711 & TST & \\
\hline CHEMBL1214116 & 647228 & 6.4191 & 6.4643 & TRN & \\
\hline CHEMBL1214595 & 647228 & 6.0419 & 5.773 & TST & \\
\hline CHEMBL1213933 & 647228 & 6.7375 & 6.0121 & TRN & \\
\hline CHEMBL1086756 & 647228 & 6.3768 & 6.8258 & TRN & \\
\hline CHEMBL1214367 & 647228 & 6.8894 & 6.9387 & TRN & \\
\hline CHEMBL1214596 & 647228 & 6.5986 & 5.8389 & TST & \\
\hline CHEMBL1214302 & 647228 & 6.7905 & 6.7533 & TST & \\
\hline CHEMBL1213985 & 647228 & 6.5229 & 6.9768 & TST & \\
\hline CHEMBL1213932 & 647228 & 5.9 & 5.6816 & TRN & \\
\hline CHEMBL1214488 & 647228 & 6.2013 & 7.0136 & TRN & \\
\hline CHEMBL3216259 & 647228 & 6.9586 & 6.8699 & TRN & \\
\hline CHEMBL1214426 & 647228 & 6.8827 & 6.8158 & TRN & \\
\hline CHEMBL1086626 & 647228 & 6.8633 & 7.4649 & TRN & \\
\hline CHEMBL1214114 & 647228 & 5.7031 & 5.5757 & TRN & \\
\hline CHEMBL1214178 & 647228 & 6.9914 & 7.0873 & TRN & \\
\hline CHEMBL1214366 & 647228 & 7.7212 & 7.5164 & TRN & \\
\hline CHEMBL1214305 & 647228 & 7.4437 & 6.7983 & TST & \\
\hline CHEMBL1213675 & 647228 & 5.149 & 6.7793 & TRN & \\
\hline CHEMBL 2447969 & 647228 & 7.2441 & 6.8712 & TRN & \\
\hline CHEMBL1214489 & 647228 & 5.9359 & 6.8482 & TRN & \\
\hline CHEMBL1213676 & 647228 & 7.2676 & 6.00700 & 0000000001 & TST \\
\hline CHEMBL1214115 & 647228 & 6.0685 & 6.7474 & TST & \\
\hline CHEMBL1214177 & 647228 & 7.0088 & 6.9474 & TRN & \\
\hline CHEMBL1214428 & 647228 & 6.1349 & 6.9184 & TRN & \\
\hline CHEMBL1086613 & 647228 & 7.4437 & 6.7726 & TRN & \\
\hline CHEMBL1214425 & 647228 & 7.0315 & 6.9791 & TRN & \\
\hline CHEMBL1214046 & 647228 & 6.6478 & 6.3911 & TRN & \\
\hline CHEMBL1212957 & 647228 & 8.1549 & 7.2869 & TRN & \\
\hline CHEMBL3216707 & 647228 & 4.0 & 5.6843 & TRN & \\
\hline CHEMBL1080726 & 647228 & 7.9586 & 7.0853 & TRN & \\
\hline CHEMBL1213856 & 647228 & 7.6383 & 7.3205 & TRN & \\
\hline CHEMBL 3217141 & 647228 & 7.5528 & 7.2243 & TRN & \\
\hline CHEMBL1081644 & 647228 & 7.9208 & 6.7883 & TRN & \\
\hline CHEMBL1081468 & 647228 & 7.1135 & 7.2773 & TST & \\
\hline CHEMBL1086754 & 647228 & 7.2076 & 6.9442 & TRN & \\
\hline CHEMBL1214175 & 647228 & 7.0862 & 6.8989 & TST & \\
\hline CHEMBL1213934 & 647228 & 7.6576 & 7.0137 & TST & \\
\hline
\end{tabular}


Supplemental Table S2.txt

\begin{tabular}{|c|c|c|c|c|}
\hline CHEMBL 1214176 & 647228 & 6.7878 & 6.8691 & TRN \\
\hline CHEMBL1214547 & 647228 & 7.0706 & 6.8434 & TRN \\
\hline CHEMBL1214303 & 647228 & 7.1079 & 6.4416 & TST \\
\hline CHEMBL1213674 & 647228 & 6.426 & 6.1522 & TST \\
\hline CHEMBL3942616 & 1642107 & 8.5686 & 7.8353 & TST \\
\hline CHEMBL3943962 & 1642107 & 6.7212 & 6.1123 & TRN \\
\hline CHEMBL 3900292 & 1642107 & 6.0 & 6.3228 & TRN \\
\hline CHEMBL3932117 & 1642107 & 5.7235 & 6.2081 & TRN \\
\hline CHEMBL 3914240 & 1642107 & 6.0 & 6.8189 & TRN \\
\hline CHEMBL3946171 & 1642107 & 6.0315 & 6.6906 & TRN \\
\hline CHEMBL3928190 & 1642107 & 6.0 & 5.8644 & TRN \\
\hline CHEMBL3959501 & 1642107 & 6.1221 & 7.8304 & TST \\
\hline CHEMBL3951213 & 1642107 & 6.0 & 5.2654 & TRN \\
\hline CHEMBL3906866 & 1642107 & 8.1308 & 7.6798 & TRN \\
\hline CHEMBL3945941 & 1642107 & 5.9318 & 6.7404 & TRN \\
\hline CHEMBL3943194 & 1642107 & 6.6778 & 7.1071 & TRN \\
\hline CHEMBL3896402 & 1642107 & 8.2716 & 8.6031 & TRN \\
\hline CHEMBL 3960085 & 1642107 & 6.7447 & 7.5325 & TST \\
\hline CHEMBL 3982887 & 1642107 & 7.5935 & 7.1799 & TRN \\
\hline CHEMBL3943372 & 1642107 & 6.0 & 7.46899 & 9999999999 \\
\hline CHEMBL3982651 & 1642107 & 6.0 & 6.735 & TRN \\
\hline CHEMBL 3934183 & 1642107 & 6.0 & 6.1063 & TRN \\
\hline CHEMBL 3939293 & 1642107 & 5.9767 & 5.8995 & TRN \\
\hline CHEMBL3965425 & 1642107 & 6.0 & 5.2848 & TRN \\
\hline CHEMBL3937593 & 1642107 & 6.1367 & 6.5455 & TST \\
\hline CHEMBL3899856 & 1642107 & 6.3325 & 6.5691 & TRN \\
\hline CHEMBL3959625 & 1642107 & 6.0029 & 5.4174 & TRN \\
\hline CHEMBL3916201 & 1642107 & 6.2076 & 6.4919 & TRN \\
\hline CHEMBL3937815 & 1642107 & 6.6383 & 6.5872 & TRN \\
\hline CHEMBL 3985824 & 1642107 & 6.0 & 5.796 & TRN \\
\hline CHEMBL3937167 & 1642107 & 6.0 & 6.6017 & TST \\
\hline CHEMBL3975775 & 1642107 & 6.0044 & 7.2723 & TST \\
\hline CHEMBL 3960588 & 1642107 & 8.0 & 7.7815 & TRN \\
\hline CHEMBL3967435 & 1642107 & 6.0 & 6.3231 & TRN \\
\hline CHEMBL3928651 & 1642107 & 6.0 & 6.5736 & TRN \\
\hline CHEMBL3929120 & 1642107 & 6.0 & 6.1675 & TRN \\
\hline CHEMBL3924824 & 1642107 & 5.5346 & 6.0499 & TRN \\
\hline CHEMBL 3977883 & 1642107 & 6.0 & 6.2444 & TRN \\
\hline CHEMBL 3982674 & 1642107 & 6.0 & 6.3923 & TRN \\
\hline CHEMBL3907138 & 1642107 & 6.0 & 5.9512 & TRN \\
\hline CHEMBL3977691 & 1642107 & 6.0 & 5.7911 & TRN \\
\hline CHEMBL3889835 & 1642107 & 6.0 & 7.2935 & TRN \\
\hline CHEMBL3972755 & 1642107 & 8.6108 & 8.1136 & TRN \\
\hline CHEMBL3921976 & 1642107 & 6.0 & 6.7429 & TST \\
\hline CHEMBL 3899387 & 1642107 & 6.0 & 7.218 & TST \\
\hline CHEMBL 3980782 & 1642107 & 9.2676 & 8.0475 & TRN \\
\hline CHEMBL3926333 & 1642107 & 6.6847 & 6.9618 & TRN \\
\hline CHEMBL3950879 & 1642107 & 6.2798 & 7.4409 & TST \\
\hline
\end{tabular}


Supplemental Table S2.txt

\begin{tabular}{|c|c|c|c|c|c|}
\hline CHEMBL3955335 & 1642107 & 6.9666 & 6.1545 & TRN & \\
\hline CHEMBL 3890424 & 1642107 & 5.8554 & 8.0532 & TST & \\
\hline CHEMBL3911970 & 1642107 & 6.0 & 6.1844 & TRN & \\
\hline CHEMBL3969636 & 1642107 & 6.0 & 6.0631 & TRN & \\
\hline CHEMBL3951319 & 1642107 & 8.8447 & 7.4585 & TRN & \\
\hline CHEMBL 3974883 & 1642107 & 6.9893 & 6.7598 & TRN & \\
\hline CHEMBL 3946074 & 1642107 & 6.4437 & 6.7258 & TRN & \\
\hline CHEMBL3909426 & 1642107 & 6.0 & 5.4152 & TRN & \\
\hline CHEMBL3959941 & 1642107 & 7.7508 & 6.8517 & TRN & \\
\hline CHEMBL 3972320 & 1642107 & 7.7447 & 7.1654 & TRN & \\
\hline CHEMBL3966922 & 1642107 & 7.7696 & 7.7112 & TST & \\
\hline CHEMBL3961206 & 1642107 & 5.6882 & 5.9445 & TRN & \\
\hline CHEMBL3920864 & 1642107 & 5.3969 & 6.2685 & TRN & \\
\hline CHEMBL3935944 & 1642107 & 8.2218 & 5.9357 & TST & \\
\hline CHEMBL 3893777 & 1642107 & 5.4029 & 6.4481 & TST & \\
\hline CHEMBL3945501 & 1642107 & 7.2716 & 7.8133 & TST & \\
\hline CHEMBL460920 & 566939 & 7.5229 & 7.5441 & TRN & \\
\hline CHEMBL452592 & 566939 & 7.8239 & 7.7758 & TRN & \\
\hline CHEMBL460747 & 566939 & 7.9208 & 7.9075 & TST & \\
\hline CHEMBL454402 & 566939 & 7.5686 & 7.153 & TRN & \\
\hline CHEMBL453628 & 566939 & 7.8239 & 7.8951 & TRN & \\
\hline CHEMBL452585 & 566939 & 7.4815 & 7.081 & TRN & \\
\hline CHEMBL464208 & 566939 & 7.6778 & 7.6318 & TST & \\
\hline CHEMBL460326 & 566939 & 6.8861 & 7.0062 & TRN & \\
\hline CHEMBL464209 & 566939 & 7.0 & 6.9051 & TRN & \\
\hline CHEMBL462834 & 566939 & 7.9586 & 7.6906 & TRN & \\
\hline CHEMBL459477 & 566939 & 7.0555 & 7.7217 & TRN & \\
\hline CHEMBL464412 & 566939 & 6.0655 & 6.8461 & TRN & \\
\hline CHEMBL454630 & 566939 & 8.3979 & 7.7364 & TST & \\
\hline CHEMBL463813 & 566939 & 7.7447 & 8.2191 & TRN & \\
\hline CHEMBL452595 & 566939 & 8.3979 & 7.5603 & TST & \\
\hline CHEMBL474754 & 566939 & 6.7212 & 6.8834 & TRN & \\
\hline CHEMBL463615 & 566939 & 8.3979 & 7.9635 & TRN & \\
\hline CHEMBL460324 & 566939 & 7.1427 & 7.0337 & TRN & \\
\hline CHEMBL463027 & 566939 & 6.9208 & 6.8369 & TRN & \\
\hline CHEMBL453627 & 566939 & 8.3979 & 8.0391 & TRN & \\
\hline CHEMBL517320 & 566939 & 6.6198 & 6.8646 & TRN & \\
\hline CHEMBL509169 & 566939 & 7.8861 & 7.7796 & TRN & \\
\hline CHEMBL454631 & 566939 & 7.1308 & 7.13700 & 00000000005 & TRN \\
\hline CHEMBL463222 & 566939 & 8.0969 & 8.227 & TRN & \\
\hline CHEMBL463419 & 566939 & 7.9208 & 8.1864 & TRN & \\
\hline CHEMBL462833 & 566939 & 7.8861 & 7.7767 & TRN & \\
\hline CHEMBL510325 & 566939 & 7.1308 & 7.0574 & TRN & \\
\hline CHEMBL506391 & 566939 & 7.1487 & 6.9578 & TRN & \\
\hline CHEMBL508274 & 566939 & 7.0969 & 7.8127 & TRN & \\
\hline CHEMBL518695 & 566939 & 8.3979 & 8.3517 & TRN & \\
\hline CHEMBL461170 & 566939 & 7.6021 & 7.7666 & TRN & \\
\hline CHEMBL454633 & 566939 & 8.699 & 7.9605 & TST & \\
\hline
\end{tabular}




\begin{tabular}{|c|c|c|c|c|c|}
\hline \multicolumn{6}{|c|}{ Supplemental Table S2.txt } \\
\hline CHEMBL453393 & 566939 & 8.699 & 8.1122 & TRN & \\
\hline CHEMBL452594 & 566939 & 7.9208 & 7.4956 & TST & \\
\hline CHEMBL454634 & 566939 & 7.6383 & 7.8274 & TRN & \\
\hline CHEMBL460113 & 566939 & 7.7212 & 7.42899 & э999999999 & TRN \\
\hline CHEMBL517020 & 566939 & 8.3979 & 7.9351 & TRN & \\
\hline CHEMBL509168 & 566939 & 8.1549 & 8.0029 & TRN & \\
\hline CHEMBL510837 & 566939 & 8.2218 & 7.8693 & TST & \\
\hline CHEMBL518319 & 566939 & 7.7212 & 7.8396 & TRN & \\
\hline CHEMBL454629 & 566939 & 7.4202 & 7.7121 & TRN & \\
\hline CHEMBL460540 & 566939 & 7.3565 & 7.1952 & TRN & \\
\hline CHEMBL459692 & 566939 & 8.0458 & 8.2618 & TRN & \\
\hline CHEMBL455436 & 566939 & 7.3768 & 7.6055 & TRN & \\
\hline CHEMBL463423 & 566939 & 8.0969 & 7.9189 & TST & \\
\hline CHEMBL460748 & 566939 & 7.5376 & 7.8093 & TRN & \\
\hline CHEMBL510083 & 566939 & 7.5528 & 7.2931 & TST & \\
\hline CHEMBL463812 & 566939 & 7.699 & 7.6413 & TRN & \\
\hline CHEMBL462829 & 566939 & 8.3979 & 8.0245 & TRN & \\
\hline CHEMBL453626 & 566939 & 8.2218 & 8.1252 & TRN & \\
\hline CHEMBL463614 & 566939 & 8.3979 & 8.5637 & TRN & \\
\hline CHEMBL463424 & 566939 & 7.7212 & 7.9919 & TST & \\
\hline CHEMBL508045 & 566939 & 7.0706 & 7.2919 & TST & \\
\hline CHEMBL462662 & 566939 & 7.8239 & 7.9053 & TRN & \\
\hline CHEMBL510084 & 566939 & 7.6383 & 7.9387 & TST & \\
\hline CHEMBL459691 & 566939 & 7.9586 & 7.8693 & TRN & \\
\hline CHEMBL517578 & 566939 & 8.2218 & 8.1237 & TRN & \\
\hline CHEMBL516521 & 566939 & 7.9586 & 7.9312 & TRN & \\
\hline CHEMBL517442 & 566939 & 8.0 & 8.2521 & TRN & \\
\hline CHEMBL463221 & 566939 & 8.0969 & 7.8777 & TRN & \\
\hline CHEMBL459690 & 566939 & 8.5229 & 8.3271 & TRN & \\
\hline CHEMBL474753 & 566939 & 6.8861 & 6.8007 & TRN & \\
\hline CHEMBL474356 & 566939 & 6.7212 & 7.20200 & 3000000001 & TST \\
\hline CHEMBL516949 & 566939 & 7.8239 & 7.5044 & TST & \\
\hline CHEMBL454632 & 566939 & 8.699 & 8.1685 & TST & \\
\hline CHEMBL452593 & 566939 & 7.9208 & 7.62200 & 0000000001 & TST \\
\hline CHEMBL464616 & 566939 & 7.7447 & 8.304 & TST & \\
\hline CHEMBL 3678988 & 1528178 & 6.4437 & 6.154 & TRN & \\
\hline CHEMBL 3679045 & 1528178 & 8.2596 & 8.5073 & TRN & \\
\hline CHEMBL 3679095 & 1528178 & 6.6021 & 6.6716 & TRN & \\
\hline CHEMBL 3679114 & 1528178 & 6.0 & 5.7969 & TRN & \\
\hline CHEMBL3679006 & 1528178 & 8.3565 & 5.9342 & TST & \\
\hline CHEMBL 3932547 & 1528178 & 6.0 & 6.0728 & TRN & \\
\hline CHEMBL 3679073 & 1528178 & 6.0 & 6.3449 & TRN & \\
\hline CHEMBL 3679128 & 1528178 & 6.0 & 6.0817 & TRN & \\
\hline CHEMBL 3679124 & 1528178 & 7.8239 & 5.0952 & TST & \\
\hline CHEMBL3679094 & 1528178 & 6.0 & 5.8565 & TRN & \\
\hline CHEMBL 3679026 & 1528178 & 8.9208 & 8.8368 & TRN & \\
\hline CHEMBL 3679037 & 1528178 & 6.0 & 6.3066 & TRN & \\
\hline CHEMBL 3679079 & 1528178 & 8.2757 & 7.7721 & TRN & \\
\hline
\end{tabular}


Supplemental Table S2.txt

\begin{tabular}{|c|c|c|c|c|c|}
\hline CHEMBL 3679029 & 1528178 & 9.0177 & 8.9768 & TRN & \\
\hline CHEMBL3679090 & 1528178 & 8.7959 & 8.3137 & TRN & \\
\hline CHEMBL3679113 & 1528178 & 7.0809 & 6.534 & TRN & \\
\hline CHEMBL3678989 & 1528178 & 5.6778 & 5.8064 & TRN & \\
\hline CHEMBL 3678987 & 1528178 & 6.2076 & 6.0189 & TRN & \\
\hline CHEMBL 3679144 & 1528178 & 6.0 & 7.565 & TRN & \\
\hline CHEMBL3679055 & 1528178 & 7.0269 & 6.8281 & TRN & \\
\hline CHEMBL3679039 & 1528178 & 8.7959 & 8.2375 & TRN & \\
\hline CHEMBL3679098 & 1528178 & 6.0 & 5.8776 & TRN & \\
\hline CHEMBL 3678997 & 1528178 & 6.7212 & 8.1359 & TST & \\
\hline CHEMBL 3678985 & 1528178 & 7.2076 & 6.1529 & TRN & \\
\hline CHEMBL 3679081 & 1528178 & 7.9586 & 8.0828 & TRN & \\
\hline CHEMBL 3679066 & 1528178 & 6.0 & 6.8984 & TRN & \\
\hline CHEMBL3679127 & 1528178 & 6.0 & 6.2298 & TRN & \\
\hline CHEMBL 3679100 & 1528178 & 8.0315 & 7.8833 & TRN & \\
\hline CHEMBL 3679150 & 1528178 & 6.0 & 6.1516 & TRN & \\
\hline CHEMBL3936749 & 1528178 & 8.3872 & 5.8968 & TST & \\
\hline CHEMBL 3679019 & 1528178 & 7.1079 & \multicolumn{2}{|c|}{7.832000000000001} & TRN \\
\hline CHEMBL3679107 & 1528178 & 6.0 & 6.4655 & TRN & \\
\hline CHEMBL 3679035 & 1528178 & 8.9208 & 9.5828 & TRN & \\
\hline CHEMBL3679014 & 1528178 & 6.0 & 7.3566 & TRN & \\
\hline CHEMBL3679005 & 1528178 & 9.0 & 6.7157 & TST & \\
\hline CHEMBL 3679103 & 1528178 & 6.0 & 5.5341 & TRN & \\
\hline CHEMBL3679034 & 1528178 & 6.3188 & 6.0629 & TRN & \\
\hline CHEMBL 3678993 & 1528178 & 5.4437 & 7.5165 & TST & \\
\hline CHEMBL3679001 & 1528178 & 8.6198 & 8.0327 & TST & \\
\hline CHEMBL3679040 & 1528178 & 8.041 & 7.9239 & TRN & \\
\hline CHEMBL 3679002 & 1528178 & 7.1938 & 7.461 & TRN & \\
\hline CHEMBL3639779 & 1528178 & 6.6778 & 6.0756 & TRN & \\
\hline CHEMBL 3679117 & 1528178 & 6.0 & 5.9924 & TRN & \\
\hline CHEMBL3679020 & 1528178 & 5.8239 & \multicolumn{2}{|c|}{7.2410000000000005} & TRN \\
\hline CHEMBL 3679080 & 1528178 & 8.4949 & 8.1501 & TRN & \\
\hline CHEMBL3678998 & 1528178 & 6.585 & 9.2447 & TST & \\
\hline CHEMBL3679130 & 1528178 & 7.5229 & 6.8679 & TRN & \\
\hline CHEMBL3679053 & 1528178 & 8.7959 & 7.4192 & TRN & \\
\hline CHEMBL 3679140 & 1528178 & 5.8539 & 7.1939 & TST & \\
\hline CHEMBL 3679146 & 1528178 & 5.6576 & 6.6011 & TRN & \\
\hline CHEMBL 3679043 & 1528178 & 9.2676 & 8.2244 & TRN & \\
\hline CHEMBL3679031 & 1528178 & 5.7447 & \multicolumn{2}{|c|}{7.042999999999999} & TRN \\
\hline CHEMBL3679137 & 1528178 & 5.7959 & 7.3642 & TST & \\
\hline CHEMBL3679078 & 1528178 & 8.8539 & 7.9405 & TRN & \\
\hline CHEMBL3679097 & 1528178 & 6.0 & 6.4447 & TRN & \\
\hline CHEMBL3679054 & 1528178 & 6.0 & 5.8708 & TRN & \\
\hline CHEMBL3679047 & 1528178 & 5.8861 & 7.7621 & TST & \\
\hline CHEMBL 3679007 & 1528178 & 7.5376 & \multicolumn{2}{|c|}{5.627000000000001} & TST \\
\hline CHEMBL3679051 & 1528178 & 9.1192 & 7.4637 & TRN & \\
\hline CHEMBL 3679083 & 1528178 & 6.5086 & 5.9286 & TRN & \\
\hline CHEMBL3679141 & 1528178 & 5.699 & 6.8272 & TST & \\
\hline
\end{tabular}




\begin{tabular}{|c|c|c|c|c|c|}
\hline & & & & & \\
\hline CHEMBL3679119 & 1528178 & 6.0 & 6.6705 & TRN & \\
\hline CHEMBL3679085 & 1528178 & 6.0 & 6.6484 & TST & \\
\hline CHEMBL3679134 & 1528178 & 6.0 & 6.6789 & TST & \\
\hline CHEMBL3679112 & 1528178 & 6.8239 & 6.7289 & TRN & \\
\hline CHEMBL3679046 & 1528178 & 6.9208 & 7.5518 & TST & \\
\hline CHEMBL3679056 & 1528178 & 5.7696 & 6.0642 & TRN & \\
\hline CHEMBL3679041 & 1528178 & 7.4089 & 8.186 & TRN & \\
\hline CHEMBL3678996 & 1528178 & 5.5229 & 5.6162 & TRN & \\
\hline CHEMBL3679091 & 1528178 & 7.8539 & 7.6612 & TRN & \\
\hline CHEMBL3678986 & 1528178 & 6.7696 & 6.3507 & TRN & \\
\hline CHEMBL3679089 & 1528178 & 6.0 & 5.8888 & TRN & \\
\hline CHEMBL3679104 & 1528178 & 9.0223 & 8.43799 & 9999999999 & TRN \\
\hline CHEMBL3679116 & 1528178 & 6.0 & 6.3265 & TRN & \\
\hline CHEMBL3918152 & 1528178 & 6.1938 & 5.4117 & TST & \\
\hline CHEMBL3679063 & 1528178 & 6.0 & 6.4287 & TRN & \\
\hline CHEMBL3679096 & 1528178 & 5.7959 & 5.74 & TRN & \\
\hline CHEMBL3679021 & 1528178 & 8.6383 & 7.74100 & 00000000005 & TRN \\
\hline CHEMBL3679075 & 1528178 & 8.699 & 8.4187 & TRN & \\
\hline CHEMBL3679143 & 1528178 & 6.0 & 7.1717 & TRN & \\
\hline CHEMBL3894149 & 1528178 & 7.301 & 5.9477 & TST & \\
\hline CHEMBL3679118 & 1528178 & 7.9586 & 7.1864 & TRN & \\
\hline CHEMBL3679052 & 1528178 & 6.0 & 6.3026 & TRN & \\
\hline CHEMBL3679048 & 1528178 & 6.0 & 6.3404 & TRN & \\
\hline CHEMBL3679015 & 1528178 & 7.0 & 7.96 & TRN & \\
\hline CHEMBL3679065 & 1528178 & 6.4202 & 7.3255 & TRN & \\
\hline CHEMBL3678990 & 1528178 & 5.6576 & 8.8376 & TST & \\
\hline CHEMBL3679136 & 1528178 & 6.0177 & 7.8223 & TST & \\
\hline CHEMBL3679009 & 1528178 & 6.8861 & 7.1901 & TRN & \\
\hline CHEMBL3679011 & 1528178 & 9.5528 & 8.5866 & TRN & \\
\hline CHEMBL3679058 & 1528178 & 6.0 & 6.2303 & TRN & \\
\hline CHEMBL3679077 & 1528178 & 8.1487 & 8.8992 & TRN & \\
\hline CHEMBL3679008 & 1528178 & 5.4685 & 5.7228 & TRN & \\
\hline CHEMBL3678999 & 1528178 & 5.8539 & 8.0031 & TST & \\
\hline CHEMBL3679086 & 1528178 & 6.0 & 6.0771 & TST & \\
\hline CHEMBL3679102 & 1528178 & 6.0655 & 5.8327 & TST & \\
\hline CHEMBL3678992 & 1528178 & 5.9208 & 5.8711 & TRN & \\
\hline CHEMBL3679060 & 1528178 & 6.3665 & 5.9581 & TRN & \\
\hline CHEMBL3679068 & 1528178 & 6.0 & 5.8044 & TRN & \\
\hline CHEMBL3679131 & 1528178 & 8.2076 & 7.4132 & TST & \\
\hline CHEMBL3679092 & 1528178 & 7.5229 & 7.694 & TRN & \\
\hline CHEMBL3679042 & 1528178 & 9.1487 & 8.0171 & TRN & \\
\hline CHEMBL3931081 & 1528178 & 5.3565 & 4.9253 & TST & \\
\hline CHEMBL3679142 & 1528178 & 6.0 & 6.7067 & TRN & \\
\hline CHEMBL3679110 & 1528178 & 8.6198 & 6.1947 & TRN & \\
\hline CHEMBL3679069 & 1528178 & 6.0 & 5.879 & TRN & \\
\hline CHEMBL3679032 & 1528178 & 8.585 & 7.9862 & TRN & \\
\hline CHEMBL3679152 & 1528178 & 8.7212 & 7.973 & TST & \\
\hline CHEMBL3679057 & 1528178 & 5.9208 & 5.6335 & TRN & \\
\hline
\end{tabular}


Supplemental Table S2.txt

\begin{tabular}{|c|c|c|c|c|}
\hline CHEMBL 3679027 & 1528178 & 7.284 & 7.2733 & TRN \\
\hline CHEMBL3679013 & 1528178 & 8.9208 & 8.5607 & TRN \\
\hline CHEMBL 3679044 & 1528178 & 7.3468 & 6.9647 & TRN \\
\hline CHEMBL3679059 & 1528178 & 6.0 & 6.5633 & TRN \\
\hline CHEMBL 3679138 & 1528178 & 6.0 & 5.9868 & TST \\
\hline CHEMBL3679121 & 1528178 & 6.0 & 6.2958 & TRN \\
\hline CHEMBL3908607 & 1528178 & 7.4089 & 5.3077 & TST \\
\hline CHEMBL3679149 & 1528178 & 6.0 & 6.1138 & TRN \\
\hline CHEMBL3679082 & 1528178 & 6.1805 & 6.3076 & TRN \\
\hline CHEMBL3679010 & 1528178 & 6.0969 & 6.2191 & TRN \\
\hline CHEMBL3679070 & 1528178 & 6.0 & 5.746 & TRN \\
\hline CHEMBL3679123 & 1528178 & 7.6021 & 5.6617 & TST \\
\hline CHEMBL 3679064 & 1528178 & 7.6383 & 7.7046 & TRN \\
\hline CHEMBL3679120 & 1528178 & 6.0 & 6.4791 & TRN \\
\hline CHEMBL 3679023 & 1528178 & 6.5376 & 7.3263 & TRN \\
\hline CHEMBL3679012 & 1528178 & 7.8539 & 8.0217 & TRN \\
\hline CHEMBL3679126 & 1528178 & 6.0 & 6.8588 & TST \\
\hline CHEMBL 3679132 & 1528178 & 7.9586 & 7.3803 & TST \\
\hline CHEMBL3679151 & 1528178 & 7.6198 & 6.7434 & TRN \\
\hline CHEMBL 3923594 & 1528178 & 7.2596 & 4.9392 & TST \\
\hline CHEMBL 3679145 & 1528178 & 7.2147 & 6.9508 & TRN \\
\hline CHEMBL3679050 & 1528178 & 7.8239 & 7.2527 & TRN \\
\hline CHEMBL 3679087 & 1528178 & 6.0 & 5.9946 & TRN \\
\hline CHEMBL 3679000 & 1528178 & 6.2218 & 8.4197 & TST \\
\hline CHEMBL 3679122 & 1528178 & 6.0 & 6.0222 & TST \\
\hline CHEMBL 3639778 & 1528178 & 9.1192 & 7.8642 & TRN \\
\hline CHEMBL3679109 & 1528178 & 7.0458 & 6.9535 & TRN \\
\hline CHEMBL 3679148 & 1528178 & 6.1427 & 6.1228 & TST \\
\hline CHEMBL3679074 & 1528178 & 7.3665 & 7.6799 & TST \\
\hline CHEMBL 3679024 & 1528178 & 7.3665 & 7.2506 & TRN \\
\hline CHEMBL3679115 & 1528178 & 6.0 & 6.7758 & TRN \\
\hline CHEMBL 3679018 & 1528178 & 7.1871 & 8.2675 & TRN \\
\hline CHEMBL3679036 & 1528178 & 6.0 & 6.692 & TRN \\
\hline CHEMBL3679003 & 1528178 & 5.4437 & 5.9708 & TRN \\
\hline CHEMBL3679062 & 1528178 & 8.0655 & 8.0039 & TRN \\
\hline CHEMBL3679133 & 1528178 & 6.699 & 7.7524 & TST \\
\hline CHEMBL 3679038 & 1528178 & 8.3979 & 7.6646 & TRN \\
\hline CHEMBL3679016 & 1528178 & 8.0605 & 7.5556 & TRN \\
\hline CHEMBL3679004 & 1528178 & 7.2218 & 7.3536 & TRN \\
\hline CHEMBL3679129 & 1528178 & 6.0 & 6.34 & TST \\
\hline CHEMBL3679106 & 1528178 & 6.0 & 6.9746 & TRN \\
\hline CHEMBL3679153 & 1528178 & 6.0 & 5.8405 & TRN \\
\hline CHEMBL 3679072 & 1528178 & 6.0 & \multicolumn{2}{|c|}{5.9479999999999995} \\
\hline CHEMBL3678994 & 1528178 & 5.3665 & 6.2421 & TRN \\
\hline CHEMBL 3679076 & 1528178 & 8.1367 & 8.3337 & TRN \\
\hline CHEMBL 3679022 & 1528178 & 9.0809 & 8.8483 & TRN \\
\hline CHEMBL 3679093 & 1528178 & 7.8239 & 7.5552 & TRN \\
\hline CHEMBL 3678995 & 1528178 & 6.0506 & 6.3797 & TRN \\
\hline
\end{tabular}

Page 25187 
Supplemental Table S2.txt

\begin{tabular}{|c|c|c|c|c|}
\hline CHEMBL 3679154 & 1528178 & 8.3565 & 7.0062 & TRN \\
\hline CHEMBL 3679028 & 1528178 & 8.8861 & 8.9127 & TRN \\
\hline CHEMBL 3679111 & 1528178 & 5.7212 & 6.1784 & TRN \\
\hline CHEMBL 3679049 & 1528178 & 6.0 & 7.0574 & TRN \\
\hline CHEMBL 3679025 & 1528178 & 7.3872 & 8.2315 & TRN \\
\hline CHEMBL 3679105 & 1528178 & 7.1308 & 7.103 & TST \\
\hline CHEMBL 3679125 & 1528178 & 7.8239 & 6.6959 & TRN \\
\hline CHEMBL 3679061 & 1528178 & 6.9208 & 7.4255 & TRN \\
\hline CHEMBL 3679088 & 1528178 & 6.0 & 5.5135 & TRN \\
\hline CHEMBL3679099 & 1528178 & 8.4318 & 8.0679 & TRN \\
\hline CHEMBL 3679108 & 1528178 & 8.2076 & 7.3869 & TRN \\
\hline CHEMBL 3679071 & 1528178 & 7.0458 & 8.187999 & 9999999999 \\
\hline CHEMBL 3679033 & 1528178 & 6.9208 & 6.9405 & TRN \\
\hline CHEMBL 3679030 & 1528178 & 6.8239 & 7.2793 & TRN \\
\hline CHEMBL 3679101 & 1528178 & 5.8861 & 6.2915 & TST \\
\hline CHEMBL 3679135 & 1528178 & 6.0 & 6.0203 & TST \\
\hline CHEMBL 3679139 & 1528178 & 6.0 & 5.7196 & TST \\
\hline CHEMBL 3679017 & 1528178 & 7.6021 & 8.0942 & TRN \\
\hline CHEMBL 3679147 & 1528178 & 7.0269 & 7.4428 & TST \\
\hline CHEMBL3678991 & 1528178 & 5.5376 & 8.1742 & TST \\
\hline CHEMBL 276738 & 701308 & 3.46 & 5.102 & TST \\
\hline CHEMBL145767 & 701308 & 6.85 & 6.5998 & TRN \\
\hline CHEMBL142562 & 701308 & 6.3 & 6.022 & TST \\
\hline CHEMBL 342059 & 701308 & 3.52 & 4.9633 & TST \\
\hline CHEMBL329791 & 701308 & 6.7 & 6.4554 & TRN \\
\hline CHEMBL344501 & 701308 & 6.4 & 6.0603 & TRN \\
\hline CHEMBL344706 & 701308 & 3.48 & 4.7346 & TST \\
\hline CHEMBL 302765 & 701308 & 6.22 & 6.3346 & TRN \\
\hline CHEMBL138332 & 701308 & 5.8 & 5.9514 & TRN \\
\hline CHEMBL137879 & 701308 & 3.39 & 4.9741 & TST \\
\hline CHEMBL65271 & 701308 & 6.1 & 6.3758 & TRN \\
\hline CHEMBL141154 & 701308 & 6.04 & 5.9807 & TRN \\
\hline CHEMBL304726 & 701308 & 6.32 & 5.6688 & TRN \\
\hline CHEMBL16894 & 701308 & 3.22 & 4.6806 & TST \\
\hline CHEMBL330286 & 701308 & 6.49 & 6.3235 & TRN \\
\hline CHEMBL423934 & 701308 & 6.22 & 5.8749 & TRN \\
\hline CHEMBL414620 & 701308 & 2.94 & 4.6744 & TST \\
\hline CHEMBL357663 & 701308 & 6.1 & 6.1699 & TRN \\
\hline CHEMBL344724 & 701308 & 5.56 & 5.6789 & TRN \\
\hline CHEMBL315150 & 701308 & 3.15 & 3.8085 & TST \\
\hline CHEMBL358735 & 701308 & 4.52 & 5.1385 & TRN \\
\hline CHEMBL359044 & 701308 & 4.4 & 4.7423 & TRN \\
\hline CHEMBL145623 & 701308 & 3.09 & 3.6507 & TST \\
\hline CHEMBL142926 & 701308 & 4.4 & 4.8005 & TRN \\
\hline CHEMBL 342500 & 701308 & 4.26 & 4.5084 & TRN \\
\hline CHEMBL16867 & 701308 & 3.55 & 4.5732 & TST \\
\hline CHEMBL422820 & 701308 & 6.01 & 5.6767 & TRN \\
\hline CHEMBL137950 & 701308 & 5.1 & 5.065 & TRN \\
\hline
\end{tabular}




\begin{tabular}{|c|c|c|c|c|c|c|}
\hline & & \multicolumn{5}{|c|}{ Supplemental Table S2.txt } \\
\hline CHEMBL423542 & 701308 & 3.37 & 3.8999 & TST & & \\
\hline CHEMBL139182 & 701308 & 4.4 & 4.9999 & TRN & & \\
\hline CHEMBL342906 & 701308 & 4.22 & 4.2786 & TRN & & \\
\hline CHEMBL144972 & 701308 & 2.35 & 3.3814 & TST & & \\
\hline CHEMBL359379 & 701308 & 4.6 & 4.5387 & TRN & & \\
\hline CHEMBL341852 & 701308 & 4.15 & 4.1585 & TRN & & \\
\hline CHEMBL146658 & 701308 & 2.47 & 3.6309 & TST & & \\
\hline CHEMBL145734 & 701308 & 4.8 & 4.9092 & TRN & & \\
\hline CHEMBL145123 & 701308 & 4.29 & 4.2905 & TRN & & \\
\hline CHEMBL16687 & 701308 & \multicolumn{3}{|c|}{4.071000000000001} & 5.6208 & TST \\
\hline CHEMBL144979 & 701308 & 6.854 & 6.7237 & TST & & \\
\hline CHEMBL141550 & 701308 & 6.721 & 6.4543 & TST & & \\
\hline CHEMBL324735 & 701308 & 6.8 & 6.9674 & TRN & & \\
\hline CHEMBL349019 & 701308 & 5.47 & 5.6276 & TRN & & \\
\hline CHEMBL1644525 & 701308 & 6.62 & 6.535 & TRN & & \\
\hline CHEMBL354161 & 701308 & 6.37 & 6.0678 & TRN & & \\
\hline CHEMBL351285 & 701308 & 6.51 & 6.58799 & 9999999999 & & TRN \\
\hline CHEMBL348925 & 701308 & 6.34 & 6.1037 & TRN & & \\
\hline CHEMBL572765 & 701308 & 6.47 & 6.3148 & TRN & & \\
\hline CHEMBL164686 & 701308 & 6.13 & 6.2088 & TRN & & \\
\hline CHEMBL351211 & 701308 & 6.15 & 6.4528 & TRN & & \\
\hline CHEMBL164992 & 701308 & 6.1 & 6.166 & TRN & & \\
\hline CHEMBL164281 & 701308 & 6.04 & 6.27 & TRN & & \\
\hline CHEMBL167753 & 701308 & 6.54 & 6.4888 & TRN & & \\
\hline CHEMBL352796 & 701308 & 6.74 & 6.9479 & TRN & & \\
\hline CHEMBL164275 & 701308 & 5.52 & 5.5539 & TRN & & \\
\hline CHEMBL1644526 & 701308 & 6.57 & 6.6441 & TRN & & \\
\hline CHEMBL165910 & 701308 & 6.19 & 6.1204 & TRN & & \\
\hline CHEMBL348975 & 701308 & 6.85 & 6.6381 & TRN & & \\
\hline CHEMBL165600 & 701308 & 6.43 & 6.1949 & TRN & & \\
\hline CHEMBL164685 & 701308 & 6.07 & 6.4058 & TRN & & \\
\hline CHEMBL165044 & 701308 & 6.01 & 6.3128 & TRN & & \\
\hline CHEMBL164647 & 701308 & 6.25 & 6.4502 & TRN & & \\
\hline CHEMBL164381 & 701308 & 6.07 & 6.1351 & TRN & & \\
\hline CHEMBL352345 & 701308 & 6.52 & 6.2127 & TRN & & \\
\hline CHEMBL352073 & 701308 & 6.7 & 6.4219 & TRN & & \\
\hline CHEMBL168018 & 701308 & 6.82 & 6.9295 & TRN & & \\
\hline CHEMBL353299 & 701308 & 5.6 & 5.4294 & TRN & & \\
\hline CHEMBL1644692 & 701308 & 6.52 & 6.562 & TRN & & \\
\hline CHEMBL355415 & 701308 & 6.09 & 6.108 & TRN & & \\
\hline CHEMBL351075 & 701308 & 6.4 & 6.638 & TRN & & \\
\hline CHEMBL350205 & 701308 & 6.35 & 6.1751 & TRN & & \\
\hline CHEMBL165778 & 701308 & 6.54 & 6.3921 & TRN & & \\
\hline CHEMBL164509 & 701308 & 6.29 & 6.2861 & TRN & & \\
\hline CHEMBL165560 & 701308 & 6.47 & 6.3985 & TRN & & \\
\hline CHEMBL350261 & 701308 & 6.4 & 6.0423 & TRN & & \\
\hline CHEMBL350042 & 701308 & 6.15 & 6.0975 & TRN & & \\
\hline CHEMBL164905 & 701308 & 6.47 & 6.409 & TRN & & \\
\hline
\end{tabular}




\begin{tabular}{|c|c|c|c|c|c|c|}
\hline \multicolumn{7}{|c|}{ Supplemental Table S2.txt } \\
\hline CHEMBL349240 & 701308 & 6.68 & 6.8195 & TRN & & \\
\hline CHEMBL352707 & 701308 & 5.43 & 5.2961 & TRN & & \\
\hline CHEMBL1644693 & 701308 & 6.3 & 6.434 & TRN & & \\
\hline CHEMBL167915 & 701308 & 6.26 & 6.1261 & TRN & & \\
\hline CHEMBL166684 & 701308 & 6.68 & 6.5484 & TRN & & \\
\hline CHEMBL350830 & 701308 & 6.04 & 6.0476 & TRN & & \\
\hline CHEMBL165620 & 701308 & 6.1 & 6.3126 & TRN & & \\
\hline CHEMBL349954 & 701308 & 6.14 & 6.1335 & TRN & & \\
\hline CHEMBL349611 & 701308 & 6.24 & 6.3323 & TRN & & \\
\hline CHEMBL164325 & 701308 & 6.22 & 5.9792 & TRN & & \\
\hline CHEMBL349716 & 701308 & 6.07 & 6.0224 & TRN & & \\
\hline CHEMBL424161 & 701308 & 6.37 & 6.3284 & TRN & & \\
\hline CHEMBL341376 & 701308 & 6.09 & 5.91299 & 999999999s & & TRN \\
\hline CHEMBL165073 & 701308 & 5.99 & 6.1876 & TRN & & \\
\hline CHEMBL349464 & 701308 & 6.0 & 6.0948 & TRN & & \\
\hline CHEMBL163968 & 701308 & 5.95 & 6.0264 & TRN & & \\
\hline CHEMBL361412 & 701308 & 5.05 & 4.8319 & TRN & & \\
\hline CHEMBL175494 & 701308 & 5.31 & 4.8634 & TRN & & \\
\hline CHEMBL179638 & 701308 & 4.19 & 4.1742 & TRN & & \\
\hline CHEMBL175870 & 701308 & 4.41 & 4.2278 & TRN & & \\
\hline CHEMBL368643 & 701308 & 4.68 & 5.2617 & TRN & & \\
\hline CHEMBL 263045 & 701308 & 4.82 & 5.2511 & TRN & & \\
\hline CHEMBL366864 & 701308 & 4.26 & 4.0909 & TRN & & \\
\hline CHEMBL177524 & 701308 & 4.19 & 3.9952 & TRN & & \\
\hline CHEMBL359531 & 701308 & 2.83 & 4.55 & TST & & \\
\hline CHEMBL367773 & 701308 & 2.6 & 4.1589 & TST & & \\
\hline CHEMBL176010 & 701308 & $3.7880 e$ & 00000006 & 003 & 5.0167 & TST \\
\hline CHEMBL366737 & 701308 & 4.09699 & 99999995 & 995 & 5.0836 & TST \\
\hline CHEMBL360448 & 701308 & 2.69 & 4.527 & TST & & \\
\hline CHEMBL179349 & 701308 & 2.76 & 4.2271 & TST & & \\
\hline CHEMBL362190 & 701308 & 6.0 & 5.9385 & TRN & & \\
\hline CHEMBL 362038 & 701308 & 5.71 & 5.8272 & TRN & & \\
\hline CHEMBL175922 & 701308 & 6.09 & 6.0544 & TRN & & \\
\hline CHEMBL 361401 & 701308 & 4.69 & 4.5243 & TRN & & \\
\hline CHEMBL366396 & 701308 & 5.09 & 4.7991 & TRN & & \\
\hline CHEMBL366794 & 701308 & 4.92 & 5.16206 & 0000000001 & & TRN \\
\hline CHEMBL175871 & 701308 & 5.13 & 5.4229 & TST & & \\
\hline CHEMBL180583 & 701308 & 4.79 & 5.3703 & TST & & \\
\hline CHEMBL177066 & 701308 & 5.11 & 5.5095 & TST & & \\
\hline CHEMBL179133 & 701308 & 5.0 & 5.7604 & TST & & \\
\hline CHEMBL175474 & 701308 & 5.39 & 6.2985 & TST & & \\
\hline CHEMBL175986 & 701308 & 5.17 & 5.215 & TST & & \\
\hline CHEMBL179240 & 701308 & 5.4 & 5.3556 & TST & & \\
\hline CHEMBL179315 & 701308 & 5.16 & 5.6377 & TST & & \\
\hline CHEMBL359473 & 701308 & 5.23 & 5.8929 & TST & & \\
\hline CHEMBL219609 & 901083 & 0.7324 & 0.7323 & TRN & & \\
\hline CHEMBL 220152 & 901083 & 0.7782 & 0.7703 & TRN & & \\
\hline CHEMBL373791 & 901083 & 0.5052 & 0.4887 & TRN & & \\
\hline
\end{tabular}




\begin{tabular}{|c|c|c|c|c|}
\hline & & & oplement & al $\mathrm{Tc}$ \\
\hline CHEMBL219669 & 901083 & 0.4771 & 0.5089 & TRN \\
\hline CHEMBL436514 & 901083 & 0.3617 & 0.3134 & TRN \\
\hline CHEMBL220894 & 901083 & 0.5315 & 0.5273 & TRN \\
\hline CHEMBL 387350 & 901083 & 0.301 & 0.3387 & TRN \\
\hline CHEMBL223748 & 901083 & 0.0792 & 0.0647 & TRN \\
\hline CHEMBL 222508 & 901083 & 0.4771 & 0.5047 & TRN \\
\hline CHEMBL 220224 & 901083 & 0.1139 & 0.0608 & TRN \\
\hline CHEMBL 375072 & 901083 & 0.6628 & 0.6746 & TRN \\
\hline CHEMBL427080 & 901083 & 1.4471 & 1.4155 & TRN \\
\hline CHEMBL222247 & 901083 & 1.6628 & 1.685 & TRN \\
\hline CHEMBL 220173 & 901083 & 0.3222 & 0.3013 & TRN \\
\hline CHEMBL 220662 & 901083 & 0.6435 & 0.6678 & TRN \\
\hline CHEMBL220151 & 901083 & 0.5315 & 0.5188 & TRN \\
\hline CHEMBL 219668 & 901083 & 1.2553 & 1.2346 & TRN \\
\hline CHEMBL 374545 & 901083 & 0.8389 & 0.8643 & TRN \\
\hline CHEMBL424939 & 901083 & 0.716 & 0.7278 & TRN \\
\hline CHEMBL 375427 & 901083 & 0.1139 & 0.1372 & TRN \\
\hline CHEMBL 2236890 & 901083 & 0.6021 & 0.5766 & TRN \\
\hline CHEMBL219617 & 901083 & 0.5185 & 0.5365 & TRN \\
\hline CHEMBL 2113263 & 901083 & 0.2788 & 0.2945 & TRN \\
\hline CHEMBL 375812 & 901083 & 0.3424 & 0.302 & TRN \\
\hline CHEMBL 222248 & 901083 & 0.6128 & 0.6142 & TRN \\
\hline CHEMBL 220223 & 901083 & 0.544 & 0.495 & TRN \\
\hline CHEMBL221101 & 901083 & 0.1139 & 0.1707 & TRN \\
\hline CHEMBL 374925 & 901083 & 0.6021 & 0.5922 & TRN \\
\hline CHEMBL220837 & 901083 & 0.4624 & 0.4914 & TRN \\
\hline CHEMBL 219687 & 901083 & 0.4624 & 0.447 & TRN \\
\hline CHEMBL 374090 & 901083 & 0.5185 & 0.5079 & TRN \\
\hline CHEMBL220117 & 901083 & 1.0414 & 1.068 & TRN \\
\hline CHEMBL220557 & 901083 & 0.3979 & 0.4304 & TRN \\
\hline CHEMBL 373813 & 901083 & 1.0414 & 1.0182 & TRN \\
\hline CHEMBL220635 & 901083 & 0.6435 & 0.6108 & TRN \\
\hline CHEMBL 220059 & 901083 & 0.4314 & 0.4599 & TRN \\
\hline CHEMBL 220124 & 901083 & 0.2366 & 0.2025 & TRN \\
\hline CHEMBL 374901 & 901083 & 0.2041 & 0.2636 & TRN \\
\hline CHEMBL220325 & 901083 & 0.3424 & 0.2896 & TST \\
\hline CHEMBL425116 & 901083 & 0.7482 & 0.584 & TST \\
\hline CHEMBL 220448 & 901083 & 1.0414 & 1.0571 & TRN \\
\hline CHEMBL 219944 & 901083 & 0.3617 & 0.3506 & TRN \\
\hline CHEMBL 220893 & 901083 & 0.1761 & 0.3202 & TST \\
\hline CHEMBL 376418 & 901083 & 0.5798 & 0.5989 & TRN \\
\hline CHEMBL 375748 & 901083 & 0.7709 & 0.7463 & TRN \\
\hline CHEMBL 219688 & 901083 & 0.5315 & 0.4204 & TST \\
\hline CHEMBL 220990 & 901083 & 3.3483 & 3.1281 & TST \\
\hline CHEMBL219817 & 901083 & 2.5647 & 2.3966 & TST \\
\hline CHEMBL220431 & 901083 & 1.0414 & 1.2866 & TST \\
\hline CHEMBL 220430 & 901083 & 0.3424 & 0.3714 & TRN \\
\hline CHEMBL 375747 & 901083 & 1.1461 & 1.1595 & TRN \\
\hline
\end{tabular}




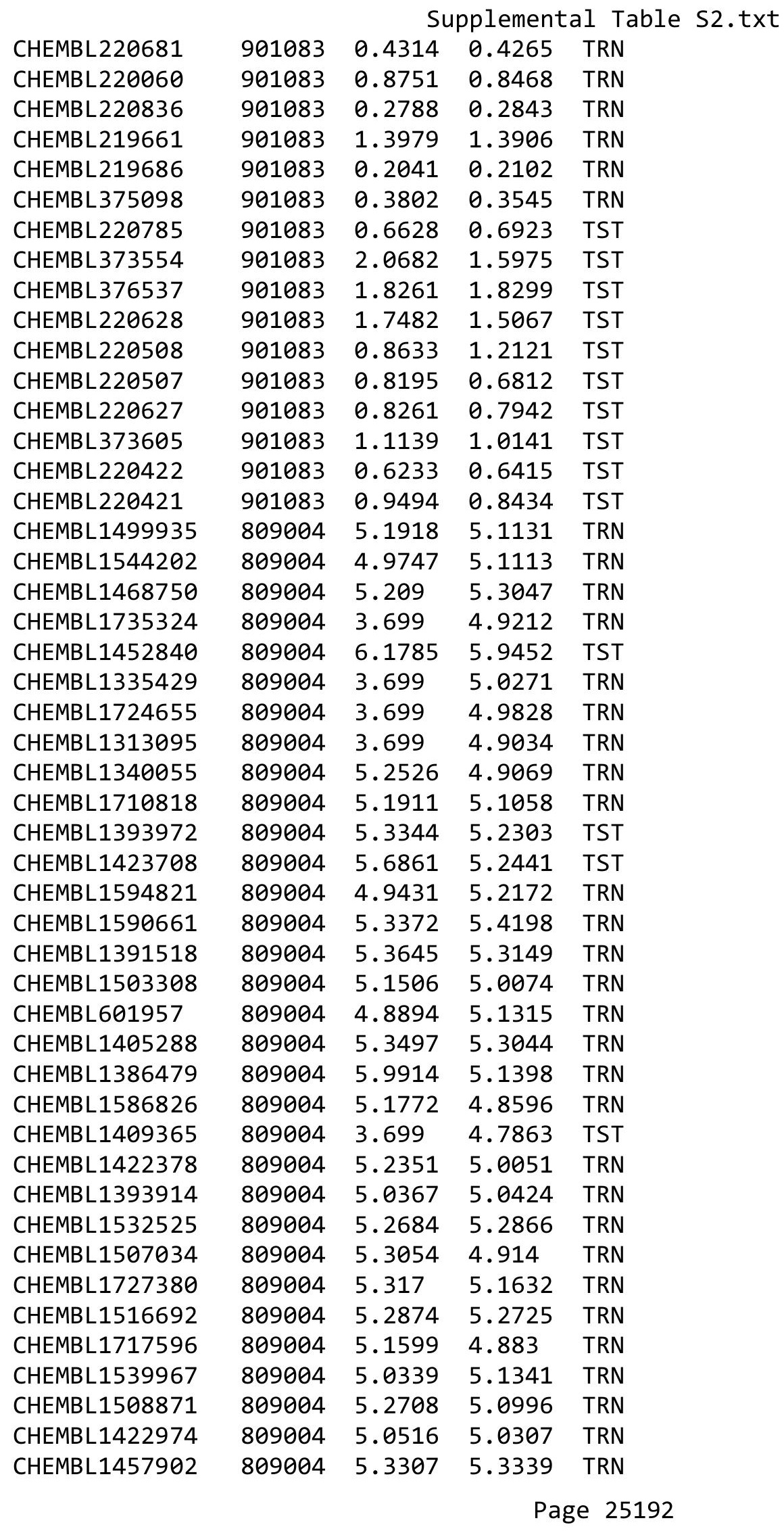




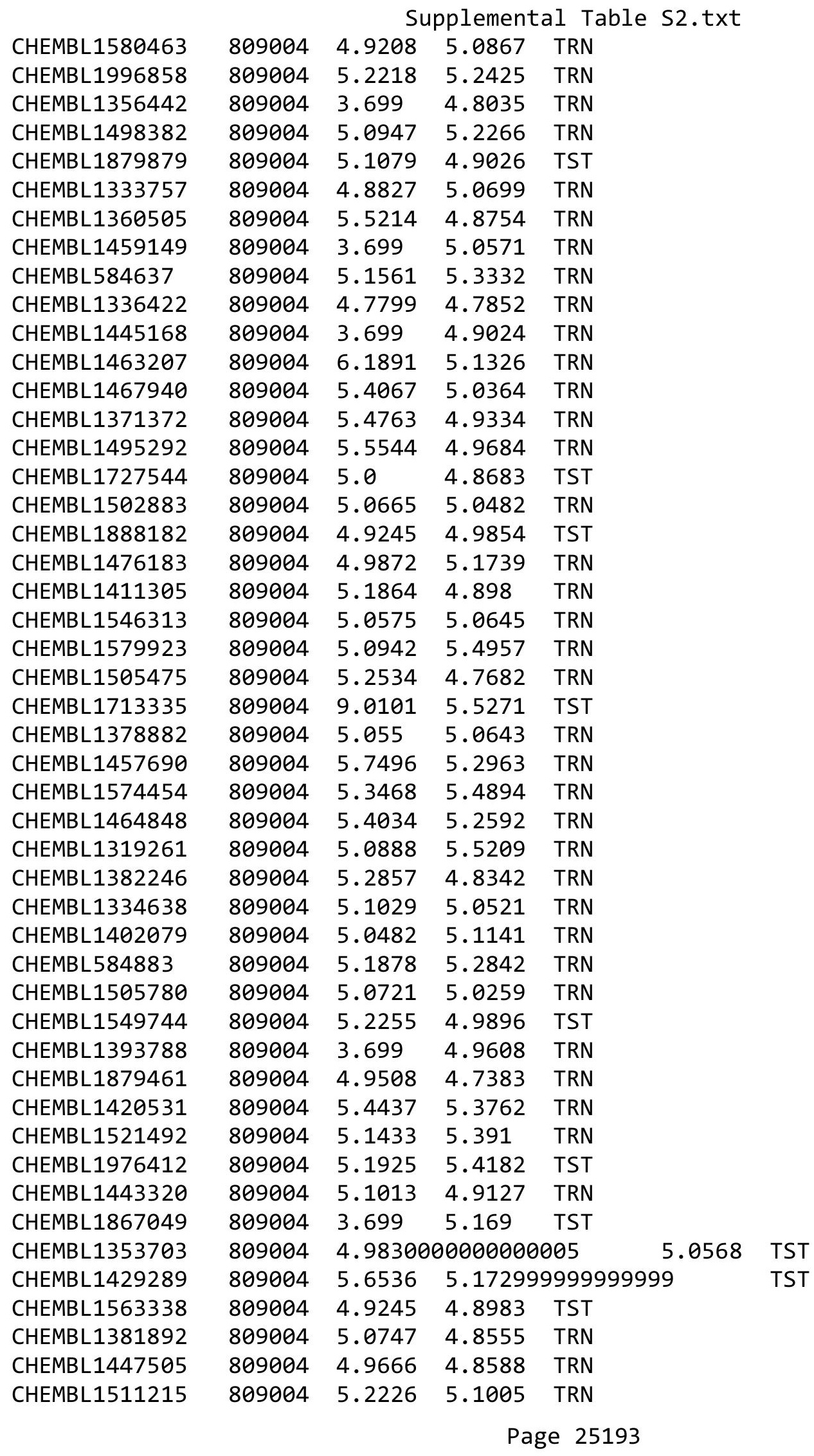




\begin{tabular}{|c|c|c|c|c|c|c|}
\hline & & \multicolumn{5}{|c|}{ Supplemental Table S2.txt } \\
\hline CHEMBL1510371 & 809004 & 3.699 & 5.2007 & TRN & & \\
\hline CHEMBL1542594 & 809004 & 5.8794 & 5.2833 & TRN & & \\
\hline CHEMBL1441701 & 809004 & 5.5331 & 4.7621 & TRN & & \\
\hline CHEMBL1606778 & 809004 & 3.699 & 5.2321 & TRN & & \\
\hline CHEMBL2006154 & 809004 & 5.3686 & 5.4058 & TRN & & \\
\hline CHEMBL1495055 & 809004 & 5.1391 & 5.0997 & TRN & & \\
\hline CHEMBL1706173 & 809004 & 5.7959 & 5.0815 & TRN & & \\
\hline CHEMBL1300724 & 809004 & 3.699 & 4.9696 & TRN & & \\
\hline CHEMBL1589053 & 809004 & 5.433 & 4.9484 & TRN & & \\
\hline CHEMBL1541725 & 809004 & 5.3233 & 5.4997 & TRN & & \\
\hline CHEMBL585221 & 809004 & 4.8297 & 5.2085 & TRN & & \\
\hline CHEMBL 2006740 & 809004 & 5.2055 & 5.3115 & TRN & & \\
\hline CHEMBL1339261 & 809004 & 5.1331 & 5.347 & TRN & & \\
\hline CHEMBL592363 & 809004 & 5.2277 & 4.8613 & TRN & & \\
\hline CHEMBL1444683 & 809004 & 5.2 & 5.1952 & TRN & & \\
\hline CHEMBL1709900 & 809004 & 4.9101 & 4.8823 & TRN & & \\
\hline CHEMBL1310132 & 809004 & 5.8996 & 5.7597 & TRN & & \\
\hline CHEMBL1427969 & 809004 & 5.1469 & 5.1626 & TRN & & \\
\hline CHEMBL1425438 & 809004 & 5.4989 & 5.1872 & TRN & & \\
\hline CHEMBL579380 & 809004 & 5.1379 & 5.0833 & TRN & & \\
\hline CHEMBL 2003587 & 809004 & $5.8210 \ell$ & 30000000 & 01 & .1576 & TRN \\
\hline CHEMBL1610706 & 809004 & 5.1884 & 4.9531 & TRN & & \\
\hline CHEMBL1477416 & 809004 & 4.9393 & 4.9108 & TRN & & \\
\hline CHEMBL1702872 & 809004 & 4.8861 & 4.8454 & TRN & & \\
\hline CHEMBL1342646 & 809004 & 3.699 & 4.9324 & TRN & & \\
\hline CHEMBL1382182 & 809004 & 4.7471 & 5.1445 & TST & & \\
\hline CHEMBL1533399 & 809004 & 5.2857 & 5.1858 & TRN & & \\
\hline CHEMBL1713017 & 809004 & 5.9914 & 5.1852 & TST & & \\
\hline CHEMBL1502771 & 809004 & 5.1135 & 4.9692 & TRN & & \\
\hline CHEMBL1360998 & 809004 & 5.4572 & 5.1866 & TRN & & \\
\hline CHEMBL1563223 & 809004 & $5.3820 €$ & 00000000 & & .2888 & TRN \\
\hline CHEMBL1718749 & 809004 & 5.251 & 4.96899 & 9999999999 & & TRN \\
\hline CHEMBL1420175 & 809004 & 5.1918 & 4.98300 & 00000000005 & & TST \\
\hline CHEMBL1509493 & 809004 & 6.2716 & 5.6628 & TRN & & \\
\hline CHEMBL1423040 & 809004 & 5.104 & 5.1398 & TST & & \\
\hline CHEMBL1475769 & 809004 & 3.699 & 5.3829 & TST & & \\
\hline CHEMBL1478200 & 809004 & 3.699 & 4.849 & TST & & \\
\hline CHEMBL1537481 & 809004 & 5.1739 & 5.086 & TRN & & \\
\hline CHEMBL579423 & 809004 & 4.7721 & 5.30399 & 9999999999 & & TRN \\
\hline CHEMBL1712491 & 809004 & 5.3979 & 4.9633 & TRN & & \\
\hline CHEMBL1478316 & 809004 & 5.1918 & 4.9728 & TRN & & \\
\hline CHEMBL1309960 & 809004 & 4.9747 & 5.3495 & TRN & & \\
\hline CHEMBL1375484 & 809004 & 3.699 & 4.7611 & TRN & & \\
\hline CHEMBL1707309 & 809004 & 5.3696 & 4.988 & TRN & & \\
\hline CHEMBL1512670 & 809004 & 5.3206 & 5.8704 & TST & & \\
\hline CHEMBL1503683 & 809004 & 4.8182 & 5.21399 & 99999999995 & & TST \\
\hline CHEMBL1471489 & 809004 & 5.1733 & 5.1921 & TRN & & \\
\hline CHEMBL1371706 & 809004 & 5.5376 & 5.5366 & TRN & & \\
\hline
\end{tabular}


Supplemental Table S2.txt

\begin{tabular}{|c|c|c|c|c|c|}
\hline CHEMBL1441617 & 809004 & 5.0726 & 5.3595 & TRN & \\
\hline CHEMBL1722169 & 809004 & 5.2125 & 5.1202 & TRN & \\
\hline CHEMBL1403955 & 809004 & 4.9626 & 4.9176 & TRN & \\
\hline CHEMBL1735871 & 809004 & 3.699 & 5.2879 & TRN & \\
\hline CHEMBL1523428 & 809004 & 6.0269 & 5.2839 & TRN & \\
\hline CHEMBL1321271 & 809004 & 5.1232 & 5.1062 & TRN & \\
\hline CHEMBL1441391 & 809004 & 5.4145 & 4.8142 & TRN & \\
\hline CHEMBL1300171 & 809004 & 5.1733 & 4.8451 & TRN & \\
\hline CHEMBL1584133 & 809004 & 5.2749 & 5.1649 & TRN & \\
\hline CHEMBL1576654 & 809004 & 3.699 & 5.1054 & TRN & \\
\hline CHEMBL1404991 & 809004 & 3.699 & 4.2644 & TRN & \\
\hline CHEMBL1400977 & 809004 & 4.7471 & 4.7519 & TST & \\
\hline CHEMBL1464433 & 809004 & 5.2857 & 5.2851 & TRN & \\
\hline CHEMBL1585578 & 809004 & 5.3675 & 5.0703 & TRN & \\
\hline CHEMBL1553954 & 809004 & 5.399 & 5.1124 & TRN & \\
\hline CHEMBL1393367 & 809004 & 6.5317 & 5.1153 & TRN & \\
\hline CHEMBL1394105 & 809004 & 5.6126 & 5.6396 & TRN & \\
\hline CHEMBL1984723 & 809004 & 5.4034 & 5.2046 & TRN & \\
\hline CHEMBL1438842 & 809004 & 6.4237 & 5.5713 & TRN & \\
\hline CHEMBL1308356 & 809004 & 5.0101 & 4.5519 & TRN & \\
\hline CHEMBL1520586 & 809004 & 5.2111 & 5.1407 & TRN & \\
\hline CHEMBL1304383 & 809004 & 5.5607 & 5.12299 & 9999999999 & TRN \\
\hline CHEMBL1547430 & 809004 & 5.0883 & 5.0842 & TRN & \\
\hline CHEMBL1509085 & 809004 & 5.4921 & 5.1231 & TRN & \\
\hline CHEMBL1983220 & 809004 & 5.3251 & 5.0003 & TST & \\
\hline CHEMBL1425183 & 809004 & 5.5544 & 5.1823 & TRN & \\
\hline CHEMBL1500973 & 809004 & 5.1007 & 4.7763 & TRN & \\
\hline CHEMBL1561304 & 809004 & 5.1124 & 4.8691 & TRN & \\
\hline CHEMBL1462989 & 809004 & 5.2757 & 5.0208 & TST & \\
\hline CHEMBL1904436 & 809004 & 3.699 & 5.2433 & TST & \\
\hline CHEMBL1348795 & 809004 & 5.0119 & 5.0331 & TRN & \\
\hline CHEMBL1466361 & 809004 & 5.3893 & 4.8332 & TRN & \\
\hline CHEMBL1992836 & 809004 & 4.8962 & 4.6038 & TST & \\
\hline CHEMBL1437648 & 809004 & 3.699 & 5.1545 & TST & \\
\hline CHEMBL1502434 & 809004 & 5.3134 & 5.5834 & TST & \\
\hline CHEMBL1986504 & 809004 & 5.3625 & 5.1644 & TRN & \\
\hline CHEMBL1457383 & 809004 & 5.2636 & 5.0978 & TRN & \\
\hline CHEMBL1971875 & 809004 & 5.266 & 5.2051 & TRN & \\
\hline CHEMBL1453469 & 809004 & 5.0531 & 5.1291 & TRN & \\
\hline CHEMBL1439475 & 809004 & 4.8386 & 5.1103 & TRN & \\
\hline CHEMBL1436618 & 809004 & 5.0964 & 4.8825 & TRN & \\
\hline CHEMBL1431232 & 809004 & 5.0462 & 5.0205 & TRN & \\
\hline CHEMBL1494441 & 809004 & 5.6402 & 5.1624 & TRN & \\
\hline CHEMBL1497081 & 809004 & 5.4437 & 4.8908 & TST & \\
\hline CHEMBL1510973 & 809004 & 5.4145 & 5.5698 & TRN & \\
\hline CHEMBL598270 & 809004 & 5.2518 & 5.0739 & TST & \\
\hline CHEMBL1415497 & 809004 & 5.2899 & 5.1522 & TRN & \\
\hline CHEMBL1379608 & 809004 & 6.0 & 4.7357 & TST & \\
\hline
\end{tabular}




\begin{tabular}{|c|c|c|c|c|c|}
\hline \multicolumn{6}{|c|}{ Supplemental Table S2.txt } \\
\hline CHEMBL1495310 & 809004 & 5.4535 & 5.004 & TRN & \\
\hline CHEMBL1375563 & 809004 & 5.1643 & 5.1424 & TRN & \\
\hline CHEMBL1736406 & 809004 & 5.3354 & 5.0917 & TRN & \\
\hline CHEMBL1715754 & 809004 & 4.7423 & 5.3077 & TST & \\
\hline CHEMBL56170 & 809004 & 5.8041 & 6.1405 & TST & \\
\hline CHEMBL1469340 & 809004 & 5.3507 & 5.0579 & TRN & \\
\hline CHEMBL1712982 & 809004 & 4.8508 & 4.8692 & TRN & \\
\hline CHEMBL1488960 & 809004 & 5.062 & 4.7724 & TST & \\
\hline CHEMBL1606066 & 809004 & 4.9872 & 5.0919 & TRN & \\
\hline CHEMBL1471200 & 809004 & 5.0057 & 5.3689 & TRN & \\
\hline CHEMBL1700973 & 809004 & 4.9281 & 5.1361 & TST & \\
\hline CHEMBL1497589 & 809004 & 5.0241 & 4.9821 & TRN & \\
\hline CHEMBL1573351 & 809004 & 5.098 & 4.8511 & TRN & \\
\hline CHEMBL1398721 & 809004 & 5.0742 & 4.8439 & TRN & \\
\hline CHEMBL1351755 & 809004 & 5.3468 & 5.4487 & TRN & \\
\hline CHEMBL1437794 & 809004 & 5.0031 & 4.8491 & TRN & \\
\hline CHEMBL1557454 & 809004 & 5.1238 & 5.0669 & TRN & \\
\hline CHEMBL1466491 & 809004 & 5.0716 & 4.8563 & TRN & \\
\hline CHEMBL1523952 & 809004 & 5.3696 & 4.8475 & TRN & \\
\hline CHEMBL1406208 & 809004 & 5.2865 & 5.8202 & TRN & \\
\hline CHEMBL1339289 & 809004 & 5.1325 & 5.1473 & TST & \\
\hline CHEMBL1558527 & 809004 & 5.1226 & 5.1528 & TRN & \\
\hline CHEMBL1402962 & 809004 & 3.699 & 4.8132 & TRN & \\
\hline CHEMBL1705009 & 809004 & 5.2573 & 5.2002 & TRN & \\
\hline CHEMBL1714938 & 809004 & 5.8928 & 5.0703 & TRN & \\
\hline CHEMBL1504590 & 809004 & 3.699 & 4.67899 & 9999999999 & TRN \\
\hline CHEMBL1340112 & 809004 & 5.0915 & 5.0733 & TRN & \\
\hline CHEMBL1329678 & 809004 & 5.1931 & 4.8807 & TRN & \\
\hline CHEMBL1458569 & 809004 & 5.2933 & 4.7897 & TRN & \\
\hline CHEMBL1535959 & 809004 & 5.289 & 5.3193 & TRN & \\
\hline CHEMBL1423564 & 809004 & 5.7033 & 5.1667 & TST & \\
\hline CHEMBL1982569 & 809004 & 5.2549 & 5.4582 & TRN & \\
\hline CHEMBL1445929 & 809004 & 5.3595 & 5.0687 & TST & \\
\hline CHEMBL1336211 & 809004 & 6.3757 & 5.2817 & TST & \\
\hline CHEMBL1726266 & 809004 & 5.1209 & 5.3516 & TRN & \\
\hline CHEMBL1401057 & 809004 & 6.0521 & 5.6645 & TRN & \\
\hline CHEMBL1383742 & 809004 & 5.0985 & 5.1227 & TRN & \\
\hline CHEMBL1993889 & 809004 & 5.5072 & 5.2809 & TRN & \\
\hline CHEMBL1387401 & 809004 & 5.8153 & 5.4181 & TRN & \\
\hline CHEMBL1346409 & 809004 & 4.7282 & 4.7374 & TRN & \\
\hline CHEMBL1461774 & 809004 & 5.066 & 4.8506 & TRN & \\
\hline CHEMBL1965236 & 809004 & 4.7852 & 5.1831 & TRN & \\
\hline CHEMBL147514 & 809004 & 5.6003 & 5.0879 & TST & \\
\hline CHEMBL1530686 & 809004 & 5.5654 & 5.6615 & TRN & \\
\hline CHEMBL1561486 & 809004 & 4.7721 & 4.8307 & TRN & \\
\hline CHEMBL1712776 & 809004 & 4.7878 & 4.8939 & TRN & \\
\hline CHEMBL1410925 & 809004 & 5.8327 & 5.3758 & TRN & \\
\hline CHEMBL1447768 & 809004 & 5.3757 & 5.1387 & TRN & \\
\hline
\end{tabular}




\begin{tabular}{|c|c|c|c|c|c|c|}
\hline \multirow[b]{2}{*}{ CHEMBL1383397 } & \multicolumn{6}{|c|}{ Supplemental Table S2.txt } \\
\hline & 809004 & 5.1273 & 5.6259 & TRN & & \\
\hline CHEMBL1325180 & 809004 & 4.76699 & 99999999 & 995 & & TRN \\
\hline CHEMBL1312636 & 809004 & 5.32700 & 00000000 & 01 & & TRN \\
\hline CHEMBL1306079 & 809004 & 5.007 & 5.1785 & TST & & \\
\hline CHEMBL1446412 & 809004 & 5.0985 & 5.033 & TRN & & \\
\hline CHEMBL1340874 & 809004 & 3.699 & 5.1 & TST & & \\
\hline CHEMBL1526479 & 809004 & 5.0716 & 5.1317 & TRN & & \\
\hline CHEMBL1486435 & 809004 & 3.699 & 4.8772 & TRN & & \\
\hline CHEMBL1481162 & 809004 & 5.1244 & 4.9785 & TRN & & \\
\hline CHEMBL1416934 & 809004 & 5.2464 & 4.8327 & TRN & & \\
\hline CHEMBL1565005 & 809004 & 5.4157 & 5.2029 & TRN & & \\
\hline CHEMBL1606622 & 809004 & 5.0405 & 4.9435 & TRN & & \\
\hline CHEMBL1573186 & 809004 & 5.7011 & 5.2226 & TRN & & \\
\hline CHEMBL1716472 & 809004 & 5.2526 & 5.0257 & TRN & & \\
\hline CHEMBL1976317 & 809004 & 5.9508 & 5.3788 & TRN & & \\
\hline CHEMBL1418975 & 809004 & 3.699 & 4.8409 & TRN & & \\
\hline CHEMBL1732831 & 809004 & 3.699 & 5.1722 & TST & & \\
\hline CHEMBL1564773 & 809004 & 4.8928 & 4.92 & TRN & & \\
\hline CHEMBL1544743 & 809004 & 5.4828 & 5.3336 & TRN & & \\
\hline CHEMBL1524030 & 809004 & 5.1203 & 5.091 & TRN & & \\
\hline CHEMBL1875002 & 809004 & 5.098 & 5.3191 & TRN & & \\
\hline CHEMBL1412273 & 809004 & 5.6421 & 4.8802 & TRN & & \\
\hline CHEMBL1704624 & 809004 & 5.1152 & 5.0084 & TST & & \\
\hline CHEMBL1337862 & 809004 & 5.2111 & 5.2048 & TRN & & \\
\hline CHEMBL1445198 & 809004 & 5.0665 & 4.9315 & TRN & & \\
\hline CHEMBL1353790 & 809004 & 5.1824 & 5.2665 & TRN & & \\
\hline CHEMBL1541720 & 809004 & 5.0348 & 4.8038 & TRN & & \\
\hline CHEMBL1346801 & 809004 & 4.9872 & 5.1423 & TRN & & \\
\hline CHEMBL531079 & 809004 & 5.0867 & 5.3779 & TRN & & \\
\hline CHEMBL1479560 & 809004 & 5.0123 & 5.21700 & 00000 & & TRN \\
\hline CHEMBL1412298 & 809004 & 3.699 & 4.887 & TRN & & \\
\hline CHEMBL1986741 & 809004 & 5.0947 & 4.7469 & TST & & \\
\hline CHEMBL1468344 & 809004 & 5.2534 & 5.1695 & TRN & & \\
\hline CHEMBL1973669 & 809004 & 5.1445 & 5.6753 & TST & & \\
\hline CHEMBL1401089 & 809004 & 4.699 & 4.7352 & TRN & & \\
\hline CHEMBL1534358 & 809004 & 6.1129 & 5.3473 & TRN & & \\
\hline CHEMBL1992330 & 809004 & 4.9245 & 4.8596 & TRN & & \\
\hline CHEMBL1397674 & 809004 & 3.699 & 4.5971 & TRN & & \\
\hline CHEMBL1462076 & 809004 & 5.3143 & 5.0261 & TRN & & \\
\hline CHEMBL 2000175 & 809004 & 5.0964 & 5.2093 & TST & & \\
\hline CHEMBL1421500 & 809004 & 5.0395 & 5.1016 & TRN & & \\
\hline CHEMBL1313263 & 809004 & 4.7144 & 4.7395 & TST & & \\
\hline CHEMBL1524592 & 809004 & 4.9957 & 5.1974 & TRN & & \\
\hline CHEMBL1300193 & 809004 & 5.9747 & 5.3083 & TRN & & \\
\hline CHEMBL1483380 & 809004 & 4.9393 & 4.9795 & TRN & & \\
\hline CHEMBL1327413 & 809004 & 5.3595 & 5.2638 & TRN & & \\
\hline CHEMBL1203698 & 809004 & 5.52 & 4.9338 & TRN & & \\
\hline CHEMBL1367466 & 809004 & 5.2328 & 5.2643 & TRN & & \\
\hline
\end{tabular}


Supplemental Table S2.txt

\begin{tabular}{|c|c|c|c|c|c|}
\hline CHEMBL1325769 & 809004 & 3.699 & 4.8661 & TRN & \\
\hline CHEMBL1483731 & 809004 & 5.4168 & 5.4387 & TRN & \\
\hline CHEMBL1445414 & 809004 & 5.3224 & 4.9951 & TRN & \\
\hline CHEMBL1358447 & 809004 & 5.0443 & 4.91 & TRN & \\
\hline CHEMBL1537758 & 809004 & 4.8601 & 4.7837 & TRN & \\
\hline CHEMBL1573929 & 809004 & 4.9101 & 4.8058 & TRN & \\
\hline CHEMBL1728743 & 809004 & 5.4622 & 4.984 & TRN & \\
\hline CHEMBL1417242 & 809004 & 5.1494 & 5.53299 & 79999999995 & TRN \\
\hline CHEMBL1437997 & 809004 & 5.1331 & 5.0923 & TRN & \\
\hline CHEMBL1543903 & 809004 & 4.9245 & 4.6216 & TRN & \\
\hline CHEMBL1714867 & 809004 & 5.2652 & 5.4652 & TRN & \\
\hline CHEMBL1345933 & 809004 & 5.3251 & 5.0969 & TRN & \\
\hline CHEMBL1349485 & 809004 & 5.1818 & 5.2034 & TRN & \\
\hline CHEMBL1507347 & 809004 & 6.0205 & 5.2338 & TRN & \\
\hline CHEMBL1444328 & 809004 & 4.9431 & 5.2907 & TRN & \\
\hline CHEMBL1588217 & 809004 & 5.0794 & 5.1188 & TRN & \\
\hline CHEMBL1536193 & 809004 & 4.8827 & 4.578 & TST & \\
\hline CHEMBL1601942 & 809004 & 5.2 & 4.8894 & TRN & \\
\hline CHEMBL1422962 & 809004 & 5.015 & 5.5621 & TRN & \\
\hline CHEMBL1497797 & 809004 & 5.6946 & 5.3801 & TST & \\
\hline CHEMBL1547707 & 809004 & 5.2248 & 5.3481 & TRN & \\
\hline CHEMBL1525599 & 809004 & 5.4401 & 5.135 & TRN & \\
\hline CHEMBL1553515 & 809004 & 5.1007 & 5.0961 & TRN & \\
\hline CHEMBL1543258 & 809004 & 6.4342 & 5.2227 & TST & \\
\hline CHEMBL589479 & 809004 & 4.9586 & 5.3236 & TRN & \\
\hline CHEMBL1470466 & 809004 & 5.27 & 5.2888 & TST & \\
\hline CHEMBL1377352 & 809004 & 3.699 & 4.8855 & TRN & \\
\hline CHEMBL1562110 & 809004 & 5.0074 & 5.0668 & TRN & \\
\hline CHEMBL1572685 & 809004 & 5.4498 & 5.0988 & TRN & \\
\hline CHEMBL1449912 & 809004 & 5.0545 & 4.9365 & TRN & \\
\hline CHEMBL1326139 & 809004 & 3.699 & 4.8611 & TST & \\
\hline CHEMBL1404419 & 809004 & 5.0894 & 5.0903 & TST & \\
\hline CHEMBL1722668 & 809004 & 3.699 & 4.9627 & TST & \\
\hline CHEMBL1415172 & 809004 & \multicolumn{3}{|c|}{5.0680000000000005} & TST \\
\hline CHEMBL1504531 & 809004 & 5.279 & 4.9007 & TST & \\
\hline CHEMBL528647 & 809004 & 5.4134 & 5.0428 & TST & \\
\hline CHEMBL1553781 & 809004 & 6.1337 & 5.5024 & TST & \\
\hline CHEMBL1444749 & 809004 & 5.0814 & 4.8546 & TST & \\
\hline CHEMBL1335443 & 809004 & 5.4179 & 4.9872 & TST & \\
\hline CHEMBL1323954 & 809004 & \multicolumn{3}{|c|}{5.0569999999999995} & נו \\
\hline CHEMBL1705113 & 809004 & 5.6737 & 4.8407 & TST & \\
\hline CHEMBL1309985 & 809004 & 5.0017 & 5.0219 & TST & \\
\hline CHEMBL1305122 & 809004 & 5.1249 & 4.8375 & TST & \\
\hline CHEMBL1310430 & 809004 & 4.8861 & 4.9935 & TST & \\
\hline CHEMBL1588264 & 809004 & 4.9245 & 4.9944 & TST & \\
\hline CHEMBL1500404 & 809004 & 5.5986 & 5.1033 & TST & \\
\hline CHEMBL1313133 & 809004 & 4.9914 & 5.2184 & TST & \\
\hline CHEMBL1327863 & 809004 & 5.1524 & 5.1428 & TST & \\
\hline
\end{tabular}




\begin{tabular}{|c|c|c|c|c|}
\hline & & & oplement & al $\mathrm{T}$ \\
\hline CHEMBL1586226 & 809004 & 4.9666 & 4.9389 & TST \\
\hline CHEMBL1581759 & 809004 & 6.2083 & 5.1173 & TST \\
\hline CHEMBL1405331 & 809004 & 5.0825 & 5.3307 & TST \\
\hline CHEMBL1731213 & 809004 & 5.1785 & 4.7018 & TST \\
\hline CHEMBL1725453 & 809004 & 5.3251 & 5.1007 & TST \\
\hline CHEMBL1613581 & 809004 & 5.1811 & 5.0409 & TST \\
\hline CHEMBL1600678 & 809004 & 5.2857 & 5.0721 & TST \\
\hline CHEMBL1347090 & 809004 & 4.8996 & 4.9732 & TST \\
\hline CHEMBL 2003688 & 809004 & 5.3575 & 5.2512 & TST \\
\hline CHEMBL1402847 & 809004 & 5.06 & 4.934 & TST \\
\hline CHEMBL1440967 & 809004 & 5.067 & 5.1413 & TST \\
\hline CHEMBL1608965 & 809004 & 4.9136 & 5.079 & TST \\
\hline CHEMBL1699107 & 809004 & 4.9136 & 4.8784 & TST \\
\hline CHEMBL1643959 & 954469 & 4.7619 & 4.7282 & TRN \\
\hline CHEMBL65 & 954469 & 9.5626 & 9.5334 & TRN \\
\hline CHEMBL220241 & 954469 & 4.8896 & 4.9809 & TRN \\
\hline CHEMBL 209148 & 954469 & 5.056 & 5.0391 & TRN \\
\hline CHEMBL379300 & 954469 & 7.5592 & 7.6041 & TRN \\
\hline CHEMBL1256459 & 954469 & 7.4913 & 7.4746 & TRN \\
\hline CHEMBL399530 & 954469 & 4.9319 & 4.8423 & TRN \\
\hline CHEMBL210618 & 954469 & 3.9567 & 3.8713 & TRN \\
\hline CHEMBL3186408 & 954469 & 4.1162 & 3.5258 & TST \\
\hline CHEMBL92309 & 954469 & 4.2395 & 3.0452 & TST \\
\hline CHEMBL 213100 & 954469 & 6.5398 & 6.4171 & TRN \\
\hline CHEMBL9470 & 954469 & 6.8429 & 6.3879 & TST \\
\hline CHEMBL 255342 & 954469 & 3.4926 & 3.4149 & TRN \\
\hline CHEMBL512504 & 954469 & 4.2209 & 4.2682 & TRN \\
\hline CHEMBL1788116 & 954469 & 3.885 & 3.7968 & TRN \\
\hline CHEMBL483849 & 954469 & 1.4701 & 1.8802 & TST \\
\hline CHEMBL515416 & 954469 & 4.2547 & 4.2156 & TRN \\
\hline CHEMBL1909414 & 954469 & 3.3531 & 3.2517 & TRN \\
\hline CHEMBL180127 & 954469 & 4.8898 & 4.8723 & TRN \\
\hline CHEMBL509032 & 954469 & 6.4763 & 6.4146 & TRN \\
\hline CHEMBL 2137530 & 954469 & 4.4946 & 4.5933 & TRN \\
\hline CHEMBL 258844 & 954469 & 4.1579 & 4.1872 & TRN \\
\hline CHEMBL585951 & 954469 & 6.5008 & 6.5405 & TRN \\
\hline CHEMBL 300389 & 954469 & 7.2938 & 7.3074 & TRN \\
\hline CHEMBL189584 & 954469 & 5.5179 & 5.4671 & TRN \\
\hline CHEMBL472940 & 954469 & 3.2394 & 3.343 & TRN \\
\hline CHEMBL379975 & 954469 & 5.3874 & 5.4522 & TRN \\
\hline CHEMBL 240954 & 954469 & 4.2439 & 3.7847 & TST \\
\hline CHEMBL573107 & 954469 & 4.9768 & 4.8882 & TRN \\
\hline CHEMBL2363137 & 954469 & 5.8452 & 5.9812 & TRN \\
\hline CHEMBL1190711 & 954469 & 5.7067 & 5.6688 & TRN \\
\hline CHEMBL259181 & 954469 & 4.5579 & 4.6589 & TRN \\
\hline CHEMBL1230020 & 954469 & 4.1823 & 4.0301 & TRN \\
\hline CHEMBL2144069 & 954469 & 4.7853 & 4.7836 & TRN \\
\hline CHEMBL3199475 & 954469 & 4.4951 & 4.5356 & TRN \\
\hline
\end{tabular}




\begin{tabular}{|c|c|c|c|c|c|c|}
\hline & & & oplement & & s2.txt & \\
\hline CHEMBL393929 & 954469 & 4.3929 & 4.4752 & TRN & & \\
\hline CHEMBL412142 & 954469 & 3.4861 & 3.50399 & 99999999 & 996 & TRN \\
\hline CHEMBL558642 & 954469 & 5.45 & 5.4935 & TRN & & \\
\hline CHEMBL191334 & 954469 & 4.9726 & 4.9361 & TRN & & \\
\hline CHEMBL188678 & 954469 & 4.4938 & 4.5597 & TRN & & \\
\hline CHEMBL483847 & 954469 & 4.457 & 4.6557 & TRN & & \\
\hline CHEMBL 1357247 & 954469 & 3.1629 & 3.2019 & TRN & & \\
\hline CHEMBL392695 & 954469 & 4.9933 & 5.0658 & TRN & & \\
\hline CHEMBL1404918 & 954469 & 3.8266 & 3.5588 & TRN & & \\
\hline CHEMBL 2134202 & 954469 & 3.7656 & 3.7446 & TRN & & \\
\hline CHEMBL577784 & 954469 & 5.9675 & 5.9331 & TRN & & \\
\hline CHEMBL102714 & 954469 & 3.8356 & 3.7877 & TRN & & \\
\hline CHEMBL3349342 & 954469 & 5.2679 & 5.1911 & TRN & & \\
\hline CHEMBL514499 & 954469 & 7.7605 & 7.6278 & TRN & & \\
\hline CHEMBL1673039 & 954469 & 5.3412 & 5.3036 & TRN & & \\
\hline CHEMBL 2005886 & 954469 & 6.5892 & 6.7158 & TRN & & \\
\hline CHEMBL3392440 & 954469 & 4.2118 & 4.2646 & TRN & & \\
\hline CHEMBL1590308 & 954469 & 4.3695 & 3.4422 & TST & & \\
\hline CHEMBL373751 & 954469 & 3.5236 & 3.7794 & TRN & & \\
\hline CHEMBL135561 & 954469 & 4.4535 & 4.9652 & TST & & \\
\hline CHEMBL1186585 & 954469 & 3.3735 & 4.1844 & TST & & \\
\hline CHEMBL192566 & 954469 & 9.3847 & 9.408 & TST & & \\
\hline CHEMBL217354 & 954469 & 6.7781 & 7.0287 & TST & & \\
\hline CHEMBL1516890 & 954469 & 4.524 & 4.6802 & TST & & \\
\hline CHEMBL449158 & 954469 & 6.7221 & 7.5213 & TST & & \\
\hline CHEMBL 221137 & 954469 & 5.7969 & 5.3357 & TST & & \\
\hline CHEMBL222102 & 954469 & 3.895 & 4.1305 & TST & & \\
\hline CHEMBL1970879 & 954469 & 5.1057 & 5.296 & TST & & \\
\hline CHEMBL202721 & 954469 & 4.7123 & 5.5905 & TST & & \\
\hline CHEMBL1242367 & 954469 & 5.0966 & 4.426 & TST & & \\
\hline CHEMBL373751 & 955086 & 3.4091 & 3.4141 & TRN & & \\
\hline CHEMBL514499 & 955086 & 7.0614 & 7.0196 & TRN & & \\
\hline CHEMBL483849 & 955086 & 3.0968 & 3.1539 & TRN & & \\
\hline CHEMBL192566 & 955086 & 6.5456 & 6.7797 & TST & & \\
\hline CHEMBL558642 & 955086 & 2.3666 & 2.7467 & TRN & & \\
\hline CHEMBL189584 & 955086 & 4.9395 & 4.9354 & TRN & & \\
\hline CHEMBL2144069 & 955086 & 4.0985 & 4.1985 & TRN & & \\
\hline CHEMBL379975 & 955086 & 4.9708 & 5.2059 & TRN & & \\
\hline CHEMBL1230020 & 955086 & 4.4202 & 4.0507 & TRN & & \\
\hline CHEMBL1516890 & 955086 & 3.8276 & 3.8088 & TRN & & \\
\hline CHEMBL1256459 & 955086 & 6.1848 & 6.4135 & TRN & & \\
\hline CHEMBL1404918 & 955086 & 3.03899 & 99999999 & 997 & 2.6851 & TRN \\
\hline CHEMBL65 & 955086 & 8.9252 & 8.7574 & TRN & & \\
\hline CHEMBL509032 & 955086 & 4.13 & 3.8117 & TRN & & \\
\hline CHEMBL3186408 & 955086 & 4.6393 & 3.3135 & TST & & \\
\hline CHEMBL191334 & 955086 & 3.8816 & 3.906 & TRN & & \\
\hline CHEMBL483847 & 955086 & 3.7167 & 3.9611 & TRN & & \\
\hline CHEMBL1788116 & 955086 & 3.7208 & 3.3991 & TRN & & \\
\hline
\end{tabular}

Page 25200 


\begin{tabular}{|c|c|c|c|c|c|}
\hline \multirow[b]{2}{*}{ CHEMBL1357247 } & \multicolumn{5}{|c|}{ Supplemental Table s2.txt } \\
\hline & 955086 & 2.2887 & 2.2056 & TRN & \\
\hline CHEMBL512504 & 955086 & 5.8942 & 5.7842 & TRN & \\
\hline CHEMBL577784 & 955086 & 5.5696 & 5.4437 & TRN & \\
\hline CHEMBL220241 & 955086 & 4.8434 & 4.8822 & TRN & \\
\hline CHEMBL300389 & 955086 & 5.4432 & 5.7563 & TRN & \\
\hline CHEMBL 2363137 & 955086 & 2.6484 & 2.7882 & TRN & \\
\hline CHEMBL573107 & 955086 & 4.8454 & 5.2336 & TRN & \\
\hline CHEMBL202721 & 955086 & 5.5177 & 5.6437 & TRN & \\
\hline CHEMBL180127 & 955086 & 4.2408 & 4.117 & TRN & \\
\hline CHEMBL1242367 & 955086 & 3.9071 & 3.5021 & TRN & \\
\hline CHEMBL258844 & 955086 & 3.1802 & 3.2372 & TRN & \\
\hline CHEMBL92309 & 955086 & 2.8112 & 2.4727 & TST & \\
\hline CHEMBL1643959 & 955086 & 2.6488 & 2.8215 & TRN & \\
\hline CHEMBL 2005886 & 955086 & 3.3266 & 3.2418 & TRN & \\
\hline CHEMBL210618 & 955086 & 3.1685 & 3.3611 & TRN & \\
\hline CHEMBL213100 & 955086 & 3.1421 & 3.4987 & TRN & \\
\hline CHEMBL1673039 & 955086 & 3.4479 & 3.7973 & TRN & \\
\hline CHEMBL135561 & 955086 & 3.6863 & 3.7677 & TRN & \\
\hline CHEMBL515416 & 955086 & 4.0155 & 4.012 & TRN & \\
\hline CHEMBL1190711 & 955086 & 4.6391 & 4.456 & TRN & \\
\hline CHEMBL472940 & 955086 & 2.9008 & 3.3142 & TRN & \\
\hline CHEMBL9470 & 955086 & 2.6992 & 4.7106 & TST & \\
\hline CHEMBL449158 & 955086 & 5.8879 & 6.16100 & 00000000005 & TST \\
\hline CHEMBL1970879 & 955086 & 4.0281 & 3.6336 & TRN & \\
\hline CHEMBL222102 & 955086 & 4.0783 & 4.2145 & TRN & \\
\hline CHEMBL393929 & 955086 & 3.6064 & 4.0028 & TRN & \\
\hline CHEMBL585951 & 955086 & 5.5799 & 5.2519 & TRN & \\
\hline CHEMBL392695 & 955086 & 5.4201 & 5.0169 & TRN & \\
\hline CHEMBL240954 & 955086 & 4.298 & 4.1467 & TST & \\
\hline CHEMBL102714 & 955086 & 3.5638 & 3.2424 & TRN & \\
\hline CHEMBL188678 & 955086 & 4.9651 & 4.9077 & TRN & \\
\hline CHEMBL412142 & 955086 & 3.0872 & 2.8699 & TRN & \\
\hline CHEMBL1909414 & 955086 & 4.558 & 4.3081 & TST & \\
\hline CHEMBL379300 & 955086 & 6.2488 & 5.4672 & TST & \\
\hline CHEMBL221137 & 955086 & 3.9413 & 3.95300 & 00000000003 & TST \\
\hline CHEMBL259181 & 955086 & 4.5733 & 3.4772 & TST & \\
\hline CHEMBL3349342 & 955086 & 4.0511 & 4.0647 & TST & \\
\hline CHEMBL3392440 & 955086 & 3.3481 & 3.3534 & TST & \\
\hline CHEMBL209148 & 955086 & 2.8059 & 3.8432 & TST & \\
\hline CHEMBL3199475 & 955086 & 3.3648 & 4.1033 & TST & \\
\hline CHEMBL1590308 & 955086 & 2.432 & 3.1176 & TST & \\
\hline CHEMBL 2449003 & 688259 & 5.85 & 7.3489 & TRN & \\
\hline CHEMBL34730 & 688259 & 10.25 & 7.2263 & TRN & \\
\hline CHEMBL1256484 & 688259 & 4.85 & 5.2095 & TRN & \\
\hline CHEMBL296586 & 688259 & 4.25 & 4.7543 & TRN & \\
\hline CHEMBL1256761 & 688259 & 4.35 & 6.1433 & TRN & \\
\hline CHEMBL1255662 & 688259 & 9.0 & 6.9968 & TRN & \\
\hline CHEMBL1256646 & 688259 & 4.45 & 5.1756 & TRN & \\
\hline
\end{tabular}




\begin{tabular}{|c|c|c|c|c|c|}
\hline \multicolumn{6}{|c|}{ Supplemental Table S2.txt } \\
\hline CHEMBL1082832 & 688259 & 5.1 & 6.6327 & TRN & \\
\hline CHEMBL26320 & 688259 & 4.25 & 6.7446 & TRN & \\
\hline CHEMBL1414452 & 688259 & 4.45 & 5.0843 & TST & \\
\hline CHEMBL1256647 & 688259 & 7.15 & 7.5592 & TRN & \\
\hline CHEMBL1161461 & 688259 & 6.5501 & 7.2797 & TRN & \\
\hline CHEMBL334378 & 688259 & 4.4 & 5.0898 & TRN & \\
\hline CHEMBL1330357 & 688259 & 4.55 & 6.2693 & TRN & \\
\hline CHEMBL275311 & 688259 & 4.4 & 6.2385 & TRN & \\
\hline CHEMBL576349 & 688259 & 4.8 & 5.7972 & TRN & \\
\hline CHEMBL1255660 & 688259 & 6.0 & 6.67700 & 00000000005 & TRN \\
\hline CHEMBL1531754 & 688259 & 6.25 & 6.9672 & TRN & \\
\hline CHEMBL1320310 & 688259 & 5.8 & 6.4214 & TRN & \\
\hline CHEMBL2373666 & 688259 & 8.5528 & 7.75299 & 9999999999 & TRN \\
\hline CHEMBL18238 & 688259 & 7.15 & 7.1597 & TRN & \\
\hline CHEMBL68534 & 688259 & 4.95 & 4.1981 & TRN & \\
\hline CHEMBL1256576 & 688259 & 7.0 & 6.6711 & TRN & \\
\hline CHEMBL153036 & 688259 & 9.301 & 6.5155 & TRN & \\
\hline CHEMBL484928 & 688259 & 7.4498 & 6.4734 & TRN & \\
\hline CHEMBL77030 & 688259 & 4.9 & 3.4634 & TRN & \\
\hline CHEMBL1256813 & 688259 & 4.55 & 6.1762 & TRN & \\
\hline CHEMBL1331957 & 688259 & 6.45 & 7.2142 & TRN & \\
\hline CHEMBL351042 & 688259 & 4.55 & 5.4315 & TRN & \\
\hline CHEMBL137743 & 688259 & 6.0 & 5.49299 & 9999999999 & TRN \\
\hline CHEMBL47940 & 688259 & 4.65 & 6.1439 & TRN & \\
\hline CHEMBL263972 & 688259 & 5.4 & 5.9311 & TRN & \\
\hline CHEMBL1256573 & 688259 & 10.3 & 6.4794 & TRN & \\
\hline CHEMBL1255578 & 688259 & 8.5528 & 6.8109 & TRN & \\
\hline CHEMBL402468 & 688259 & 4.3 & 6.2989 & TRN & \\
\hline CHEMBL121915 & 688259 & 9.0 & 7.07100 & 0000000001 & TRN \\
\hline CHEMBL 8145 & 688259 & 6.3 & 5.0314 & TRN & \\
\hline CHEMBL1440857 & 688259 & 4.5 & 5.6023 & TRN & \\
\hline CHEMBL338790 & 688259 & 4.55 & 5.5228 & TRN & \\
\hline CHEMBL1527722 & 688259 & 7.699 & 6.8026 & TRN & \\
\hline CHEMBL500996 & 688259 & 4.75 & 6.9744 & TRN & \\
\hline CHEMBL66105 & 688259 & 4.8 & 6.2725 & TRN & \\
\hline CHEMBL79824 & 688259 & 8.4949 & 6.7356 & TST & \\
\hline CHEMBL604119 & 688259 & 5.5 & 5.84 & TRN & \\
\hline CHEMBL1526852 & 688259 & 9.0969 & 6.6306 & TRN & \\
\hline CHEMBL1355634 & 688259 & 7.15 & 7.6973 & TRN & \\
\hline CHEMBL10247 & 688259 & 5.55 & 6.8219 & TRN & \\
\hline CHEMBL45244 & 688259 & 9.0969 & 7.1387 & TRN & \\
\hline CHEMBL1255657 & 688259 & 4.9 & 6.9419 & TRN & \\
\hline CHEMBL310798 & 688259 & 4.65 & 4.237 & TRN & \\
\hline CHEMBL433238 & 688259 & 7.8013 & 7.3178 & TRN & \\
\hline CHEMBL570383 & 688259 & 4.75 & 6.6002 & TRN & \\
\hline CHEMBL1255758 & 688259 & 6.9 & 6.0875 & TST & \\
\hline CHEMBL1426948 & 688259 & 8.5528 & 6.4161 & TRN & \\
\hline CHEMBL56731 & 688259 & 4.65 & 3.7637 & TRN & \\
\hline
\end{tabular}




\begin{tabular}{|c|c|c|c|c|c|}
\hline \multicolumn{6}{|c|}{ Supplemental Table S2.txt } \\
\hline CHEMBL1256147 & 688259 & 6.8 & 6.7314 & TRN & \\
\hline CHEMBL1412842 & 688259 & 8.4949 & 7.2216 & TRN & \\
\hline CHEMBL1435381 & 688259 & 4.45 & 5.6405 & TRN & \\
\hline CHEMBL2374058 & 688259 & 4.7 & 5.343 & TST & \\
\hline CHEMBL1256186 & 688259 & 6.45 & 6.7348 & TRN & \\
\hline CHEMBL1590552 & 688259 & 8.5528 & 7.0945 & TRN & \\
\hline CHEMBL109037 & 688259 & 5.5 & 6.1135 & TRN & \\
\hline CHEMBL544115 & 688259 & 4.75 & 5.44799 & 99999999995 & TRN \\
\hline CHEMBL578741 & 688259 & 4.65 & 4.9326 & TRN & \\
\hline CHEMBL441282 & 688259 & 4.7 & 6.0413 & TRN & \\
\hline CHEMBL1256839 & 688259 & 8.7959 & 7.4928 & TRN & \\
\hline CHEMBL1626274 & 688259 & 3.95 & 6.5851 & TRN & \\
\hline CHEMBL1256663 & 688259 & 8.2007 & 7.5523 & TRN & \\
\hline CHEMBL1603820 & 688259 & 4.75 & 7.8014 & TRN & \\
\hline CHEMBL326958 & 688259 & 9.0969 & 6.9967 & TRN & \\
\hline CHEMBL1608298 & 688259 & 4.9 & 7.0283 & TRN & \\
\hline CHEMBL1434513 & 688259 & 4.45 & 4.987 & TRN & \\
\hline CHEMBL10347 & 688259 & 4.7 & 6.1394 & TRN & \\
\hline CHEMBL1256740 & 688259 & 9.3979 & 6.481 & TRN & \\
\hline CHEMBL192566 & 688259 & 4.9 & 4.1838 & TST & \\
\hline CHEMBL431504 & 688259 & 6.0 & 7.3263 & TRN & \\
\hline CHEMBL85139 & 688259 & 4.7 & 5.5581 & TRN & \\
\hline CHEMBL1256865 & 688259 & 4.8 & 6.9084 & TRN & \\
\hline CHEMBL1490919 & 688259 & 4.95 & 5.2654 & TST & \\
\hline CHEMBL39879 & 688259 & 7.8508 & 5.9027 & TRN & \\
\hline CHEMBL1256875 & 688259 & 8.9586 & 7.0064 & TRN & \\
\hline CHEMBL1442153 & 688259 & 6.5 & 7.034 & TRN & \\
\hline CHEMBL 2448607 & 688259 & 7.1002 & 7.2642 & TRN & \\
\hline CHEMBL433461 & 688259 & 3.95 & 5.6881 & TST & \\
\hline CHEMBL10284 & 688259 & 4.6 & 5.9353 & TRN & \\
\hline CHEMBL274619 & 688259 & 4.7 & 6.3496 & TRN & \\
\hline CHEMBL153057 & 688259 & 4.3 & 6.5684 & TRN & \\
\hline CHEMBL1590980 & 688259 & 8.4949 & 6.885 & TRN & \\
\hline CHEMBL110739 & 688259 & 4.05 & 6.2901 & TRN & \\
\hline CHEMBL507122 & 688259 & 3.4 & 5.9601 & TST & \\
\hline CHEMBL1256772 & 688259 & 8.0 & 7.8024 & TRN & \\
\hline CHEMBL161343 & 688259 & 5.55 & 6.4501 & TRN & \\
\hline CHEMBL1256511 & 688259 & 8.5528 & 7.2077 & TRN & \\
\hline CHEMBL2374062 & 688259 & 6.7501 & 5.7476 & TRN & \\
\hline CHEMBL1436882 & 688259 & 8.0 & 6.5088 & TRN & \\
\hline CHEMBL1554717 & 688259 & 4.25 & 6.8532 & TRN & \\
\hline CHEMBL47529 & 688259 & 8.9586 & 6.4753 & TRN & \\
\hline CHEMBL394171 & 688259 & 9.5229 & 7.018 & TRN & \\
\hline CHEMBL 78150 & 688259 & 4.6 & 4.566 & TRN & \\
\hline CHEMBL 260374 & 688259 & 9.2218 & 7.3227 & TST & \\
\hline CHEMBL1461491 & 688259 & 8.2518 & 5.9882 & TRN & \\
\hline CHEMBL1323714 & 688259 & 6.9 & 5.9445 & TST & \\
\hline CHEMBL1255934 & 688259 & 8.2007 & 5.9857 & TST & \\
\hline
\end{tabular}




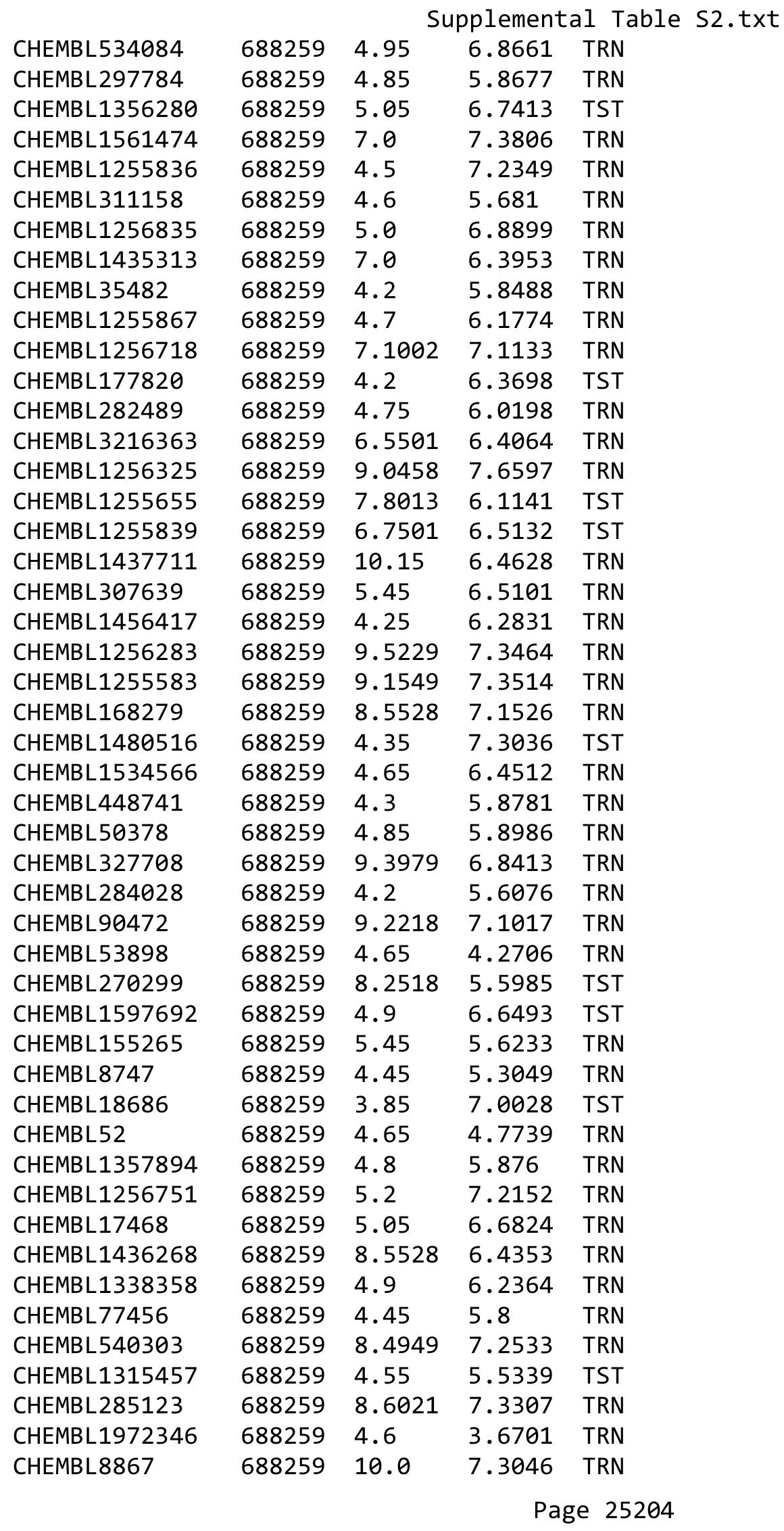




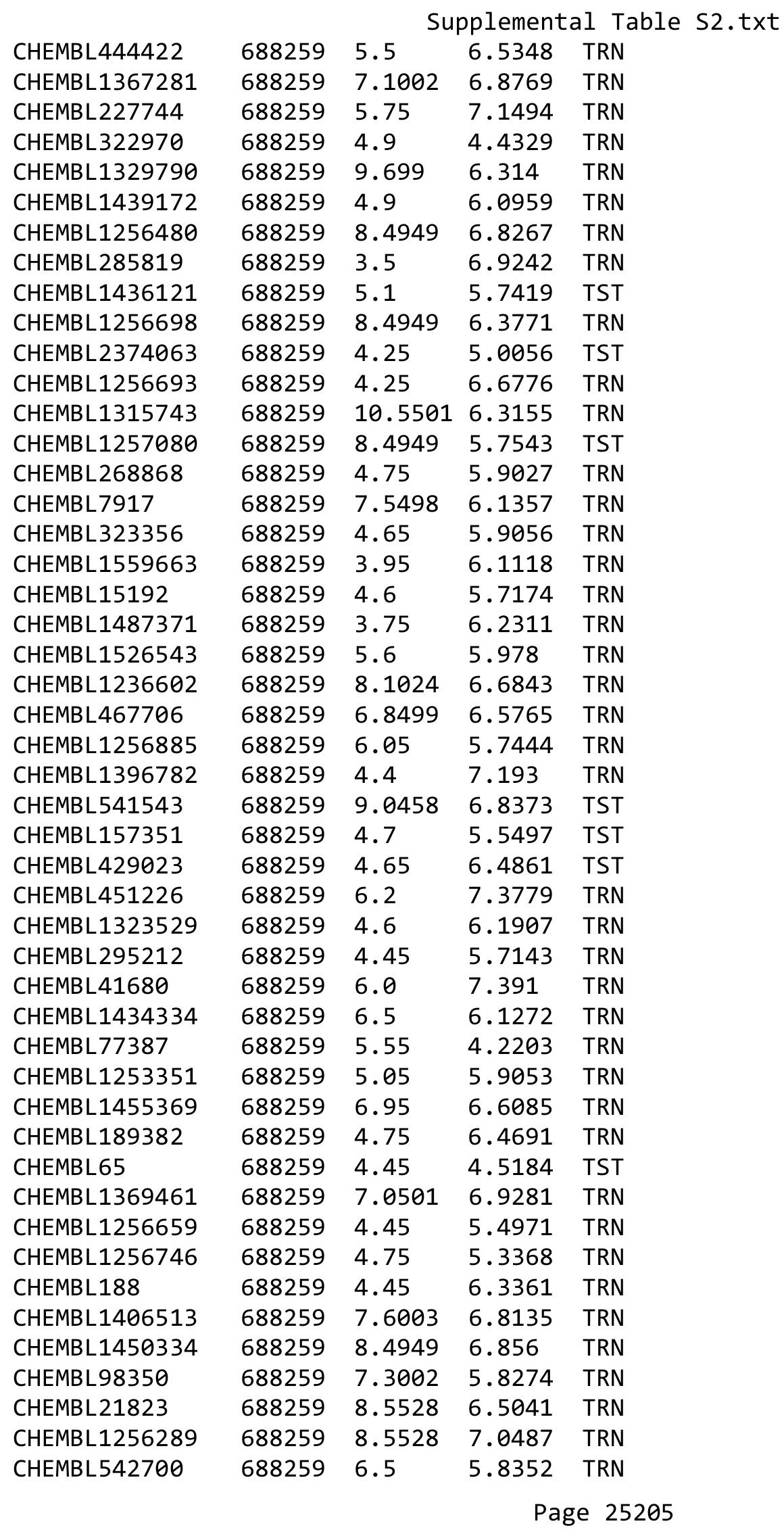




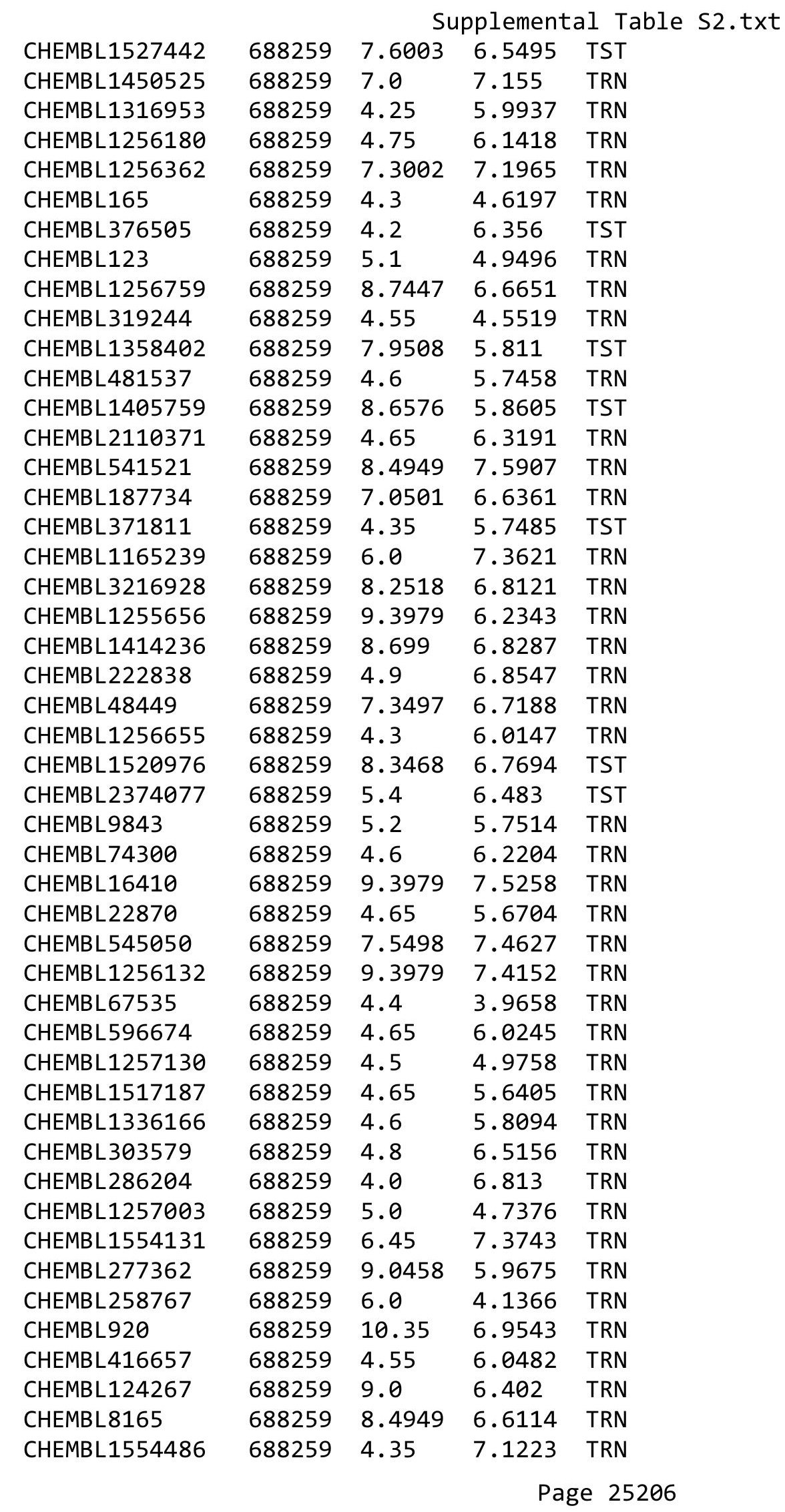




\begin{tabular}{|c|c|c|c|c|c|}
\hline \multicolumn{6}{|c|}{ Supplemental Table S2.txt } \\
\hline CHEMBL 294590 & 688259 & 3.65 & 6.7939 & TRN & \\
\hline CHEMBL68500 & 688259 & 3.8 & 5.4479 & TRN & \\
\hline CHEMBL1173475 & 688259 & 4.55 & 4.0191 & TRN & \\
\hline CHEMBL1357401 & 688259 & 9.0458 & 6.5398 & TRN & \\
\hline CHEMBL1480136 & 688259 & 9.3979 & 6.8821 & TRN & \\
\hline CHEMBL321691 & 688259 & 8.5528 & 6.9751 & TRN & \\
\hline CHEMBL72631 & 688259 & 4.35 & 7.1014 & TRN & \\
\hline CHEMBL66 & 688259 & 5.35 & 4.6326 & TRN & \\
\hline CHEMBL1453208 & 688259 & 4.35 & 5.5145 & TRN & \\
\hline CHEMBL269733 & 688259 & 4.55 & 4.9446 & TRN & \\
\hline CHEMBL540294 & 688259 & 4.9 & 6.1177 & TRN & \\
\hline CHEMBL1256623 & 688259 & 5.2 & 4.665 & TRN & \\
\hline CHEMBL1316314 & 688259 & 3.85 & \multicolumn{2}{|c|}{5.9639999999999995} & TRN \\
\hline CHEMBL1398537 & 688259 & 4.35 & 6.5967 & TRN & \\
\hline CHEMBL1255966 & 688259 & 9.0969 & 6.6064 & TRN & \\
\hline CHEMBL 276727 & 688259 & 6.2 & 7.053 & TRN & \\
\hline CHEMBL80155 & 688259 & 4.6 & 4.9978 & TRN & \\
\hline CHEMBL1255837 & 688259 & 4.35 & 6.8562 & TST & \\
\hline CHEMBL1062 & 688259 & 5.3 & 6.1837 & TRN & \\
\hline CHEMBL60518 & 688259 & 4.65 & 6.0968 & TRN & \\
\hline CHEMBL1378659 & 688259 & 5.2 & 5.6485 & TRN & \\
\hline CHEMBL553503 & 688259 & 4.25 & 5.5264 & TRN & \\
\hline CHEMBL 28862 & 688259 & 5.35 & 7.0821 & TRN & \\
\hline CHEMBL402063 & 688259 & 4.05 & 5.7201 & TRN & \\
\hline CHEMBL88584 & 688259 & 8.5528 & 6.2052 & TRN & \\
\hline CHEMBL605003 & 688259 & 6.05 & 5.0402 & TRN & \\
\hline CHEMBL23832 & 688259 & 10.0 & 6.7176 & TRN & \\
\hline CHEMBL1255653 & 688259 & 8.6576 & 6.5102 & TST & \\
\hline CHEMBL6634 & 688259 & 6.95 & 7.4807 & TRN & \\
\hline CHEMBL399043 & 688259 & 6.5 & 5.2174 & TST & \\
\hline CHEMBL 247378 & 688259 & 8.8539 & 6.0737 & TRN & \\
\hline CHEMBL539947 & 688259 & 4.75 & 4.6161 & TRN & \\
\hline CHEMBL336467 & 688259 & 4.7 & 5.9584 & TST & \\
\hline CHEMBL 328710 & 688259 & 4.65 & 4.6103 & TRN & \\
\hline CHEMBL1596271 & 688259 & 5.1 & 5.6489 & TRN & \\
\hline CHEMBL1354492 & 688259 & 4.8 & 6.9952 & TRN & \\
\hline CHEMBL1256191 & 688259 & 9.0458 & 5.3983 & TRN & \\
\hline CHEMBL 8211 & 688259 & 3.75 & 6.9267 & TST & \\
\hline CHEMBL1256878 & 688259 & 4.55 & 6.0995 & TRN & \\
\hline CHEMBL56 & 688259 & 6.6499 & 6.7516 & TRN & \\
\hline CHEMBL1256131 & 688259 & 8.5528 & 6.9656 & TRN & \\
\hline CHEMBL1256866 & 688259 & 6.0 & 7.1046 & TRN & \\
\hline CHEMBL280065 & 688259 & 4.7 & 5.9553 & TRN & \\
\hline CHEMBL 282038 & 688259 & 4.8 & 6.7212 & TRN & \\
\hline CHEMBL 280998 & 688259 & 4.35 & 5.5083 & TRN & \\
\hline CHEMBL1284 & 688259 & 5.2 & 5.6245 & TRN & \\
\hline CHEMBL1256916 & 688259 & 6.05 & \multicolumn{2}{|c|}{6.832000000000001} & TRN \\
\hline \multirow[t]{2}{*}{ CHEMBL16081 } & 688259 & 8.9586 & 7.2198 & TRN & \\
\hline & & & & 25207 & \\
\hline
\end{tabular}




\begin{tabular}{|c|c|c|c|c|c|}
\hline & & \multicolumn{4}{|c|}{ Supplemental Table S2.txt } \\
\hline CHEMBL1608159 & 688259 & 8.9586 & 7.0296 & TRN & \\
\hline CHEMBL1256911 & 688259 & 4.75 & 5.8412 & TRN & \\
\hline CHEMBL56393 & 688259 & 5.05 & 3.8168 & TRN & \\
\hline CHEMBL1457622 & 688259 & 7.4498 & 7.0673 & TRN & \\
\hline CHEMBL434063 & 688259 & 6.35 & 6.2687 & TRN & \\
\hline CHEMBL180427 & 688259 & 8.4949 & 5.9866 & TRN & \\
\hline CHEMBL 275938 & 688259 & 6.1 & 5.2515 & TRN & \\
\hline CHEMBL1224512 & 688259 & 5.35 & 3.7871 & TRN & \\
\hline CHEMBL20936 & 688259 & 7.0501 & 6.8701 & TRN & \\
\hline CHEMBL1255841 & 688259 & 9.699 & 7.3182 & TRN & \\
\hline CHEMBL33171 & 688259 & 8.3468 & 6.2581 & TRN & \\
\hline CHEMBL1600325 & 688259 & 8.4949 & 7.0901 & TRN & \\
\hline CHEMBL1590378 & 688259 & 4.65 & 6.04299 & 9999999999 & TRN \\
\hline CHEMBL1255647 & 688259 & 4.65 & 5.6856 & TRN & \\
\hline CHEMBL34704 & 688259 & 8.2518 & 5.8273 & TST & \\
\hline CHEMBL 7634 & 688259 & 7.6003 & 6.4972 & TST & \\
\hline CHEMBL1413371 & 688259 & 4.05 & 5.7449 & TST & \\
\hline CHEMBL1371781 & 688259 & 4.55 & 6.3027 & TRN & \\
\hline CHEMBL1256625 & 688259 & 8.4949 & 6.2482 & TRN & \\
\hline CHEMBL17331 & 688259 & 4.7 & 5.5948 & TRN & \\
\hline CHEMBL289277 & 688259 & 5.45 & 5.2891 & TRN & \\
\hline CHEMBL536950 & 688259 & 7.6003 & 6.3753 & TRN & \\
\hline CHEMBL1372997 & 688259 & 4.95 & 6.8269 & TRN & \\
\hline CHEMBL355496 & 688259 & 5.15 & 4.4585 & TRN & \\
\hline CHEMBL1591158 & 688259 & 5.6 & 6.8979 & TRN & \\
\hline CHEMBL1394801 & 688259 & 8.6021 & 7.0862 & TRN & \\
\hline CHEMBL164 & 688259 & 4.85 & 4.6286 & TRN & \\
\hline CHEMBL93655 & 688259 & 4.7 & 6.7112 & TRN & \\
\hline CHEMBL876 & 688259 & 8.3979 & 6.5123 & TRN & \\
\hline CHEMBL574181 & 688259 & 4.6 & 6.5946 & TRN & \\
\hline CHEMBL313938 & 688259 & 6.2 & 6.1996 & TRN & \\
\hline CHEMBL311389 & 688259 & 7.7496 & 5.9511 & TRN & \\
\hline CHEMBL1556654 & 688259 & 8.5528 & 6.7682 & TST & \\
\hline CHEMBL29726 & 688259 & 9.699 & 6.7095 & TRN & \\
\hline CHEMBL67378 & 688259 & 6.9 & 6.7575 & TRN & \\
\hline CHEMBL1318512 & 688259 & 9.0458 & 7.4753 & TRN & \\
\hline CHEMBL 26138 & 688259 & 4.85 & 5.6101 & TRN & \\
\hline CHEMBL1322478 & 688259 & 9.301 & 5.8564 & TRN & \\
\hline CHEMBL111545 & 688259 & 4.8 & 6.2179 & TRN & \\
\hline CHEMBL1256687 & 688259 & 4.7 & 6.7193 & TRN & \\
\hline CHEMBL11608 & 688259 & 6.45 & 6.0557 & TRN & \\
\hline CHEMBL1365553 & 688259 & 5.2 & 4.2676 & TRN & \\
\hline CHEMBL 258893 & 688259 & 5.5 & 6.1449 & TRN & \\
\hline CHEMBL97760 & 688259 & 7.9508 & 5.1426 & TRN & \\
\hline CHEMBL1399702 & 688259 & 8.9586 & 6.9653 & TRN & \\
\hline CHEMBL 267373 & 688259 & 8.5528 & 6.8046 & TRN & \\
\hline CHEMBL 72365 & 688259 & 4.35 & 4.3367 & TRN & \\
\hline CHEMBL1158 & 688259 & 6.2 & 6.9056 & TRN & \\
\hline
\end{tabular}




\begin{tabular}{|c|c|c|c|c|c|}
\hline \multicolumn{6}{|c|}{ Supplemental Table S2.txt } \\
\hline CHEMBL429095 & 688259 & 4.55 & 6.0659 & TRN & \\
\hline CHEMBL63329 & 688259 & 5.0 & 6.3013 & TST & \\
\hline CHEMBL12014 & 688259 & 4.7 & 5.4196 & TRN & \\
\hline CHEMBL418509 & 688259 & 7.8996 & 7.3356 & TRN & \\
\hline CHEMBL331372 & 688259 & 9.2218 & 7.0522 & TRN & \\
\hline CHEMBL164747 & 688259 & 7.5498 & 6.1224 & TRN & \\
\hline CHEMBL33103 & 688259 & 8.4949 & 6.2155 & TRN & \\
\hline CHEMBL28626 & 688259 & 4.7 & 4.5531 & TRN & \\
\hline CHEMBL310578 & 688259 & 9.1549 & 7.7501 & TST & \\
\hline CHEMBL 1256719 & 688259 & 4.65 & 6.6736 & TRN & \\
\hline CHEMBL261642 & 688259 & 8.301 & 6.9358 & TRN & \\
\hline CHEMBL1256943 & 688259 & 9.0969 & 7.1042 & TRN & \\
\hline CHEMBL299052 & 688259 & 5.9 & 6.9667 & TRN & \\
\hline CHEMBL1320902 & 688259 & 5.25 & 4.8238 & TRN & \\
\hline CHEMBL1256959 & 688259 & 9.3979 & 6.1018 & TRN & \\
\hline CHEMBL478 & 688259 & 9.3979 & 6.6288 & TRN & \\
\hline CHEMBL309176 & 688259 & 8.5528 & 7.6517 & TRN & \\
\hline CHEMBL1256019 & 688259 & 4.95 & 7.4747 & TRN & \\
\hline CHEMBL 66654 & 688259 & 10.1 & 6.4858 & TRN & \\
\hline CHEMBL1208858 & 688259 & 4.55 & 5.5068 & TST & \\
\hline CHEMBL1395737 & 688259 & 8.301 & 6.8528 & TRN & \\
\hline CHEMBL 8320 & 688259 & 8.7959 & 6.5596 & TST & \\
\hline CHEMBL275854 & 688259 & 8.699 & 6.2138 & TRN & \\
\hline CHEMBL397209 & 688259 & 7.8508 & 6.6462 & TRN & \\
\hline CHEMBL1506225 & 688259 & 4.6 & 6.7862 & TRN & \\
\hline CHEMBL26915 & 688259 & 4.55 & 6.3182 & TRN & \\
\hline CHEMBL316966 & 688259 & 8.4559 & 6.8677 & TRN & \\
\hline CHEMBL391997 & 688259 & 4.7 & 6.00200 & 0000000001 & TRN \\
\hline CHEMBL299613 & 688259 & 8.1487 & 6.1982 & TRN & \\
\hline CHEMBL30432 & 688259 & 5.95 & 5.5319 & TRN & \\
\hline CHEMBL1528565 & 688259 & 9.699 & 5.5299 & TST & \\
\hline CHEMBL 299683 & 688259 & 6.45 & 7.1191 & TRN & \\
\hline CHEMBL 288174 & 688259 & 4.6 & 5.7006 & TST & \\
\hline CHEMBL1335406 & 688259 & 5.8 & 6.1555 & TST & \\
\hline CHEMBL407874 & 688259 & 7.8013 & 6.4571 & TRN & \\
\hline CHEMBL602375 & 688259 & 4.9 & 5.9797 & TST & \\
\hline CHEMBL 1256851 & 688259 & 4.6 & 5.9653 & TRN & \\
\hline CHEMBL1256667 & 688259 & 4.2 & 6.1538 & TST & \\
\hline CHEMBL 28449 & 688259 & 5.5 & 7.3677 & TRN & \\
\hline CHEMBL1256177 & 688259 & 4.6 & 7.1114 & TRN & \\
\hline CHEMBL1408519 & 688259 & 6.5501 & 7.0207 & TRN & \\
\hline CHEMBL 21241 & 688259 & 4.55 & 7.2513 & TST & \\
\hline CHEMBL70880 & 688259 & 6.3 & 6.0678 & TRN & \\
\hline CHEMBL1096400 & 688259 & 9.0458 & 7.3905 & TRN & \\
\hline CHEMBL293749 & 688259 & 4.5 & 4.4936 & TRN & \\
\hline CHEMBL479014 & 688259 & 7.8996 & 6.1025 & TRN & \\
\hline CHEMBL 1256844 & 688259 & 8.3979 & 6.9134 & TRN & \\
\hline CHEMBL126077 & 688259 & 4.4 & 4.5865 & TRN & \\
\hline
\end{tabular}




\begin{tabular}{|c|c|c|c|c|c|}
\hline \multicolumn{6}{|c|}{ Supplemental Table S2.txt } \\
\hline CHEMBL77971 & 688259 & 5.8 & 5.9847 & TRN & \\
\hline CHEMBL18132 & 688259 & 4.3 & 5.7213 & TRN & \\
\hline CHEMBL408982 & 688259 & 8.4949 & 6.4027 & TRN & \\
\hline CHEMBL313833 & 688259 & 4.6 & 6.7884 & TRN & \\
\hline CHEMBL 1335356 & 688259 & 4.65 & 6.9814 & TST & \\
\hline CHEMBL288096 & 688259 & 4.7 & 5.6014 & TRN & \\
\hline CHEMBL14276 & 688259 & 4.35 & 6.1442 & TRN & \\
\hline CHEMBL538595 & 688259 & 8.4949 & 6.6868 & TRN & \\
\hline CHEMBL252909 & 688259 & 8.6576 & 7.0662 & TRN & \\
\hline CHEMBL1556000 & 688259 & 8.4949 & 6.9532 & TST & \\
\hline CHEMBL58033 & 688259 & 4.7 & 7.17299 & 9999999999 & TRN \\
\hline CHEMBL1180496 & 688259 & 8.5528 & 7.4151 & TRN & \\
\hline CHEMBL1255940 & 688259 & 5.7 & 6.3775 & TRN & \\
\hline CHEMBL76904 & 688259 & 4.4 & 3.3767 & TRN & \\
\hline CHEMBL274438 & 688259 & 4.65 & 6.5718 & TRN & \\
\hline CHEMBL 86676 & 688259 & 4.35 & 6.0537 & TST & \\
\hline CHEMBL40998 & 688259 & 6.05 & 6.12700 & 0000000001 & TRN \\
\hline CHEMBL216504 & 688259 & 5.6 & 5.813 & TRN & \\
\hline CHEMBL1553428 & 688259 & 5.05 & 7.1535 & TRN & \\
\hline CHEMBL1255733 & 688259 & 8.5528 & 5.9975 & TST & \\
\hline CHEMBL60718 & 688259 & 4.3 & 6.6368 & TRN & \\
\hline CHEMBL182461 & 688259 & 4.35 & 7.1195 & TRN & \\
\hline CHEMBL8151 & 688259 & 8.9586 & 6.8147 & TST & \\
\hline CHEMBL 24983 & 688259 & 7.0 & 5.6093 & TRN & \\
\hline CHEMBL441618 & 688259 & 4.35 & 6.2228 & TRN & \\
\hline CHEMBL1437846 & 688259 & 5.85 & 5.4438 & TRN & \\
\hline CHEMBL113180 & 688259 & 8.6021 & 6.6045 & TRN & \\
\hline CHEMBL1256776 & 688259 & 4.7 & 6.9977 & TRN & \\
\hline CHEMBL1523894 & 688259 & 9.3979 & 6.3291 & TST & \\
\hline CHEMBL1256716 & 688259 & 7.8996 & 7.1919 & TRN & \\
\hline CHEMBL107514 & 688259 & 7.8013 & 5.9258 & TRN & \\
\hline CHEMBL1491258 & 688259 & 4.85 & 5.6273 & TRN & \\
\hline CHEMBL1373007 & 688259 & 5.25 & 5.3345 & TRN & \\
\hline CHEMBL1256924 & 688259 & 8.4559 & 7.9064 & TRN & \\
\hline CHEMBL 76589 & 688259 & 4.85 & 4.8595 & TRN & \\
\hline CHEMBL13790 & 688259 & 4.7 & 6.0799 & TRN & \\
\hline CHEMBL1255659 & 688259 & 4.3 & 5.2813 & TRN & \\
\hline CHEMBL64239 & 688259 & 6.4 & 6.7451 & TRN & \\
\hline CHEMBL 275516 & 688259 & 4.2 & 7.2359 & TRN & \\
\hline CHEMBL47814 & 688259 & 9.3979 & 7.1254 & TRN & \\
\hline CHEMBL1520394 & 688259 & 6.25 & 6.1031 & TRN & \\
\hline CHEMBL 24510 & 688259 & 8.4949 & 7.2154 & TRN & \\
\hline CHEMBL1255755 & 688259 & 4.9 & 4.8546 & TRN & \\
\hline CHEMBL1355762 & 688259 & 4.7 & 6.1429 & TRN & \\
\hline CHEMBL1256364 & 688259 & 8.4559 & 6.2241 & TRN & \\
\hline CHEMBL286077 & 688259 & 6.25 & 6.7404 & TRN & \\
\hline CHEMBL1231330 & 688259 & 7.5498 & 7.1846 & TRN & \\
\hline CHEMBL1256797 & 688259 & 4.95 & 6.641 & TRN & \\
\hline
\end{tabular}




\begin{tabular}{|c|c|c|c|c|}
\hline \multicolumn{5}{|c|}{ Supplemental Table S2.txt } \\
\hline CHEMBL1376723 & 688259 & 5.8 & 4.5582 & TRN \\
\hline CHEMBL1607062 & 688259 & 6.5501 & 6.5222 & TST \\
\hline CHEMBL1256836 & 688259 & 4.1 & 5.5921 & TRN \\
\hline CHEMBL1554098 & 688259 & 4.0 & 5.6071 & TRN \\
\hline CHEMBL1366616 & 688259 & 4.7 & 5.7125 & TRN \\
\hline CHEMBL 302783 & 688259 & 8.301 & 6.8441 & TRN \\
\hline CHEMBL1451377 & 688259 & 8.0 & 5.857 & TST \\
\hline CHEMBL338314 & 688259 & 5.0 & 5.4004 & TRN \\
\hline CHEMBL464859 & 688259 & 9.0969 & 7.3372 & TRN \\
\hline CHEMBL129795 & 688259 & 4.3 & 4.6488 & TRN \\
\hline CHEMBL1554479 & 688259 & 6.5 & 6.8319 & TRN \\
\hline CHEMBL1092473 & 688259 & 5.6 & 6.3413 & TST \\
\hline CHEMBL50267 & 688259 & 8.5528 & 5.8548 & TRN \\
\hline CHEMBL1448979 & 688259 & 4.9 & 5.7592 & TST \\
\hline CHEMBL 286722 & 688259 & 9.3979 & 6.5894 & TRN \\
\hline CHEMBL1256910 & 688259 & 4.1 & 6.7833 & TST \\
\hline CHEMBL1255936 & 688259 & 4.85 & 6.3761 & TST \\
\hline CHEMBL1256396 & 688259 & 4.9 & 6.402 & TST \\
\hline CHEMBL1329033 & 688259 & 4.6 & \multicolumn{2}{|c|}{5.236000000000001} \\
\hline CHEMBL1493117 & 688259 & 8.4949 & 6.1211 & TST \\
\hline CHEMBL 20730 & 688259 & 8.5528 & 7.2213 & TST \\
\hline CHEMBL1257014 & 688259 & 7.6498 & 7.2614 & TST \\
\hline CHEMBL1585944 & 688259 & 7.2503 & 5.8669 & TST \\
\hline CHEMBL56543 & 688259 & 4.6 & 4.1954 & TST \\
\hline CHEMBL1354914 & 688259 & 8.4949 & 6.3144 & TST \\
\hline CHEMBL1319469 & 688259 & 7.0 & 6.8834 & TST \\
\hline CHEMBL45281 & 688259 & 5.4 & \multicolumn{2}{|c|}{6.1579999999999995} \\
\hline CHEMBL1255650 & 688259 & 8.5528 & 6.2777 & TST \\
\hline CHEMBL1491340 & 688259 & 7.7496 & 6.4217 & TST \\
\hline CHEMBL 36028 & 688259 & 8.5528 & 5.9107 & TST \\
\hline CHEMBL1256181 & 688259 & 8.5528 & 6.8865 & TST \\
\hline CHEMBL45245 & 688259 & 4.55 & \multicolumn{2}{|c|}{5.412000000000001} \\
\hline CHEMBL1256984 & 688259 & 4.55 & 5.7551 & TST \\
\hline CHEMBL 278332 & 688259 & 6.7001 & 7.0165 & TST \\
\hline CHEMBL1555810 & 688259 & 4.55 & 6.7862 & TST \\
\hline CHEMBL1531863 & 688259 & 2.2 & 7.1406 & TST \\
\hline CHEMBL88621 & 688259 & 6.25 & 7.4611 & TST \\
\hline CHEMBL250711 & 688259 & 4.7 & 4.5435 & TST \\
\hline CHEMBL 384903 & 688259 & 4.4 & 5.0443 & TST \\
\hline CHEMBL362863 & 688259 & 8.4949 & 6.7478 & TST \\
\hline CHEMBL62350 & 688259 & 6.5501 & 6.4093 & TST \\
\hline CHEMBL1256291 & 688259 & 4.65 & 5.3977 & TST \\
\hline CHEMBL34241 & 688259 & 4.5 & 5.1849 & TST \\
\hline CHEMBL559612 & 688259 & 4.55 & 5.336 & TST \\
\hline CHEMBL1394945 & 688259 & 8.0506 & 6.7544 & TST \\
\hline CHEMBL1257106 & 688259 & 6.6 & 7.5963 & TST \\
\hline CHEMBL432608 & 688259 & 8.4949 & 6.2868 & TST \\
\hline CHEMBL26318 & 688259 & 8.6021 & 6.8813 & TST \\
\hline
\end{tabular}




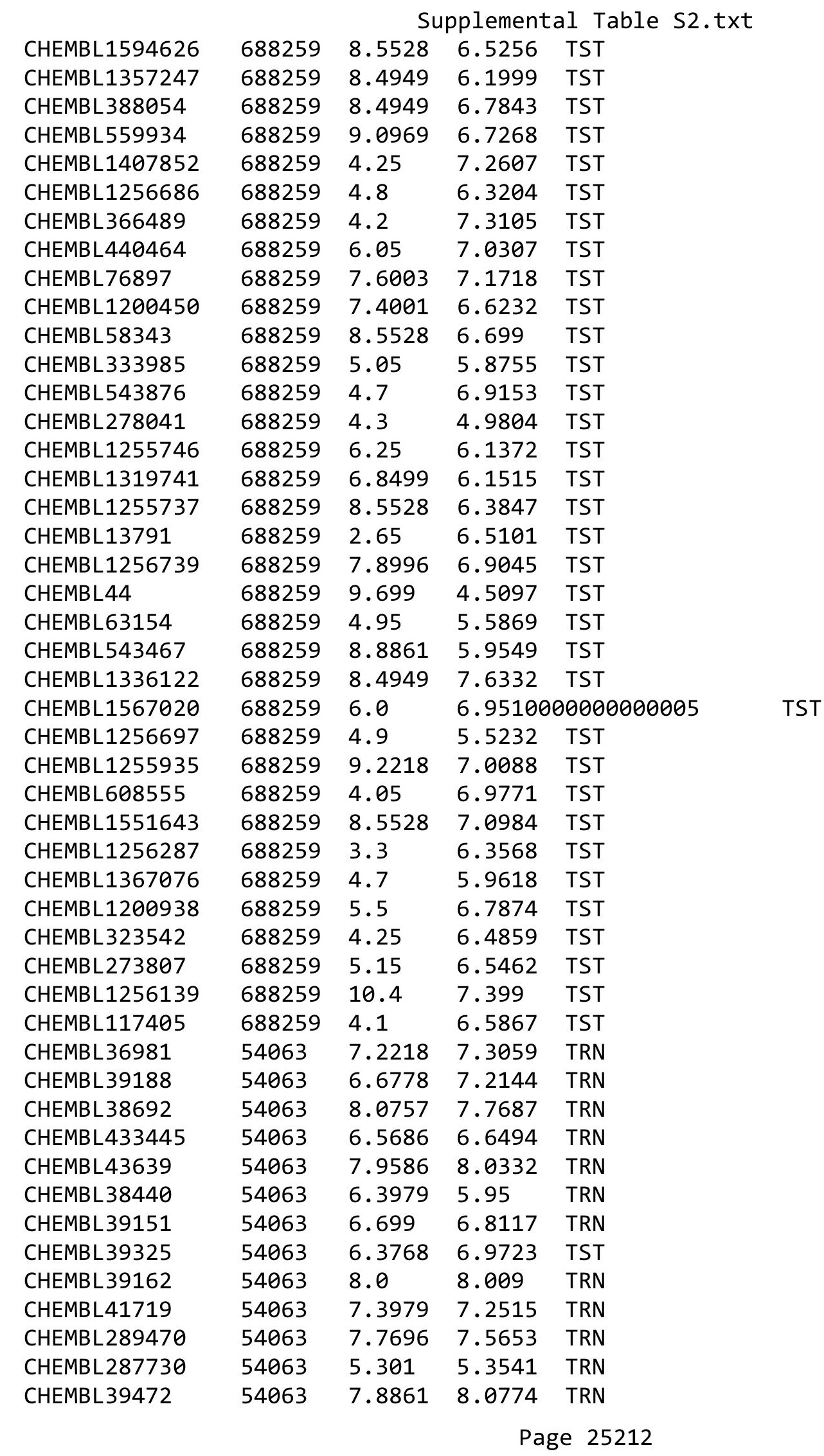




\begin{tabular}{|c|c|c|c|c|}
\hline & & & pplement & al $\mathrm{T}$ \\
\hline CHEMBL38639 & 54063 & 6.8539 & 6.4417 & TRN \\
\hline CHEMBL 290674 & 54063 & 7.2007 & 6.7354 & TRN \\
\hline CHEMBL40220 & 54063 & 6.6576 & 7.0196 & TRN \\
\hline CHEMBL39128 & 54063 & 5.301 & 5.5118 & TRN \\
\hline CHEMBL 38614 & 54063 & 7.5376 & 7.8435 & TRN \\
\hline CHEMBL 38620 & 54063 & 5.301 & 5.2523 & TRN \\
\hline CHEMBL416057 & 54063 & 7.3979 & 7.2339 & TRN \\
\hline CHEMBL 289854 & 54063 & 6.301 & 7.7347 & TST \\
\hline CHEMBL40182 & 54063 & 6.8239 & 6.9855 & TRN \\
\hline CHEMBL38242 & 54063 & 7.4202 & 7.1004 & TRN \\
\hline CHEMBL40093 & 54063 & 7.8861 & 7.8697 & TRN \\
\hline CHEMBL38421 & 54063 & 7.6198 & 7.8968 & TRN \\
\hline CHEMBL39167 & 54063 & 5.301 & 5.4074 & TRN \\
\hline CHEMBL440660 & 54063 & 5.301 & 6.8831 & TST \\
\hline CHEMBL39448 & 54063 & 8.7696 & 8.6745 & TRN \\
\hline CHEMBL289071 & 54063 & 6.6778 & 7.2386 & TST \\
\hline CHEMBL39397 & 54063 & 5.301 & 5.5237 & TRN \\
\hline CHEMBL 288852 & 54063 & 5.301 & 7.3543 & TST \\
\hline CHEMBL43638 & 54063 & 5.301 & 5.1104 & TRN \\
\hline CHEMBL 288708 & 54063 & 8.0969 & 7.4125 & TRN \\
\hline CHEMBL291268 & 54063 & 5.301 & 5.3307 & TRN \\
\hline CHEMBL290910 & 54063 & 8.0 & 7.8282 & TRN \\
\hline CHEMBL43521 & 54063 & 5.301 & 5.8046 & TRN \\
\hline CHEMBL38997 & 54063 & 5.301 & 5.7813 & TRN \\
\hline CHEMBL41799 & 54063 & 7.2518 & 7.3541 & TRN \\
\hline CHEMBL288137 & 54063 & 5.301 & 5.1348 & TRN \\
\hline CHEMBL39971 & 54063 & 7.3188 & 7.5442 & TST \\
\hline CHEMBL38978 & 54063 & 7.301 & 7.6149 & TRN \\
\hline CHEMBL288381 & 54063 & 6.4089 & 5.892 & TRN \\
\hline CHEMBL40846 & 54063 & 7.6021 & 7.6657 & TRN \\
\hline CHEMBL38476 & 54063 & 6.6383 & 6.9391 & TRN \\
\hline CHEMBL38986 & 54063 & 7.699 & 7.4734 & TRN \\
\hline CHEMBL418062 & 54063 & 5.301 & 7.7783 & TST \\
\hline CHEMBL36047 & 54063 & 7.5229 & 7.2119 & TST \\
\hline CHEMBL38953 & 54063 & 5.301 & 5.4322 & TST \\
\hline CHEMBL38669 & 54063 & 6.6778 & 7.8513 & TST \\
\hline CHEMBL39191 & 54063 & 5.301 & 6.2506 & TST \\
\hline CHEMBL 289555 & 54063 & 6.5229 & 6.5607 & TST \\
\hline CHEMBL38820 & 54063 & 5.301 & 8.0701 & TST \\
\hline CHEMBL39396 & 54063 & 7.5528 & 7.6783 & TST \\
\hline CHEMBL3680418 & 1534778 & 8.2291 & 8.8089 & TST \\
\hline CHEMBL 3675533 & 1534778 & 7.6778 & 7.7343 & TRN \\
\hline CHEMBL 3670434 & 1534778 & 6.3768 & 6.4513 & TRN \\
\hline CHEMBL3680521 & 1534778 & 7.7959 & 8.0721 & TRN \\
\hline CHEMBL 3675441 & 1534778 & 9.6021 & 9.2123 & TRN \\
\hline CHEMBL3670453 & 1534778 & 7.6576 & 7.4289 & TRN \\
\hline CHEMBL 3680393 & 1534778 & 8.1079 & 8.3268 & TST \\
\hline CHEMBL3680601 & 1534778 & 8.1675 & 8.2906 & TRN \\
\hline
\end{tabular}


Supplemental Table S2.txt

\begin{tabular}{|c|c|c|c|c|}
\hline CHEMBL3685242 & 1534778 & 8.7696 & 9.3633 & TST \\
\hline CHEMBL3670466 & 1534778 & 7.6383 & 7.4965 & TST \\
\hline CHEMBL 3680584 & 1534778 & 7.7696 & 8.3217 & TRN \\
\hline CHEMBL 3675442 & 1534778 & 8.6198 & 8.2424 & TRN \\
\hline CHEMBL3964083 & 1534778 & 8.5229 & 9.8355 & TST \\
\hline CHEMBL 3675320 & 1534778 & 5.9747 & 6.3353 & TRN \\
\hline CHEMBL 3680451 & 1534778 & 7.8861 & 7.2541 & TRN \\
\hline CHEMBL 3680588 & 1534778 & 9.301 & 8.8253 & TRN \\
\hline CHEMBL3685249 & 1534778 & 9.301 & 9.1304 & TRN \\
\hline CHEMBL 3680590 & 1534778 & 8.2596 & 7.7247 & TRN \\
\hline CHEMBL 3680556 & 1534778 & 9.0 & 8.7555 & TRN \\
\hline CHEMBL 3680421 & 1534778 & 9.2366 & 8.8151 & TST \\
\hline CHEMBL3670439 & 1534778 & 7.9586 & 8.443999 & 9999999999 \\
\hline CHEMBL3675466 & 1534778 & 9.1805 & 9.0144 & TRN \\
\hline CHEMBL 3685250 & 1534778 & 9.4202 & 9.5653 & TRN \\
\hline CHEMBL3685216 & 1534778 & 7.699 & 7.7566 & TST \\
\hline CHEMBL3685229 & 1534778 & 7.2291 & 8.5141 & TST \\
\hline CHEMBL 3685256 & 1534778 & 8.1612 & 8.4587 & TST \\
\hline CHEMBL3685239 & 1534778 & 8.1871 & 8.2567 & TRN \\
\hline CHEMBL3685275 & 1534778 & 8.301 & 8.3158 & TRN \\
\hline CHEMBL 3670504 & 1534778 & 9.0 & 7.8131 & TRN \\
\hline CHEMBL 3670467 & 1534778 & 9.4559 & 9.0793 & TRN \\
\hline CHEMBL 3680554 & 1534778 & 9.5229 & 9.1578 & TRN \\
\hline CHEMBL 3670491 & 1534778 & 7.0555 & 7.2579 & TST \\
\hline CHEMBL3685269 & 1534778 & 6.8861 & 7.8272 & TRN \\
\hline CHEMBL 3675355 & 1534778 & 6.1549 & 7.3294 & TRN \\
\hline CHEMBL 3670476 & 1534778 & 8.7696 & 8.8535 & TRN \\
\hline CHEMBL 3670446 & 1534778 & 5.7447 & 6.827006 & 3000000001 \\
\hline CHEMBL 3680387 & 1534778 & 7.9586 & 8.8982 & TRN \\
\hline CHEMBL3675518 & 1534778 & 8.3468 & 9.0328 & TRN \\
\hline CHEMBL 3680586 & 1534778 & 8.0269 & 8.2185 & TST \\
\hline CHEMBL 3680602 & 1534778 & 8.3768 & 8.6184 & TRN \\
\hline CHEMBL 3685308 & 1534778 & 9.1675 & 9.4128 & TST \\
\hline CHEMBL 3685210 & 1534778 & 8.7959 & 8.0865 & TRN \\
\hline CHEMBL 3680444 & 1534778 & 10.3768 & 9.4247 & TRN \\
\hline CHEMBL 3675480 & 1534778 & 8.8861 & 8.8023 & TRN \\
\hline CHEMBL 3675478 & 1534778 & 8.0177 & 8.4044 & TRN \\
\hline CHEMBL 3680542 & 1534778 & 9.0269 & 9.1213 & TRN \\
\hline CHEMBL 3685258 & 1534778 & 8.699 & 7.9704 & TRN \\
\hline CHEMBL 3675487 & 1534778 & 8.8539 & 9.12 & TRN \\
\hline CHEMBL 3685211 & 1534778 & 7.4949 & 8.4045 & TRN \\
\hline CHEMBL3685273 & 1534778 & 7.4685 & 7.114 & TRN \\
\hline CHEMBL 3670425 & 1534778 & 8.2518 & 7.9035 & TRN \\
\hline CHEMBL 3685252 & 1534778 & 9.4202 & 9.4998 & TRN \\
\hline CHEMBL 3670505 & 1534778 & 8.3979 & 7.9929 & TRN \\
\hline CHEMBL 3685306 & 1534778 & 9.6576 & 9.1909 & TRN \\
\hline CHEMBL 3685285 & 1534778 & 8.4815 & 7.6244 & TRN \\
\hline CHEMBL 3685244 & 1534778 & 8.5686 & 8.9017 & TRN \\
\hline
\end{tabular}

Page 25214 
Supplemental Table S2.txt

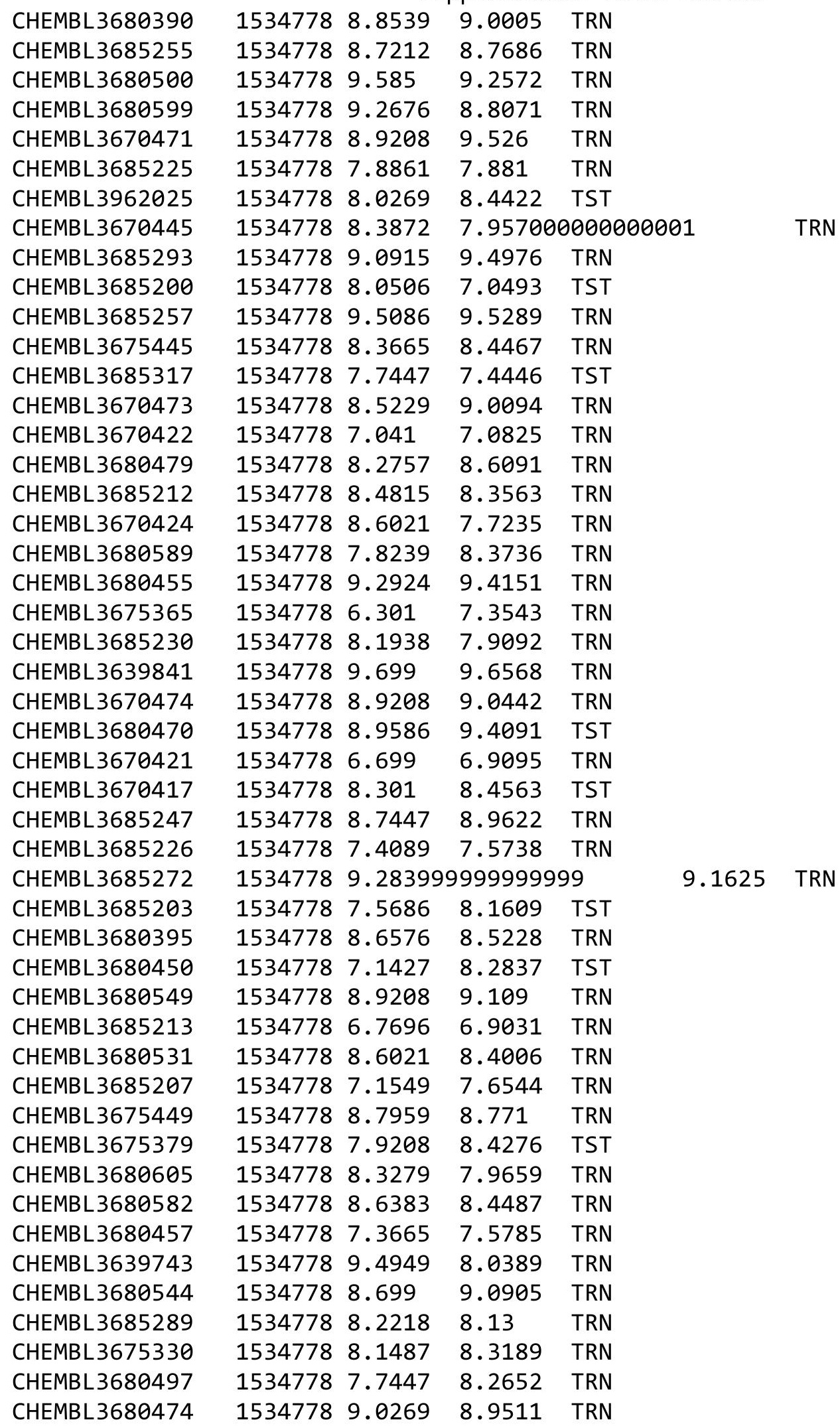

Page 25215 
Supplemental Table S2.txt

\begin{tabular}{|c|c|c|c|c|c|}
\hline CHEMBL3685218 & 1534778 & 7.7959 & 7.7498 & TST & \\
\hline CHEMBL3670472 & 1534778 & 8.6778 & 8.3786 & TRN & \\
\hline CHEMBL3670493 & 1534778 & 7.6021 & 7.9859 & TRN & \\
\hline CHEMBL3685318 & 1534778 & 6.7959 & 6.9614 & TST & \\
\hline CHEMBL3685254 & 1534778 & 8.7959 & 8.0504 & TRN & \\
\hline CHEMBL3685202 & 1534778 & 7.7447 & 7.8107 & TRN & \\
\hline CHEMBL3675381 & 1534778 & 7.8861 & 7.7823 & TRN & \\
\hline CHEMBL 3680411 & 1534778 & 8.4559 & 7.7344 & TRN & \\
\hline CHEMBL3685217 & 1534778 & 8.301 & 8.5952 & TRN & \\
\hline CHEMBL3675491 & 1534778 & 8.9208 & 9.2659 & TRN & \\
\hline CHEMBL 3685241 & 1534778 & 8.9208 & 9.0731 & TRN & \\
\hline CHEMBL3685288 & 1534778 & 8.5528 & 7.848 & TRN & \\
\hline CHEMBL 3670464 & 1534778 & 8.8539 & 8.2426 & TRN & \\
\hline CHEMBL 3680436 & 1534778 & 8.6383 & 8.6279 & TST & \\
\hline CHEMBL3670487 & 1534778 & 8.5376 & 8.5279 & TRN & \\
\hline CHEMBL3685279 & 1534778 & 8.0088 & 8.7466 & TRN & \\
\hline CHEMBL3685237 & 1534778 & 9.4815 & 9.3401 & TRN & \\
\hline CHEMBL 3670478 & 1534778 & 8.7959 & 8.6402 & TRN & \\
\hline CHEMBL3680539 & 1534778 & 7.3665 & 8.509 & TST & \\
\hline CHEMBL3680417 & 1534778 & 9.3372 & 9.6184 & TRN & \\
\hline CHEMBL3685215 & 1534778 & 8.3565 & 8.2228 & TRN & \\
\hline CHEMBL 3680440 & 1534778 & 6.4318 & 6.2442 & TRN & \\
\hline CHEMBL 3675510 & 1534778 & 9.3279 & 9.0313 & TST & \\
\hline CHEMBL 3680552 & 1534778 & 10.2218 & 9.3195 & TRN & \\
\hline CHEMBL3685263 & 1534778 & 7.8539 & 8.1538 & TRN & \\
\hline CHEMBL3685267 & 1534778 & 9.0969 & 9.3069 & TRN & \\
\hline CHEMBL3685222 & 1534778 & 8.7212 & 8.4235 & TST & \\
\hline CHEMBL3943502 & 1534778 & 7.8861 & 8.3622 & TST & \\
\hline CHEMBL 3675459 & 1534778 & 9.4559 & 9.2402 & TRN & \\
\hline CHEMBL3680596 & 1534778 & 9.7447 & 9.0732 & TRN & \\
\hline CHEMBL3675352 & 1534778 & 8.1192 & 7.7396 & TRN & \\
\hline CHEMBL3670416 & 1534778 & 8.0862 & 8.2595 & TST & \\
\hline CHEMBL 3685214 & 1534778 & 8.8239 & 8.4602 & TRN & \\
\hline CHEMBL 3675368 & 1534778 & 6.4815 & 7.6006 & TRN & \\
\hline CHEMBL 3685243 & 1534778 & 10.2147 & 9.4594 & TRN & \\
\hline CHEMBL3675453 & 1534778 & 8.9586 & 8.6376 & TRN & \\
\hline CHEMBL3675406 & 1534778 & 8.8539 & 8.9218 & TRN & \\
\hline CHEMBL 3675328 & 1534778 & 6.7696 & 7.2752 & TRN & \\
\hline CHEMBL3956997 & 1534778 & 8.301 & 8.969 & TST & \\
\hline CHEMBL3675329 & 1534778 & 7.3188 & 7.49100 & 30000000005 & TRN \\
\hline CHEMBL3680532 & 1534778 & 8.7447 & 9.6518 & TRN & \\
\hline CHEMBL3675325 & 1534778 & 8.7959 & 8.0472 & TRN & \\
\hline CHEMBL3685262 & 1534778 & 9.7447 & 9.8575 & TRN & \\
\hline CHEMBL 3670454 & 1534778 & 8.3665 & 8.464 & TRN & \\
\hline CHEMBL 3685297 & 1534778 & 8.2757 & 8.5565 & TRN & \\
\hline CHEMBL3680509 & 1534778 & 8.4437 & 8.8072 & TRN & \\
\hline CHEMBL3685224 & 1534778 & 7.4202 & 7.6032 & TRN & \\
\hline CHEMBL3685266 & 1534778 & 9.0555 & 9.0712 & TRN & \\
\hline
\end{tabular}


Supplemental Table S2.txt

\begin{tabular}{|c|c|c|c|c|c|}
\hline CHEMBL3685245 & 1534778 & 9.6778 & 9.3977 & TRN & \\
\hline CHEMBL3680571 & 1534778 & 9.1367 & 9.0395 & TRN & \\
\hline CHEMBL3680458 & 1534778 & 8.0362 & 8.2426 & TRN & \\
\hline CHEMBL 3685286 & 1534778 & 8.8239 & 8.8933 & TRN & \\
\hline CHEMBL3675371 & 1534778 & 8.8239 & 8.0299 & TRN & \\
\hline CHEMBL3685219 & 1534778 & 6.8539 & 6.9964 & TRN & \\
\hline CHEMBL3675506 & 1534778 & 9.1612 & 9.2645 & TRN & \\
\hline CHEMBL3639794 & 1534778 & 7.7959 & 8.0167 & TRN & \\
\hline CHEMBL 3680464 & 1534778 & 8.6383 & 8.6942 & TRN & \\
\hline CHEMBL3680492 & 1534778 & 8.2366 & 8.1425 & TST & \\
\hline CHEMBL 3680574 & 1534778 & 8.1871 & 8.8376 & TRN & \\
\hline CHEMBL3675341 & 1534778 & 6.4112 & 7.0299 & TRN & \\
\hline CHEMBL 3680567 & 1534778 & 9.0177 & 8.8824 & TRN & \\
\hline CHEMBL 3670450 & 1534778 & 6.301 & 7.0351 & TST & \\
\hline CHEMBL3685232 & 1534778 & 8.0605 & 7.3382 & TRN & \\
\hline CHEMBL3670496 & 1534778 & 5.6021 & 6.3073 & TRN & \\
\hline CHEMBL3685270 & 1534778 & 7.4815 & 7.7559 & TRN & \\
\hline CHEMBL3685248 & 1534778 & 8.9586 & 9.3612 & TRN & \\
\hline CHEMBL3680518 & 1534778 & 7.9586 & 8.3446 & TRN & \\
\hline CHEMBL 3685320 & 1534778 & 6.9586 & 6.4594 & TST & \\
\hline CHEMBL3685264 & 1534778 & 7.7959 & 8.0005 & TRN & \\
\hline CHEMBL3680597 & 1534778 & 8.6021 & \multicolumn{2}{|c|}{8.437000000000001} & TRN \\
\hline CHEMBL3675385 & 1534778 & 6.1675 & 5.7626 & TRN & \\
\hline CHEMBL3680476 & 1534778 & 9.0 & 8.7469 & TRN & \\
\hline CHEMBL3675431 & 1534778 & 8.7212 & 9.4357 & TST & \\
\hline CHEMBL 3680557 & 1534778 & 8.6576 & 8.7739 & TRN & \\
\hline CHEMBL 3680587 & 1534778 & 9.301 & \multicolumn{2}{|c|}{8.937000000000001} & TRN \\
\hline CHEMBL3675525 & 1534778 & 9.7696 & 9.9219 & TRN & \\
\hline CHEMBL3685261 & 1534778 & 8.6198 & 8.7224 & TRN & \\
\hline CHEMBL3639693 & 1534778 & 8.585 & 8.4425 & TRN & \\
\hline CHEMBL3685253 & 1534778 & 7.8861 & 7.9654 & TRN & \\
\hline CHEMBL 3680447 & 1534778 & 10.3372 & 9.5802 & TRN & \\
\hline CHEMBL3680391 & 1534778 & 8.6383 & 9.0442 & TST & \\
\hline CHEMBL 3680548 & 1534778 & 9.0 & 8.772 & TRN & \\
\hline CHEMBL3685309 & 1534778 & 8.4202 & 8.8139 & TRN & \\
\hline CHEMBL 3680410 & 1534778 & 7.8861 & 7.7596 & TRN & \\
\hline CHEMBL 3685277 & 1534778 & 10.0506 & 9.2659 & TRN & \\
\hline CHEMBL3675538 & 1534778 & 8.5086 & 8.8349 & TRN & \\
\hline CHEMBL 3680508 & 1534778 & 10.3468 & 9.2965 & TRN & \\
\hline CHEMBL3680481 & 1534778 & 8.8239 & \multicolumn{2}{|c|}{8.902000000000001} & TRN \\
\hline CHEMBL 3680467 & 1534778 & 9.2366 & 8.4359 & TST & \\
\hline CHEMBL 3680403 & 1534778 & 9.5229 & 9.3389 & TRN & \\
\hline CHEMBL3680577 & 1534778 & 9.1192 & 9.2807 & TRN & \\
\hline CHEMBL3680551 & 1534778 & 9.1308 & 9.4465 & TRN & \\
\hline CHEMBL 3675438 & 1534778 & 9.3665 & \multicolumn{2}{|c|}{8.982999999999999} & TRN \\
\hline CHEMBL 3670497 & 1534778 & 9.0269 & 9.2225 & TRN & \\
\hline CHEMBL 3675446 & 1534778 & 9.4559 & 9.7108 & TRN & \\
\hline CHEMBL 3680480 & 1534778 & 8.6778 & 8.5632 & TRN & \\
\hline
\end{tabular}

Page 25217 
Supplemental Table S2.txt

\begin{tabular}{|c|c|c|c|c|c|c|}
\hline CHEMBL3670485 & 1534778 & 9.3372 & 9.6119 & TRN & & \\
\hline CHEMBL3685231 & 1534778 & 7.6576 & 7.428 & TST & & \\
\hline CHEMBL 3675493 & 1534778 & 9.3979 & 9.0415 & TRN & & \\
\hline CHEMBL 3675520 & 1534778 & 9.0506 & 9.2607 & TRN & & \\
\hline CHEMBL3675504 & 1534778 & 8.6021 & 8.6376 & TST & & \\
\hline CHEMBL3670479 & 1534778 & 8.1079 & 8.3165 & TRN & & \\
\hline CHEMBL3685259 & 1534778 & 8.3372 & 8.7627 & TRN & & \\
\hline CHEMBL 3685280 & 1534778 & 8.699 & 8.6473 & TRN & & \\
\hline CHEMBL 3675516 & 1534778 & 8.7447 & 9.078 & TRN & & \\
\hline CHEMBL3685240 & 1534778 & 8.6383 & 9.203 & TRN & & \\
\hline CHEMBL3675321 & 1534778 & 7.5686 & 7.5079 & TRN & & \\
\hline CHEMBL 3680572 & 1534778 & 9.4089 & 9.5964 & TRN & & \\
\hline CHEMBL 3675323 & 1534778 & 8.2076 & 7.6868 & TRN & & \\
\hline CHEMBL 3670465 & 1534778 & 8.6576 & 8.4313 & TRN & & \\
\hline CHEMBL3639742 & 1534778 & 9.2291 & 8.8417 & TRN & & \\
\hline CHEMBL3675353 & 1534778 & 8.4089 & 9.2724 & TRN & & \\
\hline CHEMBL3685246 & 1534778 & 7.9208 & 8.7235 & TRN & & \\
\hline CHEMBL 3680523 & 1534778 & 7.699 & 7.9377 & TRN & & \\
\hline CHEMBL3675337 & 1534778 & 8.8239 & 7.6365 & TRN & & \\
\hline CHEMBL3680522 & 1534778 & 9.301 & 8.9469 & TRN & & \\
\hline CHEMBL3670506 & 1534778 & 6.2218 & 6.7692 & TRN & & \\
\hline CHEMBL3680388 & 1534778 & 8.6198 & 8.6897 & TST & & \\
\hline CHEMBL3675439 & 1534778 & 9.5686 & 7.8991 & TST & & \\
\hline CHEMBL 3675444 & 1534778 & 9.3979 & 7.9045 & TST & & \\
\hline CHEMBL 3670470 & 1534778 & 9.28399 & 79999999 & 99 & 9.4696 & TST \\
\hline CHEMBL 3685238 & 1534778 & 7.8239 & 8.1975 & TST & & \\
\hline CHEMBL3675342 & 1534778 & 9.0862 & 7.7251 & TST & & \\
\hline CHEMBL3680604 & 1534778 & 7.8239 & 9.3205 & TST & & \\
\hline CHEMBL3685268 & 1534778 & 9.2076 & 8.7357 & TST & & \\
\hline CHEMBL 3680578 & 1534778 & 8.3279 & 8.4684 & TST & & \\
\hline CHEMBL 3685295 & 1534778 & 8.8239 & 7.8115 & TST & & \\
\hline CHEMBL3685307 & 1534778 & 9.2218 & 8.8331 & TST & & \\
\hline CHEMBL3680507 & 1534778 & 9.0862 & 9.2564 & TST & & \\
\hline CHEMBL 3680392 & 1534778 & 8.6778 & 8.4733 & TST & & \\
\hline CHEMBL3675363 & 1534778 & 5.6021 & 7.1619 & TST & & \\
\hline CHEMBL 3685251 & 1534778 & 9.1024 & 8.7653 & TST & & \\
\hline CHEMBL3670498 & 1534778 & 9.1367 & 8.3967 & TST & & \\
\hline CHEMBL 3685221 & 1534778 & 8.301 & 8.292 & TST & & \\
\hline CHEMBL 3685265 & 1534778 & 8.5686 & 8.43 & TST & & \\
\hline CHEMBL3670499 & 1534778 & 9.6198 & 8.309 & TST & & \\
\hline CHEMBL3675465 & 1534778 & 8.8861 & 7.9145 & TST & & \\
\hline CHEMBL3685302 & 1534778 & 6.3979 & 6.9607 & TST & & \\
\hline CHEMBL 3670427 & 1534778 & 8.4089 & 8.497 & TST & & \\
\hline CHEMBL3670468 & 1534778 & 9.1487 & 9.1097 & TST & & \\
\hline CHEMBL3685287 & 1534778 & 8.7447 & 8.8934 & TST & & \\
\hline CHEMBL 3680483 & 1534778 & 6.7447 & 7.0459 & TST & & \\
\hline CHEMBL3940268 & 1641997 & 2.699 & 3.7323 & TRN & & \\
\hline CHEMBL3964053 & 1641997 & 2.699 & 4.4487 & TRN & & \\
\hline
\end{tabular}


Supplemental Table S2.txt

\begin{tabular}{|c|c|c|c|c|c|}
\hline CHEMBL3945031 & 1641997 & 6.1039 & 7.0529 & TRN & \\
\hline CHEMBL3952294 & 1641997 & 2.699 & 4.4318 & TRN & \\
\hline CHEMBL3890655 & 1641997 & 2.699 & 3.5546 & TRN & \\
\hline CHEMBL3925461 & 1641997 & 5.9978 & 4.6438 & TRN & \\
\hline CHEMBL3964571 & 1641997 & 5.6325 & 5.5131 & TRN & \\
\hline CHEMBL3935417 & 1641997 & 6.1532 & 5.9715 & TRN & \\
\hline CHEMBL3984619 & 1641997 & 4.8336 & 5.6911 & TST & \\
\hline CHEMBL3942489 & 1641997 & 6.2379 & 5.3478 & TRN & \\
\hline CHEMBL3940025 & 1641997 & 4.7537 & 6.0625 & TRN & \\
\hline CHEMBL3910278 & 1641997 & 7.8962 & 5.7475 & TRN & \\
\hline CHEMBL3961125 & 1641997 & 2.699 & 3.8526 & TRN & \\
\hline CHEMBL3970877 & 1641997 & 2.699 & 4.3436 & TRN & \\
\hline CHEMBL3926042 & 1641997 & 4.7774 & 6.1024 & TRN & \\
\hline CHEMBL3933752 & 1641997 & 5.5607 & 6.5792 & TRN & \\
\hline CHEMBL3947934 & 1641997 & 2.699 & 5.2443 & TST & \\
\hline CHEMBL3963340 & 1641997 & 2.699 & 4.3362 & TRN & \\
\hline CHEMBL3906893 & 1641997 & 8.1701 & 5.7971 & TRN & \\
\hline CHEMBL3924605 & 1641997 & 2.699 & 4.6256 & TRN & \\
\hline CHEMBL3908662 & 1641997 & 5.6774 & 4.8692 & TST & \\
\hline CHEMBL 3890527 & 1641997 & 2.699 & 4.5117 & TRN & \\
\hline CHEMBL3923032 & 1641997 & 7.359 & 5.1358 & TRN & \\
\hline CHEMBL3906641 & 1641997 & 7.3035 & 5.1899 & TRN & \\
\hline CHEMBL3936251 & 1641997 & 2.699 & 4.2555 & TRN & \\
\hline CHEMBL3902087 & 1641997 & 8.0173 & 5.1828 & TRN & \\
\hline CHEMBL 3904456 & 1641997 & 6.8303 & 7.6732 & TRN & \\
\hline CHEMBL3918919 & 1641997 & 2.699 & 5.2491 & TST & \\
\hline CHEMBL3943339 & 1641997 & 6.0 & 7.1833 & TRN & \\
\hline CHEMBL3913034 & 1641997 & 5.3369 & 6.5652 & TRN & \\
\hline CHEMBL3922780 & 1641997 & 6.3886 & 5.6081 & TRN & \\
\hline CHEMBL 3924522 & 1641997 & 5.148 & 6.0009 & TRN & \\
\hline CHEMBL3942020 & 1641997 & 7.9872 & 4.4962 & TRN & \\
\hline CHEMBL3974742 & 1641997 & 6.3344 & 6.5714 & TST & \\
\hline CHEMBL3917710 & 1641997 & 4.9831 & 6.1536 & TRN & \\
\hline CHEMBL3971169 & 1641997 & 6.0 & 4.1334 & TRN & \\
\hline CHEMBL3980453 & 1641997 & 2.699 & 3.9594 & TRN & \\
\hline CHEMBL3965507 & 1641997 & 5.9003 & 5.2216 & TRN & \\
\hline CHEMBL3970590 & 1641997 & 8.0155 & 5.2321 & TRN & \\
\hline CHEMBL3956841 & 1641997 & 2.699 & 3.6366 & TRN & \\
\hline CHEMBL3891748 & 1641997 & 7.7305 & 4.9622 & TRN & \\
\hline CHEMBL3949645 & 1641997 & 5.4688 & 5.1287 & TRN & \\
\hline CHEMBL3945152 & 1641997 & 2.699 & 3.6644 & TST & \\
\hline CHEMBL3951204 & 1641997 & 5.1694 & 6.1879 & TRN & \\
\hline CHEMBL3935138 & 1641997 & 2.699 & 3.3588 & TRN & \\
\hline CHEMBL3963622 & 1641997 & $6.2360 e$ & 200000006 & 01 & 4.6044 \\
\hline CHEMBL3925186 & 1641997 & 2.699 & 4.2696 & TST & \\
\hline CHEMBL 3895514 & 1641997 & 5.9382 & 5.6577 & TRN & \\
\hline CHEMBL 3927022 & 1641997 & 6.3315 & 4.9792 & TST & \\
\hline CHEMBL3932040 & 1641997 & 2.699 & 4.7933 & TST & \\
\hline
\end{tabular}


Supplemental Table S2.txt

\begin{tabular}{|c|c|c|c|c|c|}
\hline CHEMBL3968263 & 1641997 & 2.699 & 3.5889 & TST & \\
\hline CHEMBL3918073 & 1641997 & 4.9375 & 5.5106 & TST & \\
\hline CHEMBL3928981 & 1641997 & 2.699 & 4.5241 & TST & \\
\hline CHEMBL3892711 & 1641997 & 4.9334 & 5.926 & TST & \\
\hline CHEMBL3908066 & 1641997 & 6.3406 & 6.2702 & TST & \\
\hline CHEMBL1684768 & 899885 & 4.9991 & 4.9851 & TRN & \\
\hline CHEMBL 2237655 & 899885 & 4.6962 & 4.744 & TRN & \\
\hline CHEMBL 2237653 & 899885 & 5.4908 & 5.5144 & TRN & \\
\hline CHEMBL1684767 & 899885 & 4.5232 & 4.4936 & TRN & \\
\hline CHEMBL1684770 & 899885 & 4.2408 & 4.2472 & TRN & \\
\hline CHEMBL1684778 & 899885 & 4.3644 & 4.2527 & TST & \\
\hline CHEMBL1684639 & 899885 & 5.0521 & 5.0984 & TRN & \\
\hline CHEMBL193585 & 899885 & 4.927 & 4.8775 & TRN & \\
\hline CHEMBL1684757 & 899885 & 5.8827 & 5.8018 & TRN & \\
\hline CHEMBL1353302 & 899885 & 4.7142 & 4.7196 & TRN & \\
\hline CHEMBL1684774 & 899885 & 4.6712 & 4.8622 & TRN & \\
\hline CHEMBL 2237656 & 899885 & 4.7696 & 4.7824 & TRN & \\
\hline CHEMBL1684646 & 899885 & 5.1163 & 5.1225 & TRN & \\
\hline CHEMBL 2237892 & 899885 & 4.6759 & 4.5133 & TST & \\
\hline CHEMBL1209915 & 899885 & 4.7479 & 4.7254 & TRN & \\
\hline CHEMBL1684754 & 899885 & 5.4283 & 5.4242 & TRN & \\
\hline CHEMBL1224508 & 899885 & 5.3439 & 5.2932 & TRN & \\
\hline CHEMBL1684638 & 899885 & 5.4486 & 5.3502 & TRN & \\
\hline CHEMBL1684759 & 899885 & 5.9957 & 6.0117 & TRN & \\
\hline CHEMBL1684642 & 899885 & 5.0491 & 5.0074 & TRN & \\
\hline CHEMBL 2237897 & 899885 & 4.9017 & 4.9825 & TST & \\
\hline CHEMBL 2237896 & 899885 & 5.4401 & 5.5169 & TST & \\
\hline CHEMBL1684643 & 899885 & 5.0857 & 5.0614 & TRN & \\
\hline CHEMBL1684777 & 899885 & 4.9952 & 4.944 & TRN & \\
\hline CHEMBL 2237895 & 899885 & 5.9957 & 6.1307 & TST & \\
\hline CHEMBL1684644 & 899885 & 5.1073 & 5.1265 & TRN & \\
\hline CHEMBL1684635 & 899885 & 4.8368 & 4.9554 & TRN & \\
\hline CHEMBL 2237902 & 899885 & 5.9914 & 6.0045 & TST & \\
\hline CHEMBL1684761 & 899885 & 5.9469 & 6.0134 & TRN & \\
\hline CHEMBL562142 & 899885 & 5.1051 & 5.1974 & TRN & \\
\hline CHEMBL1684756 & 899885 & 5.4023 & 5.3425 & TST & \\
\hline CHEMBL1684755 & 899885 & 5.0052 & 4.9644 & TRN & \\
\hline CHEMBL1684779 & 899885 & 4.6992 & 4.737 & TRN & \\
\hline CHEMBL1684769 & 899885 & 4.6617 & 4.6665 & TRN & \\
\hline CHEMBL 2237903 & 899885 & 5.0565 & 5.0147 & TST & \\
\hline CHEMBL1684764 & 899885 & 6.7212 & 6.74799 & 9999999999 & TRN \\
\hline CHEMBL1684637 & 899885 & 5.3019 & 5.3142 & TRN & \\
\hline CHEMBL1684758 & 899885 & 5.9872 & 5.9656 & TRN & \\
\hline CHEMBL1684636 & 899885 & 4.62 & 4.5321 & TRN & \\
\hline CHEMBL1684753 & 899885 & 5.3893 & 5.3681 & TRN & \\
\hline CHEMBL 2237893 & 899885 & 5.0757 & 5.1235 & TST & \\
\hline CHEMBL1209917 & 899885 & 4.5561 & 4.5113 & TRN & \\
\hline CHEMBL1684641 & 899885 & 5.0595 & 5.0267 & TRN & \\
\hline
\end{tabular}


Supplemental Table S2.txt

\begin{tabular}{|c|c|c|c|c|}
\hline CHEMBL1684762 & 899885 & 4.7757 & 4.7592 & TRN \\
\hline CHEMBL 2237898 & 899885 & 6.2757 & 6.07 & TST \\
\hline CHEMBL1684775 & 899885 & 5.0004 & 4.8848 & TRN \\
\hline CHEMBL1684645 & 899885 & 4.5592 & 4.6234 & TRN \\
\hline CHEMBL1449501 & 899885 & 4.2905 & 4.3361 & TRN \\
\hline CHEMBL1684771 & 899885 & 4.8058 & 4.8199 & TRN \\
\hline CHEMBL 2237900 & 899885 & 5.9626 & 5.7213 & TST \\
\hline CHEMBL 2237905 & 899885 & 5.8894 & 5.91100 & 0000000005 \\
\hline CHEMBL 2237901 & 899885 & 5.9957 & 5.8892 & TST \\
\hline CHEMBL1542147 & 899885 & 5.1772 & 5.1627 & TRN \\
\hline CHEMBL1209130 & 899885 & 4.9714 & 4.9565 & TRN \\
\hline CHEMBL1684765 & 899885 & 4.4936 & 4.5147 & TRN \\
\hline CHEMBL1684763 & 899885 & 5.9706 & 5.9706 & TRN \\
\hline CHEMBL1684640 & 899885 & 4.3012 & 4.375 & TRN \\
\hline CHEMBL1684773 & 899885 & 4.8748 & 4.8631 & TRN \\
\hline CHEMBL 2237654 & 899885 & 6.7696 & 6.309 & TST \\
\hline CHEMBL 2237904 & 899885 & 4.7212 & 4.9123 & TST \\
\hline CHEMBL2237899 & 899885 & 6.2291 & 6.1418 & TST \\
\hline CHEMBL1684751 & 899885 & 4.9504 & 4.9639 & TRN \\
\hline CHEMBL1684776 & 899885 & 5.1746 & 5.1602 & TRN \\
\hline CHEMBL1684766 & 899885 & 4.3198 & 4.6985 & TST \\
\hline CHEMBL 2237894 & 899885 & 5.4123 & 5.4296 & TST \\
\hline CHEMBL1684772 & 899885 & 4.7964 & 4.7128 & TRN \\
\hline CHEMBL1589983 & 752335 & 3.0969 & 3.3424 & TRN \\
\hline CHEMBL602720 & 752335 & 4.734 & 4.7025 & TRN \\
\hline CHEMBL1885971 & 752335 & 4.9846 & 4.7777 & TRN \\
\hline CHEMBL1412002 & 752335 & 4.3851 & 4.5572 & TRN \\
\hline CHEMBL257286 & 752335 & 3.0969 & 4.4811 & TST \\
\hline CHEMBL1902224 & 752335 & 5.082 & 4.6875 & TRN \\
\hline CHEMBL1473749 & 752335 & 4.4486 & 3.5587 & TRN \\
\hline CHEMBL1522043 & 752335 & 3.0969 & 4.9985 & TST \\
\hline CHEMBL590927 & 752335 & 6.0 & 5.2378 & TRN \\
\hline CHEMBL1448282 & 752335 & 4.8901 & 4.8833 & TRN \\
\hline CHEMBL1313520 & 752335 & 4.6882 & 4.598 & TRN \\
\hline CHEMBL1889367 & 752335 & 4.6631 & 4.8499 & TRN \\
\hline CHEMBL1364289 & 752335 & 3.0969 & 3.14 & TRN \\
\hline CHEMBL1866713 & 752335 & 4.1273 & 3.6902 & TRN \\
\hline CHEMBL1330279 & 752335 & 4.6946 & 4.6436 & TRN \\
\hline CHEMBL1339830 & 752335 & 4.3625 & 4.2295 & TRN \\
\hline CHEMBL590665 & 752335 & 4.5719 & 4.5667 & TRN \\
\hline CHEMBL1529188 & 752335 & 4.3726 & 4.7637 & TRN \\
\hline CHEMBL1903712 & 752335 & 4.4101 & 3.8057 & TRN \\
\hline CHEMBL1717263 & 752335 & 3.0969 & 3.4844 & TST \\
\hline CHEMBL1885380 & 752335 & 4.6478 & 4.8681 & TRN \\
\hline CHEMBL1866926 & 752335 & 4.2411 & 4.6277 & TRN \\
\hline CHEMBL1892870 & 752335 & 3.0969 & 3.5124 & TRN \\
\hline CHEMBL585827 & 752335 & 4.9759 & 4.8375 & TRN \\
\hline CHEMBL1902827 & 752335 & 3.0969 & 3.3487 & TRN \\
\hline
\end{tabular}

Page 25221 


\begin{tabular}{|c|c|c|c|c|c|}
\hline \multicolumn{6}{|c|}{ Supplemental Table S2.txt } \\
\hline CHEMBL99932 & 752335 & 3.0969 & 4.1403 & TST & \\
\hline CHEMBL1876892 & 752335 & 4.4012 & 3.7756 & TRN & \\
\hline CHEMBL1488229 & 752335 & 3.0969 & 2.9999 & TRN & \\
\hline CHEMBL1396186 & 752335 & 3.0969 & 3.7557 & TRN & \\
\hline CHEMBL1880467 & 752335 & 3.0969 & 3.1765 & TRN & \\
\hline CHEMBL1874653 & 752335 & 5.2034 & 4.9564 & TRN & \\
\hline CHEMBL1864401 & 752335 & 3.0969 & 2.7672 & TRN & \\
\hline CHEMBL1901771 & 752335 & 3.0969 & 3.4702 & TRN & \\
\hline CHEMBL1525213 & 752335 & 4.4078 & 3.7771 & TST & \\
\hline CHEMBL1875095 & 752335 & 3.0969 & 4.5905 & TST & \\
\hline CHEMBL548670 & 752335 & 4.6778 & 4.7835 & TRN & \\
\hline CHEMBL1871601 & 752335 & 3.0969 & 3.1341 & TRN & \\
\hline CHEMBL1895997 & 752335 & 4.3072 & 3.984 & TRN & \\
\hline CHEMBL1900654 & 752335 & 3.0969 & 3.8633 & TST & \\
\hline CHEMBL1902332 & 752335 & 4.2255 & 4.3859 & TRN & \\
\hline CHEMBL1899071 & 752335 & 4.3726 & 3.566999 & 99999999997 & TRN \\
\hline CHEMBL1519450 & 752335 & 4.38399 & 999999999 & 4.7697 & TRN \\
\hline CHEMBL1902496 & 752335 & 3.0969 & 4.5413 & TST & \\
\hline CHEMBL1864059 & 752335 & 3.0969 & 4.6067 & TST & \\
\hline CHEMBL1445134 & 752335 & 3.0969 & 3.0953 & TRN & \\
\hline CHEMBL1503124 & 752335 & 6.0 & 3.5869 & TRN & \\
\hline CHEMBL1890781 & 752335 & 4.4584 & 4.2086 & TRN & \\
\hline CHEMBL1445650 & 752335 & 3.0969 & 4.3872 & TST & \\
\hline CHEMBL1430579 & 752335 & 3.0969 & 3.2515 & TRN & \\
\hline CHEMBL1878290 & 752335 & 3.0969 & 3.1303 & TRN & \\
\hline CHEMBL1888041 & 752335 & 3.0969 & 2.5976 & TRN & \\
\hline CHEMBL1864233 & 752335 & 4.6556 & 4.6 & TRN & \\
\hline CHEMBL1452490 & 752335 & 3.0969 & 4.1094 & TST & \\
\hline CHEMBL1883543 & 752335 & 4.2518 & 3.7058 & TRN & \\
\hline CHEMBL1897899 & 752335 & 4.782 & 4.809 & TRN & \\
\hline CHEMBL1864414 & 752335 & 4.1925 & 3.4836 & TRN & \\
\hline CHEMBL1443069 & 752335 & 4.1586 & 4.9435 & TRN & \\
\hline CHEMBL1555271 & 752335 & 5.0022 & 5.043 & TRN & \\
\hline CHEMBL1485824 & 752335 & 3.0969 & 3.2061 & TRN & \\
\hline CHEMBL591412 & 752335 & 6.0 & 5.3711 & TRN & \\
\hline CHEMBL1890613 & 752335 & 4.5842 & 4.7684 & TRN & \\
\hline CHEMBL592600 & 752335 & 4.251 & 4.6511 & TRN & \\
\hline CHEMBL1864990 & 752335 & 4.3747 & 4.3145 & TST & \\
\hline CHEMBL1519480 & 752335 & 4.1599 & 3.8675 & TRN & \\
\hline CHEMBL1486651 & 752335 & 3.0969 & 3.9958 & TRN & \\
\hline CHEMBL1313101 & 752335 & 4.3251 & 4.3385 & TRN & \\
\hline CHEMBL1905647 & 752335 & 3.0969 & 3.3994 & TRN & \\
\hline CHEMBL1903426 & 752335 & 4.6957 & 4.7462 & TRN & \\
\hline CHEMBL1876714 & 752335 & 4.2255 & 4.4283 & TST & \\
\hline CHEMBL580530 & 752335 & 4.3478 & 4.718 & TRN & \\
\hline CHEMBL1878645 & 752335 & 3.0969 & 3.8471 & TST & \\
\hline CHEMBL1872480 & 752335 & 3.0969 & 3.9226 & TRN & \\
\hline CHEMBL1887169 & 752335 & 4.1469 & 4.5768 & TRN & \\
\hline
\end{tabular}


Supplemental Table S2.txt

\begin{tabular}{|c|c|c|c|c|}
\hline CHEMBL1879735 & 752335 & 3.0969 & 3.9018 & TST \\
\hline CHEMBL1905394 & 752335 & 3.0969 & 3.4346 & TRN \\
\hline CHEMBL1491842 & 752335 & 4.2958 & 4.43 & TRN \\
\hline CHEMBL1316506 & 752335 & 4.7282 & 4.4932 & TST \\
\hline CHEMBL251603 & 752335 & 4.6271 & 4.3556 & TST \\
\hline CHEMBL1379416 & 752335 & 4.1733 & 4.1247 & TRN \\
\hline CHEMBL1487635 & 752335 & 4.2457 & 4.4356 & TST \\
\hline CHEMBL1893772 & 752335 & 3.0969 & 3.3901 & TRN \\
\hline CHEMBL1899180 & 752335 & 5.1118 & 4.9191 & TRN \\
\hline CHEMBL1438842 & 752335 & 3.0969 & 3.4594 & TRN \\
\hline CHEMBL1906106 & 752335 & 4.7455 & 4.6711 & TRN \\
\hline CHEMBL1906519 & 752335 & 3.0969 & 3.7416 & TRN \\
\hline CHEMBL1871544 & 752335 & 3.0969 & 3.5313 & TRN \\
\hline CHEMBL1379163 & 752335 & 4.3768 & 4.498 & TST \\
\hline CHEMBL1902698 & 752335 & 4.4089 & 3.5425 & TRN \\
\hline CHEMBL1475270 & 752335 & 3.0969 & 3.928 & TRN \\
\hline CHEMBL1894788 & 752335 & 3.0969 & 4.0332 & TST \\
\hline CHEMBL1514530 & 752335 & 4.6326 & 4.6828 & TRN \\
\hline CHEMBL1416756 & 752335 & 5.0947 & 4.0338 & TST \\
\hline CHEMBL1321754 & 752335 & 3.0969 & 3.8643 & TST \\
\hline CHEMBL1604735 & 752335 & 4.308 & 4.6054 & TST \\
\hline CHEMBL1864954 & 752335 & 3.0969 & 3.3455 & TRN \\
\hline CHEMBL1888988 & 752335 & 3.0969 & 2.8697 & TRN \\
\hline CHEMBL1894463 & 752335 & 3.0969 & 3.3968 & TRN \\
\hline CHEMBL1522618 & 752335 & 3.0969 & 4.77800 & 00000000005 \\
\hline CHEMBL1393944 & 752335 & 3.0969 & 4.0541 & TST \\
\hline CHEMBL1891946 & 752335 & 5.4023 & 5.3256 & TRN \\
\hline CHEMBL1890205 & 752335 & 3.0969 & 3.2954 & TRN \\
\hline CHEMBL1373096 & 752335 & 4.6676 & 4.8051 & TRN \\
\hline CHEMBL1299637 & 752335 & 4.308 & 4.1561 & TRN \\
\hline CHEMBL600862 & 752335 & 4.4559 & 4.6478 & TRN \\
\hline CHEMBL1759 & 752335 & 4.365 & 4.0839 & TST \\
\hline CHEMBL580955 & 752335 & 4.6055 & 5.0531 & TRN \\
\hline CHEMBL1559811 & 752335 & 4.1494 & 3.5066 & TRN \\
\hline CHEMBL601768 & 752335 & 6.0 & 5.0734 & TRN \\
\hline CHEMBL547285 & 752335 & 6.0 & 5.1549 & TRN \\
\hline CHEMBL1882757 & 752335 & 3.0969 & 2.7157 & TRN \\
\hline CHEMBL1313027 & 752335 & 3.0969 & 2.7183 & TRN \\
\hline CHEMBL1871971 & 752335 & 4.5229 & 3.6701 & TRN \\
\hline CHEMBL1871385 & 752335 & 3.0969 & 3.4354 & TRN \\
\hline CHEMBL1899890 & 752335 & 3.0969 & 3.8409 & TRN \\
\hline CHEMBL1883427 & 752335 & 3.0969 & 3.5907 & TRN \\
\hline CHEMBL1496891 & 752335 & 3.0969 & 3.3455 & TRN \\
\hline CHEMBL1530766 & 752335 & 4.2857 & 4.4043 & TRN \\
\hline CHEMBL1890797 & 752335 & 3.0969 & 3.9397 & TST \\
\hline CHEMBL1578584 & 752335 & 6.0 & 4.3951 & TRN \\
\hline CHEMBL1890162 & 752335 & 4.1871 & 4.6299 & TRN \\
\hline CHEMBL1419414 & 752335 & 3.0969 & 4.7491 & TST \\
\hline
\end{tabular}




\begin{tabular}{|c|c|c|c|c|c|}
\hline \multirow[b]{2}{*}{ CHEMBL1876790 } & \multicolumn{5}{|c|}{ Supplemental Table s2.txt } \\
\hline & 752335 & 3.0969 & 3.2061 & TRN & \\
\hline CHEMBL1576870 & 752335 & 3.0969 & 3.3956 & TRN & \\
\hline CHEMBL1878922 & 752335 & 3.0969 & 3.8003 & TRN & \\
\hline CHEMBL1735962 & 752335 & 4.1593 & 4.5642 & TST & \\
\hline CHEMBL1872637 & 752335 & 3.0969 & 3.2996 & TRN & \\
\hline CHEMBL1503612 & 752335 & 3.0969 & 4.0557 & TST & \\
\hline CHEMBL1876834 & 752335 & 4.9527 & 4.8651 & TRN & \\
\hline CHEMBL1863881 & 752335 & 4.2218 & 4.3911 & TST & \\
\hline CHEMBL1885580 & 752335 & 3.0969 & 4.5086 & TST & \\
\hline CHEMBL1877680 & 752335 & 3.0969 & 3.378 & TRN & \\
\hline CHEMBL1894075 & 752335 & 3.0969 & 3.6044 & TRN & \\
\hline CHEMBL1891571 & 752335 & 4.1232 & 3.4836 & TRN & \\
\hline CHEMBL1410925 & 752335 & 3.0969 & 3.5418 & TRN & \\
\hline CHEMBL1889931 & 752335 & 3.0969 & 3.2903 & TRN & \\
\hline CHEMBL1892943 & 752335 & 3.0969 & 3.713 & TRN & \\
\hline CHEMBL1905329 & 752335 & 3.0969 & 3.3769 & TRN & \\
\hline CHEMBL1880835 & 752335 & 4.4949 & 4.5325 & TST & \\
\hline CHEMBL1865457 & 752335 & 3.0969 & 3.6947 & TST & \\
\hline CHEMBL1865312 & 752335 & 3.0969 & 3.0323 & TRN & \\
\hline CHEMBL1873656 & 752335 & 3.0969 & 2.7305 & TRN & \\
\hline CHEMBL1865271 & 752335 & 3.0969 & 3.7265 & TRN & \\
\hline CHEMBL1496048 & 752335 & 3.0969 & 4.1231 & TST & \\
\hline CHEMBL1572920 & 752335 & 4.2573 & 4.5423 & TST & \\
\hline CHEMBL1393161 & 688357 & 4.7234 & 3.5739 & TRN & \\
\hline CHEMBL2007422 & 688357 & 4.4465 & 3.3756 & TRN & \\
\hline CHEMBL1996451 & 688357 & 2.4559 & 3.1335 & TRN & \\
\hline CHEMBL3208038 & 688357 & 2.4559 & 3.32800 & 00000000003 & TST \\
\hline CHEMBL3197648 & 688357 & 2.4559 & 2.5202 & TRN & \\
\hline CHEMBL1414933 & 688357 & 4.4388 & 2.7167 & TRN & \\
\hline CHEMBL1446484 & 688357 & 2.4559 & 2.9412 & TRN & \\
\hline CHEMBL1503134 & 688357 & 2.4559 & 2.9461 & TST & \\
\hline CHEMBL1580671 & 688357 & 5.09399 & 99999999 & 4.0484 & TRN \\
\hline CHEMBL1342139 & 688357 & 2.4559 & 3.1228 & TRN & \\
\hline CHEMBL1469499 & 688357 & 2.4559 & 2.7232 & TRN & \\
\hline CHEMBL3208672 & 688357 & 2.4559 & 2.9171 & TRN & \\
\hline CHEMBL1310347 & 688357 & 2.4559 & 2.2708 & TRN & \\
\hline CHEMBL1578275 & 688357 & 2.4559 & 2.7727 & TST & \\
\hline CHEMBL1549286 & 688357 & 2.4559 & 2.5268 & TRN & \\
\hline CHEMBL1309934 & 688357 & 2.4559 & 2.6246 & TST & \\
\hline CHEMBL3210267 & 688357 & 2.4559 & 3.4433 & TRN & \\
\hline CHEMBL3211923 & 688357 & 2.4559 & 2.8244 & TRN & \\
\hline CHEMBL1399991 & 688357 & 2.4559 & 2.9386 & TRN & \\
\hline CHEMBL1438833 & 688357 & 2.4559 & 2.7591 & TST & \\
\hline CHEMBL405072 & 688357 & 2.4559 & 2.98 & TRN & \\
\hline CHEMBL1477905 & 688357 & 2.4559 & 2.4613 & TRN & \\
\hline CHEMBL3196191 & 688357 & 2.4559 & 3.4573 & TRN & \\
\hline CHEMBL1972216 & 688357 & 2.4559 & 2.7821 & TRN & \\
\hline CHEMBL1502020 & 688357 & 2.4559 & 2.3238 & TRN & \\
\hline
\end{tabular}

Page 25224 


\begin{tabular}{|c|c|c|c|c|c|}
\hline & & \multicolumn{4}{|c|}{ Supplemental Table S2.txt } \\
\hline CHEMBL1338762 & 688357 & 2.4559 & 2.39 & TRN & \\
\hline CHEMBL1343630 & 688357 & 2.4559 & 2.5651 & TRN & \\
\hline CHEMBL1520801 & 688357 & 2.4559 & 2.9715 & TRN & \\
\hline CHEMBL1558391 & 688357 & 2.4559 & 2.4943 & TRN & \\
\hline CHEMBL1337202 & 688357 & 2.4559 & 2.7368 & TST & \\
\hline CHEMBL 3198576 & 688357 & 2.4559 & 3.0661 & TRN & \\
\hline CHEMBL1412278 & 688357 & 2.4559 & 2.7975 & TRN & \\
\hline CHEMBL1453106 & 688357 & 2.4559 & 2.9283 & TRN & \\
\hline CHEMBL1452116 & 688357 & 2.4559 & 2.8466 & TST & \\
\hline CHEMBL1497494 & 688357 & 4.3156 & 2.8009 & TRN & \\
\hline CHEMBL1458299 & 688357 & 2.4559 & 2.7371 & TST & \\
\hline CHEMBL1594367 & 688357 & 2.4559 & 2.9351 & TRN & \\
\hline CHEMBL1456520 & 688357 & 2.4559 & 2.6128 & TRN & \\
\hline CHEMBL1352148 & 688357 & 2.4559 & 2.6277 & TRN & \\
\hline CHEMBL1347533 & 688357 & 4.5464 & 3.6074 & TRN & \\
\hline CHEMBL1519450 & 688357 & 2.4559 & 2.8211 & TRN & \\
\hline CHEMBL1498475 & 688357 & 4.3479 & 2.8936 & TRN & \\
\hline CHEMBL 3210442 & 688357 & 2.4559 & 2.8559 & TST & \\
\hline CHEMBL 3193766 & 688357 & 2.4559 & 2.5087 & TRN & \\
\hline CHEMBL1570335 & 688357 & 2.4559 & 2.5551 & TST & \\
\hline CHEMBL1581217 & 688357 & 2.4559 & 2.595 & TRN & \\
\hline CHEMBL1538667 & 688357 & 2.4559 & 2.3544 & TRN & \\
\hline CHEMBL1454024 & 688357 & 2.4559 & 2.75399 & 99999999996 & TRN \\
\hline CHEMBL1471741 & 688357 & 5.1246 & 3.6732 & TRN & \\
\hline CHEMBL 3190974 & 688357 & 2.4559 & 2.8777 & TRN & \\
\hline CHEMBL3196181 & 688357 & 2.4559 & 2.3434 & TRN & \\
\hline CHEMBL3192306 & 688357 & 2.4559 & 3.1942 & TRN & \\
\hline CHEMBL1475128 & 688357 & 5.5929 & 3.4922 & TRN & \\
\hline CHEMBL1480006 & 688357 & 2.4559 & 2.6446 & TRN & \\
\hline CHEMBL 3191445 & 688357 & 2.4559 & 2.7956 & TRN & \\
\hline CHEMBL3208894 & 688357 & 4.4307 & 3.6625 & TRN & \\
\hline CHEMBL1415958 & 688357 & 2.4559 & 3.3905 & TRN & \\
\hline CHEMBL1336804 & 688357 & 2.4559 & 2.7201 & TRN & \\
\hline CHEMBL1409965 & 688357 & 2.4559 & 3.0185 & TRN & \\
\hline CHEMBL1573077 & 688357 & 2.4559 & 2.4886 & TRN & \\
\hline CHEMBL1547884 & 688357 & 5.1133 & 2.8928 & TRN & \\
\hline CHEMBL1990091 & 688357 & 2.4559 & 3.1947 & TRN & \\
\hline CHEMBL1563912 & 688357 & 2.4559 & 2.6936 & TRN & \\
\hline CHEMBL592068 & 688357 & 4.4171 & 3.344 & TRN & \\
\hline CHEMBL 3194778 & 688357 & 4.5438 & 3.1338 & TRN & \\
\hline CHEMBL1455216 & 688357 & 2.4559 & 2.8877 & TRN & \\
\hline CHEMBL1569142 & 688357 & 2.4559 & 2.9038 & TST & \\
\hline CHEMBL3198824 & 688357 & 2.4559 & 2.8105 & TRN & \\
\hline CHEMBL 3189549 & 688357 & 2.4559 & 2.9534 & TRN & \\
\hline CHEMBL1451959 & 688357 & 2.4559 & 2.3737 & TRN & \\
\hline CHEMBL1571002 & 688357 & 2.4559 & 2.972 & TRN & \\
\hline CHEMBL1429929 & 688357 & 4.3625 & 2.3153 & TRN & \\
\hline CHEMBL1444021 & 688357 & 2.4559 & 2.4701 & TRN & \\
\hline
\end{tabular}




\begin{tabular}{|c|c|c|c|c|}
\hline \multicolumn{5}{|c|}{ Supplemental Tab. } \\
\hline CHEMBL1421893 & 688357 & 2.4559 & 2.5783 & TRN \\
\hline CHEMBL528694 & 688357 & 5.4626 & 4.2044 & TRN \\
\hline CHEMBL1503190 & 688357 & 2.4559 & 2.4627 & TST \\
\hline CHEMBL1561112 & 688357 & 2.4559 & 2.6814 & TST \\
\hline CHEMBL1400298 & 688357 & 4.3874 & 3.2654 & TRN \\
\hline CHEMBL1405454 & 688357 & 2.4559 & 2.6028 & TRN \\
\hline CHEMBL1526751 & 688357 & 4.2875 & 2.0883 & TRN \\
\hline CHEMBL1532722 & 688357 & 2.4559 & 2.6058 & TRN \\
\hline CHEMBL590665 & 688357 & 2.4559 & 2.8667 & TRN \\
\hline CHEMBL1309345 & 688357 & 2.4559 & 2.3647 & TRN \\
\hline CHEMBL1576248 & 688357 & 2.4559 & 3.3427 & TST \\
\hline CHEMBL3189344 & 688357 & 2.4559 & 3.2772 & TRN \\
\hline CHEMBL1332756 & 688357 & 2.4559 & 2.7604 & TRN \\
\hline CHEMBL1542905 & 688357 & 4.61 & 2.5947 & TRN \\
\hline CHEMBL1318882 & 688357 & 2.4559 & 2.9241 & TST \\
\hline CHEMBL1392652 & 688357 & 4.1757 & 2.3765 & TRN \\
\hline CHEMBL1612985 & 688357 & 2.4559 & 2.3587 & TRN \\
\hline CHEMBL1301096 & 688357 & 4.1363 & 2.9482 & TRN \\
\hline CHEMBL1520529 & 688357 & 2.4559 & 2.5936 & TRN \\
\hline CHEMBL1493541 & 688357 & 2.4559 & 2.782 & TRN \\
\hline CHEMBL1588513 & 688357 & 2.4559 & 3.7169 & TRN \\
\hline CHEMBL3199034 & 688357 & 4.9833 & 3.7052 & TRN \\
\hline CHEMBL1400933 & 688357 & 2.4559 & 2.5558 & TRN \\
\hline CHEMBL1548606 & 688357 & 2.4559 & 3.0298 & TST \\
\hline CHEMBL1305748 & 688357 & 2.4559 & 2.3483 & TRN \\
\hline CHEMBL3191831 & 688357 & 4.555 & 3.5034 & TRN \\
\hline CHEMBL1477835 & 688357 & 2.4559 & 2.327 & TRN \\
\hline CHEMBL1354757 & 688357 & 2.4559 & 2.7525 & TST \\
\hline CHEMBL1985330 & 688357 & 2.4559 & 3.4099 & TRN \\
\hline CHEMBL3209493 & 688357 & 2.4559 & 2.6632 & TRN \\
\hline CHEMBL1466064 & 688357 & 2.4559 & 2.7172 & TRN \\
\hline CHEMBL1321544 & 688357 & 2.4559 & 2.8669 & TRN \\
\hline CHEMBL1454825 & 688357 & 2.4559 & 2.6074 & TRN \\
\hline CHEMBL1495747 & 688357 & 2.4559 & 2.1315 & TRN \\
\hline CHEMBL1350475 & 688357 & 2.4559 & 3.4396 & TRN \\
\hline CHEMBL1326076 & 688357 & 2.4559 & 2.4352 & TRN \\
\hline CHEMBL1380245 & 688357 & 2.4559 & 2.7757 & TST \\
\hline CHEMBL1337242 & 688357 & 5.0265 & 3.6949 & TRN \\
\hline CHEMBL1585477 & 688357 & 3.8837 & 3.7564 & TRN \\
\hline CHEMBL1417577 & 688357 & 2.4559 & 2.8507 & TRN \\
\hline CHEMBL1413610 & 688357 & 4.2492 & 2.9523 & TRN \\
\hline CHEMBL1500552 & 688357 & 2.4559 & 2.6809 & TRN \\
\hline CHEMBL1574317 & 688357 & 2.4559 & 2.3193 & TRN \\
\hline CHEMBL1499860 & 688357 & 2.4559 & 2.3611 & TRN \\
\hline CHEMBL1468793 & 688357 & 4.3595 & 2.8456 & TRN \\
\hline CHEMBL1360504 & 688357 & 2.4559 & 2.8196 & TRN \\
\hline CHEMBL1305313 & 688357 & 2.4559 & 2.4028 & TST \\
\hline CHEMBL3210502 & 688357 & 2.4559 & 2.7484 & TST \\
\hline
\end{tabular}




\begin{tabular}{|c|c|c|c|c|c|}
\hline \multirow[b]{2}{*}{ CHEMBL3198332 } & \multicolumn{5}{|c|}{ Supplemental Table S2.txt } \\
\hline & 688357 & 4.3981 & 3.1688 & TRN & \\
\hline CHEMBL1543918 & 688357 & 2.4559 & 2.1763 & TRN & \\
\hline CHEMBL1604463 & 688357 & 2.4559 & 3.1449 & TRN & \\
\hline CHEMBL1580858 & 688357 & 2.4559 & 2.6406 & TRN & \\
\hline CHEMBL1332450 & 688357 & 2.4559 & 2.5771 & TRN & \\
\hline CHEMBL1519644 & 688357 & 4.2822 & 3.1943 & TRN & \\
\hline CHEMBL1319311 & 688357 & 2.4559 & 2.5288 & TRN & \\
\hline CHEMBL1410860 & 688357 & 2.4559 & 3.0308 & TRN & \\
\hline CHEMBL1557443 & 688357 & 2.4559 & 3.0755 & TRN & \\
\hline CHEMBL1331702 & 688357 & 2.4559 & 3.6041 & TRN & \\
\hline CHEMBL199868 & 688357 & 5.0374 & 3.0208 & TRN & \\
\hline CHEMBL1576719 & 688357 & 2.4559 & 2.8094 & TRN & \\
\hline CHEMBL 2094833 & 688357 & 2.4559 & 3.4632 & TRN & \\
\hline CHEMBL1333738 & 688357 & 5.604 & 3.1441 & TRN & \\
\hline CHEMBL1984190 & 688357 & 5.3956 & 4.155 & TRN & \\
\hline CHEMBL3210964 & 688357 & 2.4559 & 2.9093 & TRN & \\
\hline CHEMBL1333575 & 688357 & 2.4559 & 2.3998 & TRN & \\
\hline CHEMBL1533242 & 688357 & 4.6969 & 2.7157 & TST & \\
\hline CHEMBL1341102 & 688357 & 2.4559 & 1.9781 & TRN & \\
\hline CHEMBL1424535 & 688357 & 4.3428 & 2.7687 & TRN & \\
\hline CHEMBL1472270 & 688357 & 2.4559 & 2.5048 & TRN & \\
\hline CHEMBL1568114 & 688357 & 2.4559 & 2.4473 & TRN & \\
\hline CHEMBL1502992 & 688357 & 3.9366 & 2.7602 & TST & \\
\hline CHEMBL1319359 & 688357 & 2.4559 & 2.7021 & TRN & \\
\hline CHEMBL1384672 & 688357 & 2.4559 & 2.8906 & TST & \\
\hline CHEMBL3194449 & 688357 & 2.4559 & 3.1642 & TRN & \\
\hline CHEMBL1548492 & 688357 & 2.4559 & 2.6277 & TRN & \\
\hline CHEMBL1352094 & 688357 & 2.4559 & 3.1544 & TRN & \\
\hline CHEMBL1329235 & 688357 & 2.4559 & 2.6706 & TRN & \\
\hline CHEMBL1388922 & 688357 & 4.1921 & 3.3518 & TRN & \\
\hline CHEMBL1570492 & 688357 & 2.4559 & 2.4245 & TRN & \\
\hline CHEMBL1606890 & 688357 & 2.4559 & 2.9103 & TRN & \\
\hline CHEMBL1979295 & 688357 & 5.1411 & 4.55399 & 9999999999 & TRN \\
\hline CHEMBL1389695 & 688357 & 5.2355 & 4.1363 & TRN & \\
\hline CHEMBL1987472 & 688357 & 5.1348 & 3.31 & TRN & \\
\hline CHEMBL1439752 & 688357 & 2.4559 & 2.2171 & TRN & \\
\hline CHEMBL 1443775 & 688357 & 4.3591 & 3.2525 & TRN & \\
\hline CHEMBL1588483 & 688357 & 4.6632 & 2.6086 & TRN & \\
\hline CHEMBL3189827 & 688357 & 2.4559 & 2.8315 & TRN & \\
\hline CHEMBL3190967 & 688357 & 3.7648 & 3.7512 & TRN & \\
\hline CHEMBL1585206 & 688357 & 2.4559 & 2.775 & TRN & \\
\hline CHEMBL3190986 & 688357 & 4.5048 & 2.9013 & TRN & \\
\hline CHEMBL1299877 & 688357 & 2.4559 & 2.7718 & TST & \\
\hline CHEMBL1533979 & 688357 & 2.4559 & 2.81100 & 00000000004 & TRN \\
\hline CHEMBL1555488 & 688357 & 2.4559 & 2.9002 & TRN & \\
\hline CHEMBL1542554 & 688357 & 4.3269 & 4.0834 & TRN & \\
\hline CHEMBL1563297 & 688357 & 2.4559 & 2.2189 & TRN & \\
\hline CHEMBL1537759 & 688357 & 2.4559 & 2.7905 & TRN & \\
\hline
\end{tabular}

Page 25227 


\begin{tabular}{|c|c|c|c|c|c|}
\hline \multicolumn{6}{|c|}{ Supplemental Table S2.txt } \\
\hline CHEMBL1526951 & 688357 & 2.4559 & 3.0357 & TRN & \\
\hline CHEMBL1565084 & 688357 & 2.4559 & 2.3803 & TRN & \\
\hline CHEMBL1371415 & 688357 & 2.4559 & 2.9293 & TST & \\
\hline CHEMBL1339870 & 688357 & 2.4559 & 2.6482 & TRN & \\
\hline CHEMBL 3198618 & 688357 & 2.4559 & 3.4261 & TRN & \\
\hline CHEMBL1323744 & 688357 & 2.4559 & 3.1781 & TRN & \\
\hline CHEMBL1534781 & 688357 & 2.4559 & 3.2083 & TRN & \\
\hline CHEMBL1299757 & 688357 & 2.4559 & 3.3719 & TRN & \\
\hline CHEMBL1557337 & 688357 & 2.4559 & 2.4637 & TRN & \\
\hline CHEMBL1368680 & 688357 & 4.2358 & 2.4459 & TRN & \\
\hline CHEMBL1578009 & 688357 & 2.4559 & 2.8101 & TRN & \\
\hline CHEMBL1468065 & 688357 & 2.4559 & 2.8524 & TRN & \\
\hline CHEMBL1523792 & 688357 & 2.4559 & 3.1939 & TRN & \\
\hline CHEMBL1543279 & 688357 & 2.4559 & 2.6728 & TST & \\
\hline CHEMBL1414814 & 688357 & 2.4559 & 2.7071 & TRN & \\
\hline CHEMBL1359577 & 688357 & 2.4559 & 3.0913 & TRN & \\
\hline CHEMBL1332873 & 688357 & 2.4559 & 2.5805 & TRN & \\
\hline CHEMBL1596072 & 688357 & 4.2869 & 3.8223 & TRN & \\
\hline CHEMBL1549214 & 688357 & 2.4559 & 2.5245 & TRN & \\
\hline CHEMBL 1487460 & 688357 & 2.4559 & 2.615 & TRN & \\
\hline CHEMBL3198368 & 688357 & 2.4559 & 2.7644 & TRN & \\
\hline CHEMBL1391799 & 688357 & 2.4559 & 2.9018 & TRN & \\
\hline CHEMBL1582437 & 688357 & 2.4559 & 2.6278 & TRN & \\
\hline CHEMBL1519141 & 688357 & 2.4559 & 2.5341 & TRN & \\
\hline CHEMBL1597530 & 688357 & 2.4559 & 2.3872 & TST & \\
\hline CHEMBL1312428 & 688357 & 2.4559 & 3.1639 & TST & \\
\hline CHEMBL1611843 & 688357 & 2.4559 & 2.4567 & TRN & \\
\hline CHEMBL1461115 & 688357 & 2.4559 & 2.6013 & TRN & \\
\hline CHEMBL1600390 & 688357 & 2.4559 & 2.3343 & TRN & \\
\hline CHEMBL1364028 & 688357 & 2.4559 & 2.4503 & TRN & \\
\hline CHEMBL1306267 & 688357 & 2.4559 & 2.9741 & TRN & \\
\hline CHEMBL578675 & 688357 & 2.4559 & 2.93399 & 99999999997 & TRN \\
\hline CHEMBL3196364 & 688357 & 2.4559 & 3.3599 & TRN & \\
\hline CHEMBL1533431 & 688357 & 2.4559 & 2.6338 & TRN & \\
\hline CHEMBL1419228 & 688357 & 2.4559 & 3.25 & TST & \\
\hline CHEMBL1483037 & 688357 & 2.4559 & 3.3429 & TRN & \\
\hline CHEMBL1384178 & 688357 & 2.4559 & 2.6521 & TRN & \\
\hline CHEMBL1964464 & 688357 & 4.2397 & 2.9222 & TRN & \\
\hline CHEMBL1327569 & 688357 & 2.4559 & 2.2041 & TRN & \\
\hline CHEMBL1453214 & 688357 & 4.2985 & 3.6631 & TRN & \\
\hline CHEMBL1368242 & 688357 & 2.4559 & 2.7173 & TRN & \\
\hline CHEMBL1301465 & 688357 & 2.4559 & 2.6419 & TRN & \\
\hline CHEMBL3192021 & 688357 & 2.4559 & 3.0913 & TRN & \\
\hline CHEMBL1526469 & 688357 & 2.4559 & 2.6325 & TRN & \\
\hline CHEMBL1302327 & 688357 & 2.4559 & 2.7398 & TRN & \\
\hline CHEMBL3191242 & 688357 & 2.4559 & 3.4451 & TRN & \\
\hline CHEMBL3189416 & 688357 & 2.4559 & 3.491 & TRN & \\
\hline CHEMBL1351950 & 688357 & 2.4559 & 2.4001 & TST & \\
\hline
\end{tabular}


Supplemental Table S2.txt

\begin{tabular}{|c|c|c|c|c|c|}
\hline CHEMBL1524026 & 688357 & 4.9929 & 3.2645 & TRN & \\
\hline CHEMBL3210587 & 688357 & 4.4402 & 2.6417 & TRN & \\
\hline CHEMBL1442358 & 688357 & 2.4559 & 2.5272 & TRN & \\
\hline CHEMBL1579122 & 688357 & 2.4559 & 2.873 & TRN & \\
\hline CHEMBL534244 & 688357 & 2.4559 & 2.8198 & TRN & \\
\hline CHEMBL3199539 & 688357 & 2.4559 & 3.8512 & TRN & \\
\hline CHEMBL1564136 & 688357 & 2.4559 & 3.0386 & TST & \\
\hline CHEMBL1344163 & 688357 & 2.4559 & \multicolumn{2}{|c|}{3.4819999999999998} & TRN \\
\hline CHEMBL1572312 & 688357 & 2.4559 & 1.989 & TRN & \\
\hline CHEMBL1558070 & 688357 & 2.4559 & 3.3078 & TST & \\
\hline CHEMBL1958251 & 688357 & 2.4559 & 3.1524 & TRN & \\
\hline CHEMBL1370278 & 688357 & 2.4559 & 2.8219 & TRN & \\
\hline CHEMBL583603 & 688357 & 4.1 & 2.8207 & TRN & \\
\hline CHEMBL2002465 & 688357 & 2.4559 & 3.0131 & TRN & \\
\hline CHEMBL1575087 & 688357 & 2.4559 & \multicolumn{2}{|c|}{2.7230000000000003} & TRN \\
\hline CHEMBL1430905 & 688357 & 4.3859 & 2.3942 & TRN & \\
\hline CHEMBL1389763 & 688357 & 3.8097 & 3.012 & TRN & \\
\hline CHEMBL1490332 & 688357 & 2.4559 & 2.8891 & TRN & \\
\hline CHEMBL1986418 & 688357 & 2.4559 & 3.3921 & TRN & \\
\hline CHEMBL1305609 & 688357 & 2.4559 & 2.3431 & TRN & \\
\hline CHEMBL3199483 & 688357 & 2.4559 & 3.1723 & TRN & \\
\hline CHEMBL1385369 & 688357 & 2.4559 & 2.241 & TRN & \\
\hline CHEMBL1353289 & 688357 & 3.8575 & 2.9834 & TRN & \\
\hline CHEMBL1593768 & 688357 & 2.4559 & 2.7982 & TST & \\
\hline CHEMBL1967081 & 688357 & 2.4559 & 3.6569 & TRN & \\
\hline CHEMBL3194213 & 688357 & 2.4559 & 2.5718 & TRN & \\
\hline CHEMBL1488450 & 688357 & 2.4559 & 3.3285 & TRN & \\
\hline CHEMBL1453719 & 688357 & 2.4559 & 2.7774 & TRN & \\
\hline CHEMBL3196124 & 688357 & 4.0692 & 3.0607 & TRN & \\
\hline CHEMBL1502412 & 688357 & 2.4559 & 2.544 & TST & \\
\hline CHEMBL 3194563 & 688357 & 4.4193 & 3.3487 & TRN & \\
\hline CHEMBL1434383 & 688357 & 2.4559 & 2.6919 & TRN & \\
\hline CHEMBL1425140 & 688357 & 2.4559 & 2.4156 & TST & \\
\hline CHEMBL1462385 & 688357 & 4.2476 & 3.5433 & TRN & \\
\hline CHEMBL3199737 & 688357 & 4.3257 & 3.5953 & TRN & \\
\hline CHEMBL1444563 & 688357 & 2.4559 & 2.6193 & TRN & \\
\hline CHEMBL1430249 & 688357 & 2.4559 & 3.0337 & TRN & \\
\hline CHEMBL1454395 & 688357 & 4.0097 & 2.6608 & TRN & \\
\hline CHEMBL1527311 & 688357 & 4.1742 & 2.4125 & TRN & \\
\hline CHEMBL1431432 & 688357 & 2.4559 & 2.9536 & TST & \\
\hline CHEMBL1432028 & 688357 & 2.4559 & 2.5445 & TST & \\
\hline CHEMBL3192648 & 688357 & 2.4559 & 2.7005 & TRN & \\
\hline CHEMBL400912 & 688357 & 2.4559 & 3.0926 & TRN & \\
\hline CHEMBL1462239 & 688357 & 2.4559 & 2.5047 & TRN & \\
\hline CHEMBL1533210 & 688357 & 2.4559 & 3.3629 & TST & \\
\hline CHEMBL3191443 & 688357 & 2.4559 & 2.781 & TRN & \\
\hline CHEMBL1506679 & 688357 & 2.4559 & 2.9272 & TST & \\
\hline CHEMBL1973629 & 688357 & 4.6251 & 3.0803 & TRN & \\
\hline
\end{tabular}

Page 25229 


\begin{tabular}{|c|c|c|c|c|c|}
\hline & & \multicolumn{4}{|c|}{ Supplemental Table S2.txt } \\
\hline CHEMBL1493298 & 688357 & 2.4559 & 3.0721 & TRN & \\
\hline CHEMBL1353839 & 688357 & 2.4559 & 2.0873 & TRN & \\
\hline CHEMBL607140 & 688357 & 2.4559 & 2.7608 & TRN & \\
\hline CHEMBL1529400 & 688357 & 2.4559 & 2.6128 & TST & \\
\hline CHEMBL1557680 & 688357 & 2.4559 & 2.5143 & TST & \\
\hline CHEMBL210145 & 688357 & 2.4559 & 2.6689 & TRN & \\
\hline CHEMBL1421524 & 688357 & 2.4559 & 3.0013 & TST & \\
\hline CHEMBL3196457 & 688357 & 2.4559 & 2.9352 & TRN & \\
\hline CHEMBL1441528 & 688357 & 2.4559 & 2.3975 & TRN & \\
\hline CHEMBL1331866 & 688357 & 2.4559 & 2.5999 & TST & \\
\hline CHEMBL1603584 & 688357 & 2.4559 & 2.9992 & TRN & \\
\hline CHEMBL1499324 & 688357 & 2.4559 & 2.6281 & TRN & \\
\hline CHEMBL1389020 & 688357 & 2.4559 & 2.8878 & TRN & \\
\hline CHEMBL1344700 & 688357 & 2.4559 & 2.5239 & TST & \\
\hline CHEMBL1996749 & 688357 & 4.2331 & 3.4785 & TRN & \\
\hline CHEMBL1332165 & 688357 & 2.4559 & 2.8414 & TRN & \\
\hline CHEMBL1514530 & 688357 & 4.2223 & 2.7051 & TRN & \\
\hline CHEMBL1568022 & 688357 & 2.4559 & 2.0465 & TRN & \\
\hline CHEMBL1337611 & 688357 & 2.4559 & 2.8057 & TRN & \\
\hline CHEMBL1394571 & 688357 & 2.4559 & 2.63199 & 99999999997 & TRN \\
\hline CHEMBL1985759 & 688357 & 2.4559 & 3.4092 & TRN & \\
\hline CHEMBL1386014 & 688357 & 2.4559 & 2.6207 & TST & \\
\hline CHEMBL3189519 & 688357 & 4.4453 & 3.1699 & TRN & \\
\hline CHEMBL1603830 & 688357 & 2.4559 & 2.7644 & TRN & \\
\hline CHEMBL1424966 & 688357 & 2.4559 & 3.0445 & TRN & \\
\hline CHEMBL1335030 & 688357 & 4.4119 & 3.0002 & TRN & \\
\hline CHEMBL1424181 & 688357 & 2.4559 & 3.0994 & TST & \\
\hline CHEMBL1411930 & 688357 & 2.4559 & 2.2839 & TRN & \\
\hline CHEMBL1326504 & 688357 & 2.4559 & 2.8823 & TRN & \\
\hline CHEMBL1387740 & 688357 & 2.4559 & 2.6181 & TST & \\
\hline CHEMBL1532068 & 688357 & 2.4559 & 2.7482 & TRN & \\
\hline CHEMBL1304318 & 688357 & 2.4559 & 2.755 & TST & \\
\hline CHEMBL1351145 & 688357 & 2.4559 & 2.4908 & TRN & \\
\hline CHEMBL1564943 & 688357 & 2.4559 & 2.5812 & TRN & \\
\hline CHEMBL1334272 & 688357 & 4.606 & 3.5555 & TRN & \\
\hline CHEMBL1990786 & 688357 & 2.4559 & 3.1699 & TRN & \\
\hline CHEMBL1330501 & 688357 & 2.4559 & 2.2366 & TRN & \\
\hline CHEMBL1411542 & 688357 & 3.4699 & 3.1716 & TRN & \\
\hline CHEMBL1505604 & 688357 & 5.1436 & 4.3642 & TRN & \\
\hline CHEMBL1606291 & 688357 & 2.4559 & 3.1391 & TRN & \\
\hline CHEMBL1091556 & 688357 & 2.4559 & 3.4747 & TRN & \\
\hline CHEMBL1323011 & 688357 & 2.4559 & 2.8486 & TRN & \\
\hline CHEMBL1411247 & 688357 & 2.4559 & 2.8747 & TRN & \\
\hline CHEMBL1387060 & 688357 & 2.4559 & 2.559 & TRN & \\
\hline CHEMBL1486691 & 688357 & 2.4559 & 3.0605 & TST & \\
\hline CHEMBL1402114 & 688357 & 2.4559 & 2.4471 & TRN & \\
\hline CHEMBL3197343 & 688357 & 2.4559 & 3.3526 & TRN & \\
\hline CHEMBL1524692 & 688357 & 2.4559 & 2.7194 & TRN & \\
\hline
\end{tabular}




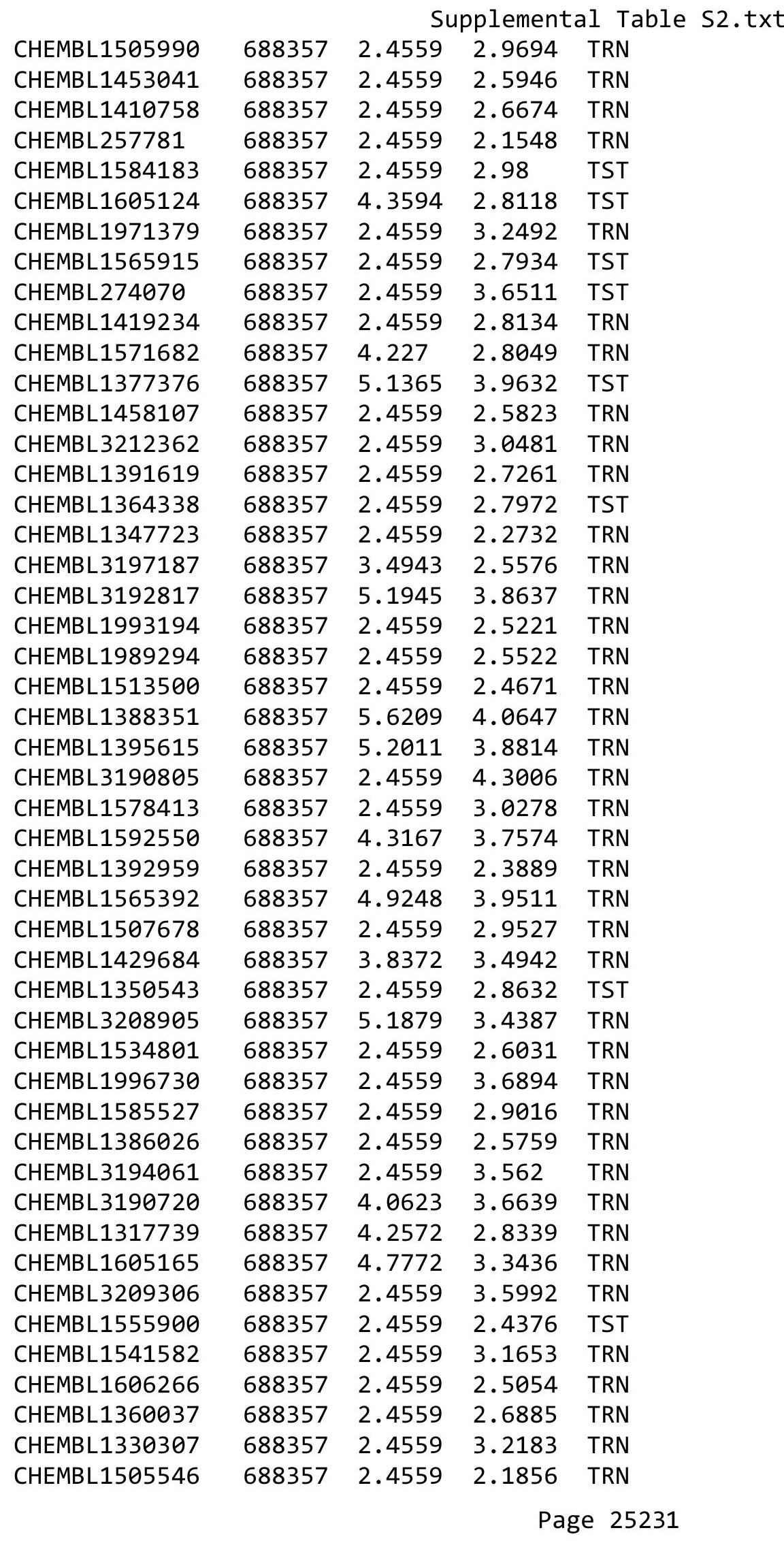




\begin{tabular}{|c|c|c|c|c|c|}
\hline \multicolumn{6}{|c|}{ Supplemental Table S2.txt } \\
\hline CHEMBL600778 & 688357 & 2.4559 & 2.9986 & TRN & \\
\hline CHEMBL1977301 & 688357 & 2.4559 & 3.2014 & TRN & \\
\hline CHEMBL1465665 & 688357 & 2.4559 & 2.9681 & TST & \\
\hline CHEMBL3196499 & 688357 & 4.5905 & 3.1706 & TRN & \\
\hline CHEMBL1423601 & 688357 & 2.4559 & 2.8232 & TRN & \\
\hline CHEMBL3212954 & 688357 & 2.4559 & 2.6871 & TST & \\
\hline CHEMBL585827 & 688357 & 2.4559 & 2.8134 & TRN & \\
\hline CHEMBL1606525 & 688357 & 2.4559 & 2.8836 & TST & \\
\hline CHEMBL1369853 & 688357 & 2.4559 & 2.7322 & TRN & \\
\hline CHEMBL199405 & 688357 & 2.4559 & 3.2343 & TRN & \\
\hline CHEMBL1559260 & 688357 & 2.4559 & 3.0313 & TST & \\
\hline CHEMBL1610062 & 688357 & 2.4559 & 2.7712 & TST & \\
\hline CHEMBL1610242 & 688357 & 4.2642 & 2.5733 & TRN & \\
\hline CHEMBL1520745 & 688357 & 2.4559 & 2.69100 & 00000000003 & TST \\
\hline CHEMBL3196282 & 688357 & 3.5826 & 2.9774 & TRN & \\
\hline CHEMBL1418534 & 688357 & 2.4559 & 2.5447 & TRN & \\
\hline CHEMBL1345825 & 688357 & 2.4559 & 2.9736 & TRN & \\
\hline CHEMBL1366228 & 688357 & 2.4559 & 2.5079 & TRN & \\
\hline CHEMBL1535919 & 688357 & 4.5656 & 3.2852 & TRN & \\
\hline CHEMBL3190293 & 688357 & 2.4559 & 3.0274 & TRN & \\
\hline CHEMBL1308598 & 688357 & 2.4559 & 2.9558 & TRN & \\
\hline CHEMBL1564742 & 688357 & 2.4559 & 2.5815 & TRN & \\
\hline CHEMBL581452 & 688357 & 4.2806 & 2.8261 & TRN & \\
\hline CHEMBL1300421 & 688357 & 2.4559 & 2.7173 & TRN & \\
\hline CHEMBL455284 & 688357 & 2.4559 & 4.7604 & TRN & \\
\hline CHEMBL3198227 & 688357 & 2.4559 & 3.5001 & TRN & \\
\hline CHEMBL1987419 & 688357 & 4.5754 & 4.2138 & TRN & \\
\hline CHEMBL1323557 & 688357 & 2.4559 & 2.5203 & TRN & \\
\hline CHEMBL1988042 & 688357 & 2.4559 & 3.3958 & TRN & \\
\hline CHEMBL1387605 & 688357 & 4.7801 & 4.8022 & TRN & \\
\hline CHEMBL1478971 & 688357 & 2.4559 & 2.7195 & TST & \\
\hline CHEMBL546170 & 688357 & 5.1605 & 2.8471 & TRN & \\
\hline CHEMBL3198720 & 688357 & 2.4559 & 3.7321 & TRN & \\
\hline CHEMBL1991242 & 688357 & 4.4121 & 3.1162 & TRN & \\
\hline CHEMBL1990959 & 688357 & 4.247 & 3.9012 & TRN & \\
\hline CHEMBL3195036 & 688357 & 2.4559 & 2.8977 & TRN & \\
\hline CHEMBL 1480983 & 688357 & 2.4559 & 3.1608 & TRN & \\
\hline CHEMBL1372698 & 688357 & 2.4559 & 2.4543 & TRN & \\
\hline CHEMBL1548609 & 688357 & 2.4559 & 2.6718 & TRN & \\
\hline CHEMBL1493490 & 688357 & 2.4559 & 2.9909 & TRN & \\
\hline CHEMBL1410130 & 688357 & 4.9231 & 3.1901 & TRN & \\
\hline CHEMBL1536972 & 688357 & 2.4559 & 2.5618 & TRN & \\
\hline CHEMBL1583715 & 688357 & 2.4559 & 2.8112 & TRN & \\
\hline CHEMBL3196163 & 688357 & 2.4559 & 2.9012 & TRN & \\
\hline CHEMBL1964480 & 688357 & 2.4559 & 3.1099 & TRN & \\
\hline CHEMBL1370523 & 688357 & 3.7729 & 2.8353 & TRN & \\
\hline CHEMBL1583292 & 688357 & 2.4559 & 3.0777 & TST & \\
\hline CHEMBL1490617 & 688357 & 4.227 & 4.0091 & TRN & \\
\hline
\end{tabular}




\begin{tabular}{|c|c|c|c|c|c|}
\hline \multirow[b]{2}{*}{ CHEMBL 3191025} & \multicolumn{5}{|c|}{ Supplemental Table S2.txt } \\
\hline & 688357 & 2.4559 & 3.1299 & TRN & \\
\hline CHEMBL1468264 & 688357 & 2.4559 & 3.2401 & TST & \\
\hline CHEMBL 2006168 & 688357 & 2.4559 & 3.55899 & 99999999997 & TRN \\
\hline CHEMBL1446962 & 688357 & 4.2499 & 2.8747 & TRN & \\
\hline CHEMBL534353 & 688357 & 2.4559 & 2.8379 & TRN & \\
\hline CHEMBL1469884 & 688357 & 2.4559 & 2.425 & TRN & \\
\hline CHEMBL1541658 & 688357 & 2.4559 & 2.5799 & TST & \\
\hline CHEMBL1370513 & 688357 & 2.4559 & 2.7525 & TRN & \\
\hline CHEMBL1583414 & 688357 & 5.3571 & 3.8767 & TRN & \\
\hline CHEMBL3190900 & 688357 & 2.4559 & 3.4411 & TRN & \\
\hline CHEMBL3195241 & 688357 & 2.4559 & 3.2424 & TRN & \\
\hline CHEMBL1326110 & 688357 & 4.2635 & 3.5244 & TST & \\
\hline CHEMBL1527214 & 688357 & 4.5968 & 4.1735 & TRN & \\
\hline CHEMBL1612656 & 688357 & 2.4559 & 3.5262 & TRN & \\
\hline CHEMBL1503200 & 688357 & 2.4559 & 2.7288 & TRN & \\
\hline CHEMBL1314042 & 688357 & 2.4559 & 2.2257 & TRN & \\
\hline CHEMBL1556113 & 688357 & 2.4559 & 2.8824 & TRN & \\
\hline CHEMBL1324281 & 688357 & 2.4559 & 2.3539 & TRN & \\
\hline CHEMBL1385117 & 688357 & 2.4559 & 2.5125 & TRN & \\
\hline CHEMBL1522014 & 688357 & 2.4559 & 2.6968 & TRN & \\
\hline CHEMBL1563702 & 688357 & 4.1946 & 3.8113 & TRN & \\
\hline CHEMBL1404027 & 688357 & 2.4559 & 3.0188 & TRN & \\
\hline CHEMBL1519928 & 688357 & 2.4559 & 2.0708 & TRN & \\
\hline CHEMBL1575341 & 688357 & 2.4559 & 3.3477 & TRN & \\
\hline CHEMBL1451784 & 688357 & 2.4559 & 2.6678 & TRN & \\
\hline CHEMBL1332664 & 688357 & 4.1366 & 2.7134 & TRN & \\
\hline CHEMBL1472175 & 688357 & 2.4559 & 3.1821 & TRN & \\
\hline CHEMBL1381135 & 688357 & 3.6687 & 3.0488 & TRN & \\
\hline CHEMBL3197760 & 688357 & 2.4559 & 2.7193 & TRN & \\
\hline CHEMBL1338677 & 688357 & 2.4559 & 2.4465 & TRN & \\
\hline CHEMBL1352764 & 688357 & 2.4559 & 2.5147 & TST & \\
\hline CHEMBL1416015 & 688357 & 2.4559 & 2.8522 & TRN & \\
\hline CHEMBL1403100 & 688357 & 2.4559 & 2.9185 & TST & \\
\hline CHEMBL1326294 & 688357 & 2.4559 & 2.9489 & TRN & \\
\hline CHEMBL1448284 & 688357 & 2.4559 & 2.8138 & TRN & \\
\hline CHEMBL1432177 & 688357 & 2.4559 & 2.6184 & TRN & \\
\hline CHEMBL1560590 & 688357 & 2.4559 & 3.5587 & TRN & \\
\hline CHEMBL1330279 & 688357 & 2.4559 & 2.7824 & TRN & \\
\hline CHEMBL1487598 & 688357 & 2.4559 & 3.1393 & TST & \\
\hline CHEMBL3198765 & 688357 & 2.4559 & 2.8248 & TRN & \\
\hline CHEMBL1508925 & 688357 & 2.4559 & 2.60699 & 99999999998 & TST \\
\hline CHEMBL1300836 & 688357 & 5.2988 & 4.2655 & TRN & \\
\hline CHEMBL606532 & 688357 & 2.4559 & 2.8229 & TRN & \\
\hline CHEMBL1993522 & 688357 & 2.4559 & 3.1267 & TRN & \\
\hline CHEMBL1368262 & 688357 & 2.4559 & 2.9416 & TST & \\
\hline CHEMBL1527696 & 688357 & 2.4559 & 2.5994 & TST & \\
\hline CHEMBL1314676 & 688357 & 2.4559 & 2.0417 & TRN & \\
\hline CHEMBL1487964 & 688357 & 2.4559 & 2.4586 & TRN & \\
\hline
\end{tabular}




CHEMBL1485099
CHEMBL1387536
CHEMBL3212085
CHEMBL3194209
CHEMBL1485516
CHEMBL1303189
CHEMBL2028179
CHEMBL1351924
CHEMBL1374434
CHEMBL1400058
CHEMBL3191011
CHEMBL1573551
CHEMBL1579064
CHEMBL590927
CHEMBL1983418
CHEMBL1311879
CHEMBL1434720
CHEMBL1582111
CHEMBL1887153
CHEMBL1524927
CHEMBL577928
CHEMBL1418230
CHEMBL547285
CHEMBL1997797
CHEMBL2000750
CHEMBL1577606
CHEMBL1558065
CHEMBL1479049
CHEMBL 2004809
CHEMBL1462446
CHEMBL1555271
CHEMBL1300409
CHEMBL1577759
CHEMBLI 1430971
CHEMBL1547951
CHEMBL3195732
CHEMBL1548689
CHEMBL1312668
CHEMBL3194899
CHEMBL1548290
CHEMBL1598010
CHEMBL3194752
CHEMBL1541834
CHEMBL1440352
CHEMBL1449923

Supplemental Table S2.txt

\begin{tabular}{llll}
688357 & 4.1047 & 2.8735 & TRN \\
688357 & 3.8279 & 2.6844 & TRN \\
688357 & 2.4559 & 2.9431 & TRN \\
688357 & 2.4559 & 3.3586 & TRN \\
688357 & 2.4559 & 3.2973 & TRN \\
688357 & 2.4559 & 3.5173 & TRN \\
688357 & 2.4559 & 2.6701 & TST \\
688357 & 2.4559 & 2.8905 & TRN \\
688357 & 2.4559 & 2.3667 & TRN \\
688357 & 2.4559 & 3.5427 & TST \\
688357 & 2.4559 & 2.5959 & TRN \\
688357 & 2.4559 & 2.5704 & TRN \\
688357 & 4.9284 & 3.9127 & TRN \\
688357 & 2.4559 & 2.7067 & TRN \\
688357 & 2.4559 & 3.0713 & TRN \\
688357 & 5.1894 & 3.8117 & TRN \\
688357 & 2.4559 & 2.7974 & TRN \\
688357 & 2.4559 & 3.5926 & TRN \\
688357 & 2.4559 & 3.3425 & TRN \\
688357 & 4.1772 & 3.5492 & TRN \\
688357 & 2.4559 & 2.593 & TRN \\
688357 & 2.4559 & 3.2009 & TRN \\
688357 & 2.4559 & 2.6842 & TRN \\
688357 & 2.4559 & 3.0903 & TST \\
688357 & 2.4559 & 3.3359 & TRN \\
688357 & 2.4559 & 2.4482 & TRN \\
688357 & 2.4559 & 3.015 & TRN \\
688357 & 2.4559 & 2.8825 & TRN \\
688357 & 2.4559 & 3.0894 & TRN \\
688357 & 2.4559 & 2.8182 & TRN \\
688357 & 2.4559 & 2.7494 & TRN \\
688357 & 2.4559 & 2.6128 & TRN \\
688357 & 2.4559 & 3.4556 & TRN \\
688357 & 2.4559 & 2.6674 & TRN \\
688357 & 4.5587 & 3.968 & TRN \\
68835757 & 2.4559 & 3.4456 & TRN \\
688357 & 2.4559 & 3.1172 & TRN \\
688357 & 3.7967 & 3.2075 & TRN \\
688357 & 2.4559 & 2.6903 & TST \\
688357 & 2.4559 & 2.4733 & TST \\
688357 & 2.4559 & 3.1386 & TRN \\
688357 & 2.4559 & 2.4109 & TRN \\
688357 & 2.4559 & 2.6292 & TRN \\
688357 & 2.4559 & 2.7176 & TRN \\
688357 & 2.4559 & 2.9843 & TRN \\
6859 & 2.3104 & TRN \\
\hline
\end{tabular}

Page 25234 
Supplemental Table S2.txt

\begin{tabular}{|c|c|c|c|c|}
\hline CHEMBL1327873 & 688357 & 2.4559 & 2.7686 & TRN \\
\hline CHEMBL1333387 & 688357 & 2.4559 & 3.13 & TRN \\
\hline CHEMBL1566300 & 688357 & 2.4559 & 2.613 & TRN \\
\hline CHEMBL1465294 & 688357 & 2.4559 & 2.5617 & TRN \\
\hline CHEMBL1430053 & 688357 & 5.3291 & 3.9919 & TRN \\
\hline CHEMBL1303891 & 688357 & 2.4559 & 2.8982 & TRN \\
\hline CHEMBL1348691 & 688357 & 3.8424 & 3.4534 & TRN \\
\hline CHEMBL3197978 & 688357 & 2.4559 & 2.9905 & TRN \\
\hline CHEMBL1392818 & 688357 & 2.4559 & 2.5586 & TRN \\
\hline CHEMBL1415705 & 688357 & 4.2136 & 2.8968 & TST \\
\hline CHEMBL1317657 & 688357 & 3.8639 & 2.9756 & TRN \\
\hline CHEMBL3195688 & 688357 & 2.4559 & 3.1644 & TRN \\
\hline CHEMBL592359 & 688357 & 2.4559 & 2.3007 & TRN \\
\hline CHEMBL1304509 & 688357 & 2.4559 & 2.5279 & TRN \\
\hline CHEMBL 3199550 & 688357 & 2.4559 & 3.4237 & TRN \\
\hline CHEMBL1428692 & 688357 & 4.1387 & 2.6777 & TST \\
\hline CHEMBL1609234 & 688357 & 4.1312 & 2.7829 & TRN \\
\hline CHEMBL1523550 & 688357 & 4.6391 & 3.0967 & TRN \\
\hline CHEMBL1413505 & 688357 & 2.4559 & 2.961999 & 9999999997 \\
\hline CHEMBL1413464 & 688357 & 2.4559 & 3.0145 & TRN \\
\hline CHEMBL1464109 & 688357 & 2.4559 & 2.3383 & TRN \\
\hline CHEMBL1452421 & 688357 & 2.4559 & 2.7819 & TRN \\
\hline CHEMBL1994034 & 688357 & 2.4559 & 3.0748 & TRN \\
\hline CHEMBL1414754 & 688357 & 5.2162 & 3.7927 & TRN \\
\hline CHEMBL1369012 & 688357 & 2.4559 & 2.8426 & TRN \\
\hline CHEMBL1456267 & 688357 & 2.4559 & 2.8312 & TRN \\
\hline CHEMBL1390364 & 688357 & 2.4559 & 3.0728 & TRN \\
\hline CHEMBL1982569 & 688357 & 2.4559 & 2.9124 & TRN \\
\hline CHEMBL1335107 & 688357 & 2.4559 & 2.5712 & TRN \\
\hline CHEMBL579045 & 688357 & 2.4559 & 2.6441 & TRN \\
\hline CHEMBL1965132 & 688357 & 4.78 & 3.9709 & TRN \\
\hline CHEMBL1396523 & 688357 & 2.4559 & 3.2468 & TRN \\
\hline CHEMBL1373763 & 688357 & 2.4559 & 2.5317 & TRN \\
\hline CHEMBL1426720 & 688357 & 4.4905 & 3.5121 & TRN \\
\hline CHEMBL1532964 & 688357 & 2.4559 & 2.6765 & TRN \\
\hline CHEMBL3197126 & 688357 & 2.4559 & 3.1067 & TRN \\
\hline CHEMBL1989897 & 688357 & 4.8181 & 3.3816 & TRN \\
\hline CHEMBL1407259 & 688357 & 3.7419 & 2.6864 & TRN \\
\hline CHEMBL1501587 & 688357 & 4.4614 & 4.3674 & TRN \\
\hline CHEMBL1330475 & 688357 & 4.2748 & 2.8345 & TRN \\
\hline CHEMBL3199599 & 688357 & 2.4559 & 3.32 & TRN \\
\hline CHEMBL1389460 & 688357 & 2.4559 & 2.4258 & TRN \\
\hline CHEMBL1331523 & 688357 & 2.4559 & 2.6467 & TRN \\
\hline CHEMBL1321916 & 688357 & 2.4559 & 2.6123 & TRN \\
\hline CHEMBL1307871 & 688357 & 2.4559 & 2.9412 & TRN \\
\hline CHEMBL 1577274 & 688357 & 2.4559 & 2.7476 & TRN \\
\hline CHEMBL 2359467 & 688357 & 2.4559 & 3.1921 & TRN \\
\hline CHEMBL1985667 & 688357 & 2.4559 & 3.5017 & TRN \\
\hline
\end{tabular}

Page 25235 


\begin{tabular}{|c|c|c|c|c|c|}
\hline \multirow[b]{2}{*}{ CHEMBL1579117 } & \multicolumn{5}{|c|}{ Supplemental Table S2.txt } \\
\hline & 688357 & 2.4559 & 2.9378 & TST & \\
\hline CHEMBL1300398 & 688357 & 2.4559 & 2.65100 & 00000000002 & TRN \\
\hline CHEMBL1334393 & 688357 & 2.4559 & 3.1384 & TRN & \\
\hline CHEMBL1374144 & 688357 & 4.4517 & 2.8959 & TRN & \\
\hline CHEMBL1327067 & 688357 & 2.4559 & 3.0837 & TRN & \\
\hline CHEMBL1428353 & 688357 & 2.4559 & 2.634 & TRN & \\
\hline CHEMBL600862 & 688357 & 2.4559 & 2.8612 & TRN & \\
\hline CHEMBL1352843 & 688357 & 2.4559 & 2.8869 & TRN & \\
\hline CHEMBL1439833 & 688357 & 2.4559 & 2.3437 & TRN & \\
\hline CHEMBL1598785 & 688357 & 2.4559 & 2.6954 & TRN & \\
\hline CHEMBL 2359911 & 688357 & 2.4559 & 2.9296 & TRN & \\
\hline CHEMBL1613247 & 688357 & 2.4559 & 2.8926 & TST & \\
\hline CHEMBL1321065 & 688357 & 2.4559 & 2.9235 & TST & \\
\hline CHEMBL450802 & 688357 & 2.4559 & 2.86899 & 99999999998 & TRN \\
\hline CHEMBL1421529 & 688357 & 2.4559 & 2.8399 & TRN & \\
\hline CHEMBL1598129 & 688357 & 2.4559 & 2.9838 & TST & \\
\hline CHEMBL1401521 & 688357 & 2.4559 & 2.6907 & TRN & \\
\hline CHEMBL1427622 & 688357 & 2.4559 & 2.5662 & TRN & \\
\hline CHEMBL1612069 & 688357 & 2.4559 & 2.411 & TRN & \\
\hline CHEMBL1607681 & 688357 & 2.4559 & 2.1954 & TRN & \\
\hline CHEMBL1320702 & 688357 & 2.4559 & 4.0278 & TRN & \\
\hline CHEMBL1500265 & 688357 & 2.4559 & 2.9484 & TRN & \\
\hline CHEMBL1381206 & 688357 & 3.7559 & 3.0393 & TRN & \\
\hline CHEMBL1584327 & 688357 & 2.4559 & 2.8312 & TRN & \\
\hline CHEMBL1348966 & 688357 & 2.4559 & 2.7963 & TRN & \\
\hline CHEMBL1502859 & 688357 & 2.4559 & 2.5514 & TRN & \\
\hline CHEMBL3191962 & 688357 & 5.1318 & 3.8186 & TRN & \\
\hline CHEMBL1499293 & 688357 & 2.4559 & 2.5974 & TRN & \\
\hline CHEMBL1992912 & 688357 & 2.4559 & 3.6331 & TRN & \\
\hline CHEMBL1996068 & 688357 & 5.1196 & 4.8109 & TRN & \\
\hline CHEMBL1573589 & 688357 & 4.3042 & 2.5227 & TRN & \\
\hline CHEMBL1581904 & 688357 & 2.4559 & 2.3594 & TRN & \\
\hline CHEMBL1559980 & 688357 & 2.4559 & 2.4203 & TST & \\
\hline CHEMBL1995169 & 688357 & 3.7193 & 3.8499 & TRN & \\
\hline CHEMBL585622 & 688357 & 4.5328 & 2.6341 & TRN & \\
\hline CHEMBL1300608 & 688357 & 2.4559 & 2.9505 & TRN & \\
\hline CHEMBL1422822 & 688357 & 2.4559 & 3.0951 & TRN & \\
\hline CHEMBL1462882 & 688357 & 5.1255 & 3.8269 & TRN & \\
\hline CHEMBL1983939 & 688357 & 4.4277 & 3.3623 & TRN & \\
\hline CHEMBL1368998 & 688357 & 2.4559 & 2.5411 & TRN & \\
\hline CHEMBL1582032 & 688357 & 4.3279 & 2.7455 & TRN & \\
\hline CHEMBL1332539 & 688357 & 2.4559 & 2.7055 & TST & \\
\hline CHEMBL1401911 & 688357 & 2.4559 & 2.6102 & TRN & \\
\hline CHEMBL3196134 & 688357 & 2.4559 & 3.1116 & TRN & \\
\hline CHEMBL3190517 & 688357 & 2.4559 & 2.9695 & TST & \\
\hline CHEMBL1970924 & 688357 & 2.4559 & 2.9458 & TRN & \\
\hline CHEMBL1976225 & 688357 & 2.4559 & 2.8697 & TRN & \\
\hline CHEMBL1577613 & 688357 & 4.5059 & 4.2264 & TRN & \\
\hline
\end{tabular}




\begin{tabular}{|c|c|c|c|c|}
\hline & & & oplement & al $\mathrm{T}$ \\
\hline CHEMBL3189791 & 688357 & 2.4559 & 3.2474 & TRN \\
\hline CHEMBL1550931 & 688357 & 4.5042 & 3.3868 & TRN \\
\hline CHEMBL1349631 & 688357 & 2.4559 & 3.4946 & TRN \\
\hline CHEMBL1516347 & 688357 & 4.3813 & 2.6504 & TST \\
\hline CHEMBL1511422 & 688357 & 2.4559 & 2.4385 & TRN \\
\hline CHEMBL3212629 & 688357 & 3.5254 & 2.7126 & TRN \\
\hline CHEMBL1540630 & 688357 & 2.4559 & 2.6547 & TRN \\
\hline CHEMBL1522631 & 688357 & 2.4559 & 3.0246 & TRN \\
\hline CHEMBL1416745 & 688357 & 2.4559 & 2.8093 & TRN \\
\hline CHEMBL1570835 & 688357 & 2.4559 & 2.6726 & TRN \\
\hline CHEMBL1374937 & 688357 & 2.4559 & 2.6671 & TRN \\
\hline CHEMBL1458314 & 688357 & 2.4559 & 2.3984 & TRN \\
\hline CHEMBL1505090 & 688357 & 2.4559 & 3.5379 & TRN \\
\hline CHEMBL1501755 & 688357 & 2.4559 & 2.0841 & TRN \\
\hline CHEMBL1594475 & 688357 & 2.4559 & 2.9301 & TRN \\
\hline CHEMBL1453076 & 688357 & 2.4559 & 2.9773 & TRN \\
\hline CHEMBL1431477 & 688357 & 2.4559 & 2.2766 & TRN \\
\hline CHEMBL1607403 & 688357 & 2.4559 & 2.8183 & TRN \\
\hline CHEMBL588804 & 688357 & 2.4559 & 2.995 & TRN \\
\hline CHEMBL1454436 & 688357 & 2.4559 & 2.4984 & TRN \\
\hline CHEMBL1536861 & 688357 & 2.4559 & 2.8144 & TRN \\
\hline CHEMBL1330370 & 688357 & 2.4559 & 2.5539 & TST \\
\hline CHEMBL1573531 & 688357 & 2.4559 & 2.3606 & TRN \\
\hline CHEMBL487356 & 688357 & 2.4559 & 3.1213 & TRN \\
\hline CHEMBL1308089 & 688357 & 2.4559 & 2.3733 & TRN \\
\hline CHEMBL 3191874 & 688357 & 4.7489 & 2.8827 & TRN \\
\hline CHEMBL1309853 & 688357 & 2.4559 & 2.9363 & TRN \\
\hline CHEMBL1348683 & 688357 & 2.4559 & 2.8186 & TRN \\
\hline CHEMBL1440167 & 688357 & 2.4559 & 2.8007 & TRN \\
\hline CHEMBL1500469 & 688357 & 2.4559 & 2.5418 & TRN \\
\hline CHEMBL 2005895 & 688357 & 4.8991 & 4.0956 & TRN \\
\hline CHEMBL1543723 & 688357 & 4.253 & 3.0853 & TRN \\
\hline CHEMBL1463491 & 688357 & 4.6742 & 1.933 & TST \\
\hline CHEMBL1600263 & 688357 & 2.4559 & 2.9103 & TST \\
\hline CHEMBL1522258 & 688357 & 2.4559 & 2.2158 & TRN \\
\hline CHEMBL1454517 & 688357 & 4.2838 & 2.9633 & TRN \\
\hline CHEMBL602218 & 688357 & 2.4559 & 3.227 & TRN \\
\hline CHEMBL1440238 & 688357 & 4.6784 & 3.8571 & TRN \\
\hline CHEMBL548540 & 688357 & 2.4559 & 2.9558 & TRN \\
\hline CHEMBL1595676 & 688357 & 2.4559 & 2.3524 & TRN \\
\hline CHEMBL3192078 & 688357 & 2.4559 & 3.2604 & TRN \\
\hline CHEMBL3195682 & 688357 & 2.4559 & 3.23 & TRN \\
\hline CHEMBL1389940 & 688357 & 4.7094 & 2.8992 & TRN \\
\hline CHEMBL1979784 & 688357 & 4.5452 & 2.5872 & TRN \\
\hline CHEMBL1382583 & 688357 & 2.4559 & 2.6361 & TRN \\
\hline CHEMBL3197127 & 688357 & 2.4559 & 3.682 & TRN \\
\hline CHEMBL1978901 & 688357 & 2.4559 & 3.312 & TRN \\
\hline CHEMBL1523867 & 688357 & 2.4559 & 2.4106 & TRN \\
\hline
\end{tabular}




\begin{tabular}{|c|c|c|c|c|c|}
\hline & & \multicolumn{4}{|c|}{ Supplemental Table S2.txt } \\
\hline CHEMBL1303082 & 688357 & 2.4559 & 2.9009 & TRN & \\
\hline CHEMBL1612424 & 688357 & 4.4221 & 2.7031 & TRN & \\
\hline CHEMBL3189323 & 688357 & 4.4463 & 3.4017 & TRN & \\
\hline CHEMBL 3195273 & 688357 & 2.4559 & 2.5932 & TRN & \\
\hline CHEMBL1359902 & 688357 & 4.4652 & 2.5777 & TRN & \\
\hline CHEMBL1490566 & 688357 & 2.4559 & 2.3421 & TRN & \\
\hline CHEMBL1491222 & 688357 & 2.4559 & 2.1956 & TRN & \\
\hline CHEMBL1519731 & 688357 & 5.1821 & 4.0685 & TRN & \\
\hline CHEMBL479368 & 688357 & 2.4559 & 2.8927 & TRN & \\
\hline CHEMBL1613672 & 688357 & 2.4559 & 2.9917 & TRN & \\
\hline CHEMBL104732 & 688357 & 5.2134 & 3.6886 & TRN & \\
\hline CHEMBL1331881 & 688357 & 2.4559 & 2.4837 & TRN & \\
\hline CHEMBL1313406 & 688357 & 2.4559 & 3.1377 & TRN & \\
\hline CHEMBL1446214 & 688357 & 2.4559 & 2.3195 & TRN & \\
\hline CHEMBL1993190 & 688357 & 5.1375 & 4.1165 & TRN & \\
\hline CHEMBL 3194562 & 688357 & 2.4559 & 3.5916 & TRN & \\
\hline CHEMBL1468804 & 688357 & 2.4559 & 2.8909 & TST & \\
\hline CHEMBL1340698 & 688357 & 2.4559 & 2.8776 & TRN & \\
\hline CHEMBL1472304 & 688357 & 2.4559 & 3.0027 & TRN & \\
\hline CHEMBL1573309 & 688357 & 2.4559 & 2.992 & TRN & \\
\hline CHEMBL1323804 & 688357 & 2.4559 & 3.3076 & TST & \\
\hline CHEMBL 3039775 & 688357 & 2.4559 & 2.9585 & TRN & \\
\hline CHEMBL3145071 & 688357 & 2.4559 & 2.7572 & TRN & \\
\hline CHEMBL592600 & 688357 & 2.4559 & 2.7891 & TRN & \\
\hline CHEMBL1449883 & 688357 & 2.4559 & 2.6621 & TRN & \\
\hline CHEMBL1590254 & 688357 & 2.4559 & 2.2395 & TRN & \\
\hline CHEMBL1547019 & 688357 & 2.4559 & 2.6389 & TRN & \\
\hline CHEMBL1568712 & 688357 & 2.4559 & 3.1634 & TRN & \\
\hline CHEMBL1398764 & 688357 & 2.4559 & 2.4338 & TRN & \\
\hline CHEMBL1371386 & 688357 & 2.4559 & 3.5475 & TRN & \\
\hline CHEMBL1435474 & 688357 & 2.4559 & 2.7294 & TST & \\
\hline CHEMBL1537451 & 688357 & 4.2895 & 2.9936 & TRN & \\
\hline CHEMBL1536148 & 688357 & 2.4559 & 2.439 & TRN & \\
\hline CHEMBL1982662 & 688357 & 4.8592 & 4.1168 & TRN & \\
\hline CHEMBL3199045 & 688357 & 2.4559 & 3.4129 & TRN & \\
\hline CHEMBL1412396 & 688357 & 5.301 & 3.2959 & TRN & \\
\hline CHEMBL1552813 & 688357 & 2.4559 & 2.4579 & TST & \\
\hline CHEMBL1300235 & 688357 & 2.4559 & 2.6163 & TST & \\
\hline CHEMBL1516498 & 688357 & 2.4559 & 2.6364 & TRN & \\
\hline CHEMBL1306283 & 688357 & 4.3406 & 3.2653 & TRN & \\
\hline CHEMBL1969300 & 688357 & 2.4559 & 2.8965 & TRN & \\
\hline CHEMBL1473419 & 688357 & 2.4559 & 2.6474 & TRN & \\
\hline CHEMBL1484284 & 688357 & 2.4559 & 2.9978 & TST & \\
\hline CHEMBL3191106 & 688357 & 2.4559 & 2.4193 & TRN & \\
\hline CHEMBL1581517 & 688357 & 2.4559 & 2.2487 & TRN & \\
\hline CHEMBL1928483 & 688357 & 4.3497 & 3.3141 & TRN & \\
\hline CHEMBL1460230 & 688357 & 2.4559 & 2.56699 & 9999999999 & TRN \\
\hline CHEMBL1381877 & 688357 & 2.4559 & 2.9467 & TRN & \\
\hline
\end{tabular}






\begin{tabular}{|c|c|c|c|c|c|}
\hline \multicolumn{6}{|c|}{ Supplemental Table S2.txt } \\
\hline CHEMBL1329160 & 688357 & 2.4559 & 3.0055 & TST & \\
\hline CHEMBL1462710 & 688357 & 5.1486 & 3.7964 & TRN & \\
\hline CHEMBL1972347 & 688357 & 3.917 & 3.0879 & TRN & \\
\hline CHEMBL1864040 & 688357 & 2.4559 & 3.6235 & TRN & \\
\hline CHEMBL3213645 & 688357 & 2.4559 & 2.89300 & 00000000002 & TRN \\
\hline CHEMBL1330749 & 688357 & 2.4559 & 2.8942 & TST & \\
\hline CHEMBL1497551 & 688357 & 2.4559 & 2.9593 & TST & \\
\hline CHEMBL3192035 & 688357 & 4.6382 & 3.8018 & TRN & \\
\hline CHEMBL1575392 & 688357 & 2.4559 & 2.3056 & TRN & \\
\hline CHEMBL1572849 & 688357 & 2.4559 & 2.5302 & TRN & \\
\hline CHEMBL3193308 & 688357 & 2.4559 & 2.6602 & TRN & \\
\hline CHEMBL1382534 & 688357 & 4.0082 & 2.6364 & TST & \\
\hline CHEMBL1366411 & 688357 & 2.4559 & 2.2459 & TRN & \\
\hline CHEMBL1520101 & 688357 & 2.4559 & 3.39899 & 99999999996 & TRN \\
\hline CHEMBL3207682 & 688357 & 2.4559 & 3.3952 & TRN & \\
\hline CHEMBL1528138 & 688357 & 2.4559 & 2.526 & TRN & \\
\hline CHEMBL1426556 & 688357 & 2.4559 & 2.6754 & TRN & \\
\hline CHEMBL1538056 & 688357 & 5.3566 & 4.8719 & TRN & \\
\hline CHEMBL1408798 & 688357 & 2.4559 & 3.5571 & TRN & \\
\hline CHEMBL1588691 & 688357 & 2.4559 & 2.6411 & TRN & \\
\hline CHEMBL3191914 & 688357 & 4.4482 & 4.6826 & TST & \\
\hline CHEMBL1481509 & 688357 & 2.4559 & 2.2508 & TST & \\
\hline CHEMBL1366987 & 688357 & 2.4559 & 3.3991 & TST & \\
\hline CHEMBL1479134 & 688357 & 2.4559 & 2.5926 & TRN & \\
\hline CHEMBL3195142 & 688357 & 4.0508 & 3.0378 & TRN & \\
\hline CHEMBL3194900 & 688357 & 2.4559 & 3.1502 & TRN & \\
\hline CHEMBL1449796 & 688357 & 2.4559 & 2.8217 & TRN & \\
\hline CHEMBL1579360 & 688357 & 2.4559 & 2.9073 & TRN & \\
\hline CHEMBL3195409 & 688357 & 4.0807 & 3.3632 & TRN & \\
\hline CHEMBL1973139 & 688357 & 4.3514 & 3.2117 & TRN & \\
\hline CHEMBL1601275 & 688357 & 4.3832 & 3.4995 & TRN & \\
\hline CHEMBL3196374 & 688357 & 5.2228 & 2.9863 & TRN & \\
\hline CHEMBL3196355 & 688357 & 2.4559 & 3.06399 & 99999999996 & TRN \\
\hline CHEMBL1607964 & 688357 & 2.4559 & 2.4878 & TST & \\
\hline CHEMBL1558381 & 688357 & 2.4559 & 2.6039 & TRN & \\
\hline CHEMBL1550039 & 688357 & 3.6953 & 2.7026 & TRN & \\
\hline CHEMBL1421807 & 688357 & 4.052 & 3.6734 & TRN & \\
\hline CHEMBL3209846 & 688357 & 2.4559 & 3.2391 & TRN & \\
\hline CHEMBL3198588 & 688357 & 2.4559 & 2.888 & TRN & \\
\hline CHEMBL1401323 & 688357 & 4.2403 & 2.4751 & TRN & \\
\hline CHEMBL1405150 & 688357 & 2.4559 & 2.7152 & TRN & \\
\hline CHEMBL1414130 & 688357 & 2.4559 & 2.6195 & TRN & \\
\hline CHEMBL3191182 & 688357 & 2.4559 & 2.8993 & TRN & \\
\hline CHEMBL1485833 & 688357 & 2.4559 & 2.8302 & TST & \\
\hline CHEMBL1304504 & 688357 & 2.4559 & 2.545 & TRN & \\
\hline CHEMBL1567827 & 688357 & 4.54 & 2.6737 & TRN & \\
\hline CHEMBL1457254 & 688357 & 2.4559 & 2.5447 & TRN & \\
\hline CHEMBL3192181 & 688357 & 3.938 & 3.5731 & TRN & \\
\hline
\end{tabular}




\begin{tabular}{|c|c|c|c|c|c|}
\hline \multicolumn{6}{|c|}{ Supplemental Table S2.txt } \\
\hline CHEMBL1581613 & 688357 & 2.4559 & 2.7421 & TRN & \\
\hline CHEMBL1514126 & 688357 & 2.4559 & 3.0056 & TST & \\
\hline CHEMBL1448563 & 688357 & 2.4559 & 3.5134 & TRN & \\
\hline CHEMBL1307273 & 688357 & 2.4559 & 2.3852 & TRN & \\
\hline CHEMBL1536986 & 688357 & 2.4559 & 2.6035 & TRN & \\
\hline CHEMBL1466751 & 688357 & 2.4559 & 2.8487 & TRN & \\
\hline CHEMBL1339535 & 688357 & 2.4559 & 2.4992 & TRN & \\
\hline CHEMBL591412 & 688357 & 2.4559 & 2.8083 & TRN & \\
\hline CHEMBL1509929 & 688357 & 4.534 & 4.1074 & TRN & \\
\hline CHEMBL1468673 & 688357 & 4.3582 & 2.5433 & TRN & \\
\hline CHEMBL1382425 & 688357 & 2.4559 & 2.7155 & TRN & \\
\hline CHEMBL1597454 & 688357 & 2.4559 & 2.9158 & TST & \\
\hline CHEMBL3192194 & 688357 & 4.1209 & 3.5407 & TRN & \\
\hline CHEMBL1601296 & 688357 & 2.4559 & 2.931 & TRN & \\
\hline CHEMBL1518335 & 688357 & 2.4559 & 2.6945 & TRN & \\
\hline CHEMBL1490459 & 688357 & 2.4559 & 3.4143 & TRN & \\
\hline CHEMBL1549433 & 688357 & 2.4559 & 2.7284 & TRN & \\
\hline CHEMBL1352060 & 688357 & 2.4559 & 2.7115 & TST & \\
\hline CHEMBL601768 & 688357 & 2.4559 & 2.588 & TRN & \\
\hline CHEMBL1980848 & 688357 & 2.4559 & 3.04100 & 00000000004 & TRN \\
\hline CHEMBL1983839 & 688357 & 2.4559 & 3.2138 & TRN & \\
\hline CHEMBL533226 & 688357 & 2.4559 & 3.0289 & TRN & \\
\hline CHEMBL1354350 & 688357 & 2.4559 & 2.7502 & TRN & \\
\hline CHEMBL1577246 & 688357 & 2.4559 & 2.6125 & TRN & \\
\hline CHEMBL1449664 & 688357 & 2.4559 & 3.3102 & TRN & \\
\hline CHEMBL3193902 & 688357 & 2.4559 & 2.9812 & TRN & \\
\hline CHEMBL1421630 & 688357 & 2.4559 & 3.4805 & TRN & \\
\hline CHEMBL1373096 & 688357 & 2.4559 & 2.9264 & TRN & \\
\hline CHEMBL1348582 & 688357 & 2.4559 & 2.3135 & TRN & \\
\hline CHEMBL1606589 & 688357 & 2.4559 & 2.6677 & TRN & \\
\hline CHEMBL1364640 & 688357 & 2.4559 & 2.5422 & TRN & \\
\hline CHEMBL1459709 & 688357 & 5.504 & 3.6689 & TST & \\
\hline CHEMBL1362984 & 688357 & 2.4559 & 3.5323 & TRN & \\
\hline CHEMBL1557348 & 688357 & 2.4559 & 2.6462 & TST & \\
\hline CHEMBL1536005 & 688357 & 2.4559 & 2.7507 & TRN & \\
\hline CHEMBL1308352 & 688357 & 2.4559 & 3.0063 & TRN & \\
\hline CHEMBL1341116 & 688357 & 2.4559 & 2.5008 & TRN & \\
\hline CHEMBL3193510 & 688357 & 5.2464 & 3.6002 & TRN & \\
\hline CHEMBL1383180 & 688357 & 2.4559 & 2.3288 & TRN & \\
\hline CHEMBL 1424062 & 688357 & 4.1778 & 3.2282 & TRN & \\
\hline CHEMBL1994599 & 688357 & 2.4559 & 2.938 & TRN & \\
\hline CHEMBL494838 & 688357 & 2.4559 & 2.589 & TRN & \\
\hline CHEMBL3189342 & 688357 & 2.4559 & 3.4479 & TRN & \\
\hline CHEMBL1582605 & 688357 & 2.4559 & 2.7729 & TRN & \\
\hline CHEMBL1333939 & 688357 & 2.4559 & 2.8314 & TRN & \\
\hline CHEMBL1489081 & 688357 & 2.4559 & 2.1551 & TRN & \\
\hline CHEMBL 3194301 & 688357 & 4.774 & 3.1689 & TRN & \\
\hline CHEMBL3194964 & 688357 & 4.3044 & 3.2017 & TRN & \\
\hline
\end{tabular}




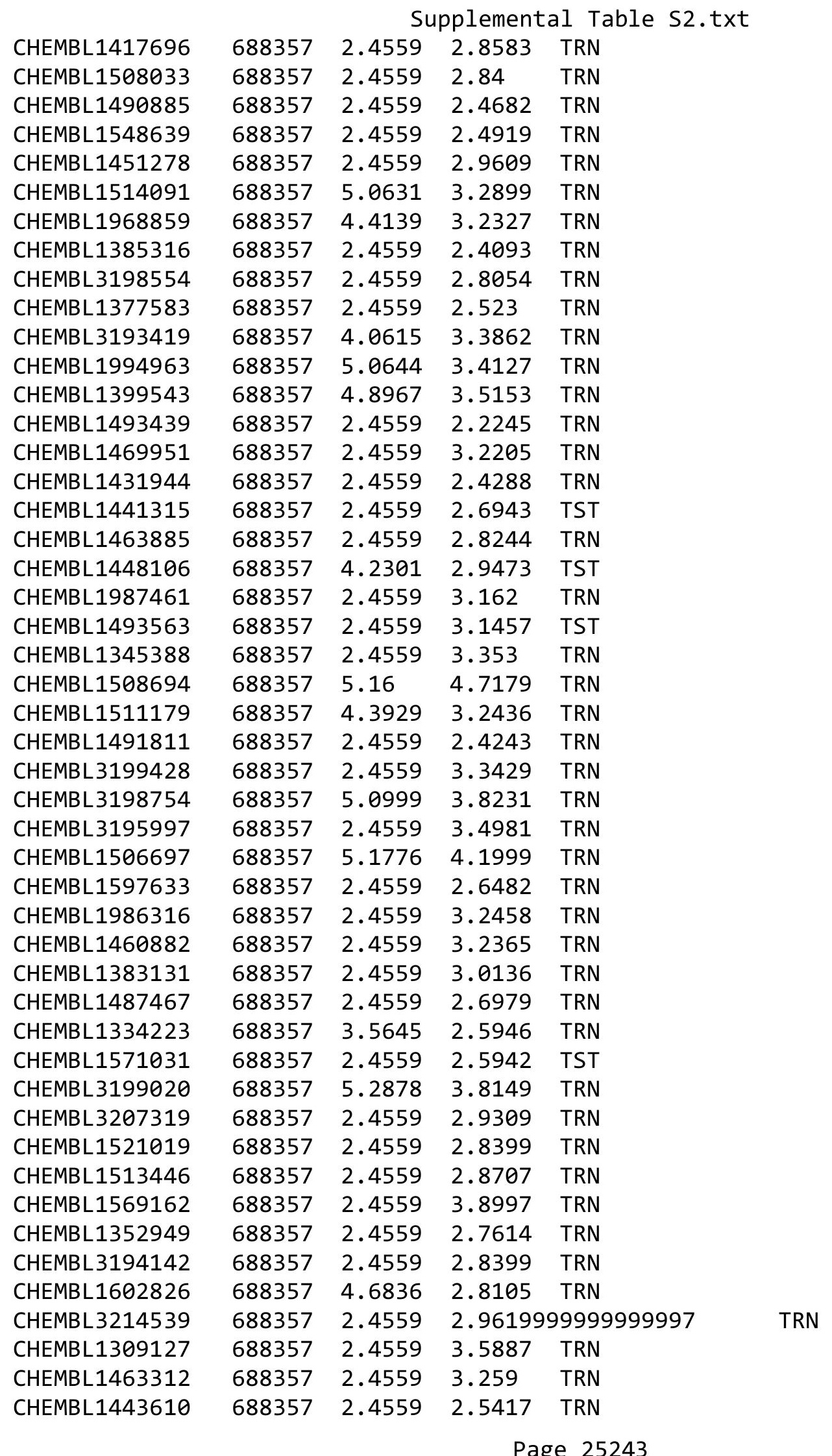





\begin{tabular}{|c|c|c|c|c|c|}
\hline \multirow[b]{2}{*}{ CHEMBL1306948 } & \multicolumn{5}{|c|}{ Supplemental Table s2.txt } \\
\hline & 688357 & 2.4559 & 2.7973 & TRN & \multirow[b]{2}{*}{ TRN } \\
\hline CHEMBL1527192 & 688357 & 2.4559 & \multicolumn{2}{|c|}{2.9960000000000004} & \\
\hline CHEMBL1327350 & 688357 & 5.1237 & 4.1084 & TRN & \\
\hline CHEMBL1314070 & 688357 & 4.2504 & 2.7081 & TRN & \\
\hline CHEMBL1531184 & 688357 & 2.4559 & 2.7765 & TRN & \\
\hline CHEMBL1335843 & 688357 & 5.2312 & 3.9508 & TRN & \\
\hline CHEMBL1964614 & 688357 & 2.4559 & 3.5292 & TRN & \\
\hline CHEMBL3197594 & 688357 & 2.4559 & 3.486 & TRN & \\
\hline CHEMBL1558295 & 688357 & 2.4559 & 2.9098 & TST & \\
\hline CHEMBL1323308 & 688357 & 5.154 & 3.594 & TRN & \\
\hline CHEMBL1506745 & 688357 & 2.4559 & 2.6981 & TRN & \\
\hline CHEMBL1322059 & 688357 & 2.4559 & 2.39 & TRN & \\
\hline CHEMBL1321526 & 688357 & 2.4559 & 2.4028 & TRN & \\
\hline CHEMBL1571994 & 688357 & 2.4559 & 2.8232 & TST & \\
\hline CHEMBL1399035 & 688357 & 2.4559 & 3.6043 & TST & \\
\hline CHEMBL1495072 & 688357 & 2.4559 & 2.6448 & TST & \\
\hline CHEMBL1491721 & 688357 & 2.4559 & 2.9325 & TST & \\
\hline CHEMBL3197748 & 688357 & 2.4559 & 3.365 & TST & \\
\hline CHEMBL1467606 & 688357 & 2.4559 & 2.5256 & TST & \\
\hline CHEMBL3192547 & 688357 & 5.0088 & 3.7286 & TST & \\
\hline CHEMBL1348657 & 688357 & 2.4559 & 2.4982 & TST & \\
\hline CHEMBL3197902 & 688357 & 2.4559 & 2.8845 & TST & \\
\hline CHEMBL1409266 & 688357 & 2.4559 & 2.455 & TST & \\
\hline CHEMBL3211277 & 688357 & 2.4559 & 3.1454 & TST & \\
\hline CHEMBL3191817 & 688357 & 2.4559 & 3.5563 & TST & \\
\hline CHEMBL1575502 & 688357 & 2.4559 & 4.0741 & TST & \\
\hline CHEMBL1379519 & 688357 & 2.4559 & 3.3078 & TST & \\
\hline CHEMBL1466643 & 688357 & 2.4559 & 2.9889 & TST & \\
\hline CHEMBL1575152 & 688357 & 2.4559 & 3.341 & TST & \\
\hline CHEMBL1445048 & 688357 & 2.4559 & 2.4475 & TST & \\
\hline CHEMBL1982774 & 688357 & 5.1929 & 4.5531 & TST & \\
\hline CHEMBL1482988 & 688357 & 4.5155 & 2.807 & TST & \\
\hline CHEMBL1422078 & 688357 & 4.33 & 2.7784 & TST & \\
\hline CHEMBL1488885 & 688357 & 2.4559 & 2.9794 & TST & \\
\hline CHEMBL1578975 & 688357 & 2.4559 & 2.4864 & TST & \\
\hline CHEMBL1471382 & 688357 & 2.4559 & 2.1944 & TST & \\
\hline CHEMBL1564837 & 688357 & 4.4572 & 3.2064 & TST & \\
\hline CHEMBL1386118 & 688357 & 4.2804 & 2.8342 & TST & \\
\hline CHEMBL1600203 & 688357 & 2.4559 & 3.0699 & TST & \\
\hline CHEMBL1384998 & 688357 & 5.1302 & 3.918 & TST & \\
\hline CHEMBL1307630 & 688357 & 2.4559 & 2.7852 & TST & \\
\hline CHEMBL1446069 & 688357 & 4.2809 & 2.4348 & TST & \\
\hline CHEMBL1597031 & 688357 & 2.4559 & 2.6016 & TST & \\
\hline CHEMBL3208249 & 688357 & 2.4559 & 2.7946 & TST & \\
\hline CHEMBL1402200 & 688357 & 2.4559 & 2.807 & TST & \\
\hline CHEMBL1542994 & 688357 & 2.4559 & 2.605 & TST & \\
\hline CHEMBL1541716 & 688357 & 4.3407 & 2.59800 & 20000000003 & TST \\
\hline CHEMBL1503145 & 688357 & 5.1305 & 3.4686 & TST & \\
\hline & & & & 25245 & \\
\hline
\end{tabular}


Supplemental Table S2.txt

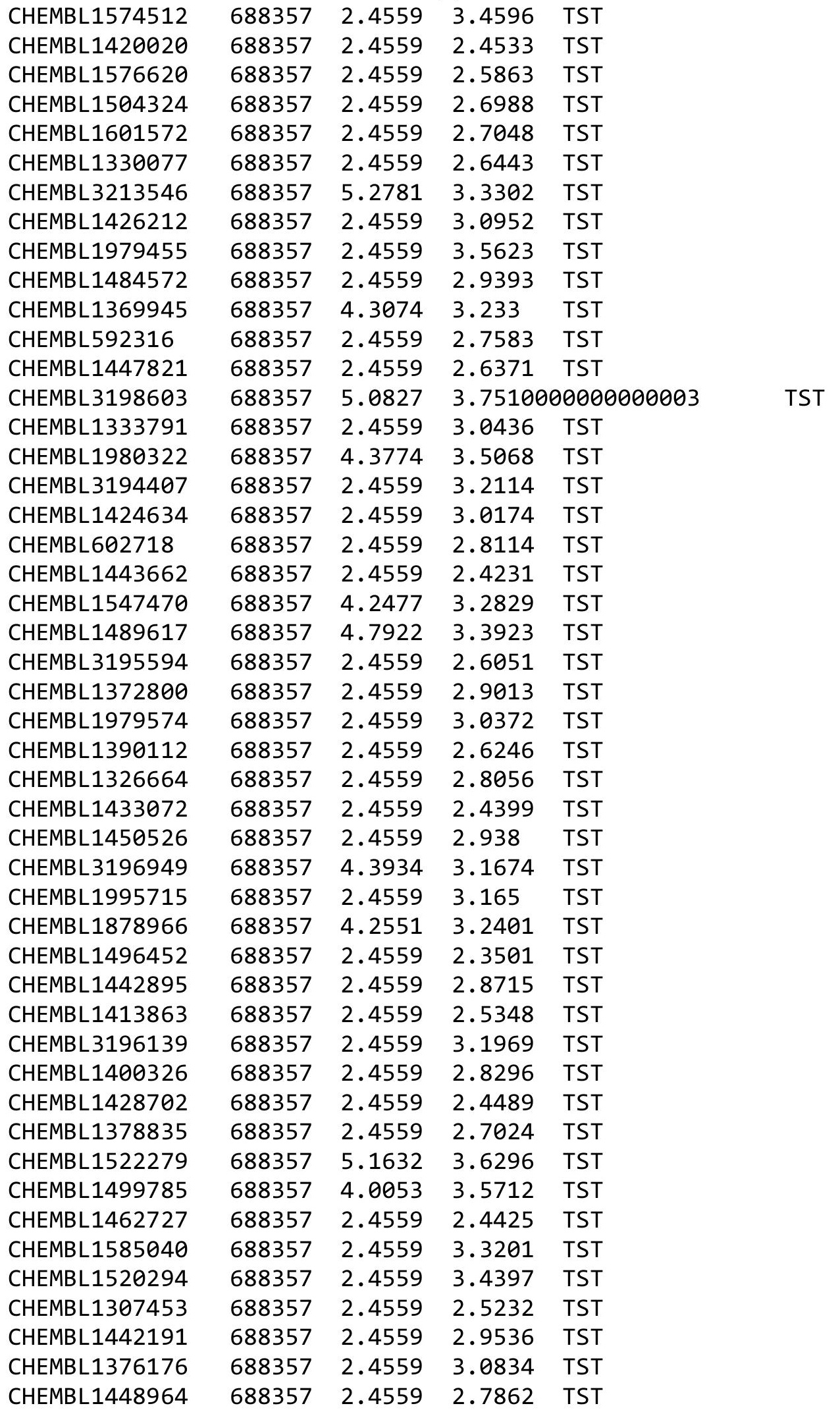

Page 25246 


\begin{tabular}{|c|c|c|c|c|c|}
\hline \multicolumn{6}{|c|}{ Supplemental Table S2.txt } \\
\hline CHEMBL1613483 & 688357 & 2.4559 & 3.3595 & TST & \\
\hline CHEMBL1350460 & 688357 & 4.6536 & 2.9595 & TST & \\
\hline CHEMBL1595632 & 688357 & 5.1473 & 4.5741 & TST & \\
\hline CHEMBL1333685 & 688357 & 2.4559 & 2.6906 & TST & \\
\hline CHEMBL1445189 & 688357 & 2.4559 & 2.5423 & TST & \\
\hline CHEMBL3199736 & 688357 & 2.4559 & 3.2112 & TST & \\
\hline CHEMBL1406638 & 688357 & 2.4559 & 2.8498 & TST & \\
\hline CHEMBL3190190 & 688357 & 2.4559 & 2.8417 & TST & \\
\hline CHEMBL1324958 & 688357 & 2.4559 & 2.4396 & TST & \\
\hline CHEMBL3190125 & 688357 & 2.4559 & 3.6542 & TST & \\
\hline CHEMBL3189613 & 688357 & 2.4559 & 2.8307 & TST & \\
\hline CHEMBL1569989 & 688357 & 2.4559 & 2.7021 & TST & \\
\hline CHEMBL1327979 & 688357 & 2.4559 & 3.2877 & TST & \\
\hline CHEMBL1313892 & 688357 & 2.4559 & 2.5668 & TST & \\
\hline CHEMBL1412002 & 688357 & 2.4559 & 2.7066 & TST & \\
\hline CHEMBL1478708 & 688357 & 2.4559 & 2.736 & TST & \\
\hline CHEMBL1611371 & 688357 & 2.4559 & 2.8973 & TST & \\
\hline CHEMBL580955 & 688357 & 2.4559 & 2.6621 & TST & \\
\hline CHEMBL1381603 & 688357 & 2.4559 & 2.9403 & TST & \\
\hline CHEMBL1381322 & 688357 & 5.1438 & 5.4016 & TST & \\
\hline CHEMBL3194040 & 688357 & 2.4559 & 2.9182 & TST & \\
\hline CHEMBL1977570 & 688357 & 5.1264 & 3.8694 & TST & \\
\hline CHEMBL1580892 & 688357 & 2.4559 & 2.3775 & TST & \\
\hline CHEMBL1348053 & 688357 & 2.4559 & 3.2048 & TST & \\
\hline CHEMBL1534503 & 688357 & 2.4559 & 1.8815 & TST & \\
\hline CHEMBL1377009 & 688357 & 2.4559 & 2.9279 & TST & \\
\hline CHEMBL3145060 & 688357 & 2.4559 & 3.5542 & TST & \\
\hline CHEMBL1384437 & 688357 & 2.4559 & 2.7396 & TST & \\
\hline CHEMBL1423014 & 688357 & 2.4559 & 2.8518 & TST & \\
\hline CHEMBL1565821 & 688357 & 2.4559 & 2.7341 & TST & \\
\hline CHEMBL1408691 & 688357 & 2.4559 & 2.4582 & TST & \\
\hline CHEMBL1461551 & 688357 & 2.4559 & 2.5002 & TST & \\
\hline CHEMBL1303844 & 688357 & 4.8201 & 3.2752 & TST & \\
\hline CHEMBL1443339 & 688357 & 2.4559 & 2.76899 & 99999999997 & TST \\
\hline CHEMBL 2000222 & 688357 & 2.4559 & 3.5476 & TST & \\
\hline CHEMBL1579666 & 688357 & 2.4559 & 2.6091 & TST & \\
\hline CHEMBL3208685 & 688357 & 2.4559 & 2.6321 & TST & \\
\hline CHEMBL1587868 & 688357 & 2.4559 & 2.5723 & TST & \\
\hline CHEMBL1444376 & 688357 & 2.4559 & 2.2346 & TST & \\
\hline CHEMBL1426169 & 688357 & 2.4559 & 2.5534 & TST & \\
\hline CHEMBL1525944 & 688357 & 2.4559 & 2.3927 & TST & \\
\hline CHEMBL1329750 & 688357 & 4.6369 & 4.0401 & TST & \\
\hline CHEMBL1964389 & 688357 & 2.4559 & 2.9109 & TST & \\
\hline CHEMBL1563339 & 688357 & 2.4559 & 2.8113 & TST & \\
\hline CHEMBL1527460 & 688357 & 2.4559 & 2.5956 & TST & \\
\hline CHEMBL1323688 & 688357 & 2.4559 & 2.4799 & TST & \\
\hline CHEMBL1328381 & 688357 & 2.4559 & 2.5918 & TST & \\
\hline CHEMBL1376732 & 688357 & 2.4559 & 3.0981 & TST & \\
\hline
\end{tabular}




\begin{tabular}{|c|c|c|c|c|c|}
\hline \multicolumn{6}{|c|}{ Supplemental Table S2.txt } \\
\hline CHEMBL 3214310 & 688357 & 2.4559 & 3.1743 & TST & \\
\hline CHEMBL1432409 & 688357 & 2.4559 & 2.8149 & TST & \\
\hline CHEMBL1516914 & 688357 & 2.4559 & 3.8537 & TST & \\
\hline CHEMBL1338805 & 688357 & 2.4559 & 2.9787 & TST & \\
\hline CHEMBL1475059 & 688357 & 4.3931 & 2.9251 & TST & \\
\hline CHEMBL3194211 & 688357 & 2.4559 & 3.0844 & TST & \\
\hline CHEMBL1437483 & 688357 & 4.5108 & 2.9598 & TST & \\
\hline CHEMBL1535361 & 688357 & 2.4559 & 2.7421 & TST & \\
\hline CHEMBL1533459 & 688357 & 2.4559 & 2.2338 & TST & \\
\hline CHEMBL3199335 & 688357 & 4.496 & 3.1302 & TST & \\
\hline CHEMBL1544598 & 688357 & 2.4559 & 2.481 & TST & \\
\hline CHEMBL1987820 & 688357 & 4.0106 & 4.8574 & TST & \\
\hline CHEMBL1481220 & 688357 & 2.4559 & 2.8878 & TST & \\
\hline CHEMBL1485106 & 688357 & 2.4559 & 2.2754 & TST & \\
\hline CHEMBL3194477 & 688357 & 2.4559 & 3.7988 & TST & \\
\hline CHEMBL1448282 & 688357 & 2.4559 & 2.5922 & TST & \\
\hline CHEMBL1379327 & 688357 & 2.4559 & 2.7885 & TST & \\
\hline CHEMBL1556390 & 688357 & 4.1547 & 2.7581 & TST & \\
\hline CHEMBL523687 & 539663 & 2.0 & 2.0137 & TST & \\
\hline CHEMBL493501 & 539663 & 2.0 & 1.9937 & TST & \\
\hline CHEMBL523041 & 539663 & 2.0 & 2.1008 & TRN & \\
\hline CHEMBL523837 & 539663 & 2.0 & 1.7205 & TRN & \\
\hline CHEMBL524173 & 539663 & 2.0 & 2.293 & TRN & \\
\hline CHEMBL494491 & 539663 & 5.7447 & 5.6756 & TRN & \\
\hline CHEMBL492262 & 539663 & 5.1612 & 3.2021 & TRN & \\
\hline CHEMBL493700 & 539663 & 2.0 & 2.2411 & TST & \\
\hline CHEMBL492454 & 539663 & 2.0 & 2.4783 & TRN & \\
\hline CHEMBL522341 & 539663 & 2.0 & 1.8865 & TST & \\
\hline CHEMBL502155 & 539663 & 2.0 & 1.9602 & TRN & \\
\hline CHEMBL495137 & 539663 & 2.0 & 2.6084 & TRN & \\
\hline CHEMBL493097 & 539663 & 5.0088 & 4.5779 & TRN & \\
\hline CHEMBL494321 & 539663 & 2.0 & 2.1519 & TST & \\
\hline CHEMBL522206 & 539663 & 2.0 & 2.0936 & TRN & \\
\hline CHEMBL492875 & 539663 & 5.2596 & 4.8731 & TRN & \\
\hline CHEMBL494705 & 539663 & 2.0 & 1.6454 & TRN & \\
\hline CHEMBL494121 & 539663 & 5.0809 & 5.0952 & TRN & \\
\hline CHEMBL523514 & 539663 & 2.0 & 2.4194 & TRN & \\
\hline CHEMBL494912 & 539663 & 2.0 & 1.9238 & TST & \\
\hline CHEMBL484451 & 539663 & 5.1367 & 5.83799 & 9999999999 & TRN \\
\hline CHEMBL494698 & 539663 & 5.1739 & 5.1959 & TRN & \\
\hline CHEMBL495325 & 539663 & 2.0 & 2.4523 & TRN & \\
\hline CHEMBL493096 & 539663 & 4.9208 & 3.2806 & TRN & \\
\hline CHEMBL494319 & 539663 & 2.0 & 1.8962 & TRN & \\
\hline CHEMBL499809 & 539663 & 2.0 & 2.2519 & TST & \\
\hline CHEMBL494716 & 539663 & 2.0 & 1.6893 & TST & \\
\hline CHEMBL492453 & 539663 & 2.0 & 2.2808 & TRN & \\
\hline CHEMBL522032 & 539663 & 2.0 & 2.1731 & TST & \\
\hline CHEMBL347927 & 539663 & 5.5086 & 5.9327 & TRN & \\
\hline
\end{tabular}




\begin{tabular}{|c|c|c|c|c|}
\hline \multirow[b]{2}{*}{ CHEMBL492494 } & \multicolumn{4}{|c|}{ Supplemental Table S2.tx } \\
\hline & 539663 & 2.0 & 2.0636 & TRN \\
\hline CHEMBL495135 & 539663 & 5.3468 & 5.6383 & TRN \\
\hline CHEMBL523380 & 539663 & 2.0 & 1.8728 & TST \\
\hline CHEMBL492874 & 539663 & 2.0 & 2.6063 & TRN \\
\hline CHEMBL495136 & 539663 & 2.0 & 1.8959 & TRN \\
\hline CHEMBL495326 & 539663 & 5.3565 & 5.0044 & TRN \\
\hline CHEMBL352024 & 539663 & 4.8861 & 4.6226 & TST \\
\hline CHEMBL494911 & 539663 & 2.0 & 2.8417 & TRN \\
\hline CHEMBL493703 & 539663 & 5.0223 & 4.8797 & TRN \\
\hline CHEMBL495337 & 539663 & 5.7212 & 6.1069 & TRN \\
\hline CHEMBL448274 & 539663 & 2.0 & 1.6119 & TRN \\
\hline CHEMBL494492 & 539663 & 5.3872 & 5.0238 & TRN \\
\hline CHEMBL522823 & 539663 & 5.6778 & 4.9006 & TRN \\
\hline CHEMBL494320 & 539663 & 2.0 & 2.3554 & TRN \\
\hline CHEMBL158017 & 539663 & 2.0 & 2.5908 & TRN \\
\hline CHEMBL493490 & 539663 & 5.1612 & 4.7964 & TRN \\
\hline CHEMBL523707 & 539663 & 2.0 & 2.1008 & TRN \\
\hline CHEMBL494493 & 539663 & 5.2366 & 5.9647 & TRN \\
\hline CHEMBL494706 & 539663 & 5.6198 & 5.5237 & TRN \\
\hline CHEMBL451143 & 539663 & 5.0132 & 4.7125 & TST \\
\hline CHEMBL494717 & 539663 & 5.6778 & 5.7907 & TST \\
\hline CHEMBL3325896 & 1454018 & 7.3188 & 7.0862 & TRN \\
\hline CHEMBL3325659 & 1454018 & 7.3872 & 7.4145 & TRN \\
\hline CHEMBL3326902 & 1454018 & 7.0969 & 7.1832 & TST \\
\hline CHEMBL3325789 & 1454018 & 7.6576 & 7.1927 & TRN \\
\hline CHEMBL3325637 & 1454018 & 7.2147 & 6.7525 & TRN \\
\hline CHEMBL3325806 & 1454018 & 6.4737 & 7.1193 & TRN \\
\hline CHEMBL3325785 & 1454018 & 7.8239 & 7.4999 & TRN \\
\hline CHEMBL3325803 & 1454018 & 7.9586 & 7.5401 & TRN \\
\hline CHEMBL3325796 & 1454018 & 6.8601 & 7.1592 & TRN \\
\hline CHEMBL3325787 & 1454018 & 7.1549 & 7.3966 & TRN \\
\hline CHEMBL3325641 & 1454018 & 7.1487 & 6.8311 & TRN \\
\hline CHEMBL3325645 & 1454018 & 6.9393 & 7.2453 & TRN \\
\hline CHEMBL3326901 & 1454018 & 5.8996 & 7.053 & TST \\
\hline CHEMBL3325644 & 1454018 & 7.1487 & 7.2582 & TRN \\
\hline CHEMBL3326908 & 1454018 & 6.5171 & 7.8608 & TST \\
\hline CHEMBL3325640 & 1454018 & 7.3279 & 7.1468 & TRN \\
\hline CHEMBL3325632 & 1454018 & 7.2147 & 6.9835 & TRN \\
\hline CHEMBL3325634 & 1454018 & 7.0362 & 6.9026 & TRN \\
\hline CHEMBL3325643 & 1454018 & 7.0223 & 7.0599 & TRN \\
\hline CHEMBL3325783 & 1454018 & 7.7212 & 7.3573 & TRN \\
\hline CHEMBL3325635 & 1454018 & 6.7122 & 6.8327 & TRN \\
\hline CHEMBL3325648 & 1454018 & 7.3372 & 7.2684 & TRN \\
\hline CHEMBL3325658 & 1454018 & 6.9172 & 7.4606 & TRN \\
\hline CHEMBL3326904 & 1454018 & 7.3279 & 8.2632 & TST \\
\hline CHEMBL3325899 & 1454018 & 6.2526 & 7.0 & TST \\
\hline CHEMBL3325653 & 1454018 & 6.9318 & 7.0733 & TRN \\
\hline CHEMBL3325452 & 1454018 & 7.5686 & 7.3969 & TRN \\
\hline
\end{tabular}

Page 25249 
Supplemental Table S2.txt

\begin{tabular}{|c|c|c|c|c|c|}
\hline CHEMBL 3325630 & 1454018 & 7.4089 & 7.3366 & TRN & \\
\hline CHEMBL3325631 & 1454018 & 7.5086 & 7.0884 & TRN & \\
\hline CHEMBL3325804 & 1454018 & 7.9586 & 7.9306 & TRN & \\
\hline CHEMBL3326905 & 1454018 & 7.6198 & 8.0543 & TRN & \\
\hline CHEMBL3325797 & 1454018 & 7.0044 & 7.169 & TRN & \\
\hline CHEMBL3325625 & 1454018 & 7.0757 & 8.1777 & TST & \\
\hline CHEMBL 3325786 & 1454018 & 7.0655 & 7.1188 & TRN & \\
\hline CHEMBL 3325638 & 1454018 & 7.0555 & 7.1723 & TRN & \\
\hline CHEMBL3326906 & 1454018 & 8.1549 & 7.9934 & TRN & \\
\hline CHEMBL3325651 & 1454018 & 6.9547 & 7.3367 & TST & \\
\hline CHEMBL3325801 & 1454018 & 7.8239 & 7.735 & TRN & \\
\hline CHEMBL3325633 & 1454018 & 7.0269 & 7.2159 & TRN & \\
\hline CHEMBL3325627 & 1454018 & 8.2924 & 8.4509 & TRN & \\
\hline CHEMBL3325781 & 1454018 & 7.585 & 7.5306 & TRN & \\
\hline CHEMBL3325652 & 1454018 & 7.0 & 7.2887 & TST & \\
\hline CHEMBL3325650 & 1454018 & 7.1367 & 7.256 & TRN & \\
\hline CHEMBL3325647 & 1454018 & 7.0605 & 7.2431 & TRN & \\
\hline CHEMBL3325660 & 1454018 & 7.699 & 7.4876 & TRN & \\
\hline CHEMBL3325639 & 1454018 & 6.857 & 6.9409 & TRN & \\
\hline CHEMBL3325780 & 1454018 & 7.5528 & 7.3649 & TRN & \\
\hline CHEMBL3325898 & 1454018 & 6.5751 & 6.8522 & TRN & \\
\hline CHEMBL3325655 & 1454018 & 6.9747 & \multicolumn{2}{|c|}{6.997999999999999} & TRN \\
\hline CHEMBL 3325791 & 1454018 & 7.3188 & 7.0542 & TRN & \\
\hline CHEMBL3326907 & 1454018 & 9.0458 & 8.1382 & TRN & \\
\hline CHEMBL 3325656 & 1454018 & 7.4815 & 7.3757 & TRN & \\
\hline CHEMBL3325802 & 1454018 & 7.9586 & 7.7199 & TRN & \\
\hline CHEMBL3325662 & 1454018 & 7.3565 & 7.3142 & TRN & \\
\hline CHEMBL 3325788 & 1454018 & 7.9208 & 7.8525 & TRN & \\
\hline CHEMBL3325894 & 1454018 & 8.1549 & 7.0305 & TST & \\
\hline CHEMBL3325779 & 1454018 & 6.9914 & 7.3476 & TRN & \\
\hline CHEMBL3325628 & 1454018 & 7.0315 & 7.3778 & TRN & \\
\hline CHEMBL 3325782 & 1454018 & 7.7212 & 7.4256 & TRN & \\
\hline CHEMBL 3325654 & 1454018 & 7.0506 & 7.1505 & TRN & \\
\hline CHEMBL3325629 & 1454018 & 7.5086 & \multicolumn{2}{|c|}{7.8020000000000005} & TRN \\
\hline CHEMBL 3325665 & 1454018 & 7.3372 & 7.0612 & TRN & \\
\hline CHEMBL3325792 & 1454018 & 7.301 & 7.1616 & TRN & \\
\hline CHEMBL3325798 & 1454018 & 6.8477 & 7.2457 & TRN & \\
\hline CHEMBL3325666 & 1454018 & 7.5686 & \multicolumn{2}{|c|}{7.252000000000001} & TRN \\
\hline CHEMBL3325626 & 1454018 & 6.5654 & 7.3918 & TRN & \\
\hline CHEMBL 3325657 & 1454018 & 7.1805 & 7.3857 & TRN & \\
\hline CHEMBL3325646 & 1454018 & 7.0269 & 7.2296 & TRN & \\
\hline CHEMBL3326900 & 1454018 & 5.8125 & 6.6191 & TST & \\
\hline CHEMBL3325636 & 1454018 & 6.9066 & 7.4091 & TRN & \\
\hline CHEMBL3325649 & 1454018 & 7.1871 & 7.2568 & TRN & \\
\hline CHEMBL3325790 & 1454018 & 7.3188 & 7.3401 & TRN & \\
\hline CHEMBL3325663 & 1454018 & 7.1192 & 7.0965 & TRN & \\
\hline CHEMBL3325897 & 1454018 & 7.1249 & 7.2113 & TRN & \\
\hline CHEMBL3325642 & 1454018 & 7.0757 & 6.9298 & TRN & \\
\hline
\end{tabular}

Page 25250 
Supplemental Table S2.txt

\begin{tabular}{|c|c|c|c|c|c|}
\hline CHEMBL3325893 & 1454018 & 7.3979 & 6.7337 & TST & \\
\hline CHEMBL3326903 & 1454018 & 7.7696 & 8.0504 & TST & \\
\hline CHEMBL3325793 & 1454018 & 7.4685 & 7.2036 & TRN & \\
\hline CHEMBL3325807 & 1454018 & 6.8447 & 6.9806 & TST & \\
\hline CHEMBL3325795 & 1454018 & 6.9281 & 6.9846 & TST & \\
\hline CHEMBL3325661 & 1454018 & 7.5376 & 7.2281 & TST & \\
\hline CHEMBL3325664 & 1454018 & 7.0862 & 7.3729 & TST & \\
\hline CHEMBL3325891 & 1454018 & 7.7696 & 7.0847 & TST & \\
\hline CHEMBL 3325892 & 1454018 & 6.5607 & 7.1031 & TST & \\
\hline CHEMBL3325784 & 1454018 & 7.1805 & 7.4934 & TST & \\
\hline CHEMBL3325895 & 1454018 & 6.3188 & 7.5773 & TST & \\
\hline CHEMBL3325794 & 1454018 & 7.1192 & 7.0906 & TST & \\
\hline CHEMBL3325808 & 1454018 & 6.2411 & 7.3678 & TST & \\
\hline CHEMBL1761944 & 813068 & 4.0 & 4.4407 & TST & \\
\hline CHEMBL 2018764 & 813068 & 4.0 & 4.2368 & TRN & \\
\hline CHEMBL1278149 & 813068 & 5.2291 & 4.7491 & TST & \\
\hline CHEMBL 2018748 & 813068 & 5.1518 & 5.4192 & TRN & \\
\hline CHEMBL 2018775 & 813068 & 4.0 & 4.258 & TST & \\
\hline CHEMBL 2018774 & 813068 & 4.0 & 4.187 & TRN & \\
\hline CHEMBL1761937 & 813068 & 4.0 & 3.9955 & TRN & \\
\hline CHEMBL1277620 & 813068 & 5.2441 & 5.1374 & TST & \\
\hline CHEMBL1761938 & 813068 & 4.0 & 3.7858 & TRN & \\
\hline CHEMBL 2018754 & 813068 & 5.1938 & 5.8587 & TRN & \\
\hline CHEMBL 2018757 & 813068 & 6.0458 & 5.6241 & TRN & \\
\hline CHEMBL 2018746 & 813068 & 4.0 & 4.1229 & TRN & \\
\hline CHEMBL 2018765 & 813068 & 5.0044 & 4.2672 & TST & \\
\hline CHEMBL 2018776 & 813068 & 4.0 & 4.1885 & TRN & \\
\hline CHEMBL 2018750 & 813068 & 5.3188 & 5.0863 & TRN & \\
\hline CHEMBL 2018770 & 813068 & 4.0 & \multicolumn{2}{|c|}{3.8080000000000003} & TRN \\
\hline CHEMBL 2018771 & 813068 & 4.0 & 4.187 & TRN & \\
\hline CHEMBL 2016600 & 813068 & 4.0 & 4.167 & TRN & \\
\hline CHEMBL1761931 & 813068 & 4.0 & 4.9795 & TRN & \\
\hline CHEMBL 2018773 & 813068 & 5.041 & 4.1367 & TST & \\
\hline CHEMBL 2018756 & 813068 & 6.0458 & 5.2586 & TRN & \\
\hline CHEMBL 2018763 & 813068 & 4.0 & 4.0186 & TRN & \\
\hline CHEMBL 2018752 & 813068 & 6.0 & 5.5207 & TRN & \\
\hline CHEMBL 2018886 & 813068 & 4.0 & 4.0528 & TRN & \\
\hline CHEMBL94191 & 813068 & 5.3665 & 5.4677 & TRN & \\
\hline CHEMBL1761932 & 813068 & 4.0 & 4.3792 & TRN & \\
\hline CHEMBL 2018759 & 813068 & 5.2366 & 5.2699 & TRN & \\
\hline CHEMBL 2018879 & 813068 & 4.0 & 4.3284 & TRN & \\
\hline CHEMBL 2018769 & 813068 & 4.0 & 4.4586 & TRN & \\
\hline CHEMBL 2018760 & 813068 & 6.0458 & 5.6819 & TRN & \\
\hline CHEMBL 2018766 & 813068 & 4.0 & 4.1367 & TST & \\
\hline CHEMBL1278148 & 813068 & 4.0 & 4.8249 & TST & \\
\hline CHEMBL 2018768 & 813068 & 4.0 & 4.0855 & TRN & \\
\hline CHEMBL1761939 & 813068 & 4.0 & 3.9266 & TRN & \\
\hline CHEMBL 2018881 & 813068 & 4.0 & 3.8087 & TRN & \\
\hline
\end{tabular}




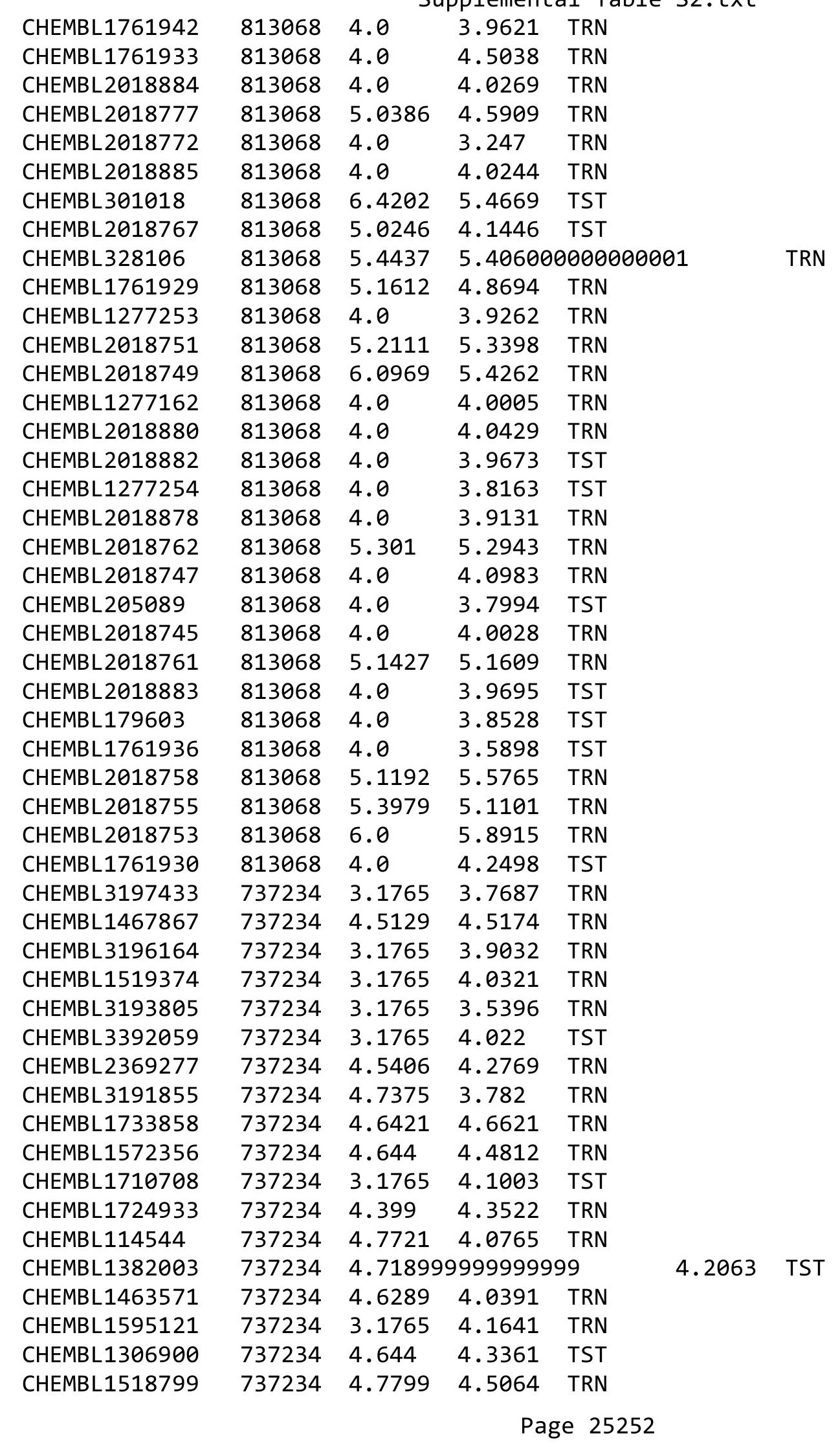


Supplemental Table S2.txt

\begin{tabular}{|c|c|c|c|c|c|c|}
\hline CHEMBL 3145316 & 737234 & 4.6716 & 4.6273 & TRN & & \\
\hline CHEMBL1374840 & 737234 & 4.5017 & 4.5439 & TRN & & \\
\hline CHEMBL3196326 & 737234 & 4.618 & 4.6172 & TRN & & \\
\hline CHEMBL1546440 & 737234 & 4.5952 & 4.5362 & TRN & & \\
\hline CHEMBL1372850 & 737234 & 4.7645 & 3.9411 & TRN & & \\
\hline CHEMBL1541594 & 737234 & 4.7825 & 4.3646 & TRN & & \\
\hline CHEMBL1969046 & 737234 & 4.399 & 4.0216 & TRN & & \\
\hline CHEMBL1496231 & 737234 & 4.5528 & 4.3599 & TRN & & \\
\hline CHEMBL1491015 & 737234 & 3.1765 & 4.1656 & TRN & & \\
\hline CHEMBL1583665 & 737234 & 4.556 & 4.5981 & TRN & & \\
\hline CHEMBL1359359 & 737234 & 4.6289 & 3.8825 & TST & & \\
\hline CHEMBL1717415 & 737234 & 3.1765 & 4.1788 & TST & & \\
\hline CHEMBL1539107 & 737234 & 4.5719 & 4.4118 & TST & & \\
\hline CHEMBL1336535 & 737234 & 4.7721 & 4.8901 & TRN & & \\
\hline CHEMBL1563335 & 737234 & 3.1765 & 3.9912 & TRN & & \\
\hline CHEMBL1310804 & 737234 & 4.5287 & 4.2056 & TRN & & \\
\hline CHEMBL1430235 & 737234 & 4.6421 & 4.2993 & TRN & & \\
\hline CHEMBL387762 & 737234 & 4.6421 & 4.7039 & TST & & \\
\hline CHEMBL1443778 & 737234 & 4.8268 & 4.4902 & TST & & \\
\hline CHEMBL212504 & 737234 & 3.1765 & 4.0809 & TRN & & \\
\hline CHEMBL3198396 & 737234 & 3.1765 & 3.9168 & TRN & & \\
\hline CHEMBL1483161 & 737234 & 4.7033 & 4.2356 & TST & & \\
\hline CHEMBL1310449 & 737234 & 4.6271 & 4.7108 & TRN & & \\
\hline CHEMBL1487183 & 737234 & 4.5867 & 4.2973 & TST & & \\
\hline CHEMBL1708074 & 737234 & 4.5452 & 4.461 & TST & & \\
\hline CHEMBL1427185 & 737234 & 4.7986 & 4.4522 & TST & & \\
\hline CHEMBL1497049 & 737234 & 4.1824 & 4.3429 & TRN & & \\
\hline CHEMBL1335002 & 737234 & 4.7496 & 4.3623 & TRN & & \\
\hline CHEMBL1702614 & 737234 & \multicolumn{3}{|c|}{4.4510000000000005} & 4.5327 & TST \\
\hline CHEMBL1729300 & 737234 & 4.7212 & 4.5338 & TRN & & \\
\hline CHEMBL1472570 & 737234 & 4.5452 & 4.391 & TRN & & \\
\hline CHEMBL1410616 & 737234 & 3.1765 & 3.6932 & TRN & & \\
\hline CHEMBL1570845 & 737234 & 4.7399 & 4.717 & TRN & & \\
\hline CHEMBL1555566 & 737234 & 4.7122 & 4.729 & TRN & & \\
\hline CHEMBL1608392 & 737234 & 4.7122 & 4.2699 & TRN & & \\
\hline CHEMBL3197831 & 737234 & 4.6478 & 4.2165 & TRN & & \\
\hline CHEMBL1997450 & 737234 & 4.4473 & 3.7734 & TRN & & \\
\hline CHEMBL1698492 & 737234 & 4.5544 & 4.2673 & TRN & & \\
\hline CHEMBL1734467 & 737234 & 3.1765 & 4.1717 & TRN & & \\
\hline CHEMBL1595015 & 737234 & 4.6162 & 4.369 & TRN & & \\
\hline CHEMBL3195721 & 737234 & 3.1765 & 4.5343 & TST & & \\
\hline CHEMBL 2004847 & 737234 & 4.4461 & 4.0475 & TRN & & \\
\hline CHEMBL1700182 & 737234 & 4.6126 & 4.6502 & TST & & \\
\hline CHEMBL1517470 & 737234 & 4.5702 & 4.2851 & TRN & & \\
\hline CHEMBL1724522 & 737234 & 4.4908 & 4.6015 & TST & & \\
\hline CHEMBL1997098 & 737234 & 4.5918 & 4.1992 & TRN & & \\
\hline CHEMBL1363242 & 737234 & 3.1765 & 3.6928 & TRN & & \\
\hline CHEMBL242163 & 737234 & 4.3116 & 3.9647 & TST & & \\
\hline
\end{tabular}

Page 25253 
Supplemental Table S2.txt

\begin{tabular}{|c|c|c|c|c|c|}
\hline CHEMBL1371649 & 737234 & 4.5452 & 4.2103 & TRN & \\
\hline CHEMBL1356395 & 737234 & 3.1765 & 3.715 & TRN & \\
\hline CHEMBL1212972 & 737234 & 3.1765 & 4.1617 & TST & \\
\hline CHEMBL1610008 & 737234 & 4.7258 & 4.0361 & TRN & \\
\hline CHEMBL1420064 & 737234 & 4.4237 & 4.0785 & TRN & \\
\hline CHEMBL42288 & 737234 & 4.5361 & 4.5004 & TRN & \\
\hline CHEMBL1379713 & 737234 & 4.5654 & 4.2632 & TRN & \\
\hline CHEMBL1500450 & 737234 & 4.4776 & \multicolumn{2}{|c|}{3.8930000000000002} & TRN \\
\hline CHEMBL1698464 & 737234 & 4.6576 & 4.1838 & TRN & \\
\hline CHEMBL1430795 & 737234 & 4.6676 & 4.27 & TRN & \\
\hline CHEMBL1713323 & 737234 & 4.567 & 4.5017 & TST & \\
\hline CHEMBL1490887 & 737234 & 4.4377 & 4.2406 & TST & \\
\hline CHEMBL1557648 & 737234 & 4.684 & 4.4569 & TRN & \\
\hline CHEMBL1491847 & 737234 & 4.6696 & 3.7832 & TRN & \\
\hline CHEMBL363491 & 737234 & 4.4597 & 4.3583 & TRN & \\
\hline CHEMBL1370183 & 737234 & 4.3737 & 4.5221 & TRN & \\
\hline CHEMBL1424264 & 737234 & 4.3197 & 4.2996 & TRN & \\
\hline CHEMBL1421589 & 737234 & 4.5114 & 4.074 & TRN & \\
\hline CHEMBL1491719 & 737234 & 3.1765 & 3.8304 & TRN & \\
\hline CHEMBL1535150 & 737234 & 4.2284 & 4.8785 & TRN & \\
\hline CHEMBL1351473 & 737234 & 3.1765 & 4.1436 & TST & \\
\hline CHEMBL3196451 & 737234 & 3.1765 & 3.7011 & TRN & \\
\hline CHEMBL1450616 & 737234 & 4.7212 & 4.4329 & TRN & \\
\hline CHEMBL1458147 & 737234 & 4.382 & 4.4397 & TRN & \\
\hline CHEMBL1387248 & 737234 & 4.6459 & 4.8129 & TRN & \\
\hline CHEMBL1359949 & 737234 & 4.4425 & 4.1779 & TRN & \\
\hline CHEMBL1721159 & 737234 & 4.5654 & 4.7295 & TRN & \\
\hline CHEMBL1713376 & 737234 & 3.1765 & 3.8899 & TRN & \\
\hline CHEMBL1542492 & 737234 & 4.7033 & 4.0529 & TRN & \\
\hline CHEMBL1446971 & 737234 & 4.5751 & 4.4793 & TRN & \\
\hline CHEMBL1570871 & 737234 & 4.3778 & 4.1759 & TRN & \\
\hline CHEMBL1462873 & 737234 & 4.3706 & 4.6524 & TRN & \\
\hline CHEMBL1464853 & 737234 & 3.1765 & 4.1552 & TRN & \\
\hline CHEMBL1716038 & 737234 & 3.1765 & 4.1415 & TST & \\
\hline CHEMBL3197091 & 737234 & 4.5171 & 3.9307 & TRN & \\
\hline CHEMBL1382317 & 737234 & 4.4802 & 4.4921 & TRN & \\
\hline CHEMBL3195277 & 737234 & 3.1765 & 4.2147 & TRN & \\
\hline CHEMBL1570587 & 737234 & 4.5498 & 4.5161 & TRN & \\
\hline CHEMBL1485277 & 737234 & 4.4597 & 4.146 & TRN & \\
\hline CHEMBL1485865 & 737234 & 4.6696 & 4.4969 & TST & \\
\hline CHEMBL1406895 & 737234 & 4.8508 & 4.5938 & TRN & \\
\hline CHEMBL1706492 & 737234 & 4.6676 & 4.5982 & TRN & \\
\hline CHEMBL1403869 & 737234 & 4.6819 & 5.0406 & TRN & \\
\hline CHEMBL1965403 & 737234 & 4.6108 & 4.1504 & TRN & \\
\hline CHEMBL309474 & 737234 & 4.5986 & 4.272 & TST & \\
\hline CHEMBL1584752 & 737234 & 4.2111 & 4.5103 & TRN & \\
\hline CHEMBL1504875 & 737234 & 3.1765 & 4.2564 & TRN & \\
\hline CHEMBL1730238 & 737234 & 3.1765 & 4.2793 & TRN & \\
\hline
\end{tabular}

Page 25254 


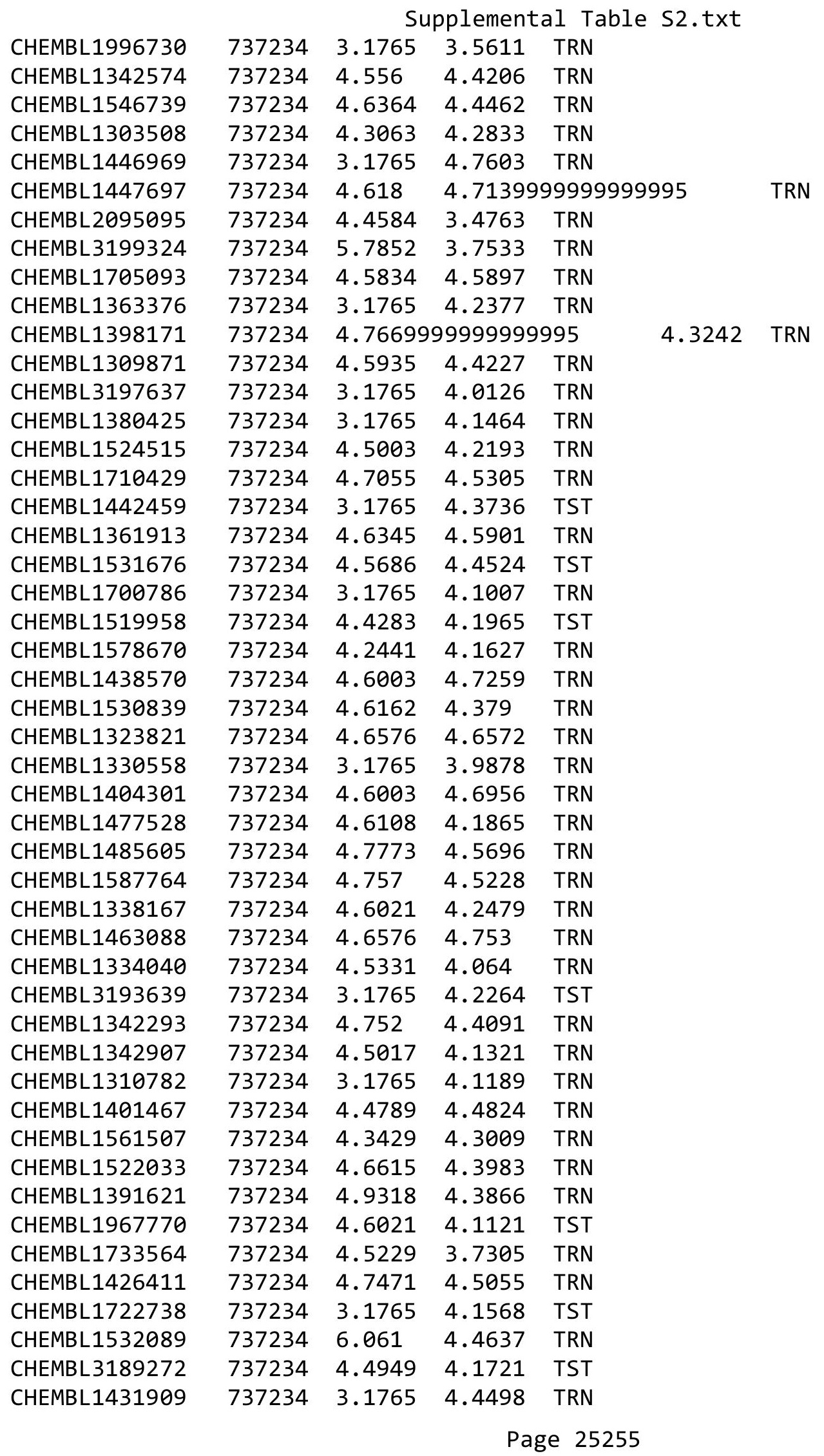


Supplemental Table S2.txt

\begin{tabular}{|c|c|c|c|c|c|}
\hline CHEMBL1483287 & 737234 & 4.6596 & 4.5764 & TRN & \\
\hline CHEMBL1391094 & 737234 & 4.8069 & 4.6804 & TRN & \\
\hline CHEMBL3195347 & 737234 & 4.7645 & 4.32 & TRN & \\
\hline CHEMBL3196732 & 737234 & 3.1765 & 3.836999 & 9999999997 & TRN \\
\hline CHEMBL1723955 & 737234 & 4.6536 & 4.1414 & TRN & \\
\hline CHEMBL1510905 & 737234 & 3.1765 & 3.8941 & TRN & \\
\hline CHEMBL393287 & 737234 & 3.1765 & 4.2867 & TRN & \\
\hline CHEMBL355496 & 737234 & 3.1765 & 4.101 & TRN & \\
\hline CHEMBL1527565 & 737234 & 4.7932 & 4.4353 & TST & \\
\hline CHEMBL3196572 & 737234 & 4.7825 & 4.1152 & TRN & \\
\hline CHEMBL1712082 & 737234 & 4.4976 & 4.1622 & TST & \\
\hline CHEMBL1447124 & 737234 & 4.4449 & 4.6658 & TRN & \\
\hline CHEMBL1524932 & 737234 & 4.5622 & 4.5815 & TRN & \\
\hline CHEMBL3191445 & 737234 & 3.1765 & 3.9708 & TRN & \\
\hline CHEMBL1528425 & 737234 & 4.8013 & 4.3508 & TRN & \\
\hline CHEMBL1324005 & 737234 & 4.6596 & 4.643 & TRN & \\
\hline CHEMBL3197639 & 737234 & 4.5086 & 4.0684 & TST & \\
\hline CHEMBL3192924 & 737234 & 4.4724 & 3.756000 & 0000000002 & TRN \\
\hline CHEMBL3189325 & 737234 & 3.1765 & 3.6389 & TRN & \\
\hline CHEMBL 1447350 & 737234 & 4.6576 & 4.8157 & TRN & \\
\hline CHEMBL1585777 & 737234 & 4.3233 & 4.4202 & TRN & \\
\hline CHEMBL1300729 & 737234 & 4.6576 & 4.4854 & TRN & \\
\hline CHEMBL1463647 & 737234 & 4.9547 & 4.7637 & TST & \\
\hline CHEMBL1987894 & 737234 & 3.1765 & 3.5846 & TRN & \\
\hline CHEMBL1313592 & 737234 & 3.1765 & 4.0404 & TRN & \\
\hline CHEMBL1510664 & 737234 & 4.2175 & 4.3361 & TRN & \\
\hline CHEMBL1545697 & 737234 & 4.3862 & 4.0213 & TRN & \\
\hline CHEMBL1534949 & 737234 & 4.3726 & 4.4194 & TRN & \\
\hline CHEMBL1470925 & 737234 & 3.1765 & 4.0015 & TRN & \\
\hline CHEMBL1506256 & 737234 & 4.7282 & 4.5163 & TRN & \\
\hline CHEMBL3192555 & 737234 & 3.1765 & 3.7363 & TRN & \\
\hline CHEMBL1580684 & 737234 & 4.4023 & 4.2154 & TRN & \\
\hline CHEMBL1458840 & 737234 & 4.4449 & 4.0721 & TST & \\
\hline CHEMBL1500256 & 737234 & 3.1765 & 4.3124 & TRN & \\
\hline CHEMBL1727268 & 737234 & 4.8827 & 4.9075 & TRN & \\
\hline CHEMBL1461196 & 737234 & 4.4895 & 4.1199 & TRN & \\
\hline CHEMBL1506728 & 737234 & 4.4789 & 4.5071 & TRN & \\
\hline CHEMBL1543371 & 737234 & 4.52 & 4.5192 & TRN & \\
\hline CHEMBL592124 & 737234 & 4.8153 & 4.1248 & TRN & \\
\hline CHEMBL1717890 & 737234 & 3.1765 & 4.3412 & TRN & \\
\hline CHEMBL1904956 & 737234 & 4.5361 & \multicolumn{2}{|c|}{4.0760000000000005} & TRN \\
\hline CHEMBL1426562 & 737234 & 4.71899 & 999999999 & 4.3276 & TRN \\
\hline CHEMBL3191691 & 737234 & 4.4737 & 3.9325 & TST & \\
\hline CHEMBL1504403 & 737234 & 6.2262 & 4.6233 & TRN & \\
\hline CHEMBL1571835 & 737234 & 4.8239 & 4.617 & TRN & \\
\hline CHEMBL1487205 & 737234 & 4.4318 & 4.4421 & TRN & \\
\hline CHEMBL1600326 & 737234 & 3.1765 & 4.5777 & TRN & \\
\hline CHEMBL1607475 & 737234 & 3.1765 & 4.0967 & TRN & \\
\hline
\end{tabular}

Page 25256 
Supplemental Table S2.txt

\begin{tabular}{|c|c|c|c|c|}
\hline 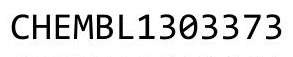 & & & & \\
\hline HEMBL1510964 & 37234 & 1765 & 1792 & \\
\hline HEMBL1548252 & 37234 & & 2735 & \\
\hline IEMBL1 & 234 & & 2517 & \\
\hline EMBL14 & 37234 & & 4.5276 & \\
\hline HEMBL1318103 & 37234 & 234 & .4845 & \\
\hline HEMBL1968732 & 37234 & 5.5058 & 4.2587 & \\
\hline HEMBL131 & & & 4599 & \\
\hline IEMBL13S & 34 & & 345 & \\
\hline IEMBL134 & 37234 & & 5619 & \\
\hline HEMBL1309890 & 37234 & 22 & 2023 & \\
\hline HEMBL1720855 & 37234 & & 1537 & \\
\hline HEMBL1382320 & 34 & & 4.2872 & \\
\hline AEMBL14 & 34 & & 7083 & \\
\hline AEMBL15 & 34 & & 7347 & \\
\hline HEMBL13. & 34 & & 2079 & \\
\hline HEMBL156 & & & 48 & \\
\hline HEMBL 148 & 34 & & 7516 & \\
\hline HEMBL17 & 34 & & 5554 & \\
\hline HEMBL15 & 34 & & 972 & \\
\hline HEMBL134 & 34 & & 7082 & \\
\hline HEMBL1428258 & & & & \\
\hline HEMBL 14 & 34 & & 534 & RN \\
\hline HEMBL14 & & & 126 & RIV \\
\hline HEME & 34 & & 3313 & $\mathrm{RN}$ \\
\hline HEMBL1508121 & & & & RIN \\
\hline AEMBL1735062 & & & 051 & SI \\
\hline HEMBL14 & 34 & & 836 & $\mathrm{RN}$ \\
\hline HEM & 4 & & 93 & KIV \\
\hline HEM & & & 803 & RN \\
\hline HEMBL172 & & & & S \\
\hline HEMBL1463974 & 34 & & 078 & TRN \\
\hline HEMBL13 & 34 & & 916 & RN \\
\hline 6 & 34 & & 11 & RN \\
\hline HEMBL 145 & & & 941 & $\mathrm{RN}$ \\
\hline HEMBL1982845 & & & 3217 & ГST \\
\hline HEMBL1729008 & 34 & & 104 & ГST \\
\hline 政T & & & 389 & $\mathrm{RN}$ \\
\hline רי וחיוזו & & & & I \\
\hline HEMBL1509216 & & & 865 & ST \\
\hline HEMBL1524916 & 34 & & .786 & RN \\
\hline HEMBL31C & 34 & & 097 & RN \\
\hline 157 & & & & \\
\hline CHEMBL 3191459 & & & 5989 & RIN \\
\hline HEMBL1734152 & 37234 & & 272 & RN \\
\hline HEMBL1716008 & 37234 & 4. & 5181 & RN \\
\hline HEM & & & & \\
\hline م & & & & \\
\hline
\end{tabular}

Page 25257 
Supplemental Table S2.txt

\begin{tabular}{|c|c|c|c|c|c|c|}
\hline CHEMBL1700323 & 737234 & 4.6757 & 4.6498 & TST & & \\
\hline CHEMBL1437683 & 737234 & 4.8356 & 4.1959 & TST & & \\
\hline CHEMBL1964407 & 737234 & 4.4776 & 4.3623 & TST & & \\
\hline CHEMBL1561133 & 737234 & 4.6091 & 4.4671 & TST & & \\
\hline CHEMBL1522846 & 37234 & 4.7773 & 4.1981 & TST & & \\
\hline CHEMBL1431608 & 737234 & 4.7122 & 4.4299 & TST & & \\
\hline CHEMBL1965860 & 737234 & \multicolumn{3}{|c|}{4.821000000000001} & 4.0767 & TST \\
\hline CHEMBL1422976 & 737234 & 4.8297 & 4.5967 & TST & & \\
\hline CHEMBL1321614 & 737234 & 4.4389 & 4.5531 & TST & & \\
\hline CHEMBL1714002 & 737234 & 3.1765 & 4.5559 & TST & & \\
\hline CHEMBL1341008 & 737234 & \multicolumn{3}{|c|}{4.7669999999999995} & 4.2644 & TST \\
\hline CHEMBL1287980 & 737234 & 4.4962 & 4.0148 & TST & & \\
\hline HEMBL1318526 & 737234 & 4.6655 & 4.1641 & TST & & \\
\hline HEMBL1529115 & 737234 & 4.5544 & 4.3414 & TST & & \\
\hline HEMBL1366012 & 737234 & 4.7352 & 4.2783 & TST & & \\
\hline HEMBL1582121 & 737234 & 3.1765 & 4.5044 & TST & & \\
\hline HEMBL1309432 & 737234 & 3.1765 & 3.8902 & TST & & \\
\hline HEMBL1400481 & 737234 & 4.6198 & 4.3668 & TST & & \\
\hline CHEMBL1412087 & 737234 & 4.5214 & 4.0059 & TST & & \\
\hline HEMBL1726134 & 737234 & 4.752 & 4.2774 & TST & & \\
\hline HEMBL1574132 & 737234 & 3.1765 & 4.3646 & TST & & \\
\hline CHEMBL1580311 & 737234 & 4.3747 & 4.2118 & TST & & \\
\hline CHEMBL210136 & 685562 & \multicolumn{3}{|c|}{6.252000000000001} & 5.4867 & TRN \\
\hline CHEMBL516333 & 685562 & 6.018 & 5.4944 & TRN & & \\
\hline HEMBL458989 & 685562 & 5.796 & 5.3673 & TRN & & \\
\hline HEMBL458102 & 685562 & 6.398 & 5.8152 & TRN & & \\
\hline CHEMBL457917 & 685562 & 5.721 & 5.1778 & TRN & & \\
\hline CHEMBL516160 & 685562 & 5.481 & \multicolumn{3}{|c|}{5.207999999999999} & TRN \\
\hline CHEMBL515998 & 685562 & \multicolumn{3}{|c|}{5.1370000000000005} & 5.5388 & TRN \\
\hline CHEMBL458103 & 685562 & 4.456 & 4.7333 & TRN & & \\
\hline CHEMBL458104 & 685562 & \multicolumn{3}{|c|}{ 4.0089999999999995 } & 4.7837 & TRN \\
\hline CHEMBL509302 & 685562 & 4.638 & 5.2914 & TRN & & \\
\hline CHEMBL513435 & 685562 & 4.229 & 5.4626 & TRN & & \\
\hline CHEMBL512558 & 685562 & 4.008 & 5.42200 & 000000000 & & TST \\
\hline CHEMBL463586 & 685562 & 4.055 & 5.2004 & TST & & \\
\hline CHEMBL463587 & 685562 & \multicolumn{3}{|c|}{6.207000000000001} & 5.6695 & TST \\
\hline CHEMBL462790 & 685562 & 6.0 & 5.0044 & TST & & \\
\hline CHEMBL462988 & 685562 & 4.0 & 5.6257 & TST & & \\
\hline CHEMBL458550 & 685562 & 5.468 & 5.4873 & TST & & \\
\hline CHEMBL458551 & 685562 & 4.602 & 5.7311 & TST & & \\
\hline CHEMBL518534 & 685562 & \multicolumn{3}{|c|}{6.1739999999999995} & 4.6543 & TST \\
\hline CHEMBL295960 & 685562 & 4.187 & 4.2011 & TRN & & \\
\hline CHEMBL53153 & 685562 & 5.301 & 5.0301 & TRN & & \\
\hline CHEMBL 298564 & 685562 & 5.432 & 5.0281 & TRN & & \\
\hline CHEMBL54094 & 685562 & \multicolumn{3}{|c|}{ 4. 2219999999999995} & 4.6572 & TRN \\
\hline CHEMBL 298397 & 685562 & 4.677 & 4.6615 & TRN & & \\
\hline CHEMBL299079 & 685562 & \multicolumn{3}{|c|}{4.5680000000000005} & 4.3452 & I RIN \\
\hline CHEMBL298794 & 685562 & \multicolumn{3}{|c|}{4.2669999999999995} & 4.313 & TRN \\
\hline
\end{tabular}




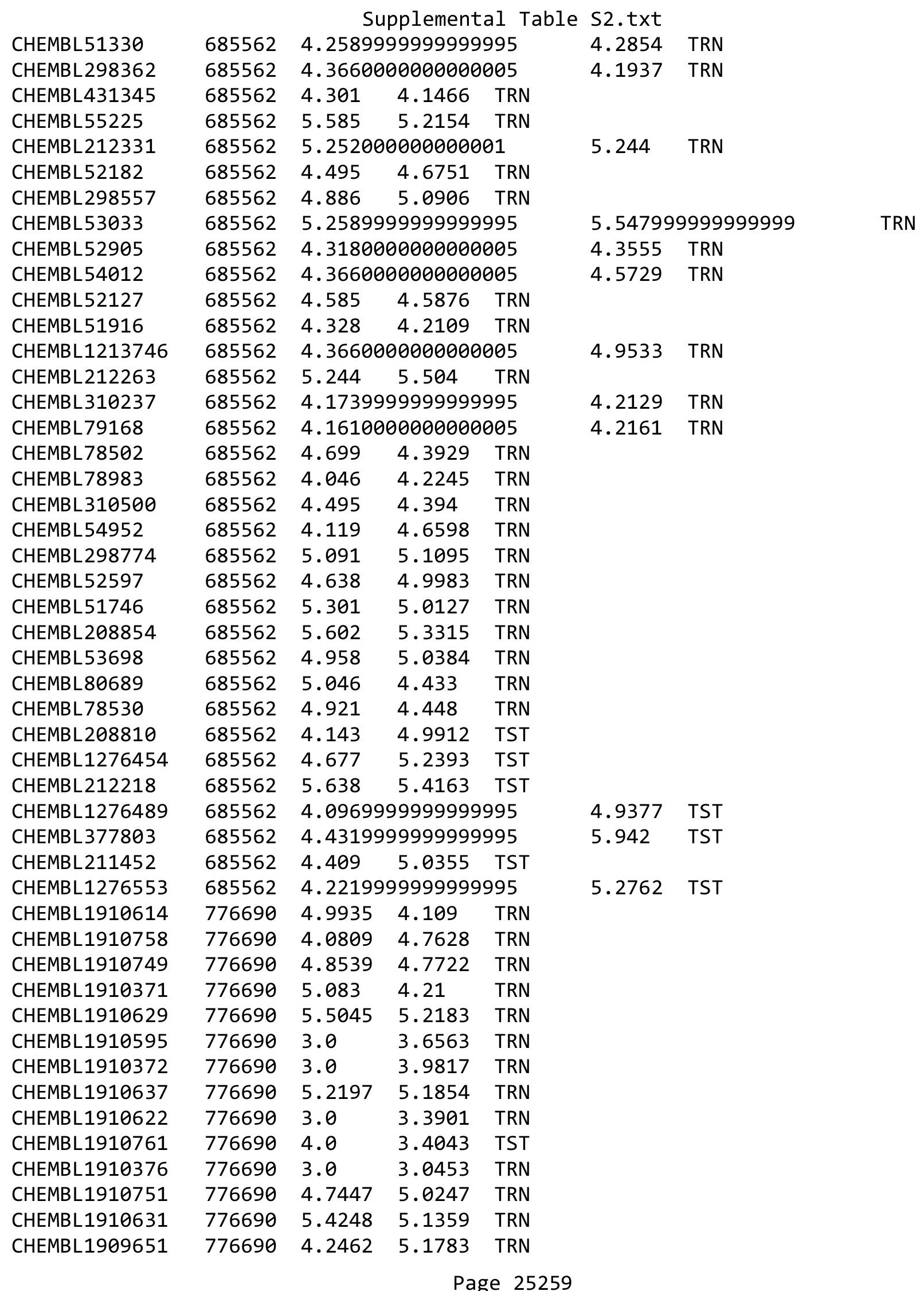




\begin{tabular}{|c|c|c|c|c|c|}
\hline & & \multicolumn{4}{|c|}{ Supplemental Table S2.txt } \\
\hline CHEMBL1910608 & 776690 & 5.9101 & 6.0696 & TRN & \\
\hline CHEMBL1910374 & 776690 & 5.4056 & 4.9684 & TRN & \\
\hline CHEMBL1910606 & 776690 & 4.5133 & 4.4537 & TRN & \\
\hline CHEMBL1910600 & 776690 & 3.0 & 3.6126 & TRN & \\
\hline CHEMBL1910750 & 776690 & 4.757 & 4.6884 & TRN & \\
\hline CHEMBL1910604 & 776690 & 3.0 & 3.0183 & TRN & \\
\hline CHEMBL1910635 & 776690 & 5.2269 & 4.7327 & TRN & \\
\hline CHEMBL1910627 & 776690 & 5.5391 & 4.7828 & TRN & \\
\hline CHEMBL1910598 & 776690 & 3.0 & 2.656 & TRN & \\
\hline CHEMBL1910756 & 776690 & 4.3487 & 4.6459 & TRN & \\
\hline CHEMBL1910746 & 776690 & 4.9431 & 4.7115 & TST & \\
\hline CHEMBL1910745 & 776690 & 5.1355 & 4.9311 & TRN & \\
\hline CHEMBL1910632 & 776690 & 5.3439 & 4.6569 & TRN & \\
\hline CHEMBL1910616 & 776690 & 4.9208 & 3.6231 & TST & \\
\hline CHEMBL1910752 & 776690 & 4.7328 & 4.7529 & TRN & \\
\hline CHEMBL1910624 & 776690 & 3.0 & 3.511 & TST & \\
\hline CHEMBL1910762 & 776690 & 4.0 & 3.33106 & 00000000004 & TST \\
\hline CHEMBL1910630 & 776690 & 5.4461 & 4.4065 & TRN & \\
\hline CHEMBL1910760 & 776690 & 4.0066 & 4.2542 & TRN & \\
\hline CHEMBL1910599 & 776690 & 3.0 & 2.5325 & TRN & \\
\hline CHEMBL1910617 & 776690 & 3.0 & 3.7117 & TST & \\
\hline CHEMBL1910636 & 776690 & 5.224 & 4.7547 & TRN & \\
\hline CHEMBL1910603 & 776690 & 3.0 & 3.5973 & TRN & \\
\hline CHEMBL1910747 & 776690 & 4.8778 & 4.7951 & TRN & \\
\hline CHEMBL1910626 & 776690 & 5.5528 & 5.7125 & TRN & \\
\hline CHEMBL1910610 & 776690 & 3.0 & 4.4082 & TST & \\
\hline CHEMBL1910607 & 776690 & 5.6676 & 5.5814 & TRN & \\
\hline CHEMBL1910753 & 776690 & 4.6882 & 5.1466 & TST & \\
\hline CHEMBL1910602 & 776690 & 4.2696 & 4.5013 & TRN & \\
\hline CHEMBL1910601 & 776690 & 3.0 & 3.1649 & TRN & \\
\hline CHEMBL1910757 & 776690 & 4.1024 & 3.9071 & TRN & \\
\hline CHEMBL1910759 & 776690 & 4.0269 & 4.3416 & TRN & \\
\hline CHEMBL1910633 & 776690 & 5.2472 & 5.7513 & TRN & \\
\hline CHEMBL1910375 & 776690 & $5.0680 e$ & 00000006 & 5.5045 & TRN \\
\hline CHEMBL1910628 & 776690 & 5.5229 & 4.4556 & TRN & \\
\hline CHEMBL1910634 & 776690 & 5.2328 & 5.5609 & TRN & \\
\hline CHEMBL1910597 & 776690 & 3.0 & 3.3932 & TRN & \\
\hline CHEMBL1910744 & 776690 & 5.1918 & 5.2237 & TRN & \\
\hline CHEMBL1910609 & 776690 & 3.0 & 4.272 & TST & \\
\hline CHEMBL1910605 & 776690 & 3.0 & 3.4229 & TRN & \\
\hline CHEMBL1910748 & 776690 & 4.856 & 4.7298 & TST & \\
\hline CHEMBL1910754 & 776690 & 4.6788 & 5.7907 & TST & \\
\hline CHEMBL1910623 & 776690 & 5.1079 & 3.9214 & TST & \\
\hline CHEMBL1910625 & 776690 & 6.0132 & 6.2148 & TST & \\
\hline CHEMBL1910373 & 776690 & 4.0655 & 3.9547 & TST & \\
\hline CHEMBL1910755 & 776690 & 4.5768 & 3.845 & TST & \\
\hline CHEMBL140183 & 39639 & 5.8861 & 7.6878 & TST & \\
\hline CHEMBL113436 & 39639 & 8.6383 & 8.6409 & TRN & \\
\hline
\end{tabular}




\begin{tabular}{|c|c|c|c|c|}
\hline \multirow[b]{2}{*}{ CHEMBL140912 } & \multicolumn{4}{|c|}{ Supplemental Tabl } \\
\hline & 39639 & 8.4815 & 8.6028 & TRN \\
\hline CHEMBL139246 & 39639 & 7.6021 & 8.2158 & TRN \\
\hline CHEMBL106369 & 39639 & 6.8097 & 6.6413 & TRN \\
\hline CHEMBL138879 & 39639 & 7.3665 & 8.0024 & TRN \\
\hline CHEMBL107092 & 39639 & 7.6021 & 7.2623 & TRN \\
\hline CHEMBL140003 & 39639 & 6.5229 & 6.9371 & TRN \\
\hline CHEMBL336246 & 39639 & 8.1549 & 8.2662 & TRN \\
\hline CHEMBL138274 & 39639 & 8.3565 & 8.1456 & TST \\
\hline CHEMBL139253 & 39639 & 6.5229 & 7.9281 & TRN \\
\hline CHEMBL113042 & 39639 & 8.301 & 7.9568 & TRN \\
\hline CHEMBL140490 & 39639 & 7.4202 & 8.4185 & TRN \\
\hline CHEMBL 292625 & 39639 & 8.1549 & 7.335 & TST \\
\hline CHEMBL 343520 & 39639 & 8.2757 & 8.1588 & TRN \\
\hline CHEMBL113154 & 39639 & 7.9208 & 8.092 & TRN \\
\hline CHEMBL337340 & 39639 & 8.4685 & 8.1959 & TRN \\
\hline CHEMBL108569 & 39639 & 7.5376 & 7.4646 & TST \\
\hline CHEMBL325276 & 39639 & 8.301 & 8.3468 & TRN \\
\hline CHEMBL138028 & 39639 & 7.585 & 7.7931 & TRN \\
\hline CHEMBL 344607 & 39639 & 7.9208 & 7.7828 & TRN \\
\hline CHEMBL 322251 & 39639 & 8.1549 & 8.2863 & TRN \\
\hline CHEMBL108845 & 39639 & 6.2248 & 6.5279 & TRN \\
\hline CHEMBL106406 & 39639 & 7.4815 & 6.9342 & TRN \\
\hline CHEMBL115487 & 39639 & 9.0 & 8.1112 & TRN \\
\hline CHEMBL138502 & 39639 & 8.2815 & 8.6254 & TRN \\
\hline CHEMBL141683 & 39639 & 8.2441 & 8.1907 & TRN \\
\hline CHEMBL140922 & 39639 & 6.5229 & 7.4499 & TRN \\
\hline CHEMBL343826 & 39639 & 8.2518 & 8.0269 & TST \\
\hline CHEMBL113648 & 39639 & 7.2076 & 7.329 & TST \\
\hline CHEMBL139701 & 39639 & 7.3665 & 8.3605 & TRN \\
\hline CHEMBL139607 & 39639 & 7.7959 & 7.6758 & TRN \\
\hline CHEMBL317476 & 39639 & 7.2596 & 7.0058 & TRN \\
\hline CHEMBL139459 & 39639 & 7.7447 & 7.8411 & TRN \\
\hline CHEMBL137934 & 39639 & 8.6383 & 8.2407 & TRN \\
\hline CHEMBL138285 & 39639 & 8.9586 & 8.4786 & TRN \\
\hline CHEMBL 341945 & 39639 & 8.1192 & 8.0775 & TST \\
\hline CHEMBL341758 & 39639 & 8.0915 & 8.491 & TRN \\
\hline CHEMBL139029 & 39639 & 8.3468 & 7.9391 & TRN \\
\hline CHEMBL337364 & 39639 & 8.0458 & 7.9115 & TRN \\
\hline CHEMBL140201 & 39639 & 7.2218 & 8.1135 & TRN \\
\hline CHEMBL115716 & 39639 & 8.301 & 7.7932 & TRN \\
\hline CHEMBL140552 & 39639 & 8.4949 & 8.4217 & TRN \\
\hline CHEMBL113072 & 39639 & 8.5229 & 7.6717 & TRN \\
\hline CHEMBL140390 & 39639 & 8.699 & 8.3697 & TRN \\
\hline CHEMBL337776 & 39639 & 9.1549 & 8.0105 & TRN \\
\hline CHEMBL335794 & 39639 & 9.3979 & 8.3956 & TRN \\
\hline CHEMBL138198 & 39639 & 7.7212 & 7.96200 & 0000000001 \\
\hline CHEMBL342706 & 39639 & 6.5017 & 8.0654 & TRN \\
\hline CHEMBL141202 & 39639 & 8.3279 & 8.458 & TRN \\
\hline
\end{tabular}




\begin{tabular}{|c|c|c|c|c|}
\hline & & & oplement & al Ta \\
\hline CHEMBL112659 & 39639 & 7.699 & 7.5922 & TST \\
\hline CHEMBL141301 & 39639 & 8.2757 & 8.2754 & TST \\
\hline CHEMBL140283 & 39639 & 6.5229 & 7.3562 & TRN \\
\hline CHEMBL106299 & 39639 & 7.1675 & 6.8663 & TRN \\
\hline CHEMBL138640 & 39639 & 8.9208 & 8.1559 & TRN \\
\hline CHEMBL140706 & 39639 & 7.9586 & 8.4216 & TRN \\
\hline CHEMBL111982 & 39639 & 6.3565 & 7.1221 & TST \\
\hline CHEMBL140827 & 39639 & 9.1549 & 8.7716 & TRN \\
\hline CHEMBL311795 & 39639 & 8.5229 & 8.6121 & TRN \\
\hline CHEMBL106264 & 39639 & 6.4437 & 6.1157 & TRN \\
\hline CHEMBL140887 & 39639 & 6.5229 & 7.6058 & TRN \\
\hline CHEMBL325556 & 39639 & 8.0969 & 7.5051 & TST \\
\hline CHEMBL335120 & 39639 & 8.6778 & 8.1997 & TRN \\
\hline CHEMBL116008 & 39639 & 7.5229 & 7.3189 & TST \\
\hline CHEMBL138263 & 39639 & 7.699 & 7.8205 & TST \\
\hline CHEMBL141802 & 39639 & 7.4815 & 7.6055 & TRN \\
\hline CHEMBL423000 & 39639 & 8.5229 & 8.3397 & TST \\
\hline CHEMBL261950 & 39639 & 8.4202 & 8.3284 & TST \\
\hline CHEMBL341928 & 39639 & 7.4815 & 7.6478 & TRN \\
\hline CHEMBL106209 & 39639 & 7.2676 & 7.5802 & TRN \\
\hline CHEMBL138655 & 39639 & 7.5229 & 7.7412 & TST \\
\hline CHEMBL140418 & 39639 & 8.8861 & 8.2231 & TRN \\
\hline CHEMBL323454 & 39639 & 6.7212 & 7.5357 & TST \\
\hline CHEMBL107154 & 39639 & 8.0969 & 7.8393 & TRN \\
\hline CHEMBL112299 & 39639 & 7.8239 & 7.7138 & TRN \\
\hline CHEMBL140484 & 39639 & 10.0 & 8.5382 & TRN \\
\hline CHEMBL344435 & 39639 & 7.9586 & 8.1759 & TRN \\
\hline CHEMBL142021 & 39639 & 8.6576 & 8.3757 & TRN \\
\hline CHEMBL342137 & 39639 & 8.0 & 8.4574 & TRN \\
\hline CHEMBL137856 & 39639 & 8.0555 & 7.9687 & TRN \\
\hline CHEMBL138975 & 39639 & 8.3979 & 8.0795 & TRN \\
\hline CHEMBL110463 & 39639 & 7.0655 & 6.8032 & TRN \\
\hline CHEMBL106982 & 39639 & 7.4815 & 6.8135 & TST \\
\hline CHEMBL110786 & 39639 & 6.9586 & 6.6582 & TST \\
\hline CHEMBL139559 & 39639 & 8.9586 & 8.5529 & TRN \\
\hline CHEMBL141699 & 39639 & 7.7447 & 8.3459 & TRN \\
\hline CHEMBL111998 & 39639 & 8.301 & 8.1432 & TRN \\
\hline CHEMBL326020 & 39639 & 8.1549 & 7.8367 & TRN \\
\hline CHEMBL337820 & 39639 & 8.0 & 8.5059 & TRN \\
\hline CHEMBL335365 & 39639 & 9.5229 & 8.299 & TRN \\
\hline CHEMBL106247 & 39639 & 7.2366 & 6.8832 & TST \\
\hline CHEMBL141345 & 39639 & 7.5229 & 7.8873 & TST \\
\hline CHEMBL342452 & 39639 & 7.1079 & 7.5604 & TRN \\
\hline CHEMBL141201 & 39639 & 7.8539 & 8.4892 & TRN \\
\hline CHEMBL110871 & 39639 & 7.2076 & 7.6038 & TST \\
\hline CHEMBL138143 & 39639 & 7.6198 & 7.9148 & TST \\
\hline CHEMBL334470 & 39639 & 8.5686 & 8.4936 & TRN \\
\hline CHEMBL142022 & 39639 & 6.2291 & 6.4336 & TST \\
\hline
\end{tabular}


Supplemental Table S2.txt

\begin{tabular}{|c|c|c|c|c|}
\hline 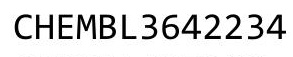 & 527771 & & 6977 & 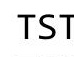 \\
\hline HEMBL437328 & 527771 & 7.3605 & 4316 & \\
\hline AEMBL3642242 & 527771 & 6.5605 & 2985 & \\
\hline AEM & 527771 & 848 & 1977 & \\
\hline AEMBL215025 & 527771 & 301 & 5289 & \\
\hline AEMBL214568 & 527771 & 5.5887 & 8204 & \\
\hline AEMBL385348 & 527771 & 6.5943 & 2133 & \\
\hline AEMBL 384075 & & 685 & & \\
\hline IEMBL21 & 527771 & 778 & 3682 & \\
\hline AEMBL3642244 & 527771 & 482 & 9988 & \\
\hline AEMBL 384280 & 1527771 & 8.7447 & 8987 & \\
\hline AEMBL215827 & 527771 & 8.0458 & 3847 & \\
\hline AEMBL214883 & 71 & 8. & 1724 & \\
\hline AEMBL3642247 & 771 & 08 & 326 & \\
\hline HEMBL43 & 771 & 386 & 196 & \\
\hline AEMBL214884 & 527771 & 926 & 3021 & \\
\hline AEMBL3642241 & 771 & 979 & 937 & \\
\hline AEMBL36 & 152 & 4. & 726 & \\
\hline AEMBL21 & 71 & $\partial 9$ & & \\
\hline AEMBL38 & 71 & 57 & 43 & \\
\hline AEMBL38 & 771 & 192 & 763 & \\
\hline AEMBL 214644 & 71 & 96 & & \\
\hline AEMBL3640214 & 152 & 8 . & & \\
\hline AEMBL36 & 71 & 77 & & \\
\hline HEMBL38 & 71 & 281 & 472 & \\
\hline AEMBL3642246 & & 979 & 598 & \\
\hline IEMBL426340 & 52 & & 216 & \\
\hline IEMBL38 & 52 & 582 & 42 & \\
\hline 25 & 71 & 34 & 98 & \\
\hline AFMRI 21 & 71 & 76 & 552 & \\
\hline AEMBL 215161 & 771 & 208 & 053 & \\
\hline AEMBL 214735 & 52 & 6.3903 & 9225 & \\
\hline 2. & 71 & 44 & 91 & \\
\hline 36 & 71 & 57 & 78 & \\
\hline HEMBL 216016 & 771 & & 8.6246 & \\
\hline HEMBL 215069 & 527771 & 8.2676 & 193 & F \\
\hline AEMBL3642237 & 527771 & 5.6353 & 7252 & \\
\hline AEMRI 361 & 71 & 58 & 303 & \\
\hline 8 & 71 & & 829 & RI \\
\hline HEMBL215999 & 1527771 & 8.9586 & 8.3864 & $\mathrm{RN}$ \\
\hline AEMBL3642235 & 771 & 5.2992 & 267 & is \\
\hline EMBL364 & 152 & 405 & 023 & TS \\
\hline & 1527771 & 125 & 5.7087 & \\
\hline CHEMBL1257880 & 1527771 & 9.0969 & .1284 & $\Gamma S T$ \\
\hline HEMBL1668928 & 1527771 & 7.5591 & 7.847 & RI \\
\hline AEMBL3640212 & 1527771 & 4.8669 & 7.3681 & ra \\
\hline & 152 & 605 & & \\
\hline & גרירתז & & & \\
\hline
\end{tabular}

Page 25263 
Supplemental Table S2.txt

\begin{tabular}{|c|c|c|c|c|}
\hline CHEMBL214179 & 1527771 & 8.7696 & 8.7309 & TRN \\
\hline CHEMBI 3640218 & 527771 & 5.8762 & 6.2241 & TST \\
\hline HEMBL3640216 & 527771 & 7.0605 & 2874 & \\
\hline HEMBL 217758 & 527771 & 6.0 & 2481 & \\
\hline HEMBL3642243 & 527771 & 5.3758 & 4.6804 & \\
\hline HEMBL3642240 & 527771 & 8.3188 & 6168 & \\
\hline HEMBL1668934 & 527771 & 7.9393 & 005 & \\
\hline HEMBL214127 & 527771 & 8.7447 & 7.358 & RN \\
\hline HEMBL1668935 & 527771 & 8.8539 & 8.9549 & \\
\hline HEMBL3642238 & 527771 & 6.2505 & 9376 & \\
\hline HEMBL1257759 & 527771 & 9.3979 & 8.9871 & ST \\
\hline HEMBL 214 & 1527771 & 8.1739 & 8.2671 & \\
\hline HEMBL 385946 & 527771 & 7.9957 & 7.8279 & TRN \\
\hline HEMBL 214505 & .527771 & 8.5686 & 8.6274 & \\
\hline HEMBL3642236 & 1527771 & 6. & 6.2728 & \\
\hline HEMBL & 527771 & 15 & 489 & RN \\
\hline HEMBL; & 771 & 52 & 5622 & \\
\hline HEMBL 215146 & 1527771 & 6.9508 & 7.1122 & $2 \mathrm{~N}$ \\
\hline HEMBL 364 & 527771 & 4. & 5.93 & \\
\hline HEMBL2 & 71 & 921 & 1965 & KIV \\
\hline HEMBL & 771 & 5 . & 479 & RN \\
\hline HEMBL & 771 & 35 & 3855 & RN \\
\hline HEMBL125 & 527771 & 9. & 6.6341 & TST \\
\hline HEMBL3640213 & 71 & 7.3 & 5031 & 15 \\
\hline HEMBL 397 & 1640001 & 6. & 5.9997 & RN \\
\hline HEMBL & 001 & 8. & 9501 & RN \\
\hline HEMBL & 301 & 8.0 & 7.5454 & RN \\
\hline HEMBL3979525 & 1640001 & 8.0 & 8.1707 & TRN \\
\hline HEMBL3933706 & 640001 & 8.6 & 9701 & TRN \\
\hline IHEMBL 395 & 1640001 & 6. & 6.0582 & ГRN \\
\hline HEMBL & 01 & 8 . & 7.8601 & $\mathrm{RN}$ \\
\hline LHEMBL & 01 & 7.0 & 7.1815 & TRN \\
\hline HEMBL3962115 & 640001 & 6.0 & & TST \\
\hline HEMBL3926363 & 640001 & 8 . & 0137 & TRN \\
\hline CHEMBL3 & 001 & 8 & 7.9825 & TRN \\
\hline HEMBL & 01 & 4 & 3.6501 & ГST \\
\hline LHEMBL 395 & 01 & 7.0 & 7.0648 & TRN \\
\hline HEMBL3907576 & 1640001 & 8.0 & 8.1239 & TRN \\
\hline CHEMBL 396942 & 640001 & 8 & 8.0844 & TRN \\
\hline CHEMBL. & 01 & 8 . & 7.8768 & TRN \\
\hline CHEMBL3 & 1640001 & 4. & 3.8074 & TRN \\
\hline CHEMBL3946558 & 1640001 & 6.0 & 5.1906 & TST \\
\hline CHEMBL390042 & 1640001 & 4.0 & 4.92 & TST \\
\hline CHEMBL 3902749 & 1640001 & 8.6 & 7.9297 & TRN \\
\hline CHEMBL398 & 1640001 & 6 . & 5.8706 & \\
\hline CHEMBL3932536 & 1640001 & 8.0 & 7.8955 & TRN \\
\hline CHEMBL3942608 & 1640001 & 8.0 & 7.9188 & TST \\
\hline CHEMBL3932622 & 1640001 & 7.0 & 7.0618 & TR \\
\hline
\end{tabular}

Page 25264 


\begin{tabular}{|c|c|c|c|}
\hline & & & \\
\hline CHEMBL3940197 & 16400014.0 & 3.89 & TST \\
\hline CHEMBL3966934 & 16400017.0 & 7.0937 & TRN \\
\hline CHEMBL3889881 & 16400014.0 & 4.0133 & TRN \\
\hline CHEMBL3959600 & 16400018.0 & 7.3053 & TRN \\
\hline CHEMBL3969503 & 16400018.0 & 7.984 & TRN \\
\hline CHEMBL3894025 & 16400018.0 & 8.3074 & TRN \\
\hline CHEMBL 3917641 & 16400017.0 & 6.5779 & TRN \\
\hline CHEMBL3917582 & 16400014.0 & 5.3431 & TST \\
\hline CHEMBL3979291 & 16400014.0 & 5.3465 & TST \\
\hline CHEMBL3964285 & 16400014.0 & 3.7053 & TST \\
\hline CHEMBL3939558 & 16400018.0 & 7.3938 & TST \\
\hline CHEMBL 3948783 & 16400017.0 & 7.6655 & TRN \\
\hline CHEMBL3986543 & 16400018.0 & 8.0307 & TRN \\
\hline CHEMBL3943118 & 16400014.0 & 4.5989 & TST \\
\hline CHEMBL3928629 & 16400014.0 & 3.2937 & TST \\
\hline CHEMBL3970988 & 16400018.0 & 7.7059 & TRN \\
\hline CHEMBL3901146 & 16400018.0 & 7.9344 & TRN \\
\hline CHEMBL3944834 & 16400017.0 & 6.8841 & TRN \\
\hline CHEMBL3945760 & 16400018.0 & 7.9684 & TRN \\
\hline CHEMBL3973546 & 16400018.0 & 7.7337 & TRN \\
\hline CHEMBL3955737 & 16400018.0 & 8.0416 & TRN \\
\hline CHEMBL3909114 & 16400016.0 & 6.0438 & TRN \\
\hline CHEMBL3931030 & 16400017.0 & 6.3294 & TRN \\
\hline CHEMBL3959362 & 16400018.0 & 7.8369 & TRN \\
\hline CHEMBL3895663 & 16400018.0 & 7.8877 & TRN \\
\hline CHEMBL3909553 & 16400018.0 & 7.3592 & TRN \\
\hline CHEMBL 3940480 & 16400016.0 & 4.8763 & TST \\
\hline CHEMBL3921838 & 16400018.0 & 7.9497 & TRN \\
\hline CHEMBL3939435 & 16400018.0 & 7.8525 & TRN \\
\hline CHEMBL3931102 & 16400018.0 & 7.8946 & TRN \\
\hline CHEMBL3943247 & 16400018.0 & 8.0198 & TRN \\
\hline CHEMBL 3981288 & 16400017.0 & 6.3089 & TST \\
\hline CHEMBL3891883 & 16400014.0 & 3.2188 & TST \\
\hline CHEMBL 3910274 & 16400018.0 & 7.566 & TRN \\
\hline CHEMBL 3944184 & 16400016.0 & 6.1451 & TRN \\
\hline CHEMBL3918000 & 16400017.0 & 7.0238 & TRN \\
\hline CHEMBL3935921 & 16400018.0 & 7.9201 & TRN \\
\hline CHEMBL3914000 & 16400018.0 & 7.871 & TRN \\
\hline CHEMBL3908455 & 16400018.0 & 7.9201 & TRN \\
\hline CHEMBL3984031 & 16400018.0 & 7.9966 & TRN \\
\hline CHEMBL3901021 & 16400016.0 & 5.9731 & TRN \\
\hline CHEMBL 3958812 & 16400018.0 & 7.9926 & TST \\
\hline CHEMBL3986191 & 16400018.0 & 7.8145 & TRN \\
\hline CHEMBL3920214 & 16400017.0 & 7.09 & TRN \\
\hline CHEMBL 3979227 & 16400017.0 & 6.1528 & TRN \\
\hline CHEMBL 3932888 & 16400016.0 & 5.8854 & TRN \\
\hline CHEMBL 3924801 & 16400018.0 & 7.6919 & TRN \\
\hline CHEMBL3977911 & 16400018.0 & 8.2793 & TST \\
\hline
\end{tabular}




\begin{tabular}{|c|c|c|c|}
\hline & & pplement & al Ta \\
\hline CHEMBL3947729 & 16400014.0 & 4.3987 & TRN \\
\hline CHEMBL3928989 & 16400018.0 & 7.8037 & TRN \\
\hline CHEMBL3937421 & 16400014.0 & 3.4567 & TST \\
\hline CHEMBL3983221 & 16400017.0 & 6.7748 & TRN \\
\hline CHEMBL 3916543 & 16400016.0 & 5.2248 & TRN \\
\hline CHEMBL3941667 & 16400018.0 & 8.1336 & TRN \\
\hline CHEMBL3944905 & 16400014.0 & 3.4375 & TST \\
\hline CHEMBL3895867 & 16400018.0 & 7.8881 & TRN \\
\hline CHEMBL3972019 & 16400014.0 & 3.4022 & TST \\
\hline CHEMBL3949483 & 16400018.0 & 8.0597 & TRN \\
\hline CHEMBL 3978172 & 16400014.0 & 4.2646 & TRN \\
\hline CHEMBL3933953 & 16400016.0 & 6.4409 & TRN \\
\hline CHEMBL3899779 & 16400016.0 & 5.7755 & TRN \\
\hline CHEMBL3975651 & 16400016.0 & 5.9281 & TRN \\
\hline CHEMBL3966310 & 16400018.0 & 8.0538 & TRN \\
\hline CHEMBL3915517 & 16400014.0 & 3.3025 & TST \\
\hline CHEMBL3928258 & 16400018.0 & 8.1765 & TRN \\
\hline CHEMBL3953942 & 16400017.0 & 6.9939 & TRN \\
\hline CHEMBL3899555 & 16400018.0 & 7.9675 & TRN \\
\hline CHEMBL 3938488 & 16400017.0 & 6.9054 & TRN \\
\hline CHEMBL3916234 & 16400016.0 & 6.4081 & TRN \\
\hline CHEMBL3977852 & 16400018.0 & 7.8912 & TST \\
\hline CHEMBL3912868 & 16400018.0 & 7.9797 & TRN \\
\hline CHEMBL3910459 & 16400018.0 & 8.0148 & TRN \\
\hline CHEMBL 3969477 & 16400018.0 & 8.0795 & TRN \\
\hline CHEMBL3908146 & 16400018.0 & 7.9117 & TRN \\
\hline CHEMBL3952387 & 16400018.0 & 8.2528 & TST \\
\hline CHEMBL3909916 & 16400016.0 & 6.1502 & TRN \\
\hline CHEMBL3890638 & 16400018.0 & 8.0937 & TRN \\
\hline CHEMBL 3943347 & 16400014.0 & 3.7854 & TST \\
\hline CHEMBL3986777 & 16400018.0 & 7.9255 & TRN \\
\hline CHEMBL3897055 & 16400014.0 & 3.8295 & TRN \\
\hline CHEMBL3910964 & 16400016.0 & 6.3329 & TRN \\
\hline CHEMBL3970673 & 16400018.0 & 7.0075 & TRN \\
\hline CHEMBL 3924015 & 16400016.0 & 6.0256 & TST \\
\hline CHEMBL3949857 & 16400016.0 & 5.6661 & TST \\
\hline CHEMBL 3973080 & 16400018.0 & 8.0091 & TRN \\
\hline CHEMBL3967006 & 16400014.0 & 3.2487 & TST \\
\hline CHEMBL3932042 & 16400018.0 & 7.8933 & TRN \\
\hline CHEMBL 3938119 & 16400016.0 & 5.6867 & TST \\
\hline CHEMBL3952219 & 16400017.0 & 7.6217 & TRN \\
\hline CHEMBL 3907167 & 16400018.0 & 7.6364 & TRN \\
\hline CHEMBL3925138 & 16400018.0 & 8.0772 & TRN \\
\hline CHEMBL 3974840 & 16400018.0 & 7.6827 & TST \\
\hline CHEMBL 3897556 & 16400016.0 & 6.4178 & TRN \\
\hline CHEMBL3977336 & 16400018.0 & 8.2187 & TRN \\
\hline CHEMBL 3916734 & 16400018.0 & 7.7845 & TRN \\
\hline CHEMBL3891219 & 16400016.0 & 6.4819 & TST \\
\hline
\end{tabular}




\begin{tabular}{|c|c|c|c|c|}
\hline & & & & \\
\hline CHEMBL3904984 & 16400017.0 & 6.9781 & TRN & \\
\hline CHEMBL3927404 & 16400018.0 & 8.1358 & TRN & \\
\hline CHEMBL3950764 & 16400016.0 & 6.8308 & TRN & \\
\hline CHEMBL3906103 & 16400017.0 & 6.7874 & TST & \\
\hline CHEMBL3928812 & 16400016.0 & 6.8464 & TRN & \\
\hline CHEMBL3987021 & 16400018.0 & 7.4551 & TST & \\
\hline CHEMBL3895242 & 16400016.0 & 5.5982 & TST & \\
\hline CHEMBL3977083 & 16400016.0 & 6.5136 & TRN & \\
\hline CHEMBL3966949 & 16400018.0 & 8.0078 & TRN & \\
\hline CHEMBL3976013 & 16400016.0 & 5.6718 & TST & \\
\hline CHEMBL3914011 & 16400018.0 & 7.6741 & TRN & \\
\hline CHEMBL3933226 & 16400014.0 & 3.3198 & TST & \\
\hline CHEMBL3927071 & 16400017.0 & 5.7051 & TST & \\
\hline CHEMBL3917411 & 16400018.0 & 8.0117 & TST & \\
\hline CHEMBL3984062 & 16400018.0 & 8.1316 & TRN & \\
\hline CHEMBL 3936484 & 16400016.0 & 6.2049 & TRN & \\
\hline CHEMBL3980773 & 16400017.0 & 6.5959 & TRN & \\
\hline CHEMBL3915612 & 16400018.0 & 8.1594 & TRN & \\
\hline CHEMBL3899830 & 16400018.0 & 7.8756 & TRN & \\
\hline CHEMBL3918398 & 16400018.0 & 7.6674 & TRN & \\
\hline CHEMBL3890032 & 16400018.0 & 8.2269 & TRN & \\
\hline CHEMBL3970569 & 16400016.0 & 6.1649 & TRN & \\
\hline CHEMBL3926327 & 16400016.0 & 6.1085 & TST & \\
\hline CHEMBL3909927 & 16400018.0 & 8.2806 & TRN & \\
\hline CHEMBL3927298 & 16400018.0 & 7.6874 & TRN & \\
\hline CHEMBL 3957627 & 16400018.0 & 7.9156 & TST & \\
\hline CHEMBL3890661 & 16400014.0 & 3.5607 & TST & \\
\hline CHEMBL3918099 & 16400018.0 & 7.9605 & TRN & \\
\hline CHEMBL3983280 & 16400017.0 & 6.4611 & TRN & \\
\hline CHEMBL3971430 & 16400018.0 & 7.9171 & TRN & \\
\hline CHEMBL3907117 & 16400018.0 & 8.1786 & TRN & \\
\hline CHEMBL3971958 & 16400014.0 & 3.49399 & 99999999998 & TST \\
\hline CHEMBL 3970324 & 16400018.0 & 8.1079 & TRN & \\
\hline CHEMBL3918799 & 16400018.0 & 8.1657 & TRN & \\
\hline CHEMBL3940926 & 16400018.0 & 8.157 & TRN & \\
\hline CHEMBL3909984 & 16400018.0 & 7.7884 & TRN & \\
\hline CHEMBL3950389 & 16400018.0 & 7.5708 & TRN & \\
\hline CHEMBL3903202 & 16400018.0 & 8.2901 & TRN & \\
\hline CHEMBL3970597 & 16400018.0 & 8.0742 & TRN & \\
\hline CHEMBL3962041 & 16400017.0 & 6.6386 & TRN & \\
\hline CHEMBL3941642 & 16400016.0 & 5.999 & TRN & \\
\hline CHEMBL3902864 & 16400018.0 & 7.9232 & TRN & \\
\hline CHEMBL3898105 & 16400018.0 & 8.0068 & TRN & \\
\hline CHEMBL3904666 & 16400018.0 & 7.1057 & TRN & \\
\hline CHEMBL3901474 & 16400018.0 & 7.909 & TRN & \\
\hline CHEMBL 3966378 & 16400017.0 & 7.1085 & TRN & \\
\hline CHEMBL 3898336 & 16400018.0 & 7.9574 & TRN & \\
\hline CHEMBL3936719 & 16400018.0 & 7.91200 & $\partial 000000001$ & TRN \\
\hline & & & 25267 & \\
\hline
\end{tabular}




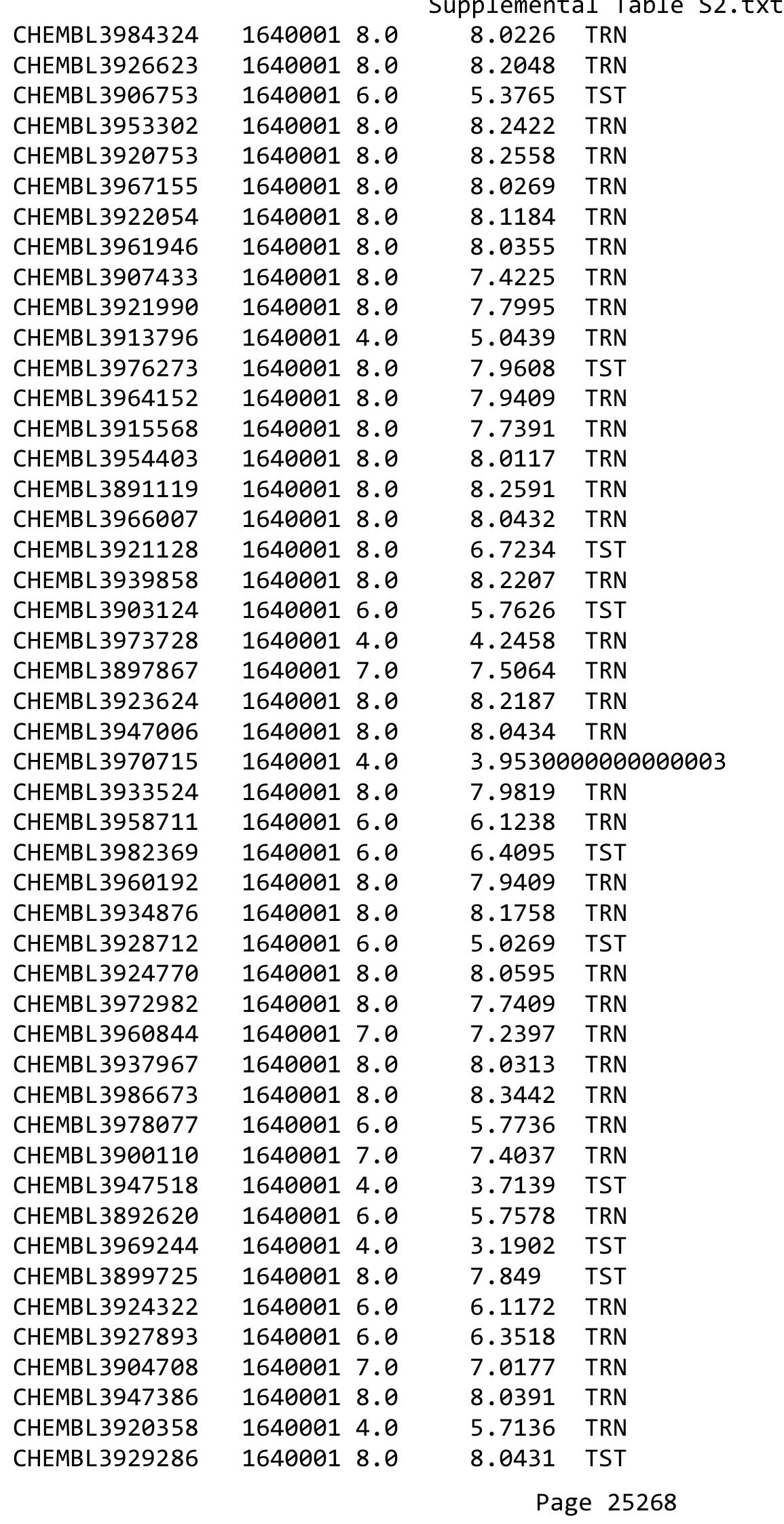




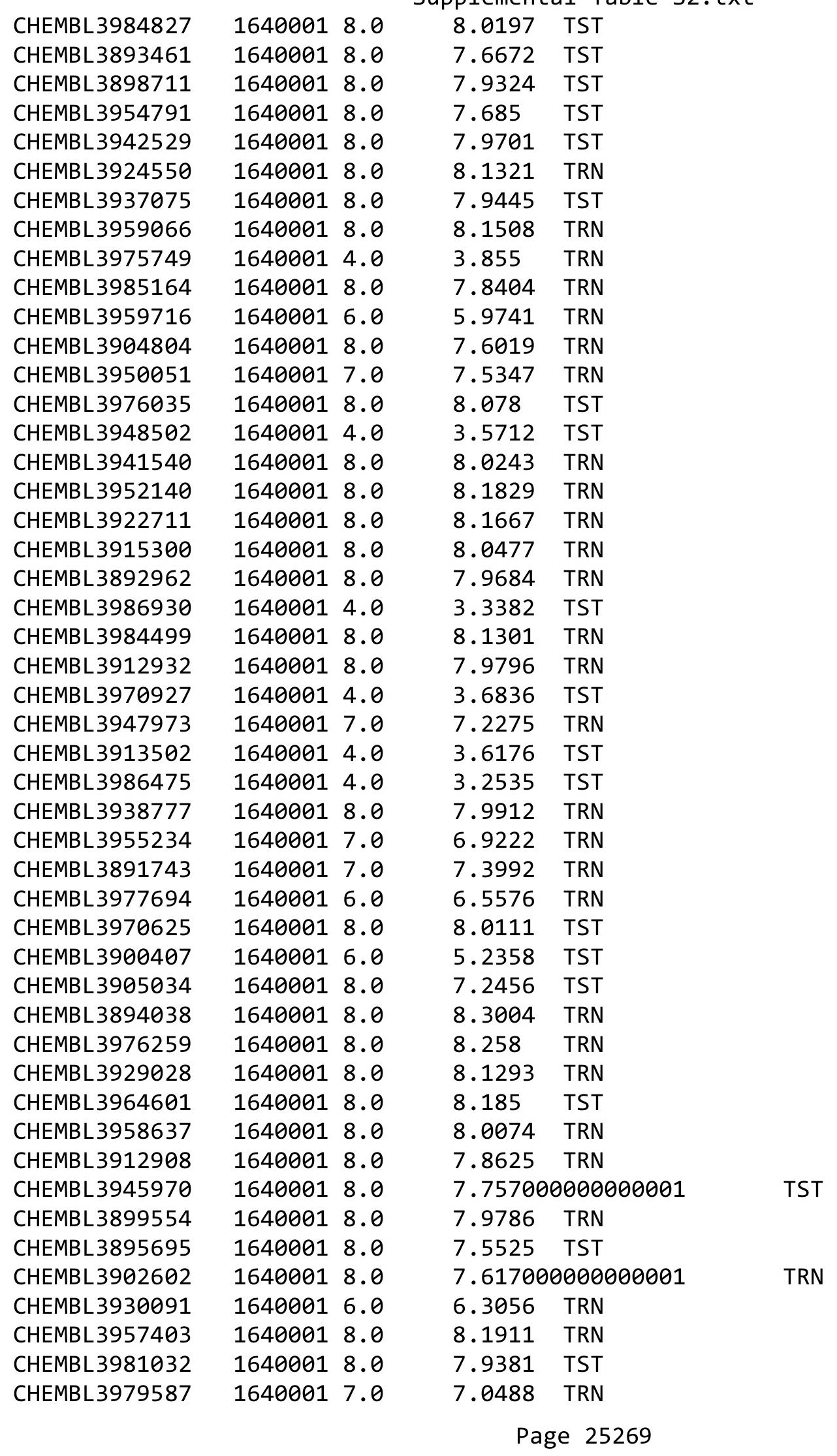




\begin{tabular}{|c|c|c|c|c|}
\hline \\
\hline CHEMBL3976175 & 16400016.0 & 5.7019 & TRN & \\
\hline CHEMBL3946440 & 16400017.0 & 6.8871 & TRN & \\
\hline CHEMBL3957501 & 16400018.0 & 8.0934 & TRN & \\
\hline CHEMBL3941495 & 16400018.0 & 7.7294 & TRN & \\
\hline CHEMBL3920728 & 16400018.0 & 7.6548 & TRN & \\
\hline CHEMBL3944225 & 16400018.0 & 8.1564 & TRN & \\
\hline CHEMBL3946129 & 16400017.0 & 7.7423 & TRN & \\
\hline CHEMBL3967991 & 16400014.0 & 3.5071 & TST & \\
\hline CHEMBL3938682 & 16400017.0 & 7.0587 & TRN & \\
\hline CHEMBL3935590 & 16400017.0 & 7.2123 & TRN & \\
\hline CHEMBL3906845 & 16400018.0 & 8.0865 & TRN & \\
\hline CHEMBL 3927073 & 16400018.0 & 7.8521 & TRN & \\
\hline CHEMBL3966875 & 16400018.0 & 7.4979 & TRN & \\
\hline CHEMBL3980228 & 16400018.0 & 7.9394 & TST & \\
\hline CHEMBL3957394 & 16400018.0 & 7.8973 & TRN & \\
\hline CHEMBL3912623 & 16400018.0 & 7.9351 & TRN & \\
\hline CHEMBL 3902344 & 16400017.0 & 7.4773 & TRN & \\
\hline CHEMBL3922513 & 16400014.0 & 3.8502 & TST & \\
\hline CHEMBL 3927204 & 16400016.0 & 5.9951 & TRN & \\
\hline CHEMBL3984011 & 16400017.0 & 6.6659 & TRN & \\
\hline CHEMBL3935700 & 16400018.0 & 7.9602 & TRN & \\
\hline CHEMBL 3900630 & 16400016.0 & 6.1787 & TRN & \\
\hline CHEMBL3893926 & 16400016.0 & 6.0857 & TRN & \\
\hline CHEMBL3969603 & 16400014.0 & 4.1529 & TRN & \\
\hline CHEMBL 3952619 & 16400014.0 & 3.76800 & 00000000002 & TST \\
\hline CHEMBL3916640 & 16400018.0 & 7.9458 & TRN & \\
\hline CHEMBL3977957 & 16400018.0 & 8.1334 & TRN & \\
\hline CHEMBL3919453 & 16400018.0 & 7.9763 & TST & \\
\hline CHEMBL 3986250 & 16400018.0 & 7.2585 & TRN & \\
\hline CHEMBL3922123 & 16400018.0 & 7.9753 & TRN & \\
\hline CHEMBL3911888 & 16400018.0 & 7.8717 & TRN & \\
\hline CHEMBL 3909298 & 16400018.0 & 7.5135 & TRN & \\
\hline CHEMBL3901717 & 16400018.0 & 8.14299 & 9999999999 & TRN \\
\hline CHEMBL3919386 & 16400018.0 & 8.0969 & TRN & \\
\hline CHEMBL3900361 & 16400014.0 & 4.1257 & TRN & \\
\hline CHEMBL3980197 & 16400014.0 & 4.5495 & TRN & \\
\hline CHEMBL 3895060 & 16400018.0 & 7.8915 & TRN & \\
\hline CHEMBL 3927054 & 16400018.0 & 7.6964 & TRN & \\
\hline CHEMBL3935093 & 16400014.0 & 3.54699 & 99999999997 & TST \\
\hline CHEMBL3931903 & 16400018.0 & 7.8903 & TRN & \\
\hline CHEMBL3920152 & 16400018.0 & 7.9381 & TRN & \\
\hline CHEMBL 3943723 & 16400017.0 & 6.8952 & TRN & \\
\hline CHEMBL3945323 & 16400018.0 & 7.7819 & TRN & \\
\hline CHEMBL3919345 & 16400018.0 & 8.0518 & TRN & \\
\hline CHEMBL 3929763 & 16400014.0 & 3.8919 & TST & \\
\hline CHEMBL3936915 & 16400014.0 & 3.8324 & TST & \\
\hline CHEMBL 3895431 & 16400018.0 & 8.0812 & TRN & \\
\hline CHEMBL3981991 & 16400018.0 & 8.111 & TST & \\
\hline
\end{tabular}




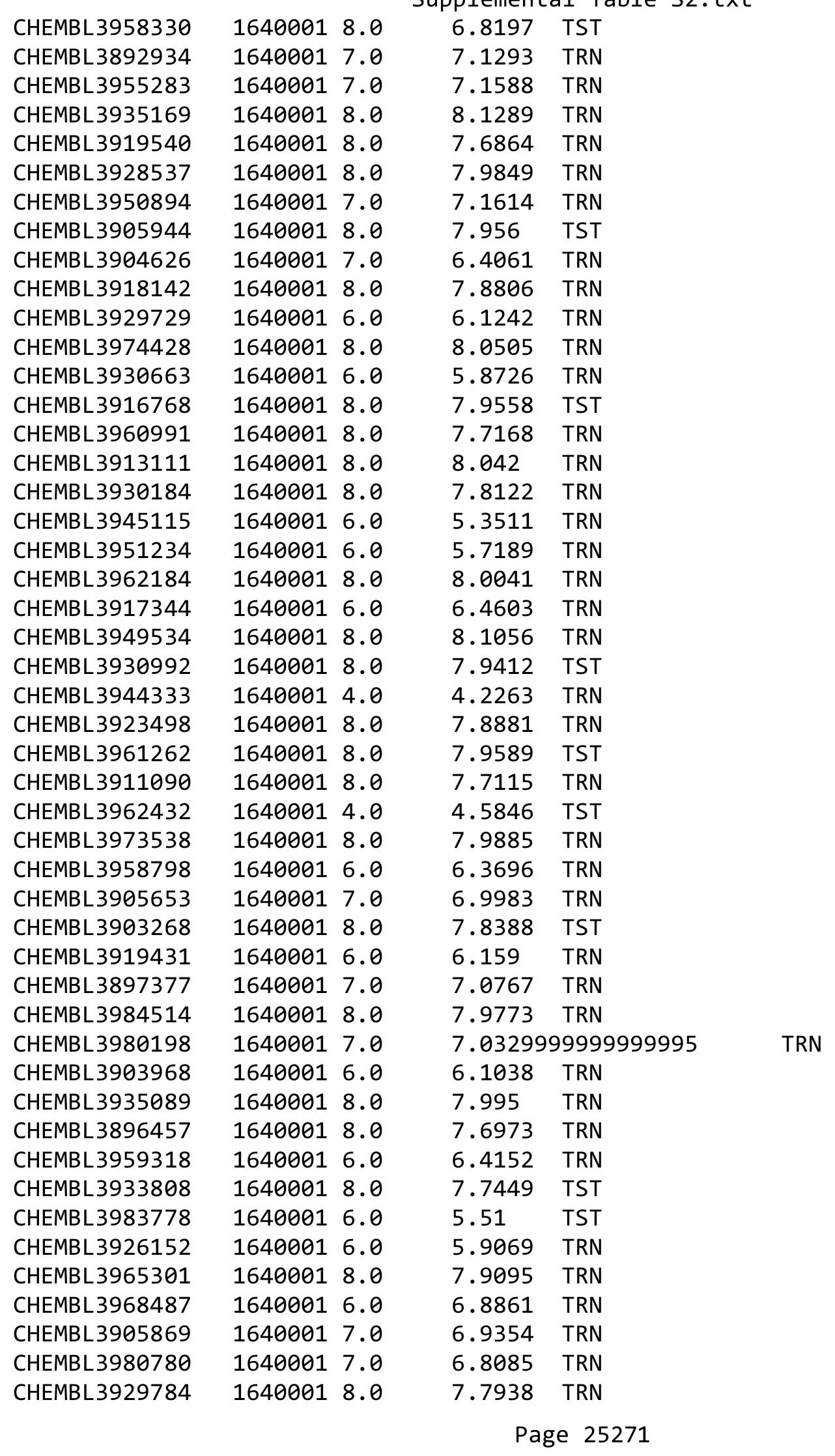




\begin{tabular}{|c|c|c|c|}
\hline & \multicolumn{2}{|c|}{ al lable S2. } \\
\hline CHEMBL3910376 & 16400018.0 & 8.1255 & TRN \\
\hline CHEMBL3942857 & 16400017.0 & 7.1888 & TRN \\
\hline CHEMBL3921633 & 16400018.0 & 8.1577 & TRN \\
\hline CHEMBL3922597 & 16400016.0 & 6.1846 & TRN \\
\hline CHEMBL3967373 & 16400018.0 & 8.2593 & TRN \\
\hline CHEMBL3925259 & 16400014.0 & 3.2925 & TST \\
\hline CHEMBL3970918 & 16400018.0 & 7.5629 & TRN \\
\hline CHEMBL3919040 & 16400018.0 & 8.1809 & TRN \\
\hline CHEMBL3905527 & 16400018.0 & 8.1126 & TRN \\
\hline CHEMBL3964369 & 16400018.0 & 7.8244 & TRN \\
\hline CHEMBL3912249 & 16400018.0 & 7.7696 & TRN \\
\hline CHEMBL3936983 & 16400018.0 & 7.1408 & TRN \\
\hline CHEMBL3947160 & 16400014.0 & 3.7103 & TST \\
\hline CHEMBL3936806 & 16400018.0 & 8.0155 & TST \\
\hline CHEMBL3910201 & 16400017.0 & 6.7838 & TRN \\
\hline CHEMBL3973795 & 16400018.0 & 8.1928 & TRN \\
\hline CHEMBL3919095 & 16400018.0 & 8.1083 & TRN \\
\hline CHEMBL3912984 & 16400014.0 & 3.1216 & TST \\
\hline CHEMBL 3899373 & 16400018.0 & 8.0762 & TRN \\
\hline CHEMBL3959107 & 16400018.0 & 8.17 & TRN \\
\hline CHEMBL 3908184 & 16400017.0 & 6.5747 & TRN \\
\hline CHEMBL 3906444 & 16400018.0 & 7.74299 & 9999999999 \\
\hline CHEMBL3953994 & 16400018.0 & 8.126 & TRN \\
\hline CHEMBL3980367 & 16400014.0 & 3.8504 & TRN \\
\hline CHEMBL3891234 & 16400018.0 & 8.1817 & TRN \\
\hline CHEMBL 3902307 & 16400018.0 & 7.9831 & TRN \\
\hline CHEMBL3981965 & 16400016.0 & 6.362 & TRN \\
\hline CHEMBL 3932484 & 16400017.0 & 7.6905 & TST \\
\hline CHEMBL 3933037 & 16400018.0 & 7.6356 & TST \\
\hline CHEMBL3924269 & 16400016.0 & 5.9203 & TST \\
\hline CHEMBL3912822 & 16400014.0 & 3.7769 & TST \\
\hline CHEMBL3905522 & 16400018.0 & 7.7883 & TST \\
\hline CHEMBL3922085 & 16400016.0 & 6.2375 & TRN \\
\hline CHEMBL3906156 & 16400016.0 & 5.3299 & TRN \\
\hline CHEMBL3978390 & 16400018.0 & 7.7785 & TST \\
\hline CHEMBL3960908 & 16400018.0 & 8.1597 & TRN \\
\hline CHEMBL3893012 & 16400017.0 & 7.2396 & TRN \\
\hline CHEMBL3949703 & 16400018.0 & 8.119 & TRN \\
\hline CHEMBL3965978 & 16400016.0 & 6.7962 & TRN \\
\hline CHEMBL3973374 & 16400018.0 & 7.8702 & TST \\
\hline CHEMBL 3976828 & 16400014.0 & 3.7749 & TST \\
\hline CHEMBL3909653 & 16400016.0 & 5.9586 & TST \\
\hline CHEMBL3984321 & 16400018.0 & 8.1342 & TRN \\
\hline CHEMBL 3982007 & 16400018.0 & 7.8922 & TRN \\
\hline CHEMBL3935926 & 16400018.0 & 7.9229 & TRN \\
\hline CHEMBL 3930538 & 16400014.0 & 3.8243 & TST \\
\hline CHEMBL3948255 & 16400018.0 & 8.2521 & TRN \\
\hline CHEMBL 3898644 & 16400018.0 & 7.6529 & TRN \\
\hline
\end{tabular}




\begin{tabular}{|c|c|c|c|c|c|}
\hline \multirow{2}{*}{ CHEMBL3952084 } & \multirow{2}{*}{1640001} & \\
\hline & & 8.0 & 7.9674 & TRN & \\
\hline CHEMBL3895329 & 1640001 & 8.0 & 7.9934 & TRN & \\
\hline CHEMBL3901260 & 1640001 & 8.0 & 7.89 & TRN & \\
\hline CHEMBL3901924 & 1640001 & 8.0 & 7.6029 & TRN & \\
\hline CHEMBL 3952670 & 1640001 & 8.0 & 7.2435 & TRN & \\
\hline CHEMBL3921291 & 1640001 & 7.0 & 6.7565 & TST & \\
\hline CHEMBL3959882 & 1640001 & 6.0 & 5.4629 & TRN & \\
\hline CHEMBL 3126887 & 1294962 & 3.699 & 3.72300 & 00000000003 & TRN \\
\hline CHEMBL403715 & 1294962 & 3.699 & 4.3585 & TST & \\
\hline CHEMBL3126883 & 1294962 & 3.699 & 4.1239 & TRN & \\
\hline CHEMBL3126901 & 1294962 & 4.9281 & 4.4857 & TRN & \\
\hline CHEMBL3127063 & 1294962 & 5.0482 & 4.2491 & TRN & \\
\hline CHEMBL 3126888 & 1294962 & 3.8239 & 3.8379 & TRN & \\
\hline CHEMBL 3126870 & 1294962 & 3.699 & 3.7182 & TRN & \\
\hline CHEMBL 3127068 & 1294962 & 6.8861 & 6.9954 & TRN & \\
\hline CHEMBL3126905 & 1294962 & 6.5376 & 6.8229 & TST & \\
\hline CHEMBL3127057 & 1294962 & 7.301 & 6.4328 & TST & \\
\hline CHEMBL3126897 & 1294962 & 3.699 & 4.0282 & TST & \\
\hline CHEMBL3126892 & 1294962 & 3.699 & 3.8555 & TRN & \\
\hline CHEMBL 3127052 & 1294962 & 5.3382 & 5.3642 & TRN & \\
\hline CHEMBL3126886 & 1294962 & 3.699 & 3.7205 & TRN & \\
\hline CHEMBL3126885 & 1294962 & 3.699 & 3.6409 & TRN & \\
\hline CHEMBL3126915 & 1294962 & 5.5768 & 5.7145 & TST & \\
\hline CHEMBL3127049 & 1294962 & 6.9208 & 6.9155 & TRN & \\
\hline CHEMBL3126912 & 1294962 & 3.699 & 3.5412 & TRN & \\
\hline CHEMBL3126866 & 1294962 & 3.699 & 3.7411 & TRN & \\
\hline CHEMBL3127060 & 1294962 & 3.699 & 4.1457 & TRN & \\
\hline CHEMBL3126872 & 1294962 & 3.699 & 4.0003 & TST & \\
\hline CHEMBL319177 & 1294962 & 3.699 & 3.4699 & TST & \\
\hline CHEMBL 3126873 & 1294962 & 3.699 & 3.69 & TRN & \\
\hline CHEMBL3127066 & 1294962 & 6.8239 & 6.9264 & TRN & \\
\hline CHEMBL 3127047 & 1294962 & 6.7212 & 6.5757 & TST & \\
\hline CHEMBL3127067 & 1294962 & 7.0969 & 7.3373 & TRN & \\
\hline CHEMBL3126875 & 1294962 & 3.699 & 3.60399 & 99999999996 & TRN \\
\hline CHEMBL3127062 & 1294962 & 3.699 & 3.5852 & TRN & \\
\hline CHEMBL3126900 & 1294962 & 5.9355 & 5.7921 & TRN & \\
\hline CHEMBL 3127061 & 1294962 & 3.699 & 3.948 & TRN & \\
\hline CHEMBL3126878 & 1294962 & 3.699 & 3.4156 & TRN & \\
\hline CHEMBL3126896 & 1294962 & 3.699 & 3.8772 & TST & \\
\hline CHEMBL 3126910 & 1294962 & 5.2418 & 4.9462 & TRN & \\
\hline CHEMBL3126899 & 1294962 & 6.6576 & 6.8496 & TRN & \\
\hline CHEMBL3126889 & 1294962 & 3.8239 & 3.8297 & TRN & \\
\hline CHEMBL3126898 & 1294962 & 4.8928 & 3.8517 & TST & \\
\hline CHEMBL3126881 & 1294962 & 4.9208 & 4.6415 & TRN & \\
\hline CHEMBL 3127045 & 1294962 & 3.699 & 3.9222 & TRN & \\
\hline CHEMBL3126865 & 1294962 & 5.6882 & 4.8461 & TST & \\
\hline CHEMBL 3126882 & 1294962 & 3.699 & 3.8474 & TRN & \\
\hline CHEMBL 3126868 & 1294962 & 3.699 & 3.7533 & TRN & \\
\hline & & & & 25273 & \\
\hline
\end{tabular}


Supplemental Table S2.txt

\begin{tabular}{|c|c|c|c|c|c|}
\hline CHEMBL3127065 & 1294962 & 7.0 & 6.7124 & TRN & \\
\hline CHEMBL3126890 & 1294962 & 3.699 & 3.7177 & TRN & \\
\hline CHEMBL3126871 & 1294962 & 3.699 & 3.8136 & TRN & \\
\hline CHEMBL3127055 & 1294962 & 7.301 & 7.4088 & TST & \\
\hline CHEMBL1814768 & 1294962 & 6.0223 & 5.6121 & TRN & \\
\hline CHEMBL 3127044 & 1294962 & 5.1403 & 5.2806 & TST & \\
\hline CHEMBL3126891 & 1294962 & 3.699 & 3.4324 & TRN & \\
\hline CHEMBL 3127064 & 1294962 & 5.0429 & 4.0679 & TST & \\
\hline CHEMBL 3127058 & 1294962 & 6.2076 & 6.3284 & TRN & \\
\hline CHEMBL3126877 & 1294962 & 3.699 & 3.6055 & TRN & \\
\hline CHEMBL3126903 & 1294962 & 3.699 & 3.6475 & TRN & \\
\hline CHEMBL3126874 & 1294962 & 3.8239 & 4.2076 & TRN & \\
\hline CHEMBL 3127054 & 1294962 & 5.9172 & 5.6666 & TRN & \\
\hline CHEMBL3126909 & 1294962 & 3.8239 & 4.2506 & TRN & \\
\hline CHEMBL3126880 & 1294962 & 5.1959 & 5.1352 & TRN & \\
\hline CHEMBL3126906 & 1294962 & 6.0605 & 5.9211 & TST & \\
\hline CHEMBL3126911 & 1294962 & 6.4559 & 6.3487 & TRN & \\
\hline CHEMBL3126895 & 1294962 & 3.699 & 3.6012 & TRN & \\
\hline CHEMBL3126914 & 1294962 & 5.9547 & 5.2106 & TST & \\
\hline CHEMBL3126913 & 1294962 & 3.699 & 4.5467 & TRN & \\
\hline CHEMBL3126902 & 1294962 & 5.7167 & 5.63700 & 00000000005 & TRN \\
\hline CHEMBL3126879 & 1294962 & 5.6576 & 5.8187 & TRN & \\
\hline CHEMBL3126884 & 1294962 & 3.699 & 3.6461 & TRN & \\
\hline CHEMBL3126908 & 1294962 & 6.6778 & 6.6403 & TRN & \\
\hline CHEMBL3127050 & 1294962 & 6.4437 & 6.2211 & TRN & \\
\hline CHEMBL3127053 & 1294962 & 3.699 & 3.8559 & TRN & \\
\hline CHEMBL 3126867 & 1294962 & 3.699 & 3.6356 & TRN & \\
\hline CHEMBL3126893 & 1294962 & 3.699 & 3.7609 & TRN & \\
\hline CHEMBL3127051 & 1294962 & 5.9469 & 6.0817 & TRN & \\
\hline CHEMBL3126894 & 1294962 & 3.699 & 3.6396 & TRN & \\
\hline CHEMBL3127059 & 1294962 & 3.8239 & 3.6958 & TRN & \\
\hline CHEMBL 3127046 & 1294962 & 5.3497 & 4.9901 & TRN & \\
\hline CHEMBL3126876 & 1294962 & 3.699 & 3.5838 & TRN & \\
\hline CHEMBL3126904 & 1294962 & 3.699 & 3.8392 & TRN & \\
\hline CHEMBL3126907 & 1294962 & 7.301 & 6.8331 & TST & \\
\hline CHEMBL1269812 & 1294962 & 7.699 & 7.5647 & TST & \\
\hline CHEMBL1814767 & 1294962 & 4.9355 & 5.1588 & TRN & \\
\hline CHEMBL 3127048 & 1294962 & 5.6383 & 5.2287 & TST & \\
\hline CHEMBL 3124960 & 1294962 & 3.699 & 4.4946 & TST & \\
\hline CHEMBL3127056 & 1294962 & 5.1433 & 4.8459 & TST & \\
\hline CHEMBL3126869 & 1294962 & 3.699 & 3.8341 & TRN & \\
\hline CHEMBL3919626 & 1636657 & 2.301 & 2.2989 & TRN & \\
\hline CHEMBL3974614 & 1636657 & 6.3143 & 6.3026 & TRN & \\
\hline CHEMBL3895455 & 1636657 & 2.2041 & 3.7895 & TST & \\
\hline CHEMBL3978933 & 1636657 & 3.3152 & 3.3266 & TRN & \\
\hline CHEMBL3925700 & 1636657 & 4.6364 & 4.5949 & TRN & \\
\hline CHEMBL3924053 & 1636657 & 1.6021 & 1.6142 & TRN & \\
\hline CHEMBL 3908781 & 1636657 & 2.8861 & 2.8983 & TRN & \\
\hline
\end{tabular}

Page 25274 
Supplemental Table S2.txt

\begin{tabular}{|c|c|c|c|c|c|}
\hline CHEMBL 3901641 & 1636657 & 4.1337 & 4.2679 & TRN & \\
\hline CHEMBL3950984 & 1636657 & 2.9543 & 2.9773 & TRN & \\
\hline CHEMBL3908056 & 1636657 & 3.8327 & 3.8042 & TRN & \\
\hline CHEMBL3936361 & 1636657 & 4.8013 & 4.6837 & TRN & \\
\hline CHEMBL3984245 & 1636657 & 4.6364 & 4.6345 & TRN & \\
\hline CHEMBL 3917382 & 1636657 & 3.85699 & 99999999 & 998 & 3.9227 \\
\hline CHEMBL3908653 & 1636657 & 3.6271 & 3.5965 & TRN & \\
\hline CHEMBL 3933268 & 1636657 & 4.6536 & 4.6356 & TRN & \\
\hline CHEMBL 3935254 & 1636657 & 4.7011 & 4.7043 & TRN & \\
\hline CHEMBL3920594 & 1636657 & 3.6055 & 3.6298 & TRN & \\
\hline CHEMBL3910083 & 1636657 & 2.8911 & 2.9167 & TRN & \\
\hline CHEMBL3960872 & 1636657 & 2.5045 & 2.4948 & TST & \\
\hline CHEMBL3914213 & 1636657 & 4.9872 & 5.0084 & TRN & \\
\hline CHEMBL 3897952 & 1636657 & 3.4437 & 3.4553 & TRN & \\
\hline CHEMBL3909905 & 1636657 & 2.5045 & 4.5662 & TST & \\
\hline CHEMBL3956130 & 1636657 & 3.9914 & 3.9686 & TRN & \\
\hline CHEMBL3889490 & 1636657 & 3.2757 & 3.2526 & TRN & \\
\hline CHEMBL3973700 & 1636657 & 4.9914 & 4.9914 & TRN & \\
\hline CHEMBL 3890631 & 1636657 & 3.0491 & 2.9834 & TRN & \\
\hline CHEMBL3943890 & 1636657 & 5.0809 & 5.0894 & TRN & \\
\hline CHEMBL3967690 & 1636657 & 2.301 & 2.353 & TRN & \\
\hline CHEMBL3964957 & 1636657 & 4.9469 & 4.9444 & TRN & \\
\hline CHEMBL3926494 & 1636657 & 2.301 & 2.2583 & TRN & \\
\hline CHEMBL 3938624 & 1636657 & 4.5834 & 4.6029 & TRN & \\
\hline CHEMBL 3945267 & 1636657 & 4.6216 & 4.6367 & TRN & \\
\hline CHEMBL3979005 & 1636657 & 3.1959 & 3.1629 & TRN & \\
\hline CHEMBL 3966747 & 1636657 & 5.684 & 5.6982 & TRN & \\
\hline CHEMBL 3927463 & 1636657 & 3.3768 & 1.5759 & TST & \\
\hline CHEMBL 3905364 & 1636657 & 4.6536 & 4.7093 & TRN & \\
\hline CHEMBL3904389 & 1636657 & 4.4672 & 4.4269 & TRN & \\
\hline CHEMBL 3901542 & 1636657 & 5.5406 & 5.5256 & TRN & \\
\hline CHEMBL 3907470 & 1636657 & 2.9208 & 2.9623 & TRN & \\
\hline CHEMBL3955618 & 1636657 & 3.6635 & 3.6565 & TRN & \\
\hline CHEMBL 3908568 & 1636657 & 1.6021 & 1.5703 & TRN & \\
\hline CHEMBL3929601 & 1636657 & 3.6635 & 3.5383 & TRN & \\
\hline CHEMBL3928909 & 1636657 & 4.6946 & 4.6983 & TRN & \\
\hline CHEMBL 3892598 & 1636657 & 5.0757 & 5.0732 & TRN & \\
\hline CHEMBL3938116 & 1636657 & 2.9851 & 2.9881 & TRN & \\
\hline CHEMBL 3980064 & 1636657 & 2.6021 & 2.8048 & TST & \\
\hline CHEMBL 3981004 & 1636657 & 4.1192 & 4.136 & TRN & \\
\hline CHEMBL3976207 & 1636657 & 3.71 & 3.7758 & TST & \\
\hline CHEMBL3979926 & 1636657 & 1.6021 & 1.7022 & TRN & \\
\hline CHEMBL3947426 & 1636657 & 3.8268 & 3.8262 & TRN & \\
\hline CHEMBL 3900846 & 1636657 & 2.2041 & 3.7231 & TST & \\
\hline CHEMBL3986776 & 1636657 & 4.3851 & 4.4086 & TRN & \\
\hline CHEMBL 3944370 & 1636657 & 2.9031 & 2.9412 & TRN & \\
\hline CHEMBL3983745 & 1636657 & 3.0061 & 2.9822 & TRN & \\
\hline CHEMBL3915927 & 1636657 & 1.6021 & 1.5788 & TRN & \\
\hline
\end{tabular}

Page 25275 
Supplemental Table S2.txt

\begin{tabular}{|c|c|c|c|c|}
\hline CHEMBL3926030 & 1636657 & 5.2441 & 5.1949 & TRN \\
\hline CHEMBL3925433 & 1636657 & 1.6021 & 1.632 & TRN \\
\hline CHEMBL3952177 & 1636657 & 2.5045 & 4.0584 & TST \\
\hline CHEMBL3935411 & 1636657 & 2.8554 & 2.9372 & TRN \\
\hline CHEMBL 3962745 & 1636657 & 5.1772 & 5.2734 & TRN \\
\hline CHEMBL3916433 & 1636657 & 2.301 & 2.1168 & TRN \\
\hline CHEMBL 3984707 & 1636657 & 1.6021 & 1.6218 & TRN \\
\hline CHEMBL3960727 & 1636657 & 4.4112 & 4.3523 & TRN \\
\hline CHEMBL3946910 & 1636657 & 2.301 & 2.3407 & TRN \\
\hline CHEMBL3955099 & 1636657 & 4.9208 & 5.066 & TST \\
\hline CHEMBL 3898445 & 1636657 & 3.4179 & 3.9628 & TST \\
\hline CHEMBL3899009 & 1636657 & 3.8477 & 4.6172 & TST \\
\hline CHEMBL 3891863 & 1636657 & 2.5045 & 2.5098 & TST \\
\hline CHEMBL3971994 & 1636657 & 2.2041 & 3.9764 & TST \\
\hline CHEMBL3959702 & 1636657 & 1.6021 & 3.9196 & TST \\
\hline CHEMBL3942246 & 1636657 & 3.5817 & 3.5947 & TST \\
\hline CHEMBL3971851 & 1636657 & 2.7033 & 3.9837 & TST \\
\hline CHEMBL3934806 & 1636657 & 1.6021 & 3.1138 & TST \\
\hline CHEMBL 3910672 & 1636657 & 3.4962 & 2.7586 & TST \\
\hline CHEMBL3917513 & 1636657 & 2.9014 & 3.8371 & TST \\
\hline CHEMBL2179966 & 872708 & 7.2757 & 7.6829 & TRN \\
\hline CHEMBL 2179521 & 872708 & 7.4089 & 7.6871 & TRN \\
\hline CHEMBL 2179516 & 872708 & 7.2218 & 7.443 & TRN \\
\hline CHEMBL 2179519 & 872708 & 8.9586 & 8.1498 & TRN \\
\hline CHEMBL 2179971 & 872708 & 7.699 & 7.8666 & TRN \\
\hline CHEMBL 2179535 & 872708 & 7.301 & 7.17700 & 00000000005 \\
\hline CHEMBL 2179532 & 872708 & 6.6198 & 6.7691 & TRN \\
\hline CHEMBL 2179560 & 872708 & 6.3279 & 7.3723 & TST \\
\hline CHEMBL 2179527 & 872708 & 7.4437 & 7.6565 & TRN \\
\hline CHEMBL 2179965 & 872708 & 6.0 & 6.6424 & TST \\
\hline CHEMBL 2179559 & 872708 & 7.2757 & 7.5428 & TRN \\
\hline CHEMBL 2179536 & 872708 & 6.9208 & 7.3942 & TRN \\
\hline CHEMBL 2179546 & 872708 & 7.0 & 6.5399 & TRN \\
\hline CHEMBL 2179553 & 872708 & 6.1871 & 6.6394 & TRN \\
\hline CHEMBL 2179533 & 872708 & 7.041 & 7.4179 & TRN \\
\hline CHEMBL3094096 & 872708 & 7.5376 & 7.3168 & TRN \\
\hline CHEMBL 2179544 & 872708 & 7.3979 & 7.4225 & TRN \\
\hline CHEMBL 2179523 & 872708 & 6.4202 & 6.8471 & TST \\
\hline CHEMBL 2179962 & 872708 & 8.699 & 6.9072 & TST \\
\hline CHEMBL 2179545 & 872708 & 6.9208 & 7.1764 & TRN \\
\hline CHEMBL 2179551 & 872708 & 6.5528 & 6.8953 & TRN \\
\hline CHEMBL 2179531 & 872708 & 7.9208 & 7.8101 & TRN \\
\hline CHEMBL 2179537 & 872708 & 7.1675 & 7.312 & TRN \\
\hline CHEMBL 2179538 & 872708 & 6.6383 & 6.7546 & TRN \\
\hline CHEMBL 2179542 & 872708 & 6.6778 & 6.9042 & TRN \\
\hline CHEMBL 2179552 & 872708 & 6.6198 & 6.5163 & TRN \\
\hline CHEMBL 2179550 & 872708 & 7.5686 & 7.065 & TRN \\
\hline CHEMBL 2179530 & 872708 & 7.1871 & 7.7526 & TRN \\
\hline
\end{tabular}

Page 25276 


\begin{tabular}{|c|c|c|c|c|c|}
\hline \multicolumn{6}{|c|}{ Supplemental Table S2.txt } \\
\hline CHEMBL 2179518 & 872708 & 6.4685 & 7.8756 & TST & \\
\hline CHEMBL 2179543 & 872708 & 8.1549 & 7.1567 & TRN & \\
\hline CHEMBL1876219 & 872708 & 8.2218 & 6.5591 & TST & \\
\hline CHEMBL 2179549 & 872708 & 7.1079 & 6.8425 & TRN & \\
\hline CHEMBL 2179517 & 872708 & 6.7959 & 7.8211 & TST & \\
\hline CHEMBL 2179558 & 872708 & 6.0 & 6.354 & TRN & \\
\hline CHEMBL 2179541 & 872708 & 7.5528 & 7.3516 & TRN & \\
\hline CHEMBL 2179520 & 872708 & 6.8539 & 7.2348 & TST & \\
\hline CHEMBL 2179956 & 872708 & 7.3279 & 7.3151 & TRN & \\
\hline CHEMBL 2179540 & 872708 & 7.8239 & 7.2923 & TRN & \\
\hline CHEMBL 2179528 & 872708 & 7.2676 & 7.3897 & TRN & \\
\hline CHEMBL 2179961 & 872708 & 8.1549 & 7.3216 & TST & \\
\hline CHEMBL 2179534 & 872708 & 8.0969 & 7.5902 & TRN & \\
\hline CHEMBL 2179555 & 872708 & 6.9208 & 6.8385 & TRN & \\
\hline CHEMBL 2179548 & 872708 & 6.8861 & 6.9765 & TRN & \\
\hline CHEMBL 2179957 & 872708 & 6.8861 & 7.6122 & TST & \\
\hline CHEMBL 2179524 & 872708 & 7.2441 & 7.3245 & TST & \\
\hline CHEMBL 2179539 & 872708 & 7.6576 & 7.0937 & TRN & \\
\hline CHEMBL 3094074 & 872708 & 5.7696 & 7.71200 & 0000000001 & TST \\
\hline CHEMBL 2179547 & 872708 & 7.2441 & 7.1924 & TRN & \\
\hline CHEMBL 2179525 & 872708 & 7.6021 & 7.0625 & TST & \\
\hline CHEMBL 2179526 & 872708 & 7.2924 & 7.5899 & TRN & \\
\hline CHEMBL339498 & 211254 & 5.9586 & 6.0968 & TRN & \\
\hline CHEMBL 338984 & 211254 & 5.7696 & 5.943 & TRN & \\
\hline CHEMBL129983 & 211254 & 5.4202 & 5.5505 & TRN & \\
\hline CHEMBL131388 & 211254 & 5.0362 & 5.3934 & TRN & \\
\hline CHEMBL128194 & 211254 & 4.8861 & 4.8427 & TST & \\
\hline CHEMBL336992 & 211254 & 4.8239 & 5.1502 & TRN & \\
\hline CHEMBL130803 & 211254 & 4.5229 & 4.5681 & TRN & \\
\hline CHEMBL334610 & 211254 & 5.2924 & 4.9501 & TRN & \\
\hline CHEMBL127445 & 211254 & 5.3098 & 5.3739 & TRN & \\
\hline CHEMBL131477 & 211254 & 6.5528 & 6.1854 & TRN & \\
\hline CHEMBL336857 & 211254 & 4.0 & 4.5423 & TRN & \\
\hline CHEMBL 335876 & 211254 & 4.5229 & 4.4415 & TRN & \\
\hline CHEMBL341339 & 211254 & 4.1549 & 4.1302 & TRN & \\
\hline CHEMBL434993 & 211254 & 4.5229 & 4.35800 & 00000000005 & TRN \\
\hline CHEMBL435613 & 211254 & 5.0 & 5.0139 & TRN & \\
\hline CHEMBL339357 & 211254 & 4.5229 & 5.0251 & TST & \\
\hline CHEMBL 341470 & 211254 & 4.0 & 4.3774 & TST & \\
\hline CHEMBL338177 & 211254 & 4.7447 & 4.9008 & TRN & \\
\hline CHEMBL339155 & 211254 & 5.284 & 5.3422 & TRN & \\
\hline CHEMBL132157 & 211254 & 5.1739 & 5.6289 & TRN & \\
\hline CHEMBL130768 & 211254 & 4.5229 & 4.8414 & TRN & \\
\hline CHEMBL421090 & 211254 & 4.5229 & 4.6946 & TRN & \\
\hline CHEMBL336742 & 211254 & 5.5229 & 4.5592 & TRN & \\
\hline CHEMBL128680 & 211254 & 5.0 & 4.5656 & TRN & \\
\hline CHEMBL 337842 & 211254 & 4.8861 & 4.664 & TST & \\
\hline CHEMBL132064 & 211254 & 4.5229 & 4.5488 & TRN & \\
\hline
\end{tabular}




\begin{tabular}{|c|c|c|c|c|c|}
\hline \multicolumn{6}{|c|}{ Supplemental Table S2.txt } \\
\hline CHEMBL435409 & 211254 & 5.0655 & 4.9897 & TRN & \\
\hline CHEMBL435019 & 211254 & 5.7696 & 5.4084 & TRN & \\
\hline CHEMBL130476 & 211254 & 5.5229 & 5.61 & TRN & \\
\hline CHEMBL337667 & 211254 & 5.0 & 4.9568 & TRN & \\
\hline CHEMBL339524 & 211254 & 6.3468 & 6.2905 & TST & \\
\hline CHEMBL128422 & 211254 & 4.6778 & 4.9186 & TRN & \\
\hline CHEMBL337888 & 211254 & 5.5229 & 5.2557 & TRN & \\
\hline CHEMBL128489 & 211254 & 5.3768 & 5.489 & TRN & \\
\hline CHEMBL338951 & 211254 & 5.8239 & 5.8205 & TRN & \\
\hline CHEMBL340772 & 211254 & 4.0 & 4.2193 & TRN & \\
\hline CHEMBL341338 & 211254 & 5.1249 & 5.1188 & TRN & \\
\hline CHEMBL339768 & 211254 & 6.1308 & 6.22 & TST & \\
\hline CHEMBL128327 & 211254 & 4.5229 & 4.859 & TST & \\
\hline CHEMBL340639 & 211254 & 5.1739 & 5.1059 & TRN & \\
\hline CHEMBL129971 & 211254 & 4.5229 & 5.1311 & TRN & \\
\hline CHEMBL128163 & 211254 & 5.5229 & 5.4648 & TRN & \\
\hline CHEMBL132496 & 211254 & 5.0269 & 5.2323 & TRN & \\
\hline CHEMBL128219 & 211254 & 5.7447 & 5.7372 & TRN & \\
\hline CHEMBL338118 & 211254 & 5.2147 & 5.4085 & TRN & \\
\hline CHEMBL132210 & 211254 & 6.0 & 5.5224 & TRN & \\
\hline CHEMBL423156 & 211254 & 4.5229 & 4.3579 & TRN & \\
\hline CHEMBL128388 & 211254 & 4.9208 & 4.9747 & TST & \\
\hline CHEMBL338921 & 211254 & 6.2076 & 5.8324 & TRN & \\
\hline CHEMBL132389 & 211254 & 5.6576 & 5.2749 & TRN & \\
\hline CHEMBL421248 & 211254 & 4.8539 & 4.8346 & TRN & \\
\hline CHEMBL339124 & 211254 & 5.1871 & 5.3378 & TRN & \\
\hline CHEMBL 340150 & 211254 & 4.5229 & 4.4093 & TRN & \\
\hline CHEMBL435009 & 211254 & 4.5229 & 4.8489 & TRN & \\
\hline CHEMBL335886 & 211254 & 4.5229 & 5.0269 & TRN & \\
\hline CHEMBL276079 & 211254 & 4.0 & 4.3338 & TRN & \\
\hline CHEMBL336195 & 211254 & 5.2596 & 5.2476 & TST & \\
\hline CHEMBL339464 & 211254 & 4.5229 & 4.4654 & TRN & \\
\hline CHEMBL341289 & 211254 & 6.0 & 5.7884 & TST & \\
\hline CHEMBL 339783 & 211254 & 4.0 & 4.1806 & TRN & \\
\hline CHEMBL422612 & 211254 & 4.5229 & 4.9722 & TRN & \\
\hline CHEMBL433662 & 211254 & 6.2441 & 6.0951 & TST & \\
\hline CHEMBL340362 & 211254 & 5.2596 & 4.9448 & TRN & \\
\hline CHEMBL2111851 & 211254 & 6.0 & 5.5496 & TRN & \\
\hline CHEMBL435398 & 211254 & 4.0 & 4.4867 & TRN & \\
\hline CHEMBL131538 & 211254 & 4.7959 & 4.88399 & 99999999995 & TST \\
\hline CHEMBL338635 & 211254 & 5.0315 & 4.9176 & TST & \\
\hline CHEMBL130891 & 211254 & 6.1805 & 6.4487 & TST & \\
\hline CHEMBL128216 & 211254 & 4.5229 & 4.7122 & TRN & \\
\hline CHEMBL129234 & 211254 & 5.0 & 4.7844 & TST & \\
\hline CHEMBL128417 & 211254 & 4.5229 & 5.1418 & TRN & \\
\hline CHEMBL128712 & 211254 & 5.6778 & 5.7399 & TST & \\
\hline CHEMBL436189 & 211254 & 5.6021 & 6.1228 & TRN & \\
\hline CHEMBL132391 & 211254 & 5.2076 & 5.4325 & TRN & \\
\hline
\end{tabular}




\begin{tabular}{|c|c|c|c|c|c|}
\hline \\
\hline CHEMBL131269 & 211254 & 5.0 & 4.7245 & TRN & \\
\hline CHEMBL419973 & 211254 & 5.4685 & 5.3542 & TRN & \\
\hline CHEMBL340016 & 211254 & 4.8861 & 4.6159 & TRN & \\
\hline CHEMBL128383 & 211254 & 5.4949 & 5.6627 & TST & \\
\hline CHEMBL130770 & 211254 & 4.0 & 4.2758 & TRN & \\
\hline CHEMBL339096 & 211254 & 4.7959 & 5.1107 & TST & \\
\hline CHEMBL131581 & 211254 & 4.8239 & 5.1935 & TRN & \\
\hline CHEMBL130887 & 211254 & 5.4437 & 5.1255 & TRN & \\
\hline CHEMBL131235 & 211254 & 4.699 & 4.8732 & TST & \\
\hline CHEMBL339929 & 211254 & 5.5229 & 5.66 & TRN & \\
\hline CHEMBL338576 & 211254 & 5.7212 & 5.5801 & TRN & \\
\hline CHEMBL 338383 & 211254 & 5.6778 & 5.3914 & TST & \\
\hline CHEMBL339132 & 211254 & 5.5686 & 5.728 & TST & \\
\hline CHEMBL335944 & 211254 & 5.2596 & 5.5316 & TRN & \\
\hline CHEMBL337889 & 211254 & 6.2676 & 5.983 & TRN & \\
\hline CHEMBL337615 & 211254 & 5.0 & 4.5318 & TRN & \\
\hline CHEMBL128328 & 211254 & 5.0177 & 5.0199 & TRN & \\
\hline CHEMBL340676 & 211254 & 5.2676 & 5.3365 & TRN & \\
\hline CHEMBL422080 & 211254 & 4.5229 & 4.9538 & TRN & \\
\hline CHEMBL341507 & 211254 & 4.8539 & 4.9112 & TRN & \\
\hline CHEMBL130993 & 211254 & 5.585 & 5.2102 & TRN & \\
\hline CHEMBL130848 & 211254 & 5.5229 & 5.26200 & 00000000005 & TRN \\
\hline CHEMBL 338503 & 211254 & 5.1805 & 5.48799 & 99999999995 & TST \\
\hline CHEMBL339433 & 211254 & 5.1308 & 4.7701 & TRN & \\
\hline CHEMBL128652 & 211254 & 5.5229 & 5.4483 & TRN & \\
\hline CHEMBL131613 & 211254 & 6.0 & 4.6722 & TRN & \\
\hline CHEMBL 335634 & 211254 & 5.1871 & 4.8784 & TRN & \\
\hline CHEMBL449399 & 211254 & 5.3565 & 5.5902 & TST & \\
\hline CHEMBL337853 & 211254 & 5.3188 & 5.4343 & TRN & \\
\hline CHEMBL339366 & 211254 & 4.5229 & 4.4332 & TRN & \\
\hline CHEMBL337221 & 211254 & 5.6021 & 5.4212 & TST & \\
\hline CHEMBL 128228 & 211254 & 5.0757 & 5.2767 & TRN & \\
\hline CHEMBL336362 & 211254 & 4.0 & 4.3696 & TRN & \\
\hline CHEMBL341311 & 211254 & 5.2596 & 5.2874 & TRN & \\
\hline CHEMBL128423 & 211254 & 5.3279 & 5.2285 & TRN & \\
\hline CHEMBL 2112663 & 211254 & 5.5229 & 5.4944 & TST & \\
\hline CHEMBL338636 & 211254 & 5.0 & 4.6998 & TRN & \\
\hline CHEMBL341049 & 211254 & 6.0269 & 5.9201 & TST & \\
\hline CHEMBL338499 & 211254 & 4.8861 & 5.044 & TRN & \\
\hline CHEMBL340915 & 211254 & 5.1308 & 5.2484 & TRN & \\
\hline CHEMBL128749 & 211254 & 5.8861 & 5.8849 & TRN & \\
\hline CHEMBL131101 & 211254 & 4.0 & 4.2069 & TST & \\
\hline CHEMBL131499 & 211254 & 4.0 & 4.1796 & TRN & \\
\hline CHEMBL420144 & 211254 & 4.0 & 3.9803 & TST & \\
\hline CHEMBL 340388 & 211254 & 5.7212 & 6.0316 & TST & \\
\hline CHEMBL 276906 & 211254 & 4.6383 & 4.4798 & TRN & \\
\hline CHEMBL131168 & 211254 & 4.5229 & 4.876 & TRN & \\
\hline CHEMBL131564 & 211254 & 4.5229 & 5.0579 & TST & \\
\hline
\end{tabular}




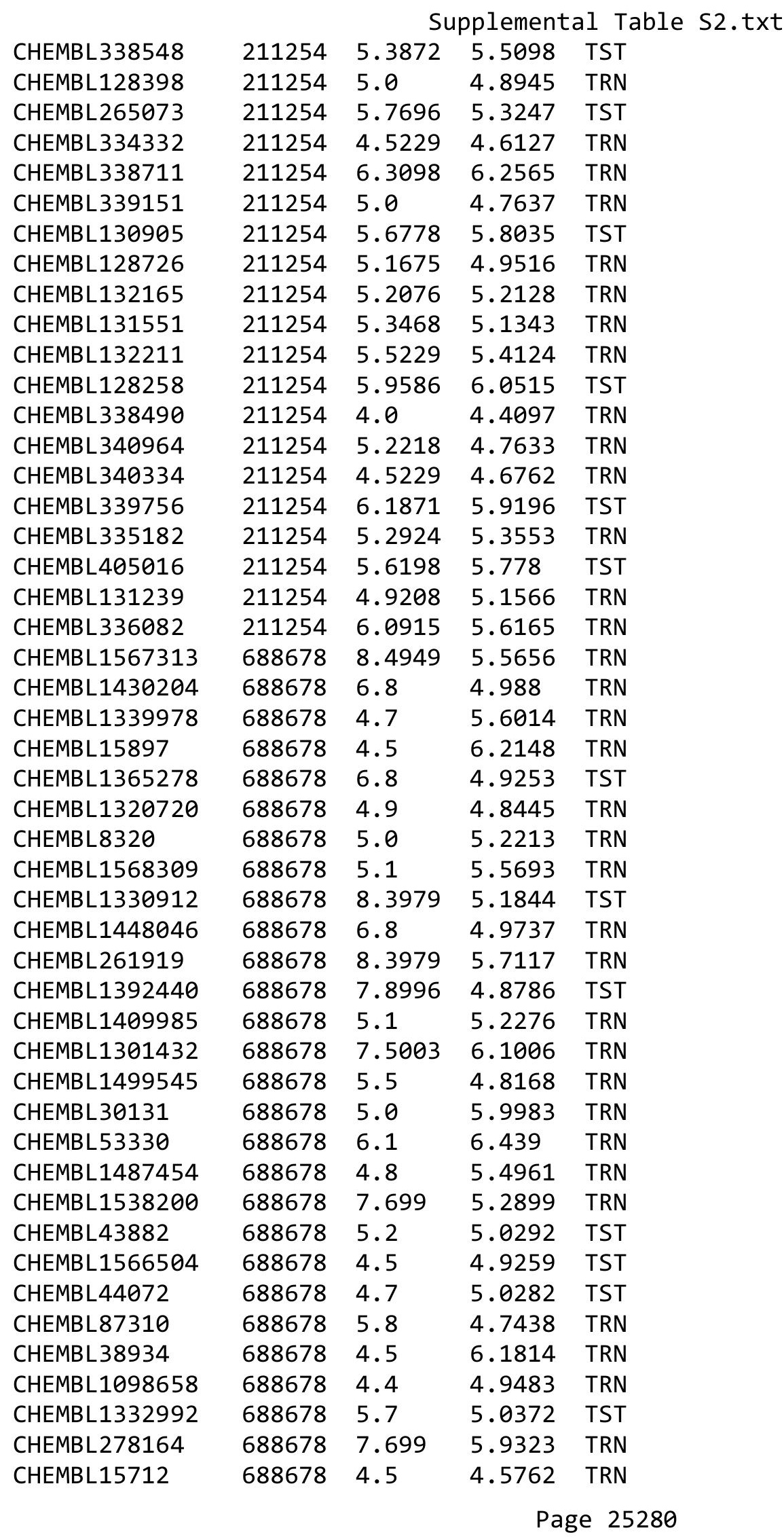




\begin{tabular}{|c|c|c|c|c|c|}
\hline & & & & & \\
\hline CHEMBL1492884 & 688678 & 4.5 & 5.6379 & TRN & \\
\hline CHEMBL18104 & 688678 & 4.6 & 4.7042 & TRN & \\
\hline CHEMBL1325152 & 688678 & 4.7 & 5.2121 & TRN & \\
\hline CHEMBL1477797 & 688678 & 4.5 & 4.773 & TRN & \\
\hline CHEMBL460124 & 688678 & 4.5 & 5.8518 & TRN & \\
\hline CHEMBL 26215 & 688678 & 4.8 & 4.7989 & TRN & \\
\hline CHEMBL1491397 & 688678 & 4.8 & 4.8637 & TRN & \\
\hline CHEMBL1487011 & 688678 & 6.8 & 4.9322 & TRN & \\
\hline CHEMBL1566132 & 688678 & 4.9 & 4.8398 & TRN & \\
\hline CHEMBL195953 & 688678 & 4.9 & 5.1721 & TST & \\
\hline CHEMBL234926 & 688678 & 4.4 & 4.8972 & TRN & \\
\hline CHEMBL1557091 & 688678 & 7.1002 & 5.7629 & TRN & \\
\hline CHEMBL1527556 & 688678 & 4.5 & 4.9278 & TRN & \\
\hline CHEMBL228511 & 688678 & 4.9 & 5.3391 & TRN & \\
\hline CHEMBL1516868 & 688678 & 7.0 & 5.7005 & TRN & \\
\hline CHEMBL402063 & 688678 & 6.0 & 4.9219 & TST & \\
\hline CHEMBL1531586 & 688678 & 4.5 & 5.70299 & 9999999999 & TRN \\
\hline CHEMBL509531 & 688678 & 5.5 & 4.6016 & TST & \\
\hline CHEMBL 1447588 & 688678 & 4.5 & 5.1976 & TST & \\
\hline CHEMBL1562104 & 688678 & 5.3 & 4.8514 & TRN & \\
\hline CHEMBL1378095 & 688678 & 4.8 & 4.9019 & TRN & \\
\hline CHEMBL1242017 & 688678 & 7.8013 & 5.5105 & TRN & \\
\hline CHEMBL16435 & 688678 & 6.5 & 6.0843 & TRN & \\
\hline CHEMBL 363803 & 688678 & 4.5 & 5.0496 & TRN & \\
\hline CHEMBL1369406 & 688678 & 4.4 & 5.1102 & TRN & \\
\hline CHEMBL196537 & 688678 & 4.6 & 5.07600 & 00000000005 & TST \\
\hline CHEMBL1308088 & 688678 & 5.1 & 6.0932 & TRN & \\
\hline CHEMBL1576153 & 688678 & 4.8 & 5.7919 & TRN & \\
\hline CHEMBL1341097 & 688678 & 4.8 & 5.5966 & TRN & \\
\hline CHEMBL1514512 & 688678 & 4.6 & 5.0405 & TRN & \\
\hline CHEMBL1413787 & 688678 & 4.6 & 5.5051 & TRN & \\
\hline CHEMBL1325964 & 688678 & 8.7959 & 6.5025 & TRN & \\
\hline CHEMBL309917 & 688678 & 4.6 & 5.0372 & TRN & \\
\hline CHEMBL 388676 & 688678 & 5.3 & 5.2604 & TST & \\
\hline CHEMBL315348 & 688678 & 4.6 & 4.7574 & TRN & \\
\hline CHEMBL1509442 & 688678 & 4.5 & 4.9934 & TST & \\
\hline CHEMBL1503330 & 688678 & 4.6 & 5.4219 & TRN & \\
\hline CHEMBL1612246 & 688678 & 4.8 & 5.1449 & TRN & \\
\hline CHEMBL153062 & 688678 & 4.6 & 4.8044 & TRN & \\
\hline CHEMBL1200471 & 688678 & 5.8 & 6.0171 & TRN & \\
\hline CHEMBL1526319 & 688678 & 4.5 & 4.8046 & TRN & \\
\hline CHEMBL1449018 & 688678 & 4.9 & 6.0537 & TRN & \\
\hline CHEMBL 284588 & 688678 & 8.0 & 4.814 & TRN & \\
\hline CHEMBL 288998 & 688678 & 7.0 & 5.1312 & TRN & \\
\hline CHEMBL551154 & 688678 & 7.2 & 5.3477 & TRN & \\
\hline CHEMBL 329673 & 688678 & 4.6 & 5.4613 & TRN & \\
\hline CHEMBL157026 & 688678 & 4.8 & 5.1023 & TRN & \\
\hline CHEMBL1603264 & 688678 & 4.5 & 4.9584 & TRN & \\
\hline
\end{tabular}




\begin{tabular}{|c|c|c|c|c|}
\hline \multicolumn{5}{|c|}{ Supplemental Table s2.txt } \\
\hline CHEMBL1428964 & 688678 & 4.7 & 5.7672 & TRN \\
\hline CHEMBL1492978 & 688678 & 5.4 & 5.084 & TST \\
\hline CHEMBL1329734 & 688678 & 6.8 & 5.8747 & TRN \\
\hline CHEMBL1613534 & 688678 & 4.6 & 5.1525 & TRN \\
\hline CHEMBL1528479 & 688678 & 4.4 & 5.0231 & TRN \\
\hline CHEMBL1304981 & 688678 & 4.8 & 4.8318 & TRN \\
\hline CHEMBL267373 & 688678 & 7.3002 & 6.353 & TRN \\
\hline CHEMBL1488467 & 688678 & 4.9 & 5.1656 & TRN \\
\hline CHEMBL1569493 & 688678 & 5.5 & 5.3057 & TRN \\
\hline CHEMBL327919 & 688678 & 4.8 & 5.2752 & TRN \\
\hline CHEMBL1331128 & 688678 & 4.8 & 4.9765 & TRN \\
\hline CHEMBL140 & 688678 & 4.5 & 4.8806 & TRN \\
\hline CHEMBL1143 & 688678 & 5.0 & 5.08 & TRN \\
\hline CHEMBL84963 & 688678 & 4.5 & 5.8205 & TRN \\
\hline CHEMBL1580759 & 688678 & 4.9 & 4.9126 & TRN \\
\hline CHEMBL1530684 & 688678 & 4.5 & 4.7712 & TRN \\
\hline CHEMBL1471289 & 688678 & 4.9 & 5.4365 & TRN \\
\hline CHEMBL170408 & 688678 & 4.5 & 6.0144 & TRN \\
\hline CHEMBL175296 & 688678 & 7.5003 & 6.2568 & TRN \\
\hline CHEMBL538 & 688678 & 7.6003 & 6.3489 & TRN \\
\hline CHEMBL1517425 & 688678 & 4.5 & 4.9194 & TRN \\
\hline CHEMBL321029 & 688678 & 9.0969 & 5.6305 & TRN \\
\hline CHEMBL1232659 & 688678 & 6.7001 & 6.2196 & TRN \\
\hline CHEMBL1429506 & 688678 & 5.1 & 4.8843 & TRN \\
\hline CHEMBL1496957 & 688678 & 4.6 & 4.8312 & TRN \\
\hline CHEMBL491 & 688678 & 4.9 & 5.6205 & TRN \\
\hline CHEMBL1533629 & 688678 & 6.3 & 6.1851 & TRN \\
\hline CHEMBL1478 & 688678 & 4.6 & 5.0262 & TST \\
\hline CHEMBL263116 & 688678 & 8.1024 & 5.9605 & TRN \\
\hline CHEMBL1524617 & 688678 & 5.0 & 5.1613 & TST \\
\hline CHEMBL1567912 & 688678 & 5.4 & 5.3376 & TRN \\
\hline CHEMBL1455972 & 688678 & 7.4001 & 4.8481 & TST \\
\hline CHEMBL1334784 & 688678 & 4.5 & 5.5291 & TRN \\
\hline CHEMBL1559341 & 688678 & 4.6 & 4.7574 & TRN \\
\hline CHEMBL1480173 & 688678 & 4.5 & 5.0749 & TRN \\
\hline CHEMBL1320187 & 688678 & 8.0 & 5.0923 & TST \\
\hline CHEMBL1427293 & 688678 & 4.5 & 4.7777 & TRN \\
\hline CHEMBL1600998 & 688678 & 5.4 & 6.2057 & TRN \\
\hline CHEMBL1596847 & 688678 & 4.6 & 5.078 & TRN \\
\hline CHEMBL1408847 & 688678 & 4.8 & 5.2055 & TRN \\
\hline CHEMBL1343147 & 688678 & 4.8 & 4.7599 & TST \\
\hline CHEMBL1375444 & 688678 & 4.6 & 5.1199 & TST \\
\hline CHEMBL1450327 & 688678 & 4.8 & 5.6544 & TRN \\
\hline CHEMBL114719 & 688678 & 8.301 & 6.6085 & TRN \\
\hline CHEMBL443949 & 688678 & 4.9 & 4.7016 & TRN \\
\hline CHEMBL1325985 & 688678 & 5.9 & 5.0692 & TST \\
\hline CHEMBL 70971 & 688678 & 5.5 & 5.6444 & TRN \\
\hline CHEMBL1329372 & 688678 & 5.8 & 5.6279 & TRN \\
\hline
\end{tabular}




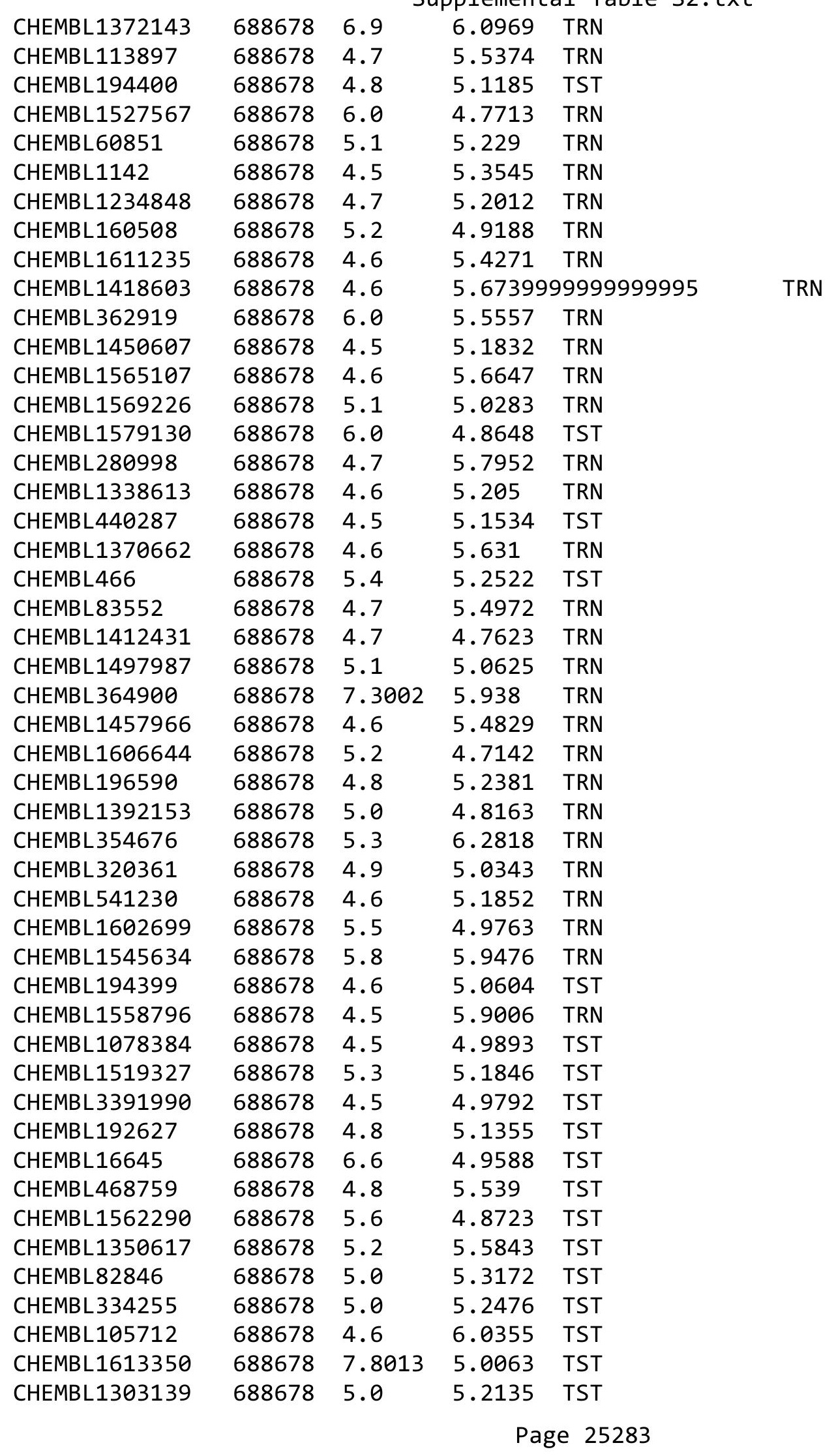




\begin{tabular}{|c|c|c|c|c|c|}
\hline \multicolumn{6}{|c|}{ Supplemental Table S2.txt } \\
\hline CHEMBL1423658 & 688678 & 4.9 & 5.2991 & TST & \\
\hline CHEMBL1344952 & 688678 & 5.4 & 5.8811 & TST & \\
\hline CHEMBL154533 & 688678 & 5.3 & 4.7179 & TST & \\
\hline CHEMBL162598 & 688678 & 9.0969 & 5.1216 & TST & \\
\hline CHEMBL1543632 & 688678 & 4.9 & 6.051 & TST & \\
\hline CHEMBL1203530 & 75907 & 5.9208 & 5.7123 & TRN & \\
\hline CHEMBL1203508 & 75907 & 5.3979 & 4.9474 & TRN & \\
\hline CHEMBL1203532 & 75907 & 6.0269 & 5.985 & TRN & \\
\hline CHEMBL1203510 & 75907 & 5.284 & 5.0773 & TRN & \\
\hline CHEMBL1203511 & 75907 & 5.041 & 5.1484 & TRN & \\
\hline CHEMBL1203506 & 75907 & 5.8239 & 5.8303 & TRN & \\
\hline CHEMBL1237144 & 75907 & 4.7959 & 4.9718 & TRN & \\
\hline CHEMBL1202267 & 75907 & 5.041 & 5.2606 & TRN & \\
\hline CHEMBL1203505 & 75907 & 4.5528 & 4.8835 & TRN & \\
\hline CHEMBL1203482 & 75907 & 5.699 & 5.7016 & TRN & \\
\hline CHEMBL1203491 & 75907 & 5.0088 & 4.8963 & TRN & \\
\hline CHEMBL1203529 & 75907 & 5.7447 & 5.8447 & TRN & \\
\hline CHEMBL 2448020 & 75907 & 5.9586 & 5.9153 & TRN & \\
\hline CHEMBL1202286 & 75907 & 4.699 & 4.7555 & TRN & \\
\hline CHEMBL153719 & 75907 & 4.6234 & 4.7434 & TRN & \\
\hline CHEMBL1744212 & 75907 & 5.0458 & 4.8951 & TRN & \\
\hline CHEMBL1203502 & 75907 & 5.1024 & 5.2085 & TRN & \\
\hline CHEMBL1203483 & 75907 & 5.3665 & 5.6338 & TRN & \\
\hline CHEMBL357482 & 75907 & 5.1549 & 4.6567 & TST & \\
\hline CHEMBL1203527 & 75907 & 5.1192 & 5.4507 & TRN & \\
\hline CHEMBL1202282 & 75907 & 5.6383 & 5.4412 & TRN & \\
\hline CHEMBL1203513 & 75907 & 4.4949 & 4.6158 & TRN & \\
\hline CHEMBL1744198 & 75907 & 5.2218 & 5.2835 & TRN & \\
\hline CHEMBL2448018 & 75907 & 6.2218 & 5.8664 & TST & \\
\hline CHEMBL1203469 & 75907 & 5.5686 & 5.7771 & TRN & \\
\hline CHEMBL1744210 & 75907 & 5.0458 & 4.8468 & TRN & \\
\hline CHEMBL1203520 & 75907 & 6.0177 & 5.9836 & TRN & \\
\hline CHEMBL153322 & 75907 & 5.8861 & 6.1858 & TRN & \\
\hline CHEMBL357729 & 75907 & 6.2291 & 5.9064 & TST & \\
\hline CHEMBL1202272 & 75907 & 4.2757 & 4.3171 & TRN & \\
\hline CHEMBL1203519 & 75907 & 6.1549 & 6.2662 & TRN & \\
\hline CHEMBL153567 & 75907 & 5.9208 & 5.3132 & TRN & \\
\hline CHEMBL1203485 & 75907 & 4.8239 & $4.7780 e$ & 00000000005 & TRN \\
\hline CHEMBL153465 & 75907 & 5.1192 & 5.5309 & TST & \\
\hline CHEMBL1203526 & 75907 & 6.0 & 5.8558 & TRN & \\
\hline CHEMBL1202278 & 75907 & 4.5686 & 5.0017 & TRN & \\
\hline CHEMBL1203525 & 75907 & 5.7696 & 5.528 & TRN & \\
\hline CHEMBL1203487 & 75907 & 4.585 & 5.5413 & TST & \\
\hline CHEMBL1203488 & 75907 & 5.1549 & 5.3139 & TRN & \\
\hline CHEMBL1203528 & 75907 & 5.0458 & 5.1985 & TST & \\
\hline CHEMBL1744203 & 75907 & 4.6198 & 4.7011 & TRN & \\
\hline CHEMBL1202258 & 75907 & 5.0 & 5.2017 & TRN & \\
\hline CHEMBL1203493 & 75907 & 4.7696 & 4.5385 & TST & \\
\hline
\end{tabular}




\begin{tabular}{|c|c|c|c|c|c|}
\hline & & \multicolumn{4}{|c|}{ Supplemental Table S2.txt } \\
\hline CHEMBL1203492 & 75907 & 5.699 & 5.5162 & TRN & \\
\hline CHEMBL1202276 & 75907 & 4.8539 & 4.6467 & TRN & \\
\hline CHEMBL152894 & 75907 & 5.4815 & 5.4532 & TRN & \\
\hline CHEMBL1203480 & 75907 & 4.4318 & 4.2859 & TRN & \\
\hline CHEMBL358692 & 75907 & 4.4559 & 4.5147 & TRN & \\
\hline CHEMBL153222 & 75907 & 5.1549 & 5.5089 & TST & \\
\hline CHEMBL1744209 & 75907 & 4.3468 & 4.6975 & TRN & \\
\hline CHEMBL 2448019 & 75907 & 5.7447 & 5.638 & TRN & \\
\hline CHEMBL1203497 & 75907 & 5.0458 & 5.2724 & TRN & \\
\hline CHEMBL1203475 & 75907 & 5.1739 & 5.0045 & TRN & \\
\hline CHEMBL1203522 & 75907 & 5.8239 & 5.5538 & TRN & \\
\hline CHEMBL1744200 & 75907 & 5.1549 & 4.9248 & TST & \\
\hline CHEMBL1202262 & 75907 & 5.2218 & 5.18 & TRN & \\
\hline CHEMBL1202273 & 75907 & 5.7959 & 6.1272 & TST & \\
\hline CHEMBL1203533 & 75907 & 5.7447 & 5.7238 & TST & \\
\hline CHEMBL149689 & 75907 & 4.6021 & 4.8646 & TST & \\
\hline CHEMBL1202261 & 75907 & 4.4949 & 4.4936 & TST & \\
\hline CHEMBL1203474 & 75907 & 5.5086 & 5.3389 & TRN & \\
\hline CHEMBL1202266 & 75907 & 4.6383 & 4.4649 & TRN & \\
\hline CHEMBL1202274 & 75907 & 5.3768 & 5.7301 & TST & \\
\hline CHEMBL153461 & 75907 & 5.1549 & 5.2488 & TRN & \\
\hline CHEMBL153055 & 75907 & 5.1549 & 5.0925 & TRN & \\
\hline CHEMBL1203501 & 75907 & 5.5376 & 5.5851 & TST & \\
\hline CHEMBL1203503 & 75907 & 6.5229 & 6.1752 & TRN & \\
\hline CHEMBL1203518 & 75907 & 5.1308 & 5.5018 & TRN & \\
\hline CHEMBL1744211 & 75907 & 4.5229 & 4.3763 & TRN & \\
\hline CHEMBL150906 & 75907 & 6.1549 & 5.91700 & 0000000001 & TRN \\
\hline CHEMBL1203512 & 75907 & 5.8861 & 5.1696 & TST & \\
\hline CHEMBL1203478 & 75907 & 5.7959 & 5.8793 & TRN & \\
\hline CHEMBL145703 & 75907 & 4.3979 & 4.2577 & TRN & \\
\hline CHEMBL1202279 & 75907 & 4.8539 & 4.6567 & TST & \\
\hline CHEMBL422329 & 75907 & 5.2218 & 4.5791 & TST & \\
\hline CHEMBL2448017 & 75907 & 6.1549 & 5.9795 & TRN & \\
\hline CHEMBL1203509 & 75907 & 5.0555 & 5.2136 & TRN & \\
\hline CHEMBL153711 & 75907 & 4.2218 & 4.3563 & TST & \\
\hline CHEMBL1203479 & 75907 & 4.7212 & 5.3069 & TST & \\
\hline CHEMBL1202271 & 75907 & 5.0 & 4.7842 & TRN & \\
\hline CHEMBL1202264 & 75907 & 4.9586 & 5.3089 & TRN & \\
\hline CHEMBL1744201 & 75907 & 4.9586 & 4.7947 & TST & \\
\hline CHEMBL1203481 & 75907 & 4.4815 & 4.6168 & TRN & \\
\hline CHEMBL1744197 & 75907 & 4.9586 & 5.0928 & TRN & \\
\hline CHEMBL1362247 & 688194 & 3.699 & 3.4709 & TRN & \\
\hline CHEMBL1440703 & 688194 & 5.1993 & 4.936 & TST & \\
\hline CHEMBL 2006590 & 688194 & 3.699 & 3.8099 & TRN & \\
\hline CHEMBL1564071 & 688194 & 3.699 & 3.5965 & TRN & \\
\hline CHEMBL1560229 & 688194 & 5.1124 & 5.1077 & TST & \\
\hline CHEMBL1489578 & 688194 & 3.699 & 3.7899 & TRN & \\
\hline CHEMBL1493896 & 688194 & 3.699 & 3.7943 & TRN & \\
\hline
\end{tabular}




\begin{tabular}{|c|c|c|c|c|c|c|}
\hline & & \multicolumn{5}{|c|}{ Supplemental Table S2.txt } \\
\hline CHEMBL3197897 & 688194 & 4.9446 & 3.8515 & TST & & \\
\hline CHEMBL1387313 & 688194 & 4.7878 & 5.0698 & TST & & \\
\hline CHEMBL1540956 & 688194 & 5.3799 & 5.1486 & TRN & & \\
\hline CHEMBL1411785 & 688194 & 3.699 & 3.7374 & TRN & & \\
\hline CHEMBL1390573 & 688194 & 5.0264 & 4.8875 & TRN & & \\
\hline CHEMBL1567944 & 688194 & 7.0458 & 6.6093 & TST & & \\
\hline CHEMBL1458840 & 688194 & 5.4622 & 5.3319 & TRN & & \\
\hline CHEMBL1412573 & 688194 & 5.1427 & 4.2024 & TRN & & \\
\hline CHEMBL1470473 & 688194 & 3.699 & 3.7472 & TRN & & \\
\hline CHEMBL1608535 & 688194 & 5.4295 & 5.1005 & TST & & \\
\hline CHEMBL1605161 & 688194 & 5.0405 & 5.0515 & TRN & & \\
\hline CHEMBL1492648 & 688194 & 5.3188 & 5.4984 & TRN & & \\
\hline CHEMBL1588679 & 688194 & 5.0443 & 5.1466 & TRN & & \\
\hline CHEMBL1526331 & 688194 & 3.699 & 4.6499 & TST & & \\
\hline CHEMBL1497853 & 688194 & 4.9626 & 5.0291 & TRN & & \\
\hline CHEMBL1584754 & 688194 & 5.0074 & 5.2876 & TRN & & \\
\hline CHEMBL1505878 & 688194 & 4.8665 & 4.7557 & TRN & & \\
\hline CHEMBL1710 & 688194 & 5.1124 & 4.99 & TRN & & \\
\hline CHEMBL1304814 & 688194 & 4.9739 & 4.7369 & TST & & \\
\hline CHEMBL1545288 & 688194 & 3.699 & 4.8074 & TRN & & \\
\hline CHEMBL591126 & 688194 & $4.9830 e$ & 00000000 & 205 & 5.0079 & TRN \\
\hline CHEMBL1348813 & 688194 & 5.1778 & 5.0743 & TRN & & \\
\hline CHEMBL1312228 & 688194 & 3.699 & 3.804 & TRN & & \\
\hline CHEMBL1307769 & 688194 & 3.699 & 4.0995 & TRN & & \\
\hline CHEMBL1540093 & 688194 & 3.699 & 3.8434 & TRN & & \\
\hline CHEMBL1337193 & 688194 & 3.699 & 3.8276 & TRN & & \\
\hline CHEMBL1611371 & 688194 & 5.0022 & 4.9496 & TRN & & \\
\hline CHEMBL1605094 & 688194 & 4.9212 & 4.822 & TRN & & \\
\hline CHEMBL1458697 & 688194 & 3.699 & 3.708 & TRN & & \\
\hline CHEMBL1522582 & 688194 & 3.699 & 4.5248 & TRN & & \\
\hline CHEMBL1526405 & 688194 & 5.0114 & 5.1102 & TRN & & \\
\hline CHEMBL1409110 & 688194 & 3.699 & 3.8132 & TRN & & \\
\hline CHEMBL1538493 & 688194 & 4.8847 & 4.8961 & TST & & \\
\hline CHEMBL123 & 688194 & 5.6198 & 5.186 & TRN & & \\
\hline CHEMBL1543189 & 688194 & 3.699 & 3.5983 & TRN & & \\
\hline CHEMBL165 & 688194 & 3.699 & 4.9565 & TRN & & \\
\hline CHEMBL1526910 & 688194 & 5.0101 & 4.828 & TRN & & \\
\hline CHEMBL1423205 & 688194 & 3.699 & 3.6594 & TRN & & \\
\hline CHEMBL1336847 & 688194 & 3.699 & 3.9001 & TRN & & \\
\hline CHEMBL1516772 & 688194 & 4.9245 & 5.0333 & TRN & & \\
\hline CHEMBL1323835 & 688194 & 3.699 & 5.9373 & TRN & & \\
\hline CHEMBL1329237 & 688194 & 5.9747 & 5.6194 & TRN & & \\
\hline CHEMBL1588463 & 688194 & 4.9333 & 4.915 & TRN & & \\
\hline CHEMBL1539075 & 688194 & 5.3335 & 4.8489 & TRN & & \\
\hline CHEMBL1535668 & 688194 & 3.699 & 3.7443 & TST & & \\
\hline CHEMBL1463540 & 688194 & 4.8814 & 4.7826 & TRN & & \\
\hline CHEMBL1401668 & 688194 & 5.341 & 5.3825 & TRN & & \\
\hline CHEMBL1532544 & 688194 & 5.6234 & 5.371 & TRN & & \\
\hline
\end{tabular}




\begin{tabular}{|c|c|c|c|c|c|}
\hline & & \multicolumn{4}{|c|}{ Supplemental Table S2.txt } \\
\hline CHEMBL1490887 & 688194 & 5.3575 & 5.0083 & TRN & \\
\hline CHEMBL1418818 & 688194 & 5.4989 & 5.2237 & TRN & \\
\hline CHEMBL1527929 & 688194 & 5.058 & 5.044 & TRN & \\
\hline CHEMBL1455826 & 688194 & 3.699 & 3.9117 & TST & \\
\hline CHEMBL1488889 & 688194 & 4.8729 & 4.8037 & TRN & \\
\hline CHEMBL1560366 & 688194 & 4.8798 & 4.7911 & TRN & \\
\hline CHEMBL1491541 & 688194 & 5.1791 & 4.9044 & TRN & \\
\hline CHEMBL1366282 & 688194 & 3.699 & 3.5084 & TRN & \\
\hline CHEMBL1422128 & 688194 & 3.699 & 3.7442 & TRN & \\
\hline CHEMBL1585481 & 688194 & 3.699 & 3.8831 & TRN & \\
\hline CHEMBL1427637 & 688194 & 5.0883 & 5.0372 & TST & \\
\hline CHEMBL1455020 & 688194 & 4.8649 & 5.0298 & TRN & \\
\hline CHEMBL1598807 & 688194 & 5.0773 & 5.0685 & TRN & \\
\hline CHEMBL1589298 & 688194 & 5.1062 & 4.6123 & TRN & \\
\hline CHEMBL1327738 & 688194 & 5.3862 & 5.2338 & TST & \\
\hline CHEMBL1374482 & 688194 & 5.0491 & 5.1972 & TRN & \\
\hline CHEMBL1432468 & 688194 & 3.699 & 3.7696 & TRN & \\
\hline CHEMBL1557303 & 688194 & 3.699 & 3.8931 & TRN & \\
\hline CHEMBL1521239 & 688194 & 4.76699 & 9999999 & 4.6974 & TRN \\
\hline CHEMBL1416112 & 688194 & 4.908 & 4.6606 & TRN & \\
\hline CHEMBL1347369 & 688194 & 5.0195 & 5.015 & TRN & \\
\hline CHEMBL1465527 & 688194 & 5.6021 & 5.4963 & TRN & \\
\hline CHEMBL1588513 & 688194 & 5.2083 & 4.8305 & TRN & \\
\hline CHEMBL1303635 & 688194 & 3.699 & 5.0782 & TRN & \\
\hline CHEMBL1342173 & 688194 & 5.2255 & 5.2571 & TRN & \\
\hline CHEMBL1381306 & 688194 & 3.699 & 3.9435 & TRN & \\
\hline CHEMBL1342448 & 688194 & 5.51 & 5.5948 & TRN & \\
\hline CHEMBL1468811 & 688194 & 5.3161 & 5.1142 & TRN & \\
\hline CHEMBL1491228 & 688194 & 5.2132 & 4.8392 & TRN & \\
\hline CHEMBL1502512 & 688194 & 5.6778 & 5.6681 & TRN & \\
\hline CHEMBL140 & 688194 & 5.1568 & 4.8976 & TRN & \\
\hline CHEMBL1370413 & 688194 & 3.699 & 3.7976 & TRN & \\
\hline CHEMBL1455056 & 688194 & 5.0555 & 5.0461 & TRN & \\
\hline CHEMBL1389722 & 688194 & 3.699 & 3.7215 & TST & \\
\hline CHEMBL1555898 & 688194 & 4.8182 & 4.94300 & 00000000005 & TRN \\
\hline CHEMBL1523174 & 688194 & 3.699 & 3.8922 & TRN & \\
\hline CHEMBL 1372751 & 688194 & 3.699 & 4.4374 & TRN & \\
\hline CHEMBL1490048 & 688194 & 5.1681 & 5.17 & TRN & \\
\hline CHEMBL1331809 & 688194 & 5.426 & 5.4787 & TRN & \\
\hline CHEMBL1455957 & 688194 & 5.3335 & 5.0778 & TRN & \\
\hline CHEMBL1335944 & 688194 & 5.1918 & 4.9213 & TRN & \\
\hline CHEMBL1407659 & 688194 & 5.0716 & 4.8077 & TRN & \\
\hline CHEMBL1372207 & 688194 & 3.699 & 4.7226 & TST & \\
\hline CHEMBL1438081 & 688194 & 4.8601 & 4.7617 & TRN & \\
\hline CHEMBL1456177 & 688194 & 3.699 & 3.5746 & TRN & \\
\hline CHEMBL1305911 & 688194 & 5.0535 & 4.848 & TRN & \\
\hline CHEMBL1509576 & 688194 & 3.699 & 3.7872 & TST & \\
\hline CHEMBL1462334 & 688194 & 3.699 & 3.7939 & TRN & \\
\hline
\end{tabular}


Supplemental Table S2.txt

\begin{tabular}{|c|c|c|c|c|}
\hline CHEMBL1556596 & 688194 & 3.699 & 3.9352 & TRN \\
\hline CHEMBL1424253 & 688194 & 3.699 & 3.8486 & TRN \\
\hline CHEMBL1565033 & 688194 & 4.9129 & 4.7665 & TRN \\
\hline CHEMBL1588762 & 688194 & 5.9547 & 4.0858 & TRN \\
\hline CHEMBL1598493 & 688194 & 6.6778 & 6.4379 & TRN \\
\hline CHEMBL1564871 & 688194 & 4.8665 & 4.757 & TRN \\
\hline CHEMBL1486934 & 688194 & 5.2041 & 5.16 & TRN \\
\hline CHEMBL3145067 & 688194 & 5.6556 & 5.3999 & TRN \\
\hline CHEMBL1577591 & 688194 & 4.971 & 4.9046 & TRN \\
\hline CHEMBL1451327 & 688194 & 4.9469 & 4.8551 & TST \\
\hline CHEMBL1342736 & 688194 & 5.1637 & 4.907 & TRN \\
\hline CHEMBL1424968 & 688194 & 5.1284 & 5.0924 & TRN \\
\hline CHEMBL1444859 & 688194 & 5.2248 & 5.4366 & TRN \\
\hline CHEMBL1327137 & 688194 & 5.1759 & 5.2333 & TRN \\
\hline CHEMBL1584720 & 688194 & 5.1226 & 5.144 & TRN \\
\hline CHEMBL1311755 & 688194 & 5.3546 & 5.2362 & TRN \\
\hline CHEMBL1383144 & 688194 & 5.6126 & 4.6097 & TRN \\
\hline CHEMBL1371774 & 688194 & 5.4597 & 5.5526 & TRN \\
\hline CHEMBL1588072 & 688194 & 3.699 & 3.6864 & TRN \\
\hline CHEMBL1368226 & 688194 & 3.699 & 3.9974 & TRN \\
\hline CHEMBL1501475 & 688194 & 3.699 & 4.5474 & TRN \\
\hline CHEMBL1368302 & 688194 & 4.8794 & 4.7308 & TRN \\
\hline CHEMBL1381668 & 688194 & 4.7773 & 4.7097 & TRN \\
\hline CHEMBL1429775 & 688194 & 4.9401 & 4.8835 & TRN \\
\hline CHEMBL1565776 & 688194 & 5.1537 & 5.1006 & TRN \\
\hline CHEMBL1567179 & 688194 & 5.0595 & \multicolumn{2}{|c|}{5.247000000000001} \\
\hline CHEMBL1340321 & 688194 & 4.8536 & 4.668 & TRN \\
\hline CHEMBL1558159 & 688194 & 5.1409 & 5.0004 & TRN \\
\hline CHEMBL1569782 & 688194 & 5.2807 & 5.2477 & TRN \\
\hline CHEMBL1444650 & 688194 & 3.699 & 3.8496 & TST \\
\hline CHEMBL1310482 & 688194 & 3.699 & 3.8197 & TRN \\
\hline CHEMBL1439271 & 688194 & 4.8022 & 4.0888 & TRN \\
\hline CHEMBL1362096 & 688194 & 5.4101 & 5.1952 & TRN \\
\hline CHEMBL1301213 & 688194 & 5.2534 & 5.3344 & TRN \\
\hline CHEMBL1480465 & 688194 & 4.8729 & 4.9264 & TST \\
\hline CHEMBL1385971 & 688194 & 4.8386 & 3.8026 & TRN \\
\hline CHEMBL1563323 & 688194 & 4.8962 & 5.2978 & TRN \\
\hline CHEMBL1488021 & 688194 & 4.8894 & 4.9106 & TST \\
\hline CHEMBL1557648 & 688194 & 5.5017 & 5.1974 & TRN \\
\hline CHEMBL1348071 & 688194 & 4.9226 & 4.4993 & TRN \\
\hline CHEMBL1346468 & 688194 & 5.2457 & 4.8509 & TRN \\
\hline CHEMBL1437943 & 688194 & 5.0477 & 4.8373 & TRN \\
\hline CHEMBL1439672 & 688194 & 5.0721 & 5.1459 & TRN \\
\hline CHEMBL1371777 & 688194 & 4.8125 & 4.7252 & TRN \\
\hline CHEMBL1506496 & 688194 & 5.1918 & 5.0958 & TRN \\
\hline CHEMBL1562775 & 688194 & 3.699 & 3.9091 & TRN \\
\hline CHEMBL418068 & 688194 & 5.2848 & 4.6067 & TST \\
\hline CHEMBL1582505 & 688194 & 5.8268 & 5.6456 & TRN \\
\hline
\end{tabular}

Page 25288 


\begin{tabular}{|c|c|c|c|c|c|}
\hline \multirow[b]{2}{*}{ CHEMBL1580990 } & \multirow{2}{*}{688194} & \\
\hline & & 5.0477 & 4.8526 & TRN & \\
\hline CHEMBL3196589 & 688194 & 5.0052 & 4.8837 & TRN & \\
\hline CHEMBL1505922 & 688194 & 5.3706 & 4.9718 & TRN & \\
\hline CHEMBL1539236 & 688194 & 5.2048 & 5.1973 & TRN & \\
\hline CHEMBL1485132 & 688194 & 3.699 & 3.8009 & TRN & \\
\hline CHEMBL1453673 & 688194 & 5.2269 & 5.1395 & TRN & \\
\hline CHEMBL1428417 & 688194 & 5.1361 & 5.0247 & TRN & \\
\hline CHEMBL1568312 & 688194 & 3.699 & 3.7134 & TRN & \\
\hline CHEMBL1533366 & 688194 & 5.2534 & 5.0605 & TRN & \\
\hline CHEMBL1500966 & 688194 & 5.063 & 5.28799 & 9999999999 & TRN \\
\hline CHEMBL1464723 & 688194 & 5.0155 & 4.8958 & TRN & \\
\hline CHEMBL1303518 & 688194 & 3.699 & 3.5966 & TRN & \\
\hline CHEMBL546597 & 688194 & 4.8794 & 4.9238 & TRN & \\
\hline CHEMBL1360170 & 688194 & 4.9872 & 4.5733 & TRN & \\
\hline CHEMBL16223 & 688194 & 5.9431 & 5.7424 & TRN & \\
\hline CHEMBL1569203 & 688194 & 3.699 & 4.9524 & TRN & \\
\hline CHEMBL1403575 & 688194 & 4.8416 & 4.8176 & TRN & \\
\hline CHEMBL3193689 & 688194 & 3.699 & 4.8426 & TRN & \\
\hline CHEMBL1578082 & 688194 & 3.699 & 4.504 & TST & \\
\hline CHEMBL1567855 & 688194 & 4.8573 & 4.6398 & TRN & \\
\hline CHEMBL1546822 & 688194 & 3.699 & 3.7276 & TRN & \\
\hline CHEMBL1733605 & 688194 & 3.699 & 3.9191 & TRN & \\
\hline CHEMBL1412821 & 688194 & 3.699 & 3.7503 & TST & \\
\hline CHEMBL1300317 & 688194 & 5.1707 & 4.8786 & TRN & \\
\hline CHEMBL1496341 & 688194 & 5.2692 & 5.0875 & TRN & \\
\hline CHEMBL1200792 & 688194 & 5.015 & 4.9506 & TRN & \\
\hline CHEMBL1372884 & 688194 & 3.699 & 3.7276 & TRN & \\
\hline CHEMBL1341981 & 688194 & 4.9234 & 4.983006 & 00000000005 & TRN \\
\hline CHEMBL1363615 & 688194 & 4.9255 & 4.9744 & TRN & \\
\hline CHEMBL1525916 & 688194 & 4.9355 & 4.8494 & TRN & \\
\hline CHEMBL1603229 & 688194 & 3.699 & 3.9617 & TST & \\
\hline CHEMBL1423096 & 688194 & 4.7416 & 4.7592 & TRN & \\
\hline CHEMBL1454820 & 688194 & 4.8268 & 4.7204 & TRN & \\
\hline CHEMBL1527360 & 688194 & 3.699 & 3.7715 & TRN & \\
\hline CHEMBL1504324 & 688194 & 5.2848 & 5.1369 & TRN & \\
\hline CHEMBL1374260 & 688194 & 5.2233 & 5.1417 & TRN & \\
\hline CHEMBL1341815 & 688194 & 4.7924 & 4.9798 & TRN & \\
\hline CHEMBL1384436 & 688194 & 5.0173 & 5.0619 & TST & \\
\hline CHEMBL539027 & 688194 & 5.2328 & 5.2584 & TRN & \\
\hline CHEMBL1440291 & 688194 & 4.7476 & 4.7597 & TRN & \\
\hline CHEMBL1302028 & 688194 & 5.1898 & 5.2161 & TRN & \\
\hline CHEMBL1596484 & 688194 & 3.699 & 4.0464 & TRN & \\
\hline CHEMBL1494038 & 688194 & 5.2733 & 5.1756 & TRN & \\
\hline CHEMBL1422158 & 688194 & 5.2967 & 5.114 & TRN & \\
\hline CHEMBL1481374 & 688194 & 4.8729 & 5.1889 & TRN & \\
\hline CHEMBL1329396 & 688194 & 4.7347 & 4.8308 & TRN & \\
\hline CHEMBL1455122 & 688194 & 3.699 & 3.8259 & TRN & \\
\hline CHEMBL587884 & 688194 & 5.75200 & t00000006 & 5.3503 & TST \\
\hline & & & & 25289 & \\
\hline
\end{tabular}




\begin{tabular}{|c|c|c|c|c|c|c|}
\hline & & \multicolumn{5}{|c|}{ Supplemental Table S2.txt } \\
\hline CHEMBL1974112 & 688194 & 4.9586 & 4.6967 & TRN & & \\
\hline CHEMBL567130 & 688194 & 4.8052 & 4.9248 & TRN & & \\
\hline CHEMBL1392315 & 688194 & 3.699 & 3.8456 & TRN & & \\
\hline CHEMBL1309621 & 688194 & 3.699 & 3.8706 & TRN & & \\
\hline CHEMBL1526325 & 688194 & 3.699 & 3.5194 & TRN & & \\
\hline CHEMBL1508182 & 688194 & 3.699 & 4.7615 & TRN & & \\
\hline CHEMBL1607660 & 688194 & 3.699 & 3.8525 & TRN & & \\
\hline CHEMBL1467245 & 688194 & 3.699 & 3.6229 & TRN & & \\
\hline CHEMBL1382277 & 688194 & 4.9469 & 4.9244 & TRN & & \\
\hline CHEMBL1571874 & 688194 & \multicolumn{3}{|c|}{5.4510000000000005} & 5.2 & TRN \\
\hline CHEMBL1609777 & 688194 & 3.699 & 3.8479 & TRN & & \\
\hline CHEMBL1595564 & 688194 & 3.699 & 4.6382 & TRN & & \\
\hline CHEMBL1497812 & 688194 & 3.699 & 3.8397 & TRN & & \\
\hline CHEMBL1328193 & 688194 & 4.8884 & 4.7664 & TRN & & \\
\hline CHEMBL1420053 & 688194 & 3.699 & 3.7234 & TRN & & \\
\hline CHEMBL1324051 & 688194 & 5.2255 & 4.8823 & TRN & & \\
\hline CHEMBL19980 & 688194 & 6.6198 & 6.3217 & TST & & \\
\hline CHEMBL1517889 & 688194 & 3.699 & 3.8338 & TRN & & \\
\hline CHEMBL1561281 & 688194 & 4.7773 & 4.8258 & TRN & & \\
\hline CHEMBL1325494 & 688194 & 4.945 & 4.8203 & TRN & & \\
\hline CHEMBL601952 & 688194 & 4.8125 & 4.8473 & TST & & \\
\hline CHEMBL1409056 & 688194 & 3.699 & 3.991 & TRN & & \\
\hline CHEMBL1441325 & 688194 & 3.699 & 3.7067 & TRN & & \\
\hline CHEMBL1506967 & 688194 & 5.0097 & 4.9594 & TRN & & \\
\hline CHEMBL1975458 & 688194 & 5.2457 & 4.7796 & TRN & & \\
\hline CHEMBL1495589 & 688194 & 4.9658 & 4.7915 & TRN & & \\
\hline CHEMBL1346595 & 688194 & 5.1415 & 4.9292 & TRN & & \\
\hline CHEMBL1604546 & 688194 & 5.1506 & 5.0892 & TST & & \\
\hline CHEMBL448741 & 688194 & 5.0031 & 4.7017 & TST & & \\
\hline CHEMBL1346587 & 688194 & 5.6676 & 5.5921 & TRN & & \\
\hline CHEMBL1350845 & 688194 & 3.699 & 3.7191 & TRN & & \\
\hline CHEMBL1529687 & 688194 & 5.0846 & 5.0711 & TRN & & \\
\hline CHEMBL1445142 & 688194 & 4.7867 & 4.6072 & TRN & & \\
\hline CHEMBL1300938 & 688194 & 3.699 & 3.7166 & TRN & & \\
\hline CHEMBL1531073 & 688194 & 5.0246 & 5.1693 & TRN & & \\
\hline CHEMBL393287 & 688194 & 5.1543 & 5.0703 & TRN & & \\
\hline CHEMBL1479249 & 688194 & 3.699 & 4.9356 & TRN & & \\
\hline CHEMBL1612390 & 688194 & 4.8665 & 5.0084 & TRN & & \\
\hline CHEMBL1531839 & 688194 & 3.699 & 3.9643 & TST & & \\
\hline CHEMBL1453264 & 688194 & 3.699 & 3.9149 & TRN & & \\
\hline CHEMBL1586980 & 688194 & 4.8508 & 4.7011 & TRN & & \\
\hline CHEMBL1606330 & 688194 & 4.8508 & 4.9079 & TRN & & \\
\hline CHEMBL1598791 & 688194 & 5.0039 & 4.9999 & TST & & \\
\hline CHEMBL1981770 & 688194 & 5.9245 & 5.6878 & TRN & & \\
\hline CHEMBL1427004 & 688194 & 4.9991 & 4.8497 & TRN & & \\
\hline CHEMBL1540038 & 688194 & 5.4342 & 5.3934 & TRN & & \\
\hline CHEMBL1544371 & 688194 & 5.0711 & 4.75899 & 99999 & ; & TRN \\
\hline CHEMBL1314042 & 688194 & 5.1979 & 5.1689 & TRN & & \\
\hline
\end{tabular}




\begin{tabular}{|c|c|c|c|c|c|}
\hline \multirow[b]{2}{*}{ CHEMBL1352062 } & \multirow[b]{2}{*}{688194} & \multicolumn{4}{|c|}{ Supplemental Table S2.txt } \\
\hline & & 4.7282 & 4.9021 & TRN & \\
\hline CHEMBL1454533 & 688194 & 3.699 & 3.5816 & TRN & \\
\hline CHEMBL1410260 & 688194 & 4.857 & 4.6785 & TRN & \\
\hline CHEMBL1426137 & 688194 & 3.699 & 4.0359 & TST & \\
\hline CHEMBL1508674 & 688194 & 4.8781 & 4.9233 & TRN & \\
\hline CHEMBL581194 & 688194 & 5.0039 & 4.7938 & TRN & \\
\hline CHEMBL1488723 & 688194 & 5.0883 & 4.9518 & TRN & \\
\hline CHEMBL 259388 & 688194 & 4.7595 & 4.803 & TRN & \\
\hline CHEMBL1488251 & 688194 & 3.699 & 3.8721 & TRN & \\
\hline CHEMBL1596996 & 688194 & 5.1549 & 5.2247 & TST & \\
\hline CHEMBL1330307 & 688194 & 3.699 & 4.544 & TRN & \\
\hline CHEMBL1299470 & 688194 & 4.7747 & 4.9749 & TRN & \\
\hline CHEMBL1496004 & 688194 & 4.8297 & 4.8999 & TRN & \\
\hline CHEMBL1586817 & 688194 & 5.1574 & 5.228 & TRN & \\
\hline CHEMBL1391184 & 688194 & 4.927 & 4.7408 & TRN & \\
\hline CHEMBL1528712 & 688194 & 3.699 & 3.8743 & TRN & \\
\hline CHEMBL2003973 & 688194 & 5.0079 & 4.9263 & TST & \\
\hline CHEMBL1602058 & 688194 & 5.1965 & 4.9867 & TRN & \\
\hline CHEMBL1586975 & 688194 & 4.8125 & 4.8665 & TST & \\
\hline CHEMBL1418843 & 688194 & 4.7878 & 4.6777 & TRN & \\
\hline CHEMBL1530097 & 688194 & 3.699 & 3.8987 & TRN & \\
\hline CHEMBL487356 & 688194 & 5.2147 & 5.1203 & TRN & \\
\hline CHEMBL1312502 & 688194 & 4.7905 & 4.7548 & TRN & \\
\hline CHEMBL1345124 & 688194 & 3.699 & 3.8027 & TRN & \\
\hline CHEMBL1353353 & 688194 & 4.9212 & 4.8472 & TST & \\
\hline CHEMBL3190220 & 688194 & 5.5317 & 5.4963 & TRN & \\
\hline CHEMBL1415885 & 688194 & 4.7696 & $5.1320 e$ & 3000000001 & TRN \\
\hline CHEMBL1329561 & 688194 & 3.699 & 4.0143 & TRN & \\
\hline CHEMBL1429929 & 688194 & 5.3565 & 5.362 & TRN & \\
\hline CHEMBL1608078 & 688194 & 4.98300 & 00000000 & 5.0914 & TRN \\
\hline CHEMBL1410021 & 688194 & 3.699 & 3.8821 & TRN & \\
\hline CHEMBL1370387 & 688194 & 5.3251 & 5.0481 & TRN & \\
\hline CHEMBL1541774 & 688194 & 3.699 & 3.9776 & TST & \\
\hline CHEMBL1557782 & 688194 & 5.2118 & 5.206 & TRN & \\
\hline CHEMBL3196476 & 688194 & 4.9825 & 4.8657 & TRN & \\
\hline CHEMBL261131 & 688194 & 5.3757 & 5.2356 & TRN & \\
\hline CHEMBL1458873 & 688194 & 4.9183 & 4.9975 & TRN & \\
\hline CHEMBL1607568 & 688194 & 5.5017 & 5.3943 & TRN & \\
\hline CHEMBL1542010 & 688194 & 3.699 & 3.3748 & TRN & \\
\hline CHEMBL1469736 & 688194 & 5.0044 & 5.1044 & TRN & \\
\hline CHEMBL1429245 & 688194 & 5.0747 & 4.9444 & TRN & \\
\hline CHEMBL 1445710 & 688194 & 5.5214 & 5.2851 & TRN & \\
\hline CHEMBL1480579 & 688194 & 3.699 & 3.4493 & TRN & \\
\hline CHEMBL1305312 & 688194 & 4.8781 & 4.8367 & TRN & \\
\hline CHEMBL1562591 & 688194 & 3.699 & 3.5934 & TRN & \\
\hline CHEMBL1555899 & 688194 & 5.0074 & 4.9542 & TRN & \\
\hline CHEMBL1548229 & 688194 & 4.9374 & 4.8138 & TRN & \\
\hline CHEMBL1349063 & 688194 & 6.4089 & 5.9191 & TRN & \\
\hline
\end{tabular}


Supplemental Table S2.txt

CHEMBL1324079
CHEMBL1485168
CHEMBL1417970
CHEMBL578512
CHEMBL582444
CHEMBL1573627
CHEMBL1386178
CHEMBL3208118
CHEMBL1347618
CHEMBL1438768
CHEMBL1314070
CHEMBL1569370
CHEMBL1084643
CHEMBL1386456
CHEMBL1529647
CHEMBL1430895
CHEMBL1302523
CHEMBL1376120
CHEMBL1344791
CHEMBL1417243
CHEMBL1483522
CHEMBL1586326
CHEMBL1320633
CHEMBL251785
CHEMBL1491007
CHEMBL1603776
CHEMBL1546068
CHEMBL1572266
CHEMBL1310766
CHEMBL1523206
CHEMBL1478852
CHEMBL1486699
CHEMBL1336709
CHEMBL1445768
CHEMBL1414133
CHEMBL52
CHEMBL3193792
CHEMBL1566928
CHEMBL1527768
CHEMBL1414783
CHEMBL1571157
CHEMBL1504557
CHEMBL3197060
CHEMBL1331573
CHEMBL1472193

$\begin{array}{llll}688194 & 4.9208 & 4.7755 & \text { TRN } \\ 688194 & 4.9872 & 4.725 & \text { TRN } \\ 688194 & 5.2182 & 5.3531 & \text { TRN } \\ 688194 & 6.1938 & 5.9182 & \text { TST } \\ 688194 & 3.699 & 3.8082 & \text { TST } \\ 688194 & 4.9045 & 4.9244 & \text { TRN } \\ 688194 & 4.8416 & 5.0845 & \text { TRN } \\ 688194 & 5.1945 & 5.1451 & \text { TRN } \\ 688194 & 5.8153 & 5.4209 & \text { TST } \\ 688194 & 3.699 & 3.7923 & \text { TRN } \\ 688194 & 3.699 & 3.8892 & \text { TRN } \\ 688194 & 4.9245 & 5.0705 & \text { TRN } \\ 688194 & 3.699 & 3.6387 & \text { TST } \\ 688194 & 4.8239 & 4.8784 & \text { TRN } \\ 688194 & 4.9586 & 4.7851 & \text { TRN } \\ 688194 & 5.5638 & 5.6763 & \text { TRN } \\ 688194 & 5.0097 & 5.0852 & \text { TRN } \\ 688194 & 5.0269 & 4.82 & \text { TST } \\ 688194 & 4.9714 & 4.9411 & \text { TST } \\ 688194 & 4.9914 & 5.0105 & \text { TST } \\ 688194 & 5.1135 & 5.1541 & \text { TST } \\ 688194 & 5.1445 & 4.9117 & \text { TST } \\ 688194 & 5.1445 & 4.765 & \text { TST } \\ 688194 & 6.5229 & 5.9469 & \text { TST } \\ 688194 & 5.0665 & 5.0545 & \text { TST } \\ 688194 & 4.8416 & 4.6916 & \text { TST } \\ 688194 & 5.2358 & 5.2349 & \text { TST } \\ 688194 & 4.7162 & 4.6078 & \text { TST } \\ 688194 & 3.699 & 3.9429 & \text { TST } \\ 688194 & 5.6615 & 5.6417 & \text { TST } \\ 688194 & 4.8962 & 5.1289 & \text { TST } \\ 688194 & 3.699 & 4.715 & \text { TST } \\ 688194 & 4.9809 & 4.8608 & \text { TST } \\ 688194 & 5.3585 & 5.2526 & \text { TST } \\ 688194 & 3.699 & 3.7242 & \text { TST } \\ 688194 & 4.9516 & 4.7524 & \text { TST } \\ 688194 & 5.5482 & 5.482 & \text { TST } \\ 688194 & 5.6819 & 5.3757 & \text { TST } \\ 688194 & 3.699 & 3.9107 & \text { TST } \\ 688194 & 3.699 & 3.7878 & \text { TST } \\ 688194 & 4.8761 & 4.989 & \text { TST } \\ 688194 & 3.699 & 3.7262 & \text { TST } \\ 688194 & 4.9385 & 4.986000000000001 \\ 688194 & 5.5143 & 5.3573 & \text { TST } \\ 688194 & 4.8633 & 4.9235 & \text { TST } \\ 688194 & 4.9027 & 4.4999 & \text { TST } \\ 688194 & 3.699 & 4.6905 & \text { TST } \\ 688194 & 5.5952 & 5.0881 & \text { TST }\end{array}$




\begin{tabular}{|c|c|c|c|c|c|}
\hline & & \multicolumn{4}{|c|}{ Supplemental Table S2.txt } \\
\hline CHEMBL1578064 & 688194 & 5.0942 & 5.1288 & TST & \\
\hline CHEMBL1455310 & 688194 & 3.699 & 3.9201 & TST & \\
\hline CHEMBL1577745 & 688194 & 5.0306 & 4.918 & TST & \\
\hline CHEMBL1329458 & 688194 & 3.699 & 4.7652 & TST & \\
\hline CHEMBL1522275 & 688194 & 5.1018 & 5.1522 & TST & \\
\hline CHEMBL1584452 & 688194 & 4.8645 & 4.7965 & TST & \\
\hline CHEMBL1373432 & 688194 & 5.1118 & 4.8824 & TST & \\
\hline CHEMBL1572060 & 688194 & 3.699 & 3.7326 & TST & \\
\hline CHEMBL1335963 & 688194 & 3.699 & 3.7334 & TST & \\
\hline CHEMBL1402855 & 688194 & 3.699 & 3.6798 & TST & \\
\hline CHEMBL1503426 & 688194 & 4.8013 & 4.8372 & TST & \\
\hline CHEMBL1555886 & 688194 & 5.0799 & 4.8049 & TST & \\
\hline CHEMBL1378851 & 688194 & 5.2741 & 5.5007 & TST & \\
\hline CHEMBL3189713 & 688194 & 4.9658 & 4.8363 & TST & \\
\hline CHEMBL1533433 & 688194 & 3.699 & 3.6704 & TST & \\
\hline CHEMBL1352844 & 688194 & 4.752 & 4.6469 & TST & \\
\hline CHEMBL1379362 & 688194 & 4.8665 & 4.6906 & TST & \\
\hline CHEMBL 3642455 & 1527820 & 9.28399 & (99999999 & 9.6359 & TS \\
\hline CHEMBL3640335 & 1527820 & 9.5045 & 9.5366 & TRN & \\
\hline CHEMBL 3640320 & 1527820 & 9.0862 & 8.3335 & TST & \\
\hline CHEMBL3642518 & 1527820 & 10.0 & 9.4786 & TST & \\
\hline CHEMBL 3642461 & 1527820 & 9.6021 & 9.5402 & TRN & \\
\hline CHEMBL 3642467 & 1527820 & 9.6021 & 9.6032 & TRN & \\
\hline CHEMBL 3640334 & 1527820 & 9.1367 & 9.2452 & TRN & \\
\hline CHEMBL3642436 & 1527820 & 9.0269 & 9.1175 & TRN & \\
\hline CHEMBL3642453 & 1527820 & 9.3665 & 9.7679 & TST & \\
\hline CHEMBL 3640301 & 1527820 & 9.5086 & 9.4519 & TRN & \\
\hline CHEMBL 3640332 & 1527820 & 9.2782 & 9.1102 & TRN & \\
\hline CHEMBL 3640313 & 1527820 & 9.3125 & 9.2753 & TRN & \\
\hline CHEMBL3640390 & 1527820 & 9.4089 & 9.6465 & TRN & \\
\hline CHEMBL 3640374 & 1527820 & 9.4711 & 9.6018 & TRN & \\
\hline CHEMBL 3642514 & 1527820 & 9.9208 & 9.8342 & TRN & \\
\hline CHEMBL 3640414 & 1527820 & 9.5229 & 9.4669 & TRN & \\
\hline CHEMBL3642472 & 1527820 & 7.5817 & 8.7843 & TST & \\
\hline CHEMBL3640308 & 1527820 & 9.567 & 9.7206 & TRN & \\
\hline CHEMBL3642521 & 1527820 & 9.5528 & 9.6098 & TRN & \\
\hline CHEMBL3640315 & 1527820 & 9.4881 & 9.44399 & 9999999999 & TRI \\
\hline CHEMBL3640359 & 1527820 & 8.8268 & 8.7151 & TRN & \\
\hline CHEMBL3642465 & 1527820 & 9.0223 & 8.8734 & TRN & \\
\hline CHEMBL3640387 & 1527820 & 9.6576 & 9.6047 & TRN & \\
\hline CHEMBL3640386 & 1527820 & 9.7212 & 9.7335 & TRN & \\
\hline CHEMBL 3642442 & 1527820 & 6.0 & 6.0367 & TRN & \\
\hline CHEMBL3640318 & 1527820 & 9.1024 & 9.1769 & TRN & \\
\hline CHEMBL3640324 & 1527820 & 9.4202 & 9.2929 & TRN & \\
\hline CHEMBL3640358 & 1527820 & 9.0783 & 8.7797 & TRN & \\
\hline CHEMBL 3642497 & 1527820 & 9.4089 & 9.2424 & TRN & \\
\hline CHEMBL 3640304 & 1527820 & 9.4078 & 8.2049 & TST & \\
\hline CHEMBL 3640433 & 1527820 & 9.2076 & 9.3614 & TST & \\
\hline
\end{tabular}


Supplemental Table S2.txt

\begin{tabular}{|c|c|c|c|c|c|}
\hline CHEMBL3642502 & 1527820 & 9.8239 & 9.7216 & TRN & \\
\hline CHEMBL3640351 & 1527820 & 10.0119 & 10.0582 & TRN & \\
\hline CHEMBL3640396 & 1527820 & 8.8928 & 8.8392 & TRN & \\
\hline CHEMBL3640376 & 1527820 & 9.2218 & 8.5812 & TST & \\
\hline CHEMBL3642486 & 1527820 & 9.3565 & 9.6391 & TRN & \\
\hline CHEMBL3640299 & 1527820 & 10.5229 & 10.4612 & TRN & \\
\hline CHEMBL3640406 & 1527820 & 9.7447 & 9.6104 & TRN & \\
\hline CHEMBL3642495 & 1527820 & 9.7447 & 9.5292 & TRN & \\
\hline CHEMBL 3642547 & 1527820 & 9.0809 & 9.0169 & TRN & \\
\hline CHEMBL3642475 & 1527820 & 9.4306 & 9.5352 & TRN & \\
\hline CHEMBL3640392 & 1527820 & 9.699 & 9.6943 & TRN & \\
\hline CHEMBL3640339 & 1527820 & 10.2807 & 10.2149 & TRN & \\
\hline CHEMBL3919481 & 1527820 & 10.0315 & 10.169 & TST & \\
\hline CHEMBL 3640395 & 1527820 & 8.4522 & 8.4691 & TRN & \\
\hline CHEMBL3642491 & 1527820 & 9.7959 & 9.722999 & 7999999999 & TRN \\
\hline CHEMBL3640382 & 1527820 & 9.5686 & 9.5232 & TRN & \\
\hline CHEMBL3640323 & 1527820 & 9.2518 & 8.115 & TST & \\
\hline CHEMBL3642438 & 1527820 & 9.3665 & 9.6249 & TST & \\
\hline CHEMBL 3642504 & 1527820 & 9.4949 & 9.5643 & TRN & \\
\hline CHEMBL3642459 & 1527820 & 10.2218 & 10.1853 & TRN & \\
\hline CHEMBL3985542 & 1527820 & 9.6198 & 9.1341 & TST & \\
\hline CHEMBL3642450 & 1527820 & 9.699 & 10.1105 & TST & \\
\hline CHEMBL 3640310 & 1527820 & 9.5969 & 9.5092 & TRN & \\
\hline CHEMBL 3642468 & 1527820 & 9.2518 & 9.202 & TST & \\
\hline CHEMBL3640362 & 1527820 & 9.301 & 9.3608 & TRN & \\
\hline CHEMBL1287882 & 1527820 & 9.2147 & 9.3468 & TRN & \\
\hline CHEMBL3640425 & 1527820 & 8.9586 & 9.4334 & TST & \\
\hline CHEMBL 3642426 & 1527820 & 8.8153 & 8.6708 & TST & \\
\hline CHEMBL 3642517 & 1527820 & 9.7447 & 9.7833 & TRN & \\
\hline CHEMBL3640361 & 1527820 & 9.3675 & 9.4346 & TRN & \\
\hline CHEMBL3640317 & 1527820 & 9.4572 & 9.4092 & TRN & \\
\hline CHEMBL3640419 & 1527820 & 9.5376 & 9.5632 & TRN & \\
\hline CHEMBL3640409 & 1527820 & 8.6946 & 8.6996 & TRN & \\
\hline CHEMBL 3642460 & 1527820 & 9.585 & 9.6131 & TRN & \\
\hline CHEMBL3642448 & 1527820 & 9.6021 & 9.0152 & TST & \\
\hline CHEMBL3642556 & 1527820 & 9.2076 & 9.1707 & TRN & \\
\hline CHEMBL3640333 & 1527820 & 8.9172 & 9.0368 & TRN & \\
\hline CHEMBL 3640417 & 1527820 & 9.9586 & 9.9336 & TST & \\
\hline CHEMBL 3640331 & 1527820 & 9.3595 & 9.2936 & TRN & \\
\hline CHEMBL 3642515 & 1527820 & 9.6778 & 9.8077 & TRN & \\
\hline CHEMBL3640399 & 1527820 & 8.9208 & 8.8473 & TRN & \\
\hline CHEMBL3640341 & 1527820 & 9.71 & 9.7516 & TRN & \\
\hline CHEMBL3640429 & 1527820 & 8.752 & 8.6393 & TST & \\
\hline CHEMBL 3642441 & 1527820 & 9.6576 & 9.6252 & TRN & \\
\hline CHEMBL3642539 & 1527820 & 8.7773 & 8.8764 & TRN & \\
\hline CHEMBL3640410 & 1527820 & 8.8665 & 8.7417 & TRN & \\
\hline CHEMBL3640303 & 1527820 & 6.0 & 9.3404 & TST & \\
\hline CHEMBL3642473 & 1527820 & 6.0 & 9.9649 & TST & \\
\hline
\end{tabular}




\begin{tabular}{|c|c|c|c|c|c|c|}
\hline \multicolumn{7}{|c|}{ Supplemental Table S2.txt } \\
\hline CHEMBL3640380 & 1527820 & 6.0 & 5.8972 & TRN & & \\
\hline CHEMBL 3640428 & 1527820 & 8.8182 & 8.9313 & TRN & & \\
\hline CHEMBL3642452 & 1527820 & 9.3565 & 9.3106 & TRN & & \\
\hline CHEMBL3640302 & 1527820 & 6.0 & 8.3528 & TST & & \\
\hline CHEMBL 3640353 & 1527820 & 9.9393 & 9.8486 & TRN & & \\
\hline CHEMBL3640300 & 1527820 & 9.4547 & 9.3628 & TRN & & \\
\hline CHEMBL 3642530 & 1527820 & 9.4437 & 9.4361 & TRN & & \\
\hline CHEMBL 3642470 & 1527820 & 9.5528 & 9.5785 & TRN & & \\
\hline CHEMBL3640345 & 1527820 & 9.3098 & 9.326 & TRN & & \\
\hline CHEMBL3642463 & 1527820 & 9.7696 & 9.5037 & TRN & & \\
\hline CHEMBL 3640321 & 1527820 & 9.28399 & 999999999 & 99 & 8.7141 & TST \\
\hline CHEMBL 3642449 & 1527820 & 9.2007 & 9.2104 & TRN & & \\
\hline CHEMBL 3642440 & 1527820 & 9.4283 & 9.4415 & TRN & & \\
\hline CHEMBL 3642478 & 1527820 & 9.5031 & 9.4916 & TRN & & \\
\hline CHEMBL 3642535 & 1527820 & 9.7212 & 9.8279 & TRN & & \\
\hline CHEMBL3640307 & 1527820 & 9.3215 & 9.2749 & TRN & & \\
\hline CHEMBL 3642490 & 1527820 & 9.7959 & 10.154 & TRN & & \\
\hline CHEMBL 3962608 & 1527820 & 9.5686 & 9.9813 & TST & & \\
\hline CHEMBL 3642545 & 1527820 & 9.1308 & 9.1137 & TRN & & \\
\hline CHEMBL 3640343 & 1527820 & 9.4214 & 9.5364 & TRN & & \\
\hline CHEMBL 3640388 & 1527820 & 9.7212 & 9.8992 & TRN & & \\
\hline CHEMBL 3642476 & 1527820 & 9.7959 & 9.8818 & TRN & & \\
\hline CHEMBL 3642481 & 1527820 & 6.0 & 6.0141 & TRN & & \\
\hline CHEMBL 3642429 & 1527820 & 8.9914 & 8.9015 & TST & & \\
\hline CHEMBL3640397 & 1527820 & 9.4685 & 9.4673 & TRN & & \\
\hline CHEMBL3642469 & 1527820 & 9.585 & 9.5962 & TRN & & \\
\hline CHEMBL 3640357 & 1527820 & 9.4559 & 9.5426 & TRN & & \\
\hline CHEMBL 3642462 & 1527820 & 9.1226 & 9.204 & TRN & & \\
\hline CHEMBL 3640347 & 1527820 & 6.0 & 6.7185 & TRN & & \\
\hline CHEMBL 3642555 & 1527820 & 9.1675 & 9.302 & TRN & & \\
\hline CHEMBL3640356 & 1527820 & 9.5528 & 9.5447 & TRN & & \\
\hline CHEMBL 3640394 & 1527820 & 9.3468 & 9.3528 & TRN & & \\
\hline CHEMBL 3640404 & 1527820 & 9.6198 & 9.5302 & TRN & & \\
\hline CHEMBL3911628 & 1527820 & 9.0061 & 9.1338 & TST & & \\
\hline CHEMBL3640306 & 1527820 & 9.2832 & 9.2789 & TRN & & \\
\hline CHEMBL 3640370 & 1527820 & 10.118 & 10.2484 & TRN & & \\
\hline CHEMBL 3642522 & 1527820 & 9.5229 & 9.4621 & TRN & & \\
\hline CHEMBL 3640328 & 1527820 & 9.3449 & 9.2187 & TRN & & \\
\hline CHEMBL1288211 & 1527820 & 9.3768 & 9.3796 & TRN & & \\
\hline CHEMBL 3640400 & 1527820 & 8.4306 & 8.8227 & TST & & \\
\hline CHEMBL3640355 & 1527820 & 9.1555 & 9.3169 & TRN & & \\
\hline CHEMBL 3640413 & 1527820 & 9.2218 & 9.2788 & TRN & & \\
\hline CHEMBL3640326 & 1527820 & 9.4389 & 9.5991 & TRN & & \\
\hline CHEMBL 3642488 & 1527820 & 9.7447 & 9.7338 & TRN & & \\
\hline CHEMBL3642549 & 1527820 & 9.3665 & 9.343 & TRN & & \\
\hline CHEMBL3642566 & 1527820 & 7.5157 & 9.373 & TST & & \\
\hline CHEMBL 3642435 & 1527820 & 10.5229 & 10.4102 & TRN & & \\
\hline CHEMBL 3642528 & 1527820 & 9.9586 & 10.0038 & TRN & & \\
\hline
\end{tabular}

Page 25295 
Supplemental Table S2.txt

\begin{tabular}{|c|c|c|c|c|}
\hline CHEMBL 3640432 & 1527820 & 9.0315 & 9.1944 & TST \\
\hline CHEMBL 3642431 & 1527820 & 9.2596 & 9.236 & TRN \\
\hline CHEMBL3642443 & 1527820 & 9.0915 & 9.081 & TRN \\
\hline CHEMBL1288000 & 1527820 & 10.1308 & 10.1977 & TRN \\
\hline CHEMBL 3640430 & 1527820 & 9.3706 & 8.9068 & TST \\
\hline CHEMBL3642531 & 1527820 & 9.5086 & 9.4449 & TRN \\
\hline CHEMBL 3642524 & 1527820 & 9.699 & 9.8253 & TRN \\
\hline CHEMBL3642500 & 1527820 & 9.9586 & 10.0466 & TRN \\
\hline CHEMBL 3640342 & 1527820 & 9.2596 & 9.3672 & TRN \\
\hline CHEMBL 3640360 & 1527820 & 9.2907 & 9.4725 & TRN \\
\hline CHEMBL 3642559 & 1527820 & 9.585 & 9.647 & TRN \\
\hline CHEMBL 3642548 & 1527820 & 9.7212 & 9.4989 & TRN \\
\hline CHEMBL 3642456 & 1527820 & 9.041 & 7.5182 & TST \\
\hline CHEMBL 3640367 & 1527820 & 10.1135 & 9.9741 & TRN \\
\hline CHEMBL 3642501 & 1527820 & 10.2007 & 10.0466 & TRN \\
\hline CHEMBL 3642513 & 1527820 & 9.9208 & 9.896 & TRN \\
\hline CHEMBL 3640378 & 1527820 & 9.4815 & 9.6144 & TRN \\
\hline CHEMBL 3642427 & 1527820 & 8.9914 & 9.4027 & TST \\
\hline CHEMBL 3640366 & 1527820 & 10.1073 & 10.2301 & TRN \\
\hline CHEMBL 3640418 & 1527820 & 9.4815 & 9.3986 & TRN \\
\hline CHEMBL 3642471 & 1527820 & 8.6289 & 8.533999 & 999999999 \\
\hline CHEMBL 3640349 & 1527820 & 9.2933 & 9.5809 & TRN \\
\hline CHEMBL 3642454 & 1527820 & 8.9626 & 9.374 & TST \\
\hline CHEMBL 3642525 & 1527820 & 9.6576 & 9.6826 & TRN \\
\hline CHEMBL 3642532 & 1527820 & 9.2441 & 8.5837 & TST \\
\hline CHEMBL 3640368 & 1527820 & 10.083 & 10.3053 & TRN \\
\hline CHEMBL 3642509 & 1527820 & 9.8861 & 9.8529 & TRN \\
\hline CHEMBL 3640393 & 1527820 & 9.5528 & 9.6409 & TRN \\
\hline CHEMBL 3642494 & 1527820 & 9.6198 & 9.7375 & TRN \\
\hline CHEMBL 3640398 & 1527820 & 9.2757 & 8.0125 & TST \\
\hline CHEMBL 3642464 & 1527820 & 9.4815 & 9.5712 & TRN \\
\hline CHEMBL 3640424 & 1527820 & 6.0 & 6.0767 & TRN \\
\hline CHEMBL 3642541 & 1527820 & 9.2291 & 9.3629 & TRN \\
\hline CHEMBL 3640314 & 1527820 & 9.4724 & 9.5278 & TRN \\
\hline CHEMBL 3642483 & 1527820 & 9.1367 & 8.8887 & TRN \\
\hline CHEMBL3640423 & 1527820 & 9.6021 & 10.0175 & TST \\
\hline CHEMBL 3642512 & 1527820 & 9.7696 & 9.6961 & TRN \\
\hline CHEMBL 3640379 & 1527820 & 9.3565 & 9.3447 & TRN \\
\hline CHEMBL 3640346 & 1527820 & 9.4112 & 9.1483 & TRN \\
\hline CHEMBL 3640373 & 1527820 & 9.0362 & 9.0897 & TRN \\
\hline CHEMBL 3640402 & 1527820 & 9.9208 & 9.9164 & TRN \\
\hline CHEMBL 3642527 & 1527820 & 9.9208 & 9.9847 & TRN \\
\hline CHEMBL 3642543 & 1527820 & 9.2676 & 9.352 & TRN \\
\hline CHEMBL 3642542 & 1527820 & 8.8539 & 8.81200 & 000000001 \\
\hline CHEMBL 3640329 & 1527820 & 9.2815 & 9.3835 & TRN \\
\hline CHEMBL 3642503 & 1527820 & 9.3372 & 9.7735 & TST \\
\hline CHEMBL 3642484 & 1527820 & 6.3002 & 6.2462 & TRN \\
\hline CHEMBL 3640377 & 1527820 & 9.1249 & 8.9821 & TRN \\
\hline
\end{tabular}

Page 25296 
Supplemental Table S2.txt

CHEMBL3642511

CHEMBL3642554

CHEMBL 3642510

CHEMBL3642533

CHEMBL 3642447

CHEMBL 3642498

CHEMBL 3640407

CHEMBL 3640385

CHEMBL 3642458

CHEMBL3640363

CHEMBL3640369

CHEMBL3642526

CHEMBL3642538

CHEMBL3640312

CHEMBL3640412

CHEMBL 3640389

CHEMBL3642446

CHEMBL3640297

CHEMBL3642457

CHEMBL 3640327

CHEMBL3642433

CHEMBL3640337

CHEMBL 3640384

CHEMBL 3642487

CHEMBL3642432

CHEMBL3640336

CHEMBL3640416

CHEMBL3642537

CHEMBL3642553

CHEMBL3640311

CHEMBL 3894908

CHEMBL3642534

CHEMBL 3640296

CHEMBL3642520

CHEMBL3642444

CHEMBL 3642485

CHEMBL 3640405

CHEMBL 3642496

CHEMBL1288726

CHEMBL3642434

CHEMBL 3642516

CHEMBL3639392

CHEMBL3642489

CHEMBL 3642439

CHEMBL3640325

CHEMBL3640434

CHEMBL1287881

CHEMBL 3640403 $\begin{array}{lll}1527820 & 10.0809 & 10.1157 \text { TRN }\end{array}$

$\begin{array}{llll}1527820 & 9.1675 & 9.0862 & \text { TRN }\end{array}$

$\begin{array}{llll}1527820 & 9.7212 & 9.967 & \text { TRN }\end{array}$

$\begin{array}{lll}1527820 & 9.6021 & 8.613999999999999\end{array}$

$\begin{array}{llll}1527820 & 9.8239 & 8.6859 & \text { TST }\end{array}$

$\begin{array}{llll}1527820 & 9.1487 & 8.9965 & \text { TRN }\end{array}$

$\begin{array}{llll}1527820 & 9.4559 & 9.5966 & \text { TRN }\end{array}$

$\begin{array}{llll}1527820 & 9.1675 & 9.0827 & \text { TRN }\end{array}$

$\begin{array}{llll}1527820 & 9.3468 & 9.4102 & \text { TRN }\end{array}$

$\begin{array}{llll}1527820 & 8.4622 & 8.7796 & \text { TRN }\end{array}$

$\begin{array}{llll}1527820 & 8.9626 & 8.8826 & \text { TRN }\end{array}$

$\begin{array}{llll}1527820 & 9.1675 & 9.9 & \text { TST }\end{array}$

$\begin{array}{llll}1527820 & 9.5482 & 9.6456 & \text { TRN }\end{array}$

$\begin{array}{llll}1527820 & 9.6253 & 9.4712 & \text { TRN }\end{array}$

$\begin{array}{llll}1527820 & 9.1135 & 9.0285 & \text { TRN }\end{array}$

$\begin{array}{llll}1527820 & 9.7212 & 8.2361 & \text { TST }\end{array}$

$\begin{array}{llll}1527820 & 9.6778 & 9.2193 & \text { TST }\end{array}$

$\begin{array}{llll}1527820 & 9.4572 & 9.4139 & \text { TRN }\end{array}$

$\begin{array}{llll}1527820 & 9.8239 & 9.6596 & \text { TRN }\end{array}$

$\begin{array}{llll}1527820 & 9.4179 & 9.4458 & \text { TRN }\end{array}$

$\begin{array}{llll}1527820 & 8.8633 & 9.1171 & \text { TST }\end{array}$

$\begin{array}{lll}1527820 & 10.186410 .2611 \text { TRN }\end{array}$

$\begin{array}{llll}1527820 & 9.4437 & 9.3599 & \text { TRN }\end{array}$

$\begin{array}{llll}1527820 & 9.3768 & 9.3249 & \text { TRN }\end{array}$

$\begin{array}{llll}1527820 & 9.0088 & 9.721 & \text { TST }\end{array}$

$\begin{array}{lll}1527820 & 10.2549 & 10.0199 \\ \text { TRN }\end{array}$

$\begin{array}{llll}1527820 & 8.9393 & 8.9863 & \text { TRN }\end{array}$

$\begin{array}{llll}1527820 & 9.6778 & 9.3273 & \text { TST }\end{array}$

$\begin{array}{llll}1527820 & 9.3665 & 9.2105 & \text { TRN }\end{array}$

$\begin{array}{llll}1527820 & 9.5867 & 9.448 & \text { TRN }\end{array}$

$\begin{array}{llll}1527820 & 9.7212 & 9.4025 & \text { TST }\end{array}$

$\begin{array}{llll}1527820 & 9.4685 & 7.572 & \text { TST }\end{array}$

$\begin{array}{llll}1527820 & 9.5143 & 9.4696 & \text { TRN }\end{array}$

$\begin{array}{llll}1527820 & 9.4089 & 9.3617 & \text { TRN }\end{array}$

$\begin{array}{llll}1527820 & 9.7212 & 9.4502 & \text { TRN }\end{array}$

$\begin{array}{llll}1527820 & 9.7696 & 9.8118 & \text { TRN }\end{array}$

$\begin{array}{llll}1527820 & 9.1135 & 7.3941 & \text { TST }\end{array}$

$\begin{array}{lll}1527820 & 10.1427 & 10.1153 \text { TRN }\end{array}$

$\begin{array}{llll}1527820 & 10.0052 & 9.7661 & \text { TRN }\end{array}$

$\begin{array}{llll}1527820 & 9.6198 & 9.729 & \text { TRN }\end{array}$

$\begin{array}{llll}1527820 & 9.6778 & 9.6963 & \text { TRN }\end{array}$

$\begin{array}{llll}1527820 & 9.6383 & 9.532 & \text { TRN }\end{array}$

$\begin{array}{llll}1527820 & 9.6576 & 9.6927 & \text { TRN }\end{array}$

$\begin{array}{llll}1527820 & 9.301 & 9.4561 & \text { TRN }\end{array}$

$\begin{array}{llll}1527820 & 9.4949 & 9.7718 & \text { TRN }\end{array}$

$\begin{array}{llll}1527820 & 9.0458 & 8.485 & \text { TST }\end{array}$

$\begin{array}{llll}1527820 & 9.5376 & 9.4857 & \text { TRN }\end{array}$

$\begin{array}{llll}1527820 & 9.4202 & 9.5087 & \text { TRN }\end{array}$ 


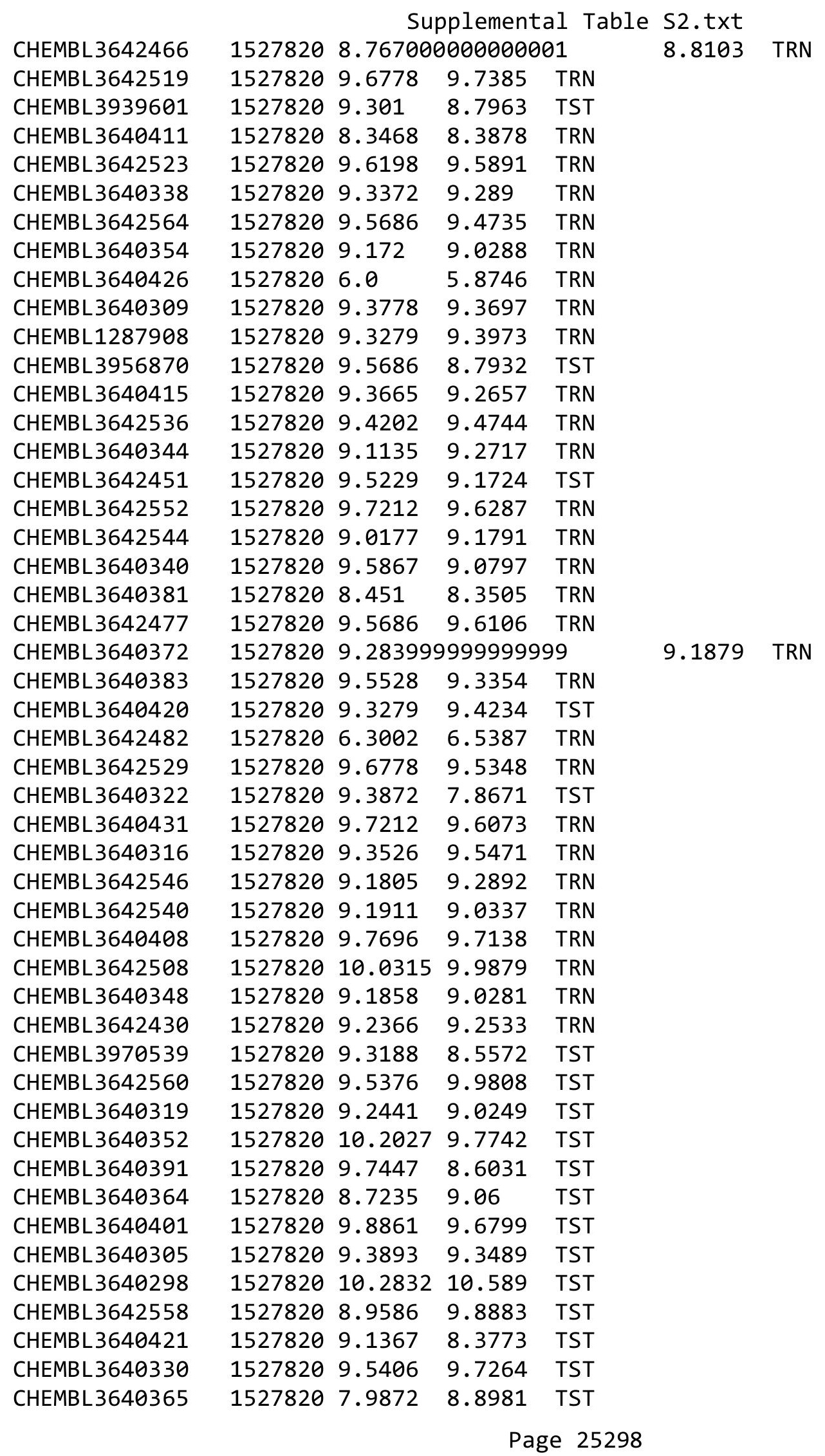


Supplemental Table S2.txt

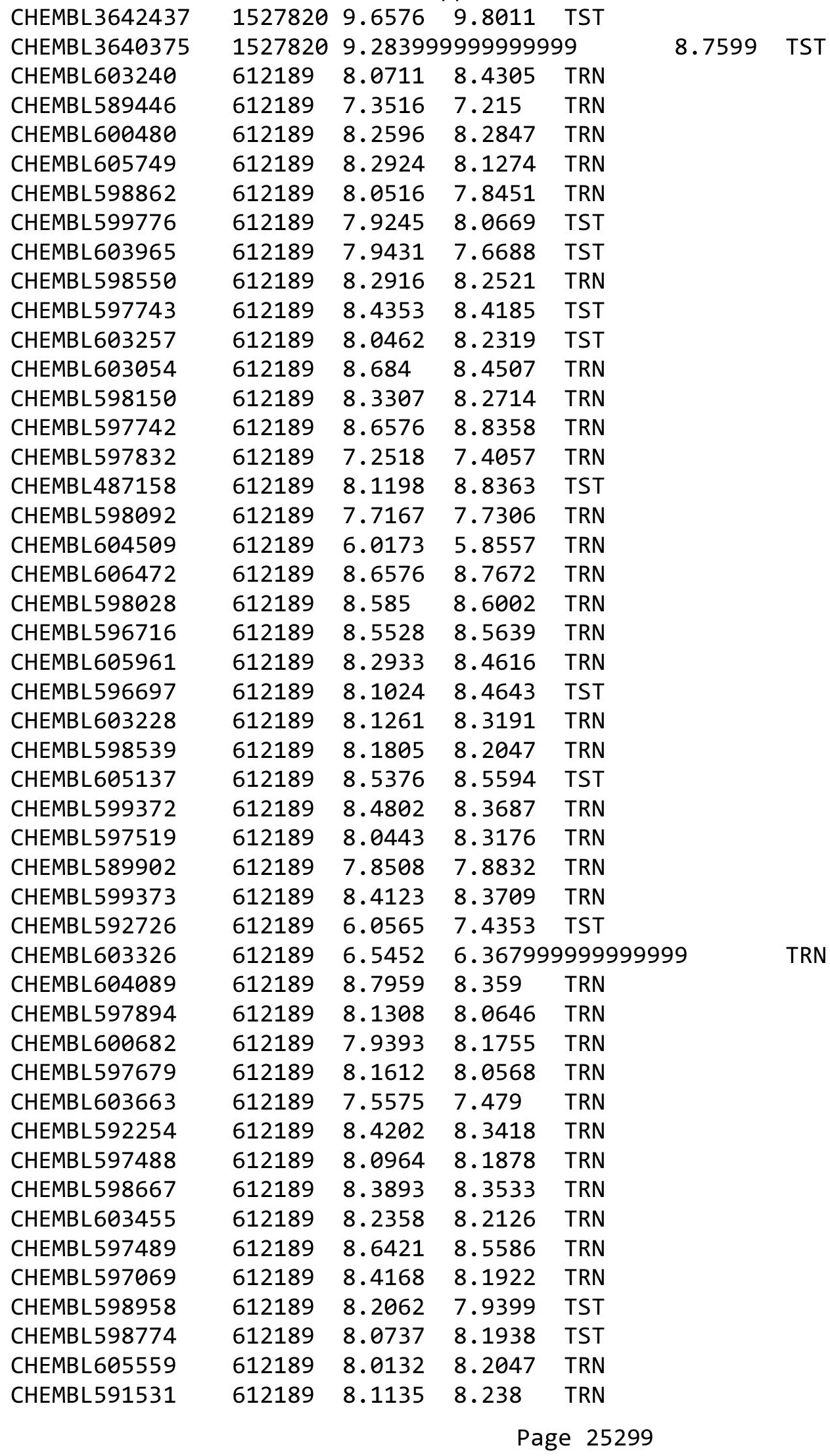




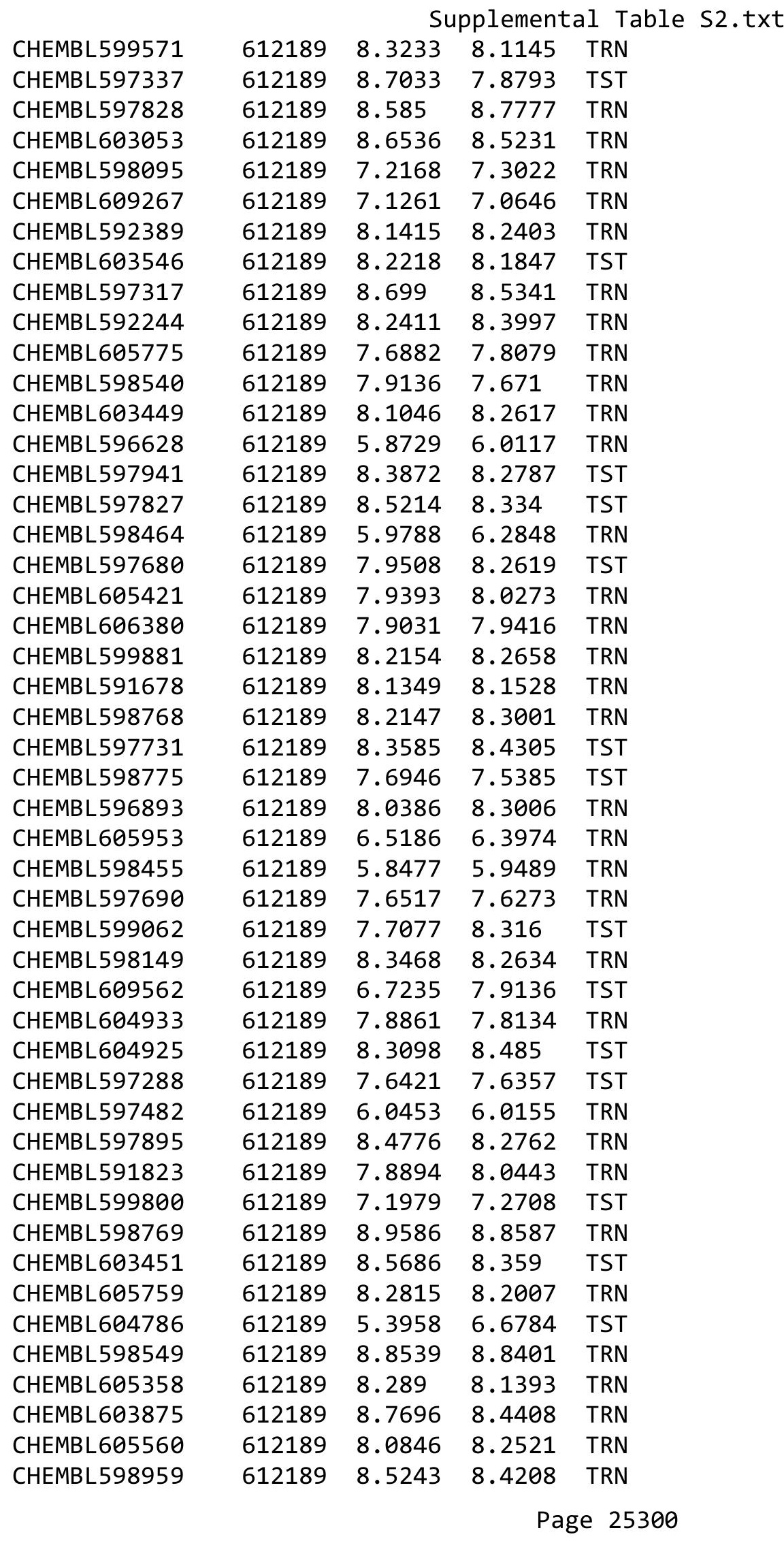




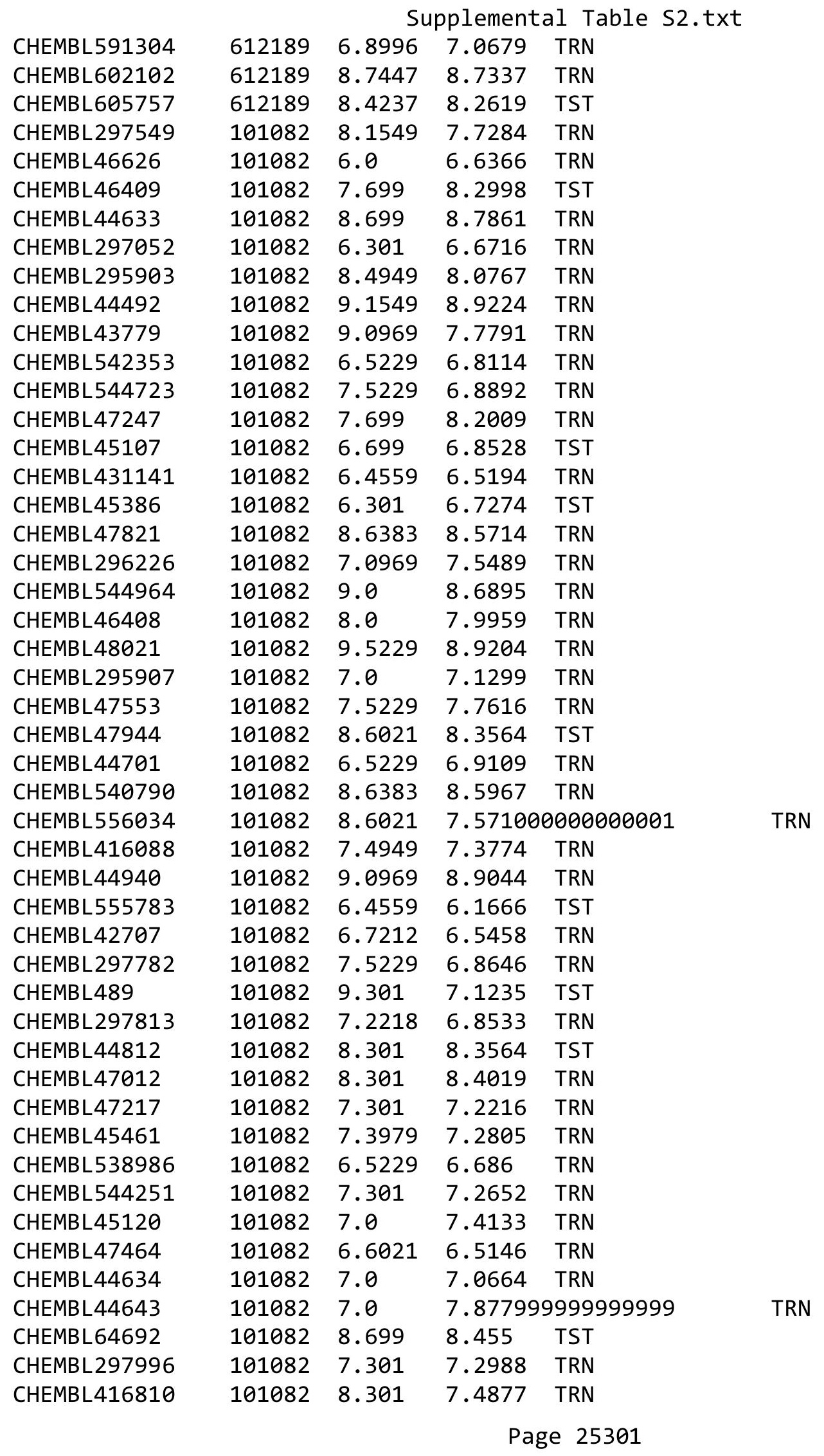




\begin{tabular}{|c|c|c|c|c|c|c|}
\hline & & \multicolumn{5}{|c|}{ Supplemental Table S2.txt } \\
\hline CHEMBL47811 & 101082 & 7.699 & 7.3314 & TRN & & \\
\hline CHEMBL47358 & 101082 & 8.5229 & 8.0517 & TRN & & \\
\hline CHEMBL44158 & 101082 & 8.699 & 8.6252 & TRN & & \\
\hline CHEMBL44792 & 101082 & 5.0 & 6.2786 & TRN & & \\
\hline CHEMBL46806 & 101082 & 8.0 & 8.7956 & TRN & & \\
\hline CHEMBL538492 & 101082 & 7.4559 & 6.8675 & TRN & & \\
\hline CHEMBL295111 & 101082 & 8.6021 & 8.8295 & TRN & & \\
\hline CHEMBL296759 & 101082 & 7.0 & 6.4788 & TST & & \\
\hline CHEMBL46622 & 101082 & 6.2218 & 6.2366 & TRN & & \\
\hline CHEMBL1160091 & 101082 & 7.0 & 6.1196 & TRN & & \\
\hline CHEMBL416268 & 101082 & 6.699 & 7.2818 & TRN & & \\
\hline CHEMBL296875 & 101082 & 8.5229 & 8.4123 & TST & & \\
\hline CHEMBL43936 & 101082 & 7.4559 & 8.4075 & TRN & & \\
\hline CHEMBL42018 & 101082 & 7.0 & 7.2052 & TRN & & \\
\hline CHEMBL297830 & 101082 & 6.6778 & 7.2549 & TST & & \\
\hline CHEMBL264302 & 101082 & 6.0 & 6.9715 & TRN & & \\
\hline CHEMBL44797 & 101082 & 7.0 & 7.8777 & TRN & & \\
\hline CHEMBL555102 & 101082 & 6.5229 & 6.1781 & TRN & & \\
\hline CHEMBL46921 & 101082 & 7.699 & 7.4174 & TRN & & \\
\hline CHEMBL296526 & 101082 & 6.301 & 6.358 & TRN & & \\
\hline CHEMBL43775 & 101082 & 9.0 & 7.8481 & TST & & \\
\hline CHEMBL48079 & 101082 & 8.699 & 8.9072 & TST & & \\
\hline CHEMBL46937 & 101082 & 8.0 & 7.5339 & TST & & \\
\hline CHEMBL544727 & 101082 & 6.0 & 8.2847 & TST & & \\
\hline CHEMBL46982 & 101082 & 6.3979 & 7.0108 & TST & & \\
\hline CHEMBL47087 & 101082 & 6.301 & 7.3975 & TST & & \\
\hline CHEMBL295540 & 101082 & 6.4881 & 7.145 & TST & & \\
\hline CHEMBL3197637 & 752423 & $5.2020 e$ & 00000000 & $\partial 1$ & 5.3182 & TRN \\
\hline CHEMBL230683 & 752423 & 4.7471 & 4.3852 & TRN & & \\
\hline CHEMBL1309059 & 752423 & 4.4498 & 4.63 & TRN & & \\
\hline CHEMBL1514790 & 752423 & 4.0462 & 4.4054 & TST & & \\
\hline CHEMBL1305658 & 752423 & 4.8447 & 4.4432 & TST & & \\
\hline CHEMBL1450086 & 752423 & 3.0 & 4.7393 & TRN & & \\
\hline CHEMBL193872 & 752423 & 4.7235 & 4.5547 & TST & & \\
\hline CHEMBL1583199 & 752423 & 6.6799 & 6.3077 & TST & & \\
\hline CHEMBL1563939 & 752423 & 5.1891 & 4.9562 & TST & & \\
\hline CHEMBL1995769 & 752423 & 4.8928 & 4.5987 & TRN & & \\
\hline CHEMBL1499792 & 752423 & 4.3757 & 4.6616 & TRN & & \\
\hline CHEMBL1351750 & 752423 & 4.556 & 4.5951 & TRN & & \\
\hline CHEMBL1522827 & 752423 & 5.8633 & 5.7827 & TRN & & \\
\hline CHEMBL1387843 & 752423 & 5.7122 & 5.2432 & TRN & & \\
\hline CHEMBL1422481 & 752423 & 4.7258 & 4.3239 & TST & & \\
\hline CHEMBL1486690 & 752423 & 4.7747 & 4.6325 & TST & & \\
\hline CHEMBL3191689 & 752423 & 5.1073 & 4.9784 & TRN & & \\
\hline CHEMBL1503359 & 752423 & 5.1643 & 5.1558 & TRN & & \\
\hline CHEMBL3196491 & 752423 & 4.9355 & 4.8723 & TRN & & \\
\hline CHEMBL1527008 & 752423 & 4.58 & 4.5047 & TRN & & \\
\hline CHEMBL1581674 & 752423 & 4.6073 & 4.1558 & TRN & & \\
\hline
\end{tabular}




\begin{tabular}{|c|c|c|c|c|}
\hline & & & oplement & al $\mathrm{T}$ \\
\hline CHEMBL3190880 & 752423 & 5.1169 & 5.1407 & TRN \\
\hline CHEMBL1428504 & 752423 & 4.585 & 4.8269 & TRN \\
\hline CHEMBL1548086 & 752423 & 4.7235 & 4.4219 & TST \\
\hline CHEMBL1370471 & 752423 & 4.9172 & 5.0309 & TRN \\
\hline CHEMBL1235966 & 752423 & 5.3665 & 4.6764 & TRN \\
\hline CHEMBL1496705 & 752423 & 4.6778 & 4.9525 & TRN \\
\hline CHEMBL1598762 & 752423 & 5.3737 & 4.965 & TRN \\
\hline CHEMBL1302199 & 752423 & 5.4815 & 4.7956 & TST \\
\hline CHEMBL1500125 & 752423 & 5.5157 & 4.9367 & TST \\
\hline CHEMBL3187596 & 752423 & 5.6655 & 5.3504 & TRN \\
\hline CHEMBL429095 & 752423 & 5.0074 & 4.9791 & TRN \\
\hline CHEMBL1334307 & 752423 & 4.8996 & 4.7264 & TRN \\
\hline CHEMBL1982305 & 752423 & 4.9586 & 5.2372 & TRN \\
\hline CHEMBL1550490 & 752423 & 5.2426 & 5.3214 & TRN \\
\hline CHEMBL1335505 & 752423 & 4.9626 & 4.5897 & TRN \\
\hline CHEMBL36654 & 752423 & 5.5638 & 4.9858 & TRN \\
\hline CHEMBL3191991 & 752423 & 5.5361 & 5.1478 & TRN \\
\hline CHEMBL1511981 & 752423 & 5.0706 & 4.6705 & TRN \\
\hline CHEMBL3144917 & 752423 & 4.3363 & 4.8475 & TRN \\
\hline CHEMBL1341841 & 752423 & 5.1349 & 5.0374 & TRN \\
\hline CHEMBL1321075 & 752423 & 4.8729 & 4.7681 & TRN \\
\hline CHEMBL1589837 & 752423 & 5.3233 & 4.8441 & TRN \\
\hline CHEMBL1484549 & 752423 & 4.8041 & 4.8282 & TRN \\
\hline CHEMBL1559948 & 752423 & 4.9872 & 4.8923 & TST \\
\hline CHEMBL1301183 & 752423 & 4.9872 & 4.9633 & TST \\
\hline CHEMBL1479680 & 752423 & 5.1319 & 4.7991 & TST \\
\hline CHEMBL1391527 & 752423 & 4.9747 & 4.694 & TRN \\
\hline CHEMBL1727035 & 752423 & 3.0 & 4.2444 & TRN \\
\hline CHEMBL1441739 & 752423 & 4.9172 & 5.1178 & TRN \\
\hline CHEMBL1347107 & 752423 & 4.6091 & 4.618 & TST \\
\hline CHEMBL1347697 & 752423 & 4.752 & 4.7417 & TST \\
\hline CHEMBL1527778 & 752423 & 4.6478 & 4.3904 & TST \\
\hline CHEMBL1308687 & 752423 & 4.9788 & 5.142 & TRN \\
\hline CHEMBL1375971 & 752423 & 4.8153 & 4.872 & TST \\
\hline CHEMBL1496231 & 752423 & 4.7959 & 4.5091 & TRN \\
\hline CHEMBL1453498 & 752423 & 4.7212 & 4.5428 & TRN \\
\hline CHEMBL1430635 & 752423 & 6.1379 & 5.584 & TRN \\
\hline CHEMBL1351074 & 752423 & 5.2233 & 4.5428 & TST \\
\hline CHEMBL1555556 & 752423 & 4.0969 & 4.8344 & TST \\
\hline CHEMBL1405449 & 752423 & 4.8013 & 4.7796 & TRN \\
\hline CHEMBL2006418 & 752423 & 4.6904 & 4.6506 & TRN \\
\hline CHEMBL3210366 & 752423 & 5.1701 & 4.817 & TRN \\
\hline CHEMBL1542453 & 752423 & 4.032 & 4.5701 & TRN \\
\hline CHEMBL601757 & 752423 & 7.5918 & 6.8541 & TST \\
\hline CHEMBL1098875 & 752423 & 4.2218 & 5.2363 & TRN \\
\hline CHEMBL1324826 & 752423 & 4.9788 & 4.8877 & TRN \\
\hline CHEMBL1459985 & 752423 & 5.4225 & 5.2021 & TRN \\
\hline CHEMBL1482438 & 752423 & 4.6968 & 4.6656 & TRN \\
\hline
\end{tabular}


Supplemental Table S2.txt

\begin{tabular}{|c|c|c|c|c|c|}
\hline CHEMBL1318103 & 752423 & 5.1481 & 4.8951 & TST & \\
\hline CHEMBL 3145280 & 752423 & 5.1273 & 5.0034 & TRN & \\
\hline CHEMBL1342248 & 752423 & 4.8477 & 4.6715 & TRN & \\
\hline CHEMBL1572498 & 752423 & 4.7212 & 4.5145 & TRN & \\
\hline CHEMBL1437516 & 752423 & 4.4935 & 4.5816 & TRN & \\
\hline CHEMBL1535375 & 752423 & 4.8827 & 4.5037 & TRN & \\
\hline CHEMBL1304024 & 752423 & 4.9281 & 4.8873 & TST & \\
\hline CHEMBL1441794 & 752423 & 5.0343 & 4.6191 & TRN & \\
\hline CHEMBL 3144906 & 752423 & 5.1681 & 5.1915 & TRN & \\
\hline CHEMBL1389406 & 752423 & 4.6556 & 4.7151 & TRN & \\
\hline CHEMBL1318757 & 752423 & 5.0205 & 4.5419 & TRN & \\
\hline CHEMBL3199870 & 752423 & 5.0119 & 4.7128 & TRN & \\
\hline CHEMBL1376540 & 752423 & 5.1129 & 5.3575 & TRN & \\
\hline CHEMBL1347600 & 752423 & 4.2027 & 4.2008 & TRN & \\
\hline CHEMBL1394969 & 752423 & 5.2573 & 5.119 & TRN & \\
\hline CHEMBL1339245 & 752423 & 4.4547 & 4.6514 & TRN & \\
\hline CHEMBL1969672 & 752423 & 4.9208 & 4.9407 & TRN & \\
\hline CHEMBL57013 & 752423 & 5.2899 & 5.2695 & TRN & \\
\hline CHEMBL1451538 & 752423 & 4.8097 & 4.4979 & TST & \\
\hline CHEMBL1432476 & 752423 & 4.5186 & 4.5201 & TST & \\
\hline CHEMBL1378634 & 752423 & 5.3072 & 5.5104 & TRN & \\
\hline CHEMBL1527341 & 752423 & 4.9626 & 4.6826 & TRN & \\
\hline CHEMBL1864348 & 752423 & 5.2644 & 6.0129 & TRN & \\
\hline CHEMBL1530147 & 752423 & 4.9469 & 4.738 & TRN & \\
\hline CHEMBL1543705 & 752423 & 4.6778 & 4.45100 & 00000000005 & TRN \\
\hline CHEMBL1492305 & 752423 & 4.3883 & 4.677 & TRN & \\
\hline CHEMBL1338004 & 752423 & 4.8041 & 5.2405 & TRN & \\
\hline CHEMBL1410383 & 752423 & 4.7773 & 4.6164 & TST & \\
\hline CHEMBL1520131 & 752423 & 4.8327 & 4.7447 & TRN & \\
\hline CHEMBL1339777 & 752423 & 4.6091 & 4.2668 & TST & \\
\hline CHEMBL1712864 & 752423 & 5.5768 & 5.2054 & TRN & \\
\hline CHEMBL1422056 & 752423 & 4.9957 & 5.0009 & TRN & \\
\hline CHEMBL1531512 & 752423 & 5.2 & 4.8111 & TRN & \\
\hline CHEMBL1463659 & 752423 & 6.8386 & 6.8323 & TST & \\
\hline CHEMBL600175 & 752423 & 4.9208 & 4.9831 & TRN & \\
\hline CHEMBL3196451 & 752423 & 6.061 & 6.296 & TRN & \\
\hline CHEMBL1700040 & 752423 & 6.5391 & 5.5255 & TRN & \\
\hline CHEMBL1491494 & 752423 & 5.1778 & 4.621 & TRN & \\
\hline CHEMBL1581013 & 752423 & 5.0386 & 4.8693 & TST & \\
\hline CHEMBL3194941 & 752423 & 5.58 & 5.1882 & TRN & \\
\hline CHEMBL3196591 & 752423 & 5.6003 & 5.9115 & TRN & \\
\hline CHEMBL1596811 & 752423 & 4.9101 & 4.6888 & TST & \\
\hline CHEMBL1475692 & 752423 & 4.8928 & 4.7409 & TRN & \\
\hline CHEMBL1347328 & 752423 & 4.567 & 4.5244 & TRN & \\
\hline CHEMBL581868 & 752423 & 4.4123 & 4.5226 & TRN & \\
\hline CHEMBL1417517 & 752423 & 4.2882 & 4.992 & TST & \\
\hline CHEMBL 3192555 & 752423 & 6.1618 & 6.3382 & TRN & \\
\hline CHEMBL81782 & 752423 & 4.2774 & 4.6574 & TST & \\
\hline
\end{tabular}




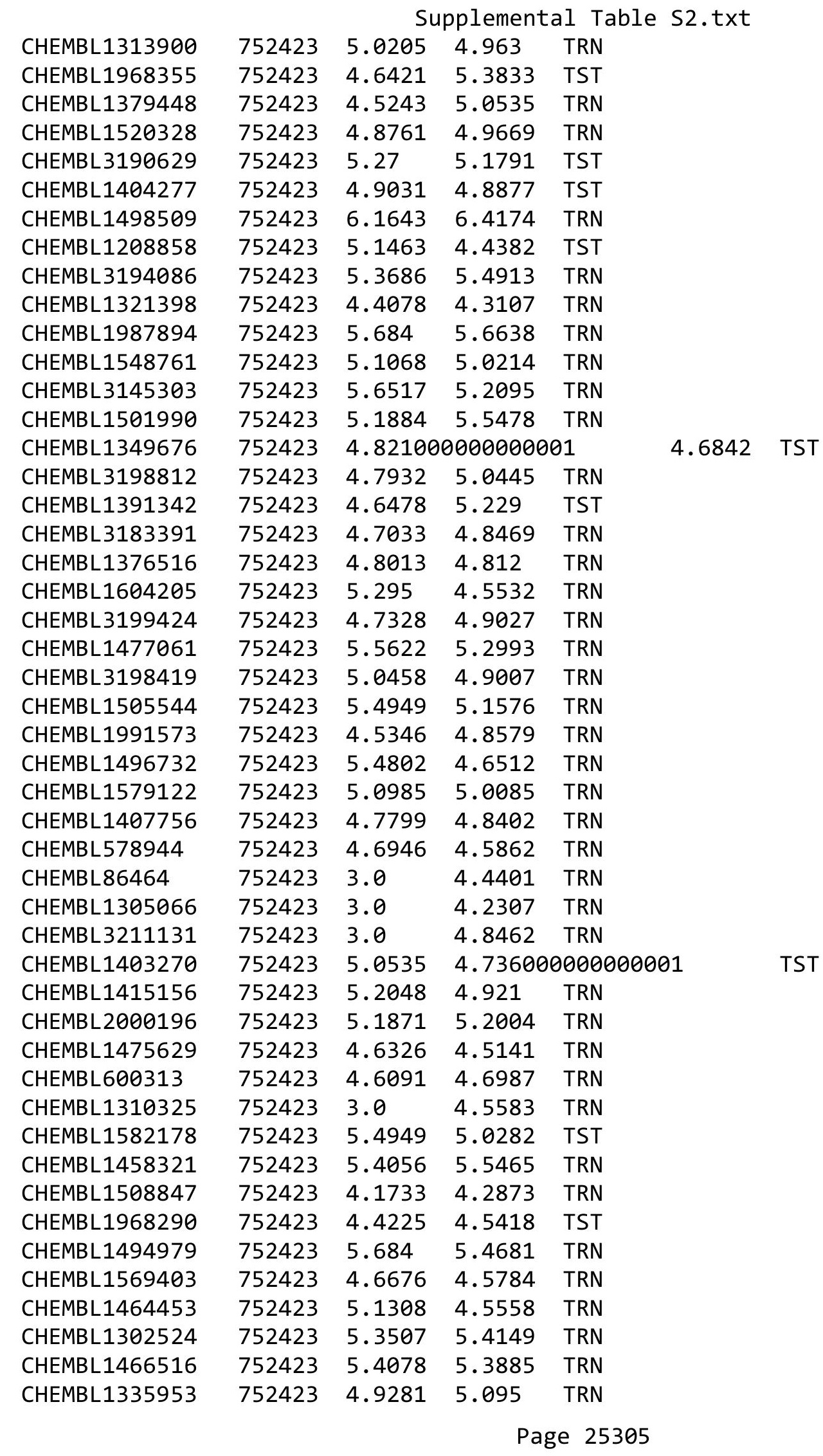




\begin{tabular}{|c|c|c|c|c|c|}
\hline \multirow[b]{2}{*}{ CHEMBL278037 } & \multicolumn{5}{|c|}{ Supplemental Table S2.txt } \\
\hline & 752423 & 4.8386 & 4.3623 & TST & \\
\hline CHEMBL1582771 & 752423 & 4.9666 & 4.697 & TRN & \\
\hline CHEMBL1437496 & 752423 & 5.032 & 4.4379 & TRN & \\
\hline CHEMBL1360539 & 752423 & 5.3726 & 5.334 & TRN & \\
\hline CHEMBL1555406 & 752423 & 3.0 & 4.0393 & TRN & \\
\hline CHEMBL1572216 & 752423 & 5.067 & 4.7587 & TST & \\
\hline CHEMBL1483235 & 752423 & 4.8125 & 4.9051 & TRN & \\
\hline CHEMBL1469091 & 752423 & 5.0017 & 4.8108 & TST & \\
\hline CHEMBL1707033 & 752423 & 5.8327 & 5.6005 & TRN & \\
\hline CHEMBL1974537 & 752423 & 3.0 & 3.9841 & TST & \\
\hline CHEMBL1438627 & 752423 & 5.0467 & 4.8323 & TRN & \\
\hline CHEMBL1481509 & 752423 & 5.2418 & 5.1011 & TST & \\
\hline CHEMBL1448592 & 752423 & 3.0 & 4.6155 & TRN & \\
\hline CHEMBL1393283 & 752423 & 4.7959 & 4.6589 & TRN & \\
\hline CHEMBL1531788 & 752423 & 5.0414 & 4.9651 & TRN & \\
\hline CHEMBL599924 & 752423 & 7.2848 & 6.8073 & TST & \\
\hline CHEMBL1458860 & 752423 & 4.9706 & 4.9005 & TST & \\
\hline CHEMBL1380131 & 752423 & 5.1959 & 5.5022 & TRN & \\
\hline CHEMBL1608143 & 752423 & 4.2557 & 4.4657 & TRN & \\
\hline CHEMBL1408398 & 752423 & 5.2226 & 4.855 & TRN & \\
\hline CHEMBL1576896 & 752423 & 5.3036 & 4.8621 & TRN & \\
\hline CHEMBL1308783 & 752423 & 5.0742 & 5.0547 & TRN & \\
\hline CHEMBL1529201 & 752423 & 4.8386 & 4.8486 & TST & \\
\hline CHEMBL1996376 & 752423 & 5.4202 & 5.5048 & TRN & \\
\hline CHEMBL1478825 & 752423 & 5.3233 & 4.7471 & TRN & \\
\hline CHEMBL1485023 & 752423 & 4.7352 & 4.6655 & TRN & \\
\hline CHEMBL1329140 & 752423 & 5.0026 & 5.0317 & TRN & \\
\hline CHEMBL1392394 & 752423 & 4.618 & 4.4224 & TRN & \\
\hline CHEMBL3197208 & 752423 & 5.0031 & 5.2178 & TRN & \\
\hline CHEMBL1544377 & 752423 & 5.0762 & 4.2728 & TRN & \\
\hline CHEMBL1362933 & 752423 & 4.6696 & 4.6718 & TST & \\
\hline CHEMBL1600763 & 752423 & 4.9245 & 4.91 & TST & \\
\hline CHEMBL1969046 & 752423 & 5.38200 & $00000000 t$ & 5.3058 & TRN \\
\hline CHEMBL1464975 & 752423 & 4.8125 & $4.66100 t$ & 00000000005 & TRN \\
\hline CHEMBL584626 & 752423 & 5.4828 & 5.2741 & TRN & \\
\hline CHEMBL1449923 & 752423 & 5.52 & 4.5445 & TRN & \\
\hline CHEMBL3192178 & 752423 & 4.6308 & 4.4235 & TRN & \\
\hline CHEMBL3196108 & 752423 & 5.4078 & 5.5677 & TRN & \\
\hline CHEMBL1509377 & 752423 & 4.0079 & 4.4896 & TRN & \\
\hline CHEMBL1331573 & 752423 & 4.76699 & 99999999 & 4.4367 & TRN \\
\hline CHEMBL270362 & 752423 & 4.8794 & 4.5277 & TST & \\
\hline CHEMBL1454614 & 752423 & 5.8153 & 5.8269 & TRN & \\
\hline CHEMBL1596475 & 752423 & 5.0232 & 5.0393 & TRN & \\
\hline CHEMBL3144856 & 752423 & 4.71899 & 99999999 & 4.8461 & TRN \\
\hline CHEMBL 3144962 & 752423 & 4.7905 & 4.6609 & TRN & \\
\hline CHEMBL1348993 & 752423 & 5.3197 & 4.9891 & TRN & \\
\hline CHEMBL602990 & 752423 & 4.8761 & 4.8565 & TRN & \\
\hline CHEMBL3192701 & 752423 & 5.3143 & 4.7801 & TRN & \\
\hline
\end{tabular}

Page 25306 
Supplemental Table S2.txt

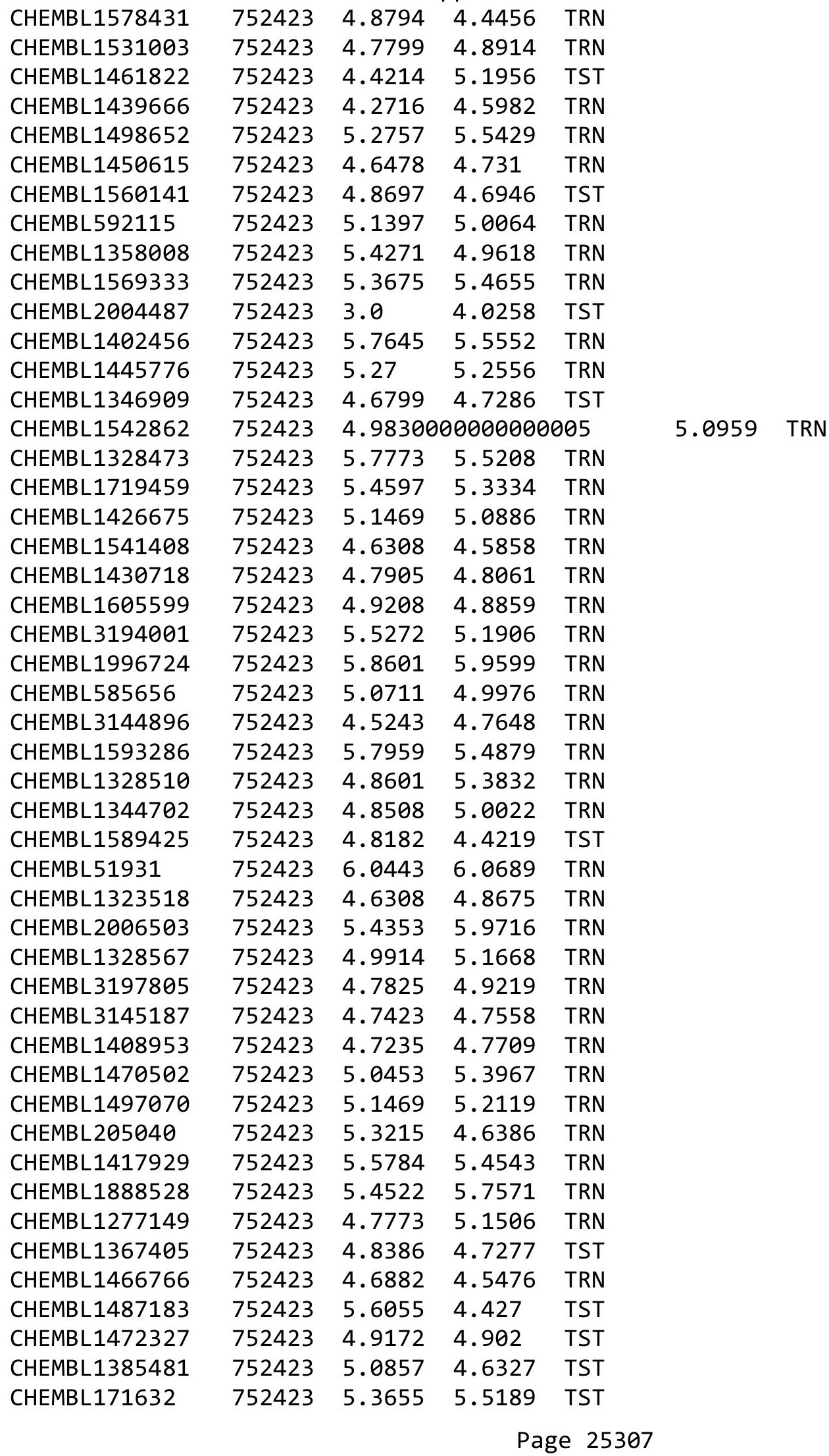




\begin{tabular}{|c|c|c|c|c|c|}
\hline & & \multicolumn{4}{|c|}{ Supplemental Table S2.txt } \\
\hline CHEMBL1526391 & 752423 & 5.1481 & 4.8597 & TRN & \\
\hline CHEMBL3145304 & 752423 & 5.1325 & 4.8427 & TRN & \\
\hline CHEMBL1299200 & 752423 & 4.7852 & 4.6299 & TST & \\
\hline CHEMBL3193347 & 752423 & 5.1681 & 5.3649 & TRN & \\
\hline CHEMBL1518827 & 752423 & 5.153 & 4.5317 & TRN & \\
\hline CHEMBL1545927 & 752423 & 3.0 & 4.4923 & TRN & \\
\hline CHEMBL3191855 & 752423 & 6.0283 & 6.1093 & TRN & \\
\hline CHEMBL1343853 & 752423 & 3.0 & 4.2445 & TRN & \\
\hline CHEMBL3195749 & 752423 & 5.58 & 5.9028 & TRN & \\
\hline CHEMBL1585740 & 752423 & 4.9393 & 5.0857 & TRN & \\
\hline CHEMBL175434 & 752423 & 5.2708 & 5.6777 & TRN & \\
\hline CHEMBL1995152 & 752423 & 4.4609 & 4.1278 & TRN & \\
\hline CHEMBL1382884 & 752423 & 3.0 & 4.6286 & TRN & \\
\hline CHEMBL1524916 & 752423 & 4.752 & 4.6608 & TRN & \\
\hline CHEMBL1999630 & 752423 & 5.5114 & 5.6927 & TRN & \\
\hline CHEMBL477139 & 752423 & 4.9245 & 4.4756 & TRN & \\
\hline CHEMBL3195410 & 752423 & 4.9872 & 5.1469 & TRN & \\
\hline CHEMBL1558928 & 752423 & 4.9393 & 4.9345 & TRN & \\
\hline CHEMBL1996133 & 752423 & 3.0 & 3.958 & TST & \\
\hline CHEMBL1501505 & 752423 & 4.9101 & 4.8593 & TRN & \\
\hline CHEMBL3199411 & 752423 & 5.0996 & 4.8914 & TRN & \\
\hline CHEMBL1504738 & 752423 & 4.7773 & 4.4861 & TRN & \\
\hline CHEMBL1507051 & 752423 & 4.7212 & 4.7369 & TRN & \\
\hline CHEMBL1308668 & 752423 & 5.266 & 4.5334 & TRN & \\
\hline CHEMBL417727 & 752423 & 6.1918 & 6.03600 & 00000000005 & TRN \\
\hline CHEMBL1313554 & 752423 & 5.1561 & 4.7064 & TRN & \\
\hline CHEMBL 2003651 & 752423 & 5.3696 & 5.4536 & TRN & \\
\hline CHEMBL1998302 & 752423 & 5.5157 & 5.4674 & TRN & \\
\hline CHEMBL1307714 & 752423 & 4.8894 & 4.4356 & TRN & \\
\hline CHEMBL3197601 & 752423 & 4.7122 & 4.9451 & TRN & \\
\hline CHEMBL1413806 & 752423 & 5.0009 & 5.3748 & TRN & \\
\hline CHEMBL1330787 & 752423 & 5.1965 & 4.7368 & TRN & \\
\hline CHEMBL1542809 & 752423 & 4.7471 & 4.9015 & TRN & \\
\hline CHEMBL1520017 & 752423 & 5.1427 & 4.8699 & TRN & \\
\hline CHEMBL299853 & 752423 & 5.4522 & 5.6877 & TRN & \\
\hline CHEMBL1477200 & 752423 & 4.52 & 5.3433 & TRN & \\
\hline CHEMBL3197091 & 752423 & 5.3507 & 5.2471 & TRN & \\
\hline CHEMBL1902079 & 752423 & 4.2373 & 5.1964 & TRN & \\
\hline CHEMBL1443251 & 752423 & 4.7471 & 4.6597 & TRN & \\
\hline CHEMBL1463829 & 752423 & 5.21399 & 99999999 & 4.6705 & TRN \\
\hline CHEMBL1576310 & 752423 & 4.6402 & 4.7485 & TRN & \\
\hline CHEMBL590691 & 752423 & 4.8962 & 4.7713 & TRN & \\
\hline CHEMBL1440235 & 752423 & 4.7905 & 4.5038 & TRN & \\
\hline CHEMBL1209369 & 752423 & 5.1427 & 4.7659 & TRN & \\
\hline CHEMBL1497838 & 752423 & 5.0052 & 4.8481 & TST & \\
\hline CHEMBL1277060 & 752423 & 4.9245 & 4.7421 & TRN & \\
\hline CHEMBL1346883 & 752423 & 4.9914 & 4.7531 & TRN & \\
\hline CHEMBL1575869 & 752423 & 4.9208 & 4.7766 & TRN & \\
\hline
\end{tabular}


Supplemental Table S2.txt

\begin{tabular}{|c|c|c|c|c|c|c|}
\hline CHEMBL1436778 & 752423 & 5.2226 & 4.7063 & TRN & & \\
\hline CHEMBL1331912 & 752423 & 5.7905 & 5.3933 & TRN & & \\
\hline CHEMBL 3182716 & 752423 & 4.6946 & 4.8488 & TRN & & \\
\hline CHEMBL 2000342 & 752423 & \multicolumn{3}{|c|}{4.9830000000000005} & 4.9058 & TST \\
\hline CHEMBL1898479 & 752423 & 4.9031 & 5.7596 & TRN & & \\
\hline CHEMBL1395907 & 752423 & 5.8356 & 5.7466 & TRN & & \\
\hline CHEMBL1573910 & 752423 & 5.0155 & 4.8798 & TRN & & \\
\hline CHEMBL1345824 & 752423 & 4.5607 & 4.7388 & TRN & & \\
\hline CHEMBL1415290 & 752423 & 4.4776 & 4.5359 & TST & & \\
\hline CHEMBL1444349 & 752423 & 4.3536 & 4.8096 & TST & & \\
\hline CHEMBL1400929 & 752423 & 4.6799 & 4.6378 & TRN & & \\
\hline CHEMBL1379918 & 752423 & 5.1605 & 4.8882 & TRN & & \\
\hline CHEMBL1719244 & 752423 & 5.9706 & 5.6733 & TRN & & \\
\hline CHEMBL1427763 & 752423 & 3.0 & 4.5492 & TRN & & \\
\hline CHEMBL1562466 & 752423 & 4.9355 & 5.066 & TRN & & \\
\hline CHEMBL1384702 & 752423 & 5.1046 & 5.221 & TRN & & \\
\hline CHEMBL1979756 & 752423 & 5.0386 & 4.644 & TST & & \\
\hline CHEMBL1303970 & 752423 & 4.9393 & 5.088 & TRN & & \\
\hline CHEMBL527336 & 752423 & 5.4283 & 5.2379 & TRN & & \\
\hline CHEMBL1526855 & 752423 & 5.3363 & 5.3852 & TRN & & \\
\hline CHEMBL1403154 & 752423 & \multicolumn{3}{|c|}{ 5.218999999999999 } & 5.1456 & TRN \\
\hline CHEMBL1334390 & 752423 & 4.8153 & 4.5201 & TST & & \\
\hline CHEMBL1534533 & 752423 & 4.9666 & 5.0276 & TRN & & \\
\hline CHEMBL1335869 & 752423 & 4.6326 & 4.8362 & TRN & & \\
\hline CHEMBL1450505 & 752423 & 4.6144 & 4.6183 & TST & & \\
\hline CHEMBL1226 & 752423 & 3.0 & 4.0271 & TRN & & \\
\hline CHEMBL1509380 & 752423 & 4.6536 & 4.7786 & TRN & & \\
\hline CHEMBL1600855 & 752423 & 3.0 & 4.7057 & TST & & \\
\hline CHEMBL1510959 & 752423 & 5.5361 & 5.2082 & TRN & & \\
\hline CHEMBL1469246 & 752423 & 4.7423 & 4.6222 & TRN & & \\
\hline CHEMBL1572924 & 752423 & 4.9957 & 4.878 & TRN & & \\
\hline CHEMBL1417815 & 752423 & 5.2233 & 4.5965 & TRN & & \\
\hline CHEMBL1580572 & 752423 & 5.0237 & 4.6861 & TRN & & \\
\hline CHEMBL1392911 & 752423 & 5.1791 & 4.8549 & TRN & & \\
\hline CHEMBL1465938 & 752423 & 4.7645 & 4.4308 & TRN & & \\
\hline CHEMBL1522941 & 752423 & 5.8356 & 5.4691 & TRN & & \\
\hline CHEMBL1583566 & 752423 & 3.0 & 4.1207 & TRN & & \\
\hline CHEMBL1577193 & 752423 & 5.5302 & 5.3261 & TRN & & \\
\hline CHEMBL1501694 & 752423 & 5.104 & 4.8112 & TST & & \\
\hline CHEMBL1520694 & 752423 & 5.0246 & 5.0226 & TRN & & \\
\hline CHEMBL586031 & 752423 & 5.4935 & 5.3052 & TRN & & \\
\hline CHEMBL1605867 & 752423 & 4.8601 & 5.0782 & TRN & & \\
\hline CHEMBL1427539 & 752423 & 4.5272 & 4.7306 & TRN & & \\
\hline CHEMBL1730189 & 752423 & 3.0 & 3.7955 & TRN & & \\
\hline CHEMBL 3193011 & 752423 & 5.9355 & 5.5558 & TRN & & \\
\hline CHEMBL1421377 & 752423 & 5.0814 & 4.7322 & TST & & \\
\hline CHEMBL582722 & 752423 & 4.6144 & 4.7555 & TRN & & \\
\hline CHEMBL 3190539 & 752423 & 5.4962 & 5.0667 & TRN & & \\
\hline
\end{tabular}

Page 25309 
Supplemental Table S2.txt

\begin{tabular}{|c|c|c|c|c|}
\hline CHEMBL1331178 & 752423 & 4.2676 & 4.6169 & TRN \\
\hline CHEMBL1583807 & 752423 & 4.0241 & 4.1419 & TRN \\
\hline CHEMBL1524109 & 752423 & 5.1925 & 4.6733 & TRN \\
\hline CHEMBL1459778 & 752423 & 4.1681 & 4.5285 & TRN \\
\hline CHEMBL1370841 & 752423 & 4.8416 & 4.664 & TST \\
\hline CHEMBL1611833 & 752423 & 5.295 & 5.3003 & TRN \\
\hline CHEMBL1493281 & 752423 & 5.3536 & 5.0541 & TRN \\
\hline CHEMBL1434767 & 752423 & 5.6536 & 5.7332 & TRN \\
\hline CHEMBL1450648 & 752423 & 4.8539 & 4.4194 & TRN \\
\hline CHEMBL1379048 & 752423 & 5.0991 & 4.8471 & TST \\
\hline CHEMBL1605094 & 752423 & 5.032 & 4.3603 & TRN \\
\hline CHEMBL1976638 & 752423 & 4.9914 & 4.7217 & TST \\
\hline CHEMBL3192939 & 752423 & 5.4012 & 4.5212 & TRN \\
\hline CHEMBL1404493 & 752423 & 3.0 & 4.3235 & TST \\
\hline CHEMBL1541973 & 752423 & 5.2161 & 5.2618 & TRN \\
\hline CHEMBL1407514 & 752423 & 6.466 & 5.7393 & TRN \\
\hline CHEMBL1599965 & 752423 & 4.752 & 4.9482 & TRN \\
\hline CHEMBL1490793 & 752423 & 5.9547 & 5.1676 & TRN \\
\hline CHEMBL1432707 & 752423 & 5.8416 & 5.6729 & TRN \\
\hline CHEMBL339561 & 752423 & 5.2013 & 4.7757 & TRN \\
\hline CHEMBL1872457 & 752423 & 4.9706 & 5.6788 & TRN \\
\hline CHEMBL405110 & 752423 & 4.7696 & 4.6955 & TST \\
\hline CHEMBL3198784 & 752423 & 4.5331 & 4.7755 & TRN \\
\hline CHEMBL1409219 & 752423 & 3.0 & 4.1093 & TRN \\
\hline CHEMBL1406738 & 752423 & 3.0 & 4.1937 & TRN \\
\hline CHEMBL1472773 & 752423 & 5.1029 & 4.6452 & TST \\
\hline CHEMBL1369304 & 752423 & 5.2581 & 4.9143 & TRN \\
\hline CHEMBL1608044 & 752423 & 4.9788 & 4.6511 & TRN \\
\hline CHEMBL1548822 & 752423 & 4.757 & 4.2845 & TRN \\
\hline CHEMBL1537872 & 752423 & 5.1238 & 4.9134 & TRN \\
\hline CHEMBL600336 & 752423 & 3.0 & 4.8266 & TST \\
\hline CHEMBL1371869 & 752423 & 4.6615 & 4.7069 & TST \\
\hline CHEMBL1340633 & 752423 & 4.7399 & 4.7572 & TST \\
\hline CHEMBL1361173 & 752423 & 5.2993 & 4.7923 & TST \\
\hline CHEMBL1409039 & 752423 & 5.4271 & 5.641 & TST \\
\hline CHEMBL1277150 & 752423 & 4.7375 & 4.9829 & TST \\
\hline CHEMBL1371864 & 752423 & 4.8996 & 4.8358 & TST \\
\hline CHEMBL1328578 & 752423 & 4.2907 & 4.6317 & TST \\
\hline CHEMBL1584037 & 752423 & 4.7905 & 5.0026 & TST \\
\hline CHEMBL1531169 & 752423 & 4.1267 & 4.3534 & TST \\
\hline CHEMBL1535503 & 752423 & 5.6696 & 5.0666 & TST \\
\hline CHEMBL1995720 & 752423 & 3.0 & 4.0075 & TST \\
\hline CHEMBL3189714 & 752423 & 6.2612 & 6.4218 & TST \\
\hline CHEMBL3194415 & 752423 & 4.9957 & 4.61100 & 0000000001 \\
\hline CHEMBL1703515 & 752423 & 4.9431 & 4.8709 & TST \\
\hline CHEMBL1502394 & 752423 & 4.7033 & 4.9715 & TST \\
\hline CHEMBL567967 & 752423 & 5.1965 & 5.1572 & TST \\
\hline CHEMBL 2138014 & 752423 & 4.9318 & 4.6784 & TST \\
\hline
\end{tabular}




\begin{tabular}{|c|c|c|c|c|c|}
\hline & & \multicolumn{4}{|c|}{ Supplemental Table S2.txt } \\
\hline CHEMBL1427637 & 752423 & 4.9626 & 4.8568 & TST & \\
\hline CHEMBL3194328 & 752423 & 3.0 & 4.6313 & TST & \\
\hline CHEMBL578905 & 752423 & 5.3883 & 5.346 & TST & \\
\hline CHEMBL187266 & 752423 & 4.9508 & 5.2028 & TST & \\
\hline CHEMBL1989853 & 752423 & 5.5735 & 5.4087 & TST & \\
\hline CHEMBL1967479 & 752423 & 4.7496 & 4.4515 & TST & \\
\hline CHEMBL228698 & 440670 & 5.3468 & 4.4539 & TRN & \\
\hline CHEMBL396776 & 440670 & 3.0 & 3.2093 & TRN & \\
\hline CHEMBL228879 & 440670 & 4.4572 & 4.0209 & TRN & \\
\hline CHEMBL228930 & 440670 & 3.983 & 4.3674 & TRN & \\
\hline CHEMBL388072 & 440670 & 3.0 & 2.71199 & و9999999997 & TRN \\
\hline CHEMBL228476 & 440670 & 3.0 & 2.9486 & TRN & \\
\hline CHEMBL228609 & 440670 & 3.0 & 2.8022 & TST & \\
\hline CHEMBL390522 & 440670 & 3.0 & 3.04699 & 99999999997 & TRN \\
\hline CHEMBL228922 & 440670 & 3.0 & 2.9531 & TRN & \\
\hline CHEMBL228557 & 440670 & 3.0 & 2.8297 & TST & \\
\hline CHEMBL438679 & 440670 & 3.0 & 2.9375 & TRN & \\
\hline CHEMBL243751 & 440670 & 4.9136 & 4.8894 & TRN & \\
\hline CHEMBL228975 & 440670 & 3.0 & 2.6572 & TST & \\
\hline CHEMBL228425 & 440670 & 3.0 & 2.6464 & TRN & \\
\hline CHEMBL389445 & 440670 & 3.0 & 3.0615 & TRN & \\
\hline CHEMBL228974 & 440670 & 3.0 & 2.8549 & TRN & \\
\hline CHEMBL228532 & 440670 & 4.9788 & 4.9846 & TRN & \\
\hline CHEMBL229079 & 440670 & 5.0458 & 5.1697 & TRN & \\
\hline CHEMBL442226 & 440670 & 3.0 & 2.62 & TST & \\
\hline CHEMBL228714 & 440670 & 3.0 & 2.9663 & TRN & \\
\hline CHEMBL228871 & 440670 & 3.0 & 2.9987 & TRN & \\
\hline CHEMBL228982 & 440670 & 3.0 & 3.1506 & TRN & \\
\hline CHEMBL242659 & 440670 & 3.0 & 3.3532 & TRN & \\
\hline CHEMBL228765 & 440670 & 3.0 & 3.0232 & TRN & \\
\hline CHEMBL228923 & 440670 & 3.0 & 2.7635 & TRN & \\
\hline CHEMBL228589 & 440670 & 3.0 & 2.9887 & TRN & \\
\hline CHEMBL448429 & 440670 & 3.0 & 2.5981 & TRN & \\
\hline CHEMBL427465 & 440670 & 3.0 & 2.9632 & TST & \\
\hline CHEMBL228446 & 440670 & 3.0 & 4.3446 & TRN & \\
\hline CHEMBL397225 & 440670 & 3.0 & 2.9211 & TRN & \\
\hline CHEMBL228820 & 440670 & 3.0 & 3.7304 & TRN & \\
\hline CHEMBL228713 & 440670 & 3.0 & 3.177 & TRN & \\
\hline CHEMBL397019 & 440670 & 3.0 & 3.4432 & TRN & \\
\hline CHEMBL243533 & 440670 & 3.0 & 3.1052 & TRN & \\
\hline CHEMBL387903 & 440670 & 4.7878 & 4.4359 & TRN & \\
\hline CHEMBL228819 & 440670 & 3.0 & 2.898 & TRN & \\
\hline CHEMBL228590 & 440670 & 3.0 & 3.4168 & TRN & \\
\hline CHEMBL228662 & 440670 & 3.0 & 2.9585 & TRN & \\
\hline CHEMBL228906 & 440670 & 3.0 & 2.7319 & TST & \\
\hline CHEMBL228531 & 440670 & 3.0 & 3.0278 & TST & \\
\hline CHEMBL387902 & 440670 & 3.0 & 3.8535 & TST & \\
\hline CHEMBL389689 & 440670 & 5.3468 & 4.9635 & TRN & \\
\hline
\end{tabular}




\begin{tabular}{|c|c|c|c|c|c|}
\hline \multicolumn{6}{|c|}{ splemental lable s2.tx } \\
\hline CHEMBL228905 & 440670 & 3.0 & 3.0654 & TRN & \\
\hline CHEMBL 268533 & 440670 & 3.0 & 2.8064 & TRN & \\
\hline CHEMBL 228448 & 440670 & 3.0 & 2.9181 & TRN & \\
\hline CHEMBL 228973 & 440670 & 3.0 & 2.9227 & TRN & \\
\hline CHEMBL 390523 & 440670 & 5.6383 & 4.8502 & TRN & \\
\hline CHEMBL 228931 & 440670 & 3.0 & 3.9884 & TRN & \\
\hline CHEMBL 228533 & 440670 & 3.0 & 3.0287 & TRN & \\
\hline CHEMBL 228873 & 440670 & 4.8182 & 4.2419 & TRN & \\
\hline CHEMBL 228475 & 440670 & 3.0 & 2.8977 & TST & \\
\hline CHEMBL 228640 & 440670 & 3.0 & 2.9528 & TST & \\
\hline CHEMBL 228556 & 440670 & 3.0 & 2.7746 & TST & \\
\hline CHEMBL268532 & 440670 & 3.0 & 2.86 & TST & \\
\hline CHEMBL 228921 & 440670 & 3.0 & 2.93300 & 00000000003 & TRN \\
\hline CHEMBL 390744 & 440670 & 3.0 & 3.1112 & TST & \\
\hline CHEMBL229026 & 440670 & 4.5482 & 4.4998 & TRN & \\
\hline CHEMBL 228868 & 440670 & 3.0 & 3.1927 & TST & \\
\hline CHEMBL426909 & 440670 & 3.0 & 3.5426 & TRN & \\
\hline CHEMBL 228869 & 440670 & 3.0 & 2.9441 & TST & \\
\hline CHEMBL 228877 & 440670 & 3.0 & 3.0576 & TRN & \\
\hline CHEMBL 229028 & 440670 & 3.0 & 2.9685 & TRN & \\
\hline CHEMBL 242871 & 440670 & 3.0 & 3.0081 & TRN & \\
\hline CHEMBL 229027 & 440670 & 3.0 & 2.9489 & TST & \\
\hline CHEMBL 229080 & 440670 & 4.05699 & & 3.597 & TRN \\
\hline CHEMBL 389471 & 440670 & 5.4949 & 4.1317 & TST & \\
\hline CHEMBL556438 & 583012 & 7.0 & 6.9739 & TRN & \\
\hline CHEMBL539652 & 583012 & 6.4 & 6.4095 & TRN & \\
\hline CHEMBL541969 & 583012 & 6.4 & 6.3897 & TRN & \\
\hline CHEMBL539212 & 583012 & 6.3 & 6.6169 & TST & \\
\hline CHEMBL556235 & 583012 & 7.9 & 7.9002 & TRN & \\
\hline CHEMBL551535 & 583012 & 7.0 & 6.9139 & TRN & \\
\hline CHEMBL551614 & 583012 & 6.8 & 6.82299 & 99999999995 & TRN \\
\hline CHEMBL550064 & 583012 & 7.4 & 8.3626 & TST & \\
\hline CHEMBL552796 & 583012 & 1.0 & 8.2571 & TST & \\
\hline CHEMBL61130 & 583012 & 6.7 & 7.71299 & 9999999999 & TST \\
\hline CHEMBL551820 & 583012 & 7.8 & 7.6572 & TST & \\
\hline CHEMBL560940 & 583012 & 7.8 & 7.4375 & TST & \\
\hline CHEMBL553658 & 583012 & 6.5 & 6.8037 & TST & \\
\hline CHEMBL550459 & 583012 & 8.1 & 7.5615 & TST & \\
\hline CHEMBL551743 & 583012 & 5.6 & 6.7656 & TST & \\
\hline CHEMBL570780 & 583012 & 5.2 & 6.194 & TST & \\
\hline CHEMBL558757 & 583012 & 1.0 & 6.38200 & 0000000001 & TST \\
\hline CHEMBL553688 & 583012 & 1.0 & 6.9508 & TST & \\
\hline CHEMBL570074 & 583012 & 7.1 & 7.2209 & TRN & \\
\hline CHEMBL557053 & 583012 & 7.6 & 7.48799 & 99999999995 & TRN \\
\hline CHEMBL551940 & 583012 & 7.4 & 7.4004 & TRN & \\
\hline CHEMBL552218 & 583012 & 7.5 & 7.5264 & TRN & \\
\hline CHEMBL551941 & 583012 & 7.4 & 7.4498 & TRN & \\
\hline CHEMBL562400 & 583012 & 7.4 & 7.371 & TRN & \\
\hline
\end{tabular}




\begin{tabular}{|c|c|c|c|c|c|}
\hline & & & & & \\
\hline CHEMBL562477 & 583012 & 7.2 & 7.2393 & TRN & \\
\hline CHEMBL552693 & 583012 & 7.8 & 7.7809 & TRN & \\
\hline CHEMBL555447 & 583012 & 7.8 & 7.7809 & TRN & \\
\hline CHEMBL552420 & 583012 & 7.5 & 7.5151 & TRN & \\
\hline CHEMBL563261 & 583012 & 7.6 & 7.7129 & TRN & \\
\hline CHEMBL560876 & 583012 & 7.8 & 7.7129 & TRN & \\
\hline CHEMBL563276 & 583012 & 6.2 & 6.1876 & TRN & \\
\hline CHEMBL557867 & 583012 & 8.3 & 8.411 & TRN & \\
\hline CHEMBL559548 & 583012 & 8.5 & 8.411 & TRN & \\
\hline CHEMBL563799 & 583012 & 7.1 & 7.0959 & TRN & \\
\hline CHEMBL559317 & 583012 & 7.6 & 7.4344 & TRN & \\
\hline CHEMBL556279 & 583012 & 7.3 & 7.4344 & TRN & \\
\hline CHEMBL560597 & 583012 & 5.8 & 5.9348 & TRN & \\
\hline CHEMBL551678 & 583012 & 6.4 & 6.1414 & TRN & \\
\hline CHEMBL549998 & 583012 & 6.0 & 6.1414 & TRN & \\
\hline CHEMBL552075 & 583012 & 8.2 & 8.163 & TRN & \\
\hline CHEMBL559746 & 583012 & 7.9 & 7.8113 & TRN & \\
\hline CHEMBL550122 & 583012 & 7.7 & 7.8113 & TRN & \\
\hline CHEMBL563445 & 583012 & 7.0 & 6.8851 & TRN & \\
\hline CHEMBL562902 & 583012 & 8.3 & 8.4073 & TRN & \\
\hline CHEMBL562636 & 583012 & 8.5 & 8.4073 & TST & \\
\hline CHEMBL558259 & 583012 & 8.0 & 8.0247 & TRN & \\
\hline CHEMBL558719 & 583012 & 9.0 & 8.9216 & TRN & \\
\hline CHEMBL538706 & 583012 & 8.9 & 8.9216 & TRN & \\
\hline CHEMBL550530 & 583012 & 7.7 & 6.874 & TST & \\
\hline CHEMBL558924 & 583012 & 7.9 & 7.9103 & TST & \\
\hline CHEMBL558261 & 583012 & 7.4 & 7.9103 & TST & \\
\hline CHEMBL565146 & 583012 & 8.2 & 8.1994 & TRN & \\
\hline CHEMBL553685 & 583012 & 8.9 & 8.6757 & TRN & \\
\hline CHEMBL556326 & 583012 & 8.5 & 8.6757 & TRN & \\
\hline CHEMBL556595 & 583012 & 7.8 & 8.8566 & TST & \\
\hline CHEMBL561278 & 583012 & 8.9 & 9.7464 & TST & \\
\hline CHEMBL552484 & 583012 & 9.1 & 9.7464 & TST & \\
\hline CHEMBL541223 & 583012 & 8.9 & 8.9583 & TRN & \\
\hline CHEMBL558163 & 583012 & 9.2 & 9.0797 & TRN & \\
\hline CHEMBL555210 & 583012 & 9.0 & 9.0797 & TRN & \\
\hline CHEMBL558855 & 583012 & 8.4 & 8.7313 & TRN & \\
\hline CHEMBL539713 & 583012 & 9.4 & 9.0583 & TRN & \\
\hline CHEMBL540980 & 583012 & 8.6 & 8.5867 & TRN & \\
\hline CHEMBL538956 & 583012 & 8.5 & 8.5721 & TRN & \\
\hline CHEMBL549449 & 583012 & 8.8 & 8.7416 & TRN & \\
\hline CHEMBL555693 & 583012 & 8.6 & 8.6757 & TRN & \\
\hline CHEMBL549650 & 583012 & 8.6 & 8.4911 & TRN & \\
\hline CHEMBL559322 & 583012 & 8.6 & 8.6702 & TRN & \\
\hline CHEMBL559050 & 583012 & 8.0 & 7.95799 & 9999999999 & TRN \\
\hline CHEMBL553404 & 583012 & 9.2 & 9.2236 & TRN & \\
\hline CHEMBL555222 & 583012 & 9.1 & 8.7477 & TRN & \\
\hline CHEMBL539651 & 583012 & 8.1 & 8.4747 & TRN & \\
\hline & & & & 25313 & \\
\hline
\end{tabular}




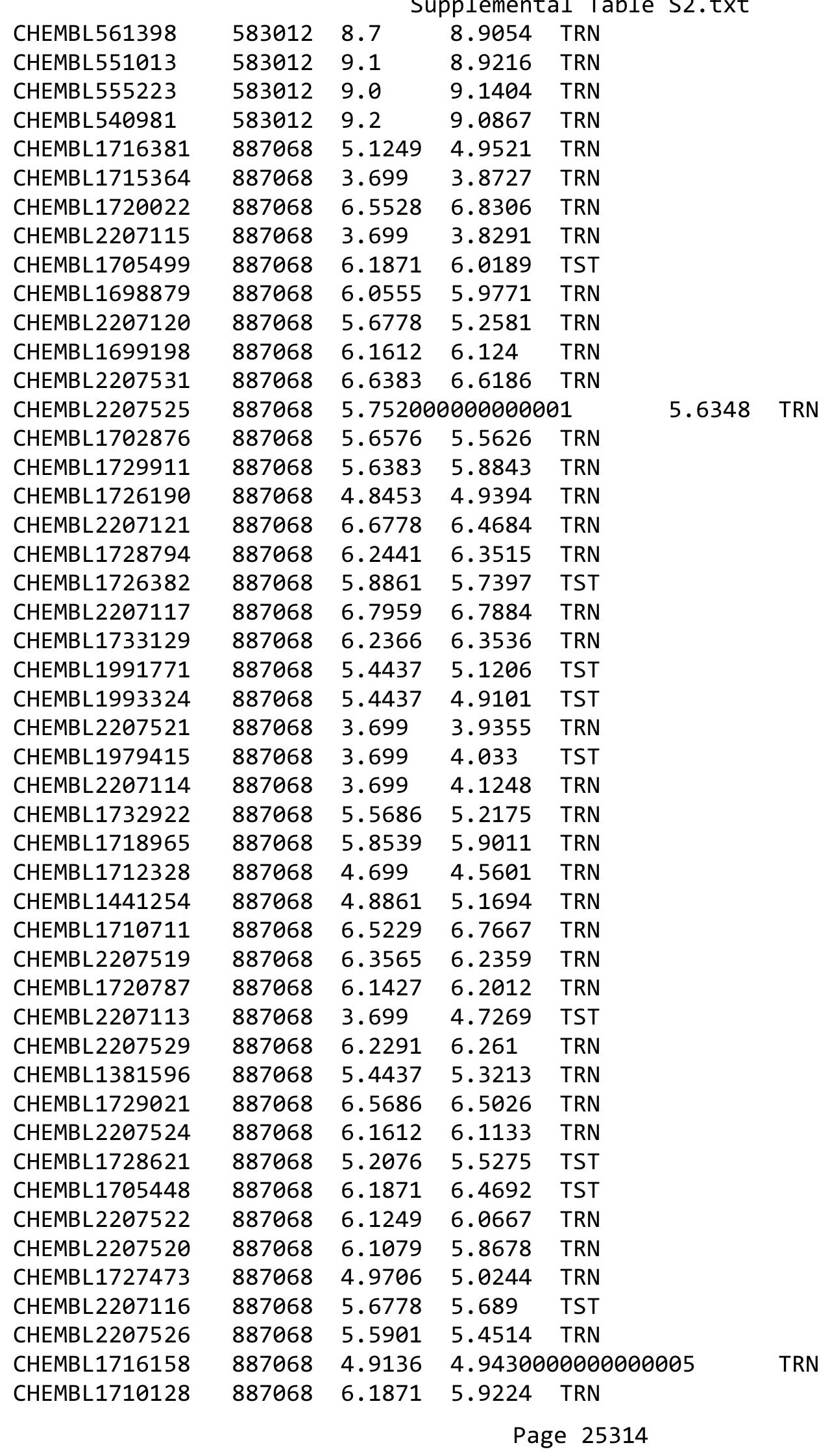




\begin{tabular}{|c|c|c|c|c|c|}
\hline & & & & & \\
\hline CHEMBL1721648 & 887068 & 6.4437 & 6.1895 & TST & \\
\hline CHEMBL2207523 & 887068 & 6.1135 & 6.0904 & TRN & \\
\hline CHEMBL2207118 & 887068 & 5.8861 & 5.8908 & TRN & \\
\hline CHEMBL1700476 & 887068 & 6.3872 & 6.5738 & TRN & \\
\hline CHEMBL1717450 & 887068 & 6.1871 & 6.4248 & TRN & \\
\hline CHEMBL 2207530 & 887068 & 6.1487 & 6.4351 & TRN & \\
\hline CHEMBL1703562 & 887068 & 6.1675 & 6.3076 & TRN & \\
\hline CHEMBL1698337 & 887068 & 5.2076 & 5.0834 & TRN & \\
\hline CHEMBL1710499 & 887068 & 5.3768 & 5.3707 & TRN & \\
\hline CHEMBL1709509 & 887068 & 6.5686 & 6.1948 & TRN & \\
\hline CHEMBL1584538 & 887068 & 5.6576 & 5.9285 & TRN & \\
\hline CHEMBL1703918 & 887068 & 5.9586 & 5.9284 & TRN & \\
\hline CHEMBL1707743 & 887068 & 5.6198 & 5.3964 & TRN & \\
\hline CHEMBL 2207528 & 887068 & 6.0088 & 5.9912 & TRN & \\
\hline CHEMBL1703414 & 887068 & 4.699 & 4.52 & TRN & \\
\hline CHEMBL 2207119 & 887068 & 5.3188 & 5.7354 & TST & \\
\hline CHEMBL1706758 & 887068 & 6.0044 & 6.2573 & TST & \\
\hline CHEMBL 2207527 & 887068 & 5.767 & 5.1308 & TST & \\
\hline CHEMBL1735852 & 887068 & 6.1427 & 5.8631 & TST & \\
\hline CHEMBL1706988 & 887068 & 6.1675 & 5.8277 & TST & \\
\hline CHEMBL1713871 & 887068 & 5.2518 & 4.9108 & TST & \\
\hline CHEMBL1730555 & 887068 & 5.9208 & 5.96299 & 9999999999 & TST \\
\hline CHEMBL1554937 & 688395 & 4.9 & 4.5147 & TRN & \\
\hline CHEMBL1553741 & 688395 & 4.55 & 4.62 & TST & \\
\hline CHEMBL1438690 & 688395 & 4.6 & 4.3852 & TRN & \\
\hline CHEMBL1366732 & 688395 & 4.6 & 4.5745 & TRN & \\
\hline CHEMBL1517718 & 688395 & 5.7 & 5.95799 & 9999999999 & TRN \\
\hline CHEMBL1611646 & 688395 & 4.8 & 4.668 & TRN & \\
\hline CHEMBL1492229 & 688395 & 4.55 & 4.6943 & TRN & \\
\hline CHEMBL1434006 & 688395 & 4.9 & 4.7862 & TRN & \\
\hline CHEMBL1474281 & 688395 & 4.95 & 4.7883 & TRN & \\
\hline CHEMBL1554579 & 688395 & 5.55 & 5.4404 & TST & \\
\hline CHEMBL1552172 & 688395 & 4.55 & 4.573 & TST & \\
\hline CHEMBL1596872 & 688395 & 4.55 & 4.5119 & TRN & \\
\hline CHEMBL495068 & 688395 & 4.85 & 5.0059 & TRN & \\
\hline CHEMBL1600210 & 688395 & 4.55 & 4.5658 & TRN & \\
\hline CHEMBL1435520 & 688395 & 4.8 & 4.6885 & TRN & \\
\hline CHEMBL1561888 & 688395 & 5.1 & 5.0447 & TRN & \\
\hline CHEMBL1456454 & 688395 & 4.8 & 4.784 & TRN & \\
\hline CHEMBL1474927 & 688395 & 4.55 & 4.5087 & TRN & \\
\hline CHEMBL1473809 & 688395 & 5.1 & 5.1645 & TST & \\
\hline CHEMBL1590230 & 688395 & 4.4 & 4.5996 & TRN & \\
\hline CHEMBL1316979 & 688395 & 4.45 & 4.7246 & TST & \\
\hline CHEMBL1475366 & 688395 & 5.4 & 5.5239 & TRN & \\
\hline CHEMBL1405744 & 688395 & 5.4 & 5.7544 & TRN & \\
\hline CHEMBL1603418 & 688395 & 6.15 & 6.2323 & TRN & \\
\hline CHEMBL1592289 & 688395 & 4.45 & 4.5947 & TRN & \\
\hline CHEMBL1450521 & 688395 & 4.5 & 4.4885 & TRN & \\
\hline
\end{tabular}




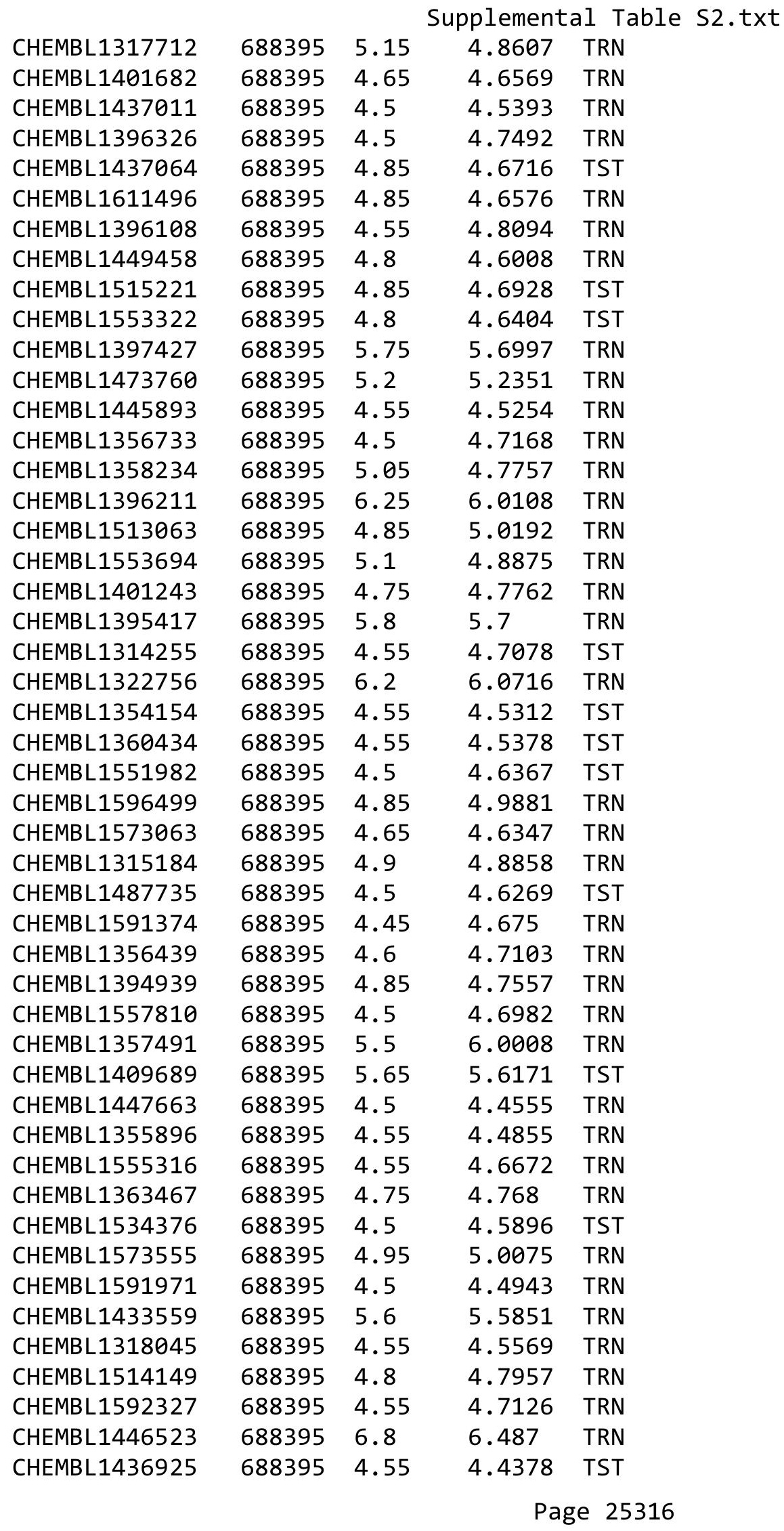




\begin{tabular}{|c|c|c|c|c|}
\hline \multicolumn{5}{|c|}{ Supplemental Table S2.txt } \\
\hline CHEMBL1396407 & 688395 & 4.85 & 5.1296 & TRN \\
\hline CHEMBL1366926 & 688395 & 4.5 & 4.5915 & TST \\
\hline CHEMBL1514505 & 688395 & 4.45 & 4.4776 & TST \\
\hline CHEMBL1438674 & 688395 & 4.9 & 4.3957 & TST \\
\hline CHEMBL1439665 & 688395 & 4.5 & 4.6449 & TRN \\
\hline CHEMBL1516530 & 688395 & 5.05 & 4.8755 & TRN \\
\hline CHEMBL1590123 & 688395 & 5.5 & 5.5676 & TRN \\
\hline CHEMBL428814 & 688395 & 5.5 & 4.961 & TRN \\
\hline CHEMBL489534 & 688395 & 4.8 & 4.6425 & TRN \\
\hline CHEMBL1452413 & 688395 & 4.9 & 4.8803 & TRN \\
\hline CHEMBL1533853 & 688395 & 5.0 & 4.7943 & TRN \\
\hline CHEMBL1514607 & 688395 & 5.15 & 4.9024 & TRN \\
\hline CHEMBL1315845 & 688395 & 4.65 & 4.8227 & TRN \\
\hline CHEMBL1554577 & 688395 & 4.55 & 4.5172 & TRN \\
\hline CHEMBL1358244 & 688395 & 4.75 & 4.7773 & TST \\
\hline CHEMBL1372133 & 688395 & 4.45 & 4.4661 & TST \\
\hline CHEMBL1396595 & 688395 & 5.35 & 5.3211 & TST \\
\hline CHEMBL1440715 & 688395 & 4.5 & 4.5639 & TST \\
\hline CHEMBL1374355 & 688395 & 6.25 & 6.3595 & TRN \\
\hline CHEMBL1555014 & 688395 & 4.85 & 4.79 & TST \\
\hline CHEMBL1331037 & 688395 & 4.95 & 4.9045 & TST \\
\hline CHEMBL1473472 & 688395 & 4.4 & 4.4253 & TRN \\
\hline CHEMBL1416207 & 688395 & 5.7 & 5.6492 & TRN \\
\hline CHEMBL1601477 & 688395 & 4.9 & 4.9595 & TRN \\
\hline CHEMBL1473996 & 688395 & 5.0 & 4.7601 & TRN \\
\hline CHEMBL1436715 & 688395 & 4.55 & 4.56 & TST \\
\hline CHEMBL1491966 & 688395 & 4.5 & 4.5643 & TRN \\
\hline CHEMBL1437056 & 688395 & 4.5 & 4.4962 & TST \\
\hline CHEMBL1474410 & 688395 & 4.8 & 4.7514 & TRN \\
\hline CHEMBL1355307 & 688395 & 4.5 & 4.5789 & TRN \\
\hline CHEMBL1490139 & 688395 & 4.45 & 4.7321 & TRN \\
\hline CHEMBL1314625 & 688395 & 4.45 & 4.6088 & TRN \\
\hline CHEMBL1479792 & 688395 & 4.45 & 4.5466 & TST \\
\hline CHEMBL1316408 & 688395 & 4.55 & 4.4875 & TRN \\
\hline CHEMBL1551200 & 688395 & 5.1 & 4.9687 & TRN \\
\hline CHEMBL1480219 & 688395 & 6.6499 & 6.4334 & TRN \\
\hline CHEMBL1323385 & 688395 & 5.15 & 5.6366 & TRN \\
\hline CHEMBL1597474 & 688395 & 4.45 & 4.5938 & TRN \\
\hline CHEMBL1437747 & 688395 & 4.85 & 4.9206 & TRN \\
\hline CHEMBL1472955 & 688395 & 5.0 & 4.8709 & TRN \\
\hline CHEMBL1356135 & 688395 & 5.25 & 4.7057 & TRN \\
\hline CHEMBL1357724 & 688395 & 4.45 & 4.9424 & TRN \\
\hline CHEMBL1322233 & 688395 & 5.05 & 4.7897 & TST \\
\hline CHEMBL1553185 & 688395 & 4.6 & 4.8086 & TRN \\
\hline CHEMBL1592209 & 688395 & 4.65 & 4.6478 & TST \\
\hline CHEMBL1314647 & 688395 & 5.35 & 5.4977 & TRN \\
\hline CHEMBL1322757 & 688395 & 4.55 & 4.4967 & TRN \\
\hline CHEMBL1592804 & 688395 & 4.7 & 4.6768 & TRN \\
\hline
\end{tabular}




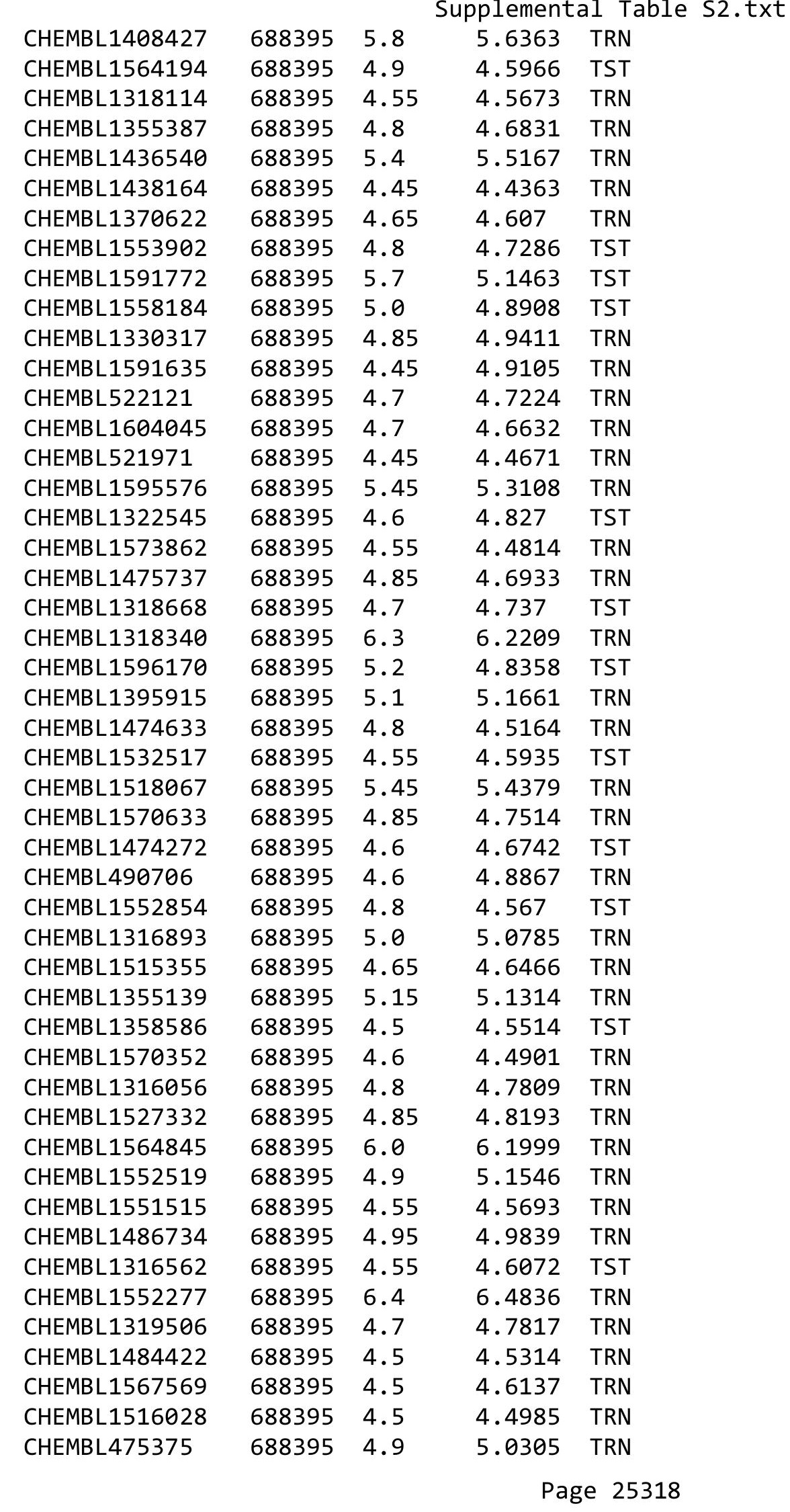




\begin{tabular}{|c|c|c|c|c|c|}
\hline CHEMBL541847 & 688395 & 5.9 & $5.4920 e$ & j000000001 & TRN \\
\hline CHEMBL1356630 & 688395 & 4.5 & 4.6755 & TRN & \\
\hline CHEMBL1406851 & 688395 & 4.45 & 4.544 & TRN & \\
\hline CHEMBL1394964 & 688395 & 5.1 & 5.3765 & TRN & \\
\hline CHEMBL1475951 & 688395 & 4.55 & 4.548 & TRN & \\
\hline CHEMBL1512250 & 688395 & 4.9 & 4.792 & TST & \\
\hline CHEMBL1590261 & 688395 & 4.5 & 4.6062 & TRN & \\
\hline CHEMBL1456015 & 688395 & 5.0 & 4.8116 & TRN & \\
\hline CHEMBL1403562 & 688395 & 5.3 & 4.9031 & TRN & \\
\hline CHEMBL1593774 & 688395 & 4.9 & 4.8309 & TRN & \\
\hline CHEMBL1475487 & 688395 & 5.15 & 4.9863 & TRN & \\
\hline CHEMBL1394854 & 688395 & 4.65 & 4.6275 & TRN & \\
\hline CHEMBL1322584 & 688395 & 5.55 & 5.4852 & TRN & \\
\hline CHEMBL1334321 & 688395 & 6.05 & 6.171 & TRN & \\
\hline CHEMBL1316775 & 688395 & 4.45 & 4.6786 & TST & \\
\hline CHEMBL1601908 & 688395 & 5.0 & 4.6836 & TST & \\
\hline CHEMBL1551841 & 688395 & 5.15 & 5.1879 & TRN & \\
\hline CHEMBL1477964 & 688395 & 4.8 & 4.7776 & TRN & \\
\hline CHEMBL568379 & 688395 & 6.35 & 6.1152 & TRN & \\
\hline CHEMBL1512540 & 688395 & 4.55 & 4.5503 & TRN & \\
\hline CHEMBL1355256 & 688395 & 4.45 & 4.775 & TRN & \\
\hline CHEMBL1398810 & 688395 & 4.45 & 4.5313 & TRN & \\
\hline CHEMBL1475689 & 688395 & 4.75 & 4.6248 & TRN & \\
\hline CHEMBL1404451 & 688395 & 4.85 & 4.7191 & TRN & \\
\hline CHEMBL1315292 & 688395 & 4.75 & 4.8123 & TST & \\
\hline CHEMBL1394783 & 688395 & 4.45 & 4.5434 & TRN & \\
\hline CHEMBL1563497 & 688395 & 4.55 & 4.6231 & TRN & \\
\hline CHEMBL1395605 & 688395 & 4.6 & 4.6889 & TRN & \\
\hline CHEMBL1485219 & 688395 & 4.6 & 4.7438 & TRN & \\
\hline CHEMBL1327945 & 688395 & 4.45 & 4.5312 & TRN & \\
\hline CHEMBL1395792 & 688395 & 4.6 & 4.9416 & TST & \\
\hline CHEMBL1472651 & 688395 & 4.65 & 4.6647 & TST & \\
\hline CHEMBL1484944 & 688395 & 5.8 & 5.6916 & TRN & \\
\hline CHEMBL1375753 & 688395 & 6.1 & 6.0264 & TRN & \\
\hline CHEMBL1437226 & 688395 & 5.0 & 4.8667 & TRN & \\
\hline CHEMBL1495150 & 688395 & 4.55 & 4.7137 & TRN & \\
\hline CHEMBL1316516 & 688395 & 4.55 & 4.5194 & TST & \\
\hline CHEMBL1526697 & 688395 & 6.0 & 6.215 & TRN & \\
\hline CHEMBL1418387 & 688395 & 6.2 & 6.4448 & TRN & \\
\hline CHEMBL1552720 & 688395 & 4.5 & 4.5675 & TRN & \\
\hline CHEMBL1558569 & 688395 & 4.55 & 4.6065 & TRN & \\
\hline CHEMBL1437364 & 688395 & 6.5 & 6.6195 & TRN & \\
\hline CHEMBL1354596 & 688395 & 4.45 & 4.4493 & TRN & \\
\hline CHEMBL1433798 & 688395 & 4.5 & 4.6102 & TRN & \\
\hline CHEMBL1317761 & 688395 & 4.55 & 4.5738 & TST & \\
\hline CHEMBL1314388 & 688395 & 4.5 & 4.4596 & TST & \\
\hline CHEMBL 259140 & 688395 & 5.4 & 5.0595 & TRN & \\
\hline CHEMBL1355002 & 688395 & 4.6 & 4.698 & TRN & \\
\hline
\end{tabular}




\begin{tabular}{|c|c|c|c|c|c|}
\hline \multicolumn{6}{|c|}{ Supplemental Table S2.txt } \\
\hline CHEMBL1590106 & 688395 & 6.2 & 6.2192 & TRN & \\
\hline CHEMBL1355677 & 688395 & 6.0 & 6.114 & TRN & \\
\hline CHEMBL1484253 & 688395 & 5.0 & 4.7714 & TRN & \\
\hline CHEMBL1371140 & 688395 & 5.05 & 4.8234 & TRN & \\
\hline CHEMBL510009 & 688395 & 5.1 & 5.4395 & TRN & \\
\hline CHEMBL1438688 & 688395 & 4.8 & 5.1983 & TRN & \\
\hline CHEMBL1606727 & 688395 & 4.8 & 4.9197 & TRN & \\
\hline CHEMBL1552517 & 688395 & 4.5 & 4.4997 & TST & \\
\hline CHEMBL1395850 & 688395 & 4.8 & 4.8825 & TRN & \\
\hline CHEMBL1551919 & 688395 & 4.95 & 5.0965 & TRN & \\
\hline CHEMBL1435447 & 688395 & 4.8 & 4.7477 & TRN & \\
\hline CHEMBL1356808 & 688395 & 6.15 & 5.825 & TST & \\
\hline CHEMBL1475338 & 688395 & 4.55 & 4.6692 & TRN & \\
\hline CHEMBL1315083 & 688395 & 5.0 & 4.8086 & TRN & \\
\hline CHEMBL1590857 & 688395 & 4.55 & 4.6123 & TRN & \\
\hline CHEMBL1403488 & 688395 & 4.5 & 4.5703 & TST & \\
\hline CHEMBL1403505 & 688395 & 4.8 & 4.7511 & TRN & \\
\hline CHEMBL1526043 & 688395 & 4.55 & 4.7073 & TST & \\
\hline CHEMBL1512023 & 688395 & 5.2 & 5.0114 & TRN & \\
\hline CHEMBL1325735 & 688395 & 4.55 & 4.5722 & TRN & \\
\hline CHEMBL1327681 & 688395 & 4.9 & 4.995 & TRN & \\
\hline CHEMBL1554588 & 688395 & 4.5 & 4.629 & TRN & \\
\hline CHEMBL1473379 & 688395 & 4.5 & 4.5387 & TRN & \\
\hline CHEMBL1552396 & 688395 & 4.45 & 4.5019 & TRN & \\
\hline CHEMBL1496560 & 688395 & 4.8 & 4.6642 & TRN & \\
\hline CHEMBL1403793 & 688395 & 6.25 & 6.3479 & TRN & \\
\hline CHEMBL1368113 & 688395 & 4.55 & 4.5035 & TRN & \\
\hline CHEMBL1318495 & 688395 & 4.5 & 4.6226 & TST & \\
\hline CHEMBL1590821 & 688395 & 4.8 & 4.7169 & TRN & \\
\hline CHEMBL1406782 & 688395 & 5.2 & 5.1842 & TRN & \\
\hline CHEMBL1436179 & 688395 & 4.55 & 4.90600 & 0000000001 & TRN \\
\hline CHEMBL1373326 & 688395 & 4.8 & 4.6601 & TST & \\
\hline CHEMBL1437667 & 688395 & 4.6 & 4.6099 & TRN & \\
\hline CHEMBL1434715 & 688395 & 4.5 & 4.5324 & TRN & \\
\hline CHEMBL1593134 & 688395 & 5.25 & 4.7618 & TRN & \\
\hline CHEMBL1435032 & 688395 & 5.35 & 4.8904 & TRN & \\
\hline CHEMBL1436024 & 688395 & 4.55 & 4.6398 & TRN & \\
\hline CHEMBL1524001 & 688395 & 4.55 & 4.6611 & TST & \\
\hline CHEMBL1446323 & 688395 & 5.05 & 4.7964 & TRN & \\
\hline CHEMBL1513030 & 688395 & 4.8 & 4.7371 & TRN & \\
\hline CHEMBL1317358 & 688395 & 4.85 & 4.6786 & TST & \\
\hline CHEMBL1326341 & 688395 & 4.75 & 4.8243 & TRN & \\
\hline CHEMBL1433783 & 688395 & 4.5 & 4.8178 & TST & \\
\hline CHEMBL1602710 & 688395 & 4.45 & 4.5037 & TST & \\
\hline CHEMBL1333968 & 688395 & 4.6 & 4.6403 & TST & \\
\hline CHEMBL1594134 & 688395 & 4.45 & 4.4868 & TRN & \\
\hline CHEMBL1533214 & 688395 & 4.55 & 4.7572 & TST & \\
\hline CHEMBL1553963 & 688395 & 4.9 & 4.745 & TST & \\
\hline
\end{tabular}




\begin{tabular}{|c|c|c|c|c|}
\hline & & & pplement & \\
\hline CHEMBL1401859 & 688395 & 5.5 & 5.4732 & TRN \\
\hline CHEMBL1447909 & 688395 & 5.0 & 4.8557 & TST \\
\hline CHEMBL1597037 & 688395 & 5.15 & 4.8399 & TRN \\
\hline CHEMBL1482759 & 688395 & 4.55 & 4.6366 & TRN \\
\hline CHEMBL1611261 & 688395 & 4.6 & 4.7795 & TRN \\
\hline CHEMBL1591487 & 688395 & 4.55 & 4.5323 & TRN \\
\hline CHEMBL516075 & 688395 & 5.65 & 5.7828 & TRN \\
\hline CHEMBL1512833 & 688395 & 4.6 & 4.6391 & TRN \\
\hline CHEMBL1553766 & 688395 & 4.45 & 4.71 & TRN \\
\hline CHEMBL1404954 & 688395 & 6.15 & 5.4423 & TRN \\
\hline CHEMBL1568575 & 688395 & 4.75 & 4.5823 & TRN \\
\hline CHEMBL1593827 & 688395 & 5.5 & 5.2054 & TRN \\
\hline CHEMBL1512708 & 688395 & 4.8 & 4.7593 & TRN \\
\hline CHEMBL1315373 & 688395 & 5.5 & 5.2575 & TST \\
\hline CHEMBL1472926 & 688395 & 6.5 & 6.2494 & TRN \\
\hline CHEMBL1435409 & 688395 & 5.15 & 5.0957 & TST \\
\hline CHEMBL1553114 & 688395 & 4.45 & 4.4676 & TRN \\
\hline CHEMBL1590818 & 688395 & 4.5 & 4.6776 & TST \\
\hline CHEMBL1436075 & 688395 & 4.5 & 5.0498 & TRN \\
\hline CHEMBL1484261 & 688395 & 4.65 & 4.5669 & TRN \\
\hline CHEMBL1452250 & 688395 & 4.5 & 4.5984 & TRN \\
\hline CHEMBL1554745 & 688395 & 4.5 & 4.6968 & TRN \\
\hline CHEMBL1592803 & 688395 & 5.85 & 6.1618 & TRN \\
\hline CHEMBL1357444 & 688395 & 4.5 & 4.6792 & TST \\
\hline CHEMBL1495665 & 688395 & 4.55 & 4.5566 & TRN \\
\hline CHEMBL1594372 & 688395 & 4.85 & 4.4699 & TRN \\
\hline CHEMBL1354563 & 688395 & 5.05 & 4.99 & TRN \\
\hline CHEMBL1473755 & 688395 & 4.65 & 4.5736 & TST \\
\hline CHEMBL1318042 & 688395 & 4.55 & 4.6255 & TRN \\
\hline CHEMBL1336060 & 688395 & 5.05 & 4.909 & TRN \\
\hline CHEMBL1357553 & 688395 & 5.2 & 5.2953 & TST \\
\hline CHEMBL1321094 & 688395 & 4.45 & 4.4836 & TRN \\
\hline CHEMBL1442250 & 688395 & 4.5 & 4.7687 & TRN \\
\hline CHEMBL1314222 & 688395 & 5.1 & 5.126 & TRN \\
\hline CHEMBL1561023 & 688395 & 5.05 & 5.0484 & TRN \\
\hline CHEMBL1436272 & 688395 & 5.05 & 5.4589 & TRN \\
\hline CHEMBL1316656 & 688395 & 4.45 & 4.4621 & TST \\
\hline CHEMBL1357293 & 688395 & 5.15 & 5.0358 & TRN \\
\hline CHEMBL1369318 & 688395 & 4.45 & 4.4692 & TRN \\
\hline CHEMBL1557841 & 688395 & 4.5 & 4.5364 & TST \\
\hline CHEMBL1592464 & 688395 & 5.0 & 4.7443 & TRN \\
\hline CHEMBL1512562 & 688395 & 5.15 & 4.7603 & TST \\
\hline CHEMBL545523 & 688395 & 4.9 & 5.0862 & TRN \\
\hline CHEMBL1552540 & 688395 & 4.5 & 4.7147 & TRN \\
\hline CHEMBL1327355 & 688395 & 5.15 & 4.9893 & TRN \\
\hline CHEMBL1589893 & 688395 & 4.5 & 4.5658 & TRN \\
\hline CHEMBL1394137 & 688395 & 5.2 & 5.0905 & TRN \\
\hline CHEMBL1323051 & 688395 & 4.5 & 4.677 & TRN \\
\hline
\end{tabular}




\begin{tabular}{|c|c|c|c|c|}
\hline \multicolumn{5}{|c|}{ Supplemental Table s2.txt } \\
\hline CHEMBL1455926 & 688395 & 6.0 & 6.0651 & TRN \\
\hline CHEMBL1360310 & 688395 & 4.95 & 5.0319 & TRN \\
\hline CHEMBL1601662 & 688395 & 4.55 & 4.6369 & TRN \\
\hline CHEMBL1555713 & 688395 & 4.65 & 4.5682 & TST \\
\hline CHEMBL1358983 & 688395 & 4.7 & 4.7529 & TST \\
\hline CHEMBL1315091 & 688395 & 4.45 & 4.61 & TRN \\
\hline CHEMBL1356652 & 688395 & 6.7001 & 6.6827 & TST \\
\hline CHEMBL1554637 & 688395 & 4.5 & 4.6743 & TRN \\
\hline CHEMBL1554935 & 688395 & 4.6 & 4.5873 & TST \\
\hline CHEMBL1475428 & 688395 & 4.45 & 4.5161 & TST \\
\hline CHEMBL1565927 & 688395 & 6.5 & 6.4736 & TRN \\
\hline CHEMBL1551818 & 688395 & 4.5 & 4.5679 & TRN \\
\hline CHEMBL1394714 & 688395 & 5.1 & 4.8702 & TST \\
\hline CHEMBL1513669 & 688395 & 5.35 & 4.9898 & TRN \\
\hline CHEMBL1490292 & 688395 & 4.45 & 4.5062 & TRN \\
\hline CHEMBL1594612 & 688395 & 5.2 & 5.0561 & TST \\
\hline CHEMBL1593128 & 688395 & 4.5 & 4.5707 & TST \\
\hline CHEMBL1610082 & 688395 & 4.85 & 4.791 & TRN \\
\hline CHEMBL1446539 & 688395 & 5.2 & 5.0373 & TRN \\
\hline CHEMBL1513282 & 688395 & 4.55 & 4.7299 & TST \\
\hline CHEMBL1335654 & 688395 & 4.55 & 4.7288 & TRN \\
\hline CHEMBL1558843 & 688395 & 4.65 & 4.6247 & TRN \\
\hline CHEMBL1591677 & 688395 & 4.6 & 4.6332 & TRN \\
\hline CHEMBL1366061 & 688395 & 5.65 & 5.8755 & TRN \\
\hline CHEMBL490744 & 688395 & 4.85 & 4.7251 & TRN \\
\hline CHEMBL1435907 & 688395 & 4.85 & 5.042 & TRN \\
\hline CHEMBL1533734 & 688395 & 4.6 & 4.5503 & TST \\
\hline CHEMBL1496934 & 688395 & 4.45 & 4.603 & TRN \\
\hline CHEMBL1410859 & 688395 & 6.45 & 6.5103 & TRN \\
\hline CHEMBL1478761 & 688395 & 5.15 & 5.0281 & TRN \\
\hline CHEMBL1513485 & 688395 & 4.9 & 4.845 & TRN \\
\hline CHEMBL1417552 & 688395 & 4.55 & 4.6387 & TST \\
\hline CHEMBL1409830 & 688395 & 4.5 & 4.43 & TST \\
\hline CHEMBL1552985 & 688395 & 4.45 & 4.4344 & TRN \\
\hline CHEMBL1551557 & 688395 & 4.45 & 4.4773 & TRN \\
\hline CHEMBL1563047 & 688395 & 4.9 & 4.7656 & TST \\
\hline CHEMBL1554567 & 688395 & 5.15 & 4.7496 & TRN \\
\hline CHEMBL1440157 & 688395 & 5.7 & 5.3846 & TRN \\
\hline CHEMBL1437095 & 688395 & 4.45 & 4.5107 & TRN \\
\hline CHEMBL1477982 & 688395 & 4.8 & 4.6721 & TRN \\
\hline CHEMBL1442538 & 688395 & 4.5 & 4.5919 & TST \\
\hline CHEMBL1356118 & 688395 & 4.55 & 4.6056 & TRN \\
\hline CHEMBL1404501 & 688395 & 4.65 & 4.8575 & TRN \\
\hline CHEMBL1497006 & 688395 & 4.55 & 4.6736 & TST \\
\hline CHEMBL1610375 & 688395 & 4.5 & 4.4486 & TRN \\
\hline CHEMBL1515540 & 688395 & 4.9 & 4.6761 & TRN \\
\hline CHEMBL1475083 & 688395 & 4.6 & 4.5871 & TRN \\
\hline CHEMBL1483032 & 688395 & 4.65 & 4.5822 & TST \\
\hline
\end{tabular}




\begin{tabular}{|c|c|c|c|c|c|}
\hline \multicolumn{6}{|c|}{ Supplemental Table S2.txt } \\
\hline CHEMBL1369871 & 688395 & 4.6 & 4.5737 & TRN & \\
\hline CHEMBL1329823 & 688395 & 4.65 & 4.7184 & TRN & \\
\hline CHEMBL491952 & 688395 & 4.45 & 4.9961 & TRN & \\
\hline CHEMBL1323759 & 688395 & 4.45 & 4.6138 & TRN & \\
\hline CHEMBL1318064 & 688395 & 4.5 & 4.5849 & TRN & \\
\hline CHEMBL1475255 & 688395 & 4.95 & 4.8458 & TST & \\
\hline CHEMBL1373621 & 688395 & 5.1 & 4.899 & TRN & \\
\hline CHEMBL1315802 & 688395 & 4.85 & 4.7868 & TST & \\
\hline CHEMBL1567472 & 688395 & 4.8 & 4.5558 & TST & \\
\hline CHEMBL491748 & 688395 & 4.8 & 5.2237 & TRN & \\
\hline CHEMBL1534237 & 688395 & 4.5 & 4.4418 & TRN & \\
\hline CHEMBL1568854 & 688395 & 4.6 & 4.4609 & TRN & \\
\hline CHEMBL1437075 & 688395 & 5.15 & 4.8395 & TRN & \\
\hline CHEMBL1474114 & 688395 & 4.55 & 4.603 & TRN & \\
\hline CHEMBL1394706 & 688395 & 4.6 & 4.6198 & TST & \\
\hline CHEMBL1325766 & 688395 & 4.95 & 4.6334 & TRN & \\
\hline CHEMBL1535931 & 688395 & 4.8 & 5.0788 & TRN & \\
\hline CHEMBL1591275 & 688395 & 4.9 & 5.2011 & TRN & \\
\hline CHEMBL 1442440 & 688395 & 5.0 & 4.6974 & TST & \\
\hline CHEMBL1494452 & 688395 & 4.8 & 4.8789 & TRN & \\
\hline CHEMBL1592388 & 688395 & 4.8 & 4.6678 & TRN & \\
\hline CHEMBL585861 & 688395 & 6.05 & 5.9126 & TRN & \\
\hline CHEMBL1552588 & 688395 & 7.4001 & 5.6545 & TRN & \\
\hline CHEMBL1362079 & 688395 & 4.5 & 4.63899 & 9999999999 & TRN \\
\hline CHEMBL1568735 & 688395 & 4.85 & 4.5387 & TRN & \\
\hline CHEMBL1513800 & 688395 & 4.55 & 4.7864 & TST & \\
\hline CHEMBL1366393 & 688395 & 5.2 & 5.0557 & TRN & \\
\hline CHEMBL447507 & 688395 & 4.6 & 4.4587 & TRN & \\
\hline CHEMBL1357857 & 688395 & 4.8 & 4.8431 & TRN & \\
\hline CHEMBL1488990 & 688395 & 4.6 & 4.6768 & TRN & \\
\hline CHEMBL1433730 & 688395 & 4.5 & 4.5325 & TRN & \\
\hline CHEMBL1592982 & 688395 & 6.5501 & 6.529 & TRN & \\
\hline CHEMBL1314799 & 688395 & 4.55 & 4.5031 & TRN & \\
\hline CHEMBL1438323 & 688395 & 5.65 & 5.4943 & TRN & \\
\hline CHEMBL1396377 & 688395 & 4.85 & 4.8956 & TRN & \\
\hline CHEMBL1355408 & 688395 & 5.65 & 5.2493 & TST & \\
\hline CHEMBL1600340 & 688395 & 4.45 & 4.5827 & TST & \\
\hline CHEMBL1554622 & 688395 & 4.55 & 4.6169 & TRN & \\
\hline CHEMBL1516054 & 688395 & 6.8 & 6.9705 & TRN & \\
\hline CHEMBL1454049 & 688395 & 4.5 & 4.6552 & TRN & \\
\hline CHEMBL1316956 & 688395 & 4.6 & 4.7568 & TRN & \\
\hline CHEMBL1320469 & 688395 & 5.1 & 5.0493 & TST & \\
\hline CHEMBL1591896 & 688395 & 4.55 & 4.7071 & TRN & \\
\hline CHEMBL1397636 & 688395 & 4.9 & 4.7436 & TST & \\
\hline CHEMBL1483855 & 688395 & 5.3 & 5.1858 & TRN & \\
\hline CHEMBL1473430 & 688395 & 5.1 & 4.8474 & TRN & \\
\hline CHEMBL1361750 & 688395 & 4.6 & 4.692 & TRN & \\
\hline CHEMBL1517884 & 688395 & 4.5 & 4.579 & TRN & \\
\hline
\end{tabular}




\begin{tabular}{|c|c|c|c|c|c|}
\hline \multicolumn{6}{|c|}{ Supplemental Table S2.txt } \\
\hline CHEMBL1512919 & 688395 & 4.55 & 4.5942 & TRN & \\
\hline CHEMBL1398013 & 688395 & 4.9 & 4.7603 & TST & \\
\hline CHEMBL1439401 & 688395 & 4.75 & 4.7357 & TRN & \\
\hline CHEMBL1551518 & 688395 & 4.85 & 4.71399 & 99999999995 & TST \\
\hline CHEMBL1339209 & 688395 & 4.9 & 4.6845 & TRN & \\
\hline CHEMBL1566571 & 688395 & 4.9 & 5.0389 & TRN & \\
\hline CHEMBL1316075 & 688395 & 5.25 & 5.0849 & TRN & \\
\hline CHEMBL1558834 & 688395 & 4.55 & 4.6341 & TST & \\
\hline CHEMBL1436956 & 688395 & 5.45 & 5.2216 & TRN & \\
\hline CHEMBL1394113 & 688395 & 4.5 & 4.6947 & TRN & \\
\hline CHEMBL1455570 & 688395 & 5.5 & 5.166 & TRN & \\
\hline CHEMBL1378755 & 688395 & 4.6 & 4.7598 & TST & \\
\hline CHEMBL1324494 & 688395 & 4.85 & 4.7574 & TST & \\
\hline CHEMBL1412390 & 688395 & 4.9 & 4.743 & TRN & \\
\hline CHEMBL489935 & 688395 & 4.45 & 4.4834 & TRN & \\
\hline CHEMBL1407035 & 688395 & 6.5501 & 6.8145 & TRN & \\
\hline CHEMBL1512988 & 688395 & 5.5 & 5.648 & TRN & \\
\hline CHEMBL1591956 & 688395 & 4.65 & 4.6923 & TRN & \\
\hline CHEMBL1595002 & 688395 & 4.45 & $4.5680 e$ & 00000000005 & TRN \\
\hline CHEMBL1518035 & 688395 & 4.55 & 4.716 & TST & \\
\hline CHEMBL1404317 & 688395 & 4.85 & 4.8097 & TST & \\
\hline CHEMBL1357168 & 688395 & 4.45 & 4.6657 & TRN & \\
\hline CHEMBL1316353 & 688395 & 5.1 & 5.0912 & TRN & \\
\hline CHEMBL566899 & 688395 & 5.55 & 5.6658 & TRN & \\
\hline CHEMBL1417771 & 688395 & 5.15 & 4.8614 & TRN & \\
\hline CHEMBL1417837 & 688395 & 5.6 & 5.6675 & TRN & \\
\hline CHEMBL1362892 & 688395 & 4.55 & 4.6325 & TST & \\
\hline CHEMBL1480806 & 688395 & 4.95 & 5.0771 & TRN & \\
\hline CHEMBL1403333 & 688395 & 5.1 & 5.0155 & TRN & \\
\hline CHEMBL1452408 & 688395 & 4.6 & 4.6321 & TST & \\
\hline CHEMBL1531899 & 688395 & 5.0 & 4.6901 & TST & \\
\hline CHEMBL 1355720 & 688395 & 4.85 & 4.8525 & TRN & \\
\hline CHEMBL1474195 & 688395 & 4.65 & 4.863 & TRN & \\
\hline CHEMBL1475541 & 688395 & 4.45 & 4.459 & TST & \\
\hline CHEMBL1594030 & 688395 & 4.45 & 4.586 & TST & \\
\hline CHEMBL1436682 & 688395 & 4.9 & 5.0653 & TRN & \\
\hline CHEMBL1519435 & 688395 & 4.45 & 4.5414 & TRN & \\
\hline CHEMBL1406082 & 688395 & 4.5 & 4.5783 & TST & \\
\hline CHEMBL1355881 & 688395 & 4.55 & 4.7194 & TRN & \\
\hline CHEMBL1524520 & 688395 & 4.75 & 4.6543 & TRN & \\
\hline CHEMBL475376 & 688395 & 5.35 & 5.2948 & TRN & \\
\hline CHEMBL1435077 & 688395 & 5.15 & 4.9068 & TRN & \\
\hline CHEMBL1434817 & 688395 & 4.55 & 4.6013 & TST & \\
\hline CHEMBL1433668 & 688395 & 4.6 & 4.8872 & TRN & \\
\hline CHEMBL1559654 & 688395 & 5.0 & 4.9315 & TST & \\
\hline CHEMBL1472765 & 688395 & 6.15 & 6.2422 & TRN & \\
\hline CHEMBL1361513 & 688395 & 4.8 & 4.8641 & TST & \\
\hline CHEMBL1314674 & 688395 & 5.05 & 4.7333 & TRN & \\
\hline
\end{tabular}




\begin{tabular}{|c|c|c|c|c|}
\hline & & & pplement & al $\mathrm{T}$ \\
\hline CHEMBL1355840 & 688395 & 4.5 & 4.6122 & TRN \\
\hline CHEMBL1315820 & 688395 & 4.5 & 4.6742 & TRN \\
\hline CHEMBL1480350 & 688395 & 6.35 & 6.1447 & TRN \\
\hline CHEMBL1551913 & 688395 & 4.95 & 4.8356 & TST \\
\hline CHEMBL1591543 & 688395 & 4.85 & 4.8121 & TRN \\
\hline CHEMBL1522370 & 688395 & 4.6 & 4.5295 & TRN \\
\hline CHEMBL1533572 & 688395 & 4.8 & 4.9716 & TRN \\
\hline CHEMBL1482582 & 688395 & 4.5 & 4.6807 & TRN \\
\hline CHEMBL1515246 & 688395 & 5.65 & 5.6899 & TRN \\
\hline CHEMBL1395089 & 688395 & 4.45 & 4.5078 & TRN \\
\hline CHEMBL1447959 & 688395 & 4.8 & 4.5286 & TRN \\
\hline CHEMBL491547 & 688395 & 4.6 & 4.8392 & TRN \\
\hline CHEMBL1320765 & 688395 & 4.4 & 4.6022 & TRN \\
\hline CHEMBL1473834 & 688395 & 5.3 & 5.0949 & TRN \\
\hline CHEMBL1490195 & 688395 & 4.5 & 4.5797 & TRN \\
\hline CHEMBL1314367 & 688395 & 4.45 & 4.6775 & TST \\
\hline CHEMBL1593158 & 688395 & 4.55 & 4.6472 & TRN \\
\hline CHEMBL1521490 & 688395 & 4.85 & 4.828 & TRN \\
\hline CHEMBL1364871 & 688395 & 4.85 & 4.8063 & TRN \\
\hline CHEMBL1354600 & 688395 & 4.8 & 4.7974 & TRN \\
\hline CHEMBL1395882 & 688395 & 4.45 & 4.7388 & TRN \\
\hline CHEMBL1515366 & 688395 & 4.8 & 4.6677 & TRN \\
\hline CHEMBL1517241 & 688395 & 4.45 & 4.5949 & TST \\
\hline CHEMBL1590598 & 688395 & 5.7 & 4.8853 & TRN \\
\hline CHEMBL1337092 & 688395 & 4.6 & 4.6743 & TRN \\
\hline CHEMBL1571264 & 688395 & 4.85 & 4.8361 & TRN \\
\hline CHEMBL1491332 & 688395 & 4.95 & 4.7648 & TRN \\
\hline CHEMBL1591140 & 688395 & 4.85 & 4.6569 & TRN \\
\hline CHEMBL1556701 & 688395 & 4.55 & 4.6153 & TST \\
\hline CHEMBL1558777 & 688395 & 4.55 & 4.617 & TRN \\
\hline CHEMBL1513077 & 688395 & 4.55 & 4.6374 & TRN \\
\hline CHEMBL1356336 & 688395 & 4.5 & 4.9448 & TRN \\
\hline CHEMBL491939 & 688395 & 4.55 & 4.8272 & TRN \\
\hline CHEMBL1315129 & 688395 & 4.6 & 4.5785 & TRN \\
\hline CHEMBL475198 & 688395 & 5.1 & 5.2089 & TRN \\
\hline CHEMBL1363594 & 688395 & 4.5 & 4.6225 & TRN \\
\hline CHEMBL1513990 & 688395 & 5.3 & 5.4591 & TRN \\
\hline CHEMBL1551534 & 688395 & 4.45 & 4.5666 & TRN \\
\hline CHEMBL1315318 & 688395 & 4.55 & 4.7206 & TST \\
\hline CHEMBL1436976 & 688395 & 4.5 & 4.5781 & TRN \\
\hline CHEMBL1436045 & 688395 & 4.55 & 4.5491 & TRN \\
\hline CHEMBL1433724 & 688395 & 4.5 & 4.6209 & TRN \\
\hline CHEMBL1357018 & 688395 & 7.0 & 6.2985 & TRN \\
\hline CHEMBL1473317 & 688395 & 4.5 & 4.6155 & TST \\
\hline CHEMBL1474402 & 688395 & 7.0501 & 6.6066 & TRN \\
\hline CHEMBL1318067 & 688395 & 4.7 & 4.5208 & TST \\
\hline CHEMBL1455018 & 688395 & 4.5 & 4.5166 & TRN \\
\hline CHEMBL1356794 & 688395 & 5.35 & 4.828 & TRN \\
\hline
\end{tabular}




\begin{tabular}{|c|c|c|c|c|}
\hline \multicolumn{5}{|c|}{ Supplemental Table S2.txt } \\
\hline CHEMBL1357551 & 688395 & 4.55 & 4.6936 & TRN \\
\hline CHEMBL1525602 & 688395 & 4.95 & 4.8014 & TRN \\
\hline CHEMBL1565525 & 688395 & 4.5 & 4.6138 & TST \\
\hline CHEMBL1434747 & 688395 & 4.5 & 4.6792 & TST \\
\hline CHEMBL1318041 & 688395 & 4.55 & 4.5913 & TST \\
\hline CHEMBL1514719 & 688395 & 4.8 & 4.5992 & TRN \\
\hline CHEMBL1396109 & 688395 & 4.55 & 4.6406 & TRN \\
\hline CHEMBL1364711 & 688395 & 4.5 & 4.588 & TST \\
\hline CHEMBL1513578 & 688395 & 4.8 & 4.651 & TRN \\
\hline CHEMBL1551979 & 688395 & 5.1 & 4.9158 & TRN \\
\hline CHEMBL492611 & 688395 & 4.55 & 4.7632 & TRN \\
\hline CHEMBL1437273 & 688395 & 5.2 & 5.5015 & TRN \\
\hline CHEMBL1417025 & 688395 & 5.45 & 5.4947 & TRN \\
\hline CHEMBL1332033 & 688395 & 6.95 & 6.7324 & TRN \\
\hline CHEMBL1532720 & 688395 & 5.05 & 4.8396 & TST \\
\hline CHEMBL1441787 & 688395 & 4.45 & 4.6027 & TRN \\
\hline CHEMBL1374585 & 688395 & 4.8 & 4.5608 & TRN \\
\hline CHEMBL1606199 & 688395 & 4.6 & 4.7107 & TST \\
\hline CHEMBL1359691 & 688395 & 4.8 & 4.5114 & TRN \\
\hline CHEMBL1400043 & 688395 & 4.85 & 4.9205 & TRN \\
\hline CHEMBL1534738 & 688395 & 4.55 & 4.6132 & TST \\
\hline CHEMBL1357067 & 688395 & 5.45 & 5.0826 & TRN \\
\hline CHEMBL1433752 & 688395 & 6.15 & 6.0854 & TRN \\
\hline CHEMBL1513121 & 688395 & 4.75 & 4.7676 & TRN \\
\hline CHEMBL1396611 & 688395 & 4.8 & 4.5994 & TST \\
\hline CHEMBL1478772 & 688395 & 5.25 & 5.27 & TRN \\
\hline CHEMBL1589925 & 688395 & 4.85 & 5.042 & TRN \\
\hline CHEMBL1454544 & 688395 & 4.55 & 4.6621 & TRN \\
\hline CHEMBL1592211 & 688395 & 4.55 & 4.563 & TRN \\
\hline CHEMBL1415790 & 688395 & 4.5 & 4.635 & TST \\
\hline CHEMBL1490477 & 688395 & 5.0 & 4.9321 & TRN \\
\hline CHEMBL1318509 & 688395 & 4.85 & 4.7628 & TRN \\
\hline CHEMBL119841 & 688395 & 4.95 & 5.1564 & TRN \\
\hline CHEMBL1317009 & 688395 & 4.9 & 4.6877 & TST \\
\hline CHEMBL1316709 & 688395 & 6.1 & 6.2304 & TRN \\
\hline CHEMBL1394520 & 688395 & 4.95 & 4.7447 & TRN \\
\hline CHEMBL1433596 & 688395 & 4.85 & 4.756 & TRN \\
\hline CHEMBL1395527 & 688395 & 4.85 & 4.7335 & TRN \\
\hline CHEMBL491943 & 688395 & 4.45 & 4.5915 & TRN \\
\hline CHEMBL1449350 & 688395 & 4.95 & 4.7927 & TRN \\
\hline CHEMBL1436355 & 688395 & 5.05 & 4.7772 & TRN \\
\hline CHEMBL1496596 & 688395 & 4.55 & 4.7403 & TST \\
\hline CHEMBL1438371 & 688395 & 4.6 & 4.5241 & TRN \\
\hline CHEMBL1443323 & 688395 & 4.7 & 4.8282 & TRN \\
\hline CHEMBL1395241 & 688395 & 4.4 & 4.5788 & TST \\
\hline CHEMBL1568250 & 688395 & 5.2 & 4.9314 & TRN \\
\hline CHEMBL1475902 & 688395 & 5.15 & 5.1021 & TRN \\
\hline CHEMBL1552572 & 688395 & 4.9 & 4.8887 & TST \\
\hline
\end{tabular}




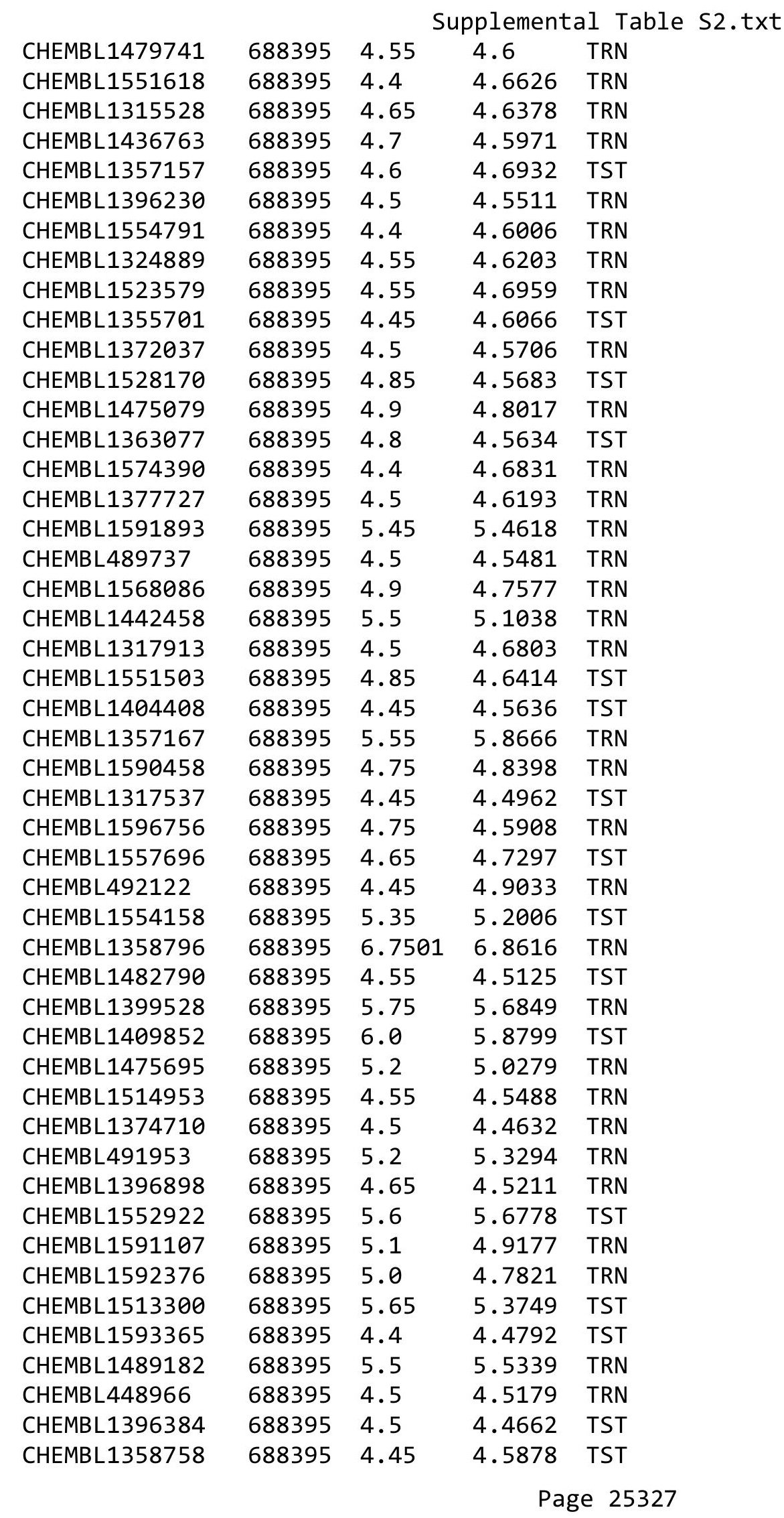




\begin{tabular}{|c|c|c|c|c|c|}
\hline \multicolumn{6}{|c|}{ Supplemental Table S2.txt } \\
\hline CHEMBL1316055 & 688395 & 4.6 & 4.8767 & TRN & \\
\hline CHEMBL1322216 & 688395 & 6.0 & 5.7448 & TRN & \\
\hline CHEMBL1418420 & 688395 & 4.5 & 4.5791 & TRN & \\
\hline CHEMBL 3687153 & 1528254 & 7.6778 & 7.2442 & TRN & \\
\hline CHEMBL 3682431 & 1528254 & 8.5229 & 8.381 & TRN & \\
\hline CHEMBL 3687152 & 1528254 & 6.9208 & 7.0603 & TRN & \\
\hline CHEMBL 3687147 & 1528254 & 6.0915 & 6.001 & TST & \\
\hline CHEMBL 3687130 & 1528254 & 7.8539 & 7.5806 & TRN & \\
\hline CHEMBL 3687131 & 1528254 & 6.4559 & 6.5142 & TRN & \\
\hline CHEMBL 3687124 & 1528254 & 7.8539 & 8.0541 & TRN & \\
\hline CHEMBL 3687127 & 1528254 & 7.9586 & 7.5675 & TRN & \\
\hline CHEMBL 3687160 & 1528254 & 8.0969 & 7.7909 & TRN & \\
\hline CHEMBL 3687184 & 1528254 & 7.1549 & 7.401 & TRN & \\
\hline CHEMBL 3682434 & 1528254 & 8.301 & 8.0985 & TRN & \\
\hline CHEMBL3687110 & 1528254 & 6.6383 & 6.6531 & TRN & \\
\hline CHEMBL 3687173 & 1528254 & 6.0655 & 5.9941 & TRN & \\
\hline CHEMBL 3687179 & 1528254 & 6.3372 & 6.3835 & TRN & \\
\hline CHEMBL 3687128 & 1528254 & 8.301 & 8.0547 & TRN & \\
\hline CHEMBL 3687185 & 1528254 & 8.301 & 8.1261 & TRN & \\
\hline CHEMBL 3687117 & 1528254 & 6.5229 & 6.5927 & TST & \\
\hline CHEMBL 3687180 & 1528254 & 7.7959 & 7.67299 & 9999999999 & TRN \\
\hline CHEMBL 3687142 & 1528254 & 7.1871 & 7.254 & TST & \\
\hline CHEMBL 3682425 & 1528254 & 5.7959 & 5.9692 & TRN & \\
\hline CHEMBL 3687149 & 1528254 & 7.4685 & 7.3726 & TRN & \\
\hline CHEMBL 3687121 & 1528254 & 7.4949 & 7.9574 & TRN & \\
\hline CHEMBL 3682426 & 1528254 & 6.7447 & 6.8328 & TRN & \\
\hline CHEMBL 3687112 & 1528254 & 6.6383 & 6.6999 & TRN & \\
\hline CHEMBL 3687181 & 1528254 & 8.1549 & 8.334 & TRN & \\
\hline CHEMBL 3687122 & 1528254 & 6.0706 & 6.0833 & TST & \\
\hline CHEMBL 3687159 & 1528254 & 7.1487 & 7.7248 & TRN & \\
\hline CHEMBL 3682420 & 1528254 & 8.2218 & 8.2161 & TRN & \\
\hline CHEMBL 3687141 & 1528254 & 7.0506 & 7.1692 & TRN & \\
\hline CHEMBL3687167 & 1528254 & 6.5376 & 7.021 & TRN & \\
\hline CHEMBL 3687165 & 1528254 & 6.9208 & 6.7809 & TRN & \\
\hline CHEMBL 3687176 & 1528254 & 8.2218 & 7.9865 & TRN & \\
\hline CHEMBL 3682427 & 1528254 & 7.6778 & 8.1214 & TRN & \\
\hline CHEMBL 3687139 & 1528254 & 6.4202 & 6.6599 & TST & \\
\hline CHEMBL3687156 & 1528254 & 6.5086 & 6.4878 & TRN & \\
\hline CHEMBL 3687148 & 1528254 & 7.0809 & 7.3517 & TRN & \\
\hline CHEMBL 3687164 & 1528254 & 7.0 & 6.7042 & TRN & \\
\hline CHEMBL 3687168 & 1528254 & 7.7447 & 7.2917 & TRN & \\
\hline CHEMBL 3687140 & 1528254 & 6.3098 & 7.0122 & TRN & \\
\hline CHEMBL3687111 & 1528254 & 7.8539 & 7.8201 & TRN & \\
\hline CHEMBL 3966676 & 1528254 & 8.0 & 8.1653 & TRN & \\
\hline CHEMBL 3687123 & 1528254 & 6.2596 & 6.37 & TRN & \\
\hline CHEMBL 3687182 & 1528254 & 7.9208 & 7.9102 & TRN & \\
\hline CHEMBL 3687158 & 1528254 & 7.8539 & 7.8504 & TRN & \\
\hline CHEMBL3687144 & 1528254 & 5.2596 & 5.9195 & TST & \\
\hline
\end{tabular}


Supplemental Table S2.txt

\begin{tabular}{|c|c|c|c|c|}
\hline CHEMBL 3687174 & 1528254 & 6.8861 & 6.9504 & TRN \\
\hline CHEMBL 3682432 & 1528254 & 7.5686 & 7.3087 & TST \\
\hline CHEMBL3687132 & 1528254 & 8.1549 & 8.2196 & TRN \\
\hline CHEMBL 3682430 & 1528254 & 8.699 & 8.6345 & TRN \\
\hline CHEMBL 3687154 & 1528254 & 6.6021 & 6.9977 & TRN \\
\hline CHEMBL 3687151 & 1528254 & 8.0969 & 7.6321 & TRN \\
\hline CHEMBL3682433 & 1528254 & 7.5229 & 7.829 & TRN \\
\hline CHEMBL 3682422 & 1528254 & 7.0 & 7.0642 & TRN \\
\hline CHEMBL 3687163 & 1528254 & 7.1549 & 7.2968 & TRN \\
\hline CHEMBL3687116 & 1528254 & 6.5376 & 6.3538 & TST \\
\hline CHEMBL3687113 & 1528254 & 7.2218 & 7.3653 & TRN \\
\hline CHEMBL3687157 & 1528254 & 6.1739 & 5.8959 & TRN \\
\hline CHEMBL 3687136 & 1528254 & 7.3872 & 7.4883 & TRN \\
\hline CHEMBL 3682421 & 1528254 & 6.7696 & 6.6672 & TRN \\
\hline CHEMBL 3687126 & 1528254 & 7.6198 & 7.4809 & TRN \\
\hline CHEMBL3687178 & 1528254 & 7.4949 & 7.5075 & TRN \\
\hline CHEMBL3687133 & 1528254 & 7.6198 & 7.8062 & TRN \\
\hline CHEMBL 3687120 & 1528254 & 7.0555 & 7.0012 & TRN \\
\hline CHEMBL 3687155 & 1528254 & 7.5229 & 7.2479 & TRN \\
\hline CHEMBL 3687138 & 1528254 & 7.6383 & 7.43 & TRN \\
\hline CHEMBL 3687175 & 1528254 & 8.2218 & 7.8604 & TST \\
\hline CHEMBL3687137 & 1528254 & 7.301 & 7.2413 & TST \\
\hline CHEMBL 3687186 & 1528254 & 8.699 & 8.4687 & TRN \\
\hline CHEMBL3687134 & 1528254 & 6.3372 & 6.7598 & TST \\
\hline CHEMBL 3687115 & 1528254 & 6.4815 & 6.5328 & TRN \\
\hline CHEMBL 3687143 & 1528254 & 7.2676 & 7.0514 & TRN \\
\hline CHEMBL3687169 & 1528254 & 7.0706 & 7.0213 & TRN \\
\hline CHEMBL 3687129 & 1528254 & 8.2218 & 7.9506 & TRN \\
\hline CHEMBL 3687114 & 1528254 & 6.4559 & 6.5873 & TRN \\
\hline CHEMBL 3687161 & 1528254 & 5.7212 & 6.21399 & 99999999995 \\
\hline CHEMBL 3687145 & 1528254 & 5.8239 & 5.9171 & TST \\
\hline CHEMBL 3682424 & 1528254 & 6.7959 & 6.4426 & TRN \\
\hline CHEMBL3912495 & 1528254 & 8.2218 & 8.3611 & TST \\
\hline CHEMBL3687162 & 1528254 & 7.2596 & 7.1961 & TST \\
\hline CHEMBL3687170 & 1528254 & 6.5528 & 7.2451 & TST \\
\hline CHEMBL3687172 & 1528254 & 7.3768 & 6.9425 & TST \\
\hline CHEMBL 3682435 & 1528254 & 6.9208 & 6.9859 & TST \\
\hline CHEMBL 3682428 & 1528254 & 8.0 & 8.0706 & TRN \\
\hline CHEMBL3687171 & 1528254 & 6.9208 & 6.8088 & TST \\
\hline CHEMBL3687150 & 1528254 & 7.0132 & 6.978 & TRN \\
\hline CHEMBL 3687118 & 1528254 & 7.3872 & 7.5512 & TRN \\
\hline CHEMBL 3687166 & 1528254 & 6.9586 & 6.8326 & TST \\
\hline CHEMBL3687135 & 1528254 & 6.6576 & 7.0572 & TST \\
\hline CHEMBL3687146 & 1528254 & 5.1805 & 6.2542 & TST \\
\hline CHEMBL 3687119 & 1528254 & 6.8539 & 6.8159 & TRN \\
\hline CHEMBL 3687183 & 1528254 & 8.0 & 7.4362 & TST \\
\hline CHEMBL224988 & 429507 & 3.0 & 2.8428 & TRN \\
\hline CHEMBL374758 & 429507 & 5.1308 & 4.0625 & TRN \\
\hline
\end{tabular}

Page 25329 


\begin{tabular}{|c|c|c|c|c|c|}
\hline \\
\hline CHEMBL375078 & 429507 & 3.0 & 2.887 & TRN & \\
\hline CHEMBL385799 & 429507 & 3.0 & 3.0548 & TST & \\
\hline CHEMBL222988 & 429507 & 3.0 & 2.9023 & TRN & \\
\hline CHEMBL225169 & 429507 & 3.0 & 3.6537 & TST & \\
\hline CHEMBL222712 & 429507 & 3.0 & 4.0446 & TRN & \\
\hline CHEMBL222149 & 429507 & 4.7235 & 4.1606 & TRN & \\
\hline CHEMBL385800 & 429507 & 3.0 & 3.0412 & TST & \\
\hline CHEMBL222795 & 429507 & 4.0048 & 3.4737 & TRN & \\
\hline CHEMBL116040 & 429507 & 3.0 & 2.82 & TRN & \\
\hline CHEMBL222292 & 429507 & 3.0 & 2.9541 & TRN & \\
\hline CHEMBL221669 & 429507 & 3.0 & 2.9282 & TRN & \\
\hline CHEMBL373715 & 429507 & 3.0 & 2.9916 & TRN & \\
\hline CHEMBL117447 & 429507 & 4.1624 & 3.4827 & TST & \\
\hline CHEMBL118883 & 429507 & 3.0 & 2.7956 & TST & \\
\hline CHEMBL376291 & 429507 & 4.6596 & 3.9315 & TRN & \\
\hline CHEMBL 223000 & 429507 & 4.5513 & 3.7462 & TRN & \\
\hline CHEMBL118305 & 429507 & 3.0 & 2.8875 & TST & \\
\hline CHEMBL375304 & 429507 & 4.6778 & 3.9402 & TRN & \\
\hline CHEMBL374629 & 429507 & 3.0 & 3.0443 & TST & \\
\hline CHEMBL222891 & 429507 & 3.0 & 3.2612 & TRN & \\
\hline CHEMBL374905 & 429507 & 3.0 & 3.38100 & $\partial 0000000002$ & TRN \\
\hline CHEMBL426562 & 429507 & 4.9101 & 4.16100 & 00000000005 & TRN \\
\hline CHEMBL 221362 & 429507 & 3.0 & 3.8507 & TRN & \\
\hline CHEMBL222190 & 429507 & 4.5143 & 3.0223 & TRN & \\
\hline CHEMBL375126 & 429507 & 4.8996 & 4.0262 & TRN & \\
\hline CHEMBL223254 & 429507 & 3.0 & 2.8742 & TRN & \\
\hline CHEMBL 376435 & 429507 & 3.0 & 3.2159 & TRN & \\
\hline CHEMBL 221873 & 429507 & 3.0 & 3.6148 & TRN & \\
\hline CHEMBL115897 & 429507 & 3.0 & 2.9603 & TST & \\
\hline CHEMBL 325480 & 429507 & 3.0 & 2.8958 & TST & \\
\hline CHEMBL333636 & 429507 & 3.0 & 2.8142 & TRN & \\
\hline CHEMBL79466 & 429507 & 3.0 & 3.3597 & TRN & \\
\hline CHEMBL222851 & 429507 & 4.7423 & 4.0238 & TRN & \\
\hline CHEMBL222989 & 429507 & 3.0 & 3.3681 & TRN & \\
\hline CHEMBL 222660 & 429507 & 3.0 & 2.8127 & TST & \\
\hline CHEMBL 374331 & 429507 & 5.6216 & 4.058 & TRN & \\
\hline CHEMBL 223785 & 429507 & 3.0 & 2.8798 & TRN & \\
\hline CHEMBL 223001 & 429507 & 3.0 & 3.2073 & TRN & \\
\hline CHEMBL225175 & 429507 & 3.0 & 3.4248 & TRN & \\
\hline CHEMBL373781 & 429507 & 5.1733 & 3.6134 & TRN & \\
\hline CHEMBL222849 & 429507 & 3.0 & 3.4526 & TRN & \\
\hline CHEMBL 221512 & 429507 & 3.0 & 3.8251 & TRN & \\
\hline CHEMBL376228 & 429507 & 3.0 & 2.9731 & TST & \\
\hline CHEMBL376290 & 429507 & 3.0 & 2.9595 & TRN & \\
\hline CHEMBL 386000 & 429507 & 3.0 & 3.3241 & TRN & \\
\hline CHEMBL 224822 & 429507 & 3.0 & 2.9142 & TST & \\
\hline CHEMBL60569 & 429507 & 3.0 & 3.3399 & TRN & \\
\hline CHEMBL222711 & 429507 & 3.0 & 3.8929 & TRN & \\
\hline
\end{tabular}




\begin{tabular}{|c|c|c|c|c|c|c|}
\hline \multicolumn{7}{|c|}{ oplemental Ta } \\
\hline CHEMBL116649 & 429507 & 3.0 & 3.0941 & TST & & \\
\hline CHEMBL115581 & 429507 & 3.0 & 3.7721 & TRN & & \\
\hline CHEMBL223039 & 429507 & 3.0 & 3.0312 & TRN & & \\
\hline CHEMBL374970 & 429507 & 3.0 & 3.4232 & TRN & & \\
\hline CHEMBL222999 & 429507 & 3.0 & 3.3073 & TRN & & \\
\hline CHEMBL327012 & 429507 & 3.0 & 2.99 & TST & & \\
\hline CHEMBL374740 & 429507 & 3.0 & 3.0425 & TRN & & \\
\hline CHEMBL385132 & 429507 & 3.0 & 4.0965 & TRN & & \\
\hline CHEMBL 221830 & 429507 & 4.248 & 3.0362 & TST & & \\
\hline CHEMBL326294 & 429507 & 3.0 & 2.8233 & TST & & \\
\hline CHEMBL442046 & 429507 & 3.0 & 3.0233 & TST & & \\
\hline CHEMBL222752 & 429507 & 3.0 & 3.9848 & TRN & & \\
\hline CHEMBL222644 & 429507 & 3.0 & 3.8251 & TRN & & \\
\hline CHEMBL224884 & 429507 & 3.0 & 2.8484 & TRN & & \\
\hline CHEMBL 376518 & 429507 & 3.0 & 3.6423 & TRN & & \\
\hline CHEMBL1590308 & 954660 & 4.0042 & 3.4222 & TST & & \\
\hline CHEMBL392695 & 954660 & 5.9652 & 5.9652 & TRN & & \\
\hline CHEMBL 9470 & 954660 & 5.9225 & 5.524 & TST & & \\
\hline CHEMBL449158 & 954660 & 6.4727 & 6.9818 & TST & & \\
\hline CHEMBL2363137 & 954660 & 5.1232 & 5.1232 & TRN & & \\
\hline CHEMBL1909414 & 954660 & 4.2594 & 4.2594 & TRN & & \\
\hline CHEMBL180127 & 954660 & 5.0826 & 5.0826 & TRN & & \\
\hline CHEMBL558642 & 954660 & 3.6115 & 3.6115 & TRN & & \\
\hline CHEMBL509032 & 954660 & 4.1148 & 4.1148 & TRN & & \\
\hline CHEMBL 379300 & 954660 & 6.2991 & 6.2991 & TRN & & \\
\hline CHEMBL259181 & 954660 & 4.7395 & 4.7395 & TRN & & \\
\hline CHEMBL3199475 & 954660 & 4.8437 & 4.8437 & TRN & & \\
\hline CHEMBL220241 & 954660 & 6.8514 & 6.8514 & TRN & & \\
\hline CHEMBL1788116 & 954660 & 4.6269 & 4.6269 & TRN & & \\
\hline CHEMBL1970879 & 954660 & 4.5241 & 4.5241 & TRN & & \\
\hline CHEMBL472940 & 954660 & 3.7179 & 3.7179 & TRN & & \\
\hline CHEMBL3186408 & 954660 & 3.0173 & 3.8958 & TST & & \\
\hline CHEMBL 2144069 & 954660 & 6.0938 & 6.0938 & TRN & & \\
\hline CHEMBL189584 & 954660 & 4.9723 & 4.9723 & TRN & & \\
\hline CHEMBL 373751 & 954660 & 3.056 & 3.056 & TRN & & \\
\hline CHEMBL258844 & 954660 & 4.9174 & 4.9174 & TRN & & \\
\hline CHEMBL1516890 & 954660 & 4.0365 & 4.0365 & TRN & & \\
\hline CHEMBL 2005886 & 954660 & 5.1173 & 5.1173 & TRN & & \\
\hline CHEMBL393929 & 954660 & 3.4572 & 3.4572 & TRN & & \\
\hline CHEMBL202721 & 954660 & 6.0736 & 6.0736 & TRN & & \\
\hline CHEMBL191334 & 954660 & 4.4479 & 4.4479 & TRN & & \\
\hline CHEMBL240954 & 954660 & 3.8464 & 3.7674 & TST & & \\
\hline CHEMBL379975 & 954660 & 5.58200 & 000000000 & $\partial 1$ & 5.582000000000001 & TRN \\
\hline CHEMBL1242367 & 954660 & 4.6579 & 4.6579 & TRN & & \\
\hline CHEMBL514499 & 954660 & 7.9578 & 7.9578 & TRN & & \\
\hline CHEMBL 300389 & 954660 & 7.1142 & 7.1142 & TRN & & \\
\hline CHEMBL192566 & 954660 & 8.1337 & 8.6004 & TST & & \\
\hline CHEMBL1190711 & 954660 & 5.5684 & 5.5684 & TRN & & \\
\hline
\end{tabular}




\begin{tabular}{|c|c|c|c|c|c|c|}
\hline \multicolumn{6}{|c|}{ Supplemental Table S2.txt } & \\
\hline CHEMBL1256459 & 954660 & 7.4249 & 7.4249 & TRN & & \\
\hline CHEMBL585951 & 954660 & 5.9598 & 5.9598 & TRN & & \\
\hline CHEMBL1643959 & 954660 & 4.3641 & 4.3641 & TRN & & \\
\hline CHEMBL512504 & 954660 & 3.701 & 3.701 & TRN & & \\
\hline CHEMBL483849 & 954660 & 3.4383 & 3.4383 & TRN & & \\
\hline CHEMBL515416 & 954660 & 4.8558 & 4.8558 & TRN & & \\
\hline CHEMBL 210618 & 954660 & 3.0456 & 3.0456 & TRN & & \\
\hline CHEMBL412142 & 954660 & 4.3825 & 4.3825 & TRN & & \\
\hline CHEMBL1673039 & 954660 & 3.4754 & 3.4754 & TRN & & \\
\hline CHEMBL3349342 & 954660 & 3.8488 & 3.8488 & TRN & & \\
\hline CHEMBL1230020 & 954660 & 4.2318 & 4.2318 & TRN & & \\
\hline CHEMBL188678 & 954660 & 4.6653 & 4.6653 & TRN & & \\
\hline CHEMBL483847 & 954660 & \multicolumn{3}{|c|}{4.781000000000001} & 4.781000000000001 & TRN \\
\hline CHEMBL577784 & 954660 & 6.152 & 6.152 & TRN & & \\
\hline CHEMBL1404918 & 954660 & 2.9371 & 2.9371 & TRN & & \\
\hline CHEMBL573107 & 954660 & 5.7994 & 5.7994 & TRN & & \\
\hline CHEMBL3392440 & 954660 & 4.08 & 4.08 & TRN & & \\
\hline CHEMBL 213100 & 954660 & 2.8313 & 4.8214 & TST & & \\
\hline CHEMBL 209148 & 954660 & 4.937 & 4.9573 & TST & & \\
\hline CHEMBL92309 & 954660 & 3.7448 & 3.2869 & TST & & \\
\hline CHEMBL1357247 & 954660 & 3.0033 & 3.4175 & TST & & \\
\hline CHEMBL 221137 & 954660 & 4.6394 & 4.8858 & TST & & \\
\hline CHEMBL 222102 & 954660 & 3.977 & 4.0087 & TST & & \\
\hline CHEMBL65 & 954660 & 8.3407 & 8.4048 & TST & & \\
\hline CHEMBL102714 & 954660 & 4.4114 & 3.865 & TST & & \\
\hline CHEMBL135561 & 954660 & 4.0769 & 4.7388 & TST & & \\
\hline CHEMBL193830 & 877369 & 9.0 & 7.3902 & TST & & \\
\hline CHEMBL 2179878 & 877369 & 9.0 & 7.3225 & TST & & \\
\hline CHEMBL 2179841 & 877369 & 6.2218 & 5.9539 & TRN & & \\
\hline CHEMBL 2180262 & 877369 & 6.8539 & 6.324 & TST & & \\
\hline CHEMBL 2179846 & 877369 & 6.0 & 6.0543 & TRN & & \\
\hline CHEMBL2179856 & 877369 & 6.301 & 6.0151 & TRN & & \\
\hline CHEMBL 2179840 & 877369 & 5.6383 & 4.9041 & TRN & & \\
\hline CHEMBL2180260 & 877369 & 5.8239 & 6.5326 & TRN & & \\
\hline CHEMBL 2180254 & 877369 & 7.301 & 7.1948 & TRN & & \\
\hline CHEMBL 2179837 & 877369 & 5.5229 & 5.2627 & TRN & & \\
\hline CHEMBL 2179844 & 877369 & 7.2218 & 6.7834 & TRN & & \\
\hline CHEMBL 365992 & 877369 & 7.5229 & 7.1385 & TST & & \\
\hline CHEMBL370523 & 877369 & 7.2218 & 6.5804 & TRN & & \\
\hline CHEMBL 2179872 & 877369 & 7.8539 & 6.7216 & TST & & \\
\hline CHEMBL 2179875 & 877369 & 6.8861 & 7.2612 & TST & & \\
\hline CHEMBL 2179876 & 877369 & 6.4089 & 6.5956 & TST & & \\
\hline CHEMBL2179873 & 877369 & 7.9586 & 7.3356 & TST & & \\
\hline CHEMBL 2180253 & 877369 & 7.5229 & 7.5509 & TRN & & \\
\hline CHEMBL 2179857 & 877369 & 6.5686 & 6.0487 & TRN & & \\
\hline CHEMBL 2179848 & 877369 & 5.1487 & 5.1747 & TRN & & \\
\hline CHEMBL 2179858 & 877369 & 5.3872 & 5.7205 & TRN & & \\
\hline CHEMBL2179866 & 877369 & 5.9208 & 6.1262 & TRN & & \\
\hline
\end{tabular}

Page 25332 


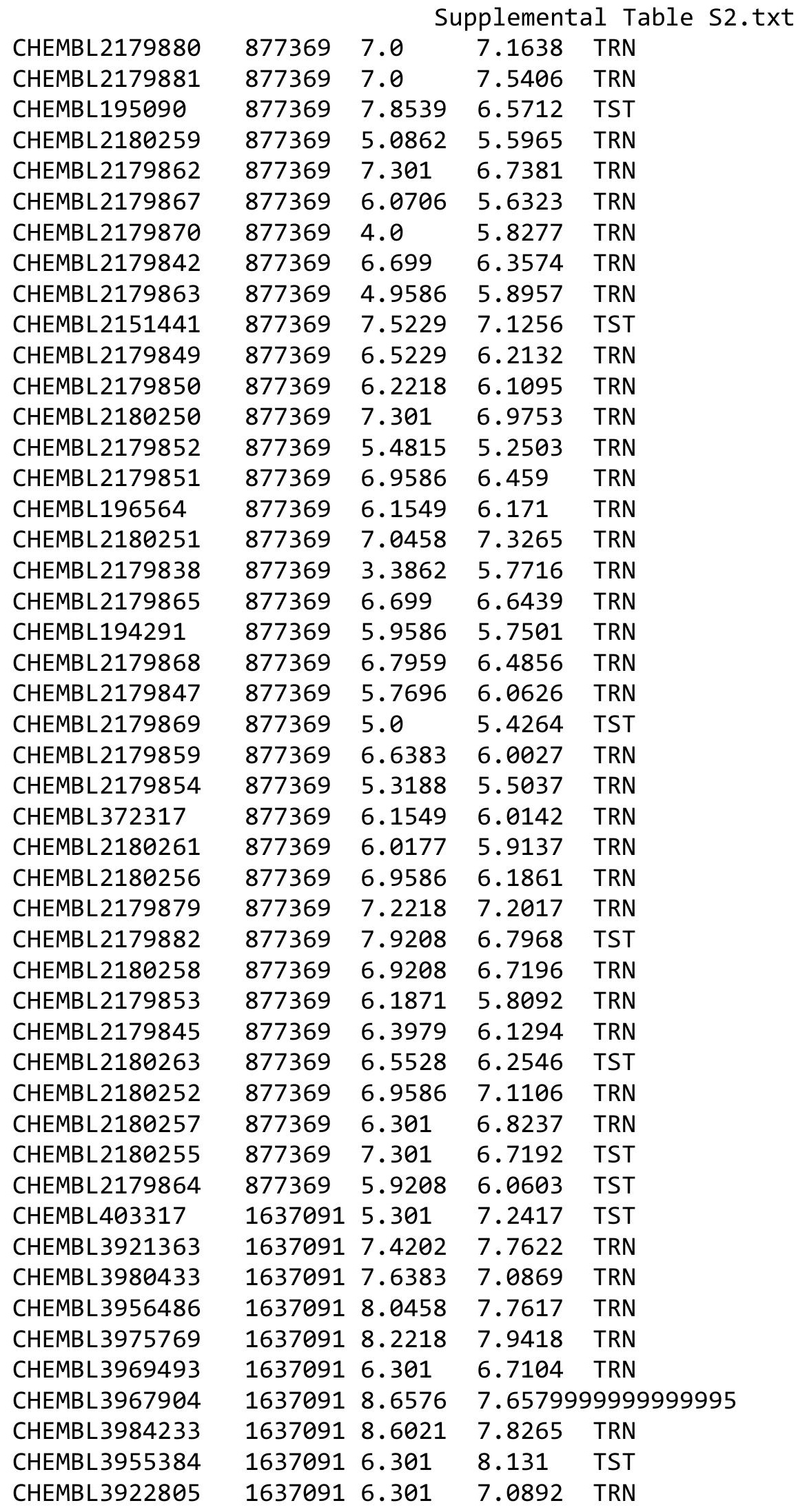


Supplemental Table S2.txt

\begin{tabular}{|c|c|c|c|c|c|}
\hline CHEMBL3897431 & 1637091 & 7.4437 & 8.3481 & TST & \\
\hline CHEMBL3892523 & 1637091 & 7.6383 & 7.6016 & TRN & \\
\hline CHEMBL3898895 & 1637091 & 7.8539 & 7.7471 & TRN & \\
\hline CHEMBL 3944228 & 1637091 & 7.4949 & 7.0302 & TRN & \\
\hline CHEMBL3889538 & 1637091 & 8.0969 & 7.472 & TST & \\
\hline CHEMBL 3927633 & 1637091 & 8.6021 & 8.464 & TRN & \\
\hline CHEMBL3956432 & 1637091 & 7.4437 & 7.4383 & TRN & \\
\hline CHEMBL3911182 & 1637091 & 6.301 & 7.3208 & TRN & \\
\hline CHEMBL 3985283 & 1637091 & 8.5229 & 8.8944 & TRN & \\
\hline CHEMBL3939034 & 1637091 & 8.2366 & 8.4397 & TRN & \\
\hline CHEMBL 3947283 & 1637091 & 8.1549 & 7.8849 & TRN & \\
\hline CHEMBL 3908441 & 1637091 & 7.4437 & 7.6911 & TRN & \\
\hline CHEMBL3908400 & 1637091 & 7.585 & 7.7619 & TRN & \\
\hline CHEMBL3949652 & 1637091 & 8.0 & 7.9494 & TRN & \\
\hline CHEMBL3915029 & 1637091 & 8.1549 & 7.9105 & TRN & \\
\hline CHEMBL3891679 & 1637091 & 6.301 & 6.7076 & TRN & \\
\hline CHEMBL3911959 & 1637091 & 6.301 & 6.3206 & TRN & \\
\hline CHEMBL3905562 & 1637091 & 8.3979 & 7.6911 & TRN & \\
\hline CHEMBL3956532 & 1637091 & 7.4685 & 7.1255 & TRN & \\
\hline CHEMBL3940112 & 1637091 & 7.6198 & 7.5763 & TRN & \\
\hline CHEMBL3895261 & 1637091 & 8.1549 & 7.6101 & TRN & \\
\hline CHEMBL3906078 & 1637091 & 7.699 & \multicolumn{2}{|c|}{7.7860000000000005} & TRN \\
\hline CHEMBL3978275 & 1637091 & 6.301 & 6.6147 & TRN & \\
\hline CHEMBL3908469 & 1637091 & 8.301 & 7.9957 & TRN & \\
\hline CHEMBL 3928975 & 1637091 & 8.2596 & 7.8242 & TRN & \\
\hline CHEMBL 3974200 & 1637091 & 7.3468 & 7.7622 & TRN & \\
\hline CHEMBL 3974250 & 1637091 & 8.0 & 8.0576 & TRN & \\
\hline CHEMBL3960431 & 1637091 & 7.5229 & 7.7135 & TRN & \\
\hline CHEMBL3953912 & 1637091 & 6.301 & 7.343 & TRN & \\
\hline CHEMBL 3932925 & 1637091 & 6.6198 & 6.8546 & TRN & \\
\hline CHEMBL 3946241 & 1637091 & 7.6383 & 7.3727 & TRN & \\
\hline CHEMBL 3963000 & 1637091 & 6.4365 & 6.6134 & TRN & \\
\hline CHEMBL3921255 & 1637091 & 7.2757 & 7.909 & TST & \\
\hline CHEMBL 3917761 & 1637091 & 7.9586 & \multicolumn{2}{|c|}{7.582999999999999} & TRN \\
\hline CHEMBL3971676 & 1637091 & 8.3468 & 8.5286 & TRN & \\
\hline CHEMBL3925628 & 1637091 & 8.301 & 8.2982 & TRN & \\
\hline CHEMBL3909750 & 1637091 & 8.301 & 8.2327 & TRN & \\
\hline CHEMBL 3932563 & 1637091 & 7.7033 & 7.6863 & TRN & \\
\hline CHEMBL3982672 & 1637091 & 8.0969 & 8.2112 & TRN & \\
\hline CHEMBL3942065 & 1637091 & 6.4365 & 6.7816 & TRN & \\
\hline CHEMBL3921397 & 1637091 & 7.4437 & 7.9032 & TRN & \\
\hline CHEMBL3951758 & 1637091 & 8.0 & 8.0775 & TRN & \\
\hline CHEMBL3941990 & 1637091 & 8.3188 & 8.6526 & TRN & \\
\hline CHEMBL3926872 & 1637091 & 6.301 & 7.2125 & TST & \\
\hline CHEMBL3966858 & 1637091 & 7.3979 & 7.775 & TRN & \\
\hline CHEMBL3909253 & 1637091 & 6.301 & \multicolumn{2}{|c|}{6.3660000000000005} & TRN \\
\hline CHEMBL3983862 & 1637091 & 8.301 & 8.1021 & TRN & \\
\hline CHEMBL 3967320 & 1637091 & 7.4559 & 7.1318 & TRN & \\
\hline
\end{tabular}


Supplemental Table S2.txt

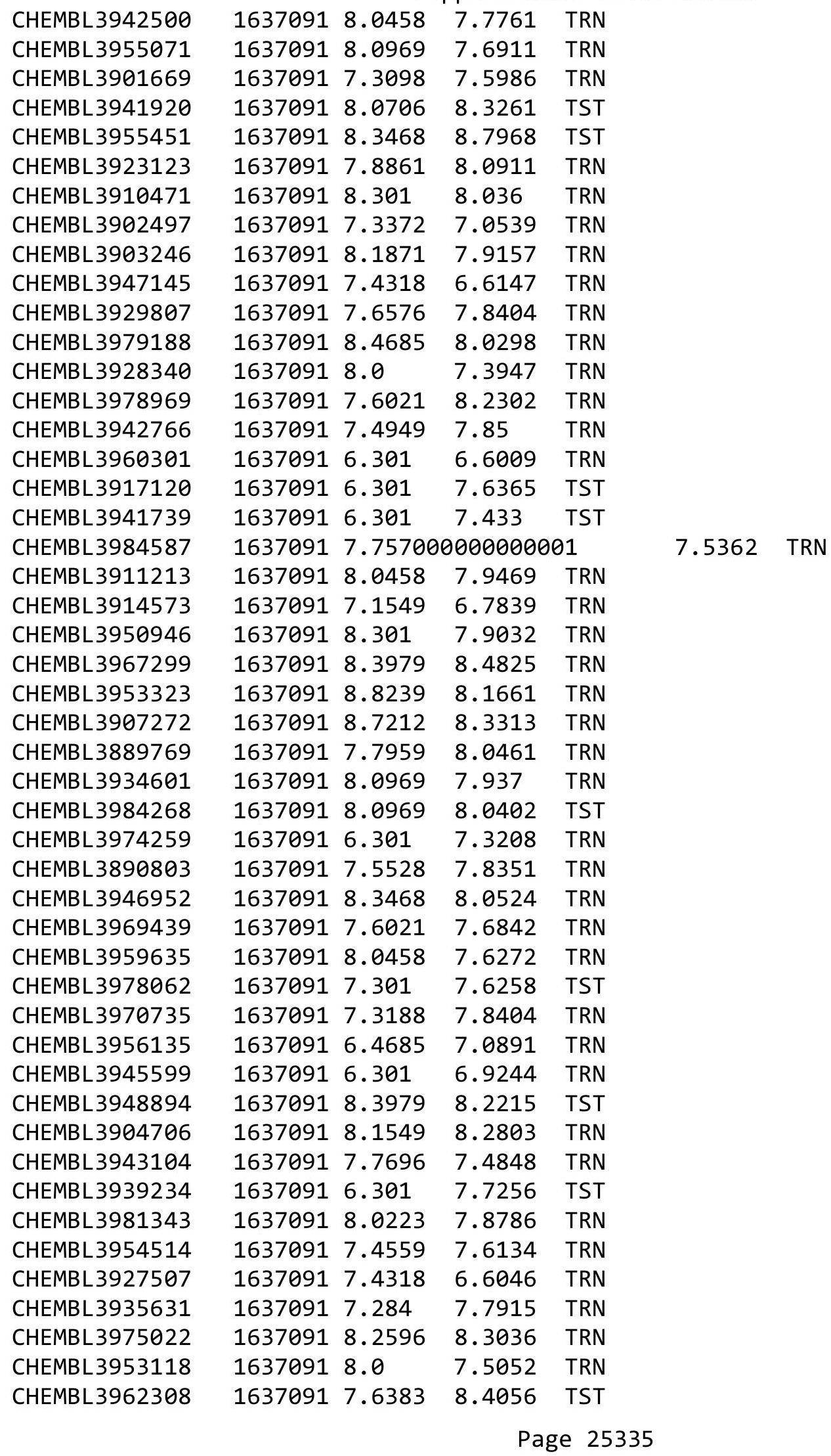


Supplemental Table S2.txt

\begin{tabular}{|c|c|c|c|c|}
\hline CHEMBL3962383 & 1637091 & 7.3665 & 7.5021 & TRN \\
\hline CHEMBL3974709 & 1637091 & 8.1249 & 7.564 & TRN \\
\hline CHEMBL3951943 & 1637091 & 7.284 & 6.9328 & TRN \\
\hline CHEMBL3927340 & 1637091 & 8.8239 & 8.8501 & TRN \\
\hline CHEMBL3901298 & 1637091 & 6.433 & 8.1051 & TST \\
\hline CHEMBL 3889574 & 1637091 & 8.2218 & 8.2167 & TRN \\
\hline CHEMBL3895934 & 1637091 & 6.301 & 7.195 & TST \\
\hline CHEMBL3906942 & 1637091 & 8.3468 & 8.1242 & TRN \\
\hline CHEMBL3952441 & 1637091 & 8.1079 & 8.0717 & TRN \\
\hline CHEMBL3954296 & 1637091 & 8.5229 & 8.1259 & TST \\
\hline CHEMBL3980591 & 1637091 & 6.301 & 7.9178 & TST \\
\hline CHEMBL3958775 & 1637091 & 7.8861 & 7.9303 & TRN \\
\hline CHEMBL3939368 & 1637091 & 7.9586 & 7.5854 & TRN \\
\hline CHEMBL3954412 & 1637091 & 7.7696 & 7.9539 & TRN \\
\hline CHEMBL3947163 & 1637091 & 7.9586 & 8.005 & TRN \\
\hline CHEMBL3963362 & 1637091 & 8.6021 & 8.9608 & TRN \\
\hline CHEMBL3935535 & 1637091 & 8.3468 & 8.0983 & TRN \\
\hline CHEMBL3946856 & 1637091 & 8.1249 & 8.0911 & TST \\
\hline CHEMBL3903401 & 1637091 & 7.3768 & 7.6623 & TST \\
\hline CHEMBL3952732 & 1637091 & 8.1549 & 8.0058 & TRN \\
\hline CHEMBL3976771 & 1637091 & 7.4437 & 7.2737 & TRN \\
\hline CHEMBL3927306 & 1637091 & 6.301 & 7.2408 & TST \\
\hline CHEMBL3924581 & 1637091 & 8.3979 & 8.0735 & TRN \\
\hline CHEMBL3951222 & 1637091 & 8.3979 & 8.426 & TRN \\
\hline CHEMBL3976709 & 1637091 & 7.4437 & 7.9418 & TST \\
\hline CHEMBL3894747 & 1637091 & 7.8861 & 8.0596 & TRN \\
\hline CHEMBL3906914 & 1637091 & 7.6021 & 7.33299 & 9999999999 \\
\hline CHEMBL3904512 & 1637091 & 8.699 & 8.0911 & TST \\
\hline CHEMBL3917426 & 1637091 & 7.9393 & 7.4684 & TST \\
\hline CHEMBL3982939 & 1637091 & 7.6021 & 7.8404 & TST \\
\hline CHEMBL3891981 & 1637091 & 7.8539 & 7.8805 & TRN \\
\hline CHEMBL3978233 & 1637091 & 8.3468 & 8.3492 & TST \\
\hline CHEMBL3970741 & 1637091 & 8.0969 & 8.4397 & TRN \\
\hline CHEMBL3986732 & 1637091 & 7.3768 & 7.5131 & TRN \\
\hline CHEMBL3972207 & 1637091 & 7.9586 & 7.7103 & TST \\
\hline CHEMBL3962352 & 1637091 & 6.301 & 6.8768 & TST \\
\hline CHEMBL3941432 & 1637091 & 7.426 & 7.7708 & TRN \\
\hline CHEMBL3890461 & 1637091 & 7.6576 & 7.96299 & 9999999999 \\
\hline CHEMBL3972172 & 1637091 & 7.4202 & 7.5567 & TST \\
\hline CHEMBL3950418 & 1637091 & 6.301 & 6.4086 & TST \\
\hline CHEMBL3924852 & 1637091 & 8.3979 & 7.78600 & 00000000005 \\
\hline CHEMBL3902429 & 1637091 & 8.4202 & 7.8289 & TST \\
\hline CHEMBL3922105 & 1637091 & 6.0 & 6.4799 & TRN \\
\hline CHEMBL3949860 & 1637091 & 8.0969 & 8.3137 & TRN \\
\hline CHEMBL3950452 & 1637091 & 8.4559 & 8.1661 & TRN \\
\hline CHEMBL3944194 & 1637091 & 6.3468 & 7.0663 & TST \\
\hline CHEMBL 3894546 & 1637091 & 7.5229 & 7.6821 & TRN \\
\hline CHEMBL3953851 & 1637091 & 7.4437 & 7.5765 & TST \\
\hline
\end{tabular}


Supplemental Table S2.txt

\begin{tabular}{|c|c|c|c|c|}
\hline CHEMBL3917368 & 1637091 & 8.3979 & 7.8851 & TST \\
\hline CHEMBL 3904006 & 1637091 & 5.0969 & 7.7845 & \\
\hline HEMBL3963460 & 637091 & 8.301 & 7.9553 & \\
\hline HEMBL 3900523 & 1637091 & 8.301 & 8.2 & RN \\
\hline HEMBL3960359 & 637091 & 8.4559 & 8.4989 & RN \\
\hline HEMBL3910138 & 637100 & 4.0 & 3.8524 & $\mathrm{RN}$ \\
\hline HEMBL3951888 & 637100 & 4.0 & .0759 & RN \\
\hline HEMBL3958796 & 1637100 & 4.0 & 3.9803 & RN \\
\hline HEMBL3961908 & 1637100 & 4.0 & 4.1766 & RN \\
\hline HEMBL3907481 & 1637100 & 4.0 & 3.5271 & $\mathrm{RN}$ \\
\hline CHEMBL3925005 & 1637100 & 4.0 & 3.9149 & $\mathrm{RN}$ \\
\hline HEMBL3925129 & 1637100 & 6.0 & 5.1941 & ST \\
\hline HEMBL3979857 & 1637100 & 4.0 & 3.7994 & RN \\
\hline HEMBL3955031 & 1637100 & 7.0 & 5.9137 & ST \\
\hline HEMBL3974367 & 1637100 & 6.0 & 5.6433 & RN \\
\hline CHEMBL3908718 & 1637100 & 4.0 & 4.2211 & $\mathrm{RN}$ \\
\hline HEMBL3942249 & 1637100 & 4. & 4.2707 & SI \\
\hline CHEMBL3939713 & 1637100 & 4.0 & 4.2397 & RN \\
\hline HEMBL3976027 & 1637100 & 5.0 & 6.6944 & $\mathrm{RN}$ \\
\hline CHEMBL3958272 & 1637100 & 4.0 & 3.8138 & TRN \\
\hline CHEMBL2216876 & 1637100 & 6 . & 5.7509 & RN \\
\hline HEMBL392 & 1637100 & 6. & 5.8162 & $\mathrm{RN}$ \\
\hline CHEMBL3923285 & 1637100 & 7.0 & 5.7074 & ST \\
\hline CHEMBL3969116 & 1637100 & 4.0 & 3.6939 & TRN \\
\hline CHEMBL3932968 & 1637100 & 4.0 & 3.8668 & TRN \\
\hline CHEMBL391 & 1637100 & 4. & 4.4244 & IRN \\
\hline HEMBL394 & 1637100 & 5 . & 5.0509 & TRN \\
\hline CHEMBL3978509 & 1637100 & 4.0 & 4.0882 & TST \\
\hline CHEMBL3908417 & 1637100 & 4.0 & 4.0377 & TRN \\
\hline CHEMBL 3947356 & 1637100 & 4.0 & 4.0015 & TRN \\
\hline CHEMBL3969273 & 1637100 & 6. & 5.6408 & TRN \\
\hline CHEMBL395 & 1637100 & 4. & 4.019 & TRN \\
\hline CHEMBL3982444 & 1637100 & 4.0 & 4.0058 & TRN \\
\hline CHEMBL3932332 & 1637100 & 4.0 & 4.6889 & TST \\
\hline CHEMBL3920973 & 1637100 & 7.0 & 6.1324 & TRN \\
\hline CHEMBL 3903621 & 1637100 & 4 . & 4.3641 & TST \\
\hline CHEMBL39e & 1637100 & 4.0 & 4.8218 & TRN \\
\hline CHEMBL3950472 & 1637100 & 4.0 & 4.213 & TRN \\
\hline CHEMBL3940977 & 1637100 & 4.0 & 3.9616 & TRN \\
\hline CHEMBL3903458 & 1637100 & 4.0 & 4.2917 & TRN \\
\hline CHEMBL 3984208 & 1637100 & 4.0 & 5.5723 & TRN \\
\hline CHEMBL3960932 & 1637100 & 4.0 & 4.7801 & TST \\
\hline CHEMBL3893129 & 1637100 & 4.0 & 4.2939 & TRN \\
\hline CHEMBL3929045 & 1637100 & 4.0 & 4.5588 & TRN \\
\hline CHEMBL3967531 & 1637100 & 4.0 & 3.8827 & TST \\
\hline CHEMBL3972055 & 1637100 & 4.0 & 4.3257 & IRIV \\
\hline CHEMBL3900898 & 1637100 & 4.0 & 4.9474 & | \\
\hline CHEMBL3904707 & 1637100 & 4.0 & 3.4195 & TRN \\
\hline
\end{tabular}

Page 25337 


\begin{tabular}{|c|c|c|c|c|}
\hline \multicolumn{5}{|c|}{ 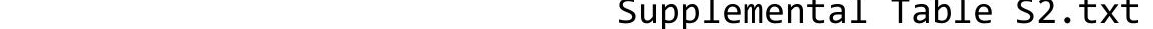 } \\
\hline CHEMBL3914753 & 1637100 & 4.0 & 4.0755 & TST \\
\hline CHEMBL3955440 & 1637100 & 7.0 & 4.7053 & TRN \\
\hline CHEMBL3981735 & 1637100 & 4.0 & 3.8892 & TRN \\
\hline CHEMBL3958075 & 1637100 & 7.0 & 5.9656 & TRN \\
\hline CHEMBL 3920754 & 1637100 & 4.0 & 3.8794 & TRN \\
\hline CHEMBL3896670 & 1637100 & 4.0 & 4.0315 & TRN \\
\hline CHEMBL3932981 & 1637100 & 4.0 & 3.9809 & TRN \\
\hline CHEMBL3969492 & 1637100 & 6.0 & 5.1825 & TRN \\
\hline CHEMBL3911175 & 1637100 & 4.0 & 4.2943 & TST \\
\hline CHEMBL3966914 & 1637100 & 4.0 & 4.0936 & TRN \\
\hline CHEMBL3934621 & 1637100 & 4.0 & 4.0909 & TST \\
\hline CHEMBL3967525 & 1637100 & 4.0 & 4.5032 & TST \\
\hline CHEMBL3954146 & 1637100 & 5.0 & 5.4356 & TRN \\
\hline CHEMBL3965684 & 1637100 & 5.0 & 4.9376 & TRN \\
\hline CHEMBL 3920543 & 1637100 & 4.0 & 4.5105 & TRN \\
\hline CHEMBL3929242 & 1637100 & 6.0 & 5.3294 & TRN \\
\hline CHEMBL3941010 & 1637100 & 4.0 & 5.2533 & TRN \\
\hline CHEMBL 3910674 & 1637100 & 6.0 & 5.7227 & TRN \\
\hline CHEMBL3986207 & 1637100 & 4.0 & 3.727 & TST \\
\hline CHEMBL3957119 & 1637100 & 4.0 & 4.4566 & TRN \\
\hline CHEMBL3919001 & 1637100 & 4.0 & 4.0427 & TST \\
\hline CHEMBL3979467 & 1637100 & 7.0 & 5.4969 & TRN \\
\hline CHEMBL3929965 & 1637100 & 4.0 & 4.4624 & TRN \\
\hline CHEMBL 3891083 & 1637100 & 4.0 & 4.6134 & TST \\
\hline CHEMBL 3978013 & 1637100 & 6.0 & 5.2892 & TRN \\
\hline CHEMBL3974743 & 1637100 & 7.0 & 6.0601 & TRN \\
\hline CHEMBL3927780 & 1637100 & 5.0 & 5.6188 & TRN \\
\hline CHEMBL3922769 & 1637100 & 4.0 & 5.2391 & TST \\
\hline CHEMBL3907079 & 1637100 & 6.0 & 5.9384 & TRN \\
\hline CHEMBL 3917537 & 1637100 & 4.0 & 5.0468 & TRN \\
\hline CHEMBL3918112 & 1637100 & 4.0 & 4.6806 & TST \\
\hline CHEMBL3955730 & 1637100 & 4.0 & 4.852 & TRN \\
\hline CHEMBL3965512 & 1637100 & 5.0 & 5.5211 & TRN \\
\hline CHEMBL3953621 & 1637100 & 4.0 & 3.9414 & TRN \\
\hline CHEMBL 3915312 & 1637100 & 6.0 & 6.1055 & TST \\
\hline CHEMBL3942692 & 1637100 & 7.0 & 5.7956 & TRN \\
\hline CHEMBL3905598 & 1637100 & 4.0 & 3.8155 & TRN \\
\hline CHEMBL3986800 & 1637100 & 6.0 & 5.0381 & TRN \\
\hline CHEMBL3966565 & 1637100 & 4.0 & 4.3527 & TRN \\
\hline CHEMBL 3972637 & 1637100 & 4.0 & 4.4447 & TST \\
\hline CHEMBL3974173 & 1637100 & 4.0 & 4.1028 & TST \\
\hline CHEMBL 3932626 & 1637100 & 5.0 & 5.8843 & TRN \\
\hline CHEMBL 3985040 & 1637100 & 6.0 & 5.7353 & TRN \\
\hline CHEMBL3917027 & 1637100 & 4.0 & 4.2379 & TRN \\
\hline CHEMBL 3986828 & 1637100 & 4.0 & 4.0163 & TRN \\
\hline CHEMBL 3949241 & 1637100 & 4.0 & 4.9928 & TRN \\
\hline CHEMBL 3917082 & 1637100 & 4.0 & 4.0683 & TST \\
\hline CHEMBL 3889687 & 1637100 & 4.0 & 4.1135 & TRN \\
\hline
\end{tabular}




\begin{tabular}{|c|c|c|c|c|c|}
\hline & & & & & \\
\hline CHEMBL3896375 & 1637100 & 5.0 & 5.8268 & TRN & \\
\hline CHEMBL3961040 & 1637100 & 4.0 & 4.5116 & TRN & \\
\hline CHEMBL3935435 & 1637100 & 4.0 & 4.5195 & TRN & \\
\hline CHEMBL3969965 & 1637100 & 7.0 & 5.4353 & TST & \\
\hline CHEMBL3961109 & 1637100 & 4.0 & 4.8203 & TRN & \\
\hline CHEMBL3979331 & 1637100 & 4.0 & 4.3421 & TRN & \\
\hline CHEMBL3983816 & 1637100 & 4.0 & 3.3003 & TRN & \\
\hline CHEMBL3948766 & 1637100 & 4.0 & 4.098 & TRN & \\
\hline CHEMBL3893036 & 1637100 & 4.0 & 3.8649 & TRN & \\
\hline CHEMBL3915590 & 1637100 & 4.0 & 4.6579 & TST & \\
\hline CHEMBL3898101 & 1637100 & 5.0 & 5.4553 & TRN & \\
\hline CHEMBL3941416 & 1637100 & 4.0 & 4.6378 & TST & \\
\hline CHEMBL3962439 & 1637100 & 4.0 & 3.9922 & TRN & \\
\hline CHEMBL3911108 & 1637100 & 6.0 & 4.6933 & TRN & \\
\hline CHEMBL3936944 & 1637100 & 4.0 & 4.1078 & TRN & \\
\hline CHEMBL3891191 & 1637100 & 6.0 & 5.5465 & TRN & \\
\hline CHEMBL3895375 & 1637100 & 4.0 & 4.1397 & TRN & \\
\hline CHEMBL3938839 & 1637100 & 4.0 & 5.1679 & TST & \\
\hline CHEMBL3949014 & 1637100 & 4.0 & 5.0932 & TRN & \\
\hline CHEMBL3980419 & 1637100 & 4.0 & 4.5534 & TST & \\
\hline CHEMBL3892265 & 1637100 & 4.0 & 5.5323 & TST & \\
\hline CHEMBL3966038 & 1637100 & 4.0 & 5.2417 & TST & \\
\hline CHEMBL 3980844 & 1637100 & 4.0 & 3.9135 & TRN & \\
\hline CHEMBL3892415 & 1637100 & 4.0 & 3.7604 & TRN & \\
\hline CHEMBL3971177 & 1637100 & 6.0 & 5.2446 & TRN & \\
\hline CHEMBL3890604 & 1637100 & 4.0 & 3.5964 & TST & \\
\hline CHEMBL3962591 & 1637100 & 7.0 & 6.0397 & TST & \\
\hline CHEMBL3954505 & 1637100 & 4.0 & $3.7510 e$ & 00000000003 & TRN \\
\hline CHEMBL3956971 & 1637100 & 5.0 & 4.8767 & TRN & \\
\hline CHEMBL3928104 & 1637100 & 5.0 & 5.2947 & TRN & \\
\hline CHEMBL3971853 & 1637100 & 4.0 & 3.6949 & TRN & \\
\hline CHEMBL3946559 & 1637100 & 4.0 & 4.772 & TST & \\
\hline CHEMBL3907233 & 1637100 & 4.0 & 4.2074 & TRN & \\
\hline CHEMBL3960548 & 1637100 & 4.0 & 3.6449 & TRN & \\
\hline CHEMBL3980892 & 1637100 & 4.0 & 3.9261 & TST & \\
\hline CHEMBL3901409 & 1637100 & 4.0 & 4.5526 & TRN & \\
\hline CHEMBL3975137 & 1637100 & 4.0 & 4.0016 & TST & \\
\hline CHEMBL3944680 & 1637100 & 7.0 & 6.1884 & TRN & \\
\hline CHEMBL3903046 & 1637100 & 7.0 & 6.5699 & TRN & \\
\hline CHEMBL3912775 & 1637100 & 4.0 & 4.2812 & TRN & \\
\hline CHEMBL3978491 & 1637100 & 6.0 & 6.2767 & TRN & \\
\hline CHEMBL3927115 & 1637100 & 4.0 & 3.6872 & TRN & \\
\hline CHEMBL3949025 & 1637100 & 4.0 & 4.2262 & TRN & \\
\hline CHEMBL3975881 & 1637100 & 4.0 & 3.9815 & TRN & \\
\hline CHEMBL3910833 & 1637100 & 4.0 & 4.8551 & TST & \\
\hline CHEMBL 3918477 & 1637100 & 4.0 & 3.6486 & TRN & \\
\hline CHEMBL3969058 & 1637100 & 4.0 & 3.7471 & TRN & \\
\hline CHEMBL3965714 & 1637100 & 7.0 & 5.9577 & TST & \\
\hline & & & & 25339 & \\
\hline
\end{tabular}




\begin{tabular}{|c|c|c|c|c|}
\hline & & & ent & al T \\
\hline CHEMBL3922621 & 1637100 & 4.0 & 5.1286 & TST \\
\hline CHEMBL3985393 & 1637100 & 4.0 & 3.6806 & TRN \\
\hline CHEMBL3915193 & 1637100 & 4.0 & 3.6914 & TRN \\
\hline CHEMBL 3907964 & 1637100 & 6.0 & 4.9024 & TRN \\
\hline CHEMBL3936676 & 1637100 & 7.0 & 6.319 & TRN \\
\hline CHEMBL 3947509 & 1637100 & 4.0 & 4.3692 & TST \\
\hline CHEMBL3911404 & 1637100 & 7.0 & 6.2204 & TST \\
\hline CHEMBL3915138 & 1637100 & 4.0 & 4.9235 & TRN \\
\hline CHEMBL 3934207 & 1637100 & 4.0 & 4.4863 & TRN \\
\hline CHEMBL 3927820 & 1637100 & 4.0 & 3.658 & TRN \\
\hline CHEMBL 3889587 & 1637100 & 6.0 & 5.8296 & TRN \\
\hline CHEMBL3905132 & 1637100 & 4.0 & 4.802 & TRN \\
\hline CHEMBL 3946345 & 1637100 & 4.0 & 4.7886 & TST \\
\hline CHEMBL 3912530 & 1637100 & 4.0 & 4.7312 & TRN \\
\hline CHEMBL3981328 & 1637100 & 4.0 & 4.1694 & TRN \\
\hline CHEMBL 3966715 & 1637100 & 4.0 & 4.5515 & TRN \\
\hline CHEMBL 3907677 & 1637100 & 6.0 & 5.2601 & TRN \\
\hline CHEMBL 3959902 & 1637100 & 6.0 & 5.9098 & TST \\
\hline CHEMBL 3957361 & 1637100 & 6.0 & 5.4029 & TRN \\
\hline CHEMBL 3952948 & 1637100 & 4.0 & 3.8213 & TRN \\
\hline CHEMBL 3932575 & 1637100 & 6.0 & 5.1568 & TST \\
\hline CHEMBL 3964189 & 1637100 & 4.0 & 4.8567 & TRN \\
\hline CHEMBL 3944018 & 1637100 & 6.0 & 6.0291 & TRN \\
\hline CHEMBL 3949031 & 1637100 & 4.0 & 4.2653 & TRN \\
\hline CHEMBL 3946653 & 1637100 & 4.0 & 4.2235 & TRN \\
\hline CHEMBL3917917 & 1637100 & 6.0 & 4.9895 & TRN \\
\hline CHEMBL3901585 & 1637100 & 4.0 & 5.4791 & TST \\
\hline CHEMBL 3953679 & 1637100 & 5.0 & 6.3814 & TRN \\
\hline CHEMBL 3974628 & 1637100 & 4.0 & 4.0991 & TRN \\
\hline CHEMBL 3924168 & 1637100 & 6.0 & 5.3003 & TRN \\
\hline CHEMBL 3948376 & 1637100 & 4.0 & 4.0391 & TRN \\
\hline CHEMBL3905580 & 1637100 & 4.0 & 4.0329 & TRN \\
\hline CHEMBL 3957628 & 1637100 & 7.0 & 5.7765 & TST \\
\hline CHEMBL3958438 & 1637100 & 4.0 & 3.7285 & TRN \\
\hline CHEMBL 3902945 & 1637100 & 6.0 & 5.5629 & TRN \\
\hline CHEMBL3986855 & 1637100 & 6.0 & 6.4097 & TRN \\
\hline CHEMBL 3938644 & 1637100 & 4.0 & 4.4866 & TST \\
\hline CHEMBL 3905612 & 1637100 & 4.0 & 4.1009 & TRN \\
\hline CHEMBL3969911 & 1637100 & 4.0 & 4.7791 & TRN \\
\hline CHEMBL 3894255 & 1637100 & 4.0 & 4.0784 & TRN \\
\hline CHEMBL3920111 & 1637100 & 4.0 & 4.2266 & TRN \\
\hline CHEMBL 3977312 & 1637100 & 4.0 & 4.5596 & TRN \\
\hline CHEMBL 3892966 & 1637100 & 4.0 & 4.0764 & TRN \\
\hline CHEMBL3900764 & 1637100 & 4.0 & 3.9941 & TRN \\
\hline CHEMBL 3972206 & 1637100 & 6.0 & 6.3785 & TRN \\
\hline CHEMBL 3913415 & 1637100 & 4.0 & 4.6717 & TRN \\
\hline CHEMBL 3945850 & 1637100 & 6.0 & 5.1834 & TRN \\
\hline CHEMBL 3962562 & 1637100 & 5.0 & 5.3036 & TRN \\
\hline
\end{tabular}




\begin{tabular}{|c|c|c|c|c|c|}
\hline \multirow{3}{*}{ CHEMBL 3957623} & \multirow{2}{*}{1637100} & \multirow[b]{2}{*}{4.0} & \multirow{2}{*}{\multicolumn{3}{|c|}{4.2164 TRN }} \\
\hline & & & & & \\
\hline & 1637100 & 5.0 & 5.7641 & TRN & \\
\hline CHEMBL3959833 & 1637100 & 4.0 & 4.1196 & TRN & \\
\hline CHEMBL3981071 & 1637100 & 4.0 & 4.4786 & TRN & \\
\hline CHEMBL3977886 & 1637100 & 4.0 & 4.4138 & TRN & \\
\hline CHEMBL3924404 & 1637100 & 4.0 & 3.7926 & TRN & \\
\hline CHEMBL3971985 & 1637100 & 6.0 & 5.148 & TRN & \\
\hline CHEMBL3905246 & 1637100 & 4.0 & 4.3417 & TRN & \\
\hline CHEMBL3916649 & 1637100 & 4.0 & 4.7069 & TRN & \\
\hline CHEMBL3951879 & 1637100 & 4.0 & 3.8969 & TRN & \\
\hline CHEMBL3981434 & 1637100 & 6.0 & 5.5495 & TRN & \\
\hline CHEMBL3922817 & 1637100 & 4.0 & 4.0193 & TRN & \\
\hline CHEMBL3962803 & 1637100 & 4.0 & 4.8979 & TRN & \\
\hline CHEMBL3969470 & 1637100 & 4.0 & 4.1593 & TRN & \\
\hline CHEMBL3954736 & 1637100 & 4.0 & 4.2699 & TST & \\
\hline CHEMBL3924650 & 1637100 & 4.0 & 3.497 & TST & \\
\hline CHEMBL3931462 & 1637100 & 7.0 & 5.8084 & TST & \\
\hline CHEMBL3919842 & 1637100 & 4.0 & 3.8958 & TRN & \\
\hline CHEMBL3935330 & 1637100 & 7.0 & 5.7757 & TRN & \\
\hline CHEMBL3973711 & 1637100 & 4.0 & 4.9721 & TST & \\
\hline CHEMBL2216897 & 1637100 & 7.0 & 5.2113 & TRN & \\
\hline CHEMBL3986283 & 1637100 & 4.0 & 3.892 & TST & \\
\hline CHEMBL3919763 & 1637100 & 6.0 & 4.9499 & TRN & \\
\hline CHEMBL3981319 & 1637100 & 4.0 & 4.4862 & TRN & \\
\hline CHEMBL3971922 & 1637100 & 4.0 & 4.8441 & TRN & \\
\hline CHEMBL 3898709 & 1637100 & 4.0 & 3.5385 & TRN & \\
\hline CHEMBL3891079 & 1637100 & 6.0 & 5.5957 & TRN & \\
\hline CHEMBL3947007 & 1637100 & 4.0 & 3.5341 & TRN & \\
\hline CHEMBL3939576 & 1637100 & 7.0 & $5.3820 e$ & 0000000001 & TST \\
\hline CHEMBL3937104 & 1637100 & 4.0 & 4.3245 & TRN & \\
\hline CHEMBL 3913845 & 1637100 & 4.0 & 4.3879 & TRN & \\
\hline CHEMBL3895608 & 1637100 & 4.0 & 4.2767 & TRN & \\
\hline CHEMBL3969872 & 1637100 & 6.0 & 5.271 & TRN & \\
\hline CHEMBL3934197 & 1637100 & 4.0 & 5.3822 & TST & \\
\hline CHEMBL3898290 & 1637100 & 4.0 & 4.4041 & TST & \\
\hline CHEMBL3903495 & 1637100 & 4.0 & 4.9612 & TRN & \\
\hline CHEMBL3943361 & 1637100 & 4.0 & 4.3448 & TRN & \\
\hline CHEMBL3984694 & 1637100 & 4.0 & 3.8136 & TST & \\
\hline CHEMBL3919689 & 1637100 & 6.0 & 5.8484 & TRN & \\
\hline CHEMBL3940957 & 1637100 & 7.0 & 5.9139 & TRN & \\
\hline CHEMBL3950901 & 1637100 & 4.0 & 3.9783 & TRN & \\
\hline CHEMBL3985711 & 1637100 & 4.0 & $4.7360 e$ & 0000000001 & TRN \\
\hline CHEMBL3978357 & 1637100 & 4.0 & 4.1325 & TRN & \\
\hline CHEMBL3896177 & 1637100 & 6.0 & 5.6055 & TST & \\
\hline CHEMBL3941546 & 1637100 & 4.0 & 3.6579 & TRN & \\
\hline CHEMBL 3926573 & 1637100 & 4.0 & 4.2942 & TRN & \\
\hline CHEMBL3939554 & 1637100 & 6.0 & 5.6 & TRN & \\
\hline CHEMBL3928309 & 1637100 & 4.0 & 3.8018 & TRN & \\
\hline & & & & 25341 & \\
\hline
\end{tabular}




\begin{tabular}{|c|c|c|c|c|c|}
\hline & & & & & \\
\hline CHEMBL3905083 & 1637100 & 4.0 & 3.4321 & TRN & \\
\hline CHEMBL 3972202 & 1637100 & 4.0 & 3.4912 & TRN & \\
\hline CHEMBL3934193 & 1637100 & 4.0 & 4.2919 & TST & \\
\hline CHEMBL3985764 & 1637100 & 4.0 & 4.3869 & TST & \\
\hline CHEMBL 3933033 & 1637100 & 6.0 & 5.7552 & TST & \\
\hline CHEMBL3919824 & 1637100 & 4.0 & 3.7373 & TRN & \\
\hline CHEMBL3918109 & 1637100 & 4.0 & 3.7196 & TST & \\
\hline CHEMBL 3982498 & 1637100 & 4.0 & 4.161000 & 00000000005 & TST \\
\hline CHEMBL 3978714 & 1637100 & 6.0 & 5.4599 & TST & \\
\hline CHEMBL 3944887 & 1637100 & 6.0 & 5.4645 & TRN & \\
\hline CHEMBL3918763 & 1637100 & 4.0 & 4.0999 & TRN & \\
\hline CHEMBL 3895422 & 1637100 & 4.0 & 3.9953 & TRN & \\
\hline CHEMBL 3931051 & 1637100 & 4.0 & 4.1363 & TRN & \\
\hline CHEMBL395971 & 446257 & 9.63 & 9.5771 & TRN & \\
\hline CHEMBL 244362 & 446257 & 10.24 & 10.2391 & TRN & \\
\hline CHEMBL395972 & 446257 & 10.22 & 10.2041 & TRN & \\
\hline CHEMBL395973 & 446257 & 9.85 & 9.9576 & TRN & \\
\hline CHEMBL266108 & 446257 & 8.86 & 8.8374 & TRN & \\
\hline CHEMBL395974 & 446257 & 10.01 & 9.9858 & TRN & \\
\hline CHEMBL 242631 & 446257 & 9.18 & 8.9613 & TRN & \\
\hline CHEMBL243711 & 446257 & 10.28 & 10.1552 & TRN & \\
\hline CHEMBL394543 & 446257 & 7.52 & 8.5952 & TST & \\
\hline CHEMBL395975 & 446257 & 9.43 & 9.3906 & TRN & \\
\hline CHEMBL 244566 & 446257 & 9.55 & 9.5439 & TRN & \\
\hline CHEMBL 244364 & 446257 & 8.82 & 8.988999 & 9999999999 & TRN \\
\hline CHEMBL244363 & 446257 & 8.54 & 8.5161 & TRN & \\
\hline CHEMBL 389744 & 446257 & 9.07 & 8.9903 & TRN & \\
\hline CHEMBL 243498 & 446257 & 9.26 & 9.6115 & TRN & \\
\hline CHEMBL243497 & 446257 & 8.71 & 8.9312 & TRN & \\
\hline CHEMBL243496 & 446257 & 9.65 & 9.554 & TRN & \\
\hline CHEMBL220365 & 446257 & 8.71 & 8.7016 & TRN & \\
\hline CHEMBL394607 & 446257 & 8.93 & 8.8736 & TRN & \\
\hline CHEMBL242619 & 446257 & 9.05 & 8.947000 & $\partial 000000001$ & TRN \\
\hline CHEMBL242626 & 446257 & 9.93 & 9.8732 & TRN & \\
\hline CHEMBL242625 & 446257 & 8.97 & 8.9946 & TRN & \\
\hline CHEMBL394350 & 446257 & 9.12 & 8.8719 & TRN & \\
\hline CHEMBL 242624 & 446257 & 8.33 & 8.4792 & TRN & \\
\hline CHEMBL 244766 & 446257 & 8.31 & 9.4808 & TST & \\
\hline CHEMBL437164 & 446257 & 8.07 & 9.4594 & TST & \\
\hline CHEMBL243278 & 446257 & 8.42 & 8.6838 & TST & \\
\hline CHEMBL231173 & 446257 & 8.69 & 8.7209 & TRN & \\
\hline CHEMBL394780 & 446257 & 9.88 & 9.9064 & TRN & \\
\hline CHEMBL428217 & 446257 & 8.5 & 8.5207 & TRN & \\
\hline CHEMBL2113292 & 446257 & 9.09 & 9.0648 & TRN & \\
\hline CHEMBL389355 & 446257 & 9.37 & 9.3576 & TRN & \\
\hline CHEMBL 394531 & 446257 & 8.03 & 8.1829 & TST & \\
\hline CHEMBL 230424 & 446257 & 9.12 & 9.1298 & TRN & \\
\hline CHEMBL 230324 & 446257 & 8.8 & 8.8127 & TRN & \\
\hline & & & & 25342 & \\
\hline
\end{tabular}




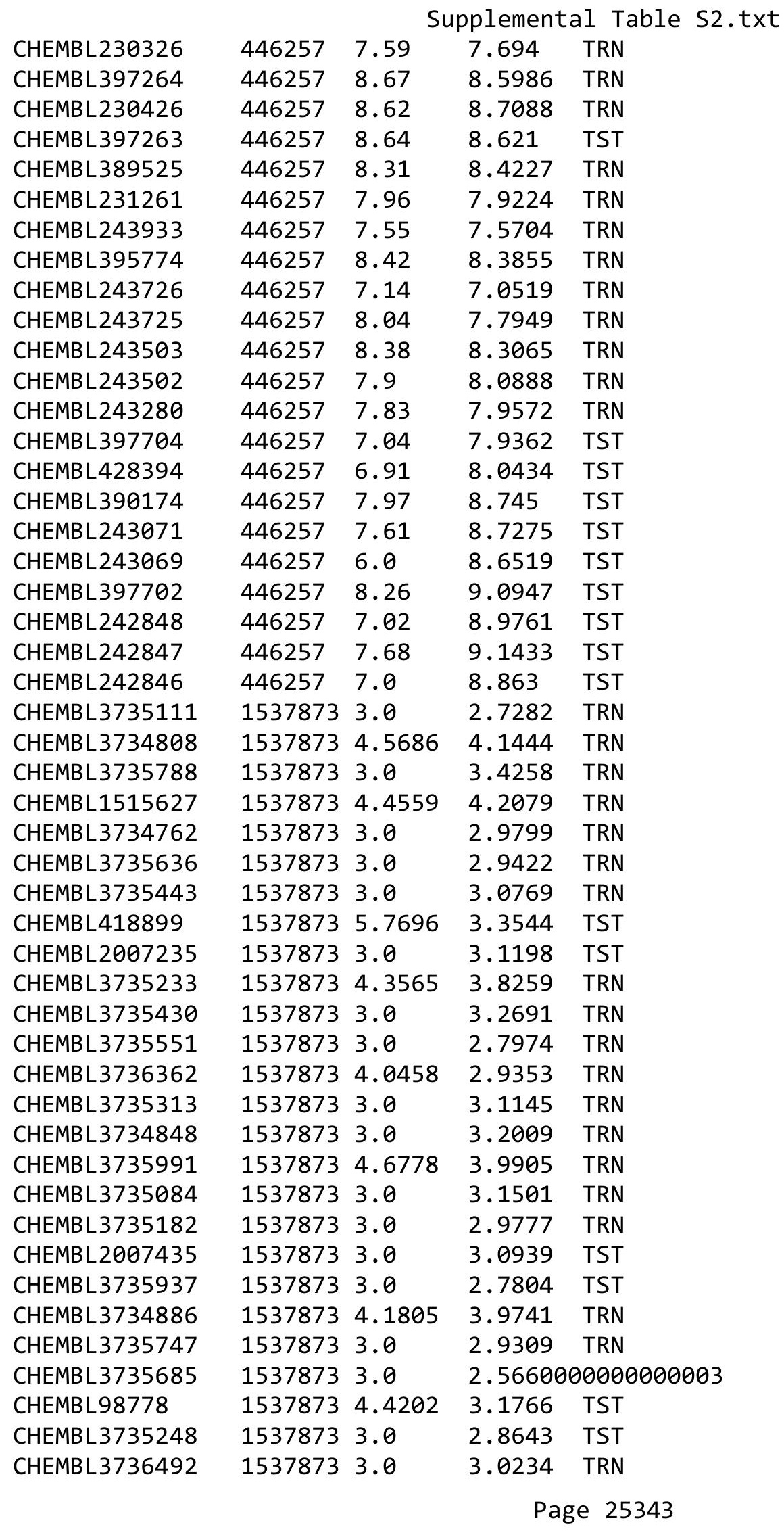

TRN 
Supplemental Table S2.txt

\begin{tabular}{|c|c|c|c|c|}
\hline CHEMBL 3734841 & 537873 & 4.5229 & 4.2745 & $\cdots$ \\
\hline CHEMBL3735299 & 537873 & 4.7696 & 4.665 & \\
\hline FMB 1 & 537873 & 3.0 & 9288 & \\
\hline AEMBL564201 & 537873 & 3.0 & 2112 & \\
\hline HEMBL3736087 & 537873 & 3.0 & 1006 & \\
\hline HEMBL 3735377 & 537873 & 4.1549 & 1869 & \\
\hline 35922 & 537873 & 3.0 & 843 & \\
\hline 34945 & 373 & 3.0 & 468 & \\
\hline AEMBL3735615 & 1537873 & 3.0 & 2.9287 & \\
\hline HEMBL3736487 & 537873 & 3.0 & 146 & \\
\hline 35258 & 73 & 3.0 & 5 & \\
\hline 5768 & 73 & 3.0 & 109 & \\
\hline 5807 & 73 & 3.0 & 581 & \\
\hline AEMBL3736284 & 1537873 & 3.0 & 7044 & \\
\hline HEMBL3735946 & 73 & 3.0 & 663 & \\
\hline 35729 & 153 & 3. & 194 & \\
\hline 6249 & 153 & $4 . \varepsilon$ & 23 & \\
\hline 35742 & 153 & 3.0 & 635 & \\
\hline 736258 & 1537873 & 3.0 & 602 & \\
\hline 36351 & & 3. & 227 & \\
\hline 6357 & 153 & 3. & 66 & \\
\hline 1874 & 3 & 3. & 81 & \\
\hline 5786 & 153 & 4. & 538 & \\
\hline 36219 & 73 & 3.0 & 537 & \\
\hline 36497 & & 3. & 835 & \\
\hline CHEMBL & 153 & 3. & 35 & \\
\hline $\mathrm{CHE}$ & 3 & 4. & 48 & \\
\hline 292 & 153 & 4. & 018 & \\
\hline 35328 & 153 & 3.0 & 746 & \\
\hline 736102 & 153 & 3.0 & 77 & \\
\hline CHEMBL & 15 & 3. & 79 & \\
\hline $\mathrm{CH}$ & 3 & 3. & 88 & \\
\hline 43 & 3 & 3.0 & 351 & \\
\hline 35442 & 153 & 3.0 & 322 & 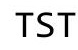 \\
\hline CHEMBL3735011 & 1537 & 3. & 378 & \\
\hline & & 3. & & \\
\hline $\mathrm{CH}$ & 3 & 3. & 77 & \\
\hline 35595 & 153 & 3.0 & 059 & r. \\
\hline CHEMBL418665 & 158139 & 6.15 & 7535 & TR \\
\hline 790 & 150 & & 058 & 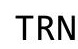 \\
\hline CHEMBL & $15 \varepsilon$ & & 247 & 11 \\
\hline CHEMBL & 158 & 6.301 & 657 & \\
\hline CHEMBL & 158 & 6.699 & 6.5938 & $\Gamma R$ \\
\hline CHEMBL $\epsilon$ & 158139 & 5.2924 & 5071 & $\Gamma R$ \\
\hline CHEMBL & 15813 & 6.0969 & 5.5388 & \\
\hline CHEMBL & 158 & 6.0 & 5.6646 & \\
\hline CHEMBL302414 & 158139 & 4.8539 & 5.6914 & \\
\hline CHEMBL64304 & 158139 & 5.1249 & 5.0709 & \\
\hline
\end{tabular}

Page 25344 


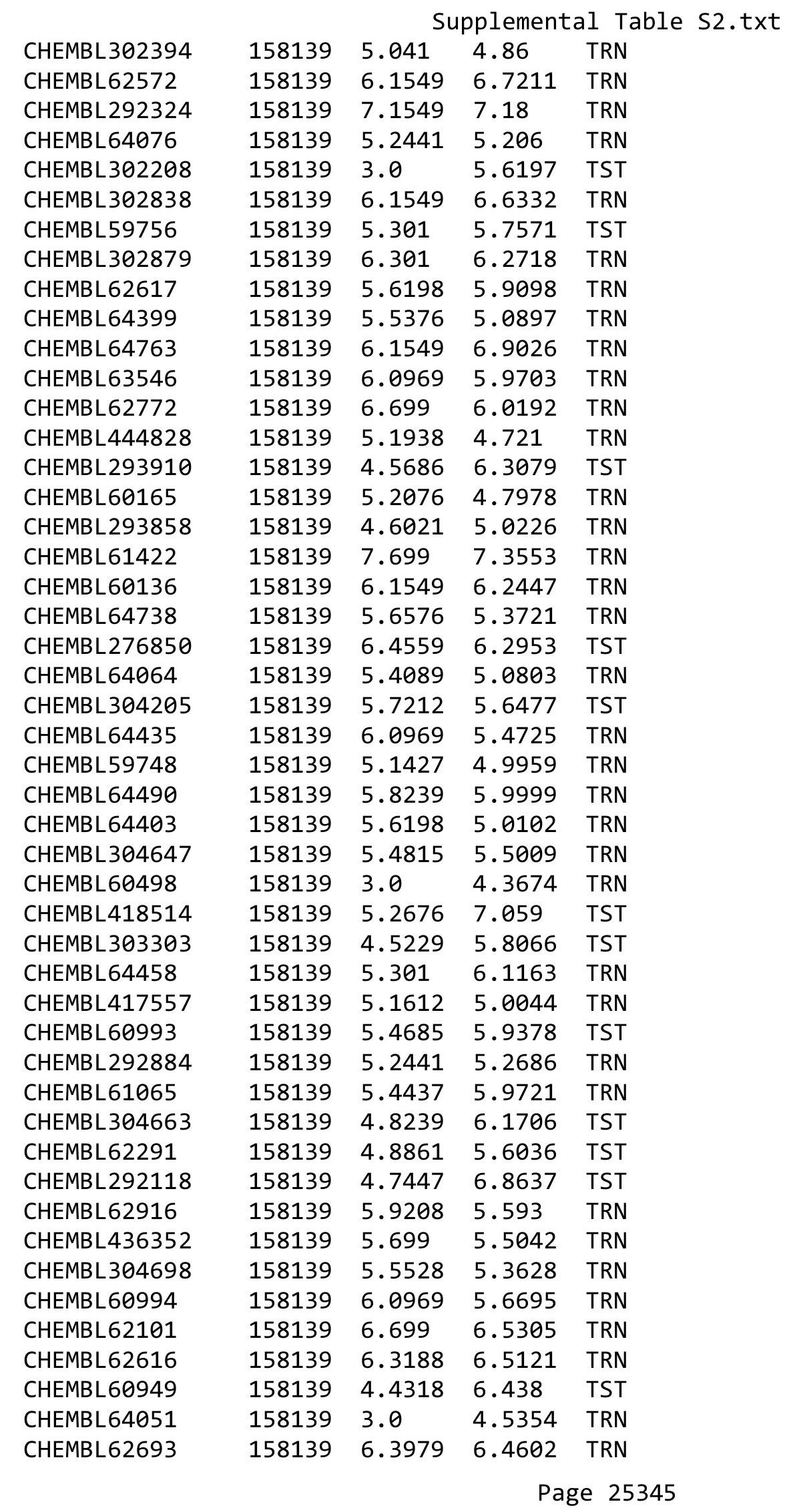




\begin{tabular}{|c|c|c|c|c|c|}
\hline \multicolumn{6}{|c|}{ Supplemental Table S2.txt } \\
\hline CHEMBL64370 & 158139 & 7.0 & 6.2847 & TRN & \\
\hline CHEMBL293617 & 158139 & 6.699 & 6.5766 & TRN & \\
\hline CHEMBL60499 & 158139 & 5.4559 & 5.5533 & TST & \\
\hline CHEMBL64342 & 158139 & 3.0 & 5.7907 & TST & \\
\hline CHEMBL64822 & 158139 & 3.0 & 5.0468 & TST & \\
\hline CHEMBL62817 & 158139 & 4.8539 & 5.6037 & TST & \\
\hline CHEMBL430724 & 321440 & 7.6021 & 6.5271 & TRN & \\
\hline CHEMBL25867 & 321440 & 7.6021 & 6.5412 & TRN & \\
\hline CHEMBL 26892 & 321440 & 5.6021 & 5.9655 & TST & \\
\hline CHEMBL281252 & 321440 & 5.6021 & 6.595 & TST & \\
\hline CHEMBL 282610 & 321440 & 5.6021 & 5.9038 & TRN & \\
\hline CHEMBL26369 & 321440 & 5.6021 & 5.99799 & 9999999999 & TRN \\
\hline CHEMBL285343 & 321440 & 7.6021 & 7.0499 & TRN & \\
\hline CHEMBL 286963 & 321440 & 5.6021 & 6.0816 & TRN & \\
\hline CHEMBL 27834 & 321440 & 5.6021 & 5.6902 & TRN & \\
\hline CHEMBL 26707 & 321440 & 5.6021 & 5.2909 & TRN & \\
\hline CHEMBL30052 & 321440 & 7.6021 & 7.6177 & TRN & \\
\hline CHEMBL283255 & 321440 & 5.6021 & 6.1373 & TRN & \\
\hline CHEMBL 27823 & 321440 & 5.6021 & 5.4801 & TRN & \\
\hline CHEMBL 26017 & 321440 & 5.6021 & 5.4514 & TRN & \\
\hline CHEMBL198146 & 321440 & 5.6021 & 5.7887 & TRN & \\
\hline CHEMBL26795 & 321440 & 7.6021 & 7.3587 & TRN & \\
\hline CHEMBL439727 & 321440 & 7.6021 & 7.0829 & TRN & \\
\hline CHEMBL 27452 & 321440 & 5.6021 & 6.0736 & TST & \\
\hline CHEMBL25905 & 321440 & 7.6021 & 8.144 & TRN & \\
\hline CHEMBL431503 & 321440 & 5.6021 & 5.8581 & TRN & \\
\hline CHEMBL 29631 & 321440 & 5.6021 & 6.1541 & TRN & \\
\hline CHEMBL 27634 & 321440 & 5.6021 & 5.3526 & TST & \\
\hline CHEMBL430925 & 321440 & 5.6021 & 6.6434 & TST & \\
\hline CHEMBL281743 & 321440 & 5.6021 & 8.4548 & TST & \\
\hline CHEMBL 27415 & 321440 & 7.6021 & 7.4986 & TRN & \\
\hline CHEMBL27524 & 321440 & 5.6021 & 5.1147 & TST & \\
\hline CHEMBL 287181 & 321440 & 5.6021 & 5.6717 & TRN & \\
\hline CHEMBL 283438 & 321440 & 7.6021 & 6.976 & TRN & \\
\hline CHEMBL 27257 & 321440 & 7.6021 & 7.0968 & TRN & \\
\hline CHEMBL 27172 & 321440 & 5.6021 & 6.0633 & TRN & \\
\hline CHEMBL281496 & 321440 & 7.6021 & 7.3199 & TRN & \\
\hline CHEMBL26530 & 321440 & 5.6021 & 5.8247 & TRN & \\
\hline CHEMBL282151 & 321440 & 5.6021 & 5.8983 & TST & \\
\hline CHEMBL26485 & 321440 & 7.6021 & 8.2247 & TRN & \\
\hline CHEMBL 27128 & 321440 & 7.6021 & 7.7805 & TST & \\
\hline CHEMBL 26934 & 321440 & 5.6021 & 6.065 & TRN & \\
\hline CHEMBL286948 & 321440 & 5.6021 & 6.1723 & TRN & \\
\hline CHEMBL284676 & 321440 & 7.6021 & 7.5738 & TRN & \\
\hline CHEMBL 285830 & 321440 & 5.6021 & 5.3468 & TRN & \\
\hline CHEMBL 27497 & 321440 & 5.6021 & 5.7845 & TRN & \\
\hline CHEMBL 27007 & 321440 & 7.6021 & 7.5078 & TRN & \\
\hline CHEMBL26686 & 321440 & 5.6021 & 6.2276 & TRN & \\
\hline
\end{tabular}




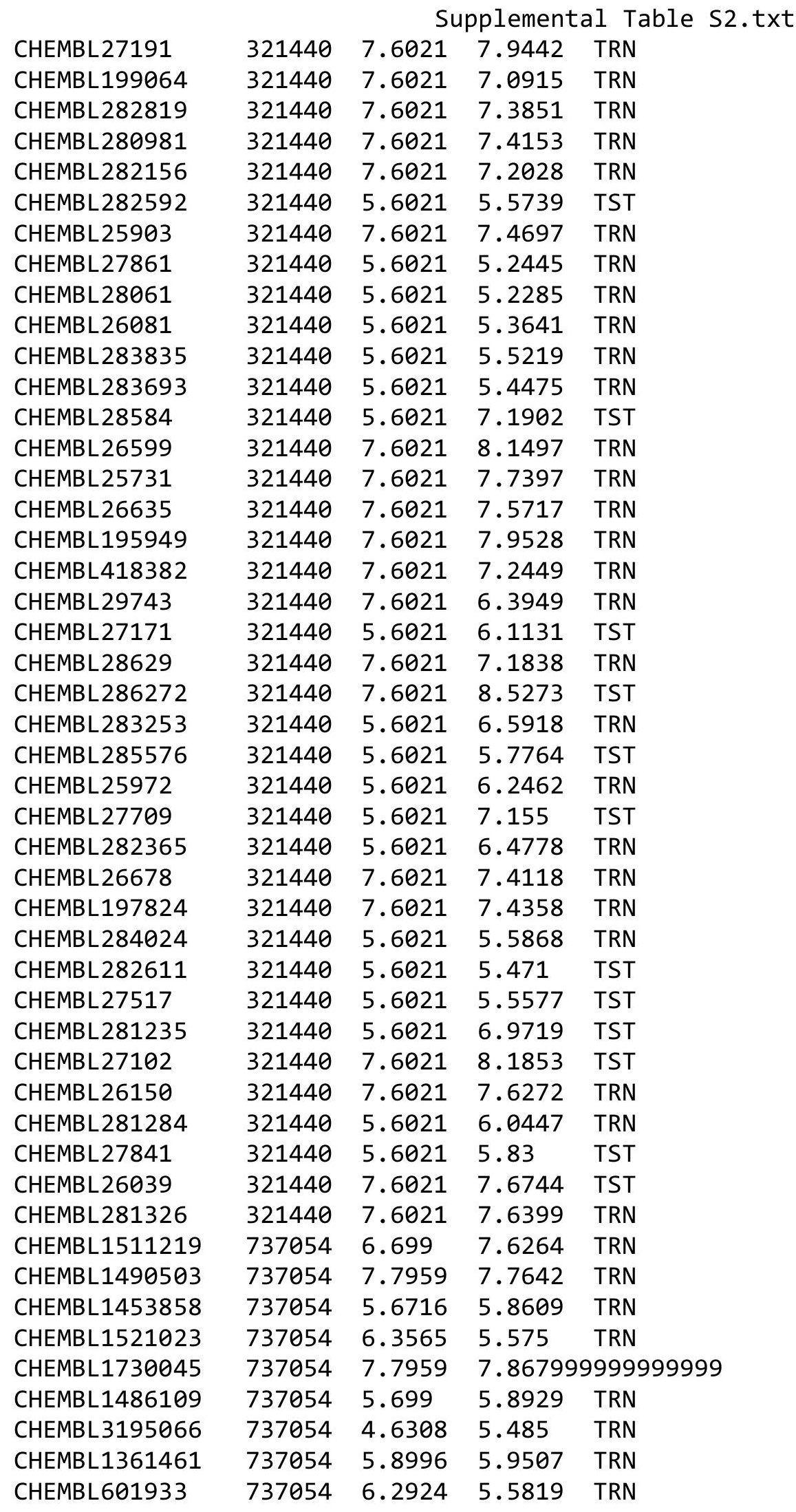




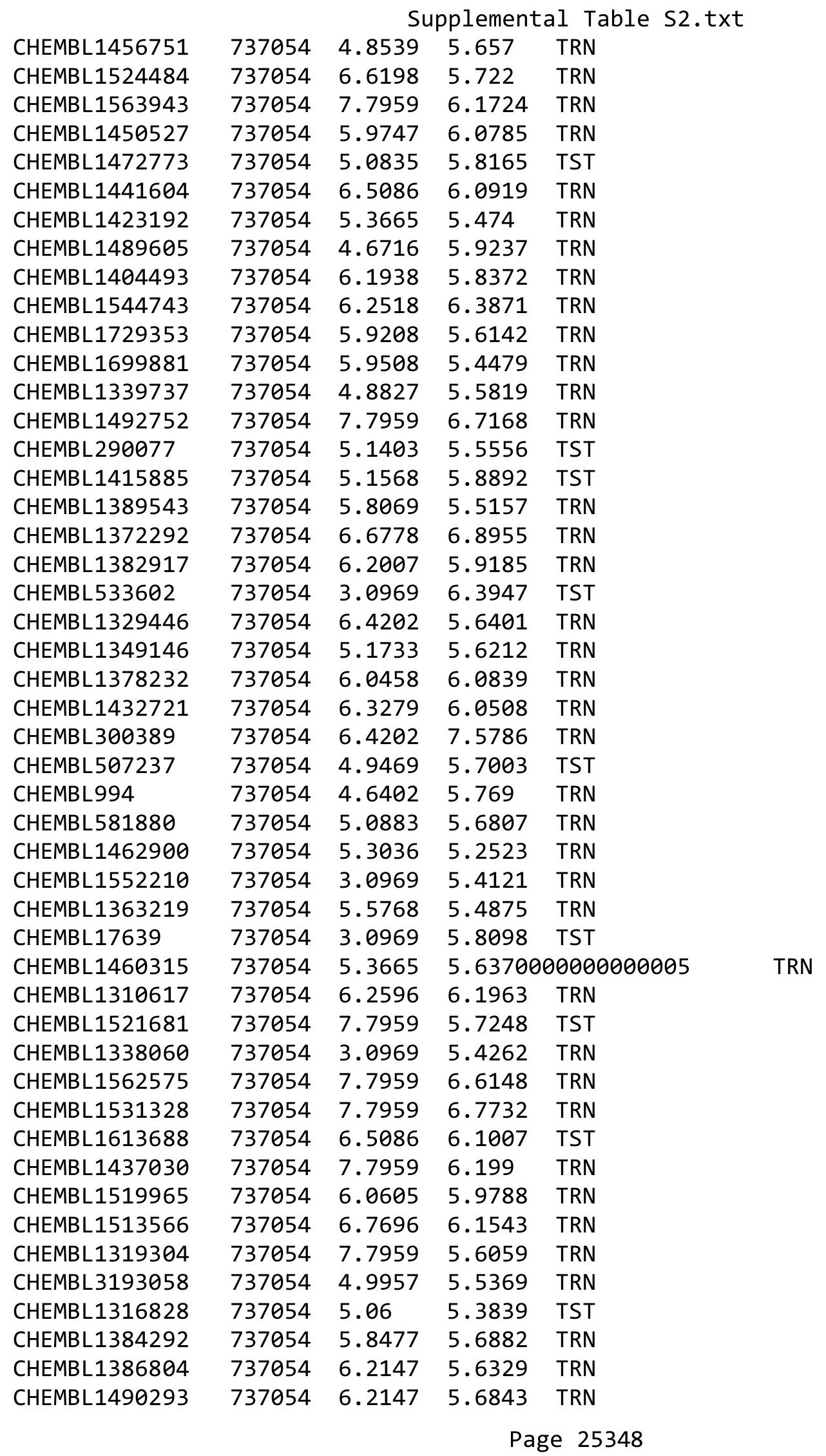




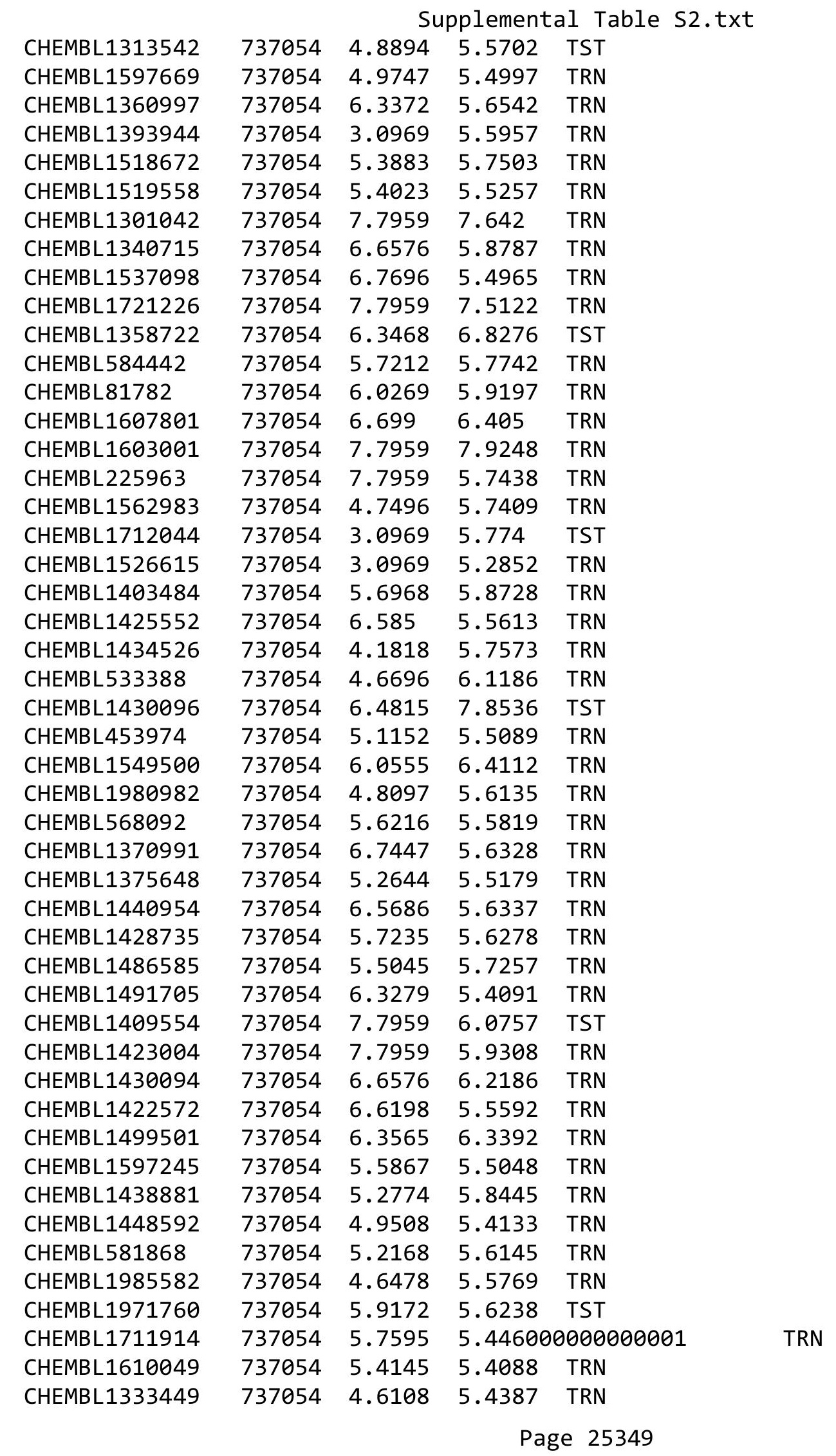




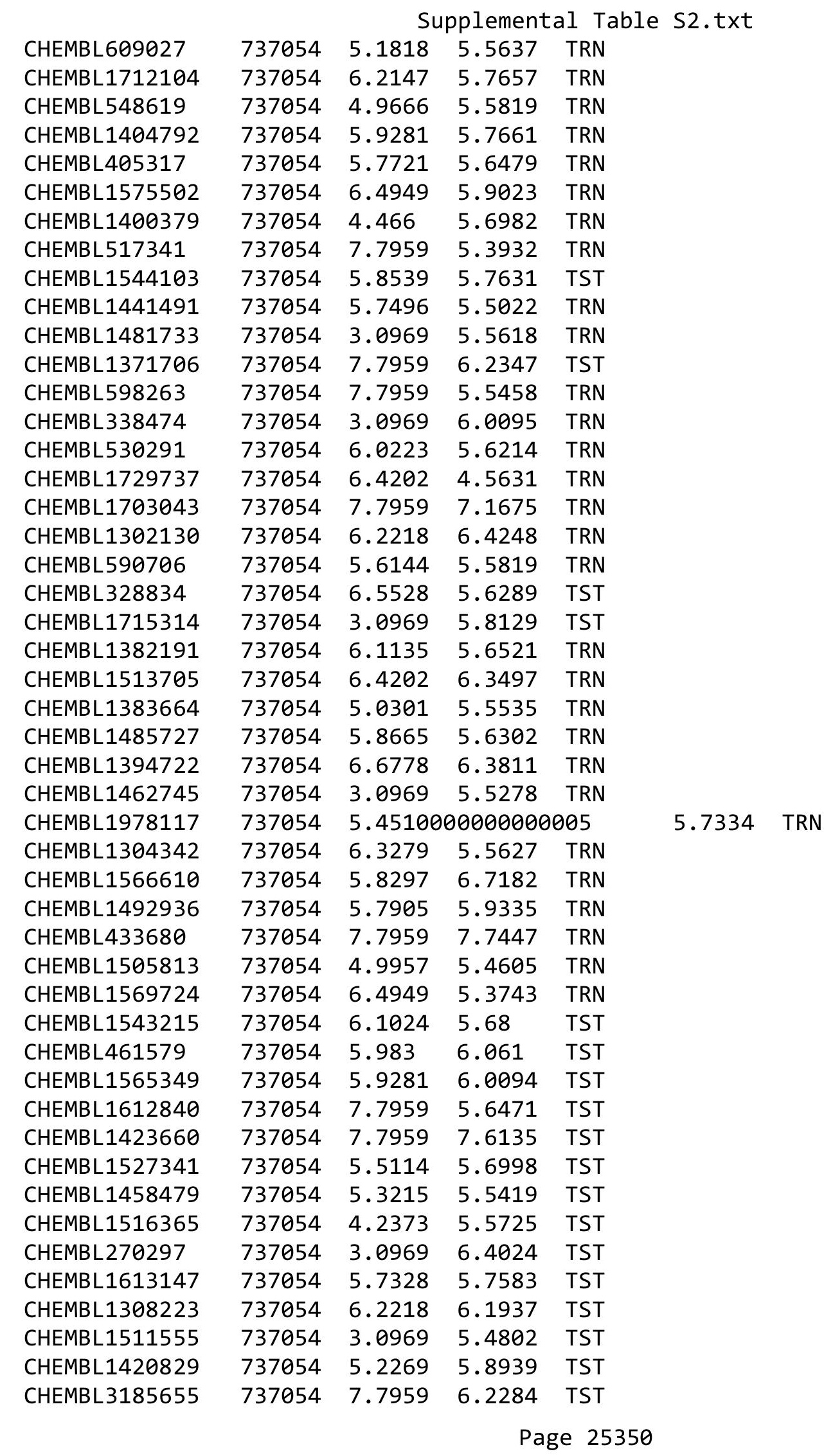


Supplemental Table S2.txt

\begin{tabular}{|c|c|c|c|c|}
\hline CHEMBL1459468 & 737054 & 6.0969 & 6.3129 & TST \\
\hline CHEMBL1559529 & 737054 & 5.6635 & 5.6331 & TST \\
\hline CHEMBL3191989 & 737054 & 4.6778 & 5.6068 & TST \\
\hline CHEMBL 267099 & 737054 & 5.1296 & 5.7131 & TST \\
\hline CHEMBL3189250 & 737054 & 6.3872 & 5.8121 & TST \\
\hline CHEMBL1589677 & 737054 & 5.6696 & 5.8304 & TST \\
\hline CHEMBL3318464 & 1456602 & 3.0 & 2.9827 & TRN \\
\hline CHEMBL3318462 & 1456602 & 3.1938 & 3.0362 & TRN \\
\hline CHEMBL3318427 & 1456602 & 3.0 & 3.1079 & TRN \\
\hline CHEMBL3318428 & 1456602 & 3.0 & 2.8866 & TRN \\
\hline CHEMBL3318509 & 1456602 & 3.0 & 3.0955 & TRN \\
\hline CHEMBL3318519 & 1456602 & 5.2518 & 4.1698 & TST \\
\hline CHEMBL3318455 & 1456602 & 3.0 & 3.5543 & TRN \\
\hline CHEMBL3318460 & 1456602 & 4.6198 & 3.8942 & TRN \\
\hline CHEMBL3318439 & 1456602 & 3.0 & 3.1695 & TRN \\
\hline CHEMBL3318482 & 1456602 & 3.0 & 3.3721 & TRN \\
\hline CHEMBL3318475 & 1456602 & 3.0 & 2.6252 & TRN \\
\hline CHEMBL3318419 & 1456602 & 3.0 & 3.6926 & TRN \\
\hline CHEMBL3318466 & 1456602 & 3.0 & 2.8727 & TRN \\
\hline CHEMBL3318412 & 1456602 & 5.7696 & 4.5403 & TRN \\
\hline CHEMBL 3318520 & 1456602 & 4.7447 & 5.1491 & TRN \\
\hline CHEMBL3318505 & 1456602 & 3.0 & 3.6272 & TST \\
\hline CHEMBL3318465 & 1456602 & 3.0 & 3.3809 & TRN \\
\hline CHEMBL3318421 & 1456602 & 3.0 & 3.8622 & TRN \\
\hline CHEMBL3318429 & 1456602 & 3.0 & 2.6892 & TRN \\
\hline CHEMBL3318485 & 1456602 & 3.0 & 3.1134 & TRN \\
\hline CHEMBL3318528 & 1456602 & 5.6383 & 5.3877 & TRN \\
\hline CHEMBL3318501 & 1456602 & 3.0 & 3.3046 & TRN \\
\hline CHEMBL 3318478 & 1456602 & 3.0 & 3.5654 & TRN \\
\hline CHEMBL3318433 & 1456602 & 3.0 & 2.1737 & TRN \\
\hline CHEMBL3318503 & 1456602 & 3.0 & 3.1979 & TRN \\
\hline CHEMBL3318524 & 1456602 & 6.2366 & 5.6283 & TRN \\
\hline CHEMBL3318456 & 1456602 & 4.2007 & 3.5428 & TRN \\
\hline CHEMBL3318472 & 1456602 & 3.0 & 2.906 & TRN \\
\hline CHEMBL3318533 & 1456602 & 4.7696 & 4.9706 & TRN \\
\hline CHEMBL3318454 & 1456602 & 3.0 & 2.895 & TRN \\
\hline CHEMBL3318508 & 1456602 & 3.0 & 3.1293 & TST \\
\hline CHEMBL3318463 & 1456602 & 3.0 & 3.2225 & TRN \\
\hline CHEMBL3318453 & 1456602 & 3.0 & 3.2805 & TRN \\
\hline CHEMBL3318444 & 1456602 & 3.0 & \multicolumn{2}{|c|}{3.3160000000000003} \\
\hline CHEMBL3318438 & 1456602 & 3.0 & 3.1976 & TRN \\
\hline CHEMBL3318445 & 1456602 & 3.0 & 2.823 & TRN \\
\hline CHEMBL3318507 & 1456602 & 3.0 & 3.0566 & TST \\
\hline CHEMBL3318425 & 1456602 & 3.0 & 3.2045 & TRN \\
\hline CHEMBL3318440 & 1456602 & 3.0 & 3.1475 & TRN \\
\hline CHEMBL3318481 & 1456602 & 3.0 & 3.2738 & TRN \\
\hline CHEMBL3318461 & 1456602 & 3.0 & 3.3245 & TRN \\
\hline CHEMBL3318536 & 1456602 & 6.1938 & 4.336 & TST \\
\hline
\end{tabular}




\begin{tabular}{|c|c|c|c|c|c|}
\hline \multicolumn{6}{|c|}{ Supplemental Table S2.txt } \\
\hline CHEMBL3318447 & 1456602 & 3.0 & 3.1937 & TRN & \\
\hline CHEMBL3318450 & 1456602 & 3.0 & 3.3955 & TRN & \\
\hline CHEMBL3318526 & 1456602 & 5.1308 & 5.5923 & TRN & \\
\hline CHEMBL 3318504 & 1456602 & 3.0 & 3.2631 & TRN & \\
\hline CHEMBL3318420 & 1456602 & 4.4437 & 3.83100 & 00000000004 & TRN \\
\hline CHEMBL3318437 & 1456602 & 3.0 & 3.1034 & TRN & \\
\hline CHEMBL3318527 & 1456602 & 6.5686 & 4.6241 & TRN & \\
\hline CHEMBL 3318430 & 1456602 & 3.0 & 3.15100 & 00000000002 & TRN \\
\hline CHEMBL3318530 & 1456602 & 4.8239 & 5.1628 & TRN & \\
\hline CHEMBL3318523 & 1456602 & 5.4318 & 5.4087 & TST & \\
\hline CHEMBL3318521 & 1456602 & 4.7212 & 5.1389 & TRN & \\
\hline CHEMBL3318467 & 1456602 & 3.0 & 3.5426 & TRN & \\
\hline CHEMBL15976 & 1456602 & 4.2426 & 4.011 & TST & \\
\hline CHEMBL3318515 & 1456602 & 3.0 & 3.7005 & TRN & \\
\hline CHEMBL3318451 & 1456602 & 3.0 & 2.8566 & TRN & \\
\hline CHEMBL3318471 & 1456602 & 3.0 & 3.2301 & TRN & \\
\hline CHEMBL3318525 & 1456602 & 6.0 & 5.9235 & TRN & \\
\hline CHEMBL3318470 & 1456602 & 3.0 & 3.3625 & TRN & \\
\hline CHEMBL3318516 & 1456602 & 3.0 & 3.6925 & TRN & \\
\hline CHEMBL3318511 & 1456602 & 3.0 & 2.583 & TRN & \\
\hline CHEMBL3318500 & 1456602 & 3.0 & 2.5584 & TRN & \\
\hline CHEMBL 3318443 & 1456602 & 3.0 & 2.8369 & TRN & \\
\hline CHEMBL3318449 & 1456602 & 3.0 & 2.5869 & TRN & \\
\hline CHEMBL 3318434 & 1456602 & 3.0 & 2.2176 & TRN & \\
\hline CHEMBL3318535 & 1456602 & 6.3468 & 4.1888 & TST & \\
\hline CHEMBL3318458 & 1456602 & 3.0 & 3.2628 & TRN & \\
\hline CHEMBL3318415 & 1456602 & 5.3372 & 3.7569 & TRN & \\
\hline CHEMBL3318457 & 1456602 & 4.9208 & 3.3258 & TRN & \\
\hline CHEMBL3318517 & 1456602 & 3.0 & 3.7203 & TRN & \\
\hline CHEMBL3318468 & 1456602 & 3.0 & 3.35600 & 00000000003 & TRN \\
\hline CHEMBL3318414 & 1456602 & 4.2757 & 3.92 & TRN & \\
\hline CHEMBL 3318432 & 1456602 & 3.0 & 2.5636 & TRN & \\
\hline CHEMBL3318532 & 1456602 & 5.1675 & 4.8098 & TRN & \\
\hline CHEMBL3318476 & 1456602 & 3.0 & 3.5275 & TRN & \\
\hline CHEMBL3318518 & 1456602 & 5.2518 & 4.5118 & TST & \\
\hline CHEMBL3318512 & 1456602 & 3.0 & 2.8856 & TRN & \\
\hline CHEMBL3318423 & 1456602 & 5.7959 & 4.184 & TRN & \\
\hline CHEMBL3318506 & 1456602 & 3.0 & 3.4667 & TRN & \\
\hline CHEMBL3318435 & 1456602 & 3.0 & 3.0033 & TRN & \\
\hline CHEMBL3318522 & 1456602 & 6.0605 & 4.6519 & TST & \\
\hline CHEMBL3318473 & 1456602 & 3.0 & 2.8726 & TRN & \\
\hline CHEMBL3318417 & 1456602 & 3.0 & 3.6147 & TRN & \\
\hline CHEMBL3318422 & 1456602 & 3.0 & 3.1962 & TRN & \\
\hline CHEMBL3318459 & 1456602 & 3.0 & 3.0707 & TRN & \\
\hline CHEMBL3318418 & 1456602 & 3.1805 & 3.637 & TRN & \\
\hline CHEMBL3318513 & 1456602 & 3.0 & 2.9971 & TRN & \\
\hline CHEMBL3318483 & 1456602 & 3.0 & 3.1355 & TRN & \\
\hline CHEMBL3318537 & 1456602 & 5.6778 & 4.0699 & TST & \\
\hline
\end{tabular}


Supplemental Table S2.txt

\begin{tabular}{|c|c|c|c|c|}
\hline CHEMBL 3318413 & 1456602 & 3.0 & 3.0734 & TRN \\
\hline CHEMBL3318416 & 1456602 & 4.2757 & 3.9892 & TRN \\
\hline CHEMBL3318484 & 1456602 & 3.0 & 3.0613 & TRN \\
\hline CHEMBL3318436 & 1456602 & 3.0 & 3.2806 & TRN \\
\hline CHEMBL3318469 & 1456602 & 3.0 & 3.0949 & TRN \\
\hline CHEMBL 3318514 & 1456602 & 3.0 & 2.9962 & TST \\
\hline CHEMBL3318446 & 1456602 & 3.0 & 3.2485 & TRN \\
\hline CHEMBL 3317461 & 1456602 & 3.0 & 3.8268 & TRN \\
\hline CHEMBL 3318448 & 1456602 & 3.0 & 3.3888 & TST \\
\hline CHEMBL3318424 & 1456602 & 3.0 & 3.8985 & TST \\
\hline CHEMBL3318479 & 1456602 & 3.0 & 3.1836 & TST \\
\hline CHEMBL3318534 & 1456602 & 6.0809 & \multicolumn{2}{|c|}{5.952000000000001} \\
\hline CHEMBL3318502 & 1456602 & 3.0 & 3.7405 & TST \\
\hline CHEMBL3318538 & 1456602 & 6.7447 & 4.8048 & TST \\
\hline CHEMBL3318452 & 1456602 & 3.0 & 2.3005 & TST \\
\hline CHEMBL3318529 & 1456602 & 6.301 & 5.0664 & TST \\
\hline CHEMBL3318480 & 1456602 & 3.0 & 3.9081 & TST \\
\hline CHEMBL3318510 & 1456602 & 3.0 & 3.3772 & TST \\
\hline CHEMBL3318426 & 1456602 & 3.0 & 3.9384 & TST \\
\hline CHEMBL3318477 & 1456602 & 3.0 & 2.7385 & TST \\
\hline CHEMBL3318442 & 1456602 & 3.0 & 2.7248 & TST \\
\hline CHEMBL3318474 & 1456602 & 3.0 & 2.7571 & TST \\
\hline CHEMBL3318531 & 1456602 & 5.5086 & 4.9893 & TST \\
\hline CHEMBL3318441 & 1456602 & 3.0 & 2.7593 & TST \\
\hline CHEMBL3318431 & 1456602 & 3.0 & 2.4223 & TST \\
\hline CHEMBL1449253 & 688767 & 2.9634 & 3.1245 & TRN \\
\hline CHEMBL1515153 & 688767 & 2.9634 & 3.4176 & TRN \\
\hline CHEMBL1449836 & 688767 & 2.9634 & 3.0567 & TRN \\
\hline CHEMBL1579209 & 688767 & 4.5585 & 4.0248 & TRN \\
\hline CHEMBL1606013 & 688767 & 2.9634 & 3.3239 & TRN \\
\hline CHEMBL1413866 & 688767 & 4.0155 & 3.7469 & TRN \\
\hline CHEMBL1200938 & 688767 & 4.6453 & 3.0583 & TST \\
\hline CHEMBL1499658 & 688767 & 2.9634 & 2.8562 & TRN \\
\hline CHEMBL1468800 & 688767 & 2.9634 & 3.1271 & TRN \\
\hline CHEMBL1410381 & 688767 & 2.9634 & 3.2761 & TRN \\
\hline CHEMBL1990772 & 688767 & 2.9634 & 2.9416 & TRN \\
\hline CHEMBL1576140 & 688767 & 2.9634 & 3.1588 & TRN \\
\hline CHEMBL1609276 & 688767 & 2.9634 & 3.1564 & TST \\
\hline CHEMBL1423852 & 688767 & 2.9634 & 3.0961 & TRN \\
\hline CHEMBL1964442 & 688767 & 2.9634 & 2.8438 & TRN \\
\hline CHEMBL1384172 & 688767 & 2.9634 & 2.8682 & TRN \\
\hline CHEMBL234338 & 688767 & 2.9634 & 3.0843 & TRN \\
\hline CHEMBL1595621 & 688767 & 2.9634 & 3.674 & TRN \\
\hline CHEMBL1377223 & 688767 & 2.9634 & 2.6013 & TRN \\
\hline CHEMBL11875 & 688767 & 2.9634 & 3.0816 & TRN \\
\hline CHEMBL1311053 & 688767 & 2.9634 & 3.833 & TST \\
\hline CHEMBL1427879 & 688767 & 2.9634 & 2.9784 & TRN \\
\hline CHEMBL1416189 & 688767 & 2.9634 & 3.3621 & TRN \\
\hline
\end{tabular}




\begin{tabular}{|c|c|c|c|c|c|}
\hline & & & 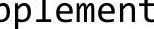 & & \\
\hline CHEMBL1344422 & 688767 & 2.9634 & 3.4549 & TRN & \\
\hline CHEMBL458328 & 688767 & 2.9634 & 3.5276 & TST & \\
\hline CHEMBL1490685 & 688767 & 4.1989 & 3.653 & TRN & \\
\hline CHEMBL1408747 & 688767 & 3.9832 & 3.34800 & 00000000003 & TRN \\
\hline CHEMBL1467730 & 688767 & 2.9634 & 2.9009 & TRN & \\
\hline CHEMBL3197662 & 688767 & 4.2582 & 3.6339 & TRN & \\
\hline CHEMBL1981243 & 688767 & 2.9634 & 3.3981 & TRN & \\
\hline CHEMBL1350435 & 688767 & 2.9634 & 3.4185 & TRN & \\
\hline CHEMBL1985327 & 688767 & 2.9634 & 3.4615 & TRN & \\
\hline CHEMBL1519408 & 688767 & 2.9634 & 3.1654 & TRN & \\
\hline CHEMBL1451039 & 688767 & 4.2178 & 3.2295 & TST & \\
\hline CHEMBL1595525 & 688767 & 2.9634 & 3.194 & TRN & \\
\hline CHEMBL165064 & 688767 & 2.9634 & 3.08 & TRN & \\
\hline CHEMBL1419305 & 688767 & 2.9634 & 3.0023 & TRN & \\
\hline CHEMBL3189416 & 688767 & 2.9634 & 2.98100 & 00000000003 & TRN \\
\hline CHEMBL1336615 & 688767 & 2.9634 & 3.5147 & TRN & \\
\hline CHEMBL1543134 & 688767 & 4.431 & 3.5814 & TRN & \\
\hline CHEMBL1365170 & 688767 & 2.9634 & 3.2485 & TRN & \\
\hline CHEMBL1342429 & 688767 & 2.9634 & 3.4375 & TST & \\
\hline CHEMBL1978364 & 688767 & 2.9634 & 2.9248 & TRN & \\
\hline CHEMBL1574133 & 688767 & 4.1828 & 3.6789 & TRN & \\
\hline CHEMBL1337575 & 688767 & 2.9634 & 2.6334 & TRN & \\
\hline CHEMBL1432884 & 688767 & 2.9634 & 2.7455 & TRN & \\
\hline CHEMBL1512376 & 688767 & 2.9634 & 3.2951 & TRN & \\
\hline CHEMBL1418601 & 688767 & 2.9634 & 3.4589 & TRN & \\
\hline CHEMBL1571442 & 688767 & 2.9634 & 2.6953 & TRN & \\
\hline CHEMBL3193176 & 688767 & 2.9634 & 2.8736 & TRN & \\
\hline CHEMBL1315784 & 688767 & 2.9634 & 3.0193 & TRN & \\
\hline CHEMBL1348946 & 688767 & 2.9634 & 3.6221 & TRN & \\
\hline CHEMBL3191557 & 688767 & 2.9634 & 3.2995 & TRN & \\
\hline CHEMBL1373095 & 688767 & 2.9634 & 2.6823 & TRN & \\
\hline CHEMBL1301692 & 688767 & 2.9634 & 3.1907 & TRN & \\
\hline CHEMBL 2028179 & 688767 & 2.9634 & 3.5111 & TRN & \\
\hline CHEMBL 2007178 & 688767 & 2.9634 & 2.9292 & TRN & \\
\hline CHEMBL1440415 & 688767 & 2.9634 & 3.1956 & TRN & \\
\hline CHEMBL1453402 & 688767 & 2.9634 & 3.2543 & TRN & \\
\hline CHEMBL1543965 & 688767 & 4.1628 & 3.2278 & TRN & \\
\hline CHEMBL1991426 & 688767 & 2.9634 & 3.266 & TRN & \\
\hline CHEMBL1319129 & 688767 & 2.9634 & 2.7176 & TRN & \\
\hline CHEMBL3193581 & 688767 & 2.9634 & 2.8441 & TRN & \\
\hline CHEMBL1449334 & 688767 & 2.9634 & 2.95899 & 99999999996 & TRN \\
\hline CHEMBL1308606 & 688767 & 2.9634 & 3.2984 & TRN & \\
\hline CHEMBL1330042 & 688767 & 2.9634 & 2.9538 & TRN & \\
\hline CHEMBL3192011 & 688767 & 2.9634 & 2.4796 & TRN & \\
\hline CHEMBL1348273 & 688767 & 2.9634 & 3.2677 & TRN & \\
\hline CHEMBL1387693 & 688767 & 2.9634 & 3.1567 & TRN & \\
\hline CHEMBL1465511 & 688767 & 2.9634 & 3.6276 & TST & \\
\hline CHEMBL1981150 & 688767 & 2.9634 & 3.0299 & TRN & \\
\hline
\end{tabular}




\begin{tabular}{|c|c|c|c|c|c|}
\hline & & \multicolumn{4}{|c|}{ Supplemental Table s2.txt } \\
\hline CHEMBL 3197557 & 688767 & 2.9634 & 3.1984 & TRN & \\
\hline CHEMBL578585 & 688767 & 4.2741 & 3.3913 & TRN & \\
\hline CHEMBL1459125 & 688767 & 2.9634 & 2.9226 & TRN & \\
\hline CHEMBL1454531 & 688767 & 2.9634 & 3.0289 & TRN & \\
\hline CHEMBL1446458 & 688767 & 2.9634 & 2.8415 & TRN & \\
\hline CHEMBL1465739 & 688767 & 4.0451 & 3.4347 & TRN & \\
\hline CHEMBL571296 & 688767 & 3.4405 & 3.3648 & TRN & \\
\hline CHEMBL1538897 & 688767 & 4.4922 & 3.5493 & TRN & \\
\hline CHEMBL1518374 & 688767 & 2.9634 & 2.8115 & TRN & \\
\hline CHEMBL1439414 & 688767 & 3.9176 & 4.0942 & TRN & \\
\hline CHEMBL1538505 & 688767 & 2.9634 & 3.1903 & TRN & \\
\hline CHEMBL1968789 & 688767 & 2.9634 & 3.1539 & TRN & \\
\hline CHEMBL1307648 & 688767 & 4.8094 & 3.4566 & TRN & \\
\hline CHEMBL119171 & 688767 & 4.4684 & 3.2378 & TST & \\
\hline CHEMBL1299990 & 688767 & 2.9634 & 2.9565 & TRN & \\
\hline CHEMBL1510117 & 688767 & 2.9634 & 2.8591 & TRN & \\
\hline CHEMBL1699206 & 688767 & 2.9634 & 3.1425 & TRN & \\
\hline CHEMBL1981200 & 688767 & 2.9634 & 3.0533 & TRN & \\
\hline CHEMBL1417701 & 688767 & 4.03 & 3.4208 & TRN & \\
\hline CHEMBL1507764 & 688767 & 2.9634 & 3.3973 & TST & \\
\hline CHEMBL1482959 & 688767 & 2.9634 & 3.2564 & TRN & \\
\hline CHEMBL1345135 & 688767 & 2.9634 & 2.9617 & TRN & \\
\hline CHEMBL1359782 & 688767 & 4.7538 & 4.146 & TRN & \\
\hline CHEMBL1580684 & 688767 & 2.9634 & 3.2317 & TRN & \\
\hline CHEMBL1592276 & 688767 & 4.5976 & 3.2196 & TST & \\
\hline CHEMBL1312212 & 688767 & 4.1879 & 2.9014 & TST & \\
\hline CHEMBL1415426 & 688767 & 2.9634 & 3.3894 & TRN & \\
\hline CHEMBL1514693 & 688767 & 2.9634 & 3.5021 & TST & \\
\hline CHEMBL1312353 & 688767 & 2.9634 & 3.1056 & TRN & \\
\hline CHEMBL1488981 & 688767 & 2.9634 & 3.4583 & TST & \\
\hline CHEMBL1503852 & 688767 & 2.9634 & 3.0264 & TRN & \\
\hline CHEMBL1397916 & 688767 & 2.9634 & 2.8188 & TRN & \\
\hline CHEMBL1417070 & 688767 & 4.2942 & 3.5365 & TST & \\
\hline CHEMBL1435948 & 688767 & 2.9634 & 2.8978 & TRN & \\
\hline CHEMBL1520254 & 688767 & 2.9634 & 3.2715 & TST & \\
\hline CHEMBL1401406 & 688767 & 4.5646 & 3.4029 & TST & \\
\hline CHEMBL1966952 & 688767 & 5.1417 & 4.3395 & TRN & \\
\hline CHEMBL3192179 & 688767 & 2.9634 & 3.1365 & TRN & \\
\hline CHEMBL1310309 & 688767 & 2.9634 & 2.9703 & TRN & \\
\hline CHEMBL1706577 & 688767 & 2.9634 & 2.82899 & 99999999997 & TRN \\
\hline CHEMBL1532198 & 688767 & 2.9634 & 3.9307 & TRN & \\
\hline CHEMBL3199065 & 688767 & 2.9634 & 3.4756 & TST & \\
\hline CHEMBL1316816 & 688767 & 4.5176 & 3.3335 & TST & \\
\hline CHEMBL1453409 & 688767 & 4.6718 & 3.3362 & TST & \\
\hline CHEMBL1360150 & 688767 & 2.9634 & 3.1025 & TST & \\
\hline CHEMBL1359564 & 688767 & 2.9634 & 3.1845 & TST & \\
\hline CHEMBL469424 & 688767 & 4.2659 & 2.9666 & TST & \\
\hline CHEMBL1397359 & 688767 & 2.9634 & 3.0511 & TST & \\
\hline
\end{tabular}




\begin{tabular}{|c|c|c|c|c|c|c|}
\hline \multicolumn{7}{|c|}{ Supplemental Table S2.txt } \\
\hline CHEMBL1601742 & 688767 & 2.9634 & 3.0632 & TST & & \\
\hline CHEMBL1385808 & 688767 & 2.9634 & 3.1351 & TST & & \\
\hline CHEMBL3195986 & 688767 & 2.9634 & 3.5171 & TST & & \\
\hline CHEMBL1558195 & 688767 & 2.9634 & 2.6903 & TST & & \\
\hline CHEMBL1346029 & 688767 & 2.9634 & 3.6731 & TST & & \\
\hline CHEMBL3199337 & 688767 & 2.9634 & 3.5049 & TST & & \\
\hline CHEMBL1318277 & 688767 & 2.9634 & 3.6293 & TST & & \\
\hline CHEMBL1476707 & 688767 & 2.9634 & 2.7863 & TST & & \\
\hline CHEMBL1597177 & 688767 & 2.9634 & 3.025 & TST & & \\
\hline CHEMBL 3982555 & 1641842 & 7.1249 & 7.0444 & TRN & & \\
\hline CHEMBL 3941210 & 1641842 & 8.8013 & 8.8147 & TRN & & \\
\hline CHEMBL 3893621 & 1641842 & 8.0269 & 8.0335 & TRN & & \\
\hline CHEMBL 3947188 & 1641842 & 7.9355 & 7.9147 & TRN & & \\
\hline CHEMBL 3973355 & 1641842 & 10.6778 & 10.6107 & TRN & & \\
\hline CHEMBL3910173 & 1641842 & 10.3188 & 10.3446 & TRN & & \\
\hline CHEMBL3963263 & 1641842 & 10.7212 & 10.7476 & TRN & & \\
\hline CHEMBL3975459 & 1641842 & 9.9136 & 9.889 & TRN & & \\
\hline CHEMBL3921508 & 1641842 & 10.69906 & g0000000e & 002 & 10.7137 & TRN \\
\hline CHEMBL3916764 & 1641842 & 8.8153 & 8.8215 & TRN & & \\
\hline CHEMBL3953868 & 1641842 & 7.3706 & 7.412000 & 0000000001 & & TRN \\
\hline CHEMBL3898291 & 1641842 & 8.8861 & 8.8333 & TRN & & \\
\hline CHEMBL 3942661 & 1641842 & 11.30099 & 999999999 & 998 & 11.3289 & TRN \\
\hline CHEMBL3902348 & 1641842 & 9.1512 & 9.128 & TRN & & \\
\hline CHEMBL3933910 & 1641842 & 10.2366 & 10.3047 & TRN & & \\
\hline CHEMBL3969948 & 1641842 & 9.3251 & 9.3105 & TRN & & \\
\hline CHEMBL3915528 & 1641842 & 9.4685 & 9.4722 & TRN & & \\
\hline CHEMBL3956358 & 1641842 & 10.5528 & 10.5803 & TRN & & \\
\hline CHEMBL3965778 & 1641842 & 10.3372 & 10.3477 & TRN & & \\
\hline CHEMBL 3974553 & 1641842 & 8.2291 & 9.9236 & TST & & \\
\hline CHEMBL 3980614 & 1641842 & 10.0506 & 10.0502 & TRN & & \\
\hline CHEMBL3962372 & 1641842 & 9.757 & 9.7203 & TRN & & \\
\hline CHEMBL 3955755 & 1641842 & 8.0048 & 7.9888 & TRN & & \\
\hline CHEMBL3938407 & 1641842 & 8.2441 & 8.235 & TRN & & \\
\hline CHEMBL 3905279 & 1641842 & 10.4685 & 10.495 & TRN & & \\
\hline CHEMBL 3928111 & 1641842 & 11.0458 & 11.0418 & TRN & & \\
\hline CHEMBL3955738 & 1641842 & 9.0405 & 10.0861 & TST & & \\
\hline CHEMBL 3889820 & 1641842 & 11.5229 & 11.5253 & TRN & & \\
\hline CHEMBL3979226 & 1641842 & 9.5591 & 9.5658 & TRN & & \\
\hline CHEMBL 3961238 & 1641842 & 8.8239 & 8.8428 & TRN & & \\
\hline CHEMBL 3949154 & 1641842 & 9.7167 & 9.7092 & TRN & & \\
\hline CHEMBL3937305 & 1641842 & 7.3143 & 7.3021 & TRN & & \\
\hline CHEMBL 3934239 & 1641842 & 11.3979 & 11.3514 & TRN & & \\
\hline CHEMBL3985293 & 1641842 & 10.0132 & 10.0776 & TRN & & \\
\hline CHEMBL 3896868 & 1641842 & 10.0 & 9.9395 & TRN & & \\
\hline CHEMBL3913333 & 1641842 & 8.5686 & 8.5854 & TRN & & \\
\hline CHEMBL3928374 & 1641842 & 9.2716 & 9.3101 & TRN & & \\
\hline CHEMBL 3898060 & 1641842 & 10.8239 & 10.8807 & TRN & & \\
\hline CHEMBL 3954196 & 1641842 & 10.6021 & 10.6383 & TRN & & \\
\hline
\end{tabular}

Page 25356 


$$
\text { Supplemental Table S2.txt }
$$

\begin{tabular}{|c|c|c|c|c|c|c|}
\hline CHEMBL3917834 & 1641842 & 10.6383 & 10.6327 & TRN & & \\
\hline CHEMBL3933911 & 1641842 & 9.1068 & 9.1098 & TRN & & \\
\hline CHEMBL3961736 & 1641842 & 11.6990 & 000000000 & 302 & 11.6839 & TRN \\
\hline CHEMBL 3924527 & 1641842 & 11.3979 & 11.376 & TRN & & \\
\hline CHEMBL3915854 & 1641842 & 10.3098 & 10.3139 & TRN & & \\
\hline CHEMBL3979761 & 1641842 & 10.4815 & 10.5387 & TRN & & \\
\hline CHEMBL3902469 & 1641842 & 9.2993 & 9.3132 & TRN & & \\
\hline CHEMBL3935876 & 1641842 & 9.9626 & 9.9551 & TRN & & \\
\hline CHEMBL3978289 & 1641842 & 10.0044 & 10.0303 & TRN & & \\
\hline CHEMBL3932558 & 1641842 & 7.2907 & 9.2573 & TST & & \\
\hline CHEMBL 3932216 & 1641842 & 8.0857 & 8.0865 & TRN & & \\
\hline CHEMBL3902343 & 1641842 & 10.0867 & 10.0335 & TRN & & \\
\hline CHEMBL3904007 & 1641842 & 8.8861 & 8.9336 & TRN & & \\
\hline CHEMBL3966396 & 1641842 & 8.4685 & 8.8302 & TST & & \\
\hline CHEMBL3969471 & 1641842 & 10.4089 & 10.4375 & TRN & & \\
\hline CHEMBL 3962468 & 1641842 & 8.8962 & 8.9388 & TRN & & \\
\hline CHEMBL3979718 & 1641842 & 8.7685 & 8.7831 & TRN & & \\
\hline CHEMBL3904733 & 1641842 & 9.9172 & 9.9124 & TRN & & \\
\hline CHEMBL3907044 & 1641842 & 10.4949 & 10.4618 & TRN & & \\
\hline CHEMBL 3949303 & 1641842 & 9.7545 & 9.7055 & TRN & & \\
\hline CHEMBL3928472 & 1641842 & 9.5302 & 9.5009 & TRN & & \\
\hline CHEMBL3961126 & 1641842 & 9.0937 & 9.0689 & TRN & & \\
\hline CHEMBL3985299 & 1641842 & 10.3468 & 10.3327 & TRN & & \\
\hline CHEMBL3924853 & 1641842 & 9.3872 & 9.4134 & TRN & & \\
\hline CHEMBL3931531 & 1641842 & 10.1805 & 10.1728 & TRN & & \\
\hline CHEMBL3968235 & 1641842 & 11.0 & 10.9952 & TRN & & \\
\hline CHEMBL3933438 & 1641842 & \multicolumn{3}{|c|}{11.699000000000002} & 11.6146 & TRN \\
\hline CHEMBL3974676 & 1641842 & 8.9586 & 8.9251 & TST & & \\
\hline CHEMBL3906953 & 1641842 & 12.0 & 12.0755 & TRN & & \\
\hline CHEMBL3971173 & 1641842 & 8.2299 & 8.264 & TRN & & \\
\hline CHEMBL3931653 & 1641842 & 10.9586 & 10.97 & TRN & & \\
\hline CHEMBL3953639 & 1641842 & 10.2518 & 9.7901 & TST & & \\
\hline CHEMBL3986492 & 1641842 & 9.8601 & 9.846 & TRN & & \\
\hline CHEMBL3952553 & 1641842 & 7.2588 & 7.2523 & TRN & & \\
\hline CHEMBL3975523 & 1641842 & 8.2757 & 8.2612 & TRN & & \\
\hline CHEMBL3896962 & 1641842 & 11.3979 & 9.3929 & TST & & \\
\hline CHEMBL3926138 & 1641842 & 9.8041 & 9.715 & TRN & & \\
\hline CHEMBL3960105 & 1641842 & 9.0434 & 11.4657 & TST & & \\
\hline CHEMBL3925336 & 1641842 & 9.4202 & 9.4106 & TRN & & \\
\hline CHEMBL3919091 & 1641842 & 9.4342 & 9.4076 & TRN & & \\
\hline CHEMBL 3917253 & 1641842 & \multicolumn{3}{|c|}{11.699000000000002} & 11.508 & TST \\
\hline CHEMBL3932883 & 1641842 & 9.3224 & 9.296 & TRN & & \\
\hline CHEMBL3973332 & 1641842 & 7.1249 & 8.5119 & TST & & \\
\hline CHEMBL3931706 & 1641842 & 8.4437 & 8.4642 & TRN & & \\
\hline CHEMBL3891500 & 1641842 & 7.1249 & 7.1478 & TRN & & \\
\hline CHEMBL3962830 & 1641842 & 10.0506 & 9.9977 & TRN & & \\
\hline CHEMBL3941708 & 1641842 & 10.1308 & 10.1238 & TRN & & \\
\hline CHEMBL3910310 & 1641842 & 10.2924 & 10.325 & TRN & & \\
\hline
\end{tabular}

Page 25357 
Supplemental Table S2.txt

CHEMBL3947028

CHEMBL3904215

CHEMBL 3918290

CHEMBL 3910475

CHEMBL3893353

CHEMBL3946634

CHEMBL3947678

CHEMBL 3965874

CHEMBL3892294

CHEMBL 3931986

CHEMBL3978277

CHEMBL3900007

CHEMBL3909059

CHEMBL3980705

CHEMBL 3895303

CHEMBL 3974253

CHEMBL3986999

CHEMBL3905901

CHEMBL3932735

CHEMBL 3919565

CHEMBL3918483

CHEMBL 3907760

CHEMBL3986382

CHEMBL 3946797

CHEMBL 3957961

CHEMBL 3890298

CHEMBL 3979208

CHEMBL 3977766

CHEMBL 3895080

CHEMBL3911732

CHEMBL3942871

CHEMBL3971648

CHEMBL3961236

CHEMBL3946200

CHEMBL3971060

CHEMBL3948217

CHEMBL 3959478

CHEMBL3919236

CHEMBL3906070

CHEMBL 3934061

CHEMBL 3954540

CHEMBL 3894490

CHEMBL 3893247

CHEMBL3944237

CHEMBL3964946

CHEMBL 3967370

CHEMBL3966746

CHEMBL 3913622
164184211.522911 .5016 TRN

$\begin{array}{llll}1641842 & 7.9296 & 7.9591 & \text { TRN }\end{array}$

$\begin{array}{llll}1641842 & 7.7799 & 7.782 & \text { TRN }\end{array}$

$\begin{array}{lll}1641842 & 10.2757 & 10.2788 \text { TRN }\end{array}$

$\begin{array}{llll}1641842 & 9.3206 & 9.2831 & \text { TRN }\end{array}$

$\begin{array}{lll}1641842 & 10.6778 & 10.633\end{array}$

$\begin{array}{llll}1641842 & 8.3872 & 8.4102 & \text { TRN }\end{array}$

$\begin{array}{llll}1641842 & 9.1884 & 9.2039 & \text { TRN }\end{array}$

$16418426.0 \quad 11.4166$ TST

$\begin{array}{lll}1641842 & 11.0969 & 11.1079 \text { TRN }\end{array}$

$\begin{array}{lll}1641842 & 7.1249 & 9.3535\end{array}$

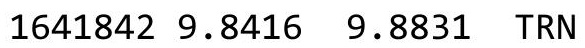

$\begin{array}{lll}1641842 & 10.8539 & 10.7484 \\ \text { TRN }\end{array}$

$\begin{array}{llll}1641842 & 8.1024 & 8.7518 & \text { TST }\end{array}$

$\begin{array}{llll}1641842 & 6.0 & 6.8643 & \text { TST }\end{array}$

$\begin{array}{llll}1641842 & 9.2581 & 9.3026 & \text { TRN }\end{array}$

164184211.699000000000002

$\begin{array}{lll}1641842 & 10.5686 & 10.5359\end{array}$

$\begin{array}{lll}1641842 & 10.1427 & 10.213\end{array}$

$\begin{array}{llll}1641842 & 11.3979 & 9.0358 & \text { TST }\end{array}$

$\begin{array}{llll}1641842 & 7.9872 & 7.6977 & \text { TST }\end{array}$

$\begin{array}{llll}1641842 & 8.8993 & 8.9016 & \text { TRN }\end{array}$

$\begin{array}{lll}1641842 & 10.3565 & 10.4336\end{array}$

$\begin{array}{llll}1641842 & 7.1249 & 8.3723 & \text { TST }\end{array}$

$\begin{array}{lll}1641842 & 10.1938 & 10.2283\end{array}$

164184211.300999999999998

$\begin{array}{lll}1641842 & 11.1549 & 11.5267\end{array}$

$\begin{array}{llll}1641842 & 8.2441 & 8.5699 & \text { TST }\end{array}$

$\begin{array}{lll}1641842 & 10.4318 & 10.5926\end{array}$

$\begin{array}{lll}1641842 & 10.8861 & 9.1534\end{array}$

$\begin{array}{llll}1641842 & 9.5834 & 9.1729 & \text { TST }\end{array}$

$\begin{array}{lll}1641842 & 12.0 & 11.872\end{array}$

$\begin{array}{lll}1641842 & 10.7212 & 10.3293\end{array}$

$\begin{array}{llll}1641842 & 7.4908 & 7.7793 & \text { TST }\end{array}$

$\begin{array}{lll}1641842 & 10.3188 & 9.6586\end{array}$

$\begin{array}{lll}1641842 & 11.1549 & 11.0123 \\ \text { TST }\end{array}$

$\begin{array}{lll}1641842 & 8.5528 & 10.7855\end{array}$

$\begin{array}{llll}1641842 & 8.8904 & 9.0059 & \text { TST }\end{array}$

$\begin{array}{llll}1642535 & 7.8539 & 7.3416 & \text { TST }\end{array}$

$\begin{array}{llll}1642535 & 8.6778 & 8.1385 & \text { TST }\end{array}$

$\begin{array}{llll}1642535 & 7.7959 & 7.9343 & \text { TRN }\end{array}$

$\begin{array}{llll}1642535 & 7.7447 & 7.6919 & \text { TRN }\end{array}$

$\begin{array}{llll}1642535 & 8.1938 & 8.213 & \text { TRN }\end{array}$

$\begin{array}{llll}1642535 & 7.5686 & 7.5485 & \text { TRN }\end{array}$

$\begin{array}{llll}1642535 & 7.9208 & 7.9777 & \text { TRN }\end{array}$

$\begin{array}{llll}1642535 & 7.9208 & 7.8822 & \text { TRN }\end{array}$

$\begin{array}{llll}1642535 & 7.4685 & 7.6993 & \text { TRN }\end{array}$

$\begin{array}{llll}1642535 & 7.7447 & 7.6384 & \text { TRN }\end{array}$
$11.609000000000002 \quad$ TST

10.8307 TST

Page 25358 
Supplemental Table S2.txt

\begin{tabular}{|c|c|c|c|c|}
\hline - & & 5198 & & \\
\hline & & 7.9586 & & \\
\hline & & & & \\
\hline HEMBL 391 & & & & \\
\hline AEMBL3949226 & נכט & 3098 & & \\
\hline HEMBL3952936 & 64 & 7.5229 & 4356 & \\
\hline 972 & & & & \\
\hline IFMBI 380 & & & & \\
\hline HEMBL3892991 & & & 7.7455 & \\
\hline HEMBL3976846 & 6 & 96 & .8204 & \\
\hline HEMBL3936358 & 62 & 8.0915 & 7.9999 & \\
\hline AEMBL39e & $0<$ & & 834 & \\
\hline AEMBL39 & & & & \\
\hline HEMBL3896236 & 6 & & 6.8105 & \\
\hline HEMBL394 & 6 & & 8497 & \\
\hline AEMBL393 & 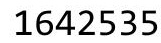 & 76 & 6287 & \\
\hline HEMBL39 & 0 & & 7739 & \\
\hline HEMBL39 & & & .9216 & \\
\hline HEMBL397 & & 98 & .1652 & \\
\hline AEMBL39 & & & & \\
\hline HEIMBLSS & 62 & 7. & 53 & Niv \\
\hline HEMBL3S & & & 47 & וזנה \\
\hline HEMBL3\& & & & 266 & \\
\hline HEMBL 392 & & & 9063 & \\
\hline JEMBL 39 & & & & 15 \\
\hline HEMBL3S & 6 & & 38 & $\Gamma \mathrm{RN}$ \\
\hline HEMBL3S & & & 88 & No \\
\hline HFMBI $3 c$ & & & 58 & \\
\hline HEMBL39e & & & 7.4485 & Ih \\
\hline HEMBL 398 & & & 7.7152 & is \\
\hline HEMBL39 & & & 2362 & RN \\
\hline HEMBL3 & & & 278 & RN \\
\hline HEMBL3S & & 7. & 7.3899 & גח \\
\hline HEMBL396 & 62 & & 339 & IRN \\
\hline HEMBL3986613 & 62 & & 7.8587 & TST \\
\hline HEMBL 394 & 6 & 7. & 7.6172 & RN \\
\hline HFMRI 3 & & & 963 & $\Gamma \mathrm{RN}$ \\
\hline HEMBL3 & & & 8.0913 & IRN \\
\hline HEMBL3961430 & 2 & 8.1871 & 8.2175 & TRN \\
\hline HEMBL 392 & 6 & 7 & 7.0695 & TRN \\
\hline HEMBL 398 & 6 & & 7.6705 & DN \\
\hline CHEMBL396 & & & 8.1423 & TRN \\
\hline HEMBL394 & & 7. & 7.7973 & TRN \\
\hline HEMBL3980883 & 535 & 6.9 & 5.5421 & TS \\
\hline$M B \mid 3$ & & & 7.7031 & IRN \\
\hline HEMBL389 & & & 5.5597 & \\
\hline CHEMBL3916308 & & & 8.1166 & \\
\hline THEMBL3936693 & 1642535 & 7.6383 & 7.5377 & ГRN \\
\hline
\end{tabular}

Page 25359 
Supplemental Table S2.txt

\begin{tabular}{|c|c|c|c|c|c|}
\hline CHEMBL 3896113 & 1642535 & 8.7212 & 8.6324 & TRN & \\
\hline CHEMBL3911589 & 1642535 & 8.1192 & \multicolumn{2}{|c|}{7.9110000000000005} & TST \\
\hline CHEMBL3913143 & 1642535 & 6.8239 & 6.7928 & TRN & \\
\hline CHEMBL 3983594 & 1642535 & 7.8239 & 7.7992 & TRN & \\
\hline CHEMBL3952221 & 1642535 & 8.1192 & 8.1265 & TRN & \\
\hline CHEMBL3963389 & 1642535 & 8.0 & 7.7202 & TST & \\
\hline CHEMBL3985528 & 1642535 & 7.6198 & 7.5156 & TST & \\
\hline CHEMBL3930342 & 1642535 & 8.3372 & 8.1002 & TST & \\
\hline CHEMBL3933776 & 1642535 & 7.7212 & 7.6263 & TST & \\
\hline CHEMBL2397980 & 967317 & 7.1549 & 7.1637 & TRN & \\
\hline CHEMBL2397990 & 967317 & 7.3979 & 7.709 & TST & \\
\hline CHEMBL463270 & 967317 & 5.0 & 5.4247 & TST & \\
\hline CHEMBL 2397966 & 967317 & 4.0 & 3.9685 & TRN & \\
\hline CHEMBL2397977 & 967317 & 5.1249 & 5.1438 & TRN & \\
\hline CHEMBL2397995 & 967317 & 4.0 & 4.0198 & TRN & \\
\hline CHEMBL2397998 & 967317 & 4.0 & 4.0037 & TRN & \\
\hline CHEMBL2398006 & 967317 & 4.8239 & \multicolumn{2}{|c|}{4.821000000000001} & TRN \\
\hline CHEMBL2397981 & 967317 & 6.426 & 6.4873 & TRN & \\
\hline CHEMBL2397959 & 967317 & 7.1249 & 7.1366 & TRN & \\
\hline CHEMBL2397964 & 967317 & 5.301 & 5.3429 & TRN & \\
\hline CHEMBL2397965 & 967317 & 5.0 & 4.9393 & TRN & \\
\hline CHEMBL2398005 & 967317 & 5.301 & 5.2803 & TRN & \\
\hline CHEMBL 2397960 & 967317 & 7.1249 & 7.1284 & TRN & \\
\hline CHEMBL2397961 & 967317 & 7.1249 & 7.1109 & TRN & \\
\hline CHEMBL2397970 & 967317 & 4.4559 & 4.8402 & TST & \\
\hline CHEMBL2397971 & 967317 & 6.4559 & 6.4072 & TRN & \\
\hline CHEMBL2397988 & 967317 & 7.5229 & 7.5505 & TRN & \\
\hline CHEMBL 2397994 & 967317 & 4.4559 & 4.4812 & TRN & \\
\hline CHEMBL2397976 & 967317 & 5.301 & 5.1951 & TST & \\
\hline CHEMBL2397963 & 967317 & 5.6021 & 5.6228 & TRN & \\
\hline CHEMBL2397975 & 967317 & 5.6021 & 4.9409 & TST & \\
\hline CHEMBL2397974 & 967317 & 5.6021 & 5.6382 & TST & \\
\hline CHEMBL2397991 & 967317 & 5.6021 & 5.5754 & TRN & \\
\hline CHEMBL2398003 & 967317 & 5.0 & 4.9788 & TRN & \\
\hline CHEMBL2397993 & 967317 & 4.1249 & 4.1492 & TRN & \\
\hline CHEMBL2398002 & 967317 & 5.0 & 4.9931 & TRN & \\
\hline CHEMBL2397969 & 967317 & 4.4559 & 4.4167 & TRN & \\
\hline CHEMBL 2397996 & 967317 & 5.0 & 4.9929 & TRN & \\
\hline CHEMBL2397987 & 967317 & 6.699 & \multicolumn{2}{|c|}{6.707999999999999} & TRN \\
\hline CHEMBL2397984 & 967317 & 5.0 & 4.9823 & TRN & \\
\hline CHEMBL2397997 & 967317 & 5.0 & 4.9936 & TRN & \\
\hline CHEMBL2397962 & 967317 & 6.6021 & 6.6799 & TST & \\
\hline CHEMBL2397978 & 967317 & 6.3979 & 6.9145 & TST & \\
\hline CHEMBL2397968 & 967317 & 4.0 & 4.024 & TRN & \\
\hline CHEMBL2397982 & 967317 & 6.699 & 6.6881 & TRN & \\
\hline CHEMBL2397983 & 967317 & 4.4559 & 4.4007 & TRN & \\
\hline CHEMBL2398001 & 967317 & 4.699 & 5.3178 & TST & \\
\hline CHEMBL2396669 & 967317 & 5.1249 & 5.1453 & TRN & \\
\hline
\end{tabular}

Page 25360 


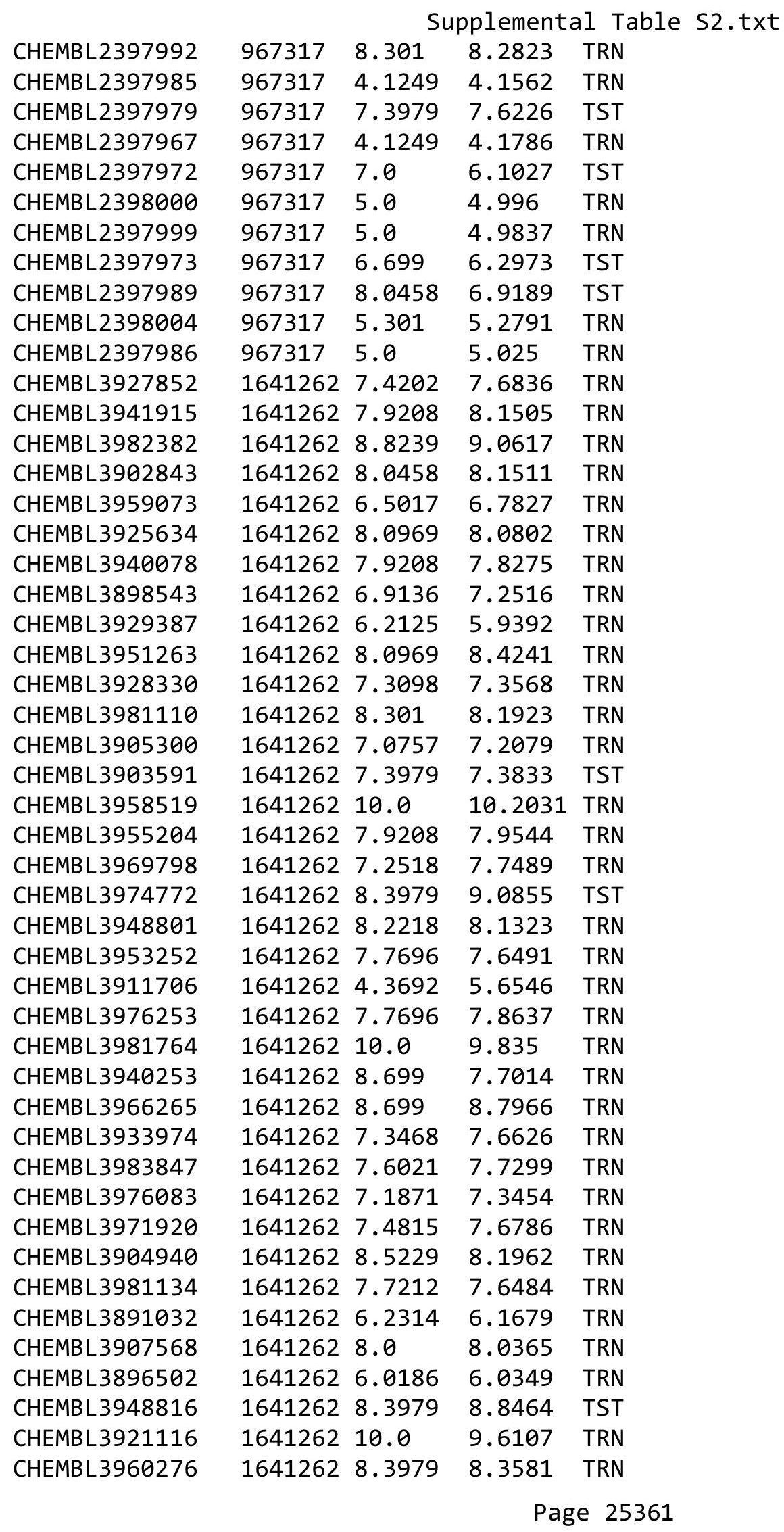


Supplemental Table S2.txt

\begin{tabular}{|c|c|c|c|c|c|}
\hline CHEMBL3980827 & 1641262 & 8.699 & 8.596 & TRN & \\
\hline CHEMBL3897434 & 1641262 & 7.3768 & 7.1198 & TRN & \\
\hline CHEMBL3910910 & 1641262 & 7.2596 & 7.5982 & TRN & \\
\hline CHEMBL3920293 & 1641262 & 8.2218 & 8.5965 & TRN & \\
\hline CHEMBL3921967 & 1641262 & 9.0 & 9.0336 & TST & \\
\hline CHEMBL3940882 & 1641262 & 7.3768 & 7.0655 & TRN & \\
\hline CHEMBL3984983 & 1641262 & 7.4202 & 7.6601 & TRN & \\
\hline CHEMBL3945381 & 1641262 & 7.6198 & 7.7452 & TRN & \\
\hline CHEMBL3946837 & 1641262 & 8.3979 & 8.2549 & TRN & \\
\hline CHEMBL3936473 & 1641262 & 8.3979 & 8.1952 & TST & \\
\hline CHEMBL3919924 & 1641262 & 8.0 & 7.8203 & TST & \\
\hline CHEMBL3967471 & 1641262 & 8.1549 & 8.266 & TST & \\
\hline CHEMBL3959552 & 1641262 & 6.4802 & 6.6958 & TRN & \\
\hline CHEMBL3939680 & 1641262 & 7.6198 & 7.4781 & TST & \\
\hline CHEMBL3933557 & 1641262 & 10.0 & 8.4105 & TST & \\
\hline CHEMBL3893126 & 1641262 & 8.3979 & 9.2666 & TST & \\
\hline CHEMBL3952650 & 1641262 & 7.6021 & 7.382006 & 0000000001 & TRN \\
\hline CHEMBL3959773 & 1641262 & 7.699 & 7.4307 & TRN & \\
\hline CHEMBL3954102 & 1641262 & 7.7447 & 7.7436 & TRN & \\
\hline CHEMBL3969316 & 1641262 & 8.2218 & 5.5073 & TST & \\
\hline CHEMBL3969732 & 1641262 & 8.0458 & 8.1741 & TST & \\
\hline CHEMBL3930764 & 1641262 & 8.699 & 9.0117 & TRN & \\
\hline CHEMBL3899871 & 1641262 & 6.0164 & 5.8455 & TRN & \\
\hline CHEMBL3955946 & 1641262 & 6.6073 & 6.9206 & TRN & \\
\hline CHEMBL3948935 & 1641262 & 10.0 & 9.501 & TRN & \\
\hline CHEMBL3915940 & 1641262 & 7.041 & 7.1437 & TRN & \\
\hline CHEMBL3941097 & 1641262 & 7.9586 & 8.1771 & TST & \\
\hline CHEMBL3971233 & 1641262 & 6.2741 & 6.2105 & TRN & \\
\hline CHEMBL3958013 & 1641262 & 7.6021 & 6.7537 & TST & \\
\hline CHEMBL3928822 & 1641262 & 8.3979 & 8.2863 & TST & \\
\hline CHEMBL3984305 & 1641262 & 6.0721 & 6.4155 & TRN & \\
\hline CHEMBL3962841 & 1641262 & 8.3979 & 7.9015 & TST & \\
\hline CHEMBL3983892 & 1641262 & 8.5229 & 8.0575 & TRN & \\
\hline CHEMBL3962278 & 1641262 & 8.2218 & 8.0632 & TRN & \\
\hline CHEMBL3913940 & 1641262 & 6.1397 & 6.4972 & TRN & \\
\hline CHEMBL3891697 & 1641262 & 7.4437 & 5.902 & TRN & \\
\hline CHEMBL3950647 & 1641262 & 7.3372 & 7.6926 & TRN & \\
\hline CHEMBL3946694 & 1641262 & 7.2076 & 6.8101 & TRN & \\
\hline CHEMBL3941052 & 1641262 & 7.6021 & 7.3331 & TRN & \\
\hline CHEMBL3936177 & 1641262 & 8.1549 & 7.9587 & TRN & \\
\hline CHEMBL3892730 & 1641262 & 8.3979 & 8.8055 & TRN & \\
\hline CHEMBL3972809 & 1641262 & 8.3979 & 7.9078 & TRN & \\
\hline CHEMBL3919745 & 1641262 & 7.5376 & 7.5338 & TRN & \\
\hline CHEMBL3906666 & 1641262 & 8.699 & 8.3409 & TRN & \\
\hline CHEMBL3934271 & 1641262 & 8.5229 & 8.543 & TRN & \\
\hline CHEMBL3943616 & 1641262 & 8.5229 & 8.3638 & TST & \\
\hline CHEMBL3897060 & 1641262 & 8.3979 & \multicolumn{2}{|c|}{8.277000000000001} & TRN \\
\hline CHEMBL3893413 & 1641262 & 7.4437 & 7.2189 & TST & \\
\hline
\end{tabular}


Supplemental Table S2.txt

\begin{tabular}{|c|c|c|c|c|}
\hline HEM & 1262 & 599 & 8.9867 & TRN \\
\hline HEMBL3891930 & 641262 & 7.7959 & 7.8323 & TRN \\
\hline HEMBL 3899331 & 262 & 8.699 & 9939 & \\
\hline HEMBL3916209 & 641262 & 8.3979 & 7419 & \\
\hline HEMBL3921431 & 641262 & 7.4949 & 2841 & \\
\hline HEMBL3944316 & 641262 & 8.301 & .6332 & \\
\hline HEMBL3919092 & 262 & 6.2076 & 539 & \\
\hline AEMBL3953021 & 262 & 8.0458 & 1328 & ST \\
\hline AEMBL3944279 & 641262 & 10.0 & 6489 & \\
\hline HEMBL3906975 & 641262 & 7.6383 & .0543 & ST \\
\hline HEMBL3931017 & 262 & 8.0 & .8468 & \\
\hline HEMBL3919427 & 262 & 8.3979 & .2613 & \\
\hline HEMBL3958242 & 262 & & .8286 & RN \\
\hline HEMBL3980570 & 262 & 7.7696 & 7.7739 & \\
\hline HEMBL3967436 & 262 & 10.0 & 0.0114 & \\
\hline AEMBL3956390 & 262 & 8.2218 & 8.0671 & דו \\
\hline HEMBL3915776 & 62 & 8.3979 & 2086 & KIV \\
\hline HEMBL3911540 & 62 & 7.4815 & 1698 & \\
\hline HEMBL3948277 & 62 & 7.9586 & . 6992 & \\
\hline HEMBL3891211 & 52 & 7.6383 & 319 & RN \\
\hline HEMBL3905405 & $6<$ & 6.2832 & 3797 & ו ו \\
\hline HEMBL3955263 & 2 & 458 & 1376 & $\mathrm{RN}$ \\
\hline HEMBL3924940 & 52 & 147 & 5789 & \\
\hline HEMBL3919726 & 62 & 6.8182 & . 9472 & RN \\
\hline HEMBL3967061 & 52 & 7.3665 & 14 & TRN \\
\hline HEMBL11 & 27 & 6. & 3104 & RIN \\
\hline HEMBL3e & 2 & & 5713 & RN \\
\hline HEMBL2e & 5 & 7.66 & 7923 & $2 N$ \\
\hline HEMBL132241 & 27 & 7 & 7786 & 31 \\
\hline HEMBL3084892 & 27 & 7. & 6424 & TRN \\
\hline HEMBL 336186 & 27 & & 512 & RN \\
\hline HEMBL4 & 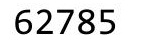 & & 53 & RN \\
\hline HEMBL1 & & & 05 & RN \\
\hline HEMBL3084869 & 27 & 7 & 2831 & IRN \\
\hline HEMBL3084896 & 27 & 7.72 & .7752 & TRN \\
\hline HEMBL133735 & 27 & 2 & .6755 & RN \\
\hline LHEMBL2 & 27 & & 86 & ו \\
\hline HEMBL3084878 & 627 & & 5.6368 & TRN \\
\hline HEMBL336345 & 27 & & .3302 & TRN \\
\hline HEMBL339396 & 27 & & . 3912 & 「RN \\
\hline CHEMBL130630 & 627 & & .3605 & $\mathrm{RN}$ \\
\hline CHEMBL339395 & & & 5.937 & RIN \\
\hline HEMBL341431 & 27 & 7.79 & . 7457 & TRN \\
\hline HEMBL82027 & 27 & 8 & . 1592 & $R$ \\
\hline HEMBL127 & 627 & & . 3913 & T18 \\
\hline CHEMBL3084909 & 62785 & 7.32 & .1679 & RIN \\
\hline CHEMBL3084872 & 62785 & 6.53 & .6663 & N \\
\hline CHEMBL 3084897 & 62785 & 7.04 & 7.2013 & RN \\
\hline
\end{tabular}

Page 25363 


\begin{tabular}{|c|c|c|c|c|c|}
\hline \multicolumn{6}{|c|}{ Supplemental Table S2.txt } \\
\hline CHEMBL133884 & 62785 & 5.28 & 7.0041 & TST & \\
\hline CHEMBL317757 & 62785 & 7.93 & 7.4685 & TRN & \\
\hline CHEMBL 3084880 & 62785 & 7.1 & 6.5688 & TRN & \\
\hline CHEMBL132958 & 62785 & 6.67 & 6.6191 & TRN & \\
\hline CHEMBL 336300 & 62785 & 6.51 & 6.4676 & TRN & \\
\hline CHEMBL 3084867 & 62785 & 5.7 & 6.11700 & 0000000001 & TRN \\
\hline CHEMBL423529 & 62785 & 6.51 & 6.2717 & TRN & \\
\hline CHEMBL37065 & 62785 & 4.95 & 6.4983 & TST & \\
\hline CHEMBL 3084901 & 62785 & 6.72 & 6.5809 & TRN & \\
\hline CHEMBL 3084907 & 62785 & 7.16 & 7.2269 & TRN & \\
\hline CHEMBL134214 & 62785 & 7.79 & 7.8769 & TRN & \\
\hline CHEMBL131957 & 62785 & 7.55 & 7.5681 & TRN & \\
\hline CHEMBL 305881 & 62785 & 5.27 & 5.3057 & TRN & \\
\hline CHEMBL 3084884 & 62785 & 7.7 & 7.4575 & TRN & \\
\hline CHEMBL 3084873 & 62785 & 6.2 & 6.2657 & TRN & \\
\hline CHEMBL135045 & 62785 & 5.07 & 5.0231 & TRN & \\
\hline CHEMBL 26320 & 62785 & 7.89 & 7.9166 & TRN & \\
\hline CHEMBL 310310 & 62785 & 7.52 & 7.7156 & TRN & \\
\hline CHEMBL 3084891 & 62785 & 5.73 & 5.6926 & TRN & \\
\hline CHEMBL 3084900 & 62785 & 6.71 & 6.6272 & TRN & \\
\hline CHEMBL305438 & 62785 & 6.25 & 6.4008 & TRN & \\
\hline CHEMBL 3084910 & 62785 & 6.64 & 6.6226 & TRN & \\
\hline CHEMBL133697 & 62785 & 7.64 & 7.7493 & TRN & \\
\hline CHEMBL 3084908 & 62785 & 7.55 & 7.6845 & TRN & \\
\hline CHEMBL133282 & 62785 & 7.66 & 7.6406 & TRN & \\
\hline CHEMBL 3084882 & 62785 & 7.42 & 7.468 & TRN & \\
\hline CHEMBL132730 & 62785 & 7.7 & 7.4556 & TST & \\
\hline CHEMBL1790051 & 62785 & 7.06 & 7.6636 & TST & \\
\hline CHEMBL337064 & 62785 & 6.21 & 5.4111 & TST & \\
\hline CHEMBL 3084881 & 62785 & 6.73 & 7.7105 & TST & \\
\hline CHEMBL 3084906 & 62785 & 7.63 & 7.4279 & TST & \\
\hline CHEMBL14391 & 62785 & 8.68 & 7.9155 & TST & \\
\hline CHEMBL133422 & 62785 & 7.52 & 7.3385 & TST & \\
\hline CHEMBL 306208 & 62785 & 8.7 & 8.0831 & TST & \\
\hline CHEMBL 3084870 & 62785 & 7.66 & 7.3991 & TST & \\
\hline CHEMBL335390 & 62785 & 6.73 & 7.3025 & TST & \\
\hline CHEMBL 279556 & 62785 & 8.0 & 6.5487 & TST & \\
\hline CHEMBL 201808 & 334895 & 6.301 & 6.2677 & TRN & \\
\hline CHEMBL 201915 & 334895 & 5.9208 & 6.0204 & TRN & \\
\hline CHEMBL202574 & 334895 & 6.0 & 5.9166 & TRN & \\
\hline CHEMBL438254 & 334895 & 6.0 & 6.0462 & TRN & \\
\hline CHEMBL 204255 & 334895 & 5.301 & 5.2696 & TRN & \\
\hline CHEMBL 204485 & 334895 & 5.7212 & 5.73799 & 99999999995 & TRN \\
\hline CHEMBL 381818 & 334895 & 5.1549 & 6.1617 & TST & \\
\hline CHEMBL203541 & 334895 & 6.2218 & 6.0212 & TRN & \\
\hline CHEMBL425400 & 334895 & 5.8239 & 5.7981 & TRN & \\
\hline CHEMBL426668 & 334895 & 6.1549 & 6.1645 & TRN & \\
\hline CHEMBL 203798 & 334895 & 5.6021 & 5.7304 & TRN & \\
\hline
\end{tabular}




\begin{tabular}{|c|c|c|c|c|c|}
\hline \multicolumn{6}{|c|}{ Supplemental Table S2.txt } \\
\hline CHEMBL380826 & 334895 & 5.9586 & 5.9877 & TRN & \\
\hline CHEMBL 205069 & 334895 & 5.2218 & 6.3742 & TST & \\
\hline CHEMBL201671 & 334895 & 6.0969 & 5.6311 & TST & \\
\hline CHEMBL 202480 & 334895 & 4.0 & 4.0223 & TRN & \\
\hline CHEMBL425404 & 334895 & 5.301 & 6.2728 & TST & \\
\hline CHEMBL440219 & 334895 & 6.2596 & 6.2465 & TRN & \\
\hline CHEMBL 204545 & 334895 & 5.2007 & 5.1555 & TRN & \\
\hline CHEMBL 204803 & 334895 & 5.699 & 5.6726 & TRN & \\
\hline CHEMBL 204492 & 334895 & 6.0458 & 5.945 & TRN & \\
\hline CHEMBL204437 & 334895 & 5.6021 & 6.0934 & TST & \\
\hline CHEMBL 205020 & 334895 & 6.301 & 6.3092 & TRN & \\
\hline CHEMBL 202532 & 334895 & 5.8539 & 5.865 & TST & \\
\hline CHEMBL 202113 & 334895 & 5.8539 & 5.9922 & TRN & \\
\hline CHEMBL373068 & 334895 & 6.3768 & 6.3675 & TRN & \\
\hline CHEMBL426839 & 334895 & 6.0 & 6.1078 & TRN & \\
\hline CHEMBL381841 & 334895 & 6.2924 & 6.3329 & TRN & \\
\hline CHEMBL382455 & 334895 & 5.7447 & 5.9866 & TRN & \\
\hline CHEMBL 382901 & 334895 & 5.5229 & 6.166 & TST & \\
\hline CHEMBL 202572 & 334895 & 6.3468 & 6.32600 & 00000000005 & TRN \\
\hline CHEMBL 202422 & 334895 & 5.0 & 6.2295 & TST & \\
\hline CHEMBL 78293 & 334895 & 4.3468 & 6.3876 & TST & \\
\hline CHEMBL 381150 & 334895 & 5.6021 & 5.5825 & TRN & \\
\hline CHEMBL 202692 & 334895 & 5.0969 & 5.0927 & TRN & \\
\hline CHEMBL381920 & 334895 & 5.9208 & 5.8051 & TRN & \\
\hline CHEMBL382657 & 334895 & 5.301 & 5.3426 & TRN & \\
\hline CHEMBL382154 & 334895 & 6.3188 & 6.3305 & TRN & \\
\hline CHEMBL 202475 & 334895 & 6.3768 & 6.3818 & TRN & \\
\hline CHEMBL 203647 & 334895 & 6.2218 & 5.9513 & TST & \\
\hline CHEMBL 203927 & 334895 & 5.3979 & 6.0746 & TST & \\
\hline CHEMBL 379468 & 334895 & 5.9208 & 6.0886 & TST & \\
\hline CHEMBL 203852 & 334895 & 6.2218 & 6.0808 & TRN & \\
\hline CHEMBL 381476 & 334895 & 5.8239 & 5.4916 & TRN & \\
\hline CHEMBL 201466 & 334895 & 5.2366 & 5.5137 & TRN & \\
\hline CHEMBL 204256 & 334895 & 5.7696 & 5.5094 & TST & \\
\hline CHEMBL382099 & 334895 & 5.0555 & 5.0846 & TRN & \\
\hline CHEMBL 204695 & 334895 & 6.1549 & 6.074 & TRN & \\
\hline CHEMBL424852 & 334895 & 5.9208 & 5.9794 & TRN & \\
\hline CHEMBL 204088 & 334895 & 6.1249 & 6.0689 & TRN & \\
\hline CHEMBL 202082 & 334895 & 5.0969 & 6.3348 & TST & \\
\hline CHEMBL426482 & 334895 & 6.3979 & 6.3634 & TRN & \\
\hline CHEMBL 202344 & 334895 & 6.1549 & 6.0997 & TRN & \\
\hline CHEMBL203909 & 334895 & 5.9208 & 5.9164 & TRN & \\
\hline CHEMBL 380723 & 334895 & 5.699 & 5.91 & TST & \\
\hline CHEMBL 383465 & 334895 & 5.9208 & 5.987 & TRN & \\
\hline CHEMBL 204111 & 334895 & 6.1675 & 6.2024 & TRN & \\
\hline CHEMBL 202906 & 334895 & 6.301 & 6.3226 & TRN & \\
\hline CHEMBL 3667883 & 1641081 & 9.6198 & 9.4299 & TRN & \\
\hline CHEMBL3667882 & 1641081 & 9.3372 & 8.9796 & TRN & \\
\hline
\end{tabular}


Supplemental Table S2.txt

\begin{tabular}{|c|c|c|c|c|c|}
\hline CHEMBL3672861 & 1641081 & 8.618 & 8.5012 & TRN & \\
\hline CHEMBL3667912 & 1641081 & 8.5918 & 8.7684 & TST & \\
\hline CHEMBL3667892 & 1641081 & 9.0044 & 9.0889 & TRN & \\
\hline CHEMBL3667909 & 1641081 & 8.9666 & 9.1863 & TRN & \\
\hline CHEMBL 3672858 & 1641081 & 8.3841 & 8.2528 & TRN & \\
\hline CHEMBL3672891 & 1641081 & 8.9508 & 9.0537 & TRN & \\
\hline CHEMBL 3667894 & 1641081 & 8.9586 & 8.9077 & TRN & \\
\hline CHEMBL3667879 & 1641081 & 9.8539 & 10.0577 & TST & \\
\hline CHEMBL3672852 & 1641081 & 8.1215 & 8.2147 & TRN & \\
\hline CHEMBL3672876 & 1641081 & 9.2757 & 9.3497 & TRN & \\
\hline CHEMBL 3667904 & 1641081 & 8.8761 & 8.4595 & TRN & \\
\hline CHEMBL 3903777 & 1641081 & 6.0 & 5.9775 & TST & \\
\hline CHEMBL3667898 & 1641081 & 8.5834 & 8.6287 & TRN & \\
\hline CHEMBL3667893 & 1641081 & 9.0757 & 9.0907 & TRN & \\
\hline CHEMBL3672854 & 1641081 & 8.8013 & 8.7876 & TRN & \\
\hline CHEMBL3639717 & 1641081 & 9.0088 & 8.9974 & TRN & \\
\hline CHEMBL3977688 & 1641081 & 9.6198 & 8.721 & TST & \\
\hline CHEMBL3672873 & 1641081 & 8.9136 & 9.0176 & TRN & \\
\hline CHEMBL3893916 & 1641081 & 9.0757 & 9.0397 & TRN & \\
\hline CHEMBL3892801 & 1641081 & 8.4535 & 8.3809 & TRN & \\
\hline CHEMBL3667905 & 1641081 & 9.1367 & 9.3463 & TRN & \\
\hline CHEMBL3672872 & 1641081 & 9.5086 & 9.5621 & TRN & \\
\hline CHEMBL3667907 & 1641081 & 8.9281 & 8.9035 & TRN & \\
\hline CHEMBL3672855 & 1641081 & 8.7721 & 8.5541 & TRN & \\
\hline CHEMBL3667901 & 1641081 & 8.7423 & 8.6365 & TRN & \\
\hline CHEMBL3957967 & 1641081 & 8.4868 & 8.4648 & TRN & \\
\hline CHEMBL3667899 & 1641081 & 9.0555 & 9.0464 & TRN & \\
\hline CHEMBL3975448 & 1641081 & 9.2596 & 9.0201 & TRN & \\
\hline CHEMBL3667906 & 1641081 & 9.1871 & 9.0606 & TRN & \\
\hline CHEMBL3949541 & 1641081 & 6.0 & 6.1204 & TRN & \\
\hline CHEMBL3672864 & 1641081 & 8.426 & 8.1233 & TST & \\
\hline CHEMBL 3672883 & 1641081 & 8.3036 & 8.447006 & 0000000001 & TRN \\
\hline CHEMBL3672865 & 1641081 & 8.2573 & 8.5502 & TRN & \\
\hline CHEMBL 3672880 & 1641081 & 9.6198 & 9.7732 & TRN & \\
\hline CHEMBL3672859 & 1641081 & 8.2782 & 8.2694 & TRN & \\
\hline CHEMBL3951198 & 1641081 & 9.0915 & 9.6518 & TST & \\
\hline CHEMBL3667880 & 1641081 & 9.1367 & 9.6991 & TST & \\
\hline CHEMBL 3672860 & 1641081 & 9.2757 & 9.367 & TRN & \\
\hline CHEMBL3672888 & 1641081 & 9.1739 & 9.2214 & TRN & \\
\hline CHEMBL3672871 & 1641081 & 9.1487 & 9.0234 & TRN & \\
\hline CHEMBL 3672863 & 1641081 & 8.4609 & 8.5593 & TST & \\
\hline CHEMBL 3920800 & 1641081 & 9.1427 & 9.0863 & TRN & \\
\hline CHEMBL3672893 & 1641081 & 8.9208 & 9.0467 & TRN & \\
\hline CHEMBL3667885 & 1641081 & 9.3872 & 9.4785 & TRN & \\
\hline CHEMBL3672877 & 1641081 & 9.2757 & 9.4223 & TRN & \\
\hline CHEMBL 3672853 & 1641081 & 8.1765 & 8.4795 & TRN & \\
\hline CHEMBL3672878 & 1641081 & 9.1487 & 9.0414 & TRN & \\
\hline CHEMBL3959237 & 1641081 & 8.8861 & 9.0393 & TST & \\
\hline
\end{tabular}


Supplemental Table S2.txt

\begin{tabular}{|c|c|c|c|c|}
\hline CHEMBL 3672870 & 1641081 & 9.1739 & 9.3597 & TRN \\
\hline CHEMBL 3672866 & 1641081 & 8.5702 & 8.5512 & TRN \\
\hline CHEMBL 3667887 & 1641081 & 9.1024 & 9.1647 & TRN \\
\hline CHEMBL 3667884 & 1641081 & 9.1612 & 9.1916 & TRN \\
\hline CHEMBL3959399 & 1641081 & 9.0 & 9.0105 & TRN \\
\hline CHEMBL3667891 & 1641081 & 8.8069 & 8.9749 & TRN \\
\hline CHEMBL 3672892 & 1641081 & 8.8761 & 8.968 & TRN \\
\hline CHEMBL 3672879 & 1641081 & 8.4283 & 8.4374 & TRN \\
\hline CHEMBL 3891548 & 1641081 & 9.3665 & 8.5421 & TST \\
\hline CHEMBL 3672885 & 1641081 & 8.618 & 8.6969 & TRN \\
\hline CHEMBL 3667886 & 1641081 & 9.0605 & 8.7677 & TRN \\
\hline CHEMBL 3667897 & 1641081 & 6.0 & 6.2579 & TRN \\
\hline CHEMBL 3667888 & 1641081 & 9.3098 & 9.4421 & TRN \\
\hline CHEMBL 3667902 & 1641081 & 6.0 & 6.0973 & TRN \\
\hline CHEMBL 3672889 & 1641081 & 9.1612 & 9.0104 & TRN \\
\hline CHEMBL 3667913 & 1641081 & 6.0 & 6.0095 & TRN \\
\hline CHEMBL3672857 & 1641081 & 9.1739 & 8.6531 & TRN \\
\hline CHEMBL 3897603 & 1641081 & 9.4089 & 9.2845 & TRN \\
\hline CHEMBL 3672850 & 1641081 & 6.0 & 5.8337 & TRN \\
\hline CHEMBL 3672869 & 1641081 & 9.2924 & 9.3554 & TRN \\
\hline CHEMBL 3667910 & 1641081 & 8.8447 & 8.939 & TST \\
\hline CHEMBL3667908 & 1641081 & 9.0269 & 9.139 & TST \\
\hline CHEMBL3667896 & 1641081 & 8.9066 & 8.9002 & TST \\
\hline CHEMBL 3937222 & 1641081 & 9.5229 & 9.7221 & TST \\
\hline CHEMBL 3672875 & 1641081 & 8.5376 & 8.775 & TST \\
\hline CHEMBL 3672882 & 1641081 & 6.0 & 6.5553 & TST \\
\hline CHEMBL 3672868 & 1641081 & 8.6003 & 8.5361 & TST \\
\hline CHEMBL 3672884 & 1641081 & 9.2007 & 8.8967 & TST \\
\hline CHEMBL 3667895 & 1641081 & 6.0 & 6.0863 & TST \\
\hline CHEMBL 3672887 & 1641081 & 9.4089 & 9.5625 & TST \\
\hline CHEMBL 3667881 & 1641081 & 9.5376 & 9.5515 & TST \\
\hline CHEMBL 3600620 & 1508821 & 4.2197 & 4.5753 & TRN \\
\hline CHEMBL3601667 & 1508821 & 2.699 & 3.31699 & 99999999997 \\
\hline CHEMBL 3601828 & 1508821 & 2.699 & 3.50399 & \\
\hline CHEMBL 3601825 & 1508821 & 4.7077 & 4.7201 & TRN \\
\hline CHEMBL 3601809 & 1508821 & 5.3372 & 4.6675 & TRN \\
\hline CHEMBL 3601680 & 1508821 & 2.699 & 2.4275 & TRN \\
\hline CHEMBL 3600930 & 1508821 & 9.5229 & 9.3343 & TRN \\
\hline CHEMBL 3601806 & 1508821 & 2.699 & 4.2208 & TRN \\
\hline CHEMBL 3600612 & 1508821 & 6.0969 & 6.7334 & TRN \\
\hline CHEMBL 3601521 & 1508821 & 2.699 & 2.9631 & TST \\
\hline CHEMBL3600616 & 1508821 & 9.5229 & 9.1975 & TRN \\
\hline CHEMBL3601523 & 1508821 & 4.4413 & 4.3792 & TST \\
\hline CHEMBL3601659 & 1508821 & 4.3768 & 3.9922 & TST \\
\hline CHEMBL 3601525 & 1508821 & 4.4908 & 5.5777 & TST \\
\hline CHEMBL 3601813 & 1508821 & 3.8049 & 3.553 & TRN \\
\hline CHEMBL 3601819 & 1508821 & 2.699 & 2.6012 & TRN \\
\hline CHEMBL 3601672 & 1508821 & 4.0122 & 4.3772 & TRN \\
\hline
\end{tabular}

Page 25367 
Supplemental Table S2.txt

\begin{tabular}{|c|c|c|c|c|c|}
\hline CHEMBL3601665 & 1508821 & 4.1599 & 4.5218 & TST & \\
\hline CHEMBL3601669 & 1508821 & 9.5229 & 8.2091 & TRN & \\
\hline CHEMBL3601671 & 1508821 & 4.4664 & 3.836999 & 99999999997 & TRN \\
\hline CHEMBL 3601810 & 1508821 & 3.7033 & 3.1143 & TRN & \\
\hline CHEMBL473368 & 1508821 & 5.5229 & 4.9814 & TRN & \\
\hline CHEMBL3601666 & 1508821 & 4.5467 & 4.3974 & TST & \\
\hline CHEMBL3601673 & 1508821 & 4.6602 & 4.0385 & TRN & \\
\hline CHEMBL3601658 & 1508821 & 3.6847 & 3.0182 & TST & \\
\hline CHEMBL3600613 & 1508821 & 6.2218 & 6.6695 & TRN & \\
\hline CHEMBL3601522 & 1508821 & 2.699 & 5.1614 & TST & \\
\hline CHEMBL3600924 & 1508821 & 4.0721 & 5.3946 & TRN & \\
\hline CHEMBL3600928 & 1508821 & 9.5229 & 8.9492 & TRN & \\
\hline CHEMBL3601811 & 1508821 & 4.5817 & 3.6516 & TRN & \\
\hline CHEMBL3601675 & 1508821 & 3.7675 & 4.0934 & TRN & \\
\hline CHEMBL3601817 & 1508821 & 5.1487 & 5.5185 & TRN & \\
\hline CHEMBL3601524 & 1508821 & 4.3098 & 4.0575 & TST & \\
\hline CHEMBL3600618 & 1508821 & 5.5686 & 6.0007 & TRN & \\
\hline CHEMBL3601829 & 1508821 & 2.699 & 3.7796 & TRN & \\
\hline CHEMBL3600608 & 1508821 & 4.1791 & 4.7141 & TRN & \\
\hline CHEMBL3601674 & 1508821 & 4.2812 & 3.7618 & TRN & \\
\hline CHEMBL3601678 & 1508821 & 6.2218 & 5.4616 & TRN & \\
\hline CHEMBL3600619 & 1508821 & 5.3188 & 5.1029 & TRN & \\
\hline CHEMBL3600625 & 1508821 & 4.3556 & 5.1551 & TRN & \\
\hline CHEMBL3601520 & 1508821 & 2.699 & 2.7602 & TST & \\
\hline CHEMBL3600926 & 1508821 & 2.699 & 2.566999 & 99999999997 & TST \\
\hline CHEMBL3601668 & 1508821 & 5.8539 & 6.2798 & TRN & \\
\hline CHEMBL3601820 & 1508821 & 4.4584 & 3.5382 & TRN & \\
\hline CHEMBL3600615 & 1508821 & 6.5229 & 5.5662 & TRN & \\
\hline CHEMBL 3600388 & 1508821 & 7.2218 & 8.2249 & TRN & \\
\hline CHEMBL3601804 & 1508821 & 2.699 & 3.406 & TST & \\
\hline CHEMBL3600932 & 1508821 & 2.699 & 4.2378 & TST & \\
\hline CHEMBL3601815 & 1508821 & 4.4389 & 4.4683 & TRN & \\
\hline CHEMBL3600610 & 1508821 & 9.5229 & 8.7151 & TRN & \\
\hline CHEMBL3601679 & 1508821 & 5.4318 & 5.2056 & TRN & \\
\hline CHEMBL3600624 & 1508821 & 5.4089 & 4.9244 & TRN & \\
\hline CHEMBL3600925 & 1508821 & 2.699 & 2.0061 & TST & \\
\hline CHEMBL65 & 1508821 & 6.0 & 5.7112 & TST & \\
\hline CHEMBL3600617 & 1508821 & 5.2924 & 5.983 & TRN & \\
\hline CHEMBL 3601803 & 1508821 & 4.8477 & 4.5871 & TRN & \\
\hline CHEMBL3600923 & 1508821 & 3.9136 & 4.8157 & TRN & \\
\hline CHEMBL3600606 & 1508821 & 4.5331 & 4.7677 & TRN & \\
\hline CHEMBL3601670 & 1508821 & 4.7721 & 5.0631 & TRN & \\
\hline CHEMBL3600929 & 1508821 & 9.5229 & 9.2593 & TRN & \\
\hline CHEMBL 3601823 & 1508821 & 3.8781 & 4.4036 & TRN & \\
\hline CHEMBL3601816 & 1508821 & 5.6198 & 5.9958 & TRN & \\
\hline CHEMBL3601824 & 1508821 & 4.9318 & 4.5626 & TRN & \\
\hline CHEMBL3601662 & 1508821 & 2.699 & 2.7476 & TST & \\
\hline CHEMBL3601827 & 1508821 & 2.699 & 3.1748 & TRN & \\
\hline
\end{tabular}


Supplemental Table S2.txt

\begin{tabular}{|c|c|c|c|c|c|}
\hline CHEMBL3601826 & 1508821 & 2.699 & 2.9194 & TRN & \\
\hline CHEMBL3600623 & 1508821 & 4.4112 & 3.8102 & TRN & \\
\hline CHEMBL3600605 & 1508821 & 4.3737 & 3.1908 & TRN & \\
\hline CHEMBL486598 & 1508821 & 4.6556 & 1.9671 & TST & \\
\hline CHEMBL3601805 & 1508821 & 4.1487 & 4.2031 & TRN & \\
\hline CHEMBL3601812 & 1508821 & 2.699 & 2.7494 & TRN & \\
\hline CHEMBL3600614 & 1508821 & 9.5229 & 9.0325 & TRN & \\
\hline CHEMBL3600621 & 1508821 & 5.3468 & 5.1452 & TRN & \\
\hline CHEMBL3600609 & 1508821 & 5.1487 & \multicolumn{2}{|c|}{5.4639999999999995} & TRN \\
\hline CHEMBL3601807 & 1508821 & 5.2526 & 5.2527 & TRN & \\
\hline CHEMBL3601660 & 1508821 & 4.9318 & 5.3876 & TST & \\
\hline CHEMBL3600622 & 1508821 & 2.699 & 2.4535 & TRN & \\
\hline CHEMBL3600927 & 1508821 & 2.699 & 2.3525 & TST & \\
\hline CHEMBL3601663 & 1508821 & 2.699 & 3.8668 & TST & \\
\hline CHEMBL3600611 & 1508821 & 4.9788 & 5.4909 & TRN & \\
\hline CHEMBL3601661 & 1508821 & 3.7409 & 2.8156 & TST & \\
\hline CHEMBL3601664 & 1508821 & 2.699 & 2.7322 & TST & \\
\hline CHEMBL3601677 & 1508821 & 4.3363 & 4.6248 & TRN & \\
\hline CHEMBL3601676 & 1508821 & 2.699 & 4.5166 & TRN & \\
\hline CHEMBL3601818 & 1508821 & 2.699 & 2.6001 & TRN & \\
\hline CHEMBL3601821 & 1508821 & 4.5086 & 2.7675 & TRN & \\
\hline CHEMBL3601822 & 1508821 & 5.041 & 5.1268 & TRN & \\
\hline CHEMBL3601814 & 1508821 & 4.9957 & 4.6143 & TRN & \\
\hline CHEMBL472784 & 1508821 & 2.699 & 2.9267 & TRN & \\
\hline CHEMBL3600931 & 1508821 & 9.5229 & 9.3983 & TRN & \\
\hline CHEMBL3601808 & 1508821 & 4.0964 & 3.805 & TRN & \\
\hline CHEMBL3600607 & 1508821 & 4.9393 & 5.551 & TRN & \\
\hline CHEMBL504104 & 702737 & 7.8539 & 6.7226 & TRN & \\
\hline CHEMBL1649996 & 702737 & 7.5229 & 7.2776 & TRN & \\
\hline CHEMBL1650183 & 702737 & 7.6778 & 7.6641 & TRN & \\
\hline CHEMBL1650210 & 702737 & 7.3979 & 7.2249 & TRN & \\
\hline CHEMBL1650187 & 702737 & 7.2291 & 7.909 & TRN & \\
\hline CHEMBL1649992 & 702737 & 5.301 & 5.4109 & TRN & \\
\hline CHEMBL1650185 & 702737 & 7.699 & 7.6643 & TRN & \\
\hline CHEMBL1649986 & 702737 & 6.0 & 6.0378 & TRN & \\
\hline CHEMBL501816 & 702737 & 7.8539 & 7.1379 & TRN & \\
\hline CHEMBL1650186 & 702737 & 7.7447 & 7.8304 & TRN & \\
\hline CHEMBL1649991 & 702737 & 5.0969 & 5.6282 & TRN & \\
\hline CHEMBL1650196 & 702737 & 6.5229 & 6.3793 & TRN & \\
\hline CHEMBL1650199 & 702737 & 6.0665 & 7.0195 & TRN & \\
\hline CHEMBL1650218 & 702737 & 5.8861 & 6.297006 & 0000000001 & TST \\
\hline CHEMBL1650215 & 702737 & 7.301 & 6.7972 & TST & \\
\hline CHEMBL1649995 & 702737 & 6.301 & 6.9746 & TRN & \\
\hline CHEMBL1650181 & 702737 & 7.9208 & 7.311 & TRN & \\
\hline CHEMBL1649994 & 702737 & 6.9208 & 7.0712 & TRN & \\
\hline CHEMBL1650189 & 702737 & 6.2518 & 6.8566 & TRN & \\
\hline CHEMBL1650206 & 702737 & 7.4949 & 7.6869 & TRN & \\
\hline CHEMBL1650214 & 702737 & 5.0 & 5.3703 & TRN & \\
\hline
\end{tabular}




\begin{tabular}{|c|c|c|c|c|c|}
\hline \multicolumn{6}{|c|}{ Supplemental Table S2.txt } \\
\hline CHEMBL1649590 & 702737 & 7.7959 & 7.0774 & TRN & \\
\hline CHEMBL1650209 & 702737 & 7.9208 & 7.6933 & TRN & \\
\hline CHEMBL1650213 & 702737 & 4.0 & 5.8578 & TST & \\
\hline CHEMBL1650200 & 702737 & 7.3665 & 7.2947 & TRN & \\
\hline CHEMBL1649983 & 702737 & 7.0969 & 6.3514 & TRN & \\
\hline CHEMBL1650197 & 702737 & 5.7696 & 6.4004 & TRN & \\
\hline CHEMBL1650211 & 702737 & 7.3565 & 6.8962 & TRN & \\
\hline CHEMBL1649993 & 702737 & 6.3468 & 6.5494 & TRN & \\
\hline CHEMBL1650222 & 702737 & 7.0969 & 6.6841 & TST & \\
\hline CHEMBL1649989 & 702737 & 6.301 & 6.2582 & TRN & \\
\hline CHEMBL1650204 & 702737 & 7.7959 & 8.0303 & TRN & \\
\hline CHEMBL509861 & 702737 & 7.7959 & 7.4664 & TRN & \\
\hline CHEMBL495498 & 702737 & 7.6021 & 6.9743 & TRN & \\
\hline CHEMBL1650188 & 702737 & 6.8239 & 6.4785 & TRN & \\
\hline CHEMBL1650180 & 702737 & 7.2441 & 7.3277 & TRN & \\
\hline CHEMBL1650178 & 702737 & 7.6576 & 8.1765 & TRN & \\
\hline CHEMBL1649980 & 702737 & 6.6576 & 6.33700 & 0000000001 & TRN \\
\hline CHEMBL1649981 & 702737 & 6.301 & 6.261 & TRN & \\
\hline CHEMBL1650192 & 702737 & 7.0 & 6.8737 & TRN & \\
\hline CHEMBL1650191 & 702737 & 7.301 & 7.2192 & TRN & \\
\hline CHEMBL1650203 & 702737 & 7.8539 & 7.8726 & TRN & \\
\hline CHEMBL1649988 & 702737 & 5.5607 & 6.2342 & TRN & \\
\hline CHEMBL1649997 & 702737 & 7.5528 & 7.57 & TRN & \\
\hline CHEMBL1650220 & 702737 & 6.8697 & 6.9482 & TRN & \\
\hline CHEMBL1649985 & 702737 & 5.699 & 5.8633 & TRN & \\
\hline CHEMBL1649978 & 702737 & 6.3979 & 6.5383 & TRN & \\
\hline CHEMBL1650182 & 702737 & 7.7212 & 7.61600 & 00000000005 & TRN \\
\hline CHEMBL570790 & 702737 & 7.0458 & 7.4631 & TST & \\
\hline CHEMBL1649982 & 702737 & 6.7447 & 6.4038 & TRN & \\
\hline CHEMBL1650190 & 702737 & 7.1549 & 7.2024 & TRN & \\
\hline CHEMBL1649977 & 702737 & 7.0 & 6.3119 & TRN & \\
\hline CHEMBL1649987 & 702737 & 5.0 & 5.7264 & TRN & \\
\hline CHEMBL482734 & 702737 & 6.0969 & 6.681 & TST & \\
\hline CHEMBL1650193 & 702737 & 7.4815 & 7.3193 & TRN & \\
\hline CHEMBL1650221 & 702737 & 6.6778 & 7.6175 & TST & \\
\hline CHEMBL1650205 & 702737 & 7.8861 & 8.3478 & TRN & \\
\hline CHEMBL1650217 & 702737 & 5.699 & 6.1576 & TST & \\
\hline CHEMBL1650179 & 702737 & 7.6778 & 7.8684 & TRN & \\
\hline CHEMBL1650207 & 702737 & 7.3872 & 7.5781 & TRN & \\
\hline CHEMBL1650201 & 702737 & 7.6778 & 7.7951 & TRN & \\
\hline CHEMBL1650195 & 702737 & 7.6198 & 7.2349 & TRN & \\
\hline CHEMBL 1650212 & 702737 & 4.0 & 6.6345 & TST & \\
\hline CHEMBL1650184 & 702737 & 8.0 & 7.7589 & TST & \\
\hline CHEMBL1650216 & 702737 & 6.0223 & 5.8907 & TST & \\
\hline CHEMBL1650219 & 702737 & 6.6021 & 6.807 & TST & \\
\hline CHEMBL1649979 & 702737 & 5.9208 & 6.5611 & TST & \\
\hline CHEMBL 1650202 & 702737 & 7.0555 & 8.0608 & TST & \\
\hline CHEMBL1649990 & 702737 & 4.8697 & 5.5813 & TST & \\
\hline
\end{tabular}


Supplemental Table S2.txt

\begin{tabular}{|c|c|c|c|c|}
\hline HEMBL1650194 & $\partial 2737$ & 7.6198 & 7.4488 & 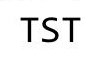 \\
\hline HEMBL1649984 & 02737 & 6.0506 & 6.5282 & \\
\hline 98 & 2737 & & & \\
\hline EMBL165 & 2737 & 1685 & & \\
\hline AEMBL532987 & 369400 & 6.1273 & 7917 & \\
\hline JEMBL124006 & 369400 & 6.7212 & 6.6066 & \\
\hline AEMBL585264 & 369400 & 5.301 & 1918 & \\
\hline EMBL 206540 & 400 & 6.5214 & 2826 & \\
\hline AEMBL535730 & 369400 & 6.5751 & 5.4437 & \\
\hline HEMBL587083 & 369400 & 7.3979 & 7.2914 & \\
\hline JEMBL 601771 & 369400 & 5.301 & 5.2492 & \\
\hline IEMBL533017 & 369400 & 7.1367 & .2814 & \\
\hline EMBL585243 & & & 6.3268 & \\
\hline HEMBL580381 & 369400 & 6.0511 & 5.9944 & \\
\hline IEMBL548399 & 369400 & 5.0 & 5.2011 & \\
\hline HEMBL 261693 & 1369400 & 5.301 & 5907 & \\
\hline IEMBL546994 & 100 & 5.301 & 5.3523 & \\
\hline AEMBL547488 & $\theta 0$ & 5.0 & 5.1072 & 17 \\
\hline AEMBL586704 & 100 & 6.67 & 6.6662 & D \\
\hline IEMBL601957 & 100 & 6. & & \\
\hline HEMBL549210 & 1369400 & 6.54 & 6.7479 & Тונ \\
\hline 15697 & 100 & 5 . & 4.9527 & ST \\
\hline AEMBL596852 & $\partial 0$ & & 5.1325 & \\
\hline IEMBL581175 & $\theta 0$ & 6.75 & .7471 & \\
\hline IEMBL602413 & $\theta 0$ & & & RN \\
\hline IEMBL529773 & 369400 & 6. & 6.3894 & RI \\
\hline EMBL531290 & 400 & 6. & 672 & 西 \\
\hline FMBI & 00 & 31 & 744 & \\
\hline 8042 & $\theta 0$ & 7.2 & 7.1212 & RN \\
\hline IEMBL470514 & 00 & 5 . & & rRN \\
\hline EMBL587288 & 369400 & 6. & 97 & RI \\
\hline 364 & 400 & 7. & 129 & . \\
\hline 476 & $\theta 0$ & 6. & 14 & ST \\
\hline 281 & & 6 . & 148 & RN \\
\hline AEMBL534190 & 369400 & & 6.3 & rR \\
\hline 459 & 100 & 91 & 6.7234 & RI \\
\hline 323 & $\theta 0$ & 4. & .9229 & $\mathrm{nI}$ \\
\hline & & & & RN \\
\hline AEMBL580580 & 369400 & 6.5482 & 6.5705 & RI \\
\hline IEMBL579443 & 369400 & 5 . & 4.8933 & $\mathrm{RI}$ \\
\hline IEMBL582666 & 100 & 5.8416 & 5.3943 & $R$ \\
\hline HEMBL600305 & 1369400 & 5.0 & 4.9137 & RIV \\
\hline HEMBL524784 & 369400 & 5.0 & 5.1052 & RI \\
\hline EMBL1459149 & 369400 & 5.0 & 5.0258 & R \\
\hline 36 & 00 & 6.23 & 6.2129 & $\mathrm{R}$ \\
\hline HEMBL526981 & 1369400 & 6. & 6.4339 & $\mathrm{R}$ \\
\hline CHEMBL494669 & 1369400 & 6.8962 & 6.8815 & $\mathrm{R}$ \\
\hline CHEMBL1460047 & 1369400 & 6.4815 & 6.2949 & TR \\
\hline
\end{tabular}

Page 25371 


\begin{tabular}{|c|c|c|c|c|c|}
\hline \multicolumn{6}{|c|}{ Supplemental Table S2.txt } \\
\hline CHEMBL527593 & 1369400 & 5.0 & 5.117 & TRN & \\
\hline CHEMBL587989 & 1369400 & 5.0 & 4.8869 & TRN & \\
\hline CHEMBL533563 & 1369400 & 6.8894 & 6.6403 & TRN & \\
\hline CHEMBL590674 & 1369400 & 6.767 & 6.92200 & 0000000001 & TRN \\
\hline CHEMBL590888 & 1369400 & 6.0259 & 6.1234 & TRN & \\
\hline CHEMBL535514 & 1369400 & 5.0 & 4.9482 & TRN & \\
\hline CHEMBL 2028053 & 1369400 & 5.301 & 5.5333 & TST & \\
\hline CHEMBL 2028055 & 1369400 & 6.4868 & 6.2007 & TST & \\
\hline CHEMBL 587410 & 1369400 & 6.1062 & 5.7386 & TST & \\
\hline CHEMBL587022 & 1369400 & 6.983 & 6.9014 & TST & \\
\hline CHEMBL530223 & 1369400 & 6.7011 & 6.5168 & TST & \\
\hline CHEMBL106525 & 1369400 & 7.0088 & 6.5892 & TST & \\
\hline CHEMBL529732 & 1369400 & 5.0 & 4.6832 & TST & \\
\hline CHEMBL580353 & 1369400 & 7.6778 & 7.4381 & TST & \\
\hline CHEMBL601348 & 1369400 & 5.0 & 5.1466 & TST & \\
\hline CHEMBL534589 & 1369400 & 5.0 & 4.6842 & TST & \\
\hline CHEMBL 2028051 & 1369400 & 6.3716 & 6.0482 & TST & \\
\hline CHEMBL 3669560 & 1535342 & 7.6383 & 6.7779 & TST & \\
\hline CHEMBL3669499 & 1535342 & 6.0851 & 6.45 & TRN & \\
\hline CHEMBL 3669508 & 1535342 & 7.301 & 7.3406 & TRN & \\
\hline CHEMBL 3669458 & 1535342 & 6.7959 & 6.2501 & TRN & \\
\hline CHEMBL 3669576 & 1535342 & 6.4647 & 6.6861 & TST & \\
\hline CHEMBL 3669462 & 1535342 & 6.5498 & 6.7726 & TRN & \\
\hline CHEMBL3669506 & 1535342 & 8.0969 & 7.6063 & TRN & \\
\hline CHEMBL 3669487 & 1535342 & 6.5884 & 6.2689 & TRN & \\
\hline CHEMBL2435409 & 1535342 & 8.5229 & 7.6426 & TST & \\
\hline CHEMBL 3669494 & 1535342 & 6.6345 & 6.4648 & TST & \\
\hline CHEMBL 2435411 & 1535342 & 9.0 & 7.6064 & TST & \\
\hline CHEMBL3669554 & 1535342 & 7.7212 & 7.234 & TRN & \\
\hline CHEMBL 3669486 & 1535342 & 6.7878 & 7.0993 & TRN & \\
\hline CHEMBL 3669541 & 1535342 & 6.7328 & 7.1823 & TST & \\
\hline CHEMBL 3669574 & 1535342 & 6.2716 & 6.8214 & TRN & \\
\hline CHEMBL3669531 & 1535342 & 6.8539 & 6.3897 & TRN & \\
\hline CHEMBL3669435 & 1535342 & 7.3372 & 7.1836 & TRN & \\
\hline CHEMBL 3669542 & 1535342 & 7.9586 & 7.018 & TST & \\
\hline CHEMBL3669452 & 1535342 & 7.2924 & 7.4107 & TRN & \\
\hline CHEMBL3669496 & 1535342 & 5.8016 & 5.9342 & TRN & \\
\hline CHEMBL 3669510 & 1535342 & 6.6478 & 6.5562 & TRN & \\
\hline CHEMBL 3669578 & 1535342 & 7.8861 & 7.2689 & TRN & \\
\hline CHEMBL 3669491 & 1535342 & 6.7328 & 6.7691 & TST & \\
\hline CHEMBL3669521 & 1535342 & 7.0862 & 6.8622 & TRN & \\
\hline CHEMBL3669556 & 1535342 & 6.1707 & 6.4894 & TRN & \\
\hline CHEMBL3669476 & 1535342 & 7.0362 & 6.8831 & TRN & \\
\hline CHEMBL3669553 & 1535342 & 8.1549 & 7.8337 & TRN & \\
\hline CHEMBL 3669470 & 1535342 & 7.4089 & 6.7454 & TRN & \\
\hline CHEMBL 3669530 & 1535342 & 6.1397 & 6.6256 & TST & \\
\hline CHEMBL 3669513 & 1535342 & 5.8595 & 6.6243 & TRN & \\
\hline CHEMBL 3669546 & 1535342 & 7.0915 & 7.0419 & TST & \\
\hline
\end{tabular}


Supplemental Table S2.txt

\begin{tabular}{|c|c|c|c|c|c|}
\hline CHEMBL3669523 & 1535342 & 5.9197 & 6.4559 & TRN & \\
\hline CHEMBL3669446 & 1535342 & 6.9469 & 6.3089 & TRN & \\
\hline CHEMBL3669518 & 1535342 & 6.0246 & 6.2726 & TRN & \\
\hline CHEMBL3669501 & 1535342 & 6.1314 & 6.4729 & TRN & \\
\hline CHEMBL 3669514 & 1535342 & 5.8671 & 6.1155 & TRN & \\
\hline CHEMBL3669439 & 1535342 & 7.4559 & 7.1488 & TRN & \\
\hline CHEMBL3928435 & 1535342 & 6.7352 & 6.5433 & TST & \\
\hline CHEMBL3669459 & 1535342 & 6.2118 & 6.7652 & TST & \\
\hline CHEMBL3669467 & 1535342 & 7.3188 & 7.1433 & TST & \\
\hline CHEMBL3669527 & 1535342 & 6.5361 & 7.1647 & TRN & \\
\hline CHEMBL3669504 & 1535342 & 6.8013 & 6.6225 & TRN & \\
\hline CHEMBL3669516 & 1535342 & 6.7077 & 6.9764 & TRN & \\
\hline CHEMBL3669539 & 1535342 & 6.2557 & 6.9141 & TRN & \\
\hline CHEMBL3669563 & 1535342 & 6.1278 & 6.5816 & TRN & \\
\hline CHEMBL3669480 & 1535342 & 6.0794 & 6.15 & TRN & \\
\hline CHEMBL3669512 & 1535342 & 6.9747 & 7.4396 & TRN & \\
\hline CHEMBL3669445 & 1535342 & 6.8097 & 6.7274 & TRN & \\
\hline CHEMBL3669557 & 1535342 & 7.1612 & 6.7371 & TRN & \\
\hline CHEMBL3669493 & 1535342 & 7.0088 & 6.9942 & TRN & \\
\hline CHEMBL3669549 & 1535342 & 7.4089 & 6.9745 & TST & \\
\hline CHEMBL3669463 & 1535342 & 7.0555 & 7.1204 & TRN & \\
\hline CHEMBL3669457 & 1535342 & 7.0757 & 6.5897 & TRN & \\
\hline CHEMBL 3669543 & 1535342 & 6.1831 & 7.7876 & TST & \\
\hline CHEMBL3669526 & 1535342 & 6.7055 & 6.2651 & TRN & \\
\hline CHEMBL 3669477 & 1535342 & 6.6635 & 7.032 & TRN & \\
\hline CHEMBL3669533 & 1535342 & 6.5735 & 6.5577 & TRN & \\
\hline CHEMBL 3669575 & 1535342 & 6.1046 & 6.98799 & 99999999995 & TRN \\
\hline CHEMBL 3669525 & 1535342 & 6.6038 & 6.4598 & TST & \\
\hline CHEMBL2435415 & 1535342 & 6.7932 & 6.6256 & TST & \\
\hline CHEMBL 3669522 & 1535342 & 6.0804 & 7.0112 & TST & \\
\hline CHEMBL3669479 & 1535342 & 7.2076 & 6.8686 & TRN & \\
\hline CHEMBL 3669474 & 1535342 & $6.82100 t$ & 00000000 & 7.1043 & TRN \\
\hline CHEMBL 3669441 & 1535342 & 6.8996 & 6.6344 & TRN & \\
\hline CHEMBL3669466 & 1535342 & 7.0088 & 7.1749 & TRN & \\
\hline CHEMBL 3669540 & 1535342 & 6.6126 & 6.4883 & TRN & \\
\hline CHEMBL3669559 & 1535342 & 6.6216 & 6.7586 & TST & \\
\hline CHEMBL 3669481 & 1535342 & 7.0809 & 6.3737 & TRN & \\
\hline CHEMBL 3669517 & 1535342 & 5.907995 & 99999999 & 5.7634 & TRN \\
\hline CHEMBL 3669450 & 1535342 & 6.6882 & 6.5398 & TRN & \\
\hline CHEMBL 3669485 & 1535342 & 6.0809 & 6.2768 & TRN & \\
\hline CHEMBL3669440 & 1535342 & 5.9718 & 5.9771 & TRN & \\
\hline CHEMBL 3669443 & 1535342 & 7.4559 & 7.2096 & TRN & \\
\hline CHEMBL3669490 & 1535342 & 7.2596 & 7.1061 & TRN & \\
\hline CHEMBL3669528 & 1535342 & 6.9031 & 6.742006 & 0000000001 & TRN \\
\hline CHEMBL3669460 & 1535342 & 5.9296 & 6.6669 & TST & \\
\hline CHEMBL3669529 & 1535342 & 5.7791 & 6.4614 & TRN & \\
\hline CHEMBL 3669449 & 1535342 & 6.3054 & 6.4828 & TRN & \\
\hline CHEMBL3669484 & 1535342 & 6.52 & 6.3138 & TST & \\
\hline
\end{tabular}


Supplemental Table S2.txt

\begin{tabular}{|c|c|c|}
\hline 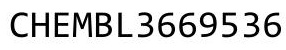 & & \\
\hline CHEMBL3669500 & 35342 & \\
\hline HEMBL3669532 & 535342 & \\
\hline HEMBL 3669558 & 535342 & \\
\hline HEMBL3669489 & 35342 & \\
\hline CHEMBL3970573 & 535342 & \\
\hline HEMBL3669535 & 1535342 & \\
\hline CHEMBL3669538 & 1535342 & \\
\hline CHEMBL3669478 & L535342 & \\
\hline HEMBL3669545 & 535342 & \\
\hline CHEMBL3669515 & 1535342 & \\
\hline CHEMBL3669469 & 1535342 & \\
\hline CHEMBL3669570 & 1535342 & \\
\hline CHEMBL3669497 & 1535342 & \\
\hline HEMBL3669520 & 1535342 & \\
\hline CHEMBL3669483 & 1535342 & \\
\hline CHEMBL2413514 & 1535342 & \\
\hline CHEMBL3669482 & 535342 & \\
\hline CHEMBL3669537 & 1535342 & \\
\hline HEMBL3669447 & 1535342 & \\
\hline CHEMBL3669473 & 1535342 & \\
\hline CHEMBL3669573 & 1535342 & \\
\hline CHEMBL3669436 & 535342 & \\
\hline CHEMBL3669569 & 1535342 & \\
\hline CHEMBL3669507 & 1535342 & \\
\hline CHEMBL2435413 & 1535342 & \\
\hline CHEMBL3669475 & 1535342 & \\
\hline CHEMBL3669577 & 535342 & \\
\hline CHEMBL3669550 & 1535342 & \\
\hline CHEMBL3669552 & 1535342 & \\
\hline CHEMBL3669564 & 1535342 & \\
\hline CHEMBL3669561 & 1535342 & 6 \\
\hline CHEMBL3669544 & 1535342 & \\
\hline CHEMBL3669565 & 1535342 & \\
\hline CHEMBL 2435412 & 1535342 & \\
\hline CHEMBL3669568 & 1535342 & \\
\hline CHEMBL3669465 & 1535342 & 6.7 \\
\hline CHEMBL2435408 & 1535342 & 7.2 \\
\hline CHEMBL3669562 & 1535342 & \\
\hline CHEMBL3669444 & 1535342 & \\
\hline CHEMBL3669511 & 1535342 & \\
\hline CHEMBL3669567 & 1535342 & 6.3 \\
\hline CHEMBL3669464 & 1535342 & \\
\hline CHEMBL3669468 & 1535342 & \\
\hline CHEMBL3669519 & 1535342 & \\
\hline CHEMBL3669472 & 1535342 & \\
\hline CHEMBL2435414 & 1535342 & \\
\hline CHEMBL3669495 & 1535342 & 7.6 \\
\hline
\end{tabular}

$\begin{array}{ll}6.6112 & \text { TST } \\ 6.4275 & \text { TRN } \\ 6.4683 & \text { TRN } \\ 7.2228 & \text { TRN } \\ 6.5305 & \text { TRN }\end{array}$

6.672999999999999

TST

6.8015 TRN

6.8581 TRN

6.8304 TRN

7.0617 TST

6.8625 TRN

6.9575 TRN

6.768 TRN

6.6593 TST

6.1628 TST

7.2374 TRN

7.2856 TRN

6.3692 TRN

6.7207 TRN

6.7635 TRN

7.1755 TRN

7.0348 TRN

7.2072 TRN

7.0625 TRN

6.7893 TRN

6.8515 TST

6.4099 TRN

6.9786 TST

6.8719 TRN

6.3903 TRN

7.1143 TRN

6.3258 TRN

7.2221 TST

6.4982 TRN

7.0972 TST

7.5323 TRN

6.9918 TRN

7.2798 TRN

6.3015 TRN

6.7811 TRN

6.5307 TRN

6.5435 TRN

6.7107 TRN

6.7992 TRN

6.4364 TRN

6.9576 TRN

6.3339 TRN

6.9534 TRN

Page 25374 
Supplemental Table S2.txt

\begin{tabular}{|c|c|c|c|c|c|}
\hline CHEMBL3669453 & 1535342 & 6.5528 & 6.3171 & TRN & \\
\hline CHEMBL3669488 & 1535342 & 6.3316 & 6.3703 & TRN & \\
\hline CHEMBL 2435407 & 1535342 & 7.5229 & 7.1273 & TRN & \\
\hline CHEMBL 3669534 & 1535342 & 6.5243 & 6.4164 & TRN & \\
\hline CHEMBL3669555 & 1535342 & 7.3468 & 7.3053 & TRN & \\
\hline CHEMBL3669551 & 1535342 & 6.1965 & 6.4977 & TRN & \\
\hline CHEMBL3669503 & 1535342 & 6.1878 & 6.6303 & TRN & \\
\hline CHEMBL3669566 & 1535342 & 6.2487 & 6.8417 & TST & \\
\hline CHEMBL3669461 & 1535342 & 6.8601 & 7.2019 & TRN & \\
\hline CHEMBL 3669547 & 1535342 & 6.3936 & 7.0098 & TST & \\
\hline CHEMBL3639683 & 1535342 & 6.8477 & 6.2791 & TRN & \\
\hline CHEMBL3669509 & 1535342 & 5.8595 & 5.7768 & TRN & \\
\hline CHEMBL3669456 & 1535342 & 6.7747 & 6.9831 & TRN & \\
\hline CHEMBL 3669448 & 1535342 & 6.1068 & 6.8665 & TRN & \\
\hline CHEMBL3669451 & 1535342 & 6.6716 & 6.8631 & TRN & \\
\hline CHEMBL3669498 & 1535342 & 7.0969 & 6.5176 & TRN & \\
\hline CHEMBL3669548 & 1535342 & 6.6737 & 6.3571 & TST & \\
\hline CHEMBL3669571 & 1535342 & 7.0915 & 6.5318 & TST & \\
\hline CHEMBL3669434 & 1535342 & 7.5229 & 7.2051 & TST & \\
\hline CHEMBL3669438 & 1535342 & 6.399 & 6.5277 & TST & \\
\hline CHEMBL3669505 & 1535342 & 6.5498 & 6.0932 & TST & \\
\hline CHEMBL3931098 & 1641660 & 6.5702 & 6.6392 & TRN & \\
\hline CHEMBL3939856 & 1641660 & 7.8633 & 6.8848 & TST & \\
\hline CHEMBL3962959 & 1641660 & 7.0026 & 7.0393 & TST & \\
\hline CHEMBL3917770 & 1641660 & 7.7144 & 7.8705 & TRN & \\
\hline CHEMBL 3976264 & 1641660 & 8.2851 & 7.7616 & TRN & \\
\hline CHEMBL3979634 & 1641660 & 8.1415 & 7.5693 & TRN & \\
\hline CHEMBL3918776 & 1641660 & 7.8356 & 7.4337 & TRN & \\
\hline CHEMBL 3891808 & 1641660 & 6.129 & 6.246 & TRN & \\
\hline CHEMBL 3976272 & 1641660 & 7.1367 & \multicolumn{2}{|c|}{7.571000000000001} & TRN \\
\hline CHEMBL3904853 & 1641660 & 8.4672 & 7.6586 & TST & \\
\hline CHEMBL3971721 & 1641660 & 6.0 & 6.5294 & TRN & \\
\hline CHEMBL3910906 & 1641660 & 7.1681 & 7.0497 & TRN & \\
\hline CHEMBL 3889882 & 1641660 & 6.8644 & 6.6388 & TST & \\
\hline CHEMBL3900485 & 1641660 & 7.7696 & 7.9962 & TRN & \\
\hline CHEMBL3900941 & 1641660 & 8.644 & 8.2432 & TRN & \\
\hline CHEMBL3899998 & 1641660 & 6.0 & 6.7326 & TRN & \\
\hline CHEMBL3902577 & 1641660 & 8.0395 & 7.4436 & TST & \\
\hline CHEMBL3930824 & 1641660 & 6.0 & 6.1403 & TRN & \\
\hline CHEMBL3961275 & 1641660 & 6.6271 & 6.3176 & TRN & \\
\hline CHEMBL 3914522 & 1641660 & 5.5887 & 6.9017 & TST & \\
\hline CHEMBL3965657 & 1641660 & 6.6421 & 6.8764 & TRN & \\
\hline CHEMBL3901398 & 1641660 & 7.2958 & 6.9905 & TRN & \\
\hline CHEMBL3945531 & 1641660 & 7.4698 & 7.1477 & TRN & \\
\hline CHEMBL3925084 & 1641660 & 7.5834 & 7.4843 & TRN & \\
\hline CHEMBL 3889913 & 1641660 & 8.2125 & 6.6531 & TST & \\
\hline CHEMBL3937919 & 1641660 & 7.2262 & 6.8629 & TRN & \\
\hline CHEMBL3945831 & 1641660 & 6.9488 & 6.7086 & TRN & \\
\hline
\end{tabular}

Page 25375 
Supplemental Table S2.txt

\begin{tabular}{|c|c|c|c|c|c|c|}
\hline CHEMBL 3908800 & 1641660 & 7.2549 & 7.0738 & TRN & & \\
\hline CHEMBL3968894 & 1641660 & 7.7258 & 8.1464 & TRN & & \\
\hline CHEMBL3903197 & 1641660 & 7.2949 & 7.2608 & TRN & & \\
\hline CHEMBL3903971 & 1641660 & 7.0814 & 7.0737 & TRN & & \\
\hline CHEMBL3984589 & 1641660 & 6.767 & 7.2921 & TRN & & \\
\hline CHEMBL3890064 & 1641660 & 8.7595 & 8.5904 & TRN & & \\
\hline CHEMBL3935420 & 1641660 & 7.7224 & 7.4926 & TST & & \\
\hline CHEMBL3977660 & 1641660 & 7.7033 & 7.0063 & TRN & & \\
\hline CHEMBL3925441 & 1641660 & 7.6799 & 7.2315 & TST & & \\
\hline CHEMBL3917779 & 1641660 & 7.317 & 6.9302 & TRN & & \\
\hline CHEMBL3956159 & 1641660 & 7.4622 & 7.7236 & TRN & & \\
\hline CHEMBL3946499 & 1641660 & 7.1002 & 7.2441 & TST & & \\
\hline CHEMBL 3962281 & 1641660 & 7.1815 & 7.2101 & TRN & & \\
\hline CHEMBL3914730 & 1641660 & 6.7649 & 6.3673 & TST & & \\
\hline CHEMBL3904254 & 1641660 & 8.0921 & 7.7104 & TST & & \\
\hline CHEMBL3950400 & 1641660 & 8.5157 & 8.4078 & TRN & & \\
\hline CHEMBL3968965 & 1641660 & 7.3573 & 6.5258 & TST & & \\
\hline CHEMBL3948987 & 1641660 & 8.0259 & 7.8401 & TRN & & \\
\hline CHEMBL 3935042 & 1641660 & 7.4855 & 7.8584 & TRN & & \\
\hline CHEMBL3909171 & 1641660 & 5.0626 & 5.7455 & TST & & \\
\hline CHEMBL3898634 & 1641660 & 6.1965 & 6.6866 & TRN & & \\
\hline CHEMBL3925889 & 1641660 & 7.4954 & 7.2618 & TRN & & \\
\hline CHEMBL3895981 & 1641660 & 7.7986 & 7.6545 & TRN & & \\
\hline CHEMBL3967906 & 1641660 & 8.34100 & 0000000 & & 7.9161 & TST \\
\hline CHEMBL3898126 & 1641660 & 6.32700 & 0000000 & 1 & 6.845 & TRN \\
\hline CHEMBL3930448 & 1641660 & 6.1765 & 6.7642 & TRN & & \\
\hline CHEMBL3948196 & 1641660 & 7.4134 & 7.4365 & TRN & & \\
\hline CHEMBL 3920074 & 1641660 & 7.2668 & 6.8847 & TST & & \\
\hline CHEMBL 3914861 & 1641660 & 7.5817 & 7.0498 & TRN & & \\
\hline CHEMBL3922204 & 1641660 & 7.7645 & 8.1257 & TRN & & \\
\hline CHEMBL3903947 & 1641660 & 8.308 & 8.3601 & TRN & & \\
\hline CHEMBL3927315 & 1641660 & 7.7305 & 7.5718 & TRN & & \\
\hline CHEMBL3982790 & 1641660 & 6.8861 & 6.6397 & TRN & & \\
\hline CHEMBL3906802 & 1641660 & 7.6813 & 6.84 & TST & & \\
\hline CHEMBL3946766 & 1641660 & 7.4559 & 7.3709 & TRN & & \\
\hline CHEMBL3931763 & 1641660 & 8.6946 & 8.9786 & TRN & & \\
\hline CHEMBL3979991 & 1641660 & 8.3116 & 7.9709 & TST & & \\
\hline CHEMBL 3956444 & 1641660 & 8.1169 & 8.4169 & TRN & & \\
\hline CHEMBL3938899 & 1641660 & 6.7496 & 6.85 & TRN & & \\
\hline CHEMBL3953530 & 1641660 & 7.8508 & 7.8305 & TRN & & \\
\hline CHEMBL3945038 & 1641660 & 7.7399 & 7.2282 & TRN & & \\
\hline CHEMBL3930567 & 1641660 & 8.4881 & 7.8633 & TRN & & \\
\hline CHEMBL3960599 & 1641660 & 7.0575 & 7.0617 & TST & & \\
\hline CHEMBL3983549 & 1641660 & 7.2596 & 6.6933 & TRN & & \\
\hline CHEMBL3942166 & 1641660 & 8.1391 & 8.1384 & TRN & & \\
\hline CHEMBL3986217 & 1641660 & 7.9208 & 7.9138 & TRN & & \\
\hline CHEMBL3946561 & 1641660 & 6.9957 & 7.0232 & TST & & \\
\hline CHEMBL3916378 & 1641660 & 7.9318 & 7.8742 & TRN & & \\
\hline
\end{tabular}

Page 25376 


$$
\text { Supplemental Table S2.txt }
$$

\begin{tabular}{|c|c|c|c|c|c|c|}
\hline CHEMBL3936859 & 1641660 & 7.4949 & 7.5127 & TRN & & \\
\hline CHEMBL 3922194 & 1641660 & 8.2248 & 7.9602 & TST & & \\
\hline CHEMBL3910586 & 1641660 & 8.291 & 8.1141 & TRN & & \\
\hline CHEMBL3923463 & 1641660 & 7.20200 & 00000000 & $\partial 1$ & 6.8316 & TST \\
\hline CHEMBL 3986421 & 1641660 & 7.6757 & 7.7853 & TRN & & \\
\hline CHEMBL3891117 & 1641660 & 6.0 & 6.6437 & TRN & & \\
\hline CHEMBL 3976580 & 1641660 & 7.9747 & 7.7675 & TRN & & \\
\hline CHEMBL 3924483 & 1641660 & 7.6716 & 7.2394 & TST & & \\
\hline CHEMBL 3898230 & 1641660 & 7.8416 & 7.9176 & TRN & & \\
\hline CHEMBL3893887 & 1641660 & 7.4413 & 6.8247 & TRN & & \\
\hline CHEMBL3966463 & 1641660 & 7.8665 & 7.8462 & TRN & & \\
\hline CHEMBL 3946111 & 1641660 & 7.6968 & 6.6649 & TST & & \\
\hline CHEMBL3969736 & 1641660 & 6.0 & 6.6415 & TRN & & \\
\hline CHEMBL 3890415 & 1641660 & 7.3851 & 7.1181 & TRN & & \\
\hline CHEMBL3923135 & 1641660 & 7.3565 & 7.3506 & TST & & \\
\hline CHEMBL3909391 & 1641660 & 7.9066 & 8.1397 & TRN & & \\
\hline CHEMBL3911127 & 1641660 & 8.0146 & 7.6301 & TRN & & \\
\hline CHEMBL3908308 & 1641660 & 6.8794 & 6.7393 & TRN & & \\
\hline CHEMBL3971019 & 1641660 & 6.0 & 6.6317 & TRN & & \\
\hline CHEMBL3938891 & 1641660 & 7.1192 & 6.5845 & TRN & & \\
\hline CHEMBL3984178 & 1641660 & 8.3233 & 7.2074 & TST & & \\
\hline CHEMBL 3973143 & 1641660 & 7.6946 & 7.5327 & TRN & & \\
\hline CHEMBL3977573 & 1641660 & 6.0 & 6.9686 & TRN & & \\
\hline CHEMBL 3893745 & 1641660 & 7.3807 & 7.2503 & TRN & & \\
\hline CHEMBL3938489 & 1641660 & 7.9805 & 7.6219 & TRN & & \\
\hline CHEMBL3894935 & 1641660 & 7.8013 & 7.4655 & TST & & \\
\hline CHEMBL3958596 & 1641660 & 6.3675 & 6.8836 & TRN & & \\
\hline CHEMBL3938551 & 1641660 & 7.7852 & 7.4173 & TRN & & \\
\hline CHEMBL 3969324 & 1641660 & 5.8041 & 6.9683 & TRN & & \\
\hline CHEMBL3966284 & 1641660 & \multicolumn{3}{|c|}{6.617999999999999} & 7.1359 & TRN \\
\hline CHEMBL3944203 & 1641660 & 6.9281 & 7.0615 & TRN & & \\
\hline CHEMBL3927675 & 1641660 & 7.5892 & 8.0081 & TRN & & \\
\hline CHEMBL3904898 & 1641660 & 7.2045 & 7.0561 & TST & & \\
\hline CHEMBL 3927736 & 1641660 & 7.9914 & 8.0661 & TRN & & \\
\hline CHEMBL 3927362 & 1641660 & 7.3316 & 7.047006 & 0000000001 & & TRN \\
\hline CHEMBL3971923 & 1641660 & 7.6459 & 7.8248 & TRN & & \\
\hline CHEMBL3929199 & 1641660 & 6.7986 & 6.3517 & TRN & & \\
\hline CHEMBL3941776 & 1641660 & 6.5258 & 6.381 & TRN & & \\
\hline CHEMBL 3892392 & 1641660 & 7.5482 & 7.1502 & TRN & & \\
\hline CHEMBL3939436 & 1641660 & 7.8601 & 8.1799 & TRN & & \\
\hline CHEMBL3961333 & 1641660 & 5.0625 & 6.5408 & TRN & & \\
\hline CHEMBL3967617 & 1641660 & 8.4401 & 7.7179 & TST & & \\
\hline CHEMBL3961064 & 1641660 & 7.2118 & 6.8884 & TRN & & \\
\hline CHEMBL3931775 & 1641660 & 7.1635 & 6.7887 & TST & & \\
\hline CHEMBL3935696 & 1641660 & 7.1831 & 7.3897 & TST & & \\
\hline CHEMBL3933154 & 1641660 & 8.0788 & 8.2814 & TRN & & \\
\hline CHEMBL3985003 & 1641660 & 8.0287 & 8.2869 & TST & & \\
\hline CHEMBL 3945140 & 1641660 & 7.6925 & 7.7541 & TRN & & \\
\hline
\end{tabular}


Supplemental Table S2.txt

\begin{tabular}{|c|c|c|c|c|c|c|}
\hline CHEMBL 3890973 & 1641660 & 7.8962 & 7.7092 & TRN & & \\
\hline CHEMBL 3912891 & 1641660 & 8.0778 & 7.4142 & TRN & & \\
\hline CHEMBL3935113 & 1641660 & 7.1942 & 6.818 & TRN & & \\
\hline CHEMBL3984317 & 1641660 & 8.4062 & 7.3684 & TST & & \\
\hline CHEMBL3913048 & 1641660 & 6.0 & 6.433 & TRN & & \\
\hline CHEMBL3910990 & 1641660 & 6.7471 & 6.627006 & 000000000 & & TRN \\
\hline CHEMBL3954979 & 1641660 & 6.0 & 6.6075 & TRN & & \\
\hline CHEMBL3946090 & 1641660 & 7.0372 & 7.2935 & TRN & & \\
\hline CHEMBL3929962 & 1641660 & 7.5361 & 6.9 & TRN & & \\
\hline CHEMBL3916118 & 1641660 & 6.0 & 6.4432 & TRN & & \\
\hline CHEMBL3915459 & 1641660 & 8.1158 & 6.8572 & TRN & & \\
\hline CHEMBL 3975993 & 1641660 & 6.0 & 6.4538 & TRN & & \\
\hline CHEMBL3911218 & 1641660 & 6.0 & 6.739 & TRN & & \\
\hline CHEMBL3928352 & 1641660 & 7.7423 & 7.6124 & TST & & \\
\hline CHEMBL3959916 & 1641660 & 6.0 & 7.0547 & TRN & & \\
\hline CHEMBL3965043 & 1641660 & 7.068 & 7.0314 & TRN & & \\
\hline CHEMBL3903435 & 1641660 & 7.3778 & 6.7735 & TRN & & \\
\hline CHEMBL 3894864 & 1641660 & 7.7282 & 8.0339 & TRN & & \\
\hline CHEMBL3939098 & 1641660 & 6.3161 & 6.5652 & TRN & & \\
\hline CHEMBL3966692 & 1641660 & 6.4685 & 6.393 & TRN & & \\
\hline CHEMBL3978780 & 1641660 & 6.4763 & 6.4059 & TRN & & \\
\hline CHEMBL3908953 & 1641660 & 8.6108 & 7.4676 & TST & & \\
\hline CHEMBL 3890462 & 1641660 & 7.3536 & 7.603 & TRN & & \\
\hline CHEMBL3919919 & 1641660 & 7.4959 & 7.4243 & TRN & & \\
\hline CHEMBL3959453 & 1641660 & \multicolumn{3}{|c|}{7.718999999999999} & 7.5765 & TRN \\
\hline CHEMBL3947308 & 1641660 & 7.7352 & 7.2367 & TRN & & \\
\hline CHEMBL 3936480 & 1641660 & 6.0 & 6.8198 & TRN & & \\
\hline CHEMBL3956635 & 1641660 & 7.7055 & 7.7178 & TRN & & \\
\hline CHEMBL 3949328 & 1641660 & 7.6655 & 7.6515 & TRN & & \\
\hline CHEMBL3961246 & 1641660 & 8.0414 & 7.315 & TST & & \\
\hline CHEMBL3946977 & 1641660 & 7.3191 & 6.6736 & TRN & & \\
\hline CHEMBL 3904287 & 1641660 & 8.752 & 7.9988 & TST & & \\
\hline CHEMBL 3894830 & 1641660 & 6.2351 & 7.0749 & TRN & & \\
\hline CHEMBL 3984188 & 1641660 & \multicolumn{3}{|c|}{6.3839999999999995} & 7.0197 & TST \\
\hline CHEMBL3981810 & 1641660 & 6.4365 & 7.0761 & TRN & & \\
\hline CHEMBL3943012 & 1641660 & 7.4609 & 7.579 & TST & & \\
\hline CHEMBL 3954937 & 1641660 & 8.1018 & 7.684 & TST & & \\
\hline CHEMBL3952602 & 1641660 & 6.7011 & 6.6625 & TRN & & \\
\hline CHEMBL3902023 & 1641660 & 6.983 & 6.6908 & TRN & & \\
\hline CHEMBL3903398 & 1641660 & 5.8327 & 6.459 & TST & & \\
\hline CHEMBL3898571 & 1641660 & 8.6861 & 8.3019 & TRN & & \\
\hline CHEMBL3967035 & 1641660 & 7.5784 & 6.5442 & TST & & \\
\hline CHEMBL3961433 & 1641660 & 6.8861 & 7.001 & TST & & \\
\hline CHEMBL 3959308 & 1641660 & 7.0665 & 6.2345 & TST & & \\
\hline CHEMBL 3984848 & 1641660 & 6.0615 & 6.4321 & TRN & & \\
\hline CHEMBL 3895250 & 1641660 & 8.2557 & 7.3187 & TRN & & \\
\hline CHEMBL3980502 & 1641660 & 6.4661 & 6.5891 & TST & & \\
\hline CHEMBL 3982895 & 1641660 & 7.4908 & 7.2966 & TRN & & \\
\hline
\end{tabular}

Page 25378 
Supplemental Table S2.txt

\begin{tabular}{|c|c|c|c|c|}
\hline CHEMBL 3986667 & 1641660 & 6.7852 & 6.9739 & TRN \\
\hline CHEMBL3915924 & 1641660 & 5.6216 & 6.8997 & TRN \\
\hline CHEMBL3904345 & 1641660 & 6.9957 & 6.9478 & TRN \\
\hline CHEMBL3986328 & 1641660 & 6.9957 & 6.6467 & TRN \\
\hline CHEMBL3914783 & 1641660 & 7.3307 & 6.8236 & TRN \\
\hline CHEMBL 3901473 & 1641660 & 7.1209 & 7.6086 & TRN \\
\hline CHEMBL3927116 & 1641660 & 7.5031 & 7.5292 & TST \\
\hline CHEMBL 3960672 & 1641660 & 8.2147 & 8.2185 & TRN \\
\hline CHEMBL 3955113 & 1641660 & 7.6696 & 7.1631 & TRN \\
\hline CHEMBL3967923 & 1641660 & 6.8471 & 6.7539 & TRN \\
\hline CHEMBL 3962178 & 1641660 & 7.1203 & 6.5846 & TRN \\
\hline CHEMBL3982749 & 1641660 & 7.7423 & 7.2873 & TRN \\
\hline CHEMBL 3952980 & 1641660 & 8.14299 & 79999999 & 8.6743 \\
\hline CHEMBL3961646 & 1641660 & 8.2125 & 7.7652 & TRN \\
\hline CHEMBL3951264 & 1641660 & 7.3531 & 7.0069 & TST \\
\hline CHEMBL3915329 & 1641660 & 7.2328 & 6.1031 & TRN \\
\hline CHEMBL3984265 & 1641660 & 7.0301 & 7.1569 & TST \\
\hline CHEMBL3943464 & 1641660 & 7.2457 & 6.7911 & TRN \\
\hline CHEMBL 3895091 & 1641660 & 7.1726 & 6.5041 & TST \\
\hline CHEMBL3966169 & 1641660 & 8.5969 & 8.0539 & TST \\
\hline CHEMBL 3974544 & 1641660 & 7.8894 & 7.8908 & TST \\
\hline CHEMBL3951091 & 1641660 & 6.2161 & 6.0614 & TRN \\
\hline CHEMBL3954365 & 1641660 & 8.2118 & 7.0753 & TST \\
\hline CHEMBL3962949 & 1641660 & 7.9872 & 7.86700 & 0000000001 \\
\hline CHEMBL 3942627 & 1641660 & 8.1543 & 8.0541 & TRN \\
\hline CHEMBL3961366 & 1641660 & 7.3595 & 6.7477 & TRN \\
\hline CHEMBL3923546 & 1641660 & 7.1292 & 6.7576 & TRN \\
\hline CHEMBL3945468 & 1641660 & 6.0 & 6.2471 & TRN \\
\hline CHEMBL 3952902 & 1641660 & 7.6498 & 6.5764 & TRN \\
\hline CHEMBL3959373 & 1641660 & 7.0306 & 7.5091 & TST \\
\hline CHEMBL3940450 & 1641660 & 6.0 & 6.7229 & TRN \\
\hline CHEMBL3970760 & 1641660 & 6.7447 & 7.0648 & TRN \\
\hline CHEMBL3905169 & 1641660 & 7.4802 & 6.8332 & TRN \\
\hline CHEMBL 3906482 & 1641660 & 7.2343 & 7.5854 & TRN \\
\hline CHEMBL 3942060 & 1641660 & 6.0 & 6.5305 & TRN \\
\hline CHEMBL3934727 & 1641660 & 8.0477 & 7.1331 & TRN \\
\hline CHEMBL3935593 & 1641660 & 6.5686 & 6.8312 & TRN \\
\hline CHEMBL3916625 & 1641660 & 6.0 & 7.027 & TRN \\
\hline CHEMBL 3900384 & 1641660 & 7.8386 & 7.1786 & TRN \\
\hline CHEMBL3979452 & 1641660 & 7.2976 & 7.6406 & TRN \\
\hline CHEMBL 3924608 & 1641660 & 7.4855 & 7.0254 & TST \\
\hline CHEMBL3932683 & 1641660 & 7.9172 & 7.5375 & TRN \\
\hline CHEMBL3952153 & 1641660 & 5.8928 & 6.7814 & TST \\
\hline CHEMBL 3889774 & 1641660 & 7.4214 & 6.7126 & TST \\
\hline CHEMBL3960847 & 1641660 & 6.4449 & 6.7221 & TRN \\
\hline CHEMBL3948918 & 1641660 & 8.2907 & 7.6351 & TRN \\
\hline CHEMBL3971310 & 1641660 & 7.4962 & 8.0233 & TST \\
\hline CHEMBL3939943 & 1641660 & 7.9318 & 7.2221 & TST \\
\hline
\end{tabular}

Page 25379 
Supplemental Table S2.txt

\begin{tabular}{|c|c|c|c|c|c|}
\hline CHEMBL3977444 & 1641660 & 7.9281 & 7.4132 & TST & \\
\hline CHEMBL3984271 & 1641660 & 6.0 & 7.5286 & TST & \\
\hline CHEMBL3901949 & 1641660 & 7.7122 & 7.9678 & TRN & \\
\hline CHEMBL3933689 & 1641660 & 6.6757 & 7.4362 & TST & \\
\hline CHEMBL3905559 & 1641660 & 7.2815 & 7.2714 & TST & \\
\hline CHEMBL3898180 & 1641660 & 7.3391 & 6.2673 & TRN & \\
\hline CHEMBL3953413 & 1641660 & 7.2396 & 7.0935 & TRN & \\
\hline CHEMBL3977208 & 1641660 & 6.0 & 6.4112 & TRN & \\
\hline CHEMBL 3954984 & 1641660 & 6.0 & 6.8073 & TRN & \\
\hline CHEMBL3930932 & 1641660 & 6.066 & 6.2008 & TRN & \\
\hline CHEMBL3934688 & 1641660 & 7.2358 & 6.7678 & TST & \\
\hline CHEMBL3977951 & 1641660 & 7.5031 & 7.1892 & TRN & \\
\hline CHEMBL3948323 & 1641660 & 6.9788 & 6.9838 & TRN & \\
\hline CHEMBL3899260 & 1641660 & 6.8962 & 7.1801 & TST & \\
\hline CHEMBL3978675 & 1641660 & 7.8861 & 7.3948 & TRN & \\
\hline CHEMBL3952297 & 1641660 & 7.51 & 7.8884 & TRN & \\
\hline CHEMBL3955639 & 1641660 & 6.4685 & 6.9286 & TRN & \\
\hline CHEMBL3972609 & 1641660 & 6.2628 & 6.8523 & TST & \\
\hline CHEMBL3958931 & 1641660 & 8.0026 & 8.0983 & TRN & \\
\hline CHEMBL3943397 & 1641660 & 8.0516 & 7.9448 & TRN & \\
\hline CHEMBL3956535 & 1641660 & 8.1421 & 7.3698 & TRN & \\
\hline CHEMBL3961511 & 1641660 & 6.0 & 6.6094 & TRN & \\
\hline CHEMBL3932232 & 1641660 & 6.6517 & 7.232 & TRN & \\
\hline CHEMBL3902322 & 1641660 & 6.32700 & 0000000 & 7.1678 & TRN \\
\hline CHEMBL3910955 & 1641660 & 7.5114 & 7.819 & TRN & \\
\hline CHEMBL3984026 & 1641660 & 7.4401 & 7.4494 & TRN & \\
\hline CHEMBL3944140 & 1641660 & 7.6364 & 6.8059 & TRN & \\
\hline CHEMBL3950705 & 1641660 & 6.6968 & 6.8016 & TST & \\
\hline CHEMBL3944923 & 1641660 & 7.4179 & 7.4761 & TRN & \\
\hline CHEMBL3927845 & 1641660 & 7.7399 & 8.0091 & TRN & \\
\hline CHEMBL3945591 & 1641660 & 8.1662 & 7.7549 & TRN & \\
\hline CHEMBL3941729 & 1641660 & 7.8239 & 8.0301 & TRN & \\
\hline CHEMBL 3917254 & 1641660 & 7.4763 & 7.53299 & 99999999995 & TRN \\
\hline CHEMBL3953511 & 1641660 & 7.2226 & 6.9901 & TRN & \\
\hline CHEMBL3915622 & 1641660 & 6.7235 & 7.1303 & TRN & \\
\hline CHEMBL3987005 & 1641660 & 7.0482 & 6.9287 & TRN & \\
\hline CHEMBL3908445 & 1641660 & 6.2418 & 5.90799 & 99999999995 & TRN \\
\hline CHEMBL3986329 & 1641660 & 7.8239 & 7.9543 & TRN & \\
\hline CHEMBL 3941491 & 1641660 & 8.1726 & 7.0856 & TRN & \\
\hline CHEMBL3891940 & 1641660 & 6.9914 & 6.8685 & TST & \\
\hline CHEMBL3915218 & 1641660 & 6.0 & 6.3247 & TRN & \\
\hline CHEMBL3967935 & 1641660 & 7.6091 & 7.0524 & TRN & \\
\hline CHEMBL3932813 & 1641660 & 7.3478 & 7.4879 & TRN & \\
\hline CHEMBL3962599 & 1641660 & 8.5528 & 8.169 & TRN & \\
\hline CHEMBL3981396 & 1641660 & 8.3468 & 6.9961 & TRN & \\
\hline CHEMBL 3974598 & 1641660 & 6.0 & 6.8004 & TRN & \\
\hline CHEMBL3900261 & 1641660 & 7.433 & 8.4553 & TST & \\
\hline \multirow[t]{2}{*}{ CHEMBL3937901 } & 1641660 & 6.9355 & 7.41200 & 0000000001 & TST \\
\hline & & \multicolumn{4}{|c|}{ Page 25380} \\
\hline
\end{tabular}


Supplemental Table S2.txt

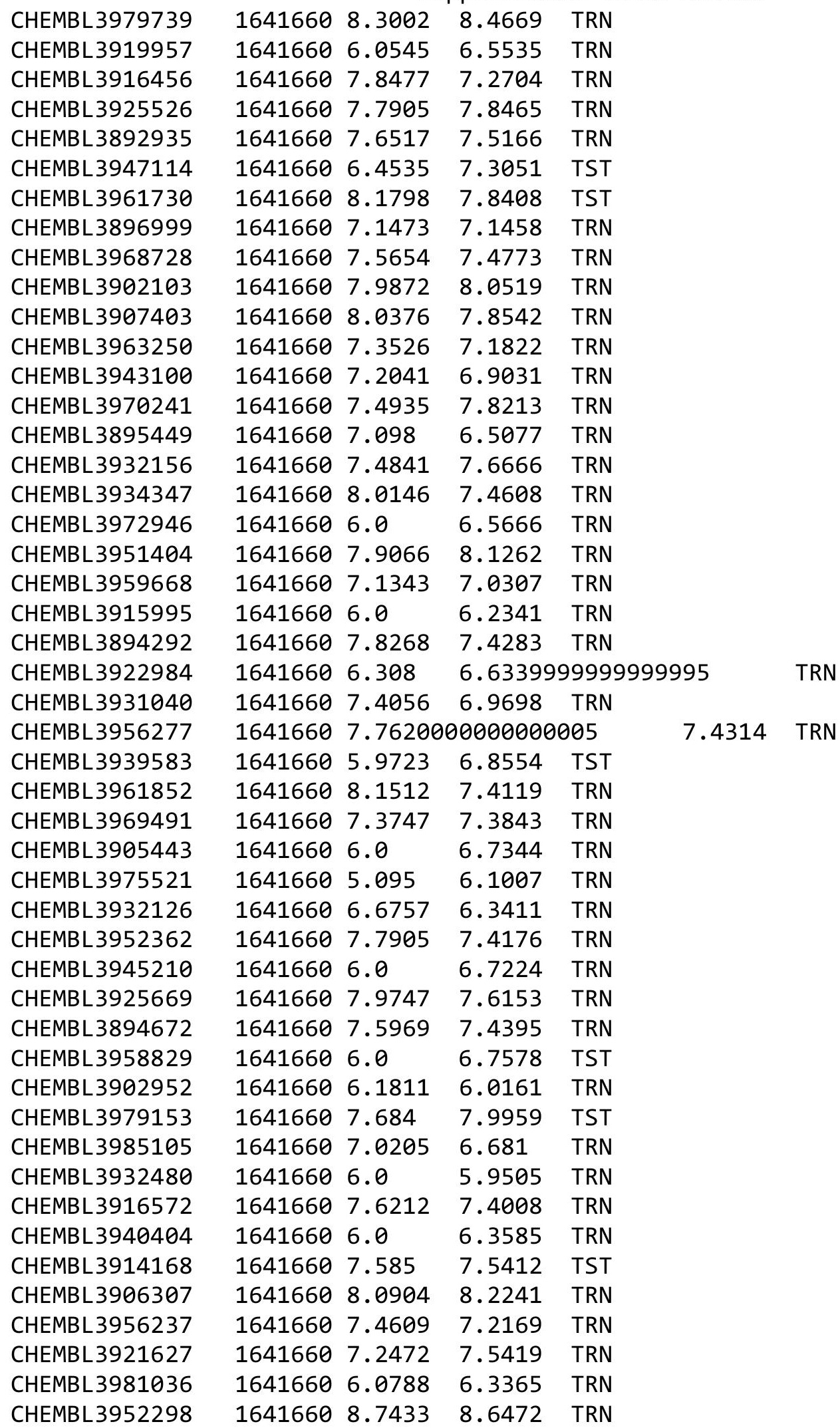

Page 25381 
Supplemental Table S2.txt

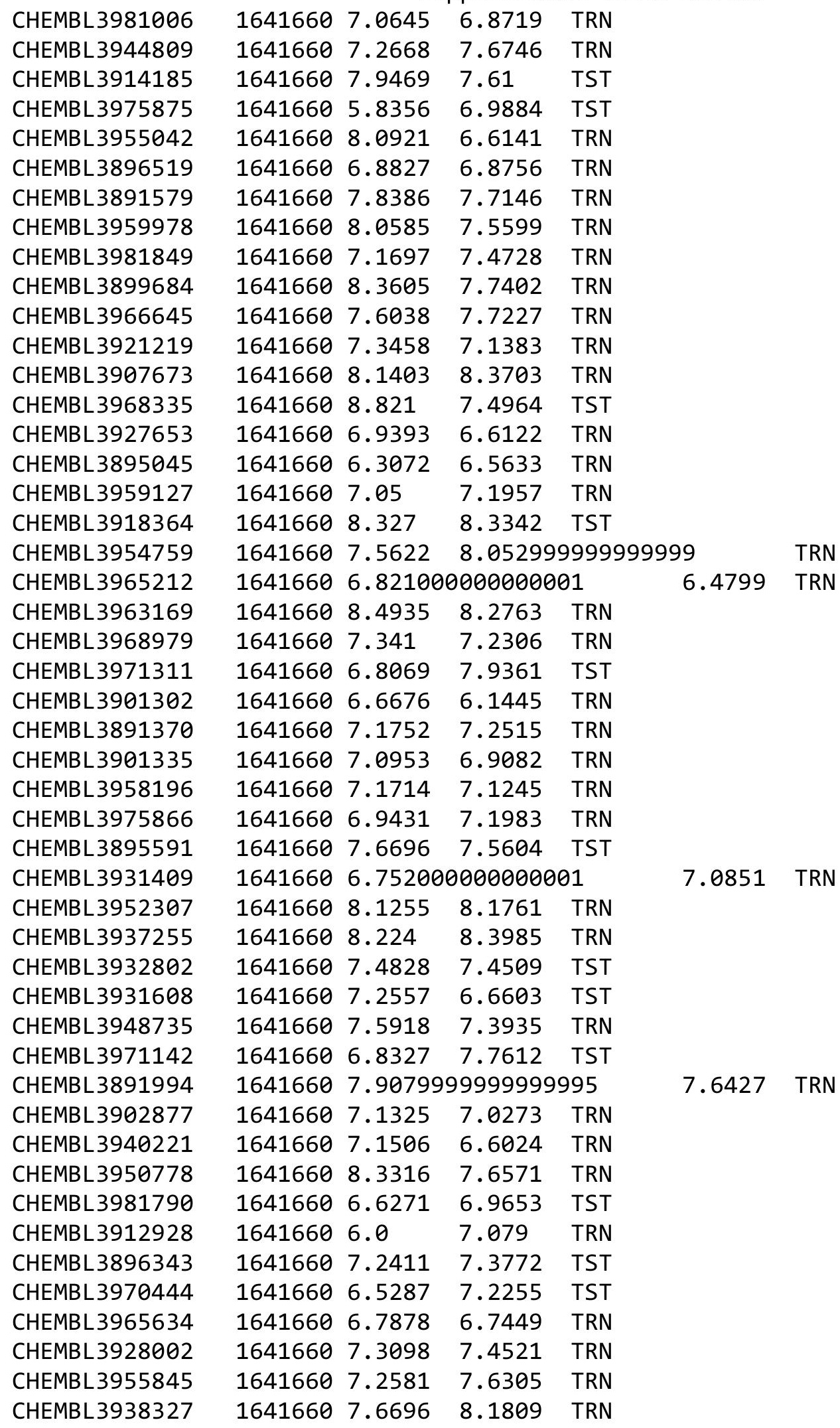

Page 25382 
Supplemental Table S2.txt

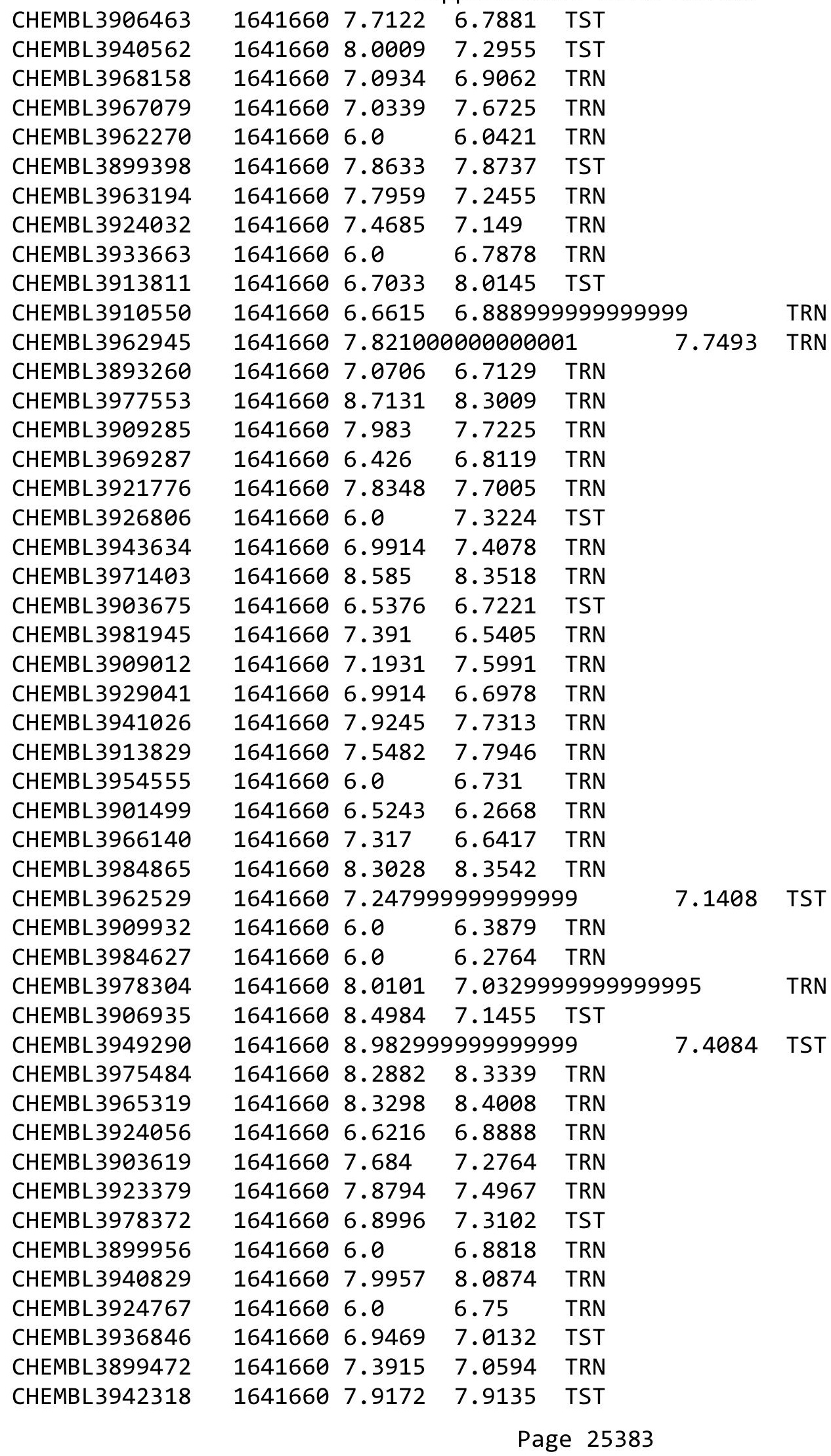


Supplemental Table S2.txt

\begin{tabular}{|c|c|c|c|c|c|}
\hline CHEMBL3942676 & 1641660 & 8.1959 & 7.7322 & TRN & \\
\hline CHEMBL3903796 & 1641660 & 8.1986 & 7.1581 & TRN & \\
\hline CHEMBL3916300 & 1641660 & 5.0343 & 7.4567 & TST & \\
\hline CHEMBL3937094 & 1641660 & 4.8438 & 7.0706 & TST & \\
\hline CHEMBL3910605 & 1641660 & 8.1487 & 7.4488 & TRN & \\
\hline CHEMBL3911492 & 1641660 & 7.6126 & 6.7932 & TRN & \\
\hline CHEMBL3966986 & 1641660 & 7.9872 & 7.635 & TRN & \\
\hline CHEMBL3973490 & 1641660 & 6.7471 & 6.8119 & TST & \\
\hline CHEMBL3910261 & 1641660 & 8.0044 & 7.3873 & TRN & \\
\hline CHEMBL3979094 & 1641660 & 6.0 & 6.5054 & TRN & \\
\hline CHEMBL3896217 & 1641660 & 7.9281 & 7.3326 & TRN & \\
\hline CHEMBL 3979424 & 1641660 & 8.3089 & 8.0955 & TRN & \\
\hline CHEMBL 3958583 & 1641660 & 6.0 & 7.03 & TRN & \\
\hline CHEMBL3972242 & 1641660 & 7.466 & 7.5415 & TRN & \\
\hline CHEMBL 3947343 & 1641660 & 7.8297 & 7.1165 & TST & \\
\hline CHEMBL3965303 & 1641660 & 7.6126 & 7.3201 & TRN & \\
\hline CHEMBL3971279 & 1641660 & 8.0894 & 7.5099 & TRN & \\
\hline CHEMBL3910609 & 1641660 & 7.5935 & 6.7955 & TRN & \\
\hline CHEMBL3919937 & 1641660 & 6.5376 & 7.4651 & TRN & \\
\hline CHEMBL 3960424 & 1641660 & \multicolumn{3}{|c|}{ 7.752000000000001 } & TRN \\
\hline CHEMBL3986385 & 1641660 & 6.0 & 6.8687 & TRN & \\
\hline CHEMBL3928301 & 1641660 & 7.3669 & 7.3088 & TRN & \\
\hline CHEMBL3962069 & 1641660 & 7.6757 & 8.0968 & TST & \\
\hline CHEMBL3979491 & 1641660 & 7.7258 & 7.7958 & TRN & \\
\hline CHEMBL3954101 & 1641660 & 7.1561 & 7.5148 & TRN & \\
\hline CHEMBL 3922093 & 1641660 & 7.5528 & 7.6187 & TRN & \\
\hline CHEMBL3964072 & 1641660 & 6.8928 & 6.1867 & TRN & \\
\hline CHEMBL3924188 & 1641660 & 7.2083 & 6.9075 & TST & \\
\hline CHEMBL3892259 & 1641660 & 8.5287 & 6.9744 & TRN & \\
\hline CHEMBL3949666 & 1641660 & 7.4647 & 6.6619 & TST & \\
\hline CHEMBL3965236 & 1641660 & 7.8356 & 7.9342 & TRN & \\
\hline CHEMBL 3938328 & 1641660 & 7.0074 & 6.9496 & TRN & \\
\hline CHEMBL 3924262 & 1641660 & 7.9136 & 7.3784 & TRN & \\
\hline CHEMBL3985524 & 1641660 & 6.9404 & 7.1124 & TRN & \\
\hline CHEMBL3933210 & 1641660 & 8.4672 & 7.5895 & TST & \\
\hline CHEMBL3896555 & 1641660 & 6.9031 & 7.361000 & 0000000001 & $1 \mathrm{~K}$ \\
\hline CHEMBL3937196 & 1641660 & 8.0218 & 7.9929 & TRN & \\
\hline CHEMBL 3952879 & 1641660 & 7.4584 & 6.6189 & TST & \\
\hline CHEMBL3917004 & 1641660 & 7.7696 & 7.2522 & TRN & \\
\hline CHEMBL3978213 & 1641660 & 6.0 & 6.4874 & TRN & \\
\hline CHEMBL 3899561 & 1641660 & $8.7670 e$ & 000000000 & 7.4517 & TST \\
\hline CHEMBL 3947102 & 1641660 & 7.8928 & 7.4597 & TRN & \\
\hline CHEMBL 3930943 & 1641660 & 7.9245 & 8.0182 & TRN & \\
\hline CHEMBL3945998 & 1641660 & 7.2832 & 7.4093 & TST & \\
\hline CHEMBL3925547 & 1641660 & 6.9398 & 7.3867 & TST & \\
\hline CHEMBL3981019 & 1641660 & 7.0645 & 6.9096 & TST & \\
\hline CHEMBL 3954100 & 1641660 & 6.5952 & 7.0463 & TRN & \\
\hline CHEMBL 3890285 & 1641660 & 6.0 & 6.9052 & TRN & \\
\hline
\end{tabular}


Supplemental Table S2.txt

\begin{tabular}{|c|c|c|c|c|c|}
\hline CHEMBL3904686 & 1641660 & 7.8861 & 7.4953 & TRN & \\
\hline CHEMBL3973053 & 1641660 & 6.1487 & 6.0097 & TST & \\
\hline CHEMBL3971589 & 1641660 & 6.0 & 7.2038 & TST & \\
\hline CHEMBL3958167 & 1641660 & 7.0472 & 7.2358 & TRN & \\
\hline CHEMBL3946109 & 1641660 & 6.0 & 6.8019 & TRN & \\
\hline CHEMBL3898652 & 1641660 & 6.0 & 7.4036 & TRN & \\
\hline CHEMBL3944231 & 1641660 & 6.2227 & 7.0624 & TST & \\
\hline CHEMBL3968034 & 1641660 & 5.2798 & 6.86299 & 99999999995 & TST \\
\hline CHEMBL3979029 & 1641660 & 7.129 & 6.8174 & TST & \\
\hline CHEMBL3953642 & 1641660 & 7.9666 & 6.9656 & TRN & \\
\hline CHEMBL3900437 & 1641660 & 6.0 & 6.4082 & TRN & \\
\hline CHEMBL3937639 & 1641660 & 7.5302 & 7.5599 & TRN & \\
\hline CHEMBL3983857 & 1641660 & 7.3799 & 7.3496 & TRN & \\
\hline CHEMBL3979992 & 1641660 & 6.8601 & 6.28600 & 00000000005 & TRN \\
\hline CHEMBL3962859 & 1641660 & 8.3958 & 7.3503 & TRN & \\
\hline CHEMBL3921870 & 1641660 & 7.6498 & 7.9073 & TRN & \\
\hline CHEMBL3966206 & 1641660 & 7.5768 & 6.5807 & TRN & \\
\hline CHEMBL3915038 & 1641660 & 7.8891 & 7.4532 & TRN & \\
\hline CHEMBL3919939 & 1641660 & 6.5969 & 7.3817 & TRN & \\
\hline CHEMBL3980356 & 1641660 & 8.0458 & 7.5083 & TRN & \\
\hline CHEMBL3921196 & 1641660 & 7.3757 & 7.4047 & TRN & \\
\hline CHEMBL3949689 & 1641660 & 7.3439 & 7.2872 & TRN & \\
\hline CHEMBL 3913552 & 1641660 & 7.9208 & 7.1617 & TRN & \\
\hline CHEMBL3890687 & 1641660 & 7.6356 & 6.8073 & TST & \\
\hline CHEMBL3963775 & 1641660 & 7.9531 & 6.5218 & TST & \\
\hline CHEMBL3978433 & 1641660 & 6.9208 & 7.2428 & TRN & \\
\hline CHEMBL3986165 & 1641660 & 6.0 & 6.7689 & TRN & \\
\hline CHEMBL3940925 & 1641660 & 6.7235 & 7.2276 & TRN & \\
\hline CHEMBL3891529 & 1641660 & 7.5114 & 7.2867 & TRN & \\
\hline CHEMBL3942546 & 1641660 & \multicolumn{3}{|c|}{8.767000000000001} & \\
\hline CHEMBL3966361 & 1641660 & 5.7167 & 6.9824 & TRN & \\
\hline CHEMBL3963962 & 1641660 & 8.9318 & 7.6856 & TST & \\
\hline CHEMBL 3935148 & 1641660 & 6.0 & 6.8291 & TRN & \\
\hline CHEMBL3954096 & 1641660 & 7.7729 & 7.1237 & TST & \\
\hline CHEMBL3955773 & 1641660 & 6.0 & 6.5986 & TRN & \\
\hline CHEMBL3918222 & 1641660 & 6.8499 & 6.7825 & TRN & \\
\hline CHEMBL3891858 & 1641660 & 7.5528 & 7.3378 & TRN & \\
\hline CHEMBL3951822 & 1641660 & 7.0205 & 7.3246 & TST & \\
\hline CHEMBL3973166 & 1641660 & 6.0 & 5.7369 & TRN & \\
\hline CHEMBL3923207 & 1641660 & 7.5867 & 7.8998 & TRN & \\
\hline CHEMBL3972993 & 1641660 & 7.2147 & 6.8231 & TRN & \\
\hline CHEMBL3953169 & 1641660 & 7.1221 & 7.2089 & TRN & \\
\hline CHEMBL3935446 & 1641660 & 8.1878 & 7.5256 & TST & \\
\hline CHEMBL3898330 & 1641660 & 6.0 & 6.4628 & TRN & \\
\hline CHEMBL3923892 & 1641660 & 7.8729 & 7.9943 & TRN & \\
\hline CHEMBL3928864 & 1641660 & 6.0 & 6.7889 & TRN & \\
\hline CHEMBL3960940 & 1641660 & 7.8996 & 7.4969 & TRN & \\
\hline CHEMBL3917758 & 1641660 & 8.0506 & 7.5177 & TRN & \\
\hline
\end{tabular}

Page 25385 
Supplemental Table S2.txt

\begin{tabular}{|c|c|c|c|c|c|}
\hline CHEMBL3945994 & 1641660 & 6.8359 & 7.2613 & TST & \\
\hline CHEMBL3921223 & 1641660 & 6.0 & 6.5474 & TST & \\
\hline CHEMBL3932891 & 1641660 & 7.2983 & 7.4521 & TRN & \\
\hline CHEMBL3931261 & 1641660 & 6.9369 & 6.0073 & TRN & \\
\hline CHEMBL3931552 & 1641660 & 6.1759 & 7.3305 & TRN & \\
\hline CHEMBL3914544 & 1641660 & 8.1337 & 8.1734 & TRN & \\
\hline CHEMBL3929871 & 1641660 & 6.9355 & 6.4998 & TRN & \\
\hline CHEMBL3911631 & 1641660 & 7.6968 & 7.1342 & TRN & \\
\hline CHEMBL3905830 & 1641660 & 8.0521 & 7.044 & TRN & \\
\hline CHEMBL3934538 & 1641660 & 6.0 & 6.7485 & TRN & \\
\hline CHEMBL3955865 & 1641660 & 7.5867 & 7.5109 & TRN & \\
\hline CHEMBL3976655 & 1641660 & 7.3089 & 6.8232 & TST & \\
\hline CHEMBL3922325 & 1641660 & 7.8125 & 7.44 & TRN & \\
\hline CHEMBL 3940072 & 1641660 & 7.9914 & 7.4049 & TRN & \\
\hline CHEMBL3944978 & 1641660 & 6.7545 & 7.3483 & TRN & \\
\hline CHEMBL3985440 & 1641660 & 7.5935 & 7.38200 & 0000000001 & TRN \\
\hline CHEMBL3978061 & 1641660 & 6.0 & 7.0222 & TRN & \\
\hline CHEMBL3908183 & 1641660 & 6.7799 & 7.2679 & TRN & \\
\hline CHEMBL3981676 & 1641660 & 6.0 & 6.768 & TRN & \\
\hline CHEMBL3911040 & 1641660 & 7.6757 & 7.1176 & TRN & \\
\hline CHEMBL3951420 & 1641660 & 8.6091 & 7.8428 & TRN & \\
\hline CHEMBL3894112 & 1641660 & 7.5467 & 7.3789 & TRN & \\
\hline CHEMBL3927719 & 1641660 & 7.2716 & 7.0021 & TRN & \\
\hline CHEMBL 3979274 & 1641660 & 7.1007 & 6.7274 & TRN & \\
\hline CHEMBL3957626 & 1641660 & 7.2147 & 6.893 & TRN & \\
\hline CHEMBL3930367 & 1641660 & 8.3747 & 7.8545 & TRN & \\
\hline CHEMBL3961591 & 1641660 & 7.6073 & \multicolumn{2}{|c|}{7.9510000000000005} & TRN \\
\hline CHEMBL3986146 & 1641660 & 6.4271 & 7.7119 & TST & \\
\hline CHEMBL 3978622 & 1641660 & 6.0501 & 6.9013 & TRN & \\
\hline CHEMBL3954486 & 1641660 & 6.0 & 7.0242 & TRN & \\
\hline CHEMBL3962152 & 1641660 & 8.5258 & 7.6303 & TST & \\
\hline CHEMBL3925877 & 1641660 & 7.2899 & 7.5519 & TRN & \\
\hline CHEMBL3894154 & 1641660 & 8.041 & 8.2072 & TRN & \\
\hline CHEMBL 3972258 & 1641660 & 6.8539 & 7.2461 & TRN & \\
\hline CHEMBL3900102 & 1641660 & 6.0 & 6.7606 & TRN & \\
\hline CHEMBL3965999 & 1641660 & 7.6946 & 8.033 & TRN & \\
\hline CHEMBL3945668 & 1641660 & 7.6421 & 7.3283 & TRN & \\
\hline CHEMBL3925931 & 1641660 & 8.1367 & 7.7816 & TST & \\
\hline CHEMBL3951281 & 1641660 & 7.0862 & 7.9306 & TST & \\
\hline CHEMBL3890683 & 1641660 & 6.8239 & 7.2897 & TRN & \\
\hline CHEMBL3970836 & 1641660 & 8.2255 & 7.4545 & TST & \\
\hline CHEMBL3919326 & 1641660 & 7.4145 & 7.3236 & TRN & \\
\hline CHEMBL3932808 & 1641660 & 8.5467 & 7.0958 & TST & \\
\hline CHEMBL3953524 & 1641660 & 6.8309 & 6.5824 & TRN & \\
\hline CHEMBL3902805 & 1641660 & 7.58 & 7.0742 & TRN & \\
\hline CHEMBL3918858 & 1641660 & 7.7545 & 7.6229 & TST & \\
\hline CHEMBL3949749 & 1641660 & 7.0625 & 7.0414 & TRN & \\
\hline CHEMBL3911052 & 1641660 & 7.0186 & 7.2134 & TRN & \\
\hline
\end{tabular}




\begin{tabular}{|c|c|c|c|c|c|}
\hline \multicolumn{5}{|c|}{ Supplemental Table S2.txt } & \\
\hline CHEMBL3963650 & 1641660 & 6.0 & 6.2345 & TRN & \\
\hline CHEMBL3926665 & 1641660 & 6.0 & 7.1695 & TRN & \\
\hline CHEMBL3905936 & 1641660 & 7.1805 & 7.0649 & TST & \\
\hline CHEMBL3904043 & 1641660 & 7.9586 & 7.8489 & TRN & \\
\hline CHEMBL3929403 & 1641660 & 6.0 & 5.8138 & TRN & \\
\hline CHEMBL3896188 & 1641660 & 8.0846 & 8.1253 & TRN & \\
\hline CHEMBL3947043 & 1641660 & 7.71 & 7.888999 & 9999999999 & TRN \\
\hline CHEMBL3933852 & 1641660 & 7.8041 & 7.4647 & TRN & \\
\hline CHEMBL3925991 & 1641660 & 7.466 & 7.7743 & TRN & \\
\hline CHEMBL3939890 & 1641660 & 7.6904 & 6.8261 & TRN & \\
\hline CHEMBL3930935 & 1641660 & 8.3036 & 8.0251 & TRN & \\
\hline CHEMBL3950667 & 1641660 & 7.8477 & 7.231 & TST & \\
\hline CHEMBL3899756 & 1641660 & 7.5086 & 7.0637 & TST & \\
\hline CHEMBL3952185 & 1641660 & 8.0283 & 7.8825 & TRN & \\
\hline CHEMBL3908458 & 1641660 & 6.4461 & 7.1126 & TRN & \\
\hline CHEMBL3940552 & 1641660 & 8.3363 & 7.8035 & TRN & \\
\hline CHEMBL3962488 & 1641660 & 7.3575 & 7.1625 & TRN & \\
\hline CHEMBL3922137 & 1641660 & 6.4949 & 5.9876 & TRN & \\
\hline CHEMBL3900929 & 1641660 & 7.5735 & 7.6773 & TRN & \\
\hline CHEMBL3904887 & 1641660 & 6.0 & 6.925 & TRN & \\
\hline CHEMBL3936001 & 1641660 & 7.8904 & 7.2782 & TST & \\
\hline CHEMBL3943028 & 1641660 & 6.0 & 6.8081 & TRN & \\
\hline CHEMBL3975127 & 1641660 & 8.1386 & 7.1271 & TST & \\
\hline CHEMBL3981851 & 1641660 & 7.3706 & 7.1558 & TRN & \\
\hline CHEMBL3931147 & 1641660 & 6.0 & 6.8288 & TRN & \\
\hline CHEMBL3981617 & 1641660 & 6.2125 & 7.8555 & TST & \\
\hline CHEMBL3927344 & 1641660 & 8.2628 & 8.3319 & TRN & \\
\hline CHEMBL3954366 & 1641660 & 6.9957 & 7.6866 & TRN & \\
\hline CHEMBL 3938490 & 1641660 & 6.0 & 6.4791 & TRN & \\
\hline CHEMBL3923378 & 1641660 & 7.556 & 7.2986 & TRN & \\
\hline CHEMBL3973508 & 1641660 & 8.0186 & 7.7358 & TRN & \\
\hline CHEMBL3900922 & 1641660 & 6.0 & 6.504 & TRN & \\
\hline CHEMBL3956053 & 1641660 & 8.06 & 7.7885 & TRN & \\
\hline CHEMBL3941732 & 1641660 & 7.5607 & 7.8548 & TST & \\
\hline CHEMBL3964192 & 1641660 & 7.7747 & 7.3296 & TRN & \\
\hline CHEMBL3911025 & 1641660 & 6.0 & 5.8961 & TRN & \\
\hline CHEMBL3984887 & 1641660 & 7.8633 & 7.4305 & TRN & \\
\hline CHEMBL3936597 & 1641660 & 8.0241 & 8.0922 & TRN & \\
\hline CHEMBL3918645 & 1641660 & 7.3915 & 6.8399 & TRN & \\
\hline CHEMBL3970717 & 1641660 & 7.32700 & 000000000 & 7.3119 & TST \\
\hline CHEMBL3906314 & 1641660 & 6.2668 & 6.842000 & 00000000005 & \\
\hline CHEMBL3939948 & 1641660 & 6.2147 & 6.1473 & TRN & \\
\hline CHEMBL3964965 & 1641660 & 8.1198 & 7.8326 & TRN & \\
\hline CHEMBL3903228 & 1641660 & 7.4001 & 6.5906 & TRN & \\
\hline CHEMBL3945983 & 1641660 & 7.2976 & 7.2949 & TRN & \\
\hline CHEMBL3969376 & 1641660 & 7.4572 & 6.505 & TST & \\
\hline CHEMBL3895939 & 1641660 & 7.3406 & 7.4359 & TRN & \\
\hline CHEMBL3937102 & 1641660 & 7.8962 & 7.6118 & TST & \\
\hline
\end{tabular}




\begin{tabular}{|c|c|c|c|c|c|}
\hline \multirow[b]{2}{*}{ CHEMBL 3918789} & \multicolumn{5}{|c|}{ Supplemental Table S2.txt } \\
\hline & 1641660 & 6.0 & 7.1564 & TRN & \\
\hline CHEMBL3927534 & 1641660 & 7.5977 & 6.4648 & TST & \\
\hline CHEMBL3984288 & 1641660 & 6.6946 & 7.1373 & TRN & \\
\hline CHEMBL3971172 & 1641660 & 6.0 & 7.2739 & TRN & \\
\hline CHEMBL3921753 & 1641660 & 7.3215 & 7.5007 & TRN & \\
\hline CHEMBL3958643 & 1641660 & 7.4584 & 7.2776 & TRN & \\
\hline CHEMBL3914367 & 1641660 & 6.0 & 6.4919 & TRN & \\
\hline CHEMBL3895402 & 1641660 & 8.1273 & 6.7321 & TRN & \\
\hline CHEMBL3975626 & 1641660 & 6.0 & 6.8053 & TRN & \\
\hline CHEMBL3894182 & 1641660 & 8.8447 & 7.5321 & TST & \\
\hline CHEMBL3929284 & 1641660 & 7.4318 & 7.6961 & TRN & \\
\hline CHEMBL3913260 & 1641660 & 7.6192 & 6.1241 & TST & \\
\hline CHEMBL3942722 & 1641660 & 4.301 & 6.9974 & TST & \\
\hline CHEMBL3975560 & 1641660 & 6.6716 & 6.272 & TRN & \\
\hline CHEMBL3914199 & 1641660 & 7.6737 & 8.0479 & TRN & \\
\hline CHEMBL3986349 & 1641660 & 6.0 & 6.16200 & 0000000001 & TRN \\
\hline CHEMBL3967771 & 1641660 & 6.063 & 6.8818 & TRN & \\
\hline CHEMBL3901257 & 1641660 & 6.0953 & 6.8857 & TRN & \\
\hline CHEMBL3927356 & 1641660 & 7.2628 & 6.6425 & TRN & \\
\hline CHEMBL3905222 & 1641660 & 7.8477 & 7.8321 & TRN & \\
\hline CHEMBL3911502 & 1641660 & 7.2064 & 7.4288 & TRN & \\
\hline CHEMBL 3942351 & 1641660 & 7.1681 & 6.4646 & TRN & \\
\hline CHEMBL3970377 & 1641660 & 8.0315 & 7.7392 & TRN & \\
\hline CHEMBL 3985674 & 1641660 & 6.5575 & 7.2345 & TRN & \\
\hline CHEMBL3969737 & 1641660 & 7.4112 & 7.1215 & TRN & \\
\hline CHEMBL3954181 & 1641660 & 7.6576 & 7.21700 & 00000000005 & TST \\
\hline CHEMBL3978099 & 1641660 & 7.9101 & 7.8722 & TRN & \\
\hline CHEMBL3978118 & 1641660 & 7.4202 & 7.6199 & TRN & \\
\hline CHEMBL3910479 & 1641660 & 7.6596 & 7.1953 & TRN & \\
\hline CHEMBL3947946 & 1641660 & 6.0 & 6.731 & TRN & \\
\hline CHEMBL3915172 & 1641660 & 8.9914 & 7.7795 & TST & \\
\hline CHEMBL3955011 & 1641660 & 6.9772 & 6.364 & TRN & \\
\hline CHEMBL3956433 & 1641660 & 6.5735 & 6.2994 & TRN & \\
\hline CHEMBL3901944 & 1641660 & 7.1244 & 7.3206 & TRN & \\
\hline CHEMBL3960566 & 1641660 & 7.6055 & 6.8858 & TRN & \\
\hline CHEMBL3984672 & 1641660 & 7.4306 & 7.1394 & TRN & \\
\hline CHEMBL3928677 & 1641660 & 6.4855 & 6.4566 & TST & \\
\hline CHEMBL3969108 & 1641660 & 6.9355 & 7.1686 & TST & \\
\hline CHEMBL 3976084 & 1641660 & 7.7033 & 6.7203 & TRN & \\
\hline CHEMBL3935216 & 1641660 & 6.0 & 7.0501 & TRN & \\
\hline CHEMBL3901470 & 1641660 & 6.0 & 6.756 & TRN & \\
\hline CHEMBL3963864 & 1641660 & 6.6696 & 7.5377 & TST & \\
\hline CHEMBL3903432 & 1641660 & 6.7077 & 7.4519 & TRN & \\
\hline CHEMBL3909333 & 1641660 & 8.1759 & 8.2238 & TRN & \\
\hline CHEMBL3963305 & 1641660 & 6.3563 & 6.2098 & TST & \\
\hline CHEMBL3897605 & 1641660 & 8.4921 & 8.4759 & TRN & \\
\hline CHEMBL3983172 & 1641660 & 7.644 & 6.9455 & TRN & \\
\hline CHEMBL3917638 & 1641660 & 6.0 & 6.3267 & TRN & \\
\hline
\end{tabular}


Supplemental Table S2.txt

\begin{tabular}{|c|c|c|c|c|}
\hline CHEMBL3900362 & 1641660 & 5.7043 & 6.7002 & TST \\
\hline CHEMBL3961944 & 1641660 & 6.0 & 7.0116 & TRN \\
\hline CHEMBL3954487 & 1641660 & 8.3307 & 7.8385 & TRN \\
\hline CHEMBL3916159 & 1641660 & 6.0 & 6.8967 & TRN \\
\hline CHEMBL3985346 & 1641660 & 8.5768 & 7.7567 & TST \\
\hline CHEMBL3940135 & 1641660 & 7.7471 & 7.4047 & TRN \\
\hline CHEMBL3929818 & 1641660 & 6.8861 & 6.2986 & TRN \\
\hline CHEMBL3958310 & 1641660 & 7.4559 & 7.6759 & TST \\
\hline CHEMBL 3898851 & 1641660 & 8.3179 & 7.2338 & TST \\
\hline CHEMBL3959618 & 1641660 & 6.0 & 6.4674 & TRN \\
\hline CHEMBL3971956 & 1641660 & 6.0 & 6.5854 & TRN \\
\hline CHEMBL3892553 & 1641660 & 6.6556 & 5.8495 & TRN \\
\hline CHEMBL3901023 & 1641660 & 6.0 & 6.6563 & TRN \\
\hline CHEMBL3971130 & 1641660 & 7.1255 & 6.4244 & TST \\
\hline CHEMBL3905943 & 1641660 & 6.6528 & 6.4461 & TST \\
\hline CHEMBL3964727 & 1641660 & 7.0867 & 6.4801 & TRN \\
\hline CHEMBL3950641 & 1641660 & 7.4473 & 7.345 & TRN \\
\hline CHEMBL3967942 & 1641660 & 6.0 & 6.6855 & TRN \\
\hline CHEMBL3978060 & 1641660 & 5.9547 & 6.5685 & TRN \\
\hline CHEMBL3933181 & 1641660 & 7.0052 & 7.0366 & TRN \\
\hline CHEMBL3937886 & 1641660 & 8.0655 & 7.5219 & TRN \\
\hline CHEMBL3953112 & 1641660 & 6.8416 & 6.4911 & TST \\
\hline CHEMBL3918571 & 1641660 & 7.7986 & 7.1222 & TST \\
\hline CHEMBL3975036 & 1641660 & 8.4724 & 6.8158 & TST \\
\hline CHEMBL3978831 & 1641660 & 8.1574 & 8.01700 & 3000000001 \\
\hline CHEMBL3956133 & 1641660 & 7.4202 & 7.3345 & TST \\
\hline CHEMBL3939550 & 1641660 & 6.0 & 6.6133 & TST \\
\hline CHEMBL3956659 & 1641660 & 7.2125 & 6.8546 & TST \\
\hline CHEMBL3954019 & 1641660 & 6.6517 & 6.3329 & TST \\
\hline CHEMBL3947229 & 1641660 & 6.0 & 6.3834 & TST \\
\hline CHEMBL3976789 & 1641660 & 6.0 & 7.2285 & TST \\
\hline CHEMBL3182461 & 1442190 & 6.7212 & 6.6916 & TRN \\
\hline CHEMBL3356521 & 1442190 & 6.9208 & 7.0441 & TRN \\
\hline CHEMBL 3182437 & 1442190 & 7.1192 & 7.0441 & TRN \\
\hline CHEMBL3356103 & 1442190 & 5.3188 & 5.2891 & TRN \\
\hline CHEMBL3187140 & 1442190 & 5.699 & 5.7375 & TRN \\
\hline CHEMBL3356520 & 1442190 & 6.1192 & 6.4359 & TST \\
\hline CHEMBL3356104 & 1442190 & 5.0506 & 5.0159 & TRN \\
\hline CHEMBL3356112 & 1442190 & 5.3098 & 5.3408 & TRN \\
\hline CHEMBL3182817 & 1442190 & 5.0088 & 5.0011 & TRN \\
\hline CHEMBL3182040 & 1442190 & 5.0506 & 5.36100 & 0000000001 \\
\hline CHEMBL3356519 & 1442190 & 7.0 & 7.0441 & TST \\
\hline CHEMBL3181856 & 1442190 & 7.0969 & 6.4661 & TST \\
\hline CHEMBL3183200 & 1442190 & 5.9586 & 5.9542 & TRN \\
\hline CHEMBL3184249 & 1442190 & 5.8861 & 5.9059 & TRN \\
\hline CHEMBL3189120 & 1442190 & 6.9586 & 6.9722 & TRN \\
\hline CHEMBL3184785 & 1442190 & 5.6778 & 5.682 & TRN \\
\hline CHEMBL3187391 & 1442190 & 6.8239 & 6.8179 & TRN \\
\hline
\end{tabular}




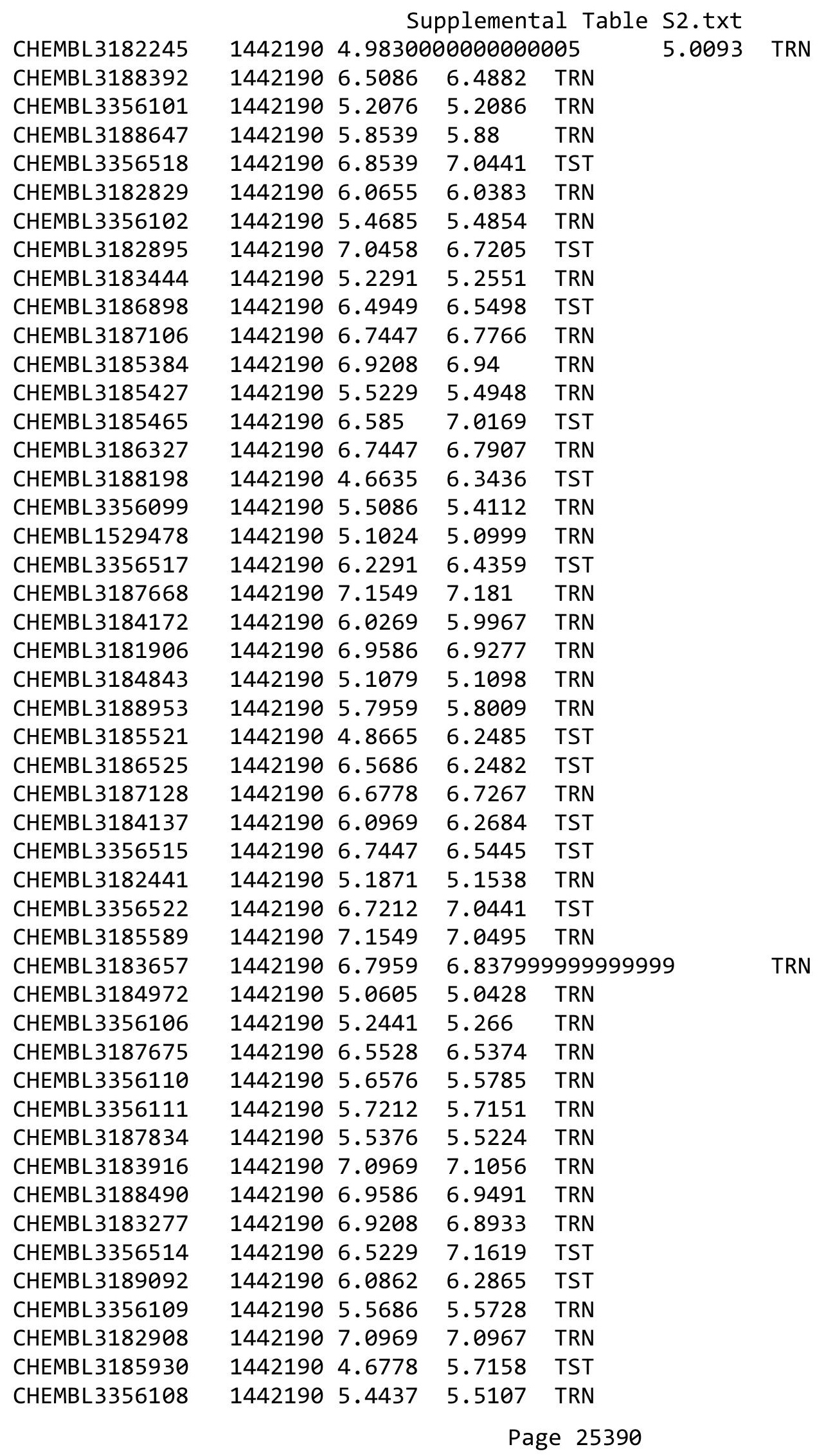


Supplemental Table S2.txt

\begin{tabular}{|c|c|c|c|c|c|c|}
\hline CHEMBL3186151 & 1442190 & 6.8861 & 6.8717 & TRN & & \\
\hline CHEMBL3356098 & 1442190 & 5.2924 & 5.2666 & TRN & & \\
\hline CHEMBL3356107 & 1442190 & 5.4318 & 5.4948 & TRN & & \\
\hline CHEMBL 3356105 & 1442190 & \multicolumn{3}{|c|}{4.9830000000000005} & 5.0351 & TRN \\
\hline CHEMBL 3183116 & 1442190 & 6.1079 & 6.1424 & TRN & & \\
\hline CHEMBL 3184350 & 1442190 & 4.9788 & 4.9719 & TRN & & \\
\hline CHEMBL 3187225 & 1442190 & 6.8539 & 6.1477 & TST & & \\
\hline CHEMBL 3187556 & 1442190 & 5.9586 & 5.9727 & TRN & & \\
\hline CHEMBL 3356100 & 1442190 & 5.0757 & 5.0802 & TRN & & \\
\hline CHEMBL3182033 & 1442190 & 7.301 & 7.2636 & TRN & & \\
\hline CHEMBL 274863 & 124487 & 6.3188 & 7.1492 & TST & & \\
\hline CHEMBL 275798 & 124487 & 7.7212 & 7.2966 & TRN & & \\
\hline CHEMBL13972 & 124487 & \multicolumn{3}{|c|}{6.752000000000001} & 6.6352 & TRN \\
\hline CHEMBL14682 & 124487 & 7.7212 & 7.6239 & TRN & & \\
\hline CHEMBL428877 & 124487 & 8.1308 & 7.7975 & TRN & & \\
\hline CHEMBL 264227 & 124487 & 6.6676 & 6.7043 & TRN & & \\
\hline CHEMBL275200 & 124487 & 7.1024 & 7.0912 & TRN & & \\
\hline CHEMBL 273525 & 124487 & 6.9245 & 7.1123 & TRN & & \\
\hline CHEMBL14763 & 124487 & 7.8539 & 7.7818 & TRN & & \\
\hline CHEMBL14329 & 124487 & 7.8861 & 7.66 & TRN & & \\
\hline CHEMBL 276576 & 124487 & 7.9706 & 7.8887 & TRN & & \\
\hline CHEMBL417804 & 124487 & 7.6021 & 7.8881 & TRN & & \\
\hline CHEMBL13830 & 124487 & 6.3915 & 6.349 & TRN & & \\
\hline CHEMBL 279416 & 124487 & 7.2218 & 7.0924 & TST & & \\
\hline CHEMBL277521 & 124487 & 7.4647 & 7.5702 & TRN & & \\
\hline CHEMBL14187 & 124487 & 7.2218 & 7.2454 & TRN & & \\
\hline CHEMBL14697 & 124487 & 7.1249 & 6.9674 & TRN & & \\
\hline CHEMBL417079 & 124487 & 7.3872 & 7.2507 & TRN & & \\
\hline CHEMBL 276094 & 124487 & 6.7235 & 6.8226 & TRN & & \\
\hline CHEMBL13836 & 124487 & 7.8239 & 7.7991 & TRN & & \\
\hline CHEMBL14014 & 124487 & 7.0223 & 7.1938 & TRN & & \\
\hline CHEMBL10 & 124487 & 7.3188 & 6.8389 & TST & & \\
\hline CHEMBL 275724 & 124487 & 7.0472 & 7.1615 & TRN & & \\
\hline CHEMBL13868 & 124487 & 6.8861 & 7.2155 & TRN & & \\
\hline CHEMBL 268946 & 124487 & 7.2518 & 7.2543 & TRN & & \\
\hline CHEMBL 274064 & 124487 & 7.699 & 7.3855 & TST & & \\
\hline CHEMBL 269450 & 124487 & 6.5229 & 7.1716 & TRN & & \\
\hline CHEMBL 275271 & 124487 & 6.7825 & 6.629 & TRN & & \\
\hline CHEMBL14112 & 124487 & 5.8861 & 6.9214 & TST & & \\
\hline CHEMBL14300 & 124487 & 7.7282 & 7.7291 & TRN & & \\
\hline CHEMBL 273611 & 124487 & 7.6383 & 7.5935 & TRN & & \\
\hline CHEMBL418348 & 124487 & 6.1871 & 5.9171 & TRN & & \\
\hline CHEMBL 273432 & 124487 & 8.1805 & 8.1857 & TRN & & \\
\hline CHEMBL14252 & 124487 & 6.2226 & 6.136 & TRN & & \\
\hline CHEMBL14565 & 124487 & 6.8729 & 6.8753 & TRN & & \\
\hline CHEMBL417255 & 124487 & 7.3872 & 7.4013 & TRN & & \\
\hline CHEMBL14026 & 124487 & 7.0685 & 7.1499 & TRN & & \\
\hline CHEMBL14339 & 124487 & 6.6799 & 6.9051 & TRN & & \\
\hline
\end{tabular}




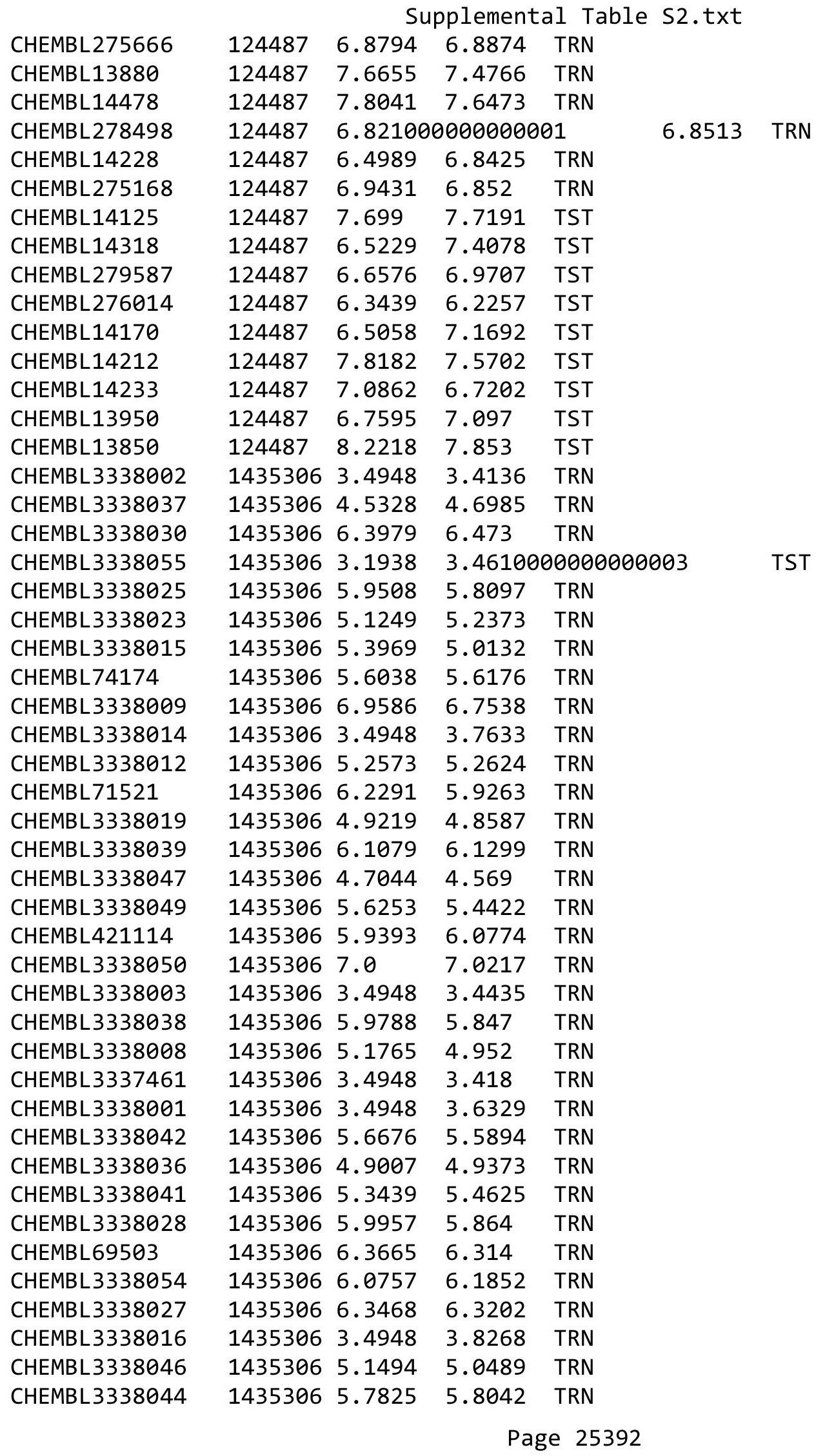


Supplemental Table S2.txt

\begin{tabular}{|c|c|c|c|c|c|}
\hline CHEMBL3338020 & 1435306 & 5.4935 & 5.7042 & TRN & \\
\hline CHEMBL3338010 & 1435306 & 5.5287 & 5.9926 & TRN & \\
\hline CHEMBL3338026 & 1435306 & 5.8386 & 5.849 & TRN & \\
\hline CHEMBL3338011 & 1435306 & 3.4948 & 3.5403 & TRN & \\
\hline CHEMBL3338005 & 1435306 & 4.4145 & 4.5355 & TST & \\
\hline CHEMBL3338004 & 1435306 & 3.4948 & 3.3951 & TRN & \\
\hline CHEMBL 71728 & 1435306 & 5.0964 & 5.1176 & TRN & \\
\hline CHEMBL3338029 & 1435306 & 5.6882 & 5.6936 & TRN & \\
\hline CHEMBL3338021 & 1435306 & 4.5112 & 4.5904 & TRN & \\
\hline CHEMBL3338045 & 1435306 & 5.8356 & 5.8256 & TRN & \\
\hline CHEMBL3338031 & 1435306 & 4.9516 & 5.0376 & TRN & \\
\hline CHEMBL3338013 & 1435306 & 5.6198 & 5.536000 & 00000000005 & TRN \\
\hline CHEMBL3338033 & 1435306 & 5.9136 & 5.885 & TRN & \\
\hline CHEMBL3338048 & 1435306 & 4.6696 & 4.8908 & TRN & \\
\hline CHEMBL3338024 & 1435306 & 5.4101 & 5.3816 & TRN & \\
\hline CHEMBL3338032 & 1435306 & 6.4318 & 6.5628 & TRN & \\
\hline CHEMBL3337998 & 1435306 & 5.4157 & 4.5167 & TST & \\
\hline CHEMBL3338040 & 1435306 & 5.0706 & 5.2626 & TRN & \\
\hline CHEMBL3338017 & 1435306 & 4.8771 & 4.3781 & TRN & \\
\hline CHEMBL 71659 & 1435306 & 6.3372 & 6.3554 & TRN & \\
\hline CHEMBL578061 & 1435306 & 5.5969 & 4.1173 & TST & \\
\hline CHEMBL54893 & 1435306 & 4.4145 & 3.7913 & TST & \\
\hline CHEMBL3338051 & 1435306 & 5.7144 & 5.77 & TRN & \\
\hline CHEMBL3338053 & 1435306 & 6.6198 & 6.7233 & TST & \\
\hline CHEMBL470025 & 1435306 & 7.0969 & 6.7744 & TST & \\
\hline CHEMBL3338007 & 1435306 & 6.2366 & 4.8989 & TST & \\
\hline CHEMBL3338052 & 1435306 & 6.1487 & 5.8269 & TST & \\
\hline CHEMBL3338000 & 1435306 & 4.4004 & 2.8953 & TST & \\
\hline CHEMBL3338022 & 1435306 & 5.0615 & 5.4052 & TST & \\
\hline CHEMBL3338035 & 1435306 & 5.2351 & 4.519 & TST & \\
\hline CHEMBL3338018 & 1435306 & 5.5467 & 5.3225 & TST & \\
\hline CHEMBL3337999 & 1435306 & 5.3979 & 2.7991 & TST & \\
\hline CHEMBL3338034 & 1435306 & 6.0862 & 6.3584 & TST & \\
\hline CHEMBL3338006 & 1435306 & 3.1938 & 3.0412 & TST & \\
\hline CHEMBL3338043 & 1435306 & 5.6757 & 5.0494 & TST & \\
\hline CHEMBL302791 & 1435306 & 6.4559 & 5.5295 & TST & \\
\hline CHEMBL1307177 & 1301771 & 4.9706 & 4.9688 & TRN & \\
\hline CHEMBL1543453 & 1301771 & 5.4634 & 5.2995 & TRN & \\
\hline CHEMBL1340186 & 1301771 & 4.8598 & 5.1093 & TRN & \\
\hline CHEMBL 1458782 & 1301771 & 5.3298 & 5.4602 & TRN & \\
\hline CHEMBL1567488 & 1301771 & 5.2823 & 5.2184 & TST & \\
\hline CHEMBL1352969 & 1301771 & 4.3056 & 5.3424 & TRN & \\
\hline CHEMBL1358447 & 1301771 & 5.5834 & 5.2021 & TRN & \\
\hline CHEMBL1535665 & 1301771 & 5.7055 & 5.6555 & TRN & \\
\hline CHEMBL1501495 & 1301771 & 5.3316 & 5.1333 & TRN & \\
\hline CHEMBL1555449 & 1301771 & 4.909 & 5.1406 & TST & \\
\hline CHEMBL1527502 & 1301771 & 5.45100 & 000000000 & 5.2607 & RI \\
\hline CHEMBL1490987 & 1301771 & 5.6882 & 5.7964 & TRN & \\
\hline
\end{tabular}


Supplemental Table S2.txt

\begin{tabular}{|c|c|c|c|c|}
\hline ILT & 301771 & 5.2104 & & \\
\hline & 301771 & 5.3645 & & \\
\hline FM & 01771 & & & \\
\hline IEMBL1 & 771 & 285 & 569 & \\
\hline AEMBL1461730 & 301771 & 5784 & & \\
\hline HEMBL1327783 & 301771 & 5.6144 & & \\
\hline 8765 & 301771 & 449 & & \\
\hline AEMBL1 & 771 & 161 & & \\
\hline HEMBL47940 & 301771 & 5.3161 & & \\
\hline HEMBL1310852 & 301771 & 5.3161 & & \\
\hline HEMBL1 & 71 & & & \\
\hline AEMBL2 & 71 & 28 & & \\
\hline AEMBL1 & & & & \\
\hline HEMBL1886345 & 301771 & 305 & & \\
\hline AEMBL1 & 71 & & & \\
\hline AEMBL1 & 1 & & & RIN \\
\hline AEMBL] & 61 & & & (1) \\
\hline HEMBL1 & 71 & 696 & & \\
\hline HEMBL1 & 771 & 6 . & & \\
\hline AEMBL1 & & 023 & & KIN \\
\hline HEMBL: & $\perp$ & & & ГRN \\
\hline HEM & 71 & & & RN \\
\hline AEMBL & 71 & & & BN \\
\hline HEMBLI & & & & TRN \\
\hline AEMBL 2 & & 63 & & RN \\
\hline HEMBL1 & 71 & 23 & & RN \\
\hline HEMBL & 71 & & & RN \\
\hline 48 & & & & RN \\
\hline AEMBLI & & & & $1 \mathrm{~K}$ \\
\hline AEMBL1 & 771 & 86 & & TRN \\
\hline HEMBL1 & 71 & 04 & & RN \\
\hline 8 & 71 & & & 「RN \\
\hline 594 & & & & 「RN \\
\hline HEMBL1 & 1 & & & 「RN \\
\hline HEMBL1 & 771 & 68 & & RN \\
\hline 071 & 71 & & & TRN \\
\hline 5 & & & & ГRN \\
\hline HEMBL1 & & & & TRN \\
\hline HEMBL1 & 71 & 68 & & $\Gamma R$ \\
\hline LTIL & 1 & & & N \\
\hline HEMBL1 & 61 & & & TRN \\
\hline & & & & 「RN \\
\hline HEMBL1 & 771 & 5.7747 & & {$[R$} \\
\hline HEMBL1 & 71 & & & TR \\
\hline 22 & & & & \\
\hline HEMBL1 & 130 & & & \\
\hline HEMBL1 & 1301771 & 83 & 548 & \\
\hline CHEMBL1384550 & 1301771 & 5.0975 & 5.4324 & \\
\hline
\end{tabular}

Page 25394 
Supplemental Table S2.txt

\begin{tabular}{|c|c|c|c|c|c|c|}
\hline CHEMBL1401779 & 1301771 & 4.7607 & 5.4794 & TRN & & \\
\hline CHEMBL1506503 & 1301771 & 7.8697 & 6.5175 & TRN & & \\
\hline CHEMBL1310617 & 1301771 & 5.567 & 5.7611 & TRN & & \\
\hline CHEMBL1335146 & 1301771 & 5.644 & 5.5317 & TRN & & \\
\hline CHEMBL1447350 & 1301771 & 5.2865 & 5.2083 & TRN & & \\
\hline CHEMBL1554436 & 1301771 & 5.5591 & 5.3951 & TRN & & \\
\hline CHEMBL1518163 & 1301771 & 4.4983 & 5.1626 & TRN & & \\
\hline CHEMBL1526446 & 1301771 & 5.6799 & 5.3601 & TRN & & \\
\hline CHEMBL1353317 & 1301771 & 5.8894 & 5.5578 & TRN & & \\
\hline CHEMBL1985527 & 1301771 & 6.1726 & 6.0108 & TRN & & \\
\hline CHEMBL1308223 & 1301771 & 5.8665 & 5.8131 & TRN & & \\
\hline CHEMBL1553183 & 1301771 & 5.2351 & 6.1698 & TST & & \\
\hline CHEMBL1472681 & 1301771 & 5.2692 & 5.435 & TRN & & \\
\hline CHEMBL1351584 & 1301771 & 5.301 & 5.5777 & TRN & & \\
\hline CHEMBL1510261 & 1301771 & 5.4711 & 5.4286 & TRN & & \\
\hline CHEMBL1995375 & 1301771 & 5.2815 & 5.8354 & TRN & & \\
\hline CHEMBL1387462 & 1301771 & 5.8125 & 5.8036 & TRN & & \\
\hline CHEMBL1392142 & 1301771 & 7.8697 & 7.2819 & TRN & & \\
\hline CHEMBL1478220 & 1301771 & 5.6716 & 5.5319 & TRN & & \\
\hline CHEMBL1425438 & 1301771 & 5.8297 & 5.5831 & TRN & & \\
\hline CHEMBL1468075 & 1301771 & 5.9914 & 5.7388 & TRN & & \\
\hline CHEMBL1509727 & 1301771 & 5.6882 & 5.2076 & TRN & & \\
\hline CHEMBL1570216 & 1301771 & 5.3242 & 5.4243 & TRN & & \\
\hline CHEMBL1482188 & 1301771 & 5.6635 & 5.3869 & TRN & & \\
\hline CHEMBL1464730 & 1301771 & 5.6517 & 5.6592 & TRN & & \\
\hline CHEMBL1566487 & 1301771 & 5.9281 & 5.3979 & TRN & & \\
\hline CHEMBL1354881 & 1301771 & 4.6457 & 4.9343 & TRN & & \\
\hline CHEMBL1392611 & 1301771 & \multicolumn{3}{|c|}{5.752000000000001} & 6.0765 & TRN \\
\hline CHEMBL1876267 & 1301771 & 5.4012 & 5.261 & TST & & \\
\hline CHEMBL1609580 & 1301771 & 5.5768 & 5.534 & TST & & \\
\hline CHEMBL1707874 & 1301771 & 5.3675 & \multicolumn{3}{|c|}{5.497000000000001} & TST \\
\hline CHEMBL1301851 & 1301771 & 5.4486 & 5.3303 & TST & & \\
\hline CHEMBL1521492 & 1301771 & 5.6038 & 5.795 & TST & & \\
\hline CHEMBL1582580 & 1301771 & 5.5768 & 5.5645 & TST & & \\
\hline CHEMBL1300295 & 1301771 & 5.5952 & 5.6404 & TST & & \\
\hline CHEMBL1353194 & 1301771 & 5.2967 & 5.4137 & TST & & \\
\hline CHEMBL1611162 & 1301771 & 5.1844 & 4.9228 & TST & & \\
\hline CHEMBL2005493 & 1301771 & 5.3565 & 5.2351 & TST & & \\
\hline CHEMBL1440422 & 1301771 & 5.1118 & 5.4261 & TST & & \\
\hline CHEMBL1312083 & 1301771 & 5.585 & 5.4433 & TST & & \\
\hline CHEMBL1605956 & 1301771 & 5.433 & 5.3154 & TST & & \\
\hline CHEMBL1358184 & 1301771 & 5.4168 & 5.1678 & TST & & \\
\hline CHEMBL1882193 & 1301771 & 5.5229 & 5.3687 & TST & & \\
\hline CHEMBL1607435 & 1301771 & \multicolumn{3}{|c|}{5.0680000000000005} & 4.8654 & TST \\
\hline CHEMBL1569501 & 1301771 & 5.2299 & 5.1671 & TST & & \\
\hline CHEMBL1301232 & 1301771 & 5.3958 & 5.1324 & TST & & \\
\hline CHEMBL1315469 & 1301771 & 5.6778 & 5.5983 & TST & & \\
\hline CHEMBL1443900 & 1301771 & 6.3251 & 6.0932 & TST & & \\
\hline
\end{tabular}

Page 25395 
Supplemental Table S2.txt

\begin{tabular}{|c|c|c|c|c|}
\hline CHEMBL1420175 & 1301771 & 5.585 & 5.4304 & TST \\
\hline CHEMBL8739 & 688255 & 4.1 & 4.1074 & TRN \\
\hline CHEMBL1517425 & 88255 & 4.0 & 3.9519 & TRN \\
\hline HEMBL334255 & 688255 & 4.4 & 4.6303 & $\mathrm{RN}$ \\
\hline CHEMBL 1142 & 88255 & 4.1 & 4.376 & RN \\
\hline CHEMBL1612246 & 588255 & 4.3 & 4.277 & TRN \\
\hline HEMBL1549844 & 88255 & 4.4 & 4.5235 & TRN \\
\hline HEMBL1524617 & 688255 & 5.0 & 5.3689 & IST \\
\hline HEMBL1451833 & 688255 & 4.3 & 4.9813 & ST \\
\hline CHEMBL1449018 & 688255 & 4.3 & 4.4447 & TRN \\
\hline CHEMBL1535689 & 688255 & 4.4 & 4.7854 & TRN \\
\hline HEMBL1530684 & 88255 & 4.3 & 3.8764 & RN \\
\hline CHEMBL1407826 & 688255 & 4.4 & 4.888 & ST \\
\hline CHEMBL1595914 & 688255 & 9.5229 & 5.4476 & TRN \\
\hline CHEMBL1569493 & 688255 & 5.6 & 6.0901 & RN \\
\hline CHEMBL1565705 & 688255 & 4.3 & 5.1833 & TRN \\
\hline CHEMBL1430204 & 588255 & 4.3 & 5.0478 & RN \\
\hline CHEMBL 1476371 & 688255 & 4.4 & 4.1858 & $\mathrm{RN}$ \\
\hline CHEMBL1496957 & 688255 & 4.5 & 4.5829 & $\mathrm{RN}$ \\
\hline CHEMBL1569226 & 688255 & 5.1 & 4.9095 & RN \\
\hline CHEMBL1487011 & 688255 & 5 . & 5.3978 & TRN \\
\hline CHEMBL1409985 & 688255 & 5 & 5.1511 & $\mathrm{RN}$ \\
\hline CHEMBL 1448387 & 688255 & 4.3 & 4.7276 & TRN \\
\hline CHEMBL195953 & 688255 & 4.3 & 3.827 & TST \\
\hline CHEMBL1492104 & 588255 & 4.4 & 5.1857 & TST \\
\hline CHEMBL82492 & 688255 & 9. & 6.1788 & TRN \\
\hline CHEMBL338686 & 688255 & 6.7 & 4.7938 & TRN \\
\hline CHEMBL162598 & 688255 & 4.3 & 6.6359 & TST \\
\hline CHEMBL1499545 & 688255 & 4.9 & 5.3151 & TRN \\
\hline CHEMBL1566504 & 688255 & 4.1 & 4.3344 & TST \\
\hline CHEMBL1562104 & 688255 & 5 . & 5.3713 & TRN \\
\hline CHEMBL15 & 688255 & 6.5 & 6.644 & TRN \\
\hline CHEMBL1580759 & 688255 & 4.2 & 4.7647 & TRN \\
\hline CHEMBL1366408 & 688255 & 4.3 & 4.8564 & TRN \\
\hline CHEMBL39763 & 688255 & 4.3 & 4.8475 & TRN \\
\hline CHEMBL15 & 688255 & 4. & 4.7216 & TRN \\
\hline CHEMBL13 & 688255 & 5.0 & 5.1349 & TRN \\
\hline CHEMBL1559341 & 688255 & 4.4 & 4.2881 & TRN \\
\hline CHEMBL1450607 & 688255 & 4.5 & 4.3116 & TST \\
\hline CHEMBL1492729 & 688255 & 4.6 & 4.5829 & TRN \\
\hline CHEMBL1558796 & 688255 & 4.1 & 4.2467 & TRN \\
\hline CHEMBL1200471 & 688255 & 6.5 & 7.1341 & TRN \\
\hline CHEMBL402063 & 688255 & 4.3 & 4.9734 & TST \\
\hline CHEMBL443949 & 688255 & 4.1 & 4.345 & TRN \\
\hline CHEMBL1600998 & 688255 & 5.0 & 5.5641 & TRN \\
\hline CHEMBL1526319 & 688255 & 4.4 & 4.0963 & I KIV \\
\hline CHEMBL509531 & 688255 & 4.6 & 5.1212 & | \\
\hline CHEMBL36296 & 688255 & 4.3 & 4.3157 & RN \\
\hline
\end{tabular}

Page 25396 


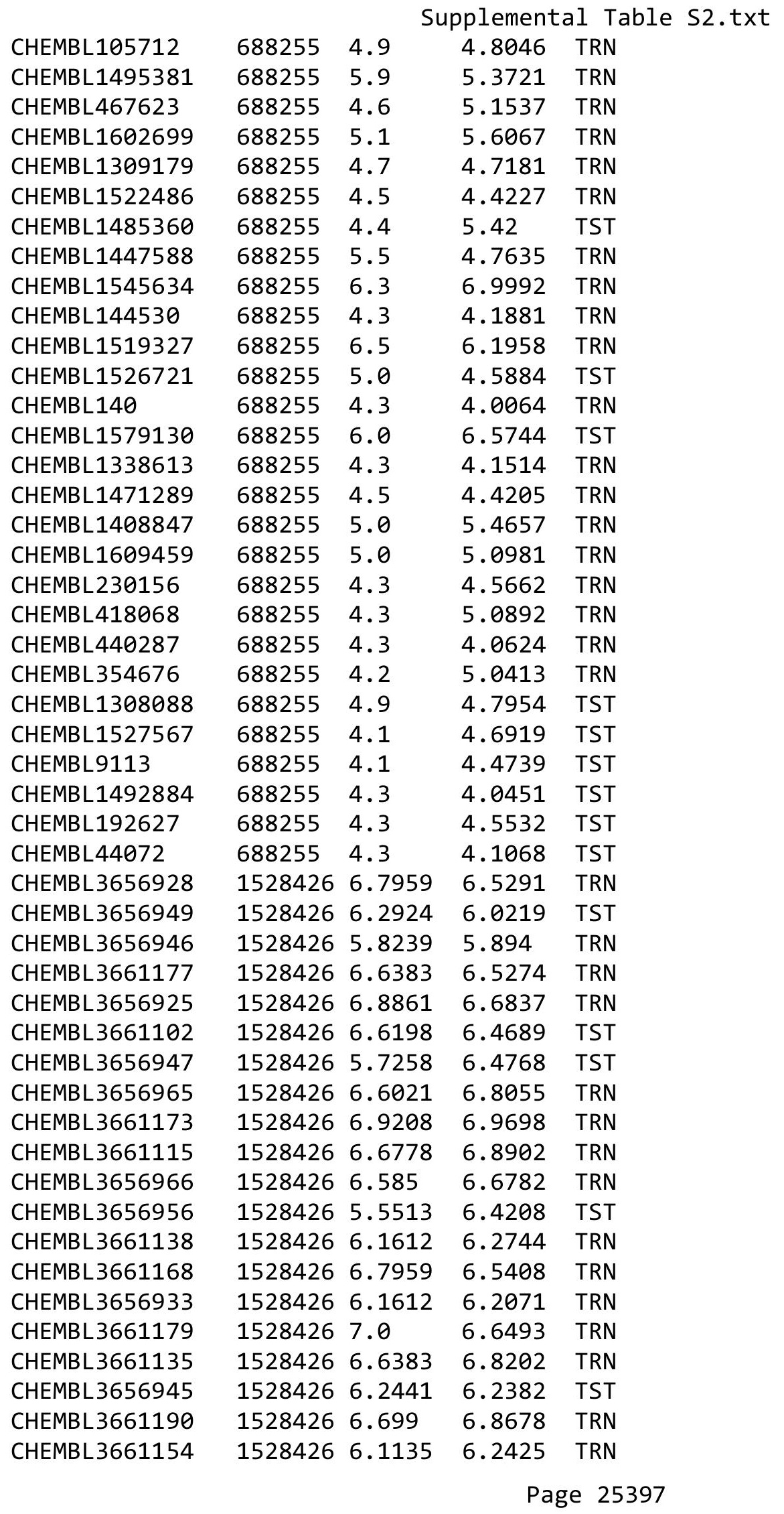


Supplemental Table S2.txt

\begin{tabular}{|c|c|c|c|c|}
\hline CHEMBL3661152 & 1528426 & 6.3768 & 6.5857 & TRN \\
\hline CHEMBL3656941 & 1528426 & 6.3979 & 6.3615 & TST \\
\hline CHEMBL 3661188 & 1528426 & 6.7212 & \multicolumn{2}{|c|}{6.7989999999999995} \\
\hline CHEMBL 3661175 & 1528426 & 7.0 & \multicolumn{2}{|c|}{6.867999999999999} \\
\hline CHEMBL 3661106 & 1528426 & 6.6383 & 6.5232 & TRN \\
\hline CHEMBL3661123 & 1528426 & 6.7212 & 6.5647 & TRN \\
\hline CHEMBL3656971 & 1528426 & 6.7447 & 6.5115 & TST \\
\hline CHEMBL 3656940 & 1528426 & 6.6198 & 6.3109 & TST \\
\hline CHEMBL3661195 & 1528426 & 3.0 & 6.3843 & TST \\
\hline CHEMBL 3656924 & 1528426 & 6.9208 & \multicolumn{2}{|c|}{6.707000000000001} \\
\hline CHEMBL3661103 & 1528426 & 6.8539 & 6.2994 & TST \\
\hline CHEMBL3661189 & 1528426 & 6.8539 & 6.6221 & TRN \\
\hline CHEMBL3661149 & 1528426 & 6.3872 & 6.4745 & TRN \\
\hline CHEMBL 3656967 & 1528426 & 6.2291 & 6.7191 & TST \\
\hline CHEMBL3661165 & 1528426 & 6.8861 & 6.6396 & TRN \\
\hline CHEMBL3661161 & 1528426 & 6.8861 & 6.4148 & TRN \\
\hline CHEMBL3661127 & 1528426 & 6.7959 & 6.5764 & TRN \\
\hline CHEMBL3661159 & 1528426 & 6.1805 & 5.8913 & TRN \\
\hline CHEMBL3656974 & 1528426 & 6.3279 & 6.349 & TST \\
\hline CHEMBL3661126 & 1528426 & 6.3098 & 6.3461 & TRN \\
\hline CHEMBL3656953 & 1528426 & 7.0458 & 6.9014 & TRN \\
\hline CHEMBL3661116 & 1528426 & 6.9208 & 6.9381 & TRN \\
\hline CHEMBL3656936 & 1528426 & 6.7447 & 6.3888 & TST \\
\hline CHEMBL3661114 & 1528426 & 6.6576 & 6.7442 & TRN \\
\hline CHEMBL3661163 & 1528426 & 6.9586 & 6.9807 & TRN \\
\hline CHEMBL3661109 & 1528426 & 6.3279 & 6.7051 & TST \\
\hline CHEMBL3661155 & 1528426 & 6.0915 & 6.0825 & TRN \\
\hline CHEMBL3661200 & 1528426 & 3.0 & 5.8854 & TST \\
\hline CHEMBL 3661128 & 1528426 & 6.6778 & 6.5414 & TRN \\
\hline CHEMBL3661133 & 1528426 & 6.4559 & 6.4256 & TRN \\
\hline CHEMBL3661139 & 1528426 & 6.1549 & 6.4252 & TRN \\
\hline CHEMBL3656970 & 1528426 & 6.7212 & 6.5528 & TRN \\
\hline CHEMBL3656948 & 1528426 & 6.6021 & 6.4923 & TRN \\
\hline CHEMBL3661172 & 1528426 & 6.9586 & 6.7747 & TRN \\
\hline CHEMBL3661156 & 1528426 & 6.3979 & 6.3317 & TST \\
\hline CHEMBL3661181 & 1528426 & 6.9208 & 6.9576 & TRN \\
\hline CHEMBL3661171 & 1528426 & 7.0 & 7.0373 & TRN \\
\hline CHEMBL3661178 & 1528426 & 6.6778 & 6.7241 & TRN \\
\hline CHEMBL3661137 & 1528426 & 6.5376 & 6.5045 & TRN \\
\hline CHEMBL3661125 & 1528426 & 6.585 & 6.4528 & TRN \\
\hline CHEMBL3656973 & 1528426 & 6.6021 & 6.4767 & TRN \\
\hline CHEMBL3661187 & 1528426 & 6.4202 & 6.3937 & TRN \\
\hline CHEMBL3661160 & 1528426 & 5.9957 & 5.8274 & TRN \\
\hline CHEMBL3661153 & 1528426 & 6.2007 & 6.05 & TRN \\
\hline CHEMBL3661129 & 1528426 & 6.699 & 6.8108 & TRN \\
\hline CHEMBL3661147 & 1528426 & 6.2441 & 6.4133 & TRN \\
\hline CHEMBL3661196 & 1528426 & 3.0 & 6.5589 & TST \\
\hline CHEMBL3661119 & 1528426 & 6.4685 & 6.5302 & TRN \\
\hline
\end{tabular}

Page 25398 
Supplemental Table S2.txt

\begin{tabular}{|c|c|c|c|c|}
\hline 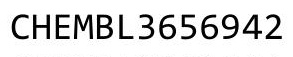 & & & & \\
\hline HEMBL3661144 & 528426 & 6.8861 & 765 & \\
\hline HEMBL3 & 528426 & 6.7212 & 7436 & \\
\hline 952 & 426 & 7.0 & 9136 & \\
\hline 186 & 28426 & 6.2757 & 993 & \\
\hline HEMBL3661182 & 528426 & 6.4949 & 6922 & \\
\hline HEMBL3661104 & 528426 & 6.1675 & .5149 & \\
\hline HEMBL3661118 & 528426 & 6.8539 & 8748 & \\
\hline 958 & 528426 & 3633 & 2491 & \\
\hline IEMBL & 528426 & 6.9586 & 944 & \\
\hline HEMBL3661167 & 528426 & 6.6778 & 8135 & \\
\hline HEMBL3656943 & 528426 & 6.4815 & .4877 & \\
\hline HEMBL3661180 & $2<0$ & 706 & 7366 & \\
\hline 193 & 528426 & 969 & 2962 & \\
\hline 131 & 528426 & 447 & 9373 & \\
\hline HEMBL3661150 & 528426 & 6.9208 & 6.7723 & \\
\hline HEMBL3661151 & 528426 & 6.7696 & 6.5982 & \\
\hline HEMBL36 & $5<8<4$ & 086 & 5.5344 & \\
\hline HEMBL36 & 26 & & 95 & \\
\hline 961 & 26 & 279 & 13 & \\
\hline HEMBL36 & 26 & 79 & & \\
\hline AEMBL3661176 & 26 & 49 & & \\
\hline HEMBL36 & 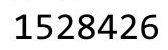 & 83 & & KIN \\
\hline HEMBL; & 26 & & & RN \\
\hline 166 & 26 & 7. & 905 & RN \\
\hline 959 & 26 & 6 & & \\
\hline HEMBL366 & 26 & & 859 & I RN \\
\hline HEMBL36 & 26 & & 76 & $\mathrm{RN}$ \\
\hline 191 & 6 & & & KIV \\
\hline 146 & & 212 & 46 & RN \\
\hline HEMBL36 & 6 & & & IST \\
\hline AEMBL36 & 528426 & 959 & 4166 & TRN \\
\hline HEMBL & & & 53 & Niv \\
\hline 30 & 6 & & & RN \\
\hline HEMBL36 & & & 767 & ST \\
\hline HEMBL3661141 & 528 & & & IRN \\
\hline HEMBL3656944 & 528426 & 431 & 3049 & ST \\
\hline HEMBL36 & 6 & 68 & 849 & $\mathrm{RN}$ \\
\hline 51 & 6 & $\partial 8$ & & RN \\
\hline HEMBL36 & & 7. & 6.5767 & ST \\
\hline HEMBL3656972 & 528426 & & 43 & RN \\
\hline HEMBL36 & 52 & & 286 & RN \\
\hline HEMBL 36 & 528 & 98 & 5375 & \\
\hline HEMBL 36 & & & 2109 & ST \\
\hline HEMBL3656938 & 26 & .6383 & 5.5532 & RN \\
\hline HEMBL3656975 & 528 & 5.9872 & 2001 & ST \\
\hline 34 & & & & \\
\hline תר יחנזי & - ل & & & \\
\hline
\end{tabular}

Page 25399 
Supplemental Table S2.txt

\begin{tabular}{|c|c|c|c|c|}
\hline 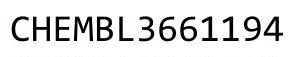 & & 6.2076 & & \\
\hline HEMPI 2661191 & 528426 & 7.0 & 6.4607 & \\
\hline & 26 & 6.0315 & & \\
\hline AEMBL & 28426 & 7.1549 & & \\
\hline HEMBL & 528426 & 6.2147 & 205 & \\
\hline HEMBL3661130 & 528426 & 6.7447 & 8467 & \\
\hline 964 & 26 & 6.6383 & 417 & \\
\hline 50 & & & & 等 \\
\hline HEMBL & 528426 & 6.3098 & 547 & \\
\hline HEMBL3661148 & 528426 & 6.1192 & & \\
\hline AEMBL3661113 & 528426 & 6.8239 & 504 & \\
\hline IEMBL: & 26 & 14 & 861 & \\
\hline AEMBL & & & & \\
\hline HEMBL36 & 528426 & 6.7212 & 389 & \\
\hline AEMBL36 & 26 & 5528 & 883 & \\
\hline AEMBL366 & 528 & 979 & & \\
\hline AEMBL3 & -6 & 6 & 178 & \\
\hline HEMBL3 & 26 & 39 & & \\
\hline HEMBL36 & 528426 & 6. & 529 & \\
\hline IEMBL36 & 26 & & & \\
\hline HEMBL & 6 & 6 & 48 & NIV \\
\hline AEMBL & 26 & & & הות \\
\hline AEMBL & 26 & 18 & 14 & \\
\hline 120 & & & & \\
\hline AEMBL36 & & & & ISI \\
\hline HEMBL; & 6 & 9 & 12 & I RN \\
\hline HEMBL & 6 & 39 & & RN \\
\hline HFMRI & 26 & 86 & 394 & \\
\hline HEMBL3 & & 6 . & & 「RN \\
\hline HEMBL 365 & 26 & 6. & 085 & TRN \\
\hline HEMBL3 & 6 & 35 & & SI \\
\hline HEMBL & 6 & & 31 & RN \\
\hline 64 & 26 & 19 & 29 & RN \\
\hline HEMBL36 & 52 & 861 & 861 & is \\
\hline HEMBL3656935 & 528 & 5.92 & 996 & TRN \\
\hline HEMBL3 & 26 & 9 & 528 & ST \\
\hline HFMDI. & 6 & & 61 & $\Gamma \mathrm{RN}$ \\
\hline HEMBL & 26 & 6.6021 & 038 & IRN \\
\hline HEMBL3661199 & 528426 & & 2304 & TST \\
\hline IEMBL3 & 520 & 5 & 967 & TST \\
\hline HEMBL3 & 0 & 8 & 019 & \\
\hline HEMBL3 & & & 3.1901 & II \\
\hline HEMBL3 & & & .9838 & RN \\
\hline AEMBL3\& & 583242 & 4 & 1016 & TR \\
\hline$-7+3$ & & & 1029 & $\mathrm{~N}$ \\
\hline HEMBL3 & & 832 & 2392 & \\
\hline HEMBL 3 & & 4.3957 & .5545 & \\
\hline HEMBL3814839 & 1583242 & 4.5045 & 4.5069 & RN \\
\hline
\end{tabular}

Page 25400 
Supplemental Table S2.txt

\begin{tabular}{|c|c|c|c|c|c|c|}
\hline CHEMBL3814439 & 1583242 & 5.067 & 4.9857 & TRN & & \\
\hline CHEMBL 3814271 & 1583242 & 3.0 & 3.0855 & TRN & & \\
\hline CHEMBL3814989 & 1583242 & 4.3431 & 4.1438 & TST & & \\
\hline CHEMBL 3814450 & 1583242 & 3.0 & 3.0918 & TRN & & \\
\hline CHEMBL 3814218 & 1583242 & 4.6572 & 4.7064 & TRN & & \\
\hline CHEMBL3815133 & 1583242 & 4.6859 & 4.7073 & TRN & & \\
\hline CHEMBL3814396 & 1583242 & 3.0 & 2.9577 & TRN & & \\
\hline CHEMBL3815019 & 1583242 & 3.0 & 3.057 & TRN & & \\
\hline CHEMBL3814984 & 1583242 & 4.4851 & 4.4025 & TRN & & \\
\hline CHEMBL3815035 & 1583242 & 4.4342 & 4.2259 & TRN & & \\
\hline CHEMBL 3814622 & 1583242 & 4.4532 & 4.4291 & TRN & & \\
\hline CHEMBL3814046 & 1583242 & 4.6878 & 4.8011 & TRN & & \\
\hline CHEMBL3814880 & 1583242 & 5.3605 & 5.1502 & TRN & & \\
\hline CHEMBL 3813951 & 1583242 & 4.4271 & 4.7599 & TRN & & \\
\hline CHEMBL 3813988 & 1583242 & 4.2619 & 4.3849 & TRN & & \\
\hline CHEMBL3815127 & 1583242 & 4.7342 & 4.7173 & TRN & & \\
\hline CHEMBL3814285 & 1583242 & 4.3395 & 4.3883 & TST & & \\
\hline CHEMBL3813765 & 1583242 & 4.7889 & 4.3832 & TRN & & \\
\hline CHEMBL3815047 & 1583242 & 4.0693 & 3.1523 & TST & & \\
\hline CHEMBL 3814886 & 1583242 & 4.7084 & 4.6686 & TRN & & \\
\hline CHEMBL 3813857 & 1583242 & 3.0 & 3.0098 & TRN & & \\
\hline CHEMBL3814952 & 1583242 & 3.0 & 3.0154 & TRN & & \\
\hline CHEMBL3814810 & 1583242 & 4.1584 & 4.2982 & TST & & \\
\hline CHEMBL3814728 & 1583242 & 4.8088 & 4.8399 & TRN & & \\
\hline CHEMBL 3814087 & 1583242 & 3.0 & 3.0215 & TRN & & \\
\hline CHEMBL3813759 & 1583242 & 4.39199 & 99999999 & 995 & 4.4315 & TRN \\
\hline CHEMBL 3814488 & 1583242 & 4.8236 & 4.8352 & TST & & \\
\hline CHEMBL322333 & 1583242 & 4.2962 & 4.9481 & TST & & \\
\hline CHEMBL3813749 & 1583242 & 3.0 & 2.9431 & TRN & & \\
\hline CHEMBL 3813893 & 1583242 & 4.5965 & 4.8219 & TRN & & \\
\hline CHEMBL3814127 & 1583242 & 4.783 & 4.8484 & TST & & \\
\hline CHEMBL3814312 & 1583242 & 3.0 & 3.0041 & TRN & & \\
\hline CHEMBL3814059 & 1583242 & 3.0 & 2.9634 & TRN & & \\
\hline CHEMBL3814912 & 1583242 & 3.0 & 4.1249 & TST & & \\
\hline CHEMBL3813986 & 1583242 & 3.0 & 2.9032 & TRN & & \\
\hline CHEMBL3814091 & 1583242 & 3.0 & 3.0276 & TRN & & \\
\hline CHEMBL 3813800 & 1583242 & 3.0 & 2.9949 & TRN & & \\
\hline CHEMBL3813816 & 1583242 & 3.0 & 2.8981 & TST & & \\
\hline CHEMBL3813737 & 1583242 & 3.0 & 3.0537 & TRN & & \\
\hline CHEMBL 3814697 & 1583242 & 3.0 & 2.9515 & TST & & \\
\hline CHEMBL 3814930 & 1583242 & 4.3392 & 4.3125 & TRN & & \\
\hline CHEMBL3814709 & 1583242 & 4.5569 & 4.6013 & TST & & \\
\hline CHEMBL3814779 & 1583242 & 3.0 & 4.3858 & TST & & \\
\hline CHEMBL3814524 & 1583242 & 3.0 & 2.9452 & TRN & & \\
\hline CHEMBL 3814178 & 1583242 & 3.0 & 2.9807 & TRN & & \\
\hline CHEMBL3639643 & 1527626 & 8.5229 & 8.2038 & TRN & & \\
\hline CHEMBL 3665470 & 1527626 & 8.5229 & 8.3016 & TRN & & \\
\hline CHEMBL3665531 & 1527626 & 8.4089 & 8.03 & TRN & & \\
\hline
\end{tabular}


Supplemental Table S2.txt

\begin{tabular}{|c|c|c|c|c|}
\hline HEMBL & 527626 & & & \\
\hline HГMD & 527626 & 8.5229 & 8.5671 & \\
\hline HIN & 526 & & & \\
\hline HEMBL & 27626 & & & \\
\hline HEMBL3 & 527626 & & & \\
\hline HEMBL3665446 & 527626 & 8.5229 & 3.2243 & \\
\hline HEMBL & 526 & 29 & .6181 & \\
\hline IEMBL: & 626 & & & \\
\hline HEMBL3 & 626 & & 8.536 & \\
\hline HEMBL3660859 & 527626 & & 8.3677 & \\
\hline HEMBL3660807 & 626 & & 8.2243 & \\
\hline AEMBL3 & 26 & 29 & .9334 & \\
\hline AEMBL & & & & \\
\hline HEMBL3 & 526 & 8.52 & 8.5888 & \\
\hline AEMBL36 & 26 & & 53 & \\
\hline AEMBL3660814 & 20 & 8 & 8.5778 & \\
\hline HEMBL3 & $=0$ & & .3675 & \\
\hline HEMBL3 & & & 8.7 & \\
\hline HEMBL3660880 & 26 & & 8.2807 & \\
\hline AEMBL36 & & 9 . & 49 & \\
\hline HEMBL3 & $=0$ & 8 . & 3301 & RIV \\
\hline HEMBL: & & & 93 & +2 \\
\hline HEMBL; & 26 & & 96 & \\
\hline 65469 & & & 8.0612 & \\
\hline AEMBL3665523 & & & 3576 & וכוז \\
\hline HEMBL & 26 & & 13 & IS \\
\hline HEMBL; & & & 23 & \\
\hline HEMBL & 26 & & 23 & RN \\
\hline HEMBL3665491 & & & & I KIV \\
\hline HEMBL 366546 & & & 8.4779 & ISI \\
\hline HEMBL3665508 & 26 & & & RN \\
\hline HEMBL & & & $\partial 1$ & RN \\
\hline HEMBL3 & 26 & & 02 & RN \\
\hline HEMBL3660856 & & & 8.3401 & TST \\
\hline HEMBL3660842 & 26 & & 8.7847 & TRN \\
\hline HEMBL36 & & & 8.3909 & 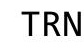 \\
\hline HFMRI: & & & 59 & RIN \\
\hline HEMBL & & & 8.7191 & RN \\
\hline HEMBL3665457 & 26 & 8.699 & 8.7514 & $\Gamma \mathrm{RN}$ \\
\hline AEMBL 366 & 26 & 9 & .5183 & $\Gamma \mathrm{RN}$ \\
\hline HEMBL3660829 & & & .0397 & \\
\hline CHEMBL 3943383 & & & 8.4726 & TST \\
\hline HEMBL3665475 & 626 & & 8.342 & RN \\
\hline HEMBL3660884 & 527626 & 8.699 & 266 & TRN \\
\hline$M B L 3$ & & & 5165 & \\
\hline HEMBL3665510 & & & 8.3259 & \\
\hline CHEMBL3660809 & 527626 & 8.3979 & 8.2808 & \\
\hline HEMBL3660862 & 1527626 & 9.0 & 8.6982 & ГRN \\
\hline
\end{tabular}

Page 25402 
Supplemental Table S2.txt

\begin{tabular}{|c|c|c|c|c|c|}
\hline CHEMBL3660850 & 1527626 & 8.5229 & 8.2258 & TRN & \\
\hline CHEMBL3660845 & 1527626 & 8.699 & 8.5763 & TST & \\
\hline CHEMBL3660885 & 1527626 & 8.5229 & 8.4172 & TRN & \\
\hline CHEMBL3660813 & 1527626 & 9.0 & 8.0981 & TRN & \\
\hline CHEMBL3660867 & 1527626 & 8.699 & 8.5579 & TRN & \\
\hline CHEMBL3660863 & 1527626 & 8.5229 & 8.6444 & TRN & \\
\hline CHEMBL3660846 & 1527626 & 8.699 & 8.703 & TRN & \\
\hline CHEMBL 3660840 & 1527626 & 8.699 & 8.7341 & TRN & \\
\hline CHEMBL 3665500 & 1527626 & 8.3979 & 8.4207 & TRN & \\
\hline CHEMBL3665452 & 1527626 & 8.5229 & 8.196 & TRN & \\
\hline CHEMBL3660883 & 1527626 & 8.699 & 8.6056 & TRN & \\
\hline CHEMBL3665499 & 1527626 & 8.5229 & 8.4458 & TST & \\
\hline CHEMBL3660832 & 1527626 & 8.5229 & 8.9361 & TRN & \\
\hline CHEMBL3948721 & 1527626 & 8.5229 & 8.5181 & TST & \\
\hline CHEMBL3665517 & 1527626 & 8.6576 & 8.43100 & 9000000001 & TRN \\
\hline CHEMBL3660821 & 1527626 & 8.3979 & 8.907 & TRN & \\
\hline CHEMBL3660833 & 1527626 & 8.699 & 8.6051 & TRN & \\
\hline CHEMBL3660828 & 1527626 & 8.301 & 8.7632 & TST & \\
\hline CHEMBL 3660834 & 1527626 & 8.301 & 8.6005 & TRN & \\
\hline CHEMBL3665478 & 1527626 & 8.5229 & 8.2665 & TRN & \\
\hline CHEMBL3660869 & 1527626 & 8.3979 & 9.0831 & TRN & \\
\hline CHEMBL3665506 & 1527626 & 8.3979 & 8.3412 & TRN & \\
\hline CHEMBL3665503 & 1527626 & 8.5229 & 8.3796 & TRN & \\
\hline CHEMBL 3665497 & 1527626 & 8.3979 & 8.5502 & TST & \\
\hline CHEMBL3660830 & 1527626 & 8.699 & 8.4946 & TST & \\
\hline CHEMBL3660806 & 1527626 & 8.699 & 9.1838 & TST & \\
\hline CHEMBL3660836 & 1527626 & 8.3979 & 8.5979 & TRN & \\
\hline CHEMBL3980304 & 1527626 & 6.0 & 8.551 & TST & \\
\hline CHEMBL 3660861 & 1527626 & 8.5229 & 8.5914 & TRN & \\
\hline CHEMBL3665494 & 1527626 & 8.3979 & 8.5916 & TST & \\
\hline CHEMBL3665519 & 1527626 & 8.3098 & 8.3493 & TRN & \\
\hline CHEMBL3660839 & 1527626 & 8.699 & 8.661 & TRN & \\
\hline CHEMBL3660865 & 1527626 & 8.3979 & 8.6386 & TRN & \\
\hline CHEMBL 3665496 & 1527626 & 8.5229 & 8.616 & TST & \\
\hline CHEMBL3665511 & 1527626 & 8.699 & 8.5862 & TRN & \\
\hline CHEMBL3665527 & 1527626 & 6.0 & 8.1569 & TRN & \\
\hline CHEMBL3660882 & 1527626 & 8.699 & 8.2804 & TRN & \\
\hline CHEMBL 3665515 & 1527626 & 8.4815 & 8.4778 & TRN & \\
\hline CHEMBL 3660874 & 1527626 & 8.5229 & 8.6746 & TRN & \\
\hline CHEMBL 3660881 & 1527626 & 8.3979 & 8.2077 & TRN & \\
\hline CHEMBL3660854 & 1527626 & 9.0 & 8.5933 & TRN & \\
\hline CHEMBL3665489 & 1527626 & 8.5229 & 8.3317 & TRN & \\
\hline CHEMBL3660838 & 1527626 & 8.699 & 8.5672 & TRN & \\
\hline CHEMBL 3665455 & 1527626 & 9.0 & 8.5771 & TRN & \\
\hline CHEMBL3665451 & 1527626 & 9.0 & 8.3682 & TRN & \\
\hline CHEMBL3665534 & 1527626 & 8.3979 & 8.3055 & TRN & \\
\hline CHEMBL3665512 & 1527626 & 8.7696 & 8.5848 & TRN & \\
\hline CHEMBL3660871 & 1527626 & 9.0 & 8.7648 & TRN & \\
\hline
\end{tabular}


Supplemental Table S2.txt

\begin{tabular}{|c|c|c|c|c|}
\hline CHEMBL 3660849 & & & 965 & \\
\hline HFMBI 3665595 & 527626 & 8.3979 & 8.338 & \\
\hline HEMBL3665466 & 27626 & 8.699 & & \\
\hline AEMBL3665482 & 527626 & 8.5229 & & \\
\hline HEMBL3665526 & 527626 & 8.1739 & 4916 & \\
\hline HEMBL3665485 & 527626 & 8.699 & 861 & \\
\hline HEMBL366 & 27626 & & & \\
\hline HEMBL3660818 & 527626 & 8.5229 & 338 & \\
\hline HEMBL3665456 & 527626 & 8.699 & 8.6123 & \\
\hline HEMBL3665448 & 527626 & 8.699 & & \\
\hline HEMBL3660870 & 27626 & 8.5229 & 35 & \\
\hline HEMBL366 & 626 & & & \\
\hline HEMBL3665459 & .527626 & 9.0 & & \\
\hline HEMBL3930681 & 527626 & 6.0 & 631 & \\
\hline HEMBL3665453 & 626 & 8.65 & 3891 & \\
\hline HEMBL366 & 26 & 59 & 786 & \\
\hline HEMBL36 & & & & \\
\hline HEMBL3660852 & 526 & 8.699 & 538 & \\
\hline AEMBL3974 & & 76 & & \\
\hline AEMBL3665 & 6 & 8. & 75 & \\
\hline HEMBL36 & 26 & 29 & & \\
\hline HEMBL3 & & & & \\
\hline HEMBL36 & 26 & 9.0 & 45 & \\
\hline HEMBL 366 & & & & \\
\hline HEMBL 3665 & 26 & 8. & 52 & \\
\hline JEMBL366 & 6 & & & \\
\hline HEMBL: & & & & \\
\hline - & & & & \\
\hline AEMBL36 & & & & \\
\hline HEMBL3665507 & 626 & 8. & 671 & \\
\hline HEMBL36 & 526 & 8 . & 825 & \\
\hline HFME & & & & \\
\hline & & & & \\
\hline HEMBL3665484 & & & & \\
\hline HEMBL3660886 & 626 & 8.39 & 453 & \\
\hline HEMBL366 & 26 & 8 . & 67 & \\
\hline & & & & \\
\hline HEMBL3660872 & & 9.0 & & \\
\hline HEMBL3665532 & 26 & 6 . & 157 & \\
\hline EMBL3 & 26 & 8. & 206 & \\
\hline HEMBL 3665521 & 26 & 8.76 & 3.3667 & \\
\hline CHEMBL3660837 & & 9.0 & & \\
\hline CHEMBL3660825 & & 8.65 & 8.9418 & \\
\hline HEMBL3660851 & 26 & & & \\
\hline MRI: & & & 531 & \\
\hline HEMBL3665476 & -807 & 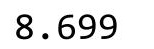 & .5053 & \\
\hline CHEMBL 3660824 & 15276 & 8.5225 & 8.5702 & \\
\hline CHEMBL3660858 & 1527626 & 6.0 & 7.973 & \\
\hline
\end{tabular}

Page 25404 
Supplemental Table S2.txt

\begin{tabular}{|c|c|c|c|c|}
\hline HEMBL3929686 & & 8.699 & 8.8456 & TS \\
\hline HEMRI 3665192 & 527626 & & 8.6663 & \\
\hline HEMBL & 27626 & 3979 & & \\
\hline AEMBL 3665481 & 527626 & 229 & 5066 & \\
\hline HEMBL3660810 & 527626 & 3.699 & 4392 & \\
\hline HEMBL; & 27626 & 599 & 5025 & \\
\hline AEMBL & & & & \\
\hline HEMBL & 626 & 301 & 5244 & \\
\hline HEMBL3660878 & 527626 & .699 & 3607 & \\
\hline HEMBL3660831 & 527626 & 8.5229 & 4606 & \\
\hline AEMBL3 & 626 & 301 & 3049 & \\
\hline HEMBL; & & & 5241 & \\
\hline HEMBL & 626 & 599 & 2179 & \\
\hline AEMBL3 & 626 & 6. & 285 & \\
\hline AEMBL3660826 & 626 & & 138 & \\
\hline AEMBL & 26 & 229 & 984 & \\
\hline AEMBL & & & & \\
\hline AEMBL & 526 & 229 & & \\
\hline AEMBL & 526 & & 694 & \\
\hline AEMBL3660815 & 26 & 229 & 243 & ID \\
\hline IEMBL & 26 & & 73 & RN \\
\hline AEMBL: & & 39 & 29 & NIV \\
\hline HEMBL & & 49 & 028 & \\
\hline AEMBL1 & & & & \\
\hline HEMBL122. & 59 & 8 & 584 & RN \\
\hline AEMBL1 & & & 593 & RN \\
\hline EMBL & & & 75 & RN \\
\hline 8 & & & 529 & \\
\hline AEMBL1 & & & & IRN \\
\hline AEMBL1222222 & 59 & 5.9041 & 064 & RN \\
\hline AEMBL1 & & & 531 & $\mathrm{RN}$ \\
\hline AFM & & & & $\mathrm{RN}$ \\
\hline & & & & RN \\
\hline AEMBL1221792 & & & & 「RN \\
\hline AEMBL1222020 & & & 979 & RN \\
\hline AEMBL1 & & 02 & 232 & RN \\
\hline ל & & & & \\
\hline AEMBL1 & & & & ST \\
\hline AEMBL1221967 & & 69 & 824 & 「RN \\
\hline EMBL1 & & 076 & 791 & R \\
\hline HEMBL1 & & 7.6198 & 94 & \\
\hline HEMBL1 & & & 581 & RN \\
\hline HEMBL1. & & 7.8239 & 8385 & TRN \\
\hline AEMBL12 & 59 & 372 & 23 & TS \\
\hline (1) & & & 527 & \\
\hline HEMBL1221968 & & & 6.3368 & \\
\hline CHEMBL1221629 & & 7.7696 & 7.6765 & \\
\hline CHEMBL1221726 & 651359 & 7.7447 & 7.7822 & \\
\hline
\end{tabular}

Page 25405 


\begin{tabular}{|c|c|c|c|c|c|}
\hline \multirow{3}{*}{$\begin{array}{l}\text { CHEMBL1222018 } \\
\text { CHFMBI } 1221491\end{array}$} & & \multicolumn{4}{|c|}{ Supplemental Table S2.txt } \\
\hline & 651359 & 6.0915 & 6.24799 & 7999999999 & TRN \\
\hline & 651359 & 7.3979 & 7.6286 & TRN & \\
\hline CHEMBL1222019 & 651359 & 6.7167 & 6.5922 & TRN & \\
\hline CHEMBL1222342 & 651359 & 7.3768 & 7.2613 & TST & \\
\hline CHEMBL1222128 & 651359 & 6.8861 & 7.0706 & TRN & \\
\hline CHEMBL1221851 & 651359 & 7.699 & 7.5407 & TRN & \\
\hline CHEMBL1222285 & 651359 & 5.7498 & 5.8066 & TRN & \\
\hline CHEMBL1221537 & 651359 & 7.6198 & 7.1457 & TST & \\
\hline CHEMBL1222286 & 651359 & 6.9066 & 6.3923 & TST & \\
\hline CHEMBL1221674 & 651359 & 8.0 & 7.9353 & TRN & \\
\hline CHEMBL1221580 & 651359 & 7.6576 & 7.4567 & TRN & \\
\hline CHEMBL1221849 & 651359 & 7.9586 & 8.022 & TRN & \\
\hline CHEMBL1222284 & 651359 & 7.5086 & 7.6025 & TRN & \\
\hline CHEMBL1221417 & 651359 & 6.3344 & 6.324 & TRN & \\
\hline CHEMBL1222223 & 651359 & 6.3757 & 6.5118 & TRN & \\
\hline CHEMBL 3979386 & 651359 & 5.5229 & 6.2627 & TST & \\
\hline CHEMBL1221535 & 651359 & 6.9208 & 7.066 & TRN & \\
\hline CHEMBL1221850 & 651359 & 7.3768 & 7.4606 & TRN & \\
\hline CHEMBL1221673 & 651359 & 8.0969 & 8.0915 & TRN & \\
\hline CHEMBL1221791 & 651359 & 7.3372 & 7.3601 & TRN & \\
\hline CHEMBL1221628 & 651359 & 8.0458 & 7.6661 & TST & \\
\hline CHEMBL1222344 & 651359 & 7.3979 & 6.8998 & TST & \\
\hline CHEMBL1221489 & 651359 & 7.6576 & 7.9383 & TST & \\
\hline CHEMBL1221488 & 651359 & 6.6968 & 7.0257 & TST & \\
\hline CHEMBL1221915 & 651359 & 7.8239 & 7.916 & TST & \\
\hline CHEMBL1221914 & 651359 & 7.2596 & 7.2005 & TST & \\
\hline CHEMBL1221675 & 651359 & 7.2676 & 7.3498 & TST & \\
\hline CHEMBL1221579 & 651359 & 7.6198 & 7.6774 & TST & \\
\hline CHEMBL 3695382 & 1528370 & 6.8199 & 6.6019 & TRN & \\
\hline CHEMBL 3695358 & 1528370 & 6.5262 & 6.7988 & TRN & \\
\hline CHEMBL3695391 & 1528370 & 6.3053 & 6.0582 & TRN & \\
\hline CHEMBL 3695423 & 1528370 & 6.7104 & 6.6732 & TST & \\
\hline CHEMBL 3695402 & 1528370 & 6.8611 & 7.4539 & TST & \\
\hline CHEMBL 3695418 & 1528370 & 6.4421 & 6.2614 & TRN & \\
\hline CHEMBL3695361 & 1528370 & 6.1871 & 6.3416 & TRN & \\
\hline CHEMBL3695363 & 1528370 & 6.5913 & 6.6436 & TRN & \\
\hline CHEMBL3695394 & 1528370 & 6.9062 & 6.268 & TST & \\
\hline CHEMBL 3695408 & 1528370 & 6.8551 & 7.0227 & TRN & \\
\hline CHEMBL 3695433 & 1528370 & 6.7066 & 6.7241 & TRN & \\
\hline CHEMBL3695373 & 1528370 & 6.2434 & 6.6991 & TRN & \\
\hline CHEMBL3695359 & 1528370 & 6.2929 & 6.3236 & TRN & \\
\hline CHEMBL3695406 & 1528370 & 6.4288 & 6.1717 & TRN & \\
\hline CHEMBL 3695371 & 1528370 & 6.4627 & 6.7861 & TRN & \\
\hline CHEMBL 3695368 & 1528370 & 6.3781 & 7.0075 & TRN & \\
\hline CHEMBL3695397 & 1528370 & 6.8324 & 6.7698 & TRN & \\
\hline CHEMBL 3695398 & 1528370 & 6.7172 & 6.6373 & TRN & \\
\hline CHEMBL3695399 & 1528370 & 6.0364 & 5.5701 & TRN & \\
\hline CHEMBL 3695362 & 1528370 & 7.0367 & 7.1778 & TRN & \\
\hline
\end{tabular}


Supplemental Table S2.txt

\begin{tabular}{|c|c|c|c|c|c|}
\hline CHEMBL3695415 & 1528370 & 5.9203 & 5.9447 & TRN & \\
\hline CHEMBL3695417 & 1528370 & 6.3939 & 6.7312 & TRN & \\
\hline CHEMBL3695365 & 1528370 & 6.6596 & 6.7823 & TST & \\
\hline CHEMBL3695422 & 1528370 & 5.4285 & 5.7724 & TST & \\
\hline CHEMBL3695379 & 1528370 & 6.8392 & 6.4712 & TRN & \\
\hline CHEMBL3695388 & 1528370 & 7.1325 & 7.1478 & TRN & \\
\hline CHEMBL3695445 & 1528370 & 7.0009 & 6.5718 & TRN & \\
\hline CHEMBL3695387 & 1528370 & 7.1433 & 7.4208 & TRN & \\
\hline CHEMBL3695409 & 1528370 & 5.6435 & 6.0198 & TRN & \\
\hline CHEMBL3695370 & 1528370 & 6.4966 & 6.3763 & TRN & \\
\hline CHEMBL3695427 & 1528370 & 6.5969 & 6.557 & TRN & \\
\hline CHEMBL3695419 & 1528370 & 6.2105 & 6.4084 & TST & \\
\hline CHEMBL3695366 & 1528370 & 6.4613 & 6.7751 & TRN & \\
\hline CHEMBL3695414 & 1528370 & 6.6275 & 6.9573 & TRN & \\
\hline CHEMBL3695354 & 1528370 & 6.7291 & 7.1653 & TST & \\
\hline CHEMBL3695405 & 1528370 & 6.8697 & 6.3552 & TRN & \\
\hline CHEMBL3695381 & 1528370 & 6.5249 & 6.7752 & TRN & \\
\hline CHEMBL3695393 & 1528370 & 6.2495 & 6.4811 & TST & \\
\hline CHEMBL3695401 & 1528370 & 6.4776 & 6.7042 & TST & \\
\hline CHEMBL3695411 & 1528370 & 6.4229 & 5.9929 & TRN & \\
\hline CHEMBL3695404 & 1528370 & 6.6005 & 6.629 & TST & \\
\hline CHEMBL3695432 & 1528370 & 6.0922 & 5.9986 & TRN & \\
\hline CHEMBL3695400 & 1528370 & 6.4839 & 7.1419 & TST & \\
\hline CHEMBL3695426 & 1528370 & 6.706 & 6.3174 & TRN & \\
\hline CHEMBL3695407 & 1528370 & 6.1986 & 5.9916 & TRN & \\
\hline CHEMBL3695367 & 1528370 & 6.1731 & 6.3211 & TRN & \\
\hline CHEMBL3695439 & 1528370 & 6.9266 & 7.0993 & TRN & \\
\hline CHEMBL3695443 & 1528370 & 7.0701 & 6.8842 & TRN & \\
\hline CHEMBL 3695410 & 1528370 & 5.8353 & 5.4576 & TRN & \\
\hline CHEMBL3695372 & 1528370 & 6.2676 & 6.3133 & TST & \\
\hline CHEMBL3695380 & 1528370 & 6.4631 & 6.6569 & TRN & \\
\hline CHEMBL3695357 & 1528370 & 6.66 & 6.7135 & TST & \\
\hline CHEMBL3695364 & 1528370 & 6.8128 & 7.2468 & TST & \\
\hline CHEMBL3695428 & 1528370 & 5.9716 & 6.2285 & TRN & \\
\hline CHEMBL3695376 & 1528370 & 6.5452 & 6.5078 & TRN & \\
\hline CHEMBL3695395 & 1528370 & $6.8210 e$ & 000000000 & 31 & 6.8352 \\
\hline CHEMBL3976966 & 1528370 & 5.4884 & 5.7683 & TST & \\
\hline CHEMBL3695356 & 1528370 & 6.5157 & 6.6304 & TST & \\
\hline CHEMBL 3695424 & 1528370 & 1.0 & 1.8067 & TRN & \\
\hline CHEMBL3936847 & 1528370 & 6.6209 & 5.9825 & TST & \\
\hline CHEMBL3695355 & 1528370 & 6.5412 & 6.6959 & TST & \\
\hline CHEMBL3695425 & 1528370 & 6.7557 & 6.2366 & TRN & \\
\hline CHEMBL3695383 & 1528370 & 6.5727 & 6.7589 & TRN & \\
\hline CHEMBL3695360 & 1528370 & 6.1449 & 6.2731 & TRN & \\
\hline CHEMBL3695447 & 1528370 & 6.7918 & 6.8566 & TRN & \\
\hline CHEMBL3695421 & 1528370 & 5.7696 & 6.216 & TRN & \\
\hline CHEMBL3695396 & 1528370 & 6.5396 & 6.8399 & TRN & \\
\hline CHEMBL3695430 & 1528370 & 6.4827 & 6.566 & TRN & \\
\hline
\end{tabular}


Supplemental Table S2.txt

\begin{tabular}{|c|c|c|c|c|}
\hline CHEMBL3695386 & 1528370 & 6.8925 & 6.4075 & TRN \\
\hline CHEMBL3695420 & 1528370 & 6.2126 & 6.2304 & TST \\
\hline CHEMBL3695416 & 1528370 & 5.9733 & 6.175 & TRN \\
\hline CHEMBL3695442 & 1528370 & 6.6317 & 7.0846 & TRN \\
\hline CHEMBL3695437 & 1528370 & 7.1314 & 7.2374 & TRN \\
\hline CHEMBL3695440 & 1528370 & 6.7768 & 6.8737 & TST \\
\hline CHEMBL3695429 & 1528370 & 6.3862 & 6.2285 & TRN \\
\hline CHEMBL3695403 & 1528370 & 6.9796 & 8.1063 & TST \\
\hline CHEMBL3695413 & 1528370 & 6.5211 & 6.5541 & TRN \\
\hline CHEMBL3900833 & 1528370 & 6.4488 & 5.1957 & TST \\
\hline CHEMBL 3695444 & 1528370 & 6.2998 & 6.2392 & TRN \\
\hline CHEMBL3695377 & 1528370 & 6.6724 & 6.5838 & TRN \\
\hline CHEMBL3639943 & 1528370 & 6.1419 & 5.8136 & TRN \\
\hline CHEMBL 3695438 & 1528370 & 6.3588 & 6.0637 & TRN \\
\hline CHEMBL3695436 & 1528370 & 7.1555 & 6.6015 & TRN \\
\hline CHEMBL3695441 & 1528370 & 1.0 & 0.9829 & TRN \\
\hline CHEMBL3695435 & 1528370 & 6.4364 & 6.3011 & TRN \\
\hline CHEMBL3695392 & 1528370 & 6.515 & 6.3538 & TRN \\
\hline CHEMBL3695390 & 1528370 & 6.6189 & 6.644 & TRN \\
\hline CHEMBL3695412 & 1528370 & 6.4041 & 6.1198 & TRN \\
\hline CHEMBL3695446 & 1528370 & 6.6133 & 6.6713 & TST \\
\hline CHEMBL23584 & 53465 & 7.5229 & 7.2168 & TRN \\
\hline CHEMBL 23288 & 53465 & 6.8861 & 6.3284 & TRN \\
\hline CHEMBL 23657 & 53465 & 5.7328 & 5.7815 & TRN \\
\hline CHEMBL276954 & 53465 & 6.0862 & 5.5726 & TRN \\
\hline CHEMBL23076 & 53465 & 7.4202 & 7.5922 & TRN \\
\hline CHEMBL 26006 & 53465 & 7.1192 & 5.83200 & 0000000001 \\
\hline CHEMBL 22623 & 53465 & 8.3979 & 8.141 & TRN \\
\hline CHEMBL 24344 & 53465 & 7.2441 & 7.2994 & TRN \\
\hline CHEMBL 23787 & 53465 & 4.7747 & 5.13899 & 9999999999 \\
\hline CHEMBL23459 & 53465 & 6.0 & 5.9054 & TRN \\
\hline CHEMBL279243 & 53465 & 6.1135 & 5.2253 & TST \\
\hline CHEMBL 22543 & 53465 & 6.6778 & 6.2494 & TRN \\
\hline CHEMBL277217 & 53465 & 6.9586 & 7.3377 & TRN \\
\hline CHEMBL 279679 & 53465 & 7.6576 & 7.7593 & TRN \\
\hline CHEMBL22672 & 53465 & 6.2291 & 5.8121 & TST \\
\hline CHEMBL 23380 & 53465 & 5.7959 & 5.5727 & TST \\
\hline CHEMBL23227 & 53465 & 7.4815 & 6.6443 & TST \\
\hline CHEMBL287511 & 53465 & 5.2676 & 5.8122 & TRN \\
\hline CHEMBL 281648 & 53465 & 7.6576 & 7.7945 & TRN \\
\hline CHEMBL23911 & 53465 & 7.2007 & 7.2807 & TRN \\
\hline CHEMBL286820 & 53465 & 5.7447 & 5.71700 & 00000000005 \\
\hline CHEMBL 23092 & 53465 & 7.1249 & 6.4461 & TST \\
\hline CHEMBL 23705 & 53465 & 7.2757 & 7.655 & TRN \\
\hline CHEMBL 283518 & 53465 & 8.5686 & 8.18799 & 9999999999 \\
\hline CHEMBL 22434 & 53465 & 5.1549 & 5.3723 & TST \\
\hline CHEMBL 282948 & 53465 & 7.585 & 7.7433 & TRN \\
\hline CHEMBL23425 & 53465 & 4.8239 & 5.6081 & TST \\
\hline
\end{tabular}




\begin{tabular}{|c|c|c|c|c|c|}
\hline \multicolumn{6}{|c|}{ Supplemental Table S2.txt } \\
\hline CHEMBL23492 & 53465 & 6.5229 & 6.1461 & TST & \\
\hline CHEMBL23383 & 53465 & 7.7959 & 7.9748 & TRN & \\
\hline CHEMBL23560 & 53465 & 6.3565 & 5.8333 & TRN & \\
\hline CHEMBL22924 & 53465 & 6.8239 & 6.1733 & TST & \\
\hline CHEMBL279983 & 53465 & 8.0 & 7.8352 & TRN & \\
\hline CHEMBL23466 & 53465 & 6.0506 & 5.9593 & TRN & \\
\hline CHEMBL281131 & 53465 & 7.0 & 7.5368 & TRN & \\
\hline CHEMBL23416 & 53465 & 7.4949 & 7.7665 & TRN & \\
\hline CHEMBL23713 & 53465 & 7.6383 & 7.8745 & TRN & \\
\hline CHEMBL23454 & 53465 & 6.8539 & 6.443 & TST & \\
\hline CHEMBL23021 & 53465 & 7.8539 & 7.9562 & TRN & \\
\hline CHEMBL23146 & 53465 & 4.8539 & 5.5138 & TST & \\
\hline CHEMBL23272 & 53465 & 7.1871 & 7.4116 & TRN & \\
\hline CHEMBL23919 & 53465 & 6.9586 & 6.0492 & TRN & \\
\hline CHEMBL23211 & 53465 & 7.5686 & 6.3988 & TST & \\
\hline CHEMBL23220 & 53465 & 7.7959 & 7.7466 & TRN & \\
\hline CHEMBL279705 & 53465 & 7.8239 & 7.9824 & TRN & \\
\hline CHEMBL23844 & 53465 & 7.5376 & 7.5046 & TRN & \\
\hline CHEMBL22677 & 53465 & 7.0458 & 7.0975 & TRN & \\
\hline CHEMBL23532 & 53465 & 8.5686 & 8.1789 & TRN & \\
\hline CHEMBL 24007 & 53465 & 7.0458 & 7.266 & TRN & \\
\hline CHEMBL23569 & 53465 & 8.4559 & 8.0951 & TRN & \\
\hline CHEMBL 23374 & 53465 & 7.585 & 7.5679 & TRN & \\
\hline CHEMBL409194 & 53465 & 5.2441 & 5.1645 & TST & \\
\hline CHEMBL23382 & 53465 & 8.1427 & 7.8188 & TRN & \\
\hline CHEMBL 23286 & 53465 & 4.6345 & 5.4634 & TST & \\
\hline CHEMBL 23244 & 53465 & 7.5229 & 7.32100 & 0000000001 & TRN \\
\hline CHEMBL 23867 & 53465 & 6.6198 & 7.5281 & TRN & \\
\hline CHEMBL279680 & 53465 & 8.5376 & 8.0601 & TRN & \\
\hline CHEMBL281803 & 53465 & 7.5528 & 7.6811 & TRN & \\
\hline CHEMBL291239 & 53465 & 7.4685 & 7.25299 & 9999999999 & TRN \\
\hline CHEMBL23495 & 53465 & 4.9747 & 5.5964 & TRN & \\
\hline CHEMBL23963 & 53465 & 7.7447 & 7.9723 & TRN & \\
\hline CHEMBL 23402 & 53465 & 5.1612 & 5.6771 & TRN & \\
\hline CHEMBL284544 & 53465 & 8.1024 & 7.5951 & TRN & \\
\hline CHEMBL 2181691 & 877428 & 7.0 & 7.0 & TRN & \\
\hline CHEMBL 2181689 & 877428 & 6.4 & 6.4 & TRN & \\
\hline CHEMBL 2181688 & 877428 & 6.3 & 6.3001 & TRN & \\
\hline CHEMBL 2181687 & 877428 & 6.8 & 6.8 & TRN & \\
\hline CHEMBL 2181686 & 877428 & 6.4 & 6.4 & TRN & \\
\hline CHEMBL 2181685 & 877428 & 4.0 & 4.0 & TRN & \\
\hline CHEMBL 2181684 & 877428 & 4.0 & 4.0 & TRN & \\
\hline CHEMBL 2181683 & 877428 & 6.1 & 6.1 & TRN & \\
\hline CHEMBL 2181682 & 877428 & 6.6 & 6.6 & TRN & \\
\hline CHEMBL 2181681 & 877428 & 6.9 & 6.9 & TRN & \\
\hline CHEMBL 2181680 & 877428 & 4.0 & 4.0 & TRN & \\
\hline CHEMBL 2181679 & 877428 & 4.0 & 4.0001 & TRN & \\
\hline CHEMBL 2181678 & 877428 & 7.1 & 7.1 & TRN & \\
\hline
\end{tabular}




\begin{tabular}{|c|c|c|c|c|}
\hline & & & & al Table S \\
\hline CHEMBL 2181677 & 877428 & 6.2 & 6.1999 & TRN \\
\hline CHEMBL 2181676 & 877428 & 5.7 & 5.7 & TRN \\
\hline CHEMBL2181675 & 877428 & 4.0 & 4.0 & TRN \\
\hline CHEMBL 2177775 & 877428 & 6.1 & 6.1 & TRN \\
\hline CHEMBL 2177774 & 877428 & 6.6 & 5.279 & TST \\
\hline CHEMBL 2177773 & 877428 & 7.0 & 7.0 & TRN \\
\hline CHEMBL 2177772 & 877428 & 6.9 & 6.9 & TRN \\
\hline CHEMBL 2177771 & 877428 & 5.7 & 5.0408 & TST \\
\hline CHEMBL 2177770 & 877428 & 7.1 & 5.4812 & TST \\
\hline CHEMBL2177769 & 877428 & 7.3 & 0.5489 & TST \\
\hline CHEMBL 2177768 & 877428 & 6.5 & 1.3347 & TST \\
\hline CHEMBL 2177767 & 877428 & 4.0 & 4.0 & TRN \\
\hline CHEMBL 2177766 & 877428 & 6.4 & 6.4 & TRN \\
\hline CHEMBL 2177765 & 877428 & 5.9 & 5.9 & TRN \\
\hline CHEMBL 2177764 & 877428 & 5.8 & 5.7999 & TRN \\
\hline CHEMBL 2177763 & 877428 & 7.9 & 7.9 & TRN \\
\hline CHEMBL 2177762 & 877428 & 8.0 & 7.9999 & TRN \\
\hline CHEMBL 2177761 & 877428 & 7.5 & 7.5 & TRN \\
\hline CHEMBL 2177760 & 877428 & 6.6 & 6.6 & TRN \\
\hline CHEMBL2177759 & 877428 & 6.5 & 6.5 & TRN \\
\hline CHEMBL2181696 & 877428 & 6.3 & 6.3 & TRN \\
\hline CHEMBL 2181695 & 877428 & 7.4 & 7.4 & TRN \\
\hline CHEMBL 2181694 & 877428 & 7.6 & 7.6 & TRN \\
\hline CHEMBL2181693 & 877428 & 7.3 & 7.3 & TRN \\
\hline CHEMBL2181692 & 877428 & 7.1 & 7.1001 & TRN \\
\hline CHEMBL 2177787 & 877428 & 6.6 & 6.6001 & TRN \\
\hline CHEMBL 2177786 & 877428 & 6.5 & 6.5 & TRN \\
\hline CHEMBL 2177785 & 877428 & 7.7 & 7.7 & TRN \\
\hline CHEMBL 2177784 & 877428 & 6.8 & 6.8 & TRN \\
\hline CHEMBL 2177783 & 877428 & 7.1 & 6.5345 & TST \\
\hline CHEMBL 2177782 & 877428 & 7.2 & 6.7608 & TST \\
\hline CHEMBL 2177781 & 877428 & 6.9 & 7.1737 & TST \\
\hline CHEMBL 2177780 & 877428 & 6.0 & 5.2962 & TST \\
\hline CHEMBL 2177779 & 877428 & 6.8 & 5.5629 & TST \\
\hline CHEMBL 2177778 & 877428 & 6.2 & 4.204 & TST \\
\hline CHEMBL 2177777 & 877428 & 7.3 & 7.2747 & TST \\
\hline CHEMBL 2177776 & 877428 & 6.3 & 5.44600 & 0000000001 \\
\hline CHEMBL 3216434 & 566776 & 4.1451 & 4.128 & TRN \\
\hline CHEMBL3215782 & 566776 & 3.9788 & 3.1841 & TRN \\
\hline CHEMBL 3215764 & 566776 & 4.4622 & 4.7363 & TRN \\
\hline CHEMBL3216894 & 566776 & 2.821 & 2.4174 & TRN \\
\hline CHEMBL3217109 & 566776 & 5.5086 & 3.3808 & TST \\
\hline CHEMBL3216889 & 566776 & 3.9706 & 3.0589 & TRN \\
\hline CHEMBL22998 & 566776 & 5.3279 & 5.0429 & TRN \\
\hline CHEMBL494404 & 566776 & 2.7773 & 3.1901 & TRN \\
\hline CHEMBL3215763 & 566776 & 2.8069 & 2.1565 & TRN \\
\hline CHEMBL3216216 & 566776 & 2.7595 & 3.895 & TST \\
\hline CHEMBL 3216902 & 566776 & 4.9788 & 5.0908 & TRN \\
\hline
\end{tabular}




\begin{tabular}{|c|c|c|c|c|c|c|}
\hline \multirow[b]{2}{*}{ CHEMBL3216217 } & & \multicolumn{5}{|c|}{ Supplemental Table S2.txt } \\
\hline & 566776 & 3.8239 & 3.1394 & TRN & & \\
\hline CHEMBL3215570 & 566776 & 4.163 & 3.9689 & TRN & & \\
\hline CHEMBL3216016 & 566776 & 3.9208 & 4.1561 & TRN & & \\
\hline CHEMBL3215771 & 566776 & 2.7282 & 3.4725 & TRN & & \\
\hline CHEMBL3215765 & 566776 & 3.85699 & 99999999 & 998 & 3.82 & TRN \\
\hline CHEMBL 3215578 & 566776 & 2.767 & 2.9735 & TRN & & \\
\hline CHEMBL492579 & 566776 & 6.0223 & 5.4804 & TST & & \\
\hline CHEMBL3216214 & 566776 & 2.75699 & Э9999999 & 997 & 3.0589 & TRN \\
\hline CHEMBL522874 & 566776 & 2.7545 & 2.958 & TST & & \\
\hline CHEMBL494957 & 566776 & 3.9031 & 3.8849 & TRN & & \\
\hline CHEMBL495012 & 566776 & 3.7773 & 3.6395 & TRN & & \\
\hline CHEMBL 3216034 & 566776 & 4.9626 & 4.8748 & TRN & & \\
\hline CHEMBL3217113 & 566776 & 2.7825 & 3.1467 & TRN & & \\
\hline CHEMBL 3217107 & 566776 & 2.7747 & 3.425 & TRN & & \\
\hline CHEMBL3216427 & 566776 & 4.1232 & 3.6449 & TRN & & \\
\hline CHEMBL3217116 & 566776 & 4.7905 & 4.7118 & TRN & & \\
\hline CHEMBL3216660 & 566776 & 3.9431 & 3.6679 & TRN & & \\
\hline CHEMBL3216890 & 566776 & 4.6345 & 4.4763 & TRN & & \\
\hline CHEMBL3216435 & 566776 & 3.7905 & 3.6039 & TRN & & \\
\hline CHEMBL935 & 566776 & 5.4202 & 5.0908 & TRN & & \\
\hline CHEMBL3216229 & 566776 & 2.7825 & 2.9891 & TRN & & \\
\hline CHEMBL3215565 & 566776 & 2.7328 & 3.6914 & TRN & & \\
\hline CHEMBL3216658 & 566776 & 4.6055 & 5.0142 & TST & & \\
\hline CHEMBL3216901 & 566776 & 4.4283 & 3.8688 & TST & & \\
\hline CHEMBL3216228 & 566776 & 2.8601 & 2.661 & TRN & & \\
\hline CHEMBL3216033 & 566776 & 2.8182 & 3.07 & TST & & \\
\hline CHEMBL3216030 & 566776 & 2.8013 & 3.1418 & TRN & & \\
\hline CHEMBL3216903 & 566776 & 2.7375 & 3.0666 & TRN & & \\
\hline CHEMBL3215766 & 566776 & 2.7167 & 3.1677 & TRN & & \\
\hline CHEMBL3216663 & 566776 & 2.7852 & 3.1041 & TRN & & \\
\hline CHEMBL3216017 & 566776 & 4.9355 & 4.6135 & TRN & & \\
\hline CHEMBL3215566 & 566776 & 4.7352 & 4.7369 & TRN & & \\
\hline CHEMBL3217106 & 566776 & 5.1612 & 5.2988 & TRN & & \\
\hline CHEMBL3216225 & 566776 & 4.9508 & 4.9324 & TST & & \\
\hline CHEMBL3216670 & 566776 & 2.8416 & 1.6338 & TST & & \\
\hline CHEMBL3216423 & 566776 & 3.8827 & 4.0208 & TRN & & \\
\hline CHEMBL3215569 & 566776 & 4.6421 & 3.8141 & TST & & \\
\hline CHEMBL3216032 & 566776 & 4.7959 & 4.6655 & TRN & & \\
\hline CHEMBL3217105 & 566776 & 4.0 & 3.7745 & TRN & & \\
\hline CHEMBL494956 & 566776 & 2.7496 & 3.8442 & TRN & & \\
\hline CHEMBL3217108 & 566776 & 3.8182 & 3.7875 & TRN & & \\
\hline CHEMBL3215567 & 566776 & 2.7721 & 2.8845 & TRN & & \\
\hline CHEMBL3216657 & 566776 & 4.0044 & 3.7745 & TRN & & \\
\hline CHEMBL3216426 & 566776 & 5.0555 & 5.0951 & TRN & & \\
\hline CHEMBL3216215 & 566776 & 4.76699 & 79999999 & 995 & 4.7369 & TRN \\
\hline CHEMBL 2360824 & 566776 & 5.1938 & 4.4906 & TST & & \\
\hline CHEMBL 3215577 & 566776 & 4.3615 & 3.7698 & TRN & & \\
\hline CHEMBL3216031 & 566776 & 4.2027 & 3.7619 & TRN & & \\
\hline
\end{tabular}




\begin{tabular}{|c|c|c|c|c|c|}
\hline & & \multicolumn{4}{|c|}{ Supplemental Table S2.txt } \\
\hline CHEMBL3216891 & 566776 & 5.1079 & 4.8538 & TST & \\
\hline CHEMBL3216436 & 566776 & 2.8539 & 2.2157 & TST & \\
\hline CHEMBL3216013 & 566776 & 3.752 & 2.9822 & TST & \\
\hline CHEMBL3216662 & 566776 & 4.3686 & 3.7806 & TST & \\
\hline CHEMBL 3215568 & 566776 & 2.71 & 3.2082 & TRN & \\
\hline CHEMBL 3216425 & 566776 & 2.6946 & 3.4505 & TST & \\
\hline CHEMBL3216424 & 566776 & 2.6402 & 3.4012 & TST & \\
\hline CHEMBL83322 & 140872 & 5.3468 & 5.3406 & TRN & \\
\hline CHEMBL 274588 & 140872 & 7.1308 & 7.1027 & TRN & \\
\hline CHEMBL267504 & 140872 & 5.3979 & 6.8524 & TST & \\
\hline CHEMBL81025 & 140872 & 5.585 & 5.5845 & TRN & \\
\hline CHEMBL86164 & 140872 & 4.7773 & 4.7855 & TRN & \\
\hline CHEMBL83902 & 140872 & 4.5575 & 4.5545 & TRN & \\
\hline CHEMBL420392 & 140872 & 6.1487 & 6.1691 & TRN & \\
\hline CHEMBL8967 & 140872 & 4.4776 & 4.4824 & TRN & \\
\hline CHEMBL 81367 & 140872 & 5.2924 & 5.2924 & TRN & \\
\hline CHEMBL 79312 & 140872 & 5.4559 & 5.4365 & TRN & \\
\hline CHEMBL 79505 & 140872 & 5.9586 & 5.9673 & TRN & \\
\hline CHEMBL 84283 & 140872 & 6.2441 & 6.2315 & TRN & \\
\hline CHEMBL 311860 & 140872 & 4.1002 & 4.1126 & TRN & \\
\hline CHEMBL 320952 & 140872 & 4.475 & 4.4712 & TRN & \\
\hline CHEMBL8693 & 140872 & 6.7212 & 6.9848 & TST & \\
\hline CHEMBL131258 & 140872 & 4.9747 & 4.97199 & 99999999995 & TRN \\
\hline CHEMBL450008 & 140872 & 5.9586 & 5.9581 & TRN & \\
\hline CHEMBL106088 & 140872 & 5.3188 & 5.3215 & TRN & \\
\hline CHEMBL334667 & 140872 & 4.2441 & 4.3437 & TST & \\
\hline CHEMBL 310014 & 140872 & 5.6576 & 5.6807 & TRN & \\
\hline CHEMBL9037 & 140872 & 4.9747 & 6.1067 & TST & \\
\hline CHEMBL 310544 & 140872 & 3.0 & 2.9885 & TRN & \\
\hline CHEMBL128824 & 140872 & 5.3188 & 5.3181 & TRN & \\
\hline CHEMBL83855 & 140872 & 4.0545 & 4.0913 & TRN & \\
\hline CHEMBL 325988 & 140872 & 4.9897 & 4.9627 & TRN & \\
\hline CHEMBL 79556 & 140872 & 5.7447 & 5.7614 & TRN & \\
\hline CHEMBL131012 & 140872 & 4.7212 & 4.7282 & TRN & \\
\hline CHEMBL311221 & 140872 & 6.8539 & 6.6093 & TST & \\
\hline CHEMBL310352 & 140872 & 5.9586 & 5.9485 & TRN & \\
\hline CHEMBL 83446 & 140872 & 5.0177 & 5.0126 & TRN & \\
\hline CHEMBL 275106 & 140872 & 6.6198 & 6.2735 & TST & \\
\hline CHEMBL131309 & 140872 & 6.7959 & 6.9757 & TST & \\
\hline CHEMBL81874 & 140872 & 6.1487 & 6.1448 & TRN & \\
\hline CHEMBL341209 & 140872 & 4.5528 & 4.5561 & TRN & \\
\hline CHEMBL313269 & 140872 & 5.0555 & 5.0561 & TRN & \\
\hline CHEMBL326678 & 140872 & 4.6383 & 4.6289 & TRN & \\
\hline CHEMBL82050 & 140872 & 6.4089 & 6.4089 & TRN & \\
\hline CHEMBL83901 & 140872 & 5.2676 & 5.2591 & TRN & \\
\hline CHEMBL82684 & 140872 & 5.1871 & 5.1906 & TRN & \\
\hline CHEMBL309206 & 140872 & 5.1249 & 5.1244 & TRN & \\
\hline CHEMBL8910 & 140872 & 5.8508 & 5.5704 & TST & \\
\hline
\end{tabular}


Supplemental Table S2.txt

\begin{tabular}{|c|c|c|c|c|}
\hline HEN & & 862 & 45 & TS \\
\hline HFMBI 309441 & 40872 & 5.9586 & 5.9551 & \\
\hline HEMBL8992 & 872 & 699 & & \\
\hline HEMBL83551 & 40872 & 7696 & 8153 & \\
\hline HEMBL84094 & 40872 & 5.0132 & 0086 & \\
\hline HEMBL315484 & 40872 & 0511 & 7193 & \\
\hline HEMBL8995 & 0872 & 3188 & & \\
\hline HEMBL9253 & 40872 & 5768 & 4628 & \\
\hline HEMBL 82295 & 40872 & 5.1427 & 151 & \\
\hline HEMBL432781 & 40872 & 5.4437 & 4463 & \\
\hline HEMBL83919 & 40872 & 229 & 1797 & \\
\hline HEMBL131 & 872 & 809 & & \\
\hline HEMBL 3103019 & 285219 & 6.567 & 767 & \\
\hline HEMBL3102999 & 285219 & 1675 & 426 & \\
\hline HEMBL3103017 & 85219 & 669 & 3005 & \\
\hline AEMBL31e & 219 & 212 & 54 & \\
\hline HEMBL31 & 219 & 685 & & \\
\hline HEMBL3103035 & 5219 & 7.3188 & 3071 & \\
\hline HEMBL 310 & 219 & 655 & 2341 & \\
\hline AEMBL3103042 & 219 & 7.2676 & 555 & \\
\hline AEMBL31 & 219 & 685 & 501 & \\
\hline AEMBL31 & 219 & 88 & & \\
\hline HEMBL1C & 219 & 676 & 3969 & \\
\hline HEMBL 213 & 219 & 72 & & \\
\hline AEMBL31 & 19 & 6.8665 & 3749 & RIV \\
\hline AEMBL: & 19 & 212 & 947 & RN \\
\hline HEMBL & 19 & & & \\
\hline 29 & & 3671 & 241 & \\
\hline HEMBL 310 & & & & RIN \\
\hline HEMBL 310 & 219 & 162 & 3969 & RN \\
\hline HEMBL & 19 & 66 & 307 & Notr \\
\hline AEMBL & 19 & 88 & 02 & \\
\hline IEMBL: & & & & RN \\
\hline HEMBL 310 & 219 & 7. & 263 & R \\
\hline HEMBL 31 & 219 & 576 & 373 & RN \\
\hline AFMRI & 19 & 76 & 531 & $\mathrm{RN}$ \\
\hline 50 & 19 & 86 & & 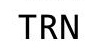 \\
\hline HEMBL310 & 35219 & 675 & 4782 & TS \\
\hline HEMBL3103006 & 5219 & 202 & 022 & TS \\
\hline HEMBL & & & 042 & RN \\
\hline HEMBL3 & 19 & & 969 & \\
\hline HEMBL310 & 35219 & 6.4168 & 7373 & TST \\
\hline AEMBL3102994 & 285219 & 7.6576 & 4475 & TST \\
\hline HEMBL 310 & 5219 & 171 & 167 & TS \\
\hline HEME & & & & \\
\hline HEMBL3 & 5219 & & $\partial 207$ & \\
\hline HEMBL3103015 & 285219 & 6.2168 & 6.9359 & TST \\
\hline CHEMBL3103012 & 1285219 & 6.7167 & 6.6429 & TS \\
\hline
\end{tabular}

Page 25413 
Supplemental Table S2.txt

\begin{tabular}{|c|c|c|c|c|}
\hline CHEMBL3103038 & 1285219 & 7.7212 & 7.876 & TRN \\
\hline CHEMBL3103001 & 1285219 & 7.1192 & 7.04299 & 9999999999 \\
\hline CHEMBL3103007 & 1285219 & 5.9674 & 6.8539 & TST \\
\hline CHEMBL3103020 & 1285219 & 7.3188 & 7.35 & TRN \\
\hline CHEMBL3103034 & 1285219 & 7.7212 & 7.7051 & TRN \\
\hline CHEMBL3103023 & 1285219 & 7.1192 & 6.5938 & TRN \\
\hline CHEMBL3103003 & 1285219 & 7.0655 & 7.5165 & TST \\
\hline CHEMBL3103031 & 1285219 & 5.5171 & 5.3411 & TRN \\
\hline CHEMBL3103033 & 1285219 & 7.9208 & 7.7268 & TRN \\
\hline CHEMBL3103024 & 1285219 & 5.817 & 6.0424 & TRN \\
\hline CHEMBL3103016 & 1285219 & 5.4171 & 6.8351 & TST \\
\hline CHEMBL3103037 & 1285219 & 6.767 & 6.978 & TRN \\
\hline CHEMBL3103036 & 1285219 & 7.1675 & 7.2878 & TRN \\
\hline CHEMBL3103022 & 1285219 & 7.1675 & 6.9785 & TRN \\
\hline CHEMBL3103027 & 1285219 & 6.3675 & 6.7577 & TRN \\
\hline CHEMBL3103025 & 1285219 & 6.4168 & 6.4816 & TRN \\
\hline CHEMBL3103028 & 1285219 & 6.0173 & 6.2264 & TRN \\
\hline CHEMBL3103030 & 1285219 & 5.567 & 5.5373 & TRN \\
\hline CHEMBL3103043 & 1285219 & 7.4685 & 7.4787 & TRN \\
\hline CHEMBL3667880 & 1528160 & 8.3872 & 8.8024 & TST \\
\hline CHEMBL 3672850 & 1528160 & 6.0 & 5.9915 & TRN \\
\hline CHEMBL3667907 & 1528160 & 8.4157 & 8.3965 & TRN \\
\hline CHEMBL3667897 & 1528160 & 6.0 & 6.0335 & TRN \\
\hline CHEMBL3672887 & 1528160 & 8.4295 & 8.4364 & TRN \\
\hline CHEMBL3667896 & 1528160 & 8.6038 & 8.6001 & TRN \\
\hline CHEMBL3672852 & 1528160 & 8.4437 & 8.4599 & TRN \\
\hline CHEMBL3949541 & 1528160 & 8.699 & 9.2236 & TST \\
\hline CHEMBL3672871 & 1528160 & 8.7986 & 8.8062 & TRN \\
\hline CHEMBL3672873 & 1528160 & 8.9914 & 8.9634 & TRN \\
\hline CHEMBL3667912 & 1528160 & 8.5638 & 8.3797 & TST \\
\hline CHEMBL3672857 & 1528160 & 8.7721 & 8.7529 & TRN \\
\hline CHEMBL3667906 & 1528160 & 8.7144 & 8.7256 & TRN \\
\hline CHEMBL3672864 & 1528160 & 8.7282 & 8.5674 & TST \\
\hline CHEMBL3672853 & 1528160 & 8.3429 & 8.3443 & TRN \\
\hline CHEMBL3667898 & 1528160 & 8.1018 & 8.103 & TRN \\
\hline CHEMBL3672885 & 1528160 & 8.4377 & 8.4144 & TRN \\
\hline CHEMBL3957967 & 1528160 & 8.7055 & 8.7732 & TST \\
\hline CHEMBL 3672888 & 1528160 & 8.6968 & 8.6997 & TRN \\
\hline CHEMBL3672877 & 1528160 & 9.1249 & 9.1317 & TRN \\
\hline CHEMBL3672854 & 1528160 & 8.4112 & 8.1674 & TST \\
\hline CHEMBL3672892 & 1528160 & 8.3307 & 8.3277 & TRN \\
\hline CHEMBL3672865 & 1528160 & 8.2381 & 8.2445 & TRN \\
\hline CHEMBL3639717 & 1528160 & 8.2865 & 8.3152 & TRN \\
\hline CHEMBL3672863 & 1528160 & 8.4572 & 8.405 & TST \\
\hline CHEMBL3903777 & 1528160 & 8.9431 & 8.632 & TST \\
\hline CHEMBL3672855 & 1528160 & 8.4112 & 8.433 & TRN \\
\hline CHEMBL3672893 & 1528160 & 8.451 & 8.4683 & TRN \\
\hline CHEMBL3672859 & 1528160 & 8.4101 & 8.3306 & TST \\
\hline
\end{tabular}


Supplemental Table S2.txt

\begin{tabular}{|c|c|c|c|c|}
\hline CHEMBL 3667902 & 1528160 & 6.0 & 5.9715 & TRN \\
\hline CHEMBL 3667908 & 1528160 & 8.5638 & 8.5567 & TRN \\
\hline CHEMBL3667884 & 1528160 & 9.0223 & 9.0075 & TRN \\
\hline CHEMBL 3667887 & 1528160 & 8.6946 & 8.7034 & TRN \\
\hline CHEMBL 3667883 & 1528160 & 9.301 & 9.3177 & TRN \\
\hline CHEMBL 3672879 & 1528160 & 8.3565 & 8.4031 & TRN \\
\hline CHEMBL 3667888 & 1528160 & 8.8239 & 8.8211 & TRN \\
\hline CHEMBL 3667885 & 1528160 & 8.8761 & 8.8809 & TRN \\
\hline CHEMBL3667894 & 1528160 & 8.0809 & 8.0972 & TRN \\
\hline CHEMBL 3672880 & 1528160 & 9.6778 & 9.6724 & TRN \\
\hline CHEMBL 3667881 & 1528160 & 9.3768 & 9.3964 & TRN \\
\hline CHEMBL 3667904 & 1528160 & 8.5086 & 8.5596 & TST \\
\hline CHEMBL 3667893 & 1528160 & 8.7595 & 8.7636 & TRN \\
\hline CHEMBL 3672870 & 1528160 & 8.9957 & 9.0169 & TRN \\
\hline CHEMBL 3672875 & 1528160 & 8.4377 & 8.4412 & TRN \\
\hline CHEMBL 3667910 & 1528160 & 9.1549 & 9.1646 & TRN \\
\hline CHEMBL 3667886 & 1528160 & 8.7721 & 8.3026 & TST \\
\hline CHEMBL 3672882 & 1528160 & 6.0 & 6.254 & TST \\
\hline CHEMBL3672869 & 1528160 & 8.8268 & 8.8038 & TRN \\
\hline CHEMBL 3672884 & 1528160 & 8.7328 & 8.992 & TST \\
\hline CHEMBL 3672883 & 1528160 & 8.0964 & 8.0687 & TRN \\
\hline CHEMBL 3672866 & 1528160 & 8.0329 & 8.0396 & TRN \\
\hline CHEMBL 3667891 & 1528160 & 8.2857 & 8.2678 & TRN \\
\hline CHEMBL3672872 & 1528160 & 9.3098 & 9.3159 & TRN \\
\hline CHEMBL 3667901 & 1528160 & 8.4989 & 8.5037 & TRN \\
\hline CHEMBL3667892 & 1528160 & 8.6021 & 8.6211 & TRN \\
\hline CHEMBL 3667882 & 1528160 & 9.1249 & 9.1119 & TRN \\
\hline CHEMBL3667889 & 1528160 & 6.0 & 6.0019 & TRN \\
\hline CHEMBL3672861 & 1528160 & 8.475 & 8.4549 & TRN \\
\hline CHEMBL 3672878 & 1528160 & 8.8013 & 8.7677 & TRN \\
\hline CHEMBL 3672858 & 1528160 & 8.4737 & 8.4745 & TRN \\
\hline CHEMBL 3672876 & 1528160 & 8.7959 & 8.7811 & TRN \\
\hline CHEMBL 3672891 & 1528160 & 8.6596 & 8.6671 & TRN \\
\hline CHEMBL3667879 & 1528160 & 9.2147 & 9.1984 & TST \\
\hline CHEMBL3667895 & 1528160 & 6.0 & 5.8595 & TST \\
\hline CHEMBL3667899 & 1528160 & 8.7545 & 8.7329 & TRN \\
\hline CHEMBL 3667909 & 1528160 & 8.5391 & 8.5362 & TRN \\
\hline CHEMBL 3672889 & 1528160 & 8.8477 & 8.8258 & TRN \\
\hline CHEMBL 3667905 & 1528160 & 8.7773 & 8.9084 & TST \\
\hline CHEMBL 3672860 & 1528160 & 9.0362 & 8.9956 & TST \\
\hline CHEMBL 3672868 & 1528160 & 8.4815 & 8.3226 & TST \\
\hline CHEMBL 293428 & 70331 & 6.0 & 7.1031 & TRN \\
\hline CHEMBL64295 & 70331 & 6.0 & 6.0713 & TRN \\
\hline CHEMBL293231 & 70331 & 6.0 & 6.2802 & TRN \\
\hline CHEMBL59693 & 70331 & 6.0 & 6.3115 & TRN \\
\hline CHEMBL1790445 & 70331 & 6.0 & 6.3741 & TST \\
\hline CHEMBL64388 & 70331 & 7.9208 & 8.2934 & TRN \\
\hline CHEMBL281813 & 70331 & 6.0 & 6.2443 & TRN \\
\hline
\end{tabular}




\begin{tabular}{|c|c|c|c|c|c|}
\hline \multicolumn{6}{|c|}{ Supplemental Table s2.txt } \\
\hline CHEMBL62562 & 70331 & 6.0 & 5.8758 & TRN & \\
\hline CHEMBL60388 & 70331 & 6.0 & 5.7048 & TRN & \\
\hline CHEMBL417553 & 70331 & 6.8761 & 7.5093 & TST & \\
\hline CHEMBL 293214 & 70331 & 8.5376 & 7.7945 & TRN & \\
\hline CHEMBL423490 & 70331 & 6.0 & 6.0667 & TRN & \\
\hline CHEMBL1790446 & 70331 & 6.0 & 5.8161 & TRN & \\
\hline CHEMBL304228 & 70331 & 7.0809 & 6.3795 & TRN & \\
\hline CHEMBL416855 & 70331 & 6.6364 & 7.0053 & TRN & \\
\hline CHEMBL431952 & 70331 & 6.0 & 6.023 & TRN & \\
\hline CHEMBL64748 & 70331 & 6.6198 & 6.9608 & TRN & \\
\hline CHEMBL444306 & 70331 & 6.0 & 6.0254 & TRN & \\
\hline CHEMBL64629 & 70331 & 7.5229 & 6.9616 & TST & \\
\hline CHEMBL64550 & 70331 & 7.1549 & 7.2612 & TST & \\
\hline CHEMBL62932 & 70331 & 6.0 & 6.9319 & TRN & \\
\hline CHEMBL60947 & 70331 & 6.0 & 6.6947 & TRN & \\
\hline CHEMBL62519 & 70331 & 7.9208 & 7.1385 & TST & \\
\hline CHEMBL1790452 & 70331 & 6.0 & 5.9659 & TRN & \\
\hline CHEMBL65138 & 70331 & 7.9208 & 7.5296 & TRN & \\
\hline CHEMBL430978 & 70331 & 8.585 & 7.3745 & TRN & \\
\hline CHEMBL 293908 & 70331 & 6.0 & 6.4154 & TRN & \\
\hline CHEMBL305324 & 70331 & 6.0 & 6.3011 & TST & \\
\hline CHEMBL64299 & 70331 & 6.9788 & 7.3675 & TST & \\
\hline CHEMBL291579 & 70331 & 6.0 & 5.8231 & TRN & \\
\hline CHEMBL411943 & 70331 & 6.0 & 6.149 & TRN & \\
\hline CHEMBL305337 & 70331 & 8.6778 & 7.971 & TRN & \\
\hline CHEMBL 293861 & 70331 & 6.8794 & 6.7868 & TRN & \\
\hline CHEMBL63031 & 70331 & 6.0 & 5.4201 & TRN & \\
\hline CHEMBL430560 & 70331 & 6.0 & 5.779 & TRN & \\
\hline CHEMBL431373 & 70331 & 7.7212 & 7.4674 & TRN & \\
\hline CHEMBL66530 & 70331 & 6.0 & 6.01399 & 9999999999 & TRN \\
\hline CHEMBL62394 & 70331 & 6.3625 & 7.2649 & TST & \\
\hline CHEMBL 302465 & 70331 & 6.0 & 8.0622 & TST & \\
\hline CHEMBL64787 & 70331 & 8.6021 & 7.5001 & TRN & \\
\hline CHEMBL 302646 & 70331 & 8.3468 & 8.454 & TST & \\
\hline CHEMBL408766 & 70331 & 8.4089 & 7.7266 & TRN & \\
\hline CHEMBL62969 & 70331 & 6.0 & 6.1691 & TRN & \\
\hline CHEMBL292743 & 70331 & 6.0 & 6.2201 & TRN & \\
\hline CHEMBL432725 & 70331 & 7.1249 & 7.4896 & TRN & \\
\hline CHEMBL 304405 & 70331 & 6.0 & 6.5062 & TST & \\
\hline CHEMBL302682 & 70331 & 8.0969 & 7.84399 & 9999999999 & TST \\
\hline CHEMBL65442 & 70331 & 6.0 & 6.4009 & TRN & \\
\hline CHEMBL292527 & 70331 & 6.0 & 6.6971 & TRN & \\
\hline CHEMBL62921 & 70331 & 7.7447 & 8.4055 & TRN & \\
\hline CHEMBL294318 & 70331 & 6.0 & 5.779 & TRN & \\
\hline CHEMBL304864 & 70331 & 6.301 & 7.1524 & TST & \\
\hline CHEMBL62910 & 70331 & 8.3768 & 7.39 & TRN & \\
\hline CHEMBL293417 & 70331 & 6.0 & 6.4631 & TRN & \\
\hline CHEMBL62458 & 70331 & 6.0 & 5.63 & TRN & \\
\hline
\end{tabular}




\begin{tabular}{|c|c|c|c|c|c|}
\hline \multicolumn{6}{|c|}{ Supplemental Table S2.txt } \\
\hline CHEMBL1790443 & 70331 & 6.0 & 7.0749 & TRN & \\
\hline CHEMBL65517 & 70331 & 6.0 & 6.1942 & TRN & \\
\hline CHEMBL59747 & 70331 & 6.0 & 8.3993 & TST & \\
\hline CHEMBL62970 & 70331 & 8.2218 & 8.0992 & TST & \\
\hline CHEMBL62989 & 70331 & 6.0 & 5.419 & TRN & \\
\hline CHEMBL3407875 & 1629193 & 7.0458 & 6.9647 & TRN & \\
\hline CHEMBL3896367 & 1629193 & 6.0044 & 6.3311 & TST & \\
\hline CHEMBL3407879 & 1629193 & 7.3979 & 7.3589 & TRN & \\
\hline CHEMBL3983459 & 1629193 & 8.9208 & 8.7228 & TRN & \\
\hline CHEMBL3407880 & 1629193 & 8.0 & 7.6786 & TRN & \\
\hline CHEMBL3964171 & 1629193 & 5.3979 & 6.5757 & TST & \\
\hline CHEMBL 3407874 & 1629193 & 8.4949 & 8.3372 & TRN & \\
\hline CHEMBL3924368 & 1629193 & 8.699 & 8.514 & TRN & \\
\hline CHEMBL3952066 & 1629193 & 7.9208 & 7.8125 & TRN & \\
\hline CHEMBL3407881 & 1629193 & 6.585 & 6.7558 & TRN & \\
\hline CHEMBL3407867 & 1629193 & 7.4202 & 7.2105 & TRN & \\
\hline CHEMBL3907526 & 1629193 & 7.2441 & 7.2793 & TRN & \\
\hline CHEMBL3939321 & 1629193 & 8.301 & 7.8271 & TRN & \\
\hline CHEMBL 3407878 & 1629193 & 6.8539 & 6.5635 & TRN & \\
\hline CHEMBL3931378 & 1629193 & 7.0809 & 6.7379 & TRN & \\
\hline CHEMBL3903832 & 1629193 & 9.699 & 9.6339 & TRN & \\
\hline CHEMBL 3912403 & 1629193 & 7.2218 & 7.5824 & TRN & \\
\hline CHEMBL3947833 & 1629193 & 5.6716 & 5.8126 & TST & \\
\hline CHEMBL 3915370 & 1629193 & 8.6778 & 9.0018 & TRN & \\
\hline CHEMBL3921825 & 1629193 & 9.5229 & 9.5979 & TRN & \\
\hline CHEMBL3894894 & 1629193 & 9.5229 & 9.4969 & TRN & \\
\hline CHEMBL3922876 & 1629193 & 9.0458 & 9.2732 & TRN & \\
\hline CHEMBL3949189 & 1629193 & 9.1549 & 8.7048 & TRN & \\
\hline CHEMBL 3977350 & 1629193 & 7.7696 & 7.595 & TRN & \\
\hline CHEMBL3977740 & 1629193 & 7.1192 & 7.4888 & TRN & \\
\hline CHEMBL3407882 & 1629193 & 7.4815 & 7.5092 & TRN & \\
\hline CHEMBL3971724 & 1629193 & 7.4949 & 7.38 & TRN & \\
\hline CHEMBL 3940840 & 1629193 & 5.7696 & 6.2237 & TST & \\
\hline CHEMBL3956495 & 1629193 & 5.8861 & 6.4284 & TST & \\
\hline CHEMBL3949609 & 1629193 & 7.7212 & 8.0441 & TRN & \\
\hline CHEMBL 3948527 & 1629193 & 7.4202 & 7.3769 & TRN & \\
\hline CHEMBL3960765 & 1629193 & 9.301 & 8.8193 & TRN & \\
\hline CHEMBL3967583 & 1629193 & 6.4685 & 4.919 & TST & \\
\hline CHEMBL3936708 & 1629193 & 7.9208 & 8.3621 & TRN & \\
\hline CHEMBL3407877 & 1629193 & 8.2218 & 8.4337 & TRN & \\
\hline CHEMBL3903406 & 1629193 & 5.6882 & 5.7429 & TRN & \\
\hline CHEMBL3407866 & 1629193 & 9.2218 & 9.4027 & TRN & \\
\hline CHEMBL3931822 & 1629193 & 9.699 & 9.734 & TRN & \\
\hline CHEMBL3917417 & 1629193 & 6.2596 & 6.2901 & TRN & \\
\hline CHEMBL3978057 & 1629193 & 6.3665 & 6.88399 & 99999999995 & TRN \\
\hline CHEMBL3965088 & 1629193 & 8.2218 & 8.4396 & TRN & \\
\hline CHEMBL3974009 & 1629193 & 6.5686 & 6.4477 & TRN & \\
\hline CHEMBL3948107 & 1629193 & 5.1864 & 5.421 & TRN & \\
\hline
\end{tabular}


Supplemental Table S2.txt

\begin{tabular}{|c|c|c|c|c|}
\hline CHEMBL3912846 & 1629193 & 7.9586 & 8.0056 & TRN \\
\hline CHEMBL3933304 & 1629193 & 7.3098 & 8.0974 & TST \\
\hline CHEMBL3407865 & 1629193 & 9.301 & 9.0122 & TST \\
\hline CHEMBL3985161 & 1629193 & 4.7773 & 4.7362 & TST \\
\hline CHEMBL3930333 & 1629193 & 9.0458 & 9.2082 & TST \\
\hline CHEMBL3968864 & 1629193 & 7.6576 & 7.141 & TST \\
\hline CHEMBL3407885 & 1629193 & 7.6021 & 7.5805 & TST \\
\hline CHEMBL3977081 & 1629193 & 5.0223 & 5.8648 & TST \\
\hline CHEMBL3207582 & 688432 & 4.25 & 4.5961 & TRN \\
\hline CHEMBL1455256 & 688432 & 4.3 & 4.8569 & TST \\
\hline CHEMBL477139 & 688432 & 4.7 & 5.2674 & TRN \\
\hline CHEMBL1547587 & 688432 & 4.35 & 4.7174 & TRN \\
\hline CHEMBL1599533 & 688432 & 4.35 & 4.4868 & TRN \\
\hline CHEMBL1326262 & 688432 & 4.1 & 4.7586 & TRN \\
\hline CHEMBL1529016 & 688432 & 4.1 & 4.9037 & TST \\
\hline CHEMBL1084441 & 688432 & 4.45 & 4.6555 & TRN \\
\hline CHEMBL269733 & 688432 & 4.85 & 4.5491 & TRN \\
\hline CHEMBL1303641 & 688432 & 4.5 & 4.4577 & TRN \\
\hline CHEMBL3199716 & 688432 & 4.15 & 4.4145 & TRN \\
\hline CHEMBL1469874 & 688432 & 7.1002 & 4.9786 & TRN \\
\hline CHEMBL1495539 & 688432 & 4.4 & 4.4253 & TRN \\
\hline CHEMBL1469246 & 688432 & 4.55 & 4.6095 & TRN \\
\hline CHEMBL1376161 & 688432 & 5.15 & 4.8092 & TST \\
\hline CHEMBL1418460 & 688432 & 4.4 & 4.5229 & TRN \\
\hline CHEMBL1575276 & 688432 & 4.0 & 4.5953 & TRN \\
\hline CHEMBL1512372 & 688432 & 4.95 & 4.7411 & TRN \\
\hline CHEMBL1430956 & 688432 & 4.35 & 4.8927 & TRN \\
\hline CHEMBL1566927 & 688432 & 4.55 & 4.806 & TST \\
\hline CHEMBL1461796 & 688432 & 4.1 & 4.8369 & TRN \\
\hline CHEMBL1437749 & 688432 & 4.25 & 4.6945 & TST \\
\hline CHEMBL1327102 & 688432 & 4.1 & 4.6914 & TRN \\
\hline CHEMBL1489386 & 688432 & 4.85 & 4.9445 & TRN \\
\hline CHEMBL1340437 & 688432 & 4.5 & 4.6786 & TRN \\
\hline CHEMBL1572445 & 688432 & 5.75 & 4.6696 & TRN \\
\hline CHEMBL1165553 & 688432 & 3.9 & 4.787 & TST \\
\hline CHEMBL1543963 & 688432 & 7.9508 & 5.4731 & TRN \\
\hline CHEMBL1539121 & 688432 & 4.75 & 4.6751 & TRN \\
\hline CHEMBL1405147 & 688432 & 4.3 & 4.5287 & TRN \\
\hline CHEMBL1403564 & 688432 & 5.2 & 4.7234 & TRN \\
\hline CHEMBL45068 & 688432 & 4.35 & 4.502 & TRN \\
\hline CHEMBL1527068 & 688432 & 4.0 & 4.8833 & TRN \\
\hline CHEMBL1470184 & 688432 & 4.7 & 4.5623 & TST \\
\hline CHEMBL1469242 & 688432 & 4.45 & 4.7327 & TRN \\
\hline CHEMBL3392427 & 688432 & 4.35 & 4.5792 & TRN \\
\hline CHEMBL1438567 & 688432 & 4.55 & 4.6134 & TRN \\
\hline CHEMBL1354818 & 688432 & 5.0 & 4.8212 & TRN \\
\hline CHEMBL1376246 & 688432 & 4.45 & 5.6924 & TRN \\
\hline CHEMBL1410173 & 688432 & 4.1 & 4.4466 & TRN \\
\hline
\end{tabular}




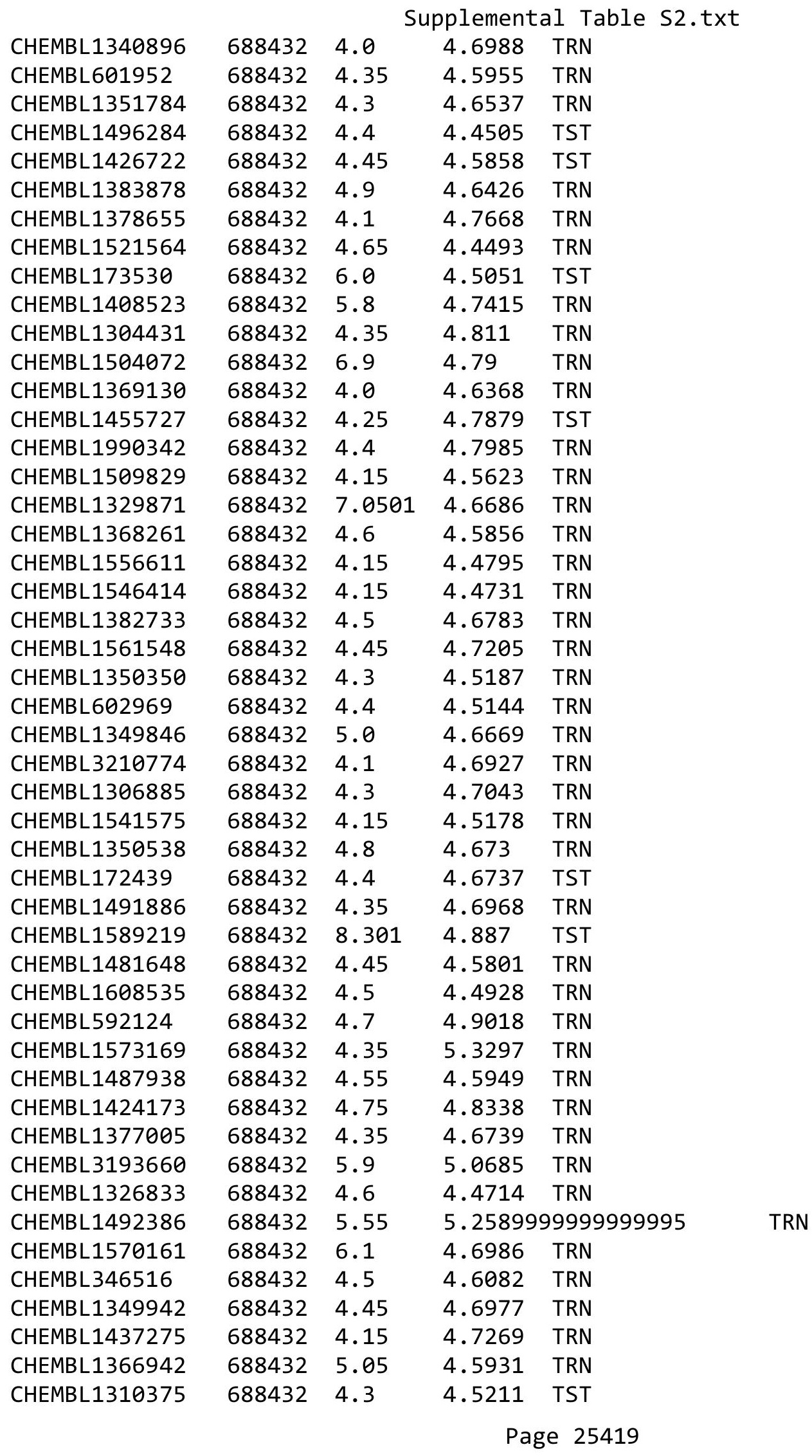




\begin{tabular}{|c|c|c|c|c|c|}
\hline \multicolumn{6}{|c|}{ Supplemental Table S2.txt } \\
\hline CHEMBL3197678 & 688432 & 4.85 & 4.8073 & TRN & \\
\hline CHEMBL1492541 & 688432 & 4.35 & 4.6628 & TRN & \\
\hline CHEMBL1529749 & 688432 & 4.15 & 4.2369 & TRN & \\
\hline CHEMBL1417735 & 688432 & 4.75 & 4.763 & TRN & \\
\hline CHEMBL1415635 & 688432 & 6.15 & 5.0286 & TRN & \\
\hline CHEMBL1532571 & 688432 & 4.7 & 4.6811 & TST & \\
\hline CHEMBL1346879 & 688432 & 4.5 & 4.7507 & TRN & \\
\hline CHEMBL 279731 & 688432 & 4.15 & 4.7132 & TST & \\
\hline CHEMBL3191815 & 688432 & 3.95 & 4.6772 & TST & \\
\hline CHEMBL1360102 & 688432 & 4.5 & 4.5712 & TRN & \\
\hline CHEMBL3191078 & 688432 & 4.8 & 4.5761 & TRN & \\
\hline CHEMBL1568936 & 688432 & 4.45 & 4.6462 & TRN & \\
\hline CHEMBL1402494 & 688432 & 4.55 & 4.9544 & TRN & \\
\hline CHEMBL1492833 & 688432 & 6.5501 & 4.6615 & TST & \\
\hline CHEMBL1507172 & 688432 & 4.3 & 4.8423 & TRN & \\
\hline CHEMBL1549801 & 688432 & 4.65 & 4.8818 & TRN & \\
\hline CHEMBL1522993 & 688432 & 5.45 & 5.8174 & TRN & \\
\hline CHEMBL582507 & 688432 & 4.5 & 4.7843 & TRN & \\
\hline CHEMBL1496866 & 688432 & 4.1 & 4.76699 & 99999999995 & TRN \\
\hline CHEMBL1567682 & 688432 & 4.6 & 4.4718 & TRN & \\
\hline CHEMBL1384302 & 688432 & 5.15 & 4.8397 & TRN & \\
\hline CHEMBL1361456 & 688432 & 4.6 & 4.5778 & TRN & \\
\hline CHEMBL1369501 & 688432 & 4.4 & 4.7014 & TRN & \\
\hline CHEMBL1432627 & 688432 & 4.95 & 4.4713 & TRN & \\
\hline CHEMBL1438907 & 688432 & 5.05 & 4.5404 & TRN & \\
\hline CHEMBL1324032 & 688432 & 4.15 & 4.5009 & TRN & \\
\hline CHEMBL550826 & 688432 & 5.45 & 4.6499 & TRN & \\
\hline CHEMBL1468277 & 688432 & 4.4 & 4.667 & TRN & \\
\hline CHEMBL1562005 & 688432 & 4.25 & 4.5415 & TRN & \\
\hline CHEMBL1318708 & 688432 & 4.6 & 4.563 & TRN & \\
\hline CHEMBL1305771 & 688432 & 4.95 & 4.529 & TRN & \\
\hline CHEMBL 258893 & 688432 & 4.15 & 4.7279 & TST & \\
\hline CHEMBL1530147 & 688432 & 4.5 & 4.7437 & TRN & \\
\hline CHEMBL1418754 & 688432 & 4.15 & 4.5348 & TRN & \\
\hline CHEMBL1367813 & 688432 & 6.95 & 4.5138 & TRN & \\
\hline CHEMBL1502002 & 688432 & 4.3 & 4.5148 & TRN & \\
\hline CHEMBL 1356812 & 688432 & 4.85 & 4.6779 & TRN & \\
\hline CHEMBL1326593 & 688432 & 4.55 & 4.819 & TRN & \\
\hline CHEMBL1515575 & 688432 & 4.7 & 4.9867 & TRN & \\
\hline CHEMBL1539384 & 688432 & 4.55 & 4.4933 & TRN & \\
\hline CHEMBL1965814 & 688432 & 4.35 & 4.4861 & TRN & \\
\hline CHEMBL1160160 & 688432 & 4.6 & 4.8022 & TST & \\
\hline CHEMBL63354 & 688432 & 4.25 & 4.5178 & TRN & \\
\hline CHEMBL1352607 & 688432 & 4.8 & 4.5601 & TRN & \\
\hline CHEMBL1346753 & 688432 & 4.4 & 4.5218 & TRN & \\
\hline CHEMBL3192559 & 688432 & 4.3 & 4.6001 & TST & \\
\hline CHEMBL1357562 & 688432 & 4.6 & 4.4697 & TST & \\
\hline CHEMBL1475817 & 688432 & 4.15 & 4.4809 & TRN & \\
\hline
\end{tabular}




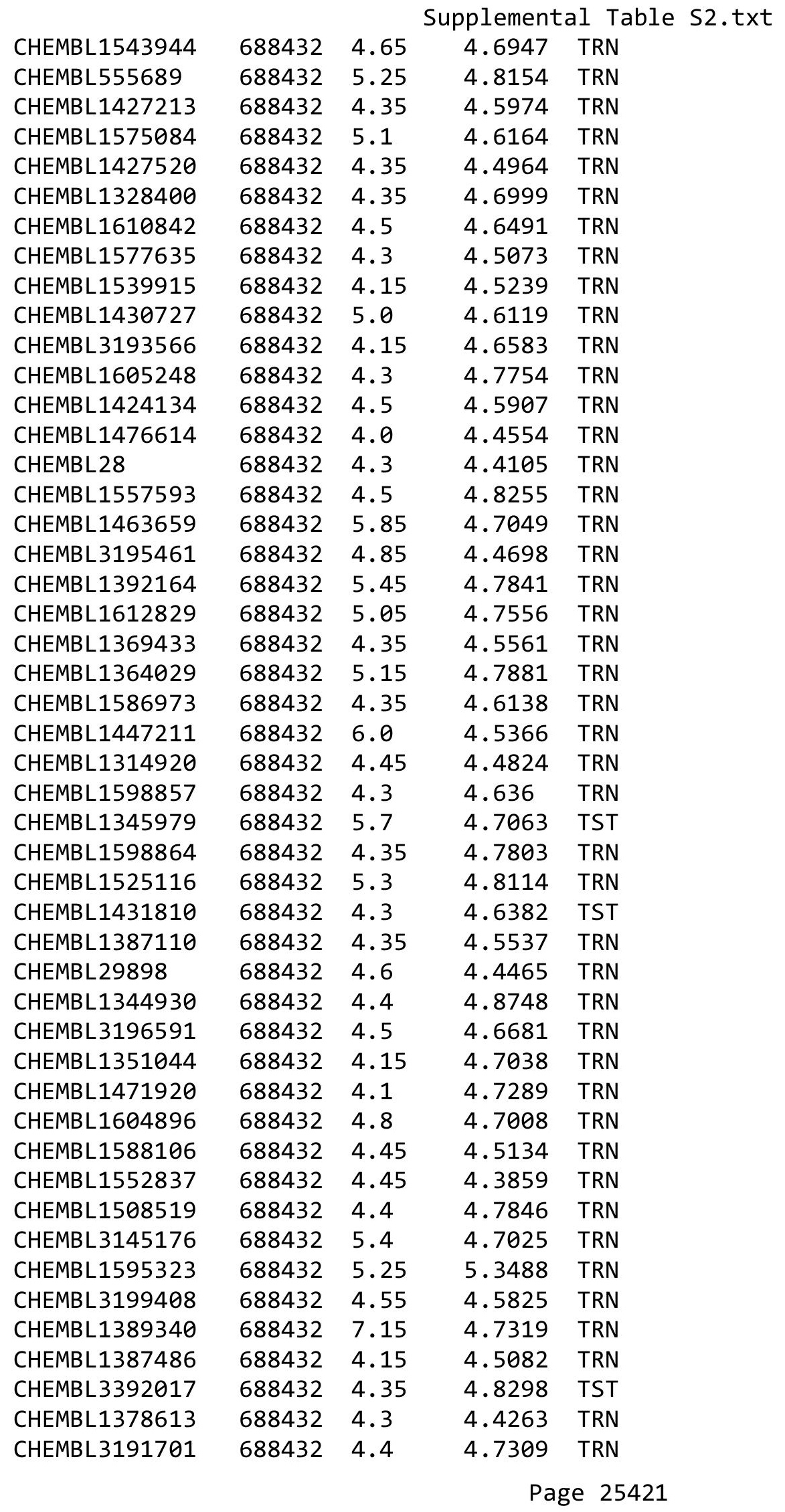




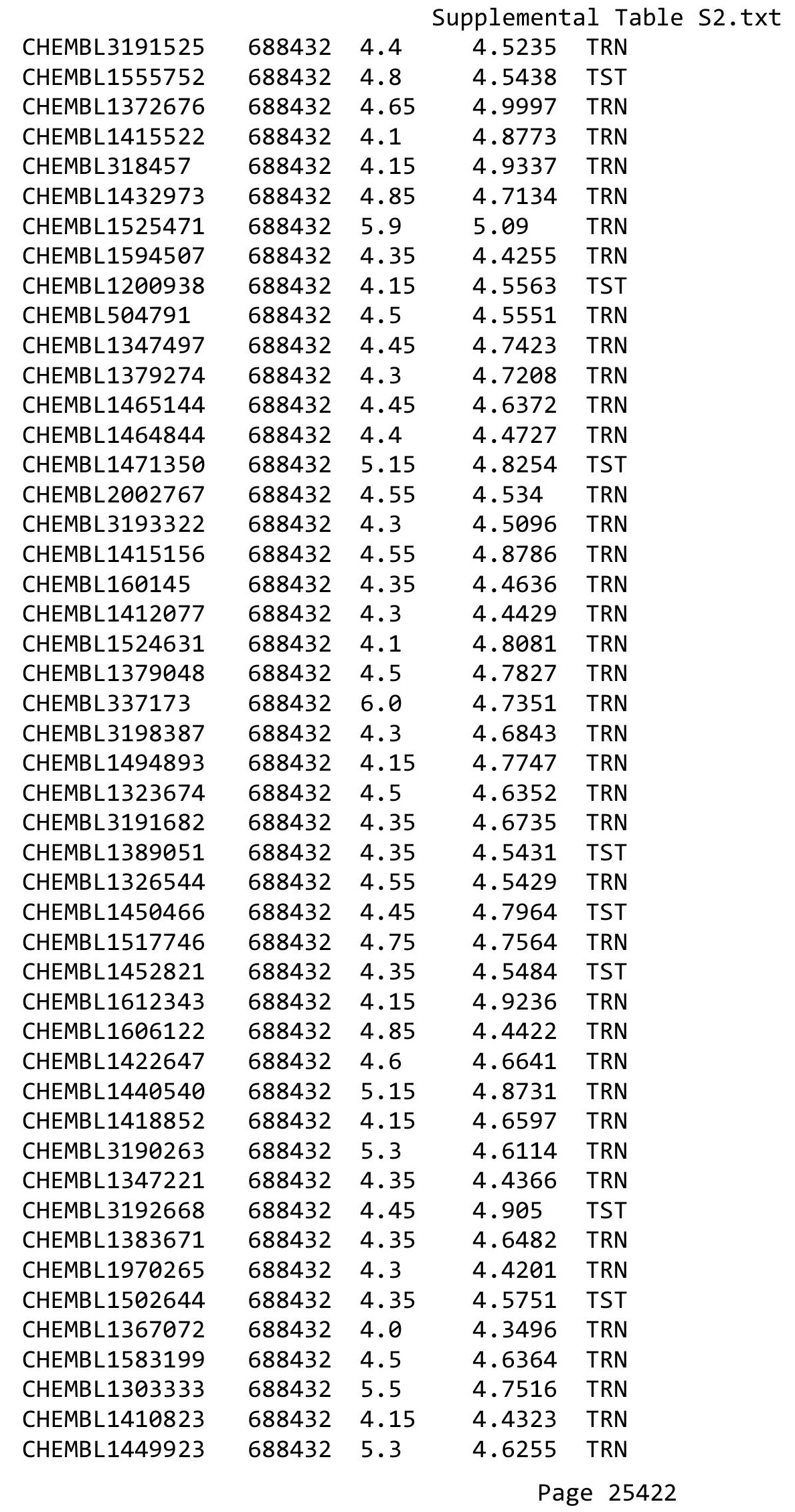




\begin{tabular}{|c|c|c|c|c|c|}
\hline \multicolumn{6}{|c|}{ Supplemental Table S2.txt } \\
\hline CHEMBL1530561 & 688432 & 4.9 & 4.4841 & TRN & \\
\hline CHEMBL3191602 & 688432 & 4.1 & 4.87 & TRN & \\
\hline CHEMBL1351250 & 688432 & 4.3 & 4.5357 & TRN & \\
\hline CHEMBL1972346 & 688432 & 4.15 & 4.3875 & TRN & \\
\hline CHEMBL1537149 & 688432 & 4.85 & 4.6813 & TRN & \\
\hline CHEMBL1524365 & 688432 & 4.5 & 4.8576 & TRN & \\
\hline CHEMBL1354219 & 688432 & 4.05 & 4.7754 & TRN & \\
\hline CHEMBL1545983 & 688432 & 4.05 & 4.6681 & TRN & \\
\hline CHEMBL236033 & 688432 & 4.8 & 4.7872 & TRN & \\
\hline CHEMBL1597580 & 688432 & 4.35 & 4.7025 & TRN & \\
\hline CHEMBL1528749 & 688432 & 4.3 & 4.6409 & TRN & \\
\hline CHEMBL1585437 & 688432 & 4.15 & 4.4894 & TRN & \\
\hline CHEMBL1338295 & 688432 & 4.35 & 4.3845 & TRN & \\
\hline CHEMBL1381318 & 688432 & 4.35 & 4.4403 & TRN & \\
\hline CHEMBL1515743 & 688432 & 6.5 & 5.1082 & TRN & \\
\hline CHEMBL1422601 & 688432 & 4.5 & 4.8406 & TRN & \\
\hline CHEMBL3197060 & 688432 & 4.5 & 4.463 & TRN & \\
\hline CHEMBL1304066 & 688432 & 4.85 & 4.5949 & TRN & \\
\hline CHEMBL1593426 & 688432 & 4.45 & 4.6088 & TRN & \\
\hline CHEMBL1368166 & 688432 & 4.5 & 4.9173 & TRN & \\
\hline CHEMBL1609715 & 688432 & 4.65 & 4.6094 & TRN & \\
\hline CHEMBL1564291 & 688432 & 6.0 & 5.2302 & TRN & \\
\hline CHEMBL1401657 & 688432 & 4.5 & 4.6466 & TST & \\
\hline CHEMBL1467058 & 688432 & 4.1 & 4.5378 & TST & \\
\hline CHEMBL 30707 & 688432 & 4.0 & 4.4715 & TRN & \\
\hline CHEMBL1300914 & 688432 & 3.95 & 4.739 & TRN & \\
\hline CHEMBL1417815 & 688432 & 5.15 & 4.6735 & TRN & \\
\hline CHEMBL1488366 & 688432 & 7.3002 & 4.7578 & TRN & \\
\hline CHEMBL3197308 & 688432 & 4.35 & 4.4421 & TRN & \\
\hline CHEMBL1563370 & 688432 & 4.25 & 4.6964 & TST & \\
\hline CHEMBL1401379 & 688432 & 4.45 & 4.7526 & TRN & \\
\hline CHEMBL1314585 & 688432 & 4.1 & 5.0937 & TRN & \\
\hline CHEMBL1302175 & 688432 & 4.15 & 4.4631 & TRN & \\
\hline CHEMBL1451438 & 688432 & 7.1002 & 5.02800 & 00000000005 & TST \\
\hline CHEMBL1588368 & 688432 & 4.45 & 4.5219 & TRN & \\
\hline CHEMBL1611739 & 688432 & 6.8 & 5.1046 & TRN & \\
\hline CHEMBL 3197248 & 688432 & 4.3 & 4.5043 & TRN & \\
\hline CHEMBL523663 & 688432 & 4.5 & 4.6838 & TRN & \\
\hline CHEMBL587884 & 688432 & 4.3 & 4.4737 & TST & \\
\hline CHEMBL1358678 & 688432 & 4.25 & 4.6044 & TRN & \\
\hline CHEMBL1518926 & 688432 & 4.3 & 4.5069 & TRN & \\
\hline CHEMBL1430473 & 688432 & 4.35 & 4.6304 & TST & \\
\hline CHEMBL1442104 & 688432 & 4.15 & 4.4594 & TRN & \\
\hline CHEMBL1568978 & 688432 & 4.1 & 4.5914 & TRN & \\
\hline CHEMBL1379677 & 688432 & 4.8 & 4.47199 & 99999999995 & TRN \\
\hline CHEMBL1444985 & 688432 & 4.1 & 4.8235 & TST & \\
\hline CHEMBL1552430 & 688432 & 5.0 & 4.8527 & TRN & \\
\hline CHEMBL1550129 & 688432 & 4.4 & 4.4652 & TRN & \\
\hline
\end{tabular}




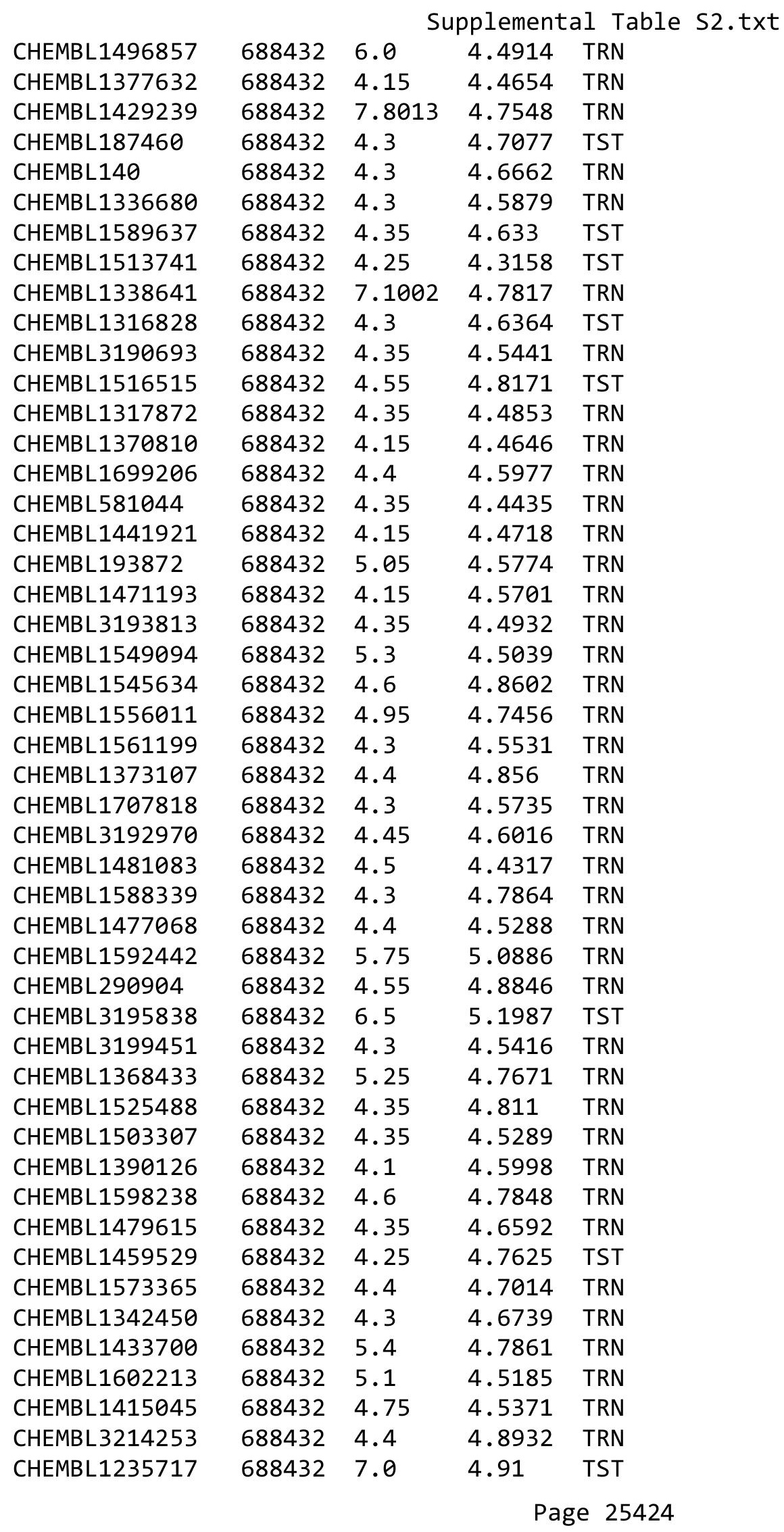




\begin{tabular}{|c|c|c|c|c|c|}
\hline \multicolumn{6}{|c|}{ Supplemental Table S2.txt } \\
\hline CHEMBL1370401 & 688432 & 4.3 & 4.7292 & TRN & \\
\hline CHEMBL1499258 & 688432 & 4.75 & 4.5459 & TRN & \\
\hline CHEMBL1507162 & 688432 & 5.3 & 4.6323 & TRN & \\
\hline CHEMBL1343078 & 688432 & 5.15 & 4.85800 & 00000000005 & TRN \\
\hline CHEMBL1391629 & 688432 & 4.3 & 4.5188 & TST & \\
\hline CHEMBL1530677 & 688432 & 3.9 & 4.7251 & TST & \\
\hline CHEMBL1379505 & 688432 & 4.3 & 4.7091 & TRN & \\
\hline CHEMBL3199302 & 688432 & 4.3 & 4.9528 & TRN & \\
\hline CHEMBL1518073 & 688432 & 6.0 & 4.5498 & TRN & \\
\hline CHEMBL1569910 & 688432 & 5.05 & 4.4997 & TRN & \\
\hline CHEMBL1471289 & 688432 & 4.3 & 4.5139 & TRN & \\
\hline CHEMBL1505129 & 688432 & 4.3 & 4.55699 & 99999999995 & TRN \\
\hline CHEMBL1466913 & 688432 & 4.5 & 4.4807 & TRN & \\
\hline CHEMBL1533713 & 688432 & 4.4 & 4.9238 & TRN & \\
\hline CHEMBL1421559 & 688432 & 4.7 & 4.709 & TRN & \\
\hline CHEMBL1350152 & 688432 & 4.5 & 4.4799 & TRN & \\
\hline CHEMBL1549641 & 688432 & 5.45 & 4.8766 & TRN & \\
\hline CHEMBL1450834 & 688432 & 4.25 & 4.5834 & TST & \\
\hline CHEMBL1303139 & 688432 & 4.35 & 4.5237 & TRN & \\
\hline CHEMBL9637 & 688432 & 5.15 & 4.6799 & TRN & \\
\hline CHEMBL 2004160 & 688432 & 4.4 & 4.4956 & TRN & \\
\hline CHEMBL1321739 & 688432 & 4.45 & 4.8364 & TRN & \\
\hline CHEMBL1319648 & 688432 & 4.45 & 4.5704 & TST & \\
\hline CHEMBL1440703 & 688432 & 5.8 & 4.7467 & TRN & \\
\hline CHEMBL1522355 & 688432 & 7.1002 & 4.5857 & TRN & \\
\hline CHEMBL1580759 & 688432 & 5.6 & 4.962 & TST & \\
\hline CHEMBL1549333 & 688432 & 4.3 & 4.6132 & TRN & \\
\hline CHEMBL1446063 & 688432 & 6.9 & 5.0271 & TRN & \\
\hline CHEMBL1456438 & 688432 & 4.65 & 4.8093 & TRN & \\
\hline CHEMBL1415660 & 688432 & 4.15 & 4.4597 & TRN & \\
\hline CHEMBL1309987 & 688432 & 4.4 & 4.6063 & TST & \\
\hline CHEMBL1308842 & 688432 & 5.5 & 4.6807 & TRN & \\
\hline CHEMBL1498702 & 688432 & 4.45 & 4.539 & TRN & \\
\hline CHEMBL1325945 & 688432 & 5.8 & 4.6715 & TRN & \\
\hline CHEMBL1406555 & 688432 & 4.6 & 4.7218 & TRN & \\
\hline CHEMBL1495722 & 688432 & 4.3 & 5.0855 & TRN & \\
\hline CHEMBL1440853 & 688432 & 5.05 & 4.7335 & TRN & \\
\hline CHEMBL1232286 & 688432 & 4.0 & 4.3411 & TRN & \\
\hline CHEMBL1556290 & 688432 & 4.15 & 4.5251 & TRN & \\
\hline CHEMBL1508716 & 688432 & 4.35 & 4.4085 & TRN & \\
\hline CHEMBL1333604 & 688432 & 3.9 & 4.4764 & TRN & \\
\hline CHEMBL1598676 & 688432 & 4.6 & 4.5564 & TRN & \\
\hline CHEMBL1545093 & 688432 & 4.15 & 4.5509 & TRN & \\
\hline CHEMBL1346049 & 688432 & 4.95 & 4.7142 & TRN & \\
\hline CHEMBL1300574 & 688432 & 4.4 & 4.5424 & TRN & \\
\hline CHEMBL303579 & 688432 & 4.5 & 4.8889 & TST & \\
\hline CHEMBL1411407 & 688432 & 4.1 & 4.8531 & TRN & \\
\hline CHEMBL426404 & 688432 & 3.95 & 4.3868 & TST & \\
\hline
\end{tabular}




\begin{tabular}{|c|c|c|c|c|c|}
\hline \multicolumn{6}{|c|}{ Supplemental Table S2.txt } \\
\hline CHEMBL1423708 & 688432 & 5.6 & 4.5006 & TRN & \\
\hline CHEMBL1449047 & 688432 & 4.0 & 4.427 & TRN & \\
\hline CHEMBL1548822 & 688432 & 4.9 & 4.6551 & TRN & \\
\hline CHEMBL1599965 & 688432 & 4.25 & 4.5997 & TRN & \\
\hline CHEMBL1432963 & 688432 & 4.4 & 4.4866 & TRN & \\
\hline CHEMBL1525389 & 688432 & 4.45 & 5.3193 & TRN & \\
\hline CHEMBL 275938 & 688432 & 5.0 & 4.7102 & TRN & \\
\hline CHEMBL1492010 & 688432 & 4.1 & 4.4572 & TRN & \\
\hline CHEMBL1410548 & 688432 & 4.5 & 4.5701 & TRN & \\
\hline CHEMBL1543904 & 688432 & 4.35 & 4.681 & TRN & \\
\hline CHEMBL1414678 & 688432 & 6.6 & 5.1302 & TRN & \\
\hline CHEMBL1547630 & 688432 & 6.4 & 4.7558 & TRN & \\
\hline CHEMBL1388300 & 688432 & 4.65 & 4.7016 & TRN & \\
\hline CHEMBL1351168 & 688432 & 5.35 & 4.8266 & TST & \\
\hline CHEMBL1605813 & 688432 & 4.15 & 4.4819 & TRN & \\
\hline CHEMBL1585268 & 688432 & 4.1 & 4.5988 & TRN & \\
\hline CHEMBL 2000670 & 688432 & 4.4 & 4.4993 & TRN & \\
\hline CHEMBL1600397 & 688432 & 4.15 & 4.81800 & 00000000005 & TRN \\
\hline CHEMBL1316166 & 688432 & 4.25 & 4.3729 & TRN & \\
\hline CHEMBL133576 & 688432 & 4.35 & 4.5847 & TRN & \\
\hline CHEMBL1983745 & 688432 & 4.15 & 4.4511 & TRN & \\
\hline CHEMBL1525219 & 688432 & 5.4 & 5.1395 & TRN & \\
\hline CHEMBL1586726 & 688432 & 4.8 & 4.4793 & TRN & \\
\hline CHEMBL1517908 & 688432 & 4.0 & 5.1367 & TRN & \\
\hline CHEMBL1477505 & 688432 & 5.05 & 5.0779 & TRN & \\
\hline CHEMBL1323879 & 688432 & 4.05 & 5.2557 & TRN & \\
\hline CHEMBL1477399 & 688432 & 4.25 & 4.859 & TRN & \\
\hline CHEMBL1399215 & 688432 & 4.9 & 4.7117 & TST & \\
\hline CHEMBL1446863 & 688432 & 4.6 & 4.5874 & TRN & \\
\hline CHEMBL1555717 & 688432 & 5.15 & 4.706 & TRN & \\
\hline CHEMBL1454001 & 688432 & 6.8499 & 5.3605 & TRN & \\
\hline CHEMBL1575869 & 688432 & 5.05 & 4.7346 & TRN & \\
\hline CHEMBL1367882 & 688432 & 4.3 & 4.9178 & TRN & \\
\hline CHEMBL1372240 & 688432 & 4.15 & 4.4897 & TRN & \\
\hline CHEMBL1541259 & 688432 & 4.5 & 4.6778 & TRN & \\
\hline CHEMBL1370741 & 688432 & 4.35 & 4.7035 & TRN & \\
\hline CHEMBL1562712 & 688432 & 4.35 & 4.7048 & TRN & \\
\hline CHEMBL1426288 & 688432 & 4.15 & 4.9653 & TRN & \\
\hline CHEMBL1421993 & 688432 & 4.4 & 4.6558 & TRN & \\
\hline CHEMBL1390633 & 688432 & 5.2 & 4.4827 & TST & \\
\hline CHEMBL1142 & 688432 & 4.45 & 4.4531 & TRN & \\
\hline CHEMBL1393457 & 688432 & 4.15 & 4.8228 & TST & \\
\hline CHEMBL3196164 & 688432 & 4.4 & 4.4888 & TRN & \\
\hline CHEMBL1483809 & 688432 & 4.5 & 4.6653 & TRN & \\
\hline CHEMBL1432476 & 688432 & 4.3 & 4.56 & TRN & \\
\hline CHEMBL1316831 & 688432 & 4.9 & 4.6346 & TST & \\
\hline CHEMBL1368936 & 688432 & 4.15 & 4.9184 & TRN & \\
\hline CHEMBL120526 & 688432 & 4.3 & 4.8727 & TST & \\
\hline
\end{tabular}




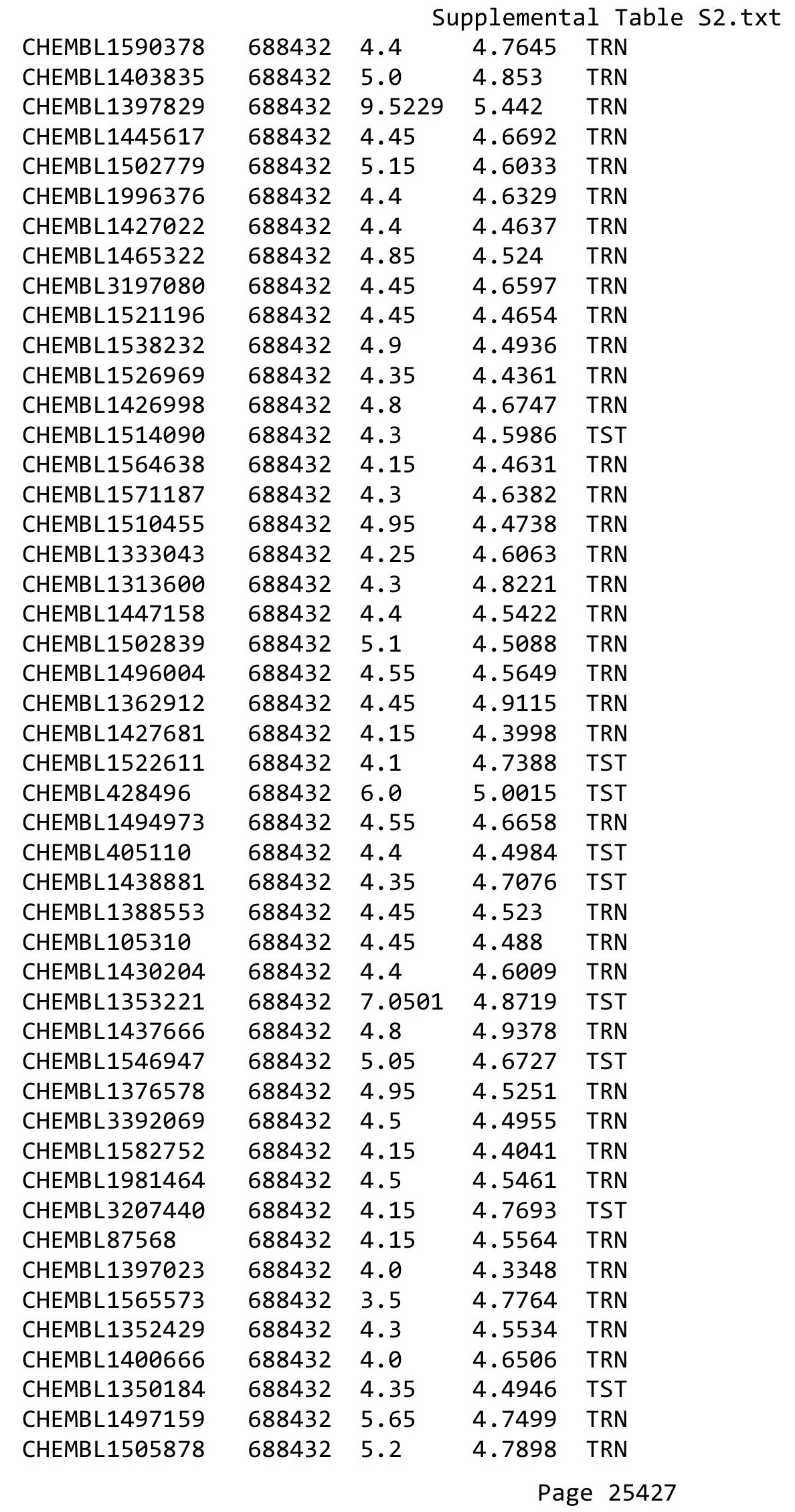




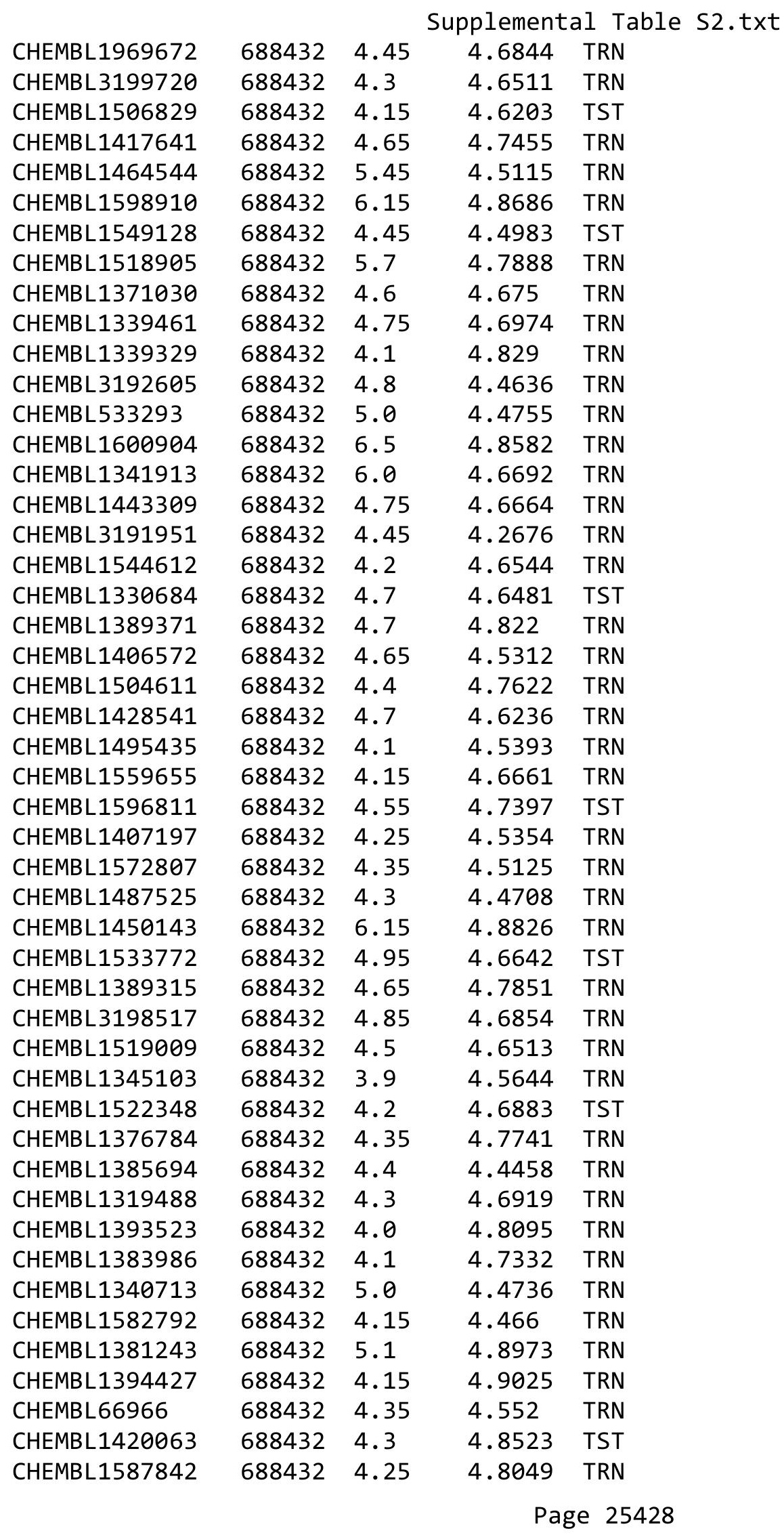




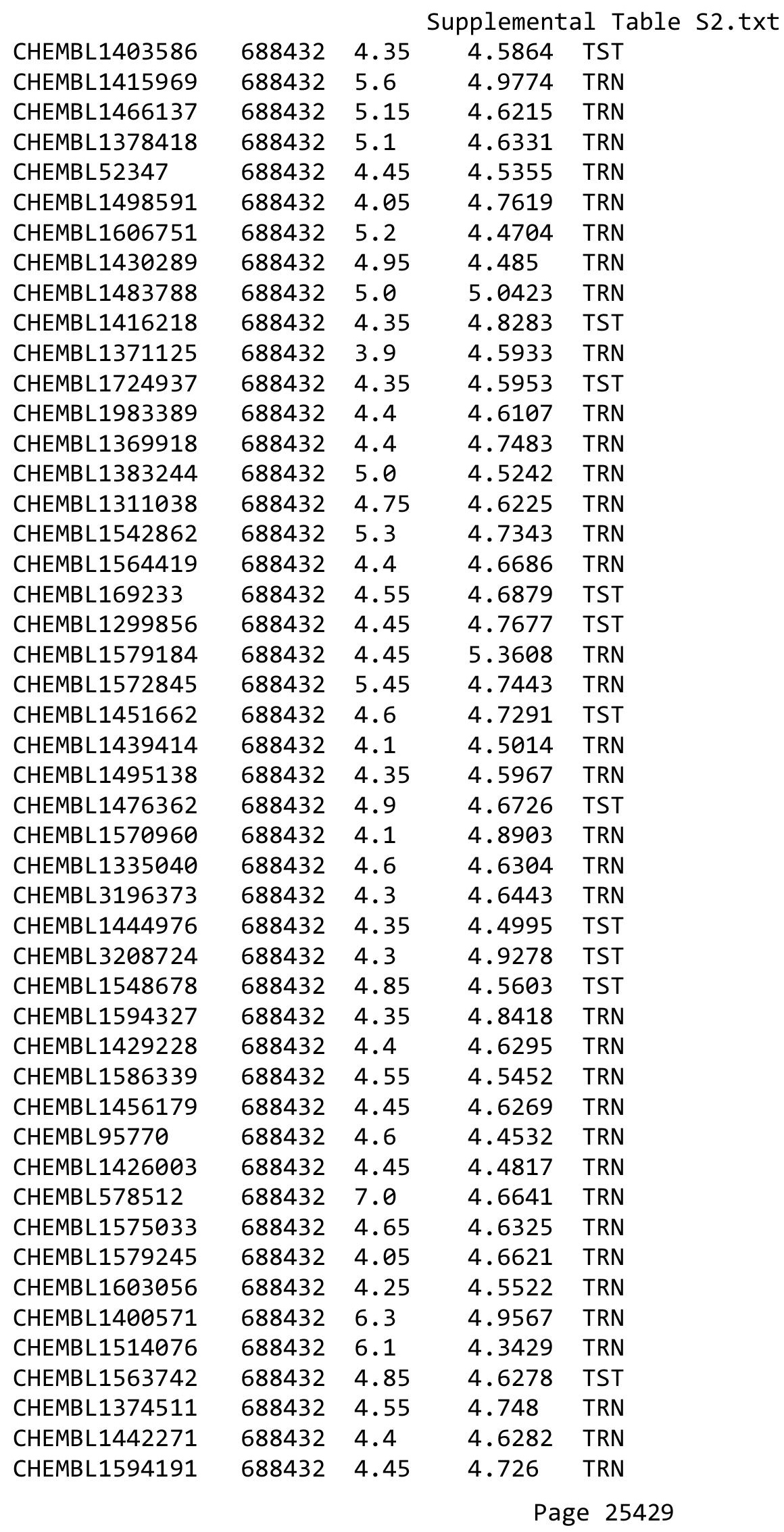




\begin{tabular}{|c|c|c|c|c|}
\hline \multicolumn{5}{|c|}{ Supplemental Table S2.txt } \\
\hline CHEMBL3195977 & 688432 & 5.2 & 4.5849 & TRN \\
\hline CHEMBL1366767 & 688432 & 4.3 & 4.6332 & TRN \\
\hline CHEMBL1533336 & 688432 & 4.45 & 4.6835 & TRN \\
\hline CHEMBL1968316 & 688432 & 4.45 & 4.5338 & TRN \\
\hline CHEMBL1608275 & 688432 & 4.1 & 4.6643 & TRN \\
\hline CHEMBL1443157 & 688432 & 4.3 & 4.565 & TST \\
\hline CHEMBL1362935 & 688432 & 4.25 & 4.5803 & TST \\
\hline CHEMBL1561455 & 688432 & 4.35 & 4.484 & TRN \\
\hline CHEMBL1428123 & 688432 & 4.65 & 4.7771 & TRN \\
\hline CHEMBL1368444 & 688432 & 4.1 & 4.627 & TRN \\
\hline CHEMBL 3210227 & 688432 & 4.75 & 4.6679 & TRN \\
\hline CHEMBL1397308 & 688432 & 4.4 & 4.4933 & TST \\
\hline CHEMBL1340722 & 688432 & 4.1 & 4.6848 & TRN \\
\hline CHEMBL1324024 & 688432 & 4.4 & 4.4346 & TRN \\
\hline CHEMBL3196335 & 688432 & 4.6 & 4.6529 & TRN \\
\hline CHEMBL1535693 & 688432 & 4.15 & 4.8897 & TRN \\
\hline CHEMBL1586884 & 688432 & 4.35 & 4.8876 & TRN \\
\hline CHEMBL1470135 & 688432 & 4.6 & 4.7249 & TRN \\
\hline CHEMBL1306658 & 688432 & 4.1 & 4.8268 & TRN \\
\hline CHEMBL1485865 & 688432 & 4.65 & 4.6416 & TRN \\
\hline CHEMBL1473264 & 688432 & 4.55 & 4.9317 & TRN \\
\hline CHEMBL1542128 & 688432 & 4.85 & 4.4312 & TRN \\
\hline CHEMBL1513776 & 688432 & 5.05 & 4.8046 & TRN \\
\hline CHEMBL1494098 & 688432 & 4.5 & 5.2841 & TRN \\
\hline CHEMBL1428442 & 688432 & 4.1 & 4.63 & TRN \\
\hline CHEMBL1370416 & 688432 & 6.45 & 4.4046 & TRN \\
\hline CHEMBL3198838 & 688432 & 4.35 & 4.4626 & TRN \\
\hline CHEMBL1424694 & 688432 & 4.6 & 4.6517 & TST \\
\hline CHEMBL1312214 & 688432 & 4.35 & 4.4719 & TRN \\
\hline CHEMBL3192031 & 688432 & 4.35 & 4.8685 & TRN \\
\hline CHEMBL1532072 & 688432 & 4.55 & 4.5274 & TRN \\
\hline CHEMBL1517255 & 688432 & 5.1 & 4.5822 & TRN \\
\hline CHEMBL1414871 & 688432 & 4.3 & 4.6063 & TRN \\
\hline CHEMBL1611620 & 688432 & 4.25 & 4.5068 & TRN \\
\hline CHEMBL1494571 & 688432 & 4.3 & 4.9396 & TRN \\
\hline CHEMBL1421172 & 688432 & 4.45 & 4.5863 & TRN \\
\hline CHEMBL1384279 & 688432 & 4.3 & 4.7497 & TRN \\
\hline CHEMBL1489356 & 688432 & 4.1 & 4.9086 & TRN \\
\hline CHEMBL1592221 & 688432 & 4.45 & 5.2105 & TRN \\
\hline CHEMBL1340678 & 688432 & 4.1 & 4.6602 & TRN \\
\hline CHEMBL1457022 & 688432 & 4.4 & 4.6286 & TRN \\
\hline CHEMBL1412163 & 688432 & 5.2 & 4.7141 & TST \\
\hline CHEMBL1596115 & 688432 & 4.45 & 4.4931 & TRN \\
\hline CHEMBL1387693 & 688432 & 4.3 & 4.5945 & TRN \\
\hline CHEMBL1975523 & 688432 & 4.3 & 4.4863 & TRN \\
\hline CHEMBL1482115 & 688432 & 4.1 & 4.8519 & TRN \\
\hline CHEMBL1358724 & 688432 & 4.35 & 4.7408 & TST \\
\hline CHEMBL1332010 & 688432 & 4.75 & 4.9396 & TRN \\
\hline
\end{tabular}




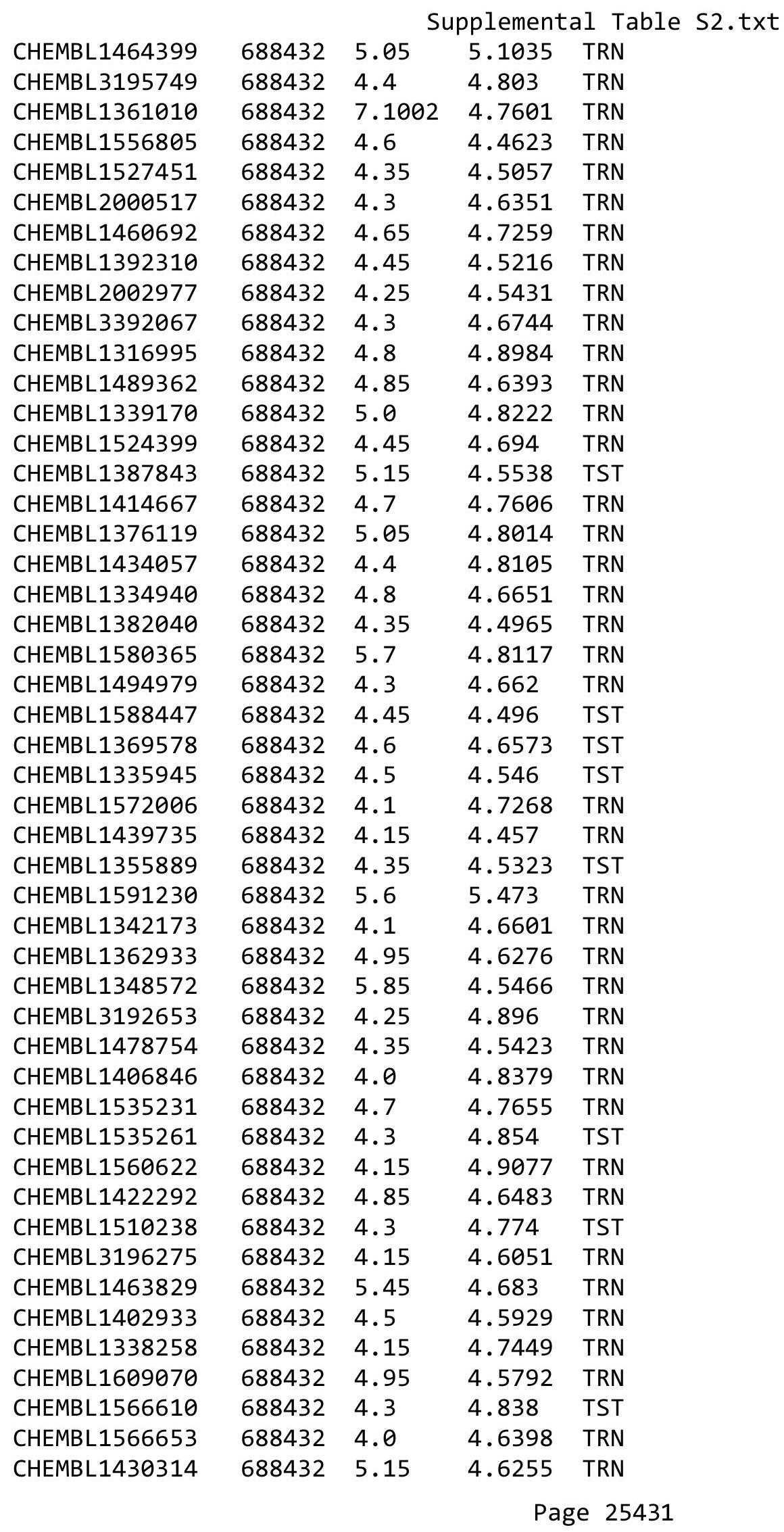




\begin{tabular}{|c|c|c|c|c|}
\hline & & & pplement & al Table S \\
\hline CHEMBL1403154 & 688432 & 4.55 & 4.7791 & TRN \\
\hline CHEMBL1566786 & 688432 & 4.8 & 4.6481 & TRN \\
\hline CHEMBL1301127 & 688432 & 5.3 & 4.6604 & TST \\
\hline CHEMBL1403748 & 688432 & 4.1 & 4.5235 & TRN \\
\hline CHEMBL1502381 & 688432 & 4.3 & 4.62 & TRN \\
\hline CHEMBL1439895 & 688432 & 4.5 & 4.6037 & TRN \\
\hline CHEMBL1490449 & 688432 & 4.3 & 4.6707 & TST \\
\hline CHEMBL1454269 & 688432 & 4.55 & 4.4665 & TRN \\
\hline CHEMBL1346640 & 688432 & 4.6 & 4.7574 & TRN \\
\hline CHEMBL1443088 & 688432 & 4.7 & 4.4544 & TRN \\
\hline CHEMBL1521960 & 688432 & 5.2 & 4.7577 & TRN \\
\hline CHEMBL1553873 & 688432 & 4.6 & 4.6635 & TRN \\
\hline CHEMBL1603047 & 688432 & 5.4 & 4.6189 & TRN \\
\hline CHEMBL1330802 & 688432 & 4.35 & 4.7158 & TRN \\
\hline CHEMBL1363197 & 688432 & 4.35 & 4.4779 & TRN \\
\hline CHEMBL1458799 & 688432 & 5.1 & 4.6961 & TRN \\
\hline CHEMBL1509349 & 688432 & 4.5 & 4.5969 & TRN \\
\hline CHEMBL1569846 & 688432 & 4.75 & 4.7594 & TRN \\
\hline CHEMBL1506031 & 688432 & 5.2 & 4.6005 & TRN \\
\hline CHEMBL1420075 & 688432 & 4.6 & 4.6572 & TRN \\
\hline CHEMBL1389346 & 688432 & 4.25 & 4.7663 & TST \\
\hline CHEMBL1576254 & 688432 & 4.35 & 4.6422 & TRN \\
\hline CHEMBL1502681 & 688432 & 4.0 & 4.6778 & TRN \\
\hline CHEMBL 258728 & 688432 & 4.15 & 4.7895 & TST \\
\hline CHEMBL1573910 & 688432 & 4.75 & 4.822 & TRN \\
\hline CHEMBL1598092 & 688432 & 4.45 & 4.5816 & TRN \\
\hline CHEMBL1339311 & 688432 & 4.35 & 4.4673 & TST \\
\hline CHEMBL1540209 & 688432 & 4.35 & 4.4967 & TRN \\
\hline CHEMBL1524608 & 688432 & 4.1 & 4.4656 & TRN \\
\hline CHEMBL1368165 & 688432 & 4.45 & 4.5916 & TST \\
\hline CHEMBL1974319 & 688432 & 4.15 & 4.5215 & TRN \\
\hline CHEMBL1347877 & 688432 & 5.4 & 4.8774 & TRN \\
\hline CHEMBL1569232 & 688432 & 4.45 & 4.4465 & TRN \\
\hline CHEMBL1525860 & 688432 & 4.5 & 4.7487 & TST \\
\hline CHEMBL478 & 688432 & 5.05 & 4.5015 & TRN \\
\hline CHEMBL1373781 & 688432 & 4.3 & 4.7444 & TRN \\
\hline CHEMBL1427637 & 688432 & 4.7 & 4.7393 & TRN \\
\hline CHEMBL1386493 & 688432 & 5.05 & 4.6057 & TRN \\
\hline CHEMBL1465049 & 688432 & 6.0 & 4.458 & TRN \\
\hline CHEMBL3192017 & 688432 & 4.3 & $4.7360 e$ & 0000000001 \\
\hline CHEMBL 3145187 & 688432 & 5.45 & 4.7803 & TST \\
\hline CHEMBL1494557 & 688432 & 4.55 & 4.648 & TRN \\
\hline CHEMBL1513351 & 688432 & 6.05 & 5.095 & TRN \\
\hline CHEMBL1451264 & 688432 & 5.35 & 4.3905 & TRN \\
\hline CHEMBL1533561 & 688432 & 4.4 & 4.5965 & TRN \\
\hline CHEMBL1380403 & 688432 & 4.15 & 4.7057 & TRN \\
\hline CHEMBL1445776 & 688432 & 4.4 & 4.6922 & TRN \\
\hline CHEMBL602561 & 688432 & 4.3 & 4.4971 & TRN \\
\hline
\end{tabular}




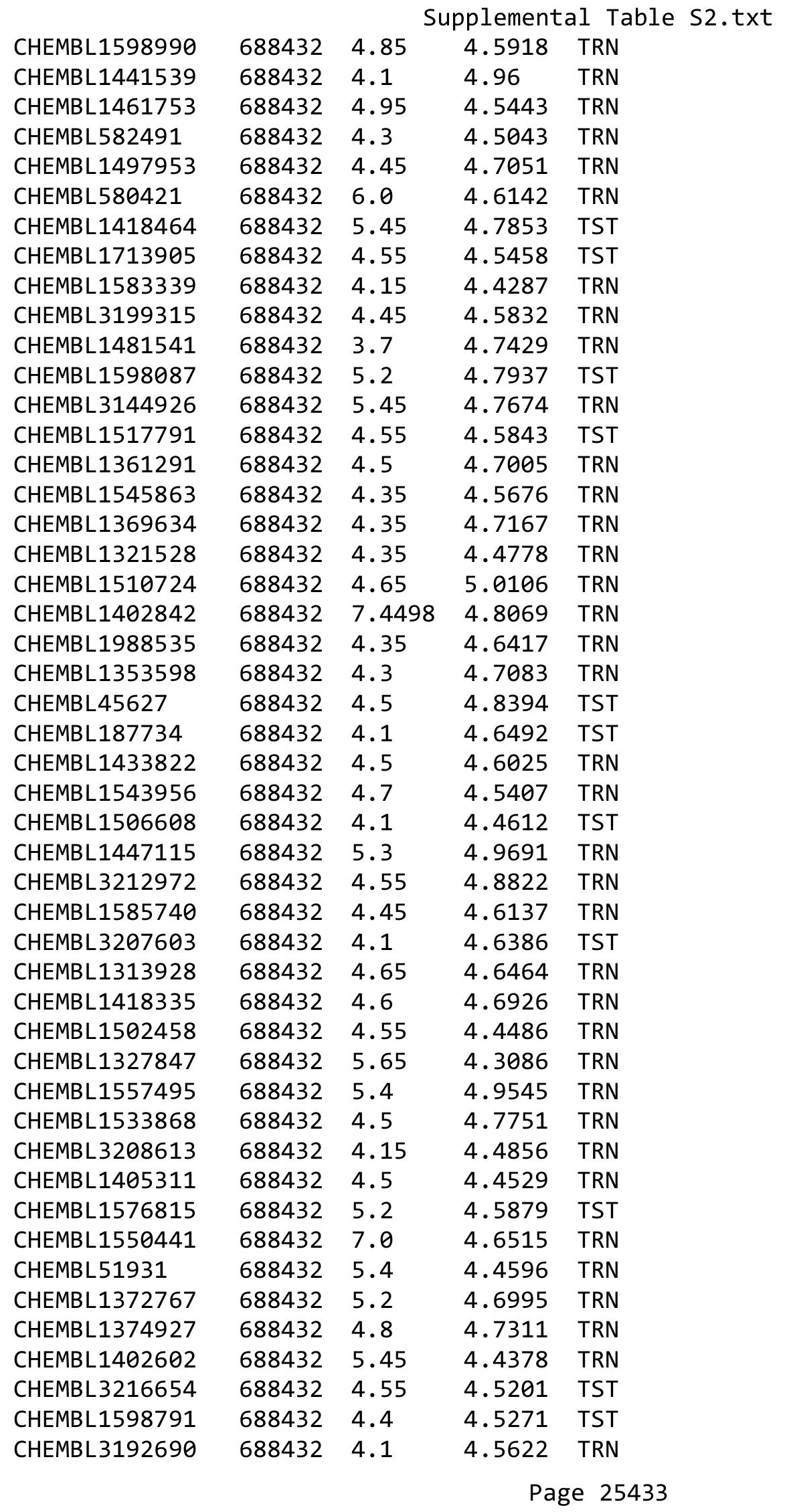




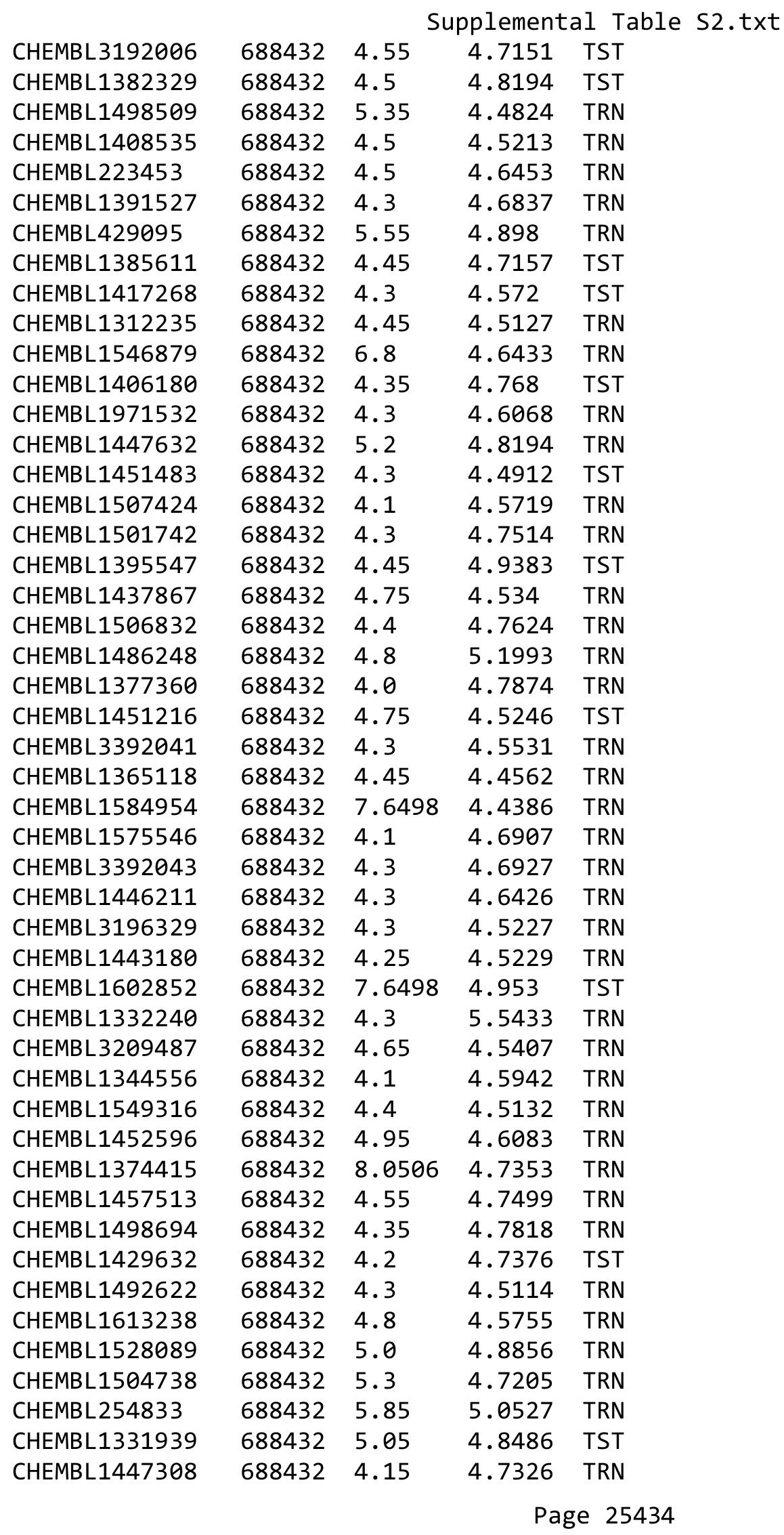




\begin{tabular}{|c|c|c|c|c|c|}
\hline \multicolumn{6}{|c|}{ Supplemental Table S2.txt } \\
\hline CHEMBL1996858 & 688432 & 4.3 & 4.4283 & TRN & \\
\hline CHEMBL1471607 & 688432 & 3.95 & 4.7895 & TST & \\
\hline CHEMBL1505494 & 688432 & 4.4 & 4.7578 & TRN & \\
\hline CHEMBL1536418 & 688432 & 4.65 & 4.6929 & TST & \\
\hline CHEMBL 366861 & 688432 & 4.5 & 4.7166 & TST & \\
\hline CHEMBL1432849 & 688432 & 4.35 & 4.6893 & TRN & \\
\hline CHEMBL1514696 & 688432 & 4.45 & 4.0123 & TRN & \\
\hline CHEMBL1548770 & 688432 & 4.4 & 4.7303 & TRN & \\
\hline CHEMBL1489685 & 688432 & 4.3 & 4.8042 & TRN & \\
\hline CHEMBL1391326 & 688432 & 4.7 & 4.4374 & TRN & \\
\hline CHEMBL1607905 & 688432 & 4.6 & 4.6214 & TRN & \\
\hline CHEMBL1453329 & 688432 & 4.65 & $4.5280 e$ & 00000000005 & TRN \\
\hline CHEMBL1438240 & 688432 & 4.2 & 4.7633 & TRN & \\
\hline CHEMBL1351687 & 688432 & 4.5 & 4.8489 & TRN & \\
\hline CHEMBL1434121 & 688432 & 5.3 & 4.7794 & TRN & \\
\hline CHEMBL1562963 & 688432 & 4.6 & 4.6848 & TRN & \\
\hline CHEMBL1561086 & 688432 & 4.3 & 4.8997 & TRN & \\
\hline CHEMBL1497014 & 688432 & 5.5 & 4.6973 & TRN & \\
\hline CHEMBL1419637 & 688432 & 4.4 & 4.4827 & TST & \\
\hline CHEMBL1966792 & 688432 & 4.4 & 4.6898 & TRN & \\
\hline CHEMBL1316440 & 688432 & 3.5 & 4.6145 & TRN & \\
\hline CHEMBL1553510 & 688432 & 5.1 & 4.7894 & TRN & \\
\hline CHEMBL1319963 & 688432 & 4.1 & 4.9495 & TRN & \\
\hline CHEMBL1412914 & 688432 & 4.4 & 4.779 & TRN & \\
\hline CHEMBL446315 & 688432 & 4.3 & 4.6446 & TST & \\
\hline CHEMBL1365627 & 688432 & 5.05 & 4.7237 & TRN & \\
\hline CHEMBL1456904 & 688432 & 4.95 & 4.6815 & TRN & \\
\hline CHEMBL1559341 & 688432 & 4.4 & 4.6308 & TRN & \\
\hline CHEMBL1522369 & 688432 & 4.15 & 4.8813 & TRN & \\
\hline CHEMBL1342410 & 688432 & 4.55 & 4.6766 & TRN & \\
\hline CHEMBL1319476 & 688432 & 4.45 & 4.7247 & TRN & \\
\hline CHEMBL1309430 & 688432 & 4.65 & 4.4992 & TRN & \\
\hline CHEMBL1364176 & 688432 & 5.15 & 4.5462 & TRN & \\
\hline CHEMBL1474161 & 688432 & 4.2 & 4.8504 & TRN & \\
\hline CHEMBL1445088 & 688432 & 4.25 & 4.7632 & TST & \\
\hline CHEMBL1484663 & 688432 & 4.55 & 4.7195 & TRN & \\
\hline CHEMBL1528757 & 688432 & 4.3 & 4.5477 & TST & \\
\hline CHEMBL1449979 & 688432 & 6.5 & 4.6971 & TRN & \\
\hline CHEMBL1321789 & 688432 & 4.4 & 4.7424 & TRN & \\
\hline CHEMBL345635 & 688432 & 4.6 & 4.5075 & TRN & \\
\hline CHEMBL1358778 & 688432 & 4.45 & 4.4741 & TRN & \\
\hline CHEMBL1327521 & 688432 & 4.15 & 4.4265 & TRN & \\
\hline CHEMBL1470648 & 688432 & 4.45 & 4.6097 & TST & \\
\hline CHEMBL1399458 & 688432 & 4.55 & 4.6403 & TRN & \\
\hline CHEMBL1503962 & 688432 & 4.7 & 4.5566 & TRN & \\
\hline CHEMBL1397470 & 688432 & 4.15 & 4.334 & TRN & \\
\hline CHEMBL1596192 & 688432 & 5.55 & 4.9237 & TRN & \\
\hline CHEMBL1444690 & 688432 & 4.4 & 4.6817 & TST & \\
\hline
\end{tabular}




\begin{tabular}{|c|c|c|c|c|c|}
\hline \multirow[b]{2}{*}{ CHEMBL1421298 } & \multicolumn{5}{|c|}{ Supplemental Table S2.txt } \\
\hline & 688432 & 7.0501 & 4.783 & TST & \\
\hline CHEMBL1302599 & 688432 & 4.35 & 4.5017 & TRN & \\
\hline CHEMBL3191837 & 688432 & 4.15 & 4.8316 & TRN & \\
\hline CHEMBL584759 & 688432 & 6.0 & 4.918 & TST & \\
\hline CHEMBL1510145 & 688432 & 7.4498 & 4.77800 & 00000000005 & TRN \\
\hline CHEMBL1543877 & 688432 & 4.55 & 4.8005 & TRN & \\
\hline CHEMBL1604942 & 688432 & 4.05 & 4.7791 & TRN & \\
\hline CHEMBL1368178 & 688432 & 4.35 & 4.4321 & TRN & \\
\hline CHEMBL1402202 & 688432 & 4.0 & 4.7294 & TRN & \\
\hline CHEMBL1538354 & 688432 & 5.1 & 4.7573 & TRN & \\
\hline CHEMBL1584415 & 688432 & 4.4 & 4.6942 & TRN & \\
\hline CHEMBL1990774 & 688432 & 4.4 & 4.4449 & TRN & \\
\hline CHEMBL1455567 & 688432 & 4.3 & 4.4929 & TRN & \\
\hline CHEMBL1540330 & 688432 & 4.9 & 4.7173 & TRN & \\
\hline CHEMBL1603478 & 688432 & 4.0 & 4.6643 & TRN & \\
\hline CHEMBL1398383 & 688432 & 3.95 & 4.3591 & TRN & \\
\hline CHEMBL 2018847 & 688432 & 4.4 & 4.5248 & TRN & \\
\hline CHEMBL3193878 & 688432 & 4.5 & 4.4381 & TRN & \\
\hline CHEMBL1368428 & 688432 & 4.45 & 4.4316 & TRN & \\
\hline CHEMBL1603994 & 688432 & 4.0 & 4.8218 & TRN & \\
\hline CHEMBL1304179 & 688432 & 4.15 & 4.6268 & TRN & \\
\hline CHEMBL1318425 & 688432 & 5.15 & 4.6271 & TRN & \\
\hline CHEMBL1600163 & 688432 & 4.35 & 4.5035 & TST & \\
\hline CHEMBL1584739 & 688432 & 4.6 & 4.7973 & TRN & \\
\hline CHEMBL1443679 & 688432 & 4.45 & 4.7704 & TRN & \\
\hline CHEMBL1328361 & 688432 & 4.15 & 4.4847 & TRN & \\
\hline CHEMBL1318943 & 688432 & 4.5 & 4.6817 & TRN & \\
\hline CHEMBL1343118 & 688432 & 4.85 & 4.7592 & TRN & \\
\hline CHEMBL1429882 & 688432 & 4.15 & 4.7344 & TRN & \\
\hline CHEMBL1411246 & 688432 & 6.0 & 4.9348 & TST & \\
\hline CHEMBL1256751 & 688432 & 4.45 & 4.6911 & TRN & \\
\hline CHEMBL1451931 & 688432 & 4.45 & 4.7046 & TRN & \\
\hline CHEMBL1580845 & 688432 & 4.4 & 4.4373 & TRN & \\
\hline CHEMBL1412821 & 688432 & 4.25 & 4.7988 & TST & \\
\hline CHEMBL1404241 & 688432 & 4.3 & 4.4743 & TRN & \\
\hline CHEMBL1500751 & 688432 & 4.95 & 4.7184 & TST & \\
\hline CHEMBL1482003 & 688432 & 4.45 & 4.5571 & TRN & \\
\hline CHEMBL1570240 & 688432 & 4.35 & 4.7781 & TRN & \\
\hline CHEMBL1496575 & 688432 & 5.05 & 4.579 & TST & \\
\hline CHEMBL1419141 & 688432 & 4.25 & 4.7604 & TST & \\
\hline CHEMBL1364416 & 688432 & 4.45 & 4.5722 & TRN & \\
\hline CHEMBL1370456 & 688432 & 4.55 & 4.5629 & TST & \\
\hline CHEMBL1968732 & 688432 & 4.55 & 4.8713 & TRN & \\
\hline CHEMBL1460266 & 688432 & 4.1 & 4.6928 & TRN & \\
\hline CHEMBL1566891 & 688432 & 4.95 & 4.6602 & TRN & \\
\hline CHEMBL1299407 & 688432 & 4.65 & 4.7563 & TRN & \\
\hline CHEMBL1306199 & 688432 & 5.4 & 4.6842 & TRN & \\
\hline CHEMBL1320414 & 688432 & 4.5 & 4.7206 & TRN & \\
\hline
\end{tabular}




\begin{tabular}{|c|c|c|c|c|c|}
\hline & & \multicolumn{4}{|c|}{ Supplemental Table S2.txt } \\
\hline CHEMBL1336082 & 688432 & 4.25 & 4.8328 & TRN & \\
\hline CHEMBL 1435318 & 688432 & 4.3 & 4.6308 & TRN & \\
\hline CHEMBL1567974 & 688432 & 4.15 & 4.851 & TRN & \\
\hline CHEMBL1516568 & 688432 & 4.4 & 4.2954 & TRN & \\
\hline CHEMBL1369200 & 688432 & 4.3 & 4.5748 & TRN & \\
\hline CHEMBL1570497 & 688432 & 4.95 & 4.5635 & TST & \\
\hline CHEMBL 3192687 & 688432 & 4.55 & 4.5121 & TRN & \\
\hline CHEMBL1414022 & 688432 & 4.4 & 5.0159 & TRN & \\
\hline CHEMBL1442893 & 688432 & 4.35 & 4.4813 & TRN & \\
\hline CHEMBL1554411 & 688432 & 4.15 & 4.6366 & TRN & \\
\hline CHEMBL1510156 & 688432 & 5.8 & 4.862 & TST & \\
\hline CHEMBL1301512 & 688432 & 4.35 & 4.4222 & TST & \\
\hline CHEMBL1528787 & 688432 & 4.35 & 4.52800 & 00000000005 & TST \\
\hline CHEMBL1581746 & 688432 & 4.3 & 4.6562 & TRN & \\
\hline CHEMBL1335844 & 688432 & 4.15 & 4.6723 & TRN & \\
\hline CHEMBL1540929 & 688432 & 4.5 & 4.77800 & 00000000005 & TRN \\
\hline CHEMBL1494100 & 688432 & 4.65 & 4.7326 & TRN & \\
\hline CHEMBL 267548 & 688432 & 6.0 & 4.9354 & TST & \\
\hline CHEMBL1596521 & 688432 & 5.6 & 4.7729 & TRN & \\
\hline CHEMBL1587837 & 688432 & 4.3 & 4.6182 & TRN & \\
\hline CHEMBL1528308 & 688432 & 4.35 & 4.7787 & TST & \\
\hline CHEMBL1307406 & 688432 & 6.3 & 4.7817 & TRN & \\
\hline CHEMBL1404346 & 688432 & 5.95 & 5.3972 & TRN & \\
\hline CHEMBL1416493 & 688432 & 4.5 & 4.8164 & TRN & \\
\hline CHEMBL1558240 & 688432 & 4.45 & 4.4548 & TRN & \\
\hline CHEMBL3211976 & 688432 & 4.7 & 4.5823 & TRN & \\
\hline CHEMBL1534863 & 688432 & 4.1 & 4.5343 & TST & \\
\hline CHEMBL1978236 & 688432 & 4.45 & 4.4783 & TRN & \\
\hline CHEMBL 1357842 & 688432 & 4.3 & 4.4422 & TRN & \\
\hline CHEMBL1308993 & 688432 & 4.4 & 4.4603 & TRN & \\
\hline CHEMBL1571034 & 688432 & 4.8 & 4.4564 & TRN & \\
\hline CHEMBL376503 & 688432 & 4.65 & 4.5941 & TRN & \\
\hline CHEMBL1408705 & 688432 & 4.3 & 4.6243 & TRN & \\
\hline CHEMBL1537553 & 688432 & 5.1 & 4.6973 & TRN & \\
\hline CHEMBL1443059 & 688432 & 4.25 & 4.5239 & TRN & \\
\hline CHEMBL1401486 & 688432 & 4.55 & 4.5404 & TRN & \\
\hline CHEMBL1378396 & 688432 & 4.1 & 4.7202 & TRN & \\
\hline CHEMBL1423479 & 688432 & 4.6 & 4.7055 & TRN & \\
\hline CHEMBL1302756 & 688432 & 4.7 & 4.4754 & TRN & \\
\hline CHEMBL1483547 & 688432 & 4.6 & 4.5377 & TRN & \\
\hline CHEMBL97453 & 688432 & 4.3 & 4.9136 & TRN & \\
\hline CHEMBL3190629 & 688432 & 4.45 & 4.5807 & TRN & \\
\hline CHEMBL1355965 & 688432 & 4.15 & 4.5503 & TST & \\
\hline CHEMBL1310738 & 688432 & 4.75 & 4.7907 & TRN & \\
\hline CHEMBL1331134 & 688432 & 4.4 & 4.6091 & TRN & \\
\hline CHEMBL15766 & 688432 & 4.3 & 4.546 & TST & \\
\hline CHEMBL1548993 & 688432 & 7.0501 & 5.2174 & TRN & \\
\hline CHEMBL1572216 & 688432 & 4.9 & 4.6839 & TRN & \\
\hline
\end{tabular}




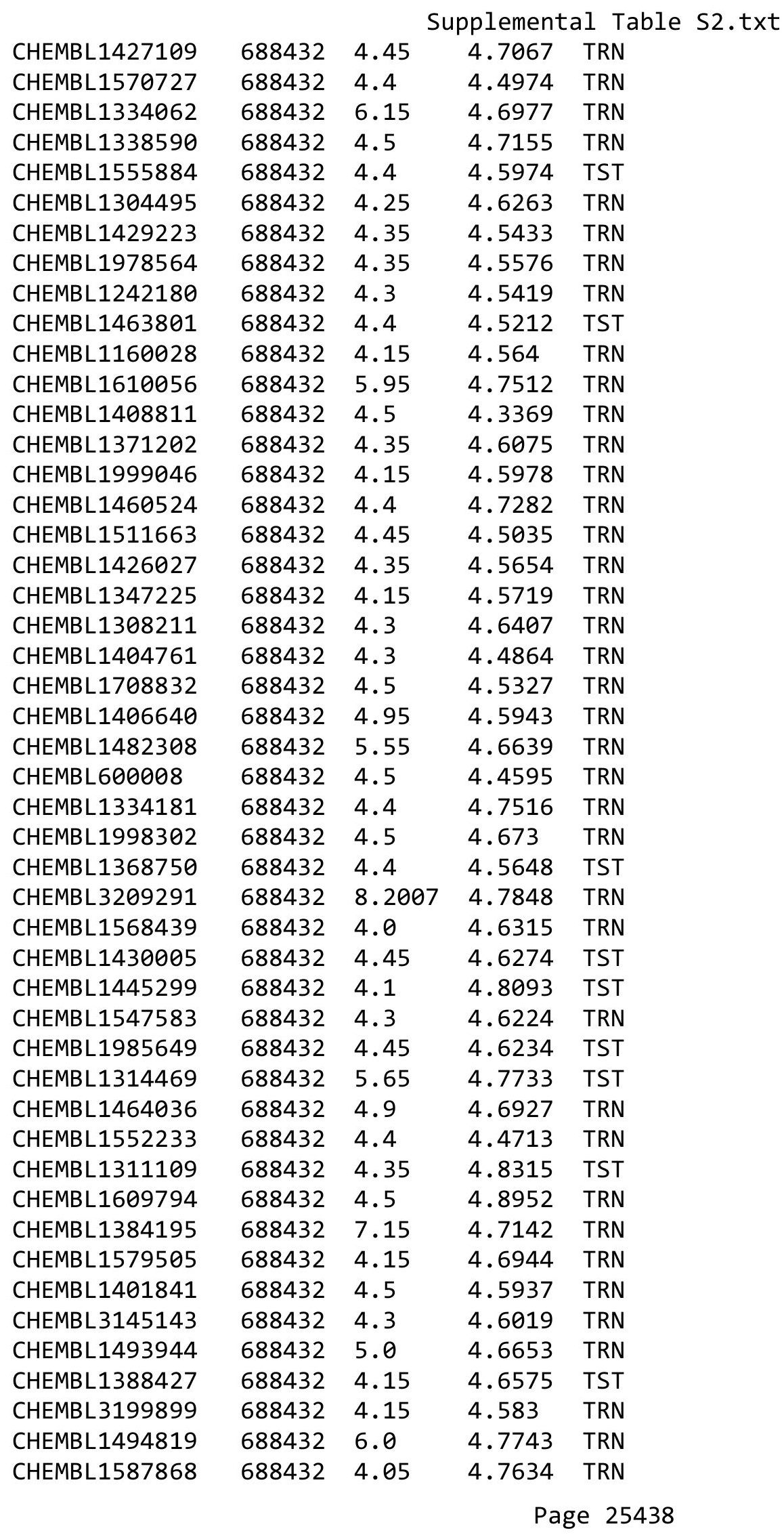




\begin{tabular}{|c|c|c|c|c|c|}
\hline \multicolumn{6}{|c|}{ Supplemental Table S2.txt } \\
\hline CHEMBL1518189 & 688432 & 4.45 & 4.9279 & TRN & \\
\hline CHEMBL1550490 & 688432 & 4.55 & 4.7912 & TRN & \\
\hline CHEMBL1606342 & 688432 & 4.3 & 4.4825 & TRN & \\
\hline CHEMBL1305272 & 688432 & 6.7501 & 4.7563 & TRN & \\
\hline CHEMBL1397959 & 688432 & 5.7 & 4.68199 & 99999999995 & TRN \\
\hline CHEMBL1358777 & 688432 & 4.5 & 4.6972 & TRN & \\
\hline CHEMBL1539317 & 688432 & 4.15 & 4.4142 & TRN & \\
\hline CHEMBL1563624 & 688432 & 5.0 & 4.5249 & TST & \\
\hline CHEMBL1573361 & 688432 & 5.0 & 5.0095 & TRN & \\
\hline CHEMBL43612 & 688432 & 6.0 & 4.9197 & TRN & \\
\hline CHEMBL3193785 & 688432 & 4.75 & 4.4593 & TRN & \\
\hline CHEMBL1596755 & 688432 & 4.4 & 4.5431 & TRN & \\
\hline CHEMBL1572280 & 688432 & 4.65 & 4.5548 & TRN & \\
\hline CHEMBL1511437 & 688432 & 4.35 & 4.4127 & TRN & \\
\hline CHEMBL3191236 & 688432 & 4.4 & 4.4592 & TRN & \\
\hline CHEMBL1464832 & 688432 & 4.3 & 4.7073 & TRN & \\
\hline CHEMBL1560141 & 688432 & 5.1 & 4.6656 & TST & \\
\hline CHEMBL1434137 & 688432 & 4.15 & 4.4346 & TST & \\
\hline CHEMBL 2132953 & 688432 & 4.55 & 4.4503 & TST & \\
\hline CHEMBL1494097 & 688432 & 4.65 & 4.7758 & TST & \\
\hline CHEMBL1468371 & 688432 & 4.45 & 4.6303 & TST & \\
\hline CHEMBL1367772 & 688432 & 4.1 & 4.836 & TST & \\
\hline CHEMBL1532953 & 688432 & 4.45 & 4.7445 & TST & \\
\hline CHEMBL1600976 & 688432 & 4.15 & 4.7834 & TST & \\
\hline CHEMBL1566134 & 688432 & 4.45 & 4.5938 & TST & \\
\hline CHEMBL3351065 & 688432 & 4.95 & 4.6603 & TST & \\
\hline CHEMBL3191652 & 688432 & 6.5501 & 4.7098 & TST & \\
\hline CHEMBL1596010 & 688432 & 3.95 & 4.728 & TST & \\
\hline CHEMBL1564294 & 688432 & 4.5 & 4.5279 & TST & \\
\hline CHEMBL1504073 & 688432 & 4.25 & 4.4829 & TST & \\
\hline CHEMBL1470357 & 688432 & 5.2 & 4.6438 & TST & \\
\hline CHEMBL1306960 & 688432 & 4.95 & 4.5162 & TST & \\
\hline CHEMBL3196260 & 688432 & 4.0 & 4.665 & TST & \\
\hline CHEMBL3192098 & 688432 & 4.45 & 4.4927 & TST & \\
\hline CHEMBL1312363 & 688432 & 5.45 & 4.6152 & TST & \\
\hline CHEMBL1405834 & 688432 & 4.5 & 4.7107 & TST & \\
\hline CHEMBL 1462270 & 688432 & 4.25 & 4.7168 & TST & \\
\hline CHEMBL 2003840 & 688432 & 4.0 & 4.6278 & TST & \\
\hline CHEMBL1583838 & 688432 & 4.4 & 4.4712 & TST & \\
\hline CHEMBL8260 & 688432 & 4.35 & 4.4657 & TST & \\
\hline CHEMBL1384253 & 688432 & 5.45 & 4.651 & TST & \\
\hline CHEMBL1390166 & 688432 & 4.05 & 4.7803 & TST & \\
\hline CHEMBL3196552 & 688432 & 4.45 & 4.4462 & TST & \\
\hline CHEMBL1497611 & 688432 & 5.35 & 4.5767 & TST & \\
\hline CHEMBL1491456 & 688432 & 4.35 & 4.6496 & TST & \\
\hline CHEMBL286494 & 688432 & 6.0 & 4.8768 & TST & \\
\hline CHEMBL 1437100 & 688432 & 4.15 & 4.9028 & TST & \\
\hline CHEMBL1541005 & 688432 & 4.6 & 4.5724 & TST & \\
\hline
\end{tabular}




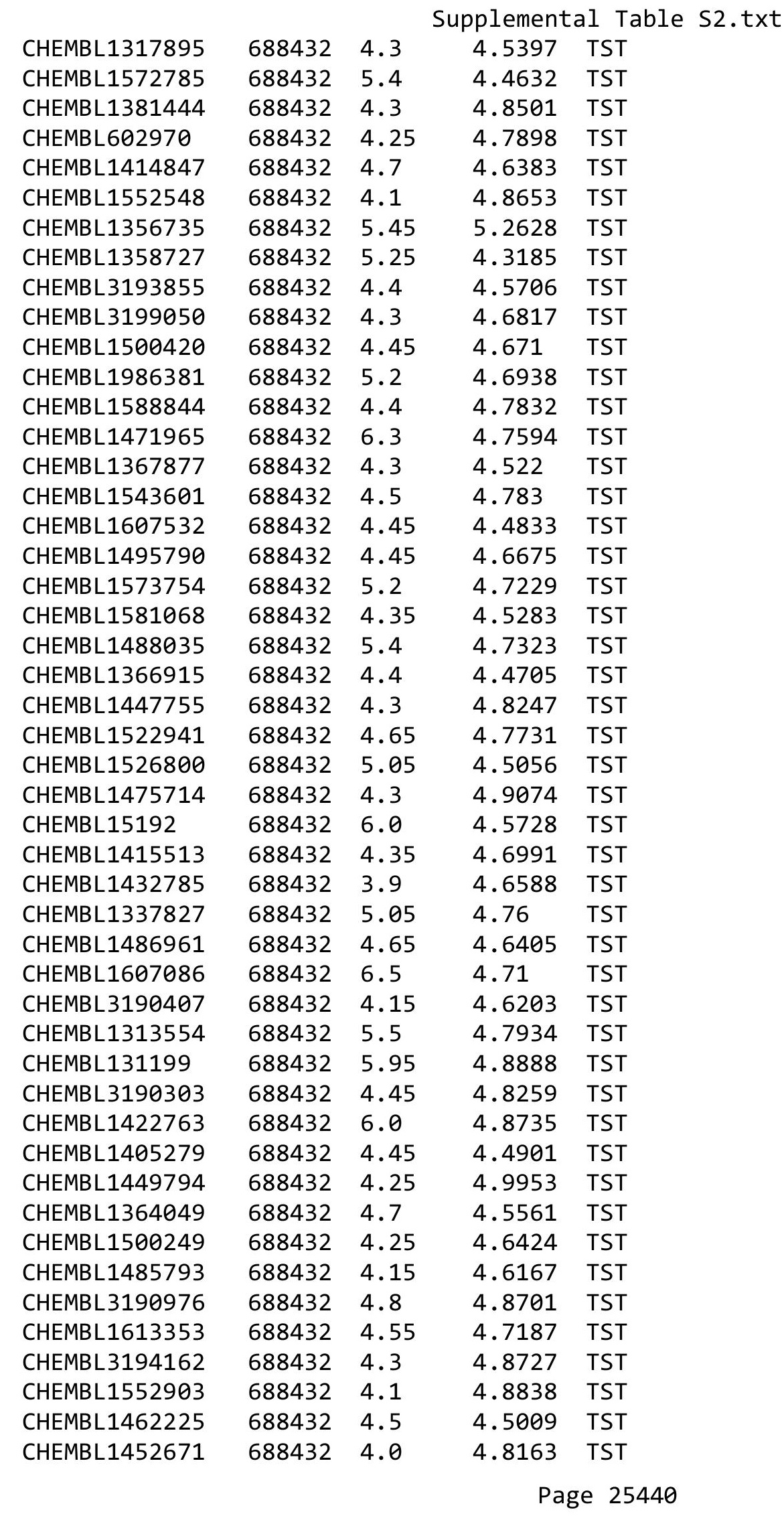




\begin{tabular}{|c|c|c|c|c|c|}
\hline \multicolumn{6}{|c|}{ Supplemental Table S2.txt } \\
\hline CHEMBL3197709 & 688432 & 4.3 & 4.6151 & TST & \\
\hline CHEMBL1544436 & 688432 & 4.1 & 4.7067 & TST & \\
\hline CHEMBL1413806 & 688432 & 4.5 & 4.5825 & TST & \\
\hline CHEMBL1483485 & 688432 & 4.0 & 4.4957 & TST & \\
\hline CHEMBL1436782 & 688432 & 5.0 & 4.6174 & TST & \\
\hline CHEMBL1597358 & 688432 & 5.1 & 4.6561 & TST & \\
\hline CHEMBL1431643 & 688432 & 5.85 & 4.5243 & TST & \\
\hline CHEMBL1432342 & 688432 & 4.35 & 4.698 & TST & \\
\hline CHEMBL1305427 & 688432 & 4.5 & 4.9533 & TST & \\
\hline CHEMBL1982477 & 688432 & 5.1 & 4.5636 & TST & \\
\hline CHEMBL1396343 & 688432 & 4.3 & 4.4316 & TST & \\
\hline CHEMBL 2003886 & 688432 & 4.5 & 4.6129 & TST & \\
\hline CHEMBL1412698 & 688432 & 4.55 & 4.5281 & TST & \\
\hline CHEMBL1558721 & 688432 & 6.9 & 4.6472 & TST & \\
\hline CHEMBL1309765 & 688432 & 4.3 & 4.52 & TST & \\
\hline CHEMBL3195176 & 688432 & 4.35 & 4.4491 & TST & \\
\hline CHEMBL1449836 & 688432 & 4.55 & 4.4847 & TST & \\
\hline CHEMBL1411044 & 688432 & 4.15 & 4.7122 & TST & \\
\hline CHEMBL1516834 & 688432 & 4.6 & 4.67399 & 99999999995 & TST \\
\hline CHEMBL1391798 & 688432 & 4.35 & 4.6746 & TST & \\
\hline CHEMBL1364619 & 688432 & 4.75 & 4.7405 & TST & \\
\hline CHEMBL22304 & 688432 & 4.5 & 5.034 & TST & \\
\hline CHEMBL1561935 & 688432 & 4.3 & 4.8319 & TST & \\
\hline CHEMBL1468635 & 688432 & 4.5 & 4.7481 & TST & \\
\hline CHEMBL3193151 & 688432 & 4.35 & 4.6107 & TST & \\
\hline CHEMBL1366479 & 688432 & 4.5 & 4.494 & TST & \\
\hline CHEMBL1325143 & 688432 & 4.4 & 4.4768 & TST & \\
\hline CHEMBL1454493 & 688432 & 4.1 & 4.7206 & TST & \\
\hline CHEMBL1598623 & 688432 & 4.4 & 4.5824 & TST & \\
\hline CHEMBL1384064 & 688432 & 4.55 & 4.4991 & TST & \\
\hline CHEMBL1428003 & 688432 & 4.3 & 4.7093 & TST & \\
\hline CHEMBL1577860 & 688432 & 5.45 & 4.9025 & TST & \\
\hline CHEMBL1519313 & 688432 & 4.65 & 4.7408 & TST & \\
\hline CHEMBL3899187 & 1639955 & 7.0 & 7.3049 & TRN & \\
\hline CHEMBL3915704 & 1639955 & 6.0 & 6.0468 & TST & \\
\hline CHEMBL3909290 & 1639955 & 6.0 & 5.8679 & TRN & \\
\hline CHEMBL3921763 & 1639955 & 7.0 & 6.835 & TRN & \\
\hline CHEMBL3954626 & 1639955 & 8.0 & 7.3866 & TRN & \\
\hline CHEMBL3955058 & 1639955 & 7.0 & 7.0827 & TRN & \\
\hline CHEMBL3939322 & 1639955 & 7.0 & 7.1735 & TRN & \\
\hline CHEMBL3965793 & 1639955 & 6.0 & 6.25 & TRN & \\
\hline CHEMBL3944996 & 1639955 & 7.0 & 7.4169 & TRN & \\
\hline CHEMBL3930063 & 1639955 & 7.0 & 6.9612 & TRN & \\
\hline CHEMBL3934007 & 1639955 & 6.0 & 5.9538 & TRN & \\
\hline CHEMBL3930109 & 1639955 & 8.0 & 8.0129 & TRN & \\
\hline CHEMBL3909078 & 1639955 & 8.0 & 7.7001 & TRN & \\
\hline CHEMBL3894764 & 1639955 & 7.0 & 6.9624 & TST & \\
\hline CHEMBL3936743 & 1639955 & 8.0 & 8.0658 & TRN & \\
\hline
\end{tabular}




\begin{tabular}{|c|c|c|c|c|c|}
\hline \multirow{2}{*}{ CHEMBL3976089 } & \multirow{2}{*}{1639955} & \multirow[b]{2}{*}{8.0} & \\
\hline & & & 7.7809 & TRN & \\
\hline CHEMBL3946402 & 1639955 & 7.0 & 7.4646 & TST & \\
\hline CHEMBL3981990 & 1639955 & 6.0 & 5.9016 & TRN & \\
\hline CHEMBL3939157 & 1639955 & 8.0 & 7.3514 & TRN & \\
\hline CHEMBL 3971495 & 1639955 & 8.0 & 7.9163 & TRN & \\
\hline CHEMBL3910022 & 1639955 & 7.0 & 6.8763 & TRN & \\
\hline CHEMBL 3892588 & 1639955 & 6.0 & 6.7757 & TST & \\
\hline CHEMBL3950917 & 1639955 & 8.0 & 7.9945 & TRN & \\
\hline CHEMBL 3937323 & 1639955 & 7.0 & 7.2932 & TRN & \\
\hline CHEMBL 3906492 & 1639955 & 7.0 & 7.2813 & TRN & \\
\hline CHEMBL3977460 & 1639955 & 6.0 & 6.0116 & TRN & \\
\hline CHEMBL 3934045 & 1639955 & 7.0 & 7.0245 & TRN & \\
\hline CHEMBL3903125 & 1639955 & 7.0 & 6.8062 & TRN & \\
\hline CHEMBL 3967114 & 1639955 & 7.0 & \multicolumn{2}{|c|}{7.252999999999999} & TRN \\
\hline CHEMBL 3979837 & 1639955 & 7.0 & 6.7976 & TST & \\
\hline CHEMBL3948278 & 1639955 & 8.0 & 7.7772 & TRN & \\
\hline CHEMBL3975985 & 1639955 & 8.0 & 7.9927 & TRN & \\
\hline CHEMBL3927351 & 1639955 & 7.0 & 7.0269 & TRN & \\
\hline CHEMBL3970317 & 1639955 & 6.0 & 6.0647 & TRN & \\
\hline CHEMBL3966039 & 1639955 & 6.0 & 6.1258 & TRN & \\
\hline CHEMBL3925179 & 1639955 & 7.0 & 6.9878 & TRN & \\
\hline CHEMBL3929057 & 1639955 & 8.0 & 7.7809 & TRN & \\
\hline CHEMBL3955601 & 1639955 & 6.0 & 5.8384 & TST & \\
\hline CHEMBL3910786 & 1639955 & 8.0 & 7.8554 & TRN & \\
\hline CHEMBL 3953389 & 1639955 & 6.0 & 6.6529 & TST & \\
\hline CHEMBL3959845 & 1639955 & 7.0 & 6.8058 & TST & \\
\hline CHEMBL3930632 & 1639955 & 8.0 & 7.8326 & TRN & \\
\hline CHEMBL3906764 & 1639955 & 6.0 & 6.2368 & TRN & \\
\hline CHEMBL3903726 & 1639955 & 8.0 & 7.5855 & TST & \\
\hline CHEMBL3905798 & 1639955 & 6.0 & 6.7363 & TRN & \\
\hline CHEMBL3942299 & 1639955 & 7.0 & 7.2775 & TRN & \\
\hline CHEMBL3986696 & 1639955 & 8.0 & 7.9858 & TRN & \\
\hline CHEMBL3898393 & 1639955 & 6.0 & 7.2547 & TST & \\
\hline CHEMBL3978073 & 1639955 & 8.0 & \multicolumn{2}{|c|}{7.912000000000001} & TRN \\
\hline CHEMBL 3974732 & 1639955 & 7.0 & 8.3042 & TST & \\
\hline CHEMBL3955346 & 1639955 & 7.0 & 6.6407 & TRN & \\
\hline CHEMBL 3983372 & 1639955 & 8.0 & \multicolumn{2}{|c|}{7.207000000000001} & TST \\
\hline CHEMBL3961874 & 1639955 & 7.0 & 7.2838 & TST & \\
\hline CHEMBL3915100 & 1639955 & 7.0 & 6.8741 & TRN & \\
\hline CHEMBL 3959946 & 1639955 & 8.0 & 8.0799 & TRN & \\
\hline CHEMBL 3912445 & 1639955 & 7.0 & 6.9429 & TRN & \\
\hline CHEMBL 3951798 & 1639955 & 6.0 & 6.0906 & TST & \\
\hline CHEMBL 3967640 & 1639955 & 6.0 & \multicolumn{2}{|c|}{6.2829999999999995} & TRN \\
\hline CHEMBL3902706 & 1639955 & 7.0 & 7.1992 & TRN & \\
\hline CHEMBL 3983876 & 1639955 & 7.0 & 6.8268 & TRN & \\
\hline CHEMBL 3927084 & 1639955 & 7.0 & 7.1246 & TRN & \\
\hline CHEMBL 3972256 & 1639955 & 8.0 & 7.6674 & TRN & \\
\hline \multirow[t]{2}{*}{ CHEMBL3940076 } & 1639955 & 8.0 & 7.9378 & TRN & \\
\hline & & & \multicolumn{2}{|c|}{ Page 25442} & \\
\hline
\end{tabular}




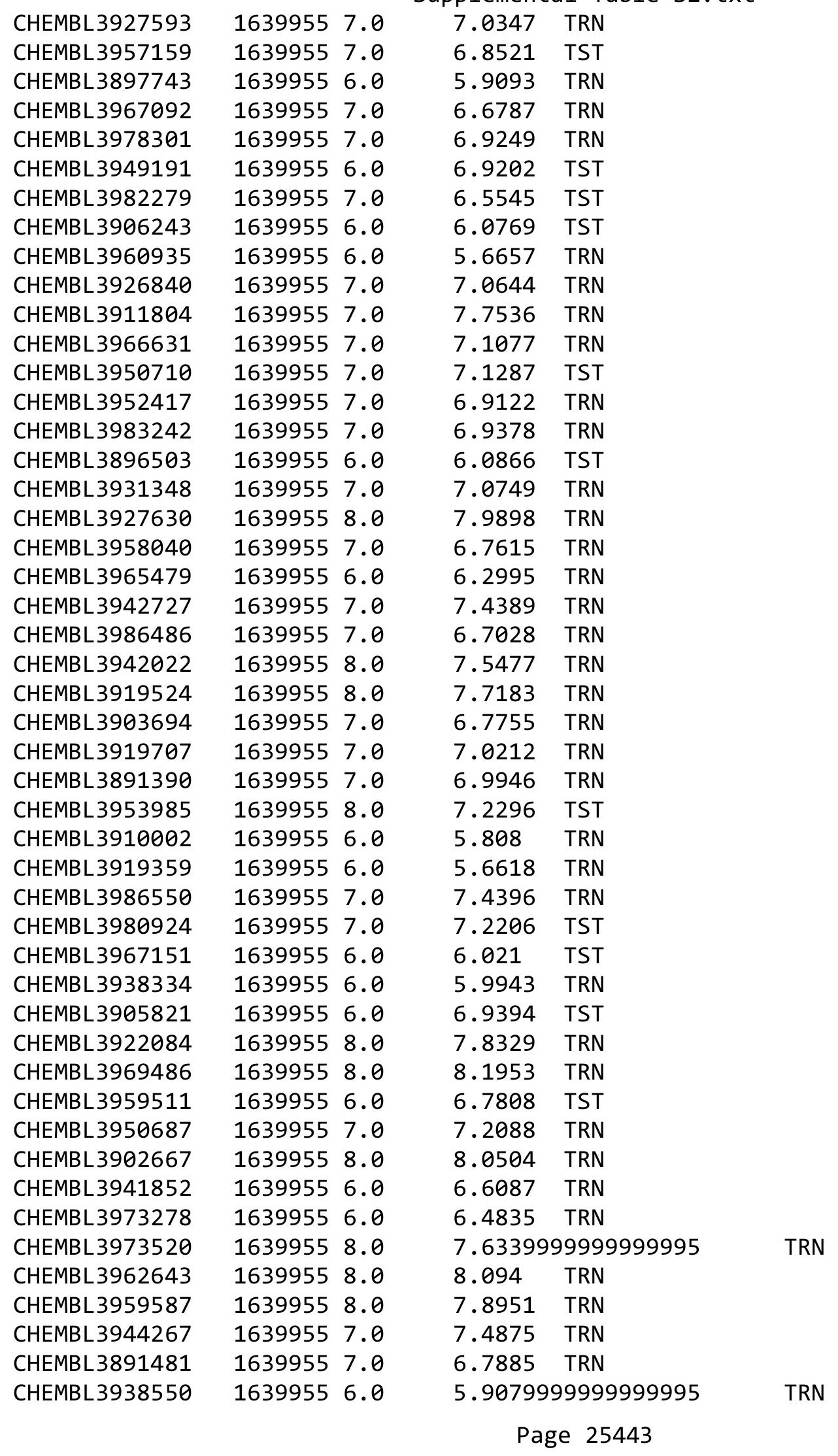




\begin{tabular}{|c|c|c|c|c|c|}
\hline \\
\hline CHEMBL3895940 & 1639955 & 6.0 & 6.0734 & TRN & \\
\hline CHEMBL3896685 & 1639955 & 8.0 & 7.8381 & TRN & \\
\hline CHEMBL3929514 & 1639955 & 7.0 & 6.9828 & TRN & \\
\hline CHEMBL3957247 & 1639955 & 7.0 & 6.6007 & TRN & \\
\hline CHEMBL3975414 & 1639955 & 8.0 & 7.5601 & TRN & \\
\hline CHEMBL3948598 & 1639955 & 7.0 & 6.9426 & TST & \\
\hline CHEMBL3933708 & 1639955 & 6.0 & 7.0633 & TST & \\
\hline CHEMBL3953149 & 1639955 & 8.0 & 8.0187 & TRN & \\
\hline CHEMBL3969729 & 1639955 & 6.0 & 6.5505 & TST & \\
\hline CHEMBL3889851 & 1639955 & 6.0 & 6.3182 & TST & \\
\hline CHEMBL3922623 & 1639955 & 7.0 & 7.4281 & TRN & \\
\hline CHEMBL3889599 & 1639955 & 7.0 & 7.3925 & TRN & \\
\hline CHEMBL3958192 & 1639955 & 8.0 & 7.314 & TRN & \\
\hline CHEMBL3923355 & 1639955 & 7.0 & 7.2904 & TST & \\
\hline CHEMBL3915663 & 1639955 & 7.0 & 6.8422 & TST & \\
\hline CHEMBL3948829 & 1639955 & 7.0 & 7.4623 & TST & \\
\hline CHEMBL3956883 & 1639955 & 8.0 & 7.9827 & TRN & \\
\hline CHEMBL3971008 & 1639955 & 6.0 & 6.5524 & TRN & \\
\hline CHEMBL3916441 & 1639955 & 6.0 & 7.2812 & TST & \\
\hline CHEMBL3922446 & 1639955 & 7.0 & 7.1292 & TRN & \\
\hline CHEMBL3920191 & 1639955 & 6.0 & 6.8577 & TRN & \\
\hline CHEMBL3899393 & 1639955 & 8.0 & 7.7487 & TRN & \\
\hline CHEMBL3986419 & 1639955 & 6.0 & 5.6062 & TRN & \\
\hline CHEMBL3927397 & 1639955 & 8.0 & 8.1061 & TRN & \\
\hline CHEMBL3958236 & 1639955 & 6.0 & 6.2305 & TST & \\
\hline CHEMBL3965473 & 1639955 & 6.0 & 6.9946 & TST & \\
\hline CHEMBL3934557 & 1639955 & 7.0 & 6.9876 & TRN & \\
\hline CHEMBL3912449 & 1639955 & 8.0 & 7.9364 & TRN & \\
\hline CHEMBL 3893223 & 1639955 & 8.0 & 7.8093 & TRN & \\
\hline CHEMBL3973612 & 1639955 & 7.0 & 6.6865 & TST & \\
\hline CHEMBL1372692 & 688798 & 4.75 & 4.8948 & TST & \\
\hline CHEMBL1329248 & 688798 & 3.4 & 5.67899 & 9999999999 & TRN \\
\hline CHEMBL1524608 & 688798 & 4.15 & 4.8782 & TRN & \\
\hline CHEMBL1511969 & 688798 & 4.75 & 5.4191 & TRN & \\
\hline CHEMBL1528814 & 688798 & 4.4 & 5.1488 & TST & \\
\hline CHEMBL1368972 & 688798 & 4.75 & 5.197 & TRN & \\
\hline CHEMBL1358127 & 688798 & 7.6003 & 5.5425 & TRN & \\
\hline CHEMBL1555818 & 688798 & 8.1487 & 5.4015 & TRN & \\
\hline CHEMBL1470184 & 688798 & 4.55 & 5.0288 & TST & \\
\hline CHEMBL1435564 & 688798 & 4.7 & 5.5818 & TRN & \\
\hline CHEMBL1511851 & 688798 & 4.05 & 5.6622 & TRN & \\
\hline CHEMBL1524893 & 688798 & 4.75 & 6.0927 & TRN & \\
\hline CHEMBL1314892 & 688798 & 4.75 & 5.3144 & TRN & \\
\hline CHEMBL1494986 & 688798 & 4.75 & 5.4511 & TRN & \\
\hline CHEMBL1512891 & 688798 & 5.3 & 5.5881 & TRN & \\
\hline CHEMBL1473923 & 688798 & 4.95 & 5.3315 & TRN & \\
\hline CHEMBL581044 & 688798 & 4.4 & 5.0047 & TRN & \\
\hline CHEMBL1571793 & 688798 & 4.85 & 5.7163 & TRN & \\
\hline
\end{tabular}




\begin{tabular}{|c|c|c|c|c|c|}
\hline \multicolumn{6}{|c|}{ Supplemental Table S2.txt } \\
\hline CHEMBL1419884 & 688798 & 3.35 & 5.2772 & TST & \\
\hline CHEMBL1403868 & 688798 & 4.15 & 5.499 & TRN & \\
\hline CHEMBL1591977 & 688798 & 5.4 & 5.3355 & TRN & \\
\hline CHEMBL1434572 & 688798 & 4.85 & 5.24 & TRN & \\
\hline CHEMBL1492650 & 688798 & 6.7501 & 5.303 & TRN & \\
\hline CHEMBL3193660 & 688798 & 6.45 & 5.5523 & TRN & \\
\hline CHEMBL1433640 & 688798 & 3.6 & 5.2843 & TRN & \\
\hline CHEMBL3208613 & 688798 & 4.15 & 5.3018 & TRN & \\
\hline CHEMBL1449693 & 688798 & 10.1 & 5.7724 & TRN & \\
\hline CHEMBL1420761 & 688798 & 7.0 & 5.2435 & TST & \\
\hline CHEMBL1437107 & 688798 & 7.5498 & 5.5517 & TRN & \\
\hline CHEMBL 273807 & 688798 & 5.4 & 5.5738 & TRN & \\
\hline CHEMBL1326544 & 688798 & 4.5 & 5.44 & TRN & \\
\hline CHEMBL1386511 & 688798 & 4.05 & 5.1783 & TST & \\
\hline CHEMBL1371753 & 688798 & 8.6021 & 5.7588 & TRN & \\
\hline CHEMBL1303333 & 688798 & 5.5 & 4.8337 & TRN & \\
\hline CHEMBL1373167 & 688798 & 5.6 & 5.8795 & TRN & \\
\hline CHEMBL3189508 & 688798 & 4.35 & 5.0765 & TRN & \\
\hline CHEMBL1464844 & 688798 & 4.35 & 4.907 & TRN & \\
\hline CHEMBL1371705 & 688798 & 6.1 & 5.4923 & TST & \\
\hline CHEMBL1558142 & 688798 & 4.9 & 5.5739 & TRN & \\
\hline CHEMBL1552783 & 688798 & 10.25 & 5.7869 & TRN & \\
\hline CHEMBL1600636 & 688798 & 4.65 & 5.4073 & TRN & \\
\hline CHEMBL1367813 & 688798 & 3.95 & 5.5008 & TRN & \\
\hline CHEMBL1354549 & 688798 & 5.0 & 5.7925 & TRN & \\
\hline CHEMBL1573529 & 688798 & 6.0 & 5.0623 & TRN & \\
\hline CHEMBL1394220 & 688798 & 5.55 & 5.13200 & 0000000001 & TST \\
\hline CHEMBL1487922 & 688798 & 7.3497 & 5.359 & TRN & \\
\hline CHEMBL1080503 & 688798 & 4.7 & 5.2908 & TRN & \\
\hline CHEMBL1612922 & 688798 & 5.45 & 5.3348 & TRN & \\
\hline CHEMBL1380782 & 688798 & 9.2218 & 5.4771 & TRN & \\
\hline CHEMBL1354313 & 688798 & 4.0 & 5.5472 & TRN & \\
\hline CHEMBL1406384 & 688798 & 2.9 & 5.2414 & TRN & \\
\hline CHEMBL1384515 & 688798 & 4.45 & 4.9243 & TRN & \\
\hline CHEMBL1538321 & 688798 & 6.3 & 4.8817 & TRN & \\
\hline CHEMBL1433968 & 688798 & 4.65 & 5.8422 & TRN & \\
\hline CHEMBL1356910 & 688798 & 9.1549 & 5.3716 & TRN & \\
\hline CHEMBL1591952 & 688798 & 3.95 & 5.1994 & TST & \\
\hline CHEMBL1553261 & 688798 & 9.0458 & 5.3517 & TRN & \\
\hline CHEMBL1556806 & 688798 & 8.1487 & 5.6813 & TRN & \\
\hline CHEMBL1594495 & 688798 & 4.75 & 5.7147 & TRN & \\
\hline CHEMBL1523971 & 688798 & 4.95 & 5.6633 & TRN & \\
\hline CHEMBL1436127 & 688798 & 5.0 & 5.7068 & TRN & \\
\hline CHEMBL3209772 & 688798 & 4.45 & 5.1007 & TRN & \\
\hline CHEMBL1473334 & 688798 & 4.65 & 5.7581 & TRN & \\
\hline CHEMBL1517506 & 688798 & 3.9 & 5.4765 & TRN & \\
\hline CHEMBL1592588 & 688798 & 4.55 & 4.978 & TRN & \\
\hline CHEMBL1555080 & 688798 & 4.0 & 5.8712 & TRN & \\
\hline
\end{tabular}




\begin{tabular}{|c|c|c|c|c|c|}
\hline \multirow{3}{*}{$\begin{array}{l}\text { CHEMBL1398136 } \\
\text { CHFMBI 1605327 }\end{array}$} & & \multicolumn{4}{|c|}{ Supplemental Table s2.txt } \\
\hline & 688798 & 8.7959 & 5.20200 & 0000000001 & TRN \\
\hline & 688798 & 5.75 & 5.4913 & TRN & \\
\hline CHEMBL1553466 & 688798 & 3.0 & 5.5225 & TRN & \\
\hline CHEMBL 1476074 & 688798 & 3.25 & 5.5042 & TRN & \\
\hline CHEMBL1557007 & 688798 & 7.5498 & 4.9234 & TST & \\
\hline CHEMBL1593113 & 688798 & 9.0969 & 5.3384 & TRN & \\
\hline CHEMBL3195437 & 688798 & 2.4 & 4.8082 & TRN & \\
\hline CHEMBL1536775 & 688798 & 4.2 & 5.0253 & TST & \\
\hline CHEMBL1323661 & 688798 & 8.2518 & 5.2664 & TRN & \\
\hline CHEMBL1317255 & 688798 & 4.5 & 5.6985 & TRN & \\
\hline CHEMBL 2004160 & 688798 & 4.4 & 5.3193 & TRN & \\
\hline CHEMBL1397691 & 688798 & 7.4498 & 5.5761 & TRN & \\
\hline CHEMBL1372011 & 688798 & 7.1002 & 5.1667 & TRN & \\
\hline CHEMBL1314732 & 688798 & 5.4 & 5.6673 & TRN & \\
\hline CHEMBL1557624 & 688798 & 4.7 & 5.7409 & TRN & \\
\hline CHEMBL1375762 & 688798 & 10.1 & 5.725 & TRN & \\
\hline CHEMBL3191951 & 688798 & 3.35 & 5.0137 & TRN & \\
\hline CHEMBL1355958 & 688798 & 4.55 & 5.2612 & TRN & \\
\hline CHEMBL1452023 & 688798 & 4.05 & 5.42399 & 99999999995 & TRN \\
\hline CHEMBL316992 & 688798 & 6.95 & 4.3577 & TRN & \\
\hline CHEMBL1335945 & 688798 & 4.45 & 4.8966 & TST & \\
\hline CHEMBL1967241 & 688798 & 4.3 & 5.2625 & TST & \\
\hline CHEMBL1590245 & 688798 & 10.9 & 5.2535 & TST & \\
\hline CHEMBL1312079 & 688798 & 4.35 & 5.195 & TST & \\
\hline CHEMBL1555685 & 688798 & 8.1024 & 5.5033 & TRN & \\
\hline CHEMBL1362913 & 688798 & 8.6021 & 4.8383 & TRN & \\
\hline CHEMBL1415660 & 688798 & 4.3 & 4.8929 & TRN & \\
\hline CHEMBL1597379 & 688798 & 4.8 & 5.6335 & TRN & \\
\hline CHEMBL1610183 & 688798 & 7.4498 & 5.7388 & TRN & \\
\hline CHEMBL1528388 & 688798 & 4.05 & 5.052 & TRN & \\
\hline CHEMBL1492925 & 688798 & 6.45 & 5.8213 & TRN & \\
\hline CHEMBL1515165 & 688798 & 5.9 & 5.5504 & TRN & \\
\hline CHEMBL1525310 & 688798 & 3.85 & 5.6759 & TRN & \\
\hline CHEMBL404406 & 688798 & 3.95 & 5.1046 & TST & \\
\hline CHEMBL1561869 & 688798 & 9.0969 & 5.8422 & TRN & \\
\hline CHEMBL463175 & 688798 & 4.35 & 4.5034 & TST & \\
\hline CHEMBL1314540 & 688798 & 10.25 & 4.8884 & TRN & \\
\hline CHEMBL1328101 & 688798 & 3.5 & 5.2724 & TRN & \\
\hline CHEMBL1384764 & 688798 & 8.1024 & 5.5643 & TST & \\
\hline CHEMBL1553359 & 688798 & 4.0 & 5.7513 & TRN & \\
\hline CHEMBL1315421 & 688798 & 7.2 & 5.3964 & TRN & \\
\hline CHEMBL1591808 & 688798 & 5.55 & 5.4164 & TRN & \\
\hline CHEMBL1591946 & 688798 & 4.6 & 5.221 & TRN & \\
\hline CHEMBL1515008 & 688798 & 4.05 & 5.0332 & TST & \\
\hline CHEMBL1356695 & 688798 & 4.45 & 5.8716 & TRN & \\
\hline CHEMBL1611986 & 688798 & 6.5 & 4.9225 & TRN & \\
\hline CHEMBL1530594 & 688798 & 4.7 & 5.5465 & TRN & \\
\hline CHEMBL1340784 & 688798 & 4.25 & 4.9459 & TRN & \\
\hline
\end{tabular}




\begin{tabular}{|c|c|c|c|c|c|}
\hline \multicolumn{6}{|c|}{ Supplemental Table S2.txt } \\
\hline CHEMBL1411981 & 688798 & 5.85 & 5.2753 & TRN & \\
\hline CHEMBL1458799 & 688798 & 4.4 & 5.7024 & TRN & \\
\hline CHEMBL1590683 & 688798 & 8.1024 & 5.30399 & 9999999999 & TRN \\
\hline CHEMBL1334570 & 688798 & 4.3 & 5.1154 & TRN & \\
\hline CHEMBL67311 & 688798 & 5.65 & 5.2534 & TST & \\
\hline CHEMBL1525389 & 688798 & 7.5003 & 5.30399 & 9999999999 & TRN \\
\hline CHEMBL1408696 & 688798 & 6.5501 & 5.4309 & TRN & \\
\hline CHEMBL59201 & 688798 & 6.35 & 5.642 & TST & \\
\hline CHEMBL1555171 & 688798 & 4.3 & 4.8259 & TRN & \\
\hline CHEMBL1436071 & 688798 & 3.65 & 5.6734 & TRN & \\
\hline CHEMBL1357414 & 688798 & 4.8 & 5.7272 & TRN & \\
\hline CHEMBL1477511 & 688798 & 3.95 & 5.4516 & TRN & \\
\hline CHEMBL1391380 & 688798 & 4.15 & 4.8409 & TST & \\
\hline CHEMBL1315970 & 688798 & 9.0458 & 5.444 & TRN & \\
\hline CHEMBL1567047 & 688798 & 7.1002 & 5.7624 & TRN & \\
\hline CHEMBL1314637 & 688798 & 4.6 & 5.50899 & 99999999995 & TRN \\
\hline CHEMBL1417075 & 688798 & 4.1 & 5.4847 & TRN & \\
\hline CHEMBL1372782 & 688798 & 4.85 & 5.2585 & TRN & \\
\hline CHEMBL1475261 & 688798 & 4.75 & 5.7355 & TRN & \\
\hline CHEMBL1369364 & 688798 & 8.6576 & 5.5486 & TRN & \\
\hline CHEMBL1412644 & 688798 & 4.0 & 5.8751 & TRN & \\
\hline CHEMBL1473471 & 688798 & 6.1 & 5.1529 & TRN & \\
\hline CHEMBL88584 & 688798 & 9.0 & 4.9379 & TST & \\
\hline CHEMBL1364547 & 688798 & 4.3 & 5.322 & TRN & \\
\hline CHEMBL1594544 & 688798 & 7.5003 & 5.6583 & TRN & \\
\hline CHEMBL1609386 & 688798 & 4.7 & 5.5107 & TRN & \\
\hline CHEMBL1398227 & 688798 & 4.55 & 5.1744 & TRN & \\
\hline CHEMBL1458807 & 688798 & 5.3 & 5.4849 & TRN & \\
\hline CHEMBL1593875 & 688798 & 6.5501 & 5.729 & TRN & \\
\hline CHEMBL1552784 & 688798 & 4.75 & 5.26200 & 00000000005 & TRN \\
\hline CHEMBL1574680 & 688798 & 7.6003 & 5.346 & TRN & \\
\hline CHEMBL3194597 & 688798 & 8.4559 & 4.8065 & TRN & \\
\hline CHEMBL1341830 & 688798 & 5.55 & 4.7341 & TST & \\
\hline CHEMBL 302783 & 688798 & 3.4 & 4.9569 & TST & \\
\hline CHEMBL1515011 & 688798 & 4.85 & 5.6436 & TRN & \\
\hline CHEMBL1430031 & 688798 & 9.2218 & 4.9489 & TRN & \\
\hline CHEMBL3196867 & 688798 & 4.25 & 5.1683 & TRN & \\
\hline CHEMBL1321437 & 688798 & 10.0 & 5.3457 & TST & \\
\hline CHEMBL1611326 & 688798 & 4.2 & 5.6901 & TRN & \\
\hline CHEMBL1526301 & 688798 & 5.6 & 5.7099 & TRN & \\
\hline CHEMBL1424561 & 688798 & 8.5528 & 5.3843 & TRN & \\
\hline CHEMBL1427991 & 688798 & 10.0 & 4.9528 & TST & \\
\hline CHEMBL1561455 & 688798 & 4.35 & 5.2163 & TRN & \\
\hline CHEMBL1433822 & 688798 & 4.5 & 5.5104 & TRN & \\
\hline CHEMBL1467430 & 688798 & 4.65 & 5.3306 & TRN & \\
\hline CHEMBL1399793 & 688798 & 9.0458 & 5.1916 & TRN & \\
\hline CHEMBL1317047 & 688798 & 3.65 & 5.4758 & TRN & \\
\hline CHEMBL1590365 & 688798 & 4.75 & 5.6162 & TRN & \\
\hline
\end{tabular}




\begin{tabular}{|c|c|c|c|c|c|}
\hline \multirow[b]{2}{*}{ CHEMBL1526815 } & \multicolumn{5}{|c|}{ Supplemental Table S2.txt } \\
\hline & 688798 & 7.1002 & 5.6021 & TRN & \\
\hline CHEMBL1511437 & 688798 & 4.35 & 5.06800 & 00000000005 & TRN \\
\hline CHEMBL1358703 & 688798 & 3.85 & 5.697 & TRN & \\
\hline CHEMBL1423021 & 688798 & 3.95 & 5.6363 & TRN & \\
\hline CHEMBL1593816 & 688798 & 5.8 & 5.3587 & TRN & \\
\hline CHEMBL 76897 & 688798 & 3.55 & 5.2508 & TST & \\
\hline CHEMBL1438211 & 688798 & 4.5 & 5.5865 & TRN & \\
\hline CHEMBL1299285 & 688798 & 4.05 & 5.5665 & TRN & \\
\hline CHEMBL1558401 & 688798 & 9.0458 & 5.3376 & TRN & \\
\hline CHEMBL316966 & 688798 & 9.2218 & 4.6055 & TST & \\
\hline CHEMBL1515482 & 688798 & 8.1487 & 5.8465 & TRN & \\
\hline CHEMBL1300574 & 688798 & 4.35 & 5.25799 & 9999999999 & TST \\
\hline CHEMBL1467415 & 688798 & 8.9586 & 5.2963 & TRN & \\
\hline CHEMBL1554447 & 688798 & 9.0458 & 5.6748 & TRN & \\
\hline CHEMBL1553043 & 688798 & 4.05 & 5.4775 & TRN & \\
\hline CHEMBL1530131 & 688798 & 4.7 & 5.7104 & TRN & \\
\hline CHEMBL1358754 & 688798 & 9.0 & 5.5891 & TRN & \\
\hline CHEMBL 2018847 & 688798 & 4.5 & 4.9602 & TRN & \\
\hline CHEMBL1365069 & 688798 & 4.3 & 5.0185 & TST & \\
\hline CHEMBL1478349 & 688798 & 6.95 & 5.7357 & TRN & \\
\hline CHEMBL1435953 & 688798 & 3.45 & 5.0199 & TRN & \\
\hline CHEMBL1367834 & 688798 & 5.45 & 5.8737 & TRN & \\
\hline CHEMBL1593932 & 688798 & 5.9 & 5.3402 & TRN & \\
\hline CHEMBL1589853 & 688798 & 7.9508 & 4.6373 & TRN & \\
\hline CHEMBL1553609 & 688798 & 3.0 & 5.25799 & 9999999999 & TRN \\
\hline CHEMBL1434226 & 688798 & 8.6021 & 5.4629 & TRN & \\
\hline CHEMBL1356353 & 688798 & 4.4 & 5.1672 & TRN & \\
\hline CHEMBL1316831 & 688798 & 4.85 & 5.0659 & TST & \\
\hline CHEMBL1396752 & 688798 & 3.85 & 5.1732 & TRN & \\
\hline CHEMBL1555687 & 688798 & 10.7001 & 5.188 & TRN & \\
\hline CHEMBL1412065 & 688798 & 9.5229 & 5.2651 & TRN & \\
\hline CHEMBL1589898 & 688798 & 4.7 & 5.2704 & TRN & \\
\hline CHEMBL1566029 & 688798 & 4.85 & 5.5161 & TRN & \\
\hline CHEMBL1513036 & 688798 & 8.4559 & 5.5481 & TRN & \\
\hline CHEMBL1970780 & 688798 & 3.95 & 4.6596 & TST & \\
\hline CHEMBL1566469 & 688798 & 4.45 & 5.6884 & TRN & \\
\hline CHEMBL 3195588 & 688798 & 3.85 & 5.2205 & TRN & \\
\hline CHEMBL1355169 & 688798 & 4.65 & 5.3576 & TRN & \\
\hline CHEMBL1446742 & 688798 & 3.8 & 5.3255 & TRN & \\
\hline CHEMBL1438513 & 688798 & 7.2 & 5.0369 & TRN & \\
\hline CHEMBL1412077 & 688798 & 4.35 & 5.1284 & TRN & \\
\hline CHEMBL1447303 & 688798 & 4.95 & 5.6311 & TRN & \\
\hline CHEMBL1476745 & 688798 & 3.4 & 5.1915 & TRN & \\
\hline CHEMBL1483547 & 688798 & 4.6 & 5.6306 & TRN & \\
\hline CHEMBL1566831 & 688798 & 5.15 & 5.4055 & TRN & \\
\hline CHEMBL1525294 & 688798 & 7.4498 & 5.796 & TRN & \\
\hline CHEMBL1476414 & 688798 & 7.4498 & 5.1939 & TRN & \\
\hline CHEMBL 3189305 & 688798 & 9.2218 & 5.2989 & TRN & \\
\hline
\end{tabular}




\begin{tabular}{|c|c|c|c|c|c|}
\hline \multirow[b]{2}{*}{ CHEMBL1591761 } & \multicolumn{5}{|c|}{ Supplemental Table S2.txt } \\
\hline & 688798 & 4.85 & 5.6271 & TRN & \\
\hline CHEMBL1528523 & 688798 & 5.05 & 5.29799 & 9999999999 & TRN \\
\hline CHEMBL1428262 & 688798 & 4.0 & 5.6835 & TRN & \\
\hline CHEMBL1539384 & 688798 & 4.35 & 4.9494 & TRN & \\
\hline CHEMBL1317854 & 688798 & 5.1 & 5.5074 & TRN & \\
\hline CHEMBL1346317 & 688798 & 3.95 & 5.1741 & TRN & \\
\hline CHEMBL1331144 & 688798 & 5.95 & 5.864 & TRN & \\
\hline CHEMBL1545207 & 688798 & 4.0 & 5.0404 & TRN & \\
\hline CHEMBL1520322 & 688798 & 6.7001 & 5.606 & TRN & \\
\hline CHEMBL1377941 & 688798 & 4.85 & 5.4077 & TRN & \\
\hline CHEMBL1515384 & 688798 & 4.6 & 5.4805 & TRN & \\
\hline CHEMBL1353623 & 688798 & 3.1 & 4.6551 & TST & \\
\hline CHEMBL1379677 & 688798 & 4.35 & 5.0222 & TRN & \\
\hline CHEMBL1549094 & 688798 & 4.5 & 4.9589 & TRN & \\
\hline CHEMBL1476963 & 688798 & 4.3 & 5.524 & TRN & \\
\hline CHEMBL1551309 & 688798 & 4.65 & 5.1402 & TRN & \\
\hline CHEMBL1482240 & 688798 & 5.55 & 5.5133 & TRN & \\
\hline CHEMBL1437230 & 688798 & 3.9 & 5.0274 & TRN & \\
\hline CHEMBL1477997 & 688798 & 7.6003 & 5.3977 & TRN & \\
\hline CHEMBL1448432 & 688798 & 8.301 & 5.7367 & TRN & \\
\hline CHEMBL1354323 & 688798 & 6.45 & 5.8847 & TRN & \\
\hline CHEMBL1451327 & 688798 & 4.15 & 4.6178 & TST & \\
\hline CHEMBL1562860 & 688798 & 4.65 & 5.3503 & TRN & \\
\hline CHEMBL1368249 & 688798 & 4.3 & 5.4233 & TRN & \\
\hline CHEMBL1356550 & 688798 & 4.05 & 4.85800 & 00000000005 & TRN \\
\hline CHEMBL1437302 & 688798 & 4.7 & 5.3553 & TRN & \\
\hline CHEMBL1515178 & 688798 & 6.0 & 5.4871 & TRN & \\
\hline CHEMBL1513270 & 688798 & 7.4498 & 5.2442 & TRN & \\
\hline CHEMBL1365051 & 688798 & 7.4498 & 5.4375 & TRN & \\
\hline CHEMBL1448985 & 688798 & 4.55 & 5.3556 & TRN & \\
\hline CHEMBL1475091 & 688798 & 2.85 & 5.4291 & TRN & \\
\hline CHEMBL1554069 & 688798 & 8.4949 & 5.2545 & TRN & \\
\hline CHEMBL1358309 & 688798 & 4.0 & 5.1227 & TRN & \\
\hline CHEMBL1520458 & 688798 & 9.1549 & 5.2669 & TRN & \\
\hline CHEMBL1513676 & 688798 & 4.95 & 5.3439 & TRN & \\
\hline CHEMBL1376161 & 688798 & 5.45 & 5.2126 & TRN & \\
\hline CHEMBL1978236 & 688798 & 4.3 & 4.9303 & TST & \\
\hline CHEMBL1454321 & 688798 & 8.3979 & 5.5451 & TRN & \\
\hline CHEMBL1310907 & 688798 & 4.3 & 5.38299 & 9999999999 & TRN \\
\hline CHEMBL1607905 & 688798 & 4.75 & 4.7542 & TST & \\
\hline CHEMBL1595622 & 688798 & 5.9 & 5.83700 & 0000000001 & TRN \\
\hline CHEMBL1357099 & 688798 & 4.8 & 5.0029 & TRN & \\
\hline CHEMBL1365991 & 688798 & 5.25 & 5.7039 & TRN & \\
\hline CHEMBL1317257 & 688798 & 4.75 & 5.4563 & TRN & \\
\hline CHEMBL1393295 & 688798 & 4.35 & 4.8692 & TST & \\
\hline CHEMBL1319540 & 688798 & 5.75 & 5.4195 & TRN & \\
\hline CHEMBL1449742 & 688798 & 6.5 & 5.4078 & TST & \\
\hline CHEMBL1321528 & 688798 & 4.35 & 5.0581 & TST & \\
\hline
\end{tabular}




\begin{tabular}{|c|c|c|c|c|c|}
\hline & & \multicolumn{4}{|c|}{ Supplemental Table S2.txt } \\
\hline CHEMBL1484504 & 688798 & 9.1549 & 5.7818 & TRN & \\
\hline CHEMBL1418885 & 688798 & 4.35 & 4.8352 & TST & \\
\hline CHEMBL1405723 & 688798 & 3.95 & 5.5867 & TRN & \\
\hline CHEMBL1363299 & 688798 & 7.2503 & 5.3407 & TRN & \\
\hline CHEMBL1525614 & 688798 & 5.0 & 5.4873 & TRN & \\
\hline CHEMBL1335550 & 688798 & 8.6021 & 5.9421 & TRN & \\
\hline CHEMBL1547972 & 688798 & 7.2503 & 5.09399 & 9999999999 & TRN \\
\hline CHEMBL1518895 & 688798 & 5.35 & 5.0033 & TST & \\
\hline CHEMBL1321366 & 688798 & 7.2 & 4.7596 & TRN & \\
\hline CHEMBL1375489 & 688798 & 6.0 & 5.3437 & TRN & \\
\hline CHEMBL3190370 & 688798 & 4.45 & 5.2089 & TRN & \\
\hline CHEMBL1410059 & 688798 & 3.35 & 5.3179 & TRN & \\
\hline CHEMBL1442104 & 688798 & 4.3 & 5.229 & TRN & \\
\hline CHEMBL1406641 & 688798 & 4.55 & 5.5864 & TRN & \\
\hline CHEMBL1396428 & 688798 & 3.95 & 5.0032 & TRN & \\
\hline CHEMBL1333068 & 688798 & 4.45 & 5.001 & TST & \\
\hline CHEMBL1474227 & 688798 & 4.65 & 5.4543 & TRN & \\
\hline CHEMBL3209991 & 688798 & 4.15 & 5.4653 & TRN & \\
\hline CHEMBL1376274 & 688798 & 5.0 & 5.5796 & TRN & \\
\hline CHEMBL1547684 & 688798 & 4.4 & 4.7534 & TRN & \\
\hline CHEMBL1317195 & 688798 & 7.8508 & 5.5659 & TRN & \\
\hline CHEMBL1441755 & 688798 & 4.95 & 5.7357 & TRN & \\
\hline CHEMBL1442122 & 688798 & 4.65 & 5.8163 & TRN & \\
\hline CHEMBL3144999 & 688798 & 6.45 & 4.8429 & TST & \\
\hline CHEMBL3193415 & 688798 & 6.25 & 4.9342 & TRN & \\
\hline CHEMBL1435790 & 688798 & 8.6021 & 5.2004 & TST & \\
\hline CHEMBL1398492 & 688798 & 5.4 & 5.4069 & TRN & \\
\hline CHEMBL1397256 & 688798 & 9.0458 & 5.6013 & TRN & \\
\hline CHEMBL1376491 & 688798 & 3.0 & 5.5457 & TRN & \\
\hline CHEMBL1478188 & 688798 & 7.15 & 5.1487 & TST & \\
\hline CHEMBL1523480 & 688798 & 4.95 & 5.4461 & TRN & \\
\hline CHEMBL1566165 & 688798 & 4.65 & 4.9598 & TRN & \\
\hline CHEMBL1441988 & 688798 & 3.55 & 5.3587 & TRN & \\
\hline CHEMBL1378047 & 688798 & 4.45 & 5.1656 & TRN & \\
\hline CHEMBL1372069 & 688798 & 4.65 & 5.2776 & TRN & \\
\hline CHEMBL1602213 & 688798 & 4.45 & 4.8333 & TRN & \\
\hline CHEMBL 3210833 & 688798 & 9.2218 & 5.5259 & TRN & \\
\hline CHEMBL1317237 & 688798 & 5.1 & 5.3733 & TST & \\
\hline CHEMBL1534470 & 688798 & 4.3 & 4.5825 & TRN & \\
\hline CHEMBL1331425 & 688798 & 4.1 & 5.0768 & TRN & \\
\hline CHEMBL1087887 & 688798 & 4.65 & 5.3105 & TRN & \\
\hline CHEMBL1484606 & 688798 & 5.1 & 5.5649 & TRN & \\
\hline CHEMBL1593055 & 688798 & 4.8 & 5.6877 & TRN & \\
\hline CHEMBL1394147 & 688798 & 5.75 & 5.6451 & TRN & \\
\hline CHEMBL584759 & 688798 & 6.0 & 5.1869 & TST & \\
\hline CHEMBL1413171 & 688798 & 4.3 & 5.5557 & TRN & \\
\hline CHEMBL1372832 & 688798 & 4.2 & 5.2592 & TRN & \\
\hline CHEMBL1403006 & 688798 & 4.95 & 5.1623 & TRN & \\
\hline
\end{tabular}




\begin{tabular}{|c|c|c|c|c|c|}
\hline \\
\hline CHEMBL1554700 & 688798 & 4.0 & 5.1899 & TST & \\
\hline CHEMBL1440126 & 688798 & 6.0 & 5.4843 & TRN & \\
\hline CHEMBL1449836 & 688798 & 4.55 & 4.9836 & TRN & \\
\hline CHEMBL1446073 & 688798 & 3.15 & 5.5119 & TRN & \\
\hline CHEMBL1325689 & 688798 & 5.4 & 5.2108 & TRN & \\
\hline CHEMBL1358442 & 688798 & 4.65 & 5.3852 & TRN & \\
\hline CHEMBL1518741 & 688798 & 8.6576 & 5.8898 & TRN & \\
\hline CHEMBL1523393 & 688798 & 3.95 & 5.37799 & 9999999999 & TRN \\
\hline CHEMBL1370073 & 688798 & 4.35 & 5.2126 & TRN & \\
\hline CHEMBL3189657 & 688798 & 4.4 & 4.7342 & TST & \\
\hline CHEMBL1514696 & 688798 & 2.7 & 5.4834 & TRN & \\
\hline CHEMBL1557464 & 688798 & 4.0 & 5.5194 & TRN & \\
\hline CHEMBL1368023 & 688798 & 7.699 & 5.6851 & TRN & \\
\hline CHEMBL1377990 & 688798 & 4.0 & 5.21299 & 9999999999 & TRN \\
\hline CHEMBL1593435 & 688798 & 2.6 & 5.6607 & TRN & \\
\hline CHEMBL1599533 & 688798 & 4.35 & 5.6845 & TRN & \\
\hline CHEMBL1472605 & 688798 & 6.45 & 5.7229 & TRN & \\
\hline CHEMBL1434513 & 688798 & 4.3 & 4.6693 & TRN & \\
\hline CHEMBL1608535 & 688798 & 4.35 & 4.9584 & TRN & \\
\hline CHEMBL1600613 & 688798 & 6.0 & 5.2289 & TRN & \\
\hline CHEMBL1419100 & 688798 & 4.3 & 5.206 & TRN & \\
\hline CHEMBL1417280 & 688798 & 7.0501 & 5.3299 & TRN & \\
\hline CHEMBL1555535 & 688798 & 4.55 & 4.8315 & TST & \\
\hline CHEMBL1524077 & 688798 & 5.0 & 4.9963 & TRN & \\
\hline CHEMBL1405312 & 688798 & 3.9 & 5.4592 & TRN & \\
\hline CHEMBL1316925 & 688798 & 4.85 & 5.6649 & TRN & \\
\hline CHEMBL1562194 & 688798 & 7.0 & 5.6051 & TRN & \\
\hline CHEMBL1473159 & 688798 & 7.8508 & 5.1078 & TRN & \\
\hline CHEMBL1551541 & 688798 & 4.65 & 5.4891 & TRN & \\
\hline CHEMBL1489661 & 688798 & 4.8 & 5.5312 & TRN & \\
\hline CHEMBL1406177 & 688798 & 4.5 & 5.294 & TRN & \\
\hline CHEMBL1556914 & 688798 & 4.4 & 4.8473 & TRN & \\
\hline CHEMBL1435631 & 688798 & 4.0 & 5.5484 & TRN & \\
\hline CHEMBL1437456 & 688798 & 4.0 & 4.9101 & TRN & \\
\hline CHEMBL1553193 & 688798 & 3.05 & 5.4872 & TRN & \\
\hline CHEMBL1331734 & 688798 & 4.25 & 5.0926 & TST & \\
\hline CHEMBL1434600 & 688798 & 4.05 & 5.6618 & TRN & \\
\hline CHEMBL1454572 & 688798 & 4.75 & 5.4215 & TRN & \\
\hline CHEMBL1492386 & 688798 & 7.0 & 5.5252 & TRN & \\
\hline CHEMBL1451416 & 688798 & 6.0 & 5.5651 & TRN & \\
\hline CHEMBL1515056 & 688798 & 5.0 & 5.3885 & TRN & \\
\hline CHEMBL1394650 & 688798 & 5.6 & 5.8252 & TRN & \\
\hline CHEMBL1373346 & 688798 & 4.6 & 5.8355 & TRN & \\
\hline CHEMBL1552195 & 688798 & 8.5528 & 5.6529 & TRN & \\
\hline CHEMBL1315577 & 688798 & 4.7 & 5.2477 & TRN & \\
\hline CHEMBL1332495 & 688798 & 8.6021 & 5.3772 & TRN & \\
\hline CHEMBL1595047 & 688798 & 4.75 & 5.0879 & TST & \\
\hline CHEMBL1359746 & 688798 & 8.2007 & 5.6349 & TRN & \\
\hline
\end{tabular}




\begin{tabular}{|c|c|c|c|c|c|}
\hline \multicolumn{6}{|c|}{ Supplemental Table S2.txt } \\
\hline CHEMBL1398348 & 688798 & 4.7 & 5.4942 & TRN & \\
\hline CHEMBL144366 & 688798 & 9.301 & 4.7074 & TST & \\
\hline CHEMBL1986380 & 688798 & 7.1002 & 5.3337 & TRN & \\
\hline CHEMBL1591108 & 688798 & 2.95 & 4.9964 & TRN & \\
\hline CHEMBL1435789 & 688798 & 6.35 & 5.466 & TRN & \\
\hline CHEMBL1533743 & 688798 & 6.5 & 5.0116 & TRN & \\
\hline CHEMBL1564638 & 688798 & 4.15 & 4.6485 & TST & \\
\hline CHEMBL1352429 & 688798 & 4.3 & 5.2031 & TST & \\
\hline CHEMBL1399531 & 688798 & 4.15 & 5.2154 & TRN & \\
\hline CHEMBL1453340 & 688798 & 7.9508 & 5.6688 & TRN & \\
\hline CHEMBL1571199 & 688798 & 4.6 & 5.1627 & TRN & \\
\hline CHEMBL1541575 & 688798 & 4.15 & 4.9932 & TRN & \\
\hline CHEMBL1396504 & 688798 & 3.5 & 5.5601 & TRN & \\
\hline CHEMBL1528499 & 688798 & 4.2 & 5.5284 & TRN & \\
\hline CHEMBL1438377 & 688798 & 4.9 & 5.7225 & TRN & \\
\hline CHEMBL1306638 & 688798 & 4.65 & 5.3 & TRN & \\
\hline CHEMBL1587286 & 688798 & 7.6498 & 4.9522 & TST & \\
\hline CHEMBL1397659 & 688798 & 4.55 & 5.5558 & TRN & \\
\hline CHEMBL1592703 & 688798 & 3.55 & 5.4344 & TRN & \\
\hline CHEMBL1256623 & 688798 & 4.65 & 4.5266 & TST & \\
\hline CHEMBL1314262 & 688798 & 4.2 & 5.5788 & TRN & \\
\hline CHEMBL1601272 & 688798 & 7.9508 & 5.6495 & TRN & \\
\hline CHEMBL1593422 & 688798 & 5.8 & 4.7264 & TST & \\
\hline CHEMBL1579999 & 688798 & 3.25 & 4.7768 & TRN & \\
\hline CHEMBL1554615 & 688798 & 3.95 & 5.6349 & TRN & \\
\hline CHEMBL1339311 & 688798 & 4.35 & 4.7062 & TST & \\
\hline CHEMBL1422918 & 688798 & 3.25 & 5.3367 & TRN & \\
\hline CHEMBL1441891 & 688798 & 3.9 & 5.1761 & TRN & \\
\hline CHEMBL1474753 & 688798 & 6.8499 & 5.4027 & TRN & \\
\hline CHEMBL1326377 & 688798 & 4.35 & 4.6669 & TRN & \\
\hline CHEMBL1337424 & 688798 & 2.65 & 4.9326 & TST & \\
\hline CHEMBL1398539 & 688798 & 4.65 & 5.485 & TRN & \\
\hline CHEMBL1513415 & 688798 & 3.6 & 5.2913 & TRN & \\
\hline CHEMBL1485849 & 688798 & 4.25 & 5.9538 & TRN & \\
\hline CHEMBL3198838 & 688798 & 4.3 & 4.4933 & TST & \\
\hline CHEMBL1480283 & 688798 & 3.8 & 5.8329 & TRN & \\
\hline CHEMBL1600300 & 688798 & 8.0 & 5.5393 & TRN & \\
\hline CHEMBL1594507 & 688798 & 4.35 & 5.0817 & TRN & \\
\hline CHEMBL1306259 & 688798 & 3.5 & 5.5013 & TRN & \\
\hline CHEMBL1580759 & 688798 & 6.0 & 4.8892 & TST & \\
\hline CHEMBL1485865 & 688798 & 4.8 & 5.157 & TRN & \\
\hline CHEMBL1514972 & 688798 & 5.05 & 5.1539 & TRN & \\
\hline CHEMBL1474810 & 688798 & 8.5528 & 5.6671 & TRN & \\
\hline CHEMBL1327893 & 688798 & 2.95 & 5.2213 & TRN & \\
\hline CHEMBL1572732 & 688798 & 4.45 & 5.1571 & TRN & \\
\hline CHEMBL1514893 & 688798 & 3.7 & 5.3804 & TRN & \\
\hline CHEMBL1583071 & 688798 & 9.0458 & 5.0083 & TST & \\
\hline CHEMBL1307394 & 688798 & 4.5 & 5.29299 & 999999999 & TST \\
\hline & & & & 25452 & \\
\hline
\end{tabular}




\begin{tabular}{|c|c|c|c|c|}
\hline & & & pplemen & al $\mathrm{T}$ \\
\hline CHEMBL 3196584 & 688798 & 5.8 & 5.0592 & TST \\
\hline CHEMBL1456374 & 688798 & 7.0 & 5.6983 & TRN \\
\hline CHEMBL1354448 & 688798 & 6.5 & 5.2544 & TRN \\
\hline CHEMBL1593819 & 688798 & 4.8 & 5.5592 & TRN \\
\hline CHEMBL1599747 & 688798 & 4.6 & 5.7269 & TRN \\
\hline CHEMBL1598676 & 688798 & 4.6 & 5.2475 & TRN \\
\hline CHEMBL1554271 & 688798 & 4.8 & 5.4611 & TRN \\
\hline CHEMBL1476824 & 688798 & 6.5 & 5.5753 & TRN \\
\hline CHEMBL1362844 & 688798 & 3.0 & 5.204 & TRN \\
\hline CHEMBL3191137 & 688798 & 5.65 & 4.9003 & TST \\
\hline CHEMBL1324663 & 688798 & 3.9 & 5.2772 & TRN \\
\hline CHEMBL1402003 & 688798 & 4.75 & 5.4005 & TRN \\
\hline CHEMBL1503310 & 688798 & 3.95 & 5.2438 & TRN \\
\hline CHEMBL1571251 & 688798 & 4.3 & 5.2735 & TRN \\
\hline CHEMBL1329252 & 688798 & 5.0 & 5.6944 & TRN \\
\hline CHEMBL1355594 & 688798 & 8.3979 & 5.2863 & TRN \\
\hline CHEMBL1581251 & 688798 & 4.3 & 5.2671 & TRN \\
\hline CHEMBL1316026 & 688798 & 5.2 & 5.6767 & TRN \\
\hline CHEMBL3193119 & 688798 & 7.9508 & 5.1225 & TST \\
\hline CHEMBL1552603 & 688798 & 4.55 & 5.5797 & TRN \\
\hline CHEMBL1455520 & 688798 & 5.25 & 5.2841 & TRN \\
\hline CHEMBL1491304 & 688798 & 3.8 & 5.2424 & TRN \\
\hline CHEMBL1401736 & 688798 & 4.6 & 5.0813 & TRN \\
\hline CHEMBL1311043 & 688798 & 4.1 & 5.8693 & TRN \\
\hline CHEMBL1451049 & 688798 & 5.45 & 5.2316 & TRN \\
\hline CHEMBL1337979 & 688798 & 4.3 & 5.5515 & TRN \\
\hline CHEMBL460433 & 688798 & 4.35 & 5.4155 & TST \\
\hline CHEMBL1311961 & 688798 & 4.1 & 5.6817 & TRN \\
\hline CHEMBL1406640 & 688798 & 4.55 & 5.4302 & TRN \\
\hline CHEMBL1367969 & 688798 & 7.5498 & 5.3697 & TRN \\
\hline CHEMBL1411109 & 688798 & 7.6003 & 5.7937 & TRN \\
\hline CHEMBL1412466 & 688798 & 4.75 & 5.24 & TRN \\
\hline CHEMBL1463082 & 688798 & 4.9 & 4.7798 & TST \\
\hline CHEMBL1600157 & 688798 & 5.05 & 5.4836 & TRN \\
\hline CHEMBL1482511 & 688798 & 2.3 & 5.6609 & TRN \\
\hline CHEMBL1435139 & 688798 & 6.05 & 5.3837 & TST \\
\hline CHEMBL1473998 & 688798 & 4.6 & 5.3855 & TRN \\
\hline CHEMBL1376272 & 688798 & 4.45 & 5.664 & TRN \\
\hline CHEMBL1572280 & 688798 & 4.4 & 4.9253 & TST \\
\hline CHEMBL1402933 & 688798 & 4.6 & 5.5462 & TRN \\
\hline CHEMBL3198772 & 688798 & 7.5003 & 5.3661 & TRN \\
\hline CHEMBL1512566 & 688798 & 4.1 & 5.4439 & TRN \\
\hline CHEMBL1590853 & 688798 & 4.65 & 5.6634 & TRN \\
\hline CHEMBL1386015 & 688798 & 4.3 & 5.449 & TRN \\
\hline CHEMBL1436407 & 688798 & 5.8 & 5.6857 & TRN \\
\hline CHEMBL6497 & 688798 & 9.1549 & 4.8873 & TST \\
\hline CHEMBL1403748 & 688798 & 4.15 & 5.1234 & TRN \\
\hline CHEMBL1393442 & 688798 & 3.55 & 5.3065 & TRN \\
\hline
\end{tabular}




\begin{tabular}{|c|c|c|c|c|c|}
\hline \multicolumn{6}{|c|}{ Supplemental Table S2.txt } \\
\hline CHEMBL1326685 & 688798 & 3.85 & 5.4106 & TRN & \\
\hline CHEMBL1405937 & 688798 & 4.0 & 5.4886 & TRN & \\
\hline CHEMBL1414750 & 688798 & 3.65 & 5.3951 & TRN & \\
\hline CHEMBL 2004884 & 688798 & 4.3 & 5.0427 & TRN & \\
\hline CHEMBL1538976 & 688798 & 4.4 & 5.1305 & TST & \\
\hline CHEMBL1403166 & 688798 & 4.75 & 5.4906 & TRN & \\
\hline CHEMBL1589300 & 688798 & 4.4 & 4.8388 & TRN & \\
\hline CHEMBL1514216 & 688798 & 7.0501 & 5.308 & TRN & \\
\hline CHEMBL1337703 & 688798 & 3.95 & 5.5861 & TRN & \\
\hline CHEMBL1331601 & 688798 & 3.55 & 5.37 & TRN & \\
\hline CHEMBL1350152 & 688798 & 4.35 & 5.0911 & TRN & \\
\hline CHEMBL1334269 & 688798 & 4.9 & 5.4114 & TRN & \\
\hline CHEMBL1500079 & 688798 & 7.1002 & 5.2229 & TRN & \\
\hline CHEMBL1531357 & 688798 & 6.3 & 5.2872 & TRN & \\
\hline CHEMBL1437311 & 688798 & 5.05 & 5.7141 & TRN & \\
\hline CHEMBL1494759 & 688798 & 8.5528 & 5.2061 & TRN & \\
\hline CHEMBL308688 & 688798 & 3.95 & 5.2356 & TRN & \\
\hline CHEMBL1436319 & 688798 & 6.3 & 5.1742 & TRN & \\
\hline CHEMBL 9850 & 688798 & 8.0 & 4.5276 & TST & \\
\hline CHEMBL1399234 & 688798 & 4.7 & 4.935 & TRN & \\
\hline CHEMBL1609508 & 688798 & 4.7 & 5.30399 & 9999999999 & TRN \\
\hline CHEMBL1475766 & 688798 & 4.1 & 5.223 & TRN & \\
\hline CHEMBL1357562 & 688798 & 4.35 & 4.8267 & TST & \\
\hline CHEMBL 3209812 & 688798 & 2.9 & 5.0984 & TRN & \\
\hline CHEMBL1332954 & 688798 & 7.6003 & 5.2047 & TRN & \\
\hline CHEMBL1596192 & 688798 & 5.6 & 5.6785 & TRN & \\
\hline CHEMBL1590325 & 688798 & 5.35 & 5.5231 & TRN & \\
\hline CHEMBL1553938 & 688798 & 5.9 & 5.5613 & TRN & \\
\hline CHEMBL1395468 & 688798 & 4.65 & 5.5224 & TRN & \\
\hline CHEMBL1316854 & 688798 & 9.2218 & 5.7831 & TRN & \\
\hline CHEMBL1381612 & 688798 & 4.45 & 4.9272 & TST & \\
\hline CHEMBL1553128 & 688798 & 4.65 & 4.9872 & TST & \\
\hline CHEMBL1494588 & 688798 & 4.8 & 5.4696 & TRN & \\
\hline CHEMBL1486608 & 688798 & 4.7 & 5.4131 & TRN & \\
\hline CHEMBL1364590 & 688798 & 4.8 & 5.0975 & TRN & \\
\hline CHEMBL1445091 & 688798 & 4.05 & 5.8592 & TRN & \\
\hline CHEMBL1424694 & 688798 & 4.75 & 5.07100 & 0000000001 & TST \\
\hline CHEMBL1513291 & 688798 & 6.7001 & 5.6026 & TRN & \\
\hline CHEMBL1513503 & 688798 & 4.65 & 5.4918 & TRN & \\
\hline CHEMBL1504321 & 688798 & 5.0 & 5.3525 & TRN & \\
\hline CHEMBL1255870 & 688798 & 3.95 & 4.5913 & TST & \\
\hline CHEMBL1336907 & 688798 & 4.15 & 5.2611 & TRN & \\
\hline CHEMBL1337827 & 688798 & 5.5 & 5.1365 & TRN & \\
\hline CHEMBL1587257 & 688798 & 1.55 & 5.2298 & TRN & \\
\hline CHEMBL1463548 & 688798 & 6.1 & 5.3103 & TRN & \\
\hline CHEMBL1474665 & 688798 & 5.35 & 5.5953 & TRN & \\
\hline CHEMBL1397016 & 688798 & 5.0 & 5.1227 & TRN & \\
\hline CHEMBL1338513 & 688798 & 4.05 & 5.5123 & TRN & \\
\hline
\end{tabular}




\begin{tabular}{|c|c|c|c|c|c|}
\hline \multicolumn{6}{|c|}{ Supplemental Table S2.txt } \\
\hline CHEMBL1398173 & 688798 & 3.6 & 5.561 & TRN & \\
\hline CHEMBL1435808 & 688798 & 8.1487 & 5.4756 & TRN & \\
\hline CHEMBL1489807 & 688798 & 3.5 & 5.6743 & TRN & \\
\hline CHEMBL1553583 & 688798 & 5.85 & 5.6146 & TRN & \\
\hline CHEMBL1966952 & 688798 & 4.35 & 4.9789 & TST & \\
\hline CHEMBL1361175 & 688798 & 3.85 & 5.4062 & TRN & \\
\hline CHEMBL1358760 & 688798 & 7.0 & 5.2833 & TRN & \\
\hline CHEMBL1551915 & 688798 & 4.45 & 5.1434 & TST & \\
\hline CHEMBL1481083 & 688798 & 4.35 & 5.3234 & TRN & \\
\hline CHEMBL1440763 & 688798 & 7.5003 & 5.5841 & TRN & \\
\hline CHEMBL1081641 & 688798 & 4.5 & 5.0141 & TRN & \\
\hline CHEMBL3207447 & 688798 & 7.2 & 5.3968 & TRN & \\
\hline CHEMBL1355571 & 688798 & 7.5498 & 5.3055 & TST & \\
\hline CHEMBL1586897 & 688798 & 4.35 & 5.3156 & TRN & \\
\hline CHEMBL1353221 & 688798 & 5.8 & 4.7002 & TST & \\
\hline CHEMBL1546414 & 688798 & 4.15 & 5.3288 & TRN & \\
\hline CHEMBL1322569 & 688798 & 8.301 & 5.5686 & TRN & \\
\hline CHEMBL1434862 & 688798 & 8.0506 & 5.5107 & TRN & \\
\hline CHEMBL1517540 & 688798 & 4.7 & 5.5655 & TRN & \\
\hline CHEMBL1552954 & 688798 & 5.4 & 5.5267 & TRN & \\
\hline CHEMBL3198004 & 688798 & 5.7 & 5.3854 & TRN & \\
\hline CHEMBL1515392 & 688798 & 4.6 & 5.70100 & 00000000005 & TRN \\
\hline CHEMBL1394732 & 688798 & 2.25 & 5.4126 & TRN & \\
\hline CHEMBL1336680 & 688798 & 4.35 & 5.5059 & TRN & \\
\hline CHEMBL1342059 & 688798 & 4.5 & 5.6232 & TRN & \\
\hline CHEMBL1318956 & 688798 & 4.3 & 5.0956 & TRN & \\
\hline CHEMBL1449717 & 688798 & 7.5003 & 5.4528 & TRN & \\
\hline CHEMBL1480888 & 688798 & 4.55 & 5.6243 & TRN & \\
\hline CHEMBL 262670 & 688798 & 3.95 & 5.4108 & TRN & \\
\hline CHEMBL1315028 & 688798 & 4.65 & 5.2656 & TRN & \\
\hline CHEMBL195008 & 688798 & 7.1002 & 4.9101 & TST & \\
\hline CHEMBL1431991 & 688798 & 9.3979 & 5.0407 & TRN & \\
\hline CHEMBL1482674 & 688798 & 5.05 & 5.4913 & TRN & \\
\hline CHEMBL1438907 & 688798 & 4.35 & 5.1394 & TRN & \\
\hline CHEMBL1325049 & 688798 & 4.95 & 5.5788 & TRN & \\
\hline CHEMBL1495485 & 688798 & 4.45 & 5.5659 & TRN & \\
\hline CHEMBL1554706 & 688798 & 7.2 & 5.5687 & TST & \\
\hline CHEMBL1594142 & 688798 & 4.0 & 4.7874 & TRN & \\
\hline CHEMBL1437562 & 688798 & 9.2218 & 5.7497 & TRN & \\
\hline CHEMBL1436495 & 688798 & 9.5229 & 5.7635 & TRN & \\
\hline CHEMBL1447702 & 688798 & 4.25 & 5.1679 & TRN & \\
\hline CHEMBL1486604 & 688798 & 4.95 & 5.6048 & TRN & \\
\hline CHEMBL1435044 & 688798 & 9.0458 & 5.3414 & TRN & \\
\hline CHEMBL187349 & 688798 & 4.15 & 5.1262 & TRN & \\
\hline CHEMBL1504201 & 688798 & 6.35 & 5.4699 & TRN & \\
\hline CHEMBL1553875 & 688798 & 5.45 & 5.4662 & TRN & \\
\hline CHEMBL1351044 & 688798 & 4.15 & 5.2191 & TRN & \\
\hline CHEMBL1373649 & 688798 & 4.35 & 5.358 & TRN & \\
\hline
\end{tabular}




\begin{tabular}{|c|c|c|c|c|c|}
\hline \multicolumn{6}{|c|}{ Supplemental Table s2.txt } \\
\hline CHEMBL66966 & 688798 & 4.6 & 4.8852 & TRN & \\
\hline CHEMBL1361082 & 688798 & 7.4498 & 5.5996 & TRN & \\
\hline CHEMBL3216654 & 688798 & 4.35 & 5.2173 & TST & \\
\hline CHEMBL1394554 & 688798 & 9.301 & 5.4594 & TRN & \\
\hline CHEMBL1355054 & 688798 & 7.15 & 5.4193 & TST & \\
\hline CHEMBL1396560 & 688798 & 3.1 & 5.2122 & TST & \\
\hline CHEMBL1515111 & 688798 & 4.45 & 5.3498 & TRN & \\
\hline CHEMBL1599719 & 688798 & 6.5501 & 5.5867 & TRN & \\
\hline CHEMBL1318477 & 688798 & 4.95 & 5.3657 & TRN & \\
\hline CHEMBL1395004 & 688798 & 4.7 & 5.8306 & TRN & \\
\hline CHEMBL1489386 & 688798 & 6.05 & 5.8364 & TRN & \\
\hline CHEMBL1977191 & 688798 & 4.0 & 5.1078 & TRN & \\
\hline CHEMBL1600501 & 688798 & 3.05 & 5.4492 & TRN & \\
\hline CHEMBL1554769 & 688798 & 4.45 & 5.5545 & TRN & \\
\hline CHEMBL1554727 & 688798 & 2.65 & 5.5032 & TRN & \\
\hline CHEMBL1541948 & 688798 & 2.45 & 5.0157 & TST & \\
\hline CHEMBL1580365 & 688798 & 5.5 & 5.2399 & TRN & \\
\hline CHEMBL1590363 & 688798 & 7.8996 & 5.3987 & TST & \\
\hline CHEMBL1331136 & 688798 & 5.85 & 5.7696 & TRN & \\
\hline CHEMBL1981657 & 688798 & 4.3 & 4.6879 & TRN & \\
\hline CHEMBL1610689 & 688798 & 3.95 & 5.1931 & TST & \\
\hline CHEMBL1366915 & 688798 & 4.35 & 4.774 & TRN & \\
\hline CHEMBL1356640 & 688798 & 7.6003 & 5.6101 & TRN & \\
\hline CHEMBL1433969 & 688798 & 3.7 & 5.2288 & TRN & \\
\hline CHEMBL1405432 & 688798 & 3.5 & 5.4243 & TRN & \\
\hline CHEMBL1526627 & 688798 & 7.4498 & 6.00299 & 9999999999 & TRN \\
\hline CHEMBL1396973 & 688798 & 5.9 & 5.5338 & TRN & \\
\hline CHEMBL3192605 & 688798 & 4.45 & 4.4212 & TST & \\
\hline CHEMBL1324032 & 688798 & 4.15 & 5.0932 & TST & \\
\hline CHEMBL1452438 & 688798 & 4.9 & 4.9775 & TRN & \\
\hline CHEMBL1410979 & 688798 & 3.85 & 5.5532 & TRN & \\
\hline CHEMBL1990774 & 688798 & 4.3 & 5.1195 & TST & \\
\hline CHEMBL1314953 & 688798 & 4.55 & 5.8411 & TRN & \\
\hline CHEMBL1355749 & 688798 & 4.0 & 5.5752 & TRN & \\
\hline CHEMBL1427681 & 688798 & 4.15 & 4.9608 & TRN & \\
\hline CHEMBL1436173 & 688798 & 6.5501 & 5.5699 & TRN & \\
\hline CHEMBL1515121 & 688798 & 4.7 & 5.557 & TRN & \\
\hline CHEMBL1540256 & 688798 & 7.5003 & 5.0009 & TRN & \\
\hline CHEMBL1373366 & 688798 & 4.9 & 5.2022 & TRN & \\
\hline CHEMBL1418147 & 688798 & 9.5229 & 5.17399 & 99999999995 & TRN \\
\hline CHEMBL1445596 & 688798 & 5.95 & 5.6536 & TRN & \\
\hline CHEMBL1966691 & 688798 & 6.05 & 4.9163 & TRN & \\
\hline CHEMBL3211933 & 688798 & 5.35 & 5.695 & TRN & \\
\hline CHEMBL1437415 & 688798 & 3.15 & 5.3461 & TRN & \\
\hline CHEMBL1467680 & 688798 & 8.1024 & 5.6 & TRN & \\
\hline CHEMBL1428894 & 688798 & 3.3 & 5.1667 & TRN & \\
\hline CHEMBL1398100 & 688798 & 4.25 & 5.3757 & TRN & \\
\hline CHEMBL1317760 & 688798 & 4.65 & 5.3193 & TRN & \\
\hline
\end{tabular}




\begin{tabular}{|c|c|c|c|c|c|}
\hline \multicolumn{6}{|c|}{ pıemental } \\
\hline CHEMBL1476236 & 688798 & 3.4 & 4.9254 & TST & \\
\hline CHEMBL1512085 & 688798 & 7.4498 & 5.8936 & TRN & \\
\hline CHEMBL1591083 & 688798 & 7.5498 & 5.4259 & TRN & \\
\hline CHEMBL1475345 & 688798 & 4.7 & 5.55399 & 9999999999 & TRN \\
\hline CHEMBL1472976 & 688798 & 4.85 & 5.0571 & TRN & \\
\hline CHEMBL3199590 & 688798 & 4.35 & 5.2999 & TRN & \\
\hline CHEMBL1577055 & 688798 & 7.5003 & 5.7268 & TRN & \\
\hline CHEMBL1443088 & 688798 & 4.35 & 4.9373 & TRN & \\
\hline CHEMBL1572545 & 688798 & 4.4 & 5.2358 & TRN & \\
\hline CHEMBL1473605 & 688798 & 5.6 & 5.437 & TRN & \\
\hline CHEMBL1316081 & 688798 & 4.5 & 4.8797 & TST & \\
\hline CHEMBL1472959 & 688798 & 4.9 & 5.67299 & 9999999999 & TRN \\
\hline CHEMBL1435460 & 688798 & 3.95 & 5.3097 & TRN & \\
\hline CHEMBL1532186 & 688798 & 4.25 & 4.9162 & TRN & \\
\hline CHEMBL1515105 & 688798 & 5.0 & 5.1601 & TRN & \\
\hline CHEMBL1592442 & 688798 & 6.5 & 5.1415 & TRN & \\
\hline CHEMBL1571952 & 688798 & 4.7 & 5.4755 & TRN & \\
\hline CHEMBL1594267 & 688798 & 4.9 & 5.5527 & TRN & \\
\hline CHEMBL1593500 & 688798 & 4.0 & 5.6084 & TRN & \\
\hline CHEMBL1451502 & 688798 & 8.1024 & 5.8581 & TRN & \\
\hline CHEMBL1475269 & 688798 & 7.1002 & 5.3301 & TRN & \\
\hline CHEMBL1569742 & 688798 & 4.5 & 5.0465 & TRN & \\
\hline CHEMBL1324033 & 688798 & 3.95 & 5.511 & TRN & \\
\hline CHEMBL1518813 & 688798 & 7.7496 & 5.2269 & TRN & \\
\hline CHEMBL1473203 & 688798 & 6.3 & 5.2466 & TRN & \\
\hline CHEMBL1335178 & 688798 & 4.95 & 5.266 & TRN & \\
\hline CHEMBL1473481 & 688798 & 8.0506 & 5.7002 & TRN & \\
\hline CHEMBL1554857 & 688798 & 5.95 & 5.3851 & TRN & \\
\hline CHEMBL1404752 & 688798 & 4.7 & 5.5005 & TRN & \\
\hline CHEMBL1362406 & 688798 & 4.8 & 5.4346 & TRN & \\
\hline CHEMBL1415635 & 688798 & 6.5 & 5.2886 & TRN & \\
\hline CHEMBL1472650 & 688798 & 5.6 & 5.6336 & TST & \\
\hline CHEMBL3193339 & 688798 & 5.25 & 5.3881 & TRN & \\
\hline CHEMBL1478431 & 688798 & 10.1 & 5.5057 & TRN & \\
\hline CHEMBL1316103 & 688798 & 9.5229 & 5.7859 & TRN & \\
\hline CHEMBL1557495 & 688798 & 5.5 & 5.5016 & TRN & \\
\hline CHEMBL1364326 & 688798 & 3.5 & 5.6777 & TRN & \\
\hline CHEMBL1514234 & 688798 & 7.2503 & 5.5317 & TRN & \\
\hline CHEMBL1314590 & 688798 & 5.05 & 5.2393 & TRN & \\
\hline CHEMBL1476359 & 688798 & 6.6499 & 5.91299 & 9999999999 & TRN \\
\hline CHEMBL533772 & 688798 & 5.85 & 5.0949 & TST & \\
\hline CHEMBL1382785 & 688798 & 4.35 & 5.1617 & TRN & \\
\hline CHEMBL563294 & 688798 & 4.5 & 4.8645 & TRN & \\
\hline CHEMBL1560786 & 688798 & 4.3 & 5.6237 & TRN & \\
\hline CHEMBL1360745 & 688798 & 4.65 & 5.4943 & TRN & \\
\hline CHEMBL1378347 & 688798 & 4.95 & 5.2693 & TRN & \\
\hline CHEMBL1335824 & 688798 & 6.05 & 5.4808 & TRN & \\
\hline CHEMBL1552730 & 688798 & 4.7 & 5.6658 & TRN & \\
\hline
\end{tabular}




\begin{tabular}{|c|c|c|c|c|c|}
\hline \multicolumn{6}{|c|}{ Supplemental Table S2.txt } \\
\hline CHEMBL3209569 & 688798 & 4.0 & 5.1496 & TST & \\
\hline CHEMBL1567862 & 688798 & 6.05 & 5.3821 & TRN & \\
\hline CHEMBL1322259 & 688798 & 5.5 & 5.5947 & TRN & \\
\hline CHEMBL1512965 & 688798 & 4.5 & 5.7061 & TRN & \\
\hline CHEMBL1356756 & 688798 & 4.0 & 5.1473 & TRN & \\
\hline CHEMBL1591049 & 688798 & 3.85 & 5.4815 & TRN & \\
\hline CHEMBL 3144984 & 688798 & 4.45 & 5.0886 & TST & \\
\hline CHEMBL1491139 & 688798 & 8.3979 & 5.42 & TRN & \\
\hline CHEMBL374107 & 688798 & 4.1 & 4.666 & TST & \\
\hline CHEMBL1395258 & 688798 & 6.25 & 5.6494 & TRN & \\
\hline CHEMBL1316217 & 688798 & 4.85 & 5.3861 & TRN & \\
\hline CHEMBL1610041 & 688798 & 6.25 & 5.3292 & TRN & \\
\hline CHEMBL1320759 & 688798 & 7.4498 & 5.8223 & TRN & \\
\hline CHEMBL1573377 & 688798 & 4.8 & 5.1319 & TST & \\
\hline CHEMBL1299449 & 688798 & 5.05 & 5.7478 & TRN & \\
\hline CHEMBL1495736 & 688798 & 4.7 & 5.0835 & TRN & \\
\hline CHEMBL1552837 & 688798 & 4.0 & 4.5074 & TST & \\
\hline CHEMBL1357249 & 688798 & 9.2218 & 5.234 & TRN & \\
\hline CHEMBL1595808 & 688798 & 7.4498 & 5.1747 & TRN & \\
\hline CHEMBL1377881 & 688798 & 8.6576 & 5.4954 & TRN & \\
\hline CHEMBL1514834 & 688798 & 9.0458 & $5.2170 e$ & 00000000005 & TRN \\
\hline CHEMBL1318473 & 688798 & 3.0 & 5.3828 & TRN & \\
\hline CHEMBL1516223 & 688798 & 5.0 & 5.7513 & TRN & \\
\hline CHEMBL1593659 & 688798 & 6.5 & 5.6093 & TRN & \\
\hline CHEMBL1410621 & 688798 & 4.65 & 5.2599 & TRN & \\
\hline CHEMBL1476658 & 688798 & 7.5498 & 5.3955 & TRN & \\
\hline CHEMBL1579747 & 688798 & 3.8 & 5.2893 & TST & \\
\hline CHEMBL1555269 & 688798 & 3.65 & 5.5341 & TRN & \\
\hline CHEMBL1302321 & 688798 & 4.3 & 5.6182 & TRN & \\
\hline CHEMBL3214488 & 688798 & 4.1 & 5.2172 & TRN & \\
\hline CHEMBL1555244 & 688798 & 5.55 & 5.1904 & TRN & \\
\hline CHEMBL1468771 & 688798 & 3.95 & 5.1774 & TRN & \\
\hline CHEMBL1590157 & 688798 & 3.7 & 5.4837 & TRN & \\
\hline CHEMBL1482689 & 688798 & 4.05 & 5.3521 & TRN & \\
\hline CHEMBL1530461 & 688798 & 4.0 & 5.5649 & TRN & \\
\hline CHEMBL1466239 & 688798 & 4.3 & 5.2055 & TRN & \\
\hline CHEMBL1436076 & 688798 & 3.7 & 5.5693 & TRN & \\
\hline CHEMBL1522999 & 688798 & 4.45 & 5.7514 & TRN & \\
\hline CHEMBL1592380 & 688798 & 4.65 & 5.6866 & TRN & \\
\hline CHEMBL1358479 & 688798 & 4.0 & 5.0053 & TRN & \\
\hline CHEMBL1514480 & 688798 & 6.4 & 5.3383 & TRN & \\
\hline CHEMBL1523013 & 688798 & 7.5498 & 5.4168 & TRN & \\
\hline CHEMBL1555512 & 688798 & 4.1 & 5.2861 & TRN & \\
\hline CHEMBL1594589 & 688798 & 3.55 & 5.6827 & TRN & \\
\hline CHEMBL1591078 & 688798 & 5.75 & 5.1834 & TRN & \\
\hline CHEMBL 244948 & 688798 & 5.55 & 4.4553 & TST & \\
\hline CHEMBL1401939 & 688798 & 4.3 & 5.5358 & TST & \\
\hline CHEMBL1405688 & 688798 & 7.4498 & 5.0867 & TRN & \\
\hline
\end{tabular}




\begin{tabular}{|c|c|c|c|c|c|}
\hline \multicolumn{6}{|c|}{ Supplemental Table S2.txt } \\
\hline CHEMBL1553670 & 688798 & 3.35 & 5.1918 & TRN & \\
\hline CHEMBL1316086 & 688798 & 5.4 & 5.545 & TRN & \\
\hline CHEMBL1456546 & 688798 & 5.0 & 5.3725 & TRN & \\
\hline CHEMBL1355928 & 688798 & 4.95 & 5.8327 & TRN & \\
\hline CHEMBL1428725 & 688798 & 7.15 & 5.4418 & TRN & \\
\hline CHEMBL1356670 & 688798 & 8.7447 & 4.8193 & TRN & \\
\hline CHEMBL1548935 & 688798 & 6.1 & 4.97199 & 99999999995 & TRN \\
\hline CHEMBL1396075 & 688798 & 3.0 & 5.6077 & TRN & \\
\hline CHEMBL1529378 & 688798 & 4.05 & 5.0904 & TRN & \\
\hline CHEMBL1584922 & 688798 & 3.7 & 5.2463 & TST & \\
\hline CHEMBL1474020 & 688798 & 3.85 & 5.5148 & TRN & \\
\hline CHEMBL1338089 & 688798 & 3.3 & 5.4366 & TRN & \\
\hline CHEMBL1412693 & 688798 & 4.1 & 5.5086 & TRN & \\
\hline CHEMBL45244 & 688798 & 5.55 & 5.2186 & TRN & \\
\hline CHEMBL1452815 & 688798 & 4.95 & 5.7053 & TRN & \\
\hline CHEMBL1506436 & 688798 & 4.95 & 5.521 & TRN & \\
\hline CHEMBL1309430 & 688798 & 4.35 & 5.2188 & TRN & \\
\hline CHEMBL1317223 & 688798 & 4.95 & 5.5041 & TRN & \\
\hline CHEMBL 89697 & 688798 & 6.95 & 4.8697 & TRN & \\
\hline CHEMBL1395903 & 688798 & 7.2 & 5.5855 & TRN & \\
\hline CHEMBL1560930 & 688798 & 5.65 & 4.8313 & TST & \\
\hline CHEMBL1315493 & 688798 & 7.8013 & 5.6238 & TRN & \\
\hline CHEMBL1447158 & 688798 & 4.4 & 5.4281 & TRN & \\
\hline CHEMBL1472890 & 688798 & 3.4 & 5.4113 & TRN & \\
\hline CHEMBL1551219 & 688798 & 3.0 & 5.255 & TRN & \\
\hline CHEMBL1256019 & 688798 & 4.25 & 4.8007 & TST & \\
\hline CHEMBL1433612 & 688798 & 4.7 & 5.271 & TRN & \\
\hline CHEMBL1416748 & 688798 & 5.35 & 4.8979 & TST & \\
\hline CHEMBL1536057 & 688798 & 7.5003 & 5.276 & TRN & \\
\hline CHEMBL1312363 & 688798 & 4.95 & 4.8169 & TRN & \\
\hline CHEMBL1516568 & 688798 & 3.65 & 5.5579 & TRN & \\
\hline CHEMBL1525773 & 688798 & 8.0506 & 5.5449 & TRN & \\
\hline CHEMBL1502528 & 688798 & 7.5498 & 5.3582 & TRN & \\
\hline CHEMBL1478264 & 688798 & 4.8 & 5.5913 & TRN & \\
\hline CHEMBL1587837 & 688798 & 4.45 & 5.3877 & TRN & \\
\hline CHEMBL1501265 & 688798 & 5.45 & 4.8571 & TST & \\
\hline CHEMBL1401538 & 688798 & 8.4949 & 5.4841 & TRN & \\
\hline CHEMBL1587091 & 688798 & 7.0 & 5.0866 & TST & \\
\hline CHEMBL1394048 & 688798 & 8.2007 & 4.8661 & TST & \\
\hline CHEMBL1356759 & 688798 & 6.5501 & 4.8128 & TST & \\
\hline CHEMBL1436840 & 688798 & 4.6 & 5.4385 & TRN & \\
\hline CHEMBL1449047 & 688798 & 4.1 & 5.4133 & TRN & \\
\hline CHEMBL1493752 & 688798 & 4.75 & 5.1365 & TRN & \\
\hline CHEMBL1481377 & 688798 & 5.5 & 5.1731 & TRN & \\
\hline CHEMBL1556917 & 688798 & 4.3 & 5.2832 & TRN & \\
\hline CHEMBL1375243 & 688798 & 5.9 & 4.7464 & TST & \\
\hline CHEMBL1317193 & 688798 & 4.95 & 5.6375 & TRN & \\
\hline CHEMBL1508886 & 688798 & 7.9508 & 5.2025 & TRN & \\
\hline
\end{tabular}




\begin{tabular}{|c|c|c|c|c|c|}
\hline \multicolumn{6}{|c|}{ Supplemental Table S2.txt } \\
\hline CHEMBL3199716 & 688798 & 4.1 & 5.1035 & TRN & \\
\hline CHEMBL1360081 & 688798 & 5.3 & 5.7269 & TRN & \\
\hline CHEMBL1368165 & 688798 & 4.5 & 5.3287 & TST & \\
\hline CHEMBL576997 & 688798 & 7.2 & 5.0961 & TST & \\
\hline CHEMBL1427520 & 688798 & 4.3 & 5.2685 & TRN & \\
\hline CHEMBL1461147 & 688798 & 4.0 & 5.1831 & TRN & \\
\hline CHEMBL1552331 & 688798 & 5.35 & 5.5984 & TRN & \\
\hline CHEMBL1443059 & 688798 & 4.4 & 4.9051 & TRN & \\
\hline CHEMBL1474792 & 688798 & 5.55 & 5.5325 & TRN & \\
\hline CHEMBL1472937 & 688798 & 3.5 & 5.3405 & TST & \\
\hline CHEMBL1558240 & 688798 & 4.4 & 4.4379 & TST & \\
\hline CHEMBL1479626 & 688798 & 6.8 & 5.5276 & TRN & \\
\hline CHEMBL1532430 & 688798 & 5.55 & 5.315 & TRN & \\
\hline CHEMBL1477497 & 688798 & 4.75 & 4.9761 & TRN & \\
\hline CHEMBL1476118 & 688798 & 4.55 & 5.1334 & TRN & \\
\hline CHEMBL1534879 & 688798 & 4.75 & 5.1949 & TRN & \\
\hline CHEMBL1317371 & 688798 & 8.1487 & 5.3045 & TRN & \\
\hline CHEMBL1441094 & 688798 & 3.7 & 5.1905 & TRN & \\
\hline CHEMBL1461753 & 688798 & 4.4 & 5.0441 & TRN & \\
\hline CHEMBL1553894 & 688798 & 5.45 & 5.5506 & TRN & \\
\hline CHEMBL1325257 & 688798 & 4.7 & 5.4066 & TRN & \\
\hline CHEMBL1315783 & 688798 & 5.0 & 5.2255 & TRN & \\
\hline CHEMBL1495625 & 688798 & 6.5 & 5.392 & TRN & \\
\hline CHEMBL1600976 & 688798 & 5.5 & 4.8284 & TRN & \\
\hline CHEMBL1533669 & 688798 & 10.05 & 5.8393 & TRN & \\
\hline CHEMBL1996858 & 688798 & 4.3 & 4.78 & TRN & \\
\hline CHEMBL1550862 & 688798 & 1.5 & 5.1733 & TRN & \\
\hline CHEMBL1532885 & 688798 & 9.0458 & 5.4653 & TRN & \\
\hline CHEMBL1436280 & 688798 & 8.699 & 5.24700 & 0000000001 & TRN \\
\hline CHEMBL1317044 & 688798 & 4.05 & 5.4064 & TRN & \\
\hline CHEMBL1454089 & 688798 & 7.2503 & 5.3986 & TRN & \\
\hline CHEMBL1612608 & 688798 & 7.0501 & 5.2408 & TRN & \\
\hline CHEMBL1368531 & 688798 & 9.1549 & 5.8062 & TRN & \\
\hline CHEMBL603024 & 688798 & 6.05 & 4.8918 & TST & \\
\hline CHEMBL1437245 & 688798 & 4.65 & 5.2639 & TRN & \\
\hline CHEMBL1571908 & 688798 & 4.4 & 5.8488 & TRN & \\
\hline CHEMBL1512154 & 688798 & 4.85 & 5.5346 & TRN & \\
\hline CHEMBL1355836 & 688798 & 4.05 & 4.8923 & TRN & \\
\hline CHEMBL1354553 & 688798 & 7.2 & 5.5983 & TRN & \\
\hline CHEMBL1515761 & 688798 & 6.2 & 5.3207 & TRN & \\
\hline CHEMBL1314803 & 688798 & 6.5 & 5.3051 & TRN & \\
\hline CHEMBL1506608 & 688798 & 4.0 & 5.504 & TST & \\
\hline CHEMBL1530283 & 688798 & 7.6003 & 5.0498 & TST & \\
\hline CHEMBL1428566 & 688798 & 10.0 & 5.0918 & TST & \\
\hline CHEMBL1596705 & 688798 & 4.45 & 5.4958 & TRN & \\
\hline CHEMBL1200938 & 688798 & 4.15 & 5.3146 & TST & \\
\hline CHEMBL1473810 & 688798 & 9.0458 & 5.2716 & TRN & \\
\hline CHEMBL1451465 & 688798 & 5.2 & 5.2805 & TRN & \\
\hline
\end{tabular}




\begin{tabular}{|c|c|c|c|c|}
\hline \multicolumn{5}{|c|}{ Supplemental Table S2.txt } \\
\hline CHEMBL1334633 & 688798 & 4.45 & 5.1673 & TST \\
\hline CHEMBL1394059 & 688798 & 3.95 & 5.3379 & TRN \\
\hline CHEMBL1447092 & 688798 & 4.75 & 5.5538 & TRN \\
\hline CHEMBL1398121 & 688798 & 7.2 & 5.5249 & TRN \\
\hline CHEMBL3194432 & 688798 & 4.35 & 5.193 & TRN \\
\hline CHEMBL1396894 & 688798 & 6.5 & 5.5001 & TRN \\
\hline CHEMBL1447338 & 688798 & 5.9 & 4.9177 & TRN \\
\hline CHEMBL1411805 & 688798 & 6.05 & 5.9746 & TRN \\
\hline CHEMBL1320615 & 688798 & 6.5 & 5.2139 & TRN \\
\hline CHEMBL3190262 & 688798 & 4.65 & 5.23 & TRN \\
\hline CHEMBL3198299 & 688798 & 7.1002 & 4.9136 & TRN \\
\hline CHEMBL1488991 & 688798 & 4.0 & 5.5151 & TRN \\
\hline CHEMBL1436561 & 688798 & 7.5498 & 5.7534 & TRN \\
\hline CHEMBL1358801 & 688798 & 5.55 & 5.3699 & TRN \\
\hline CHEMBL1455238 & 688798 & 3.8 & 5.8883 & TRN \\
\hline CHEMBL1526312 & 688798 & 4.75 & 4.944 & TRN \\
\hline CHEMBL1495041 & 688798 & 4.15 & 5.2988 & TRN \\
\hline CHEMBL1601430 & 688798 & 6.6499 & 5.7466 & TST \\
\hline CHEMBL1365457 & 688798 & 4.5 & 5.1738 & TRN \\
\hline CHEMBL1426722 & 688798 & 4.45 & 5.3824 & TST \\
\hline CHEMBL1595741 & 688798 & 4.75 & 5.6459 & TRN \\
\hline CHEMBL1418492 & 688798 & 5.3 & 5.7168 & TST \\
\hline CHEMBL1434130 & 688798 & 4.7 & 5.0372 & TRN \\
\hline CHEMBL3211272 & 688798 & 10.2 & 5.4224 & TRN \\
\hline CHEMBL1490035 & 688798 & 5.95 & 5.3599 & TRN \\
\hline CHEMBL1315440 & 688798 & 4.6 & 5.5344 & TRN \\
\hline CHEMBL1511502 & 688798 & 3.9 & 5.2349 & TRN \\
\hline CHEMBL 270271 & 688798 & 4.1 & 5.0735 & TST \\
\hline CHEMBL1331245 & 688798 & 4.55 & 4.5001 & TST \\
\hline CHEMBL1478175 & 688798 & 2.1 & 5.4671 & TRN \\
\hline CHEMBL1457100 & 688798 & 4.7 & 5.685 & TRN \\
\hline CHEMBL500830 & 688798 & 3.9 & 5.4885 & TRN \\
\hline CHEMBL1506716 & 688798 & 4.3 & 4.9341 & TST \\
\hline CHEMBL1465322 & 688798 & 4.35 & 5.0196 & TRN \\
\hline CHEMBL1328809 & 688798 & 7.6003 & 5.52 & TRN \\
\hline CHEMBL1477532 & 688798 & 8.1487 & 5.5521 & TRN \\
\hline CHEMBL1398141 & 688798 & 3.95 & 5.5748 & TRN \\
\hline CHEMBL1561149 & 688798 & 7.2503 & 5.5707 & TRN \\
\hline CHEMBL1330161 & 688798 & 4.5 & 4.8571 & TST \\
\hline CHEMBL1512916 & 688798 & 4.35 & 5.6828 & TRN \\
\hline CHEMBL3197907 & 688798 & 7.1002 & 5.3648 & TRN \\
\hline CHEMBL1573448 & 688798 & 7.3497 & 5.4882 & TRN \\
\hline CHEMBL1443827 & 688798 & 4.3 & 5.364 & TRN \\
\hline CHEMBL1551502 & 688798 & 5.7 & 5.5503 & TRN \\
\hline CHEMBL1436271 & 688798 & 4.65 & 4.8769 & TRN \\
\hline CHEMBL1332164 & 688798 & 3.9 & 4.9998 & TRN \\
\hline CHEMBL1542128 & 688798 & 4.3 & 5.006 & TRN \\
\hline CHEMBL1368673 & 688798 & 4.35 & 5.466 & TRN \\
\hline
\end{tabular}




\begin{tabular}{|c|c|c|c|c|c|}
\hline & & \multicolumn{4}{|c|}{ Supplemental Table S2.txt } \\
\hline CHEMBL1433566 & 688798 & 9.0458 & 5.7212 & TRN & \\
\hline CHEMBL1406395 & 688798 & 7.5498 & 5.5734 & TRN & \\
\hline CHEMBL162783 & 688798 & 4.5 & 4.5004 & TST & \\
\hline CHEMBL1598901 & 688798 & 4.75 & 5.6993 & TRN & \\
\hline CHEMBL1315914 & 688798 & 3.2 & 5.4996 & TRN & \\
\hline CHEMBL1437557 & 688798 & 7.0501 & 5.4853 & TRN & \\
\hline CHEMBL1592084 & 688798 & 4.9 & 5.3228 & TRN & \\
\hline CHEMBL1505694 & 688798 & 5.45 & 5.2471 & TST & \\
\hline CHEMBL1596233 & 688798 & 5.3 & 5.8299 & TRN & \\
\hline CHEMBL1400556 & 688798 & 5.0 & 5.6246 & TST & \\
\hline CHEMBL1514076 & 688798 & 4.0 & 5.0692 & TRN & \\
\hline CHEMBL1321733 & 688798 & 5.3 & 5.641 & TRN & \\
\hline CHEMBL1509116 & 688798 & 4.6 & 5.3277 & TRN & \\
\hline CHEMBL1524821 & 688798 & 4.7 & 5.41299 & 9999999999 & TRN \\
\hline CHEMBL1330875 & 688798 & 6.95 & 5.5226 & TRN & \\
\hline CHEMBL1358179 & 688798 & 8.8539 & 5.1195 & TRN & \\
\hline CHEMBL1445898 & 688798 & 4.9 & 5.5436 & TRN & \\
\hline CHEMBL1520988 & 688798 & 5.3 & 5.3387 & TRN & \\
\hline CHEMBL1397056 & 688798 & 7.6498 & 5.6618 & TRN & \\
\hline CHEMBL1554746 & 688798 & 8.9586 & 5.5118 & TRN & \\
\hline CHEMBL1535115 & 688798 & 9.0458 & 5.6535 & TRN & \\
\hline CHEMBL1511287 & 688798 & 4.4 & 5.1646 & TRN & \\
\hline CHEMBL1397602 & 688798 & 6.0 & 5.2092 & TST & \\
\hline CHEMBL1339100 & 688798 & 3.95 & 4.6929 & TST & \\
\hline CHEMBL1394103 & 688798 & 4.8 & 5.4095 & TRN & \\
\hline CHEMBL1333456 & 688798 & 3.0 & 5.5112 & TRN & \\
\hline CHEMBL3193785 & 688798 & 4.35 & 4.7261 & TST & \\
\hline CHEMBL1518787 & 688798 & 2.15 & 5.1975 & TRN & \\
\hline CHEMBL1592719 & 688798 & 2.7 & 5.7592 & TRN & \\
\hline CHEMBL1494006 & 688798 & 6.7501 & 5.1516 & TRN & \\
\hline CHEMBL1397441 & 688798 & 4.8 & 5.038 & TRN & \\
\hline CHEMBL1595323 & 688798 & 7.5498 & 5.511 & TRN & \\
\hline CHEMBL1308993 & 688798 & 4.3 & 5.0791 & TST & \\
\hline CHEMBL1435353 & 688798 & 5.85 & 5.4761 & TRN & \\
\hline CHEMBL454739 & 688798 & 3.35 & 4.7669 & TST & \\
\hline CHEMBL1599753 & 688798 & 6.7001 & 4.9585 & TST & \\
\hline CHEMBL1587511 & 688798 & 4.4 & 4.9816 & TST & \\
\hline CHEMBL1378476 & 688798 & 7.4498 & 5.3014 & TRN & \\
\hline CHEMBL1526089 & 688798 & 5.95 & 6.0127 & TRN & \\
\hline CHEMBL1539579 & 688798 & 4.4 & 5.2337 & TST & \\
\hline CHEMBL3193322 & 688798 & 4.35 & 4.8929 & TRN & \\
\hline CHEMBL1416753 & 688798 & 4.8 & 5.1702 & TST & \\
\hline CHEMBL1365553 & 688798 & 4.65 & 4.9748 & TRN & \\
\hline CHEMBL1508641 & 688798 & 6.05 & 5.244 & TRN & \\
\hline CHEMBL1512269 & 688798 & 4.65 & 5.6278 & TRN & \\
\hline CHEMBL52347 & 688798 & 4.4 & 4.782 & TRN & \\
\hline CHEMBL1500600 & 688798 & 4.45 & 5.1576 & TRN & \\
\hline CHEMBL1464399 & 688798 & 6.5 & 5.1426 & TRN & \\
\hline
\end{tabular}




\begin{tabular}{|c|c|c|c|c|c|}
\hline \multicolumn{6}{|c|}{ Supplemental Table S2.txt } \\
\hline CHEMBL1422097 & 688798 & 4.3 & 4.8881 & TST & \\
\hline CHEMBL1561704 & 688798 & 9.2218 & 5.1894 & TST & \\
\hline CHEMBL1476678 & 688798 & 2.85 & 5.5865 & TRN & \\
\hline CHEMBL1367735 & 688798 & 5.55 & 5.4095 & TST & \\
\hline CHEMBL1352069 & 688798 & 4.5 & 4.5884 & TST & \\
\hline CHEMBL1357518 & 688798 & 5.15 & 5.5236 & TRN & \\
\hline CHEMBL1356735 & 688798 & 7.0501 & 5.3205 & TRN & \\
\hline CHEMBL1555248 & 688798 & 6.5501 & 5.9563 & TRN & \\
\hline CHEMBL131091 & 688798 & 6.0 & 4.63899 & 9999999999 & TST \\
\hline CHEMBL1479536 & 688798 & 3.9 & 5.3906 & TRN & \\
\hline CHEMBL1557583 & 688798 & 5.8 & 5.0754 & TRN & \\
\hline CHEMBL1362461 & 688798 & 5.1 & 5.756 & TRN & \\
\hline CHEMBL1505276 & 688798 & 5.3 & 5.414 & TRN & \\
\hline CHEMBL1437749 & 688798 & 5.05 & 5.3444 & TST & \\
\hline CHEMBL1316886 & 688798 & 4.75 & 5.731 & TRN & \\
\hline CHEMBL1611159 & 688798 & 4.3 & 5.6218 & TRN & \\
\hline CHEMBL1435446 & 688798 & 8.3468 & 5.6783 & TRN & \\
\hline CHEMBL1319733 & 688798 & 4.75 & 5.1062 & TST & \\
\hline CHEMBL1578235 & 688798 & 4.15 & 4.9749 & TRN & \\
\hline CHEMBL1353073 & 688798 & 8.4949 & 5.1335 & TRN & \\
\hline CHEMBL3192741 & 688798 & 3.4 & 4.9437 & TRN & \\
\hline CHEMBL1318138 & 688798 & 4.9 & 5.222 & TRN & \\
\hline CHEMBL586005 & 688798 & 8.1024 & 5.5939 & TRN & \\
\hline CHEMBL1397889 & 688798 & 7.5003 & 5.3091 & TRN & \\
\hline CHEMBL1516081 & 688798 & 2.95 & 5.7692 & TRN & \\
\hline CHEMBL1395897 & 688798 & 4.7 & 5.1444 & TRN & \\
\hline CHEMBL1553510 & 688798 & 4.65 & 5.6316 & TRN & \\
\hline CHEMBL3191212 & 688798 & 5.85 & 5.3353 & TRN & \\
\hline CHEMBL1399640 & 688798 & 9.5229 & 5.2838 & TST & \\
\hline CHEMBL1512069 & 688798 & 4.0 & 5.7569 & TRN & \\
\hline CHEMBL1315804 & 688798 & 8.5528 & $5.6170 e$ & 0000000001 & TRN \\
\hline CHEMBL3195461 & 688798 & 4.35 & 4.8383 & TST & \\
\hline CHEMBL1553683 & 688798 & 4.7 & 5.4106 & TRN & \\
\hline CHEMBL1410754 & 688798 & 8.0506 & 4.9639 & TRN & \\
\hline CHEMBL1553428 & 688798 & 5.45 & 5.2526 & TST & \\
\hline CHEMBL1436706 & 688798 & 4.85 & 5.3059 & TRN & \\
\hline CHEMBL1446552 & 688798 & 4.75 & 5.7027 & TRN & \\
\hline CHEMBL1434426 & 688798 & 3.95 & 5.5614 & TRN & \\
\hline CHEMBL1511993 & 688798 & 7.5003 & 5.4098 & TRN & \\
\hline CHEMBL1304623 & 688798 & 4.35 & 5.2628 & TRN & \\
\hline CHEMBL1417934 & 688798 & 4.35 & 5.1995 & TRN & \\
\hline CHEMBL1590793 & 688798 & 7.4498 & 5.9285 & TRN & \\
\hline CHEMBL223453 & 688798 & 4.8 & 4.8169 & TST & \\
\hline CHEMBL1484483 & 688798 & 3.15 & 5.6306 & TRN & \\
\hline CHEMBL1398525 & 688798 & 4.65 & 5.1443 & TRN & \\
\hline CHEMBL1428936 & 688798 & 5.1 & 4.978 & TST & \\
\hline CHEMBL1397525 & 688798 & 6.5 & 5.646 & TRN & \\
\hline CHEMBL1391452 & 688798 & 5.65 & 4.8092 & TST & \\
\hline
\end{tabular}




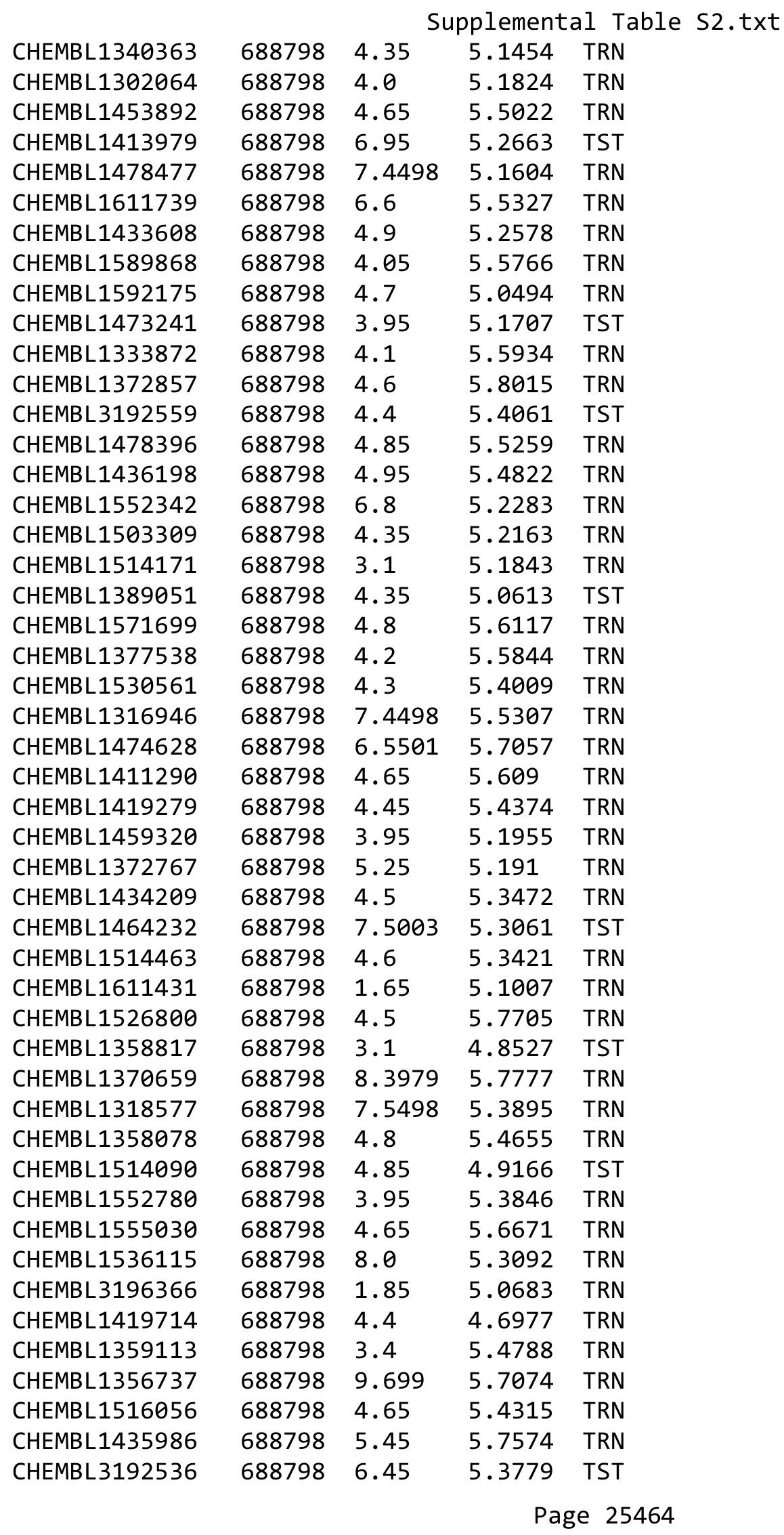




\begin{tabular}{|c|c|c|c|c|c|}
\hline \\
\hline CHEMBL1430920 & 688798 & 6.4 & 5.023 & TRN & \\
\hline CHEMBL1340713 & 688798 & 4.35 & 4.8705 & TRN & \\
\hline CHEMBL1525488 & 688798 & 5.5 & 5.6519 & TRN & \\
\hline CHEMBL1551243 & 688798 & 5.2 & 5.5527 & TRN & \\
\hline CHEMBL1494106 & 688798 & 6.95 & 5.5451 & TRN & \\
\hline CHEMBL1314945 & 688798 & 5.9 & 5.9819 & TRN & \\
\hline CHEMBL1353080 & 688798 & 6.1 & 5.5318 & TRN & \\
\hline CHEMBL1485462 & 688798 & 4.75 & 5.546 & TRN & \\
\hline CHEMBL1439041 & 688798 & 7.2 & 5.5458 & TRN & \\
\hline CHEMBL1434846 & 688798 & 3.55 & 5.5413 & TRN & \\
\hline CHEMBL1597612 & 688798 & 7.7496 & 4.7291 & TST & \\
\hline CHEMBL1486313 & 688798 & 4.45 & 5.4408 & TRN & \\
\hline CHEMBL1515085 & 688798 & 4.0 & 5.2507 & TRN & \\
\hline CHEMBL1322375 & 688798 & 4.25 & 4.6773 & TRN & \\
\hline CHEMBL1523836 & 688798 & 4.4 & 4.9911 & TRN & \\
\hline CHEMBL1396739 & 688798 & 10.0 & 5.3404 & TRN & \\
\hline CHEMBL1475308 & 688798 & 5.05 & 5.2263 & TRN & \\
\hline CHEMBL1494950 & 688798 & 9.3979 & 5.4567 & TRN & \\
\hline CHEMBL169 & 688798 & 4.6 & 4.8137 & TST & \\
\hline CHEMBL1320839 & 688798 & 4.35 & 5.5687 & TRN & \\
\hline CHEMBL1396213 & 688798 & 3.0 & 5.4755 & TRN & \\
\hline CHEMBL1319960 & 688798 & 5.0 & 5.2063 & TRN & \\
\hline CHEMBL1556239 & 688798 & 4.3 & 4.74 & TST & \\
\hline CHEMBL1401332 & 688798 & 4.0 & 5.2797 & TRN & \\
\hline CHEMBL1476622 & 688798 & 2.2 & 5.0923 & TST & \\
\hline CHEMBL1355273 & 688798 & 4.95 & 5.5976 & TRN & \\
\hline CHEMBL1435113 & 688798 & 7.0501 & 5.7524 & TRN & \\
\hline CHEMBL1394522 & 688798 & 4.75 & 5.409 & TRN & \\
\hline CHEMBL1487478 & 688798 & 4.45 & 5.54899 & 99999999995 & TRN \\
\hline CHEMBL1502458 & 688798 & 4.35 & 4.8242 & TRN & \\
\hline CHEMBL1441121 & 688798 & 3.15 & 5.4542 & TRN & \\
\hline CHEMBL1383254 & 688798 & 5.25 & 5.0738 & TRN & \\
\hline CHEMBL1317464 & 688798 & 7.0 & 5.7383 & TRN & \\
\hline CHEMBL1406195 & 688798 & 4.35 & 5.1746 & TRN & \\
\hline CHEMBL1426003 & 688798 & 4.35 & 5.1954 & TRN & \\
\hline CHEMBL1339178 & 688798 & 4.35 & 4.9919 & TST & \\
\hline CHEMBL1401920 & 688798 & 4.1 & 5.6596 & TRN & \\
\hline CHEMBL1475814 & 688798 & 3.95 & 5.2779 & TRN & \\
\hline CHEMBL1438185 & 688798 & 4.0 & 5.1229 & TRN & \\
\hline CHEMBL1434722 & 688798 & 7.5003 & 5.61100 & 3000000001 & TRN \\
\hline CHEMBL1404363 & 688798 & 4.35 & 4.695 & TRN & \\
\hline CHEMBL1436691 & 688798 & 9.0458 & 5.5938 & TRN & \\
\hline CHEMBL1419637 & 688798 & 4.5 & 4.9412 & TST & \\
\hline CHEMBL1318425 & 688798 & 4.65 & 5.5002 & TST & \\
\hline CHEMBL1307635 & 688798 & 2.95 & 5.1504 & TRN & \\
\hline CHEMBL1317768 & 688798 & 3.35 & 5.319 & TRN & \\
\hline CHEMBL1553378 & 688798 & 8.6576 & 5.0787 & TST & \\
\hline CHEMBL1448563 & 688798 & 4.5 & 4.8172 & TRN & \\
\hline
\end{tabular}




\begin{tabular}{|c|c|c|c|c|c|}
\hline \multicolumn{6}{|c|}{ Supplemental Table S2.txt } \\
\hline CHEMBL1471712 & 688798 & 4.45 & 5.0635 & TST & \\
\hline CHEMBL1491996 & 688798 & 4.45 & 5.0271 & TST & \\
\hline CHEMBL266084 & 688798 & 8.8539 & 5.1419 & TRN & \\
\hline CHEMBL1454590 & 688798 & 3.9 & 4.6883 & TST & \\
\hline CHEMBL1513885 & 688798 & 4.55 & 4.9414 & TRN & \\
\hline CHEMBL1413384 & 688798 & 3.45 & 5.6637 & TRN & \\
\hline CHEMBL1354697 & 688798 & 5.5 & 5.5749 & TRN & \\
\hline CHEMBL1316279 & 688798 & 7.4498 & 5.08899 & 99999999995 & TRN \\
\hline CHEMBL1407954 & 688798 & 3.95 & 5.2692 & TRN & \\
\hline CHEMBL1557189 & 688798 & 6.5 & 5.6216 & TRN & \\
\hline CHEMBL1413756 & 688798 & 8.1487 & 5.7645 & TRN & \\
\hline CHEMBL366861 & 688798 & 5.15 & 4.9428 & TST & \\
\hline CHEMBL1982304 & 688798 & 4.35 & 4.8756 & TRN & \\
\hline CHEMBL1598898 & 688798 & 5.05 & 5.6531 & TRN & \\
\hline CHEMBL1601638 & 688798 & 5.05 & 5.5214 & TRN & \\
\hline CHEMBL1420224 & 688798 & 5.55 & 5.331 & TRN & \\
\hline CHEMBL1358727 & 688798 & 3.3 & 5.6077 & TRN & \\
\hline CHEMBL1359824 & 688798 & 3.95 & 5.4976 & TRN & \\
\hline CHEMBL1501796 & 688798 & 6.5 & 4.8863 & TRN & \\
\hline CHEMBL1473063 & 688798 & 8.4559 & 5.5731 & TRN & \\
\hline CHEMBL1376246 & 688798 & 9.3979 & 5.3285 & TRN & \\
\hline CHEMBL1528803 & 688798 & 4.9 & 5.4525 & TRN & \\
\hline CHEMBL1422873 & 688798 & 4.75 & 5.3514 & TRN & \\
\hline CHEMBL1354483 & 688798 & 4.0 & 5.6142 & TRN & \\
\hline CHEMBL1592108 & 688798 & 7.2503 & 5.0848 & TST & \\
\hline CHEMBL1430650 & 688798 & 4.75 & 5.4093 & TRN & \\
\hline CHEMBL1358391 & 688798 & 3.6 & 5.3217 & TRN & \\
\hline CHEMBL1376816 & 688798 & 3.95 & 5.55200 & 00000000005 & TRN \\
\hline CHEMBL1973626 & 688798 & 4.0 & 5.2518 & TRN & \\
\hline CHEMBL1350350 & 688798 & 4.3 & 5.515 & TRN & \\
\hline CHEMBL1544913 & 688798 & 7.9508 & 5.3472 & TST & \\
\hline CHEMBL1477348 & 688798 & 5.65 & 5.1754 & TRN & \\
\hline CHEMBL1397702 & 688798 & 4.25 & 5.4616 & TRN & \\
\hline CHEMBL1515693 & 688798 & 7.0501 & 5.1677 & TRN & \\
\hline CHEMBL1475391 & 688798 & 3.95 & 5.3726 & TRN & \\
\hline CHEMBL1492716 & 688798 & 4.35 & 4.6748 & TRN & \\
\hline CHEMBL1335570 & 688798 & 7.2 & 4.74100 & 00000000005 & TRN \\
\hline CHEMBL1552450 & 688798 & 4.0 & 4.9675 & TRN & \\
\hline CHEMBL3192728 & 688798 & 6.45 & 4.8731 & TRN & \\
\hline CHEMBL1596652 & 688798 & 2.45 & 5.7508 & TRN & \\
\hline CHEMBL1572585 & 688798 & 3.0 & 5.1031 & TST & \\
\hline CHEMBL1598816 & 688798 & 8.5528 & 5.308 & TRN & \\
\hline CHEMBL1455927 & 688798 & 6.5 & 5.2994 & TRN & \\
\hline CHEMBL1405646 & 688798 & 4.5 & 5.6492 & TRN & \\
\hline CHEMBL1322065 & 688798 & 4.0 & 5.5674 & TRN & \\
\hline CHEMBL1475871 & 688798 & 6.7501 & 5.3908 & TRN & \\
\hline CHEMBL1317551 & 688798 & 5.65 & 5.4142 & TRN & \\
\hline CHEMBL1324071 & 688798 & 6.1 & 5.7241 & TRN & \\
\hline
\end{tabular}




\begin{tabular}{|c|c|c|c|c|c|}
\hline \multicolumn{6}{|c|}{ Supplemental Table S2.txt } \\
\hline CHEMBL1514125 & 688798 & 2.7 & 5.6278 & TRN & \\
\hline CHEMBL1397809 & 688798 & 3.95 & 5.5121 & TRN & \\
\hline CHEMBL1369443 & 688798 & 9.0458 & 5.7964 & TRN & \\
\hline CHEMBL 267548 & 688798 & 6.0 & 5.0376 & TST & \\
\hline CHEMBL1396902 & 688798 & 5.95 & 5.4894 & TRN & \\
\hline CHEMBL1486961 & 688798 & 4.85 & 5.6464 & TRN & \\
\hline CHEMBL1514585 & 688798 & 5.75 & 5.5733 & TRN & \\
\hline CHEMBL1317872 & 688798 & 4.4 & 5.0104 & TRN & \\
\hline CHEMBL1478567 & 688798 & 4.0 & 5.3969 & TRN & \\
\hline CHEMBL1529749 & 688798 & 2.95 & 5.4239 & TRN & \\
\hline CHEMBL1435020 & 688798 & 3.9 & 5.7794 & TRN & \\
\hline CHEMBL1311292 & 688798 & 4.15 & 5.6451 & TST & \\
\hline CHEMBL1316171 & 688798 & 4.0 & 5.5825 & TRN & \\
\hline CHEMBL1355632 & 688798 & 3.75 & 5.5 & TRN & \\
\hline CHEMBL1579184 & 688798 & 7.6003 & 5.3738 & TRN & \\
\hline CHEMBL1510661 & 688798 & 4.3 & 5.3499 & TRN & \\
\hline CHEMBL1403586 & 688798 & 4.35 & 5.2555 & TST & \\
\hline CHEMBL1554788 & 688798 & 5.9 & 5.05699 & 99999999995 & TST \\
\hline CHEMBL1318117 & 688798 & 5.6 & 4.8147 & TST & \\
\hline CHEMBL1479689 & 688798 & 6.5 & 5.295 & TRN & \\
\hline CHEMBL1548993 & 688798 & 7.0501 & 5.2823 & TRN & \\
\hline CHEMBL3210287 & 688798 & 6.1 & 5.586 & TRN & \\
\hline CHEMBL1367877 & 688798 & 4.3 & 5.0872 & TST & \\
\hline CHEMBL1472916 & 688798 & 6.5 & 5.6712 & TRN & \\
\hline CHEMBL1469246 & 688798 & 4.9 & 5.4115 & TRN & \\
\hline CHEMBL1396048 & 688798 & 8.2518 & 5.6304 & TRN & \\
\hline CHEMBL1429070 & 688798 & 4.9 & 4.5741 & TST & \\
\hline CHEMBL1384302 & 688798 & 5.6 & 5.2949 & TRN & \\
\hline CHEMBL1326348 & 688798 & 4.95 & 5.0064 & TRN & \\
\hline CHEMBL1603637 & 688798 & 4.75 & 5.4053 & TST & \\
\hline CHEMBL1409438 & 688798 & 4.95 & 5.5636 & TRN & \\
\hline CHEMBL1530712 & 688798 & 4.55 & 4.3788 & TST & \\
\hline CHEMBL1350444 & 688798 & 6.2 & 5.5988 & TST & \\
\hline CHEMBL1513498 & 688798 & 5.6 & 5.5478 & TRN & \\
\hline CHEMBL1312214 & 688798 & 4.35 & 5.1927 & TRN & \\
\hline CHEMBL1478811 & 688798 & 9.2218 & 4.6903 & TRN & \\
\hline CHEMBL1518316 & 688798 & 4.5 & 4.9706 & TST & \\
\hline CHEMBL1575767 & 688798 & 4.8 & 5.0055 & TRN & \\
\hline CHEMBL1452952 & 688798 & 4.25 & 5.1998 & TST & \\
\hline CHEMBL1476680 & 688798 & 4.95 & 5.5235 & TRN & \\
\hline CHEMBL1455936 & 688798 & 4.95 & 5.3641 & TST & \\
\hline CHEMBL1317895 & 688798 & 4.35 & 5.4575 & TRN & \\
\hline CHEMBL 255311 & 688798 & 4.15 & 4.8798 & TRN & \\
\hline CHEMBL1571034 & 688798 & 4.4 & 4.8534 & TRN & \\
\hline CHEMBL1477142 & 688798 & 5.15 & 5.6896 & TRN & \\
\hline CHEMBL1324138 & 688798 & 4.7 & 5.2209 & TRN & \\
\hline CHEMBL1552231 & 688798 & 4.7 & 4.9859 & TRN & \\
\hline CHEMBL1449781 & 688798 & 3.95 & 5.4856 & TRN & \\
\hline
\end{tabular}




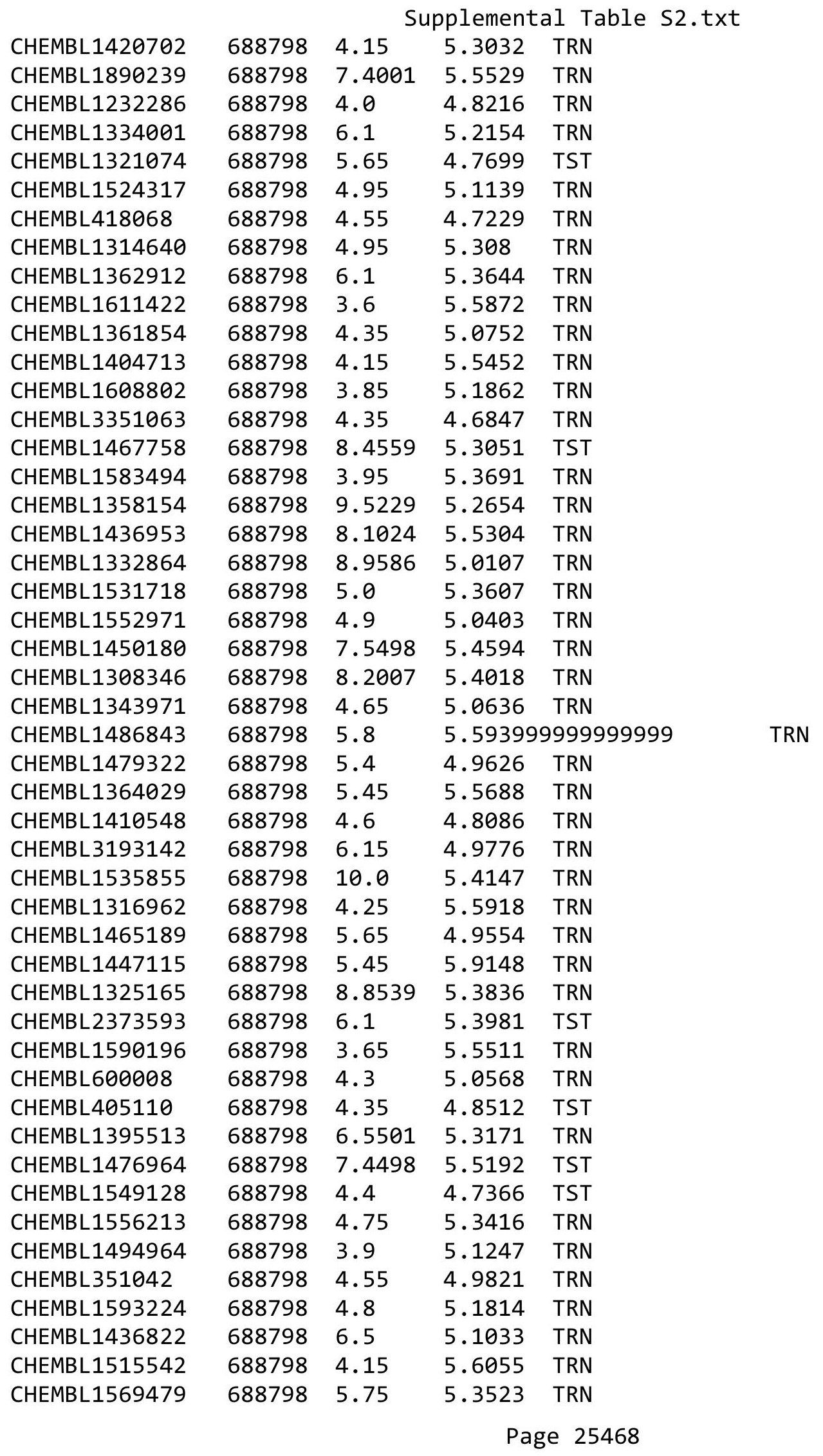




\begin{tabular}{|c|c|c|c|c|c|}
\hline \multicolumn{6}{|c|}{ Supplemental Table S2.txt } \\
\hline CHEMBL484663 & 688798 & 3.95 & 4.6042 & TRN & \\
\hline CHEMBL1348572 & 688798 & 4.75 & 4.9477 & TRN & \\
\hline CHEMBL1446863 & 688798 & 4.6 & 4.9816 & TST & \\
\hline CHEMBL1612025 & 688798 & 5.05 & 5.0905 & TRN & \\
\hline CHEMBL 1315450 & 688798 & 3.95 & 4.907 & TRN & \\
\hline CHEMBL1471193 & 688798 & 4.15 & 5.1242 & TRN & \\
\hline CHEMBL1597100 & 688798 & 7.4498 & 5.5502 & TRN & \\
\hline CHEMBL103955 & 688798 & 8.4559 & 5.1162 & TST & \\
\hline CHEMBL1399843 & 688798 & 4.4 & 5.4802 & TRN & \\
\hline CHEMBL1552808 & 688798 & 4.95 & 5.4045 & TST & \\
\hline CHEMBL1592221 & 688798 & 7.1002 & 5.3938 & TRN & \\
\hline CHEMBL1593963 & 688798 & 7.4498 & 5.6176 & TRN & \\
\hline CHEMBL1598959 & 688798 & 7.4498 & 5.4607 & TRN & \\
\hline CHEMBL1603765 & 688798 & 3.55 & 5.4915 & TRN & \\
\hline CHEMBL1474213 & 688798 & 4.4 & 5.5597 & TRN & \\
\hline CHEMBL1593119 & 688798 & 5.95 & 5.6579 & TRN & \\
\hline CHEMBL1516323 & 688798 & 5.5 & 5.44799 & 99999999995 & TRN \\
\hline CHEMBL1482375 & 688798 & 4.1 & 4.8278 & TST & \\
\hline CHEMBL1440145 & 688798 & 8.3979 & 5.5488 & TST & \\
\hline CHEMBL1476389 & 688798 & 3.4 & 5.1373 & TST & \\
\hline CHEMBL1301127 & 688798 & 5.0 & 4.9385 & TST & \\
\hline CHEMBL1407049 & 688798 & 7.2 & 5.5174 & TRN & \\
\hline CHEMBL1483611 & 688798 & 4.4 & 5.2329 & TRN & \\
\hline CHEMBL1707818 & 688798 & 4.45 & 5.1559 & TRN & \\
\hline CHEMBL1523658 & 688798 & 5.4 & 4.9223 & TRN & \\
\hline CHEMBL1515148 & 688798 & 4.5 & 5.64 & TRN & \\
\hline CHEMBL1513997 & 688798 & 7.3002 & 5.062 & TRN & \\
\hline CHEMBL1541471 & 688798 & 6.15 & 5.4142 & TRN & \\
\hline CHEMBL1447278 & 688798 & 4.5 & 5.2575 & TST & \\
\hline CHEMBL1479034 & 688798 & 4.4 & 5.4818 & TRN & \\
\hline CHEMBL1317600 & 688798 & 7.0501 & 5.4734 & TRN & \\
\hline CHEMBL1488631 & 688798 & 9.0969 & 5.393 & TRN & \\
\hline CHEMBL1394538 & 688798 & 4.0 & 5.6241 & TRN & \\
\hline CHEMBL1395968 & 688798 & 7.6003 & 5.6632 & TRN & \\
\hline CHEMBL1407388 & 688798 & 4.15 & 5.8125 & TRN & \\
\hline CHEMBL1462225 & 688798 & 4.35 & 5.3345 & TRN & \\
\hline CHEMBL1451264 & 688798 & 4.0 & 4.8245 & TRN & \\
\hline CHEMBL1400011 & 688798 & 5.3 & 5.5538 & TRN & \\
\hline CHEMBL1496004 & 688798 & 4.5 & 5.3151 & TST & \\
\hline CHEMBL1607532 & 688798 & 4.35 & 4.9752 & TST & \\
\hline CHEMBL1553734 & 688798 & 7.5498 & 5.6309 & TRN & \\
\hline CHEMBL1541005 & 688798 & 4.75 & 4.7508 & TRN & \\
\hline CHEMBL1706577 & 688798 & 4.5 & 5.0541 & TRN & \\
\hline CHEMBL1402957 & 688798 & 4.45 & 5.2418 & TST & \\
\hline CHEMBL1598791 & 688798 & 4.35 & 4.7518 & TST & \\
\hline CHEMBL1518242 & 688798 & 9.699 & 5.1182 & TRN & \\
\hline CHEMBL1593463 & 688798 & 3.6 & 5.6744 & TRN & \\
\hline CHEMBL1516318 & 688798 & 10.0 & 5.4115 & TST & \\
\hline
\end{tabular}




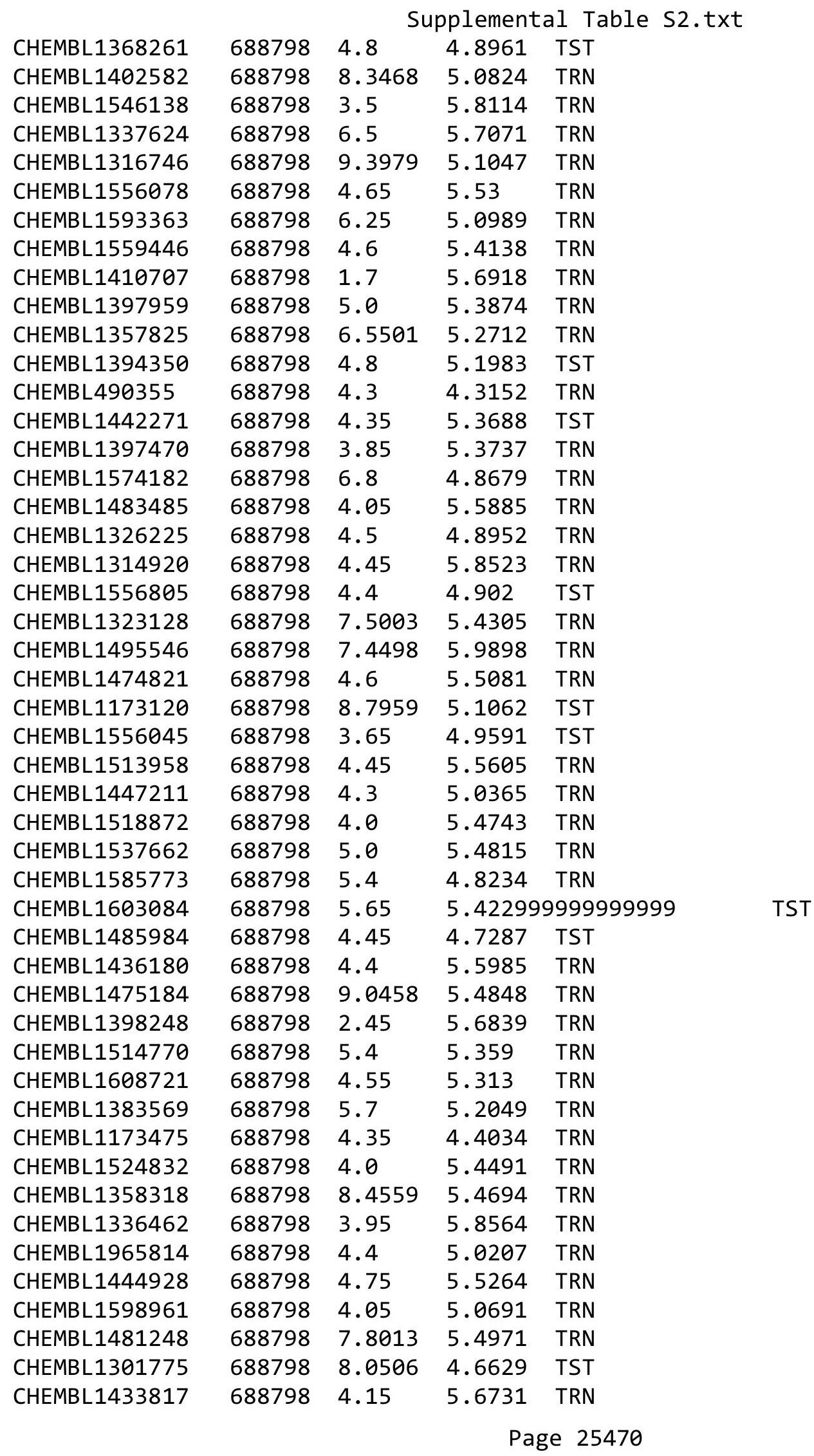




\begin{tabular}{|c|c|c|c|c|c|}
\hline \multicolumn{6}{|c|}{ Supplemental Table S2.txt } \\
\hline CHEMBL1539915 & 688798 & 4.15 & 5.3492 & TRN & \\
\hline CHEMBL1442675 & 688798 & 2.65 & 4.8166 & TRN & \\
\hline CHEMBL1407197 & 688798 & 4.4 & 5.1465 & TRN & \\
\hline CHEMBL1551565 & 688798 & 4.95 & 5.4027 & TRN & \\
\hline CHEMBL1462198 & 688798 & 5.15 & 5.28100 & 0000000001 & TST \\
\hline CHEMBL1243269 & 688798 & 9.699 & 5.0744 & TST & \\
\hline CHEMBL1554305 & 688798 & 7.8013 & 5.3069 & TST & \\
\hline CHEMBL1503502 & 688798 & 7.4498 & 5.0926 & TST & \\
\hline CHEMBL1479844 & 688798 & 7.9508 & 4.9939 & TRN & \\
\hline CHEMBL1494098 & 688798 & 7.5003 & 5.7163 & TRN & \\
\hline CHEMBL1512741 & 688798 & 7.4498 & 5.6298 & TRN & \\
\hline CHEMBL1365118 & 688798 & 4.35 & 5.0296 & TRN & \\
\hline CHEMBL1513409 & 688798 & 5.1 & 5.3208 & TRN & \\
\hline CHEMBL1463801 & 688798 & 4.35 & 4.7604 & TRN & \\
\hline CHEMBL1473348 & 688798 & 4.0 & 5.0105 & TRN & \\
\hline CHEMBL1609715 & 688798 & 4.65 & 5.46299 & 9999999999 & TRN \\
\hline CHEMBL1344248 & 688798 & 4.3 & 5.562 & TRN & \\
\hline CHEMBL1417305 & 688798 & 10.0 & 5.5842 & TRN & \\
\hline CHEMBL1357400 & 688798 & 9.0969 & 4.917 & TRN & \\
\hline CHEMBL1521196 & 688798 & 4.35 & 4.9077 & TST & \\
\hline CHEMBL87426 & 688798 & 7.1002 & 4.6894 & TST & \\
\hline CHEMBL1449089 & 688798 & 9.1549 & 5.4419 & TRN & \\
\hline CHEMBL1435558 & 688798 & 4.5 & 4.9168 & TST & \\
\hline CHEMBL1371585 & 688798 & 7.2 & 5.1807 & TRN & \\
\hline CHEMBL1518821 & 688798 & 4.45 & 5.078 & TRN & \\
\hline CHEMBL236615 & 688798 & 6.0 & 4.9422 & TRN & \\
\hline CHEMBL1601507 & 688798 & 7.4498 & 5.6168 & TRN & \\
\hline CHEMBL1549416 & 688798 & 7.6003 & 5.1318 & TST & \\
\hline CHEMBL1525219 & 688798 & 7.1002 & 4.9957 & TRN & \\
\hline CHEMBL1591810 & 688798 & 5.9 & 5.5663 & TRN & \\
\hline CHEMBL1436317 & 688798 & 4.6 & 4.9899 & TRN & \\
\hline CHEMBL1332138 & 688798 & 6.45 & 5.3907 & TRN & \\
\hline CHEMBL1475369 & 688798 & 6.35 & 5.4386 & TRN & \\
\hline CHEMBL1399249 & 688798 & 8.5528 & 5.2977 & TST & \\
\hline CHEMBL1514946 & 688798 & 5.1 & 5.2915 & TRN & \\
\hline CHEMBL3194633 & 688798 & 3.5 & 5.0622 & TRN & \\
\hline CHEMBL1515607 & 688798 & 5.7 & 5.5483 & TRN & \\
\hline CHEMBL1451483 & 688798 & 4.35 & 4.7143 & TST & \\
\hline CHEMBL3197308 & 688798 & 4.35 & 4.9112 & TST & \\
\hline CHEMBL1319888 & 688798 & 6.95 & 5.3472 & TRN & \\
\hline CHEMBL1397467 & 688798 & 8.8861 & 5.0255 & TRN & \\
\hline CHEMBL1476666 & 688798 & 4.9 & 5.282 & TRN & \\
\hline CHEMBL1528320 & 688798 & 4.3 & 5.819 & TRN & \\
\hline CHEMBL1440031 & 688798 & 6.0 & 5.0023 & TRN & \\
\hline CHEMBL1447053 & 688798 & 8.8539 & 5.3486 & TRN & \\
\hline CHEMBL1605460 & 688798 & 3.45 & 4.9652 & TST & \\
\hline CHEMBL1559859 & 688798 & 7.4498 & 5.9642 & TRN & \\
\hline CHEMBL1346078 & 688798 & 8.7959 & 4.8963 & TST & \\
\hline
\end{tabular}




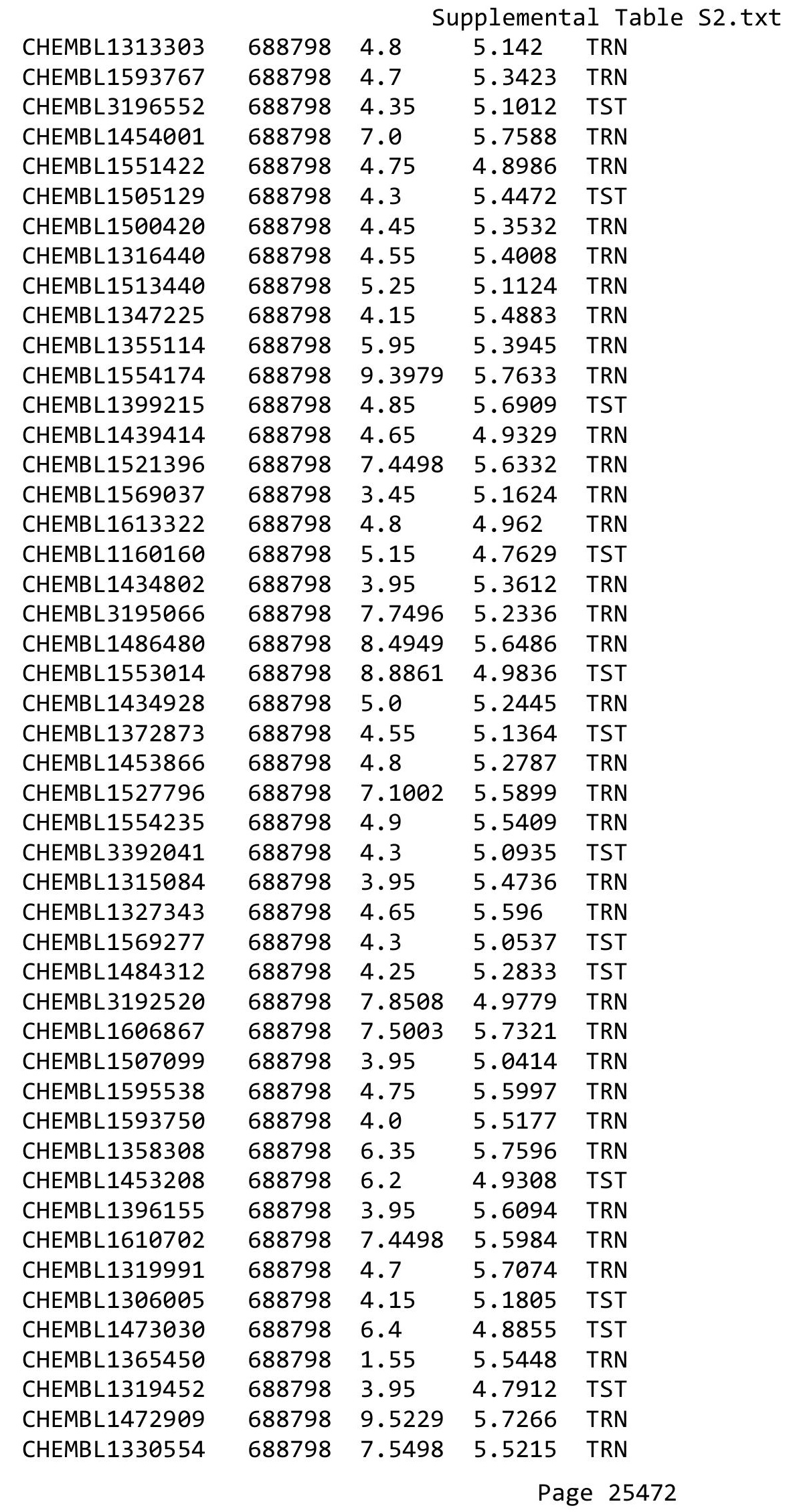




\begin{tabular}{|c|c|c|c|c|c|}
\hline \multicolumn{6}{|c|}{ Supplemental Table S2.txt } \\
\hline CHEMBL1339239 & 688798 & 2.8 & 5.294 & TRN & \\
\hline CHEMBL1563649 & 688798 & 6.1 & 5.7101 & TRN & \\
\hline CHEMBL1356448 & 688798 & 4.8 & 5.2283 & TRN & \\
\hline CHEMBL1531231 & 688798 & 4.85 & 5.688 & TRN & \\
\hline CHEMBL1514436 & 688798 & 6.05 & 5.9664 & TRN & \\
\hline CHEMBL1326314 & 688798 & 4.4 & 4.8017 & TRN & \\
\hline CHEMBL1552411 & 688798 & 8.0506 & 5.3623 & TRN & \\
\hline CHEMBL1441489 & 688798 & 4.25 & 5.141 & TST & \\
\hline CHEMBL1319549 & 688798 & 3.95 & 5.2592 & TRN & \\
\hline CHEMBL1517255 & 688798 & 4.9 & 4.792 & TRN & \\
\hline CHEMBL1383244 & 688798 & 4.55 & 4.7833 & TRN & \\
\hline CHEMBL1554253 & 688798 & 2.85 & 5.4201 & TRN & \\
\hline CHEMBL1395521 & 688798 & 6.3 & 5.2584 & TRN & \\
\hline CHEMBL1337683 & 688798 & 3.2 & 5.0597 & TST & \\
\hline CHEMBL1570993 & 688798 & 5.7 & 4.6415 & TST & \\
\hline CHEMBL1485753 & 688798 & 4.7 & 5.6339 & TRN & \\
\hline CHEMBL1480214 & 688798 & 6.15 & 5.7411 & TRN & \\
\hline CHEMBL1514780 & 688798 & 8.5528 & 5.3093 & TRN & \\
\hline CHEMBL160145 & 688798 & 4.4 & 4.7552 & TST & \\
\hline CHEMBL 1435578 & 688798 & 7.15 & 5.3067 & TRN & \\
\hline CHEMBL1564127 & 688798 & 4.05 & 5.2215 & TRN & \\
\hline CHEMBL1395152 & 688798 & 2.95 & 5.1098 & TST & \\
\hline CHEMBL1337984 & 688798 & 4.1 & 4.7914 & TRN & \\
\hline CHEMBL1595156 & 688798 & 4.05 & 5.3052 & TRN & \\
\hline CHEMBL1334452 & 688798 & 4.45 & 5.0963 & TRN & \\
\hline CHEMBL1402602 & 688798 & 3.95 & 5.2842 & TRN & \\
\hline CHEMBL1324207 & 688798 & 3.9 & 5.4142 & TRN & \\
\hline CHEMBL 3191022 & 688798 & 4.15 & 5.1031 & TRN & \\
\hline CHEMBL1394329 & 688798 & 4.7 & 5.6305 & TRN & \\
\hline CHEMBL 1514466 & 688798 & 7.8996 & 5.4664 & TRN & \\
\hline CHEMBL1473392 & 688798 & 4.0 & 5.3331 & TRN & \\
\hline CHEMBL 1447396 & 688798 & 7.0 & 5.0788 & TRN & \\
\hline CHEMBL1315426 & 688798 & 2.9 & 5.414 & TRN & \\
\hline CHEMBL1317815 & 688798 & 5.35 & 5.4668 & TRN & \\
\hline CHEMBL1722566 & 688798 & 4.35 & 5.1514 & TRN & \\
\hline CHEMBL1327513 & 688798 & 5.0 & 5.8031 & TRN & \\
\hline CHEMBL1514441 & 688798 & 3.9 & 5.3138 & TRN & \\
\hline CHEMBL1397082 & 688798 & 5.2 & 5.6957 & TRN & \\
\hline CHEMBL1316741 & 688798 & 9.0458 & 5.1961 & TRN & \\
\hline CHEMBL 73930 & 688798 & 9.2218 & 5.181 & TRN & \\
\hline CHEMBL1573117 & 688798 & 4.05 & 5.2882 & TRN & \\
\hline CHEMBL1317156 & 688798 & 4.6 & 5.4799 & TRN & \\
\hline CHEMBL1565042 & 688798 & 9.0458 & 5.6797 & TRN & \\
\hline CHEMBL1515092 & 688798 & 5.15 & $5.2410 e$ & 00000000005 & TRN \\
\hline CHEMBL1256720 & 688798 & 5.8 & 5.1544 & TST & \\
\hline CHEMBL1319681 & 688798 & 4.45 & 4.9551 & TST & \\
\hline CHEMBL1394655 & 688798 & 3.95 & 5.5824 & TRN & \\
\hline CHEMBL1554720 & 688798 & 4.65 & 5.5987 & TRN & \\
\hline & & & & 25473 & \\
\hline
\end{tabular}




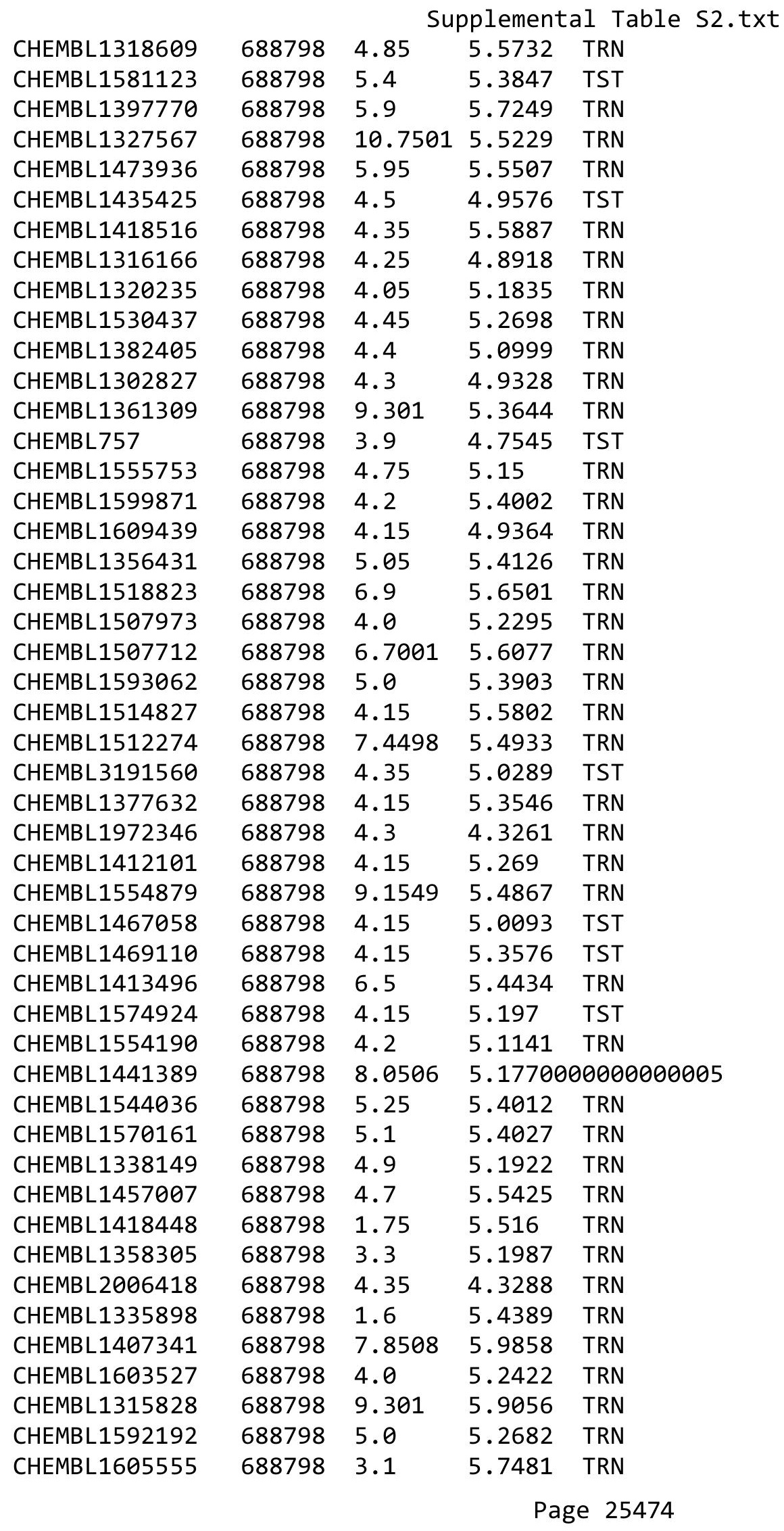




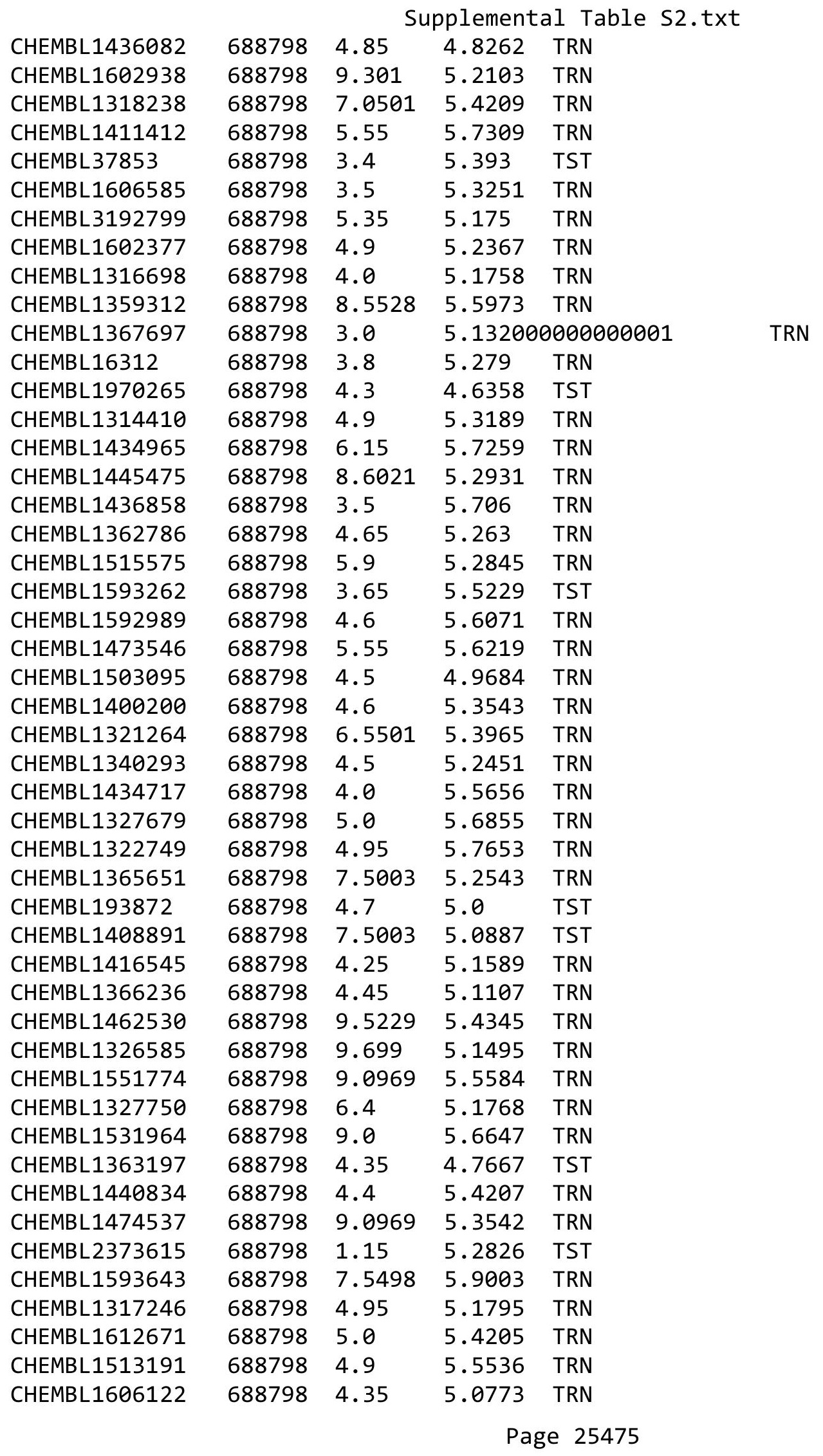




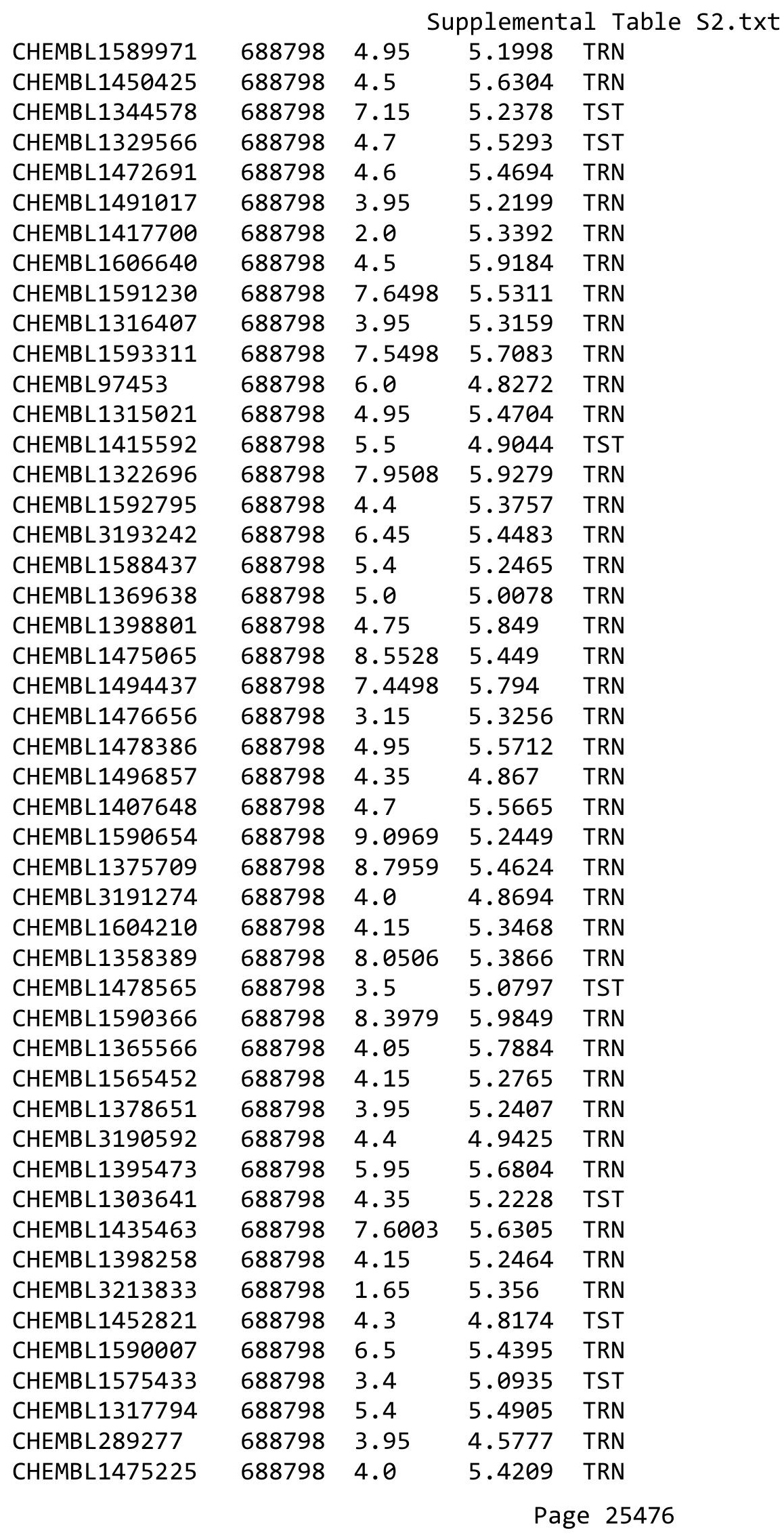




\begin{tabular}{|c|c|c|c|c|c|}
\hline \multirow[b]{2}{*}{ CHEMBL16687 } & \multicolumn{5}{|c|}{ Supplemental Table S2.txt } \\
\hline & 688798 & 9.2218 & 4.9554 & TRN & \\
\hline CHEMBL1488664 & 688798 & 4.2 & 5.5972 & TRN & \\
\hline CHEMBL1433782 & 688798 & 8.2518 & 5.3514 & TRN & \\
\hline CHEMBL1518133 & 688798 & 5.15 & 5.5406 & TRN & \\
\hline CHEMBL1372258 & 688798 & 7.8508 & 5.2038 & TRN & \\
\hline CHEMBL1473552 & 688798 & 3.0 & 4.8215 & TST & \\
\hline CHEMBL1509005 & 688798 & 3.95 & 5.1469 & TRN & \\
\hline CHEMBL1502002 & 688798 & 4.3 & 4.897 & TRN & \\
\hline CHEMBL1316239 & 688798 & 9.0458 & 5.1126 & TST & \\
\hline CHEMBL1314328 & 688798 & 6.2 & 5.3913 & TRN & \\
\hline CHEMBL1341636 & 688798 & 3.0 & 5.3084 & TRN & \\
\hline CHEMBL3214416 & 688798 & 4.15 & 5.6037 & TRN & \\
\hline CHEMBL1370456 & 688798 & 4.6 & 4.61100 & 3000000001 & TST \\
\hline CHEMBL1517495 & 688798 & 5.8 & 5.67700 & 00000000005 & TRN \\
\hline CHEMBL1404292 & 688798 & 9.0458 & 5.7145 & TRN & \\
\hline CHEMBL1472923 & 688798 & 7.4498 & 5.8608 & TRN & \\
\hline CHEMBL1553955 & 688798 & 4.5 & 5.3753 & TRN & \\
\hline CHEMBL1338273 & 688798 & 2.9 & 4.7353 & TRN & \\
\hline CHEMBL1440581 & 688798 & 4.7 & 5.6909 & TRN & \\
\hline CHEMBL1731995 & 688798 & 4.7 & 5.1775 & TRN & \\
\hline CHEMBL1608508 & 688798 & 8.6021 & 5.5424 & TRN & \\
\hline CHEMBL1564291 & 688798 & 6.45 & 5.496 & TRN & \\
\hline CHEMBL1301791 & 688798 & 5.1 & 5.0988 & TRN & \\
\hline CHEMBL1360989 & 688798 & 4.6 & 5.4845 & TRN & \\
\hline CHEMBL1593327 & 688798 & 4.45 & 5.1663 & TRN & \\
\hline CHEMBL1433749 & 688798 & 3.95 & 5.3703 & TRN & \\
\hline CHEMBL1468169 & 688798 & 8.5528 & 5.0979 & TRN & \\
\hline CHEMBL1582792 & 688798 & 4.15 & 5.3685 & TRN & \\
\hline CHEMBL3208339 & 688798 & 3.9 & 5.5933 & TRN & \\
\hline CHEMBL1515902 & 688798 & 5.4 & 5.5989 & TRN & \\
\hline CHEMBL1348721 & 688798 & 4.75 & 5.2039 & TRN & \\
\hline CHEMBL1515612 & 688798 & 3.5 & 5.5261 & TRN & \\
\hline CHEMBL1396006 & 688798 & 4.65 & 5.6349 & TRN & \\
\hline CHEMBL1591341 & 688798 & 3.95 & 5.29 & TRN & \\
\hline CHEMBL1508357 & 688798 & 4.4 & 4.9387 & TRN & \\
\hline CHEMBL1516336 & 688798 & 3.8 & 5.7325 & TRN & \\
\hline CHEMBL1318376 & 688798 & 9.0458 & 5.5411 & TRN & \\
\hline CHEMBL1591594 & 688798 & 8.5528 & 5.4672 & TRN & \\
\hline CHEMBL1397939 & 688798 & 7.5498 & 5.6275 & TRN & \\
\hline CHEMBL1576219 & 688798 & 2.95 & 5.1338 & TST & \\
\hline CHEMBL1592261 & 688798 & 3.05 & 5.4237 & TRN & \\
\hline CHEMBL1336257 & 688798 & 4.55 & 5.3325 & TRN & \\
\hline CHEMBL1405652 & 688798 & 4.35 & 4.91100 & 00000000005 & TST \\
\hline CHEMBL1355880 & 688798 & 4.0 & 5.3063 & TRN & \\
\hline CHEMBL1353798 & 688798 & 6.0 & 5.3716 & TRN & \\
\hline CHEMBL1567682 & 688798 & 4.35 & 5.1454 & TRN & \\
\hline CHEMBL1473804 & 688798 & 4.55 & 5.5405 & TRN & \\
\hline CHEMBL1562283 & 688798 & 4.0 & 5.07600 & 20000000005 & TST \\
\hline & & & & 25477 & \\
\hline
\end{tabular}




\begin{tabular}{|c|c|c|c|c|c|}
\hline & & \multicolumn{4}{|c|}{ Supplemental Table S2.txt } \\
\hline CHEMBL1598932 & 688798 & 6.8499 & 5.1037 & TRN & \\
\hline CHEMBL1555647 & 688798 & 4.6 & 5.2633 & TST & \\
\hline CHEMBL1475316 & 688798 & 4.4 & 5.2845 & TRN & \\
\hline CHEMBL1474239 & 688798 & 2.9 & 5.3741 & TRN & \\
\hline CHEMBL1362935 & 688798 & 4.65 & 4.8993 & TRN & \\
\hline CHEMBL1591337 & 688798 & 6.5 & 5.5308 & TRN & \\
\hline CHEMBL1397570 & 688798 & 7.4001 & 5.5169 & TRN & \\
\hline CHEMBL1354606 & 688798 & 5.95 & 5.7313 & TRN & \\
\hline CHEMBL1316542 & 688798 & 4.0 & 5.4001 & TRN & \\
\hline CHEMBL1527348 & 688798 & 3.6 & 5.5322 & TRN & \\
\hline CHEMBL1363346 & 688798 & 4.3 & 5.2201 & TRN & \\
\hline CHEMBL1366942 & 688798 & 4.9 & 4.8583 & TST & \\
\hline CHEMBL1561610 & 688798 & 4.65 & 5.3969 & TRN & \\
\hline CHEMBL1355147 & 688798 & 4.25 & 5.8873 & TRN & \\
\hline CHEMBL1410178 & 688798 & 11.0 & 5.6562 & TRN & \\
\hline CHEMBL1514217 & 688798 & 7.5003 & 5.3948 & TRN & \\
\hline CHEMBL1358412 & 688798 & 2.6 & 5.5529 & TRN & \\
\hline CHEMBL1534218 & 688798 & 3.0 & 5.4209 & TRN & \\
\hline CHEMBL1436281 & 688798 & 6.6 & 5.2134 & TRN & \\
\hline CHEMBL602969 & 688798 & 4.35 & 4.9387 & TST & \\
\hline CHEMBL1364468 & 688798 & 8.699 & 5.4038 & TRN & \\
\hline CHEMBL1331758 & 688798 & 6.95 & 5.3843 & TRN & \\
\hline CHEMBL1400852 & 688798 & 4.3 & 5.17299 & 9999999999 & TRN \\
\hline CHEMBL1555010 & 688798 & 8.6576 & 5.5453 & TRN & \\
\hline CHEMBL1514486 & 688798 & 4.75 & 4.9829 & TST & \\
\hline CHEMBL1434046 & 688798 & 4.6 & 5.5292 & TRN & \\
\hline CHEMBL1317029 & 688798 & 4.9 & 4.8002 & TRN & \\
\hline CHEMBL1373104 & 688798 & 2.6 & 5.4532 & TRN & \\
\hline CHEMBL1376640 & 688798 & 6.5 & 5.2021 & TRN & \\
\hline CHEMBL1364094 & 688798 & 5.0 & 5.5553 & TRN & \\
\hline CHEMBL1558231 & 688798 & 3.65 & 5.1282 & TRN & \\
\hline CHEMBL1365574 & 688798 & 3.0 & 5.4893 & TRN & \\
\hline CHEMBL1563387 & 688798 & 4.3 & 5.5672 & TRN & \\
\hline CHEMBL1320230 & 688798 & 4.4 & 4.7266 & TRN & \\
\hline CHEMBL876 & 688798 & 6.35 & 5.2665 & TST & \\
\hline CHEMBL1417973 & 688798 & 3.2 & 5.2683 & TRN & \\
\hline CHEMBL1579785 & 688798 & 5.95 & 5.1295 & TRN & \\
\hline CHEMBL1315837 & 688798 & 4.65 & 5.6764 & TRN & \\
\hline CHEMBL1317455 & 688798 & 7.4498 & 4.879 & TRN & \\
\hline CHEMBL3193897 & 688798 & 10.0 & 4.6771 & TRN & \\
\hline CHEMBL1515509 & 688798 & 7.5003 & 5.3415 & TRN & \\
\hline CHEMBL1463952 & 688798 & 7.5498 & 5.027 & TST & \\
\hline CHEMBL1495153 & 688798 & 4.05 & 5.5154 & TRN & \\
\hline CHEMBL1518905 & 688798 & 5.55 & 4.8377 & TRN & \\
\hline CHEMBL1531862 & 688798 & 9.3979 & 5.7465 & TRN & \\
\hline CHEMBL1312953 & 688798 & 4.35 & 5.17899 & 9999999999 & TST \\
\hline CHEMBL1326167 & 688798 & 4.5 & 5.0525 & TST & \\
\hline CHEMBL1438762 & 688798 & 4.65 & 5.6526 & TRN & \\
\hline
\end{tabular}




\begin{tabular}{|c|c|c|c|c|}
\hline \multicolumn{5}{|c|}{ Supplemental Table S2.txt } \\
\hline CHEMBL1538474 & 688798 & 6.9 & 4.9107 & TST \\
\hline CHEMBL 1493528 & 688798 & 4.45 & 4.8759 & TST \\
\hline CHEMBL1555301 & 688798 & 6.3 & 5.5776 & TRN \\
\hline CHEMBL1318670 & 688798 & 3.0 & 4.9236 & TST \\
\hline CHEMBL1487884 & 688798 & 4.75 & 5.3625 & TRN \\
\hline CHEMBL1484923 & 688798 & 8.5528 & 4.8403 & TST \\
\hline CHEMBL1355592 & 688798 & 5.0 & 5.1823 & TRN \\
\hline CHEMBL1476362 & 688798 & 4.55 & 5.1182 & TST \\
\hline CHEMBL1590626 & 688798 & 9.699 & 5.3241 & TRN \\
\hline CHEMBL1594315 & 688798 & 9.3979 & 5.4779 & TRN \\
\hline CHEMBL1491425 & 688798 & 3.2 & 5.6147 & TRN \\
\hline CHEMBL1354484 & 688798 & 6.5501 & 5.0566 & TRN \\
\hline CHEMBL1442028 & 688798 & 3.2 & 5.5138 & TRN \\
\hline CHEMBL1483499 & 688798 & 4.6 & 5.2053 & TRN \\
\hline CHEMBL1554014 & 688798 & 4.2 & 5.2155 & TST \\
\hline CHEMBL1532453 & 688798 & 4.45 & 4.9565 & TST \\
\hline CHEMBL1565004 & 688798 & 9.3979 & 4.9807 & TRN \\
\hline CHEMBL1516012 & 688798 & 5.3 & 5.773 & TRN \\
\hline CHEMBL1437734 & 688798 & 7.3497 & 5.5673 & TRN \\
\hline CHEMBL1376578 & 688798 & 4.5 & 4.7148 & TRN \\
\hline CHEMBL1357181 & 688798 & 4.7 & 5.7724 & TRN \\
\hline CHEMBL1415045 & 688798 & 4.35 & 4.8025 & TST \\
\hline CHEMBL1409603 & 688798 & 4.4 & 5.1493 & TRN \\
\hline CHEMBL1314947 & 688798 & 2.8 & 5.3542 & TRN \\
\hline CHEMBL1485410 & 688798 & 8.5528 & 5.7812 & TRN \\
\hline CHEMBL1529367 & 688798 & 4.1 & 5.2614 & TRN \\
\hline CHEMBL1531434 & 688798 & 3.4 & 5.5801 & TRN \\
\hline CHEMBL1405638 & 688798 & 6.05 & 5.5633 & TRN \\
\hline CHEMBL1486128 & 688798 & 2.1 & 5.2942 & TRN \\
\hline CHEMBL1160028 & 688798 & 4.55 & 4.8272 & TST \\
\hline CHEMBL1391829 & 688798 & 6.45 & 4.8032 & TRN \\
\hline CHEMBL1552273 & 688798 & 4.55 & 5.1051 & TRN \\
\hline CHEMBL1323065 & 688798 & 4.05 & 5.6487 & TRN \\
\hline CHEMBL1357755 & 688798 & 4.95 & 5.1193 & TRN \\
\hline CHEMBL1399042 & 688798 & 4.0 & 5.2845 & TST \\
\hline CHEMBL449362 & 688798 & 4.4 & 4.8018 & TST \\
\hline CHEMBL1613008 & 688798 & 8.6021 & 5.1371 & TRN \\
\hline CHEMBL1556994 & 688798 & 9.0458 & 5.1831 & TRN \\
\hline CHEMBL1322777 & 688798 & 6.05 & 5.0962 & TRN \\
\hline CHEMBL1563624 & 688798 & 4.35 & 4.8685 & TRN \\
\hline CHEMBL1364049 & 688798 & 4.35 & 5.4517 & TST \\
\hline CHEMBL1592903 & 688798 & 4.5 & 5.2384 & TRN \\
\hline CHEMBL1330176 & 688798 & 6.1 & 5.6648 & TRN \\
\hline CHEMBL1311038 & 688798 & 4.8 & 4.9122 & TRN \\
\hline CHEMBL1487827 & 688798 & 4.65 & 5.4743 & TRN \\
\hline CHEMBL1375409 & 688798 & 7.2503 & 5.1173 & TST \\
\hline CHEMBL 30707 & 688798 & 4.3 & 4.6134 & TRN \\
\hline CHEMBL1432963 & 688798 & 4.35 & 4.6935 & TRN \\
\hline
\end{tabular}




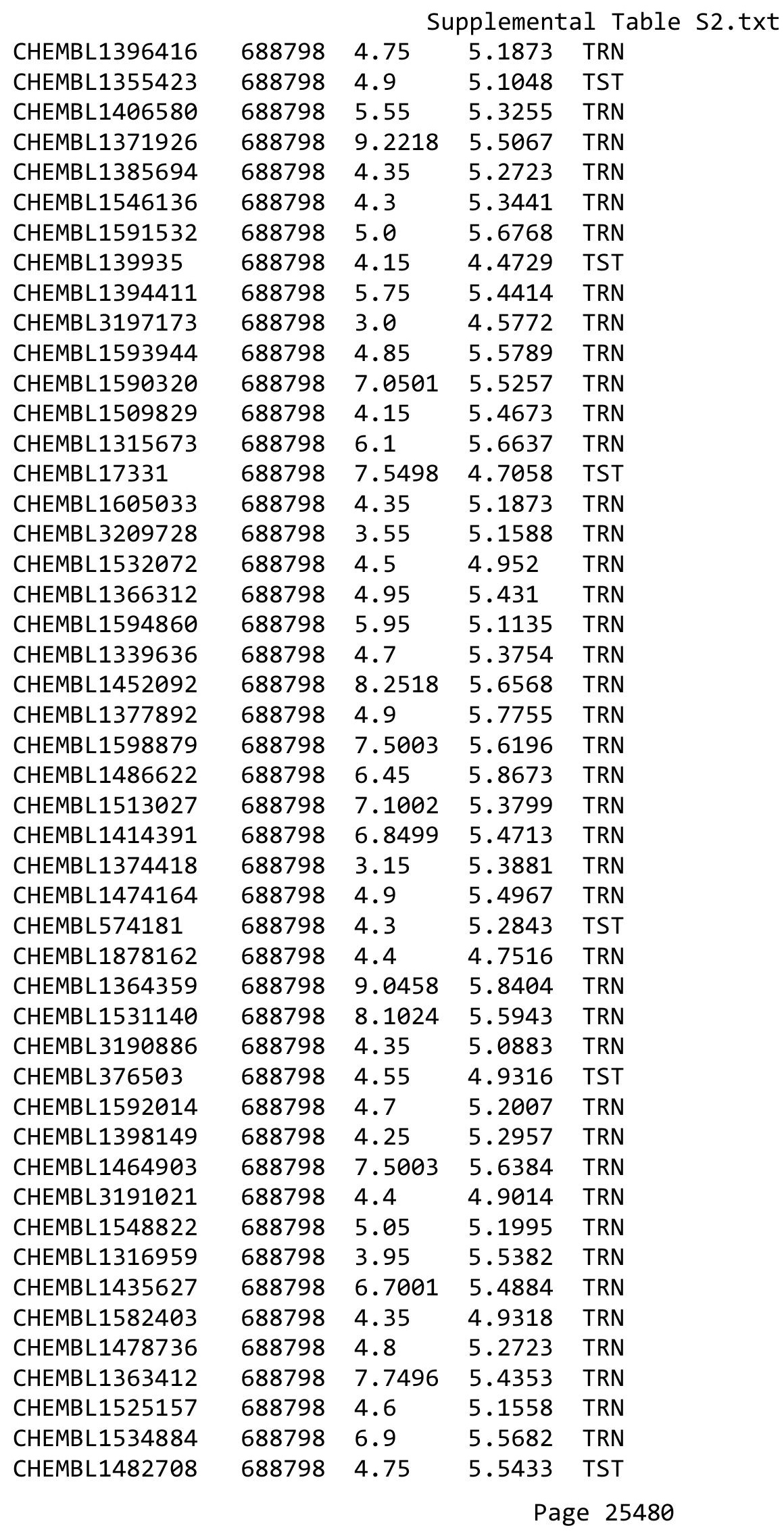




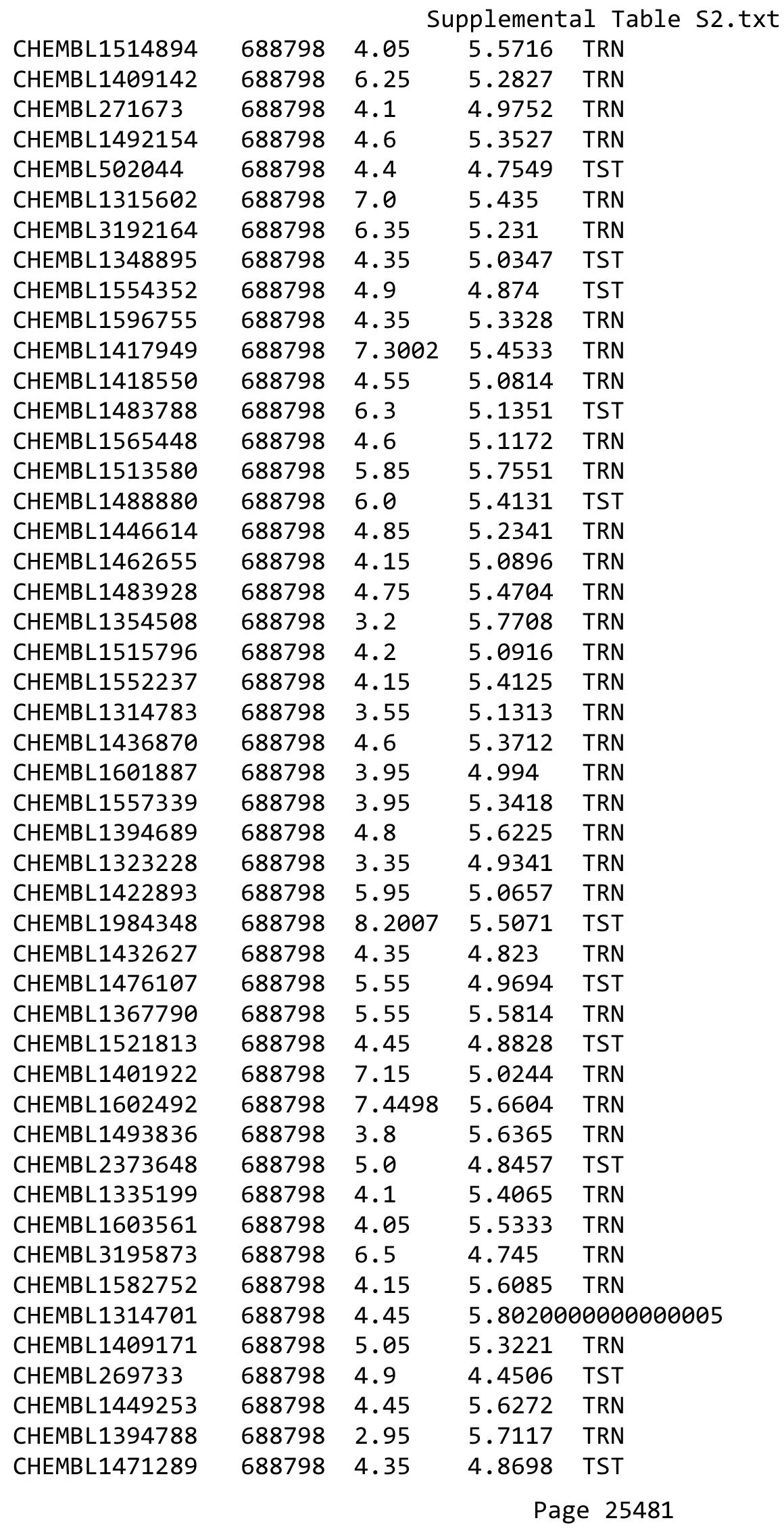

TRN 


\begin{tabular}{|c|c|c|c|c|c|}
\hline \multicolumn{6}{|c|}{ Supplemental Table S2.txt } \\
\hline CHEMBL1424452 & 688798 & 4.0 & 5.4178 & TRN & \\
\hline CHEMBL1597511 & 688798 & 4.7 & 5.49 & TRN & \\
\hline CHEMBL1527066 & 688798 & 4.0 & 5.3548 & TRN & \\
\hline CHEMBL1546066 & 688798 & 7.5498 & 4.6498 & TST & \\
\hline CHEMBL1398307 & 688798 & 4.65 & 5.1303 & TRN & \\
\hline CHEMBL1408682 & 688798 & 4.7 & 5.2939 & TRN & \\
\hline CHEMBL1411117 & 688798 & 3.8 & 5.7265 & TRN & \\
\hline CHEMBL1356599 & 688798 & 7.4498 & 5.1351 & TST & \\
\hline CHEMBL1328484 & 688798 & 8.5528 & 4.7928 & TST & \\
\hline CHEMBL1474733 & 688798 & 7.5498 & 5.119 & TRN & \\
\hline CHEMBL1395648 & 688798 & 3.9 & 5.54 & TRN & \\
\hline CHEMBL1317975 & 688798 & 6.8 & 5.3283 & TRN & \\
\hline CHEMBL1474284 & 688798 & 4.7 & 5.5832 & TRN & \\
\hline CHEMBL1478163 & 688798 & 4.55 & 5.3142 & TRN & \\
\hline CHEMBL523844 & 688798 & 4.3 & 4.9093 & TRN & \\
\hline CHEMBL1525528 & 688798 & 5.4 & 5.38899 & 9999999999 & TRN \\
\hline CHEMBL1428882 & 688798 & 5.25 & 5.1246 & TST & \\
\hline CHEMBL1475757 & 688798 & 7.4001 & 5.41 & TRN & \\
\hline CHEMBL1395316 & 688798 & 6.0 & 5.6246 & TRN & \\
\hline CHEMBL1545863 & 688798 & 4.35 & 5.4293 & TRN & \\
\hline CHEMBL313737 & 688798 & 4.6 & 4.8734 & TST & \\
\hline CHEMBL1337960 & 688798 & 6.4 & 5.0124 & TST & \\
\hline CHEMBL1594506 & 688798 & 4.4 & 5.5543 & TRN & \\
\hline CHEMBL255881 & 688798 & 4.4 & 4.8562 & TRN & \\
\hline CHEMBL1611584 & 688798 & 3.0 & 4.9503 & TRN & \\
\hline CHEMBL3392069 & 688798 & 4.35 & 4.6991 & TRN & \\
\hline CHEMBL1410173 & 688798 & 4.15 & 5.28 & TRN & \\
\hline CHEMBL1533404 & 688798 & 4.2 & 5.7346 & TRN & \\
\hline CHEMBL1449886 & 688798 & 4.6 & 4.8371 & TST & \\
\hline CHEMBL1367573 & 688798 & 2.7 & 5.3699 & TRN & \\
\hline CHEMBL1453073 & 688798 & 6.9 & 5.5157 & TST & \\
\hline CHEMBL1415426 & 688798 & 4.5 & 5.4084 & TRN & \\
\hline CHEMBL1601266 & 688798 & 7.8996 & 5.1933 & TRN & \\
\hline CHEMBL1321918 & 688798 & 3.95 & 5.5881 & TRN & \\
\hline CHEMBL1395361 & 688798 & 3.35 & 5.6001 & TRN & \\
\hline CHEMBL478629 & 688798 & 3.15 & 5.0052 & TST & \\
\hline CHEMBL1305425 & 688798 & 3.0 & 5.1589 & TRN & \\
\hline CHEMBL1374105 & 688798 & 3.0 & 5.3473 & TRN & \\
\hline CHEMBL1318928 & 688798 & 4.45 & 5.29299 & 9999999999 & TRN \\
\hline CHEMBL1474982 & 688798 & 6.5 & 5.3298 & TRN & \\
\hline CHEMBL1328015 & 688798 & 9.0969 & 5.3576 & TRN & \\
\hline CHEMBL1589575 & 688798 & 7.0501 & 4.8603 & TST & \\
\hline CHEMBL179583 & 688798 & 4.5 & 5.3221 & TST & \\
\hline CHEMBL1564565 & 688798 & 4.55 & 5.8791 & TRN & \\
\hline CHEMBL1392154 & 688798 & 7.2 & 5.4939 & TRN & \\
\hline CHEMBL1334352 & 688798 & 6.25 & 5.5048 & TRN & \\
\hline CHEMBL1533774 & 688798 & 4.7 & 5.3854 & TRN & \\
\hline CHEMBL1525751 & 688798 & 3.2 & 4.901 & TRN & \\
\hline
\end{tabular}




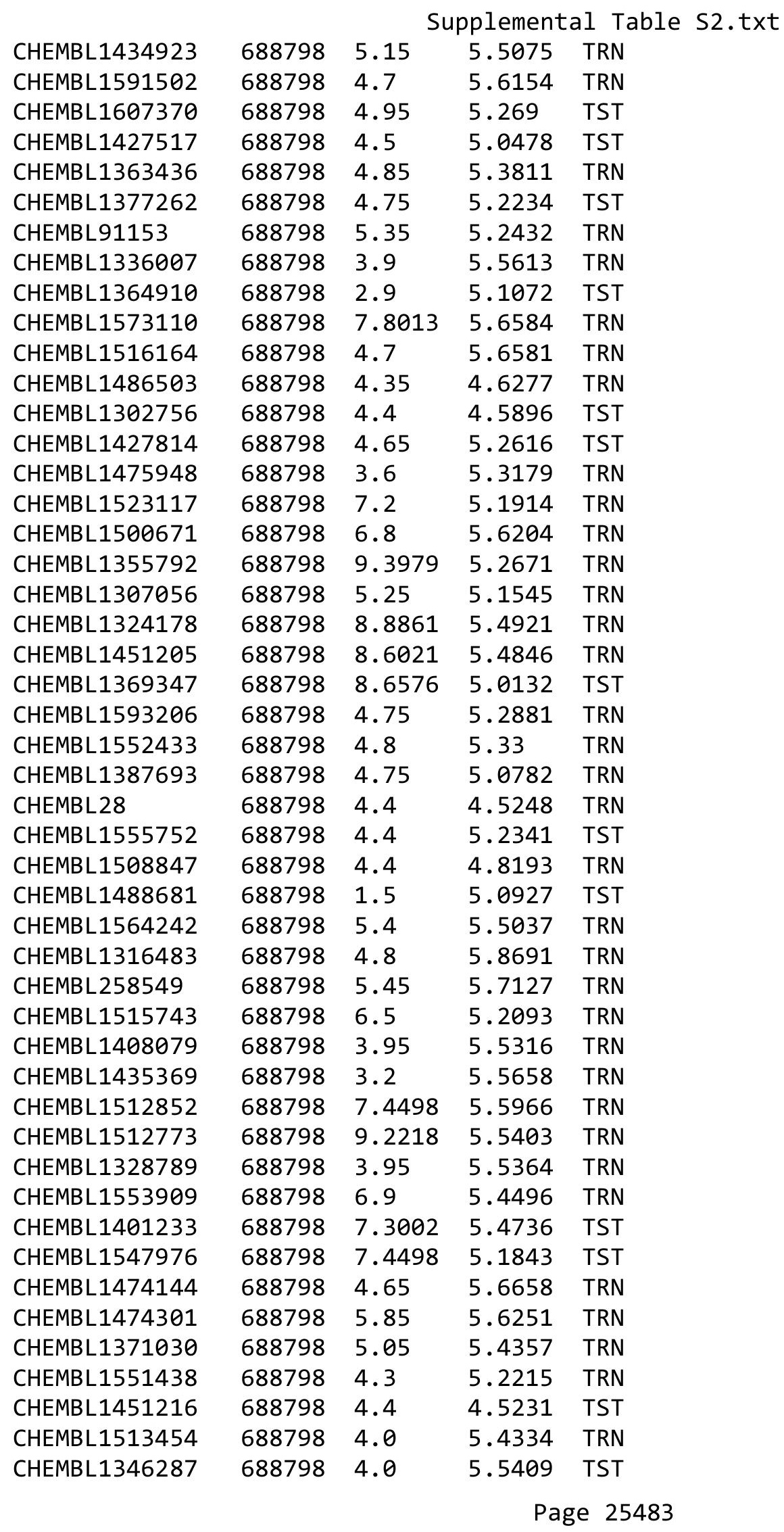




\begin{tabular}{|c|c|c|c|c|}
\hline \multicolumn{5}{|c|}{ Supplemental Table S2.txt } \\
\hline CHEMBL1532428 & 688798 & 4.95 & 5.3728 & TST \\
\hline CHEMBL1377924 & 688798 & 7.4498 & 5.2608 & TRN \\
\hline CHEMBL1513132 & 688798 & 6.1 & 5.6275 & TRN \\
\hline CHEMBL1513399 & 688798 & 4.0 & 5.4937 & TRN \\
\hline CHEMBL1401579 & 688798 & 8.6576 & 5.5449 & TRN \\
\hline CHEMBL1412918 & 688798 & 2.5 & 4.9847 & TRN \\
\hline CHEMBL1553720 & 688798 & 5.0 & 5.3146 & TST \\
\hline CHEMBL1414716 & 688798 & 9.2218 & 4.9155 & TST \\
\hline CHEMBL1412087 & 688798 & 4.55 & 5.1527 & TRN \\
\hline CHEMBL1313058 & 688798 & 3.65 & 5.6874 & TRN \\
\hline CHEMBL1414171 & 688798 & 9.3979 & 5.1934 & TRN \\
\hline CHEMBL3193892 & 688798 & 7.8996 & 5.3618 & TST \\
\hline CHEMBL1476318 & 688798 & 5.05 & 5.4998 & TRN \\
\hline CHEMBL1333884 & 688798 & 6.35 & 4.5806 & TST \\
\hline CHEMBL1317696 & 688798 & 9.0458 & 5.1044 & TST \\
\hline CHEMBL1525476 & 688798 & 4.7 & 5.2757 & TRN \\
\hline CHEMBL347862 & 688798 & 3.15 & 5.0128 & TST \\
\hline CHEMBL1572054 & 688798 & 4.7 & 5.6124 & TRN \\
\hline CHEMBL1404136 & 688798 & 4.75 & 5.7778 & TRN \\
\hline CHEMBL1475794 & 688798 & 4.95 & 5.5497 & TRN \\
\hline CHEMBL1413706 & 688798 & 4.6 & 5.6479 & TRN \\
\hline CHEMBL1571442 & 688798 & 4.35 & 5.5809 & TRN \\
\hline CHEMBL1357116 & 688798 & 6.4 & 5.5284 & TRN \\
\hline CHEMBL1539720 & 688798 & 4.6 & 4.6855 & TRN \\
\hline CHEMBL1366167 & 688798 & 8.1487 & 5.2575 & TRN \\
\hline CHEMBL1351792 & 688798 & 3.95 & 5.3523 & TRN \\
\hline CHEMBL1524642 & 688798 & 3.9 & 5.6572 & TRN \\
\hline CHEMBL1610020 & 688798 & 2.0 & 5.4028 & TRN \\
\hline CHEMBL1513548 & 688798 & 6.3 & 5.4269 & TRN \\
\hline CHEMBL1490696 & 688798 & 7.5498 & 5.4312 & TRN \\
\hline CHEMBL1375237 & 688798 & 7.7496 & 5.8075 & TRN \\
\hline CHEMBL1525471 & 688798 & 7.0 & 4.8933 & TRN \\
\hline CHEMBL1551549 & 688798 & 4.75 & 5.1637 & TRN \\
\hline CHEMBL1597114 & 688798 & 6.1 & 5.4139 & TRN \\
\hline CHEMBL1437401 & 688798 & 4.7 & 5.6422 & TRN \\
\hline CHEMBL1316174 & 688798 & 3.15 & 5.635 & TRN \\
\hline CHEMBL1433900 & 688798 & 8.4559 & 5.4368 & TRN \\
\hline CHEMBL1596451 & 688798 & 3.45 & 5.5531 & TRN \\
\hline CHEMBL1552408 & 688798 & 9.0969 & 5.4948 & TRN \\
\hline CHEMBL1699206 & 688798 & 4.8 & 4.9748 & TRN \\
\hline CHEMBL1336481 & 688798 & 5.35 & 5.4607 & TRN \\
\hline CHEMBL1490349 & 688798 & 4.6 & 5.6795 & TRN \\
\hline CHEMBL1530570 & 688798 & 4.5 & 5.4476 & TRN \\
\hline CHEMBL1355013 & 688798 & 4.7 & 5.603 & TRN \\
\hline CHEMBL1376552 & 688798 & 7.4498 & 5.8079 & TRN \\
\hline CHEMBL1347221 & 688798 & 4.35 & 5.1076 & TRN \\
\hline CHEMBL1356180 & 688798 & 4.55 & 5.376 & TRN \\
\hline CHEMBL1327098 & 688798 & 4.45 & 5.5997 & TRN \\
\hline
\end{tabular}




\begin{tabular}{|c|c|c|c|c|}
\hline & & & oplement & al $\mathrm{T}$ \\
\hline CHEMBL1313928 & 688798 & 4.65 & 5.5097 & TRN \\
\hline CHEMBL1609673 & 688798 & 4.2 & 5.2298 & TRN \\
\hline CHEMBL1583838 & 688798 & 4.35 & 4.8999 & TRN \\
\hline CHEMBL1333551 & 688798 & 3.4 & 5.5234 & TRN \\
\hline CHEMBL1473763 & 688798 & 4.55 & 5.7066 & TRN \\
\hline CHEMBL1397006 & 688798 & 5.0 & 5.5973 & TRN \\
\hline CHEMBL1403669 & 688798 & 4.7 & 5.7844 & TRN \\
\hline CHEMBL3198925 & 688798 & 4.15 & 5.2881 & TRN \\
\hline CHEMBL3189459 & 688798 & 6.2 & 5.3505 & TRN \\
\hline CHEMBL3192774 & 688798 & 10.0 & 5.4573 & TRN \\
\hline CHEMBL1438156 & 688798 & 6.4 & 5.5285 & TRN \\
\hline CHEMBL1463491 & 688798 & 6.1 & 5.1487 & TRN \\
\hline CHEMBL1611620 & 688798 & 4.6 & 4.8909 & TRN \\
\hline CHEMBL1390633 & 688798 & 4.45 & 4.8933 & TST \\
\hline CHEMBL1548678 & 688798 & 4.6 & 4.5296 & TST \\
\hline CHEMBL1584869 & 688798 & 4.5 & 5.6998 & TRN \\
\hline CHEMBL1547055 & 688798 & 4.55 & 5.6471 & TRN \\
\hline CHEMBL1395229 & 688798 & 6.3 & 5.6045 & TRN \\
\hline CHEMBL578741 & 688798 & 6.0 & 4.7021 & TST \\
\hline CHEMBL1448008 & 688798 & 4.7 & 5.4989 & TRN \\
\hline CHEMBL1612790 & 688798 & 4.7 & 5.3491 & TST \\
\hline CHEMBL1524374 & 688798 & 7.9508 & 5.2822 & TRN \\
\hline CHEMBL1475543 & 688798 & 4.6 & 5.5299 & TRN \\
\hline CHEMBL1422647 & 688798 & 4.95 & 4.7074 & TRN \\
\hline CHEMBL1572903 & 688798 & 7.6498 & 5.6833 & TRN \\
\hline CHEMBL1435833 & 688798 & 5.0 & 5.3994 & TRN \\
\hline CHEMBL1433075 & 688798 & 4.5 & 5.0695 & TST \\
\hline CHEMBL1514413 & 688798 & 3.55 & 5.5123 & TRN \\
\hline CHEMBL1528690 & 688798 & 6.7501 & 5.1156 & TST \\
\hline CHEMBL1415863 & 688798 & 6.5 & 5.5433 & TRN \\
\hline CHEMBL1474060 & 688798 & 7.5498 & 5.0136 & TRN \\
\hline CHEMBL1309875 & 688798 & 4.9 & 5.0828 & TST \\
\hline CHEMBL1521980 & 688798 & 6.15 & 5.1538 & TRN \\
\hline CHEMBL1358506 & 688798 & 2.55 & 5.5985 & TRN \\
\hline CHEMBL1317488 & 688798 & 9.5229 & 5.7605 & TRN \\
\hline CHEMBL1318152 & 688798 & 7.3497 & 5.5792 & TRN \\
\hline CHEMBL1492532 & 688798 & 4.15 & 4.9294 & TRN \\
\hline CHEMBL1448245 & 688798 & 5.8 & 5.2337 & TRN \\
\hline CHEMBL3189397 & 688798 & 3.35 & 4.8924 & TST \\
\hline CHEMBL1399979 & 688798 & 4.35 & 5.2348 & TRN \\
\hline CHEMBL1552578 & 688798 & 4.65 & 5.4331 & TRN \\
\hline CHEMBL1404567 & 688798 & 5.25 & 5.3064 & TRN \\
\hline CHEMBL1435041 & 688798 & 4.95 & 5.8604 & TRN \\
\hline CHEMBL1573467 & 688798 & 8.0506 & 5.3985 & TRN \\
\hline CHEMBL1316892 & 688798 & 4.9 & 5.5132 & TRN \\
\hline CHEMBL1343282 & 688798 & 9.301 & 5.2257 & TST \\
\hline CHEMBL1515920 & 688798 & 5.35 & 5.5418 & TRN \\
\hline CHEMBL1354312 & 688798 & 8.2518 & 5.6523 & TRN \\
\hline
\end{tabular}




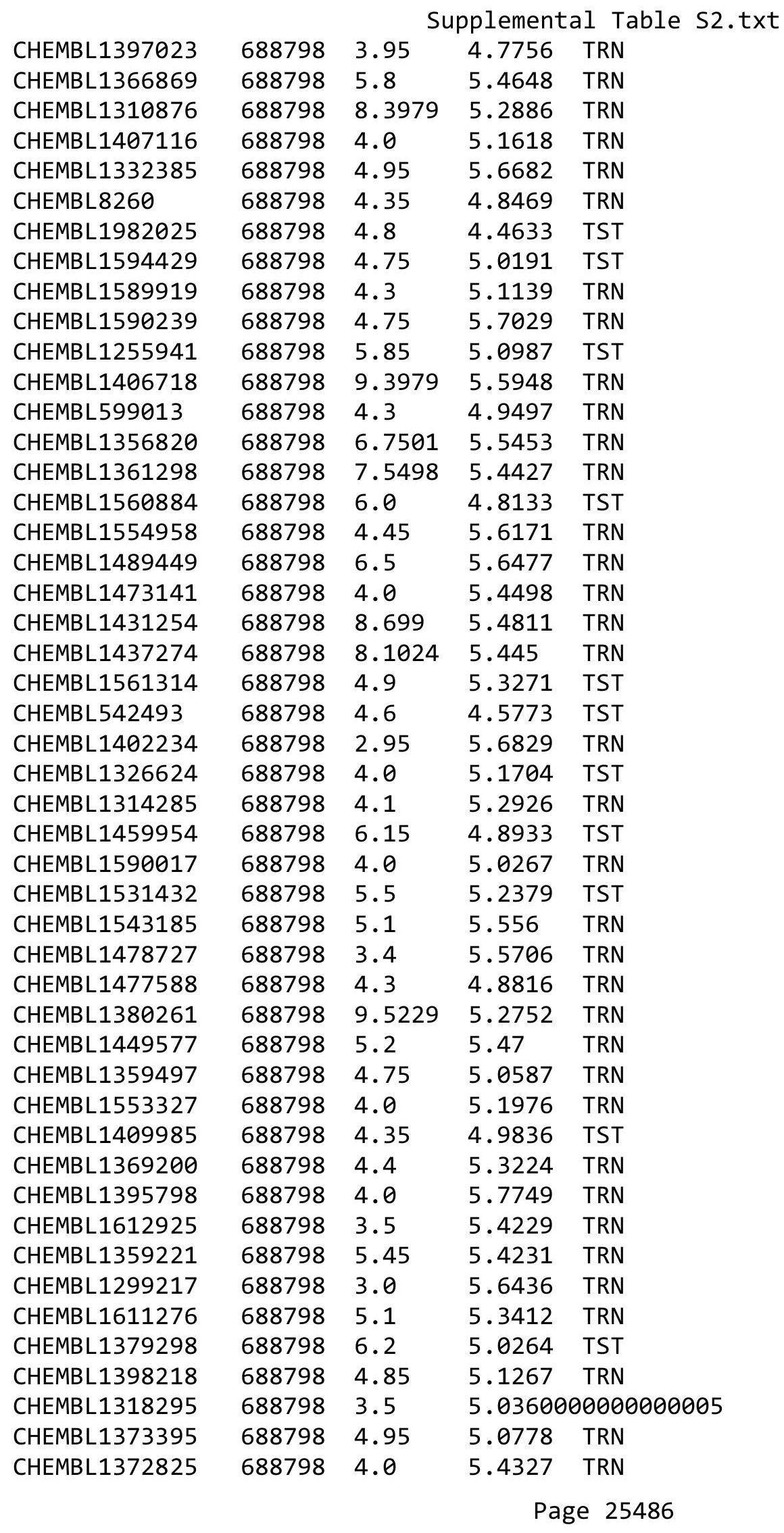

TRN 


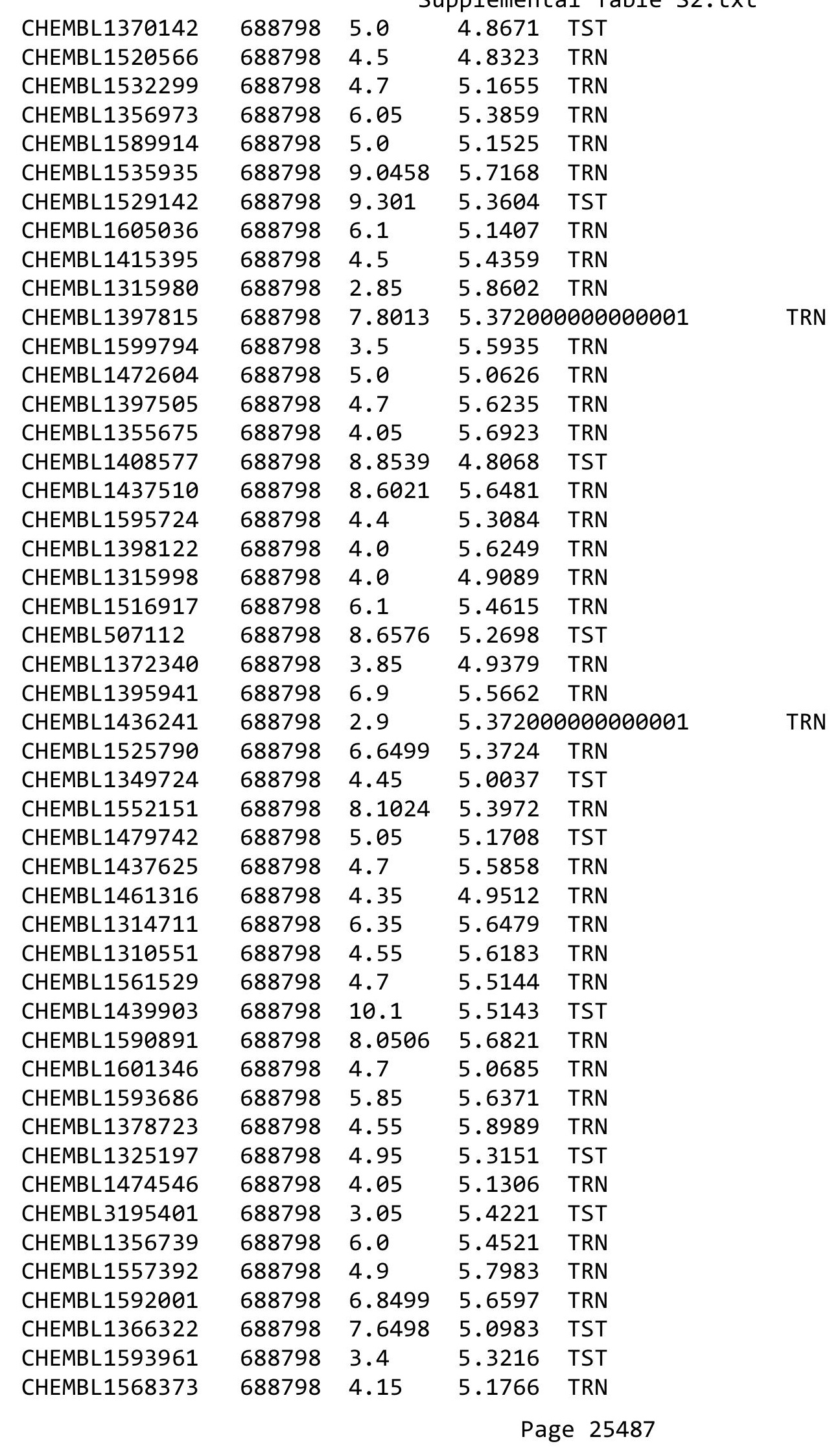




\begin{tabular}{|c|c|c|c|c|c|}
\hline \multicolumn{6}{|c|}{ Supplemental Table S2.txt } \\
\hline CHEMBL1450127 & 688798 & 5.25 & 4.7777 & TST & \\
\hline CHEMBL1416427 & 688798 & 5.35 & 5.1739 & TRN & \\
\hline CHEMBL1492679 & 688798 & 5.35 & 5.7401 & TRN & \\
\hline CHEMBL1399962 & 688798 & 4.15 & 4.7712 & TRN & \\
\hline CHEMBL1369363 & 688798 & 10.0 & 5.8401 & TRN & \\
\hline CHEMBL 2003887 & 688798 & 4.35 & 4.6422 & TRN & \\
\hline CHEMBL1553013 & 688798 & 8.0 & 5.7446 & TRN & \\
\hline CHEMBL1449018 & 688798 & 4.35 & 5.0541 & TST & \\
\hline CHEMBL1076722 & 688798 & 4.35 & 5.3057 & TRN & \\
\hline CHEMBL1317083 & 688798 & 6.8 & 5.5214 & TRN & \\
\hline CHEMBL1613238 & 688798 & 4.5 & 4.8337 & TST & \\
\hline CHEMBL1300118 & 688798 & 6.45 & 5.2813 & TRN & \\
\hline CHEMBL1395111 & 688798 & 4.55 & 5.5845 & TRN & \\
\hline CHEMBL1326971 & 688798 & 4.85 & 5.3275 & TRN & \\
\hline CHEMBL1398221 & 688798 & 4.7 & 4.9859 & TRN & \\
\hline CHEMBL1436225 & 688798 & 1.05 & 5.4354 & TRN & \\
\hline CHEMBL1397857 & 688798 & 8.3468 & 5.3242 & TRN & \\
\hline CHEMBL1363489 & 688798 & 3.55 & 5.7141 & TRN & \\
\hline CHEMBL1436642 & 688798 & 7.1002 & 5.6794 & TRN & \\
\hline CHEMBL1496308 & 688798 & 3.95 & 5.4714 & TST & \\
\hline CHEMBL1355733 & 688798 & 8.0 & 5.5714 & TRN & \\
\hline CHEMBL1317824 & 688798 & 5.15 & 5.3294 & TRN & \\
\hline CHEMBL1314547 & 688798 & 3.75 & 5.3062 & TST & \\
\hline CHEMBL1594376 & 688798 & 4.95 & 5.1777 & TRN & \\
\hline CHEMBL1496762 & 688798 & 8.699 & 5.7524 & TRN & \\
\hline CHEMBL 28626 & 688798 & 4.05 & 4.2984 & TRN & \\
\hline CHEMBL1465964 & 688798 & 3.95 & 5.3608 & TST & \\
\hline CHEMBL1576658 & 688798 & 4.5 & 4.7761 & TST & \\
\hline CHEMBL1437716 & 688798 & 4.7 & 5.1512 & TRN & \\
\hline CHEMBL1395374 & 688798 & 7.2 & 5.6197 & TRN & \\
\hline CHEMBL1337071 & 688798 & 3.0 & 5.3351 & TRN & \\
\hline CHEMBL1613462 & 688798 & 4.85 & 5.4035 & TRN & \\
\hline CHEMBL1501988 & 688798 & 1.95 & 5.2409 & TRN & \\
\hline CHEMBL1576094 & 688798 & 4.3 & 4.8953 & TRN & \\
\hline CHEMBL1435589 & 688798 & 3.4 & 5.34399 & 9999999999 & TRN \\
\hline CHEMBL1437303 & 688798 & 5.7 & 5.4054 & TRN & \\
\hline CHEMBL1535007 & 688798 & 9.1549 & 5.5884 & TRN & \\
\hline CHEMBL1394331 & 688798 & 5.55 & 5.0592 & TRN & \\
\hline CHEMBL 2004417 & 688798 & 4.8 & 4.516 & TRN & \\
\hline CHEMBL1387824 & 688798 & 4.3 & 5.3529 & TRN & \\
\hline CHEMBL1610745 & 688798 & 3.35 & 5.4518 & TRN & \\
\hline CHEMBL1333604 & 688798 & 4.05 & 5.159 & TRN & \\
\hline CHEMBL1406443 & 688798 & 4.7 & 5.4869 & TRN & \\
\hline CHEMBL1547042 & 688798 & 4.4 & 4.8548 & TRN & \\
\hline CHEMBL1535979 & 688798 & 4.0 & 5.4664 & TST & \\
\hline CHEMBL599307 & 688798 & 5.15 & 5.1703 & TRN & \\
\hline CHEMBL1573169 & 688798 & 7.6003 & 5.4125 & TRN & \\
\hline CHEMBL1574599 & 688798 & 4.6 & 5.3889 & TRN & \\
\hline
\end{tabular}




\begin{tabular}{|c|c|c|c|c|c|}
\hline & & \multicolumn{4}{|c|}{ Supplemental Table S2.txt } \\
\hline CHEMBL1323879 & 688798 & 6.8499 & 5.6228 & TRN & \\
\hline CHEMBL1358394 & 688798 & 4.65 & 5.6792 & TRN & \\
\hline CHEMBL1592459 & 688798 & 5.2 & 5.8836 & TRN & \\
\hline CHEMBL1601381 & 688798 & 6.6 & 5.5926 & TRN & \\
\hline CHEMBL1592135 & 688798 & 4.0 & 5.5698 & TRN & \\
\hline CHEMBL1554885 & 688798 & 6.5 & 5.5962 & TRN & \\
\hline CHEMBL1417686 & 688798 & 5.95 & 5.4694 & TRN & \\
\hline CHEMBL1316615 & 688798 & 6.7501 & 5.6997 & TRN & \\
\hline CHEMBL1590549 & 688798 & 2.75 & 5.4019 & TRN & \\
\hline CHEMBL1308068 & 688798 & 4.4 & 5.6037 & TRN & \\
\hline CHEMBL429095 & 688798 & 6.0 & 4.9498 & TST & \\
\hline CHEMBL1563960 & 688798 & 4.0 & 5.0751 & TRN & \\
\hline CHEMBL1369092 & 688798 & 9.699 & 4.8584 & TRN & \\
\hline CHEMBL1590716 & 688798 & 4.05 & 5.2231 & TRN & \\
\hline CHEMBL1358239 & 688798 & 3.9 & 5.46 & TRN & \\
\hline CHEMBL1302175 & 688798 & 4.1 & 4.9967 & TRN & \\
\hline CHEMBL1315172 & 688798 & 4.0 & 5.58700 & 0000000001 & TRN \\
\hline CHEMBL1369419 & 688798 & 4.75 & 5.59 & TRN & \\
\hline CHEMBL3198239 & 688798 & 10.5 & 4.7963 & TST & \\
\hline CHEMBL1551183 & 688798 & 5.2 & 5.5672 & TRN & \\
\hline CHEMBL1312611 & 688798 & 5.9 & 5.2717 & TRN & \\
\hline CHEMBL1481648 & 688798 & 4.5 & 5.4519 & TRN & \\
\hline CHEMBL1322770 & 688798 & 2.0 & 5.4734 & TRN & \\
\hline CHEMBL1474161 & 688798 & 5.5 & 5.4807 & TRN & \\
\hline CHEMBL1485566 & 688798 & 4.7 & 5.4837 & TRN & \\
\hline CHEMBL45176 & 688798 & 3.85 & 4.9916 & TRN & \\
\hline CHEMBL1320520 & 688798 & 4.8 & 5.602 & TRN & \\
\hline CHEMBL1504113 & 688798 & 4.55 & 4.9078 & TST & \\
\hline CHEMBL1542852 & 688798 & 4.4 & 5.0459 & TST & \\
\hline CHEMBL1482141 & 688798 & 4.95 & 5.1905 & TRN & \\
\hline CHEMBL 2219815 & 688798 & 7.4498 & 4.7525 & TST & \\
\hline CHEMBL1491024 & 688798 & 4.75 & 5.4861 & TRN & \\
\hline CHEMBL 224877 & 688798 & 3.45 & 5.2324 & TST & \\
\hline CHEMBL1474910 & 688798 & 3.65 & 5.2596 & TRN & \\
\hline CHEMBL1593983 & 688798 & 4.45 & 4.962 & TST & \\
\hline CHEMBL1475290 & 688798 & 9.0458 & 5.9078 & TRN & \\
\hline CHEMBL1566414 & 688798 & 5.0 & 5.3483 & TRN & \\
\hline CHEMBL1514927 & 688798 & 4.75 & 5.7623 & TRN & \\
\hline CHEMBL1517677 & 688798 & 5.0 & 5.4393 & TRN & \\
\hline CHEMBL1425680 & 688798 & 4.4 & 5.2829 & TRN & \\
\hline CHEMBL1435739 & 688798 & 6.05 & 5.6124 & TRN & \\
\hline CHEMBL1601375 & 688798 & 6.7501 & 5.5643 & TRN & \\
\hline CHEMBL1473709 & 688798 & 6.5 & 5.3995 & TRN & \\
\hline CHEMBL1440696 & 688798 & 7.4498 & 5.3721 & TST & \\
\hline CHEMBL1595235 & 688798 & 4.4 & 4.7232 & TRN & \\
\hline CHEMBL1520109 & 688798 & 4.3 & 5.4997 & TRN & \\
\hline CHEMBL1604785 & 688798 & 5.0 & 5.4428 & TRN & \\
\hline CHEMBL1462243 & 688798 & 3.0 & 5.3877 & TRN & \\
\hline
\end{tabular}




\begin{tabular}{|c|c|c|c|c|c|}
\hline \multicolumn{6}{|c|}{ Supplemental Table s2.txt } \\
\hline CHEMBL1876078 & 688798 & 4.25 & 5.2047 & TRN & \\
\hline CHEMBL1447612 & 688798 & 7.4498 & \multicolumn{2}{|c|}{5.707999999999999} & TRN \\
\hline CHEMBL1606587 & 688798 & 5.4 & 5.8813 & TRN & \\
\hline CHEMBL1554141 & 688798 & 8.1024 & 5.2993 & TST & \\
\hline CHEMBL1404455 & 688798 & 3.95 & 5.3704 & TRN & \\
\hline CHEMBL1362240 & 688798 & 3.95 & 5.8565 & TRN & \\
\hline CHEMBL15766 & 688798 & 4.25 & 5.1458 & TST & \\
\hline CHEMBL1324998 & 688798 & 4.5 & 5.1217 & TRN & \\
\hline CHEMBL1535411 & 688798 & 5.85 & \multicolumn{2}{|c|}{5.013999999999999} & TRN \\
\hline CHEMBL1591962 & 688798 & 4.9 & 5.6135 & TRN & \\
\hline CHEMBL1519214 & 688798 & 4.6 & 5.4971 & TRN & \\
\hline CHEMBL1451946 & 688798 & 4.35 & 5.2712 & TRN & \\
\hline CHEMBL1408140 & 688798 & 4.0 & 5.4719 & TRN & \\
\hline CHEMBL1530447 & 688798 & 5.35 & 5.6099 & TRN & \\
\hline CHEMBL1361971 & 688798 & 4.3 & 5.1049 & TRN & \\
\hline CHEMBL1551010 & 688798 & 8.3468 & 5.644 & TRN & \\
\hline CHEMBL1315763 & 688798 & 6.5501 & 5.3165 & TRN & \\
\hline CHEMBL1484232 & 688798 & 5.0 & 5.6231 & TRN & \\
\hline CHEMBL1998531 & 688798 & 8.7447 & 5.1663 & TRN & \\
\hline CHEMBL1600731 & 688798 & 4.6 & 5.178 & TRN & \\
\hline CHEMBL1501502 & 688798 & 6.95 & 5.1779 & TST & \\
\hline CHEMBL47 & 688798 & 5.65 & 4.9662 & TST & \\
\hline CHEMBL1450458 & 688798 & 4.3 & 5.2437 & TRN & \\
\hline CHEMBL1481586 & 688798 & 7.5498 & 5.6321 & TRN & \\
\hline CHEMBL1541495 & 688798 & 5.4 & 5.5497 & TST & \\
\hline CHEMBL1510670 & 688798 & 8.6021 & \multicolumn{2}{|c|}{5.6770000000000005} & TRN \\
\hline CHEMBL1448404 & 688798 & 6.5 & 5.4704 & TRN & \\
\hline CHEMBL1416527 & 688798 & 8.5528 & 5.6543 & TRN & \\
\hline CHEMBL1515711 & 688798 & 4.7 & 5.8337 & TRN & \\
\hline CHEMBL3208294 & 688798 & 4.45 & 5.3449 & TST & \\
\hline CHEMBL1479619 & 688798 & 5.7 & 5.5 & TRN & \\
\hline CHEMBL22304 & 688798 & 6.45 & 4.9232 & TST & \\
\hline CHEMBL1424293 & 688798 & 7.2503 & \multicolumn{2}{|c|}{5.372000000000001} & TRN \\
\hline CHEMBL1555785 & 688798 & 9.699 & 5.6437 & TRN & \\
\hline CHEMBL1473732 & 688798 & 4.7 & 4.8994 & TRN & \\
\hline CHEMBL1410006 & 688798 & 5.4 & 5.1361 & TRN & \\
\hline CHEMBL1436005 & 688798 & 4.3 & 5.7137 & TRN & \\
\hline CHEMBL1597062 & 688798 & 4.5 & 5.6642 & TRN & \\
\hline CHEMBL1372402 & 688798 & 4.7 & 5.1678 & TRN & \\
\hline CHEMBL246446 & 688798 & 4.15 & 4.823 & TRN & \\
\hline CHEMBL1555203 & 688798 & 5.2 & 5.6179 & TRN & \\
\hline CHEMBL1400947 & 688798 & 4.0 & 5.206 & TRN & \\
\hline CHEMBL1330528 & 688798 & 4.7 & 5.4687 & TRN & \\
\hline CHEMBL1398339 & 688798 & 7.4498 & 5.6036 & TRN & \\
\hline CHEMBL3196638 & 688798 & 6.5501 & 5.5635 & TRN & \\
\hline CHEMBL1399154 & 688798 & 3.55 & 5.2799 & TRN & \\
\hline CHEMBL1372455 & 688798 & 3.85 & 5.6677 & TRN & \\
\hline CHEMBL1524644 & 688798 & 4.8 & 5.7573 & TRN & \\
\hline
\end{tabular}




\begin{tabular}{|c|c|c|c|c|c|}
\hline \multirow[b]{2}{*}{ CHEMBL1456233 } & \multicolumn{5}{|c|}{ Supplemental Table S2.txt } \\
\hline & 688798 & 7.5498 & 5.3542 & TRN & \\
\hline CHEMBL1591164 & 688798 & 6.0 & 5.2689 & TRN & \\
\hline CHEMBL1512292 & 688798 & 6.3 & 5.8435 & TRN & \\
\hline CHEMBL1578128 & 688798 & 4.4 & 5.15799 & 99999999995 & TRN \\
\hline CHEMBL1606751 & 688798 & 4.4 & 4.9932 & TRN & \\
\hline CHEMBL1398360 & 688798 & 8.2518 & 5.8621 & TRN & \\
\hline CHEMBL1365178 & 688798 & 4.6 & 4.9266 & TRN & \\
\hline CHEMBL1436511 & 688798 & 4.05 & 5.065 & TRN & \\
\hline CHEMBL1433545 & 688798 & 5.0 & 5.2512 & TST & \\
\hline CHEMBL1398261 & 688798 & 6.5501 & 5.6988 & TRN & \\
\hline CHEMBL 2002767 & 688798 & 4.45 & 4.9665 & TRN & \\
\hline CHEMBL1563091 & 688798 & 2.85 & 5.5646 & TST & \\
\hline CHEMBL1556425 & 688798 & 4.85 & 5.4958 & TRN & \\
\hline CHEMBL1357639 & 688798 & 4.75 & 5.722 & TRN & \\
\hline CHEMBL23236 & 688798 & 8.4559 & 4.9043 & TST & \\
\hline CHEMBL1374530 & 688798 & 6.9 & 5.5862 & TRN & \\
\hline CHEMBL1594080 & 688798 & 5.45 & 5.7799 & TRN & \\
\hline CHEMBL1315088 & 688798 & 4.65 & 5.5438 & TRN & \\
\hline CHEMBL1561841 & 688798 & 4.8 & 5.5337 & TRN & \\
\hline CHEMBL1475352 & 688798 & 4.05 & 5.2777 & TRN & \\
\hline CHEMBL1597297 & 688798 & 7.4498 & 5.4004 & TRN & \\
\hline CHEMBL1515103 & 688798 & 3.95 & 5.7985 & TRN & \\
\hline CHEMBL1983745 & 688798 & 4.15 & 5.0653 & TRN & \\
\hline CHEMBL1514604 & 688798 & 6.6 & 5.1814 & TST & \\
\hline CHEMBL1475918 & 688798 & 2.35 & 5.1372 & TRN & \\
\hline CHEMBL1515844 & 688798 & 3.45 & 5.2428 & TRN & \\
\hline CHEMBL1495539 & 688798 & 4.35 & 4.8072 & TRN & \\
\hline CHEMBL1444976 & 688798 & 4.3 & 5.2518 & TST & \\
\hline CHEMBL1591159 & 688798 & 8.0506 & 5.8751 & TRN & \\
\hline CHEMBL1453916 & 688798 & 2.55 & 5.4828 & TST & \\
\hline CHEMBL1324024 & 688798 & 4.35 & 5.1296 & TRN & \\
\hline CHEMBL1516309 & 688798 & 4.15 & 5.5796 & TRN & \\
\hline CHEMBL3199242 & 688798 & 3.95 & 5.5541 & TRN & \\
\hline CHEMBL1394377 & 688798 & 9.0458 & 5.5418 & TRN & \\
\hline CHEMBL1314721 & 688798 & 4.0 & 5.6438 & TRN & \\
\hline CHEMBL1325716 & 688798 & 4.75 & 5.5425 & TRN & \\
\hline CHEMBL1334484 & 688798 & 4.45 & 4.5451 & TRN & \\
\hline CHEMBL 3145214 & 688798 & 4.3 & 5.0924 & TST & \\
\hline CHEMBL3199434 & 688798 & 5.55 & 5.4133 & TRN & \\
\hline CHEMBL1355585 & 688798 & 4.7 & 5.5424 & TRN & \\
\hline CHEMBL1315397 & 688798 & 8.0506 & 5.4826 & TRN & \\
\hline CHEMBL1564787 & 688798 & 3.55 & 4.8679 & TRN & \\
\hline CHEMBL1480653 & 688798 & 4.55 & 4.9509 & TRN & \\
\hline CHEMBL1592923 & 688798 & 4.7 & 5.6982 & TRN & \\
\hline CHEMBL1561199 & 688798 & 4.35 & 5.6208 & TRN & \\
\hline CHEMBL1434962 & 688798 & 4.0 & 5.5943 & TRN & \\
\hline CHEMBL1314589 & 688798 & 4.75 & 5.7076 & TRN & \\
\hline CHEMBL1534357 & 688798 & 9.5229 & 5.4564 & TRN & \\
\hline
\end{tabular}




\begin{tabular}{|c|c|c|c|c|c|}
\hline \multicolumn{6}{|c|}{ Supplemental Table s2.txt } \\
\hline CHEMBL1379535 & 688798 & 4.3 & 4.703 & TRN & \\
\hline CHEMBL1590548 & 688798 & 5.35 & 5.8072 & TRN & \\
\hline CHEMBL1476618 & 688798 & 3.2 & 5.3838 & TRN & \\
\hline CHEMBL1454948 & 688798 & 7.5003 & 5.6992 & TRN & \\
\hline CHEMBL1408383 & 688798 & 4.8 & 5.7959 & TRN & \\
\hline CHEMBL1433584 & 688798 & 5.95 & 5.5103 & TRN & \\
\hline CHEMBL1988535 & 688798 & 4.35 & 5.3126 & TRN & \\
\hline CHEMBL1457109 & 688798 & 5.75 & 5.7094 & TRN & \\
\hline CHEMBL1317645 & 688798 & 5.0 & 4.829 & TRN & \\
\hline CHEMBL1551029 & 688798 & 3.95 & 5.6498 & TRN & \\
\hline CHEMBL1425920 & 688798 & 4.15 & 5.5397 & TRN & \\
\hline CHEMBL92024 & 688798 & 5.4 & 5.1272 & TRN & \\
\hline CHEMBL1343341 & 688798 & 4.4 & 5.0379 & TRN & \\
\hline CHEMBL11475 & 688798 & 4.65 & 4.6024 & TRN & \\
\hline CHEMBL1374242 & 688798 & 4.85 & 5.2389 & TRN & \\
\hline CHEMBL1430727 & 688798 & 4.55 & 4.7971 & TRN & \\
\hline CHEMBL1302372 & 688798 & 8.1487 & 5.6426 & TRN & \\
\hline CHEMBL1606342 & 688798 & 4.3 & 5.54899 & 99999999995 & TRN \\
\hline CHEMBL1512686 & 688798 & 4.7 & 5.7991 & TRN & \\
\hline CHEMBL3190505 & 688798 & 8.7447 & 5.6256 & TRN & \\
\hline CHEMBL1356615 & 688798 & 7.1002 & 5.3384 & TRN & \\
\hline CHEMBL1603056 & 688798 & 4.4 & 5.1009 & TRN & \\
\hline CHEMBL1326440 & 688798 & 8.2007 & 5.4346 & TRN & \\
\hline CHEMBL1393573 & 688798 & 4.05 & 5.5783 & TST & \\
\hline CHEMBL1357426 & 688798 & 7.1002 & 5.444 & TRN & \\
\hline CHEMBL1328893 & 688798 & 7.15 & 5.0667 & TST & \\
\hline CHEMBL1592433 & 688798 & 4.0 & 5.5179 & TRN & \\
\hline CHEMBL 243751 & 688798 & 5.6 & 5.2586 & TRN & \\
\hline CHEMBL1411617 & 688798 & 8.6021 & 5.0171 & TRN & \\
\hline CHEMBL1555006 & 688798 & 6.7001 & 5.5706 & TRN & \\
\hline CHEMBL41680 & 688798 & 3.45 & 4.8537 & TST & \\
\hline CHEMBL1357467 & 688798 & 4.85 & 5.3121 & TRN & \\
\hline CHEMBL1354955 & 688798 & 8.2518 & 5.5771 & TRN & \\
\hline CHEMBL1361503 & 688798 & 2.6 & 5.145 & TRN & \\
\hline CHEMBL1331795 & 688798 & 6.5 & 5.3975 & TRN & \\
\hline CHEMBL1408169 & 688798 & 3.55 & 5.3741 & TRN & \\
\hline CHEMBL1079460 & 688798 & 10.45 & 4.9153 & TST & \\
\hline CHEMBL1611318 & 688798 & 7.2503 & 5.2491 & TRN & \\
\hline CHEMBL1324584 & 688798 & 3.9 & 5.09699 & 99999999995 & TRN \\
\hline CHEMBL1589875 & 688798 & 5.2 & 5.3979 & TRN & \\
\hline CHEMBL1478240 & 688798 & 6.45 & 5.4222 & TRN & \\
\hline CHEMBL1556611 & 688798 & 4.15 & 5.4845 & TRN & \\
\hline CHEMBL1406201 & 688798 & 2.9 & 5.3737 & TRN & \\
\hline CHEMBL1437724 & 688798 & 5.1 & 5.159 & TRN & \\
\hline CHEMBL1522129 & 688798 & 4.5 & 4.8005 & TST & \\
\hline CHEMBL1325198 & 688798 & 5.5 & 5.1013 & TRN & \\
\hline CHEMBL310396 & 688798 & 8.4949 & 4.7208 & TRN & \\
\hline CHEMBL1611575 & 688798 & 6.3 & 5.506 & TRN & \\
\hline
\end{tabular}




\begin{tabular}{|c|c|c|c|c|c|}
\hline \multicolumn{6}{|c|}{ Supplemental Table S2.txt } \\
\hline CHEMBL1608167 & 688798 & 4.15 & 5.4051 & TRN & \\
\hline CHEMBL1413414 & 688798 & 4.25 & 5.1671 & TRN & \\
\hline CHEMBL1985795 & 688798 & 6.15 & 5.3969 & TRN & \\
\hline CHEMBL1553901 & 688798 & 4.05 & 5.6876 & TRN & \\
\hline CHEMBL1490821 & 688798 & 4.5 & 5.3289 & TRN & \\
\hline CHEMBL1408262 & 688798 & 5.55 & 5.6636 & TRN & \\
\hline CHEMBL1513102 & 688798 & 4.65 & 5.038 & TRN & \\
\hline CHEMBL1475122 & 688798 & 7.4498 & 5.4649 & TRN & \\
\hline CHEMBL1482337 & 688798 & 4.95 & 5.5039 & TRN & \\
\hline CHEMBL44664 & 688798 & 3.9 & 5.0455 & TST & \\
\hline CHEMBL1529207 & 688798 & 6.45 & 5.4587 & TRN & \\
\hline CHEMBL1327853 & 688798 & 4.2 & 5.0296 & TRN & \\
\hline CHEMBL1568683 & 688798 & 6.9 & 5.5443 & TRN & \\
\hline CHEMBL1436907 & 688798 & 4.85 & 5.568 & TRN & \\
\hline CHEMBL1324086 & 688798 & 7.0501 & 5.5375 & TRN & \\
\hline CHEMBL1999810 & 688798 & 5.5 & 5.3142 & TRN & \\
\hline CHEMBL1396423 & 688798 & 4.2 & 5.8188 & TRN & \\
\hline CHEMBL1609254 & 688798 & 4.8 & 5.4478 & TRN & \\
\hline CHEMBL1435529 & 688798 & 4.45 & 5.5287 & TRN & \\
\hline CHEMBL1514262 & 688798 & 3.25 & 4.8304 & TRN & \\
\hline CHEMBL426404 & 688798 & 3.9 & 4.8624 & TST & \\
\hline CHEMBL1407262 & 688798 & 4.3 & 5.6132 & TRN & \\
\hline CHEMBL1301433 & 688798 & 4.4 & 5.2443 & TRN & \\
\hline CHEMBL1450134 & 688798 & 4.9 & 5.364 & TRN & \\
\hline CHEMBL1403091 & 688798 & 6.1 & 5.6095 & TRN & \\
\hline CHEMBL1377118 & 688798 & 4.4 & 5.2704 & TRN & \\
\hline CHEMBL1314471 & 688798 & 4.65 & 5.2571 & TRN & \\
\hline CHEMBL1356614 & 688798 & 7.8996 & 5.2224 & TRN & \\
\hline CHEMBL1572268 & 688798 & 10.0 & 4.9529 & TRN & \\
\hline CHEMBL1478954 & 688798 & 4.75 & 5.8248 & TRN & \\
\hline CHEMBL1309941 & 688798 & 4.3 & 5.4218 & TRN & \\
\hline CHEMBL1521968 & 688798 & 7.4498 & 5.4043 & TST & \\
\hline CHEMBL1302599 & 688798 & 4.4 & 4.9116 & TRN & \\
\hline CHEMBL1363229 & 688798 & 5.5 & 5.15799 & 99999999995 & TST \\
\hline CHEMBL1589884 & 688798 & 7.15 & 5.4536 & TRN & \\
\hline CHEMBL1541456 & 688798 & 4.5 & 5.4945 & TST & \\
\hline CHEMBL1395217 & 688798 & 3.95 & 5.858 & TRN & \\
\hline CHEMBL1358755 & 688798 & 4.3 & 5.545 & TRN & \\
\hline CHEMBL1487995 & 688798 & 4.8 & 5.5178 & TRN & \\
\hline CHEMBL1368178 & 688798 & 4.35 & 5.0835 & TRN & \\
\hline CHEMBL1573136 & 688798 & 8.6021 & 5.5667 & TRN & \\
\hline CHEMBL1316896 & 688798 & 9.301 & 5.6877 & TRN & \\
\hline CHEMBL1375708 & 688798 & 4.6 & 5.0669 & TRN & \\
\hline CHEMBL1600904 & 688798 & 5.55 & 5.3459 & TRN & \\
\hline CHEMBL1514824 & 688798 & 3.95 & 5.5836 & TRN & \\
\hline CHEMBL1492562 & 688798 & 4.8 & 5.3302 & TRN & \\
\hline CHEMBL1355703 & 688798 & 4.0 & 5.0593 & TST & \\
\hline CHEMBL1410735 & 688798 & 3.55 & 5.3916 & TRN & \\
\hline
\end{tabular}




\begin{tabular}{|c|c|c|c|c|c|}
\hline \multicolumn{6}{|c|}{ Supplemental Table S2.txt } \\
\hline CHEMBL1590993 & 688798 & 5.0 & 5.3154 & TRN & \\
\hline CHEMBL1535926 & 688798 & 4.7 & 5.1654 & TRN & \\
\hline CHEMBL1474140 & 688798 & 3.8 & 5.5339 & TRN & \\
\hline CHEMBL1437240 & 688798 & 6.9 & 5.1803 & TRN & \\
\hline CHEMBL1314203 & 688798 & 4.05 & 4.9195 & TRN & \\
\hline CHEMBL1550129 & 688798 & 4.4 & 4.9418 & TRN & \\
\hline CHEMBL3351065 & 688798 & 4.95 & 5.0657 & TRN & \\
\hline CHEMBL1492129 & 688798 & 4.45 & 4.9268 & TST & \\
\hline CHEMBL1500500 & 688798 & 5.9 & 5.1879 & TRN & \\
\hline CHEMBL1451797 & 688798 & 4.6 & 5.4244 & TRN & \\
\hline CHEMBL1524799 & 688798 & 5.25 & 5.2423 & TST & \\
\hline CHEMBL1467803 & 688798 & 3.2 & 5.4529 & TRN & \\
\hline CHEMBL1437308 & 688798 & 4.0 & 5.7023 & TRN & \\
\hline CHEMBL1563417 & 688798 & 6.5501 & 5.7919 & TRN & \\
\hline CHEMBL1586726 & 688798 & 4.35 & 4.8951 & TST & \\
\hline CHEMBL3210773 & 688798 & 3.4 & 5.3631 & TRN & \\
\hline CHEMBL1318216 & 688798 & 3.95 & 5.5835 & TRN & \\
\hline CHEMBL1430289 & 688798 & 4.4 & 5.0836 & TST & \\
\hline CHEMBL3193859 & 688798 & 9.699 & 5.2259 & TRN & \\
\hline CHEMBL1597995 & 688798 & 4.7 & 5.7584 & TRN & \\
\hline CHEMBL1551234 & 688798 & 8.0506 & 5.6119 & TRN & \\
\hline CHEMBL1350184 & 688798 & 4.35 & 5.4044 & TST & \\
\hline CHEMBL1522506 & 688798 & 7.0501 & 5.8383 & TRN & \\
\hline CHEMBL1329176 & 688798 & 6.5 & 5.5946 & TRN & \\
\hline CHEMBL1434959 & 688798 & 4.95 & 5.1482 & TST & \\
\hline CHEMBL1474996 & 688798 & 4.65 & 5.351 & TST & \\
\hline CHEMBL1513152 & 688798 & 3.65 & 5.1906 & TRN & \\
\hline CHEMBL1531030 & 688798 & 6.5501 & 5.4301 & TRN & \\
\hline CHEMBL1552541 & 688798 & 3.95 & 5.0385 & TRN & \\
\hline CHEMBL1325089 & 688798 & 4.85 & 5.3302 & TRN & \\
\hline CHEMBL1356819 & 688798 & 2.9 & 5.4539 & TRN & \\
\hline CHEMBL1551712 & 688798 & 3.95 & 5.4597 & TRN & \\
\hline CHEMBL1357265 & 688798 & 5.65 & 4.9865 & TST & \\
\hline CHEMBL1544163 & 688798 & 4.35 & 4.886 & TRN & \\
\hline CHEMBL1397628 & 688798 & 4.5 & 5.5068 & TRN & \\
\hline CHEMBL1608853 & 688798 & 4.35 & 4.8059 & TRN & \\
\hline CHEMBL 1409310 & 688798 & 4.25 & 5.75799 & 9999999999 & TRN \\
\hline CHEMBL1503138 & 688798 & 9.2218 & 5.5921 & TRN & \\
\hline CHEMBL1487660 & 688798 & 5.2 & 4.4605 & TRN & \\
\hline CHEMBL1437740 & 688798 & 7.7496 & 5.9785 & TRN & \\
\hline CHEMBL1985759 & 688798 & 5.5 & 5.0247 & TRN & \\
\hline CHEMBL1553015 & 688798 & 3.55 & 5.4231 & TRN & \\
\hline CHEMBL1394494 & 688798 & 8.9586 & 5.681 & TRN & \\
\hline CHEMBL1526171 & 688798 & 4.35 & 5.2348 & TRN & \\
\hline CHEMBL1436350 & 688798 & 8.7959 & 5.4061 & TRN & \\
\hline CHEMBL1443918 & 688798 & 5.25 & 5.5881 & TRN & \\
\hline CHEMBL1494252 & 688798 & 3.85 & 5.1431 & TRN & \\
\hline CHEMBL1571949 & 688798 & 7.3002 & 5.5295 & TRN & \\
\hline
\end{tabular}




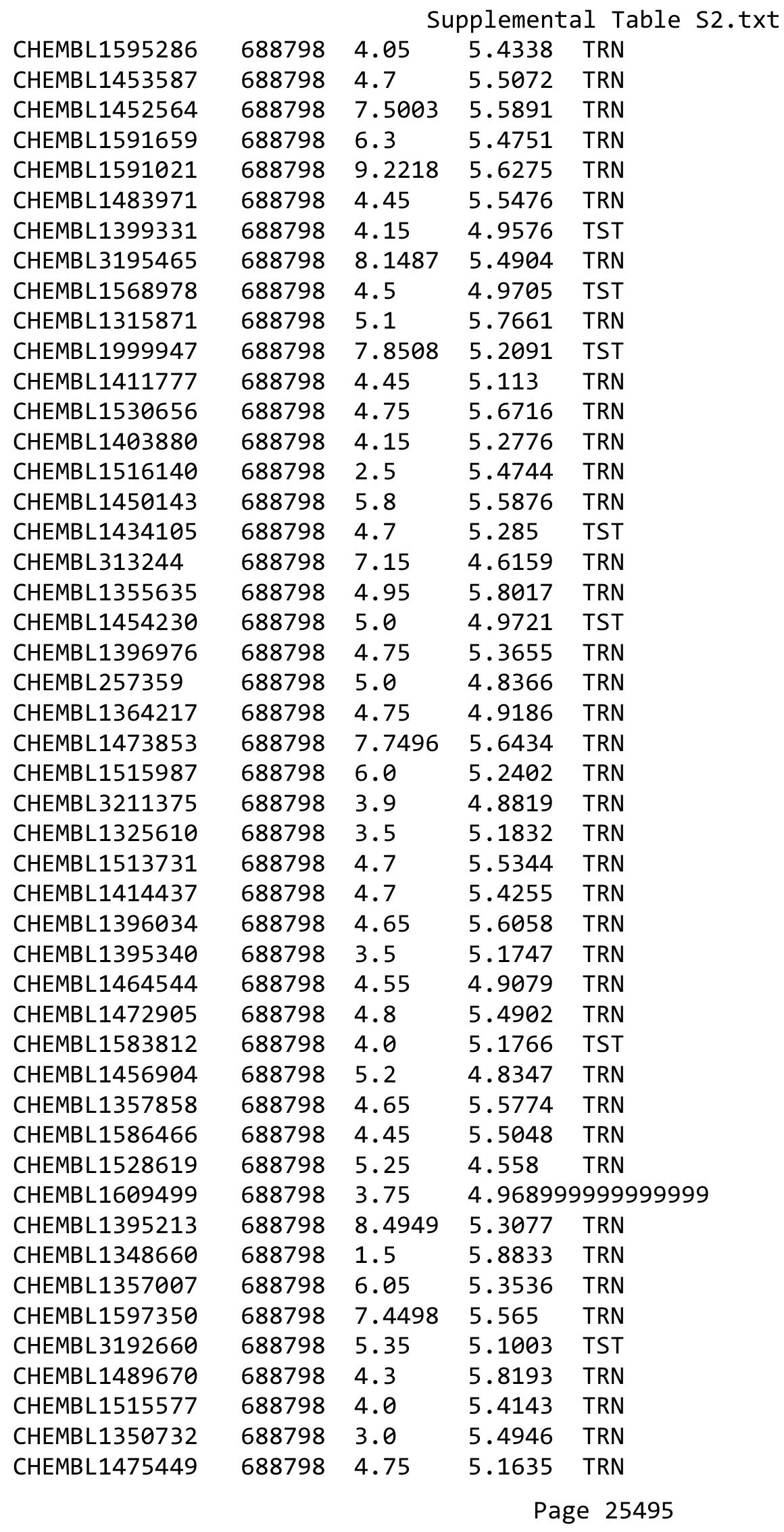




\begin{tabular}{|c|c|c|c|c|c|}
\hline \multicolumn{6}{|c|}{ Supplemental Table S2.txt } \\
\hline CHEMBL3190756 & 688798 & 4.15 & 4.8648 & TST & \\
\hline CHEMBL1466305 & 688798 & 3.55 & 4.8756 & TRN & \\
\hline CHEMBL1434633 & 688798 & 4.65 & 5.5409 & TRN & \\
\hline CHEMBL1560610 & 688798 & 8.0506 & 4.9916 & TRN & \\
\hline CHEMBL1358471 & 688798 & 5.4 & 5.1198 & TST & \\
\hline CHEMBL1590411 & 688798 & 4.85 & 5.5845 & TRN & \\
\hline CHEMBL1310375 & 688798 & 4.35 & 5.1338 & TST & \\
\hline CHEMBL1443463 & 688798 & 4.7 & 5.7091 & TRN & \\
\hline CHEMBL1326346 & 688798 & 4.5 & 5.2175 & TST & \\
\hline CHEMBL1474019 & 688798 & 4.6 & 5.3534 & TRN & \\
\hline CHEMBL1596521 & 688798 & 4.45 & 5.7926 & TRN & \\
\hline CHEMBL1398092 & 688798 & 6.45 & 5.3651 & TRN & \\
\hline CHEMBL1582495 & 688798 & 7.5498 & 5.6235 & TRN & \\
\hline CHEMBL1547638 & 688798 & 4.9 & 4.8254 & TRN & \\
\hline CHEMBL1436827 & 688798 & 4.75 & 5.6055 & TRN & \\
\hline CHEMBL109037 & 688798 & 4.95 & 4.9273 & TRN & \\
\hline CHEMBL1495450 & 688798 & 3.6 & 5.0697 & TST & \\
\hline CHEMBL1418779 & 688798 & 2.9 & 4.9584 & TST & \\
\hline CHEMBL1368240 & 688798 & 5.0 & 5.5635 & TRN & \\
\hline CHEMBL1398256 & 688798 & 4.8 & 5.0288 & TRN & \\
\hline CHEMBL1316077 & 688798 & 3.3 & 5.8589 & TRN & \\
\hline CHEMBL3199158 & 688798 & 6.45 & 4.9376 & TRN & \\
\hline CHEMBL1521153 & 688798 & 5.45 & 5.2071 & TRN & \\
\hline CHEMBL1435730 & 688798 & 6.95 & 5.3911 & TRN & \\
\hline CHEMBL1396419 & 688798 & 4.1 & 5.5632 & TRN & \\
\hline CHEMBL1571028 & 688798 & 4.65 & 5.5654 & TRN & \\
\hline CHEMBL1433502 & 688798 & 9.0 & 5.5294 & TRN & \\
\hline CHEMBL1433554 & 688798 & 4.7 & 5.7876 & TRN & \\
\hline CHEMBL1433896 & 688798 & 4.95 & 5.185 & TST & \\
\hline CHEMBL1598943 & 688798 & 5.35 & 5.2403 & TRN & \\
\hline CHEMBL1512525 & 688798 & 5.5 & 5.40799 & 99999999995 & TRN \\
\hline CHEMBL1561605 & 688798 & 6.15 & 5.1712 & TRN & \\
\hline CHEMBL1571663 & 688798 & 7.9508 & 5.6988 & TRN & \\
\hline CHEMBL1593522 & 688798 & 6.5 & 5.2681 & TRN & \\
\hline CHEMBL1441198 & 688798 & 5.0 & 5.5935 & TRN & \\
\hline CHEMBL1396910 & 688798 & 7.5003 & 5.093 & TRN & \\
\hline CHEMBL1345430 & 688798 & 3.2 & 5.6496 & TRN & \\
\hline CHEMBL1410051 & 688798 & 4.6 & 5.4738 & TRN & \\
\hline CHEMBL1436148 & 688798 & 9.0458 & 5.46700 & 00000000005 & TRN \\
\hline CHEMBL1473415 & 688798 & 3.5 & 5.3351 & TRN & \\
\hline CHEMBL1534963 & 688798 & 6.4 & 5.5177 & TRN & \\
\hline CHEMBL19980 & 688798 & 6.15 & 4.7214 & TST & \\
\hline CHEMBL1495758 & 688798 & 7.5003 & 5.6866 & TRN & \\
\hline CHEMBL1565335 & 688798 & 7.0501 & 5.4 & TST & \\
\hline CHEMBL1375611 & 688798 & 3.9 & 5.4977 & TRN & \\
\hline CHEMBL1477695 & 688798 & 7.7496 & 5.5111 & TRN & \\
\hline CHEMBL1572528 & 688798 & 5.45 & 5.0238 & TST & \\
\hline CHEMBL1255578 & 688798 & 6.9 & 4.7633 & TST & \\
\hline
\end{tabular}




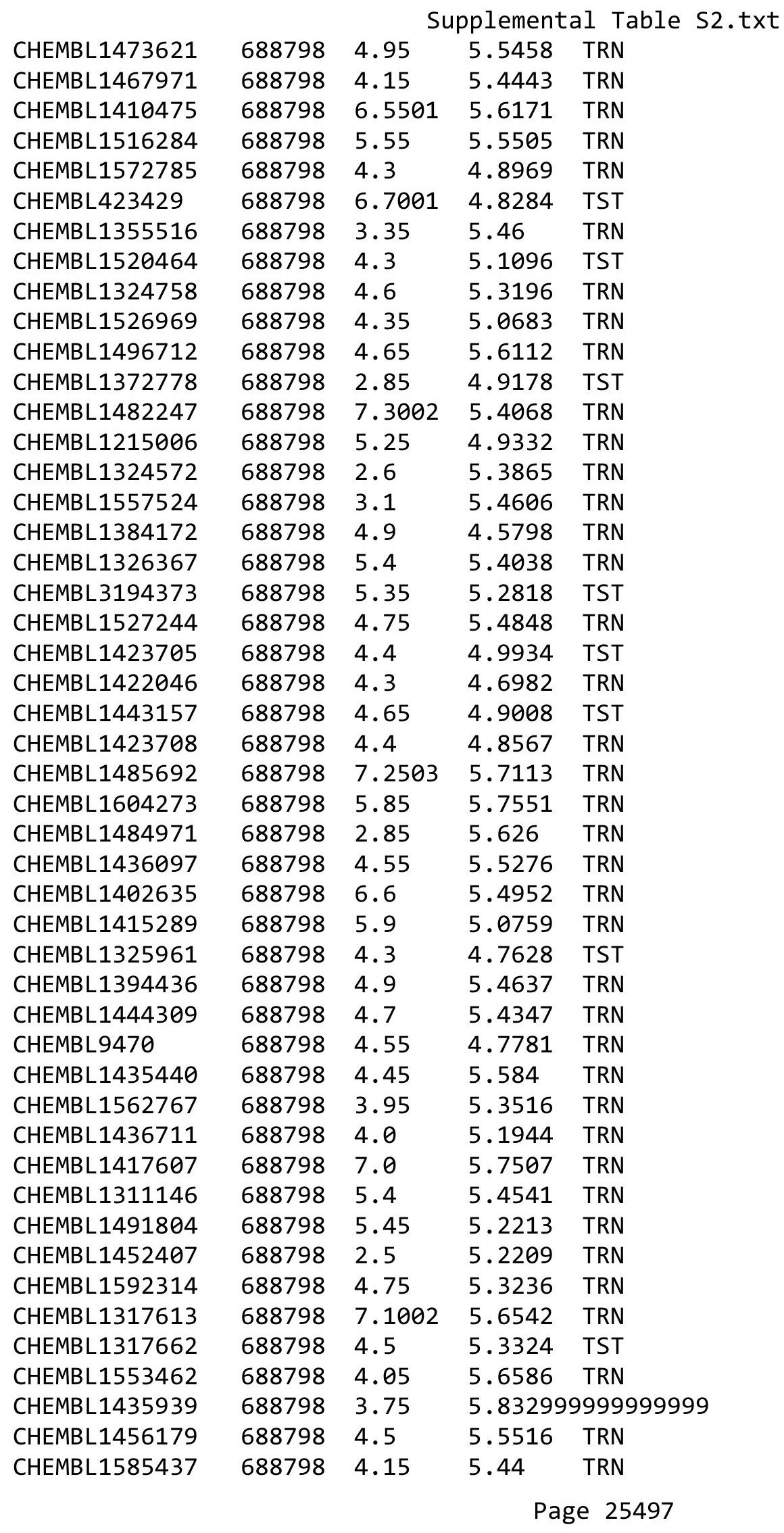

TRN 


\begin{tabular}{|c|c|c|c|c|c|}
\hline & & \multicolumn{4}{|c|}{ Supplemental Table S2.txt } \\
\hline CHEMBL1358129 & 688798 & 8.5528 & 5.7172 & TRN & \\
\hline CHEMBL3207827 & 688798 & 2.95 & 5.1363 & TRN & \\
\hline CHEMBL217894 & 688798 & 4.05 & 5.1291 & TST & \\
\hline CHEMBL1339248 & 688798 & 4.2 & 5.0997 & TRN & \\
\hline CHEMBL117405 & 688798 & 7.0501 & 5.2102 & TST & \\
\hline CHEMBL1491161 & 688798 & 7.5003 & 5.5278 & TRN & \\
\hline CHEMBL1589738 & 688798 & 3.5 & 5.1432 & TRN & \\
\hline CHEMBL584508 & 688798 & 9.0458 & 5.3844 & TRN & \\
\hline CHEMBL1315282 & 688798 & 4.65 & 5.1941 & TRN & \\
\hline CHEMBL1434541 & 688798 & 10.45 & 5.6153 & TRN & \\
\hline CHEMBL1395780 & 688798 & 4.95 & \multicolumn{2}{|c|}{5.292000000000001} & TRN \\
\hline CHEMBL1411955 & 688798 & 4.3 & 5.1178 & TST & \\
\hline CHEMBL1513977 & 688798 & 4.8 & 5.8654 & TRN & \\
\hline CHEMBL1526804 & 688798 & 3.95 & 5.8758 & TRN & \\
\hline CHEMBL1551532 & 688798 & 5.2 & 5.3676 & TRN & \\
\hline CHEMBL1513701 & 688798 & 8.5528 & 5.4211 & TRN & \\
\hline CHEMBL1511963 & 688798 & 7.4498 & 5.3435 & TRN & \\
\hline CHEMBL1475273 & 688798 & 8.5528 & 5.8477 & TRN & \\
\hline CHEMBL1515259 & 688798 & 4.55 & 5.0834 & TRN & \\
\hline CHEMBL1355214 & 688798 & 4.2 & 5.902 & TRN & \\
\hline CHEMBL3191714 & 688798 & 4.4 & 5.0232 & TRN & \\
\hline CHEMBL1322954 & 688798 & 8.5528 & 5.4729 & TRN & \\
\hline CHEMBL1357708 & 688798 & 4.75 & 5.7098 & TRN & \\
\hline CHEMBL1513993 & 688798 & 3.9 & 5.3771 & TST & \\
\hline CHEMBL1552351 & 688798 & 4.85 & 5.255 & TRN & \\
\hline CHEMBL1526153 & 688798 & 8.2007 & 5.1636 & TRN & \\
\hline CHEMBL1408436 & 688798 & 5.1 & 5.3414 & TRN & \\
\hline CHEMBL1355128 & 688798 & 4.0 & 5.3786 & TRN & \\
\hline CHEMBL1519903 & 688798 & 2.8 & 5.4232 & TRN & \\
\hline CHEMBL1512945 & 688798 & 3.35 & \multicolumn{2}{|c|}{5.2620000000000005} & TRN \\
\hline CHEMBL1357839 & 688798 & 4.4 & 5.8002 & TRN & \\
\hline CHEMBL1318584 & 688798 & 4.7 & 4.9292 & TRN & \\
\hline CHEMBL1435356 & 688798 & 7.6003 & 5.3901 & TRN & \\
\hline CHEMBL1568055 & 688798 & 4.35 & 5.4732 & TRN & \\
\hline CHEMBL1367795 & 688798 & 6.7501 & 5.2386 & TRN & \\
\hline CHEMBL1339127 & 688798 & 3.95 & 5.532 & TST & \\
\hline CHEMBL1474624 & 688798 & 3.95 & 5.6049 & TRN & \\
\hline CHEMBL1592828 & 688798 & 5.95 & 5.3757 & TRN & \\
\hline CHEMBL1560794 & 688798 & 4.6 & 4.8637 & TRN & \\
\hline CHEMBL1558022 & 688798 & 7.0 & 5.5854 & TRN & \\
\hline CHEMBL1563515 & 688798 & 6.5 & 5.7473 & TRN & \\
\hline CHEMBL1321036 & 688798 & 7.5498 & 5.5782 & TRN & \\
\hline CHEMBL1602511 & 688798 & 4.9 & 5.1563 & TRN & \\
\hline CHEMBL1408018 & 688798 & 3.9 & 5.1735 & TRN & \\
\hline CHEMBL1418464 & 688798 & 5.25 & 5.0953 & TST & \\
\hline CHEMBL1521205 & 688798 & 5.0 & 5.8898 & TRN & \\
\hline CHEMBL1589749 & 688798 & 6.3 & \multicolumn{2}{|c|}{5.4510000000000005} & TRN \\
\hline CHEMBL1472696 & 688798 & 9.699 & 5.5257 & TRN & \\
\hline
\end{tabular}




\begin{tabular}{|c|c|c|c|c|}
\hline \multicolumn{5}{|c|}{ Supplemental Table S2.txt } \\
\hline CHEMBL1358167 & 688798 & 5.8 & 5.6445 & TRN \\
\hline CHEMBL1321789 & 688798 & 5.0 & 5.6744 & TRN \\
\hline CHEMBL1568134 & 688798 & 5.0 & 5.3347 & TST \\
\hline CHEMBL1567703 & 688798 & 5.7 & 5.192 & TRN \\
\hline CHEMBL1551349 & 688798 & 6.25 & 5.779 & TRN \\
\hline CHEMBL586982 & 688798 & 8.8539 & 5.4665 & TRN \\
\hline CHEMBL3213289 & 688798 & 5.8 & 5.471 & TRN \\
\hline CHEMBL1316551 & 688798 & 4.9 & 5.5966 & TRN \\
\hline CHEMBL1551074 & 688798 & 6.45 & 5.2172 & TRN \\
\hline CHEMBL1431093 & 688798 & 3.0 & 5.2312 & TRN \\
\hline CHEMBL1397453 & 688798 & 3.75 & 4.9594 & TRN \\
\hline CHEMBL1565671 & 688798 & 4.7 & 5.6066 & TRN \\
\hline CHEMBL1535073 & 688798 & 4.75 & 5.4527 & TRN \\
\hline CHEMBL1610506 & 688798 & 4.8 & 4.936 & TRN \\
\hline CHEMBL1423692 & 688798 & 5.25 & 5.3961 & TRN \\
\hline CHEMBL1318304 & 688798 & 4.75 & 5.1524 & TRN \\
\hline CHEMBL1514210 & 688798 & 7.8996 & 5.7349 & TRN \\
\hline CHEMBL1415969 & 688798 & 6.05 & 5.2883 & TRN \\
\hline CHEMBL1349715 & 688798 & 2.8 & 4.9085 & TST \\
\hline CHEMBL1415556 & 688798 & 4.0 & 5.5084 & TRN \\
\hline CHEMBL1394384 & 688798 & 7.5498 & 5.6744 & TRN \\
\hline CHEMBL1603904 & 688798 & 4.05 & 5.5065 & TRN \\
\hline CHEMBL1304979 & 688798 & 4.55 & 5.319 & TRN \\
\hline CHEMBL151 & 688798 & 4.35 & 4.4973 & TRN \\
\hline CHEMBL1592978 & 688798 & 4.5 & 5.4 & TRN \\
\hline CHEMBL1497611 & 688798 & 4.45 & 5.8095 & TRN \\
\hline CHEMBL1563742 & 688798 & 4.8 & 5.1325 & TRN \\
\hline CHEMBL1434137 & 688798 & 4.1 & 4.9607 & TST \\
\hline CHEMBL1426974 & 688798 & 4.85 & 5.0775 & TST \\
\hline CHEMBL1433650 & 688798 & 4.8 & 5.2235 & TRN \\
\hline CHEMBL1574213 & 688798 & 4.3 & 5.1996 & TRN \\
\hline CHEMBL1394584 & 688798 & 9.2218 & 5.4538 & TRN \\
\hline CHEMBL1437256 & 688798 & 3.7 & 5.5749 & TRN \\
\hline CHEMBL1595917 & 688798 & 4.0 & 5.1607 & TRN \\
\hline CHEMBL1489687 & 688798 & 6.5 & 5.1146 & TRN \\
\hline CHEMBL1358386 & 688798 & 5.55 & 5.459 & TRN \\
\hline CHEMBL1402306 & 688798 & 4.65 & 5.619 & TRN \\
\hline CHEMBL1521824 & 688798 & 4.25 & 5.6089 & TRN \\
\hline CHEMBL1589860 & 688798 & 4.9 & 5.5005 & TRN \\
\hline CHEMBL1412810 & 688798 & 7.4498 & 5.0454 & TST \\
\hline CHEMBL1472973 & 688798 & 3.0 & 5.7788 & TRN \\
\hline CHEMBL1358608 & 688798 & 6.5 & 5.3705 & TRN \\
\hline CHEMBL1414678 & 688798 & 7.0501 & 5.3782 & TRN \\
\hline CHEMBL1477791 & 688798 & 3.95 & 5.2485 & TST \\
\hline CHEMBL3195669 & 688798 & 5.85 & 5.126 & TST \\
\hline CHEMBL1376780 & 688798 & 4.35 & 5.3315 & TRN \\
\hline CHEMBL 1473785 & 688798 & 9.0458 & 5.7939 & TRN \\
\hline CHEMBL1605522 & 688798 & 4.15 & 5.482 & TRN \\
\hline
\end{tabular}




\begin{tabular}{|c|c|c|c|c|c|}
\hline \multicolumn{6}{|c|}{ Supplemental Table S2.txt } \\
\hline CHEMBL1318013 & 688798 & 5.55 & 5.3073 & TRN & \\
\hline CHEMBL1431490 & 688798 & 4.35 & 5.3482 & TRN & \\
\hline CHEMBL1419977 & 688798 & 4.5 & 5.5924 & TRN & \\
\hline CHEMBL1398918 & 688798 & 3.95 & 5.4086 & TRN & \\
\hline CHEMBL1524493 & 688798 & 7.2 & 5.7139 & TRN & \\
\hline CHEMBL3196329 & 688798 & 4.35 & 5.2935 & TRN & \\
\hline CHEMBL1396573 & 688798 & 6.5 & 5.5658 & TRN & \\
\hline CHEMBL1472989 & 688798 & 5.85 & 5.2703 & TST & \\
\hline CHEMBL1500509 & 688798 & 4.5 & 5.3617 & TST & \\
\hline CHEMBL1330550 & 688798 & 4.75 & 5.70100 & 00000000005 & TRN \\
\hline CHEMBL1384775 & 688798 & 5.3 & 5.3749 & TRN & \\
\hline CHEMBL1398095 & 688798 & 4.8 & 5.3843 & TRN & \\
\hline CHEMBL1358895 & 688798 & 3.65 & 5.6065 & TRN & \\
\hline CHEMBL1530221 & 688798 & 6.1 & 5.3543 & TST & \\
\hline CHEMBL1590217 & 688798 & 4.55 & 5.1096 & TST & \\
\hline CHEMBL1358106 & 688798 & 7.1002 & 5.2009 & TRN & \\
\hline CHEMBL1405311 & 688798 & 4.4 & 4.7145 & TRN & \\
\hline CHEMBL1362865 & 688798 & 8.6021 & 5.4235 & TRN & \\
\hline CHEMBL1445528 & 688798 & 6.1 & 5.7242 & TRN & \\
\hline CHEMBL87568 & 688798 & 4.85 & 4.5863 & TRN & \\
\hline CHEMBL1357069 & 688798 & 7.5003 & 5.269 & TRN & \\
\hline CHEMBL1518982 & 688798 & 5.9 & 5.1022 & TRN & \\
\hline CHEMBL1473021 & 688798 & 8.0506 & 5.1682 & TST & \\
\hline CHEMBL1410729 & 688798 & 6.15 & 5.6225 & TRN & \\
\hline CHEMBL1371139 & 688798 & 4.9 & 5.3045 & TRN & \\
\hline CHEMBL1317331 & 688798 & 9.3979 & 5.8231 & TRN & \\
\hline CHEMBL1445978 & 688798 & 5.05 & 5.5209 & TRN & \\
\hline CHEMBL1396725 & 688798 & 6.5501 & 5.291 & TRN & \\
\hline CHEMBL1598311 & 688798 & 6.8499 & 5.3296 & TRN & \\
\hline CHEMBL1315314 & 688798 & 4.95 & 5.3264 & TRN & \\
\hline CHEMBL1405006 & 688798 & 4.25 & 5.4492 & TRN & \\
\hline CHEMBL1513289 & 688798 & 3.5 & 4.8451 & TRN & \\
\hline CHEMBL1441416 & 688798 & 1.6 & 5.0434 & TST & \\
\hline CHEMBL428496 & 688798 & 6.0 & 5.087 & TST & \\
\hline CHEMBL1519430 & 688798 & 5.25 & 4.6285 & TST & \\
\hline CHEMBL1551273 & 688798 & 3.95 & 5.4239 & TRN & \\
\hline CHEMBL1384639 & 688798 & 4.15 & 5.0421 & TST & \\
\hline CHEMBL1530732 & 688798 & 4.1 & 5.5117 & TRN & \\
\hline CHEMBL1569097 & 688798 & 6.15 & 5.329 & TRN & \\
\hline CHEMBL1510724 & 688798 & 6.3 & 5.6555 & TST & \\
\hline CHEMBL1456555 & 688798 & 10.0 & 5.5724 & TRN & \\
\hline CHEMBL1490084 & 688798 & 1.65 & 5.6675 & TRN & \\
\hline CHEMBL1525049 & 688798 & 5.7 & 5.4632 & TRN & \\
\hline CHEMBL1515402 & 688798 & 4.05 & 5.6133 & TRN & \\
\hline CHEMBL1221601 & 688798 & 3.95 & 5.2112 & TST & \\
\hline CHEMBL1408811 & 688798 & 3.4 & 5.3372 & TRN & \\
\hline CHEMBL1591623 & 688798 & 6.5 & 5.7036 & TRN & \\
\hline CHEMBL1370617 & 688798 & 5.65 & 5.5094 & TRN & \\
\hline
\end{tabular}




\begin{tabular}{|c|c|c|c|c|c|}
\hline \multicolumn{6}{|c|}{ Supplemental Table S2.txt } \\
\hline CHEMBL1368753 & 688798 & 4.95 & 5.335 & TRN & \\
\hline CHEMBL1374998 & 688798 & 4.75 & 5.6246 & TRN & \\
\hline CHEMBL1493277 & 688798 & 4.6 & 5.6174 & TRN & \\
\hline CHEMBL1389425 & 688798 & 3.3 & 4.8183 & TRN & \\
\hline CHEMBL1551899 & 688798 & 3.9 & 5.1036 & TST & \\
\hline CHEMBL1375602 & 688798 & 7.5498 & 5.3431 & TRN & \\
\hline CHEMBL1551401 & 688798 & 4.7 & 5.0103 & TRN & \\
\hline CHEMBL1608479 & 688798 & 5.35 & 5.3761 & TRN & \\
\hline CHEMBL1479349 & 688798 & 4.0 & 5.6282 & TRN & \\
\hline CHEMBL1451059 & 688798 & 4.4 & 4.7315 & TST & \\
\hline CHEMBL1553960 & 688798 & 7.15 & 5.49700 & 0000000001 & TRN \\
\hline CHEMBL1375339 & 688798 & 7.15 & 5.6166 & TRN & \\
\hline CHEMBL1554967 & 688798 & 3.75 & 5.4184 & TRN & \\
\hline CHEMBL1559040 & 688798 & 4.0 & 5.4676 & TRN & \\
\hline CHEMBL1575047 & 688798 & 3.45 & 4.9225 & TRN & \\
\hline CHEMBL1970812 & 688798 & 9.5229 & 5.2645 & TRN & \\
\hline CHEMBL1436120 & 688798 & 4.75 & 5.6844 & TRN & \\
\hline CHEMBL1469691 & 688798 & 2.95 & 5.2098 & TRN & \\
\hline CHEMBL1590480 & 688798 & 4.55 & 5.8313 & TRN & \\
\hline CHEMBL1336004 & 688798 & 3.65 & 5.4118 & TRN & \\
\hline CHEMBL1603130 & 688798 & 6.45 & 5.511 & TRN & \\
\hline CHEMBL1595709 & 688798 & 7.4498 & 5.4049 & TST & \\
\hline CHEMBL1534985 & 688798 & 5.4 & 5.4643 & TRN & \\
\hline CHEMBL1474013 & 688798 & 4.95 & 5.7008 & TRN & \\
\hline CHEMBL1436210 & 688798 & 3.0 & 5.5327 & TRN & \\
\hline CHEMBL1611864 & 688798 & 2.4 & 5.2924 & TRN & \\
\hline CHEMBL1514020 & 688798 & 3.9 & 5.4966 & TRN & \\
\hline CHEMBL1985327 & 688798 & 4.3 & 4.606 & TRN & \\
\hline CHEMBL1486491 & 688798 & 4.7 & 5.1181 & TRN & \\
\hline CHEMBL1476263 & 688798 & 6.35 & 5.3081 & TRN & \\
\hline CHEMBL1503962 & 688798 & 4.7 & 5.0239 & TRN & \\
\hline CHEMBL1339400 & 688798 & 7.15 & 5.5176 & TRN & \\
\hline CHEMBL1489392 & 688798 & 5.75 & 4.7055 & TST & \\
\hline CHEMBL1593426 & 688798 & 4.45 & 5.7785 & TRN & \\
\hline CHEMBL1411768 & 688798 & 3.9 & 5.1413 & TST & \\
\hline CHEMBL1338429 & 688798 & 5.35 & 5.4241 & TRN & \\
\hline CHEMBL1590681 & 688798 & 5.35 & 4.9872 & TST & \\
\hline CHEMBL1599148 & 688798 & 4.4 & 5.5843 & TRN & \\
\hline CHEMBL1314469 & 688798 & 5.2 & 4.772 & TST & \\
\hline CHEMBL1521597 & 688798 & 7.4498 & 5.8698 & TRN & \\
\hline CHEMBL3197060 & 688798 & 4.3 & 4.9397 & TST & \\
\hline CHEMBL1527068 & 688798 & 5.85 & 5.5978 & TRN & \\
\hline CHEMBL1396657 & 688798 & 4.75 & 5.5697 & TRN & \\
\hline CHEMBL597242 & 688798 & 5.6 & 4.7896 & TRN & \\
\hline CHEMBL1305771 & 688798 & 4.5 & 5.0993 & TRN & \\
\hline CHEMBL1608422 & 688798 & 3.95 & 5.1355 & TST & \\
\hline CHEMBL3190263 & 688798 & 4.5 & 5.0464 & TRN & \\
\hline CHEMBL1552781 & 688798 & 9.699 & 5.7319 & TRN & \\
\hline
\end{tabular}




\begin{tabular}{|c|c|c|c|c|c|}
\hline \multicolumn{6}{|c|}{ Supplemental Table s2.txt } \\
\hline CHEMBL1329286 & 688798 & 4.45 & 4.9064 & TST & \\
\hline CHEMBL3199768 & 688798 & 6.45 & 5.232 & TRN & \\
\hline CHEMBL1394654 & 688798 & 7.5003 & 5.5551 & TRN & \\
\hline CHEMBL1461865 & 688798 & 6.95 & 5.5335 & TST & \\
\hline CHEMBL1365398 & 688798 & 7.4498 & 5.7353 & TRN & \\
\hline CHEMBL1503307 & 688798 & 4.35 & 5.4855 & TST & \\
\hline CHEMBL1330368 & 688798 & 8.0506 & 5.3113 & TRN & \\
\hline CHEMBL1473247 & 688798 & 4.1 & 5.5146 & TRN & \\
\hline CHEMBL1473332 & 688798 & 5.0 & 5.6782 & TRN & \\
\hline CHEMBL1355950 & 688798 & 7.8508 & 5.4588 & TRN & \\
\hline CHEMBL1360200 & 688798 & 5.3 & 5.1873 & TRN & \\
\hline CHEMBL1567028 & 688798 & 5.45 & 5.6092 & TRN & \\
\hline CHEMBL1492931 & 688798 & 7.1002 & 5.71200 & 0000000001 & TRN \\
\hline CHEMBL1394513 & 688798 & 3.85 & 4.9731 & TRN & \\
\hline CHEMBL1232805 & 688798 & 4.6 & 4.88899 & 9999999999 & TST \\
\hline CHEMBL1475525 & 688798 & 7.5003 & 5.2457 & TRN & \\
\hline CHEMBL1320317 & 688798 & 3.0 & 5.1329 & TRN & \\
\hline CHEMBL1477815 & 688798 & 4.35 & 5.74700 & 0000000001 & TRN \\
\hline CHEMBL1518926 & 688798 & 4.45 & 5.425 & TRN & \\
\hline CHEMBL1515955 & 688798 & 4.95 & 5.5054 & TRN & \\
\hline CHEMBL3196913 & 688798 & 2.85 & 5.2349 & TRN & \\
\hline CHEMBL1411246 & 688798 & 6.0 & 4.8528 & TST & \\
\hline CHEMBL1591221 & 688798 & 4.75 & 4.8191 & TRN & \\
\hline CHEMBL1354707 & 688798 & 6.05 & 5.7161 & TRN & \\
\hline CHEMBL1528810 & 688798 & 4.55 & 5.0113 & TRN & \\
\hline CHEMBL1338316 & 688798 & 4.65 & 5.6047 & TRN & \\
\hline CHEMBL3208860 & 688798 & 6.95 & 5.6503 & TRN & \\
\hline CHEMBL1318581 & 688798 & 4.0 & 5.8344 & TRN & \\
\hline CHEMBL1502839 & 688798 & 4.4 & 5.3259 & TRN & \\
\hline CHEMBL1318241 & 688798 & 3.0 & 5.6473 & TRN & \\
\hline CHEMBL 305695 & 688798 & 3.15 & 4.3677 & TRN & \\
\hline CHEMBL1357333 & 688798 & 4.7 & 5.5678 & TRN & \\
\hline CHEMBL1592400 & 688798 & 7.699 & 5.4191 & TRN & \\
\hline CHEMBL1312608 & 688798 & 4.9 & 5.4325 & TRN & \\
\hline CHEMBL1472827 & 688798 & 5.15 & 5.4281 & TRN & \\
\hline CHEMBL1311138 & 688798 & 7.5003 & 5.3968 & TRN & \\
\hline CHEMBL1321470 & 688798 & 5.9 & 4.6746 & TST & \\
\hline CHEMBL1473527 & 688798 & 1.1 & 5.558 & TRN & \\
\hline CHEMBL1449221 & 688798 & 6.15 & 5.6763 & TRN & \\
\hline CHEMBL1613532 & 688798 & 4.5 & 5.4341 & TRN & \\
\hline CHEMBL1317711 & 688798 & 5.05 & 5.33299 & 9999999999 & TRN \\
\hline CHEMBL1533544 & 688798 & 8.3979 & 5.2754 & TST & \\
\hline CHEMBL1491261 & 688798 & 4.65 & 5.4986 & TRN & \\
\hline CHEMBL1567790 & 688798 & 4.55 & 5.1498 & TRN & \\
\hline CHEMBL478 & 688798 & 4.55 & 4.8953 & TRN & \\
\hline CHEMBL1611562 & 688798 & 7.0501 & 5.001 & TRN & \\
\hline CHEMBL1554886 & 688798 & 5.5 & 5.3399 & TRN & \\
\hline CHEMBL1396343 & 688798 & 4.2 & 5.3823 & TRN & \\
\hline
\end{tabular}




\begin{tabular}{|c|c|c|c|c|c|}
\hline \multicolumn{6}{|c|}{ Supplemental Table s2.txt } \\
\hline CHEMBL1475817 & 688798 & 4.15 & 5.2955 & TRN & \\
\hline CHEMBL1512669 & 688798 & 4.65 & 5.2894 & TRN & \\
\hline CHEMBL546257 & 688798 & 8.1024 & 5.4798 & TST & \\
\hline CHEMBL1330887 & 688798 & 3.3 & 5.21899 & 9999999999 & TRN \\
\hline CHEMBL1507437 & 688798 & 4.15 & 4.8725 & TRN & \\
\hline CHEMBL1398493 & 688798 & 5.0 & 6.0167 & TRN & \\
\hline CHEMBL1473619 & 688798 & 8.1024 & 5.4459 & TRN & \\
\hline CHEMBL1392203 & 688798 & 7.5003 & 5.2372 & TRN & \\
\hline CHEMBL1403208 & 688798 & 4.7 & 5.8321 & TRN & \\
\hline CHEMBL2132953 & 688798 & 4.35 & 5.0549 & TST & \\
\hline CHEMBL1410616 & 688798 & 4.35 & 4.8796 & TRN & \\
\hline CHEMBL1445193 & 688798 & 7.15 & 5.2892 & TRN & \\
\hline CHEMBL1535474 & 688798 & 4.7 & 5.8204 & TRN & \\
\hline CHEMBL1331939 & 688798 & 5.65 & 4.7745 & TST & \\
\hline CHEMBL1307227 & 688798 & 4.15 & 5.3381 & TST & \\
\hline CHEMBL1605861 & 688798 & 4.95 & 5.4215 & TRN & \\
\hline CHEMBL1435913 & 688798 & 3.15 & 4.9908 & TRN & \\
\hline CHEMBL1410531 & 688798 & 3.95 & 5.1666 & TRN & \\
\hline CHEMBL1522993 & 688798 & 9.2218 & 5.61600 & 00000000005 & TRN \\
\hline CHEMBL1315927 & 688798 & 8.1487 & 5.2933 & TST & \\
\hline CHEMBL1302249 & 688798 & 6.25 & 5.3736 & TST & \\
\hline CHEMBL1549316 & 688798 & 4.35 & 5.0819 & TST & \\
\hline CHEMBL1704267 & 688798 & 4.5 & 5.1092 & TRN & \\
\hline CHEMBL1377437 & 688798 & 10.9 & 5.4073 & TRN & \\
\hline CHEMBL1529508 & 688798 & 7.5003 & 5.7139 & TRN & \\
\hline CHEMBL1593069 & 688798 & 4.5 & 5.3309 & TRN & \\
\hline CHEMBL1552073 & 688798 & 4.5 & 5.3867 & TRN & \\
\hline CHEMBL1552233 & 688798 & 4.35 & 4.8855 & TRN & \\
\hline CHEMBL1353683 & 688798 & 4.5 & 5.3167 & TRN & \\
\hline CHEMBL1453329 & 688798 & 4.35 & 5.0768 & TST & \\
\hline CHEMBL1434166 & 688798 & 3.55 & 5.5054 & TRN & \\
\hline CHEMBL1590603 & 688798 & 7.699 & 5.8693 & TRN & \\
\hline CHEMBL1356946 & 688798 & 7.8508 & 5.2954 & TRN & \\
\hline CHEMBL1444358 & 688798 & 4.65 & 5.3455 & TRN & \\
\hline CHEMBL1403418 & 688798 & 4.75 & 5.6488 & TRN & \\
\hline CHEMBL1590072 & 688798 & 5.05 & 5.0412 & TRN & \\
\hline CHEMBL1590733 & 688798 & 5.65 & 5.4247 & TRN & \\
\hline CHEMBL1552084 & 688798 & 3.5 & 5.5791 & TRN & \\
\hline CHEMBL1412542 & 688798 & 4.85 & 5.2357 & TRN & \\
\hline CHEMBL1536812 & 688798 & 7.4498 & 5.3215 & TRN & \\
\hline CHEMBL1519358 & 688798 & 2.6 & 5.1173 & TST & \\
\hline CHEMBL1572565 & 688798 & 3.95 & 5.1082 & TRN & \\
\hline CHEMBL1500335 & 688798 & 6.2 & 5.6278 & TRN & \\
\hline CHEMBL72365 & 688798 & 6.0 & 4.60800 & 00000000005 & TST \\
\hline CHEMBL1396485 & 688798 & 4.35 & 5.37700 & 0000000001 & TRN \\
\hline CHEMBL1438922 & 688798 & 2.6 & 4.977 & TST & \\
\hline CHEMBL1394900 & 688798 & 4.65 & 5.4416 & TRN & \\
\hline CHEMBL1522125 & 688798 & 4.15 & 5.4213 & TRN & \\
\hline
\end{tabular}




\begin{tabular}{|c|c|c|c|c|c|}
\hline \multicolumn{6}{|c|}{ Supplemental Table S2.txt } \\
\hline CHEMBL1578537 & 688798 & 3.25 & 5.0136 & TRN & \\
\hline CHEMBL1405522 & 688798 & 4.8 & 5.8211 & TRN & \\
\hline CHEMBL1481641 & 688798 & 3.75 & 5.9912 & TRN & \\
\hline CHEMBL1442242 & 688798 & 4.9 & 5.1801 & TRN & \\
\hline CHEMBL1379861 & 688798 & 7.15 & 5.34399 & 7999999999 & TRN \\
\hline CHEMBL1395046 & 688798 & 4.25 & 5.4959 & TRN & \\
\hline CHEMBL1400468 & 688798 & 6.5 & 5.6545 & TRN & \\
\hline CHEMBL1395154 & 688798 & 5.4 & 5.4753 & TRN & \\
\hline CHEMBL1336061 & 688798 & 4.8 & 5.318 & TRN & \\
\hline CHEMBL1434421 & 688798 & 8.0506 & 5.7402 & TRN & \\
\hline CHEMBL1593865 & 688798 & 2.95 & 4.8488 & TST & \\
\hline CHEMBL1395902 & 688798 & 10.15 & 5.4321 & TRN & \\
\hline CHEMBL1512609 & 688798 & 8.2518 & 5.6672 & TRN & \\
\hline CHEMBL1597488 & 688798 & 4.4 & 5.012 & TRN & \\
\hline CHEMBL1536756 & 688798 & 6.6499 & 5.1959 & TRN & \\
\hline CHEMBL1592816 & 688798 & 4.7 & 5.5223 & TRN & \\
\hline CHEMBL275938 & 688798 & 5.1 & 4.7551 & TST & \\
\hline CHEMBL1474235 & 688798 & 3.25 & 5.3366 & TRN & \\
\hline CHEMBL1522819 & 688798 & 7.2503 & 5.5863 & TRN & \\
\hline CHEMBL1436353 & 688798 & 5.0 & 5.4624 & TRN & \\
\hline CHEMBL1554514 & 688798 & 8.7959 & 5.3303 & TRN & \\
\hline CHEMBL1606331 & 688798 & 8.0 & 5.5496 & TRN & \\
\hline CHEMBL1394576 & 688798 & 3.9 & 5.2842 & TRN & \\
\hline CHEMBL1484358 & 688798 & 5.8 & 5.3052 & TRN & \\
\hline CHEMBL1556661 & 688798 & 4.7 & 4.885 & TST & \\
\hline CHEMBL1515430 & 688798 & 3.55 & 5.2605 & TRN & \\
\hline CHEMBL1607356 & 688798 & 4.85 & 5.2862 & TRN & \\
\hline CHEMBL1454269 & 688798 & 4.3 & 5.2387 & TRN & \\
\hline CHEMBL1603463 & 688798 & 3.25 & 5.5093 & TRN & \\
\hline CHEMBL338790 & 688798 & 4.15 & 4.6781 & TST & \\
\hline CHEMBL1305450 & 688798 & 4.4 & 4.93199 & 99999999995 & TRN \\
\hline CHEMBL1600163 & 688798 & 4.3 & 4.7815 & TST & \\
\hline CHEMBL1513351 & 688798 & 7.0501 & 5.4199 & TRN & \\
\hline CHEMBL1450364 & 688798 & 6.5 & 5.3748 & TRN & \\
\hline CHEMBL1558272 & 688798 & 9.0458 & 5.4851 & TRN & \\
\hline CHEMBL1604792 & 688798 & 6.2 & 5.567 & TRN & \\
\hline CHEMBL1554022 & 688798 & 8.699 & 5.644 & TRN & \\
\hline CHEMBL1480183 & 688798 & 6.6499 & 5.0785 & TRN & \\
\hline CHEMBL1415539 & 688798 & 6.0 & 5.66100 & 00000000005 & TRN \\
\hline CHEMBL1439735 & 688798 & 4.3 & 4.9223 & TRN & \\
\hline CHEMBL1256998 & 688798 & 5.45 & 5.1837 & TST & \\
\hline CHEMBL1408485 & 688798 & 4.7 & 5.5583 & TRN & \\
\hline CHEMBL1545639 & 688798 & 5.35 & 5.1562 & TRN & \\
\hline CHEMBL1406979 & 688798 & 4.25 & 5.4302 & TRN & \\
\hline CHEMBL3191831 & 688798 & 3.95 & 4.9682 & TRN & \\
\hline CHEMBL1472808 & 688798 & 7.4001 & 5.0974 & TRN & \\
\hline CHEMBL1535962 & 688798 & 5.05 & 5.5863 & TRN & \\
\hline CHEMBL1982450 & 688798 & 5.95 & 5.4566 & TRN & \\
\hline
\end{tabular}




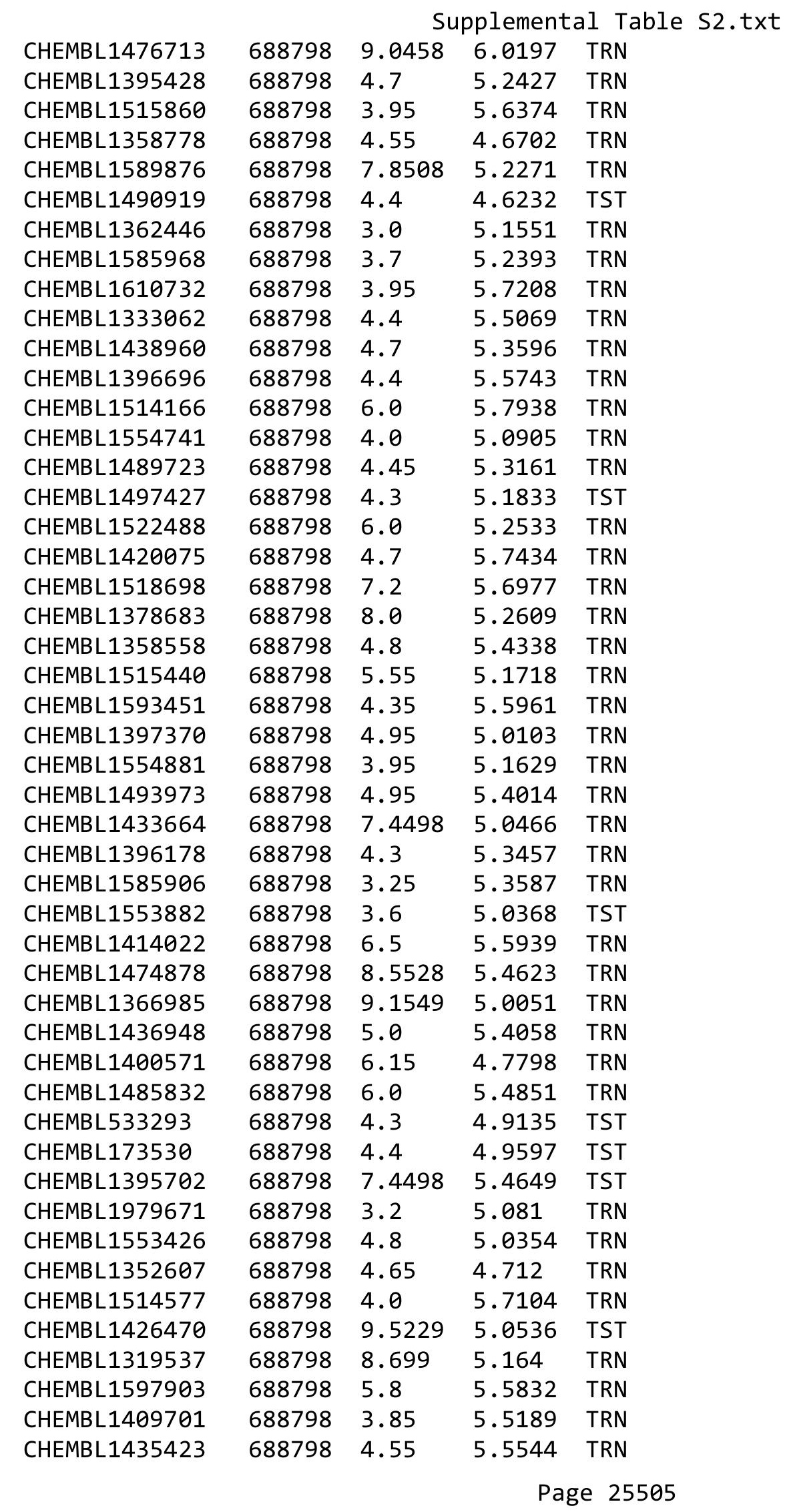




\begin{tabular}{|c|c|c|c|c|c|}
\hline \multicolumn{6}{|c|}{ Supplemental Table S2.txt } \\
\hline CHEMBL1438521 & 688798 & 3.6 & 5.2399 & TRN & \\
\hline CHEMBL1324229 & 688798 & 6.1 & 5.6266 & TRN & \\
\hline CHEMBL1415352 & 688798 & 8.6021 & 5.7255 & TRN & \\
\hline CHEMBL 3192098 & 688798 & 4.55 & 4.7806 & TRN & \\
\hline CHEMBL1405571 & 688798 & 3.95 & 5.6354 & TRN & \\
\hline CHEMBL1551247 & 688798 & 3.6 & 5.7342 & TRN & \\
\hline CHEMBL1458412 & 688798 & 5.25 & 5.0903 & TST & \\
\hline CHEMBL1397777 & 688798 & 4.5 & 5.6285 & TRN & \\
\hline CHEMBL1394883 & 688798 & 5.0 & 5.4925 & TST & \\
\hline CHEMBL1533672 & 688798 & 6.5 & 5.4211 & TST & \\
\hline CHEMBL1325361 & 688798 & 8.6576 & 5.5836 & TRN & \\
\hline CHEMBL1306003 & 688798 & 4.9 & 5.7226 & TRN & \\
\hline CHEMBL1359460 & 688798 & 6.05 & 5.0205 & TST & \\
\hline CHEMBL1472853 & 688798 & 4.35 & 5.2386 & TST & \\
\hline CHEMBL444449 & 688798 & 2.85 & 5.11 & TRN & \\
\hline CHEMBL1373779 & 688798 & 4.45 & 5.2257 & TST & \\
\hline CHEMBL1567187 & 688798 & 5.9 & 5.2653 & TRN & \\
\hline CHEMBL1591117 & 688798 & 7.6003 & 5.6203 & TRN & \\
\hline CHEMBL1558220 & 688798 & 4.95 & 5.3017 & TRN & \\
\hline CHEMBL1597345 & 688798 & 4.85 & 5.2528 & TRN & \\
\hline CHEMBL1515873 & 688798 & 3.55 & 5.6526 & TRN & \\
\hline CHEMBL1373263 & 688798 & 9.3979 & 5.7205 & TRN & \\
\hline CHEMBL1485799 & 688798 & 6.05 & 5.3446 & TRN & \\
\hline CHEMBL1318122 & 688798 & 9.0458 & 5.1866 & TRN & \\
\hline CHEMBL1373007 & 688798 & 5.8 & 4.9397 & TST & \\
\hline CHEMBL1988857 & 688798 & 5.4 & 5.0132 & TST & \\
\hline CHEMBL1315241 & 688798 & 3.95 & 5.41299 & 9999999999 & TRN \\
\hline CHEMBL1326227 & 688798 & 5.95 & 5.6972 & TRN & \\
\hline CHEMBL1454409 & 688798 & 3.3 & 5.6298 & TRN & \\
\hline CHEMBL 1457622 & 688798 & 4.0 & 4.6587 & TST & \\
\hline CHEMBL1398151 & 688798 & 3.95 & 5.4681 & TRN & \\
\hline CHEMBL1404473 & 688798 & 5.0 & 5.6839 & TST & \\
\hline CHEMBL 3191405 & 688798 & 2.2 & 5.3873 & TRN & \\
\hline CHEMBL1314457 & 688798 & 7.4001 & 5.5584 & TRN & \\
\hline CHEMBL2146209 & 688798 & 4.4 & 4.5867 & TST & \\
\hline CHEMBL1473739 & 688798 & 7.5498 & 5.7543 & TRN & \\
\hline CHEMBL1562299 & 688798 & 4.45 & 5.3283 & TRN & \\
\hline CHEMBL459939 & 688798 & 8.8861 & 5.1912 & TST & \\
\hline CHEMBL1430473 & 688798 & 4.9 & 4.6758 & TST & \\
\hline CHEMBL1611215 & 688798 & 4.9 & 5.5604 & TRN & \\
\hline CHEMBL1368044 & 688798 & 7.4001 & 5.2504 & TRN & \\
\hline CHEMBL1533227 & 688798 & 4.6 & 5.3013 & TRN & \\
\hline CHEMBL1314837 & 688798 & 4.1 & 5.1228 & TRN & \\
\hline CHEMBL1606416 & 688798 & 6.8499 & 5.5961 & TRN & \\
\hline CHEMBL3210896 & 688798 & 7.0501 & 5.4937 & TRN & \\
\hline CHEMBL1314580 & 688798 & 7.1002 & 5.2111 & TRN & \\
\hline CHEMBL1592361 & 688798 & 2.8 & 5.1109 & TRN & \\
\hline CHEMBL1588106 & 688798 & 4.55 & 4.92399 & 99999999995 & TRN \\
\hline & & & & 2550 & \\
\hline
\end{tabular}




\begin{tabular}{|c|c|c|c|c|c|}
\hline & & & & & \\
\hline CHEMBL1435607 & 688798 & 4.9 & 5.1432 & TRN & \\
\hline CHEMBL 8234 & 688798 & 4.2 & 5.4221 & TRN & \\
\hline CHEMBL1436531 & 688798 & 3.5 & 5.95100 & 00000000005 & TRN \\
\hline CHEMBL1371409 & 688798 & 4.0 & 4.3682 & TRN & \\
\hline CHEMBL1354441 & 688798 & 5.05 & 5.8656 & TRN & \\
\hline CHEMBL1439977 & 688798 & 3.7 & 5.7938 & TRN & \\
\hline CHEMBL1428284 & 688798 & 4.2 & 5.5884 & TRN & \\
\hline CHEMBL1326401 & 688798 & 6.05 & 4.7596 & TST & \\
\hline CHEMBL1506371 & 688798 & 7.8013 & 5.2453 & TST & \\
\hline CHEMBL1370810 & 688798 & 4.15 & 5.1778 & TRN & \\
\hline CHEMBL1392507 & 688798 & 4.4 & 5.3079 & TRN & \\
\hline CHEMBL1386894 & 688798 & 4.3 & 4.8806 & TST & \\
\hline CHEMBL1396946 & 688798 & 9.2218 & 5.6583 & TRN & \\
\hline CHEMBL3210038 & 688798 & 5.6 & 5.41100 & 00000000005 & TST \\
\hline CHEMBL1546195 & 688798 & 7.5498 & 5.5819 & TRN & \\
\hline CHEMBL1325504 & 688798 & 3.95 & 5.4764 & TRN & \\
\hline CHEMBL3195717 & 688798 & 4.4 & 4.9158 & TRN & \\
\hline CHEMBL1589782 & 688798 & 4.25 & 5.5436 & TRN & \\
\hline CHEMBL1343531 & 688798 & 3.0 & 5.1324 & TST & \\
\hline CHEMBL1534863 & 688798 & 4.15 & 5.3614 & TRN & \\
\hline CHEMBL1435935 & 688798 & 3.95 & 4.9944 & TRN & \\
\hline CHEMBL1355587 & 688798 & 5.15 & 5.8071 & TRN & \\
\hline CHEMBL1481487 & 688798 & 3.0 & 5.652 & TRN & \\
\hline CHEMBL1554596 & 688798 & 5.0 & 5.3814 & TRN & \\
\hline CHEMBL1290347 & 688798 & 8.7447 & 5.1914 & TRN & \\
\hline CHEMBL1507342 & 688798 & 4.25 & 5.1125 & TRN & \\
\hline CHEMBL1435796 & 688798 & 5.6 & 5.1192 & TRN & \\
\hline CHEMBL1327357 & 688798 & 4.45 & 5.605 & TRN & \\
\hline CHEMBL1535837 & 688798 & 7.4498 & 5.3127 & TRN & \\
\hline CHEMBL1308055 & 688798 & 4.0 & 5.0409 & TRN & \\
\hline CHEMBL1255839 & 688798 & 2.55 & 4.6634 & TST & \\
\hline CHEMBL1515686 & 688798 & 6.6 & 5.9369 & TRN & \\
\hline CHEMBL1376119 & 688798 & 5.35 & 5.4859 & TRN & \\
\hline CHEMBL1522692 & 688798 & 7.5498 & 5.5836 & TRN & \\
\hline CHEMBL1589501 & 688798 & 7.0 & 5.7484 & TRN & \\
\hline CHEMBL1610889 & 688798 & 9.2218 & 5.3474 & TRN & \\
\hline CHEMBL1383099 & 688798 & 2.95 & 4.8469 & TST & \\
\hline CHEMBL1395927 & 688798 & 4.7 & 5.7653 & TRN & \\
\hline CHEMBL1356928 & 688798 & 6.05 & 5.2668 & TRN & \\
\hline CHEMBL1592440 & 688798 & 4.15 & 5.7082 & TRN & \\
\hline CHEMBL1375499 & 688798 & 4.3 & 4.4709 & TRN & \\
\hline CHEMBL1580375 & 688798 & 4.35 & 5.1943 & TRN & \\
\hline CHEMBL1593616 & 688798 & 9.0458 & 5.3583 & TRN & \\
\hline CHEMBL1380158 & 688798 & 3.65 & 5.1498 & TRN & \\
\hline CHEMBL1308389 & 688798 & 3.9 & 5.2487 & TRN & \\
\hline CHEMBL1330861 & 688798 & 4.7 & 5.3616 & TRN & \\
\hline CHEMBL1488406 & 688798 & 7.3002 & 4.9105 & TST & \\
\hline CHEMBL1596700 & 688798 & 5.95 & 5.8717 & TRN & \\
\hline
\end{tabular}




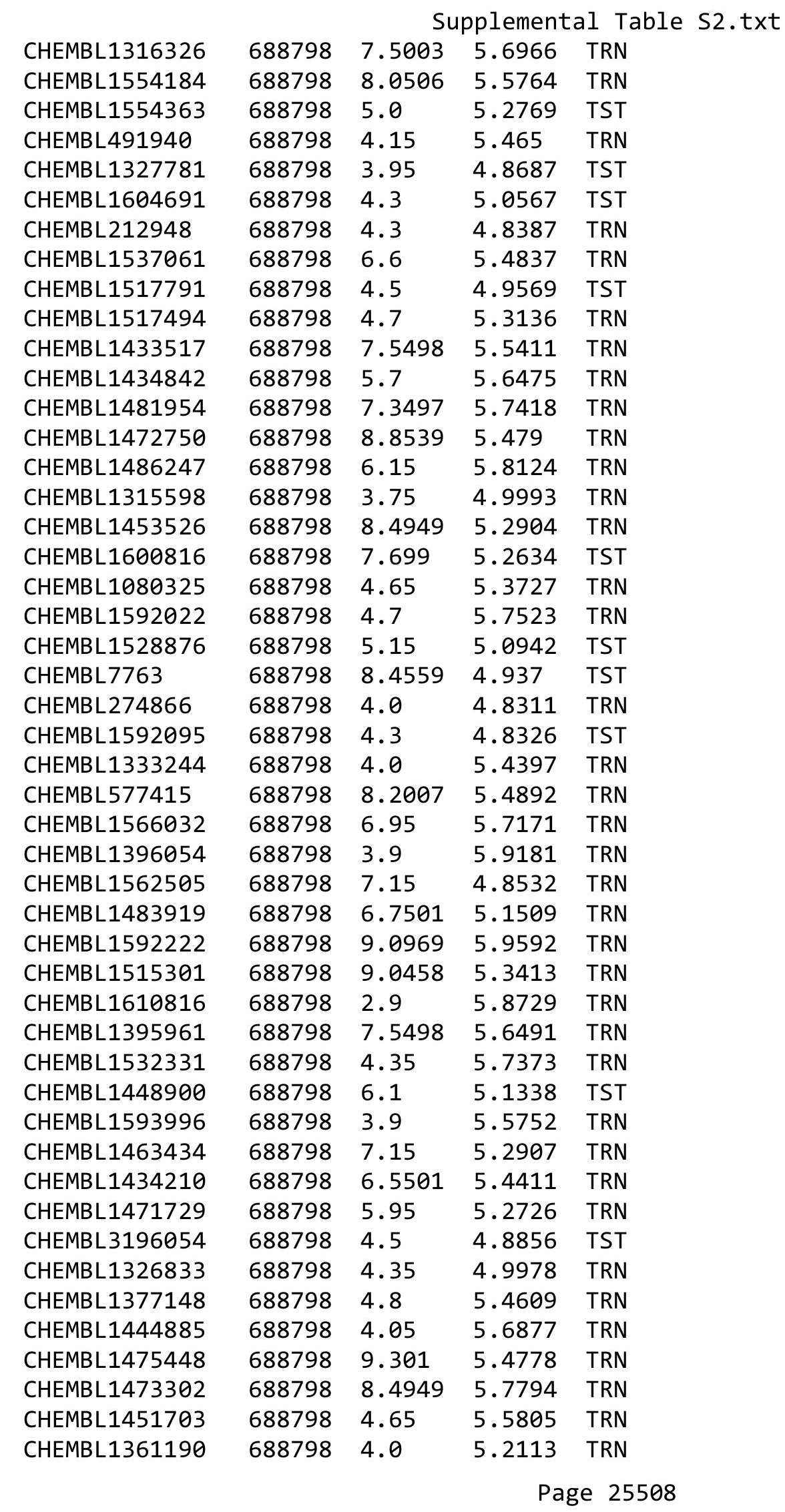




\begin{tabular}{|c|c|c|c|c|}
\hline & & & pplement & \\
\hline CHEMBL3211062 & 688798 & 6.5 & 5.2169 & TST \\
\hline CHEMBL1475999 & 688798 & 4.25 & 4.6941 & TST \\
\hline CHEMBL1406605 & 688798 & 4.8 & 5.4523 & TRN \\
\hline CHEMBL1551350 & 688798 & 4.5 & 5.4031 & TRN \\
\hline CHEMBL1525116 & 688798 & 5.45 & 5.317 & TRN \\
\hline CHEMBL1337516 & 688798 & 7.9508 & 5.3003 & TRN \\
\hline CHEMBL1435964 & 688798 & 3.95 & 5.2005 & TRN \\
\hline CHEMBL145 & 688798 & 4.9 & 4.5116 & TRN \\
\hline CHEMBL1320521 & 688798 & 4.35 & 5.6291 & TRN \\
\hline CHEMBL1601023 & 688798 & 3.65 & 4.9318 & TRN \\
\hline CHEMBL1527290 & 688798 & 6.5 & 5.5368 & TRN \\
\hline CHEMBL1482702 & 688798 & 5.55 & 5.5989 & TRN \\
\hline CHEMBL1516680 & 688798 & 7.4498 & 5.5655 & TRN \\
\hline CHEMBL1554903 & 688798 & 6.05 & 5.4006 & TRN \\
\hline CHEMBL3190776 & 688798 & 5.55 & 5.3111 & TRN \\
\hline CHEMBL1405147 & 688798 & 4.4 & 5.0801 & TRN \\
\hline CHEMBL1555884 & 688798 & 4.35 & 5.0149 & TST \\
\hline CHEMBL1563686 & 688798 & 4.9 & 4.8352 & TRN \\
\hline CHEMBL1518389 & 688798 & 3.55 & 5.2884 & TRN \\
\hline CHEMBL1396908 & 688798 & 7.3497 & 5.5351 & TRN \\
\hline CHEMBL1540921 & 688798 & 5.65 & 5.5297 & TRN \\
\hline CHEMBL1513586 & 688798 & 4.45 & 5.6232 & TRN \\
\hline CHEMBL1439826 & 688798 & 5.9 & 5.9467 & TRN \\
\hline CHEMBL1404436 & 688798 & 4.65 & 5.8671 & TRN \\
\hline CHEMBL1356786 & 688798 & 5.45 & 5.0239 & TST \\
\hline CHEMBL1317791 & 688798 & 4.75 & 5.0941 & TRN \\
\hline CHEMBL1569752 & 688798 & 6.1 & 5.5957 & TRN \\
\hline CHEMBL1397219 & 688798 & 4.7 & 5.3141 & TRN \\
\hline CHEMBL1323240 & 688798 & 4.65 & 5.7844 & TRN \\
\hline CHEMBL1418439 & 688798 & 7.4498 & 5.8293 & TRN \\
\hline CHEMBL1323591 & 688798 & 4.35 & 5.2804 & TRN \\
\hline CHEMBL1567054 & 688798 & 4.1 & 5.3701 & TST \\
\hline CHEMBL1518444 & 688798 & 5.0 & 5.6011 & TRN \\
\hline CHEMBL1602758 & 688798 & 6.15 & 5.8674 & TRN \\
\hline CHEMBL1412956 & 688798 & 4.9 & 5.5864 & TRN \\
\hline CHEMBL1590801 & 688798 & 4.25 & 5.5545 & TRN \\
\hline CHEMBL1410862 & 688798 & 7.8013 & 5.5796 & TRN \\
\hline CHEMBL1446347 & 688798 & 4.95 & 5.0513 & TRN \\
\hline CHEMBL1357486 & 688798 & 4.95 & 5.7544 & TRN \\
\hline CHEMBL1394822 & 688798 & 4.45 & 5.4369 & TRN \\
\hline CHEMBL1553209 & 688798 & 9.699 & 5.8048 & TRN \\
\hline CHEMBL1403072 & 688798 & 4.5 & 5.0101 & TRN \\
\hline CHEMBL1515759 & 688798 & 5.6 & 5.4145 & TRN \\
\hline CHEMBL1418754 & 688798 & 4.15 & 5.1994 & TRN \\
\hline CHEMBL1432717 & 688798 & 4.3 & 4.7738 & TRN \\
\hline CHEMBL1611673 & 688798 & 5.15 & 5.4826 & TRN \\
\hline CHEMBL1411662 & 688798 & 4.15 & 5.3225 & TST \\
\hline CHEMBL1364558 & 688798 & 6.5 & 6.0698 & TRN \\
\hline
\end{tabular}




\begin{tabular}{|c|c|c|c|c|c|}
\hline \multicolumn{6}{|c|}{ Supplemental Table S2.txt } \\
\hline CHEMBL1343222 & 688798 & 4.45 & 5.2323 & TRN & \\
\hline CHEMBL1436261 & 688798 & 4.5 & 5.3702 & TRN & \\
\hline CHEMBL1610740 & 688798 & 7.2 & 5.3 & TRN & \\
\hline CHEMBL1474048 & 688798 & 4.9 & 5.5604 & TRN & \\
\hline CHEMBL1314281 & 688798 & 4.95 & 5.3118 & TRN & \\
\hline CHEMBL1359806 & 688798 & 4.4 & 4.8652 & TRN & \\
\hline CHEMBL1453139 & 688798 & 5.7 & 5.58299 & 9999999999 & TRN \\
\hline CHEMBL1431643 & 688798 & 4.55 & 4.9067 & TRN & \\
\hline CHEMBL3199463 & 688798 & 3.5 & 5.1532 & TST & \\
\hline CHEMBL 1496237 & 688798 & 4.3 & 5.5033 & TRN & \\
\hline CHEMBL1324358 & 688798 & 4.85 & 5.2775 & TRN & \\
\hline CHEMBL1545873 & 688798 & 4.3 & 4.9512 & TRN & \\
\hline CHEMBL1440965 & 688798 & 8.9586 & 5.15 & TRN & \\
\hline CHEMBL1335003 & 688798 & 7.4498 & 5.5864 & TRN & \\
\hline CHEMBL1398448 & 688798 & 4.7 & 5.4509 & TRN & \\
\hline CHEMBL1556031 & 688798 & 6.5 & 5.1175 & TRN & \\
\hline CHEMBL1456448 & 688798 & 8.6021 & 5.5708 & TRN & \\
\hline CHEMBL1414596 & 688798 & 7.4498 & 5.5574 & TRN & \\
\hline CHEMBL1487934 & 688798 & 4.4 & 5.0986 & TRN & \\
\hline CHEMBL1355793 & 688798 & 4.15 & 5.4026 & TRN & \\
\hline CHEMBL1559325 & 688798 & 4.05 & 5.5464 & TRN & \\
\hline CHEMBL66105 & 688798 & 6.0 & 4.7465 & TRN & \\
\hline CHEMBL 3189748 & 688798 & 4.95 & 5.4362 & TRN & \\
\hline CHEMBL1528196 & 688798 & 2.95 & 5.6044 & TRN & \\
\hline CHEMBL1602555 & 688798 & 4.8 & 5.5205 & TRN & \\
\hline CHEMBL1611080 & 688798 & 3.75 & 5.63899 & 9999999999 & TRN \\
\hline CHEMBL1338364 & 688798 & 5.65 & 5.1705 & TRN & \\
\hline CHEMBL 1445580 & 688798 & 4.5 & 5.1725 & TRN & \\
\hline CHEMBL1554426 & 688798 & 4.05 & 5.5084 & TRN & \\
\hline CHEMBL1570653 & 688798 & 10.05 & 5.1926 & TRN & \\
\hline CHEMBL1371537 & 688798 & 3.9 & 5.3994 & TRN & \\
\hline CHEMBL1551059 & 688798 & 9.0458 & 5.6206 & TRN & \\
\hline CHEMBL1552169 & 688798 & 3.45 & 5.5485 & TRN & \\
\hline CHEMBL1397696 & 688798 & 9.0458 & 5.2029 & TRN & \\
\hline CHEMBL1356440 & 688798 & 5.2 & 5.9284 & TRN & \\
\hline CHEMBL1588368 & 688798 & 4.5 & 5.0261 & TRN & \\
\hline CHEMBL1325143 & 688798 & 4.35 & 4.7066 & TST & \\
\hline CHEMBL1467386 & 688798 & 4.15 & 5.2265 & TST & \\
\hline CHEMBL1316036 & 688798 & 7.4498 & 5.6793 & TRN & \\
\hline CHEMBL1590887 & 688798 & 4.85 & 5.5784 & TRN & \\
\hline CHEMBL1356748 & 688798 & 5.55 & 5.0052 & TST & \\
\hline CHEMBL1354748 & 688798 & 3.15 & 5.6035 & TRN & \\
\hline CHEMBL1336229 & 688798 & 4.8 & 5.2354 & TRN & \\
\hline CHEMBL1553682 & 688798 & 2.75 & 5.5639 & TRN & \\
\hline CHEMBL1381995 & 688798 & 9.0458 & 5.3701 & TST & \\
\hline CHEMBL1338295 & 688798 & 4.25 & 4.9364 & TRN & \\
\hline CHEMBL1530039 & 688798 & 4.1 & 5.4033 & TRN & \\
\hline CHEMBL1569114 & 688798 & 4.15 & 5.3698 & TRN & \\
\hline
\end{tabular}




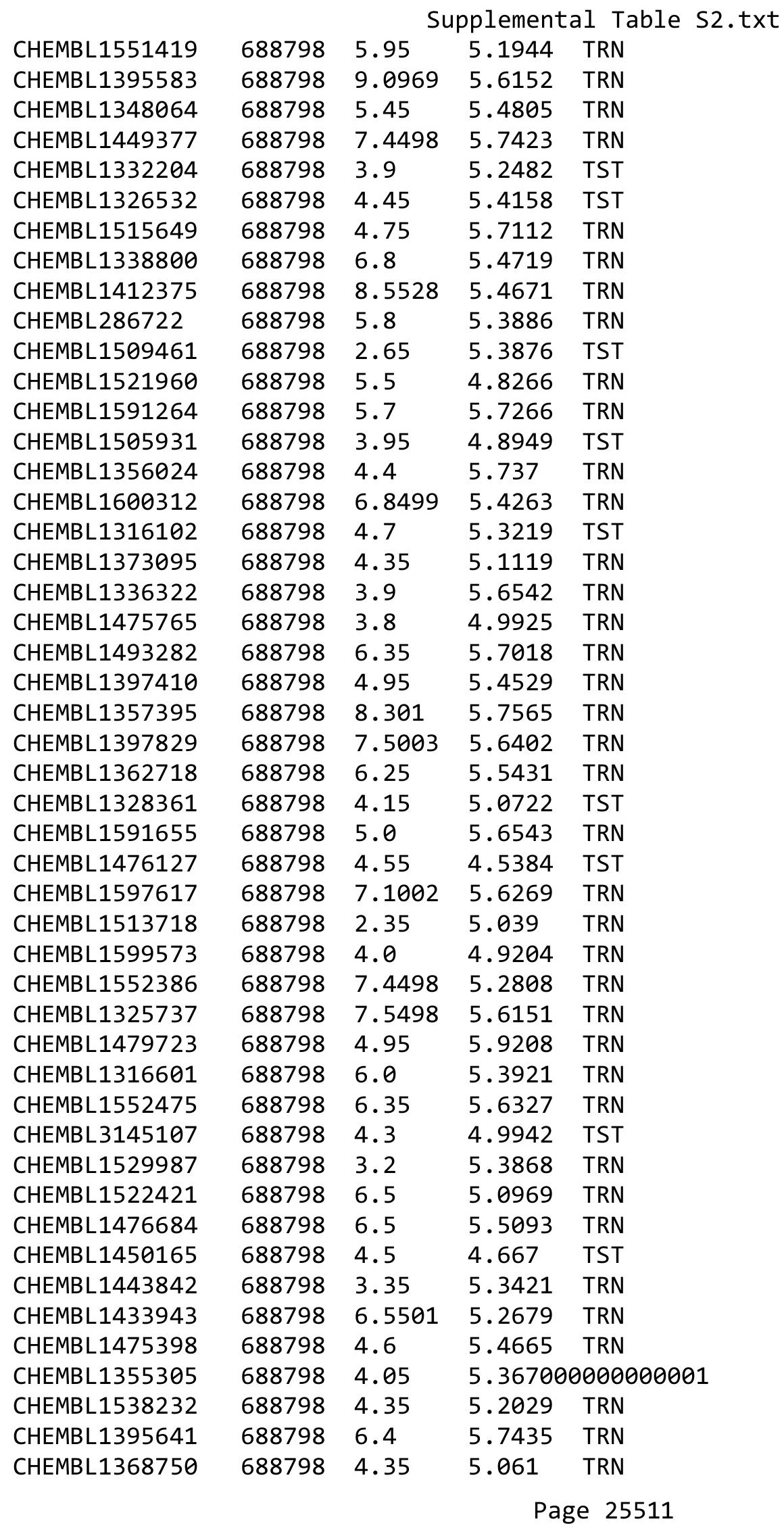

TRN 


\begin{tabular}{|c|c|c|c|c|c|}
\hline \\
\hline CHEMBL1397384 & 688798 & 5.2 & 5.3833 & TRN & \\
\hline CHEMBL1395686 & 688798 & 8.0 & 5.2493 & TRN & \\
\hline CHEMBL1975746 & 688798 & 4.35 & 4.9919 & TRN & \\
\hline CHEMBL1475246 & 688798 & 4.05 & 5.6155 & TRN & \\
\hline CHEMBL1436963 & 688798 & 6.25 & 5.3403 & TRN & \\
\hline CHEMBL1355481 & 688798 & 4.65 & 5.5306 & TRN & \\
\hline CHEMBL1335508 & 688798 & 3.95 & 5.9161 & TRN & \\
\hline CHEMBL1554458 & 688798 & 6.45 & 5.7037 & TRN & \\
\hline CHEMBL1528828 & 688798 & 8.6576 & 5.4124 & TRN & \\
\hline CHEMBL1560176 & 688798 & 6.2 & 5.5028 & TRN & \\
\hline CHEMBL1412698 & 688798 & 4.55 & 4.976 & TRN & \\
\hline CHEMBL1442167 & 688798 & 5.1 & 5.3974 & TRN & \\
\hline CHEMBL1375426 & 688798 & 7.2 & 5.4294 & TRN & \\
\hline CHEMBL1410911 & 688798 & 4.35 & 5.5678 & TRN & \\
\hline CHEMBL1489740 & 688798 & 3.1 & 5.4523 & TRN & \\
\hline CHEMBL3212644 & 688798 & 4.45 & 5.5793 & TRN & \\
\hline CHEMBL1504073 & 688798 & 4.15 & 5.2491 & TRN & \\
\hline CHEMBL222519 & 688798 & 4.0 & 4.38399 & 99999999995 & TST \\
\hline CHEMBL 3214401 & 688798 & 5.8 & 5.0628 & TST & \\
\hline CHEMBL1994456 & 688798 & 4.5 & 5.1358 & TRN & \\
\hline CHEMBL1476760 & 688798 & 5.65 & 5.1073 & TRN & \\
\hline CHEMBL3191105 & 688798 & 6.6499 & 5.1593 & TRN & \\
\hline CHEMBL1543963 & 688798 & 8.1024 & 5.4551 & TRN & \\
\hline CHEMBL3209925 & 688798 & 4.9 & 5.5295 & TRN & \\
\hline CHEMBL3207398 & 688798 & 3.75 & 5.1705 & TRN & \\
\hline CHEMBL1339561 & 688798 & 7.3497 & 5.7577 & TRN & \\
\hline CHEMBL1435280 & 688798 & 3.95 & 5.2086 & TST & \\
\hline CHEMBL1512440 & 688798 & 4.55 & 4.5683 & TST & \\
\hline CHEMBL1346753 & 688798 & 4.35 & 5.1302 & TRN & \\
\hline CHEMBL1446544 & 688798 & 2.8 & 4.957 & TRN & \\
\hline CHEMBL1411511 & 688798 & 7.2503 & 5.1752 & TRN & \\
\hline CHEMBL1402286 & 688798 & 4.85 & 5.3542 & TRN & \\
\hline CHEMBL1315679 & 688798 & 4.5 & 5.4102 & TRN & \\
\hline CHEMBL1314239 & 688798 & 4.8 & 5.6218 & TRN & \\
\hline CHEMBL1317528 & 688798 & 9.699 & 5.5019 & TRN & \\
\hline CHEMBL1355276 & 688798 & 3.6 & 5.7866 & TRN & \\
\hline CHEMBL1409267 & 688798 & 4.55 & 5.6061 & TST & \\
\hline CHEMBL591628 & 688798 & 4.35 & 4.9434 & TST & \\
\hline CHEMBL172439 & 688798 & 4.95 & 4.8256 & TST & \\
\hline CHEMBL1456261 & 688798 & 4.45 & 5.0372 & TRN & \\
\hline CHEMBL1373192 & 688798 & 7.15 & 5.24700 & 0000000001 & TRN \\
\hline CHEMBL1436339 & 688798 & 4.7 & 5.5682 & TRN & \\
\hline CHEMBL1299502 & 688798 & 3.85 & 5.3876 & TST & \\
\hline CHEMBL1402825 & 688798 & 7.2 & 5.0346 & TRN & \\
\hline CHEMBL1418460 & 688798 & 4.35 & 5.2087 & TST & \\
\hline CHEMBL1356811 & 688798 & 4.95 & 5.4378 & TRN & \\
\hline CHEMBL1564151 & 688798 & 3.9 & 5.2516 & TRN & \\
\hline CHEMBL1972915 & 688798 & 4.15 & 4.9999 & TRN & \\
\hline
\end{tabular}




\begin{tabular}{|c|c|c|c|c|c|}
\hline \multicolumn{6}{|c|}{ Supplemental Table s2.txt } \\
\hline CHEMBL1483588 & 688798 & 4.75 & 5.5964 & TRN & \\
\hline CHEMBL1553704 & 688798 & 3.95 & 5.0713 & TRN & \\
\hline CHEMBL1473984 & 688798 & 9.0 & 5.5695 & TRN & \\
\hline CHEMBL1301512 & 688798 & 4.35 & 4.9168 & TST & \\
\hline CHEMBL1487571 & 688798 & 7.5498 & 5.5108 & TRN & \\
\hline CHEMBL1437419 & 688798 & 4.0 & 5.3647 & TRN & \\
\hline CHEMBL1560281 & 688798 & 4.9 & 5.4378 & TRN & \\
\hline CHEMBL1592444 & 688798 & 6.3 & 4.7858 & TST & \\
\hline CHEMBL1363696 & 688798 & 3.55 & 5.1908 & TRN & \\
\hline CHEMBL1519113 & 688798 & 7.5003 & 5.2397 & TRN & \\
\hline CHEMBL1435436 & 688798 & 4.4 & \multicolumn{2}{|c|}{5.417000000000001} & TRN \\
\hline CHEMBL3190746 & 688798 & 4.35 & 5.0055 & TRN & \\
\hline CHEMBL172350 & 688798 & 4.3 & 4.7849 & TRN & \\
\hline CHEMBL1554260 & 688798 & 4.85 & 5.4637 & TRN & \\
\hline CHEMBL1315339 & 688798 & 4.75 & 5.9142 & TRN & \\
\hline CHEMBL1357842 & 688798 & 4.4 & 5.3678 & TRN & \\
\hline CHEMBL1519811 & 688798 & 6.5 & 5.5165 & TRN & \\
\hline CHEMBL1378234 & 688798 & 9.0969 & 5.5103 & TRN & \\
\hline CHEMBL3194876 & 688798 & 4.15 & 4.7773 & TRN & \\
\hline CHEMBL1517414 & 688798 & 5.1 & 5.1689 & TRN & \\
\hline CHEMBL1473584 & 688798 & 7.4498 & 5.0673 & TST & \\
\hline CHEMBL1539317 & 688798 & 4.15 & 5.0939 & TRN & \\
\hline CHEMBL 286494 & 688798 & 6.0 & 4.6459 & TST & \\
\hline CHEMBL 296586 & 688798 & 4.1 & 4.7693 & TST & \\
\hline CHEMBL1473824 & 688798 & 7.5498 & 5.6372 & TST & \\
\hline CHEMBL3214382 & 688798 & 4.5 & 5.5376 & TRN & \\
\hline CHEMBL1445946 & 688798 & 8.0 & 5.4055 & TST & \\
\hline CHEMBL1396703 & 688798 & 7.0501 & 5.2855 & TRN & \\
\hline CHEMBL1411970 & 688798 & 6.45 & 5.2894 & TRN & \\
\hline CHEMBL610198 & 688798 & 5.25 & 5.0185 & TRN & \\
\hline CHEMBL1368109 & 688798 & 6.45 & 5.6603 & TRN & \\
\hline CHEMBL1589354 & 688798 & 4.5 & 5.4636 & TRN & \\
\hline CHEMBL1533118 & 688798 & 4.15 & 5.3026 & TRN & \\
\hline CHEMBL1338536 & 688798 & 1.25 & 5.6981 & TRN & \\
\hline CHEMBL1408306 & 688798 & 7.15 & 5.5743 & TRN & \\
\hline CHEMBL1314648 & 688798 & 5.05 & 5.4681 & TRN & \\
\hline CHEMBL1560159 & 688798 & 2.6 & 5.5052 & TRN & \\
\hline CHEMBL302213 & 688798 & 4.05 & 5.2355 & TST & \\
\hline CHEMBL1437140 & 688798 & 5.05 & 5.6574 & TRN & \\
\hline CHEMBL1416231 & 688798 & 7.8508 & 5.4327 & TST & \\
\hline CHEMBL1327072 & 688798 & 5.5 & 5.472 & TRN & \\
\hline CHEMBL1435727 & 688798 & 3.85 & 5.2462 & TST & \\
\hline CHEMBL1435358 & 688798 & 4.3 & 5.7615 & TRN & \\
\hline CHEMBL1545724 & 688798 & 2.85 & 5.5191 & TST & \\
\hline CHEMBL1486248 & 688798 & 7.0501 & 5.0655 & TRN & \\
\hline CHEMBL1558893 & 688798 & 5.65 & 5.1721 & TST & \\
\hline CHEMBL1360116 & 688798 & 8.2518 & 4.7657 & TRN & \\
\hline \multirow[t]{2}{*}{ CHEMBL1603987 } & 688798 & 4.15 & \multicolumn{2}{|c|}{5.377000000000001} & TRN \\
\hline & & & & 25513 & \\
\hline
\end{tabular}




\begin{tabular}{|c|c|c|c|c|c|}
\hline \multicolumn{6}{|c|}{ Supplemental Table S2.txt } \\
\hline CHEMBL1597186 & 688798 & 4.0 & 5.6895 & TRN & \\
\hline CHEMBL1358158 & 688798 & 4.0 & 5.407 & TRN & \\
\hline CHEMBL3196164 & 688798 & 4.4 & 4.9238 & TRN & \\
\hline CHEMBL1436909 & 688798 & 5.25 & 5.3286 & TST & \\
\hline CHEMBL1488981 & 688798 & 4.15 & 5.3568 & TST & \\
\hline CHEMBL1562764 & 688798 & 7.0501 & 5.1983 & TRN & \\
\hline CHEMBL1391063 & 688798 & 4.35 & 4.8846 & TST & \\
\hline CHEMBL1438186 & 688798 & 5.35 & 5.3691 & TRN & \\
\hline CHEMBL1366521 & 688798 & 4.7 & 5.4007 & TRN & \\
\hline CHEMBL1449178 & 688798 & 4.95 & 5.591 & TRN & \\
\hline CHEMBL1474860 & 688798 & 3.65 & 5.3417 & TRN & \\
\hline CHEMBL1435076 & 688798 & 7.8996 & 5.6448 & TRN & \\
\hline CHEMBL1515379 & 688798 & 6.25 & 5.6599 & TRN & \\
\hline CHEMBL3211976 & 688798 & 4.45 & 5.4517 & TRN & \\
\hline CHEMBL1468796 & 688798 & 4.4 & 4.677 & TRN & \\
\hline CHEMBL1374536 & 688798 & 4.4 & 5.2157 & TRN & \\
\hline CHEMBL1526044 & 688798 & 5.0 & 5.5293 & TRN & \\
\hline CHEMBL1601234 & 688798 & 8.1487 & 5.3291 & TRN & \\
\hline CHEMBL1394373 & 688798 & 4.15 & 5.7921 & TRN & \\
\hline CHEMBL1463595 & 688798 & 4.35 & 4.7397 & TRN & \\
\hline CHEMBL1404241 & 688798 & 4.4 & 5.6236 & TRN & \\
\hline CHEMBL2369231 & 688798 & 6.8499 & 5.0027 & TST & \\
\hline CHEMBL1990772 & 688798 & 4.4 & 5.0152 & TRN & \\
\hline CHEMBL1303880 & 688798 & 8.8539 & 5.4512 & TRN & \\
\hline CHEMBL1436156 & 688798 & 4.6 & 5.5521 & TRN & \\
\hline CHEMBL1368415 & 688798 & 4.95 & 5.7472 & TRN & \\
\hline CHEMBL1443611 & 688798 & 3.7 & 4.9766 & TRN & \\
\hline CHEMBL1473702 & 688798 & 4.65 & 5.5067 & TRN & \\
\hline CHEMBL1357775 & 688798 & 4.0 & 5.1103 & TRN & \\
\hline CHEMBL 1437760 & 688798 & 4.85 & 5.5425 & TRN & \\
\hline CHEMBL1322843 & 688798 & 6.15 & 5.6059 & TRN & \\
\hline CHEMBL1314750 & 688798 & 7.15 & 5.6595 & TRN & \\
\hline CHEMBL479368 & 688798 & 4.5 & 5.3256 & TRN & \\
\hline CHEMBL1477068 & 688798 & 4.65 & 5.5329 & TST & \\
\hline CHEMBL1566071 & 688798 & 1.25 & 4.9468 & TRN & \\
\hline CHEMBL3195838 & 688798 & 7.1002 & 4.9565 & TST & \\
\hline CHEMBL1554874 & 688798 & 4.35 & 5.0814 & TRN & \\
\hline CHEMBL1318027 & 688798 & 7.1002 & 5.4624 & TRN & \\
\hline CHEMBL1448761 & 688798 & 4.0 & 5.2244 & TRN & \\
\hline CHEMBL165 & 688798 & 3.95 & 4.3896 & TRN & \\
\hline CHEMBL1473564 & 688798 & 5.0 & 5.6452 & TRN & \\
\hline CHEMBL1387486 & 688798 & 4.15 & 5.4537 & TRN & \\
\hline CHEMBL1605289 & 688798 & 7.4498 & 5.1225 & TRN & \\
\hline CHEMBL1468366 & 688798 & 5.15 & 5.1709 & TRN & \\
\hline CHEMBL1520623 & 688798 & 9.3979 & 5.7373 & TRN & \\
\hline CHEMBL1590795 & 688798 & 5.5 & 5.1178 & TRN & \\
\hline CHEMBL1402603 & 688798 & 6.45 & 5.5479 & TRN & \\
\hline CHEMBL1397883 & 688798 & 4.6 & $5.4860 e$ & 0000000001 & TRN \\
\hline & & & & 25514 & \\
\hline
\end{tabular}




\begin{tabular}{|c|c|c|c|c|c|}
\hline \multicolumn{6}{|c|}{ Supplemental Table S2.txt } \\
\hline CHEMBL 3210227 & 688798 & 4.85 & 4.7382 & TRN & \\
\hline CHEMBL1314389 & 688798 & 8.699 & 5.8485 & TRN & \\
\hline CHEMBL1968978 & 688798 & 4.4 & 5.2049 & TRN & \\
\hline CHEMBL1513171 & 688798 & 7.1002 & 5.1556 & TRN & \\
\hline CHEMBL1513758 & 688798 & 4.7 & 5.45700 & 0000000001 & TRN \\
\hline CHEMBL408994 & 688798 & 4.5 & 5.3304 & TRN & \\
\hline CHEMBL1396179 & 688798 & 4.5 & 5.3099 & TRN & \\
\hline CHEMBL1362294 & 688798 & 4.55 & 5.5152 & TRN & \\
\hline CHEMBL1400726 & 688798 & 4.15 & 5.3263 & TRN & \\
\hline CHEMBL1339155 & 688798 & 5.6 & 5.5 & TRN & \\
\hline CHEMBL 3193263 & 688798 & 8.2518 & 5.2143 & TST & \\
\hline CHEMBL1439405 & 688798 & 6.3 & 5.5205 & TRN & \\
\hline CHEMBL1396117 & 688798 & 7.0501 & 5.0639 & TST & \\
\hline CHEMBL 29898 & 688798 & 4.35 & 4.3922 & TRN & \\
\hline CHEMBL1609294 & 688798 & 4.45 & 5.7373 & TRN & \\
\hline CHEMBL1473653 & 688798 & 5.0 & 5.4421 & TRN & \\
\hline CHEMBL1552323 & 688798 & 4.85 & 5.2726 & TRN & \\
\hline CHEMBL1493453 & 688798 & 4.0 & 5.3846 & TRN & \\
\hline CHEMBL1525770 & 688798 & 3.55 & 5.3114 & TRN & \\
\hline CHEMBL1335447 & 688798 & 5.55 & 5.6387 & TRN & \\
\hline CHEMBL1474916 & 688798 & 9.3979 & 4.9502 & TST & \\
\hline CHEMBL1356503 & 688798 & 4.45 & 5.5841 & TRN & \\
\hline CHEMBL1356001 & 688798 & 4.9 & 5.3998 & TRN & \\
\hline CHEMBL1515915 & 688798 & 4.0 & 5.4446 & TRN & \\
\hline CHEMBL1552581 & 688798 & 4.75 & 5.5904 & TRN & \\
\hline CHEMBL1580845 & 688798 & 4.35 & 4.6149 & TRN & \\
\hline CHEMBL1565911 & 688798 & 4.35 & 4.897 & TRN & \\
\hline CHEMBL1338231 & 688798 & 4.7 & 5.3305 & TRN & \\
\hline CHEMBL1552280 & 688798 & 3.9 & 5.4177 & TRN & \\
\hline CHEMBL1488385 & 688798 & 7.4001 & 5.9298 & TRN & \\
\hline CHEMBL1433978 & 688798 & 5.5 & 5.6142 & TRN & \\
\hline CHEMBL1514499 & 688798 & 3.65 & 5.0617 & TST & \\
\hline CHEMBL1551853 & 688798 & 5.2 & 5.2584 & TRN & \\
\hline CHEMBL1328879 & 688798 & 7.0501 & 5.5425 & TST & \\
\hline CHEMBL1555135 & 688798 & 10.15 & 5.6154 & TRN & \\
\hline CHEMBL1526532 & 688798 & 3.05 & 5.5324 & TRN & \\
\hline CHEMBL1395664 & 688798 & 4.7 & 5.5844 & TRN & \\
\hline CHEMBL1593540 & 688798 & 5.1 & 5.4599 & TRN & \\
\hline CHEMBL1434511 & 688798 & 6.25 & 5.32100 & 0000000001 & TRN \\
\hline CHEMBL1553460 & 688798 & 4.0 & 5.3084 & TRN & \\
\hline CHEMBL1593578 & 688798 & 3.5 & 5.44799 & 99999999995 & TRN \\
\hline CHEMBL1255837 & 688798 & 4.55 & 5.3759 & TST & \\
\hline CHEMBL1387110 & 688798 & 4.5 & 5.2628 & TRN & \\
\hline CHEMBL1480189 & 688798 & 4.5 & 5.3102 & TRN & \\
\hline CHEMBL1598990 & 688798 & 4.85 & 5.211 & TRN & \\
\hline CHEMBL1509050 & 688798 & 4.4 & 5.3785 & TRN & \\
\hline CHEMBL1330152 & 688798 & 4.2 & 5.2297 & TRN & \\
\hline CHEMBL1394733 & 688798 & 4.2 & 5.7025 & TRN & \\
\hline
\end{tabular}




\begin{tabular}{|c|c|c|c|c|c|}
\hline & & & & & \\
\hline CHEMBL1407238 & 688798 & 4.9 & 5.2825 & TST & \\
\hline CHEMBL1358419 & 688798 & 3.9 & 5.6461 & TRN & \\
\hline CHEMBL1545634 & 688798 & 6.0 & 4.9425 & TRN & \\
\hline CHEMBL1386934 & 688798 & 6.7001 & 5.0274 & TST & \\
\hline CHEMBL1477251 & 688798 & 3.7 & 5.49700 & 0000000001 & TRN \\
\hline CHEMBL1321880 & 688798 & 5.15 & 5.5018 & TRN & \\
\hline CHEMBL1475628 & 688798 & 4.85 & 5.4457 & TST & \\
\hline CHEMBL1441921 & 688798 & 4.15 & 5.0698 & TRN & \\
\hline CHEMBL1314646 & 688798 & 4.0 & 5.5418 & TRN & \\
\hline CHEMBL1552383 & 688798 & 5.05 & 5.7993 & TRN & \\
\hline CHEMBL1525885 & 688798 & 4.2 & 5.6356 & TRN & \\
\hline CHEMBL1482320 & 688798 & 4.05 & 5.75299 & 9999999999 & TRN \\
\hline CHEMBL1396564 & 688798 & 6.5 & 5.66200 & 0000000001 & TRN \\
\hline CHEMBL 2003808 & 688798 & 6.1 & 4.7606 & TRN & \\
\hline CHEMBL1508716 & 688798 & 4.3 & 5.1384 & TRN & \\
\hline CHEMBL1397508 & 688798 & 3.7 & 5.7251 & TRN & \\
\hline CHEMBL1592500 & 688798 & 9.1549 & 4.8308 & TST & \\
\hline CHEMBL1425014 & 688798 & 5.5 & 5.4128 & TRN & \\
\hline CHEMBL1466913 & 688798 & 4.3 & 5.1485 & TRN & \\
\hline CHEMBL1558449 & 688798 & 9.5229 & 5.3727 & TRN & \\
\hline CHEMBL1543756 & 688798 & 7.8013 & 5.7292 & TRN & \\
\hline CHEMBL1475989 & 688798 & 4.0 & 5.6426 & TRN & \\
\hline CHEMBL1366479 & 688798 & 4.55 & 5.1393 & TRN & \\
\hline CHEMBL1480958 & 688798 & 2.9 & 5.527 & TRN & \\
\hline CHEMBL1555258 & 688798 & 3.6 & 5.812 & TRN & \\
\hline CHEMBL1551793 & 688798 & 4.5 & 5.4158 & TRN & \\
\hline CHEMBL1368428 & 688798 & 4.35 & 4.6645 & TST & \\
\hline CHEMBL 1384217 & 688798 & 5.0 & 5.2977 & TRN & \\
\hline CHEMBL1560040 & 688798 & 8.6576 & 5.4106 & TRN & \\
\hline CHEMBL1465049 & 688798 & 4.3 & 5.239 & TRN & \\
\hline CHEMBL1490110 & 688798 & 7.5498 & 5.6694 & TRN & \\
\hline CHEMBL98245 & 688798 & 6.5501 & 5.0017 & TRN & \\
\hline CHEMBL1437808 & 688798 & 4.8 & 5.6484 & TRN & \\
\hline CHEMBL1429223 & 688798 & 4.3 & 5.1834 & TRN & \\
\hline CHEMBL1455567 & 688798 & 4.35 & 5.0598 & TST & \\
\hline CHEMBL1521710 & 688798 & 4.1 & 5.1149 & TRN & \\
\hline CHEMBL1355498 & 688798 & 4.55 & 5.3162 & TRN & \\
\hline CHEMBL1404789 & 688798 & 9.0969 & 5.4999 & TRN & \\
\hline CHEMBL1396507 & 688798 & 7.4498 & 5.6844 & TRN & \\
\hline CHEMBL1477680 & 688798 & 6.8 & 5.1081 & TST & \\
\hline CHEMBL1534745 & 688798 & 4.15 & 5.4927 & TST & \\
\hline CHEMBL1530333 & 688798 & 7.5498 & 5.6093 & TRN & \\
\hline CHEMBL1355340 & 688798 & 7.4498 & 5.2181 & TST & \\
\hline CHEMBL1410207 & 688798 & 5.05 & 5.4651 & TRN & \\
\hline CHEMBL1518843 & 688798 & 4.7 & 5.2537 & TRN & \\
\hline CHEMBL1316744 & 688798 & 4.8 & 5.6582 & TRN & \\
\hline CHEMBL1591256 & 688798 & 4.0 & 5.3955 & TRN & \\
\hline CHEMBL1465297 & 688798 & 4.6 & 4.8834 & TRN & \\
\hline
\end{tabular}




\begin{tabular}{|c|c|c|c|c|c|}
\hline \multicolumn{6}{|c|}{ Supplemental Table S2.txt } \\
\hline CHEMBL1553752 & 688798 & 4.05 & 5.7142 & TRN & \\
\hline CHEMBL1434267 & 688798 & 8.8861 & 5.7112 & TRN & \\
\hline CHEMBL1400915 & 688798 & 3.5 & 5.678 & TRN & \\
\hline CHEMBL1445021 & 688798 & 4.7 & 5.5246 & TRN & \\
\hline CHEMBL1551204 & 688798 & 4.6 & 5.4922 & TRN & \\
\hline CHEMBL1476361 & 688798 & 9.3979 & 5.0948 & TRN & \\
\hline CHEMBL1367072 & 688798 & 4.0 & 4.8429 & TST & \\
\hline CHEMBL1340288 & 688798 & 4.35 & 4.9669 & TRN & \\
\hline CHEMBL1355965 & 688798 & 4.5 & 4.708 & TST & \\
\hline CHEMBL1551608 & 688798 & 3.95 & 5.6922 & TRN & \\
\hline CHEMBL1318086 & 688798 & 5.05 & 5.5304 & TRN & \\
\hline CHEMBL1552061 & 688798 & 3.95 & 5.4783 & TRN & \\
\hline CHEMBL1385217 & 688798 & 3.9 & 5.1712 & TRN & \\
\hline CHEMBL1383523 & 688798 & 4.25 & 4.9768 & TRN & \\
\hline CHEMBL1424878 & 688798 & 4.5 & 4.9438 & TRN & \\
\hline CHEMBL1316660 & 688798 & 7.1002 & 5.2362 & TRN & \\
\hline CHEMBL1420957 & 688798 & 4.35 & 5.1696 & TRN & \\
\hline CHEMBL1320999 & 688798 & 4.75 & 5.8475 & TRN & \\
\hline CHEMBL1607093 & 688798 & 7.5003 & 5.3844 & TRN & \\
\hline CHEMBL1576913 & 688798 & 4.35 & 4.6564 & TRN & \\
\hline CHEMBL1592928 & 688798 & 6.0 & 5.6031 & TRN & \\
\hline CHEMBL1569232 & 688798 & 4.35 & 4.9231 & TRN & \\
\hline CHEMBL3193878 & 688798 & 4.35 & 4.8246 & TRN & \\
\hline CHEMBL1545456 & 688798 & 4.0 & 5.0984 & TRN & \\
\hline CHEMBL1410823 & 688798 & 4.15 & 4.846 & TRN & \\
\hline CHEMBL1346172 & 688798 & 4.4 & 5.1203 & TRN & \\
\hline CHEMBL1333545 & 688798 & 9.0458 & 5.6651 & TRN & \\
\hline CHEMBL1513621 & 688798 & 4.05 & 5.1027 & TST & \\
\hline CHEMBL1395614 & 688798 & 7.5003 & 5.13200 & 0000000001 & TRN \\
\hline CHEMBL1315331 & 688798 & 2.95 & 5.7681 & TRN & \\
\hline CHEMBL1485698 & 688798 & 5.8 & 5.3657 & TRN & \\
\hline CHEMBL1473862 & 688798 & 3.95 & 5.2188 & TRN & \\
\hline CHEMBL1350755 & 688798 & 4.35 & 5.104 & TST & \\
\hline CHEMBL1364015 & 688798 & 4.5 & 4.9144 & TST & \\
\hline CHEMBL1318410 & 688798 & 3.5 & 5.2509 & TST & \\
\hline CHEMBL1443421 & 688798 & 7.4498 & 5.2546 & TRN & \\
\hline CHEMBL1475152 & 688798 & 7.4498 & 5.4525 & TRN & \\
\hline CHEMBL1404915 & 688798 & 4.3 & 5.0369 & TST & \\
\hline CHEMBL1339258 & 688798 & 2.55 & 4.84699 & 99999999995 & TST \\
\hline CHEMBL3192687 & 688798 & 4.5 & 4.7489 & TRN & \\
\hline CHEMBL1598817 & 688798 & 6.5501 & 5.4701 & TRN & \\
\hline CHEMBL1484582 & 688798 & 7.4498 & 4.9888 & TST & \\
\hline CHEMBL1552765 & 688798 & 4.6 & 5.4855 & TRN & \\
\hline CHEMBL1321259 & 688798 & 6.05 & 5.1851 & TRN & \\
\hline CHEMBL549321 & 688798 & 4.45 & 4.6914 & TRN & \\
\hline CHEMBL 247378 & 688798 & 4.35 & 4.6212 & TST & \\
\hline CHEMBL1366693 & 688798 & 2.85 & 5.6646 & TRN & \\
\hline CHEMBL1571410 & 688798 & 3.65 & 5.3741 & TST & \\
\hline
\end{tabular}




\begin{tabular}{|c|c|c|c|c|}
\hline \multicolumn{5}{|c|}{ Supplemental Table S2.txt } \\
\hline CHEMBL1490138 & 688798 & 6.1 & 5.6263 & TRN \\
\hline CHEMBL1333662 & 688798 & 9.0 & 5.3208 & TST \\
\hline CHEMBL1369792 & 688798 & 4.0 & 5.4792 & TRN \\
\hline CHEMBL1374593 & 688798 & 2.4 & 5.5192 & TRN \\
\hline CHEMBL1397583 & 688798 & 3.95 & 5.3615 & TRN \\
\hline CHEMBL1473825 & 688798 & 8.7447 & 5.5068 & TRN \\
\hline CHEMBL1476648 & 688798 & 5.65 & 5.1377 & TRN \\
\hline CHEMBL1551840 & 688798 & 4.6 & 5.0907 & TRN \\
\hline CHEMBL1337740 & 688798 & 6.0 & 5.4164 & TST \\
\hline CHEMBL1531367 & 688798 & 3.5 & 5.1234 & TRN \\
\hline CHEMBL1512302 & 688798 & 4.6 & 5.3225 & TRN \\
\hline CHEMBL1512335 & 688798 & 4.45 & 5.3497 & TST \\
\hline CHEMBL1316246 & 688798 & 9.1549 & 5.6446 & TRN \\
\hline CHEMBL1474584 & 688798 & 7.8996 & 5.7585 & TRN \\
\hline CHEMBL1475174 & 688798 & 5.55 & 5.3634 & TST \\
\hline CHEMBL1320770 & 688798 & 4.3 & 5.2168 & TST \\
\hline CHEMBL1554195 & 688798 & 8.9586 & 5.6934 & TRN \\
\hline CHEMBL1397627 & 688798 & 6.5 & 5.522 & TRN \\
\hline CHEMBL1476614 & 688798 & 3.95 & 5.4778 & TRN \\
\hline CHEMBL1556355 & 688798 & 8.1024 & 5.4484 & TRN \\
\hline CHEMBL1473802 & 688798 & 5.2 & 5.4568 & TRN \\
\hline CHEMBL1525117 & 688798 & 6.4 & 5.4551 & TRN \\
\hline CHEMBL1597744 & 688798 & 4.7 & 5.4841 & TRN \\
\hline CHEMBL1475240 & 688798 & 4.0 & 5.4045 & TRN \\
\hline CHEMBL1395092 & 688798 & 4.3 & 5.4464 & TRN \\
\hline CHEMBL1318389 & 688798 & 4.8 & 5.4673 & TRN \\
\hline CHEMBL1395061 & 688798 & 4.7 & 5.0583 & TRN \\
\hline CHEMBL1406572 & 688798 & 4.35 & 5.0393 & TRN \\
\hline CHEMBL1394532 & 688798 & 7.2 & 5.2083 & TRN \\
\hline CHEMBL1398235 & 688798 & 5.75 & 5.6466 & TRN \\
\hline CHEMBL1480588 & 688798 & 3.0 & 5.4403 & TRN \\
\hline CHEMBL1607221 & 688798 & 3.9 & 5.5727 & TRN \\
\hline CHEMBL1512803 & 688798 & 7.0 & 4.7602 & TST \\
\hline CHEMBL1573691 & 688798 & 4.5 & 5.2453 & TRN \\
\hline CHEMBL1610008 & 688798 & 4.45 & 4.9326 & TRN \\
\hline CHEMBL1574655 & 688798 & 8.0 & 5.0554 & TRN \\
\hline CHEMBL1530731 & 688798 & 3.55 & 5.6848 & TRN \\
\hline CHEMBL1356937 & 688798 & 5.9 & 5.4297 & TRN \\
\hline CHEMBL1317829 & 688798 & 4.7 & 5.6272 & TRN \\
\hline CHEMBL1423698 & 688798 & 8.0506 & 5.5561 & TRN \\
\hline CHEMBL1235717 & 688798 & 6.05 & 4.9762 & TST \\
\hline CHEMBL1404761 & 688798 & 4.35 & 4.7526 & TRN \\
\hline CHEMBL1317490 & 688798 & 7.5498 & 5.5183 & TRN \\
\hline CHEMBL1594356 & 688798 & 4.95 & 4.927 & TRN \\
\hline CHEMBL69612 & 688798 & 4.7 & 4.3939 & TRN \\
\hline CHEMBL1554825 & 688798 & 6.5 & 5.6671 & TRN \\
\hline CHEMBL1584954 & 688798 & 4.05 & 5.0198 & TRN \\
\hline CHEMBL1452716 & 688798 & 3.9 & 5.3277 & TST \\
\hline
\end{tabular}




\begin{tabular}{|c|c|c|c|c|}
\hline \multicolumn{5}{|c|}{ Supplemental Table s2.txt } \\
\hline CHEMBL1491502 & 688798 & 8.699 & 5.3097 & TRN \\
\hline CHEMBL1551516 & 688798 & 6.45 & 4.8964 & TST \\
\hline CHEMBL1531734 & 688798 & 5.1 & 5.2737 & TRN \\
\hline CHEMBL66953 & 688798 & 4.5 & 4.667 & TRN \\
\hline CHEMBL1553880 & 688798 & 7.0501 & 5.4885 & TRN \\
\hline CHEMBL1593008 & 688798 & 4.55 & 4.9058 & TRN \\
\hline CHEMBL1361246 & 688798 & 3.55 & 5.6651 & TRN \\
\hline CHEMBL1361383 & 688798 & 4.6 & 5.5641 & TRN \\
\hline CHEMBL 2001396 & 688798 & 4.3 & 5.0022 & TRN \\
\hline CHEMBL1551446 & 688798 & 5.05 & 5.5585 & TRN \\
\hline CHEMBL1523514 & 688798 & 5.1 & 5.6115 & TRN \\
\hline CHEMBL1354390 & 688798 & 4.7 & 5.6132 & TRN \\
\hline CHEMBL1482917 & 688798 & 5.55 & 5.5346 & TRN \\
\hline CHEMBL1321609 & 688798 & 4.45 & 5.3667 & TRN \\
\hline CHEMBL1322758 & 688798 & 3.2 & 5.431 & TRN \\
\hline CHEMBL1543956 & 688798 & 4.5 & 5.0531 & TST \\
\hline CHEMBL1590721 & 688798 & 4.1 & 4.9216 & TRN \\
\hline CHEMBL1514100 & 688798 & 4.75 & 5.2584 & TRN \\
\hline CHEMBL3199451 & 688798 & 4.6 & 4.3703 & TRN \\
\hline CHEMBL1569250 & 688798 & 3.55 & 5.2979 & TRN \\
\hline CHEMBL1400963 & 688798 & 4.7 & 5.4537 & TRN \\
\hline CHEMBL1398232 & 688798 & 5.4 & 5.5101 & TRN \\
\hline CHEMBL1314174 & 688798 & 4.3 & 4.7947 & TST \\
\hline CHEMBL1596115 & 688798 & 4.3 & 5.4578 & TRN \\
\hline CHEMBL1405279 & 688798 & 4.35 & 5.039 & TRN \\
\hline CHEMBL1433667 & 688798 & 5.35 & 5.3561 & TRN \\
\hline CHEMBL1436637 & 688798 & 6.4 & 5.8378 & TRN \\
\hline CHEMBL1589866 & 688798 & 4.05 & 5.4168 & TRN \\
\hline CHEMBL1513145 & 688798 & 8.5528 & 5.6089 & TRN \\
\hline CHEMBL1361154 & 688798 & 6.15 & 5.6209 & TRN \\
\hline CHEMBL1372157 & 688798 & 5.35 & 5.2736 & TST \\
\hline CHEMBL1448937 & 688798 & 5.05 & 5.2307 & TST \\
\hline CHEMBL1516171 & 688798 & 6.8 & 5.3331 & TRN \\
\hline CHEMBL1390868 & 688798 & 2.65 & 5.0158 & TST \\
\hline CHEMBL1498702 & 688798 & 4.35 & 5.0125 & TST \\
\hline CHEMBL1369691 & 688798 & 4.35 & 4.6028 & TRN \\
\hline CHEMBL1600290 & 688798 & 2.9 & 5.61 & TRN \\
\hline CHEMBL1326111 & 688798 & 5.15 & 4.8974 & TRN \\
\hline CHEMBL 2358966 & 688798 & 7.4498 & 5.5949 & TRN \\
\hline CHEMBL1514403 & 688798 & 5.95 & 5.1143 & TRN \\
\hline CHEMBL1493109 & 688798 & 6.5501 & 4.9844 & TRN \\
\hline CHEMBL1361224 & 688798 & 8.3468 & 5.3361 & TST \\
\hline CHEMBL1552605 & 688798 & 2.9 & 5.5097 & TRN \\
\hline CHEMBL1512324 & 688798 & 7.3002 & 5.1002 & TRN \\
\hline CHEMBL1443639 & 688798 & 2.5 & 5.8482 & TRN \\
\hline CHEMBL1557321 & 688798 & 4.45 & 5.5719 & TRN \\
\hline CHEMBL1315480 & 688798 & 4.85 & 5.6048 & TRN \\
\hline CHEMBL1501198 & 688798 & 7.5003 & 5.3093 & TRN \\
\hline
\end{tabular}




\begin{tabular}{|c|c|c|c|c|c|}
\hline \multicolumn{6}{|c|}{ Supplemental Table S2.txt } \\
\hline CHEMBL1590719 & 688798 & 5.75 & 5.5213 & TRN & \\
\hline CHEMBL1543617 & 688798 & 4.35 & 4.9526 & TST & \\
\hline CHEMBL1405997 & 688798 & 4.85 & 5.7167 & TRN & \\
\hline CHEMBL1426349 & 688798 & 8.6021 & 4.8227 & TST & \\
\hline CHEMBL1396522 & 688798 & 5.4 & 5.3389 & TRN & \\
\hline CHEMBL1396026 & 688798 & 4.95 & 5.7017 & TRN & \\
\hline CHEMBL1557748 & 688798 & 5.85 & 5.6277 & TRN & \\
\hline CHEMBL1566644 & 688798 & 4.8 & 5.2009 & TRN & \\
\hline CHEMBL1314717 & 688798 & 5.1 & 5.3558 & TRN & \\
\hline CHEMBL 1451860 & 688798 & 5.0 & 5.3761 & TRN & \\
\hline CHEMBL1475551 & 688798 & 2.95 & 5.8659 & TRN & \\
\hline CHEMBL406946 & 688798 & 3.6 & 5.5277 & TRN & \\
\hline CHEMBL1300008 & 688798 & 4.4 & 5.4657 & TRN & \\
\hline CHEMBL1315215 & 688798 & 4.0 & 5.13399 & 99999999995 & TRN \\
\hline CHEMBL1590087 & 688798 & 4.1 & 5.3696 & TRN & \\
\hline CHEMBL1327847 & 688798 & 3.4 & 5.2051 & TRN & \\
\hline CHEMBL1426427 & 688798 & 4.05 & 5.4175 & TRN & \\
\hline CHEMBL1354466 & 688798 & 4.9 & 5.7703 & TRN & \\
\hline CHEMBL1535001 & 688798 & 10.7501 & 4.9389 & TRN & \\
\hline CHEMBL1316940 & 688798 & 4.95 & 5.6555 & TRN & \\
\hline CHEMBL1605286 & 688798 & 5.55 & 4.6499 & TST & \\
\hline CHEMBL1524370 & 688798 & 3.9 & 4.9366 & TRN & \\
\hline CHEMBL 1457025 & 688798 & 2.95 & 5.6459 & TRN & \\
\hline CHEMBL1520687 & 688798 & 8.0 & 5.3907 & TRN & \\
\hline CHEMBL1490421 & 688798 & 3.55 & 5.0554 & TRN & \\
\hline CHEMBL1462814 & 688798 & 4.15 & 5.0157 & TST & \\
\hline CHEMBL1535657 & 688798 & 4.8 & 5.6698 & TRN & \\
\hline CHEMBL1610219 & 688798 & 4.4 & 4.9903 & TST & \\
\hline CHEMBL1371672 & 688798 & 7.4498 & 5.3348 & TRN & \\
\hline CHEMBL1375329 & 688798 & 5.3 & 4.8813 & TRN & \\
\hline CHEMBL1334684 & 688798 & 4.85 & 4.9657 & TST & \\
\hline CHEMBL1552656 & 688798 & 3.55 & 5.2325 & TST & \\
\hline CHEMBL1512989 & 688798 & 4.85 & 5.6239 & TRN & \\
\hline CHEMBL1330977 & 688798 & 4.35 & 5.0756 & TRN & \\
\hline CHEMBL1493332 & 688798 & 4.85 & 5.8997 & TRN & \\
\hline CHEMBL1348456 & 688798 & 4.55 & 4.897 & TRN & \\
\hline CHEMBL3197851 & 688798 & 4.35 & 5.115 & TST & \\
\hline CHEMBL1478754 & 688798 & 4.3 & 5.2104 & TST & \\
\hline CHEMBL1597473 & 688798 & 5.5 & 5.7693 & TRN & \\
\hline CHEMBL1356325 & 688798 & 7.4498 & 5.5167 & TRN & \\
\hline CHEMBL1578890 & 688798 & 9.0458 & 5.6047 & TRN & \\
\hline CHEMBL1335321 & 688798 & 4.45 & 4.9621 & TRN & \\
\hline CHEMBL1475095 & 688798 & 5.5 & 5.6892 & TRN & \\
\hline CHEMBL1365887 & 688798 & 9.0969 & 5.4645 & TRN & \\
\hline CHEMBL3195176 & 688798 & 4.35 & 5.141 & TST & \\
\hline CHEMBL3192970 & 688798 & 4.85 & 4.9677 & TST & \\
\hline CHEMBL 1370822 & 688798 & 4.05 & 5.2208 & TRN & \\
\hline CHEMBL65374 & 688798 & 4.3 & 4.9427 & TRN & \\
\hline
\end{tabular}




\begin{tabular}{|c|c|c|c|c|c|}
\hline \multicolumn{6}{|c|}{ 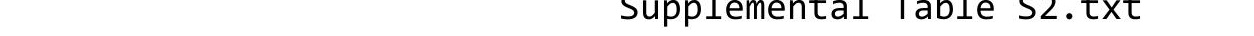 } \\
\hline CHEMBL1499258 & 688798 & 4.5 & 5.0437 & TRN & \\
\hline CHEMBL1336676 & 688798 & 6.95 & 5.1741 & TRN & \\
\hline CHEMBL3191525 & 688798 & 4.35 & 5.1929 & TRN & \\
\hline CHEMBL1414179 & 688798 & 8.1024 & 5.8364 & TRN & \\
\hline CHEMBL1492565 & 688798 & 4.25 & 5.07100 & 0000000001 & TRN \\
\hline CHEMBL1527520 & 688798 & 4.3 & 4.7097 & TST & \\
\hline CHEMBL1551348 & 688798 & 8.1024 & 5.5112 & TRN & \\
\hline CHEMBL1451457 & 688798 & 2.8 & 5.6332 & TRN & \\
\hline CHEMBL1317130 & 688798 & 9.1549 & 5.6627 & TRN & \\
\hline CHEMBL1598269 & 688798 & 6.25 & 5.9249 & TRN & \\
\hline CHEMBL1394708 & 688798 & 8.4949 & 4.8753 & TST & \\
\hline CHEMBL1513547 & 688798 & 6.4 & 5.3447 & TRN & \\
\hline CHEMBL1394704 & 688798 & 5.95 & 5.5074 & TRN & \\
\hline CHEMBL1405196 & 688798 & 4.75 & 5.4533 & TRN & \\
\hline CHEMBL1518939 & 688798 & 7.0501 & 4.9963 & TRN & \\
\hline CHEMBL1514924 & 688798 & 8.5528 & 5.443 & TRN & \\
\hline CHEMBL1303296 & 688798 & 5.15 & 5.2082 & TRN & \\
\hline CHEMBL345124 & 688798 & 6.0 & 5.0825 & TST & \\
\hline CHEMBL1405437 & 688798 & 8.1024 & 5.6338 & TRN & \\
\hline CHEMBL1452120 & 688798 & 7.5498 & 5.2424 & TRN & \\
\hline CHEMBL1401049 & 688798 & 4.8 & 5.4634 & TRN & \\
\hline CHEMBL1356691 & 688798 & 3.1 & 5.50299 & 9999999999 & TRN \\
\hline CHEMBL1611749 & 688798 & 4.95 & 5.25 & TRN & \\
\hline CHEMBL1427379 & 688798 & 3.95 & 5.346 & TRN & \\
\hline CHEMBL1413186 & 688798 & 7.8013 & 5.3731 & TRN & \\
\hline CHEMBL1408616 & 688798 & 3.5 & 5.0326 & TRN & \\
\hline CHEMBL1342736 & 688798 & 4.4 & 5.1826 & TST & \\
\hline CHEMBL1395091 & 688798 & 3.6 & 5.3242 & TRN & \\
\hline CHEMBL1328285 & 688798 & 4.35 & 5.3203 & TRN & \\
\hline CHEMBL1409317 & 688798 & 5.5 & 5.1648 & TRN & \\
\hline CHEMBL3192503 & 688798 & 7.2 & 5.5255 & TRN & \\
\hline CHEMBL1577635 & 688798 & 4.35 & 5.3525 & TRN & \\
\hline CHEMBL1472904 & 688798 & 4.0 & 5.205 & TRN & \\
\hline CHEMBL1436613 & 688798 & 3.9 & 5.2482 & TRN & \\
\hline CHEMBL1481914 & 688798 & 4.6 & 5.13700 & 20000000005 & TRN \\
\hline CHEMBL1525777 & 688798 & 4.65 & 5.4516 & TRN & \\
\hline CHEMBL1512052 & 688798 & 4.9 & 5.4551 & TRN & \\
\hline CHEMBL1200567 & 688798 & 4.2 & 4.7134 & TST & \\
\hline CHEMBL1396674 & 688798 & 6.5 & 5.7039 & TRN & \\
\hline CHEMBL1394239 & 688798 & 4.25 & 4.5447 & TRN & \\
\hline CHEMBL1512695 & 688798 & 4.0 & 5.5163 & TRN & \\
\hline CHEMBL1518923 & 688798 & 6.0 & 5.2553 & TRN & \\
\hline CHEMBL1434994 & 688798 & 4.4 & 4.9206 & TRN & \\
\hline CHEMBL1418426 & 688798 & 7.1002 & 5.0204 & TRN & \\
\hline CHEMBL1520152 & 688798 & 4.75 & 5.7445 & TRN & \\
\hline CHEMBL1558513 & 688798 & 3.95 & 5.0082 & TRN & \\
\hline CHEMBL1972037 & 688798 & 4.4 & 4.2934 & TRN & \\
\hline CHEMBL1358505 & 688798 & 4.95 & 4.9759 & TST & \\
\hline
\end{tabular}




\begin{tabular}{|c|c|c|c|c|c|}
\hline \multicolumn{6}{|c|}{ Supplemental Table S2.txt } \\
\hline CHEMBL1592909 & 688798 & 4.7 & 5.053 & TRN & \\
\hline CHEMBL1417268 & 688798 & 4.35 & 5.23799 & 99999999995 & TST \\
\hline CHEMBL1318708 & 688798 & 4.6 & 4.8605 & TST & \\
\hline CHEMBL1456696 & 688798 & 7.0501 & 5.2166 & TST & \\
\hline CHEMBL1447002 & 688798 & 4.55 & 5.3314 & TST & \\
\hline CHEMBL1357591 & 688798 & 4.65 & 5.0651 & TRN & \\
\hline CHEMBL1397155 & 688798 & 8.7959 & 5.6837 & TRN & \\
\hline CHEMBL1551063 & 688798 & 4.85 & 5.5348 & TRN & \\
\hline CHEMBL1549893 & 688798 & 7.4498 & 4.9538 & TRN & \\
\hline CHEMBL1355106 & 688798 & 3.0 & 5.2763 & TRN & \\
\hline CHEMBL1360153 & 688798 & 6.5 & 5.3335 & TRN & \\
\hline CHEMBL1557484 & 688798 & 10.25 & 5.3147 & TRN & \\
\hline CHEMBL1588447 & 688798 & 4.45 & 5.1869 & TST & \\
\hline CHEMBL1464347 & 688798 & 5.15 & 5.0629 & TST & \\
\hline CHEMBL1418056 & 688798 & 4.6 & 5.5732 & TRN & \\
\hline CHEMBL1357024 & 688798 & 3.5 & 5.6107 & TRN & \\
\hline CHEMBL1355791 & 688798 & 7.5003 & 5.6677 & TRN & \\
\hline CHEMBL1435347 & 688798 & 4.7 & 5.2945 & TRN & \\
\hline CHEMBL1471965 & 688798 & 5.5 & 4.8508 & TRN & \\
\hline CHEMBL1434079 & 688798 & 1.95 & 5.7001 & TRN & \\
\hline CHEMBL1256291 & 688798 & 4.25 & 4.7282 & TST & \\
\hline CHEMBL1702181 & 688798 & 4.5 & 5.1674 & TRN & \\
\hline CHEMBL1516388 & 688798 & 6.0 & 4.6838 & TST & \\
\hline CHEMBL1496284 & 688798 & 4.35 & 4.9565 & TST & \\
\hline CHEMBL1372117 & 688798 & 6.6 & 5.8023 & TRN & \\
\hline CHEMBL1527451 & 688798 & 4.35 & 5.4188 & TRN & \\
\hline CHEMBL95770 & 688798 & 4.35 & 5.1328 & TRN & \\
\hline CHEMBL1435445 & 688798 & 4.85 & 4.8802 & TRN & \\
\hline CHEMBL1513053 & 688798 & 5.0 & 5.1618 & TRN & \\
\hline CHEMBL1605813 & 688798 & 4.15 & 4.8091 & TST & \\
\hline CHEMBL1362243 & 688798 & 5.0 & 5.3959 & TRN & \\
\hline CHEMBL1487525 & 688798 & 4.4 & 5.1364 & TRN & \\
\hline CHEMBL10347 & 688798 & 4.4 & 5.2504 & TST & \\
\hline CHEMBL1476138 & 688798 & 4.15 & 5.545 & TRN & \\
\hline CHEMBL1433987 & 688798 & 6.05 & 5.3643 & TRN & \\
\hline CHEMBL1453342 & 688798 & 4.7 & 5.5864 & TRN & \\
\hline CHEMBL1594079 & 688798 & 8.5528 & 5.559 & TRN & \\
\hline CHEMBL1337338 & 688798 & 7.8996 & 5.4396 & TRN & \\
\hline CHEMBL1476224 & 688798 & 5.85 & 5.7429 & TRN & \\
\hline CHEMBL1476591 & 688798 & 10.0 & 5.5793 & TRN & \\
\hline CHEMBL1555152 & 688798 & 8.5528 & 5.3269 & TRN & \\
\hline CHEMBL1309765 & 688798 & 4.5 & 5.0801 & TRN & \\
\hline CHEMBL1514999 & 688798 & 7.15 & 5.6372 & TRN & \\
\hline CHEMBL1402189 & 688798 & 4.55 & 5.6109 & TRN & \\
\hline CHEMBL1394999 & 688798 & 3.95 & 5.0766 & TRN & \\
\hline CHEMBL1315748 & 688798 & 4.9 & 5.5934 & TRN & \\
\hline CHEMBL1370478 & 688798 & 3.3 & 5.6445 & TRN & \\
\hline CHEMBL 1457178 & 688798 & 4.95 & 5.6721 & TRN & \\
\hline
\end{tabular}




\begin{tabular}{|c|c|c|c|c|c|}
\hline \multicolumn{6}{|c|}{ Supplemental Table S2.txt } \\
\hline CHEMBL1365015 & 688798 & 4.05 & 5.2467 & TRN & \\
\hline CHEMBL1434124 & 688798 & 6.8499 & 5.3248 & TRN & \\
\hline CHEMBL1397650 & 688798 & 7.15 & 5.61700 & 0000000001 & TRN \\
\hline CHEMBL1598824 & 688798 & 6.7001 & 5.41200 & 0000000001 & TRN \\
\hline CHEMBL1511955 & 688798 & 8.1024 & 4.6195 & TST & \\
\hline CHEMBL1487669 & 688798 & 6.05 & 5.4076 & TRN & \\
\hline CHEMBL1355959 & 688798 & 4.0 & 5.0474 & TRN & \\
\hline CHEMBL1484149 & 688798 & 3.95 & 5.1751 & TRN & \\
\hline CHEMBL1396292 & 688798 & 4.65 & 5.5721 & TRN & \\
\hline CHEMBL1361035 & 688798 & 8.8861 & 5.371 & TRN & \\
\hline CHEMBL1612178 & 688798 & 4.75 & 5.2742 & TRN & \\
\hline CHEMBL1409447 & 688798 & 7.5003 & 5.2496 & TRN & \\
\hline CHEMBL1443086 & 688798 & 7.8508 & 5.3825 & TRN & \\
\hline CHEMBL1501132 & 688798 & 4.55 & 5.3938 & TRN & \\
\hline CHEMBL1435764 & 688798 & 3.2 & 5.1288 & TRN & \\
\hline CHEMBL1449187 & 688798 & 3.95 & 5.2039 & TRN & \\
\hline CHEMBL1536258 & 688798 & 4.35 & 4.9512 & TST & \\
\hline CHEMBL1452561 & 688798 & 6.6 & 4.9709 & TRN & \\
\hline CHEMBL1334267 & 688798 & 6.35 & 5.4545 & TRN & \\
\hline CHEMBL1332398 & 688798 & 8.5528 & 5.3516 & TRN & \\
\hline CHEMBL1318621 & 688798 & 5.9 & 5.5121 & TRN & \\
\hline CHEMBL1321920 & 688798 & 3.5 & 5.4142 & TRN & \\
\hline CHEMBL1513200 & 688798 & 8.4559 & 5.5443 & TRN & \\
\hline CHEMBL 3145086 & 688798 & 4.3 & 5.2637 & TST & \\
\hline CHEMBL1502712 & 688798 & 3.95 & 5.358 & TST & \\
\hline CHEMBL1397092 & 688798 & 4.4 & 5.5188 & TRN & \\
\hline CHEMBL1476630 & 688798 & 8.6021 & 5.8165 & TRN & \\
\hline CHEMBL1590405 & 688798 & 6.7001 & 5.4913 & TRN & \\
\hline CHEMBL1358581 & 688798 & 6.6499 & 5.66299 & 7999999999 & TRN \\
\hline CHEMBL1434354 & 688798 & 7.6003 & 5.1307 & TRN & \\
\hline CHEMBL1405394 & 688798 & 7.5003 & 5.7413 & TRN & \\
\hline CHEMBL1988401 & 688798 & 4.45 & 5.3319 & TRN & \\
\hline CHEMBL1367523 & 688798 & 5.65 & 5.3375 & TRN & \\
\hline CHEMBL1569393 & 688798 & 4.0 & 5.3596 & TRN & \\
\hline CHEMBL1435239 & 688798 & 6.05 & 5.3923 & TRN & \\
\hline CHEMBL1450539 & 688798 & 2.9 & 5.4662 & TST & \\
\hline CHEMBL1598302 & 688798 & 2.85 & 5.6228 & TST & \\
\hline CHEMBL1395770 & 688798 & 4.95 & 5.4714 & TST & \\
\hline CHEMBL1435867 & 688798 & 4.75 & 5.4629 & TST & \\
\hline CHEMBL1402194 & 688798 & 4.9 & 5.3305 & TST & \\
\hline CHEMBL1354798 & 688798 & 5.2 & 5.5998 & TST & \\
\hline CHEMBL1316632 & 688798 & 7.5498 & 5.8285 & TST & \\
\hline CHEMBL1428415 & 688798 & 5.75 & 5.4949 & TST & \\
\hline CHEMBL1443658 & 688798 & 4.9 & 5.7933 & TST & \\
\hline CHEMBL1362485 & 688798 & 7.2 & 5.3385 & TST & \\
\hline CHEMBL1435768 & 688798 & 6.6 & 5.5604 & TST & \\
\hline CHEMBL1558877 & 688798 & 4.65 & 5.5645 & TST & \\
\hline CHEMBL1574458 & 688798 & 7.4001 & 5.025 & TST & \\
\hline
\end{tabular}




\begin{tabular}{|c|c|c|c|c|c|}
\hline \multicolumn{6}{|c|}{ oplemental labıe s2 } \\
\hline CHEMBL1513368 & 688798 & 8.0 & 5.8164 & TST & \\
\hline CHEMBL1472876 & 688798 & 4.8 & 5.0848 & TST & \\
\hline CHEMBL1436631 & 688798 & 7.8508 & 5.3707 & TST & \\
\hline CHEMBL1442153 & 688798 & 8.2007 & 4.7703 & TST & \\
\hline CHEMBL1499053 & 688798 & 6.4 & 5.4178 & TST & \\
\hline CHEMBL1358777 & 688798 & 5.35 & 4.9482 & TST & \\
\hline CHEMBL1327846 & 688798 & 4.45 & 5.3658 & TST & \\
\hline CHEMBL1526897 & 688798 & 4.7 & 5.1903 & TST & \\
\hline CHEMBL1457502 & 688798 & 4.7 & 5.3442 & TST & \\
\hline CHEMBL1476218 & 688798 & 6.1 & 5.5263 & TST & \\
\hline CHEMBL3195977 & 688798 & 4.5 & 4.8513 & TST & \\
\hline CHEMBL1388553 & 688798 & 4.35 & 4.90600 & 0000000001 & TST \\
\hline CHEMBL1446668 & 688798 & 4.35 & 5.2969 & TST & \\
\hline CHEMBL1436807 & 688798 & 5.9 & 5.6852 & TST & \\
\hline CHEMBL1591937 & 688798 & 4.7 & 5.2302 & TST & \\
\hline CHEMBL1354581 & 688798 & 4.85 & 5.3934 & TST & \\
\hline CHEMBL1506256 & 688798 & 6.5 & 5.1141 & TST & \\
\hline CHEMBL1399989 & 688798 & 4.6 & 5.3364 & TST & \\
\hline CHEMBL1360253 & 688798 & 9.699 & 5.4184 & TST & \\
\hline CHEMBL1514551 & 688798 & 4.65 & 5.3767 & TST & \\
\hline CHEMBL1357247 & 688798 & 5.15 & 4.7892 & TST & \\
\hline CHEMBL1314706 & 688798 & 3.85 & 5.5781 & TST & \\
\hline CHEMBL1476493 & 688798 & 4.9 & 5.3852 & TST & \\
\hline CHEMBL1521564 & 688798 & 4.35 & 5.44600 & 0000000001 & TST \\
\hline CHEMBL1383878 & 688798 & 4.9 & 4.8896 & TST & \\
\hline CHEMBL1604731 & 688798 & 4.55 & 5.2024 & TST & \\
\hline CHEMBL1360549 & 688798 & 4.1 & 5.1458 & TST & \\
\hline CHEMBL1360264 & 688798 & 4.3 & 5.40799 & 99999999995 & TST \\
\hline CHEMBL1317928 & 688798 & 3.9 & 4.8485 & TST & \\
\hline CHEMBL1377634 & 688798 & 4.85 & 5.4683 & TST & \\
\hline CHEMBL1713905 & 688798 & 4.35 & 5.1095 & TST & \\
\hline CHEMBL1316550 & 688798 & 8.6576 & 5.2732 & TST & \\
\hline CHEMBL1597992 & 688798 & 8.8539 & 5.2481 & TST & \\
\hline CHEMBL1496575 & 688798 & 4.4 & 4.7608 & TST & \\
\hline CHEMBL1382617 & 688798 & 7.0 & 5.1374 & TST & \\
\hline CHEMBL1396125 & 688798 & 3.0 & 5.346 & TST & \\
\hline CHEMBL1549333 & 688798 & 4.45 & 5.4433 & TST & \\
\hline CHEMBL1358017 & 688798 & 6.0 & 5.9094 & TST & \\
\hline CHEMBL1417346 & 688798 & 3.95 & 5.1876 & TST & \\
\hline CHEMBL1372055 & 688798 & 7.8508 & 4.9277 & TST & \\
\hline CHEMBL1552501 & 688798 & 4.65 & 5.4062 & TST & \\
\hline CHEMBL1542423 & 688798 & 10.0 & 5.2429 & TST & \\
\hline CHEMBL1492214 & 688798 & 8.4559 & 5.151 & TST & \\
\hline CHEMBL1471287 & 688798 & 4.25 & 5.4773 & TST & \\
\hline CHEMBL1396197 & 688798 & 4.9 & 5.6174 & TST & \\
\hline CHEMBL1434519 & 688798 & 4.7 & 5.4036 & TST & \\
\hline CHEMBL1591985 & 688798 & 4.05 & 5.6626 & TST & \\
\hline CHEMBL1436142 & 688798 & 6.5 & 5.6072 & TST & \\
\hline
\end{tabular}




\begin{tabular}{|c|c|c|c|c|c|}
\hline \multicolumn{6}{|c|}{ Supplemental Table s2.txt } \\
\hline CHEMBL1354222 & 688798 & 6.1 & 5.8141 & TST & \\
\hline CHEMBL1378613 & 688798 & 4.35 & 5.1102 & TST & \\
\hline CHEMBL1610529 & 688798 & 4.0 & 5.5312 & TST & \\
\hline CHEMBL1494557 & 688798 & 4.5 & 4.8438 & TST & \\
\hline CHEMBL1361456 & 688798 & 4.45 & 5.0238 & TST & \\
\hline CHEMBL1377689 & 688798 & 5.05 & 5.4243 & TST & \\
\hline CHEMBL1315360 & 688798 & 8.3468 & 5.4306 & TST & \\
\hline CHEMBL1080860 & 688798 & 4.75 & 5.0854 & TST & \\
\hline CHEMBL1429064 & 688798 & 4.5 & 5.4505 & TST & \\
\hline CHEMBL1334548 & 688798 & 4.75 & 5.7856 & TST & \\
\hline CHEMBL1368388 & 688798 & 2.95 & 5.4912 & TST & \\
\hline CHEMBL1607948 & 688798 & 3.0 & 5.2248 & TST & \\
\hline CHEMBL1566736 & 688798 & 5.3 & 5.4716 & TST & \\
\hline CHEMBL1437867 & 688798 & 4.3 & 5.0799 & TST & \\
\hline CHEMBL1533561 & 688798 & 4.75 & 5.3067 & TST & \\
\hline CHEMBL1366547 & 688798 & 3.8 & 5.836 & TST & \\
\hline CHEMBL1354571 & 688798 & 1.85 & 5.5898 & TST & \\
\hline CHEMBL1473218 & 688798 & 4.7 & 5.6879 & TST & \\
\hline CHEMBL3195680 & 688798 & 5.15 & 5.435 & TST & \\
\hline CHEMBL1380806 & 688798 & 5.65 & 5.4337 & TST & \\
\hline CHEMBL1513656 & 688798 & 6.2 & 5.3911 & TST & \\
\hline CHEMBL1394675 & 688798 & 4.65 & 5.2401 & TST & \\
\hline CHEMBL1316392 & 688798 & 5.45 & 5.6821 & TST & \\
\hline CHEMBL1352778 & 688798 & 4.35 & 4.9875 & TST & \\
\hline CHEMBL1612049 & 688798 & 6.0 & 5.8772 & TST & \\
\hline CHEMBL1435880 & 688798 & 7.4498 & 5.4607 & TST & \\
\hline CHEMBL1464108 & 688798 & 10.0 & 5.1748 & TST & \\
\hline CHEMBL1570727 & 688798 & 4.35 & 5.3758 & TST & \\
\hline CHEMBL1398526 & 688798 & 5.0 & 5.1926 & TST & \\
\hline CHEMBL1511628 & 688798 & 4.0 & 5.4926 & TST & \\
\hline CHEMBL1314999 & 688798 & 7.5003 & 5.4761 & TST & \\
\hline CHEMBL1414186 & 688798 & 3.9 & 5.0186 & TST & \\
\hline CHEMBL1364048 & 688798 & 7.1002 & 5.5168 & TST & \\
\hline CHEMBL1476194 & 688798 & 7.15 & 5.5334 & TST & \\
\hline CHEMBL1513737 & 688798 & 3.85 & 5.30399 & 9999999999 & TST \\
\hline CHEMBL1512239 & 688798 & 4.1 & 5.5074 & TST & \\
\hline CHEMBL1401486 & 688798 & 4.25 & 5.5324 & TST & \\
\hline CHEMBL1494519 & 688798 & 5.35 & 5.6174 & TST & \\
\hline CHEMBL1517672 & 688798 & 6.45 & 5.3224 & TST & \\
\hline CHEMBL1513417 & 688798 & 4.25 & 5.6577 & TST & \\
\hline CHEMBL1583339 & 688798 & 4.1 & 4.8124 & TST & \\
\hline CHEMBL1396998 & 688798 & 6.5501 & 5.475 & TST & \\
\hline CHEMBL1318685 & 688798 & 6.6 & 5.6664 & TST & \\
\hline CHEMBL1396112 & 688798 & 9.3979 & 5.2532 & TST & \\
\hline CHEMBL1546039 & 688798 & 5.05 & 5.5861 & TST & \\
\hline CHEMBL1612174 & 688798 & 8.6576 & 5.0484 & TST & \\
\hline CHEMBL1525977 & 688798 & 5.75 & 5.7053 & TST & \\
\hline CHEMBL1314121 & 688798 & 8.4949 & 5.5886 & TST & \\
\hline
\end{tabular}




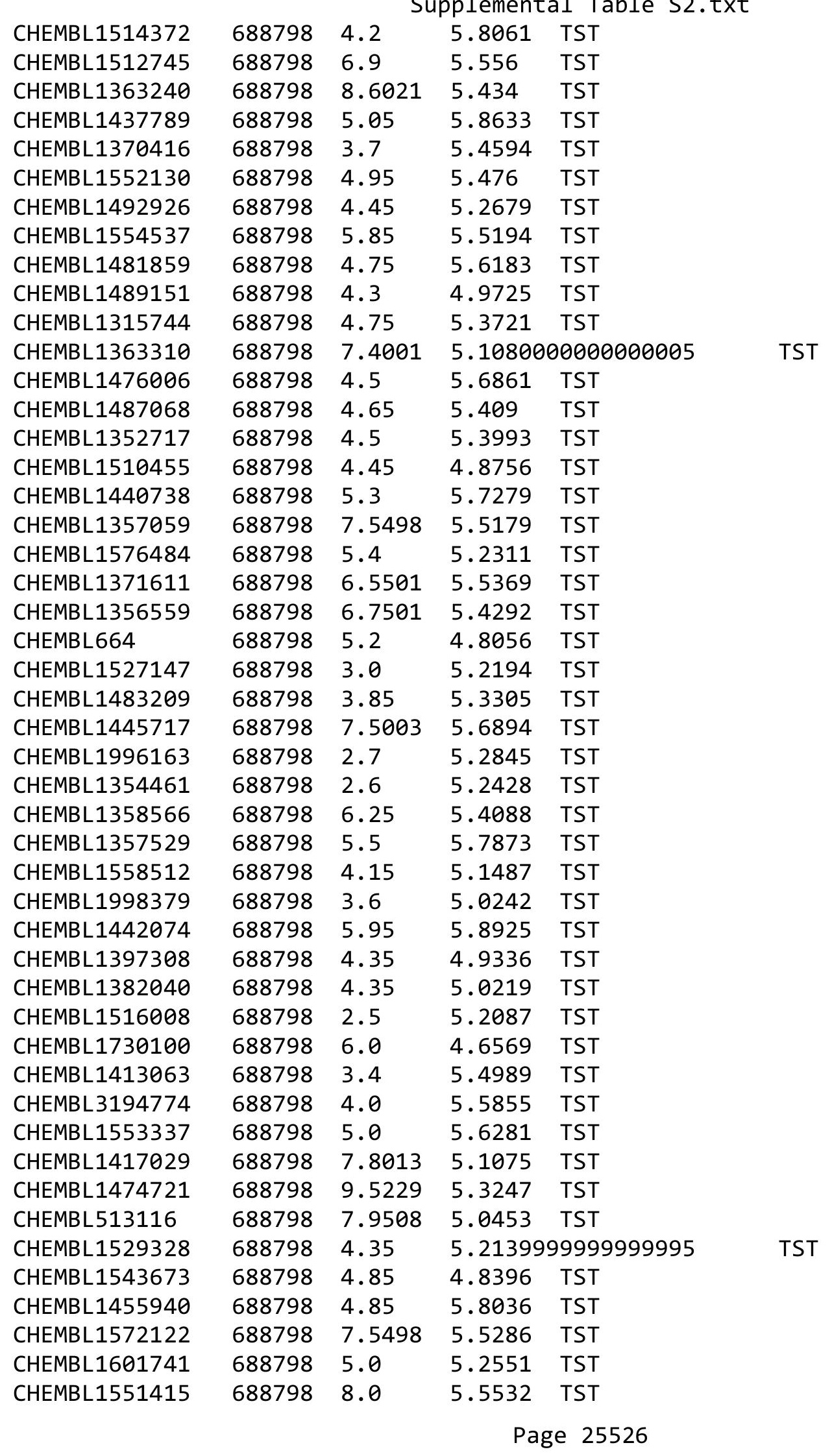




\begin{tabular}{|c|c|c|c|c|}
\hline \multicolumn{5}{|c|}{ Supplemental Table S2.txt } \\
\hline CHEMBL1519783 & 688798 & 7.5003 & 5.694 & TST \\
\hline CHEMBL1391629 & 688798 & 4.4 & 5.0565 & TST \\
\hline CHEMBL1559256 & 688798 & 7.2503 & 4.9023 & TST \\
\hline CHEMBL1321764 & 688798 & 4.95 & 5.1643 & TST \\
\hline CHEMBL1395479 & 688798 & 5.65 & 5.6699 & TST \\
\hline CHEMBL1592258 & 688798 & 4.0 & 5.6035 & TST \\
\hline CHEMBL1434447 & 688798 & 5.85 & 5.0587 & TST \\
\hline CHEMBL1362386 & 688798 & 6.1 & 5.57799 & 9999999999 \\
\hline CHEMBL1562005 & 688798 & 4.3 & 5.1671 & TST \\
\hline CHEMBL1485150 & 688798 & 5.7 & 5.2262 & TST \\
\hline CHEMBL1322168 & 688798 & 5.25 & 5.4561 & TST \\
\hline CHEMBL1373466 & 688798 & 5.85 & 4.7409 & TST \\
\hline CHEMBL1529033 & 688798 & 4.75 & 5.5013 & TST \\
\hline CHEMBL1412468 & 688798 & 3.8 & 5.2285 & TST \\
\hline CHEMBL1376453 & 688798 & 8.4949 & 4.9612 & TST \\
\hline CHEMBL1355826 & 688798 & 4.75 & 5.3945 & TST \\
\hline CHEMBL1558721 & 688798 & 3.65 & 5.8009 & TST \\
\hline CHEMBL1315973 & 688798 & 3.25 & 5.126 & TST \\
\hline CHEMBL1610168 & 688798 & 3.0 & 5.8968 & TST \\
\hline CHEMBL1512225 & 688798 & 4.0 & 5.6315 & TST \\
\hline CHEMBL 1554032 & 688798 & 8.4949 & 5.4536 & TST \\
\hline CHEMBL1356481 & 688798 & 4.75 & 5.3501 & TST \\
\hline CHEMBL1512175 & 688798 & 4.75 & 5.3723 & TST \\
\hline CHEMBL1378563 & 688798 & 4.85 & 5.3122 & TST \\
\hline CHEMBL1474794 & 688798 & 4.45 & 5.6354 & TST \\
\hline CHEMBL1435401 & 688798 & 4.0 & 5.1837 & TST \\
\hline CHEMBL1321799 & 688798 & 4.25 & 5.3675 & TST \\
\hline CHEMBL1407074 & 688798 & 4.6 & 5.7931 & TST \\
\hline CHEMBL1496931 & 688798 & 7.5498 & 5.1081 & TST \\
\hline CHEMBL1554931 & 688798 & 5.0 & 5.6775 & TST \\
\hline CHEMBL1316811 & 688798 & 4.75 & 5.8258 & TST \\
\hline CHEMBL1606755 & 688798 & 4.0 & 5.5808 & TST \\
\hline CHEMBL1590866 & 688798 & 6.15 & 5.4866 & TST \\
\hline CHEMBL1427022 & 688798 & 4.35 & 5.3156 & TST \\
\hline CHEMBL1568936 & 688798 & 4.45 & 5.6599 & TST \\
\hline CHEMBL 302562 & 688798 & 6.3 & 5.0316 & TST \\
\hline CHEMBL1561141 & 688798 & 9.3979 & 5.5774 & TST \\
\hline CHEMBL1314300 & 688798 & 4.05 & 5.5117 & TST \\
\hline CHEMBL1370801 & 688798 & 4.45 & 5.7359 & TST \\
\hline CHEMBL1522155 & 688798 & 4.5 & 4.2877 & TST \\
\hline CHEMBL1515383 & 688798 & 6.5 & 5.561 & TST \\
\hline CHEMBL1581410 & 688798 & 4.35 & 4.8095 & TST \\
\hline CHEMBL1592947 & 688798 & 6.5501 & 4.9458 & TST \\
\hline CHEMBL1553746 & 688798 & 4.55 & 5.2257 & TST \\
\hline CHEMBL1492622 & 688798 & 4.35 & 5.3946 & TST \\
\hline CHEMBL1583087 & 688798 & 7.9508 & 5.4764 & TST \\
\hline CHEMBL1495435 & 688798 & 4.15 & 5.8558 & TST \\
\hline CHEMBL1597420 & 688798 & 5.7 & 5.6289 & TST \\
\hline
\end{tabular}




\begin{tabular}{|c|c|c|c|c|c|}
\hline \multicolumn{6}{|c|}{ Supplemental Table S2.txt } \\
\hline CHEMBL1505467 & 688798 & 4.35 & 5.1198 & TST & \\
\hline CHEMBL3193813 & 688798 & 4.35 & 5.2982 & TST & \\
\hline CHEMBL1476537 & 688798 & 8.0506 & 5.5821 & TST & \\
\hline CHEMBL1325005 & 688798 & 7.8013 & 4.8722 & TST & \\
\hline CHEMBL1555035 & 688798 & 4.6 & 5.8633 & TST & \\
\hline CHEMBL1405455 & 688798 & 7.4498 & 5.4533 & TST & \\
\hline CHEMBL1517748 & 688798 & 8.8861 & 5.6942 & TST & \\
\hline CHEMBL1556290 & 688798 & 4.15 & 5.1435 & TST & \\
\hline CHEMBL1444278 & 688798 & 9.301 & 5.6461 & TST & \\
\hline CHEMBL1514850 & 688798 & 2.95 & 5.4243 & TST & \\
\hline CHEMBL1572807 & 688798 & 4.35 & 4.6412 & TST & \\
\hline CHEMBL1435199 & 688798 & 4.05 & 5.3071 & TST & \\
\hline CHEMBL1306347 & 688798 & 4.25 & 4.9181 & TST & \\
\hline CHEMBL1512038 & 688798 & 4.45 & 5.6508 & TST & \\
\hline CHEMBL1597146 & 688798 & 1.55 & 4.9436 & TST & \\
\hline CHEMBL1909455 & 688798 & 4.65 & 4.7726 & TST & \\
\hline CHEMBL312163 & 688798 & 6.0 & 4.7596 & TST & \\
\hline CHEMBL1349333 & 688798 & 7.3497 & 5.3564 & TST & \\
\hline CHEMBL1537344 & 688798 & 4.4 & 4.8023 & TST & \\
\hline CHEMBL3191279 & 688798 & 2.35 & 4.8551 & TST & \\
\hline CHEMBL1447680 & 688798 & 3.1 & 5.7138 & TST & \\
\hline CHEMBL1487938 & 688798 & 4.45 & 5.3844 & TST & \\
\hline CHEMBL1370733 & 688798 & 4.3 & 5.3541 & TST & \\
\hline CHEMBL1080918 & 688798 & 4.7 & 5.204 & TST & \\
\hline CHEMBL1474813 & 688798 & 4.6 & 5.6576 & TST & \\
\hline CHEMBL1394473 & 688798 & 6.1 & 5.629 & TST & \\
\hline CHEMBL1473186 & 688798 & 7.15 & 5.2697 & TST & \\
\hline CHEMBL1405834 & 688798 & 5.4 & 4.7626 & TST & \\
\hline CHEMBL1443180 & 688798 & 4.3 & 4.8537 & TST & \\
\hline CHEMBL400777 & 688798 & 10.2 & 5.2169 & TST & \\
\hline CHEMBL1575084 & 688798 & 4.9 & 5.19600 & 0000000001 & TST \\
\hline CHEMBL1558501 & 688798 & 3.45 & 5.36299 & 99999999995 & TST \\
\hline CHEMBL1358623 & 688798 & 4.5 & 5.2809 & TST & \\
\hline CHEMBL1485640 & 688798 & 3.9 & 5.4847 & TST & \\
\hline CHEMBL1391976 & 688798 & 4.7 & 5.5084 & TST & \\
\hline CHEMBL1384064 & 688798 & 4.45 & 5.1354 & TST & \\
\hline CHEMBL1528787 & 688798 & 4.4 & 5.1154 & TST & \\
\hline CHEMBL1319648 & 688798 & 4.35 & 5.1122 & TST & \\
\hline CHEMBL1474287 & 688798 & 10.15 & 4.9328 & TST & \\
\hline CHEMBL1513710 & 688798 & 7.6498 & 5.6298 & TST & \\
\hline CHEMBL1317910 & 688798 & 4.5 & 5.3277 & TST & \\
\hline CHEMBL1516402 & 688798 & 4.55 & 5.4919 & TST & \\
\hline CHEMBL1334722 & 688798 & 5.0 & 5.2501 & TST & \\
\hline CHEMBL1402494 & 688798 & 5.9 & 5.4349 & TST & \\
\hline CHEMBL1357555 & 688798 & 7.15 & 5.0451 & TST & \\
\hline CHEMBL1306960 & 688798 & 4.4 & 5.4267 & TST & \\
\hline CHEMBL1535663 & 688798 & 4.75 & 5.4942 & TST & \\
\hline CHEMBL1477257 & 688798 & 2.95 & 5.3889 & TST & \\
\hline
\end{tabular}




\begin{tabular}{|c|c|c|c|c|c|}
\hline \multicolumn{6}{|c|}{ Supplemental Table S2.txt } \\
\hline CHEMBL1398383 & 688798 & 4.0 & 4.8606 & TST & \\
\hline CHEMBL1315108 & 688798 & 9.2218 & 5.3955 & TST & \\
\hline CHEMBL1396083 & 688798 & 4.45 & 5.5495 & TST & \\
\hline CHEMBL1445042 & 688798 & 4.5 & 5.58299 & 9999999999 & TST \\
\hline CHEMBL1404346 & 688798 & 7.8013 & 5.275 & TST & \\
\hline CHEMBL1354675 & 688798 & 8.1024 & 5.2972 & TST & \\
\hline CHEMBL1523898 & 688798 & 3.55 & 5.5505 & TST & \\
\hline CHEMBL1484402 & 688798 & 2.75 & 5.7125 & TST & \\
\hline CHEMBL1365665 & 688798 & 8.0 & 5.2416 & TST & \\
\hline CHEMBL1312235 & 688798 & 4.4 & 4.914 & TST & \\
\hline CHEMBL1565767 & 688798 & 4.15 & 4.6989 & TST & \\
\hline CHEMBL1970711 & 688798 & 2.05 & 5.3781 & TST & \\
\hline CHEMBL1601306 & 688798 & 4.15 & 4.9792 & TST & \\
\hline CHEMBL1381318 & 688798 & 4.35 & 4.5855 & TST & \\
\hline CHEMBL1396582 & 688798 & 3.95 & 5.5318 & TST & \\
\hline CHEMBL1520224 & 688798 & 5.0 & 5.6599 & TST & \\
\hline CHEMBL1453348 & 688798 & 3.0 & 5.3109 & TST & \\
\hline CHEMBL1406391 & 688798 & 4.35 & 5.5955 & TST & \\
\hline CHEMBL1589888 & 688798 & 6.35 & 5.8305 & TST & \\
\hline CHEMBL1433739 & 688798 & 9.0458 & 5.2621 & TST & \\
\hline CHEMBL1397683 & 688798 & 7.2 & 5.4097 & TST & \\
\hline CHEMBL1522401 & 688798 & 3.95 & 5.0775 & TST & \\
\hline CHEMBL1518510 & 688798 & 5.2 & 5.3673 & TST & \\
\hline CHEMBL1442552 & 688798 & 4.35 & 5.5009 & TST & \\
\hline CHEMBL1318291 & 688798 & 3.55 & 5.5327 & TST & \\
\hline CHEMBL1596533 & 688798 & 9.2218 & 5.4973 & TST & \\
\hline CHEMBL1551508 & 688798 & 4.9 & 5.0399 & TST & \\
\hline CHEMBL1498431 & 688798 & 5.65 & 5.0831 & TST & \\
\hline CHEMBL1355287 & 688798 & 4.7 & 5.3282 & TST & \\
\hline CHEMBL1437666 & 688798 & 5.8 & 5.1434 & TST & \\
\hline CHEMBL1334631 & 688798 & 4.8 & 5.4022 & TST & \\
\hline CHEMBL1439410 & 688798 & 5.85 & 5.6217 & TST & \\
\hline CHEMBL1596141 & 688798 & 4.9 & 5.1155 & TST & \\
\hline CHEMBL1554213 & 688798 & 9.0458 & 5.7124 & TST & \\
\hline CHEMBL1324624 & 688798 & 5.05 & 4.973 & TST & \\
\hline CHEMBL1319059 & 688798 & 4.9 & 5.3957 & TST & \\
\hline CHEMBL1327128 & 688798 & 10.95 & 5.6292 & TST & \\
\hline CHEMBL1544241 & 688798 & 4.4 & 5.5122 & TST & \\
\hline CHEMBL1315752 & 688798 & 4.55 & 5.593 & TST & \\
\hline CHEMBL1590531 & 688798 & 2.8 & 5.3982 & TST & \\
\hline CHEMBL1358504 & 688798 & 3.95 & 5.8969 & TST & \\
\hline CHEMBL1496708 & 688798 & 4.95 & 5.3966 & TST & \\
\hline CHEMBL1513480 & 688798 & 4.7 & 5.5231 & TST & \\
\hline CHEMBL1396767 & 688798 & 5.05 & 5.2549 & TST & \\
\hline CHEMBL1586973 & 688798 & 4.95 & 5.5858 & TST & \\
\hline CHEMBL1459125 & 688798 & 5.15 & 5.2726 & TST & \\
\hline CHEMBL1355047 & 688798 & 3.3 & 5.4612 & TST & \\
\hline CHEMBL1574122 & 688798 & 4.85 & 4.9822 & TST & \\
\hline
\end{tabular}




\begin{tabular}{|c|c|c|c|c|c|}
\hline \multirow[b]{2}{*}{ CHEMBL1372240 } & \multicolumn{5}{|c|}{ Supplemental Table S2.txt } \\
\hline & 688798 & 4.15 & 5.4174 & TST & \\
\hline CHEMBL1358905 & 688798 & 3.95 & 5.6627 & TST & \\
\hline CHEMBL1494039 & 688798 & 5.2 & 5.24799 & 9999999999 & TST \\
\hline CHEMBL1395520 & 688798 & 4.7 & 5.6284 & TST & \\
\hline CHEMBL1599161 & 688798 & 4.6 & 5.2514 & TST & \\
\hline CHEMBL1343277 & 688798 & 2.95 & 5.593 & TST & \\
\hline CHEMBL1429570 & 688798 & 4.25 & 4.721 & TST & \\
\hline CHEMBL458603 & 688798 & 3.95 & 5.3789 & TST & \\
\hline CHEMBL1426027 & 688798 & 4.4 & 5.0268 & TST & \\
\hline CHEMBL1552146 & 688798 & 5.15 & 5.3047 & TST & \\
\hline CHEMBL1405102 & 688798 & 9.0458 & 5.4677 & TST & \\
\hline CHEMBL1555541 & 688798 & 3.1 & 4.8958 & TST & \\
\hline CHEMBL1355889 & 688798 & 4.35 & 5.1303 & TST & \\
\hline CHEMBL1465769 & 688798 & 3.95 & 5.5433 & TST & \\
\hline CHEMBL3209649 & 688798 & 7.5003 & 5.4012 & TST & \\
\hline CHEMBL1492823 & 688798 & 3.95 & 5.3318 & TST & \\
\hline CHEMBL1476211 & 688798 & 7.5003 & 5.7134 & TST & \\
\hline CHEMBL1326875 & 688798 & 5.5 & 5.0863 & TST & \\
\hline CHEMBL1559740 & 688798 & 4.2 & 5.2827 & TST & \\
\hline CHEMBL1444086 & 688798 & 5.5 & 5.484 & TST & \\
\hline CHEMBL1530340 & 688798 & 7.5498 & 5.6655 & TST & \\
\hline CHEMBL1503050 & 688798 & 4.4 & 4.8869 & TST & \\
\hline CHEMBL1317966 & 688798 & 3.75 & 5.2496 & TST & \\
\hline CHEMBL1367244 & 688798 & 4.25 & 5.2332 & TST & \\
\hline CHEMBL1378418 & 688798 & 5.0 & 5.1321 & TST & \\
\hline CHEMBL1563511 & 688798 & 7.1002 & 5.141 & TST & \\
\hline CHEMBL1528257 & 688798 & 7.2 & 5.0308 & TST & \\
\hline CHEMBL43612 & 688798 & 6.0 & 4.5926 & TST & \\
\hline CHEMBL1513741 & 688798 & 4.0 & 5.1836 & TST & \\
\hline CHEMBL1434579 & 688798 & 4.7 & 5.7149 & TST & \\
\hline CHEMBL1562700 & 688798 & 4.8 & 5.2235 & TST & \\
\hline CHEMBL1378109 & 688798 & 4.0 & 5.4383 & TST & \\
\hline CHEMBL1438204 & 688798 & 5.1 & 5.2754 & TST & \\
\hline CHEMBL1332959 & 688798 & 4.2 & 5.1781 & TST & \\
\hline CHEMBL1452048 & 688798 & 5.1 & 5.6849 & TST & \\
\hline CHEMBL1513049 & 688798 & 4.6 & 5.1728 & TST & \\
\hline CHEMBL 1340578 & 688798 & 6.45 & 5.2337 & TST & \\
\hline CHEMBL1236854 & 688798 & 7.4498 & 4.7146 & TST & \\
\hline CHEMBL1356146 & 688798 & 9.3979 & 5.5309 & TST & \\
\hline CHEMBL1333575 & 688798 & 3.5 & 5.2978 & TST & \\
\hline CHEMBL1513288 & 688798 & 7.0 & 5.3754 & TST & \\
\hline CHEMBL1561795 & 688798 & 4.65 & 4.8519 & TST & \\
\hline CHEMBL1473767 & 688798 & 5.35 & 5.5534 & TST & \\
\hline CHEMBL1476992 & 688798 & 3.1 & 5.499 & TST & \\
\hline CHEMBL1592042 & 688798 & 5.0 & 5.2838 & TST & \\
\hline CHEMBL1541779 & 688798 & 4.3 & 5.131 & TST & \\
\hline CHEMBL1428658 & 688798 & 5.25 & 5.4568 & TST & \\
\hline CHEMBL1435229 & 688798 & 9.5229 & 5.2929 & TST & \\
\hline
\end{tabular}




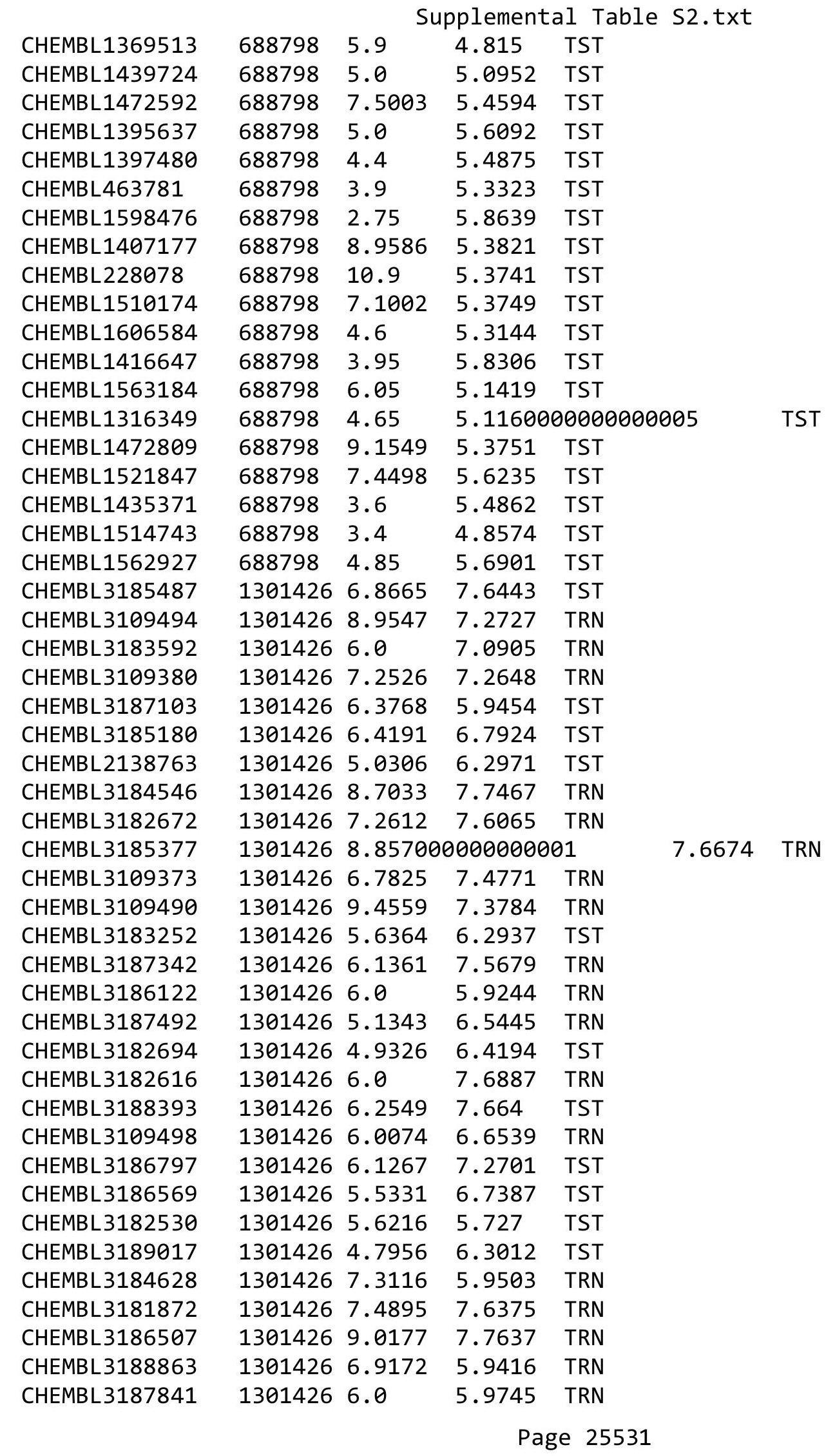


Supplemental Table S2.txt

\begin{tabular}{|c|c|c|c|c|c|}
\hline CHEMBL3109486 & 1301426 & 8.1713 & \multicolumn{2}{|c|}{ 7.662999999999999 } & TRN \\
\hline CHEMBL 3182981 & 1301426 & 6.0 & 5.8132 & TRN & \\
\hline CHEMBL3188806 & 1301426 & 5.9788 & 7.505 & TST & \\
\hline CHEMBL 3184630 & 1301426 & 5.0711 & \multicolumn{2}{|c|}{5.797999999999999} & TST \\
\hline CHEMBL1885107 & 1301426 & 5.5638 & 6.8386 & TST & \\
\hline CHEMBL 3109484 & 1301426 & 7.2418 & 7.7189 & TRN & \\
\hline CHEMBL3109376 & 1301426 & 7.1079 & 7.2092 & TRN & \\
\hline CHEMBL1459090 & 1301426 & 7.2299 & 6.2233 & TST & \\
\hline CHEMBL 3188556 & 1301426 & 5.3757 & 5.9036 & TRN & \\
\hline CHEMBL3188295 & 1301426 & 8.4868 & 7.7337 & TRN & \\
\hline CHEMBL 3185620 & 1301426 & 8.2958 & 7.1607 & TRN & \\
\hline CHEMBL3189079 & 1301426 & 5.3468 & 6.1427 & TRN & \\
\hline CHEMBL3185125 & 1301426 & 5.7077 & 6.9303 & TRN & \\
\hline CHEMBL3185941 & 1301426 & 5.5622 & 5.9268 & TRN & \\
\hline CHEMBL3185191 & 1301426 & 6.4763 & 7.2953 & TRN & \\
\hline CHEMBL 3182469 & 1301426 & 6.51 & 5.7237 & TRN & \\
\hline CHEMBL3181880 & 1301426 & 6.5867 & 6.0426 & TRN & \\
\hline CHEMBL3183494 & 1301426 & 5.9281 & 7.1975 & TST & \\
\hline CHEMBL3185067 & 1301426 & 7.2048 & \multicolumn{2}{|c|}{7.3420000000000005} & TRN \\
\hline CHEMBL3187180 & 1301426 & 6.0 & 5.8849 & TRN & \\
\hline CHEMBL 3187578 & 1301426 & 5.8477 & 5.7544 & TRN & \\
\hline CHEMBL3185971 & 1301426 & 7.6904 & 6.9629 & TRN & \\
\hline CHEMBL3188197 & 1301426 & 5.4306 & 6.2868 & TST & \\
\hline CHEMBL3187157 & 1301426 & 6.3947 & 6.4771 & TST & \\
\hline CHEMBL 3184219 & 1301426 & 6.7471 & 7.1414 & TST & \\
\hline CHEMBL 3109383 & 1301426 & 7.5935 & 7.5329 & TRN & \\
\hline CHEMBL 3182845 & 1301426 & 6.0757 & \multicolumn{2}{|c|}{6.082999999999999} & TST \\
\hline CHEMBL3182989 & 1301426 & 6.644 & 5.9401 & TRN & \\
\hline CHEMBL1328878 & 1301426 & 6.5986 & 6.1259 & TST & \\
\hline CHEMBL 2143130 & 1301426 & 6.0 & 7.228 & TRN & \\
\hline CHEMBL 3186842 & 1301426 & 6.5986 & 7.2416 & TST & \\
\hline CHEMBL 3187519 & 1301426 & 6.9208 & 7.4343 & TRN & \\
\hline CHEMBL 3182083 & 1301426 & 5.5918 & 5.8074 & TRN & \\
\hline CHEMBL 3186882 & 1301426 & 6.5243 & 7.2277 & TRN & \\
\hline CHEMBL3183345 & 1301426 & 5.6716 & 6.2284 & TST & \\
\hline CHEMBL3187125 & 1301426 & 5.6091 & 6.2432 & TRN & \\
\hline CHEMBL3181792 & 1301426 & 6.0 & 7.0487 & TRN & \\
\hline CHEMBL 3183940 & 1301426 & 5.7258 & 5.7327 & TRN & \\
\hline CHEMBL3182581 & 1301426 & 6.2832 & 7.3344 & TRN & \\
\hline CHEMBL3185391 & 1301426 & 6.0 & 5.8653 & TRN & \\
\hline CHEMBL3109371 & 1301426 & 6.0 & 7.1849 & TRN & \\
\hline CHEMBL 3184870 & 1301426 & 5.9066 & 5.9583 & TRN & \\
\hline CHEMBL3181797 & 1301426 & 6.0 & 7.6837 & TRN & \\
\hline CHEMBL3188400 & 1301426 & 6.0 & 7.6521 & TRN & \\
\hline CHEMBL3188154 & 1301426 & 6.3344 & 7.3987 & TST & \\
\hline CHEMBL3182166 & 1301426 & 6.0 & 5.8468 & TRN & \\
\hline CHEMBL3109493 & 1301426 & 9.2668 & 7.7791 & TRN & \\
\hline CHEMBL3183138 & 1301426 & 5.3063 & 5.777 & TRN & \\
\hline
\end{tabular}


Supplemental Table S2.txt

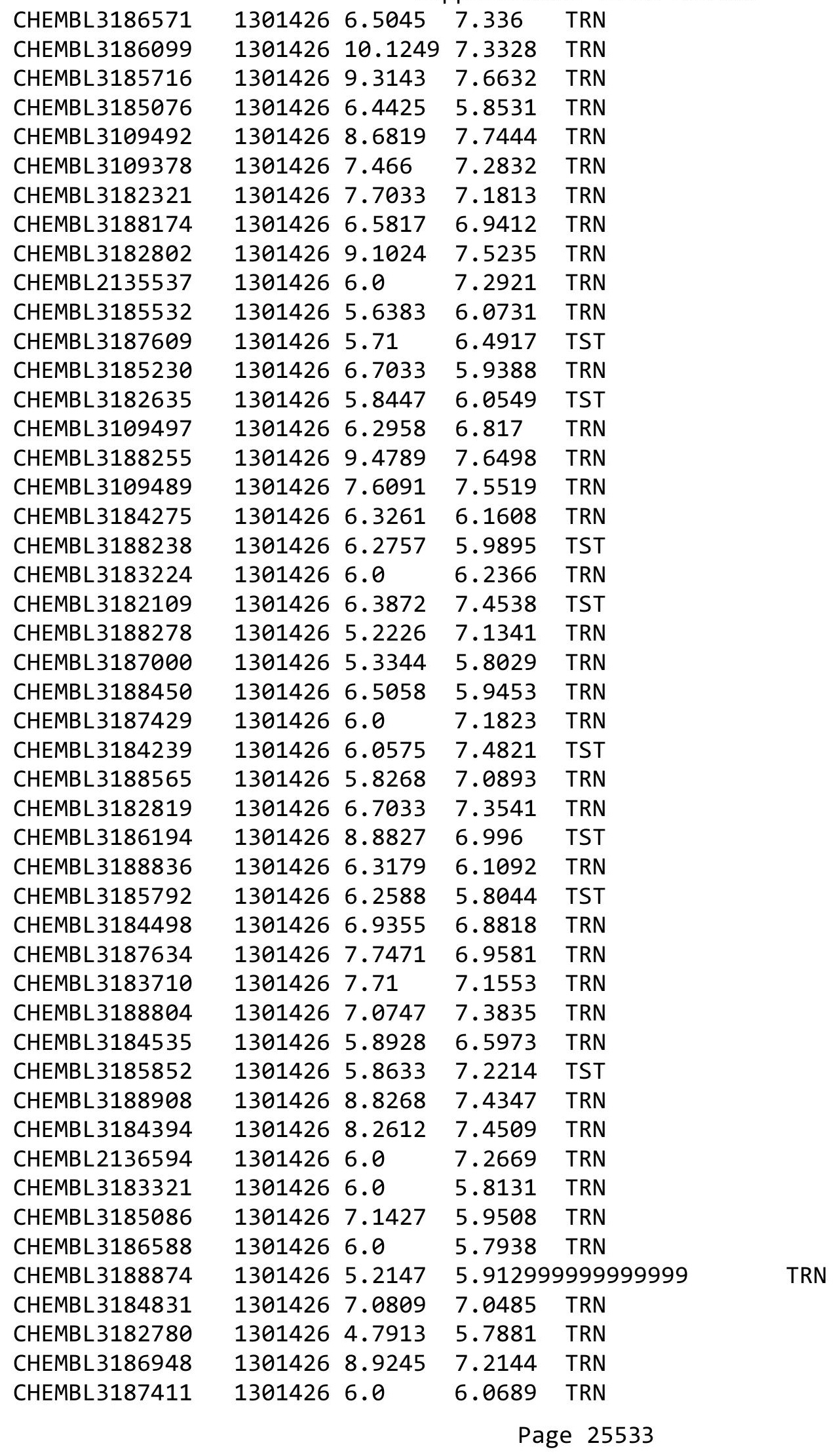


Supplemental Table S2.txt

\begin{tabular}{|c|c|c|c|c|c|}
\hline CHEMBL3187198 & 1301426 & 6.7328 & 5.8629 & TRN & \\
\hline CHEMBL3187823 & 1301426 & 5.0991 & 6.3349 & TST & \\
\hline CHEMBL2143553 & 1301426 & 6.0 & 7.3294 & TRN & \\
\hline CHEMBL3109487 & 1301426 & 7.9788 & 7.6554 & TRN & \\
\hline CHEMBL3109377 & 1301426 & 7.2457 & 7.3103 & TRN & \\
\hline CHEMBL576295 & 600391 & 5.7212 & 5.8168 & TRN & \\
\hline CHEMBL576677 & 600391 & 5.8861 & 5.8915 & TRN & \\
\hline CHEMBL568898 & 600391 & 3.3979 & 3.3084 & TRN & \\
\hline CHEMBL566695 & 600391 & 5.7959 & 5.853 & TRN & \\
\hline CHEMBL572007 & 600391 & 5.6021 & 5.5618 & TRN & \\
\hline CHEMBL389506 & 600391 & 5.585 & 5.2813 & TST & \\
\hline CHEMBL229399 & 600391 & 5.585 & 4.631 & TST & \\
\hline CHEMBL569126 & 600391 & 5.5686 & 5.655 & TRN & \\
\hline CHEMBL577092 & 600391 & 3.3979 & 3.0836 & TST & \\
\hline CHEMBL571155 & 600391 & 3.3979 & 3.3664 & TRN & \\
\hline CHEMBL568377 & 600391 & 5.7696 & 5.8149 & TRN & \\
\hline CHEMBL202029 & 600391 & 5.5376 & 5.5966 & TRN & \\
\hline CHEMBL397485 & 600391 & 5.4559 & 5.38899 & 9999999999 & TRN \\
\hline CHEMBL577955 & 600391 & 3.3979 & 3.4696 & TRN & \\
\hline CHEMBL570493 & 600391 & 5.699 & 5.7675 & TRN & \\
\hline CHEMBL570498 & 600391 & 3.3979 & 3.3857 & TRN & \\
\hline CHEMBL578385 & 600391 & 5.4685 & 5.5817 & TRN & \\
\hline CHEMBL568394 & 600391 & 5.3872 & 5.1531 & TST & \\
\hline CHEMBL570717 & 600391 & 5.3768 & 5.3508 & TRN & \\
\hline CHEMBL572008 & 600391 & 3.3979 & 3.4831 & TST & \\
\hline CHEMBL577093 & 600391 & 3.3979 & 2.8305 & TST & \\
\hline CHEMBL585718 & 600391 & 6.0044 & 5.8422 & TRN & \\
\hline CHEMBL569798 & 600391 & 4.8861 & 4.9014 & TRN & \\
\hline CHEMBL583267 & 600391 & 3.3979 & 3.4454 & TRN & \\
\hline CHEMBL569207 & 600391 & 3.3979 & 2.458 & TST & \\
\hline CHEMBL566725 & 600391 & 3.3979 & 3.0365 & TST & \\
\hline CHEMBL567328 & 600391 & 5.7959 & 5.7436 & TRN & \\
\hline CHEMBL569799 & 600391 & 3.3979 & 1.8786 & TST & \\
\hline CHEMBL570495 & 600391 & 4.4949 & 3.6823 & TST & \\
\hline CHEMBL569785 & 600391 & 5.2676 & 5.2846 & TRN & \\
\hline CHEMBL576042 & 600391 & 4.6198 & 4.7372 & TRN & \\
\hline CHEMBL381933 & 600391 & 5.6021 & 5.6926 & TRN & \\
\hline CHEMBL586053 & 600391 & 5.7959 & 5.7415 & TRN & \\
\hline CHEMBL568393 & 600391 & 5.7696 & 5.6414 & TRN & \\
\hline CHEMBL582796 & 600391 & 3.3979 & 2.3301 & TST & \\
\hline CHEMBL585343 & 600391 & 5.585 & 5.7399 & TRN & \\
\hline CHEMBL585678 & 600391 & 3.3979 & 3.4258 & TRN & \\
\hline CHEMBL570940 & 600391 & 5.8861 & 6.0265 & TRN & \\
\hline CHEMBL577954 & 600391 & 4.5528 & 4.4692 & TRN & \\
\hline CHEMBL567969 & 600391 & 5.8539 & 5.8083 & TRN & \\
\hline CHEMBL570726 & 600391 & 5.585 & 5.6599 & TRN & \\
\hline CHEMBL389169 & 600391 & 5.5376 & 5.5205 & TRN & \\
\hline \multirow[t]{2}{*}{ CHEMBL576675 } & 600391 & 5.7959 & 5.28700 & 2000000001 & TST \\
\hline & & \multicolumn{4}{|c|}{ Page 25534} \\
\hline
\end{tabular}


Supplemental Table S2.txt

\begin{tabular}{|c|c|c|c|c|c|}
\hline CHEMBL582814 & 600391 & 3.3979 & \multicolumn{2}{|c|}{3.4419999999999997} & TRN \\
\hline CHEMBL578602 & 600391 & 3.3979 & 3.3515 & TRN & \\
\hline CHEMBL67 & 600391 & 5.9586 & 3.7707 & TST & \\
\hline CHEMBL569205 & 600391 & 5.6021 & 5.5938 & TRN & \\
\hline CHEMBL568181 & 600391 & 5.6198 & 5.6664 & TRN & \\
\hline CHEMBL566696 & 600391 & 6.1739 & 5.8841 & TRN & \\
\hline CHEMBL570250 & 600391 & 5.8539 & 5.6586 & TRN & \\
\hline CHEMBL570494 & 600391 & 3.3979 & 3.4462 & TRN & \\
\hline CHEMBL576867 & 600391 & 3.3979 & 3.6514 & TST & \\
\hline CHEMBL585907 & 600391 & 5.5528 & 5.586 & TRN & \\
\hline CHEMBL576279 & 600391 & 4.8539 & 4.7271 & TRN & \\
\hline CHEMBL 381787 & 600391 & 5.6576 & 5.6739 & TRN & \\
\hline CHEMBL 3897687 & 1640572 & 5.1367 & 5.395 & TRN & \\
\hline CHEMBL 3914402 & 1640572 & 5.6198 & 5.5106 & TRN & \\
\hline CHEMBL 3934373 & 1640572 & 6.4437 & 6.6311 & TRN & \\
\hline CHEMBL 3958782 & 1640572 & 6.1871 & 5.7565 & TRN & \\
\hline CHEMBL3911159 & 1640572 & 6.8239 & 6.2709 & TRN & \\
\hline CHEMBL 3962976 & 1640572 & 5.9586 & 6.2028 & TRN & \\
\hline CHEMBL3941128 & 1640572 & 5.2147 & 5.5207 & TRN & \\
\hline CHEMBL 3932675 & 1640572 & 6.6576 & 6.3155 & TRN & \\
\hline CHEMBL3975393 & 1640572 & 6.8861 & 6.6202 & TRN & \\
\hline CHEMBL3965987 & 1640572 & 5.8861 & 5.6669 & TRN & \\
\hline CHEMBL 3942426 & 1640572 & 5.1192 & 5.0575 & TST & \\
\hline CHEMBL 3968505 & 1640572 & 6.7212 & 6.7177 & TRN & \\
\hline CHEMBL 3959989 & 1640572 & 6.8861 & 6.6894 & TRN & \\
\hline CHEMBL3930981 & 1640572 & 7.1249 & 6.9617 & TRN & \\
\hline CHEMBL 3921028 & 1640572 & 5.8539 & 6.0169 & TRN & \\
\hline CHEMBL 3957120 & 1640572 & 7.041 & 6.5686 & TRN & \\
\hline CHEMBL3977385 & 1640572 & 5.9208 & 6.3358 & TRN & \\
\hline CHEMBL 3972879 & 1640572 & 6.5229 & 6.4898 & TRN & \\
\hline CHEMBL3922188 & 1640572 & 5.0362 & 5.2044 & TRN & \\
\hline CHEMBL 3909647 & 1640572 & 6.1675 & 6.3857 & TRN & \\
\hline CHEMBL3975935 & 1640572 & 5.2441 & 4.945 & TRN & \\
\hline CHEMBL3963017 & 1640572 & 5.5229 & 5.2283 & TRN & \\
\hline CHEMBL3925816 & 1640572 & 5.7959 & 6.2055 & TRN & \\
\hline CHEMBL3979332 & 1640572 & 5.9208 & 6.0626 & TRN & \\
\hline CHEMBL 3948148 & 1640572 & 5.8539 & 6.0463 & TRN & \\
\hline CHEMBL3956881 & 1640572 & 5.9586 & 5.6895 & TRN & \\
\hline CHEMBL3934329 & 1640572 & 5.4949 & 6.1012 & TRN & \\
\hline CHEMBL3957650 & 1640572 & 6.5686 & 6.5799 & TRN & \\
\hline CHEMBL3934319 & 1640572 & 6.1192 & 6.1651 & TRN & \\
\hline CHEMBL3963653 & 1640572 & 5.2076 & 5.7746 & TRN & \\
\hline CHEMBL 3892814 & 1640572 & 5.284 & 5.4717 & TST & \\
\hline CHEMBL3956879 & 1640572 & 5.3098 & 5.5198 & TRN & \\
\hline CHEMBL 3889743 & 1640572 & 6.1871 & 6.3566 & TRN & \\
\hline CHEMBL3960851 & 1640572 & 6.2518 & 6.1236 & TRN & \\
\hline CHEMBL 3913683 & 1640572 & 6.7447 & 7.1634 & TRN & \\
\hline CHEMBL 3897379 & 1640572 & 7.3979 & 7.155 & TRN & \\
\hline
\end{tabular}


Supplemental Table S2.txt

\begin{tabular}{|c|c|c|c|c|c|}
\hline CHEMBL3906406 & 1640572 & 6.6576 & 5.9557 & TRN & \\
\hline CHEMBL3936192 & 1640572 & 6.1308 & 6.1485 & TRN & \\
\hline CHEMBL3964770 & 1640572 & 6.0706 & 6.4495 & TRN & \\
\hline CHEMBL3978120 & 1640572 & 5.2076 & \multicolumn{2}{|c|}{4.986000000000001} & TRN \\
\hline CHEMBL 3987152 & 1640572 & 5.5376 & 5.8709 & TRN & \\
\hline CHEMBL 3898288 & 1640572 & 5.2924 & 5.4443 & TRN & \\
\hline CHEMBL3914128 & 1640572 & 6.2291 & 5.6454 & TST & \\
\hline CHEMBL 3974887 & 1640572 & 5.3188 & 5.1126 & TST & \\
\hline CHEMBL3979776 & 1640572 & 5.1024 & 5.2942 & TRN & \\
\hline CHEMBL 3949032 & 1640572 & 5.1938 & 5.4604 & TRN & \\
\hline CHEMBL 3957007 & 1640572 & 6.5528 & 6.5157 & TRN & \\
\hline CHEMBL 3905142 & 1640572 & 5.8861 & 5.7413 & TRN & \\
\hline CHEMBL3974957 & 1640572 & 5.3372 & 5.5538 & TRN & \\
\hline CHEMBL3958405 & 1640572 & 6.5686 & 6.5041 & TRN & \\
\hline CHEMBL 3980697 & 1640572 & 6.0605 & 6.3243 & TRN & \\
\hline CHEMBL3910342 & 1640572 & 5.5086 & 4.5896 & TST & \\
\hline CHEMBL3957530 & 1640572 & 5.9208 & 5.8946 & TST & \\
\hline CHEMBL 3943346 & 1640572 & 7.2596 & \multicolumn{2}{|c|}{7.247999999999999} & TRN \\
\hline CHEMBL3915479 & 1640572 & 5.2441 & 5.4822 & TRN & \\
\hline CHEMBL 3903992 & 1640572 & 6.8861 & 6.4916 & TRN & \\
\hline CHEMBL3890512 & 1640572 & 5.8861 & 5.6818 & TRN & \\
\hline CHEMBL3931035 & 1640572 & 5.2007 & 5.4967 & TRN & \\
\hline CHEMBL3977611 & 1640572 & 6.6576 & \multicolumn{2}{|c|}{6.162000000000001} & TRN \\
\hline CHEMBL3972046 & 1640572 & 5.6778 & 4.8665 & TST & \\
\hline CHEMBL 3890439 & 1640572 & 6.1549 & 4.8617 & TST & \\
\hline CHEMBL3950804 & 1640572 & 6.0 & 6.1641 & TRN & \\
\hline CHEMBL 3981844 & 1640572 & 6.3468 & 6.0418 & TST & \\
\hline CHEMBL 3966442 & 1640572 & 7.1308 & 6.7396 & TRN & \\
\hline CHEMBL3971573 & 1640572 & 5.6198 & 4.7584 & TST & \\
\hline CHEMBL 3961959 & 1640572 & 7.3872 & 7.4989 & TRN & \\
\hline CHEMBL3958349 & 1640572 & 5.6021 & 5.39 & TRN & \\
\hline CHEMBL 3978854 & 1640572 & 5.8539 & 5.7972 & TRN & \\
\hline CHEMBL3926129 & 1640572 & 6.2147 & 5.5034 & TST & \\
\hline CHEMBL3957960 & 1640572 & 5.7447 & 5.8678 & TRN & \\
\hline CHEMBL 3891842 & 1640572 & 5.041 & 5.9568 & TST & \\
\hline CHEMBL3952567 & 1640572 & 5.6198 & 5.7759 & TRN & \\
\hline CHEMBL 3980128 & 1640572 & 5.2676 & 5.2949 & TRN & \\
\hline CHEMBL3941676 & 1640572 & 6.9586 & 6.8556 & TRN & \\
\hline CHEMBL3976177 & 1640572 & 6.2076 & 6.3049 & TRN & \\
\hline CHEMBL3959590 & 1640572 & 5.9586 & 6.7867 & TST & \\
\hline CHEMBL3962498 & 1640572 & 6.5376 & 6.2972 & TRN & \\
\hline CHEMBL3973991 & 1640572 & 6.1249 & 6.0109 & TRN & \\
\hline CHEMBL3973725 & 1640572 & 5.9586 & 6.1606 & TRN & \\
\hline CHEMBL3914890 & 1640572 & 5.1805 & 5.0022 & TRN & \\
\hline CHEMBL3948341 & 1640572 & 6.5686 & 6.1617 & TRN & \\
\hline CHEMBL3982964 & 1640572 & 5.7959 & 6.5553 & TST & \\
\hline CHEMBL3960306 & 1640572 & 6.7696 & 7.0663 & TRN & \\
\hline CHEMBL3906349 & 1640572 & 6.8539 & 7.091 & TRN & \\
\hline
\end{tabular}


Supplemental Table S2.txt

\begin{tabular}{|c|c|c|c|c|c|}
\hline CHEMBL3948469 & 1640572 & 5.4815 & 5.4513 & TRN & \\
\hline CHEMBL3898952 & 1640572 & 7.1024 & 6.9565 & TRN & \\
\hline CHEMBL3891513 & 1640572 & 6.5086 & 6.4227 & TRN & \\
\hline CHEMBL3942190 & 1640572 & 5.8861 & 6.0367 & TRN & \\
\hline CHEMBL3942994 & 1640572 & 7.1135 & 6.8399 & TRN & \\
\hline CHEMBL3946465 & 1640572 & 7.0 & 6.9374 & TRN & \\
\hline CHEMBL3951825 & 1640572 & 6.8861 & 6.2129 & TRN & \\
\hline CHEMBL3950093 & 1640572 & 6.5376 & 6.4075 & TRN & \\
\hline CHEMBL 3981068 & 1640572 & 5.9586 & 5.6361 & TRN & \\
\hline CHEMBL3936811 & 1640572 & 6.3372 & 5.9994 & TST & \\
\hline CHEMBL3941564 & 1640572 & 5.5086 & 5.1901 & TRN & \\
\hline CHEMBL3964934 & 1640572 & 6.5229 & 6.6137 & TRN & \\
\hline CHEMBL3917419 & 1640572 & 6.1427 & 6.1928 & TRN & \\
\hline CHEMBL3979799 & 1640572 & 6.3098 & 6.059 & TRN & \\
\hline CHEMBL3956021 & 1640572 & 6.4318 & 6.6188 & TRN & \\
\hline CHEMBL3979731 & 1640572 & 5.2596 & 5.5136 & TRN & \\
\hline CHEMBL3957390 & 1640572 & 6.4202 & 6.4383 & TRN & \\
\hline CHEMBL3947639 & 1640572 & 5.9586 & 5.7634 & TRN & \\
\hline CHEMBL3923779 & 1640572 & 6.7212 & 6.8115 & TRN & \\
\hline CHEMBL 3928542 & 1640572 & 5.5528 & 5.3599 & TRN & \\
\hline CHEMBL3905408 & 1640572 & 5.8239 & 6.1379 & TRN & \\
\hline CHEMBL3932167 & 1640572 & 5.8539 & 5.8653 & TRN & \\
\hline CHEMBL3968541 & 1640572 & 5.0315 & 4.9791 & TRN & \\
\hline CHEMBL3965498 & 1640572 & 7.2441 & \multicolumn{2}{|c|}{7.0489999999999995} & TRN \\
\hline CHEMBL3960221 & 1640572 & 5.5086 & 5.9862 & TRN & \\
\hline CHEMBL3955507 & 1640572 & 5.3979 & 5.5736 & TRN & \\
\hline CHEMBL3928817 & 1640572 & 5.7696 & 5.308 & TRN & \\
\hline CHEMBL3898673 & 1640572 & 5.3188 & 5.5728 & TRN & \\
\hline CHEMBL3896314 & 1640572 & 5.6576 & 4.8976 & TST & \\
\hline CHEMBL 3890484 & 1640572 & 5.3098 & 5.7152 & TST & \\
\hline CHEMBL3943328 & 1640572 & 6.3098 & \multicolumn{2}{|c|}{5.992000000000001} & TRN \\
\hline CHEMBL3928194 & 1640572 & 6.7212 & 6.5136 & TRN & \\
\hline CHEMBL3972371 & 1640572 & 5.5376 & 5.9466 & TRN & \\
\hline CHEMBL3967516 & 1640572 & 5.2147 & 5.1899 & TRN & \\
\hline CHEMBL3921201 & 1640572 & 5.041 & 5.1229 & TRN & \\
\hline CHEMBL3955177 & 1640572 & 6.3665 & 6.305 & TRN & \\
\hline CHEMBL 3890428 & 1640572 & 6.5376 & \multicolumn{2}{|c|}{6.617000000000001} & TRN \\
\hline CHEMBL3979763 & 1640572 & 6.2007 & 6.4338 & TRN & \\
\hline CHEMBL 3962769 & 1640572 & 5.3279 & 5.2754 & TRN & \\
\hline CHEMBL3939389 & 1640572 & 5.5686 & 5.3795 & TRN & \\
\hline CHEMBL3942873 & 1640572 & 6.2441 & \multicolumn{2}{|c|}{6.377000000000001} & TRN \\
\hline CHEMBL3930458 & 1640572 & 5.5376 & 5.0304 & TST & \\
\hline CHEMBL3986331 & 1640572 & 7.5086 & 7.2337 & TRN & \\
\hline CHEMBL3899058 & 1640572 & 6.4815 & 6.6032 & TRN & \\
\hline CHEMBL3960671 & 1640572 & 6.3665 & 6.1583 & TRN & \\
\hline CHEMBL3973712 & 1640572 & 5.0809 & 4.7233 & TST & \\
\hline CHEMBL3943912 & 1640572 & 6.8539 & 6.4081 & TRN & \\
\hline CHEMBL3965953 & 1640572 & 6.2441 & 6.1882 & TRN & \\
\hline
\end{tabular}

Page 25537 
Supplemental Table S2.txt

\begin{tabular}{|c|c|c|c|c|}
\hline Th & 540572 & & & \\
\hline & 640572 & & & \\
\hline & & & & \\
\hline AEMBL: & 572 & 5.585 & & \\
\hline AEMBL3920223 & 640572 & & & \\
\hline HEMBL3952720 & 640572 & 5.6576 & 3445 & \\
\hline HEMBL3980880 & 572 & & 786 & \\
\hline 3010 & 572 & & & \\
\hline AEMBL3896616 & 572 & & 4569 & \\
\hline HEMBL3962955 & 640572 & 76 & 3493 & \\
\hline HEMBL3956095 & 640572 & 12 & & \\
\hline IEMBL 3935282 & 72 & 72 & & \\
\hline AEMBL3S & & & & \\
\hline HEMBL3908925 & 52 & & 1359 & \\
\hline AEMBL3902127 & 572 & & & \\
\hline AEMBL3935976 & 72 & 15 & & \\
\hline AEMBL39 & 72 & & 61 & \\
\hline HEMBL39 & & & & \\
\hline HEMBL3950838 & 72 & & 86 & \\
\hline AEMBL39 & 72 & & & \\
\hline HEIMBLSS & 64 & & 02 & Niv \\
\hline AEMBL: & 2 & & 67 & \\
\hline AEMBL & & & & \\
\hline AFMRI 390 & & & & \\
\hline AEMBL39 & & & & I RIV \\
\hline HEMBL39 & 64 & & & RIN \\
\hline AEMBL3 & 2 & & & RN \\
\hline HFMBI 36 & 72 & & 58 & \\
\hline AEMBL38 & & & & IRIN \\
\hline HEMBL3964392 & 64 & & & 15 \\
\hline HEMBL3958446 & 64 & & 576 & RN \\
\hline AFMBI 3 & 2 & & 59 & RN \\
\hline 9 & & & 363 & \\
\hline HEMBL3911878 & 72 & & & T \\
\hline HEMBL 389114 & 640 & & & 「RN \\
\hline HEMBL3974876 & 2 & & & RN \\
\hline HFMRI 3 & & & 23 & TRN \\
\hline HEMBL3 & & & & RIV \\
\hline HEMBL3907244 & 640572 & & 1665 & TST \\
\hline AEMBL39327 & 72 & & & TRN \\
\hline HEMBL396 & 64 & & 263 & RN \\
\hline HEMBL3968427 & & & & ST \\
\hline HEMBL3957896 & 1640572 & & 143 & TRN \\
\hline AEMBL3928928 & 640572 & 76 & 3532 & TS \\
\hline MRI 3 & & & & $1 \mathrm{~S}$ \\
\hline CHEMBL3963768 & 1640572 & & & \\
\hline CHEMBL 3932985 & 1640 & 5.2291 & & \\
\hline SHEMBL3942701 & 1640572 & 5.6576 & 5.2465 & IST \\
\hline
\end{tabular}

Page 25538 
Supplemental Table S2.txt

\begin{tabular}{|c|c|c|c|c|}
\hline CHEMBL 3889985 & 1640572 & 6.9208 & 7.2694 & TRN \\
\hline CHEMBL3981835 & 1640572 & 5.7696 & 5.6588 & TST \\
\hline CHEMBL3899994 & 1640572 & 6.2757 & 6.0175 & TRN \\
\hline CHEMBL 3904890 & 1640572 & 5.6021 & 5.9427 & TRN \\
\hline CHEMBL3951095 & 1640572 & 7.0757 & \multicolumn{2}{|c|}{6.803999999999999} \\
\hline CHEMBL 3896259 & 1640572 & 5.7959 & 6.0606 & TRN \\
\hline CHEMBL3918599 & 1640572 & 6.3768 & 6.4968 & TRN \\
\hline CHEMBL 3950393 & 1640572 & 6.0223 & \multicolumn{2}{|c|}{6.3389999999999995} \\
\hline CHEMBL 3933853 & 1640572 & 5.8539 & 6.1635 & TRN \\
\hline CHEMBL3916565 & 1640572 & 5.2175 & 5.3589 & TRN \\
\hline CHEMBL3916008 & 1640572 & 5.4202 & 5.6754 & TRN \\
\hline CHEMBL 3948734 & 1640572 & 5.3768 & 5.2682 & TRN \\
\hline CHEMBL3953096 & 1640572 & 5.2924 & 4.7644 & TST \\
\hline CHEMBL 3907650 & 1640572 & 6.8861 & 6.6808 & TRN \\
\hline CHEMBL3913979 & 1640572 & 5.1739 & 4.2819 & TST \\
\hline CHEMBL 3968523 & 1640572 & 7.1308 & 7.0827 & TRN \\
\hline CHEMBL3904203 & 1640572 & 7.4437 & 7.4048 & TRN \\
\hline CHEMBL3973988 & 1640572 & 5.4202 & 5.0927 & TRN \\
\hline CHEMBL3911599 & 1640572 & 6.3768 & 6.3439 & TRN \\
\hline CHEMBL3969497 & 1640572 & 5.0177 & 5.6429 & TRN \\
\hline CHEMBL3915546 & 1640572 & 5.2757 & 5.4565 & TRN \\
\hline CHEMBL3970264 & 1640572 & 5.8539 & 5.8555 & TRN \\
\hline CHEMBL3936128 & 1640572 & 5.3279 & 5.2059 & TRN \\
\hline CHEMBL 3943504 & 1640572 & 7.3565 & 7.2185 & TRN \\
\hline CHEMBL 3980646 & 1640572 & 5.4089 & 5.8427 & TRN \\
\hline CHEMBL 3960258 & 1640572 & 6.3768 & 6.4622 & TRN \\
\hline CHEMBL 3937378 & 1640572 & 6.284 & 5.3687 & TST \\
\hline CHEMBL3965135 & 1640572 & 6.284 & 6.4012 & TRN \\
\hline CHEMBL 3971793 & 1640572 & 5.6383 & 5.5959 & TRN \\
\hline CHEMBL3891610 & 1640572 & 6.5229 & 6.6059 & TRN \\
\hline CHEMBL3969005 & 1640572 & 5.6778 & 5.6479 & TRN \\
\hline CHEMBL3926392 & 1640572 & 5.4089 & 5.1549 & TRN \\
\hline CHEMBL3930931 & 1640572 & 5.6021 & 6.0216 & TST \\
\hline CHEMBL 3950294 & 1640572 & 5.585 & 5.404 & TRN \\
\hline CHEMBL 3945428 & 1640572 & 5.8861 & 6.5089 & TRN \\
\hline CHEMBL3910817 & 1640572 & 6.0 & 5.4476 & TST \\
\hline CHEMBL3926649 & 1640572 & 6.6576 & 6.2412 & TST \\
\hline CHEMBL 3943968 & 1640572 & 5.0809 & 5.5821 & TST \\
\hline CHEMBL 3906373 & 1640572 & 5.0088 & 5.38299 & 9999999999 \\
\hline CHEMBL3948025 & 1640572 & 5.4318 & 4.7284 & TST \\
\hline CHEMBL3960265 & 1640572 & 6.7959 & 6.329 & TST \\
\hline CHEMBL 3904425 & 1640572 & 5.4559 & 5.5434 & TST \\
\hline CHEMBL 3922244 & 1640572 & 6.4949 & 6.0308 & TST \\
\hline CHEMBL3944815 & 1640572 & 5.4685 & 5.7843 & TST \\
\hline CHEMBL3936090 & 1640572 & 5.0044 & 5.0623 & TST \\
\hline CHEMBL3895929 & 1640572 & 6.1938 & 6.2118 & TST \\
\hline CHEMBL3889961 & 1640572 & 5.6383 & 5.8923 & TST \\
\hline CHEMBL3961503 & 1640572 & 6.5686 & 6.7693 & TST \\
\hline
\end{tabular}


Supplemental Table S2.txt

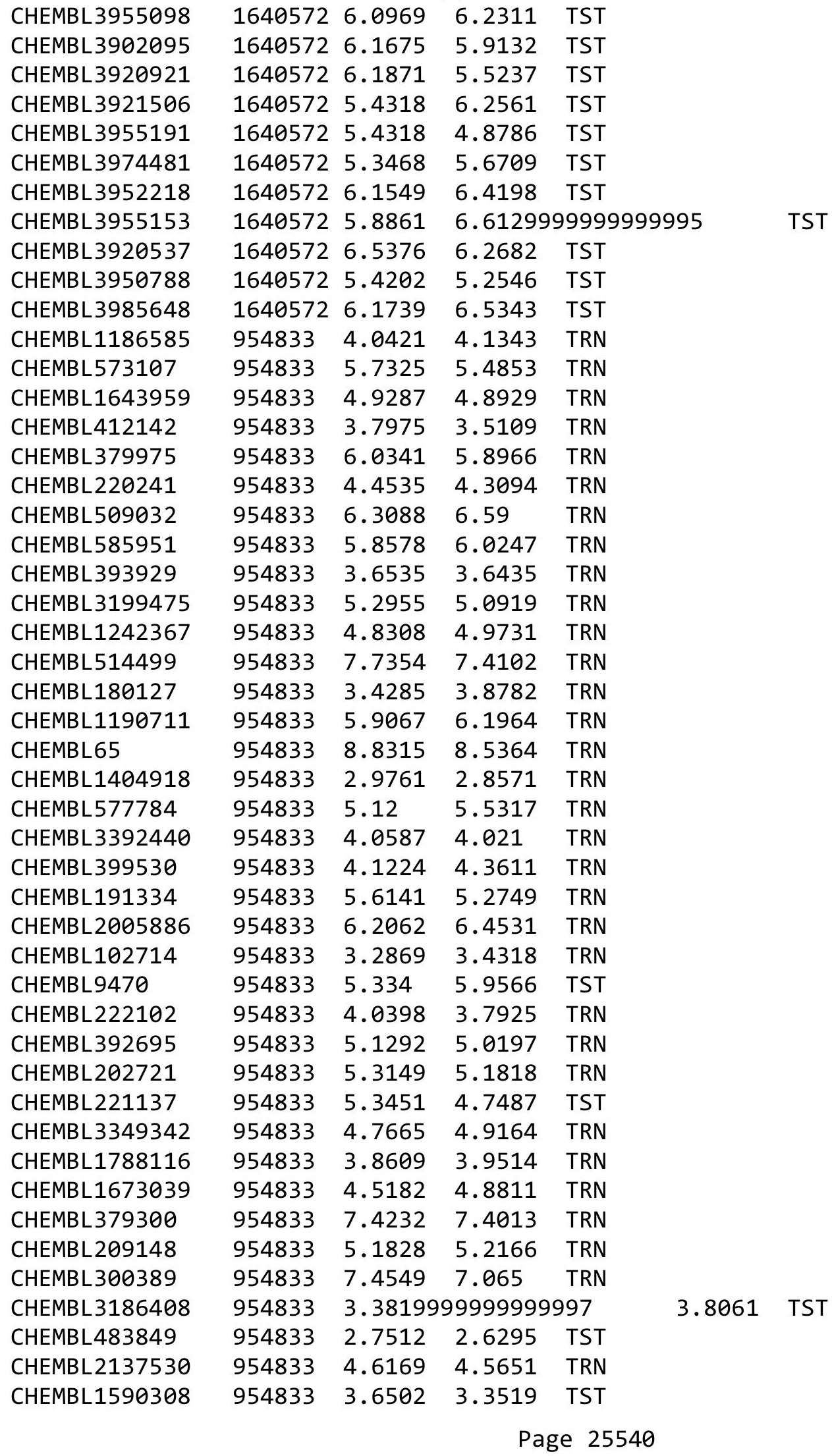


Supplemental Table S2.txt

\begin{tabular}{|c|c|c|c|c|}
\hline The & & & & \\
\hline HEMBL 259181 & 54833 & 5.0703 & 5.3098 & \\
\hline & & 242 & 359 & \\
\hline AEMBL 21 & 33 & 852 & 7725 & \\
\hline AEMBL1909414 & 54833 & 548 & 9367 & \\
\hline HEMBL 373751 & 54833 & .5083 & .7606 & \\
\hline HEMBL 558642 & 33 & 3914 & .4784 & \\
\hline IEMBL189584 & 33 & 22 & 9968 & \\
\hline AEMBL1256459 & & 0811 & 3092 & \\
\hline HEMBL192566 & 54 & .8834 & 5749 & \\
\hline HEMBL 515416 & 54 & .8607 & 2254 & \\
\hline AEMBL188678 & 33 & 1896 & 3362 & \\
\hline HEMBL92309 & 3 & 385 & 157 & \\
\hline HEMBL123002 & 3 & 504 & 3015 & \\
\hline HEMBL 255342 & 33 & 752 & 1501 & \\
\hline AEMBL472940 & 33 & 5803 & 78 & \\
\hline HEMBL1516890 & 33 & 076 & 373 & \\
\hline HEMBL483847 & & 94 & & \\
\hline HEMBL5: & & 371 & 05 & \\
\hline HEMBL449158 & 33 & 448 & 378 & ST \\
\hline AEMBL 210618 & 33 & 65 & 563 & $\Delta 1$ \\
\hline HEMBL 236313 & 33 & $\partial 7$ & 86 & SI \\
\hline HEMBL 258844 & & 26 & 59 & ST \\
\hline HEMBL1357247 & & 07 & 53 & ST \\
\hline HEMBL2144069 & & 192 & & I \\
\hline HEMBL1970879 & 3 & 823 & 339 & SI \\
\hline HEMBL 217354 & & 873 & 3612 & ST \\
\hline HEMBL 240 & & 95 & 74 & ST \\
\hline HEMBL 2018 & & & 91 & ST \\
\hline AEMBL2018619 & & & & RIN \\
\hline HEMBL2018607 & & 586 & 3614 & ST \\
\hline HEMBL2018601 & & & 593 & RN \\
\hline HEMBL2018742 & & & 597 & ST \\
\hline 3L201 & & & 691 & RN \\
\hline HEMBL2018729 & & & & ST \\
\hline HEMBL2018728 & & 861 & 799 & ST \\
\hline HEMBL2018621 & & 861 & 368 & RN \\
\hline HEMBL2018734 & & & & RN \\
\hline HEMBL2018741 & & & 793 & ST \\
\hline HEMBL2018606 & & 56 & 295 & ST \\
\hline HEMBL2018609 & & 757 & 512 & ST \\
\hline HEMBL2018600 & & 4.8239 & 711 & \\
\hline CHEMBL2018737 & & & & RN \\
\hline HEMBL 2018727 & & 5.7959 & 7272 & RN \\
\hline HEMBL2018732 & 54 & 5.9208 & 3495 & $N$ \\
\hline EMBL201 & & & & \\
\hline CHEMBL 201874 & & 3.699 & & \\
\hline & & 5.823 & & \\
\hline
\end{tabular}

Page 25541 


\begin{tabular}{|c|c|c|c|c|c|}
\hline \multicolumn{6}{|c|}{ Supplemental Table S2.txt } \\
\hline CHEMBL 2018595 & 813064 & 5.7447 & 5.5488 & TRN & \\
\hline CHEMBL 2018620 & 813064 & 4.8861 & 5.0875 & TRN & \\
\hline CHEMBL 2018740 & 813064 & 3.699 & 4.994 & TST & \\
\hline CHEMBL 2018739 & 813064 & 5.3372 & 5.1571 & TRN & \\
\hline CHEMBL 2018618 & 813064 & 5.5528 & 5.681 & TRN & \\
\hline CHEMBL 2018738 & 813064 & 5.2518 & 5.397 & TRN & \\
\hline CHEMBL 2018614 & 813064 & 5.8239 & 5.7691 & TRN & \\
\hline CHEMBL 2018623 & 813064 & 6.0458 & 5.9191 & TRN & \\
\hline CHEMBL 2018625 & 813064 & 5.5376 & 5.6013 & TRN & \\
\hline CHEMBL 2018624 & 813064 & 5.3565 & 5.5922 & TRN & \\
\hline CHEMBL 2018602 & 813064 & 5.0 & 4.8337 & TRN & \\
\hline CHEMBL 2018605 & 813064 & 5.8239 & 5.7829 & TRN & \\
\hline CHEMBL569102 & 813064 & 5.7959 & 5.6737 & TRN & \\
\hline CHEMBL 2018731 & 813064 & 5.1612 & 4.8725 & TRN & \\
\hline CHEMBL 2018610 & 813064 & 5.3098 & 5.193 & TST & \\
\hline CHEMBL 2018611 & 813064 & 5.5376 & 5.6737 & TRN & \\
\hline CHEMBL 2018626 & 813064 & 5.9586 & 5.699 & TRN & \\
\hline CHEMBL 2018615 & 813064 & 5.8539 & 5.7385 & TRN & \\
\hline CHEMBL 2018730 & 813064 & 5.1675 & 5.3248 & TRN & \\
\hline CHEMBL 2018613 & 813064 & 5.5686 & 5.5966 & TRN & \\
\hline CHEMBL 2018604 & 813064 & 5.699 & 5.7148 & TRN & \\
\hline CHEMBL 2018598 & 813064 & 5.8539 & 5.7116 & TRN & \\
\hline CHEMBL 2018596 & 813064 & 5.0 & 4.7993 & TRN & \\
\hline CHEMBL 2018612 & 813064 & 5.7212 & 5.7116 & TRN & \\
\hline CHEMBL 2018616 & 813064 & 4.8539 & 5.0178 & TRN & \\
\hline CHEMBL 2018735 & 813064 & 5.699 & 5.8884 & TRN & \\
\hline CHEMBL 2018597 & 813064 & 5.7696 & 5.7691 & TRN & \\
\hline CHEMBL 2018603 & 813064 & 3.699 & 3.99600 & 00000000004 & TRN \\
\hline CHEMBL 2018736 & 813064 & 5.2441 & 5.45100 & 00000000005 & TRN \\
\hline CHEMBL 2018617 & 813064 & 5.7212 & 5.9691 & TRN & \\
\hline CHEMBL 2018743 & 813064 & 3.699 & 5.2656 & TST & \\
\hline CHEMBL 2018733 & 813064 & 5.7959 & 5.876 & TST & \\
\hline CHEMBL 2018726 & 813064 & 6.2218 & 6.0195 & TST & \\
\hline CHEMBL521498 & 521749 & 7.34 & 7.2502 & TRN & \\
\hline CHEMBL485105 & 521749 & 6.79 & 6.6956 & TRN & \\
\hline CHEMBL485308 & 521749 & 4.3 & 4.11100 & 0000000001 & TRN \\
\hline CHEMBL485309 & 521749 & 5.0 & 4.9189 & TRN & \\
\hline CHEMBL485310 & 521749 & 5.0 & 5.0148 & TRN & \\
\hline CHEMBL453781 & 521749 & 4.64 & 4.716 & TST & \\
\hline CHEMBL443332 & 521749 & 4.49 & 4.5533 & TRN & \\
\hline CHEMBL485311 & 521749 & 6.17 & 5.8048 & TST & \\
\hline CHEMBL66704 & 521749 & 5.66 & 5.53 & TRN & \\
\hline CHEMBL163883 & 521749 & 4.13 & 4.1488 & TRN & \\
\hline CHEMBL519675 & 521749 & 4.9 & 5.0502 & TRN & \\
\hline CHEMBL168190 & 521749 & 3.74 & 3.8053 & TRN & \\
\hline CHEMBL484904 & 521749 & 4.32 & 4.3243 & TRN & \\
\hline CHEMBL163910 & 521749 & 4.08 & 4.0155 & TST & \\
\hline CHEMBL526680 & 521749 & 4.92 & 5.0778 & TRN & \\
\hline
\end{tabular}




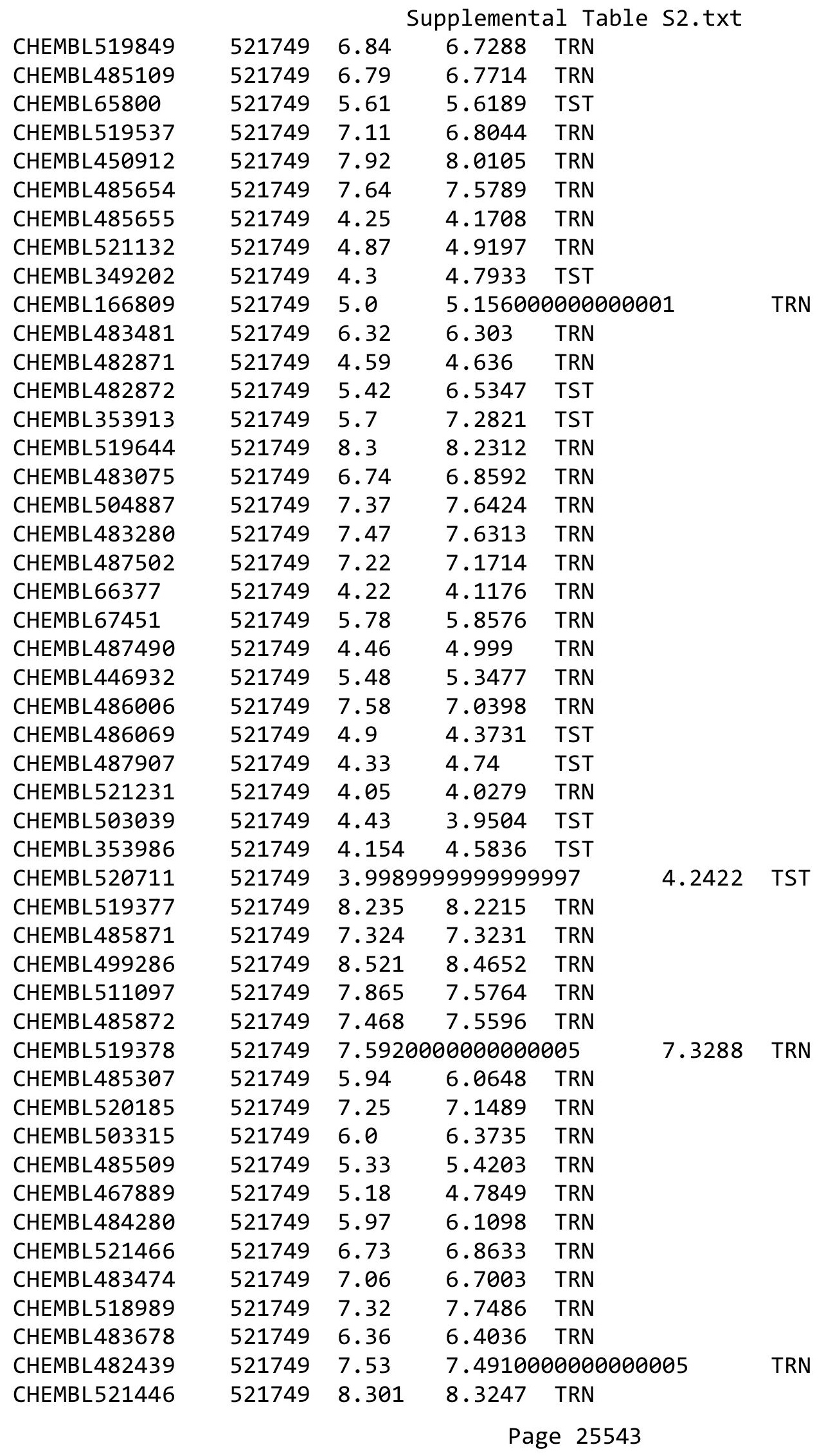




\begin{tabular}{|c|c|c|c|c|c|c|}
\hline \multirow[b]{2}{*}{ CHEMBL484287 } & & \multicolumn{5}{|c|}{ Supplemental Table S2.txt } \\
\hline & 521749 & 7.018 & 7.0138 & TRN & & \\
\hline CHEMBL484490 & 521749 & 5.197 & 5.1211 & TRN & & \\
\hline CHEMBL291565 & 521749 & 4.476 & 5.5003 & TST & & \\
\hline CHEMBL164233 & 521749 & 3.071 & 5.3977 & TST & & \\
\hline CHEMBL349465 & 521749 & $5.1770 e$ & 00000006 & 205 & 5.7013 & TST \\
\hline CHEMBL165335 & 521749 & 4.218 & 5.261 & TST & & \\
\hline CHEMBL167459 & 521749 & $5.1770 e$ & 00000006 & 205 & 5.511 & TST \\
\hline CHEMBL60982 & 521749 & $5.6110 e$ & 00000006 & $\partial 1$ & 6.6616 & TST \\
\hline CHEMBL520619 & 521749 & 7.602 & 7.8551 & TRN & & \\
\hline CHEMBL 3342043 & 1437514 & 5.4318 & 5.4663 & TRN & & \\
\hline CHEMBL 3344446 & 1437514 & 3.6021 & 3.6119 & TRN & & \\
\hline CHEMBL 3344447 & 1437514 & 3.6021 & 3.6068 & TRN & & \\
\hline CHEMBL3342034 & 1437514 & 7.0458 & 7.0104 & TRN & & \\
\hline CHEMBL 3187997 & 1437514 & 6.3979 & 6.3979 & TRN & & \\
\hline CHEMBL 3342041 & 1437514 & 4.6517 & 4.6729 & TRN & & \\
\hline CHEMBL 3181850 & 1437514 & 6.699 & 6.7616 & TRN & & \\
\hline CHEMBL3183397 & 1437514 & 5.1938 & 5.2115 & TRN & & \\
\hline CHEMBL 3344439 & 1437514 & 3.6021 & 3.5818 & TRN & & \\
\hline CHEMBL 3344440 & 1437514 & 3.6021 & 3.5639 & TRN & & \\
\hline CHEMBL 3342037 & 1437514 & 3.6021 & 3.5906 & TRN & & \\
\hline CHEMBL 3183844 & 1437514 & 7.3979 & 7.3871 & TRN & & \\
\hline CHEMBL 3189043 & 1437514 & 7.301 & 7.3168 & TRN & & \\
\hline CHEMBL 3182305 & 1437514 & 6.3979 & 6.432 & TRN & & \\
\hline CHEMBL 3342036 & 1437514 & 5.4318 & 5.4467 & TRN & & \\
\hline CHEMBL 3182102 & 1437514 & 6.699 & 6.6591 & TRN & & \\
\hline CHEMBL 3187777 & 1437514 & 5.9586 & 5.9414 & TRN & & \\
\hline CHEMBL 3183411 & 1437514 & 5.3279 & 5.3631 & TRN & & \\
\hline CHEMBL 3342031 & 1437514 & 4.4724 & 4.4959 & TRN & & \\
\hline CHEMBL3344450 & 1437514 & 3.6021 & 3.6223 & TRN & & \\
\hline CHEMBL 3344438 & 1437514 & 3.6021 & 3.5853 & TRN & & \\
\hline CHEMBL 3344454 & 1437514 & 3.6021 & 3.5826 & TRN & & \\
\hline CHEMBL 3184344 & 1437514 & 5.9586 & 5.8691 & TRN & & \\
\hline CHEMBL 3183668 & 1437514 & 6.699 & 6.684 & TRN & & \\
\hline CHEMBL 3342033 & 1437514 & 7.0 & 6.9772 & TRN & & \\
\hline CHEMBL3342035 & 1437514 & 3.6021 & 3.6074 & TRN & & \\
\hline CHEMBL 3344453 & 1437514 & 3.6021 & 3.6341 & TRN & & \\
\hline CHEMBL3184211 & 1437514 & 6.0969 & 6.1307 & TRN & & \\
\hline CHEMBL 3342032 & 1437514 & 5.0915 & 5.7578 & TST & & \\
\hline CHEMBL 3184472 & 1437514 & 6.0969 & 5.9247 & TST & & \\
\hline CHEMBL1537833 & 1437514 & 5.0605 & 5.0539 & TRN & & \\
\hline CHEMBL3186609 & 1437514 & 6.0969 & 6.066 & TRN & & \\
\hline CHEMBL1399083 & 1437514 & 6.0969 & 6.2206 & TRN & & \\
\hline CHEMBL 3185321 & 1437514 & 5.4437 & 5.6838 & TST & & \\
\hline CHEMBL 3344452 & 1437514 & 3.6021 & 3.5848 & TRN & & \\
\hline CHEMBL3342038 & 1437514 & 5.0757 & 6.6805 & TST & & \\
\hline CHEMBL 3344441 & 1437514 & 3.6021 & 3.4458 & TST & & \\
\hline CHEMBL 3344455 & 1437514 & 3.6021 & 3.5695 & TRN & & \\
\hline CHEMBL 3344442 & 1437514 & 3.6021 & 3.6124 & TRN & & \\
\hline
\end{tabular}


Supplemental Table S2.txt

\begin{tabular}{|c|c|c|c|c|c|c|}
\hline CHEMBL3344449 & 1437514 & 3.6021 & 3.5848 & TRN & & \\
\hline CHEMBL3342030 & 1437514 & 6.301 & 5.981 & TST & & \\
\hline CHEMBL3185317 & 1437514 & 5.2924 & 5.3265 & TRN & & \\
\hline CHEMBL 3344443 & 1437514 & 3.6021 & 3.6367 & TRN & & \\
\hline CHEMBL3187669 & 1437514 & 4.76699 & 99999999 & 995 & 4.7701 & TRN \\
\hline CHEMBL3342042 & 1437514 & 6.3979 & 5.8706 & TST & & \\
\hline CHEMBL3185443 & 1437514 & 6.2218 & 6.1426 & TST & & \\
\hline CHEMBL3181976 & 1437514 & 7.0 & 5.1221 & TST & & \\
\hline CHEMBL3185516 & 1437514 & 6.699 & 6.6213 & TRN & & \\
\hline CHEMBL3344444 & 1437514 & 3.6021 & 2.8086 & TST & & \\
\hline CHEMBL3342040 & 1437514 & 5.3565 & 5.1146 & TST & & \\
\hline CHEMBL3342039 & 1437514 & 3.6021 & 4.6453 & TST & & \\
\hline CHEMBL3188049 & 1437514 & 6.5229 & 6.4629 & TRN & & \\
\hline CHEMBL3186385 & 1437514 & 6.0458 & 6.114 & TRN & & \\
\hline CHEMBL3344451 & 1437514 & 3.6021 & 3.8693 & TST & & \\
\hline CHEMBL3185438 & 1437514 & 5.8539 & 5.8341 & TRN & & \\
\hline CHEMBL3344437 & 1437514 & 3.6021 & 3.5812 & TRN & & \\
\hline CHEMBL3186763 & 1437514 & 7.5229 & 7.3344 & TST & & \\
\hline CHEMBL 3344448 & 1437514 & 3.6021 & 3.6074 & TRN & & \\
\hline CHEMBL3342044 & 1437514 & 5.699 & 4.5163 & TST & & \\
\hline CHEMBL3188318 & 1437514 & 5.3565 & 5.3308 & TRN & & \\
\hline CHEMBL3344445 & 1437514 & 3.6021 & 2.5704 & TST & & \\
\hline CHEMBL76929 & 506200 & 5.699 & 6.7703 & TRN & & \\
\hline CHEMBL296407 & 506200 & 5.0 & 4.9601 & TRN & & \\
\hline CHEMBL483234 & 506200 & 4.3979 & 4.4828 & TRN & & \\
\hline CHEMBL309016 & 506200 & 5.0969 & 5.5499 & TST & & \\
\hline CHEMBL520493 & 506200 & 5.0 & 5.4567 & TRN & & \\
\hline CHEMBL79064 & 506200 & 3.301 & 3.7211 & TRN & & \\
\hline CHEMBL490775 & 506200 & 5.1549 & 4.7348 & TRN & & \\
\hline CHEMBL490774 & 506200 & 5.699 & 6.1288 & TRN & & \\
\hline CHEMBL418907 & 506200 & 5.5229 & 5.9326 & TRN & & \\
\hline CHEMBL 78280 & 506200 & 5.3979 & 5.7566 & TRN & & \\
\hline CHEMBL309598 & 506200 & 5.0 & 5.1665 & TRN & & \\
\hline CHEMBL56393 & 506200 & 6.3979 & 5.4025 & TRN & & \\
\hline CHEMBL489349 & 506200 & 3.2218 & 3.2438 & TRN & & \\
\hline CHEMBL 26001 & 506200 & 3.699 & 4.4069 & TST & & \\
\hline CHEMBL307481 & 506200 & 5.0 & 4.5097 & TST & & \\
\hline CHEMBL309334 & 506200 & 5.5229 & 5.8761 & TRN & & \\
\hline CHEMBL 77803 & 506200 & 6.301 & 6.7875 & TRN & & \\
\hline CHEMBL489147 & 506200 & 5.2218 & 5.233 & TST & & \\
\hline CHEMBL490577 & 506200 & 7.0 & 6.5357 & TRN & & \\
\hline CHEMBL53898 & 506200 & 6.1549 & 6.2142 & TRN & & \\
\hline CHEMBL78257 & 506200 & 6.0969 & 6.205 & TRN & & \\
\hline CHEMBL453502 & 506200 & 6.301 & 7.0034 & TST & & \\
\hline CHEMBL 77100 & 506200 & 5.301 & 5.4467 & TRN & & \\
\hline CHEMBL490987 & 506200 & 6.0 & 4.9443 & TRN & & \\
\hline CHEMBL3965817 & 506200 & 3.699 & 4.207 & TRN & & \\
\hline CHEMBL505705 & 506200 & 6.2218 & 6.7841 & TST & & \\
\hline
\end{tabular}




\begin{tabular}{|c|c|c|c|c|c|}
\hline \multicolumn{6}{|c|}{ Supplemental Table S2.txt } \\
\hline CHEMBL77030 & 506200 & 5.5229 & 5.5681 & TRN & \\
\hline CHEMBL 74432 & 506200 & 6.3979 & 5.6171 & TRN & \\
\hline CHEMBL444470 & 506200 & 3.301 & 4.2498 & TRN & \\
\hline CHEMBL485065 & 506200 & 5.301 & 5.4421 & TRN & \\
\hline CHEMBL489148 & 506200 & 3.0458 & 4.8234 & TST & \\
\hline CHEMBL55204 & 506200 & 6.2218 & 5.74700 & 0000000001 & TRN \\
\hline CHEMBL77688 & 506200 & 6.5229 & 6.69600 & 0000000001 & TRN \\
\hline CHEMBL449114 & 506200 & 3.3979 & 4.8685 & TST & \\
\hline CHEMBL56543 & 506200 & 5.699 & 5.9481 & TRN & \\
\hline CHEMBL59145 & 506200 & 5.699 & 5.5653 & TRN & \\
\hline CHEMBL76589 & 506200 & 7.0 & 5.0921 & TRN & \\
\hline CHEMBL 308048 & 506200 & 3.0969 & 4.1897 & TRN & \\
\hline CHEMBL56132 & 506200 & 6.0 & 5.7936 & TRN & \\
\hline CHEMBL 80745 & 506200 & 6.0 & 6.1642 & TRN & \\
\hline CHEMBL454002 & 506200 & 5.0 & 4.4451 & TST & \\
\hline CHEMBL474267 & 506200 & 5.0 & 4.7802 & TST & \\
\hline CHEMBL76958 & 506200 & 6.0 & 5.6501 & TRN & \\
\hline CHEMBL 293749 & 506200 & 6.0458 & 6.2422 & TRN & \\
\hline CHEMBL492199 & 506200 & 5.5229 & 5.0283 & TST & \\
\hline CHEMBL77401 & 506200 & 5.699 & 5.5513 & TRN & \\
\hline CHEMBL449093 & 506200 & 7.301 & 6.9615 & TRN & \\
\hline CHEMBL 145 & 506200 & 3.0 & 4.9143 & TST & \\
\hline CHEMBL418906 & 506200 & 6.0 & 5.075 & TRN & \\
\hline CHEMBL77397 & 506200 & 5.5229 & 5.7947 & TRN & \\
\hline CHEMBL501368 & 506200 & 4.699 & 4.5831 & TRN & \\
\hline CHEMBL450319 & 506200 & 3.2218 & 3.4924 & TST & \\
\hline CHEMBL56731 & 506200 & 6.1549 & 5.9635 & TRN & \\
\hline CHEMBL488101 & 506200 & 4.699 & 4.5074 & TRN & \\
\hline CHEMBL 78224 & 506200 & 5.0458 & 5.6132 & TST & \\
\hline CHEMBL56879 & 506200 & 5.699 & 5.8108 & TRN & \\
\hline CHEMBL78049 & 506200 & 5.0458 & 5.3916 & TST & \\
\hline CHEMBL 73820 & 506200 & 4.5229 & 5.0533 & TRN & \\
\hline CHEMBL54471 & 506200 & 6.0458 & 5.7805 & TRN & \\
\hline CHEMBL600461 & 1301646 & 5.0083 & 4.9555 & TRN & \\
\hline CHEMBL3185393 & 1301646 & 5.2916 & 5.2324 & TRN & \\
\hline CHEMBL597469 & 1301646 & 3.1549 & 4.4651 & TST & \\
\hline CHEMBL 3187258 & 1301646 & 5.5317 & 5.4791 & TRN & \\
\hline CHEMBL3185103 & 1301646 & 5.6655 & 5.6357 & TRN & \\
\hline CHEMBL3182296 & 1301646 & 5.8297 & 5.6427 & TRN & \\
\hline CHEMBL3184036 & 1301646 & 4.3905 & 4.4122 & TRN & \\
\hline CHEMBL3185661 & 1301646 & 5.4437 & 5.4436 & TRN & \\
\hline CHEMBL 3184233 & 1301646 & 5.3197 & 5.3351 & TRN & \\
\hline CHEMBL597649 & 1301646 & 5.6498 & 5.8287 & TRN & \\
\hline CHEMBL 3188789 & 1301646 & 5.0501 & 5.0064 & TRN & \\
\hline CHEMBL 3187431 & 1301646 & 4.9722 & 5.1492 & TRN & \\
\hline CHEMBL601071 & 1301646 & 5.0168 & 5.1509 & TRN & \\
\hline CHEMBL 3187435 & 1301646 & 5.6073 & 5.6132 & TRN & \\
\hline CHEMBL3187292 & 1301646 & 5.699 & 5.4621 & TRN & \\
\hline
\end{tabular}


Supplemental Table S2.txt

\begin{tabular}{|c|c|c|c|c|c|c|}
\hline CHEMBL3188948 & 1301646 & 5.082 & 5.0688 & TRN & & \\
\hline CHEMBL 312487 & 1301646 & 6.383999 & 999999999 & 995 & 4.5735 & TST \\
\hline CHEMBL3182144 & 1301646 & 5.3526 & 5.1356 & TRN & & \\
\hline CHEMBL3186072 & 1301646 & 5.2549 & 4.9809 & TRN & & \\
\hline CHEMBL 2414130 & 1301646 & 4.8447 & 4.7785 & TRN & & \\
\hline CHEMBL3182129 & 1301646 & 5.9355 & 4.1387 & TST & & \\
\hline CHEMBL3182636 & 1301646 & 5.1778 & 5.0792 & TRN & & \\
\hline CHEMBL3187855 & 1301646 & 3.1549 & 4.1968 & TST & & \\
\hline CHEMBL3183427 & 1301646 & 6.1694 & 6.2086 & TRN & & \\
\hline CHEMBL3186937 & 1301646 & 4.6221 & 4.7812 & TST & & \\
\hline CHEMBL 3187262 & 1301646 & 4.6225 & 4.7386 & TST & & \\
\hline CHEMBL3184991 & 1301646 & 6.2343 & 6.0406 & TRN & & \\
\hline CHEMBL3188071 & 1301646 & 5.61799 & 999999999 & & 5.6237 & \\
\hline CHEMBL 3188163 & 1301646 & 4.8834 & 5.0199 & TRN & & \\
\hline CHEMBL3187950 & 1301646 & 4.9662 & 5.202999 & 9999999999 & & \\
\hline CHEMBL3189083 & 1301646 & 5.16299 & 999999999 & 99 & 5.0873 & \\
\hline CHEMBL3188422 & 1301646 & 4.7585 & 5.0373 & TRN & & \\
\hline CHEMBL 3182425 & 1301646 & 6.0311 & 6.0761 & TRN & & \\
\hline CHEMBL 3185435 & 1301646 & 5.2668 & 4.5538 & TST & & \\
\hline CHEMBL583997 & 1301646 & 5.6055 & 5.6217 & TRN & & \\
\hline CHEMBL1631464 & 1301646 & 4.7916 & 4.8878 & TST & & \\
\hline CHEMBL3186241 & 1301646 & 5.0762 & 5.0814 & TRN & & \\
\hline CHEMBL3183728 & 1301646 & 5.4572 & 5.4442 & TRN & & \\
\hline CHEMBL 3187093 & 1301646 & 5.1355 & 5.23 & TRN & & \\
\hline CHEMBL3183472 & 1301646 & 4.7242 & 4.8456 & TST & & \\
\hline CHEMBL3188555 & 1301646 & 5.4609 & 5.2962 & TRN & & \\
\hline CHEMBL3182615 & 1301646 & 5.4622 & 5.5648 & TRN & & \\
\hline CHEMBL3185479 & 1301646 & 5.5287 & 5.6342 & TRN & & \\
\hline CHEMBL3185050 & 1301646 & 5.4841 & 5.4815 & TRN & & \\
\hline CHEMBL3186593 & 1301646 & 5.2708 & 5.2234 & TRN & & \\
\hline CHEMBL2334467 & 1301646 & 3.1549 & 4.3195 & TST & & \\
\hline CHEMBL3185841 & 1301646 & 5.2848 & 4.3092 & TST & & \\
\hline CHEMBL3185242 & 1301646 & 5.4584 & 5.5783 & TRN & & \\
\hline CHEMBL3185552 & 1301646 & 5.1818 & 4.5902 & TST & & \\
\hline CHEMBL597060 & 1301646 & 5.5421 & 5.5575 & TRN & & \\
\hline CHEMBL3186663 & 1301646 & 4.6029 & 4.673 & TRN & & \\
\hline CHEMBL3185596 & 1301646 & 5.5986 & 5.6226 & TRN & & \\
\hline CHEMBL3186880 & 1301646 & 5.4935 & 5.4577 & TST & & \\
\hline CHEMBL3181966 & 1301646 & 4.857 & 4.4157 & TST & & \\
\hline CHEMBL3944421 & 1642076 & 10.1549 & 10.2758 & TST & & \\
\hline CHEMBL3947143 & 1642076 & 9.7011 & 9.8592 & TRN & & \\
\hline CHEMBL3897388 & 1642076 & 6.0768 & 6.0368 & TRN & & \\
\hline CHEMBL3957954 & 1642076 & 9.5229 & 9.5129 & TRN & & \\
\hline CHEMBL 3948310 & 1642076 & 9.0 & 9.4238 & TRN & & \\
\hline CHEMBL3934590 & 1642076 & 8.7932 & 8.4417 & TRN & & \\
\hline CHEMBL3903663 & 1642076 & 8.0605 & 8.3395 & TRN & & \\
\hline CHEMBL3939400 & 1642076 & 7.9872 & 7.2027 & TRN & & \\
\hline CHEMBL3986680 & 1642076 & 8.6364 & 8.4519 & TST & & \\
\hline
\end{tabular}




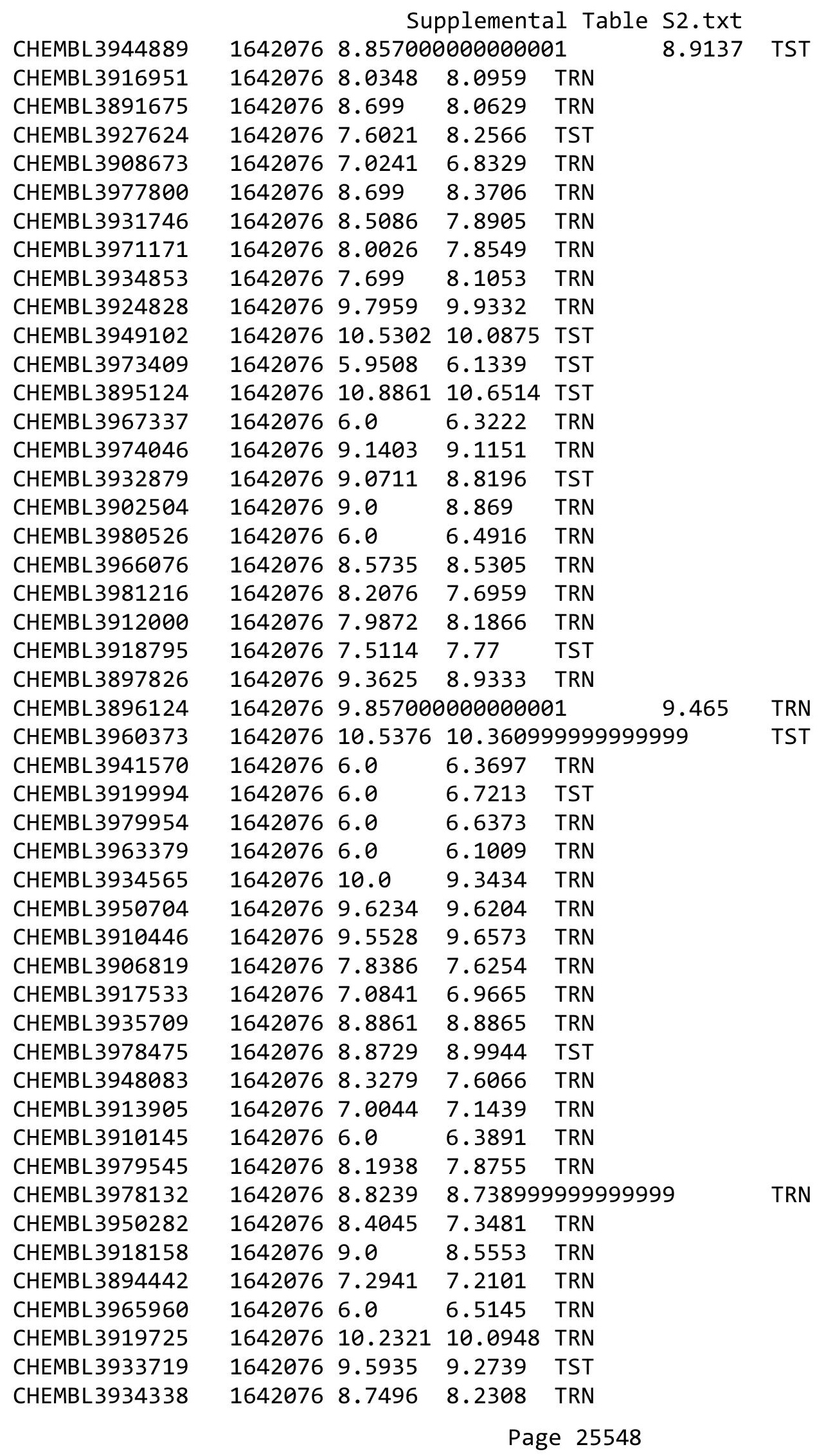


Supplemental Table S2.txt

\begin{tabular}{|c|c|c|c|c|}
\hline & & & & \\
\hline HEMBL 3943301 & 642076 & 6.0 & 6651 & \\
\hline AEMBL3 & 276 & 544 & & \\
\hline & 76 & & & \\
\hline 176 & 976 & 591 & & \\
\hline IEMBL 3951627 & 642076 & 8.4685 & 932 & \\
\hline AEMBL 3926451 & 642076 & 8.4498 & 326 & \\
\hline AEMBL. & & & & \\
\hline 050 & 276 & 10.1871 & 10.2789 & \\
\hline EMBL & 076 & 3372 & 9.8574 & \\
\hline AEMBL3972296 & 642076 & 8.5952 & 8.5719 & \\
\hline 4543 & 076 & & & \\
\hline 234 & 76 & & & \\
\hline 716 & 76 & & & \\
\hline 291 & 76 & 49 & 927 & \\
\hline IEMBL: & 76 & & 58 & \\
\hline 131 & 76 & & & \\
\hline 82 & 6 & & 16 & \\
\hline 20 & & & & \\
\hline 10 & 6 & 9. & & \\
\hline 526 & 6 & & & \\
\hline 584 & & & & \\
\hline 58 & 164 & & & \\
\hline 18 & & & & \\
\hline 979 & 6 & & & \\
\hline 506 & & & & \\
\hline 727 & & & & \\
\hline 862 & & & 314 & \\
\hline 63 & & & & \\
\hline 458 & & & & \\
\hline & & & & \\
\hline 991 & o & & & \\
\hline & & & & \\
\hline 6 & & & & \\
\hline & & & & \\
\hline 455 & & & & \\
\hline 370 & 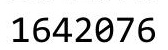 & & & \\
\hline & & & & \\
\hline 5 & & & & \\
\hline 384 & & 7.5867 & & \\
\hline AEMBL: & 164 & & & \\
\hline 22 & 164 & & & \\
\hline & & & 73 & \\
\hline 917 & & & 946 & \\
\hline 273 & 1642076 & & 9.809 & \\
\hline 049 & 164 & 12 & 7.3269 & \\
\hline & & & & \\
\hline & 542076 & 9.2218 & 9.2197 & \\
\hline
\end{tabular}

Page 25549 
Supplemental Table S2.txt

\begin{tabular}{|c|c|c|c|c|c|}
\hline CHEMBL 3938995 & 1642076 & 7.399 & 7.2356 & TRN & \\
\hline CHEMBL 3894660 & 1642076 & 8.1549 & 8.0276 & TRN & \\
\hline CHEMBL 3977535 & 1642076 & 7.9626 & 7.801 & TRN & \\
\hline CHEMBL 3980532 & 1642076 & 8.3665 & 8.283 & TRN & \\
\hline CHEMBL 3972842 & 1642076 & 8.1079 & 8.1885 & TRN & \\
\hline CHEMBL 3933056 & 1642076 & 10.4698 & 9.9356 & TST & \\
\hline CHEMBL 3891362 & 1642076 & 8.5361 & 8.7136 & TST & \\
\hline CHEMBL 3957539 & 1642076 & 6.0 & 5.8636 & TRN & \\
\hline CHEMBL 3922035 & 1642076 & 7.9431 & 8.1 & TRN & \\
\hline CHEMBL3918647 & 1642076 & 8.8729 & 9.5004 & TRN & \\
\hline CHEMBL 3983621 & 1642076 & 9.2565 & 9.0306 & TST & \\
\hline CHEMBL3966109 & 1642076 & 8.3904 & 7.8461 & TRN & \\
\hline CHEMBL 3940085 & 1642076 & 7.0655 & 7.1613 & TST & \\
\hline CHEMBL 3932604 & 1642076 & 7.0061 & 6.7788 & TRN & \\
\hline CHEMBL 3911461 & 1642076 & 9.699 & 10.1135 & TRN & \\
\hline CHEMBL 3916993 & 1642076 & 8.5498 & 8.8029 & TRN & \\
\hline CHEMBL 3948078 & 1642076 & 7.8633 & 7.4638 & TRN & \\
\hline CHEMBL 3940808 & 1642076 & 8.7212 & 9.1379 & TRN & \\
\hline CHEMBL 3984961 & 1642076 & 10.0 & 9.8977 & TST & \\
\hline CHEMBL 3919294 & 1642076 & 8.7447 & 8.4187 & TRN & \\
\hline CHEMBL 3904050 & 1642076 & 9.5229 & 9.5356 & TRN & \\
\hline CHEMBL 3954143 & 1642076 & 6.4067 & 6.795 & TRN & \\
\hline CHEMBL 3903730 & 1642076 & 7.3526 & 7.4634 & TRN & \\
\hline CHEMBL 3943561 & 1642076 & 7.8794 & 7.2141 & TRN & \\
\hline CHEMBL 3894748 & 1642076 & 6.0 & 6.9387 & TRN & \\
\hline CHEMBL 3889998 & 1642076 & 8.699 & 8.1998 & TRN & \\
\hline CHEMBL 3890346 & 1642076 & 9.7496 & 9.709 & TRN & \\
\hline CHEMBL 3963777 & 1642076 & 8.7959 & 8.5979 & TRN & \\
\hline CHEMBL 3926975 & 1642076 & 8.699 & 8.4694 & TRN & \\
\hline CHEMBL 3956734 & 1642076 & 7.6162 & 7.1757 & TRN & \\
\hline CHEMBL 3916569 & 1642076 & 7.8539 & 8.1728 & TRN & \\
\hline CHEMBL 3947213 & 1642076 & 6.0 & 6.0682 & TRN & \\
\hline CHEMBL3906911 & 1642076 & 8.1175 & 7.9717 & TRN & \\
\hline CHEMBL 3910979 & 1642076 & 8.8861 & 8.2974 & TRN & \\
\hline CHEMBL 3894496 & 1642076 & 8.1739 & 8.2148 & TRN & \\
\hline CHEMBL 3925309 & 1642076 & 8.0969 & 8.1485 & TRN & \\
\hline CHEMBL 3900670 & 1642076 & 8.5086 & 8.3212 & TRN & \\
\hline CHEMBL 3986733 & 1642076 & 7.1433 & 7.7017 & TRN & \\
\hline CHEMBL 3926062 & 1642076 & 7.5768 & 7.5626 & TST & \\
\hline CHEMBL 3955880 & 1642076 & 9.2924 & 9.2257 & TRN & \\
\hline CHEMBL 3897690 & 1642076 & 8.6421 & 8.7193 & TRN & \\
\hline CHEMBL 3946176 & 1642076 & 9.0969 & 9.1385 & TRN & \\
\hline CHEMBL 3909184 & 1642076 & 7.4535 & 7.5061 & TRN & \\
\hline CHEMBL 3930939 & 1642076 & 6.0 & 6.3285 & TRN & \\
\hline CHEMBL 3919362 & 1642076 & 9.4881 & 9.7233 & TRN & \\
\hline CHEMBL 3949896 & 1642076 & 7.4989 & 8.047 & TRN & \\
\hline CHEMBL 3975613 & 1642076 & 8.1612 & 8.0303 & TRN & \\
\hline CHEMBL 3943059 & 1642076 & 7.172000 & 0000000 & & 7.0747 \\
\hline
\end{tabular}


Supplemental Table S2.txt

\begin{tabular}{|c|c|c|c|c|}
\hline CHEMBL3901445 & 1642076 & 8.219 & 7.5489 & TRN \\
\hline CHEMBL 3904282 & 1642076 & 9.0969 & 9.3892 & TRN \\
\hline CHEMBL3895191 & 1642076 & 7.0414 & 8.7255 & TST \\
\hline CHEMBL 3896195 & 1642076 & 9.6091 & 9.6178 & TST \\
\hline CHEMBL 3926620 & 1642076 & 9.5421 & 9.5034 & TRN \\
\hline CHEMBL3934584 & 1642076 & 8.699 & 8.3862 & TRN \\
\hline CHEMBL3933159 & 1642076 & 8.7799 & 8.338 & TRN \\
\hline CHEMBL 3902148 & 1642076 & 10.9208 & 10.7328 & TST \\
\hline CHEMBL3925989 & 1642076 & 6.6345 & 7.2198 & TRN \\
\hline CHEMBL3909351 & 1642076 & 10.3979 & 10.2585 & TRN \\
\hline CHEMBL3970766 & 1642076 & 8.7447 & 8.56 & TRN \\
\hline CHEMBL3913376 & 1642076 & 8.5086 & 8.866 & TRN \\
\hline CHEMBL 3980483 & 1642076 & 6.0 & 6.6334 & TRN \\
\hline CHEMBL3892102 & 1642076 & 8.2284 & 8.3444 & TRN \\
\hline CHEMBL 3899535 & 1642076 & 8.7773 & 9.0847 & TRN \\
\hline CHEMBL3934918 & 1642076 & 8.9136 & 8.7425 & TST \\
\hline CHEMBL3912577 & 1642076 & 9.1439 & 8.6927 & TRN \\
\hline CHEMBL3961358 & 1642076 & 7.295 & 6.9088 & TRN \\
\hline CHEMBL3933668 & 1642076 & 8.699 & 7.8611 & TRN \\
\hline CHEMBL3914535 & 1642076 & 9.567 & 9.4276 & TRN \\
\hline CHEMBL 3899420 & 1642076 & 8.2676 & 8.1736 & TRN \\
\hline CHEMBL3933088 & 1642076 & 7.0768 & 7.0191 & TRN \\
\hline CHEMBL3963838 & 1642076 & 8.6021 & 8.6711 & TRN \\
\hline CHEMBL3956884 & 1642076 & 9.3979 & 9.3475 & TRN \\
\hline CHEMBL 3962427 & 1642076 & 7.7235 & \multicolumn{2}{|c|}{7.656000000000001} \\
\hline CHEMBL3926513 & 1642076 & 7.2815 & 6.8297 & TRN \\
\hline CHEMBL3962885 & 1642076 & 8.1113 & 8.6788 & TST \\
\hline CHEMBL3901766 & 1642076 & 10.0 & 9.7461 & TRN \\
\hline CHEMBL3969013 & 1642076 & 8.1643 & 7.9707 & TRN \\
\hline CHEMBL3910799 & 1642076 & 7.4437 & 7.6476 & TRN \\
\hline CHEMBL 3892409 & 1642076 & 8.9208 & 8.6797 & TRN \\
\hline CHEMBL3931685 & 1642076 & 8.4001 & 8.3967 & TST \\
\hline CHEMBL 3913500 & 1642076 & 8.2291 & 8.198 & TST \\
\hline CHEMBL3894757 & 1642076 & 8.342 & 8.0412 & TRN \\
\hline CHEMBL 3986937 & 1642076 & 7.4473 & 7.1764 & TRN \\
\hline CHEMBL3979182 & 1642076 & 6.0 & 6.7007 & TST \\
\hline CHEMBL 3952715 & 1642076 & 7.2708 & 7.5877 & TRN \\
\hline CHEMBL3905144 & 1642076 & 6.0 & 6.8312 & TRN \\
\hline CHEMBL3903837 & 1642076 & 9.4622 & 9.0604 & TRN \\
\hline CHEMBL 3897988 & 1642076 & 9.6038 & 9.6456 & TST \\
\hline CHEMBL3978539 & 1642076 & 6.0 & 6.2105 & TRN \\
\hline CHEMBL 3962064 & 1642076 & 9.7447 & 9.3235 & TST \\
\hline CHEMBL3918907 & 1642076 & 6.0 & 10.076 & TRN \\
\hline CHEMBL3939819 & 1642076 & 8.7352 & 8.4163 & TRN \\
\hline CHEMBL3926782 & 1642076 & 9.699 & 9.3539 & TRN \\
\hline CHEMBL 3934276 & 1642076 & 8.0458 & 8.0303 & TRN \\
\hline CHEMBL 3922362 & 1642076 & 8.8861 & 8.8 & TST \\
\hline CHEMBL3946889 & 1642076 & 7.4437 & 7.1824 & TRN \\
\hline
\end{tabular}


Supplemental Table S2.txt

\begin{tabular}{|c|c|c|c|c|}
\hline CHEMBL3933867 & 1642076 & 7.1772 & 6.6232 & TRN \\
\hline CHEMBL3913792 & 1642076 & 7.3516 & 7.4194 & TRN \\
\hline CHEMBL3941161 & 1642076 & 6.7852 & 6.7593 & TST \\
\hline CHEMBL 3965643 & 1642076 & 9.699 & 9.548 & TRN \\
\hline CHEMBL3932047 & 1642076 & 9.0458 & 9.6977 & TST \\
\hline CHEMBL 3893675 & 1642076 & 8.9245 & 8.3452 & TRN \\
\hline CHEMBL3941086 & 1642076 & 7.4089 & 7.5248 & TST \\
\hline CHEMBL3919616 & 1642076 & 9.9208 & 9.9422 & TST \\
\hline CHEMBL 3913446 & 1642076 & 9.3002 & 9.2895 & TRN \\
\hline CHEMBL3979464 & 1642076 & 7.5513 & 7.6488 & TRN \\
\hline CHEMBL 3891287 & 1642076 & 8.3468 & 7.9775 & TRN \\
\hline CHEMBL3929651 & 1642076 & 8.7878 & 8.7375 & TRN \\
\hline CHEMBL3970207 & 1642076 & 8.5686 & 8.8945 & TRN \\
\hline CHEMBL 3896761 & 1642076 & 7.6556 & 7.7257 & TRN \\
\hline CHEMBL3918196 & 1642076 & 9.0 & 8.8127 & TRN \\
\hline CHEMBL3986567 & 1642076 & 8.7959 & 8.8146 & TST \\
\hline CHEMBL3936529 & 1642076 & 6.8761 & 7.1239 & TRN \\
\hline CHEMBL3958307 & 1642076 & 6.0 & 7.8507 & TRN \\
\hline CHEMBL3891942 & 1642076 & 8.2757 & 8.1372 & TST \\
\hline CHEMBL3976306 & 1642076 & 8.585 & 8.3329 & TRN \\
\hline CHEMBL3966072 & 1642076 & 6.0 & 6.1825 & TRN \\
\hline CHEMBL3940411 & 1642076 & 8.9281 & 8.8819 & TRN \\
\hline CHEMBL3915882 & 1642076 & 8.4535 & 8.15299 & 9999999999 \\
\hline CHEMBL3966323 & 1642076 & 6.8386 & 7.1311 & TRN \\
\hline CHEMBL3916316 & 1642076 & 8.1871 & 8.831 & TRN \\
\hline CHEMBL3961776 & 1642076 & 8.9031 & 8.7485 & TRN \\
\hline CHEMBL3964978 & 1642076 & 8.3098 & 8.2903 & TRN \\
\hline CHEMBL3965003 & 1642076 & 8.3665 & 8.2071 & TRN \\
\hline CHEMBL 3905644 & 1642076 & 7.7399 & 7.9701 & TRN \\
\hline CHEMBL 3964367 & 1642076 & 9.2041 & 9.0232 & TST \\
\hline CHEMBL 3936412 & 1642076 & 8.6345 & 8.4712 & TRN \\
\hline CHEMBL 3909785 & 1642076 & 9.4763 & 9.5359 & TRN \\
\hline CHEMBL3945507 & 1642076 & 6.699 & 6.4952 & TRN \\
\hline CHEMBL 3809623 & 1642076 & 8.5086 & 8.4678 & TST \\
\hline CHEMBL3924143 & 1642076 & 9.5331 & 9.5645 & TRN \\
\hline CHEMBL3919258 & 1642076 & 8.762 & 8.8568 & TRN \\
\hline CHEMBL3916196 & 1642076 & 8.3768 & 8.5964 & TRN \\
\hline CHEMBL3912094 & 1642076 & 7.9101 & 7.6476 & TST \\
\hline CHEMBL3918209 & 1642076 & 9.1549 & 9.0981 & TRN \\
\hline CHEMBL3906357 & 1642076 & 6.0 & 6.9291 & TRN \\
\hline CHEMBL3949318 & 1642076 & 6.0 & 7.0917 & TST \\
\hline CHEMBL3974890 & 1642076 & 6.6737 & 6.63299 & 7999999999 \\
\hline CHEMBL3937248 & 1642076 & 7.6162 & 7.479 & TRN \\
\hline CHEMBL3916586 & 1642076 & 7.71 & 7.6469 & TRN \\
\hline CHEMBL3926862 & 1642076 & 6.0 & 6.2179 & TRN \\
\hline CHEMBL3933742 & 1642076 & 9.3979 & 9.3814 & TST \\
\hline CHEMBL 3903686 & 1642076 & 10.2233 & 9.951 & TRN \\
\hline CHEMBL3946152 & 1642076 & 9.7447 & 9.5786 & TST \\
\hline
\end{tabular}




\begin{tabular}{|c|c|c|c|c|c|c|}
\hline \multicolumn{7}{|c|}{ Supplemental Table S2.txt } \\
\hline CHEMBL3907325 & 1642076 & 8.58 & 8.1759 & TRN & & \\
\hline CHEMBL3918771 & 1642076 & 6.0 & 6.6655 & TST & & \\
\hline CHEMBL3923078 & 1642076 & 8.9586 & 8.2573 & TST & & \\
\hline CHEMBL3918797 & 1642076 & 9.1549 & 8.669 & TRN & & \\
\hline CHEMBL3975814 & 1642076 & 6.383999 & t9999999 & 995 & 6.6803 & TRN \\
\hline CHEMBL3898395 & 1642076 & 8.9788 & 8.7826 & TRN & & \\
\hline CHEMBL 3962883 & 1642076 & 7.6326 & 6.9314 & TRN & & \\
\hline CHEMBL3979678 & 1642076 & 6.0 & 7.2082 & TST & & \\
\hline CHEMBL3949174 & 1642076 & 8.5686 & 8.249 & TRN & & \\
\hline CHEMBL3940464 & 1642076 & 8.2924 & 8.4165 & TST & & \\
\hline CHEMBL3935407 & 1642076 & 9.0 & 8.8512 & TST & & \\
\hline CHEMBL3918021 & 1642076 & 8.2218 & 8.0056 & TRN & & \\
\hline CHEMBL3905697 & 1642076 & 6.0 & 6.617006 & 0000000001 & & TRN \\
\hline CHEMBL3944136 & 1642076 & 9.2941 & 9.2671 & TST & & \\
\hline CHEMBL3942637 & 1642076 & 7.266 & 7.4392 & TRN & & \\
\hline CHEMBL3937682 & 1642076 & 7.51 & 7.167006 & 0000000001 & & TRN \\
\hline CHEMBL3902617 & 1642076 & 7.058 & 7.8652 & TRN & & \\
\hline CHEMBL3934242 & 1642076 & 8.7471 & 8.5479 & TRN & & \\
\hline CHEMBL3949953 & 1642076 & 8.0223 & 7.8376 & TST & & \\
\hline CHEMBL3961328 & 1642076 & 9.1586 & 9.0421 & TRN & & \\
\hline CHEMBL3966363 & 1642076 & 6.0 & 6.3172 & TRN & & \\
\hline CHEMBL3960320 & 1642076 & 8.7959 & 8.8501 & TRN & & \\
\hline CHEMBL3909217 & 1642076 & 10.0862 & 10.2318 & TST & & \\
\hline CHEMBL3968854 & 1642076 & 10.1308 & 9.9343 & TST & & \\
\hline CHEMBL3895552 & 1642076 & 7.2381 & 6.8478 & TRN & & \\
\hline CHEMBL3952993 & 1642076 & 7.699 & $6.94600 t$ & 0000000001 & & TRN \\
\hline CHEMBL3985959 & 1642076 & 9.3979 & 9.1218 & TRN & & \\
\hline CHEMBL3891786 & 1642076 & 8.6737 & 8.7445 & TRN & & \\
\hline CHEMBL3934697 & 1641456 & 6.1487 & 6.5315 & TST & & \\
\hline CHEMBL3972522 & 1641456 & 7.2218 & 6.6027 & TST & & \\
\hline CHEMBL3927443 & 1641456 & 7.2218 & 6.7456 & TST & & \\
\hline CHEMBL3910104 & 1641456 & 8.0 & 7.5578 & TRN & & \\
\hline CHEMBL3964184 & 1641456 & 6.7212 & 6.7855 & TRN & & \\
\hline CHEMBL3980681 & 1641456 & 5.7545 & 6.6476 & TST & & \\
\hline CHEMBL3899788 & 1641456 & 7.699 & 7.3657 & TST & & \\
\hline CHEMBL3926559 & 1641456 & 7.1549 & 7.501 & TRN & & \\
\hline CHEMBL3125710 & 1641456 & 8.0 & 8.1643 & TRN & & \\
\hline CHEMBL3904755 & 1641456 & 7.5229 & 7.6682 & TRN & & \\
\hline CHEMBL3901116 & 1641456 & 6.8861 & 6.8667 & TRN & & \\
\hline CHEMBL3980966 & 1641456 & 6.0 & 6.7442 & TRN & & \\
\hline CHEMBL3926383 & 1641456 & 7.699 & 7.5226 & TRN & & \\
\hline CHEMBL3125704 & 1641456 & 7.1549 & 7.6139 & TRN & & \\
\hline CHEMBL3969208 & 1641456 & 7.3979 & 7.4005 & TRN & & \\
\hline CHEMBL3980672 & 1641456 & 8.0 & 7.1914 & TRN & & \\
\hline CHEMBL3977218 & 1641456 & 6.7696 & 6.7622 & TRN & & \\
\hline CHEMBL3952130 & 1641456 & 7.3979 & 6.9762 & TRN & & \\
\hline CHEMBL3981933 & 1641456 & 6.0 & 6.9217 & TST & & \\
\hline CHEMBL3329608 & 1641456 & 7.0969 & 7.3602 & TRN & & \\
\hline
\end{tabular}


Supplemental Table S2.txt

\begin{tabular}{|c|c|c|c|c|c|}
\hline CHEMBL3894955 & 1641456 & 6.1549 & 5.8829 & TRN & \\
\hline CHEMBL3955799 & 1641456 & 6.6576 & \multicolumn{2}{|c|}{5.843999999999999} & TRN \\
\hline CHEMBL3935351 & 1641456 & 7.699 & 7.526 & TRN & \\
\hline CHEMBL3911064 & 1641456 & 7.301 & 6.8963 & TRN & \\
\hline CHEMBL3917573 & 1641456 & 7.5229 & 7.3763 & TRN & \\
\hline CHEMBL3967086 & 1641456 & 6.8539 & 6.8829 & TRN & \\
\hline CHEMBL3950289 & 1641456 & 6.0 & 6.7208 & TRN & \\
\hline CHEMBL3966894 & 1641456 & 8.0 & 7.8116 & TRN & \\
\hline CHEMBL3986029 & 1641456 & 7.3979 & 7.276 & TRN & \\
\hline CHEMBL3941666 & 1641456 & 7.699 & 7.4355 & TRN & \\
\hline CHEMBL3329620 & 1641456 & 7.5229 & 7.5171 & TRN & \\
\hline CHEMBL3125703 & 1641456 & 8.0 & 7.721 & TRN & \\
\hline CHEMBL3949273 & 1641456 & 6.5229 & 7.3949 & TST & \\
\hline CHEMBL3909508 & 1641456 & 8.0 & 7.0496 & TST & \\
\hline CHEMBL3962786 & 1641456 & 8.0 & 7.9179 & TRN & \\
\hline CHEMBL3959811 & 1641456 & 7.3979 & 7.1452 & TRN & \\
\hline CHEMBL3923514 & 1641456 & 6.6576 & 7.0496 & TST & \\
\hline CHEMBL3956860 & 1641456 & 7.3979 & 7.0881 & TRN & \\
\hline CHEMBL3953174 & 1641456 & 6.0 & 7.5563 & TRN & \\
\hline CHEMBL3910494 & 1641456 & 7.699 & 7.1043 & TST & \\
\hline CHEMBL3893802 & 1641456 & 8.0 & 8.3081 & TRN & \\
\hline CHEMBL3902756 & 1641456 & 8.0 & 7.8095 & TRN & \\
\hline CHEMBL3938935 & 1641456 & 7.0969 & 7.1852 & TRN & \\
\hline CHEMBL3914715 & 1641456 & 7.699 & 7.7075 & TRN & \\
\hline CHEMBL3935760 & 1641456 & 6.5229 & 6.3161 & TRN & \\
\hline CHEMBL3329606 & 1641456 & 7.2218 & 7.1205 & TRN & \\
\hline CHEMBL3942923 & 1641456 & 6.8861 & 6.8257 & TST & \\
\hline CHEMBL3965528 & 1641456 & 6.0 & 7.2056 & TST & \\
\hline CHEMBL3891039 & 1641456 & 7.1549 & 7.0077 & TRN & \\
\hline CHEMBL3919602 & 1641456 & 6.5686 & 6.857 & TRN & \\
\hline CHEMBL3899355 & 1641456 & 7.699 & 7.6168 & TRN & \\
\hline CHEMBL3980413 & 1641456 & 8.0 & 7.8936 & TRN & \\
\hline CHEMBL3918280 & 1641456 & 6.0 & 6.7998 & TRN & \\
\hline CHEMBL3329612 & 1641456 & 7.0969 & 7.3653 & TRN & \\
\hline CHEMBL3962186 & 1641456 & 6.3872 & 6.7274 & TRN & \\
\hline CHEMBL3927464 & 1641456 & 7.0969 & 7.4288 & TRN & \\
\hline CHEMBL3950753 & 1641456 & 7.2218 & 6.6764 & TRN & \\
\hline CHEMBL3919530 & 1641456 & 6.3098 & 7.0535 & TST & \\
\hline CHEMBL3895254 & 1641456 & 8.0 & 7.5455 & TRN & \\
\hline CHEMBL3329607 & 1641456 & 7.3979 & 7.1883 & TRN & \\
\hline CHEMBL3962737 & 1641456 & 6.6383 & 7.1209 & TST & \\
\hline CHEMBL3928821 & 1641456 & 6.0 & 7.2903 & TRN & \\
\hline CHEMBL3904550 & 1641456 & 7.699 & 7.676 & TRN & \\
\hline CHEMBL3987205 & 1641456 & 5.7696 & 5.5131 & TRN & \\
\hline CHEMBL3906565 & 1641456 & 6.2441 & 6.7532 & TRN & \\
\hline CHEMBL3329224 & 1641456 & 8.0 & 7.5472 & TRN & \\
\hline CHEMBL2059435 & 1641456 & 6.0 & 6.4792 & TRN & \\
\hline CHEMBL3966228 & 1641456 & 7.5229 & 7.6807 & TRN & \\
\hline
\end{tabular}

Page 25554 


\begin{tabular}{|c|c|c|c|c|c|}
\hline \multicolumn{6}{|c|}{ Supplemental Table s2.txt } \\
\hline CHEMBL 3948090 & 1641456 & 8.0 & 7.4381 & TRN & \\
\hline CHEMBL3921531 & 1641456 & 8.0 & 8.0855 & TRN & \\
\hline CHEMBL3963764 & 1641456 & 7.5229 & 7.1241 & TRN & \\
\hline CHEMBL 3938020 & 1641456 & 6.0 & 6.7988 & TRN & \\
\hline CHEMBL3918513 & 1641456 & 5.7055 & 5.7862 & TRN & \\
\hline CHEMBL3936183 & 1641456 & 6.6778 & 7.2791 & TST & \\
\hline CHEMBL3897717 & 1641456 & 8.0 & 7.9696 & TRN & \\
\hline CHEMBL 3895600 & 1641456 & 8.0 & 7.7767 & TRN & \\
\hline CHEMBL 3985724 & 1641456 & 7.699 & 6.9912 & TST & \\
\hline CHEMBL3977986 & 1641456 & 6.0 & 5.7919 & TST & \\
\hline CHEMBL 3942754 & 1641456 & 8.0 & 7.3068 & TRN & \\
\hline CHEMBL3971595 & 1641456 & 5.6234 & 5.8391 & TRN & \\
\hline CHEMBL3924972 & 1641456 & 7.699 & 7.7421 & TRN & \\
\hline CHEMBL3963837 & 1641456 & 7.0458 & 6.0814 & TST & \\
\hline CHEMBL3980222 & 1641456 & 8.0 & 7.8081 & TRN & \\
\hline CHEMBL3952928 & 1641456 & 8.0 & 7.6603 & TRN & \\
\hline CHEMBL3977225 & 1641456 & 7.5229 & 7.9584 & TRN & \\
\hline CHEMBL3934369 & 1641456 & 6.0757 & 7.129 & TRN & \\
\hline CHEMBL 3962770 & 1641456 & 9.0 & 8.4052 & TRN & \\
\hline CHEMBL3933882 & 1641456 & 5.7033 & 6.6633 & TST & \\
\hline CHEMBL3985402 & 1641456 & 7.0 & 7.3671 & TRN & \\
\hline CHEMBL3895563 & 1641456 & 7.3979 & 7.2218 & TRN & \\
\hline CHEMBL3961139 & 1641456 & 6.0 & 6.6889 & TRN & \\
\hline CHEMBL3903095 & 1641456 & 7.699 & 7.38700 & 00000000005 & TRN \\
\hline CHEMBL3923297 & 1641456 & 7.5229 & 7.2244 & TRN & \\
\hline CHEMBL3955127 & 1641456 & 5.5143 & 5.6642 & TRN & \\
\hline CHEMBL3941874 & 1641456 & 7.699 & 7.8663 & TRN & \\
\hline CHEMBL3904690 & 1641456 & 6.9586 & 6.9845 & TST & \\
\hline CHEMBL 3967148 & 1641456 & 8.0 & 8.0223 & TRN & \\
\hline CHEMBL3954030 & 1641456 & 8.0 & 8.1597 & TRN & \\
\hline CHEMBL 3940228 & 1641456 & 7.0458 & 6.8303 & TRN & \\
\hline CHEMBL 2177191 & 1641456 & 7.699 & 7.8563 & TRN & \\
\hline CHEMBL3890577 & 1641456 & 7.5229 & 7.1587 & TST & \\
\hline CHEMBL3959723 & 1641456 & 7.3979 & 7.3127 & TRN & \\
\hline CHEMBL3911334 & 1641456 & 6.0 & 6.6842 & TRN & \\
\hline CHEMBL 3942905 & 1641456 & 6.3468 & 6.5617 & TRN & \\
\hline CHEMBL3899191 & 1641456 & 6.7212 & 7.2028 & TST & \\
\hline CHEMBL3955489 & 1641456 & 8.0 & 7.7299 & TRN & \\
\hline CHEMBL3966282 & 1641456 & 5.7959 & 5.6383 & TST & \\
\hline CHEMBL3963132 & 1641456 & 7.699 & 7.7169 & TRN & \\
\hline CHEMBL3950605 & 1641456 & 7.5229 & 7.6939 & TRN & \\
\hline CHEMBL3963943 & 1641456 & 8.0 & 7.2408 & TST & \\
\hline CHEMBL3948736 & 1641456 & 8.0 & 7.5288 & TRN & \\
\hline CHEMBL3895079 & 1641456 & 6.9586 & 6.8691 & TRN & \\
\hline CHEMBL3929164 & 1641456 & 7.5229 & 7.279 & TST & \\
\hline CHEMBL3975518 & 1641456 & 7.0969 & 6.58899 & 99999999995 & TRN \\
\hline CHEMBL3934687 & 1641456 & 6.5686 & 6.7481 & TRN & \\
\hline CHEMBL3930665 & 1641456 & 9.0 & 7.886 & TRN & \\
\hline
\end{tabular}


Supplemental Table S2.txt

\begin{tabular}{|c|c|c|c|c|c|}
\hline CHEMBL3910330 & 1641456 & 7.699 & 7.4835 & TRN & \\
\hline CHEMBL3933945 & 1641456 & 6.3872 & 6.4917 & TRN & \\
\hline CHEMBL3931331 & 1641456 & 7.5229 & 7.0152 & TRN & \\
\hline CHEMBL3898769 & 1641456 & 7.5229 & 7.2368 & TRN & \\
\hline CHEMBL3972181 & 1641456 & 7.5229 & 7.6602 & TRN & \\
\hline CHEMBL3915542 & 1641456 & 6.3098 & 6.9359 & TRN & \\
\hline CHEMBL3921471 & 1641456 & 6.4685 & 6.9847 & TST & \\
\hline CHEMBL3895235 & 1641456 & 7.301 & 7.1797 & TRN & \\
\hline CHEMBL3950087 & 1641456 & 6.0 & 6.2761 & TST & \\
\hline CHEMBL3892703 & 1641456 & 6.0 & 7.2786 & TRN & \\
\hline CHEMBL3979481 & 1641456 & 6.5086 & 5.6071 & TST & \\
\hline CHEMBL3932462 & 1641456 & 6.2757 & 7.0896 & TST & \\
\hline CHEMBL3125705 & 1641456 & 8.0 & 7.8861 & TRN & \\
\hline CHEMBL3329604 & 1641456 & 7.301 & 7.1897 & TRN & \\
\hline CHEMBL3903889 & 1641456 & 5.7235 & 6.6327 & TST & \\
\hline CHEMBL3970386 & 1641456 & 8.0 & 8.128 & TRN & \\
\hline CHEMBL3964874 & 1641456 & 7.3979 & 7.5716 & TRN & \\
\hline CHEMBL3893633 & 1641456 & 6.3665 & 6.2643 & TST & \\
\hline CHEMBL3965449 & 1641456 & 6.2147 & 7.0108 & TST & \\
\hline CHEMBL3938040 & 1641456 & 7.5229 & 7.7007 & TRN & \\
\hline CHEMBL3977644 & 1641456 & 7.699 & 7.4798 & TRN & \\
\hline CHEMBL 3894020 & 1641456 & 7.5229 & 7.1542 & TST & \\
\hline CHEMBL3897002 & 1641456 & 5.4401 & 5.8047 & TRN & \\
\hline CHEMBL3930163 & 1641456 & 7.0969 & 6.6417 & TST & \\
\hline CHEMBL3930864 & 1641456 & 7.5229 & 7.5979 & TRN & \\
\hline CHEMBL3967551 & 1641456 & 7.699 & 7.53299 & 99999999995 & TRN \\
\hline CHEMBL3932275 & 1641456 & 6.0 & 6.3957 & TRN & \\
\hline CHEMBL3919318 & 1641456 & 7.3979 & 7.6655 & TRN & \\
\hline CHEMBL3925071 & 1641456 & 7.699 & 7.5955 & TRN & \\
\hline CHEMBL3913666 & 1641456 & 7.5229 & 6.6511 & TST & \\
\hline CHEMBL3902289 & 1641456 & 7.301 & 7.2665 & TRN & \\
\hline CHEMBL 3892158 & 1641456 & 6.7447 & 6.7652 & TRN & \\
\hline CHEMBL3959464 & 1641456 & 7.2218 & 7.3294 & TRN & \\
\hline CHEMBL3894532 & 1641456 & 8.0 & 7.7495 & TRN & \\
\hline CHEMBL3957985 & 1641456 & 8.0 & 7.9968 & TRN & \\
\hline CHEMBL3919031 & 1641456 & 7.3979 & 7.5199 & TRN & \\
\hline CHEMBL3910590 & 1641456 & 7.5229 & 6.9537 & TST & \\
\hline CHEMBL3951659 & 1641456 & 7.5229 & 7.302006 & 00000000005 & TRN \\
\hline CHEMBL3949847 & 1641456 & 6.8861 & 6.7528 & TRN & \\
\hline CHEMBL3961625 & 1641456 & 8.0 & 8.1075 & TRN & \\
\hline CHEMBL3125517 & 1641456 & 9.0 & 8.8308 & TRN & \\
\hline CHEMBL 2177189 & 1641456 & 8.0 & 7.3816 & TRN & \\
\hline CHEMBL3904258 & 1641456 & 6.7696 & 5.8181 & TRN & \\
\hline CHEMBL3902189 & 1641456 & 6.2366 & 7.0889 & TST & \\
\hline CHEMBL3940102 & 1641456 & 7.301 & 7.6198 & TRN & \\
\hline CHEMBL3900467 & 1641456 & 6.0809 & 5.8167 & TRN & \\
\hline CHEMBL3926199 & 1641456 & 6.0 & 7.1447 & TST & \\
\hline CHEMBL3928504 & 1641456 & 6.0 & 5.4968 & TRN & \\
\hline
\end{tabular}


Supplemental Table S2.txt

\begin{tabular}{|c|c|c|c|c|c|}
\hline CHEMBL 3941435 & 1641456 & 7.1549 & 7.2796 & TST & \\
\hline CHEMBL 3926751 & 1641456 & 7.699 & 7.6873 & TRN & \\
\hline CHEMBL3957996 & 1641456 & 6.585 & 6.9165 & TST & \\
\hline CHEMBL 3978255 & 1641456 & 6.0 & 5.8043 & TRN & \\
\hline CHEMBL 3946679 & 1641456 & 6.0 & 7.5237 & TST & \\
\hline CHEMBL3925692 & 1641456 & 7.699 & 7.3825 & TRN & \\
\hline CHEMBL3978907 & 1641456 & 5.6799 & 6.8112 & TST & \\
\hline CHEMBL3921122 & 1641456 & 6.0 & 7.0512 & TRN & \\
\hline CHEMBL 3954881 & 1641456 & 6.0 & 5.8719 & TST & \\
\hline CHEMBL 3907720 & 1641456 & 7.2218 & 6.5787 & TST & \\
\hline CHEMBL3329605 & 1641456 & 7.5229 & 7.1578 & TRN & \\
\hline CHEMBL3945035 & 1641456 & 7.5229 & 7.4303 & TRN & \\
\hline CHEMBL366031 & 304901 & 3.0 & 3.0001 & TRN & \\
\hline CHEMBL191769 & 304901 & 3.0 & 2.9985 & TRN & \\
\hline CHEMBL195205 & 304901 & 3.0 & 2.9991 & TRN & \\
\hline CHEMBL192425 & 304901 & 3.0 & 3.0042 & TRN & \\
\hline CHEMBL191858 & 304901 & 3.0 & 3.0006 & TRN & \\
\hline CHEMBL370072 & 304901 & 3.0 & 3.0011 & TRN & \\
\hline CHEMBL195739 & 304901 & 4.2366 & 3.5923 & TST & \\
\hline CHEMBL191354 & 304901 & 3.0 & 3.0019 & TRN & \\
\hline CHEMBL364057 & 304901 & 4.7696 & 4.7693 & TRN & \\
\hline CHEMBL195755 & 304901 & 3.0 & 2.9955 & TRN & \\
\hline CHEMBL192117 & 304901 & 3.0 & 2.99899 & 99999999997 & TRN \\
\hline CHEMBL192396 & 304901 & 3.0 & 2.8696 & TST & \\
\hline CHEMBL369888 & 304901 & 3.0 & 3.0019 & TRN & \\
\hline CHEMBL190454 & 304901 & 3.0 & 3.0 & TRN & \\
\hline CHEMBL370033 & 304901 & 4.2596 & 4.2596 & TRN & \\
\hline CHEMBL191933 & 304901 & 4.0706 & 4.0701 & TRN & \\
\hline CHEMBL365996 & 304901 & 3.0 & 3.0006 & TRN & \\
\hline CHEMBL365575 & 304901 & 3.0 & 2.9947 & TRN & \\
\hline CHEMBL195862 & 304901 & 3.0 & 3.0008 & TRN & \\
\hline CHEMBL195173 & 304901 & 4.3768 & 4.3764 & TRN & \\
\hline CHEMBL363175 & 304901 & 3.0 & 2.9956 & TRN & \\
\hline CHEMBL362973 & 304901 & 3.0 & 2.9992 & TRN & \\
\hline CHEMBL191514 & 304901 & 4.1135 & 4.1126 & TRN & \\
\hline CHEMBL365953 & 304901 & 3.0 & 2.99899 & 99999999997 & TRN \\
\hline CHEMBL372472 & 304901 & 3.0 & 3.0005 & TRN & \\
\hline CHEMBL195443 & 304901 & 4.1308 & 4.1293 & TRN & \\
\hline CHEMBL191823 & 304901 & 3.0 & 2.9987 & TRN & \\
\hline CHEMBL278729 & 304901 & 3.0 & 3.0003 & TRN & \\
\hline CHEMBL371846 & 304901 & 3.0 & 3.0003 & TRN & \\
\hline CHEMBL362976 & 304901 & 3.0 & 2.9999 & TRN & \\
\hline CHEMBL191652 & 304901 & 3.0 & 2.9998 & TRN & \\
\hline CHEMBL195667 & 304901 & 3.0 & 3.4632 & TST & \\
\hline CHEMBL195905 & 304901 & 4.3279 & 4.3264 & TRN & \\
\hline CHEMBL189881 & 304901 & 4.0555 & 4.0604 & TRN & \\
\hline CHEMBL 370240 & 304901 & 3.0 & 3.0019 & TRN & \\
\hline CHEMBL192421 & 304901 & 4.4089 & 4.4096 & TRN & \\
\hline
\end{tabular}




\begin{tabular}{|c|c|c|c|c|c|}
\hline \multicolumn{6}{|c|}{ Supplemental Table s2.txt } \\
\hline CHEMBL 362930 & 304901 & 3.0 & 3.0016 & TRN & \\
\hline CHEMBL194437 & 304901 & 3.0 & 3.0006 & TRN & \\
\hline CHEMBL370734 & 304901 & 3.0 & 2.9989 & TRN & \\
\hline CHEMBL193887 & 304901 & 3.0 & 2.9977 & TRN & \\
\hline CHEMBL192983 & 304901 & 3.0 & 3.0166 & TST & \\
\hline CHEMBL 365780 & 304901 & 4.6383 & 4.6388 & TRN & \\
\hline CHEMBL195378 & 304901 & 3.0 & 2.9986 & TRN & \\
\hline CHEMBL192980 & 304901 & 4.1938 & 4.1938 & TRN & \\
\hline CHEMBL190979 & 304901 & 3.0 & 3.00100 & 00000000003 & TRN \\
\hline CHEMBL552788 & 304901 & 4.2007 & 2.3086 & TST & \\
\hline CHEMBL366173 & 304901 & 3.0 & 3.0022 & TRN & \\
\hline CHEMBL 263326 & 304901 & 3.0 & 3.002 & TRN & \\
\hline CHEMBL191906 & 304901 & 3.0 & 3.0037 & TRN & \\
\hline CHEMBL 364093 & 304901 & 4.2441 & 4.2434 & TRN & \\
\hline CHEMBL195270 & 304901 & 3.0 & 2.6774 & TST & \\
\hline CHEMBL194489 & 304901 & 3.0 & 3.1513 & TST & \\
\hline CHEMBL192365 & 304901 & 4.2147 & 3.1381 & TST & \\
\hline CHEMBL191812 & 304901 & 5.0088 & 4.1261 & TST & \\
\hline CHEMBL 22310 & 304901 & 6.0031 & 3.7369 & TST & \\
\hline CHEMBL370079 & 304901 & 3.0 & 1.8958 & TST & \\
\hline CHEMBL192449 & 304901 & 4.2441 & 2.844 & TST & \\
\hline CHEMBL363584 & 304901 & 3.0 & 3.0745 & TST & \\
\hline CHEMBL425375 & 304901 & 3.0 & 3.3008 & TST & \\
\hline CHEMBL192781 & 304901 & 3.0 & 3.0587 & TST & \\
\hline CHEMBL1333555 & 737125 & 5.0362 & 5.1512 & TRN & \\
\hline CHEMBL1456035 & 737125 & 4.8477 & 4.9768 & TRN & \\
\hline CHEMBL1371869 & 737125 & 5.1675 & 4.9593 & TRN & \\
\hline CHEMBL1363132 & 737125 & 3.0 & 3.4801 & TRN & \\
\hline CHEMBL1353227 & 737125 & 4.6696 & 4.3605 & TST & \\
\hline CHEMBL501993 & 737125 & 5.2924 & 5.0388 & TST & \\
\hline CHEMBL1490701 & 737125 & 5.4685 & 5.4291 & TRN & \\
\hline CHEMBL1608654 & 737125 & 4.8601 & 4.9311 & TRN & \\
\hline CHEMBL1443006 & 737125 & 3.0 & 2.8609 & TRN & \\
\hline CHEMBL1334633 & 737125 & 4.8327 & 4.6962 & TRN & \\
\hline CHEMBL492894 & 737125 & 4.2941 & 4.6858 & TRN & \\
\hline CHEMBL1493399 & 737125 & 3.0 & 2.8194 & TRN & \\
\hline CHEMBL1400895 & 737125 & 3.0 & 3.0638 & TST & \\
\hline CHEMBL1333592 & 737125 & 3.0 & 3.0241 & TRN & \\
\hline CHEMBL1495142 & 737125 & 3.0 & 2.82800 & 00000000003 & TRN \\
\hline CHEMBL1328309 & 737125 & 3.0 & 3.1763 & TRN & \\
\hline CHEMBL1606056 & 737125 & 3.0 & 2.9727 & TRN & \\
\hline CHEMBL1319451 & 737125 & 3.0 & 2.9802 & TST & \\
\hline CHEMBL1373495 & 737125 & 3.0 & 3.2355 & TRN & \\
\hline CHEMBL1373509 & 737125 & 3.0 & 3.0826 & TRN & \\
\hline CHEMBL1403497 & 737125 & 3.0 & 3.8849 & TST & \\
\hline CHEMBL1328398 & 737125 & 3.0 & 3.2256 & TST & \\
\hline CHEMBL1607735 & 737125 & 4.8508 & 4.9441 & TRN & \\
\hline CHEMBL1449334 & 737125 & 4.0947 & 4.8651 & TST & \\
\hline
\end{tabular}




\begin{tabular}{|c|c|c|c|c|c|}
\hline \multirow[b]{2}{*}{ CHEMBL1491991 } & \multicolumn{5}{|c|}{ Supplemental Table s2.txt } \\
\hline & 737125 & 4.3565 & 4.4796 & TRN & \\
\hline CHEMBL1567279 & 737125 & 3.0 & 2.9039 & TRN & \\
\hline CHEMBL1570803 & 737125 & 4.3788 & 4.7617 & TRN & \\
\hline CHEMBL1371777 & 737125 & 4.5058 & 5.2681 & TST & \\
\hline CHEMBL259355 & 737125 & 3.0 & 3.0384 & TRN & \\
\hline CHEMBL1517389 & 737125 & 4.3706 & 4.2138 & TRN & \\
\hline CHEMBL 1554052 & 737125 & 3.0 & 3.4584 & TRN & \\
\hline CHEMBL1491672 & 737125 & 3.0 & 3.0638 & TST & \\
\hline CHEMBL1565097 & 737125 & 3.0 & 2.9467 & TRN & \\
\hline CHEMBL1527023 & 737125 & 3.0 & 2.8865 & TRN & \\
\hline CHEMBL1441239 & 737125 & 3.0 & 3.03800 & 00000000003 & TRN \\
\hline CHEMBL1359394 & 737125 & 3.0 & 2.8242 & TRN & \\
\hline CHEMBL1426947 & 737125 & 3.0 & 2.7836 & TST & \\
\hline CHEMBL1452440 & 737125 & 4.2823 & 4.2668 & TRN & \\
\hline CHEMBL1333960 & 737125 & 3.0 & 3.1814 & TST & \\
\hline CHEMBL1328729 & 737125 & 3.0 & 2.9812 & TRN & \\
\hline CHEMBL1491520 & 737125 & 3.0 & 3.0113 & TRN & \\
\hline CHEMBL1328061 & 737125 & 3.0 & 3.04399 & 99999999996 & TRN \\
\hline CHEMBL1606748 & 737125 & 3.0 & 3.0433 & TRN & \\
\hline CHEMBL1525859 & 737125 & 3.0 & 2.9549 & TST & \\
\hline CHEMBL1448629 & 737125 & 3.0 & 3.1249 & TRN & \\
\hline CHEMBL1530046 & 737125 & 3.0 & 3.1316 & TRN & \\
\hline CHEMBL1447034 & 737125 & 5.2076 & 4.8585 & TRN & \\
\hline CHEMBL1374065 & 737125 & 3.0 & 3.0946 & TST & \\
\hline CHEMBL1482473 & 737125 & 3.0 & 3.1834 & TRN & \\
\hline CHEMBL1412998 & 737125 & 3.0 & 2.8053 & TRN & \\
\hline CHEMBL1491919 & 737125 & 3.0 & 2.7331 & TST & \\
\hline CHEMBL1449836 & 737125 & 4.6216 & 5.1833 & TST & \\
\hline CHEMBL1603381 & 737125 & 5.3565 & 5.33700 & 0000000001 & TRN \\
\hline CHEMBL 244695 & 737125 & 4.7496 & 4.5137 & TRN & \\
\hline CHEMBL1448320 & 737125 & 3.0 & 3.1363 & TRN & \\
\hline CHEMBL1451516 & 737125 & 4.3757 & 5.0605 & TST & \\
\hline CHEMBL1526610 & 737125 & 3.0 & 3.4052 & TST & \\
\hline CHEMBL1597781 & 737125 & 3.0 & 3.0772 & TRN & \\
\hline CHEMBL1376870 & 737125 & 5.0969 & 4.7511 & TRN & \\
\hline CHEMBL1492035 & 737125 & 4.2798 & 4.2034 & TRN & \\
\hline CHEMBL 2448605 & 737125 & 3.0 & 2.8507 & TRN & \\
\hline CHEMBL1608153 & 737125 & 4.6925 & 4.5621 & TRN & \\
\hline CHEMBL1329983 & 737125 & 3.0 & 2.8995 & TST & \\
\hline CHEMBL1447461 & 737125 & 3.0 & 2.8627 & TRN & \\
\hline CHEMBL1483741 & 737125 & 3.0 & 3.0234 & TRN & \\
\hline CHEMBL1490321 & 737125 & 3.0 & 3.1569 & TRN & \\
\hline CHEMBL1334412 & 737125 & 4.38399 & 99999999 & 4.0249 & TRN \\
\hline CHEMBL1483335 & 737125 & 5.0655 & 4.8803 & TRN & \\
\hline CHEMBL1526353 & 737125 & 3.0 & 3.2594 & TST & \\
\hline CHEMBL1489665 & 737125 & 3.0 & 2.5167 & TST & \\
\hline CHEMBL1489917 & 737125 & 3.0 & 3.2242 & TRN & \\
\hline CHEMBL1480807 & 737125 & 3.0 & 2.9742 & TRN & \\
\hline
\end{tabular}




\begin{tabular}{|c|c|c|c|c|}
\hline \multicolumn{5}{|c|}{ Supplemental Table S2.txt } \\
\hline CHEMBL1408008 & 737125 & 3.0 & 2.8964 & TRN \\
\hline CHEMBL1606543 & 737125 & 4.7696 & 4.6943 & TRN \\
\hline CHEMBL1530080 & 737125 & 5.0458 & 4.9292 & TRN \\
\hline CHEMBL1414381 & 737125 & 3.0 & 3.0481 & TRN \\
\hline CHEMBL1608225 & 737125 & 4.2104 & 3.5618 & TRN \\
\hline CHEMBL1403754 & 737125 & 3.0 & 3.2055 & TST \\
\hline CHEMBL1535445 & 737125 & 3.0 & 3.1865 & TRN \\
\hline CHEMBL1528814 & 737125 & 4.8539 & 4.7194 & TRN \\
\hline CHEMBL1409373 & 737125 & 3.0 & 3.1824 & TRN \\
\hline CHEMBL1410909 & 737125 & 3.0 & 3.9261 & TRN \\
\hline CHEMBL1531431 & 737125 & 3.0 & 2.997 & TRN \\
\hline CHEMBL 271690 & 737125 & 4.2321 & 4.547 & TRN \\
\hline CHEMBL1363824 & 737125 & 4.1972 & 4.4279 & TRN \\
\hline CHEMBL1427609 & 737125 & 5.1612 & 4.7638 & TST \\
\hline CHEMBL1526669 & 737125 & 4.3098 & 4.3041 & TRN \\
\hline CHEMBL1407027 & 737125 & 3.0 & 2.6111 & TRN \\
\hline CHEMBL1602524 & 737125 & 3.0 & 2.9081 & TRN \\
\hline CHEMBL 1454310 & 737125 & 3.0 & 2.8916 & TRN \\
\hline CHEMBL1599376 & 737125 & 3.0 & 3.2682 & TST \\
\hline CHEMBL312097 & 737125 & 3.0 & 2.9693 & TRN \\
\hline CHEMBL1570401 & 737125 & 4.284 & 4.0916 & TRN \\
\hline CHEMBL578585 & 737125 & 4.8153 & 4.2557 & TST \\
\hline CHEMBL1430473 & 737125 & 4.4342 & 4.3796 & TRN \\
\hline CHEMBL1452974 & 737125 & 3.0 & 3.4381 & TRN \\
\hline CHEMBL1492839 & 737125 & 3.0 & 3.5019 & TST \\
\hline CHEMBL1566708 & 737125 & 3.0 & 2.907 & TRN \\
\hline CHEMBL1527941 & 737125 & 4.475 & 4.4484 & TRN \\
\hline CHEMBL1331645 & 737125 & 4.7033 & 4.9942 & TRN \\
\hline CHEMBL1368913 & 737125 & 4.7696 & 4.7804 & TRN \\
\hline CHEMBL1527520 & 737125 & 5.0706 & 4.3626 & TRN \\
\hline CHEMBL1386069 & 737125 & 3.0 & 3.4125 & TST \\
\hline CHEMBL1373046 & 737125 & 4.317 & 4.1431 & TRN \\
\hline CHEMBL458328 & 737125 & 4.6003 & 3.986 & TST \\
\hline CHEMBL1568844 & 737125 & 3.0 & 3.0332 & TRN \\
\hline CHEMBL201289 & 737125 & 4.8928 & 4.8484 & TRN \\
\hline CHEMBL1557930 & 737125 & 3.0 & 3.0638 & TST \\
\hline CHEMBL1489230 & 737125 & 4.6576 & 4.7413 & TRN \\
\hline CHEMBL3693661 & 1527954 & 5.7328 & 5.6532 & TRN \\
\hline CHEMBL 3693667 & 1527954 & 7.8861 & 7.9495 & TRN \\
\hline CHEMBL 3693664 & 1527954 & 6.5171 & 6.5612 & TRN \\
\hline CHEMBL3693683 & 1527954 & 6.5186 & 6.4688 & TRN \\
\hline CHEMBL3693650 & 1527954 & 7.1938 & 7.2998 & TRN \\
\hline CHEMBL3693677 & 1527954 & 7.0862 & 7.1254 & TRN \\
\hline CHEMBL3693694 & 1527954 & 7.8239 & 7.8774 & TRN \\
\hline CHEMBL 3693638 & 1527954 & 6.4559 & 6.3942 & TRN \\
\hline CHEMBL3693659 & 1527954 & 5.2967 & 5.2941 & TRN \\
\hline CHEMBL 3693662 & 1527954 & 5.6038 & 5.6509 & TRN \\
\hline CHEMBL3693696 & 1527954 & 7.2441 & 7.1775 & TST \\
\hline
\end{tabular}


Supplemental Table S2.txt

\begin{tabular}{|c|c|c|c|c|}
\hline CHEMBL3693699 & 1527954 & 5.9586 & 6.5329 & TST \\
\hline CHEMBL3693668 & 1527954 & 7.3188 & 7.2206 & TRN \\
\hline CHEMBL3639925 & 1527954 & 7.1367 & 7.1882 & TRN \\
\hline CHEMBL 3693695 & 1527954 & 6.6478 & 6.6847 & TRN \\
\hline CHEMBL3693647 & 1527954 & 7.6198 & 7.4612 & TST \\
\hline CHEMBL 3693645 & 1527954 & 6.5935 & 6.5834 & TRN \\
\hline CHEMBL3693690 & 1527954 & 6.8633 & 5.5718 & TST \\
\hline CHEMBL 3693673 & 1527954 & 6.8416 & 6.8253 & TRN \\
\hline CHEMBL 3693698 & 1527954 & 5.8894 & 5.8366 & TRN \\
\hline CHEMBL3693682 & 1527954 & 6.4828 & 6.5036 & TRN \\
\hline CHEMBL3693689 & 1527954 & 7.8239 & 7.3823 & TST \\
\hline CHEMBL3693657 & 1527954 & 7.4685 & 7.4313 & TRN \\
\hline CHEMBL3693697 & 1527954 & 6.1688 & 6.2613 & TRN \\
\hline CHEMBL 3693663 & 1527954 & 7.1805 & \multicolumn{2}{|c|}{7.2170000000000005} \\
\hline CHEMBL3693676 & 1527954 & 6.3382 & 6.3995 & TRN \\
\hline CHEMBL3693637 & 1527954 & 6.5376 & 6.4983 & TRN \\
\hline CHEMBL3693692 & 1527954 & 6.6576 & 6.7506 & TRN \\
\hline CHEMBL3693691 & 1527954 & 6.0287 & 6.0336 & TRN \\
\hline CHEMBL3693649 & 1527954 & 7.0315 & 7.0434 & TRN \\
\hline CHEMBL3693688 & 1527954 & 6.857 & 6.9798 & TST \\
\hline CHEMBL3693680 & 1527954 & 8.0969 & 8.0162 & TRN \\
\hline CHEMBL3693635 & 1527954 & 5.9666 & 5.975 & TRN \\
\hline CHEMBL3693675 & 1527954 & 7.6383 & 7.5792 & TRN \\
\hline CHEMBL3693636 & 1527954 & 5.3478 & 6.0259 & TST \\
\hline CHEMBL 3693679 & 1527954 & 6.4609 & 6.3511 & TRN \\
\hline CHEMBL3693660 & 1527954 & 5.7375 & 5.8165 & TRN \\
\hline CHEMBL 3693643 & 1527954 & 6.9666 & 6.8963 & TRN \\
\hline CHEMBL3693639 & 1527954 & 6.2976 & 6.2922 & TRN \\
\hline CHEMBL 3693653 & 1527954 & 6.8928 & 6.5274 & TST \\
\hline CHEMBL 3693651 & 1527954 & 6.8794 & 6.6307 & TST \\
\hline CHEMBL 3693642 & 1527954 & 6.068 & 5.9035 & TST \\
\hline CHEMBL3693693 & 1527954 & 7.0969 & 7.1262 & TRN \\
\hline CHEMBL3693652 & 1527954 & 6.1079 & 6.0494 & TST \\
\hline CHEMBL 3693700 & 1527954 & 7.5229 & 7.4549 & TRN \\
\hline CHEMBL 3693654 & 1527954 & 7.1135 & 6.425 & TST \\
\hline CHEMBL 3693644 & 1527954 & 7.5528 & 7.5154 & TRN \\
\hline CHEMBL3693666 & 1527954 & 8.0458 & 8.1556 & TRN \\
\hline CHEMBL3693670 & 1527954 & 8.0 & 7.8139 & TRN \\
\hline CHEMBL3693687 & 1527954 & 7.0506 & 6.9632 & TRN \\
\hline CHEMBL 3693674 & 1527954 & 7.2007 & 6.949 & TST \\
\hline CHEMBL 3693641 & 1527954 & 6.1355 & 6.1372 & TRN \\
\hline CHEMBL3693648 & 1527954 & 7.7212 & 7.7387 & TRN \\
\hline CHEMBL3693681 & 1527954 & 7.5686 & 7.4493 & TRN \\
\hline CHEMBL3693684 & 1527954 & 7.2076 & 7.2232 & TRN \\
\hline CHEMBL3693672 & 1527954 & 7.585 & 7.6445 & TST \\
\hline CHEMBL3693646 & 1527954 & 7.1249 & 7.0964 & TRN \\
\hline CHEMBL3693658 & 1527954 & 7.1308 & 7.3459 & TRN \\
\hline CHEMBL3693665 & 1527954 & 6.2487 & 6.1556 & TRN \\
\hline
\end{tabular}

Page 25561 
Supplemental Table S2.txt

\begin{tabular}{|c|c|c|c|c|}
\hline CHEMBL 3693656 & 1527954 & 6.2628 & 6.3802 & TRN \\
\hline CHEMBL3693669 & 1527954 & 7.7447 & 7.7398 & TRN \\
\hline CHEMBL3693671 & 1527954 & 7.3665 & 7.4328 & TRN \\
\hline CHEMBL 3693678 & 1527954 & 6.475 & 7.1165 & TST \\
\hline CHEMBL3693640 & 1527954 & 5.5986 & 5.6386 & TRN \\
\hline CHEMBL 3693686 & 1527954 & 6.3851 & 6.3198 & TRN \\
\hline CHEMBL 3693655 & 1527954 & 6.7721 & \multicolumn{2}{|c|}{6.4110000000000005} \\
\hline CHEMBL3693685 & 1527954 & 7.0809 & 6.9621 & TST \\
\hline CHEMBL 370295 & 1637647 & 4.301 & 4.1771 & TRN \\
\hline CHEMBL3928814 & 1637647 & 5.7945 & 5.1791 & TRN \\
\hline CHEMBL 373300 & 1637647 & 5.8601 & 5.2161 & TRN \\
\hline CHEMBL364317 & 1637647 & 7.0915 & 6.5093 & TRN \\
\hline CHEMBL191138 & 1637647 & 4.301 & 4.1273 & TRN \\
\hline CHEMBL 3962672 & 1637647 & 4.301 & 4.4908 & TRN \\
\hline CHEMBL190804 & 1637647 & 4.301 & 4.4679 & TRN \\
\hline CHEMBL192749 & 1637647 & 4.301 & 3.9471 & TRN \\
\hline CHEMBL3970752 & 1637647 & 6.0269 & 6.2703 & TRN \\
\hline CHEMBL193177 & 1637647 & 4.301 & 4.4377 & TRN \\
\hline CHEMBL 3973692 & 1637647 & 7.0969 & 6.4721 & TRN \\
\hline CHEMBL190302 & 1637647 & 4.301 & 3.833 & TST \\
\hline CHEMBL3968467 & 1637647 & 4.301 & 5.0792 & TRN \\
\hline CHEMBL189937 & 1637647 & 5.7595 & 5.7877 & TRN \\
\hline CHEMBL189308 & 1637647 & 4.301 & 4.0539 & TST \\
\hline CHEMBL 372712 & 1637647 & 4.301 & 4.2379 & TRN \\
\hline CHEMBL 3977079 & 1637647 & 4.301 & 4.7529 & TRN \\
\hline CHEMBL3918866 & 1637647 & 5.6073 & 4.5685 & TST \\
\hline CHEMBL3935761 & 1637647 & 6.8153 & 6.5102 & TRN \\
\hline CHEMBL3976143 & 1637647 & 5.9863 & 5.1176 & TRN \\
\hline CHEMBL 3897354 & 1637647 & 6.8665 & 6.3497 & TRN \\
\hline CHEMBL189978 & 1637647 & 4.301 & 3.9336 & TRN \\
\hline CHEMBL 3954838 & 1637647 & 5.4042 & 5.8098 & TRN \\
\hline CHEMBL3907408 & 1637647 & 4.301 & 5.1488 & TRN \\
\hline CHEMBL359761 & 1637647 & 5.2882 & 3.8144 & TST \\
\hline CHEMBL140272 & 1637647 & 5.5258 & 5.37799 & 9999999999 \\
\hline CHEMBL371198 & 1637647 & 4.301 & 5.07600 & 00000000005 \\
\hline CHEMBL365339 & 1637647 & 5.3497 & 5.0694 & TRN \\
\hline CHEMBL3920898 & 1637647 & 4.301 & 5.184 & TRN \\
\hline CHEMBL360675 & 1637647 & 5.9674 & 6.0012 & TRN \\
\hline CHEMBL3960859 & 1637647 & 5.3615 & 6.4817 & TRN \\
\hline CHEMBL3908855 & 1637647 & 6.0044 & 5.098 & TRN \\
\hline CHEMBL3950533 & 1637647 & 7.3768 & 6.2239 & TRN \\
\hline CHEMBL 3895532 & 1637647 & 4.301 & 4.3385 & TST \\
\hline CHEMBL1908963 & 1637647 & 4.301 & 4.4983 & TRN \\
\hline CHEMBL3895953 & 1637647 & 6.1481 & 6.0508 & TRN \\
\hline CHEMBL364029 & 1637647 & 4.301 & 5.0481 & TRN \\
\hline CHEMBL3983877 & 1637647 & 4.301 & 6.1968 & TRN \\
\hline CHEMBL 3941758 & 1637647 & 4.301 & 5.3591 & TRN \\
\hline CHEMBL3973181 & 1637647 & 5.6737 & 5.2148 & TRN \\
\hline
\end{tabular}




\begin{tabular}{|c|c|c|c|c|c|}
\hline \multicolumn{6}{|c|}{ Supplemental Table S2.txt } \\
\hline CHEMBL189848 & 1637647 & 4.301 & 4.2327 & TRN & \\
\hline CHEMBL3952178 & 1637647 & 5.3585 & 5.1318 & TRN & \\
\hline CHEMBL3895697 & 1637647 & 6.2716 & 6.30200 & 00000000005 & TRN \\
\hline CHEMBL189732 & 1637647 & 4.301 & 3.9947 & TST & \\
\hline CHEMBL189745 & 1637647 & 4.301 & 4.3951 & TST & \\
\hline CHEMBL189579 & 1637647 & 4.301 & 4.5201 & TST & \\
\hline CHEMBL189317 & 1637647 & 4.301 & 4.7488 & TRN & \\
\hline CHEMBL 3927156 & 1637647 & 7.0655 & 6.4684 & TRN & \\
\hline CHEMBL192060 & 1637647 & 5.8182 & 5.1902 & TRN & \\
\hline CHEMBL425546 & 1637647 & 4.301 & 4.7836 & TRN & \\
\hline CHEMBL3901003 & 1637647 & 5.7375 & 5.7793 & TRN & \\
\hline CHEMBL3964646 & 1637647 & 7.0555 & 6.5435 & TRN & \\
\hline CHEMBL3979462 & 1637647 & 4.301 & 4.7856 & TST & \\
\hline CHEMBL 3907135 & 1637647 & 4.301 & 4.2506 & TST & \\
\hline CHEMBL3960034 & 1637647 & 4.301 & 3.7886 & TRN & \\
\hline CHEMBL193184 & 1637647 & 4.301 & 4.0197 & TRN & \\
\hline CHEMBL190332 & 1637647 & 4.301 & 5.0888 & TST & \\
\hline CHEMBL 3958430 & 1637647 & 5.7411 & 5.2126 & TST & \\
\hline CHEMBL189490 & 1637647 & 4.301 & 4.1286 & TST & \\
\hline CHEMBL3903712 & 1637647 & 4.301 & 5.0098 & TST & \\
\hline CHEMBL189543 & 1637647 & 4.301 & 5.0562 & TST & \\
\hline CHEMBL1964290 & 809233 & 5.2 & 5.1067 & TST & \\
\hline CHEMBL 213505 & 809233 & 5.2 & 5.4398 & TRN & \\
\hline CHEMBL202721 & 809233 & 4.6 & 5.4916 & TRN & \\
\hline CHEMBL1987034 & 809233 & 7.0 & 6.6562 & TRN & \\
\hline CHEMBL1993941 & 809233 & 8.9 & 8.6109 & TRN & \\
\hline CHEMBL377383 & 809233 & 5.2 & 5.1913 & TRN & \\
\hline CHEMBL 2005886 & 809233 & 6.6 & 6.5291 & TRN & \\
\hline CHEMBL481491 & 809233 & 5.2 & 5.0204 & TST & \\
\hline CHEMBL1682345 & 809233 & 5.2 & 5.2298 & TRN & \\
\hline CHEMBL 388311 & 809233 & 7.2 & 7.3979 & TRN & \\
\hline CHEMBL1973145 & 809233 & 5.2 & 5.9765 & TRN & \\
\hline CHEMBL1982924 & 809233 & 5.2 & 5.5556 & TRN & \\
\hline CHEMBL 2005936 & 809233 & 5.2 & 5.1195 & TRN & \\
\hline CHEMBL1807515 & 809233 & 5.2 & 5.4476 & TRN & \\
\hline CHEMBL1964948 & 809233 & 4.4 & 4.3972 & TRN & \\
\hline CHEMBL1971141 & 809233 & 5.2 & 5.02 & TRN & \\
\hline CHEMBL1995813 & 809233 & 5.2 & 5.308 & TRN & \\
\hline CHEMBL206236 & 809233 & 5.2 & 5.32600 & 00000000005 & TRN \\
\hline CHEMBL1989834 & 809233 & 3.9 & 4.0129 & TRN & \\
\hline CHEMBL523823 & 809233 & 5.2 & 4.9756 & TST & \\
\hline CHEMBL1973178 & 809233 & 6.7 & 6.0143 & TRN & \\
\hline CHEMBL1987430 & 809233 & 4.5 & 4.8232 & TRN & \\
\hline CHEMBL244378 & 809233 & 5.2 & 6.1728 & TRN & \\
\hline CHEMBL1988778 & 809233 & 5.2 & 5.7495 & TRN & \\
\hline CHEMBL 2001957 & 809233 & 5.2 & 5.0266 & TRN & \\
\hline CHEMBL1969372 & 809233 & 5.2 & 5.0506 & TRN & \\
\hline CHEMBL1990583 & 809233 & 5.2 & 5.629 & TRN & \\
\hline
\end{tabular}




\begin{tabular}{|c|c|c|c|c|c|}
\hline \\
\hline CHEMBL1986943 & 809233 & 6.2 & 5.7468 & TRN & \\
\hline CHEMBL289959 & 809233 & 4.4 & 4.6 & TRN & \\
\hline CHEMBL1993584 & 809233 & 5.2 & 5.2696 & TRN & \\
\hline CHEMBL1986263 & 809233 & 5.2 & 5.2741 & TRN & \\
\hline CHEMBL 2000114 & 809233 & 5.2 & 5.1219 & TRN & \\
\hline CHEMBL210618 & 809233 & 5.2 & 4.8534 & TRN & \\
\hline CHEMBL1986265 & 809233 & 4.6 & 4.3238 & TRN & \\
\hline CHEMBL1975647 & 809233 & 5.2 & 5.2914 & TRN & \\
\hline CHEMBL1968380 & 809233 & 5.2 & 5.1007 & TRN & \\
\hline CHEMBL1991734 & 809233 & 6.2 & 6.0528 & TST & \\
\hline CHEMBL1981782 & 809233 & 5.2 & 5.1863 & TRN & \\
\hline CHEMBL1970142 & 809233 & 8.4 & 8.5436 & TRN & \\
\hline CHEMBL1990912 & 809233 & 5.2 & 5.3 & TRN & \\
\hline CHEMBL1991782 & 809233 & 3.3 & 3.8184 & TRN & \\
\hline CHEMBL 2002105 & 809233 & 4.1 & 4.5048 & TRN & \\
\hline CHEMBL1983348 & 809233 & 5.7 & 5.6526 & TRN & \\
\hline CHEMBL1975128 & 809233 & 5.2 & 5.114 & TRN & \\
\hline CHEMBL1980671 & 809233 & 5.7 & 5.0925 & TRN & \\
\hline CHEMBL1986177 & 809233 & 4.6 & 4.9568 & TRN & \\
\hline CHEMBL1969735 & 809233 & 5.2 & 5.0694 & TRN & \\
\hline CHEMBL 2003524 & 809233 & 5.2 & 4.9816 & TST & \\
\hline CHEMBL 2002649 & 809233 & 5.2 & 5.6603 & TRN & \\
\hline CHEMBL1985367 & 809233 & 6.0 & 5.3759 & TST & \\
\hline CHEMBL437747 & 809233 & 5.2 & 5.0213 & TRN & \\
\hline CHEMBL 2001584 & 809233 & 4.6 & 4.7898 & TST & \\
\hline CHEMBL507936 & 809233 & 5.2 & 5.3009 & TRN & \\
\hline CHEMBL104264 & 809233 & 5.2 & $5.3210 e$ & 0000000001 & TST \\
\hline CHEMBL1994321 & 809233 & 7.1 & 7.0798 & TRN & \\
\hline CHEMBL1978562 & 809233 & 6.1 & 5.5875 & TST & \\
\hline CHEMBL1997129 & 809233 & 6.3 & 5.59399 & 9999999999 & TRN \\
\hline CHEMBL229799 & 809233 & 5.2 & 4.8908 & TRN & \\
\hline CHEMBL1974875 & 809233 & 4.2 & 4.6242 & TST & \\
\hline CHEMBL1964307 & 809233 & 5.2 & 4.8416 & TRN & \\
\hline CHEMBL1989471 & 809233 & 6.6 & 5.6539 & TST & \\
\hline CHEMBL1991095 & 809233 & 4.1 & 4.9233 & TST & \\
\hline CHEMBL 2000508 & 809233 & 5.2 & 5.263 & TRN & \\
\hline CHEMBL 2001547 & 809233 & 5.2 & 5.0713 & TRN & \\
\hline CHEMBL 210928 & 809233 & 5.2 & 5.0637 & TRN & \\
\hline CHEMBL1978195 & 809233 & 4.6 & 4.9018 & TRN & \\
\hline CHEMBL1994361 & 809233 & 5.2 & 5.2073 & TRN & \\
\hline CHEMBL1972840 & 809233 & 5.2 & 4.6122 & TRN & \\
\hline CHEMBL1977148 & 809233 & 9.6 & 8.8407 & TRN & \\
\hline CHEMBL1966842 & 809233 & 5.7 & 5.0741 & TRN & \\
\hline CHEMBL 2003286 & 809233 & 5.2 & 5.0817 & TRN & \\
\hline CHEMBL1992306 & 809233 & 6.2 & 6.0351 & TRN & \\
\hline CHEMBL 2002165 & 809233 & 9.1 & 8.6777 & TRN & \\
\hline CHEMBL1998585 & 809233 & 7.5 & 7.1115 & TRN & \\
\hline CHEMBL519697 & 809233 & 5.2 & 4.7228 & TST & \\
\hline
\end{tabular}




\begin{tabular}{|c|c|c|c|c|c|}
\hline \\
\hline CHEMBL2004934 & 809233 & 5.2 & 5.0156 & TRN & \\
\hline CHEMBL 2000652 & 809233 & 6.3 & 5.8643 & TRN & \\
\hline CHEMBL1996345 & 809233 & 4.6 & 4.8389 & TST & \\
\hline CHEMBL 2004025 & 809233 & 5.7 & 5.9043 & TRN & \\
\hline CHEMBL1996048 & 809233 & 5.7 & 5.4494 & TST & \\
\hline CHEMBL461876 & 809233 & 4.6 & 4.8276 & TRN & \\
\hline CHEMBL1965033 & 809233 & 4.6 & 4.8523 & TRN & \\
\hline CHEMBL2001485 & 809233 & 7.6 & 7.9866 & TRN & \\
\hline CHEMBL1971519 & 809233 & 4.8 & 4.8721 & TRN & \\
\hline CHEMBL504950 & 809233 & 5.2 & 4.9329 & TRN & \\
\hline CHEMBL1997335 & 809233 & 4.6 & 5.1151 & TRN & \\
\hline CHEMBL1984363 & 809233 & 5.2 & 4.8506 & TRN & \\
\hline CHEMBL1978099 & 809233 & 5.2 & 6.2311 & TRN & \\
\hline CHEMBL1977041 & 809233 & 6.9 & 6.1342 & TRN & \\
\hline CHEMBL1968070 & 809233 & 5.2 & 5.3523 & TRN & \\
\hline CHEMBL1988608 & 809233 & 5.2 & 5.2532 & TRN & \\
\hline CHEMBL184847 & 809233 & 5.2 & 5.1143 & TRN & \\
\hline CHEMBL1994808 & 809233 & 4.0 & $4.6610 e$ & 20000000005 & TRN \\
\hline CHEMBL1984367 & 809233 & 5.2 & 5.1461 & TRN & \\
\hline CHEMBL226898 & 809233 & 5.2 & 4.7351 & TRN & \\
\hline CHEMBL1982563 & 809233 & 5.2 & 5.0067 & TRN & \\
\hline CHEMBL1991377 & 809233 & 4.4 & 4.5455 & TRN & \\
\hline CHEMBL539474 & 809233 & 5.2 & 5.3185 & TST & \\
\hline CHEMBL575824 & 809233 & 5.2 & 5.1544 & TRN & \\
\hline CHEMBL1988387 & 809233 & 8.6 & 8.9082 & TRN & \\
\hline CHEMBL1973868 & 809233 & 4.6 & 5.1712 & TRN & \\
\hline CHEMBL1990288 & 809233 & 5.2 & 5.2181 & TRN & \\
\hline CHEMBL1989708 & 809233 & 7.4 & 8.4845 & TRN & \\
\hline CHEMBL1970074 & 809233 & 5.2 & 5.284 & TRN & \\
\hline CHEMBL1986970 & 809233 & 5.2 & 5.1537 & TRN & \\
\hline CHEMBL1958401 & 809233 & 5.2 & 5.2323 & TRN & \\
\hline CHEMBL1966816 & 809233 & 5.2 & 5.1668 & TRN & \\
\hline CHEMBL1972584 & 809233 & 5.2 & 6.0613 & TRN & \\
\hline CHEMBL 2002992 & 809233 & 5.2 & 5.0833 & TRN & \\
\hline CHEMBL1982700 & 809233 & 4.6 & 4.5633 & TST & \\
\hline CHEMBL1968791 & 809233 & 5.2 & 4.8714 & TRN & \\
\hline CHEMBL326282 & 809233 & 5.2 & 5.1908 & TST & \\
\hline CHEMBL1977634 & 809233 & 4.6 & 4.5346 & TRN & \\
\hline CHEMBL1992732 & 809233 & 5.2 & 4.9818 & TST & \\
\hline CHEMBL1971186 & 809233 & 5.2 & 5.3093 & TRN & \\
\hline CHEMBL1976872 & 809233 & 4.2 & 4.4583 & TRN & \\
\hline CHEMBL1969156 & 809233 & 4.6 & 4.5827 & TRN & \\
\hline CHEMBL1973211 & 809233 & 6.6 & 6.7361 & TRN & \\
\hline CHEMBL1984700 & 809233 & 5.2 & 5.1298 & TRN & \\
\hline CHEMBL 2007151 & 809233 & 5.2 & 5.0737 & TRN & \\
\hline CHEMBL1972125 & 809233 & 5.2 & 5.184 & TRN & \\
\hline CHEMBL1999120 & 809233 & 4.2 & 4.53 & TST & \\
\hline CHEMBL1976134 & 809233 & 7.3 & 5.8946 & TRN & \\
\hline
\end{tabular}




\begin{tabular}{|c|c|c|c|c|}
\hline \multicolumn{5}{|c|}{ pplemental T } \\
\hline CHEMBL1972158 & 809233 & 5.2 & 4.9174 & TRN \\
\hline CHEMBL1981215 & 809233 & 4.5 & 5.2742 & TRN \\
\hline CHEMBL1999414 & 809233 & 8.1 & 8.015 & TRN \\
\hline CHEMBL1967336 & 809233 & 4.4 & 4.8326 & TRN \\
\hline CHEMBL 2001228 & 809233 & 5.9 & 5.3475 & TRN \\
\hline CHEMBL 2006581 & 809233 & 5.2 & 5.1807 & TRN \\
\hline CHEMBL1970340 & 809233 & 5.0 & 4.7613 & TRN \\
\hline CHEMBL1967992 & 809233 & 4.6 & 4.8081 & TRN \\
\hline CHEMBL1975534 & 809233 & 5.2 & 4.9579 & TRN \\
\hline CHEMBL1966703 & 809233 & 5.2 & 5.0314 & TST \\
\hline CHEMBL 2001987 & 809233 & 4.4 & 4.9344 & TRN \\
\hline CHEMBL1969561 & 809233 & 5.2 & 5.2985 & TRN \\
\hline CHEMBL1994555 & 809233 & 5.7 & 5.6143 & TST \\
\hline CHEMBL1983640 & 809233 & 6.4 & 5.9636 & TRN \\
\hline CHEMBL1997023 & 809233 & 5.2 & 4.8348 & TST \\
\hline CHEMBL1964687 & 809233 & 5.2 & 5.03 & TRN \\
\hline CHEMBL1971943 & 809233 & 5.2 & 4.5637 & TST \\
\hline CHEMBL1999918 & 809233 & 5.2 & 5.3065 & TRN \\
\hline CHEMBL1974254 & 809233 & 9.2 & 8.9086 & TRN \\
\hline CHEMBL1997924 & 809233 & 8.0 & 7.5633 & TRN \\
\hline CHEMBL1988537 & 809233 & 5.2 & 5.0426 & TST \\
\hline CHEMBL1969049 & 809233 & 5.2 & 4.885 & TRN \\
\hline CHEMBL 2005828 & 809233 & 5.2 & 5.1633 & TRN \\
\hline CHEMBL1978267 & 809233 & 4.6 & 4.2605 & TRN \\
\hline CHEMBL485556 & 809233 & 5.2 & 5.136 & TST \\
\hline CHEMBL1975900 & 809233 & 5.2 & 5.0079 & TRN \\
\hline CHEMBL 255822 & 809233 & 5.2 & 5.0347 & TRN \\
\hline CHEMBL1972221 & 809233 & 5.2 & 5.3166 & TRN \\
\hline CHEMBL 2006778 & 809233 & 8.7 & 8.1127 & TRN \\
\hline CHEMBL 378627 & 809233 & 5.2 & 4.9871 & TRN \\
\hline CHEMBL1996979 & 809233 & 8.0 & 6.6739 & TRN \\
\hline CHEMBL1968406 & 809233 & 5.2 & 5.0389 & TRN \\
\hline CHEMBL1975921 & 809233 & 4.8 & 4.4103 & TRN \\
\hline CHEMBL1982476 & 809233 & 9.3 & 8.7632 & TRN \\
\hline CHEMBL1998545 & 809233 & 5.2 & 5.1576 & TRN \\
\hline CHEMBL1986869 & 809233 & 5.2 & 5.2722 & TRN \\
\hline CHEMBL1975923 & 809233 & 4.9 & 5.2868 & TST \\
\hline CHEMBL 2005449 & 809233 & 6.1 & 6.2816 & TRN \\
\hline CHEMBL1987998 & 809233 & 4.6 & 4.4749 & TRN \\
\hline CHEMBL1682558 & 809233 & 5.2 & 5.0039 & TRN \\
\hline CHEMBL1971534 & 809233 & 4.1 & 4.7674 & TRN \\
\hline CHEMBL1990496 & 809233 & 4.7 & 4.8643 & TRN \\
\hline CHEMBL242865 & 809233 & 6.1 & 5.5298 & TRN \\
\hline CHEMBL1997623 & 809233 & 5.2 & 5.9468 & TRN \\
\hline CHEMBL 2002479 & 809233 & 5.2 & 4.9015 & TRN \\
\hline CHEMBL1967094 & 809233 & 5.2 & 5.0308 & TRN \\
\hline CHEMBL 2003341 & 809233 & 5.2 & 5.2771 & TRN \\
\hline CHEMBL1998110 & 809233 & 4.6 & 4.6067 & TRN \\
\hline
\end{tabular}




\begin{tabular}{|c|c|c|c|c|}
\hline & & & pplement & al $\mathrm{Ta}$ \\
\hline CHEMBL1999590 & 809233 & 6.3 & 5.6849 & TST \\
\hline CHEMBL1981079 & 809233 & 5.2 & 5.1907 & TST \\
\hline CHEMBL1978166 & 809233 & 6.9 & 6.8798 & TRN \\
\hline CHEMBL1980489 & 809233 & 5.2 & 4.9655 & TRN \\
\hline CHEMBL 2000832 & 809233 & 5.2 & 5.4092 & TRN \\
\hline CHEMBL1967116 & 809233 & 8.8 & 8.7664 & TRN \\
\hline CHEMBL1990590 & 809233 & 4.4 & 4.4829 & TRN \\
\hline CHEMBL1970709 & 809233 & 5.2 & 5.2647 & TRN \\
\hline CHEMBL1965660 & 809233 & 5.2 & 5.2853 & TST \\
\hline CHEMBL1992125 & 809233 & 5.7 & 5.4648 & TRN \\
\hline CHEMBL1998112 & 809233 & 5.2 & 5.4993 & TRN \\
\hline CHEMBL1993996 & 809233 & 5.2 & 5.645 & TRN \\
\hline CHEMBL1969126 & 809233 & 5.2 & 5.4514 & TRN \\
\hline CHEMBL1980896 & 809233 & 5.2 & 5.73 & TRN \\
\hline CHEMBL1970104 & 809233 & 6.8 & 6.2864 & TRN \\
\hline CHEMBL1999714 & 809233 & 5.2 & 4.5235 & TRN \\
\hline CHEMBL1994040 & 809233 & 5.2 & 5.2103 & TRN \\
\hline CHEMBL388978 & 809233 & 7.0 & 8.1554 & TST \\
\hline CHEMBL579246 & 809233 & 5.2 & 4.8094 & TRN \\
\hline CHEMBL 2004716 & 809233 & 8.6 & 8.1111 & TRN \\
\hline CHEMBL1968127 & 809233 & 5.2 & 5.1465 & TRN \\
\hline CHEMBL1975233 & 809233 & 5.2 & 4.9455 & TRN \\
\hline CHEMBL1985406 & 809233 & 5.2 & 4.9804 & TRN \\
\hline CHEMBL 207400 & 809233 & 5.2 & 4.9796 & TST \\
\hline CHEMBL 2000894 & 809233 & 5.2 & 5.0471 & TST \\
\hline CHEMBL1421720 & 809233 & 4.6 & 5.6883 & TRN \\
\hline CHEMBL1968130 & 809233 & 4.6 & 4.686 & TRN \\
\hline CHEMBL1982135 & 809233 & 5.2 & 4.9527 & TRN \\
\hline CHEMBL1976090 & 809233 & 5.2 & 4.8352 & TRN \\
\hline CHEMBL 2004771 & 809233 & 5.2 & 4.6681 & TRN \\
\hline CHEMBL1992922 & 809233 & 5.2 & 5.5161 & TRN \\
\hline CHEMBL399021 & 809233 & 5.2 & 4.928 & TRN \\
\hline CHEMBL1997597 & 809233 & 5.2 & 5.2465 & TRN \\
\hline CHEMBL1969537 & 809233 & 7.1 & 5.3001 & TST \\
\hline CHEMBL1976093 & 809233 & 5.2 & 5.0551 & TRN \\
\hline CHEMBL1975256 & 809233 & 5.2 & 5.1593 & TST \\
\hline CHEMBL508928 & 809233 & 7.6 & 7.4194 & TRN \\
\hline CHEMBL1949855 & 809233 & 4.4 & 5.2665 & TRN \\
\hline CHEMBL1727312 & 809233 & 3.4 & 4.4345 & TRN \\
\hline CHEMBL1990223 & 809233 & 4.6 & 4.3025 & TRN \\
\hline CHEMBL1969879 & 809233 & 5.2 & 4.9115 & TRN \\
\hline CHEMBL1964382 & 809233 & 4.6 & 4.7932 & TST \\
\hline CHEMBL101311 & 809233 & 6.7 & 6.072 & TRN \\
\hline CHEMBL1981720 & 809233 & 5.2 & 5.2432 & TRN \\
\hline CHEMBL419932 & 809233 & 5.2 & 5.3344 & TRN \\
\hline CHEMBL 262433 & 809233 & 5.2 & 5.5926 & TRN \\
\hline CHEMBL 373798 & 809233 & 6.5 & 5.8745 & TRN \\
\hline CHEMBL 306380 & 809233 & 6.6 & 6.4372 & TRN \\
\hline
\end{tabular}




\begin{tabular}{|c|c|c|c|c|c|}
\hline \multicolumn{6}{|c|}{ plementa } \\
\hline CHEMBL1988581 & 809233 & 7.1 & 6.8224 & TST & \\
\hline CHEMBL2005699 & 809233 & 4.6 & 4.4204 & TRN & \\
\hline CHEMBL1975500 & 809233 & 5.2 & 5.7115 & TRN & \\
\hline CHEMBL394619 & 809233 & 6.4 & 6.055 & TRN & \\
\hline CHEMBL2006564 & 809233 & 7.0 & 6.92200 & $\partial 000000001$ & TRN \\
\hline CHEMBL1964399 & 809233 & 5.2 & 5.3427 & TRN & \\
\hline CHEMBL1996831 & 809233 & 5.2 & 5.1008 & TST & \\
\hline CHEMBL411903 & 809233 & 5.2 & 6.2023 & TRN & \\
\hline CHEMBL1978167 & 809233 & 5.9 & 4.8832 & TST & \\
\hline CHEMBL1965988 & 809233 & 6.6 & 6.9846 & TRN & \\
\hline CHEMBL418203 & 809233 & 4.8 & 4.77 & TST & \\
\hline CHEMBL1989646 & 809233 & 5.2 & 4.8719 & TRN & \\
\hline CHEMBL1682357 & 809233 & 5.2 & 5.0335 & TRN & \\
\hline CHEMBL225519 & 809233 & 4.8 & 4.9297 & TRN & \\
\hline CHEMBL209534 & 809233 & 5.2 & 4.9766 & TRN & \\
\hline CHEMBL1978200 & 809233 & 5.2 & 5.1882 & TRN & \\
\hline CHEMBL1994159 & 809233 & 4.3 & 4.541 & TRN & \\
\hline CHEMBL1970522 & 809233 & 5.2 & 5.1421 & TRN & \\
\hline CHEMBL402846 & 809233 & 5.2 & 5.1951 & TRN & \\
\hline CHEMBL1964692 & 809233 & 5.2 & 5.8453 & TRN & \\
\hline CHEMBL1964413 & 809233 & 5.2 & 5.2309 & TRN & \\
\hline CHEMBL1973483 & 809233 & 5.2 & 5.3664 & TRN & \\
\hline CHEMBL1984432 & 809233 & 5.2 & 4.7615 & TRN & \\
\hline CHEMBL 219722 & 809233 & 5.2 & 5.7174 & TRN & \\
\hline CHEMBL1975903 & 809233 & 6.3 & 5.3705 & TRN & \\
\hline CHEMBL1997340 & 809233 & 5.2 & 5.0412 & TRN & \\
\hline CHEMBL1522508 & 809233 & 4.6 & 4.6148 & TRN & \\
\hline CHEMBL 210887 & 809233 & 5.2 & 5.3518 & TST & \\
\hline CHEMBL1988805 & 809233 & 4.6 & 4.7699 & TST & \\
\hline CHEMBL458997 & 809233 & 4.8 & 5.2061 & TRN & \\
\hline CHEMBL1971021 & 809233 & 5.2 & 5.1609 & TRN & \\
\hline CHEMBL 227271 & 809233 & 5.2 & 4.9745 & TRN & \\
\hline CHEMBL583144 & 809233 & 5.2 & 5.3015 & TRN & \\
\hline CHEMBL1974310 & 809233 & 5.2 & 5.1548 & TRN & \\
\hline CHEMBL1969942 & 809233 & 4.6 & 5.1303 & TRN & \\
\hline CHEMBL1978567 & 809233 & 4.6 & 4.6067 & TRN & \\
\hline CHEMBL1982660 & 809233 & 5.2 & 5.6164 & TRN & \\
\hline CHEMBL1994693 & 809233 & 5.2 & 5.19799 & 99999999995 & TRN \\
\hline CHEMBL1982957 & 809233 & 7.3 & 5.8234 & TRN & \\
\hline CHEMBL1725279 & 809233 & 5.2 & 5.5009 & TST & \\
\hline CHEMBL424872 & 809233 & 5.2 & 5.058 & TRN & \\
\hline CHEMBL1971947 & 809233 & 7.2 & 7.09200 & 00000000005 & TRN \\
\hline CHEMBL412142 & 809233 & 5.2 & 5.3893 & TST & \\
\hline CHEMBL 2003271 & 809233 & 5.2 & 5.3382 & TRN & \\
\hline CHEMBL1966808 & 809233 & 5.2 & 4.8537 & TRN & \\
\hline CHEMBL1996255 & 809233 & 6.3 & 5.6669 & TRN & \\
\hline CHEMBL1983111 & 809233 & 6.6 & 7.3202 & TRN & \\
\hline CHEMBL260135 & 809233 & 5.2 & 4.7387 & TRN & \\
\hline
\end{tabular}




\begin{tabular}{|c|c|c|c|c|c|}
\hline \multicolumn{6}{|c|}{ Supplemental Table S2.txt } \\
\hline CHEMBL220241 & 809233 & 5.2 & 4.6336 & TRN & \\
\hline CHEMBL1988141 & 809233 & 6.0 & 6.1839 & TST & \\
\hline CHEMBL1982610 & 809233 & 5.2 & 5.5798 & TST & \\
\hline CHEMBL1977134 & 809233 & 6.7 & 6.6716 & TRN & \\
\hline CHEMBL1970873 & 809233 & 3.7 & 4.3785 & TRN & \\
\hline CHEMBL 2006933 & 809233 & 5.2 & 5.0577 & TST & \\
\hline CHEMBL1985206 & 809233 & 4.6 & 4.475 & TST & \\
\hline CHEMBL1988300 & 809233 & 7.3 & 7.6006 & TRN & \\
\hline CHEMBL1991078 & 809233 & 5.2 & 6.0175 & TRN & \\
\hline CHEMBL1987359 & 809233 & 5.2 & 4.8316 & TST & \\
\hline CHEMBL1977749 & 809233 & 4.6 & 5.1973 & TST & \\
\hline CHEMBL1975212 & 809233 & 5.6 & 5.57 & TRN & \\
\hline CHEMBL 2000685 & 809233 & 5.2 & 4.9967 & TRN & \\
\hline CHEMBL2001613 & 809233 & 4.4 & 4.8613 & TRN & \\
\hline CHEMBL1997275 & 809233 & 5.9 & 5.2897 & TRN & \\
\hline CHEMBL1993904 & 809233 & 5.8 & 5.6657 & TRN & \\
\hline CHEMBL1980376 & 809233 & 4.6 & 4.4929 & TRN & \\
\hline CHEMBL1967513 & 809233 & 5.7 & 5.0391 & TRN & \\
\hline CHEMBL 2000724 & 809233 & 4.4 & 4.2817 & TRN & \\
\hline CHEMBL1985311 & 809233 & 5.2 & 5.6351 & TRN & \\
\hline CHEMBL1982413 & 809233 & 4.6 & 5.3379 & TST & \\
\hline CHEMBL1969502 & 809233 & 7.0 & 6.3576 & TST & \\
\hline CHEMBL1965910 & 809233 & 5.2 & 4.9613 & TRN & \\
\hline CHEMBL1682553 & 809233 & 5.2 & 5.2186 & TRN & \\
\hline CHEMBL1983963 & 809233 & 6.7 & 6.0092 & TRN & \\
\hline CHEMBL 2000271 & 809233 & 5.2 & 5.3867 & TRN & \\
\hline CHEMBL1981792 & 809233 & 4.4 & 5.1218 & TRN & \\
\hline CHEMBL1987535 & 809233 & 4.6 & 4.8925 & TRN & \\
\hline CHEMBL1985092 & 809233 & 5.2 & 5.1554 & TRN & \\
\hline CHEMBL1981410 & 809233 & 5.2 & 5.6718 & TRN & \\
\hline CHEMBL 2002586 & 809233 & 5.9 & 5.3285 & TRN & \\
\hline CHEMBL1996234 & 809233 & 5.2 & 4.7665 & TST & \\
\hline CHEMBL383264 & 809233 & 4.4 & 4.6393 & TRN & \\
\hline CHEMBL1967544 & 809233 & 5.2 & 5.1643 & TRN & \\
\hline CHEMBL1973138 & 809233 & 4.6 & 4.7356 & TST & \\
\hline CHEMBL223367 & 809233 & 5.2 & 5.2646 & TST & \\
\hline CHEMBL1992673 & 809233 & 4.4 & 4.8131 & TST & \\
\hline CHEMBL340384 & 809233 & 5.2 & 5.2064 & TST & \\
\hline CHEMBL1969151 & 809233 & 4.4 & 5.3862 & TRN & \\
\hline CHEMBL1981492 & 809233 & 4.0 & 4.6315 & TRN & \\
\hline CHEMBL1993335 & 809233 & 6.8 & 5.8888 & TST & \\
\hline CHEMBL1988692 & 809233 & 6.6 & 6.2237 & TRN & \\
\hline CHEMBL1964804 & 809233 & 5.2 & 5.2743 & TRN & \\
\hline CHEMBL 2000354 & 809233 & 5.2 & 5.12799 & 7999999999 & TRN \\
\hline CHEMBL1965507 & 809233 & 5.2 & 5.4679 & TRN & \\
\hline CHEMBL274064 & 809233 & 5.2 & 5.1897 & TRN & \\
\hline CHEMBL1998680 & 809233 & 4.6 & 4.4466 & TRN & \\
\hline CHEMBL1967564 & 809233 & 5.2 & 5.06 & TRN & \\
\hline
\end{tabular}




\begin{tabular}{|c|c|c|c|c|}
\hline \multicolumn{5}{|c|}{ Supplemental Table S2.txt } \\
\hline CHEMBL592030 & 809233 & 4.6 & 4.3079 & TST \\
\hline CHEMBL 2000071 & 809233 & 5.2 & 5.5814 & TRN \\
\hline CHEMBL1979176 & 809233 & 5.2 & 5.4074 & TRN \\
\hline CHEMBL1985491 & 809233 & 5.2 & 5.1188 & TRN \\
\hline CHEMBL1970317 & 809233 & 8.7 & 8.5328 & TRN \\
\hline CHEMBL 2000408 & 809233 & 5.2 & 5.0179 & TRN \\
\hline CHEMBL248757 & 809233 & 5.2 & 5.5239 & TST \\
\hline CHEMBL1978014 & 809233 & 5.2 & 4.9936 & TRN \\
\hline CHEMBL1997007 & 809233 & 4.6 & 5.0195 & TRN \\
\hline CHEMBL1994538 & 809233 & 5.2 & 5.2996 & TRN \\
\hline CHEMBL 2002690 & 809233 & 4.6 & 4.8649 & TRN \\
\hline CHEMBL1986139 & 809233 & 5.2 & 5.1935 & TRN \\
\hline CHEMBL1975503 & 809233 & 4.3 & 4.688 & TRN \\
\hline CHEMBL 383527 & 809233 & 5.2 & 5.0457 & TRN \\
\hline CHEMBL1980540 & 809233 & 5.2 & 5.4546 & TRN \\
\hline CHEMBL 278041 & 809233 & 4.6 & 5.0372 & TRN \\
\hline CHEMBL1979883 & 809233 & 6.8 & 7.0375 & TRN \\
\hline CHEMBL1984162 & 809233 & 6.4 & 6.8072 & TRN \\
\hline CHEMBL1997051 & 809233 & 4.6 & 5.3646 & TRN \\
\hline CHEMBL491758 & 809233 & 5.2 & 6.2351 & TRN \\
\hline CHEMBL1986590 & 809233 & 5.9 & 5.6793 & TRN \\
\hline CHEMBL1970189 & 809233 & 5.2 & 4.7685 & TRN \\
\hline CHEMBL1996791 & 809233 & 5.2 & 5.4519 & TRN \\
\hline CHEMBL371206 & 809233 & 6.7 & 5.9756 & TRN \\
\hline CHEMBL1974664 & 809233 & 7.2 & 6.3056 & TST \\
\hline CHEMBL406845 & 809233 & 7.1 & 6.2111 & TRN \\
\hline CHEMBL1974288 & 809233 & 5.2 & 5.2256 & TRN \\
\hline CHEMBL196363 & 809233 & 6.8 & 6.8802 & TRN \\
\hline CHEMBL1190711 & 809233 & 5.2 & 5.4377 & TRN \\
\hline CHEMBL1964718 & 809233 & 4.0 & 4.5187 & TST \\
\hline CHEMBL1968705 & 809233 & 5.2 & 5.2216 & TRN \\
\hline CHEMBL1964441 & 809233 & 6.8 & 6.6582 & TRN \\
\hline CHEMBL546797 & 809233 & 5.9 & 5.6458 & TRN \\
\hline CHEMBL404367 & 809233 & 5.2 & 5.1093 & TRN \\
\hline CHEMBL1966343 & 809233 & 5.2 & 5.0575 & TRN \\
\hline CHEMBL1978271 & 809233 & 4.4 & 4.5885 & TRN \\
\hline CHEMBL1967887 & 809233 & 5.2 & 5.227 & TRN \\
\hline CHEMBL 2007266 & 809233 & 4.6 & 4.5698 & TRN \\
\hline CHEMBL 2000568 & 809233 & 4.8 & 5.2674 & TRN \\
\hline CHEMBL 2000335 & 809233 & 6.5 & 6.4518 & TRN \\
\hline CHEMBL 2007097 & 809233 & 4.2 & 4.5703 & TRN \\
\hline CHEMBL1988717 & 809233 & 7.8 & 7.7717 & TRN \\
\hline CHEMBL1974328 & 809233 & 6.6 & 5.9717 & TRN \\
\hline CHEMBL509032 & 809233 & 6.6 & 6.7177 & TRN \\
\hline CHEMBL1973808 & 809233 & 5.2 & 5.4265 & TRN \\
\hline CHEMBL 2000429 & 809233 & 5.2 & 5.1477 & TRN \\
\hline CHEMBL1972576 & 809233 & 5.2 & 5.4016 & TRN \\
\hline CHEMBL1992342 & 809233 & 5.2 & 5.2992 & TRN \\
\hline
\end{tabular}




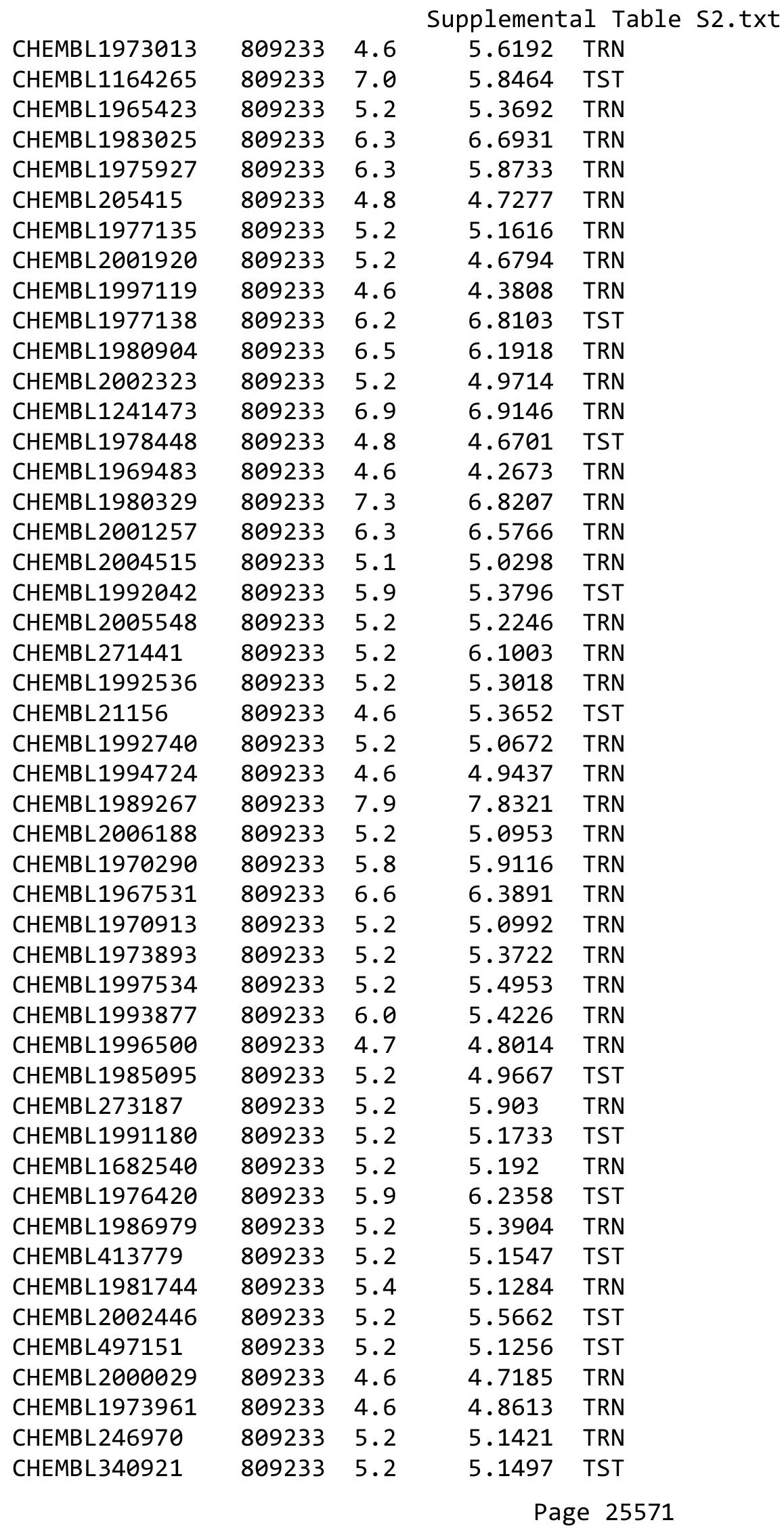




\begin{tabular}{|c|c|c|c|c|}
\hline & & & pplement & al $\mathrm{Ta}$ \\
\hline CHEMBL1994977 & 809233 & 4.4 & 4.5515 & TRN \\
\hline CHEMBL373598 & 809233 & 5.2 & 5.1028 & TST \\
\hline CHEMBL1999718 & 809233 & 5.2 & 5.3244 & TRN \\
\hline CHEMBL 2000078 & 809233 & 4.6 & 4.5438 & TRN \\
\hline CHEMBL 2005478 & 809233 & 6.7 & 5.7296 & TST \\
\hline CHEMBL1276446 & 809233 & 5.2 & 6.9119 & TST \\
\hline CHEMBL1996646 & 809233 & 6.4 & 6.3177 & TRN \\
\hline CHEMBL1979773 & 809233 & 4.4 & 4.4461 & TRN \\
\hline CHEMBL1971649 & 809233 & 5.2 & 5.2291 & TRN \\
\hline CHEMBL2003657 & 809233 & 6.3 & 5.7149 & TRN \\
\hline CHEMBL 2005482 & 809233 & 4.6 & 5.3763 & TRN \\
\hline CHEMBL1996702 & 809233 & 6.6 & 5.8404 & TRN \\
\hline CHEMBL1997909 & 809233 & 4.6 & 4.5204 & TRN \\
\hline CHEMBL 2007124 & 809233 & 4.6 & 5.1499 & TRN \\
\hline CHEMBL2006439 & 809233 & 5.2 & 5.2949 & TRN \\
\hline CHEMBL1985681 & 809233 & 4.6 & 5.2258 & TST \\
\hline CHEMBL1969190 & 809233 & 6.3 & 5.5812 & TRN \\
\hline CHEMBL1973937 & 809233 & 5.2 & 5.3625 & TRN \\
\hline CHEMBL1991674 & 809233 & 5.2 & 5.271 & TRN \\
\hline CHEMBL1982711 & 809233 & 6.0 & 5.1923 & TRN \\
\hline CHEMBL262623 & 809233 & 5.4 & 4.8077 & TRN \\
\hline CHEMBL1984842 & 809233 & 4.8 & 4.8264 & TRN \\
\hline CHEMBL1969102 & 809233 & 8.8 & 8.291 & TRN \\
\hline CHEMBL 2004118 & 809233 & 5.8 & 4.9862 & TRN \\
\hline CHEMBL1682346 & 809233 & 5.2 & 5.1788 & TRN \\
\hline CHEMBL 2007044 & 809233 & 5.2 & 4.9025 & TST \\
\hline CHEMBL 2001998 & 809233 & 5.2 & 5.0641 & TST \\
\hline CHEMBL1994241 & 809233 & 5.2 & 5.138 & TRN \\
\hline CHEMBL223460 & 809233 & 5.2 & 5.5538 & TST \\
\hline CHEMBL50894 & 809233 & 5.8 & 5.6512 & TRN \\
\hline CHEMBL1988838 & 809233 & 6.7 & 6.6541 & TRN \\
\hline CHEMBL1981725 & 809233 & 5.2 & 6.2257 & TRN \\
\hline CHEMBL 375284 & 809233 & 5.2 & 5.0698 & TRN \\
\hline CHEMBL 2006299 & 809233 & 4.4 & 4.7217 & TRN \\
\hline CHEMBL1965169 & 809233 & 6.1 & 4.4987 & TST \\
\hline CHEMBL1081312 & 809233 & 7.8 & 6.7254 & TRN \\
\hline CHEMBL1965170 & 809233 & 8.7 & 8.3757 & TRN \\
\hline CHEMBL1982866 & 809233 & 5.2 & 4.9442 & TST \\
\hline CHEMBL 2005792 & 809233 & 4.8 & 4.8002 & TRN \\
\hline CHEMBL1984206 & 809233 & 5.2 & 5.0558 & TRN \\
\hline CHEMBL1965570 & 809233 & 7.0 & 7.4246 & TRN \\
\hline CHEMBL1972355 & 809233 & 6.1 & 6.1603 & TRN \\
\hline CHEMBL1997892 & 809233 & 4.6 & 5.4025 & TRN \\
\hline CHEMBL1997193 & 809233 & 4.6 & 5.4052 & TST \\
\hline CHEMBL 210963 & 809233 & 5.2 & 4.9812 & TRN \\
\hline CHEMBL1964902 & 809233 & 4.6 & 4.3988 & TRN \\
\hline CHEMBL1082440 & 809233 & 5.2 & 5.181 & TST \\
\hline CHEMBL1972362 & 809233 & 5.2 & 5.1996 & TRN \\
\hline
\end{tabular}




\begin{tabular}{|c|c|c|c|c|c|}
\hline \\
\hline CHEMBL1984633 & 809233 & 5.2 & 5.1273 & TRN & \\
\hline CHEMBL1965845 & 809233 & 5.2 & 5.1678 & TRN & \\
\hline CHEMBL1998228 & 809233 & 4.2 & 4.9852 & TST & \\
\hline CHEMBL1983715 & 809233 & 6.6 & 6.745 & TRN & \\
\hline CHEMBL1971017 & 809233 & 5.2 & 5.2817 & TRN & \\
\hline CHEMBL1990482 & 809233 & 5.2 & 5.2363 & TRN & \\
\hline CHEMBL1990904 & 809233 & 5.2 & 5.1553 & TRN & \\
\hline CHEMBL2005475 & 809233 & 5.2 & 4.9169 & TRN & \\
\hline CHEMBL 2000104 & 809233 & 5.2 & 5.1169 & TRN & \\
\hline CHEMBL183844 & 809233 & 5.2 & 4.9032 & TRN & \\
\hline CHEMBL220057 & 809233 & 5.2 & 5.4928 & TRN & \\
\hline CHEMBL 383541 & 809233 & 5.2 & 5.1435 & TRN & \\
\hline CHEMBL2001224 & 809233 & 5.2 & 4.8731 & TRN & \\
\hline CHEMBL10 & 809233 & 4.5 & 4.8603 & TRN & \\
\hline CHEMBL1964937 & 809233 & 5.2 & 5.1682 & TRN & \\
\hline CHEMBL1980763 & 809233 & 5.6 & 5.1814 & TRN & \\
\hline CHEMBL590109 & 809233 & 5.2 & 4.5977 & TST & \\
\hline CHEMBL1977931 & 809233 & 4.1 & 4.6096 & TRN & \\
\hline CHEMBL1970879 & 809233 & 6.8 & 6.4471 & TRN & \\
\hline CHEMBL1989856 & 809233 & 5.2 & 5.1059 & TST & \\
\hline CHEMBL 2005899 & 809233 & 5.2 & $5.1320 e$ & 0000000001 & TRN \\
\hline CHEMBL1682552 & 809233 & 5.2 & 5.0848 & TRN & \\
\hline CHEMBL 259850 & 809233 & 5.2 & 5.2414 & TRN & \\
\hline CHEMBL 2007479 & 809233 & 4.6 & 4.6189 & TRN & \\
\hline CHEMBL1971223 & 809233 & 4.4 & 4.6974 & TRN & \\
\hline CHEMBL105739 & 809233 & 5.2 & 5.8691 & TRN & \\
\hline CHEMBL1972220 & 809233 & 8.8 & 9.1255 & TRN & \\
\hline CHEMBL 379300 & 809233 & 5.2 & 4.8862 & TRN & \\
\hline CHEMBL 2003785 & 809233 & 4.3 & 5.0391 & TST & \\
\hline CHEMBL1973720 & 809233 & 5.8 & 5.51 & TRN & \\
\hline CHEMBL1969523 & 809233 & 5.2 & 5.3793 & TRN & \\
\hline CHEMBL207995 & 809233 & 5.2 & 5.0568 & TRN & \\
\hline CHEMBL 2001923 & 809233 & 5.2 & 4.5576 & TRN & \\
\hline CHEMBL1986781 & 809233 & 5.2 & 5.2688 & TRN & \\
\hline CHEMBL1983070 & 809233 & 4.4 & 4.388 & TRN & \\
\hline CHEMBL526133 & 809233 & 5.2 & 5.1867 & TRN & \\
\hline CHEMBL 2003514 & 809233 & 4.4 & 4.9024 & TRN & \\
\hline CHEMBL1966836 & 809233 & 6.7 & 5.6677 & TRN & \\
\hline CHEMBL1989043 & 809233 & 4.6 & 4.5787 & TRN & \\
\hline CHEMBL1979057 & 809233 & 5.2 & 4.8288 & TRN & \\
\hline CHEMBL1981045 & 809233 & 5.2 & 4.8002 & TRN & \\
\hline CHEMBL387971 & 809233 & 5.2 & 5.8241 & TST & \\
\hline CHEMBL1975418 & 809233 & 5.2 & 5.1476 & TRN & \\
\hline CHEMBL1164180 & 809233 & 6.1 & 5.9538 & TST & \\
\hline CHEMBL 223257 & 809233 & 5.2 & 5.2297 & TST & \\
\hline CHEMBL1999428 & 809233 & 5.2 & 5.0846 & TRN & \\
\hline CHEMBL1967560 & 809233 & 5.2 & 5.2116 & TRN & \\
\hline CHEMBL211378 & 809233 & 5.2 & 5.289 & TRN & \\
\hline
\end{tabular}




\begin{tabular}{|c|c|c|c|c|c|}
\hline & & & & & \\
\hline CHEMBL1982465 & 809233 & 7.4 & 6.7702 & TRN & \\
\hline CHEMBL 2001751 & 809233 & 5.2 & 6.2477 & TRN & \\
\hline CHEMBL1984586 & 809233 & 5.2 & 5.0975 & TRN & \\
\hline CHEMBL 272938 & 809233 & 6.2 & 5.9925 & TRN & \\
\hline CHEMBL1972659 & 809233 & 5.2 & 5.1108 & TST & \\
\hline CHEMBL1973395 & 809233 & 5.2 & 5.3462 & TRN & \\
\hline CHEMBL 272453 & 809233 & 5.2 & 5.5665 & TRN & \\
\hline CHEMBL1970217 & 809233 & 5.2 & 4.9543 & TRN & \\
\hline CHEMBL1984686 & 809233 & 4.6 & 4.791 & TRN & \\
\hline CHEMBL185569 & 809233 & 5.2 & 5.5803 & TRN & \\
\hline CHEMBL1969843 & 809233 & 5.2 & 5.0103 & TRN & \\
\hline CHEMBL 2007002 & 809233 & 5.2 & 5.5274 & TRN & \\
\hline CHEMBL1973793 & 809233 & 4.6 & 5.0455 & TST & \\
\hline CHEMBL1969588 & 809233 & 6.3 & 6.6085 & TRN & \\
\hline CHEMBL1984711 & 809233 & 5.2 & 6.2024 & TRN & \\
\hline CHEMBL484390 & 809233 & 5.2 & 4.7723 & TST & \\
\hline CHEMBL1979252 & 809233 & 6.4 & 5.0617 & TRN & \\
\hline CHEMBL1986143 & 809233 & 4.4 & $4.9460 e$ & 3000000001 & TRN \\
\hline CHEMBL1972934 & 809233 & 4.7 & 4.4187 & TRN & \\
\hline CHEMBL 2007559 & 809233 & 4.6 & 5.2424 & TRN & \\
\hline CHEMBL1992581 & 809233 & 6.7 & 5.8412 & TRN & \\
\hline CHEMBL1682341 & 809233 & 5.2 & 4.8609 & TRN & \\
\hline CHEMBL 2004290 & 809233 & 8.5 & 8.6598 & TRN & \\
\hline CHEMBL1986499 & 809233 & 5.2 & 5.1467 & TRN & \\
\hline CHEMBL1972937 & 809233 & 5.2 & $5.0360 e$ & 00000000005 & TRN \\
\hline CHEMBL1972250 & 809233 & 5.2 & 4.7893 & TST & \\
\hline CHEMBL 2000393 & 809233 & 5.2 & 5.8896 & TST & \\
\hline CHEMBL403402 & 809233 & 7.1 & 6.3188 & TRN & \\
\hline CHEMBL1983573 & 809233 & 4.4 & 5.07 & TRN & \\
\hline CHEMBL2004311 & 809233 & 6.2 & 5.2888 & TRN & \\
\hline CHEMBL1992634 & 809233 & 5.2 & 5.2497 & TRN & \\
\hline CHEMBL1242373 & 809233 & 5.2 & 5.0887 & TRN & \\
\hline CHEMBL1984847 & 809233 & 4.4 & 4.5772 & TRN & \\
\hline CHEMBL316264 & 809233 & 5.2 & 5.0125 & TRN & \\
\hline CHEMBL1988075 & 809233 & 7.4 & 7.3029 & TRN & \\
\hline CHEMBL1996576 & 809233 & 4.6 & 4.6833 & TST & \\
\hline CHEMBL1988076 & 809233 & 4.6 & 4.8716 & TRN & \\
\hline CHEMBL1991678 & 809233 & 4.6 & 4.8087 & TRN & \\
\hline CHEMBL2001239 & 809233 & 5.2 & 5.2901 & TST & \\
\hline CHEMBL1988594 & 809233 & 5.2 & 5.5946 & TRN & \\
\hline CHEMBL 2001288 & 809233 & 5.2 & 4.9909 & TRN & \\
\hline CHEMBL 260092 & 809233 & 7.1 & 6.1762 & TRN & \\
\hline CHEMBL1999811 & 809233 & 6.4 & 5.6737 & TRN & \\
\hline CHEMBL1965495 & 809233 & 5.2 & 5.142 & TRN & \\
\hline CHEMBL235157 & 809233 & 4.4 & 4.3389 & TST & \\
\hline CHEMBL 2000481 & 809233 & 5.2 & 5.3139 & TRN & \\
\hline CHEMBL1982874 & 809233 & 5.2 & 5.3354 & TRN & \\
\hline CHEMBL1991725 & 809233 & 5.2 & 5.2 & TRN & \\
\hline & & & & 25574 & \\
\hline
\end{tabular}




\begin{tabular}{|c|c|c|c|c|c|}
\hline & & & & & \\
\hline CHEMBL1992242 & 809233 & 5.2 & 5.1121 & TRN & \\
\hline CHEMBL 2007296 & 809233 & 5.2 & 5.0651 & TRN & \\
\hline CHEMBL396523 & 809233 & 6.3 & 6.3094 & TRN & \\
\hline CHEMBL 2004159 & 809233 & 4.4 & 4.6713 & TRN & \\
\hline CHEMBL1978371 & 809233 & 5.9 & 5.2371 & TST & \\
\hline CHEMBL1970203 & 809233 & 5.2 & 5.3761 & TRN & \\
\hline CHEMBL1986530 & 809233 & 5.2 & 5.1216 & TST & \\
\hline CHEMBL1999321 & 809233 & 5.2 & 5.1776 & TRN & \\
\hline CHEMBL1968590 & 809233 & 7.3 & 7.7117 & TRN & \\
\hline CHEMBL1999749 & 809233 & 5.2 & 5.7104 & TRN & \\
\hline CHEMBL2005375 & 809233 & 5.2 & 5.1404 & TRN & \\
\hline CHEMBL1984191 & 809233 & 5.2 & 4.8884 & TST & \\
\hline CHEMBL1971029 & 809233 & 5.2 & 6.8301 & TRN & \\
\hline CHEMBL394790 & 809233 & 5.2 & 5.7527 & TRN & \\
\hline CHEMBL226471 & 809233 & 5.2 & $5.4510 e$ & 00000000005 & TRN \\
\hline CHEMBL1974702 & 809233 & 5.2 & 4.9158 & TRN & \\
\hline CHEMBL1996111 & 809233 & 5.2 & 5.0606 & TRN & \\
\hline CHEMBL1966175 & 809233 & 4.4 & 5.0063 & TRN & \\
\hline CHEMBL1965589 & 809233 & 5.2 & 5.1343 & TRN & \\
\hline CHEMBL 2007375 & 809233 & 4.4 & 4.7159 & TRN & \\
\hline CHEMBL1998193 & 809233 & 5.2 & 4.8039 & TRN & \\
\hline CHEMBL379975 & 809233 & 6.8 & 5.83899 & 99999999995 & TST \\
\hline CHEMBL474432 & 809233 & 5.2 & 5.7737 & TST & \\
\hline CHEMBL1965387 & 809233 & 4.6 & 4.3892 & TRN & \\
\hline CHEMBL1988153 & 809233 & 5.2 & 5.1469 & TST & \\
\hline CHEMBL550418 & 809233 & 6.1 & 5.0545 & TRN & \\
\hline CHEMBL1971289 & 809233 & 4.6 & 4.7013 & TRN & \\
\hline CHEMBL1988437 & 809233 & 8.5 & 6.6004 & TST & \\
\hline CHEMBL1968245 & 809233 & 5.2 & 5.3929 & TRN & \\
\hline CHEMBL1979577 & 809233 & 6.5 & 6.9509 & TRN & \\
\hline CHEMBL1998121 & 809233 & 5.2 & 5.4031 & TRN & \\
\hline CHEMBL1233887 & 809233 & 4.4 & 5.1451 & TST & \\
\hline CHEMBL1991800 & 809233 & 5.2 & 5.1542 & TRN & \\
\hline CHEMBL1985566 & 809233 & 5.2 & 4.7294 & TRN & \\
\hline CHEMBL1979357 & 809233 & 5.2 & 5.0911 & TRN & \\
\hline CHEMBL1980802 & 809233 & 5.2 & 5.2661 & TST & \\
\hline CHEMBL1996649 & 809233 & 8.1 & 8.0175 & TRN & \\
\hline CHEMBL1996817 & 809233 & 5.2 & 5.2929 & TRN & \\
\hline CHEMBL1979554 & 809233 & 5.2 & 5.3126 & TRN & \\
\hline CHEMBL1986756 & 809233 & 4.4 & 5.0114 & TRN & \\
\hline CHEMBL409349 & 809233 & 6.3 & 5.6861 & TRN & \\
\hline CHEMBL 2004355 & 809233 & 5.2 & 5.1539 & TRN & \\
\hline CHEMBL468280 & 809233 & 5.2 & 4.8354 & TST & \\
\hline CHEMBL1990884 & 809233 & 7.0 & 6.1451 & TRN & \\
\hline CHEMBL 3109278 & 809233 & 5.5 & 5.8923 & TRN & \\
\hline CHEMBL 256835 & 809233 & 5.2 & 5.2012 & TRN & \\
\hline CHEMBL1974998 & 809233 & 4.4 & 4.5315 & TRN & \\
\hline CHEMBL1980142 & 809233 & 5.2 & 5.3079 & TRN & \\
\hline & & & & 25575 & \\
\hline
\end{tabular}




\begin{tabular}{|c|c|c|c|c|c|}
\hline \multicolumn{6}{|c|}{ Supplemental Table S2.txt } \\
\hline CHEMBL41783 & 809233 & 5.2 & 5.1125 & TRN & \\
\hline CHEMBL 2004438 & 809233 & 4.8 & 5.4919 & TRN & \\
\hline CHEMBL191003 & 809233 & 6.4 & 5.7975 & TRN & \\
\hline CHEMBL 271381 & 809233 & 5.3 & 5.78799 & 9999999999 & TRN \\
\hline CHEMBL 2006785 & 809233 & 5.2 & 5.1163 & TRN & \\
\hline CHEMBL1982466 & 809233 & 8.6 & 8.4977 & TRN & \\
\hline CHEMBL1973359 & 809233 & 6.4 & 6.3483 & TST & \\
\hline CHEMBL1994638 & 809233 & 5.2 & 5.5432 & TRN & \\
\hline CHEMBL1995740 & 809233 & 5.2 & 5.2169 & TRN & \\
\hline CHEMBL1985888 & 809233 & 6.7 & 6.0347 & TRN & \\
\hline CHEMBL1979690 & 809233 & 7.0 & 7.3944 & TRN & \\
\hline CHEMBL234085 & 809233 & 4.4 & 4.6971 & TRN & \\
\hline CHEMBL1995832 & 809233 & 5.2 & 5.0307 & TRN & \\
\hline CHEMBL1969042 & 809233 & 5.2 & 5.1802 & TRN & \\
\hline CHEMBL 2000345 & 809233 & 5.2 & 4.7286 & TRN & \\
\hline CHEMBL1999931 & 809233 & 5.2 & 5.7187 & TRN & \\
\hline CHEMBL1976376 & 809233 & 4.6 & 5.7197 & TRN & \\
\hline CHEMBL1983575 & 809233 & 6.2 & 6.6403 & TRN & \\
\hline CHEMBL1968868 & 809233 & 5.6 & 5.1784 & TRN & \\
\hline CHEMBL302449 & 809233 & 5.2 & 5.4985 & TST & \\
\hline CHEMBL 2007064 & 809233 & 5.2 & 6.1484 & TRN & \\
\hline CHEMBL1981047 & 809233 & 8.6 & 7.33700 & 0000000001 & TRN \\
\hline CHEMBL 229968 & 809233 & 5.2 & 4.7603 & TRN & \\
\hline CHEMBL1976196 & 809233 & 5.6 & 4.931 & TST & \\
\hline CHEMBL 2002432 & 809233 & 7.1 & 5.7636 & TRN & \\
\hline CHEMBL1976240 & 809233 & 5.2 & 5.055 & TRN & \\
\hline CHEMBL1997197 & 809233 & 4.6 & 4.3225 & TRN & \\
\hline CHEMBL1983630 & 809233 & 4.1 & 4.803 & TRN & \\
\hline CHEMBL1979093 & 809233 & 5.2 & 5.5984 & TRN & \\
\hline CHEMBL1968151 & 809233 & 5.2 & 5.0075 & TRN & \\
\hline CHEMBL1987009 & 809233 & 5.2 & 4.9307 & TRN & \\
\hline CHEMBL 379218 & 809233 & 5.2 & 5.0843 & TRN & \\
\hline CHEMBL 2003817 & 809233 & 5.2 & 5.4491 & TRN & \\
\hline CHEMBL336961 & 809233 & 6.2 & 5.7877 & TRN & \\
\hline CHEMBL1994830 & 809233 & 5.2 & 5.0935 & TST & \\
\hline CHEMBL1987054 & 809233 & 6.3 & 6.8442 & TRN & \\
\hline CHEMBL1970083 & 809233 & 8.0 & 8.2175 & TRN & \\
\hline CHEMBL226403 & 809233 & 5.2 & 5.4869 & TRN & \\
\hline CHEMBL2005631 & 809233 & 8.7 & 7.9766 & TRN & \\
\hline CHEMBL1977223 & 809233 & 5.2 & 5.1076 & TRN & \\
\hline CHEMBL1995765 & 809233 & 4.9 & 4.621 & TST & \\
\hline CHEMBL1966279 & 809233 & 5.2 & 5.4225 & TRN & \\
\hline CHEMBL1997846 & 809233 & 5.2 & 5.064 & TRN & \\
\hline CHEMBL1984760 & 809233 & 4.6 & 5.1733 & TRN & \\
\hline CHEMBL 2004419 & 809233 & 5.2 & 5.3102 & TRN & \\
\hline CHEMBL360847 & 809233 & 4.6 & 4.4888 & TST & \\
\hline CHEMBL 2007073 & 809233 & 4.4 & 4.5536 & TRN & \\
\hline CHEMBL1995811 & 809233 & 4.6 & 5.0135 & TRN & \\
\hline
\end{tabular}




\begin{tabular}{|c|c|c|c|c|c|}
\hline \\
\hline CHEMBL1975787 & 809233 & 5.2 & 5.2759 & TRN & \\
\hline CHEMBL 2002407 & 809233 & 5.2 & 5.2497 & TRN & \\
\hline CHEMBL1992937 & 809233 & 6.1 & 4.9401 & TST & \\
\hline CHEMBL95692 & 809233 & 5.2 & 5.1562 & TRN & \\
\hline CHEMBL1090356 & 809233 & 5.2 & 5.1324 & TRN & \\
\hline CHEMBL 2002450 & 809233 & 4.2 & 4.5213 & TRN & \\
\hline CHEMBL1986507 & 809233 & 5.2 & 5.4659 & TRN & \\
\hline CHEMBL1976455 & 809233 & 5.2 & 5.4283 & TRN & \\
\hline CHEMBL261849 & 809233 & 4.4 & 4.5894 & TST & \\
\hline CHEMBL1983923 & 809233 & 6.7 & 6.7718 & TRN & \\
\hline CHEMBL1983534 & 809233 & 5.2 & 5.3564 & TRN & \\
\hline CHEMBL1982361 & 809233 & 5.2 & 4.9914 & TST & \\
\hline CHEMBL1999112 & 809233 & 7.1 & 5.6875 & TST & \\
\hline CHEMBL1982122 & 809233 & 5.2 & 5.3038 & TST & \\
\hline CHEMBL 2000801 & 809233 & 5.2 & 5.20799 & 9999999999 & TST \\
\hline CHEMBL1682546 & 809233 & 5.2 & 5.2978 & TST & \\
\hline CHEMBL1991395 & 809233 & 5.2 & 5.0547 & TST & \\
\hline CHEMBL1971245 & 809233 & 5.2 & 5.2957 & TST & \\
\hline CHEMBL1987648 & 809233 & 5.2 & 4.8756 & TST & \\
\hline CHEMBL1996780 & 809233 & 5.2 & 5.0117 & TST & \\
\hline CHEMBL1972142 & 809233 & 5.2 & 5.6027 & TST & \\
\hline CHEMBL1966514 & 809233 & 7.5 & 7.70100 & 00000000005 & TST \\
\hline CHEMBL2003638 & 809233 & 5.2 & 5.7369 & TST & \\
\hline CHEMBL296586 & 809233 & 6.8 & 5.7073 & TST & \\
\hline CHEMBL1996066 & 809233 & 8.0 & 5.5389 & TST & \\
\hline CHEMBL1983393 & 809233 & 4.6 & 5.0552 & TST & \\
\hline CHEMBL516429 & 809233 & 5.2 & 4.6988 & TST & \\
\hline CHEMBL1993722 & 809233 & 5.2 & 5.8212 & TST & \\
\hline CHEMBL 2006674 & 809233 & 4.6 & 4.4449 & TST & \\
\hline CHEMBL1984236 & 809233 & 4.6 & 4.6402 & TST & \\
\hline CHEMBL1992371 & 809233 & 4.6 & 5.4123 & TST & \\
\hline CHEMBL1375640 & 809233 & 5.2 & 5.0866 & TST & \\
\hline CHEMBL1979970 & 809233 & 5.2 & 4.9224 & TST & \\
\hline CHEMBL2002599 & 809233 & 4.4 & 4.717 & TST & \\
\hline CHEMBL249282 & 809233 & 5.2 & 4.6417 & TST & \\
\hline CHEMBL1967252 & 809233 & 4.6 & 4.8444 & TST & \\
\hline CHEMBL1992473 & 809233 & 6.3 & 4.8587 & TST & \\
\hline CHEMBL2004637 & 809233 & 5.8 & 5.4414 & TST & \\
\hline CHEMBL1993374 & 809233 & 4.6 & 4.9928 & TST & \\
\hline CHEMBL1969264 & 809233 & 5.2 & 5.5596 & TST & \\
\hline CHEMBL1999506 & 809233 & 4.4 & 4.553 & TST & \\
\hline CHEMBL1572266 & 809233 & 5.2 & 5.1207 & TST & \\
\hline CHEMBL1605605 & 809233 & 4.6 & 4.6544 & TST & \\
\hline CHEMBL1989029 & 809233 & 5.2 & 5.511 & TST & \\
\hline CHEMBL514499 & 809233 & 5.2 & 5.1983 & TST & \\
\hline CHEMBL1970352 & 809233 & 4.6 & 5.2081 & TST & \\
\hline CHEMBL1965631 & 809233 & 5.2 & 5.2372 & TST & \\
\hline CHEMBL1980144 & 809233 & 5.2 & 5.3902 & TST & \\
\hline & & & & 2557 & \\
\hline
\end{tabular}




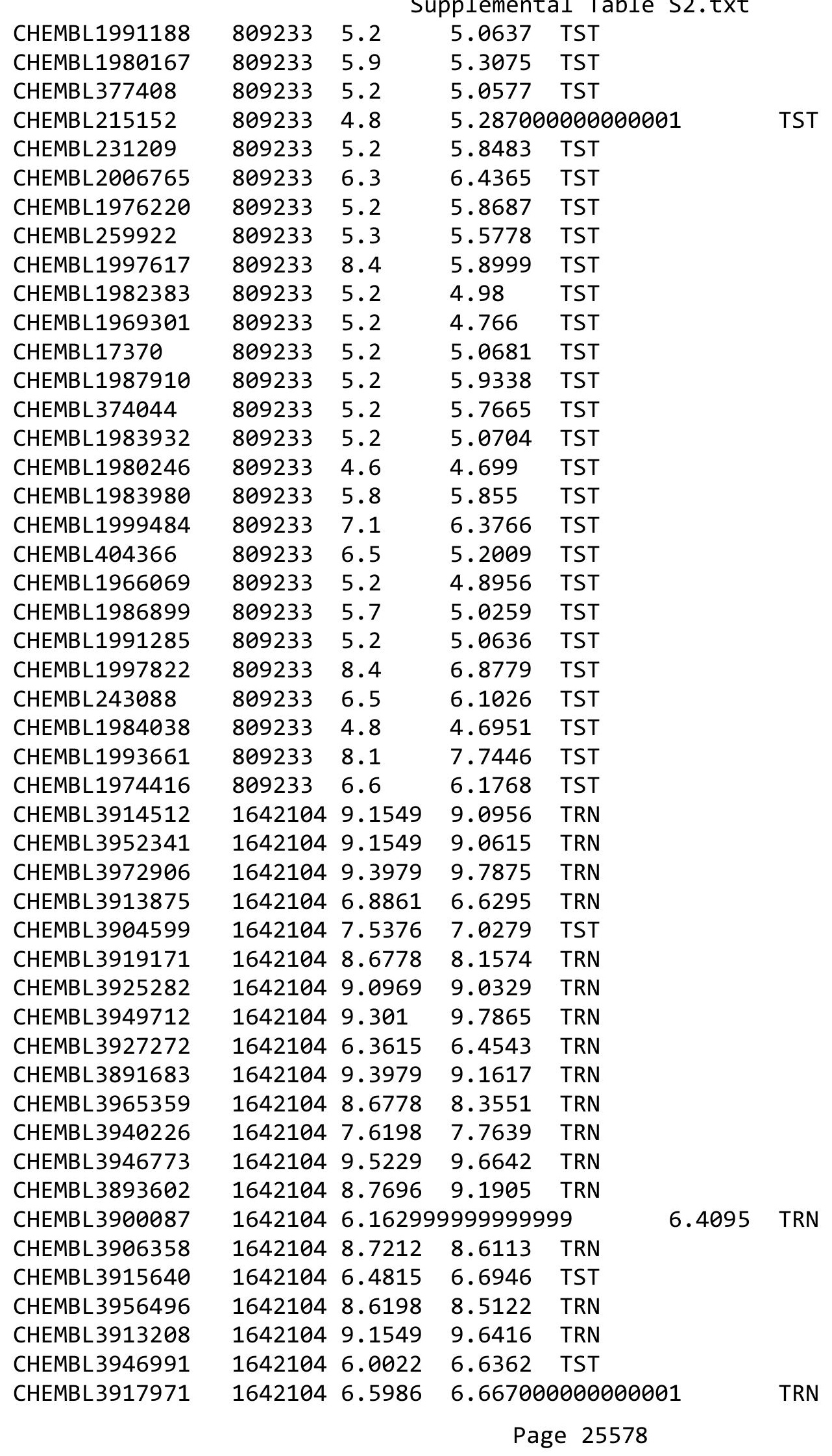


Supplemental Table S2.txt

\begin{tabular}{|c|c|c|c|c|}
\hline CHEMBL3931185 & 1642104 & 9.5229 & 9.6103 & TRN \\
\hline CHEMBL3911643 & 1642104 & 6.6198 & 6.7598 & TRN \\
\hline CHEMBL3984523 & 1642104 & 6.5528 & 7.1934 & TST \\
\hline CHEMBL 3891004 & 1642104 & 8.4949 & 8.6038 & TRN \\
\hline CHEMBL3947325 & 1642104 & 9.2218 & 9.1114 & TRN \\
\hline CHEMBL3935017 & 1642104 & 9.5229 & 8.6894 & TRN \\
\hline CHEMBL3891944 & 1642104 & 9.1549 & 8.9921 & TRN \\
\hline CHEMBL3937399 & 1642104 & 8.6021 & 9.0135 & TRN \\
\hline CHEMBL3978916 & 1642104 & 9.0969 & 8.4465 & TST \\
\hline CHEMBL3974331 & 1642104 & 7.699 & 7.8815 & TRN \\
\hline CHEMBL3962181 & 1642104 & 9.1549 & 8.9041 & TRN \\
\hline CHEMBL3922694 & 1642104 & 9.3979 & 9.787 & TRN \\
\hline CHEMBL3910445 & 1642104 & 7.2441 & 6.1368 & TST \\
\hline CHEMBL3935703 & 1642104 & 9.1549 & 9.1004 & TRN \\
\hline CHEMBL3928395 & 1642104 & 6.4949 & 6.8084 & TRN \\
\hline CHEMBL3899243 & 1642104 & 6.6021 & 6.4611 & TRN \\
\hline CHEMBL3951546 & 1642104 & 6.2168 & 6.2543 & TRN \\
\hline CHEMBL3928950 & 1642104 & 9.0458 & 8.8183 & TRN \\
\hline CHEMBL3897901 & 1642104 & 7.6383 & 8.2791 & TRN \\
\hline CHEMBL3962246 & 1642104 & 8.5086 & 8.4123 & TRN \\
\hline CHEMBL3930956 & 1642104 & 7.4559 & 8.147 & TRN \\
\hline CHEMBL3979834 & 1642104 & 8.7447 & 8.0853 & TST \\
\hline CHEMBL3957460 & 1642104 & 9.0969 & 8.4867 & TRN \\
\hline CHEMBL3896522 & 1642104 & 9.301 & 8.9184 & TRN \\
\hline CHEMBL3905317 & 1642104 & 8.2218 & 8.381 & TRN \\
\hline CHEMBL3940045 & 1642104 & 6.2255 & 6.6574 & TRN \\
\hline CHEMBL3919064 & 1642104 & 7.6198 & 7.202006 & 0000000001 \\
\hline CHEMBL 3980542 & 1642104 & 7.4089 & 7.2529 & TRN \\
\hline CHEMBL3943444 & 1642104 & 8.301 & 8.1816 & TRN \\
\hline CHEMBL3979421 & 1642104 & 6.1391 & 6.5203 & TRN \\
\hline CHEMBL 3949284 & 1642104 & 8.0 & 8.4682 & TST \\
\hline CHEMBL3903397 & 1642104 & 8.9586 & 8.6408 & TRN \\
\hline CHEMBL3950883 & 1642104 & 9.0969 & 8.7933 & TST \\
\hline CHEMBL3941315 & 1642104 & 9.3979 & 9.1758 & TRN \\
\hline CHEMBL3933416 & 1642104 & 7.2596 & 7.3804 & TRN \\
\hline CHEMBL3916283 & 1642104 & 8.699 & 8.2681 & TRN \\
\hline CHEMBL3981976 & 1642104 & 8.2291 & 8.344 & TRN \\
\hline CHEMBL 3970184 & 1642104 & 7.5528 & 7.2284 & TRN \\
\hline CHEMBL3933531 & 1642104 & 6.2366 & 6.6774 & TST \\
\hline CHEMBL3934643 & 1642104 & 9.1549 & 9.2536 & TRN \\
\hline CHEMBL3950414 & 1642104 & 9.301 & 8.9004 & TRN \\
\hline CHEMBL3948577 & 1642104 & 7.8861 & 7.5731 & TRN \\
\hline CHEMBL3930973 & 1642104 & 6.6676 & 7.1007 & TRN \\
\hline CHEMBL3986847 & 1642104 & 8.6383 & 8.2392 & TRN \\
\hline CHEMBL3903535 & 1642104 & 6.301 & 6.5261 & TRN \\
\hline CHEMBL3931577 & 1642104 & 8.8539 & 8.4948 & TRN \\
\hline CHEMBL3966953 & 1642104 & 6.1739 & 6.2817 & TST \\
\hline CHEMBL3937098 & 1642104 & 8.4089 & 7.9898 & TRN \\
\hline
\end{tabular}

Page 25579 
Supplemental Table S2.txt

\begin{tabular}{|c|c|c|c|c|}
\hline CHEMBL3944654 & 1642104 & 9.2218 & 8.8523 & TRN \\
\hline CHEMBL3906508 & 1642104 & 7.3872 & 7.1685 & TRN \\
\hline CHEMBL3937750 & 1642104 & 9.0969 & 9.0602 & TRN \\
\hline CHEMBL3928113 & 1642104 & 7.4318 & 7.45 & TRN \\
\hline CHEMBL3899033 & 1642104 & 7.7212 & 7.5449 & TRN \\
\hline CHEMBL3950106 & 1642104 & 9.5229 & 9.1728 & TRN \\
\hline CHEMBL3978122 & 1642104 & 9.3979 & 9.2122 & TRN \\
\hline CHEMBL3974502 & 1642104 & 8.8239 & 7.5782 & TST \\
\hline CHEMBL3972985 & 1642104 & 6.4202 & 6.5741 & TST \\
\hline CHEMBL3955562 & 1642104 & 9.2218 & 8.6157 & TST \\
\hline CHEMBL3985854 & 1642104 & 6.4559 & 6.2722 & TRN \\
\hline CHEMBL3939050 & 1642104 & 9.0458 & 8.7735 & TRN \\
\hline CHEMBL3922220 & 1642104 & 6.9586 & 6.9631 & TRN \\
\hline CHEMBL3978387 & 1642104 & 9.0 & 9.187999 & 9999999999 \\
\hline CHEMBL3910280 & 1642104 & 6.9031 & 7.1139 & TRN \\
\hline CHEMBL3921135 & 1642104 & 6.6383 & 6.1672 & TRN \\
\hline CHEMBL3972900 & 1642104 & 8.1079 & 7.7652 & TST \\
\hline CHEMBL3905136 & 1642104 & 7.284 & 6.2625 & TST \\
\hline CHEMBL3927973 & 1642104 & 7.3665 & 7.6002 & TRN \\
\hline CHEMBL3974004 & 1642104 & 8.5528 & 8.1056 & TST \\
\hline CHEMBL3980988 & 1642104 & 8.9208 & 8.3864 & TRN \\
\hline CHEMBL3919576 & 1642104 & 7.0862 & 6.9767 & TRN \\
\hline CHEMBL3953220 & 1642104 & 9.1549 & 9.2344 & TRN \\
\hline CHEMBL3951244 & 1642104 & 8.8861 & 9.1926 & TRN \\
\hline CHEMBL3917113 & 1642104 & 7.041 & 6.7693 & TRN \\
\hline CHEMBL3981291 & 1642104 & 7.1487 & 6.1328 & TST \\
\hline CHEMBL3953768 & 1642104 & 7.2441 & 7.6378 & TRN \\
\hline CHEMBL3979351 & 1642104 & 7.1871 & 8.326 & TST \\
\hline CHEMBL3938204 & 1642104 & 6.2218 & 5.8106 & TST \\
\hline CHEMBL3905415 & 1642104 & 7.2757 & 7.3442 & TRN \\
\hline CHEMBL3915487 & 1642104 & 8.1024 & 7.9743 & TRN \\
\hline CHEMBL3951276 & 1642104 & 6.0088 & 5.6621 & TST \\
\hline CHEMBL3919736 & 1642104 & 8.9586 & 9.0187 & TRN \\
\hline CHEMBL3931060 & 1642104 & 8.1739 & 8.2654 & TRN \\
\hline CHEMBL3986617 & 1642104 & 7.2366 & 7.8358 & TST \\
\hline CHEMBL3916453 & 1642104 & 9.5229 & 9.3843 & TRN \\
\hline CHEMBL3961664 & 1642104 & 8.7212 & 8.7329 & TRN \\
\hline CHEMBL3958412 & 1642104 & 8.9208 & 9.1548 & TRN \\
\hline CHEMBL3937186 & 1642104 & 9.5229 & 9.4598 & TRN \\
\hline CHEMBL3975340 & 1642104 & 7.2518 & 7.5495 & TRN \\
\hline CHEMBL3942395 & 1642104 & 8.3372 & 7.9778 & TRN \\
\hline CHEMBL 3907748 & 1642104 & 8.301 & 8.7212 & TRN \\
\hline CHEMBL3964941 & 1642104 & 6.3883 & 6.1728 & TRN \\
\hline CHEMBL3959050 & 1642104 & 6.6576 & 6.874 & TRN \\
\hline CHEMBL3904741 & 1642104 & 7.3279 & 7.5537 & TRN \\
\hline CHEMBL3973452 & 1642104 & 8.0506 & 8.2229 & TRN \\
\hline CHEMBL3918264 & 1642104 & 6.4559 & 6.6708 & TRN \\
\hline CHEMBL3929545 & 1642104 & 7.585 & 7.7575 & TRN \\
\hline
\end{tabular}




\begin{tabular}{|c|c|c|c|c|c|c|}
\hline & & \multicolumn{5}{|c|}{ Supplemental Table S2.txt } \\
\hline CHEMBL 3903050 & 1642104 & 8.0315 & 7.9538 & TST & & \\
\hline CHEMBL 3926238 & 1642104 & 6.1397 & 6.4819 & TRN & & \\
\hline CHEMBL3961382 & 1642104 & 9.301 & 9.0759 & TRN & & \\
\hline CHEMBL3927089 & 1642104 & \multicolumn{3}{|c|}{6.757000000000001} & 6.9753 & TRN \\
\hline CHEMBL 3920770 & 1642104 & 6.9393 & 7.0991 & TRN & & \\
\hline CHEMBL 3967647 & 1642104 & 6.9788 & 7.2909 & TST & & \\
\hline CHEMBL 3961891 & 1642104 & 9.3979 & 9.0476 & TRN & & \\
\hline CHEMBL3978451 & 1642104 & 9.5229 & 8.9775 & TRN & & \\
\hline CHEMBL 3953853 & 1642104 & 9.5229 & 9.3062 & TRN & & \\
\hline CHEMBL3969768 & 1642104 & 9.1549 & 9.8851 & TRN & & \\
\hline CHEMBL 3923530 & 1642104 & 9.2218 & 9.5681 & TRN & & \\
\hline CHEMBL 3963905 & 1642104 & 7.8239 & 8.1577 & TRN & & \\
\hline CHEMBL3959425 & 1642104 & 9.301 & 8.9496 & TRN & & \\
\hline CHEMBL 3977173 & 1642104 & 6.1135 & 6.1699 & TRN & & \\
\hline CHEMBL3958633 & 1642104 & 9.301 & 9.077 & TRN & & \\
\hline CHEMBL3967111 & 1642104 & 8.6778 & 8.6129 & TRN & & \\
\hline CHEMBL3976004 & 1642104 & 9.5229 & 9.8832 & TRN & & \\
\hline CHEMBL 3970232 & 1642104 & 9.3979 & 9.9069 & TRN & & \\
\hline CHEMBL3967691 & 1642104 & 9.301 & 7.3052 & TST & & \\
\hline CHEMBL3949425 & 1642104 & 6.5272 & 7.0877 & TRN & & \\
\hline CHEMBL 3912828 & 1642104 & 8.0362 & 8.0834 & TRN & & \\
\hline CHEMBL 3963344 & 1642104 & 7.4685 & 7.4915 & TRN & & \\
\hline CHEMBL3891050 & 1642104 & 7.2076 & 7.7642 & TRN & & \\
\hline CHEMBL 3967492 & 1642104 & 9.5229 & 8.576 & TRN & & \\
\hline CHEMBL 3898278 & 1642104 & 9.5229 & 9.3442 & TRN & & \\
\hline CHEMBL 3966853 & 1642104 & 7.7447 & 7.6238 & TRN & & \\
\hline CHEMBL3921668 & 1642104 & 9.2218 & 9.4799 & TRN & & \\
\hline CHEMBL3922986 & 1642104 & 9.3979 & 9.2129 & TST & & \\
\hline CHEMBL3892165 & 1642104 & 6.4685 & 7.3447 & TST & & \\
\hline CHEMBL3952966 & 1642104 & 9.5229 & 9.6705 & TRN & & \\
\hline CHEMBL 3980186 & 1642104 & 6.1308 & 7.0707 & TST & & \\
\hline CHEMBL3987103 & 1642104 & 9.0 & 8.8052 & TRN & & \\
\hline CHEMBL 3957706 & 1642104 & 9.5229 & 9.9925 & TRN & & \\
\hline CHEMBL3952312 & 1642104 & 6.5607 & 7.0051 & TST & & \\
\hline CHEMBL3959116 & 1642104 & 6.9586 & 7.0012 & TRN & & \\
\hline CHEMBL 3957563 & 1642104 & 6.9788 & 6.9463 & TRN & & \\
\hline CHEMBL3913891 & 1642104 & 8.9208 & 7.8632 & TST & & \\
\hline CHEMBL 3981888 & 1642104 & 8.4949 & 8.0035 & TST & & \\
\hline CHEMBL3924319 & 1642104 & 8.699 & 8.6319 & TRN & & \\
\hline CHEMBL3952381 & 1642104 & 8.8861 & 8.8864 & TRN & & \\
\hline CHEMBL 3924803 & 1642104 & 7.2518 & 7.3368 & TRN & & \\
\hline CHEMBL3975599 & 1642104 & 9.5229 & 9.2617 & TST & & \\
\hline CHEMBL 3894567 & 1642104 & 6.0088 & 6.5559 & TST & & \\
\hline CHEMBL3953431 & 1642104 & 8.5086 & 8.5726 & TST & & \\
\hline CHEMBL3897310 & 1642104 & 8.6383 & 10.2429 & TST & & \\
\hline CHEMBL 3956530 & 1642104 & 6.8861 & 7.5929 & TST & & \\
\hline CHEMBL3985644 & 1642104 & 6.9586 & 6.7293 & TST & & \\
\hline CHEMBL3925805 & 1642104 & 9.0458 & 8.8625 & TST & & \\
\hline
\end{tabular}




\begin{tabular}{|c|c|c|c|c|c|c|}
\hline \multicolumn{7}{|c|}{ Supplemental Table S2.txt } \\
\hline CHEMBL3928007 & 1642104 & 6.585 & 5.5665 & TST & & \\
\hline CHEMBL3943979 & 1642104 & 9.301 & 9.2326 & TST & & \\
\hline CHEMBL3934386 & 1642104 & 8.2147 & 9.4362 & TST & & \\
\hline CHEMBL3960447 & 1641066 & 7.9285 & 8.0324 & TRN & & \\
\hline CHEMBL3960438 & 1641066 & 6.58299 & 99999999 & 99 & 7.3679 & TRN \\
\hline CHEMBL3954701 & 1641066 & 6.303 & 6.5473 & TRN & & \\
\hline CHEMBL3897068 & 1641066 & 9.0315 & 8.2646 & TST & & \\
\hline CHEMBL3980076 & 1641066 & 7.0795 & 7.00299 & 999999999 & & TRN \\
\hline CHEMBL3910267 & 1641066 & 7.0834 & 8.0487 & TRN & & \\
\hline CHEMBL3938819 & 1641066 & 7.03299 & 99999999 & 995 & 7.5436 & TRN \\
\hline CHEMBL3978134 & 1641066 & 8.6882 & 7.9229 & TRN & & \\
\hline CHEMBL3908063 & 1641066 & 8.266 & 7.5853 & TRN & & \\
\hline CHEMBL3960787 & 1641066 & 7.4255 & 7.9391 & TRN & & \\
\hline CHEMBL3985625 & 1641066 & 6.2638 & 6.4986 & TRN & & \\
\hline CHEMBL3951909 & 1641066 & 7.218 & 6.9427 & TST & & \\
\hline CHEMBL3927878 & 1641066 & 7.7124 & 7.6942 & TRN & & \\
\hline CHEMBL 3946475 & 1641066 & 6.6657 & 6.3353 & TRN & & \\
\hline CHEMBL3930729 & 1641066 & 7.6124 & 7.1911 & TST & & \\
\hline CHEMBL3907607 & 1641066 & 7.7862 & 8.0991 & TRN & & \\
\hline CHEMBL3939440 & 1641066 & 6.8681 & 6.3639 & TRN & & \\
\hline CHEMBL3984591 & 1641066 & 6.5056 & 6.4142 & TRN & & \\
\hline CHEMBL 3896260 & 1641066 & 5.9977 & 6.1334 & TRN & & \\
\hline CHEMBL3956140 & 1641066 & 6.03299 & 99999999 & 995 & 6.4438 & TST \\
\hline CHEMBL3957345 & 1641066 & 8.1085 & 7.4194 & TRN & & \\
\hline CHEMBL3961698 & 1641066 & 8.4789 & 7.9448 & TRN & & \\
\hline CHEMBL3911178 & 1641066 & 7.75899 & 99999999 & 995 & 8.7568 & TRN \\
\hline CHEMBL3959095 & 1641066 & 7.2916 & 6.3353 & TRN & & \\
\hline CHEMBL3920595 & 1641066 & 7.3012 & 7.2595 & TST & & \\
\hline CHEMBL 3936020 & 1641066 & 7.2209 & 7.4418 & TRN & & \\
\hline CHEMBL3985467 & 1641066 & 8.7545 & 8.4817 & TRN & & \\
\hline CHEMBL3977305 & 1641066 & 8.8761 & 8.7272 & TST & & \\
\hline CHEMBL3976519 & 1641066 & 6.7864 & 6.9856 & TRN & & \\
\hline CHEMBL3946094 & 1641066 & 6.8273 & 6.6807 & TST & & \\
\hline CHEMBL3915085 & 1641066 & 7.8005 & 6.6431 & TST & & \\
\hline CHEMBL3943062 & 1641066 & 8.3556 & 8.2488 & TRN & & \\
\hline CHEMBL3935949 & 1641066 & 6.5112 & 6.1542 & TRN & & \\
\hline CHEMBL3914891 & 1641066 & 7.0562 & 6.3639 & TRN & & \\
\hline CHEMBL3954782 & 1641066 & 9.7212 & 8.9487 & TRN & & \\
\hline CHEMBL3916122 & 1641066 & 8.8182 & 8.2627 & TRN & & \\
\hline CHEMBL3933629 & 1641066 & 6.4699 & 7.1958 & TRN & & \\
\hline CHEMBL3933635 & 1641066 & 7.684 & 7.7818 & TST & & \\
\hline CHEMBL3980450 & 1641066 & 8.1373 & 7.6451 & TRN & & \\
\hline CHEMBL3927136 & 1641066 & 9.8239 & 8.9712 & TRN & & \\
\hline CHEMBL3971756 & 1641066 & 5.8113 & 6.0527 & TST & & \\
\hline CHEMBL3969293 & 1641066 & 7.8213 & 6.7654 & TST & & \\
\hline CHEMBL3935620 & 1641066 & 7.5327 & 7.6164 & TRN & & \\
\hline CHEMBL3916653 & 1641066 & 6.4668 & 6.8739 & TRN & & \\
\hline CHEMBL3919268 & 1641066 & 7.4462 & 7.4213 & TRN & & \\
\hline
\end{tabular}


Supplemental Table S2.txt

\begin{tabular}{|c|c|c|c|c|}
\hline 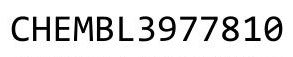 & 641066 & 252 & & \\
\hline HEMBL3895580 & 641066 & 6.5169 & 6.9404 & \\
\hline & & & 532 & \\
\hline EMBL & 066 & 3831 & 62 & \\
\hline IEMBL 3979649 & 066 & 382 & 323 & \\
\hline HEMBL3899017 & 641066 & 6.4416 & 8433 & \\
\hline HEMBL3923805 & 066 & 706 & .2611 & \\
\hline IEMBL3S & 66 & 5906 & & \\
\hline IEMBL3946612 & $\partial 66$ & 8533 & .9473 & \\
\hline HEMBL3971535 & .066 & 8.061 & 8.1714 & \\
\hline HEMBL3965843 & 066 & 7.2555 & .5989 & \\
\hline HEMBL3914777 & 366 & 6.7522 & 124 & \\
\hline AEMBL3 & & 288 & & \\
\hline HEMBL39 & & 7.3075 & & \\
\hline HEMBL3948050 & 366 & 7.7632 & 1241 & \\
\hline HEMBL3902466 & & 8.1726 & & \\
\hline AEMBL39 & 66 & 7.2658 & 84 & \\
\hline HEMBL3S & & 28 & & \\
\hline HEMBL3 & & 943 & & \\
\hline HEMBL39 & & 7.7203 & & RN \\
\hline AEMBL3972343 & 66 & 32 & 7. & 1 \\
\hline HEMBL 39 & 066 & 18 & 92 & SI \\
\hline HEMBL3S & & 71 & & RN \\
\hline HEMBL 39 & & 53 & & ST \\
\hline HEMBL392 & & & & RN \\
\hline EMBL3930597 & 66 & 6. & & RN \\
\hline HEMBL393 & 366 & 8 & 18 & 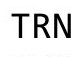 \\
\hline HEMBL3S & & & 18 & RN \\
\hline 79 & & & & RN \\
\hline AEMBL39 & & & & RIN \\
\hline AEMBL396 & 66 & 61 & 732 & RN \\
\hline HEMBL396 & 6 & 762 & 105 & KIV \\
\hline HEMBL39 & & & 14 & RN \\
\hline & & & & I \\
\hline AEMBL3907239 & 66 & & 36 & ST \\
\hline AEMBL3930454 & 66 & & 7.5991 & RN \\
\hline HEMBL3896667 & 6 & 78 & .5042 & Niv \\
\hline & & & & RN \\
\hline HEMBL3938757 & & & 91 & ST \\
\hline HEMBL3974588 & 66 & 6.8079 & 376 & RN \\
\hline HEMBL 39 & 66 & 63 & 577 & RN \\
\hline HEMBL3909928 & & & 7.6322 & Niv \\
\hline HEMBL39 & & & & ST \\
\hline HEMBL3985058 & 266 & 7.8245 & 4194 & TST \\
\hline HEMBL3939745 & 266 & 8.8539 & 565 & ST \\
\hline EML32 & & & & \\
\hline HEM & & & 356 & \\
\hline HEMBL323025 & 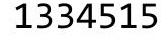 & & 95 & \\
\hline
\end{tabular}

Page 25583 


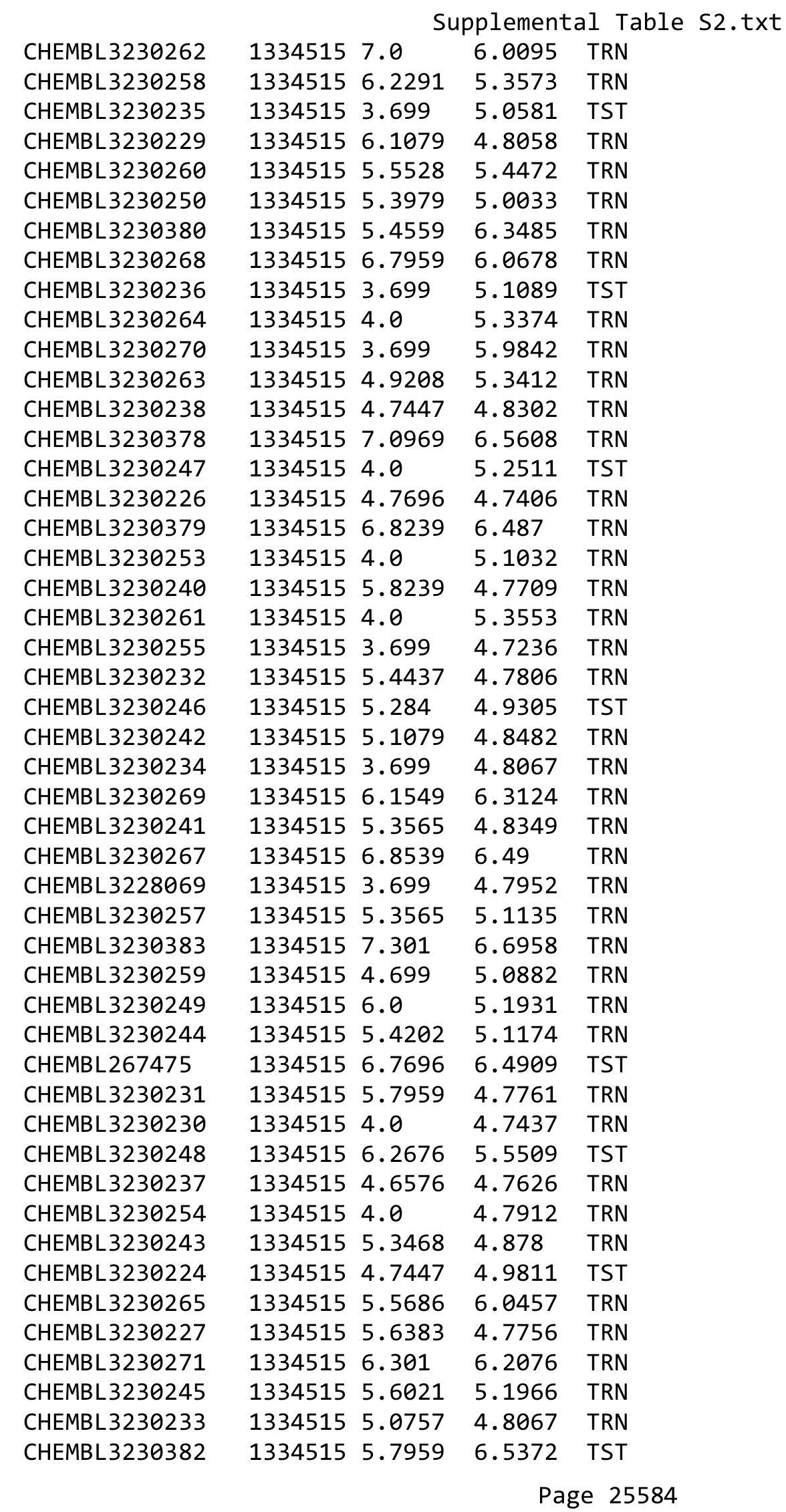


Supplemental Table S2.txt

\begin{tabular}{|c|c|c|c|c|}
\hline CHEMBL3230251 & 1334515 & 4.3979 & 5.1073 & TST \\
\hline CHEMBL3230228 & 1334515 & 5.699 & 4.8058 & TST \\
\hline CHEMBL3230266 & 1334515 & 6.9586 & 6.1811 & TST \\
\hline CHEMBL3230256 & 1334515 & 5.3468 & 5.0758 & TST \\
\hline CHEMBL3230239 & 1334515 & 5.2596 & 4.8477 & TST \\
\hline CHEMBL3230381 & 1334515 & 7.6021 & 6.6618 & TST \\
\hline CHEMBL3899429 & 1640918 & 8.2596 & 8.1238 & TRN \\
\hline CHEMBL3919790 & 1640918 & 8.1739 & 8.0952 & TRN \\
\hline CHEMBL3965784 & 1640918 & 8.1739 & 7.9967 & TST \\
\hline CHEMBL3928700 & 1640918 & 8.2518 & 8.1055 & TRN \\
\hline CHEMBL3906724 & 1640918 & 7.7447 & 7.4898 & TST \\
\hline CHEMBL3919266 & 1640918 & 6.284 & 7.6073 & TST \\
\hline CHEMBL3943677 & 1640918 & 8.0757 & 7.7203 & TST \\
\hline CHEMBL 3891380 & 1640918 & 8.1487 & 7.2273 & TST \\
\hline CHEMBL3919830 & 1640918 & 6.9208 & 6.8857 & TRN \\
\hline CHEMBL3934704 & 1640918 & 7.8861 & 7.4757 & TST \\
\hline CHEMBL3951334 & 1640918 & 7.6576 & 7.7272 & TRN \\
\hline CHEMBL3936426 & 1640918 & 8.6198 & 8.0841 & TRN \\
\hline CHEMBL3984670 & 1640918 & 7.4437 & 8.0128 & TRN \\
\hline CHEMBL 3892192 & 1640918 & 8.0 & 7.9704 & TRN \\
\hline CHEMBL3922046 & 1640918 & 7.9586 & 8.1168 & TRN \\
\hline CHEMBL3954133 & 1640918 & 7.7696 & 8.0653 & TRN \\
\hline CHEMBL3936526 & 1640918 & 7.4437 & 6.9546 & TRN \\
\hline CHEMBL3971767 & 1640918 & 7.1938 & 8.0515 & TRN \\
\hline CHEMBL3927554 & 1640918 & 6.7825 & 6.791 & TRN \\
\hline CHEMBL3952552 & 1640918 & 8.1192 & 8.0585 & TRN \\
\hline CHEMBL3955159 & 1640918 & 7.7696 & 8.0553 & TRN \\
\hline CHEMBL3985729 & 1640918 & 6.0 & 7.7163 & TRN \\
\hline CHEMBL3897652 & 1640918 & 6.0031 & 7.4242 & TST \\
\hline CHEMBL3904995 & 1640918 & 6.5157 & 6.794 & TRN \\
\hline CHEMBL3944734 & 1640918 & 8.4089 & 8.1335 & TRN \\
\hline CHEMBL3890816 & 1640918 & 8.1675 & 7.3589 & TST \\
\hline CHEMBL3976059 & 1640918 & 9.0 & 8.0723 & TRN \\
\hline CHEMBL 3966248 & 1640918 & 6.6676 & 6.8545 & TRN \\
\hline CHEMBL3907145 & 1640918 & 7.0088 & 6.8176 & TRN \\
\hline CHEMBL3959409 & 1640918 & 7.2007 & 8.0939 & TRN \\
\hline CHEMBL3916341 & 1640918 & 6.9245 & 8.0908 & TRN \\
\hline CHEMBL3979142 & 1640918 & 8.2147 & 8.1246 & TRN \\
\hline CHEMBL3901693 & 1640918 & 5.7352 & 7.7958 & TST \\
\hline CHEMBL3953531 & 1640918 & 7.6383 & 7.4489 & TST \\
\hline CHEMBL3891742 & 1640918 & 8.3188 & 8.1248 & TRN \\
\hline CHEMBL 3889944 & 1640918 & 7.8239 & 8.0529 & TRN \\
\hline CHEMBL3959763 & 1640918 & 6.9208 & 6.7844 & TRN \\
\hline CHEMBL3945786 & 1640918 & 8.4685 & 8.101 & TRN \\
\hline CHEMBL3892733 & 1640918 & 4.699 & 7.977 & TST \\
\hline CHEMBL3950700 & 1640918 & 6.8239 & 6.8083 & TRN \\
\hline CHEMBL 3977184 & 1640918 & 8.0 & \multicolumn{2}{|c|}{7.781000000000001} \\
\hline CHEMBL3923312 & 1640918 & 8.2757 & 7.5005 & TST \\
\hline
\end{tabular}


Supplemental Table S2.txt

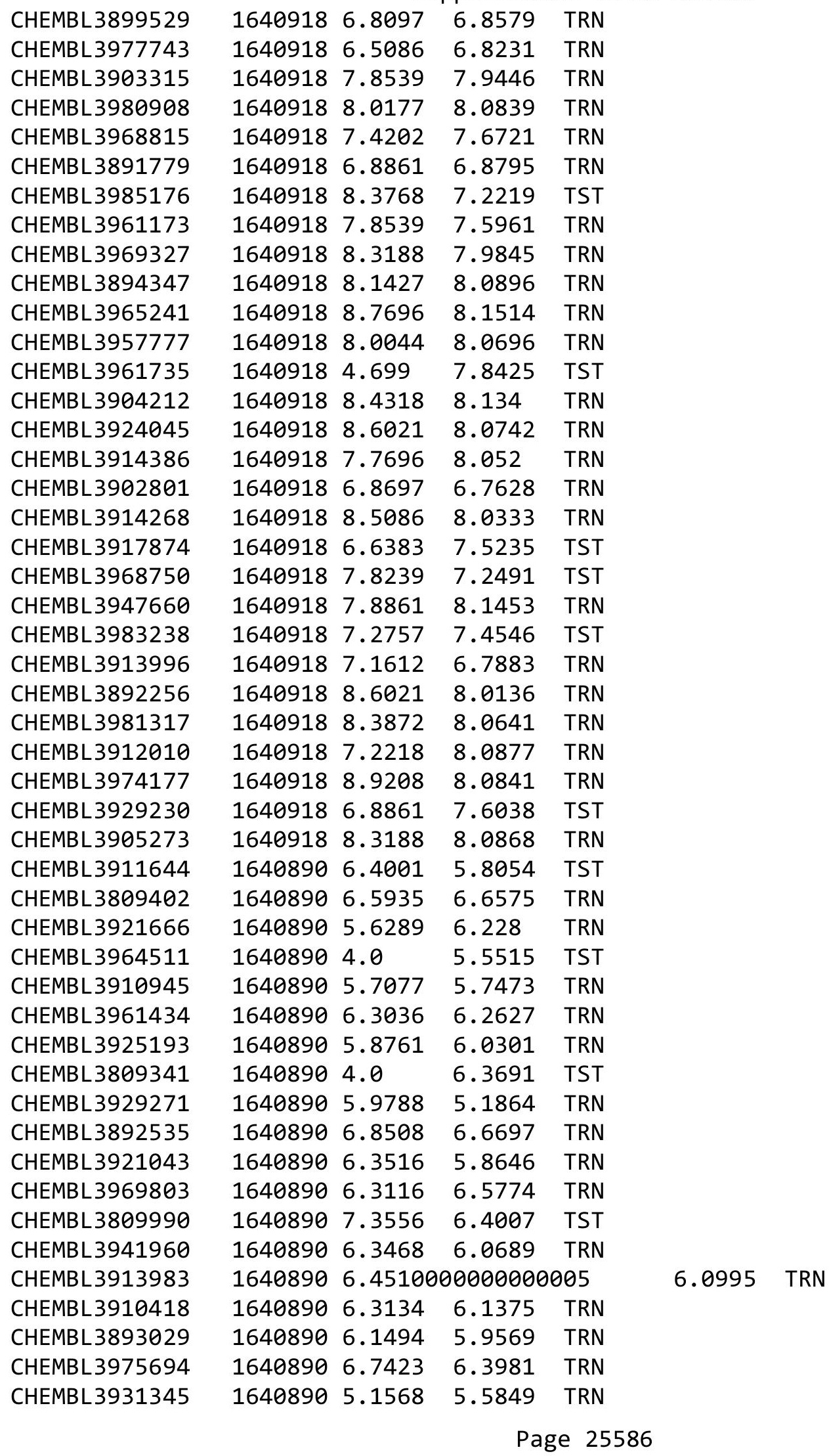




\begin{tabular}{|c|c|c|c|c|c|c|}
\hline \multicolumn{7}{|c|}{ Supplemental Table S2.txt } \\
\hline CHEMBL 3947876 & 1640890 & 5.4815 & 5.894 & TRN & & \\
\hline CHEMBL 3960293 & 1640890 & 4.0 & 5.2687 & TRN & & \\
\hline CHEMBL3954184 & 1640890 & 5.0841 & 6.0895 & TST & & \\
\hline CHEMBL3984173 & 1640890 & 6.9318 & 6.4363 & TRN & & \\
\hline CHEMBL3892447 & 1640890 & 5.7627 & 6.0982 & TRN & & \\
\hline CHEMBL3970768 & 1640890 & 6.6038 & 5.1527 & TRN & & \\
\hline CHEMBL 3930344 & 1640890 & 6.0283 & 5.9464 & TRN & & \\
\hline CHEMBL3910947 & 1640890 & 5.301 & 5.9419 & TST & & \\
\hline CHEMBL3935314 & 1640890 & 6.5003 & 5.7961 & TRN & & \\
\hline CHEMBL3984752 & 1640890 & 5.9788 & 5.8927 & TRN & & \\
\hline CHEMBL 3956107 & 1640890 & 6.3344 & 5.9347 & TRN & & \\
\hline CHEMBL3970594 & 1640890 & 5.9905 & 6.3815 & TRN & & \\
\hline CHEMBL3895941 & 1640890 & 6.0273 & 6.2757 & TRN & & \\
\hline CHEMBL3966945 & 1640890 & 5.9706 & 6.016 & TRN & & \\
\hline CHEMBL3934325 & 1640890 & 5.857 & 6.08200 & 2000000001 & & TRN \\
\hline CHEMBL 3932737 & 1640890 & 5.8894 & 5.4734 & TRN & & \\
\hline CHEMBL3928878 & 1640890 & 5.7932 & 5.8269 & TRN & & \\
\hline CHEMBL3940968 & 1640890 & 5.4365 & 5.7836 & TRN & & \\
\hline CHEMBL3927279 & 1640890 & 6.4921 & 6.04200 & 0000000001 & & TRN \\
\hline CHEMBL3810375 & 1640890 & 6.5317 & 6.7827 & TRN & & \\
\hline CHEMBL 3890158 & 1640890 & 6.7167 & 6.5322 & TRN & & \\
\hline CHEMBL3810148 & 1640890 & 6.5058 & 6.4701 & TST & & \\
\hline CHEMBL3950312 & 1640890 & 5.71 & 6.0568 & TRN & & \\
\hline CHEMBL3952753 & 1640890 & 5.4908 & 6.1261 & TST & & \\
\hline CHEMBL3920531 & 1640890 & 7.0555 & 6.5688 & TRN & & \\
\hline CHEMBL3901396 & 1640890 & 5.9743 & 6.099 & TRN & & \\
\hline CHEMBL3808634 & 1640890 & 6.2976 & 6.6275 & TST & & \\
\hline CHEMBL 3934074 & 1640890 & 6.7696 & 5.8225 & TST & & \\
\hline CHEMBL3972975 & 1640890 & 5.6091 & 6.064 & TRN & & \\
\hline CHEMBL3947399 & 1640890 & 5.5327 & 6.0953 & TRN & & \\
\hline CHEMBL 3959217 & 1640890 & 6.2716 & 6.4432 & TRN & & \\
\hline CHEMBL3810046 & 1640890 & 5.9957 & 6.4767 & TST & & \\
\hline CHEMBL3958116 & 1640890 & 6.3969 & 6.0929 & TRN & & \\
\hline CHEMBL3984753 & 1640890 & 5.3206 & 5.8193 & TST & & \\
\hline CHEMBL3904734 & 1640890 & 4.0 & 5.1637 & TRN & & \\
\hline CHEMBL3931820 & 1640890 & 6.5391 & 6.1447 & TRN & & \\
\hline CHEMBL3808861 & 1640890 & 6.857 & 6.604 & TST & & \\
\hline CHEMBL 3918824 & 1640890 & 5.82100 & 30000000 & 01 & 5.9785 & TRN \\
\hline CHEMBL3939625 & 1640890 & 7.3019 & 5.9213 & TST & & \\
\hline CHEMBL3940130 & 1640890 & 5.426 & 5.9067 & TST & & \\
\hline CHEMBL3912127 & 1640890 & 5.0191 & 5.5943 & TST & & \\
\hline CHEMBL3956361 & 1640890 & 5.055 & 5.8265 & TRN & & \\
\hline CHEMBL3895942 & 1640890 & 5.5258 & 5.4197 & TRN & & \\
\hline CHEMBL3926543 & 1640890 & 4.0 & 6.0986 & TST & & \\
\hline CHEMBL3925341 & 1640890 & 6.1656 & 5.8497 & TRN & & \\
\hline CHEMBL 3986822 & 1640890 & 6.567 & 6.4246 & TRN & & \\
\hline CHEMBL1317220 & 688305 & 5.5018 & 5.7451 & TRN & & \\
\hline CHEMBL1501056 & 688305 & 4.6018 & 4.6834 & TRN & & \\
\hline
\end{tabular}




\begin{tabular}{|c|c|c|c|c|c|}
\hline & & \multicolumn{4}{|c|}{ Supplemental Table S2.txt } \\
\hline CHEMBL1584921 & 688305 & 4.8018 & 5.4479 & TRN & \\
\hline CHEMBL1469561 & 688305 & 5.1018 & 5.6719 & TRN & \\
\hline CHEMBL1310884 & 688305 & 4.6518 & 5.0895 & TRN & \\
\hline CHEMBL1463697 & 688305 & 4.6018 & 4.8717 & TRN & \\
\hline CHEMBL1472925 & 688305 & 5.4018 & 5.5063 & TRN & \\
\hline CHEMBL1418001 & 688305 & 4.5018 & 5.0608 & TRN & \\
\hline CHEMBL1511507 & 688305 & 4.5518 & 4.8436 & TRN & \\
\hline CHEMBL1486324 & 688305 & 5.0018 & 5.1664 & TRN & \\
\hline CHEMBL495123 & 688305 & 5.2017 & 4.98 & TST & \\
\hline CHEMBL1302682 & 688305 & 6.9017 & 6.0304 & TRN & \\
\hline CHEMBL1567097 & 688305 & 4.9518 & 4.715 & TRN & \\
\hline CHEMBL1558185 & 688305 & 9.3979 & 6.279 & TRN & \\
\hline CHEMBL260624 & 688305 & 6.0517 & 5.9317 & TRN & \\
\hline CHEMBL1534102 & 688305 & 8.4559 & 5.4812 & TST & \\
\hline CHEMBL1571186 & 688305 & 5.5518 & 5.2676 & TRN & \\
\hline CHEMBL1311158 & 688305 & 5.0018 & 5.4714 & TRN & \\
\hline CHEMBL 2003741 & 688305 & 5.9518 & 5.9242 & TRN & \\
\hline CHEMBL165 & 688305 & 5.4018 & 5.6707 & TST & \\
\hline CHEMBL1321582 & 688305 & 5.1517 & 4.9512 & TRN & \\
\hline CHEMBL169 & 688305 & 6.3017 & 5.5208 & TST & \\
\hline CHEMBL1303929 & 688305 & 4.6018 & 4.8165 & TRN & \\
\hline CHEMBL1428848 & 688305 & 4.5018 & 4.8937 & TRN & \\
\hline CHEMBL1312681 & 688305 & 7.1518 & 6.6029 & TRN & \\
\hline CHEMBL3197225 & 688305 & 4.8018 & 5.7866 & TRN & \\
\hline CHEMBL1501623 & 688305 & 4.9018 & 5.3669 & TRN & \\
\hline CHEMBL1492573 & 688305 & 6.4517 & 5.1179 & TRN & \\
\hline CHEMBL1310753 & 688305 & 6.3017 & 5.5195 & TRN & \\
\hline CHEMBL1507186 & 688305 & 5.0018 & 4.6412 & TRN & \\
\hline CHEMBL1461930 & 688305 & 4.7518 & 4.9855 & TRN & \\
\hline CHEMBL1432583 & 688305 & 5.6518 & 5.9116 & TRN & \\
\hline CHEMBL1472095 & 688305 & 4.4518 & 5.1955 & TRN & \\
\hline CHEMBL1403535 & 688305 & 4.6018 & 5.0997 & TST & \\
\hline CHEMBL3193537 & 688305 & 6.1018 & 5.5469 & TRN & \\
\hline CHEMBL1524333 & 688305 & 5.5018 & 5.3961 & TRN & \\
\hline CHEMBL1611258 & 688305 & 5.2017 & 6.25 & TRN & \\
\hline CHEMBL1517984 & 688305 & 5.0518 & 5.6553 & TRN & \\
\hline CHEMBL1608301 & 688305 & 6.4018 & 6.138999 & 9999999999 & TRN \\
\hline CHEMBL1299649 & 688305 & 4.8018 & 5.4347 & TRN & \\
\hline CHEMBL1524122 & 688305 & 4.7018 & 4.5302 & TRN & \\
\hline CHEMBL1492936 & 688305 & 5.6017 & 5.4941 & TRN & \\
\hline CHEMBL1499411 & 688305 & 6.9017 & 5.7919 & TRN & \\
\hline CHEMBL1589478 & 688305 & 6.3017 & 6.045 & TRN & \\
\hline CHEMBL1450954 & 688305 & 6.4517 & 5.0301 & TRN & \\
\hline CHEMBL1597241 & 688305 & 5.0018 & 5.5329 & TRN & \\
\hline CHEMBL1479362 & 688305 & 4.9518 & 5.0369 & TRN & \\
\hline CHEMBL1338427 & 688305 & 5.0018 & 4.9748 & TRN & \\
\hline CHEMBL1443793 & 688305 & 5.2017 & 5.0645 & TRN & \\
\hline CHEMBL1985895 & 688305 & 5.4018 & 5.4409 & TST & \\
\hline
\end{tabular}




\begin{tabular}{|c|c|c|c|c|c|}
\hline & & \multicolumn{4}{|c|}{ Supplemental Table S2.txt } \\
\hline CHEMBL1585626 & 688305 & 4.8018 & 5.3825 & TRN & \\
\hline CHEMBL1569240 & 688305 & 4.7518 & 5.4258 & TRN & \\
\hline CHEMBL1428717 & 688305 & 4.4518 & 4.928 & TRN & \\
\hline CHEMBL1316921 & 688305 & 4.8518 & 4.8769 & TRN & \\
\hline CHEMBL1353759 & 688305 & 6.5017 & 6.4501 & TRN & \\
\hline CHEMBL1608942 & 688305 & 5.5518 & 5.3401 & TRN & \\
\hline CHEMBL1351387 & 688305 & 4.5018 & 5.6502 & TST & \\
\hline CHEMBL1594753 & 688305 & 6.6017 & 6.2458 & TRN & \\
\hline CHEMBL1507490 & 688305 & 5.2017 & 5.0787 & TRN & \\
\hline CHEMBL1407667 & 688305 & 4.9518 & 5.5956 & TRN & \\
\hline CHEMBL 2001936 & 688305 & 4.5518 & 4.6497 & TST & \\
\hline CHEMBL1379761 & 688305 & 5.5018 & 5.4053 & TST & \\
\hline CHEMBL1429179 & 688305 & 4.9518 & 4.7534 & TRN & \\
\hline CHEMBL504977 & 688305 & 6.8517 & 6.6308 & TST & \\
\hline CHEMBL1428738 & 688305 & 4.8518 & 5.46700 & 00000000005 & TRN \\
\hline CHEMBL1577315 & 688305 & 5.7518 & 4.5815 & TRN & \\
\hline CHEMBL1457688 & 688305 & 5.3518 & 5.8411 & TRN & \\
\hline CHEMBL1525534 & 688305 & 8.1024 & 5.3886 & TRN & \\
\hline CHEMBL 3212254 & 688305 & 9.3979 & 5.3748 & TST & \\
\hline CHEMBL1428580 & 688305 & 5.3018 & 5.44600 & 0000000001 & TST \\
\hline CHEMBL1423968 & 688305 & 6.2018 & 5.9395 & TRN & \\
\hline CHEMBL1429422 & 688305 & 4.7518 & 4.8186 & TRN & \\
\hline CHEMBL582073 & 688305 & 4.7018 & 4.99 & TRN & \\
\hline CHEMBL1479851 & 688305 & 7.8508 & 5.2981 & TRN & \\
\hline CHEMBL1528007 & 688305 & 4.7518 & 5.037 & TST & \\
\hline CHEMBL1328353 & 688305 & 4.8018 & 5.0182 & TST & \\
\hline CHEMBL1605875 & 688305 & 5.1018 & 5.3333 & TRN & \\
\hline CHEMBL1337366 & 688305 & 5.8518 & 5.3056 & TRN & \\
\hline CHEMBL1527131 & 688305 & 5.0518 & 5.2994 & TRN & \\
\hline CHEMBL 1496629 & 688305 & 4.8018 & 4.9711 & TRN & \\
\hline CHEMBL1303266 & 688305 & 5.2017 & 5.1074 & TST & \\
\hline CHEMBL 3197477 & 688305 & 4.5518 & 4.9228 & TST & \\
\hline CHEMBL1424207 & 688305 & 5.8018 & 5.4969 & TRN & \\
\hline CHEMBL1385312 & 688305 & 5.1517 & 4.6526 & TRN & \\
\hline CHEMBL1481195 & 688305 & 5.0018 & 4.9223 & TRN & \\
\hline CHEMBL1568012 & 688305 & 4.9518 & 5.4165 & TST & \\
\hline CHEMBL1992346 & 688305 & 6.7018 & 5.2775 & TST & \\
\hline CHEMBL1368666 & 688305 & 4.8018 & 5.0157 & TRN & \\
\hline CHEMBL1565115 & 688305 & 6.5518 & 5.312 & TST & \\
\hline CHEMBL 1407140 & 688305 & 4.4518 & 5.2939 & TRN & \\
\hline CHEMBL1556193 & 688305 & 5.0018 & 5.2449 & TST & \\
\hline CHEMBL1507537 & 688305 & 5.0518 & 5.4979 & TRN & \\
\hline CHEMBL1439668 & 688305 & 6.7018 & 5.0539 & TRN & \\
\hline CHEMBL1489893 & 688305 & 4.9518 & 5.2259 & TRN & \\
\hline CHEMBL3213530 & 688305 & 6.0517 & 5.0811 & TST & \\
\hline CHEMBL1346972 & 688305 & 5.6518 & 5.0977 & TRN & \\
\hline CHEMBL1388388 & 688305 & 7.1018 & 6.6356 & TRN & \\
\hline CHEMBL1362677 & 688305 & 5.4018 & 5.928 & TRN & \\
\hline
\end{tabular}


Supplemental Table S2.txt

\begin{tabular}{|c|c|c|c|c|}
\hline CHEMBL1487201 & 688305 & 4.6018 & 4.9075 & TRN \\
\hline CHEMBL1420365 & 688305 & 5.7018 & 6.5342 & TRN \\
\hline CHEMBL1538160 & 688305 & 4.9018 & 5.3935 & TRN \\
\hline CHEMBL1303623 & 688305 & 5.2517 & 5.8437 & TRN \\
\hline CHEMBL1507096 & 688305 & 4.6518 & 5.2487 & TST \\
\hline CHEMBL1602788 & 688305 & 7.7011 & 7.2149 & TRN \\
\hline CHEMBL1407203 & 688305 & 4.6518 & 4.62 & TRN \\
\hline CHEMBL1598827 & 688305 & 5.7518 & 5.7664 & TRN \\
\hline CHEMBL1441067 & 688305 & 4.4518 & 4.85800 & 20000000005 \\
\hline CHEMBL1387681 & 688305 & 4.5018 & 5.6706 & TRN \\
\hline CHEMBL1555516 & 688305 & 5.5518 & 4.88899 & 9999999999 \\
\hline CHEMBL1498082 & 688305 & 5.2017 & 5.1293 & TRN \\
\hline CHEMBL1586932 & 688305 & 4.9018 & 5.7881 & TRN \\
\hline CHEMBL1300319 & 688305 & 6.0017 & 6.0665 & TRN \\
\hline CHEMBL1469029 & 688305 & 5.3018 & 5.3252 & TST \\
\hline CHEMBL1569975 & 688305 & 5.8018 & 6.2637 & TRN \\
\hline CHEMBL1326212 & 688305 & 5.5018 & 5.8982 & TRN \\
\hline CHEMBL1593559 & 688305 & 4.8518 & 5.4615 & TRN \\
\hline CHEMBL1549188 & 688305 & 4.9518 & 5.3996 & TRN \\
\hline CHEMBL1348037 & 688305 & 5.2017 & 5.2128 & TRN \\
\hline CHEMBL1449281 & 688305 & 5.1018 & 5.4134 & TRN \\
\hline CHEMBL1340626 & 688305 & 5.2017 & 6.0541 & TRN \\
\hline CHEMBL1426505 & 688305 & 4.8518 & 5.1214 & TRN \\
\hline CHEMBL1321046 & 688305 & 5.6518 & 5.0997 & TRN \\
\hline CHEMBL1343922 & 688305 & 4.8518 & 5.5241 & TRN \\
\hline CHEMBL1579509 & 688305 & 5.0518 & 5.4562 & TRN \\
\hline CHEMBL1303619 & 688305 & 4.8018 & 5.294 & TRN \\
\hline CHEMBL1459674 & 688305 & 6.0517 & 4.8288 & TST \\
\hline CHEMBL 3191708 & 688305 & 4.5018 & 5.1413 & TRN \\
\hline CHEMBL1587117 & 688305 & 5.6017 & 5.9629 & TRN \\
\hline CHEMBL1367761 & 688305 & 5.5018 & 5.5387 & TRN \\
\hline CHEMBL1477366 & 688305 & 6.9017 & 6.6552 & TRN \\
\hline CHEMBL1375274 & 688305 & 5.0518 & 4.9085 & TRN \\
\hline CHEMBL1300968 & 688305 & 5.3518 & 5.3288 & TRN \\
\hline CHEMBL1360288 & 688305 & 7.5017 & 5.2351 & TST \\
\hline CHEMBL1311542 & 688305 & 4.4518 & 4.7244 & TRN \\
\hline CHEMBL1597878 & 688305 & 5.1517 & 5.434 & TRN \\
\hline CHEMBL1303129 & 688305 & 9.301 & 6.5091 & TRN \\
\hline CHEMBL590706 & 688305 & 5.6518 & 5.5033 & TST \\
\hline CHEMBL1302596 & 688305 & 6.9017 & 6.654 & TRN \\
\hline CHEMBL1469838 & 688305 & 4.5018 & 5.0704 & TRN \\
\hline CHEMBL1545639 & 688305 & 6.9516 & 5.7128 & TRN \\
\hline CHEMBL1444259 & 688305 & 6.1517 & 5.2729 & TRN \\
\hline CHEMBL 3194887 & 688305 & 6.0017 & 5.3896 & TRN \\
\hline CHEMBL1457420 & 688305 & 4.8018 & 4.5884 & TST \\
\hline CHEMBL1340765 & 688305 & 6.6017 & 5.4634 & TRN \\
\hline CHEMBL1449083 & 688305 & 4.9018 & 4.7985 & TRN \\
\hline CHEMBL1380046 & 688305 & 5.1517 & 5.67 & TRN \\
\hline
\end{tabular}




\begin{tabular}{|c|c|c|c|c|c|}
\hline \multicolumn{6}{|c|}{ Supplemental Table S2.txt } \\
\hline CHEMBL1480457 & 688305 & 5.1517 & 5.3575 & TRN & \\
\hline CHEMBL1460492 & 688305 & 5.2517 & 5.1248 & TRN & \\
\hline CHEMBL1544371 & 688305 & 5.8018 & 5.4499 & TST & \\
\hline CHEMBL1607143 & 688305 & 4.9518 & 5.6642 & TRN & \\
\hline CHEMBL1543688 & 688305 & 4.8518 & 5.2492 & TRN & \\
\hline CHEMBL1323861 & 688305 & 4.5018 & 5.5277 & TRN & \\
\hline CHEMBL1579663 & 688305 & 5.1018 & 5.2737 & TRN & \\
\hline CHEMBL1490716 & 688305 & 5.2017 & 5.5432 & TRN & \\
\hline CHEMBL1607661 & 688305 & 5.5518 & 4.6622 & TST & \\
\hline CHEMBL1536140 & 688305 & 4.4518 & 5.8293 & TRN & \\
\hline CHEMBL1577178 & 688305 & 7.4522 & 5.3749 & TRN & \\
\hline CHEMBL1342290 & 688305 & 5.0018 & 5.15 & TRN & \\
\hline CHEMBL3213431 & 688305 & 8.8539 & 5.0591 & TST & \\
\hline CHEMBL1578586 & 688305 & 4.9518 & 5.9 & TRN & \\
\hline CHEMBL1348747 & 688305 & 4.6018 & 5.1279 & TRN & \\
\hline CHEMBL1427621 & 688305 & 5.8518 & 6.3192 & TRN & \\
\hline CHEMBL1313520 & 688305 & 7.0017 & 6.4416 & TRN & \\
\hline CHEMBL1520671 & 688305 & 5.5018 & 5.4336 & TRN & \\
\hline CHEMBL1571360 & 688305 & 4.7018 & 4.8905 & TST & \\
\hline CHEMBL1373256 & 688305 & 4.8518 & 5.5004 & TRN & \\
\hline CHEMBL1397089 & 688305 & 5.3018 & 5.8138 & TST & \\
\hline CHEMBL1391684 & 688305 & 6.7018 & 6.4819 & TRN & \\
\hline CHEMBL1391358 & 688305 & 4.9518 & 5.1099 & TRN & \\
\hline CHEMBL1361585 & 688305 & 4.9518 & 5.2303 & TRN & \\
\hline CHEMBL1485734 & 688305 & 5.0018 & 5.1086 & TRN & \\
\hline CHEMBL1311543 & 688305 & 5.6017 & 4.9703 & TRN & \\
\hline CHEMBL1445134 & 688305 & 5.4018 & 5.5578 & TRN & \\
\hline CHEMBL1370172 & 688305 & 5.0018 & 5.407 & TRN & \\
\hline CHEMBL1465628 & 688305 & 4.9518 & 4.6898 & TRN & \\
\hline CHEMBL1330575 & 688305 & 7.9031 & 5.2636 & TRN & \\
\hline CHEMBL1337528 & 688305 & 5.5518 & 5.48 & TRN & \\
\hline CHEMBL1486455 & 688305 & 4.8018 & 5.1435 & TRN & \\
\hline CHEMBL1492752 & 688305 & 5.4018 & 5.3301 & TRN & \\
\hline CHEMBL1465899 & 688305 & 4.9518 & 5.3486 & TRN & \\
\hline CHEMBL1510524 & 688305 & 4.4518 & 4.5341 & TRN & \\
\hline CHEMBL1478282 & 688305 & 6.0017 & 6.2162 & TRN & \\
\hline CHEMBL1339737 & 688305 & 5.5018 & 5.5033 & TST & \\
\hline CHEMBL1457058 & 688305 & 5.4018 & 5.0785 & TRN & \\
\hline CHEMBL374632 & 688305 & 5.4018 & 5.02800 & 00000000005 & TRN \\
\hline CHEMBL1364855 & 688305 & 5.1517 & 4.8342 & TRN & \\
\hline CHEMBL1482717 & 688305 & 5.4018 & 5.4709 & TRN & \\
\hline CHEMBL1477421 & 688305 & 4.6018 & 5.4455 & TRN & \\
\hline CHEMBL1463050 & 688305 & 5.8018 & 5.7983 & TRN & \\
\hline CHEMBL1532970 & 688305 & 5.2517 & 4.9731 & TRN & \\
\hline CHEMBL1495977 & 688305 & 6.5017 & 6.3977 & TRN & \\
\hline CHEMBL1493769 & 688305 & 4.9018 & 5.0971 & TRN & \\
\hline CHEMBL1461196 & 688305 & 5.7018 & 6.2948 & TRN & \\
\hline CHEMBL1596709 & 688305 & 4.6018 & 5.7079 & TRN & \\
\hline
\end{tabular}

Page 25591 
Supplemental Table S2.txt

\begin{tabular}{|c|c|c|c|c|}
\hline CHEMBL1325413 & 688305 & 7.0017 & 6.0574 & TST \\
\hline CHEMBL1504153 & 688305 & 5.6017 & 5.346 & TST \\
\hline CHEMBL1546713 & 688305 & 5.8518 & 5.1901 & TST \\
\hline CHEMBL1409209 & 688305 & 7.2518 & 6.3339 & TST \\
\hline CHEMBL1359734 & 688305 & 4.5018 & 5.7199 & TST \\
\hline CHEMBL1306518 & 688305 & 6.5518 & 4.8675 & TST \\
\hline CHEMBL1429861 & 688305 & 6.4018 & 6.1293 & TST \\
\hline CHEMBL1547784 & 688305 & 4.6018 & 5.133999 & 99999999995 \\
\hline CHEMBL1597726 & 688305 & 8.0506 & 5.7673 & TST \\
\hline CHEMBL1529310 & 688305 & 7.20200 & 00000006 & 6.9510000000000005 \\
\hline CHEMBL1598614 & 688305 & 6.4018 & 6.1041 & 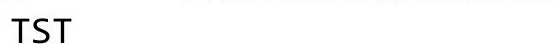 \\
\hline CHEMBL1465051 & 688305 & 4.8018 & 5.409 & TST \\
\hline CHEMBL1587870 & 688305 & 5.9017 & 6.1065 & TST \\
\hline CHEMBL1535417 & 688305 & 7.5017 & 5.1824 & TST \\
\hline CHEMBL1461412 & 688305 & 5.1018 & 5.4207 & TST \\
\hline CHEMBL1503124 & 688305 & 6.8016 & 6.6257 & TST \\
\hline CHEMBL1418758 & 688305 & 8.5086 & 5.7572 & TST \\
\hline CHEMBL1561348 & 688305 & 4.7018 & 5.2759 & TST \\
\hline CHEMBL578512 & 688305 & 6.0017 & 6.4179 & TST \\
\hline CHEMBL1327692 & 688305 & 8.8861 & 5.3802 & TST \\
\hline CHEMBL1469531 & 688305 & 4.7518 & 5.14 & TST \\
\hline CHEMBL3199475 & 954945 & 3.7414 & 3.6868 & TRN \\
\hline CHEMBL585951 & 954945 & 4.15 & 4.3994 & TRN \\
\hline CHEMBL483849 & 954945 & 2.4759 & 2.4151 & TRN \\
\hline CHEMBL3392440 & 954945 & 3.1797 & 3.3074 & TRN \\
\hline CHEMBL1357247 & 954945 & 2.4533 & 2.6285 & TRN \\
\hline CHEMBL509032 & 954945 & 4.723 & 4.7526 & TRN \\
\hline CHEMBL1909414 & 954945 & 3.3772 & 3.303 & TRN \\
\hline CHEMBL221137 & 954945 & 4.4986 & 3.9009 & TST \\
\hline CHEMBL483847 & 954945 & 6.4426 & 6.3141 & TRN \\
\hline CHEMBL180127 & 954945 & 4.9579 & 5.1843 & TRN \\
\hline CHEMBL189584 & 954945 & 4.5215 & 4.3853 & TRN \\
\hline CHEMBL 2144069 & 954945 & 6.1759 & 6.3385 & TRN \\
\hline CHEMBL240954 & 954945 & 3.7358 & 3.522 & TST \\
\hline CHEMBL258844 & 954945 & 3.4167 & 3.4115 & TRN \\
\hline CHEMBL573107 & 954945 & 3.7773 & 3.5491 & TRN \\
\hline CHEMBL 9470 & 954945 & 3.9745 & 4.6374 & TST \\
\hline CHEMBL209148 & 954945 & 4.4109 & 4.3037 & TRN \\
\hline CHEMBL102714 & 954945 & 3.285 & 3.5786 & TRN \\
\hline CHEMBL412142 & 954945 & 4.2059 & 3.9667 & TRN \\
\hline CHEMBL449158 & 954945 & 5.7659 & 4.9792 & TST \\
\hline CHEMBL515416 & 954945 & 5.0922 & 5.0302 & TRN \\
\hline CHEMBL373751 & 954945 & 3.077 & 3.1285 & TRN \\
\hline CHEMBL512504 & 954945 & 4.6595 & 4.6371 & TRN \\
\hline CHEMBL1230020 & 954945 & 3.4811 & 3.6382 & TRN \\
\hline CHEMBL379300 & 954945 & 6.4141 & 6.4719 & TRN \\
\hline CHEMBL472940 & 954945 & 3.3531 & 3.667 & TRN \\
\hline CHEMBL300389 & 954945 & 6.2878 & 6.3149 & TRN \\
\hline
\end{tabular}


Supplemental Table S2.txt

\begin{tabular}{|c|c|c|c|c|}
\hline CHEMBL202721 & 954945 & 3.2486 & 3.2075 & TRN \\
\hline CHEMBL1516890 & 954945 & 3.9791 & 4.04 & TRN \\
\hline CHEMBL 2363137 & 954945 & 4.5699 & 4.6558 & TRN \\
\hline CHEMBL1643959 & 954945 & 4.1289 & 3.8275 & TRN \\
\hline CHEMBL65 & 954945 & 5.9675 & 5.6742 & TRN \\
\hline CHEMBL1256459 & 954945 & 7.04 & 7.3248 & TRN \\
\hline CHEMBL1590308 & 954945 & 3.8988 & 3.5945 & TST \\
\hline CHEMBL92309 & 954945 & 2.6921 & 2.987 & TST \\
\hline CHEMBL1788116 & 954945 & 3.0122 & 3.3399 & TRN \\
\hline CHEMBL210618 & 954945 & 3.1867 & 2.9453 & TRN \\
\hline CHEMBL1673039 & 954945 & 4.9383 & 4.84699 & 9999999995 \\
\hline CHEMBL3349342 & 954945 & 3.4434 & 3.5473 & TRN \\
\hline CHEMBL 213100 & 954945 & 9.7913 & 9.8203 & TRN \\
\hline CHEMBL1242367 & 954945 & 4.6484 & 4.636 & TRN \\
\hline CHEMBL393929 & 954945 & 3.426 & 3.4749 & TRN \\
\hline CHEMBL379975 & 954945 & 4.176 & 4.2212 & TRN \\
\hline CHEMBL188678 & 954945 & 4.7013 & 4.208 & TRN \\
\hline CHEMBL1404918 & 954945 & 3.7806 & 3.4212 & TRN \\
\hline CHEMBL 259181 & 954945 & 4.8231 & 4.6484 & TRN \\
\hline CHEMBL514499 & 954945 & 7.2262 & 7.1594 & TRN \\
\hline CHEMBL 222102 & 954945 & 3.0895 & 3.4635 & TRN \\
\hline CHEMBL192566 & 954945 & 6.5151 & 5.7671 & TST \\
\hline CHEMBL135561 & 954945 & 3.8354 & 4.0402 & TRN \\
\hline CHEMBL3186408 & 954945 & 4.2691 & 3.60600 & 0000000003 \\
\hline CHEMBL392695 & 954945 & 5.8125 & 5.569 & TRN \\
\hline CHEMBL577784 & 954945 & 3.0897 & 4.4361 & TST \\
\hline CHEMBL191334 & 954945 & 3.1292 & 3.7973 & TST \\
\hline CHEMBL1970879 & 954945 & 6.4069 & 6.4487 & TST \\
\hline CHEMBL1190711 & 954945 & 4.5012 & 4.7533 & TST \\
\hline CHEMBL558642 & 954945 & 4.4223 & 4.2128 & TST \\
\hline CHEMBL2005886 & 954945 & 5.1072 & 5.0621 & TST \\
\hline CHEMBL 220241 & 954945 & 4.2841 & 4.4316 & TST \\
\hline CHEMBL1474402 & 688781 & 6.8499 & 6.8815 & TRN \\
\hline CHEMBL1333968 & 688781 & 4.65 & 4.6911 & TST \\
\hline CHEMBL1513063 & 688781 & 5.35 & 4.7606 & TRN \\
\hline CHEMBL1551913 & 688781 & 4.9 & 4.9292 & TST \\
\hline CHEMBL1512250 & 688781 & 4.9 & 4.8586 & TST \\
\hline CHEMBL1596756 & 688781 & 4.65 & 4.6999 & TRN \\
\hline CHEMBL1403562 & 688781 & 5.3 & 5.0665 & TRN \\
\hline CHEMBL1495150 & 688781 & 4.6 & 4.6628 & TRN \\
\hline CHEMBL1354563 & 688781 & 5.0 & 5.0557 & TRN \\
\hline CHEMBL1523579 & 688781 & 4.8 & 4.5963 & TST \\
\hline CHEMBL1491966 & 688781 & 4.55 & 4.5749 & TST \\
\hline CHEMBL495068 & 688781 & 4.95 & 4.82600 & 0000000005 \\
\hline CHEMBL1394137 & 688781 & 5.2 & 5.1176 & TRN \\
\hline CHEMBL1474633 & 688781 & 4.55 & 4.7186 & TRN \\
\hline CHEMBL1551534 & 688781 & 4.5 & 4.529 & TRN \\
\hline CHEMBL1395527 & 688781 & 4.85 & 4.7865 & TRN \\
\hline
\end{tabular}




\begin{tabular}{|c|c|c|c|c|c|}
\hline \multicolumn{6}{|c|}{ Supplemental Table S2.txt } \\
\hline CHEMBL1394939 & 688781 & 4.9 & 4.835 & TRN & \\
\hline CHEMBL1512833 & 688781 & 4.55 & 4.6844 & TRN & \\
\hline CHEMBL1568854 & 688781 & 4.55 & 4.5651 & TRN & \\
\hline CHEMBL1361750 & 688781 & 4.55 & 4.6428 & TRN & \\
\hline CHEMBL1363077 & 688781 & 4.45 & 4.7706 & TST & \\
\hline CHEMBL1600340 & 688781 & 4.5 & 4.5721 & TST & \\
\hline CHEMBL1369318 & 688781 & 4.55 & 4.5065 & TRN & \\
\hline CHEMBL1455926 & 688781 & 6.05 & 6.1289 & TRN & \\
\hline CHEMBL1318045 & 688781 & 4.5 & 4.5879 & TST & \\
\hline CHEMBL1512919 & 688781 & 4.6 & 4.6572 & TRN & \\
\hline CHEMBL1514953 & 688781 & 4.55 & 4.5849 & TRN & \\
\hline CHEMBL475376 & 688781 & 5.35 & 5.2659 & TRN & \\
\hline CHEMBL1436540 & 688781 & 5.45 & 5.4774 & TRN & \\
\hline CHEMBL1568575 & 688781 & 4.6 & 4.78100 & 0000000001 & TRN \\
\hline CHEMBL1357018 & 688781 & 7.2 & 6.3755 & TRN & \\
\hline CHEMBL1473379 & 688781 & 4.5 & 4.5947 & TRN & \\
\hline CHEMBL1314799 & 688781 & 4.5 & 4.6042 & TRN & \\
\hline CHEMBL1445893 & 688781 & 4.5 & 4.6318 & TRN & \\
\hline CHEMBL1472955 & 688781 & 4.9 & 4.968 & TRN & \\
\hline CHEMBL1436763 & 688781 & 4.55 & 4.7084 & TRN & \\
\hline CHEMBL1314388 & 688781 & 4.55 & 4.5385 & TRN & \\
\hline CHEMBL1554935 & 688781 & 4.6 & 4.6528 & TRN & \\
\hline CHEMBL1442538 & 688781 & 4.65 & 4.5526 & TRN & \\
\hline CHEMBL1558184 & 688781 & 5.0 & 4.9287 & TRN & \\
\hline CHEMBL1360310 & 688781 & 5.05 & 4.9483 & TRN & \\
\hline CHEMBL1552172 & 688781 & 4.55 & 4.6123 & TST & \\
\hline CHEMBL541847 & 688781 & 5.8 & 5.5916 & TRN & \\
\hline CHEMBL1403333 & 688781 & 5.15 & 5.0923 & TRN & \\
\hline CHEMBL1594134 & 688781 & 4.55 & 4.4959 & TRN & \\
\hline CHEMBL1395605 & 688781 & 4.55 & 4.6774 & TRN & \\
\hline CHEMBL1474890 & 688781 & 4.5 & 4.6292 & TRN & \\
\hline CHEMBL1409830 & 688781 & 4.5 & 4.5112 & TST & \\
\hline CHEMBL1449350 & 688781 & 4.95 & 5.0041 & TRN & \\
\hline CHEMBL1518035 & 688781 & 4.65 & 4.6366 & TRN & \\
\hline CHEMBL1316956 & 688781 & 5.05 & 4.6254 & TRN & \\
\hline CHEMBL1553322 & 688781 & 4.8 & 4.7307 & TST & \\
\hline CHEMBL1513990 & 688781 & 5.5 & 5.2768 & TRN & \\
\hline CHEMBL1475083 & 688781 & 4.6 & 4.6601 & TRN & \\
\hline CHEMBL1592804 & 688781 & 4.55 & 4.7329 & TRN & \\
\hline CHEMBL1590123 & 688781 & 5.65 & 5.4162 & TRN & \\
\hline CHEMBL1573862 & 688781 & 4.5 & 4.5665 & TRN & \\
\hline CHEMBL1440715 & 688781 & 4.5 & 4.4889 & TST & \\
\hline CHEMBL1494452 & 688781 & 4.85 & 4.9141 & TRN & \\
\hline CHEMBL491953 & 688781 & 5.4 & 5.1819 & TRN & \\
\hline CHEMBL1357444 & 688781 & 4.6 & 4.7939 & TST & \\
\hline CHEMBL568379 & 688781 & 6.3 & 6.1222 & TRN & \\
\hline CHEMBL1552519 & 688781 & 4.85 & 5.2537 & TRN & \\
\hline CHEMBL1564194 & 688781 & 4.55 & 4.8105 & TRN & \\
\hline
\end{tabular}




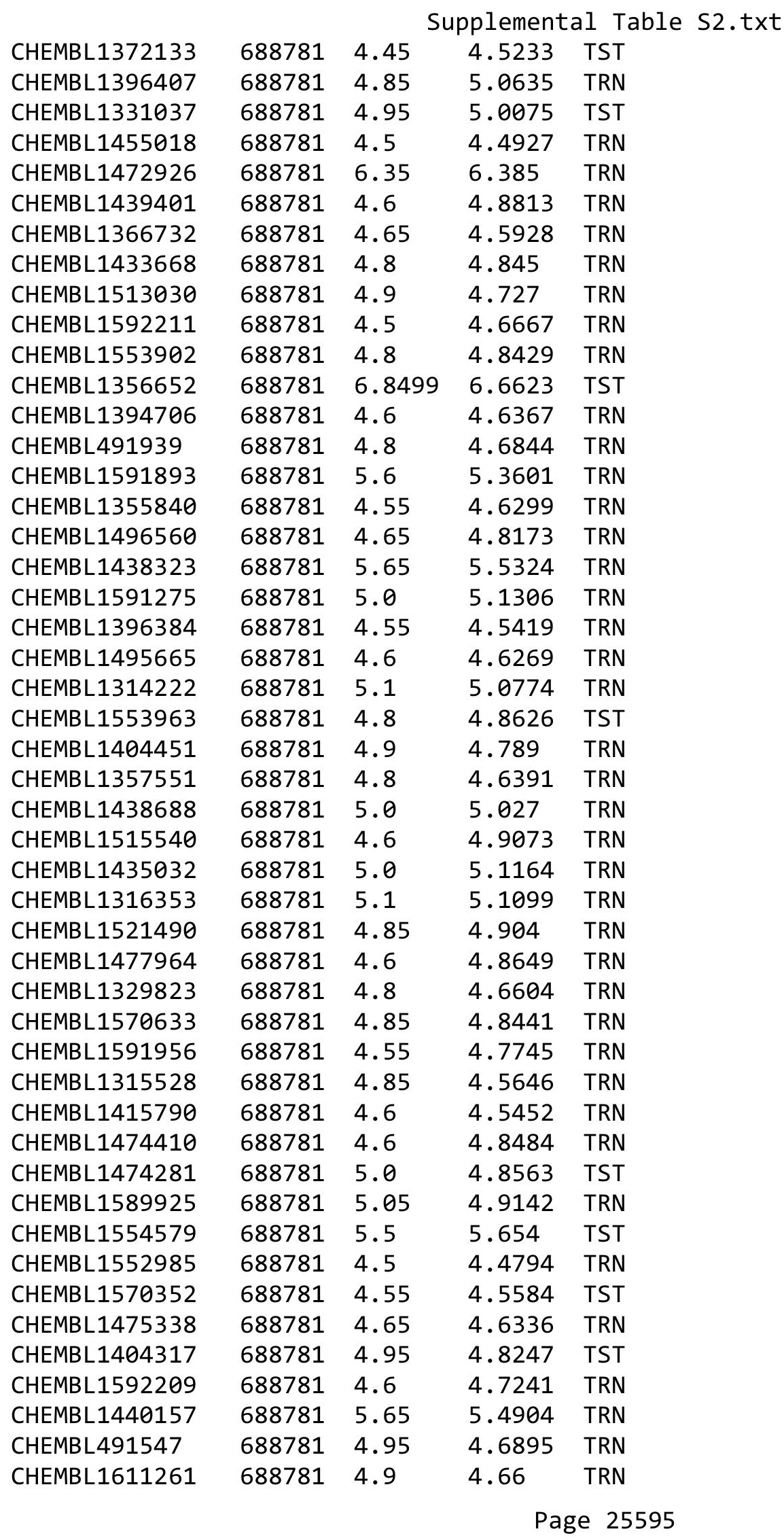




\begin{tabular}{|c|c|c|c|c|c|}
\hline \multicolumn{6}{|c|}{ Supplemental Table S2.txt } \\
\hline CHEMBL1355896 & 688781 & 4.55 & 4.5731 & TRN & \\
\hline CHEMBL1497006 & 688781 & 4.8 & 4.5761 & TST & \\
\hline CHEMBL1447909 & 688781 & 4.95 & 5.0514 & TST & \\
\hline CHEMBL1357167 & 688781 & 5.7 & 5.7297 & TRN & \\
\hline CHEMBL1370622 & 688781 & 4.65 & 4.6599 & TRN & \\
\hline CHEMBL1401859 & 688781 & 5.35 & 5.5652 & TRN & \\
\hline CHEMBL1477982 & 688781 & 4.8 & 4.7072 & TRN & \\
\hline CHEMBL1593774 & 688781 & 4.95 & 4.8086 & TRN & \\
\hline CHEMBL1358244 & 688781 & 4.9 & 4.7725 & TST & \\
\hline CHEMBL1406782 & 688781 & 5.15 & 5.3669 & TRN & \\
\hline CHEMBL1314255 & 688781 & 4.8 & 4.54899 & 99999999995 & TST \\
\hline CHEMBL1374355 & 688781 & 6.3 & 6.37200 & 0000000001 & TRN \\
\hline CHEMBL1512562 & 688781 & 4.95 & 5.0493 & TRN & \\
\hline CHEMBL1591772 & 688781 & 5.55 & 5.3975 & TST & \\
\hline CHEMBL1437667 & 688781 & 4.6 & 4.6136 & TRN & \\
\hline CHEMBL1434715 & 688781 & 4.5 & 4.5169 & TRN & \\
\hline CHEMBL1322756 & 688781 & 6.15 & 6.1798 & TRN & \\
\hline CHEMBL1317712 & 688781 & 5.15 & 5.0006 & TRN & \\
\hline CHEMBL1435907 & 688781 & 5.2 & 4.8288 & TRN & \\
\hline CHEMBL1317009 & 688781 & 4.9 & 4.8932 & TRN & \\
\hline CHEMBL1368113 & 688781 & 4.5 & 4.5288 & TRN & \\
\hline CHEMBL1356808 & 688781 & 6.1 & 5.8856 & TST & \\
\hline CHEMBL1452408 & 688781 & 4.55 & 4.6528 & TRN & \\
\hline CHEMBL1486734 & 688781 & 4.85 & 5.0145 & TRN & \\
\hline CHEMBL1571264 & 688781 & 4.8 & 4.8775 & TRN & \\
\hline CHEMBL1323759 & 688781 & 4.55 & 4.5178 & TRN & \\
\hline CHEMBL1534376 & 688781 & 4.55 & 4.581 & TST & \\
\hline CHEMBL1475541 & 688781 & 4.45 & 4.5519 & TST & \\
\hline CHEMBL1516028 & 688781 & 4.5 & 4.5448 & TRN & \\
\hline CHEMBL1406851 & 688781 & 4.6 & 4.4836 & TRN & \\
\hline CHEMBL1357491 & 688781 & 5.8 & 5.8094 & TRN & \\
\hline CHEMBL1483855 & 688781 & 5.1 & 5.3746 & TRN & \\
\hline CHEMBL1522370 & 688781 & 4.55 & 4.5481 & TRN & \\
\hline CHEMBL1322216 & 688781 & 5.75 & 5.9153 & TRN & \\
\hline CHEMBL1437056 & 688781 & 4.6 & 4.4661 & TST & \\
\hline CHEMBL1316055 & 688781 & 4.85 & 4.752 & TRN & \\
\hline CHEMBL1378755 & 688781 & 4.8 & 4.6718 & TST & \\
\hline CHEMBL1332033 & 688781 & 6.95 & 6.7808 & TRN & \\
\hline CHEMBL1314647 & 688781 & 5.85 & 5.3288 & TRN & \\
\hline CHEMBL1375753 & 688781 & 6.15 & 6.1122 & TRN & \\
\hline CHEMBL1610375 & 688781 & 4.55 & 4.5562 & TRN & \\
\hline CHEMBL1318495 & 688781 & 4.7 & 4.5276 & TST & \\
\hline CHEMBL1374585 & 688781 & 4.6 & 4.7575 & TRN & \\
\hline CHEMBL1553766 & 688781 & 4.5 & 4.5962 & TRN & \\
\hline CHEMBL1592438 & 688781 & 4.5 & 4.8214 & TRN & \\
\hline CHEMBL1363594 & 688781 & 4.7 & 4.4921 & TRN & \\
\hline CHEMBL1318042 & 688781 & 4.6 & 4.574 & TRN & \\
\hline CHEMBL1355387 & 688781 & 4.8 & 4.8262 & TRN & \\
\hline
\end{tabular}




\begin{tabular}{|c|c|c|c|c|}
\hline \multicolumn{5}{|c|}{ Supplemental Table s2.txt } \\
\hline CHEMBL1518067 & 688781 & 5.2 & 5.6106 & TRN \\
\hline CHEMBL1354154 & 688781 & 4.55 & 4.5787 & TST \\
\hline CHEMBL1436355 & 688781 & 5.05 & 4.942 & TRN \\
\hline CHEMBL1489182 & 688781 & 5.5 & 5.4127 & TRN \\
\hline CHEMBL1318041 & 688781 & 4.7 & 4.5897 & TRN \\
\hline CHEMBL1591140 & 688781 & 4.85 & 4.7799 & TRN \\
\hline CHEMBL1554622 & 688781 & 4.5 & 4.621 & TRN \\
\hline CHEMBL1555316 & 688781 & 4.55 & 4.6661 & TRN \\
\hline CHEMBL1551557 & 688781 & 4.45 & 4.5667 & TRN \\
\hline CHEMBL1593128 & 688781 & 4.4 & 4.6397 & TST \\
\hline CHEMBL1434817 & 688781 & 4.7 & 4.6046 & TRN \\
\hline CHEMBL1559654 & 688781 & 5.05 & 4.9933 & TST \\
\hline CHEMBL1355720 & 688781 & 4.55 & 4.9378 & TRN \\
\hline CHEMBL1314674 & 688781 & 4.95 & 4.9221 & TRN \\
\hline CHEMBL1480350 & 688781 & 6.45 & 6.2301 & TRN \\
\hline CHEMBL1339209 & 688781 & 4.85 & 4.8135 & TRN \\
\hline CHEMBL1594372 & 688781 & 4.45 & 4.754 & TRN \\
\hline CHEMBL1446523 & 688781 & 6.7001 & 6.6503 & TRN \\
\hline CHEMBL1513282 & 688781 & 4.75 & 4.6702 & TRN \\
\hline CHEMBL1417837 & 688781 & 5.4 & 5.8251 & TRN \\
\hline CHEMBL1553741 & 688781 & 4.55 & 4.6331 & TST \\
\hline CHEMBL1364711 & 688781 & 4.55 & 4.5512 & TST \\
\hline CHEMBL1552396 & 688781 & 4.45 & 4.5196 & TRN \\
\hline CHEMBL522121 & 688781 & 4.6 & 4.7633 & TRN \\
\hline CHEMBL491748 & 688781 & 5.15 & 4.8598 & TRN \\
\hline CHEMBL1555014 & 688781 & 4.95 & 4.8756 & TST \\
\hline CHEMBL1475487 & 688781 & 5.1 & 5.0697 & TRN \\
\hline CHEMBL1436976 & 688781 & 4.5 & 4.6246 & TST \\
\hline CHEMBL1551503 & 688781 & 4.75 & 4.8472 & TST \\
\hline CHEMBL1406082 & 688781 & 4.55 & 4.6232 & TRN \\
\hline CHEMBL1475737 & 688781 & 4.6 & 4.863 & TRN \\
\hline CHEMBL1472765 & 688781 & 6.1 & 6.2806 & TRN \\
\hline CHEMBL1552572 & 688781 & 5.0 & 4.9542 & TST \\
\hline CHEMBL1593365 & 688781 & 4.45 & 4.4793 & TRN \\
\hline CHEMBL1316516 & 688781 & 4.5 & 4.5963 & TST \\
\hline CHEMBL1318340 & 688781 & 6.3 & 6.2655 & TRN \\
\hline CHEMBL1591543 & 688781 & 4.95 & 4.8924 & TRN \\
\hline CHEMBL1315129 & 688781 & 4.5 & 4.6755 & TRN \\
\hline CHEMBL1558569 & 688781 & 4.55 & 4.6304 & TRN \\
\hline CHEMBL1512708 & 688781 & 4.85 & 4.7583 & TRN \\
\hline CHEMBL1601477 & 688781 & 4.9 & 4.982 & TRN \\
\hline CHEMBL1326341 & 688781 & 4.9 & 4.8873 & TRN \\
\hline CHEMBL1590458 & 688781 & 4.8 & 4.8253 & TRN \\
\hline CHEMBL1552277 & 688781 & 6.5501 & 6.5664 & TRN \\
\hline CHEMBL1554567 & 688781 & 4.9 & 4.9749 & TST \\
\hline CHEMBL1595576 & 688781 & 5.4 & 5.3566 & TRN \\
\hline CHEMBL1475951 & 688781 & 4.55 & 4.5774 & TRN \\
\hline CHEMBL1366061 & 688781 & 6.05 & 5.8419 & TRN \\
\hline
\end{tabular}




\begin{tabular}{|c|c|c|c|c|c|}
\hline \multicolumn{6}{|c|}{ Supplemental Table S2.txt } \\
\hline CHEMBL1454049 & 688781 & 4.5 & 4.6746 & TRN & \\
\hline CHEMBL1355256 & 688781 & 5.05 & 4.5365 & TRN & \\
\hline CHEMBL1515355 & 688781 & 4.65 & 4.6948 & TRN & \\
\hline CHEMBL1358983 & 688781 & 4.8 & 4.7579 & TST & \\
\hline CHEMBL1394113 & 688781 & 4.6 & 4.6477 & TRN & \\
\hline CHEMBL1516005 & 688781 & 4.35 & 4.5571 & TRN & \\
\hline CHEMBL1482790 & 688781 & 4.6 & 4.5967 & TRN & \\
\hline CHEMBL1362079 & 688781 & 4.6 & 4.6357 & TRN & \\
\hline CHEMBL1517718 & 688781 & 5.85 & 5.8348 & TRN & \\
\hline CHEMBL1357857 & 688781 & 4.95 & 4.8148 & TRN & \\
\hline CHEMBL1400043 & 688781 & 4.85 & 4.9528 & TRN & \\
\hline CHEMBL1591971 & 688781 & 4.45 & 4.5536 & TRN & \\
\hline CHEMBL1318067 & 688781 & 4.55 & 4.7053 & TST & \\
\hline CHEMBL1399528 & 688781 & 5.7 & 5.7603 & TRN & \\
\hline CHEMBL1478772 & 688781 & 5.5 & 5.2402 & TRN & \\
\hline CHEMBL1450521 & 688781 & 4.45 & 4.5451 & TRN & \\
\hline CHEMBL1517999 & 688781 & 4.6 & 4.6051 & TST & \\
\hline CHEMBL1514505 & 688781 & 4.45 & 4.5173 & TST & \\
\hline CHEMBL1355307 & 688781 & 4.55 & 4.4764 & TRN & \\
\hline CHEMBL1484422 & 688781 & 4.45 & 4.5662 & TRN & \\
\hline CHEMBL1404408 & 688781 & 4.55 & 4.4911 & TRN & \\
\hline CHEMBL1554791 & 688781 & 4.45 & 4.5062 & TRN & \\
\hline CHEMBL1318668 & 688781 & 4.75 & 4.7814 & TST & \\
\hline CHEMBL1452250 & 688781 & 4.45 & 4.7387 & TST & \\
\hline CHEMBL1534237 & 688781 & 4.55 & 4.4906 & TRN & \\
\hline CHEMBL1320765 & 688781 & 4.45 & 4.5325 & TRN & \\
\hline CHEMBL1534738 & 688781 & 4.65 & 4.5997 & TRN & \\
\hline CHEMBL1555713 & 688781 & 4.55 & 4.6788 & TST & \\
\hline CHEMBL566899 & 688781 & 5.55 & 5.6648 & TRN & \\
\hline CHEMBL1355677 & 688781 & 6.05 & 6.1477 & TRN & \\
\hline CHEMBL1357157 & 688781 & 4.75 & 4.6737 & TST & \\
\hline CHEMBL1442250 & 688781 & 4.75 & 4.6939 & TRN & \\
\hline CHEMBL1356439 & 688781 & 4.9 & 4.6601 & TRN & \\
\hline CHEMBL1436179 & 688781 & 4.85 & 4.6826 & TRN & \\
\hline CHEMBL1372037 & 688781 & 4.55 & 4.5553 & TRN & \\
\hline CHEMBL1455570 & 688781 & 5.5 & 5.414 & TRN & \\
\hline CHEMBL1315373 & 688781 & 5.7 & 5.3659 & TRN & \\
\hline CHEMBL1484944 & 688781 & 5.85 & 5.7516 & TRN & \\
\hline CHEMBL1316656 & 688781 & 4.5 & 4.5241 & TST & \\
\hline CHEMBL1474114 & 688781 & 4.65 & 4.5939 & TRN & \\
\hline CHEMBL1355701 & 688781 & 4.65 & 4.4908 & TRN & \\
\hline CHEMBL1315802 & 688781 & 4.8 & $4.9510 e$ & 00000000005 & TST \\
\hline CHEMBL1513300 & 688781 & 5.5 & 5.4401 & TRN & \\
\hline CHEMBL1437747 & 688781 & 5.1 & 4.824 & TRN & \\
\hline CHEMBL1446323 & 688781 & 4.85 & 5.0179 & TRN & \\
\hline CHEMBL1591374 & 688781 & 4.65 & 4.4843 & TRN & \\
\hline CHEMBL1409852 & 688781 & 6.05 & 6.0005 & TRN & \\
\hline CHEMBL1315820 & 688781 & 4.55 & 4.638 & TRN & \\
\hline
\end{tabular}




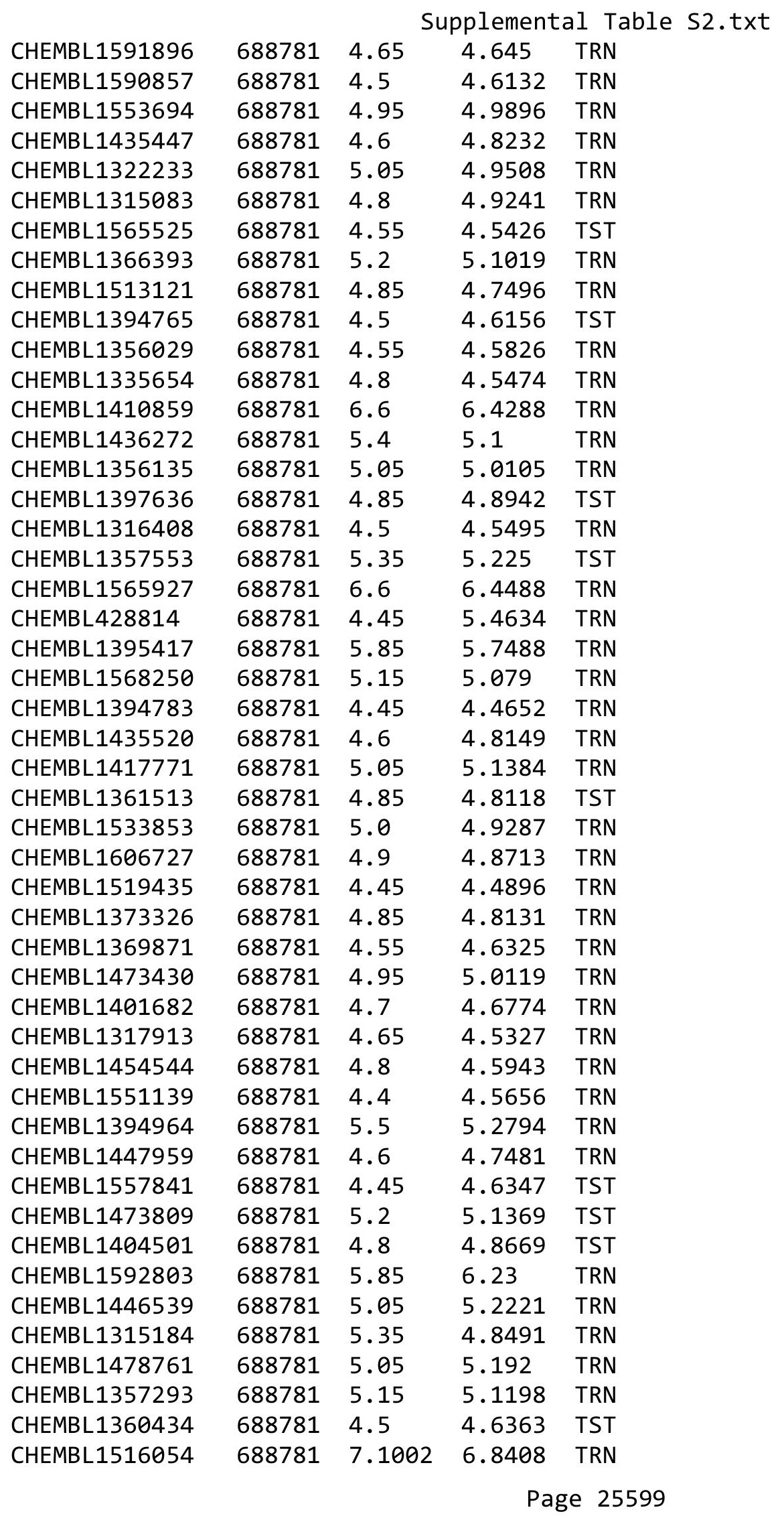




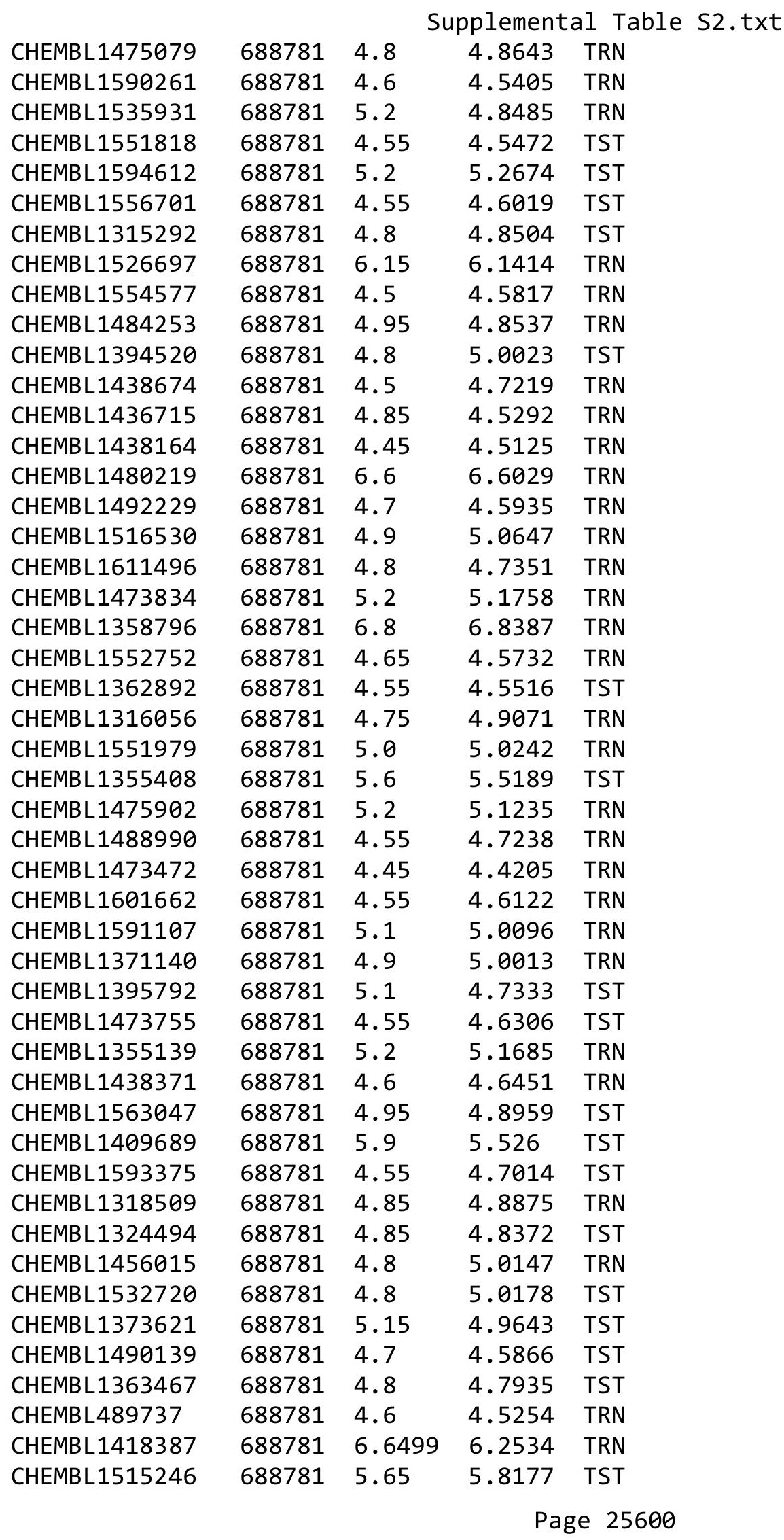




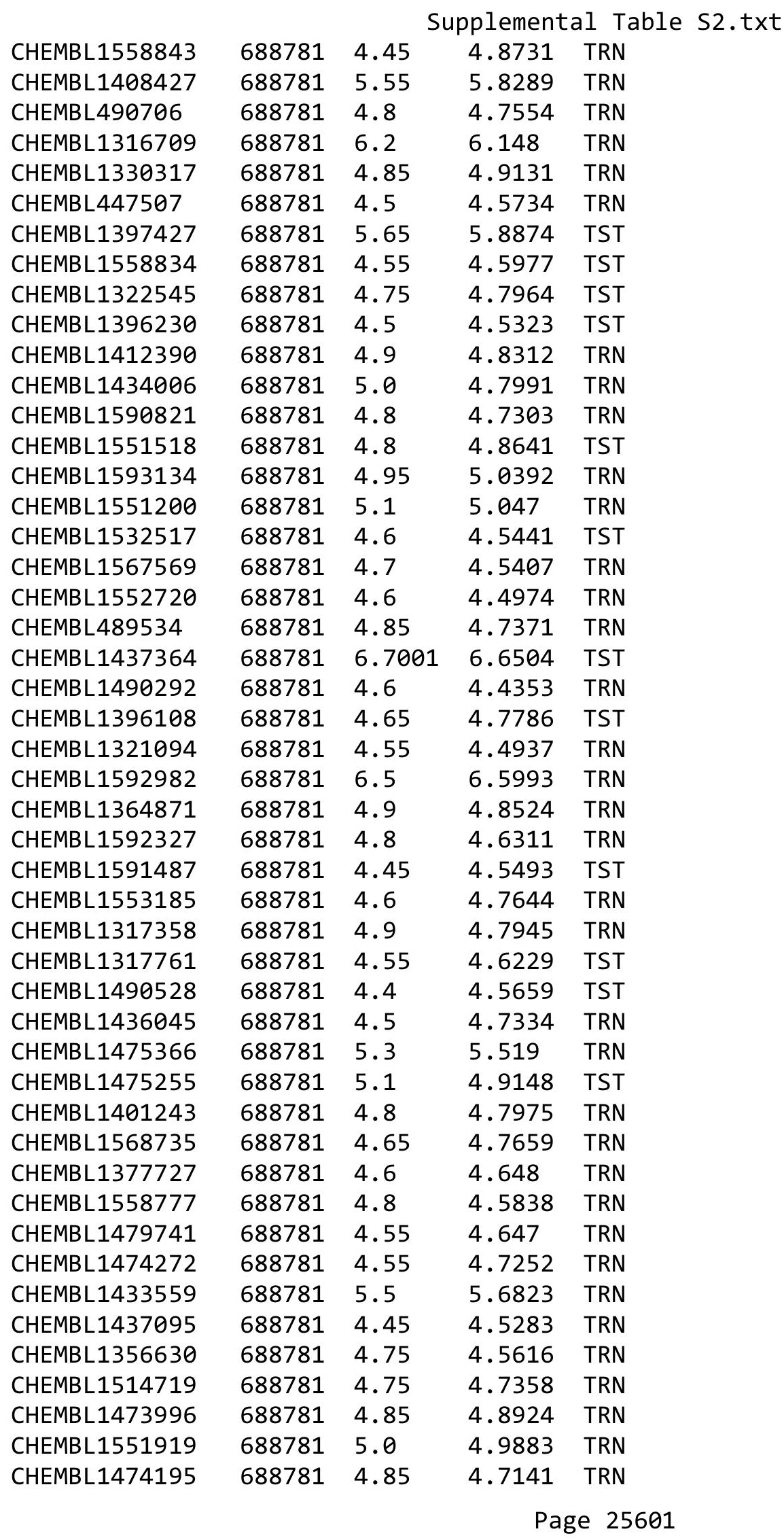




\begin{tabular}{|c|c|c|c|c|}
\hline \multicolumn{5}{|c|}{ Supplemental Table S2.txt } \\
\hline CHEMBL1595002 & 688781 & 4.6 & 4.5687 & TRN \\
\hline CHEMBL1531899 & 688781 & 4.8 & 4.899 & TST \\
\hline CHEMBL1563497 & 688781 & 4.6 & 4.6054 & TRN \\
\hline CHEMBL475198 & 688781 & 5.2 & 5.1392 & TRN \\
\hline CHEMBL1416207 & 688781 & 5.75 & 5.6368 & TRN \\
\hline CHEMBL1356118 & 688781 & 4.7 & 4.5314 & TST \\
\hline CHEMBL1596170 & 688781 & 4.95 & 5.0722 & TRN \\
\hline CHEMBL1358586 & 688781 & 4.55 & 4.534 & TST \\
\hline CHEMBL1512023 & 688781 & 5.1 & 5.2473 & TST \\
\hline CHEMBL1512988 & 688781 & 5.45 & 5.66799 & 9999999999 \\
\hline CHEMBL1441787 & 688781 & 4.55 & 4.4916 & TRN \\
\hline CHEMBL1439665 & 688781 & 4.65 & 4.5948 & TRN \\
\hline CHEMBL1442440 & 688781 & 4.7 & 4.9386 & TST \\
\hline CHEMBL1396377 & 688781 & 4.85 & 4.8888 & TRN \\
\hline CHEMBL1479792 & 688781 & 4.55 & 4.5433 & TRN \\
\hline CHEMBL1396326 & 688781 & 4.55 & 4.6251 & TRN \\
\hline CHEMBL1334321 & 688781 & 6.15 & 6.1355 & TRN \\
\hline CHEMBL1433596 & 688781 & 4.8 & 4.8268 & TRN \\
\hline CHEMBL1472651 & 688781 & 4.8 & 4.6415 & TST \\
\hline CHEMBL1557696 & 688781 & 4.85 & 4.7011 & TST \\
\hline CHEMBL1357724 & 688781 & 4.65 & 4.6109 & TRN \\
\hline CHEMBL1322584 & 688781 & 5.6 & 5.527 & TRN \\
\hline CHEMBL1449458 & 688781 & 4.6 & 4.7179 & TRN \\
\hline CHEMBL1437226 & 688781 & 4.9 & 4.9658 & TRN \\
\hline CHEMBL1596499 & 688781 & 4.9 & 4.8899 & TRN \\
\hline CHEMBL1396611 & 688781 & 4.6 & 4.7181 & TST \\
\hline CHEMBL1456454 & 688781 & 4.85 & 4.8295 & TRN \\
\hline CHEMBL1327945 & 688781 & 4.55 & 4.4888 & TRN \\
\hline CHEMBL1437064 & 688781 & 4.85 & 4.7041 & TST \\
\hline CHEMBL1573555 & 688781 & 4.9 & 5.0474 & TST \\
\hline CHEMBL1433798 & 688781 & 4.5 & 4.6359 & TST \\
\hline CHEMBL489935 & 688781 & 4.55 & 4.5173 & TRN \\
\hline CHEMBL585861 & 688781 & 6.05 & 5.9859 & TRN \\
\hline CHEMBL1396898 & 688781 & 4.5 & 4.6311 & TRN \\
\hline CHEMBL1593827 & 688781 & 5.4 & 5.4131 & TRN \\
\hline CHEMBL1564845 & 688781 & 6.05 & 6.184 & TRN \\
\hline CHEMBL1561888 & 688781 & 5.2 & 4.9682 & TRN \\
\hline CHEMBL1603418 & 688781 & 6.2 & 6.2827 & TRN \\
\hline CHEMBL1395882 & 688781 & 4.5 & 4.704 & TST \\
\hline CHEMBL1336060 & 688781 & 5.05 & 4.9814 & TRN \\
\hline CHEMBL1327355 & 688781 & 4.95 & 5.1179 & TRN \\
\hline CHEMBL1396211 & 688781 & 6.15 & 6.1642 & TRN \\
\hline CHEMBL1524520 & 688781 & 4.8 & 4.6999 & TST \\
\hline CHEMBL1316075 & 688781 & 5.2 & 5.1603 & TRN \\
\hline CHEMBL1602710 & 688781 & 4.6 & 4.5461 & TST \\
\hline CHEMBL1473760 & 688781 & 5.35 & 5.1453 & TRN \\
\hline CHEMBL1394854 & 688781 & 4.6 & 4.6514 & TRN \\
\hline CHEMBL1452413 & 688781 & 4.95 & 4.8738 & TRN \\
\hline
\end{tabular}




\begin{tabular}{|c|c|c|c|c|c|}
\hline \multicolumn{6}{|c|}{ Supplemental Table S2.txt } \\
\hline CHEMBL1357067 & 688781 & 5.4 & 5.3714 & TRN & \\
\hline CHEMBL119841 & 688781 & 5.15 & 5.0061 & TRN & \\
\hline CHEMBL1436024 & 688781 & 4.8 & 4.6488 & TRN & \\
\hline CHEMBL1405744 & 688781 & 5.5 & 5.6745 & TST & \\
\hline CHEMBL1590818 & 688781 & 4.55 & 4.5926 & TST & \\
\hline CHEMBL1515366 & 688781 & 4.65 & 4.7682 & TRN & \\
\hline CHEMBL1597037 & 688781 & 4.95 & 5.007 & TRN & \\
\hline CHEMBL1512540 & 688781 & 4.5 & 4.5339 & TRN & \\
\hline CHEMBL1568086 & 688781 & 4.9 & 4.8805 & TRN & \\
\hline CHEMBL1491332 & 688781 & 4.85 & 4.9563 & TST & \\
\hline CHEMBL1354600 & 688781 & 4.8 & 4.752 & TRN & \\
\hline CHEMBL1318114 & 688781 & 4.6 & 4.6344 & TRN & \\
\hline CHEMBL1484261 & 688781 & 4.7 & 4.6181 & TRN & \\
\hline CHEMBL1433730 & 688781 & 4.55 & 4.5491 & TRN & \\
\hline CHEMBL1514149 & 688781 & 4.8 & 4.8559 & TRN & \\
\hline CHEMBL1513578 & 688781 & 4.6 & 4.8363 & TRN & \\
\hline CHEMBL1490195 & 688781 & 4.5 & 4.5655 & TRN & \\
\hline CHEMBL1323215 & 688781 & 4.55 & 4.5755 & TST & \\
\hline CHEMBL448966 & 688781 & 4.5 & 4.5766 & TRN & \\
\hline CHEMBL1433752 & 688781 & 6.1 & 6.2203 & TRN & \\
\hline CHEMBL1398013 & 688781 & 4.8 & 4.8353 & TST & \\
\hline CHEMBL545523 & 688781 & 5.15 & 4.9727 & TRN & \\
\hline CHEMBL521971 & 688781 & 4.5 & 4.4493 & TRN & \\
\hline CHEMBL1315845 & 688781 & 4.9 & 4.668 & TRN & \\
\hline CHEMBL1319506 & 688781 & 4.8 & 4.7165 & TST & \\
\hline CHEMBL1483032 & 688781 & 4.6 & 4.6386 & TST & \\
\hline CHEMBL1554745 & 688781 & 4.5 & 4.8107 & TRN & \\
\hline CHEMBL1592464 & 688781 & 4.9 & 4.8844 & TRN & \\
\hline CHEMBL1395089 & 688781 & 4.45 & 4.4955 & TRN & \\
\hline CHEMBL1355881 & 688781 & 4.75 & 4.5421 & TST & \\
\hline CHEMBL1418420 & 688781 & 4.6 & 4.5795 & TRN & \\
\hline CHEMBL1317537 & 688781 & 4.45 & 4.5706 & TRN & \\
\hline CHEMBL1398810 & 688781 & 4.5 & 4.5182 & TRN & \\
\hline CHEMBL1316893 & 688781 & 5.05 & 5.05399 & 9999999999 & TRN \\
\hline CHEMBL1592388 & 688781 & 4.85 & 4.7355 & TRN & \\
\hline CHEMBL1436682 & 688781 & 4.9 & 5.0495 & TRN & \\
\hline CHEMBL1554158 & 688781 & 5.15 & 5.3305 & TST & \\
\hline CHEMBL1354596 & 688781 & 4.45 & 4.4731 & TRN & \\
\hline CHEMBL1442458 & 688781 & 5.5 & 5.2094 & TRN & \\
\hline CHEMBL1435409 & 688781 & 5.1 & 5.0732 & TST & \\
\hline CHEMBL1552517 & 688781 & 4.45 & 4.5579 & TST & \\
\hline CHEMBL490744 & 688781 & 4.9 & 4.7933 & TRN & \\
\hline CHEMBL1515221 & 688781 & 4.8 & 4.8245 & TRN & \\
\hline CHEMBL1496596 & 688781 & 4.8 & 4.5978 & TRN & \\
\hline CHEMBL1407035 & 688781 & 7.0 & 6.5638 & TST & \\
\hline CHEMBL1482582 & 688781 & 4.55 & 4.6208 & TRN & \\
\hline CHEMBL1513485 & 688781 & 4.45 & 5.0947 & TST & \\
\hline CHEMBL1490477 & 688781 & 5.1 & 4.9314 & TRN & \\
\hline
\end{tabular}




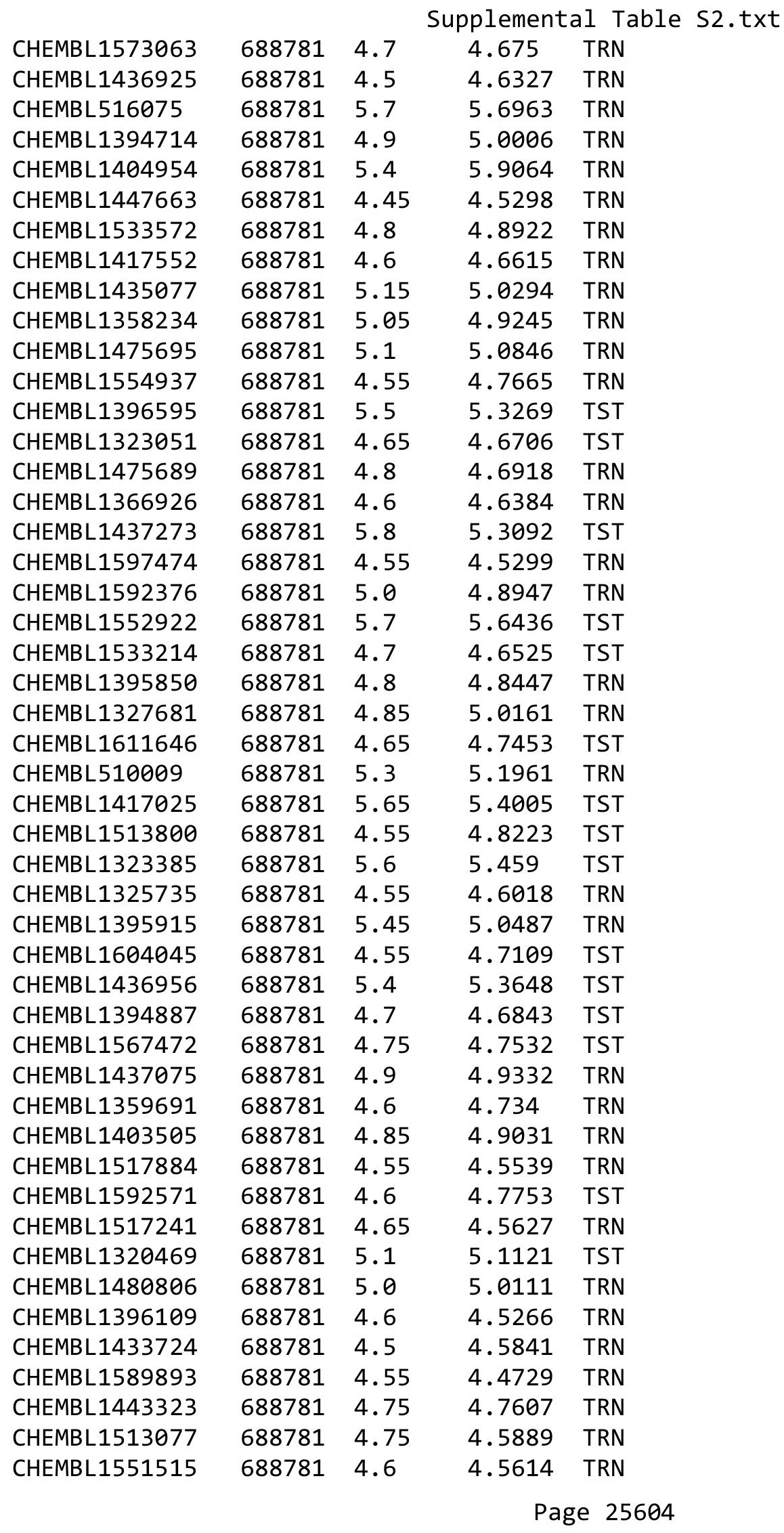




\begin{tabular}{|c|c|c|c|c|}
\hline & & & pplement & al Table \\
\hline CHEMBL1514607 & 688781 & 4.95 & 5.0617 & TRN \\
\hline CHEMBL1590106 & 688781 & 6.05 & 6.4422 & TRN \\
\hline CHEMBL1610082 & 688781 & 4.85 & 4.8651 & TRN \\
\hline CHEMBL1533734 & 688781 & 4.5 & 4.6054 & TST \\
\hline CHEMBL1528170 & 688781 & 4.6 & 4.7808 & TST \\
\hline CHEMBL1561023 & 688781 & 5.45 & 4.9784 & TRN \\
\hline CHEMBL1318064 & 688781 & 4.5 & 4.6112 & TRN \\
\hline CHEMBL1527332 & 688781 & 4.8 & 4.8183 & TRN \\
\hline CHEMBL1482759 & 688781 & 4.65 & 4.6103 & TST \\
\hline CHEMBL1322757 & 688781 & 4.5 & 4.6238 & TRN \\
\hline CHEMBL1473317 & 688781 & 4.7 & 4.5562 & TST \\
\hline CHEMBL1403793 & 688781 & 6.5501 & 6.3615 & TRN \\
\hline CHEMBL1606199 & 688781 & 4.85 & 4.6905 & TST \\
\hline CHEMBL1438690 & 688781 & 4.4 & 4.5915 & TRN \\
\hline CHEMBL601771 & 1369401 & 5.301 & 5.1491 & TRN \\
\hline CHEMBL581175 & 1369401 & 6.7305 & 6.7448 & TRN \\
\hline CHEMBL524784 & 1369401 & 5.0 & 4.9608 & TRN \\
\hline CHEMBL525486 & 1369401 & 6.1713 & 5.9474 & TRN \\
\hline CHEMBL534190 & 1369401 & 6.5302 & 6.0375 & TRN \\
\hline CHEMBL587022 & 1369401 & 6.9172 & 6.5131 & TST \\
\hline CHEMBL535730 & 1369401 & 6.5575 & 6.1343 & TST \\
\hline CHEMBL587083 & 1369401 & 6.8097 & 6.9931 & TRN \\
\hline CHEMBL605751 & 1369401 & 7.1938 & 7.0448 & TRN \\
\hline CHEMBL1615697 & 1369401 & 5.0 & 5.3291 & TST \\
\hline CHEMBL546994 & 1369401 & 5.301 & 5.39 & TRN \\
\hline CHEMBL605281 & 1369401 & 6.4318 & 6.4296 & TRN \\
\hline CHEMBL529773 & 1369401 & 6.1057 & 6.3644 & TRN \\
\hline CHEMBL527593 & 1369401 & 5.0 & 4.961 & TRN \\
\hline CHEMBL317364 & 1369401 & 7.0269 & 7.1377 & TRN \\
\hline CHEMBL 2028042 & 1369401 & 6.8794 & 7.2016 & TRN \\
\hline CHEMBL580381 & 1369401 & 5.901 & 6.0085 & TRN \\
\hline CHEMBL596852 & 1369401 & 5.0 & 5.0884 & TRN \\
\hline CHEMBL533563 & 1369401 & 6.8416 & 6.5849 & TRN \\
\hline CHEMBL533017 & 1369401 & 7.1487 & 7.08 & TRN \\
\hline CHEMBL585264 & 1369401 & 5.301 & 5.3236 & TRN \\
\hline CHEMBL598369 & 1369401 & 6.7721 & 7.0216 & TRN \\
\hline CHEMBL582666 & 1369401 & 5.0 & 5.6489 & TRN \\
\hline CHEMBL602413 & 1369401 & 6.4881 & 6.6964 & TRN \\
\hline CHEMBL 2028055 & 1369401 & 6.0701 & 6.065 & TRN \\
\hline CHEMBL601957 & 1369401 & 6.4498 & 6.3546 & TRN \\
\hline CHEMBL601348 & 1369401 & 5.0 & 5.152 & TRN \\
\hline CHEMBL590674 & 1369401 & 6.8962 & 6.7198 & TRN \\
\hline CHEMBL587989 & 1369401 & 5.0 & 5.0383 & TRN \\
\hline CHEMBL 2028051 & 1369401 & 5.9504 & 6.5122 & TST \\
\hline CHEMBL124006 & 1369401 & 6.2262 & 6.4815 & TRN \\
\hline CHEMBL206540 & 1369401 & 6.3893 & 6.5132 & TRN \\
\hline CHEMBL470514 & 1369401 & 5.0 & 4.9303 & TRN \\
\hline CHEMBL579459 & 1369401 & 6.6904 & 6.5455 & TRN \\
\hline
\end{tabular}




\begin{tabular}{|c|c|c|c|c|}
\hline \multicolumn{5}{|c|}{ Supplemental Table S2.txt } \\
\hline CHEMBL547488 & 1369401 & 5.0 & 4.7849 & TRN \\
\hline CHEMBL106525 & 1369401 & 6.5702 & 6.5172 & TRN \\
\hline CHEMBL580353 & 1369401 & 7.3979 & 7.1068 & TRN \\
\hline CHEMBL604323 & 1369401 & 4.699 & 4.702 & TRN \\
\hline CHEMBL526981 & 1369401 & 6.3335 & 6.2576 & TRN \\
\hline CHEMBL586704 & 1369401 & 6.4145 & 6.4619 & TRN \\
\hline CHEMBL600305 & 1369401 & 5.0 & 5.0937 & TRN \\
\hline CHEMBL 261693 & 1369401 & 5.301 & 5.2685 & TRN \\
\hline CHEMBL548399 & 1369401 & 5.0 & 5.0151 & TRN \\
\hline CHEMBL549210 & 1369401 & 6.7773 & 6.3504 & TRN \\
\hline CHEMBL1459149 & 1369401 & 5.0 & 5.0176 & TRN \\
\hline CHEMBL585243 & 1369401 & 6.4413 & 6.5033 & TST \\
\hline CHEMBL547476 & 1369401 & 6.4597 & 6.331 & TST \\
\hline CHEMBL587288 & 1369401 & 6.3645 & 6.3056 & TRN \\
\hline CHEMBL579443 & 1369401 & 5.0 & 5.1357 & TRN \\
\hline CHEMBL534589 & 1369401 & 5.0 & 4.9928 & TRN \\
\hline CHEMBL580580 & 1369401 & 6.4789 & 6.369 & TRN \\
\hline CHEMBL 2028053 & 1369401 & 5.301 & 5.2874 & TST \\
\hline CHEMBL587410 & 1369401 & 6.1487 & 6.0118 & TST \\
\hline CHEMBL529732 & 1369401 & 5.0 & 4.8513 & TST \\
\hline CHEMBL590888 & 1369401 & 6.1029 & 6.3066 & TST \\
\hline CHEMBL532987 & 1369401 & 6.0079 & 5.8737 & TST \\
\hline CHEMBL1460047 & 1369401 & 6.3401 & 6.3773 & TST \\
\hline CHEMBL531290 & 1369401 & 6.7423 & 6.5629 & TST \\
\hline CHEMBL494669 & 1369401 & 6.6596 & 6.5313 & TST \\
\hline CHEMBL535514 & 1369401 & 5.0 & 4.8498 & TST \\
\hline CHEMBL530223 & 1369401 & 6.4572 & 6.3492 & TST \\
\hline CHEMBL3673160 & 1528404 & 6.3457 & 7.1851 & TST \\
\hline CHEMBL3673134 & 1528404 & 5.9176 & 5.897 & TRN \\
\hline CHEMBL3673129 & 1528404 & 6.0 & 5.8512 & TST \\
\hline CHEMBL 3673178 & 1528404 & 6.3583 & 6.3938 & TRN \\
\hline CHEMBL3673166 & 1528404 & 6.794 & 6.7964 & TRN \\
\hline CHEMBL3673158 & 1528404 & 7.2055 & 6.29 & TST \\
\hline CHEMBL3673133 & 1528404 & 6.0 & 5.9944 & TRN \\
\hline CHEMBL3673157 & 1528404 & 7.2612 & 6.1529 & TST \\
\hline CHEMBL3673139 & 1528404 & 6.1605 & 6.1733 & TRN \\
\hline CHEMBL3673165 & 1528404 & 6.4283 & 6.8305 & TST \\
\hline CHEMBL3673136 & 1528404 & 6.0 & 6.3421 & TST \\
\hline CHEMBL3673142 & 1528404 & 5.5333 & 5.5397 & TRN \\
\hline CHEMBL3673180 & 1528404 & 5.0812 & 5.0854 & TRN \\
\hline CHEMBL3673145 & 1528404 & 5.9914 & 6.0086 & TRN \\
\hline CHEMBL3673164 & 1528404 & 6.8094 & 6.7912 & TRN \\
\hline CHEMBL3673173 & 1528404 & 6.6859 & 6.6945 & TRN \\
\hline CHEMBL3673144 & 1528404 & 6.0338 & 6.0371 & TRN \\
\hline CHEMBL3673131 & 1528404 & 6.563 & 6.5758 & TRN \\
\hline CHEMBL 3673128 & 1528404 & 6.415 & 6.3755 & TRN \\
\hline CHEMBL 3673162 & 1528404 & 6.83 & 6.8152 & TRN \\
\hline CHEMBL3673141 & 1528404 & 6.4159 & 6.4207 & TRN \\
\hline
\end{tabular}


Supplemental Table S2.txt

\begin{tabular}{|c|c|c|c|c|c|c|}
\hline CHEMBL 3673168 & 1528404 & 6.8529 & 6.8638 & TRN & & \\
\hline CHEMBL 3673132 & 1528404 & 6.0 & 6.0577 & TRN & & \\
\hline CHEMBL 3673156 & 1528404 & \multicolumn{3}{|c|}{6.367000000000001} & 6.3932 & TRN \\
\hline CHEMBL3673169 & 1528404 & 6.9492 & 6.9738 & TRN & & \\
\hline CHEMBL 3673140 & 1528404 & 6.5776 & 6.5371 & TRN & & \\
\hline CHEMBL 3673167 & 1528404 & 7.4547 & 7.4512 & TRN & & \\
\hline CHEMBL 3639720 & 1528404 & 5.9792 & 5.9805 & TRN & & \\
\hline CHEMBL 3673155 & 1528404 & 6.0408 & 6.0136 & TRN & & \\
\hline CHEMBL 3673161 & 1528404 & 7.2716 & 7.2743 & TRN & & \\
\hline CHEMBL 3673175 & 1528404 & 6.2669 & 6.4185 & TST & & \\
\hline CHEMBL 3673170 & 1528404 & 6.8745 & 6.8707 & TRN & & \\
\hline CHEMBL 3673153 & 1528404 & 5.2627 & 5.2441 & TRN & & \\
\hline CHEMBL 3673138 & 1528404 & 6.0548 & 6.0593 & TRN & & \\
\hline CHEMBL 3673146 & 1528404 & 5.8111 & 5.8132 & TRN & & \\
\hline CHEMBL 3673130 & 1528404 & 7.1518 & 7.1403 & TRN & & \\
\hline CHEMBL 3673163 & 1528404 & 7.1013 & 7.1227 & TRN & & \\
\hline CHEMBL 3673171 & 1528404 & 6.3461 & 6.3239 & TRN & & \\
\hline CHEMBL 3673143 & 1528404 & 5.6373 & 5.6374 & TRN & & \\
\hline CHEMBL 3673151 & 1528404 & 6.3645 & 6.3669 & TRN & & \\
\hline CHEMBL 3673149 & 1528404 & 5.2731 & 6.73 & TST & & \\
\hline CHEMBL3673152 & 1528404 & 6.4492 & 6.4711 & TRN & & \\
\hline CHEMBL3952992 & 1528404 & 6.5193 & 6.4974 & TRN & & \\
\hline CHEMBL 3673150 & 1528404 & 6.4063 & 6.4086 & TRN & & \\
\hline CHEMBL 3673147 & 1528404 & 6.0937 & 6.6832 & TST & & \\
\hline CHEMBL 3673172 & 1528404 & 6.6358 & 6.6372 & TRN & & \\
\hline CHEMBL 3673179 & 1528404 & 7.2534 & 7.2408 & TRN & & \\
\hline CHEMBL 3673174 & 1528404 & 6.4627 & 6.4358 & TRN & & \\
\hline CHEMBL 3673159 & 1528404 & 6.9245 & 6.8461 & TST & & \\
\hline CHEMBL 3673177 & 1528404 & 6.0 & 6.0086 & TST & & \\
\hline CHEMBL 3673154 & 1528404 & 6.90799 & 999999999 & 995 & 6.7631 & TST \\
\hline CHEMBL 3673148 & 1528404 & 6.7557 & 7.1452 & TST & & \\
\hline CHEMBL 3673127 & 1528404 & 6.1706 & 6.1168 & TST & & \\
\hline CHEMBL 2315434 & 934532 & 5.0376 & 4.9315 & TRN & & \\
\hline CHEMBL 2315430 & 934532 & 5.2581 & 5.3397 & TRN & & \\
\hline CHEMBL 2315451 & 934532 & 5.3904 & 4.9127 & TRN & & \\
\hline CHEMBL2315419 & 934532 & 4.0 & 4.1304 & TST & & \\
\hline CHEMBL 2315455 & 934532 & 4.8199 & 4.837 & TRN & & \\
\hline CHEMBL 2315452 & 934532 & 4.8431 & 4.857 & TRN & & \\
\hline CHEMBL 2315453 & 934532 & 4.8044 & 4.7837 & TRN & & \\
\hline CHEMBL 2315418 & 934532 & 4.0 & 4.0105 & TRN & & \\
\hline CHEMBL 2315448 & 934532 & 3.699 & 4.3027 & TRN & & \\
\hline CHEMBL 2315413 & 934532 & 4.0 & 4.0365 & TRN & & \\
\hline CHEMBL 2315444 & 934532 & 3.699 & 3.6366 & TRN & & \\
\hline CHEMBL 2315447 & 934532 & 3.699 & 3.7922 & TRN & & \\
\hline CHEMBL 2315435 & 934532 & 4.0 & 4.4543 & TST & & \\
\hline CHEMBL 2315458 & 934532 & 4.7416 & 4.691 & TRN & & \\
\hline CHEMBL 2315808 & 934532 & 3.699 & 4.5155 & TST & & \\
\hline CHEMBL2315439 & 934532 & 4.0 & 4.0869 & TRN & & \\
\hline
\end{tabular}




\begin{tabular}{|c|c|c|c|c|}
\hline \multicolumn{5}{|c|}{ Supplemental Table S2.txt } \\
\hline CHEMBL 2315449 & 934532 & 3.699 & 3.596 & TRN \\
\hline CHEMBL 2315425 & 934532 & 5.5003 & 5.5966 & TRN \\
\hline CHEMBL2315811 & 934532 & 3.699 & 3.7107 & TRN \\
\hline CHEMBL2315431 & 934532 & 5.1911 & 5.1796 & TRN \\
\hline CHEMBL2315424 & 934532 & 5.8297 & 5.7832 & TRN \\
\hline CHEMBL2315443 & 934532 & 3.699 & 3.6545 & TRN \\
\hline CHEMBL 2315437 & 934532 & 4.0 & 3.8996 & TRN \\
\hline CHEMBL2315415 & 934532 & 4.0 & 4.8996 & TST \\
\hline CHEMBL 2315438 & 934532 & 4.0 & 4.5185 & TRN \\
\hline CHEMBL2315427 & 934532 & 5.5045 & 5.4806 & TRN \\
\hline CHEMBL2315432 & 934532 & 5.5186 & 4.7936 & TST \\
\hline CHEMBL2315416 & 934532 & 4.0 & 4.8297 & TST \\
\hline CHEMBL2315456 & 934532 & 4.7395 & 4.7482 & TRN \\
\hline CHEMBL2315436 & 934532 & 4.0 & 4.0566 & TRN \\
\hline CHEMBL2315417 & 934532 & 4.0 & 4.0135 & TRN \\
\hline CHEMBL2315428 & 934532 & 5.7595 & 5.447 & TST \\
\hline CHEMBL 2315450 & 934532 & 4.8262 & 4.7998 & TRN \\
\hline CHEMBL2315457 & 934532 & 4.8136 & 4.8917 & TRN \\
\hline CHEMBL2315440 & 934532 & 4.0 & 4.0023 & TRN \\
\hline CHEMBL2315422 & 934532 & 5.7399 & 5.6972 & TST \\
\hline CHEMBL 2315414 & 934532 & 4.0 & 3.9009 & TRN \\
\hline CHEMBL 2311578 & 934532 & 6.4202 & 5.6027 & TST \\
\hline CHEMBL2315454 & 934532 & 4.8551 & 4.9026 & TRN \\
\hline CHEMBL 2315421 & 934532 & 5.3372 & 6.0964 & TST \\
\hline CHEMBL2315429 & 934532 & 5.8633 & 4.9365 & TST \\
\hline CHEMBL 2315423 & 934532 & 5.3028 & 5.8279 & TST \\
\hline CHEMBL2315792 & 934532 & 3.699 & 3.7179 & TRN \\
\hline CHEMBL 2315433 & 934532 & 5.1314 & 5.0251 & TST \\
\hline CHEMBL2315810 & 934532 & 3.699 & 3.7745 & TRN \\
\hline CHEMBL 2315441 & 934532 & 3.699 & 3.7238 & TRN \\
\hline CHEMBL 2315442 & 934532 & 3.699 & 3.6244 & TRN \\
\hline CHEMBL2315445 & 934532 & 4.7426 & 4.2391 & TRN \\
\hline CHEMBL 2315420 & 934532 & 5.6946 & 5.6246 & TRN \\
\hline CHEMBL2315809 & 934532 & 3.699 & 3.6592 & TRN \\
\hline CHEMBL 2315426 & 934532 & 3.699 & 3.6698 & TRN \\
\hline CHEMBL2315446 & 934532 & 3.699 & 3.6925 & TRN \\
\hline CHEMBL 3667242 & 1528204 & 8.699 & 8.2098 & TRN \\
\hline CHEMBL 3672370 & 1528204 & 8.0809 & 7.5867 & TRN \\
\hline CHEMBL3941124 & 1528204 & 8.8539 & 7.7529 & TST \\
\hline CHEMBL 3667250 & 1528204 & 9.1739 & 8.2284 & TRN \\
\hline CHEMBL3667206 & 1528204 & 7.9208 & 8.2872 & TRN \\
\hline CHEMBL 3667207 & 1528204 & 9.1079 & 8.2541 & TST \\
\hline CHEMBL3639660 & 1528204 & 8.3768 & 8.0364 & TRN \\
\hline CHEMBL 3672231 & 1528204 & 7.6383 & 8.1281 & TST \\
\hline CHEMBL 3672250 & 1528204 & 8.4089 & 7.8494 & TRN \\
\hline CHEMBL 3672335 & 1528204 & 7.4815 & 7.1719 & TRN \\
\hline CHEMBL 3672382 & 1528204 & 7.1549 & 7.4102 & TRN \\
\hline CHEMBL3917737 & 1528204 & 7.585 & 7.5772 & TST \\
\hline
\end{tabular}


Supplemental Table S2.txt

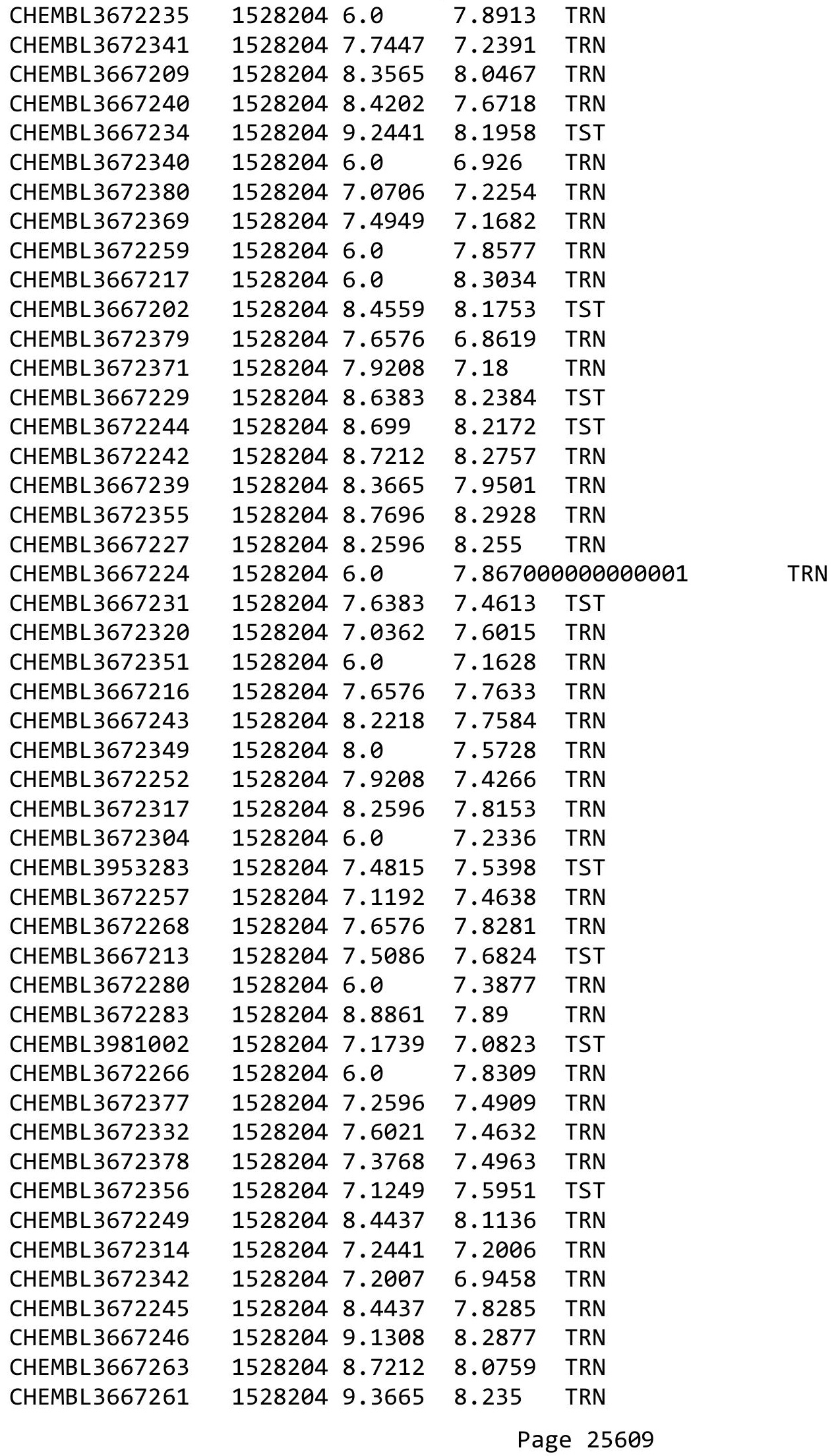


Supplemental Table S2.txt

\begin{tabular}{|c|c|c|c|c|}
\hline CHEMBL 3672255 & 1528204 & 8.6021 & 7.4154 & TRN \\
\hline CHEMBL3667210 & 1528204 & 7.9208 & 8.1393 & TST \\
\hline CHEMBL 3672331 & 1528204 & 8.0177 & 7.5416 & TRN \\
\hline CHEMBL 3667225 & 1528204 & 8.3468 & 7.8358 & TRN \\
\hline CHEMBL3667249 & 1528204 & 9.301 & 8.1968 & TRN \\
\hline CHEMBL3893179 & 1528204 & 7.7447 & 7.4577 & TST \\
\hline CHEMBL3667220 & 1528204 & 8.1079 & 7.7376 & TRN \\
\hline CHEMBL 3672329 & 1528204 & 8.8539 & 7.8849 & TRN \\
\hline CHEMBL 3667253 & 1528204 & 7.6383 & 8.0579 & TRN \\
\hline CHEMBL3667228 & 1528204 & 7.6778 & 7.5301 & TRN \\
\hline CHEMBL3667221 & 1528204 & 6.0 & 7.8721 & TRN \\
\hline CHEMBL 3667237 & 1528204 & 7.585 & 7.4019 & TRN \\
\hline CHEMBL 3672232 & 1528204 & 7.5086 & 7.6623 & TST \\
\hline CHEMBL 3672368 & 1528204 & 7.0177 & 7.4631 & TRN \\
\hline CHEMBL3667251 & 1528204 & 9.0132 & 8.1774 & TST \\
\hline CHEMBL3667252 & 1528204 & 8.4949 & 8.3247 & TRN \\
\hline CHEMBL3672347 & 1528204 & 6.0 & 6.8632 & TRN \\
\hline CHEMBL 3672246 & 1528204 & 9.0362 & 7.8329 & TRN \\
\hline CHEMBL3667211 & 1528204 & 8.0269 & 7.6781 & TST \\
\hline CHEMBL3667208 & 1528204 & 8.2676 & 8.1741 & TRN \\
\hline CHEMBL3672309 & 1528204 & 7.8239 & 7.9032 & TST \\
\hline CHEMBL3672308 & 1528204 & 7.699 & 7.0775 & TRN \\
\hline CHEMBL 3672256 & 1528204 & 6.0 & 7.2106 & TRN \\
\hline CHEMBL3672354 & 1528204 & 7.4949 & 6.8097 & TRN \\
\hline CHEMBL 3672324 & 1528204 & 7.6383 & 7.5824 & TRN \\
\hline CHEMBL3667215 & 1528204 & 8.1612 & 8.1518 & TRN \\
\hline CHEMBL 3672312 & 1528204 & 7.7212 & 7.8283 & TRN \\
\hline CHEMBL 3672303 & 1528204 & 8.5229 & 7.3393 & TRN \\
\hline CHEMBL3667230 & 1528204 & 7.0862 & 7.4171 & TRN \\
\hline CHEMBL3968715 & 1528204 & 8.4949 & 7.7451 & TST \\
\hline CHEMBL 3672291 & 1528204 & 7.8861 & 8.0131 & TRN \\
\hline CHEMBL3667262 & 1528204 & 7.8861 & 8.0667 & TRN \\
\hline CHEMBL 3672306 & 1528204 & 6.0 & 7.2052 & TRN \\
\hline CHEMBL3672385 & 1528204 & 7.2924 & 7.8454 & TRN \\
\hline CHEMBL 3672350 & 1528204 & 6.0 & 7.2596 & TRN \\
\hline CHEMBL 3672311 & 1528204 & 7.7959 & 7.809 & TRN \\
\hline CHEMBL3672343 & 1528204 & 7.6576 & 7.5214 & TRN \\
\hline CHEMBL3667223 & 1528204 & 8.5528 & 7.955 & TRN \\
\hline CHEMBL3672372 & 1528204 & 7.4202 & 6.8608 & TRN \\
\hline CHEMBL 3639711 & 1528204 & 7.1549 & 7.6193 & TST \\
\hline CHEMBL3672238 & 1528204 & 6.0 & 7.88399 & 99999999995 \\
\hline CHEMBL3667255 & 1528204 & 7.0809 & 8.0337 & TST \\
\hline CHEMBL 3672251 & 1528204 & 7.3279 & 7.4404 & TRN \\
\hline CHEMBL3667260 & 1528204 & 8.5528 & 7.9351 & TRN \\
\hline CHEMBL 3672358 & 1528204 & 7.8239 & 6.8564 & TRN \\
\hline CHEMBL3667218 & 1528204 & 8.1135 & 8.1236 & TRN \\
\hline CHEMBL3672326 & 1528204 & 7.3468 & 7.678 & TRN \\
\hline CHEMBL3667236 & 1528204 & 8.6021 & 7.8286 & TRN \\
\hline
\end{tabular}

Page 25610 
Supplemental Table S2.txt

\begin{tabular}{|c|c|c|c|c|c|}
\hline CHEMBL3672281 & 1528204 & 7.3468 & 7.8754 & TRN & \\
\hline CHEMBL3667226 & 1528204 & 7.9469 & 8.1197 & TST & \\
\hline CHEMBL3667258 & 1528204 & 8.5528 & 8.1802 & TRN & \\
\hline CHEMBL3672376 & 1528204 & 7.9586 & 6.8734 & TRN & \\
\hline CHEMBL 3672241 & 1528204 & 8.0362 & 7.6006 & TST & \\
\hline CHEMBL3672297 & 1528204 & 8.8239 & 7.8224 & TRN & \\
\hline CHEMBL3672346 & 1528204 & 7.301 & 7.1638 & TRN & \\
\hline CHEMBL 3672384 & 1528204 & 7.2218 & 7.4135 & TRN & \\
\hline CHEMBL3672236 & 1528204 & 6.0 & 7.4494 & TRN & \\
\hline CHEMBL3672330 & 1528204 & 8.3872 & 7.4523 & TRN & \\
\hline CHEMBL3672386 & 1528204 & 7.0862 & 7.1973 & TRN & \\
\hline CHEMBL3672327 & 1528204 & 7.1427 & 7.79700 & 0000000001 & TRN \\
\hline CHEMBL 3672293 & 1528204 & 7.2366 & 7.6958 & TRN & \\
\hline CHEMBL3954310 & 1528204 & 7.5229 & 7.5308 & TST & \\
\hline CHEMBL3639712 & 1528204 & 7.1192 & 7.1296 & TRN & \\
\hline CHEMBL3672301 & 1528204 & 6.0 & 7.7673 & TRN & \\
\hline CHEMBL3672298 & 1528204 & 7.7696 & 7.4021 & TRN & \\
\hline CHEMBL 3667212 & 1528204 & 7.3279 & 7.6257 & TST & \\
\hline CHEMBL3672353 & 1528204 & 7.4559 & 7.2427 & TRN & \\
\hline CHEMBL 3672321 & 1528204 & 7.4089 & 7.574 & TRN & \\
\hline CHEMBL3672363 & 1528204 & 7.7212 & 7.4693 & TRN & \\
\hline CHEMBL 3672344 & 1528204 & 8.0 & 7.8063 & TRN & \\
\hline CHEMBL 3667244 & 1528204 & 7.5086 & 7.8165 & TRN & \\
\hline CHEMBL 3672243 & 1528204 & 8.7212 & 7.8533 & TRN & \\
\hline CHEMBL3672315 & 1528204 & 8.3279 & 7.5295 & TRN & \\
\hline CHEMBL3667203 & 1528204 & 8.7447 & 8.2842 & TRN & \\
\hline CHEMBL 3672336 & 1528204 & 8.5229 & 7.4945 & TRN & \\
\hline CHEMBL3672247 & 1528204 & 7.4949 & 8.2871 & TRN & \\
\hline CHEMBL 3672261 & 1528204 & 7.7959 & 7.4519 & TRN & \\
\hline CHEMBL 3672265 & 1528204 & 7.3872 & 7.4901 & TRN & \\
\hline CHEMBL 3667264 & 1528204 & 7.7959 & 7.7967 & TRN & \\
\hline CHEMBL3978926 & 1528204 & 7.3768 & 7.5556 & TST & \\
\hline CHEMBL3672233 & 1528204 & 8.0 & 7.7916 & TRN & \\
\hline CHEMBL3667219 & 1528204 & 9.0458 & 8.1851 & TRN & \\
\hline CHEMBL3672282 & 1528204 & 7.8861 & 8.0551 & TST & \\
\hline CHEMBL3672263 & 1528204 & 8.8861 & 7.9296 & TRN & \\
\hline CHEMBL3981191 & 1528204 & 7.3279 & 7.5718 & TST & \\
\hline CHEMBL3943459 & 1528204 & 7.9208 & 7.4101 & TST & \\
\hline CHEMBL 3672286 & 1528204 & 8.0269 & 7.4458 & TRN & \\
\hline CHEMBL3672318 & 1528204 & 8.1938 & 8.1581 & TST & \\
\hline CHEMBL 3672310 & 1528204 & 8.7447 & 8.2137 & TRN & \\
\hline CHEMBL3672359 & 1528204 & 6.0 & 7.11799 & 7999999999 & TRN \\
\hline CHEMBL3672305 & 1528204 & 7.7212 & 7.5667 & TRN & \\
\hline CHEMBL 3667254 & 1528204 & 7.8861 & 8.0654 & TST & \\
\hline CHEMBL 3672264 & 1528204 & 7.4815 & 7.4903 & TRN & \\
\hline CHEMBL 3672323 & 1528204 & 8.3372 & 8.0936 & TRN & \\
\hline CHEMBL 3672360 & 1528204 & 9.1308 & 7.9114 & TRN & \\
\hline CHEMBL3667232 & 1528204 & 6.0 & 7.4199 & TRN & \\
\hline
\end{tabular}


Supplemental Table S2.txt

\begin{tabular}{|c|c|c|c|c|c|}
\hline CHEMBL 3672278 & 1528204 & 7.699 & 7.8571 & TRN & \\
\hline CHEMBL3667235 & 1528204 & 8.5229 & 7.96399 & 99999999995 & TRN \\
\hline CHEMBL 3667204 & 1528204 & 6.0 & 8.2522 & TRN & \\
\hline CHEMBL 3672262 & 1528204 & 8.0 & 8.0441 & TST & \\
\hline CHEMBL3672333 & 1528204 & 7.1249 & 7.7825 & TRN & \\
\hline CHEMBL 3672345 & 1528204 & 7.3279 & 6.9654 & TRN & \\
\hline CHEMBL 3667257 & 1528204 & 7.3468 & 8.1841 & TRN & \\
\hline CHEMBL 3672295 & 1528204 & 6.0 & 7.175 & TRN & \\
\hline CHEMBL 3672299 & 1528204 & 8.5229 & 7.4025 & TRN & \\
\hline CHEMBL3667205 & 1528204 & 8.585 & 8.2145 & TRN & \\
\hline CHEMBL3667238 & 1528204 & 7.8239 & 8.2003 & TRN & \\
\hline CHEMBL 3672373 & 1528204 & 7.3665 & 7.3785 & TRN & \\
\hline CHEMBL 3672240 & 1528204 & 8.9208 & 8.1918 & TST & \\
\hline CHEMBL 3672267 & 1528204 & 6.0 & 7.8115 & TRN & \\
\hline CHEMBL3667214 & 1528204 & 7.9586 & 7.7024 & TRN & \\
\hline CHEMBL3890637 & 1528204 & 8.0655 & 7.5446 & TST & \\
\hline CHEMBL3672239 & 1528204 & 7.4685 & 7.4326 & TST & \\
\hline CHEMBL 3672348 & 1528204 & 7.699 & 7.2755 & TRN & \\
\hline CHEMBL 3672338 & 1528204 & 8.4089 & 7.8015 & TRN & \\
\hline CHEMBL3672328 & 1528204 & 7.2596 & 7.2092 & TRN & \\
\hline CHEMBL3672254 & 1528204 & 7.5086 & 7.8603 & TST & \\
\hline CHEMBL3667201 & 1528204 & 7.1079 & 8.0499 & TST & \\
\hline CHEMBL 3672325 & 1528204 & 7.4318 & 7.2861 & TRN & \\
\hline CHEMBL3672339 & 1528204 & 9.0 & 8.1128 & TST & \\
\hline CHEMBL 3672316 & 1528204 & 7.0605 & 7.4195 & TST & \\
\hline CHEMBL 3672237 & 1528204 & 8.4318 & 7.9133 & TST & \\
\hline CHEMBL3672381 & 1528204 & 8.4318 & 7.1707 & TST & \\
\hline CHEMBL 3672375 & 1528204 & 8.3979 & 7.1834 & TST & \\
\hline CHEMBL3672352 & 1528204 & 7.7696 & 7.2206 & TST & \\
\hline CHEMBL 3667259 & 1528204 & 8.699 & 7.8729 & TST & \\
\hline CHEMBL 3672260 & 1528204 & 6.0 & 7.4149 & TST & \\
\hline CHEMBL3667241 & 1528204 & 9.1079 & 8.2327 & TST & \\
\hline CHEMBL405483 & 80294 & 3.301 & 4.0049 & TRN & \\
\hline CHEMBL267982 & 80294 & 3.301 & 3.7947 & TST & \\
\hline CHEMBL267216 & 80294 & 4.9586 & 4.8842 & TST & \\
\hline CHEMBL415673 & 80294 & 4.7696 & 4.4358 & TRN & \\
\hline CHEMBL415792 & 80294 & 5.4559 & 5.5379 & TRN & \\
\hline CHEMBL413864 & 80294 & 4.4318 & 4.9529 & TRN & \\
\hline CHEMBL437476 & 80294 & 5.4559 & 5.4505 & TRN & \\
\hline CHEMBL411363 & 80294 & 5.2366 & 4.9278 & TRN & \\
\hline CHEMBL264829 & 80294 & 4.0706 & 4.21 & TST & \\
\hline CHEMBL 2370216 & 80294 & 2.6021 & 2.935 & TRN & \\
\hline CHEMBL409706 & 80294 & 4.699 & 4.3972 & TRN & \\
\hline CHEMBL263998 & 80294 & 4.7696 & 4.8515 & TRN & \\
\hline CHEMBL412977 & 80294 & 4.0 & 3.9104 & TRN & \\
\hline CHEMBL411769 & 80294 & 2.6021 & 2.5247 & TRN & \\
\hline CHEMBL269379 & 80294 & 5.0969 & 4.9422 & TRN & \\
\hline CHEMBL3215342 & 80294 & 4.0 & 3.3293 & TST & \\
\hline
\end{tabular}




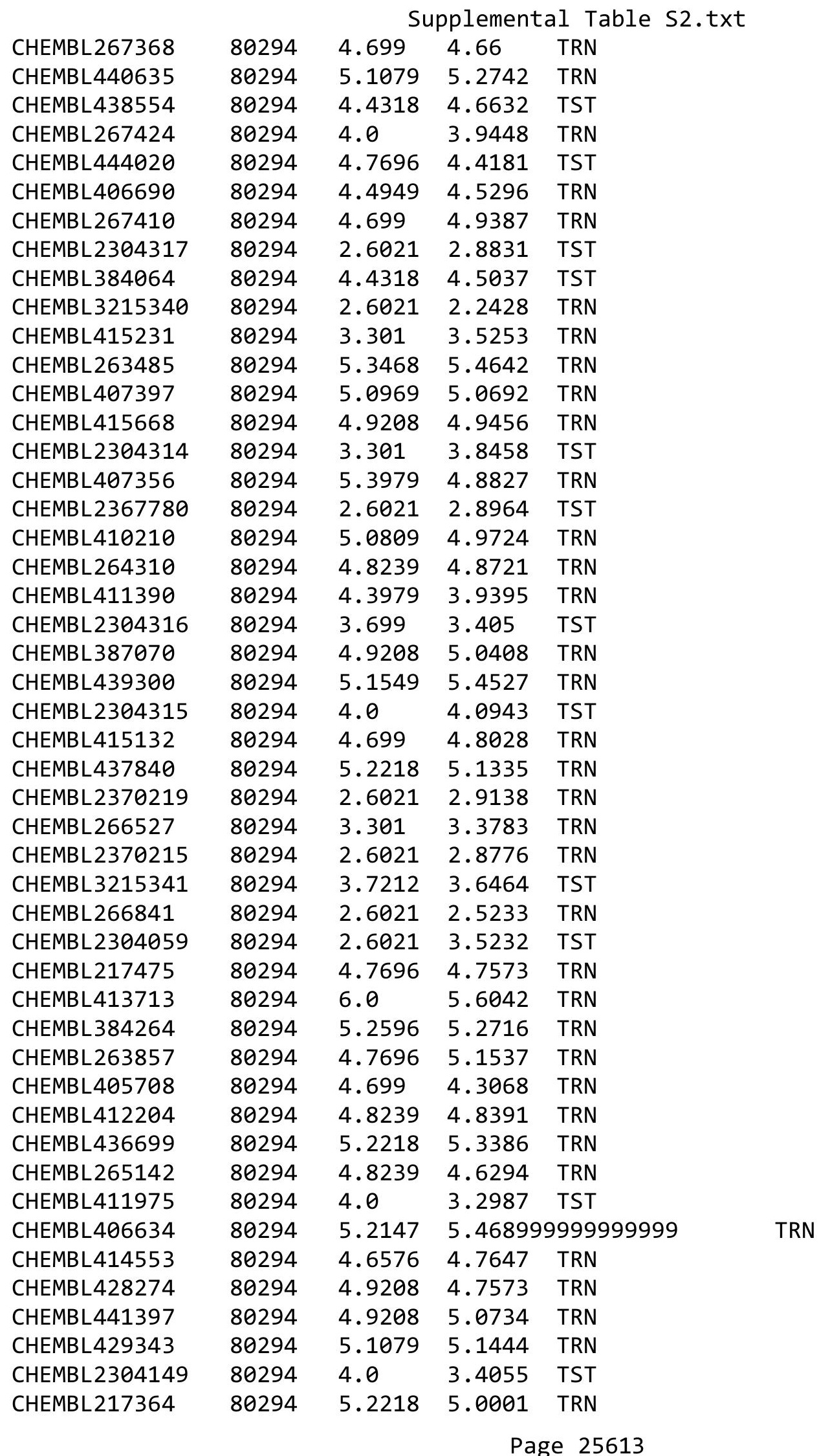




\begin{tabular}{|c|c|c|c|c|}
\hline \multicolumn{5}{|c|}{ Supplementa: } \\
\hline AEMLL4 & & & & \\
\hline HEMBL 262586 & 30294 & מים & 1071 & \\
\hline HEMBL3939960 & 641779 & & 02 & \\
\hline HEMBL3919722 & 641779 & & & \\
\hline AEMBL3908065 & 641779 & 8.32 & 8656 & \\
\hline HEMBL3928773 & 641779 & 7.8729 & 9015 & \\
\hline HEMBL3959491 & 641779 & 8.3979 & .6264 & \\
\hline HEMBL3 & 79 & & & \\
\hline AEMBL & 779 & 76 & 2969 & \\
\hline HEMBL & & & & \\
\hline HEMBL3970018 & 641779 & 8.3279 & 8.6278 & \\
\hline HEMBL; & 641779 & 7.2434 & 8.2213 & \\
\hline HEMBL3 & 79 & 7.8 & 78 & \\
\hline HEMBL & 79 & & 61 & \\
\hline HEMBL & & & & \\
\hline HEMBL & 779 & & 8.3751 & \\
\hline HEMBL & 79 & & & \\
\hline HEMBL & 79 & & 94 & \\
\hline HEMBL & 79 & 8. & .8188 & \\
\hline HEMBL & 79 & 9.0 & & \\
\hline 111 & & & & \\
\hline HEMBL: & & & & \\
\hline HEMBL & 79 & 8. & • 9127 & \\
\hline 10 & 79 & & & \\
\hline 92 & 79 & & & \\
\hline 785 & & & & \\
\hline HEMBL: & 79 & 8 & & \\
\hline HEMBL: & 79 & & 53 & \\
\hline ABL & 79 & & 52 & \\
\hline 58 & 79 & 8 . & 36 & \\
\hline 912 & & & & \\
\hline HEMBL & 79 & & 54 & \\
\hline$-x_{0}$ & & & & \\
\hline 40 & 79 & 8. & 49 & \\
\hline 76 & 79 & 6. & 76 & \\
\hline 3128 & 779 & & & TR \\
\hline HEMBL3 & 779 & 8.3665 & & \\
\hline & & & & 1 \\
\hline 31 & 79 & 8 & 21 & TR \\
\hline 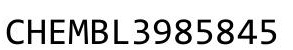 & & 7. & 55 & TR \\
\hline HEMBL & 779 & 7.3072 & 7.9749 & TR \\
\hline HEMBL; & 779 & 8.6198 & 91 & TR \\
\hline & & & & $\mathrm{TR}$ \\
\hline CHEMBL & 779 & 8.6383 & 7.8538 & $\mathrm{TR}$ \\
\hline CHEMBL & 779 & 10.0 & 8.2377 & $\mathrm{TR}$ \\
\hline$M B L 3$ & 541779 & 8.6778 & 8.8193 & TR \\
\hline CHEMBL & 79 & 8.8239 & 8.4086 & TR \\
\hline CHEMBL 3947453 & 1641779 & 8.4318 & 8.5892 & $T R$ \\
\hline
\end{tabular}

Page 25614 


\begin{tabular}{|c|c|c|c|c|c|}
\hline \multicolumn{6}{|c|}{ Supplemental Table S2.txt } \\
\hline CHEMBL3927913 & 1641779 & 6.0 & 7.8403 & TRN & \\
\hline CHEMBL3953410 & 1641779 & 6.0 & 8.0869 & TRN & \\
\hline CHEMBL3957593 & 1641779 & 6.0 & 8.0295 & TRN & \\
\hline CHEMBL3929071 & 1641779 & 7.6108 & 8.0358 & TRN & \\
\hline CHEMBL3946427 & 1641779 & 8.8239 & 8.1081 & TRN & \\
\hline CHEMBL 3893560 & 1641779 & 8.0655 & 7.9309 & TST & \\
\hline CHEMBL 3973416 & 1641779 & 8.0269 & 8.0092 & TST & \\
\hline CHEMBL 3950310 & 1641779 & 7.6576 & 8.083 & TST & \\
\hline CHEMBL 3897617 & 1641779 & 8.6021 & 8.9243 & TST & \\
\hline CHEMBL3923566 & 1641779 & 8.7696 & 7.9229 & TST & \\
\hline CHEMBL3986298 & 1641779 & 8.585 & 7.9257 & TST & \\
\hline CHEMBL 3973290 & 1641779 & 8.6021 & 7.7955 & TST & \\
\hline CHEMBL3944990 & 1641779 & 8.4815 & 7.84200 & 00000000005 & TST \\
\hline CHEMBL3964865 & 1641779 & 8.1367 & 8.0781 & TST & \\
\hline CHEMBL 252226 & 461948 & 6.9208 & 4.8464 & TRN & \\
\hline CHEMBL 251812 & 461948 & 6.1024 & 4.7017 & TRN & \\
\hline CHEMBL398539 & 461948 & 6.3098 & 5.6929 & TRN & \\
\hline CHEMBL 253841 & 461948 & 4.0 & 5.0218 & TRN & \\
\hline CHEMBL398908 & 461948 & 4.0 & 4.7517 & TRN & \\
\hline CHEMBL251981 & 461948 & 4.0 & 4.9294 & TRN & \\
\hline CHEMBL 254462 & 461948 & 6.3215 & 4.9704 & TST & \\
\hline CHEMBL398275 & 461948 & 5.3737 & 4.855 & TRN & \\
\hline CHEMBL398909 & 461948 & 4.0 & 4.8206 & TRN & \\
\hline CHEMBL 254044 & 461948 & 4.0 & 5.2745 & TRN & \\
\hline CHEMBL 252225 & 461948 & 4.0 & 4.4767 & TRN & \\
\hline CHEMBL 253843 & 461948 & 6.0177 & 6.5152 & TRN & \\
\hline CHEMBL 252988 & 461948 & 5.4841 & 6.6595 & TRN & \\
\hline CHEMBL 252014 & 461948 & 4.0 & 4.5033 & TRN & \\
\hline CHEMBL254047 & 461948 & 4.0 & 5.0463 & TRN & \\
\hline CHEMBL400295 & 461948 & 4.0 & 4.6046 & TST & \\
\hline CHEMBL400372 & 461948 & 5.4498 & 5.3004 & TRN & \\
\hline CHEMBL253406 & 461948 & 4.0 & 5.0999 & TRN & \\
\hline CHEMBL400880 & 461948 & 6.4318 & 5.0197 & TRN & \\
\hline CHEMBL 254671 & 461948 & 5.1337 & 5.3302 & TRN & \\
\hline CHEMBL253194 & 461948 & 5.9355 & 5.2882 & TRN & \\
\hline CHEMBL 254251 & 461948 & 4.0 & 5.0005 & TRN & \\
\hline CHEMBL 254252 & 461948 & 4.0 & 4.8279 & TRN & \\
\hline CHEMBL437587 & 461948 & 5.8539 & 4.90600 & $\partial 000000001$ & TST \\
\hline CHEMBL 253842 & 461948 & 5.9101 & 6.0824 & TRN & \\
\hline CHEMBL254877 & 461948 & 5.7852 & 5.1264 & TRN & \\
\hline CHEMBL438345 & 461948 & 7.6383 & 6.8353 & TRN & \\
\hline CHEMBL 254046 & 461948 & 4.0 & 4.3185 & TRN & \\
\hline CHEMBL252786 & 461948 & 5.295 & 5.4342 & TRN & \\
\hline CHEMBL 258008 & 461948 & 5.4572 & 5.1446 & TRN & \\
\hline CHEMBL437395 & 461948 & 4.0 & 5.3493 & TRN & \\
\hline CHEMBL252986 & 461948 & 6.6576 & 4.8493 & TRN & \\
\hline CHEMBL251781 & 461948 & 5.4295 & 5.5373 & TRN & \\
\hline CHEMBL 252785 & 461948 & 6.2596 & 6.6364 & TRN & \\
\hline
\end{tabular}




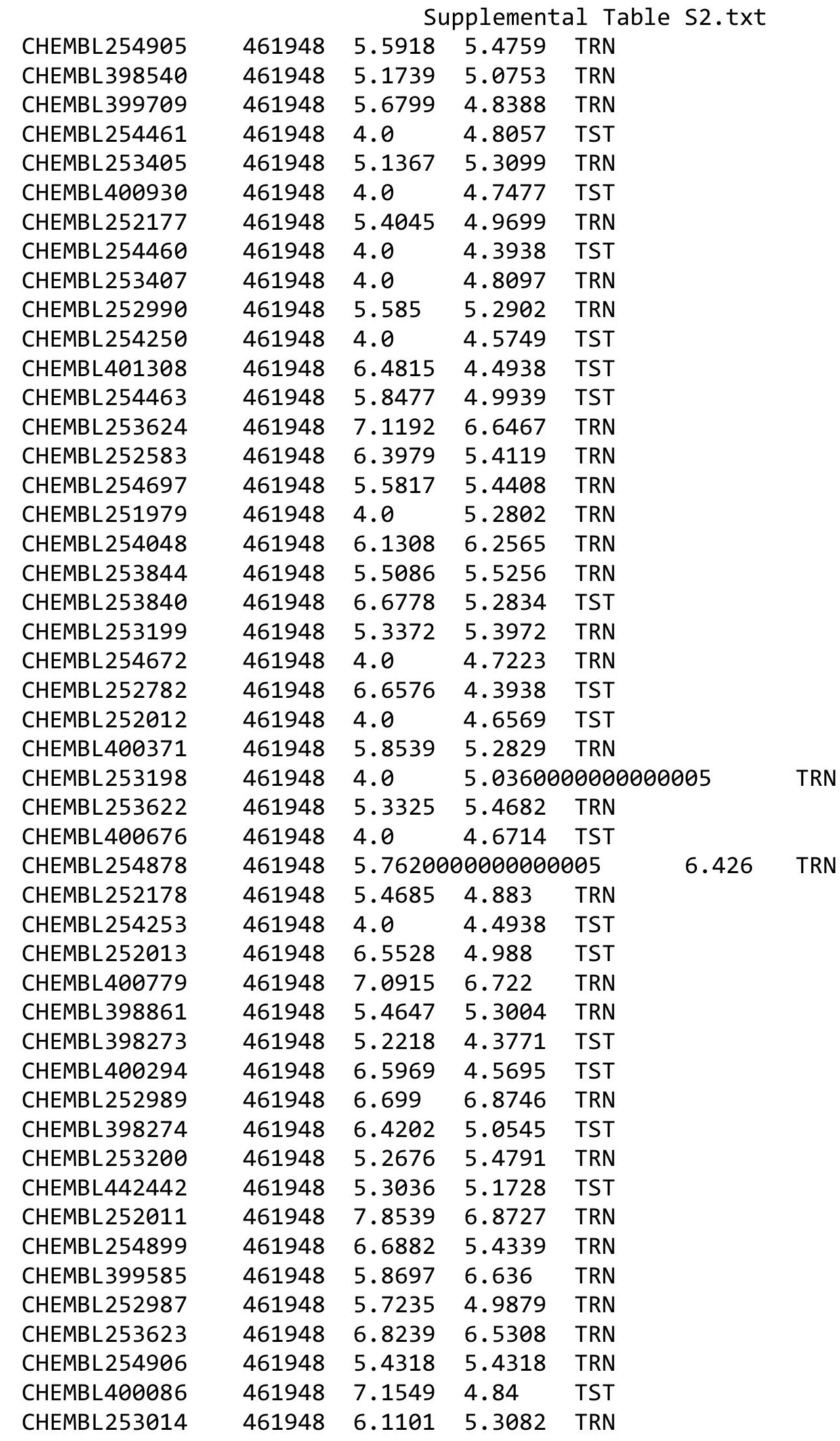

Page 25616 


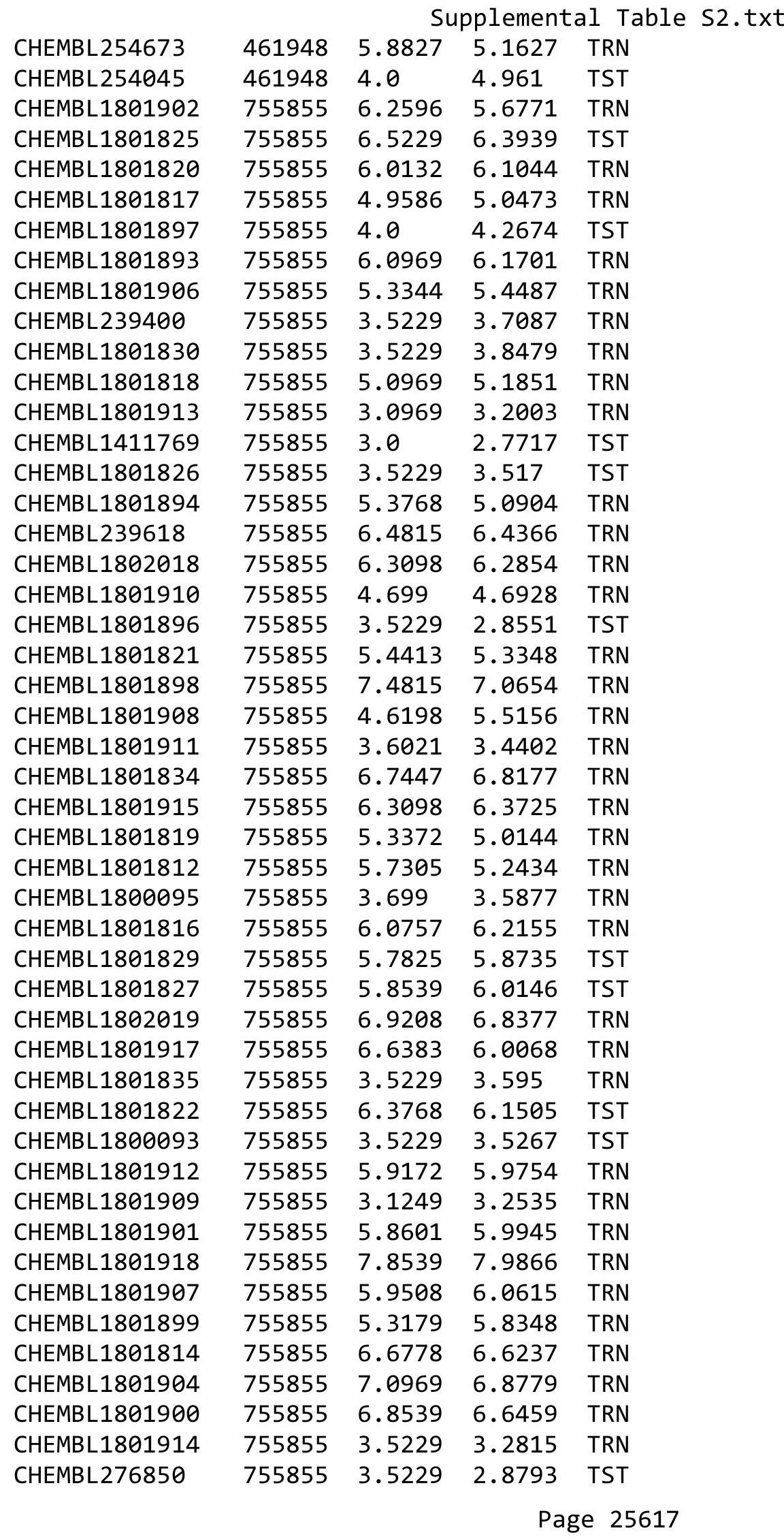




\begin{tabular}{|c|c|c|c|c|c|}
\hline & & \multicolumn{4}{|c|}{ Supplemental Table s2.txt } \\
\hline CHEMBL1801828 & 755855 & 4.4559 & 4.8956 & TST & \\
\hline CHEMBL1801916 & 755855 & 6.7959 & 7.2285 & TRN & \\
\hline CHEMBL1801832 & 755855 & 5.585 & 5.4759 & TRN & \\
\hline CHEMBL1801895 & 755855 & 5.8013 & 6.0653 & TRN & \\
\hline CHEMBL1801823 & 755855 & 5.0953 & 5.0182 & TST & \\
\hline CHEMBL1801813 & 755855 & 3.5229 & 3.5167 & TRN & \\
\hline CHEMBL1801831 & 755855 & 6.5528 & 6.5641 & TRN & \\
\hline CHEMBL1801815 & 755855 & 3.5229 & 3.6467 & TST & \\
\hline CHEMBL1802017 & 755855 & 7.9586 & 8.2197 & TST & \\
\hline CHEMBL3968775 & 1641706 & 7.1427 & 7.3205 & TST & \\
\hline CHEMBL3911136 & 1641706 & 6.0 & 5.5534 & TRN & \\
\hline CHEMBL3915696 & 1641706 & 6.8153 & 7.2728 & TRN & \\
\hline CHEMBL3911885 & 1641706 & 6.0443 & 6.5925 & TRN & \\
\hline CHEMBL 3976766 & 1641706 & 6.2351 & 6.1753 & TRN & \\
\hline CHEMBL3967557 & 1641706 & 6.38299 & 79999999 & 6.9352 & TST \\
\hline CHEMBL3961060 & 1641706 & 5.9983 & 5.8472 & TRN & \\
\hline CHEMBL3932064 & 1641706 & 8.699 & 8.6256 & TST & \\
\hline CHEMBL3920570 & 1641706 & 6.0 & 5.4998 & TRN & \\
\hline CHEMBL3953411 & 1641706 & 6.9101 & 6.8575 & TRN & \\
\hline CHEMBL3924793 & 1641706 & 8.5229 & 8.4554 & TRN & \\
\hline CHEMBL3897680 & 1641706 & 6.7471 & 6.6031 & TST & \\
\hline CHEMBL 3891000 & 1641706 & 7.3565 & 7.7583 & TRN & \\
\hline CHEMBL3963750 & 1641706 & 7.0132 & 7.2172 & TRN & \\
\hline CHEMBL3941640 & 1641706 & 7.5528 & 7.9881 & TST & \\
\hline CHEMBL3930143 & 1641706 & 6.6162 & 6.2812 & TST & \\
\hline CHEMBL 3944548 & 1641706 & 5.9281 & 6.0232 & TRN & \\
\hline CHEMBL3903224 & 1641706 & 6.4976 & 6.4501 & TRN & \\
\hline CHEMBL3933409 & 1641706 & 8.0458 & 8.1403 & TRN & \\
\hline CHEMBL 3974409 & 1641706 & 6.9788 & 7.0713 & TST & \\
\hline CHEMBL3945622 & 1641706 & 8.5229 & 8.3598 & TRN & \\
\hline CHEMBL3930265 & 1641706 & 7.6198 & 7.9629 & TRN & \\
\hline CHEMBL3931150 & 1641706 & 9.0969 & 8.686 & TRN & \\
\hline CHEMBL3907611 & 1641706 & 7.3188 & 7.2808 & TRN & \\
\hline CHEMBL3936802 & 1641706 & 7.0809 & 6.9846 & TRN & \\
\hline CHEMBL3889517 & 1641706 & 7.7959 & 7.6018 & TRN & \\
\hline CHEMBL3939451 & 1641706 & 6.1079 & 6.3681 & TRN & \\
\hline CHEMBL3945594 & 1641706 & 8.699 & 8.5227 & TRN & \\
\hline CHEMBL3985566 & 1641706 & 7.699 & 7.5974 & TRN & \\
\hline CHEMBL3964431 & 1641706 & 6.0921 & 6.2802 & TRN & \\
\hline CHEMBL3943646 & 1641706 & 7.0177 & 7.08899 & 99999999995 & TRI \\
\hline CHEMBL3909449 & 1641706 & 6.5528 & 6.5875 & TST & \\
\hline CHEMBL3938195 & 1641706 & 8.5229 & 7.6749 & TST & \\
\hline CHEMBL3974368 & 1641706 & 6.8761 & 6.9162 & TST & \\
\hline CHEMBL3938918 & 1641706 & 8.5229 & 8.275 & TRN & \\
\hline CHEMBL3919061 & 1641706 & 7.8239 & 7.9753 & TRN & \\
\hline CHEMBL3947243 & 1641706 & 7.3979 & 7.5583 & TRN & \\
\hline CHEMBL3949065 & 1641706 & 8.2218 & 8.2681 & TRN & \\
\hline CHEMBL3899765 & 1641706 & 7.6198 & 7.6245 & TST & \\
\hline
\end{tabular}


Supplemental Table S2.txt

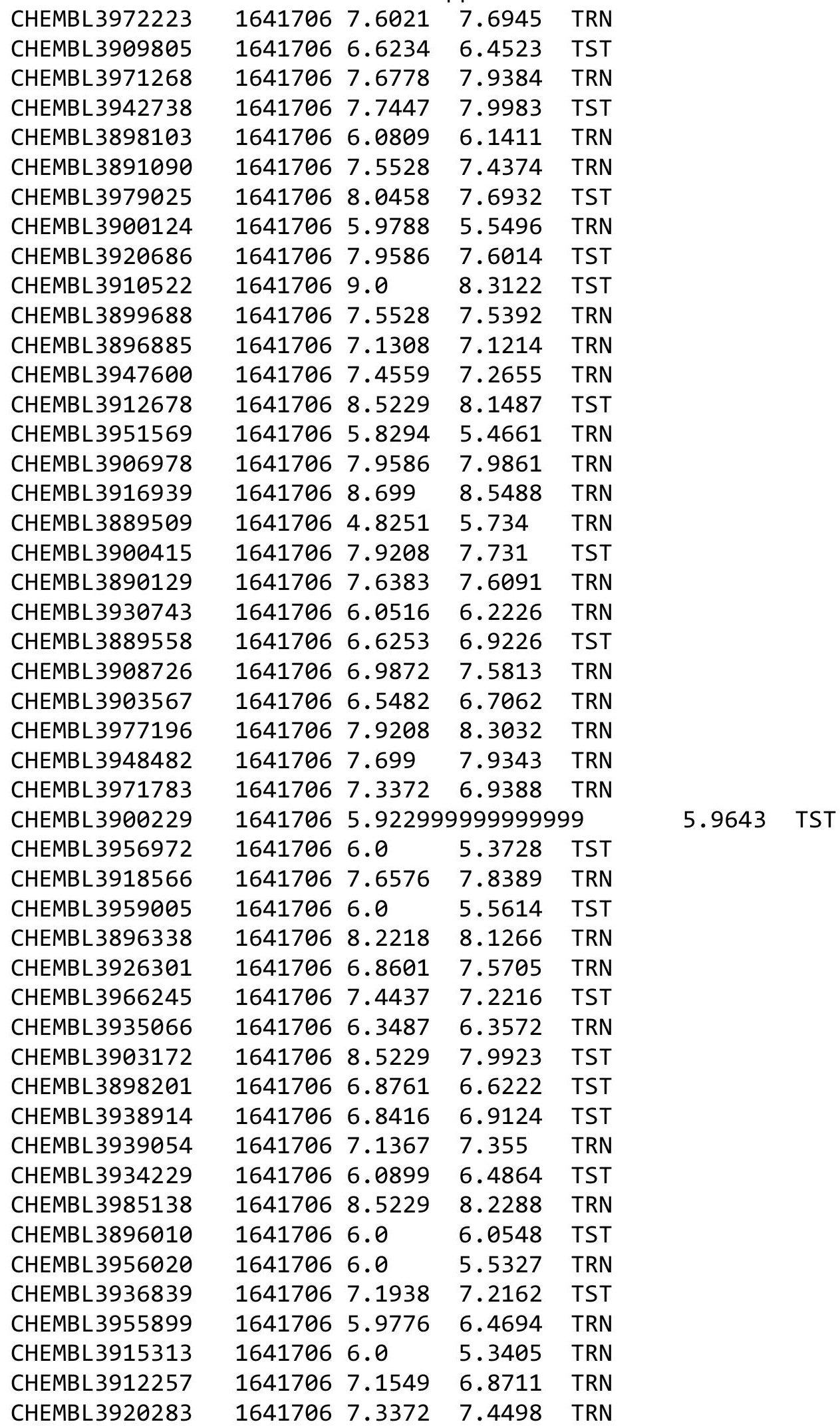

Page 25619 
Supplemental Table S2.txt

\begin{tabular}{|c|c|c|}
\hline & & \\
\hline AEMBL3948300 & & \\
\hline IEMBL3901465 & 541706 & t \\
\hline AEMBL3925830 & 641706 & 1 \\
\hline & 1706 & 497 \\
\hline IEMBL 3983487 & 641706 & 690 \\
\hline AEMBL3976529 & 641706 & 7.080 \\
\hline AEMBL3969454 & 641706 & 7.154 \\
\hline AEMBL3948386 & 1706 & 7.677 \\
\hline IEMBL395 & 706 & 7.886 \\
\hline AEMBL3955591 & 706 & -60 \\
\hline AEMBL3944536 & 641706 & 8.221 \\
\hline AEMBL3929554 & 641706 & 8.699 \\
\hline AEMBL3918263 & 706 & 6.978 \\
\hline IEMBL 3895300 & 706 & 329 \\
\hline AEMBL3942660 & 706 & 29 \\
\hline AEMBL3916493 & .706 & 7.431 \\
\hline AEMBL3912216 & 706 & 5.8867 \\
\hline AEMBL 3944 & 706 & \\
\hline AEMBL395 & 706 & 1976 \\
\hline AEMBL 394 & 706 & 3861 \\
\hline HEMBL3892313 & 706 & \\
\hline AEMBL3965904 & & 599 \\
\hline HEMBL 393 & 706 & 6.71 \\
\hline HEMBL39 & 706 & 7.4318 \\
\hline AEMBL39 & 706 & 7.1487 \\
\hline HEMBL3931808 & 706 & 6.1267 \\
\hline IEMBL 3985654 & & 7.8861 \\
\hline AEMBL3982094 & 706 & 599 \\
\hline HEMBL3896 & 706 & 311 \\
\hline HEMBL3915 & 706 & \\
\hline AEMBL3901595 & 706 & 8.2218 \\
\hline AEMBL3982364 & 706 & 7.3979 \\
\hline AEMBL3968473 & 16 & 8.699 \\
\hline HEMBL 391 & 106 & 8.5229 \\
\hline 45 & 706 & 5498 \\
\hline AEMBL3908935 & 706 & 7.5528 \\
\hline AEMBL3980335 & 706 & 6.0752 \\
\hline AEMBL 393 & 706 & 6.7375 \\
\hline בחב וסבינ & 706 & 6.6778 \\
\hline 55 & 706 & 6.3439 \\
\hline HEMBL3909826 & 1641706 & 4.8251 \\
\hline AEMBL3932352 & 706 & 8.699 \\
\hline HEMBL 398 & & 7.4202 \\
\hline CHEMBL 3944980 & 16 & 7.2291 \\
\hline CHEMBL397 & 1641706 & 6.1278 \\
\hline HEMBL3960656 & 1641706 & 6.6308 \\
\hline HFMBI 3953137 & 1611796 & 6310 \\
\hline
\end{tabular}

6.8393 TRN

8.1994 TRN

8.2427 TRN

6.8476 TRN

6.7358 TRN

8.1659 TST

7.3012 TRN

7.0496 TRN

7.7132 TRN

7.5948 TRN

7.505 TRN

7.6809 TRN

8.2119 TST

6.4999 TST

6.1081 TRN

5.6747 TRN

7.5227 TRN

5.8984 TRN

7.57 TST

7.1771 TRN

7.7166 TRN

5.6472 TRN

8.4254 TST

6.5360000000000005 TST

7.522 TRN

7.6211 TRN

6.0278 TST

7.5045 TST

8.3347 TRN

7.3527 TST

8.0844 TRN

7.6179 TST

7.2081 TRN

8.1826 TRN

8.4571 TRN

6.6926 TRN

7.581 TRN

6.4448 TRN

6.8031 TRN

6.7793 TRN

6.0038 TRN

5.9654 TST

8.5179 TRN

7.5113 TRN

6.7194 TRN

6.6327 TRN

6.1033 TRN

6.2537 TST

Page 25620 
Supplemental Table S2.txt

\begin{tabular}{|c|c|c|c|c|}
\hline CHEMBL3968639 & 1641706 & 6.9318 & 6.6984 & TRN \\
\hline CHEMBL3962407 & 1641706 & 7.3979 & 7.8597 & TRN \\
\hline CHEMBL3900832 & 1641706 & 6.7305 & 6.5477 & TRN \\
\hline CHEMBL3914149 & 1641706 & 8.5229 & 8.4675 & TRN \\
\hline CHEMBL3960177 & 1641706 & 4.8251 & 5.2944 & TST \\
\hline CHEMBL3960898 & 1641706 & 6.9747 & 7.0318 & TST \\
\hline CHEMBL3922412 & 1641706 & 6.4737 & 6.4655 & TRN \\
\hline CHEMBL3957158 & 1641706 & 7.6383 & 7.7741 & TST \\
\hline CHEMBL3927070 & 1641706 & 6.857 & 7.0922 & TRN \\
\hline CHEMBL3980737 & 1641706 & 6.0 & 5.1264 & TST \\
\hline CHEMBL3946481 & 1641706 & 6.0 & 5.79200 & 0000000001 \\
\hline CHEMBL3940150 & 1641706 & 6.6144 & 6.4243 & TRN \\
\hline CHEMBL3920671 & 1641706 & 7.0223 & 6.9974 & TRN \\
\hline CHEMBL3908148 & 1641706 & 7.4559 & 7.1492 & TST \\
\hline CHEMBL3952669 & 1641706 & 8.0458 & 7.8537 & TST \\
\hline CHEMBL3941235 & 1641706 & 6.4559 & 6.2536 & TRN \\
\hline CHEMBL3948522 & 1641706 & 7.4089 & 6.8388 & TRN \\
\hline CHEMBL 3954817 & 1641706 & 5.8294 & 5.2441 & TRN \\
\hline CHEMBL3899546 & 1641706 & 7.4815 & 7.7086 & TRN \\
\hline CHEMBL3946178 & 1641706 & 7.5229 & 7.4798 & TST \\
\hline CHEMBL3909340 & 1641706 & 7.9586 & 7.7211 & TRN \\
\hline CHEMBL3889909 & 1641706 & 8.301 & 8.0202 & TRN \\
\hline CHEMBL3914703 & 1641706 & 6.0 & 5.4362 & TST \\
\hline CHEMBL3931250 & 1641706 & 9.1549 & 8.7177 & TRN \\
\hline CHEMBL3905278 & 1641706 & 8.3979 & 8.2703 & TRN \\
\hline CHEMBL3969967 & 1641706 & 6.6655 & 6.9196 & TST \\
\hline CHEMBL3949472 & 1641706 & 9.0 & 8.7425 & TRN \\
\hline CHEMBL3938017 & 1641706 & 8.301 & 8.1093 & TRN \\
\hline CHEMBL3978603 & 1641706 & 8.5229 & 8.0327 & TST \\
\hline CHEMBL3940215 & 1641706 & 6.9393 & 6.7825 & TRN \\
\hline CHEMBL3923856 & 1641706 & 6.5817 & 6.8463 & TRN \\
\hline CHEMBL3932767 & 1641706 & 7.2218 & 7.4049 & TST \\
\hline CHEMBL3947540 & 1641706 & 6.0 & 5.3309 & TST \\
\hline CHEMBL3984895 & 1641706 & 8.3979 & 8.1684 & TRN \\
\hline CHEMBL3951407 & 1641706 & 7.1487 & 7.1564 & TRN \\
\hline CHEMBL3907066 & 1641706 & 8.0458 & 7.4346 & TST \\
\hline CHEMBL3940820 & 1641706 & 6.0921 & 6.2198 & TRN \\
\hline CHEMBL3924220 & 1641706 & 8.1549 & 7.9046 & TRN \\
\hline CHEMBL3939999 & 1641706 & 4.8251 & 5.5941 & TST \\
\hline CHEMBL3890238 & 1641706 & 6.9872 & 8.0654 & TST \\
\hline CHEMBL3932209 & 1641706 & 6.5186 & 6.6164 & TST \\
\hline CHEMBL3890522 & 1641706 & 8.301 & 8.001 & TRN \\
\hline CHEMBL3983335 & 1641706 & 7.7212 & 7.6982 & TRN \\
\hline CHEMBL3905008 & 1641706 & 8.0969 & 8.3019 & TRN \\
\hline CHEMBL3931541 & 1641706 & 7.4559 & \multicolumn{2}{|c|}{7.417999999999999} \\
\hline CHEMBL3950253 & 1641706 & 6.0 & 5.7039 & TRN \\
\hline CHEMBL3959656 & 1641706 & 7.699 & 7.9355 & TRN \\
\hline CHEMBL3933703 & 1641706 & 6.6038 & 7.0186 & TRN \\
\hline
\end{tabular}


Supplemental Table S2.txt

\begin{tabular}{|c|c|c|c|c|}
\hline CHEMBL3981986 & 1641706 & 6.8928 & 6.8951 & TRN \\
\hline CHEMBL3933330 & 1641706 & 8.3979 & 7.8242 & TRN \\
\hline CHEMBL3891348 & 1641706 & 7.9586 & 8.1399 & TRN \\
\hline CHEMBL3916449 & 1641706 & 6.0 & 5.6795 & TRN \\
\hline CHEMBL3915503 & 1641706 & 6.5768 & 6.5578 & TST \\
\hline CHEMBL3933191 & 1641706 & 7.9586 & 7.2682 & TRN \\
\hline CHEMBL3936267 & 1641706 & 7.8861 & 7.3903 & TST \\
\hline CHEMBL3952017 & 1641706 & 7.0915 & 7.1308 & TRN \\
\hline CHEMBL3922934 & 1641706 & 7.6383 & 8.2747 & TRN \\
\hline CHEMBL3901174 & 1641706 & 6.2984 & 6.5511 & TRN \\
\hline CHEMBL3892891 & 1641706 & 5.9961 & 6.3676 & TRN \\
\hline CHEMBL3958723 & 1641706 & 5.8294 & 6.0556 & TRN \\
\hline CHEMBL3900321 & 1641706 & 6.9914 & 6.6063 & TRN \\
\hline CHEMBL3939808 & 1641706 & 7.7959 & 7.4262 & TRN \\
\hline CHEMBL3895654 & 1641706 & 8.5229 & 8.2326 & TRN \\
\hline CHEMBL3892955 & 1641706 & 7.1079 & 7.3322 & TRN \\
\hline CHEMBL3911044 & 1641706 & 6.0 & 5.6262 & TRN \\
\hline CHEMBL3974477 & 1641706 & 8.5229 & 8.5443 & TRN \\
\hline CHEMBL3957574 & 1641706 & 6.0 & 7.2168 & TRN \\
\hline CHEMBL3920087 & 1641706 & 7.0706 & 7.4186 & TRN \\
\hline CHEMBL3895727 & 1641706 & 6.0 & 5.6161 & TRN \\
\hline CHEMBL3903692 & 1641706 & 7.8861 & 7.9942 & TRN \\
\hline CHEMBL3892671 & 1641706 & 7.4685 & 7.1565 & TRN \\
\hline CHEMBL3937127 & 1641706 & 6.0 & 5.3627 & TRN \\
\hline CHEMBL3971912 & 1641706 & 6.2351 & 6.1489 & TRN \\
\hline CHEMBL3911418 & 1641706 & 6.5421 & 6.7522 & TRN \\
\hline CHEMBL3955398 & 1641706 & 8.1549 & 8.299 & TRN \\
\hline CHEMBL3964474 & 1641706 & 6.1481 & 5.9503 & TRN \\
\hline CHEMBL3931158 & 1641706 & 7.4318 & 7.4177 & TRN \\
\hline CHEMBL3953465 & 1641706 & 7.4559 & 7.3625 & TRN \\
\hline CHEMBL3938257 & 1641706 & 6.3298 & 6.5321 & TRN \\
\hline CHEMBL3922069 & 1641706 & 9.301 & 8.7304 & TRN \\
\hline CHEMBL3927869 & 1641706 & 7.0177 & 7.3259 & TRN \\
\hline CHEMBL 3980147 & 1641706 & 6.9393 & 6.9576 & TRN \\
\hline CHEMBL3901464 & 1641706 & 7.6198 & 6.9076 & TST \\
\hline CHEMBL3942917 & 1641706 & 9.1549 & 8.5723 & TRN \\
\hline CHEMBL3955361 & 1641706 & 6.5031 & 6.1089 & TST \\
\hline CHEMBL3902563 & 1641706 & 9.1549 & 8.6851 & TRN \\
\hline CHEMBL 3981780 & 1641706 & 8.0458 & 8.1661 & TRN \\
\hline CHEMBL3919793 & 1641706 & 6.8125 & 6.8405 & TRN \\
\hline CHEMBL3979073 & 1641706 & 6.8069 & 6.79200 & 3000000001 \\
\hline CHEMBL3966967 & 1641706 & 5.8294 & 5.7827 & TRN \\
\hline CHEMBL3979997 & 1641706 & 8.301 & 8.0001 & TRN \\
\hline CHEMBL3946034 & 1641706 & 5.848 & 6.1896 & TRN \\
\hline CHEMBL3980404 & 1641706 & 6.9914 & 6.9026 & TRN \\
\hline CHEMBL3951300 & 1641706 & 6.0 & 5.6027 & TRN \\
\hline CHEMBL3936674 & 1641706 & 7.2757 & 7.1057 & TST \\
\hline CHEMBL3952595 & 1641706 & 5.9842 & 6.4749 & TST \\
\hline
\end{tabular}


Supplemental Table S2.txt

\begin{tabular}{|c|c|c|c|c|}
\hline HEM & 541706 & 747 & 5.9992 & \\
\hline & 641706 & 6.7878 & 5054 & \\
\hline 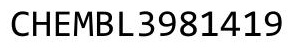 & 06 & & & \\
\hline AEMBL3945721 & 706 & 0315 & & \\
\hline AEMBL3954129 & 706 & 383 & 3518 & \\
\hline HEMBL3944827 & 641706 & 7.3979 & 4413 & \\
\hline HEMBL392 & 706 & & 072 & \\
\hline IFMRI 393 & & & & \\
\hline AEMBL3931206 & 706 & & 9688 & \\
\hline HEMBL3958613 & 706 & 21 & 8972 & \\
\hline HEMBL3973935 & 706 & 4 . & .7963 & \\
\hline IEMBL391 & 106 & 59 & 061 & \\
\hline AEMBL39 & & & & \\
\hline HEMBL389 & 706 & & 2466 & \\
\hline HEMBL389 & 106 & 9. & 3752 & \\
\hline IEMBL392 & 26 & 57 & 341 & \\
\hline AEMBL39 & 06 & & 112 & \\
\hline HEMBL 39 & & & 156 & \\
\hline HEMBL 393 & 106 & & 6141 & \\
\hline AEMBL 391 & & & 971 & \\
\hline HEIMBLSS & 06 & 8 & 14 & \\
\hline AEMBL39 & & & 38 & \\
\hline HEMBL3S & & 815 & 35 & \\
\hline 309 & & 8 . & 3324 & \\
\hline HEMBL 389 & & & & \\
\hline HEMBL398 & 36 & 7. & 5816 & RN \\
\hline HEMBL39 & & 6 & 7744 & \\
\hline HFMBI 30 & $\partial 6$ & 6. & 3622 & \\
\hline HEMBL 39 & & 8 . & 8.5798 & 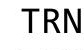 \\
\hline HEMBL 389 & 36 & & & r \\
\hline HEMBL 389 & 06 & & 867 & SI \\
\hline HEMBL3S & & & 69 & Niv \\
\hline HEMBL3 & & & 712 & \\
\hline HEMBL3897371 & & & 9891 & IR \\
\hline HEMBL3963309 & 36 & & 8408 & TRN \\
\hline HEMBL39 & & & 7794 & RIN \\
\hline HFMRI 3 & & & 764 & RN \\
\hline HEMBL3 & & 7. & 7.9143 & RN \\
\hline HEMBL3974509 & & 6 & 1427 & $\Gamma \mathrm{RN}$ \\
\hline HEMBL389 & $\partial 6$ & & 1367 & TST \\
\hline HEMBL 397 & 06 & & 7213 & \\
\hline CHEMBL389 & & & 7.211 & RN \\
\hline HEMBL392 & 706 & 7. & 7.5815 & RN \\
\hline AEMBL3975194 & 706 & 6.3 & 6.3176 & ГST \\
\hline MBL3 & & & 456 & \\
\hline HEMBL397 & & 87 & 5.881 & \\
\hline CHEMBL 391 & 16 & 6.3936 & .2543 & \\
\hline HEMBL 394984 & 1641706 & 8.301 & 8.3908 & ГRN \\
\hline
\end{tabular}

Page 25623 
Supplemental Table S2.txt

\begin{tabular}{|c|c|c|c|c|}
\hline HEMBL 390678 & 66 & 9 & 61 & \\
\hline 5369 & 641706 & 5.8564 & .2128 & \\
\hline 53 & 06 & & 3022 & \\
\hline AEMBL & 706 & 28 & & \\
\hline AEMBL3941871 & 706 & & 9403 & \\
\hline HEMBL3935508 & 641706 & 9.0 & . 3316 & \\
\hline 1829 & & 7 & 789 & \\
\hline |FMRI: & & & 3663 & \\
\hline AEMBL3905158 & 706 & 807 & 5.7867 & \\
\hline HEMBL3986677 & 706 & 986 & 8722 & \\
\hline HEMBL3933722 & 706 & 458 & .0545 & \\
\hline IEMBL 38 & 106 & 99 & 5813 & \\
\hline AEMBL & & & & \\
\hline HEMBL3S & 706 & 6.66 & 5.3618 & \\
\hline AEMBL38 & 106 & 125 & 9527 & \\
\hline AEMBL3962716 & 26 & 6. & 6542 & \\
\hline AEMBL3S & 96 & & 043 & \\
\hline HEMBL3S & & & & \\
\hline AEMBL39 & & 979 & 8.1504 & \\
\hline AEMBL39 & & 92 & & \\
\hline HEMBLS & 0 & & 509 & NIV \\
\hline AEMBL & & 55 & 706 & \\
\hline HEMBL & & 319 & 544 & \\
\hline 977 & & 6 & 5265 & \\
\hline AEMBL3\& & & & & \\
\hline HEMBL & 26 & 7. & 926 & IS \\
\hline AEMBL; & & 65 & 323 & RN \\
\hline $\mathrm{AFMBI}=$ & & 34 & 36 & \\
\hline HEMBL3 & & & 7.2448 & 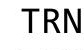 \\
\hline HEMBL 39471 & & & & s \\
\hline HEMBL3S & & & 273 & RN \\
\hline HEMBL & & $\partial 8$ & 13 & Niv \\
\hline 47 & & 61 & 86 & M \\
\hline HEMBL 392 & & 376 & 55 & R \\
\hline HEMBL3947490 & & & 6.4292 & TRN \\
\hline HEMBL3S & & & 7.2543 & וد \\
\hline HFMRI & & & 188 & ST \\
\hline HEMBL3 & & & 729 & RN \\
\hline HEMBL 3982523 & & 5.8294 & 5.7297 & $\Gamma \mathrm{RN}$ \\
\hline AEMBL392 & & & 7.8221 & TRN \\
\hline HEMBL390 & $\partial 6$ & 47 & 7.7035 & 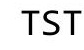 \\
\hline LHEMBL3892636 & & & 6.8309 & RN \\
\hline HEMBL3978395 & 706 & 6.4962 & 6.5108 & TST \\
\hline HEMBL3938031 & 706 & & .9525 & TST \\
\hline $\mathrm{MRI}=$ & & & 1256 & 1 \\
\hline HEMBL39 & & 1881 & 5.6023 & \\
\hline CHEMBL 3977268 & & .8251 & 5.4994 & \\
\hline THEMBL3950086 & 1641706 & 7.3098 & 7.4782 & RN \\
\hline
\end{tabular}

Page 25624 
Supplemental Table S2.txt

\begin{tabular}{|c|c|c|c|c|}
\hline CHEMBL 3983423 & 1641706 & 6.7375 & 7.1492 & TRN \\
\hline CHEMBL3946164 & 1641706 & 7.3565 & 7.3909 & TRN \\
\hline CHEMBL3942622 & 1641706 & 7.5086 & 7.4758 & TRN \\
\hline CHEMBL3935881 & 1641706 & 6.9208 & 7.0827 & TRN \\
\hline CHEMBL 3924664 & 1641706 & 7.4202 & 7.3987 & TRN \\
\hline CHEMBL3927787 & 1641706 & 8.2218 & 8.3425 & TRN \\
\hline CHEMBL3981942 & 1641706 & 7.8861 & 7.4167 & TRN \\
\hline CHEMBL3908597 & 1641706 & 6.8356 & 7.2101 & TRN \\
\hline CHEMBL3958942 & 1641706 & 8.699 & 8.2572 & TRN \\
\hline CHEMBL3899110 & 1641706 & 8.0 & 8.1796 & TRN \\
\hline CHEMBL3938455 & 1641706 & 8.2218 & 8.2342 & TRN \\
\hline CHEMBL 3893735 & 1641706 & 6.0 & 5.8968 & TRN \\
\hline CHEMBL3914600 & 1641706 & 9.0 & 8.8185 & TRN \\
\hline CHEMBL3939533 & 1641706 & 7.4202 & 6.976 & TST \\
\hline CHEMBL 3948006 & 1641706 & 6.8327 & 6.9415 & TRN \\
\hline CHEMBL 3960876 & 1641706 & 8.2218 & 8.1438 & TRN \\
\hline CHEMBL3977249 & 1641706 & 6.9872 & 7.0861 & TRN \\
\hline CHEMBL3963918 & 1641706 & 8.0969 & 8.0306 & TRN \\
\hline CHEMBL3917676 & 1641706 & 7.4202 & 7.5071 & TRN \\
\hline CHEMBL3984315 & 1641706 & 8.301 & 8.3048 & TRN \\
\hline CHEMBL3911100 & 1641706 & 6.3372 & 5.8729 & TRN \\
\hline CHEMBL3946078 & 1641706 & 7.1612 & 8.0612 & TST \\
\hline CHEMBL3954311 & 1641706 & 6.8996 & 6.8436 & TRN \\
\hline CHEMBL 3890579 & 1641706 & 6.8069 & 7.1377 & TRN \\
\hline CHEMBL3951123 & 1641706 & 8.5229 & 8.1438 & TRN \\
\hline CHEMBL3969761 & 1641706 & 6.7352 & 7.2116 & TRN \\
\hline CHEMBL3909552 & 1641706 & 6.8761 & 6.8088 & TST \\
\hline CHEMBL3955861 & 1641706 & 7.0555 & 7.3297 & TRN \\
\hline CHEMBL3911564 & 1641706 & 6.5784 & 6.6166 & TST \\
\hline CHEMBL3911822 & 1641706 & 7.6576 & 7.66299 & 9999999999 \\
\hline CHEMBL3983711 & 1641706 & 6.0 & 5.3487 & TST \\
\hline CHEMBL3958861 & 1641706 & 8.0969 & 7.8727 & TRN \\
\hline CHEMBL3917637 & 1641706 & 8.699 & 8.2169 & TST \\
\hline CHEMBL 3894262 & 1641706 & 7.6021 & 7.4394 & TRN \\
\hline CHEMBL3891171 & 1641706 & 7.6778 & 7.6274 & TRN \\
\hline CHEMBL 3938808 & 1641706 & 8.301 & 8.1655 & TRN \\
\hline CHEMBL3943909 & 1641706 & 6.0 & 5.4966 & TRN \\
\hline CHEMBL3905579 & 1641706 & 8.0969 & 8.1043 & TRN \\
\hline CHEMBL 3899737 & 1641706 & 6.6968 & 7.206 & TRN \\
\hline CHEMBL 3924811 & 1641706 & 7.1249 & 7.4201 & TRN \\
\hline CHEMBL 3930998 & 1641706 & 7.3768 & 7.6069 & TRN \\
\hline CHEMBL 3960729 & 1641706 & 7.3279 & 7.0942 & TRN \\
\hline CHEMBL3962864 & 1641706 & 7.2007 & 7.1915 & TRN \\
\hline CHEMBL 3899162 & 1641706 & 8.2218 & 8.1542 & TRN \\
\hline CHEMBL 3967992 & 1641706 & 8.0458 & 8.4399 & TRN \\
\hline CHEMBL 3893183 & 1641706 & 7.2366 & 7.1825 & TRN \\
\hline CHEMBL3916587 & 1641706 & 8.2218 & 8.387 & TST \\
\hline CHEMBL 3902783 & 1641706 & 7.4815 & 7.7553 & TRN \\
\hline
\end{tabular}

Page 25625 
Supplemental Table S2.txt

\begin{tabular}{|c|c|c|c|c|c|c|}
\hline CHEMBL3946128 & 1641706 & 8.301 & 8.3694 & TRN & & \\
\hline CHEMBL3984973 & 1641706 & 7.0132 & 7.0563 & TRN & & \\
\hline CHEMBL3968445 & 1641706 & 8.5229 & 8.6108 & TRN & & \\
\hline CHEMBL3930874 & 1641706 & 6.7423 & 6.7369 & TRN & & \\
\hline CHEMBL3925801 & 1641706 & 4.8251 & 5.4704 & TST & & \\
\hline CHEMBL3908733 & 1641706 & 7.3372 & 7.1368 & TST & & \\
\hline CHEMBL3982398 & 1641706 & 8.3979 & 8.6558 & TRN & & \\
\hline CHEMBL3965488 & 1641706 & 6.9136 & 6.622999 & 99999999 & & TST \\
\hline CHEMBL3971438 & 1641706 & 4.8251 & 5.5204 & TRN & & \\
\hline CHEMBL3950104 & 1641706 & 6.8386 & 7.05 & TRN & & \\
\hline CHEMBL3901812 & 1641706 & 8.5229 & 8.5893 & TRN & & \\
\hline CHEMBL3972275 & 1641706 & 5.8294 & 5.8829 & TRN & & \\
\hline CHEMBL3982937 & 1641706 & 7.2007 & 7.3368 & TRN & & \\
\hline CHEMBL3936186 & 1641706 & 7.8539 & 7.8172 & TRN & & \\
\hline CHEMBL3953347 & 1641706 & 8.1549 & 8.1806 & TRN & & \\
\hline CHEMBL3895843 & 1641706 & 7.3979 & 7.273 & TRN & & \\
\hline CHEMBL3961250 & 1641706 & 6.7399 & 6.4784 & TRN & & \\
\hline CHEMBL3904265 & 1641706 & 6.0 & 5.5283 & TRN & & \\
\hline CHEMBL3954705 & 1641706 & 6.0 & 5.6091 & TRN & & \\
\hline CHEMBL3908689 & 1641706 & 8.0969 & 7.061 & TST & & \\
\hline CHEMBL3969943 & 1641706 & 7.585 & 7.3502 & TRN & & \\
\hline CHEMBL3917536 & 1641706 & 7.1739 & 7.2472 & TRN & & \\
\hline CHEMBL3934244 & 1641706 & 6.5258 & 6.5104 & TRN & & \\
\hline CHEMBL3974659 & 1641706 & 6.8794 & 7.2744 & TST & & \\
\hline CHEMBL3981696 & 1641706 & 6.6696 & 7.3044 & TST & & \\
\hline CHEMBL3942765 & 1641706 & 5.8294 & 6.3192 & TRN & & \\
\hline CHEMBL3911273 & 1641706 & 7.4089 & 7.2305 & TRN & & \\
\hline CHEMBL3929898 & 1641706 & 6.0083 & 6.2582 & TST & & \\
\hline CHEMBL3914684 & 1641706 & 6.6799 & 6.8814 & TRN & & \\
\hline CHEMBL3943338 & 1641706 & 6.6757 & 6.5856 & TRN & & \\
\hline CHEMBL3922288 & 1641706 & 8.0458 & 7.9529 & TRN & & \\
\hline CHEMBL3974257 & 1641706 & 7.0177 & 7.2668 & TRN & & \\
\hline CHEMBL3969749 & 1641706 & 7.3565 & 7.3998 & TRN & & \\
\hline CHEMBL3948843 & 1641706 & 6.8013 & 6.8656 & TST & & \\
\hline CHEMBL3906618 & 1641706 & 8.3979 & 8.353 & TRN & & \\
\hline CHEMBL3905548 & 1641706 & 6.5331 & 6.3353 & TRN & & \\
\hline CHEMBL 3962429 & 1641706 & 7.4202 & 7.4935 & TRN & & \\
\hline CHEMBL3933102 & 1641706 & 9.0 & 8.7093 & TRN & & \\
\hline CHEMBL3914049 & 1641706 & 7.8239 & 8.2066 & TRN & & \\
\hline CHEMBL3950965 & 1641706 & 6.0 & 5.3205 & TST & & \\
\hline CHEMBL3931224 & 1641706 & \multicolumn{3}{|c|}{5.957000000000001} & 6.0465 & $\mathrm{TR}$ \\
\hline CHEMBL3951373 & 1641706 & 6.3316 & 6.7072 & TRN & & \\
\hline CHEMBL3938472 & 1641706 & 7.1487 & 7.0113 & TRN & & \\
\hline CHEMBL3965345 & 1641706 & 7.7959 & 7.3711 & TRN & & \\
\hline CHEMBL 3892372 & 1641706 & 6.9469 & 6.9034 & TST & & \\
\hline CHEMBL3956546 & 1641706 & 7.3872 & 7.4141 & TRN & & \\
\hline CHEMBL3921761 & 1641706 & \multicolumn{3}{|c|}{6.718999999999999} & 6.8284 & R RN \\
\hline CHEMBL3907706 & 1641706 & 7.7959 & 7.8332 & TRN & & \\
\hline
\end{tabular}


Supplemental Table S2.txt

\begin{tabular}{|c|c|c|c|c|c|c|}
\hline CHEMBL 3977394 & 1641706 & 7.6198 & 7.4874 & TRN & & \\
\hline CHEMBL3903164 & 1641706 & 6.7545 & 6.5489 & TRN & & \\
\hline CHEMBL3905110 & 1641706 & 7.0 & 6.8481 & TRN & & \\
\hline CHEMBL 3954866 & 1641706 & 6.75200 & 00000000 & 01 & 7.2467 & TST \\
\hline CHEMBL 3964457 & 1641706 & 7.1549 & 7.4499 & TRN & & \\
\hline CHEMBL3952853 & 1641706 & 7.1938 & 7.3339 & TST & & \\
\hline CHEMBL3958656 & 1641706 & 6.6198 & 7.0014 & TRN & & \\
\hline CHEMBL3979560 & 1641706 & 6.1198 & 6.6534 & TRN & & \\
\hline CHEMBL3939638 & 1641706 & 8.0 & 7.9486 & TRN & & \\
\hline CHEMBL3920825 & 1641706 & 7.585 & 7.5533 & TRN & & \\
\hline CHEMBL3957604 & 1641706 & 7.1367 & 7.1846 & TRN & & \\
\hline CHEMBL 3914006 & 1641706 & 7.0862 & 7.1148 & TRN & & \\
\hline CHEMBL 3906584 & 1641706 & 6.1107 & 6.8619 & TST & & \\
\hline CHEMBL 3935250 & 1641706 & 7.1367 & 7.2571 & TRN & & \\
\hline CHEMBL 3935010 & 1641706 & 8.2218 & 7.7035 & TST & & \\
\hline CHEMBL3967827 & 1641706 & 7.0362 & 6.7679 & TST & & \\
\hline CHEMBL3894307 & 1641706 & 6.4584 & 7.1826 & TRN & & \\
\hline CHEMBL3946652 & 1641706 & 6.8697 & 6.5456 & TRN & & \\
\hline CHEMBL 3898987 & 1641706 & 6.4498 & 6.6896 & TRN & & \\
\hline CHEMBL 3984652 & 1641706 & 7.3188 & 7.0395 & TST & & \\
\hline CHEMBL 3953266 & 1641706 & 6.9208 & 7.1208 & TRN & & \\
\hline CHEMBL 3973424 & 1641706 & 8.699 & 8.5259 & TRN & & \\
\hline CHEMBL 3944488 & 1641706 & 8.2218 & 8.3852 & TRN & & \\
\hline CHEMBL 3904021 & 1641706 & 8.699 & 8.3862 & TRN & & \\
\hline CHEMBL 3986584 & 1641706 & 7.7959 & 8.0008 & TRN & & \\
\hline CHEMBL 3898832 & 1641706 & 6.0376 & 6.2265 & TRN & & \\
\hline CHEMBL3896471 & 1641706 & 7.2676 & 7.4388 & TRN & & \\
\hline CHEMBL3908325 & 1641706 & 6.6478 & 6.8043 & TST & & \\
\hline CHEMBL 3923710 & 1641706 & 7.3565 & 7.5544 & TRN & & \\
\hline CHEMBL 3900700 & 1641706 & 8.0 & 8.7814 & TRN & & \\
\hline CHEMBL3958399 & 1641706 & 7.8861 & 8.01 & TRN & & \\
\hline CHEMBL 3923655 & 1641706 & 6.0 & 5.218 & TST & & \\
\hline CHEMBL 3947800 & 1641706 & 4.8251 & 5.5374 & TRN & & \\
\hline CHEMBL3915170 & 1641706 & 7.6576 & 6.8389 & TST & & \\
\hline CHEMBL3951216 & 1641706 & 7.4318 & 7.5415 & TRN & & \\
\hline CHEMBL 3972281 & 1641706 & 6.9914 & 7.2714 & TRN & & \\
\hline CHEMBL 3956583 & 1641706 & 6.5272 & 6.3331 & TST & & \\
\hline CHEMBL 3898144 & 1641706 & 7.4202 & 7.415 & TRN & & \\
\hline CHEMBL 3893763 & 1641706 & 6.9706 & 7.3525 & TRN & & \\
\hline CHEMBL 3902263 & 1641706 & 8.301 & 8.1005 & TRN & & \\
\hline CHEMBL3976977 & 1641706 & 8.2218 & 8.4886 & TRN & & \\
\hline CHEMBL 3965448 & 1641706 & 10.0 & 8.6748 & TRN & & \\
\hline CHEMBL 3984300 & 1641706 & 9.2218 & 8.8233 & TRN & & \\
\hline CHEMBL 3894399 & 1641706 & 6.098 & 6.4698 & TRN & & \\
\hline CHEMBL 3935178 & 1641706 & 9.2218 & 8.7618 & TRN & & \\
\hline CHEMBL 3892613 & 1641706 & 7.6778 & 7.841 & TRN & & \\
\hline CHEMBL 3952926 & 1641706 & 7.6778 & 8.023 & TRN & & \\
\hline CHEMBL3923485 & 1641706 & 7.4318 & 6.8314 & TRN & & \\
\hline
\end{tabular}


Supplemental Table S2.txt

\begin{tabular}{|c|c|c|c|c|c|}
\hline CHEMBL3910324 & 1641706 & 6.0701 & 6.4469 & TRN & \\
\hline CHEMBL 3908774 & 1641706 & 7.7959 & 7.579 & TRN & \\
\hline CHEMBL3951449 & 1641706 & 6.4976 & 6.5638 & TRN & \\
\hline CHEMBL3973507 & 1641706 & 6.8894 & 7.7842 & TST & \\
\hline CHEMBL 3894605 & 1641706 & 6.0894 & 6.6503 & TST & \\
\hline CHEMBL3947883 & 1641706 & 6.6289 & 6.6264 & TRN & \\
\hline CHEMBL3912439 & 1641706 & 7.5686 & 7.3728 & TRN & \\
\hline CHEMBL3973996 & 1641706 & 7.2441 & 7.0945 & TST & \\
\hline CHEMBL3932521 & 1641706 & 6.0 & 5.8182 & TRN & \\
\hline CHEMBL3919665 & 1641706 & 6.0 & 6.0692 & TST & \\
\hline CHEMBL 3906220 & 1641706 & 6.7905 & 6.5232 & TRN & \\
\hline CHEMBL3929513 & 1641706 & 9.301 & 8.9995 & TRN & \\
\hline CHEMBL3961164 & 1641706 & 7.301 & 7.5806 & TRN & \\
\hline CHEMBL3949440 & 1641706 & 7.3768 & 7.3605 & TRN & \\
\hline CHEMBL3926399 & 1641706 & 6.0186 & 6.0698 & TRN & \\
\hline CHEMBL3889521 & 1641706 & 7.0506 & 7.2385 & TRN & \\
\hline CHEMBL3911561 & 1641706 & 6.7144 & 6.6712 & TRN & \\
\hline CHEMBL 3944525 & 1641706 & 7.2291 & 7.2296 & TST & \\
\hline CHEMBL 3973093 & 1641706 & $6.7570 e$ & 00000000 & 7.188 & TST \\
\hline CHEMBL 3893756 & 1641706 & 6.2832 & 6.3134 & TST & \\
\hline CHEMBL 3907084 & 1641706 & 4.8251 & 5.4915 & TST & \\
\hline CHEMBL3930514 & 1641706 & 6.4295 & 6.61700 & 0000000001 & TRN \\
\hline CHEMBL3976884 & 1641706 & 7.1135 & 7.0759 & TRN & \\
\hline CHEMBL 3936727 & 1641706 & 7.6778 & 8.0724 & TRN & \\
\hline CHEMBL3956730 & 1641706 & 6.2526 & 6.2708 & TRN & \\
\hline CHEMBL 3896424 & 1641706 & 6.9957 & 7.195 & TRN & \\
\hline CHEMBL3922799 & 1641706 & 8.3979 & 7.9168 & TRN & \\
\hline CHEMBL3939566 & 1641706 & 7.041 & 7.1865 & TRN & \\
\hline CHEMBL3930900 & 1641706 & 8.2218 & 8.5196 & TRN & \\
\hline CHEMBL3953692 & 1641706 & 6.3979 & 6.4412 & TST & \\
\hline CHEMBL3953419 & 1641706 & 6.5302 & 6.3686 & TRN & \\
\hline CHEMBL 3935528 & 1641706 & 6.6819 & 6.7013 & TRN & \\
\hline CHEMBL3933592 & 1641706 & 7.8239 & 7.8775 & TRN & \\
\hline CHEMBL3918828 & 1641706 & 7.2596 & 7.1297 & TRN & \\
\hline CHEMBL3962314 & 1641706 & 7.1427 & 7.41 & TST & \\
\hline CHEMBL3903806 & 1641706 & 5.9776 & 5.914 & TRN & \\
\hline CHEMBL3901593 & 1641706 & 8.0458 & 8.16 & TRN & \\
\hline CHEMBL3986976 & 1641706 & 8.5229 & 7.9215 & TRN & \\
\hline CHEMBL3909334 & 1641706 & 6.5528 & 6.5402 & TRN & \\
\hline CHEMBL3927951 & 1641706 & 6.7496 & 6.58200 & 0000000001 & TRN \\
\hline CHEMBL3935566 & 1641706 & 6.6819 & 6.4668 & TST & \\
\hline CHEMBL3902507 & 1641706 & 8.5229 & 7.791 & TST & \\
\hline CHEMBL 3896068 & 1641706 & 9.2218 & 9.4133 & TRN & \\
\hline CHEMBL3948069 & 1641706 & 7.699 & 8.0147 & TRN & \\
\hline CHEMBL3975786 & 1641706 & 7.1675 & 7.1962 & TRN & \\
\hline CHEMBL3325680 & 1457671 & 3.0 & 2.8853 & TRN & \\
\hline CHEMBL 3325681 & 1457671 & 3.0 & 2.8418 & TRN & \\
\hline CHEMBL3325840 & 1457671 & 5.301 & 3.6025 & TRN & \\
\hline
\end{tabular}


Supplemental Table S2.txt

\begin{tabular}{|c|c|c|c|c|}
\hline CHEMBL3325825 & 1457671 & 4.8239 & 3.9641 & TRN \\
\hline CHEMBL3325677 & 1457671 & 3.0 & 3.3416 & TRN \\
\hline CHEMBL3325674 & 1457671 & 3.0 & 3.3065 & TRN \\
\hline CHEMBL3325669 & 1457671 & 4.2007 & 3.6331 & TRN \\
\hline CHEMBL1922082 & 1457671 & 4.6021 & 3.4311 & TRN \\
\hline CHEMBL3325823 & 1457671 & 5.0458 & 4.657 & TRN \\
\hline CHEMBL3325682 & 1457671 & 3.0 & 2.8415 & TRN \\
\hline CHEMBL3325939 & 1457671 & 3.0 & 3.3149 & TRN \\
\hline CHEMBL3325684 & 1457671 & 3.0 & 3.5933 & TST \\
\hline CHEMBL351569 & 1457671 & 3.0 & 2.8662 & TRN \\
\hline CHEMBL3325822 & 1457671 & 4.9208 & 4.4948 & TRN \\
\hline CHEMBL3325949 & 1457671 & 4.6576 & 3.5422 & TRN \\
\hline CHEMBL3325950 & 1457671 & 3.0 & 3.5642 & TRN \\
\hline CHEMBL3325941 & 1457671 & 3.0 & 3.6446 & TRN \\
\hline CHEMBL1526476 & 1457671 & 3.0 & 2.778 & TRN \\
\hline CHEMBL3325937 & 1457671 & 5.0458 & 3.7625 & TRN \\
\hline CHEMBL3325675 & 1457671 & 3.0 & 3.5941 & TRN \\
\hline CHEMBL3325683 & 1457671 & 5.0458 & 3.1589 & TST \\
\hline CHEMBL3325837 & 1457671 & 3.0 & 3.7556 & TRN \\
\hline CHEMBL3325938 & 1457671 & 3.0 & 3.6624 & TRN \\
\hline CHEMBL3325835 & 1457671 & 3.0 & 3.1336 & TRN \\
\hline CHEMBL564201 & 1457671 & 5.9208 & 3.283 & TST \\
\hline CHEMBL3325821 & 1457671 & 3.0 & 4.4145 & TRN \\
\hline CHEMBL3325820 & 1457671 & 3.0 & 3.6312 & TRN \\
\hline CHEMBL2112432 & 1457671 & 3.0 & 3.338 & TST \\
\hline CHEMBL3325946 & 1457671 & 3.0 & 3.138 & TRN \\
\hline CHEMBL3325667 & 1457671 & 3.0 & 2.7796 & TRN \\
\hline CHEMBL3325685 & 1457671 & 3.0 & 3.5386 & TRN \\
\hline CHEMBL3325943 & 1457671 & 3.0 & 3.3409 & TRN \\
\hline CHEMBL3325944 & 1457671 & 3.0 & 2.9222 & TRN \\
\hline CHEMBL3325935 & 1457671 & 4.699 & 3.8575 & TRN \\
\hline CHEMBL3325953 & 1457671 & 3.0 & 3.0827 & TRN \\
\hline CHEMBL3325451 & 1457671 & 3.0 & 3.6562 & TRN \\
\hline CHEMBL3325945 & 1457671 & 3.0 & 3.3096 & TRN \\
\hline CHEMBL573352 & 1457671 & 3.0 & 3.3304 & TST \\
\hline CHEMBL3325676 & 1457671 & 3.0 & 3.4545 & TRN \\
\hline CHEMBL3327379 & 1457671 & 3.0 & 2.7969 & TRN \\
\hline CHEMBL3325686 & 1457671 & 4.1249 & 3.6245 & TRN \\
\hline CHEMBL3325833 & 1457671 & 3.0 & 3.2562 & TRN \\
\hline CHEMBL3325948 & 1457671 & 3.0 & 3.475 & TRN \\
\hline CHEMBL3325947 & 1457671 & 3.0 & 3.5222 & TRN \\
\hline CHEMBL3325690 & 1457671 & 3.0 & 3.1426 & TRN \\
\hline CHEMBL3325689 & 1457671 & 3.0 & 3.4304 & TRN \\
\hline CHEMBL3325936 & 1457671 & 3.0 & 3.3678 & TRN \\
\hline CHEMBL3325827 & 1457671 & 4.6021 & 4.0224 & TRN \\
\hline CHEMBL3325836 & 1457671 & 3.0 & 2.7122 & TRN \\
\hline CHEMBL3325834 & 1457671 & 3.0 & 2.9303 & TRN \\
\hline CHEMBL3325954 & 1457671 & 3.0 & 2.8672 & TST \\
\hline
\end{tabular}




\begin{tabular}{|c|c|c|c|c|c|}
\hline & & & & & \\
\hline CHEMBL3325688 & 1457671 & 3.0 & 3.1182 & TST & \\
\hline CHEMBL3325832 & 1457671 & 3.0 & 3.2094 & TST & \\
\hline CHEMBL3325838 & 1457671 & 3.0 & 3.824 & TST & \\
\hline CHEMBL3325839 & 1457671 & 3.0 & 4.0141 & TST & \\
\hline CHEMBL418899 & 1457671 & 3.0 & 3.227 & TST & \\
\hline CHEMBL3325668 & 1457671 & 3.0 & 3.4208 & TST & \\
\hline CHEMBL3325952 & 1457671 & 4.6576 & 2.8744 & TST & \\
\hline CHEMBL3325687 & 1457671 & 4.3979 & 3.4087 & TST & \\
\hline CHEMBL3325951 & 1457671 & 3.0 & 3.6111 & TST & \\
\hline CHEMBL2070958 & 835825 & 6.0 & 5.9573 & TRN & \\
\hline CHEMBL2070974 & 835825 & 3.5229 & 3.6307 & TRN & \\
\hline CHEMBL 2070988 & 835825 & 6.2218 & 6.2599 & TRN & \\
\hline CHEMBL2070989 & 835825 & 3.5229 & 3.6667 & TRN & \\
\hline CHEMBL2070981 & 835825 & 5.2125 & 3.9308 & TST & \\
\hline CHEMBL 2070960 & 835825 & 5.7496 & 5.8372 & TRN & \\
\hline CHEMBL2070955 & 835825 & 5.5867 & 5.6484 & TRN & \\
\hline CHEMBL2070983 & 835825 & 3.5229 & 5.1646 & TST & \\
\hline CHEMBL2070964 & 835825 & 6.0555 & 5.9219 & TRN & \\
\hline CHEMBL2071008 & 835825 & 3.5229 & 3.6037 & TRN & \\
\hline CHEMBL2070982 & 835825 & 5.0883 & 3.7418 & TST & \\
\hline CHEMBL2070953 & 835825 & 6.585 & 5.6211 & TRN & \\
\hline CHEMBL2071007 & 835825 & 3.5229 & 3.6627 & TRN & \\
\hline CHEMBL2070968 & 835825 & 6.1367 & 6.1171 & TRN & \\
\hline CHEMBL2071004 & 835825 & 5.8794 & 5.9996 & TRN & \\
\hline CHEMBL2070996 & 835825 & 3.5229 & 3.4067 & TRN & \\
\hline CHEMBL2070973 & 835825 & 3.5229 & 3.4996 & TRN & \\
\hline CHEMBL2070959 & 835825 & 5.767 & 5.7626 & TRN & \\
\hline CHEMBL2070976 & 835825 & 3.5229 & 3.3538 & TRN & \\
\hline CHEMBL2071009 & 835825 & 3.5229 & 3.50399 & 99999999996 & TRN \\
\hline CHEMBL2071010 & 835825 & 3.5229 & 3.5722 & TRN & \\
\hline CHEMBL2070993 & 835825 & 3.5229 & 2.7183 & TST & \\
\hline CHEMBL2070832 & 835825 & 5.8601 & 6.1442 & TRN & \\
\hline CHEMBL2070977 & 835825 & 5.0985 & 5.1781 & TST & \\
\hline CHEMBL2070965 & 835825 & 5.7878 & 5.6934 & TRN & \\
\hline CHEMBL2070961 & 835825 & 6.0915 & 6.1517 & TRN & \\
\hline CHEMBL2070956 & 835825 & 3.5229 & 3.4461 & TRN & \\
\hline CHEMBL 2070992 & 835825 & 3.5229 & 3.4553 & TST & \\
\hline CHEMBL2070986 & 835825 & 3.5229 & 3.4714 & TRN & \\
\hline CHEMBL2070980 & 835825 & 3.5229 & 3.5327 & TRN & \\
\hline CHEMBL2070987 & 835825 & 5.3585 & 5.3401 & TRN & \\
\hline CHEMBL2070954 & 835825 & 6.1549 & 6.2226 & TRN & \\
\hline CHEMBL 2070966 & 835825 & 5.9355 & 6.0477 & TRN & \\
\hline CHEMBL2070957 & 835825 & 5.3242 & 5.2144 & TRN & \\
\hline CHEMBL2070971 & 835825 & 3.5229 & 3.4929 & TRN & \\
\hline CHEMBL2071005 & 835825 & 3.5229 & 3.4392 & TRN & \\
\hline CHEMBL2071001 & 835825 & 3.5229 & 3.5558 & TRN & \\
\hline CHEMBL 2070969 & 835825 & 5.8508 & 5.7731 & TRN & \\
\hline CHEMBL2070975 & 835825 & 3.5229 & 3.6253 & TRN & \\
\hline
\end{tabular}


Supplemental Table S2.txt

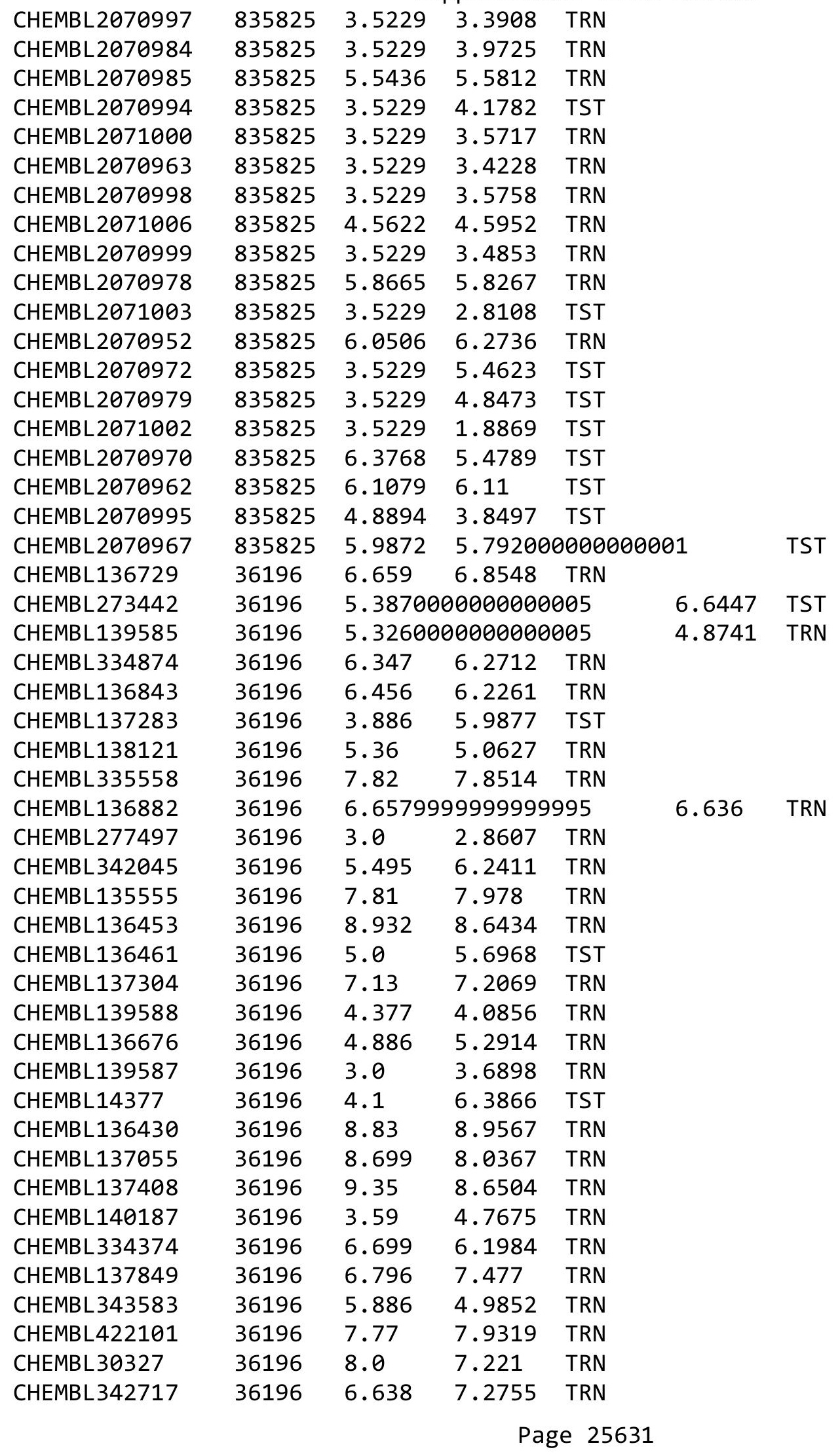




\begin{tabular}{|c|c|c|c|c|c|c|}
\hline & & \multicolumn{5}{|c|}{ Supplemental Table s2.txt } \\
\hline CHEMBL342696 & 36196 & 6.886 & 7.1173 & TST & & \\
\hline CHEMBL136222 & 36196 & 6.1 & 6.9033 & TST & & \\
\hline CHEMBL139414 & 36196 & 6.53 & 6.9615 & TRN & & \\
\hline CHEMBL337817 & 36196 & 4.07 & 4.5451 & TRN & & \\
\hline CHEMBL139204 & 36196 & 4.721 & 5.4137 & TRN & & \\
\hline CHEMBL136844 & 36196 & 6.0 & 5.9048 & TRN & & \\
\hline CHEMBL136129 & 36196 & 5.301 & 7.3067 & TST & & \\
\hline CHEMBL341968 & 36196 & 8.824 & 8.0323 & TRN & & \\
\hline CHEMBL137418 & 36196 & 4.699 & 4.8793 & TRN & & \\
\hline CHEMBL136496 & 36196 & 5.149 & 7.4645 & TST & & \\
\hline CHEMBL344919 & 36196 & 6.921 & 5.5346 & TRN & & \\
\hline CHEMBL137799 & 36196 & 4.553 & 6.2998 & TST & & \\
\hline CHEMBL136116 & 36196 & 6.553 & 6.9847 & TRN & & \\
\hline CHEMBL139202 & 36196 & 4.004 & 6.3559 & TST & & \\
\hline CHEMBL134683 & 36196 & 6.456 & 6.0318 & TRN & & \\
\hline CHEMBL135026 & 36196 & 7.032 & 7.5248 & TRN & & \\
\hline CHEMBL344922 & 36196 & 3.553 & 3.3076 & TRN & & \\
\hline CHEMBL136889 & 36196 & 5.081 & 6.0249 & TRN & & \\
\hline CHEMBL337805 & 36196 & 5.19 & 6.0415 & TRN & & \\
\hline CHEMBL136151 & 36196 & 4.796 & 6.7738 & TST & & \\
\hline CHEMBL136335 & 36196 & 7.149 & 6.91 & TRN & & \\
\hline CHEMBL137665 & 36196 & 8.18 & 8.1168 & TRN & & \\
\hline CHEMBL136570 & 36196 & 5.0 & 4.5868 & TRN & & \\
\hline CHEMBL342648 & 36196 & 6.699 & 6.4116 & TRN & & \\
\hline CHEMBL341816 & 36196 & 5.37 & 7.3883 & TST & & \\
\hline CHEMBL 343500 & 36196 & 3.609 & 4.2925 & TRN & & \\
\hline CHEMBL136782 & 36196 & 7.169 & 6.4061 & TRN & & \\
\hline CHEMBL336463 & 36196 & 7.6 & 7.4301 & TRN & & \\
\hline CHEMBL14328 & 36196 & \multicolumn{3}{|c|}{3.8539999999999996} & 5.5916 & TST \\
\hline CHEMBL137220 & 36196 & 7.1 & 7.3789 & TRN & & \\
\hline CHEMBL137620 & 36196 & 4.0 & 5.3886 & TST & & \\
\hline CHEMBL138223 & 36196 & 7.939 & 8.8763 & TRN & & \\
\hline CHEMBL136345 & 36196 & 5.886 & 6.0669 & TRN & & \\
\hline CHEMBL343049 & 36196 & 7.33 & 7.2885 & TRN & & \\
\hline CHEMBL136982 & 36196 & \multicolumn{3}{|c|}{5.5089999999999995} & 4.8124 & TRN \\
\hline CHEMBL137264 & 36196 & 5.041 & 6.7456 & TST & & \\
\hline CHEMBL136710 & 36196 & \multicolumn{3}{|c|}{7.3870000000000005} & 6.6428 & TRN \\
\hline CHEMBL336698 & 36196 & 5.959 & 6.6568 & TST & & \\
\hline CHEMBL134370 & 36196 & 6.398 & 6.0458 & TRN & & \\
\hline CHEMBL344161 & 36196 & 6.149 & 6.9201 & TST & & \\
\hline CHEMBL137662 & 36196 & 4.85 & 6.3136 & TST & & \\
\hline CHEMBL136184 & 36196 & \multicolumn{3}{|c|}{6.6579999999999995} & 6.6865 & TST \\
\hline CHEMBL137477 & 36196 & 6.699 & 6.474 & TRN & & \\
\hline CHEMBL343494 & 36196 & 6.569 & 7.1673 & TRN & & \\
\hline CHEMBL420367 & 627868 & 7.34 & 7.3446 & TRN & & \\
\hline CHEMBL69674 & 627868 & 6.79 & 6.773 & TRN & & \\
\hline CHEMBL167498 & 627868 & 4.3 & 4.2521 & TRN & & \\
\hline CHEMBL1094318 & 627868 & 5.0 & 5.0524 & TRN & & \\
\hline
\end{tabular}




\begin{tabular}{|c|c|c|c|c|c|}
\hline \multicolumn{6}{|c|}{ Supplemental Table S2.txt } \\
\hline CHEMBL1096921 & 627868 & 5.0 & 4.9977 & TRN & \\
\hline CHEMBL348749 & 627868 & 4.64 & 4.6253 & TRN & \\
\hline CHEMBL68175 & 627868 & 4.49 & 4.4614 & TRN & \\
\hline CHEMBL308222 & 627868 & 6.17 & 6.2027 & TRN & \\
\hline CHEMBL66704 & 627868 & 5.66 & 5.6373 & TRN & \\
\hline CHEMBL163883 & 627868 & 4.13 & 4.1168 & TRN & \\
\hline CHEMBL69775 & 627868 & 4.9 & 4.9149 & TRN & \\
\hline CHEMBL168190 & 627868 & 3.74 & 3.7373 & TRN & \\
\hline CHEMBL304317 & 627868 & 4.32 & 4.3247 & TRN & \\
\hline CHEMBL163910 & 627868 & 4.08 & 4.0794 & TRN & \\
\hline CHEMBL69517 & 627868 & 4.92 & 4.87 & TRN & \\
\hline CHEMBL420740 & 627868 & 6.84 & 6.7132 & TRN & \\
\hline CHEMBL307994 & 627868 & 6.79 & 6.8861 & TRN & \\
\hline CHEMBL65800 & 627868 & 5.61 & 5.67399 & 99999999995 & TRN \\
\hline CHEMBL65881 & 627868 & 7.11 & 7.1289 & TRN & \\
\hline CHEMBL66155 & 627868 & 7.92 & 8.0133 & TRN & \\
\hline CHEMBL304294 & 627868 & 7.64 & 7.5592 & TRN & \\
\hline CHEMBL1097948 & 627868 & 4.25 & 4.2375 & TRN & \\
\hline CHEMBL521132 & 627868 & 4.87 & 4.801 & TRN & \\
\hline CHEMBL349202 & 627868 & 4.3 & 5.345 & TST & \\
\hline CHEMBL1097196 & 627868 & 5.0 & 5.8859 & TST & \\
\hline CHEMBL164075 & 627868 & 6.32 & 6.3187 & TRN & \\
\hline CHEMBL1098605 & 627868 & 4.59 & 4.6152 & TRN & \\
\hline CHEMBL482872 & 627868 & 5.42 & 6.1224 & TST & \\
\hline CHEMBL353913 & 627868 & 5.7 & 6.7359 & TST & \\
\hline CHEMBL82396 & 627868 & 6.74 & 6.735 & TRN & \\
\hline CHEMBL293498 & 627868 & 7.37 & 7.3471 & TRN & \\
\hline CHEMBL483280 & 627868 & 7.47 & 7.472 & TRN & \\
\hline CHEMBL487502 & 627868 & 7.22 & 7.3098 & TRN & \\
\hline CHEMBL66377 & 627868 & 4.22 & 4.0483 & TRN & \\
\hline CHEMBL67451 & 627868 & 5.78 & 5.8394 & TRN & \\
\hline CHEMBL65801 & 627868 & 4.46 & 4.6557 & TRN & \\
\hline CHEMBL292197 & 627868 & 5.48 & 5.5267 & TRN & \\
\hline CHEMBL1098620 & 627868 & 7.58 & 7.4024 & TRN & \\
\hline CHEMBL1097200 & 627868 & 4.9 & 4.9603 & TRN & \\
\hline CHEMBL1098621 & 627868 & 4.33 & 4.2912 & TRN & \\
\hline CHEMBL521231 & 627868 & 4.05 & 4.0973 & TRN & \\
\hline CHEMBL1098622 & 627868 & 4.43 & 4.4144 & TRN & \\
\hline CHEMBL353986 & 627868 & 4.15 & 4.1717 & TRN & \\
\hline CHEMBL520711 & 627868 & 4.0 & 4.0093 & TRN & \\
\hline CHEMBL58119 & 627868 & 8.24 & 8.2081 & TRN & \\
\hline CHEMBL58952 & 627868 & 7.32 & 7.34399 & 9999999999 & TRN \\
\hline CHEMBL354989 & 627868 & 8.52 & 8.5268 & TRN & \\
\hline CHEMBL59279 & 627868 & 7.87 & 7.8193 & TRN & \\
\hline CHEMBL433931 & 627868 & 7.47 & 7.5695 & TST & \\
\hline CHEMBL293814 & 627868 & 7.59 & 7.6246 & TRN & \\
\hline CHEMBL293271 & 627868 & 5.94 & 6.2899 & TST & \\
\hline CHEMBL58506 & 627868 & 7.25 & 7.4387 & TST & \\
\hline
\end{tabular}




\begin{tabular}{|c|c|c|c|c|}
\hline \multicolumn{5}{|c|}{ Supplemental Table S2.txt } \\
\hline CHEMBL58493 & 627868 & 6.0 & 6.5457 & TST \\
\hline CHEMBL353297 & 627868 & 5.33 & 6.4583 & TST \\
\hline CHEMBL166769 & 627868 & 5.18 & 5.3396 & TST \\
\hline CHEMBL432516 & 627868 & 5.97 & 7.2703 & TST \\
\hline CHEMBL58453 & 627868 & 6.73 & 7.6814 & TST \\
\hline CHEMBL167851 & 627868 & 7.06 & 6.6044 & TST \\
\hline CHEMBL352425 & 627868 & 7.32 & 7.7804 & TST \\
\hline CHEMBL298626 & 627868 & 6.36 & 6.6519 & TST \\
\hline CHEMBL58811 & 627868 & 7.53 & 7.7513 & TST \\
\hline CHEMBL256918 & 467656 & 8.301 & 7.9656 & TRN \\
\hline CHEMBL256324 & 467656 & 6.1249 & 5.9491 & TRN \\
\hline CHEMBL256323 & 467656 & 6.585 & 6.6721 & TRN \\
\hline CHEMBL403642 & 467656 & 6.6021 & 6.7216 & TRN \\
\hline CHEMBL399631 & 467656 & 6.3979 & 6.3079 & TST \\
\hline CHEMBL436646 & 467656 & 5.8239 & 5.9005 & TRN \\
\hline CHEMBL259995 & 467656 & 8.301 & 8.2416 & TRN \\
\hline CHEMBL402125 & 467656 & 6.8239 & 7.0131 & TRN \\
\hline CHEMBL254163 & 467656 & 6.8539 & 6.8071 & TRN \\
\hline CHEMBL 260084 & 467656 & 6.0969 & 6.0992 & TRN \\
\hline CHEMBL255239 & 467656 & 7.3872 & 7.3496 & TRN \\
\hline CHEMBL411407 & 467656 & 8.0458 & 8.2065 & TRN \\
\hline CHEMBL265924 & 467656 & 7.699 & 7.6259 & TRN \\
\hline CHEMBL256741 & 467656 & 7.0969 & 7.4337 & TRN \\
\hline CHEMBL 255441 & 467656 & 4.7959 & 4.6702 & TRN \\
\hline CHEMBL255901 & 467656 & 8.0969 & 7.4011 & TST \\
\hline CHEMBL261697 & 467656 & 7.2218 & 7.3238 & TRN \\
\hline CHEMBL259349 & 467656 & 6.9208 & 6.9639 & TRN \\
\hline CHEMBL411288 & 467656 & 7.6198 & 7.5636 & TRN \\
\hline CHEMBL253963 & 467656 & 7.3372 & 7.3439 & TRN \\
\hline CHEMBL262327 & 467656 & 6.4437 & 6.535 & TRN \\
\hline CHEMBL261300 & 467656 & 8.301 & 8.4592 & TRN \\
\hline CHEMBL258027 & 467656 & 6.7212 & 6.8613 & TRN \\
\hline CHEMBL401769 & 467656 & 5.3188 & 6.0461 & TST \\
\hline CHEMBL402191 & 467656 & 5.7447 & 5.53 & TRN \\
\hline CHEMBL 257195 & 467656 & 7.8239 & 7.1906 & TRN \\
\hline CHEMBL256949 & 467656 & 7.1612 & 7.2645 & TRN \\
\hline CHEMBL 265447 & 467656 & 5.8239 & 5.8614 & TRN \\
\hline CHEMBL257409 & 467656 & 7.3665 & 7.4803 & TRN \\
\hline CHEMBL258236 & 467656 & 7.3979 & 7.0003 & TRN \\
\hline CHEMBL261698 & 467656 & 7.5229 & 7.5111 & TRN \\
\hline CHEMBL255240 & 467656 & 4.9586 & 5.1196 & TRN \\
\hline CHEMBL410688 & 467656 & 6.7959 & 6.8151 & TRN \\
\hline CHEMBL258028 & 467656 & 5.4815 & 5.9221 & TRN \\
\hline CHEMBL 261298 & 467656 & 7.7212 & 7.8239 & TRN \\
\hline CHEMBL261686 & 467656 & 4.8239 & 4.7605 & TRN \\
\hline CHEMBL409248 & 467656 & 8.3979 & 7.9946 & TRN \\
\hline CHEMBL260083 & 467656 & 5.983 & 5.9741 & TST \\
\hline CHEMBL408675 & 467656 & 7.6383 & 7.0576 & TST \\
\hline
\end{tabular}


Supplemental Table S2.txt

\begin{tabular}{|c|c|c|c|c|c|}
\hline CHEMBL 259741 & 467656 & 8.0969 & 8.2171 & TRN & \\
\hline CHEMBL401595 & 467656 & 6.8861 & 6.8705 & TRN & \\
\hline CHEMBL259781 & 467656 & 8.1549 & 7.5915 & TST & \\
\hline CHEMBL409672 & 467656 & 6.3872 & 6.9114 & TST & \\
\hline CHEMBL 258899 & 467656 & 6.0915 & 6.6167 & TST & \\
\hline CHEMBL262065 & 467656 & 6.2518 & 5.8616 & TST & \\
\hline CHEMBL410687 & 467656 & 7.0 & 6.7479 & TST & \\
\hline CHEMBL 257408 & 467656 & 7.7959 & 7.7765 & TRN & \\
\hline CHEMBL 265190 & 467656 & 6.2757 & 6.2647 & TST & \\
\hline CHEMBL 258459 & 467656 & 7.7959 & 7.772 & TRN & \\
\hline CHEMBL402906 & 467656 & 6.3768 & 6.3047 & TRN & \\
\hline CHEMBL403641 & 467656 & 7.4685 & 7.8441 & TRN & \\
\hline CHEMBL401825 & 467656 & 8.301 & 8.0382 & TST & \\
\hline CHEMBL 256948 & 467656 & 7.4949 & 7.6289 & TRN & \\
\hline CHEMBL 260255 & 467656 & 5.9586 & 6.311 & TST & \\
\hline CHEMBL 258237 & 467656 & 6.1192 & 6.0551 & TRN & \\
\hline CHEMBL 259335 & 467656 & 6.6778 & 5.9381 & TST & \\
\hline CHEMBL402234 & 467656 & 8.1549 & 8.0214 & TRN & \\
\hline CHEMBL403189 & 467656 & 8.1549 & 7.9963 & TRN & \\
\hline CHEMBL 254164 & 467656 & 6.9586 & 5.3531 & TST & \\
\hline CHEMBL355453 & 70137 & 6.0706 & 6.1925 & TRN & \\
\hline CHEMBL352653 & 70137 & 6.2757 & 5.7599 & TST & \\
\hline CHEMBL354331 & 70137 & 5.4318 & 5.88700 & 00000000005 & TRN \\
\hline CHEMBL353906 & 70137 & 6.0458 & 5.90799 & 99999999995 & TRN \\
\hline CHEMBL170428 & 70137 & 5.9788 & 6.1521 & TRN & \\
\hline CHEMBL355717 & 70137 & 6.0 & 5.5257 & TRN & \\
\hline CHEMBL170295 & 70137 & 4.399 & 5.1624 & TST & \\
\hline CHEMBL144031 & 70137 & 6.0 & 6.0254 & TRN & \\
\hline CHEMBL170014 & 70137 & 5.2441 & 5.5935 & TRN & \\
\hline CHEMBL169130 & 70137 & 5.4437 & 5.0084 & TRN & \\
\hline CHEMBL171785 & 70137 & 5.301 & 5.5897 & TRN & \\
\hline CHEMBL422723 & 70137 & 5.3098 & 5.254 & TRN & \\
\hline CHEMBL 366550 & 70137 & 6.2007 & 6.5936 & TRN & \\
\hline CHEMBL171097 & 70137 & 5.7696 & 6.575 & TRN & \\
\hline CHEMBL352930 & 70137 & 6.0315 & 5.4169 & TRN & \\
\hline CHEMBL355632 & 70137 & 5.6198 & 5.4885 & TRN & \\
\hline CHEMBL 354427 & 70137 & 4.9208 & 4.61 & TST & \\
\hline CHEMBL367172 & 70137 & 6.4559 & 6.0802 & TRN & \\
\hline CHEMBL 334749 & 70137 & 6.0 & 5.7 & TRN & \\
\hline CHEMBL171751 & 70137 & 4.9393 & 5.106 & TRN & \\
\hline CHEMBL170891 & 70137 & 5.1871 & 5.2943 & TRN & \\
\hline CHEMBL 341393 & 70137 & 5.301 & 5.1759 & TRN & \\
\hline CHEMBL172397 & 70137 & 5.1549 & 5.4156 & TRN & \\
\hline CHEMBL 305798 & 70137 & 6.0 & 5.9769 & TRN & \\
\hline CHEMBL172580 & 70137 & 4.9547 & 4.9705 & TRN & \\
\hline CHEMBL368295 & 70137 & 6.4202 & 6.3322 & TRN & \\
\hline CHEMBL171484 & 70137 & 5.6576 & 5.2646 & TRN & \\
\hline CHEMBL171938 & 70137 & 5.2924 & 4.9004 & TRN & \\
\hline
\end{tabular}




\begin{tabular}{|c|c|c|c|c|}
\hline & & & oplement & al $\mathrm{Tc}$ \\
\hline CHEMBL 311310 & 70137 & 5.4318 & 5.6188 & TRN \\
\hline CHEMBL172097 & 70137 & 5.8239 & 6.1207 & TST \\
\hline CHEMBL354221 & 70137 & 6.0506 & 5.8125 & TRN \\
\hline CHEMBL354588 & 70137 & 7.6021 & 6.727 & TRN \\
\hline CHEMBL 336370 & 70137 & 5.8861 & 4.8583 & TST \\
\hline CHEMBL172779 & 70137 & 6.0 & 5.5179 & TST \\
\hline CHEMBL171463 & 70137 & 6.3468 & 5.4806 & TRN \\
\hline CHEMBL352727 & 70137 & 5.2218 & 5.3619 & TRN \\
\hline CHEMBL171186 & 70137 & 3.699 & 4.3365 & TRN \\
\hline CHEMBL170887 & 70137 & 5.2366 & 5.3981 & TRN \\
\hline CHEMBL169867 & 70137 & 6.2218 & 6.4701 & TST \\
\hline CHEMBL 335871 & 70137 & 4.9208 & 5.1764 & TRN \\
\hline CHEMBL355534 & 70137 & 5.2147 & 5.4338 & TRN \\
\hline CHEMBL 336597 & 70137 & 4.9788 & 5.0545 & TST \\
\hline CHEMBL172387 & 70137 & 6.3468 & 6.1009 & TST \\
\hline CHEMBL355335 & 70137 & 5.301 & 5.3712 & TRN \\
\hline CHEMBL369047 & 70137 & 6.1249 & 6.0253 & TST \\
\hline CHEMBL169934 & 70137 & 4.301 & 5.8936 & TST \\
\hline CHEMBL352918 & 70137 & 6.0 & 6.1022 & TST \\
\hline CHEMBL425133 & 70137 & 5.4318 & 5.6694 & TRN \\
\hline CHEMBL354747 & 70137 & 6.2291 & 6.1396 & TST \\
\hline CHEMBL171443 & 70137 & 5.2924 & 5.7466 & TRN \\
\hline CHEMBL331467 & 646857 & 4.0809 & 3.9941 & TRN \\
\hline CHEMBL 333481 & 646857 & 5.3979 & 5.1786 & TRN \\
\hline CHEMBL1214243 & 646857 & 4.6383 & 3.8526 & TST \\
\hline CHEMBL128441 & 646857 & 4.7212 & 4.7081 & TRN \\
\hline CHEMBL119649 & 646857 & 5.699 & 5.8966 & TRN \\
\hline CHEMBL440898 & 646857 & 4.4949 & 4.7864 & TRN \\
\hline CHEMBL118343 & 646857 & 4.4949 & 4.4884 & TRN \\
\hline CHEMBL129569 & 646857 & 5.5229 & 5.604 & TRN \\
\hline CHEMBL1213124 & 646857 & 4.1549 & 4.2098 & TRN \\
\hline CHEMBL118916 & 646857 & 4.9208 & 4.9409 & TRN \\
\hline CHEMBL418484 & 646857 & 5.0 & 4.1665 & TST \\
\hline CHEMBL1213461 & 646857 & 4.4949 & 4.53 & TRN \\
\hline CHEMBL117064 & 646857 & 5.3979 & 5.2525 & TRN \\
\hline CHEMBL339048 & 646857 & 4.7212 & 4.4239 & TRN \\
\hline CHEMBL132400 & 646857 & 4.8861 & 4.9176 & TRN \\
\hline CHEMBL115433 & 646857 & 4.7959 & 4.6786 & TRN \\
\hline CHEMBL128963 & 646857 & 5.0969 & 5.1817 & TRN \\
\hline CHEMBL118855 & 646857 & 5.2218 & 5.1415 & TRN \\
\hline CHEMBL131783 & 646857 & 4.3979 & 4.0686 & TST \\
\hline CHEMBL338108 & 646857 & 4.8239 & 4.7912 & TRN \\
\hline CHEMBL1214241 & 646857 & 6.0 & 3.9544 & TST \\
\hline CHEMBL1214242 & 646857 & 6.0 & 3.8207 & TST \\
\hline CHEMBL340459 & 646857 & 4.9586 & 4.8435 & TRN \\
\hline CHEMBL118066 & 646857 & 4.7959 & 4.914 & TRN \\
\hline CHEMBL337943 & 646857 & 4.8239 & 4.7176 & TRN \\
\hline CHEMBL1213463 & 646857 & 4.4949 & 4.5769 & TRN \\
\hline
\end{tabular}




\begin{tabular}{|c|c|c|c|c|c|c|}
\hline \multicolumn{7}{|c|}{ Supplemental Table S2.txt } \\
\hline CHEMBL324315 & 646857 & 5.1549 & 4.2663 & TST & & \\
\hline CHEMBL128274 & 646857 & 4.2218 & 4.2119 & TRN & & \\
\hline CHEMBL1213123 & 646857 & 4.1549 & 4.186 & TRN & & \\
\hline CHEMBL1214311 & 646857 & 6.0 & 4.2551 & TST & & \\
\hline CHEMBL432423 & 646857 & 5.3979 & 5.263 & TRN & & \\
\hline CHEMBL340280 & 646857 & 4.7959 & 4.8337 & TRN & & \\
\hline CHEMBL340651 & 646857 & 4.2076 & 4.28 & TRN & & \\
\hline CHEMBL1213993 & 646857 & 4.0915 & 4.1302 & TST & & \\
\hline CHEMBL128504 & 646857 & 4.7212 & 4.74 & TRN & & \\
\hline CHEMBL129012 & 646857 & 4.4815 & 4.6453 & TRN & & \\
\hline CHEMBL131616 & 646857 & 4.699 & 4.6625 & TRN & & \\
\hline CHEMBL1214312 & 646857 & 4.301 & 4.0074 & TST & & \\
\hline CHEMBL331616 & 646857 & 4.1805 & 4.618 & TST & & \\
\hline CHEMBL 332479 & 646857 & 4.7212 & 4.4419 & TST & & \\
\hline CHEMBL119102 & 646857 & 4.4949 & 4.6485 & TRN & & \\
\hline CHEMBL1214310 & 646857 & 4.1871 & 4.0011 & TST & & \\
\hline CHEMBL128211 & 646857 & 4.3372 & 4.2624 & TRN & & \\
\hline CHEMBL127668 & 646857 & 4.9208 & 4.9182 & TRN & & \\
\hline CHEMBL119475 & 646857 & 4.4949 & 4.4868 & TRN & & \\
\hline CHEMBL332122 & 646857 & 3.9393 & 3.9657 & TST & & \\
\hline CHEMBL338406 & 646857 & 4.7696 & 4.9541 & TRN & & \\
\hline CHEMBL39581 & 646857 & 5.699 & 4.9613 & TRN & & \\
\hline CHEMBL128021 & 646857 & 4.4949 & 4.6574 & TRN & & \\
\hline CHEMBL131106 & 646857 & 4.2218 & 4.5482 & TRN & & \\
\hline CHEMBL118703 & 646857 & 4.0177 & 4.3147 & TST & & \\
\hline CHEMBL1213462 & 646857 & 6.0 & 5.8456 & TRN & & \\
\hline CHEMBL118340 & 646857 & 4.7447 & 4.8929 & TRN & & \\
\hline CHEMBL485019 & 646857 & 4.7696 & 4.9812 & TRN & & \\
\hline CHEMBL1213034 & 646857 & 5.0 & 5.0452 & TRN & & \\
\hline CHEMBL340071 & 646857 & 4.7959 & 4.6054 & TRN & & \\
\hline CHEMBL128180 & 646857 & 4.0 & 4.3095 & TRN & & \\
\hline CHEMBL1213253 & 646857 & 4.3768 & 4.4678 & TST & & \\
\hline CHEMBL1213173 & 646857 & 4.1549 & 3.9225 & TRN & & \\
\hline CHEMBL1214240 & 646857 & 6.0 & 3.8066 & TST & & \\
\hline CHEMBL117831 & 646857 & 4.4949 & 4.4344 & TRN & & \\
\hline CHEMBL1516890 & 954641 & 3.8105 & 3.8099 & TRN & & \\
\hline CHEMBL 209148 & 954641 & 4.0975 & 4.0981 & TRN & & \\
\hline CHEMBL259181 & 954641 & 3.0706 & 3.0716 & TRN & & \\
\hline CHEMBL412142 & 954641 & 5.5113 & 5.5115 & TRN & & \\
\hline CHEMBL258844 & 954641 & 4.3938 & 4.3931 & TRN & & \\
\hline CHEMBL3349342 & 954641 & 5.3283 & 5.3296 & TRN & & \\
\hline CHEMBL472940 & 954641 & 3.06600 & 30000000 & 003 & 3.0639999999999996 & TRN \\
\hline CHEMBL2363137 & 954641 & 5.5882 & 5.5877 & TRN & & \\
\hline CHEMBL1186585 & 954641 & 3.9137 & 3.9147 & TRN & & \\
\hline CHEMBL 379300 & 954641 & 6.5834 & 6.5825 & TRN & & \\
\hline CHEMBL 9470 & 954641 & 5.5679 & 5.5915 & TST & & \\
\hline CHEMBL483849 & 954641 & 2.5961 & 2.5959 & TRN & & \\
\hline CHEMBL1788116 & 954641 & 4.405 & 4.4035 & TRN & & \\
\hline
\end{tabular}


Supplemental Table S2.txt

\begin{tabular}{|c|c|c|c|c|c|}
\hline CHEMBL1357247 & 954641 & 4.4214 & 4.4213 & TRN & \\
\hline CHEMBL 240954 & 954641 & 2.7394 & 4.6423 & TST & \\
\hline CHEMBL1643959 & 954641 & 4.2089 & 4.2098 & TRN & \\
\hline CHEMBL2005886 & 954641 & 5.9823 & 5.984 & TRN & \\
\hline CHEMBL573107 & 954641 & 5.0233 & 5.0211 & TRN & \\
\hline CHEMBL92309 & 954641 & 2.9447 & 3.1197 & TST & \\
\hline CHEMBL577784 & 954641 & 4.527 & 4.5284 & TRN & \\
\hline CHEMBL300389 & 954641 & 6.2538 & 6.2529 & TRN & \\
\hline CHEMBL585951 & 954641 & 6.3552 & 6.3558 & TRN & \\
\hline CHEMBL392695 & 954641 & 3.6612 & 3.6597 & TRN & \\
\hline CHEMBL221137 & 954641 & 4.9643 & 4.8848 & TST & \\
\hline CHEMBL1256459 & 954641 & 7.0114 & 7.0123 & TRN & \\
\hline CHEMBL509032 & 954641 & 5.8772 & 5.8772 & TRN & \\
\hline CHEMBL189584 & 954641 & 5.3678 & 5.3674 & TRN & \\
\hline CHEMBL3392440 & 954641 & 4.1708 & 4.1694 & TRN & \\
\hline CHEMBL512504 & 954641 & 4.0184 & 4.6453 & TST & \\
\hline CHEMBL135561 & 954641 & 4.7891 & 4.7886 & TRN & \\
\hline CHEMBL515416 & 954641 & 4.6432 & 4.6438 & TRN & \\
\hline CHEMBL151176 & 954641 & 6.3125 & 6.3137 & TRN & \\
\hline CHEMBL1404918 & 954641 & 2.7801 & 2.7808 & TRN & \\
\hline CHEMBL514499 & 954641 & 5.5687 & 5.5713 & TRN & \\
\hline CHEMBL188678 & 954641 & 5.3557 & 5.3509 & TRN & \\
\hline CHEMBL558642 & 954641 & 4.7534 & 4.7548 & TRN & \\
\hline CHEMBL1970879 & 954641 & 5.9401 & 5.9368 & TRN & \\
\hline CHEMBL222102 & 954641 & 4.7027 & 4.7099 & TRN & \\
\hline CHEMBL191334 & 954641 & 4.1142 & 4.1136 & TRN & \\
\hline CHEMBL210618 & 954641 & 2.8809 & 2.8822 & TRN & \\
\hline CHEMBL 255342 & 954641 & 3.6846 & 3.6853 & TRN & \\
\hline CHEMBL1190711 & 954641 & 3.5632 & 3.5617 & TRN & \\
\hline CHEMBL65 & 954641 & 7.8139 & 7.8139 & TRN & \\
\hline CHEMBL483847 & 954641 & 4.5181 & 4.51699 & 99999999995 & TRN \\
\hline CHEMBL202721 & 954641 & 4.6298 & 4.6288 & TRN & \\
\hline CHEMBL1242367 & 954641 & 3.7562 & 4.744 & TST & \\
\hline CHEMBL3199475 & 954641 & 5.0142 & 4.3974 & TST & \\
\hline CHEMBL393929 & 954641 & 4.9858 & 4.084 & TST & \\
\hline CHEMBL1230020 & 954641 & 4.6475 & 4.7212 & TST & \\
\hline CHEMBL449158 & 954641 & 6.4951 & 7.3373 & TST & \\
\hline CHEMBL1909414 & 954641 & 3.2638 & 3.6813 & TST & \\
\hline CHEMBL102714 & 954641 & 4.4659 & 4.2374 & TST & \\
\hline CHEMBL 213100 & 954641 & 8.8969 & 6.0586 & TST & \\
\hline CHEMBL192566 & 954641 & 6.6065 & 6.8213 & TST & \\
\hline CHEMBL1802587 & 755797 & 5.0969 & 6.2932 & TST & \\
\hline CHEMBL1802590 & 755797 & 6.1024 & 6.3922 & TST & \\
\hline CHEMBL1802822 & 755797 & 5.8239 & 5.2897 & TRN & \\
\hline CHEMBL1802602 & 755797 & 7.9208 & 6.6208 & TRN & \\
\hline CHEMBL1802585 & 755797 & 5.9586 & 6.2747 & TST & \\
\hline CHEMBL1802832 & 755797 & 7.0177 & 7.0605 & TRN & \\
\hline CHEMBL1802827 & 755797 & 5.2596 & 6.666 & TRN & \\
\hline
\end{tabular}




\begin{tabular}{|c|c|c|c|c|c|}
\hline \multicolumn{6}{|c|}{ Supplemental Table S } \\
\hline CHEMBL1802604 & 755797 & 6.4437 & 6.7184 & TST & \\
\hline CHEMBL1802906 & 755797 & 7.9208 & 6.8068 & TRN & \\
\hline CHEMBL1802905 & 755797 & 6.1249 & 6.3675 & TRN & \\
\hline CHEMBL1803004 & 755797 & 5.6021 & 5.1979 & TRN & \\
\hline CHEMBL1802831 & 755797 & 6.5376 & 7.1741 & TST & \\
\hline CHEMBL1802824 & 755797 & 5.0458 & 5.1568 & TRN & \\
\hline CHEMBL1802909 & 755797 & 7.1249 & 7.0681 & TRN & \\
\hline CHEMBL1802600 & 755797 & 6.6778 & 5.9411 & TRN & \\
\hline CHEMBL1802596 & 755797 & 5.6021 & 5.5592 & TRN & \\
\hline CHEMBL1802912 & 755797 & 7.5528 & 6.96899 & 9999999999 & TRN \\
\hline CHEMBL1802836 & 755797 & 7.699 & 7.1336 & TRN & \\
\hline CHEMBL1802586 & 755797 & 5.699 & 6.3241 & TST & \\
\hline CHEMBL1802595 & 755797 & 6.1249 & 5.7661 & TRN & \\
\hline CHEMBL1802826 & 755797 & 6.2366 & 6.6625 & TRN & \\
\hline CHEMBL1802911 & 755797 & 7.1487 & 6.9104 & TRN & \\
\hline CHEMBL1802589 & 755797 & 6.8539 & 6.399 & TST & \\
\hline CHEMBL1802903 & 755797 & 7.9208 & 7.3292 & TRN & \\
\hline CHEMBL1802599 & 755797 & 5.8239 & 5.891 & TRN & \\
\hline CHEMBL1802829 & 755797 & 7.0969 & 7.0647 & TRN & \\
\hline CHEMBL1802588 & 755797 & 6.1192 & 6.1322 & TST & \\
\hline CHEMBL1802606 & 755797 & 6.4318 & 6.728 & TRN & \\
\hline CHEMBL1802825 & 755797 & 5.6383 & 6.7919 & TRN & \\
\hline CHEMBL1802828 & 755797 & 5.1367 & 6.7683 & TRN & \\
\hline CHEMBL1802823 & 755797 & 5.0458 & 5.2443 & TRN & \\
\hline CHEMBL1802904 & 755797 & 7.1308 & 7.3058 & TRN & \\
\hline CHEMBL1802605 & 755797 & 7.0969 & 6.811 & TRN & \\
\hline CHEMBL1802591 & 755797 & 5.699 & 6.1209 & TST & \\
\hline CHEMBL1802592 & 755797 & 5.0458 & 5.34 & TRN & \\
\hline CHEMBL1800104 & 755797 & 6.0 & 6.893 & TRN & \\
\hline CHEMBL1802915 & 755797 & 6.6778 & 7.2317 & TRN & \\
\hline CHEMBL1802914 & 755797 & 7.2757 & 7.2496 & TRN & \\
\hline CHEMBL1802835 & 755797 & 7.0706 & 7.0893 & TRN & \\
\hline CHEMBL1802907 & 755797 & 7.9208 & 6.8739 & TRN & \\
\hline CHEMBL1802913 & 755797 & 7.2366 & 7.1985 & TRN & \\
\hline CHEMBL1802908 & 755797 & 6.9586 & 6.9778 & TRN & \\
\hline CHEMBL1802598 & 755797 & 5.2596 & 6.0039 & TRN & \\
\hline CHEMBL1802593 & 755797 & 5.2757 & 5.4895 & TRN & \\
\hline CHEMBL1802834 & 755797 & 7.3979 & 6.981 & TRN & \\
\hline CHEMBL1802603 & 755797 & 6.9586 & 6.7919 & TRN & \\
\hline CHEMBL1802601 & 755797 & 5.8539 & 5.9057 & TRN & \\
\hline CHEMBL1802910 & 755797 & 5.9208 & 6.5317 & TST & \\
\hline CHEMBL1802833 & 755797 & 7.5686 & 7.0177 & TST & \\
\hline CHEMBL1802597 & 755797 & 5.0458 & 5.8847 & TST & \\
\hline CHEMBL1802594 & 755797 & 5.2676 & 5.7475 & TST & \\
\hline CHEMBL54697 & 106145 & 7.8539 & 7.8932 & TRN & \\
\hline CHEMBL52531 & 106145 & 7.2676 & 7.1845 & TST & \\
\hline CHEMBL54965 & 106145 & 7.6198 & 7.5875 & TST & \\
\hline CHEMBL417200 & 106145 & 7.4815 & 7.3737 & TST & \\
\hline
\end{tabular}





\begin{tabular}{|c|c|c|c|c|}
\hline \multicolumn{5}{|c|}{ Supplemental Table S2.txt } \\
\hline CHEMBL54566 & 106145 & 6.0 & 6.1991 & TRN \\
\hline CHEMBL416304 & 106145 & 7.0269 & 6.6899 & TRN \\
\hline CHEMBL292431 & 106145 & 7.7447 & 7.6564 & TST \\
\hline CHEMBL55154 & 106145 & 7.6021 & 7.9216 & TST \\
\hline CHEMBL55236 & 106145 & 7.0605 & 7.0436 & TRN \\
\hline CHEMBL55984 & 106145 & 7.3098 & 7.1125 & TRN \\
\hline CHEMBL52532 & 106145 & 7.0506 & 6.6023 & TRN \\
\hline CHEMBL301977 & 106145 & 7.6021 & 7.5708 & TRN \\
\hline CHEMBL439931 & 106145 & 7.2147 & 7.2814 & TRN \\
\hline CHEMBL55110 & 106145 & 7.2076 & 7.1582 & TRN \\
\hline CHEMBL56065 & 106145 & 7.5229 & 7.61 & TST \\
\hline CHEMBL301786 & 106145 & 8.0458 & 8.0019 & TRN \\
\hline CHEMBL417749 & 106145 & 7.2076 & 7.1574 & TRN \\
\hline CHEMBL301085 & 106145 & 7.2366 & 7.1232 & TRN \\
\hline CHEMBL293774 & 106145 & 7.5528 & 7.5969 & TRN \\
\hline CHEMBL51862 & 106145 & 7.7212 & 7.5064 & TST \\
\hline CHEMBL556473 & 575603 & 4.6021 & 4.1022 & TRN \\
\hline CHEMBL554974 & 575603 & 2.4776 & 2.96 & TRN \\
\hline CHEMBL557899 & 575603 & 4.0506 & 4.2058 & TRN \\
\hline CHEMBL560644 & 575603 & 4.1024 & 3.7102 & TST \\
\hline CHEMBL565197 & 575603 & 2.4776 & 3.2536 & TRN \\
\hline CHEMBL560706 & 575603 & 3.7721 & 3.9112 & TRN \\
\hline CHEMBL555979 & 575603 & 2.4776 & 2.9722 & TRN \\
\hline CHEMBL569371 & 575603 & 2.4776 & 3.0677 & TRN \\
\hline CHEMBL562110 & 575603 & 4.2676 & 3.6151 & TRN \\
\hline CHEMBL550494 & 575603 & 4.1427 & 3.9571 & TRN \\
\hline CHEMBL561709 & 575603 & 4.1675 & 3.7135 & TST \\
\hline CHEMBL559284 & 575603 & 4.8539 & 4.8258 & TRN \\
\hline CHEMBL539708 & 575603 & 4.1427 & 3.5702 & TRN \\
\hline CHEMBL563783 & 575603 & 4.9586 & 5.0592 & TRN \\
\hline CHEMBL540719 & 575603 & 4.1427 & 4.1077 & TRN \\
\hline CHEMBL560769 & 575603 & 4.3872 & 4.0511 & TST \\
\hline CHEMBL564499 & 575603 & 4.0458 & 3.7122 & TST \\
\hline CHEMBL572338 & 575603 & 4.0706 & 4.5241 & TRN \\
\hline CHEMBL550776 & 575603 & 4.7447 & 4.7682 & TRN \\
\hline CHEMBL569135 & 575603 & 3.8153 & 3.5548 & TRN \\
\hline CHEMBL563507 & 575603 & 4.1427 & 4.351 & TRN \\
\hline CHEMBL550086 & 575603 & 2.4776 & 3.1069 & TRN \\
\hline CHEMBL569376 & 575603 & 4.2366 & 4.6846 & TRN \\
\hline CHEMBL549966 & 575603 & 4.8539 & 4.7376 & TRN \\
\hline CHEMBL551559 & 575603 & 4.3188 & 4.5096 & TRN \\
\hline CHEMBL560202 & 575603 & 4.4318 & 3.2531 & TRN \\
\hline CHEMBL561646 & 575603 & 2.4776 & 3.0282 & TRN \\
\hline CHEMBL540720 & 575603 & 4.0132 & 4.0506 & TRN \\
\hline CHEMBL561164 & 575603 & 3.6234 & 3.9214 & TRN \\
\hline CHEMBL564594 & 575603 & 3.5784 & 4.0237 & TRN \\
\hline CHEMBL552566 & 575603 & 4.7959 & 3.9611 & TST \\
\hline CHEMBL559852 & 575603 & 4.6198 & 4.2591 & TST \\
\hline
\end{tabular}




\begin{tabular}{|c|c|c|c|c|}
\hline & & & 016 & \\
\hline CHEMBL550978 & 575603 & 4.4685 & 3.7325 & TST \\
\hline CHEMBL562442 & 575603 & 3.6383 & 3.3588 & TRN \\
\hline CHEMBL563256 & 575603 & 3.6326 & 3.8896 & TRN \\
\hline CHEMBL551568 & 575603 & 5.0458 & 4.1514 & TST \\
\hline CHEMBL561848 & 575603 & 2.4776 & 2.9594 & TRN \\
\hline CHEMBL549415 & 575603 & 3.8013 & 3.9592 & TST \\
\hline CHEMBL549886 & 575603 & 4.4437 & 3.455 & TRN \\
\hline CHEMBL564147 & 575603 & 4.2218 & 4.0737 & TST \\
\hline CHEMBL553173 & 575603 & 4.7447 & 4.2464 & TST \\
\hline CHEMBL550574 & 575603 & 4.9586 & 5.2572 & TRN \\
\hline CHEMBL551560 & 575603 & 3.9872 & 3.9433 & TST \\
\hline CHEMBL561565 & 575603 & 2.4776 & 3.2678 & TRN \\
\hline CHEMBL561849 & 575603 & 4.0044 & 4.0247 & TRN \\
\hline CHEMBL572334 & 575603 & 5.0 & 4.6938 & TRN \\
\hline CHEMBL560218 & 575603 & 4.1487 & 3.2461 & TRN \\
\hline CHEMBL562366 & 575603 & 4.5686 & 5.0107 & TRN \\
\hline CHEMBL569375 & 575603 & 4.7959 & 4.6461 & TST \\
\hline CHEMBL563552 & 575603 & 4.2676 & 3.8692 & TST \\
\hline CHEMBL561770 & 575603 & 4.7696 & 4.6591 & TRN \\
\hline CHEMBL557898 & 575603 & 4.4685 & 4.4577 & TRN \\
\hline CHEMBL551241 & 575603 & 5.0969 & 4.5521 & TRN \\
\hline CHEMBL564630 & 575603 & 4.9586 & 4.6257 & TRN \\
\hline CHEMBL550838 & 575603 & 4.7447 & 3.4363 & TRN \\
\hline CHEMBL1766786 & 743384 & 4.0969 & 4.5397 & TRN \\
\hline CHEMBL104468 & 743384 & 6.6383 & 4.8707 & TST \\
\hline CHEMBL1766760 & 743384 & 4.0969 & 4.0633 & TRN \\
\hline CHEMBL1766785 & 743384 & 5.1549 & 4.8858 & TRN \\
\hline CHEMBL1766763 & 743384 & 4.0969 & 4.355 & TRN \\
\hline CHEMBL1766803 & 743384 & 5.5376 & 5.2218 & TST \\
\hline CHEMBL1766795 & 743384 & 4.0969 & 5.1119 & TRN \\
\hline CHEMBL1766781 & 743384 & 5.1805 & 5.0206 & TRN \\
\hline CHEMBL 222102 & 743384 & 5.6021 & 4.7761 & TST \\
\hline CHEMBL1766766 & 743384 & 5.699 & 5.1942 & TRN \\
\hline CHEMBL1766779 & 743384 & 5.3565 & 4.9322 & TRN \\
\hline CHEMBL1766788 & 743384 & 5.5528 & 4.7659 & TRN \\
\hline CHEMBL1766796 & 743384 & 4.0969 & 4.835 & TRN \\
\hline CHEMBL1766768 & 743384 & 4.0969 & 4.6549 & TRN \\
\hline CHEMBL1766790 & 743384 & 4.0969 & 4.35 & TRN \\
\hline CHEMBL1766761 & 743384 & 4.0969 & 4.4006 & TRN \\
\hline CHEMBL1766773 & 743384 & 6.1308 & 5.3968 & TRN \\
\hline CHEMBL1766800 & 743384 & 4.0969 & 3.4926 & TRN \\
\hline CHEMBL1766793 & 743384 & 5.2518 & 5.1882 & TRN \\
\hline CHEMBL1766794 & 743384 & 4.0969 & 4.6859 & TRN \\
\hline CHEMBL1766801 & 743384 & 5.6778 & 5.8766 & TST \\
\hline CHEMBL1766776 & 743384 & 4.0969 & 5.0558 & TRN \\
\hline CHEMBL1766772 & 743384 & 5.6576 & 6.072 & TRN \\
\hline CHEMBL1766759 & 743384 & 4.0969 & 4.8629 & TRN \\
\hline CHEMBL1766789 & 743384 & 4.0969 & 4.856 & TRN \\
\hline
\end{tabular}




\begin{tabular}{|c|c|c|c|c|}
\hline \multicolumn{5}{|c|}{ Supplemental Table S2.txt } \\
\hline CHEMBL1766767 & 743384 & 4.0969 & 4.9365 & TRN \\
\hline CHEMBL1766804 & 743384 & 5.6198 & 4.7622 & TST \\
\hline CHEMBL1766765 & 743384 & 6.1427 & 5.728 & TRN \\
\hline CHEMBL1766798 & 743384 & 5.4949 & 5.2715 & TRN \\
\hline CHEMBL1766780 & 743384 & 5.7447 & 4.8835 & TRN \\
\hline CHEMBL1766791 & 743384 & 5.1675 & 5.0992 & TRN \\
\hline CHEMBL1766792 & 743384 & 5.2366 & 4.8866 & TRN \\
\hline CHEMBL1766771 & 743384 & 5.8539 & 4.7487 & TRN \\
\hline CHEMBL1766774 & 743384 & 5.6576 & 5.4584 & TRN \\
\hline CHEMBL479488 & 743384 & -1.0 & 3.9601 & TST \\
\hline CHEMBL1766784 & 743384 & 5.9208 & 4.6604 & TRN \\
\hline CHEMBL1766799 & 743384 & 5.3565 & 5.1765 & TRN \\
\hline CHEMBL1766787 & 743384 & 4.0969 & 4.2476 & TRN \\
\hline CHEMBL1766775 & 743384 & 5.3768 & 5.5069 & TRN \\
\hline CHEMBL1766764 & 743384 & 5.301 & 5.1491 & TRN \\
\hline CHEMBL1766770 & 743384 & 5.4202 & 4.7568 & TRN \\
\hline CHEMBL1766783 & 743384 & 4.0969 & 4.7017 & TRN \\
\hline CHEMBL1766769 & 743384 & 4.0969 & 4.3739 & TRN \\
\hline CHEMBL1766802 & 743384 & 5.8539 & 5.7434 & TST \\
\hline CHEMBL1766762 & 743384 & 4.0969 & 4.1036 & TST \\
\hline CHEMBL1766797 & 743384 & 4.0969 & 5.0132 & TST \\
\hline CHEMBL1766778 & 743384 & 4.0969 & 5.6856 & TST \\
\hline CHEMBL1766777 & 743384 & 4.0969 & 5.1862 & TST \\
\hline CHEMBL1765107 & 743384 & 4.0969 & 5.2868 & TST \\
\hline CHEMBL1766782 & 743384 & 4.0969 & 4.6087 & TST \\
\hline CHEMBL32176 & 66267 & 5.7959 & 5.7641 & TRN \\
\hline CHEMBL33119 & 66267 & 5.5528 & 5.0674 & TRN \\
\hline CHEMBL32998 & 66267 & 3.301 & 3.2324 & TRN \\
\hline CHEMBL285552 & 66267 & 5.6021 & 5.1551 & TRN \\
\hline CHEMBL 33840 & 66267 & 5.7959 & 6.0876 & TRN \\
\hline CHEMBL286357 & 66267 & 5.6576 & 5.915 & TRN \\
\hline CHEMBL33634 & 66267 & 3.301 & 3.6188 & TRN \\
\hline CHEMBL33283 & 66267 & 5.8861 & 5.4994 & TRN \\
\hline CHEMBL33817 & 66267 & 5.8539 & 5.6856 & TRN \\
\hline CHEMBL417492 & 66267 & 6.1938 & 6.732 & TRN \\
\hline CHEMBL33715 & 66267 & 4.4815 & 3.9614 & TRN \\
\hline CHEMBL33299 & 66267 & 6.9586 & 6.1737 & TRN \\
\hline CHEMBL33413 & 66267 & 4.5229 & 4.6183 & TRN \\
\hline CHEMBL33166 & 66267 & 5.2676 & 4.7049 & TRN \\
\hline CHEMBL33456 & 66267 & 5.8861 & 5.3893 & TST \\
\hline CHEMBL 285392 & 66267 & 5.8239 & 5.4352 & TRN \\
\hline CHEMBL34052 & 66267 & 3.301 & 3.5651 & TRN \\
\hline CHEMBL285034 & 66267 & 3.5229 & 3.8932 & TRN \\
\hline CHEMBL34060 & 66267 & 3.301 & 3.4241 & TRN \\
\hline CHEMBL432078 & 66267 & 4.9586 & 4.4297 & TST \\
\hline CHEMBL6367 & 66267 & 11.0 & 4.2189 & TST \\
\hline CHEMBL33095 & 66267 & 3.301 & 3.1644 & TST \\
\hline CHEMBL33553 & 66267 & 3.301 & 2.8657 & TRN \\
\hline
\end{tabular}




\begin{tabular}{|c|c|c|c|c|}
\hline & & \multicolumn{3}{|c|}{ Supplemental Table } \\
\hline CHEMBL32508 & 66267 & 5.1192 & 4.9367 & TRN \\
\hline CHEMBL32414 & 66267 & 3.301 & 3.4344 & TRN \\
\hline CHEMBL34403 & 66267 & 4.8861 & 4.8697 & TRN \\
\hline CHEMBL291230 & 66267 & 5.4089 & 4.8765 & TST \\
\hline CHEMBL417316 & 66267 & 5.9208 & 5.8162 & TRN \\
\hline CHEMBL286167 & 66267 & 3.301 & 2.6432 & TRN \\
\hline CHEMBL33802 & 66267 & 3.301 & 3.705 & TRN \\
\hline CHEMBL33701 & 66267 & 4.6576 & 4.3598 & TST \\
\hline CHEMBL291232 & 66267 & 4.4318 & 4.5687 & TRN \\
\hline CHEMBL33094 & 66267 & 9.0 & 4.4259 & TST \\
\hline CHEMBL284461 & 66267 & 5.3768 & 4.9681 & TRN \\
\hline CHEMBL33581 & 66267 & 3.301 & 3.9307 & TRN \\
\hline CHEMBL34559 & 66267 & 3.301 & 3.8952 & TRN \\
\hline CHEMBL34001 & 66267 & 5.6198 & 5.1847 & TST \\
\hline CHEMBL33395 & 66267 & 4.8861 & 5.3787 & TRN \\
\hline CHEMBL286152 & 66267 & 6.1427 & 6.4518 & TRN \\
\hline CHEMBL284114 & 66267 & 3.301 & 4.1628 & TRN \\
\hline CHEMBL32121 & 66267 & 3.301 & 3.6393 & TRN \\
\hline CHEMBL33597 & 66267 & 3.301 & 2.5528 & TST \\
\hline CHEMBL32258 & 66267 & 4.4949 & 4.3325 & TRN \\
\hline CHEMBL33406 & 66267 & 5.9586 & 6.2099 & TST \\
\hline CHEMBL441421 & 66267 & 4.4089 & 4.5715 & TRN \\
\hline CHEMBL33555 & 66267 & 3.301 & 4.0238 & TST \\
\hline CHEMBL34673 & 66267 & 3.301 & 3.7454 & TST \\
\hline CHEMBL33114 & 66267 & 4.3768 & 4.1409 & TRN \\
\hline CHEMBL34746 & 66267 & 4.4815 & 4.2595 & TST \\
\hline CHEMBL34230 & 66267 & 5.3279 & 4.6084 & TRN \\
\hline CHEMBL33728 & 66267 & 3.4815 & 4.81 & TST \\
\hline CHEMBL33612 & 66267 & 5.0223 & 5.5918 & TRN \\
\hline CHEMBL34691 & 66267 & 4.6576 & 4.5346 & TRN \\
\hline CHEMBL88220 & 89920 & 5.5686 & 5.5209 & TRN \\
\hline CHEMBL 88134 & 89920 & 6.2596 & 6.3096 & TRN \\
\hline CHEMBL313743 & 89920 & 6.1192 & 6.1348 & TRN \\
\hline CHEMBL88979 & 89920 & 6.699 & 6.6267 & TRN \\
\hline CHEMBL92535 & 89920 & 6.3979 & 6.5972 & TRN \\
\hline CHEMBL89045 & 89920 & 6.5528 & 6.6613 & TRN \\
\hline CHEMBL315393 & 89920 & 6.7447 & 6.7867 & TRN \\
\hline CHEMBL92385 & 89920 & 5.4202 & 5.5575 & TST \\
\hline CHEMBL 23725 & 89920 & 5.8539 & 5.4857 & TST \\
\hline CHEMBL89179 & 89920 & 6.301 & 6.3315 & TRN \\
\hline CHEMBL90262 & 89920 & 6.1549 & 6.1431 & TRN \\
\hline CHEMBL417537 & 89920 & 5.7447 & 5.54799 & 9999999999 \\
\hline CHEMBL419865 & 89920 & 7.0 & 7.0327 & TRN \\
\hline CHEMBL 88291 & 89920 & 6.3098 & 5.9007 & TST \\
\hline CHEMBL89426 & 89920 & 6.699 & 6.6527 & TRN \\
\hline CHEMBL314428 & 89920 & 6.5229 & 6.4155 & TRN \\
\hline CHEMBL92546 & 89920 & 6.6198 & 6.5273 & TRN \\
\hline CHEMBL90499 & 89920 & 5.699 & 5.973 & TRN \\
\hline
\end{tabular}




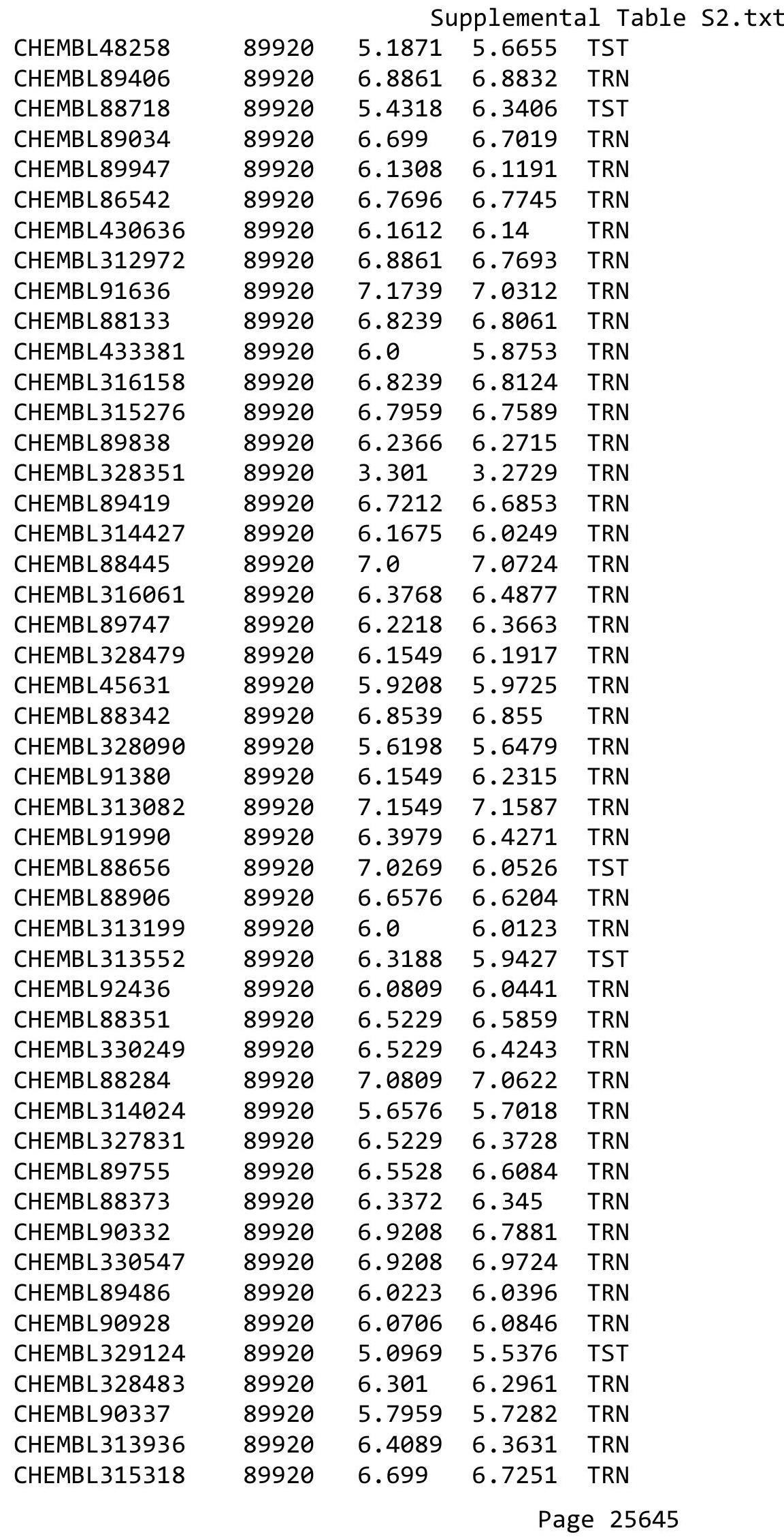




\begin{tabular}{|c|c|c|c|c|c|c|}
\hline & & \multicolumn{5}{|c|}{ Supplemental Table S2.txt } \\
\hline CHEMBL90850 & 89920 & 5.9318 & 6.4482 & TST & & \\
\hline CHEMBL89335 & 89920 & 6.699 & 6.6453 & TRN & & \\
\hline CHEMBL91120 & 89920 & 5.9208 & 5.9052 & TRN & & \\
\hline CHEMBL 330723 & 89920 & 6.699 & 6.711 & TRN & & \\
\hline CHEMBL327677 & 89920 & 6.5686 & 6.5661 & TRN & & \\
\hline CHEMBL88456 & 89920 & 5.6021 & 5.5158 & TRN & & \\
\hline CHEMBL313047 & 89920 & 6.3098 & 6.3122 & TRN & & \\
\hline CHEMBL327639 & 89920 & 6.6778 & 6.6347 & TRN & & \\
\hline CHEMBL 315721 & 89920 & 6.699 & 6.7403 & TRN & & \\
\hline CHEMBL88427 & 89920 & 5.6383 & 5.7435 & TRN & & \\
\hline CHEMBL91317 & 89920 & 6.0 & 6.346 & TST & & \\
\hline CHEMBL313376 & 89920 & \multicolumn{3}{|c|}{5.821000000000001} & 5.8821 & TRN \\
\hline CHEMBL88520 & 89920 & 6.6576 & 6.7593 & TST & & \\
\hline CHEMBL89374 & 89920 & 6.5229 & 5.7586 & TST & & \\
\hline CHEMBL330468 & 89920 & 6.0315 & 7.0196 & TST & & \\
\hline CHEMBL88651 & 89920 & 6.8861 & 6.2853 & TST & & \\
\hline CHEMBL92067 & 89920 & 6.0862 & 6.2671 & TST & & \\
\hline CHEMBL 2115226 & 89920 & 6.0 & 6.8852 & TST & & \\
\hline CHEMBL91425 & 89920 & 6.5686 & 6.3405 & TST & & \\
\hline CHEMBL90727 & 89920 & 7.1549 & 6.9854 & TST & & \\
\hline CHEMBL330513 & 89920 & 7.0706 & 6.6754 & TST & & \\
\hline CHEMBL431008 & 89920 & 6.9208 & 6.4131 & TST & & \\
\hline CHEMBL89512 & 89920 & 6.301 & 6.5463 & TST & & \\
\hline CHEMBL 24761 & 89920 & 5.8861 & 5.6809 & TST & & \\
\hline CHEMBL 258844 & 954792 & 3.8039 & 3.8039 & TRN & & \\
\hline CHEMBL9470 & 954792 & 5.36 & 5.4177 & TST & & \\
\hline CHEMBL514499 & 954792 & 4.9895 & 4.9895 & TRN & & \\
\hline CHEMBL1516890 & 954792 & 4.1699 & 4.1699 & TRN & & \\
\hline CHEMBL 220241 & 954792 & 5.0688 & 5.0688 & TRN & & \\
\hline CHEMBL 3392440 & 954792 & 4.1757 & 4.1757 & TRN & & \\
\hline CHEMBL 3199475 & 954792 & 3.8485 & 3.8485 & TRN & & \\
\hline CHEMBL 255342 & 954792 & 3.7503 & 3.7503 & TRN & & \\
\hline CHEMBL515416 & 954792 & 3.6164 & 3.6165 & TRN & & \\
\hline CHEMBL1643959 & 954792 & 3.3297 & 3.3297 & TRN & & \\
\hline CHEMBL 2137530 & 954792 & 4.4212 & 4.4212 & TRN & & \\
\hline CHEMBL188678 & 954792 & 4.2077 & 4.2077 & TRN & & \\
\hline CHEMBL180127 & 954792 & 4.1912 & 4.1912 & TRN & & \\
\hline CHEMBL191334 & 954792 & 5.527 & 5.527 & TRN & & \\
\hline CHEMBL1590308 & 954792 & 4.2871 & 3.4985 & TST & & \\
\hline CHEMBL392695 & 954792 & 3.5724 & 3.5724 & TRN & & \\
\hline CHEMBL393929 & 954792 & 4.3061 & 4.3061 & TRN & & \\
\hline CHEMBL 379300 & 954792 & 5.4842 & 5.4842 & TRN & & \\
\hline CHEMBL573107 & 954792 & 5.5128 & 5.5128 & TRN & & \\
\hline CHEMBL 2005886 & 954792 & 4.1233 & 4.1233 & TRN & & \\
\hline CHEMBL1909414 & 954792 & 4.7157 & 4.7157 & TRN & & \\
\hline CHEMBL1404918 & 954792 & 2.8249 & 2.8249 & TRN & & \\
\hline CHEMBL585951 & 954792 & 5.9793 & 5.9793 & TRN & & \\
\hline CHEMBL 1186585 & 954792 & 3.1699 & 3.1699 & TRN & & \\
\hline
\end{tabular}

Page 25646 
Supplemental Table S2.txt

\begin{tabular}{|c|c|c|c|c|c|}
\hline CHEMBL102714 & 954792 & 3.9428 & 3.9428 & TRN & \\
\hline CHEMBL 240954 & 954792 & 3.3057 & 3.3689 & TST & \\
\hline CHEMBL1673039 & 954792 & 4.8557 & 4.8557 & TRN & \\
\hline CHEMBL2363137 & 954792 & 6.2169 & 6.2169 & TRN & \\
\hline CHEMBL483849 & 954792 & 1.6152 & 1.9471 & TST & \\
\hline CHEMBL1190711 & 954792 & 3.8639 & 3.8639 & TRN & \\
\hline CHEMBL 202721 & 954792 & 5.4012 & 5.4012 & TRN & \\
\hline CHEMBL1357247 & 954792 & 3.4265 & 3.4265 & TRN & \\
\hline CHEMBL379975 & 954792 & 4.9775 & 4.9775 & TRN & \\
\hline CHEMBL189584 & 954792 & 4.5467 & 4.5467 & TRN & \\
\hline CHEMBL577784 & 954792 & 5.2027 & 5.2027 & TRN & \\
\hline CHEMBL1230020 & 954792 & 4.3101 & 4.3101 & TRN & \\
\hline CHEMBL 210618 & 954792 & 3.4594 & 3.4594 & TRN & \\
\hline CHEMBL 3186408 & 954792 & 4.279 & 3.8415 & TST & \\
\hline CHEMBL1242367 & 954792 & 3.7735 & 3.7735 & TRN & \\
\hline CHEMBL 2144069 & 954792 & 5.6456 & 5.6456 & TRN & \\
\hline CHEMBL300389 & 954792 & 5.7312 & 5.7312 & TRN & \\
\hline CHEMBL192566 & 954792 & 6.4645 & 7.1221 & TST & \\
\hline CHEMBL1788116 & 954792 & 3.6147 & 3.6147 & TRN & \\
\hline CHEMBL1256459 & 954792 & 4.3573 & 4.3573 & TRN & \\
\hline CHEMBL 2134202 & 954792 & 3.4585 & 3.4585 & TRN & \\
\hline CHEMBL1970879 & 954792 & 3.716 & 3.716 & TRN & \\
\hline CHEMBL92309 & 954792 & 1.8861 & 2.7158 & TST & \\
\hline CHEMBL135561 & 954792 & 4.2763 & 4.2763 & TRN & \\
\hline CHEMBL472940 & 954792 & 2.50699 & 999999999 & 997 & 2.5069999999999997 \\
\hline CHEMBL 222102 & 954792 & 3.5859 & 3.5859 & TRN & \\
\hline CHEMBL65 & 954792 & 7.6461 & 7.6461 & TRN & \\
\hline CHEMBL213100 & 954792 & 3.9154 & 3.9154 & TRN & \\
\hline CHEMBL512504 & 954792 & 4.5175 & 4.5175 & TRN & \\
\hline CHEMBL412142 & 954792 & 3.4612 & 3.4612 & TRN & \\
\hline CHEMBL558642 & 954792 & 2.8645 & 2.8645 & TRN & \\
\hline CHEMBL373751 & 954792 & 3.5451 & 3.7003 & TST & \\
\hline CHEMBL217354 & 954792 & 5.3079 & 6.1553 & TST & \\
\hline CHEMBL3349342 & 954792 & 5.419 & 5.584 & TST & \\
\hline CHEMBL483847 & 954792 & 3.8836 & 3.6764 & TST & \\
\hline CHEMBL 209148 & 954792 & 3.1133 & 3.9581 & TST & \\
\hline CHEMBL449158 & 954792 & 7.7768 & 6.5067 & TST & \\
\hline CHEMBL259181 & 954792 & 2.8934 & 3.9316 & TST & \\
\hline CHEMBL399530 & 954792 & 3.4065 & 4.4086 & TST & \\
\hline CHEMBL509032 & 954792 & 4.2225 & 5.5206 & TST & \\
\hline CHEMBL221137 & 954792 & 3.4681 & 4.2904 & TST & \\
\hline CHEMBL3985062 & 1641125 & 7.8861 & 7.0267 & TRN & \\
\hline CHEMBL3909765 & 1641125 & 6.7747 & 7.0078 & TST & \\
\hline CHEMBL3910601 & 1641125 & 5.8147 & 6.2455 & TST & \\
\hline CHEMBL3963774 & 1641125 & 7.8239 & 6.7201 & TRN & \\
\hline CHEMBL3897775 & 1641125 & 6.9469 & 6.6093 & TRN & \\
\hline CHEMBL 3948070 & 1641125 & 6.7878 & 6.9275 & TST & \\
\hline CHEMBL3906382 & 1641125 & 6.0 & 7.1512 & TRN & \\
\hline
\end{tabular}


Supplemental Table S2.txt

\begin{tabular}{|c|c|c|c|c|c|}
\hline CHEMBL3930301 & 1641125 & 6.0 & 6.2836 & TRN & \\
\hline CHEMBL3918694 & 1641125 & 4.777 & 6.5327 & TST & \\
\hline CHEMBL 3986863 & 1641125 & 6.3862 & \multicolumn{2}{|c|}{7.417000000000001} & TRN \\
\hline CHEMBL3928776 & 1641125 & 6.6778 & 7.095 & TRN & \\
\hline CHEMBL3915290 & 1641125 & 6.8996 & 6.9563 & TRN & \\
\hline CHEMBL3890106 & 1641125 & 6.9626 & 7.0451 & TRN & \\
\hline CHEMBL3911214 & 1641125 & 7.4318 & 7.0985 & TST & \\
\hline CHEMBL3977205 & 1641125 & 6.0 & 6.6849 & TRN & \\
\hline CHEMBL 3918640 & 1641125 & 8.3979 & 9.1825 & TRN & \\
\hline CHEMBL3910387 & 1641125 & 6.9914 & 7.4683 & TST & \\
\hline CHEMBL 3894088 & 1641125 & 7.8861 & 7.0852 & TRN & \\
\hline CHEMBL3930198 & 1641125 & 6.5498 & 7.1815 & TRN & \\
\hline CHEMBL3963629 & 1641125 & 7.3468 & 7.1549 & TRN & \\
\hline CHEMBL3919277 & 1641125 & 6.0 & 6.7863 & TRN & \\
\hline CHEMBL3961186 & 1641125 & 5.2675 & 6.4416 & TST & \\
\hline CHEMBL3926326 & 1641125 & 6.6536 & 7.949 & TRN & \\
\hline CHEMBL3904214 & 1641125 & 7.8239 & 7.5211 & TRN & \\
\hline CHEMBL 3984454 & 1641125 & 8.1549 & \multicolumn{2}{|c|}{7.531000000000001} & TRN \\
\hline CHEMBL3927515 & 1641125 & 8.1549 & 6.9783 & TRN & \\
\hline CHEMBL 3923767 & 1641125 & 7.4089 & 5.7392 & TST & \\
\hline CHEMBL3926585 & 1641125 & 5.9129 & 7.3533 & TRN & \\
\hline CHEMBL3911689 & 1641125 & 7.7959 & 7.535 & TRN & \\
\hline CHEMBL3964553 & 1641125 & 6.0 & 6.9333 & TRN & \\
\hline CHEMBL3937526 & 1641125 & 8.2218 & 6.584 & TST & \\
\hline CHEMBL3925862 & 1641125 & 6.3757 & 6.471 & TRN & \\
\hline CHEMBL3972581 & 1641125 & 6.6402 & 6.6533 & TRN & \\
\hline CHEMBL3961584 & 1641125 & 6.6696 & 6.9406 & TRN & \\
\hline CHEMBL3984655 & 1641125 & 7.4685 & 6.8861 & TRN & \\
\hline CHEMBL3916598 & 1641125 & 6.109 & 7.3466 & TST & \\
\hline CHEMBL3958228 & 1641125 & 6.3809 & 6.6961 & TRN & \\
\hline CHEMBL3917264 & 1641125 & 6.0 & 7.1254 & TST & \\
\hline CHEMBL3934088 & 1641125 & 6.0 & 6.4254 & TRN & \\
\hline CHEMBL3903041 & 1641125 & 7.3565 & 7.2727 & TRN & \\
\hline CHEMBL3925829 & 1641125 & 8.5229 & 7.9393 & TRN & \\
\hline CHEMBL3907612 & 1641125 & 8.301 & 7.5198 & TRN & \\
\hline CHEMBL3970669 & 1641125 & 5.2912 & 7.0029 & TRN & \\
\hline CHEMBL3907486 & 1641125 & 7.3979 & 7.0302 & TRN & \\
\hline CHEMBL3942087 & 1641125 & 8.699 & 7.854 & TRN & \\
\hline CHEMBL3937830 & 1641125 & 7.1192 & \multicolumn{2}{|c|}{7.002999999999999} & TRN \\
\hline CHEMBL 3892785 & 1641125 & 7.8239 & 7.4067 & TRN & \\
\hline CHEMBL3898538 & 1641125 & 7.0177 & 6.6554 & TRN & \\
\hline CHEMBL3920071 & 1641125 & 8.5229 & 8.2981 & TRN & \\
\hline CHEMBL 3897628 & 1641125 & 7.9586 & 7.0349 & TRN & \\
\hline CHEMBL3947433 & 1641125 & 5.9359 & 7.4158 & TST & \\
\hline CHEMBL3936621 & 1641125 & 8.699 & 9.3317 & TRN & \\
\hline CHEMBL3894145 & 1641125 & 8.5229 & 8.477 & TRN & \\
\hline CHEMBL3945101 & 1641125 & 6.1537 & 6.9056 & TRN & \\
\hline CHEMBL3942089 & 1641125 & 5.9154 & 7.16200 & 0000000001 & I RN \\
\hline
\end{tabular}

Page 25648 
Supplemental Table S2.txt

\begin{tabular}{|c|c|c|c|c|c|}
\hline CHEMBL 3896139 & 1641125 & 7.2441 & 7.385 & TRN & \\
\hline CHEMBL 3963027 & 1641125 & 6.8182 & 6.9318 & TRN & \\
\hline CHEMBL3973736 & 1641125 & 7.4318 & 7.0756 & TRN & \\
\hline CHEMBL 3901379 & 1641125 & 8.0969 & 8.29 & TRN & \\
\hline CHEMBL 3930463 & 1641125 & 8.0969 & 7.4123 & TRN & \\
\hline CHEMBL 3937187 & 1641125 & 9.0 & 8.2504 & TRN & \\
\hline CHEMBL3903039 & 1641125 & 6.1349 & 6.7056 & TRN & \\
\hline CHEMBL3986392 & 1641125 & 7.7959 & 6.8978 & TST & \\
\hline CHEMBL3967669 & 1641125 & 6.6799 & 7.1683 & TRN & \\
\hline CHEMBL3974906 & 1641125 & 8.699 & 8.1716 & TRN & \\
\hline CHEMBL 3901434 & 1641125 & 7.0044 & 7.2077 & TRN & \\
\hline CHEMBL3953569 & 1641125 & 7.2218 & 6.184 & TRN & \\
\hline CHEMBL3955611 & 1641125 & 5.6885 & 7.0854 & TST & \\
\hline CHEMBL 3895659 & 1641125 & 7.8861 & 8.288 & TRN & \\
\hline CHEMBL3940319 & 1641125 & 6.5952 & 6.7988 & TRN & \\
\hline CHEMBL 3943120 & 1641125 & 6.0 & 6.8808 & TRN & \\
\hline CHEMBL3924256 & 1641125 & 7.3279 & 6.5475 & TST & \\
\hline CHEMBL 3899052 & 1641125 & 5.6885 & 5.7724 & TST & \\
\hline CHEMBL 3977050 & 1641125 & 6.0 & 7.2223 & TRN & \\
\hline CHEMBL 3977988 & 1641125 & 7.1135 & 7.081 & TRN & \\
\hline CHEMBL3903094 & 1641125 & 8.3979 & 7.4393 & TRN & \\
\hline CHEMBL 3913378 & 1641125 & 6.9788 & 7.5069 & TRN & \\
\hline CHEMBL 3942655 & 1641125 & 7.7212 & 6.9503 & TST & \\
\hline CHEMBL 3900943 & 1641125 & 7.6778 & 7.7409 & TRN & \\
\hline CHEMBL 3938442 & 1641125 & 6.4841 & 7.0138 & TRN & \\
\hline CHEMBL3931508 & 1641125 & 6.6144 & 6.8872 & TRN & \\
\hline CHEMBL 3927100 & 1641125 & 8.5229 & 6.7118 & TST & \\
\hline CHEMBL 3972459 & 1641125 & 6.0 & 6.6047 & TRN & \\
\hline CHEMBL 3897918 & 1641125 & 8.699 & \multicolumn{2}{|c|}{8.142000000000001} & TRN \\
\hline CHEMBL 3966615 & 1641125 & 5.6885 & 7.1517 & TST & \\
\hline CHEMBL 3944534 & 1641125 & 6.4841 & 7.6555 & TST & \\
\hline CHEMBL 3945212 & 1641125 & 8.1549 & 8.1239 & TRN & \\
\hline CHEMBL 3890409 & 1641125 & 8.0458 & 7.6353 & TRN & \\
\hline CHEMBL 3921377 & 1641125 & 6.5986 & 7.649 & TRN & \\
\hline CHEMBL 3932589 & 1641125 & 8.301 & 7.8508 & TRN & \\
\hline CHEMBL3946881 & 1641125 & 6.2581 & 6.131 & TRN & \\
\hline CHEMBL 3985290 & 1641125 & 6.0511 & 6.8381 & TRN & \\
\hline CHEMBL 3890851 & 1641125 & 6.1524 & 6.7061 & TRN & \\
\hline CHEMBL 3970305 & 1641125 & 6.8601 & 7.0644 & TST & \\
\hline CHEMBL3913095 & 1641125 & 6.3107 & 6.481 & TRN & \\
\hline CHEMBL 3904013 & 1641125 & 7.3372 & 7.028 & TRN & \\
\hline CHEMBL3965170 & 1641125 & 6.7905 & 6.6984 & TST & \\
\hline CHEMBL3932213 & 1641125 & 8.1549 & 7.2035 & TRN & \\
\hline CHEMBL 3943591 & 1641125 & 6.4486 & 6.7784 & TST & \\
\hline CHEMBL 3985857 & 1641125 & 7.9208 & 6.955 & TST & \\
\hline CHEMBL 3981752 & 1641125 & 7.9586 & 6.6446 & TRN & \\
\hline CHEMBL 3895643 & 1641125 & 7.0757 & 7.4207 & TRN & \\
\hline CHEMBL 3942300 & 1641125 & 6.399 & 6.1031 & TST & \\
\hline
\end{tabular}


Supplemental Table S2.txt

\begin{tabular}{|c|c|c|c|c|}
\hline CHEMBL3950677 & 1641125 & 8.699 & 8.2551 & TRN \\
\hline CHEMBL 3905674 & 1641125 & 7.4815 & 7.1189 & TRN \\
\hline CHEMBL3903831 & 1641125 & 8.3979 & 7.2145 & TRN \\
\hline CHEMBL3982452 & 1641125 & 6.4271 & 6.3484 & TST \\
\hline CHEMBL 2441600 & 1641125 & 6.0 & 6.9494 & TRN \\
\hline CHEMBL3928233 & 1641125 & 8.1549 & 6.4732 & TST \\
\hline CHEMBL3911572 & 1641125 & 6.9666 & 7.2024 & TRN \\
\hline CHEMBL3925995 & 1641125 & 5.9212 & 6.2196 & TRN \\
\hline CHEMBL3917249 & 1641125 & 5.6882 & 6.4755 & TST \\
\hline CHEMBL3941018 & 1641125 & 6.3757 & 6.815 & TRN \\
\hline CHEMBL3897522 & 1641125 & 8.3979 & 7.1295 & TRN \\
\hline CHEMBL3902676 & 1641125 & 8.3979 & 7.2559 & TRN \\
\hline CHEMBL3978174 & 1641125 & 6.3565 & 6.651 & TRN \\
\hline CHEMBL3894666 & 1641125 & 8.0 & 7.1489 & TST \\
\hline CHEMBL3934758 & 1641125 & 8.699 & 8.5101 & TRN \\
\hline CHEMBL3900395 & 1641125 & 7.4559 & 6.796 & TRN \\
\hline CHEMBL3964365 & 1641125 & 6.0 & 6.3818 & TRN \\
\hline CHEMBL3965215 & 1641125 & 9.0 & 8.4687 & TRN \\
\hline CHEMBL3969862 & 1641125 & 7.8239 & 7.3185 & TRN \\
\hline CHEMBL3961201 & 1641125 & 8.699 & 7.9781 & TRN \\
\hline CHEMBL3955972 & 1641125 & 6.0 & 6.9758 & TRN \\
\hline CHEMBL3910148 & 1641125 & 7.6198 & 6.7737 & TRN \\
\hline CHEMBL3940547 & 1641125 & 8.0969 & 7.7353 & TRN \\
\hline CHEMBL3911717 & 1641125 & 6.0 & 7.605 & TRN \\
\hline CHEMBL3898522 & 1641125 & 8.3979 & 6.8913 & TST \\
\hline CHEMBL3977537 & 1641125 & 6.0 & 6.6031 & TST \\
\hline CHEMBL 3898104 & 1641125 & 7.0132 & 7.0661 & TRN \\
\hline CHEMBL3948419 & 1641125 & 7.699 & 7.9381 & TRN \\
\hline CHEMBL3922576 & 1641125 & 7.0315 & 6.13 & TRN \\
\hline CHEMBL3957613 & 1641125 & 8.2218 & 7.4918 & TST \\
\hline CHEMBL3955945 & 1641125 & 7.6198 & 8.2915 & TRN \\
\hline CHEMBL3967703 & 1641125 & 6.8962 & 7.3422 & TST \\
\hline CHEMBL 2441599 & 1641125 & 6.9172 & 6.4452 & TST \\
\hline CHEMBL3892111 & 1641125 & 8.2218 & 7.8321 & TRN \\
\hline CHEMBL3977318 & 1641125 & 5.9788 & 7.6426 & TRN \\
\hline CHEMBL3892481 & 1641125 & 7.0223 & 7.199 & TRN \\
\hline CHEMBL 3925532 & 1641125 & 7.2518 & 7.5901 & TRN \\
\hline CHEMBL3986380 & 1641125 & 6.7799 & 7.1099 & TRN \\
\hline CHEMBL3910068 & 1641125 & 7.7212 & 8.4057 & TRN \\
\hline CHEMBL3973230 & 1641125 & 7.2291 & 7.6626 & TRN \\
\hline CHEMBL3912704 & 1641125 & 6.0074 & 5.7743 & TRN \\
\hline CHEMBL3916973 & 1641125 & 7.8861 & 7.8905 & TRN \\
\hline CHEMBL3940914 & 1641125 & 7.699 & 6.9057 & TRN \\
\hline CHEMBL 3977567 & 1641125 & 5.817 & 7.8305 & TST \\
\hline CHEMBL3916628 & 1641125 & 7.7959 & 6.6767 & TST \\
\hline CHEMBL3932509 & 1641125 & 6.0 & 7.2744 & TRN \\
\hline CHEMBL3967950 & 1641125 & 7.8539 & \multicolumn{2}{|c|}{7.417000000000001} \\
\hline CHEMBL 3943482 & 1641125 & 6.0 & 6.6889 & TRN \\
\hline
\end{tabular}


Supplemental Table S2.txt

\begin{tabular}{|c|c|c|c|c|}
\hline HEMBL & 1125 & 5229 & & 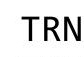 \\
\hline & 641125 & 8.0969 & .3828 & \\
\hline 78 & 125 & & & \\
\hline HEMBL3918163 & & 3979 & 7198 & \\
\hline HEMBL3981198 & 641125 & 9.0 & 3872 & \\
\hline HEMBL3890110 & 641125 & 7.6778 & .8752 & \\
\hline HEMBL389 & 125 & 872 & .789 & \\
\hline AEMBL39e & & & 2268 & \\
\hline AEMBL3970593 & 25 & 7.5229 & .1254 & RN \\
\hline HEMBL3964622 & 64 & 7.699 & 4106 & \\
\hline HEMBL3967215 & 64 & 6.0 & . 6492 & \\
\hline AEMBL39 & 6 & 174 & .9865 & \\
\hline AEMBL3S & & & & \\
\hline HEMBL3924889 & 5 & 0757 & 6.8502 & \\
\hline HEMBL392 & 5 & 208 & 1869 & \\
\hline AEMBL396 & 62 & 6.0996 & 6.0171 & \\
\hline HEMBL38 & 62 & & 7.1448 & 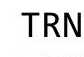 \\
\hline HEMBL39 & & & 8.105 & \\
\hline HEMBL39 & & 8.0 & 7.8024 & \\
\hline AEMBL39 & & 9 & & $T$ \\
\hline HEIMBLSS & 6 & 7. & 95 & I RIV \\
\hline HEMBL3 & & & 06 & RN \\
\hline HEMBL3S & & 7. & 32 & \\
\hline HEMBL39 & & & 7.2427 & 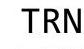 \\
\hline AEMBL39 & & & & 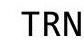 \\
\hline HEMBL3 & 6 & 9 & 294 & I RN \\
\hline HEMBL3 & & & 63 & RN \\
\hline HEMBL 3 & & 7. & 179 & RN \\
\hline HEMBL3893594 & & & 8.0401 & TIV \\
\hline HEMBL39261 & & & & I RIV \\
\hline HEMBL39 & 6 & & 486 & RN \\
\hline HEMBL3 & & 37 & 33 & RN \\
\hline HEMBL; & & 7. & 108 & N \\
\hline HEMBL3986742 & 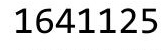 & 8.3979 & 7.8865 & IRN \\
\hline HEMBL 3961967 & 62 & 9.0 & 8.5388 & TRN \\
\hline HEMBL39 & & & 6.7385 & \\
\hline HFMRI & & 2 & 955 & RN \\
\hline HEMBL3 & & 6. & 5.7778 & IRN \\
\hline HEMBL3966409 & 2 & 8.699 & 8.4916 & TRN \\
\hline AEMBL 392 & 62 & & 9665 & TST \\
\hline HEMBL392 & 6 & 991 & .6468 & \\
\hline CHEMBL3937275 & & & 8.1291 & RN \\
\hline HEMBL3940699 & 16 & 5.892 & 5.7312 & $\Gamma \mathrm{RN}$ \\
\hline HEMBL3963586 & 6 & 6 & 7152 & TRN \\
\hline MBL3 & & & 745 & \\
\hline HEMBL390 & & . & .1644 & \\
\hline CHEMBL 3951482 & & 5.72 & 6.3248 & \\
\hline THEMBL3909361 & 1641125 & 7.2147 & 7.7142 & ГRN \\
\hline
\end{tabular}

Page 25651 
Supplemental Table S2.txt

\begin{tabular}{|c|c|c|c|c|}
\hline CHEMBL3934531 & 1641125 & 6.9172 & 7.3373 & TRN \\
\hline CHEMBL3973007 & 1641125 & 6.0 & 6.9486 & TRN \\
\hline CHEMBL3984215 & 1641125 & 6.0 & 6.6784 & TRN \\
\hline CHEMBL 3931072 & 1641125 & 8.3979 & 7.1211 & TRN \\
\hline CHEMBL 3934793 & 1641125 & 7.1249 & 7.0893 & TRN \\
\hline CHEMBL 3979985 & 1641125 & 7.1079 & 7.6405 & TST \\
\hline CHEMBL 3922078 & 1641125 & 6.5986 & 7.1261 & TRN \\
\hline CHEMBL3954459 & 1641125 & 8.699 & 8.0499 & TRN \\
\hline CHEMBL 3918228 & 1641125 & 7.2518 & 6.9198 & TST \\
\hline CHEMBL 3967083 & 1641125 & 8.301 & 8.1836 & TRN \\
\hline CHEMBL 3926001 & 1641125 & 6.7375 & 7.0717 & TST \\
\hline CHEMBL 3964250 & 1641125 & 6.1945 & 7.4447 & TRN \\
\hline CHEMBL3978182 & 1641125 & 7.6198 & 7.2606 & TST \\
\hline CHEMBL 3928508 & 1641125 & 6.3635 & 7.17899 & 9999999999 \\
\hline CHEMBL 3979778 & 1641125 & 8.5229 & 7.5018 & TRN \\
\hline CHEMBL 3934122 & 1641125 & 7.5376 & 7.0248 & TRN \\
\hline CHEMBL3973406 & 1641125 & 6.6073 & 7.3059 & TRN \\
\hline CHEMBL3929197 & 1641125 & 6.7496 & 6.7816 & TST \\
\hline CHEMBL3960892 & 1641125 & 5.8444 & 6.0749 & TRN \\
\hline CHEMBL 3894584 & 1641125 & 8.5229 & 8.0235 & TRN \\
\hline CHEMBL3961365 & 1641125 & 8.2218 & 7.3023 & TRN \\
\hline CHEMBL 3920128 & 1641125 & 7.699 & 7.8084 & TRN \\
\hline CHEMBL 3949100 & 1641125 & 6.6696 & 6.3972 & TST \\
\hline CHEMBL3978481 & 1641125 & 5.8027 & 6.0086 & TRN \\
\hline CHEMBL 3904511 & 1641125 & 7.5528 & 7.6659 & TRN \\
\hline CHEMBL3915919 & 1641125 & 6.0985 & 6.4733 & TST \\
\hline CHEMBL3907985 & 1641125 & 7.1938 & 7.6856 & TRN \\
\hline CHEMBL 3947233 & 1641125 & 6.7496 & 6.8451 & TST \\
\hline CHEMBL3912709 & 1641125 & 8.5229 & 8.1537 & TRN \\
\hline CHEMBL 3902649 & 1641125 & 7.6778 & 7.4138 & TST \\
\hline CHEMBL3895568 & 1641125 & 7.0269 & 7.7701 & TRN \\
\hline CHEMBL 3957294 & 1641125 & 6.7696 & 7.399 & TRN \\
\hline CHEMBL3978021 & 1641125 & 8.0 & 7.4202 & TRN \\
\hline CHEMBL3983628 & 1641125 & 8.1549 & 6.6975 & TST \\
\hline CHEMBL3964709 & 1641125 & 5.2366 & 6.0406 & TST \\
\hline CHEMBL3972745 & 1641125 & 8.699 & 7.6051 & TRN \\
\hline CHEMBL 3986942 & 1641125 & 5.9602 & 6.9894 & TRN \\
\hline CHEMBL3958506 & 1641125 & 6.3382 & 7.3917 & TRN \\
\hline CHEMBL 3933693 & 1641125 & 7.8861 & 7.3096 & TRN \\
\hline CHEMBL3909786 & 1641125 & 6.8861 & 7.3363 & TRN \\
\hline CHEMBL3985668 & 1641125 & 6.8097 & 7.0958 & TRN \\
\hline CHEMBL 3897024 & 1641125 & 7.2007 & 7.4683 & TST \\
\hline CHEMBL 3919451 & 1641125 & 6.5171 & 7.19799 & 99999999995 \\
\hline CHEMBL3909151 & 1641125 & 7.6576 & 7.3362 & TRN \\
\hline CHEMBL 3891440 & 1641125 & 7.9586 & 6.8656 & TRN \\
\hline CHEMBL3949041 & 1641125 & 6.9281 & 6.7563 & TRN \\
\hline CHEMBL 3902554 & 1641125 & 7.2218 & 7.4683 & TST \\
\hline CHEMBL 3901484 & 1641125 & 8.3979 & 8.0728 & TST \\
\hline
\end{tabular}


Supplemental Table S2.txt

\begin{tabular}{|c|c|c|c|c|c|c|}
\hline CHEMBL3964314 & 1641125 & 6.7328 & \multicolumn{3}{|c|}{7.0829999999999999} & TST \\
\hline CHEMBL3905911 & 1641125 & 6.1904 & 7.4087 & TST & & \\
\hline CHEMBL3927024 & 1641125 & 6.5784 & 7.6338 & TST & & \\
\hline CHEMBL3950805 & 1641125 & 8.5229 & 8.5236 & TRN & & \\
\hline CHEMBL3929176 & 1641125 & 8.1549 & 8.0879 & TRN & & \\
\hline CHEMBL3981365 & 1641125 & 7.9208 & 7.6271 & TRN & & \\
\hline CHEMBL3916021 & 1641125 & 7.2924 & 7.1961 & TRN & & \\
\hline CHEMBL3969193 & 1641125 & 7.9586 & 6.5304 & TST & & \\
\hline CHEMBL3954288 & 1641125 & 6.0 & 7.0434 & TRN & & \\
\hline CHEMBL3963495 & 1641125 & 5.9634 & 7.8573 & TST & & \\
\hline CHEMBL220064 & 428500 & 7.1739 & 7.1571 & TRN & & \\
\hline CHEMBL374300 & 428500 & 7.7696 & 7.6675 & TRN & & \\
\hline CHEMBL220558 & 428500 & 6.2684 & 6.3478 & TRN & & \\
\hline CHEMBL220559 & 428500 & 7.9586 & 5.3606 & TST & & \\
\hline CHEMBL373868 & 428500 & 6.8239 & 7.0997 & TRN & & \\
\hline CHEMBL223782 & 428500 & 9.1739 & 9.4626 & TRN & & \\
\hline CHEMBL223614 & 428500 & 7.1805 & 6.8869 & TRN & & \\
\hline CHEMBL426377 & 428500 & 6.0 & 5.8054 & TRN & & \\
\hline CHEMBL436535 & 428500 & 8.5229 & 8.7744 & TRN & & \\
\hline CHEMBL387348 & 428500 & 8.4559 & 8.519 & TRN & & \\
\hline CHEMBL223840 & 428500 & 6.7447 & 6.7086 & TRN & & \\
\hline CHEMBL221208 & 428500 & 9.28399 & 99999999 & 99 & 8.9608 & \\
\hline CHEMBL220269 & 428500 & 7.6021 & 7.1067 & TRN & & \\
\hline CHEMBL374552 & 428500 & 8.0 & 7.9099 & TRN & & \\
\hline CHEMBL266768 & 428500 & 7.4559 & 7.4064 & TRN & & \\
\hline CHEMBL223384 & 428500 & 9.0 & 8.7514 & TRN & & \\
\hline CHEMBL435924 & 428500 & 6.0 & 6.3974 & TRN & & \\
\hline CHEMBL220122 & 428500 & 7.9208 & 8.1584 & TST & & \\
\hline CHEMBL374125 & 428500 & 6.0 & 6.1126 & TRN & & \\
\hline CHEMBL219792 & 428500 & 8.0706 & 8.356 & TST & & \\
\hline CHEMBL223045 & 428500 & 7.1805 & 7.2841 & TRN & & \\
\hline CHEMBL220630 & 428500 & 7.2007 & 7.1112 & TRN & & \\
\hline CHEMBL223838 & 428500 & 8.9586 & 9.0013 & TRN & & \\
\hline CHEMBL223792 & 428500 & 9.0969 & 8.852 & TRN & & \\
\hline CHEMBL221320 & 428500 & 7.0 & 7.504 & TST & & \\
\hline CHEMBL374132 & 428500 & 9.0 & 8.7892 & TRN & & \\
\hline CHEMBL223634 & 428500 & 9.0 & 8.9342 & TRN & & \\
\hline CHEMBL219896 & 428500 & 6.5686 & 6.3777 & TRN & & \\
\hline CHEMBL373919 & 428500 & 7.1612 & 7.2175 & TRN & & \\
\hline CHEMBL220121 & 428500 & 8.8239 & 8.8186 & TRN & & \\
\hline CHEMBL387349 & 428500 & 8.4318 & 8.3355 & TRN & & \\
\hline CHEMBL376733 & 428500 & 9.5528 & 9.7413 & TRN & & \\
\hline CHEMBL373623 & 428500 & 9.3188 & 9.314 & TRN & & \\
\hline CHEMBL220834 & 428500 & 9.0 & 9.49 & TRN & & \\
\hline CHEMBL220932 & 428500 & 9.301 & 9.4397 & TRN & & \\
\hline CHEMBL374681 & 428500 & 9.0969 & 8.8394 & TRN & & \\
\hline CHEMBL223788 & 428500 & 9.3098 & 9.1158 & TRN & & \\
\hline CHEMBL221264 & 428500 & 8.3872 & 8.8783 & TRN & & \\
\hline
\end{tabular}

Page 25653 


\begin{tabular}{|c|c|c|c|c|c|}
\hline \multicolumn{6}{|c|}{ Supplemental Table s2.txt } \\
\hline CHEMBL223839 & 428500 & 6.5482 & 6.2787 & TRN & \\
\hline CHEMBL 376713 & 428500 & 9.301 & 9.3551 & TRN & \\
\hline CHEMBL373942 & 428500 & 5.7435 & 5.5949 & TST & \\
\hline CHEMBL 375404 & 428500 & 9.0 & 8.9912 & TRN & \\
\hline CHEMBL220213 & 428500 & 7.1135 & 7.8647 & TST & \\
\hline CHEMBL223615 & 428500 & 7.9208 & 7.9326 & TRN & \\
\hline CHEMBL222364 & 428500 & 9.0315 & 8.6201 & TRN & \\
\hline CHEMBL223385 & 428500 & 8.8539 & 8.8607 & TRN & \\
\hline CHEMBL 220880 & 428500 & 9.8861 & 9.76 & TRN & \\
\hline CHEMBL374486 & 428500 & 6.7747 & 6.8417 & TRN & \\
\hline CHEMBL220123 & 428500 & 7.6021 & 8.5374 & TST & \\
\hline CHEMBL 373881 & 428500 & 9.1549 & 9.4156 & TRN & \\
\hline CHEMBL223047 & 428500 & 4.0 & 4.5711 & TRN & \\
\hline CHEMBL 220270 & 428500 & 7.7212 & 7.6914 & TRN & \\
\hline CHEMBL220898 & 428500 & 6.0 & 6.7079 & TST & \\
\hline CHEMBL376237 & 428500 & 8.2441 & 8.5111 & TRN & \\
\hline CHEMBL223791 & 428500 & 9.0177 & 9.1176 & TRN & \\
\hline CHEMBL 220632 & 428500 & 9.9208 & 10.1392 & TRN & \\
\hline CHEMBL222619 & 428500 & 8.2676 & 8.1126 & TST & \\
\hline CHEMBL424756 & 428500 & 7.9208 & 7.86299 & 99999999995 & TST \\
\hline CHEMBL385334 & 428500 & 9.301 & 9.2338 & TRN & \\
\hline CHEMBL223515 & 428500 & 7.284 & 7.5232 & TRN & \\
\hline CHEMBL411343 & 428500 & 9.2596 & 9.3561 & TRN & \\
\hline CHEMBL 385325 & 428500 & 9.5528 & 8.88 & TST & \\
\hline CHEMBL427062 & 428500 & 9.3188 & 8.9252 & TST & \\
\hline CHEMBL 223442 & 428500 & 8.699 & 8.5347 & TRN & \\
\hline CHEMBL374319 & 428500 & 9.0605 & 9.1734 & TRN & \\
\hline CHEMBL442041 & 428500 & 9.301 & 8.6561 & TRN & \\
\hline CHEMBL424928 & 428500 & 9.2366 & 8.8608 & TRN & \\
\hline CHEMBL223005 & 428500 & 6.0531 & 6.5203 & TST & \\
\hline CHEMBL 223044 & 428500 & 6.0 & 7.0971 & TST & \\
\hline CHEMBL220156 & 428500 & 8.5686 & 8.4001 & TST & \\
\hline CHEMBL 290548 & 428500 & 6.0 & 9.2729 & TST & \\
\hline CHEMBL 223043 & 428500 & 7.6383 & 8.1627 & TST & \\
\hline CHEMBL373546 & 428500 & 7.4815 & 8.4692 & TST & \\
\hline CHEMBL1092115 & 688245 & 5.0 & 5.018 & TST & \\
\hline CHEMBL1527124 & 688245 & 4.5 & 4.7684 & TRN & \\
\hline CHEMBL1324051 & 688245 & 4.9 & 4.69 & TRN & \\
\hline CHEMBL1397899 & 688245 & 4.5 & 4.627 & TRN & \\
\hline CHEMBL1437024 & 688245 & 4.95 & 5.0109 & TRN & \\
\hline CHEMBL1473800 & 688245 & 5.45 & 5.5125 & TRN & \\
\hline CHEMBL3194842 & 688245 & 4.8 & 4.6256 & TST & \\
\hline CHEMBL567783 & 688245 & 5.55 & 5.917006 & 0000000001 & TRN \\
\hline CHEMBL3194962 & 688245 & 4.85 & 4.8905 & TST & \\
\hline CHEMBL3193305 & 688245 & 5.35 & 4.9512 & TST & \\
\hline CHEMBL565866 & 688245 & 5.9 & 5.814 & TRN & \\
\hline CHEMBL1431490 & 688245 & 4.6 & 4.7221 & TRN & \\
\hline CHEMBL568171 & 688245 & 6.5 & 6.38299 & 9999999999 & TRN \\
\hline & & & & 25654 & \\
\hline
\end{tabular}




\begin{tabular}{|c|c|c|c|c|c|}
\hline \multicolumn{6}{|c|}{ Supplemental Table S2.txt } \\
\hline CHEMBL1408367 & 688245 & 5.6 & 5.5691 & TRN & \\
\hline CHEMBL1522920 & 688245 & 5.45 & 5.5285 & TRN & \\
\hline CHEMBL1321641 & 688245 & 6.0 & 5.7574 & TRN & \\
\hline CHEMBL567137 & 688245 & 5.65 & 5.684 & TRN & \\
\hline CHEMBL1411358 & 688245 & 6.0 & 5.735 & TRN & \\
\hline CHEMBL568172 & 688245 & 5.85 & 5.9395 & TRN & \\
\hline CHEMBL1355124 & 688245 & 5.7 & 5.67299 & 9999999999 & TRN \\
\hline CHEMBL1397496 & 688245 & 4.9 & 4.9534 & TRN & \\
\hline CHEMBL1361261 & 688245 & 5.95 & 6.2021 & TRN & \\
\hline CHEMBL1582053 & 688245 & 4.55 & 4.7966 & TRN & \\
\hline CHEMBL1452239 & 688245 & 4.8 & 4.652 & TRN & \\
\hline CHEMBL1492311 & 688245 & 4.85 & 4.8976 & TRN & \\
\hline CHEMBL1566266 & 688245 & 4.85 & 4.6619 & TRN & \\
\hline CHEMBL577764 & 688245 & 6.0 & 5.5667 & TRN & \\
\hline CHEMBL1427136 & 688245 & 4.9 & 4.5956 & TST & \\
\hline CHEMBL1419509 & 688245 & 4.55 & 5.1766 & TRN & \\
\hline CHEMBL1435685 & 688245 & 4.6 & 4.8817 & TRN & \\
\hline CHEMBL1466625 & 688245 & 4.4 & 4.4589 & TRN & \\
\hline CHEMBL 370152 & 688245 & 4.55 & 4.4268 & TRN & \\
\hline CHEMBL1409603 & 688245 & 4.55 & 4.5011 & TRN & \\
\hline CHEMBL1552229 & 688245 & 4.45 & 4.7069 & TST & \\
\hline CHEMBL1373890 & 688245 & 5.05 & 5.1328 & TRN & \\
\hline CHEMBL1552075 & 688245 & 4.5 & 4.6706 & TRN & \\
\hline CHEMBL1610339 & 688245 & 5.0 & 4.8955 & TRN & \\
\hline CHEMBL1408468 & 688245 & 4.75 & 4.7992 & TST & \\
\hline CHEMBL1328046 & 688245 & 4.85 & 4.7264 & TRN & \\
\hline CHEMBL567161 & 688245 & 5.25 & 5.8125 & TRN & \\
\hline CHEMBL1593399 & 688245 & 4.8 & 4.7772 & TRN & \\
\hline CHEMBL1371902 & 688245 & 5.5 & 5.3246 & TRN & \\
\hline CHEMBL1488244 & 688245 & 4.5 & 4.5531 & TRN & \\
\hline CHEMBL567784 & 688245 & 6.5 & 6.3557 & TRN & \\
\hline CHEMBL1453827 & 688245 & 5.55 & 5.6508 & TRN & \\
\hline CHEMBL1355261 & 688245 & 5.0 & 5.4687 & TRN & \\
\hline CHEMBL1338958 & 688245 & 4.8 & 4.9692 & TRN & \\
\hline CHEMBL1433908 & 688245 & 5.55 & 5.2917 & TRN & \\
\hline CHEMBL567354 & 688245 & 5.65 & 5.7018 & TRN & \\
\hline CHEMBL1494881 & 688245 & 6.0 & 5.5804 & TRN & \\
\hline CHEMBL1405327 & 688245 & 5.4 & 5.2753 & TRN & \\
\hline CHEMBL567785 & 688245 & 6.05 & 5.9088 & TRN & \\
\hline CHEMBL1570044 & 688245 & 4.8 & 5.13200 & 0000000001 & TRN \\
\hline CHEMBL1559134 & 688245 & 4.8 & 4.8498 & TRN & \\
\hline CHEMBL1351979 & 688245 & 4.55 & 4.4945 & TST & \\
\hline CHEMBL1521871 & 688245 & 6.25 & 6.1385 & TRN & \\
\hline CHEMBL1551555 & 688245 & 5.9 & 5.7371 & TRN & \\
\hline CHEMBL566069 & 688245 & 6.35 & 5.8777 & TRN & \\
\hline CHEMBL1974901 & 688245 & 5.55 & 4.9216 & TST & \\
\hline CHEMBL1407458 & 688245 & 4.8 & 4.5379 & TST & \\
\hline CHEMBL1530797 & 688245 & 4.55 & 4.5497 & TRN & \\
\hline
\end{tabular}




\begin{tabular}{|c|c|c|c|c|}
\hline \multicolumn{5}{|c|}{ Supplemental Table S2.txt } \\
\hline CHEMBL1371567 & 688245 & 4.55 & 4.3426 & TRN \\
\hline CHEMBL1605676 & 688245 & 4.95 & 5.4014 & TRN \\
\hline CHEMBL1591862 & 688245 & 4.6 & 4.6256 & TRN \\
\hline CHEMBL1321452 & 688245 & 5.1 & 4.9657 & TST \\
\hline CHEMBL1365696 & 688245 & 4.9 & 5.081 & TRN \\
\hline CHEMBL1611662 & 688245 & 5.8 & 4.7898 & TST \\
\hline CHEMBL566924 & 688245 & 5.9 & 6.1087 & TRN \\
\hline CHEMBL1580372 & 688245 & 4.6 & 4.3751 & TRN \\
\hline CHEMBL1334432 & 688245 & 4.6 & 5.1514 & TST \\
\hline CHEMBL1316790 & 688245 & 5.65 & 5.5765 & TRN \\
\hline CHEMBL1559057 & 688245 & 4.8 & 4.8658 & TRN \\
\hline CHEMBL566691 & 688245 & 5.65 & 5.8164 & TRN \\
\hline CHEMBL1356904 & 688245 & 5.7 & 5.8285 & TRN \\
\hline CHEMBL1448568 & 688245 & 4.5 & 4.6078 & TRN \\
\hline CHEMBL1359564 & 688245 & 5.45 & 5.0561 & TRN \\
\hline CHEMBL1554756 & 688245 & 6.0 & 5.1005 & TRN \\
\hline CHEMBL154580 & 688245 & 4.9 & 4.797 & TRN \\
\hline CHEMBL 3196157 & 688245 & 5.55 & 5.0133 & TST \\
\hline CHEMBL1488604 & 688245 & 4.55 & 4.8553 & TRN \\
\hline CHEMBL1327765 & 688245 & 4.6 & 5.1163 & TST \\
\hline CHEMBL566067 & 688245 & 6.0 & 5.907 & TRN \\
\hline CHEMBL1394078 & 688245 & 5.3 & 5.57299 & 99999999995 \\
\hline CHEMBL1555958 & 688245 & 6.0 & 5.5491 & TRN \\
\hline CHEMBL 3196233 & 688245 & 5.95 & 4.8714 & TST \\
\hline CHEMBL3196087 & 688245 & 5.9 & 5.2433 & TST \\
\hline CHEMBL1595730 & 688245 & 4.8 & 4.7427 & TRN \\
\hline CHEMBL1516776 & 688245 & 5.35 & 5.4383 & TRN \\
\hline CHEMBL1316434 & 688245 & 5.05 & 4.8575 & TRN \\
\hline CHEMBL1433846 & 688245 & 4.65 & 4.8335 & TRN \\
\hline CHEMBL1500229 & 688245 & 4.8 & 5.19 & TRN \\
\hline CHEMBL576847 & 688245 & 6.0 & 5.8593 & TRN \\
\hline CHEMBL60718 & 688245 & 4.8 & 4.9034 & TRN \\
\hline CHEMBL1327669 & 688245 & 4.9 & 4.7936 & TRN \\
\hline CHEMBL1570004 & 688245 & 4.9 & 4.7404 & TRN \\
\hline CHEMBL1525892 & 688245 & 4.95 & 5.4287 & TRN \\
\hline CHEMBL1433496 & 688245 & 4.5 & 4.6966 & TRN \\
\hline CHEMBL1443494 & 688245 & 4.95 & 4.8933 & TRN \\
\hline CHEMBL1523699 & 688245 & 5.25 & 4.8711 & TRN \\
\hline CHEMBL1555272 & 688245 & 4.6 & 4.7941 & TRN \\
\hline CHEMBL1414011 & 688245 & 5.65 & 5.7211 & TRN \\
\hline CHEMBL567341 & 688245 & 6.5229 & 6.3134 & TRN \\
\hline CHEMBL1348345 & 688245 & 4.8 & 4.7372 & TRN \\
\hline CHEMBL1458713 & 688245 & 8.0 & 5.1076 & TST \\
\hline CHEMBL576648 & 688245 & 6.35 & 6.1736 & TRN \\
\hline CHEMBL1334452 & 688245 & 4.5 & 4.5388 & TRN \\
\hline CHEMBL1357592 & 688245 & 6.0 & 4.9452 & TST \\
\hline CHEMBL1609513 & 688245 & 4.55 & 4.8103 & TST \\
\hline CHEMBL1334631 & 688245 & 5.0 & 4.828 & TRN \\
\hline
\end{tabular}




\begin{tabular}{|c|c|c|c|c|}
\hline \multicolumn{5}{|c|}{ Supplemental Table S2.txt } \\
\hline CHEMBL566273 & 688245 & 5.6 & 5.6487 & TRN \\
\hline CHEMBL1397499 & 688245 & 4.85 & 4.7368 & TST \\
\hline CHEMBL567135 & 688245 & 5.9 & 5.6438 & TRN \\
\hline CHEMBL 303579 & 688245 & 5.3 & 5.1953 & TRN \\
\hline CHEMBL1509422 & 688245 & 4.95 & 4.6652 & TRN \\
\hline CHEMBL1419212 & 688245 & 4.9 & 5.1374 & TST \\
\hline CHEMBL1442864 & 688245 & 4.8 & 4.6864 & TRN \\
\hline CHEMBL1484052 & 688245 & 6.5501 & 6.2352 & TRN \\
\hline CHEMBL1567904 & 688245 & 4.55 & 4.8084 & TRN \\
\hline CHEMBL1402055 & 688245 & 4.55 & 5.0447 & TST \\
\hline CHEMBL1307622 & 688245 & 5.25 & 5.186 & TRN \\
\hline CHEMBL1317780 & 688245 & 5.6 & 5.6613 & TRN \\
\hline CHEMBL1612858 & 688245 & 4.55 & 4.6683 & TST \\
\hline CHEMBL1514618 & 688245 & 5.0 & 4.8503 & TRN \\
\hline CHEMBL18879 & 688245 & 5.35 & 4.6911 & TST \\
\hline CHEMBL 224214 & 688245 & 4.55 & 5.0232 & TRN \\
\hline CHEMBL1256974 & 688245 & 5.4 & 5.186 & TRN \\
\hline CHEMBL567147 & 688245 & 6.35 & 6.3893 & TRN \\
\hline CHEMBL1395288 & 688245 & 5.05 & 4.9423 & TRN \\
\hline CHEMBL1531241 & 688245 & 4.6 & 4.959 & TRN \\
\hline CHEMBL1312804 & 688245 & 5.3 & 5.0877 & TRN \\
\hline CHEMBL1977007 & 688245 & 4.85 & 4.6547 & TRN \\
\hline CHEMBL1402796 & 688245 & 4.8 & 4.8537 & TRN \\
\hline CHEMBL1464803 & 688245 & 5.1 & 5.0396 & TRN \\
\hline CHEMBL1508826 & 688245 & 4.8 & 5.0964 & TRN \\
\hline CHEMBL1568318 & 688245 & 4.55 & 4.685 & TRN \\
\hline CHEMBL1572238 & 688245 & 5.4 & 5.6064 & TRN \\
\hline CHEMBL1990036 & 688245 & 5.2 & 4.8761 & TST \\
\hline CHEMBL1599136 & 688245 & 5.5 & 5.7465 & TRN \\
\hline CHEMBL1517083 & 688245 & 6.0 & 5.8329 & TRN \\
\hline CHEMBL 3197081 & 688245 & 4.6 & 4.7801 & TST \\
\hline CHEMBL1314700 & 688245 & 5.7 & 5.6631 & TRN \\
\hline CHEMBL1446626 & 688245 & 4.9 & 4.8005 & TRN \\
\hline CHEMBL 223453 & 688245 & 5.35 & 4.7176 & TST \\
\hline CHEMBL1523723 & 688245 & 5.3 & 5.6605 & TRN \\
\hline CHEMBL1557810 & 688245 & 4.85 & 4.9353 & TST \\
\hline CHEMBL1404402 & 688245 & 4.7 & 4.4069 & TRN \\
\hline CHEMBL1328481 & 688245 & 6.0 & 5.5833 & TST \\
\hline CHEMBL1415584 & 688245 & 5.65 & 5.6093 & TST \\
\hline CHEMBL1310699 & 688245 & 4.85 & 4.6653 & TST \\
\hline CHEMBL1328753 & 688245 & 4.8 & 5.1968 & TST \\
\hline CHEMBL1420906 & 688245 & 4.85 & 5.0965 & TST \\
\hline CHEMBL1496776 & 688245 & 6.0 & 5.8092 & TST \\
\hline CHEMBL1395922 & 688245 & 5.4 & 5.6842 & TST \\
\hline CHEMBL417727 & 688245 & 4.8 & 4.967 & TST \\
\hline CHEMBL567145 & 688245 & 4.5 & 4.7694 & TST \\
\hline CHEMBL1495609 & 688245 & 4.55 & 4.8125 & TST \\
\hline CHEMBL1427330 & 688346 & 5.0 & 4.6171 & TRN \\
\hline
\end{tabular}




\begin{tabular}{|c|c|c|c|c|c|}
\hline \\
\hline CHEMBL3199475 & 688346 & 4.95 & 5.0967 & TRN & \\
\hline CHEMBL1978364 & 688346 & 6.35 & 5.2242 & TRN & \\
\hline CHEMBL1392900 & 688346 & 4.3 & 4.7034 & TRN & \\
\hline CHEMBL1546656 & 688346 & 4.3 & 5.3207 & TRN & \\
\hline CHEMBL80941 & 688346 & 5.1 & 4.7171 & TRN & \\
\hline CHEMBL1385694 & 688346 & 5.15 & 4.7145 & TRN & \\
\hline CHEMBL1600012 & 688346 & 3.95 & 5.0136 & TRN & \\
\hline CHEMBL1518838 & 688346 & 4.55 & 4.8654 & TRN & \\
\hline CHEMBL1522300 & 688346 & 4.25 & 5.0581 & TRN & \\
\hline CHEMBL1606794 & 688346 & 4.15 & 5.402 & TRN & \\
\hline CHEMBL1491095 & 688346 & 4.05 & 5.2176 & TRN & \\
\hline CHEMBL3195977 & 688346 & 5.2 & 4.9367 & TST & \\
\hline CHEMBL1429273 & 688346 & 3.6 & 4.8208 & TRN & \\
\hline CHEMBL1701224 & 688346 & 5.0 & 5.1272 & TRN & \\
\hline CHEMBL1589385 & 688346 & 4.9 & 4.5344 & TRN & \\
\hline CHEMBL106525 & 688346 & 4.45 & 4.8854 & TRN & \\
\hline CHEMBL1402957 & 688346 & 5.1 & 5.0004 & TST & \\
\hline CHEMBL1324247 & 688346 & 6.25 & 5.15799 & 99999999995 & TRN \\
\hline CHEMBL1585318 & 688346 & 4.3 & 5.2672 & TRN & \\
\hline CHEMBL1374219 & 688346 & 3.6 & 5.0983 & TRN & \\
\hline CHEMBL1429135 & 688346 & 4.6 & 5.0567 & TRN & \\
\hline CHEMBL1502839 & 688346 & 5.7 & 4.8961 & TRN & \\
\hline CHEMBL1571704 & 688346 & 4.15 & 5.0249 & TRN & \\
\hline CHEMBL1256646 & 688346 & 6.0 & 4.6682 & TST & \\
\hline CHEMBL493863 & 688346 & 7.6003 & 5.4162 & TRN & \\
\hline CHEMBL1332402 & 688346 & 4.75 & 4.7481 & TRN & \\
\hline CHEMBL1326191 & 688346 & 5.25 & 4.8992 & TRN & \\
\hline CHEMBL1508406 & 688346 & 4.35 & 4.9234 & TRN & \\
\hline CHEMBL1374242 & 688346 & 4.55 & 4.9686 & TRN & \\
\hline CHEMBL1706577 & 688346 & 4.75 & 5.3582 & TRN & \\
\hline CHEMBL1481914 & 688346 & 4.4 & 4.4994 & TRN & \\
\hline CHEMBL1526624 & 688346 & 5.6 & 5.3276 & TRN & \\
\hline CHEMBL1611800 & 688346 & 5.05 & 4.5487 & TST & \\
\hline CHEMBL1472249 & 688346 & 4.55 & 5.1048 & TST & \\
\hline CHEMBL1580036 & 688346 & 4.25 & 5.0399 & TRN & \\
\hline CHEMBL1462808 & 688346 & 4.4 & 4.6635 & TRN & \\
\hline CHEMBL580421 & 688346 & 5.05 & 5.2483 & TRN & \\
\hline CHEMBL1425636 & 688346 & 4.55 & 4.9644 & TRN & \\
\hline CHEMBL1454269 & 688346 & 4.25 & 4.8736 & TRN & \\
\hline CHEMBL1495790 & 688346 & 4.25 & 5.011 & TST & \\
\hline CHEMBL504791 & 688346 & 4.3 & 5.1074 & TRN & \\
\hline CHEMBL1343341 & 688346 & 3.85 & 4.7444 & TRN & \\
\hline CHEMBL1325440 & 688346 & 4.35 & 4.7019 & TRN & \\
\hline CHEMBL1313635 & 688346 & 9.301 & 5.078 & TRN & \\
\hline CHEMBL1538232 & 688346 & 5.65 & 4.7399 & TRN & \\
\hline CHEMBL1401747 & 688346 & 4.9 & 4.823 & TRN & \\
\hline CHEMBL1461136 & 688346 & 6.6499 & 5.3642 & TRN & \\
\hline CHEMBL1464373 & 688346 & 4.4 & 5.0699 & TRN & \\
\hline
\end{tabular}




\begin{tabular}{|c|c|c|c|c|}
\hline \multicolumn{5}{|c|}{ Supplemental Table S2.txt } \\
\hline CHEMBL578741 & 688346 & 4.55 & 5.0012 & TRN \\
\hline CHEMBL399043 & 688346 & 4.95 & 4.3626 & TST \\
\hline CHEMBL1314174 & 688346 & 5.0 & 4.3937 & TST \\
\hline CHEMBL 3198756 & 688346 & 8.4559 & 5.4878 & TRN \\
\hline CHEMBL1393131 & 688346 & 4.4 & 5.269 & TRN \\
\hline CHEMBL1522129 & 688346 & 4.35 & 5.1521 & TST \\
\hline CHEMBL1426001 & 688346 & 4.15 & 5.2946 & TRN \\
\hline CHEMBL1588434 & 688346 & 5.45 & 4.9967 & TRN \\
\hline CHEMBL1346456 & 688346 & 4.3 & 4.9801 & TST \\
\hline CHEMBL1474286 & 688346 & 5.0 & 4.8676 & TRN \\
\hline CHEMBL1527799 & 688346 & 5.2 & 5.0273 & TRN \\
\hline CHEMBL1305289 & 688346 & 4.25 & 5.2245 & TRN \\
\hline CHEMBL3189657 & 688346 & 4.45 & 5.1811 & TRN \\
\hline CHEMBL1373095 & 688346 & 4.4 & 4.7431 & TRN \\
\hline CHEMBL1364573 & 688346 & 4.85 & 4.5491 & TRN \\
\hline CHEMBL530280 & 688346 & 8.1024 & 5.0906 & TRN \\
\hline CHEMBL1445850 & 688346 & 4.35 & 4.643 & TRN \\
\hline CHEMBL3195611 & 688346 & 4.45 & 4.7939 & TRN \\
\hline CHEMBL 351042 & 688346 & 6.0 & 5.1592 & TRN \\
\hline CHEMBL1548055 & 688346 & 8.0506 & 5.3277 & TST \\
\hline CHEMBL1491702 & 688346 & 4.65 & 4.9068 & TST \\
\hline CHEMBL1530561 & 688346 & 5.35 & 4.663 & TRN \\
\hline CHEMBL1340399 & 688346 & 4.35 & 5.3381 & TST \\
\hline CHEMBL1333879 & 688346 & 4.0 & 5.3985 & TRN \\
\hline CHEMBL52 & 688346 & 5.05 & 5.1584 & TRN \\
\hline CHEMBL1419637 & 688346 & 6.05 & 4.5028 & TRN \\
\hline CHEMBL1503307 & 688346 & 4.4 & 5.2717 & TRN \\
\hline CHEMBL1390716 & 688346 & 6.05 & 5.4713 & TRN \\
\hline CHEMBL1347829 & 688346 & 5.8 & 4.7259 & TRN \\
\hline CHEMBL1381551 & 688346 & 4.35 & 4.6709 & TST \\
\hline CHEMBL 97453 & 688346 & 4.35 & 4.774 & TRN \\
\hline CHEMBL1553873 & 688346 & 3.9 & 4.7956 & TRN \\
\hline CHEMBL1993613 & 688346 & 4.35 & 5.022 & TRN \\
\hline CHEMBL599013 & 688346 & 4.4 & 5.4069 & TRN \\
\hline CHEMBL1578687 & 688346 & 4.3 & 5.2643 & TRN \\
\hline CHEMBL1367444 & 688346 & 4.25 & 4.8323 & TRN \\
\hline CHEMBL1390419 & 688346 & 7.1002 & 5.2967 & TRN \\
\hline CHEMBL1344810 & 688346 & 4.0 & 5.0715 & TRN \\
\hline CHEMBL 3198782 & 688346 & 4.2 & 4.9507 & TST \\
\hline CHEMBL1604163 & 688346 & 4.35 & 5.0353 & TRN \\
\hline CHEMBL1595235 & 688346 & 4.85 & 4.9183 & TRN \\
\hline CHEMBL1312514 & 688346 & 6.7501 & 5.4363 & TRN \\
\hline CHEMBL1373527 & 688346 & 4.2 & 4.823 & TRN \\
\hline CHEMBL 286494 & 688346 & 6.8499 & 4.7156 & TST \\
\hline CHEMBL3194626 & 688346 & 4.05 & 4.809 & TRN \\
\hline CHEMBL1427289 & 688346 & 4.25 & 5.2485 & TRN \\
\hline CHEMBL1558621 & 688346 & 5.2 & 4.5297 & TST \\
\hline CHEMBL1594299 & 688346 & 4.4 & 4.7813 & TRN \\
\hline
\end{tabular}




\begin{tabular}{|c|c|c|c|c|}
\hline \multicolumn{5}{|c|}{ Supplemental Table S2.txt } \\
\hline CHEMBL1451483 & 688346 & 5.35 & 4.3536 & TRN \\
\hline CHEMBL43612 & 688346 & 5.7 & 5.1971 & TRN \\
\hline CHEMBL1607723 & 688346 & 5.55 & 5.0084 & TRN \\
\hline CHEMBL1310907 & 688346 & 4.3 & 5.1042 & TRN \\
\hline CHEMBL1200938 & 688346 & 6.05 & 4.791 & TST \\
\hline CHEMBL1539325 & 688346 & 7.8508 & 4.4075 & TST \\
\hline CHEMBL1429158 & 688346 & 4.45 & 4.841 & TRN \\
\hline CHEMBL1571649 & 688346 & 5.95 & 4.6595 & TRN \\
\hline CHEMBL1480797 & 688346 & 4.2 & 4.5116 & TRN \\
\hline CHEMBL1422559 & 688346 & 5.95 & 4.8102 & TRN \\
\hline CHEMBL1471965 & 688346 & 5.05 & 4.9723 & TRN \\
\hline CHEMBL1350435 & 688346 & 4.3 & 4.9444 & TRN \\
\hline CHEMBL1578278 & 688346 & 8.4559 & 5.2025 & TRN \\
\hline CHEMBL1555752 & 688346 & 3.9 & 4.6239 & TST \\
\hline CHEMBL1515873 & 688346 & 3.95 & 5.3336 & TRN \\
\hline CHEMBL1452561 & 688346 & 5.4 & 4.9637 & TRN \\
\hline CHEMBL1385679 & 688346 & 4.15 & 4.9147 & TRN \\
\hline CHEMBL1560128 & 688346 & 4.05 & 4.7124 & TRN \\
\hline CHEMBL1704267 & 688346 & 4.4 & 5.3838 & TRN \\
\hline CHEMBL584759 & 688346 & 6.0 & 5.4029 & TRN \\
\hline CHEMBL1523286 & 688346 & 5.15 & 4.3492 & TST \\
\hline CHEMBL1462793 & 688346 & 6.1 & 5.034 & TRN \\
\hline CHEMBL1567099 & 688346 & 4.55 & 5.4128 & TRN \\
\hline CHEMBL1589300 & 688346 & 4.9 & 4.6501 & TRN \\
\hline CHEMBL1381627 & 688346 & 3.9 & 4.9947 & TRN \\
\hline CHEMBL1373950 & 688346 & 4.8 & 4.5189 & TST \\
\hline CHEMBL1416563 & 688346 & 4.95 & 5.2707 & TRN \\
\hline CHEMBL1522761 & 688346 & 5.2 & 4.6114 & TRN \\
\hline CHEMBL1349382 & 688346 & 4.85 & 4.6608 & TRN \\
\hline CHEMBL1305393 & 688346 & 4.25 & 5.0658 & TRN \\
\hline CHEMBL1316831 & 688346 & 6.05 & 5.2969 & TRN \\
\hline CHEMBL187460 & 688346 & 4.55 & 4.8032 & TRN \\
\hline CHEMBL1309506 & 688346 & 4.05 & 5.2442 & TRN \\
\hline CHEMBL1481162 & 688346 & 8.1487 & 4.9579 & TRN \\
\hline CHEMBL1464853 & 688346 & 4.35 & 4.4935 & TST \\
\hline CHEMBL1557372 & 688346 & 4.4 & 4.4708 & TRN \\
\hline CHEMBL1366812 & 688346 & 5.35 & 4.9466 & TRN \\
\hline CHEMBL1580779 & 688346 & 4.65 & 4.9858 & TRN \\
\hline CHEMBL1344392 & 688346 & 7.6003 & 4.8297 & TRN \\
\hline CHEMBL1385157 & 688346 & 3.65 & 5.3264 & TRN \\
\hline CHEMBL1407306 & 688346 & 8.0506 & 4.8314 & TRN \\
\hline CHEMBL160053 & 688346 & 5.2 & 5.2803 & TST \\
\hline CHEMBL1324853 & 688346 & 3.7 & 4.9301 & TRN \\
\hline CHEMBL1527095 & 688346 & 4.3 & 5.0666 & TRN \\
\hline CHEMBL1560884 & 688346 & 6.0 & 5.0311 & TRN \\
\hline CHEMBL1511287 & 688346 & 6.9 & 4.6494 & TRN \\
\hline CHEMBL1397270 & 688346 & 5.2 & 4.8018 & TST \\
\hline CHEMBL15192 & 688346 & 5.0 & 5.1356 & TRN \\
\hline
\end{tabular}




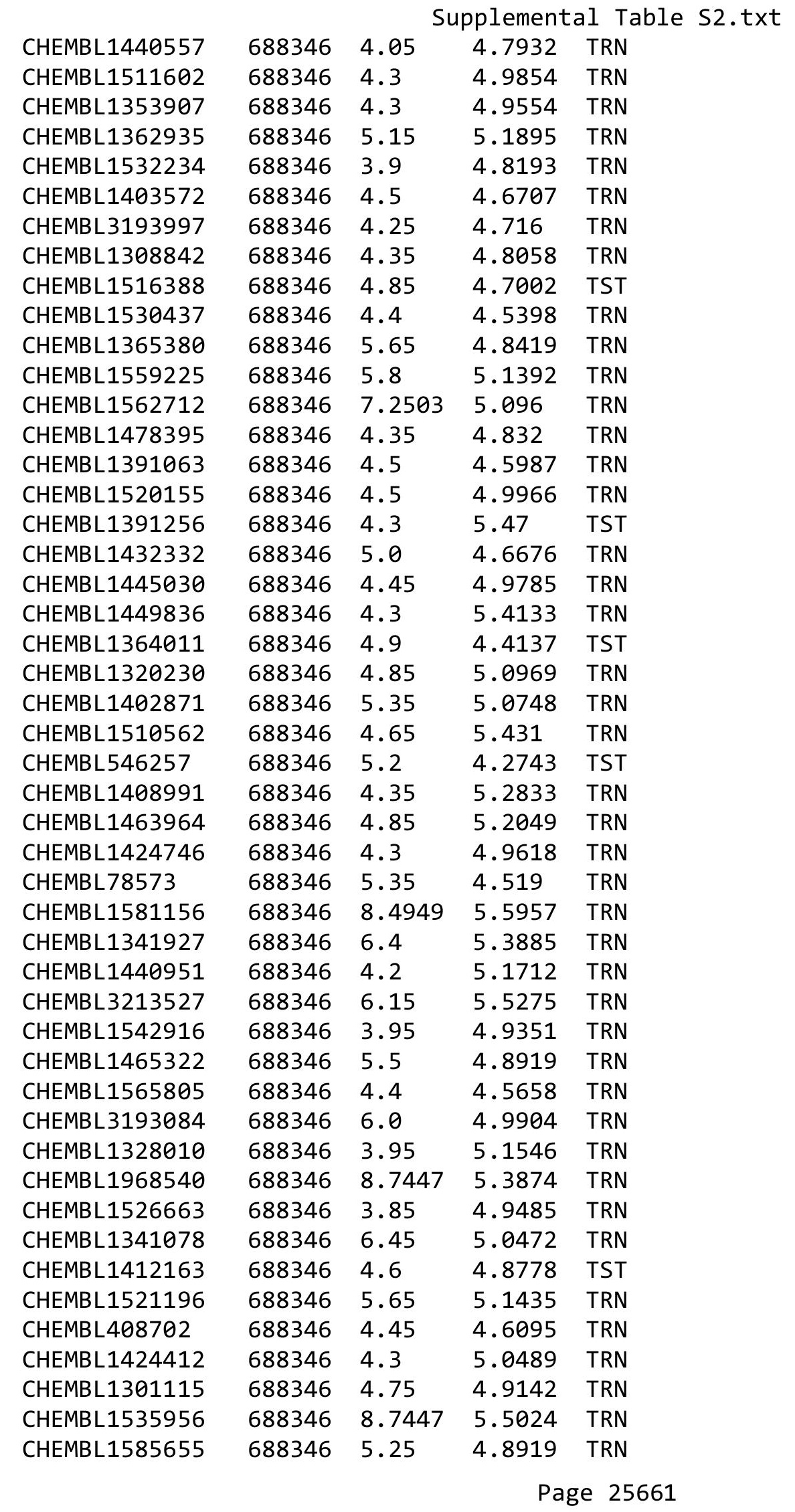




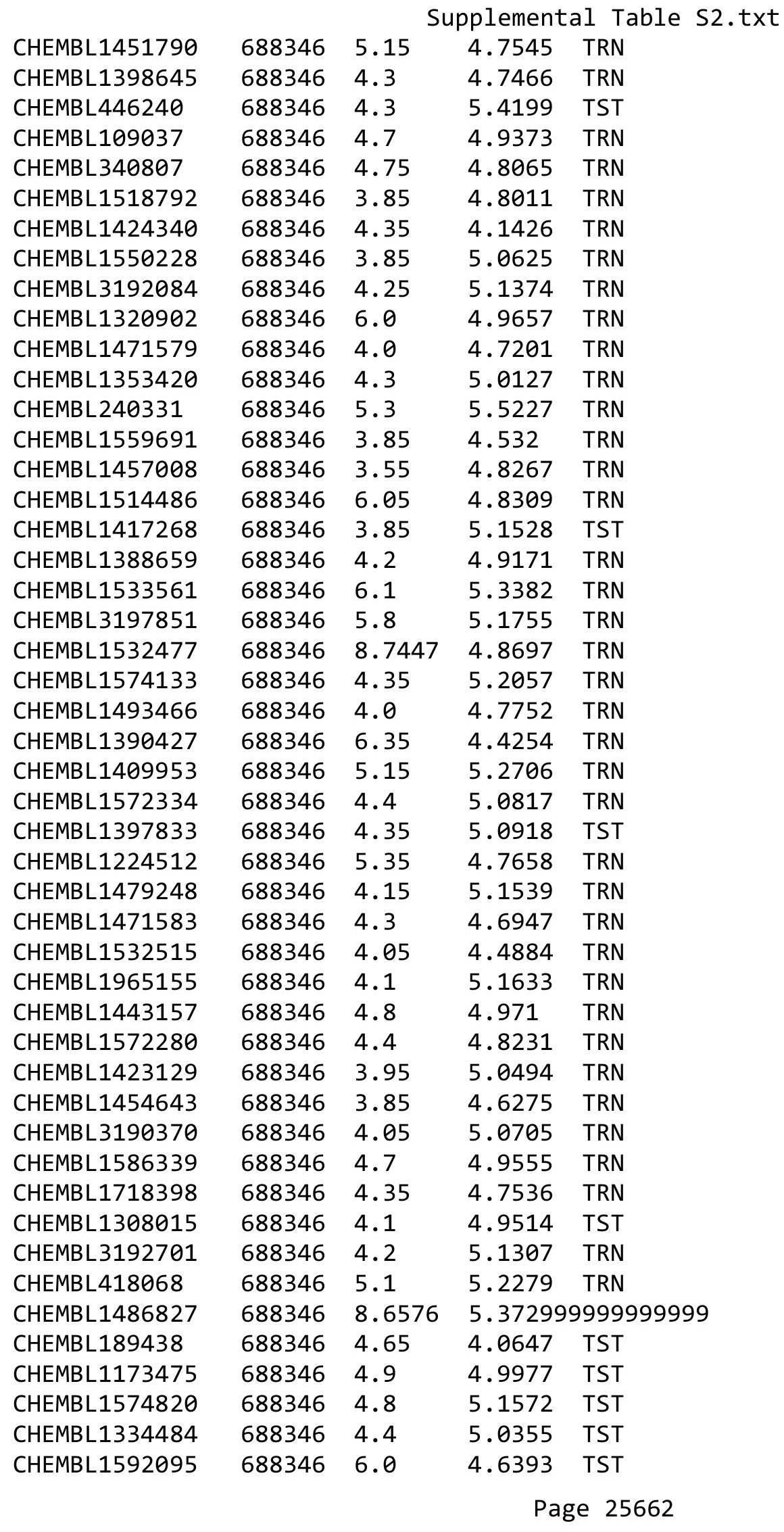




\begin{tabular}{|c|c|c|c|c|c|}
\hline CHEMBL1494334 & 688346 & $4.35^{S 1}$ & $\begin{array}{l}\text { oplement } \\
4.91100\end{array}$ & $\begin{array}{l}\text { al Table S2 } \\
00000000005\end{array}$ & TST \\
\hline CHEMBL1365599 & 688346 & 4.45 & 4.8605 & TST & \\
\hline CHEMBL1981243 & 688346 & 4.35 & 5.1542 & TST & \\
\hline CHEMBL1431875 & 688346 & 4.2 & 4.5077 & TST & \\
\hline CHEMBL1581326 & 688346 & 4.35 & 4.6408 & TST & \\
\hline CHEMBL1498884 & 688346 & 4.4 & 5.374 & TST & \\
\hline CHEMBL1493956 & 688346 & 4.3 & 4.6834 & TST & \\
\hline CHEMBL1730100 & 688346 & 5.5 & 4.628 & TST & \\
\hline CHEMBL1527684 & 688346 & 4.15 & 4.9355 & TST & \\
\hline CHEMBL1606751 & 688346 & 6.8499 & 4.9438 & TST & \\
\hline CHEMBL1589017 & 688346 & 4.2 & 4.8932 & TST & \\
\hline CHEMBL1609550 & 688346 & 4.3 & 4.7866 & TST & \\
\hline CHEMBL1469647 & 688346 & 4.35 & 5.0593 & TST & \\
\hline CHEMBL1505467 & 688346 & 4.5 & 4.6514 & TST & \\
\hline CHEMBL1460436 & 688346 & 4.5 & 4.6502 & TST & \\
\hline CHEMBL1352844 & 688346 & 4.85 & 4.8501 & TST & \\
\hline CHEMBL1539384 & 688346 & 4.4 & 5.1277 & TST & \\
\hline CHEMBL1423705 & 688346 & 4.35 & 4.1669 & TST & \\
\hline CHEMBL1973050 & 688346 & 4.6 & 5.2094 & TST & \\
\hline CHEMBL1358777 & 688346 & 5.55 & 5.4241 & TST & \\
\hline CHEMBL1441990 & 688346 & 3.95 & 4.9621 & TST & \\
\hline CHEMBL1455554 & 688346 & 3.9 & 5.2064 & TST & \\
\hline CHEMBL1434137 & 688346 & 3.95 & 5.50200 & 0000000001 & TST \\
\hline CHEMBL1509210 & 688346 & 3.9 & 5.1529 & TST & \\
\hline CHEMBL1366929 & 688346 & 5.15 & 5.6244 & TST & \\
\hline CHEMBL1531008 & 688346 & 4.0 & 4.8891 & TST & \\
\hline CHEMBL1597993 & 688346 & 4.5 & 5.4459 & TST & \\
\hline CHEMBL1346592 & 688346 & 4.35 & 4.9623 & TST & \\
\hline CHEMBL 3687235 & 1528260 & 7.5031 & 7.8388 & TRN & \\
\hline CHEMBL 3687242 & 1528260 & 8.2147 & 8.5488 & TRN & \\
\hline CHEMBL 3687309 & 1528260 & 8.0706 & 8.1847 & TRN & \\
\hline CHEMBL 3687265 & 1528260 & 8.2218 & 7.9315 & TRN & \\
\hline CHEMBL 3691703 & 1528260 & 8.7696 & 8.4284 & TRN & \\
\hline CHEMBL3691708 & 1528260 & 8.9586 & 8.5424 & TRN & \\
\hline CHEMBL 3691720 & 1528260 & 8.7447 & 8.4989 & TST & \\
\hline CHEMBL 3687261 & 1528260 & 8.3565 & 8.5671 & TRN & \\
\hline CHEMBL 3687243 & 1528260 & 8.3768 & 8.5226 & TRN & \\
\hline CHEMBL 3687288 & 1528260 & 8.1079 & 7.9192 & TRN & \\
\hline CHEMBL 3687232 & 1528260 & 8.0044 & 7.9333 & TRN & \\
\hline CHEMBL 3687270 & 1528260 & 8.3872 & 8.4321 & TRN & \\
\hline CHEMBL 3687257 & 1528260 & 8.2076 & 7.9121 & TRN & \\
\hline CHEMBL 3687247 & 1528260 & 8.5229 & 8.5341 & TRN & \\
\hline CHEMBL 3687229 & 1528260 & 8.0555 & 7.9093 & TRN & \\
\hline CHEMBL 3687264 & 1528260 & 7.9208 & 7.8978 & TRN & \\
\hline CHEMBL 3687267 & 1528260 & 8.6021 & 8.4544 & TST & \\
\hline CHEMBL 3687281 & 1528260 & 8.1612 & 8.0182 & TRN & \\
\hline CHEMBL 3691694 & 1528260 & 8.7212 & 8.5857 & TRN & \\
\hline CHEMBL3691705 & 1528260 & 8.6576 & 8.5326 & TRN & \\
\hline
\end{tabular}


Supplemental Table S2.txt

\begin{tabular}{|c|c|c|c|c|c|c|}
\hline CHEMBL 3687236 & 1528260 & 7.7799 & 7.9034 & TRN & & \\
\hline CHEMBL 3687231 & 1528260 & 8.3188 & 7.9701 & TRN & & \\
\hline CHEMBL3687263 & 1528260 & 7.9431 & 8.0756 & TRN & & \\
\hline CHEMBL 3687234 & 1528260 & 8.0506 & 7.9262 & TRN & & \\
\hline CHEMBL 3687308 & 1528260 & 7.6345 & 7.9485 & TRN & & \\
\hline CHEMBL 3687306 & 1528260 & 8.585 & 8.4258 & TRN & & \\
\hline CHEMBL3691707 & 1528260 & 7.9706 & 8.5243 & TRN & & \\
\hline CHEMBL3687284 & 1528260 & 8.1675 & 7.9723 & TRN & & \\
\hline CHEMBL 3687314 & 1528260 & 7.0794 & 8.48 & TRN & & \\
\hline CHEMBL3691716 & 1528260 & 7.6478 & 7.9527 & TRN & & \\
\hline CHEMBL 3687311 & 1528260 & 8.6383 & 8.3921 & TRN & & \\
\hline CHEMBL 3687238 & 1528260 & 7.3799 & 8.5435 & TRN & & \\
\hline CHEMBL3691772 & 1528260 & 9.1549 & 8.6141 & TRN & & \\
\hline CHEMBL3687249 & 1528260 & 8.6778 & 8.6228 & TRN & & \\
\hline CHEMBL 3687258 & 1528260 & 8.3768 & 8.0839 & TRN & & \\
\hline CHEMBL 3687240 & 1528260 & 7.4698 & 7.9051 & TST & & \\
\hline CHEMBL3687246 & 1528260 & 8.3565 & 8.4849 & TRN & & \\
\hline CHEMBL 3687292 & 1528260 & 8.7447 & 8.2215 & TRN & & \\
\hline CHEMBL 3687244 & 1528260 & 8.5528 & 8.6078 & TRN & & \\
\hline CHEMBL3691699 & 1528260 & 8.4202 & 8.4957 & TRN & & \\
\hline CHEMBL 3687255 & 1528260 & 8.0915 & 7.9144 & TRN & & \\
\hline CHEMBL3691715 & 1528260 & 8.6778 & 8.4761 & TRN & & \\
\hline CHEMBL 3687272 & 1528260 & 8.4685 & 8.2992 & TRN & & \\
\hline CHEMBL 3687273 & 1528260 & 8.5686 & 8.5578 & TRN & & \\
\hline CHEMBL 3687317 & 1528260 & 8.28399 & 999999995 & 99 & 8.2059 & TST \\
\hline CHEMBL 3691704 & 1528260 & 8.8861 & 8.5581 & TRN & & \\
\hline CHEMBL 3687253 & 1528260 & 8.6576 & 8.5832 & TRN & & \\
\hline CHEMBL 3687260 & 1528260 & 8.0555 & 7.9309 & TRN & & \\
\hline CHEMBL3687299 & 1528260 & 8.4949 & 8.2055 & TRN & & \\
\hline CHEMBL 3687251 & 1528260 & 8.6576 & 8.4031 & TRN & & \\
\hline CHEMBL 3691719 & 1528260 & 6.9582 & 7.9216 & TST & & \\
\hline CHEMBL 3687277 & 1528260 & 8.8239 & 8.623 & TRN & & \\
\hline CHEMBL 3687275 & 1528260 & 8.9586 & 8.7246 & TRN & & \\
\hline CHEMBL 3687256 & 1528260 & 7.7144 & 8.2257 & TST & & \\
\hline CHEMBL3687316 & 1528260 & 8.7959 & 8.3474 & TST & & \\
\hline CHEMBL 3687304 & 1528260 & 8.2518 & 7.9741 & TRN & & \\
\hline CHEMBL 3691735 & 1528260 & 6.0 & 7.9417 & TRN & & \\
\hline CHEMBL 3687310 & 1528260 & 8.7212 & 8.362 & TRN & & \\
\hline CHEMBL3687239 & 1528260 & 8.1024 & 7.9646 & TST & & \\
\hline CHEMBL3691692 & 1528260 & 8.2441 & 8.5542 & TST & & \\
\hline CHEMBL3691697 & 1528260 & 8.699 & 8.881 & TRN & & \\
\hline CHEMBL3687266 & 1528260 & 8.699 & 8.5003 & TRN & & \\
\hline CHEMBL3691698 & 1528260 & 8.7447 & 8.8514 & TRN & & \\
\hline CHEMBL 3687294 & 1528260 & 7.6126 & 8.4423 & TST & & \\
\hline CHEMBL3691701 & 1528260 & 8.5376 & 8.5822 & TRN & & \\
\hline CHEMBL 3687282 & 1528260 & 8.1367 & 7.9586 & TRN & & \\
\hline CHEMBL 3687248 & 1528260 & 8.6198 & 8.5784 & TRN & & \\
\hline CHEMBL3691712 & 1528260 & 8.0809 & 7.9475 & TRN & & \\
\hline
\end{tabular}

Page 25664 
Supplemental Table S2.txt

\begin{tabular}{|c|c|c|c|c|c|c|}
\hline CHEMBL 3687252 & 1528260 & 8.5086 & 8.538 & TRN & & \\
\hline CHEMBL3691776 & 1528260 & 9.2218 & 8.5461 & TST & & \\
\hline CHEMBL3691711 & 1528260 & 8.4202 & 8.4947 & TRN & & \\
\hline CHEMBL 3687278 & 1528260 & 7.6162 & 7.8772 & TRN & & \\
\hline CHEMBL 3687318 & 1528260 & 8.4685 & 8.3367 & TST & & \\
\hline CHEMBL 3687245 & 1528260 & 8.5376 & 8.5606 & TRN & & \\
\hline CHEMBL 3687279 & 1528260 & 7.6882 & 7.9829 & TRN & & \\
\hline CHEMBL 3687293 & 1528260 & 8.699 & 8.1899 & TRN & & \\
\hline CHEMBL 3687305 & 1528260 & 8.0757 & 8.0074 & TRN & & \\
\hline CHEMBL 3687313 & 1528260 & \multicolumn{3}{|c|}{8.283999999999999} & 8.4165 & TST \\
\hline CHEMBL 3687283 & 1528260 & 7.8794 & 7.9535 & TRN & & \\
\hline CHEMBL3691693 & 1528260 & 8.2076 & 8.356 & TRN & & \\
\hline CHEMBL3691722 & 1528260 & 8.9208 & 8.6981 & TRN & & \\
\hline CHEMBL 3687291 & 1528260 & \multicolumn{3}{|c|}{6.9670000000000005} & 7.9098 & TRN \\
\hline CHEMBL 3691739 & 1528260 & 6.0 & 8.4729 & TRN & & \\
\hline CHEMBL3687298 & 1528260 & 7.983 & 7.965 & TRN & & \\
\hline CHEMBL3691710 & 1528260 & 8.9586 & 8.8104 & TRN & & \\
\hline CHEMBL3691717 & 1528260 & 8.1612 & 8.1492 & TRN & & \\
\hline CHEMBL 3639860 & 1528260 & 8.2757 & 7.8834 & TRN & & \\
\hline CHEMBL 3687274 & 1528260 & 7.6757 & 8.3976 & TST & & \\
\hline CHEMBL 3687297 & 1528260 & 8.1487 & 8.3241 & TST & & \\
\hline CHEMBL 3687268 & 1528260 & 9.1549 & 8.4912 & TRN & & \\
\hline CHEMBL3691706 & 1528260 & 8.9208 & 8.5302 & TRN & & \\
\hline CHEMBL 3687271 & 1528260 & 8.7696 & 8.5084 & TRN & & \\
\hline CHEMBL3691718 & 1528260 & 8.6021 & 8.6091 & TRN & & \\
\hline CHEMBL 3691714 & 1528260 & 8.1427 & 8.5024 & TRN & & \\
\hline CHEMBL 3687302 & 1528260 & 8.3872 & 8.2005 & TRN & & \\
\hline CHEMBL3691695 & 1528260 & 8.8239 & 8.3155 & TST & & \\
\hline CHEMBL 3687254 & 1528260 & 7.5346 & 7.9023 & TRN & & \\
\hline CHEMBL 3691696 & 1528260 & 8.8861 & 8.3587 & TST & & \\
\hline CHEMBL 3687286 & 1528260 & 7.8327 & 7.9621 & TRN & & \\
\hline CHEMBL 3687287 & 1528260 & 7.9393 & 8.0644 & TRN & & \\
\hline CHEMBL3687296 & 1528260 & 7.7447 & 7.9713 & TRN & & \\
\hline CHEMBL 3687269 & 1528260 & 8.3979 & 7.9582 & TRN & & \\
\hline CHEMBL 3687227 & 1528260 & 7.9469 & 7.869 & TRN & & \\
\hline CHEMBL 3687226 & 1528260 & 8.1079 & 7.8973 & TRN & & \\
\hline CHEMBL 3687312 & 1528260 & 8.9586 & 8.4395 & TST & & \\
\hline CHEMBL3687259 & 1528260 & 8.2076 & 7.891 & TRN & & \\
\hline CHEMBL 3687250 & 1528260 & 8.8539 & 8.4361 & TRN & & \\
\hline CHEMBL 3687237 & 1528260 & 8.0506 & 8.0281 & TST & & \\
\hline CHEMBL 3687230 & 1528260 & 7.7305 & 7.9651 & TST & & \\
\hline CHEMBL 3687303 & 1528260 & 8.4949 & 8.0493 & TRN & & \\
\hline CHEMBL3687276 & 1528260 & 8.7959 & 8.5945 & TRN & & \\
\hline CHEMBL 3687262 & 1528260 & 8.585 & 8.3141 & TRN & & \\
\hline CHEMBL 3691700 & 1528260 & 8.6778 & 8.5861 & TRN & & \\
\hline CHEMBL 3687295 & 1528260 & 8.5229 & 8.468 & TST & & \\
\hline CHEMBL 3687301 & 1528260 & 7.8069 & 7.9752 & TST & & \\
\hline CHEMBL3691702 & 1528260 & 8.6778 & 8.8078 & TST & & \\
\hline
\end{tabular}


Supplemental Table S2.txt

\begin{tabular}{|c|c|c|c|c|c|c|}
\hline CHEMBL 3687233 & 1528260 & 7.6421 & 7.8897 & TST & & \\
\hline CHEMBL 3687290 & 1528260 & 8.4815 & 8.2004 & TST & & \\
\hline CHEMBL3691709 & 1528260 & 8.9586 & 8.497 & TST & & \\
\hline CHEMBL 3687285 & 1528260 & 7.684 & 7.9872 & TST & & \\
\hline CHEMBL3687289 & 1528260 & 8.1739 & 8.1463 & TST & & \\
\hline CHEMBL 3687241 & 1528260 & 7.7905 & 7.9267 & TST & & \\
\hline CHEMBL 3691721 & 1528260 & 8.7696 & 8.7713 & TST & & \\
\hline CHEMBL 3687300 & 1528260 & 7.8447 & 7.9424 & TST & & \\
\hline CHEMBL 3687228 & 1528260 & 8.3979 & 7.9267 & TST & & \\
\hline CHEMBL3287726 & 1361352 & 6.6819 & 6.9579 & TRN & & \\
\hline CHEMBL3287713 & 1361352 & 6.9469 & 6.9201 & TRN & & \\
\hline CHEMBL371464 & 1361352 & 4.0 & 6.4638 & TST & & \\
\hline CHEMBL 3287703 & 1361352 & 6.7932 & 7.022 & TRN & & \\
\hline CHEMBL 3287724 & 1361352 & 7.3279 & 6.9811 & TRN & & \\
\hline CHEMBL3287680 & 1361352 & 6.475 & 6.152 & TST & & \\
\hline CHEMBL 3287710 & 1361352 & 7.2076 & 6.7969 & TST & & \\
\hline CHEMBL3287709 & 1361352 & 6.7905 & 7.0131 & TRN & & \\
\hline CHEMBL 3287671 & 1361352 & 6.9136 & 6.6922 & TRN & & \\
\hline CHEMBL3287689 & 1361352 & 6.3429 & 6.662999 & 999999999 & & TRN \\
\hline CHEMBL3287696 & 1361352 & 6.6421 & 6.2954 & TRN & & \\
\hline CHEMBL3287700 & 1361352 & 6.2487 & 6.1471 & TRN & & \\
\hline CHEMBL3287681 & 1361352 & 4.0 & 5.581 & TRN & & \\
\hline CHEMBL 3287701 & 1361352 & 6.8097 & 6.8042 & TRN & & \\
\hline CHEMBL 3287694 & 1361352 & 6.1945 & 6.5275 & TRN & & \\
\hline CHEMBL 3287688 & 1361352 & 6.1555 & 6.3744 & TRN & & \\
\hline CHEMBL3287695 & 1361352 & 7.3979 & 6.8524 & TRN & & \\
\hline CHEMBL3287692 & 1361352 & 6.2161 & 6.3455 & TRN & & \\
\hline CHEMBL 3287717 & 1361352 & 6.6308 & 6.8589 & TRN & & \\
\hline CHEMBL3287711 & 1361352 & 6.9066 & 6.9939 & TRN & & \\
\hline CHEMBL 3287675 & 1361352 & 6.6536 & 6.6152 & TRN & & \\
\hline CHEMBL 3287706 & 1361352 & 6.5867 & 6.9584 & TRN & & \\
\hline CHEMBL 3287678 & 1361352 & 5.5882 & 5.6772 & TST & & \\
\hline CHEMBL 3287672 & 1361352 & 6.0841 & 6.2726 & TRN & & \\
\hline CHEMBL3287691 & 1361352 & 6.7167 & 6.7823 & TRN & & \\
\hline CHEMBL 3287707 & 1361352 & 7.301 & 6.9576 & TRN & & \\
\hline CHEMBL3287719 & 1361352 & 6.9872 & 6.9919 & TRN & & \\
\hline CHEMBL3287682 & 1361352 & 5.6171 & 5.2063 & TRN & & \\
\hline CHEMBL 3287684 & 1361352 & 6.2924 & 5.7018 & TRN & & \\
\hline CHEMBL 3287697 & 1361352 & 7.0177 & 6.4521 & TRN & & \\
\hline CHEMBL 3287714 & 1361352 & 6.9355 & 6.8729 & TRN & & \\
\hline CHEMBL3287716 & 1361352 & 6.767 & 6.8522 & TRN & & \\
\hline CHEMBL 3287708 & 1361352 & 6.9431 & 7.0624 & TRN & & \\
\hline CHEMBL3287705 & 1361352 & 6.699 & 6.7649 & TST & & \\
\hline CHEMBL3287699 & 1361352 & \multicolumn{3}{|c|}{6.7620000000000005} & 6.5655 & TRN \\
\hline CHEMBL 3287715 & 1361352 & 6.8268 & 6.6471 & TST & & \\
\hline CHEMBL3287720 & 1361352 & 7.284 & 6.7823 & TST & & \\
\hline CHEMBL3287679 & 1361352 & 6.3820 & 00000000 & & 6.568 & \\
\hline CHEMBL3287683 & 1361352 & 6.82100 & 000000000 & & 6.0885 & 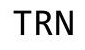 \\
\hline
\end{tabular}

Page 25666 
Supplemental Table S2.txt

\begin{tabular}{|c|c|c|c|c|c|c|c|}
\hline CHEMBL 3287693 & 1361352 & 6.9914 & 6.9492 & TRN & & & \\
\hline CHEMBL3287712 & 1361352 & 7.0862 & 6.9953 & TRN & & & \\
\hline CHEMBL 3287702 & 1361352 & 6.3716 & 6.3842 & TRN & & & \\
\hline CHEMBL 3287721 & 1361352 & 7.1308 & 6.9724 & TRN & & & \\
\hline CHEMBL193982 & 1361352 & 5.61100 & 000000000 & & .7467 & TST & \\
\hline CHEMBL 3287677 & 1361352 & 6.0106 & \multicolumn{3}{|c|}{6.077999999999999} & TST & \\
\hline CHEMBL3287690 & 1361352 & 5.8894 & 6.2346 & TRN & & & \\
\hline CHEMBL 3287687 & 1361352 & 6.8153 & 6.7808 & TRN & & & \\
\hline CHEMBL 3287718 & 1361352 & 7.4685 & 6.8349 & TST & & & \\
\hline CHEMBL3287676 & 1361352 & 6.3458 & 6.2005 & TRN & & & \\
\hline CHEMBL 3287723 & 1361352 & 6.7352 & 6.9316 & TRN & & & \\
\hline CHEMBL3287725 & 1361352 & 6.8665 & 6.7678 & TST & & & \\
\hline CHEMBL 3287722 & 1361352 & 6.983 & 6.9747 & TRN & & & \\
\hline CHEMBL 3287698 & 1361352 & 6.6253 & 6.0382 & TST & & & \\
\hline CHEMBL3287704 & 1361352 & 5.9622 & 6.9716 & TST & & & \\
\hline CHEMBL1951875 & 803066 & 7.0555 & 6.9826 & TRN & & & \\
\hline CHEMBL1951886 & 803066 & 7.8239 & 7.7932 & TRN & & & \\
\hline CHEMBL1951679 & 803066 & 5.0 & 5.052 & TRN & & & \\
\hline CHEMBL1951668 & 803066 & 8.301 & 7.6996 & TST & & & \\
\hline CHEMBL1951888 & 803066 & 7.5086 & 7.4989 & TRN & & & \\
\hline CHEMBL1951687 & 803066 & 7.7696 & 7.7841 & TRN & & & \\
\hline CHEMBL1951690 & 803066 & 8.699 & 8.6829 & TRN & & & \\
\hline CHEMBL1951658 & 803066 & 8.2007 & 8.282 & TRN & & & \\
\hline CHEMBL1951678 & 803066 & 5.0 & 7.577999 & 9999999999 & & TST & \\
\hline CHEMBL1951872 & 803066 & 9.0969 & 8.8092 & TRN & & & \\
\hline CHEMBL1951662 & 803066 & 8.2441 & 8.607000 & 0000000001 & & TRN & \\
\hline CHEMBL1951889 & 803066 & 7.8239 & 7.758999 & 99999999995 & & TRN & \\
\hline CHEMBL1951660 & 803066 & 8.28399 & 999999999 & 99 & .8829 & 9999999999 & TRN \\
\hline CHEMBL1951666 & 803066 & 8.4089 & 8.3717 & TRN & & & \\
\hline CHEMBL1951890 & 803066 & 7.9208 & 8.0718 & TRN & & & \\
\hline CHEMBL1951671 & 803066 & 6.9281 & 6.9092 & TRN & & & \\
\hline CHEMBL1951684 & 803066 & 6.9066 & 6.91 & TRN & & & \\
\hline CHEMBL1951887 & 803066 & 8.1739 & 8.0923 & TRN & & & \\
\hline CHEMBL1951685 & 803066 & 6.7167 & 6.6779 & TRN & & & \\
\hline CHEMBL1951878 & 803066 & 8.0088 & 8.1167 & TRN & & & \\
\hline CHEMBL1951673 & 803066 & 7.0706 & 7.2856 & TST & & & \\
\hline CHEMBL1951681 & 803066 & 7.8239 & 7.7871 & TRN & & & \\
\hline CHEMBL1951670 & 803066 & 8.2007 & 8.3325 & TRN & & & \\
\hline CHEMBL1951672 & 803066 & 5.0 & 7.0254 & TST & & & \\
\hline CHEMBL1951686 & 803066 & 6.8761 & 6.9052 & TRN & & & \\
\hline CHEMBL1951885 & 803066 & 7.4685 & 7.4853 & TRN & & & \\
\hline CHEMBL1951682 & 803066 & 7.2596 & 7.2042 & TRN & & & \\
\hline CHEMBL1951669 & 803066 & 8.5086 & 7.6084 & TST & & & \\
\hline CHEMBL1951883 & 803066 & 8.1938 & 8.1901 & TRN & & & \\
\hline CHEMBL1951663 & 803066 & 8.0 & 8.0818 & TRN & & & \\
\hline CHEMBL1951877 & 803066 & 8.1135 & 8.166 & TRN & & & \\
\hline CHEMBL1951688 & 803066 & 8.4685 & 8.3333 & TRN & & & \\
\hline CHEMBL1951659 & 803066 & 8.3279 & 8.2303 & TRN & & & \\
\hline
\end{tabular}




\begin{tabular}{|c|c|c|c|c|c|}
\hline \multicolumn{6}{|c|}{ Supplemental Table S2.txt } \\
\hline CHEMBL1951884 & 803066 & 7.0555 & 7.0039 & TRN & \\
\hline CHEMBL1951876 & 803066 & 7.3279 & 7.69 & TST & \\
\hline CHEMBL1951674 & 803066 & 7.2676 & 7.6515 & TST & \\
\hline CHEMBL1951881 & 803066 & 8.699 & 8.6964 & TRN & \\
\hline CHEMBL1951683 & 803066 & 7.9208 & 7.8053 & TRN & \\
\hline CHEMBL1951680 & 803066 & 7.5686 & 7.6295 & TRN & \\
\hline CHEMBL1951882 & 803066 & 8.6383 & 8.5899 & TRN & \\
\hline CHEMBL1951676 & 803066 & 7.1024 & 7.03799 & 9999999999 & TRN \\
\hline CHEMBL1951879 & 803066 & 8.5229 & 8.6281 & TRN & \\
\hline CHEMBL1951667 & 803066 & 7.8539 & 7.8999 & TRN & \\
\hline CHEMBL1951880 & 803066 & 8.3565 & 8.308 & TRN & \\
\hline CHEMBL1951689 & 803066 & 7.1675 & 7.5468 & TRN & \\
\hline CHEMBL1951675 & 803066 & 7.4559 & 7.4987 & TRN & \\
\hline CHEMBL1951665 & 803066 & 8.0915 & 7.33799 & 9999999999 & TST \\
\hline CHEMBL1951873 & 803066 & 6.6925 & 8.0862 & TST & \\
\hline CHEMBL1951874 & 803066 & 7.1249 & 7.9784 & TST & \\
\hline CHEMBL1951661 & 803066 & 9.3979 & 8.6999 & TST & \\
\hline CHEMBL1951664 & 803066 & 8.0862 & 7.4649 & TST & \\
\hline CHEMBL1951677 & 803066 & 8.2676 & 7.3438 & TST & \\
\hline CHEMBL 2070757 & 835072 & 4.0 & 3.57899 & 99999999997 & TRN \\
\hline CHEMBL 2070736 & 835072 & 8.3768 & 8.1463 & TRN & \\
\hline CHEMBL 2070923 & 835072 & 7.1273 & 6.6727 & TST & \\
\hline CHEMBL 2070738 & 835072 & 5.3947 & 4.9492 & TRN & \\
\hline CHEMBL 2070906 & 835072 & 7.1113 & 6.6824 & TRN & \\
\hline CHEMBL 2070590 & 835072 & 6.153 & 5.4165 & TRN & \\
\hline CHEMBL 2070748 & 835072 & 5.2518 & 4.8854 & TRN & \\
\hline CHEMBL 2070742 & 835072 & 4.0 & 4.2135 & TRN & \\
\hline CHEMBL 2070898 & 835072 & 7.1385 & 6.916 & TRN & \\
\hline CHEMBL2070732 & 835072 & 8.7959 & 8.8576 & TRN & \\
\hline CHEMBL 2070935 & 835072 & 8.1681 & 7.2489 & TST & \\
\hline CHEMBL 2070599 & 835072 & 6.6144 & 7.2826 & TRN & \\
\hline CHEMBL 2070753 & 835072 & 5.5575 & 5.2503 & TRN & \\
\hline CHEMBL 2070900 & 835072 & 6.7305 & 6.8327 & TRN & \\
\hline CHEMBL 2070925 & 835072 & 7.5017 & 7.7529 & TRN & \\
\hline CHEMBL 2070589 & 835072 & 7.0506 & 3.3702 & TST & \\
\hline CHEMBL 2070729 & 835072 & 7.6383 & 7.6112 & TRN & \\
\hline CHEMBL 2070771 & 835072 & 7.0737 & 7.2102 & TRN & \\
\hline CHEMBL 2070603 & 835072 & 7.0655 & 6.1876 & TST & \\
\hline CHEMBL 2070915 & 835072 & 6.2588 & 5.8239 & TST & \\
\hline CHEMBL 2070760 & 835072 & 4.0 & 4.417 & TRN & \\
\hline CHEMBL 2070920 & 835072 & 7.4989 & 6.9451 & TST & \\
\hline CHEMBL 2070609 & 835072 & 7.0362 & 6.8902 & TRN & \\
\hline CHEMBL 2070929 & 835072 & 7.1057 & 7.6555 & TST & \\
\hline CHEMBL 2070752 & 835072 & 4.0 & 4.1148 & TRN & \\
\hline CHEMBL 2070593 & 835072 & 5.8539 & 5.6819 & TRN & \\
\hline CHEMBL 2070766 & 835072 & 7.0424 & 6.3276 & TST & \\
\hline CHEMBL 2070596 & 835072 & 7.041 & 7.3895 & TRN & \\
\hline CHEMBL2070756 & 835072 & 4.0 & 4.5186 & TRN & \\
\hline
\end{tabular}




\begin{tabular}{|c|c|c|c|c|c|}
\hline & & & & & \\
\hline CHEMBL 2070907 & 835072 & 7.8827 & 7.9253 & TRN & \\
\hline CHEMBL2070751 & 835072 & 4.0 & 4.3954 & TRN & \\
\hline CHEMBL2070908 & 835072 & 6.4112 & 6.8909 & TRN & \\
\hline CHEMBL2070918 & 835072 & 7.1002 & 6.6518 & TST & \\
\hline CHEMBL2070740 & 835072 & 4.0 & 3.9433 & TRN & \\
\hline CHEMBL 2070917 & 835072 & 7.2588 & 7.1557 & TST & \\
\hline CHEMBL 2070928 & 835072 & 6.3391 & 7.3098 & TST & \\
\hline CHEMBL 2070896 & 835072 & 6.4962 & 6.4795 & TRN & \\
\hline CHEMBL 2070931 & 835072 & 6.6478 & 6.7636 & TST & \\
\hline CHEMBL2070733 & 835072 & 9.0458 & 8.3891 & TRN & \\
\hline CHEMBL 2070606 & 835072 & 7.0315 & 7.9206 & TST & \\
\hline CHEMBL2070594 & 835072 & 7.3468 & 7.3445 & TRN & \\
\hline CHEMBL 2070605 & 835072 & 6.8665 & 6.2227 & TST & \\
\hline CHEMBL 2070919 & 835072 & 7.767 & 7.1183 & TST & \\
\hline CHEMBL 2070741 & 835072 & 4.0 & 3.9332 & TRN & \\
\hline CHEMBL 2070922 & 835072 & 7.3575 & 7.709 & TST & \\
\hline CHEMBL 2070754 & 835072 & 4.0 & 4.0993 & TRN & \\
\hline CHEMBL 2070772 & 835072 & 6.4802 & 6.6501 & TRN & \\
\hline CHEMBL 2070932 & 835072 & 7.75200 & 000000006 & 6.9495 & TST \\
\hline CHEMBL 2070897 & 835072 & 6.6421 & 6.9618 & TRN & \\
\hline CHEMBL 2070763 & 835072 & 4.0 & 4.0076 & TRN & \\
\hline CHEMBL2070739 & 835072 & 5.3768 & 5.3883 & TRN & \\
\hline CHEMBL 2070901 & 835072 & 7.9172 & 7.7857 & TRN & \\
\hline CHEMBL 2070903 & 835072 & 6.9031 & 6.9668 & TRN & \\
\hline CHEMBL 2070764 & 835072 & 4.0 & 3.85699 & 99999999998 & TRN \\
\hline CHEMBL 2070597 & 835072 & 7.0757 & 6.912006 & 0000000001 & TRN \\
\hline CHEMBL2070899 & 835072 & 7.2132 & 6.8644 & TRN & \\
\hline CHEMBL 2070910 & 835072 & 5.9547 & 6.4853 & TRN & \\
\hline CHEMBL 2070735 & 835072 & 8.8861 & 8.3987 & TRN & \\
\hline CHEMBL 2070762 & 835072 & 4.0 & 3.8086 & TRN & \\
\hline CHEMBL 2070744 & 835072 & 4.0 & 3.7075 & TRN & \\
\hline CHEMBL 2070934 & 835072 & 7.2692 & 7.8684 & TST & \\
\hline CHEMBL2070912 & 835072 & 7.767 & 7.7204 & TRN & \\
\hline CHEMBL 2070927 & 835072 & 7.4112 & 7.2296 & TST & \\
\hline CHEMBL 2070758 & 835072 & 4.0 & 4.1836 & TRN & \\
\hline CHEMBL 2070598 & 835072 & 6.7959 & 6.8644 & TRN & \\
\hline CHEMBL 2070773 & 835072 & 7.6655 & 7.6211 & TRN & \\
\hline CHEMBL 2070595 & 835072 & 8.0 & 7.5864 & TRN & \\
\hline CHEMBL 2070731 & 835072 & 7.3872 & 7.1788 & TRN & \\
\hline CHEMBL 2070745 & 835072 & 4.0 & 3.57899 & 99999999997 & TRN \\
\hline CHEMBL2069322 & 835072 & 4.0 & 4.5643 & TRN & \\
\hline CHEMBL 2070909 & 835072 & 6.7399 & 6.8202 & TRN & \\
\hline CHEMBL 2070761 & 835072 & 4.0 & 4.2347 & TRN & \\
\hline CHEMBL2070768 & 835072 & 7.4067 & 7.0507 & TRN & \\
\hline CHEMBL 2070933 & 835072 & 7.6696 & 6.9081 & TST & \\
\hline CHEMBL 2070769 & 835072 & 7.767 & 8.0272 & TRN & \\
\hline CHEMBL 2070608 & 835072 & 4.0 & 4.0556 & TRN & \\
\hline CHEMBL 2070604 & 835072 & 8.1675 & 7.0897 & TST & \\
\hline
\end{tabular}




\begin{tabular}{|c|c|c|c|c|c|c|}
\hline & & \multicolumn{5}{|c|}{ Supplemental Table s2.txt } \\
\hline CHEMBL 2070734 & 835072 & 7.6383 & 7.6564 & TRN & & \\
\hline CHEMBL 2070904 & 835072 & 6.1118 & 6.2557 & TRN & & \\
\hline CHEMBL 2070770 & 835072 & 7.1506 & 6.6652 & TRN & & \\
\hline CHEMBL 2070914 & 835072 & 8.4401 & 8.3468 & TRN & & \\
\hline CHEMBL 2070921 & 835072 & 7.2807 & 6.5181 & TST & & \\
\hline CHEMBL 2070750 & 835072 & 4.0 & 4.4682 & TRN & & \\
\hline CHEMBL 2070765 & 835072 & 4.0 & 3.8852 & TRN & & \\
\hline CHEMBL 2070902 & 835072 & \multicolumn{3}{|c|}{6.752000000000001} & 7.3596 & TRN \\
\hline CHEMBL 2070591 & 835072 & 7.8539 & 8.1877 & TRN & & \\
\hline CHEMBL 2070610 & 835072 & 6.6861 & 7.11 & TRN & & \\
\hline CHEMBL 2070755 & 835072 & 4.0 & 4.3602 & TRN & & \\
\hline CHEMBL 2070746 & 835072 & 4.0 & 4.2623 & TRN & & \\
\hline CHEMBL 2070775 & 835072 & 7.0595 & 7.4335 & TRN & & \\
\hline CHEMBL 2070895 & 835072 & 6.5952 & 6.6301 & TRN & & \\
\hline CHEMBL 2070747 & 835072 & 4.0 & 4.0553 & TRN & & \\
\hline CHEMBL 2070913 & 835072 & 6.5513 & 6.5663 & TRN & & \\
\hline CHEMBL 2070743 & 835072 & 4.0 & 3.7973 & TRN & & \\
\hline CHEMBL 2070607 & 835072 & 4.699 & 4.623 & TRN & & \\
\hline CHEMBL 2070911 & 835072 & 6.6021 & 6.7409 & TRN & & \\
\hline CHEMBL 2070759 & 835072 & 4.0 & 3.55899 & 999999999 & 97 & TRN \\
\hline CHEMBL 2070600 & 835072 & 7.6021 & 6.7758 & TRN & & \\
\hline CHEMBL 2070905 & 835072 & 6.2874 & 6.3521 & TRN & & \\
\hline CHEMBL 2070730 & 835072 & 5.4413 & 5.4695 & TRN & & \\
\hline CHEMBL 2070592 & 835072 & 7.8539 & 7.3682 & TRN & & \\
\hline CHEMBL 2070767 & 835072 & 6.5986 & 6.4617 & TST & & \\
\hline CHEMBL 2070749 & 835072 & 5.2684 & 5.3934 & TRN & & \\
\hline CHEMBL 2070737 & 835072 & 7.7212 & 7.7443 & TRN & & \\
\hline CHEMBL 2070926 & 835072 & 7.3152 & 7.5154 & TST & & \\
\hline CHEMBL 2070602 & 835072 & 6.0339 & 6.6724 & TRN & & \\
\hline CHEMBL 2070601 & 835072 & 6.8239 & 6.5847 & TRN & & \\
\hline CHEMBL 2070774 & 835072 & 6.6073 & 7.3968 & TST & & \\
\hline CHEMBL2070916 & 835072 & 7.5935 & 6.9899 & TST & & \\
\hline CHEMBL 2070924 & 835072 & 6.8665 & 7.7772 & TST & & \\
\hline CHEMBL 2070930 & 835072 & \multicolumn{3}{|c|}{6.3420000000000005} & 7.5563 & TST \\
\hline CHEMBL3664814 & 1535448 & 8.3019 & 8.2187 & TRN & & \\
\hline CHEMBL 3664840 & 1535448 & 8.1238 & 8.1226 & TRN & & \\
\hline CHEMBL3664822 & 1535448 & 8.4401 & 8.22 & TRN & & \\
\hline CHEMBL 3664886 & 1535448 & 8.2907 & 7.99 & TST & & \\
\hline CHEMBL3664846 & 1535448 & 6.0 & 5.7912 & TRN & & \\
\hline CHEMBL3664877 & 1535448 & 8.0414 & 8.3011 & TRN & & \\
\hline CHEMBL 3664823 & 1535448 & 8.4001 & 8.2064 & TRN & & \\
\hline CHEMBL 3664890 & 1535448 & 7.9359 & 8.0381 & TST & & \\
\hline CHEMBL 3664843 & 1535448 & 8.2765 & 8.2279 & TRN & & \\
\hline CHEMBL3664863 & 1535448 & 7.8586 & 7.6171 & TRN & & \\
\hline CHEMBL3664839 & 1535448 & 8.1124 & 8.1125 & TRN & & \\
\hline CHEMBL 3664828 & 1535448 & 7.9344 & 8.0973 & TST & & \\
\hline CHEMBL 3664861 & 1535448 & 8.2154 & 8.2263 & TRN & & \\
\hline CHEMBL3664872 & 1535448 & 8.172 & 8.1218 & TRN & & \\
\hline
\end{tabular}


Supplemental Table S2.txt

\begin{tabular}{|c|c|c|}
\hline & & \\
\hline HEMBL3664850 & 35448 & 8.3107 \\
\hline AEMBL3664834 & 35448 & 984 \\
\hline & 448 & 35 \\
\hline HEMBL366 & 5448 & \\
\hline AEMBL3664837 & 535448 & 8.301 \\
\hline HEMBL 3664827 & .535448 & 8.108 \\
\hline HEMBL 3664 & .535448 & 8.58 \\
\hline AEMBL366 & 35448 & 193 \\
\hline AEMBL 366 & & \\
\hline HEMBL3664880 & 1535448 & 7.704 \\
\hline AEMBL3664867 & .535448 & 8.334 \\
\hline AEMBL 3664 & .535448 & 906 \\
\hline IEMBL 366 & 48 & 8899 \\
\hline JEMBL 366 & & 543 \\
\hline HEMBL3664859 & 1535448 & 8.118 \\
\hline HEMBL 3664 & & 8.214 \\
\hline HEMBL 366 & 48 & 8.2441 \\
\hline JEMBL366 & & 8.1965 \\
\hline HEMBL366 & & 8.2351 \\
\hline AEMBL 3664 & & 905 \\
\hline IEMBL 3664 & & $431 \varepsilon$ \\
\hline HEMBL 366 & 48 & 8.924 \\
\hline HEMBL366 & & 113 \\
\hline AEMBL 36 & & 058 \\
\hline HEMBL 366 & & 8.377 \\
\hline AEMBL 3664 & & 7.757 \\
\hline HEMBL 366 & 48 & 8 . \\
\hline AEMBL & & 3879 \\
\hline HFMRI 366 & 48 & 8.1965 \\
\hline HEMBL 3664 & & 7.7883 \\
\hline AEMBL 3664 & 48 & 7.7455 \\
\hline AEMBL366 & & \\
\hline AFME & & $84 \varepsilon$ \\
\hline IEN & 48 & 83 \\
\hline HEMBL 3664 & 15354 & 7.4825 \\
\hline HEMBL 3664 & & 7.9952 \\
\hline & & 7. \\
\hline סM & 8 & 8 . \\
\hline HEMBL366 & 48 & 8.4377 \\
\hline HEMBL 3664 & 1535448 & 7.859 \\
\hline HEMBL 3664 & 1535448 & \\
\hline & & \\
\hline HEMBL 366 & & 8.3958 \\
\hline HEMBL 3664 & 1535448 & 7.4094 \\
\hline HEMBL 3664 & 15354 & 6.0 \\
\hline CHEMBL3664889 & 15354 & 7.626 \\
\hline 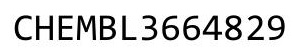 & 15354 & 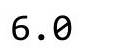 \\
\hline
\end{tabular}

8.2184 TRN

8.3871 TRN

8.0223 TRN

8.0606 TRN

7.5065 TRN

8.2376 TRN

8.1979 TRN

8.4156 TST

8.3126 TRN

7.6694 TRN

7.726 TRN

8.3775 TRN

8.1271 TRN

8.0632 TRN

7.5163 TRN

7.9959 TRN

8.4341 TST

8.3679 TRN

8.1736 TRN

8.2191 TRN

8.1459 TST

8.4103 TRN

8.5482 TST

7.8254 TRN

8.5595 TRN

8.3564 TRN

7.5618 TRN

8.2568 TRN

7.4562 TRN

8.3208 TRN

7.849 TRN

7.9108 TRN

8.2724 TRN

8.1588 TRN

8.0918 TRN

7.4696 TRN

7.9399 TRN

7.9941 TST

8.193 TRN

8.2777 TST

8.0055 TRN

6.3959 TRN

7.6952 TRN

8.2124 TRN

7.787999999999999 TST

6.0416 TRN

8.5343 TST

7.1105 TST

Page 25671 
Supplemental Table S2.txt

\begin{tabular}{|c|c|c|c|c|}
\hline 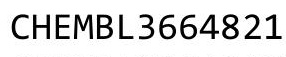 & 1535448 & 8.5952 & 8.4081 & 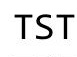 \\
\hline CHEMBL3664848 & 1535448 & 8.2277 & 8.3146 & TST \\
\hline HEMBL3664885 & 535448 & 7.6704 & .7718 & \\
\hline HEMBL 3664879 & 535448 & 7.4136 & 7.5951 & \\
\hline CHEMBL3664869 & 535448 & 8.2104 & 8.1679 & \\
\hline HEMBL64587 & 51699 & 7.8861 & 8.1744 & \\
\hline HEMBL445097 & 51699 & 6.6576 & 7.7031 & \\
\hline CHEMBL 294589 & 51699 & 7.8477 & 7.6528 & \\
\hline HEMBL 64745 & 51699 & 7.8633 & 8.4604 & \\
\hline CHEMBL62942 & 51699 & 8.3565 & 8.4289 & \\
\hline HEMBL62497 & 51699 & 8.7959 & 8.1274 & \\
\hline HEMBL 60676 & 51699 & 7.1135 & 7.5443 & \\
\hline CHEMBL64621 & 51699 & 8.4437 & 8.2833 & \\
\hline HEMBL 292508 & 151699 & 7.8928 & 7.4689 & \\
\hline CHEMBL 62722 & 51699 & 8.0915 & 8.369 & \\
\hline HEMBL 62530 & 51699 & 7.5157 & 8.3468 & N \\
\hline HEMBL539263 & 51699 & 7.4855 & 7.94 & \\
\hline CHEMBL64449 & 151699 & 7.4976 & 8.3199 & SI \\
\hline HEMBL64428 & 151699 & 8.9208 & 8.0443 & \\
\hline HEMBL417 & 51699 & 8.699 & 8.5547 & \\
\hline HEMBL 64464 & 51699 & 8.8239 & 8.3119 & N \\
\hline HEMBL545684 & 51699 & 7.5229 & 7.9608 & \\
\hline CHEMBL 293259 & 151699 & 8.6198 & 8.1623 & RN \\
\hline HEMBL430 & 151699 & 7.8041 & 7.5703 & \\
\hline CHEMBL61936 & 51699 & 7.3979 & 8.2696 & $\mathrm{RN}$ \\
\hline HEMBL 302683 & 51699 & 8.2076 & 7.9686 & N \\
\hline IHEMBL64882 & 51699 & 8.0223 & 7.5983 & IV \\
\hline CHEMBL60081 & 51699 & 8. & 8.286 & RN \\
\hline HEMBL64 & 51699 & 7. & 8.0765 & RN \\
\hline CHEMBL61384 & 51699 & 7.6882 & 8.4009 & RN \\
\hline CHEMBL62815 & 51699 & 8.4685 & 7.6772 & $\mathbf{N}$ \\
\hline CHEMBL64035 & 51699 & 8.4685 & 8.7074 & TRN \\
\hline HEMBL 292860 & 51699 & & 8.4107 & RN \\
\hline HEMBL 6 & 99 & 7. & 8.0227 & RN \\
\hline CHEMBL552673 & 151699 & 7.8268 & 8.1668 & TST \\
\hline HEMBL 64194 & 51699 & 6.2218 & 7.7502 & TST \\
\hline CHEMBL 64860 & 51699 & 8.5229 & 8.5393 & TRN \\
\hline CHEMBL 30 & 9 & & 7.8618 & RN \\
\hline CHEMBL 304 & 151699 & 7. & 8.2725 & RN \\
\hline CHEMBL60477 & 151699 & 8.0555 & 8.3417 & TRN \\
\hline CHEMBL 64034 & 151699 & 8.0555 & 8.4396 & TRN \\
\hline CHEMBL555553 & 51699 & 7.5258 & 8.1173 & RN \\
\hline CHEMBL64493 & 151699 & & 8.1527 & SI \\
\hline CHEMBL 64125 & 151699 & 8.0223 & 7.8368 & TRN \\
\hline CHEMBL303357 & 151699 & 8.1135 & 8.1401 & TST \\
\hline CHEMBL418125 & 151699 & 8.2441 & 7.9723 & RN \\
\hline CHEMBL 305372 & 151699 & 8.8861 & 8.496 & RN \\
\hline CHEMBL 302900 & 151699 & 7.4377 & 8.0429 & \\
\hline
\end{tabular}

Page 25672 


\begin{tabular}{|c|c|c|c|c|c|}
\hline \multicolumn{6}{|c|}{ Supplemental Table S2.txt } \\
\hline CHEMBL64285 & 151699 & 7.5768 & 8.0002 & TRN & \\
\hline CHEMBL 293916 & 151699 & 7.058 & 7.5208 & TRN & \\
\hline CHEMBL 29067 & 151699 & 8.1487 & 7.7363 & TST & \\
\hline CHEMBL439937 & 151699 & 8.7959 & 8.0938 & TST & \\
\hline CHEMBL 305145 & 151699 & 8.0 & 8.4226 & TRN & \\
\hline CHEMBL64472 & 151699 & 8.301 & 8.1356 & TRN & \\
\hline CHEMBL 293653 & 151699 & 7.063 & 7.8166 & TRN & \\
\hline CHEMBL60996 & 151699 & 8.1079 & 8.1133 & TRN & \\
\hline CHEMBL 293862 & 151699 & 8.2518 & 8.1964 & TRN & \\
\hline CHEMBL442170 & 151699 & 8.0862 & 8.36399 & 9999999999 & TRN \\
\hline CHEMBL64462 & 151699 & 6.6819 & 8.3059 & TST & \\
\hline CHEMBL64636 & 151699 & 8.7212 & 8.3053 & TRN & \\
\hline CHEMBL64180 & 151699 & 7.6478 & 7.6758 & TST & \\
\hline CHEMBL62725 & 151699 & 7.6021 & 8.044 & TRN & \\
\hline CHEMBL64691 & 151699 & 9.0 & 8.6366 & TRN & \\
\hline CHEMBL539673 & 151699 & 9.0 & 8.5158 & TRN & \\
\hline CHEMBL 293641 & 151699 & 8.0 & 8.2482 & TRN & \\
\hline CHEMBL64716 & 151699 & 6.5626 & 8.4444 & TST & \\
\hline CHEMBL302696 & 151699 & 8.4685 & 7.8163 & TRN & \\
\hline CHEMBL 292550 & 151699 & 7.4413 & 7.4731 & TRN & \\
\hline CHEMBL 293906 & 151699 & 8.8539 & 8.369 & TRN & \\
\hline CHEMBL554536 & 151699 & 7.6289 & 8.2312 & TST & \\
\hline CHEMBL 293457 & 151699 & 8.6576 & 8.709 & TRN & \\
\hline CHEMBL61416 & 151699 & 9.0 & 8.6678 & TRN & \\
\hline CHEMBL63100 & 151699 & 9.2218 & 8.5746 & TRN & \\
\hline CHEMBL62983 & 151699 & 8.2441 & 8.07200 & 0000000001 & TRN \\
\hline CHEMBL62830 & 151699 & 8.7959 & 8.3638 & TRN & \\
\hline CHEMBL64057 & 151699 & 9.0969 & 8.4883 & TRN & \\
\hline CHEMBL61937 & 151699 & 7.7447 & 8.1996 & TRN & \\
\hline CHEMBL62219 & 151699 & 8.1871 & 8.0265 & TST & \\
\hline CHEMBL62424 & 151699 & 5.011 & 7.7426 & TST & \\
\hline CHEMBL 293662 & 151699 & 8.8539 & 8.564 & TRN & \\
\hline CHEMBL64214 & 151699 & 9.0 & 8.5409 & TRN & \\
\hline CHEMBL 291372 & 151699 & 8.7447 & 8.7122 & TRN & \\
\hline CHEMBL62284 & 151699 & 6.6478 & 7.7413 & TST & \\
\hline CHEMBL60359 & 151699 & 8.5229 & 8.3854 & TRN & \\
\hline CHEMBL 293642 & 151699 & 8.0362 & 8.5234 & TRN & \\
\hline CHEMBL 292704 & 151699 & 7.0223 & 8.0922 & TST & \\
\hline CHEMBL64669 & 151699 & 7.4815 & 7.6738 & TST & \\
\hline CHEMBL64445 & 151699 & 8.3372 & 8.2534 & TRN & \\
\hline CHEMBL304879 & 151699 & 8.2676 & 8.1496 & TRN & \\
\hline CHEMBL63383 & 151699 & 8.7212 & 8.6819 & TRN & \\
\hline CHEMBL 299944 & 151699 & 7.8697 & 7.4682 & TST & \\
\hline CHEMBL64198 & 151699 & 7.2882 & 8.1587 & TST & \\
\hline CHEMBL 292734 & 151699 & 4.7508 & 7.4063 & TST & \\
\hline CHEMBL62308 & 151699 & 7.9031 & 8.4101 & TRN & \\
\hline CHEMBL3769608 & 1556480 & 3.301 & 3.9122 & TRN & \\
\hline CHEMBL3770494 & 1556480 & 3.301 & 3.4898 & TRN & \\
\hline
\end{tabular}


Supplemental Table S2.txt

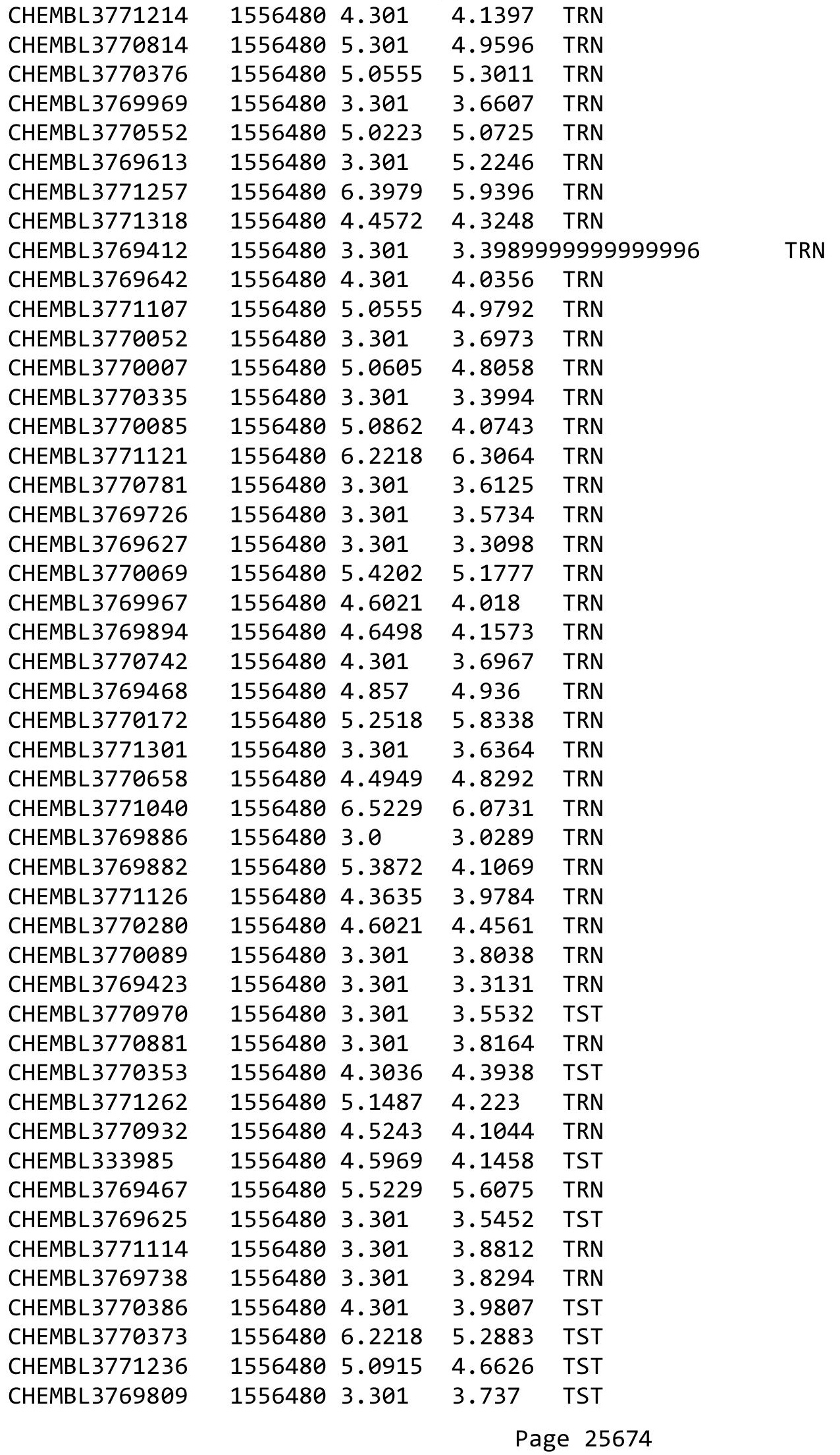


Supplemental Table S2.txt

\begin{tabular}{|c|c|c|c|c|c|}
\hline CHEMBL 3770296 & 1556480 & 4.6021 & 3.8757 & TST & \\
\hline CHEMBL3769955 & 1556480 & 5.3565 & 4.5761 & TST & \\
\hline CHEMBL3771097 & 1556480 & 3.301 & 4.5815 & TST & \\
\hline CHEMBL3769549 & 1556480 & 3.301 & 3.7732 & TST & \\
\hline CHEMBL3769884 & 1556480 & 4.3747 & 3.6741 & TST & \\
\hline CHEMBL3770937 & 1556480 & 5.3979 & 5.1032 & TST & \\
\hline CHEMBL 3087481 & 1275453 & 6.1772 & 6.0403 & TRN & \\
\hline CHEMBL 3086682 & 1275453 & 6.1175 & 5.6889 & TST & \\
\hline CHEMBL3086702 & 1275453 & 7.3872 & 7.194 & TRN & \\
\hline CHEMBL3086692 & 1275453 & 6.9872 & 6.8746 & TRN & \\
\hline CHEMBL 376855 & 1275453 & 6.6216 & 6.7171 & TRN & \\
\hline CHEMBL10 & 1275453 & 7.3188 & 6.56 & TST & \\
\hline CHEMBL 3086698 & 1275453 & 6.8356 & 6.8732 & TRN & \\
\hline CHEMBL3086676 & 1275453 & 6.9957 & 7.1182 & TRN & \\
\hline CHEMBL 3086675 & 1275453 & 6.0 & 6.6385 & TRN & \\
\hline CHEMBL3086111 & 1275453 & 6.6615 & 6.7233 & TRN & \\
\hline CHEMBL 2152778 & 1275453 & 7.3565 & 7.4173 & TRN & \\
\hline CHEMBL 3087489 & 1275453 & 7.1427 & 7.0842 & TRN & \\
\hline CHEMBL515727 & 1275453 & 5.3768 & 6.9086 & TST & \\
\hline CHEMBL 3087478 & 1275453 & 6.7959 & 7.0847 & TRN & \\
\hline CHEMBL3086108 & 1275453 & 6.0 & 6.1389 & TRN & \\
\hline CHEMBL 3087470 & 1275453 & 8.7447 & 7.0905 & TST & \\
\hline CHEMBL 3086691 & 1275453 & 6.9547 & 7.0411 & TRN & \\
\hline CHEMBL 3087484 & 1275453 & 7.6778 & 7.405 & TRN & \\
\hline CHEMBL 3087487 & 1275453 & 7.0605 & 7.0261 & TRN & \\
\hline CHEMBL3086693 & 1275453 & 7.1308 & 7.2096 & TRN & \\
\hline CHEMBL 3087480 & 1275453 & 7.2757 & 7.2655 & TRN & \\
\hline CHEMBL 3087482 & 1275453 & 6.2874 & 6.4804 & TRN & \\
\hline CHEMBL 3086680 & 1275453 & 8.0969 & 7.7847 & TRN & \\
\hline CHEMBL 3087469 & 1275453 & 8.7696 & 8.3103 & TST & \\
\hline CHEMBL 3086697 & 1275453 & 6.9706 & 7.1024 & TRN & \\
\hline CHEMBL3086696 & 1275453 & 7.6778 & 7.6217 & TRN & \\
\hline CHEMBL 3086684 & 1275453 & 6.0867 & 5.984 & TRN & \\
\hline CHEMBL3086699 & 1275453 & 6.8794 & 6.3596 & TST & \\
\hline CHEMBL 2152941 & 1275453 & 7.8861 & 8.3535 & TRN & \\
\hline CHEMBL 3087485 & 1275453 & 7.2007 & 7.2368 & TRN & \\
\hline CHEMBL3086695 & 1275453 & 6.9136 & 6.8682 & TRN & \\
\hline CHEMBL 3087473 & 1275453 & 8.0 & 8.1155 & TRN & \\
\hline CHEMBL 3087468 & 1275453 & 6.5528 & 6.6022 & TRN & \\
\hline CHEMBL 3087479 & 1275453 & 6.2541 & 6.4713 & TRN & \\
\hline CHEMBL515407 & 1275453 & 7.0223 & 7.3338 & TST & \\
\hline CHEMBL 3086688 & 1275453 & 6.82100 & 000000000 & $\partial 1$ & 6.8661 \\
\hline CHEMBL 3086683 & 1275453 & 7.5528 & 7.39 & TRN & \\
\hline CHEMBL3087486 & 1275453 & 7.0269 & 6.9827 & TRN & \\
\hline CHEMBL 3086679 & 1275453 & 7.699 & 7.6961 & TRN & \\
\hline CHEMBL 3086677 & 1275453 & 7.1024 & 6.6153 & TRN & \\
\hline CHEMBL 3086687 & 1275453 & 7.3665 & 7.218 & TRN & \\
\hline CHEMBL3086686 & 1275453 & 8.5229 & 8.6265 & TRN & \\
\hline
\end{tabular}


Supplemental Table S2.txt

\begin{tabular}{|c|c|c|c|c|}
\hline CHEMBL3086701 & 1275453 & 6.8327 & 7.0045 & TRN \\
\hline CHEMBL 3087488 & 1275453 & 7.4685 & 7.369 & TRN \\
\hline CHEMBL3087477 & 1275453 & 7.0706 & 7.0501 & TRN \\
\hline CHEMBL 3087471 & 1275453 & 8.7959 & 7.2765 & TST \\
\hline CHEMBL3086689 & 1275453 & 6.6882 & 6.6387 & TRN \\
\hline CHEMBL 2152946 & 1275453 & 7.7696 & 7.2361 & TRN \\
\hline CHEMBL3086681 & 1275453 & 7.6576 & 7.7135 & TRN \\
\hline CHEMBL 3087474 & 1275453 & 7.6021 & 7.4503 & TRN \\
\hline CHEMBL3086685 & 1275453 & 9.0 & 8.9245 & TRN \\
\hline CHEMBL3086694 & 1275453 & 6.9393 & 6.8535 & TRN \\
\hline CHEMBL 3087472 & 1275453 & 7.7696 & \multicolumn{2}{|c|}{8.812999999999999} \\
\hline CHEMBL 2152940 & 1275453 & 7.7212 & 8.2754 & TST \\
\hline CHEMBL 3087483 & 1275453 & 7.5686 & 6.5447 & TST \\
\hline CHEMBL 3086690 & 1275453 & 6.1864 & 6.4694 & TST \\
\hline CHEMBL 3087490 & 1275453 & 6.2434 & 6.4055 & TST \\
\hline CHEMBL3086700 & 1275453 & 7.4815 & 7.4903 & TST \\
\hline CHEMBL 2152793 & 1275453 & 7.3098 & 7.4836 & TST \\
\hline CHEMBL1508938 & 688636 & 5.0 & 4.88 & TRN \\
\hline CHEMBL1312190 & 688636 & 4.55 & \multicolumn{2}{|c|}{4.6530000000000005} \\
\hline CHEMBL1337737 & 688636 & 4.25 & 4.7397 & TRN \\
\hline CHEMBL1594645 & 688636 & 4.45 & 4.712 & TRN \\
\hline CHEMBL3192727 & 688636 & 4.3 & 4.8093 & TRN \\
\hline CHEMBL1443234 & 688636 & 5.15 & 4.897 & TRN \\
\hline CHEMBL1429456 & 688636 & 4.35 & 4.6476 & TRN \\
\hline CHEMBL1604884 & 688636 & 5.6 & 4.8074 & TRN \\
\hline CHEMBL1409610 & 688636 & 6.7501 & 4.7297 & TRN \\
\hline CHEMBL1312201 & 688636 & 4.3 & 4.6909 & TRN \\
\hline CHEMBL1372925 & 688636 & 4.3 & 4.6904 & TRN \\
\hline CHEMBL1422754 & 688636 & 4.3 & 4.7713 & TST \\
\hline CHEMBL1536856 & 688636 & 4.25 & \multicolumn{2}{|c|}{4.7669999999999995} \\
\hline CHEMBL3193774 & 688636 & 4.8 & 4.7933 & TST \\
\hline CHEMBL1499181 & 688636 & 5.7 & 4.8525 & TRN \\
\hline CHEMBL1384345 & 688636 & 4.9 & 4.569 & TRN \\
\hline CHEMBL1334619 & 688636 & 4.45 & 4.6475 & TRN \\
\hline CHEMBL1377287 & 688636 & 4.55 & 4.8135 & TRN \\
\hline CHEMBL1529108 & 688636 & 5.6 & 4.7239 & TRN \\
\hline CHEMBL1577799 & 688636 & 5.45 & 4.9428 & TRN \\
\hline CHEMBL1487712 & 688636 & 4.3 & 4.7416 & TRN \\
\hline CHEMBL3197304 & 688636 & 4.9 & 4.753 & TST \\
\hline CHEMBL 1381742 & 688636 & 4.95 & 4.9228 & TST \\
\hline CHEMBL1533789 & 688636 & 4.4 & 4.8128 & TRN \\
\hline CHEMBL1390321 & 688636 & 4.3 & 4.7697 & TRN \\
\hline CHEMBL1490388 & 688636 & 4.5 & 4.7146 & TRN \\
\hline CHEMBL3194167 & 688636 & 5.25 & 4.8619 & TST \\
\hline CHEMBL1448393 & 688636 & 5.25 & 4.6376 & TST \\
\hline CHEMBL1372147 & 688636 & 6.7501 & 4.8829 & TRN \\
\hline CHEMBL1367098 & 688636 & 4.9 & 4.9254 & TRN \\
\hline CHEMBL1569449 & 688636 & 5.0 & 4.9185 & TRN \\
\hline
\end{tabular}




\begin{tabular}{|c|c|c|c|c|c|}
\hline \multicolumn{6}{|c|}{ Supplemental Table S2.txt } \\
\hline CHEMBL1304569 & 688636 & 5.45 & 4.8506 & TRN & \\
\hline CHEMBL1331931 & 688636 & 4.4 & 4.7296 & TRN & \\
\hline CHEMBL1965471 & 688636 & 5.2 & 4.6502 & TRN & \\
\hline CHEMBL1385886 & 688636 & 4.35 & 4.9645 & TST & \\
\hline CHEMBL1520818 & 688636 & 6.7501 & 4.9557 & TRN & \\
\hline CHEMBL1564965 & 688636 & 4.25 & 4.7651 & TST & \\
\hline CHEMBL1536465 & 688636 & 5.15 & 4.7763 & TRN & \\
\hline CHEMBL1579392 & 688636 & 4.35 & 4.913 & TRN & \\
\hline CHEMBL 3207370 & 688636 & 4.95 & 4.947 & TST & \\
\hline CHEMBL1419558 & 688636 & 4.3 & 4.6404 & TRN & \\
\hline CHEMBL282003 & 688636 & 4.9 & 4.7322 & TST & \\
\hline CHEMBL1538928 & 688636 & 4.5 & 4.6785 & TRN & \\
\hline CHEMBL 3208047 & 688636 & 4.3 & 4.7126 & TRN & \\
\hline CHEMBL 3213492 & 688636 & 4.45 & 4.6745 & TRN & \\
\hline CHEMBL1419878 & 688636 & 4.95 & 4.9144 & TST & \\
\hline CHEMBL1415657 & 688636 & 4.35 & 4.9723 & TRN & \\
\hline CHEMBL1404447 & 688636 & 4.5 & 4.862 & TRN & \\
\hline CHEMBL1536734 & 688636 & 5.5 & 4.9296 & TRN & \\
\hline CHEMBL1347600 & 688636 & 4.9 & 4.7404 & TRN & \\
\hline CHEMBL1502099 & 688636 & 4.45 & 5.01 & TRN & \\
\hline CHEMBL3194348 & 688636 & 5.55 & 4.7575 & TRN & \\
\hline CHEMBL1431256 & 688636 & 4.35 & 4.7665 & TRN & \\
\hline CHEMBL1433307 & 688636 & 5.9 & 4.9949 & TRN & \\
\hline CHEMBL1412370 & 688636 & 4.55 & 4.7947 & TRN & \\
\hline CHEMBL1576694 & 688636 & 5.9 & 4.6547 & TRN & \\
\hline CHEMBL1461362 & 688636 & 5.1 & 4.8038 & TRN & \\
\hline CHEMBL1603365 & 688636 & 4.45 & 4.6716 & TRN & \\
\hline CHEMBL1360872 & 688636 & 4.5 & 4.8835 & TST & \\
\hline CHEMBL1503523 & 688636 & 4.8 & 4.6558 & TRN & \\
\hline CHEMBL1508557 & 688636 & 4.95 & 4.9323 & TRN & \\
\hline CHEMBL1344865 & 688636 & 4.55 & 4.8707 & TRN & \\
\hline CHEMBL1392039 & 688636 & 4.45 & 4.6783 & TRN & \\
\hline CHEMBL1301189 & 688636 & 4.35 & 4.9217 & TRN & \\
\hline CHEMBL1310090 & 688636 & 5.6 & 4.6514 & TRN & \\
\hline CHEMBL1302511 & 688636 & 5.5 & 4.994 & TRN & \\
\hline CHEMBL1531706 & 688636 & 4.95 & 4.9345 & TRN & \\
\hline CHEMBL1386501 & 688636 & 6.1 & 5.0477 & TRN & \\
\hline CHEMBL1389470 & 688636 & 4.95 & 4.8746 & TST & \\
\hline CHEMBL3190641 & 688636 & 4.25 & 4.8392 & TRN & \\
\hline CHEMBL1398965 & 688636 & 4.55 & 4.7424 & TRN & \\
\hline CHEMBL1550270 & 688636 & 6.1 & 4.8219 & TST & \\
\hline CHEMBL1420787 & 688636 & 4.95 & 4.9214 & TRN & \\
\hline CHEMBL473106 & 688636 & 4.65 & 4.9124 & TRN & \\
\hline CHEMBL1363090 & 688636 & 4.45 & 4.6743 & TRN & \\
\hline CHEMBL1581145 & 688636 & 4.4 & 4.8454 & TRN & \\
\hline CHEMBL1362154 & 688636 & 4.4 & 4.6735 & TRN & \\
\hline CHEMBL1384905 & 688636 & 4.25 & 4.5725 & TST & \\
\hline CHEMBL1413587 & 688636 & 4.3 & 5.03100 & 000000001 & TRN \\
\hline & & & & 25677 & \\
\hline
\end{tabular}




\begin{tabular}{|c|c|c|c|c|}
\hline \multicolumn{5}{|c|}{ Supplemental Table S2.txt } \\
\hline CHEMBL1404515 & 688636 & 6.8 & 4.9323 & TST \\
\hline CHEMBL1522657 & 688636 & 4.4 & 4.6862 & TRN \\
\hline CHEMBL1313486 & 688636 & 4.45 & 4.8612 & TRN \\
\hline CHEMBL1327766 & 688636 & 5.25 & 4.8026 & TRN \\
\hline CHEMBL1404915 & 688636 & 5.3 & 4.6418 & TRN \\
\hline CHEMBL1299296 & 688636 & 4.25 & 4.7889 & TRN \\
\hline CHEMBL1981008 & 688636 & 4.25 & 4.8493 & TST \\
\hline CHEMBL1536626 & 688636 & 4.3 & 4.8134 & TST \\
\hline CHEMBL1454898 & 688636 & 5.15 & 4.6939 & TRN \\
\hline CHEMBL1546727 & 688636 & 6.7001 & 4.8711 & TST \\
\hline CHEMBL1463977 & 688636 & 4.25 & 4.9655 & TRN \\
\hline CHEMBL1319461 & 688636 & 4.3 & 4.7713 & TST \\
\hline CHEMBL1465236 & 688636 & 4.95 & 4.921 & TRN \\
\hline CHEMBL1498488 & 688636 & 5.25 & 4.6477 & TST \\
\hline CHEMBL1537558 & 688636 & 4.25 & 4.7031 & TRN \\
\hline CHEMBL1563068 & 688636 & 4.9 & 4.7504 & TRN \\
\hline CHEMBL1371946 & 688636 & 4.3 & 4.7415 & TST \\
\hline CHEMBL1495592 & 688636 & 4.25 & 4.6753 & TST \\
\hline CHEMBL1345040 & 688636 & 4.65 & 4.8427 & TRN \\
\hline CHEMBL1321933 & 688636 & 6.05 & 4.8691 & TRN \\
\hline CHEMBL1502300 & 688636 & 4.4 & 4.822 & TST \\
\hline CHEMBL1319353 & 688636 & 4.9 & 4.8996 & TRN \\
\hline CHEMBL1567716 & 688636 & 4.35 & 4.9062 & TRN \\
\hline CHEMBL1385519 & 688636 & 4.95 & 4.6748 & TST \\
\hline CHEMBL1353713 & 688636 & 5.9 & 4.8418 & TRN \\
\hline CHEMBL1359796 & 688636 & 4.5 & 4.8778 & TRN \\
\hline CHEMBL1611594 & 688636 & 4.25 & 4.8587 & TRN \\
\hline CHEMBL1300306 & 688636 & 4.3 & 4.6683 & TST \\
\hline CHEMBL1311514 & 688636 & 5.25 & 4.9662 & TRN \\
\hline CHEMBL1460018 & 688636 & 4.6 & 4.6938 & TRN \\
\hline CHEMBL1459122 & 688636 & 4.5 & 4.7729 & TST \\
\hline CHEMBL1454025 & 688636 & 4.55 & 4.7234 & TRN \\
\hline CHEMBL1420777 & 688636 & 4.95 & 4.9852 & TST \\
\hline CHEMBL1572629 & 688636 & 4.95 & 4.6986 & TRN \\
\hline CHEMBL1489629 & 688636 & 4.6 & 4.9264 & TST \\
\hline CHEMBL1465239 & 688636 & 4.25 & 4.6203 & TRN \\
\hline CHEMBL1455218 & 688636 & 5.2 & 5.0088 & TRN \\
\hline CHEMBL1443319 & 688636 & 4.55 & 4.6715 & TRN \\
\hline CHEMBL1305255 & 688636 & 5.1 & 4.6462 & TRN \\
\hline CHEMBL1385555 & 688636 & 4.3 & 4.8431 & TRN \\
\hline CHEMBL1527581 & 688636 & 4.25 & 4.7017 & TST \\
\hline CHEMBL1465433 & 688636 & 5.65 & 4.6974 & TRN \\
\hline CHEMBL1588737 & 688636 & 6.3 & 5.0993 & TRN \\
\hline CHEMBL1597880 & 688636 & 4.35 & 4.8498 & TST \\
\hline CHEMBL1339657 & 688636 & 4.3 & 4.9109 & TST \\
\hline CHEMBL1485593 & 688636 & 4.3 & 4.7202 & TST \\
\hline CHEMBL1607006 & 688636 & 4.55 & 4.8358 & TST \\
\hline CHEMBL1094842 & 688636 & 4.35 & 4.8127 & TRN \\
\hline
\end{tabular}




\begin{tabular}{|c|c|c|c|c|c|}
\hline \\
\hline CHEMBL1562854 & 688636 & 4.5 & 4.9312 & TST & \\
\hline CHEMBL1503812 & 688636 & 4.25 & 5.0725 & TST & \\
\hline CHEMBL1501883 & 688636 & 6.1 & 5.0433 & TRN & \\
\hline CHEMBL1573798 & 688636 & 4.25 & 4.976 & TRN & \\
\hline CHEMBL1419940 & 688636 & 5.15 & 4.69300 & 30000000005 & TRN \\
\hline CHEMBL1573791 & 688636 & 4.35 & 4.7356 & TST & \\
\hline CHEMBL1393495 & 688636 & 4.5 & 4.7182 & TRN & \\
\hline CHEMBL1325724 & 688636 & 5.9 & 4.8073 & TST & \\
\hline CHEMBL1558081 & 688636 & 5.85 & 4.6976 & TRN & \\
\hline CHEMBL1579222 & 688636 & 4.5 & 4.7033 & TST & \\
\hline CHEMBL1373342 & 688636 & 5.5 & 4.9443 & TRN & \\
\hline CHEMBL1479154 & 688636 & 4.9 & 4.7202 & TST & \\
\hline CHEMBL1378073 & 688636 & 4.45 & 4.6487 & TRN & \\
\hline CHEMBL1602767 & 688636 & 4.4 & 4.7013 & TRN & \\
\hline CHEMBL1365623 & 688636 & 4.25 & 4.8442 & TRN & \\
\hline CHEMBL1438859 & 688636 & 4.6 & 4.6807 & TRN & \\
\hline CHEMBL1342903 & 688636 & 6.6499 & 4.8508 & TST & \\
\hline CHEMBL1303488 & 688636 & 4.3 & 4.8664 & TST & \\
\hline CHEMBL1343088 & 688636 & 6.3 & 4.6163 & TRN & \\
\hline CHEMBL1385292 & 688636 & 4.45 & 4.7028 & TRN & \\
\hline CHEMBL1525346 & 688636 & 4.4 & 4.6243 & TRN & \\
\hline CHEMBL1439549 & 688636 & 4.4 & 4.7244 & TRN & \\
\hline CHEMBL1528629 & 688636 & 4.55 & 4.7538 & TRN & \\
\hline CHEMBL1319831 & 688636 & 4.95 & 4.9074 & TRN & \\
\hline CHEMBL3195193 & 688636 & 4.25 & 4.8305 & TRN & \\
\hline CHEMBL1393739 & 688636 & 4.9 & 4.894 & TRN & \\
\hline CHEMBL1532496 & 688636 & 4.25 & 4.8948 & TST & \\
\hline CHEMBL1520433 & 688636 & 4.8 & 4.6377 & TRN & \\
\hline CHEMBL1565229 & 688636 & 5.0 & 4.613 & TRN & \\
\hline CHEMBL1502409 & 688636 & 4.3 & 4.8025 & TRN & \\
\hline CHEMBL1321034 & 688636 & 4.25 & 4.6031 & TRN & \\
\hline CHEMBL1540147 & 688636 & 4.4 & 4.9672 & TRN & \\
\hline CHEMBL1486834 & 688636 & 4.4 & 4.8411 & TRN & \\
\hline CHEMBL1403940 & 688636 & 4.55 & 4.6669 & TRN & \\
\hline CHEMBL1457031 & 688636 & 4.5 & 4.7171 & TRN & \\
\hline CHEMBL3212922 & 688636 & 4.25 & 4.7099 & TRN & \\
\hline CHEMBL1505868 & 688636 & 4.45 & 4.8457 & TRN & \\
\hline CHEMBL1580529 & 688636 & 4.4 & 4.7041 & TRN & \\
\hline CHEMBL1376341 & 688636 & 4.6 & 4.7587 & TRN & \\
\hline CHEMBL1599750 & 688636 & 4.25 & 4.8296 & TST & \\
\hline CHEMBL1588086 & 688636 & 4.45 & 4.6758 & TRN & \\
\hline CHEMBL1418706 & 688636 & 4.25 & 4.9395 & TRN & \\
\hline CHEMBL1482050 & 688636 & 5.45 & 4.7871 & TRN & \\
\hline CHEMBL1419846 & 688636 & 5.45 & 4.936 & TRN & \\
\hline CHEMBL1341644 & 688636 & 5.05 & 4.8951 & TRN & \\
\hline CHEMBL1382785 & 688636 & 4.45 & 4.5973 & TRN & \\
\hline CHEMBL1589094 & 688636 & 4.7 & 4.815 & TST & \\
\hline CHEMBL3210653 & 688636 & 5.1 & 4.823 & TST & \\
\hline
\end{tabular}




\begin{tabular}{|c|c|c|c|c|c|}
\hline \multirow[b]{2}{*}{ CHEMBL1348194 } & \multicolumn{5}{|c|}{ oplemental Table S } \\
\hline & 688636 & 4.25 & 4.9282 & TST & \\
\hline CHEMBL1389608 & 688636 & 4.3 & 4.63899 & 9999999999 & TRN \\
\hline CHEMBL1308749 & 688636 & 4.3 & 4.7445 & TRN & \\
\hline CHEMBL1463703 & 688636 & 4.5 & 4.7613 & TRN & \\
\hline CHEMBL1566863 & 688636 & 4.9 & 4.8656 & TRN & \\
\hline CHEMBL1332208 & 688636 & 5.85 & 4.7504 & TRN & \\
\hline CHEMBL1338125 & 688636 & 4.5 & 4.8784 & TRN & \\
\hline CHEMBL1496126 & 688636 & 4.4 & 4.8414 & TRN & \\
\hline CHEMBL1336418 & 688636 & 5.05 & 4.849 & TRN & \\
\hline CHEMBL3189581 & 688636 & 4.45 & 4.6235 & TRN & \\
\hline CHEMBL1531197 & 688636 & 4.7 & 4.9219 & TRN & \\
\hline CHEMBL1535919 & 688636 & 4.45 & 4.6267 & TRN & \\
\hline CHEMBL3207519 & 688636 & 4.3 & 4.808 & TST & \\
\hline CHEMBL1533809 & 688636 & 4.25 & 4.7915 & TRN & \\
\hline CHEMBL1412026 & 688636 & 5.45 & 4.9757 & TST & \\
\hline CHEMBL1463870 & 688636 & 6.7501 & 4.9068 & TRN & \\
\hline CHEMBL1500538 & 688636 & 5.4 & 4.7705 & TRN & \\
\hline CHEMBL1335121 & 688636 & 4.3 & 4.6682 & TRN & \\
\hline CHEMBL3198286 & 688636 & 4.8 & 4.8805 & TRN & \\
\hline CHEMBL1507013 & 688636 & 4.45 & 4.7553 & TRN & \\
\hline CHEMBL1303056 & 688636 & 4.5 & 4.8004 & TRN & \\
\hline CHEMBL1308625 & 688636 & 4.3 & 5.0977 & TRN & \\
\hline CHEMBL1486992 & 688636 & 4.45 & 4.6348 & TRN & \\
\hline CHEMBL1535388 & 688636 & 4.25 & 4.7514 & TRN & \\
\hline CHEMBL1411186 & 688636 & 4.3 & 4.7805 & TST & \\
\hline CHEMBL1455516 & 688636 & 4.65 & 4.6879 & TRN & \\
\hline CHEMBL1541840 & 688636 & 4.5 & 4.6968 & TRN & \\
\hline CHEMBL1563947 & 688636 & 4.45 & 4.6049 & TRN & \\
\hline CHEMBL1385800 & 688636 & 5.25 & 4.9457 & TRN & \\
\hline CHEMBL1378360 & 688636 & 4.6 & 4.7687 & TRN & \\
\hline CHEMBL1366730 & 688636 & 4.5 & 4.8506 & TRN & \\
\hline CHEMBL1520147 & 688636 & 4.65 & 4.8419 & TRN & \\
\hline CHEMBL1484625 & 688636 & 4.6 & 4.8309 & TRN & \\
\hline CHEMBL1441372 & 688636 & 4.3 & 4.8474 & TRN & \\
\hline CHEMBL1506402 & 688636 & 4.3 & 4.8071 & TRN & \\
\hline CHEMBL1602312 & 688636 & 4.95 & 4.9436 & TRN & \\
\hline CHEMBL1368060 & 688636 & 4.65 & 4.843 & TRN & \\
\hline CHEMBL1382979 & 688636 & 5.15 & 4.636 & TRN & \\
\hline CHEMBL1470911 & 688636 & 4.25 & 4.90600 & 2000000001 & TST \\
\hline CHEMBL1439049 & 688636 & 5.95 & 4.9711 & TRN & \\
\hline CHEMBL1380312 & 688636 & 4.6 & 4.8107 & TRN & \\
\hline CHEMBL3208091 & 688636 & 4.55 & 4.9367 & TRN & \\
\hline CHEMBL1328353 & 688636 & 5.65 & 4.8987 & TST & \\
\hline CHEMBL1496095 & 688636 & 4.55 & 4.6158 & TRN & \\
\hline CHEMBL1371062 & 688636 & 4.3 & 4.9446 & TRN & \\
\hline CHEMBL1424121 & 688636 & 4.45 & 4.7687 & TRN & \\
\hline CHEMBL1604702 & 688636 & 4.45 & 5.1241 & TST & \\
\hline CHEMBL1584442 & 688636 & 4.25 & 4.8217 & TRN & \\
\hline
\end{tabular}




\begin{tabular}{|c|c|c|c|c|}
\hline & & & pplement & al $\mathrm{T}$ \\
\hline CHEMBL1583802 & 688636 & 4.6 & 4.8331 & TST \\
\hline CHEMBL1401417 & 688636 & 5.8 & 4.8576 & TRN \\
\hline CHEMBL1433148 & 688636 & 4.55 & 4.5584 & TRN \\
\hline CHEMBL1581745 & 688636 & 6.5501 & 4.6875 & TRN \\
\hline CHEMBL1498334 & 688636 & 4.45 & 4.9064 & TRN \\
\hline CHEMBL1601617 & 688636 & 4.4 & 4.5957 & TST \\
\hline CHEMBL1519843 & 688636 & 4.7 & 4.8243 & TRN \\
\hline CHEMBL1462142 & 688636 & 4.35 & 4.7746 & TRN \\
\hline CHEMBL1310918 & 688636 & 4.25 & 4.9018 & TRN \\
\hline CHEMBL1611229 & 688636 & 5.2 & 4.8757 & TST \\
\hline CHEMBL1612204 & 688636 & 4.35 & 5.0267 & TRN \\
\hline CHEMBL1430500 & 688636 & 5.1 & 4.7324 & TRN \\
\hline CHEMBL1528046 & 688636 & 4.45 & 4.9114 & TRN \\
\hline CHEMBL 3207448 & 688636 & 4.25 & 4.7296 & TRN \\
\hline CHEMBL1505266 & 688636 & 4.4 & 4.6816 & TRN \\
\hline CHEMBL1329359 & 688636 & 4.3 & 4.7721 & TRN \\
\hline CHEMBL1499762 & 688636 & 4.55 & 4.5852 & TRN \\
\hline CHEMBL3213612 & 688636 & 4.9 & 4.8124 & TRN \\
\hline CHEMBL1322111 & 688636 & 4.4 & 4.8975 & TRN \\
\hline CHEMBL1325890 & 688636 & 4.9 & 4.7387 & TST \\
\hline CHEMBL1422475 & 688636 & 6.05 & 4.7713 & TRN \\
\hline CHEMBL1407267 & 688636 & 4.3 & 4.7037 & TRN \\
\hline CHEMBL1524152 & 688636 & 6.1 & 4.8631 & TRN \\
\hline CHEMBL1369154 & 688636 & 4.3 & 4.7732 & TRN \\
\hline CHEMBL1347247 & 688636 & 4.4 & 4.6921 & TRN \\
\hline CHEMBL1607677 & 688636 & 4.25 & 4.7217 & TST \\
\hline CHEMBL1977983 & 688636 & 4.5 & 4.7056 & TRN \\
\hline CHEMBL1545922 & 688636 & 4.95 & 4.702 & TRN \\
\hline CHEMBL1550359 & 688636 & 5.0 & 4.8021 & TST \\
\hline CHEMBL1447979 & 688636 & 4.3 & 4.629 & TRN \\
\hline CHEMBL1403905 & 688636 & 4.3 & 4.6536 & TRN \\
\hline CHEMBL1531053 & 688636 & 4.3 & 4.8615 & TRN \\
\hline CHEMBL3210359 & 688636 & 4.25 & 4.6849 & TRN \\
\hline CHEMBL1601517 & 688636 & 5.4 & 4.8892 & TST \\
\hline CHEMBL3191299 & 688636 & 4.8 & 4.7186 & TRN \\
\hline CHEMBL1410455 & 688636 & 6.7501 & 4.914 & TST \\
\hline CHEMBL1301470 & 688636 & 5.7 & 4.8812 & TRN \\
\hline CHEMBL1336678 & 688636 & 5.3 & 4.7609 & TRN \\
\hline CHEMBL1467268 & 688636 & 4.4 & 4.9226 & TST \\
\hline CHEMBL1338839 & 688636 & 4.45 & 4.758 & TRN \\
\hline CHEMBL1311539 & 688636 & 4.6 & 4.7196 & TST \\
\hline CHEMBL1527522 & 688636 & 5.4 & 4.9591 & TST \\
\hline CHEMBL1378242 & 688636 & 6.7501 & 4.9447 & TRN \\
\hline CHEMBL1577633 & 688636 & 4.25 & 4.7951 & TST \\
\hline CHEMBL235929 & 688636 & 4.5 & 4.7843 & TRN \\
\hline CHEMBL1519955 & 688636 & 4.55 & 4.8376 & TST \\
\hline CHEMBL1546757 & 688636 & 4.95 & 4.7462 & TST \\
\hline CHEMBL1305740 & 688636 & 4.25 & 4.8032 & TRN \\
\hline
\end{tabular}




\begin{tabular}{|c|c|c|c|c|c|}
\hline \\
\hline CHEMBL1518944 & 688636 & 4.25 & 4.68199 & 99999999995 & TRN \\
\hline CHEMBL1464355 & 688636 & 4.25 & 4.8782 & TRN & \\
\hline CHEMBL1441412 & 688636 & 4.85 & 4.702 & TRN & \\
\hline CHEMBL1611013 & 688636 & 4.45 & 4.9048 & TST & \\
\hline CHEMBL1406660 & 688636 & 4.45 & 4.6062 & TRN & \\
\hline CHEMBL1556644 & 688636 & 4.65 & 4.5152 & TRN & \\
\hline CHEMBL1562864 & 688636 & 4.5 & 4.6566 & TRN & \\
\hline CHEMBL1507997 & 688636 & 4.45 & 4.6849 & TRN & \\
\hline CHEMBL1507662 & 688636 & 4.3 & 4.7091 & TST & \\
\hline CHEMBL1585428 & 688636 & 4.25 & 4.8047 & TRN & \\
\hline CHEMBL1601337 & 688636 & 4.25 & 4.856 & TRN & \\
\hline CHEMBL1599683 & 688636 & 4.25 & 4.8146 & TST & \\
\hline CHEMBL1448647 & 688636 & 5.15 & 4.8859 & TRN & \\
\hline CHEMBL3193716 & 688636 & 6.8 & 4.8879 & TRN & \\
\hline CHEMBL1570765 & 688636 & 4.3 & 4.7048 & TST & \\
\hline CHEMBL1335491 & 688636 & 5.5 & 4.5925 & TRN & \\
\hline CHEMBL1600213 & 688636 & 4.25 & 4.7992 & TST & \\
\hline CHEMBL1438102 & 688636 & 4.5 & 4.9264 & TRN & \\
\hline CHEMBL3194094 & 688636 & 4.95 & 4.8023 & TST & \\
\hline CHEMBL1404428 & 688636 & 4.3 & 4.891 & TST & \\
\hline CHEMBL3190528 & 688636 & 5.85 & 4.8835 & TRN & \\
\hline CHEMBL1584215 & 688636 & 6.4 & 4.7659 & TRN & \\
\hline CHEMBL1348666 & 688636 & 4.65 & 4.8615 & TRN & \\
\hline CHEMBL1470092 & 688636 & 4.7 & 4.9085 & TRN & \\
\hline CHEMBL1339597 & 688636 & 4.45 & 4.6758 & TRN & \\
\hline CHEMBL1492427 & 688636 & 4.95 & 4.8206 & TST & \\
\hline CHEMBL1542779 & 688636 & 4.9 & 4.7604 & TRN & \\
\hline CHEMBL1558971 & 688636 & 4.45 & 4.9221 & TST & \\
\hline CHEMBL1575033 & 688636 & 4.95 & 4.7302 & TRN & \\
\hline CHEMBL1585325 & 688636 & 4.95 & 4.85 & TST & \\
\hline CHEMBL1369155 & 688636 & 5.2 & 4.9865 & TRN & \\
\hline CHEMBL1556395 & 688636 & 4.45 & 4.6846 & TRN & \\
\hline CHEMBL1320292 & 688636 & 4.9 & 4.7195 & TST & \\
\hline CHEMBL1864436 & 688636 & 4.3 & 4.7088 & TST & \\
\hline CHEMBL512749 & 688636 & 4.95 & 4.918 & TRN & \\
\hline CHEMBL1305761 & 688636 & 5.2 & 4.7023 & TRN & \\
\hline CHEMBL1335367 & 688636 & 4.4 & 4.5864 & TRN & \\
\hline CHEMBL1518445 & 688636 & 6.6 & 4.8883 & TRN & \\
\hline CHEMBL1504498 & 688636 & 4.45 & 4.6709 & TRN & \\
\hline CHEMBL1484276 & 688636 & 4.95 & 4.8387 & TRN & \\
\hline CHEMBL1599808 & 688636 & 4.5 & 4.8435 & TST & \\
\hline CHEMBL1322170 & 688636 & 5.95 & 4.904 & TST & \\
\hline CHEMBL1607424 & 688636 & 5.3 & 5.0249 & TRN & \\
\hline CHEMBL1341575 & 688636 & 4.6 & 4.769 & TRN & \\
\hline CHEMBL1471738 & 688636 & 4.55 & 4.8017 & TRN & \\
\hline CHEMBL1426086 & 688636 & 6.7501 & 4.8843 & TRN & \\
\hline CHEMBL1441637 & 688636 & 5.65 & 4.9403 & TRN & \\
\hline CHEMBL1422879 & 688636 & 5.65 & 4.9872 & TST & \\
\hline
\end{tabular}




\begin{tabular}{|c|c|c|c|c|c|}
\hline \multicolumn{6}{|c|}{ Supplemental Table S2.txt } \\
\hline CHEMBL1468264 & 688636 & 5.25 & 4.6571 & TRN & \\
\hline CHEMBL1558040 & 688636 & 4.3 & 4.9149 & TST & \\
\hline CHEMBL1489342 & 688636 & 5.9 & 4.8618 & TST & \\
\hline CHEMBL1418179 & 688636 & 4.45 & 4.6712 & TRN & \\
\hline CHEMBL1533972 & 688636 & 4.4 & 4.8255 & TRN & \\
\hline CHEMBL1373082 & 688636 & 4.25 & 4.5591 & TRN & \\
\hline CHEMBL1429627 & 688636 & 4.3 & 4.6898 & TRN & \\
\hline CHEMBL1308694 & 688636 & 4.45 & 4.8231 & TRN & \\
\hline CHEMBL1521859 & 688636 & 4.35 & 4.8159 & TST & \\
\hline CHEMBL1572758 & 688636 & 4.8 & 4.7273 & TRN & \\
\hline CHEMBL3208314 & 688636 & 4.55 & 4.6147 & TRN & \\
\hline CHEMBL1533529 & 688636 & 5.15 & 4.7279 & TRN & \\
\hline CHEMBL1308435 & 688636 & 4.45 & 4.7664 & TRN & \\
\hline CHEMBL3190449 & 688636 & 4.35 & 4.6101 & TRN & \\
\hline CHEMBL1350727 & 688636 & 4.55 & 4.7966 & TRN & \\
\hline CHEMBL1457363 & 688636 & 4.25 & 4.8607 & TRN & \\
\hline CHEMBL1413929 & 688636 & 4.45 & 4.86 & TST & \\
\hline CHEMBL1585321 & 688636 & 6.1 & 4.9545 & TRN & \\
\hline CHEMBL1503668 & 688636 & 6.05 & 4.8054 & TRN & \\
\hline CHEMBL1419157 & 688636 & 4.3 & 4.6356 & TRN & \\
\hline CHEMBL1486342 & 688636 & 4.35 & 4.9833 & TST & \\
\hline CHEMBL1582442 & 688636 & 5.75 & 4.794 & TST & \\
\hline CHEMBL1371360 & 688636 & 5.0 & 4.894 & TST & \\
\hline CHEMBL1531244 & 688636 & 5.1 & 4.8955 & TRN & \\
\hline CHEMBL1454462 & 688636 & 5.25 & 4.9151 & TST & \\
\hline CHEMBL1525956 & 688636 & 4.25 & 4.57600 & 00000000005 & TRN \\
\hline CHEMBL1336106 & 688636 & 4.4 & 4.7267 & TRN & \\
\hline CHEMBL1499768 & 688636 & 4.25 & 4.7005 & TST & \\
\hline CHEMBL1543648 & 688636 & 4.75 & 4.7534 & TST & \\
\hline CHEMBL1529937 & 688636 & 4.25 & 4.8688 & TRN & \\
\hline CHEMBL1440459 & 688636 & 4.25 & 4.7081 & TRN & \\
\hline CHEMBL1407622 & 688636 & 5.15 & 4.7847 & TST & \\
\hline CHEMBL1587815 & 688636 & 4.3 & 4.7909 & TRN & \\
\hline CHEMBL1303031 & 688636 & 4.3 & 4.8257 & TRN & \\
\hline CHEMBL1306540 & 688636 & 4.5 & 4.7904 & TST & \\
\hline CHEMBL1425848 & 688636 & 4.5 & 4.8119 & TRN & \\
\hline CHEMBL1484561 & 688636 & 4.3 & 4.6918 & TST & \\
\hline CHEMBL1336009 & 688636 & 4.3 & 4.8589 & TRN & \\
\hline CHEMBL1569994 & 688636 & 4.3 & 5.044 & TST & \\
\hline CHEMBL3213540 & 688636 & 6.7501 & 4.885 & TST & \\
\hline CHEMBL1300612 & 688636 & 4.5 & 4.8042 & TRN & \\
\hline CHEMBL1519317 & 688636 & 6.8 & 4.7352 & TRN & \\
\hline CHEMBL1359725 & 688636 & 4.3 & 4.772 & TRN & \\
\hline CHEMBL1535152 & 688636 & 5.75 & 4.852 & TRN & \\
\hline CHEMBL1457199 & 688636 & 4.45 & 4.6257 & TST & \\
\hline CHEMBL1467492 & 688636 & 6.7501 & 4.7822 & TRN & \\
\hline CHEMBL1478562 & 688636 & 4.25 & 4.7238 & TRN & \\
\hline CHEMBL1469167 & 688636 & 6.8 & 4.8768 & TRN & \\
\hline
\end{tabular}




\begin{tabular}{|c|c|c|c|c|c|}
\hline & & \\
\hline CHEMBL1527774 & 688636 & 5.6 & 4.9251 & TST & \\
\hline CHEMBL1502936 & 688636 & 4.6 & 4.8808 & TRN & \\
\hline CHEMBL1579333 & 688636 & 4.45 & 4.7688 & TRN & \\
\hline CHEMBL1460416 & 688636 & 5.2 & 4.9767 & TRN & \\
\hline CHEMBL1361867 & 688636 & 4.4 & 4.7211 & TRN & \\
\hline CHEMBL1451411 & 688636 & 4.5 & 4.762 & TRN & \\
\hline CHEMBL1401643 & 688636 & 4.4 & 4.8303 & TRN & \\
\hline CHEMBL1482782 & 688636 & 5.0 & 4.6057 & TRN & \\
\hline CHEMBL1351046 & 688636 & 4.55 & 4.8522 & TRN & \\
\hline CHEMBL1399930 & 688636 & 6.15 & 4.8311 & TRN & \\
\hline CHEMBL1568974 & 688636 & 5.2 & 4.6184 & TRN & \\
\hline CHEMBL1448050 & 688636 & 4.3 & 4.6944 & TRN & \\
\hline CHEMBL1424455 & 688636 & 4.45 & 4.7367 & TRN & \\
\hline CHEMBL448868 & 688636 & 4.25 & 4.7019 & TST & \\
\hline CHEMBL1537146 & 688636 & 4.6 & 4.4962 & TRN & \\
\hline CHEMBL1522395 & 688636 & 5.15 & 4.8242 & TST & \\
\hline CHEMBL1573763 & 688636 & 4.6 & 4.8537 & TRN & \\
\hline CHEMBL3196716 & 688636 & 6.7501 & 4.8983 & TST & \\
\hline CHEMBL1425599 & 688636 & 4.25 & 5.0495 & TRN & \\
\hline CHEMBL1547058 & 688636 & 4.45 & 4.8624 & TST & \\
\hline CHEMBL1556020 & 688636 & 4.45 & 4.7663 & TRN & \\
\hline CHEMBL1601256 & 688636 & 4.25 & 4.8359 & TST & \\
\hline CHEMBL1563597 & 688636 & 4.3 & 4.8511 & TST & \\
\hline CHEMBL1583148 & 688636 & 5.1 & 4.6989 & TST & \\
\hline CHEMBL1418843 & 688636 & 4.8 & 4.836 & TRN & \\
\hline CHEMBL 1403276 & 688636 & 5.9 & 4.8031 & TRN & \\
\hline CHEMBL1424158 & 688636 & 4.85 & 4.8847 & TST & \\
\hline CHEMBL1326442 & 688636 & 5.2 & 4.7831 & TST & \\
\hline CHEMBL1411576 & 688636 & 4.65 & 4.851 & TST & \\
\hline CHEMBL1331747 & 688636 & 4.95 & 4.7087 & TST & \\
\hline CHEMBL1304416 & 688636 & 6.8 & 4.8513 & TRN & \\
\hline CHEMBL1497260 & 688636 & 5.7 & 4.9766 & TRN & \\
\hline CHEMBL1376444 & 688636 & 4.35 & 4.7398 & TRN & \\
\hline CHEMBL1486925 & 688636 & 4.25 & 4.9247 & TRN & \\
\hline CHEMBL1530190 & 688636 & 4.5 & 4.944 & TRN & \\
\hline CHEMBL1300884 & 688636 & 4.25 & 4.8483 & TRN & \\
\hline CHEMBL1519945 & 688636 & 4.4 & 4.8683 & TRN & \\
\hline CHEMBL1471791 & 688636 & 4.35 & 4.8035 & TRN & \\
\hline CHEMBL1411636 & 688636 & 4.9 & 4.93 & TRN & \\
\hline CHEMBL1309126 & 688636 & 4.5 & 4.71899 & 9999999999 & TST \\
\hline CHEMBL1423671 & 688636 & 6.0 & 4.9218 & TRN & \\
\hline CHEMBL1522379 & 688636 & 4.5 & 4.78600 & 00000000005 & TRN \\
\hline CHEMBL1304743 & 688636 & 4.45 & 4.6996 & TRN & \\
\hline CHEMBL1609413 & 688636 & 4.4 & 4.6113 & TRN & \\
\hline CHEMBL1379879 & 688636 & 4.4 & 4.9091 & TRN & \\
\hline CHEMBL 1478590 & 688636 & 4.75 & 4.9346 & TRN & \\
\hline CHEMBL1583255 & 688636 & 4.9 & 4.9131 & TRN & \\
\hline CHEMBL1444360 & 688636 & 5.1 & 4.81 & TRN & \\
\hline & & & & 25684 & \\
\hline
\end{tabular}




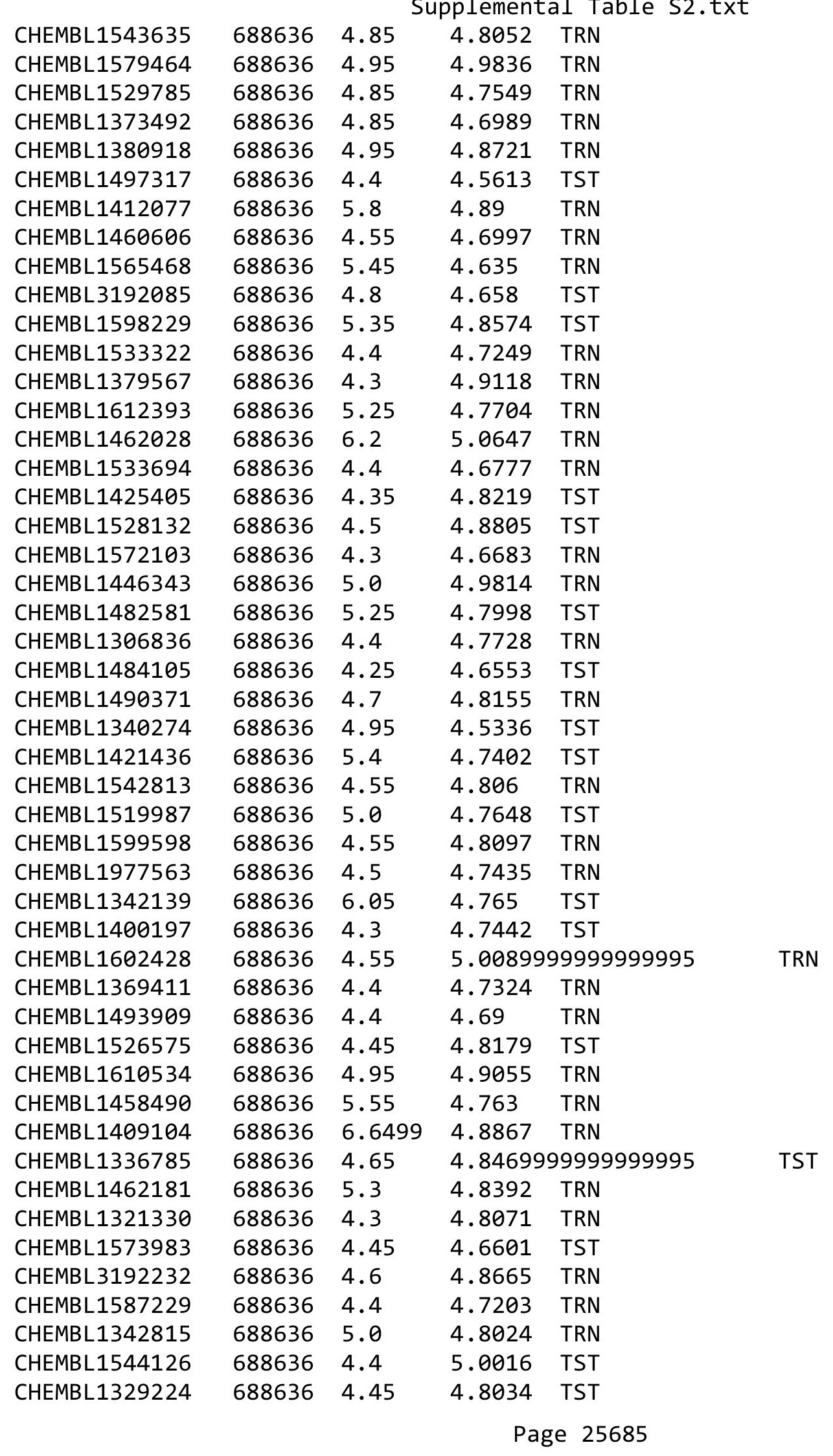




\begin{tabular}{|c|c|c|c|c|c|}
\hline \\
\hline CHEMBL1497238 & 688636 & 4.5 & 4.8484 & TRN & \\
\hline CHEMBL1419754 & 688636 & 4.55 & 4.9981 & TST & \\
\hline CHEMBL1382085 & 688636 & 4.9 & 4.9181 & TRN & \\
\hline CHEMBL1366274 & 688636 & 4.9 & 5.023 & TRN & \\
\hline CHEMBL1565423 & 688636 & 4.45 & 4.9018 & TST & \\
\hline CHEMBL1524104 & 688636 & 4.35 & 4.8116 & TRN & \\
\hline CHEMBL1500597 & 688636 & 5.2 & 4.7363 & TRN & \\
\hline CHEMBL1326644 & 688636 & 4.4 & 4.8185 & TRN & \\
\hline CHEMBL3191300 & 688636 & 5.15 & 4.8947 & TRN & \\
\hline CHEMBL1978584 & 688636 & 4.35 & 4.9266 & TRN & \\
\hline CHEMBL1429302 & 688636 & 6.05 & 4.8011 & TRN & \\
\hline CHEMBL1563936 & 688636 & 4.45 & 4.7734 & TRN & \\
\hline CHEMBL3198757 & 688636 & 4.4 & 4.9123 & TST & \\
\hline CHEMBL1559344 & 688636 & 4.3 & 4.7743 & TST & \\
\hline CHEMBL1416442 & 688636 & 4.4 & 4.7248 & TST & \\
\hline CHEMBL1350689 & 688636 & 4.55 & 4.69600 & 0000000001 & TRN \\
\hline CHEMBL1480388 & 688636 & 6.05 & 4.7595 & TRN & \\
\hline CHEMBL1370346 & 688636 & 6.1 & 4.8086 & TST & \\
\hline CHEMBL1383360 & 688636 & 4.3 & 4.8588 & TRN & \\
\hline CHEMBL3190518 & 688636 & 5.25 & 4.9923 & TRN & \\
\hline CHEMBL1464886 & 688636 & 5.1 & 4.9714 & TRN & \\
\hline CHEMBL1566565 & 688636 & 4.4 & 4.7908 & TST & \\
\hline CHEMBL1586636 & 688636 & 5.9 & 4.7699 & TST & \\
\hline CHEMBL1540563 & 688636 & 5.25 & 5.0264 & TRN & \\
\hline CHEMBL3198914 & 688636 & 4.4 & 4.9102 & TRN & \\
\hline CHEMBL1486619 & 688636 & 4.4 & 4.7416 & TRN & \\
\hline CHEMBL1606908 & 688636 & 4.6 & 4.8445 & TRN & \\
\hline CHEMBL1531658 & 688636 & 5.85 & 4.6955 & TST & \\
\hline CHEMBL1556453 & 688636 & 5.0 & 4.724 & TST & \\
\hline CHEMBL1342669 & 688636 & 4.95 & 4.937 & TRN & \\
\hline CHEMBL1333898 & 688636 & 4.4 & 4.7779 & TRN & \\
\hline CHEMBL1365001 & 688636 & 4.55 & 4.833 & TRN & \\
\hline CHEMBL1379587 & 688636 & 4.45 & 4.7996 & TRN & \\
\hline CHEMBL1559467 & 688636 & 4.5 & 4.8194 & TRN & \\
\hline CHEMBL3196052 & 688636 & 5.0 & 4.5914 & TRN & \\
\hline CHEMBL1595937 & 688636 & 4.5 & 5.0701 & TRN & \\
\hline CHEMBL1325328 & 688636 & 4.25 & 4.8165 & TRN & \\
\hline CHEMBL1538375 & 688636 & 4.3 & 4.7464 & TRN & \\
\hline CHEMBL1330131 & 688636 & 4.45 & 4.8037 & TRN & \\
\hline CHEMBL1322501 & 688636 & 4.4 & 4.9006 & TRN & \\
\hline CHEMBL605753 & 688636 & 4.3 & 4.6718 & TRN & \\
\hline CHEMBL1402794 & 688636 & 4.25 & 4.8948 & TST & \\
\hline CHEMBL1422808 & 688636 & 4.35 & 5.1012 & TRN & \\
\hline CHEMBL515248 & 688636 & 4.35 & 4.6331 & TST & \\
\hline CHEMBL1464925 & 688636 & 5.25 & 4.8133 & TRN & \\
\hline CHEMBL577420 & 688636 & 5.55 & 4.9593 & TST & \\
\hline CHEMBL1445076 & 688636 & 5.45 & 4.7991 & TST & \\
\hline CHEMBL1383785 & 688636 & 4.3 & 4.8257 & TRN & \\
\hline
\end{tabular}




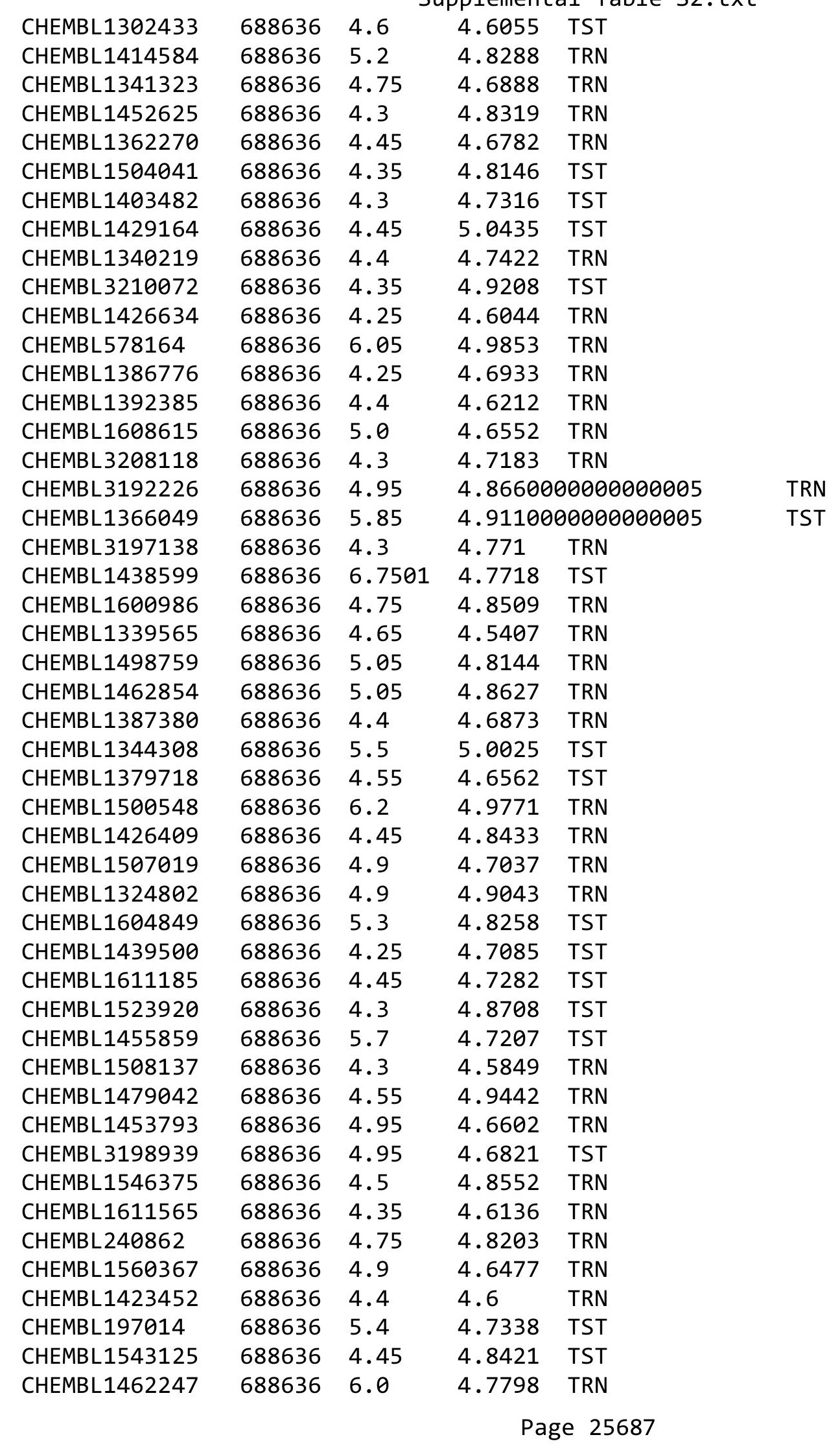




\begin{tabular}{|c|c|c|c|c|c|}
\hline \multicolumn{6}{|c|}{ Supplemental Table s2.txt } \\
\hline CHEMBL1546364 & 688636 & 4.45 & 4.8126 & TRN & \\
\hline CHEMBL1566737 & 688636 & 5.4 & 4.6746 & TRN & \\
\hline CHEMBL1443166 & 688636 & 4.95 & 4.8751 & TRN & \\
\hline CHEMBL3191738 & 688636 & 4.9 & 4.7989 & TRN & \\
\hline CHEMBL1589643 & 688636 & 4.9 & 4.8032 & TRN & \\
\hline CHEMBL1308408 & 688636 & 5.0 & 4.7194 & TRN & \\
\hline CHEMBL3190622 & 688636 & 4.75 & 4.867 & TRN & \\
\hline CHEMBL1539194 & 688636 & 4.65 & 4.8441 & TST & \\
\hline CHEMBL1504336 & 688636 & 4.4 & 4.8419 & TRN & \\
\hline CHEMBL1366712 & 688636 & 4.25 & 4.7345 & TRN & \\
\hline CHEMBL1308352 & 688636 & 5.0 & 4.8473 & TRN & \\
\hline CHEMBL3196877 & 688636 & 4.95 & 4.7174 & TRN & \\
\hline CHEMBL1505957 & 688636 & 5.7 & 4.7466 & TST & \\
\hline CHEMBL1978186 & 688636 & 4.25 & 4.9845 & TRN & \\
\hline CHEMBL1485346 & 688636 & 4.3 & 4.9582 & TRN & \\
\hline CHEMBL1501041 & 688636 & 4.45 & 4.7165 & TRN & \\
\hline CHEMBL1537647 & 688636 & 4.45 & 4.8086 & TRN & \\
\hline CHEMBL1472228 & 688636 & 4.45 & 4.7001 & TRN & \\
\hline CHEMBL1342030 & 688636 & 4.95 & 4.7321 & TRN & \\
\hline CHEMBL1329398 & 688636 & 4.75 & 4.8117 & TRN & \\
\hline CHEMBL1560446 & 688636 & 5.5 & 4.7763 & TST & \\
\hline CHEMBL1490148 & 688636 & 4.55 & 4.7084 & TRN & \\
\hline CHEMBL1458844 & 688636 & 4.4 & 4.7617 & TST & \\
\hline CHEMBL1483228 & 688636 & 4.95 & 4.6425 & TRN & \\
\hline CHEMBL1549986 & 688636 & 4.4 & 4.615 & TRN & \\
\hline CHEMBL1548075 & 688636 & 4.5 & 4.671 & TST & \\
\hline CHEMBL1542186 & 688636 & 5.7 & 4.8026 & TRN & \\
\hline CHEMBL1492009 & 688636 & 4.3 & 4.8646 & TRN & \\
\hline CHEMBL1310690 & 688636 & 5.15 & 4.50899 & 99999999995 & TRN \\
\hline CHEMBL1414895 & 688636 & 4.4 & 4.8844 & TRN & \\
\hline CHEMBL1458041 & 688636 & 5.15 & 4.7556 & TRN & \\
\hline CHEMBL1524954 & 688636 & 6.1 & 4.9201 & TRN & \\
\hline CHEMBL3210688 & 688636 & 4.85 & 4.7373 & TRN & \\
\hline CHEMBL1308381 & 688636 & 4.25 & 4.7305 & TRN & \\
\hline CHEMBL1342153 & 688636 & 5.25 & 5.0687 & TRN & \\
\hline CHEMBL1577030 & 688636 & 4.6 & 4.7754 & TRN & \\
\hline CHEMBL1447331 & 688636 & 4.95 & 5.0066 & TRN & \\
\hline CHEMBL1375134 & 688636 & 4.55 & 4.8507 & TRN & \\
\hline CHEMBL1545999 & 688636 & 4.9 & 4.8266 & TRN & \\
\hline CHEMBL3197111 & 688636 & 4.95 & 4.7186 & TRN & \\
\hline CHEMBL1563022 & 688636 & 5.55 & 4.901 & TRN & \\
\hline CHEMBL1388461 & 688636 & 4.95 & 4.6915 & TRN & \\
\hline CHEMBL1489118 & 688636 & 4.25 & 4.7625 & TRN & \\
\hline CHEMBL1393398 & 688636 & 4.3 & 4.6464 & TRN & \\
\hline CHEMBL1597305 & 688636 & 4.25 & 4.9193 & TRN & \\
\hline CHEMBL1548245 & 688636 & 4.45 & 4.8025 & TST & \\
\hline CHEMBL1345904 & 688636 & 5.95 & 5.0305 & TRN & \\
\hline CHEMBL1522200 & 688636 & 4.25 & 4.9517 & TST & \\
\hline
\end{tabular}




\begin{tabular}{|c|c|c|c|c|}
\hline \multicolumn{5}{|c|}{ Supplemental Table S2.txt } \\
\hline CHEMBL2004351 & 688636 & 5.1 & 4.7931 & TST \\
\hline CHEMBL1337784 & 688636 & 4.3 & 4.9409 & TRN \\
\hline CHEMBL1527122 & 688636 & 4.3 & 4.806 & TRN \\
\hline CHEMBL1604389 & 688636 & 4.25 & 4.5412 & TRN \\
\hline CHEMBL201152 & 688636 & 4.45 & 4.7642 & TRN \\
\hline CHEMBL1313895 & 688636 & 5.55 & 4.8801 & TST \\
\hline CHEMBL1603613 & 688636 & 4.3 & 4.8596 & TRN \\
\hline CHEMBL1424346 & 688636 & 4.25 & 4.926 & TST \\
\hline CHEMBL1431373 & 688636 & 4.9 & 4.8256 & TRN \\
\hline CHEMBL1423145 & 688636 & 4.4 & 4.8717 & TRN \\
\hline CHEMBL1427701 & 688636 & 5.1 & 4.6023 & TRN \\
\hline CHEMBL1602017 & 688636 & 5.5 & 4.9333 & TRN \\
\hline CHEMBL1502976 & 688636 & 5.05 & 4.8918 & TRN \\
\hline CHEMBL3211767 & 688636 & 5.35 & 4.9173 & TST \\
\hline CHEMBL1372040 & 688636 & 4.3 & 4.743 & TRN \\
\hline CHEMBL1519109 & 688636 & 4.35 & 4.8594 & TRN \\
\hline CHEMBL1327062 & 688636 & 5.5 & 4.9492 & TRN \\
\hline CHEMBL1581388 & 688636 & 4.65 & 4.6499 & TRN \\
\hline CHEMBL3144999 & 688636 & 5.45 & 4.9746 & TRN \\
\hline CHEMBL1600001 & 688636 & 4.25 & 4.9649 & TST \\
\hline CHEMBL1322401 & 688636 & 4.75 & 4.7985 & TRN \\
\hline CHEMBL1341464 & 688636 & 4.25 & 4.8496 & TRN \\
\hline CHEMBL1467288 & 688636 & 4.45 & 4.6916 & TRN \\
\hline CHEMBL1556640 & 688636 & 4.35 & 4.8196 & TST \\
\hline CHEMBL1325962 & 688636 & 4.95 & 4.7139 & TRN \\
\hline CHEMBL1454277 & 688636 & 4.95 & 4.92 & TST \\
\hline CHEMBL1560101 & 688636 & 4.55 & 4.5239 & TRN \\
\hline CHEMBL1400226 & 688636 & 6.7501 & 4.9223 & TST \\
\hline CHEMBL1374693 & 688636 & 4.3 & 4.8882 & TST \\
\hline CHEMBL1345906 & 688636 & 4.25 & 4.6869 & TRN \\
\hline CHEMBL1328266 & 688636 & 4.4 & 4.8288 & TRN \\
\hline CHEMBL1450788 & 688636 & 4.6 & 4.7979 & TST \\
\hline CHEMBL1424957 & 688636 & 4.25 & 4.7795 & TRN \\
\hline CHEMBL1530441 & 688636 & 4.25 & 4.9431 & TRN \\
\hline CHEMBL1428984 & 688636 & 4.55 & 4.6934 & TRN \\
\hline CHEMBL2369160 & 688636 & 4.55 & 4.7949 & TRN \\
\hline CHEMBL1336082 & 688636 & 4.95 & 4.8052 & TST \\
\hline CHEMBL1464203 & 688636 & 4.55 & 4.7836 & TST \\
\hline CHEMBL1495892 & 688636 & 4.65 & 4.9758 & TST \\
\hline CHEMBL1431331 & 688636 & 4.9 & 4.7835 & TRN \\
\hline CHEMBL1471119 & 688636 & 4.25 & 4.9664 & TRN \\
\hline CHEMBL1311710 & 688636 & 4.3 & 4.8925 & TRN \\
\hline CHEMBL1326866 & 688636 & 4.6 & 4.8892 & TRN \\
\hline CHEMBL1364799 & 688636 & 6.25 & 4.9137 & TRN \\
\hline CHEMBL1359333 & 688636 & 4.25 & 4.6259 & TST \\
\hline CHEMBL1567234 & 688636 & 4.3 & 4.7818 & TRN \\
\hline CHEMBL1588350 & 688636 & 6.05 & 4.8499 & TST \\
\hline CHEMBL1334197 & 688636 & 4.5 & 4.9466 & TST \\
\hline
\end{tabular}




\begin{tabular}{|c|c|c|c|c|c|}
\hline \\
\hline CHEMBL1550042 & 688636 & 5.3 & 4.8312 & TRN & \\
\hline CHEMBL1525868 & 688636 & 4.25 & 4.9017 & TRN & \\
\hline CHEMBL1504168 & 688636 & 4.55 & 4.8507 & TST & \\
\hline CHEMBL1378123 & 688636 & 4.25 & 4.7704 & TRN & \\
\hline CHEMBL1312470 & 688636 & 4.65 & 4.8904 & TRN & \\
\hline CHEMBL1456659 & 688636 & 4.65 & 4.6691 & TRN & \\
\hline CHEMBL541521 & 688636 & 4.25 & 5.0946 & TRN & \\
\hline CHEMBL1471369 & 688636 & 5.25 & 4.6941 & TRN & \\
\hline CHEMBL1493197 & 688636 & 4.65 & 4.7866 & TRN & \\
\hline CHEMBL2369296 & 688636 & 4.25 & 4.8041 & TST & \\
\hline CHEMBL1517768 & 688636 & 4.25 & 4.6248 & TRN & \\
\hline CHEMBL1418186 & 688636 & 5.8 & 4.8447 & TST & \\
\hline CHEMBL1425295 & 688636 & 4.55 & 4.7274 & TRN & \\
\hline CHEMBL1460513 & 688636 & 4.75 & 4.5101 & TRN & \\
\hline CHEMBL1606539 & 688636 & 4.2 & 4.9295 & TRN & \\
\hline CHEMBL1561885 & 688636 & 4.75 & 4.7685 & TRN & \\
\hline CHEMBL1336972 & 688636 & 4.45 & 4.6746 & TRN & \\
\hline CHEMBL1607307 & 688636 & 4.35 & 4.9431 & TRN & \\
\hline CHEMBL1388753 & 688636 & 4.35 & 4.8547 & TST & \\
\hline CHEMBL1583388 & 688636 & 4.3 & 4.7952 & TRN & \\
\hline CHEMBL1568920 & 688636 & 4.3 & 4.6891 & TRN & \\
\hline CHEMBL1442621 & 688636 & 6.8 & 4.9229 & TRN & \\
\hline CHEMBL1583462 & 688636 & 4.75 & 4.9253 & TRN & \\
\hline CHEMBL1393097 & 688636 & 4.25 & 4.7687 & TST & \\
\hline CHEMBL1421360 & 688636 & 5.0 & 5.098 & TRN & \\
\hline CHEMBL3193282 & 688636 & 4.3 & 4.76399 & 9999999999 & TRN \\
\hline CHEMBL1543541 & 688636 & 4.3 & 4.907 & TST & \\
\hline CHEMBL1604057 & 688636 & 4.45 & 4.9269 & TRN & \\
\hline CHEMBL1386472 & 688636 & 6.15 & 4.7639 & TST & \\
\hline CHEMBL1386945 & 688636 & 4.45 & 4.7893 & TRN & \\
\hline CHEMBL1303054 & 688636 & 4.4 & 4.7291 & TRN & \\
\hline CHEMBL3191770 & 688636 & 5.3 & 4.6413 & TRN & \\
\hline CHEMBL1510330 & 688636 & 4.55 & 4.5879 & TRN & \\
\hline CHEMBL1491264 & 688636 & 4.65 & 4.7364 & TST & \\
\hline CHEMBL1366112 & 688636 & 4.3 & 4.6636 & TRN & \\
\hline CHEMBL1500702 & 688636 & 4.6 & 4.5973 & TST & \\
\hline CHEMBL1313467 & 688636 & 4.55 & 4.6962 & TRN & \\
\hline CHEMBL3209423 & 688636 & 5.6 & 4.9425 & TST & \\
\hline CHEMBL1421895 & 688636 & 4.65 & 4.7101 & TRN & \\
\hline CHEMBL1480238 & 688636 & 5.2 & 4.7306 & TRN & \\
\hline CHEMBL1213966 & 688636 & 4.95 & 4.8562 & TRN & \\
\hline CHEMBL1484830 & 688636 & 6.8 & 4.9926 & TST & \\
\hline CHEMBL1368039 & 688636 & 4.7 & 4.8465 & TRN & \\
\hline CHEMBL1530609 & 688636 & 4.45 & 4.6354 & TST & \\
\hline CHEMBL1418855 & 688636 & 4.65 & 4.8243 & TRN & \\
\hline CHEMBL1504631 & 688636 & 5.45 & 4.9068 & TST & \\
\hline CHEMBL1546187 & 688636 & 4.75 & 4.7287 & TRN & \\
\hline CHEMBL1408369 & 688636 & 4.3 & 4.7295 & TRN & \\
\hline & & & & 25690 & \\
\hline
\end{tabular}




\begin{tabular}{|c|c|c|c|c|}
\hline \multicolumn{5}{|c|}{ Supplemental Table S2.txt } \\
\hline CHEMBL1511792 & 688636 & 4.25 & 4.6961 & TRN \\
\hline CHEMBL3190332 & 688636 & 4.65 & 4.7426 & TRN \\
\hline CHEMBL1385977 & 688636 & 4.5 & 5.0 & TST \\
\hline CHEMBL1381637 & 688636 & 4.25 & 4.6551 & TST \\
\hline CHEMBL1410321 & 688636 & 4.45 & 4.8391 & TRN \\
\hline CHEMBL1422066 & 688636 & 5.4 & 4.9965 & TST \\
\hline CHEMBL405844 & 688636 & 4.9 & 4.8191 & TRN \\
\hline CHEMBL1342840 & 688636 & 4.4 & 4.7156 & TRN \\
\hline CHEMBL1445318 & 688636 & 4.5 & 4.8416 & TRN \\
\hline CHEMBL1456011 & 688636 & 5.4 & 4.7585 & TRN \\
\hline CHEMBL47875 & 688636 & 4.55 & 4.7129 & TRN \\
\hline CHEMBL1569780 & 688636 & 4.35 & 4.7833 & TRN \\
\hline CHEMBL1365177 & 688636 & 5.4 & 4.8501 & TST \\
\hline CHEMBL1580755 & 688636 & 5.45 & 4.8344 & TST \\
\hline CHEMBL1570008 & 688636 & 4.85 & 4.7635 & TRN \\
\hline CHEMBL1340756 & 688636 & 6.7501 & 4.8972 & TRN \\
\hline CHEMBL1404565 & 688636 & 4.3 & 4.6698 & TST \\
\hline CHEMBL1370495 & 688636 & 4.3 & 4.7577 & TST \\
\hline CHEMBL1425672 & 688636 & 6.1 & 4.9241 & TRN \\
\hline CHEMBL1471021 & 688636 & 4.85 & 4.5974 & TST \\
\hline CHEMBL1455904 & 688636 & 4.35 & 4.5914 & TRN \\
\hline CHEMBL1345080 & 688636 & 5.05 & 4.6474 & TST \\
\hline CHEMBL1562060 & 688636 & 4.3 & 4.8783 & TST \\
\hline CHEMBL1413172 & 688636 & 4.95 & 4.7727 & TRN \\
\hline CHEMBL1611753 & 688636 & 4.5 & 4.5922 & TRN \\
\hline CHEMBL1375278 & 688636 & 4.25 & 5.013 & TRN \\
\hline CHEMBL1589491 & 688636 & 5.15 & 4.7645 & TRN \\
\hline CHEMBL1371629 & 688636 & 4.85 & 4.9107 & TRN \\
\hline CHEMBL1381480 & 688636 & 6.1 & 4.7297 & TST \\
\hline CHEMBL1609267 & 688636 & 6.1 & 4.8906 & TRN \\
\hline CHEMBL1348730 & 688636 & 4.5 & 4.7028 & TRN \\
\hline CHEMBL1367899 & 688636 & 4.5 & 4.6222 & TRN \\
\hline CHEMBL1421876 & 688636 & 5.1 & 4.8289 & TRN \\
\hline CHEMBL3209844 & 688636 & 5.6 & 4.7621 & TST \\
\hline CHEMBL1573928 & 688636 & 4.55 & 4.9375 & TRN \\
\hline CHEMBL177122 & 688636 & 4.9 & 4.8138 & TRN \\
\hline CHEMBL 1478048 & 688636 & 4.95 & 4.9643 & TRN \\
\hline CHEMBL3195241 & 688636 & 4.4 & 4.5646 & TRN \\
\hline CHEMBL1557869 & 688636 & 4.85 & 4.726 & TRN \\
\hline CHEMBL1426399 & 688636 & 5.3 & 4.7879 & TRN \\
\hline CHEMBL1445309 & 688636 & 5.9 & 4.7796 & TRN \\
\hline CHEMBL3199900 & 688636 & 4.4 & 4.5918 & TRN \\
\hline CHEMBL1387421 & 688636 & 5.45 & 4.7254 & TST \\
\hline CHEMBL1375830 & 688636 & 4.3 & 4.7429 & TRN \\
\hline CHEMBL1612222 & 688636 & 4.7 & 4.834 & TRN \\
\hline CHEMBL1439561 & 688636 & 6.7501 & 4.7459 & TST \\
\hline CHEMBL1384724 & 688636 & 4.4 & 4.8578 & TRN \\
\hline CHEMBL1313666 & 688636 & 4.6 & 4.8014 & TRN \\
\hline
\end{tabular}




\begin{tabular}{|c|c|c|c|c|c|}
\hline \multicolumn{6}{|c|}{ Supplemental Table S2.txt } \\
\hline CHEMBL1565749 & 688636 & 4.75 & 4.7362 & TST & \\
\hline CHEMBL1305468 & 688636 & 6.7501 & 4.6232 & TRN & \\
\hline CHEMBL1337265 & 688636 & 5.9 & 4.8926 & TRN & \\
\hline CHEMBL1392137 & 688636 & 4.75 & 4.6337 & TRN & \\
\hline CHEMBL3194360 & 688636 & 4.65 & 4.5983 & TRN & \\
\hline CHEMBL1325274 & 688636 & 4.6 & 4.7339 & TRN & \\
\hline CHEMBL1331705 & 688636 & 5.7 & 4.7657 & TST & \\
\hline CHEMBL1387767 & 688636 & 4.35 & 4.8165 & TST & \\
\hline CHEMBL1384289 & 688636 & 5.15 & 4.8691 & TRN & \\
\hline CHEMBL1312941 & 688636 & 4.3 & 4.9376 & TRN & \\
\hline CHEMBL1505041 & 688636 & 4.3 & 4.7719 & TRN & \\
\hline CHEMBL1391341 & 688636 & 4.25 & 4.7902 & TRN & \\
\hline CHEMBL1498688 & 688636 & 4.5 & 4.6987 & TST & \\
\hline CHEMBL1419348 & 688636 & 4.95 & 4.8559 & TST & \\
\hline CHEMBL1307172 & 688636 & 5.5 & 4.7123 & TRN & \\
\hline CHEMBL1410906 & 688636 & 5.2 & 4.9456 & TRN & \\
\hline CHEMBL1401357 & 688636 & 4.55 & 4.9066 & TRN & \\
\hline CHEMBL1332626 & 688636 & 4.65 & 4.8737 & TRN & \\
\hline CHEMBL1480540 & 688636 & 4.6 & 4.7834 & TRN & \\
\hline CHEMBL1412961 & 688636 & 4.7 & 4.8387 & TRN & \\
\hline CHEMBL1508361 & 688636 & 4.95 & 4.6893 & TRN & \\
\hline CHEMBL1308386 & 688636 & 4.75 & 4.7928 & TRN & \\
\hline CHEMBL1380257 & 688636 & 5.8 & 4.8352 & TST & \\
\hline CHEMBL1576368 & 688636 & 5.7 & 4.80399 & 9999999999 & TRN \\
\hline CHEMBL1369249 & 688636 & 4.25 & 4.9153 & TST & \\
\hline CHEMBL1610379 & 688636 & 6.5501 & 4.8971 & TRN & \\
\hline CHEMBL1451267 & 688636 & 4.55 & 4.8662 & TST & \\
\hline CHEMBL1566762 & 688636 & 4.3 & 4.7657 & TST & \\
\hline CHEMBL3208357 & 688636 & 4.3 & 4.7776 & TRN & \\
\hline CHEMBL1573166 & 688636 & 5.35 & 4.8995 & TRN & \\
\hline CHEMBL1613397 & 688636 & 6.7501 & 4.8242 & TST & \\
\hline CHEMBL1541593 & 688636 & 4.4 & 4.7904 & TRN & \\
\hline CHEMBL1338416 & 688636 & 4.35 & 4.8 & TRN & \\
\hline CHEMBL1368935 & 688636 & 4.75 & 4.8819 & TRN & \\
\hline CHEMBL1324559 & 688636 & 4.7 & 4.785 & TST & \\
\hline CHEMBL1443662 & 688636 & 4.25 & 4.7265 & TRN & \\
\hline CHEMBL1429914 & 688636 & 4.3 & 4.9575 & TRN & \\
\hline CHEMBL1451984 & 688636 & 4.25 & 4.9242 & TRN & \\
\hline CHEMBL1440186 & 688636 & 4.5 & 4.7777 & TRN & \\
\hline CHEMBL1480533 & 688636 & 6.1 & 4.8165 & TRN & \\
\hline CHEMBL1372596 & 688636 & 6.1 & 4.8658 & TRN & \\
\hline CHEMBL1545521 & 688636 & 4.3 & 5.0109 & TRN & \\
\hline CHEMBL1384366 & 688636 & 4.8 & 4.7417 & TST & \\
\hline CHEMBL1384137 & 688636 & 4.85 & 4.9491 & TRN & \\
\hline CHEMBL1505563 & 688636 & 4.45 & 4.7245 & TRN & \\
\hline CHEMBL1320506 & 688636 & 4.45 & 4.6741 & TRN & \\
\hline CHEMBL1478406 & 688636 & 4.3 & 4.6005 & TRN & \\
\hline CHEMBL1573524 & 688636 & 4.3 & 4.6906 & TRN & \\
\hline
\end{tabular}




\begin{tabular}{|c|c|c|c|c|c|}
\hline \multicolumn{6}{|c|}{ Supplemental Table S2.txt } \\
\hline CHEMBL1975504 & 688636 & 5.4 & 4.8691 & TRN & \\
\hline CHEMBL1540177 & 688636 & 4.5 & 4.822 & TRN & \\
\hline CHEMBL1311703 & 688636 & 4.5 & 4.8463 & TRN & \\
\hline CHEMBL1603798 & 688636 & 4.3 & 4.9867 & TRN & \\
\hline CHEMBL1451554 & 688636 & 4.9 & 4.8869 & TRN & \\
\hline CHEMBL3198667 & 688636 & 4.4 & 4.7921 & TRN & \\
\hline CHEMBL1424982 & 688636 & 4.25 & 4.8534 & TRN & \\
\hline CHEMBL1373244 & 688636 & 4.55 & 4.8688 & TST & \\
\hline CHEMBL1482177 & 688636 & 4.45 & 4.7087 & TRN & \\
\hline CHEMBL1449034 & 688636 & 5.95 & 4.6881 & TST & \\
\hline CHEMBL1545173 & 688636 & 4.45 & 4.8278 & TRN & \\
\hline CHEMBL1310601 & 688636 & 4.45 & 4.7776 & TST & \\
\hline CHEMBL1574788 & 688636 & 4.5 & 4.7808 & TST & \\
\hline CHEMBL1568689 & 688636 & 4.4 & 4.8957 & TRN & \\
\hline CHEMBL3210106 & 688636 & 6.1 & 4.6967 & TST & \\
\hline CHEMBL1472362 & 688636 & 5.0 & 4.8295 & TRN & \\
\hline CHEMBL1440880 & 688636 & 4.3 & 4.8181 & TRN & \\
\hline CHEMBL1461734 & 688636 & 4.95 & 4.8927 & TRN & \\
\hline CHEMBL1448557 & 688636 & 4.6 & 4.879 & TST & \\
\hline CHEMBL1391267 & 688636 & 4.4 & 4.8924 & TRN & \\
\hline CHEMBL1386971 & 688636 & 5.05 & 5.0305 & TST & \\
\hline CHEMBL1497297 & 688636 & 6.25 & 4.9392 & TRN & \\
\hline CHEMBL1300141 & 688636 & 5.15 & 4.803 & TST & \\
\hline CHEMBL1379178 & 688636 & 4.45 & 4.7061 & TRN & \\
\hline CHEMBL1568497 & 688636 & 4.3 & 4.7418 & TRN & \\
\hline CHEMBL1486184 & 688636 & 4.3 & 4.6781 & TST & \\
\hline CHEMBL1455542 & 688636 & 4.55 & 4.5746 & TRN & \\
\hline CHEMBL1603266 & 688636 & 4.8 & 4.6449 & TST & \\
\hline CHEMBL1569472 & 688636 & 4.4 & 4.7526 & TRN & \\
\hline CHEMBL1393235 & 688636 & 4.9 & 4.9056 & TRN & \\
\hline CHEMBL1307186 & 688636 & 4.25 & 4.6212 & TRN & \\
\hline CHEMBL1568694 & 688636 & 4.95 & 4.9141 & TRN & \\
\hline CHEMBL1490447 & 688636 & 4.45 & 4.7524 & TRN & \\
\hline CHEMBL1361817 & 688636 & 4.45 & 4.79899 & 99999999995 & TRN \\
\hline CHEMBL1323298 & 688636 & 6.8 & 4.9169 & TRN & \\
\hline CHEMBL1406588 & 688636 & 4.45 & 4.6616 & TRN & \\
\hline CHEMBL1455689 & 688636 & 4.5 & 4.7782 & TRN & \\
\hline CHEMBL1378045 & 688636 & 4.6 & 4.6738 & TRN & \\
\hline CHEMBL1410021 & 688636 & 5.4 & 4.7502 & TRN & \\
\hline CHEMBL1334583 & 688636 & 6.5 & 4.9311 & TRN & \\
\hline CHEMBL1528648 & 688636 & 5.5 & 4.8682 & TST & \\
\hline CHEMBL3213891 & 688636 & 5.2 & 4.9707 & TST & \\
\hline CHEMBL1321915 & 688636 & 4.5 & 4.6267 & TRN & \\
\hline CHEMBL1541223 & 688636 & 4.9 & 4.9527 & TRN & \\
\hline CHEMBL1343674 & 688636 & 5.05 & 4.7735 & TRN & \\
\hline CHEMBL1502739 & 688636 & 6.15 & 4.644 & TRN & \\
\hline CHEMBL1556143 & 688636 & 4.5 & 4.8504 & TRN & \\
\hline CHEMBL1425688 & 688636 & 4.4 & 4.7194 & TRN & \\
\hline
\end{tabular}




\begin{tabular}{|c|c|c|c|c|}
\hline \multicolumn{5}{|c|}{ Supplemental Table S2.txt } \\
\hline CHEMBL1490441 & 688636 & 4.95 & 4.7136 & TRN \\
\hline CHEMBL1429476 & 688636 & 4.55 & 4.7032 & TRN \\
\hline CHEMBL1352156 & 688636 & 5.25 & 4.6094 & TRN \\
\hline CHEMBL1539688 & 688636 & 5.95 & 4.7878 & TRN \\
\hline CHEMBL1510055 & 688636 & 4.4 & 4.7133 & TRN \\
\hline CHEMBL1389272 & 688636 & 5.1 & 4.9444 & TRN \\
\hline CHEMBL1454798 & 688636 & 4.6 & 4.9828 & TRN \\
\hline CHEMBL1419176 & 688636 & 5.35 & 4.7121 & TST \\
\hline CHEMBL1447340 & 688636 & 6.45 & 4.8116 & TRN \\
\hline CHEMBL1309401 & 688636 & 4.3 & 4.8262 & TRN \\
\hline CHEMBL1347266 & 688636 & 4.95 & 4.7271 & TRN \\
\hline CHEMBL1311844 & 688636 & 5.7 & 4.9059 & TRN \\
\hline CHEMBL1508882 & 688636 & 4.3 & 4.7768 & TRN \\
\hline CHEMBL1325753 & 688636 & 4.45 & 4.7385 & TST \\
\hline CHEMBL1350637 & 688636 & 4.45 & 4.6901 & TRN \\
\hline CHEMBL1431403 & 688636 & 5.15 & 4.6351 & TRN \\
\hline CHEMBL1351388 & 688636 & 5.2 & 4.9519 & TRN \\
\hline CHEMBL1335507 & 688636 & 6.7501 & 4.8616 & TRN \\
\hline CHEMBL1427838 & 688636 & 4.75 & 4.6591 & TRN \\
\hline CHEMBL1517769 & 688636 & 5.7 & 4.8159 & TRN \\
\hline CHEMBL1330854 & 688636 & 5.25 & 4.7658 & TRN \\
\hline CHEMBL1612519 & 688636 & 4.4 & 4.8411 & TRN \\
\hline CHEMBL1498922 & 688636 & 4.95 & 4.9101 & TST \\
\hline CHEMBL1456662 & 688636 & 4.45 & 4.9513 & TRN \\
\hline CHEMBL1490225 & 688636 & 4.9 & 4.8131 & TRN \\
\hline CHEMBL1468369 & 688636 & 5.1 & 4.784 & TST \\
\hline CHEMBL1585966 & 688636 & 6.15 & 4.8856 & TST \\
\hline CHEMBL1416598 & 688636 & 5.55 & 5.0485 & TRN \\
\hline CHEMBL1387086 & 688636 & 4.3 & 4.9903 & TST \\
\hline CHEMBL1320909 & 688636 & 4.55 & 4.7646 & TST \\
\hline CHEMBL1312250 & 688636 & 4.85 & 4.6003 & TRN \\
\hline CHEMBL3199697 & 688636 & 4.25 & 4.8071 & TRN \\
\hline CHEMBL1566542 & 688636 & 4.75 & 4.8584 & TRN \\
\hline CHEMBL1510145 & 688636 & 5.85 & 5.0565 & TRN \\
\hline CHEMBL1561923 & 688636 & 5.15 & 4.8474 & TST \\
\hline CHEMBL3189717 & 688636 & 4.9 & 4.9517 & TST \\
\hline CHEMBL1579827 & 688636 & 4.35 & 4.8426 & TRN \\
\hline CHEMBL1522391 & 688636 & 4.4 & 5.0527 & TRN \\
\hline CHEMBL1382352 & 688636 & 5.85 & 4.852 & TRN \\
\hline CHEMBL1582127 & 688636 & 4.45 & 4.7593 & TST \\
\hline CHEMBL1600163 & 688636 & 4.4 & 4.8131 & TRN \\
\hline CHEMBL1505299 & 688636 & 4.5 & 4.7644 & TST \\
\hline CHEMBL1308512 & 688636 & 5.25 & 4.9744 & TST \\
\hline CHEMBL1573013 & 688636 & 4.3 & 4.5865 & TRN \\
\hline CHEMBL1602587 & 688636 & 4.25 & 4.8509 & TRN \\
\hline CHEMBL1364445 & 688636 & 4.4 & 4.9103 & TRN \\
\hline CHEMBL1586419 & 688636 & 5.3 & 4.73 & TRN \\
\hline CHEMBL1557483 & 688636 & 4.25 & 4.9994 & TST \\
\hline
\end{tabular}




\begin{tabular}{|c|c|c|c|c|}
\hline \multirow[b]{2}{*}{ CHEMBL1587552 } & \multicolumn{4}{|c|}{ Supplemental Table S2.tx } \\
\hline & 688636 & 6.5 & 4.8397 & TST \\
\hline CHEMBL1319306 & 688636 & 4.95 & 4.7211 & TRN \\
\hline CHEMBL1415504 & 688636 & 4.55 & 4.7595 & TST \\
\hline CHEMBL1509989 & 688636 & 4.7 & 4.7017 & TRN \\
\hline CHEMBL3209059 & 688636 & 5.25 & 4.901 & TRN \\
\hline CHEMBL1541529 & 688636 & 6.5 & 4.8227 & TRN \\
\hline CHEMBL1479660 & 688636 & 5.35 & 4.7372 & TRN \\
\hline CHEMBL 3192946 & 688636 & 4.45 & 4.5965 & TRN \\
\hline CHEMBL1346991 & 688636 & 4.25 & 4.8203 & TST \\
\hline CHEMBL1601300 & 688636 & 4.65 & 4.6901 & TRN \\
\hline CHEMBL 287193 & 688636 & 4.6 & 4.7256 & TRN \\
\hline CHEMBL1612488 & 688636 & 4.25 & 4.8542 & TRN \\
\hline CHEMBL1460619 & 688636 & 4.45 & 4.7132 & TRN \\
\hline CHEMBL1492178 & 688636 & 4.35 & 4.7412 & TRN \\
\hline CHEMBL1528219 & 688636 & 4.95 & 4.6587 & TRN \\
\hline CHEMBL3197612 & 688636 & 5.1 & 4.7679 & TRN \\
\hline CHEMBL1388022 & 688636 & 4.45 & 4.6888 & TRN \\
\hline CHEMBL1561192 & 688636 & 4.45 & 4.5901 & TRN \\
\hline CHEMBL1409049 & 688636 & 4.3 & 4.7575 & TRN \\
\hline CHEMBL1444530 & 688636 & 4.9 & 4.976 & TRN \\
\hline CHEMBL1559787 & 688636 & 4.7 & 4.7386 & TRN \\
\hline CHEMBL1511787 & 688636 & 5.85 & 4.761 & TST \\
\hline CHEMBL1542155 & 688636 & 4.95 & 4.7733 & TRN \\
\hline CHEMBL1301246 & 688636 & 4.7 & 4.8909 & TST \\
\hline CHEMBL1332838 & 688636 & 5.15 & 4.6969 & TRN \\
\hline CHEMBL1540099 & 688636 & 4.9 & 4.7032 & TRN \\
\hline CHEMBL1409927 & 688636 & 4.5 & 4.7844 & TRN \\
\hline CHEMBL1610566 & 688636 & 7.0 & 4.8172 & TRN \\
\hline CHEMBL1373002 & 688636 & 4.45 & 4.8454 & TRN \\
\hline CHEMBL1392386 & 688636 & 4.45 & 4.5816 & TRN \\
\hline CHEMBL1471212 & 688636 & 4.3 & 4.9326 & TRN \\
\hline CHEMBL1369568 & 688636 & 4.25 & 4.9889 & TST \\
\hline CHEMBL1333143 & 688636 & 4.4 & 4.6938 & TRN \\
\hline CHEMBL1352979 & 688636 & 4.85 & 4.7726 & TRN \\
\hline CHEMBL1580091 & 688636 & 4.9 & 4.8646 & TST \\
\hline CHEMBL1380987 & 688636 & 5.45 & 4.7466 & TRN \\
\hline CHEMBL1608804 & 688636 & 4.95 & 4.9702 & TST \\
\hline CHEMBL1524363 & 688636 & 4.55 & 4.7037 & TRN \\
\hline CHEMBL1305469 & 688636 & 5.45 & 4.6537 & TRN \\
\hline CHEMBL1564945 & 688636 & 4.65 & 4.6586 & TST \\
\hline CHEMBL1307875 & 688636 & 5.45 & 4.8794 & TST \\
\hline CHEMBL1452457 & 688636 & 6.8 & 4.9273 & TST \\
\hline CHEMBL162783 & 688636 & 4.5 & 4.6484 & TST \\
\hline CHEMBL584225 & 688636 & 4.35 & 4.8634 & TST \\
\hline CHEMBL1399059 & 688636 & 5.3 & 4.7302 & TST \\
\hline CHEMBL1443258 & 688636 & 6.05 & 4.7872 & TST \\
\hline CHEMBL3208084 & 688636 & 5.95 & 4.8215 & TST \\
\hline CHEMBL1535697 & 688636 & 4.95 & 4.6812 & TRN \\
\hline
\end{tabular}




\begin{tabular}{|c|c|c|c|c|}
\hline \multicolumn{5}{|c|}{ Supplemental Table } \\
\hline CHEMBL1467106 & 688636 & 4.5 & 4.9704 & TRN \\
\hline CHEMBL1571651 & 688636 & 4.6 & 4.7438 & TRN \\
\hline CHEMBL1440954 & 688636 & 5.95 & 4.9413 & TRN \\
\hline CHEMBL1500235 & 688636 & 4.25 & 5.0059 & TRN \\
\hline CHEMBL1607932 & 688636 & 4.6 & 4.6498 & TRN \\
\hline CHEMBL1557200 & 688636 & 5.25 & 4.7576 & TRN \\
\hline CHEMBL1532953 & 688636 & 4.3 & 4.5681 & TRN \\
\hline CHEMBL1564028 & 688636 & 4.4 & 4.8129 & TRN \\
\hline CHEMBL1527578 & 688636 & 4.7 & 4.7879 & TRN \\
\hline CHEMBL1269508 & 688636 & 4.9 & 4.7941 & TRN \\
\hline CHEMBL1490581 & 688636 & 4.7 & 4.8069 & TRN \\
\hline CHEMBL1483687 & 688636 & 4.95 & 4.7039 & TRN \\
\hline CHEMBL1389950 & 688636 & 4.6 & 5.0189 & TRN \\
\hline CHEMBL1304749 & 688636 & 5.05 & 4.7776 & TRN \\
\hline CHEMBL1604376 & 688636 & 4.95 & 4.8844 & TRN \\
\hline CHEMBL1382745 & 688636 & 4.3 & 4.7765 & TST \\
\hline CHEMBL1606494 & 688636 & 6.05 & 4.8905 & TRN \\
\hline CHEMBL1390191 & 688636 & 4.45 & 4.8648 & TST \\
\hline CHEMBL1430373 & 688636 & 4.95 & 4.916 & TST \\
\hline CHEMBL1384130 & 688636 & 4.35 & 4.8647 & TST \\
\hline CHEMBL1346733 & 688636 & 4.45 & 4.8376 & TST \\
\hline CHEMBL1410260 & 688636 & 6.05 & 4.7204 & TRN \\
\hline CHEMBL1601674 & 688636 & 4.95 & 4.8894 & TRN \\
\hline CHEMBL1303864 & 688636 & 4.35 & 4.8778 & TRN \\
\hline CHEMBL1502853 & 688636 & 4.4 & 4.8728 & TRN \\
\hline CHEMBL1517069 & 688636 & 6.7501 & 4.9681 & TST \\
\hline CHEMBL1339665 & 688636 & 4.95 & 4.8887 & TST \\
\hline CHEMBL1469957 & 688636 & 4.45 & 4.6377 & TRN \\
\hline CHEMBL1495160 & 688636 & 4.9 & 4.6296 & TRN \\
\hline CHEMBL1338005 & 688636 & 4.3 & 4.8417 & TST \\
\hline CHEMBL3192679 & 688636 & 4.25 & 4.6323 & TRN \\
\hline CHEMBL1453248 & 688636 & 4.25 & 4.9487 & TRN \\
\hline CHEMBL1302144 & 688636 & 5.5 & 4.7642 & TRN \\
\hline CHEMBL1559688 & 688636 & 5.3 & 4.8308 & TRN \\
\hline CHEMBL1568312 & 688636 & 4.25 & 4.6647 & TST \\
\hline CHEMBL1382077 & 688636 & 4.3 & 4.8302 & TRN \\
\hline CHEMBL1558928 & 688636 & 4.65 & 4.6429 & TRN \\
\hline CHEMBL1561918 & 688636 & 4.3 & 4.7444 & TRN \\
\hline CHEMBL1988042 & 688636 & 4.85 & 4.5003 & TRN \\
\hline CHEMBL1348803 & 688636 & 4.35 & 4.6617 & TRN \\
\hline CHEMBL1411318 & 688636 & 5.85 & 4.5688 & TRN \\
\hline CHEMBL1445083 & 688636 & 4.3 & 4.8454 & TRN \\
\hline CHEMBL3189467 & 688636 & 4.25 & 4.7387 & TST \\
\hline CHEMBL1385967 & 688636 & 4.3 & 4.824 & TRN \\
\hline CHEMBL1452075 & 688636 & 6.05 & 4.8991 & TRN \\
\hline CHEMBL1382135 & 688636 & 4.25 & 4.7288 & TRN \\
\hline CHEMBL1404536 & 688636 & 4.65 & 4.7493 & TRN \\
\hline CHEMBL3212712 & 688636 & 4.9 & 4.864 & TST \\
\hline
\end{tabular}




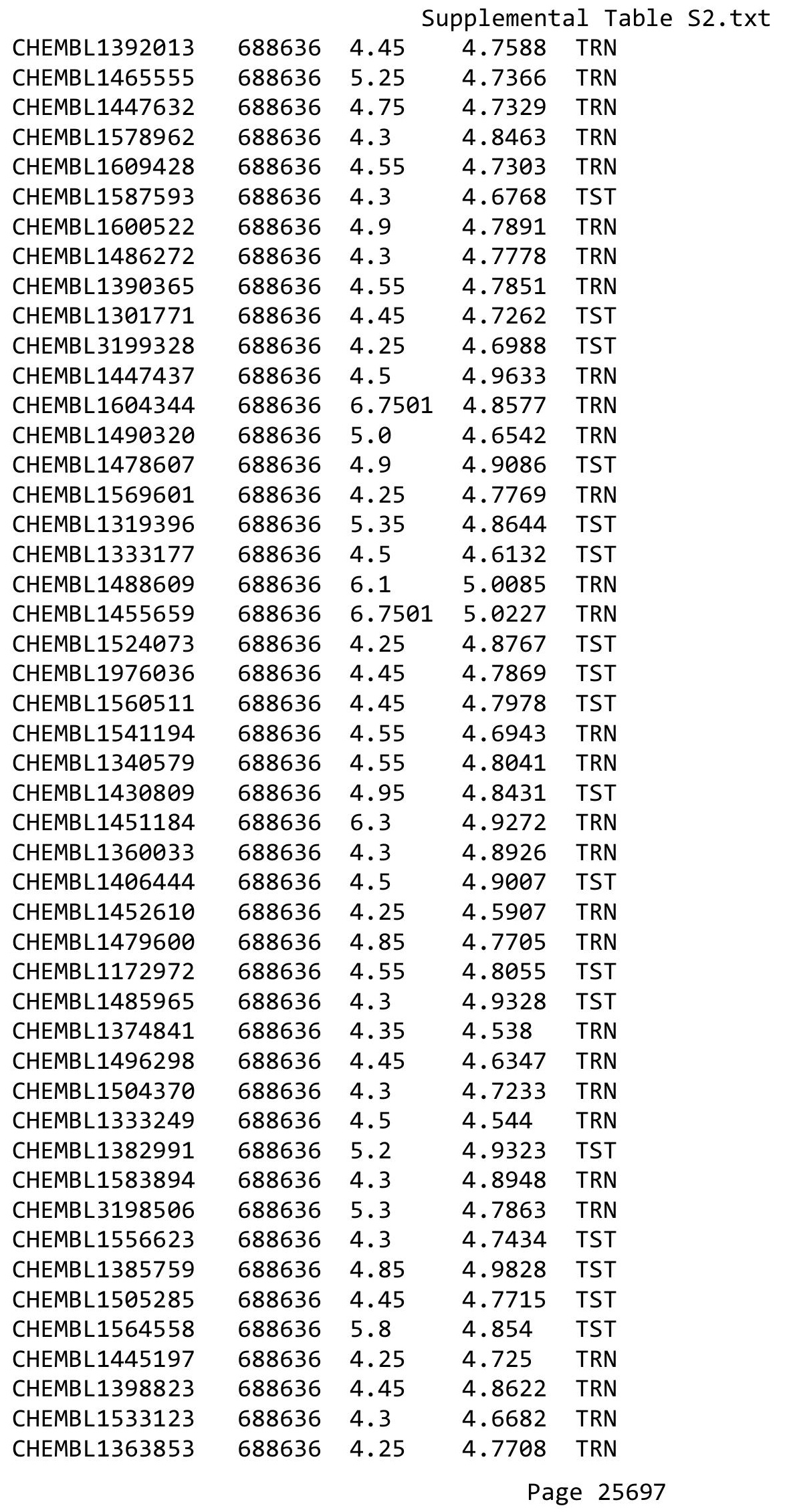




\begin{tabular}{|c|c|c|c|c|}
\hline \multicolumn{5}{|c|}{ Supplemental Table } \\
\hline CHEMBL1537583 & 688636 & 4.35 & 4.6926 & TRN \\
\hline CHEMBL104916 & 688636 & 6.7501 & 4.8543 & TST \\
\hline CHEMBL1337038 & 688636 & 4.3 & 4.897 & TST \\
\hline CHEMBL1432264 & 688636 & 4.55 & 4.9492 & TST \\
\hline CHEMBL1381437 & 688636 & 4.25 & 4.8392 & TRN \\
\hline CHEMBL1525535 & 688636 & 5.2 & 5.0405 & TST \\
\hline CHEMBL1467214 & 688636 & 5.5 & 4.5757 & TRN \\
\hline CHEMBL1545869 & 688636 & 4.25 & 4.8154 & TRN \\
\hline CHEMBL1596357 & 688636 & 5.15 & 4.8391 & TRN \\
\hline CHEMBL1561308 & 688636 & 5.2 & 4.9399 & TST \\
\hline CHEMBL1427888 & 688636 & 4.5 & 4.6062 & TRN \\
\hline CHEMBL1510208 & 688636 & 4.3 & 4.6541 & TRN \\
\hline CHEMBL1374073 & 688636 & 6.1 & 4.7733 & TST \\
\hline CHEMBL1572082 & 688636 & 5.75 & 4.9528 & TRN \\
\hline CHEMBL1485942 & 688636 & 4.55 & 4.8504 & TRN \\
\hline CHEMBL1347686 & 688636 & 4.6 & 4.8686 & TRN \\
\hline CHEMBL1533620 & 688636 & 4.55 & 4.5756 & TRN \\
\hline CHEMBL1365957 & 688636 & 5.0 & 4.7495 & TRN \\
\hline CHEMBL1306582 & 688636 & 5.4 & 4.728 & TST \\
\hline CHEMBL1542804 & 688636 & 4.4 & 4.6913 & TRN \\
\hline CHEMBL1537860 & 688636 & 4.3 & 4.6961 & TRN \\
\hline CHEMBL1424517 & 688636 & 4.35 & 4.7949 & TST \\
\hline CHEMBL1419867 & 688636 & 5.75 & 4.8889 & TST \\
\hline CHEMBL1433084 & 688636 & 4.6 & 4.6852 & TRN \\
\hline CHEMBL1416704 & 688636 & 4.45 & 4.9314 & TRN \\
\hline CHEMBL1451834 & 688636 & 4.8 & 4.8603 & TRN \\
\hline CHEMBL1458744 & 688636 & 4.45 & 4.6541 & TRN \\
\hline CHEMBL1322240 & 688636 & 4.6 & 4.7083 & TRN \\
\hline CHEMBL1362660 & 688636 & 4.3 & 4.8282 & TST \\
\hline CHEMBL1533157 & 688636 & 5.1 & 4.8725 & TRN \\
\hline CHEMBL1541360 & 688636 & 4.55 & 4.8249 & TRN \\
\hline CHEMBL1299357 & 688636 & 5.45 & 4.6616 & TRN \\
\hline CHEMBL1418880 & 688636 & 4.45 & 4.7055 & TRN \\
\hline CHEMBL1360699 & 688636 & 6.7501 & 4.8227 & TST \\
\hline CHEMBL1578109 & 688636 & 5.85 & 4.7768 & TRN \\
\hline CHEMBL3212931 & 688636 & 6.05 & 4.7474 & TRN \\
\hline CHEMBL1441612 & 688636 & 4.9 & 4.8407 & TST \\
\hline CHEMBL1373223 & 688636 & 4.6 & 4.8798 & TRN \\
\hline CHEMBL1484458 & 688636 & 4.6 & 4.703 & TST \\
\hline CHEMBL1445901 & 688636 & 4.35 & 4.7694 & TRN \\
\hline CHEMBL1534817 & 688636 & 5.85 & 4.8968 & TST \\
\hline CHEMBL1430314 & 688636 & 4.35 & 4.5548 & TST \\
\hline CHEMBL1544704 & 688636 & 4.45 & 4.7243 & TRN \\
\hline CHEMBL1578288 & 688636 & 4.3 & 5.0475 & TRN \\
\hline CHEMBL1487537 & 688636 & 5.25 & 4.9486 & TRN \\
\hline CHEMBL3210383 & 688636 & 4.5 & 4.835 & TRN \\
\hline CHEMBL 1607146 & 688636 & 4.45 & 4.7332 & TRN \\
\hline CHEMBL1495845 & 688636 & 4.6 & 4.7064 & TRN \\
\hline
\end{tabular}




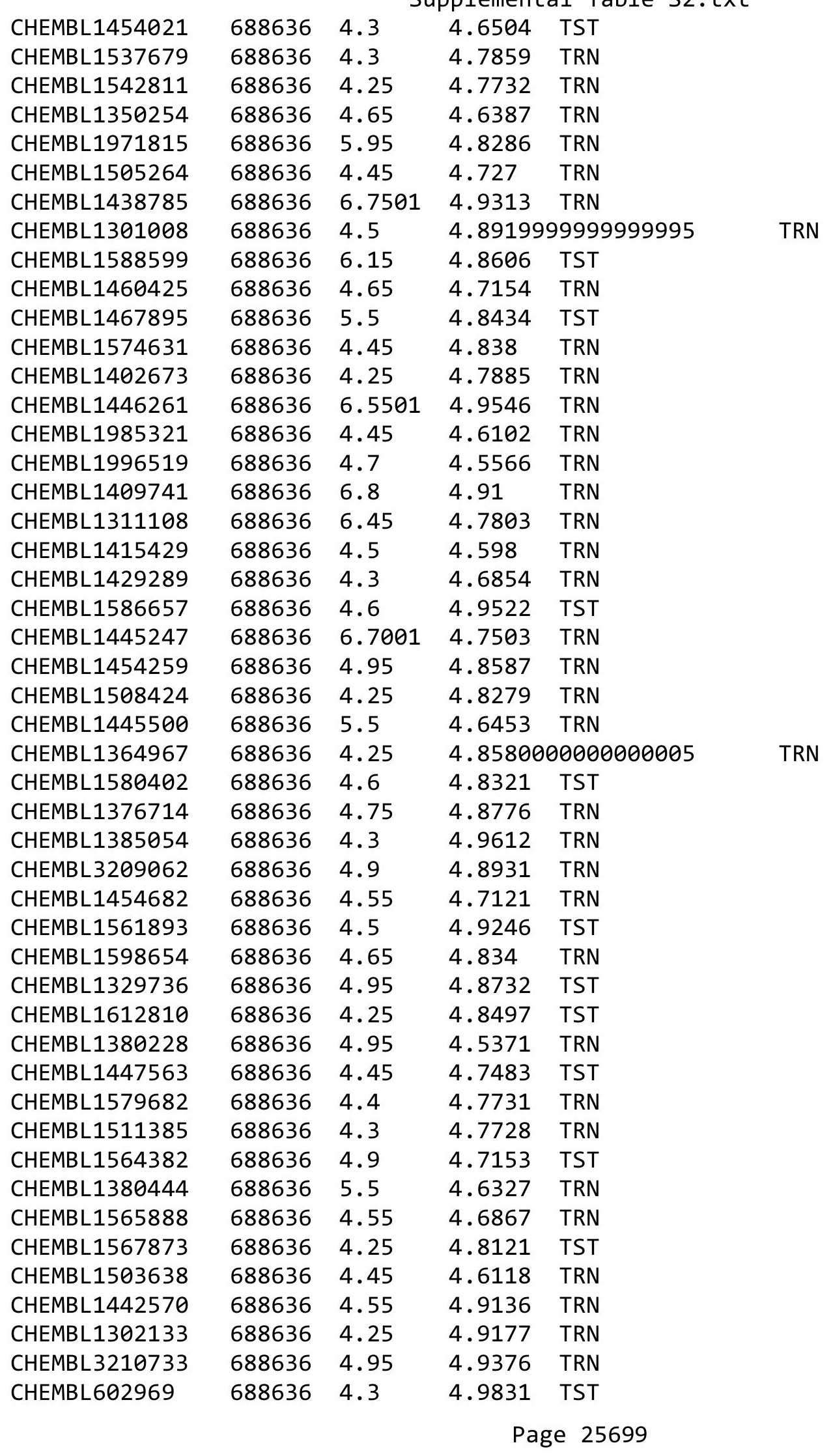




\begin{tabular}{|c|c|c|c|c|c|}
\hline & & & & & \\
\hline CHEMBL1582229 & 688636 & 4.5 & 4.5997 & TST & \\
\hline CHEMBL3210723 & 688636 & 4.5 & 4.7283 & TRN & \\
\hline CHEMBL1463576 & 688636 & 4.45 & 4.5451 & TRN & \\
\hline CHEMBL1600913 & 688636 & 5.55 & 4.7601 & TRN & \\
\hline CHEMBL1469431 & 688636 & 4.5 & 4.7829 & TRN & \\
\hline CHEMBL1353757 & 688636 & 4.25 & 4.5922 & TRN & \\
\hline CHEMBL1497764 & 688636 & 4.9 & 4.79899 & 99999999995 & TRN \\
\hline CHEMBL1301324 & 688636 & 4.3 & 4.7704 & TRN & \\
\hline CHEMBL1352127 & 688636 & 4.5 & 4.9148 & TRN & \\
\hline CHEMBL1549290 & 688636 & 4.35 & 4.6736 & TST & \\
\hline CHEMBL1444825 & 688636 & 4.25 & 4.7793 & TRN & \\
\hline CHEMBL1334117 & 688636 & 5.85 & 4.8478 & TST & \\
\hline CHEMBL1452101 & 688636 & 5.0 & 4.7782 & TRN & \\
\hline CHEMBL1347805 & 688636 & 4.3 & 4.9268 & TRN & \\
\hline CHEMBL1341971 & 688636 & 5.15 & 4.9648 & TST & \\
\hline CHEMBL1341626 & 688636 & 4.45 & 4.865 & TRN & \\
\hline CHEMBL3194359 & 688636 & 4.55 & 4.6722 & TRN & \\
\hline CHEMBL1364945 & 688636 & 4.25 & 4.8725 & TST & \\
\hline CHEMBL1471848 & 688636 & 4.9 & 4.9285 & TST & \\
\hline CHEMBL1584632 & 688636 & 4.3 & 4.7537 & TRN & \\
\hline CHEMBL538430 & 688636 & 5.25 & 4.93199 & 99999999995 & TRN \\
\hline CHEMBL1612700 & 688636 & 4.45 & 4.8289 & TRN & \\
\hline CHEMBL3193689 & 688636 & 4.55 & 4.6627 & TRN & \\
\hline CHEMBL1613716 & 688636 & 5.15 & 4.7479 & TRN & \\
\hline CHEMBL1478577 & 688636 & 4.75 & 4.824 & TRN & \\
\hline CHEMBL1322929 & 688636 & 4.45 & 4.6905 & TRN & \\
\hline CHEMBL1387124 & 688636 & 5.3 & 4.76699 & 99999999995 & TRN \\
\hline CHEMBL1544951 & 688636 & 4.45 & 4.8669 & TST & \\
\hline CHEMBL1456547 & 688636 & 4.9 & 4.7806 & TRN & \\
\hline CHEMBL1322914 & 688636 & 4.45 & 4.6599 & TRN & \\
\hline CHEMBL1329027 & 688636 & 4.35 & 4.7504 & TRN & \\
\hline CHEMBL1542752 & 688636 & 4.45 & 4.7484 & TRN & \\
\hline CHEMBL1426998 & 688636 & 5.65 & 4.9819 & TRN & \\
\hline CHEMBL1605917 & 688636 & 5.35 & 4.4654 & TRN & \\
\hline CHEMBL1323402 & 688636 & 4.3 & 4.9184 & TRN & \\
\hline CHEMBL1422873 & 688636 & 4.5 & 4.8037 & TRN & \\
\hline CHEMBL1465615 & 688636 & 4.45 & 4.8673 & TRN & \\
\hline CHEMBL1349952 & 688636 & 4.45 & 4.7129 & TRN & \\
\hline CHEMBL1583907 & 688636 & 4.5 & 4.86 & TRN & \\
\hline CHEMBL1453050 & 688636 & 4.45 & 4.8263 & TRN & \\
\hline CHEMBL595438 & 688636 & 5.35 & 4.8351 & TST & \\
\hline CHEMBL1561119 & 688636 & 4.55 & 4.8342 & TST & \\
\hline CHEMBL1509985 & 688636 & 4.45 & 4.7339 & TRN & \\
\hline CHEMBL1601115 & 688636 & 4.85 & 4.715 & TRN & \\
\hline CHEMBL3196812 & 688636 & 4.3 & 4.7657 & TRN & \\
\hline CHEMBL1577846 & 688636 & 4.9 & 4.7334 & TRN & \\
\hline CHEMBL1543490 & 688636 & 4.5 & 4.9602 & TST & \\
\hline CHEMBL1520474 & 688636 & 4.4 & 4.8126 & TRN & \\
\hline & & & & 25700 & \\
\hline
\end{tabular}




\begin{tabular}{|c|c|c|c|c|c|}
\hline \multicolumn{6}{|c|}{ Supplemental Table S2.txt } \\
\hline CHEMBL1424584 & 688636 & 4.95 & 4.9837 & TRN & \\
\hline CHEMBL 2005411 & 688636 & 4.7 & 4.7098 & TRN & \\
\hline CHEMBL1507028 & 688636 & 5.15 & 4.8711 & TST & \\
\hline CHEMBL1608848 & 688636 & 4.25 & 4.7214 & TRN & \\
\hline CHEMBL1369370 & 688636 & 5.45 & 4.8512 & TRN & \\
\hline CHEMBL1344746 & 688636 & 5.05 & 4.7459 & TRN & \\
\hline CHEMBL1549217 & 688636 & 4.4 & 4.8723 & TRN & \\
\hline CHEMBL1333938 & 688636 & 4.2 & 4.7574 & TRN & \\
\hline CHEMBL1312134 & 688636 & 4.55 & 4.8115 & TRN & \\
\hline CHEMBL1561977 & 688636 & 4.25 & 4.6748 & TRN & \\
\hline CHEMBL1348085 & 688636 & 4.95 & 4.8087 & TST & \\
\hline CHEMBL1547559 & 688636 & 4.55 & 4.621 & TST & \\
\hline CHEMBL1575196 & 688636 & 4.55 & 4.8707 & TRN & \\
\hline CHEMBL1345169 & 688636 & 5.15 & 4.9636 & TRN & \\
\hline CHEMBL1312646 & 688636 & 5.2 & 4.5719 & TRN & \\
\hline CHEMBL1607976 & 688636 & 4.25 & 4.7796 & TRN & \\
\hline CHEMBL1384111 & 688636 & 4.35 & 4.8209 & TRN & \\
\hline CHEMBL1466660 & 688636 & 5.45 & 4.9062 & TRN & \\
\hline CHEMBL1528533 & 688636 & 5.05 & 4.8641 & TRN & \\
\hline CHEMBL1519926 & 688636 & 4.95 & 4.9867 & TST & \\
\hline CHEMBL1305166 & 688636 & 4.3 & 4.6027 & TRN & \\
\hline CHEMBL1380910 & 688636 & 4.45 & 5.0368 & TRN & \\
\hline CHEMBL1571407 & 688636 & 4.7 & 4.6998 & TRN & \\
\hline CHEMBL107639 & 688636 & 4.25 & 4.8512 & TRN & \\
\hline CHEMBL3197580 & 688636 & 4.9 & 4.6768 & TST & \\
\hline CHEMBL1500269 & 688636 & 4.3 & 4.8796 & TST & \\
\hline CHEMBL1423861 & 688636 & 5.15 & 4.855 & TST & \\
\hline CHEMBL1416974 & 688636 & 4.45 & 4.8469 & TRN & \\
\hline CHEMBL1459536 & 688636 & 4.45 & 4.6432 & TRN & \\
\hline CHEMBL1401425 & 688636 & 5.2 & 4.8922 & TRN & \\
\hline CHEMBL1361030 & 688636 & 4.9 & 4.798 & TRN & \\
\hline CHEMBL1309006 & 688636 & 4.45 & 4.762 & TRN & \\
\hline CHEMBL1485809 & 688636 & 5.25 & 4.84399 & & TST \\
\hline CHEMBL1304431 & 688636 & 4.45 & 4.5812 & TRN & \\
\hline CHEMBL1469884 & 688636 & 4.45 & 4.954 & TRN & \\
\hline CHEMBL1460631 & 688636 & 4.9 & 4.8761 & TST & \\
\hline CHEMBL1325473 & 688636 & 4.95 & 4.9827 & TRN & \\
\hline CHEMBL1335492 & 688636 & 4.55 & 4.7087 & TRN & \\
\hline CHEMBL1345586 & 688636 & 4.3 & 4.6645 & TST & \\
\hline CHEMBL1458176 & 688636 & 6.0 & 4.7986 & TST & \\
\hline CHEMBL1605612 & 688636 & 4.25 & 4.898 & TST & \\
\hline CHEMBL3192400 & 688636 & 4.25 & 4.6804 & TRN & \\
\hline CHEMBL1472101 & 688636 & 4.25 & 4.7584 & TRN & \\
\hline CHEMBL1372844 & 688636 & 4.45 & 4.8042 & TRN & \\
\hline CHEMBL1550962 & 688636 & 4.55 & 4.7842 & TRN & \\
\hline CHEMBL1516829 & 688636 & 4.3 & 4.7091 & TST & \\
\hline CHEMBL1402031 & 688636 & 4.25 & 4.8262 & TRN & \\
\hline CHEMBL1534196 & 688636 & 4.95 & 4.9203 & TRN & \\
\hline
\end{tabular}




\begin{tabular}{|c|c|c|c|c|c|}
\hline \\
\hline CHEMBL1550855 & 688636 & 4.5 & 4.7406 & TRN & \\
\hline CHEMBL1609610 & 688636 & 4.3 & 4.6152 & TRN & \\
\hline CHEMBL1484160 & 688636 & 4.85 & 4.8049 & TST & \\
\hline CHEMBL1543536 & 688636 & 4.6 & 4.7182 & TRN & \\
\hline CHEMBL1559245 & 688636 & 4.55 & 4.6772 & TRN & \\
\hline CHEMBL1461430 & 688636 & 4.25 & 5.058 & TRN & \\
\hline CHEMBL1299326 & 688636 & 5.5 & 5.0311 & TRN & \\
\hline CHEMBL1594218 & 688636 & 5.8 & 4.8781 & TST & \\
\hline CHEMBL1501533 & 688636 & 5.1 & 4.9673 & TRN & \\
\hline CHEMBL1401987 & 688636 & 4.25 & 4.8023 & TST & \\
\hline CHEMBL1562230 & 688636 & 4.6 & 4.9543 & TRN & \\
\hline CHEMBL1333507 & 688636 & 4.6 & 4.7192 & TRN & \\
\hline CHEMBL1589236 & 688636 & 4.25 & 4.9681 & TRN & \\
\hline CHEMBL1571703 & 688636 & 4.4 & 4.7576 & TST & \\
\hline CHEMBL1527872 & 688636 & 4.45 & 4.73300 & 30000000005 & TST \\
\hline CHEMBL1479259 & 688636 & 4.45 & 4.6291 & TRN & \\
\hline CHEMBL1443893 & 688636 & 4.95 & 4.5968 & TRN & \\
\hline CHEMBL1586798 & 688636 & 4.3 & 4.648 & TRN & \\
\hline CHEMBL1339161 & 688636 & 4.6 & 4.9167 & TRN & \\
\hline CHEMBL1404655 & 688636 & 5.2 & 4.7663 & TRN & \\
\hline CHEMBL1429836 & 688636 & 4.5 & 4.8623 & TST & \\
\hline CHEMBL1329259 & 688636 & 4.3 & 4.8164 & TST & \\
\hline CHEMBL1428728 & 688636 & 4.4 & 4.6152 & TST & \\
\hline CHEMBL1546502 & 688636 & 4.9 & 4.899 & TRN & \\
\hline CHEMBL1560264 & 688636 & 4.3 & 4.9064 & TRN & \\
\hline CHEMBL1587837 & 688636 & 4.55 & 4.5817 & TST & \\
\hline CHEMBL1578843 & 688636 & 4.35 & 4.8156 & TST & \\
\hline CHEMBL1493394 & 688636 & 4.4 & 4.7256 & TRN & \\
\hline CHEMBL1531336 & 688636 & 4.4 & 4.7169 & TRN & \\
\hline CHEMBL1563624 & 688636 & 4.45 & 4.8073 & TRN & \\
\hline CHEMBL1445742 & 688636 & 4.25 & 5.0009 & TRN & \\
\hline CHEMBL1427863 & 688636 & 4.4 & 4.7854 & TRN & \\
\hline CHEMBL1402713 & 688636 & 4.25 & 4.9938 & TRN & \\
\hline CHEMBL1304179 & 688636 & 4.45 & 4.6548 & TRN & \\
\hline CHEMBL1417197 & 688636 & 4.4 & 4.8878 & TRN & \\
\hline CHEMBL1471143 & 688636 & 4.7 & 4.5652 & TRN & \\
\hline CHEMBL1411635 & 688636 & 4.9 & 4.6785 & TRN & \\
\hline CHEMBL1988679 & 688636 & 5.3 & 4.8632 & TST & \\
\hline CHEMBL1339850 & 688636 & 4.25 & 4.6955 & TST & \\
\hline CHEMBL1478570 & 688636 & 4.45 & 4.7091 & TRN & \\
\hline CHEMBL1600641 & 688636 & 4.9 & 4.9855 & TRN & \\
\hline CHEMBL1366156 & 688636 & 4.7 & 4.8455 & TST & \\
\hline CHEMBL1545510 & 688636 & 4.25 & 4.8407 & TST & \\
\hline CHEMBL1599210 & 688636 & 5.2 & 4.5529 & TRN & \\
\hline CHEMBL1531357 & 688636 & 4.75 & 4.7607 & TST & \\
\hline CHEMBL2007056 & 688636 & 6.0 & 4.7622 & TST & \\
\hline CHEMBL1416843 & 688636 & 4.45 & 4.7161 & TRN & \\
\hline CHEMBL1563287 & 688636 & 5.8 & 4.8853 & TRN & \\
\hline
\end{tabular}




\begin{tabular}{|c|c|c|c|c|c|}
\hline \multicolumn{6}{|c|}{ Supplemental Table S2.txt } \\
\hline CHEMBL3190497 & 688636 & 4.25 & 4.688 & TRN & \\
\hline CHEMBL1323967 & 688636 & 4.5 & 4.7707 & TRN & \\
\hline CHEMBL1586166 & 688636 & 4.75 & 4.6975 & TRN & \\
\hline CHEMBL1503627 & 688636 & 4.55 & 4.8748 & TRN & \\
\hline CHEMBL1426432 & 688636 & 4.9 & 4.7834 & TRN & \\
\hline CHEMBL1420885 & 688636 & 4.3 & 4.9172 & TST & \\
\hline CHEMBL1587477 & 688636 & 4.3 & 4.7355 & TRN & \\
\hline CHEMBL1310515 & 688636 & 4.4 & 4.8385 & TRN & \\
\hline CHEMBL1336208 & 688636 & 5.25 & 4.7954 & TRN & \\
\hline CHEMBL1530482 & 688636 & 5.15 & 4.8479 & TRN & \\
\hline CHEMBL1499671 & 688636 & 5.45 & 4.8133 & TST & \\
\hline CHEMBL1304982 & 688636 & 5.3 & 4.8699 & TST & \\
\hline CHEMBL1468097 & 688636 & 4.45 & 4.7886 & TRN & \\
\hline CHEMBL1736377 & 688636 & 4.45 & 4.6274 & TRN & \\
\hline CHEMBL1538539 & 688636 & 4.7 & 4.8151 & TRN & \\
\hline CHEMBL1523550 & 688636 & 4.25 & 4.7049 & TST & \\
\hline CHEMBL1438939 & 688636 & 6.15 & 4.828 & TRN & \\
\hline CHEMBL1426618 & 688636 & 6.7501 & 4.84399 & & TRN \\
\hline CHEMBL1339787 & 688636 & 4.4 & 4.8209 & TRN & \\
\hline CHEMBL1529818 & 688636 & 5.15 & 4.8586 & TRN & \\
\hline CHEMBL1401912 & 688636 & 5.65 & 4.898 & TRN & \\
\hline CHEMBL1412201 & 688636 & 4.25 & 4.9724 & TRN & \\
\hline CHEMBL1483332 & 688636 & 5.2 & 4.7396 & TRN & \\
\hline CHEMBL1575548 & 688636 & 4.3 & 4.8916 & TRN & \\
\hline CHEMBL1424253 & 688636 & 4.45 & 4.9153 & TRN & \\
\hline CHEMBL1349012 & 688636 & 4.9 & 4.7513 & TST & \\
\hline CHEMBL1485470 & 688636 & 4.3 & 4.8927 & TST & \\
\hline CHEMBL1570792 & 688636 & 4.45 & 4.817 & TRN & \\
\hline CHEMBL1459899 & 688636 & 4.95 & 4.8013 & TRN & \\
\hline CHEMBL1489104 & 688636 & 4.25 & 4.8144 & TRN & \\
\hline CHEMBL3211842 & 688636 & 4.9 & 4.9117 & TST & \\
\hline CHEMBL1370011 & 688636 & 4.45 & 4.6147 & TRN & \\
\hline CHEMBL1491910 & 688636 & 4.4 & 4.7387 & TRN & \\
\hline CHEMBL3196446 & 688636 & 4.35 & 4.6774 & TRN & \\
\hline CHEMBL1322582 & 688636 & 4.7 & 4.5624 & TRN & \\
\hline CHEMBL1380451 & 688636 & 5.5 & 4.9099 & TRN & \\
\hline CHEMBL1510059 & 688636 & 4.8 & 4.9505 & TST & \\
\hline CHEMBL1582935 & 688636 & 4.55 & 4.7298 & TRN & \\
\hline CHEMBL1540038 & 688636 & 4.45 & 4.4806 & TST & \\
\hline CHEMBL1507868 & 688636 & 4.35 & 4.6846 & TRN & \\
\hline CHEMBL1312375 & 688636 & 4.3 & 5.0147 & TST & \\
\hline CHEMBL1423158 & 688636 & 5.1 & 4.7351 & TRN & \\
\hline CHEMBL1995112 & 688636 & 4.3 & 4.6281 & TRN & \\
\hline CHEMBL1497731 & 688636 & 4.25 & 4.8316 & TRN & \\
\hline CHEMBL1502661 & 688636 & 4.45 & 4.7162 & TRN & \\
\hline CHEMBL1345212 & 688636 & 4.45 & 4.7659 & TRN & \\
\hline CHEMBL1559485 & 688636 & 4.6 & 4.9039 & TRN & \\
\hline CHEMBL1346401 & 688636 & 5.3 & 4.8506 & TRN & \\
\hline
\end{tabular}




\begin{tabular}{|c|c|c|c|c|}
\hline \multicolumn{5}{|c|}{ Supplemental Table S2.txt } \\
\hline CHEMBL1343473 & 688636 & 4.45 & 4.7527 & TRN \\
\hline CHEMBL1607561 & 688636 & 4.3 & 4.9376 & TRN \\
\hline CHEMBL1382103 & 688636 & 4.5 & 4.6674 & TRN \\
\hline CHEMBL1312058 & 688636 & 4.45 & 4.9181 & TST \\
\hline CHEMBL1510396 & 688636 & 4.3 & 4.8034 & TRN \\
\hline CHEMBL1495645 & 688636 & 4.45 & 4.8222 & TRN \\
\hline CHEMBL1366184 & 688636 & 5.15 & 4.9126 & TRN \\
\hline CHEMBL1605054 & 688636 & 4.95 & 4.9139 & TRN \\
\hline CHEMBL1531849 & 688636 & 4.4 & 4.6871 & TRN \\
\hline CHEMBL1511108 & 688636 & 4.3 & 4.6804 & TRN \\
\hline CHEMBL1541769 & 688636 & 4.45 & 4.5977 & TRN \\
\hline CHEMBL1586127 & 688636 & 4.3 & 4.8805 & TRN \\
\hline CHEMBL1577399 & 688636 & 4.25 & 4.7492 & TRN \\
\hline CHEMBL1391774 & 688636 & 4.8 & 4.6036 & TRN \\
\hline CHEMBL1381717 & 688636 & 5.95 & 4.9417 & TRN \\
\hline CHEMBL3190368 & 688636 & 4.4 & 4.7529 & TST \\
\hline CHEMBL1485002 & 688636 & 4.5 & 4.6483 & TRN \\
\hline CHEMBL1326161 & 688636 & 4.9 & 4.8728 & TRN \\
\hline CHEMBL1385973 & 688636 & 4.45 & 4.6096 & TRN \\
\hline CHEMBL1485374 & 688636 & 5.0 & 4.7059 & TRN \\
\hline CHEMBL1400326 & 688636 & 4.9 & 4.8464 & TST \\
\hline CHEMBL3189659 & 688636 & 6.7501 & 4.8069 & TRN \\
\hline CHEMBL1560945 & 688636 & 4.65 & 4.7715 & TRN \\
\hline CHEMBL1602410 & 688636 & 4.55 & 4.8041 & TRN \\
\hline CHEMBL1380787 & 688636 & 4.8 & 4.8899 & TRN \\
\hline CHEMBL1467005 & 688636 & 4.4 & 4.8169 & TST \\
\hline CHEMBL1509159 & 688636 & 4.3 & 4.836 & TRN \\
\hline CHEMBL1313724 & 688636 & 4.65 & 4.7037 & TST \\
\hline CHEMBL1302009 & 688636 & 4.25 & 4.6812 & TST \\
\hline CHEMBL1539606 & 688636 & 4.6 & 4.9177 & TRN \\
\hline CHEMBL1303527 & 688636 & 4.25 & 4.8563 & TST \\
\hline CHEMBL1584248 & 688636 & 6.05 & 4.9331 & TST \\
\hline CHEMBL1451275 & 688636 & 4.85 & 4.9332 & TRN \\
\hline CHEMBL1346204 & 688636 & 4.65 & 4.6621 & TST \\
\hline CHEMBL1990573 & 688636 & 5.95 & 4.7503 & TST \\
\hline CHEMBL1526099 & 688636 & 4.9 & 4.8055 & TRN \\
\hline CHEMBL 1352286 & 688636 & 4.25 & 4.7386 & TRN \\
\hline CHEMBL3208873 & 688636 & 4.3 & 4.9314 & TRN \\
\hline CHEMBL1972915 & 688636 & 4.4 & 4.6297 & TRN \\
\hline CHEMBL1451016 & 688636 & 4.3 & 4.6594 & TRN \\
\hline CHEMBL1346112 & 688636 & 4.45 & 4.8297 & TRN \\
\hline CHEMBL1455829 & 688636 & 4.3 & 5.0155 & TRN \\
\hline CHEMBL1468635 & 688636 & 4.6 & 4.6422 & TRN \\
\hline CHEMBL1383487 & 688636 & 5.15 & 4.794 & TST \\
\hline CHEMBL1371716 & 688636 & 4.45 & 4.6142 & TRN \\
\hline CHEMBL1313989 & 688636 & 5.25 & 4.8579 & TRN \\
\hline CHEMBL1534011 & 688636 & 6.7501 & 4.7436 & TRN \\
\hline CHEMBL1506609 & 688636 & 4.4 & 4.5452 & TRN \\
\hline
\end{tabular}




\begin{tabular}{|c|c|c|c|c|}
\hline \multicolumn{5}{|c|}{ Supplemental Table S2.txt } \\
\hline CHEMBL1487346 & 688636 & 4.55 & 4.7336 & TRN \\
\hline CHEMBL1490256 & 688636 & 4.35 & 4.7502 & TRN \\
\hline CHEMBL1426380 & 688636 & 4.4 & 5.0758 & TRN \\
\hline CHEMBL1577483 & 688636 & 4.6 & 4.9458 & TRN \\
\hline CHEMBL1339864 & 688636 & 6.3 & 4.711 & TST \\
\hline CHEMBL1507628 & 688636 & 4.35 & 4.7065 & TRN \\
\hline CHEMBL1581482 & 688636 & 6.8 & 4.8496 & TST \\
\hline CHEMBL1500639 & 688636 & 6.8 & 5.077 & TRN \\
\hline CHEMBL1485295 & 688636 & 4.5 & 4.61 & TRN \\
\hline CHEMBL1576513 & 688636 & 4.6 & 4.8009 & TRN \\
\hline CHEMBL1491750 & 688636 & 5.85 & 4.7002 & TST \\
\hline CHEMBL1549407 & 688636 & 4.95 & 4.8641 & TRN \\
\hline CHEMBL1432607 & 688636 & 4.3 & 4.6254 & TRN \\
\hline CHEMBL3192281 & 688636 & 6.2 & 4.9049 & TRN \\
\hline CHEMBL1443853 & 688636 & 4.7 & 4.7524 & TRN \\
\hline CHEMBL1447442 & 688636 & 4.4 & 4.7983 & TRN \\
\hline CHEMBL1578388 & 688636 & 4.3 & 4.8337 & TRN \\
\hline CHEMBL3192357 & 688636 & 5.1 & 4.6015 & TRN \\
\hline CHEMBL1606800 & 688636 & 4.5 & 4.7688 & TRN \\
\hline CHEMBL1503314 & 688636 & 4.4 & 4.9167 & TRN \\
\hline CHEMBL1465997 & 688636 & 4.25 & 4.8934 & TRN \\
\hline CHEMBL1516762 & 688636 & 4.3 & 4.8473 & TST \\
\hline CHEMBL1525213 & 688636 & 4.4 & 4.6947 & TRN \\
\hline CHEMBL1404777 & 688636 & 4.4 & 4.9516 & TRN \\
\hline CHEMBL1352491 & 688636 & 5.35 & 4.5829 & TRN \\
\hline CHEMBL1547783 & 688636 & 4.45 & 4.9171 & TRN \\
\hline CHEMBL1498351 & 688636 & 5.25 & 4.8031 & TRN \\
\hline CHEMBL3199778 & 688636 & 6.5501 & 4.8759 & TST \\
\hline CHEMBL1325022 & 688636 & 6.7501 & 4.8448 & TRN \\
\hline CHEMBL1543427 & 688636 & 4.3 & 4.8992 & TRN \\
\hline CHEMBL1305402 & 688636 & 6.05 & 4.6853 & TRN \\
\hline CHEMBL1493266 & 688636 & 4.55 & 5.0024 & TST \\
\hline CHEMBL1547422 & 688636 & 4.3 & 4.9014 & TST \\
\hline CHEMBL1349585 & 688636 & 5.95 & 4.7504 & TRN \\
\hline CHEMBL1558479 & 688636 & 5.1 & 4.8465 & TRN \\
\hline CHEMBL1393150 & 688636 & 6.05 & 4.9147 & TST \\
\hline CHEMBL1490374 & 688636 & 5.5 & 4.9572 & TST \\
\hline CHEMBL1415571 & 688636 & 4.3 & 4.794 & TRN \\
\hline CHEMBL1502892 & 688636 & 4.3 & 4.7194 & TRN \\
\hline CHEMBL1399104 & 688636 & 4.25 & 4.7137 & TRN \\
\hline CHEMBL1499553 & 688636 & 4.25 & 4.8183 & TRN \\
\hline CHEMBL1420421 & 688636 & 4.95 & 5.0455 & TST \\
\hline CHEMBL1354125 & 688636 & 5.25 & 4.6188 & TRN \\
\hline CHEMBL1448440 & 688636 & 4.3 & 4.7211 & TST \\
\hline CHEMBL1340530 & 688636 & 4.45 & 4.8514 & TST \\
\hline CHEMBL1368688 & 688636 & 6.5501 & 4.7736 & TRN \\
\hline CHEMBL1380182 & 688636 & 4.3 & 4.7064 & TST \\
\hline CHEMBL1374531 & 688636 & 4.25 & 4.9693 & TST \\
\hline
\end{tabular}




\begin{tabular}{|c|c|c|c|c|c|}
\hline \multicolumn{6}{|c|}{ Supplemental Table S2.txt } \\
\hline CHEMBL1485007 & 688636 & 4.55 & 4.9086 & TRN & \\
\hline CHEMBL1526600 & 688636 & 4.45 & 4.7778 & TRN & \\
\hline CHEMBL1449930 & 688636 & 4.5 & 4.8814 & TRN & \\
\hline CHEMBL3192632 & 688636 & 5.05 & 4.5195 & TRN & \\
\hline CHEMBL1481106 & 688636 & 4.6 & 4.9026 & TST & \\
\hline CHEMBL1427554 & 688636 & 4.9 & 4.8903 & TRN & \\
\hline CHEMBL1566982 & 688636 & 4.55 & 4.9065 & TST & \\
\hline CHEMBL1327069 & 688636 & 6.5 & 4.552 & TRN & \\
\hline CHEMBL1525894 & 688636 & 5.0 & 4.8155 & TRN & \\
\hline CHEMBL1596765 & 688636 & 4.6 & 4.8282 & TST & \\
\hline CHEMBL3196798 & 688636 & 4.25 & 4.8681 & TRN & \\
\hline CHEMBL1469460 & 688636 & 4.25 & 4.8896 & TST & \\
\hline CHEMBL1300650 & 688636 & 4.25 & 4.9568 & TRN & \\
\hline CHEMBL1586310 & 688636 & 4.25 & 4.6401 & TRN & \\
\hline CHEMBL1541733 & 688636 & 4.45 & 4.6302 & TRN & \\
\hline CHEMBL1322331 & 688636 & 4.6 & 4.7896 & TRN & \\
\hline CHEMBL1330609 & 688636 & 4.35 & 4.6919 & TRN & \\
\hline CHEMBL 3208253 & 688636 & 4.25 & 4.7012 & TRN & \\
\hline CHEMBL1386210 & 688636 & 4.45 & 4.7543 & TRN & \\
\hline CHEMBL1529597 & 688636 & 6.05 & 4.8625 & TRN & \\
\hline CHEMBL1607659 & 688636 & 5.65 & 4.7887 & TRN & \\
\hline CHEMBL1562276 & 688636 & 5.0 & 4.7111 & TRN & \\
\hline CHEMBL1577430 & 688636 & 4.4 & 4.7316 & TRN & \\
\hline CHEMBL1578187 & 688636 & 4.85 & 4.76399 & 9999999999 & TRN \\
\hline CHEMBL1447372 & 688636 & 6.0 & 4.8599 & TRN & \\
\hline CHEMBL1498811 & 688636 & 4.55 & 4.6711 & TRN & \\
\hline CHEMBL1387555 & 688636 & 5.1 & 4.8998 & TRN & \\
\hline CHEMBL1323931 & 688636 & 6.7501 & 5.0687 & TRN & \\
\hline CHEMBL1378551 & 688636 & 4.55 & 4.8583 & TST & \\
\hline CHEMBL1478720 & 688636 & 4.95 & 4.8194 & TST & \\
\hline CHEMBL1428024 & 688636 & 4.4 & 4.7069 & TRN & \\
\hline CHEMBL1540343 & 688636 & 4.3 & 4.6353 & TRN & \\
\hline CHEMBL1310777 & 688636 & 4.3 & 4.82100 & 2000000001 & TRN \\
\hline CHEMBL1341676 & 688636 & 4.35 & 4.8415 & TST & \\
\hline CHEMBL1525941 & 688636 & 5.0 & 4.7722 & TST & \\
\hline CHEMBL1390669 & 688636 & 4.45 & 4.6341 & TRN & \\
\hline CHEMBL1384630 & 688636 & 4.55 & 4.8745 & TRN & \\
\hline CHEMBL1449473 & 688636 & 4.45 & 4.7339 & TST & \\
\hline CHEMBL1573944 & 688636 & 4.3 & 4.73300 & 00000000005 & TRN \\
\hline CHEMBL1445506 & 688636 & 4.3 & 4.8036 & TRN & \\
\hline CHEMBL1415534 & 688636 & 4.3 & 4.8486 & TRN & \\
\hline CHEMBL1516957 & 688636 & 4.55 & 4.7315 & TRN & \\
\hline CHEMBL1419585 & 688636 & 4.25 & 4.9057 & TST & \\
\hline CHEMBL 224343 & 688636 & 4.4 & 4.6202 & TRN & \\
\hline CHEMBL1534269 & 688636 & 4.3 & 4.8374 & TRN & \\
\hline CHEMBL1401594 & 688636 & 4.55 & 4.9415 & TRN & \\
\hline CHEMBL1532962 & 688636 & 4.55 & 4.7942 & TRN & \\
\hline CHEMBL1423492 & 688636 & 4.3 & 4.7377 & TRN & \\
\hline
\end{tabular}




\begin{tabular}{|c|c|c|c|c|}
\hline \multicolumn{5}{|c|}{ plemental } \\
\hline CHEMBL1537596 & 688636 & 4.3 & 4.9141 & TST \\
\hline CHEMBL1331125 & 688636 & 4.3 & 4.732 & TRN \\
\hline CHEMBL1377282 & 688636 & 4.45 & 4.9356 & TRN \\
\hline CHEMBL1404154 & 688636 & 5.15 & 4.723 & TRN \\
\hline CHEMBL3211667 & 688636 & 4.45 & 4.7404 & TRN \\
\hline CHEMBL1524910 & 688636 & 4.75 & 4.937 & TRN \\
\hline CHEMBL1486599 & 688636 & 4.4 & 4.6634 & TRN \\
\hline CHEMBL1404909 & 688636 & 6.5 & 4.731 & TRN \\
\hline CHEMBL1575981 & 688636 & 5.9 & 4.7966 & TRN \\
\hline CHEMBL1517918 & 688636 & 4.25 & 4.5438 & TRN \\
\hline CHEMBL1570903 & 688636 & 4.2 & 4.6368 & TRN \\
\hline CHEMBL1332909 & 688636 & 4.45 & 4.8162 & TST \\
\hline CHEMBL1393866 & 688636 & 6.0 & 4.6793 & TRN \\
\hline CHEMBL1510853 & 688636 & 4.4 & 4.8928 & TST \\
\hline CHEMBL1562898 & 688636 & 5.6 & 4.8598 & TRN \\
\hline CHEMBL1373722 & 688636 & 4.55 & 4.8679 & TRN \\
\hline CHEMBL3194088 & 688636 & 4.45 & 4.7261 & TRN \\
\hline CHEMBL1611907 & 688636 & 4.95 & 4.9927 & TST \\
\hline CHEMBL3193924 & 688636 & 4.3 & 4.8639 & TRN \\
\hline CHEMBL 3197548 & 688636 & 4.5 & 4.8131 & TRN \\
\hline CHEMBL3194850 & 688636 & 6.05 & 4.8094 & TST \\
\hline CHEMBL1494100 & 688636 & 4.75 & 4.6278 & TRN \\
\hline CHEMBL1603871 & 688636 & 5.45 & 4.8821 & TST \\
\hline CHEMBL1608247 & 688636 & 4.25 & 5.0095 & TRN \\
\hline CHEMBL1568569 & 688636 & 5.25 & 4.8493 & TRN \\
\hline CHEMBL1387559 & 688636 & 5.25 & 4.716 & TRN \\
\hline CHEMBL1313077 & 688636 & 6.7001 & 4.9755 & TRN \\
\hline CHEMBL1977078 & 688636 & 4.85 & 4.7067 & TRN \\
\hline CHEMBL1549514 & 688636 & 4.9 & 4.8019 & TRN \\
\hline CHEMBL1518102 & 688636 & 4.95 & 4.8738 & TRN \\
\hline CHEMBL1487601 & 688636 & 6.45 & 4.7748 & TRN \\
\hline CHEMBL 3210242 & 688636 & 5.9 & 4.8019 & TRN \\
\hline CHEMBL1523656 & 688636 & 5.0 & 5.0391 & TST \\
\hline CHEMBL1479489 & 688636 & 6.7501 & 4.7716 & TST \\
\hline CHEMBL1462788 & 688636 & 4.85 & 4.7459 & TRN \\
\hline CHEMBL1539030 & 688636 & 4.95 & 4.8908 & TRN \\
\hline CHEMBL3212452 & 688636 & 4.5 & 4.7092 & TRN \\
\hline CHEMBL1341104 & 688636 & 4.9 & 4.9744 & TRN \\
\hline CHEMBL1334129 & 688636 & 4.45 & 4.75 & TRN \\
\hline CHEMBL1373945 & 688636 & 4.3 & 4.5456 & TRN \\
\hline CHEMBL1484653 & 688636 & 4.25 & 4.977 & TRN \\
\hline CHEMBL1555492 & 688636 & 4.3 & 4.7444 & TRN \\
\hline CHEMBL394108 & 688636 & 4.45 & 4.9402 & TST \\
\hline CHEMBL1578210 & 688636 & 5.5 & 4.8657 & TRN \\
\hline CHEMBL1566394 & 688636 & 4.45 & 4.8036 & TST \\
\hline CHEMBL1489145 & 688636 & 4.4 & 4.6781 & TRN \\
\hline CHEMBL1414524 & 688636 & 4.65 & 4.6784 & TRN \\
\hline CHEMBL1527379 & 688636 & 5.85 & 4.7921 & TRN \\
\hline
\end{tabular}




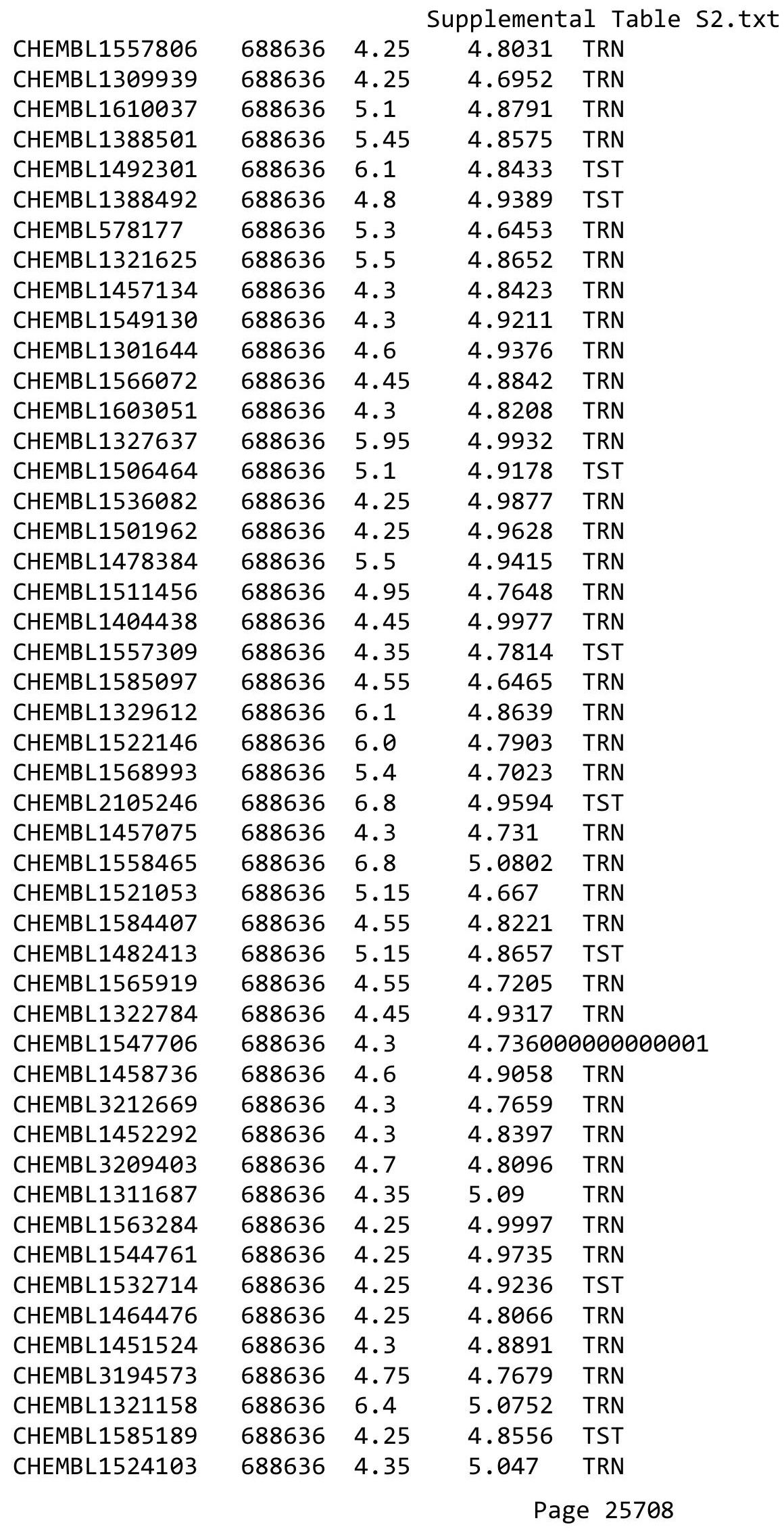




\begin{tabular}{|c|c|c|c|c|}
\hline \multicolumn{5}{|c|}{ Supplemental Table S2.txt } \\
\hline CHEMBL1411492 & 688636 & 4.45 & 4.8072 & TRN \\
\hline CHEMBL1491951 & 688636 & 4.55 & 4.4674 & TRN \\
\hline CHEMBL1537912 & 688636 & 4.6 & 4.7016 & TST \\
\hline CHEMBL1571888 & 688636 & 5.35 & 4.7708 & TST \\
\hline CHEMBL3192719 & 688636 & 4.45 & 4.8722 & TRN \\
\hline CHEMBL3213148 & 688636 & 4.95 & 4.7792 & TRN \\
\hline CHEMBL1375326 & 688636 & 4.4 & 4.8572 & TST \\
\hline CHEMBL1338317 & 688636 & 4.45 & 4.6263 & TRN \\
\hline CHEMBL1586062 & 688636 & 4.25 & 4.9267 & TST \\
\hline CHEMBL1501540 & 688636 & 5.0 & 4.7703 & TRN \\
\hline CHEMBL1569109 & 688636 & 5.5 & 4.6953 & TRN \\
\hline CHEMBL1334131 & 688636 & 5.0 & 5.0297 & TRN \\
\hline CHEMBL1370012 & 688636 & 5.55 & 4.8209 & TRN \\
\hline CHEMBL1387744 & 688636 & 4.45 & 4.7207 & TRN \\
\hline CHEMBL1303541 & 688636 & 6.7501 & 4.632 & TRN \\
\hline CHEMBL1536801 & 688636 & 4.35 & 4.9291 & TST \\
\hline CHEMBL1500410 & 688636 & 4.45 & 4.7439 & TRN \\
\hline CHEMBL1445796 & 688636 & 4.45 & 4.5959 & TRN \\
\hline CHEMBL1601720 & 688636 & 5.55 & 4.9005 & TST \\
\hline CHEMBL1576124 & 688636 & 4.35 & 4.7638 & TRN \\
\hline CHEMBL1339873 & 688636 & 4.55 & 4.655 & TRN \\
\hline CHEMBL1576690 & 688636 & 4.9 & 4.8619 & TRN \\
\hline CHEMBL3209239 & 688636 & 4.7 & 4.8345 & TRN \\
\hline CHEMBL1371657 & 688636 & 4.3 & 4.7341 & TRN \\
\hline CHEMBL1534352 & 688636 & 6.5 & 5.0398 & TRN \\
\hline CHEMBL1537567 & 688636 & 4.9 & 4.6542 & TRN \\
\hline CHEMBL1461292 & 688636 & 4.5 & 4.7443 & TRN \\
\hline CHEMBL1391933 & 688636 & 4.25 & 4.919 & TST \\
\hline CHEMBL1562379 & 688636 & 6.7501 & 4.7134 & TRN \\
\hline CHEMBL1360393 & 688636 & 5.15 & 4.6518 & TST \\
\hline CHEMBL1423146 & 688636 & 4.25 & 4.7764 & TST \\
\hline CHEMBL1477152 & 688636 & 4.9 & 4.9447 & TST \\
\hline CHEMBL1407135 & 688636 & 4.95 & 4.8318 & TRN \\
\hline CHEMBL1589415 & 688636 & 4.4 & 4.8027 & TST \\
\hline CHEMBL1402154 & 688636 & 4.4 & 4.9549 & TRN \\
\hline CHEMBL3197900 & 688636 & 4.3 & 4.7132 & TRN \\
\hline CHEMBL1364547 & 688636 & 5.15 & 4.6142 & TRN \\
\hline CHEMBL1341696 & 688636 & 5.5 & 4.8836 & TRN \\
\hline CHEMBL1510809 & 688636 & 4.35 & 4.8058 & TRN \\
\hline CHEMBL1487402 & 688636 & 4.4 & 4.6709 & TRN \\
\hline CHEMBL1452794 & 688636 & 4.3 & 4.8689 & TST \\
\hline CHEMBL1491013 & 688636 & 4.4 & 4.8296 & TST \\
\hline CHEMBL1352676 & 688636 & 6.45 & 4.7922 & TRN \\
\hline CHEMBL1334789 & 688636 & 4.7 & 4.8496 & TST \\
\hline CHEMBL1518952 & 688636 & 4.8 & 4.8368 & TST \\
\hline CHEMBL1373130 & 688636 & 4.3 & 4.7541 & TRN \\
\hline CHEMBL1583282 & 688636 & 4.75 & 4.8866 & TRN \\
\hline CHEMBL1496581 & 688636 & 4.4 & 4.7822 & TRN \\
\hline
\end{tabular}




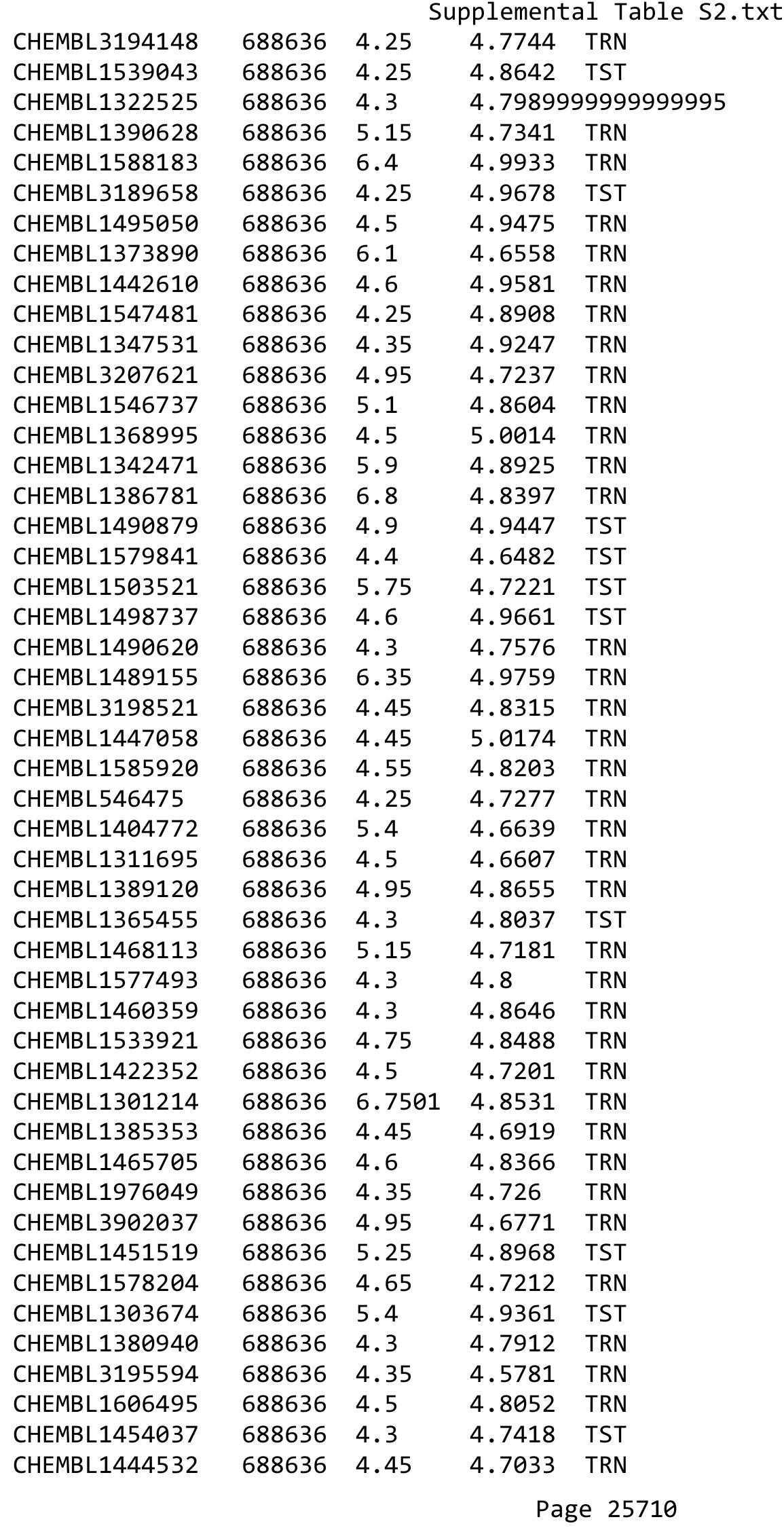




\begin{tabular}{|c|c|c|c|c|}
\hline & & & pplement & al $\mathrm{T}$ \\
\hline CHEMBL1373338 & 688636 & 6.3 & 4.8688 & TRN \\
\hline CHEMBL1534405 & 688636 & 4.6 & 4.8802 & TRN \\
\hline CHEMBL1985381 & 688636 & 4.3 & 4.7958 & TRN \\
\hline CHEMBL1573697 & 688636 & 4.45 & 4.6039 & TST \\
\hline CHEMBL1381571 & 688636 & 4.3 & 4.7968 & TRN \\
\hline CHEMBL1314100 & 688636 & 4.4 & 4.6383 & TRN \\
\hline CHEMBL1576371 & 688636 & 4.25 & 4.8774 & TST \\
\hline CHEMBL1519432 & 688636 & 4.5 & 4.7461 & TRN \\
\hline CHEMBL1377714 & 688636 & 4.5 & 4.7295 & TRN \\
\hline CHEMBL3214250 & 688636 & 4.3 & 4.8153 & TRN \\
\hline CHEMBL1444232 & 688636 & 5.45 & 4.7497 & TRN \\
\hline CHEMBL1559143 & 688636 & 5.05 & 4.7808 & TRN \\
\hline CHEMBL1422030 & 688636 & 4.55 & 4.6548 & TRN \\
\hline CHEMBL1393963 & 688636 & 5.05 & 4.9609 & TRN \\
\hline CHEMBL1414472 & 688636 & 4.95 & 4.6881 & TRN \\
\hline CHEMBL3195113 & 688636 & 4.45 & 4.7863 & TRN \\
\hline CHEMBL1342975 & 688636 & 4.4 & 4.8146 & TRN \\
\hline CHEMBL1506341 & 688636 & 4.95 & 4.8181 & TST \\
\hline CHEMBL1362163 & 688636 & 6.8 & 4.9882 & TRN \\
\hline CHEMBL1543084 & 688636 & 5.0 & 4.8312 & TRN \\
\hline CHEMBL1471353 & 688636 & 4.3 & 4.8176 & TRN \\
\hline CHEMBL1589046 & 688636 & 4.3 & 4.8418 & TRN \\
\hline CHEMBL1501007 & 688636 & 6.5501 & 4.9994 & TST \\
\hline CHEMBL1505627 & 688636 & 6.0 & 4.6755 & TRN \\
\hline CHEMBL1338784 & 688636 & 4.9 & 4.7029 & TST \\
\hline CHEMBL3208989 & 688636 & 4.35 & 4.8359 & TRN \\
\hline CHEMBL1305491 & 688636 & 5.25 & 4.8512 & TRN \\
\hline CHEMBL1363427 & 688636 & 4.3 & 4.9178 & TST \\
\hline CHEMBL1336950 & 688636 & 4.55 & 4.7684 & TST \\
\hline CHEMBL1494470 & 688636 & 5.8 & 4.8509 & TST \\
\hline CHEMBL1332775 & 688636 & 4.9 & 4.8752 & TRN \\
\hline CHEMBL1361779 & 688636 & 4.5 & 4.9484 & TRN \\
\hline CHEMBL1479290 & 688636 & 4.9 & 5.003 & TRN \\
\hline CHEMBL1330569 & 688636 & 5.3 & 4.8738 & TST \\
\hline CHEMBL1430726 & 688636 & 4.95 & 4.7928 & TRN \\
\hline CHEMBL1421005 & 688636 & 4.45 & 4.8747 & TRN \\
\hline CHEMBL1393862 & 688636 & 5.15 & 4.6055 & TST \\
\hline CHEMBL1490352 & 688636 & 4.6 & 4.7771 & TRN \\
\hline CHEMBL1485378 & 688636 & 4.5 & 4.7193 & TRN \\
\hline CHEMBL1429377 & 688636 & 4.45 & 4.8128 & TRN \\
\hline CHEMBL1511290 & 688636 & 4.95 & 4.7277 & TRN \\
\hline CHEMBL1519771 & 688636 & 4.3 & 4.8048 & TRN \\
\hline CHEMBL1363764 & 688636 & 4.55 & 4.6689 & TRN \\
\hline CHEMBL1378513 & 688636 & 4.9 & 4.8687 & TRN \\
\hline CHEMBL1578905 & 688636 & 5.3 & 4.8068 & TST \\
\hline CHEMBL1604300 & 688636 & 4.55 & 4.7386 & TRN \\
\hline CHEMBL1377480 & 688636 & 4.5 & 4.8054 & TST \\
\hline CHEMBL1308256 & 688636 & 4.25 & 5.0033 & TRN \\
\hline
\end{tabular}




\begin{tabular}{|c|c|c|c|c|}
\hline \multicolumn{5}{|c|}{ Supplemental Table } \\
\hline CHEMBL1531007 & 688636 & 4.3 & 4.8889 & TRN \\
\hline CHEMBL1573747 & 688636 & 4.3 & 4.7538 & TRN \\
\hline CHEMBL1369045 & 688636 & 4.5 & 4.7965 & TRN \\
\hline CHEMBL1348841 & 688636 & 5.1 & 4.7423 & TRN \\
\hline CHEMBL1446024 & 688636 & 6.7501 & 4.9076 & TRN \\
\hline CHEMBL1420772 & 688636 & 4.4 & 4.5463 & TRN \\
\hline CHEMBL1345642 & 688636 & 4.25 & 5.0415 & TRN \\
\hline CHEMBL1446836 & 688636 & 5.9 & 4.6204 & TRN \\
\hline CHEMBL1467024 & 688636 & 4.3 & 4.856 & TRN \\
\hline CHEMBL1329350 & 688636 & 6.7501 & 4.6656 & TRN \\
\hline CHEMBL1399924 & 688636 & 4.5 & 4.6422 & TRN \\
\hline CHEMBL1412798 & 688636 & 5.4 & 4.8675 & TRN \\
\hline CHEMBL1327670 & 688636 & 5.9 & 4.7903 & TRN \\
\hline CHEMBL1492623 & 688636 & 6.2 & 4.7659 & TST \\
\hline CHEMBL1497759 & 688636 & 4.9 & 4.8693 & TST \\
\hline CHEMBL1372603 & 688636 & 5.8 & 4.6826 & TRN \\
\hline CHEMBL1426603 & 688636 & 4.3 & 4.7016 & TST \\
\hline CHEMBL1362307 & 688636 & 4.45 & 4.6336 & TRN \\
\hline CHEMBL1405700 & 688636 & 4.55 & 4.7634 & TRN \\
\hline CHEMBL1408019 & 688636 & 5.45 & 4.8762 & TST \\
\hline CHEMBL1324646 & 688636 & 4.5 & 4.9067 & TST \\
\hline CHEMBL1374444 & 688636 & 4.3 & 4.8837 & TRN \\
\hline CHEMBL1964556 & 688636 & 4.7 & 4.8 & TRN \\
\hline CHEMBL1311962 & 688636 & 4.45 & 4.8759 & TRN \\
\hline CHEMBL1548890 & 688636 & 4.25 & 4.6406 & TRN \\
\hline CHEMBL1491624 & 688636 & 5.6 & 5.0087 & TRN \\
\hline CHEMBL1608403 & 688636 & 4.55 & 4.9298 & TRN \\
\hline CHEMBL1489523 & 688636 & 4.5 & 4.6413 & TRN \\
\hline CHEMBL1399189 & 688636 & 4.3 & 4.8154 & TRN \\
\hline CHEMBL1535009 & 688636 & 4.4 & 4.9602 & TST \\
\hline CHEMBL1501054 & 688636 & 4.5 & 4.9209 & TST \\
\hline CHEMBL1369094 & 688636 & 5.4 & 4.765 & TST \\
\hline CHEMBL1523849 & 688636 & 5.85 & 4.7223 & TRN \\
\hline CHEMBL1415440 & 688636 & 4.4 & 4.8211 & TRN \\
\hline CHEMBL1423582 & 688636 & 6.05 & 4.9937 & TRN \\
\hline CHEMBL1521512 & 688636 & 4.3 & 4.7899 & TRN \\
\hline CHEMBL1498657 & 688636 & 5.75 & 4.806 & TST \\
\hline CHEMBL1544716 & 688636 & 4.25 & 4.7818 & TRN \\
\hline CHEMBL1570753 & 688636 & 4.45 & 4.5171 & TRN \\
\hline CHEMBL1548148 & 688636 & 6.5 & 4.8516 & TST \\
\hline CHEMBL1518776 & 688636 & 5.0 & 4.9795 & TRN \\
\hline CHEMBL1495663 & 688636 & 5.1 & 4.6216 & TRN \\
\hline CHEMBL1329300 & 688636 & 4.25 & 4.5944 & TRN \\
\hline CHEMBL1320946 & 688636 & 4.45 & 4.7324 & TST \\
\hline CHEMBL1573600 & 688636 & 4.4 & 4.8341 & TRN \\
\hline CHEMBL1405834 & 688636 & 6.7501 & 4.82100 & 0000000001 \\
\hline CHEMBL1376986 & 688636 & 5.2 & 4.9465 & TRN \\
\hline CHEMBL1522679 & 688636 & 5.0 & 4.6969 & TRN \\
\hline
\end{tabular}




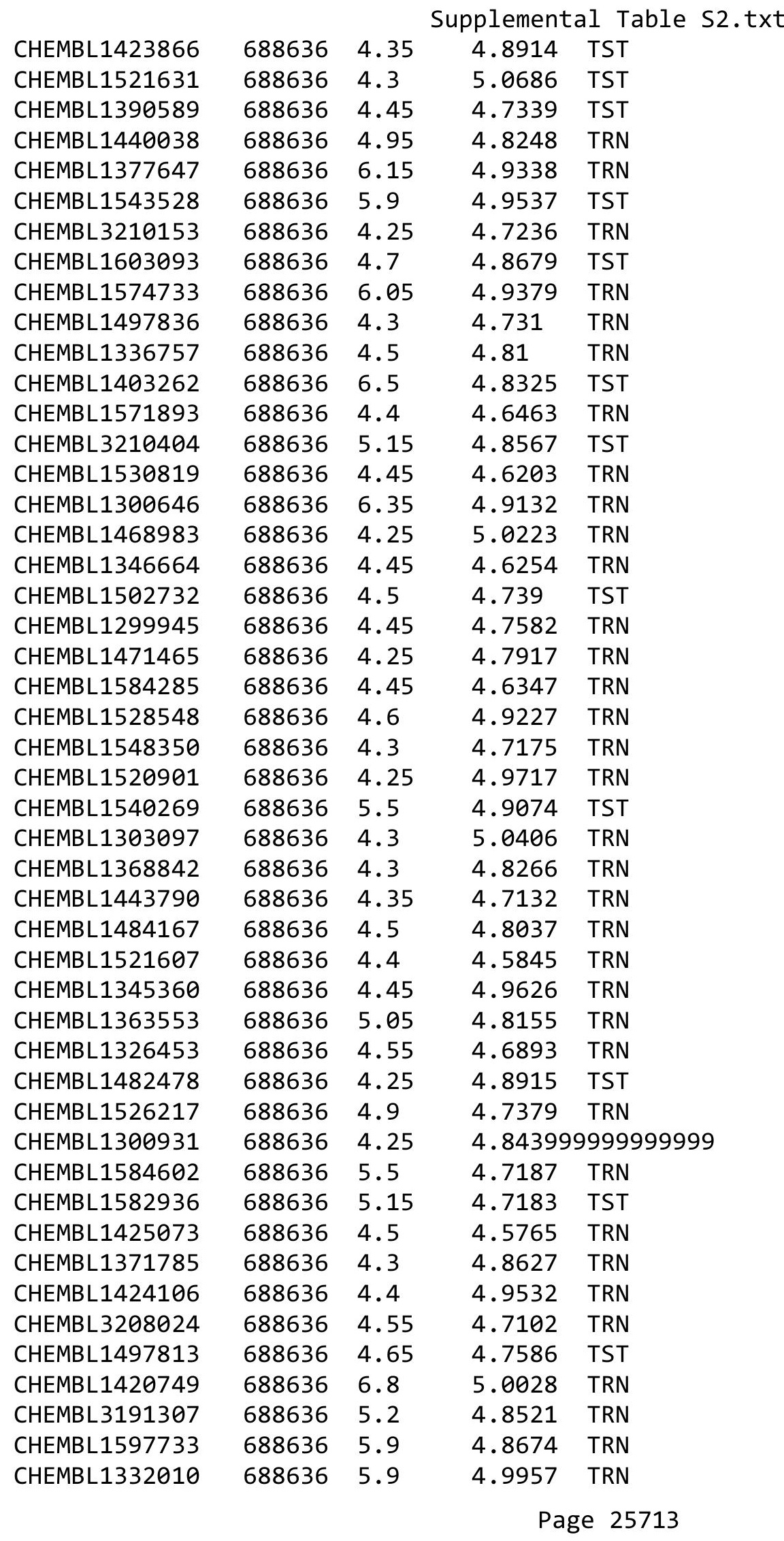




\begin{tabular}{|c|c|c|c|c|c|}
\hline & & \multicolumn{4}{|c|}{ Supplemental Table S2.txt } \\
\hline CHEMBL1610771 & 688636 & 5.4 & 4.9272 & TRN & \\
\hline CHEMBL1380859 & 688636 & 4.55 & 4.9275 & TRN & \\
\hline CHEMBL3211017 & 688636 & 4.95 & 4.7323 & TRN & \\
\hline CHEMBL1584704 & 688636 & 6.05 & 4.864 & TRN & \\
\hline CHEMBL1501839 & 688636 & 4.45 & 4.6705 & TRN & \\
\hline CHEMBL1432961 & 688636 & 4.3 & 4.9107 & TRN & \\
\hline CHEMBL1333224 & 688636 & 4.25 & 4.8267 & TRN & \\
\hline CHEMBL1345483 & 688636 & 4.45 & 4.7616 & TRN & \\
\hline CHEMBL1336444 & 688636 & 4.45 & 4.6411 & TRN & \\
\hline CHEMBL1335362 & 688636 & 4.7 & \multicolumn{2}{|c|}{4.7780000000000005} & TRN \\
\hline CHEMBL1441135 & 688636 & 4.5 & 4.6493 & TRN & \\
\hline CHEMBL1599029 & 688636 & 5.3 & 4.7601 & TRN & \\
\hline CHEMBL1309724 & 688636 & 4.3 & 5.0067 & TST & \\
\hline CHEMBL1505168 & 688636 & 4.8 & 4.9478 & TRN & \\
\hline CHEMBL1312016 & 688636 & 4.3 & 4.8862 & TRN & \\
\hline CHEMBL3193207 & 688636 & 5.2 & 4.7653 & TRN & \\
\hline CHEMBL1368940 & 688636 & 4.4 & 4.7161 & TRN & \\
\hline CHEMBL1339881 & 688636 & 4.9 & 4.7678 & TRN & \\
\hline CHEMBL1549099 & 688636 & 4.95 & 4.6724 & TRN & \\
\hline CHEMBL1548983 & 688636 & 4.55 & \multicolumn{2}{|c|}{4.7010000000000005} & TRN \\
\hline CHEMBL1371238 & 688636 & 4.4 & 4.7926 & TST & \\
\hline CHEMBL1479406 & 688636 & 4.45 & 4.793 & TRN & \\
\hline CHEMBL1511690 & 688636 & 4.45 & 4.8548 & TST & \\
\hline CHEMBL3192770 & 688636 & 4.3 & 4.9095 & TRN & \\
\hline CHEMBL1311478 & 688636 & 4.45 & 4.7417 & TRN & \\
\hline CHEMBL1589443 & 688636 & 5.25 & 5.0262 & TRN & \\
\hline CHEMBL1601862 & 688636 & 5.6 & 4.8636 & TRN & \\
\hline CHEMBL1454958 & 688636 & 4.65 & 4.6537 & TRN & \\
\hline CHEMBL1583505 & 688636 & 4.6 & 4.7384 & TRN & \\
\hline CHEMBL1526092 & 688636 & 4.25 & 5.0059 & TST & \\
\hline CHEMBL1578587 & 688636 & 5.45 & 4.8518 & TRN & \\
\hline CHEMBL1468698 & 688636 & 4.6 & 4.6262 & TST & \\
\hline CHEMBL1481662 & 688636 & 4.5 & 4.7653 & TRN & \\
\hline CHEMBL1586326 & 688636 & 6.0 & 4.6378 & TST & \\
\hline CHEMBL3198896 & 688636 & 4.5 & 4.805 & TRN & \\
\hline CHEMBL1365587 & 688636 & 4.25 & 4.8111 & TST & \\
\hline CHEMBL1578946 & 688636 & 4.45 & 4.9176 & TRN & \\
\hline CHEMBL1582162 & 688636 & 4.65 & 4.7185 & TRN & \\
\hline CHEMBL1420778 & 688636 & 4.5 & 4.6412 & TRN & \\
\hline CHEMBL1338469 & 688636 & 4.95 & 4.8338 & TRN & \\
\hline CHEMBL1581590 & 688636 & 4.3 & 4.7345 & TRN & \\
\hline CHEMBL1557120 & 688636 & 4.95 & 4.8709 & TRN & \\
\hline CHEMBL1609705 & 688636 & 5.1 & 4.8441 & TRN & \\
\hline CHEMBL1546693 & 688636 & 4.95 & 4.7768 & TRN & \\
\hline CHEMBL1507996 & 688636 & 6.4 & 4.8668 & TRN & \\
\hline CHEMBL1336926 & 688636 & 4.35 & 4.704 & TRN & \\
\hline CHEMBL1450412 & 688636 & 4.35 & 4.8256 & TRN & \\
\hline CHEMBL1582982 & 688636 & 4.7 & 4.7728 & TST & \\
\hline
\end{tabular}




\begin{tabular}{|c|c|c|c|c|}
\hline \multicolumn{5}{|c|}{ Supplemental Table S2.txt } \\
\hline CHEMBL1304580 & 688636 & 5.3 & 4.8075 & TST \\
\hline CHEMBL1386522 & 688636 & 5.3 & 4.8238 & TST \\
\hline CHEMBL1414155 & 688636 & 4.55 & 4.8681 & TST \\
\hline CHEMBL1575024 & 688636 & 4.9 & 4.9917 & TRN \\
\hline CHEMBL1596460 & 688636 & 5.1 & 4.7089 & TRN \\
\hline CHEMBL1408812 & 688636 & 4.3 & 4.783 & TST \\
\hline CHEMBL1509597 & 688636 & 5.65 & 4.8389 & TRN \\
\hline CHEMBL1359483 & 688636 & 4.45 & 4.7538 & TRN \\
\hline CHEMBL1562246 & 688636 & 5.2 & 4.7006 & TRN \\
\hline CHEMBL570844 & 688636 & 4.45 & 4.6973 & TRN \\
\hline CHEMBL1464884 & 688636 & 5.05 & 4.5938 & TST \\
\hline CHEMBL1507680 & 688636 & 5.2 & 4.8815 & TRN \\
\hline CHEMBL1299499 & 688636 & 4.45 & 4.8337 & TRN \\
\hline CHEMBL1521409 & 688636 & 4.25 & 4.8478 & TRN \\
\hline CHEMBL1402616 & 688636 & 6.7501 & 4.7722 & TRN \\
\hline CHEMBL1585666 & 688636 & 4.55 & 4.6957 & TRN \\
\hline CHEMBL1549907 & 688636 & 5.9 & 4.8571 & TRN \\
\hline CHEMBL1457955 & 688636 & 4.3 & 4.9298 & TRN \\
\hline CHEMBL1376489 & 688636 & 4.3 & 4.694 & TRN \\
\hline CHEMBL1399726 & 688636 & 5.4 & 4.6736 & TST \\
\hline CHEMBL1572143 & 688636 & 6.35 & 4.8389 & TRN \\
\hline CHEMBL1404864 & 688636 & 5.2 & 4.8238 & TST \\
\hline CHEMBL1387683 & 688636 & 4.35 & 4.7985 & TST \\
\hline CHEMBL1433010 & 688636 & 4.3 & 4.9134 & TRN \\
\hline CHEMBL1311787 & 688636 & 4.95 & 4.7423 & TRN \\
\hline CHEMBL1335410 & 688636 & 4.45 & 4.851 & TST \\
\hline CHEMBL1528677 & 688636 & 4.25 & 4.9888 & TRN \\
\hline CHEMBL1410205 & 688636 & 5.3 & 4.7913 & TRN \\
\hline CHEMBL1470076 & 688636 & 4.3 & 4.8577 & TRN \\
\hline CHEMBL1421739 & 688636 & 5.45 & 4.7479 & TST \\
\hline CHEMBL1376774 & 688636 & 4.45 & 4.7166 & TRN \\
\hline CHEMBL1304620 & 688636 & 4.3 & 4.848 & TRN \\
\hline CHEMBL1333600 & 688636 & 4.5 & 4.8553 & TST \\
\hline CHEMBL1459555 & 688636 & 6.5501 & 4.7927 & TRN \\
\hline CHEMBL1511352 & 688636 & 4.55 & 4.7671 & TRN \\
\hline CHEMBL3145372 & 688636 & 4.3 & 4.6827 & TRN \\
\hline CHEMBL1422469 & 688636 & 4.55 & 4.6823 & TRN \\
\hline CHEMBL1326489 & 688636 & 4.4 & 4.7892 & TRN \\
\hline CHEMBL1477718 & 688636 & 5.65 & 4.8825 & TRN \\
\hline CHEMBL1605219 & 688636 & 4.25 & 4.6971 & TRN \\
\hline CHEMBL1544989 & 688636 & 5.75 & 4.7828 & TRN \\
\hline CHEMBL1412617 & 688636 & 4.25 & 4.8268 & TRN \\
\hline CHEMBL1605636 & 688636 & 4.3 & 4.6757 & TRN \\
\hline CHEMBL1509756 & 688636 & 4.25 & 4.9188 & TRN \\
\hline CHEMBL3211011 & 688636 & 4.35 & 4.9164 & TRN \\
\hline CHEMBL1560731 & 688636 & 4.45 & 4.7613 & TRN \\
\hline CHEMBL1574727 & 688636 & 4.5 & 4.7832 & TST \\
\hline CHEMBL1566919 & 688636 & 4.95 & 4.8331 & TST \\
\hline
\end{tabular}




\begin{tabular}{|c|c|c|c|c|c|}
\hline \multicolumn{6}{|c|}{ Supplemental Table S2.txt } \\
\hline CHEMBL1363937 & 688636 & 4.25 & 5.0076 & TRN & \\
\hline CHEMBL1464502 & 688636 & 4.35 & 4.7373 & TRN & \\
\hline CHEMBL1537038 & 688636 & 4.35 & 4.9921 & TRN & \\
\hline CHEMBL1463198 & 688636 & 5.8 & 4.8543 & TRN & \\
\hline CHEMBL1334710 & 688636 & 5.0 & 4.7944 & TRN & \\
\hline CHEMBL1400974 & 688636 & 5.2 & 4.8689 & TST & \\
\hline CHEMBL1478659 & 688636 & 4.55 & 4.7655 & TRN & \\
\hline CHEMBL1416214 & 688636 & 4.55 & 4.6661 & TRN & \\
\hline CHEMBL1572945 & 688636 & 6.8 & 4.974 & TRN & \\
\hline CHEMBL1350911 & 688636 & 4.95 & 4.7518 & TST & \\
\hline CHEMBL1402956 & 688636 & 4.55 & 4.8496 & TRN & \\
\hline CHEMBL1378282 & 688636 & 5.3 & 4.7242 & TRN & \\
\hline CHEMBL1339237 & 688636 & 4.3 & 4.8152 & TRN & \\
\hline CHEMBL1361677 & 688636 & 6.15 & 4.8374 & TST & \\
\hline CHEMBL1374282 & 688636 & 4.35 & 4.7894 & TRN & \\
\hline CHEMBL1598510 & 688636 & 4.25 & 4.9058 & TRN & \\
\hline CHEMBL3211365 & 688636 & 4.45 & 4.5949 & TRN & \\
\hline CHEMBL1529091 & 688636 & 4.9 & 4.9352 & TRN & \\
\hline CHEMBL1418009 & 688636 & 6.05 & 4.63399 & 99999999995 & TRN \\
\hline CHEMBL1501426 & 688636 & 4.3 & 4.9677 & TRN & \\
\hline CHEMBL1585126 & 688636 & 4.45 & 4.7195 & TRN & \\
\hline CHEMBL1547757 & 688636 & 6.7501 & 4.8583 & TRN & \\
\hline CHEMBL1351687 & 688636 & 4.45 & 4.537 & TRN & \\
\hline CHEMBL1533434 & 688636 & 4.4 & 4.6968 & TRN & \\
\hline CHEMBL1566820 & 688636 & 4.25 & 4.9898 & TRN & \\
\hline CHEMBL2002776 & 688636 & 4.55 & 4.6802 & TRN & \\
\hline CHEMBL1518801 & 688636 & 4.55 & 4.7331 & TRN & \\
\hline CHEMBL1596110 & 688636 & 6.7501 & 4.9201 & TRN & \\
\hline CHEMBL1544277 & 688636 & 4.95 & 4.65 & TRN & \\
\hline CHEMBL1488625 & 688636 & 4.3 & 4.6101 & TRN & \\
\hline CHEMBL1425191 & 688636 & 4.95 & 4.9933 & TRN & \\
\hline CHEMBL1568695 & 688636 & 4.45 & 4.9322 & TRN & \\
\hline CHEMBL1446210 & 688636 & 5.3 & 4.7044 & TRN & \\
\hline CHEMBL3211638 & 688636 & 4.3 & 4.7614 & TRN & \\
\hline CHEMBL1510587 & 688636 & 4.9 & 4.8488 & TRN & \\
\hline CHEMBL3207387 & 688636 & 4.95 & 4.7378 & TRN & \\
\hline CHEMBL1581843 & 688636 & 4.3 & 4.9163 & TRN & \\
\hline CHEMBL1326295 & 688636 & 4.4 & 4.6976 & TRN & \\
\hline CHEMBL1490218 & 688636 & 5.95 & 4.853 & TRN & \\
\hline CHEMBL1340264 & 688636 & 5.0 & 4.8714 & TST & \\
\hline CHEMBL1320124 & 688636 & 5.95 & 4.7624 & TRN & \\
\hline CHEMBL3211198 & 688636 & 4.65 & 4.7761 & TRN & \\
\hline CHEMBL1408140 & 688636 & 4.25 & 4.7534 & TRN & \\
\hline CHEMBL1429110 & 688636 & 5.3 & 4.8147 & TRN & \\
\hline CHEMBL1335284 & 688636 & 4.95 & 4.949 & TRN & \\
\hline CHEMBL1608590 & 688636 & 5.2 & 4.9482 & TRN & \\
\hline CHEMBL1375224 & 688636 & 5.95 & 4.7634 & TRN & \\
\hline CHEMBL1492821 & 688636 & 4.5 & 4.7532 & TRN & \\
\hline
\end{tabular}




\begin{tabular}{|c|c|c|c|c|}
\hline \multicolumn{5}{|c|}{ Supplemental Table S2.txt } \\
\hline CHEMBL1403486 & 688636 & 4.35 & 4.8203 & TRN \\
\hline CHEMBL1349187 & 688636 & 4.45 & 4.9198 & TRN \\
\hline CHEMBL1440538 & 688636 & 5.05 & 4.8945 & TRN \\
\hline CHEMBL1538554 & 688636 & 4.25 & 4.7355 & TST \\
\hline CHEMBL1311900 & 688636 & 6.0 & 4.8685 & TST \\
\hline CHEMBL1340672 & 688636 & 4.45 & 5.0731 & TRN \\
\hline CHEMBL1300297 & 688636 & 4.5 & 4.6135 & TRN \\
\hline CHEMBL1349102 & 688636 & 5.95 & 4.7602 & TST \\
\hline CHEMBL1545592 & 688636 & 4.5 & 4.8243 & TRN \\
\hline CHEMBL1509744 & 688636 & 5.15 & 4.8306 & TRN \\
\hline CHEMBL1572913 & 688636 & 5.95 & 4.8373 & TST \\
\hline CHEMBL3214076 & 688636 & 4.45 & 4.7259 & TRN \\
\hline CHEMBL1501643 & 688636 & 4.9 & 4.9645 & TRN \\
\hline CHEMBL1532309 & 688636 & 4.25 & 4.7598 & TRN \\
\hline CHEMBL1370535 & 688636 & 6.8 & 4.9286 & TRN \\
\hline CHEMBL1520048 & 688636 & 6.15 & 4.8528 & TRN \\
\hline CHEMBL1511039 & 688636 & 4.4 & 4.8006 & TRN \\
\hline CHEMBL1601921 & 688636 & 4.55 & 4.7983 & TRN \\
\hline CHEMBL1576041 & 688636 & 4.4 & 4.8117 & TRN \\
\hline CHEMBL1323711 & 688636 & 6.7501 & 4.8515 & TRN \\
\hline CHEMBL1330907 & 688636 & 4.25 & 4.6349 & TRN \\
\hline CHEMBL1976549 & 688636 & 4.45 & 4.8787 & TST \\
\hline CHEMBL1466462 & 688636 & 4.45 & 4.646 & TRN \\
\hline CHEMBL1480549 & 688636 & 6.4 & 4.6082 & TST \\
\hline CHEMBL1544269 & 688636 & 5.4 & 4.6391 & TST \\
\hline CHEMBL1456098 & 688636 & 6.7501 & 4.8462 & TRN \\
\hline CHEMBL1361273 & 688636 & 4.9 & 4.9205 & TRN \\
\hline CHEMBL1579456 & 688636 & 4.25 & 4.7344 & TRN \\
\hline CHEMBL1559076 & 688636 & 5.4 & 4.9371 & TRN \\
\hline CHEMBL1574262 & 688636 & 4.55 & 4.6256 & TRN \\
\hline CHEMBL1585777 & 688636 & 4.65 & 4.703 & TST \\
\hline CHEMBL1460807 & 688636 & 4.5 & 4.8206 & TST \\
\hline CHEMBL1451118 & 688636 & 6.7501 & 4.7466 & TST \\
\hline CHEMBL1535094 & 688636 & 5.65 & 4.8392 & TST \\
\hline CHEMBL1413009 & 688636 & 4.95 & 4.838 & TRN \\
\hline CHEMBL1322755 & 688636 & 6.7501 & 4.7991 & TST \\
\hline CHEMBL1431857 & 688636 & 4.55 & 4.8192 & TRN \\
\hline CHEMBL1375375 & 688636 & 4.8 & 4.7407 & TRN \\
\hline CHEMBL1549862 & 688636 & 4.25 & 4.9042 & TRN \\
\hline CHEMBL1333526 & 688636 & 4.7 & 4.6328 & TRN \\
\hline CHEMBL1344974 & 688636 & 6.8 & 4.7908 & TRN \\
\hline CHEMBL1383481 & 688636 & 5.75 & 4.9363 & TRN \\
\hline CHEMBL1545967 & 688636 & 4.5 & 4.8902 & TRN \\
\hline CHEMBL1533179 & 688636 & 4.45 & 5.0345 & TRN \\
\hline CHEMBL1541977 & 688636 & 4.9 & 4.6973 & TST \\
\hline CHEMBL1602486 & 688636 & 6.7501 & 4.8736 & TRN \\
\hline CHEMBL1585432 & 688636 & 5.2 & 4.8229 & TST \\
\hline CHEMBL1612374 & 688636 & 4.45 & 4.9019 & TST \\
\hline
\end{tabular}




\begin{tabular}{|c|c|c|c|c|}
\hline & & & upplement & al $\mathrm{T}$ \\
\hline CHEMBL1332684 & 688636 & 4.85 & 4.8297 & TST \\
\hline CHEMBL1376625 & 688636 & 4.45 & 4.9584 & TST \\
\hline CHEMBL1306311 & 688636 & 4.5 & 4.8207 & TRN \\
\hline CHEMBL1567341 & 688636 & 4.25 & 4.6587 & TRN \\
\hline CHEMBL 1455256 & 688636 & 4.4 & 4.7289 & TRN \\
\hline CHEMBL1510154 & 688636 & 4.35 & 4.7877 & TRN \\
\hline CHEMBL1302354 & 688636 & 4.45 & 4.8415 & TRN \\
\hline CHEMBL1497467 & 688636 & 4.45 & 4.9461 & TRN \\
\hline CHEMBL583378 & 688636 & 4.25 & 4.7742 & TRN \\
\hline CHEMBL1534430 & 688636 & 4.4 & 4.8917 & TRN \\
\hline CHEMBL1405304 & 688636 & 4.25 & 4.9348 & TRN \\
\hline CHEMBL1453712 & 688636 & 4.6 & 4.8247 & TRN \\
\hline CHEMBL1487747 & 688636 & 5.0 & 4.7722 & TRN \\
\hline CHEMBL1547282 & 688636 & 5.0 & 4.7671 & TRN \\
\hline CHEMBL1600445 & 688636 & 4.25 & 4.4768 & TST \\
\hline CHEMBL3195553 & 688636 & 4.95 & 4.6497 & TRN \\
\hline CHEMBL1331749 & 688636 & 5.0 & 4.6366 & TRN \\
\hline CHEMBL1548717 & 688636 & 4.25 & 4.8303 & TRN \\
\hline CHEMBL1438264 & 688636 & 4.9 & 4.6488 & TRN \\
\hline CHEMBL1374469 & 688636 & 4.7 & 5.05 & TST \\
\hline CHEMBL 2006431 & 688636 & 5.15 & 4.6483 & TRN \\
\hline CHEMBL1406680 & 688636 & 4.5 & 4.8821 & TRN \\
\hline CHEMBL1351573 & 688636 & 4.8 & 4.828 & TST \\
\hline CHEMBL1401134 & 688636 & 4.85 & 4.5729 & TRN \\
\hline CHEMBL1550575 & 688636 & 4.3 & 4.9055 & TRN \\
\hline CHEMBL1577997 & 688636 & 5.7 & 4.9068 & TRN \\
\hline CHEMBL1339641 & 688636 & 4.45 & 4.591 & TRN \\
\hline CHEMBL1431112 & 688636 & 4.6 & 4.7472 & TST \\
\hline CHEMBL1604772 & 688636 & 4.45 & 4.8152 & TRN \\
\hline CHEMBL1521233 & 688636 & 4.3 & 4.758 & TRN \\
\hline CHEMBL1519711 & 688636 & 4.35 & 4.8036 & TST \\
\hline CHEMBL1448214 & 688636 & 5.4 & 4.9485 & TST \\
\hline CHEMBL1454778 & 688636 & 5.1 & 4.8968 & TRN \\
\hline CHEMBL1608286 & 688636 & 4.65 & 4.7195 & TRN \\
\hline CHEMBL3194805 & 688636 & 5.95 & 4.5036 & TST \\
\hline CHEMBL1976676 & 688636 & 5.45 & 4.7 & TST \\
\hline CHEMBL1508695 & 688636 & 5.5 & 4.8979 & TRN \\
\hline CHEMBL1423325 & 688636 & 4.65 & 4.6904 & TRN \\
\hline CHEMBL1519133 & 688636 & 4.35 & 4.9607 & TRN \\
\hline CHEMBL1486701 & 688636 & 5.4 & 4.7544 & TRN \\
\hline CHEMBL1325008 & 688636 & 6.45 & 4.9392 & TRN \\
\hline CHEMBL1337039 & 688636 & 4.25 & 4.6446 & TST \\
\hline CHEMBL1463800 & 688636 & 4.3 & 4.7404 & TRN \\
\hline CHEMBL1431560 & 688636 & 4.35 & 4.8497 & TST \\
\hline CHEMBL3144985 & 688636 & 4.25 & 4.6998 & TRN \\
\hline CHEMBL1457845 & 688636 & 4.85 & 4.6182 & TRN \\
\hline CHEMBL 1608110 & 688636 & 5.3 & 4.8486 & TRN \\
\hline CHEMBL1525055 & 688636 & 6.6 & 4.7054 & TRN \\
\hline
\end{tabular}




\begin{tabular}{|c|c|c|c|c|c|}
\hline \multicolumn{6}{|c|}{ Supplemental Table S2.txt } \\
\hline CHEMBL1386159 & 688636 & 6.0 & 4.8594 & TRN & \\
\hline CHEMBL1390276 & 688636 & 4.4 & 4.8381 & TST & \\
\hline CHEMBL1492021 & 688636 & 4.85 & 4.8237 & TRN & \\
\hline CHEMBL1379812 & 688636 & 4.6 & 4.8073 & TST & \\
\hline CHEMBL1330685 & 688636 & 6.7501 & 4.8915 & TST & \\
\hline CHEMBL1378822 & 688636 & 4.6 & 4.6997 & TRN & \\
\hline CHEMBL1525710 & 688636 & 4.4 & 4.7687 & TRN & \\
\hline CHEMBL1583743 & 688636 & 5.0 & 4.904 & TRN & \\
\hline CHEMBL1324861 & 688636 & 4.55 & 4.7161 & TRN & \\
\hline CHEMBL1517847 & 688636 & 4.4 & 4.7729 & TRN & \\
\hline CHEMBL1570620 & 688636 & 4.4 & 4.9182 & TST & \\
\hline CHEMBL1348308 & 688636 & 4.3 & 4.56 & TRN & \\
\hline CHEMBL1982539 & 688636 & 5.0 & 4.5684 & TST & \\
\hline CHEMBL1452094 & 688636 & 4.9 & 4.9803 & TRN & \\
\hline CHEMBL1330772 & 688636 & 5.45 & 4.8368 & TRN & \\
\hline CHEMBL1611034 & 688636 & 4.95 & $4.8580 \ell$ & 00000000005 & TRN \\
\hline CHEMBL1306181 & 688636 & 4.25 & 4.8801 & TRN & \\
\hline CHEMBL3191892 & 688636 & 4.5 & 4.6384 & TST & \\
\hline CHEMBL1453813 & 688636 & 4.5 & 4.6845 & TRN & \\
\hline CHEMBL 2002332 & 688636 & 5.4 & 4.9043 & TRN & \\
\hline CHEMBL1528062 & 688636 & 4.5 & 4.6915 & TRN & \\
\hline CHEMBL3190363 & 688636 & 4.8 & 4.7029 & TRN & \\
\hline CHEMBL1502287 & 688636 & 5.7 & 4.7984 & TRN & \\
\hline CHEMBL1338147 & 688636 & 5.2 & 4.9227 & TRN & \\
\hline CHEMBL1408527 & 688636 & 4.9 & 4.9177 & TRN & \\
\hline CHEMBL1563388 & 688636 & 5.65 & 4.9241 & TST & \\
\hline CHEMBL3211176 & 688636 & 4.3 & 4.7786 & TRN & \\
\hline CHEMBL1495349 & 688636 & 6.6 & 4.9393 & TRN & \\
\hline CHEMBL1483907 & 688636 & 4.7 & 4.7737 & TRN & \\
\hline CHEMBL1497662 & 688636 & 5.4 & 4.8405 & TST & \\
\hline CHEMBL1502940 & 688636 & 4.4 & 4.8094 & TRN & \\
\hline CHEMBL1483707 & 688636 & 5.1 & 4.93199 & 99999999995 & TRN \\
\hline CHEMBL1405081 & 688636 & 4.45 & 4.7003 & TRN & \\
\hline CHEMBL1453132 & 688636 & 4.4 & 4.8589 & TRN & \\
\hline CHEMBL1444990 & 688636 & 4.55 & 4.7838 & TST & \\
\hline CHEMBL1331472 & 688636 & 5.9 & 4.7428 & TST & \\
\hline CHEMBL1508681 & 688636 & 6.7501 & 4.7713 & TST & \\
\hline CHEMBL1431724 & 688636 & 6.5501 & 4.7559 & TST & \\
\hline CHEMBL1335111 & 688636 & 5.25 & 4.9673 & TST & \\
\hline CHEMBL1604728 & 688636 & 4.25 & 4.9503 & TRN & \\
\hline CHEMBL1611969 & 688636 & 4.4 & 4.9247 & TRN & \\
\hline CHEMBL1333742 & 688636 & 4.3 & 4.6751 & TRN & \\
\hline CHEMBL1417524 & 688636 & 4.95 & 4.9154 & TRN & \\
\hline CHEMBL1456826 & 688636 & 4.7 & 4.8721 & TRN & \\
\hline CHEMBL3212568 & 688636 & 4.75 & 4.7592 & TRN & \\
\hline CHEMBL1410019 & 688636 & 5.0 & 4.7831 & TRN & \\
\hline CHEMBL1497083 & 688636 & 4.45 & 4.9214 & TRN & \\
\hline CHEMBL1488104 & 688636 & 4.95 & 4.9563 & TRN & \\
\hline
\end{tabular}




\begin{tabular}{|c|c|c|c|c|}
\hline \multicolumn{5}{|c|}{ Supplemental Table S2.txt } \\
\hline CHEMBL1300344 & 688636 & 4.4 & 4.7826 & TST \\
\hline CHEMBL1510630 & 688636 & 4.5 & 4.7335 & TRN \\
\hline CHEMBL3197773 & 688636 & 4.45 & 4.8435 & TRN \\
\hline CHEMBL1529063 & 688636 & 5.3 & 4.9214 & TST \\
\hline CHEMBL1498682 & 688636 & 4.25 & 4.725 & TRN \\
\hline CHEMBL1341002 & 688636 & 4.75 & 4.8675 & TRN \\
\hline CHEMBL1565712 & 688636 & 6.0 & 4.8878 & TRN \\
\hline CHEMBL1406796 & 688636 & 4.35 & 4.8023 & TRN \\
\hline CHEMBL1588130 & 688636 & 6.0 & 4.9752 & TRN \\
\hline CHEMBL1385483 & 688636 & 4.3 & 4.9267 & TRN \\
\hline CHEMBL1573071 & 688636 & 4.3 & 4.706 & TRN \\
\hline CHEMBL1460156 & 688636 & 4.9 & 4.9836 & TST \\
\hline CHEMBL1541445 & 688636 & 5.5 & 4.7763 & TRN \\
\hline CHEMBL1978388 & 688636 & 5.2 & 4.8009 & TRN \\
\hline CHEMBL1565895 & 688636 & 5.75 & 4.6941 & TST \\
\hline CHEMBL1523350 & 688636 & 5.25 & 4.9397 & TST \\
\hline CHEMBL1583690 & 688636 & 4.5 & 4.8067 & TRN \\
\hline CHEMBL1467510 & 688636 & 4.55 & 4.7039 & TRN \\
\hline CHEMBL1423992 & 688636 & 4.25 & 4.8127 & TRN \\
\hline CHEMBL1403535 & 688636 & 4.45 & 4.7171 & TRN \\
\hline CHEMBL1348218 & 688636 & 4.25 & 5.0332 & TRN \\
\hline CHEMBL1441242 & 688636 & 5.05 & 4.798 & TRN \\
\hline CHEMBL1525169 & 688636 & 4.95 & 4.8102 & TRN \\
\hline CHEMBL1300662 & 688636 & 4.45 & 4.6375 & TRN \\
\hline CHEMBL1364803 & 688636 & 4.6 & 4.8093 & TRN \\
\hline CHEMBL1532909 & 688636 & 4.25 & 4.9406 & TST \\
\hline CHEMBL1362271 & 688636 & 4.25 & 4.9123 & TRN \\
\hline CHEMBL1365306 & 688636 & 4.4 & 4.7894 & TRN \\
\hline CHEMBL1456109 & 688636 & 4.4 & 4.5714 & TRN \\
\hline CHEMBL1530650 & 688636 & 4.5 & 4.9239 & TST \\
\hline CHEMBL1600898 & 688636 & 4.3 & 4.7586 & TRN \\
\hline CHEMBL1504967 & 688636 & 6.7501 & 4.8627 & TRN \\
\hline CHEMBL1571413 & 688636 & 4.55 & 4.737 & TRN \\
\hline CHEMBL3192852 & 688636 & 4.3 & 4.8721 & TRN \\
\hline CHEMBL1571290 & 688636 & 5.05 & 4.7546 & TST \\
\hline CHEMBL1487386 & 688636 & 6.5 & 4.8095 & TST \\
\hline CHEMBL1613552 & 688636 & 4.25 & 4.7972 & TRN \\
\hline CHEMBL1390643 & 688636 & 4.75 & 4.8117 & TRN \\
\hline CHEMBL1507968 & 688636 & 4.25 & 4.8197 & TST \\
\hline CHEMBL3192567 & 688636 & 4.7 & 4.6983 & TRN \\
\hline CHEMBL1307549 & 688636 & 5.5 & 4.7401 & TRN \\
\hline CHEMBL1381541 & 688636 & 4.3 & 4.6092 & TRN \\
\hline CHEMBL1424297 & 688636 & 4.3 & 4.6401 & TRN \\
\hline CHEMBL1532179 & 688636 & 4.6 & 4.6869 & TRN \\
\hline CHEMBL1535395 & 688636 & 4.5 & 4.706 & TRN \\
\hline CHEMBL1985327 & 688636 & 4.85 & 4.5699 & TRN \\
\hline CHEMBL1986591 & 688636 & 4.3 & 4.7147 & TRN \\
\hline CHEMBL1573282 & 688636 & 6.7501 & 4.9019 & TRN \\
\hline
\end{tabular}




\begin{tabular}{|c|c|c|c|c|c|}
\hline \multicolumn{6}{|c|}{ Supplemental Table S2.txt } \\
\hline CHEMBL1464394 & 688636 & 4.4 & 4.8208 & TRN & \\
\hline CHEMBL1608742 & 688636 & 4.55 & 4.922 & TST & \\
\hline CHEMBL1575408 & 688636 & 5.45 & 4.7121 & TRN & \\
\hline CHEMBL1301211 & 688636 & 4.5 & 4.8244 & TRN & \\
\hline CHEMBL1523218 & 688636 & 5.4 & 4.7615 & TRN & \\
\hline CHEMBL1402262 & 688636 & 4.3 & 4.7424 & TST & \\
\hline CHEMBL1503851 & 688636 & 4.9 & 4.8833 & TRN & \\
\hline CHEMBL1579268 & 688636 & 4.25 & 5.0258 & TRN & \\
\hline CHEMBL1560765 & 688636 & 6.3 & 4.9834 & TRN & \\
\hline CHEMBL1464622 & 688636 & 4.25 & 4.7527 & TRN & \\
\hline CHEMBL1583492 & 688636 & 4.55 & 4.8548 & TST & \\
\hline CHEMBL1446191 & 688636 & 4.95 & 4.8321 & TRN & \\
\hline CHEMBL1305674 & 688636 & 4.5 & 4.9289 & TST & \\
\hline CHEMBL1578960 & 688636 & 4.95 & 4.8856 & TST & \\
\hline CHEMBL1422075 & 688636 & 5.2 & 4.9168 & TRN & \\
\hline CHEMBL1426371 & 688636 & 4.25 & 4.6592 & TRN & \\
\hline CHEMBL1425166 & 688636 & 4.25 & 4.8182 & TRN & \\
\hline CHEMBL3209194 & 688636 & 4.5 & 4.7639 & TRN & \\
\hline CHEMBL1405015 & 688636 & 4.95 & 4.7546 & TRN & \\
\hline CHEMBL1306327 & 688636 & 4.25 & 4.8824 & TST & \\
\hline CHEMBL1603847 & 688636 & 4.4 & 4.896 & TRN & \\
\hline CHEMBL1421444 & 688636 & 5.0 & 4.9803 & TRN & \\
\hline CHEMBL1576112 & 688636 & 4.4 & 4.8789 & TRN & \\
\hline CHEMBL1352311 & 688636 & 4.45 & 4.6931 & TRN & \\
\hline CHEMBL1337929 & 688636 & 4.3 & 4.806 & TRN & \\
\hline CHEMBL1613003 & 688636 & 5.95 & 4.8931 & TRN & \\
\hline CHEMBL1447441 & 688636 & 4.45 & 4.6463 & TRN & \\
\hline CHEMBL1535449 & 688636 & 4.95 & 4.7052 & TRN & \\
\hline CHEMBL1391280 & 688636 & 4.95 & 4.80399 & 9999999999 & TRN \\
\hline CHEMBL3192183 & 688636 & 5.5 & 4.8335 & TRN & \\
\hline CHEMBL1605490 & 688636 & 5.3 & 4.9627 & TRN & \\
\hline CHEMBL1421221 & 688636 & 5.35 & 4.8509 & TST & \\
\hline CHEMBL1594426 & 688636 & 5.2 & 4.7391 & TRN & \\
\hline CHEMBL1391573 & 688636 & 4.5 & 4.7553 & TRN & \\
\hline CHEMBL1578790 & 688636 & 4.4 & 4.6757 & TST & \\
\hline CHEMBL1411544 & 688636 & 4.55 & 4.6259 & TRN & \\
\hline CHEMBL1451819 & 688636 & 4.45 & 4.7155 & TRN & \\
\hline CHEMBL1600349 & 688636 & 4.25 & 4.7846 & TST & \\
\hline CHEMBL1382530 & 688636 & 4.55 & 4.9014 & TST & \\
\hline CHEMBL1575996 & 688636 & 5.9 & 4.8233 & TRN & \\
\hline CHEMBL1449354 & 688636 & 4.6 & 4.8677 & TRN & \\
\hline CHEMBL1340166 & 688636 & 4.75 & 4.8258 & TRN & \\
\hline CHEMBL1311277 & 688636 & 4.3 & 4.8653 & TRN & \\
\hline CHEMBL1561936 & 688636 & 4.25 & 4.7571 & TRN & \\
\hline CHEMBL1507534 & 688636 & 4.45 & 4.8788 & TRN & \\
\hline CHEMBL1367677 & 688636 & 4.4 & 4.7162 & TRN & \\
\hline CHEMBL1579415 & 688636 & 4.25 & 4.9141 & TRN & \\
\hline CHEMBL1562936 & 688636 & 5.35 & 4.6666 & TRN & \\
\hline
\end{tabular}




\begin{tabular}{|c|c|c|c|c|}
\hline \multicolumn{5}{|c|}{ Supplemental Table S2.txt } \\
\hline CHEMBL1566583 & 688636 & 4.3 & 4.9196 & TRN \\
\hline CHEMBL1503702 & 688636 & 4.25 & 4.7959 & TRN \\
\hline CHEMBL1482555 & 688636 & 4.25 & 4.6167 & TRN \\
\hline CHEMBL1491586 & 688636 & 4.55 & 4.5552 & TRN \\
\hline CHEMBL1309014 & 688636 & 4.9 & 4.7163 & TRN \\
\hline CHEMBL1371779 & 688636 & 4.25 & 4.814 & TST \\
\hline CHEMBL1382662 & 688636 & 5.05 & 4.6994 & TST \\
\hline CHEMBL1349046 & 688636 & 6.4 & 4.8361 & TST \\
\hline CHEMBL1422167 & 688636 & 5.9 & 4.9111 & TRN \\
\hline CHEMBL1604895 & 688636 & 5.2 & 4.9478 & TRN \\
\hline CHEMBL1384738 & 688636 & 6.8 & 4.8551 & TST \\
\hline CHEMBL1375921 & 688636 & 4.4 & 4.8171 & TRN \\
\hline CHEMBL1326336 & 688636 & 4.3 & 4.7835 & TST \\
\hline CHEMBL1338205 & 688636 & 4.5 & 4.9262 & TRN \\
\hline CHEMBL1563723 & 688636 & 4.25 & 4.8161 & TRN \\
\hline CHEMBL1600412 & 688636 & 4.7 & 4.7138 & TRN \\
\hline CHEMBL1581816 & 688636 & 5.0 & 4.8236 & TST \\
\hline CHEMBL1374192 & 688636 & 4.65 & 4.8418 & TRN \\
\hline CHEMBL1497079 & 688636 & 5.55 & 4.9864 & TRN \\
\hline CHEMBL1301231 & 688636 & 4.45 & 4.955 & TRN \\
\hline CHEMBL1566005 & 688636 & 4.5 & 4.7275 & TRN \\
\hline CHEMBL1439754 & 688636 & 4.4 & 4.643 & TRN \\
\hline CHEMBL1433225 & 688636 & 4.85 & 4.7124 & TRN \\
\hline CHEMBL1348859 & 688636 & 5.3 & 4.8362 & TST \\
\hline CHEMBL1427035 & 688636 & 5.95 & 4.8422 & TRN \\
\hline CHEMBL1613219 & 688636 & 4.25 & 4.8926 & TRN \\
\hline CHEMBL1505532 & 688636 & 4.25 & 4.9383 & TST \\
\hline CHEMBL1455683 & 688636 & 4.55 & 4.78 & TST \\
\hline CHEMBL1508632 & 688636 & 4.4 & 4.7948 & TRN \\
\hline CHEMBL1334169 & 688636 & 4.6 & 4.7223 & TRN \\
\hline CHEMBL1321469 & 688636 & 4.7 & 4.5591 & TRN \\
\hline CHEMBL1327995 & 688636 & 4.35 & 4.8369 & TST \\
\hline CHEMBL1483076 & 688636 & 5.2 & 4.9098 & TRN \\
\hline CHEMBL1428621 & 688636 & 4.9 & 4.8233 & TRN \\
\hline CHEMBL1570334 & 688636 & 5.2 & 4.6731 & TRN \\
\hline CHEMBL1498973 & 688636 & 4.85 & 4.7111 & TRN \\
\hline CHEMBL1565415 & 688636 & 4.75 & 4.7305 & TRN \\
\hline CHEMBL1523058 & 688636 & 4.4 & 4.8736 & TST \\
\hline CHEMBL1386625 & 688636 & 4.45 & 4.8497 & TST \\
\hline CHEMBL1503406 & 688636 & 4.9 & 4.8891 & TRN \\
\hline CHEMBL1381114 & 688636 & 5.25 & 4.827 & TRN \\
\hline CHEMBL3194628 & 688636 & 4.25 & 4.8438 & TRN \\
\hline CHEMBL1488357 & 688636 & 5.85 & 4.8166 & TRN \\
\hline CHEMBL1461500 & 688636 & 4.85 & 4.8499 & TST \\
\hline CHEMBL1573629 & 688636 & 4.45 & 4.768 & TST \\
\hline CHEMBL1448548 & 688636 & 5.85 & 4.8751 & TRN \\
\hline CHEMBL1345078 & 688636 & 4.5 & 4.7581 & TRN \\
\hline CHEMBL1466111 & 688636 & 4.25 & 4.9787 & TRN \\
\hline
\end{tabular}




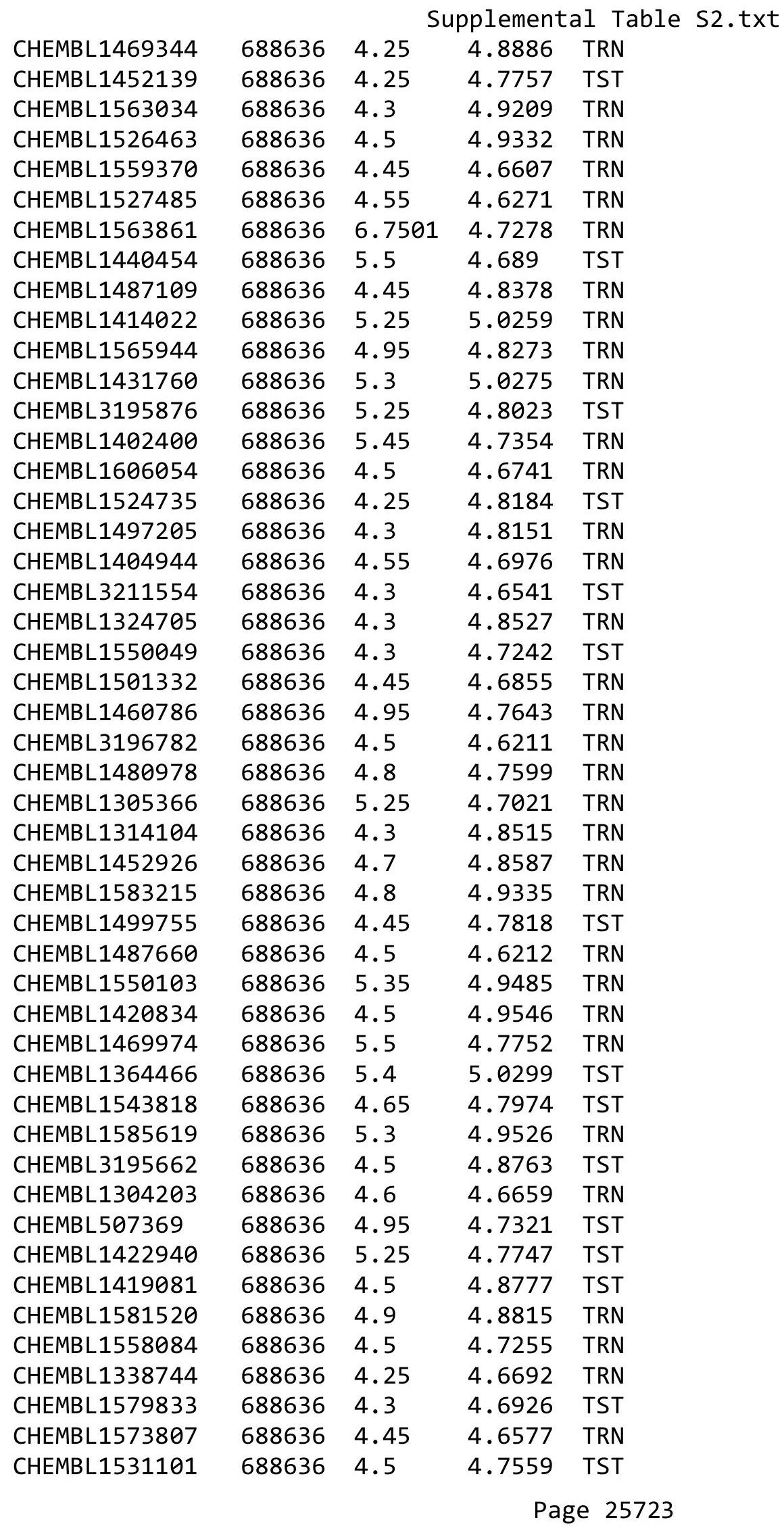




\begin{tabular}{|c|c|c|c|c|}
\hline \multicolumn{5}{|c|}{ Supplemental Table S2.txt } \\
\hline CHEMBL1340293 & 688636 & 4.55 & 4.8282 & TST \\
\hline CHEMBL1427602 & 688636 & 4.6 & 4.7281 & TRN \\
\hline CHEMBL1522803 & 688636 & 4.3 & 4.8204 & TRN \\
\hline CHEMBL1575456 & 688636 & 4.55 & 4.8087 & TRN \\
\hline CHEMBL 1408386 & 688636 & 4.3 & 4.8377 & TRN \\
\hline CHEMBL1303002 & 688636 & 6.2 & 4.9522 & TRN \\
\hline CHEMBL1393700 & 688636 & 4.5 & 4.6852 & TRN \\
\hline CHEMBL1499778 & 688636 & 4.45 & 4.8066 & TRN \\
\hline CHEMBL1403248 & 688636 & 5.4 & 4.6187 & TRN \\
\hline CHEMBL1437820 & 688636 & 4.3 & 4.6668 & TRN \\
\hline CHEMBL1490818 & 688636 & 4.6 & 4.5723 & TRN \\
\hline CHEMBL1325171 & 688636 & 4.55 & 4.8877 & TST \\
\hline CHEMBL1391097 & 688636 & 5.05 & 4.9055 & TRN \\
\hline CHEMBL 3209094 & 688636 & 4.3 & 4.6206 & TRN \\
\hline CHEMBL1359753 & 688636 & 4.3 & 4.8915 & TRN \\
\hline CHEMBL1299428 & 688636 & 4.25 & 4.8982 & TRN \\
\hline CHEMBL1545290 & 688636 & 5.75 & 5.0031 & TRN \\
\hline CHEMBL1580589 & 688636 & 4.25 & 4.6762 & TRN \\
\hline CHEMBL1353312 & 688636 & 4.35 & 4.7309 & TRN \\
\hline CHEMBL1536619 & 688636 & 5.15 & 4.8523 & TRN \\
\hline CHEMBL1439734 & 688636 & 6.5 & 4.9982 & TRN \\
\hline CHEMBL1609672 & 688636 & 5.1 & 4.6584 & TRN \\
\hline CHEMBL1443136 & 688636 & 4.3 & 4.9418 & TRN \\
\hline CHEMBL3209562 & 688636 & 4.3 & 4.7119 & TRN \\
\hline CHEMBL1443265 & 688636 & 5.85 & 4.7982 & TRN \\
\hline CHEMBL1503568 & 688636 & 5.85 & 4.7997 & TRN \\
\hline CHEMBL1446972 & 688636 & 4.9 & 4.8281 & TRN \\
\hline CHEMBL1381683 & 688636 & 4.6 & 5.0086 & TRN \\
\hline CHEMBL1544693 & 688636 & 4.55 & 4.7739 & TRN \\
\hline CHEMBL1502227 & 688636 & 4.3 & 4.8239 & TRN \\
\hline CHEMBL1969713 & 688636 & 4.7 & 4.6549 & TST \\
\hline CHEMBL1348248 & 688636 & 4.4 & 4.8887 & TST \\
\hline CHEMBL 3210188 & 688636 & 4.3 & 4.618 & TST \\
\hline CHEMBL1301967 & 688636 & 4.95 & 4.8927 & TRN \\
\hline CHEMBL1584523 & 688636 & 4.4 & 4.7128 & TRN \\
\hline CHEMBL1471287 & 688636 & 4.3 & 4.862 & TST \\
\hline CHEMBL 1477373 & 688636 & 4.45 & 4.6557 & TRN \\
\hline CHEMBL1529463 & 688636 & 5.9 & 5.063 & TRN \\
\hline CHEMBL1568723 & 688636 & 4.3 & 4.684 & TRN \\
\hline CHEMBL3192408 & 688636 & 4.3 & 4.768 & TST \\
\hline CHEMBL1562697 & 688636 & 4.55 & 4.8597 & TRN \\
\hline CHEMBL1332291 & 688636 & 4.3 & 4.8139 & TRN \\
\hline CHEMBL1516601 & 688636 & 4.7 & 4.6921 & TRN \\
\hline CHEMBL1344751 & 688636 & 5.1 & 4.8379 & TRN \\
\hline CHEMBL1440373 & 688636 & 4.25 & 4.9101 & TRN \\
\hline CHEMBL1368367 & 688636 & 4.5 & 4.8327 & TRN \\
\hline CHEMBL1309240 & 688636 & 5.1 & 4.9156 & TST \\
\hline CHEMBL1555675 & 688636 & 4.3 & 4.791 & TRN \\
\hline
\end{tabular}




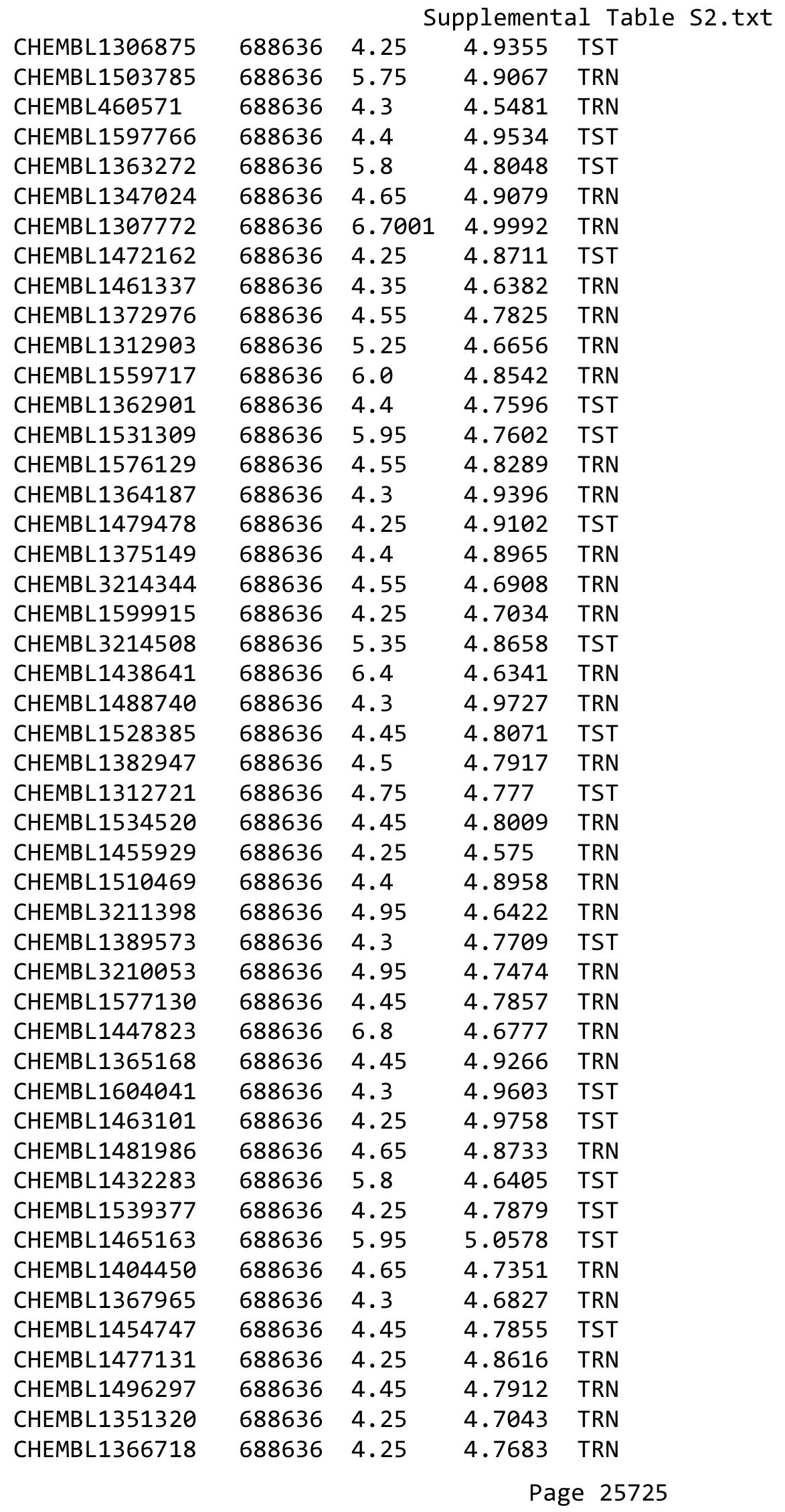




\begin{tabular}{|c|c|c|c|c|}
\hline \multicolumn{5}{|c|}{ Supplemental Table S2.txt } \\
\hline CHEMBL1558778 & 688636 & 5.45 & 4.9891 & TRN \\
\hline CHEMBL3212869 & 688636 & 4.4 & 4.8486 & TRN \\
\hline CHEMBL1560698 & 688636 & 5.15 & 5.0071 & TRN \\
\hline CHEMBL 3199774 & 688636 & 4.35 & 4.572 & TRN \\
\hline CHEMBL1579765 & 688636 & 4.4 & 4.9774 & TRN \\
\hline CHEMBL1578932 & 688636 & 4.4 & 4.6208 & TRN \\
\hline CHEMBL1325084 & 688636 & 4.25 & 4.7297 & TRN \\
\hline CHEMBL1408895 & 688636 & 4.45 & 4.8748 & TST \\
\hline CHEMBL1574560 & 688636 & 4.3 & 4.7837 & TRN \\
\hline CHEMBL1392200 & 688636 & 4.5 & 4.7619 & TRN \\
\hline CHEMBL1597693 & 688636 & 4.25 & 4.6796 & TRN \\
\hline CHEMBL1536016 & 688636 & 4.45 & 4.5761 & TRN \\
\hline CHEMBL1522566 & 688636 & 4.25 & 4.9802 & TRN \\
\hline CHEMBL1399519 & 688636 & 4.45 & 4.659 & TRN \\
\hline CHEMBL1566789 & 688636 & 5.4 & 4.8483 & TRN \\
\hline CHEMBL1499148 & 688636 & 4.25 & 4.8478 & TST \\
\hline CHEMBL1359898 & 688636 & 6.4 & 4.8781 & TST \\
\hline CHEMBL1339496 & 688636 & 5.7 & 4.9828 & TRN \\
\hline CHEMBL1463157 & 688636 & 5.9 & 4.7331 & TRN \\
\hline CHEMBL1305966 & 688636 & 4.25 & 4.8923 & TRN \\
\hline CHEMBL1499859 & 688636 & 5.85 & 5.0082 & TRN \\
\hline CHEMBL1498088 & 688636 & 4.5 & 4.7553 & TRN \\
\hline CHEMBL1409653 & 688636 & 6.7501 & 4.9096 & TST \\
\hline CHEMBL1339856 & 688636 & 4.9 & 4.8061 & TRN \\
\hline CHEMBL1419043 & 688636 & 6.15 & 4.9025 & TRN \\
\hline CHEMBL1504312 & 688636 & 5.95 & 4.8774 & TRN \\
\hline CHEMBL1478967 & 688636 & 5.0 & 4.6308 & TRN \\
\hline CHEMBL1379889 & 688636 & 4.25 & 4.8077 & TRN \\
\hline CHEMBL1608504 & 688636 & 4.3 & 4.7668 & TRN \\
\hline CHEMBL1549435 & 688636 & 4.55 & 4.7597 & TST \\
\hline CHEMBL1520735 & 688636 & 4.25 & 4.756 & TRN \\
\hline CHEMBL1595607 & 688636 & 4.4 & 4.7797 & TRN \\
\hline CHEMBL1520904 & 688636 & 4.45 & 4.8903 & TRN \\
\hline CHEMBL1422097 & 688636 & 4.95 & 4.6616 & TRN \\
\hline CHEMBL1399522 & 688636 & 4.5 & 4.85 & TST \\
\hline CHEMBL 36641 & 688636 & 4.45 & 4.922 & TRN \\
\hline CHEMBL1561590 & 688636 & 5.4 & 4.7814 & TRN \\
\hline CHEMBL1353351 & 688636 & 4.45 & 4.834 & TRN \\
\hline CHEMBL1365800 & 688636 & 4.5 & 4.8636 & TRN \\
\hline CHEMBL1521551 & 688636 & 4.55 & 4.8346 & TST \\
\hline CHEMBL1409868 & 688636 & 4.7 & 4.782 & TRN \\
\hline CHEMBL1300857 & 688636 & 5.45 & 4.6465 & TRN \\
\hline CHEMBL1406880 & 688636 & 5.45 & 4.6925 & TRN \\
\hline CHEMBL1547946 & 688636 & 6.05 & 4.8839 & TRN \\
\hline CHEMBL1425864 & 688636 & 4.3 & 4.8343 & TST \\
\hline CHEMBL1558425 & 688636 & 4.9 & 4.7774 & TRN \\
\hline CHEMBL1606122 & 688636 & 4.25 & 4.8303 & TRN \\
\hline CHEMBL1458940 & 688636 & 4.45 & 4.8919 & TRN \\
\hline
\end{tabular}




\begin{tabular}{|c|c|c|c|c|c|}
\hline \multicolumn{6}{|c|}{ Supplemental Table S2.txt } \\
\hline CHEMBL1499297 & 688636 & 4.25 & 4.8807 & TST & \\
\hline CHEMBL1423913 & 688636 & 4.45 & 4.8292 & TRN & \\
\hline CHEMBL1416288 & 688636 & 4.4 & 4.6914 & TRN & \\
\hline CHEMBL1470666 & 688636 & 5.0 & 4.7957 & TRN & \\
\hline CHEMBL1496692 & 688636 & 4.85 & 4.9294 & TRN & \\
\hline CHEMBL1557476 & 688636 & 6.15 & 4.7722 & TRN & \\
\hline CHEMBL1574469 & 688636 & 4.25 & 4.7066 & TST & \\
\hline CHEMBL1326844 & 688636 & 4.25 & 4.6918 & TRN & \\
\hline CHEMBL1342132 & 688636 & 5.65 & 4.7008 & TRN & \\
\hline CHEMBL1603787 & 688636 & 4.45 & 4.9199 & TST & \\
\hline CHEMBL1313219 & 688636 & 6.3 & 4.8529 & TRN & \\
\hline CHEMBL1575891 & 688636 & 6.4 & 4.93199 & 99999999995 & TRN \\
\hline CHEMBL1331857 & 688636 & 4.45 & 4.8084 & TRN & \\
\hline CHEMBL1527365 & 688636 & 4.25 & 4.845 & TRN & \\
\hline CHEMBL1466448 & 688636 & 4.45 & 4.785 & TRN & \\
\hline CHEMBL1504802 & 688636 & 4.3 & 4.7155 & TST & \\
\hline CHEMBL1378682 & 688636 & 4.7 & 4.8481 & TRN & \\
\hline CHEMBL1299201 & 688636 & 4.95 & 4.8985 & TRN & \\
\hline CHEMBL1562125 & 688636 & 4.6 & 4.6856 & TRN & \\
\hline CHEMBL1346240 & 688636 & 4.45 & 4.6199 & TRN & \\
\hline CHEMBL1504189 & 688636 & 4.45 & 4.8643 & TRN & \\
\hline CHEMBL1580913 & 688636 & 4.45 & 4.7347 & TRN & \\
\hline CHEMBL1447496 & 688636 & 5.0 & 4.8406 & TRN & \\
\hline CHEMBL1518723 & 688636 & 4.65 & 4.8339 & TRN & \\
\hline CHEMBL 3197882 & 688636 & 4.4 & 4.8915 & TRN & \\
\hline CHEMBL1572979 & 688636 & 4.25 & 4.8101 & TRN & \\
\hline CHEMBL1533328 & 688636 & 6.7501 & 4.7151 & TST & \\
\hline CHEMBL1468514 & 688636 & 5.25 & 4.8475 & TST & \\
\hline CHEMBL1605728 & 688636 & 4.25 & 4.8798 & TRN & \\
\hline CHEMBL1493690 & 688636 & 6.7501 & 4.8304 & TRN & \\
\hline CHEMBL1381997 & 688636 & 4.3 & 5.07100 & 0000000001 & TRN \\
\hline CHEMBL1393172 & 688636 & 4.55 & 4.7836 & TRN & \\
\hline CHEMBL3196768 & 688636 & 6.1 & 4.8165 & TST & \\
\hline CHEMBL1610525 & 688636 & 6.8 & 4.774 & TRN & \\
\hline CHEMBL1994007 & 688636 & 4.25 & 4.6771 & TRN & \\
\hline CHEMBL3190694 & 688636 & 5.7 & 4.773 & TRN & \\
\hline CHEMBL1457187 & 688636 & 4.4 & 4.7442 & TRN & \\
\hline CHEMBL1493660 & 688636 & 4.25 & 4.9518 & TST & \\
\hline CHEMBL1405863 & 688636 & 4.4 & 4.7253 & TRN & \\
\hline CHEMBL1444715 & 688636 & 4.5 & 4.8909 & TST & \\
\hline CHEMBL3192506 & 688636 & 4.65 & 4.6447 & TRN & \\
\hline CHEMBL1339327 & 688636 & 4.4 & 4.8945 & TRN & \\
\hline CHEMBL1595962 & 688636 & 5.2 & 4.9102 & TRN & \\
\hline CHEMBL1575994 & 688636 & 5.4 & 4.675 & TRN & \\
\hline CHEMBL1485356 & 688636 & 4.65 & 5.0162 & TRN & \\
\hline CHEMBL1537315 & 688636 & 4.65 & 4.7759 & TRN & \\
\hline CHEMBL1471392 & 688636 & 5.4 & 4.7655 & TRN & \\
\hline CHEMBL1511024 & 688636 & 5.7 & 4.9692 & TRN & \\
\hline
\end{tabular}




\begin{tabular}{|c|c|c|c|c|}
\hline \multirow[b]{2}{*}{ CHEMBL1345190 } & \multicolumn{4}{|c|}{ Supplemental Table S2.txt } \\
\hline & 688636 & 4.9 & 4.6834 & TRN \\
\hline CHEMBL1337832 & 688636 & 4.25 & 4.8327 & TST \\
\hline CHEMBL1386431 & 688636 & 5.35 & 4.7598 & TRN \\
\hline CHEMBL1559364 & 688636 & 4.95 & 4.9242 & TRN \\
\hline CHEMBL1509530 & 688636 & 6.1 & 4.6482 & TST \\
\hline CHEMBL579287 & 688636 & 4.95 & 4.624 & TRN \\
\hline CHEMBL1388415 & 688636 & 5.15 & 4.9512 & TST \\
\hline CHEMBL1594237 & 688636 & 4.4 & 4.6078 & TRN \\
\hline CHEMBL1364002 & 688636 & 4.65 & 4.9702 & TRN \\
\hline CHEMBL1550775 & 688636 & 4.45 & 4.6409 & TRN \\
\hline CHEMBL1606956 & 688636 & 6.3 & 4.7711 & TRN \\
\hline CHEMBL1451622 & 688636 & 4.6 & 4.7261 & TRN \\
\hline CHEMBL1464339 & 688636 & 5.15 & 4.8758 & TST \\
\hline CHEMBL1562277 & 688636 & 4.25 & 4.9449 & TRN \\
\hline CHEMBL1383587 & 688636 & 4.25 & 5.0076 & TST \\
\hline CHEMBL1385293 & 688636 & 5.8 & 4.9274 & TRN \\
\hline CHEMBL1349908 & 688636 & 4.5 & 4.7866 & TRN \\
\hline CHEMBL1492322 & 688636 & 4.5 & 4.7901 & TST \\
\hline CHEMBL1500928 & 688636 & 4.45 & 5.0255 & TRN \\
\hline CHEMBL1388564 & 688636 & 5.35 & 4.6756 & TST \\
\hline CHEMBL1577741 & 688636 & 4.5 & 4.8151 & TRN \\
\hline CHEMBL1375606 & 688636 & 5.15 & 5.046 & TRN \\
\hline CHEMBL1392492 & 688636 & 5.2 & 4.9386 & TST \\
\hline CHEMBL1362761 & 688636 & 4.35 & 4.7645 & TRN \\
\hline CHEMBL1564202 & 688636 & 5.3 & 4.8608 & TRN \\
\hline CHEMBL1558398 & 688636 & 5.85 & 4.8346 & TRN \\
\hline CHEMBL1545901 & 688636 & 5.05 & 4.7626 & TRN \\
\hline CHEMBL1346466 & 688636 & 4.9 & 4.7956 & TRN \\
\hline CHEMBL3196727 & 688636 & 4.5 & 4.6217 & TRN \\
\hline CHEMBL1430602 & 688636 & 4.55 & 4.7145 & TRN \\
\hline CHEMBL1364128 & 688636 & 4.3 & 5.1376 & TRN \\
\hline CHEMBL3191789 & 688636 & 4.3 & 4.973 & TST \\
\hline CHEMBL1484902 & 688636 & 4.3 & 4.8574 & TRN \\
\hline CHEMBL1536287 & 688636 & 5.1 & 4.9858 & TST \\
\hline CHEMBL1344800 & 688636 & 4.55 & 4.8015 & TRN \\
\hline CHEMBL3190876 & 688636 & 5.3 & 4.8425 & TRN \\
\hline CHEMBL1497964 & 688636 & 6.7501 & 4.7626 & TRN \\
\hline CHEMBL1596668 & 688636 & 4.3 & 4.9476 & TRN \\
\hline CHEMBL1440120 & 688636 & 4.25 & 4.7602 & TRN \\
\hline CHEMBL1302394 & 688636 & 5.25 & 4.9071 & TRN \\
\hline CHEMBL1522565 & 688636 & 5.95 & 4.8063 & TRN \\
\hline CHEMBL1456463 & 688636 & 5.15 & 4.7638 & TST \\
\hline CHEMBL1305639 & 688636 & 4.3 & 4.8935 & TRN \\
\hline CHEMBL3214611 & 688636 & 4.4 & 4.8279 & TRN \\
\hline CHEMBL3192884 & 688636 & 5.5 & 4.8326 & TRN \\
\hline CHEMBL1340165 & 688636 & 6.0 & 4.9851 & TST \\
\hline CHEMBL1485415 & 688636 & 4.35 & 4.6175 & TRN \\
\hline CHEMBL1424278 & 688636 & 4.3 & 4.9887 & TST \\
\hline
\end{tabular}




\begin{tabular}{|c|c|c|c|c|}
\hline \multicolumn{5}{|c|}{ Supplemental Table S2.txt } \\
\hline CHEMBL1605039 & 688636 & 4.5 & 4.9133 & TRN \\
\hline CHEMBL1330994 & 688636 & 4.65 & 4.5725 & TST \\
\hline CHEMBL1453680 & 688636 & 6.35 & 4.7699 & TRN \\
\hline CHEMBL1486533 & 688636 & 4.7 & 4.8506 & TRN \\
\hline CHEMBL1524044 & 688636 & 4.3 & 4.6528 & TRN \\
\hline CHEMBL1572195 & 688636 & 4.9 & 4.6939 & TST \\
\hline CHEMBL1595898 & 688636 & 4.65 & 4.916 & TST \\
\hline CHEMBL 3196767 & 688636 & 5.1 & 4.7998 & TRN \\
\hline CHEMBL1365898 & 688636 & 4.4 & 4.6459 & TRN \\
\hline CHEMBL1371034 & 688636 & 5.35 & 4.6693 & TRN \\
\hline CHEMBL1421382 & 688636 & 4.45 & 4.9157 & TRN \\
\hline CHEMBL1583639 & 688636 & 5.0 & 4.9474 & TRN \\
\hline CHEMBL81115 & 688636 & 6.8 & 4.8391 & TST \\
\hline CHEMBL1565775 & 688636 & 6.7501 & 4.7778 & TST \\
\hline CHEMBL 3211445 & 688636 & 4.25 & 4.507 & TRN \\
\hline CHEMBL1309754 & 688636 & 4.6 & 4.7107 & TRN \\
\hline CHEMBL1461181 & 688636 & 4.3 & 4.9166 & TST \\
\hline CHEMBL1471516 & 688636 & 4.6 & 4.9163 & TST \\
\hline CHEMBL1323753 & 688636 & 4.95 & 4.8652 & TST \\
\hline CHEMBL1399201 & 688636 & 4.3 & 4.6387 & TRN \\
\hline CHEMBL1518247 & 688636 & 4.65 & 4.8485 & TRN \\
\hline CHEMBL3194115 & 688636 & 5.2 & 4.8642 & TRN \\
\hline CHEMBL1532996 & 688636 & 4.5 & 4.7174 & TRN \\
\hline CHEMBL1399477 & 688636 & 4.3 & 4.8008 & TRN \\
\hline CHEMBL1463284 & 688636 & 5.35 & 4.9415 & TRN \\
\hline CHEMBL1595551 & 688636 & 4.3 & 4.8713 & TRN \\
\hline CHEMBL1407909 & 688636 & 4.25 & 4.9344 & TST \\
\hline CHEMBL1549006 & 688636 & 4.75 & 4.7348 & TRN \\
\hline CHEMBL1580795 & 688636 & 4.65 & 4.8797 & TST \\
\hline CHEMBL1612086 & 688636 & 4.6 & 4.6999 & TRN \\
\hline CHEMBL1561535 & 688636 & 4.5 & 4.6784 & TRN \\
\hline CHEMBL1576927 & 688636 & 4.25 & 4.8969 & TST \\
\hline CHEMBL1349705 & 688636 & 4.45 & 4.8609 & TRN \\
\hline CHEMBL1423795 & 688636 & 4.45 & 4.6762 & TST \\
\hline CHEMBL1515681 & 688636 & 4.4 & 4.8604 & TRN \\
\hline CHEMBL1596862 & 688636 & 4.55 & 4.7212 & TRN \\
\hline CHEMBL1528594 & 688636 & 4.9 & 4.6498 & TRN \\
\hline CHEMBL1339184 & 688636 & 4.95 & 4.8982 & TST \\
\hline CHEMBL1469815 & 688636 & 4.3 & 4.8621 & TRN \\
\hline CHEMBL 3190558 & 688636 & 4.45 & 4.6293 & TST \\
\hline CHEMBL3196447 & 688636 & 4.3 & 4.7999 & TRN \\
\hline CHEMBL1609555 & 688636 & 4.35 & 4.8001 & TRN \\
\hline CHEMBL1339618 & 688636 & 4.45 & 4.8166 & TRN \\
\hline CHEMBL1423062 & 688636 & 6.8 & 4.9543 & TRN \\
\hline CHEMBL1458730 & 688636 & 4.3 & 4.6819 & TRN \\
\hline CHEMBL1328835 & 688636 & 4.8 & 4.7936 & TRN \\
\hline CHEMBL1499180 & 688636 & 4.35 & 4.6211 & TRN \\
\hline CHEMBL1562873 & 688636 & 4.55 & 4.6785 & TRN \\
\hline
\end{tabular}




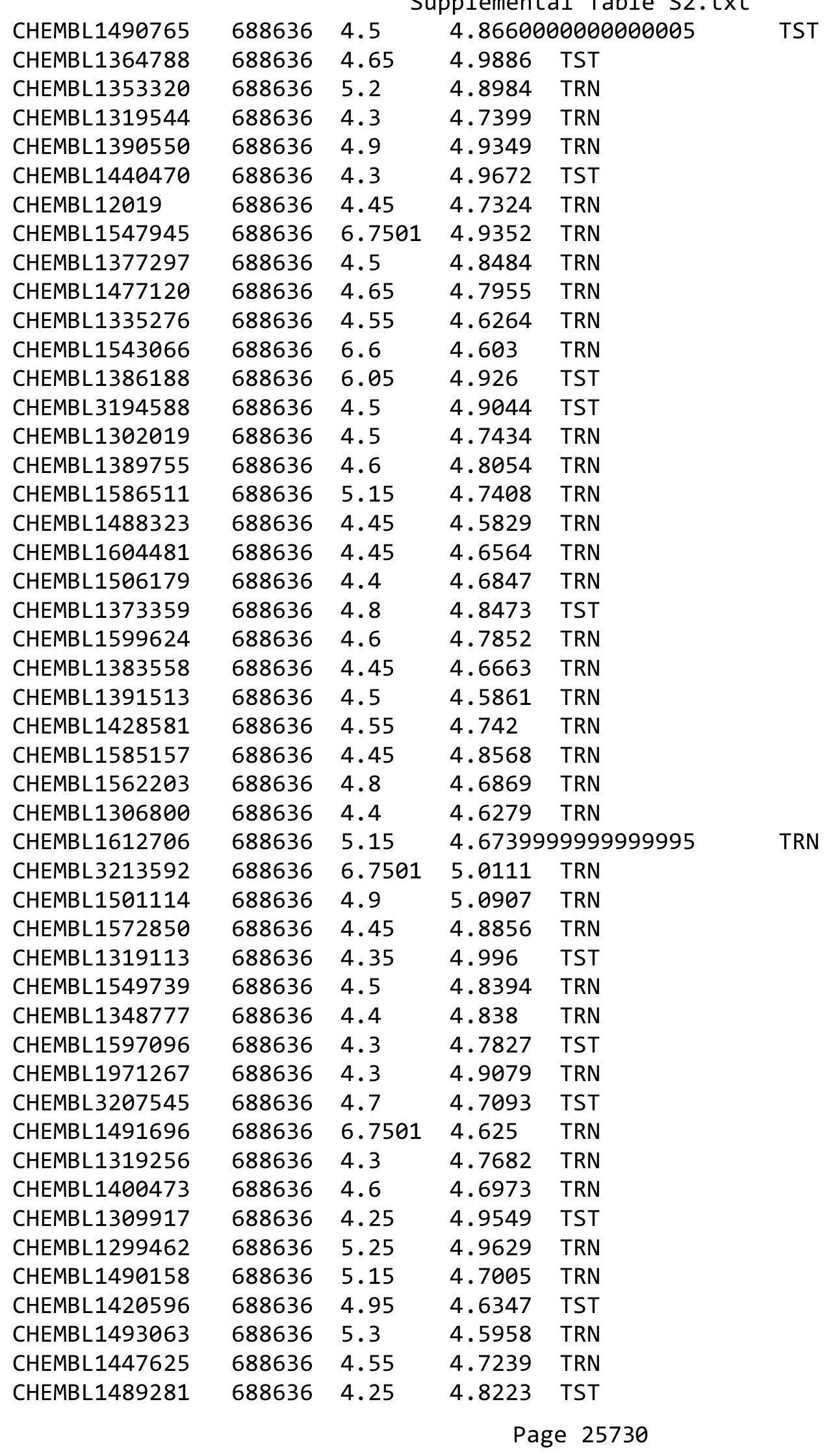




\begin{tabular}{|c|c|c|c|c|c|}
\hline \multicolumn{6}{|c|}{ Supplemental Table S2.txt } \\
\hline CHEMBL1431553 & 688636 & 4.55 & 4.8271 & TST & \\
\hline CHEMBL1549718 & 688636 & 4.35 & 4.8463 & TRN & \\
\hline CHEMBL3192701 & 688636 & 4.65 & 4.5789 & TST & \\
\hline CHEMBL1078384 & 688636 & 4.9 & 4.7338 & TST & \\
\hline CHEMBL1442070 & 688636 & 4.4 & 4.8724 & TST & \\
\hline CHEMBL1441300 & 688636 & 4.3 & 4.9359 & TRN & \\
\hline CHEMBL1353110 & 688636 & 4.4 & 4.9236 & TST & \\
\hline CHEMBL1598694 & 688636 & 4.95 & 4.675 & TST & \\
\hline CHEMBL1550093 & 688636 & 4.7 & 4.7539 & TRN & \\
\hline CHEMBL3194460 & 688636 & 4.3 & 4.7735 & TRN & \\
\hline CHEMBL1588967 & 688636 & 4.6 & 4.7883 & TRN & \\
\hline CHEMBL528086 & 688636 & 4.9 & 4.8434 & TRN & \\
\hline CHEMBL1576220 & 688636 & 4.3 & 4.8257 & TRN & \\
\hline CHEMBL1612645 & 688636 & 6.7001 & 4.7641 & TRN & \\
\hline CHEMBL1511705 & 688636 & 4.75 & 4.7765 & TRN & \\
\hline CHEMBL1414302 & 688636 & 5.35 & 4.7826 & TRN & \\
\hline CHEMBL1605094 & 688636 & 4.3 & 4.6842 & TRN & \\
\hline CHEMBL1502667 & 688636 & 4.95 & 4.7896 & TRN & \\
\hline CHEMBL1602233 & 688636 & 4.25 & 4.8963 & TST & \\
\hline CHEMBL1555417 & 688636 & 4.25 & 4.8923 & TRN & \\
\hline CHEMBL3193898 & 688636 & 6.35 & 4.79899 & 99999999995 & TRN \\
\hline CHEMBL1339432 & 688636 & 4.45 & 4.8838 & TRN & \\
\hline CHEMBL1543974 & 688636 & 4.25 & 4.9489 & TRN & \\
\hline CHEMBL 3214223 & 688636 & 4.3 & 4.68199 & 99999999995 & TRN \\
\hline CHEMBL1966025 & 688636 & 4.5 & 4.7944 & TRN & \\
\hline CHEMBL1384452 & 688636 & 5.25 & 4.9003 & TST & \\
\hline CHEMBL1588762 & 688636 & 5.2 & 4.7076 & TRN & \\
\hline CHEMBL3190070 & 688636 & 4.45 & 4.5926 & TRN & \\
\hline CHEMBL1507728 & 688636 & 4.45 & 4.8122 & TRN & \\
\hline CHEMBL1336355 & 688636 & 4.95 & 4.9046 & TST & \\
\hline CHEMBL1536914 & 688636 & 6.1 & 4.954 & TRN & \\
\hline CHEMBL1549245 & 688636 & 4.55 & 4.6198 & TRN & \\
\hline CHEMBL1444201 & 688636 & 4.55 & 4.739 & TRN & \\
\hline CHEMBL1388342 & 688636 & 4.9 & 4.8296 & TRN & \\
\hline CHEMBL1499308 & 688636 & 4.45 & 4.8849 & TRN & \\
\hline CHEMBL1541406 & 688636 & 6.8 & 4.9038 & TRN & \\
\hline CHEMBL1527837 & 688636 & 4.25 & 5.0251 & TRN & \\
\hline CHEMBL1598590 & 688636 & 4.95 & 5.1298 & TST & \\
\hline CHEMBL1477353 & 688636 & 5.05 & 4.662 & TRN & \\
\hline CHEMBL1343420 & 688636 & 4.95 & 4.705 & TRN & \\
\hline CHEMBL1542452 & 688636 & 6.6 & 5.0977 & TRN & \\
\hline CHEMBL1416762 & 688636 & 4.45 & 4.6355 & TRN & \\
\hline CHEMBL1535412 & 688636 & 4.95 & 4.8201 & TRN & \\
\hline CHEMBL1369939 & 688636 & 4.25 & 4.7062 & TST & \\
\hline CHEMBL1570746 & 688636 & 4.9 & 4.5044 & TRN & \\
\hline CHEMBL1300081 & 688636 & 5.05 & 4.7308 & TRN & \\
\hline CHEMBL1450386 & 688636 & 4.5 & 4.8721 & TRN & \\
\hline CHEMBL1504065 & 688636 & 4.4 & 4.8669 & TRN & \\
\hline
\end{tabular}




\begin{tabular}{|c|c|c|c|c|}
\hline \multicolumn{5}{|c|}{ Supplemental Table S2.txt } \\
\hline CHEMBL1364458 & 688636 & 4.45 & 4.6664 & TRN \\
\hline CHEMBL1471939 & 688636 & 4.35 & 4.9156 & TST \\
\hline CHEMBL1404255 & 688636 & 4.55 & 4.7243 & TRN \\
\hline CHEMBL1342409 & 688636 & 4.25 & 4.8085 & TRN \\
\hline CHEMBL1311630 & 688636 & 4.4 & 4.7723 & TRN \\
\hline CHEMBL1309678 & 688636 & 4.45 & 4.779 & TRN \\
\hline CHEMBL1470749 & 688636 & 4.25 & 4.8156 & TRN \\
\hline CHEMBL1490887 & 688636 & 4.5 & 4.7389 & TST \\
\hline CHEMBL1415227 & 688636 & 4.45 & 4.7972 & TRN \\
\hline CHEMBL1460907 & 688636 & 5.3 & 4.6929 & TRN \\
\hline CHEMBL1605218 & 688636 & 4.45 & 4.7699 & TRN \\
\hline CHEMBL1607379 & 688636 & 5.6 & 4.7791 & TST \\
\hline CHEMBL1471103 & 688636 & 6.8 & 4.8298 & TST \\
\hline CHEMBL 3197516 & 688636 & 4.55 & 4.726 & TRN \\
\hline CHEMBL1338871 & 688636 & 6.1 & 4.6427 & TRN \\
\hline CHEMBL1468159 & 688636 & 4.4 & 4.8548 & TRN \\
\hline CHEMBL1462259 & 688636 & 4.35 & 4.6634 & TRN \\
\hline CHEMBL1607020 & 688636 & 5.85 & 4.7739 & TRN \\
\hline CHEMBL 368655 & 688636 & 6.05 & 4.9148 & TST \\
\hline CHEMBL1555208 & 688636 & 5.3 & 4.9472 & TST \\
\hline CHEMBL1393861 & 688636 & 4.45 & 4.7353 & TRN \\
\hline CHEMBL1431569 & 688636 & 4.3 & 4.822 & TST \\
\hline CHEMBL1366034 & 688636 & 4.3 & 4.6414 & TRN \\
\hline CHEMBL 3212548 & 688636 & 4.55 & 4.8844 & TST \\
\hline CHEMBL1415040 & 688636 & 4.25 & 4.993 & TRN \\
\hline CHEMBL1458549 & 688636 & 4.95 & 4.7498 & TRN \\
\hline CHEMBL1545978 & 688636 & 4.65 & 4.8502 & TRN \\
\hline CHEMBL1570526 & 688636 & 4.3 & 4.7869 & TRN \\
\hline CHEMBL1455596 & 688636 & 4.7 & 4.739 & TRN \\
\hline CHEMBL1306388 & 688636 & 4.3 & 4.8332 & TST \\
\hline CHEMBL1326486 & 688636 & 4.3 & 4.6977 & TRN \\
\hline CHEMBL1350015 & 688636 & 4.3 & 4.7544 & TRN \\
\hline CHEMBL1582893 & 688636 & 4.3 & 4.9351 & TRN \\
\hline CHEMBL1531637 & 688636 & 4.3 & 4.7641 & TRN \\
\hline CHEMBL1406520 & 688636 & 4.35 & 4.8476 & TRN \\
\hline CHEMBL1353472 & 688636 & 5.75 & 4.8481 & TRN \\
\hline CHEMBL1541342 & 688636 & 4.4 & 4.8292 & TRN \\
\hline CHEMBL1420222 & 688636 & 6.15 & 4.8816 & TRN \\
\hline CHEMBL1505014 & 688636 & 4.95 & 4.9282 & TST \\
\hline CHEMBL1588910 & 688636 & 4.25 & 4.86 & TRN \\
\hline CHEMBL1456850 & 688636 & 4.3 & 4.8651 & TRN \\
\hline CHEMBL1527775 & 688636 & 5.5 & 4.7212 & TRN \\
\hline CHEMBL1572558 & 688636 & 4.9 & 4.6546 & TST \\
\hline CHEMBL1362030 & 688636 & 4.95 & 4.7868 & TST \\
\hline CHEMBL1585104 & 688636 & 4.3 & 4.7979 & TST \\
\hline CHEMBL1410471 & 688636 & 4.55 & 4.7487 & TST \\
\hline CHEMBL1425345 & 688636 & 4.25 & 4.8772 & TRN \\
\hline CHEMBL1456225 & 688636 & 4.45 & 4.7078 & TRN \\
\hline
\end{tabular}




\begin{tabular}{|c|c|c|c|c|c|}
\hline \multicolumn{6}{|c|}{ Supplemental Table S2.txt } \\
\hline CHEMBL1337620 & 688636 & 5.15 & 4.7145 & TST & \\
\hline CHEMBL1491248 & 688636 & 5.85 & 4.8954 & TST & \\
\hline CHEMBL1421454 & 688636 & 4.5 & 4.9155 & TST & \\
\hline CHEMBL1340571 & 688636 & 4.35 & 4.7683 & TRN & \\
\hline CHEMBL 3194845 & 688636 & 5.5 & 4.6233 & TRN & \\
\hline CHEMBL1390274 & 688636 & 4.55 & 4.7142 & TRN & \\
\hline CHEMBL1490539 & 688636 & 4.45 & 4.8973 & TRN & \\
\hline CHEMBL1460839 & 688636 & 4.55 & 4.75899 & 99999999995 & TRN \\
\hline CHEMBL1530592 & 688636 & 4.55 & 5.0981 & TRN & \\
\hline CHEMBL1612974 & 688636 & 5.35 & 4.7304 & TRN & \\
\hline CHEMBL1456276 & 688636 & 4.35 & 4.7008 & TRN & \\
\hline CHEMBL1328017 & 688636 & 5.15 & 4.9479 & TST & \\
\hline CHEMBL 3213348 & 688636 & 4.3 & 4.8561 & TST & \\
\hline CHEMBL1421866 & 688636 & 5.5 & 4.8883 & TRN & \\
\hline CHEMBL1308136 & 688636 & 6.5 & 4.8175 & TRN & \\
\hline CHEMBL1607633 & 688636 & 6.8 & 5.0772 & TRN & \\
\hline CHEMBL1991215 & 688636 & 4.5 & 4.5894 & TRN & \\
\hline CHEMBL1372518 & 688636 & 5.9 & 5.0487 & TRN & \\
\hline CHEMBL1403546 & 688636 & 4.6 & 4.6412 & TRN & \\
\hline CHEMBL1372242 & 688636 & 4.45 & 4.7503 & TRN & \\
\hline CHEMBL1326299 & 688636 & 4.7 & 4.8695 & TRN & \\
\hline CHEMBL1415561 & 688636 & 4.3 & 4.8644 & TST & \\
\hline CHEMBL1367721 & 688636 & 4.25 & 4.92899 & 9999999999 & TRN \\
\hline CHEMBL1497871 & 688636 & 4.3 & 4.8742 & TRN & \\
\hline CHEMBL1307366 & 688636 & 5.9 & 4.7841 & TST & \\
\hline CHEMBL1415300 & 688636 & 4.4 & 4.6638 & TRN & \\
\hline CHEMBL1510705 & 688636 & 4.25 & 4.7592 & TRN & \\
\hline CHEMBL1596038 & 688636 & 4.35 & 4.613 & TST & \\
\hline CHEMBL1611726 & 688636 & 4.9 & 4.913 & TRN & \\
\hline CHEMBL1419663 & 688636 & 4.4 & 4.791 & TRN & \\
\hline CHEMBL1393320 & 688636 & 4.65 & 4.6848 & TRN & \\
\hline CHEMBL1491697 & 688636 & 4.75 & 4.8181 & TRN & \\
\hline CHEMBL1391482 & 688636 & 6.7501 & 4.9686 & TST & \\
\hline CHEMBL1488994 & 688636 & 4.6 & 4.8431 & TST & \\
\hline CHEMBL1606807 & 688636 & 5.25 & 4.9176 & TRN & \\
\hline CHEMBL1376364 & 688636 & 4.95 & 4.8219 & TST & \\
\hline CHEMBL1462728 & 688636 & 4.45 & 4.8163 & TRN & \\
\hline CHEMBL1371167 & 688636 & 4.45 & 4.8308 & TRN & \\
\hline CHEMBL1404822 & 688636 & 4.25 & 4.8272 & TRN & \\
\hline CHEMBL1300318 & 688636 & 4.65 & 4.7419 & TST & \\
\hline CHEMBL1511403 & 688636 & 4.4 & 4.7294 & TRN & \\
\hline CHEMBL3196453 & 688636 & 4.4 & 4.8753 & TST & \\
\hline CHEMBL1599335 & 688636 & 5.9 & 4.8116 & TRN & \\
\hline CHEMBL1347326 & 688636 & 4.25 & 4.6992 & TRN & \\
\hline CHEMBL1560961 & 688636 & 4.9 & 4.936 & TRN & \\
\hline CHEMBL1461852 & 688636 & 4.6 & 4.7535 & TRN & \\
\hline CHEMBL1311011 & 688636 & 4.4 & 4.651 & TST & \\
\hline CHEMBL1452484 & 688636 & 5.3 & 4.7541 & TRN & \\
\hline
\end{tabular}




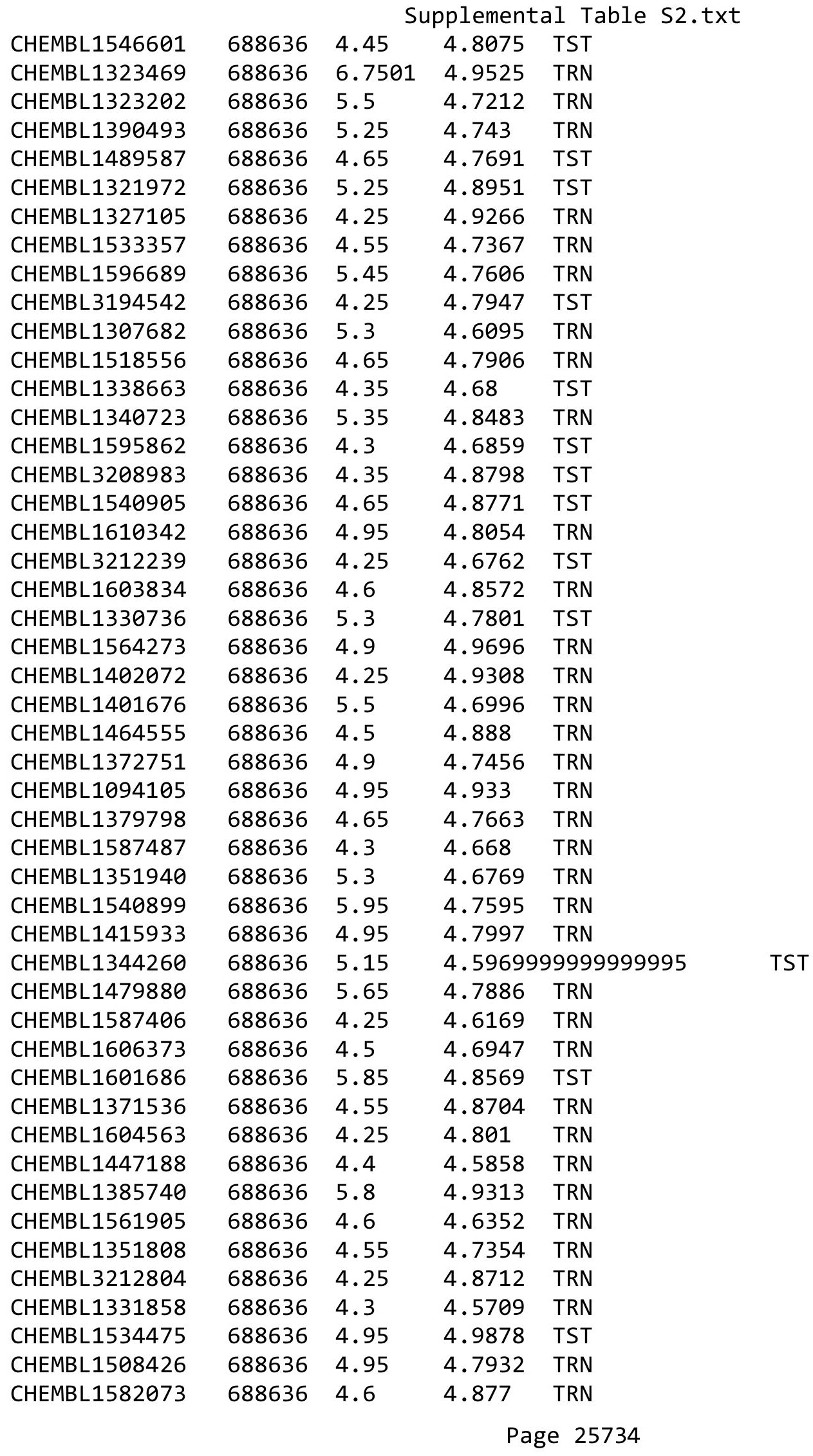




\begin{tabular}{|c|c|c|c|c|c|}
\hline \multicolumn{6}{|c|}{ Supplemental Table S2.txt } \\
\hline CHEMBL3212840 & 688636 & 4.7 & 4.6895 & TRN & \\
\hline CHEMBL1508439 & 688636 & 4.5 & 4.6539 & TRN & \\
\hline CHEMBL1508925 & 688636 & 4.3 & 4.7893 & TST & \\
\hline CHEMBL1583261 & 688636 & 6.7501 & 4.7329 & TRN & \\
\hline CHEMBL1440324 & 688636 & 4.65 & 4.65600 & 0000000001 & TRN \\
\hline CHEMBL1333833 & 688636 & 4.5 & 4.6443 & TRN & \\
\hline CHEMBL1462862 & 688636 & 4.85 & 4.7242 & TRN & \\
\hline CHEMBL1359606 & 688636 & 4.25 & 4.8057 & TRN & \\
\hline CHEMBL1506962 & 688636 & 4.4 & 4.7406 & TRN & \\
\hline CHEMBL1403650 & 688636 & 4.25 & 4.9365 & TRN & \\
\hline CHEMBL1302347 & 688636 & 5.2 & 4.588 & TRN & \\
\hline CHEMBL1463216 & 688636 & 5.1 & 4.8853 & TST & \\
\hline CHEMBL1539642 & 688636 & 6.05 & 4.8451 & TST & \\
\hline CHEMBL1496962 & 688636 & 5.95 & 4.9424 & TST & \\
\hline CHEMBL1492361 & 688636 & 4.3 & 4.7562 & TRN & \\
\hline CHEMBL1320417 & 688636 & 4.4 & 4.9023 & TRN & \\
\hline CHEMBL1311518 & 688636 & 5.45 & 4.8168 & TST & \\
\hline CHEMBL1450446 & 688636 & 4.3 & 4.7198 & TRN & \\
\hline CHEMBL1547806 & 688636 & 4.45 & 4.727 & TRN & \\
\hline CHEMBL1520539 & 688636 & 4.3 & 4.7522 & TST & \\
\hline CHEMBL1557849 & 688636 & 6.7501 & 4.7436 & TRN & \\
\hline CHEMBL1479864 & 688636 & 4.35 & 4.7845 & TRN & \\
\hline CHEMBL1320908 & 688636 & 4.4 & 4.7857 & TST & \\
\hline CHEMBL1477573 & 688636 & 4.5 & 4.7621 & TRN & \\
\hline CHEMBL1417030 & 688636 & 4.35 & 4.7995 & TRN & \\
\hline CHEMBL1546391 & 688636 & 4.3 & 5.0109 & TST & \\
\hline CHEMBL1511093 & 688636 & 4.3 & 4.8038 & TRN & \\
\hline CHEMBL1399917 & 688636 & 4.3 & 4.9461 & TRN & \\
\hline CHEMBL1464409 & 688636 & 4.35 & 4.647 & TRN & \\
\hline CHEMBL1390050 & 688636 & 4.95 & 4.765 & TRN & \\
\hline CHEMBL1375410 & 688636 & 5.3 & 4.9965 & TRN & \\
\hline CHEMBL1429521 & 688636 & 4.3 & 4.5419 & TRN & \\
\hline CHEMBL1370884 & 688636 & 5.25 & 4.7812 & TST & \\
\hline CHEMBL1518050 & 688636 & 4.45 & 4.7548 & TRN & \\
\hline CHEMBL1571803 & 688636 & 4.3 & 4.6276 & TRN & \\
\hline CHEMBL3210177 & 688636 & 5.45 & 4.6845 & TST & \\
\hline CHEMBL1508821 & 688636 & 4.3 & 4.6372 & TRN & \\
\hline CHEMBL1440331 & 688636 & 4.3 & 4.9273 & TRN & \\
\hline CHEMBL1319389 & 688636 & 4.5 & 4.6746 & TRN & \\
\hline CHEMBL3193075 & 688636 & 5.5 & 4.8653 & TRN & \\
\hline CHEMBL1581930 & 688636 & 4.85 & 4.5885 & TRN & \\
\hline CHEMBL1525221 & 688636 & 4.45 & 4.6966 & TRN & \\
\hline CHEMBL568385 & 688636 & 4.5 & 4.6032 & TRN & \\
\hline CHEMBL1477470 & 688636 & 6.7501 & 4.6208 & TRN & \\
\hline CHEMBL3194657 & 688636 & 5.6 & 4.6727 & TRN & \\
\hline CHEMBL3194740 & 688636 & 4.95 & 4.738 & TST & \\
\hline CHEMBL531451 & 688636 & 4.45 & 4.6969 & TRN & \\
\hline CHEMBL1518376 & 688636 & 4.3 & 4.7228 & TRN & \\
\hline
\end{tabular}




\begin{tabular}{|c|c|c|c|c|}
\hline & & & upplement & al \\
\hline CHEMBL1402358 & 688636 & 4.35 & 4.7429 & TRN \\
\hline CHEMBL1350710 & 688636 & 5.3 & 4.9734 & TRN \\
\hline CHEMBL1413105 & 688636 & 4.4 & 4.7912 & TST \\
\hline CHEMBL1569236 & 688636 & 4.45 & 4.7817 & TST \\
\hline CHEMBL1490573 & 688636 & 4.25 & 4.8995 & TRN \\
\hline CHEMBL1425940 & 688636 & 4.4 & 4.7796 & TRN \\
\hline CHEMBL1446309 & 688636 & 4.4 & 4.8785 & TRN \\
\hline CHEMBL1349755 & 688636 & 4.5 & 4.7686 & TRN \\
\hline CHEMBL1505672 & 688636 & 4.45 & 4.7392 & TST \\
\hline CHEMBL1586626 & 688636 & 5.35 & 4.7935 & TRN \\
\hline CHEMBL1447291 & 688636 & 4.55 & 4.7505 & TRN \\
\hline CHEMBL1480000 & 688636 & 4.45 & 4.6963 & TRN \\
\hline CHEMBL1583437 & 688636 & 4.9 & 4.9751 & TRN \\
\hline CHEMBL1344732 & 688636 & 4.9 & 4.7457 & TST \\
\hline CHEMBL1517459 & 688636 & 4.45 & 4.7666 & TRN \\
\hline CHEMBL1548616 & 688636 & 4.95 & 4.749 & TST \\
\hline CHEMBL1445916 & 688636 & 4.45 & 4.7982 & TRN \\
\hline CHEMBL1480468 & 688636 & 6.5 & 4.8691 & TRN \\
\hline CHEMBL1573210 & 688636 & 5.3 & 5.0242 & TST \\
\hline CHEMBL1996766 & 688636 & 4.95 & 4.9602 & TST \\
\hline CHEMBL1563167 & 688636 & 4.5 & 4.6032 & TRN \\
\hline CHEMBL1556983 & 688636 & 4.9 & 4.8027 & TRN \\
\hline CHEMBL1416333 & 688636 & 4.65 & 4.9021 & TRN \\
\hline CHEMBL1329914 & 688636 & 4.55 & 4.6488 & TRN \\
\hline CHEMBL1452243 & 688636 & 6.0 & 4.7793 & TRN \\
\hline CHEMBL3193046 & 688636 & 5.5 & 4.8342 & TRN \\
\hline CHEMBL1465224 & 688636 & 4.3 & 4.8394 & TST \\
\hline CHEMBL1516897 & 688636 & 4.3 & 4.8294 & TRN \\
\hline CHEMBL1323587 & 688636 & 4.9 & 4.7694 & TRN \\
\hline CHEMBL1326709 & 688636 & 4.55 & 4.676 & TRN \\
\hline CHEMBL1478644 & 688636 & 4.75 & 4.7696 & TRN \\
\hline CHEMBL1604383 & 688636 & 4.25 & 4.7535 & TRN \\
\hline CHEMBL1341114 & 688636 & 4.25 & 4.8279 & TRN \\
\hline CHEMBL1524646 & 688636 & 4.95 & 4.9454 & TST \\
\hline CHEMBL3190352 & 688636 & 5.3 & 4.9643 & TRN \\
\hline CHEMBL1303180 & 688636 & 5.5 & 4.7298 & TRN \\
\hline CHEMBL1523023 & 688636 & 4.45 & 4.8778 & TRN \\
\hline CHEMBL1373134 & 688636 & 5.9 & 4.7586 & TRN \\
\hline CHEMBL1375050 & 688636 & 4.35 & 4.6811 & TST \\
\hline CHEMBL1584927 & 688636 & 4.65 & 4.7948 & TRN \\
\hline CHEMBL1506985 & 688636 & 4.3 & 4.769 & TRN \\
\hline CHEMBL1495995 & 688636 & 4.3 & 4.8372 & TRN \\
\hline CHEMBL1486067 & 688636 & 4.95 & 4.6931 & TST \\
\hline CHEMBL1329008 & 688636 & 4.35 & 4.5424 & TRN \\
\hline CHEMBL1300763 & 688636 & 4.55 & 4.8086 & TRN \\
\hline CHEMBL1378085 & 688636 & 4.75 & 4.8022 & TST \\
\hline CHEMBL1389473 & 688636 & 4.4 & 4.8345 & TRN \\
\hline CHEMBL475742 & 688636 & 4.95 & 4.9804 & TST \\
\hline
\end{tabular}




\begin{tabular}{|c|c|c|c|c|}
\hline \multicolumn{5}{|c|}{ Supplemental Table S2.txt } \\
\hline CHEMBL1449432 & 688636 & 4.45 & 4.5921 & TRN \\
\hline CHEMBL1573293 & 688636 & 4.5 & 4.7635 & TRN \\
\hline CHEMBL1305403 & 688636 & 5.9 & 4.7368 & TRN \\
\hline CHEMBL1570750 & 688636 & 4.55 & 4.7594 & TRN \\
\hline CHEMBL3210087 & 688636 & 5.05 & 4.7075 & TRN \\
\hline CHEMBL1378553 & 688636 & 4.25 & 4.9515 & TRN \\
\hline CHEMBL1567844 & 688636 & 4.9 & 4.6064 & TRN \\
\hline CHEMBL1467503 & 688636 & 4.3 & 4.7456 & TRN \\
\hline CHEMBL1448891 & 688636 & 4.25 & 4.7401 & TRN \\
\hline CHEMBL584442 & 688636 & 4.25 & 4.7961 & TRN \\
\hline CHEMBL1985350 & 688636 & 5.1 & 4.5929 & TRN \\
\hline CHEMBL1462897 & 688636 & 4.95 & 5.0234 & TRN \\
\hline CHEMBL1384886 & 688636 & 4.25 & 4.7789 & TRN \\
\hline CHEMBL1488931 & 688636 & 4.5 & 4.7947 & TRN \\
\hline CHEMBL1490270 & 688636 & 5.7 & 4.9258 & TST \\
\hline CHEMBL1306415 & 688636 & 4.25 & 4.7611 & TRN \\
\hline CHEMBL1431881 & 688636 & 4.45 & 4.5542 & TRN \\
\hline CHEMBL1363179 & 688636 & 4.45 & 4.7684 & TRN \\
\hline CHEMBL 3207400 & 688636 & 4.55 & 4.6632 & TRN \\
\hline CHEMBL1501361 & 688636 & 5.4 & 4.7593 & TRN \\
\hline CHEMBL1469237 & 688636 & 4.95 & 4.8789 & TRN \\
\hline CHEMBL1341278 & 688636 & 4.25 & 4.6708 & TRN \\
\hline CHEMBL1346909 & 688636 & 5.7 & 4.7154 & TST \\
\hline CHEMBL1502333 & 688636 & 4.85 & 4.8368 & TST \\
\hline CHEMBL1331308 & 688636 & 4.95 & 4.8326 & TST \\
\hline CHEMBL1549775 & 688636 & 4.9 & 4.8093 & TRN \\
\hline CHEMBL1457595 & 688636 & 5.1 & 4.9022 & TRN \\
\hline CHEMBL1561313 & 688636 & 5.1 & 4.9999 & TRN \\
\hline CHEMBL1463376 & 688636 & 5.2 & 4.6177 & TRN \\
\hline CHEMBL1461188 & 688636 & 4.3 & 4.78 & TRN \\
\hline CHEMBL1402803 & 688636 & 5.3 & 4.6071 & TRN \\
\hline CHEMBL1480991 & 688636 & 4.3 & 4.7821 & TRN \\
\hline CHEMBL1463823 & 688636 & 5.65 & 4.923 & TRN \\
\hline CHEMBL1370701 & 688636 & 5.25 & 4.8943 & TST \\
\hline CHEMBL1484319 & 688636 & 4.3 & 4.5591 & TRN \\
\hline CHEMBL1573792 & 688636 & 4.55 & 4.8288 & TST \\
\hline CHEMBL1368832 & 688636 & 4.65 & 4.6739 & TST \\
\hline CHEMBL1545711 & 688636 & 4.45 & 4.7018 & TST \\
\hline CHEMBL 358644 & 688636 & 4.55 & 4.6007 & TRN \\
\hline CHEMBL1534539 & 688636 & 4.25 & 4.8514 & TRN \\
\hline CHEMBL1501331 & 688636 & 5.5 & 4.8918 & TRN \\
\hline CHEMBL1588666 & 688636 & 4.4 & 4.9059 & TST \\
\hline CHEMBL1466564 & 688636 & 4.45 & 4.7395 & TRN \\
\hline CHEMBL1543510 & 688636 & 4.3 & 4.7147 & TRN \\
\hline CHEMBL1517046 & 688636 & 4.45 & 4.7119 & TRN \\
\hline CHEMBL1559008 & 688636 & 4.25 & 4.7241 & TRN \\
\hline CHEMBL1536012 & 688636 & 4.4 & 4.9296 & TST \\
\hline CHEMBL1581251 & 688636 & 4.6 & 5.0236 & TST \\
\hline
\end{tabular}




\begin{tabular}{|c|c|c|c|c|c|}
\hline \multicolumn{6}{|c|}{ Supplemental Table s2.txt } \\
\hline CHEMBL1417811 & 688636 & 5.15 & 4.9052 & TRN & \\
\hline CHEMBL1409156 & 688636 & 4.3 & 4.9266 & TRN & \\
\hline CHEMBL1504349 & 688636 & 4.5 & 4.7777 & TST & \\
\hline CHEMBL3199107 & 688636 & 4.3 & 4.8352 & TRN & \\
\hline CHEMBL1359995 & 688636 & 4.25 & 4.853 & TRN & \\
\hline CHEMBL1302262 & 688636 & 4.3 & 4.8272 & TRN & \\
\hline CHEMBL486706 & 688636 & 4.65 & 4.8275 & TST & \\
\hline CHEMBL1588135 & 688636 & 4.55 & 5.0946 & TRN & \\
\hline CHEMBL1567420 & 688636 & 4.3 & 4.8557 & TRN & \\
\hline CHEMBL1428211 & 688636 & 4.4 & 4.7535 & TST & \\
\hline CHEMBL1300021 & 688636 & 4.35 & 4.8823 & TST & \\
\hline CHEMBL1576457 & 688636 & 4.5 & 4.9457 & TRN & \\
\hline CHEMBL1352931 & 688636 & 4.25 & 5.0648 & TRN & \\
\hline CHEMBL1539414 & 688636 & 4.3 & 4.7366 & TRN & \\
\hline CHEMBL1446674 & 688636 & 4.25 & 4.7203 & TRN & \\
\hline CHEMBL1530274 & 688636 & 4.3 & 5.0118 & TRN & \\
\hline CHEMBL1470627 & 688636 & 4.5 & 4.8439 & TST & \\
\hline CHEMBL1444063 & 688636 & 4.9 & 4.5779 & TRN & \\
\hline CHEMBL3196598 & 688636 & 5.2 & 4.8341 & TRN & \\
\hline CHEMBL1565594 & 688636 & 5.3 & 4.6569 & TRN & \\
\hline CHEMBL1336672 & 688636 & 6.1 & 4.9682 & TRN & \\
\hline CHEMBL 3214406 & 688636 & 4.4 & 4.6291 & TRN & \\
\hline CHEMBL1574408 & 688636 & 5.9 & 4.8813 & TST & \\
\hline CHEMBL1320104 & 688636 & 4.55 & 4.8656 & TRN & \\
\hline CHEMBL1454640 & 688636 & 4.7 & 4.73600 & 0000000001 & TST \\
\hline CHEMBL1563669 & 688636 & 4.45 & 4.9775 & TRN & \\
\hline CHEMBL1429397 & 688636 & 5.15 & 4.80699 & 99999999995 & TRN \\
\hline CHEMBL1404916 & 688636 & 5.45 & 4.7573 & TRN & \\
\hline CHEMBL1386270 & 688636 & 5.8 & 4.8573 & TRN & \\
\hline CHEMBL1545060 & 688636 & 6.7501 & 4.8586 & TRN & \\
\hline CHEMBL1538295 & 688636 & 4.4 & 4.9356 & TRN & \\
\hline CHEMBL3199373 & 688636 & 4.4 & 4.9176 & TST & \\
\hline CHEMBL1305069 & 688636 & 4.45 & 4.6919 & TRN & \\
\hline CHEMBL1371368 & 688636 & 4.25 & 5.02800 & 00000000005 & TRN \\
\hline CHEMBL1348726 & 688636 & 4.25 & 4.7469 & TRN & \\
\hline CHEMBL1387502 & 688636 & 5.4 & 4.8434 & TRN & \\
\hline CHEMBL1455016 & 688636 & 4.45 & 4.6853 & TRN & \\
\hline CHEMBL1539025 & 688636 & 4.5 & 4.79 & TRN & \\
\hline CHEMBL1097687 & 688636 & 4.4 & 4.7276 & TRN & \\
\hline CHEMBL1598520 & 688636 & 4.25 & 4.7696 & TRN & \\
\hline CHEMBL1387164 & 688636 & 4.35 & 4.885 & TST & \\
\hline CHEMBL1440630 & 688636 & 6.7501 & 4.9522 & TRN & \\
\hline CHEMBL1468386 & 688636 & 4.35 & 4.8897 & TST & \\
\hline CHEMBL1346794 & 688636 & 4.4 & 4.7578 & TRN & \\
\hline CHEMBL3216654 & 688636 & 5.45 & 4.8009 & TST & \\
\hline CHEMBL1452342 & 688636 & 5.45 & 4.90300 & 00000000005 & TRN \\
\hline CHEMBL1331503 & 688636 & 5.15 & 4.6369 & TRN & \\
\hline CHEMBL1388120 & 688636 & 6.45 & 4.9061 & TRN & \\
\hline
\end{tabular}




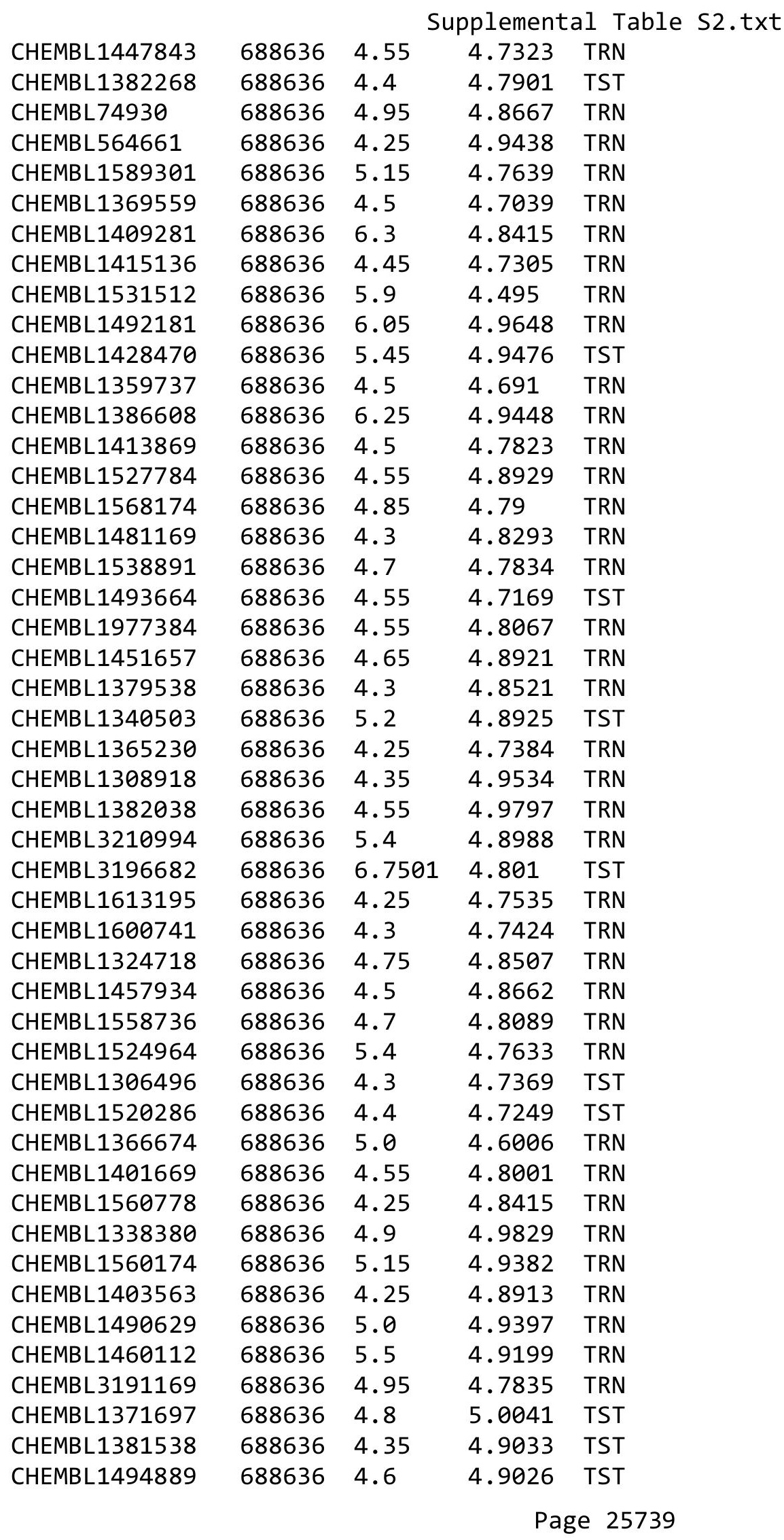




\begin{tabular}{|c|c|c|c|c|}
\hline \multicolumn{5}{|c|}{ Supplemental Table S2.txt } \\
\hline CHEMBL1385608 & 688636 & 4.3 & 4.9603 & TRN \\
\hline CHEMBL3196849 & 688636 & 4.5 & 4.7112 & TST \\
\hline CHEMBL1411140 & 688636 & 5.8 & 4.8083 & TRN \\
\hline CHEMBL1345989 & 688636 & 4.45 & 4.8011 & TRN \\
\hline CHEMBL1612842 & 688636 & 4.6 & 4.957 & TRN \\
\hline CHEMBL3195833 & 688636 & 4.45 & 4.5724 & TRN \\
\hline CHEMBL1332445 & 688636 & 4.25 & 4.8154 & TST \\
\hline CHEMBL1393502 & 688636 & 6.3 & 4.8168 & TRN \\
\hline CHEMBL1510832 & 688636 & 4.25 & 4.7354 & TRN \\
\hline CHEMBL1416184 & 688636 & 6.7001 & 4.7768 & TRN \\
\hline CHEMBL1594896 & 688636 & 4.95 & 5.0205 & TRN \\
\hline CHEMBL1532811 & 688636 & 4.4 & 4.7836 & TRN \\
\hline CHEMBL 3193274 & 688636 & 4.9 & 4.5906 & TRN \\
\hline CHEMBL1575714 & 688636 & 4.3 & 4.68 & TRN \\
\hline CHEMBL1310163 & 688636 & 4.35 & 4.9081 & TST \\
\hline CHEMBL1343400 & 688636 & 4.45 & 4.7523 & TST \\
\hline CHEMBL1338673 & 688636 & 4.35 & 4.8393 & TST \\
\hline CHEMBL1579245 & 688636 & 4.5 & 4.76 & TRN \\
\hline CHEMBL1494711 & 688636 & 4.95 & 4.9397 & TST \\
\hline CHEMBL1574743 & 688636 & 4.8 & 5.0077 & TRN \\
\hline CHEMBL1363133 & 688636 & 4.35 & 4.9639 & TRN \\
\hline CHEMBL1402771 & 688636 & 4.65 & 4.7597 & TRN \\
\hline CHEMBL1385654 & 688636 & 4.55 & 4.5914 & TRN \\
\hline CHEMBL1584508 & 688636 & 5.5 & 4.9062 & TRN \\
\hline CHEMBL1560965 & 688636 & 5.6 & 5.0037 & TST \\
\hline CHEMBL3207529 & 688636 & 4.55 & 4.8096 & TRN \\
\hline CHEMBL1599459 & 688636 & 4.4 & 5.0822 & TRN \\
\hline CHEMBL1427790 & 688636 & 4.35 & 4.7458 & TRN \\
\hline CHEMBL1471584 & 688636 & 4.55 & 4.6629 & TRN \\
\hline CHEMBL1550511 & 688636 & 4.35 & 4.8163 & TRN \\
\hline CHEMBL1331811 & 688636 & 4.8 & 4.801 & TRN \\
\hline CHEMBL 3207782 & 688636 & 4.3 & 4.7064 & TRN \\
\hline CHEMBL1302699 & 688636 & 6.3 & 4.8953 & TRN \\
\hline CHEMBL1310863 & 688636 & 4.3 & 4.668 & TRN \\
\hline CHEMBL1348159 & 688636 & 4.9 & 4.7308 & TST \\
\hline CHEMBL1476084 & 688636 & 4.6 & 4.6761 & TRN \\
\hline CHEMBL1427963 & 688636 & 6.0 & 4.7656 & TRN \\
\hline CHEMBL1546690 & 688636 & 5.45 & 4.8984 & TRN \\
\hline CHEMBL1337416 & 688636 & 4.5 & 4.7077 & TRN \\
\hline CHEMBL 3210451 & 688636 & 4.6 & 4.581 & TRN \\
\hline CHEMBL180162 & 688636 & 4.7 & 4.7711 & TRN \\
\hline CHEMBL1332130 & 688636 & 4.7 & 4.7551 & TST \\
\hline CHEMBL1307468 & 688636 & 5.45 & 4.8603 & TST \\
\hline CHEMBL1527444 & 688636 & 5.2 & 4.8351 & TST \\
\hline CHEMBL1341062 & 688636 & 4.25 & 4.7674 & TST \\
\hline CHEMBL1302494 & 688636 & 4.95 & 4.6114 & TRN \\
\hline CHEMBL1577674 & 688636 & 5.2 & 4.7538 & TRN \\
\hline CHEMBL1555850 & 688636 & 4.25 & 4.8601 & TRN \\
\hline
\end{tabular}




\begin{tabular}{|c|c|c|c|c|c|}
\hline \\
\hline CHEMBL1567908 & 688636 & 4.3 & 4.7468 & TRN & \\
\hline CHEMBL1527360 & 688636 & 4.35 & 4.6353 & TRN & \\
\hline CHEMBL1409462 & 688636 & 4.9 & 4.859 & TRN & \\
\hline CHEMBL1341813 & 688636 & 4.6 & 4.8049 & TRN & \\
\hline CHEMBL1544586 & 688636 & 6.7501 & 4.7018 & TRN & \\
\hline CHEMBL1363308 & 688636 & 4.4 & 4.6927 & TRN & \\
\hline CHEMBL1455361 & 688636 & 4.4 & 4.7587 & TST & \\
\hline CHEMBL1342058 & 688636 & 5.5 & 4.9293 & TRN & \\
\hline CHEMBL3208162 & 688636 & 5.05 & 4.7985 & TRN & \\
\hline CHEMBL1526884 & 688636 & 4.25 & 5.0175 & TRN & \\
\hline CHEMBL1525889 & 688636 & 4.5 & 4.7903 & TST & \\
\hline CHEMBL 203606 & 688636 & 4.3 & 4.9058 & TST & \\
\hline CHEMBL3199070 & 688636 & 4.45 & 4.9058 & TRN & \\
\hline CHEMBL1507525 & 688636 & 4.25 & 4.9248 & TRN & \\
\hline CHEMBL1330520 & 688636 & 4.85 & 4.9664 & TRN & \\
\hline CHEMBL1557003 & 688636 & 4.5 & 4.8806 & TRN & \\
\hline CHEMBL1452409 & 688636 & 4.45 & 4.7445 & TRN & \\
\hline CHEMBL1341055 & 688636 & 4.4 & 4.8506 & TRN & \\
\hline CHEMBL1414665 & 688636 & 4.3 & 4.7528 & TST & \\
\hline CHEMBL1375894 & 688636 & 4.9 & 4.6503 & TST & \\
\hline CHEMBL1338778 & 688636 & 6.05 & 4.9485 & TRN & \\
\hline CHEMBL1504791 & 688636 & 4.25 & 4.8554 & TRN & \\
\hline CHEMBL1471480 & 688636 & 4.3 & 4.8727 & TRN & \\
\hline CHEMBL1361889 & 688636 & 4.7 & 4.8358 & TRN & \\
\hline CHEMBL1547414 & 688636 & 4.45 & 4.8041 & TRN & \\
\hline CHEMBL3189836 & 688636 & 4.4 & 4.691 & TRN & \\
\hline CHEMBL1541623 & 688636 & 5.8 & 4.8791 & TST & \\
\hline CHEMBL1346875 & 688636 & 4.3 & 4.927 & TRN & \\
\hline CHEMBL1571743 & 688636 & 4.4 & 4.96899 & 9999999999 & TRN \\
\hline CHEMBL1421654 & 688636 & 4.35 & 4.7894 & TRN & \\
\hline CHEMBL1306507 & 688636 & 6.0 & 4.7734 & TRN & \\
\hline CHEMBL1507694 & 688636 & 6.05 & 4.9158 & TST & \\
\hline CHEMBL300685 & 688636 & 6.5 & 4.8593 & TRN & \\
\hline CHEMBL1384025 & 688636 & 4.45 & 4.6202 & TRN & \\
\hline CHEMBL1328627 & 688636 & 6.5501 & 4.961 & TRN & \\
\hline CHEMBL1300500 & 688636 & 4.5 & 4.8602 & TRN & \\
\hline CHEMBL1520823 & 688636 & 4.4 & 4.8256 & TST & \\
\hline CHEMBL1403564 & 688636 & 4.45 & 4.6171 & TRN & \\
\hline CHEMBL3210893 & 688636 & 4.25 & 4.7962 & TST & \\
\hline CHEMBL1494473 & 688636 & 5.55 & 4.9922 & TRN & \\
\hline CHEMBL3193873 & 688636 & 4.9 & 4.6828 & TST & \\
\hline CHEMBL1359670 & 688636 & 4.7 & 4.6588 & TRN & \\
\hline CHEMBL 1374556 & 688636 & 4.25 & 4.8073 & TST & \\
\hline CHEMBL1483509 & 688636 & 4.95 & 4.7954 & TST & \\
\hline CHEMBL1498154 & 688636 & 4.55 & 4.9022 & TRN & \\
\hline CHEMBL1464984 & 688636 & 4.65 & 4.862 & TRN & \\
\hline CHEMBL1549060 & 688636 & 4.3 & 4.7471 & TST & \\
\hline CHEMBL1986921 & 688636 & 5.8 & 4.8481 & TRN & \\
\hline
\end{tabular}




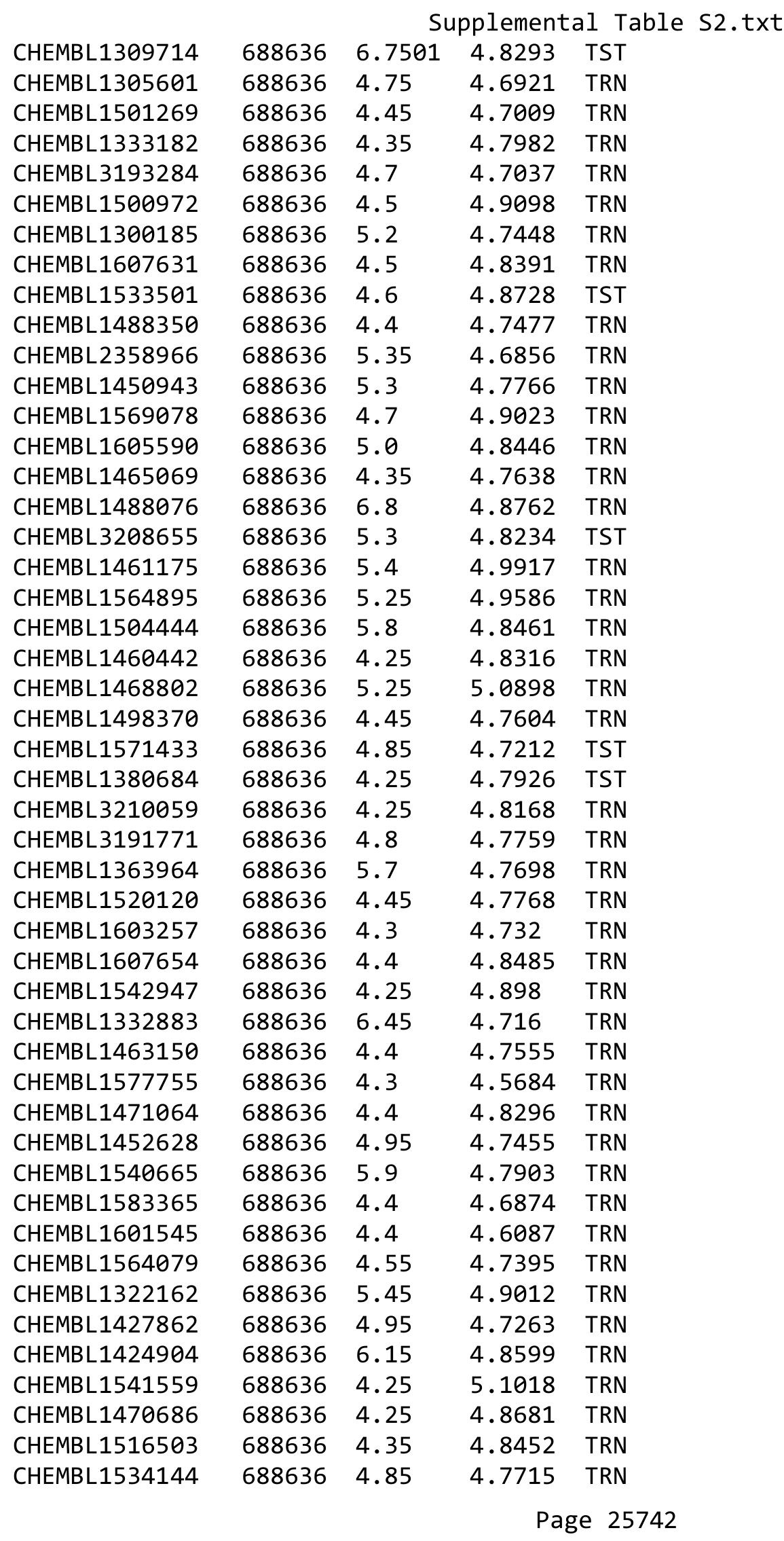




\begin{tabular}{|c|c|c|c|c|}
\hline \multicolumn{5}{|c|}{ Supplemental Table S2.txt } \\
\hline CHEMBL1601646 & 688636 & 5.25 & 4.6946 & TRN \\
\hline CHEMBL1319315 & 688636 & 4.45 & 4.7726 & TRN \\
\hline CHEMBL1470210 & 688636 & 4.45 & 4.8379 & TST \\
\hline CHEMBL1444944 & 688636 & 4.25 & 4.9169 & TRN \\
\hline CHEMBL1575166 & 688636 & 4.55 & 4.7228 & TRN \\
\hline CHEMBL1370790 & 688636 & 4.45 & 4.7083 & TRN \\
\hline CHEMBL1346666 & 688636 & 4.25 & 4.7545 & TRN \\
\hline CHEMBL3196859 & 688636 & 4.55 & 4.66 & TRN \\
\hline CHEMBL1546903 & 688636 & 5.2 & 5.0084 & TRN \\
\hline CHEMBL1416428 & 688636 & 5.25 & 4.8259 & TRN \\
\hline CHEMBL1393181 & 688636 & 4.6 & 4.9427 & TRN \\
\hline CHEMBL1500069 & 688636 & 4.5 & 4.6727 & TRN \\
\hline CHEMBL1613028 & 688636 & 5.45 & 4.7042 & TRN \\
\hline CHEMBL1487256 & 688636 & 4.55 & 4.5697 & TRN \\
\hline CHEMBL1300713 & 688636 & 4.25 & 4.8545 & TRN \\
\hline CHEMBL1562264 & 688636 & 6.8 & 4.8191 & TST \\
\hline CHEMBL1438221 & 688636 & 4.3 & 4.9337 & TRN \\
\hline CHEMBL1537572 & 688636 & 4.35 & 4.7846 & TRN \\
\hline CHEMBL3197978 & 688636 & 4.3 & 4.7257 & TRN \\
\hline CHEMBL1390853 & 688636 & 5.0 & 4.8038 & TST \\
\hline CHEMBL1610833 & 688636 & 5.4 & 4.8299 & TRN \\
\hline CHEMBL1596434 & 688636 & 5.75 & 4.7649 & TRN \\
\hline CHEMBL1380114 & 688636 & 4.5 & 4.8985 & TRN \\
\hline CHEMBL1467404 & 688636 & 4.5 & 4.6975 & TRN \\
\hline CHEMBL1517958 & 688636 & 5.15 & 4.9516 & TRN \\
\hline CHEMBL1336949 & 688636 & 4.4 & 4.7036 & TST \\
\hline CHEMBL1353834 & 688636 & 4.25 & 4.9298 & TRN \\
\hline CHEMBL1504310 & 688636 & 4.65 & 4.7392 & TST \\
\hline CHEMBL1582101 & 688636 & 6.25 & 4.81 & TRN \\
\hline CHEMBL3209163 & 688636 & 5.1 & 4.8618 & TRN \\
\hline CHEMBL1306624 & 688636 & 4.25 & 4.6799 & TST \\
\hline CHEMBL1468119 & 688636 & 6.0 & 4.8848 & TRN \\
\hline CHEMBL1299256 & 688636 & 5.2 & 4.8114 & TST \\
\hline CHEMBL1478435 & 688636 & 4.6 & 4.6356 & TST \\
\hline CHEMBL1409141 & 688636 & 5.9 & 4.8293 & TRN \\
\hline CHEMBL1312251 & 688636 & 4.3 & 4.9186 & TST \\
\hline CHEMBL311226 & 688636 & 4.95 & 5.0158 & TST \\
\hline CHEMBL1304170 & 688636 & 5.55 & 4.8563 & TRN \\
\hline CHEMBL1464085 & 688636 & 6.2 & 4.9629 & TRN \\
\hline CHEMBL1489963 & 688636 & 4.25 & 4.7942 & TRN \\
\hline CHEMBL1406951 & 688636 & 4.5 & 4.849 & TST \\
\hline CHEMBL1300055 & 688636 & 4.25 & 4.6375 & TRN \\
\hline CHEMBL1371863 & 688636 & 5.05 & 4.6424 & TRN \\
\hline CHEMBL3197460 & 688636 & 4.45 & 4.7329 & TRN \\
\hline CHEMBL3196153 & 688636 & 4.45 & 4.734 & TRN \\
\hline CHEMBL1574191 & 688636 & 4.3 & 4.7487 & TST \\
\hline CHEMBL1479927 & 688636 & 5.35 & 4.813 & TST \\
\hline CHEMBL3212379 & 688636 & 4.3 & 4.7528 & TRN \\
\hline
\end{tabular}




\begin{tabular}{|c|c|c|c|c|}
\hline & & & pplement & al $\mathrm{T}$ \\
\hline CHEMBL1523133 & 688636 & 4.65 & 4.6178 & TST \\
\hline CHEMBL3190797 & 688636 & 4.45 & 4.6034 & TRN \\
\hline CHEMBL1505511 & 688636 & 4.45 & 4.8312 & TST \\
\hline CHEMBL1581284 & 688636 & 4.4 & 4.7032 & TRN \\
\hline CHEMBL1529037 & 688636 & 4.3 & 4.6641 & TRN \\
\hline CHEMBL1439877 & 688636 & 5.4 & 4.897 & TST \\
\hline CHEMBL1537216 & 688636 & 4.4 & 4.6213 & TRN \\
\hline CHEMBL1399239 & 688636 & 4.4 & 4.7767 & TRN \\
\hline CHEMBL1443823 & 688636 & 6.7501 & 4.7749 & TRN \\
\hline CHEMBL1343216 & 688636 & 4.35 & 4.6249 & TRN \\
\hline CHEMBL3189629 & 688636 & 6.7501 & 4.867 & TRN \\
\hline CHEMBL1320195 & 688636 & 4.55 & 4.74 & TRN \\
\hline CHEMBL1369107 & 688636 & 4.3 & 4.9496 & TRN \\
\hline CHEMBL 876 & 688636 & 4.95 & 4.8984 & TST \\
\hline CHEMBL3191151 & 688636 & 5.25 & 4.6747 & TST \\
\hline CHEMBL1546597 & 688636 & 4.45 & 4.7376 & TRN \\
\hline CHEMBL1449380 & 688636 & 4.95 & 4.9029 & TRN \\
\hline CHEMBL1430325 & 688636 & 4.25 & 4.7664 & TRN \\
\hline CHEMBL1428476 & 688636 & 4.25 & 4.9497 & TST \\
\hline CHEMBL1568345 & 688636 & 4.75 & 4.7732 & TRN \\
\hline CHEMBL1573162 & 688636 & 4.3 & 4.9367 & TST \\
\hline CHEMBL1587587 & 688636 & 4.95 & 4.751 & TRN \\
\hline CHEMBL1598015 & 688636 & 5.25 & 4.7451 & TRN \\
\hline CHEMBL1605571 & 688636 & 4.5 & 4.7121 & TRN \\
\hline CHEMBL1489726 & 688636 & 5.85 & 5.0098 & TRN \\
\hline CHEMBL1572473 & 688636 & 4.75 & 4.7513 & TRN \\
\hline CHEMBL1385131 & 688636 & 5.9 & 4.7569 & TST \\
\hline CHEMBL1503616 & 688636 & 6.7501 & 4.3859 & TRN \\
\hline CHEMBL1340666 & 688636 & 6.7501 & 4.8708 & TRN \\
\hline CHEMBL1451425 & 688636 & 4.4 & 5.0602 & TRN \\
\hline CHEMBL1350203 & 688636 & 4.6 & 4.8629 & TST \\
\hline CHEMBL1519906 & 688636 & 6.35 & 4.8821 & TST \\
\hline CHEMBL1300244 & 688636 & 4.35 & 4.7998 & TST \\
\hline CHEMBL1555752 & 688636 & 4.5 & 4.7936 & TST \\
\hline CHEMBL1595442 & 688636 & 4.45 & 4.8508 & TST \\
\hline CHEMBL1333153 & 688636 & 5.55 & 4.934 & TST \\
\hline CHEMBL1393186 & 688636 & 4.3 & 4.854 & TST \\
\hline CHEMBL1905960 & 688636 & 4.35 & 4.6653 & TST \\
\hline CHEMBL1470795 & 688636 & 4.45 & 4.9059 & TRN \\
\hline CHEMBL1345676 & 688636 & 5.35 & 5.0871 & TST \\
\hline CHEMBL6390 & 688636 & 4.25 & 4.9175 & TST \\
\hline CHEMBL1352602 & 688636 & 4.45 & 4.6869 & TRN \\
\hline CHEMBL1490023 & 688636 & 6.35 & 5.0026 & TST \\
\hline CHEMBL1447121 & 688636 & 4.25 & 4.9331 & TRN \\
\hline CHEMBL1412271 & 688636 & 4.9 & 4.6043 & TRN \\
\hline CHEMBL1391649 & 688636 & 4.5 & 4.6651 & TRN \\
\hline CHEMBL1348969 & 688636 & 4.75 & 4.6003 & TRN \\
\hline CHEMBL1599848 & 688636 & 4.4 & 4.8584 & TST \\
\hline
\end{tabular}




\begin{tabular}{|c|c|c|c|c|c|}
\hline \multicolumn{6}{|c|}{ Supplemental Table S2.txt } \\
\hline CHEMBL1499149 & 688636 & 4.25 & 4.777 & TST & \\
\hline CHEMBL1541522 & 688636 & 5.15 & 4.9434 & TRN & \\
\hline CHEMBL1366118 & 688636 & 4.45 & 4.7373 & TRN & \\
\hline CHEMBL1601623 & 688636 & 4.4 & 4.7165 & TRN & \\
\hline CHEMBL1406945 & 688636 & 4.6 & 4.757 & TST & \\
\hline CHEMBL1550337 & 688636 & 4.95 & 5.0091 & TST & \\
\hline CHEMBL1372362 & 688636 & 5.65 & 4.6717 & TRN & \\
\hline CHEMBL1547683 & 688636 & 4.6 & 5.0079 & TRN & \\
\hline CHEMBL528492 & 688636 & 6.5 & 4.9275 & TRN & \\
\hline CHEMBL1493763 & 688636 & 4.35 & 4.6564 & TRN & \\
\hline CHEMBL527584 & 688636 & 4.6 & 4.8809 & TRN & \\
\hline CHEMBL1458017 & 688636 & 6.7501 & 4.914 & TST & \\
\hline CHEMBL1306292 & 688636 & 5.5 & 4.8501 & TST & \\
\hline CHEMBL1364645 & 688636 & 4.6 & 4.8926 & TRN & \\
\hline CHEMBL1345688 & 688636 & 5.15 & 4.7893 & TST & \\
\hline CHEMBL1320156 & 688636 & 4.95 & 4.8891 & TST & \\
\hline CHEMBL1459287 & 688636 & 4.95 & 4.9432 & TST & \\
\hline CHEMBL1501407 & 688636 & 4.5 & 4.5917 & TRN & \\
\hline CHEMBL1324203 & 688636 & 4.55 & 4.7082 & TRN & \\
\hline CHEMBL1441977 & 688636 & 4.3 & 4.5796 & TRN & \\
\hline CHEMBL1405208 & 688636 & 4.4 & 4.643 & TST & \\
\hline CHEMBL1597429 & 688636 & 4.95 & 4.8038 & TRN & \\
\hline CHEMBL 3197225 & 688636 & 4.3 & 4.8483 & TRN & \\
\hline CHEMBL1307969 & 688636 & 4.5 & 4.78100 & 0000000001 & TRN \\
\hline CHEMBL1582713 & 688636 & 6.2 & 4.9271 & TRN & \\
\hline CHEMBL1307513 & 688636 & 4.3 & 4.7501 & TST & \\
\hline CHEMBL 3195572 & 688636 & 4.3 & 4.8018 & TRN & \\
\hline CHEMBL1346471 & 688636 & 4.25 & 4.6768 & TRN & \\
\hline CHEMBL1596462 & 688636 & 5.15 & 4.9438 & TRN & \\
\hline CHEMBL1359105 & 688636 & 4.7 & 4.6876 & TRN & \\
\hline CHEMBL1580211 & 688636 & 5.4 & 4.6343 & TRN & \\
\hline CHEMBL1329407 & 688636 & 6.7501 & 4.8979 & TRN & \\
\hline CHEMBL1304260 & 688636 & 6.6499 & 4.9667 & TRN & \\
\hline CHEMBL1465877 & 688636 & 4.35 & 4.7345 & TRN & \\
\hline CHEMBL 3211471 & 688636 & 4.3 & 4.9426 & TST & \\
\hline CHEMBL1493783 & 688636 & 5.25 & 4.7696 & TST & \\
\hline CHEMBL1372265 & 688636 & 4.25 & 4.9225 & TST & \\
\hline CHEMBL1392922 & 688636 & 6.0 & 4.9789 & TRN & \\
\hline CHEMBL1462905 & 688636 & 4.4 & 4.8471 & TRN & \\
\hline CHEMBL1404870 & 688636 & 4.6 & 4.6259 & TRN & \\
\hline CHEMBL1572371 & 688636 & 5.45 & 4.8842 & TRN & \\
\hline CHEMBL1477620 & 688636 & 4.6 & 4.6856 & TRN & \\
\hline CHEMBL1485606 & 688636 & 4.35 & 4.7056 & TST & \\
\hline CHEMBL1579761 & 688636 & 6.1 & 4.963 & TRN & \\
\hline CHEMBL1431150 & 688636 & 5.35 & 4.9275 & TRN & \\
\hline CHEMBL1463795 & 688636 & 4.5 & 4.8152 & TST & \\
\hline CHEMBL1562749 & 688636 & 4.9 & 5.0038 & TRN & \\
\hline CHEMBL1308991 & 688636 & 5.45 & 4.7344 & TST & \\
\hline
\end{tabular}




\begin{tabular}{|c|c|c|c|c|}
\hline \multicolumn{5}{|c|}{ Supplemental Table S2.txt } \\
\hline CHEMBL1605347 & 688636 & 4.25 & 4.9225 & TRN \\
\hline CHEMBL1500113 & 688636 & 4.4 & 4.7658 & TRN \\
\hline CHEMBL1304890 & 688636 & 4.3 & 4.994 & TRN \\
\hline CHEMBL1320247 & 688636 & 4.5 & 4.782 & TRN \\
\hline CHEMBL1501900 & 688636 & 5.4 & 4.721 & TRN \\
\hline CHEMBL1360932 & 688636 & 5.4 & 4.8147 & TRN \\
\hline CHEMBL1464184 & 688636 & 5.35 & 4.9674 & TRN \\
\hline CHEMBL1445192 & 688636 & 4.3 & 4.6873 & TRN \\
\hline CHEMBL1416602 & 688636 & 4.95 & 4.7391 & TRN \\
\hline CHEMBL1361869 & 688636 & 4.5 & 4.7841 & TRN \\
\hline CHEMBL1544781 & 688636 & 4.5 & 5.005 & TRN \\
\hline CHEMBL1331901 & 688636 & 4.55 & 4.7741 & TRN \\
\hline CHEMBL1429833 & 688636 & 4.9 & 5.0281 & TST \\
\hline CHEMBL1300482 & 688636 & 5.0 & 4.8178 & TRN \\
\hline CHEMBL1569825 & 688636 & 6.15 & 4.823 & TRN \\
\hline CHEMBL1497139 & 688636 & 4.3 & 4.7468 & TRN \\
\hline CHEMBL1562294 & 688636 & 4.55 & 4.9335 & TST \\
\hline CHEMBL1493236 & 688636 & 6.7501 & 4.8813 & TRN \\
\hline CHEMBL3195002 & 688636 & 4.55 & 4.7171 & TRN \\
\hline CHEMBL1550074 & 688636 & 4.4 & 4.8666 & TRN \\
\hline CHEMBL1362169 & 688636 & 4.25 & 4.9119 & TRN \\
\hline CHEMBL1321811 & 688636 & 4.5 & 4.8218 & TRN \\
\hline CHEMBL590457 & 688636 & 5.95 & 4.6056 & TST \\
\hline CHEMBL1363833 & 688636 & 4.4 & 4.8723 & TRN \\
\hline CHEMBL1541369 & 688636 & 4.25 & 4.9478 & TRN \\
\hline CHEMBL1389174 & 688636 & 4.6 & 4.6064 & TRN \\
\hline CHEMBL1376741 & 688636 & 4.5 & 4.6959 & TRN \\
\hline CHEMBL1318735 & 688636 & 4.3 & 4.683 & TST \\
\hline CHEMBL1568026 & 688636 & 4.25 & 4.8597 & TST \\
\hline CHEMBL1304204 & 688636 & 6.7501 & 4.7488 & TRN \\
\hline CHEMBL1451865 & 688636 & 4.55 & 4.8785 & TRN \\
\hline CHEMBL1540621 & 688636 & 4.8 & 4.8724 & TRN \\
\hline CHEMBL1498044 & 688636 & 4.6 & 4.8952 & TST \\
\hline CHEMBL1309355 & 688636 & 4.3 & 4.8294 & TST \\
\hline CHEMBL1425462 & 688636 & 4.4 & 4.7415 & TRN \\
\hline CHEMBL3213021 & 688636 & 4.3 & 4.8098 & TST \\
\hline CHEMBL1469789 & 688636 & 4.45 & 4.707 & TST \\
\hline CHEMBL1602732 & 688636 & 6.3 & 4.5974 & TST \\
\hline CHEMBL1373011 & 688636 & 4.6 & 4.7164 & TRN \\
\hline CHEMBL1405193 & 688636 & 4.3 & 4.7119 & TRN \\
\hline CHEMBL1600545 & 688636 & 4.25 & 4.7924 & TRN \\
\hline CHEMBL1561044 & 688636 & 5.3 & 4.9142 & TRN \\
\hline CHEMBL1349645 & 688636 & 5.85 & 4.923 & TRN \\
\hline CHEMBL1472420 & 688636 & 5.2 & 4.7949 & TRN \\
\hline CHEMBL1540252 & 688636 & 4.75 & 4.8384 & TRN \\
\hline CHEMBL1569608 & 688636 & 5.55 & 4.6748 & TRN \\
\hline CHEMBL1369941 & 688636 & 4.95 & 4.851 & TRN \\
\hline CHEMBL1444315 & 688636 & 6.7501 & 4.4982 & TST \\
\hline
\end{tabular}




\begin{tabular}{|c|c|c|c|c|}
\hline & & & upplement & $\mathrm{T}$ \\
\hline CHEMBL1459223 & 688636 & 4.45 & 4.8337 & TRN \\
\hline CHEMBL1388127 & 688636 & 4.4 & 4.8018 & TRN \\
\hline CHEMBL1589879 & 688636 & 4.4 & 4.5992 & TST \\
\hline CHEMBL1388984 & 688636 & 5.4 & 4.9323 & TRN \\
\hline CHEMBL 291083 & 688636 & 4.45 & 4.9666 & TRN \\
\hline CHEMBL1543804 & 688636 & 4.45 & 4.8153 & TRN \\
\hline CHEMBL1379627 & 688636 & 4.25 & 4.7816 & TRN \\
\hline CHEMBL1359066 & 688636 & 4.3 & 4.7974 & TRN \\
\hline CHEMBL1441399 & 688636 & 4.45 & 4.8319 & TRN \\
\hline CHEMBL1480923 & 688636 & 4.3 & 4.8666 & TRN \\
\hline CHEMBL 3211304 & 688636 & 4.25 & 4.7285 & TRN \\
\hline CHEMBL1495401 & 688636 & 5.1 & 4.9478 & TRN \\
\hline CHEMBL1401653 & 688636 & 4.35 & 4.6113 & TST \\
\hline CHEMBL 3212829 & 688636 & 4.55 & 4.6406 & TST \\
\hline CHEMBL3210407 & 688636 & 4.35 & 4.8181 & TRN \\
\hline CHEMBL1472385 & 688636 & 6.0 & 4.8027 & TRN \\
\hline CHEMBL1613285 & 688636 & 4.6 & 4.7938 & TRN \\
\hline CHEMBL 3207620 & 688636 & 5.1 & 5.0415 & TRN \\
\hline CHEMBL1423832 & 688636 & 4.65 & 4.5713 & TRN \\
\hline CHEMBL1457947 & 688636 & 4.4 & 4.8607 & TST \\
\hline CHEMBL1606612 & 688636 & 4.25 & 4.9636 & TRN \\
\hline CHEMBL1516850 & 688636 & 4.45 & 4.7584 & TRN \\
\hline CHEMBL1318377 & 688636 & 4.5 & 4.7054 & TRN \\
\hline CHEMBL1461691 & 688636 & 4.95 & 5.0495 & TRN \\
\hline CHEMBL1343115 & 688636 & 4.65 & 4.8008 & TRN \\
\hline CHEMBL1334764 & 688636 & 4.9 & 4.6655 & TRN \\
\hline CHEMBL3192742 & 688636 & 4.55 & 4.7172 & TRN \\
\hline CHEMBL1539325 & 688636 & 4.5 & 4.7941 & TRN \\
\hline CHEMBL 3199273 & 688636 & 4.95 & 4.7548 & TST \\
\hline CHEMBL 3209164 & 688636 & 4.3 & 4.887 & TRN \\
\hline CHEMBL1549643 & 688636 & 5.9 & 4.9276 & TRN \\
\hline CHEMBL1410963 & 688636 & 4.6 & 4.8866 & TRN \\
\hline CHEMBL1447076 & 688636 & 4.5 & 4.7458 & TRN \\
\hline CHEMBL1547225 & 688636 & 4.3 & 4.8371 & TRN \\
\hline CHEMBL3207829 & 688636 & 4.6 & 4.8953 & TRN \\
\hline CHEMBL1510837 & 688636 & 4.4 & 4.8789 & TRN \\
\hline CHEMBL1362013 & 688636 & 4.6 & 4.6504 & TST \\
\hline CHEMBL1546402 & 688636 & 4.3 & 4.794 & TRN \\
\hline CHEMBL1455721 & 688636 & 5.15 & 4.8869 & TRN \\
\hline CHEMBL1393465 & 688636 & 4.3 & 4.8097 & TRN \\
\hline CHEMBL1302816 & 688636 & 4.25 & 4.7779 & TST \\
\hline CHEMBL1327701 & 688636 & 4.45 & 4.6644 & TRN \\
\hline CHEMBL1438241 & 688636 & 4.35 & 4.882 & TRN \\
\hline CHEMBL1470480 & 688636 & 4.35 & 4.5372 & TRN \\
\hline CHEMBL1602697 & 688636 & 5.4 & 4.7027 & TRN \\
\hline CHEMBL1420768 & 688636 & 4.25 & 4.9998 & TRN \\
\hline CHEMBL1571456 & 688636 & 4.9 & 4.7141 & TRN \\
\hline CHEMBL1496413 & 688636 & 4.35 & 4.8507 & TRN \\
\hline
\end{tabular}




\begin{tabular}{|c|c|c|c|c|}
\hline \multicolumn{5}{|c|}{ Supplemental Table S2.txt } \\
\hline CHEMBL1330213 & 688636 & 5.0 & 4.8491 & TRN \\
\hline CHEMBL1349526 & 688636 & 4.75 & 4.8117 & TST \\
\hline CHEMBL1502014 & 688636 & 4.25 & 4.6055 & TST \\
\hline CHEMBL1570695 & 688636 & 4.75 & 4.8537 & TRN \\
\hline CHEMBL1566900 & 688636 & 4.9 & 4.9688 & TRN \\
\hline CHEMBL1568730 & 688636 & 4.5 & 4.6782 & TST \\
\hline CHEMBL1301731 & 688636 & 4.8 & 4.7042 & TST \\
\hline CHEMBL1558696 & 688636 & 4.95 & 4.8287 & TST \\
\hline CHEMBL1381820 & 688636 & 4.55 & 4.8461 & TST \\
\hline CHEMBL1541347 & 688636 & 4.4 & 4.7044 & TRN \\
\hline CHEMBL1384050 & 688636 & 6.8 & 5.0455 & TRN \\
\hline CHEMBL1432030 & 688636 & 4.45 & 4.5176 & TRN \\
\hline CHEMBL1497386 & 688636 & 4.65 & 4.6907 & TRN \\
\hline CHEMBL1586249 & 688636 & 4.5 & 4.7225 & TRN \\
\hline CHEMBL3192989 & 688636 & 4.65 & 4.8442 & TRN \\
\hline CHEMBL1421313 & 688636 & 6.5501 & 4.9262 & TRN \\
\hline CHEMBL1560925 & 688636 & 5.05 & 4.7381 & TRN \\
\hline CHEMBL1589062 & 688636 & 4.25 & 4.803 & TST \\
\hline CHEMBL 3209112 & 688636 & 4.5 & 4.7155 & TRN \\
\hline CHEMBL1603132 & 688636 & 4.35 & 4.8296 & TRN \\
\hline CHEMBL1993788 & 688636 & 4.25 & 4.8647 & TRN \\
\hline CHEMBL1600765 & 688636 & 4.9 & 4.8063 & TST \\
\hline CHEMBL1481152 & 688636 & 4.9 & 4.877 & TST \\
\hline CHEMBL1566237 & 688636 & 4.65 & 4.6267 & TRN \\
\hline CHEMBL1409366 & 688636 & 4.55 & 4.7793 & TRN \\
\hline CHEMBL1380391 & 688636 & 5.65 & 4.7118 & TRN \\
\hline CHEMBL1347734 & 688636 & 4.55 & 4.5974 & TRN \\
\hline CHEMBL1342708 & 688636 & 4.55 & 4.8167 & TRN \\
\hline CHEMBL1503280 & 688636 & 4.3 & 4.9268 & TRN \\
\hline CHEMBL1609489 & 688636 & 5.1 & 4.8089 & TST \\
\hline CHEMBL1438798 & 688636 & 5.2 & 4.9154 & TRN \\
\hline CHEMBL1310065 & 688636 & 6.6499 & 4.8824 & TRN \\
\hline CHEMBL1478344 & 688636 & 4.3 & 4.6879 & TRN \\
\hline CHEMBL1479799 & 688636 & 5.55 & 4.8334 & TRN \\
\hline CHEMBL1312038 & 688636 & 4.25 & 4.6321 & TRN \\
\hline CHEMBL1575147 & 688636 & 4.7 & 4.7349 & TRN \\
\hline CHEMBL1578635 & 688636 & 5.4 & 4.8114 & TRN \\
\hline CHEMBL1424528 & 688636 & 5.9 & 4.7721 & TRN \\
\hline CHEMBL1462313 & 688636 & 4.95 & 4.8958 & TRN \\
\hline CHEMBL1503262 & 688636 & 4.45 & 4.7691 & TRN \\
\hline CHEMBL30707 & 688636 & 4.5 & 4.6458 & TRN \\
\hline CHEMBL1442620 & 688636 & 5.8 & 4.6486 & TRN \\
\hline CHEMBL1338958 & 688636 & 4.25 & 4.772 & TST \\
\hline CHEMBL1326063 & 688636 & 4.55 & 4.651 & TRN \\
\hline CHEMBL1545267 & 688636 & 6.0 & 4.8975 & TST \\
\hline CHEMBL1545150 & 688636 & 5.95 & 4.7417 & TRN \\
\hline CHEMBL1310214 & 688636 & 6.6 & 5.0027 & TRN \\
\hline CHEMBL1348637 & 688636 & 4.3 & 4.9459 & TRN \\
\hline
\end{tabular}




\begin{tabular}{|c|c|c|c|c|}
\hline & & & prement & \\
\hline CHEMBL1600462 & 688636 & 4.9 & 5.03 & TRN \\
\hline CHEMBL1611749 & 688636 & 5.45 & 5.0349 & TRN \\
\hline CHEMBL1532390 & 688636 & 4.6 & 4.7306 & TRN \\
\hline CHEMBL1418225 & 688636 & 4.4 & 4.7038 & TST \\
\hline CHEMBL1547342 & 688636 & 4.4 & 4.8718 & TRN \\
\hline CHEMBL1391203 & 688636 & 6.7501 & 4.91 & TRN \\
\hline CHEMBL1444916 & 688636 & 5.9 & 4.874 & TRN \\
\hline CHEMBL1460084 & 688636 & 4.55 & 4.8304 & TRN \\
\hline CHEMBL1455352 & 688636 & 6.8 & 4.9043 & TST \\
\hline CHEMBL1588707 & 688636 & 4.6 & 4.4917 & TRN \\
\hline CHEMBL1341892 & 688636 & 4.6 & 4.7577 & TRN \\
\hline CHEMBL1400512 & 688636 & 5.45 & 4.7772 & TST \\
\hline CHEMBL1547632 & 688636 & 4.45 & 4.9554 & TST \\
\hline CHEMBL1588028 & 688636 & 4.3 & 4.774 & TRN \\
\hline CHEMBL1410968 & 688636 & 6.2 & 4.8564 & TRN \\
\hline CHEMBL1484281 & 688636 & 5.15 & 4.8295 & TRN \\
\hline CHEMBL3213782 & 688636 & 4.45 & 4.8177 & TST \\
\hline CHEMBL1202929 & 688636 & 6.8 & 4.8209 & TST \\
\hline CHEMBL1309830 & 688636 & 4.35 & 4.9006 & TRN \\
\hline CHEMBL1437980 & 688636 & 6.8 & 4.9203 & TRN \\
\hline CHEMBL1422655 & 688636 & 5.85 & 4.9557 & TRN \\
\hline CHEMBL1372755 & 688636 & 4.95 & 4.8219 & TRN \\
\hline CHEMBL1387725 & 688636 & 5.05 & 4.6672 & TRN \\
\hline CHEMBL3208585 & 688636 & 4.85 & 4.7364 & TRN \\
\hline CHEMBL1381308 & 688636 & 4.45 & 4.8326 & TRN \\
\hline CHEMBL1510083 & 688636 & 4.95 & 4.8502 & TRN \\
\hline CHEMBL1585438 & 688636 & 4.25 & 4.9379 & TRN \\
\hline CHEMBL1545057 & 688636 & 4.55 & 4.7204 & TRN \\
\hline CHEMBL1348197 & 688636 & 4.45 & 4.7386 & TRN \\
\hline CHEMBL1487525 & 688636 & 5.3 & 4.6252 & TRN \\
\hline CHEMBL1589103 & 688636 & 5.3 & 4.7903 & TRN \\
\hline CHEMBL1484796 & 688636 & 4.25 & 4.8041 & TST \\
\hline CHEMBL1388206 & 688636 & 4.5 & 4.7034 & TRN \\
\hline CHEMBL1550053 & 688636 & 4.9 & 4.6302 & TRN \\
\hline CHEMBL1609216 & 688636 & 4.25 & 4.8718 & TRN \\
\hline CHEMBL3199931 & 688636 & 4.4 & 4.8952 & TRN \\
\hline CHEMBL1526547 & 688636 & 5.3 & 4.9258 & TST \\
\hline CHEMBL1366216 & 688636 & 4.5 & 4.8389 & TRN \\
\hline CHEMBL1432203 & 688636 & 4.4 & 4.6637 & TRN \\
\hline CHEMBL1323170 & 688636 & 4.9 & 4.772 & TRN \\
\hline CHEMBL1448568 & 688636 & 5.65 & 4.6515 & TST \\
\hline CHEMBL1339269 & 688636 & 4.85 & 4.8016 & TST \\
\hline CHEMBL1448053 & 688636 & 5.05 & 4.7971 & TRN \\
\hline CHEMBL536375 & 688636 & 4.3 & 4.8582 & TST \\
\hline CHEMBL1540090 & 688636 & 4.3 & 4.7109 & TRN \\
\hline CHEMBL1431810 & 688636 & 4.4 & 4.7899 & TST \\
\hline CHEMBL1390484 & 688636 & 5.15 & 5.0121 & TST \\
\hline CHEMBL1438836 & 688636 & 4.8 & 4.6655 & TRN \\
\hline
\end{tabular}




\begin{tabular}{|c|c|c|c|c|}
\hline \multicolumn{5}{|c|}{ Supplemental Table S2.txt } \\
\hline CHEMBL1332118 & 688636 & 4.25 & 4.7292 & TRN \\
\hline CHEMBL1432929 & 688636 & 4.65 & 5.0107 & TRN \\
\hline CHEMBL1352294 & 688636 & 4.55 & 4.7456 & TRN \\
\hline CHEMBL1461546 & 688636 & 4.6 & 4.8479 & TRN \\
\hline CHEMBL1462038 & 688636 & 4.45 & 4.8324 & TRN \\
\hline CHEMBL1525395 & 688636 & 4.4 & 4.9453 & TST \\
\hline CHEMBL1313330 & 688636 & 4.45 & 4.8967 & TST \\
\hline CHEMBL1467194 & 688636 & 4.25 & 4.8466 & TST \\
\hline CHEMBL1455119 & 688636 & 5.2 & 4.8557 & TRN \\
\hline CHEMBL1340641 & 688636 & 5.75 & 4.6882 & TST \\
\hline CHEMBL1613250 & 688636 & 4.7 & 4.9184 & TRN \\
\hline CHEMBL1431252 & 688636 & 4.45 & 4.6019 & TRN \\
\hline CHEMBL1500481 & 688636 & 4.55 & 4.8039 & TRN \\
\hline CHEMBL1579211 & 688636 & 6.0 & 4.7411 & TST \\
\hline CHEMBL1484092 & 688636 & 4.6 & 4.811 & TRN \\
\hline CHEMBL1490107 & 688636 & 4.3 & 4.8368 & TRN \\
\hline CHEMBL1518995 & 688636 & 4.4 & 4.6852 & TRN \\
\hline CHEMBL1399360 & 688636 & 4.55 & 4.8072 & TRN \\
\hline CHEMBL1537419 & 688636 & 5.0 & 4.9884 & TRN \\
\hline CHEMBL1343257 & 688636 & 4.85 & 4.8699 & TST \\
\hline CHEMBL1583956 & 688636 & 4.45 & 4.626 & TRN \\
\hline CHEMBL1424687 & 688636 & 4.45 & 4.8865 & TST \\
\hline CHEMBL1335538 & 688636 & 4.9 & 4.9076 & TRN \\
\hline CHEMBL1299437 & 688636 & 4.4 & 4.9049 & TST \\
\hline CHEMBL1573670 & 688636 & 4.8 & 4.8807 & TRN \\
\hline CHEMBL1565765 & 688636 & 4.45 & 4.6147 & TRN \\
\hline CHEMBL1442207 & 688636 & 4.4 & 4.8542 & TRN \\
\hline CHEMBL1568964 & 688636 & 4.25 & 4.8911 & TRN \\
\hline CHEMBL1577601 & 688636 & 4.4 & 4.5771 & TRN \\
\hline CHEMBL1603352 & 688636 & 4.6 & 4.976 & TRN \\
\hline CHEMBL1569063 & 688636 & 6.7501 & 4.9843 & TRN \\
\hline CHEMBL3214145 & 688636 & 4.6 & 4.7075 & TRN \\
\hline CHEMBL1441983 & 688636 & 4.95 & 4.9112 & TRN \\
\hline CHEMBL1458638 & 688636 & 4.45 & 4.6124 & TRN \\
\hline CHEMBL1342463 & 688636 & 4.4 & 4.8353 & TRN \\
\hline CHEMBL1507239 & 688636 & 4.45 & 4.6844 & TRN \\
\hline CHEMBL1385431 & 688636 & 4.25 & 4.9404 & TST \\
\hline CHEMBL1450406 & 688636 & 4.35 & 4.6586 & TRN \\
\hline CHEMBL1411343 & 688636 & 5.4 & 4.8983 & TST \\
\hline CHEMBL1471716 & 688636 & 4.3 & 4.9668 & TRN \\
\hline CHEMBL518575 & 688636 & 4.25 & 4.8456 & TRN \\
\hline CHEMBL1558931 & 688636 & 5.55 & 4.8368 & TRN \\
\hline CHEMBL1479036 & 688636 & 5.55 & 4.7849 & TRN \\
\hline CHEMBL1498239 & 688636 & 6.6499 & 4.7881 & TRN \\
\hline CHEMBL1575559 & 688636 & 4.8 & 4.8333 & TRN \\
\hline CHEMBL1307854 & 688636 & 4.9 & 4.8126 & TRN \\
\hline CHEMBL1332181 & 688636 & 4.25 & 4.7387 & TRN \\
\hline CHEMBL1422476 & 688636 & 4.75 & 4.7899 & TRN \\
\hline
\end{tabular}




\begin{tabular}{|c|c|c|c|c|}
\hline \multicolumn{5}{|c|}{ Supplemental Table S2.txt } \\
\hline CHEMBL1423073 & 688636 & 4.5 & 4.7029 & TRN \\
\hline CHEMBL1556503 & 688636 & 4.55 & 4.7186 & TST \\
\hline CHEMBL1256923 & 688636 & 4.75 & 4.8241 & TST \\
\hline CHEMBL1477099 & 688636 & 4.45 & 4.9295 & TST \\
\hline CHEMBL3191022 & 688636 & 4.5 & 4.6239 & TRN \\
\hline CHEMBL1523846 & 688636 & 4.5 & 4.6477 & TRN \\
\hline CHEMBL1482352 & 688636 & 4.3 & 4.7093 & TST \\
\hline CHEMBL1561030 & 688636 & 4.4 & 4.4265 & TRN \\
\hline CHEMBL1403739 & 688636 & 4.25 & 4.9546 & TST \\
\hline CHEMBL1440729 & 688636 & 4.35 & 4.9016 & TRN \\
\hline CHEMBL1506951 & 688636 & 4.4 & 4.6901 & TST \\
\hline CHEMBL1380834 & 688636 & 4.3 & 4.6254 & TRN \\
\hline CHEMBL1380346 & 688636 & 5.55 & 4.8304 & TST \\
\hline CHEMBL1529294 & 688636 & 4.55 & 4.7856 & TRN \\
\hline CHEMBL1331887 & 688636 & 6.45 & 4.8884 & TRN \\
\hline CHEMBL1561553 & 688636 & 4.6 & 4.8222 & TRN \\
\hline CHEMBL1354019 & 688636 & 4.45 & 4.621 & TRN \\
\hline CHEMBL1546182 & 688636 & 5.4 & 4.5797 & TRN \\
\hline CHEMBL1607458 & 688636 & 4.25 & 4.9042 & TRN \\
\hline CHEMBL1422445 & 688636 & 4.25 & 4.8187 & TRN \\
\hline CHEMBL1339448 & 688636 & 4.4 & 4.8589 & TRN \\
\hline CHEMBL1401502 & 688636 & 4.3 & 4.7467 & TRN \\
\hline CHEMBL1351486 & 688636 & 4.9 & 4.9485 & TRN \\
\hline CHEMBL1309506 & 688636 & 5.55 & 4.835 & TRN \\
\hline CHEMBL1462550 & 688636 & 4.35 & 4.7549 & TRN \\
\hline CHEMBL1506121 & 688636 & 4.3 & 4.8119 & TRN \\
\hline CHEMBL1537298 & 688636 & 5.25 & 4.99 & TST \\
\hline CHEMBL3191353 & 688636 & 5.75 & 4.8606 & TST \\
\hline CHEMBL1604203 & 688636 & 5.25 & 4.9907 & TRN \\
\hline CHEMBL1586981 & 688636 & 4.5 & 4.7022 & TRN \\
\hline CHEMBL 244743 & 688636 & 4.45 & 4.6941 & TST \\
\hline CHEMBL1354020 & 688636 & 4.25 & 4.8648 & TRN \\
\hline CHEMBL1339326 & 688636 & 4.35 & 4.7081 & TRN \\
\hline CHEMBL1481598 & 688636 & 5.0 & 4.8905 & TRN \\
\hline CHEMBL1548081 & 688636 & 5.6 & 5.1226 & TRN \\
\hline CHEMBL1449292 & 688636 & 5.0 & 4.7281 & TRN \\
\hline CHEMBL1498158 & 688636 & 4.95 & 4.8552 & TST \\
\hline CHEMBL1574586 & 688636 & 5.05 & 4.7906 & TRN \\
\hline CHEMBL1309199 & 688636 & 4.5 & 4.9648 & TRN \\
\hline CHEMBL1405631 & 688636 & 4.7 & 4.6647 & TST \\
\hline CHEMBL1538191 & 688636 & 4.95 & 4.96 & TST \\
\hline CHEMBL 3209267 & 688636 & 4.3 & 4.7604 & TRN \\
\hline CHEMBL1494548 & 688636 & 4.3 & 4.7504 & TRN \\
\hline CHEMBL1388001 & 688636 & 5.5 & 4.8836 & TST \\
\hline CHEMBL1429816 & 688636 & 5.5 & 4.8762 & TRN \\
\hline CHEMBL1536483 & 688636 & 4.45 & 4.7911 & TST \\
\hline CHEMBL1483311 & 688636 & 4.3 & 4.8654 & TST \\
\hline CHEMBL1583696 & 688636 & 4.3 & 4.8702 & TRN \\
\hline
\end{tabular}




\begin{tabular}{|c|c|c|c|c|}
\hline \multicolumn{5}{|c|}{ Supplemental Table S2.txt } \\
\hline CHEMBL1601868 & 688636 & 4.55 & 4.7099 & TRN \\
\hline CHEMBL1518602 & 688636 & 4.45 & 4.7009 & TRN \\
\hline CHEMBL1408794 & 688636 & 4.45 & 4.8338 & TRN \\
\hline CHEMBL1540746 & 688636 & 4.4 & 4.8418 & TRN \\
\hline CHEMBL1450035 & 688636 & 4.5 & 4.8362 & TRN \\
\hline CHEMBL1555495 & 688636 & 5.6 & 4.8585 & TST \\
\hline CHEMBL1997195 & 688636 & 4.9 & 4.64 & TRN \\
\hline CHEMBL1415613 & 688636 & 5.5 & 4.9143 & TRN \\
\hline CHEMBL1454079 & 688636 & 4.3 & 4.6292 & TRN \\
\hline CHEMBL585828 & 688636 & 4.5 & 4.9053 & TRN \\
\hline CHEMBL1481166 & 688636 & 4.7 & 4.7801 & TRN \\
\hline CHEMBL1470773 & 688636 & 5.55 & 5.0389 & TRN \\
\hline CHEMBL1576788 & 688636 & 4.55 & 4.737 & TRN \\
\hline CHEMBL1540887 & 688636 & 6.7501 & 4.8704 & TST \\
\hline CHEMBL1450429 & 688636 & 4.45 & 4.7002 & TRN \\
\hline CHEMBL1393887 & 688636 & 6.7501 & 4.8196 & TRN \\
\hline CHEMBL1581096 & 688636 & 4.65 & 4.7597 & TRN \\
\hline CHEMBL1606450 & 688636 & 4.25 & 4.7596 & TRN \\
\hline CHEMBL1342412 & 688636 & 4.3 & 4.8616 & TRN \\
\hline CHEMBL1542359 & 688636 & 4.85 & 5.0128 & TRN \\
\hline CHEMBL1558484 & 688636 & 4.85 & 4.6609 & TRN \\
\hline CHEMBL1414002 & 688636 & 4.25 & 4.8834 & TRN \\
\hline CHEMBL1313888 & 688636 & 4.75 & 4.8371 & TRN \\
\hline CHEMBL1451397 & 688636 & 4.25 & 5.0414 & TRN \\
\hline CHEMBL1492841 & 688636 & 4.3 & 4.7506 & TST \\
\hline CHEMBL1429056 & 688636 & 4.75 & 4.9359 & TST \\
\hline CHEMBL1429558 & 688636 & 4.95 & 5.0004 & TRN \\
\hline CHEMBL1500669 & 688636 & 4.3 & 4.7325 & TRN \\
\hline CHEMBL1328054 & 688636 & 4.3 & 4.7038 & TRN \\
\hline CHEMBL1596975 & 688636 & 5.35 & 4.8391 & TRN \\
\hline CHEMBL1441991 & 688636 & 5.2 & 4.9485 & TRN \\
\hline CHEMBL1345842 & 688636 & 4.25 & 4.891 & TRN \\
\hline CHEMBL1421799 & 688636 & 4.3 & 4.8455 & TRN \\
\hline CHEMBL1599400 & 688636 & 4.45 & 4.7634 & TRN \\
\hline CHEMBL1410737 & 688636 & 4.55 & 4.6963 & TRN \\
\hline CHEMBL1465256 & 688636 & 4.35 & 4.8372 & TRN \\
\hline CHEMBL1325105 & 688636 & 4.25 & 4.9769 & TRN \\
\hline CHEMBL1511397 & 688636 & 4.8 & 4.8383 & TRN \\
\hline CHEMBL1527732 & 688636 & 5.35 & 4.9776 & TRN \\
\hline CHEMBL1324815 & 688636 & 4.55 & 4.9715 & TRN \\
\hline CHEMBL1305254 & 688636 & 4.55 & 4.7779 & TST \\
\hline CHEMBL1531462 & 688636 & 6.25 & 4.6554 & TRN \\
\hline CHEMBL1427096 & 688636 & 4.3 & 4.8646 & TST \\
\hline CHEMBL1490175 & 688636 & 4.45 & 4.7931 & TST \\
\hline CHEMBL1388427 & 688636 & 4.3 & 4.8069 & TST \\
\hline CHEMBL1414425 & 688636 & 4.3 & 4.7706 & TRN \\
\hline CHEMBL1384027 & 688636 & 5.45 & 4.7905 & TRN \\
\hline CHEMBL1535182 & 688636 & 4.45 & 4.6702 & TRN \\
\hline
\end{tabular}




\begin{tabular}{|c|c|c|c|c|c|}
\hline \\
\hline CHEMBL1575385 & 688636 & 4.5 & 4.9632 & TRN & \\
\hline CHEMBL1522478 & 688636 & 4.25 & 5.0001 & TST & \\
\hline CHEMBL1366602 & 688636 & 6.8 & 4.9091 & TRN & \\
\hline CHEMBL1570896 & 688636 & 5.05 & 4.958 & TST & \\
\hline CHEMBL1547388 & 688636 & 4.95 & 4.6836 & TST & \\
\hline CHEMBL1519338 & 688636 & 4.3 & 4.8692 & TRN & \\
\hline CHEMBL1542253 & 688636 & 4.25 & 4.5496 & TRN & \\
\hline CHEMBL246448 & 688636 & 4.35 & 4.717 & TRN & \\
\hline CHEMBL1345509 & 688636 & 4.25 & 4.9275 & TRN & \\
\hline CHEMBL1402996 & 688636 & 4.35 & 4.6191 & TRN & \\
\hline CHEMBL1491901 & 688636 & 5.5 & 5.0954 & TRN & \\
\hline CHEMBL1384195 & 688636 & 4.9 & 4.8845 & TRN & \\
\hline CHEMBL1460801 & 688636 & 4.95 & 5.1564 & TRN & \\
\hline CHEMBL3190799 & 688636 & 4.5 & 4.8265 & TRN & \\
\hline CHEMBL1312081 & 688636 & 4.25 & 4.9658 & TST & \\
\hline CHEMBL1586724 & 688636 & 4.45 & 4.5766 & TRN & \\
\hline CHEMBL1707911 & 688636 & 4.25 & 4.7379 & TRN & \\
\hline CHEMBL1350872 & 688636 & 4.25 & 4.8012 & TRN & \\
\hline CHEMBL1338065 & 688636 & 5.4 & 4.791 & TST & \\
\hline CHEMBL1534873 & 688636 & 4.25 & 4.7879 & TRN & \\
\hline CHEMBL1341887 & 688636 & 6.7501 & 4.7656 & TRN & \\
\hline CHEMBL1350990 & 688636 & 4.85 & 4.8148 & TRN & \\
\hline CHEMBL1448724 & 688636 & 4.45 & 4.8319 & TST & \\
\hline CHEMBL1351988 & 688636 & 6.7001 & 4.8366 & TRN & \\
\hline CHEMBL1334472 & 688636 & 4.3 & 4.7409 & TST & \\
\hline CHEMBL1581326 & 688636 & 4.25 & 4.7694 & TST & \\
\hline CHEMBL1595618 & 688636 & 4.3 & 4.8286 & TRN & \\
\hline CHEMBL1521584 & 688636 & 4.35 & 4.7371 & TRN & \\
\hline CHEMBL1538564 & 688636 & 4.95 & 5.0563 & TST & \\
\hline CHEMBL1308168 & 688636 & 4.3 & 4.7871 & TST & \\
\hline CHEMBL1596957 & 688636 & 4.3 & $4.7860 e$ & 20000000005 & TRN \\
\hline CHEMBL1516976 & 688636 & 4.6 & 4.5691 & TRN & \\
\hline CHEMBL165188 & 688636 & 4.9 & 4.8534 & TRN & \\
\hline CHEMBL1327507 & 688636 & 5.25 & 5.079 & TRN & \\
\hline CHEMBL1341521 & 688636 & 4.55 & 4.6401 & TRN & \\
\hline CHEMBL1446426 & 688636 & 4.45 & 4.8672 & TRN & \\
\hline CHEMBL1332220 & 688636 & 4.5 & 4.6876 & TRN & \\
\hline CHEMBL1351722 & 688636 & 5.65 & 4.6152 & TRN & \\
\hline CHEMBL1401085 & 688636 & 4.3 & 4.8773 & TRN & \\
\hline CHEMBL1448296 & 688636 & 4.4 & 4.8943 & TRN & \\
\hline CHEMBL1577029 & 688636 & 4.45 & 4.7788 & TRN & \\
\hline CHEMBL1539644 & 688636 & 5.9 & 4.8571 & TRN & \\
\hline CHEMBL1455404 & 688636 & 4.55 & 4.6591 & TRN & \\
\hline CHEMBL1561200 & 688636 & 5.15 & 4.9257 & TRN & \\
\hline CHEMBL1499419 & 688636 & 5.2 & 4.8166 & TRN & \\
\hline CHEMBL1406589 & 688636 & 4.75 & 4.7544 & TRN & \\
\hline CHEMBL1523465 & 688636 & 4.3 & 4.6121 & TRN & \\
\hline CHEMBL1451156 & 688636 & 5.65 & 4.8222 & TRN & \\
\hline
\end{tabular}




\begin{tabular}{|c|c|c|c|c|c|}
\hline \\
\hline CHEMBL1360805 & 688636 & 4.5 & 4.8573 & TRN & \\
\hline CHEMBL1530677 & 688636 & 6.7501 & 4.9609 & TST & \\
\hline CHEMBL1425645 & 688636 & 4.3 & 4.8838 & TRN & \\
\hline CHEMBL1457285 & 688636 & 4.45 & 4.8095 & TRN & \\
\hline CHEMBL1424762 & 688636 & 4.5 & 4.8674 & TST & \\
\hline CHEMBL1313035 & 688636 & 6.05 & 5.0627 & TRN & \\
\hline CHEMBL3213517 & 688636 & 4.5 & 4.7612 & TRN & \\
\hline CHEMBL1446313 & 688636 & 4.9 & 4.6742 & TST & \\
\hline CHEMBL1578175 & 688636 & 4.25 & 4.7744 & TST & \\
\hline CHEMBL1509917 & 688636 & 5.25 & 5.0304 & TST & \\
\hline CHEMBL1380037 & 688636 & 5.15 & 4.78600 & 20000000005 & TRN \\
\hline CHEMBL1311887 & 688636 & 4.8 & 4.6708 & TRN & \\
\hline CHEMBL1463911 & 688636 & 4.3 & 4.9246 & TST & \\
\hline CHEMBL3195981 & 688636 & 5.25 & 4.6181 & TRN & \\
\hline CHEMBL1605404 & 688636 & 4.85 & 4.9269 & TST & \\
\hline CHEMBL1382110 & 688636 & 4.4 & 4.7795 & TRN & \\
\hline CHEMBL1538514 & 688636 & 4.6 & 5.0673 & TRN & \\
\hline CHEMBL1390049 & 688636 & 4.55 & 4.8166 & TRN & \\
\hline CHEMBL1415371 & 688636 & 4.55 & 4.6817 & TRN & \\
\hline CHEMBL1400479 & 688636 & 4.25 & 4.9957 & TST & \\
\hline CHEMBL1398824 & 688636 & 4.55 & 4.6738 & TST & \\
\hline CHEMBL1465434 & 688636 & 4.75 & 4.7373 & TRN & \\
\hline CHEMBL1344249 & 688636 & 4.5 & 4.8485 & TRN & \\
\hline CHEMBL1560337 & 688636 & 4.3 & 4.6531 & TRN & \\
\hline CHEMBL1425457 & 688636 & 4.45 & 4.9283 & TRN & \\
\hline CHEMBL1432020 & 688636 & 4.6 & 4.8077 & TRN & \\
\hline CHEMBL1516651 & 688636 & 4.55 & 4.7761 & TST & \\
\hline CHEMBL1536957 & 688636 & 4.45 & 4.6575 & TRN & \\
\hline CHEMBL1392490 & 688636 & 4.5 & 4.7018 & TRN & \\
\hline CHEMBL3208514 & 688636 & 4.7 & 4.8429 & TRN & \\
\hline CHEMBL1392284 & 688636 & 4.3 & 4.9895 & TRN & \\
\hline CHEMBL1463939 & 688636 & 4.3 & 4.7589 & TRN & \\
\hline CHEMBL1586023 & 688636 & 6.15 & 4.9166 & TST & \\
\hline CHEMBL1536467 & 688636 & 5.05 & 4.6983 & TRN & \\
\hline CHEMBL1461530 & 688636 & 6.8 & 4.7813 & TRN & \\
\hline CHEMBL1506480 & 688636 & 4.3 & 4.9985 & TRN & \\
\hline CHEMBL1560139 & 688636 & 4.55 & 4.8966 & TRN & \\
\hline CHEMBL1311145 & 688636 & 4.25 & 4.7618 & TST & \\
\hline CHEMBL1300408 & 688636 & 4.4 & 4.6589 & TRN & \\
\hline CHEMBL1328454 & 688636 & 4.3 & 4.8717 & TRN & \\
\hline CHEMBL1559539 & 688636 & 4.5 & 4.9159 & TRN & \\
\hline CHEMBL1369386 & 688636 & 4.3 & 4.8623 & TRN & \\
\hline CHEMBL1540240 & 688636 & 4.95 & 4.7546 & TRN & \\
\hline CHEMBL1378350 & 688636 & 4.4 & 4.8596 & TRN & \\
\hline CHEMBL1559624 & 688636 & 5.45 & 4.6526 & TRN & \\
\hline CHEMBL1427688 & 688636 & 4.35 & 4.8925 & TST & \\
\hline CHEMBL1380722 & 688636 & 4.55 & 4.7311 & TRN & \\
\hline CHEMBL1499289 & 688636 & 4.75 & 4.8286 & TRN & \\
\hline
\end{tabular}




\begin{tabular}{|c|c|c|c|c|}
\hline \multicolumn{5}{|c|}{ Supplemental Table S2.txt } \\
\hline CHEMBL1549887 & 688636 & 4.25 & 4.9458 & TRN \\
\hline CHEMBL1563060 & 688636 & 4.6 & 4.7968 & TRN \\
\hline CHEMBL1572134 & 688636 & 5.0 & 4.8771 & TRN \\
\hline CHEMBL1462616 & 688636 & 5.8 & 4.7608 & TST \\
\hline CHEMBL1393142 & 688636 & 4.3 & 4.7433 & TRN \\
\hline CHEMBL1527372 & 688636 & 4.3 & 5.0319 & TST \\
\hline CHEMBL1310858 & 688636 & 4.3 & 4.7415 & TRN \\
\hline CHEMBL1352710 & 688636 & 4.25 & 4.8262 & TRN \\
\hline CHEMBL1559029 & 688636 & 6.7501 & 4.8173 & TRN \\
\hline CHEMBL1345125 & 688636 & 6.7501 & 4.8163 & TST \\
\hline CHEMBL1546338 & 688636 & 4.9 & 4.8324 & TRN \\
\hline CHEMBL1603973 & 688636 & 5.05 & 4.9021 & TST \\
\hline CHEMBL1539709 & 688636 & 4.5 & 4.7666 & TRN \\
\hline CHEMBL1603792 & 688636 & 5.45 & 4.7993 & TST \\
\hline CHEMBL1522912 & 688636 & 4.95 & 4.637 & TST \\
\hline CHEMBL1322742 & 688636 & 4.55 & 5.0589 & TRN \\
\hline CHEMBL1446630 & 688636 & 4.45 & 4.7773 & TRN \\
\hline CHEMBL1566068 & 688636 & 5.2 & 4.9658 & TRN \\
\hline CHEMBL1578446 & 688636 & 4.5 & 4.8895 & TRN \\
\hline CHEMBL3197281 & 688636 & 4.35 & 4.7982 & TRN \\
\hline CHEMBL1301572 & 688636 & 4.6 & 4.8555 & TRN \\
\hline CHEMBL1299833 & 688636 & 5.4 & 4.9399 & TRN \\
\hline CHEMBL1524613 & 688636 & 4.45 & 4.5888 & TRN \\
\hline CHEMBL1467156 & 688636 & 4.4 & 4.8438 & TRN \\
\hline CHEMBL1371498 & 688636 & 4.45 & 4.6345 & TRN \\
\hline CHEMBL1540739 & 688636 & 4.4 & 4.7151 & TST \\
\hline CHEMBL1495661 & 688636 & 6.7501 & 4.7315 & TST \\
\hline CHEMBL1511895 & 688636 & 4.45 & 4.7554 & TRN \\
\hline CHEMBL3194589 & 688636 & 4.3 & 4.7082 & TRN \\
\hline CHEMBL1346929 & 688636 & 4.45 & 4.5752 & TRN \\
\hline CHEMBL1563647 & 688636 & 4.5 & 4.729 & TRN \\
\hline CHEMBL1308277 & 688636 & 4.55 & 4.782 & TRN \\
\hline CHEMBL1347736 & 688636 & 4.25 & 4.9195 & TRN \\
\hline CHEMBL1325942 & 688636 & 4.3 & 4.7652 & TST \\
\hline CHEMBL1523946 & 688636 & 4.95 & 4.898 & TST \\
\hline CHEMBL1439060 & 688636 & 6.25 & 4.8814 & TRN \\
\hline CHEMBL1539183 & 688636 & 4.3 & 4.8015 & TRN \\
\hline CHEMBL1299871 & 688636 & 4.45 & 4.7238 & TRN \\
\hline CHEMBL1404134 & 688636 & 4.25 & 4.8852 & TRN \\
\hline CHEMBL1386305 & 688636 & 5.65 & 4.8813 & TRN \\
\hline CHEMBL1429039 & 688636 & 4.3 & 4.7099 & TRN \\
\hline CHEMBL1320164 & 688636 & 4.35 & 4.6603 & TST \\
\hline CHEMBL1597359 & 688636 & 4.65 & 4.768 & TRN \\
\hline CHEMBL1550026 & 688636 & 4.55 & 4.6803 & TRN \\
\hline CHEMBL1507422 & 688636 & 5.1 & 4.7983 & TRN \\
\hline CHEMBL 2142883 & 688636 & 5.8 & 4.7925 & TST \\
\hline CHEMBL1483643 & 688636 & 4.3 & 4.9262 & TRN \\
\hline CHEMBL1468427 & 688636 & 4.6 & 4.7112 & TST \\
\hline
\end{tabular}




\begin{tabular}{|c|c|c|c|c|}
\hline \multicolumn{5}{|c|}{ Supplemental Table S2.txt } \\
\hline CHEMBL1498954 & 688636 & 5.3 & 4.8349 & TRN \\
\hline CHEMBL1498547 & 688636 & 5.25 & 5.0371 & TST \\
\hline CHEMBL3191109 & 688636 & 4.25 & 4.7267 & TRN \\
\hline CHEMBL571295 & 688636 & 6.8 & 4.8606 & TST \\
\hline CHEMBL1546512 & 688636 & 4.5 & 4.8279 & TST \\
\hline CHEMBL3192542 & 688636 & 4.55 & 4.7381 & TST \\
\hline CHEMBL1451950 & 688636 & 4.35 & 4.8964 & TST \\
\hline CHEMBL1594377 & 688636 & 5.2 & 4.9348 & TRN \\
\hline CHEMBL1339703 & 688636 & 4.35 & 4.7851 & TST \\
\hline CHEMBL1519309 & 688636 & 4.25 & 4.9529 & TRN \\
\hline CHEMBL1459532 & 688636 & 4.25 & 4.6035 & TRN \\
\hline CHEMBL1429696 & 688636 & 4.3 & 4.7109 & TRN \\
\hline CHEMBL1303926 & 688636 & 4.85 & 4.9099 & TRN \\
\hline CHEMBL1587254 & 688636 & 5.3 & 4.7869 & TST \\
\hline CHEMBL1595706 & 688636 & 4.45 & 4.5907 & TRN \\
\hline CHEMBL1344490 & 688636 & 5.4 & 4.7947 & TRN \\
\hline CHEMBL1387047 & 688636 & 4.3 & 4.9273 & TRN \\
\hline CHEMBL1331817 & 688636 & 4.55 & 4.6837 & TRN \\
\hline CHEMBL1369812 & 688636 & 4.3 & 4.7782 & TST \\
\hline CHEMBL1571016 & 688636 & 5.35 & 4.8695 & TRN \\
\hline CHEMBL1506021 & 688636 & 4.5 & 4.871 & TST \\
\hline CHEMBL1325981 & 688636 & 4.25 & 4.8161 & TRN \\
\hline CHEMBL1413404 & 688636 & 5.45 & 4.5768 & TRN \\
\hline CHEMBL1373941 & 688636 & 4.95 & 4.5524 & TRN \\
\hline CHEMBL1429669 & 688636 & 4.3 & 4.7524 & TRN \\
\hline CHEMBL1518658 & 688636 & 4.3 & 4.8342 & TRN \\
\hline CHEMBL1478454 & 688636 & 4.4 & 4.8185 & TST \\
\hline CHEMBL1982203 & 688636 & 4.45 & 4.8391 & TRN \\
\hline CHEMBL1373741 & 688636 & 4.4 & 4.8405 & TRN \\
\hline CHEMBL1401142 & 688636 & 5.0 & 5.0148 & TRN \\
\hline CHEMBL1445321 & 688636 & 5.05 & 4.8487 & TRN \\
\hline CHEMBL1611306 & 688636 & 4.4 & 4.9349 & TRN \\
\hline CHEMBL1510669 & 688636 & 5.55 & 4.8619 & TRN \\
\hline CHEMBL1499086 & 688636 & 4.3 & 4.825 & TST \\
\hline CHEMBL1367444 & 688636 & 4.6 & 4.8206 & TRN \\
\hline CHEMBL1537587 & 688636 & 5.0 & 4.7214 & TST \\
\hline CHEMBL1477649 & 688636 & 4.9 & 4.9252 & TRN \\
\hline CHEMBL155563 & 688636 & 4.95 & 4.8333 & TRN \\
\hline CHEMBL1461246 & 688636 & 5.15 & 4.6582 & TRN \\
\hline CHEMBL1428304 & 688636 & 6.05 & 4.9519 & TRN \\
\hline CHEMBL1500874 & 688636 & 4.75 & 4.6754 & TST \\
\hline CHEMBL1305425 & 688636 & 4.6 & 4.6039 & TRN \\
\hline CHEMBL1605847 & 688636 & 4.5 & 4.6948 & TRN \\
\hline CHEMBL1493077 & 688636 & 4.25 & 4.8737 & TRN \\
\hline CHEMBL1303680 & 688636 & 4.35 & 4.7664 & TRN \\
\hline CHEMBL1438733 & 688636 & 4.35 & 4.6918 & TRN \\
\hline CHEMBL1425061 & 688636 & 6.1 & 4.849 & TST \\
\hline CHEMBL1538814 & 688636 & 4.45 & 4.7027 & TRN \\
\hline
\end{tabular}




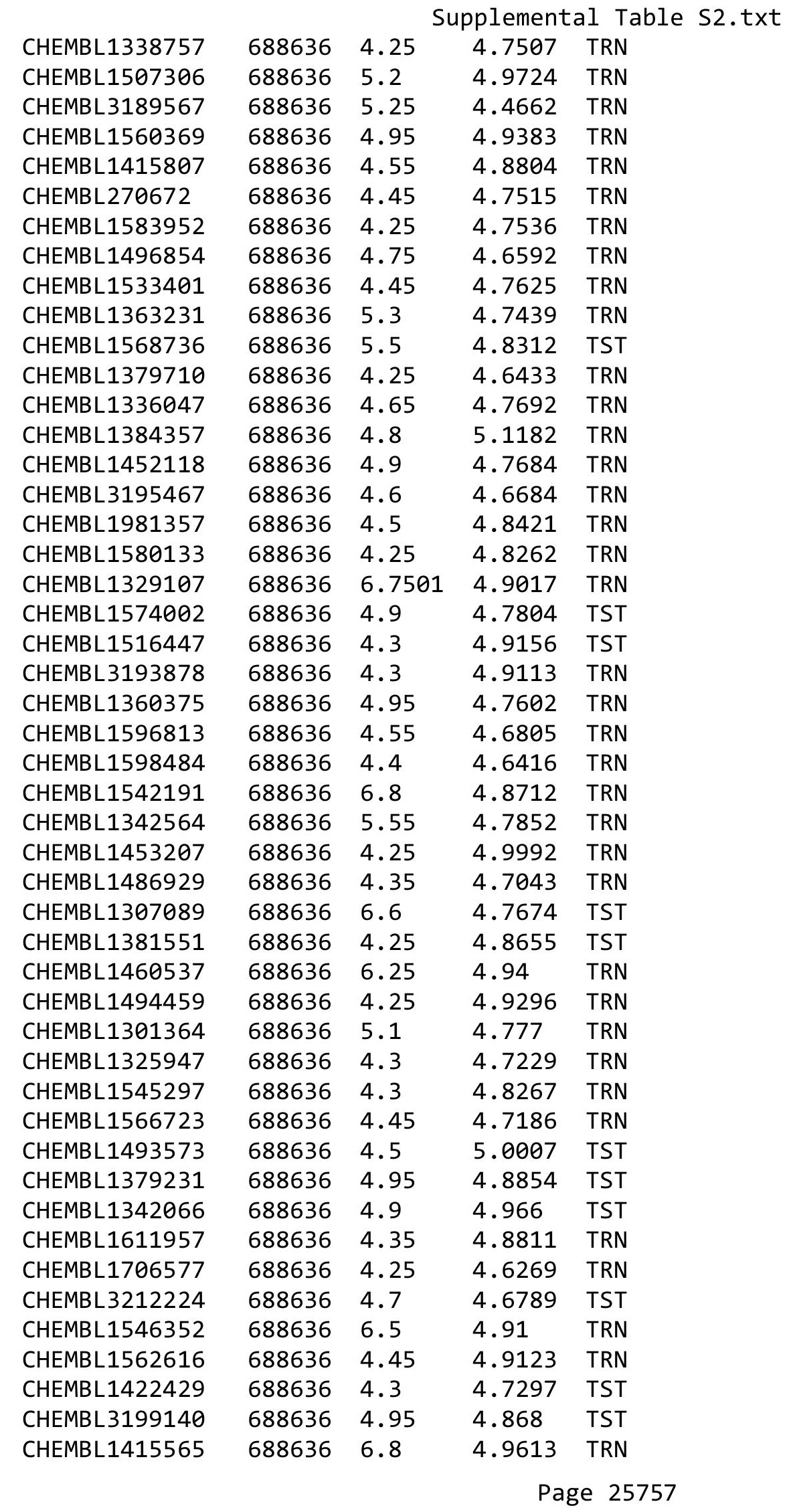




\begin{tabular}{|c|c|c|c|c|}
\hline \multicolumn{5}{|c|}{ Supplemental Table S2.txt } \\
\hline CHEMBL1408447 & 688636 & 4.45 & 4.8392 & TRN \\
\hline CHEMBL1589101 & 688636 & 4.3 & 4.6086 & TRN \\
\hline CHEMBL1503644 & 688636 & 4.55 & 4.7531 & TRN \\
\hline CHEMBL1451902 & 688636 & 4.5 & 4.8151 & TRN \\
\hline CHEMBL1482574 & 688636 & 4.4 & 4.7416 & TRN \\
\hline CHEMBL1493597 & 688636 & 5.25 & 4.8338 & TST \\
\hline CHEMBL 3196137 & 688636 & 4.3 & 4.9518 & TRN \\
\hline CHEMBL1431585 & 688636 & 4.45 & 4.6578 & TST \\
\hline CHEMBL 3192224 & 688636 & 6.7501 & 4.7159 & TST \\
\hline CHEMBL1313757 & 688636 & 4.4 & 4.7184 & TRN \\
\hline CHEMBL1328779 & 688636 & 5.45 & 4.7913 & TRN \\
\hline CHEMBL1539981 & 688636 & 4.3 & 4.7839 & TST \\
\hline CHEMBL1451779 & 688636 & 4.45 & 4.6389 & TRN \\
\hline CHEMBL1567154 & 688636 & 5.0 & 4.6653 & TRN \\
\hline CHEMBL1550441 & 688636 & 4.4 & 4.5153 & TRN \\
\hline CHEMBL1600378 & 688636 & 4.45 & 4.9016 & TRN \\
\hline CHEMBL1525045 & 688636 & 5.4 & 4.6434 & TST \\
\hline CHEMBL1368361 & 688636 & 4.55 & 4.8611 & TRN \\
\hline CHEMBL 3209588 & 688636 & 4.3 & 4.7579 & TRN \\
\hline CHEMBL1999648 & 688636 & 4.55 & 4.7487 & TST \\
\hline CHEMBL1323468 & 688636 & 4.3 & 4.9504 & TRN \\
\hline CHEMBL1403919 & 688636 & 4.95 & 4.6512 & TRN \\
\hline CHEMBL1384429 & 688636 & 4.9 & 4.8148 & TRN \\
\hline CHEMBL1443617 & 688636 & 5.85 & 4.925 & TRN \\
\hline CHEMBL1595724 & 688636 & 6.3 & 4.7663 & TST \\
\hline CHEMBL1509742 & 688636 & 4.4 & 4.745 & TRN \\
\hline CHEMBL1301759 & 688636 & 4.9 & 4.7495 & TST \\
\hline CHEMBL1508691 & 688636 & 4.6 & 4.8812 & TRN \\
\hline CHEMBL1543577 & 688636 & 4.4 & 4.8828 & TRN \\
\hline CHEMBL1579119 & 688636 & 5.75 & 4.8902 & TRN \\
\hline CHEMBL1328373 & 688636 & 5.1 & 4.6157 & TST \\
\hline CHEMBL1350075 & 688636 & 5.1 & 4.8693 & TRN \\
\hline CHEMBL1460295 & 688636 & 4.6 & 4.7868 & TRN \\
\hline CHEMBL1570863 & 688636 & 4.85 & 4.8579 & TRN \\
\hline CHEMBL1330791 & 688636 & 4.9 & 4.9533 & TRN \\
\hline CHEMBL592184 & 688636 & 4.35 & 4.7651 & TRN \\
\hline CHEMBL1486698 & 688636 & 4.6 & 4.6368 & TRN \\
\hline CHEMBL1449117 & 688636 & 5.0 & 4.9225 & TRN \\
\hline CHEMBL1509007 & 688636 & 4.95 & 4.6998 & TRN \\
\hline CHEMBL1415885 & 688636 & 4.25 & 4.8338 & TRN \\
\hline CHEMBL1380657 & 688636 & 5.25 & 5.0904 & TRN \\
\hline CHEMBL1527843 & 688636 & 5.4 & 4.9381 & TST \\
\hline CHEMBL 3197937 & 688636 & 4.95 & 4.6255 & TRN \\
\hline CHEMBL1352200 & 688636 & 4.5 & 4.8744 & TRN \\
\hline CHEMBL1381988 & 688636 & 4.5 & 4.9075 & TST \\
\hline CHEMBL1574108 & 688636 & 4.45 & 4.7928 & TRN \\
\hline CHEMBL 1582730 & 688636 & 4.95 & 4.7337 & TRN \\
\hline CHEMBL1464707 & 688636 & 4.5 & 4.9228 & TST \\
\hline
\end{tabular}




\begin{tabular}{|c|c|c|c|c|}
\hline \multicolumn{5}{|c|}{ Supplemental Table S2.txt } \\
\hline CHEMBL1444460 & 688636 & 4.3 & 4.8098 & TRN \\
\hline CHEMBL1522037 & 688636 & 4.45 & 4.8277 & TRN \\
\hline CHEMBL1531300 & 688636 & 4.9 & 4.7147 & TRN \\
\hline CHEMBL1609860 & 688636 & 4.5 & 4.7502 & TRN \\
\hline CHEMBL1545560 & 688636 & 4.3 & 4.7397 & TRN \\
\hline CHEMBL3214385 & 688636 & 5.45 & 4.7946 & TRN \\
\hline CHEMBL1402718 & 688636 & 5.4 & 4.9343 & TRN \\
\hline CHEMBL1578027 & 688636 & 4.55 & 4.8506 & TRN \\
\hline CHEMBL1574815 & 688636 & 4.5 & 4.9814 & TRN \\
\hline CHEMBL1525212 & 688636 & 4.5 & 4.6129 & TRN \\
\hline CHEMBL1548917 & 688636 & 4.9 & 4.9268 & TST \\
\hline CHEMBL1511698 & 688636 & 4.45 & 4.936 & TRN \\
\hline CHEMBL1489122 & 688636 & 4.5 & 4.8385 & TST \\
\hline CHEMBL1373652 & 688636 & 5.3 & 4.8176 & TRN \\
\hline CHEMBL1459668 & 688636 & 4.3 & 4.8978 & TST \\
\hline CHEMBL1573221 & 688636 & 4.9 & 4.7059 & TRN \\
\hline CHEMBL1337605 & 688636 & 4.65 & 4.6349 & TRN \\
\hline CHEMBL1533840 & 688636 & 4.95 & 4.8154 & TST \\
\hline CHEMBL1565101 & 688636 & 4.5 & 4.8781 & TRN \\
\hline CHEMBL1544295 & 688636 & 4.4 & 4.7145 & TRN \\
\hline CHEMBL1565059 & 688636 & 5.35 & 4.9853 & TRN \\
\hline CHEMBL1596589 & 688636 & 4.55 & 4.7976 & TRN \\
\hline CHEMBL1482493 & 688636 & 4.3 & 4.9328 & TST \\
\hline CHEMBL1522464 & 688636 & 4.9 & 4.5547 & TRN \\
\hline CHEMBL1599872 & 688636 & 6.0 & 4.8675 & TST \\
\hline CHEMBL1380245 & 688636 & 5.9 & 4.8506 & TRN \\
\hline CHEMBL3195218 & 688636 & 4.35 & 4.8335 & TRN \\
\hline CHEMBL1365806 & 688636 & 4.25 & 4.6314 & TRN \\
\hline CHEMBL1306316 & 688636 & 4.3 & 4.8164 & TST \\
\hline CHEMBL1313927 & 688636 & 4.45 & 4.6434 & TRN \\
\hline CHEMBL1543610 & 688636 & 4.3 & 4.7989 & TST \\
\hline CHEMBL1411761 & 688636 & 4.4 & 4.7856 & TRN \\
\hline CHEMBL1428534 & 688636 & 4.9 & 4.8398 & TST \\
\hline CHEMBL1564364 & 688636 & 5.95 & 4.9818 & TRN \\
\hline CHEMBL1490206 & 688636 & 4.25 & 4.9542 & TST \\
\hline CHEMBL1350607 & 688636 & 6.4 & 4.7958 & TRN \\
\hline CHEMBL1505076 & 688636 & 4.45 & 4.7271 & TRN \\
\hline CHEMBL1503686 & 688636 & 4.9 & 4.8593 & TRN \\
\hline CHEMBL1380938 & 688636 & 5.9 & 4.7024 & TRN \\
\hline CHEMBL1582072 & 688636 & 4.95 & 4.8411 & TST \\
\hline CHEMBL1589110 & 688636 & 4.45 & 4.5077 & TRN \\
\hline CHEMBL1519135 & 688636 & 4.45 & 4.8116 & TRN \\
\hline CHEMBL1486331 & 688636 & 4.3 & 4.6679 & TRN \\
\hline CHEMBL1458666 & 688636 & 4.6 & 4.9622 & TST \\
\hline CHEMBL1491482 & 688636 & 4.45 & 5.0177 & TRN \\
\hline CHEMBL1576947 & 688636 & 4.45 & 4.9329 & TRN \\
\hline CHEMBL1540464 & 688636 & 4.45 & 4.7153 & TRN \\
\hline CHEMBL253989 & 688636 & 4.95 & 4.6576 & TST \\
\hline
\end{tabular}




\begin{tabular}{|c|c|c|c|c|c|}
\hline \multirow[b]{2}{*}{ CHEMBL1430567 } & \multicolumn{5}{|c|}{ Supplemental Table S2.txt } \\
\hline & 688636 & 5.55 & 4.7596 & TRN & \\
\hline CHEMBL1308585 & 688636 & 4.6 & 4.66100 & 00000000005 & TRN \\
\hline CHEMBL1572637 & 688636 & 4.45 & 4.6989 & TRN & \\
\hline CHEMBL1602809 & 688636 & 4.3 & 4.8108 & TST & \\
\hline CHEMBL1579720 & 688636 & 4.9 & 5.0128 & TRN & \\
\hline CHEMBL1380468 & 688636 & 5.05 & 4.8126 & TRN & \\
\hline CHEMBL1542049 & 688636 & 4.35 & 4.7042 & TRN & \\
\hline CHEMBL1350883 & 688636 & 4.9 & 4.6634 & TRN & \\
\hline CHEMBL1566534 & 688636 & 4.55 & 4.7331 & TRN & \\
\hline CHEMBL1402047 & 688636 & 4.35 & 4.5376 & TRN & \\
\hline CHEMBL1535157 & 688636 & 4.5 & 4.7751 & TRN & \\
\hline CHEMBL1378685 & 688636 & 4.55 & 4.9648 & TRN & \\
\hline CHEMBL1508671 & 688636 & 4.4 & 4.8277 & TRN & \\
\hline CHEMBL1613480 & 688636 & 4.7 & 4.7867 & TRN & \\
\hline CHEMBL1574561 & 688636 & 4.35 & 4.8329 & TRN & \\
\hline CHEMBL1330917 & 688636 & 4.25 & 4.828 & TRN & \\
\hline CHEMBL3193943 & 688636 & 4.35 & 4.8143 & TRN & \\
\hline CHEMBL1536497 & 688636 & 4.25 & 4.6003 & TRN & \\
\hline CHEMBL1432151 & 688636 & 4.7 & 4.7957 & TRN & \\
\hline CHEMBL1418488 & 688636 & 5.3 & 4.8557 & TRN & \\
\hline CHEMBL1607940 & 688636 & 4.4 & 4.8514 & TRN & \\
\hline CHEMBL1359087 & 688636 & 4.6 & 4.9013 & TRN & \\
\hline CHEMBL3198037 & 688636 & 4.45 & 4.6867 & TRN & \\
\hline CHEMBL1385774 & 688636 & 6.5 & 4.9077 & TST & \\
\hline CHEMBL1398828 & 688636 & 6.8 & 4.8231 & TRN & \\
\hline CHEMBL1570306 & 688636 & 4.3 & 4.9127 & TRN & \\
\hline CHEMBL1386131 & 688636 & 4.95 & 4.8484 & TST & \\
\hline CHEMBL1419217 & 688636 & 4.3 & 4.6088 & TRN & \\
\hline CHEMBL1371776 & 688636 & 4.45 & 4.797 & TRN & \\
\hline CHEMBL592106 & 688636 & 4.3 & 4.8159 & TRN & \\
\hline CHEMBL1460668 & 688636 & 4.25 & 4.7487 & TRN & \\
\hline CHEMBL1358942 & 688636 & 4.3 & 4.7258 & TRN & \\
\hline CHEMBL1432927 & 688636 & 4.45 & 4.7139 & TRN & \\
\hline CHEMBL1519177 & 688636 & 4.25 & 4.8328 & TRN & \\
\hline CHEMBL3191372 & 688636 & 4.45 & 4.9276 & TRN & \\
\hline CHEMBL1429794 & 688636 & 4.55 & 4.5264 & TRN & \\
\hline CHEMBL1564526 & 688636 & 4.3 & 4.8636 & TRN & \\
\hline CHEMBL1378352 & 688636 & 4.4 & 4.7685 & TST & \\
\hline CHEMBL3209646 & 688636 & 4.95 & 4.9319 & TRN & \\
\hline CHEMBL1526168 & 688636 & 4.4 & 4.7085 & TRN & \\
\hline CHEMBL1501156 & 688636 & 5.2 & 4.8861 & TST & \\
\hline CHEMBL1403263 & 688636 & 4.9 & 4.7221 & TRN & \\
\hline CHEMBL1541868 & 688636 & 4.3 & 4.7235 & TRN & \\
\hline CHEMBL1462769 & 688636 & 4.55 & 4.8906 & TRN & \\
\hline CHEMBL 3213014 & 688636 & 4.25 & 4.7817 & TRN & \\
\hline CHEMBL1989636 & 688636 & 4.6 & 4.8074 & TRN & \\
\hline CHEMBL1583076 & 688636 & 4.45 & 4.7585 & TRN & \\
\hline CHEMBL1377048 & 688636 & 4.4 & 4.6006 & TRN & \\
\hline
\end{tabular}




\begin{tabular}{|c|c|c|c|c|}
\hline \\
\hline CHEMBL1450847 & 688636 & 5.4 & 4.9426 & TRN \\
\hline CHEMBL1427931 & 688636 & 4.3 & 4.7156 & TRN \\
\hline CHEMBL1479769 & 688636 & 4.4 & 4.7572 & TRN \\
\hline CHEMBL 3212644 & 688636 & 5.4 & 4.9256 & TST \\
\hline CHEMBL1487615 & 688636 & 5.2 & 4.8372 & TRN \\
\hline CHEMBL3191438 & 688636 & 5.05 & 4.7761 & TRN \\
\hline CHEMBL1415714 & 688636 & 4.95 & 4.8506 & TRN \\
\hline CHEMBL1566329 & 688636 & 4.3 & 4.6645 & TRN \\
\hline CHEMBL1462787 & 688636 & 4.45 & 4.7518 & TRN \\
\hline CHEMBL1470077 & 688636 & 4.55 & 4.7581 & TRN \\
\hline CHEMBL1305201 & 688636 & 5.55 & 4.9218 & TRN \\
\hline CHEMBL1391071 & 688636 & 5.75 & 4.6997 & TRN \\
\hline CHEMBL1320693 & 688636 & 6.7501 & 4.9007 & TRN \\
\hline CHEMBL1321938 & 688636 & 5.25 & 4.6572 & TRN \\
\hline CHEMBL1388706 & 688636 & 5.25 & 4.8562 & TRN \\
\hline CHEMBL1579296 & 688636 & 4.6 & 4.7249 & TRN \\
\hline CHEMBL1448455 & 688636 & 4.25 & 4.9961 & TRN \\
\hline CHEMBL1381936 & 688636 & 5.3 & 5.0217 & TRN \\
\hline CHEMBL3210668 & 688636 & 4.35 & 4.7718 & TST \\
\hline CHEMBL1586301 & 688636 & 4.5 & 4.8925 & TRN \\
\hline CHEMBL1577972 & 688636 & 4.65 & 4.6731 & TRN \\
\hline CHEMBL1393543 & 688636 & 4.25 & 4.9098 & TRN \\
\hline CHEMBL1323789 & 688636 & 4.25 & 4.7935 & TRN \\
\hline CHEMBL1497147 & 688636 & 4.4 & 4.8079 & TRN \\
\hline CHEMBL1565300 & 688636 & 4.55 & 4.8548 & TST \\
\hline CHEMBL3197602 & 688636 & 4.35 & 4.625 & TRN \\
\hline CHEMBL1390729 & 688636 & 4.3 & 4.6713 & TRN \\
\hline CHEMBL1360692 & 688636 & 4.95 & 4.6409 & TST \\
\hline CHEMBL1585979 & 688636 & 4.5 & 4.8796 & TRN \\
\hline CHEMBL1425822 & 688636 & 4.4 & 4.7349 & TRN \\
\hline CHEMBL1346451 & 688636 & 5.2 & 4.7094 & TST \\
\hline CHEMBL1335256 & 688636 & 4.3 & 5.02 & TST \\
\hline CHEMBL 1605742 & 688636 & 4.6 & 4.6861 & TRN \\
\hline CHEMBL1526609 & 688636 & 4.25 & 4.6861 & TRN \\
\hline CHEMBL1511350 & 688636 & 4.7 & 4.8091 & TST \\
\hline CHEMBL3208026 & 688636 & 4.6 & 4.8294 & TRN \\
\hline CHEMBL1441092 & 688636 & 4.85 & 4.7448 & TST \\
\hline CHEMBL 1462370 & 688636 & 4.3 & 4.8591 & TRN \\
\hline CHEMBL1531169 & 688636 & 4.25 & 4.8881 & TST \\
\hline CHEMBL1344411 & 688636 & 4.25 & 4.9035 & TRN \\
\hline CHEMBL1385576 & 688636 & 4.6 & 4.6998 & TRN \\
\hline CHEMBL1380198 & 688636 & 4.95 & 4.7362 & TRN \\
\hline CHEMBL1494672 & 688636 & 4.25 & 4.8856 & TST \\
\hline CHEMBL1505728 & 688636 & 4.3 & 5.0511 & TRN \\
\hline CHEMBL1418678 & 688636 & 4.5 & 4.7824 & TST \\
\hline CHEMBL504791 & 688636 & 4.5 & 4.7742 & TST \\
\hline CHEMBL1523890 & 688636 & 5.9 & 4.6911 & TRN \\
\hline CHEMBL1373517 & 688636 & 4.95 & 4.769 & TST \\
\hline
\end{tabular}




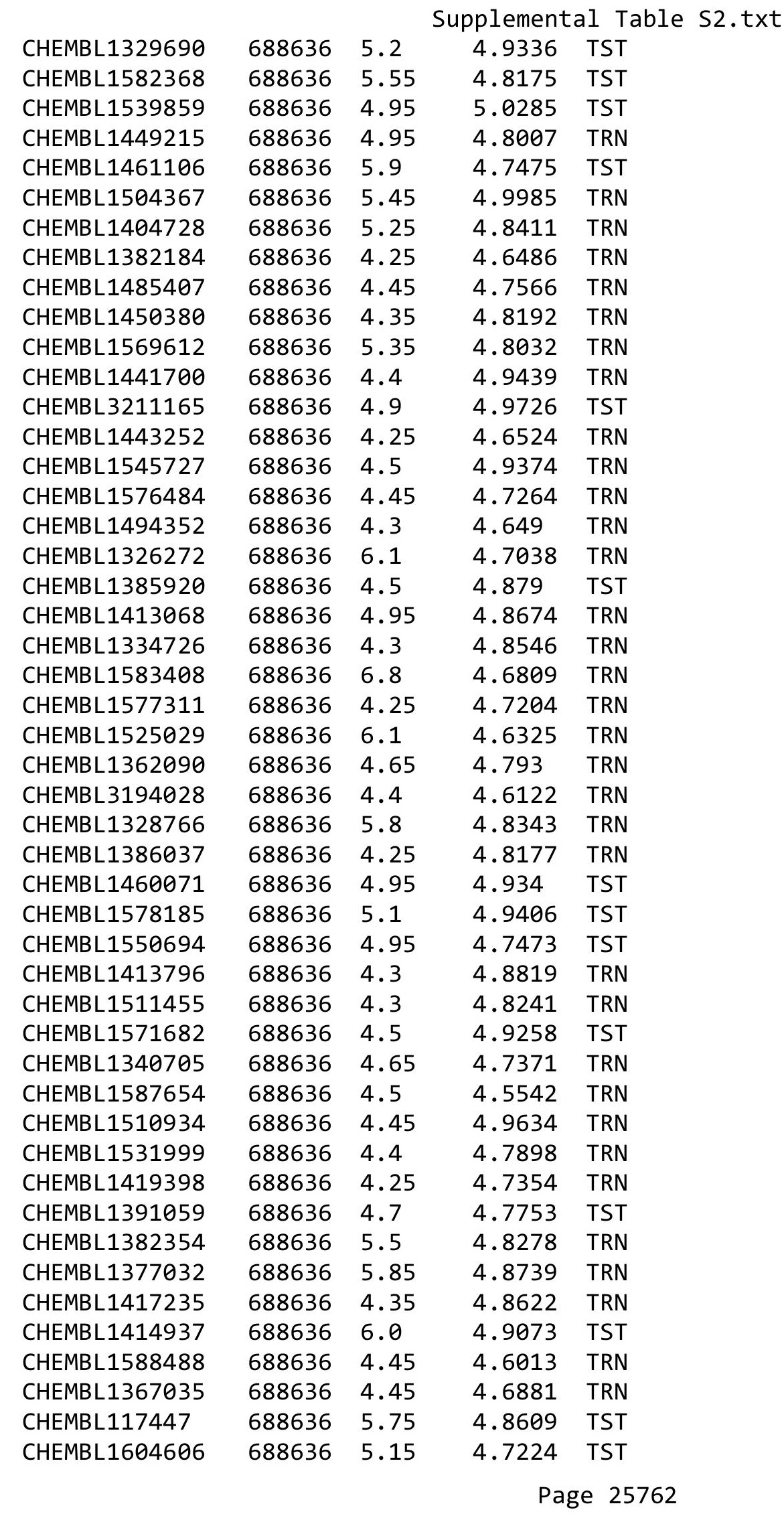




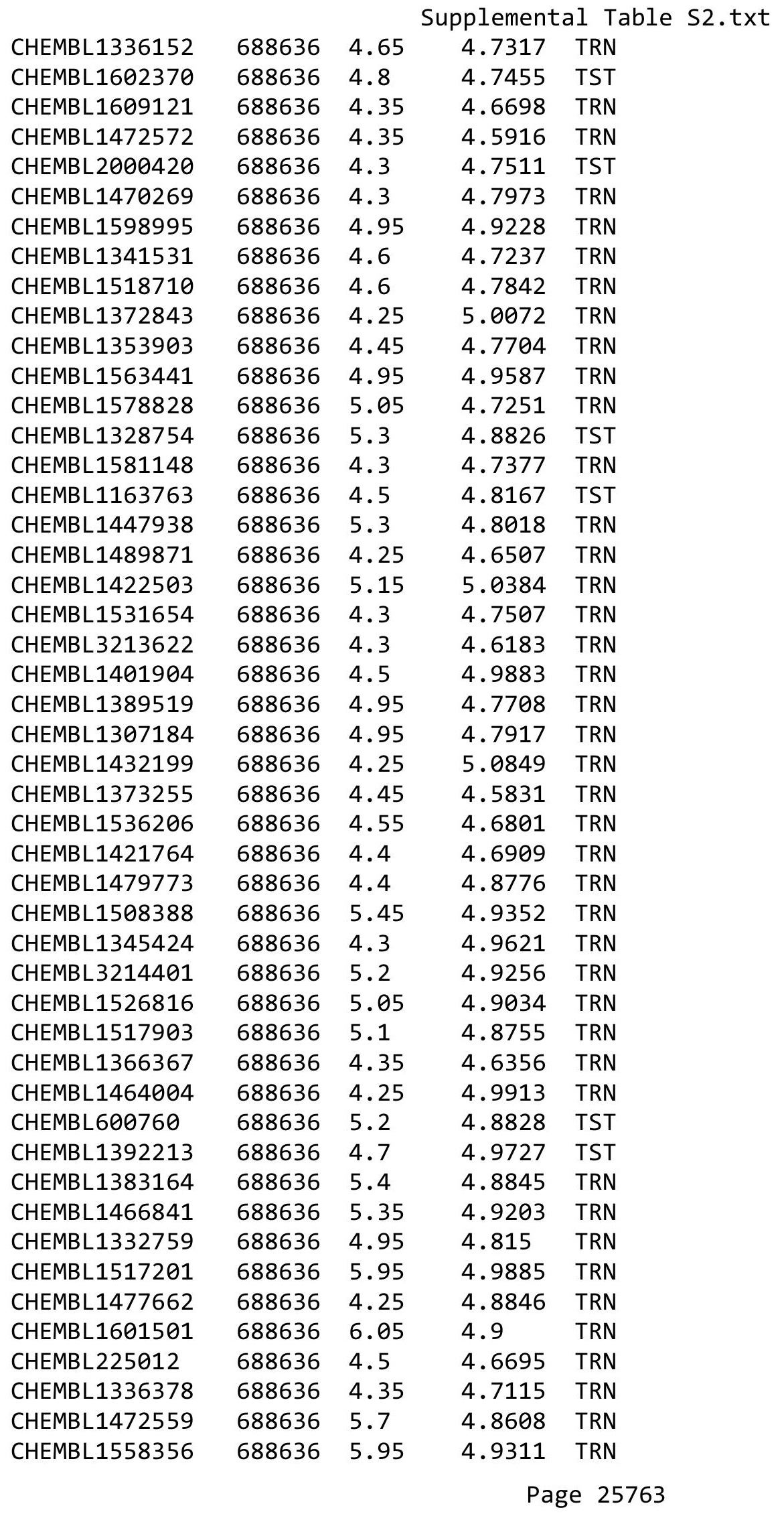




\begin{tabular}{|c|c|c|c|c|}
\hline & & & upplement & al $\mathrm{T}$ \\
\hline CHEMBL1381710 & 688636 & 5.45 & 4.7796 & TST \\
\hline CHEMBL1393104 & 688636 & 4.35 & 4.9288 & TRN \\
\hline CHEMBL1313366 & 688636 & 5.45 & 5.0736 & TRN \\
\hline CHEMBL1372941 & 688636 & 4.3 & 4.9533 & TST \\
\hline CHEMBL3194956 & 688636 & 4.4 & 4.7936 & TST \\
\hline CHEMBL1460887 & 688636 & 6.4 & 5.0081 & TRN \\
\hline CHEMBL1343493 & 688636 & 4.95 & 4.7596 & TST \\
\hline CHEMBL1495361 & 688636 & 5.15 & 4.8821 & TRN \\
\hline CHEMBL1548936 & 688636 & 4.55 & 4.5585 & TRN \\
\hline CHEMBL1547574 & 688636 & 4.45 & 4.7914 & TST \\
\hline CHEMBL 3208763 & 688636 & 4.3 & 4.6744 & TRN \\
\hline CHEMBL1300757 & 688636 & 4.95 & 4.8993 & TST \\
\hline CHEMBL1426240 & 688636 & 4.4 & 4.9425 & TRN \\
\hline CHEMBL1382842 & 688636 & 5.85 & 4.9163 & TRN \\
\hline CHEMBL1583303 & 688636 & 4.4 & 4.9268 & TRN \\
\hline CHEMBL1323694 & 688636 & 5.45 & 4.8436 & TST \\
\hline CHEMBL1545718 & 688636 & 4.95 & 4.8369 & TRN \\
\hline CHEMBL1611081 & 688636 & 4.4 & 4.8467 & TST \\
\hline CHEMBL1095804 & 688636 & 4.5 & 4.6842 & TRN \\
\hline CHEMBL1416484 & 688636 & 4.55 & 4.6611 & TRN \\
\hline CHEMBL1407854 & 688636 & 4.5 & 4.7611 & TRN \\
\hline CHEMBL1458090 & 688636 & 5.35 & 4.96 & TRN \\
\hline CHEMBL1502681 & 688636 & 4.4 & 4.7781 & TRN \\
\hline CHEMBL1376713 & 688636 & 5.0 & 4.8649 & TST \\
\hline CHEMBL1601588 & 688636 & 5.5 & 4.7764 & TRN \\
\hline CHEMBL1455898 & 688636 & 4.45 & 4.6139 & TRN \\
\hline CHEMBL1358899 & 688636 & 5.45 & 4.7174 & TRN \\
\hline CHEMBL 3214441 & 688636 & 4.25 & 4.8024 & TST \\
\hline CHEMBL1564619 & 688636 & 4.25 & 4.9053 & TST \\
\hline CHEMBL1573815 & 688636 & 5.6 & 4.8802 & TRN \\
\hline CHEMBL1313801 & 688636 & 5.35 & 4.8115 & TRN \\
\hline CHEMBL1483453 & 688636 & 4.65 & 4.7819 & TST \\
\hline CHEMBL1584581 & 688636 & 4.55 & 4.8184 & TRN \\
\hline CHEMBL1432540 & 688636 & 4.3 & 4.7421 & TST \\
\hline CHEMBL1461010 & 688636 & 4.25 & 4.7501 & TRN \\
\hline CHEMBL1582281 & 688636 & 4.25 & 4.7322 & TRN \\
\hline CHEMBL1352516 & 688636 & 4.25 & 4.7034 & TRN \\
\hline CHEMBL1577589 & 688636 & 4.95 & 4.8792 & TRN \\
\hline CHEMBL1373402 & 688636 & 4.95 & 4.8177 & TRN \\
\hline CHEMBL1502731 & 688636 & 5.8 & 4.8184 & TRN \\
\hline CHEMBL1582700 & 688636 & 4.8 & 4.8094 & TST \\
\hline CHEMBL1299731 & 688636 & 6.5 & 5.0172 & TRN \\
\hline CHEMBL1325000 & 688636 & 5.15 & 4.9294 & TRN \\
\hline CHEMBL1382568 & 688636 & 4.25 & 4.914 & TRN \\
\hline CHEMBL1416813 & 688636 & 5.2 & 4.9057 & TRN \\
\hline CHEMBL1299586 & 688636 & 4.3 & 4.6025 & TRN \\
\hline CHEMBL1568727 & 688636 & 4.3 & 4.8175 & TRN \\
\hline CHEMBL1531179 & 688636 & 4.95 & 4.828 & TRN \\
\hline
\end{tabular}




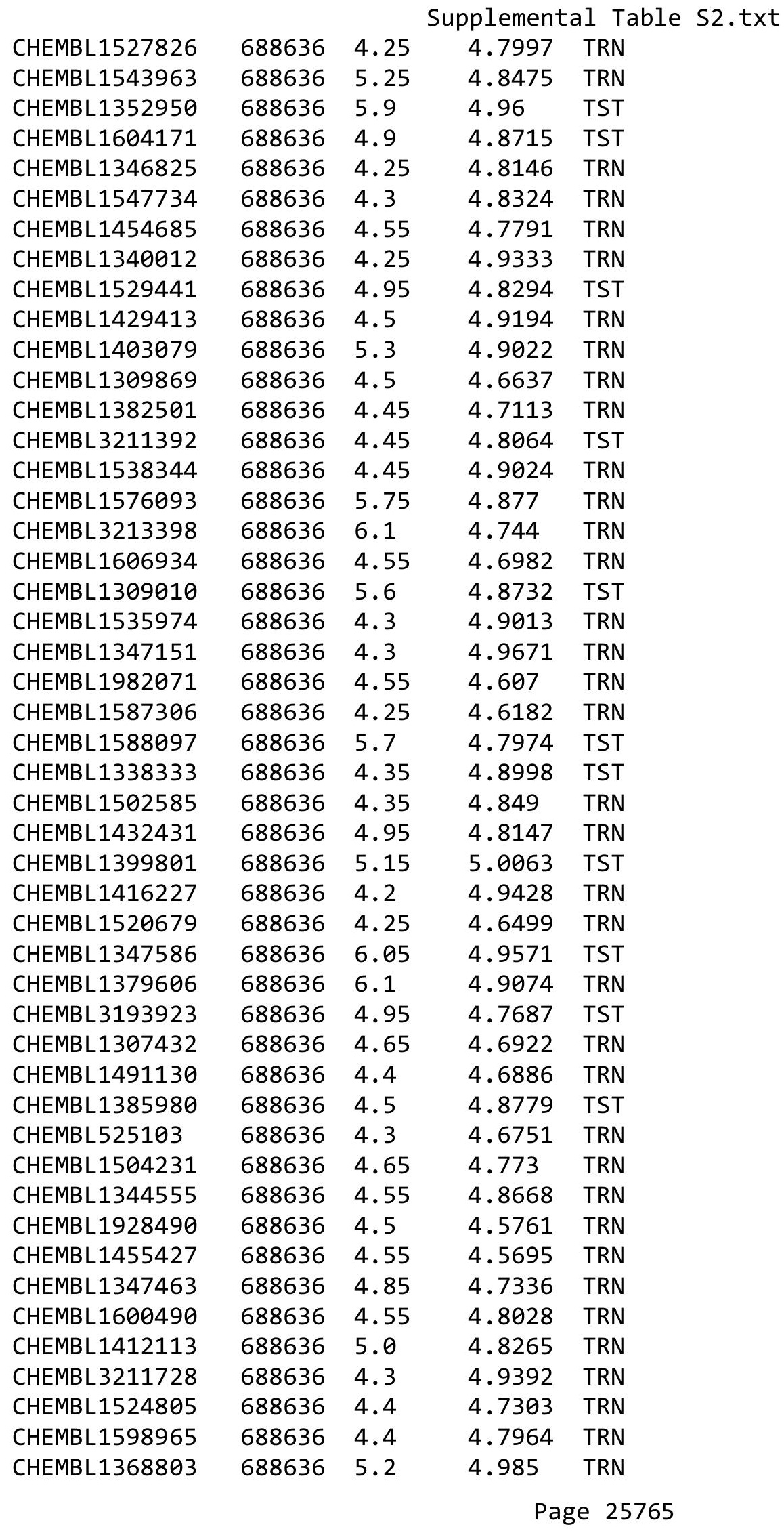




\begin{tabular}{|c|c|c|c|c|}
\hline \multicolumn{5}{|c|}{ Supplemental Table S2.txt } \\
\hline CHEMBL1325487 & 688636 & 5.85 & 4.7849 & TST \\
\hline CHEMBL1487897 & 688636 & 4.95 & 4.6208 & TRN \\
\hline CHEMBL1322374 & 688636 & 4.25 & 4.8835 & TRN \\
\hline CHEMBL1378709 & 688636 & 4.6 & 4.6997 & TST \\
\hline CHEMBL1419836 & 688636 & 4.65 & 4.7887 & TRN \\
\hline CHEMBL1565275 & 688636 & 4.3 & 4.9504 & TRN \\
\hline CHEMBL1388479 & 688636 & 4.75 & 4.8087 & TRN \\
\hline CHEMBL1447673 & 688636 & 4.3 & 4.8951 & TST \\
\hline CHEMBL1481526 & 688636 & 5.85 & 4.8612 & TRN \\
\hline CHEMBL1549197 & 688636 & 4.3 & 4.8607 & TRN \\
\hline CHEMBL1453234 & 688636 & 4.55 & 5.0066 & TRN \\
\hline CHEMBL1488279 & 688636 & 4.45 & 4.6738 & TRN \\
\hline CHEMBL1539672 & 688636 & 4.5 & 4.8264 & TRN \\
\hline CHEMBL1438721 & 688636 & 4.45 & 4.8022 & TRN \\
\hline CHEMBL1309369 & 688636 & 4.25 & 4.8294 & TRN \\
\hline CHEMBL1318797 & 688636 & 4.5 & 4.9047 & TST \\
\hline CHEMBL1570564 & 688636 & 5.3 & 4.7612 & TRN \\
\hline CHEMBL1425785 & 688636 & 5.9 & 4.6803 & TRN \\
\hline CHEMBL1478223 & 688636 & 5.9 & 4.9549 & TRN \\
\hline CHEMBL1324441 & 688636 & 6.7501 & 4.98 & TRN \\
\hline CHEMBL1588593 & 688636 & 5.65 & 4.9299 & TST \\
\hline CHEMBL1370905 & 688636 & 4.65 & 4.9984 & TRN \\
\hline CHEMBL1369340 & 688636 & 4.4 & 4.8288 & TRN \\
\hline CHEMBL499028 & 688636 & 5.4 & 4.9032 & TST \\
\hline CHEMBL1530496 & 688636 & 5.6 & 4.8719 & TST \\
\hline CHEMBL1467928 & 688636 & 4.95 & 4.881 & TST \\
\hline CHEMBL1524622 & 688636 & 4.45 & 4.9476 & TRN \\
\hline CHEMBL1563993 & 688636 & 4.45 & 4.8074 & TRN \\
\hline CHEMBL1470952 & 688636 & 4.25 & 4.6988 & TRN \\
\hline CHEMBL1529824 & 688636 & 4.8 & 4.8868 & TST \\
\hline CHEMBL1362220 & 688636 & 4.6 & 4.9625 & TRN \\
\hline CHEMBL1302175 & 688636 & 4.7 & 4.7455 & TRN \\
\hline CHEMBL1535173 & 688636 & 4.3 & 4.8363 & TRN \\
\hline CHEMBL209101 & 688636 & 4.55 & 4.5909 & TRN \\
\hline CHEMBL1323268 & 688636 & 4.25 & 4.8319 & TRN \\
\hline CHEMBL1324543 & 688636 & 6.6 & 5.103 & TST \\
\hline CHEMBL1489077 & 688636 & 4.5 & 4.7485 & TRN \\
\hline CHEMBL3193730 & 688636 & 4.45 & 4.9286 & TRN \\
\hline CHEMBL1545418 & 688636 & 4.3 & 4.7252 & TRN \\
\hline CHEMBL1430609 & 688636 & 4.3 & 4.8193 & TRN \\
\hline CHEMBL1330714 & 688636 & 4.65 & 4.7713 & TRN \\
\hline CHEMBL1439895 & 688636 & 5.0 & 4.7054 & TRN \\
\hline CHEMBL1518120 & 688636 & 5.05 & 4.8153 & TST \\
\hline CHEMBL1464390 & 688636 & 4.5 & 4.7424 & TRN \\
\hline CHEMBL1439470 & 688636 & 4.5 & 4.8973 & TRN \\
\hline CHEMBL3208639 & 688636 & 4.3 & 4.8559 & TST \\
\hline CHEMBL1456043 & 688636 & 6.8 & 4.8113 & TST \\
\hline CHEMBL1389219 & 688636 & 4.75 & 4.765 & TRN \\
\hline
\end{tabular}




\begin{tabular}{|c|c|c|c|c|}
\hline \multicolumn{5}{|c|}{ Supplemental Table S2.txt } \\
\hline CHEMBL1303580 & 688636 & 4.25 & 4.5016 & TRN \\
\hline CHEMBL1412625 & 688636 & 5.25 & 4.9702 & TST \\
\hline CHEMBL1429949 & 688636 & 4.4 & 4.7085 & TRN \\
\hline CHEMBL600971 & 688636 & 4.3 & 4.6912 & TRN \\
\hline CHEMBL1603717 & 688636 & 5.55 & 4.686 & TRN \\
\hline CHEMBL1548517 & 688636 & 4.3 & 4.8097 & TRN \\
\hline CHEMBL1582268 & 688636 & 6.5501 & 4.8205 & TRN \\
\hline CHEMBL1534629 & 688636 & 4.5 & 4.7161 & TRN \\
\hline CHEMBL1368876 & 688636 & 4.6 & 4.6726 & TRN \\
\hline CHEMBL1596298 & 688636 & 4.3 & 4.93 & TRN \\
\hline CHEMBL1574147 & 688636 & 5.45 & 4.8501 & TRN \\
\hline CHEMBL3208918 & 688636 & 4.3 & 4.7794 & TST \\
\hline CHEMBL602383 & 688636 & 4.45 & 4.5941 & TRN \\
\hline CHEMBL1462695 & 688636 & 4.45 & 4.8415 & TRN \\
\hline CHEMBL1462129 & 688636 & 5.5 & 5.008 & TRN \\
\hline CHEMBL1589378 & 688636 & 5.05 & 4.7261 & TRN \\
\hline CHEMBL1389315 & 688636 & 4.4 & 4.6304 & TRN \\
\hline CHEMBL1322778 & 688636 & 4.7 & 5.0044 & TRN \\
\hline CHEMBL1428652 & 688636 & 4.95 & 4.8877 & TRN \\
\hline CHEMBL1557238 & 688636 & 5.6 & 4.8335 & TRN \\
\hline CHEMBL1502289 & 688636 & 4.85 & 4.7849 & TST \\
\hline CHEMBL1408924 & 688636 & 4.5 & 4.9252 & TRN \\
\hline CHEMBL1353402 & 688636 & 4.35 & 4.923 & TRN \\
\hline CHEMBL1303203 & 688636 & 5.8 & 4.6332 & TRN \\
\hline CHEMBL3193562 & 688636 & 4.55 & 4.942 & TRN \\
\hline CHEMBL1536290 & 688636 & 4.85 & 4.8256 & TST \\
\hline CHEMBL1522737 & 688636 & 5.45 & 4.8825 & TST \\
\hline CHEMBL1504112 & 688636 & 4.45 & 4.7024 & TRN \\
\hline CHEMBL1400666 & 688636 & 4.6 & 4.7579 & TRN \\
\hline CHEMBL1313855 & 688636 & 6.05 & 4.9261 & TST \\
\hline CHEMBL1348564 & 688636 & 5.3 & 4.6793 & TRN \\
\hline CHEMBL1485515 & 688636 & 4.45 & 4.6749 & TRN \\
\hline CHEMBL1466194 & 688636 & 5.1 & 4.9182 & TST \\
\hline CHEMBL1332298 & 688636 & 4.3 & 4.9383 & TST \\
\hline CHEMBL1990057 & 688636 & 4.4 & 4.6876 & TRN \\
\hline CHEMBL1561376 & 688636 & 5.1 & 4.936 & TRN \\
\hline CHEMBL1599914 & 688636 & 4.6 & 4.9636 & TRN \\
\hline CHEMBL399761 & 688636 & 4.3 & 4.8028 & TRN \\
\hline CHEMBL1380881 & 688636 & 5.2 & 4.8176 & TRN \\
\hline CHEMBL1391286 & 688636 & 4.25 & 5.003 & TRN \\
\hline CHEMBL1324850 & 688636 & 4.25 & 4.8223 & TRN \\
\hline CHEMBL1401610 & 688636 & 4.4 & 4.6981 & TRN \\
\hline CHEMBL1410686 & 688636 & 4.5 & 4.6251 & TRN \\
\hline CHEMBL1391423 & 688636 & 4.25 & 4.9921 & TRN \\
\hline CHEMBL1306308 & 688636 & 5.25 & 4.794 & TRN \\
\hline CHEMBL1163279 & 688636 & 4.7 & 4.7653 & TRN \\
\hline CHEMBL3213881 & 688636 & 4.3 & 4.83 & TRN \\
\hline CHEMBL3196015 & 688636 & 4.25 & 4.7248 & TRN \\
\hline
\end{tabular}




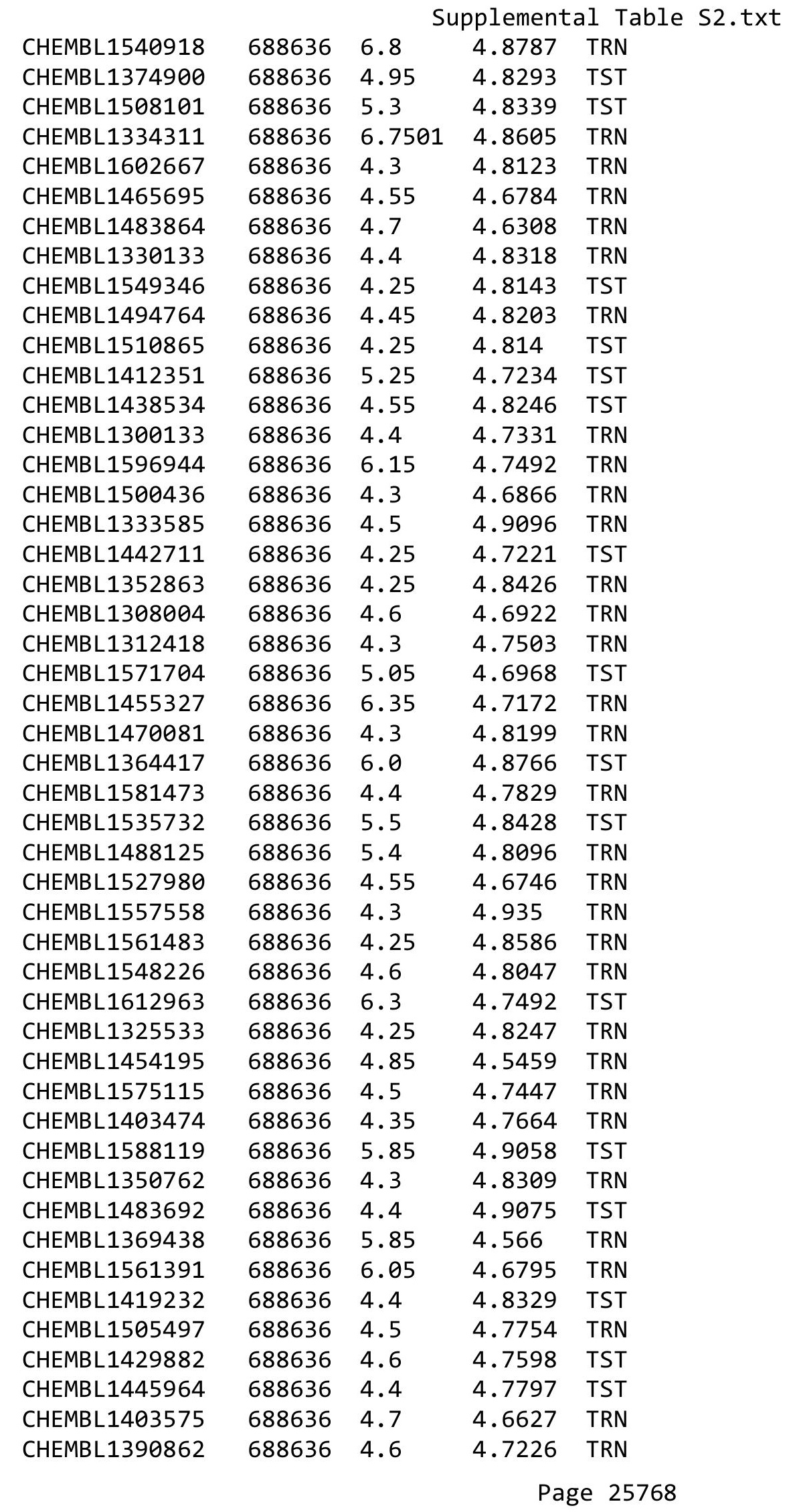




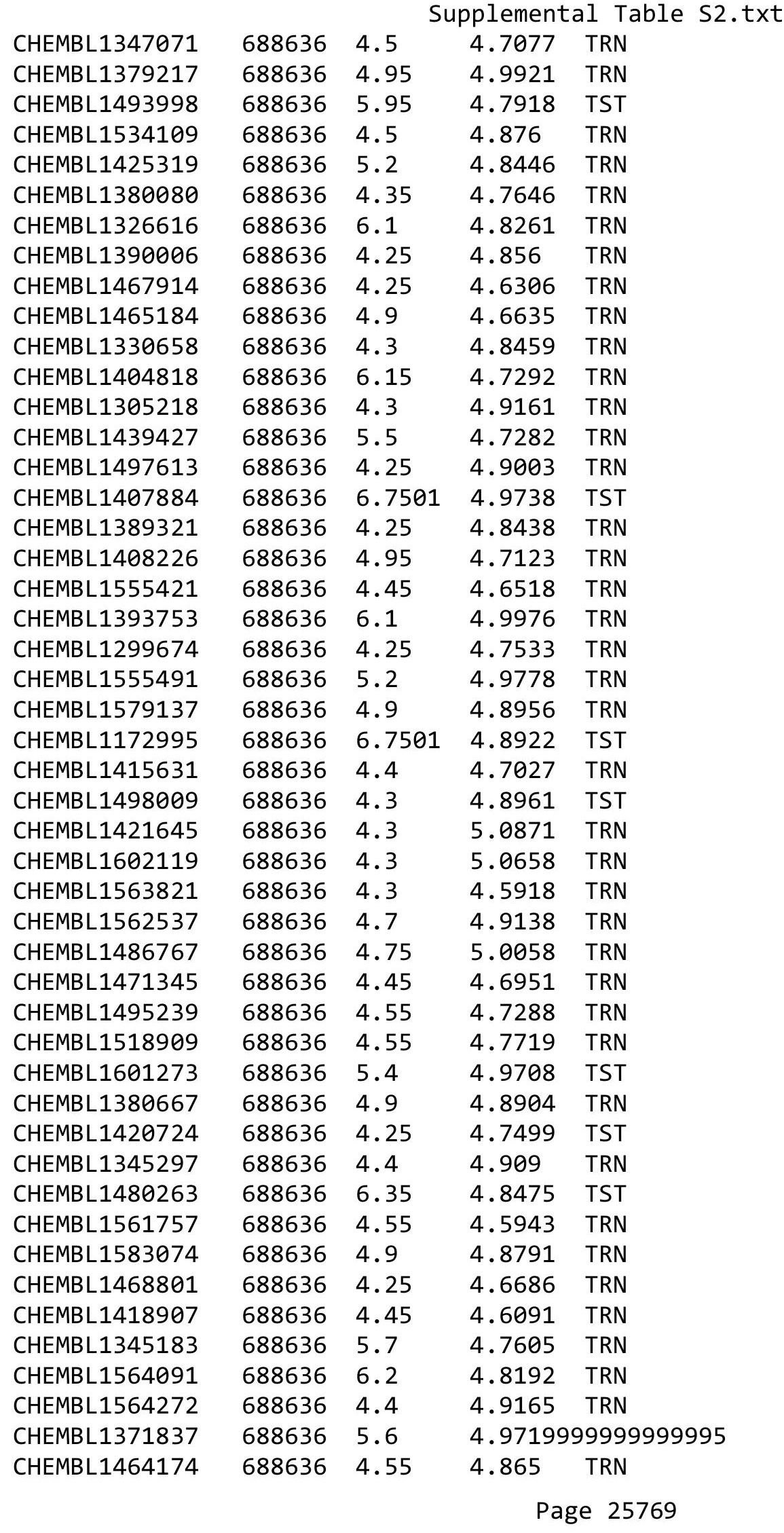




\begin{tabular}{|c|c|c|c|c|c|}
\hline \multicolumn{6}{|c|}{ Supplemental Table S2.txt } \\
\hline CHEMBL 3212100 & 688636 & 5.0 & 4.8077 & TRN & \\
\hline CHEMBL1589171 & 688636 & 4.45 & 4.7043 & TRN & \\
\hline CHEMBL1610634 & 688636 & 4.9 & 4.9284 & TST & \\
\hline CHEMBL1596356 & 688636 & 4.7 & 4.88899 & 9999999999 & TST \\
\hline CHEMBL1405590 & 688636 & 7.0501 & 5.0073 & TRN & \\
\hline CHEMBL1415135 & 688636 & 4.45 & 4.6989 & TRN & \\
\hline CHEMBL1533117 & 688636 & 4.3 & 4.787 & TRN & \\
\hline CHEMBL1464998 & 688636 & 4.4 & 4.9116 & TRN & \\
\hline CHEMBL1420161 & 688636 & 4.5 & 4.8864 & TST & \\
\hline CHEMBL1500298 & 688636 & 4.5 & 4.9659 & TST & \\
\hline CHEMBL1518586 & 688636 & 4.3 & 4.5383 & TRN & \\
\hline CHEMBL1383903 & 688636 & 5.25 & 4.9022 & TRN & \\
\hline CHEMBL1446463 & 688636 & 4.55 & 4.6792 & TRN & \\
\hline CHEMBL1426956 & 688636 & 5.15 & 4.6904 & TST & \\
\hline CHEMBL1527587 & 688636 & 5.5 & 4.8132 & TST & \\
\hline CHEMBL3210807 & 688636 & 5.05 & 4.8069 & TRN & \\
\hline CHEMBL1595127 & 688636 & 4.4 & 4.7426 & TRN & \\
\hline CHEMBL1499444 & 688636 & 4.3 & 4.6591 & TST & \\
\hline CHEMBL1323374 & 688636 & 4.3 & 4.8779 & TRN & \\
\hline CHEMBL1333500 & 688636 & 4.5 & 4.8671 & TRN & \\
\hline CHEMBL1481411 & 688636 & 5.2 & 4.95 & TRN & \\
\hline CHEMBL1341766 & 688636 & 5.5 & 5.1239 & TRN & \\
\hline CHEMBL1492684 & 688636 & 4.45 & 4.7511 & TRN & \\
\hline CHEMBL1510331 & 688636 & 4.6 & 4.5776 & TRN & \\
\hline CHEMBL3192974 & 688636 & 5.25 & 4.7577 & TRN & \\
\hline CHEMBL1580903 & 688636 & 4.3 & 4.9118 & TRN & \\
\hline CHEMBL1532017 & 688636 & 4.45 & 4.6087 & TRN & \\
\hline CHEMBL1380710 & 688636 & 6.1 & 4.9092 & TST & \\
\hline CHEMBL1495143 & 688636 & 5.55 & 4.7179 & TST & \\
\hline CHEMBL1519530 & 688636 & 5.15 & 4.7148 & TRN & \\
\hline CHEMBL1511325 & 688636 & 4.35 & 4.8279 & TST & \\
\hline CHEMBL1422076 & 688636 & 4.3 & 4.7525 & TRN & \\
\hline CHEMBL1401098 & 688636 & 4.95 & 4.7325 & TRN & \\
\hline CHEMBL1613375 & 688636 & 4.3 & 4.7591 & TRN & \\
\hline CHEMBL1544652 & 688636 & 4.45 & 4.7372 & TST & \\
\hline CHEMBL1342534 & 688636 & 4.9 & 4.8511 & TRN & \\
\hline CHEMBL1518880 & 688636 & 4.95 & 4.9106 & TRN & \\
\hline CHEMBL585591 & 688636 & 4.7 & 4.6641 & TST & \\
\hline CHEMBL1466355 & 688636 & 4.3 & 4.9014 & TRN & \\
\hline CHEMBL1428278 & 688636 & 4.3 & 4.765 & TRN & \\
\hline CHEMBL1495362 & 688636 & 4.25 & 4.7801 & TST & \\
\hline CHEMBL1468043 & 688636 & 5.7 & 4.6535 & TRN & \\
\hline CHEMBL1500570 & 688636 & 4.45 & 4.6999 & TRN & \\
\hline CHEMBL1342296 & 688636 & 5.2 & 4.7598 & TST & \\
\hline CHEMBL1526538 & 688636 & 4.25 & 4.7992 & TRN & \\
\hline CHEMBL1382670 & 688636 & 4.4 & 4.7395 & TRN & \\
\hline CHEMBL1496972 & 688636 & 4.3 & 4.8143 & TRN & \\
\hline CHEMBL1467445 & 688636 & 4.5 & 4.7875 & TRN & \\
\hline
\end{tabular}




\begin{tabular}{|c|c|c|c|c|}
\hline \multicolumn{5}{|c|}{ Supplemental Table S2.txt } \\
\hline CHEMBL3198146 & 688636 & 4.95 & 4.9875 & TRN \\
\hline CHEMBL1500973 & 688636 & 4.25 & 4.8113 & TST \\
\hline CHEMBL1482002 & 688636 & 4.55 & 4.7138 & TRN \\
\hline CHEMBL1446312 & 688636 & 5.85 & 5.0049 & TST \\
\hline CHEMBL1572194 & 688636 & 4.4 & 4.8235 & TRN \\
\hline CHEMBL1600772 & 688636 & 4.3 & 4.8716 & TST \\
\hline CHEMBL1603490 & 688636 & 4.3 & 4.7726 & TRN \\
\hline CHEMBL1447870 & 688636 & 4.45 & 4.6767 & TRN \\
\hline CHEMBL1422678 & 688636 & 6.0 & 4.6525 & TRN \\
\hline CHEMBL1305678 & 688636 & 4.25 & 4.6952 & TRN \\
\hline CHEMBL1367222 & 688636 & 4.3 & 4.5775 & TRN \\
\hline CHEMBL1390734 & 688636 & 4.65 & 4.7314 & TRN \\
\hline CHEMBL1329225 & 688636 & 4.55 & 4.738 & TRN \\
\hline CHEMBL1522181 & 688636 & 4.95 & 4.8194 & TRN \\
\hline CHEMBL1441379 & 688636 & 4.7 & 4.9559 & TST \\
\hline CHEMBL1374761 & 688636 & 4.95 & 4.9554 & TRN \\
\hline CHEMBL1569238 & 688636 & 4.3 & 4.7277 & TST \\
\hline CHEMBL1402614 & 688636 & 6.0 & 4.7227 & TST \\
\hline CHEMBL1413554 & 688636 & 4.95 & 4.7508 & TRN \\
\hline CHEMBL1499569 & 688636 & 4.55 & 4.9014 & TST \\
\hline CHEMBL1602857 & 688636 & 4.3 & 4.7348 & TRN \\
\hline CHEMBL1485296 & 688636 & 4.85 & 4.7859 & TST \\
\hline CHEMBL1548783 & 688636 & 4.3 & 4.5769 & TRN \\
\hline CHEMBL1449075 & 688636 & 4.25 & 4.8039 & TST \\
\hline CHEMBL1524496 & 688636 & 5.15 & 4.8474 & TRN \\
\hline CHEMBL1526993 & 688636 & 5.4 & 5.0188 & TRN \\
\hline CHEMBL3211830 & 688636 & 5.15 & 4.6567 & TRN \\
\hline CHEMBL1589233 & 688636 & 4.9 & 4.7465 & TRN \\
\hline CHEMBL1305537 & 688636 & 4.45 & 4.7061 & TRN \\
\hline CHEMBL1305505 & 688636 & 5.15 & 4.7046 & TST \\
\hline CHEMBL1360443 & 688636 & 4.3 & 5.0418 & TRN \\
\hline CHEMBL1543165 & 688636 & 4.95 & 4.8236 & TRN \\
\hline CHEMBL1581575 & 688636 & 4.95 & 4.9021 & TST \\
\hline CHEMBL1540367 & 688636 & 4.25 & 4.8941 & TRN \\
\hline CHEMBL1406916 & 688636 & 6.2 & 4.966 & TRN \\
\hline CHEMBL1545873 & 688636 & 4.3 & 4.5579 & TST \\
\hline CHEMBL1457571 & 688636 & 4.55 & 4.7899 & TRN \\
\hline CHEMBL1382827 & 688636 & 5.15 & 4.5153 & TRN \\
\hline CHEMBL3195373 & 688636 & 5.65 & 4.7521 & TRN \\
\hline CHEMBL1567574 & 688636 & 4.9 & 4.9242 & TRN \\
\hline CHEMBL1604736 & 688636 & 4.3 & 4.8009 & TRN \\
\hline CHEMBL1468823 & 688636 & 6.4 & 5.019 & TRN \\
\hline CHEMBL1359315 & 688636 & 4.25 & 4.9593 & TRN \\
\hline CHEMBL1485819 & 688636 & 4.95 & 4.8936 & TST \\
\hline CHEMBL1602273 & 688636 & 4.3 & 4.8651 & TST \\
\hline CHEMBL1303774 & 688636 & 4.3 & 5.0554 & TST \\
\hline CHEMBL1558249 & 688636 & 4.9 & 4.7355 & TRN \\
\hline CHEMBL1342136 & 688636 & 4.45 & 4.8506 & TRN \\
\hline
\end{tabular}




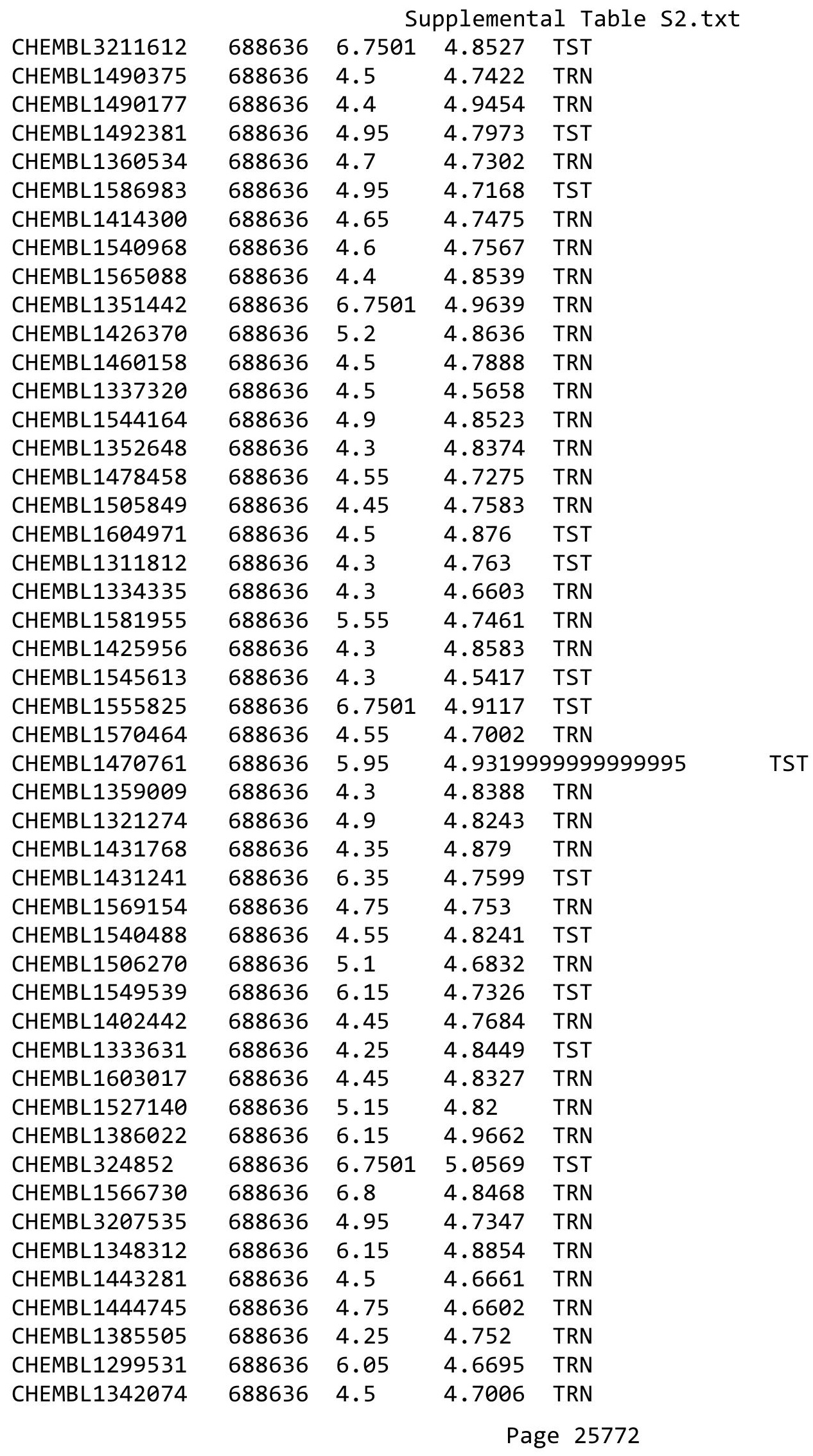




\begin{tabular}{|c|c|c|c|c|}
\hline \multicolumn{5}{|c|}{ Supplemental Table s2.txt } \\
\hline CHEMBL1490119 & 688636 & 4.3 & 4.8348 & TRN \\
\hline CHEMBL1346686 & 688636 & 6.7501 & 4.898 & TRN \\
\hline CHEMBL1459968 & 688636 & 4.35 & 4.6763 & TRN \\
\hline CHEMBL1490988 & 688636 & 4.5 & 5.0337 & TRN \\
\hline CHEMBL1339896 & 688636 & 4.25 & 4.7943 & TRN \\
\hline CHEMBL1414402 & 688636 & 4.25 & 4.9382 & TST \\
\hline CHEMBL1310746 & 688636 & 5.7 & 4.7601 & TRN \\
\hline CHEMBL 3213754 & 688636 & 5.35 & 4.7856 & TST \\
\hline CHEMBL1417451 & 688636 & 4.25 & 4.8191 & TRN \\
\hline CHEMBL1490289 & 688636 & 4.25 & 4.8765 & TST \\
\hline CHEMBL1589486 & 688636 & 5.95 & 4.7359 & TST \\
\hline CHEMBL1446633 & 688636 & 4.9 & 4.5947 & TST \\
\hline CHEMBL1301880 & 688636 & 4.35 & 4.8289 & TRN \\
\hline CHEMBL1608945 & 688636 & 4.3 & 4.6644 & TRN \\
\hline CHEMBL1492915 & 688636 & 4.45 & 4.8522 & TRN \\
\hline CHEMBL1523817 & 688636 & 4.65 & 4.8759 & TRN \\
\hline CHEMBL1504353 & 688636 & 4.3 & 4.8074 & TRN \\
\hline CHEMBL1377915 & 688636 & 4.3 & 4.8493 & TRN \\
\hline CHEMBL1586525 & 688636 & 4.4 & 4.7271 & TST \\
\hline CHEMBL1540200 & 688636 & 4.45 & 4.9853 & TRN \\
\hline CHEMBL1578700 & 688636 & 4.35 & 4.7744 & TRN \\
\hline CHEMBL1518110 & 688636 & 4.25 & 4.7068 & TRN \\
\hline CHEMBL1584238 & 688636 & 4.25 & 4.8059 & TRN \\
\hline CHEMBL1348006 & 688636 & 4.4 & 4.9403 & TST \\
\hline CHEMBL1367859 & 688636 & 5.35 & 4.8236 & TST \\
\hline CHEMBL1501236 & 688636 & 4.7 & 4.7865 & TRN \\
\hline CHEMBL1323932 & 688636 & 4.55 & 4.8316 & TRN \\
\hline CHEMBL1495208 & 688636 & 5.05 & 4.5624 & TRN \\
\hline CHEMBL1391672 & 688636 & 4.4 & 4.8216 & TRN \\
\hline CHEMBL1465462 & 688636 & 5.0 & 4.9066 & TRN \\
\hline CHEMBL3193949 & 688636 & 4.5 & 4.7679 & TST \\
\hline CHEMBL1440116 & 688636 & 4.3 & 4.8669 & TRN \\
\hline CHEMBL1444392 & 688636 & 5.3 & 4.6568 & TRN \\
\hline CHEMBL1501730 & 688636 & 4.3 & 4.7242 & TRN \\
\hline CHEMBL1488096 & 688636 & 6.8 & 4.9437 & TST \\
\hline CHEMBL1427973 & 688636 & 4.3 & 4.9143 & TRN \\
\hline CHEMBL1313554 & 688636 & 4.55 & 4.6836 & TRN \\
\hline CHEMBL1502369 & 688636 & 4.25 & 4.8859 & TRN \\
\hline CHEMBL1307165 & 688636 & 4.5 & 4.8789 & TRN \\
\hline CHEMBL1492419 & 688636 & 5.3 & 4.7935 & TRN \\
\hline CHEMBL1350255 & 688636 & 4.4 & 4.8218 & TST \\
\hline CHEMBL1306912 & 688636 & 4.9 & 4.7774 & TST \\
\hline CHEMBL1528893 & 688636 & 4.7 & 4.7058 & TRN \\
\hline CHEMBL1510409 & 688636 & 4.3 & 4.7954 & TST \\
\hline CHEMBL1543010 & 688636 & 4.95 & 4.8628 & TRN \\
\hline CHEMBL1520914 & 688636 & 5.95 & 4.7472 & TRN \\
\hline CHEMBL572774 & 688636 & 4.95 & 4.8863 & TRN \\
\hline CHEMBL1582605 & 688636 & 4.25 & 4.9565 & TST \\
\hline
\end{tabular}




\begin{tabular}{|c|c|c|c|c|c|}
\hline \\
\hline CHEMBL1613363 & 688636 & 4.5 & 4.7807 & TRN & \\
\hline CHEMBL1586988 & 688636 & 5.45 & 5.0367 & TRN & \\
\hline CHEMBL1326887 & 688636 & 4.3 & 4.9785 & TST & \\
\hline CHEMBL1384766 & 688636 & 4.55 & 4.7899 & TRN & \\
\hline CHEMBL1464287 & 688636 & 4.25 & 4.776 & TRN & \\
\hline CHEMBL1523800 & 688636 & 5.35 & 4.7921 & TRN & \\
\hline CHEMBL1428566 & 688636 & 4.5 & 4.7598 & TST & \\
\hline CHEMBL1510711 & 688636 & 4.6 & 4.7962 & TST & \\
\hline CHEMBL401743 & 688636 & 5.0 & 4.7277 & TRN & \\
\hline CHEMBL3208179 & 688636 & 4.3 & 4.9029 & TRN & \\
\hline CHEMBL1419251 & 688636 & 5.05 & 4.5678 & TRN & \\
\hline CHEMBL1323969 & 688636 & 4.3 & 4.868 & TRN & \\
\hline CHEMBL1559108 & 688636 & 4.25 & 4.8184 & TRN & \\
\hline CHEMBL1550299 & 688636 & 4.25 & 4.6942 & TRN & \\
\hline CHEMBL1327707 & 688636 & 4.45 & 4.8505 & TRN & \\
\hline CHEMBL1388072 & 688636 & 4.55 & 4.958 & TST & \\
\hline CHEMBL3199601 & 688636 & 4.3 & 4.6536 & TRN & \\
\hline CHEMBL1455036 & 688636 & 4.5 & 4.8111 & TRN & \\
\hline CHEMBL1376388 & 688636 & 4.45 & 4.867 & TRN & \\
\hline CHEMBL1588709 & 688636 & 4.7 & 4.7373 & TRN & \\
\hline CHEMBL1472031 & 688636 & 4.3 & 4.7815 & TST & \\
\hline CHEMBL1525562 & 688636 & 4.95 & 5.0358 & TRN & \\
\hline CHEMBL1471272 & 688636 & 4.95 & 4.7935 & TRN & \\
\hline CHEMBL1433306 & 688636 & 4.95 & 4.7409 & TRN & \\
\hline CHEMBL1578618 & 688636 & 4.4 & 4.6638 & TRN & \\
\hline CHEMBL1376310 & 688636 & 4.6 & 4.9763 & TRN & \\
\hline CHEMBL1419576 & 688636 & 4.9 & 4.9625 & TST & \\
\hline CHEMBL1418168 & 688636 & 4.55 & 4.9107 & TRN & \\
\hline CHEMBL1333919 & 688636 & 4.3 & 4.7273 & TRN & \\
\hline CHEMBL1310563 & 688636 & 4.55 & 4.9436 & TRN & \\
\hline CHEMBL1301938 & 688636 & 4.5 & 4.8477 & TRN & \\
\hline CHEMBL1344704 & 688636 & 4.3 & 4.8289 & TRN & \\
\hline CHEMBL1419259 & 688636 & 4.6 & 4.707 & TRN & \\
\hline CHEMBL1573091 & 688636 & 4.5 & 4.6689 & TRN & \\
\hline CHEMBL1429367 & 688636 & 4.3 & $4.8180 e$ & 00000000005 & TST \\
\hline CHEMBL1541803 & 688636 & 4.55 & 4.8557 & TST & \\
\hline CHEMBL1340677 & 688636 & 4.55 & 4.9936 & TRN & \\
\hline CHEMBL1582608 & 688636 & 5.45 & 4.8508 & TRN & \\
\hline CHEMBL1312790 & 688636 & 4.25 & 4.8358 & TRN & \\
\hline CHEMBL1339887 & 688636 & 4.9 & 4.849 & TRN & \\
\hline CHEMBL3189435 & 688636 & 4.45 & 4.8343 & TRN & \\
\hline CHEMBL1607316 & 688636 & 4.3 & 4.8646 & TST & \\
\hline CHEMBL1519057 & 688636 & 4.5 & 4.8713 & TRN & \\
\hline CHEMBL1520098 & 688636 & 4.95 & 4.9353 & TST & \\
\hline CHEMBL1382927 & 688636 & 5.3 & 4.7402 & TRN & \\
\hline CHEMBL1444947 & 688636 & 6.0 & 4.6648 & TRN & \\
\hline CHEMBL1352505 & 688636 & 5.2 & 4.8691 & TRN & \\
\hline CHEMBL1429185 & 688636 & 4.95 & 4.7201 & TRN & \\
\hline
\end{tabular}




\begin{tabular}{|c|c|c|c|c|}
\hline \multicolumn{5}{|c|}{ Supplemental Table S2.txt } \\
\hline CHEMBL1431997 & 688636 & 4.35 & 5.0066 & TST \\
\hline CHEMBL3196068 & 688636 & 4.3 & 4.8358 & TRN \\
\hline CHEMBL1338665 & 688636 & 5.0 & 4.6507 & TRN \\
\hline CHEMBL1606920 & 688636 & 5.7 & 4.8655 & TRN \\
\hline CHEMBL1471517 & 688636 & 6.7501 & 4.9538 & TST \\
\hline CHEMBL1360495 & 688636 & 5.25 & 4.6546 & TRN \\
\hline CHEMBL1968356 & 688636 & 4.6 & 4.6439 & TRN \\
\hline CHEMBL1509782 & 688636 & 5.25 & 4.8076 & TST \\
\hline CHEMBL1556751 & 688636 & 5.2 & 4.8974 & TRN \\
\hline CHEMBL1322190 & 688636 & 4.95 & 4.8645 & TRN \\
\hline CHEMBL1543129 & 688636 & 4.85 & 4.8235 & TRN \\
\hline CHEMBL1323903 & 688636 & 4.45 & 4.7341 & TRN \\
\hline CHEMBL1419982 & 688636 & 4.25 & 4.8382 & TRN \\
\hline CHEMBL1456255 & 688636 & 4.4 & 4.4757 & TRN \\
\hline CHEMBL1364398 & 688636 & 5.05 & 4.7942 & TRN \\
\hline CHEMBL1444491 & 688636 & 6.8 & 4.8684 & TRN \\
\hline CHEMBL1377346 & 688636 & 4.3 & 4.9407 & TRN \\
\hline CHEMBL1352133 & 688636 & 4.95 & 4.8279 & TRN \\
\hline CHEMBL1492497 & 688636 & 4.25 & 4.6566 & TRN \\
\hline CHEMBL1464684 & 688636 & 4.3 & 4.6655 & TRN \\
\hline CHEMBL1383390 & 688636 & 4.45 & 4.7941 & TRN \\
\hline CHEMBL1368473 & 688636 & 4.2 & 4.9295 & TST \\
\hline CHEMBL1525149 & 688636 & 4.85 & 4.7023 & TRN \\
\hline CHEMBL3199797 & 688636 & 4.3 & 4.9198 & TST \\
\hline CHEMBL1463672 & 688636 & 4.45 & 4.6879 & TRN \\
\hline CHEMBL1346882 & 688636 & 5.6 & 4.9136 & TRN \\
\hline CHEMBL1401665 & 688636 & 4.3 & 4.7316 & TRN \\
\hline CHEMBL1520131 & 688636 & 4.5 & 4.5881 & TRN \\
\hline CHEMBL1492715 & 688636 & 4.25 & 4.8012 & TST \\
\hline CHEMBL1541027 & 688636 & 4.5 & 4.6124 & TRN \\
\hline CHEMBL1388607 & 688636 & 4.3 & 4.8177 & TST \\
\hline CHEMBL1429117 & 688636 & 4.55 & 4.7586 & TRN \\
\hline CHEMBL1989858 & 688636 & 4.9 & 4.7808 & TST \\
\hline CHEMBL1588060 & 688636 & 6.3 & 4.8656 & TRN \\
\hline CHEMBL1311526 & 688636 & 4.3 & 4.6661 & TST \\
\hline CHEMBL1448911 & 688636 & 4.45 & 4.6827 & TRN \\
\hline CHEMBL1532663 & 688636 & 5.3 & 4.7438 & TRN \\
\hline CHEMBL1533034 & 688636 & 5.2 & 4.5801 & TRN \\
\hline CHEMBL1505833 & 688636 & 5.4 & 4.7279 & TRN \\
\hline CHEMBL1373078 & 688636 & 5.1 & 5.0105 & TST \\
\hline CHEMBL1339431 & 688636 & 4.3 & 4.9876 & TRN \\
\hline CHEMBL1517379 & 688636 & 4.45 & 4.7104 & TRN \\
\hline CHEMBL3192361 & 688636 & 4.7 & 4.6167 & TST \\
\hline CHEMBL1993301 & 688636 & 5.9 & 4.7049 & TRN \\
\hline CHEMBL1570730 & 688636 & 4.45 & 4.6506 & TRN \\
\hline CHEMBL1411141 & 688636 & 4.95 & 4.7297 & TRN \\
\hline CHEMBL1572601 & 688636 & 5.85 & 4.9707 & TRN \\
\hline CHEMBL1533022 & 688636 & 4.3 & 4.8448 & TRN \\
\hline
\end{tabular}




\begin{tabular}{|c|c|c|c|c|}
\hline \multicolumn{5}{|c|}{ Supplemental Table S2.txt } \\
\hline CHEMBL1587708 & 688636 & 4.4 & 4.6471 & TRN \\
\hline CHEMBL1604371 & 688636 & 4.95 & 4.8832 & TRN \\
\hline CHEMBL1453211 & 688636 & 5.35 & 4.8003 & TRN \\
\hline CHEMBL1578927 & 688636 & 4.25 & 5.0112 & TRN \\
\hline CHEMBL1347188 & 688636 & 5.85 & 4.8415 & TST \\
\hline CHEMBL1385135 & 688636 & 4.25 & 4.67 & TRN \\
\hline CHEMBL 3208898 & 688636 & 4.25 & 4.8522 & TRN \\
\hline CHEMBL1361431 & 688636 & 4.5 & 4.791 & TRN \\
\hline CHEMBL1384163 & 688636 & 6.7501 & 4.9671 & TRN \\
\hline CHEMBL1425657 & 688636 & 5.05 & 4.8262 & TRN \\
\hline CHEMBL1439163 & 688636 & 4.9 & 4.791 & TRN \\
\hline CHEMBL1363933 & 688636 & 4.6 & 4.7787 & TRN \\
\hline CHEMBL1549402 & 688636 & 5.05 & 4.6859 & TST \\
\hline CHEMBL1309786 & 688636 & 6.35 & 4.9754 & TRN \\
\hline CHEMBL1495510 & 688636 & 4.35 & 4.7079 & TRN \\
\hline CHEMBL1344042 & 688636 & 5.15 & 4.7051 & TRN \\
\hline CHEMBL1575653 & 688636 & 6.8 & 4.8831 & TRN \\
\hline CHEMBL1370330 & 688636 & 4.6 & 4.7046 & TRN \\
\hline CHEMBL1452812 & 688636 & 4.4 & 4.7725 & TRN \\
\hline CHEMBL1429202 & 688636 & 4.25 & 4.6922 & TST \\
\hline CHEMBL1498628 & 688636 & 4.95 & 5.0076 & TRN \\
\hline CHEMBL1532076 & 688636 & 4.3 & 4.9563 & TRN \\
\hline CHEMBL1456181 & 688636 & 4.45 & 4.93 & TST \\
\hline CHEMBL1362529 & 688636 & 4.3 & 4.7547 & TRN \\
\hline CHEMBL1377244 & 688636 & 5.25 & 4.8101 & TRN \\
\hline CHEMBL1330989 & 688636 & 4.3 & 4.6481 & TRN \\
\hline CHEMBL3197738 & 688636 & 5.0 & 4.8356 & TST \\
\hline CHEMBL1369860 & 688636 & 5.95 & 4.898 & TST \\
\hline CHEMBL3212981 & 688636 & 4.4 & 4.8377 & TRN \\
\hline CHEMBL1368760 & 688636 & 5.85 & 5.0073 & TRN \\
\hline CHEMBL1428477 & 688636 & 6.6499 & 4.8018 & TRN \\
\hline CHEMBL1974856 & 688636 & 4.25 & 4.5833 & TST \\
\hline CHEMBL1534549 & 688636 & 4.95 & 4.9042 & TRN \\
\hline CHEMBL1388848 & 688636 & 4.5 & 4.6805 & TRN \\
\hline CHEMBL552272 & 688636 & 4.25 & 4.8113 & TRN \\
\hline CHEMBL1490169 & 688636 & 4.55 & 4.6241 & TRN \\
\hline CHEMBL1505091 & 688636 & 4.25 & 4.7107 & TRN \\
\hline CHEMBL1421754 & 688636 & 4.45 & 4.6432 & TRN \\
\hline CHEMBL1423037 & 688636 & 4.6 & 4.7998 & TRN \\
\hline CHEMBL1526590 & 688636 & 4.3 & 5.0086 & TST \\
\hline CHEMBL3191131 & 688636 & 5.1 & 4.7319 & TRN \\
\hline CHEMBL1594449 & 688636 & 5.4 & 4.7771 & TRN \\
\hline CHEMBL1523835 & 688636 & 4.4 & 4.7156 & TST \\
\hline CHEMBL3192031 & 688636 & 4.35 & 4.6459 & TST \\
\hline CHEMBL1414084 & 688636 & 4.55 & 4.7803 & TST \\
\hline CHEMBL1358781 & 688636 & 4.45 & 4.7625 & TRN \\
\hline CHEMBL1388922 & 688636 & 4.5 & 4.7781 & TRN \\
\hline CHEMBL1516834 & 688636 & 5.4 & 4.7878 & TRN \\
\hline
\end{tabular}




\begin{tabular}{|c|c|c|c|c|}
\hline \multicolumn{5}{|c|}{ Supplemental Table S2.txt } \\
\hline CHEMBL1564995 & 688636 & 4.6 & 4.8045 & TRN \\
\hline CHEMBL1485041 & 688636 & 4.75 & 4.7554 & TRN \\
\hline CHEMBL1497609 & 688636 & 6.25 & 4.8911 & TRN \\
\hline CHEMBL1527615 & 688636 & 4.5 & 4.8227 & TRN \\
\hline CHEMBL1319701 & 688636 & 4.8 & 4.8078 & TRN \\
\hline CHEMBL1526475 & 688636 & 6.6 & 4.9005 & TRN \\
\hline CHEMBL1320603 & 688636 & 4.25 & 4.8389 & TRN \\
\hline CHEMBL1487064 & 688636 & 4.25 & 5.0105 & TRN \\
\hline CHEMBL1976563 & 688636 & 4.9 & 4.6259 & TRN \\
\hline CHEMBL1537666 & 688636 & 4.3 & 5.0108 & TRN \\
\hline CHEMBL1411034 & 688636 & 4.6 & 4.8075 & TRN \\
\hline CHEMBL1533776 & 688636 & 4.35 & 4.6381 & TRN \\
\hline CHEMBL1506661 & 688636 & 6.05 & 4.8599 & TST \\
\hline CHEMBL1580234 & 688636 & 4.25 & 4.7352 & TRN \\
\hline CHEMBL1299889 & 688636 & 4.55 & 4.7879 & TST \\
\hline CHEMBL1500504 & 688636 & 4.35 & 4.7131 & TRN \\
\hline CHEMBL3196124 & 688636 & 4.3 & 4.6267 & TRN \\
\hline CHEMBL1352062 & 688636 & 4.6 & 4.8192 & TST \\
\hline CHEMBL1572802 & 688636 & 4.65 & 5.0027 & TST \\
\hline CHEMBL1461478 & 688636 & 4.3 & 4.7678 & TST \\
\hline CHEMBL1364406 & 688636 & 4.35 & 4.8157 & TRN \\
\hline CHEMBL1301164 & 688636 & 4.3 & 4.7106 & TST \\
\hline CHEMBL1338855 & 688636 & 4.45 & 4.708 & TRN \\
\hline CHEMBL1511162 & 688636 & 4.45 & 4.8288 & TRN \\
\hline CHEMBL1493829 & 688636 & 4.45 & 4.8564 & TST \\
\hline CHEMBL1400599 & 688636 & 4.3 & 4.5955 & TRN \\
\hline CHEMBL474749 & 688636 & 4.5 & 4.9453 & TRN \\
\hline CHEMBL1519295 & 688636 & 4.25 & 4.8715 & TST \\
\hline CHEMBL1490333 & 688636 & 6.7501 & 4.9174 & TRN \\
\hline CHEMBL1483803 & 688636 & 6.0 & 4.9976 & TRN \\
\hline CHEMBL1372067 & 688636 & 4.55 & 4.8927 & TRN \\
\hline CHEMBL1529376 & 688636 & 4.95 & 5.0033 & TRN \\
\hline CHEMBL1310774 & 688636 & 4.5 & 4.8702 & TRN \\
\hline CHEMBL1367750 & 688636 & 4.65 & 4.9767 & TRN \\
\hline CHEMBL1448697 & 688636 & 5.1 & 4.6827 & TRN \\
\hline CHEMBL1425039 & 688636 & 4.45 & 4.8333 & TRN \\
\hline CHEMBL1403694 & 688636 & 5.3 & 4.8763 & TST \\
\hline CHEMBL1453902 & 688636 & 4.6 & 4.7923 & TRN \\
\hline CHEMBL1377163 & 688636 & 4.45 & 4.9318 & TRN \\
\hline CHEMBL1383269 & 688636 & 4.45 & 4.6964 & TRN \\
\hline CHEMBL1563197 & 688636 & 4.4 & 4.7967 & TRN \\
\hline CHEMBL1497403 & 688636 & 5.3 & 4.7411 & TST \\
\hline CHEMBL485636 & 688636 & 5.15 & 4.8548 & TRN \\
\hline CHEMBL1303010 & 688636 & 4.4 & 4.7573 & TRN \\
\hline CHEMBL1529320 & 688636 & 4.3 & 4.7264 & TST \\
\hline CHEMBL1601658 & 688636 & 5.35 & 4.7675 & TRN \\
\hline CHEMBL1529561 & 688636 & 5.9 & 4.9635 & TST \\
\hline CHEMBL1517079 & 688636 & 6.7501 & 4.8591 & TRN \\
\hline
\end{tabular}

Page 25777 


\begin{tabular}{|c|c|c|c|c|c|}
\hline & & \multicolumn{4}{|c|}{ Supplemental Table S2.txt } \\
\hline CHEMBL1417156 & 688636 & 4.55 & 4.5919 & TRN & \\
\hline CHEMBL1350124 & 688636 & 4.3 & 4.6835 & TST & \\
\hline CHEMBL1414975 & 688636 & 5.45 & 4.9802 & TRN & \\
\hline CHEMBL1328703 & 688636 & 4.3 & 4.9122 & TRN & \\
\hline CHEMBL1508325 & 688636 & 6.05 & 4.862 & TRN & \\
\hline CHEMBL1462912 & 688636 & 4.3 & 5.0405 & TRN & \\
\hline CHEMBL1414576 & 688636 & 4.3 & 5.0043 & TRN & \\
\hline CHEMBL1367951 & 688636 & 5.25 & 4.7496 & TRN & \\
\hline CHEMBL1368718 & 688636 & 4.95 & \multicolumn{2}{|c|}{4.906000000000001} & TRN \\
\hline CHEMBL1492107 & 688636 & 5.55 & 4.961 & TRN & \\
\hline CHEMBL1442358 & 688636 & 5.1 & 4.7755 & TST & \\
\hline CHEMBL1448411 & 688636 & 4.95 & 4.9602 & TRN & \\
\hline CHEMBL1431906 & 688636 & 5.25 & 4.8363 & TRN & \\
\hline CHEMBL1478088 & 688636 & 4.3 & 4.6572 & TRN & \\
\hline CHEMBL1573102 & 688636 & 4.25 & 4.6732 & TRN & \\
\hline CHEMBL1584771 & 688636 & 4.75 & 4.7721 & TST & \\
\hline CHEMBL1497617 & 688636 & 4.35 & 4.6854 & TRN & \\
\hline CHEMBL1492601 & 688636 & 4.95 & 4.8601 & TRN & \\
\hline CHEMBL1504156 & 688636 & 4.95 & 4.7315 & TRN & \\
\hline CHEMBL1609969 & 688636 & 4.5 & 4.7069 & TRN & \\
\hline CHEMBL1586513 & 688636 & 4.65 & 4.8329 & TST & \\
\hline CHEMBL581452 & 688636 & 4.95 & 4.9391 & TRN & \\
\hline CHEMBL1467282 & 688636 & 4.45 & 4.6773 & TRN & \\
\hline CHEMBL1352412 & 688636 & 4.6 & 4.8812 & TST & \\
\hline CHEMBL1361928 & 688636 & 6.1 & 4.8065 & TST & \\
\hline CHEMBL69151 & 688636 & 4.5 & 4.8774 & TST & \\
\hline CHEMBL1384542 & 688636 & 4.95 & 4.8741 & TRN & \\
\hline CHEMBL1497900 & 688636 & 4.3 & 4.8524 & TRN & \\
\hline CHEMBL1449127 & 688636 & 5.2 & 4.8443 & TST & \\
\hline CHEMBL1462389 & 688636 & 4.3 & 4.9942 & TST & \\
\hline CHEMBL1328616 & 688636 & 4.25 & 4.7135 & TRN & \\
\hline CHEMBL1374386 & 688636 & 4.35 & 4.8357 & TRN & \\
\hline CHEMBL1432368 & 688636 & 4.25 & 4.5979 & TRN & \\
\hline CHEMBL1443114 & 688636 & 4.4 & 4.6202 & TRN & \\
\hline CHEMBL1438878 & 688636 & 4.25 & 4.6902 & TRN & \\
\hline CHEMBL1410770 & 688636 & 4.65 & 4.7757 & TRN & \\
\hline CHEMBL1413221 & 688636 & 5.5 & 4.9721 & TRN & \\
\hline CHEMBL1609049 & 688636 & 4.3 & 4.7149 & TRN & \\
\hline CHEMBL1371394 & 688636 & 4.9 & 4.8436 & TRN & \\
\hline CHEMBL532412 & 688636 & 4.35 & 4.8556 & TST & \\
\hline CHEMBL1464916 & 688636 & 4.6 & 4.8202 & TRN & \\
\hline CHEMBL1320683 & 688636 & 4.5 & 4.8197 & TST & \\
\hline CHEMBL3193787 & 688636 & 5.4 & 4.6148 & TRN & \\
\hline CHEMBL1449194 & 688636 & 5.2 & 4.715 & TRN & \\
\hline CHEMBL1518870 & 688636 & 5.45 & 4.6523 & TRN & \\
\hline CHEMBL1495820 & 688636 & 4.25 & 4.9133 & TRN & \\
\hline CHEMBL3211694 & 688636 & 4.95 & 4.6444 & TRN & \\
\hline CHEMBL1323495 & 688636 & 6.05 & 4.9425 & TST & \\
\hline
\end{tabular}




\begin{tabular}{|c|c|c|c|c|}
\hline \multicolumn{5}{|c|}{ Supplemental Table S2.txt } \\
\hline CHEMBL1311577 & 688636 & 4.3 & 4.8038 & TRN \\
\hline CHEMBL1566398 & 688636 & 6.15 & 4.9196 & TRN \\
\hline CHEMBL1344864 & 688636 & 6.0 & 4.9023 & TRN \\
\hline CHEMBL1559806 & 688636 & 4.3 & 4.8801 & TRN \\
\hline CHEMBL1441897 & 688636 & 4.5 & 4.7208 & TRN \\
\hline CHEMBL1489771 & 688636 & 4.5 & 4.6532 & TRN \\
\hline CHEMBL3189399 & 688636 & 4.65 & 4.8404 & TRN \\
\hline CHEMBL1463701 & 688636 & 4.25 & 4.9694 & TST \\
\hline CHEMBL1344953 & 688636 & 4.5 & 4.9689 & TST \\
\hline CHEMBL1313067 & 688636 & 6.7501 & 4.8996 & TRN \\
\hline CHEMBL112666 & 688636 & 5.35 & 5.0413 & TST \\
\hline CHEMBL1323818 & 688636 & 4.45 & 4.8886 & TRN \\
\hline CHEMBL1539803 & 688636 & 4.25 & 4.9409 & TRN \\
\hline CHEMBL1510772 & 688636 & 4.45 & 5.0063 & TRN \\
\hline CHEMBL568556 & 688636 & 6.8 & 4.8063 & TRN \\
\hline CHEMBL1306019 & 688636 & 5.5 & 4.9247 & TST \\
\hline CHEMBL1461019 & 688636 & 4.4 & 4.6934 & TRN \\
\hline CHEMBL1371159 & 688636 & 4.45 & 4.8517 & TRN \\
\hline CHEMBL3197010 & 688636 & 5.15 & 4.8709 & TST \\
\hline CHEMBL1597025 & 688636 & 5.9 & 4.8303 & TRN \\
\hline CHEMBL1494191 & 688636 & 4.25 & 4.6989 & TRN \\
\hline CHEMBL1383872 & 688636 & 4.55 & 4.6416 & TRN \\
\hline CHEMBL1428977 & 688636 & 4.55 & 4.6423 & TRN \\
\hline CHEMBL1450704 & 688636 & 5.05 & 4.7975 & TRN \\
\hline CHEMBL1558926 & 688636 & 5.2 & 4.831 & TRN \\
\hline CHEMBL1607661 & 688636 & 5.05 & 4.908 & TRN \\
\hline CHEMBL1426669 & 688636 & 4.75 & 4.561 & TST \\
\hline CHEMBL1478541 & 688636 & 5.25 & 4.7474 & TST \\
\hline CHEMBL1413933 & 688636 & 4.95 & 4.805 & TST \\
\hline CHEMBL1501874 & 688636 & 4.25 & 4.6464 & TRN \\
\hline CHEMBL1448094 & 688636 & 4.3 & 4.7975 & TRN \\
\hline CHEMBL1421710 & 688636 & 4.3 & 4.7623 & TRN \\
\hline CHEMBL1557132 & 688636 & 4.25 & 4.9372 & TRN \\
\hline CHEMBL1362373 & 688636 & 6.1 & 4.9228 & TRN \\
\hline CHEMBL1531153 & 688636 & 5.0 & 4.7315 & TRN \\
\hline CHEMBL1544326 & 688636 & 4.95 & 4.7267 & TRN \\
\hline CHEMBL1338650 & 688636 & 5.95 & 4.7908 & TST \\
\hline CHEMBL1567205 & 688636 & 6.7501 & 4.8866 & TRN \\
\hline CHEMBL1324564 & 688636 & 4.25 & 4.8844 & TRN \\
\hline CHEMBL530038 & 688636 & 5.35 & 4.86 & TST \\
\hline CHEMBL1386231 & 688636 & 4.5 & 4.6994 & TRN \\
\hline CHEMBL1492274 & 688636 & 5.9 & 4.8638 & TST \\
\hline CHEMBL1544113 & 688636 & 5.3 & 4.9287 & TRN \\
\hline CHEMBL1563667 & 688636 & 4.3 & 5.0073 & TRN \\
\hline CHEMBL1595935 & 688636 & 4.5 & 4.8386 & TRN \\
\hline CHEMBL3196968 & 688636 & 4.3 & 4.8819 & TRN \\
\hline CHEMBL1549660 & 688636 & 4.5 & 4.8881 & TST \\
\hline CHEMBL1520312 & 688636 & 4.3 & 4.6693 & TST \\
\hline
\end{tabular}




\begin{tabular}{|c|c|c|c|c|c|}
\hline \multirow{3}{*}{$\begin{array}{l}\text { CHEMBL1328213 } \\
\text { CHEMBL } 1537193\end{array}$} & & \multicolumn{4}{|c|}{ Supplemental Table S2.txt } \\
\hline & 688636 & 4.45 & 4.85800 & 00000000005 & TRN \\
\hline & 688636 & 4.5 & 4.6111 & TRN & \\
\hline CHEMBL1373614 & 688636 & 4.85 & 5.0451 & TRN & \\
\hline CHEMBL1408665 & 688636 & 5.6 & 4.8783 & TST & \\
\hline CHEMBL1378839 & 688636 & 4.55 & 4.7304 & TRN & \\
\hline CHEMBL1407281 & 688636 & 4.9 & 5.1058 & TRN & \\
\hline CHEMBL1537318 & 688636 & 5.3 & 4.8845 & TRN & \\
\hline CHEMBL1440690 & 688636 & 4.3 & 4.729 & TRN & \\
\hline CHEMBL1349602 & 688636 & 4.25 & 4.9797 & TRN & \\
\hline CHEMBL1332281 & 688636 & 6.5501 & 4.8107 & TRN & \\
\hline CHEMBL1409131 & 688636 & 4.9 & 4.9201 & TRN & \\
\hline CHEMBL1549079 & 688636 & 4.45 & 4.6352 & TRN & \\
\hline CHEMBL1576996 & 688636 & 4.25 & 4.8718 & TRN & \\
\hline CHEMBL1989234 & 688636 & 5.55 & 4.7001 & TRN & \\
\hline CHEMBL1374206 & 688636 & 4.25 & 4.93 & TST & \\
\hline CHEMBL1386050 & 688636 & 6.8 & 4.9185 & TST & \\
\hline CHEMBL1550615 & 688636 & 5.3 & 4.9244 & TRN & \\
\hline CHEMBL1611814 & 688636 & 6.45 & 4.8579 & TRN & \\
\hline CHEMBL1343458 & 688636 & 4.4 & 4.6127 & TRN & \\
\hline CHEMBL1379462 & 688636 & 5.35 & 4.7878 & TRN & \\
\hline CHEMBL1607099 & 688636 & 4.3 & 5.0482 & TRN & \\
\hline CHEMBL3189194 & 688636 & 4.45 & 4.6649 & TRN & \\
\hline CHEMBL1576100 & 688636 & 6.7501 & 4.708 & TST & \\
\hline CHEMBL1516993 & 688636 & 4.3 & 5.0533 & TRN & \\
\hline CHEMBL1423108 & 688636 & 4.3 & 4.9964 & TRN & \\
\hline CHEMBL1430785 & 688636 & 4.4 & 4.6629 & TRN & \\
\hline CHEMBL1359661 & 688636 & 5.2 & 4.7594 & TRN & \\
\hline CHEMBL3211634 & 688636 & 4.35 & 4.7646 & TRN & \\
\hline CHEMBL1489522 & 688636 & 4.3 & 4.8288 & TRN & \\
\hline CHEMBL1363429 & 688636 & 4.55 & 4.9576 & TRN & \\
\hline CHEMBL3199114 & 688636 & 4.55 & 4.5921 & TRN & \\
\hline CHEMBL1414367 & 688636 & 4.5 & 4.9009 & TRN & \\
\hline CHEMBL1348845 & 688636 & 4.6 & 5.0139 & TST & \\
\hline CHEMBL1573473 & 688636 & 4.25 & 4.881 & TST & \\
\hline CHEMBL1582335 & 688636 & 6.35 & 4.7913 & TRN & \\
\hline CHEMBL1412679 & 688636 & 5.95 & 4.8323 & TST & \\
\hline CHEMBL1463293 & 688636 & 4.25 & 4.9683 & TRN & \\
\hline CHEMBL1429873 & 688636 & 4.45 & 4.6873 & TRN & \\
\hline CHEMBL1494700 & 688636 & 4.95 & 4.7361 & TRN & \\
\hline CHEMBL1996451 & 688636 & 5.9 & 4.6266 & TRN & \\
\hline CHEMBL1482075 & 688636 & 4.5 & 4.7481 & TRN & \\
\hline CHEMBL1450551 & 688636 & 4.25 & 4.9488 & TRN & \\
\hline CHEMBL1432243 & 688636 & 4.55 & 4.7397 & TRN & \\
\hline CHEMBL1335945 & 688636 & 4.35 & 4.7311 & TST & \\
\hline CHEMBL1546940 & 688636 & 4.4 & 4.80699 & 99999999995 & TST \\
\hline CHEMBL1326843 & 688636 & 4.7 & 4.7902 & TRN & \\
\hline CHEMBL1341687 & 688636 & 4.45 & 4.6715 & TST & \\
\hline CHEMBL1517081 & 688636 & 4.3 & 4.9566 & TRN & \\
\hline
\end{tabular}




\begin{tabular}{|c|c|c|c|c|c|}
\hline \multicolumn{6}{|c|}{ Supplemental Table S2.txt } \\
\hline CHEMBL1334615 & 688636 & 4.25 & 4.6709 & TRN & \\
\hline CHEMBL1375570 & 688636 & 4.65 & 4.9012 & TST & \\
\hline CHEMBL1458939 & 688636 & 4.6 & 4.675 & TRN & \\
\hline CHEMBL1365595 & 688636 & 4.25 & 4.912 & TRN & \\
\hline CHEMBL1409489 & 688636 & 5.4 & 4.8055 & TRN & \\
\hline CHEMBL1479696 & 688636 & 4.35 & 4.7277 & TRN & \\
\hline CHEMBL1498823 & 688636 & 4.9 & 4.6628 & TRN & \\
\hline CHEMBL1510332 & 688636 & 4.25 & 4.7504 & TST & \\
\hline CHEMBL3198912 & 688636 & 4.4 & 4.5729 & TST & \\
\hline CHEMBL1526690 & 688636 & 4.3 & 4.7028 & TST & \\
\hline CHEMBL1601248 & 688636 & 5.0 & 4.8199 & TRN & \\
\hline CHEMBL1333148 & 688636 & 4.95 & 4.8845 & TRN & \\
\hline CHEMBL1303623 & 688636 & 4.3 & 4.7741 & TRN & \\
\hline CHEMBL1505634 & 688636 & 4.45 & 4.6095 & TRN & \\
\hline CHEMBL1430643 & 688636 & 4.4 & 4.7242 & TRN & \\
\hline CHEMBL1568010 & 688636 & 5.0 & 4.784 & TRN & \\
\hline CHEMBL1428560 & 688636 & 4.4 & 4.8477 & TRN & \\
\hline CHEMBL1428290 & 688636 & 4.95 & 4.8743 & TRN & \\
\hline CHEMBL1438084 & 688636 & 4.6 & 4.7859 & TRN & \\
\hline CHEMBL1594637 & 688636 & 4.65 & 4.773 & TRN & \\
\hline CHEMBL1502798 & 688636 & 7.1002 & 4.836 & TST & \\
\hline CHEMBL1497912 & 688636 & 4.9 & 4.7862 & TRN & \\
\hline CHEMBL1417212 & 688636 & 4.55 & 4.8977 & TRN & \\
\hline CHEMBL1454820 & 688636 & 4.45 & 4.7651 & TST & \\
\hline CHEMBL3195890 & 688636 & 5.3 & 4.6862 & TRN & \\
\hline CHEMBL1543969 & 688636 & 4.95 & 4.9204 & TRN & \\
\hline CHEMBL1477642 & 688636 & 4.55 & 4.6484 & TRN & \\
\hline CHEMBL1578854 & 688636 & 4.65 & 4.7945 & TRN & \\
\hline CHEMBL1334866 & 688636 & 4.25 & 4.8519 & TRN & \\
\hline CHEMBL1566483 & 688636 & 4.95 & 4.7718 & TRN & \\
\hline CHEMBL1320128 & 688636 & 5.95 & 4.7843 & TRN & \\
\hline CHEMBL1550253 & 688636 & 4.45 & 4.7051 & TRN & \\
\hline CHEMBL1303347 & 688636 & 4.55 & 4.6123 & TRN & \\
\hline CHEMBL1506429 & 688636 & 6.4 & 4.8452 & TST & \\
\hline CHEMBL1385004 & 688636 & 4.65 & 4.78600 & 00000000005 & TRN \\
\hline CHEMBL1588140 & 688636 & 4.3 & 4.9729 & TRN & \\
\hline CHEMBL1404669 & 688636 & 5.25 & 4.9691 & TST & \\
\hline CHEMBL1579818 & 688636 & 6.45 & 4.7853 & TRN & \\
\hline CHEMBL1528139 & 688636 & 4.5 & 4.9088 & TRN & \\
\hline CHEMBL1549292 & 688636 & 4.5 & 4.7307 & TRN & \\
\hline CHEMBL1494955 & 688636 & 4.95 & 4.7878 & TRN & \\
\hline CHEMBL1425652 & 688636 & 4.65 & 4.9815 & TRN & \\
\hline CHEMBL1491372 & 688636 & 5.05 & 4.8891 & TRN & \\
\hline CHEMBL1351843 & 688636 & 4.3 & 4.7248 & TST & \\
\hline CHEMBL 3199381 & 688636 & 4.4 & 4.7754 & TRN & \\
\hline CHEMBL1378234 & 688636 & 4.3 & 4.7773 & TRN & \\
\hline CHEMBL1336043 & 688636 & 4.55 & 4.6799 & TRN & \\
\hline CHEMBL1575029 & 688636 & 5.05 & 4.9071 & TRN & \\
\hline
\end{tabular}




\begin{tabular}{|c|c|c|c|c|c|}
\hline \multicolumn{6}{|c|}{ Supplemental Table S2.txt } \\
\hline CHEMBL1601050 & 688636 & 5.65 & 4.7738 & TRN & \\
\hline CHEMBL1307271 & 688636 & 6.25 & 4.687 & TST & \\
\hline CHEMBL1541204 & 688636 & 4.4 & 4.7891 & TRN & \\
\hline CHEMBL1557568 & 688636 & 4.55 & 4.5672 & TRN & \\
\hline CHEMBL1565478 & 688636 & 4.6 & 4.785 & TRN & \\
\hline CHEMBL1300945 & 688636 & 4.3 & 4.863 & TRN & \\
\hline CHEMBL1507621 & 688636 & 5.6 & 4.63399 & 99999999995 & TRN \\
\hline CHEMBL 3192149 & 688636 & 5.4 & 4.7143 & TRN & \\
\hline CHEMBL1463487 & 688636 & 4.45 & 4.8075 & TRN & \\
\hline CHEMBL3192104 & 688636 & 4.4 & 4.5428 & TRN & \\
\hline CHEMBL1507613 & 688636 & 4.45 & 4.8308 & TRN & \\
\hline CHEMBL1610051 & 688636 & 5.05 & 4.7879 & TRN & \\
\hline CHEMBL1430344 & 688636 & 4.5 & 5.0163 & TST & \\
\hline CHEMBL3194118 & 688636 & 4.75 & 4.7014 & TRN & \\
\hline CHEMBL1398618 & 688636 & 5.7 & 4.6483 & TST & \\
\hline CHEMBL1308489 & 688636 & 4.95 & 4.7692 & TST & \\
\hline CHEMBL3195470 & 688636 & 4.3 & 4.8962 & TRN & \\
\hline CHEMBL1488840 & 688636 & 4.3 & 4.9144 & TST & \\
\hline CHEMBL1601047 & 688636 & 4.25 & 4.9383 & TRN & \\
\hline CHEMBL1575735 & 688636 & 4.25 & 4.7575 & TRN & \\
\hline CHEMBL1423535 & 688636 & 4.3 & 4.9253 & TRN & \\
\hline CHEMBL1337556 & 688636 & 5.9 & 4.8511 & TST & \\
\hline CHEMBL1371666 & 688636 & 5.55 & 4.8411 & TRN & \\
\hline CHEMBL1411491 & 688636 & 4.3 & 4.8621 & TRN & \\
\hline CHEMBL1493953 & 688636 & 4.3 & 4.823 & TRN & \\
\hline CHEMBL1303917 & 688636 & 4.25 & 4.7456 & TRN & \\
\hline CHEMBL1536252 & 688636 & 4.45 & 4.727 & TRN & \\
\hline CHEMBL1460871 & 688636 & 4.6 & 4.9084 & TRN & \\
\hline CHEMBL1561699 & 688636 & 4.25 & 4.8311 & TST & \\
\hline CHEMBL1488485 & 688636 & 5.05 & 4.7018 & TRN & \\
\hline CHEMBL1556059 & 688636 & 4.95 & 4.6606 & TRN & \\
\hline CHEMBL1363597 & 688636 & 4.85 & 4.7298 & TRN & \\
\hline CHEMBL1549316 & 688636 & 4.9 & 4.9574 & TST & \\
\hline CHEMBL1378722 & 688636 & 4.25 & 4.9145 & TRN & \\
\hline CHEMBL1338442 & 688636 & 5.35 & 4.6975 & TRN & \\
\hline CHEMBL3213982 & 688636 & 4.3 & 4.8415 & TRN & \\
\hline CHEMBL1410548 & 688636 & 4.4 & 4.7989 & TST & \\
\hline CHEMBL1504943 & 688636 & 4.55 & 4.6663 & TRN & \\
\hline CHEMBL1431905 & 688636 & 4.5 & 4.9199 & TRN & \\
\hline CHEMBL 3191276 & 688636 & 4.5 & 4.7766 & TRN & \\
\hline CHEMBL1530666 & 688636 & 4.5 & 4.76399 & 9999999999 & TRN \\
\hline CHEMBL1973050 & 688636 & 4.5 & 4.4771 & TRN & \\
\hline CHEMBL1526530 & 688636 & 4.3 & 4.9373 & TRN & \\
\hline CHEMBL1580063 & 688636 & 5.25 & 4.7789 & TST & \\
\hline CHEMBL1424988 & 688636 & 4.25 & 4.9319 & TRN & \\
\hline CHEMBL1547074 & 688636 & 4.45 & 4.7374 & TRN & \\
\hline CHEMBL1572491 & 688636 & 4.4 & 4.6493 & TST & \\
\hline CHEMBL1485670 & 688636 & 4.45 & 4.9981 & TRN & \\
\hline
\end{tabular}




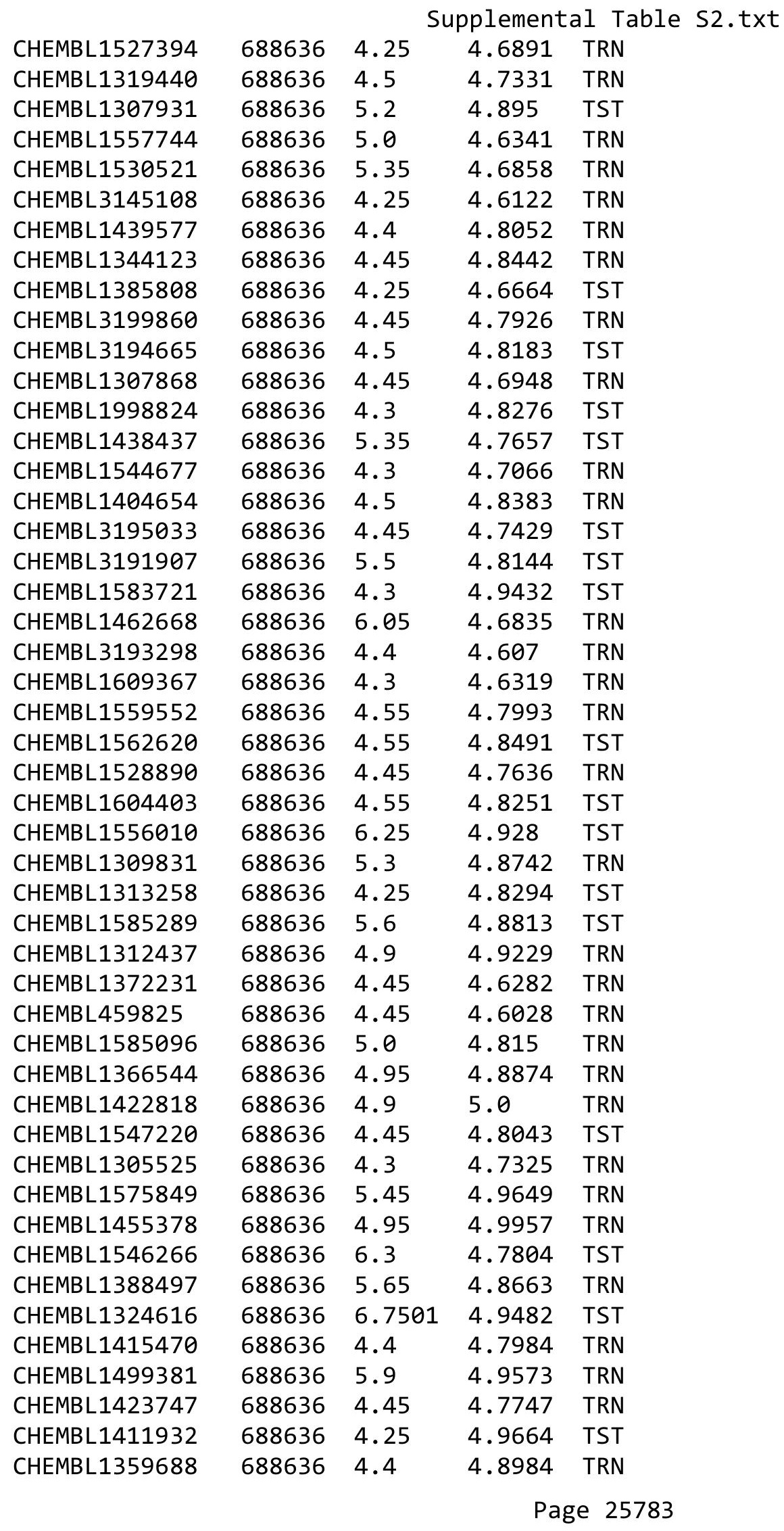




\begin{tabular}{|c|c|c|c|c|c|}
\hline \\
\hline CHEMBL1612604 & 688636 & 6.8 & 4.957 & TRN & \\
\hline CHEMBL1328056 & 688636 & 5.2 & 4.7785 & TRN & \\
\hline CHEMBL1445932 & 688636 & 6.7501 & 4.8581 & TRN & \\
\hline CHEMBL1329915 & 688636 & 4.25 & 4.7298 & TRN & \\
\hline CHEMBL1498238 & 688636 & 5.0 & 4.9602 & TST & \\
\hline CHEMBL3196622 & 688636 & 4.75 & 4.6869 & TRN & \\
\hline CHEMBL1536637 & 688636 & 4.3 & 4.8046 & TRN & \\
\hline CHEMBL1471443 & 688636 & 4.35 & 4.7512 & TRN & \\
\hline CHEMBL1497049 & 688636 & 5.05 & 4.7694 & TST & \\
\hline CHEMBL1583619 & 688636 & 5.1 & 4.6649 & TRN & \\
\hline CHEMBL1478399 & 688636 & 4.95 & 4.9007 & TRN & \\
\hline CHEMBL1504492 & 688636 & 4.3 & 4.7665 & TRN & \\
\hline CHEMBL1578074 & 688636 & 4.25 & 4.975 & TRN & \\
\hline CHEMBL1518374 & 688636 & 4.25 & 4.5702 & TRN & \\
\hline CHEMBL3194973 & 688636 & 4.3 & 4.8641 & TRN & \\
\hline CHEMBL1496517 & 688636 & 4.5 & 4.5912 & TRN & \\
\hline CHEMBL1496289 & 688636 & 4.3 & 4.9507 & TRN & \\
\hline CHEMBL1600869 & 688636 & 5.1 & 4.8413 & TRN & \\
\hline CHEMBL1311206 & 688636 & 6.0 & 4.8291 & TRN & \\
\hline CHEMBL1481790 & 688636 & 4.3 & 4.569 & TST & \\
\hline CHEMBL1507509 & 688636 & 6.05 & 4.6515 & TRN & \\
\hline CHEMBL1359414 & 688636 & 4.8 & 4.7274 & TRN & \\
\hline CHEMBL1401434 & 688636 & 5.1 & 4.9881 & TRN & \\
\hline CHEMBL1578723 & 688636 & 5.4 & 5.1875 & TRN & \\
\hline CHEMBL1505809 & 688636 & 4.25 & 4.9636 & TRN & \\
\hline CHEMBL1377177 & 688636 & 4.45 & 4.6931 & TRN & \\
\hline CHEMBL1390860 & 688636 & 4.55 & 4.5942 & TRN & \\
\hline CHEMBL1422817 & 688636 & 4.25 & 4.6006 & TST & \\
\hline CHEMBL1375740 & 688636 & 4.95 & 4.8591 & TRN & \\
\hline CHEMBL1529387 & 688636 & 6.5 & 4.8762 & TRN & \\
\hline CHEMBL1477515 & 688636 & 5.8 & 4.9296 & TRN & \\
\hline CHEMBL1383727 & 688636 & 4.9 & 4.9892 & TRN & \\
\hline CHEMBL1091787 & 688636 & 4.25 & 4.8613 & TRN & \\
\hline CHEMBL1489214 & 688636 & 4.95 & 4.9141 & TRN & \\
\hline CHEMBL1449434 & 688636 & 4.25 & 4.6403 & TRN & \\
\hline CHEMBL1548678 & 688636 & 4.4 & 4.737 & TST & \\
\hline CHEMBL1335679 & 688636 & 5.35 & 4.8163 & TRN & \\
\hline CHEMBL1339232 & 688636 & 5.2 & $4.9860 e$ & 0000000001 & TRN \\
\hline CHEMBL1531219 & 688636 & 4.3 & 4.6915 & TRN & \\
\hline CHEMBL1531919 & 688636 & 4.5 & 4.6959 & TRN & \\
\hline CHEMBL1517292 & 688636 & 4.45 & 4.7163 & TRN & \\
\hline CHEMBL1345435 & 688636 & 5.6 & 4.8782 & TRN & \\
\hline CHEMBL1498999 & 688636 & 4.35 & 4.8112 & TRN & \\
\hline CHEMBL1398737 & 688636 & 6.7501 & 4.9858 & TRN & \\
\hline CHEMBL1401112 & 688636 & 4.3 & 4.9036 & TRN & \\
\hline CHEMBL1376847 & 688636 & 4.95 & 4.9074 & TST & \\
\hline CHEMBL1500088 & 688636 & 5.25 & 5.0234 & TRN & \\
\hline CHEMBL1509427 & 688636 & 4.45 & 4.6909 & TRN & \\
\hline & & & & 704 & \\
\hline
\end{tabular}




\begin{tabular}{|c|c|c|c|c|c|}
\hline \multicolumn{6}{|c|}{ Supplemental Table S2.txt } \\
\hline CHEMBL1429881 & 688636 & 4.4 & 4.6488 & TRN & \\
\hline CHEMBL1569101 & 688636 & 5.25 & 4.9882 & TRN & \\
\hline CHEMBL1548535 & 688636 & 4.35 & 4.766 & TRN & \\
\hline CHEMBL1447362 & 688636 & 4.3 & 4.8436 & TRN & \\
\hline CHEMBL1487526 & 688636 & 4.3 & 4.8824 & TRN & \\
\hline CHEMBL1579071 & 688636 & 5.0 & 4.8088 & TRN & \\
\hline CHEMBL1359550 & 688636 & 4.55 & 4.7641 & TRN & \\
\hline CHEMBL3190541 & 688636 & 4.6 & 4.9161 & TRN & \\
\hline CHEMBL1341152 & 688636 & 4.25 & 4.6666 & TST & \\
\hline CHEMBL1306100 & 688636 & 5.95 & 4.6949 & TST & \\
\hline CHEMBL1371958 & 688636 & 4.5 & 4.7411 & TRN & \\
\hline CHEMBL1427815 & 688636 & 4.3 & 4.8474 & TRN & \\
\hline CHEMBL1372061 & 688636 & 5.45 & 4.7651 & TRN & \\
\hline CHEMBL1559155 & 688636 & 4.3 & 4.6528 & TRN & \\
\hline CHEMBL 3207803 & 688636 & 4.55 & 4.6824 & TST & \\
\hline CHEMBL1321438 & 688636 & 4.3 & 4.8376 & TRN & \\
\hline CHEMBL1579546 & 688636 & 4.55 & 4.7773 & TRN & \\
\hline CHEMBL1370411 & 688636 & 5.25 & 5.0061 & TST & \\
\hline CHEMBL1548380 & 688636 & 4.3 & 4.8299 & TST & \\
\hline CHEMBL1534834 & 688636 & 4.25 & 4.7658 & TRN & \\
\hline CHEMBL1385369 & 688636 & 4.7 & 4.7625 & TRN & \\
\hline CHEMBL1351349 & 688636 & 4.85 & 5.0209 & TRN & \\
\hline CHEMBL1535546 & 688636 & 4.35 & 4.7344 & TST & \\
\hline CHEMBL1505198 & 688636 & 4.8 & 4.8341 & TST & \\
\hline CHEMBL1324865 & 688636 & 5.95 & 4.9721 & TRN & \\
\hline CHEMBL1506533 & 688636 & 4.55 & 4.7457 & TRN & \\
\hline CHEMBL1308993 & 688636 & 4.3 & 4.8279 & TRN & \\
\hline CHEMBL1507767 & 688636 & 4.35 & 4.9519 & TRN & \\
\hline CHEMBL1547539 & 688636 & 4.25 & 4.777 & TRN & \\
\hline CHEMBL1348020 & 688636 & 5.15 & 4.7701 & TST & \\
\hline CHEMBL1601537 & 688636 & 5.35 & 4.8151 & TST & \\
\hline CHEMBL1326748 & 688636 & 5.25 & 4.7213 & TRN & \\
\hline CHEMBL1361801 & 688636 & 4.95 & 5.0566 & TRN & \\
\hline CHEMBL1303271 & 688636 & 6.8 & 4.7289 & TRN & \\
\hline CHEMBL1509139 & 688636 & 4.5 & $4.7010 e$ & 00000000005 & TRN \\
\hline CHEMBL1353609 & 688636 & 6.6499 & 4.9612 & TST & \\
\hline CHEMBL1428143 & 688636 & 4.45 & 4.9849 & TST & \\
\hline CHEMBL1562342 & 688636 & 4.45 & 4.8372 & TRN & \\
\hline CHEMBL1983549 & 688636 & 4.95 & 4.7194 & TRN & \\
\hline CHEMBL1368430 & 688636 & 5.55 & 4.8402 & TST & \\
\hline CHEMBL1381002 & 688636 & 4.5 & 4.9481 & TRN & \\
\hline CHEMBL1411399 & 688636 & 4.45 & 4.7335 & TRN & \\
\hline CHEMBL1384596 & 688636 & 5.9 & 4.9613 & TRN & \\
\hline CHEMBL1324452 & 688636 & 6.45 & 4.7383 & TRN & \\
\hline CHEMBL1537784 & 688636 & 4.35 & 4.6695 & TRN & \\
\hline CHEMBL1466809 & 688636 & 5.15 & 4.9004 & TST & \\
\hline CHEMBL1330229 & 688636 & 4.5 & 5.0407 & TRN & \\
\hline CHEMBL1507032 & 688636 & 5.15 & 4.7488 & TRN & \\
\hline
\end{tabular}




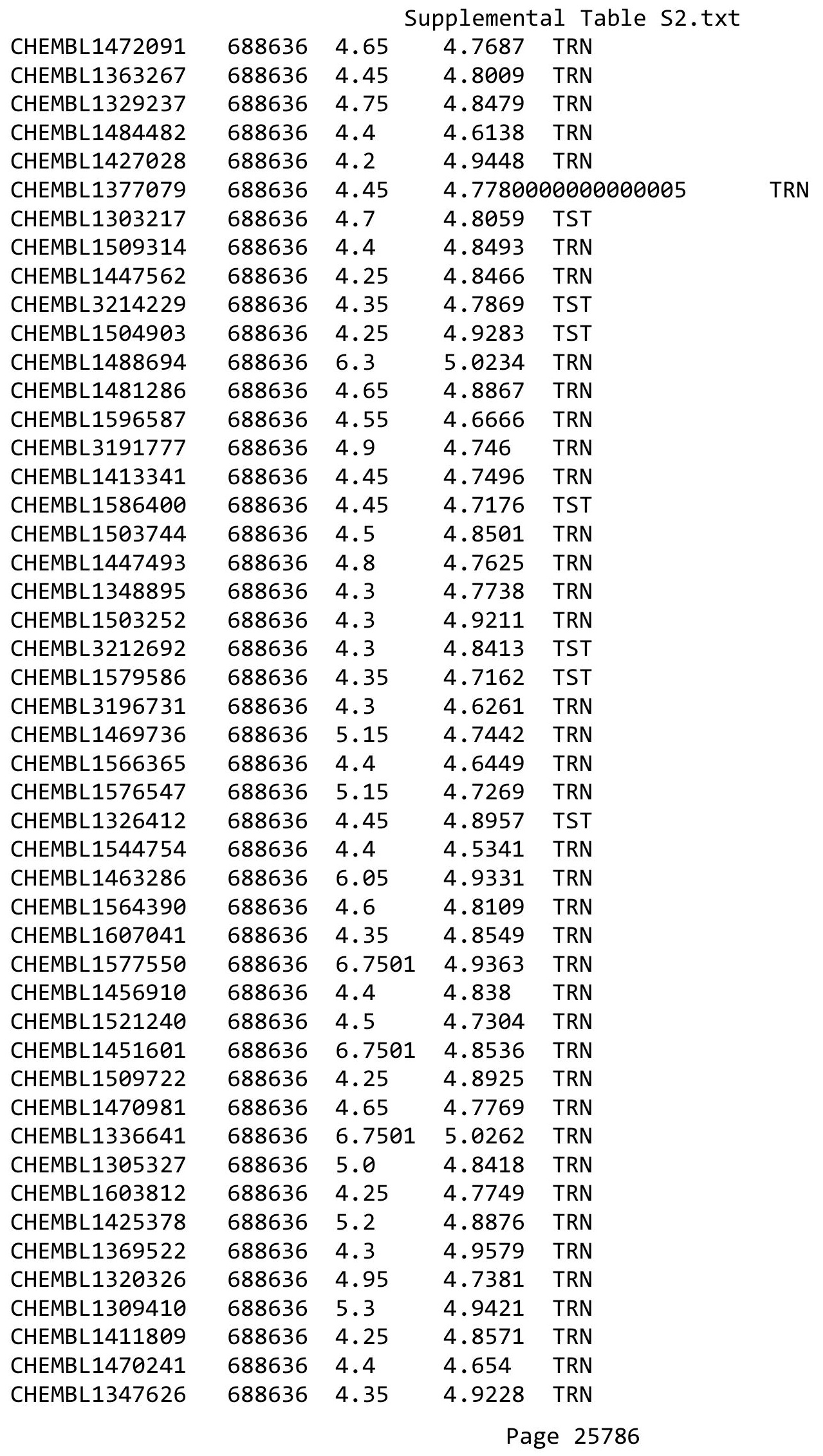




\begin{tabular}{|c|c|c|c|c|c|}
\hline & & \\
\hline CHEMBL1353890 & 688636 & 6.7501 & 4.716 & TST & \\
\hline CHEMBL1560080 & 688636 & 4.55 & 4.6881 & TRN & \\
\hline CHEMBL1581652 & 688636 & 6.05 & 4.7749 & TST & \\
\hline CHEMBL1383949 & 688636 & 4.6 & 4.7304 & TST & \\
\hline CHEMBL1409280 & 688636 & 4.7 & 4.685 & TRN & \\
\hline CHEMBL1453023 & 688636 & 5.3 & 4.7119 & TRN & \\
\hline CHEMBL1518175 & 688636 & 5.1 & 4.6561 & TRN & \\
\hline CHEMBL1518817 & 688636 & 4.4 & 4.9045 & TRN & \\
\hline CHEMBL1326779 & 688636 & 4.25 & 4.9056 & TRN & \\
\hline CHEMBL1469068 & 688636 & 4.3 & 4.8114 & TST & \\
\hline CHEMBL3189857 & 688636 & 4.75 & 4.6082 & TST & \\
\hline CHEMBL1327527 & 688636 & 4.95 & 4.8499 & TRN & \\
\hline CHEMBL142634 & 688636 & 5.3 & 4.8382 & TRN & \\
\hline CHEMBL1312593 & 688636 & 5.15 & 4.9872 & TRN & \\
\hline CHEMBL1599394 & 688636 & 4.95 & 4.8325 & TRN & \\
\hline CHEMBL1519554 & 688636 & 6.05 & 4.8379 & TRN & \\
\hline CHEMBL1601105 & 688636 & 5.5 & 4.9851 & TST & \\
\hline CHEMBL1426402 & 688636 & 4.6 & 4.5133 & TRN & \\
\hline CHEMBL1393699 & 688636 & 4.75 & 4.9283 & TRN & \\
\hline CHEMBL1535910 & 688636 & 4.5 & 4.5793 & TRN & \\
\hline CHEMBL1568212 & 688636 & 5.65 & 4.8936 & TST & \\
\hline CHEMBL1312300 & 688636 & 4.25 & 4.8177 & TRN & \\
\hline CHEMBL1481330 & 688636 & 5.45 & 4.8853 & TST & \\
\hline CHEMBL1588727 & 688636 & 4.55 & 4.7974 & TRN & \\
\hline CHEMBL1335319 & 688636 & 4.45 & 4.6607 & TRN & \\
\hline CHEMBL1490530 & 688636 & 6.15 & 4.9061 & TST & \\
\hline CHEMBL1523881 & 688636 & 4.55 & 4.7914 & TRN & \\
\hline CHEMBL1431637 & 688636 & 4.45 & 4.7058 & TRN & \\
\hline CHEMBL1579414 & 688636 & 4.55 & 4.6129 & TRN & \\
\hline CHEMBL 3212370 & 688636 & 4.55 & 4.753 & TRN & \\
\hline CHEMBL1346300 & 688636 & 4.95 & 4.6025 & TST & \\
\hline CHEMBL1413578 & 688636 & 4.95 & 4.5717 & TRN & \\
\hline CHEMBL1462151 & 688636 & 4.9 & 4.92899 & 9999999999 & TST \\
\hline CHEMBL1382344 & 688636 & 5.6 & 4.9181 & TRN & \\
\hline CHEMBL1574187 & 688636 & 6.7501 & 4.7462 & TST & \\
\hline CHEMBL1541441 & 688636 & 6.5 & 4.7602 & TST & \\
\hline CHEMBL1447230 & 688636 & 4.6 & 4.6973 & TST & \\
\hline CHEMBL1576436 & 688636 & 4.3 & 4.8723 & TRN & \\
\hline CHEMBL1311245 & 688636 & 5.4 & 4.8592 & TRN & \\
\hline CHEMBL1421603 & 688636 & 5.95 & 4.6845 & TST & \\
\hline CHEMBL1308710 & 688636 & 6.25 & 4.8503 & TRN & \\
\hline CHEMBL1444214 & 688636 & 4.95 & 4.9362 & TRN & \\
\hline CHEMBL1525130 & 688636 & 4.45 & 4.8159 & TRN & \\
\hline CHEMBL1460719 & 688636 & 4.45 & 4.8974 & TRN & \\
\hline CHEMBL3214129 & 688636 & 4.95 & 4.8196 & TST & \\
\hline CHEMBL1385745 & 688636 & 5.25 & 4.651 & TRN & \\
\hline CHEMBL1426233 & 688636 & 4.9 & 4.573 & TRN & \\
\hline CHEMBL1305004 & 688636 & 4.95 & 4.92399 & 99999999995 & TST \\
\hline & & & & 25787 & \\
\hline
\end{tabular}




\begin{tabular}{|c|c|c|c|c|c|}
\hline \multicolumn{6}{|c|}{ Supplemental Table S2.txt } \\
\hline CHEMBL1698217 & 688636 & 4.45 & 4.5895 & TRN & \\
\hline CHEMBL1579906 & 688636 & 4.65 & 4.6491 & TRN & \\
\hline CHEMBL1482857 & 688636 & 4.5 & 4.6935 & TRN & \\
\hline CHEMBL1336557 & 688636 & 6.8 & 4.8409 & TST & \\
\hline CHEMBL1536273 & 688636 & 4.5 & 4.7081 & TRN & \\
\hline CHEMBL1555510 & 688636 & 4.25 & 5.0094 & TST & \\
\hline CHEMBL1368095 & 688636 & 4.25 & 4.7239 & TST & \\
\hline CHEMBL1524963 & 688636 & 5.1 & 4.8827 & TRN & \\
\hline CHEMBL1465735 & 688636 & 6.7501 & 4.8438 & TRN & \\
\hline CHEMBL3199314 & 688636 & 4.3 & 4.8183 & TST & \\
\hline CHEMBL581574 & 688636 & 4.4 & 4.91100 & 00000000005 & TRN \\
\hline CHEMBL1374995 & 688636 & 5.4 & 5.0516 & TST & \\
\hline CHEMBL1549801 & 688636 & 4.45 & 4.6877 & TRN & \\
\hline CHEMBL1458457 & 688636 & 4.25 & 4.9014 & TRN & \\
\hline CHEMBL1503933 & 688636 & 4.95 & 4.7491 & TST & \\
\hline CHEMBL1350685 & 688636 & 4.45 & 4.628 & TRN & \\
\hline CHEMBL1488092 & 688636 & 4.55 & 4.6932 & TRN & \\
\hline CHEMBL1431456 & 688636 & 4.4 & 4.5831 & TRN & \\
\hline CHEMBL1405818 & 688636 & 4.25 & 4.8832 & TST & \\
\hline CHEMBL1461215 & 688636 & 4.9 & 4.8482 & TRN & \\
\hline CHEMBL3191643 & 688636 & 4.55 & 4.6073 & TST & \\
\hline CHEMBL1331047 & 688636 & 4.35 & 4.7483 & TRN & \\
\hline CHEMBL1439966 & 688636 & 5.6 & 4.7942 & TRN & \\
\hline CHEMBL1523229 & 688636 & 5.2 & 4.8852 & TRN & \\
\hline CHEMBL1382737 & 688636 & 4.45 & 4.9393 & TST & \\
\hline CHEMBL1583769 & 688636 & 4.35 & 4.8652 & TRN & \\
\hline CHEMBL1611299 & 688636 & 4.45 & 4.6932 & TRN & \\
\hline CHEMBL1543757 & 688636 & 4.95 & 4.7529 & TRN & \\
\hline CHEMBL1494471 & 688636 & 4.45 & 4.7056 & TRN & \\
\hline CHEMBL1580246 & 688636 & 5.95 & 5.1861 & TRN & \\
\hline CHEMBL1502129 & 688636 & 4.4 & 4.7407 & TRN & \\
\hline CHEMBL1594989 & 688636 & 4.5 & 4.6487 & TRN & \\
\hline CHEMBL1365692 & 688636 & 4.45 & 4.5846 & TRN & \\
\hline CHEMBL1519904 & 688636 & 4.45 & 4.829 & TRN & \\
\hline CHEMBL1338163 & 688636 & 4.3 & 4.9134 & TST & \\
\hline CHEMBL1562604 & 688636 & 4.25 & 4.8109 & TST & \\
\hline CHEMBL1453858 & 688636 & 4.45 & 4.7251 & TRN & \\
\hline CHEMBL1988829 & 688636 & 5.3 & 4.742 & TST & \\
\hline CHEMBL1429022 & 688636 & 4.45 & 4.9311 & TRN & \\
\hline CHEMBL1562954 & 688636 & 4.4 & 4.8785 & TST & \\
\hline CHEMBL1497405 & 688636 & 4.4 & 4.9143 & TRN & \\
\hline CHEMBL1408530 & 688636 & 4.95 & 4.6681 & TRN & \\
\hline CHEMBL1600750 & 688636 & 6.5501 & 4.7973 & TRN & \\
\hline CHEMBL1323336 & 688636 & 4.4 & 4.812 & TST & \\
\hline CHEMBL1343666 & 688636 & 5.7 & 4.6795 & TST & \\
\hline CHEMBL1549758 & 688636 & 4.25 & 4.8844 & TST & \\
\hline CHEMBL1373075 & 688636 & 5.2 & 4.9659 & TRN & \\
\hline CHEMBL3199758 & 688636 & 4.25 & 4.8438 & TST & \\
\hline
\end{tabular}




\begin{tabular}{|c|c|c|c|c|c|}
\hline \multicolumn{6}{|c|}{ Supplemental Table S2.txt } \\
\hline CHEMBL1585171 & 688636 & 4.45 & 4.7237 & TRN & \\
\hline CHEMBL1580383 & 688636 & 4.7 & 4.83 & TST & \\
\hline CHEMBL1331860 & 688636 & 4.25 & 5.0132 & TRN & \\
\hline CHEMBL1466411 & 688636 & 6.5501 & 4.7731 & TRN & \\
\hline CHEMBL1443408 & 688636 & 4.35 & 4.624 & TRN & \\
\hline CHEMBL1531432 & 688636 & 5.0 & 4.87 & TST & \\
\hline CHEMBL1504875 & 688636 & 4.3 & 5.0186 & TST & \\
\hline CHEMBL1331859 & 688636 & 5.45 & 4.8477 & TST & \\
\hline CHEMBL1383270 & 688636 & 4.45 & 4.6857 & TRN & \\
\hline CHEMBL1313370 & 688636 & 4.75 & 5.0218 & TRN & \\
\hline CHEMBL1609320 & 688636 & 4.45 & 4.989 & TRN & \\
\hline CHEMBL1501402 & 688636 & 5.15 & 4.7464 & TST & \\
\hline CHEMBL3199767 & 688636 & 4.45 & 4.837 & TRN & \\
\hline CHEMBL1549074 & 688636 & 4.75 & 4.9346 & TRN & \\
\hline CHEMBL1538676 & 688636 & 4.45 & 4.7374 & TRN & \\
\hline CHEMBL 3214548 & 688636 & 5.1 & 4.856 & TRN & \\
\hline CHEMBL1517667 & 688636 & 5.75 & 4.7395 & TST & \\
\hline CHEMBL1477725 & 688636 & 6.7501 & 4.8502 & TRN & \\
\hline CHEMBL1310211 & 688636 & 4.25 & 4.6652 & TRN & \\
\hline CHEMBL1419029 & 688636 & 4.25 & 4.58899 & 99999999995 & TRN \\
\hline CHEMBL1510797 & 688636 & 4.55 & 4.7 & TRN & \\
\hline CHEMBL581459 & 688636 & 4.3 & 4.73 & TRN & \\
\hline CHEMBL1300902 & 688636 & 4.3 & 4.788 & TRN & \\
\hline CHEMBL1438929 & 688636 & 5.0 & 4.9359 & TRN & \\
\hline CHEMBL1422960 & 688636 & 4.8 & 4.5447 & TRN & \\
\hline CHEMBL1466938 & 688636 & 4.4 & 4.927 & TRN & \\
\hline CHEMBL1587685 & 688636 & 4.5 & 4.6123 & TRN & \\
\hline CHEMBL1413717 & 688636 & 4.25 & 4.6845 & TRN & \\
\hline CHEMBL1332007 & 688636 & 5.45 & 4.922 & TST & \\
\hline CHEMBL 3213638 & 688636 & 5.15 & 4.8106 & TST & \\
\hline CHEMBL1588315 & 688636 & 6.0 & 4.8348 & TST & \\
\hline CHEMBL1538427 & 688636 & 4.55 & 4.7152 & TRN & \\
\hline CHEMBL1429057 & 688636 & 5.45 & 4.7628 & TRN & \\
\hline CHEMBL1608819 & 688636 & 4.3 & 4.7789 & TRN & \\
\hline CHEMBL1606763 & 688636 & 4.3 & 4.8606 & TRN & \\
\hline CHEMBL1537894 & 688636 & 4.35 & 5.0794 & TRN & \\
\hline CHEMBL1600848 & 688636 & 4.25 & 4.7508 & TRN & \\
\hline CHEMBL1409587 & 688636 & 4.4 & 4.8273 & TRN & \\
\hline CHEMBL1550513 & 688636 & 5.8 & 4.8921 & TST & \\
\hline CHEMBL1424047 & 688636 & 4.25 & 4.6988 & TRN & \\
\hline CHEMBL1409853 & 688636 & 4.55 & 4.6809 & TST & \\
\hline CHEMBL1567297 & 688636 & 4.4 & 4.8702 & TST & \\
\hline CHEMBL1520364 & 688636 & 4.25 & 4.632 & TRN & \\
\hline CHEMBL1398854 & 688636 & 4.55 & 4.6831 & TRN & \\
\hline CHEMBL1322661 & 688636 & 4.45 & 4.8204 & TRN & \\
\hline CHEMBL1342368 & 688636 & 4.7 & 4.6659 & TRN & \\
\hline CHEMBL1428644 & 688636 & 5.15 & 4.9884 & TRN & \\
\hline CHEMBL1565290 & 688636 & 4.5 & 4.7762 & TRN & \\
\hline
\end{tabular}




\begin{tabular}{|c|c|c|c|c|}
\hline \multirow[b]{2}{*}{ CHEMBL1497915 } & \multicolumn{4}{|c|}{ splemental T } \\
\hline & 688636 & 4.4 & 4.4807 & TRN \\
\hline CHEMBL1306263 & 688636 & 4.4 & 4.8398 & TST \\
\hline CHEMBL1582890 & 688636 & 4.95 & 4.8327 & TRN \\
\hline CHEMBL1470657 & 688636 & 5.7 & 5.0088 & TRN \\
\hline CHEMBL1561066 & 688636 & 4.35 & 4.6757 & TRN \\
\hline CHEMBL1329967 & 688636 & 4.25 & 4.5771 & TRN \\
\hline CHEMBL1526585 & 688636 & 4.95 & 4.8367 & TRN \\
\hline CHEMBL1342766 & 688636 & 4.8 & 4.7593 & TRN \\
\hline CHEMBL1479331 & 688636 & 5.0 & 4.9496 & TRN \\
\hline CHEMBL1537970 & 688636 & 4.45 & 4.7557 & TRN \\
\hline CHEMBL1484553 & 688636 & 5.45 & 4.8799 & TRN \\
\hline CHEMBL1299742 & 688636 & 4.95 & 4.9387 & TST \\
\hline CHEMBL1363140 & 688636 & 4.3 & 4.8207 & TRN \\
\hline CHEMBL1440818 & 688636 & 4.25 & 4.763 & TRN \\
\hline CHEMBL1467776 & 688636 & 4.25 & 4.8556 & TST \\
\hline CHEMBL1390524 & 688636 & 4.45 & 4.8056 & TRN \\
\hline CHEMBL1588787 & 688636 & 4.45 & 4.8857 & TRN \\
\hline CHEMBL1340990 & 688636 & 5.05 & 4.9232 & TRN \\
\hline CHEMBL1575087 & 688636 & 4.3 & 4.8406 & TRN \\
\hline CHEMBL1555882 & 688636 & 4.25 & 4.8275 & TRN \\
\hline CHEMBL1346056 & 688636 & 4.55 & 4.6914 & TRN \\
\hline CHEMBL1569028 & 688636 & 4.75 & 4.7105 & TRN \\
\hline CHEMBL1548888 & 688636 & 5.45 & 4.8436 & TST \\
\hline CHEMBL1603191 & 688636 & 4.8 & 4.7957 & TRN \\
\hline CHEMBL1564886 & 688636 & 5.9 & 4.7941 & TST \\
\hline CHEMBL3192659 & 688636 & 6.15 & 4.5915 & TRN \\
\hline CHEMBL1578159 & 688636 & 6.1 & 4.8949 & TRN \\
\hline CHEMBL1312801 & 688636 & 5.1 & 4.8831 & TRN \\
\hline CHEMBL1303482 & 688636 & 4.25 & 4.8501 & TST \\
\hline CHEMBL1466625 & 688636 & 4.6 & 4.6812 & TRN \\
\hline CHEMBL1547311 & 688636 & 4.45 & 4.7332 & TRN \\
\hline CHEMBL3213159 & 688636 & 5.9 & 4.8119 & TST \\
\hline CHEMBL1521851 & 688636 & 5.3 & 4.7652 & TST \\
\hline CHEMBL1393441 & 688636 & 5.65 & 4.7943 & TRN \\
\hline CHEMBL1305136 & 688636 & 4.25 & 4.8206 & TRN \\
\hline CHEMBL1420996 & 688636 & 4.95 & 4.7835 & TST \\
\hline CHEMBL1508375 & 688636 & 6.7501 & 4.7043 & TRN \\
\hline CHEMBL1301291 & 688636 & 4.35 & 4.7735 & TST \\
\hline CHEMBL1454307 & 688636 & 4.3 & 4.7572 & TST \\
\hline CHEMBL273101 & 688636 & 4.4 & 4.7618 & TRN \\
\hline CHEMBL1351280 & 688636 & 6.8 & 4.9931 & TRN \\
\hline CHEMBL1549392 & 688636 & 4.3 & 4.7238 & TRN \\
\hline CHEMBL1599948 & 688636 & 5.25 & 4.9533 & TRN \\
\hline CHEMBL1369590 & 688636 & 4.4 & 4.6715 & TRN \\
\hline CHEMBL1372400 & 688636 & 6.7501 & 4.6459 & TST \\
\hline CHEMBL1348849 & 688636 & 4.45 & 4.6883 & TRN \\
\hline CHEMBL1539620 & 688636 & 4.7 & 4.7058 & TRN \\
\hline CHEMBL1520738 & 688636 & 6.7501 & 4.7995 & TRN \\
\hline
\end{tabular}

Page 25790 


\begin{tabular}{|c|c|c|c|c|}
\hline & & & pplement & al $\mathrm{T}$ \\
\hline CHEMBL1597783 & 688636 & 5.6 & 4.7978 & TRN \\
\hline CHEMBL1393096 & 688636 & 4.4 & 4.8115 & TRN \\
\hline CHEMBL1460431 & 688636 & 4.5 & 4.836 & TRN \\
\hline CHEMBL1448530 & 688636 & 4.45 & 4.7983 & TRN \\
\hline CHEMBL1343650 & 688636 & 6.05 & 4.9403 & TST \\
\hline CHEMBL1346577 & 688636 & 4.25 & 4.6831 & TRN \\
\hline CHEMBL1419964 & 688636 & 4.25 & 4.8322 & TRN \\
\hline CHEMBL1566405 & 688636 & 4.45 & 4.7827 & TRN \\
\hline CHEMBL1527092 & 688636 & 4.3 & 4.8408 & TST \\
\hline CHEMBL1580923 & 688636 & 4.95 & 4.8899 & TST \\
\hline CHEMBL1491743 & 688636 & 5.35 & 4.8029 & TST \\
\hline CHEMBL1482750 & 688636 & 4.55 & 4.684 & TST \\
\hline CHEMBL1538188 & 688636 & 4.65 & 4.6957 & TRN \\
\hline CHEMBL1501439 & 688636 & 4.3 & 4.8045 & TRN \\
\hline CHEMBL1413675 & 688636 & 5.0 & 4.7137 & TRN \\
\hline CHEMBL1527827 & 688636 & 4.35 & 4.9477 & TRN \\
\hline CHEMBL1335161 & 688636 & 4.65 & 4.7657 & TRN \\
\hline CHEMBL3351142 & 688636 & 6.5501 & 4.9864 & TST \\
\hline CHEMBL1303533 & 688636 & 5.3 & 4.9708 & TRN \\
\hline CHEMBL1505053 & 688636 & 4.55 & 4.8015 & TRN \\
\hline CHEMBL1392986 & 688636 & 5.9 & 4.7832 & TST \\
\hline CHEMBL1432981 & 688636 & 6.1 & 4.9922 & TRN \\
\hline CHEMBL1449968 & 688636 & 4.45 & 4.7923 & TRN \\
\hline CHEMBL1480294 & 688636 & 4.25 & 4.7251 & TST \\
\hline CHEMBL1561528 & 688636 & 5.8 & 4.9689 & TRN \\
\hline CHEMBL1388310 & 688636 & 4.35 & 4.8219 & TST \\
\hline CHEMBL1369052 & 688636 & 4.65 & 4.6139 & TRN \\
\hline CHEMBL1362157 & 688636 & 4.5 & 4.7155 & TRN \\
\hline CHEMBL1523728 & 688636 & 6.0 & 4.9379 & TRN \\
\hline CHEMBL1602936 & 688636 & 4.5 & 4.7432 & TRN \\
\hline CHEMBL1354002 & 688636 & 4.65 & 4.8897 & TST \\
\hline CHEMBL1422094 & 688636 & 4.5 & 4.7309 & TRN \\
\hline CHEMBL1349689 & 688636 & 4.9 & 4.7375 & TRN \\
\hline CHEMBL1440558 & 688636 & 4.4 & 4.6512 & TRN \\
\hline CHEMBL1464698 & 688636 & 4.55 & 4.8145 & TRN \\
\hline CHEMBL1307769 & 688636 & 4.55 & 4.8779 & TRN \\
\hline CHEMBL1471610 & 688636 & 4.3 & 4.8545 & TST \\
\hline CHEMBL1510466 & 688636 & 4.25 & 4.8793 & TRN \\
\hline CHEMBL1310478 & 688636 & 4.3 & 4.7689 & TRN \\
\hline CHEMBL1564569 & 688636 & 5.0 & 4.7244 & TST \\
\hline CHEMBL1604505 & 688636 & 4.3 & 4.67 & TRN \\
\hline CHEMBL3198187 & 688636 & 5.0 & 4.7817 & TRN \\
\hline CHEMBL1319491 & 688636 & 4.25 & 4.8791 & TRN \\
\hline CHEMBL1323091 & 688636 & 4.3 & 4.9003 & TRN \\
\hline CHEMBL1417848 & 688636 & 5.4 & 4.853 & TRN \\
\hline CHEMBL1548993 & 688636 & 4.95 & 4.8913 & TST \\
\hline CHEMBL1609481 & 688636 & 4.45 & 4.8442 & TRN \\
\hline CHEMBL3192521 & 688636 & 4.55 & 4.8187 & TRN \\
\hline
\end{tabular}




\begin{tabular}{|c|c|c|c|c|}
\hline \multicolumn{5}{|c|}{ Supplemental Table S2.txt } \\
\hline CHEMBL1361783 & 688636 & 5.6 & 4.8939 & TST \\
\hline CHEMBL1570454 & 688636 & 5.35 & 4.8963 & TRN \\
\hline CHEMBL1341450 & 688636 & 4.45 & 4.6402 & TRN \\
\hline CHEMBL1458410 & 688636 & 4.6 & 4.7936 & TRN \\
\hline CHEMBL1477154 & 688636 & 4.25 & 4.8151 & TRN \\
\hline CHEMBL1548753 & 688636 & 4.35 & 4.8602 & TRN \\
\hline CHEMBL1561274 & 688636 & 6.25 & 4.8126 & TST \\
\hline CHEMBL1596917 & 688636 & 4.4 & 4.6778 & TST \\
\hline CHEMBL1603658 & 688636 & 4.95 & 4.8187 & TST \\
\hline CHEMBL1460216 & 688636 & 5.25 & 4.9033 & TRN \\
\hline CHEMBL1413543 & 688636 & 4.45 & 4.6818 & TRN \\
\hline CHEMBL1313247 & 688636 & 4.25 & 4.9757 & TST \\
\hline CHEMBL1432231 & 688636 & 4.25 & 4.8637 & TRN \\
\hline CHEMBL1472521 & 688636 & 4.5 & 4.6518 & TRN \\
\hline CHEMBL1536955 & 688636 & 4.9 & 4.9411 & TST \\
\hline CHEMBL1418211 & 688636 & 4.3 & 4.7717 & TRN \\
\hline CHEMBL1304460 & 688636 & 4.95 & 4.8567 & TRN \\
\hline CHEMBL3210917 & 688636 & 4.35 & 4.7049 & TRN \\
\hline CHEMBL3208607 & 688636 & 5.65 & 4.748 & TST \\
\hline CHEMBL1529689 & 688636 & 6.3 & 4.7455 & TRN \\
\hline CHEMBL1991439 & 688636 & 4.3 & 4.6696 & TST \\
\hline CHEMBL1333392 & 688636 & 4.3 & 4.9483 & TRN \\
\hline CHEMBL1330356 & 688636 & 4.25 & 4.6963 & TRN \\
\hline CHEMBL1558757 & 688636 & 6.5501 & 4.9985 & TRN \\
\hline CHEMBL1511135 & 688636 & 4.3 & 5.0588 & TRN \\
\hline CHEMBL1439488 & 688636 & 4.5 & 4.7798 & TRN \\
\hline CHEMBL1594286 & 688636 & 4.3 & 4.9099 & TST \\
\hline CHEMBL1372169 & 688636 & 5.75 & 4.7561 & TRN \\
\hline CHEMBL3211621 & 688636 & 4.25 & 4.8085 & TST \\
\hline CHEMBL1451243 & 688636 & 4.25 & 4.8546 & TRN \\
\hline CHEMBL1605598 & 688636 & 4.95 & 5.151 & TRN \\
\hline CHEMBL1502646 & 688636 & 4.35 & 4.8478 & TRN \\
\hline CHEMBL1371091 & 688636 & 5.85 & 5.0081 & TRN \\
\hline CHEMBL1496477 & 688636 & 4.3 & 4.8155 & TRN \\
\hline CHEMBL1467481 & 688636 & 5.45 & 4.7951 & TRN \\
\hline CHEMBL1510838 & 688636 & 4.25 & 4.8069 & TRN \\
\hline CHEMBL1330547 & 688636 & 4.25 & 4.8421 & TRN \\
\hline CHEMBL1541946 & 688636 & 5.15 & 4.9864 & TST \\
\hline CHEMBL1581710 & 688636 & 4.75 & 4.7212 & TRN \\
\hline CHEMBL1362962 & 688636 & 6.8 & 4.9346 & TST \\
\hline CHEMBL1309529 & 688636 & 5.1 & 4.7964 & TST \\
\hline CHEMBL1390325 & 688636 & 4.25 & 4.6315 & TRN \\
\hline CHEMBL1497991 & 688636 & 4.5 & 4.6159 & TRN \\
\hline CHEMBL1445085 & 688636 & 5.15 & 4.94 & TST \\
\hline CHEMBL353764 & 688636 & 4.6 & 4.7705 & TST \\
\hline CHEMBL1506017 & 688636 & 4.25 & 4.8043 & TRN \\
\hline CHEMBL1381712 & 688636 & 4.3 & 4.6665 & TST \\
\hline CHEMBL1535965 & 688636 & 4.3 & 4.9119 & TST \\
\hline
\end{tabular}




\begin{tabular}{|c|c|c|c|c|}
\hline & & & upplement & $\mathrm{T}$ \\
\hline CHEMBL1367453 & 688636 & 4.45 & 4.8116 & TRN \\
\hline CHEMBL1565589 & 688636 & 6.8 & 4.7794 & TST \\
\hline CHEMBL1550649 & 688636 & 4.25 & 4.8609 & TRN \\
\hline CHEMBL1415151 & 688636 & 4.35 & 5.067 & TRN \\
\hline CHEMBL1547400 & 688636 & 5.45 & 4.7519 & TRN \\
\hline CHEMBL1567538 & 688636 & 4.9 & 4.8543 & TST \\
\hline CHEMBL1422870 & 688636 & 5.45 & 4.9784 & TRN \\
\hline CHEMBL1336788 & 688636 & 4.95 & 4.6366 & TRN \\
\hline CHEMBL 3208884 & 688636 & 4.95 & 4.831 & TRN \\
\hline CHEMBL1517523 & 688636 & 4.25 & 4.8537 & TST \\
\hline CHEMBL1537944 & 688636 & 4.4 & 4.8981 & TRN \\
\hline CHEMBL1389713 & 688636 & 4.45 & 4.6608 & TRN \\
\hline CHEMBL1319124 & 688636 & 6.0 & 4.7317 & TRN \\
\hline CHEMBL 3189428 & 688636 & 6.05 & 4.654 & TRN \\
\hline CHEMBL1304449 & 688636 & 4.65 & 4.7046 & TRN \\
\hline CHEMBL1503344 & 688636 & 4.35 & 5.0554 & TST \\
\hline CHEMBL1457301 & 688636 & 4.9 & 4.7512 & TST \\
\hline CHEMBL1301060 & 688636 & 4.45 & 4.8395 & TRN \\
\hline CHEMBL1557037 & 688636 & 5.0 & 4.7419 & TRN \\
\hline CHEMBL1379681 & 688636 & 5.15 & 4.8773 & TRN \\
\hline CHEMBL1606430 & 688636 & 5.15 & 4.7548 & TRN \\
\hline CHEMBL1576114 & 688636 & 4.3 & 4.879 & TRN \\
\hline CHEMBL1404456 & 688636 & 4.25 & 4.6905 & TST \\
\hline CHEMBL1565636 & 688636 & 4.95 & 4.8437 & TRN \\
\hline CHEMBL1608065 & 688636 & 4.95 & 4.9142 & TST \\
\hline CHEMBL3199523 & 688636 & 4.65 & 4.7557 & TST \\
\hline CHEMBL3193909 & 688636 & 4.35 & 4.7154 & TST \\
\hline CHEMBL1458051 & 688636 & 4.25 & 4.9051 & TRN \\
\hline CHEMBL1415864 & 688636 & 4.4 & 4.7191 & TST \\
\hline CHEMBL1343053 & 688636 & 5.3 & 4.9063 & TRN \\
\hline CHEMBL1390794 & 688636 & 5.25 & 4.9227 & TRN \\
\hline CHEMBL1469204 & 688636 & 5.15 & 4.9655 & TRN \\
\hline CHEMBL1517728 & 688636 & 4.3 & 4.5819 & TRN \\
\hline CHEMBL1565085 & 688636 & 4.25 & 4.7747 & TRN \\
\hline CHEMBL1421531 & 688636 & 4.95 & 4.8807 & TST \\
\hline CHEMBL1307998 & 688636 & 4.35 & 4.8696 & TST \\
\hline CHEMBL 240332 & 688636 & 4.45 & 4.6393 & TST \\
\hline CHEMBL1403895 & 688636 & 4.4 & 4.9768 & TRN \\
\hline CHEMBL1344939 & 688636 & 4.3 & 4.9964 & TRN \\
\hline CHEMBL1442946 & 688636 & 4.25 & 4.9933 & TRN \\
\hline CHEMBL1427301 & 688636 & 4.4 & 4.7356 & TRN \\
\hline CHEMBL1576519 & 688636 & 4.45 & 4.913 & TST \\
\hline CHEMBL1508808 & 688636 & 4.95 & 4.6851 & TRN \\
\hline CHEMBL1530148 & 688636 & 4.5 & 4.8606 & TRN \\
\hline CHEMBL1390293 & 688636 & 5.45 & 4.7527 & TRN \\
\hline CHEMBL1344571 & 688636 & 4.3 & 4.8005 & TRN \\
\hline CHEMBL1597315 & 688636 & 4.5 & 4.9894 & TRN \\
\hline CHEMBL1481164 & 688636 & 5.5 & 4.8403 & TRN \\
\hline
\end{tabular}




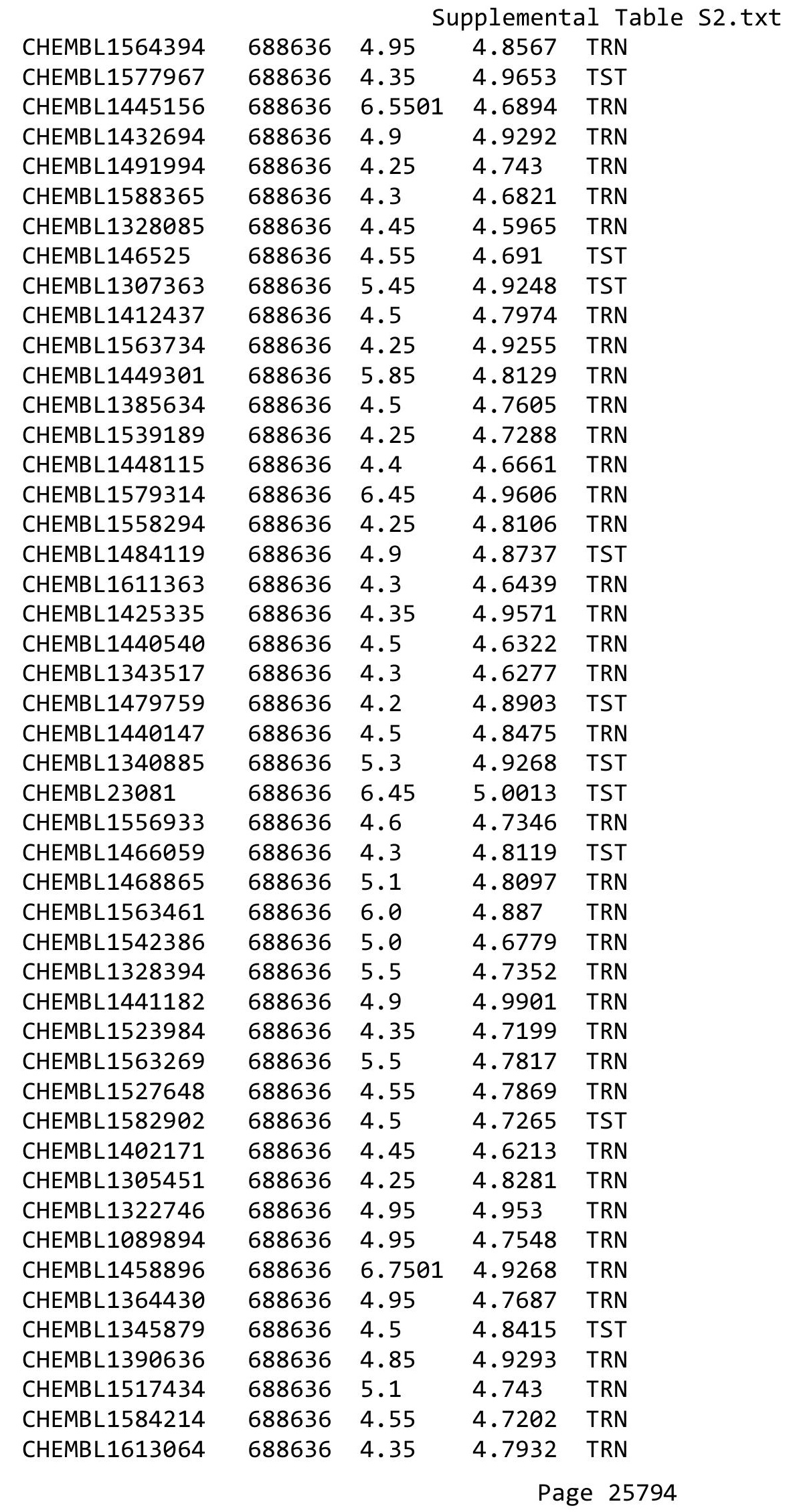




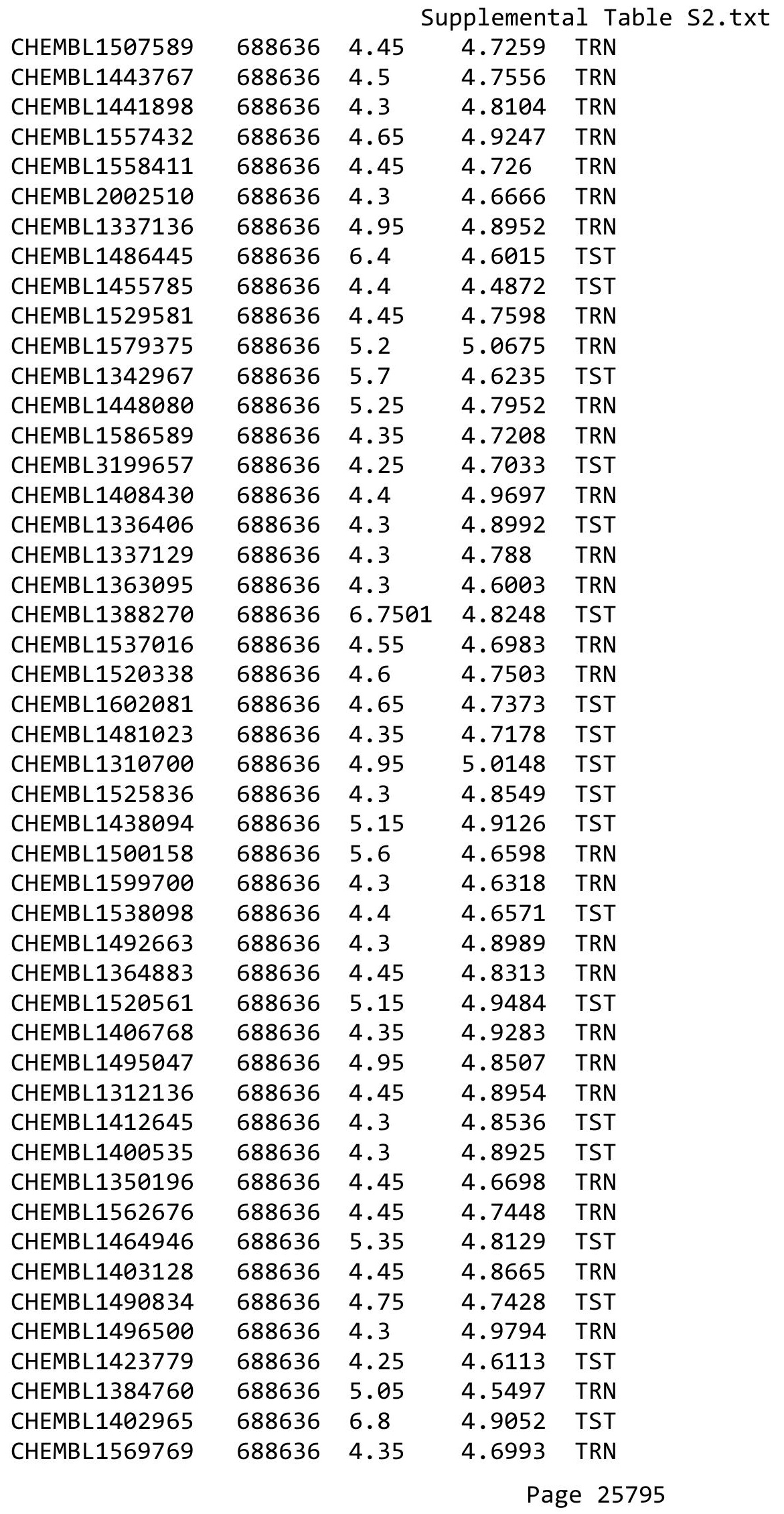




\begin{tabular}{|c|c|c|c|c|c|}
\hline \multicolumn{6}{|c|}{ Supplemental Table S2.txt } \\
\hline CHEMBL1405532 & 688636 & 4.45 & 4.7884 & TRN & \\
\hline CHEMBL1550371 & 688636 & 4.4 & 5.0089 & TRN & \\
\hline CHEMBL1500777 & 688636 & 4.55 & 4.7404 & TRN & \\
\hline CHEMBL1450827 & 688636 & 4.95 & 4.6398 & TRN & \\
\hline CHEMBL1506945 & 688636 & 5.35 & 4.8252 & TRN & \\
\hline CHEMBL1571299 & 688636 & 4.6 & 4.8118 & TRN & \\
\hline CHEMBL1546087 & 688636 & 5.5 & 4.8382 & TST & \\
\hline CHEMBL1460880 & 688636 & 4.95 & 4.796 & TRN & \\
\hline CHEMBL1531859 & 688636 & 4.7 & 4.9374 & TST & \\
\hline CHEMBL1537165 & 688636 & 4.95 & 4.7967 & TRN & \\
\hline CHEMBL1544712 & 688636 & 4.45 & 4.876 & TST & \\
\hline CHEMBL1366311 & 688636 & 4.7 & 4.6872 & TRN & \\
\hline CHEMBL3189906 & 688636 & 4.3 & 4.7961 & TRN & \\
\hline CHEMBL1309697 & 688636 & 4.3 & 4.7592 & TRN & \\
\hline CHEMBL1328430 & 688636 & 4.25 & 4.816 & TST & \\
\hline CHEMBL1410617 & 688636 & 4.4 & 4.9931 & TRN & \\
\hline CHEMBL3207751 & 688636 & 4.75 & 4.7576 & TST & \\
\hline CHEMBL1539755 & 688636 & 4.3 & 4.7539 & TRN & \\
\hline CHEMBL405914 & 688636 & 4.45 & 4.8716 & TRN & \\
\hline CHEMBL1585161 & 688636 & 4.9 & 4.8058 & TRN & \\
\hline CHEMBL1385971 & 688636 & 5.1 & 4.982 & TRN & \\
\hline CHEMBL1457442 & 688636 & 4.85 & 4.9928 & TRN & \\
\hline CHEMBL1423949 & 688636 & 4.3 & 4.7987 & TRN & \\
\hline CHEMBL1502298 & 688636 & 4.3 & 4.8847 & TST & \\
\hline CHEMBL1504768 & 688636 & 4.45 & 4.8561 & TST & \\
\hline CHEMBL1529652 & 688636 & 4.55 & 4.5969 & TRN & \\
\hline CHEMBL1478244 & 688636 & 4.85 & 4.8893 & TRN & \\
\hline CHEMBL1589573 & 688636 & 6.7501 & 5.00899 & 99999999995 & TRN \\
\hline CHEMBL1546373 & 688636 & 4.45 & 4.6153 & TST & \\
\hline CHEMBL1307638 & 688636 & 6.0 & 4.7488 & TST & \\
\hline CHEMBL1404104 & 688636 & 4.3 & 4.7689 & TRN & \\
\hline CHEMBL1425058 & 688636 & 4.4 & 4.8075 & TRN & \\
\hline CHEMBL1598860 & 688636 & 6.05 & 4.927 & TRN & \\
\hline CHEMBL3193566 & 688636 & 4.95 & 4.5006 & TRN & \\
\hline CHEMBL1429003 & 688636 & 5.1 & 4.8356 & TRN & \\
\hline CHEMBL1463728 & 688636 & 4.45 & 4.9324 & TRN & \\
\hline CHEMBL1338979 & 688636 & 4.3 & 4.9897 & TRN & \\
\hline CHEMBL1502965 & 688636 & 4.95 & 4.725 & TRN & \\
\hline CHEMBL1449038 & 688636 & 5.05 & 4.8017 & TRN & \\
\hline CHEMBL1370710 & 688636 & 4.25 & 4.8641 & TST & \\
\hline CHEMBL1583804 & 688636 & 4.4 & 4.9347 & TRN & \\
\hline CHEMBL1415036 & 688636 & 4.55 & 4.8344 & TRN & \\
\hline CHEMBL1364986 & 688636 & 4.95 & 4.7269 & TST & \\
\hline CHEMBL1425192 & 688636 & 4.4 & 4.9026 & TRN & \\
\hline CHEMBL1379135 & 688636 & 4.85 & 4.9278 & TRN & \\
\hline CHEMBL1327684 & 688636 & 4.5 & 4.6863 & TRN & \\
\hline CHEMBL1608782 & 688636 & 4.65 & 4.7318 & TRN & \\
\hline CHEMBL1609330 & 688636 & 4.4 & 4.6636 & TRN & \\
\hline
\end{tabular}




\begin{tabular}{|c|c|c|c|c|}
\hline \multicolumn{5}{|c|}{ Supplemental Table S2.txt } \\
\hline CHEMBL1480245 & 688636 & 6.8 & 4.8738 & TRN \\
\hline CHEMBL1384458 & 688636 & 4.95 & 4.6564 & TRN \\
\hline CHEMBL1545987 & 688636 & 4.95 & 4.8081 & TST \\
\hline CHEMBL1529049 & 688636 & 4.25 & 4.7117 & TRN \\
\hline CHEMBL1387929 & 688636 & 4.95 & 4.8694 & TRN \\
\hline CHEMBL3196011 & 688636 & 4.5 & 4.7707 & TRN \\
\hline CHEMBL1581335 & 688636 & 4.25 & 4.7018 & TRN \\
\hline CHEMBL1540545 & 688636 & 5.25 & 4.8884 & TRN \\
\hline CHEMBL1385824 & 688636 & 4.25 & 4.6125 & TRN \\
\hline CHEMBL1368508 & 688636 & 5.5 & 4.9648 & TRN \\
\hline CHEMBL1424675 & 688636 & 5.25 & 4.6556 & TRN \\
\hline CHEMBL1477072 & 688636 & 4.5 & 4.8956 & TRN \\
\hline CHEMBL1574416 & 688636 & 5.45 & 4.7764 & TRN \\
\hline CHEMBL1550713 & 688636 & 4.3 & 4.9754 & TST \\
\hline CHEMBL1520843 & 688636 & 4.6 & 4.8169 & TRN \\
\hline CHEMBL1519980 & 688636 & 4.45 & 4.7287 & TRN \\
\hline CHEMBL1421530 & 688636 & 4.55 & 4.644 & TRN \\
\hline CHEMBL1544333 & 688636 & 4.25 & 4.9468 & TRN \\
\hline CHEMBL1599414 & 688636 & 4.75 & 4.6243 & TRN \\
\hline CHEMBL1486034 & 688636 & 4.25 & 4.8703 & TST \\
\hline CHEMBL1308526 & 688636 & 4.25 & 4.8528 & TRN \\
\hline CHEMBL1430347 & 688636 & 5.8 & 4.7702 & TST \\
\hline CHEMBL1529631 & 688636 & 4.95 & 4.7096 & TRN \\
\hline CHEMBL1366859 & 688636 & 6.15 & 4.9389 & TRN \\
\hline CHEMBL3199850 & 688636 & 4.45 & 4.5051 & TRN \\
\hline CHEMBL1571534 & 688636 & 4.5 & 4.8183 & TRN \\
\hline CHEMBL1441339 & 688636 & 5.15 & 4.8846 & TRN \\
\hline CHEMBL1334127 & 688636 & 5.45 & 5.0297 & TRN \\
\hline CHEMBL1522492 & 688636 & 4.6 & 4.6774 & TRN \\
\hline CHEMBL1570704 & 688636 & 4.95 & 4.8505 & TST \\
\hline CHEMBL1548047 & 688636 & 6.4 & 4.5488 & TST \\
\hline CHEMBL1500459 & 688636 & 4.7 & 4.8677 & TRN \\
\hline CHEMBL1484933 & 688636 & 4.4 & 5.0523 & TRN \\
\hline CHEMBL1405815 & 688636 & 5.7 & 5.0658 & TRN \\
\hline CHEMBL1555508 & 688636 & 4.9 & 4.9121 & TRN \\
\hline CHEMBL1386372 & 688636 & 4.4 & 4.8319 & TRN \\
\hline CHEMBL1507163 & 688636 & 4.3 & 4.8074 & TRN \\
\hline CHEMBL1419681 & 688636 & 5.45 & 4.9479 & TST \\
\hline CHEMBL1443990 & 688636 & 4.9 & 4.8758 & TRN \\
\hline CHEMBL1438286 & 688636 & 4.95 & 5.0841 & TST \\
\hline CHEMBL1557597 & 688636 & 5.2 & 4.8186 & TST \\
\hline CHEMBL1377744 & 688636 & 4.3 & 4.7311 & TST \\
\hline CHEMBL1381755 & 688636 & 5.25 & 4.8995 & TRN \\
\hline CHEMBL1510434 & 688636 & 6.7501 & 4.752 & TRN \\
\hline CHEMBL1612311 & 688636 & 4.4 & 4.6775 & TRN \\
\hline CHEMBL1439887 & 688636 & 4.6 & 4.7147 & TRN \\
\hline CHEMBL1467499 & 688636 & 4.25 & 4.6199 & TRN \\
\hline CHEMBL1579407 & 688636 & 5.55 & 4.9915 & TRN \\
\hline
\end{tabular}




\begin{tabular}{|c|c|c|c|c|c|}
\hline \\
\hline CHEMBL1502451 & 688636 & 4.5 & 4.7681 & TST & \\
\hline CHEMBL1430338 & 688636 & 5.85 & 4.7968 & TRN & \\
\hline CHEMBL1352223 & 688636 & 4.5 & 4.7161 & TST & \\
\hline CHEMBL1569535 & 688636 & 4.45 & 4.6921 & TRN & \\
\hline CHEMBL1565393 & 688636 & 4.95 & 4.7846 & TRN & \\
\hline CHEMBL1541802 & 688636 & 4.75 & 4.5978 & TRN & \\
\hline CHEMBL1483415 & 688636 & 4.3 & 4.7021 & TST & \\
\hline CHEMBL1996730 & 688636 & 4.95 & 4.7672 & TRN & \\
\hline CHEMBL1528658 & 688636 & 5.9 & 4.8741 & TRN & \\
\hline CHEMBL1579644 & 688636 & 4.7 & 4.73600 & 0000000001 & TRN \\
\hline CHEMBL3196961 & 688636 & 4.65 & 4.7435 & TRN & \\
\hline CHEMBL1499111 & 688636 & 4.25 & 4.7591 & TRN & \\
\hline CHEMBL1570997 & 688636 & 6.8 & 4.9683 & TRN & \\
\hline CHEMBL1468634 & 688636 & 5.2 & 4.8943 & TST & \\
\hline CHEMBL1486610 & 688636 & 4.25 & 4.7672 & TST & \\
\hline CHEMBL1311558 & 688636 & 5.75 & 4.9117 & TRN & \\
\hline CHEMBL1332467 & 688636 & 5.0 & 4.8625 & TRN & \\
\hline CHEMBL1312549 & 688636 & 6.0 & 4.5792 & TRN & \\
\hline CHEMBL1607116 & 688636 & 5.45 & 4.7031 & TRN & \\
\hline CHEMBL1465727 & 688636 & 4.25 & 4.7179 & TRN & \\
\hline CHEMBL1454912 & 688636 & 4.25 & 4.8647 & TST & \\
\hline CHEMBL1569057 & 688636 & 5.65 & 4.7468 & TRN & \\
\hline CHEMBL1564110 & 688636 & 4.35 & 4.6251 & TRN & \\
\hline CHEMBL1404709 & 688636 & 5.15 & 4.9778 & TRN & \\
\hline CHEMBL3190774 & 688636 & 5.1 & 4.814 & TST & \\
\hline CHEMBL1414034 & 688636 & 5.35 & 4.8523 & TRN & \\
\hline CHEMBL3209049 & 688636 & 4.4 & 4.9085 & TRN & \\
\hline CHEMBL1529922 & 688636 & 4.25 & 4.8322 & TRN & \\
\hline CHEMBL1375005 & 688636 & 4.3 & 4.8177 & TRN & \\
\hline CHEMBL1422566 & 688636 & 6.7501 & 4.8864 & TRN & \\
\hline CHEMBL1572169 & 688636 & 4.25 & 4.8975 & TRN & \\
\hline CHEMBL1481614 & 688636 & 6.7501 & 4.8627 & TRN & \\
\hline CHEMBL3197981 & 688636 & 4.4 & 4.7961 & TRN & \\
\hline CHEMBL1364723 & 688636 & 4.25 & 4.837 & TST & \\
\hline CHEMBL1444613 & 688636 & 4.5 & 4.6857 & TRN & \\
\hline CHEMBL1506540 & 688636 & 5.05 & 4.9013 & TRN & \\
\hline CHEMBL1374247 & 688636 & 4.45 & 4.6486 & TRN & \\
\hline CHEMBL1362211 & 688636 & 6.5 & 4.9735 & TRN & \\
\hline CHEMBL1324817 & 688636 & 4.85 & 4.6768 & TRN & \\
\hline CHEMBL1570546 & 688636 & 4.5 & 4.7714 & TRN & \\
\hline CHEMBL1525715 & 688636 & 4.45 & 4.7508 & TRN & \\
\hline CHEMBL1370297 & 688636 & 6.6499 & 4.8097 & TRN & \\
\hline CHEMBL1579823 & 688636 & 5.15 & 4.7577 & TST & \\
\hline CHEMBL3192288 & 688636 & 4.25 & 4.8389 & TRN & \\
\hline CHEMBL1340843 & 688636 & 4.3 & 5.0208 & TST & \\
\hline CHEMBL1548672 & 688636 & 6.45 & 4.8664 & TRN & \\
\hline CHEMBL1557715 & 688636 & 4.25 & 5.0544 & TRN & \\
\hline CHEMBL1491480 & 688636 & 6.7501 & 4.7476 & TST & \\
\hline
\end{tabular}




\begin{tabular}{|c|c|c|c|c|c|}
\hline \multicolumn{6}{|c|}{ Supplemental Table S2.txt } \\
\hline CHEMBL1361859 & 688636 & 4.45 & 4.8995 & TST & \\
\hline CHEMBL1385443 & 688636 & 5.75 & 4.7738 & TRN & \\
\hline CHEMBL1563582 & 688636 & 4.5 & 4.8324 & TRN & \\
\hline CHEMBL 3198633 & 688636 & 4.95 & 4.7926 & TST & \\
\hline CHEMBL1430936 & 688636 & 4.35 & 4.6663 & TRN & \\
\hline CHEMBL1310175 & 688636 & 4.3 & 4.99 & TRN & \\
\hline CHEMBL1401226 & 688636 & 6.8 & 4.8417 & TRN & \\
\hline CHEMBL1550520 & 688636 & 6.7501 & 4.8723 & TST & \\
\hline CHEMBL1312194 & 688636 & 4.95 & 4.8404 & TRN & \\
\hline CHEMBL1430279 & 688636 & 6.5 & 4.9147 & TRN & \\
\hline CHEMBL1600878 & 688636 & 4.4 & 4.8593 & TST & \\
\hline CHEMBL1420532 & 688636 & 4.5 & 4.7575 & TRN & \\
\hline CHEMBL1542430 & 688636 & 5.35 & 4.9246 & TST & \\
\hline CHEMBL1583049 & 688636 & 4.6 & 4.6915 & TRN & \\
\hline CHEMBL1382739 & 688636 & 4.5 & 4.8627 & TRN & \\
\hline CHEMBL1346079 & 688636 & 4.4 & 4.9028 & TRN & \\
\hline CHEMBL 3210370 & 688636 & 6.8 & 4.6803 & TST & \\
\hline CHEMBL1348105 & 688636 & 5.4 & 4.846 & TRN & \\
\hline CHEMBL1463398 & 688636 & 4.45 & 4.7156 & TRN & \\
\hline CHEMBL1585962 & 688636 & 4.65 & 4.8999 & TST & \\
\hline CHEMBL1603994 & 688636 & 6.4 & 4.8834 & TRN & \\
\hline CHEMBL1312105 & 688636 & 4.8 & 4.8038 & TRN & \\
\hline CHEMBL1531707 & 688636 & 5.5 & 4.8809 & TRN & \\
\hline CHEMBL3214139 & 688636 & 4.3 & 4.9106 & TST & \\
\hline CHEMBL1570113 & 688636 & 5.2 & 4.663 & TRN & \\
\hline CHEMBL1312176 & 688636 & 4.95 & 4.8551 & TRN & \\
\hline CHEMBL1417270 & 688636 & 4.95 & 4.8985 & TRN & \\
\hline CHEMBL1340537 & 688636 & 6.8 & 4.94300 & 00000000005 & TRN \\
\hline CHEMBL1544442 & 688636 & 4.6 & 4.9498 & TRN & \\
\hline CHEMBL1601788 & 688636 & 4.55 & 4.8164 & TST & \\
\hline CHEMBL1314144 & 688636 & 5.25 & 4.6597 & TRN & \\
\hline CHEMBL1498371 & 688636 & 4.85 & 4.8869 & TRN & \\
\hline CHEMBL1597565 & 688636 & 4.35 & 4.7656 & TRN & \\
\hline CHEMBL1583118 & 688636 & 6.8 & 4.7368 & TST & \\
\hline CHEMBL1465103 & 688636 & 5.55 & 4.6794 & TST & \\
\hline CHEMBL1308037 & 688636 & 4.75 & 4.6636 & TRN & \\
\hline CHEMBL1612091 & 688636 & 5.85 & 4.8695 & TST & \\
\hline CHEMBL1571483 & 688636 & 4.95 & 4.8837 & TRN & \\
\hline CHEMBL1575075 & 688636 & 4.3 & 4.9882 & TRN & \\
\hline CHEMBL1456986 & 688636 & 6.7501 & 4.6598 & TRN & \\
\hline CHEMBL1373791 & 688636 & 4.25 & 4.8397 & TRN & \\
\hline CHEMBL1995314 & 688636 & 4.5 & 4.7147 & TRN & \\
\hline CHEMBL1386716 & 688636 & 4.5 & 4.8039 & TRN & \\
\hline CHEMBL1604101 & 688636 & 6.7501 & 4.8025 & TST & \\
\hline CHEMBL1549694 & 688636 & 5.35 & 5.0042 & TRN & \\
\hline CHEMBL1487305 & 688636 & 4.9 & 4.7646 & TST & \\
\hline CHEMBL1427111 & 688636 & 4.95 & 4.8277 & TRN & \\
\hline CHEMBL1346351 & 688636 & 5.95 & 5.0275 & TRN & \\
\hline
\end{tabular}




\begin{tabular}{|c|c|c|c|c|}
\hline \multicolumn{5}{|c|}{ Supplementa } \\
\hline CHEMBL1597433 & 688636 & 5.25 & 4.8666 & TRN \\
\hline CHEMBL1574110 & 688636 & 4.3 & 4.7514 & TST \\
\hline CHEMBL1330679 & 688636 & 4.5 & 4.8091 & TST \\
\hline CHEMBL 3189964 & 688636 & 4.75 & 4.7067 & TRN \\
\hline CHEMBL 1373528 & 688636 & 6.1 & 4.7089 & TRN \\
\hline CHEMBL1586813 & 688636 & 5.2 & 4.8394 & TRN \\
\hline CHEMBL1605537 & 688636 & 4.95 & 4.9481 & TRN \\
\hline CHEMBL1377449 & 688636 & 4.95 & 4.7517 & TRN \\
\hline CHEMBL1340083 & 688636 & 5.25 & 4.873 & TRN \\
\hline CHEMBL1336922 & 688636 & 5.35 & 4.6497 & TRN \\
\hline CHEMBL1556258 & 688636 & 4.35 & 4.7316 & TRN \\
\hline CHEMBL1453508 & 688636 & 4.65 & 4.5843 & TRN \\
\hline CHEMBL1546390 & 688636 & 6.7501 & 4.9458 & TST \\
\hline CHEMBL1561395 & 688636 & 4.25 & 4.6865 & TRN \\
\hline CHEMBL1541244 & 688636 & 4.25 & 4.758 & TRN \\
\hline CHEMBL1511140 & 688636 & 4.25 & 4.7622 & TST \\
\hline CHEMBL1559425 & 688636 & 4.3 & 4.7814 & TST \\
\hline CHEMBL1506932 & 688636 & 4.45 & 4.6216 & TST \\
\hline CHEMBL1404111 & 688636 & 4.5 & 4.824 & TRN \\
\hline CHEMBL1607695 & 688636 & 4.3 & 4.9619 & TST \\
\hline CHEMBL1569804 & 688636 & 4.4 & 4.6697 & TST \\
\hline CHEMBL1417225 & 688636 & 4.4 & 4.7732 & TRN \\
\hline CHEMBL1416042 & 688636 & 4.3 & 4.8824 & TRN \\
\hline CHEMBL1566415 & 688636 & 4.8 & 4.6813 & TRN \\
\hline CHEMBL1534470 & 688636 & 4.45 & 4.6246 & TST \\
\hline CHEMBL1566699 & 688636 & 5.4 & 5.0982 & TST \\
\hline CHEMBL1489383 & 688636 & 5.5 & 4.7403 & TRN \\
\hline CHEMBL1485577 & 688636 & 4.45 & 4.6669 & TRN \\
\hline CHEMBL1340461 & 688636 & 5.15 & 5.0796 & TRN \\
\hline CHEMBL1544531 & 688636 & 5.9 & 4.8729 & TRN \\
\hline CHEMBL1559494 & 688636 & 4.95 & 4.9115 & TRN \\
\hline CHEMBL1414120 & 688636 & 6.15 & 5.1856 & TST \\
\hline CHEMBL1492997 & 688636 & 4.3 & 4.9587 & TRN \\
\hline CHEMBL1542908 & 688636 & 4.95 & 4.5916 & TST \\
\hline CHEMBL1465475 & 688636 & 4.5 & 4.7085 & TRN \\
\hline CHEMBL1580252 & 688636 & 4.55 & 4.9677 & TST \\
\hline CHEMBL 1450836 & 688636 & 5.2 & 4.7645 & TRN \\
\hline CHEMBL1321518 & 688636 & 4.55 & 4.8309 & TRN \\
\hline CHEMBL3209715 & 688636 & 4.55 & 4.9406 & TRN \\
\hline CHEMBL1419791 & 688636 & 4.5 & 4.6727 & TRN \\
\hline CHEMBL1301468 & 688636 & 4.25 & 4.803 & TST \\
\hline CHEMBL1505943 & 688636 & 6.8 & 4.8179 & TRN \\
\hline CHEMBL1371988 & 688636 & 5.55 & 4.7658 & TRN \\
\hline CHEMBL1548314 & 688636 & 6.7501 & 4.8746 & TST \\
\hline CHEMBL1427210 & 688636 & 5.05 & 4.7531 & TRN \\
\hline CHEMBL1516629 & 688636 & 4.25 & 4.776 & TRN \\
\hline CHEMBL1303501 & 688636 & 4.95 & 4.9769 & TRN \\
\hline CHEMBL1461111 & 688636 & 4.55 & 4.8796 & TRN \\
\hline
\end{tabular}




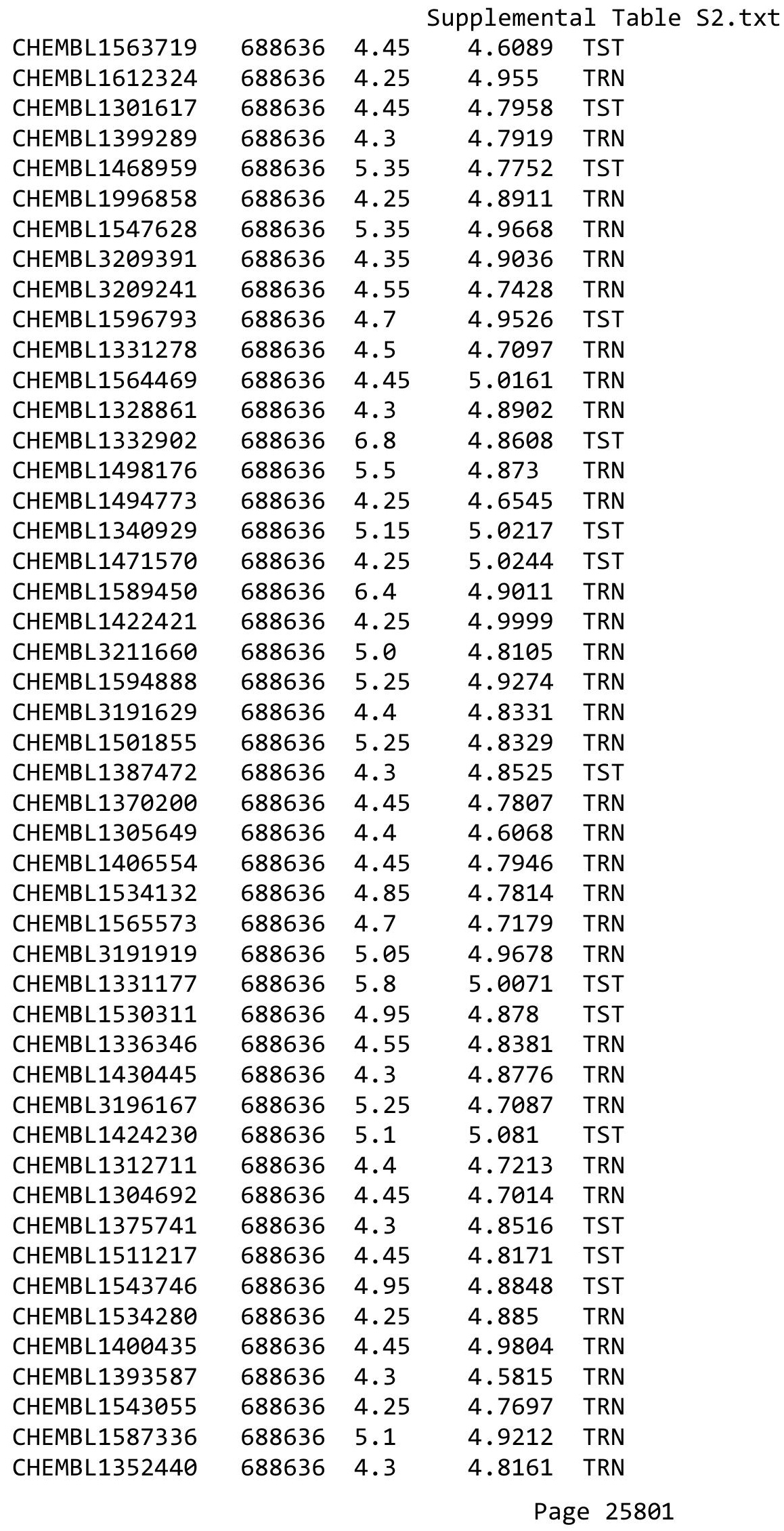




\begin{tabular}{|c|c|c|c|c|c|}
\hline \multicolumn{6}{|c|}{ Supplemental Table S2.txt } \\
\hline CHEMBL1452239 & 688636 & 5.2 & 4.7626 & TRN & \\
\hline CHEMBL1308490 & 688636 & 5.1 & 4.8888 & TRN & \\
\hline CHEMBL1359078 & 688636 & 6.8 & 4.9436 & TRN & \\
\hline CHEMBL1415503 & 688636 & 4.6 & 4.9169 & TRN & \\
\hline CHEMBL1580338 & 688636 & 4.35 & 4.8805 & TRN & \\
\hline CHEMBL1428399 & 688636 & 4.3 & 4.6895 & TST & \\
\hline CHEMBL1377010 & 688636 & 4.3 & 4.7424 & TRN & \\
\hline CHEMBL1576283 & 688636 & 4.5 & 5.0184 & TRN & \\
\hline CHEMBL1570320 & 688636 & 4.9 & 4.8174 & TST & \\
\hline CHEMBL1543280 & 688636 & 4.25 & 4.8282 & TRN & \\
\hline CHEMBL1305928 & 688636 & 4.25 & 4.825 & TRN & \\
\hline CHEMBL1588805 & 688636 & 4.95 & 4.727 & TRN & \\
\hline CHEMBL1361808 & 688636 & 5.5 & 4.8674 & TRN & \\
\hline CHEMBL1450635 & 688636 & 4.4 & 4.67899 & 9999999999 & TRN \\
\hline CHEMBL1534290 & 688636 & 6.45 & 5.0098 & TST & \\
\hline CHEMBL1332427 & 688636 & 4.75 & 4.9099 & TRN & \\
\hline CHEMBL1384561 & 688636 & 4.3 & 4.8662 & TRN & \\
\hline CHEMBL1341164 & 688636 & 4.45 & 4.7032 & TST & \\
\hline CHEMBL1300046 & 688636 & 6.15 & 4.9584 & TRN & \\
\hline CHEMBL550826 & 688636 & 4.6 & 4.6805 & TRN & \\
\hline CHEMBL1362279 & 688636 & 4.55 & 4.6873 & TST & \\
\hline CHEMBL1459370 & 688636 & 4.65 & 4.8628 & TST & \\
\hline CHEMBL1470021 & 688636 & 4.25 & 4.8281 & TRN & \\
\hline CHEMBL1384844 & 688636 & 4.95 & 4.8125 & TST & \\
\hline CHEMBL1604679 & 688636 & 4.25 & 4.8815 & TST & \\
\hline CHEMBL1363984 & 688636 & 4.25 & 4.7432 & TRN & \\
\hline CHEMBL1432104 & 688636 & 6.7501 & 4.7399 & TRN & \\
\hline CHEMBL1371148 & 688636 & 4.45 & 4.8068 & TRN & \\
\hline CHEMBL3195990 & 688636 & 4.45 & 4.5611 & TRN & \\
\hline CHEMBL3197702 & 688636 & 4.95 & 4.6438 & TST & \\
\hline CHEMBL3190659 & 688636 & 5.3 & 4.8568 & TST & \\
\hline CHEMBL1585612 & 688636 & 5.0 & 4.8075 & TST & \\
\hline CHEMBL1426578 & 688636 & 4.25 & 4.8405 & TST & \\
\hline CHEMBL1459762 & 688636 & 4.5 & 4.7073 & TRN & \\
\hline CHEMBL 213432 & 688636 & 4.25 & 4.8756 & TRN & \\
\hline CHEMBL1414858 & 688636 & 5.45 & 4.8032 & TST & \\
\hline CHEMBL1430824 & 688636 & 4.5 & 4.9907 & TRN & \\
\hline CHEMBL1526243 & 688636 & 4.5 & 4.8969 & TRN & \\
\hline CHEMBL1613437 & 688636 & 4.9 & 4.9237 & TRN & \\
\hline CHEMBL1603204 & 688636 & 4.3 & 4.9018 & TST & \\
\hline CHEMBL1610369 & 688636 & 6.05 & 5.0298 & TRN & \\
\hline CHEMBL1499134 & 688636 & 4.35 & 4.9852 & TST & \\
\hline CHEMBL1373317 & 688636 & 5.9 & 4.694 & TRN & \\
\hline CHEMBL1556313 & 688636 & 4.9 & 4.7632 & TST & \\
\hline CHEMBL1575560 & 688636 & 5.75 & 4.7972 & TRN & \\
\hline CHEMBL1398991 & 688636 & 4.55 & 4.4854 & TRN & \\
\hline CHEMBL1390969 & 688636 & 5.1 & 4.8424 & TRN & \\
\hline CHEMBL267160 & 688636 & 4.45 & 4.5781 & TRN & \\
\hline
\end{tabular}




\begin{tabular}{|c|c|c|c|c|c|}
\hline \multirow{2}{*}{ CHEMBL1528266 } & \multirow[b]{2}{*}{688636} & \\
\hline & & 5.3 & 4.845 & TRN & \\
\hline CHEMBL1523916 & 688636 & 5.0 & 4.9288 & TRN & \\
\hline CHEMBL1416611 & 688636 & 4.7 & 4.6284 & TRN & \\
\hline CHEMBL1543001 & 688636 & 4.35 & 4.7511 & TRN & \\
\hline CHEMBL1555711 & 688636 & 5.35 & 4.9324 & TRN & \\
\hline CHEMBL1538691 & 688636 & 4.6 & 5.0684 & TRN & \\
\hline CHEMBL1501050 & 688636 & 4.5 & 4.6986 & TRN & \\
\hline CHEMBL1486029 & 688636 & 4.9 & 4.7947 & TRN & \\
\hline CHEMBL1386634 & 688636 & 4.35 & 4.9304 & TRN & \\
\hline CHEMBL1560300 & 688636 & 4.3 & 4.912 & TRN & \\
\hline CHEMBL1450032 & 688636 & 5.5 & 4.6775 & TRN & \\
\hline CHEMBL1361315 & 688636 & 6.8 & 4.8866 & TRN & \\
\hline CHEMBL1350154 & 688636 & 4.4 & 4.791 & TRN & \\
\hline CHEMBL1422807 & 688636 & 4.55 & 4.6213 & TRN & \\
\hline CHEMBL1449723 & 688636 & 5.25 & 4.9821 & TST & \\
\hline CHEMBL1404077 & 688636 & 5.9 & 4.8969 & TST & \\
\hline CHEMBL1517388 & 688636 & 4.55 & 4.784 & TST & \\
\hline CHEMBL1446120 & 688636 & 4.25 & 4.9731 & TRN & \\
\hline CHEMBL1363109 & 688636 & 4.95 & 4.7544 & TST & \\
\hline CHEMBL1392709 & 688636 & 4.3 & 4.8338 & TST & \\
\hline CHEMBL1611920 & 688636 & 4.55 & 4.7838 & TRN & \\
\hline CHEMBL1596725 & 688636 & 4.3 & 4.8333 & TRN & \\
\hline CHEMBL1419119 & 688636 & 4.95 & 4.8658 & TRN & \\
\hline CHEMBL3212245 & 688636 & 4.9 & 4.8169 & TRN & \\
\hline CHEMBL3199077 & 688636 & 4.25 & 4.8757 & TRN & \\
\hline CHEMBL1478326 & 688636 & 4.4 & 4.92899 & 9999999999 & TRN \\
\hline CHEMBL1568261 & 688636 & 4.25 & 4.8233 & TST & \\
\hline CHEMBL1496696 & 688636 & 4.7 & 4.8658 & TRN & \\
\hline CHEMBL2134693 & 688636 & 4.3 & 4.7686 & TRN & \\
\hline CHEMBL1568200 & 688636 & 4.25 & 4.7339 & TST & \\
\hline CHEMBL1508340 & 688636 & 6.7501 & 4.8605 & TRN & \\
\hline CHEMBL1372826 & 688636 & 4.4 & 4.7102 & TRN & \\
\hline CHEMBL1491157 & 688636 & 5.9 & 4.9492 & TST & \\
\hline CHEMBL1570862 & 688636 & 6.0 & 4.831 & TRN & \\
\hline CHEMBL1369316 & 688636 & 4.25 & 4.8207 & TRN & \\
\hline CHEMBL1453075 & 688636 & 4.25 & 4.8068 & TRN & \\
\hline CHEMBL1347040 & 688636 & 6.5 & 4.8402 & TST & \\
\hline CHEMBL1519769 & 688636 & 5.2 & 4.83899 & 99999999995 & TRN \\
\hline CHEMBL1540341 & 688636 & 4.25 & 4.89199 & 99999999995 & TRN \\
\hline CHEMBL1465363 & 688636 & 4.45 & 4.7275 & TRN & \\
\hline CHEMBL1374654 & 688636 & 4.95 & 4.6522 & TRN & \\
\hline CHEMBL1588421 & 688636 & 4.9 & 4.984 & TST & \\
\hline CHEMBL1522711 & 688636 & 4.95 & 4.9971 & TST & \\
\hline CHEMBL1387956 & 688636 & 4.55 & 4.6844 & TRN & \\
\hline CHEMBL1448232 & 688636 & 4.55 & 4.7866 & TRN & \\
\hline CHEMBL1327319 & 688636 & 6.5 & 5.0208 & TRN & \\
\hline CHEMBL1535265 & 688636 & 4.25 & 4.7777 & TRN & \\
\hline CHEMBL1482916 & 688636 & 4.25 & 4.5575 & TRN & \\
\hline & & & & 586 & \\
\hline
\end{tabular}




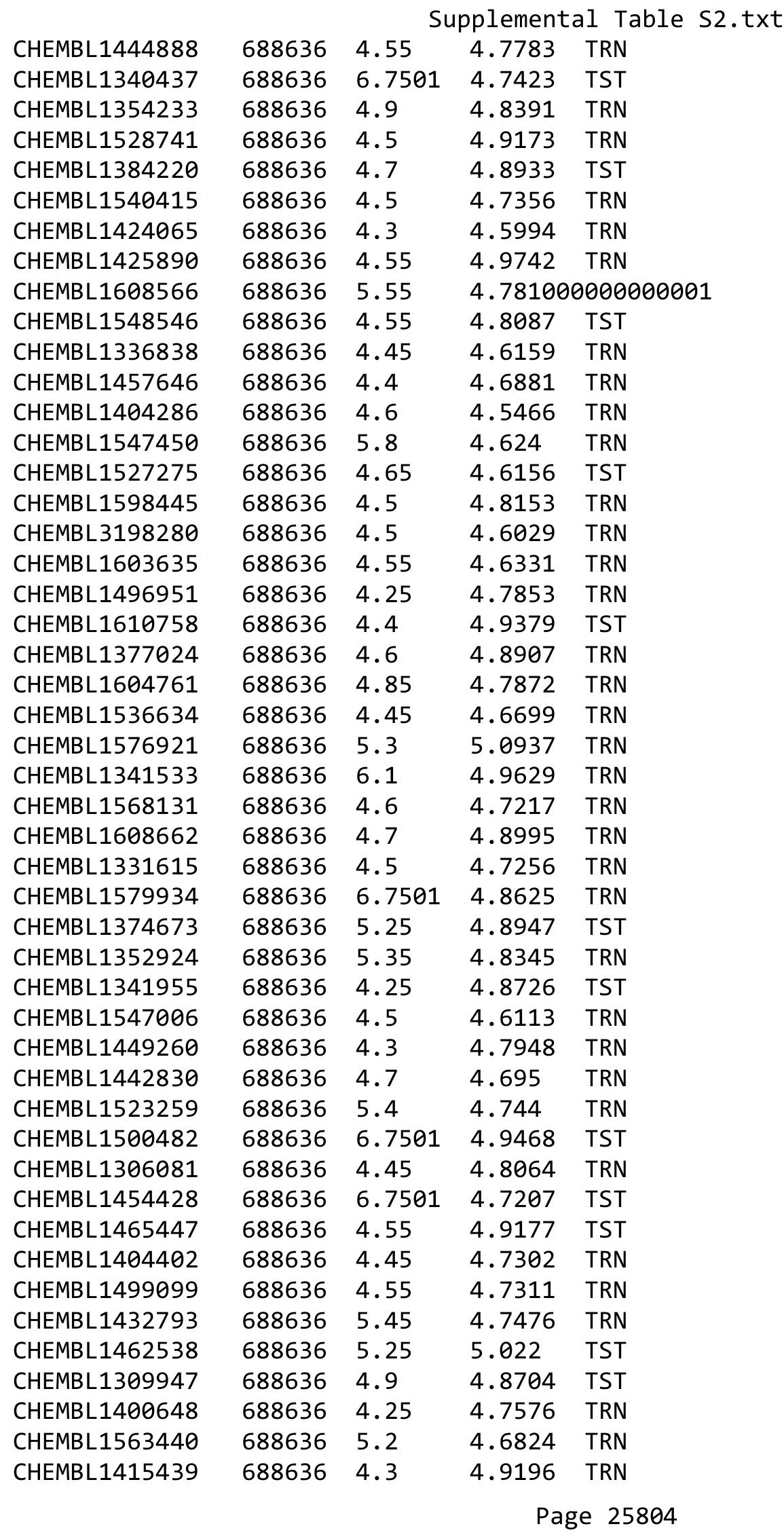




\begin{tabular}{|c|c|c|c|c|c|}
\hline \\
\hline CHEMBL1573945 & 688636 & 4.3 & 4.962 & TST & \\
\hline CHEMBL1468854 & 688636 & 4.25 & 4.8983 & TRN & \\
\hline CHEMBL1409252 & 688636 & 4.3 & 4.9288 & TRN & \\
\hline CHEMBL1369907 & 688636 & 4.45 & 4.7607 & TRN & \\
\hline CHEMBL1319343 & 688636 & 4.3 & 4.8004 & TRN & \\
\hline CHEMBL1467204 & 688636 & 5.95 & 4.6939 & TRN & \\
\hline CHEMBL1496667 & 688636 & 4.85 & 4.849 & TRN & \\
\hline CHEMBL1382476 & 688636 & 4.3 & 4.7863 & TST & \\
\hline CHEMBL1572056 & 688636 & 4.25 & 4.6945 & TRN & \\
\hline CHEMBL3213472 & 688636 & 4.8 & 4.7264 & TST & \\
\hline CHEMBL1390708 & 688636 & 4.6 & 4.7535 & TRN & \\
\hline CHEMBL1507243 & 688636 & 4.25 & 4.7594 & TRN & \\
\hline CHEMBL1561349 & 688636 & 4.55 & 4.7172 & TRN & \\
\hline CHEMBL3196541 & 688636 & 4.45 & 4.609 & TRN & \\
\hline CHEMBL1445633 & 688636 & 4.7 & 4.7841 & TRN & \\
\hline CHEMBL1576775 & 688636 & 5.05 & 4.7044 & TRN & \\
\hline CHEMBL1499883 & 688636 & 4.45 & 4.9191 & TRN & \\
\hline CHEMBL1337470 & 688636 & 4.3 & 4.7351 & TRN & \\
\hline CHEMBL1341197 & 688636 & 4.35 & 4.8947 & TRN & \\
\hline CHEMBL1407785 & 688636 & 4.9 & 4.8855 & TRN & \\
\hline CHEMBL1341941 & 688636 & 4.85 & 4.7399 & TRN & \\
\hline CHEMBL1381618 & 688636 & 4.5 & 4.814 & TRN & \\
\hline CHEMBL1584560 & 688636 & 4.45 & 4.7859 & TST & \\
\hline CHEMBL1540161 & 688636 & 4.6 & 4.95100 & 00000000005 & TRN \\
\hline CHEMBL1546246 & 688636 & 4.95 & 4.8317 & TRN & \\
\hline CHEMBL1349610 & 688636 & 4.45 & 4.8 & TRN & \\
\hline CHEMBL1604706 & 688636 & 4.25 & 4.898 & TRN & \\
\hline CHEMBL1319227 & 688636 & 4.45 & 4.7103 & TRN & \\
\hline CHEMBL1548008 & 688636 & 4.75 & 4.7423 & TRN & \\
\hline CHEMBL1538130 & 688636 & 6.7501 & 5.0206 & TST & \\
\hline CHEMBL1576994 & 688636 & 4.35 & 4.69300 & 20000000005 & TRN \\
\hline CHEMBL1471742 & 688636 & 4.35 & 4.7151 & TST & \\
\hline CHEMBL1388684 & 688636 & 5.9 & 4.8283 & TRN & \\
\hline CHEMBL1472274 & 688636 & 4.6 & 4.7451 & TRN & \\
\hline CHEMBL1595173 & 688636 & 4.45 & 4.7984 & TRN & \\
\hline CHEMBL1345418 & 688636 & 4.3 & 4.8939 & TST & \\
\hline CHEMBL1094844 & 688636 & 4.4 & 4.8146 & TRN & \\
\hline CHEMBL1418475 & 688636 & 4.75 & 4.9261 & TRN & \\
\hline CHEMBL1457311 & 688636 & 4.7 & 4.6645 & TRN & \\
\hline CHEMBL1534277 & 688636 & 4.25 & 5.0659 & TST & \\
\hline CHEMBL1380716 & 688636 & 5.9 & 4.8974 & TRN & \\
\hline CHEMBL3195531 & 688636 & 4.9 & 4.5633 & TRN & \\
\hline CHEMBL1470579 & 688636 & 4.35 & 4.9069 & TST & \\
\hline CHEMBL1439715 & 688636 & 4.8 & 4.7059 & TRN & \\
\hline CHEMBL1566217 & 688636 & 4.25 & 4.7563 & TRN & \\
\hline CHEMBL1327850 & 688636 & 4.45 & 4.7763 & TRN & \\
\hline CHEMBL1360573 & 688636 & 4.75 & 4.7033 & TRN & \\
\hline CHEMBL1509556 & 688636 & 5.2 & 4.8552 & TRN & \\
\hline
\end{tabular}




\begin{tabular}{|c|c|c|c|c|}
\hline \multicolumn{5}{|c|}{ Supplemental Table S2.txt } \\
\hline CHEMBL1611197 & 688636 & 4.5 & 4.6153 & TRN \\
\hline CHEMBL1392769 & 688636 & 4.5 & 4.7588 & TST \\
\hline CHEMBL1482321 & 688636 & 4.3 & 4.947 & TRN \\
\hline CHEMBL 3214490 & 688636 & 5.65 & 4.8723 & TRN \\
\hline CHEMBL3212442 & 688636 & 4.25 & 4.8663 & TST \\
\hline CHEMBL1538985 & 688636 & 6.1 & 4.8889 & TST \\
\hline CHEMBL1466984 & 688636 & 4.45 & 4.6977 & TRN \\
\hline CHEMBL1445764 & 688636 & 4.45 & 4.8177 & TRN \\
\hline CHEMBL1463516 & 688636 & 4.25 & 4.8227 & TST \\
\hline CHEMBL1344731 & 688636 & 4.65 & 4.7896 & TRN \\
\hline CHEMBL1429741 & 688636 & 4.45 & 4.7291 & TRN \\
\hline CHEMBL1457753 & 688636 & 4.85 & 4.6225 & TRN \\
\hline CHEMBL1511914 & 688636 & 4.4 & 4.7341 & TST \\
\hline CHEMBL1376303 & 688636 & 5.55 & 4.9834 & TRN \\
\hline CHEMBL1429971 & 688636 & 4.55 & 4.9472 & TST \\
\hline CHEMBL3209817 & 688636 & 4.5 & 4.8717 & TST \\
\hline CHEMBL1511091 & 688636 & 4.95 & 4.7428 & TRN \\
\hline CHEMBL1373504 & 688636 & 4.5 & 4.6709 & TST \\
\hline CHEMBL1366734 & 688636 & 4.4 & 4.8694 & TST \\
\hline CHEMBL1500742 & 688636 & 4.4 & 4.5866 & TRN \\
\hline CHEMBL1495681 & 688636 & 4.95 & 4.8553 & TRN \\
\hline CHEMBL1372947 & 688636 & 5.4 & 4.8622 & TRN \\
\hline CHEMBL1559235 & 688636 & 4.95 & 4.7398 & TRN \\
\hline CHEMBL1569681 & 688636 & 4.95 & 4.7807 & TST \\
\hline CHEMBL1519001 & 688636 & 5.15 & 4.9947 & TRN \\
\hline CHEMBL1311741 & 688636 & 4.5 & 4.6084 & TRN \\
\hline CHEMBL1471622 & 688636 & 4.6 & 4.7795 & TRN \\
\hline CHEMBL1391307 & 688636 & 5.85 & 4.6852 & TST \\
\hline CHEMBL1492309 & 688636 & 4.4 & 4.7091 & TRN \\
\hline CHEMBL1307376 & 688636 & 5.7 & 4.9344 & TRN \\
\hline CHEMBL1503026 & 688636 & 4.4 & 4.9692 & TST \\
\hline CHEMBL1302077 & 688636 & 5.25 & 4.619 & TRN \\
\hline CHEMBL1300592 & 688636 & 4.85 & 4.7341 & TST \\
\hline CHEMBL1601397 & 688636 & 4.4 & 4.6808 & TRN \\
\hline CHEMBL1424918 & 688636 & 4.3 & 4.676 & TST \\
\hline CHEMBL1611515 & 688636 & 5.0 & 4.747 & TRN \\
\hline CHEMBL1306926 & 688636 & 4.95 & 4.7476 & TRN \\
\hline CHEMBL1545438 & 688636 & 4.6 & 4.742 & TRN \\
\hline CHEMBL1610603 & 688636 & 5.35 & 4.6795 & TRN \\
\hline CHEMBL1382126 & 688636 & 4.95 & 4.8063 & TRN \\
\hline CHEMBL1324682 & 688636 & 5.35 & 4.9065 & TRN \\
\hline CHEMBL1350540 & 688636 & 4.95 & 4.9643 & TST \\
\hline CHEMBL1428521 & 688636 & 5.45 & 4.7763 & TRN \\
\hline CHEMBL1499052 & 688636 & 5.15 & 4.8326 & TRN \\
\hline CHEMBL1448766 & 688636 & 4.95 & 4.8293 & TRN \\
\hline CHEMBL1449506 & 688636 & 5.5 & 4.7245 & TRN \\
\hline CHEMBL1509788 & 688636 & 4.8 & 4.8136 & TRN \\
\hline CHEMBL1488759 & 688636 & 4.3 & 4.8869 & TRN \\
\hline
\end{tabular}




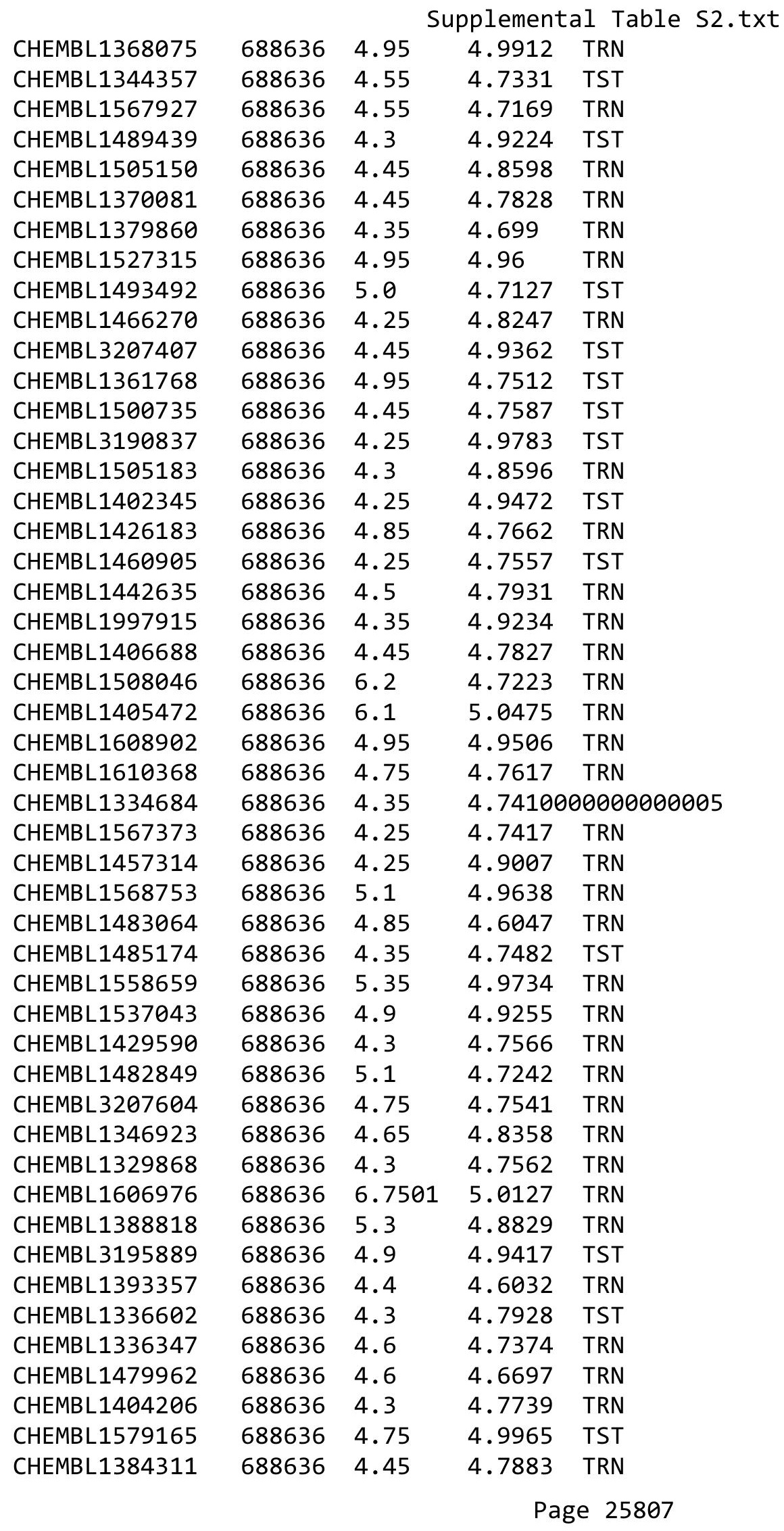




\begin{tabular}{|c|c|c|c|c|c|}
\hline & & \multicolumn{4}{|c|}{ Supplemental Table s2.txt } \\
\hline CHEMBL1340934 & 688636 & 4.25 & 4.7104 & TRN & \\
\hline CHEMBL1490621 & 688636 & 6.7501 & 4.9305 & TRN & \\
\hline CHEMBL1582769 & 688636 & 5.45 & 4.848 & TRN & \\
\hline CHEMBL1541349 & 688636 & 4.45 & 4.7976 & TRN & \\
\hline CHEMBL1453521 & 688636 & 4.45 & 4.7853 & TRN & \\
\hline CHEMBL1549345 & 688636 & 4.3 & 4.81800 & 00000000005 & TRN \\
\hline CHEMBL1521067 & 688636 & 6.8 & 4.7461 & TST & \\
\hline CHEMBL1607135 & 688636 & 4.45 & 4.6813 & TRN & \\
\hline CHEMBL1333189 & 688636 & 4.4 & 4.9823 & TRN & \\
\hline CHEMBL3193903 & 688636 & 4.55 & 4.7652 & TRN & \\
\hline CHEMBL1526431 & 688636 & 6.5 & 4.8667 & TST & \\
\hline CHEMBL1611989 & 688636 & 4.7 & 4.8195 & TRN & \\
\hline CHEMBL1379103 & 688636 & 4.7 & 4.6953 & TST & \\
\hline CHEMBL1463588 & 688636 & 4.25 & 4.9121 & TRN & \\
\hline CHEMBL1312044 & 688636 & 4.45 & 4.6532 & TRN & \\
\hline CHEMBL1330199 & 688636 & 4.45 & 4.8093 & TRN & \\
\hline CHEMBL3213527 & 688636 & 4.95 & 4.8083 & TRN & \\
\hline CHEMBL1303053 & 688636 & 4.25 & 4.8596 & TRN & \\
\hline CHEMBL1312647 & 688636 & 4.95 & 4.8492 & TRN & \\
\hline CHEMBL1466068 & 688636 & 4.35 & 4.6759 & TRN & \\
\hline CHEMBL1574601 & 688636 & 4.25 & 4.9697 & TRN & \\
\hline CHEMBL1580849 & 688636 & 4.5 & 4.8963 & TST & \\
\hline CHEMBL1563531 & 688636 & 5.7 & 4.7995 & TRN & \\
\hline CHEMBL1346710 & 688636 & 4.95 & 4.8583 & TRN & \\
\hline CHEMBL1548595 & 688636 & 4.35 & 4.875 & TRN & \\
\hline CHEMBL1468011 & 688636 & 4.45 & 4.6157 & TRN & \\
\hline CHEMBL1523271 & 688636 & 4.5 & 4.62 & TST & \\
\hline CHEMBL1303579 & 688636 & 4.5 & 4.7179 & TRN & \\
\hline CHEMBL1587017 & 688636 & 4.75 & 4.8267 & TRN & \\
\hline CHEMBL1577970 & 688636 & 4.4 & 4.7726 & TRN & \\
\hline CHEMBL1417357 & 688636 & 4.95 & 4.9647 & TRN & \\
\hline CHEMBL1576998 & 688636 & 4.55 & 4.7253 & TRN & \\
\hline CHEMBL1499110 & 688636 & 4.5 & 4.8293 & TRN & \\
\hline CHEMBL1455179 & 688636 & 4.7 & 4.8225 & TRN & \\
\hline CHEMBL1324796 & 688636 & 4.45 & 4.6297 & TRN & \\
\hline CHEMBL1557361 & 688636 & 4.3 & 4.8061 & TST & \\
\hline CHEMBL1383981 & 688636 & 4.25 & 4.7239 & TRN & \\
\hline CHEMBL1588205 & 688636 & 4.6 & 4.7615 & TRN & \\
\hline CHEMBL1589470 & 688636 & 5.1 & 4.801 & TST & \\
\hline CHEMBL1343324 & 688636 & 4.3 & 4.8966 & TST & \\
\hline CHEMBL1612392 & 688636 & 4.6 & 4.59699 & 99999999995 & TRN \\
\hline CHEMBL1375904 & 688636 & 4.6 & 4.6769 & TRN & \\
\hline CHEMBL1586031 & 688636 & 4.4 & 4.9194 & TRN & \\
\hline CHEMBL1348201 & 688636 & 4.25 & 4.7898 & TST & \\
\hline CHEMBL1390338 & 688636 & 4.35 & 4.8469 & TRN & \\
\hline CHEMBL1430660 & 688636 & 4.4 & 4.6781 & TRN & \\
\hline CHEMBL1305046 & 688636 & 4.45 & 5.0195 & TRN & \\
\hline CHEMBL1609742 & 688636 & 5.85 & 4.853 & TRN & \\
\hline
\end{tabular}




\begin{tabular}{|c|c|c|c|c|}
\hline \multicolumn{5}{|c|}{ Supplemental Table S2.txt } \\
\hline CHEMBL1516549 & 688636 & 4.5 & 4.8767 & TRN \\
\hline CHEMBL1587216 & 688636 & 4.5 & 4.9195 & TRN \\
\hline CHEMBL1362961 & 688636 & 4.4 & 4.9238 & TRN \\
\hline CHEMBL1499346 & 688636 & 4.8 & 4.6629 & TRN \\
\hline CHEMBL1463256 & 688636 & 4.55 & 4.8314 & TST \\
\hline CHEMBL1326246 & 688636 & 4.3 & 4.5644 & TRN \\
\hline CHEMBL3212159 & 688636 & 4.35 & 4.6553 & TRN \\
\hline CHEMBL1402586 & 688636 & 5.15 & 4.6435 & TST \\
\hline CHEMBL1403292 & 688636 & 4.65 & 4.9442 & TRN \\
\hline CHEMBL1573409 & 688636 & 4.95 & 4.8975 & TST \\
\hline CHEMBL1349414 & 688636 & 4.45 & 4.6764 & TRN \\
\hline CHEMBL1399417 & 688636 & 4.45 & 4.7711 & TRN \\
\hline CHEMBL1469666 & 688636 & 4.5 & 4.854 & TRN \\
\hline CHEMBL1571146 & 688636 & 4.3 & 4.709 & TRN \\
\hline CHEMBL1468990 & 688636 & 4.5 & 4.7112 & TRN \\
\hline CHEMBL1427787 & 688636 & 4.25 & 4.7312 & TRN \\
\hline CHEMBL1430621 & 688636 & 4.45 & 4.8252 & TRN \\
\hline CHEMBL1580276 & 688636 & 4.4 & 4.673 & TRN \\
\hline CHEMBL1326584 & 688636 & 4.55 & 4.6821 & TRN \\
\hline CHEMBL1430251 & 688636 & 4.3 & 4.811 & TRN \\
\hline CHEMBL3211666 & 688636 & 4.45 & 4.8794 & TST \\
\hline CHEMBL1460969 & 688636 & 5.15 & 4.8994 & TRN \\
\hline CHEMBL1412368 & 688636 & 4.25 & 4.9584 & TRN \\
\hline CHEMBL1409431 & 688636 & 4.3 & 5.0544 & TRN \\
\hline CHEMBL1481025 & 688636 & 5.55 & 4.7925 & TRN \\
\hline CHEMBL1335743 & 688636 & 4.9 & 4.8745 & TST \\
\hline CHEMBL1580511 & 688636 & 4.35 & 4.5971 & TRN \\
\hline CHEMBL1376998 & 688636 & 6.05 & 4.6633 & TST \\
\hline CHEMBL1380482 & 688636 & 4.25 & 4.8254 & TRN \\
\hline CHEMBL1383181 & 688636 & 4.95 & 4.8258 & TST \\
\hline CHEMBL1539919 & 688636 & 4.55 & 4.7716 & TST \\
\hline CHEMBL1483038 & 688636 & 5.2 & 4.7792 & TST \\
\hline CHEMBL 2007173 & 688636 & 5.65 & 4.8487 & TRN \\
\hline CHEMBL1550647 & 688636 & 5.2 & 4.6768 & TRN \\
\hline CHEMBL1516826 & 688636 & 4.95 & 4.8552 & TRN \\
\hline CHEMBL1548049 & 688636 & 6.8 & 4.7565 & TRN \\
\hline CHEMBL1364856 & 688636 & 4.45 & 4.6476 & TRN \\
\hline CHEMBL1608931 & 688636 & 4.95 & 4.7541 & TRN \\
\hline CHEMBL1304570 & 688636 & 4.3 & 4.7853 & TRN \\
\hline CHEMBL1595998 & 688636 & 5.2 & 4.9042 & TRN \\
\hline CHEMBL1601816 & 688636 & 4.45 & 4.737 & TRN \\
\hline CHEMBL1481083 & 688636 & 4.4 & 4.8605 & TRN \\
\hline CHEMBL1441756 & 688636 & 4.95 & 4.6814 & TST \\
\hline CHEMBL1305212 & 688636 & 6.1 & 5.0047 & TRN \\
\hline CHEMBL1326778 & 688636 & 4.6 & 4.6021 & TST \\
\hline CHEMBL1532324 & 688636 & 4.95 & 4.9275 & TRN \\
\hline CHEMBL1561578 & 688636 & 4.95 & 4.7177 & TST \\
\hline CHEMBL1604484 & 688636 & 5.1 & 4.7146 & TRN \\
\hline
\end{tabular}




\begin{tabular}{|c|c|c|c|c|c|}
\hline \multicolumn{6}{|c|}{ Supplemental Table S2.txt } \\
\hline CHEMBL1439732 & 688636 & 5.1 & 4.9703 & TST & \\
\hline CHEMBL1510447 & 688636 & 4.25 & 4.6391 & TRN & \\
\hline CHEMBL3189694 & 688636 & 4.35 & 4.7169 & TST & \\
\hline CHEMBL1424254 & 688636 & 4.25 & 4.8644 & TST & \\
\hline CHEMBL1589637 & 688636 & 4.25 & 4.8555 & TRN & \\
\hline CHEMBL1401165 & 688636 & 4.45 & 4.6392 & TRN & \\
\hline CHEMBL1421867 & 688636 & 4.4 & 4.7196 & TRN & \\
\hline CHEMBL1562044 & 688636 & 4.35 & 4.9062 & TRN & \\
\hline CHEMBL1367829 & 688636 & 4.25 & 4.7244 & TST & \\
\hline CHEMBL1391127 & 688636 & 5.85 & 4.9804 & TST & \\
\hline CHEMBL1393208 & 688636 & 4.25 & 4.6739 & TRN & \\
\hline CHEMBL1375449 & 688636 & 6.7501 & 4.779 & TRN & \\
\hline CHEMBL1965713 & 688636 & 4.45 & 4.7853 & TST & \\
\hline CHEMBL1403112 & 688636 & 5.65 & 4.7054 & TRN & \\
\hline CHEMBL1313114 & 688636 & 5.15 & $4.8610 e$ & 0000000001 & TST \\
\hline CHEMBL1507103 & 688636 & 4.3 & 4.9878 & TST & \\
\hline CHEMBL1402288 & 688636 & 4.5 & 4.7835 & TRN & \\
\hline CHEMBL1378995 & 688636 & 6.1 & 4.8454 & TRN & \\
\hline CHEMBL1541348 & 688636 & 6.3 & 4.7709 & TRN & \\
\hline CHEMBL1350226 & 688636 & 4.95 & 4.7735 & TRN & \\
\hline CHEMBL1330886 & 688636 & 5.15 & 4.747 & TST & \\
\hline CHEMBL1451711 & 688636 & 4.6 & 4.6999 & TRN & \\
\hline CHEMBL1377448 & 688636 & 5.0 & 4.6735 & TRN & \\
\hline CHEMBL1495026 & 688636 & 4.25 & 4.7856 & TRN & \\
\hline CHEMBL1547633 & 688636 & 4.4 & 4.7413 & TST & \\
\hline CHEMBL1507749 & 688636 & 4.6 & 4.6193 & TRN & \\
\hline CHEMBL1433183 & 688636 & 4.9 & 4.8835 & TRN & \\
\hline CHEMBL1490683 & 688636 & 6.35 & 4.7982 & TRN & \\
\hline CHEMBL1497463 & 688636 & 4.5 & 4.9435 & TRN & \\
\hline CHEMBL1376164 & 688636 & 4.95 & 4.7165 & TRN & \\
\hline CHEMBL1413235 & 688636 & 4.25 & 4.9827 & TRN & \\
\hline CHEMBL1467839 & 688636 & 4.35 & 4.7834 & TRN & \\
\hline CHEMBL1508874 & 688636 & 4.7 & 4.8645 & TRN & \\
\hline CHEMBL1300626 & 688636 & 5.85 & 4.891 & TST & \\
\hline CHEMBL1500607 & 688636 & 5.2 & 4.724 & TST & \\
\hline CHEMBL1488736 & 688636 & 4.25 & 4.8164 & TST & \\
\hline CHEMBL1497835 & 688636 & 4.95 & 4.8245 & TRN & \\
\hline CHEMBL1610284 & 688636 & 5.7 & 4.9354 & TRN & \\
\hline CHEMBL227925 & 688636 & 4.5 & 4.7201 & TRN & \\
\hline CHEMBL1381110 & 688636 & 4.25 & 4.7047 & TRN & \\
\hline CHEMBL1594679 & 688636 & 5.3 & 4.9418 & TRN & \\
\hline CHEMBL3213103 & 688636 & 6.05 & 4.7002 & TST & \\
\hline CHEMBL1327137 & 688636 & 4.45 & 4.788 & TRN & \\
\hline CHEMBL1562564 & 688636 & 4.9 & 4.8424 & TRN & \\
\hline CHEMBL1405380 & 688636 & 4.25 & 4.6932 & TRN & \\
\hline CHEMBL1408061 & 688636 & 4.35 & 4.9457 & TRN & \\
\hline CHEMBL1378821 & 688636 & 6.7501 & 4.8742 & TST & \\
\hline CHEMBL1548609 & 688636 & 4.25 & 4.9829 & TRN & \\
\hline
\end{tabular}




\begin{tabular}{|c|c|c|c|c|c|}
\hline \multirow{3}{*}{$\begin{array}{l}\text { CHEMBL } 1492033 \\
\text { CHEMBL1382392 }\end{array}$} & \multirow{3}{*}{$\begin{array}{l}688636 \\
688636\end{array}$} & \multicolumn{4}{|c|}{ Supplemental Table S2.txt } \\
\hline & & 4.55 & 4.7669 & 99999999995 & TRN \\
\hline & & 4.45 & 4.8103 & TRN & \\
\hline CHEMBL1427208 & 688636 & 4.3 & 4.77 & TRN & \\
\hline CHEMBL1517906 & 688636 & 4.9 & 4.9243 & TST & \\
\hline CHEMBL1360530 & 688636 & 6.0 & 4.9555 & TST & \\
\hline CHEMBL1971154 & 688636 & 4.65 & 4.7039 & TRN & \\
\hline CHEMBL1439292 & 688636 & 4.3 & 4.8399 & TST & \\
\hline CHEMBL1318895 & 688636 & 5.85 & 4.8768 & TRN & \\
\hline CHEMBL1413699 & 688636 & 5.15 & 4.9644 & TST & \\
\hline CHEMBL1379766 & 688636 & 4.3 & 4.9303 & TRN & \\
\hline CHEMBL1589386 & 688636 & 5.05 & 4.9237 & TRN & \\
\hline CHEMBL1430358 & 688636 & 4.45 & 4.7395 & TRN & \\
\hline CHEMBL3196087 & 688636 & 4.5 & 4.7451 & TRN & \\
\hline CHEMBL1570652 & 688636 & 4.3 & 4.7538 & TST & \\
\hline CHEMBL1470955 & 688636 & 4.25 & 4.841 & TRN & \\
\hline CHEMBL1522697 & 688636 & 5.05 & 4.7622 & TST & \\
\hline CHEMBL1319647 & 688636 & 4.6 & 4.835 & TRN & \\
\hline CHEMBL1556302 & 688636 & 4.55 & 4.7986 & TST & \\
\hline CHEMBL1379506 & 688636 & 4.35 & 4.8195 & TRN & \\
\hline CHEMBL1299399 & 688636 & 4.3 & 4.8252 & TRN & \\
\hline CHEMBL1393059 & 688636 & 4.35 & 4.8801 & TST & \\
\hline CHEMBL1487211 & 688636 & 4.25 & 4.8899 & TST & \\
\hline CHEMBL1521107 & 688636 & 4.4 & 4.5626 & TRN & \\
\hline CHEMBL1337529 & 688636 & 4.45 & 4.7301 & TRN & \\
\hline CHEMBL1380096 & 688636 & 4.25 & 4.7289 & TRN & \\
\hline CHEMBL1546972 & 688636 & 5.3 & 4.8717 & TRN & \\
\hline CHEMBL1321861 & 688636 & 4.6 & 4.7224 & TRN & \\
\hline CHEMBL1399650 & 688636 & 4.4 & 4.6947 & TRN & \\
\hline CHEMBL1485426 & 688636 & 4.3 & 4.8059 & TRN & \\
\hline CHEMBL1452978 & 688636 & 4.55 & 4.9175 & TRN & \\
\hline CHEMBL1511653 & 688636 & 5.4 & 4.8405 & TRN & \\
\hline CHEMBL1420404 & 688636 & 5.95 & 4.8684 & TRN & \\
\hline CHEMBL1499508 & 688636 & 4.7 & 4.7755 & TRN & \\
\hline CHEMBL1399315 & 688636 & 5.55 & 4.8865 & TRN & \\
\hline CHEMBL1339535 & 688636 & 4.25 & 4.8437 & TRN & \\
\hline CHEMBL1439954 & 688636 & 4.5 & 4.6079 & TRN & \\
\hline CHEMBL1523083 & 688636 & 4.95 & 4.9619 & TRN & \\
\hline CHEMBL1608513 & 688636 & 4.25 & 4.7496 & TRN & \\
\hline CHEMBL1450271 & 688636 & 5.45 & 4.8065 & TST & \\
\hline CHEMBL1333974 & 688636 & 4.95 & 4.8665 & TST & \\
\hline CHEMBL1521154 & 688636 & 4.3 & 4.8751 & TRN & \\
\hline CHEMBL3194537 & 688636 & 4.25 & 4.7959 & TRN & \\
\hline CHEMBL1535257 & 688636 & 5.05 & 4.6812 & TRN & \\
\hline CHEMBL1404748 & 688636 & 4.25 & 4.8815 & TST & \\
\hline CHEMBL1433195 & 688636 & 4.35 & 4.723 & TRN & \\
\hline CHEMBL1457918 & 688636 & 4.55 & 4.6946 & TRN & \\
\hline CHEMBL1501519 & 688636 & 4.35 & 4.8259 & TRN & \\
\hline CHEMBL1508826 & 688636 & 4.45 & 4.6921 & TRN & \\
\hline
\end{tabular}




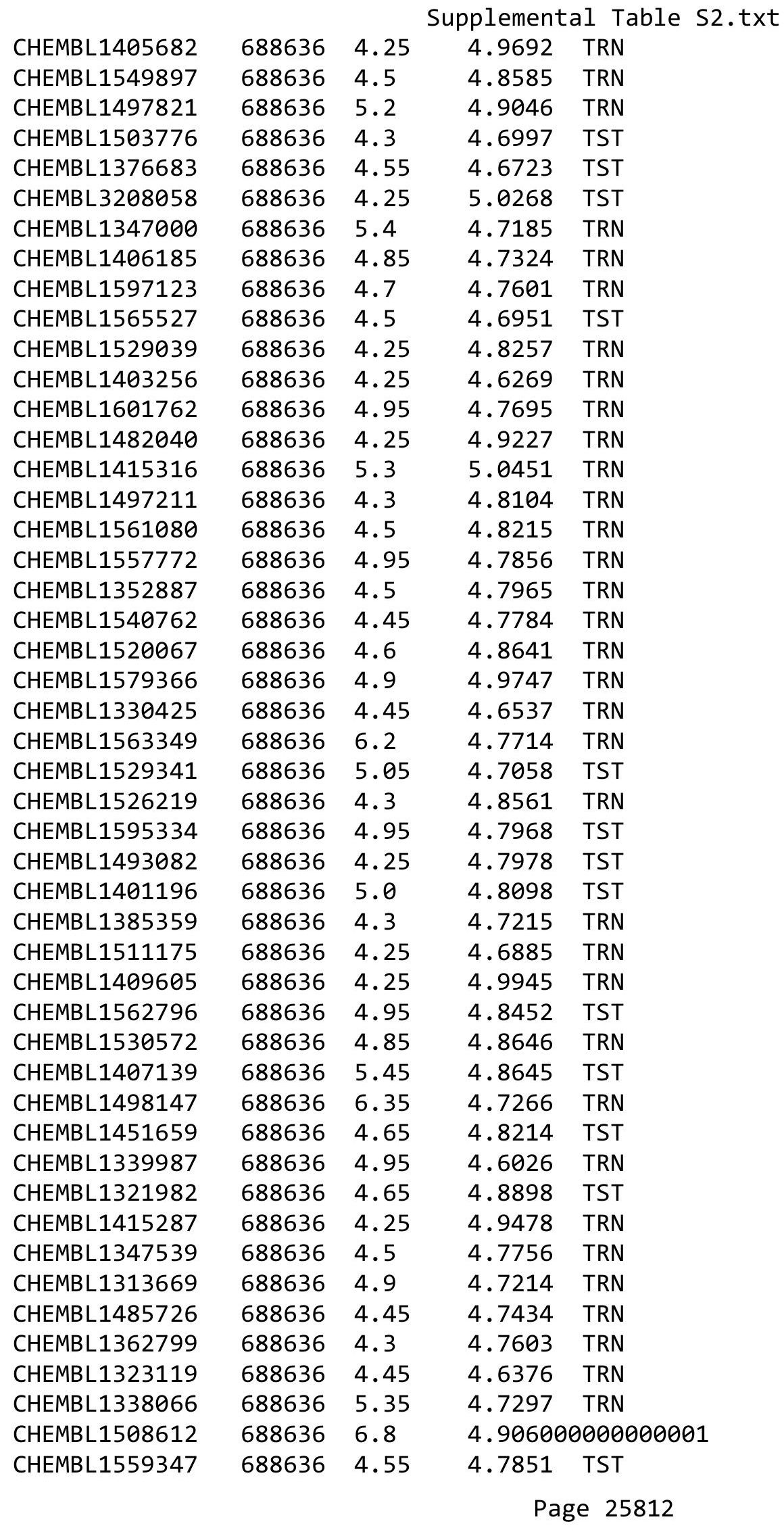

TRN 


\begin{tabular}{|c|c|c|c|c|}
\hline \multicolumn{5}{|c|}{ Supplemental Table S2.txt } \\
\hline CHEMBL1374052 & 688636 & 4.35 & 4.7838 & TRN \\
\hline CHEMBL1595628 & 688636 & 5.5 & 5.0522 & TRN \\
\hline CHEMBL1306287 & 688636 & 4.65 & 4.9329 & TST \\
\hline CHEMBL1373321 & 688636 & 5.0 & 4.7906 & TST \\
\hline CHEMBL1586297 & 688636 & 4.25 & 4.8271 & TST \\
\hline CHEMBL1327864 & 688636 & 4.4 & 4.7625 & TRN \\
\hline CHEMBL1511618 & 688636 & 5.3 & 4.8388 & TRN \\
\hline CHEMBL1377335 & 688636 & 4.3 & 4.7577 & TRN \\
\hline CHEMBL1600585 & 688636 & 5.9 & 4.6498 & TRN \\
\hline CHEMBL3194566 & 688636 & 4.35 & 4.7326 & TST \\
\hline CHEMBL1503693 & 688636 & 4.25 & 4.83 & TRN \\
\hline CHEMBL1456523 & 688636 & 4.9 & 4.5303 & TRN \\
\hline CHEMBL 30953 & 688636 & 4.45 & 4.6797 & TRN \\
\hline CHEMBL1532824 & 688636 & 6.7501 & 4.8794 & TST \\
\hline CHEMBL1404393 & 688636 & 4.9 & 4.7434 & TRN \\
\hline CHEMBL1346035 & 688636 & 4.45 & 4.4887 & TRN \\
\hline CHEMBL1519788 & 688636 & 4.95 & 4.8401 & TST \\
\hline CHEMBL1388790 & 688636 & 5.45 & 4.7086 & TRN \\
\hline CHEMBL1563285 & 688636 & 5.85 & 4.966 & TRN \\
\hline CHEMBL1306426 & 688636 & 5.95 & 4.8169 & TRN \\
\hline CHEMBL1304471 & 688636 & 4.25 & 4.6227 & TST \\
\hline CHEMBL1304634 & 688636 & 4.35 & 4.6955 & TRN \\
\hline CHEMBL1555914 & 688636 & 4.4 & 4.6036 & TRN \\
\hline CHEMBL1546428 & 688636 & 4.25 & 4.8693 & TRN \\
\hline CHEMBL1974319 & 688636 & 6.5 & 4.6439 & TST \\
\hline CHEMBL1518030 & 688636 & 6.4 & 4.8458 & TRN \\
\hline CHEMBL1365856 & 688636 & 5.2 & 4.8866 & TRN \\
\hline CHEMBL1491940 & 688636 & 4.8 & 4.9806 & TRN \\
\hline CHEMBL1508343 & 688636 & 4.6 & 4.8836 & TRN \\
\hline CHEMBL1426722 & 688636 & 4.55 & 4.9867 & TRN \\
\hline CHEMBL3211933 & 688636 & 4.25 & 4.8415 & TRN \\
\hline CHEMBL1432762 & 688636 & 4.5 & 4.725 & TRN \\
\hline CHEMBL1094843 & 688636 & 4.35 & 4.8756 & TRN \\
\hline CHEMBL1414565 & 688636 & 5.05 & 4.8985 & TST \\
\hline CHEMBL1600298 & 688636 & 4.3 & 4.7983 & TRN \\
\hline CHEMBL1403032 & 688636 & 4.45 & 4.7796 & TRN \\
\hline CHEMBL1433082 & 688636 & 4.3 & 4.7877 & TRN \\
\hline CHEMBL1328024 & 688636 & 4.35 & 5.0591 & TRN \\
\hline CHEMBL1327961 & 688636 & 6.1 & 4.8221 & TRN \\
\hline CHEMBL1409778 & 688636 & 6.1 & 4.857 & TRN \\
\hline CHEMBL1439300 & 688636 & 6.8 & 4.8043 & TRN \\
\hline CHEMBL1984804 & 688636 & 5.4 & 4.7083 & TRN \\
\hline CHEMBL1457324 & 688636 & 4.95 & 4.7364 & TRN \\
\hline CHEMBL1309148 & 688636 & 4.8 & 4.6648 & TRN \\
\hline CHEMBL1363360 & 688636 & 4.95 & 4.7641 & TRN \\
\hline CHEMBL1491601 & 688636 & 4.3 & 4.7535 & TRN \\
\hline CHEMBL1331912 & 688636 & 4.25 & 4.876 & TRN \\
\hline CHEMBL1342852 & 688636 & 6.1 & 4.8934 & TRN \\
\hline
\end{tabular}




\begin{tabular}{|c|c|c|c|c|}
\hline \multicolumn{5}{|c|}{ Supplemental Table S2.txt } \\
\hline CHEMBL1423113 & 688636 & 4.95 & 4.8269 & TST \\
\hline CHEMBL1498333 & 688636 & 4.5 & 4.7271 & TRN \\
\hline CHEMBL1578543 & 688636 & 4.25 & 4.7698 & TRN \\
\hline CHEMBL1417419 & 688636 & 4.45 & 4.8259 & TRN \\
\hline CHEMBL1411975 & 688636 & 4.6 & 4.5975 & TRN \\
\hline CHEMBL1991441 & 688636 & 4.5 & 4.7227 & TST \\
\hline CHEMBL1391811 & 688636 & 5.6 & 4.6923 & TST \\
\hline CHEMBL1320514 & 688636 & 4.6 & 4.9816 & TST \\
\hline CHEMBL1601209 & 688636 & 5.4 & 4.8289 & TST \\
\hline CHEMBL1382622 & 688636 & 4.3 & 4.7852 & TRN \\
\hline CHEMBL1334164 & 688636 & 6.25 & 4.8637 & TST \\
\hline CHEMBL1303632 & 688636 & 4.45 & 4.7636 & TRN \\
\hline CHEMBL1403539 & 688636 & 4.65 & 4.7736 & TRN \\
\hline CHEMBL1467832 & 688636 & 6.35 & 4.7494 & TRN \\
\hline CHEMBL1312924 & 688636 & 4.4 & 4.9312 & TST \\
\hline CHEMBL1543384 & 688636 & 4.55 & 4.7142 & TST \\
\hline CHEMBL1559326 & 688636 & 4.45 & 4.8524 & TRN \\
\hline CHEMBL1470923 & 688636 & 4.95 & 5.0093 & TST \\
\hline CHEMBL1609566 & 688636 & 4.25 & 4.8251 & TRN \\
\hline CHEMBL1392086 & 688636 & 5.4 & 4.6494 & TRN \\
\hline CHEMBL1453357 & 688636 & 4.45 & 4.827 & TRN \\
\hline CHEMBL1566817 & 688636 & 4.25 & 4.9442 & TRN \\
\hline CHEMBL1442764 & 688636 & 4.95 & 4.8271 & TST \\
\hline CHEMBL1499932 & 688636 & 4.45 & 4.8318 & TST \\
\hline CHEMBL1523148 & 688636 & 4.25 & 5.0542 & TRN \\
\hline CHEMBL1480741 & 688636 & 4.25 & 4.9619 & TST \\
\hline CHEMBL1568977 & 688636 & 4.95 & 4.8358 & TST \\
\hline CHEMBL1353389 & 688636 & 4.4 & 4.5642 & TRN \\
\hline CHEMBL1533127 & 688636 & 4.3 & 4.7863 & TRN \\
\hline CHEMBL3213817 & 688636 & 4.45 & 4.9283 & TRN \\
\hline CHEMBL1341609 & 688636 & 4.25 & 4.8053 & TRN \\
\hline CHEMBL3194108 & 688636 & 4.35 & 4.694 & TST \\
\hline CHEMBL1501809 & 688636 & 4.3 & 4.917 & TST \\
\hline CHEMBL1560785 & 688636 & 4.3 & 4.8596 & TRN \\
\hline CHEMBL1325651 & 688636 & 6.35 & 4.8305 & TRN \\
\hline CHEMBL3190321 & 688636 & 4.5 & 4.8274 & TRN \\
\hline CHEMBL1585982 & 688636 & 4.5 & 4.7532 & TRN \\
\hline CHEMBL1423688 & 688636 & 4.95 & 4.7851 & TST \\
\hline CHEMBL3198607 & 688636 & 4.6 & 4.9032 & TRN \\
\hline CHEMBL1438826 & 688636 & 5.3 & 4.7505 & TST \\
\hline CHEMBL1489875 & 688636 & 4.5 & 4.7137 & TST \\
\hline CHEMBL1589651 & 688636 & 6.7501 & 4.8983 & TRN \\
\hline CHEMBL1582564 & 688636 & 5.15 & 4.711 & TRN \\
\hline CHEMBL1507736 & 688636 & 4.6 & 5.0653 & TST \\
\hline CHEMBL1366745 & 688636 & 4.85 & 4.7371 & TRN \\
\hline CHEMBL1443354 & 688636 & 4.3 & 4.7697 & TST \\
\hline CHEMBL1505823 & 688636 & 4.55 & 4.6134 & TRN \\
\hline CHEMBL1530948 & 688636 & 4.55 & 4.7951 & TRN \\
\hline
\end{tabular}




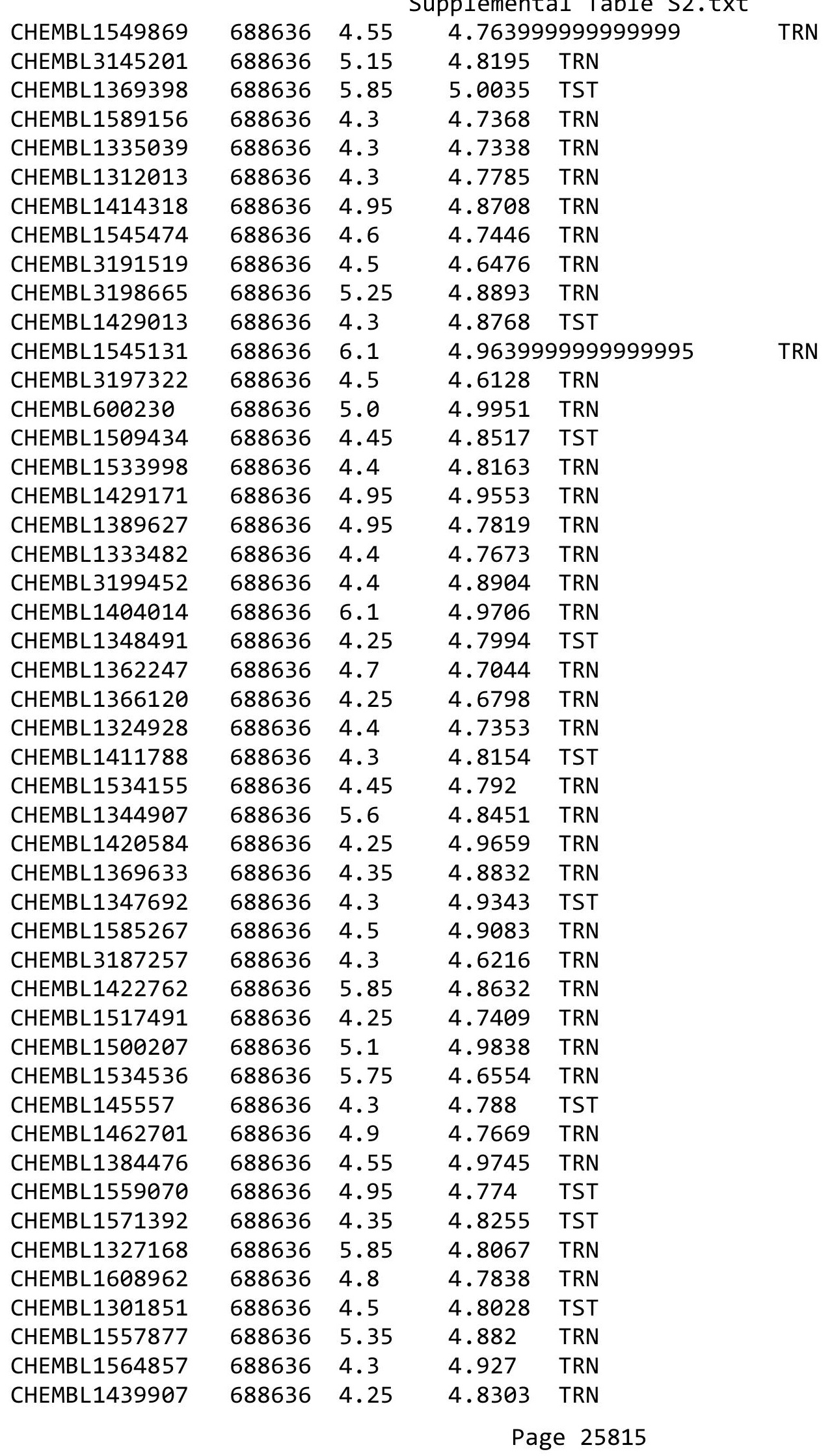




\begin{tabular}{|c|c|c|c|c|}
\hline \multicolumn{5}{|c|}{ Supplemental Table S2.txt } \\
\hline CHEMBL1491376 & 688636 & 4.25 & 4.8346 & TRN \\
\hline CHEMBL1517463 & 688636 & 4.65 & 4.8817 & TST \\
\hline CHEMBL1449433 & 688636 & 4.7 & 4.7348 & TRN \\
\hline CHEMBL1555772 & 688636 & 4.7 & 4.7717 & TRN \\
\hline CHEMBL1416891 & 688636 & 4.25 & 4.8002 & TRN \\
\hline CHEMBL1450082 & 688636 & 4.25 & 4.8332 & TRN \\
\hline CHEMBL1306667 & 688636 & 5.75 & 4.7405 & TRN \\
\hline CHEMBL1341601 & 688636 & 4.3 & 4.7629 & TST \\
\hline CHEMBL1519311 & 688636 & 4.45 & 5.0027 & TRN \\
\hline CHEMBL1597005 & 688636 & 5.35 & 4.8692 & TRN \\
\hline CHEMBL1447163 & 688636 & 5.2 & 4.8009 & TRN \\
\hline CHEMBL1608660 & 688636 & 4.3 & 4.7526 & TRN \\
\hline CHEMBL1460227 & 688636 & 5.2 & 4.8973 & TRN \\
\hline CHEMBL1360802 & 688636 & 4.5 & 4.8726 & TRN \\
\hline CHEMBL1381299 & 688636 & 4.3 & 4.8305 & TRN \\
\hline CHEMBL1581543 & 688636 & 4.95 & 4.715 & TRN \\
\hline CHEMBL1597153 & 688636 & 4.3 & 4.732 & TRN \\
\hline CHEMBL1522654 & 688636 & 5.45 & 4.8855 & TRN \\
\hline CHEMBL1430754 & 688636 & 4.7 & 4.8434 & TST \\
\hline CHEMBL1419423 & 688636 & 4.55 & 4.8476 & TRN \\
\hline CHEMBL1520132 & 688636 & 4.95 & 4.7699 & TRN \\
\hline CHEMBL1444967 & 688636 & 4.3 & 5.0727 & TRN \\
\hline CHEMBL1570999 & 688636 & 5.4 & 4.7882 & TRN \\
\hline CHEMBL1378612 & 688636 & 4.35 & 4.9236 & TRN \\
\hline CHEMBL1310972 & 688636 & 5.3 & 4.7278 & TRN \\
\hline CHEMBL1535982 & 688636 & 4.95 & 4.9532 & TRN \\
\hline CHEMBL1307622 & 688636 & 4.4 & 4.802 & TRN \\
\hline CHEMBL1570530 & 688636 & 4.45 & 4.6631 & TRN \\
\hline CHEMBL1572790 & 688636 & 4.7 & 4.7087 & TRN \\
\hline CHEMBL1489352 & 688636 & 4.7 & 4.9339 & TST \\
\hline CHEMBL1507312 & 688636 & 4.4 & 4.734 & TRN \\
\hline CHEMBL1417815 & 688636 & 4.55 & 4.652 & TRN \\
\hline CHEMBL1453979 & 688636 & 4.25 & 4.7293 & TRN \\
\hline CHEMBL1438459 & 688636 & 6.8 & 4.9071 & TRN \\
\hline CHEMBL1324487 & 688636 & 4.4 & 4.6248 & TRN \\
\hline CHEMBL1586656 & 688636 & 4.6 & 4.6734 & TRN \\
\hline CHEMBL1312186 & 688636 & 5.15 & 4.7541 & TST \\
\hline CHEMBL1301611 & 688636 & 4.55 & 4.7851 & TRN \\
\hline CHEMBL1601075 & 688636 & 5.3 & 4.8349 & TRN \\
\hline CHEMBL3194634 & 688636 & 5.35 & 4.718 & TRN \\
\hline CHEMBL1346202 & 688636 & 4.25 & 4.8384 & TST \\
\hline CHEMBL1353131 & 688636 & 5.2 & 4.9172 & TRN \\
\hline CHEMBL1605616 & 688636 & 4.55 & 4.8758 & TRN \\
\hline CHEMBL1486574 & 688636 & 4.95 & 4.773 & TRN \\
\hline CHEMBL1389013 & 688636 & 4.45 & 4.8128 & TST \\
\hline CHEMBL1517604 & 688636 & 5.4 & 4.8813 & TRN \\
\hline CHEMBL1571139 & 688636 & 4.95 & 4.8551 & TRN \\
\hline CHEMBL1470502 & 688636 & 5.15 & 4.7259 & TST \\
\hline
\end{tabular}




\begin{tabular}{|c|c|c|c|c|}
\hline \multicolumn{5}{|c|}{ Supplemental Table s2.txt } \\
\hline CHEMBL1497169 & 688636 & 6.1 & 4.8414 & TRN \\
\hline CHEMBL1501468 & 688636 & 4.6 & 4.7529 & TRN \\
\hline CHEMBL1498324 & 688636 & 4.25 & 4.9046 & TRN \\
\hline CHEMBL585221 & 688636 & 4.25 & 4.7957 & TST \\
\hline CHEMBL1539660 & 688636 & 4.25 & 4.6833 & TRN \\
\hline CHEMBL1399021 & 688636 & 4.25 & 4.9156 & TRN \\
\hline CHEMBL1362616 & 688636 & 4.3 & 4.8424 & TRN \\
\hline CHEMBL1390145 & 688636 & 5.2 & 4.862 & TRN \\
\hline CHEMBL1557372 & 688636 & 4.45 & 4.8421 & TST \\
\hline CHEMBL1986425 & 688636 & 4.45 & 4.637 & TRN \\
\hline CHEMBL1300353 & 688636 & 4.35 & 4.9905 & TST \\
\hline CHEMBL1342657 & 688636 & 4.25 & 4.793 & TST \\
\hline CHEMBL1440612 & 688636 & 5.65 & 4.8243 & TRN \\
\hline CHEMBL1602892 & 688636 & 6.45 & 4.7379 & TRN \\
\hline CHEMBL1504639 & 688636 & 4.9 & 4.8516 & TST \\
\hline CHEMBL1337232 & 688636 & 4.25 & 4.7132 & TRN \\
\hline CHEMBL1508596 & 688636 & 4.5 & 4.7487 & TRN \\
\hline CHEMBL1576918 & 688636 & 4.25 & 4.8347 & TRN \\
\hline CHEMBL1446563 & 688636 & 4.45 & 4.5444 & TRN \\
\hline CHEMBL1603958 & 688636 & 4.7 & 4.7869 & TRN \\
\hline CHEMBL1526650 & 688636 & 4.75 & 4.7098 & TRN \\
\hline CHEMBL1493628 & 688636 & 4.75 & 4.6714 & TRN \\
\hline CHEMBL1342683 & 688636 & 4.4 & 4.9784 & TRN \\
\hline CHEMBL3209847 & 688636 & 4.3 & 4.6954 & TST \\
\hline CHEMBL1478742 & 688636 & 4.5 & 4.7781 & TRN \\
\hline CHEMBL1611371 & 688636 & 6.7001 & 4.9674 & TST \\
\hline CHEMBL1304510 & 688636 & 5.2 & 4.9298 & TST \\
\hline CHEMBL1353101 & 688636 & 6.8 & 5.0979 & TRN \\
\hline CHEMBL1507211 & 688636 & 5.45 & 4.7632 & TST \\
\hline CHEMBL1547692 & 688636 & 4.45 & 4.8663 & TRN \\
\hline CHEMBL1371038 & 688636 & 4.55 & 4.904 & TST \\
\hline CHEMBL3194622 & 688636 & 4.25 & 4.7196 & TST \\
\hline CHEMBL1376989 & 688636 & 4.25 & 4.7723 & TST \\
\hline CHEMBL1426284 & 688636 & 4.45 & 4.6518 & TRN \\
\hline CHEMBL1505255 & 688636 & 4.45 & 4.5414 & TRN \\
\hline CHEMBL1370527 & 688636 & 4.35 & 4.7477 & TRN \\
\hline CHEMBL1488267 & 688636 & 4.7 & 4.8639 & TRN \\
\hline CHEMBL1322038 & 688636 & 5.65 & 4.9128 & TST \\
\hline CHEMBL1543115 & 688636 & 4.7 & 4.7576 & TRN \\
\hline CHEMBL1374718 & 688636 & 4.3 & 4.6468 & TRN \\
\hline CHEMBL1333610 & 688636 & 6.35 & 4.6903 & TRN \\
\hline CHEMBL1393735 & 688636 & 4.9 & 4.9737 & TST \\
\hline CHEMBL1542856 & 688636 & 4.95 & 4.8115 & TRN \\
\hline CHEMBL1373715 & 688636 & 5.25 & 4.747 & TRN \\
\hline CHEMBL1441735 & 688636 & 4.25 & 4.7432 & TST \\
\hline CHEMBL1452552 & 688636 & 5.3 & 4.9558 & TRN \\
\hline CHEMBL1459165 & 688636 & 4.35 & 4.7913 & TRN \\
\hline CHEMBL1419262 & 688636 & 4.25 & 4.8221 & TST \\
\hline
\end{tabular}




\begin{tabular}{|c|c|c|c|c|}
\hline & & & pplement & al \\
\hline CHEMBL1341432 & 688636 & 4.45 & 4.7914 & TRN \\
\hline CHEMBL1588672 & 688636 & 4.5 & 4.6539 & TRN \\
\hline CHEMBL1538032 & 688636 & 4.5 & 4.6911 & TRN \\
\hline CHEMBL1508548 & 688636 & 4.65 & 4.9944 & TST \\
\hline CHEMBL1517061 & 688636 & 4.25 & 4.7147 & TRN \\
\hline CHEMBL1400873 & 688636 & 4.25 & 4.6973 & TRN \\
\hline CHEMBL1559256 & 688636 & 4.5 & 4.7053 & TRN \\
\hline CHEMBL1469115 & 688636 & 4.4 & 4.8323 & TRN \\
\hline CHEMBL1458516 & 688636 & 4.45 & 4.8156 & TRN \\
\hline CHEMBL1560628 & 688636 & 4.5 & 4.5981 & TST \\
\hline CHEMBL1548324 & 688636 & 5.2 & 5.0044 & TRN \\
\hline CHEMBL1368962 & 688636 & 5.4 & 4.7965 & TRN \\
\hline CHEMBL1415366 & 688636 & 5.25 & 4.5838 & TRN \\
\hline CHEMBL3190991 & 688636 & 4.3 & 4.9272 & TRN \\
\hline CHEMBL1370548 & 688636 & 4.3 & 5.04 & TRN \\
\hline CHEMBL1440321 & 688636 & 4.35 & 4.9693 & TRN \\
\hline CHEMBL1498875 & 688636 & 4.95 & 4.8641 & TRN \\
\hline CHEMBL1522982 & 688636 & 4.85 & 4.7342 & TRN \\
\hline CHEMBL1530512 & 688636 & 4.45 & 4.8516 & TST \\
\hline CHEMBL1368196 & 688636 & 5.15 & 4.7679 & TST \\
\hline CHEMBL1468485 & 688636 & 6.1 & 4.6027 & TRN \\
\hline CHEMBL1492365 & 688636 & 5.2 & 4.7381 & TRN \\
\hline CHEMBL1308027 & 688636 & 4.7 & 4.8745 & TRN \\
\hline CHEMBL1364577 & 688636 & 4.6 & 4.5649 & TRN \\
\hline CHEMBL1570915 & 688636 & 4.25 & 4.8103 & TST \\
\hline CHEMBL1570625 & 688636 & 5.3 & 4.7549 & TRN \\
\hline CHEMBL1362112 & 688636 & 4.5 & 4.6448 & TST \\
\hline CHEMBL1531251 & 688636 & 4.3 & 4.8427 & TRN \\
\hline CHEMBL1304444 & 688636 & 4.85 & 4.7667 & TRN \\
\hline CHEMBL1426830 & 688636 & 4.25 & 4.6941 & TST \\
\hline CHEMBL1301168 & 688636 & 4.5 & 4.9637 & TRN \\
\hline CHEMBL1602965 & 688636 & 4.95 & 4.9513 & TRN \\
\hline CHEMBL1461518 & 688636 & 5.45 & 4.773 & TRN \\
\hline CHEMBL1391158 & 688636 & 5.4 & 4.9091 & TRN \\
\hline CHEMBL1363265 & 688636 & 4.25 & 4.6634 & TRN \\
\hline CHEMBL1550789 & 688636 & 4.25 & 4.765 & TRN \\
\hline CHEMBL1520244 & 688636 & 6.7501 & 4.9553 & TRN \\
\hline CHEMBL1345971 & 688636 & 4.55 & 4.9114 & TRN \\
\hline CHEMBL1570236 & 688636 & 6.8 & 4.9122 & TRN \\
\hline CHEMBL1477059 & 688636 & 5.5 & 4.6763 & TRN \\
\hline CHEMBL 2000815 & 688636 & 5.55 & 4.8185 & TST \\
\hline CHEMBL1299805 & 688636 & 4.9 & 5.0402 & TRN \\
\hline CHEMBL1495014 & 688636 & 5.85 & 5.0169 & TRN \\
\hline CHEMBL1502098 & 688636 & 4.5 & 4.5543 & TRN \\
\hline CHEMBL1489215 & 688636 & 4.4 & 4.8486 & TRN \\
\hline CHEMBL1477848 & 688636 & 4.35 & 4.7567 & TST \\
\hline CHEMBL1550662 & 688636 & 4.7 & 4.835 & TRN \\
\hline CHEMBL1461055 & 688636 & 5.45 & 4.3704 & TRN \\
\hline
\end{tabular}




\begin{tabular}{|c|c|c|c|c|}
\hline \multicolumn{5}{|c|}{ Supplemental Table S2.txt } \\
\hline CHEMBL1319983 & 688636 & 4.3 & 4.8581 & TRN \\
\hline CHEMBL3213770 & 688636 & 4.3 & 4.9054 & TST \\
\hline CHEMBL1401612 & 688636 & 4.35 & 4.8438 & TRN \\
\hline CHEMBL3194039 & 688636 & 6.7501 & 4.6958 & TRN \\
\hline CHEMBL1407234 & 688636 & 4.3 & 4.8333 & TST \\
\hline CHEMBL1603287 & 688636 & 4.9 & 4.8011 & TRN \\
\hline CHEMBL1546967 & 688636 & 5.15 & 4.8201 & TRN \\
\hline CHEMBL1485570 & 688636 & 4.5 & 4.8559 & TRN \\
\hline CHEMBL1345334 & 688636 & 4.35 & 4.7186 & TRN \\
\hline CHEMBL1466077 & 688636 & 6.0 & 4.8524 & TRN \\
\hline CHEMBL1611438 & 688636 & 4.3 & 4.8215 & TST \\
\hline CHEMBL3209606 & 688636 & 5.2 & 4.7664 & TRN \\
\hline CHEMBL1525001 & 688636 & 4.95 & 4.7328 & TST \\
\hline CHEMBL1597200 & 688636 & 4.55 & 4.8057 & TST \\
\hline CHEMBL1299351 & 688636 & 4.25 & 4.9314 & TRN \\
\hline CHEMBL1369619 & 688636 & 4.25 & 4.8004 & TST \\
\hline CHEMBL1333066 & 688636 & 4.95 & 4.8324 & TST \\
\hline CHEMBL1589181 & 688636 & 4.85 & 4.6835 & TRN \\
\hline CHEMBL1523886 & 688636 & 4.95 & 4.9025 & TST \\
\hline CHEMBL1400965 & 688636 & 4.4 & 4.7077 & TRN \\
\hline CHEMBL1370982 & 688636 & 6.5501 & 4.8773 & TRN \\
\hline CHEMBL1432633 & 688636 & 6.3 & 4.8017 & TST \\
\hline CHEMBL1585431 & 688636 & 4.35 & 4.8871 & TRN \\
\hline CHEMBL1464566 & 688636 & 5.25 & 4.7825 & TST \\
\hline CHEMBL1299795 & 688636 & 4.45 & 4.6826 & TRN \\
\hline CHEMBL1567631 & 688636 & 4.45 & 4.6542 & TRN \\
\hline CHEMBL1351160 & 688636 & 4.6 & 5.0615 & TST \\
\hline CHEMBL1574065 & 688636 & 5.1 & 4.6771 & TST \\
\hline CHEMBL1540533 & 688636 & 4.3 & 4.7553 & TRN \\
\hline CHEMBL3197144 & 688636 & 4.3 & 4.7707 & TRN \\
\hline CHEMBL1346258 & 688636 & 4.3 & 4.9644 & TRN \\
\hline CHEMBL1999182 & 688636 & 4.9 & 4.8139 & TST \\
\hline CHEMBL1398711 & 688636 & 4.95 & 4.7348 & TRN \\
\hline CHEMBL1466887 & 688636 & 4.65 & 4.8309 & TRN \\
\hline CHEMBL1581391 & 688636 & 5.95 & 4.8986 & TRN \\
\hline CHEMBL1399158 & 688636 & 5.0 & 4.7687 & TRN \\
\hline CHEMBL3210974 & 688636 & 4.5 & 4.9116 & TRN \\
\hline CHEMBL1533370 & 688636 & 4.3 & 4.8253 & TRN \\
\hline CHEMBL1321187 & 688636 & 4.5 & 4.8086 & TRN \\
\hline CHEMBL1578720 & 688636 & 4.4 & 4.7893 & TRN \\
\hline CHEMBL1335597 & 688636 & 4.6 & 4.632 & TRN \\
\hline CHEMBL1481531 & 688636 & 4.25 & 4.8233 & TRN \\
\hline CHEMBL1370991 & 688636 & 5.35 & 4.8369 & TRN \\
\hline CHEMBL3195032 & 688636 & 4.95 & 4.7957 & TST \\
\hline CHEMBL1464732 & 688636 & 5.1 & 4.9331 & TRN \\
\hline CHEMBL1362210 & 688636 & 4.25 & 4.9079 & TRN \\
\hline CHEMBL1454734 & 688636 & 5.95 & 4.8226 & TST \\
\hline CHEMBL1521379 & 688636 & 4.5 & 5.0389 & TRN \\
\hline
\end{tabular}




\begin{tabular}{|c|c|c|c|c|}
\hline \multicolumn{5}{|c|}{ Supplemental Table S2.txt } \\
\hline CHEMBL1360224 & 688636 & 5.2 & 4.7974 & TST \\
\hline CHEMBL1439595 & 688636 & 4.35 & 4.8014 & TRN \\
\hline CHEMBL1300679 & 688636 & 6.1 & 4.9668 & TRN \\
\hline CHEMBL1429198 & 688636 & 4.5 & 4.9449 & TST \\
\hline CHEMBL1578990 & 688636 & 4.25 & 5.0238 & TRN \\
\hline CHEMBL1461936 & 688636 & 4.3 & 4.7989 & TRN \\
\hline CHEMBL1401316 & 688636 & 5.2 & 4.9348 & TRN \\
\hline CHEMBL3190972 & 688636 & 4.7 & 4.9382 & TRN \\
\hline CHEMBL1505008 & 688636 & 4.95 & 4.8607 & TST \\
\hline CHEMBL1520477 & 688636 & 4.3 & 4.9739 & TRN \\
\hline CHEMBL1451029 & 688636 & 4.25 & 4.9919 & TRN \\
\hline CHEMBL3190211 & 688636 & 4.25 & 4.9881 & TRN \\
\hline CHEMBL1393659 & 688636 & 5.3 & 4.8007 & TRN \\
\hline CHEMBL1408729 & 688636 & 4.95 & 4.9578 & TRN \\
\hline CHEMBL1428542 & 688636 & 5.5 & 4.6655 & TST \\
\hline CHEMBL1460595 & 688636 & 4.65 & 4.8679 & TRN \\
\hline CHEMBL1482009 & 688636 & 4.5 & 4.7664 & TRN \\
\hline CHEMBL1398981 & 688636 & 4.45 & 4.6432 & TRN \\
\hline CHEMBL1448837 & 688636 & 5.45 & 4.8152 & TRN \\
\hline CHEMBL1448573 & 688636 & 4.85 & 4.7673 & TST \\
\hline CHEMBL1414641 & 688636 & 4.6 & 4.8402 & TRN \\
\hline CHEMBL1336445 & 688636 & 4.3 & 4.8721 & TST \\
\hline CHEMBL1500034 & 688636 & 4.25 & 4.9653 & TRN \\
\hline CHEMBL1538122 & 688636 & 6.15 & 4.7856 & TST \\
\hline CHEMBL1490788 & 688636 & 4.65 & 4.8009 & TRN \\
\hline CHEMBL1563013 & 688636 & 4.65 & 4.8026 & TRN \\
\hline CHEMBL1384201 & 688636 & 4.3 & 4.7847 & TRN \\
\hline CHEMBL1385618 & 688636 & 4.25 & 4.8279 & TRN \\
\hline CHEMBL1600853 & 688636 & 4.45 & 4.6139 & TRN \\
\hline CHEMBL1561240 & 688636 & 4.45 & 4.5715 & TRN \\
\hline CHEMBL1500690 & 688636 & 4.5 & 4.7644 & TST \\
\hline CHEMBL1469851 & 688636 & 4.45 & 4.9421 & TST \\
\hline CHEMBL1386900 & 688636 & 5.15 & 4.8017 & TRN \\
\hline CHEMBL1543241 & 688636 & 4.45 & 4.8623 & TST \\
\hline CHEMBL1522277 & 688636 & 6.7501 & 4.7748 & TRN \\
\hline CHEMBL1530556 & 688636 & 4.4 & 4.7841 & TRN \\
\hline CHEMBL1338892 & 688636 & 4.25 & 4.6991 & TRN \\
\hline CHEMBL1503618 & 688636 & 4.25 & 4.791 & TRN \\
\hline CHEMBL3199608 & 688636 & 4.35 & 4.6792 & TRN \\
\hline CHEMBL1359336 & 688636 & 4.35 & 4.7397 & TRN \\
\hline CHEMBL1461880 & 688636 & 4.35 & 4.8807 & TST \\
\hline CHEMBL1339724 & 688636 & 4.65 & 4.7228 & TRN \\
\hline CHEMBL1304805 & 688636 & 4.65 & 4.8549 & TST \\
\hline CHEMBL1579781 & 688636 & 4.3 & 4.8684 & TST \\
\hline CHEMBL3191057 & 688636 & 4.35 & 4.6576 & TRN \\
\hline CHEMBL1367063 & 688636 & 4.9 & 4.7774 & TRN \\
\hline CHEMBL1364298 & 688636 & 5.8 & 5.0054 & TRN \\
\hline CHEMBL1549599 & 688636 & 5.2 & 4.7265 & TST \\
\hline
\end{tabular}




\begin{tabular}{|c|c|c|c|c|c|}
\hline & & & & & \\
\hline CHEMBL1443903 & 688636 & 4.5 & 4.9273 & TRN & \\
\hline CHEMBL1601479 & 688636 & 4.4 & 4.8714 & TRN & \\
\hline CHEMBL1343210 & 688636 & 4.45 & 4.7619 & TST & \\
\hline CHEMBL1393485 & 688636 & 4.4 & 4.7722 & TST & \\
\hline CHEMBL1406323 & 688636 & 4.3 & 4.8986 & TST & \\
\hline CHEMBL1511051 & 688636 & 4.5 & 4.8766 & TRN & \\
\hline CHEMBL1524381 & 688636 & 4.25 & 4.8222 & TRN & \\
\hline CHEMBL1332408 & 688636 & 4.4 & 4.7781 & TRN & \\
\hline CHEMBL1595462 & 688636 & 5.2 & 4.7592 & TST & \\
\hline CHEMBL1375166 & 688636 & 5.4 & 4.4365 & TRN & \\
\hline CHEMBL1609223 & 688636 & 4.35 & 4.8121 & TRN & \\
\hline CHEMBL1353324 & 688636 & 6.7501 & 4.7478 & TRN & \\
\hline CHEMBL1469748 & 688636 & 4.6 & 4.7837 & TRN & \\
\hline CHEMBL1482951 & 688636 & 4.3 & 4.5774 & TRN & \\
\hline CHEMBL1334640 & 688636 & 4.5 & 4.9627 & TRN & \\
\hline CHEMBL13670 & 688636 & 4.3 & 4.9582 & TST & \\
\hline CHEMBL1459316 & 688636 & 4.6 & 4.8512 & TRN & \\
\hline CHEMBL1568074 & 688636 & 5.1 & 4.8379 & TRN & \\
\hline CHEMBL1575914 & 688636 & 6.2 & 4.763 & TRN & \\
\hline CHEMBL1343075 & 688636 & 4.35 & 4.7262 & TRN & \\
\hline CHEMBL1341212 & 688636 & 6.2 & 5.0098 & TRN & \\
\hline CHEMBL1577139 & 688636 & 4.95 & 4.6728 & TRN & \\
\hline CHEMBL1327376 & 688636 & 4.55 & 4.76699 & 99999999995 & TRN \\
\hline CHEMBL1391377 & 688636 & 4.25 & 4.7286 & TRN & \\
\hline CHEMBL1352669 & 688636 & 4.25 & 4.8507 & TRN & \\
\hline CHEMBL1412134 & 688636 & 4.45 & 4.9267 & TST & \\
\hline CHEMBL1608168 & 688636 & 4.55 & 4.808 & TRN & \\
\hline CHEMBL1602489 & 688636 & 5.2 & 4.7129 & TST & \\
\hline CHEMBL1572316 & 688636 & 4.5 & 4.6773 & TST & \\
\hline CHEMBL1470638 & 688636 & 5.3 & 4.6769 & TRN & \\
\hline CHEMBL1566749 & 688636 & 4.45 & 4.788 & TRN & \\
\hline CHEMBL1486592 & 688636 & 4.45 & 4.7871 & TRN & \\
\hline CHEMBL1420632 & 688636 & 4.7 & 4.8803 & TST & \\
\hline CHEMBL1384088 & 688636 & 4.3 & 4.8831 & TRN & \\
\hline CHEMBL1545979 & 688636 & 4.55 & 4.5896 & TRN & \\
\hline CHEMBL1464066 & 688636 & 4.45 & 4.9315 & TST & \\
\hline CHEMBL1526847 & 688636 & 4.3 & 4.752 & TST & \\
\hline CHEMBL1501956 & 688636 & 4.95 & 4.7642 & TRN & \\
\hline CHEMBL1533459 & 688636 & 4.3 & 4.5389 & TRN & \\
\hline CHEMBL1451241 & 688636 & 5.0 & 4.9263 & TRN & \\
\hline CHEMBL1444224 & 688636 & 4.95 & 4.95 & TST & \\
\hline CHEMBL1602721 & 688636 & 4.65 & 4.7233 & TRN & \\
\hline CHEMBL1537369 & 688636 & 5.25 & 4.9357 & TRN & \\
\hline CHEMBL1438305 & 688636 & 4.25 & 4.9434 & TRN & \\
\hline CHEMBL1455734 & 688636 & 5.1 & 4.8364 & TRN & \\
\hline CHEMBL1563296 & 688636 & 5.85 & 5.0983 & TRN & \\
\hline CHEMBL1417696 & 688636 & 4.45 & 4.6147 & TRN & \\
\hline CHEMBL1380905 & 688636 & 4.3 & 5.0974 & TRN & \\
\hline
\end{tabular}




\begin{tabular}{|c|c|c|c|c|c|}
\hline \multicolumn{6}{|c|}{ Supplemental Table S2.txt } \\
\hline CHEMBL1318802 & 688636 & 4.45 & 4.9333 & TRN & \\
\hline CHEMBL3208964 & 688636 & 5.4 & 4.7235 & TRN & \\
\hline CHEMBL1528934 & 688636 & 4.35 & 4.6155 & TRN & \\
\hline CHEMBL1481908 & 688636 & 4.45 & 4.7565 & TRN & \\
\hline CHEMBL1469044 & 688636 & 4.6 & 4.8411 & TRN & \\
\hline CHEMBL1076559 & 688636 & 4.55 & 4.6052 & TST & \\
\hline CHEMBL1571970 & 688636 & 6.05 & 4.8062 & TRN & \\
\hline CHEMBL406341 & 688636 & 4.6 & 4.7275 & TRN & \\
\hline CHEMBL1504991 & 688636 & 4.45 & 4.787 & TRN & \\
\hline CHEMBL1328291 & 688636 & 6.6 & 4.9574 & TRN & \\
\hline CHEMBL1335750 & 688636 & 4.7 & 4.9676 & TRN & \\
\hline CHEMBL1422426 & 688636 & 4.55 & 4.67899 & 9999999999 & TRN \\
\hline CHEMBL1574441 & 688636 & 4.25 & 4.9105 & TST & \\
\hline CHEMBL1545870 & 688636 & 4.9 & 4.752 & TST & \\
\hline CHEMBL1426400 & 688636 & 4.35 & 4.6206 & TRN & \\
\hline CHEMBL1335445 & 688636 & 4.5 & 4.7222 & TST & \\
\hline CHEMBL399962 & 688636 & 4.55 & 4.8967 & TRN & \\
\hline CHEMBL1538115 & 688636 & 4.3 & 4.6537 & TST & \\
\hline CHEMBL3208443 & 688636 & 5.0 & 4.8526 & TRN & \\
\hline CHEMBL1424362 & 688636 & 4.4 & 4.7797 & TRN & \\
\hline CHEMBL1386804 & 688636 & 4.25 & 4.8281 & TRN & \\
\hline CHEMBL1576162 & 688636 & 5.1 & 4.9232 & TRN & \\
\hline CHEMBL1610952 & 688636 & 5.5 & 4.636 & TRN & \\
\hline CHEMBL 3208367 & 688636 & 4.4 & 4.77 & TRN & \\
\hline CHEMBL1454166 & 688636 & 4.5 & 4.8909 & TRN & \\
\hline CHEMBL 3199243 & 688636 & 4.25 & 4.93 & TRN & \\
\hline CHEMBL1605856 & 688636 & 4.45 & 4.8628 & TRN & \\
\hline CHEMBL1407580 & 688636 & 6.7501 & 4.9174 & TRN & \\
\hline CHEMBL1375889 & 688636 & 5.4 & 4.6551 & TST & \\
\hline CHEMBL1376929 & 688636 & 5.4 & 4.6478 & TRN & \\
\hline CHEMBL1607501 & 688636 & 4.95 & 4.6515 & TST & \\
\hline CHEMBL1376836 & 688636 & 5.5 & 4.8036 & TRN & \\
\hline CHEMBL1564444 & 688636 & 4.8 & 4.8095 & TRN & \\
\hline CHEMBL1530550 & 688636 & 5.25 & 4.7611 & TRN & \\
\hline CHEMBL1424987 & 688636 & 4.4 & 4.5756 & TRN & \\
\hline CHEMBL1599486 & 688636 & 4.9 & 4.7022 & TRN & \\
\hline CHEMBL1307705 & 688636 & 4.95 & 4.9168 & TST & \\
\hline CHEMBL1333296 & 688636 & 6.45 & 4.8814 & TRN & \\
\hline CHEMBL1367710 & 688636 & 4.3 & 4.6842 & TRN & \\
\hline CHEMBL1305091 & 688636 & 4.45 & 4.5102 & TRN & \\
\hline CHEMBL1511009 & 688636 & 4.9 & 4.8736 & TRN & \\
\hline CHEMBL1310680 & 688636 & 4.75 & 4.6737 & TRN & \\
\hline CHEMBL1346247 & 688636 & 4.25 & 4.7148 & TRN & \\
\hline CHEMBL1324224 & 688636 & 4.65 & 4.8141 & TRN & \\
\hline CHEMBL1331016 & 688636 & 4.45 & 4.7351 & TRN & \\
\hline CHEMBL1602496 & 688636 & 4.35 & 5.0043 & TRN & \\
\hline CHEMBL1372527 & 688636 & 4.9 & 5.0561 & TRN & \\
\hline CHEMBL1564431 & 688636 & 6.8 & 4.8512 & TST & \\
\hline
\end{tabular}




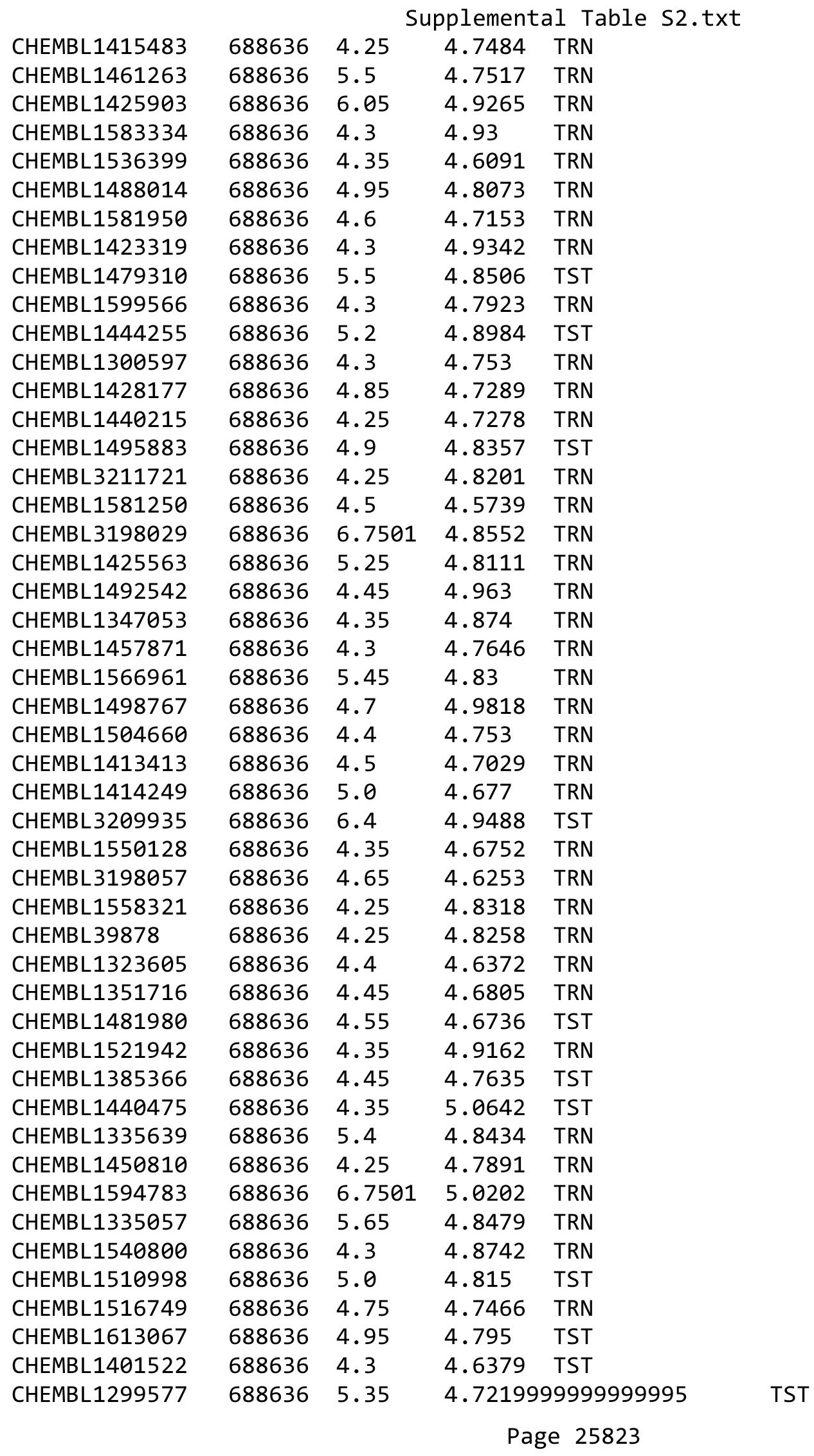




\begin{tabular}{|c|c|c|c|c|}
\hline \multicolumn{5}{|c|}{ Supplemental Table S2.txt } \\
\hline CHEMBL1376356 & 688636 & 4.3 & 4.9922 & TRN \\
\hline CHEMBL1506413 & 688636 & 4.95 & 4.606 & TRN \\
\hline CHEMBL571139 & 688636 & 5.0 & 4.9087 & TRN \\
\hline CHEMBL1408103 & 688636 & 5.4 & 4.7444 & TRN \\
\hline CHEMBL1408630 & 688636 & 4.35 & 4.7426 & TRN \\
\hline CHEMBL1601060 & 688636 & 4.4 & 4.6941 & TRN \\
\hline CHEMBL1531155 & 688636 & 5.3 & 4.8974 & TRN \\
\hline CHEMBL 3214487 & 688636 & 4.3 & 4.6813 & TST \\
\hline CHEMBL1485923 & 688636 & 4.45 & 4.7316 & TRN \\
\hline CHEMBL1507692 & 688636 & 4.3 & 4.9507 & TRN \\
\hline CHEMBL1388977 & 688636 & 4.55 & 4.8216 & TRN \\
\hline CHEMBL1429395 & 688636 & 4.4 & 4.907 & TST \\
\hline CHEMBL1452402 & 688636 & 4.45 & 4.7154 & TRN \\
\hline CHEMBL1378922 & 688636 & 4.35 & 4.7654 & TRN \\
\hline CHEMBL1376210 & 688636 & 5.2 & 4.949 & TST \\
\hline CHEMBL1471126 & 688636 & 4.25 & 4.6879 & TRN \\
\hline CHEMBL588919 & 688636 & 4.7 & 4.7032 & TRN \\
\hline CHEMBL1299749 & 688636 & 5.85 & 4.9495 & TST \\
\hline CHEMBL1526615 & 688636 & 4.4 & 4.7345 & TRN \\
\hline CHEMBL3192812 & 688636 & 4.55 & 4.7772 & TRN \\
\hline CHEMBL1605480 & 688636 & 6.7501 & 4.6967 & TRN \\
\hline CHEMBL1326478 & 688636 & 6.7501 & 4.8957 & TST \\
\hline CHEMBL1348672 & 688636 & 6.5501 & 4.5239 & TRN \\
\hline CHEMBL1526946 & 688636 & 4.25 & 4.7359 & TRN \\
\hline CHEMBL1580329 & 688636 & 5.55 & 4.9346 & TRN \\
\hline CHEMBL1527041 & 688636 & 4.7 & 4.9148 & TRN \\
\hline CHEMBL1562914 & 688636 & 5.0 & 4.7315 & TRN \\
\hline CHEMBL1500934 & 688636 & 4.4 & 4.9365 & TST \\
\hline CHEMBL1361240 & 688636 & 4.3 & 4.7079 & TRN \\
\hline CHEMBL1470205 & 688636 & 4.3 & 4.7452 & TRN \\
\hline CHEMBL1574450 & 688636 & 4.3 & 4.6849 & TRN \\
\hline CHEMBL1340288 & 688636 & 4.8 & 4.7497 & TRN \\
\hline CHEMBL1423454 & 688636 & 4.4 & 4.7859 & TRN \\
\hline CHEMBL3194351 & 688636 & 4.3 & 4.8996 & TST \\
\hline CHEMBL1459525 & 688636 & 4.3 & 4.8263 & TRN \\
\hline CHEMBL1612006 & 688636 & 5.0 & 4.6642 & TST \\
\hline CHEMBL1427160 & 688636 & 6.15 & 4.9161 & TRN \\
\hline CHEMBL1426502 & 688636 & 5.4 & 4.825 & TST \\
\hline CHEMBL1328686 & 688636 & 4.35 & 4.6688 & TRN \\
\hline CHEMBL1443784 & 688636 & 4.95 & 4.8801 & TRN \\
\hline CHEMBL1438360 & 688636 & 5.25 & 4.7523 & TRN \\
\hline CHEMBL1338131 & 688636 & 4.4 & 4.8768 & TRN \\
\hline CHEMBL1596996 & 688636 & 4.25 & 4.7445 & TRN \\
\hline CHEMBL1601296 & 688636 & 4.45 & 4.7462 & TRN \\
\hline CHEMBL3194991 & 688636 & 4.35 & 4.8425 & TST \\
\hline CHEMBL1609167 & 688636 & 4.45 & 5.05399 & 9999999999 \\
\hline CHEMBL3213752 & 688636 & 4.5 & 4.8715 & TRN \\
\hline CHEMBL1401558 & 688636 & 4.25 & 4.8143 & TRN \\
\hline
\end{tabular}




\begin{tabular}{|c|c|c|c|c|c|}
\hline & & \multicolumn{4}{|c|}{ Supplemental Table S2.txt } \\
\hline CHEMBL1352109 & 688636 & 5.85 & 4.93199 & 99999999995 & TST \\
\hline CHEMBL1484282 & 688636 & 4.3 & 4.6296 & TRN & \\
\hline CHEMBL1470281 & 688636 & 4.45 & 4.8493 & TST & \\
\hline CHEMBL1569562 & 688636 & 4.35 & 4.9355 & TST & \\
\hline CHEMBL1532758 & 688636 & 4.25 & 4.7189 & TST & \\
\hline CHEMBL1549668 & 688636 & 4.4 & 4.795 & TST & \\
\hline CHEMBL1382617 & 688636 & 5.35 & 4.5986 & TST & \\
\hline CHEMBL1550445 & 688636 & 4.3 & 4.6252 & TST & \\
\hline CHEMBL1451424 & 688636 & 4.25 & 5.0425 & TST & \\
\hline CHEMBL1607511 & 688636 & 4.4 & 4.8565 & TRN & \\
\hline CHEMBL1604992 & 688636 & 5.85 & 4.8976 & TST & \\
\hline CHEMBL1560647 & 688636 & 4.3 & 4.7947 & TRN & \\
\hline CHEMBL1500938 & 688636 & 4.7 & 4.9032 & TST & \\
\hline CHEMBL1570309 & 688636 & 5.1 & 4.8893 & TST & \\
\hline CHEMBL1586318 & 688636 & 4.95 & 4.8835 & TRN & \\
\hline CHEMBL1556186 & 688636 & 4.95 & 5.0045 & TRN & \\
\hline CHEMBL1335787 & 688636 & 4.25 & 4.7736 & TRN & \\
\hline CHEMBL1578641 & 688636 & 5.95 & 4.8277 & TRN & \\
\hline CHEMBL1324475 & 688636 & 6.2 & 4.9379 & TST & \\
\hline CHEMBL1570727 & 688636 & 6.7501 & 4.8495 & TRN & \\
\hline CHEMBL1341050 & 688636 & 4.45 & 4.7773 & TRN & \\
\hline CHEMBL1409237 & 688636 & 5.9 & 4.8804 & TST & \\
\hline CHEMBL1490943 & 688636 & 5.45 & 5.00899 & 99999999995 & TRN \\
\hline CHEMBL1454853 & 688636 & 4.4 & 4.6834 & TRN & \\
\hline CHEMBL1500499 & 688636 & 5.1 & 4.8792 & TRN & \\
\hline CHEMBL1307914 & 688636 & 6.2 & 4.96 & TRN & \\
\hline CHEMBL1569690 & 688636 & 4.8 & 4.8003 & TST & \\
\hline CHEMBL1581386 & 688636 & 4.6 & 4.8432 & TRN & \\
\hline CHEMBL1404400 & 688636 & 6.7501 & 4.8904 & TRN & \\
\hline CHEMBL1384236 & 688636 & 4.25 & 4.952 & TRN & \\
\hline CHEMBL1477655 & 688636 & 4.5 & 4.9777 & TRN & \\
\hline CHEMBL1489772 & 688636 & 4.9 & 4.9433 & TRN & \\
\hline CHEMBL1613098 & 688636 & 4.65 & 4.7833 & TRN & \\
\hline CHEMBL1344205 & 688636 & 4.45 & 4.6126 & TRN & \\
\hline CHEMBL1604658 & 688636 & 5.65 & 4.8551 & TST & \\
\hline CHEMBL1549886 & 688636 & 4.25 & 4.8092 & TRN & \\
\hline CHEMBL1485381 & 688636 & 4.55 & 4.6858 & TRN & \\
\hline CHEMBL1564327 & 688636 & 6.8 & 4.9652 & TRN & \\
\hline CHEMBL1424581 & 688636 & 6.6499 & 4.9799 & TST & \\
\hline CHEMBL1579785 & 688636 & 5.3 & 4.8898 & TST & \\
\hline CHEMBL1341627 & 688636 & 6.0 & 4.8385 & TRN & \\
\hline CHEMBL1201091 & 688636 & 6.0 & 4.6982 & TST & \\
\hline CHEMBL1572449 & 688636 & 4.95 & 4.8491 & TRN & \\
\hline CHEMBL3207466 & 688636 & 4.25 & 4.7712 & TRN & \\
\hline CHEMBL1431090 & 688636 & 5.15 & 4.8454 & TST & \\
\hline CHEMBL1524023 & 688636 & 5.4 & 4.8508 & TRN & \\
\hline CHEMBL1511757 & 688636 & 4.25 & 4.9306 & TST & \\
\hline CHEMBL1612476 & 688636 & 4.45 & 4.6429 & TRN & \\
\hline
\end{tabular}




\begin{tabular}{|c|c|c|c|c|c|}
\hline \multicolumn{6}{|c|}{ Supplemental Table s2.txt } \\
\hline CHEMBL1302857 & 688636 & 4.25 & 4.5233 & TRN & \\
\hline CHEMBL1429646 & 688636 & 5.4 & 4.7041 & TRN & \\
\hline CHEMBL1499293 & 688636 & 6.0 & 4.9895 & TRN & \\
\hline CHEMBL1384638 & 688636 & 4.25 & 4.832 & TRN & \\
\hline CHEMBL1390607 & 688636 & 4.5 & 4.8142 & TRN & \\
\hline CHEMBL1312880 & 688636 & 5.5 & 5.0777 & TRN & \\
\hline CHEMBL1399002 & 688636 & 4.3 & 4.863 & TRN & \\
\hline CHEMBL1389266 & 688636 & 5.55 & 4.8498 & TRN & \\
\hline CHEMBL1542775 & 688636 & 4.55 & 4.5436 & TRN & \\
\hline CHEMBL1413475 & 688636 & 4.3 & 4.8253 & TRN & \\
\hline CHEMBL1587447 & 688636 & 4.55 & 4.7227 & TRN & \\
\hline CHEMBL1488196 & 688636 & 4.3 & 4.7941 & TRN & \\
\hline CHEMBL1368626 & 688636 & 4.5 & 4.8804 & TRN & \\
\hline CHEMBL1583304 & 688636 & 4.85 & 4.8433 & TST & \\
\hline CHEMBL1481929 & 688636 & 4.9 & 4.9629 & TST & \\
\hline CHEMBL1527164 & 688636 & 4.55 & 4.7288 & TRN & \\
\hline CHEMBL1607290 & 688636 & 4.25 & 4.6846 & TRN & \\
\hline CHEMBL3214169 & 688636 & 4.35 & 4.8385 & TRN & \\
\hline CHEMBL1369724 & 688636 & 4.4 & 4.9574 & TRN & \\
\hline CHEMBL1424901 & 688636 & 4.25 & 4.9692 & TRN & \\
\hline CHEMBL1339759 & 688636 & 4.4 & 4.7776 & TRN & \\
\hline CHEMBL1429988 & 688636 & 4.4 & 4.675 & TRN & \\
\hline CHEMBL1594279 & 688636 & 4.3 & 4.7612 & TRN & \\
\hline CHEMBL1304841 & 688636 & 4.35 & 4.5957 & TRN & \\
\hline CHEMBL3211419 & 688636 & 4.25 & 4.7938 & TRN & \\
\hline CHEMBL1536919 & 688636 & 4.6 & 4.8558 & TRN & \\
\hline CHEMBL1347453 & 688636 & 5.35 & 5.0045 & TRN & \\
\hline CHEMBL1537481 & 688636 & 4.45 & 4.6018 & TRN & \\
\hline CHEMBL175003 & 688636 & 4.35 & 4.836 & TRN & \\
\hline CHEMBL1492263 & 688636 & 6.5501 & 4.8499 & TRN & \\
\hline CHEMBL1412454 & 688636 & 4.35 & 4.7952 & TRN & \\
\hline CHEMBL1375143 & 688636 & 5.95 & 4.9818 & TRN & \\
\hline CHEMBL1508965 & 688636 & 4.25 & 4.9397 & TRN & \\
\hline CHEMBL1305098 & 688636 & 4.3 & 4.6064 & TRN & \\
\hline CHEMBL1311672 & 688636 & 4.55 & 4.7453 & TRN & \\
\hline CHEMBL1493038 & 688636 & 5.65 & 4.846 & TST & \\
\hline CHEMBL1402578 & 688636 & 5.65 & 4.8285 & TST & \\
\hline CHEMBL1599755 & 688636 & 4.4 & 4.9641 & TRN & \\
\hline CHEMBL1606468 & 688636 & 4.3 & 4.7931 & TRN & \\
\hline CHEMBL1528443 & 688636 & 5.25 & 4.8568 & TRN & \\
\hline CHEMBL1374456 & 688636 & 4.95 & 4.8422 & TRN & \\
\hline CHEMBL1416237 & 688636 & 4.45 & 4.8377 & TRN & \\
\hline CHEMBL1365867 & 688636 & 4.95 & 4.7978 & TRN & \\
\hline CHEMBL3213988 & 688636 & 4.9 & 4.7735 & TRN & \\
\hline CHEMBL1577440 & 688636 & 4.35 & 4.7902 & TST & \\
\hline CHEMBL1559144 & 688636 & 6.7501 & 4.9738 & TRN & \\
\hline CHEMBL1388380 & 688636 & 4.95 & 4.808 & TRN & \\
\hline CHEMBL1567818 & 688636 & 4.25 & $4.7360 e$ & 0000000001 & TRN \\
\hline & & & & 25826 & \\
\hline
\end{tabular}




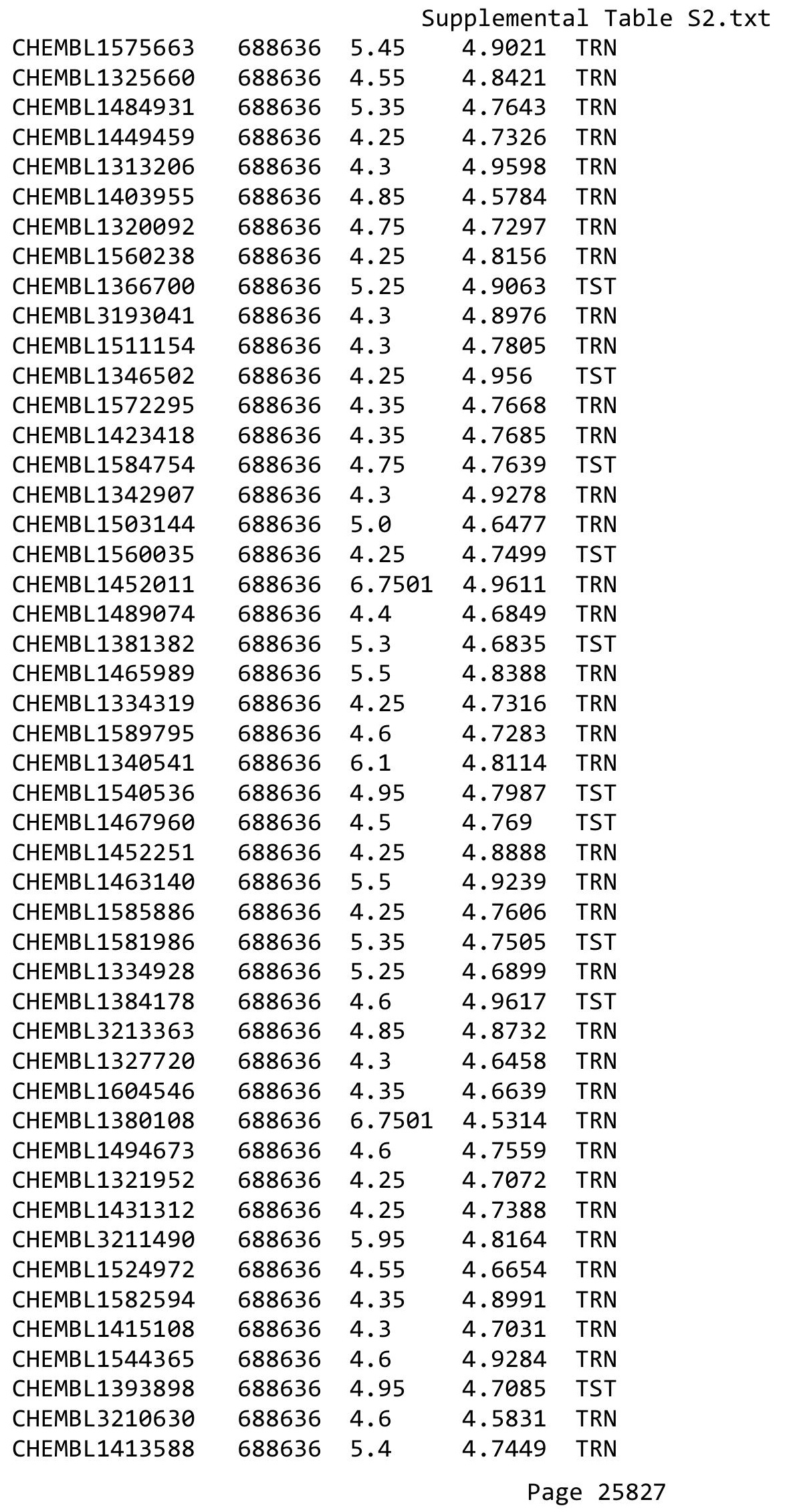




\begin{tabular}{|c|c|c|c|c|}
\hline \multicolumn{5}{|c|}{ Supplemental Table S2.txt } \\
\hline CHEMBL1345682 & 688636 & 6.8 & 4.7509 & TRN \\
\hline CHEMBL1449923 & 688636 & 4.55 & 4.5127 & TRN \\
\hline CHEMBL1345369 & 688636 & 4.85 & 4.8833 & TRN \\
\hline CHEMBL1418264 & 688636 & 5.1 & 4.757 & TST \\
\hline CHEMBL1563194 & 688636 & 4.45 & 4.9275 & TST \\
\hline CHEMBL1399612 & 688636 & 4.5 & 4.5787 & TRN \\
\hline CHEMBL1503731 & 688636 & 4.3 & 4.5138 & TRN \\
\hline CHEMBL1600939 & 688636 & 4.25 & 4.7516 & TRN \\
\hline CHEMBL3197677 & 688636 & 4.75 & 4.8081 & TST \\
\hline CHEMBL1489092 & 688636 & 4.35 & 4.8643 & TRN \\
\hline CHEMBL1324139 & 688636 & 4.5 & 4.9059 & TRN \\
\hline CHEMBL1370068 & 688636 & 4.25 & 4.8291 & TRN \\
\hline CHEMBL1321112 & 688636 & 4.5 & 4.8203 & TRN \\
\hline CHEMBL1349723 & 688636 & 4.3 & 4.7091 & TST \\
\hline CHEMBL1507659 & 688636 & 4.9 & 4.813 & TRN \\
\hline CHEMBL1391613 & 688636 & 4.4 & 4.816 & TRN \\
\hline CHEMBL1594586 & 688636 & 4.4 & 4.8461 & TRN \\
\hline CHEMBL1449013 & 688636 & 4.95 & 4.8793 & TRN \\
\hline CHEMBL1422539 & 688636 & 4.95 & 4.8485 & TST \\
\hline CHEMBL1438984 & 688636 & 6.8 & 4.7562 & TRN \\
\hline CHEMBL1502851 & 688636 & 4.4 & 4.7232 & TST \\
\hline CHEMBL1388686 & 688636 & 4.25 & 4.8928 & TST \\
\hline CHEMBL1200587 & 688636 & 4.25 & 4.8097 & TST \\
\hline CHEMBL1471180 & 688636 & 5.8 & 4.7266 & TRN \\
\hline CHEMBL1445336 & 688636 & 6.7501 & 4.7312 & TRN \\
\hline CHEMBL1517860 & 688636 & 4.45 & 4.664 & TRN \\
\hline CHEMBL1581582 & 688636 & 4.3 & 4.7704 & TST \\
\hline CHEMBL1544132 & 688636 & 4.45 & 4.7502 & TRN \\
\hline CHEMBL1399721 & 688636 & 4.9 & 4.7501 & TRN \\
\hline CHEMBL1518855 & 688636 & 4.45 & 4.7896 & TRN \\
\hline CHEMBL1413683 & 688636 & 5.4 & 4.9545 & TRN \\
\hline CHEMBL1507631 & 688636 & 4.7 & 4.8163 & TRN \\
\hline CHEMBL1470983 & 688636 & 4.55 & 4.9442 & TRN \\
\hline CHEMBL3210654 & 688636 & 4.3 & 4.7408 & TRN \\
\hline CHEMBL1306420 & 688636 & 4.4 & 4.7484 & TRN \\
\hline CHEMBL1413080 & 688636 & 4.9 & 4.7399 & TST \\
\hline CHEMBL1441619 & 688636 & 4.45 & 4.5156 & TRN \\
\hline CHEMBL1469299 & 688636 & 4.95 & 4.8758 & TST \\
\hline CHEMBL1299609 & 688636 & 4.3 & 4.7645 & TST \\
\hline CHEMBL1584952 & 688636 & 4.95 & 4.8028 & TRN \\
\hline CHEMBL1413318 & 688636 & 4.25 & 4.8442 & TST \\
\hline CHEMBL1421580 & 688636 & 4.45 & 4.8874 & TRN \\
\hline CHEMBL1583930 & 688636 & 4.5 & 4.8977 & TST \\
\hline CHEMBL249032 & 688636 & 4.55 & 4.9441 & TRN \\
\hline CHEMBL1409507 & 688636 & 4.45 & 4.6948 & TST \\
\hline CHEMBL1335718 & 688636 & 4.4 & 4.6544 & TRN \\
\hline CHEMBL1402437 & 688636 & 6.8 & 4.9294 & TRN \\
\hline CHEMBL1309643 & 688636 & 4.3 & 4.5999 & TST \\
\hline
\end{tabular}




\begin{tabular}{|c|c|c|c|c|c|}
\hline \multicolumn{6}{|c|}{ Supplemental Table S2.txt } \\
\hline CHEMBL1426096 & 688636 & 4.25 & 4.7406 & TST & \\
\hline CHEMBL1583025 & 688636 & 5.15 & 4.7052 & TRN & \\
\hline CHEMBL1348630 & 688636 & 4.5 & 4.9186 & TRN & \\
\hline CHEMBL1442585 & 688636 & 4.9 & 4.8045 & TRN & \\
\hline CHEMBL3213807 & 688636 & 4.95 & 4.8184 & TST & \\
\hline CHEMBL1460399 & 688636 & 6.8 & 4.8907 & TRN & \\
\hline CHEMBL1464288 & 688636 & 4.45 & 4.6199 & TRN & \\
\hline CHEMBL1301171 & 688636 & 4.9 & 4.9096 & TRN & \\
\hline CHEMBL1479046 & 688636 & 4.3 & 4.8808 & TRN & \\
\hline CHEMBL1575721 & 688636 & 4.45 & 4.7097 & TRN & \\
\hline CHEMBL1481813 & 688636 & 4.5 & 4.7391 & TRN & \\
\hline CHEMBL1332634 & 688636 & 4.25 & 4.7921 & TRN & \\
\hline CHEMBL1359176 & 688636 & 5.3 & 4.8082 & TST & \\
\hline CHEMBL1346069 & 688636 & 4.4 & 4.8696 & TRN & \\
\hline CHEMBL1309655 & 688636 & 4.55 & 4.8514 & TRN & \\
\hline CHEMBL1487976 & 688636 & 4.45 & 5.0554 & TRN & \\
\hline CHEMBL1341256 & 688636 & 5.2 & 4.7932 & TRN & \\
\hline CHEMBL1464850 & 688636 & 4.25 & 4.9115 & TST & \\
\hline CHEMBL1325135 & 688636 & 5.2 & 4.6644 & TRN & \\
\hline CHEMBL1310710 & 688636 & 4.6 & 4.7491 & TRN & \\
\hline CHEMBL3195735 & 688636 & 5.25 & 4.874 & TST & \\
\hline CHEMBL1429613 & 688636 & 4.25 & 4.7398 & TRN & \\
\hline CHEMBL1505859 & 688636 & 4.25 & 4.9519 & TRN & \\
\hline CHEMBL3213929 & 688636 & 4.25 & 4.7389 & TST & \\
\hline CHEMBL1404783 & 688636 & 4.25 & 4.823 & TRN & \\
\hline CHEMBL1427758 & 688636 & 4.9 & 4.8078 & TRN & \\
\hline CHEMBL1393232 & 688636 & 4.4 & 4.7076 & TRN & \\
\hline CHEMBL1446921 & 688636 & 4.3 & 4.7093 & TRN & \\
\hline CHEMBL1534378 & 688636 & 4.3 & 4.936 & TRN & \\
\hline CHEMBL1498476 & 688636 & 4.3 & 4.8762 & TRN & \\
\hline CHEMBL241898 & 688636 & 4.95 & 4.8726 & TRN & \\
\hline CHEMBL1425724 & 688636 & 4.35 & 4.7844 & TRN & \\
\hline CHEMBL1965162 & 688636 & 4.5 & 4.65300 & 20000000005 & TRN \\
\hline CHEMBL1301487 & 688636 & 4.45 & 4.6095 & TRN & \\
\hline CHEMBL3207879 & 688636 & 5.2 & 4.8674 & TRN & \\
\hline CHEMBL1485573 & 688636 & 4.5 & 4.7057 & TRN & \\
\hline CHEMBL1556061 & 688636 & 4.4 & 4.7698 & TRN & \\
\hline CHEMBL1540526 & 688636 & 4.25 & 4.9332 & TRN & \\
\hline CHEMBL1393762 & 688636 & 4.4 & 4.9673 & TRN & \\
\hline CHEMBL3190762 & 688636 & 4.95 & 4.67399 & 99999999995 & TRN \\
\hline CHEMBL1605311 & 688636 & 4.35 & 4.6243 & TRN & \\
\hline CHEMBL1458541 & 688636 & 4.5 & 4.6946 & TST & \\
\hline CHEMBL1403368 & 688636 & 4.45 & 4.7704 & TRN & \\
\hline CHEMBL1424986 & 688636 & 4.3 & 4.7615 & TRN & \\
\hline CHEMBL1608331 & 688636 & 4.5 & 4.7004 & TRN & \\
\hline CHEMBL1402408 & 688636 & 4.85 & 4.6439 & TRN & \\
\hline CHEMBL1389840 & 688636 & 6.6 & 4.9007 & TRN & \\
\hline CHEMBL1576064 & 688636 & 5.8 & 4.707 & TRN & \\
\hline
\end{tabular}




\begin{tabular}{|c|c|c|c|c|c|}
\hline \multirow[b]{2}{*}{ CHEMBL1432973 } & \\
\hline & 688636 & 4.5 & 4.6101 & TRN & \\
\hline CHEMBL1560630 & 688636 & 4.55 & 4.78100 & $\partial 000000001$ & TRN \\
\hline CHEMBL1301741 & 688636 & 5.55 & 4.8301 & TRN & \\
\hline CHEMBL3208402 & 688636 & 5.85 & 4.7924 & TRN & \\
\hline CHEMBL1472479 & 688636 & 4.9 & 4.9104 & TST & \\
\hline CHEMBL1569532 & 688636 & 4.95 & 4.6228 & TRN & \\
\hline CHEMBL1441918 & 688636 & 4.25 & 4.5818 & TST & \\
\hline CHEMBL1313073 & 688636 & 6.2 & 4.7926 & TRN & \\
\hline CHEMBL1587463 & 688636 & 4.4 & 4.6291 & TST & \\
\hline CHEMBL1540423 & 688636 & 4.35 & 4.7927 & TRN & \\
\hline CHEMBL1517045 & 688636 & 4.3 & 4.6585 & TST & \\
\hline CHEMBL1559168 & 688636 & 4.35 & 4.90600 & 0000000001 & TST \\
\hline CHEMBL1444290 & 688636 & 4.3 & 4.9523 & TST & \\
\hline CHEMBL1347710 & 688636 & 4.25 & 4.8388 & TRN & \\
\hline CHEMBL1425387 & 688636 & 6.3 & 4.9424 & TRN & \\
\hline CHEMBL1575194 & 688636 & 4.25 & 4.7776 & TRN & \\
\hline CHEMBL1321361 & 688636 & 4.5 & 4.7422 & TRN & \\
\hline CHEMBL1610306 & 688636 & 4.3 & 4.93199 & 99999999995 & TRN \\
\hline CHEMBL1460775 & 688636 & 4.35 & 4.7786 & TRN & \\
\hline CHEMBL1594604 & 688636 & 4.45 & 4.8531 & TRN & \\
\hline CHEMBL1483960 & 688636 & 4.3 & 4.9686 & TST & \\
\hline CHEMBL1594242 & 688636 & 5.85 & 4.731 & TRN & \\
\hline CHEMBL1516363 & 688636 & 4.5 & 4.897 & TST & \\
\hline CHEMBL1539843 & 688636 & 5.35 & 4.705 & TRN & \\
\hline CHEMBL1346498 & 688636 & 4.25 & 4.6815 & TRN & \\
\hline CHEMBL1336449 & 688636 & 4.25 & 4.8724 & TST & \\
\hline CHEMBL1428255 & 688636 & 4.35 & 4.8181 & TST & \\
\hline CHEMBL1370591 & 688636 & 4.25 & 5.0253 & TRN & \\
\hline CHEMBL1511361 & 688636 & 5.7 & 4.6392 & TRN & \\
\hline CHEMBL1340116 & 688636 & 6.7501 & 4.8654 & TRN & \\
\hline CHEMBL1338196 & 688636 & 4.85 & 4.6109 & TRN & \\
\hline CHEMBL1530562 & 688636 & 4.3 & 4.9842 & TRN & \\
\hline CHEMBL1393417 & 688636 & 4.55 & 4.8524 & TRN & \\
\hline CHEMBL1601731 & 688636 & 5.2 & 4.9325 & TRN & \\
\hline CHEMBL1524208 & 688636 & 4.35 & 4.7532 & TRN & \\
\hline CHEMBL1500849 & 688636 & 6.8 & 4.895 & TRN & \\
\hline CHEMBL1550675 & 688636 & 4.9 & 4.8523 & TRN & \\
\hline CHEMBL1301301 & 688636 & 4.3 & 4.7173 & TRN & \\
\hline CHEMBL1368775 & 688636 & 4.35 & 4.8295 & TRN & \\
\hline CHEMBL1459860 & 688636 & 4.75 & 4.8679 & TST & \\
\hline CHEMBL1302885 & 688636 & 4.4 & 4.6068 & TRN & \\
\hline CHEMBL1304258 & 688636 & 4.45 & 4.7563 & TRN & \\
\hline CHEMBL1465781 & 688636 & 5.45 & 4.9027 & TRN & \\
\hline CHEMBL1309782 & 688636 & 4.3 & 4.7782 & TRN & \\
\hline CHEMBL1406458 & 688636 & 5.0 & 4.8515 & TRN & \\
\hline CHEMBL1534592 & 688636 & 4.4 & 4.9167 & TRN & \\
\hline CHEMBL1526929 & 688636 & 5.75 & 4.5189 & TRN & \\
\hline CHEMBL1319860 & 688636 & 5.15 & 4.7514 & TRN & \\
\hline
\end{tabular}




\begin{tabular}{|c|c|c|c|c|}
\hline \multicolumn{5}{|c|}{ Supplemental Table S2.txt } \\
\hline CHEMBL1485453 & 688636 & 4.45 & 4.8641 & TRN \\
\hline CHEMBL1539591 & 688636 & 4.3 & 4.8518 & TST \\
\hline CHEMBL1332739 & 688636 & 4.3 & 4.7791 & TRN \\
\hline CHEMBL3198115 & 688636 & 4.35 & 4.7984 & TST \\
\hline CHEMBL1491190 & 688636 & 5.5 & 4.7964 & TRN \\
\hline CHEMBL1349978 & 688636 & 4.5 & 4.6506 & TRN \\
\hline CHEMBL1527794 & 688636 & 4.65 & 4.6097 & TRN \\
\hline CHEMBL1300082 & 688636 & 4.3 & 4.7106 & TST \\
\hline CHEMBL1443309 & 688636 & 4.45 & 4.7233 & TRN \\
\hline CHEMBL1448835 & 688636 & 6.2 & 4.7125 & TRN \\
\hline CHEMBL1327074 & 688636 & 4.25 & 4.6574 & TRN \\
\hline CHEMBL 3214058 & 688636 & 4.55 & 4.6768 & TRN \\
\hline CHEMBL1402893 & 688636 & 4.6 & 4.6805 & TRN \\
\hline CHEMBL1580874 & 688636 & 4.45 & 4.5882 & TRN \\
\hline CHEMBL3193188 & 688636 & 5.85 & 4.8583 & TRN \\
\hline CHEMBL3196132 & 688636 & 4.3 & 4.9113 & TRN \\
\hline CHEMBL1609726 & 688636 & 4.3 & 4.7234 & TRN \\
\hline CHEMBL1320026 & 688636 & 4.7 & 4.6751 & TRN \\
\hline CHEMBL1581404 & 688636 & 4.65 & 4.7919 & TRN \\
\hline CHEMBL1508555 & 688636 & 6.7501 & 4.8252 & TRN \\
\hline CHEMBL3208342 & 688636 & 5.2 & 4.9044 & TRN \\
\hline CHEMBL1447970 & 688636 & 4.7 & 4.7641 & TRN \\
\hline CHEMBL1485891 & 688636 & 5.85 & 5.1525 & TRN \\
\hline CHEMBL1409353 & 688636 & 4.95 & 4.8213 & TST \\
\hline CHEMBL1585340 & 688636 & 5.5 & 4.8091 & TST \\
\hline CHEMBL1524719 & 688636 & 5.45 & 4.9941 & TST \\
\hline CHEMBL1373654 & 688636 & 4.4 & 4.9521 & TST \\
\hline CHEMBL1426067 & 688636 & 4.65 & 4.6884 & TRN \\
\hline CHEMBL1532613 & 688636 & 4.75 & 4.614 & TRN \\
\hline CHEMBL1462961 & 688636 & 4.55 & 4.9311 & TRN \\
\hline CHEMBL1585488 & 688636 & 4.65 & 4.7951 & TRN \\
\hline CHEMBL1380101 & 688636 & 6.05 & 4.5056 & TRN \\
\hline CHEMBL1449762 & 688636 & 5.8 & 4.9408 & TST \\
\hline CHEMBL3193648 & 688636 & 4.45 & 4.7994 & TRN \\
\hline CHEMBL1387731 & 688636 & 6.1 & 4.8987 & TRN \\
\hline CHEMBL1429516 & 688636 & 4.4 & 4.9061 & TRN \\
\hline CHEMBL1484230 & 688636 & 4.45 & 4.7643 & TRN \\
\hline CHEMBL1347265 & 688636 & 5.3 & 4.8461 & TRN \\
\hline CHEMBL3190537 & 688636 & 4.9 & 4.7078 & TRN \\
\hline CHEMBL1565531 & 688636 & 4.45 & 4.6621 & TRN \\
\hline CHEMBL1319663 & 688636 & 4.25 & 4.9432 & TRN \\
\hline CHEMBL1350941 & 688636 & 4.25 & 4.6489 & TST \\
\hline CHEMBL1383329 & 688636 & 4.8 & 4.6346 & TRN \\
\hline CHEMBL3213124 & 688636 & 5.95 & 4.7428 & TRN \\
\hline CHEMBL1381668 & 688636 & 4.25 & 4.7549 & TRN \\
\hline CHEMBL1538451 & 688636 & 4.3 & 4.7705 & TRN \\
\hline CHEMBL1300335 & 688636 & 4.3 & 4.8603 & TST \\
\hline CHEMBL1543207 & 688636 & 4.4 & 4.7855 & TRN \\
\hline
\end{tabular}




\begin{tabular}{|c|c|c|c|c|c|}
\hline & & & & & \\
\hline CHEMBL1528789 & 688636 & 4.4 & 4.9047 & TST & \\
\hline CHEMBL1312995 & 688636 & 4.35 & 4.8775 & TST & \\
\hline CHEMBL1613589 & 688636 & 5.9 & 4.9167 & TST & \\
\hline CHEMBL1381674 & 688636 & 4.9 & 4.8773 & TRN & \\
\hline CHEMBL1345027 & 688636 & 4.4 & 4.9047 & TRN & \\
\hline CHEMBL1558251 & 688636 & 4.6 & 4.8394 & TST & \\
\hline CHEMBL1541174 & 688636 & 5.7 & 5.0179 & TRN & \\
\hline CHEMBL1497440 & 688636 & 4.25 & 4.8484 & TRN & \\
\hline CHEMBL1601976 & 688636 & 6.4 & 4.7594 & TRN & \\
\hline CHEMBL1610497 & 688636 & 4.25 & 4.9228 & TRN & \\
\hline CHEMBL1404914 & 688636 & 4.4 & 4.6883 & TRN & \\
\hline CHEMBL1545253 & 688636 & 4.25 & 4.9506 & TRN & \\
\hline CHEMBL1549232 & 688636 & 4.25 & 4.637 & TRN & \\
\hline CHEMBL1991112 & 688636 & 6.7501 & 4.9256 & TST & \\
\hline CHEMBL1479319 & 688636 & 4.45 & 4.6391 & TRN & \\
\hline CHEMBL1438925 & 688636 & 4.65 & 4.8215 & TRN & \\
\hline CHEMBL1578292 & 688636 & 4.35 & 4.8382 & TST & \\
\hline CHEMBL1984166 & 688636 & 4.3 & 4.6605 & TRN & \\
\hline CHEMBL1457013 & 688636 & 4.15 & 4.856 & TST & \\
\hline CHEMBL1589538 & 688636 & 4.3 & 4.775 & TRN & \\
\hline CHEMBL1425132 & 688636 & 5.9 & 4.9077 & TST & \\
\hline CHEMBL1404747 & 688636 & 4.55 & 4.8474 & TRN & \\
\hline CHEMBL577887 & 688636 & 4.5 & 4.6808 & TRN & \\
\hline CHEMBL3198298 & 688636 & 5.35 & 4.6917 & TRN & \\
\hline CHEMBL1347131 & 688636 & 4.5 & 4.6572 & TRN & \\
\hline CHEMBL1491136 & 688636 & 4.9 & 4.9479 & TRN & \\
\hline CHEMBL1326965 & 688636 & 6.5 & 4.7573 & TRN & \\
\hline CHEMBL1526221 & 688636 & 4.55 & 4.7469 & TRN & \\
\hline CHEMBL1387156 & 688636 & 4.8 & 4.707 & TRN & \\
\hline CHEMBL1477421 & 688636 & 4.45 & 4.9031 & TRN & \\
\hline CHEMBL1579463 & 688636 & 4.45 & 4.96899 & 9999999999 & TRN \\
\hline CHEMBL1450203 & 688636 & 4.3 & 4.63399 & 99999999995 & TRN \\
\hline CHEMBL1569648 & 688636 & 5.95 & 4.8848 & TRN & \\
\hline CHEMBL1533027 & 688636 & 5.1 & 4.9944 & TRN & \\
\hline CHEMBL1429674 & 688636 & 4.45 & 4.6726 & TRN & \\
\hline CHEMBL1405099 & 688636 & 4.55 & 4.8845 & TST & \\
\hline CHEMBL1450888 & 688636 & 4.35 & 4.797 & TRN & \\
\hline CHEMBL1352565 & 688636 & 4.95 & 4.8 & TRN & \\
\hline CHEMBL1345997 & 688636 & 4.25 & 4.9472 & TRN & \\
\hline CHEMBL3189270 & 688636 & 5.45 & 4.9044 & TRN & \\
\hline CHEMBL3211406 & 688636 & 4.3 & 4.6959 & TRN & \\
\hline CHEMBL1519723 & 688636 & 4.45 & 4.573 & TRN & \\
\hline CHEMBL1402793 & 688636 & 4.95 & 4.7198 & TRN & \\
\hline CHEMBL1374920 & 688636 & 4.55 & 4.8384 & TRN & \\
\hline CHEMBL1455463 & 688636 & 4.95 & 4.9631 & TRN & \\
\hline CHEMBL1528817 & 688636 & 4.4 & 4.9979 & TRN & \\
\hline CHEMBL1305679 & 688636 & 4.3 & 4.7669 & TRN & \\
\hline CHEMBL1333835 & 688636 & 5.15 & 4.8283 & TRN & \\
\hline
\end{tabular}




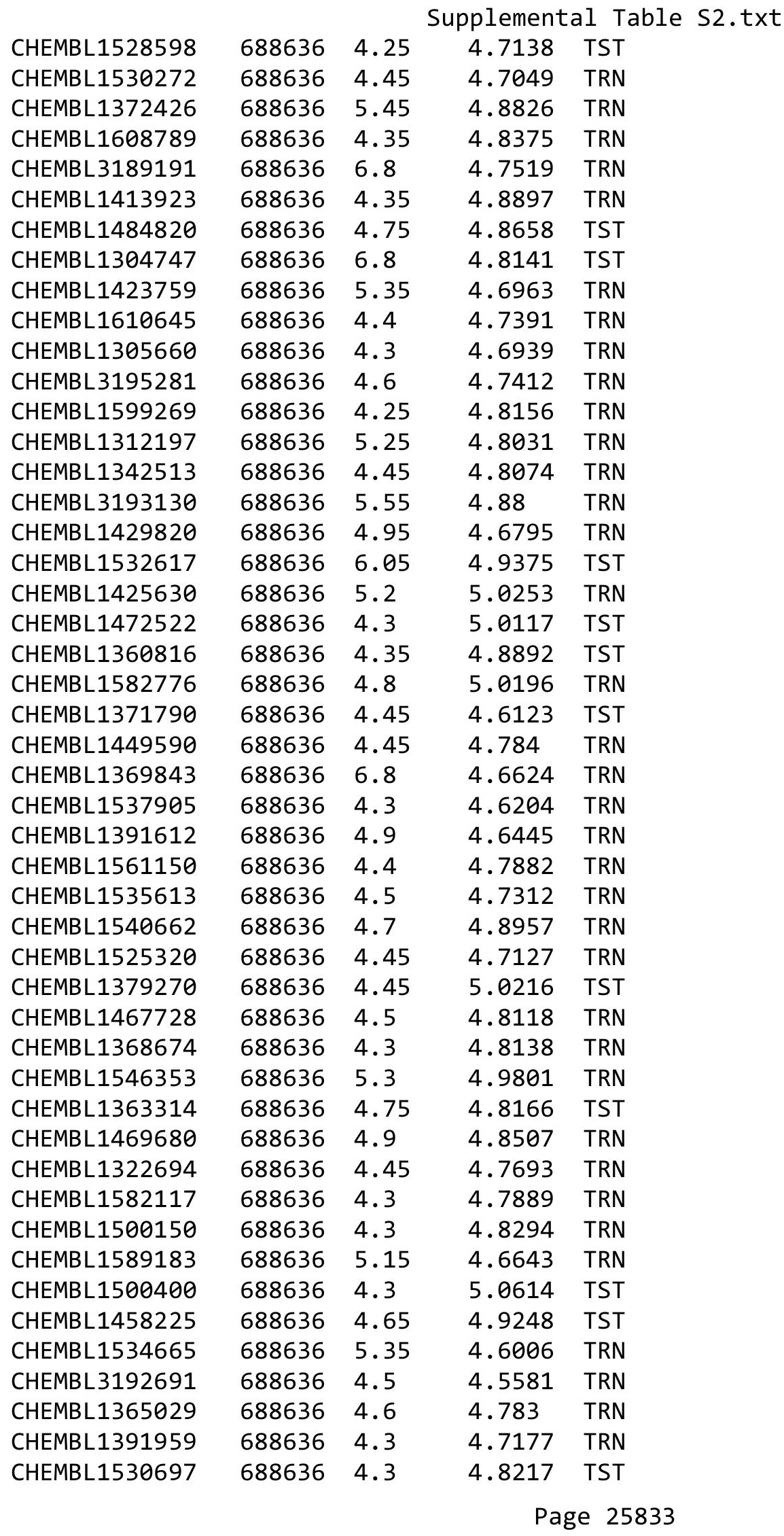




\begin{tabular}{|c|c|c|c|c|}
\hline & & & pplement & al $\mathrm{T}$ \\
\hline CHEMBL1379666 & 688636 & 4.4 & 4.7841 & TST \\
\hline CHEMBL1467655 & 688636 & 4.4 & 4.8524 & TRN \\
\hline CHEMBL1511586 & 688636 & 4.9 & 4.9375 & TRN \\
\hline CHEMBL1460175 & 688636 & 5.6 & 4.8979 & TRN \\
\hline CHEMBL315708 & 688636 & 4.95 & 4.8118 & TST \\
\hline CHEMBL1537365 & 688636 & 4.95 & 4.9565 & TST \\
\hline CHEMBL1504198 & 688636 & 5.4 & 4.7061 & TRN \\
\hline CHEMBL1544546 & 688636 & 5.35 & 5.0189 & TST \\
\hline CHEMBL1330243 & 688636 & 4.3 & 4.9098 & TRN \\
\hline CHEMBL1399358 & 688636 & 4.45 & 4.8831 & TRN \\
\hline CHEMBL1610232 & 688636 & 4.25 & 4.8858 & TRN \\
\hline CHEMBL1409869 & 688636 & 6.1 & 4.9184 & TST \\
\hline CHEMBL1469655 & 688636 & 4.95 & 4.8561 & TRN \\
\hline CHEMBL1579035 & 688636 & 4.95 & 4.9925 & TRN \\
\hline CHEMBL1390703 & 688636 & 5.45 & 4.7404 & TRN \\
\hline CHEMBL1506655 & 688636 & 5.5 & 4.823 & TST \\
\hline CHEMBL1406316 & 688636 & 4.6 & 4.6182 & TRN \\
\hline CHEMBL1561914 & 688636 & 5.2 & 4.9426 & TRN \\
\hline CHEMBL1586333 & 688636 & 6.7501 & 4.9152 & TRN \\
\hline CHEMBL1557211 & 688636 & 4.5 & 4.6461 & TRN \\
\hline CHEMBL1523016 & 688636 & 4.55 & 4.9651 & TST \\
\hline CHEMBL1510577 & 688636 & 4.25 & 4.6009 & TRN \\
\hline CHEMBL1428880 & 688636 & 4.55 & 4.5698 & TRN \\
\hline CHEMBL1506234 & 688636 & 5.5 & 4.7271 & TRN \\
\hline CHEMBL1501602 & 688636 & 5.1 & 4.6071 & TRN \\
\hline CHEMBL1487894 & 688636 & 5.55 & 4.857 & TRN \\
\hline CHEMBL3192179 & 688636 & 4.85 & 4.579 & TRN \\
\hline CHEMBL1598952 & 688636 & 4.45 & 4.6348 & TRN \\
\hline CHEMBL1305987 & 688636 & 4.35 & 4.6741 & TST \\
\hline CHEMBL1583513 & 688636 & 4.6 & 4.8094 & TRN \\
\hline CHEMBL1477958 & 688636 & 4.55 & 4.8611 & TST \\
\hline CHEMBL1595976 & 688636 & 5.6 & 4.6512 & TRN \\
\hline CHEMBL1490992 & 688636 & 5.7 & 4.7865 & TST \\
\hline CHEMBL1569856 & 688636 & 4.4 & 4.7845 & TST \\
\hline CHEMBL1487031 & 688636 & 5.8 & 4.7965 & TRN \\
\hline CHEMBL1372547 & 688636 & 4.5 & 4.6642 & TST \\
\hline CHEMBL1336661 & 688636 & 4.95 & 4.6914 & TRN \\
\hline CHEMBL1431003 & 688636 & 4.6 & 4.6577 & TRN \\
\hline CHEMBL1321992 & 688636 & 4.95 & 4.9438 & TRN \\
\hline CHEMBL1460766 & 688636 & 5.25 & 4.785 & TRN \\
\hline CHEMBL3198295 & 688636 & 4.4 & 4.765 & TRN \\
\hline CHEMBL1492859 & 688636 & 4.9 & 4.9024 & TST \\
\hline CHEMBL1442453 & 688636 & 4.3 & 4.7447 & TRN \\
\hline CHEMBL1500795 & 688636 & 4.25 & 4.6413 & TRN \\
\hline CHEMBL1505358 & 688636 & 5.75 & 4.9054 & TST \\
\hline CHEMBL1391179 & 688636 & 5.0 & 4.957 & TST \\
\hline CHEMBL1448394 & 688636 & 5.95 & 4.6362 & TRN \\
\hline CHEMBL1345563 & 688636 & 4.6 & 4.9036 & TRN \\
\hline
\end{tabular}




\begin{tabular}{|c|c|c|c|c|c|}
\hline \multicolumn{6}{|c|}{ Supplemental Table S2.txt } \\
\hline CHEMBL1391705 & 688636 & 5.3 & 4.7727 & TST & \\
\hline CHEMBL1343964 & 688636 & 4.3 & 4.9212 & TST & \\
\hline CHEMBL1540192 & 688636 & 4.3 & 4.7067 & TRN & \\
\hline CHEMBL1507893 & 688636 & 6.45 & 4.7035 & TST & \\
\hline CHEMBL 3213874 & 688636 & 4.4 & 4.7858 & TRN & \\
\hline CHEMBL1379191 & 688636 & 4.4 & 4.7229 & TST & \\
\hline CHEMBL1522883 & 688636 & 4.25 & 4.9125 & TST & \\
\hline CHEMBL1498409 & 688636 & 4.65 & 4.6969 & TRN & \\
\hline CHEMBL1386395 & 688636 & 4.95 & 4.9525 & TRN & \\
\hline CHEMBL1432279 & 688636 & 4.3 & 4.9075 & TRN & \\
\hline CHEMBL1271881 & 688636 & 4.25 & 4.8088 & TST & \\
\hline CHEMBL1585194 & 688636 & 4.25 & 4.7617 & TST & \\
\hline CHEMBL1493896 & 688636 & 4.3 & 4.816 & TRN & \\
\hline CHEMBL1382780 & 688636 & 4.8 & 4.8758 & TST & \\
\hline CHEMBL1464647 & 688636 & 4.95 & 4.8218 & TRN & \\
\hline CHEMBL1529960 & 688636 & 5.95 & 4.6476 & TST & \\
\hline CHEMBL1500336 & 688636 & 4.45 & 4.8473 & TRN & \\
\hline CHEMBL1530084 & 688636 & 4.25 & 4.7319 & TRN & \\
\hline CHEMBL1307244 & 688636 & 4.45 & 4.5989 & TRN & \\
\hline CHEMBL1546992 & 688636 & 4.45 & 4.6518 & TRN & \\
\hline CHEMBL1539124 & 688636 & 4.95 & 4.8691 & TRN & \\
\hline CHEMBL3190592 & 688636 & 4.95 & 4.7599 & TRN & \\
\hline CHEMBL1463046 & 688636 & 6.8 & 4.7975 & TRN & \\
\hline CHEMBL1584572 & 688636 & 4.45 & 4.9605 & TRN & \\
\hline CHEMBL1345017 & 688636 & 4.6 & 4.6351 & TRN & \\
\hline CHEMBL1330769 & 688636 & 4.95 & 4.8261 & TRN & \\
\hline CHEMBL1493025 & 688636 & 4.95 & 4.7996 & TRN & \\
\hline CHEMBL1310244 & 688636 & 5.25 & 4.7121 & TRN & \\
\hline CHEMBL1347685 & 688636 & 4.5 & 4.84399 & 9999999999 & TRN \\
\hline CHEMBL1366220 & 688636 & 4.5 & 4.6109 & TRN & \\
\hline CHEMBL1402555 & 688636 & 4.25 & 4.8327 & TRN & \\
\hline CHEMBL1573434 & 688636 & 4.55 & 4.7337 & TRN & \\
\hline CHEMBL3145060 & 688636 & 4.9 & 4.8103 & TRN & \\
\hline CHEMBL1599337 & 688636 & 4.9 & 4.7768 & TRN & \\
\hline CHEMBL1508743 & 688636 & 4.45 & 4.6758 & TRN & \\
\hline CHEMBL1339979 & 688636 & 4.25 & 4.867 & TST & \\
\hline CHEMBL1469198 & 688636 & 4.4 & 4.7414 & TRN & \\
\hline CHEMBL1583216 & 688636 & 5.15 & 4.809 & TRN & \\
\hline CHEMBL1426674 & 688636 & 5.3 & 4.9738 & TRN & \\
\hline CHEMBL1546422 & 688636 & 4.4 & 4.8257 & TST & \\
\hline CHEMBL1339329 & 688636 & 4.45 & 4.8154 & TRN & \\
\hline CHEMBL1385846 & 688636 & 5.9 & 4.78600 & 00000000005 & TRN \\
\hline CHEMBL1466387 & 688636 & 4.25 & 5.0068 & TRN & \\
\hline CHEMBL1417341 & 688636 & 4.6 & 4.7486 & TRN & \\
\hline CHEMBL1466624 & 688636 & 4.4 & 4.886 & TRN & \\
\hline CHEMBL1313254 & 688636 & 4.3 & 4.816 & TRN & \\
\hline CHEMBL1408982 & 688636 & 4.3 & 4.6976 & TRN & \\
\hline CHEMBL1363562 & 688636 & 4.45 & 4.8875 & TRN & \\
\hline
\end{tabular}




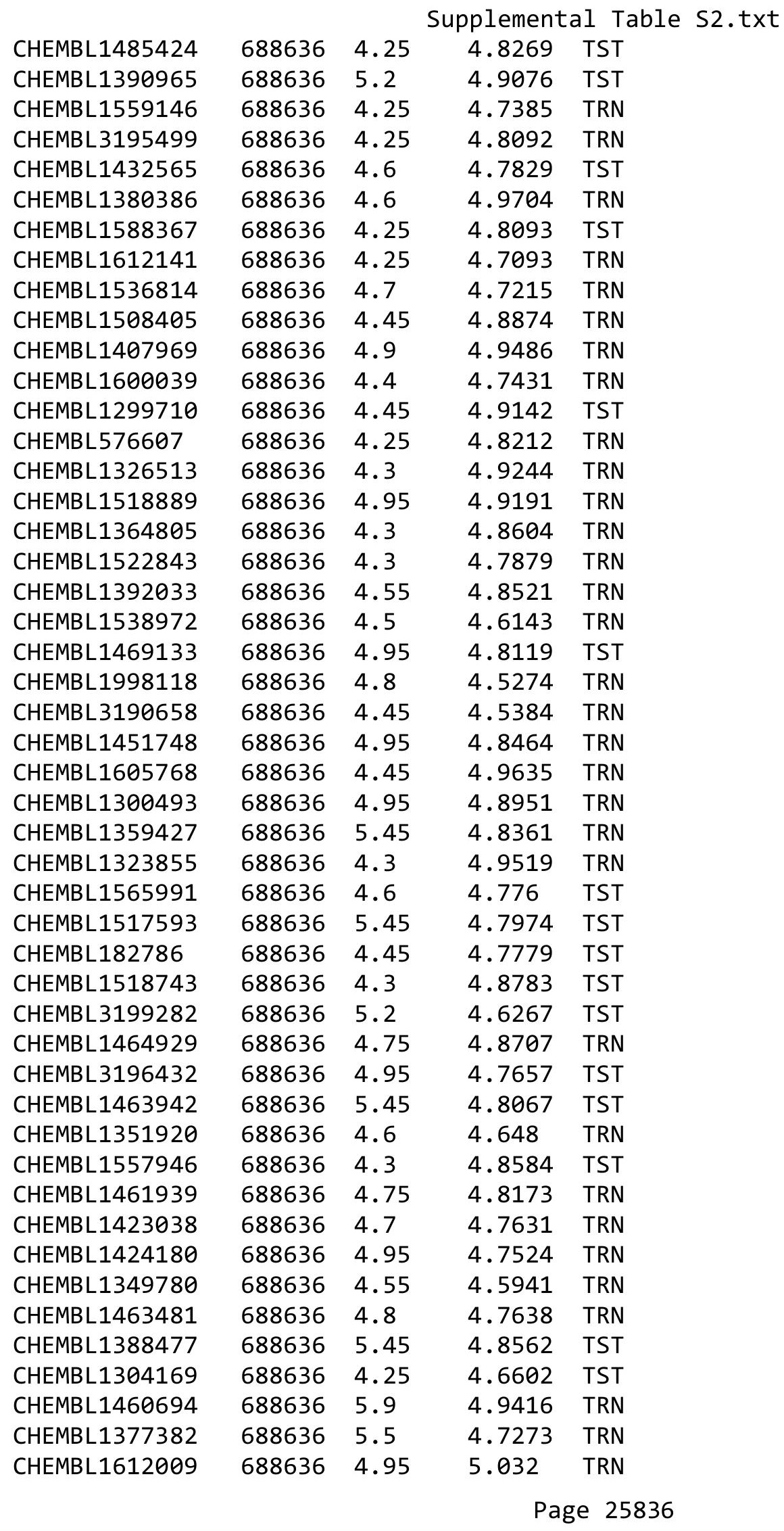




\begin{tabular}{|c|c|c|c|c|}
\hline \multicolumn{5}{|c|}{ Supplemental Table S2.txt } \\
\hline CHEMBL1399332 & 688636 & 4.45 & 4.684 & TST \\
\hline CHEMBL1453844 & 688636 & 5.2 & 4.8351 & TST \\
\hline CHEMBL1533082 & 688636 & 4.25 & 4.6216 & TRN \\
\hline CHEMBL1975892 & 688636 & 4.9 & 4.5421 & TRN \\
\hline CHEMBL1589520 & 688636 & 5.15 & 5.0521 & TRN \\
\hline CHEMBL1380212 & 688636 & 5.0 & 4.6756 & TST \\
\hline CHEMBL1604306 & 688636 & 4.65 & 4.8216 & TRN \\
\hline CHEMBL3191915 & 688636 & 5.35 & 4.859 & TST \\
\hline CHEMBL1527363 & 688636 & 4.45 & 4.9716 & TRN \\
\hline CHEMBL1596915 & 688636 & 4.25 & 4.965 & TST \\
\hline CHEMBL1478787 & 688636 & 5.0 & 4.6928 & TRN \\
\hline CHEMBL3191114 & 688636 & 6.7501 & 4.6813 & TST \\
\hline CHEMBL1454701 & 688636 & 4.45 & 4.8307 & TRN \\
\hline CHEMBL1594527 & 688636 & 4.45 & 4.7318 & TST \\
\hline CHEMBL1462124 & 688636 & 4.95 & 4.77 & TRN \\
\hline CHEMBL1488524 & 688636 & 4.25 & 4.8703 & TRN \\
\hline CHEMBL1439900 & 688636 & 4.5 & 4.8534 & TRN \\
\hline CHEMBL3209386 & 688636 & 4.4 & 4.667 & TRN \\
\hline CHEMBL 3207587 & 688636 & 4.3 & 4.8124 & TRN \\
\hline CHEMBL1447537 & 688636 & 5.2 & 4.9024 & TRN \\
\hline CHEMBL1520817 & 688636 & 4.45 & 4.7103 & TST \\
\hline CHEMBL1560303 & 688636 & 4.6 & 4.8033 & TRN \\
\hline CHEMBL1423608 & 688636 & 4.3 & 4.94 & TRN \\
\hline CHEMBL1584867 & 688636 & 4.25 & 4.7405 & TRN \\
\hline CHEMBL1599815 & 688636 & 4.95 & 4.7875 & TST \\
\hline CHEMBL1546051 & 688636 & 4.65 & 4.7918 & TRN \\
\hline CHEMBL1461169 & 688636 & 5.1 & 4.8257 & TRN \\
\hline CHEMBL1302992 & 688636 & 4.55 & 4.9055 & TRN \\
\hline CHEMBL1530955 & 688636 & 4.45 & 4.6902 & TRN \\
\hline CHEMBL1314828 & 688636 & 4.95 & 4.8407 & TST \\
\hline CHEMBL1365847 & 688636 & 4.25 & 4.6678 & TRN \\
\hline CHEMBL3196792 & 688636 & 4.45 & 4.7622 & TRN \\
\hline CHEMBL1602985 & 688636 & 4.4 & 4.7028 & TRN \\
\hline CHEMBL1460350 & 688636 & 4.3 & 4.8993 & TST \\
\hline CHEMBL1408969 & 688636 & 5.1 & 4.7292 & TRN \\
\hline CHEMBL1392256 & 688636 & 4.5 & 4.6855 & TRN \\
\hline CHEMBL1538262 & 688636 & 5.2 & 4.8877 & TST \\
\hline CHEMBL246447 & 688636 & 4.45 & 4.6718 & TRN \\
\hline CHEMBL1392683 & 688636 & 4.3 & 4.7578 & TRN \\
\hline CHEMBL1370627 & 688636 & 4.45 & 5.0402 & TRN \\
\hline CHEMBL1561380 & 688636 & 4.3 & 4.8473 & TST \\
\hline CHEMBL1572936 & 688636 & 6.45 & 4.7834 & TRN \\
\hline CHEMBL1423692 & 688636 & 4.95 & 4.9122 & TRN \\
\hline CHEMBL1580998 & 688636 & 4.25 & 4.7425 & TRN \\
\hline CHEMBL1542028 & 688636 & 4.75 & 4.7542 & TRN \\
\hline CHEMBL1588679 & 688636 & 4.25 & 4.9063 & TRN \\
\hline CHEMBL1401657 & 688636 & 4.75 & 4.9207 & TST \\
\hline CHEMBL1327880 & 688636 & 6.8 & 4.751 & TST \\
\hline
\end{tabular}




\begin{tabular}{|c|c|c|c|c|}
\hline \multicolumn{5}{|c|}{ Supplemental Table S2.txt } \\
\hline CHEMBL1337742 & 688636 & 4.3 & 4.6037 & TST \\
\hline CHEMBL1430540 & 688636 & 4.55 & 4.85 & TRN \\
\hline CHEMBL1540539 & 688636 & 5.45 & 4.8738 & TST \\
\hline CHEMBL147514 & 688636 & 4.25 & 4.881 & TST \\
\hline CHEMBL1333696 & 688636 & 4.25 & 4.7632 & TRN \\
\hline CHEMBL1546063 & 688636 & 4.6 & 4.815 & TRN \\
\hline CHEMBL1565081 & 688636 & 4.45 & 4.7125 & TST \\
\hline CHEMBL1451002 & 688636 & 4.25 & 4.9129 & TRN \\
\hline CHEMBL1429047 & 688636 & 5.4 & 4.85 & TST \\
\hline CHEMBL1430437 & 688636 & 4.35 & 4.6121 & TRN \\
\hline CHEMBL1419154 & 688636 & 6.8 & 4.9855 & TRN \\
\hline CHEMBL1337587 & 688636 & 4.3 & 4.6944 & TRN \\
\hline CHEMBL1360050 & 688636 & 6.8499 & 4.7817 & TRN \\
\hline CHEMBL 394034 & 688636 & 6.7501 & 4.9148 & TST \\
\hline CHEMBL1546594 & 688636 & 4.3 & 4.6093 & TRN \\
\hline CHEMBL1503974 & 688636 & 4.95 & 4.6896 & TRN \\
\hline CHEMBL1338140 & 688636 & 4.75 & 4.6434 & TRN \\
\hline CHEMBL1369597 & 688636 & 4.3 & 4.6332 & TRN \\
\hline CHEMBL1336709 & 688636 & 4.25 & 4.6751 & TRN \\
\hline CHEMBL1569241 & 688636 & 4.7 & 4.7129 & TRN \\
\hline CHEMBL1521944 & 688636 & 4.55 & 4.7335 & TST \\
\hline CHEMBL1495977 & 688636 & 4.9 & 4.7804 & TRN \\
\hline CHEMBL1388288 & 688636 & 6.45 & 4.9906 & TST \\
\hline CHEMBL1569981 & 688636 & 4.25 & 4.7634 & TRN \\
\hline CHEMBL1441804 & 688636 & 5.65 & 4.7171 & TRN \\
\hline CHEMBL1354108 & 688636 & 4.25 & 4.8891 & TST \\
\hline CHEMBL1535681 & 688636 & 5.25 & 4.8589 & TST \\
\hline CHEMBL3193272 & 688636 & 4.55 & 4.4523 & TRN \\
\hline CHEMBL1374546 & 688636 & 5.8 & 4.8618 & TRN \\
\hline CHEMBL1503105 & 688636 & 4.45 & 4.5259 & TRN \\
\hline CHEMBL1538429 & 688636 & 4.25 & 4.6181 & TRN \\
\hline CHEMBL1341548 & 688636 & 4.6 & 4.7858 & TRN \\
\hline CHEMBL1367116 & 688636 & 6.5501 & 4.9907 & TRN \\
\hline CHEMBL1324110 & 688636 & 4.7 & 4.9016 & TST \\
\hline CHEMBL1488143 & 688636 & 4.25 & 5.0088 & TST \\
\hline CHEMBL1454065 & 688636 & 5.2 & 4.7373 & TST \\
\hline CHEMBL1448030 & 688636 & 5.0 & 4.7717 & TRN \\
\hline CHEMBL1577518 & 688636 & 4.4 & 4.7794 & TST \\
\hline CHEMBL1466507 & 688636 & 5.4 & 5.0741 & TRN \\
\hline CHEMBL1418371 & 688636 & 4.4 & 4.8001 & TRN \\
\hline CHEMBL1399605 & 688636 & 4.75 & 4.8667 & TST \\
\hline CHEMBL1504835 & 688636 & 4.5 & 4.7867 & TST \\
\hline CHEMBL1594502 & 688636 & 4.95 & 4.99 & TRN \\
\hline CHEMBL1507367 & 688636 & 4.55 & 4.814 & TST \\
\hline CHEMBL1458862 & 688636 & 4.9 & 4.7276 & TRN \\
\hline CHEMBL1601781 & 688636 & 4.3 & 4.8952 & TST \\
\hline CHEMBL3191524 & 688636 & 4.55 & 4.86 & TRN \\
\hline CHEMBL1520296 & 688636 & 4.4 & 4.8909 & TRN \\
\hline
\end{tabular}




\begin{tabular}{|c|c|c|c|c|c|}
\hline & & \multicolumn{4}{|c|}{ Supplemental Table S2.txt } \\
\hline CHEMBL3209959 & 688636 & 4.75 & 4.859 & TRN & \\
\hline CHEMBL1391505 & 688636 & 4.25 & 4.8963 & TRN & \\
\hline CHEMBL1338457 & 688636 & 6.0 & 5.0413 & TRN & \\
\hline CHEMBL1584515 & 688636 & 6.8 & 4.8195 & TST & \\
\hline CHEMBL1351192 & 688636 & 4.3 & 4.7681 & TRN & \\
\hline CHEMBL3193798 & 688636 & 5.3 & 4.9316 & TST & \\
\hline CHEMBL1353678 & 688636 & 5.6 & 4.9266 & TRN & \\
\hline CHEMBL1386936 & 688636 & 4.8 & 4.8663 & TRN & \\
\hline CHEMBL1335123 & 688636 & 4.45 & 4.8029 & TRN & \\
\hline CHEMBL1299407 & 688636 & 5.65 & 4.5459 & TRN & \\
\hline CHEMBL1336711 & 688636 & 4.5 & 4.8594 & TST & \\
\hline CHEMBL1310964 & 688636 & 4.5 & 4.7308 & TRN & \\
\hline CHEMBL1562024 & 688636 & 5.3 & 4.9863 & TST & \\
\hline CHEMBL1502446 & 688636 & 4.8 & 4.711 & TRN & \\
\hline CHEMBL1570554 & 688636 & 4.65 & 4.8565 & TRN & \\
\hline CHEMBL1540355 & 688636 & 4.25 & 4.8442 & TRN & \\
\hline CHEMBL3214013 & 688636 & 4.65 & 4.915 & TRN & \\
\hline CHEMBL1545298 & 688636 & 4.45 & 4.8971 & TRN & \\
\hline CHEMBL1439020 & 688636 & 4.35 & 4.7079 & TRN & \\
\hline CHEMBL1331499 & 688636 & 4.5 & 4.8599 & TRN & \\
\hline CHEMBL1454487 & 688636 & 6.8 & 4.8965 & TST & \\
\hline CHEMBL1481836 & 688636 & 5.85 & 4.6454 & TRN & \\
\hline CHEMBL1402593 & 688636 & 4.25 & 4.8177 & TRN & \\
\hline CHEMBL1527117 & 688636 & 4.6 & 4.7321 & TRN & \\
\hline CHEMBL1527685 & 688636 & 4.45 & 4.9286 & TST & \\
\hline CHEMBL3193406 & 688636 & 4.55 & 4.6153 & TRN & \\
\hline CHEMBL3214473 & 688636 & 5.1 & 4.7306 & TRN & \\
\hline CHEMBL1465529 & 688636 & 4.55 & 4.7885 & TRN & \\
\hline CHEMBL1603099 & 688636 & 4.3 & 4.8332 & TRN & \\
\hline CHEMBL1301407 & 688636 & 5.25 & 4.6775 & TRN & \\
\hline CHEMBL3189678 & 688636 & 4.9 & 4.9695 & TRN & \\
\hline CHEMBL1509239 & 688636 & 4.3 & 4.7208 & TST & \\
\hline CHEMBL1322676 & 688636 & 5.15 & 4.7425 & TST & \\
\hline CHEMBL1586594 & 688636 & 5.6 & 4.7746 & TRN & \\
\hline CHEMBL1539505 & 688636 & 4.3 & 4.7637 & TRN & \\
\hline CHEMBL1385426 & 688636 & 4.45 & 4.9416 & TRN & \\
\hline CHEMBL1488025 & 688636 & 4.55 & 4.67899 & 9999999999 & TRN \\
\hline CHEMBL1362146 & 688636 & 4.65 & 4.7766 & TST & \\
\hline CHEMBL1432689 & 688636 & 6.8 & 4.766 & TST & \\
\hline CHEMBL3209384 & 688636 & 4.25 & 4.8108 & TST & \\
\hline CHEMBL1492641 & 688636 & 4.5 & 4.7219 & TRN & \\
\hline CHEMBL1388588 & 688636 & 4.55 & 4.7856 & TRN & \\
\hline CHEMBL1488708 & 688636 & 4.6 & 4.5983 & TRN & \\
\hline CHEMBL1605874 & 688636 & 5.25 & 4.9544 & TST & \\
\hline CHEMBL1586801 & 688636 & 4.3 & 4.872 & TST & \\
\hline CHEMBL1588121 & 688636 & 4.95 & 4.9048 & TRN & \\
\hline CHEMBL1398798 & 688636 & 4.25 & 4.7921 & TRN & \\
\hline CHEMBL1588029 & 688636 & 4.3 & 4.8507 & TRN & \\
\hline
\end{tabular}




\begin{tabular}{|c|c|c|c|c|c|}
\hline \multicolumn{6}{|c|}{ Supplemental Table S2.txt } \\
\hline CHEMBL1896972 & 688636 & 4.75 & 4.615 & TRN & \\
\hline CHEMBL1426477 & 688636 & 4.45 & 5.0143 & TRN & \\
\hline CHEMBL1504635 & 688636 & 4.3 & 4.9195 & TRN & \\
\hline CHEMBL1594182 & 688636 & 5.15 & 4.6685 & TST & \\
\hline CHEMBL1400275 & 688636 & 4.3 & $4.8260 e$ & 00000000005 & TST \\
\hline CHEMBL1454457 & 688636 & 4.6 & 4.89199 & 99999999995 & TST \\
\hline CHEMBL1545244 & 688636 & 4.5 & 4.7256 & TRN & \\
\hline CHEMBL1336218 & 688636 & 4.4 & 4.9053 & TRN & \\
\hline CHEMBL1485423 & 688636 & 4.3 & 4.9163 & TRN & \\
\hline CHEMBL1398704 & 688636 & 4.25 & 4.8085 & TRN & \\
\hline CHEMBL1454088 & 688636 & 4.3 & 4.8306 & TRN & \\
\hline CHEMBL1560834 & 688636 & 4.25 & 4.8856 & TST & \\
\hline CHEMBL1545403 & 688636 & 5.55 & 4.6829 & TRN & \\
\hline CHEMBL1312802 & 688636 & 4.4 & 4.713 & TRN & \\
\hline CHEMBL1456001 & 688636 & 5.4 & 4.8555 & TRN & \\
\hline CHEMBL1453006 & 688636 & 4.95 & 4.7307 & TRN & \\
\hline CHEMBL1333109 & 688636 & 4.35 & 4.8806 & TST & \\
\hline CHEMBL1534984 & 688636 & 4.55 & 4.9242 & TRN & \\
\hline CHEMBL1311422 & 688636 & 4.55 & 4.9464 & TRN & \\
\hline CHEMBL1480884 & 688636 & 4.95 & 4.8537 & TRN & \\
\hline CHEMBL1597951 & 688636 & 5.4 & 4.7118 & TRN & \\
\hline CHEMBL1307037 & 688636 & 5.35 & 4.8661 & TRN & \\
\hline CHEMBL1546548 & 688636 & 4.35 & 4.7823 & TRN & \\
\hline CHEMBL1301315 & 688636 & 4.3 & 4.6717 & TST & \\
\hline CHEMBL1568229 & 688636 & 4.3 & 4.7973 & TRN & \\
\hline CHEMBL1337673 & 688636 & 4.25 & 4.7835 & TRN & \\
\hline CHEMBL1384784 & 688636 & 4.4 & 4.763 & TRN & \\
\hline CHEMBL1598810 & 688636 & 4.6 & 4.9611 & TRN & \\
\hline CHEMBL3190492 & 688636 & 5.9 & 4.874 & TST & \\
\hline CHEMBL1300065 & 688636 & 5.3 & 4.6119 & TRN & \\
\hline CHEMBL3189223 & 688636 & 4.35 & 4.7485 & TRN & \\
\hline CHEMBL1575770 & 688636 & 4.25 & 4.6629 & TRN & \\
\hline CHEMBL1300485 & 688636 & 4.3 & 4.7919 & TST & \\
\hline CHEMBL1401588 & 688636 & 5.6 & 4.8442 & TRN & \\
\hline CHEMBL1345969 & 688636 & 4.25 & 4.6859 & TST & \\
\hline CHEMBL1486949 & 688636 & 4.3 & 4.7221 & TST & \\
\hline CHEMBL1466513 & 688636 & 4.55 & 4.9195 & TRN & \\
\hline CHEMBL1446068 & 688636 & 6.45 & 5.1102 & TRN & \\
\hline CHEMBL1442450 & 688636 & 5.6 & 4.8923 & TRN & \\
\hline CHEMBL1545657 & 688636 & 5.85 & 4.5257 & TRN & \\
\hline CHEMBL1523361 & 688636 & 4.95 & 4.9058 & TRN & \\
\hline CHEMBL1341789 & 688636 & 4.3 & 4.802 & TRN & \\
\hline CHEMBL1534939 & 688636 & 4.3 & 4.706 & TRN & \\
\hline CHEMBL1491104 & 688636 & 4.3 & 4.9287 & TST & \\
\hline CHEMBL1606346 & 688636 & 4.65 & 4.7649 & TRN & \\
\hline CHEMBL1581146 & 688636 & 5.15 & 4.5283 & TRN & \\
\hline CHEMBL1366729 & 688636 & 4.8 & 4.8824 & TRN & \\
\hline CHEMBL1444688 & 688636 & 4.3 & 4.8391 & TST & \\
\hline
\end{tabular}




\begin{tabular}{|c|c|c|c|c|c|}
\hline \multicolumn{6}{|c|}{ Supplemental Table S2.txt } \\
\hline CHEMBL1578552 & 688636 & 4.25 & 4.9779 & TRN & \\
\hline CHEMBL3194272 & 688636 & 5.85 & 4.9285 & TST & \\
\hline CHEMBL1350463 & 688636 & 6.7501 & 4.9194 & TST & \\
\hline CHEMBL1713905 & 688636 & 4.95 & 4.7542 & TRN & \\
\hline CHEMBL1406624 & 688636 & 5.8 & 4.8713 & TRN & \\
\hline CHEMBL1446348 & 688636 & 4.25 & 4.7782 & TST & \\
\hline CHEMBL452002 & 688636 & 4.35 & 4.9154 & TRN & \\
\hline CHEMBL1594911 & 688636 & 4.95 & 4.7268 & TRN & \\
\hline CHEMBL1509760 & 688636 & 4.25 & 4.8282 & TST & \\
\hline CHEMBL1342521 & 688636 & 4.5 & 4.7212 & TRN & \\
\hline CHEMBL3199136 & 688636 & 4.25 & 4.7356 & TRN & \\
\hline CHEMBL1425705 & 688636 & 4.3 & 4.6744 & TRN & \\
\hline CHEMBL1468796 & 688636 & 4.4 & 4.5998 & TRN & \\
\hline CHEMBL1440588 & 688636 & 4.6 & 4.8322 & TRN & \\
\hline CHEMBL1307745 & 688636 & 4.25 & 4.8746 & TST & \\
\hline CHEMBL1577831 & 688636 & 5.6 & 4.7657 & TRN & \\
\hline CHEMBL1388399 & 688636 & 6.8 & 4.8913 & TRN & \\
\hline CHEMBL151252 & 688636 & 4.3 & $4.8260 €$ & 00000000005 & TRN \\
\hline CHEMBL1533490 & 688636 & 4.25 & 4.7768 & TST & \\
\hline CHEMBL1393846 & 688636 & 6.8 & 4.7295 & TRN & \\
\hline CHEMBL1519112 & 688636 & 4.4 & 4.7066 & TRN & \\
\hline CHEMBL1337938 & 688636 & 4.6 & 4.8213 & TRN & \\
\hline CHEMBL1462253 & 688636 & 4.45 & 4.8864 & TST & \\
\hline CHEMBL1597860 & 688636 & 4.45 & 4.7975 & TRN & \\
\hline CHEMBL1426482 & 688636 & 4.5 & 4.8288 & TRN & \\
\hline CHEMBL1387780 & 688636 & 6.7501 & 4.8326 & TRN & \\
\hline CHEMBL1489978 & 688636 & 4.5 & 4.7485 & TRN & \\
\hline CHEMBL1421218 & 688636 & 4.65 & 4.8858 & TRN & \\
\hline CHEMBL1386584 & 688636 & 4.4 & 4.6511 & TRN & \\
\hline CHEMBL1492253 & 688636 & 6.0 & 4.9138 & TRN & \\
\hline CHEMBL1472464 & 688636 & 5.55 & 4.7564 & TST & \\
\hline CHEMBL1425096 & 688636 & 4.35 & 4.7955 & TRN & \\
\hline CHEMBL1538322 & 688636 & 4.45 & 4.6566 & TRN & \\
\hline CHEMBL1602715 & 688636 & 4.55 & 4.6072 & TRN & \\
\hline CHEMBL1528317 & 688636 & 4.85 & 4.8046 & TRN & \\
\hline CHEMBL1402205 & 688636 & 4.45 & 4.7552 & TRN & \\
\hline CHEMBL1494974 & 688636 & 4.55 & 4.8803 & TRN & \\
\hline CHEMBL1485580 & 688636 & 4.75 & 4.6842 & TRN & \\
\hline CHEMBL1365545 & 688636 & 4.5 & 4.743 & TRN & \\
\hline CHEMBL1304852 & 688636 & 4.3 & 4.6888 & TRN & \\
\hline CHEMBL1481141 & 688636 & 4.3 & 4.8086 & TRN & \\
\hline CHEMBL1501390 & 688636 & 4.3 & 4.7049 & TST & \\
\hline CHEMBL1423831 & 688636 & 4.45 & 4.8597 & TRN & \\
\hline CHEMBL1449403 & 688636 & 4.55 & 4.8455 & TRN & \\
\hline CHEMBL 3210045 & 688636 & 4.5 & 4.7255 & TRN & \\
\hline CHEMBL1584471 & 688636 & 4.4 & 4.732 & TRN & \\
\hline CHEMBL1459094 & 688636 & 4.45 & 4.8042 & TRN & \\
\hline CHEMBL1422437 & 688636 & 5.75 & 4.8084 & TRN & \\
\hline
\end{tabular}




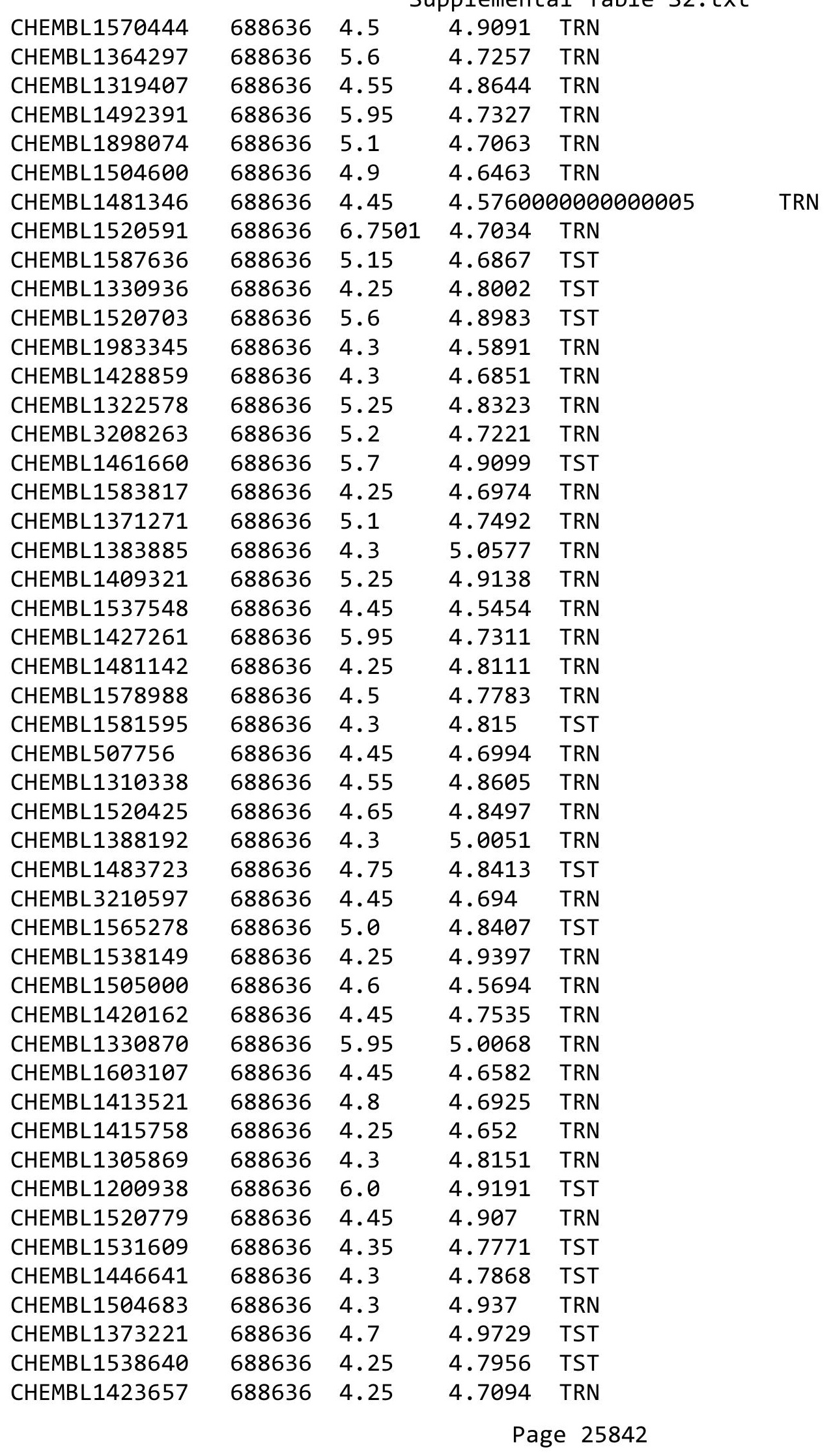




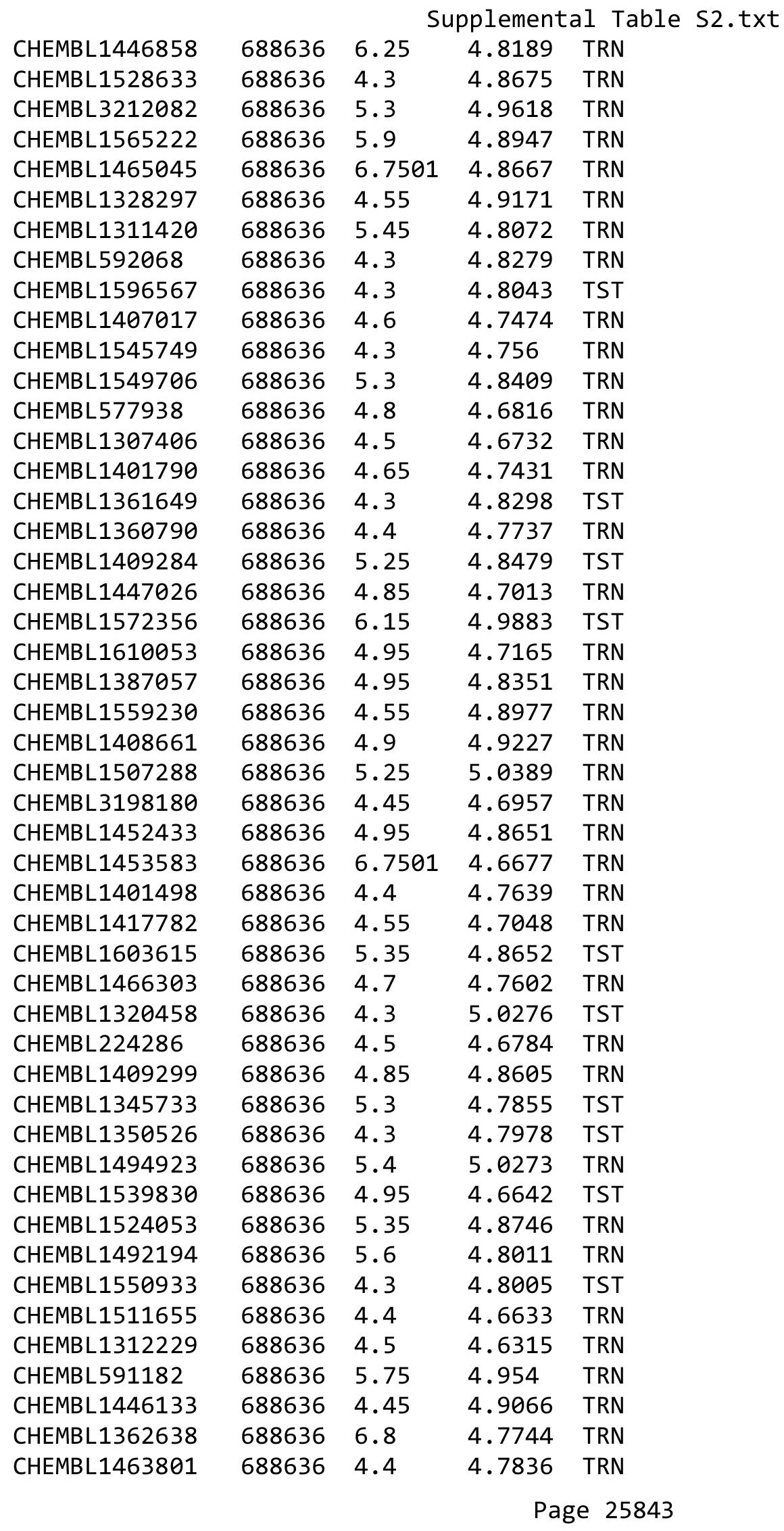




\begin{tabular}{|c|c|c|c|c|}
\hline \multicolumn{5}{|c|}{ Supplemental Table S2.txt } \\
\hline CHEMBL1329566 & 688636 & 4.3 & 4.9349 & TST \\
\hline CHEMBL3196840 & 688636 & 4.3 & 4.9548 & TST \\
\hline CHEMBL1529532 & 688636 & 5.1 & 4.8102 & TRN \\
\hline CHEMBL1583585 & 688636 & 4.3 & 4.8285 & TRN \\
\hline CHEMBL1439591 & 688636 & 4.3 & 4.7306 & TRN \\
\hline CHEMBL1417936 & 688636 & 4.3 & 4.9231 & TRN \\
\hline CHEMBL1428685 & 688636 & 4.7 & 4.7443 & TST \\
\hline CHEMBL1492031 & 688636 & 6.8 & 4.94 & TRN \\
\hline CHEMBL1594167 & 688636 & 4.4 & 4.6422 & TRN \\
\hline CHEMBL1536625 & 688636 & 4.55 & 4.6984 & TRN \\
\hline CHEMBL1598981 & 688636 & 4.5 & 4.6294 & TRN \\
\hline CHEMBL1588125 & 688636 & 5.15 & 4.8067 & TRN \\
\hline CHEMBL1417747 & 688636 & 6.15 & 4.8235 & TST \\
\hline CHEMBL1386137 & 688636 & 4.3 & 4.8146 & TST \\
\hline CHEMBL1313343 & 688636 & 5.2 & 4.8632 & TRN \\
\hline CHEMBL1373195 & 688636 & 4.9 & 5.0159 & TST \\
\hline CHEMBL1366654 & 688636 & 4.5 & 4.9898 & TRN \\
\hline CHEMBL1405908 & 688636 & 5.25 & 4.9643 & TST \\
\hline CHEMBL1574446 & 688636 & 4.25 & 4.8473 & TRN \\
\hline CHEMBL1372948 & 688636 & 4.9 & 4.9266 & TST \\
\hline CHEMBL1458496 & 688636 & 4.25 & 4.9192 & TRN \\
\hline CHEMBL1577240 & 688636 & 5.35 & 4.8375 & TRN \\
\hline CHEMBL3209643 & 688636 & 4.3 & 4.8101 & TRN \\
\hline CHEMBL1502069 & 688636 & 6.0 & 4.8836 & TRN \\
\hline CHEMBL3192061 & 688636 & 6.8 & 4.7553 & TST \\
\hline CHEMBL1346343 & 688636 & 4.4 & 4.7778 & TRN \\
\hline CHEMBL1444438 & 688636 & 4.5 & 4.9482 & TRN \\
\hline CHEMBL1532886 & 688636 & 5.7 & 4.9244 & TRN \\
\hline CHEMBL1343786 & 688636 & 4.25 & 4.8038 & TRN \\
\hline CHEMBL1382474 & 688636 & 4.65 & 4.9696 & TST \\
\hline CHEMBL1309167 & 688636 & 4.25 & 4.8303 & TST \\
\hline CHEMBL1536251 & 688636 & 5.8 & 4.9194 & TRN \\
\hline CHEMBL1490639 & 688636 & 4.65 & 4.7294 & TRN \\
\hline CHEMBL1579990 & 688636 & 4.3 & 4.9245 & TRN \\
\hline CHEMBL1327279 & 688636 & 4.65 & 4.7789 & TRN \\
\hline CHEMBL1455655 & 688636 & 5.4 & 4.7062 & TRN \\
\hline CHEMBL1464696 & 688636 & 5.45 & 4.8165 & TST \\
\hline CHEMBL1502352 & 688636 & 4.4 & 4.7866 & TST \\
\hline CHEMBL1533877 & 688636 & 5.4 & 4.753 & TRN \\
\hline CHEMBL1478511 & 688636 & 4.9 & 4.7717 & TST \\
\hline CHEMBL1601285 & 688636 & 4.3 & 4.7542 & TRN \\
\hline CHEMBL1441020 & 688636 & 4.9 & 4.7548 & TRN \\
\hline CHEMBL1582671 & 688636 & 6.7501 & 4.7953 & TRN \\
\hline CHEMBL1526305 & 688636 & 4.5 & 4.8154 & TRN \\
\hline CHEMBL1367626 & 688636 & 4.4 & 4.7673 & TST \\
\hline CHEMBL1308414 & 688636 & 4.65 & 4.7757 & TRN \\
\hline CHEMBL1442915 & 688636 & 4.45 & 4.6972 & TRN \\
\hline CHEMBL1303361 & 688636 & 5.45 & 4.9073 & TRN \\
\hline
\end{tabular}




\begin{tabular}{|c|c|c|c|c|c|}
\hline & & & & & \\
\hline CHEMBL1607286 & 688636 & 4.3 & 4.5293 & TST & \\
\hline CHEMBL1321354 & 688636 & 4.25 & 4.8297 & TRN & \\
\hline CHEMBL1427486 & 688636 & 5.4 & 4.7078 & TRN & \\
\hline CHEMBL1308013 & 688636 & 5.65 & 4.7256 & TST & \\
\hline CHEMBL1559597 & 688636 & 5.85 & 4.694 & TRN & \\
\hline CHEMBL1350520 & 688636 & 4.45 & 4.6941 & TRN & \\
\hline CHEMBL1337619 & 688636 & 5.0 & 4.9792 & TRN & \\
\hline CHEMBL 1374320 & 688636 & 4.6 & 4.7373 & TRN & \\
\hline CHEMBL1483140 & 688636 & 5.2 & 4.8318 & TRN & \\
\hline CHEMBL1504193 & 688636 & 5.1 & 4.9919 & TRN & \\
\hline CHEMBL1419529 & 688636 & 4.75 & 4.87 & TRN & \\
\hline CHEMBL3193249 & 688636 & 4.45 & 4.9242 & TST & \\
\hline CHEMBL1567633 & 688636 & 5.55 & 4.85800 & 00000000005 & TRN \\
\hline CHEMBL1530938 & 688636 & 5.25 & 4.6286 & TRN & \\
\hline CHEMBL1567532 & 688636 & 4.25 & 4.6509 & TRN & \\
\hline CHEMBL1589194 & 688636 & 4.35 & 4.7601 & TRN & \\
\hline CHEMBL1421811 & 688636 & 4.85 & 4.8511 & TRN & \\
\hline CHEMBL609606 & 688636 & 4.3 & 4.7458 & TST & \\
\hline CHEMBL1564133 & 688636 & 4.4 & 4.8658 & TRN & \\
\hline CHEMBL1376214 & 688636 & 6.1 & 4.9043 & TRN & \\
\hline CHEMBL1493129 & 688636 & 4.95 & 4.8411 & TRN & \\
\hline CHEMBL1485053 & 688636 & 4.3 & 4.849 & TRN & \\
\hline CHEMBL1491385 & 688636 & 4.9 & 4.7729 & TRN & \\
\hline CHEMBL1463529 & 688636 & 4.3 & 4.8987 & TRN & \\
\hline CHEMBL1611844 & 688636 & 5.15 & 4.7704 & TST & \\
\hline CHEMBL1364365 & 688636 & 4.45 & 4.8514 & TRN & \\
\hline CHEMBL1584411 & 688636 & 4.3 & 4.728 & TRN & \\
\hline CHEMBL1366590 & 688636 & 4.3 & 4.7451 & TRN & \\
\hline CHEMBL1371896 & 688636 & 4.95 & 4.7241 & TRN & \\
\hline CHEMBL3192170 & 688636 & 4.6 & 4.6011 & TRN & \\
\hline CHEMBL1300154 & 688636 & 4.65 & 4.6395 & TRN & \\
\hline CHEMBL3197171 & 688636 & 4.65 & 4.8022 & TRN & \\
\hline CHEMBL1486972 & 688636 & 5.05 & 4.6509 & TRN & \\
\hline CHEMBL42529 & 688636 & 4.95 & 4.8911 & TRN & \\
\hline CHEMBL3214566 & 688636 & 4.3 & 4.6491 & TRN & \\
\hline CHEMBL1586371 & 688636 & 4.3 & 4.8639 & TRN & \\
\hline CHEMBL1409430 & 688636 & 6.1 & 4.8385 & TST & \\
\hline CHEMBL1440643 & 688636 & 4.4 & 4.8116 & TRN & \\
\hline CHEMBL1457810 & 688636 & 6.7501 & 4.8698 & TRN & \\
\hline CHEMBL1322428 & 688636 & 4.9 & 4.79899 & 99999999995 & TRN \\
\hline CHEMBL1576250 & 688636 & 5.1 & 4.949 & TST & \\
\hline CHEMBL1471220 & 688636 & 5.1 & 4.8219 & TST & \\
\hline CHEMBL1509941 & 688636 & 5.05 & 4.9778 & TRN & \\
\hline CHEMBL3208060 & 688636 & 4.45 & 4.545 & TRN & \\
\hline CHEMBL1556080 & 688636 & 5.1 & 4.6577 & TRN & \\
\hline CHEMBL1350089 & 688636 & 6.8 & 4.8361 & TRN & \\
\hline CHEMBL1391851 & 688636 & 5.4 & 5.0453 & TRN & \\
\hline CHEMBL1483108 & 688636 & 4.25 & 4.7802 & TRN & \\
\hline
\end{tabular}




\begin{tabular}{|c|c|c|c|c|}
\hline \multicolumn{5}{|c|}{ Supplemental Table S2.txt } \\
\hline CHEMBL1335763 & 688636 & 4.25 & 4.7769 & TRN \\
\hline CHEMBL1556140 & 688636 & 4.3 & 4.8383 & TRN \\
\hline CHEMBL1521192 & 688636 & 5.15 & 4.7992 & TRN \\
\hline CHEMBL1596744 & 688636 & 4.7 & 4.7873 & TRN \\
\hline CHEMBL1386632 & 688636 & 4.3 & 4.6942 & TRN \\
\hline CHEMBL3198774 & 688636 & 4.95 & 4.9134 & TRN \\
\hline CHEMBL1469488 & 688636 & 5.65 & 4.6855 & TRN \\
\hline CHEMBL1319224 & 688636 & 5.35 & 4.9986 & TRN \\
\hline CHEMBL1343739 & 688636 & 4.5 & 5.0069 & TRN \\
\hline CHEMBL1384674 & 688636 & 4.6 & 4.811 & TST \\
\hline CHEMBL1485609 & 688636 & 4.9 & 4.6209 & TRN \\
\hline CHEMBL 2001887 & 688636 & 4.95 & 4.8932 & TRN \\
\hline CHEMBL1444347 & 688636 & 4.3 & 4.841 & TRN \\
\hline CHEMBL1582965 & 688636 & 6.4 & 4.8753 & TRN \\
\hline CHEMBL1613377 & 688636 & 4.25 & 4.7048 & TRN \\
\hline CHEMBL1370299 & 688636 & 5.2 & 4.6125 & TRN \\
\hline CHEMBL1309881 & 688636 & 4.85 & 4.7865 & TST \\
\hline CHEMBL1367818 & 688636 & 5.0 & 4.5901 & TRN \\
\hline CHEMBL1492798 & 688636 & 4.4 & 4.8727 & TRN \\
\hline CHEMBL1347168 & 688636 & 4.3 & 4.7178 & TRN \\
\hline CHEMBL1458966 & 688636 & 4.3 & 4.7197 & TRN \\
\hline CHEMBL1313899 & 688636 & 5.3 & 4.8514 & TRN \\
\hline CHEMBL1438290 & 688636 & 4.7 & 4.6981 & TRN \\
\hline CHEMBL1575339 & 688636 & 4.25 & 4.8961 & TRN \\
\hline CHEMBL1446254 & 688636 & 6.0 & 4.7903 & TRN \\
\hline CHEMBL1584196 & 688636 & 4.45 & 4.5787 & TRN \\
\hline CHEMBL1493526 & 688636 & 4.9 & 4.7869 & TST \\
\hline CHEMBL1405403 & 688636 & 5.75 & 4.9314 & TRN \\
\hline CHEMBL1340617 & 688636 & 5.5 & 4.5327 & TRN \\
\hline CHEMBL1346307 & 688636 & 5.0 & 4.8609 & TRN \\
\hline CHEMBL1520767 & 688636 & 4.95 & 4.9353 & TRN \\
\hline CHEMBL1497667 & 688636 & 6.1 & 4.8883 & TST \\
\hline CHEMBL1308829 & 688636 & 4.95 & 4.8073 & TRN \\
\hline CHEMBL1447876 & 688636 & 4.95 & 4.9215 & TRN \\
\hline CHEMBL1524130 & 688636 & 5.65 & 4.7456 & TST \\
\hline CHEMBL1314107 & 688636 & 4.55 & 4.7505 & TRN \\
\hline CHEMBL3145067 & 688636 & 4.8 & 4.6482 & TRN \\
\hline CHEMBL1583975 & 688636 & 6.7501 & 4.9515 & TST \\
\hline CHEMBL1430058 & 688636 & 4.25 & 4.7755 & TRN \\
\hline CHEMBL1376894 & 688636 & 4.8 & 4.718 & TRN \\
\hline CHEMBL1383144 & 688636 & 4.65 & 4.7541 & TRN \\
\hline CHEMBL1344730 & 688636 & 4.45 & 4.6911 & TRN \\
\hline CHEMBL1353936 & 688636 & 5.45 & 4.8231 & TST \\
\hline CHEMBL1595516 & 688636 & 4.35 & 4.9923 & TRN \\
\hline CHEMBL1422360 & 688636 & 4.6 & 4.8137 & TRN \\
\hline CHEMBL1559898 & 688636 & 4.65 & 4.7902 & TST \\
\hline CHEMBL1505530 & 688636 & 5.75 & 4.842 & TRN \\
\hline CHEMBL1425464 & 688636 & 4.85 & 4.788 & TRN \\
\hline
\end{tabular}




\begin{tabular}{|c|c|c|c|c|c|}
\hline \multicolumn{6}{|c|}{ Supplemental Table S2.txt } \\
\hline CHEMBL1427151 & 688636 & 4.9 & 4.7018 & TRN & \\
\hline CHEMBL1610005 & 688636 & 4.4 & 4.8879 & TST & \\
\hline CHEMBL3211851 & 688636 & 4.3 & 4.6872 & TST & \\
\hline CHEMBL1438793 & 688636 & 4.7 & 4.9004 & TRN & \\
\hline CHEMBL1567878 & 688636 & 4.6 & 4.6639 & TRN & \\
\hline CHEMBL1490850 & 688636 & 4.25 & 4.7032 & TRN & \\
\hline CHEMBL392680 & 688636 & 4.55 & 4.8107 & TRN & \\
\hline CHEMBL1607132 & 688636 & 4.45 & 4.7404 & TRN & \\
\hline CHEMBL1319619 & 688636 & 4.95 & 4.9168 & TRN & \\
\hline CHEMBL 3212750 & 688636 & 6.1 & 4.5797 & TRN & \\
\hline CHEMBL1523123 & 688636 & 4.25 & 4.8638 & TRN & \\
\hline CHEMBL1522386 & 688636 & 4.4 & 4.9246 & TST & \\
\hline CHEMBL1427525 & 688636 & 4.4 & 4.8848 & TRN & \\
\hline CHEMBL1304601 & 688636 & 4.25 & 4.7111 & TRN & \\
\hline CHEMBL1373149 & 688636 & 4.25 & 4.7814 & TST & \\
\hline CHEMBL1606905 & 688636 & 5.85 & 4.7967 & TST & \\
\hline CHEMBL1329427 & 688636 & 4.45 & 4.7022 & TRN & \\
\hline CHEMBL1541151 & 688636 & 4.95 & 4.8568 & TST & \\
\hline CHEMBL 3207860 & 688636 & 4.4 & 4.852 & TST & \\
\hline CHEMBL1502154 & 688636 & 4.45 & 4.71899 & 9999999999 & TRN \\
\hline CHEMBL1301692 & 688636 & 4.3 & 4.8163 & TST & \\
\hline CHEMBL1482280 & 688636 & 5.25 & 4.7651 & TST & \\
\hline CHEMBL1383337 & 688636 & 5.7 & 4.8704 & TRN & \\
\hline CHEMBL1455161 & 688636 & 4.4 & 4.7875 & TRN & \\
\hline CHEMBL1387074 & 688636 & 4.9 & 4.8484 & TRN & \\
\hline CHEMBL1502370 & 688636 & 4.3 & 4.69 & TRN & \\
\hline CHEMBL1350599 & 688636 & 5.7 & 4.6436 & TST & \\
\hline CHEMBL1547670 & 688636 & 5.3 & 5.0665 & TRN & \\
\hline CHEMBL1307436 & 688636 & 6.7501 & 5.0398 & TST & \\
\hline CHEMBL1565243 & 688636 & 6.7501 & 4.9154 & TST & \\
\hline CHEMBL1562263 & 688636 & 5.1 & 4.7162 & TRN & \\
\hline CHEMBL1324324 & 688636 & 4.3 & 4.9587 & TST & \\
\hline CHEMBL1464411 & 688636 & 5.95 & 4.7287 & TRN & \\
\hline CHEMBL1576244 & 688636 & 4.55 & 4.7032 & TRN & \\
\hline CHEMBL1537524 & 688636 & 5.0 & 4.8066 & TRN & \\
\hline CHEMBL1332486 & 688636 & 6.0 & 4.7316 & TRN & \\
\hline CHEMBL1545398 & 688636 & 4.4 & 4.8443 & TRN & \\
\hline CHEMBL1370954 & 688636 & 5.6 & 4.7321 & TRN & \\
\hline CHEMBL1569891 & 688636 & 4.4 & 4.7503 & TRN & \\
\hline CHEMBL1604325 & 688636 & 4.45 & 4.8121 & TST & \\
\hline CHEMBL1600734 & 688636 & 4.45 & 4.9468 & TRN & \\
\hline CHEMBL1583762 & 688636 & 5.55 & 4.8576 & TST & \\
\hline CHEMBL150924 & 688636 & 4.4 & 4.6747 & TRN & \\
\hline CHEMBL1561382 & 688636 & 5.2 & 4.8254 & TRN & \\
\hline CHEMBL1574359 & 688636 & 5.05 & 4.8398 & TST & \\
\hline CHEMBL473107 & 688636 & 4.45 & 4.8383 & TRN & \\
\hline CHEMBL1431757 & 688636 & 4.95 & 5.0243 & TRN & \\
\hline CHEMBL1419808 & 688636 & 5.5 & 5.0197 & TRN & \\
\hline
\end{tabular}




\begin{tabular}{|c|c|c|c|c|}
\hline \multicolumn{5}{|c|}{ Supplemental Table S2.txt } \\
\hline CHEMBL1447469 & 688636 & 5.5 & 4.8158 & TST \\
\hline CHEMBL1388368 & 688636 & 4.55 & 4.8634 & TRN \\
\hline CHEMBL 71271 & 688636 & 4.95 & 4.5641 & TRN \\
\hline CHEMBL1385515 & 688636 & 5.45 & 4.9106 & TRN \\
\hline CHEMBL1399504 & 688636 & 4.6 & 4.6568 & TRN \\
\hline CHEMBL1441676 & 688636 & 6.8 & 4.8452 & TRN \\
\hline CHEMBL1560020 & 688636 & 4.3 & 4.9297 & TRN \\
\hline CHEMBL1561207 & 688636 & 4.35 & 4.6402 & TRN \\
\hline CHEMBL1393058 & 688636 & 6.7501 & 4.7073 & TST \\
\hline CHEMBL1471215 & 688636 & 5.05 & 4.7948 & TRN \\
\hline CHEMBL1322690 & 688636 & 4.45 & 4.8416 & TST \\
\hline CHEMBL1324794 & 688636 & 4.45 & 4.6765 & TRN \\
\hline CHEMBL1426844 & 688636 & 4.4 & 4.809 & TRN \\
\hline CHEMBL1377992 & 688636 & 4.4 & 4.6344 & TRN \\
\hline CHEMBL1448703 & 688636 & 4.35 & 4.7685 & TRN \\
\hline CHEMBL1325519 & 688636 & 5.4 & 4.8316 & TRN \\
\hline CHEMBL1305664 & 688636 & 4.25 & 4.6831 & TRN \\
\hline CHEMBL1419983 & 688636 & 4.45 & 4.9645 & TST \\
\hline CHEMBL1539146 & 688636 & 4.55 & 4.622 & TRN \\
\hline CHEMBL1329194 & 688636 & 5.4 & 4.7879 & TST \\
\hline CHEMBL1389953 & 688636 & 4.25 & 4.5412 & TRN \\
\hline CHEMBL1425701 & 688636 & 4.3 & 4.71899 & 9999999999 \\
\hline CHEMBL1500500 & 688636 & 4.95 & 4.6533 & TRN \\
\hline CHEMBL3191763 & 688636 & 4.45 & 4.8179 & TRN \\
\hline CHEMBL1602799 & 688636 & 4.35 & 4.5844 & TRN \\
\hline CHEMBL1447565 & 688636 & 5.15 & 4.6782 & TRN \\
\hline CHEMBL1550009 & 688636 & 4.7 & 4.9705 & TST \\
\hline CHEMBL1411619 & 688636 & 4.4 & 4.6405 & TRN \\
\hline CHEMBL1983243 & 688636 & 4.4 & 4.7409 & TRN \\
\hline CHEMBL1309735 & 688636 & 5.8 & 4.72 & TRN \\
\hline CHEMBL1508752 & 688636 & 5.6 & 4.8637 & TRN \\
\hline CHEMBL1490263 & 688636 & 4.25 & 5.0531 & TRN \\
\hline CHEMBL1405615 & 688636 & 4.3 & 4.8295 & TRN \\
\hline CHEMBL1509620 & 688636 & 4.4 & 4.8901 & TRN \\
\hline CHEMBL1383570 & 688636 & 4.9 & 4.8794 & TST \\
\hline CHEMBL1319304 & 688636 & 4.55 & 4.7321 & TRN \\
\hline CHEMBL1569761 & 688636 & 4.25 & 4.7421 & TRN \\
\hline CHEMBL1517202 & 688636 & 4.35 & 4.8524 & TRN \\
\hline CHEMBL1345384 & 688636 & 4.35 & 4.7068 & TRN \\
\hline CHEMBL1576235 & 688636 & 4.45 & 4.8907 & TRN \\
\hline CHEMBL1519257 & 688636 & 4.45 & 4.7212 & TRN \\
\hline CHEMBL1500026 & 688636 & 4.6 & 4.6712 & TST \\
\hline CHEMBL1607249 & 688636 & 4.5 & 4.6293 & TRN \\
\hline CHEMBL1501637 & 688636 & 4.8 & 4.8021 & TRN \\
\hline CHEMBL3197343 & 688636 & 4.65 & 4.6781 & TST \\
\hline CHEMBL1538959 & 688636 & 4.5 & 4.7174 & TRN \\
\hline CHEMBL1599458 & 688636 & 4.55 & 4.5392 & TRN \\
\hline CHEMBL1505092 & 688636 & 4.5 & 4.8433 & TRN \\
\hline
\end{tabular}




\begin{tabular}{|c|c|c|c|c|}
\hline & & & pplement & al $\mathrm{Ta}$ \\
\hline CHEMBL1520140 & 688636 & 4.3 & 4.9251 & TST \\
\hline CHEMBL1490221 & 688636 & 4.25 & 4.6285 & TRN \\
\hline CHEMBL1589063 & 688636 & 4.55 & 4.712 & TRN \\
\hline CHEMBL 3196818 & 688636 & 5.2 & 4.7663 & TRN \\
\hline CHEMBL1344647 & 688636 & 4.3 & 4.7458 & TRN \\
\hline CHEMBL1386985 & 688636 & 4.5 & 4.8655 & TRN \\
\hline CHEMBL1557589 & 688636 & 4.25 & 5.0034 & TST \\
\hline CHEMBL1569573 & 688636 & 5.2 & 4.8952 & TRN \\
\hline CHEMBL1471453 & 688636 & 5.8 & 4.878 & TRN \\
\hline CHEMBL1459240 & 688636 & 4.6 & 4.6743 & TRN \\
\hline CHEMBL1519059 & 688636 & 5.35 & 5.0381 & TRN \\
\hline CHEMBL1345437 & 688636 & 4.95 & 4.689 & TRN \\
\hline CHEMBL1384283 & 688636 & 4.3 & 4.7265 & TRN \\
\hline CHEMBL1532046 & 688636 & 4.4 & 4.9261 & TRN \\
\hline CHEMBL1543640 & 688636 & 4.3 & 4.9146 & TST \\
\hline CHEMBL1419889 & 688636 & 4.3 & 4.7314 & TRN \\
\hline CHEMBL56654 & 688636 & 6.8 & 4.8383 & TST \\
\hline CHEMBL1524422 & 688636 & 5.95 & 4.8935 & TRN \\
\hline CHEMBL1444775 & 688636 & 5.3 & 4.7717 & TST \\
\hline CHEMBL1479334 & 688636 & 4.9 & 4.6887 & TRN \\
\hline CHEMBL1382557 & 688636 & 5.9 & 4.7856 & TST \\
\hline CHEMBL1375071 & 688636 & 4.45 & 4.827 & TRN \\
\hline CHEMBL1323672 & 688636 & 4.35 & 4.779 & TRN \\
\hline CHEMBL63273 & 688636 & 4.6 & 4.7371 & TRN \\
\hline CHEMBL1350151 & 688636 & 4.45 & 4.947 & TRN \\
\hline CHEMBL1501461 & 688636 & 4.5 & 4.7206 & TRN \\
\hline CHEMBL1493014 & 688636 & 4.5 & 4.6896 & TRN \\
\hline CHEMBL1575785 & 688636 & 6.7501 & 4.8667 & TRN \\
\hline CHEMBL1391091 & 688636 & 4.45 & 4.7063 & TRN \\
\hline CHEMBL1547955 & 688636 & 6.6499 & 4.9731 & TRN \\
\hline CHEMBL1555685 & 688636 & 6.8 & 4.8441 & TRN \\
\hline CHEMBL1352345 & 688636 & 4.45 & 4.6986 & TST \\
\hline CHEMBL1535633 & 688636 & 4.95 & 4.8326 & TST \\
\hline CHEMBL1440414 & 688636 & 4.4 & 4.9263 & TRN \\
\hline CHEMBL1478970 & 688636 & 4.45 & 4.735 & TRN \\
\hline CHEMBL3191251 & 688636 & 4.4 & 4.6143 & TRN \\
\hline CHEMBL1577461 & 688636 & 5.0 & 4.9422 & TST \\
\hline CHEMBL1500135 & 688636 & 4.55 & 4.8022 & TRN \\
\hline CHEMBL1550766 & 688636 & 4.25 & 4.8721 & TST \\
\hline CHEMBL1493613 & 688636 & 5.9 & 4.8644 & TRN \\
\hline CHEMBL1984324 & 688636 & 5.0 & 4.7343 & TST \\
\hline CHEMBL 3190778 & 688636 & 4.5 & 4.7799 & TRN \\
\hline CHEMBL1611632 & 688636 & 4.45 & 4.5988 & TRN \\
\hline CHEMBL1561455 & 688636 & 4.3 & 4.68 & TRN \\
\hline CHEMBL1324798 & 688636 & 4.3 & 4.8165 & TRN \\
\hline CHEMBL1348648 & 688636 & 4.5 & 4.6446 & TRN \\
\hline CHEMBL1373035 & 688636 & 4.3 & 4.8601 & TRN \\
\hline CHEMBL539027 & 688636 & 4.4 & 4.9857 & TRN \\
\hline
\end{tabular}




\begin{tabular}{|c|c|c|c|c|c|}
\hline \multicolumn{6}{|c|}{ Supplemental Table S2.txt } \\
\hline CHEMBL1439402 & 688636 & 5.6 & 4.8658 & TST & \\
\hline CHEMBL1409828 & 688636 & 4.45 & 4.5836 & TRN & \\
\hline CHEMBL1611722 & 688636 & 5.1 & 4.698 & TRN & \\
\hline CHEMBL1450574 & 688636 & 4.25 & 4.7472 & TRN & \\
\hline CHEMBL1402151 & 688636 & 6.7501 & 4.8356 & TRN & \\
\hline CHEMBL3197933 & 688636 & 5.4 & 4.6158 & TRN & \\
\hline CHEMBL1322754 & 688636 & 5.45 & 4.7943 & TST & \\
\hline CHEMBL1527772 & 688636 & 4.55 & 4.9742 & TRN & \\
\hline CHEMBL1415009 & 688636 & 4.25 & 4.9015 & TRN & \\
\hline CHEMBL1483372 & 688636 & 5.35 & 4.6523 & TRN & \\
\hline CHEMBL1504447 & 688636 & 7.0 & 4.7753 & TST & \\
\hline CHEMBL1574911 & 688636 & 4.25 & 4.5438 & TRN & \\
\hline CHEMBL1543063 & 688636 & 4.5 & 4.7686 & TST & \\
\hline CHEMBL1603938 & 688636 & 5.3 & 4.6673 & TRN & \\
\hline CHEMBL577752 & 688636 & 4.4 & 4.6972 & TST & \\
\hline CHEMBL1568366 & 688636 & 4.9 & 4.8138 & TRN & \\
\hline CHEMBL1581046 & 688636 & 5.85 & 4.9413 & TRN & \\
\hline CHEMBL1523556 & 688636 & 4.45 & 4.7818 & TRN & \\
\hline CHEMBL1511514 & 688636 & 4.3 & 5.0203 & TRN & \\
\hline CHEMBL1425085 & 688636 & 4.45 & 4.7174 & TRN & \\
\hline CHEMBL1521675 & 688636 & 4.55 & 4.6653 & TRN & \\
\hline CHEMBL1509998 & 688636 & 6.05 & 4.8821 & TRN & \\
\hline CHEMBL1578285 & 688636 & 5.65 & 4.9997 & TRN & \\
\hline CHEMBL3194631 & 688636 & 5.65 & 4.7922 & TRN & \\
\hline CHEMBL1455416 & 688636 & 4.9 & 4.72199 & 99999999995 & TS \\
\hline CHEMBL1544731 & 688636 & 4.45 & 4.7369 & TRN & \\
\hline CHEMBL1538147 & 688636 & 5.25 & 4.8486 & TRN & \\
\hline CHEMBL1511149 & 688636 & 4.7 & 4.7695 & TRN & \\
\hline CHEMBL3194929 & 688636 & 4.95 & 4.8364 & TRN & \\
\hline CHEMBL1438503 & 688636 & 4.55 & 4.7443 & TRN & \\
\hline CHEMBL1505234 & 688636 & 4.65 & 4.7505 & TRN & \\
\hline CHEMBL1421112 & 688636 & 4.75 & 4.6962 & TRN & \\
\hline CHEMBL1340956 & 688636 & 4.45 & 4.7609 & TRN & \\
\hline CHEMBL1496411 & 688636 & 6.5 & 4.9476 & TST & \\
\hline CHEMBL1527737 & 688636 & 4.4 & 4.7993 & TRN & \\
\hline CHEMBL1414133 & 688636 & 4.6 & 4.9819 & TRN & \\
\hline CHEMBL1327715 & 688636 & 5.55 & 4.7116 & TRN & \\
\hline CHEMBL1548353 & 688636 & 4.5 & 4.7417 & TRN & \\
\hline CHEMBL1348381 & 688636 & 5.3 & 5.0506 & TRN & \\
\hline CHEMBL1559722 & 688636 & 4.45 & 4.9013 & TRN & \\
\hline CHEMBL1469864 & 688636 & 4.95 & 4.6833 & TRN & \\
\hline CHEMBL1508677 & 688636 & 4.75 & 4.9306 & TRN & \\
\hline CHEMBL1338802 & 688636 & 4.95 & 5.0491 & TRN & \\
\hline CHEMBL1464498 & 688636 & 5.8 & 4.8313 & TST & \\
\hline CHEMBL1501458 & 688636 & 4.85 & 4.7984 & TST & \\
\hline CHEMBL1383226 & 688636 & 4.3 & 4.7635 & TRN & \\
\hline CHEMBL1575461 & 688636 & 4.85 & 4.7248 & TST & \\
\hline CHEMBL1410915 & 688636 & 4.35 & 4.7155 & TRN & \\
\hline
\end{tabular}




\begin{tabular}{|c|c|c|c|c|c|}
\hline \multicolumn{6}{|c|}{ Supplemental Table S2.txt } \\
\hline CHEMBL1538617 & 688636 & 4.7 & 4.668 & TRN & \\
\hline CHEMBL1377388 & 688636 & 4.45 & 4.6929 & TRN & \\
\hline CHEMBL1369683 & 688636 & 4.25 & 4.7809 & TRN & \\
\hline CHEMBL1310637 & 688636 & 4.35 & 4.8312 & TRN & \\
\hline CHEMBL1449816 & 688636 & 4.3 & 4.8434 & TRN & \\
\hline CHEMBL1398633 & 688636 & 4.25 & 4.8502 & TRN & \\
\hline CHEMBL1603278 & 688636 & 4.3 & 4.7788 & TRN & \\
\hline CHEMBL1477983 & 688636 & 4.45 & 4.6905 & TRN & \\
\hline CHEMBL1302260 & 688636 & 5.35 & 5.0986 & TRN & \\
\hline CHEMBL1380923 & 688636 & 5.55 & 4.8052 & TRN & \\
\hline CHEMBL1429087 & 688636 & 4.55 & 4.8677 & TRN & \\
\hline CHEMBL3190606 & 688636 & 4.95 & 4.7416 & TRN & \\
\hline CHEMBL1334994 & 688636 & 4.95 & 4.7658 & TST & \\
\hline CHEMBL1319465 & 688636 & 4.25 & 4.8005 & TRN & \\
\hline CHEMBL1596327 & 688636 & 5.0 & 4.7709 & TRN & \\
\hline CHEMBL1465383 & 688636 & 4.9 & 4.9541 & TST & \\
\hline CHEMBL1524655 & 688636 & 4.3 & 4.8366 & TRN & \\
\hline CHEMBL1572136 & 688636 & 4.25 & 4.7829 & TRN & \\
\hline CHEMBL1421413 & 688636 & 5.6 & 4.9911 & TRN & \\
\hline CHEMBL1518948 & 688636 & 4.45 & 4.7305 & TRN & \\
\hline CHEMBL1360516 & 688636 & 4.3 & 4.8534 & TRN & \\
\hline CHEMBL1456914 & 688636 & 5.5 & 4.854 & TST & \\
\hline CHEMBL1451924 & 688636 & 4.5 & 4.9027 & TST & \\
\hline CHEMBL1490561 & 688636 & 6.8 & 4.9321 & TRN & \\
\hline CHEMBL1311490 & 688636 & 4.55 & 4.8839 & TRN & \\
\hline CHEMBL1566655 & 688636 & 4.3 & 4.8237 & TRN & \\
\hline CHEMBL1537242 & 688636 & 5.0 & 5.0411 & TST & \\
\hline CHEMBL1429072 & 688636 & 4.9 & 4.8894 & TST & \\
\hline CHEMBL1401851 & 688636 & 6.7501 & 4.934 & TRN & \\
\hline CHEMBL1306078 & 688636 & 4.45 & 4.8383 & TRN & \\
\hline CHEMBL1299694 & 688636 & 6.05 & 4.7653 & TRN & \\
\hline CHEMBL1470805 & 688636 & 4.95 & 4.8976 & TRN & \\
\hline CHEMBL 3189788 & 688636 & 4.4 & 4.7985 & TST & \\
\hline CHEMBL1564376 & 688636 & 6.5 & 4.7712 & TRN & \\
\hline CHEMBL1392327 & 688636 & 4.35 & 4.8239 & TST & \\
\hline CHEMBL1407197 & 688636 & 4.95 & 4.6446 & TST & \\
\hline CHEMBL1550135 & 688636 & 5.1 & 4.7684 & TRN & \\
\hline CHEMBL1523435 & 688636 & 5.45 & 4.96399 & 99999999995 & TRN \\
\hline CHEMBL1504350 & 688636 & 4.25 & 4.8231 & TRN & \\
\hline CHEMBL1462817 & 688636 & 4.3 & 4.8783 & TRN & \\
\hline CHEMBL1451575 & 688636 & 5.75 & 4.8525 & TRN & \\
\hline CHEMBL1576161 & 688636 & 5.45 & 4.8706 & TRN & \\
\hline CHEMBL1538555 & 688636 & 4.65 & 4.7889 & TRN & \\
\hline CHEMBL1344443 & 688636 & 4.3 & 4.6321 & TRN & \\
\hline CHEMBL1509810 & 688636 & 4.45 & 4.8906 & TRN & \\
\hline CHEMBL1368467 & 688636 & 4.25 & 4.8022 & TRN & \\
\hline CHEMBL1498173 & 688636 & 4.55 & 4.8758 & TRN & \\
\hline CHEMBL1322387 & 688636 & 4.5 & 4.72199 & 99999999995 & TRN \\
\hline & & & & 25851 & \\
\hline
\end{tabular}




\begin{tabular}{|c|c|c|c|c|c|}
\hline \multicolumn{6}{|c|}{ Supplemental Table S2.txt } \\
\hline CHEMBL1318780 & 688636 & 4.45 & 4.6933 & TRN & \\
\hline CHEMBL1449702 & 688636 & 4.45 & 4.9631 & TRN & \\
\hline CHEMBL1530900 & 688636 & 4.25 & 4.8161 & TRN & \\
\hline CHEMBL1528549 & 688636 & 5.35 & 4.7895 & TRN & \\
\hline CHEMBL1401079 & 688636 & 5.0 & 4.6313 & TRN & \\
\hline CHEMBL1350176 & 688636 & 5.2 & 4.853 & TRN & \\
\hline CHEMBL1599502 & 688636 & 4.25 & 4.6471 & TRN & \\
\hline CHEMBL1467073 & 688636 & 5.35 & 4.718 & TRN & \\
\hline CHEMBL1302603 & 688636 & 5.1 & 4.9252 & TRN & \\
\hline CHEMBL1393241 & 688636 & 4.95 & 4.7375 & TST & \\
\hline CHEMBL1599063 & 688636 & 6.8 & 4.8258 & TRN & \\
\hline CHEMBL1543163 & 688636 & 4.95 & 4.7111 & TST & \\
\hline CHEMBL1379042 & 688636 & 4.7 & 4.8666 & TST & \\
\hline CHEMBL1485918 & 688636 & 5.0 & 4.842 & TRN & \\
\hline CHEMBL3189634 & 688636 & 4.7 & 4.7077 & TRN & \\
\hline CHEMBL1359486 & 688636 & 5.2 & 4.8823 & TRN & \\
\hline CHEMBL1455087 & 688636 & 5.4 & 5.081 & TRN & \\
\hline CHEMBL3193965 & 688636 & 5.3 & 4.798 & TST & \\
\hline CHEMBL1353107 & 688636 & 4.8 & 4.79899 & 99999999995 & TRN \\
\hline CHEMBL1425445 & 688636 & 6.5501 & 5.0402 & TRN & \\
\hline CHEMBL1569531 & 688636 & 5.1 & 5.1267 & TRN & \\
\hline CHEMBL3194410 & 688636 & 5.75 & 4.6761 & TRN & \\
\hline CHEMBL1542605 & 688636 & 4.3 & 4.8424 & TRN & \\
\hline CHEMBL1597644 & 688636 & 4.95 & 4.9773 & TRN & \\
\hline CHEMBL1464966 & 688636 & 5.1 & 4.8906 & TST & \\
\hline CHEMBL1602785 & 688636 & 6.4 & 4.8347 & TRN & \\
\hline CHEMBL1503165 & 688636 & 4.4 & 4.7332 & TRN & \\
\hline CHEMBL1488423 & 688636 & 4.3 & 4.7977 & TST & \\
\hline CHEMBL3199380 & 688636 & 5.45 & 4.7803 & TST & \\
\hline CHEMBL1343276 & 688636 & 4.4 & 4.8859 & TST & \\
\hline CHEMBL3194579 & 688636 & 5.45 & 4.8095 & TST & \\
\hline CHEMBL1579747 & 688636 & 4.5 & 4.5924 & TRN & \\
\hline CHEMBL1583297 & 688636 & 4.3 & 4.8112 & TRN & \\
\hline CHEMBL1500092 & 688636 & 4.5 & 4.7353 & TRN & \\
\hline CHEMBL1308796 & 688636 & 4.8 & 4.8196 & TRN & \\
\hline CHEMBL1424852 & 688636 & 4.85 & 4.7629 & TRN & \\
\hline CHEMBL1542001 & 688636 & 5.0 & 4.9713 & TST & \\
\hline CHEMBL1408800 & 688636 & 5.2 & 4.882 & TST & \\
\hline CHEMBL3193697 & 688636 & 6.4 & 4.9336 & TST & \\
\hline CHEMBL1505788 & 688636 & 6.45 & 4.9375 & TRN & \\
\hline CHEMBL3196438 & 688636 & 5.2 & 4.9463 & TRN & \\
\hline CHEMBL1411083 & 688636 & 4.45 & 4.6855 & TRN & \\
\hline CHEMBL1381559 & 688636 & 4.95 & 4.6641 & TRN & \\
\hline CHEMBL3207462 & 688636 & 4.45 & 4.8323 & TST & \\
\hline CHEMBL1480102 & 688636 & 4.45 & 4.7566 & TRN & \\
\hline CHEMBL 3197274 & 688636 & 6.8 & 4.8151 & TRN & \\
\hline CHEMBL1522371 & 688636 & 4.25 & 4.9634 & TST & \\
\hline CHEMBL3197724 & 688636 & 4.25 & 4.7739 & TRN & \\
\hline
\end{tabular}




\begin{tabular}{|c|c|c|c|c|c|}
\hline \multirow{2}{*}{ CHEMBL1502969 } & \multirow{2}{*}{688636} & \\
\hline & & 6.8 & 4.956 & \multicolumn{2}{|l|}{ TRN } \\
\hline CHEMBL1388510 & 688636 & 6.2 & 4.7165 & \multicolumn{2}{|l|}{ TRN } \\
\hline CHEMBL1450838 & 688636 & 4.55 & 4.6798 & \multicolumn{2}{|l|}{ TRN } \\
\hline CHEMBL1400297 & 688636 & 5.75 & 4.8515 & \multicolumn{2}{|l|}{ TRN } \\
\hline CHEMBL1535537 & 688636 & 4.25 & 4.8744 & \multicolumn{2}{|l|}{ TRN } \\
\hline CHEMBL1299778 & 688636 & 4.55 & 4.8828 & \multicolumn{2}{|l|}{ TRN } \\
\hline CHEMBL1442986 & 688636 & 4.5 & 4.7323 & \multicolumn{2}{|l|}{ TRN } \\
\hline CHEMBL1384250 & 688636 & 4.9 & 4.742 & \multicolumn{2}{|l|}{ TRN } \\
\hline CHEMBL1362426 & 688636 & 6.7501 & 4.7351 & \multicolumn{2}{|l|}{ TST } \\
\hline CHEMBL1457108 & 688636 & 4.75 & 4.9541 & \multicolumn{2}{|l|}{ TRN } \\
\hline CHEMBL1320222 & 688636 & 4.5 & 4.7529 & \multicolumn{2}{|l|}{ TRN } \\
\hline CHEMBL1449447 & 688636 & 4.9 & 4.8582 & \multicolumn{2}{|l|}{ TST } \\
\hline CHEMBL1500830 & 688636 & 4.3 & 4.7838 & \multicolumn{2}{|l|}{ TRN } \\
\hline CHEMBL1403707 & 688636 & 4.4 & 4.573 & \multicolumn{2}{|l|}{ TRN } \\
\hline CHEMBL3199536 & 688636 & 4.4 & 4.846 & \multicolumn{2}{|l|}{ TRN } \\
\hline CHEMBL1565376 & 688636 & 4.55 & 4.8252 & \multicolumn{2}{|l|}{ TRN } \\
\hline CHEMBL1541162 & 688636 & 6.7501 & 4.55 & \multicolumn{2}{|l|}{ TST } \\
\hline CHEMBL1558739 & 688636 & 5.45 & 4.8125 & TST & \\
\hline CHEMBL1360896 & 688636 & 4.3 & 4.7394 & TRN & \\
\hline CHEMBL1438192 & 688636 & 4.3 & 5.0637 & TST & \\
\hline CHEMBL1419687 & 688636 & 5.95 & 4.7621 & TRN & \\
\hline CHEMBL3191454 & 688636 & 4.25 & 4.8479 & TRN & \\
\hline CHEMBL1456802 & 688636 & 4.3 & 4.8642 & TST & \\
\hline CHEMBL1363830 & 688636 & 4.3 & 4.8455 & TRN & \\
\hline CHEMBL1414246 & 688636 & 4.75 & 4.77800 & 00000000005 & TRN \\
\hline CHEMBL1441914 & 688636 & 4.25 & 4.6912 & TRN & \\
\hline CHEMBL1378927 & 688636 & 6.7501 & 4.7861 & TST & \\
\hline CHEMBL1443473 & 688636 & 4.25 & 4.6861 & TRN & \\
\hline CHEMBL1504230 & 688636 & 4.3 & 4.7141 & TRN & \\
\hline CHEMBL153072 & 688636 & 4.45 & 4.6666 & TRN & \\
\hline CHEMBL1312033 & 688636 & 4.55 & 4.7732 & TRN & \\
\hline CHEMBL1345903 & 688636 & 4.8 & 4.691 & TRN & \\
\hline CHEMBL1338029 & 688636 & 4.4 & 4.7396 & TST & \\
\hline CHEMBL1305599 & 688636 & 4.95 & 4.8582 & TRN & \\
\hline CHEMBL1508357 & 688636 & 4.45 & 4.7413 & TRN & \\
\hline CHEMBL1468741 & 688636 & 4.45 & 4.7652 & TRN & \\
\hline CHEMBL1407637 & 688636 & 4.45 & 4.8909 & TRN & \\
\hline CHEMBL1383879 & 688636 & 6.25 & 4.7825 & TRN & \\
\hline CHEMBL1599655 & 688636 & 4.3 & 4.7983 & TST & \\
\hline CHEMBL1460145 & 688636 & 4.4 & 4.6283 & TST & \\
\hline CHEMBL1441505 & 688636 & 4.95 & 4.8545 & TST & \\
\hline CHEMBL1507271 & 688636 & 4.25 & 4.75899 & 99999999995 & TRN \\
\hline CHEMBL1306622 & 688636 & 4.3 & 4.9495 & TST & \\
\hline CHEMBL1537863 & 688636 & 4.6 & 4.7986 & TRN & \\
\hline CHEMBL1391098 & 688636 & 5.9 & 4.78600 & 00000000005 & TRN \\
\hline CHEMBL1095796 & 688636 & 5.1 & 4.8611 & TST & \\
\hline CHEMBL1546218 & 688636 & 4.95 & 5.1599 & TRN & \\
\hline CHEMBL1344537 & 688636 & 4.25 & 4.94300 & 00000000005 & TRN \\
\hline & & & & 25853 & \\
\hline
\end{tabular}




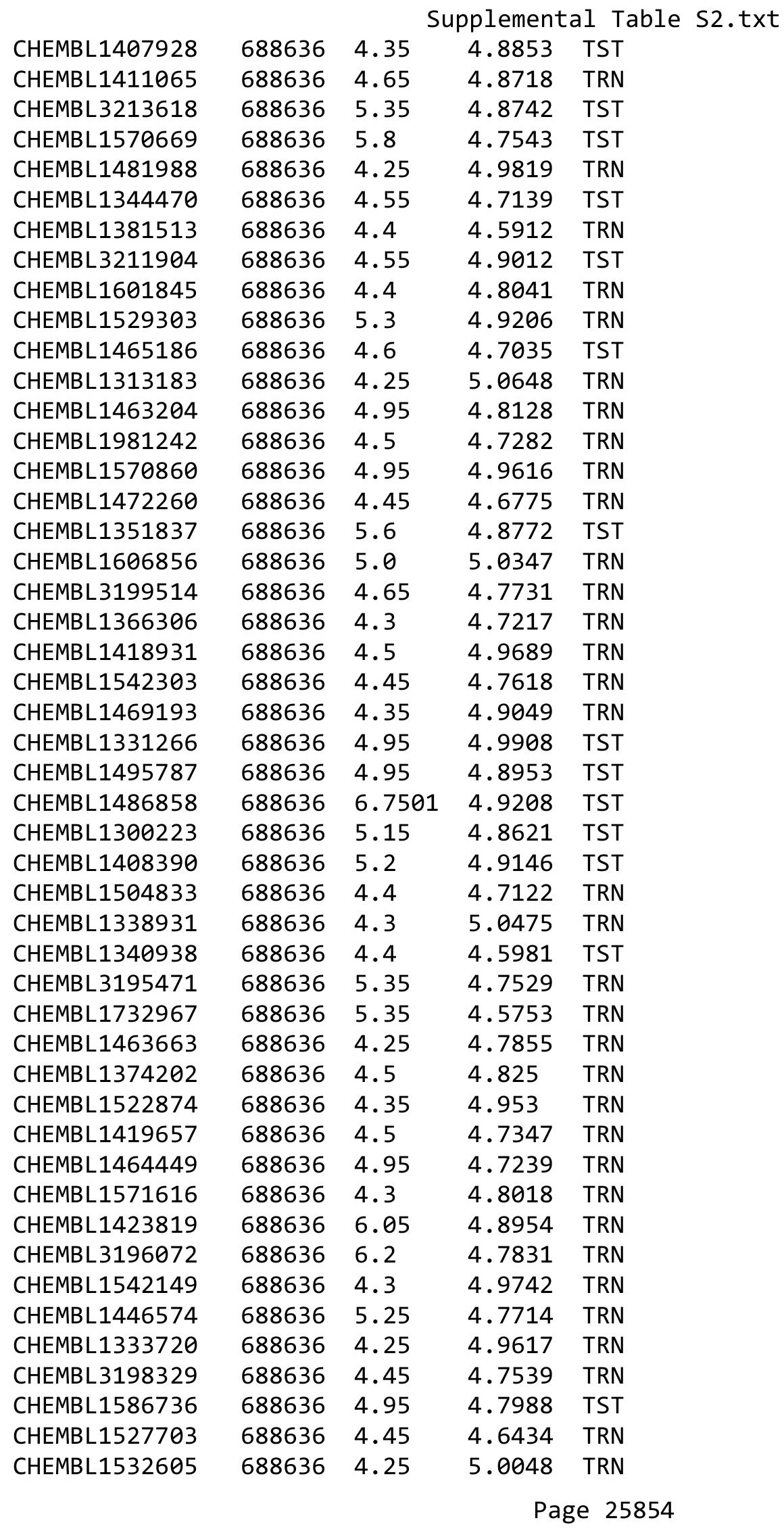




\begin{tabular}{|c|c|c|c|c|}
\hline \multicolumn{5}{|c|}{ Supplemental Table S2.txt } \\
\hline CHEMBL1387915 & 688636 & 4.45 & 4.7257 & TRN \\
\hline CHEMBL1905194 & 688636 & 4.3 & 4.7931 & TRN \\
\hline CHEMBL1444236 & 688636 & 4.5 & 4.7722 & TST \\
\hline CHEMBL1466561 & 688636 & 4.5 & 4.8279 & TRN \\
\hline CHEMBL1511722 & 688636 & 6.25 & 4.84399 & 9999999999 \\
\hline CHEMBL1366378 & 688636 & 6.7501 & 4.7176 & TST \\
\hline CHEMBL1371339 & 688636 & 4.45 & 4.6726 & TRN \\
\hline CHEMBL1324614 & 688636 & 4.4 & 4.9538 & TRN \\
\hline CHEMBL1414115 & 688636 & 6.7501 & 4.7722 & TRN \\
\hline CHEMBL1336857 & 688636 & 4.55 & 4.8126 & TRN \\
\hline CHEMBL1467125 & 688636 & 6.5501 & 4.8504 & TRN \\
\hline CHEMBL1342609 & 688636 & 4.95 & 4.7498 & TST \\
\hline CHEMBL1580220 & 688636 & 4.25 & 4.6036 & TRN \\
\hline CHEMBL1585355 & 688636 & 5.7 & 4.9123 & TST \\
\hline CHEMBL1519302 & 688636 & 6.7501 & 4.9237 & TRN \\
\hline CHEMBL1472355 & 688636 & 4.65 & 4.7778 & TST \\
\hline CHEMBL589703 & 688636 & 4.4 & 4.9172 & TRN \\
\hline CHEMBL1422562 & 688636 & 4.55 & 4.6967 & TRN \\
\hline CHEMBL1505044 & 688636 & 4.65 & 4.9349 & TST \\
\hline CHEMBL1323648 & 688636 & 5.45 & 4.9249 & TST \\
\hline CHEMBL 3194485 & 688636 & 4.55 & 4.8978 & TRN \\
\hline CHEMBL1548506 & 688636 & 4.55 & 4.7728 & TRN \\
\hline CHEMBL1502038 & 688636 & 4.9 & 4.8122 & TST \\
\hline CHEMBL1410961 & 688636 & 6.7501 & 5.0842 & TRN \\
\hline CHEMBL1478554 & 688636 & 5.0 & 4.8597 & TST \\
\hline CHEMBL1521086 & 688636 & 5.75 & 5.0112 & TST \\
\hline CHEMBL1450744 & 688636 & 6.7501 & 4.9162 & TRN \\
\hline CHEMBL1405373 & 688636 & 4.5 & 4.7334 & TRN \\
\hline CHEMBL1344023 & 688636 & 5.1 & 4.8659 & TST \\
\hline CHEMBL1327804 & 688636 & 5.3 & 4.7101 & TST \\
\hline CHEMBL3197626 & 688636 & 4.45 & 4.6729 & TRN \\
\hline CHEMBL1462046 & 688636 & 4.4 & 4.7924 & TRN \\
\hline CHEMBL1324948 & 688636 & 4.9 & 4.8534 & TST \\
\hline CHEMBL1409607 & 688636 & 4.3 & 4.957 & TRN \\
\hline CHEMBL1559397 & 688636 & 4.5 & 4.7862 & TRN \\
\hline CHEMBL1332999 & 688636 & 4.3 & 4.8373 & TRN \\
\hline CHEMBL1393118 & 688636 & 4.45 & 4.8167 & TST \\
\hline CHEMBL1378244 & 688636 & 4.4 & 4.7441 & TRN \\
\hline CHEMBL1454924 & 688636 & 6.7501 & 4.7358 & TRN \\
\hline CHEMBL1559194 & 688636 & 4.25 & 4.9023 & TST \\
\hline CHEMBL1567699 & 688636 & 6.05 & 4.9558 & TRN \\
\hline CHEMBL1564877 & 688636 & 4.45 & 4.7768 & TRN \\
\hline CHEMBL1572348 & 688636 & 4.45 & 4.6894 & TRN \\
\hline CHEMBL1463244 & 688636 & 5.4 & 4.8682 & TST \\
\hline CHEMBL1583953 & 688636 & 4.95 & 4.803 & TST \\
\hline CHEMBL582675 & 688636 & 4.7 & 4.803 & TST \\
\hline CHEMBL1405129 & 688636 & 6.5 & 4.8028 & TRN \\
\hline CHEMBL1331319 & 688636 & 4.5 & 4.9425 & TRN \\
\hline
\end{tabular}

TRN 


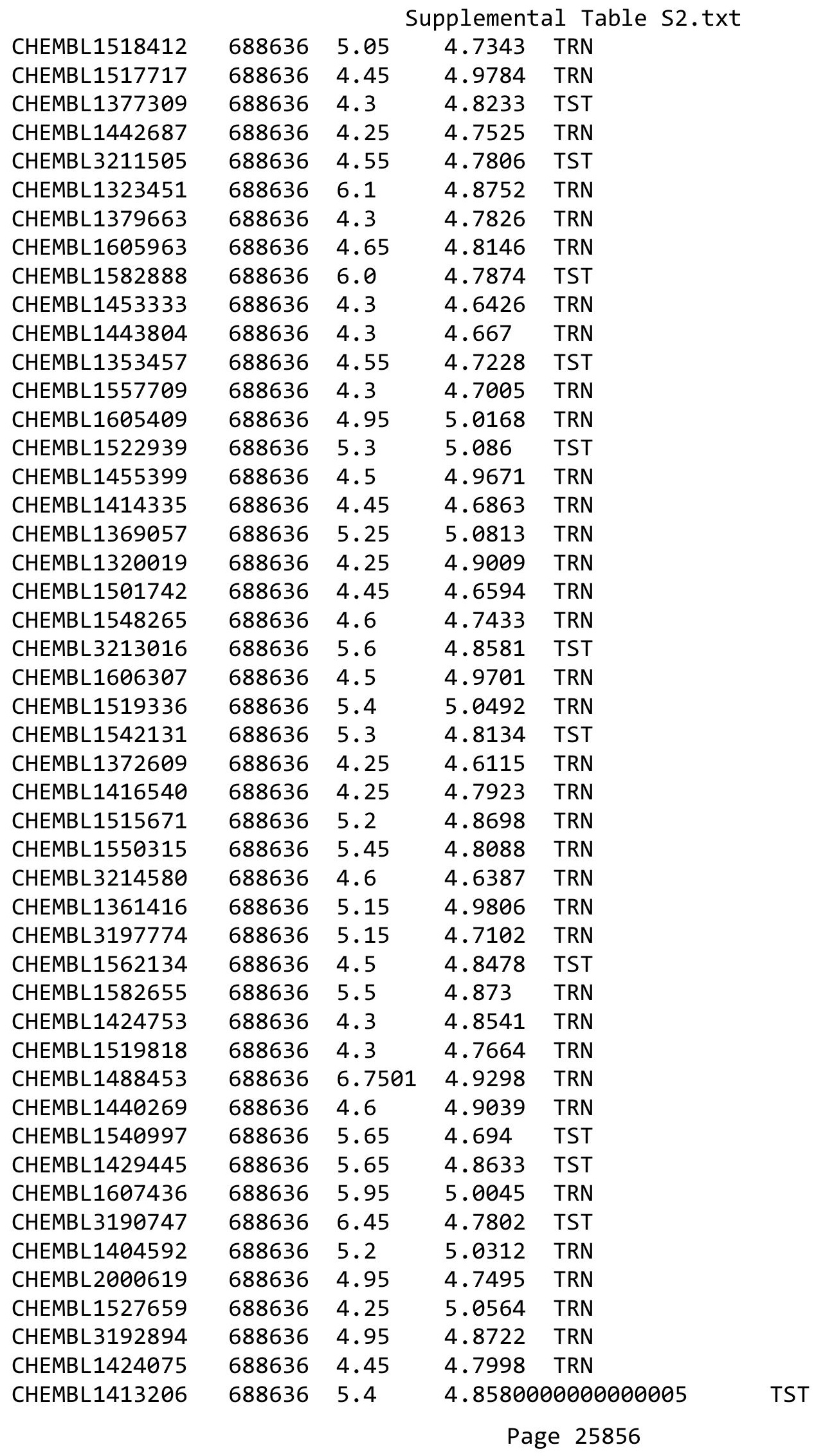




\begin{tabular}{|c|c|c|c|c|}
\hline \multicolumn{5}{|c|}{ Supplemental Table s2.txt } \\
\hline CHEMBL3207872 & 688636 & 4.5 & 4.7896 & TRN \\
\hline CHEMBL1443895 & 688636 & 4.45 & 4.8157 & TST \\
\hline CHEMBL1424034 & 688636 & 4.55 & 4.655 & TRN \\
\hline CHEMBL1574484 & 688636 & 5.3 & 4.8237 & TRN \\
\hline CHEMBL1568210 & 688636 & 6.6499 & 4.7385 & TST \\
\hline CHEMBL1417530 & 688636 & 5.35 & 4.7913 & TRN \\
\hline CHEMBL1422005 & 688636 & 5.25 & 4.7194 & TST \\
\hline CHEMBL1455956 & 688636 & 4.95 & 4.6611 & TRN \\
\hline CHEMBL1586450 & 688636 & 5.0 & 4.8608 & TRN \\
\hline CHEMBL1320414 & 688636 & 4.25 & 4.9344 & TRN \\
\hline CHEMBL1542873 & 688636 & 6.0 & 4.9554 & TRN \\
\hline CHEMBL1334506 & 688636 & 4.6 & 4.7578 & TRN \\
\hline CHEMBL1451604 & 688636 & 4.9 & 4.7449 & TRN \\
\hline CHEMBL1320424 & 688636 & 4.55 & 4.84 & TRN \\
\hline CHEMBL1375191 & 688636 & 4.25 & 4.9481 & TST \\
\hline CHEMBL1507988 & 688636 & 4.55 & 4.7156 & TRN \\
\hline CHEMBL1353229 & 688636 & 4.3 & 4.6032 & TST \\
\hline CHEMBL1510937 & 688636 & 6.6 & 4.7454 & TST \\
\hline CHEMBL1306812 & 688636 & 4.4 & 4.6006 & TRN \\
\hline CHEMBL1378151 & 688636 & 4.25 & 4.9113 & TRN \\
\hline CHEMBL1405953 & 688636 & 4.5 & 4.893 & TRN \\
\hline CHEMBL1531162 & 688636 & 4.25 & 4.7997 & TRN \\
\hline CHEMBL1459962 & 688636 & 4.75 & 4.7675 & TRN \\
\hline CHEMBL1451345 & 688636 & 4.3 & 4.8334 & TRN \\
\hline CHEMBL3196713 & 688636 & 4.25 & 4.8457 & TST \\
\hline CHEMBL1352760 & 688636 & 4.25 & 4.5626 & TST \\
\hline CHEMBL1547901 & 688636 & 4.3 & 4.6964 & TRN \\
\hline CHEMBL1458956 & 688636 & 4.25 & 4.7714 & TRN \\
\hline CHEMBL1470634 & 688636 & 6.8 & 4.8579 & TST \\
\hline CHEMBL1600146 & 688636 & 4.65 & 4.8536 & TRN \\
\hline CHEMBL1583224 & 688636 & 5.75 & 4.9311 & TST \\
\hline CHEMBL1365598 & 688636 & 4.4 & 4.8019 & TRN \\
\hline CHEMBL1373286 & 688636 & 4.35 & 4.9489 & TRN \\
\hline CHEMBL1538189 & 688636 & 4.95 & 4.9864 & TRN \\
\hline CHEMBL1449066 & 688636 & 4.45 & 4.7346 & TRN \\
\hline CHEMBL3199783 & 688636 & 5.5 & 4.8244 & TST \\
\hline CHEMBL1373172 & 688636 & 4.55 & 4.7521 & TST \\
\hline CHEMBL1353448 & 688636 & 4.45 & 4.8453 & TRN \\
\hline CHEMBL1371239 & 688636 & 4.5 & 4.8971 & TRN \\
\hline CHEMBL1506325 & 688636 & 4.45 & 4.7536 & TRN \\
\hline CHEMBL1347163 & 688636 & 4.25 & 4.7848 & TST \\
\hline CHEMBL1518767 & 688636 & 5.2 & 4.6199 & TST \\
\hline CHEMBL3213203 & 688636 & 4.5 & 4.8534 & TRN \\
\hline CHEMBL1526773 & 688636 & 4.25 & 4.9641 & TRN \\
\hline CHEMBL1486911 & 688636 & 4.3 & 4.9554 & TST \\
\hline CHEMBL3210154 & 688636 & 4.95 & 4.5425 & TRN \\
\hline CHEMBL1384971 & 688636 & 4.3 & 4.9153 & TRN \\
\hline CHEMBL1542969 & 688636 & 4.85 & 4.9326 & TST \\
\hline
\end{tabular}




\begin{tabular}{|c|c|c|c|c|}
\hline & & & pplement & al $\mathrm{T}$ \\
\hline CHEMBL1301922 & 688636 & 4.4 & 4.7382 & TST \\
\hline CHEMBL1484498 & 688636 & 4.3 & 4.8123 & TRN \\
\hline CHEMBL1470605 & 688636 & 4.25 & 5.0791 & TRN \\
\hline CHEMBL1964475 & 688636 & 4.35 & 4.6163 & TST \\
\hline CHEMBL1362308 & 688636 & 5.3 & 4.7346 & TRN \\
\hline CHEMBL3190111 & 688636 & 4.4 & 4.5884 & TRN \\
\hline CHEMBL494083 & 688636 & 6.7501 & 4.685 & TST \\
\hline CHEMBL1442950 & 688636 & 4.45 & 4.6107 & TRN \\
\hline CHEMBL1406211 & 688636 & 5.4 & 4.7418 & TST \\
\hline CHEMBL1562381 & 688636 & 4.95 & 4.5888 & TRN \\
\hline CHEMBL1461958 & 688636 & 4.25 & 4.9452 & TST \\
\hline CHEMBL1550345 & 688636 & 4.55 & 4.8113 & TST \\
\hline CHEMBL1485204 & 688636 & 4.65 & 5.0069 & TST \\
\hline CHEMBL1494071 & 688636 & 6.8 & 4.9816 & TST \\
\hline CHEMBL1529977 & 688636 & 6.5501 & 4.8357 & TRN \\
\hline CHEMBL1600492 & 688636 & 4.95 & 4.7323 & TST \\
\hline CHEMBL1335211 & 688636 & 4.55 & 5.0236 & TRN \\
\hline CHEMBL1304384 & 688636 & 4.4 & 4.8565 & TST \\
\hline CHEMBL1304190 & 688636 & 4.6 & 4.8385 & TRN \\
\hline CHEMBL1507975 & 688636 & 4.25 & 4.944 & TRN \\
\hline CHEMBL1503611 & 688636 & 4.3 & 4.6773 & TRN \\
\hline CHEMBL1347514 & 688636 & 4.5 & 4.6348 & TST \\
\hline CHEMBL1331702 & 688636 & 4.8 & 4.6695 & TST \\
\hline CHEMBL1388927 & 688636 & 4.55 & 4.6891 & TRN \\
\hline CHEMBL1393577 & 688636 & 4.65 & 4.9363 & TST \\
\hline CHEMBL1327623 & 688636 & 4.25 & 4.7189 & TRN \\
\hline CHEMBL1300755 & 688636 & 4.3 & 4.8382 & TST \\
\hline CHEMBL3197919 & 688636 & 5.95 & 4.9026 & TRN \\
\hline CHEMBL1362217 & 688636 & 4.95 & 4.7576 & TRN \\
\hline CHEMBL1480728 & 688636 & 5.85 & 4.6294 & TST \\
\hline CHEMBL 275000 & 688636 & 4.45 & 4.7003 & TRN \\
\hline CHEMBL1465841 & 688636 & 4.6 & 4.8469 & TRN \\
\hline CHEMBL1375239 & 688636 & 5.25 & 4.7068 & TRN \\
\hline CHEMBL1308183 & 688636 & 5.0 & 4.795 & TRN \\
\hline CHEMBL1346567 & 688636 & 5.15 & 4.5941 & TRN \\
\hline CHEMBL1340342 & 688636 & 4.9 & 4.8389 & TRN \\
\hline CHEMBL1350359 & 688636 & 5.1 & 4.8365 & TST \\
\hline CHEMBL1377207 & 688636 & 4.4 & 4.8437 & TST \\
\hline CHEMBL1306326 & 688636 & 4.95 & 4.8786 & TST \\
\hline CHEMBL1500811 & 688636 & 4.85 & 4.7397 & TST \\
\hline CHEMBL1409611 & 688636 & 4.25 & 4.947 & TRN \\
\hline CHEMBL1331922 & 688636 & 5.9 & 4.8059 & TST \\
\hline CHEMBL1548347 & 688636 & 4.35 & 4.8284 & TST \\
\hline CHEMBL1511032 & 688636 & 6.35 & 4.8394 & TST \\
\hline CHEMBL1310142 & 688636 & 5.4 & 4.7846 & TRN \\
\hline CHEMBL3213149 & 688636 & 4.25 & 4.7788 & TRN \\
\hline CHEMBL1467903 & 688636 & 5.2 & 4.9816 & TST \\
\hline CHEMBL1576763 & 688636 & 5.5 & 4.9211 & TRN \\
\hline
\end{tabular}




\begin{tabular}{|c|c|c|c|c|}
\hline & & & ipplement & al $\mathrm{T}$ \\
\hline CHEMBL1445388 & 688636 & 4.25 & 4.7381 & TRN \\
\hline CHEMBL1433286 & 688636 & 4.55 & 5.0089 & TST \\
\hline CHEMBL3192997 & 688636 & 4.4 & 4.9133 & TRN \\
\hline CHEMBL1305606 & 688636 & 4.5 & 4.7289 & TST \\
\hline CHEMBL1324640 & 688636 & 4.45 & 4.6078 & TRN \\
\hline CHEMBL1427746 & 688636 & 4.6 & 4.968 & TST \\
\hline CHEMBL1606298 & 688636 & 4.5 & 4.7748 & TST \\
\hline CHEMBL1516616 & 688636 & 5.45 & 4.7402 & TRN \\
\hline CHEMBL1451911 & 688636 & 5.35 & 4.647 & TRN \\
\hline CHEMBL1508579 & 688636 & 4.45 & 4.6809 & TRN \\
\hline CHEMBL1418677 & 688636 & 4.3 & 4.85 & TST \\
\hline CHEMBL1456699 & 688636 & 4.95 & 4.8505 & TRN \\
\hline CHEMBL1318743 & 688636 & 4.3 & 4.777 & TRN \\
\hline CHEMBL1557909 & 688636 & 5.15 & 4.8273 & TRN \\
\hline CHEMBL1545132 & 688636 & 4.4 & 4.9309 & TRN \\
\hline CHEMBL1446100 & 688636 & 6.05 & 4.9196 & TST \\
\hline CHEMBL1568373 & 688636 & 4.65 & 4.6513 & TRN \\
\hline CHEMBL1611336 & 688636 & 4.95 & 4.7428 & TST \\
\hline CHEMBL1537574 & 688636 & 4.85 & 4.9028 & TRN \\
\hline CHEMBL1522983 & 688636 & 4.25 & 4.7674 & TRN \\
\hline CHEMBL1580712 & 688636 & 4.35 & 4.6707 & TST \\
\hline CHEMBL1334917 & 688636 & 4.4 & 4.8121 & TRN \\
\hline CHEMBL1503118 & 688636 & 4.95 & 4.945 & TRN \\
\hline CHEMBL1489806 & 688636 & 4.25 & 4.816 & TST \\
\hline CHEMBL1524168 & 688636 & 5.35 & 4.7069 & TRN \\
\hline CHEMBL1387667 & 688636 & 5.85 & 4.953 & TRN \\
\hline CHEMBL1311634 & 688636 & 4.3 & 4.9407 & TRN \\
\hline CHEMBL 3193818 & 688636 & 4.65 & 4.738 & TRN \\
\hline CHEMBL1441682 & 688636 & 4.3 & 4.8898 & TST \\
\hline CHEMBL1329511 & 688636 & 5.1 & 4.8455 & TRN \\
\hline CHEMBL1326832 & 688636 & 4.25 & 4.6185 & TRN \\
\hline CHEMBL1410781 & 688636 & 4.45 & 4.8451 & TST \\
\hline CHEMBL1503133 & 688636 & 4.3 & 4.7958 & TRN \\
\hline CHEMBL1497278 & 688636 & 4.4 & 4.7658 & TRN \\
\hline CHEMBL1324785 & 688636 & 5.45 & 4.9737 & TRN \\
\hline CHEMBL1324853 & 688636 & 4.25 & 4.6099 & TRN \\
\hline CHEMBL1326145 & 688636 & 4.7 & 4.8563 & TST \\
\hline CHEMBL1500458 & 688636 & 5.1 & 4.9743 & TRN \\
\hline CHEMBL1361736 & 688636 & 5.4 & 4.7291 & TST \\
\hline CHEMBL1393408 & 688636 & 4.5 & 4.8036 & TRN \\
\hline CHEMBL1585706 & 688636 & 5.85 & 4.7686 & TRN \\
\hline CHEMBL1491807 & 688636 & 4.6 & 4.9127 & TRN \\
\hline CHEMBL1388769 & 688636 & 4.5 & 4.7154 & TRN \\
\hline CHEMBL1520755 & 688636 & 4.4 & 4.9015 & TRN \\
\hline CHEMBL1373698 & 688636 & 4.45 & 4.9073 & TST \\
\hline CHEMBL1409517 & 688636 & 4.3 & 4.7859 & TRN \\
\hline CHEMBL1479346 & 688636 & 4.95 & 4.8505 & TST \\
\hline CHEMBL1349078 & 688636 & 5.4 & 4.9046 & TRN \\
\hline
\end{tabular}




\begin{tabular}{|c|c|c|c|c|}
\hline & & & pplement & \\
\hline CHEMBL1350167 & 688636 & 4.55 & 4.6754 & TRN \\
\hline CHEMBL1452593 & 688636 & 5.2 & 4.8107 & TRN \\
\hline CHEMBL1409968 & 688636 & 5.1 & 4.9345 & TRN \\
\hline CHEMBL1492912 & 688636 & 4.3 & 4.7688 & TST \\
\hline CHEMBL1407659 & 688636 & 6.05 & 4.8827 & TRN \\
\hline CHEMBL1509111 & 688636 & 4.5 & 4.7356 & TRN \\
\hline CHEMBL3210786 & 688636 & 4.9 & 4.7775 & TRN \\
\hline CHEMBL1448265 & 688636 & 4.25 & 4.6377 & TRN \\
\hline CHEMBL1400518 & 688636 & 4.4 & 4.9326 & TST \\
\hline CHEMBL1557571 & 688636 & 4.95 & 4.9518 & TRN \\
\hline CHEMBL1525626 & 688636 & 4.25 & 4.6697 & TRN \\
\hline CHEMBL1305801 & 688636 & 4.3 & 4.9234 & TRN \\
\hline CHEMBL1544110 & 688636 & 4.7 & 4.6625 & TRN \\
\hline CHEMBL1385989 & 688636 & 5.45 & 4.8866 & TST \\
\hline CHEMBL1312121 & 688636 & 5.15 & 4.8561 & TRN \\
\hline CHEMBL1478612 & 688636 & 4.45 & 4.6719 & TRN \\
\hline CHEMBL1606476 & 688636 & 4.45 & 4.6987 & TRN \\
\hline CHEMBL1453625 & 688636 & 4.3 & 5.0637 & TRN \\
\hline CHEMBL1392199 & 688636 & 4.25 & 5.0033 & TRN \\
\hline CHEMBL1328478 & 688636 & 4.4 & 4.7982 & TRN \\
\hline CHEMBL1333517 & 688636 & 5.3 & 4.7168 & TRN \\
\hline CHEMBL1299332 & 688636 & 6.15 & 4.8146 & TST \\
\hline CHEMBL1381122 & 688636 & 4.45 & 4.8289 & TRN \\
\hline CHEMBL1403407 & 688636 & 5.25 & 4.7516 & TRN \\
\hline CHEMBL1486119 & 688636 & 4.45 & 4.7777 & TRN \\
\hline CHEMBL1559104 & 688636 & 4.3 & 4.9743 & TRN \\
\hline CHEMBL1600293 & 688636 & 4.3 & 4.6987 & TRN \\
\hline CHEMBL1300277 & 688636 & 4.9 & 4.8628 & TRN \\
\hline CHEMBL1373425 & 688636 & 4.25 & 4.8871 & TRN \\
\hline CHEMBL1448930 & 688636 & 4.25 & 5.0131 & TRN \\
\hline CHEMBL1561688 & 688636 & 5.15 & 4.7746 & TRN \\
\hline CHEMBL1582739 & 688636 & 4.95 & 4.8793 & TST \\
\hline CHEMBL1466973 & 688636 & 5.5 & 4.7517 & TST \\
\hline CHEMBL1531439 & 688636 & 5.25 & 4.7102 & TRN \\
\hline CHEMBL1450523 & 688636 & 4.75 & 4.7763 & TST \\
\hline CHEMBL1579834 & 688636 & 4.25 & 4.8775 & TRN \\
\hline CHEMBL1605062 & 688636 & 5.75 & 4.8867 & TRN \\
\hline CHEMBL3213062 & 688636 & 4.55 & 4.7822 & TRN \\
\hline CHEMBL1371632 & 688636 & 4.25 & 4.8762 & TRN \\
\hline CHEMBL1309733 & 688636 & 4.95 & 4.7395 & TRN \\
\hline CHEMBL1443554 & 688636 & 6.7501 & 5.0186 & TRN \\
\hline CHEMBL1351153 & 688636 & 5.8 & 5.018 & TST \\
\hline CHEMBL3210329 & 688636 & 4.8 & 4.664 & TST \\
\hline CHEMBL1570452 & 688636 & 4.95 & 5.0148 & TST \\
\hline CHEMBL1340667 & 688636 & 4.4 & 4.8123 & TRN \\
\hline CHEMBL1326451 & 688636 & 6.7501 & 4.6349 & TST \\
\hline CHEMBL1464593 & 688636 & 4.95 & 4.5887 & TST \\
\hline CHEMBL1375402 & 688636 & 4.25 & 4.7756 & TST \\
\hline
\end{tabular}




\begin{tabular}{|c|c|c|c|c|}
\hline \multicolumn{5}{|c|}{ Supplemental Table S2.txt } \\
\hline CHEMBL1611681 & 688636 & 4.45 & 4.7125 & TRN \\
\hline CHEMBL1537907 & 688636 & 4.45 & 4.8704 & TRN \\
\hline CHEMBL1465680 & 688636 & 4.25 & 4.8213 & TRN \\
\hline CHEMBL1483522 & 688636 & 4.4 & 4.709 & TRN \\
\hline CHEMBL1559102 & 688636 & 6.45 & 4.8382 & TRN \\
\hline CHEMBL1408240 & 688636 & 4.3 & 4.8836 & TRN \\
\hline CHEMBL3196264 & 688636 & 4.3 & 4.7166 & TST \\
\hline CHEMBL1516870 & 688636 & 4.45 & 4.7451 & TRN \\
\hline CHEMBL1483246 & 688636 & 4.45 & 4.7657 & TRN \\
\hline CHEMBL1521676 & 688636 & 4.95 & 4.8955 & TRN \\
\hline CHEMBL1594198 & 688636 & 4.95 & 4.9722 & TST \\
\hline CHEMBL1309461 & 688636 & 4.55 & 4.7366 & TRN \\
\hline CHEMBL3192593 & 688636 & 4.3 & 4.7566 & TRN \\
\hline CHEMBL1570407 & 688636 & 5.7 & 5.0188 & TRN \\
\hline CHEMBL1427614 & 688636 & 5.3 & 4.851 & TRN \\
\hline CHEMBL1460897 & 688636 & 4.95 & 4.8207 & TRN \\
\hline CHEMBL1488127 & 688636 & 4.3 & 4.8056 & TRN \\
\hline CHEMBL1373161 & 688636 & 4.25 & 5.0258 & TST \\
\hline CHEMBL1466471 & 688636 & 4.55 & 4.7418 & TRN \\
\hline CHEMBL1521019 & 688636 & 4.4 & 4.9443 & TRN \\
\hline CHEMBL3194961 & 688636 & 5.15 & 4.9896 & TRN \\
\hline CHEMBL1349263 & 688636 & 4.95 & 4.8939 & TRN \\
\hline CHEMBL1478366 & 688636 & 5.1 & 4.5273 & TST \\
\hline CHEMBL1542849 & 688636 & 4.9 & 4.7886 & TST \\
\hline CHEMBL3212246 & 688636 & 4.8 & 4.7886 & TRN \\
\hline CHEMBL1387044 & 688636 & 4.3 & 4.9506 & TRN \\
\hline CHEMBL1300104 & 688636 & 4.35 & 4.7765 & TRN \\
\hline CHEMBL1424064 & 688636 & 6.45 & 4.7405 & TST \\
\hline CHEMBL1335331 & 688636 & 4.6 & 4.6158 & TRN \\
\hline CHEMBL1408407 & 688636 & 4.25 & 5.0244 & TRN \\
\hline CHEMBL1497299 & 688636 & 6.2 & 4.8095 & TRN \\
\hline CHEMBL1310454 & 688636 & 6.1 & 4.7265 & TST \\
\hline CHEMBL1497366 & 688636 & 5.25 & 4.7207 & TRN \\
\hline CHEMBL1994048 & 688636 & 4.95 & 4.8105 & TRN \\
\hline CHEMBL1467442 & 688636 & 4.95 & 4.7752 & TRN \\
\hline CHEMBL1323586 & 688636 & 6.15 & 4.6874 & TST \\
\hline CHEMBL1412286 & 688636 & 4.95 & 4.9327 & TST \\
\hline CHEMBL1534129 & 688636 & 4.25 & 4.763 & TRN \\
\hline CHEMBL1409965 & 688636 & 4.3 & 4.8144 & TST \\
\hline CHEMBL1579587 & 688636 & 5.0 & 4.7502 & TRN \\
\hline CHEMBL1462143 & 688636 & 4.25 & 4.6998 & TST \\
\hline CHEMBL1334936 & 688636 & 4.35 & 4.7351 & TRN \\
\hline CHEMBL1470294 & 688636 & 5.3 & 4.9475 & TRN \\
\hline CHEMBL1570237 & 688636 & 4.5 & 4.8126 & TRN \\
\hline CHEMBL1350409 & 688636 & 4.6 & 5.0048 & TST \\
\hline CHEMBL1347337 & 688636 & 4.3 & 4.792 & TRN \\
\hline CHEMBL1577478 & 688636 & 4.25 & 5.0221 & TRN \\
\hline CHEMBL1504138 & 688636 & 4.55 & 4.8179 & TST \\
\hline
\end{tabular}




\begin{tabular}{|c|c|c|c|c|}
\hline \multicolumn{5}{|c|}{ Supplemental Table S2.txt } \\
\hline CHEMBL1527984 & 688636 & 4.9 & 4.8543 & TST \\
\hline CHEMBL1443317 & 688636 & 4.95 & 4.8112 & TRN \\
\hline CHEMBL1379890 & 688636 & 5.25 & 4.8849 & TST \\
\hline CHEMBL1491086 & 688636 & 6.8 & 4.6142 & TST \\
\hline CHEMBL1365788 & 688636 & 4.25 & 4.7406 & TRN \\
\hline CHEMBL1520555 & 688636 & 4.7 & 4.739 & TRN \\
\hline CHEMBL1536362 & 688636 & 4.3 & 4.7237 & TRN \\
\hline CHEMBL1546975 & 688636 & 4.95 & 4.7298 & TRN \\
\hline CHEMBL1556072 & 688636 & 4.9 & 4.7234 & TRN \\
\hline CHEMBL1530797 & 688636 & 4.45 & 4.7628 & TRN \\
\hline CHEMBL1343610 & 688636 & 4.3 & 5.0274 & TRN \\
\hline CHEMBL1392046 & 688636 & 4.45 & 4.8451 & TRN \\
\hline CHEMBL1504261 & 688636 & 4.5 & 4.7583 & TST \\
\hline CHEMBL1338376 & 688636 & 4.5 & 4.6966 & TRN \\
\hline CHEMBL1538023 & 688636 & 4.85 & 4.6265 & TST \\
\hline CHEMBL1385735 & 688636 & 6.8 & 4.7907 & TST \\
\hline CHEMBL1558140 & 688636 & 5.95 & 4.8099 & TRN \\
\hline CHEMBL1409319 & 688636 & 4.25 & 4.7401 & TRN \\
\hline CHEMBL 2001337 & 688636 & 4.25 & 4.83 & TRN \\
\hline CHEMBL1391963 & 688636 & 4.3 & 4.7524 & TST \\
\hline CHEMBL1345292 & 688636 & 4.95 & 4.8628 & TST \\
\hline CHEMBL1580104 & 688636 & 5.3 & 4.953 & TRN \\
\hline CHEMBL1544882 & 688636 & 4.3 & 4.5743 & TST \\
\hline CHEMBL1365920 & 688636 & 4.4 & 4.8056 & TST \\
\hline CHEMBL1310596 & 688636 & 4.55 & 4.919 & TRN \\
\hline CHEMBL1444182 & 688636 & 4.25 & 4.7324 & TRN \\
\hline CHEMBL1413275 & 688636 & 5.95 & 4.8637 & TST \\
\hline CHEMBL1457500 & 688636 & 4.5 & 4.7543 & TST \\
\hline CHEMBL 3211472 & 688636 & 4.85 & 4.7883 & TRN \\
\hline CHEMBL1589093 & 688636 & 4.25 & 4.7831 & TST \\
\hline CHEMBL3212072 & 688636 & 6.7001 & 4.8802 & TST \\
\hline CHEMBL1557859 & 688636 & 4.65 & 4.7878 & TRN \\
\hline CHEMBL1460405 & 688636 & 5.45 & 4.7237 & TRN \\
\hline CHEMBL1384307 & 688636 & 4.25 & 4.7188 & TRN \\
\hline CHEMBL1525307 & 688636 & 4.9 & 4.9084 & TRN \\
\hline CHEMBL1388162 & 688636 & 4.65 & 4.6718 & TRN \\
\hline CHEMBL1328705 & 688636 & 4.5 & 4.8071 & TST \\
\hline CHEMBL1450879 & 688636 & 5.65 & 4.7809 & TRN \\
\hline CHEMBL 3213757 & 688636 & 4.3 & 4.8304 & TRN \\
\hline CHEMBL1342702 & 688636 & 4.9 & 4.8572 & TRN \\
\hline CHEMBL1340060 & 688636 & 4.7 & 4.9372 & TRN \\
\hline CHEMBL1411005 & 688636 & 4.55 & 4.8289 & TRN \\
\hline CHEMBL1549236 & 688636 & 4.9 & 4.7242 & TRN \\
\hline CHEMBL1416381 & 688636 & 6.3 & 4.8999 & TRN \\
\hline CHEMBL1479679 & 688636 & 4.5 & 4.6718 & TRN \\
\hline CHEMBL1537410 & 688636 & 4.65 & 4.6426 & TST \\
\hline CHEMBL1502662 & 688636 & 4.95 & 4.8092 & TRN \\
\hline CHEMBL1449739 & 688636 & 4.9 & 4.7792 & TRN \\
\hline
\end{tabular}




\begin{tabular}{|c|c|c|c|c|}
\hline \multicolumn{5}{|c|}{ Supplemental Table S2.txt } \\
\hline CHEMBL1485394 & 688636 & 4.3 & 4.9148 & TRN \\
\hline CHEMBL1565528 & 688636 & 4.35 & 4.5754 & TST \\
\hline CHEMBL1413799 & 688636 & 4.9 & 4.6636 & TRN \\
\hline CHEMBL1327272 & 688636 & 4.3 & 4.7176 & TST \\
\hline CHEMBL1599779 & 688636 & 5.65 & 4.716 & TRN \\
\hline CHEMBL1375321 & 688636 & 6.7501 & 4.8992 & TRN \\
\hline CHEMBL1350952 & 688636 & 4.35 & 4.8028 & TRN \\
\hline CHEMBL1362740 & 688636 & 4.8 & 4.8971 & TST \\
\hline CHEMBL3199206 & 688636 & 5.25 & 4.9301 & TRN \\
\hline CHEMBL1526936 & 688636 & 4.55 & 4.8363 & TRN \\
\hline CHEMBL1334983 & 688636 & 5.55 & 4.9767 & TRN \\
\hline CHEMBL 258881 & 688636 & 4.3 & 4.6224 & TRN \\
\hline CHEMBL1428510 & 688636 & 4.3 & 4.8996 & TRN \\
\hline CHEMBL1595948 & 688636 & 4.45 & 4.6865 & TRN \\
\hline CHEMBL1369369 & 688636 & 5.35 & 4.5759 & TST \\
\hline CHEMBL1547105 & 688636 & 4.3 & 4.8295 & TST \\
\hline CHEMBL1576777 & 688636 & 4.25 & 4.9277 & TRN \\
\hline CHEMBL1347158 & 688636 & 5.1 & 4.7701 & TRN \\
\hline CHEMBL1452189 & 688636 & 4.55 & 4.9804 & TST \\
\hline CHEMBL3190520 & 688636 & 4.95 & 4.9676 & TST \\
\hline CHEMBL1455685 & 688636 & 4.4 & 4.8633 & TST \\
\hline CHEMBL1492834 & 688636 & 4.5 & 4.7999 & TRN \\
\hline CHEMBL1504711 & 688636 & 4.35 & 4.8742 & TST \\
\hline CHEMBL1523749 & 688636 & 6.6 & 5.0271 & TRN \\
\hline CHEMBL1306736 & 688636 & 4.55 & 4.8215 & TRN \\
\hline CHEMBL1299248 & 688636 & 4.7 & 4.8529 & TRN \\
\hline CHEMBL1375298 & 688636 & 4.25 & 4.7698 & TRN \\
\hline CHEMBL1533744 & 688636 & 4.45 & 4.7239 & TRN \\
\hline CHEMBL1535617 & 688636 & 4.55 & 4.8097 & TST \\
\hline CHEMBL1596619 & 688636 & 4.3 & 4.7453 & TRN \\
\hline CHEMBL1350579 & 688636 & 5.25 & 4.8747 & TRN \\
\hline CHEMBL1415753 & 688636 & 4.35 & 4.8209 & TST \\
\hline CHEMBL1309256 & 688636 & 4.3 & 4.8376 & TRN \\
\hline CHEMBL1586126 & 688636 & 6.1 & 4.8363 & TRN \\
\hline CHEMBL1380209 & 688636 & 4.95 & 4.7855 & TRN \\
\hline CHEMBL1568341 & 688636 & 4.55 & 4.9206 & TRN \\
\hline CHEMBL1470373 & 688636 & 4.45 & 4.8335 & TST \\
\hline CHEMBL436589 & 688636 & 4.4 & 4.9267 & TRN \\
\hline CHEMBL1349988 & 688636 & 6.8 & 4.971 & TRN \\
\hline CHEMBL3199209 & 688636 & 4.25 & 4.8 & TST \\
\hline CHEMBL1485656 & 688636 & 4.45 & 4.8641 & TST \\
\hline CHEMBL1347221 & 688636 & 4.5 & 4.7575 & TRN \\
\hline CHEMBL1413761 & 688636 & 4.3 & 4.8001 & TRN \\
\hline CHEMBL1415037 & 688636 & 4.45 & 4.8585 & TRN \\
\hline CHEMBL1467236 & 688636 & 4.3 & 4.7813 & TRN \\
\hline CHEMBL3199262 & 688636 & 4.5 & 4.8125 & TST \\
\hline CHEMBL1541880 & 688636 & 4.45 & 4.7571 & TRN \\
\hline CHEMBL3198615 & 688636 & 4.3 & 4.7546 & TRN \\
\hline
\end{tabular}




\begin{tabular}{|c|c|c|c|c|c|}
\hline \multicolumn{6}{|c|}{ oplemental la } \\
\hline CHEMBL1459956 & 688636 & 4.4 & 4.7243 & TRN & \\
\hline CHEMBL1542470 & 688636 & 4.95 & 4.952 & TRN & \\
\hline CHEMBL3209336 & 688636 & 4.3 & 4.7691 & TRN & \\
\hline CHEMBL1303812 & 688636 & 4.3 & 4.63899 & 9999999999 & TRN \\
\hline CHEMBL1589035 & 688636 & 4.55 & 4.8099 & TST & \\
\hline CHEMBL1392624 & 688636 & 4.55 & 4.7783 & TRN & \\
\hline CHEMBL3211369 & 688636 & 4.9 & 4.909 & TST & \\
\hline CHEMBL1420887 & 688636 & 4.95 & 4.752 & TRN & \\
\hline CHEMBL1328395 & 688636 & 4.5 & 4.7867 & TRN & \\
\hline CHEMBL1977602 & 688636 & 4.3 & 4.72 & TST & \\
\hline CHEMBL1456402 & 688636 & 4.85 & 4.8794 & TRN & \\
\hline CHEMBL236899 & 688636 & 6.0 & 4.7417 & TRN & \\
\hline CHEMBL1517339 & 688636 & 4.25 & 4.7299 & TRN & \\
\hline CHEMBL1439666 & 688636 & 5.4 & 4.6873 & TRN & \\
\hline CHEMBL1469494 & 688636 & 4.3 & 4.7625 & TRN & \\
\hline CHEMBL1487657 & 688636 & 4.45 & 4.6992 & TRN & \\
\hline CHEMBL1314143 & 688636 & 5.65 & 4.7522 & TRN & \\
\hline CHEMBL1581361 & 688636 & 5.3 & 4.8849 & TST & \\
\hline CHEMBL1325841 & 688636 & 5.05 & 4.9739 & TRN & \\
\hline CHEMBL1454135 & 688636 & 4.25 & 4.8093 & TRN & \\
\hline CHEMBL1541113 & 688636 & 5.1 & 5.0054 & TRN & \\
\hline CHEMBL1365949 & 688636 & 4.4 & 4.7309 & TRN & \\
\hline CHEMBL1302962 & 688636 & 5.05 & 4.813 & TRN & \\
\hline CHEMBL1594360 & 688636 & 4.5 & 4.9316 & TRN & \\
\hline CHEMBL1529636 & 688636 & 5.7 & 4.952 & TRN & \\
\hline CHEMBL1454548 & 688636 & 6.05 & 4.6926 & TRN & \\
\hline CHEMBL1366128 & 688636 & 4.9 & 4.7045 & TRN & \\
\hline CHEMBL1467672 & 688636 & 4.65 & 4.7534 & TRN & \\
\hline CHEMBL1347191 & 688636 & 4.4 & 4.7459 & TRN & \\
\hline CHEMBL1373471 & 688636 & 5.15 & 4.8445 & TST & \\
\hline CHEMBL1469898 & 688636 & 5.0 & 4.927 & TRN & \\
\hline CHEMBL1521307 & 688636 & 5.45 & 4.8603 & TRN & \\
\hline CHEMBL1485796 & 688636 & 4.55 & 4.8609 & TRN & \\
\hline CHEMBL1538502 & 688636 & 4.95 & 4.8062 & TST & \\
\hline CHEMBL1333755 & 688636 & 4.35 & 4.7621 & TRN & \\
\hline CHEMBL1548764 & 688636 & 6.6499 & 4.69600 & 0000000001 & TRN \\
\hline CHEMBL1388290 & 688636 & 4.35 & 4.6503 & TRN & \\
\hline CHEMBL1488555 & 688636 & 5.55 & 4.7814 & TST & \\
\hline CHEMBL1550592 & 688636 & 4.35 & 4.9058 & TST & \\
\hline CHEMBL1598638 & 688636 & 5.65 & 4.7732 & TRN & \\
\hline CHEMBL1483533 & 688636 & 4.35 & 4.708 & TRN & \\
\hline CHEMBL1409114 & 688636 & 4.4 & 5.1232 & TRN & \\
\hline CHEMBL1548848 & 688636 & 4.9 & 4.8446 & TST & \\
\hline CHEMBL1338422 & 688636 & 5.65 & 4.9936 & TRN & \\
\hline CHEMBL1504183 & 688636 & 4.3 & 4.7655 & TRN & \\
\hline CHEMBL1331491 & 688636 & 4.5 & 4.8203 & TRN & \\
\hline CHEMBL3193275 & 688636 & 4.3 & 4.7724 & TRN & \\
\hline CHEMBL1456345 & 688636 & 4.3 & 4.7637 & TST & \\
\hline
\end{tabular}




\begin{tabular}{|c|c|c|c|c|}
\hline \multicolumn{5}{|c|}{ Supplemental Tabl } \\
\hline CHEMBL1383669 & 688636 & 6.7501 & 4.6903 & TRN \\
\hline CHEMBL1535578 & 688636 & 4.8 & 4.6814 & TRN \\
\hline CHEMBL3192452 & 688636 & 4.4 & 4.8094 & TRN \\
\hline CHEMBL1572875 & 688636 & 5.55 & 4.9223 & TRN \\
\hline CHEMBL1372108 & 688636 & 4.45 & 4.6746 & TRN \\
\hline CHEMBL1486716 & 688636 & 4.25 & 4.9075 & TST \\
\hline CHEMBL1525732 & 688636 & 4.3 & 4.6769 & TRN \\
\hline CHEMBL1458949 & 688636 & 4.5 & 4.9511 & TST \\
\hline CHEMBL3194550 & 688636 & 4.25 & 4.7641 & TRN \\
\hline CHEMBL1432904 & 688636 & 5.1 & 4.7282 & TRN \\
\hline CHEMBL1371959 & 688636 & 4.4 & 4.6922 & TRN \\
\hline CHEMBL1583145 & 688636 & 5.35 & 4.8176 & TST \\
\hline CHEMBL1449689 & 688636 & 4.3 & 4.9181 & TRN \\
\hline CHEMBL1576747 & 688636 & 4.25 & 4.7847 & TRN \\
\hline CHEMBL1520404 & 688636 & 5.2 & 4.7527 & TRN \\
\hline CHEMBL1598989 & 688636 & 5.35 & 4.8085 & TRN \\
\hline CHEMBL1582340 & 688636 & 6.0 & 5.0597 & TRN \\
\hline CHEMBL3198540 & 688636 & 4.4 & 4.7476 & TRN \\
\hline CHEMBL1537247 & 688636 & 5.4 & 4.9183 & TRN \\
\hline CHEMBL1576025 & 688636 & 5.95 & 4.7647 & TST \\
\hline CHEMBL1964480 & 688636 & 4.3 & 4.7688 & TRN \\
\hline CHEMBL3209685 & 688636 & 4.3 & 4.7601 & TRN \\
\hline CHEMBL1577227 & 688636 & 4.3 & 4.9614 & TRN \\
\hline CHEMBL1608664 & 688636 & 6.6499 & 4.8921 & TRN \\
\hline CHEMBL1542820 & 688636 & 4.25 & 5.0347 & TRN \\
\hline CHEMBL1487978 & 688636 & 5.45 & 4.7811 & TST \\
\hline CHEMBL1599468 & 688636 & 4.25 & 4.712 & TRN \\
\hline CHEMBL1429804 & 688636 & 4.9 & 4.8521 & TRN \\
\hline CHEMBL1482449 & 688636 & 6.1 & 4.8515 & TRN \\
\hline CHEMBL1516673 & 688636 & 4.55 & 4.7016 & TRN \\
\hline CHEMBL1530503 & 688636 & 4.95 & 4.9434 & TST \\
\hline CHEMBL1603800 & 688636 & 4.65 & 4.7973 & TRN \\
\hline CHEMBL1362842 & 688636 & 4.5 & 4.7349 & TRN \\
\hline CHEMBL1597956 & 688636 & 4.45 & 4.6357 & TRN \\
\hline CHEMBL1323994 & 688636 & 4.45 & 4.7061 & TRN \\
\hline CHEMBL1569910 & 688636 & 5.85 & 4.6818 & TRN \\
\hline CHEMBL1410946 & 688636 & 6.05 & 4.9244 & TRN \\
\hline CHEMBL1405679 & 688636 & 4.5 & 4.6321 & TRN \\
\hline CHEMBL1580242 & 688636 & 5.25 & 4.9295 & TRN \\
\hline CHEMBL1313145 & 688636 & 6.0 & 4.8735 & TRN \\
\hline CHEMBL1458448 & 688636 & 4.7 & 4.7918 & TRN \\
\hline CHEMBL1549448 & 688636 & 4.45 & 4.9186 & TST \\
\hline CHEMBL1569099 & 688636 & 6.2 & 4.9374 & TRN \\
\hline CHEMBL1570580 & 688636 & 4.25 & 4.9224 & TRN \\
\hline CHEMBL1576913 & 688636 & 4.5 & 4.7801 & TRN \\
\hline CHEMBL1411720 & 688636 & 4.95 & 4.7497 & TRN \\
\hline CHEMBL1494965 & 688636 & 4.45 & 4.7263 & TRN \\
\hline CHEMBL1477127 & 688636 & 6.7501 & 5.0195 & TRN \\
\hline
\end{tabular}




\begin{tabular}{|c|c|c|c|c|}
\hline \multicolumn{5}{|c|}{ Supplemental Table S2.txt } \\
\hline CHEMBL1417717 & 688636 & 4.45 & 4.6041 & TRN \\
\hline CHEMBL1504360 & 688636 & 4.4 & 4.7105 & TRN \\
\hline CHEMBL1544426 & 688636 & 4.45 & 4.6855 & TRN \\
\hline CHEMBL1577765 & 688636 & 5.7 & 4.9085 & TRN \\
\hline CHEMBL1463527 & 688636 & 5.35 & 4.8161 & TRN \\
\hline CHEMBL3213945 & 688636 & 5.55 & 4.7524 & TRN \\
\hline CHEMBL1444402 & 688636 & 4.25 & 4.8442 & TRN \\
\hline CHEMBL3198411 & 688636 & 4.25 & 4.8152 & TRN \\
\hline CHEMBL1570199 & 688636 & 4.9 & 4.9955 & TRN \\
\hline CHEMBL1340690 & 688636 & 4.85 & 5.032 & TRN \\
\hline CHEMBL1485338 & 688636 & 4.45 & 4.868 & TRN \\
\hline CHEMBL1361855 & 688636 & 5.95 & 4.6432 & TST \\
\hline CHEMBL1401828 & 688636 & 4.25 & 4.755 & TRN \\
\hline CHEMBL1531392 & 688636 & 4.95 & 4.8533 & TRN \\
\hline CHEMBL1598241 & 688636 & 4.9 & 4.8408 & TRN \\
\hline CHEMBL1360869 & 688636 & 4.85 & 4.8281 & TRN \\
\hline CHEMBL1502857 & 688636 & 4.25 & 4.7847 & TST \\
\hline CHEMBL1547221 & 688636 & 5.7 & 4.8727 & TST \\
\hline CHEMBL1585025 & 688636 & 4.9 & 4.8944 & TRN \\
\hline CHEMBL1343101 & 688636 & 5.7 & 4.9173 & TST \\
\hline CHEMBL1324079 & 688636 & 4.25 & 4.8269 & TRN \\
\hline CHEMBL1465671 & 688636 & 4.3 & 4.9368 & TST \\
\hline CHEMBL1531276 & 688636 & 5.35 & 4.8534 & TRN \\
\hline CHEMBL1446084 & 688636 & 4.3 & 4.7223 & TRN \\
\hline CHEMBL1411139 & 688636 & 5.35 & 4.8796 & TRN \\
\hline CHEMBL1428815 & 688636 & 4.3 & 4.9609 & TRN \\
\hline CHEMBL1384706 & 688636 & 4.5 & 4.8026 & TRN \\
\hline CHEMBL1549174 & 688636 & 4.65 & 4.6431 & TRN \\
\hline CHEMBL1360892 & 688636 & 4.3 & 4.6222 & TRN \\
\hline CHEMBL1459159 & 688636 & 5.55 & 4.6195 & TST \\
\hline CHEMBL1540688 & 688636 & 5.9 & 4.7758 & TST \\
\hline CHEMBL1508106 & 688636 & 4.55 & 4.8064 & TST \\
\hline CHEMBL1411681 & 688636 & 5.05 & 4.8234 & TRN \\
\hline CHEMBL1584578 & 688636 & 4.65 & 4.7247 & TRN \\
\hline CHEMBL1506512 & 688636 & 5.75 & 4.7245 & TST \\
\hline CHEMBL1446544 & 688636 & 4.3 & 4.7049 & TRN \\
\hline CHEMBL1332221 & 688636 & 4.45 & 4.7803 & TRN \\
\hline CHEMBL1339894 & 688636 & 4.5 & 4.7405 & TRN \\
\hline CHEMBL1541260 & 688636 & 4.5 & 4.7664 & TRN \\
\hline CHEMBL1345118 & 688636 & 5.9 & 4.7811 & TST \\
\hline CHEMBL1445873 & 688636 & 5.4 & 4.6777 & TRN \\
\hline CHEMBL1498756 & 688636 & 4.65 & 4.6749 & TRN \\
\hline CHEMBL1576177 & 688636 & 4.25 & 4.8617 & TST \\
\hline CHEMBL1374437 & 688636 & 4.55 & 4.6825 & TRN \\
\hline CHEMBL1604488 & 688636 & 4.9 & 4.8909 & TRN \\
\hline CHEMBL1470580 & 688636 & 4.8 & 4.855 & TRN \\
\hline CHEMBL1381167 & 688636 & 6.4 & 5.0397 & TRN \\
\hline CHEMBL1578075 & 688636 & 4.25 & 4.7599 & TST \\
\hline
\end{tabular}




\begin{tabular}{|c|c|c|c|c|c|}
\hline \multicolumn{6}{|c|}{ Supplemental Table S2.txt } \\
\hline CHEMBL1598771 & 688636 & 6.35 & 4.9059 & TST & \\
\hline CHEMBL1598252 & 688636 & 4.95 & 4.6946 & TRN & \\
\hline CHEMBL1418998 & 688636 & 6.2 & 4.8628 & TRN & \\
\hline CHEMBL1557683 & 688636 & 4.25 & 4.7564 & TRN & \\
\hline CHEMBL1544424 & 688636 & 4.55 & 4.8218 & TRN & \\
\hline CHEMBL3199132 & 688636 & 4.7 & 4.7866 & TST & \\
\hline CHEMBL1373348 & 688636 & 4.4 & 4.5574 & TRN & \\
\hline CHEMBL1322896 & 688636 & 4.45 & 4.8331 & TRN & \\
\hline CHEMBL1420839 & 688636 & 4.95 & 4.8872 & TRN & \\
\hline CHEMBL1377923 & 688636 & 4.3 & 4.7488 & TRN & \\
\hline CHEMBL1366259 & 688636 & 4.9 & 4.8547 & TRN & \\
\hline CHEMBL1542971 & 688636 & 5.35 & 4.8452 & TRN & \\
\hline CHEMBL3191473 & 688636 & 5.2 & 4.877 & TST & \\
\hline CHEMBL1538446 & 688636 & 4.75 & 4.7061 & TRN & \\
\hline CHEMBL1367630 & 688636 & 4.45 & 4.7592 & TRN & \\
\hline CHEMBL1543079 & 688636 & 4.45 & 4.5824 & TRN & \\
\hline CHEMBL1320004 & 688636 & 4.35 & 4.6897 & TRN & \\
\hline CHEMBL3199473 & 688636 & 4.25 & 4.8227 & TST & \\
\hline CHEMBL1607909 & 688636 & 4.3 & 5.0876 & TST & \\
\hline CHEMBL1567954 & 688636 & 4.3 & 4.9616 & TRN & \\
\hline CHEMBL604100 & 688636 & 4.6 & 4.7834 & TRN & \\
\hline CHEMBL1386757 & 688636 & 4.25 & 4.7992 & TRN & \\
\hline CHEMBL1562688 & 688636 & 4.4 & 4.7782 & TRN & \\
\hline CHEMBL1409016 & 688636 & 4.45 & 4.9972 & TRN & \\
\hline CHEMBL1472401 & 688636 & 4.4 & 4.7899 & TRN & \\
\hline CHEMBL1387905 & 688636 & 6.8 & 4.8382 & TRN & \\
\hline CHEMBL1574574 & 688636 & 4.45 & 4.57100 & 0000000001 & TRN \\
\hline CHEMBL1388739 & 688636 & 4.25 & 4.9008 & TRN & \\
\hline CHEMBL1452827 & 688636 & 4.4 & 4.7461 & TRN & \\
\hline CHEMBL3196874 & 688636 & 4.55 & 4.6683 & TRN & \\
\hline CHEMBL1326823 & 688636 & 4.45 & 4.7185 & TRN & \\
\hline CHEMBL1333873 & 688636 & 4.95 & 5.0846 & TST & \\
\hline CHEMBL1477093 & 688636 & 4.45 & 4.7191 & TRN & \\
\hline CHEMBL1506640 & 688636 & 5.3 & 4.7644 & TRN & \\
\hline CHEMBL1421153 & 688636 & 4.9 & 4.8186 & TST & \\
\hline CHEMBL1366752 & 688636 & 4.9 & 4.915 & TST & \\
\hline CHEMBL1301917 & 688636 & 4.85 & 4.7021 & TRN & \\
\hline CHEMBL1306827 & 688636 & 4.4 & 4.7685 & TST & \\
\hline CHEMBL3191540 & 688636 & 6.7501 & 4.8734 & TRN & \\
\hline CHEMBL1372089 & 688636 & 4.35 & 4.8044 & TRN & \\
\hline CHEMBL1470342 & 688636 & 4.8 & 4.652 & TRN & \\
\hline CHEMBL1302215 & 688636 & 4.95 & 4.8554 & TRN & \\
\hline CHEMBL1359612 & 688636 & 4.45 & 4.7711 & TRN & \\
\hline CHEMBL1510830 & 688636 & 4.3 & 4.7571 & TST & \\
\hline CHEMBL1440622 & 688636 & 6.7501 & 4.6944 & TST & \\
\hline CHEMBL1459582 & 688636 & 4.5 & 4.875 & TRN & \\
\hline CHEMBL1376258 & 688636 & 4.45 & 4.7393 & TRN & \\
\hline CHEMBL1342093 & 688636 & 4.3 & 4.7326 & TST & \\
\hline
\end{tabular}




\begin{tabular}{|c|c|c|c|c|}
\hline \multicolumn{5}{|c|}{ Supplemental Table S2.txt } \\
\hline CHEMBL1490424 & 688636 & 4.25 & 4.8253 & TST \\
\hline CHEMBL1557267 & 688636 & 4.3 & 4.7892 & TRN \\
\hline CHEMBL1352733 & 688636 & 4.5 & 4.6841 & TRN \\
\hline CHEMBL516040 & 688636 & 4.6 & 4.9472 & TRN \\
\hline CHEMBL1613161 & 688636 & 6.05 & 5.1094 & TRN \\
\hline CHEMBL1587510 & 688636 & 4.95 & 4.851 & TRN \\
\hline CHEMBL1485362 & 688636 & 4.55 & 4.7617 & TRN \\
\hline CHEMBL1535337 & 688636 & 4.9 & 4.8383 & TRN \\
\hline CHEMBL1339514 & 688636 & 4.8 & 4.8796 & TRN \\
\hline CHEMBL3209281 & 688636 & 5.2 & 4.5499 & TRN \\
\hline CHEMBL1444769 & 688636 & 4.45 & 4.7971 & TRN \\
\hline CHEMBL1534720 & 688636 & 4.3 & 4.6944 & TRN \\
\hline CHEMBL1348104 & 688636 & 4.4 & 4.6114 & TRN \\
\hline CHEMBL1318805 & 688636 & 4.9 & 4.8667 & TRN \\
\hline CHEMBL1363204 & 688636 & 4.4 & 4.9939 & TRN \\
\hline CHEMBL1419125 & 688636 & 4.45 & 4.9771 & TRN \\
\hline CHEMBL1407650 & 688636 & 4.85 & 4.705 & TRN \\
\hline CHEMBL587856 & 688636 & 4.3 & 4.7154 & TST \\
\hline CHEMBL1596792 & 688636 & 5.15 & 4.8407 & TRN \\
\hline CHEMBL1517410 & 688636 & 5.6 & 4.7588 & TRN \\
\hline CHEMBL1423621 & 688636 & 4.55 & 4.7846 & TRN \\
\hline CHEMBL1439668 & 688636 & 5.35 & 4.6873 & TRN \\
\hline CHEMBL1453005 & 688636 & 4.3 & 4.8135 & TRN \\
\hline CHEMBL1324939 & 688636 & 4.3 & 4.8573 & TRN \\
\hline CHEMBL1352890 & 688636 & 4.3 & 4.8531 & TRN \\
\hline CHEMBL1425252 & 688636 & 4.9 & 4.6477 & TRN \\
\hline CHEMBL1399653 & 688636 & 4.55 & 4.5264 & TRN \\
\hline CHEMBL1500438 & 688636 & 4.45 & 4.6915 & TRN \\
\hline CHEMBL1608713 & 688636 & 4.3 & 4.9289 & TRN \\
\hline CHEMBL1341408 & 688636 & 6.7501 & 4.9943 & TRN \\
\hline CHEMBL1321674 & 688636 & 4.35 & 4.6937 & TRN \\
\hline CHEMBL1378243 & 688636 & 4.55 & 4.7099 & TRN \\
\hline CHEMBL1598444 & 688636 & 4.25 & 5.052 & TRN \\
\hline CHEMBL1312404 & 688636 & 4.3 & 4.8661 & TST \\
\hline CHEMBL1570002 & 688636 & 4.5 & 4.718 & TRN \\
\hline CHEMBL1375616 & 688636 & 5.45 & 4.9359 & TRN \\
\hline CHEMBL 1418278 & 688636 & 4.25 & 4.7641 & TRN \\
\hline CHEMBL1598190 & 688636 & 5.8 & 4.8662 & TRN \\
\hline CHEMBL1471737 & 688636 & 4.35 & 4.7939 & TRN \\
\hline CHEMBL1353056 & 688636 & 4.45 & 4.7349 & TRN \\
\hline CHEMBL1581746 & 688636 & 5.05 & 4.7729 & TST \\
\hline CHEMBL3189419 & 688636 & 6.3 & 4.9186 & TRN \\
\hline CHEMBL1411072 & 688636 & 6.5 & 4.7374 & TRN \\
\hline CHEMBL1497681 & 688636 & 5.6 & 4.8693 & TST \\
\hline CHEMBL1609635 & 688636 & 4.55 & 4.7441 & TRN \\
\hline CHEMBL1583050 & 688636 & 5.55 & 4.7565 & TRN \\
\hline CHEMBL 1385048 & 688636 & 4.65 & 4.7901 & TRN \\
\hline CHEMBL1469332 & 688636 & 5.4 & 4.7921 & TRN \\
\hline
\end{tabular}




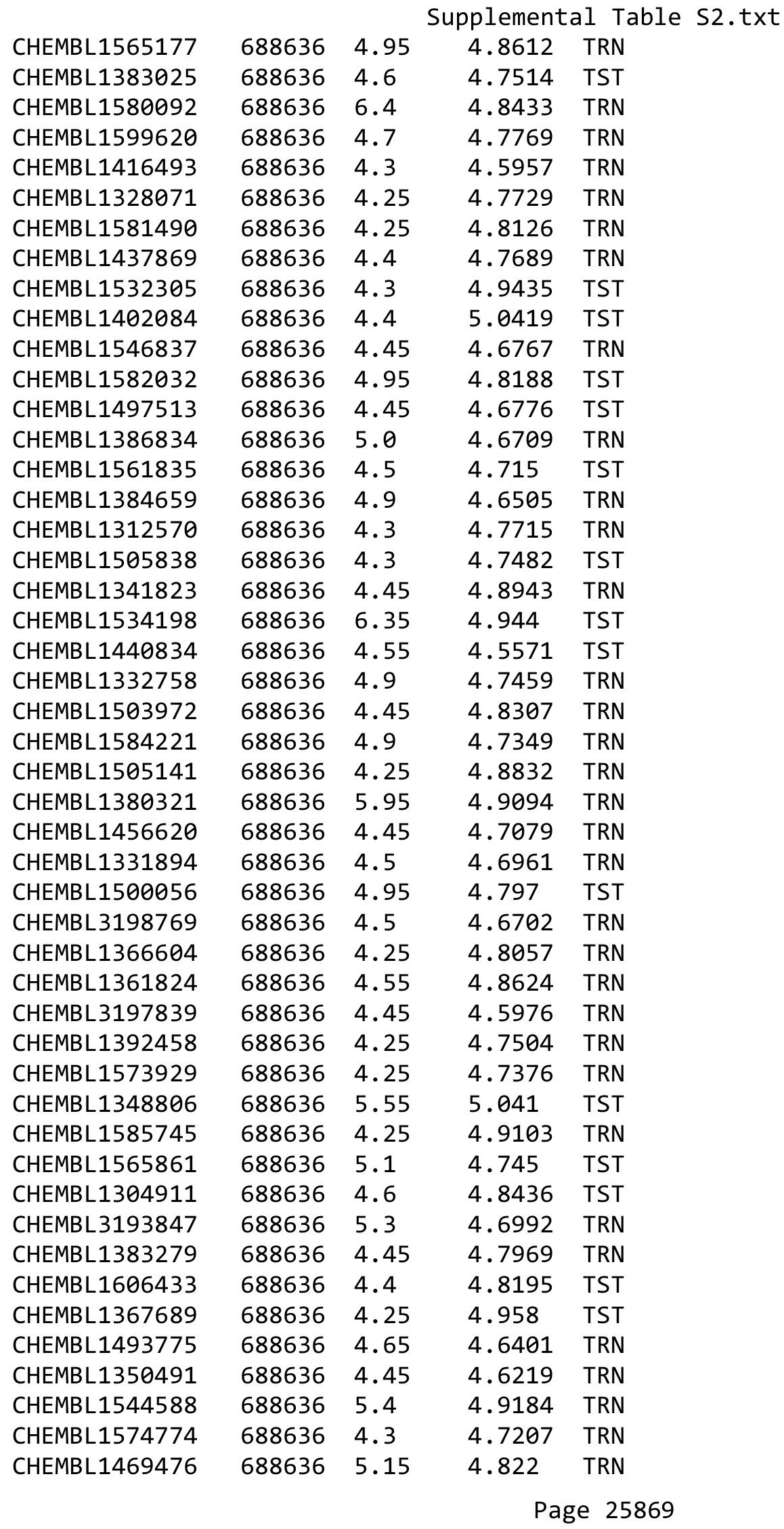




\begin{tabular}{|c|c|c|c|c|c|}
\hline \\
\hline CHEMBL1442642 & 688636 & 4.3 & 5.0437 & TRN & \\
\hline CHEMBL1411357 & 688636 & 4.55 & 4.7864 & TRN & \\
\hline CHEMBL3195995 & 688636 & 4.3 & 4.6078 & TRN & \\
\hline CHEMBL 2001996 & 688636 & 4.25 & 4.9132 & TRN & \\
\hline CHEMBL1325212 & 688636 & 4.9 & 4.9177 & TRN & \\
\hline CHEMBL1303715 & 688636 & 4.6 & 4.6951 & TRN & \\
\hline CHEMBL1333807 & 688636 & 4.5 & 4.5789 & TRN & \\
\hline CHEMBL1400057 & 688636 & 4.8 & 4.8229 & TRN & \\
\hline CHEMBL1990866 & 688636 & 4.4 & 4.825 & TST & \\
\hline CHEMBL1322862 & 688636 & 4.35 & 4.9331 & TRN & \\
\hline CHEMBL1444247 & 688636 & 5.9 & 4.8881 & TST & \\
\hline CHEMBL1536238 & 688636 & 4.95 & 4.9266 & TRN & \\
\hline CHEMBL1595788 & 688636 & 5.3 & 4.69600 & 0000000001 & TRN \\
\hline CHEMBL1419709 & 688636 & 6.05 & 4.7503 & TRN & \\
\hline CHEMBL1351356 & 688636 & 4.45 & 4.9368 & TST & \\
\hline CHEMBL1457908 & 688636 & 4.55 & 4.6835 & TRN & \\
\hline CHEMBL1526484 & 688636 & 4.95 & 4.7534 & TRN & \\
\hline CHEMBL1510741 & 688636 & 5.45 & 5.0917 & TRN & \\
\hline CHEMBL1484595 & 688636 & 4.45 & 4.5425 & TST & \\
\hline CHEMBL1545626 & 688636 & 4.3 & 4.8274 & TRN & \\
\hline CHEMBL1602059 & 688636 & 4.9 & 4.8861 & TRN & \\
\hline CHEMBL1375730 & 688636 & 4.85 & 4.9872 & TRN & \\
\hline CHEMBL1564778 & 688636 & 5.0 & 4.7155 & TRN & \\
\hline CHEMBL1605539 & 688636 & 6.0 & 4.7124 & TRN & \\
\hline CHEMBL1559575 & 688636 & 4.95 & 4.8365 & TRN & \\
\hline CHEMBL1409588 & 688636 & 4.55 & 4.9601 & TRN & \\
\hline CHEMBL 544348 & 688636 & 4.35 & 4.7576 & TRN & \\
\hline CHEMBL1351105 & 688636 & 4.65 & 4.8521 & TRN & \\
\hline CHEMBL1426849 & 688636 & 5.15 & 4.9568 & TST & \\
\hline CHEMBL1587294 & 688636 & 5.95 & 4.871 & TRN & \\
\hline CHEMBL1439184 & 688636 & 5.15 & 4.6785 & TRN & \\
\hline CHEMBL1330818 & 688636 & 6.7501 & 4.7831 & TRN & \\
\hline CHEMBL1990571 & 688636 & 4.9 & 4.6553 & TST & \\
\hline CHEMBL1575892 & 688636 & 4.8 & 4.7372 & TST & \\
\hline CHEMBL1611262 & 688636 & 6.7501 & 4.8599 & TRN & \\
\hline CHEMBL1559763 & 688636 & 4.3 & 5.0289 & TRN & \\
\hline CHEMBL 1605578 & 688636 & 4.65 & 4.6682 & TRN & \\
\hline CHEMBL 2004428 & 688636 & 4.25 & 4.78100 & 3000000001 & TRN \\
\hline CHEMBL1483742 & 688636 & 4.3 & 4.9472 & TRN & \\
\hline CHEMBL1305066 & 688636 & 4.45 & 4.7241 & TRN & \\
\hline CHEMBL1578119 & 688636 & 4.25 & 4.871 & TST & \\
\hline CHEMBL1414614 & 688636 & 5.45 & 4.916 & TRN & \\
\hline CHEMBL1574536 & 688636 & 4.4 & 4.8668 & TST & \\
\hline CHEMBL1536427 & 688636 & 4.4 & 4.9719 & TRN & \\
\hline CHEMBL1583106 & 688636 & 4.85 & 4.919 & TRN & \\
\hline CHEMBL1347950 & 688636 & 6.7501 & 4.883 & TST & \\
\hline CHEMBL1387948 & 688636 & 4.25 & 4.6147 & TRN & \\
\hline CHEMBL1319479 & 688636 & 4.95 & 4.8031 & TRN & \\
\hline
\end{tabular}




\begin{tabular}{|c|c|c|c|c|c|}
\hline \\
\hline CHEMBL1359037 & 688636 & 4.5 & 4.7258 & TRN & \\
\hline CHEMBL1375992 & 688636 & 5.0 & 4.6616 & TRN & \\
\hline CHEMBL1384793 & 688636 & 5.35 & 4.7175 & TRN & \\
\hline CHEMBL1401802 & 688636 & 6.35 & 4.7824 & TRN & \\
\hline CHEMBL1449915 & 688636 & 5.6 & 4.8559 & TRN & \\
\hline CHEMBL1453131 & 688636 & 4.4 & 4.5818 & TRN & \\
\hline CHEMBL1431776 & 688636 & 4.45 & 4.7871 & TST & \\
\hline CHEMBL1499208 & 688636 & 5.5 & 4.8971 & TST & \\
\hline CHEMBL1583405 & 688636 & 5.15 & 4.9123 & TST & \\
\hline CHEMBL1501998 & 688636 & 6.05 & 4.5549 & TRN & \\
\hline CHEMBL1558802 & 688636 & 5.2 & 4.7909 & TST & \\
\hline CHEMBL1332142 & 688636 & 6.8 & 5.0307 & TRN & \\
\hline CHEMBL1304521 & 688636 & 4.25 & 4.9284 & TRN & \\
\hline CHEMBL1407387 & 688636 & 4.45 & 4.7782 & TRN & \\
\hline CHEMBL1311403 & 688636 & 5.5 & 5.038 & TRN & \\
\hline CHEMBL1427708 & 688636 & 4.4 & 4.9238 & TRN & \\
\hline CHEMBL1310134 & 688636 & 4.9 & 4.7965 & TRN & \\
\hline CHEMBL1428482 & 688636 & 4.75 & 4.7596 & TRN & \\
\hline CHEMBL1375381 & 688636 & 4.8 & 4.6031 & TRN & \\
\hline CHEMBL3210818 & 688636 & 4.95 & 4.8509 & TST & \\
\hline CHEMBL1420949 & 688636 & 4.95 & 4.5904 & TRN & \\
\hline CHEMBL1432870 & 688636 & 4.3 & 4.8951 & TRN & \\
\hline CHEMBL1525847 & 688636 & 5.55 & 4.9424 & TRN & \\
\hline CHEMBL1488110 & 688636 & 4.25 & 4.7646 & TRN & \\
\hline CHEMBL1604515 & 688636 & 5.0 & $4.8610 e$ & 0000000001 & TRN \\
\hline CHEMBL1508189 & 688636 & 4.45 & 4.6612 & TRN & \\
\hline CHEMBL1586058 & 688636 & 4.55 & 4.7481 & TRN & \\
\hline CHEMBL1462686 & 688636 & 4.3 & 4.984 & TST & \\
\hline CHEMBL1546216 & 688636 & 4.95 & 4.8021 & TST & \\
\hline CHEMBL1518807 & 688636 & 4.4 & 4.6836 & TST & \\
\hline CHEMBL1329782 & 688636 & 4.35 & 4.9379 & TRN & \\
\hline CHEMBL1360262 & 688636 & 4.45 & 4.8665 & TRN & \\
\hline CHEMBL1479018 & 688636 & 4.6 & 5.0203 & TST & \\
\hline CHEMBL1301052 & 688636 & 5.9 & 4.6845 & TRN & \\
\hline CHEMBL1334674 & 688636 & 4.35 & 4.8099 & TRN & \\
\hline CHEMBL1414490 & 688636 & 4.25 & 5.0323 & TRN & \\
\hline CHEMBL1419686 & 688636 & 4.75 & 4.5011 & TRN & \\
\hline CHEMBL1572586 & 688636 & 5.45 & 4.7305 & TRN & \\
\hline CHEMBL1574058 & 688636 & 5.45 & 4.8854 & TRN & \\
\hline CHEMBL1523826 & 688636 & 5.3 & 4.8034 & TRN & \\
\hline CHEMBL1342526 & 688636 & 4.9 & 5.0162 & TRN & \\
\hline CHEMBL1446500 & 688636 & 4.9 & 4.6938 & TRN & \\
\hline CHEMBL1323718 & 688636 & 5.15 & 5.0229 & TRN & \\
\hline CHEMBL1425403 & 688636 & 5.1 & 4.8403 & TRN & \\
\hline CHEMBL1465814 & 688636 & 5.4 & 4.7221 & TRN & \\
\hline CHEMBL1404805 & 688636 & 6.2 & 4.9052 & TRN & \\
\hline CHEMBL1498341 & 688636 & 4.9 & 4.8625 & TRN & \\
\hline CHEMBL1393236 & 688636 & 4.4 & 4.6435 & TRN & \\
\hline & & & & 58 & \\
\hline
\end{tabular}




\begin{tabular}{|c|c|c|c|c|}
\hline \multicolumn{5}{|c|}{ Supplemental Table S2.txt } \\
\hline CHEMBL1550899 & 688636 & 5.0 & 4.8639 & TRN \\
\hline CHEMBL1351896 & 688636 & 4.5 & 4.7491 & TRN \\
\hline CHEMBL1529290 & 688636 & 4.4 & 5.0173 & TST \\
\hline CHEMBL1500231 & 688636 & 4.3 & 4.695 & TST \\
\hline CHEMBL1479862 & 688636 & 4.95 & 4.7426 & TRN \\
\hline CHEMBL1510072 & 688636 & 4.55 & 4.8338 & TRN \\
\hline CHEMBL1417090 & 688636 & 4.6 & 4.8784 & TST \\
\hline CHEMBL1439189 & 688636 & 4.5 & 4.762 & TST \\
\hline CHEMBL1503542 & 688636 & 4.45 & 4.7309 & TRN \\
\hline CHEMBL1501755 & 688636 & 4.3 & 4.7475 & TRN \\
\hline CHEMBL1342385 & 688636 & 4.3 & 4.8571 & TST \\
\hline CHEMBL1372543 & 688636 & 4.7 & 4.6521 & TRN \\
\hline CHEMBL1363032 & 688636 & 4.7 & 4.5047 & TRN \\
\hline CHEMBL1354059 & 688636 & 5.45 & 4.6882 & TRN \\
\hline CHEMBL1506604 & 688636 & 4.85 & 5.0412 & TST \\
\hline CHEMBL1529211 & 688636 & 4.45 & 4.7639 & TRN \\
\hline CHEMBL3212318 & 688636 & 4.3 & 4.7981 & TRN \\
\hline CHEMBL1461017 & 688636 & 4.25 & 4.7608 & TRN \\
\hline CHEMBL1399438 & 688636 & 4.45 & 4.8061 & TRN \\
\hline CHEMBL1370512 & 688636 & 4.3 & 4.8234 & TRN \\
\hline CHEMBL1543294 & 688636 & 4.95 & 4.9248 & TRN \\
\hline CHEMBL1481481 & 688636 & 5.9 & 4.7583 & TRN \\
\hline CHEMBL1611718 & 688636 & 4.9 & 4.9073 & TST \\
\hline CHEMBL1413715 & 688636 & 4.4 & 4.8387 & TRN \\
\hline CHEMBL1540618 & 688636 & 4.8 & 4.685 & TRN \\
\hline CHEMBL1539835 & 688636 & 4.5 & 4.6069 & TRN \\
\hline CHEMBL1456810 & 688636 & 4.65 & 4.7125 & TRN \\
\hline CHEMBL1389793 & 688636 & 4.4 & 4.7725 & TRN \\
\hline CHEMBL1387768 & 688636 & 5.65 & 4.6506 & TST \\
\hline CHEMBL1317300 & 688636 & 4.25 & 4.8045 & TST \\
\hline CHEMBL3189974 & 688636 & 4.7 & 4.9177 & TRN \\
\hline CHEMBL1303147 & 688636 & 6.5 & 4.867 & TRN \\
\hline CHEMBL1420551 & 688636 & 4.65 & 4.9818 & TRN \\
\hline CHEMBL1466527 & 688636 & 4.4 & 4.8594 & TRN \\
\hline CHEMBL1542121 & 688636 & 4.3 & 4.9285 & TRN \\
\hline CHEMBL1319600 & 688636 & 4.25 & 4.8543 & TRN \\
\hline CHEMBL 1444568 & 688636 & 4.15 & 4.7494 & TRN \\
\hline CHEMBL1572857 & 688636 & 4.55 & 4.7355 & TRN \\
\hline CHEMBL1429802 & 688636 & 4.3 & 4.6584 & TRN \\
\hline CHEMBL1383439 & 688636 & 4.95 & 4.5728 & TRN \\
\hline CHEMBL1602206 & 688636 & 4.3 & 4.6635 & TRN \\
\hline CHEMBL1491555 & 688636 & 4.25 & 4.8662 & TST \\
\hline CHEMBL1577289 & 688636 & 6.6 & 4.9358 & TRN \\
\hline CHEMBL1391033 & 688636 & 4.65 & 4.8512 & TRN \\
\hline CHEMBL1430814 & 688636 & 5.0 & 5.1156 & TRN \\
\hline CHEMBL1389300 & 688636 & 6.8 & 4.4878 & TST \\
\hline CHEMBL1580399 & 688636 & 4.3 & 4.8569 & TRN \\
\hline CHEMBL1501018 & 688636 & 4.9 & 4.8263 & TST \\
\hline
\end{tabular}




\begin{tabular}{|c|c|c|c|c|}
\hline \multicolumn{5}{|c|}{ Supplemental Table S2.txt } \\
\hline CHEMBL1445101 & 688636 & 4.95 & 4.9791 & TRN \\
\hline CHEMBL1530970 & 688636 & 5.6 & 4.6671 & TRN \\
\hline CHEMBL1596395 & 688636 & 4.75 & 4.8272 & TRN \\
\hline CHEMBL1461004 & 688636 & 4.4 & 4.7076 & TRN \\
\hline CHEMBL1421698 & 688636 & 4.45 & 4.7567 & TRN \\
\hline CHEMBL1472394 & 688636 & 4.9 & 4.5941 & TRN \\
\hline CHEMBL 2005119 & 688636 & 4.45 & 4.8349 & TRN \\
\hline CHEMBL1463178 & 688636 & 4.8 & 4.6093 & TST \\
\hline CHEMBL1414601 & 688636 & 4.35 & 4.7187 & TRN \\
\hline CHEMBL1432514 & 688636 & 4.35 & 4.7619 & TRN \\
\hline CHEMBL1600042 & 688636 & 4.25 & 4.7967 & TST \\
\hline CHEMBL1488567 & 688636 & 4.85 & 4.9848 & TST \\
\hline CHEMBL1517836 & 688636 & 5.35 & 4.9099 & TRN \\
\hline CHEMBL1085765 & 688636 & 4.3 & 4.955 & TST \\
\hline CHEMBL1580668 & 688636 & 4.55 & 4.8085 & TRN \\
\hline CHEMBL1414789 & 688636 & 4.9 & 4.6105 & TRN \\
\hline CHEMBL1388418 & 688636 & 4.7 & 4.8373 & TRN \\
\hline CHEMBL1425059 & 688636 & 4.55 & 4.8572 & TRN \\
\hline CHEMBL540851 & 688636 & 4.55 & 4.8782 & TST \\
\hline CHEMBL1352633 & 688636 & 4.55 & 4.6726 & TRN \\
\hline CHEMBL1407056 & 688636 & 4.5 & 4.6013 & TRN \\
\hline CHEMBL1362414 & 688636 & 5.5 & 4.8168 & TRN \\
\hline CHEMBL1444280 & 688636 & 4.4 & 4.6755 & TRN \\
\hline CHEMBL1523224 & 688636 & 4.5 & 4.7131 & TRN \\
\hline CHEMBL1582177 & 688636 & 6.25 & 4.8489 & TRN \\
\hline CHEMBL1586077 & 688636 & 5.3 & 4.704 & TRN \\
\hline CHEMBL1432924 & 688636 & 4.5 & 4.7689 & TRN \\
\hline CHEMBL1330339 & 688636 & 4.6 & 4.8929 & TRN \\
\hline CHEMBL1337308 & 688636 & 4.25 & 4.737 & TRN \\
\hline CHEMBL1542241 & 688636 & 4.85 & 4.7825 & TRN \\
\hline CHEMBL1343987 & 688636 & 5.95 & 4.8559 & TST \\
\hline CHEMBL1413962 & 688636 & 4.45 & 4.775 & TRN \\
\hline CHEMBL1479591 & 688636 & 4.45 & 4.8035 & TRN \\
\hline CHEMBL1410757 & 688636 & 4.4 & 4.7743 & TRN \\
\hline CHEMBL1582478 & 688636 & 6.8 & 4.9892 & TRN \\
\hline CHEMBL1605895 & 688636 & 4.55 & 4.7758 & TRN \\
\hline CHEMBL1445431 & 688636 & 4.45 & 4.6821 & TST \\
\hline CHEMBL1511388 & 688636 & 6.7501 & 4.9086 & TRN \\
\hline CHEMBL1421061 & 688636 & 5.2 & 4.8442 & TRN \\
\hline CHEMBL1492122 & 688636 & 4.3 & 4.8848 & TST \\
\hline CHEMBL1386030 & 688636 & 4.3 & 4.8193 & TST \\
\hline CHEMBL1446616 & 688636 & 4.95 & 4.8025 & TST \\
\hline CHEMBL596271 & 688636 & 5.5 & 4.8254 & TRN \\
\hline CHEMBL 3208198 & 688636 & 4.5 & 4.8691 & TRN \\
\hline CHEMBL1404385 & 688636 & 6.15 & 4.8648 & TRN \\
\hline CHEMBL1499839 & 688636 & 4.7 & 4.6826 & TST \\
\hline CHEMBL1969300 & 688636 & 4.5 & 4.8138 & TRN \\
\hline CHEMBL1528583 & 688636 & 5.4 & 4.8554 & TRN \\
\hline
\end{tabular}




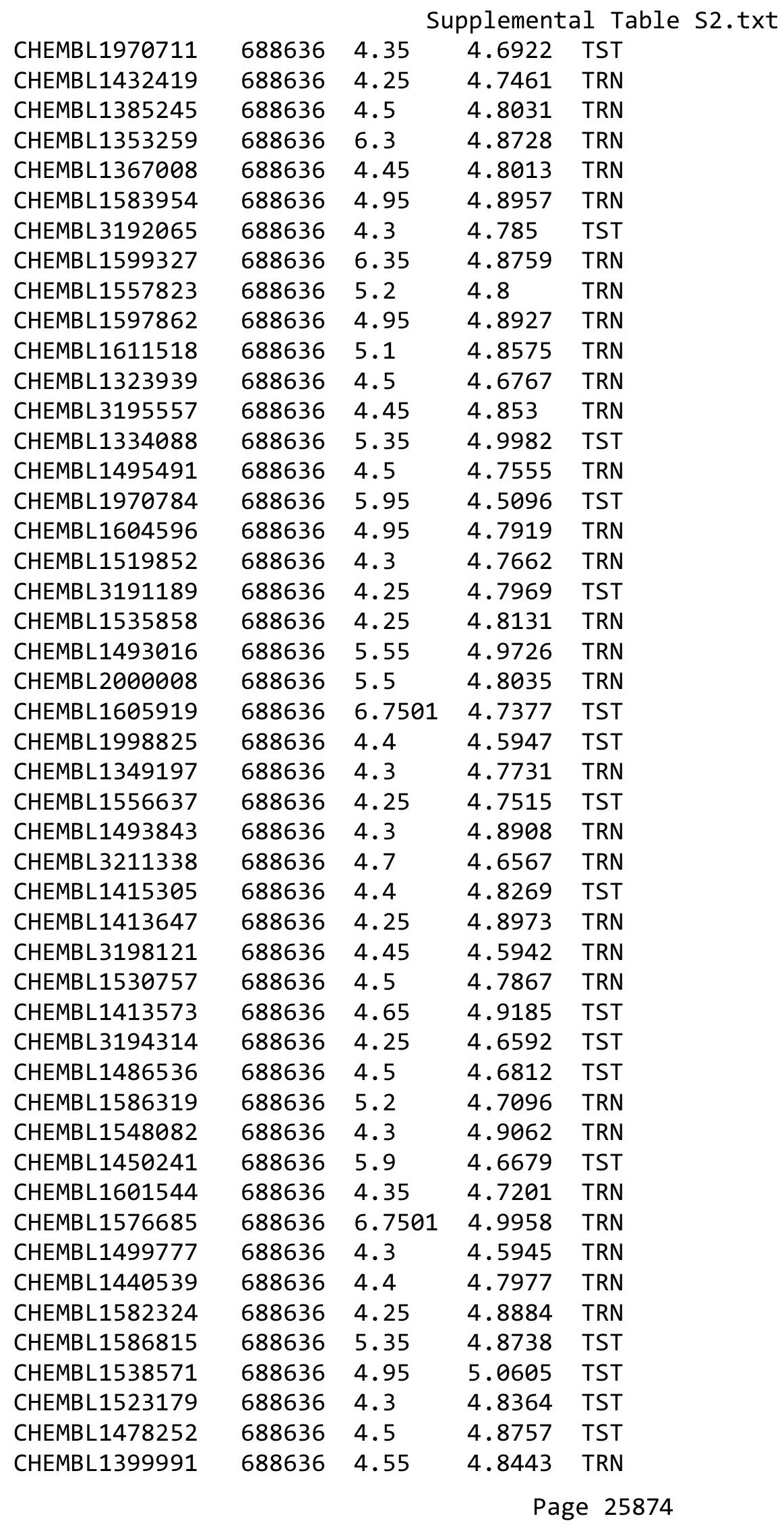




\begin{tabular}{|c|c|c|c|c|}
\hline & & & upplement & al $\mathrm{T}$ \\
\hline CHEMBL1587367 & 688636 & 5.45 & 4.7767 & TST \\
\hline CHEMBL1607629 & 688636 & 5.45 & 4.7845 & TRN \\
\hline CHEMBL1469859 & 688636 & 5.2 & 4.9048 & TRN \\
\hline CHEMBL561589 & 688636 & 5.2 & 4.752 & TRN \\
\hline CHEMBL1559342 & 688636 & 4.3 & 4.7611 & TRN \\
\hline CHEMBL1385575 & 688636 & 4.5 & 4.6669 & TRN \\
\hline CHEMBL1535408 & 688636 & 4.3 & 4.9031 & TST \\
\hline CHEMBL1559212 & 688636 & 4.35 & 4.775 & TRN \\
\hline CHEMBL1430336 & 688636 & 4.25 & 4.913 & TRN \\
\hline CHEMBL1338805 & 688636 & 5.45 & 4.8032 & TRN \\
\hline CHEMBL1521599 & 688636 & 4.3 & 4.8377 & TRN \\
\hline CHEMBL1326263 & 688636 & 4.6 & 4.8371 & TRN \\
\hline CHEMBL1464047 & 688636 & 4.25 & 5.0106 & TST \\
\hline CHEMBL1360170 & 688636 & 4.25 & 4.7464 & TRN \\
\hline CHEMBL1338069 & 688636 & 4.3 & 4.8488 & TRN \\
\hline CHEMBL1306967 & 688636 & 4.6 & 4.6168 & TRN \\
\hline CHEMBL1588098 & 688636 & 5.45 & 4.7916 & TRN \\
\hline CHEMBL1313282 & 688636 & 4.95 & 4.7607 & TST \\
\hline CHEMBL1487181 & 688636 & 4.7 & 4.9656 & TRN \\
\hline CHEMBL1329136 & 688636 & 4.4 & 4.6732 & TST \\
\hline CHEMBL1581055 & 688636 & 4.3 & 4.7983 & TST \\
\hline CHEMBL1608022 & 688636 & 5.4 & 4.9029 & TST \\
\hline CHEMBL1611909 & 688636 & 5.35 & 4.7323 & TST \\
\hline CHEMBL1389090 & 688636 & 4.25 & 4.8257 & TRN \\
\hline CHEMBL1596678 & 688636 & 4.25 & 4.9943 & TST \\
\hline CHEMBL1432137 & 688636 & 5.3 & 4.7659 & TRN \\
\hline CHEMBL1353205 & 688636 & 4.4 & 4.585 & TRN \\
\hline CHEMBL1423442 & 688636 & 4.4 & 4.7776 & TST \\
\hline CHEMBL1360226 & 688636 & 4.3 & 4.7169 & TRN \\
\hline CHEMBL1481564 & 688636 & 4.35 & 5.0967 & TST \\
\hline CHEMBL1523299 & 688636 & 4.55 & 4.8103 & TRN \\
\hline CHEMBL1420379 & 688636 & 5.0 & 4.7969 & TST \\
\hline CHEMBL1986893 & 688636 & 5.85 & 4.8171 & TST \\
\hline CHEMBL1402501 & 688636 & 4.3 & 4.7147 & TST \\
\hline CHEMBL1467088 & 688636 & 4.95 & 4.8272 & TRN \\
\hline CHEMBL1367155 & 688636 & 5.85 & 4.7456 & TRN \\
\hline CHEMBL1582645 & 688636 & 4.55 & 4.5209 & TRN \\
\hline CHEMBL1571529 & 688636 & 4.25 & 4.8995 & TST \\
\hline CHEMBL1464193 & 688636 & 5.25 & 4.5852 & TRN \\
\hline CHEMBL1380165 & 688636 & 5.05 & 4.7498 & TRN \\
\hline CHEMBL1566448 & 688636 & 5.35 & 4.8849 & TRN \\
\hline CHEMBL1966853 & 688636 & 4.4 & 4.6164 & TST \\
\hline CHEMBL1598630 & 688636 & 4.3 & 4.973 & TST \\
\hline CHEMBL3191786 & 688636 & 5.4 & 4.7686 & TST \\
\hline CHEMBL1487839 & 688636 & 4.45 & 4.6786 & TRN \\
\hline CHEMBL3198066 & 688636 & 4.25 & 4.6684 & TRN \\
\hline CHEMBL1463541 & 688636 & 4.8 & 4.7736 & TRN \\
\hline CHEMBL1331677 & 688636 & 4.6 & 4.8309 & TRN \\
\hline
\end{tabular}




\begin{tabular}{|c|c|c|c|c|}
\hline \multicolumn{5}{|c|}{ Supplemental Table S2.txt } \\
\hline CHEMBL1585792 & 688636 & 5.95 & 4.7444 & TRN \\
\hline CHEMBL1392302 & 688636 & 4.45 & 4.9831 & TRN \\
\hline CHEMBL1470471 & 688636 & 4.25 & 4.7007 & TST \\
\hline CHEMBL1349490 & 688636 & 4.25 & 4.8716 & TRN \\
\hline CHEMBL1530298 & 688636 & 5.5 & 5.044 & TST \\
\hline CHEMBL1459063 & 688636 & 4.25 & 4.7953 & TRN \\
\hline CHEMBL1525594 & 688636 & 4.95 & 5.0434 & TRN \\
\hline CHEMBL1407552 & 688636 & 4.3 & 4.6807 & TRN \\
\hline CHEMBL1468863 & 688636 & 6.0 & 4.8428 & TRN \\
\hline CHEMBL1321896 & 688636 & 4.75 & 4.7809 & TRN \\
\hline CHEMBL1328195 & 688636 & 4.65 & 4.6317 & TRN \\
\hline CHEMBL1419076 & 688636 & 4.3 & 4.9926 & TRN \\
\hline CHEMBL1369357 & 688636 & 4.6 & 4.7531 & TRN \\
\hline CHEMBL1537204 & 688636 & 4.5 & 4.692 & TRN \\
\hline CHEMBL1612736 & 688636 & 6.4 & 4.897 & TRN \\
\hline CHEMBL1341418 & 688636 & 4.25 & 4.9275 & TRN \\
\hline CHEMBL1483995 & 688636 & 4.25 & 4.7726 & TRN \\
\hline CHEMBL1603477 & 688636 & 4.4 & 4.9071 & TRN \\
\hline CHEMBL1479499 & 688636 & 4.3 & 4.8293 & TRN \\
\hline CHEMBL1401334 & 688636 & 4.3 & 4.8973 & TRN \\
\hline CHEMBL1418276 & 688636 & 5.85 & 4.7378 & TRN \\
\hline CHEMBL1400969 & 688636 & 5.1 & 4.8588 & TST \\
\hline CHEMBL1415654 & 688636 & 4.3 & 4.6878 & TRN \\
\hline CHEMBL1595148 & 688636 & 5.15 & 4.6597 & TST \\
\hline CHEMBL1608784 & 688636 & 5.5 & 4.7545 & TST \\
\hline CHEMBL1482989 & 688636 & 4.7 & 4.7072 & TRN \\
\hline CHEMBL3199854 & 688636 & 4.95 & 4.6662 & TRN \\
\hline CHEMBL1450177 & 688636 & 5.45 & 4.9043 & TRN \\
\hline CHEMBL1390706 & 688636 & 4.45 & 4.812 & TRN \\
\hline CHEMBL3191686 & 688636 & 4.25 & 4.8427 & TRN \\
\hline CHEMBL1446669 & 688636 & 4.4 & 4.9948 & TRN \\
\hline CHEMBL1326967 & 688636 & 4.45 & 4.6756 & TRN \\
\hline CHEMBL1565940 & 688636 & 5.35 & 4.904 & TRN \\
\hline CHEMBL 3198017 & 688636 & 4.65 & 4.729 & TST \\
\hline CHEMBL1519864 & 688636 & 4.25 & 4.8927 & TST \\
\hline CHEMBL1520377 & 688636 & 4.45 & 4.8016 & TRN \\
\hline CHEMBL1447306 & 688636 & 6.3 & 4.7309 & TST \\
\hline CHEMBL1426501 & 688636 & 4.55 & 4.8068 & TRN \\
\hline CHEMBL1428636 & 688636 & 4.5 & 4.7811 & TRN \\
\hline CHEMBL3392060 & 688636 & 6.05 & 4.8822 & TST \\
\hline CHEMBL1543886 & 688636 & 4.35 & 4.7592 & TRN \\
\hline CHEMBL1313033 & 688636 & 4.3 & 4.6545 & TST \\
\hline CHEMBL1532480 & 688636 & 4.25 & 4.5987 & TRN \\
\hline CHEMBL1446469 & 688636 & 4.65 & 4.8723 & TRN \\
\hline CHEMBL1421217 & 688636 & 4.55 & 4.7099 & TRN \\
\hline CHEMBL3211327 & 688636 & 4.7 & 4.6887 & TRN \\
\hline CHEMBL1352493 & 688636 & 6.2 & 4.9763 & TST \\
\hline CHEMBL1471888 & 688636 & 5.45 & 4.7266 & TRN \\
\hline
\end{tabular}




\begin{tabular}{|c|c|c|c|c|c|}
\hline & & \multicolumn{4}{|c|}{ Supplemental Table S2.txt } \\
\hline CHEMBL1547658 & 688636 & 4.35 & 4.6415 & TRN & \\
\hline CHEMBL1540231 & 688636 & 4.7 & 4.9299 & TRN & \\
\hline CHEMBL1364212 & 688636 & 5.5 & 4.6064 & TRN & \\
\hline CHEMBL447958 & 688636 & 5.6 & 4.86600 & 00000000005 & TST \\
\hline CHEMBL3209231 & 688636 & 4.25 & 4.7259 & TST & \\
\hline CHEMBL3191927 & 688636 & 4.95 & 4.8393 & TST & \\
\hline CHEMBL1307208 & 688636 & 4.65 & 4.8248 & TRN & \\
\hline CHEMBL1453739 & 688636 & 4.45 & 4.7782 & TRN & \\
\hline CHEMBL1540684 & 688636 & 4.45 & 4.7791 & TRN & \\
\hline CHEMBL1530389 & 688636 & 4.95 & 4.7465 & TRN & \\
\hline CHEMBL1421101 & 688636 & 4.75 & 4.8103 & TRN & \\
\hline CHEMBL1450920 & 688636 & 4.6 & 4.6857 & TRN & \\
\hline CHEMBL1964836 & 688636 & 4.9 & 4.7502 & TST & \\
\hline CHEMBL1545126 & 688636 & 4.45 & 4.9254 & TRN & \\
\hline CHEMBL1451004 & 688636 & 4.55 & 4.805 & TRN & \\
\hline CHEMBL1587788 & 688636 & 4.55 & 4.6885 & TRN & \\
\hline CHEMBL1301573 & 688636 & 4.6 & 4.6768 & TRN & \\
\hline CHEMBL1350868 & 688636 & 4.95 & 4.886 & TRN & \\
\hline CHEMBL1429076 & 688636 & 4.4 & 4.7162 & TRN & \\
\hline CHEMBL1340886 & 688636 & 4.5 & 4.7073 & TRN & \\
\hline CHEMBL1348241 & 688636 & 4.55 & 4.6841 & TRN & \\
\hline CHEMBL1463789 & 688636 & 5.05 & 4.8348 & TRN & \\
\hline CHEMBL1575084 & 688636 & 4.55 & 4.7743 & TRN & \\
\hline CHEMBL1595593 & 688636 & 4.25 & 4.7961 & TRN & \\
\hline CHEMBL1400284 & 688636 & 4.25 & 4.9476 & TRN & \\
\hline CHEMBL1485618 & 688636 & 4.25 & 4.8411 & TRN & \\
\hline CHEMBL1579902 & 688636 & 5.6 & 4.836 & TST & \\
\hline CHEMBL3212591 & 688636 & 4.3 & 4.7786 & TST & \\
\hline CHEMBL1424440 & 688636 & 6.4 & 4.8074 & TRN & \\
\hline CHEMBL1469206 & 688636 & 4.3 & 4.8392 & TRN & \\
\hline CHEMBL1416972 & 688636 & 4.3 & 4.8997 & TRN & \\
\hline CHEMBL1328498 & 688636 & 4.3 & 4.9494 & TRN & \\
\hline CHEMBL531709 & 688636 & 6.05 & 4.6189 & TRN & \\
\hline CHEMBL1375455 & 688636 & 4.45 & 4.7321 & TRN & \\
\hline CHEMBL1332721 & 688636 & 4.4 & 4.9055 & TRN & \\
\hline CHEMBL1372312 & 688636 & 4.95 & 4.9991 & TRN & \\
\hline CHEMBL1383237 & 688636 & 5.3 & 4.8491 & TRN & \\
\hline CHEMBL1485196 & 688636 & 4.5 & 4.887 & TST & \\
\hline CHEMBL3195697 & 688636 & 5.45 & 4.7189 & TRN & \\
\hline CHEMBL1347673 & 688636 & 4.3 & 4.6613 & TST & \\
\hline CHEMBL1380338 & 688636 & 5.0 & 4.8824 & TRN & \\
\hline CHEMBL1328051 & 688636 & 5.4 & 4.8761 & TST & \\
\hline CHEMBL1493530 & 688636 & 4.5 & 4.6138 & TRN & \\
\hline CHEMBL1328967 & 688636 & 4.55 & 4.8013 & TRN & \\
\hline CHEMBL1538067 & 688636 & 5.8 & 4.8207 & TST & \\
\hline CHEMBL1485804 & 688636 & 6.15 & 4.8206 & TRN & \\
\hline CHEMBL1390314 & 688636 & 4.9 & 4.9273 & TRN & \\
\hline CHEMBL1485132 & 688636 & 4.3 & 4.7093 & TRN & \\
\hline
\end{tabular}




\begin{tabular}{|c|c|c|c|c|c|}
\hline \multicolumn{6}{|c|}{ Supplemental Table S2.txt } \\
\hline CHEMBL1574541 & 688636 & 4.65 & 4.9052 & TST & \\
\hline CHEMBL1312737 & 688636 & 4.5 & 4.5372 & TRN & \\
\hline CHEMBL1487259 & 688636 & 5.15 & 4.7478 & TST & \\
\hline CHEMBL1521608 & 688636 & 4.4 & 4.7832 & TST & \\
\hline CHEMBL1544136 & 688636 & 4.25 & 4.5956 & TRN & \\
\hline CHEMBL1529671 & 688636 & 4.55 & 4.6707 & TRN & \\
\hline CHEMBL1483981 & 688636 & 4.95 & 4.9347 & TST & \\
\hline CHEMBL1568453 & 688636 & 5.25 & 4.9362 & TRN & \\
\hline CHEMBL1336368 & 688636 & 4.3 & 4.8943 & TRN & \\
\hline CHEMBL588907 & 688636 & 6.8 & 4.756 & TST & \\
\hline CHEMBL1570359 & 688636 & 4.5 & 4.9264 & TST & \\
\hline CHEMBL1380272 & 688636 & 4.25 & 4.9704 & TRN & \\
\hline CHEMBL1307196 & 688636 & 4.75 & 4.8881 & TRN & \\
\hline CHEMBL1467138 & 688636 & 4.65 & 4.8007 & TRN & \\
\hline CHEMBL1557485 & 688636 & 6.2 & 4.8289 & TST & \\
\hline CHEMBL1387007 & 688636 & 5.2 & 4.9333 & TST & \\
\hline CHEMBL1383950 & 688636 & 5.15 & 4.6715 & TRN & \\
\hline CHEMBL1379013 & 688636 & 4.85 & 4.7304 & TRN & \\
\hline CHEMBL1411234 & 688636 & 4.6 & 4.8068 & TRN & \\
\hline CHEMBL1501828 & 688636 & 4.3 & 5.0107 & TRN & \\
\hline CHEMBL1338596 & 688636 & 4.3 & 4.7303 & TST & \\
\hline CHEMBL1429805 & 688636 & 6.35 & 4.8129 & TRN & \\
\hline CHEMBL1421540 & 688636 & 6.7501 & 4.8644 & TST & \\
\hline CHEMBL3190899 & 688636 & 4.55 & 4.7794 & TRN & \\
\hline CHEMBL1314084 & 688636 & 4.35 & 5.0083 & TRN & \\
\hline CHEMBL1546760 & 688636 & 4.3 & 4.8403 & TST & \\
\hline CHEMBL1342247 & 688636 & 4.25 & 4.8064 & TRN & \\
\hline CHEMBL1509725 & 688636 & 4.3 & 4.8488 & TRN & \\
\hline CHEMBL1587712 & 688636 & 6.4 & 5.0559 & TRN & \\
\hline CHEMBL1365303 & 688636 & 4.95 & 4.8052 & TST & \\
\hline CHEMBL1326776 & 688636 & 5.05 & 4.8485 & TRN & \\
\hline CHEMBL1425691 & 688636 & 4.45 & 4.7557 & TRN & \\
\hline CHEMBL1300832 & 688636 & 4.7 & 4.80699 & 99999999995 & TRN \\
\hline CHEMBL1518192 & 688636 & 4.25 & 4.8845 & TST & \\
\hline CHEMBL1309123 & 688636 & 4.95 & 4.936 & TRN & \\
\hline CHEMBL1563187 & 688636 & 4.55 & 5.0341 & TRN & \\
\hline CHEMBL1573961 & 688636 & 4.45 & 4.8267 & TRN & \\
\hline CHEMBL1305292 & 688636 & 4.75 & 4.7275 & TRN & \\
\hline CHEMBL1369392 & 688636 & 4.45 & 4.6238 & TRN & \\
\hline CHEMBL 3189262 & 688636 & 4.25 & 4.6654 & TRN & \\
\hline CHEMBL1414942 & 688636 & 5.25 & 4.6937 & TRN & \\
\hline CHEMBL1594871 & 688636 & 5.55 & 4.7771 & TRN & \\
\hline CHEMBL3209943 & 688636 & 4.25 & 4.702 & TRN & \\
\hline CHEMBL1323481 & 688636 & 6.2 & 4.961 & TRN & \\
\hline CHEMBL1562147 & 688636 & 4.25 & 4.93 & TST & \\
\hline CHEMBL1549698 & 688636 & 4.3 & 4.7199 & TRN & \\
\hline CHEMBL1365822 & 688636 & 4.65 & 4.7416 & TRN & \\
\hline CHEMBL1299606 & 688636 & 4.45 & 4.7631 & TRN & \\
\hline
\end{tabular}




\begin{tabular}{|c|c|c|c|c|c|}
\hline \multicolumn{6}{|c|}{ Supplemental Table S2.txt } \\
\hline CHEMBL1574756 & 688636 & 4.25 & 4.7745 & TRN & \\
\hline CHEMBL1323772 & 688636 & 4.45 & 4.7659 & TRN & \\
\hline CHEMBL1410774 & 688636 & 4.65 & 4.8546 & TRN & \\
\hline CHEMBL1378329 & 688636 & 4.55 & 4.8623 & TRN & \\
\hline CHEMBL1496326 & 688636 & 4.25 & 4.9422 & TST & \\
\hline CHEMBL1468124 & 688636 & 4.55 & 4.6831 & TRN & \\
\hline CHEMBL1452412 & 688636 & 4.25 & 5.0065 & TRN & \\
\hline CHEMBL1442150 & 688636 & 4.25 & 4.80699 & 99999999995 & TRN \\
\hline CHEMBL1413452 & 688636 & 4.95 & 4.9807 & TRN & \\
\hline CHEMBL1370443 & 688636 & 4.25 & 4.8126 & TRN & \\
\hline CHEMBL1348305 & 688636 & 5.1 & 4.7193 & TRN & \\
\hline CHEMBL3207353 & 688636 & 5.3 & 4.8075 & TRN & \\
\hline CHEMBL1414317 & 688636 & 5.55 & 4.8325 & TST & \\
\hline CHEMBL1498142 & 688636 & 5.4 & 4.8335 & TST & \\
\hline CHEMBL1575355 & 688636 & 5.2 & 4.8633 & TRN & \\
\hline CHEMBL1502567 & 688636 & 4.5 & 4.7736 & TRN & \\
\hline CHEMBL1390315 & 688636 & 4.25 & 4.7605 & TRN & \\
\hline CHEMBL1339387 & 688636 & 5.0 & 4.8521 & TRN & \\
\hline CHEMBL1425249 & 688636 & 5.3 & 4.912 & TRN & \\
\hline CHEMBL1538818 & 688636 & 4.95 & 4.8921 & TST & \\
\hline CHEMBL1529825 & 688636 & 5.05 & 4.8335 & TST & \\
\hline CHEMBL3190178 & 688636 & 4.25 & 4.8514 & TST & \\
\hline CHEMBL1569740 & 688636 & 5.2 & 4.8474 & TRN & \\
\hline CHEMBL1416187 & 688636 & 4.45 & 4.709 & TRN & \\
\hline CHEMBL1378414 & 688636 & 4.65 & 4.8118 & TRN & \\
\hline CHEMBL1423313 & 688636 & 5.05 & 5.0369 & TRN & \\
\hline CHEMBL1371258 & 688636 & 4.6 & 4.6546 & TRN & \\
\hline CHEMBL1545071 & 688636 & 4.55 & 4.6672 & TRN & \\
\hline CHEMBL1539724 & 688636 & 4.4 & 4.8515 & TST & \\
\hline CHEMBL3193814 & 688636 & 6.7501 & 4.7666 & TST & \\
\hline CHEMBL1486039 & 688636 & 5.2 & 4.913 & TST & \\
\hline CHEMBL1444202 & 688636 & 4.9 & 4.7357 & TRN & \\
\hline CHEMBL1461207 & 688636 & 4.25 & 4.9171 & TST & \\
\hline CHEMBL1424196 & 688636 & 4.6 & 4.7266 & TRN & \\
\hline CHEMBL1486181 & 688636 & 4.45 & 4.6771 & TRN & \\
\hline CHEMBL1509378 & 688636 & 4.6 & 5.0187 & TRN & \\
\hline CHEMBL1556150 & 688636 & 4.3 & 4.8485 & TRN & \\
\hline CHEMBL1445562 & 688636 & 4.95 & 4.7162 & TRN & \\
\hline CHEMBL1375144 & 688636 & 4.25 & 4.8984 & TRN & \\
\hline CHEMBL1376177 & 688636 & 4.95 & 4.7089 & TRN & \\
\hline CHEMBL1323577 & 688636 & 4.25 & 4.8464 & TRN & \\
\hline CHEMBL1419013 & 688636 & 5.7 & 4.768 & TRN & \\
\hline CHEMBL1362310 & 688636 & 4.3 & 4.9668 & TRN & \\
\hline CHEMBL1486981 & 688636 & 4.25 & 4.7743 & TRN & \\
\hline CHEMBL1612163 & 688636 & 4.9 & 4.7148 & TRN & \\
\hline CHEMBL1472246 & 688636 & 5.85 & 4.8593 & TRN & \\
\hline CHEMBL1378953 & 688636 & 4.3 & 4.5327 & TST & \\
\hline CHEMBL1405174 & 688636 & 4.25 & 4.8751 & TST & \\
\hline
\end{tabular}




\begin{tabular}{|c|c|c|c|c|}
\hline \multicolumn{5}{|c|}{ Supplemental Table S2.txt } \\
\hline CHEMBL1560342 & 688636 & 6.8 & 4.8283 & TRN \\
\hline CHEMBL1334940 & 688636 & 4.45 & 4.6517 & TRN \\
\hline CHEMBL1557795 & 688636 & 5.45 & 4.6987 & TRN \\
\hline CHEMBL1503340 & 688636 & 4.95 & 4.7725 & TST \\
\hline CHEMBL1441603 & 688636 & 6.05 & 4.8121 & TRN \\
\hline CHEMBL1559138 & 688636 & 4.3 & 4.797 & TRN \\
\hline CHEMBL1365687 & 688636 & 4.95 & 4.9462 & TRN \\
\hline CHEMBL1341503 & 688636 & 4.95 & 4.7536 & TST \\
\hline CHEMBL1566078 & 688636 & 4.7 & 4.7328 & TRN \\
\hline CHEMBL1470935 & 688636 & 4.45 & 4.7811 & TRN \\
\hline CHEMBL1386700 & 688636 & 5.3 & 4.7367 & TRN \\
\hline CHEMBL1491218 & 688636 & 6.6 & 4.7912 & TRN \\
\hline CHEMBL1478707 & 688636 & 4.45 & 4.9301 & TRN \\
\hline CHEMBL1532729 & 688636 & 4.55 & 4.9538 & TRN \\
\hline CHEMBL2003886 & 688636 & 4.55 & 4.6909 & TRN \\
\hline CHEMBL1569473 & 688636 & 4.55 & 4.6812 & TST \\
\hline CHEMBL3208130 & 688636 & 4.6 & 4.8337 & TRN \\
\hline CHEMBL1389242 & 688636 & 5.25 & 4.8368 & TRN \\
\hline CHEMBL1299343 & 688636 & 4.75 & 4.8563 & TRN \\
\hline CHEMBL1585091 & 688636 & 4.45 & 4.7983 & TRN \\
\hline CHEMBL1469581 & 688636 & 4.5 & 4.6676 & TRN \\
\hline CHEMBL1363711 & 688636 & 4.95 & 4.6818 & TRN \\
\hline CHEMBL1349049 & 688636 & 4.25 & 4.8229 & TRN \\
\hline CHEMBL1421837 & 688636 & 4.55 & 4.7691 & TST \\
\hline CHEMBL1410641 & 688636 & 4.95 & 4.8577 & TST \\
\hline CHEMBL1569912 & 688636 & 4.95 & 4.9142 & TRN \\
\hline CHEMBL1322296 & 688636 & 4.6 & 4.7449 & TST \\
\hline CHEMBL1365495 & 688636 & 4.8 & 4.7883 & TRN \\
\hline CHEMBL1419872 & 688636 & 4.5 & 4.7149 & TRN \\
\hline CHEMBL1489843 & 688636 & 4.95 & 4.7664 & TRN \\
\hline CHEMBL1484168 & 688636 & 4.3 & 4.9349 & TRN \\
\hline CHEMBL1352458 & 688636 & 4.4 & 4.7148 & TRN \\
\hline CHEMBL1454710 & 688636 & 4.9 & 4.8999 & TRN \\
\hline CHEMBL1524758 & 688636 & 4.95 & 4.7672 & TST \\
\hline CHEMBL3212782 & 688636 & 4.35 & 4.8157 & TST \\
\hline CHEMBL1382272 & 688636 & 4.25 & 5.016 & TST \\
\hline CHEMBL 220009 & 688636 & 4.25 & 4.9956 & TRN \\
\hline CHEMBL1351880 & 688636 & 5.3 & 5.0917 & TRN \\
\hline CHEMBL1533037 & 688636 & 4.55 & 4.69 & TRN \\
\hline CHEMBL3208858 & 688636 & 4.95 & 4.8156 & TST \\
\hline CHEMBL1501053 & 688636 & 4.7 & 4.7647 & TRN \\
\hline CHEMBL1422725 & 688636 & 4.95 & 4.8445 & TRN \\
\hline CHEMBL3192311 & 688636 & 4.35 & 4.7397 & TRN \\
\hline CHEMBL1334065 & 688636 & 4.55 & 4.7986 & TRN \\
\hline CHEMBL1392911 & 688636 & 4.3 & 4.7467 & TRN \\
\hline CHEMBL1984894 & 688636 & 4.95 & 4.8629 & TST \\
\hline CHEMBL1538417 & 688636 & 5.95 & 4.6367 & TST \\
\hline CHEMBL1544483 & 688636 & 4.5 & 4.8951 & TRN \\
\hline
\end{tabular}




\begin{tabular}{|c|c|c|c|c|c|}
\hline CHEMBL1983886 & 688636 & 4.3 & 4.7416 & TRN & \\
\hline CHEMBL1536158 & 688636 & 5.2 & \multicolumn{2}{|c|}{4.928999999999999} & TRN \\
\hline CHEMBL1602224 & 688636 & 4.25 & 4.7226 & TRN & \\
\hline CHEMBL 3195020 & 688636 & 4.45 & 4.7656 & TRN & \\
\hline CHEMBL1497485 & 688636 & 4.25 & 4.9432 & TRN & \\
\hline CHEMBL1360092 & 688636 & 4.25 & 4.9728 & TRN & \\
\hline CHEMBL3214016 & 688636 & 5.35 & 4.8397 & TRN & \\
\hline CHEMBL1343685 & 688636 & 4.3 & 4.6535 & TRN & \\
\hline CHEMBL1491751 & 688636 & 4.3 & 4.9298 & TRN & \\
\hline CHEMBL1538462 & 688636 & 4.25 & 4.975 & TST & \\
\hline CHEMBL1462470 & 688636 & 6.15 & 4.6428 & TRN & \\
\hline CHEMBL1608965 & 688636 & 4.3 & 4.928 & TRN & \\
\hline CHEMBL1374259 & 688636 & 5.9 & 4.9529 & TRN & \\
\hline CHEMBL1497597 & 688636 & 6.15 & 4.8468 & TRN & \\
\hline CHEMBL1299309 & 688636 & 5.45 & 4.8727 & TRN & \\
\hline CHEMBL1310485 & 688636 & 4.35 & 4.7853 & TRN & \\
\hline CHEMBL1459197 & 688636 & 5.35 & 4.8048 & TRN & \\
\hline CHEMBL1455253 & 688636 & 4.95 & 4.6155 & TRN & \\
\hline CHEMBL1312376 & 688636 & 4.3 & \multicolumn{2}{|c|}{4.968999999999999} & TRN \\
\hline CHEMBL1350552 & 688636 & 4.35 & 4.8115 & TRN & \\
\hline CHEMBL1299932 & 688636 & 4.25 & 5.041 & TRN & \\
\hline CHEMBL1468336 & 688636 & 6.7501 & 4.8513 & TST & \\
\hline CHEMBL1493906 & 688636 & 4.25 & 4.6863 & TRN & \\
\hline CHEMBL1417714 & 688636 & 4.5 & 4.8556 & TRN & \\
\hline CHEMBL1352812 & 688636 & 4.9 & 5.0969 & TRN & \\
\hline CHEMBL1379176 & 688636 & 5.95 & 5.0461 & TST & \\
\hline CHEMBL1401824 & 688636 & 5.35 & 4.9502 & TRN & \\
\hline CHEMBL1432042 & 688636 & 4.35 & 4.7274 & TRN & \\
\hline CHEMBL1485732 & 688636 & 4.9 & 4.7299 & TRN & \\
\hline CHEMBL1401094 & 688636 & 4.3 & 4.7819 & TRN & \\
\hline CHEMBL1530054 & 688636 & 4.6 & 4.7789 & TRN & \\
\hline CHEMBL1420982 & 688636 & 5.45 & 5.0084 & TST & \\
\hline CHEMBL1571563 & 688636 & 4.5 & 4.8339 & TRN & \\
\hline CHEMBL1344335 & 688636 & 4.35 & 4.7072 & TRN & \\
\hline CHEMBL1377641 & 688636 & 4.25 & 4.7655 & TST & \\
\hline CHEMBL1428212 & 688636 & 4.3 & 4.6859 & TRN & \\
\hline CHEMBL1550190 & 688636 & 4.4 & 4.7619 & TRN & \\
\hline CHEMBL1504738 & 688636 & 4.75 & 4.6412 & TRN & \\
\hline CHEMBL1420007 & 688636 & 6.7501 & 4.9355 & TST & \\
\hline CHEMBL1578722 & 688636 & 4.3 & 4.7834 & TRN & \\
\hline CHEMBL38739 & 688636 & 5.0 & 4.8201 & TST & \\
\hline CHEMBL1575661 & 688636 & 4.55 & 4.9057 & TRN & \\
\hline CHEMBL1431276 & 688636 & 4.35 & 4.7434 & TRN & \\
\hline CHEMBL1350496 & 688636 & 4.3 & 4.6814 & TRN & \\
\hline CHEMBL1540894 & 688636 & 4.3 & 4.7568 & TRN & \\
\hline CHEMBL1443681 & 688636 & 4.3 & 4.7362 & TRN & \\
\hline CHEMBL1380946 & 688636 & 4.4 & 4.6977 & TRN & \\
\hline CHEMBL1425367 & 688636 & 5.5 & 4.8229 & TRN & \\
\hline
\end{tabular}




\begin{tabular}{|c|c|c|c|c|c|}
\hline \multicolumn{6}{|c|}{ oplemental Table Sz } \\
\hline CHEMBL1516997 & 688636 & 4.55 & 5.026 & TRN & \\
\hline CHEMBL1546668 & 688636 & 5.1 & 4.6811 & TST & \\
\hline CHEMBL1587630 & 688636 & 4.3 & 4.7477 & TRN & \\
\hline CHEMBL1503672 & 688636 & 4.5 & 4.607 & TRN & \\
\hline CHEMBL1530671 & 688636 & 4.45 & 4.7348 & TRN & \\
\hline CHEMBL1404961 & 688636 & 4.95 & 4.8614 & TRN & \\
\hline CHEMBL1420813 & 688636 & 5.9 & 4.9055 & TRN & \\
\hline CHEMBL1421681 & 688636 & 5.8 & 4.7242 & TRN & \\
\hline CHEMBL1370974 & 688636 & 4.4 & 4.9017 & TRN & \\
\hline CHEMBL1417160 & 688636 & 5.1 & 4.7609 & TST & \\
\hline CHEMBL1305429 & 688636 & 6.1 & 4.9546 & TRN & \\
\hline CHEMBL1608832 & 688636 & 4.3 & 4.83 & TRN & \\
\hline CHEMBL1411123 & 688636 & 4.4 & 4.8675 & TRN & \\
\hline CHEMBL1483780 & 688636 & 4.5 & 4.9215 & TRN & \\
\hline CHEMBL1583632 & 688636 & 5.15 & 4.8368 & TRN & \\
\hline CHEMBL1331740 & 688636 & 5.45 & 4.7846 & TRN & \\
\hline CHEMBL1518328 & 688636 & 4.3 & 4.9862 & TST & \\
\hline CHEMBL1411779 & 688636 & 4.45 & 4.7492 & TRN & \\
\hline CHEMBL1601765 & 688636 & 4.3 & 4.7014 & TRN & \\
\hline CHEMBL1423870 & 688636 & 4.4 & 4.6766 & TRN & \\
\hline CHEMBL1482670 & 688636 & 4.55 & 4.7435 & TRN & \\
\hline CHEMBL1460317 & 688636 & 5.5 & 4.80699 & 99999999995 & TST \\
\hline CHEMBL1381547 & 688636 & 4.25 & 4.6926 & TRN & \\
\hline CHEMBL1531691 & 688636 & 6.1 & 4.7528 & TRN & \\
\hline CHEMBL1467840 & 688636 & 4.35 & 4.5998 & TRN & \\
\hline CHEMBL1339108 & 688636 & 5.15 & 4.8817 & TST & \\
\hline CHEMBL1528460 & 688636 & 5.65 & 4.8799 & TST & \\
\hline CHEMBL1454703 & 688636 & 6.7501 & 4.8053 & TRN & \\
\hline CHEMBL1418995 & 688636 & 4.35 & 4.7139 & TST & \\
\hline CHEMBL1299441 & 688636 & 4.3 & 4.8171 & TST & \\
\hline CHEMBL1581558 & 688636 & 5.2 & 4.8538 & TRN & \\
\hline CHEMBL1301377 & 688636 & 4.35 & 4.8325 & TRN & \\
\hline CHEMBL1411667 & 688636 & 5.2 & 4.7259 & TST & \\
\hline CHEMBL1477193 & 688636 & 4.95 & 4.6039 & TST & \\
\hline CHEMBL1323743 & 688636 & 4.5 & 4.9725 & TRN & \\
\hline CHEMBL1299711 & 688636 & 4.6 & 4.8024 & TRN & \\
\hline CHEMBL1587977 & 688636 & 4.25 & 4.8711 & TRN & \\
\hline CHEMBL1448451 & 688636 & 4.3 & 4.7807 & TRN & \\
\hline CHEMBL1344204 & 688636 & 4.75 & 4.7115 & TRN & \\
\hline CHEMBL1381967 & 688636 & 4.65 & 4.6879 & TRN & \\
\hline CHEMBL1578661 & 688636 & 4.25 & 4.8426 & TRN & \\
\hline CHEMBL1460452 & 688636 & 4.25 & 4.5865 & TRN & \\
\hline CHEMBL1382225 & 688636 & 4.95 & 4.6911 & TRN & \\
\hline CHEMBL1313512 & 688636 & 4.3 & 4.7284 & TRN & \\
\hline CHEMBL1557520 & 688636 & 4.25 & 4.7672 & TRN & \\
\hline CHEMBL1337035 & 688636 & 4.45 & 4.6761 & TRN & \\
\hline CHEMBL1433128 & 688636 & 4.35 & 4.737 & TRN & \\
\hline CHEMBL1359188 & 688636 & 5.95 & 4.9029 & TRN & \\
\hline
\end{tabular}




\begin{tabular}{|c|c|c|c|c|}
\hline & & & premer & \\
\hline CHEMBL3199448 & 688636 & 4.8 & 4.6692 & TRN \\
\hline CHEMBL1577827 & 688636 & 6.5 & 4.9214 & TRN \\
\hline CHEMBL1504661 & 688636 & 4.25 & 4.7863 & TRN \\
\hline CHEMBL1375301 & 688636 & 6.7501 & 4.882 & TST \\
\hline CHEMBL1493374 & 688636 & 4.25 & 4.8513 & TST \\
\hline CHEMBL1608732 & 688636 & 4.3 & 4.7454 & TST \\
\hline CHEMBL1509500 & 688636 & 4.95 & 4.7576 & TRN \\
\hline CHEMBL1487077 & 688636 & 4.95 & 4.9177 & TRN \\
\hline CHEMBL1580948 & 688636 & 4.55 & 4.8275 & TST \\
\hline CHEMBL1483733 & 688636 & 4.3 & 4.8348 & TRN \\
\hline CHEMBL1491378 & 688636 & 5.25 & 4.8901 & TRN \\
\hline CHEMBL1442927 & 688636 & 6.35 & 4.8758 & TRN \\
\hline CHEMBL1524040 & 688636 & 5.9 & 4.8037 & TRN \\
\hline CHEMBL1887938 & 688636 & 4.6 & 4.774 & TRN \\
\hline CHEMBL1520408 & 688636 & 4.25 & 4.9786 & TST \\
\hline CHEMBL1348577 & 688636 & 4.25 & 4.9082 & TRN \\
\hline CHEMBL1453231 & 688636 & 4.4 & 4.6963 & TRN \\
\hline CHEMBL1346163 & 688636 & 4.55 & 4.9799 & TRN \\
\hline CHEMBL1480661 & 688636 & 4.25 & 4.774 & TRN \\
\hline CHEMBL1578704 & 688636 & 4.3 & 4.8747 & TST \\
\hline CHEMBL1611633 & 688636 & 4.25 & 4.7882 & TRN \\
\hline CHEMBL1392688 & 688636 & 4.25 & 4.9513 & TRN \\
\hline CHEMBL1560276 & 688636 & 4.5 & 4.7008 & TRN \\
\hline CHEMBL1350774 & 688636 & 4.5 & 4.6989 & TRN \\
\hline CHEMBL483324 & 688636 & 4.25 & 5.0067 & TRN \\
\hline CHEMBL1594411 & 688636 & 4.25 & 5.0248 & TST \\
\hline CHEMBL1486813 & 688636 & 4.55 & 4.7351 & TRN \\
\hline CHEMBL3211540 & 688636 & 6.7501 & 4.6976 & TRN \\
\hline CHEMBL1492868 & 688636 & 4.4 & 4.9302 & TRN \\
\hline CHEMBL1555875 & 688636 & 5.4 & 5.0572 & TRN \\
\hline CHEMBL3210377 & 688636 & 4.7 & 4.811 & TST \\
\hline CHEMBL3195143 & 688636 & 5.95 & 4.7962 & TRN \\
\hline CHEMBL1441400 & 688636 & 4.3 & 4.7237 & TRN \\
\hline CHEMBL1331718 & 688636 & 4.25 & 4.6038 & TST \\
\hline CHEMBL1352845 & 688636 & 4.45 & 4.8346 & TRN \\
\hline CHEMBL1351283 & 688636 & 4.6 & 4.9375 & TRN \\
\hline CHEMBL1789996 & 688636 & 5.15 & 4.9051 & TST \\
\hline CHEMBL1572925 & 688636 & 4.85 & 4.8257 & TRN \\
\hline CHEMBL1330661 & 688636 & 4.45 & 4.6319 & TRN \\
\hline CHEMBL1374235 & 688636 & 4.95 & 4.7581 & TRN \\
\hline CHEMBL329872 & 688636 & 4.3 & 4.8222 & TRN \\
\hline CHEMBL1470820 & 688636 & 4.25 & 4.7777 & TRN \\
\hline CHEMBL1504621 & 688636 & 4.3 & 4.8916 & TST \\
\hline CHEMBL1611398 & 688636 & 4.65 & 4.8746 & TRN \\
\hline CHEMBL1343883 & 688636 & 4.25 & 4.7831 & TRN \\
\hline CHEMBL1562711 & 688636 & 4.95 & 4.76 & TRN \\
\hline CHEMBL3211179 & 688636 & 4.45 & 4.5185 & TRN \\
\hline CHEMBL1536614 & 688636 & 6.1 & 4.8693 & TST \\
\hline
\end{tabular}




\begin{tabular}{|c|c|c|c|c|c|}
\hline \multicolumn{6}{|c|}{ Supplemental Table S2.txt } \\
\hline CHEMBL1415670 & 688636 & 4.75 & 4.689 & TRN & \\
\hline CHEMBL1498327 & 688636 & 4.35 & 4.8812 & TST & \\
\hline CHEMBL1573851 & 688636 & 5.45 & 4.574 & TRN & \\
\hline CHEMBL1328050 & 688636 & 4.5 & 4.7811 & TST & \\
\hline CHEMBL606167 & 688636 & 4.6 & 4.8855 & TST & \\
\hline CHEMBL1367355 & 688636 & 5.85 & 4.9448 & TRN & \\
\hline CHEMBL1404262 & 688636 & 6.7501 & 4.9803 & TRN & \\
\hline CHEMBL1452951 & 688636 & 4.25 & 4.8864 & TRN & \\
\hline CHEMBL1345725 & 688636 & 4.95 & 4.9213 & TRN & \\
\hline CHEMBL1379313 & 688636 & 4.6 & 4.7899 & TRN & \\
\hline CHEMBL1461508 & 688636 & 4.55 & 4.5724 & TRN & \\
\hline CHEMBL1410451 & 688636 & 4.35 & 4.6959 & TRN & \\
\hline CHEMBL1557929 & 688636 & 4.4 & 4.6754 & TRN & \\
\hline CHEMBL1996555 & 688636 & 5.35 & 4.7754 & TRN & \\
\hline CHEMBL1370656 & 688636 & 4.9 & 4.9065 & TRN & \\
\hline CHEMBL1329965 & 688636 & 4.55 & 4.8167 & TRN & \\
\hline CHEMBL3209862 & 688636 & 5.0 & 4.6872 & TRN & \\
\hline CHEMBL1449353 & 688636 & 5.5 & 4.6768 & TRN & \\
\hline CHEMBL1543839 & 688636 & 4.3 & 4.8228 & TST & \\
\hline CHEMBL1446087 & 688636 & 4.4 & 4.9812 & TST & \\
\hline CHEMBL1332499 & 688636 & 4.6 & 4.8598 & TRN & \\
\hline CHEMBL1547911 & 688636 & 4.3 & 4.6239 & TRN & \\
\hline CHEMBL1598877 & 688636 & 5.2 & 4.9331 & TRN & \\
\hline CHEMBL1548480 & 688636 & 4.95 & 4.8038 & TRN & \\
\hline CHEMBL1403830 & 688636 & 4.25 & 4.8434 & TRN & \\
\hline CHEMBL1464036 & 688636 & 4.45 & 4.5983 & TRN & \\
\hline CHEMBL1529197 & 688636 & 4.45 & 4.5874 & TRN & \\
\hline CHEMBL1429470 & 688636 & 4.25 & 4.8014 & TRN & \\
\hline CHEMBL1567768 & 688636 & 5.25 & 4.7338 & TRN & \\
\hline CHEMBL3195364 & 688636 & 4.3 & 4.7092 & TRN & \\
\hline CHEMBL1426108 & 688636 & 5.7 & 4.72199 & 99999999995 & TST \\
\hline CHEMBL1364841 & 688636 & 4.3 & 4.6386 & TRN & \\
\hline CHEMBL1406611 & 688636 & 4.35 & 4.776 & TRN & \\
\hline CHEMBL 3214232 & 688636 & 4.25 & 4.8667 & TRN & \\
\hline CHEMBL1538327 & 688636 & 4.45 & 4.9212 & TRN & \\
\hline CHEMBL1347327 & 688636 & 4.85 & 4.7339 & TRN & \\
\hline CHEMBL1559107 & 688636 & 4.5 & 4.6804 & TRN & \\
\hline CHEMBL3193318 & 688636 & 4.65 & 4.8714 & TRN & \\
\hline CHEMBL1583880 & 688636 & 4.45 & 4.7446 & TRN & \\
\hline CHEMBL1410920 & 688636 & 4.55 & 4.8021 & TST & \\
\hline CHEMBL1468969 & 688636 & 4.5 & 4.9216 & TST & \\
\hline CHEMBL1414747 & 688636 & 4.65 & 4.8329 & TRN & \\
\hline CHEMBL1417067 & 688636 & 4.7 & 4.6853 & TRN & \\
\hline CHEMBL1584624 & 688636 & 4.5 & 4.753 & TRN & \\
\hline CHEMBL1449317 & 688636 & 6.4 & 4.9402 & TRN & \\
\hline CHEMBL3195651 & 688636 & 4.45 & 4.6416 & TRN & \\
\hline CHEMBL1386332 & 688636 & 4.6 & 4.9411 & TRN & \\
\hline CHEMBL1305567 & 688636 & 5.9 & 4.8536 & TRN & \\
\hline
\end{tabular}




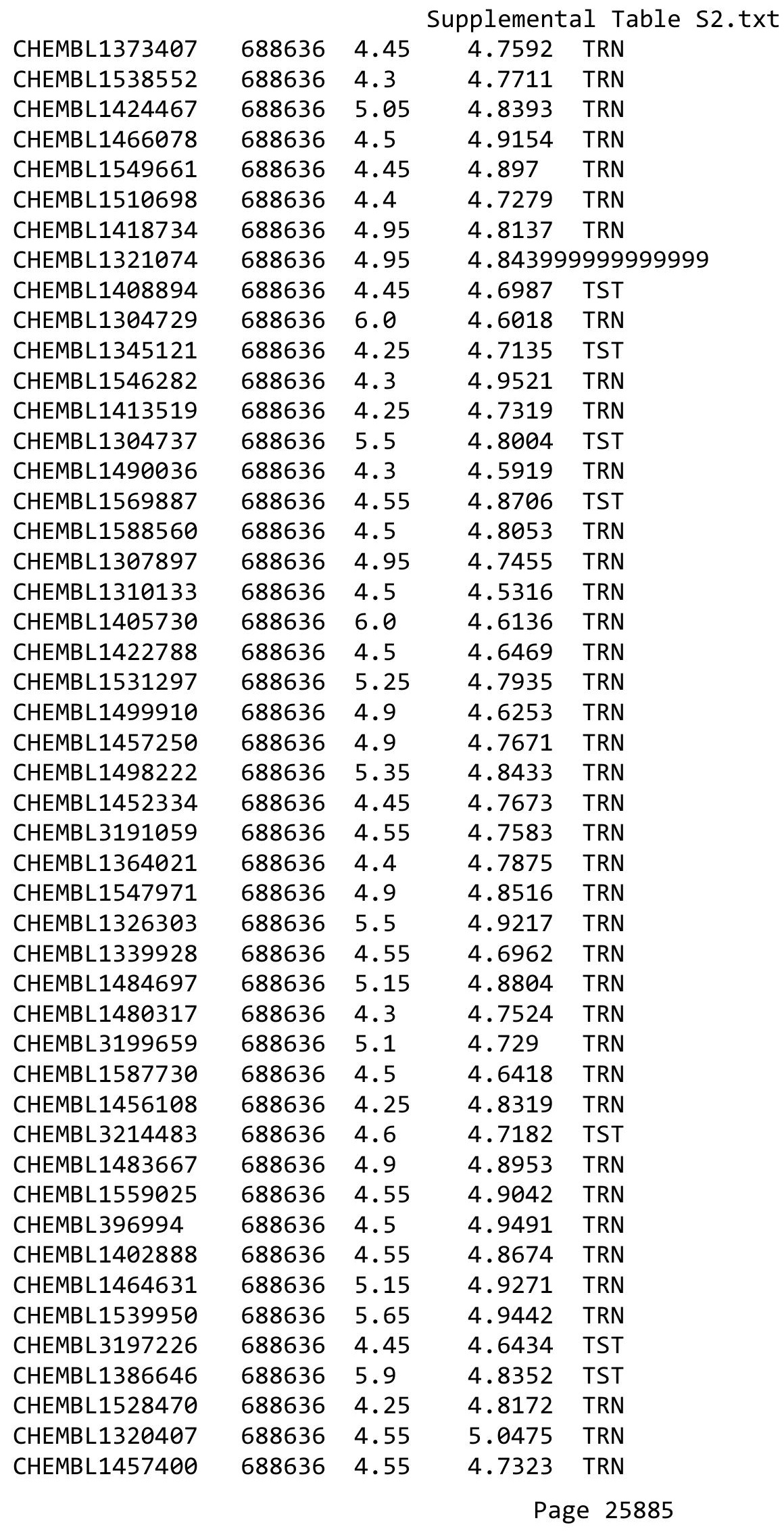




\begin{tabular}{|c|c|c|c|c|}
\hline & & & & \\
\hline CHEMBL1472368 & 688636 & 6.7501 & 4.757 & TS \\
\hline CHEMBL1496956 & 688636 & 5.15 & 4.9842 & \\
\hline CHEMBL1374746 & 88636 & 4.45 & 4.9246 & \\
\hline HEMBL1595086 & 88636 & 4.75 & 6936 & \\
\hline HEMBL1389371 & 88636 & 4.6 & .6826 & \\
\hline HEMBL1425006 & 88636 & 4.95 & 4.8751 & \\
\hline HEMBL1538312 & 88636 & 5.25 & 7854 & \\
\hline HEMBL3210829 & 88636 & 4.95 & & \\
\hline HEMBL1543095 & 588636 & 4.75 & 4.9978 & \\
\hline HEMBL1490693 & 88636 & 5.3 & 4.8737 & \\
\hline CHEMBL1 & 688636 & 4.95 & & \\
\hline HEMBL1 & 36 & 4.3 & 7398 & \\
\hline HEMBL1 & 88636 & 4.5 & & \\
\hline HEMBL13 & 688636 & 5.4 & 4.7207 & \\
\hline HEMBL3 & 588636 & 5.7 & & \\
\hline HEMBL] & 688 & 4.85 & 4.7655 & \\
\hline HEMBL: & 36 & 6 & 15 & \\
\hline HEMBL: & 88636 & 5.45 & 38 & \\
\hline HEMBL1 & 688636 & 4.25 & 4.8557 & \\
\hline HEMBL & 688636 & 4.25 & 4. & \\
\hline HEMBL: & 688 & 4 & 4.5 & \\
\hline HEMBL: & 36 & & 32 & \\
\hline HEMBL: & 36 & 4.95 & 4.6 & \\
\hline HEMBL: & 688636 & 4.25 & 05 & \\
\hline HEMBL3 & 688636 & 5.25 & 4. & \\
\hline HEMBL & 688636 & & $5 . e$ & \\
\hline HEMBL & 36 & & 4.9302 & \\
\hline HFMRI. & 36 & 4.95 & 4.6 & \\
\hline HEMBL: & 688636 & & & \\
\hline HEMBL1 & 688636 & & 4. & \\
\hline HEMBL1 & 688636 & & 4. & \\
\hline HEMBL & 36 & 5.45 & 4.7302 & \\
\hline HᄃMPI & 36 & 4.25 & $4 . \varepsilon$ & \\
\hline HEMBL & 688636 & & 4.7241 & \\
\hline HEMBL1563359 & 688636 & & 4.6526 & \\
\hline CHEMBL: & 688636 & & 4. & \\
\hline CHEMBL: & $68 \varepsilon$ & 4. & 4.6298 & \\
\hline CHEMBL: & $68 \varepsilon$ & 5.35 & 4.7878 & \\
\hline CHEMBL 1 & 688636 & 5.05 & 4.7994 & \\
\hline CHEMBL13 & 688636 & & 4.9194 & \\
\hline CHEMBL: & 688 & 4.95 & & K \\
\hline CHEMBL1 & 688636 & 4. & 4.9014 & \\
\hline CHEMBL1 & 688636 & 6.75 & 4.7387 & RN \\
\hline CHEMBL1545324 & 688636 & 6.7501 & 4.6765 & חת \\
\hline CHEMBL1588981 & 688636 & 4.3 & 4.8162 & \\
\hline CHEMBL: & 688636 & 4.45 & 4.9887 & \\
\hline CHEMBL1577959 & 688636 & 4.25 & 4.8666 & \\
\hline CHEMBL1380558 & 688636 & 4.3 & 4.7437 & \\
\hline
\end{tabular}

Page 25886 


\begin{tabular}{|c|c|c|c|c|}
\hline \multicolumn{5}{|c|}{ Supplemental Table S2.txt } \\
\hline CHEMBL1430800 & 688636 & 4.3 & 4.8387 & TRN \\
\hline CHEMBL1372378 & 688636 & 5.0 & 4.7057 & TRN \\
\hline CHEMBL1369737 & 688636 & 5.35 & 4.9144 & TRN \\
\hline CHEMBL1422144 & 688636 & 4.9 & 4.7162 & TRN \\
\hline CHEMBL1408384 & 688636 & 4.65 & 4.967 & TST \\
\hline CHEMBL1384248 & 688636 & 4.55 & 4.9804 & TRN \\
\hline CHEMBL1482064 & 688636 & 4.5 & 4.7023 & TRN \\
\hline CHEMBL1384684 & 688636 & 4.45 & 5.0543 & TRN \\
\hline CHEMBL1498043 & 688636 & 5.25 & 4.7154 & TRN \\
\hline CHEMBL1492711 & 688636 & 4.3 & 4.7289 & TRN \\
\hline CHEMBL1386068 & 688636 & 4.25 & 4.6986 & TRN \\
\hline CHEMBL1507148 & 688636 & 5.25 & 4.766 & TST \\
\hline CHEMBL1431332 & 688636 & 5.15 & 4.7784 & TST \\
\hline CHEMBL1507207 & 688636 & 4.55 & 4.7201 & TRN \\
\hline CHEMBL1995878 & 688636 & 4.3 & 4.8068 & TRN \\
\hline CHEMBL1322658 & 688636 & 5.3 & 4.7941 & TRN \\
\hline CHEMBL1332784 & 688636 & 4.4 & 4.6341 & TRN \\
\hline CHEMBL1580889 & 688636 & 6.15 & 4.8922 & TRN \\
\hline CHEMBL1531456 & 688636 & 4.4 & 4.7129 & TRN \\
\hline CHEMBL1451435 & 688636 & 4.25 & 4.8407 & TRN \\
\hline CHEMBL1449556 & 688636 & 4.25 & 4.6977 & TRN \\
\hline CHEMBL1339798 & 688636 & 4.85 & 4.7617 & TRN \\
\hline CHEMBL1500574 & 688636 & 5.8 & 4.6952 & TST \\
\hline CHEMBL1321445 & 688636 & 4.5 & 4.8024 & TRN \\
\hline CHEMBL1558735 & 688636 & 4.35 & 4.6399 & TRN \\
\hline CHEMBL1306004 & 688636 & 4.95 & 4.7367 & TST \\
\hline CHEMBL1387449 & 688636 & 4.55 & 4.6552 & TRN \\
\hline CHEMBL1478091 & 688636 & 4.45 & 4.9258 & TRN \\
\hline CHEMBL1482175 & 688636 & 4.45 & 4.7047 & TRN \\
\hline CHEMBL3209363 & 688636 & 4.95 & 4.7787 & TRN \\
\hline CHEMBL1456689 & 688636 & 4.3 & 4.9135 & TRN \\
\hline CHEMBL3209160 & 688636 & 4.55 & 4.695 & TRN \\
\hline CHEMBL1379987 & 688636 & 4.6 & 4.863 & TRN \\
\hline CHEMBL3194397 & 688636 & 4.45 & 4.5136 & TRN \\
\hline CHEMBL1419446 & 688636 & 4.4 & 4.9677 & TRN \\
\hline CHEMBL3195213 & 688636 & 5.7 & 4.8834 & TST \\
\hline CHEMBL1581733 & 688636 & 4.5 & 4.7593 & TRN \\
\hline CHEMBL1432136 & 688636 & 4.7 & 4.685 & TRN \\
\hline CHEMBL1369782 & 688636 & 5.25 & 4.8351 & TRN \\
\hline CHEMBL1368785 & 688636 & 6.8 & 5.0128 & TRN \\
\hline CHEMBL3192067 & 688636 & 6.5501 & 4.9296 & TRN \\
\hline CHEMBL1428188 & 688636 & 4.3 & 4.6219 & TRN \\
\hline CHEMBL1445106 & 688636 & 4.95 & 4.9622 & TRN \\
\hline CHEMBL1605397 & 688636 & 5.45 & 4.9015 & TST \\
\hline CHEMBL1439778 & 688636 & 5.15 & 4.8675 & TRN \\
\hline CHEMBL1302218 & 688636 & 6.45 & 4.9571 & TST \\
\hline CHEMBL1447967 & 688636 & 4.95 & 4.7555 & TRN \\
\hline CHEMBL1595579 & 688636 & 6.4 & 5.0663 & TST \\
\hline
\end{tabular}




\begin{tabular}{|c|c|c|c|c|}
\hline \multicolumn{5}{|c|}{ Supplemental Table } \\
\hline CHEMBL1339414 & 688636 & 6.15 & 5.0564 & TRN \\
\hline CHEMBL1558357 & 688636 & 4.3 & 4.8224 & TRN \\
\hline CHEMBL1428423 & 688636 & 4.45 & 4.7735 & TRN \\
\hline CHEMBL1418821 & 688636 & 4.3 & 4.815 & TRN \\
\hline CHEMBL1731995 & 688636 & 4.3 & 4.6552 & TST \\
\hline CHEMBL 2005947 & 688636 & 4.65 & 4.7246 & TST \\
\hline CHEMBL1567948 & 688636 & 5.1 & 4.9715 & TRN \\
\hline CHEMBL1391081 & 688636 & 4.95 & 4.9156 & TST \\
\hline CHEMBL1324567 & 688636 & 4.25 & 4.8436 & TRN \\
\hline CHEMBL1462721 & 688636 & 4.4 & 4.7117 & TRN \\
\hline CHEMBL1340951 & 688636 & 4.6 & 4.8795 & TST \\
\hline CHEMBL1452259 & 688636 & 4.95 & 4.8538 & TRN \\
\hline CHEMBL1429245 & 688636 & 5.2 & 4.6829 & TRN \\
\hline CHEMBL1544616 & 688636 & 4.25 & 4.7215 & TRN \\
\hline CHEMBL1471239 & 688636 & 4.25 & 4.7243 & TRN \\
\hline CHEMBL1428586 & 688636 & 4.3 & 4.7525 & TRN \\
\hline CHEMBL1307532 & 688636 & 5.05 & 4.8523 & TST \\
\hline CHEMBL1333055 & 688636 & 4.8 & 4.9291 & TRN \\
\hline CHEMBL1381212 & 688636 & 4.35 & 4.8028 & TRN \\
\hline CHEMBL1353018 & 688636 & 4.3 & 4.7578 & TRN \\
\hline CHEMBL1549266 & 688636 & 4.35 & 4.6862 & TRN \\
\hline CHEMBL1546048 & 688636 & 5.4 & 4.5431 & TST \\
\hline CHEMBL3196362 & 688636 & 4.5 & 4.6824 & TST \\
\hline CHEMBL1363953 & 688636 & 4.65 & 4.7672 & TRN \\
\hline CHEMBL1440525 & 688636 & 6.7501 & 4.8245 & TRN \\
\hline CHEMBL1390216 & 688636 & 4.4 & 4.8186 & TRN \\
\hline CHEMBL1370357 & 688636 & 4.45 & 4.6265 & TRN \\
\hline CHEMBL1575442 & 688636 & 5.4 & 4.6185 & TRN \\
\hline CHEMBL1327266 & 688636 & 4.25 & 5.0106 & TST \\
\hline CHEMBL1380418 & 688636 & 5.4 & 4.8204 & TRN \\
\hline CHEMBL1414984 & 688636 & 5.0 & 4.6594 & TRN \\
\hline CHEMBL3212521 & 688636 & 5.15 & 4.8965 & TST \\
\hline CHEMBL1427167 & 688636 & 4.5 & 4.7589 & TRN \\
\hline CHEMBL1531901 & 688636 & 4.55 & 4.6297 & TRN \\
\hline CHEMBL1301373 & 688636 & 4.95 & 4.8395 & TST \\
\hline CHEMBL1375394 & 688636 & 4.3 & 4.9581 & TRN \\
\hline CHEMBL1571914 & 688636 & 4.4 & 4.6759 & TRN \\
\hline CHEMBL1330292 & 688636 & 4.3 & 4.9674 & TRN \\
\hline CHEMBL1587149 & 688636 & 4.95 & 4.9025 & TRN \\
\hline CHEMBL1347916 & 688636 & 4.5 & 4.6755 & TRN \\
\hline CHEMBL1418822 & 688636 & 4.3 & 4.6883 & TRN \\
\hline CHEMBL1573235 & 688636 & 5.5 & 4.9038 & TRN \\
\hline CHEMBL1574031 & 688636 & 6.15 & 4.8956 & TRN \\
\hline CHEMBL1329196 & 688636 & 5.75 & 4.7283 & TST \\
\hline CHEMBL1463288 & 688636 & 4.95 & 4.9291 & TST \\
\hline CHEMBL1336866 & 688636 & 4.5 & 4.7071 & TRN \\
\hline CHEMBL3207950 & 688636 & 6.0 & 4.9819 & TRN \\
\hline CHEMBL3194053 & 688636 & 4.75 & 4.7987 & TRN \\
\hline
\end{tabular}




\begin{tabular}{|c|c|c|c|c|c|}
\hline & & & & & \\
\hline CHEMBL1414652 & 688636 & 4.9 & 4.9518 & TST & \\
\hline CHEMBL1511934 & 688636 & 4.25 & 4.9382 & TST & \\
\hline CHEMBL1366318 & 688636 & 5.3 & 4.8723 & TRN & \\
\hline CHEMBL1374854 & 688636 & 4.5 & 4.7812 & TRN & \\
\hline CHEMBL1586901 & 688636 & 5.65 & 4.7353 & TRN & \\
\hline CHEMBL1375602 & 688636 & 4.3 & 4.809 & TRN & \\
\hline CHEMBL1361705 & 688636 & 5.5 & $4.7810 €$ & 0000000001 & TRN \\
\hline CHEMBL1605727 & 688636 & 6.05 & 4.7415 & TST & \\
\hline CHEMBL1565285 & 688636 & 4.3 & 4.7657 & TRN & \\
\hline CHEMBL1405690 & 688636 & 4.45 & 4.5843 & TRN & \\
\hline CHEMBL1589153 & 688636 & 4.3 & 4.7583 & TRN & \\
\hline CHEMBL1483016 & 688636 & 4.3 & 4.7516 & TST & \\
\hline CHEMBL1328660 & 688636 & 4.5 & 4.8971 & TRN & \\
\hline CHEMBL1544574 & 688636 & 5.2 & 4.9812 & TRN & \\
\hline CHEMBL1581676 & 688636 & 4.55 & 4.7811 & TRN & \\
\hline CHEMBL1302024 & 688636 & 4.25 & 4.7627 & TRN & \\
\hline CHEMBL1595889 & 688636 & 6.4 & 4.8389 & TRN & \\
\hline CHEMBL1594486 & 688636 & 4.5 & 4.6879 & TRN & \\
\hline CHEMBL1582546 & 688636 & 6.8 & 4.7376 & TRN & \\
\hline CHEMBL1511777 & 688636 & 5.8 & 4.9934 & TRN & \\
\hline CHEMBL3208664 & 688636 & 4.55 & 4.953 & TST & \\
\hline CHEMBL1463492 & 688636 & 4.55 & 4.9168 & TST & \\
\hline CHEMBL1331563 & 688636 & 4.5 & 4.6599 & TRN & \\
\hline CHEMBL1323288 & 688636 & 4.55 & 4.9854 & TRN & \\
\hline CHEMBL1365539 & 688636 & 4.3 & 4.7607 & TRN & \\
\hline CHEMBL1383919 & 688636 & 4.55 & 4.7641 & TRN & \\
\hline CHEMBL1386794 & 688636 & 4.6 & 4.952 & TRN & \\
\hline CHEMBL1560841 & 688636 & 4.4 & 4.7968 & TST & \\
\hline CHEMBL1405295 & 688636 & 4.25 & 4.8322 & TST & \\
\hline CHEMBL1360767 & 688636 & 4.55 & 4.7309 & TRN & \\
\hline CHEMBL1403529 & 688636 & 5.75 & 4.9975 & TRN & \\
\hline CHEMBL1349134 & 688636 & 4.8 & 4.5753 & TRN & \\
\hline CHEMBL1526338 & 688636 & 5.85 & 4.9689 & TRN & \\
\hline CHEMBL1307280 & 688636 & 4.9 & 4.7784 & TST & \\
\hline CHEMBL1534628 & 688636 & 5.6 & 4.8841 & TRN & \\
\hline CHEMBL1324566 & 688636 & 4.4 & 4.744 & TST & \\
\hline CHEMBL1992164 & 688636 & 4.8 & 4.6943 & TRN & \\
\hline CHEMBL1444636 & 688636 & 4.4 & 4.7668 & TRN & \\
\hline CHEMBL1337683 & 688636 & 4.25 & 4.7922 & TRN & \\
\hline CHEMBL1595680 & 688636 & 6.7501 & 4.729 & TRN & \\
\hline CHEMBL1500643 & 688636 & 4.6 & 4.9349 & TRN & \\
\hline CHEMBL 2143754 & 688636 & 6.05 & 4.894 & TRN & \\
\hline CHEMBL1322390 & 688636 & 5.0 & 4.8379 & TRN & \\
\hline CHEMBL1430083 & 688636 & 5.2 & 4.7549 & TST & \\
\hline CHEMBL1522915 & 688636 & 5.45 & 4.9497 & TRN & \\
\hline CHEMBL1334134 & 688636 & 4.5 & 4.6432 & TRN & \\
\hline CHEMBL1438063 & 688636 & 5.05 & 4.8988 & TRN & \\
\hline CHEMBL1401428 & 688636 & 5.8 & 4.806 & TRN & \\
\hline
\end{tabular}




\begin{tabular}{|c|c|c|c|c|c|}
\hline \\
\hline CHEMBL1391038 & 688636 & 4.3 & 4.8371 & TRN & \\
\hline CHEMBL560832 & 688636 & 6.35 & 4.7821 & TRN & \\
\hline CHEMBL1467676 & 688636 & 4.4 & 4.8461 & TST & \\
\hline CHEMBL1303249 & 688636 & 5.45 & 4.8337 & TRN & \\
\hline CHEMBL1369793 & 688636 & 4.9 & 4.9582 & TST & \\
\hline CHEMBL1348651 & 688636 & 4.3 & 4.9768 & TRN & \\
\hline CHEMBL1524119 & 688636 & 4.85 & 4.904 & TRN & \\
\hline CHEMBL1392 & 688636 & 5.85 & 4.7173 & TST & \\
\hline CHEMBL1420119 & 688636 & 5.55 & 4.7404 & TST & \\
\hline CHEMBL1368519 & 688636 & 4.4 & 4.6869 & TRN & \\
\hline CHEMBL1428961 & 688636 & 4.5 & 4.7059 & TRN & \\
\hline CHEMBL1564638 & 688636 & 4.3 & 4.7565 & TRN & \\
\hline CHEMBL1530070 & 688636 & 5.45 & 4.948 & TRN & \\
\hline CHEMBL1471636 & 688636 & 4.25 & 4.9039 & TRN & \\
\hline CHEMBL1319425 & 688636 & 5.85 & 4.7629 & TST & \\
\hline CHEMBL 2005423 & 688636 & 4.35 & 4.9736 & TRN & \\
\hline CHEMBL1613583 & 688636 & 4.25 & 4.9189 & TRN & \\
\hline CHEMBL1342332 & 688636 & 4.45 & 4.6804 & TRN & \\
\hline CHEMBL1447774 & 688636 & 4.45 & 4.6594 & TRN & \\
\hline CHEMBL1504724 & 688636 & 6.7501 & 4.7088 & TST & \\
\hline CHEMBL1408346 & 688636 & 4.25 & 5.0644 & TRN & \\
\hline CHEMBL 3210323 & 688636 & 4.3 & 4.8726 & TRN & \\
\hline CHEMBL1363029 & 688636 & 5.6 & 4.76699 & 99999999995 & TRN \\
\hline CHEMBL1485763 & 688636 & 4.45 & 4.8497 & TRN & \\
\hline CHEMBL1597104 & 688636 & 4.75 & 4.6577 & TRN & \\
\hline CHEMBL1495404 & 688636 & 5.2 & 4.6438 & TRN & \\
\hline CHEMBL1468908 & 688636 & 4.85 & 4.787 & TST & \\
\hline CHEMBL1469637 & 688636 & 4.3 & 4.8929 & TST & \\
\hline CHEMBL1489263 & 688636 & 4.9 & 5.0179 & TST & \\
\hline CHEMBL1462520 & 688636 & 4.3 & 4.6851 & TRN & \\
\hline CHEMBL1471357 & 688636 & 4.9 & 4.9502 & TRN & \\
\hline CHEMBL1611423 & 688636 & 6.0 & 4.7415 & TRN & \\
\hline CHEMBL1455168 & 688636 & 4.5 & 4.5423 & TRN & \\
\hline CHEMBL1597425 & 688636 & 4.45 & 4.749 & TRN & \\
\hline CHEMBL1484484 & 688636 & 4.65 & 4.9331 & TRN & \\
\hline CHEMBL1463234 & 688636 & 4.3 & 4.7744 & TRN & \\
\hline CHEMBL1445726 & 688636 & 4.3 & 4.7121 & TST & \\
\hline CHEMBL1307025 & 688636 & 4.9 & 4.9727 & TRN & \\
\hline CHEMBL1493837 & 688636 & 4.3 & 4.8816 & TST & \\
\hline CHEMBL1540767 & 688636 & 4.45 & 4.7221 & TRN & \\
\hline CHEMBL1498042 & 688636 & 4.8 & 4.6229 & TRN & \\
\hline CHEMBL3194833 & 688636 & 4.4 & 4.8187 & TRN & \\
\hline CHEMBL1480715 & 688636 & 4.3 & 4.9123 & TST & \\
\hline CHEMBL1416068 & 688636 & 5.6 & 4.8436 & TST & \\
\hline CHEMBL585444 & 688636 & 4.35 & 4.6362 & TST & \\
\hline CHEMBL1561229 & 688636 & 4.3 & 4.8545 & TRN & \\
\hline CHEMBL1376734 & 688636 & 6.15 & 4.9823 & TRN & \\
\hline CHEMBL1468154 & 688636 & 5.3 & 4.7902 & TST & \\
\hline
\end{tabular}




\begin{tabular}{|c|c|c|c|c|}
\hline & & & oplement & al $\mathrm{T}$ \\
\hline CHEMBL1410162 & 688636 & 4.45 & 4.937 & TRN \\
\hline CHEMBL1319307 & 688636 & 5.85 & 4.813 & TRN \\
\hline CHEMBL1400811 & 688636 & 4.5 & 4.9263 & TRN \\
\hline CHEMBL3208753 & 688636 & 4.7 & 4.862 & TRN \\
\hline CHEMBL1494966 & 688636 & 4.25 & 4.724 & TRN \\
\hline CHEMBL1605642 & 688636 & 4.25 & 4.8254 & TST \\
\hline CHEMBL3193491 & 688636 & 4.5 & 4.7458 & TST \\
\hline CHEMBL3210581 & 688636 & 4.3 & 4.7401 & TST \\
\hline CHEMBL1520621 & 688636 & 4.3 & 4.6693 & TST \\
\hline CHEMBL1532487 & 688636 & 4.3 & 4.9982 & TRN \\
\hline CHEMBL1542501 & 688636 & 4.9 & 4.8882 & TRN \\
\hline CHEMBL1509904 & 688636 & 6.7001 & 4.8203 & TST \\
\hline CHEMBL3209908 & 688636 & 4.3 & 4.5172 & TST \\
\hline CHEMBL1511224 & 688636 & 4.3 & 4.806 & TRN \\
\hline CHEMBL1353900 & 688636 & 4.35 & 4.6644 & TRN \\
\hline CHEMBL1537243 & 688636 & 4.3 & 4.8976 & TRN \\
\hline CHEMBL1536585 & 688636 & 6.45 & 4.7047 & TST \\
\hline CHEMBL1497343 & 688636 & 4.25 & 4.9106 & TRN \\
\hline CHEMBL1375804 & 688636 & 4.65 & 4.8867 & TRN \\
\hline CHEMBL1471749 & 688636 & 4.6 & 4.7454 & TRN \\
\hline CHEMBL1299658 & 688636 & 5.1 & 4.855 & TRN \\
\hline CHEMBL3208614 & 688636 & 6.1 & 4.6523 & TRN \\
\hline CHEMBL1380604 & 688636 & 4.6 & 4.76 & TRN \\
\hline CHEMBL1447602 & 688636 & 4.25 & 4.9288 & TST \\
\hline CHEMBL1382648 & 688636 & 4.65 & 4.8857 & TRN \\
\hline CHEMBL1567534 & 688636 & 4.3 & 4.7444 & TRN \\
\hline CHEMBL1409480 & 688636 & 4.45 & 4.8072 & TRN \\
\hline CHEMBL1321437 & 688636 & 4.45 & 4.7177 & TRN \\
\hline CHEMBL1566698 & 688636 & 4.3 & 4.6537 & TRN \\
\hline CHEMBL1449862 & 688636 & 4.5 & 4.7233 & TRN \\
\hline CHEMBL1472163 & 688636 & 4.55 & 4.6279 & TRN \\
\hline CHEMBL1431846 & 688636 & 4.6 & 4.6887 & TRN \\
\hline CHEMBL1594541 & 688636 & 4.95 & 4.8943 & TRN \\
\hline CHEMBL1300164 & 688636 & 4.25 & 4.6619 & TST \\
\hline CHEMBL3199633 & 688636 & 4.8 & 4.8545 & TRN \\
\hline CHEMBL1526257 & 688636 & 4.6 & 4.7485 & TRN \\
\hline CHEMBL1465481 & 688636 & 4.6 & 5.0347 & TRN \\
\hline CHEMBL1359883 & 688636 & 4.65 & 4.7217 & TRN \\
\hline CHEMBL128427 & 688636 & 4.95 & 4.7275 & TST \\
\hline CHEMBL1547139 & 688636 & 6.7001 & 4.817 & TST \\
\hline CHEMBL1509783 & 688636 & 4.25 & 4.7921 & TST \\
\hline CHEMBL1543744 & 688636 & 4.25 & 4.7358 & TRN \\
\hline CHEMBL1365917 & 688636 & 6.0 & 4.8928 & TST \\
\hline CHEMBL1496695 & 688636 & 4.3 & 4.6902 & TRN \\
\hline CHEMBL3213239 & 688636 & 4.25 & 4.8186 & TRN \\
\hline CHEMBL1597496 & 688636 & 4.9 & 4.7796 & TRN \\
\hline CHEMBL1508359 & 688636 & 4.3 & 4.732 & TRN \\
\hline CHEMBL1299567 & 688636 & 4.9 & 4.7927 & TRN \\
\hline
\end{tabular}




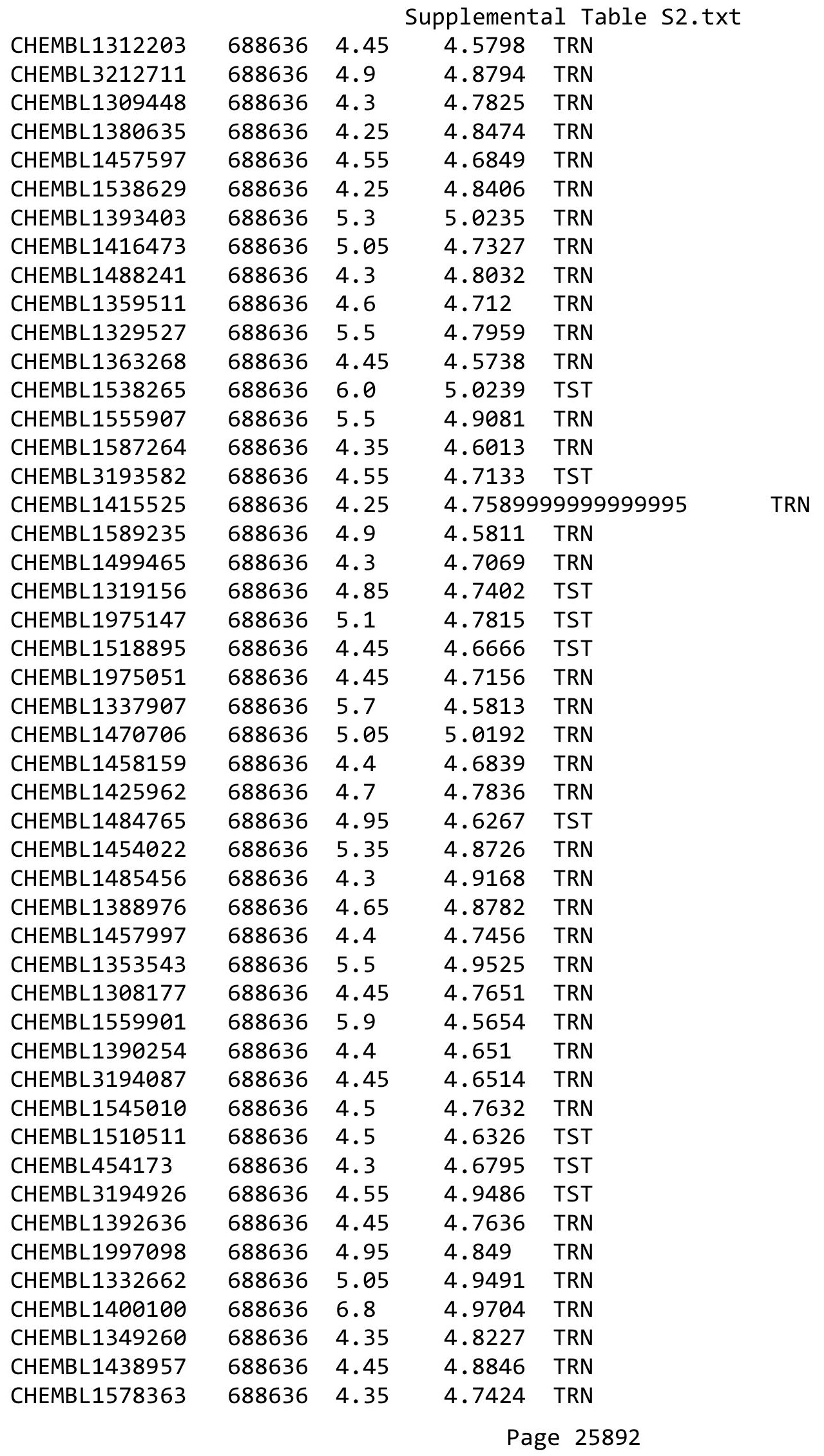




\begin{tabular}{|c|c|c|c|c|c|}
\hline & & \multicolumn{4}{|c|}{ Supplemental Table S2.txt } \\
\hline CHEMBL1391901 & 688636 & 4.95 & 4.8064 & TRN & \\
\hline CHEMBL1370245 & 688636 & 4.25 & 4.6911 & TRN & \\
\hline CHEMBL1468255 & 688636 & 4.25 & 4.834 & TRN & \\
\hline CHEMBL1486484 & 688636 & 4.95 & 4.9764 & TRN & \\
\hline CHEMBL1429387 & 688636 & 4.5 & 4.7179 & TRN & \\
\hline CHEMBL1531812 & 688636 & 4.3 & 4.8917 & TRN & \\
\hline CHEMBL1387519 & 688636 & 5.75 & 4.74100 & 00000000005 & TRN \\
\hline CHEMBL1489148 & 688636 & 5.6 & 4.6736 & TRN & \\
\hline CHEMBL1466723 & 688636 & 4.4 & 4.7845 & TRN & \\
\hline CHEMBL1336141 & 688636 & 5.5 & 4.9168 & TRN & \\
\hline CHEMBL1537194 & 688636 & 4.3 & 4.9179 & TRN & \\
\hline CHEMBL1312956 & 688636 & 4.5 & 4.8754 & TRN & \\
\hline CHEMBL1393837 & 688636 & 4.3 & 4.7373 & TRN & \\
\hline CHEMBL1606672 & 688636 & 4.75 & 4.7209 & TRN & \\
\hline CHEMBL1446183 & 688636 & 4.25 & 5.0048 & TRN & \\
\hline CHEMBL1330689 & 688636 & 4.45 & 4.9193 & TRN & \\
\hline CHEMBL1505878 & 688636 & 4.5 & 4.7129 & TRN & \\
\hline CHEMBL1329368 & 688636 & 4.5 & 4.8224 & TRN & \\
\hline CHEMBL1322482 & 688636 & 4.6 & 4.8159 & TRN & \\
\hline CHEMBL1487610 & 688636 & 4.95 & 4.849 & TRN & \\
\hline CHEMBL1446286 & 688636 & 4.35 & 4.8107 & TRN & \\
\hline CHEMBL1469461 & 688636 & 4.85 & 4.7995 & TRN & \\
\hline CHEMBL1417899 & 688636 & 4.55 & 4.6613 & TST & \\
\hline CHEMBL1608435 & 688636 & 4.3 & 4.8995 & TST & \\
\hline CHEMBL1566115 & 688636 & 4.25 & 4.8312 & TRN & \\
\hline CHEMBL1380167 & 688636 & 4.9 & 4.9714 & TRN & \\
\hline CHEMBL1483593 & 688636 & 4.5 & 4.8802 & TRN & \\
\hline CHEMBL1302597 & 688636 & 5.65 & 4.6438 & TRN & \\
\hline CHEMBL1497391 & 688636 & 4.5 & 4.5654 & TST & \\
\hline CHEMBL1362560 & 688636 & 4.4 & 4.7109 & TRN & \\
\hline CHEMBL3199675 & 688636 & 5.35 & 4.9675 & TRN & \\
\hline CHEMBL1404887 & 688636 & 4.35 & 4.7102 & TRN & \\
\hline CHEMBL1344289 & 688636 & 4.65 & 4.7638 & TRN & \\
\hline CHEMBL1489960 & 688636 & 4.3 & 4.7868 & TRN & \\
\hline CHEMBL1399755 & 688636 & 4.25 & 4.8985 & TRN & \\
\hline CHEMBL1429291 & 688636 & 5.2 & 4.6882 & TRN & \\
\hline CHEMBL3213526 & 688636 & 4.3 & 4.8602 & TRN & \\
\hline CHEMBL1405774 & 688636 & 4.5 & 4.8451 & TST & \\
\hline CHEMBL1340409 & 688636 & 4.25 & 4.8986 & TRN & \\
\hline CHEMBL1557369 & 688636 & 4.9 & 4.7714 & TRN & \\
\hline CHEMBL1302400 & 688636 & 4.5 & 4.8218 & TRN & \\
\hline CHEMBL1489981 & 688636 & 4.3 & 4.8324 & TRN & \\
\hline CHEMBL194594 & 688636 & 4.5 & 4.748 & TST & \\
\hline CHEMBL1966867 & 688636 & 5.2 & 4.7457 & TST & \\
\hline CHEMBL1431889 & 688636 & 5.25 & 4.9945 & TRN & \\
\hline CHEMBL1373759 & 688636 & 4.55 & 4.864 & TRN & \\
\hline CHEMBL1348609 & 688636 & 4.95 & 4.7462 & TST & \\
\hline CHEMBL1482109 & 688636 & 4.45 & 4.6316 & TRN & \\
\hline
\end{tabular}




\begin{tabular}{|c|c|c|c|c|c|}
\hline \\
\hline CHEMBL1594442 & 688636 & 4.9 & 4.8365 & TRN & \\
\hline CHEMBL3211937 & 688636 & 4.5 & 4.6286 & TRN & \\
\hline CHEMBL121291 & 688636 & 4.4 & 4.6774 & TRN & \\
\hline CHEMBL1348773 & 688636 & 5.2 & 4.7868 & TST & \\
\hline CHEMBL1379424 & 688636 & 4.9 & 4.8648 & TRN & \\
\hline CHEMBL1594745 & 688636 & 4.4 & 4.7485 & TRN & \\
\hline CHEMBL1373003 & 688636 & 4.35 & 4.6239 & TRN & \\
\hline CHEMBL1490864 & 688636 & 4.55 & 4.7435 & TRN & \\
\hline CHEMBL1565276 & 688636 & 4.5 & 4.6787 & TRN & \\
\hline CHEMBL1381435 & 688636 & 4.25 & 4.7533 & TRN & \\
\hline CHEMBL1362758 & 688636 & 4.5 & 4.8556 & TST & \\
\hline CHEMBL1361938 & 688636 & 4.3 & 4.9267 & TRN & \\
\hline CHEMBL1421375 & 688636 & 5.65 & 4.7601 & TRN & \\
\hline CHEMBL1346734 & 688636 & 4.6 & 4.5493 & TRN & \\
\hline CHEMBL1537864 & 688636 & 4.75 & 4.9503 & TRN & \\
\hline CHEMBL1307536 & 688636 & 4.4 & 4.7762 & TRN & \\
\hline CHEMBL1452583 & 688636 & 4.95 & 4.9097 & TRN & \\
\hline CHEMBL1586803 & 688636 & 4.4 & 4.8819 & TRN & \\
\hline CHEMBL1368068 & 688636 & 4.5 & 4.7898 & TRN & \\
\hline CHEMBL3189948 & 688636 & 4.3 & 4.732 & TRN & \\
\hline CHEMBL1425112 & 688636 & 4.5 & 4.7006 & TRN & \\
\hline CHEMBL1548536 & 688636 & 4.3 & 4.96899 & 9999999999 & TRN \\
\hline CHEMBL1393146 & 688636 & 4.4 & 4.7158 & TRN & \\
\hline CHEMBL1528346 & 688636 & 4.5 & 4.7115 & TRN & \\
\hline CHEMBL1505400 & 688636 & 4.85 & 4.8721 & TRN & \\
\hline CHEMBL1601046 & 688636 & 4.55 & 4.7182 & TRN & \\
\hline CHEMBL1587680 & 688636 & 4.75 & 4.7555 & TRN & \\
\hline CHEMBL1400980 & 688636 & 4.4 & 4.8451 & TRN & \\
\hline CHEMBL1570624 & 688636 & 5.2 & 4.7692 & TST & \\
\hline CHEMBL1442817 & 688636 & 4.25 & 4.8838 & TRN & \\
\hline CHEMBL1582589 & 688636 & 4.7 & 4.669 & TRN & \\
\hline CHEMBL 3212077 & 688636 & 4.7 & 4.7634 & TRN & \\
\hline CHEMBL1523991 & 688636 & 4.9 & 4.7914 & TRN & \\
\hline CHEMBL1520891 & 688636 & 5.4 & 4.914 & TRN & \\
\hline CHEMBL1524467 & 688636 & 5.85 & 4.9329 & TRN & \\
\hline CHEMBL3208649 & 688636 & 6.7501 & 4.9268 & TRN & \\
\hline CHEMBL3197899 & 688636 & 4.3 & 4.74100 & 00000000005 & TRN \\
\hline CHEMBL1597166 & 688636 & 5.1 & 4.9643 & TRN & \\
\hline CHEMBL1561127 & 688636 & 5.6 & 4.8919 & TST & \\
\hline CHEMBL3190609 & 688636 & 4.9 & 4.7897 & TST & \\
\hline CHEMBL1516743 & 688636 & 4.6 & 4.7894 & TRN & \\
\hline CHEMBL1375060 & 688636 & 4.7 & 4.832 & TRN & \\
\hline CHEMBL1556465 & 688636 & 4.9 & 4.8431 & TRN & \\
\hline CHEMBL1468640 & 688636 & 4.6 & 4.8317 & TST & \\
\hline CHEMBL1498499 & 688636 & 4.9 & 4.9128 & TRN & \\
\hline CHEMBL1456464 & 688636 & 4.95 & 4.9583 & TRN & \\
\hline CHEMBL1381013 & 688636 & 6.15 & 4.9911 & TRN & \\
\hline CHEMBL1423407 & 688636 & 4.5 & 4.7873 & TRN & \\
\hline
\end{tabular}




\begin{tabular}{|c|c|c|c|c|c|}
\hline \multicolumn{6}{|c|}{ Supplemental Table S2.txt } \\
\hline CHEMBL1509519 & 688636 & 4.25 & 4.9104 & TST & \\
\hline CHEMBL1487275 & 688636 & 4.4 & 4.8807 & TRN & \\
\hline CHEMBL1608778 & 688636 & 5.65 & 4.8557 & TST & \\
\hline CHEMBL1467168 & 688636 & 4.5 & 4.7049 & TRN & \\
\hline CHEMBL1577099 & 688636 & 6.5 & 4.9494 & TRN & \\
\hline CHEMBL1539968 & 688636 & 4.5 & 4.7379 & TRN & \\
\hline CHEMBL1461664 & 688636 & 4.55 & 4.8249 & TRN & \\
\hline CHEMBL1313982 & 688636 & 4.35 & 4.6957 & TST & \\
\hline CHEMBL1329331 & 688636 & 4.65 & 4.9776 & TST & \\
\hline CHEMBL1502906 & 688636 & 4.45 & 4.9096 & TST & \\
\hline CHEMBL340807 & 688636 & 4.65 & 4.7502 & TST & \\
\hline CHEMBL1358783 & 688636 & 4.9 & 4.9553 & TRN & \\
\hline CHEMBL1337068 & 688636 & 4.95 & 4.7355 & TRN & \\
\hline CHEMBL3190145 & 688636 & 4.9 & 4.6269 & TRN & \\
\hline CHEMBL1363818 & 688636 & 4.45 & 4.7448 & TRN & \\
\hline CHEMBL1546822 & 688636 & 5.05 & 4.7059 & TRN & \\
\hline CHEMBL1393494 & 688636 & 4.45 & 4.8814 & TST & \\
\hline CHEMBL1313221 & 688636 & 4.75 & 4.6553 & TRN & \\
\hline CHEMBL1507375 & 688636 & 4.9 & 4.79899 & 99999999995 & TRN \\
\hline CHEMBL1387490 & 688636 & 4.3 & 4.9507 & TST & \\
\hline CHEMBL1489687 & 688636 & 4.5 & 4.6728 & TRN & \\
\hline CHEMBL1421882 & 688636 & 6.05 & 4.8882 & TST & \\
\hline CHEMBL3198203 & 688636 & 4.55 & 4.7039 & TRN & \\
\hline CHEMBL1522917 & 688636 & 4.95 & 4.9325 & TST & \\
\hline CHEMBL1535921 & 688636 & 4.9 & 4.6721 & TRN & \\
\hline CHEMBL1463716 & 688636 & 4.3 & 4.9414 & TRN & \\
\hline CHEMBL1319533 & 688636 & 6.5 & 4.7965 & TST & \\
\hline CHEMBL3199360 & 688636 & 4.3 & 4.8876 & TRN & \\
\hline CHEMBL1412169 & 688636 & 5.45 & 4.9318 & TST & \\
\hline CHEMBL1423548 & 688636 & 4.3 & 4.6602 & TRN & \\
\hline CHEMBL3214149 & 688636 & 4.45 & 4.8336 & TRN & \\
\hline CHEMBL1378382 & 688636 & 4.45 & 4.6543 & TRN & \\
\hline CHEMBL1426813 & 688636 & 4.95 & 4.8819 & TST & \\
\hline CHEMBL1451792 & 688636 & 4.35 & 4.6701 & TRN & \\
\hline CHEMBL1403824 & 688636 & 4.55 & 4.8762 & TRN & \\
\hline CHEMBL3192462 & 688636 & 4.6 & 4.7388 & TST & \\
\hline CHEMBL3198558 & 688636 & 5.55 & 4.8823 & TRN & \\
\hline CHEMBL1573864 & 688636 & 4.45 & 4.6495 & TRN & \\
\hline CHEMBL1415272 & 688636 & 4.55 & 4.8027 & TRN & \\
\hline CHEMBL1456820 & 688636 & 4.3 & 4.8159 & TRN & \\
\hline CHEMBL1337080 & 688636 & 4.25 & 4.695 & TRN & \\
\hline CHEMBL1502487 & 688636 & 4.75 & 4.76399 & 9999999999 & TRN \\
\hline CHEMBL1973265 & 688636 & 4.75 & 4.6122 & TRN & \\
\hline CHEMBL1560055 & 688636 & 6.8 & 5.1147 & TST & \\
\hline CHEMBL1323189 & 688636 & 5.3 & 4.8873 & TST & \\
\hline CHEMBL1606515 & 688636 & 5.3 & 4.9234 & TST & \\
\hline CHEMBL1598227 & 688636 & 6.7501 & 4.8522 & TRN & \\
\hline CHEMBL1560398 & 688636 & 4.4 & 4.6443 & TRN & \\
\hline
\end{tabular}




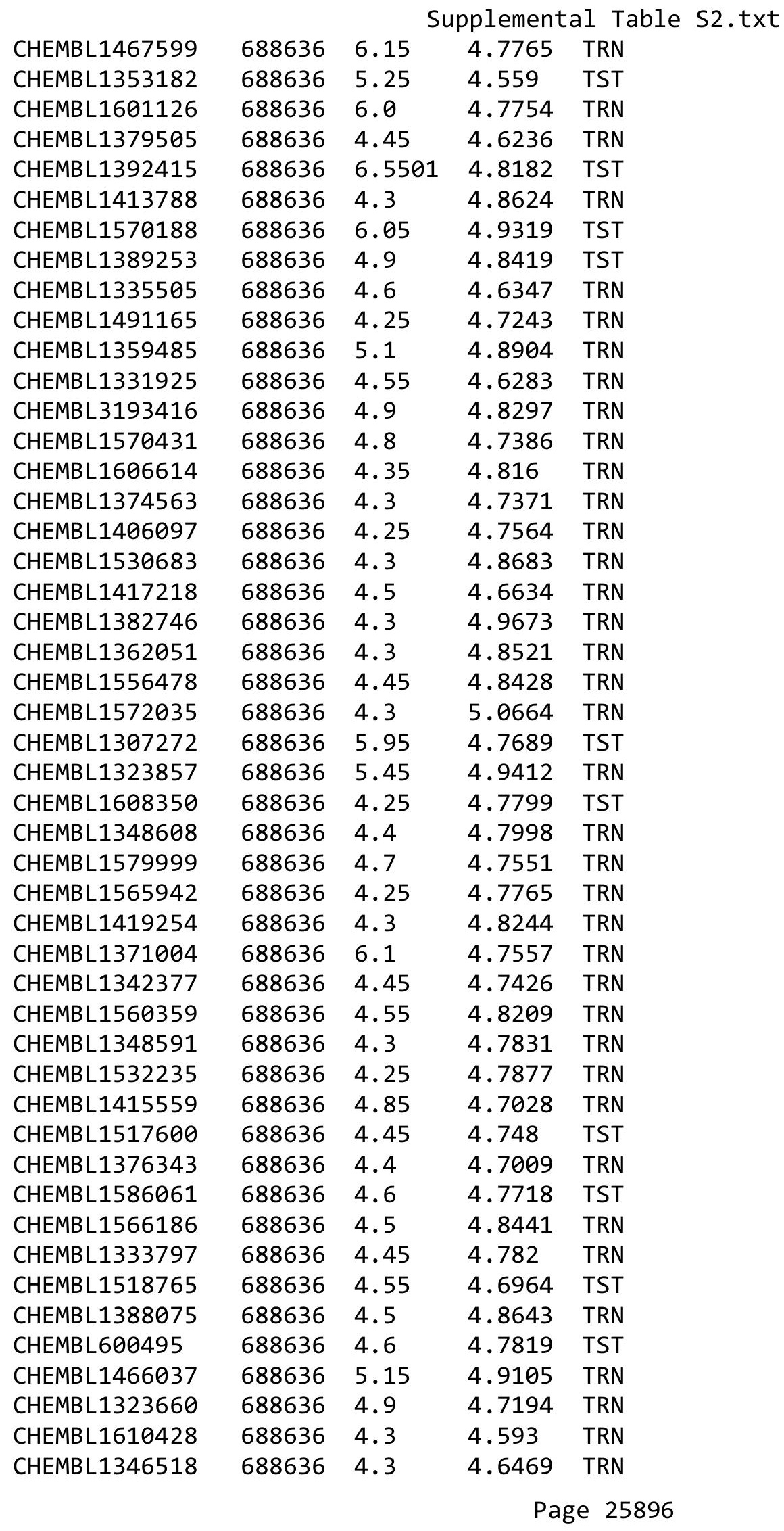




\begin{tabular}{|c|c|c|c|c|c|}
\hline \multirow{2}{*}{ CHEMBL1584294 } & \\
\hline & 688636 & 5.4 & 4.7758 & TST & \\
\hline CHEMBL1443279 & 688636 & 4.6 & 4.7309 & TRN & \\
\hline CHEMBL1572058 & 688636 & 4.25 & 4.5678 & TRN & \\
\hline CHEMBL1329073 & 688636 & 5.35 & 4.7578 & TRN & \\
\hline CHEMBL1568758 & 688636 & 6.7501 & 4.77800 & 20000000005 & TRN \\
\hline CHEMBL3208378 & 688636 & 4.55 & 4.6975 & TRN & \\
\hline CHEMBL1351610 & 688636 & 4.55 & 4.7877 & TST & \\
\hline CHEMBL1451957 & 688636 & 5.75 & 4.9866 & TRN & \\
\hline CHEMBL1409532 & 688636 & 4.4 & 4.8903 & TRN & \\
\hline CHEMBL1402852 & 688636 & 4.45 & 4.6747 & TRN & \\
\hline CHEMBL3209148 & 688636 & 5.15 & 4.5368 & TRN & \\
\hline CHEMBL1570282 & 688636 & 5.5 & 4.7309 & TRN & \\
\hline CHEMBL1565313 & 688636 & 4.35 & 4.7462 & TRN & \\
\hline CHEMBL1340302 & 688636 & 4.4 & 4.9475 & TRN & \\
\hline CHEMBL1523759 & 688636 & 5.25 & 4.8537 & TRN & \\
\hline CHEMBL1329764 & 688636 & 4.25 & 4.8703 & TRN & \\
\hline CHEMBL1440407 & 688636 & 4.95 & 4.8132 & TST & \\
\hline CHEMBL1412367 & 688636 & 4.5 & 4.6019 & TRN & \\
\hline CHEMBL1336339 & 688636 & 5.05 & 4.7355 & TRN & \\
\hline CHEMBL1427909 & 688636 & 4.95 & 5.0398 & TRN & \\
\hline CHEMBL1363626 & 688636 & 5.5 & 4.9807 & TRN & \\
\hline CHEMBL1361543 & 688636 & 4.95 & 5.038 & TRN & \\
\hline CHEMBL 1305490 & 688636 & 5.2 & 4.6844 & TRN & \\
\hline CHEMBL3193616 & 688636 & 4.25 & 4.7497 & TRN & \\
\hline CHEMBL1427031 & 688636 & 6.5 & 4.9189 & TRN & \\
\hline CHEMBL1532818 & 688636 & 4.4 & 5.081 & TRN & \\
\hline CHEMBL1453144 & 688636 & 4.45 & 4.8419 & TRN & \\
\hline CHEMBL1343954 & 688636 & 4.95 & 4.9371 & TST & \\
\hline CHEMBL1344535 & 688636 & 4.3 & 4.6632 & TRN & \\
\hline CHEMBL1351217 & 688636 & 4.95 & 4.6433 & TRN & \\
\hline CHEMBL1327130 & 688636 & 4.35 & 4.8886 & TRN & \\
\hline CHEMBL3195915 & 688636 & 4.85 & 4.959 & TST & \\
\hline CHEMBL1550200 & 688636 & 4.3 & 4.7568 & TRN & \\
\hline CHEMBL1488129 & 688636 & 4.65 & 4.9185 & TST & \\
\hline CHEMBL1450557 & 688636 & 4.65 & 4.9165 & TST & \\
\hline CHEMBL1460674 & 688636 & 4.45 & 4.8187 & TRN & \\
\hline CHEMBL1610801 & 688636 & 4.25 & 4.7642 & TST & \\
\hline CHEMBL1583793 & 688636 & 4.3 & 4.9078 & TRN & \\
\hline CHEMBL1550045 & 688636 & 4.6 & 4.8286 & TRN & \\
\hline CHEMBL3212889 & 688636 & 4.6 & 4.9238 & TRN & \\
\hline CHEMBL1326561 & 688636 & 4.4 & 4.9309 & TST & \\
\hline CHEMBL1403047 & 688636 & 5.75 & 4.979 & TRN & \\
\hline CHEMBL1333004 & 688636 & 4.75 & 4.6788 & TRN & \\
\hline CHEMBL1587526 & 688636 & 4.45 & 4.9239 & TST & \\
\hline CHEMBL1530025 & 688636 & 4.45 & 4.6711 & TRN & \\
\hline CHEMBL1299587 & 688636 & 5.0 & 4.74100 & 00000000005 & TRN \\
\hline CHEMBL1606270 & 688636 & 5.9 & 4.8313 & TRN & \\
\hline CHEMBL1557567 & 688636 & 4.25 & 4.9109 & TST & \\
\hline
\end{tabular}




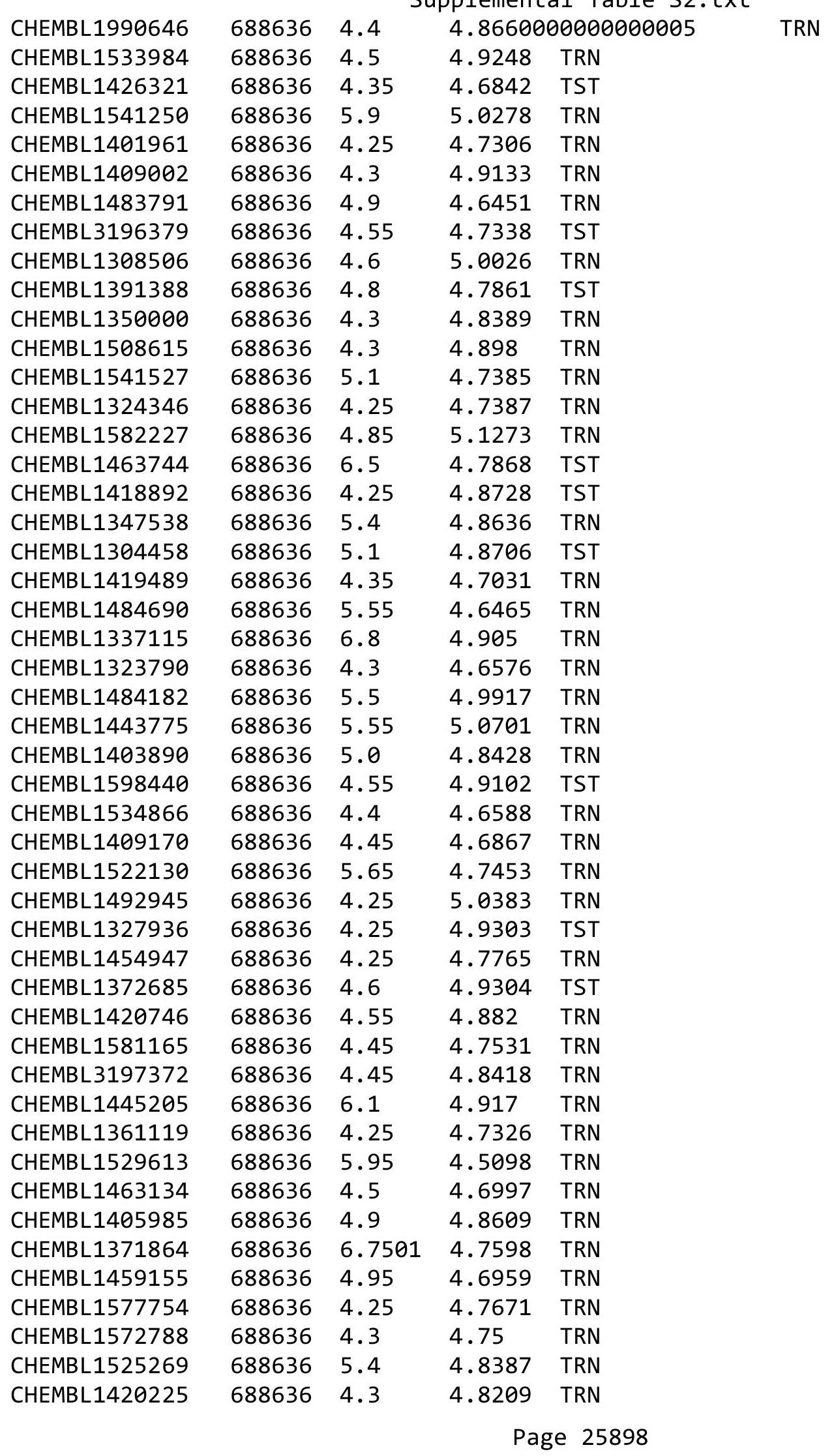




\begin{tabular}{|c|c|c|c|c|c|}
\hline \multicolumn{6}{|c|}{ Supplemental Table S2.txt } \\
\hline CHEMBL1612897 & 688636 & 5.2 & 4.7213 & TRN & \\
\hline CHEMBL1561738 & 688636 & 5.3 & 4.632 & TRN & \\
\hline CHEMBL1612354 & 688636 & 4.3 & 4.8103 & TRN & \\
\hline CHEMBL1336243 & 688636 & 4.25 & 4.9914 & TRN & \\
\hline CHEMBL1455916 & 688636 & 5.8 & 4.9412 & TRN & \\
\hline CHEMBL1363482 & 688636 & 4.6 & 4.7584 & TST & \\
\hline CHEMBL3211974 & 688636 & 5.15 & 4.8977 & TST & \\
\hline CHEMBL3196741 & 688636 & 4.55 & 4.9171 & TRN & \\
\hline CHEMBL1415438 & 688636 & 4.5 & 4.7582 & TRN & \\
\hline CHEMBL1418934 & 688636 & 4.75 & 4.8941 & TRN & \\
\hline CHEMBL1311566 & 688636 & 4.25 & 4.8898 & TRN & \\
\hline CHEMBL1300877 & 688636 & 6.2 & 4.7416 & TST & \\
\hline CHEMBL1582521 & 688636 & 4.55 & 4.9322 & TST & \\
\hline CHEMBL1374931 & 688636 & 4.4 & 4.6712 & TRN & \\
\hline CHEMBL1597293 & 688636 & 4.9 & 4.6916 & TRN & \\
\hline CHEMBL1345182 & 688636 & 4.7 & 4.9736 & TST & \\
\hline CHEMBL1387894 & 688636 & 5.05 & 4.7597 & TRN & \\
\hline CHEMBL1580584 & 688636 & 4.4 & 4.8847 & TRN & \\
\hline CHEMBL1497520 & 688636 & 4.4 & 4.8512 & TRN & \\
\hline CHEMBL1326812 & 688636 & 4.3 & 4.6977 & TRN & \\
\hline CHEMBL1971712 & 688636 & 4.25 & 4.7579 & TRN & \\
\hline CHEMBL1440249 & 688636 & 4.6 & 4.7071 & TST & \\
\hline CHEMBL 3208430 & 688636 & 4.3 & 4.94 & TST & \\
\hline CHEMBL1390126 & 688636 & 4.45 & 4.6923 & TST & \\
\hline CHEMBL1363809 & 688636 & 4.45 & 4.7353 & TRN & \\
\hline CHEMBL1493475 & 688636 & 6.05 & 4.6237 & TST & \\
\hline CHEMBL1327979 & 688636 & 4.55 & 4.7205 & TRN & \\
\hline CHEMBL1546916 & 688636 & 4.9 & 4.7479 & TRN & \\
\hline CHEMBL1493842 & 688636 & 5.45 & 4.7734 & TRN & \\
\hline CHEMBL1400777 & 688636 & 5.95 & 4.6624 & TRN & \\
\hline CHEMBL1349400 & 688636 & 6.1 & 4.8421 & TRN & \\
\hline CHEMBL1579051 & 688636 & 4.95 & 4.8367 & TRN & \\
\hline CHEMBL1516388 & 688636 & 4.35 & 4.7919 & TST & \\
\hline CHEMBL3195599 & 688636 & 4.4 & 4.7934 & TRN & \\
\hline CHEMBL1326919 & 688636 & 4.3 & 5.0049 & TRN & \\
\hline CHEMBL1429423 & 688636 & 4.25 & 4.63399 & 99999999995 & TRN \\
\hline CHEMBL1494025 & 688636 & 4.25 & 4.8018 & TRN & \\
\hline CHEMBL1584380 & 688636 & 4.9 & 5.0096 & TST & \\
\hline CHEMBL1327421 & 688636 & 5.25 & 5.0291 & TRN & \\
\hline CHEMBL1359999 & 688636 & 4.3 & 4.9279 & TRN & \\
\hline CHEMBL1376788 & 688636 & 4.3 & 4.7738 & TRN & \\
\hline CHEMBL3194214 & 688636 & 4.6 & 4.8616 & TST & \\
\hline CHEMBL1511786 & 688636 & 6.6 & 4.7009 & TRN & \\
\hline CHEMBL3197869 & 688636 & 5.3 & 4.8461 & TRN & \\
\hline CHEMBL1427890 & 688636 & 4.45 & 4.8258 & TRN & \\
\hline CHEMBL1346090 & 688636 & 4.5 & 4.7887 & TRN & \\
\hline CHEMBL1545106 & 688636 & 4.45 & 4.7451 & TST & \\
\hline CHEMBL1403067 & 688636 & 4.25 & 4.8845 & TRN & \\
\hline
\end{tabular}




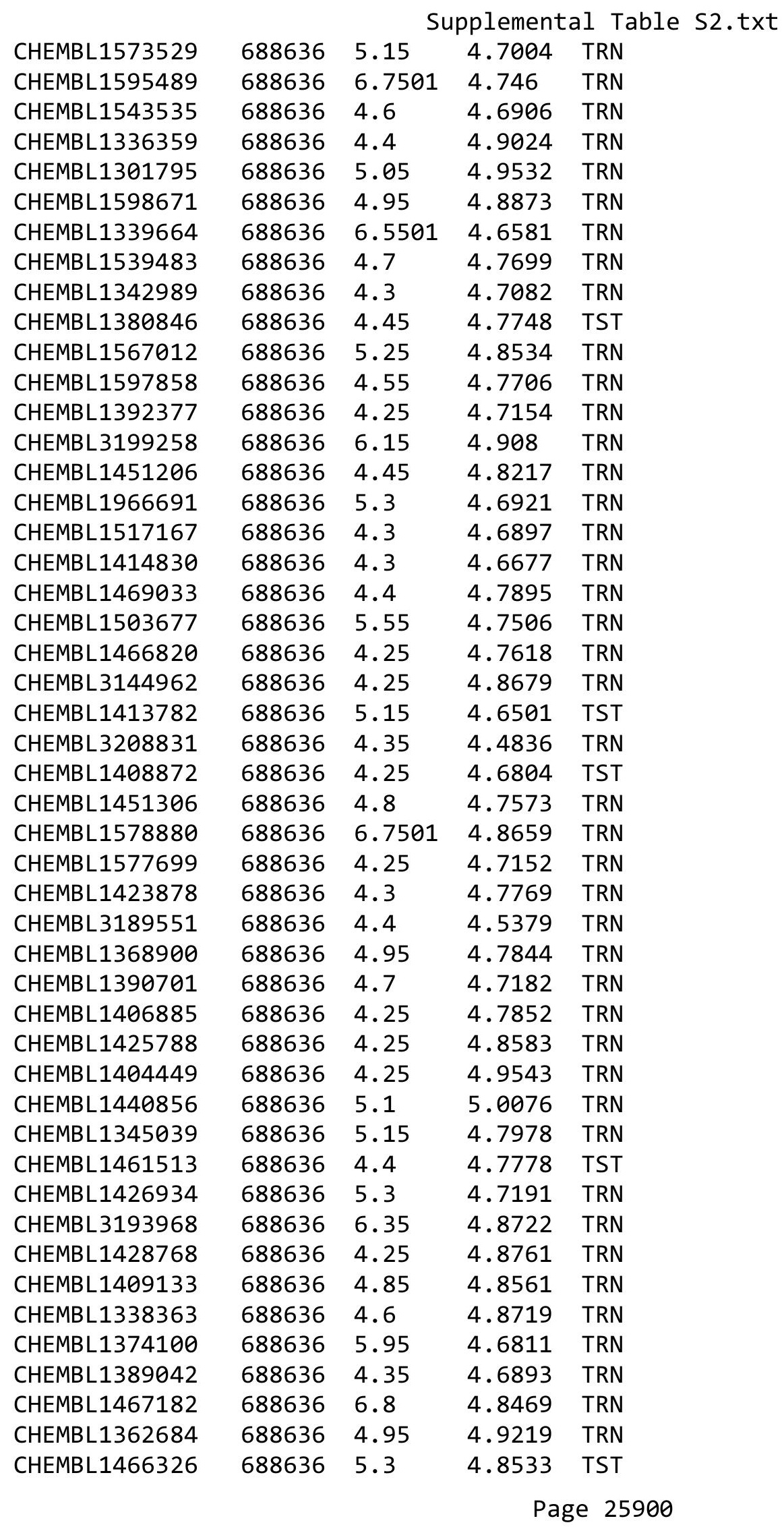




\begin{tabular}{|c|c|c|c|c|}
\hline & & & pplement & al $\mathrm{Ta}$ \\
\hline CHEMBL1503067 & 688636 & 4.3 & 4.9157 & TST \\
\hline CHEMBL1428995 & 688636 & 4.3 & 4.6123 & TRN \\
\hline CHEMBL1459529 & 688636 & 4.4 & 4.6991 & TRN \\
\hline CHEMBL1543877 & 688636 & 4.45 & 4.9637 & TRN \\
\hline CHEMBL1368871 & 688636 & 4.3 & 4.7523 & TST \\
\hline CHEMBL1341570 & 688636 & 4.3 & 4.8064 & TRN \\
\hline CHEMBL1374465 & 688636 & 5.3 & 4.7368 & TST \\
\hline CHEMBL1299245 & 688636 & 4.25 & 4.7673 & TRN \\
\hline CHEMBL1310165 & 688636 & 4.3 & 4.8831 & TST \\
\hline CHEMBL1566122 & 688636 & 4.8 & 5.1524 & TRN \\
\hline CHEMBL1714669 & 688636 & 4.4 & 4.6159 & TRN \\
\hline CHEMBL3210497 & 688636 & 5.7 & 4.8901 & TRN \\
\hline CHEMBL3214088 & 688636 & 4.3 & 4.9103 & TRN \\
\hline CHEMBL1387067 & 688636 & 4.3 & 4.8557 & TRN \\
\hline CHEMBL1470903 & 688636 & 4.95 & 4.7158 & TST \\
\hline CHEMBL1310724 & 688636 & 4.55 & 4.8589 & TRN \\
\hline CHEMBL1503071 & 688636 & 4.9 & 4.7836 & TST \\
\hline CHEMBL1307291 & 688636 & 5.9 & 4.985 & TRN \\
\hline CHEMBL1505799 & 688636 & 4.35 & 4.835 & TRN \\
\hline CHEMBL1561625 & 688636 & 4.4 & 4.8059 & TRN \\
\hline CHEMBL1445153 & 688636 & 4.5 & 4.7747 & TRN \\
\hline CHEMBL1300844 & 688636 & 4.95 & 4.8906 & TST \\
\hline CHEMBL1400756 & 688636 & 5.3 & 4.8829 & TRN \\
\hline CHEMBL1579385 & 688636 & 5.15 & 4.8612 & TRN \\
\hline CHEMBL1510840 & 688636 & 4.25 & 4.7589 & TRN \\
\hline CHEMBL1325782 & 688636 & 4.3 & 4.7715 & TRN \\
\hline CHEMBL1529055 & 688636 & 4.25 & 5.0534 & TST \\
\hline CHEMBL1339262 & 688636 & 4.95 & 4.9383 & TST \\
\hline CHEMBL1404254 & 688636 & 4.95 & 4.8464 & TRN \\
\hline CHEMBL1309390 & 688636 & 4.9 & 5.0315 & TRN \\
\hline CHEMBL1300405 & 688636 & 4.45 & 4.6291 & TRN \\
\hline CHEMBL1542101 & 688636 & 4.6 & 4.8467 & TRN \\
\hline CHEMBL1477665 & 688636 & 4.25 & 4.8914 & TRN \\
\hline CHEMBL1559867 & 688636 & 4.45 & 4.6234 & TRN \\
\hline CHEMBL1343081 & 688636 & 4.5 & 4.6169 & TRN \\
\hline CHEMBL3196100 & 688636 & 4.3 & 4.4738 & TRN \\
\hline CHEMBL1378837 & 688636 & 5.45 & 4.9929 & TRN \\
\hline CHEMBL1543114 & 688636 & 4.3 & 4.8051 & TRN \\
\hline CHEMBL1471904 & 688636 & 4.35 & 4.9304 & TRN \\
\hline CHEMBL1560885 & 688636 & 4.25 & 4.6875 & TRN \\
\hline CHEMBL1558506 & 688636 & 4.6 & 4.6438 & TRN \\
\hline CHEMBL1322396 & 688636 & 6.15 & 4.6976 & TRN \\
\hline CHEMBL286346 & 688636 & 4.5 & 4.8053 & TST \\
\hline CHEMBL1565596 & 688636 & 4.6 & 4.6867 & TRN \\
\hline CHEMBL1329337 & 688636 & 4.3 & 4.919 & TRN \\
\hline CHEMBL1381306 & 688636 & 4.8 & 4.6413 & TRN \\
\hline CHEMBL1595155 & 688636 & 4.45 & 4.7602 & TRN \\
\hline CHEMBL1522750 & 688636 & 5.0 & 4.7816 & TRN \\
\hline
\end{tabular}




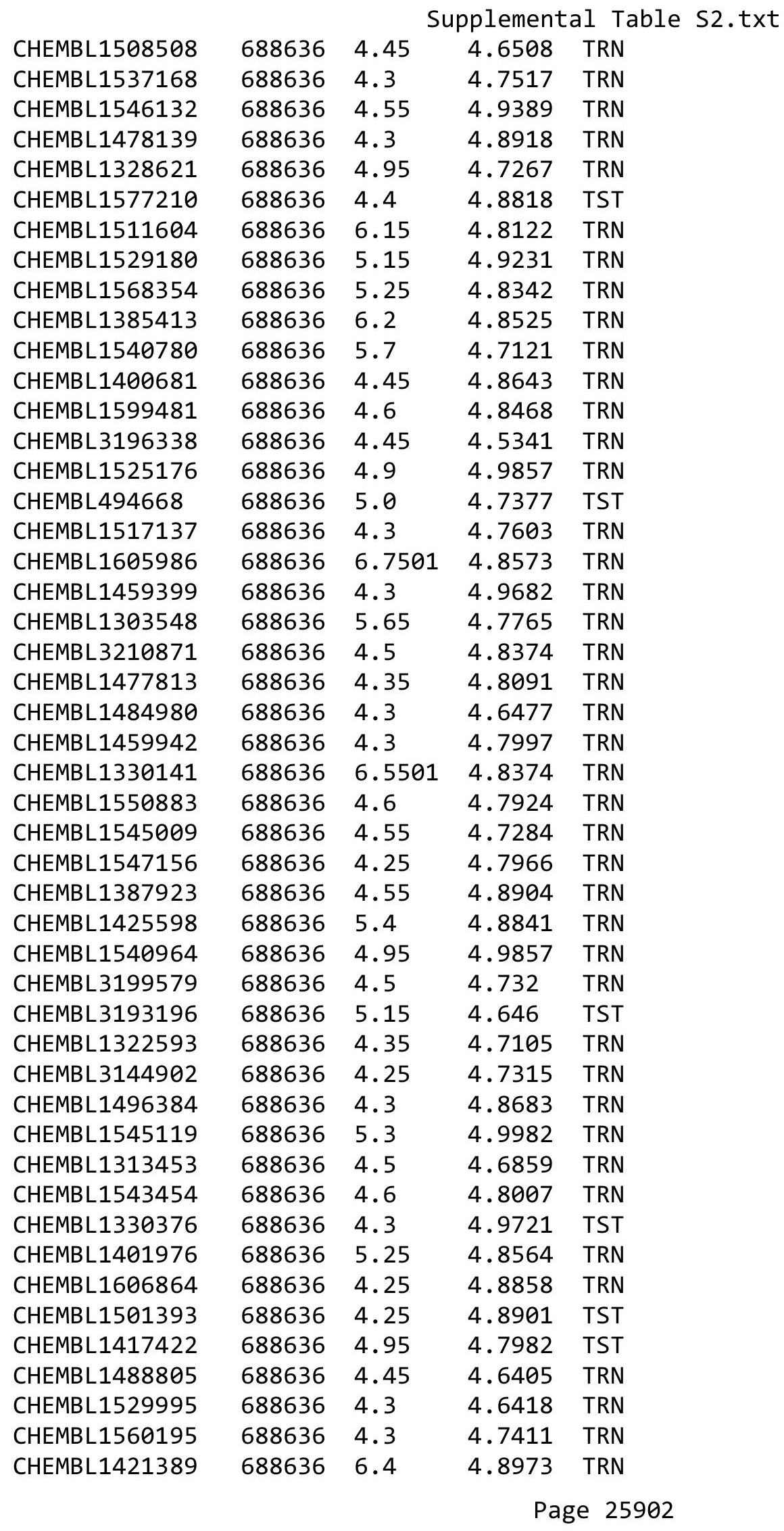




\begin{tabular}{|c|c|c|c|c|}
\hline \multicolumn{5}{|c|}{ Supplemental Table s2.txt } \\
\hline CHEMBL1588929 & 688636 & 4.45 & 4.6321 & TRN \\
\hline CHEMBL1407348 & 688636 & 4.45 & 4.8856 & TST \\
\hline CHEMBL1533487 & 688636 & 6.1 & 5.004 & TRN \\
\hline CHEMBL1491283 & 688636 & 4.25 & 5.0206 & TRN \\
\hline CHEMBL1602972 & 688636 & 4.3 & 4.9109 & TST \\
\hline CHEMBL1303040 & 688636 & 5.35 & 4.8264 & TST \\
\hline CHEMBL1517010 & 688636 & 5.9 & 4.8964 & TRN \\
\hline CHEMBL1449160 & 688636 & 4.45 & 4.7351 & TRN \\
\hline CHEMBL1497637 & 688636 & 4.25 & 4.6845 & TST \\
\hline CHEMBL1547024 & 688636 & 6.2 & 4.9124 & TRN \\
\hline CHEMBL1416517 & 688636 & 4.25 & 4.8366 & TRN \\
\hline CHEMBL1498705 & 688636 & 6.7501 & 4.9374 & TRN \\
\hline CHEMBL1582877 & 688636 & 4.35 & 4.6979 & TST \\
\hline CHEMBL1567366 & 688636 & 5.85 & 4.8453 & TRN \\
\hline CHEMBL1558283 & 688636 & 4.3 & 4.8177 & TRN \\
\hline CHEMBL1595262 & 688636 & 4.55 & 4.9675 & TRN \\
\hline CHEMBL1301239 & 688636 & 5.35 & 4.6836 & TRN \\
\hline CHEMBL1329888 & 688636 & 5.25 & 4.9673 & TRN \\
\hline CHEMBL1344025 & 688636 & 4.85 & 4.7282 & TRN \\
\hline CHEMBL1326021 & 688636 & 4.4 & 4.8145 & TST \\
\hline CHEMBL1454587 & 688636 & 4.5 & 4.7811 & TRN \\
\hline CHEMBL1546383 & 688636 & 4.85 & 4.824 & TRN \\
\hline CHEMBL1344500 & 688636 & 5.0 & 4.8946 & TRN \\
\hline CHEMBL1595160 & 688636 & 5.95 & 4.8157 & TRN \\
\hline CHEMBL1444893 & 688636 & 4.45 & 4.7565 & TRN \\
\hline CHEMBL1560535 & 688636 & 4.5 & 4.8369 & TRN \\
\hline CHEMBL1320561 & 688636 & 4.3 & 4.7566 & TRN \\
\hline CHEMBL1485887 & 688636 & 4.25 & 4.7254 & TRN \\
\hline CHEMBL1442518 & 688636 & 5.35 & 4.9733 & TRN \\
\hline CHEMBL1346580 & 688636 & 4.8 & 4.7447 & TRN \\
\hline CHEMBL1500533 & 688636 & 4.4 & 4.7821 & TRN \\
\hline CHEMBL1565338 & 688636 & 4.45 & 4.7296 & TRN \\
\hline CHEMBL1532762 & 688636 & 4.3 & 4.6929 & TRN \\
\hline CHEMBL1378572 & 688636 & 4.3 & 4.7677 & TST \\
\hline CHEMBL1334790 & 688636 & 5.15 & 4.7429 & TST \\
\hline CHEMBL1579595 & 688636 & 6.35 & 4.6634 & TRN \\
\hline CHEMBL1491566 & 688636 & 4.5 & 5.1048 & TRN \\
\hline CHEMBL1493031 & 688636 & 4.25 & 4.8539 & TRN \\
\hline CHEMBL 3198433 & 688636 & 4.45 & 4.6525 & TRN \\
\hline CHEMBL1462836 & 688636 & 4.9 & 4.6772 & TRN \\
\hline CHEMBL1342689 & 688636 & 4.85 & 4.8056 & TRN \\
\hline CHEMBL1505326 & 688636 & 4.45 & 5.0046 & TRN \\
\hline CHEMBL1345554 & 688636 & 4.4 & 4.8622 & TRN \\
\hline CHEMBL 3193170 & 688636 & 4.25 & 4.7263 & TRN \\
\hline CHEMBL1386503 & 688636 & 4.3 & 4.7475 & TRN \\
\hline CHEMBL1412093 & 688636 & 4.25 & 4.7792 & TRN \\
\hline CHEMBL1312087 & 688636 & 4.75 & 4.856 & TST \\
\hline CHEMBL1510183 & 688636 & 6.8 & 4.6876 & TRN \\
\hline
\end{tabular}




\begin{tabular}{|c|c|c|c|c|c|}
\hline \multicolumn{6}{|c|}{ Supplemental Table s2.txt } \\
\hline CHEMBL1425009 & 688636 & 4.7 & 4.7546 & TRN & \\
\hline CHEMBL1463302 & 688636 & 4.7 & 4.6988 & TRN & \\
\hline CHEMBL1387811 & 688636 & 4.35 & 4.9323 & TRN & \\
\hline CHEMBL1545168 & 688636 & 4.3 & 4.9012 & TRN & \\
\hline CHEMBL1530759 & 688636 & 4.9 & 4.5627 & TRN & \\
\hline CHEMBL1598640 & 688636 & 4.25 & 4.882 & TST & \\
\hline CHEMBL1331054 & 688636 & 4.5 & 4.825 & TRN & \\
\hline CHEMBL1432698 & 688636 & 4.25 & 4.99 & TST & \\
\hline CHEMBL1370720 & 688636 & 4.25 & 4.8947 & TRN & \\
\hline CHEMBL1480398 & 688636 & 5.05 & 4.8953 & TST & \\
\hline CHEMBL1422949 & 688636 & 4.95 & 4.8949 & TRN & \\
\hline CHEMBL1442864 & 688636 & 4.45 & 4.8087 & TST & \\
\hline CHEMBL1308105 & 688636 & 6.7501 & 4.7322 & TRN & \\
\hline CHEMBL1305264 & 688636 & 4.3 & 4.8262 & TST & \\
\hline CHEMBL1367576 & 688636 & 6.4 & 4.8998 & TRN & \\
\hline CHEMBL1388441 & 688636 & 4.45 & 4.6213 & TRN & \\
\hline CHEMBL1528112 & 688636 & 4.5 & 4.6383 & TRN & \\
\hline CHEMBL1323064 & 688636 & 5.2 & 4.6949 & TST & \\
\hline CHEMBL1510481 & 688636 & 4.95 & 4.9298 & TRN & \\
\hline CHEMBL3210527 & 688636 & 5.1 & 4.81 & TRN & \\
\hline CHEMBL1611439 & 688636 & 4.55 & 4.6665 & TRN & \\
\hline CHEMBL1488429 & 688636 & 4.6 & 4.6966 & TRN & \\
\hline CHEMBL 3213214 & 688636 & 4.25 & $4.8610 e$ & 0000000001 & TST \\
\hline CHEMBL1404096 & 688636 & 5.1 & 4.8698 & TRN & \\
\hline CHEMBL1541831 & 688636 & 4.4 & 4.8477 & TRN & \\
\hline CHEMBL1505837 & 688636 & 4.9 & 4.8933 & TRN & \\
\hline CHEMBL1422694 & 688636 & 5.05 & 4.7364 & TRN & \\
\hline CHEMBL3144995 & 688636 & 4.9 & 4.7744 & TST & \\
\hline CHEMBL1582262 & 688636 & 4.3 & 4.6073 & TRN & \\
\hline CHEMBL1366889 & 688636 & 4.4 & 4.6769 & TST & \\
\hline CHEMBL1492897 & 688636 & 4.25 & 4.7451 & TRN & \\
\hline CHEMBL1379304 & 688636 & 4.25 & 4.8455 & TRN & \\
\hline CHEMBL1301515 & 688636 & 5.0 & 4.9042 & TRN & \\
\hline CHEMBL1365022 & 688636 & 5.5 & 4.7789 & TRN & \\
\hline CHEMBL1536006 & 688636 & 6.7501 & 4.8823 & TRN & \\
\hline CHEMBL1376269 & 688636 & 4.95 & 4.8003 & TST & \\
\hline CHEMBL1471903 & 688636 & 4.3 & 4.7453 & TRN & \\
\hline CHEMBL1468987 & 688636 & 4.25 & 5.0703 & TRN & \\
\hline CHEMBL1541800 & 688636 & 4.75 & 4.7236 & TRN & \\
\hline CHEMBL1549118 & 688636 & 4.35 & 4.7466 & TRN & \\
\hline CHEMBL1466441 & 688636 & 6.05 & 4.8421 & TST & \\
\hline CHEMBL1600531 & 688636 & 4.6 & 4.8746 & TRN & \\
\hline CHEMBL1457829 & 688636 & 6.5501 & 4.706 & TRN & \\
\hline CHEMBL1424030 & 688636 & 4.35 & 4.7931 & TRN & \\
\hline CHEMBL1384528 & 688636 & 4.95 & 4.7833 & TRN & \\
\hline CHEMBL1496277 & 688636 & 5.45 & 5.0503 & TRN & \\
\hline CHEMBL1517989 & 688636 & 4.25 & 4.8892 & TST & \\
\hline CHEMBL1496889 & 688636 & 5.15 & 4.8474 & TST & \\
\hline
\end{tabular}




\begin{tabular}{|c|c|c|c|c|c|}
\hline \\
\hline CHEMBL1549487 & 688636 & 6.7501 & 4.7609 & TST & \\
\hline CHEMBL1445566 & 688636 & 4.5 & 4.7152 & TRN & \\
\hline CHEMBL1313516 & 688636 & 4.3 & 4.98 & TRN & \\
\hline CHEMBL1439596 & 688636 & 4.3 & 4.692 & TRN & \\
\hline CHEMBL1533439 & 688636 & 4.25 & 4.8926 & TST & \\
\hline CHEMBL1348753 & 688636 & 4.45 & 4.6962 & TRN & \\
\hline CHEMBL1577537 & 688636 & 4.5 & 4.8808 & TST & \\
\hline CHEMBL1507703 & 688636 & 4.85 & 4.9523 & TRN & \\
\hline CHEMBL1371438 & 688636 & 4.3 & 4.6383 & TRN & \\
\hline CHEMBL1448151 & 688636 & 4.95 & 5.0219 & TRN & \\
\hline CHEMBL1440843 & 688636 & 4.3 & 4.7931 & TRN & \\
\hline CHEMBL1425080 & 688636 & 4.45 & 4.7196 & TST & \\
\hline CHEMBL1457366 & 688636 & 5.25 & 4.7822 & TST & \\
\hline CHEMBL1385844 & 688636 & 5.6 & 4.8754 & TRN & \\
\hline CHEMBL1493695 & 688636 & 5.75 & 4.7508 & TRN & \\
\hline CHEMBL1586800 & 688636 & 4.5 & 4.6614 & TRN & \\
\hline CHEMBL1575028 & 688636 & 4.25 & 5.039 & TRN & \\
\hline CHEMBL1548712 & 688636 & 4.25 & 4.6738 & TST & \\
\hline CHEMBL1449461 & 688636 & 4.3 & 4.8547 & TST & \\
\hline CHEMBL1578017 & 688636 & 4.25 & 4.7908 & TRN & \\
\hline CHEMBL1445542 & 688636 & 5.25 & 4.7024 & TRN & \\
\hline CHEMBL1607322 & 688636 & 4.25 & 4.8356 & TRN & \\
\hline CHEMBL1348186 & 688636 & 4.8 & 4.7812 & TST & \\
\hline CHEMBL1462222 & 688636 & 5.4 & 4.7188 & TRN & \\
\hline CHEMBL1531619 & 688636 & 4.3 & 4.8851 & TRN & \\
\hline CHEMBL1366059 & 688636 & 4.5 & 4.7902 & TST & \\
\hline CHEMBL1585947 & 688636 & 4.5 & 4.7262 & TRN & \\
\hline CHEMBL1352549 & 688636 & 4.9 & 4.9279 & TRN & \\
\hline CHEMBL1537571 & 688636 & 5.25 & 4.869 & TRN & \\
\hline CHEMBL1423032 & 688636 & 4.3 & 4.7845 & TST & \\
\hline CHEMBL1501190 & 688636 & 4.6 & 4.6982 & TRN & \\
\hline CHEMBL1328544 & 688636 & 5.9 & 4.7673 & TRN & \\
\hline CHEMBL1568413 & 688636 & 4.5 & 4.6728 & TST & \\
\hline CHEMBL1360250 & 688636 & 4.25 & 4.8819 & TRN & \\
\hline CHEMBL1386430 & 688636 & 4.3 & 4.8056 & TRN & \\
\hline CHEMBL1500285 & 688636 & 4.45 & 4.7804 & TST & \\
\hline CHEMBL1540836 & 688636 & 5.2 & 4.82100 & 3000000001 & TRN \\
\hline CHEMBL1344791 & 688636 & 4.25 & 4.8638 & TRN & \\
\hline CHEMBL1463737 & 688636 & 4.45 & 4.5758 & TRN & \\
\hline CHEMBL1574044 & 688636 & 6.1 & 4.9064 & TRN & \\
\hline CHEMBL1383395 & 688636 & 4.9 & 4.9233 & TST & \\
\hline CHEMBL1326097 & 688636 & 4.3 & 4.6278 & TRN & \\
\hline CHEMBL1526133 & 688636 & 4.25 & 4.8534 & TRN & \\
\hline CHEMBL1532107 & 688636 & 4.45 & 4.856 & TRN & \\
\hline CHEMBL1367147 & 688636 & 5.0 & 4.6636 & TST & \\
\hline CHEMBL1472350 & 688636 & 4.3 & 4.8595 & TRN & \\
\hline CHEMBL1532342 & 688636 & 4.6 & 4.816 & TST & \\
\hline CHEMBL1541767 & 688636 & 4.7 & 4.7858 & TRN & \\
\hline
\end{tabular}




\begin{tabular}{|c|c|c|c|c|c|}
\hline \\
\hline CHEMBL1420677 & 688636 & 4.3 & 4.8737 & TRN & \\
\hline CHEMBL1393996 & 688636 & 4.3 & 5.0097 & TRN & \\
\hline CHEMBL1312419 & 688636 & 4.35 & 4.6877 & TRN & \\
\hline CHEMBL1413321 & 688636 & 4.3 & 4.9131 & TRN & \\
\hline CHEMBL1526651 & 688636 & 5.1 & 4.7213 & TRN & \\
\hline CHEMBL3198578 & 688636 & 5.3 & 4.6877 & TST & \\
\hline CHEMBL1566246 & 688636 & 6.7501 & 4.9657 & TRN & \\
\hline CHEMBL1524355 & 688636 & 4.3 & 4.8321 & TRN & \\
\hline CHEMBL1573414 & 688636 & 4.65 & 4.8035 & TRN & \\
\hline CHEMBL1299238 & 688636 & 4.85 & 4.8813 & TRN & \\
\hline CHEMBL1542211 & 688636 & 4.35 & 4.7627 & TRN & \\
\hline CHEMBL1544614 & 688636 & 4.25 & 4.7823 & TRN & \\
\hline CHEMBL1561694 & 688636 & 4.5 & 4.7464 & TST & \\
\hline CHEMBL1509807 & 688636 & 4.95 & 4.8203 & TST & \\
\hline CHEMBL1522815 & 688636 & 5.1 & 4.836 & TST & \\
\hline CHEMBL1331190 & 688636 & 4.95 & 4.8792 & TST & \\
\hline CHEMBL1550087 & 688636 & 4.45 & 4.6466 & TST & \\
\hline CHEMBL1480521 & 688636 & 4.3 & 4.83899 & 99999999995 & TST \\
\hline CHEMBL1443561 & 688636 & 4.3 & 4.7993 & TRN & \\
\hline CHEMBL1557704 & 688636 & 4.3 & 4.5097 & TRN & \\
\hline CHEMBL1566701 & 688636 & 4.5 & 4.8059 & TRN & \\
\hline CHEMBL1594433 & 688636 & 4.95 & 4.9013 & TRN & \\
\hline CHEMBL1528880 & 688636 & 4.65 & 4.5512 & TST & \\
\hline CHEMBL1567277 & 688636 & 5.6 & 4.6883 & TRN & \\
\hline CHEMBL1586510 & 688636 & 4.95 & 4.8969 & TST & \\
\hline CHEMBL1439981 & 688636 & 4.95 & 4.779 & TRN & \\
\hline CHEMBL1479833 & 688636 & 4.9 & 4.8384 & TRN & \\
\hline CHEMBL1404841 & 688636 & 4.45 & 4.9133 & TRN & \\
\hline CHEMBL1375235 & 688636 & 5.45 & 5.0 & TRN & \\
\hline CHEMBL3198553 & 688636 & 4.95 & 4.8308 & TRN & \\
\hline CHEMBL1504205 & 688636 & 4.85 & 4.6323 & TRN & \\
\hline CHEMBL1331723 & 688636 & 4.4 & 4.633 & TRN & \\
\hline CHEMBL1380822 & 688636 & 4.3 & 4.7912 & TST & \\
\hline CHEMBL1575536 & 688636 & 4.65 & 4.7609 & TRN & \\
\hline CHEMBL1535892 & 688636 & 4.45 & 4.5876 & TRN & \\
\hline CHEMBL1517194 & 688636 & 5.25 & 5.1541 & TST & \\
\hline CHEMBL1384049 & 688636 & 5.0 & 4.7058 & TRN & \\
\hline CHEMBL1518949 & 688636 & 4.5 & 4.7194 & TST & \\
\hline CHEMBL1480154 & 688636 & 4.85 & 4.7755 & TRN & \\
\hline CHEMBL1549477 & 688636 & 5.5 & 4.91100 & 00000000005 & TST \\
\hline CHEMBL3208660 & 688636 & 4.6 & 4.9281 & TRN & \\
\hline CHEMBL1468649 & 688636 & 6.7501 & 5.0313 & TST & \\
\hline CHEMBL1587380 & 688636 & 4.3 & 4.8956 & TRN & \\
\hline CHEMBL1387945 & 688636 & 4.6 & 4.6434 & TRN & \\
\hline CHEMBL1539409 & 688636 & 4.55 & 4.5099 & TST & \\
\hline CHEMBL1339735 & 688636 & 4.35 & 4.9012 & TRN & \\
\hline CHEMBL1441099 & 688636 & 4.4 & 4.7649 & TRN & \\
\hline CHEMBL1517577 & 688636 & 4.85 & 4.7127 & TRN & \\
\hline
\end{tabular}




\begin{tabular}{|c|c|c|c|c|}
\hline \multicolumn{5}{|c|}{ Supplemental Table S2.txt } \\
\hline CHEMBL1449992 & 688636 & 4.3 & 4.9635 & TRN \\
\hline CHEMBL533954 & 688636 & 4.25 & 4.6965 & TRN \\
\hline CHEMBL1548850 & 688636 & 4.4 & 4.9812 & TST \\
\hline CHEMBL1550068 & 688636 & 4.6 & 4.93 & TRN \\
\hline CHEMBL1439372 & 688636 & 4.3 & 4.8347 & TRN \\
\hline CHEMBL1441424 & 688636 & 4.25 & 4.83 & TRN \\
\hline CHEMBL3190134 & 688636 & 4.35 & 4.9749 & TST \\
\hline CHEMBL1407509 & 688636 & 4.3 & 4.6981 & TRN \\
\hline CHEMBL1428063 & 688636 & 4.25 & 4.8566 & TST \\
\hline CHEMBL1527641 & 688636 & 4.3 & 4.7995 & TST \\
\hline CHEMBL 3212985 & 688636 & 4.4 & 4.7134 & TRN \\
\hline CHEMBL1567996 & 688636 & 4.25 & 4.7095 & TRN \\
\hline CHEMBL 3208751 & 688636 & 4.4 & 4.8821 & TRN \\
\hline CHEMBL1479168 & 688636 & 4.25 & 4.7789 & TRN \\
\hline CHEMBL1383323 & 688636 & 4.45 & 4.6296 & TRN \\
\hline CHEMBL1550793 & 688636 & 4.25 & 4.8888 & TST \\
\hline CHEMBL1563450 & 688636 & 4.3 & 4.7957 & TRN \\
\hline CHEMBL1995645 & 688636 & 4.55 & 4.7608 & TST \\
\hline CHEMBL1549592 & 688636 & 5.85 & 4.8729 & TRN \\
\hline CHEMBL1563559 & 688636 & 4.65 & 4.8948 & TRN \\
\hline CHEMBL1542046 & 688636 & 4.45 & 4.7364 & TRN \\
\hline CHEMBL1546283 & 688636 & 4.3 & 4.6346 & TRN \\
\hline CHEMBL1352209 & 688636 & 4.35 & 4.8411 & TRN \\
\hline CHEMBL1549672 & 688636 & 5.8 & 4.8041 & TRN \\
\hline CHEMBL1522968 & 688636 & 4.45 & 4.8364 & TRN \\
\hline CHEMBL 1380570 & 688636 & 4.45 & 4.7204 & TRN \\
\hline CHEMBL1345153 & 688636 & 4.95 & 4.8752 & TRN \\
\hline CHEMBL1432875 & 688636 & 6.7501 & 4.9041 & TRN \\
\hline CHEMBL1336039 & 688636 & 4.45 & 4.6696 & TRN \\
\hline CHEMBL 3207648 & 688636 & 4.55 & 4.8053 & TRN \\
\hline CHEMBL1573147 & 688636 & 4.5 & 4.8901 & TRN \\
\hline CHEMBL1428697 & 688636 & 4.6 & 4.6131 & TRN \\
\hline CHEMBL1361117 & 688636 & 4.3 & 4.7582 & TRN \\
\hline CHEMBL1339538 & 688636 & 4.6 & 4.9241 & TRN \\
\hline CHEMBL1537908 & 688636 & 4.25 & 4.995 & TRN \\
\hline CHEMBL1452840 & 688636 & 4.55 & 4.8509 & TRN \\
\hline CHEMBL1547970 & 688636 & 5.15 & 4.7456 & TST \\
\hline CHEMBL1507438 & 688636 & 4.4 & 4.8767 & TRN \\
\hline CHEMBL1375433 & 688636 & 4.45 & 4.5626 & TRN \\
\hline CHEMBL3211199 & 688636 & 5.45 & 4.9374 & TST \\
\hline CHEMBL1562605 & 688636 & 4.45 & 4.5621 & TRN \\
\hline CHEMBL1477689 & 688636 & 4.55 & 4.8481 & TRN \\
\hline CHEMBL1607386 & 688636 & 4.3 & 4.8308 & TST \\
\hline CHEMBL1330219 & 688636 & 4.3 & 4.6366 & TRN \\
\hline CHEMBL1430904 & 688636 & 5.55 & 4.8048 & TST \\
\hline CHEMBL1601977 & 688636 & 4.8 & 4.8118 & TRN \\
\hline CHEMBL1505106 & 688636 & 5.85 & 4.7699 & TST \\
\hline CHEMBL1536842 & 688636 & 4.3 & 4.9119 & TRN \\
\hline
\end{tabular}




\begin{tabular}{|c|c|c|c|c|c|}
\hline \multicolumn{6}{|c|}{ Supplemental Table S2.txt } \\
\hline CHEMBL1492455 & 688636 & 5.85 & 4.8585 & TRN & \\
\hline CHEMBL1501453 & 688636 & 4.55 & 4.8206 & TST & \\
\hline CHEMBL373940 & 688636 & 4.4 & 4.9245 & TST & \\
\hline CHEMBL1482010 & 688636 & 5.25 & 4.59399 & 7999999999 & TST \\
\hline CHEMBL1587396 & 688636 & 5.15 & 4.7647 & TST & \\
\hline CHEMBL3207510 & 688636 & 4.45 & 4.8622 & TRN & \\
\hline CHEMBL3213875 & 688636 & 4.6 & 4.8897 & TRN & \\
\hline CHEMBL1468458 & 688636 & 4.3 & 4.6902 & TRN & \\
\hline CHEMBL1416151 & 688636 & 4.45 & 4.6008 & TRN & \\
\hline CHEMBL1517049 & 688636 & 4.95 & 4.7241 & TRN & \\
\hline CHEMBL1380290 & 688636 & 4.25 & 4.9068 & TST & \\
\hline CHEMBL1451671 & 688636 & 6.7501 & 4.8422 & TRN & \\
\hline CHEMBL1386412 & 688636 & 4.65 & 4.9156 & TRN & \\
\hline CHEMBL1497833 & 688636 & 4.95 & 4.8797 & TRN & \\
\hline CHEMBL1410698 & 688636 & 5.5 & 4.71899 & 7999999999 & TRN \\
\hline CHEMBL1420247 & 688636 & 4.7 & 4.9215 & TST & \\
\hline CHEMBL1336142 & 688636 & 4.4 & 4.7641 & TRN & \\
\hline CHEMBL3212862 & 688636 & 4.35 & 4.8554 & TST & \\
\hline CHEMBL1402286 & 688636 & 4.3 & 4.5182 & TRN & \\
\hline CHEMBL1556970 & 688636 & 4.25 & 4.7602 & TRN & \\
\hline CHEMBL1322780 & 688636 & 4.25 & 4.7151 & TST & \\
\hline CHEMBL1559312 & 688636 & 5.9 & 4.7659 & TRN & \\
\hline CHEMBL1451107 & 688636 & 4.95 & 4.7429 & TRN & \\
\hline CHEMBL1612500 & 688636 & 5.65 & 4.8647 & TST & \\
\hline CHEMBL1532991 & 688636 & 6.7501 & 5.0898 & TST & \\
\hline CHEMBL1422741 & 688636 & 4.6 & 4.797 & TRN & \\
\hline CHEMBL1600247 & 688636 & 6.7501 & 4.8176 & TRN & \\
\hline CHEMBL3194674 & 688636 & 6.15 & 4.8975 & TRN & \\
\hline CHEMBL3209791 & 688636 & 4.5 & 4.6021 & TRN & \\
\hline CHEMBL1342186 & 688636 & 5.55 & 4.8361 & TRN & \\
\hline CHEMBL1492306 & 688636 & 4.5 & 4.8384 & TRN & \\
\hline CHEMBL1561212 & 688636 & 4.3 & 4.6866 & TRN & \\
\hline CHEMBL1339385 & 688636 & 4.3 & 4.7962 & TRN & \\
\hline CHEMBL1491886 & 688636 & 5.5 & 5.0108 & TRN & \\
\hline CHEMBL3196108 & 688636 & 4.3 & 4.7 & TST & \\
\hline CHEMBL1492954 & 688636 & 4.35 & 4.6878 & TRN & \\
\hline CHEMBL1430080 & 688636 & 4.45 & 4.8239 & TST & \\
\hline CHEMBL1507666 & 688636 & 4.3 & 4.9484 & TST & \\
\hline CHEMBL1438080 & 688636 & 4.95 & 4.8342 & TRN & \\
\hline CHEMBL1557054 & 688636 & 5.4 & 4.6264 & TRN & \\
\hline CHEMBL113414 & 688636 & 5.15 & 4.8714 & TRN & \\
\hline CHEMBL1403344 & 688636 & 5.25 & 4.936 & TRN & \\
\hline CHEMBL1613468 & 688636 & 4.25 & 4.9082 & TRN & \\
\hline CHEMBL1426239 & 688636 & 4.3 & 4.6256 & TRN & \\
\hline CHEMBL1574067 & 688636 & 4.6 & 4.9165 & TST & \\
\hline CHEMBL 3189307 & 688636 & 6.05 & 4.8517 & TST & \\
\hline CHEMBL1493891 & 688636 & 4.55 & 4.6682 & TRN & \\
\hline CHEMBL1415214 & 688636 & 6.4 & 4.6987 & TRN & \\
\hline
\end{tabular}




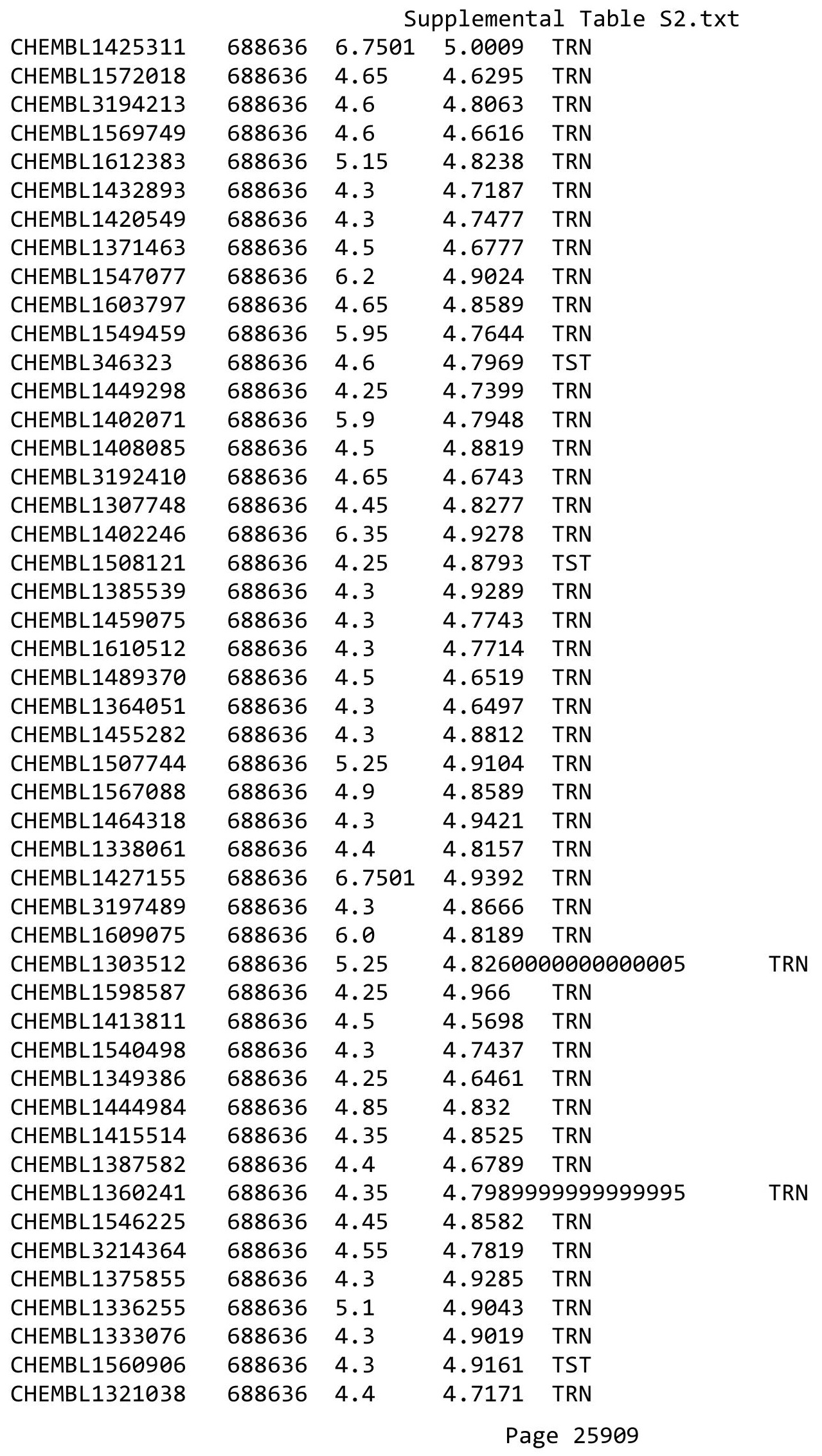




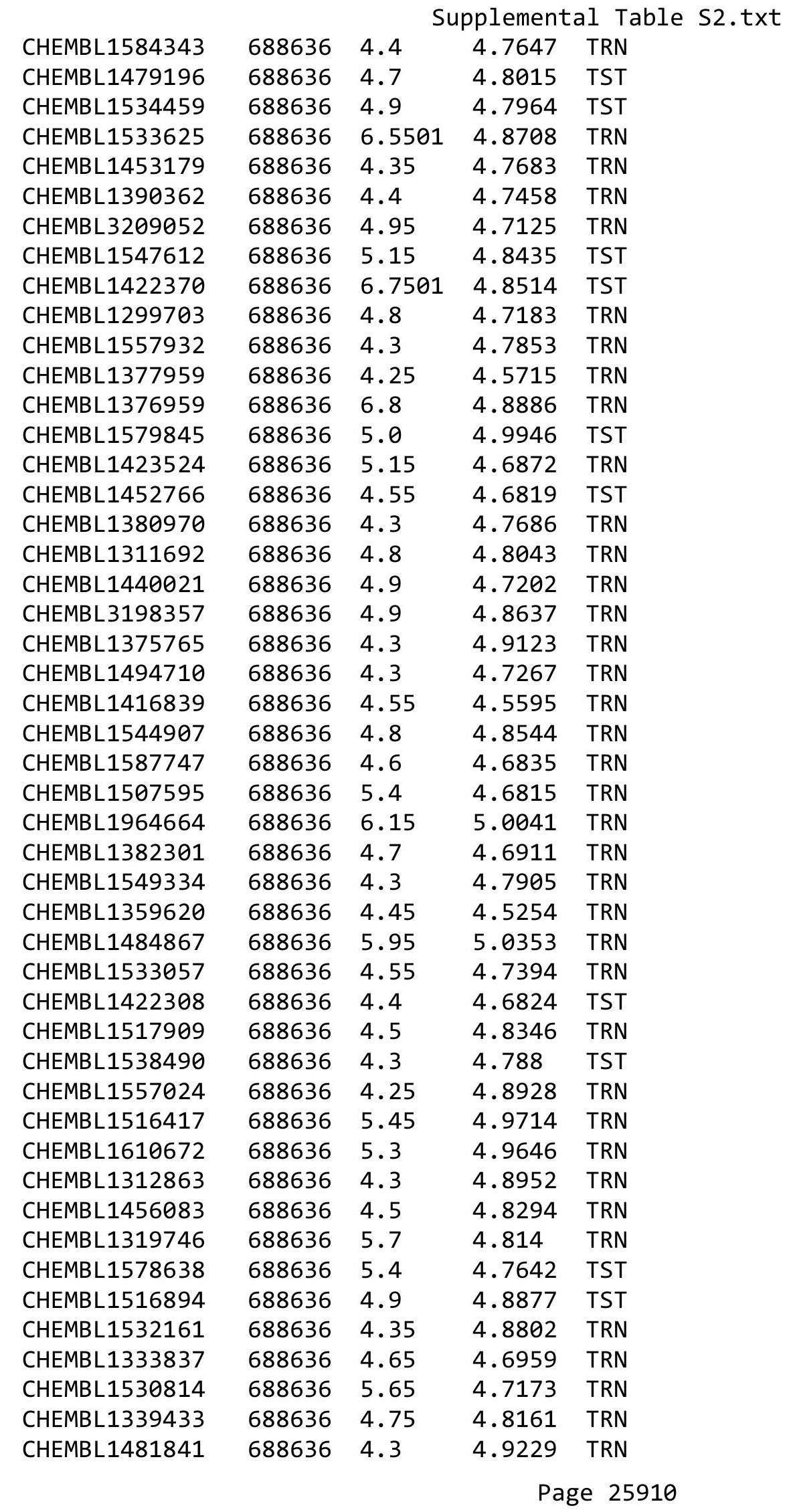




\begin{tabular}{|c|c|c|c|c|c|}
\hline \multicolumn{6}{|c|}{ Supplemental Table S2.txt } \\
\hline CHEMBL1389904 & 688636 & 4.25 & 4.9435 & TRN & \\
\hline CHEMBL1477756 & 688636 & 4.25 & 4.6984 & TRN & \\
\hline CHEMBL1580003 & 688636 & 4.25 & 4.8571 & TRN & \\
\hline CHEMBL1567802 & 688636 & 4.95 & 4.7412 & TRN & \\
\hline CHEMBL1386011 & 688636 & 6.05 & 4.7334 & TRN & \\
\hline CHEMBL1500128 & 688636 & 4.95 & 4.8557 & TST & \\
\hline CHEMBL1455633 & 688636 & 4.5 & 4.8282 & TST & \\
\hline CHEMBL1544518 & 688636 & 5.5 & 4.8119 & TRN & \\
\hline CHEMBL1557006 & 688636 & 4.95 & 4.67899 & 7999999999 & TRN \\
\hline CHEMBL1342278 & 688636 & 4.3 & 4.6746 & TRN & \\
\hline CHEMBL1340227 & 688636 & 4.35 & 4.7676 & TRN & \\
\hline CHEMBL1526192 & 688636 & 5.6 & 4.9158 & TST & \\
\hline CHEMBL1576869 & 688636 & 5.3 & 4.8143 & TRN & \\
\hline CHEMBL3192938 & 688636 & 4.5 & 4.7053 & TRN & \\
\hline CHEMBL1582179 & 688636 & 4.55 & 4.748 & TRN & \\
\hline CHEMBL1368500 & 688636 & 4.9 & 4.7883 & TRN & \\
\hline CHEMBL1340176 & 688636 & 5.15 & 4.769 & TST & \\
\hline CHEMBL50175 & 688636 & 4.55 & 4.7799 & TRN & \\
\hline CHEMBL1537441 & 688636 & 4.35 & 4.6725 & TRN & \\
\hline CHEMBL1305970 & 688636 & 5.25 & 4.9998 & TRN & \\
\hline CHEMBL1413605 & 688636 & 4.9 & 4.7087 & TRN & \\
\hline CHEMBL3208116 & 688636 & 4.7 & 4.9952 & TRN & \\
\hline CHEMBL1373817 & 688636 & 4.25 & 4.7663 & TST & \\
\hline CHEMBL1572662 & 688636 & 4.6 & 4.7713 & TRN & \\
\hline CHEMBL1432443 & 688636 & 4.4 & 4.6429 & TRN & \\
\hline CHEMBL1595623 & 688636 & 4.9 & 4.9206 & TRN & \\
\hline CHEMBL1321711 & 688636 & 4.6 & 4.8775 & TRN & \\
\hline CHEMBL1501351 & 688636 & 4.25 & 5.0214 & TRN & \\
\hline CHEMBL1511134 & 688636 & 5.35 & 4.8611 & TRN & \\
\hline CHEMBL1374755 & 688636 & 5.05 & 4.726 & TRN & \\
\hline CHEMBL1319597 & 688636 & 4.45 & 4.5714 & TRN & \\
\hline CHEMBL 3212052 & 688636 & 4.4 & 4.6956 & TST & \\
\hline CHEMBL1464507 & 688636 & 4.5 & 4.7373 & TRN & \\
\hline CHEMBL1428813 & 688636 & 6.8 & 4.8349 & TRN & \\
\hline CHEMBL1567737 & 688636 & 4.5 & 5.023 & TRN & \\
\hline CHEMBL1422079 & 688636 & 4.5 & 4.6458 & TRN & \\
\hline CHEMBL1479360 & 688636 & 5.85 & 4.7721 & TST & \\
\hline CHEMBL1501065 & 688636 & 4.45 & 4.7555 & TRN & \\
\hline CHEMBL1359892 & 688636 & 4.8 & 4.7932 & TRN & \\
\hline CHEMBL1465414 & 688636 & 5.45 & 4.8322 & TRN & \\
\hline CHEMBL1414362 & 688636 & 5.35 & 4.8565 & TRN & \\
\hline CHEMBL1464799 & 688636 & 4.5 & 4.7406 & TRN & \\
\hline CHEMBL1459570 & 688636 & 4.3 & 4.8908 & TRN & \\
\hline CHEMBL3196530 & 688636 & 5.3 & 4.604 & TRN & \\
\hline CHEMBL1529946 & 688636 & 5.25 & 4.8174 & TST & \\
\hline CHEMBL1587208 & 688636 & 4.3 & 4.8986 & TST & \\
\hline CHEMBL1521983 & 688636 & 5.25 & 4.8926 & TRN & \\
\hline CHEMBL1517319 & 688636 & 4.9 & 4.9619 & TRN & \\
\hline
\end{tabular}




\begin{tabular}{|c|c|c|c|c|c|}
\hline \multicolumn{6}{|c|}{ Supplemental Table S2.txt } \\
\hline CHEMBL1550941 & 688636 & 4.3 & 4.8918 & TRN & \\
\hline CHEMBL1530686 & 688636 & 4.75 & 4.9038 & TST & \\
\hline CHEMBL1388178 & 688636 & 5.5 & 4.822 & TRN & \\
\hline CHEMBL1492522 & 688636 & 4.3 & 4.9797 & TST & \\
\hline CHEMBL1324955 & 688636 & 4.5 & 4.8529 & TRN & \\
\hline CHEMBL1488663 & 688636 & 4.45 & 4.6114 & TRN & \\
\hline CHEMBL1503390 & 688636 & 5.9 & 4.8149 & TRN & \\
\hline CHEMBL1585529 & 688636 & 5.4 & 4.9283 & TST & \\
\hline CHEMBL1320460 & 688636 & 4.45 & 4.6762 & TRN & \\
\hline CHEMBL1574127 & 688636 & 4.25 & 4.7788 & TRN & \\
\hline CHEMBL1518920 & 688636 & 4.5 & 4.89 & TST & \\
\hline CHEMBL3198835 & 688636 & 4.3 & 4.6836 & TRN & \\
\hline CHEMBL1472312 & 688636 & 4.5 & 4.8262 & TRN & \\
\hline CHEMBL1582278 & 688636 & 4.95 & 4.7901 & TRN & \\
\hline CHEMBL1350947 & 688636 & 4.95 & 4.9374 & TRN & \\
\hline CHEMBL1496007 & 688636 & 4.55 & 4.7789 & TRN & \\
\hline CHEMBL1319815 & 688636 & 5.2 & 4.8831 & TRN & \\
\hline CHEMBL1545155 & 688636 & 4.7 & 4.8219 & TRN & \\
\hline CHEMBL1611779 & 688636 & 4.3 & 4.6603 & TRN & \\
\hline CHEMBL1558716 & 688636 & 5.0 & 4.9656 & TRN & \\
\hline CHEMBL1371511 & 688636 & 4.75 & 4.9171 & TST & \\
\hline CHEMBL1349936 & 688636 & 6.35 & 4.9 & TRN & \\
\hline CHEMBL1546017 & 688636 & 6.7501 & 4.9063 & TRN & \\
\hline CHEMBL1348391 & 688636 & 4.35 & 4.6513 & TST & \\
\hline CHEMBL1350574 & 688636 & 5.0 & 4.788 & TRN & \\
\hline CHEMBL1556365 & 688636 & 4.55 & 4.8598 & TRN & \\
\hline CHEMBL1339885 & 688636 & 5.45 & 4.9211 & TST & \\
\hline CHEMBL1585510 & 688636 & 4.25 & 4.6353 & TRN & \\
\hline CHEMBL1339022 & 688636 & 4.25 & 4.9055 & TRN & \\
\hline CHEMBL1570263 & 688636 & 5.35 & 4.9127 & TST & \\
\hline CHEMBL1567842 & 688636 & 6.4 & 4.9098 & TST & \\
\hline CHEMBL1420806 & 688636 & 4.9 & 4.842 & TRN & \\
\hline CHEMBL1510612 & 688636 & 4.25 & 4.6673 & TRN & \\
\hline CHEMBL1541966 & 688636 & 4.9 & 4.8795 & TRN & \\
\hline CHEMBL1451989 & 688636 & 4.6 & 4.7533 & TRN & \\
\hline CHEMBL3192269 & 688636 & 4.95 & 4.76699 & 99999999995 & TRN \\
\hline CHEMBL1490974 & 688636 & 4.35 & 4.9525 & TRN & \\
\hline CHEMBL1546474 & 688636 & 4.3 & 4.8182 & TRN & \\
\hline CHEMBL1524707 & 688636 & 4.25 & 4.8256 & TST & \\
\hline CHEMBL3145369 & 688636 & 4.5 & 4.8179 & TRN & \\
\hline CHEMBL1329111 & 688636 & 4.4 & 4.5997 & TRN & \\
\hline CHEMBL1542005 & 688636 & 4.3 & 4.8404 & TRN & \\
\hline CHEMBL1499125 & 688636 & 4.7 & 4.8301 & TRN & \\
\hline CHEMBL1466178 & 688636 & 4.5 & 4.8875 & TRN & \\
\hline CHEMBL1467484 & 688636 & 4.3 & 4.8364 & TRN & \\
\hline CHEMBL1309013 & 688636 & 4.3 & 4.7293 & TRN & \\
\hline CHEMBL1470406 & 688636 & 4.55 & 4.8162 & TST & \\
\hline CHEMBL1581259 & 688636 & 4.45 & 4.98600 & $\partial 000000001$ & TRN \\
\hline & & & & 25912 & \\
\hline
\end{tabular}




\begin{tabular}{|c|c|c|c|c|c|}
\hline \multicolumn{6}{|c|}{ Supplemental Table S2.txt } \\
\hline CHEMBL1609759 & 688636 & 5.35 & 4.743 & TST & \\
\hline CHEMBL1309334 & 688636 & 4.9 & 4.663 & TRN & \\
\hline CHEMBL1545480 & 688636 & 5.55 & 4.9996 & TRN & \\
\hline CHEMBL1606443 & 688636 & 4.25 & 4.7134 & TRN & \\
\hline CHEMBL1609952 & 688636 & 4.3 & 4.8658 & TRN & \\
\hline CHEMBL1400751 & 688636 & 4.3 & 4.5669 & TRN & \\
\hline CHEMBL1493515 & 688636 & 5.85 & 4.7302 & TRN & \\
\hline CHEMBL1478885 & 688636 & 4.25 & 4.774 & TST & \\
\hline CHEMBL1496641 & 688636 & 4.95 & 4.92 & TRN & \\
\hline CHEMBL1464078 & 688636 & 5.8 & 4.8296 & TRN & \\
\hline CHEMBL1361923 & 688636 & 4.75 & 4.9030 & 00000000005 & TRN \\
\hline CHEMBL1429341 & 688636 & 4.25 & 4.9276 & TRN & \\
\hline CHEMBL1345654 & 688636 & 4.55 & 4.8233 & TST & \\
\hline CHEMBL1383406 & 688636 & 6.45 & 4.9798 & TRN & \\
\hline CHEMBL1501538 & 688636 & 4.3 & 4.6582 & TRN & \\
\hline CHEMBL1450583 & 688636 & 5.4 & 4.8974 & TRN & \\
\hline CHEMBL1500294 & 688636 & 6.05 & 4.7984 & TRN & \\
\hline CHEMBL1501601 & 688636 & 4.9 & 4.8682 & TRN & \\
\hline CHEMBL1489888 & 688636 & 4.45 & 4.7139 & 99999999995 & TRN \\
\hline CHEMBL1487479 & 688636 & 4.45 & 4.675 & TRN & \\
\hline CHEMBL1518714 & 688636 & 4.25 & 4.8488 & TST & \\
\hline CHEMBL1390759 & 688636 & 4.45 & 4.7591 & TRN & \\
\hline CHEMBL1569742 & 688636 & 4.3 & 4.8006 & TRN & \\
\hline CHEMBL1594599 & 688636 & 4.9 & 4.8727 & TST & \\
\hline CHEMBL3196020 & 688636 & 4.3 & 4.8583 & TRN & \\
\hline CHEMBL1419141 & 688636 & 4.3 & 4.8181 & TST & \\
\hline CHEMBL1564874 & 688636 & 4.25 & 4.763 & TST & \\
\hline CHEMBL1471677 & 688636 & 4.4 & 4.8699 & TST & \\
\hline CHEMBL1419665 & 688636 & 4.5 & 4.8325 & TST & \\
\hline CHEMBL1611022 & 688636 & 4.9 & 4.9239 & TST & \\
\hline CHEMBL1522113 & 688636 & 5.15 & 4.8567 & TST & \\
\hline CHEMBL1557038 & 688636 & 4.5 & 4.894 & TRN & \\
\hline CHEMBL1538789 & 688636 & 4.55 & 4.7036 & TRN & \\
\hline CHEMBL1558633 & 688636 & 5.85 & 4.8691 & TST & \\
\hline CHEMBL1588880 & 688636 & 4.8 & 4.8736 & TRN & \\
\hline CHEMBL3209067 & 688636 & 4.9 & 4.9637 & TRN & \\
\hline CHEMBL1549766 & 688636 & 4.25 & 4.9081 & TRN & \\
\hline CHEMBL1599951 & 688636 & 4.9 & 4.9638 & TRN & \\
\hline CHEMBL 3213898 & 688636 & 4.9 & 4.6723 & TRN & \\
\hline CHEMBL1307379 & 688636 & 4.95 & 4.9034 & TRN & \\
\hline CHEMBL1300912 & 688636 & 4.6 & 4.7083 & TST & \\
\hline CHEMBL588859 & 688636 & 5.8 & 5.046 & TST & \\
\hline CHEMBL1405964 & 688636 & 4.45 & 4.5681 & TRN & \\
\hline CHEMBL1364272 & 688636 & 5.1 & 4.8273 & TRN & \\
\hline CHEMBL1511205 & 688636 & 6.0 & 4.8122 & TRN & \\
\hline CHEMBL1322330 & 688636 & 4.3 & 4.7836 & TRN & \\
\hline CHEMBL1528712 & 688636 & 5.15 & 4.6845 & TRN & \\
\hline CHEMBL1492388 & 688636 & 4.4 & 4.7204 & TRN & \\
\hline
\end{tabular}




\begin{tabular}{|c|c|c|c|c|}
\hline \multicolumn{5}{|c|}{ Supplemental Table S2.txt } \\
\hline CHEMBL1444536 & 688636 & 4.45 & 4.8195 & TRN \\
\hline CHEMBL1399767 & 688636 & 4.3 & 5.0237 & TRN \\
\hline CHEMBL3197141 & 688636 & 6.8 & 4.6143 & TRN \\
\hline CHEMBL 25280 & 688636 & 4.95 & 5.0565 & TST \\
\hline CHEMBL1503085 & 688636 & 4.25 & 4.8521 & TRN \\
\hline CHEMBL1588604 & 688636 & 5.3 & 4.6998 & TRN \\
\hline CHEMBL1425008 & 688636 & 5.15 & 4.877 & TST \\
\hline CHEMBL1375597 & 688636 & 4.45 & 4.6221 & TRN \\
\hline CHEMBL1550746 & 688636 & 4.5 & 4.8695 & TRN \\
\hline CHEMBL1420871 & 688636 & 4.25 & 4.8337 & TRN \\
\hline CHEMBL1425386 & 688636 & 4.45 & 4.8941 & TRN \\
\hline CHEMBL1424873 & 688636 & 6.7501 & 4.8454 & TRN \\
\hline CHEMBL1345768 & 688636 & 4.3 & 4.6404 & TRN \\
\hline CHEMBL1566877 & 688636 & 4.45 & 4.7127 & TRN \\
\hline CHEMBL1427979 & 688636 & 4.4 & 4.8845 & TRN \\
\hline CHEMBL1500696 & 688636 & 4.25 & 4.7536 & TRN \\
\hline CHEMBL1451183 & 688636 & 5.6 & 4.8853 & TRN \\
\hline CHEMBL1422500 & 688636 & 4.3 & 4.8857 & TRN \\
\hline CHEMBL1329351 & 688636 & 6.4 & 4.6776 & TST \\
\hline CHEMBL1991187 & 688636 & 5.0 & 4.5847 & TRN \\
\hline CHEMBL1549805 & 688636 & 4.45 & 4.7803 & TRN \\
\hline CHEMBL1568009 & 688636 & 4.95 & 4.6855 & TRN \\
\hline CHEMBL1305168 & 688636 & 4.3 & 4.9292 & TST \\
\hline CHEMBL1428935 & 688636 & 4.95 & 4.7286 & TRN \\
\hline CHEMBL1586097 & 688636 & 4.4 & 4.9148 & TRN \\
\hline CHEMBL1345518 & 688636 & 4.8 & 4.9125 & TRN \\
\hline CHEMBL1556807 & 688636 & 5.3 & 4.7464 & TRN \\
\hline CHEMBL1469784 & 688636 & 4.65 & 4.7677 & TRN \\
\hline CHEMBL1457449 & 688636 & 4.3 & 4.654 & TRN \\
\hline CHEMBL1485497 & 688636 & 4.25 & 4.6869 & TRN \\
\hline CHEMBL1364953 & 688636 & 4.3 & 4.8613 & TST \\
\hline CHEMBL1506815 & 688636 & 4.25 & 4.7844 & TRN \\
\hline CHEMBL1496866 & 688636 & 4.95 & 4.6751 & TRN \\
\hline CHEMBL1481576 & 688636 & 4.4 & 4.8128 & TRN \\
\hline CHEMBL3191098 & 688636 & 4.45 & 4.6528 & TRN \\
\hline CHEMBL1597480 & 688636 & 4.3 & 4.7717 & TRN \\
\hline CHEMBL1363577 & 688636 & 4.4 & 4.9517 & TRN \\
\hline CHEMBL1324523 & 688636 & 4.35 & 4.9437 & TRN \\
\hline CHEMBL1573630 & 688636 & 4.85 & 4.9082 & TST \\
\hline CHEMBL1402498 & 688636 & 4.95 & 4.6535 & TRN \\
\hline CHEMBL1421731 & 688636 & 4.25 & 4.857 & TRN \\
\hline CHEMBL1313926 & 688636 & 4.5 & 4.655 & TRN \\
\hline CHEMBL1329015 & 688636 & 4.25 & 5.0049 & TRN \\
\hline CHEMBL1342468 & 688636 & 4.55 & 4.6577 & TRN \\
\hline CHEMBL1302644 & 688636 & 4.6 & 4.7383 & TRN \\
\hline CHEMBL1336988 & 688636 & 4.3 & 4.5866 & TRN \\
\hline CHEMBL1568059 & 688636 & 4.55 & 4.7039 & TRN \\
\hline CHEMBL1403080 & 688636 & 4.4 & 4.8615 & TST \\
\hline
\end{tabular}




\begin{tabular}{|c|c|c|c|c|}
\hline \multicolumn{5}{|c|}{ Supplemental Table S2.txt } \\
\hline CHEMBL1385650 & 688636 & 4.35 & 4.6837 & TRN \\
\hline CHEMBL1458276 & 688636 & 5.15 & 4.6934 & TRN \\
\hline CHEMBL1518257 & 688636 & 5.85 & 4.9704 & TRN \\
\hline CHEMBL1382246 & 688636 & 5.05 & 4.8528 & TRN \\
\hline CHEMBL1505589 & 688636 & 4.55 & 4.8658 & TRN \\
\hline CHEMBL1311054 & 688636 & 4.6 & 4.6388 & TRN \\
\hline CHEMBL1450692 & 688636 & 4.3 & 4.8695 & TRN \\
\hline CHEMBL3192119 & 688636 & 6.7501 & 4.8226 & TST \\
\hline CHEMBL1417861 & 688636 & 4.9 & 4.9594 & TST \\
\hline CHEMBL1411571 & 688636 & 4.55 & 4.7117 & TRN \\
\hline CHEMBL1587804 & 688636 & 4.3 & 4.814 & TST \\
\hline CHEMBL1561209 & 688636 & 4.3 & 4.918 & TRN \\
\hline CHEMBL1323674 & 688636 & 4.3 & 4.7987 & TRN \\
\hline CHEMBL1389341 & 688636 & 4.4 & 4.7639 & TRN \\
\hline CHEMBL1612906 & 688636 & 4.9 & 4.9287 & TRN \\
\hline CHEMBL1384636 & 688636 & 4.6 & 4.7365 & TRN \\
\hline CHEMBL1352800 & 688636 & 4.45 & 4.832 & TRN \\
\hline CHEMBL1380068 & 688636 & 4.4 & 4.6753 & TRN \\
\hline CHEMBL1540428 & 688636 & 4.3 & 4.8831 & TRN \\
\hline CHEMBL1333187 & 688636 & 4.8 & 4.7685 & TRN \\
\hline CHEMBL1506603 & 688636 & 4.3 & 4.8202 & TST \\
\hline CHEMBL1461952 & 688636 & 4.4 & 5.0408 & TRN \\
\hline CHEMBL1415361 & 688636 & 4.25 & 4.8789 & TRN \\
\hline CHEMBL1340840 & 688636 & 4.7 & 4.87 & TRN \\
\hline CHEMBL1387192 & 688636 & 4.6 & 4.7488 & TRN \\
\hline CHEMBL1466423 & 688636 & 4.4 & 4.7671 & TRN \\
\hline CHEMBL1307871 & 688636 & 4.3 & 4.8491 & TST \\
\hline CHEMBL1420459 & 688636 & 4.4 & 4.7425 & TRN \\
\hline CHEMBL408994 & 688636 & 4.6 & 4.9661 & TST \\
\hline CHEMBL1516947 & 688636 & 4.55 & 4.7588 & TRN \\
\hline CHEMBL1543938 & 688636 & 4.3 & 4.953 & TRN \\
\hline CHEMBL1540534 & 688636 & 4.55 & 4.8691 & TRN \\
\hline CHEMBL1409460 & 688636 & 5.85 & 4.7648 & TST \\
\hline CHEMBL1504080 & 688636 & 4.5 & 4.7681 & TST \\
\hline CHEMBL1417039 & 688636 & 4.5 & 4.98 & TRN \\
\hline CHEMBL1538162 & 688636 & 4.9 & 4.8524 & TRN \\
\hline CHEMBL 1420058 & 688636 & 4.85 & 4.8569 & TRN \\
\hline CHEMBL3195474 & 688636 & 4.25 & 4.8867 & TRN \\
\hline CHEMBL1570210 & 688636 & 4.25 & 4.7693 & TRN \\
\hline CHEMBL1485414 & 688636 & 4.95 & 5.0125 & TST \\
\hline CHEMBL1539225 & 688636 & 4.4 & 4.9953 & TST \\
\hline CHEMBL1567008 & 688636 & 4.55 & 4.8183 & TRN \\
\hline CHEMBL1369848 & 688636 & 5.75 & 4.7076 & TRN \\
\hline CHEMBL1608913 & 688636 & 4.3 & 4.6392 & TRN \\
\hline CHEMBL1453553 & 688636 & 5.55 & 4.9417 & TRN \\
\hline CHEMBL1333892 & 688636 & 4.25 & 4.6506 & TRN \\
\hline CHEMBL1372404 & 688636 & 4.25 & 4.775 & TRN \\
\hline CHEMBL1581211 & 688636 & 6.1 & 4.7114 & TST \\
\hline
\end{tabular}




\begin{tabular}{|c|c|c|c|c|c|}
\hline \multirow{3}{*}{$\begin{array}{l}\text { CHEMBL1547247 } \\
\text { CHEMBL1548739 }\end{array}$} & \multirow{3}{*}{$\begin{array}{l}688636 \\
688636\end{array}$} & \multicolumn{4}{|c|}{ Supplemental Table S2.txt } \\
\hline & & 4.9 & \multicolumn{2}{|c|}{4.843999999999999} & TST \\
\hline & & 4.5 & 5.0113 & TRN & \\
\hline CHEMBL1452134 & 688636 & 4.25 & 4.9234 & TRN & \\
\hline CHEMBL1586630 & 688636 & 5.0 & 4.8914 & TRN & \\
\hline CHEMBL1359455 & 688636 & 4.5 & 4.5255 & TRN & \\
\hline CHEMBL1563513 & 688636 & 4.45 & 4.6781 & TRN & \\
\hline CHEMBL1405426 & 688636 & 4.25 & 4.9187 & TRN & \\
\hline CHEMBL1531070 & 688636 & 5.2 & 4.7749 & TST & \\
\hline CHEMBL1365184 & 688636 & 4.35 & 4.7779 & TRN & \\
\hline CHEMBL1987092 & 688636 & 4.9 & 4.6308 & TRN & \\
\hline CHEMBL1567974 & 688636 & 4.6 & 4.7699 & TST & \\
\hline CHEMBL1562517 & 688636 & 6.8 & 4.8046 & TRN & \\
\hline CHEMBL1448879 & 688636 & 5.0 & 4.8213 & TRN & \\
\hline CHEMBL1486169 & 688636 & 4.6 & 4.8219 & TRN & \\
\hline CHEMBL1537278 & 688636 & 4.3 & 4.8693 & TRN & \\
\hline CHEMBL1602028 & 688636 & 6.5501 & 5.024 & TRN & \\
\hline CHEMBL1405152 & 688636 & 6.7501 & 4.8571 & TST & \\
\hline CHEMBL1493900 & 688636 & 6.05 & 4.8374 & TST & \\
\hline CHEMBL1498161 & 688636 & 6.7501 & 4.7987 & TRN & \\
\hline CHEMBL1570319 & 688636 & 5.8 & 4.7815 & TST & \\
\hline CHEMBL1382813 & 688636 & 4.45 & 4.6876 & TRN & \\
\hline CHEMBL1523376 & 688636 & 5.3 & 4.7332 & TST & \\
\hline CHEMBL1306148 & 688636 & 4.9 & 4.9251 & TST & \\
\hline CHEMBL1604110 & 688636 & 4.25 & 4.6903 & TST & \\
\hline CHEMBL1600800 & 688636 & 4.5 & 4.7412 & TRN & \\
\hline CHEMBL1462945 & 688636 & 4.5 & 4.7322 & TRN & \\
\hline CHEMBL1580363 & 688636 & 4.3 & 4.7602 & TRN & \\
\hline CHEMBL1489177 & 688636 & 4.4 & 4.9869 & TST & \\
\hline CHEMBL1350888 & 688636 & 4.95 & 4.6356 & TRN & \\
\hline CHEMBL1603332 & 688636 & 5.0 & 4.9488 & TRN & \\
\hline CHEMBL1544060 & 688636 & 4.45 & 4.7642 & TRN & \\
\hline CHEMBL1585913 & 688636 & 5.45 & 4.6725 & TRN & \\
\hline CHEMBL1305766 & 688636 & 6.0 & 4.7639 & TST & \\
\hline CHEMBL1374915 & 688636 & 4.45 & 4.7425 & TRN & \\
\hline CHEMBL1352301 & 688636 & 4.25 & 4.749 & TRN & \\
\hline CHEMBL1341471 & 688636 & 4.3 & 4.768 & TRN & \\
\hline CHEMBL3197571 & 688636 & 4.9 & 4.5865 & TRN & \\
\hline CHEMBL1380279 & 688636 & 5.45 & 4.9711 & TRN & \\
\hline CHEMBL1501724 & 688636 & 4.3 & 4.8625 & TRN & \\
\hline CHEMBL3199022 & 688636 & 5.65 & 4.6813 & TRN & \\
\hline CHEMBL1330163 & 688636 & 4.45 & 4.8452 & TST & \\
\hline CHEMBL1511401 & 688636 & 4.85 & 4.8516 & TRN & \\
\hline CHEMBL1369781 & 688636 & 4.35 & 4.7917 & TRN & \\
\hline CHEMBL1543646 & 688636 & 6.15 & 4.8768 & TST & \\
\hline CHEMBL1369042 & 688636 & 4.9 & 4.9843 & TRN & \\
\hline CHEMBL1447396 & 688636 & 5.15 & 4.8986 & TRN & \\
\hline CHEMBL1429471 & 688636 & 4.5 & 4.7618 & TRN & \\
\hline CHEMBL1498535 & 688636 & 4.25 & 4.6 & TRN & \\
\hline
\end{tabular}




\begin{tabular}{|c|c|c|c|c|}
\hline \multicolumn{5}{|c|}{ Supplemental Table S2.txt } \\
\hline CHEMBL1581264 & 688636 & 4.25 & 4.6715 & TRN \\
\hline CHEMBL3199499 & 688636 & 4.3 & 4.7854 & TRN \\
\hline CHEMBL1345457 & 688636 & 4.6 & 4.6569 & TRN \\
\hline CHEMBL1528808 & 688636 & 6.7501 & 4.9042 & TRN \\
\hline CHEMBL1505922 & 688636 & 4.85 & 4.7393 & TRN \\
\hline CHEMBL1517908 & 688636 & 4.6 & 4.8185 & TRN \\
\hline CHEMBL1575148 & 688636 & 4.75 & 4.9316 & TRN \\
\hline CHEMBL1605082 & 688636 & 4.25 & 5.0773 & TRN \\
\hline CHEMBL1575811 & 688636 & 5.0 & 4.9023 & TST \\
\hline CHEMBL1584784 & 688636 & 4.75 & 4.7011 & TRN \\
\hline CHEMBL1534569 & 688636 & 4.25 & 4.622 & TRN \\
\hline CHEMBL1612261 & 688636 & 4.35 & 4.9088 & TRN \\
\hline CHEMBL1491648 & 688636 & 4.95 & 4.9046 & TRN \\
\hline CHEMBL1391297 & 688636 & 4.6 & 4.757 & TRN \\
\hline CHEMBL1580691 & 688636 & 6.45 & 4.8869 & TRN \\
\hline CHEMBL3194067 & 688636 & 5.55 & 4.8988 & TRN \\
\hline CHEMBL1517647 & 688636 & 4.9 & 4.7597 & TRN \\
\hline CHEMBL1304031 & 688636 & 4.6 & 4.5853 & TRN \\
\hline CHEMBL408982 & 688636 & 4.95 & 4.7374 & TST \\
\hline CHEMBL1415114 & 688636 & 4.4 & 4.6334 & TRN \\
\hline CHEMBL1363121 & 688636 & 4.25 & 4.6979 & TRN \\
\hline CHEMBL1601129 & 688636 & 4.5 & 4.8741 & TRN \\
\hline CHEMBL1526000 & 688636 & 4.55 & 4.5969 & TRN \\
\hline CHEMBL1543330 & 688636 & 4.5 & 4.9038 & TST \\
\hline CHEMBL1529887 & 688636 & 4.45 & 4.9182 & TRN \\
\hline CHEMBL1589629 & 688636 & 4.55 & 4.8499 & TRN \\
\hline CHEMBL1350647 & 688636 & 4.95 & 4.9922 & TRN \\
\hline CHEMBL1528177 & 688636 & 4.5 & 4.6436 & TRN \\
\hline CHEMBL1526157 & 688636 & 4.3 & 4.7877 & TRN \\
\hline CHEMBL1601128 & 688636 & 4.5 & 4.7785 & TRN \\
\hline CHEMBL1384662 & 688636 & 6.7001 & 5.0297 & TRN \\
\hline CHEMBL1608482 & 688636 & 4.95 & 4.8928 & TRN \\
\hline CHEMBL1342444 & 688636 & 4.45 & 4.8674 & TRN \\
\hline CHEMBL1461862 & 688636 & 5.35 & 4.7595 & TRN \\
\hline CHEMBL1307668 & 688636 & 4.6 & 4.8374 & TST \\
\hline CHEMBL1533106 & 688636 & 4.25 & 4.9484 & TRN \\
\hline CHEMBL1465533 & 688636 & 4.4 & 4.7006 & TRN \\
\hline CHEMBL1379478 & 688636 & 4.4 & 4.901 & TRN \\
\hline CHEMBL3192081 & 688636 & 4.5 & 4.8086 & TRN \\
\hline CHEMBL1339540 & 688636 & 4.45 & 4.7047 & TRN \\
\hline CHEMBL1371013 & 688636 & 4.4 & 4.7172 & TRN \\
\hline CHEMBL1334641 & 688636 & 4.35 & 4.7826 & TRN \\
\hline CHEMBL1333983 & 688636 & 4.3 & 4.8009 & TST \\
\hline CHEMBL1348338 & 688636 & 4.95 & 4.8243 & TRN \\
\hline CHEMBL1351626 & 688636 & 4.45 & 4.7323 & TRN \\
\hline CHEMBL1435313 & 688636 & 5.25 & 4.783 & TST \\
\hline CHEMBL1545220 & 688636 & 4.3 & 4.8106 & TST \\
\hline CHEMBL1536117 & 688636 & 5.65 & 4.7014 & TRN \\
\hline
\end{tabular}




\begin{tabular}{|c|c|c|c|c|}
\hline & & & pplement & $\mathrm{a} \perp \mathrm{Ta}$ \\
\hline CHEMBL3194446 & 688636 & 4.9 & 4.8999 & TST \\
\hline CHEMBL1523812 & 688636 & 4.4 & 5.0105 & TST \\
\hline CHEMBL1606284 & 688636 & 5.1 & 4.6226 & TRN \\
\hline CHEMBL1300197 & 688636 & 5.9 & 4.7371 & TST \\
\hline CHEMBL1327428 & 688636 & 4.5 & 4.8638 & TRN \\
\hline CHEMBL1420167 & 688636 & 4.25 & 4.8873 & TRN \\
\hline CHEMBL1382277 & 688636 & 4.25 & 4.7678 & TRN \\
\hline CHEMBL1471380 & 688636 & 4.3 & 4.8607 & TRN \\
\hline CHEMBL3209375 & 688636 & 4.3 & 4.8179 & TRN \\
\hline CHEMBL1585309 & 688636 & 4.3 & 4.6245 & TRN \\
\hline CHEMBL1490027 & 688636 & 5.2 & 4.746 & TRN \\
\hline CHEMBL1522691 & 688636 & 4.9 & 4.8471 & TRN \\
\hline CHEMBL1531427 & 688636 & 5.9 & 4.9088 & TRN \\
\hline CHEMBL1306215 & 688636 & 4.25 & 4.8713 & TRN \\
\hline CHEMBL1470868 & 688636 & 4.25 & 4.7859 & TRN \\
\hline CHEMBL1516960 & 688636 & 4.95 & 5.0548 & TST \\
\hline CHEMBL1311827 & 688636 & 4.55 & 4.8368 & TRN \\
\hline CHEMBL1431644 & 688636 & 4.5 & 4.827 & TRN \\
\hline CHEMBL1499870 & 688636 & 6.8 & 4.9171 & TRN \\
\hline CHEMBL3209625 & 688636 & 4.3 & 4.8646 & TRN \\
\hline CHEMBL1438751 & 688636 & 4.5 & 4.8732 & TST \\
\hline CHEMBL1326825 & 688636 & 5.15 & 4.8211 & TRN \\
\hline CHEMBL1402230 & 688636 & 4.4 & 4.8512 & TST \\
\hline CHEMBL1458610 & 688636 & 5.55 & 4.7756 & TRN \\
\hline CHEMBL1336784 & 688636 & 4.3 & 4.7102 & TRN \\
\hline CHEMBL1346462 & 688636 & 5.85 & 4.918 & TRN \\
\hline CHEMBL1340834 & 688636 & 4.7 & 4.6742 & TRN \\
\hline CHEMBL1548210 & 688636 & 4.3 & 4.7632 & TST \\
\hline CHEMBL1579264 & 688636 & 4.25 & 4.7083 & TRN \\
\hline CHEMBL3212435 & 688636 & 4.3 & 4.7553 & TST \\
\hline CHEMBL1502848 & 688636 & 5.1 & 4.9871 & TRN \\
\hline CHEMBL1381249 & 688636 & 4.35 & 4.7331 & TRN \\
\hline CHEMBL1345709 & 688636 & 4.25 & 4.7378 & TRN \\
\hline CHEMBL1532826 & 688636 & 5.4 & 4.993 & TST \\
\hline CHEMBL1405965 & 688636 & 4.8 & 4.9797 & TRN \\
\hline CHEMBL1416197 & 688636 & 4.95 & 4.7337 & TRN \\
\hline CHEMBL1531066 & 688636 & 4.3 & 4.9273 & TRN \\
\hline CHEMBL1603493 & 688636 & 5.85 & 4.6303 & TST \\
\hline CHEMBL1565685 & 688636 & 4.55 & 4.7428 & TRN \\
\hline CHEMBL6703 & 688636 & 4.45 & 4.7144 & TRN \\
\hline CHEMBL1343384 & 688636 & 5.45 & 5.0008 & TST \\
\hline CHEMBL1407524 & 688636 & 4.5 & 4.8396 & TRN \\
\hline CHEMBL1463982 & 688636 & 5.35 & 4.5037 & TRN \\
\hline CHEMBL 3212415 & 688636 & 4.25 & 4.7623 & TRN \\
\hline CHEMBL1970554 & 688636 & 4.4 & 4.7965 & TRN \\
\hline CHEMBL1381020 & 688636 & 5.15 & 4.8396 & TRN \\
\hline CHEMBL1450168 & 688636 & 5.75 & 4.8695 & TRN \\
\hline CHEMBL1483652 & 688636 & 5.65 & 4.6823 & TST \\
\hline
\end{tabular}




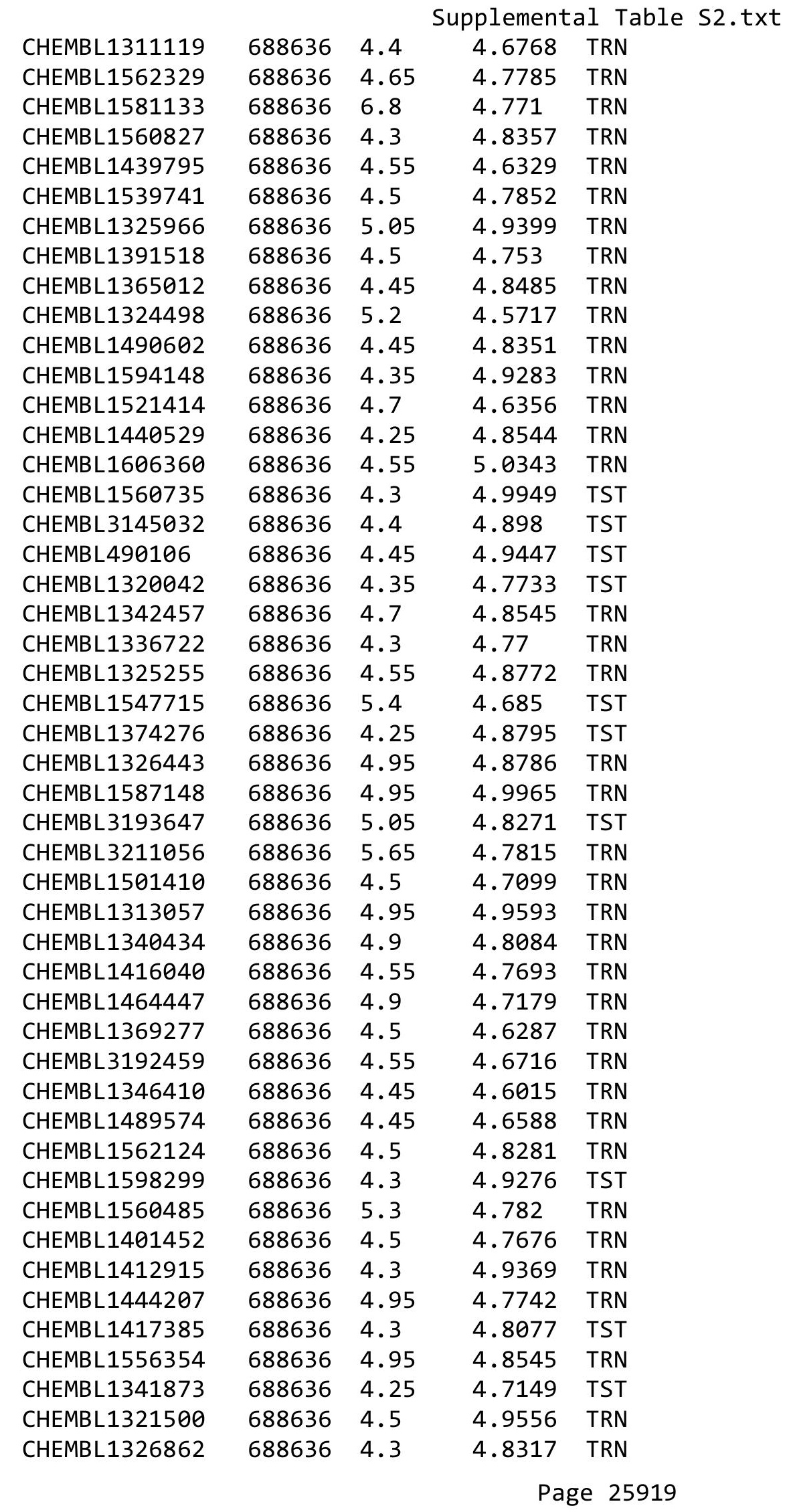




\begin{tabular}{|c|c|c|c|c|}
\hline \multicolumn{5}{|c|}{ Supplemental Table S2.txt } \\
\hline CHEMBL1468829 & 688636 & 4.55 & 4.9105 & TRN \\
\hline CHEMBL1308266 & 688636 & 5.35 & 4.6077 & TRN \\
\hline CHEMBL1372966 & 688636 & 6.35 & 4.9036 & TRN \\
\hline CHEMBL1324744 & 688636 & 4.5 & 4.8728 & TRN \\
\hline CHEMBL1342131 & 688636 & 5.5 & 4.7495 & TRN \\
\hline CHEMBL1519218 & 688636 & 5.2 & 4.7604 & TRN \\
\hline CHEMBL1550065 & 688636 & 6.1 & \multicolumn{2}{|c|}{4.8260000000000005} \\
\hline CHEMBL1410183 & 688636 & 5.35 & 4.8827 & TRN \\
\hline CHEMBL1543218 & 688636 & 5.5 & 5.0097 & TRN \\
\hline CHEMBL1531457 & 688636 & 6.45 & 4.9013 & TRN \\
\hline CHEMBL1511819 & 688636 & 6.7501 & 4.9475 & TRN \\
\hline CHEMBL1427577 & 688636 & 4.25 & 4.8994 & TRN \\
\hline CHEMBL1612331 & 688636 & 4.45 & 4.713 & TRN \\
\hline CHEMBL1601427 & 688636 & 4.35 & 4.6005 & TRN \\
\hline CHEMBL1337559 & 688636 & 4.35 & 4.7084 & TRN \\
\hline CHEMBL1423046 & 688636 & 4.3 & 4.8399 & TRN \\
\hline CHEMBL3194691 & 688636 & 4.25 & 4.7097 & TST \\
\hline CHEMBL1366042 & 688636 & 4.3 & 4.8329 & TRN \\
\hline CHEMBL1547164 & 688636 & 4.55 & 4.9758 & TRN \\
\hline CHEMBL1497409 & 688636 & 4.7 & 4.7801 & TRN \\
\hline CHEMBL1414818 & 688636 & 5.1 & 4.9526 & TRN \\
\hline CHEMBL1383884 & 688636 & 4.6 & 4.944 & TRN \\
\hline CHEMBL3193195 & 688636 & 5.4 & 4.9038 & TRN \\
\hline CHEMBL1541883 & 688636 & 4.25 & 4.7623 & TRN \\
\hline CHEMBL1534514 & 688636 & 4.25 & 4.7396 & TRN \\
\hline CHEMBL1482284 & 688636 & 5.1 & 4.7462 & TRN \\
\hline CHEMBL1405119 & 688636 & 6.05 & 4.888 & TRN \\
\hline CHEMBL3192906 & 688636 & 4.85 & 4.5602 & TRN \\
\hline CHEMBL1352605 & 688636 & 4.25 & 4.8811 & TRN \\
\hline CHEMBL1518099 & 688636 & 4.6 & 5.0262 & TRN \\
\hline CHEMBL1489240 & 688636 & 4.35 & 4.9118 & TRN \\
\hline CHEMBL1481361 & 688636 & 5.85 & 4.8115 & TST \\
\hline CHEMBL1454468 & 688636 & 4.35 & 4.6317 & TRN \\
\hline CHEMBL1564097 & 688636 & 5.15 & 4.8148 & TRN \\
\hline CHEMBL1522247 & 688636 & 4.25 & 4.9387 & TRN \\
\hline CHEMBL1352433 & 688636 & 4.3 & 4.8716 & TRN \\
\hline CHEMBL1309755 & 688636 & 4.25 & 4.8204 & TRN \\
\hline CHEMBL1328986 & 688636 & 5.6 & 4.9446 & TRN \\
\hline CHEMBL1451444 & 688636 & 5.55 & 4.7451 & TRN \\
\hline CHEMBL1363724 & 688636 & 5.65 & 4.7959 & TRN \\
\hline CHEMBL1502470 & 688636 & 4.95 & 4.8602 & TRN \\
\hline CHEMBL1575086 & 688636 & 4.5 & 4.9382 & TST \\
\hline CHEMBL1341360 & 688636 & 5.75 & 4.8802 & TST \\
\hline CHEMBL1538190 & 688636 & 5.75 & 4.795 & TST \\
\hline CHEMBL1347915 & 688636 & 4.5 & 4.7186 & TRN \\
\hline CHEMBL1477064 & 688636 & 5.05 & 4.7348 & TRN \\
\hline CHEMBL1570820 & 688636 & 4.45 & 4.6528 & TST \\
\hline CHEMBL1572827 & 688636 & 4.45 & 4.659 & TRN \\
\hline
\end{tabular}




\begin{tabular}{|c|c|c|c|c|c|}
\hline \multirow{3}{*}{$\begin{array}{l}\text { CHEMBL1586254 } \\
\text { CHEMBL } 1326868\end{array}$} & \multirow{3}{*}{$\begin{array}{l}688636 \\
688636\end{array}$} & \multicolumn{4}{|c|}{ Supplemental Table s2.txt } \\
\hline & & 5.55 & 5.02800 & 00000000005 & TST \\
\hline & & 4.3 & 4.7914 & TRN & \\
\hline CHEMBL1350432 & 688636 & 4.25 & 4.9457 & TST & \\
\hline CHEMBL1442384 & 688636 & 4.5 & 4.7529 & TST & \\
\hline CHEMBL1570481 & 688636 & 5.1 & 4.7801 & TRN & \\
\hline CHEMBL1604539 & 688636 & 5.9 & 4.8533 & TST & \\
\hline CHEMBL1488661 & 688636 & 4.8 & 4.6204 & TRN & \\
\hline CHEMBL1463899 & 688636 & 6.2 & 4.8965 & TST & \\
\hline CHEMBL1380304 & 688636 & 4.9 & 4.8437 & TRN & \\
\hline CHEMBL1562373 & 688636 & 6.7501 & 4.8146 & TRN & \\
\hline CHEMBL1374720 & 688636 & 4.6 & 4.7796 & TRN & \\
\hline CHEMBL1333792 & 688636 & 5.2 & 4.8163 & TST & \\
\hline CHEMBL1598432 & 688636 & 5.35 & 4.787 & TRN & \\
\hline CHEMBL1333340 & 688636 & 5.1 & 4.7697 & TST & \\
\hline CHEMBL1410489 & 688636 & 4.25 & 4.8481 & TST & \\
\hline CHEMBL1322647 & 688636 & 4.95 & 4.8966 & TST & \\
\hline CHEMBL1539028 & 688636 & 4.95 & 4.8195 & TST & \\
\hline CHEMBL1306680 & 688636 & 4.3 & 4.817 & TRN & \\
\hline CHEMBL1424689 & 688636 & 4.85 & 4.8912 & TST & \\
\hline CHEMBL1386612 & 688636 & 4.65 & 5.0352 & TRN & \\
\hline CHEMBL1544692 & 688636 & 4.25 & 4.8639 & TRN & \\
\hline CHEMBL1341000 & 688636 & 5.25 & 4.7045 & TRN & \\
\hline CHEMBL3196827 & 688636 & 4.95 & 4.6458 & TRN & \\
\hline CHEMBL1556582 & 688636 & 4.5 & 5.0167 & TRN & \\
\hline CHEMBL1412539 & 688636 & 4.35 & 5.0254 & TRN & \\
\hline CHEMBL1522415 & 688636 & 6.8 & 4.9394 & TST & \\
\hline CHEMBL1468594 & 688636 & 4.5 & 4.8756 & TRN & \\
\hline CHEMBL1584656 & 688636 & 4.55 & 4.7758 & TST & \\
\hline CHEMBL1465729 & 688636 & 4.25 & 4.9674 & TRN & \\
\hline CHEMBL1503201 & 688636 & 4.25 & 4.7817 & TRN & \\
\hline CHEMBL1466070 & 688636 & 4.3 & 4.794 & TRN & \\
\hline CHEMBL1365132 & 688636 & 4.65 & 4.8031 & TRN & \\
\hline CHEMBL1319984 & 688636 & 4.5 & 4.797 & TRN & \\
\hline CHEMBL1343718 & 688636 & 6.7501 & 5.0218 & TRN & \\
\hline CHEMBL1383050 & 688636 & 4.6 & 4.7791 & TRN & \\
\hline CHEMBL1365075 & 688636 & 4.9 & 4.792 & TRN & \\
\hline CHEMBL1323377 & 688636 & 4.55 & 4.5857 & TRN & \\
\hline CHEMBL1304688 & 688636 & 5.95 & 4.8728 & TST & \\
\hline CHEMBL1410782 & 688636 & 4.3 & 4.9129 & TRN & \\
\hline CHEMBL3196934 & 688636 & 4.3 & 4.6335 & TRN & \\
\hline CHEMBL1501184 & 688636 & 4.3 & 4.4892 & TRN & \\
\hline CHEMBL3196751 & 688636 & 4.7 & 4.7353 & TRN & \\
\hline CHEMBL1470728 & 688636 & 6.7501 & 4.8208 & TST & \\
\hline CHEMBL1329874 & 688636 & 6.4 & 4.8767 & TRN & \\
\hline CHEMBL1400555 & 688636 & 6.6 & 4.8462 & TST & \\
\hline CHEMBL1989414 & 688636 & 4.6 & 4.6273 & TRN & \\
\hline CHEMBL1472109 & 688636 & 4.4 & 4.801 & TRN & \\
\hline CHEMBL1433083 & 688636 & 4.65 & 4.8239 & TRN & \\
\hline
\end{tabular}




\begin{tabular}{|c|c|c|c|c|}
\hline \multicolumn{5}{|c|}{ Supplement } \\
\hline CHEMBL1464775 & 688636 & 4.3 & 4.8949 & TRN \\
\hline CHEMBL1563574 & 688636 & 4.7 & 4.748 & TRN \\
\hline CHEMBL1595562 & 688636 & 5.2 & 4.7684 & TRN \\
\hline CHEMBL1480371 & 688636 & 4.25 & 4.6025 & TRN \\
\hline CHEMBL1306433 & 688636 & 4.3 & 4.6351 & TRN \\
\hline CHEMBL1376342 & 688636 & 4.45 & 4.8865 & TST \\
\hline CHEMBL1518052 & 688636 & 4.95 & 4.7811 & TRN \\
\hline CHEMBL3195236 & 688636 & 4.85 & 4.6933 & TRN \\
\hline CHEMBL1337499 & 688636 & 4.25 & 4.8263 & TRN \\
\hline CHEMBL1429114 & 688636 & 4.55 & 4.859 & TRN \\
\hline CHEMBL1363982 & 688636 & 5.1 & 4.8785 & TST \\
\hline CHEMBL1996490 & 688636 & 4.75 & 4.8346 & TRN \\
\hline CHEMBL1573799 & 688636 & 4.5 & 4.747 & TST \\
\hline CHEMBL1583455 & 688636 & 6.05 & 4.9255 & TST \\
\hline CHEMBL1587369 & 688636 & 4.5 & 4.6805 & TRN \\
\hline CHEMBL1419900 & 688636 & 4.4 & 4.6654 & TRN \\
\hline CHEMBL3210706 & 688636 & 4.35 & 4.7127 & TRN \\
\hline CHEMBL1544505 & 688636 & 4.3 & 4.8364 & TRN \\
\hline CHEMBL1525792 & 688636 & 5.35 & 4.7044 & TST \\
\hline CHEMBL1455526 & 688636 & 4.5 & 4.9686 & TST \\
\hline CHEMBL1457794 & 688636 & 4.95 & 4.7229 & TST \\
\hline CHEMBL1596939 & 688636 & 4.55 & 4.8747 & TRN \\
\hline CHEMBL1340125 & 688636 & 4.55 & 4.5489 & TRN \\
\hline CHEMBL1344329 & 688636 & 4.3 & 4.7568 & TRN \\
\hline CHEMBL1373740 & 688636 & 4.45 & 4.7944 & TRN \\
\hline CHEMBL3208881 & 688636 & 4.45 & 4.8121 & TRN \\
\hline CHEMBL1547000 & 688636 & 6.05 & 4.8635 & TRN \\
\hline CHEMBL1575696 & 688636 & 5.45 & 4.6931 & TRN \\
\hline CHEMBL1416048 & 688636 & 4.3 & 4.9664 & TRN \\
\hline CHEMBL1447457 & 688636 & 4.3 & 4.7244 & TST \\
\hline CHEMBL1347490 & 688636 & 4.5 & 4.4866 & TRN \\
\hline CHEMBL3189951 & 688636 & 4.35 & 4.4815 & TRN \\
\hline CHEMBL1482626 & 688636 & 4.25 & 4.7677 & TRN \\
\hline CHEMBL1502516 & 688636 & 4.45 & 4.7297 & TRN \\
\hline CHEMBL81720 & 152460 & 4.8539 & 6.0028 & TST \\
\hline CHEMBL82096 & 152460 & 4.699 & 5.6548 & TST \\
\hline CHEMBL311208 & 152460 & 4.7696 & 5.87700 & 0000000001 \\
\hline CHEMBL81854 & 152460 & 4.7696 & 7.1947 & TRN \\
\hline CHEMBL 79830 & 152460 & 3.7447 & 4.9752 & TST \\
\hline CHEMBL313822 & 152460 & 4.4989 & 4.7459 & TRN \\
\hline CHEMBL419846 & 152460 & 6.0 & 6.8383 & TRN \\
\hline CHEMBL 83273 & 152460 & 8.4815 & 7.808 & TRN \\
\hline CHEMBL419665 & 152460 & 7.1549 & 6.9384 & TRN \\
\hline CHEMBL311896 & 152460 & 5.2993 & 5.185 & TRN \\
\hline CHEMBL3349326 & 152460 & 7.3098 & 7.4469 & TRN \\
\hline CHEMBL84231 & 152460 & 7.6778 & 7.2922 & TRN \\
\hline CHEMBL3349325 & 152460 & 8.041 & 7.8146 & TRN \\
\hline CHEMBL310213 & 152460 & 5.2503 & 4.7181 & TRN \\
\hline
\end{tabular}




\begin{tabular}{|c|c|c|c|c|c|c|}
\hline & & \multicolumn{5}{|c|}{ Supplemental Table S2.txt } \\
\hline CHEMBL311859 & 152460 & 5.6655 & 4.895 & TRN & & \\
\hline CHEMBL316388 & 152460 & 7.7959 & 7.2677 & TRN & & \\
\hline CHEMBL84211 & 152460 & 5.0 & 6.1853 & TRN & & \\
\hline CHEMBL84479 & 152460 & 5.5867 & 5.3361 & TRN & & \\
\hline CHEMBL84361 & 152460 & 3.5498 & 4.2322 & TRN & & \\
\hline CHEMBL80035 & 152460 & 4.7011 & 4.734 & TRN & & \\
\hline CHEMBL313878 & 152460 & 7.8447 & 7.5615 & TRN & & \\
\hline CHEMBL79791 & 152460 & 4.3279 & 4.7579 & TRN & & \\
\hline CHEMBL83816 & 152460 & 3.8239 & 4.4451 & TRN & & \\
\hline CHEMBL309318 & 152460 & 5.3809 & 4.6055 & TRN & & \\
\hline CHEMBL 79871 & 152460 & \multicolumn{3}{|c|}{6.7620000000000005} & 6.6126 & TRN \\
\hline CHEMBL311674 & 152460 & 5.699 & 6.2239 & TRN & & \\
\hline CHEMBL304292 & 152460 & 7.1024 & 6.8707 & TRN & & \\
\hline CHEMBL310295 & 152460 & 4.6216 & 4.7985 & TRN & & \\
\hline CHEMBL84185 & 152460 & 5.5467 & 5.3908 & TRN & & \\
\hline CHEMBL80049 & 152460 & 4.1308 & 3.8437 & TRN & & \\
\hline CHEMBL80034 & 152460 & 7.5528 & 7.4077 & TRN & & \\
\hline CHEMBL443012 & 152460 & 7.8861 & 7.4467 & TRN & & \\
\hline CHEMBL81085 & 152460 & 3.0 & 4.0939 & TRN & & \\
\hline CHEMBL83998 & 152460 & 4.5229 & 4.4094 & TRN & & \\
\hline CHEMBL3349327 & 152460 & 5.2218 & 5.8755 & TRN & & \\
\hline CHEMBL310999 & 152460 & 4.6383 & 5.567 & TST & & \\
\hline CHEMBL79457 & 152460 & 6.7471 & 4.7409 & TRN & & \\
\hline CHEMBL79731 & 152460 & 5.585 & 4.6917 & TRN & & \\
\hline CHEMBL1907863 & 152460 & 6.0 & 5.2597 & TRN & & \\
\hline CHEMBL309697 & 152460 & 7.3979 & 7.3116 & TRN & & \\
\hline CHEMBL311125 & 152460 & 6.0 & 7.3478 & TRN & & \\
\hline CHEMBL310879 & 152460 & 7.7033 & 7.2408 & TRN & & \\
\hline CHEMBL83496 & 152460 & 3.5086 & 4.292 & TRN & & \\
\hline CHEMBL 84406 & 152460 & 7.4089 & 7.226 & TRN & & \\
\hline CHEMBL420219 & 152460 & 5.301 & 5.4014 & TST & & \\
\hline CHEMBL315407 & 152460 & 3.3809 & 3.807 & TRN & & \\
\hline CHEMBL82585 & 152460 & 4.3279 & 5.3099 & TST & & \\
\hline CHEMBL314190 & 152460 & 7.1938 & 7.0274 & TRN & & \\
\hline CHEMBL 83151 & 152460 & 5.1739 & 5.1362 & TRN & & \\
\hline CHEMBL 84271 & 152460 & 7.6021 & 6.9265 & TRN & & \\
\hline CHEMBL83599 & 152460 & 4.6498 & 4.1528 & TRN & & \\
\hline CHEMBL 315234 & 152460 & 5.2549 & 5.0787 & TRN & & \\
\hline CHEMBL313453 & 152460 & 3.585 & 4.1818 & TRN & & \\
\hline CHEMBL 79494 & 152460 & 3.2518 & 4.5018 & TST & & \\
\hline CHEMBL316226 & 152460 & 4.8239 & 5.3682 & TST & & \\
\hline CHEMBL329794 & 152460 & 5.2076 & 5.6227 & TST & & \\
\hline CHEMBL 83502 & 152460 & 7.4437 & 6.8127 & TST & & \\
\hline CHEMBL310616 & 152460 & 5.0 & 5.5642 & TST & & \\
\hline CHEMBL313843 & 152460 & 5.4724 & 4.8596 & TST & & \\
\hline CHEMBL 81574 & 152460 & 7.7212 & 7.2906 & TST & & \\
\hline CHEMBL83727 & 152460 & 7.4318 & 6.5844 & TST & & \\
\hline CHEMBL83771 & 152460 & 6.9508 & 6.7268 & TST & & \\
\hline
\end{tabular}




\begin{tabular}{|c|c|c|c|c|c|}
\hline \multicolumn{6}{|c|}{ Supplemental Table s2.txt } \\
\hline CHEMBL1956660 & 807094 & 5.301 & 5.4793 & TRN & \\
\hline CHEMBL1956681 & 807094 & 5.699 & 6.1778 & TRN & \\
\hline CHEMBL1956655 & 807094 & 5.6778 & 5.4696 & TRN & \\
\hline CHEMBL1956672 & 807094 & 6.0044 & 5.9829 & TRN & \\
\hline CHEMBL1956679 & 807094 & 5.6198 & 6.1684 & TRN & \\
\hline CHEMBL1956669 & 807094 & 6.9208 & 6.1018 & TRN & \\
\hline CHEMBL1956636 & 807094 & 2.699 & 4.3996 & TRN & \\
\hline CHEMBL1956671 & 807094 & 6.2924 & 6.0004 & TRN & \\
\hline CHEMBL1956648 & 807094 & 4.6778 & 4.1722 & TRN & \\
\hline CHEMBL1956676 & 807094 & 6.7959 & 6.2189 & TRN & \\
\hline CHEMBL1956665 & 807094 & 5.5229 & 5.7742 & TRN & \\
\hline CHEMBL1956646 & 807094 & 5.4685 & 4.8345 & TRN & \\
\hline CHEMBL1955874 & 807094 & 6.4318 & 6.154 & TRN & \\
\hline CHEMBL1956633 & 807094 & 4.4318 & 4.7056 & TRN & \\
\hline CHEMBL1956659 & 807094 & 5.4949 & 5.6286 & TRN & \\
\hline CHEMBL1956668 & 807094 & 6.9208 & 6.0426 & TRN & \\
\hline CHEMBL1956644 & 807094 & 5.6576 & 5.2803 & TRN & \\
\hline CHEMBL1956677 & 807094 & 5.4949 & 6.0518 & TRN & \\
\hline CHEMBL1956678 & 807094 & 5.6576 & 6.1007 & TRN & \\
\hline CHEMBL1956653 & 807094 & 6.0555 & 5.4899 & TRN & \\
\hline CHEMBL1956666 & 807094 & 5.2076 & 5.4865 & TRN & \\
\hline CHEMBL1956641 & 807094 & 2.699 & 4.3956 & TST & \\
\hline CHEMBL1956667 & 807094 & 4.1675 & 5.559 & TRN & \\
\hline CHEMBL1956662 & 807094 & 6.0 & 5.5999 & TRN & \\
\hline CHEMBL1956652 & 807094 & 6.0555 & 5.4884 & TRN & \\
\hline CHEMBL1956647 & 807094 & 4.8861 & 5.0308 & TRN & \\
\hline CHEMBL1956649 & 807094 & 3.8182 & 4.0707 & TRN & \\
\hline CHEMBL1956637 & 807094 & 4.1805 & 4.1723 & TRN & \\
\hline CHEMBL1956654 & 807094 & 5.8861 & 5.67399 & 99999999995 & TRN \\
\hline CHEMBL1956642 & 807094 & 6.3565 & 5.2379 & TRN & \\
\hline CHEMBL1956670 & 807094 & 6.699 & 6.1622 & TRN & \\
\hline CHEMBL1956680 & 807094 & 5.5686 & 6.1768 & TRN & \\
\hline CHEMBL1956658 & 807094 & 5.585 & 5.6598 & TRN & \\
\hline CHEMBL1956664 & 807094 & 5.5376 & 5.8206 & TRN & \\
\hline CHEMBL1956635 & 807094 & 4.699 & 4.3814 & TST & \\
\hline CHEMBL1956634 & 807094 & 4.2366 & 4.1325 & TRN & \\
\hline CHEMBL1956650 & 807094 & 5.3098 & 4.4415 & TRN & \\
\hline CHEMBL1956639 & 807094 & 4.9586 & 4.4904 & TRN & \\
\hline CHEMBL1956674 & 807094 & 4.9208 & 5.7567 & TRN & \\
\hline CHEMBL1956645 & 807094 & 3.983 & 4.9879 & TRN & \\
\hline CHEMBL1956675 & 807094 & 6.6021 & 5.8435 & TST & \\
\hline CHEMBL1956643 & 807094 & 2.699 & 4.5479 & TST & \\
\hline CHEMBL1956673 & 807094 & 6.0915 & 5.9071 & TST & \\
\hline CHEMBL1956632 & 807094 & 2.699 & 4.6094 & TST & \\
\hline CHEMBL1956656 & 807094 & 5.6383 & 5.7815 & TST & \\
\hline CHEMBL1956661 & 807094 & 5.2366 & 5.9272 & TST & \\
\hline CHEMBL1956657 & 807094 & 5.585 & 5.7106 & TST & \\
\hline CHEMBL1956663 & 807094 & 5.699 & 5.7318 & TST & \\
\hline
\end{tabular}


Supplemental Table S2.txt

\begin{tabular}{|c|c|c|c|c|}
\hline IE & 4 & 99 & 23 & \\
\hline & 07094 & .699 & 4.1395 & \\
\hline AEN & 94 & 007 & & \\
\hline JEMBL12 & 36 & 9031 & & \\
\hline AEMBL1256382 & 346 & 5702 & & \\
\hline HEMBL1256443 & 65346 & 2789 & 4128 & \\
\hline HEMBL12 & 46 & 302 & & \\
\hline IFMBI 58 & & 101 & & \\
\hline HEMBL1255774 & & 7122 & 7225 & \\
\hline HEMBL1255776 & 46 & 7314 & 7381 & \\
\hline HEMBL1257313 & & 4724 & 32 & \\
\hline IEMBL1 & & 282 & & \\
\hline AEMBL1 & & & & \\
\hline HEMBL12 & & 847 & & \\
\hline AEMBL1255574 & & 555 & & \\
\hline AEMBL1258133 & & 637 & 282 & \\
\hline HEMBL1 & & 695 & & \\
\hline HEMBL5 & & 788 & & \\
\hline HEMBL1. & & 633 & & \\
\hline HEMBL125 & & 271 & & \\
\hline HEMBLI & & 239 & 297 & \\
\hline AEMBLI & & 696 & 82 & \\
\hline HEMBL1 & & 946 & & RN \\
\hline 544 & & 589 & & \\
\hline HEMBL125 & & 83 & & I \\
\hline HEMBL1 & & 258 & 52 & $\mathrm{RN}$ \\
\hline AEMBL1 & & 021 & 96 & RN \\
\hline AFMRI & & 38 & 68 & RN \\
\hline HEMBL1256168 & & & & TRN \\
\hline HEMBL12575 & & 244 & & KN \\
\hline HEMBL125€ & & 096 & & RIN \\
\hline AFMBI 1 & & 97 & 76 & Niv \\
\hline י & & 55 & & ST \\
\hline HEMBL1257542 & & 751 & & RN \\
\hline HEMBL 528486 & & 6.5834 & 694 & RN \\
\hline HEMBL1256315 & & 996 & 809 & RN \\
\hline HᄃMP I 1 & & & & RN \\
\hline & & & & RN \\
\hline HEMBL1258132 & & 012 & 1082 & TRN \\
\hline IEMBL1 & & 19 & & IST \\
\hline HEMBL125 & & 101 & 273 & \\
\hline HEMBL125 & & & & RN \\
\hline HEMBL125 & & 515 & 1382 & IST \\
\hline AEMBL1255775 & & 986 & 468 & TRN \\
\hline MBL1 & & 708 & & 3 \\
\hline CHEMBL1258134 & & .3755 & 2.3891 & \\
\hline CHEMBL1257903 & & .8153 & 4.8762 & \\
\hline SHEMBL1257662 & 665346 & 5.0937 & 0.7719 & ГST \\
\hline
\end{tabular}

Page 25925 


\begin{tabular}{|c|c|c|c|c|c|}
\hline \multicolumn{6}{|c|}{ Supplemental Table S2.txt } \\
\hline CHEMBL1256246 & 665346 & 4.0419 & 4.0873 & TRN & \\
\hline CHEMBL1256248 & 665346 & 6.4698 & 6.5229 & TRN & \\
\hline CHEMBL1256318 & 665346 & 3.9847 & 4.0051 & TRN & \\
\hline CHEMBL1256508 & 665346 & 2.3242 & 2.1135 & TRN & \\
\hline CHEMBL1257901 & 665346 & 4.0696 & 1.3937 & TST & \\
\hline CHEMBL1256570 & 665346 & 1.033 & 1.1909 & TRN & \\
\hline CHEMBL1257663 & 665346 & 4.0757 & 0.8275 & TST & \\
\hline CHEMBL1258247 & 665346 & 4.9747 & 4.9727 & TRN & \\
\hline CHEMBL1257786 & 665346 & 4.0757 & 0.8504 & TST & \\
\hline CHEMBL1257784 & 665346 & 5.1057 & 0.693 & TST & \\
\hline CHEMBL527822 & 665346 & 7.3316 & 7.6527 & TST & \\
\hline CHEMBL1256345 & 665346 & 4.3659 & 4.3242 & TRN & \\
\hline CHEMBL1256614 & 665346 & 1.0852 & 1.11599 & 99999999999 & TRN \\
\hline CHEMBL1256445 & 665346 & 1.8047 & 1.8599 & TRN & \\
\hline CHEMBL1256571 & 665346 & 2.4934 & 2.4917 & TRN & \\
\hline CHEMBL1255731 & 665346 & 4.5638 & 4.5794 & TRN & \\
\hline CHEMBL1256317 & 665346 & 4.0356 & 4.0734 & TRN & \\
\hline CHEMBL1256613 & 665346 & 3.4559 & 3.4286 & TRN & \\
\hline CHEMBL1256346 & 665346 & 4.0159 & 4.0129 & TRN & \\
\hline CHEMBL1257902 & 665346 & 4.0809 & 4.0251 & TRN & \\
\hline CHEMBL1256507 & 665346 & 1.055 & 0.9115 & TRN & \\
\hline CHEMBL1256383 & 665346 & 2.7786 & 2.648 & TRN & \\
\hline CHEMBL1256108 & 665346 & 4.9027 & 3.9027 & TST & \\
\hline CHEMBL1256569 & 665346 & 2.73100 & 0000000 & 2.7628 & TRN \\
\hline CHEMBL1258014 & 665346 & 5.7986 & 5.5524 & TST & \\
\hline CHEMBL537807 & 665346 & 7.4001 & 7.5868 & TST & \\
\hline CHEMBL1256247 & 665346 & 5.9337 & 5.8699 & TST & \\
\hline CHEMBL126561 & 122938 & 6.0 & 4.8178 & TRN & \\
\hline CHEMBL127758 & 122938 & 6.0 & 4.2859 & TRN & \\
\hline CHEMBL340701 & 122938 & 4.5143 & 5.0462 & TRN & \\
\hline CHEMBL125094 & 122938 & 4.301 & 5.0404 & TRN & \\
\hline CHEMBL421088 & 122938 & 4.6021 & 4.4804 & TRN & \\
\hline CHEMBL420523 & 122938 & 3.301 & 4.1343 & TRN & \\
\hline CHEMBL127983 & 122938 & 6.0 & 5.7216 & TRN & \\
\hline CHEMBL127517 & 122938 & 4.301 & 4.9673 & TRN & \\
\hline CHEMBL127622 & 122938 & 6.0 & 5.0838 & TRN & \\
\hline CHEMBL125044 & 122938 & 5.0 & 5.1105 & TRN & \\
\hline CHEMBL123894 & 122938 & 4.0 & 4.09399 & 9999999999 & ובן \\
\hline CHEMBL125843 & 122938 & 5.0 & 4.0216 & TST & \\
\hline CHEMBL124461 & 122938 & 5.0 & 5.0964 & TRN & \\
\hline CHEMBL127880 & 122938 & 4.4647 & 4.2169 & TST & \\
\hline CHEMBL123895 & 122938 & 4.0 & 4.3855 & TRN & \\
\hline CHEMBL339445 & 122938 & 4.6021 & 4.6821 & TRN & \\
\hline CHEMBL339626 & 122938 & 4.301 & 5.1036 & TRN & \\
\hline CHEMBL129270 & 122938 & 4.0 & 3.6025 & TRN & \\
\hline CHEMBL129769 & 122938 & 4.5086 & 4.6733 & TST & \\
\hline CHEMBL127077 & 122938 & 6.0 & 5.2045 & TRN & \\
\hline CHEMBL341073 & 122938 & 6.0 & 5.3818 & TRN & \\
\hline
\end{tabular}




\begin{tabular}{|c|c|c|c|c|}
\hline & & & oplement & al $\mathrm{Ta}$ \\
\hline CHEMBL126419 & 122938 & 5.0 & 5.1856 & TRN \\
\hline CHEMBL125520 & 122938 & 5.301 & 5.9118 & TRN \\
\hline CHEMBL126799 & 122938 & 4.0 & 3.9449 & TST \\
\hline CHEMBL126681 & 122938 & 4.0 & 4.3616 & TRN \\
\hline CHEMBL127182 & 122938 & 6.0 & 4.8716 & TRN \\
\hline CHEMBL126547 & 122938 & 3.301 & 3.5584 & TRN \\
\hline CHEMBL127982 & 122938 & 5.0 & 5.0766 & TRN \\
\hline CHEMBL341240 & 122938 & 4.4342 & 4.7952 & TRN \\
\hline CHEMBL127567 & 122938 & 4.301 & 4.2155 & TST \\
\hline CHEMBL419614 & 122938 & 3.301 & 4.0819 & TST \\
\hline CHEMBL125921 & 122938 & 6.0 & 5.157 & TRN \\
\hline CHEMBL123803 & 122938 & 6.0 & 5.1062 & TRN \\
\hline CHEMBL339565 & 122938 & 4.0 & 4.4434 & TRN \\
\hline CHEMBL339429 & 122938 & 4.6021 & 4.6729 & TRN \\
\hline CHEMBL339027 & 122938 & 4.0 & 4.6769 & TRN \\
\hline CHEMBL340239 & 122938 & 5.0 & 4.4065 & TRN \\
\hline CHEMBL126504 & 122938 & 4.301 & 4.1917 & TST \\
\hline CHEMBL128029 & 122938 & 4.0 & 4.1998 & TST \\
\hline CHEMBL339561 & 122938 & 5.0 & 4.2945 & TRN \\
\hline CHEMBL126830 & 122938 & 3.6021 & 4.44 & TRN \\
\hline CHEMBL338094 & 122938 & 6.0 & 5.0599 & TRN \\
\hline CHEMBL125540 & 122938 & 4.301 & 4.546 & TRN \\
\hline CHEMBL127717 & 122938 & 6.0 & 4.187 & TST \\
\hline CHEMBL127518 & 122938 & 3.301 & 4.2609 & TRN \\
\hline CHEMBL127774 & 122938 & 4.301 & 5.6637 & TRN \\
\hline CHEMBL127757 & 122938 & 3.301 & 4.6724 & TRN \\
\hline CHEMBL126886 & 122938 & 5.0 & 4.2439 & TRN \\
\hline CHEMBL126133 & 122938 & 4.0 & 4.3373 & TRN \\
\hline CHEMBL338035 & 122938 & 4.0 & 3.7456 & TRN \\
\hline CHEMBL339739 & 122938 & 6.0 & 4.6837 & TRN \\
\hline CHEMBL124935 & 122938 & 4.6021 & 5.0686 & TRN \\
\hline CHEMBL341071 & 122938 & 3.0 & 3.9139 & TRN \\
\hline CHEMBL340028 & 122938 & 4.301 & 3.9169 & TST \\
\hline CHEMBL127751 & 122938 & 5.0 & 5.0182 & TRN \\
\hline CHEMBL127347 & 122938 & 5.0 & 5.0187 & TRN \\
\hline CHEMBL127966 & 122938 & 3.699 & 4.4872 & TRN \\
\hline CHEMBL126027 & 122938 & 5.0 & 3.9012 & TST \\
\hline CHEMBL124867 & 122938 & 4.0106 & 4.0275 & TST \\
\hline CHEMBL 340130 & 122938 & 4.301 & 4.2608 & TST \\
\hline CHEMBL339794 & 122938 & 4.5867 & 4.7571 & TRN \\
\hline CHEMBL339107 & 122938 & 4.2967 & 4.1277 & TST \\
\hline CHEMBL339535 & 122938 & 6.0 & 5.1952 & TRN \\
\hline CHEMBL126505 & 122938 & 4.301 & 3.7808 & TRN \\
\hline CHEMBL339470 & 122938 & 5.301 & 5.6938 & TST \\
\hline CHEMBL126891 & 122938 & 5.0 & 4.1922 & TST \\
\hline CHEMBL1497759 & 752589 & 5.1124 & 5.1188 & TRN \\
\hline CHEMBL1508384 & 752589 & 4.7937 & 4.7992 & TRN \\
\hline CHEMBL1582537 & 752589 & 5.5735 & 5.5614 & TRN \\
\hline
\end{tabular}




\begin{tabular}{|c|c|c|c|c|}
\hline & & & oplement & al $\mathrm{T}$ \\
\hline CHEMBL1723414 & 752589 & 3.8729 & 3.8785 & TRN \\
\hline CHEMBL1349430 & 752589 & 5.2941 & 5.2911 & TRN \\
\hline CHEMBL1595644 & 752589 & 5.5114 & 5.5051 & TRN \\
\hline CHEMBL1348933 & 752589 & 3.654 & 3.6575 & TRN \\
\hline CHEMBL1386522 & 752589 & 5.251 & 5.2574 & TRN \\
\hline CHEMBL1579173 & 752589 & 3.9062 & 4.6362 & TST \\
\hline CHEMBL1552929 & 752589 & 4.1345 & 4.1243 & TRN \\
\hline CHEMBL1442237 & 752589 & 3.9503 & 3.9496 & TRN \\
\hline CHEMBL1338771 & 752589 & 5.3179 & 5.3202 & TRN \\
\hline CHEMBL1539180 & 752589 & 4.2988 & 4.3129 & TRN \\
\hline CHEMBL1334837 & 752589 & 5.5361 & 5.5303 & TRN \\
\hline CHEMBL1523890 & 752589 & 3.8502 & 3.8597 & TRN \\
\hline CHEMBL1328952 & 752589 & 4.3839 & 4.3871 & TRN \\
\hline CHEMBL1539485 & 752589 & 4.7836 & 4.7884 & TRN \\
\hline CHEMBL1887789 & 752589 & 2.4559 & 2.4495 & TRN \\
\hline CHEMBL1591436 & 752589 & 6.3401 & 6.3511 & TRN \\
\hline CHEMBL1079460 & 752589 & 4.0564 & 3.9235 & TST \\
\hline CHEMBL1388771 & 752589 & 4.923 & 4.9253 & TRN \\
\hline CHEMBL487356 & 752589 & 5.7055 & 5.7059 & TRN \\
\hline CHEMBL1403011 & 752589 & 5.4908 & 5.5015 & TRN \\
\hline CHEMBL1554818 & 752589 & 5.6536 & 5.6563 & TRN \\
\hline CHEMBL1331582 & 752589 & 4.5835 & 4.5787 & TRN \\
\hline CHEMBL1598251 & 752589 & 3.8234 & 3.82 & TRN \\
\hline CHEMBL1446364 & 752589 & 4.1483 & 4.1529 & TRN \\
\hline CHEMBL1517045 & 752589 & 4.0774 & 4.0682 & TRN \\
\hline CHEMBL1391606 & 752589 & 2.4559 & 2.4576 & TRN \\
\hline CHEMBL1301520 & 752589 & 4.3546 & 4.3505 & TRN \\
\hline CHEMBL1349092 & 752589 & 5.7144 & 5.7172 & TRN \\
\hline CHEMBL1538503 & 752589 & 4.3123 & 4.3051 & TRN \\
\hline CHEMBL1560105 & 752589 & 5.6778 & 5.6882 & TRN \\
\hline CHEMBL1538234 & 752589 & 4.1704 & 4.15 & TRN \\
\hline CHEMBL1528413 & 752589 & 5.5969 & 5.5976 & TRN \\
\hline CHEMBL1527552 & 752589 & 4.1898 & 4.1909 & TRN \\
\hline CHEMBL393136 & 752589 & 6.0921 & 5.0482 & TST \\
\hline CHEMBL1506269 & 752589 & 4.4012 & 4.3943 & TRN \\
\hline CHEMBL1526080 & 752589 & 5.0177 & 5.0169 & TRN \\
\hline CHEMBL1398268 & 752589 & 3.952 & 3.9467 & TRN \\
\hline CHEMBL1898173 & 752589 & 3.9914 & 4.6967 & TST \\
\hline CHEMBL1305413 & 752589 & 4.0684 & 4.074 & TRN \\
\hline CHEMBL1363402 & 752589 & 4.4123 & 4.4165 & TRN \\
\hline CHEMBL1902196 & 752589 & 6.3979 & 6.3904 & TRN \\
\hline CHEMBL1886283 & 752589 & 3.9905 & 3.987 & TRN \\
\hline CHEMBL1510164 & 752589 & 5.4815 & 5.4761 & TRN \\
\hline CHEMBL1488167 & 752589 & 5.7305 & 5.1943 & TST \\
\hline CHEMBL1446531 & 752589 & 3.679 & 3.6865 & TRN \\
\hline CHEMBL1424121 & 752589 & 4.6684 & 4.6505 & TRN \\
\hline CHEMBL1541596 & 752589 & 4.2276 & 4.2295 & TRN \\
\hline CHEMBL1368670 & 752589 & 4.4905 & 4.4946 & TRN \\
\hline
\end{tabular}


Supplemental Table S2.txt

\begin{tabular}{|c|c|c|c|c|}
\hline 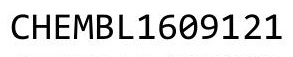 & 52589 & .0472 & 5.058 & 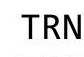 \\
\hline HEMBL1496289 & 52589 & 2933 & 5.3051 & TRN \\
\hline HEMBL1583870 & 2589 & 0044 & 0064 & \\
\hline HEM & 2589 & 3615 & & CRN \\
\hline HEMBL1310464 & 52589 & 333 & 97 & \\
\hline HEMBL1518661 & 52589 & 9706 & .9837 & \\
\hline HEMBL1457068 & 52589 & 6.7399 & 6.737 & \\
\hline HEMBL1865377 & 52589 & 4.8857 & 4.8914 & \\
\hline HEMBL1429930 & 52589 & .5011 & 4.4946 & \\
\hline HEMBL1612880 & 52589 & 4.6267 & 4.6236 & \\
\hline HEMBL1310606 & 752589 & 5.9626 & 5.9568 & \\
\hline HEMBL1425675 & 52589 & 4.5127 & 4.5185 & \\
\hline HEMBL1498627 & 52589 & 3.667 & 3.6697 & \\
\hline HEMBL1585318 & 52589 & 2738 & .9378 & \\
\hline HEMBL1715128 & 52589 & 6643 & 3.6582 & \\
\hline HEMBL1736405 & 52589 & 6.0 & 4.368 & \\
\hline HEMBL1590115 & 52589 & 125 & & \\
\hline HEMBL1376040 & 52589 & 559 & 2.9431 & \\
\hline HEMBL1406945 & 52589 & 701 & 32 & \\
\hline HEMBL1407200 & 52589 & 306 & & \\
\hline HEMBL1326404 & 52589 & 991 & & ST \\
\hline HEMBL1490267 & 52589 & 3625 & & TST \\
\hline HEMBL1498873 & 752589 & 596 & 5 . & \\
\hline HEMBL138 & 589 & 25 & & \\
\hline HEMBL1567 & 589 & 94 & & ST \\
\hline HEMBL1528672 & 88654 & & 4.8771 & RN \\
\hline HEMBL1305422 & 88654 & & 5.2 & iv \\
\hline HEMBL1554155 & 88654 & & 72 & RN \\
\hline L158 & 4 & & & RN \\
\hline HEMBL1564968 & 54 & 4. & 68 & RN \\
\hline HEMBL3193997 & & & & IRN \\
\hline HEMBL1559607 & 88654 & & 374 & TRN \\
\hline HEMBL1496788 & 54 & & 05 & RN \\
\hline HFMBI 60 & 54 & 5 & & ST \\
\hline HEMBL1396351 & 4 & & 37 & RN \\
\hline HEMBL1415374 & 88654 & & 5.4981 & TRN \\
\hline HEMBL1382649 & 88654 & & & TRN \\
\hline HEMBL 146 & 3654 & & & TST \\
\hline ר 19 & 54 & 4. & & TST \\
\hline HEMBL1533737 & & & 4.9008 & TRN \\
\hline HEMBL1571545 & 688654 & 5 & 4.7174 & TST \\
\hline HEMBL1484208 & 588654 & 5.05 & 5.2674 & TRN \\
\hline CHEMBL1560579 & 588654 & 4. & & \\
\hline CHEMBL1440503 & 88654 & 5 & .6655 & TRN \\
\hline HEMBL1486329 & & & 5.0664 & TRN \\
\hline HEMBL1456711 & 688654 & 4.75 & .8242 & TRN \\
\hline CHEMBL14 & & 4 & 4.9 & RN \\
\hline CHEMBL1372952 & 688654 & 5. & 5.2023 & \\
\hline
\end{tabular}

Page 25929 


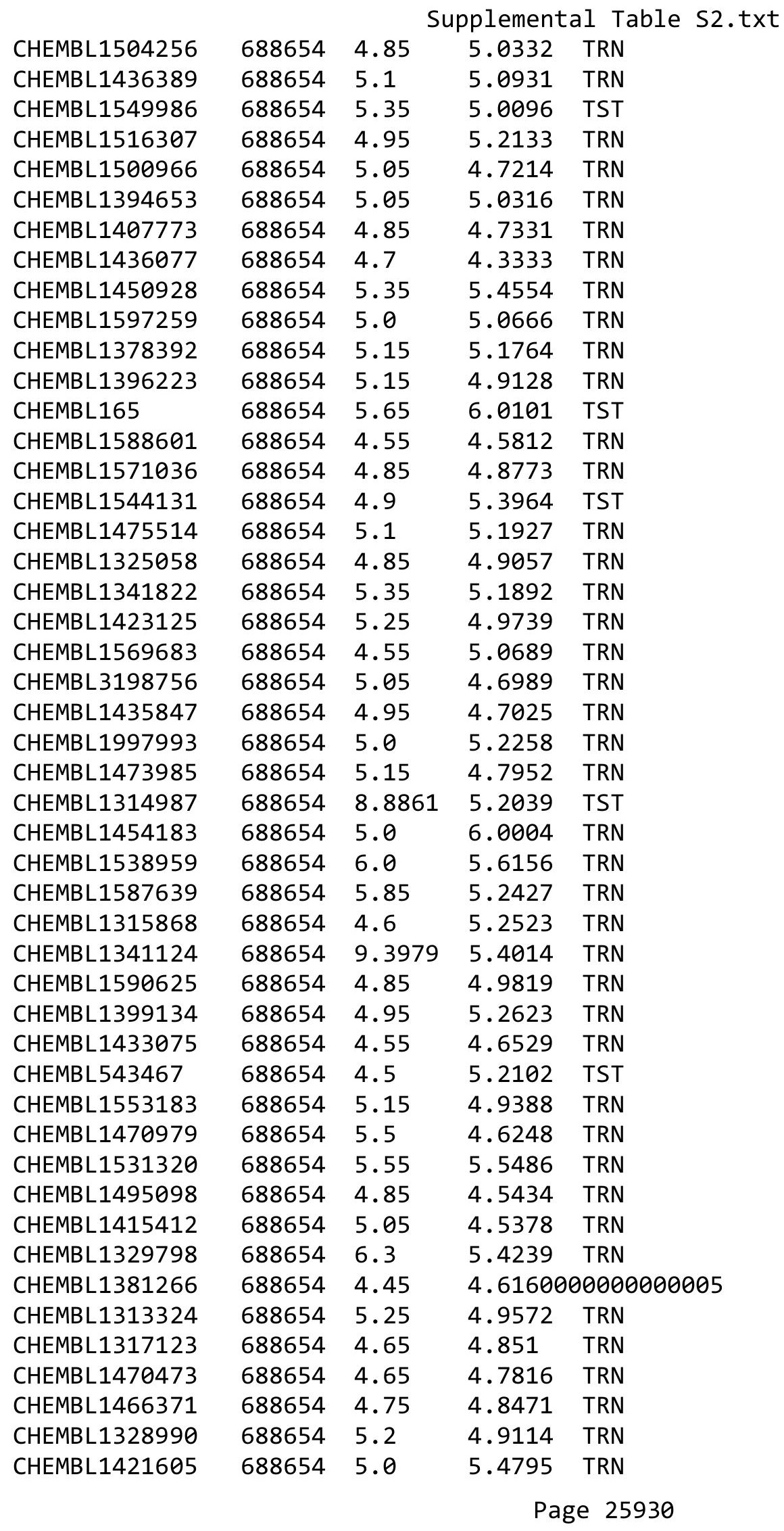

TRN 


\begin{tabular}{|c|c|c|c|c|c|}
\hline \multicolumn{6}{|c|}{ Supplemental Table S2.txt } \\
\hline CHEMBL1397580 & 688654 & 4.5 & 4.8224 & TRN & \\
\hline CHEMBL1315320 & 688654 & 4.8 & 4.8252 & TRN & \\
\hline CHEMBL 2007422 & 688654 & 4.6 & 5.3805 & TRN & \\
\hline CHEMBL126077 & 688654 & 6.0 & 5.9664 & TST & \\
\hline CHEMBL1600998 & 688654 & 5.1 & 5.4615 & TST & \\
\hline CHEMBL1315789 & 688654 & 4.9 & 4.9105 & TRN & \\
\hline CHEMBL1319866 & 688654 & 4.9 & 4.8605 & TRN & \\
\hline CHEMBL1421407 & 688654 & 5.5 & 5.1325 & TRN & \\
\hline CHEMBL1358682 & 688654 & 5.1 & 5.0954 & TRN & \\
\hline CHEMBL1516227 & 688654 & 4.8 & 4.9275 & TRN & \\
\hline CHEMBL296586 & 688654 & 6.0 & 5.4226 & TST & \\
\hline CHEMBL1420520 & 688654 & 4.95 & 5.2146 & TRN & \\
\hline CHEMBL1467851 & 688654 & 4.6 & \multicolumn{2}{|c|}{4.928999999999999} & TRN \\
\hline CHEMBL1437083 & 688654 & 5.15 & 4.9832 & TRN & \\
\hline CHEMBL102714 & 688654 & 9.0458 & 7.6908 & TRN & \\
\hline CHEMBL1324313 & 688654 & 4.9 & 4.5058 & TRN & \\
\hline CHEMBL1359120 & 688654 & 5.0 & 5.0525 & TRN & \\
\hline CHEMBL1576722 & 688654 & 4.9 & 5.4603 & TRN & \\
\hline CHEMBL1449499 & 688654 & 5.1 & 4.8553 & TRN & \\
\hline CHEMBL1347369 & 688654 & 4.85 & 5.1547 & TRN & \\
\hline CHEMBL1526989 & 688654 & 4.8 & 5.0899 & TRN & \\
\hline CHEMBL1593817 & 688654 & 4.7 & 4.8011 & TRN & \\
\hline CHEMBL1305452 & 688654 & 4.65 & 4.7887 & TRN & \\
\hline CHEMBL1518828 & 688654 & 5.1 & 5.3234 & TRN & \\
\hline CHEMBL1473735 & 688654 & 4.95 & 4.9264 & TRN & \\
\hline CHEMBL1399505 & 688654 & 10.5003 & 4.8911 & TST & \\
\hline CHEMBL1404898 & 688654 & 4.9 & 5.1136 & TRN & \\
\hline CHEMBL1446397 & 688654 & 5.15 & 5.1933 & TRN & \\
\hline CHEMBL1554143 & 688654 & 4.95 & 5.0714 & TRN & \\
\hline CHEMBL1309269 & 688654 & 4.6 & 5.4335 & TRN & \\
\hline CHEMBL1448605 & 688654 & 4.9 & 4.7883 & TRN & \\
\hline CHEMBL1545112 & 688654 & 4.9 & 5.732 & TRN & \\
\hline CHEMBL1403693 & 688654 & 4.85 & 4.8233 & TRN & \\
\hline CHEMBL1387029 & 688654 & 4.55 & 5.0848 & TST & \\
\hline CHEMBL1453483 & 688654 & 4.6 & 5.0847 & TST & \\
\hline CHEMBL1463321 & 688654 & 6.05 & 5.1367 & TST & \\
\hline CHEMBL1538342 & 688654 & 10.4498 & 4.7487 & TST & \\
\hline CHEMBL1490041 & 688654 & 4.95 & 4.9682 & TST & \\
\hline CHEMBL1476017 & 688654 & 5.15 & 4.9472 & TST & \\
\hline CHEMBL1592304 & 688654 & 4.85 & 4.9859 & TST & \\
\hline CHEMBL1447219 & 688654 & 4.45 & 5.2961 & TST & \\
\hline CHEMBL430266 & 688654 & 5.95 & 4.5 & TST & \\
\hline CHEMBL1460810 & 688654 & 5.35 & 4.6105 & TST & \\
\hline CHEMBL1423452 & 688654 & 5.6 & 4.5329 & TST & \\
\hline CHEMBL1436204 & 688654 & 4.8 & 5.1632 & TST & \\
\hline CHEMBL1451609 & 688654 & 5.5 & 5.1992 & TST & \\
\hline CHEMBL1504555 & 688654 & 5.15 & 5.0782 & TST & \\
\hline \multirow[t]{2}{*}{ CHEMBL1502651 } & 688654 & 5.85 & 5.21399 & 99999999995 & TST \\
\hline & & \multicolumn{4}{|c|}{ Page 25931} \\
\hline
\end{tabular}




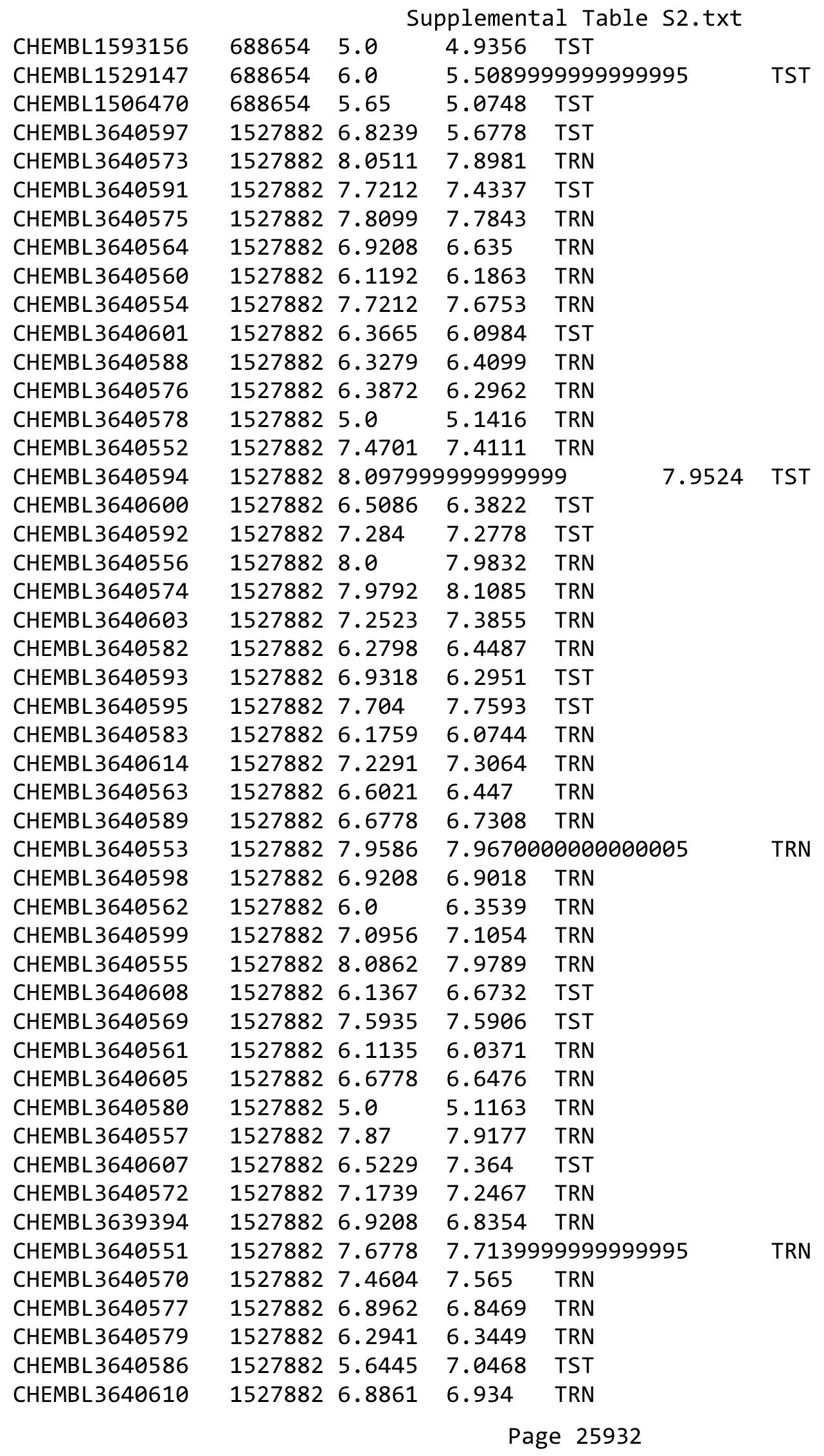


Supplemental Table S2.txt

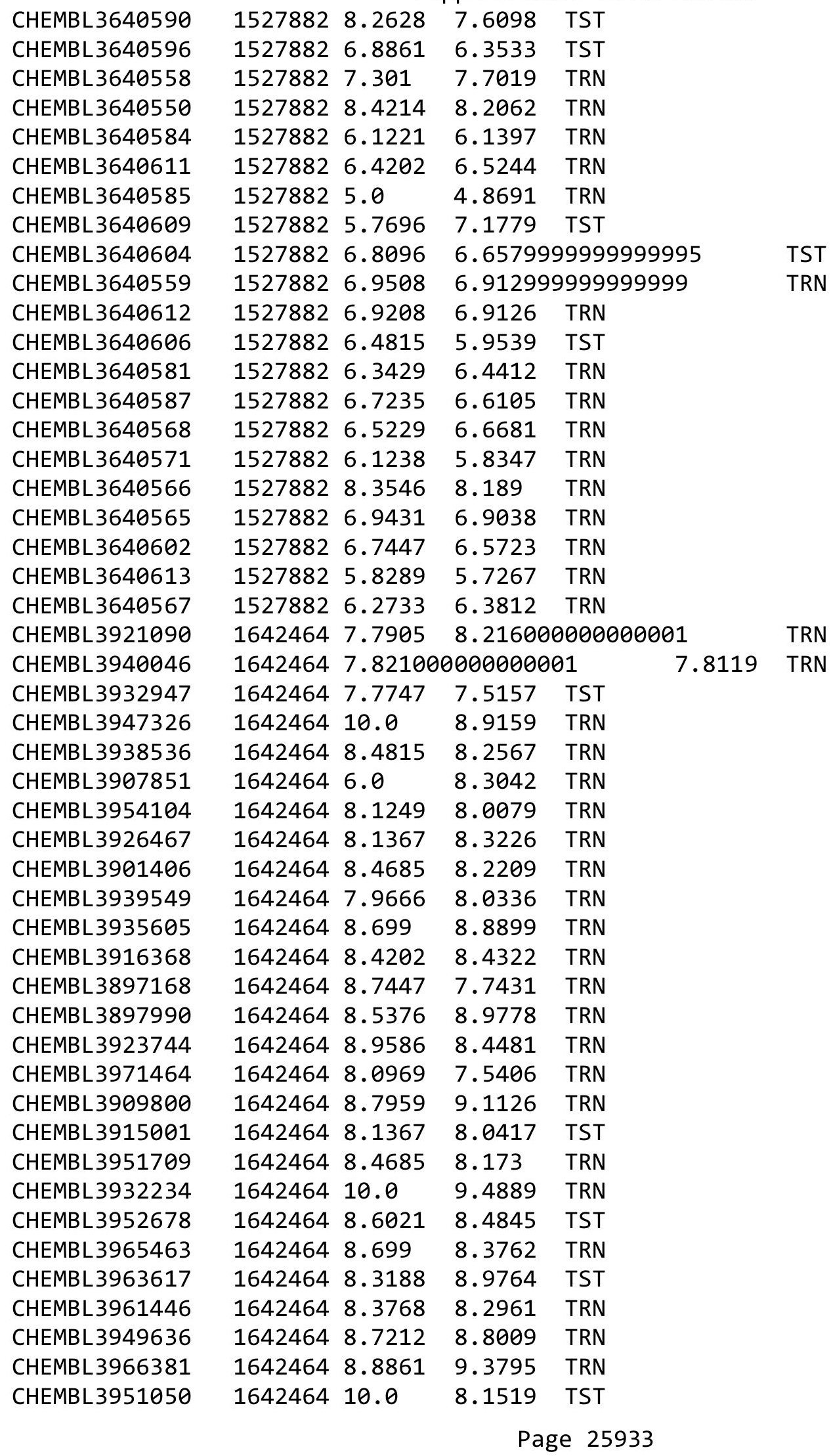


Supplemental Table S2.txt

\begin{tabular}{|c|c|c|c|c|}
\hline HEMBL & 542464 & 8.6778 & 8.5978 & \\
\hline HEMBL3902427 & 642464 & 8.2007 & 7.394 & \\
\hline 86 & & & & \\
\hline AEMBL3936041 & & 3188 & 8154 & \\
\hline AEMBL3922795 & 34 & 8539 & 1399 & \\
\hline HEMBL3893672 & 642464 & 8.3768 & .5548 & \\
\hline 04 & & 487 & & \\
\hline HEMBL396 & & & & \\
\hline HEMBL 393 & 6 & 8.1612 & 5482 & \\
\hline HEMBL397 & 64 & 8.6198 & 8.388 & \\
\hline HEMBL397 & 64 & 96 & 0542 & \\
\hline AEMBL395 & 54 & $\partial 8$ & 5442 & \\
\hline AEMBL39 & & & & \\
\hline HEMBL 393 & 54 & & 7.3233 & \\
\hline HEMBL390 & 54 & 86 & 93 & \\
\hline AEMBL394 & 04 & 65 & 7.7783 & \\
\hline HEMBL39 & 4 & 0 & 079 & \\
\hline HEMBL39 & & & 752 & \\
\hline HEMBL 395 & & & 7.541 & \\
\hline HEMBL 39 & 54 & & 47 & \\
\hline HEMBL3S & 6 & & .309 & t. \\
\hline HEMBL3S & 4 & & 2775 & 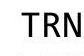 \\
\hline HEMBL3\& & & & 35 & \\
\hline HEMBL 393 & & 10.0 & & \\
\hline AEMBL39 & & & & 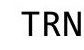 \\
\hline HEMBL3S & 62 & & 54 & I RN \\
\hline HEMBL & T & & 95 & RN \\
\hline HFMBI 36 & 54 & 6 & & \\
\hline HEMBL39 & & & 294 & TIV \\
\hline HEMBL 396 & & & & I RIV \\
\hline HEMBL3S & 62 & & 871 & RN \\
\hline HEMBL; & & & 96 & RN \\
\hline HEMBL & & 8 & 318 & s \\
\hline HEMBL390 & 62 & & 874 & IR \\
\hline HEMBL397. & & & 9.6251 & TRN \\
\hline HEMBL39 & & 29 & 354 & \\
\hline HFMRI 3 & 4 & & 85 & וכ \\
\hline HEMBL3 & & 872 & 7.8722 & RN \\
\hline HEMBL389 & 4 & & 7.7084 & $\Gamma \mathrm{RN}$ \\
\hline AEMBL39 & & & 161 & $\Gamma \mathrm{RN}$ \\
\hline HEMBL39 & $6<$ & 76 & 946 & \\
\hline CHEMBL39 & & & & IST \\
\hline HEMBL39 & 16 & 8.6198 & 9.0408 & $\Gamma \mathrm{RN}$ \\
\hline HEMBL 390 & 62 & 8.6576 & 3491 & TST \\
\hline $\mathrm{MBL}=$ & & & 8.3399 & 13 \\
\hline HEMBL 39 & & 3861 & 3.3509 & \\
\hline CHEMBL 39 & 164 & .1805 & 8.1794 & \\
\hline HEMBL3941524 & 1642464 & 10.0 & 9.6591 & ГRN \\
\hline
\end{tabular}

Page 25934 
Supplemental Table S2.txt

\begin{tabular}{|c|c|c|c|c|}
\hline 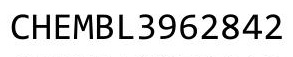 & & & & \\
\hline HEMBL3950019 & 542464 & 8.8239 & 93 & \\
\hline HEMBL3946324 & & 9.0 & 5676 & \\
\hline 35 & & 8.4685 & & \\
\hline IEMBL3 & 542464 & 8.1871 & 0733 & \\
\hline HEMBL3983625 & 642464 & 8.2076 & 9645 & \\
\hline HEMBL3974832 & 642464 & 7.9747 & 7.395 & \\
\hline HEMBL 391 & 642464 & 8.4815 & 9527 & \\
\hline IEMBL: & 642 & .2924 & 3413 & \\
\hline IEMBL 3C & 54 & 8.1249 & 8.1215 & \\
\hline HEMBL3978145 & 642464 & 8.6198 & 5554 & \\
\hline HEMBL3927141 & 642 & 8.4089 & 8.3926 & \\
\hline HEMBL 393 & 542 & .2218 & 3248 & \\
\hline HEMBL39 & 4 & 706 & .79 & \\
\hline HEMBL3S & 54 & 539 & 194 & \\
\hline HEMBL 390 & 54 & 8.4685 & 8448 & \\
\hline HEMBL3907616 & 54 & 8.2291 & 8.4246 & \\
\hline HEMBL 39 & 4 & 696 & 08 & \\
\hline HEMBL38 & & 949 & & \\
\hline HEMBL3S & 54 & 376 & & \\
\hline HEMBL 393 & 54 & 6.0 & & \\
\hline HEMBL398 & 4 & 8.2441 & 503 & \\
\hline HEMBL39 & 64 & 8.5528 & 195 & \\
\hline HEMBL3S & & 18 & & \\
\hline HEMBL & 54 & 576 & & \\
\hline HEMBL 39 & 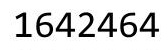 & 086 & & \\
\hline HEMBL391 & 44 & 8.1487 & 38 & RN \\
\hline HEMBL3S & 64 & 861 & 29 & \\
\hline HEM & 4 & 957 & & ST \\
\hline HEME & 54 & 6 . & & RN \\
\hline HEMBL 396 & 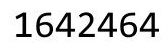 & 8 . & & RN \\
\hline HEMBL 394 & 642 & 8.5086 & 588 & RN \\
\hline HEMBL 39 & 64 & 413 & & 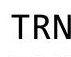 \\
\hline 2 & 4 & 38 & 79 & RN \\
\hline HEMBL39 & 64 & 212 & 8.5471 & RN \\
\hline HEMBL 390 & 64 & 8.5376 & & RN \\
\hline HEMBL3961491 & 64 & 8.5086 & 106 & RN \\
\hline HEMBL 39 & 6 & 366 & 34 & ווכ \\
\hline 0 & & 39 & & RN \\
\hline HEMBL3S & & 8.4202 & 7.977 & RN \\
\hline HEMBL 389 & 642 & 8.6198 & 645 & ST \\
\hline HEMBL3 3 & U. & 024 & 763 & $\mathrm{RN}$ \\
\hline HEMBL396 & & .2218 & 2331 & \\
\hline CHEMBL 391 & & 8.1805 & 3.2606 & RN \\
\hline HEMBL3962810 & 1642464 & 8.3872 & 8.7152 & ST \\
\hline HEMBL 398 & 1642 & 8.301 & .5067 & RN \\
\hline HEM & & .0088 & & \\
\hline & & & & \\
\hline
\end{tabular}

Page 25935 
Supplemental Table S2.txt

\begin{tabular}{|c|c|c|c|c|}
\hline CHEMBL3900859 & 1642464 & 10.0 & 8.0665 & TST \\
\hline CHEMBL 3889917 & 1642464 & 10.0 & 9.571 & TRN \\
\hline CHEMBL3924974 & 1642464 & 10.0 & 8.4473 & TST \\
\hline CHEMBL 3947054 & 1642464 & 8.2218 & 8.1753 & TRN \\
\hline CHEMBL 3986204 & 1642464 & 8.5376 & 8.3996 & TRN \\
\hline CHEMBL 3915978 & 1642464 & 8.7212 & 8.4617 & TST \\
\hline CHEMBL3985969 & 1642464 & 8.3372 & 8.0949 & TRN \\
\hline CHEMBL3923328 & 1642464 & 7.9508 & 7.4483 & TST \\
\hline CHEMBL3973572 & 1642464 & 8.3872 & 8.4077 & TRN \\
\hline CHEMBL 3984844 & 1642464 & 8.4318 & 8.0604 & TRN \\
\hline CHEMBL 3940873 & 1642464 & 8.1612 & 8.2131 & TRN \\
\hline CHEMBL 3978665 & 1642464 & 7.9626 & 7.7994 & TRN \\
\hline CHEMBL 3960429 & 1642464 & 7.4841 & 7.3566 & TRN \\
\hline CHEMBL3949810 & 1642464 & 8.8861 & 8.8495 & TRN \\
\hline CHEMBL 3969040 & 1642464 & 8.6021 & 8.0792 & TRN \\
\hline CHEMBL3963301 & 1642464 & 7.1451 & 7.4654 & TRN \\
\hline CHEMBL3941882 & 1642464 & 8.3372 & 8.0818 & TRN \\
\hline CHEMBL 3895739 & 1642464 & 6.0 & 7.58 & TRN \\
\hline CHEMBL 3976168 & 1642464 & 8.7959 & 8.7238 & TST \\
\hline CHEMBL 3891848 & 1642464 & 9.0 & 8.7441 & TRN \\
\hline CHEMBL3978704 & 1642464 & 10.0 & 9.5239 & TRN \\
\hline CHEMBL 3968285 & 1642464 & 8.6576 & 8.3104 & TRN \\
\hline CHEMBL 3945432 & 1642464 & 8.7696 & 7.2365 & TST \\
\hline CHEMBL 3950313 & 1642464 & 7.7959 & 8.2843 & TST \\
\hline CHEMBL 3935345 & 1642464 & 8.1487 & 8.8222 & TRN \\
\hline CHEMBL 3898508 & 1642464 & 8.6576 & 8.2902 & TRN \\
\hline CHEMBL 3978867 & 1642464 & 8.0915 & 8.4897 & TRN \\
\hline CHEMBL 3928751 & 1642464 & 8.3372 & 7.6857 & TST \\
\hline CHEMBL3979591 & 1642464 & 10.0 & 9.9566 & TRN \\
\hline CHEMBL 3896916 & 1642464 & 8.2441 & 8.2916 & TRN \\
\hline CHEMBL3928282 & 1642464 & 8.4089 & 8.8108 & TST \\
\hline CHEMBL 3980881 & 1642464 & 8.1192 & 7.5095 & TRN \\
\hline CHEMBL3915713 & 1642464 & 8.301 & 8.3192 & TRN \\
\hline CHEMBL3955896 & 1642464 & 8.6021 & 8.2891 & TRN \\
\hline CHEMBL3917656 & 1642464 & 7.3872 & 7.1168 & TST \\
\hline CHEMBL3939530 & 1642464 & 8.2757 & 7.718 & TRN \\
\hline CHEMBL 3923288 & 1642464 & 8.3468 & 8.4395 & TRN \\
\hline CHEMBL3929079 & 1642464 & 8.7212 & 8.5959 & TST \\
\hline CHEMBL3975702 & 1642464 & 8.2757 & 8.0933 & TRN \\
\hline CHEMBL 3924962 & 1642464 & 8.6576 & 8.1684 & TRN \\
\hline CHEMBL3902163 & 1642464 & 7.6615 & 8.469 & TST \\
\hline CHEMBL 3941581 & 1642464 & 8.1367 & 8.398 & TST \\
\hline CHEMBL 3937455 & 1642464 & 8.9208 & 8.2057 & TST \\
\hline CHEMBL3965799 & 1642464 & 8.2596 & 7.8881 & TRN \\
\hline CHEMBL1331239 & 688646 & 2.301 & 3.7811 & TST \\
\hline CHEMBL1383137 & 688646 & 2.301 & 2.9996 & TRN \\
\hline CHEMBL 397100 & 688646 & 2.301 & 2.3614 & TRN \\
\hline \multirow[t]{2}{*}{ CHEMBL1437208 } & 688646 & 3.8233 & 3.95899 & 9999999996 \\
\hline & & \multicolumn{3}{|c|}{ Page 25936} \\
\hline
\end{tabular}




\begin{tabular}{|c|c|c|c|c|c|}
\hline \multirow[b]{2}{*}{ CHEMBL1393925 } & \multicolumn{5}{|c|}{ Supplemental Table S2.txt } \\
\hline & 688646 & 2.301 & 2.2765 & TRN & \\
\hline CHEMBL1589702 & 688646 & 3.6218 & \multicolumn{2}{|c|}{2.0269999999999997} & TRN \\
\hline CHEMBL1330429 & 688646 & 2.301 & 2.254 & TRN & \\
\hline CHEMBL1487309 & 688646 & \multicolumn{3}{|c|}{4.968999999999999} & TRN \\
\hline CHEMBL1565485 & 688646 & 1.8697 & \multicolumn{2}{|c|}{3.0010000000000003} & TRN \\
\hline CHEMBL1449558 & 688646 & 2.301 & 3.0545 & TRN & \\
\hline CHEMBL1567814 & 688646 & 5.0161 & 3.8578 & TRN & \\
\hline CHEMBL1429121 & 688646 & 2.301 & 2.7426 & TRN & \\
\hline CHEMBL1380929 & 688646 & 3.2518 & 3.2227 & TRN & \\
\hline CHEMBL1369724 & 688646 & 5.0358 & 3.0181 & TRN & \\
\hline CHEMBL1351184 & 688646 & 5.3629 & 4.1866 & TRN & \\
\hline CHEMBL1341100 & 688646 & 2.301 & 2.1912 & TRN & \\
\hline CHEMBL1389601 & 688646 & 2.301 & 2.4699 & TRN & \\
\hline CHEMBL1415312 & 688646 & 2.301 & 2.5022 & TRN & \\
\hline CHEMBL1394006 & 688646 & 2.301 & 2.0165 & TRN & \\
\hline CHEMBL1544494 & 688646 & 2.301 & \multicolumn{2}{|c|}{2.8539999999999996} & TRN \\
\hline CHEMBL1333583 & 688646 & 2.301 & 3.633 & TRN & \\
\hline CHEMBL1589740 & 688646 & 2.301 & 2.1559 & TRN & \\
\hline CHEMBL1587193 & 688646 & 2.301 & 2.9506 & TRN & \\
\hline CHEMBL1533974 & 688646 & 2.301 & 2.8157 & TRN & \\
\hline CHEMBL1511808 & 688646 & 2.301 & 2.2478 & TRN & \\
\hline CHEMBL1240975 & 688646 & 2.301 & 3.1523 & TRN & \\
\hline CHEMBL1358236 & 688646 & 4.5948 & 3.6887 & TRN & \\
\hline CHEMBL1471371 & 688646 & 2.301 & 2.2099 & TRN & \\
\hline CHEMBL1478693 & 688646 & 4.5809 & 4.0538 & TRN & \\
\hline CHEMBL1407961 & 688646 & 4.7821 & 3.9896 & TRN & \\
\hline CHEMBL1302315 & 688646 & 2.301 & 3.4548 & TRN & \\
\hline CHEMBL1368435 & 688646 & 2.301 & 2.9519 & TRN & \\
\hline CHEMBL1530048 & 688646 & 4.2651 & 3.9924 & TRN & \\
\hline CHEMBL1528266 & 688646 & 2.301 & 3.4083 & TRN & \\
\hline CHEMBL1610002 & 688646 & 4.4754 & 2.8698 & TRN & \\
\hline CHEMBL1433309 & 688646 & 2.301 & 1.8487 & TRN & \\
\hline CHEMBL1472548 & 688646 & 2.301 & 2.3061 & TRN & \\
\hline CHEMBL1447853 & 688646 & 2.301 & 3.7932 & TRN & \\
\hline CHEMBL1488460 & 688646 & 5.2668 & 3.5764 & TRN & \\
\hline CHEMBL1450241 & 688646 & 2.301 & 3.0776 & TRN & \\
\hline CHEMBL 1475828 & 688646 & 2.301 & 2.2158 & TRN & \\
\hline CHEMBL1565280 & 688646 & 2.301 & 3.2056 & TRN & \\
\hline CHEMBL1314004 & 688646 & 2.301 & 2.0201 & TRN & \\
\hline CHEMBL1305704 & 688646 & 2.301 & 3.6106 & TRN & \\
\hline CHEMBL1555362 & 688646 & 5.0228 & 4.0967 & TRN & \\
\hline CHEMBL1327366 & 688646 & 2.301 & 3.1763 & TRN & \\
\hline CHEMBL1371202 & 688646 & 2.301 & 2.51800 & 00000000002 & TRN \\
\hline CHEMBL1393959 & 688646 & 6.3958 & 3.2564 & TST & \\
\hline CHEMBL1414059 & 688646 & 5.0027 & 3.5535 & TST & \\
\hline CHEMBL1394162 & 688646 & 2.301 & 2.4149 & TST & \\
\hline CHEMBL1332241 & 688646 & 2.585 & 3.1156 & TST & \\
\hline CHEMBL1606526 & 688646 & 3.9153 & 2.4953 & TST & \\
\hline
\end{tabular}




\begin{tabular}{|c|c|c|c|c|c|c|}
\hline \multirow[b]{2}{*}{ CHEMBL1343073 } & \multirow[b]{2}{*}{688646} & \multicolumn{5}{|c|}{ Supplemental Table S2.txt } \\
\hline & & 2.301 & 3.4242 & TST & & \\
\hline CHEMBL1591750 & 688646 & 2.301 & 2.4954 & TST & & \\
\hline CHEMBL1528869 & 688646 & 2.301 & 2.5985 & TST & & \\
\hline CHEMBL 3196125 & 688646 & 2.301 & 2.6078 & TST & & \\
\hline CHEMBL1336879 & 688646 & 2.301 & 3.0899 & TST & & \\
\hline CHEMBL1527478 & 688646 & 2.301 & 3.6662 & TST & & \\
\hline CHEMBL1555435 & 688646 & 2.301 & 2.8153 & TST & & \\
\hline CHEMBL1338958 & 688646 & 4.4747 & 3.5438 & TST & & \\
\hline CHEMBL1422105 & 688646 & 5.3645 & 3.3383 & TST & & \\
\hline CHEMBL1318434 & 688646 & 2.301 & 2.104 & TST & & \\
\hline CHEMBL3823386 & 1587722 & 10.1549 & 10.2978 & TRN & & \\
\hline CHEMBL 3824360 & 1587722 & 10.6990 & 000000000 & 002 & 10.2197 & TRN \\
\hline CHEMBL 3824302 & 1587722 & 10.0969 & 10.3922 & TRN & & \\
\hline CHEMBL 3822915 & 1587722 & 10.1549 & 9.8332 & TST & & \\
\hline CHEMBL3823487 & 1587722 & 10.0 & 9.7129 & TRN & & \\
\hline CHEMBL3823339 & 1587722 & 9.0 & 9.308 & TRN & & \\
\hline CHEMBL3823996 & 1587722 & 9.0 & 9.4377 & TST & & \\
\hline CHEMBL 3823778 & 1587722 & 10.5229 & 10.4668 & TRN & & \\
\hline CHEMBL 3823406 & 1587722 & 10.69906 & 000000000 & 002 & 10.18 & TRN \\
\hline CHEMBL 3823959 & 1587722 & 9.5686 & 9.9792 & TRN & & \\
\hline CHEMBL3822820 & 1587722 & 10.6990 & 000000000 & 002 & 10.7666 & TRN \\
\hline CHEMBL 3823137 & 1587722 & 9.699 & 9.8635 & TRN & & \\
\hline CHEMBL 3824320 & 1587722 & 10.3979 & 10.2202 & TRN & & \\
\hline CHEMBL 3824299 & 1587722 & 9.301 & 9.6302 & TRN & & \\
\hline CHEMBL 3824128 & 1587722 & 10.0969 & 9.6716 & TRN & & \\
\hline CHEMBL3822855 & 1587722 & 10.6990 & 000000000 & 002 & 10.626 & TRN \\
\hline CHEMBL 3824254 & 1587722 & 9.699 & 9.3326 & TRN & & \\
\hline CHEMBL 3822783 & 1587722 & 9.0458 & 8.6526 & TRN & & \\
\hline CHEMBL 3824117 & 1587722 & 9.699 & 9.7972 & TRN & & \\
\hline CHEMBL 3822665 & 1587722 & 10.3009 & 999999999 & 998 & 10.3768 & TRN \\
\hline CHEMBL3823005 & 1587722 & 9.9208 & 9.8551 & TST & & \\
\hline CHEMBL 3824242 & 1587722 & 9.0969 & 9.4619 & TRN & & \\
\hline CHEMBL 3822731 & 1587722 & 9.5229 & 9.8983 & TRN & & \\
\hline CHEMBL 3823374 & 1587722 & 10.0969 & 9.7748 & TRN & & \\
\hline CHEMBL 3823433 & 1587722 & 11.0 & 10.4785 & TRN & & \\
\hline CHEMBL 3824211 & 1587722 & 8.699 & 9.4496 & TRN & & \\
\hline CHEMBL 3822649 & 1587722 & 10.0969 & 10.2106 & TRN & & \\
\hline CHEMBL3824167 & 1587722 & 10.1549 & 10.4785 & TRN & & \\
\hline CHEMBL 3823963 & 1587722 & 9.6021 & 9.4525 & TRN & & \\
\hline CHEMBL 3823304 & 1587722 & 9.699 & 9.6795 & TRN & & \\
\hline CHEMBL3822639 & 1587722 & 10.6990 & 000000000 & 002 & 10.4524 & TRN \\
\hline CHEMBL 3823508 & 1587722 & 10.6990 & j0000000e & 002 & 10.6619 & TRN \\
\hline CHEMBL3822922 & 1587722 & 10.2218 & 10.1425 & TRN & & \\
\hline CHEMBL 3823713 & 1587722 & 9.699 & 9.7192 & TRN & & \\
\hline CHEMBL 3823064 & 1587722 & 10.3979 & 10.296 & TRN & & \\
\hline CHEMBL3823763 & 1587722 & 8.0 & 8.1005 & TRN & & \\
\hline CHEMBL 3822590 & 1587722 & 10.5229 & 10.3626 & TRN & & \\
\hline CHEMBL 3823595 & 1587722 & 10.0458 & 10.2059 & TRN & & \\
\hline
\end{tabular}




\begin{tabular}{|c|c|c|c|c|c|c|}
\hline \multicolumn{7}{|c|}{ Supplemental Table S2.txt } \\
\hline CHEMBL 3823673 & 1587722 & 10.0 & 10.6619 & TRN & & \\
\hline CHEMBL3824025 & 1587722 & 10.5229 & 10.0697 & TRN & & \\
\hline CHEMBL 3824348 & 1587722 & 9.699 & 9.7652 & TST & & \\
\hline CHEMBL 3823462 & 1587722 & 9.3979 & 9.674 & TST & & \\
\hline CHEMBL3823011 & 1587722 & 10.0 & 10.1051 & TRN & & \\
\hline CHEMBL3822708 & 1587722 & 9.699 & 10.0496 & TST & & \\
\hline CHEMBL 3823348 & 1587722 & 8.0 & 8.8851 & TST & & \\
\hline CHEMBL 3823534 & 1587722 & 10.5229 & 10.2519 & TST & & \\
\hline CHEMBL 3822868 & 1587722 & 10.5229 & 10.1403 & TST & & \\
\hline CHEMBL 3823143 & 1587722 & 10.3979 & 10.1358 & TST & & \\
\hline CHEMBL 3823065 & 1587722 & 8.699 & 9.9882 & TST & & \\
\hline CHEMBL 3823477 & 1587722 & 9.699 & 10.6792 & TST & & \\
\hline CHEMBL3823298 & 1587722 & 6.5376 & 8.5153 & TST & & \\
\hline CHEMBL3706814 & 326140 & 7.2716 & 7.4693 & TRN & & \\
\hline CHEMBL 2113174 & 326140 & 6.2517 & 5.968 & TRN & & \\
\hline CHEMBL 2113170 & 326140 & 5.0 & 5.8379 & TST & & \\
\hline CHEMBL 2113188 & 326140 & 7.2411 & 7.1549 & TRN & & \\
\hline CHEMBL3706822 & 326140 & 6.4249 & 6.6479 & TRN & & \\
\hline CHEMBL 2113190 & 326140 & 5.0 & 5.3768 & TRN & & \\
\hline CHEMBL 2113182 & 326140 & 6.6212 & 6.593 & TRN & & \\
\hline CHEMBL242555 & 326140 & 6.4364 & 6.3199 & TRN & & \\
\hline CHEMBL3706825 & 326140 & 5.0 & 5.4298 & TRN & & \\
\hline CHEMBL 2113193 & 326140 & 8.1308 & 8.4492 & TRN & & \\
\hline CHEMBL 2113163 & 326140 & 7.857 & 8.0537 & TRN & & \\
\hline CHEMBL3706841 & 326140 & 8.0044 & 7.9652 & TRN & & \\
\hline CHEMBL 2113192 & 326140 & 7.3872 & 7.5378 & TRN & & \\
\hline CHEMBL3706835 & 326140 & 7.4881 & 7.6236 & TRN & & \\
\hline CHEMBL3706837 & 326140 & 7.7825 & 7.885 & TRN & & \\
\hline CHEMBL396472 & 326140 & 6.5913 & 6.5482 & TRN & & \\
\hline CHEMBL3706817 & 326140 & 8.3188 & 8.15 & TRN & & \\
\hline CHEMBL 2113184 & 326140 & 8.2366 & 7.5092 & TST & & \\
\hline CHEMBL 2113172 & 326140 & 8.2924 & 8.061 & TRN & & \\
\hline CHEMBL 2113199 & 326140 & 8.6576 & 8.1108 & TRN & & \\
\hline CHEMBL 2113171 & 326140 & 8.5229 & 8.7673 & TRN & & \\
\hline CHEMBL 2113176 & 326140 & 5.0 & 5.0727 & TRN & & \\
\hline CHEMBL3706818 & 326140 & 5.0 & 5.2281 & TRN & & \\
\hline CHEMBL 3706824 & 326140 & 5.0 & 4.731 & TRN & & \\
\hline CHEMBL3706834 & 326140 & 7.5421 & 6.6144 & TRN & & \\
\hline CHEMBL3706836 & 326140 & 7.8633 & 7.5907 & TRN & & \\
\hline CHEMBL 200723 & 326140 & 6.8864 & 7.0105 & TST & & \\
\hline CHEMBL3706819 & 326140 & 6.9289 & 7.0919 & TRN & & \\
\hline CHEMBL 2113175 & 326140 & 7.6055 & 7.4604 & TRN & & \\
\hline CHEMBL3706839 & 326140 & 7.224 & 6.0165 & TST & & \\
\hline CHEMBL3706826 & 326140 & 8.4318 & 8.8156 & TST & & \\
\hline CHEMBL2113186 & 326140 & 5.0 & 4.6034 & TRN & & \\
\hline CHEMBL3706816 & 326140 & 8.283999 & 999999999 & 99 & 8.2849 & TRN \\
\hline CHEMBL3706815 & 326140 & 7.5287 & 7.6317 & TRN & & \\
\hline CHEMBL3706832 & 326140 & 7.0119 & 6.6741 & TRN & & \\
\hline
\end{tabular}

Page 25939 


\begin{tabular}{|c|c|c|c|c|c|}
\hline \multirow[b]{2}{*}{ CHEMBL3706842 } & \multicolumn{5}{|c|}{ Supplemental Table S2.txt } \\
\hline & 326140 & 8.7212 & 8.9948 & TRN & \\
\hline CHEMBL3706820 & 326140 & 5.0 & 5.2772 & TST & \\
\hline CHEMBL200387 & 326140 & 5.0 & 4.8752 & TRN & \\
\hline CHEMBL3706829 & 326140 & 6.0952 & 6.2868 & TRN & \\
\hline CHEMBL199455 & 326140 & 6.7997 & 6.7102 & TRN & \\
\hline CHEMBL2113173 & 326140 & 5.0 & 5.8787 & TST & \\
\hline CHEMBL 3706828 & 326140 & 5.0 & 5.1681 & TST & \\
\hline CHEMBL2113169 & 326140 & 5.0 & 5.3679 & TRN & \\
\hline CHEMBL200818 & 326140 & 5.0 & 5.7438 & TST & \\
\hline CHEMBL3706840 & 326140 & 6.3052 & 6.9031 & TRN & \\
\hline CHEMBL3706838 & 326140 & 5.0 & 4.8394 & TRN & \\
\hline CHEMBL3706830 & 326140 & 6.9404 & 6.1577 & TRN & \\
\hline CHEMBL3706843 & 326140 & 7.5834 & 7.6417 & TST & \\
\hline CHEMBL 2113167 & 326140 & 3.699 & 4.3753 & TRN & \\
\hline CHEMBL2113166 & 326140 & 6.2448 & 5.6794 & TST & \\
\hline CHEMBL 2113191 & 326140 & 6.7133 & 7.0125 & TST & \\
\hline CHEMBL2113164 & 326140 & 8.6198 & 8.5223 & TST & \\
\hline CHEMBL2113165 & 326140 & 5.0 & 5.8893 & TST & \\
\hline CHEMBL3901791 & 1641112 & 6.0 & 6.1319 & TRN & \\
\hline CHEMBL3942172 & 1641112 & 6.0 & 6.1444 & TST & \\
\hline CHEMBL3978229 & 1641112 & 6.301 & 6.4144 & TRN & \\
\hline CHEMBL3956451 & 1641112 & 6.301 & 5.1586 & TRN & \\
\hline CHEMBL3985067 & 1641112 & 6.0 & 6.2932 & TST & \\
\hline CHEMBL3984066 & 1641112 & 7.0 & 6.2865 & TRN & \\
\hline CHEMBL3937833 & 1641112 & 5.301 & 4.6205 & TRN & \\
\hline CHEMBL3935171 & 1641112 & 5.0 & 5.356 & TRN & \\
\hline CHEMBL3913646 & 1641112 & 4.0 & 4.6659 & TST & \\
\hline CHEMBL3950772 & 1641112 & 5.301 & 5.2641 & TRN & \\
\hline CHEMBL3924821 & 1641112 & 7.0 & 7.2621 & TRN & \\
\hline CHEMBL 3964204 & 1641112 & 4.0 & 4.5594 & TRN & \\
\hline CHEMBL3944246 & 1641112 & 7.0 & 6.9028 & TRN & \\
\hline CHEMBL3892920 & 1641112 & 5.5229 & 6.1302 & TRN & \\
\hline CHEMBL3967788 & 1641112 & 7.0 & 6.17899 & 9999999999 & TRN \\
\hline CHEMBL3945904 & 1641112 & 7.0 & 6.807 & TRN & \\
\hline CHEMBL3971346 & 1641112 & 6.0 & 6.5232 & TST & \\
\hline CHEMBL3955077 & 1641112 & 7.0 & 6.8423 & TRN & \\
\hline CHEMBL1085865 & 1641112 & 7.0 & 6.3167 & TST & \\
\hline CHEMBL3971951 & 1641112 & 4.0 & 4.5904 & TRN & \\
\hline CHEMBL3933366 & 1641112 & 4.0 & 4.4528 & TRN & \\
\hline CHEMBL3946395 & 1641112 & 7.0 & 7.3285 & TRN & \\
\hline CHEMBL3918086 & 1641112 & 3.5229 & 4.8185 & TST & \\
\hline CHEMBL3923960 & 1641112 & 7.0 & 6.9807 & TRN & \\
\hline CHEMBL3954508 & 1641112 & 4.0 & 3.58699 & 99999999997 & TRN \\
\hline CHEMBL3936726 & 1641112 & 7.0 & 5.9669 & TRN & \\
\hline CHEMBL3935036 & 1641112 & 7.0 & 6.8848 & TRN & \\
\hline CHEMBL3960864 & 1641112 & 6.5229 & 6.6555 & TST & \\
\hline CHEMBL3968594 & 1641112 & 6.0 & 6.0824 & TST & \\
\hline CHEMBL3890679 & 1641112 & 4.0 & 4.5416 & TRN & \\
\hline
\end{tabular}




\begin{tabular}{|c|c|c|c|c|}
\hline \multicolumn{5}{|c|}{ Supplemental Table S2.txt } \\
\hline CHEMBL3897934 & 1641112 & 4.0 & 5.5994 & TST \\
\hline CHEMBL3910828 & 1641112 & 6.0 & 6.1206 & TRN \\
\hline CHEMBL3907034 & 1641112 & 6.0 & 4.3687 & TST \\
\hline CHEMBL3983222 & 1641112 & 6.0 & 5.8124 & TRN \\
\hline CHEMBL3937620 & 1641112 & 5.0 & 5.0807 & TRN \\
\hline CHEMBL3901306 & 1641112 & 7.0 & 6.2531 & TRN \\
\hline CHEMBL 3947156 & 1641112 & 7.0 & 6.591 & TRN \\
\hline CHEMBL3896321 & 1641112 & 4.0 & 4.4329 & TRN \\
\hline CHEMBL 3932902 & 1641112 & 6.0 & 5.9651 & TRN \\
\hline CHEMBL3919373 & 1641112 & 7.0 & 6.7491 & TRN \\
\hline CHEMBL 3923042 & 1641112 & 6.0 & 5.55399 & 9999999999 \\
\hline CHEMBL 3984145 & 1641112 & 3.6021 & 3.679 & TRN \\
\hline CHEMBL3941771 & 1641112 & 6.0 & 6.1724 & TRN \\
\hline CHEMBL 3984632 & 1641112 & 7.0 & 7.0731 & TRN \\
\hline CHEMBL3959488 & 1641112 & 6.301 & 6.5662 & TRN \\
\hline CHEMBL3985587 & 1641112 & 8.0 & 7.4309 & TRN \\
\hline CHEMBL3898805 & 1641112 & 5.0 & 4.9179 & TRN \\
\hline CHEMBL3942908 & 1641112 & 5.0 & 4.7191 & TRN \\
\hline CHEMBL 3955535 & 1641112 & 7.0 & 6.9795 & TRN \\
\hline CHEMBL3931486 & 1641112 & 5.0 & 4.3313 & TST \\
\hline CHEMBL3901203 & 1641112 & 5.0 & 4.6694 & TST \\
\hline CHEMBL3958923 & 1641112 & 5.0 & 5.0241 & TRN \\
\hline CHEMBL 3941637 & 1641112 & 6.5229 & 6.5386 & TST \\
\hline CHEMBL3956920 & 1641112 & 5.0 & 5.5369 & TRN \\
\hline CHEMBL3895632 & 1641112 & 6.0 & 6.3569 & TST \\
\hline CHEMBL3899480 & 1641112 & 5.301 & 4.8899 & TRN \\
\hline CHEMBL3799591 & 1641112 & 7.0 & 5.0734 & TST \\
\hline CHEMBL3986121 & 1641112 & 7.0 & 6.7949 & TST \\
\hline CHEMBL 3972863 & 1641112 & 5.0 & 5.455 & TRN \\
\hline CHEMBL3916829 & 1641112 & 5.0 & 5.0146 & TRN \\
\hline CHEMBL3914232 & 1641112 & 6.301 & 6.0376 & TRN \\
\hline CHEMBL3965719 & 1641112 & 7.0 & 6.8197 & TRN \\
\hline CHEMBL3975152 & 1641112 & 4.0 & 4.4713 & TRN \\
\hline CHEMBL 3890141 & 1641112 & 7.0 & 6.7601 & TRN \\
\hline CHEMBL3925287 & 1641112 & 7.0 & 6.4183 & TRN \\
\hline CHEMBL3956325 & 1641112 & 7.0 & 7.4956 & TRN \\
\hline CHEMBL3925046 & 1641112 & 6.0 & 6.2658 & TRN \\
\hline CHEMBL 3932444 & 1641112 & 6.301 & 5.9465 & TRN \\
\hline CHEMBL 3900839 & 1641112 & 5.5229 & 5.3071 & TST \\
\hline CHEMBL3963809 & 1641112 & 6.0 & 6.5347 & TST \\
\hline CHEMBL3938560 & 1641112 & 5.5229 & 6.1324 & TRN \\
\hline CHEMBL3918520 & 1641112 & 7.0 & 7.0945 & TRN \\
\hline CHEMBL3934206 & 1641112 & 4.0 & 4.2004 & TRN \\
\hline CHEMBL3961339 & 1641112 & 7.0 & 7.6513 & TRN \\
\hline CHEMBL3928757 & 1641112 & 7.0 & 7.0367 & TRN \\
\hline CHEMBL3971466 & 1641112 & 7.0 & 7.0783 & TRN \\
\hline CHEMBL3975614 & 1641112 & 7.0 & 6.9654 & TRN \\
\hline CHEMBL 3967327 & 1641112 & 7.0 & 7.595 & TST \\
\hline
\end{tabular}




\begin{tabular}{|c|c|c|c|c|c|}
\hline & & & & & \\
\hline CHEMBL3981477 & 1641112 & 7.0 & 7.4854 & TRN & \\
\hline CHEMBL3966504 & 1641112 & 7.0 & 7.5139 & TRN & \\
\hline CHEMBL 3984770 & 1641112 & 5.0 & 4.9722 & TRN & \\
\hline CHEMBL 3919856 & 1641112 & 7.0 & 7.2272 & TST & \\
\hline CHEMBL1258479 & 665404 & 7.7959 & 7.9033 & TRN & \\
\hline CHEMBL1258367 & 665404 & 9.0458 & 9.0646 & TRN & \\
\hline CHEMBL1258137 & 665404 & 8.0915 & 8.0558 & TRN & \\
\hline CHEMBL1257668 & 665404 & 8.3979 & 8.3023 & TRN & \\
\hline CHEMBL1257318 & 665404 & 7.7212 & 7.6507 & TRN & \\
\hline CHEMBL1257548 & 665404 & 8.7696 & 8.773 & TRN & \\
\hline CHEMBL102718 & 665404 & 7.8761 & 7.1132 & TST & \\
\hline CHEMBL1258594 & 665404 & 6.3468 & 7.2875 & TST & \\
\hline CHEMBL1258018 & 665404 & 8.0605 & 7.9888 & TRN & \\
\hline CHEMBL1258365 & 665404 & 7.9208 & 7.9446 & TRN & \\
\hline CHEMBL1257791 & 665404 & 8.5086 & 8.5102 & TRN & \\
\hline CHEMBL1258590 & 665404 & 8.4949 & 8.5779 & TRN & \\
\hline CHEMBL1258819 & 665404 & 7.7212 & 7.82100 & 0000000001 & TRN \\
\hline CHEMBL1258591 & 665404 & 8.5686 & 8.5661 & TRN & \\
\hline CHEMBL1258138 & 665404 & 7.9586 & 8.0134 & TRN & \\
\hline CHEMBL1257908 & 665404 & 7.9586 & 8.0244 & TRN & \\
\hline CHEMBL1258020 & 665404 & 8.3279 & 8.3256 & TRN & \\
\hline CHEMBL1257667 & 665404 & 6.4949 & 6.4852 & TRN & \\
\hline CHEMBL1258254 & 665404 & 9.2218 & 9.3725 & TRN & \\
\hline CHEMBL1258366 & 665404 & 8.0506 & 8.0201 & TRN & \\
\hline CHEMBL1258935 & 665404 & 8.7959 & 8.7576 & TRN & \\
\hline CHEMBL 1257666 & 665404 & 6.6198 & 6.5952 & TRN & \\
\hline CHEMBL1258368 & 665404 & 8.4815 & 8.4629 & TRN & \\
\hline CHEMBL1257906 & 665404 & 7.1192 & 7.0846 & TRN & \\
\hline CHEMBL1257789 & 665404 & 6.9586 & 6.9712 & TRN & \\
\hline CHEMBL1257909 & 665404 & 8.9586 & 8.6972 & TRN & \\
\hline CHEMBL 1258820 & 665404 & 8.6576 & 8.5587 & TRN & \\
\hline CHEMBL1258592 & 665404 & 7.0362 & 7.3971 & TST & \\
\hline CHEMBL1258251 & 665404 & 7.6198 & 7.609 & TRN & \\
\hline CHEMBL1258252 & 665404 & 7.3565 & 7.319 & TRN & \\
\hline CHEMBL1257433 & 665404 & 7.9586 & 8.0437 & TRN & \\
\hline CHEMBL1258699 & 665404 & 8.8861 & 8.8963 & TRN & \\
\hline CHEMBL1258019 & 665404 & 8.3098 & 8.42799 & 9999999999 & TRN \\
\hline CHEMBL1257547 & 665404 & 7.699 & 7.6618 & TRN & \\
\hline CHEMBL1258593 & 665404 & 6.2218 & 6.7935 & TST & \\
\hline CHEMBL1258936 & 665404 & 8.6383 & 8.5527 & TRN & \\
\hline CHEMBL1257319 & 665404 & 7.8539 & 7.9695 & TRN & \\
\hline CHEMBL1257907 & 665404 & 7.3372 & 7.3347 & TRN & \\
\hline CHEMBL1257792 & 665404 & 8.3468 & 8.4179 & TRN & \\
\hline CHEMBL1257790 & 665404 & 7.2291 & 7.2494 & TRN & \\
\hline CHEMBL1258253 & 665404 & 9.301 & 9.1739 & TRN & \\
\hline CHEMBL1258481 & 665404 & 8.1739 & 8.4145 & TST & \\
\hline CHEMBL1258139 & 665404 & 8.8539 & 8.9041 & TRN & \\
\hline CHEMBL1258017 & 665404 & 7.1024 & 7.1057 & TRN & \\
\hline
\end{tabular}

Page 25942 


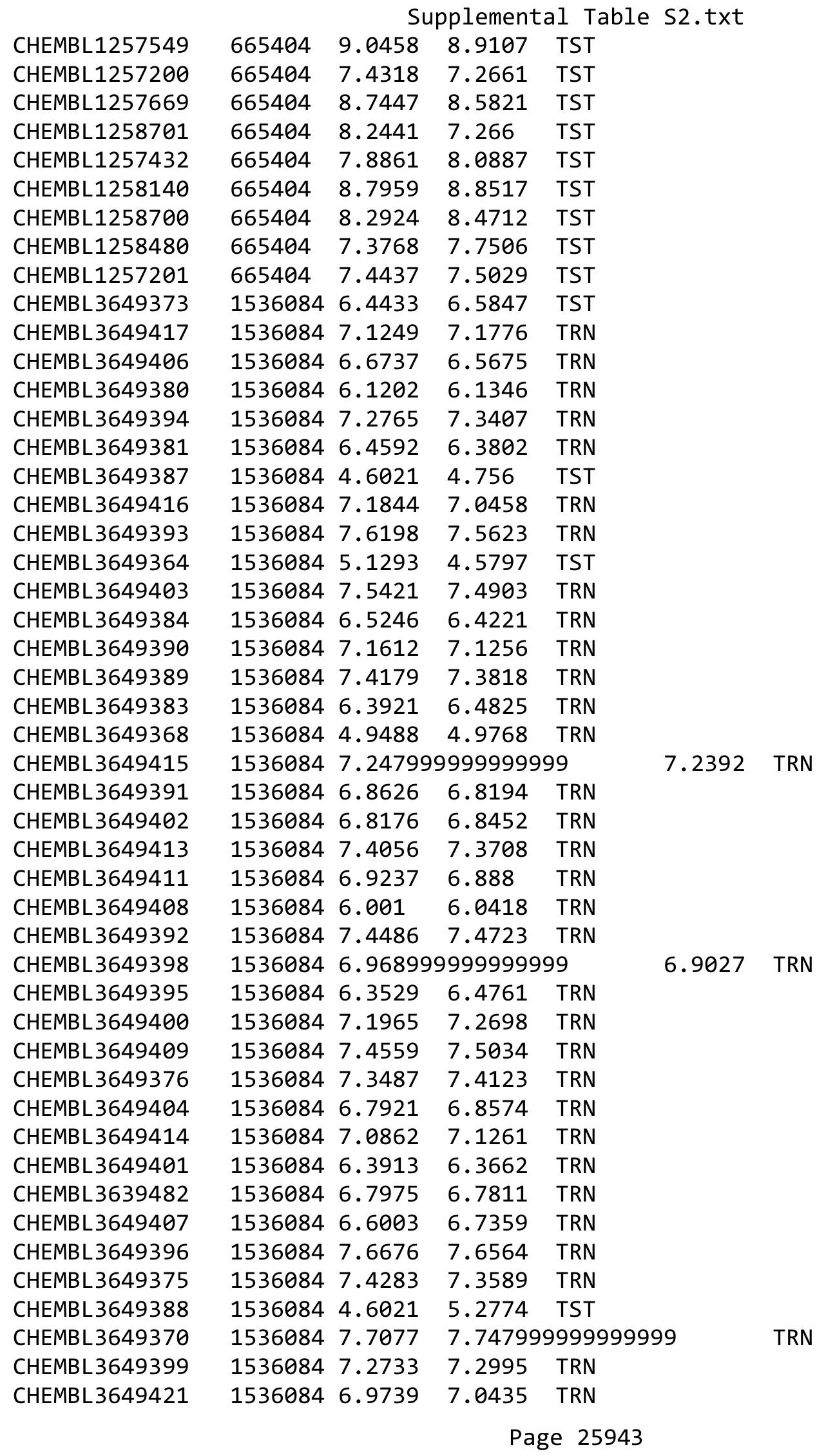


Supplemental Table S2.txt

\begin{tabular}{|c|c|c|c|c|c|}
\hline CHEMBL 3649366 & 1536084 & 4.6021 & 3.57 & TST & \\
\hline CHEMBL 3649405 & 1536084 & 7.0372 & 6.9796 & TRN & \\
\hline CHEMBL 3649377 & 1536084 & 7.6946 & 7.7216 & TRN & \\
\hline CHEMBL 3649367 & 1536084 & 6.7752 & 5.0527 & TST & \\
\hline CHEMBL 3649365 & 1536084 & 5.2297 & 4.7705 & TST & \\
\hline CHEMBL3649419 & 1536084 & 6.8496 & 6.8891 & TRN & \\
\hline CHEMBL 3649410 & 1536084 & 7.4634 & 7.3957 & TRN & \\
\hline CHEMBL 3649363 & 1536084 & 5.0256 & 4.6228 & TST & \\
\hline CHEMBL 3649378 & 1536084 & 7.5214 & 7.5662 & TRN & \\
\hline CHEMBL 3649371 & 1536084 & \multicolumn{3}{|c|}{6.9270000000000005} & TRN \\
\hline CHEMBL 3649369 & 1536084 & 7.5591 & 7.5371 & TRN & \\
\hline CHEMBL 3649386 & 1536084 & 7.0101 & \multicolumn{2}{|c|}{6.957000000000001} & TRN \\
\hline CHEMBL 3649418 & 1536084 & 7.3089 & 7.2991 & TRN & \\
\hline CHEMBL 3649382 & 1536084 & 6.3915 & 6.3164 & TRN & \\
\hline CHEMBL 3649420 & 1536084 & 6.8428 & 6.9199 & TRN & \\
\hline CHEMBL 3649374 & 1536084 & 7.1681 & 7.5694 & TST & \\
\hline CHEMBL 3649379 & 1536084 & 7.6778 & 7.8189 & TST & \\
\hline CHEMBL 3649397 & 1536084 & 6.8085 & 6.8677 & TST & \\
\hline CHEMBL 3649385 & 1536084 & 7.1445 & 7.1786 & TST & \\
\hline CHEMBL 3649372 & 1536084 & 6.4092 & 6.7443 & TST & \\
\hline CHEMBL 3649422 & 1536084 & 7.3851 & 7.2945 & TST & \\
\hline CHEMBL 3649362 & 1536084 & 5.1021 & 4.7238 & TST & \\
\hline CHEMBL 3649412 & 1536084 & 6.4995 & 6.8749 & TST & \\
\hline CHEMBL1834774 & 772809 & 5.556 & 5.7774 & TRN & \\
\hline CHEMBL1834971 & 772809 & 5.8665 & 5.9429 & TRN & \\
\hline CHEMBL1835103 & 772809 & 5.4089 & 5.6908 & TST & \\
\hline CHEMBL1834913 & 772809 & 5.8877 & 6.3871 & TST & \\
\hline CHEMBL1835111 & 772809 & 5.9076 & 5.772 & TRN & \\
\hline CHEMBL1834840 & 772809 & 7.1079 & 7.2625 & TRN & \\
\hline CHEMBL 1834844 & 772809 & 6.8928 & 7.0189 & TRN & \\
\hline CHEMBL1834771 & 772809 & 5.7345 & 5.8826 & TRN & \\
\hline CHEMBL 1834838 & 772809 & 7.301 & 7.294 & TRN & \\
\hline CHEMBL1834992 & 772809 & 5.8814 & 5.8605 & TRN & \\
\hline CHEMBL1834841 & 772809 & 7.0506 & 6.942 & TRN & \\
\hline CHEMBL 1834712 & 772809 & 6.9626 & 6.8747 & TRN & \\
\hline CHEMBL1834983 & 772809 & 5.0969 & 5.1678 & TRN & \\
\hline CHEMBL 1835096 & 772809 & 5.7802 & 5.9476 & TRN & \\
\hline CHEMBL1835088 & 772809 & 6.4908 & 6.3887 & TRN & \\
\hline CHEMBL1834713 & 772809 & 6.8697 & 6.603 & TRN & \\
\hline CHEMBL1834991 & 772809 & 6.4179 & 6.2621 & TRN & \\
\hline CHEMBL1835109 & 772809 & 5.9539 & 5.9444 & TRN & \\
\hline CHEMBL 1835093 & 772809 & 5.5834 & 5.1035 & TST & \\
\hline CHEMBL 1834776 & 772809 & 5.5042 & 5.5698 & TRN & \\
\hline CHEMBL1834839 & 772809 & 7.1612 & 7.0741 & TRN & \\
\hline CHEMBL1835106 & 772809 & 5.669 & 5.7216 & TRN & \\
\hline CHEMBL1835107 & 772809 & 6.16299 & 999999999 & 6.0291 & 151 \\
\hline CHEMBL 1834970 & 772809 & 6.5638 & 5.8536 & TST & \\
\hline CHEMBL1835089 & 772809 & 5.7138 & 6.2609 & TST & \\
\hline
\end{tabular}




\begin{tabular}{|c|c|c|c|c|}
\hline \multicolumn{5}{|c|}{ Supplemental Tab. } \\
\hline CHEMBL1834911 & 772809 & 5.9855 & 6.1099 & TRN \\
\hline CHEMBL1835091 & 772809 & 5.983 & 5.8702 & TRN \\
\hline CHEMBL1834976 & 772809 & 5.8145 & 5.928 & TRN \\
\hline CHEMBL1834708 & 772809 & 7.5086 & 7.5917 & TRN \\
\hline CHEMBL1834714 & 772809 & 6.8601 & 6.7835 & TRN \\
\hline CHEMBL1834988 & 772809 & 6.6861 & 6.6871 & TRN \\
\hline CHEMBL1834836 & 772809 & 7.3468 & 7.1509 & TRN \\
\hline CHEMBL1834762 & 772809 & 6.426 & 6.2694 & TRN \\
\hline CHEMBL1835087 & 772809 & 5.4498 & 5.5389 & TRN \\
\hline CHEMBL1834914 & 772809 & 5.7975 & 5.7796 & TRN \\
\hline CHEMBL1834847 & 772809 & 6.4881 & 6.4123 & TRN \\
\hline CHEMBL1834765 & 772809 & 6.1805 & 6.3296 & TRN \\
\hline CHEMBL1834834 & 772809 & 7.5376 & 7.4808 & TRN \\
\hline CHEMBL1834710 & 772809 & 7.0605 & 7.0605 & TRN \\
\hline CHEMBL1834768 & 772809 & 6.1007 & 6.101 & TRN \\
\hline CHEMBL1834829 & 772809 & 7.6198 & 7.6427 & TRN \\
\hline CHEMBL1835097 & 772809 & 5.7414 & 5.8295 & TRN \\
\hline CHEMBL1834842 & 772809 & 7.0132 & 7.1272 & TRN \\
\hline CHEMBL1834772 & 772809 & 5.6895 & 5.6694 & TRN \\
\hline CHEMBL1834843 & 772809 & 7.0088 & 7.1604 & TRN \\
\hline CHEMBL1834777 & 772809 & 5.4056 & 5.2874 & TRN \\
\hline CHEMBL1834910 & 772809 & 6.0123 & 6.5184 & TST \\
\hline CHEMBL1834977 & 772809 & 5.1457 & 5.1552 & TRN \\
\hline CHEMBL1834711 & 772809 & 7.0177 & 6.2171 & TST \\
\hline CHEMBL1834837 & 772809 & 7.3372 & 7.2403 & TRN \\
\hline CHEMBL1834845 & 772809 & 6.6799 & 6.6697 & TRN \\
\hline CHEMBL1834761 & 772809 & 6.4949 & 6.4455 & TRN \\
\hline CHEMBL1834707 & 772809 & 7.699 & 6.836 & TST \\
\hline CHEMBL1834979 & 772809 & 5.1567 & 5.1569 & TRN \\
\hline CHEMBL1834764 & 772809 & 6.2218 & 6.2529 & TRN \\
\hline CHEMBL1835110 & 772809 & 5.3468 & 5.2845 & TST \\
\hline CHEMBL1834990 & 772809 & 6.1002 & 5.9315 & TRN \\
\hline CHEMBL1834987 & 772809 & 5.9727 & 6.1062 & TST \\
\hline CHEMBL1835099 & 772809 & 5.3665 & 6.1088 & TST \\
\hline CHEMBL1834830 & 772809 & 7.6198 & 7.7017 & TRN \\
\hline CHEMBL1834986 & 772809 & 6.0209 & 6.1098 & TRN \\
\hline CHEMBL1834835 & 772809 & 7.4559 & 7.4807 & TRN \\
\hline CHEMBL1834828 & 772809 & 7.6383 & 8.3551 & TST \\
\hline CHEMBL1834770 & 772809 & 5.8465 & 5.9444 & TRN \\
\hline CHEMBL1834778 & 772809 & 5.3179 & 5.9581 & TST \\
\hline CHEMBL1834831 & 772809 & 7.585 & 7.6093 & TRN \\
\hline CHEMBL1834775 & 772809 & 5.5191 & 5.4261 & TRN \\
\hline CHEMBL1835105 & 772809 & 5.3271 & 5.5212 & TST \\
\hline CHEMBL1834760 & 772809 & 6.5287 & 6.505 & TRN \\
\hline CHEMBL1834827 & 772809 & 5.224 & 6.3474 & TST \\
\hline CHEMBL1834773 & 772809 & 5.6107 & 5.6593 & TRN \\
\hline CHEMBL1834969 & 772809 & 5.7131 & 5.9901 & TRN \\
\hline CHEMBL1834981 & 772809 & 5.9126 & 5.504 & TST \\
\hline
\end{tabular}




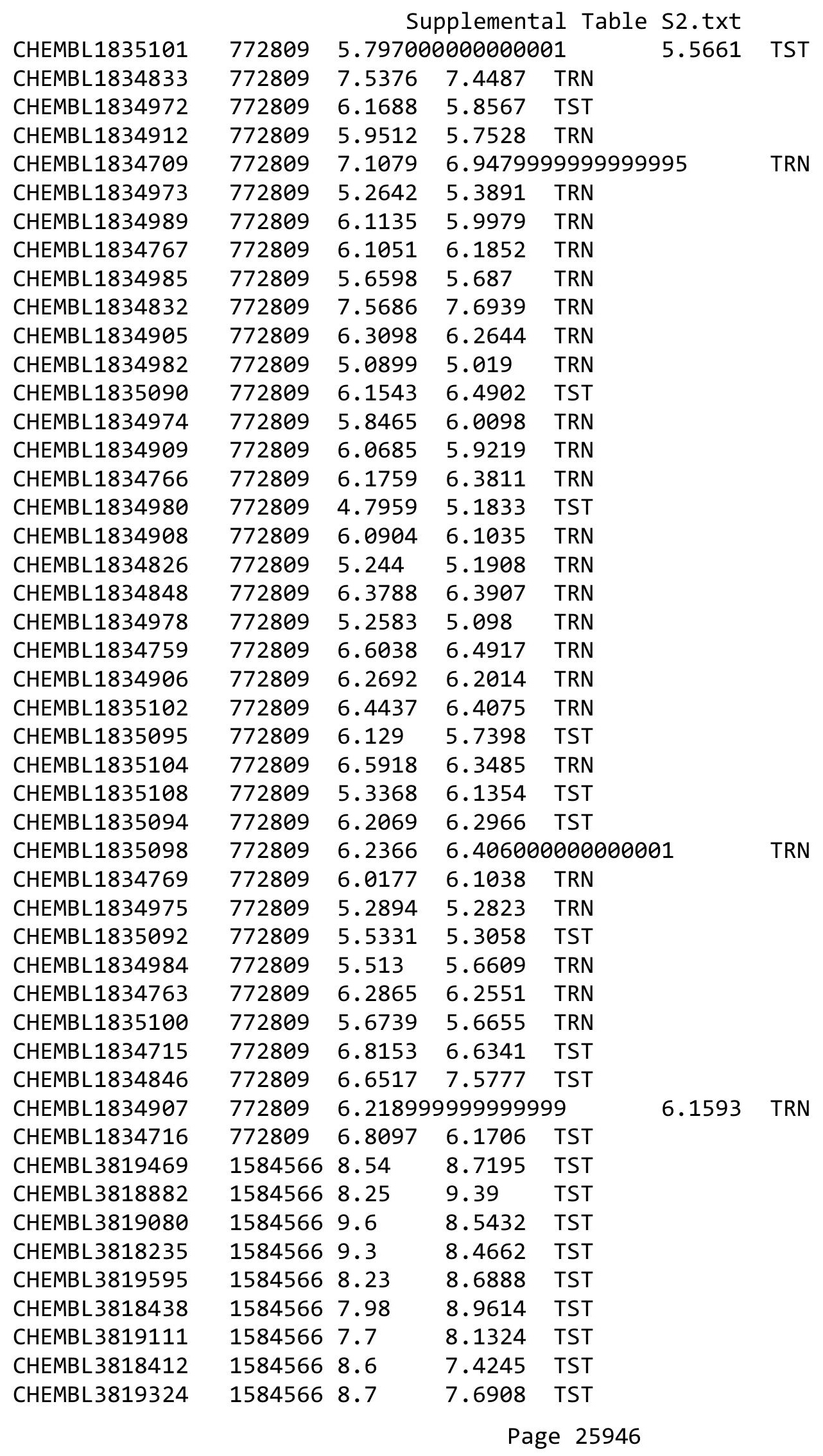




\begin{tabular}{|c|c|c|c|c|c|}
\hline CHEMBL3818942 & 1584566 & 8.7 & 7.7287 & TST & \\
\hline CHEMBL3818634 & 1584566 & 8.9 & 7.2195 & TST & \\
\hline CHEMBL3818224 & 1584566 & 8.9 & 7.4849 & TST & \\
\hline CHEMBL3818069 & 1584566 & 7.8 & 7.7653 & TRN & \\
\hline CHEMBL3817985 & 1584566 & 7.1 & 6.9536 & TRN & \\
\hline CHEMBL3818688 & 1584566 & 8.4 & 7.8169 & TRN & \\
\hline CHEMBL3818258 & 1584566 & 7.1 & 7.21299 & 9999999999 & TRN \\
\hline CHEMBL3818497 & 1584566 & 9.7 & 9.5354 & TRN & \\
\hline CHEMBL3818208 & 1584566 & 9.1 & 9.0028 & TRN & \\
\hline CHEMBL3819094 & 1584566 & 8.7 & 8.2989 & TRN & \\
\hline CHEMBL3819002 & 1584566 & 7.7 & 7.7644 & TRN & \\
\hline CHEMBL3818919 & 1584566 & 8.5 & 8.0751 & TRN & \\
\hline CHEMBL3818549 & 1584566 & 8.5 & 8.823 & TRN & \\
\hline CHEMBL3819640 & 1584566 & 9.2 & 9.3219 & TRN & \\
\hline CHEMBL3818619 & 1584566 & 9.7 & 9.6973 & TRN & \\
\hline CHEMBL3818367 & 1584566 & 9.1 & 9.1633 & TRN & \\
\hline CHEMBL3819015 & 1584566 & 8.6 & 8.6456 & TRN & \\
\hline CHEMBL 3818405 & 1584566 & 7.2 & 7.0228 & TRN & \\
\hline CHEMBL3817881 & 1584566 & 8.5 & 8.4154 & TRN & \\
\hline CHEMBL3819102 & 1584566 & 8.8 & 8.6612 & TRN & \\
\hline CHEMBL3818577 & 1584566 & 9.4 & 9.0397 & TRN & \\
\hline CHEMBL3819599 & 1584566 & 6.8 & 6.9946 & TRN & \\
\hline CHEMBL3818620 & 1584566 & 8.4 & 8.4669 & TRN & \\
\hline CHEMBL3818757 & 1584566 & 7.7 & 6.9791 & TRN & \\
\hline CHEMBL3818854 & 1584566 & 8.8 & 8.9092 & TRN & \\
\hline CHEMBL3819417 & 1584566 & 7.9 & 8.2429 & TRN & \\
\hline CHEMBL3818033 & 1584566 & 5.6 & 5.9078 & TRN & \\
\hline CHEMBL3817997 & 1584566 & 7.4 & 7.5503 & TRN & \\
\hline CHEMBL3818136 & 1584566 & 7.5 & 7.5875 & TRN & \\
\hline CHEMBL3818420 & 1584566 & 7.9 & 7.5299 & TRN & \\
\hline CHEMBL3819393 & 1584566 & 8.8 & 8.9486 & TRN & \\
\hline CHEMBL3819048 & 1584566 & 9.8 & 9.3347 & TRN & \\
\hline CHEMBL3818652 & 1584566 & 5.0 & 6.6455 & TRN & \\
\hline CHEMBL3818826 & 1584566 & 8.1 & 8.7194 & TRN & \\
\hline CHEMBL3818789 & 1584566 & 8.4 & 8.2049 & TRN & \\
\hline CHEMBL3818723 & 1584566 & 7.8 & 7.6695 & TRN & \\
\hline CHEMBL3819648 & 1584566 & 9.7 & 10.1739 & TRN & \\
\hline CHEMBL3818706 & 1584566 & 10.5 & 10.5966 & TRN & \\
\hline CHEMBL3819303 & 1584566 & 9.6 & 9.9264 & TRN & \\
\hline CHEMBL3818542 & 1584566 & 8.8 & 8.7932 & TRN & \\
\hline CHEMBL3819041 & 1584566 & 8.4 & 7.6035 & TRN & \\
\hline CHEMBL3818555 & 1584566 & 7.8 & 9.033 & TST & \\
\hline CHEMBL1097851 & 632953 & 6.0 & 5.9454 & TST & \\
\hline CHEMBL1097545 & 632953 & 4.3 & 5.7086 & TST & \\
\hline CHEMBL1099211 & 632953 & 4.2 & 4.0689 & TRN & \\
\hline CHEMBL1099210 & 632953 & 6.4 & 6.3943 & TRN & \\
\hline CHEMBL1099209 & 632953 & 6.1 & 6.125 & TRN & \\
\hline CHEMBL1099208 & 632953 & 6.3 & 6.2627 & TRN & \\
\hline
\end{tabular}




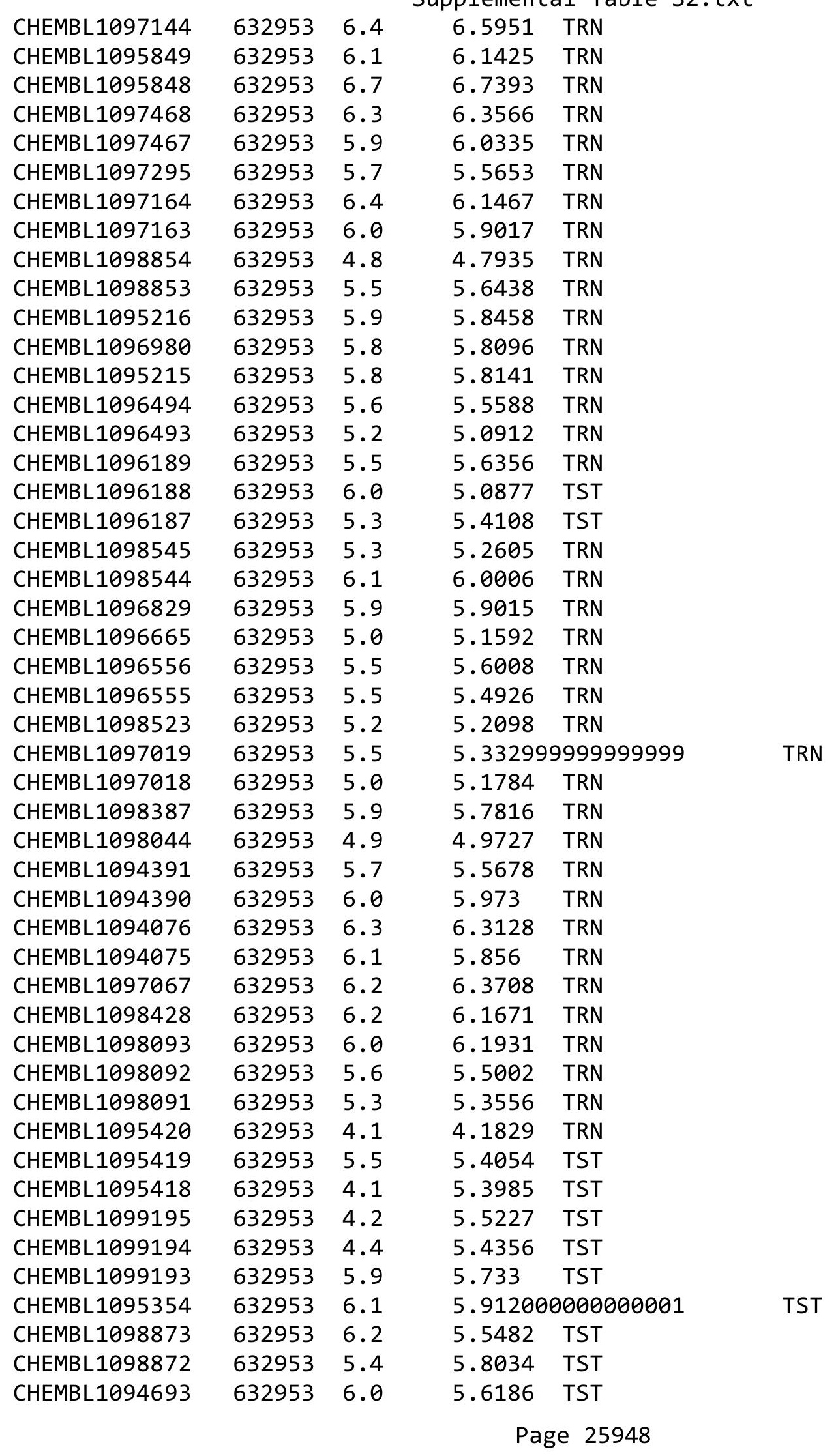




\begin{tabular}{|c|c|c|c|c|c|}
\hline \\
\hline CHEMBL1098861 & 632953 & 6.1 & 5.9712 & TST & \\
\hline CHEMBL1098860 & 632953 & 6.1 & 6.1004 & TRN & \\
\hline CHEMBL1098776 & 632953 & 5.93 & 5.6329 & TRN & \\
\hline CHEMBL1098777 & 632953 & 4.34 & 4.6427 & TRN & \\
\hline CHEMBL1098353 & 632953 & 5.71 & 5.7834 & TST & \\
\hline CHEMBL183706 & 429753 & 5.4852 & 5.6901 & TRN & \\
\hline CHEMBL373534 & 429753 & 5.7178 & 5.7254 & TRN & \\
\hline CHEMBL426786 & 429753 & 5.0407 & 5.0955 & TRN & \\
\hline CHEMBL 221730 & 429753 & 5.5144 & 5.7377 & TRN & \\
\hline CHEMBL374218 & 429753 & 5.0 & 5.0996 & TRN & \\
\hline CHEMBL 221716 & 429753 & 5.1739 & 5.5052 & TRN & \\
\hline CHEMBL222214 & 429753 & 5.2518 & 5.7344 & TRN & \\
\hline CHEMBL221678 & 429753 & 4.0 & 4.3439 & TRN & \\
\hline CHEMBL 387391 & 429753 & 5.0 & 4.9705 & TRN & \\
\hline CHEMBL 374754 & 429753 & 5.5086 & 5.6785 & TRN & \\
\hline CHEMBL 221718 & 429753 & 5.5376 & 6.1643 & TRN & \\
\hline CHEMBL221463 & 429753 & 4.0 & 4.0276 & TRN & \\
\hline CHEMBL374459 & 429753 & 5.9893 & 6.4107 & TST & \\
\hline CHEMBL 360791 & 429753 & 5.751 & 5.33899 & 99999999995 & TRN \\
\hline CHEMBL 387390 & 429753 & 5.8239 & 5.9517 & TRN & \\
\hline CHEMBL 222927 & 429753 & 8.0 & 7.7552 & TRN & \\
\hline CHEMBL 374755 & 429753 & 6.0223 & 6.3848 & TRN & \\
\hline CHEMBL 221664 & 429753 & 5.6676 & 5.8474 & TRN & \\
\hline CHEMBL 360712 & 429753 & 5.2716 & 4.9891 & TRN & \\
\hline CHEMBL385311 & 429753 & 5.6778 & 5.0278 & TRN & \\
\hline CHEMBL 361805 & 429753 & 5.731 & 5.7017 & TST & \\
\hline CHEMBL 221462 & 429753 & 6.6478 & 6.6207 & TRN & \\
\hline CHEMBL374059 & 429753 & 5.2518 & 5.4115 & TRN & \\
\hline CHEMBL222853 & 429753 & 6.1605 & 6.1593 & TRN & \\
\hline CHEMBL 222356 & 429753 & 5.8239 & 4.9579 & TRN & \\
\hline CHEMBL 223837 & 429753 & 6.0605 & 5.819 & TRN & \\
\hline CHEMBL 223025 & 429753 & 4.0 & 3.9755 & TRN & \\
\hline CHEMBL 222372 & 429753 & 5.8748 & 5.5908 & TST & \\
\hline CHEMBL 223882 & 429753 & 5.3999 & 5.2743 & TRN & \\
\hline CHEMBL 221414 & 429753 & 6.301 & 6.4421 & TST & \\
\hline CHEMBL374585 & 429753 & 6.301 & 6.0061 & TRN & \\
\hline CHEMBL222139 & 429753 & 5.5229 & 5.7786 & TRN & \\
\hline CHEMBL376025 & 429753 & 6.0706 & 6.3947 & TRN & \\
\hline CHEMBL222217 & 429753 & 5.6788 & 5.9189 & TRN & \\
\hline CHEMBL375208 & 429753 & 4.0 & 4.2402 & TRN & \\
\hline CHEMBL 376202 & 429753 & 5.4949 & 5.4188 & TRN & \\
\hline CHEMBL185489 & 429753 & 5.0 & 5.6002 & TST & \\
\hline CHEMBL222985 & 429753 & 6.2007 & 5.0214 & TST & \\
\hline CHEMBL181278 & 429753 & 6.1085 & 5.8159 & TRN & \\
\hline CHEMBL 223024 & 429753 & 6.9101 & 6.3479 & TRN & \\
\hline CHEMBL 385133 & 429753 & 5.9263 & 5.329 & TRN & \\
\hline CHEMBL222984 & 429753 & 5.5157 & 5.2878 & TRN & \\
\hline CHEMBL 222083 & 429753 & 5.8548 & 5.6799 & TRN & \\
\hline
\end{tabular}




\begin{tabular}{|c|c|c|c|c|c|}
\hline \multicolumn{6}{|c|}{ Supplemental Table S2.txt } \\
\hline CHEMBL387325 & 429753 & 4.0 & 4.6686 & TRN & \\
\hline CHEMBL374675 & 429753 & 6.0555 & 5.6159 & TST & \\
\hline CHEMBL 223889 & 429753 & 4.0 & 4.5855 & TST & \\
\hline CHEMBL 374869 & 429753 & 5.3451 & 4.87 & TST & \\
\hline CHEMBL 221413 & 429753 & 6.585 & 6.4047 & TST & \\
\hline CHEMBL222881 & 429753 & 6.301 & 5.6833 & TST & \\
\hline CHEMBL437519 & 429753 & 5.5376 & 4.9633 & TST & \\
\hline CHEMBL 222142 & 429753 & 5.4145 & 4.7346 & TST & \\
\hline CHEMBL1972119 & 809202 & 4.5 & 5.0388 & TRN & \\
\hline CHEMBL1986328 & 809202 & 4.5 & 4.668 & TST & \\
\hline CHEMBL95692 & 809202 & 4.5 & 4.8403 & TRN & \\
\hline CHEMBL1090356 & 809202 & 4.5 & 4.1039 & TRN & \\
\hline CHEMBL1976455 & 809202 & 5.9 & 5.7828 & TRN & \\
\hline CHEMBL1983923 & 809202 & 6.8 & 5.4543 & TST & \\
\hline CHEMBL1983534 & 809202 & 4.5 & 4.6762 & TRN & \\
\hline CHEMBL1970950 & 809202 & 4.5 & 5.4945 & TRN & \\
\hline CHEMBL1982361 & 809202 & 4.5 & 4.8306 & TRN & \\
\hline CHEMBL1999112 & 809202 & 4.5 & 4.9419 & TST & \\
\hline CHEMBL1982122 & 809202 & 6.0 & 4.8167 & TRN & \\
\hline CHEMBL 2000801 & 809202 & 4.5 & 5.1022 & TRN & \\
\hline CHEMBL1682546 & 809202 & 4.5 & 4.1464 & TRN & \\
\hline CHEMBL1991395 & 809202 & 4.5 & 4.3279 & TRN & \\
\hline CHEMBL1971245 & 809202 & 4.5 & 4.5562 & TRN & \\
\hline CHEMBL1972142 & 809202 & 4.5 & 4.9323 & TRN & \\
\hline CHEMBL1966514 & 809202 & 4.5 & 5.6405 & TRN & \\
\hline CHEMBL 2003638 & 809202 & 7.5 & 7.3742 & TRN & \\
\hline CHEMBL1996066 & 809202 & 4.5 & 4.1643 & TST & \\
\hline CHEMBL1993722 & 809202 & 4.5 & 5.5608 & TRN & \\
\hline CHEMBL1970806 & 809202 & 4.5 & 5.335 & TST & \\
\hline CHEMBL1375640 & 809202 & 5.6 & 5.5028 & TST & \\
\hline CHEMBL1979970 & 809202 & 4.7 & 4.7389 & TRN & \\
\hline CHEMBL 249282 & 809202 & 4.5 & 4.0802 & TST & \\
\hline CHEMBL1970821 & 809202 & 7.6 & 7.2411 & TRN & \\
\hline CHEMBL 2006237 & 809202 & 4.5 & 4.7652 & TRN & \\
\hline CHEMBL1967720 & 809202 & 4.5 & 5.6154 & TRN & \\
\hline CHEMBL 2005509 & 809202 & 7.6 & 7.61299 & 99999999995 & TRN \\
\hline CHEMBL1572266 & 809202 & 4.5 & 4.4303 & TST & \\
\hline CHEMBL1991138 & 809202 & 4.5 & 4.1105 & TRN & \\
\hline CHEMBL1979516 & 809202 & 4.7 & 5.2144 & TRN & \\
\hline CHEMBL1969755 & 809202 & 4.5 & 4.3873 & TRN & \\
\hline CHEMBL1605605 & 809202 & 4.5 & 3.9975 & TRN & \\
\hline CHEMBL1972820 & 809202 & 4.5 & 5.1958 & TST & \\
\hline CHEMBL1989029 & 809202 & 6.0 & 5.2191 & TST & \\
\hline CHEMBL392642 & 809202 & 4.5 & 5.13 & TRN & \\
\hline CHEMBL514499 & 809202 & 4.5 & 4.6788 & TST & \\
\hline CHEMBL1965631 & 809202 & 5.9 & 6.9012 & TRN & \\
\hline CHEMBL1980144 & 809202 & 4.5 & 4.9914 & TRN & \\
\hline CHEMBL1682554 & 809202 & 7.0 & 6.3126 & TRN & \\
\hline
\end{tabular}




\begin{tabular}{|c|c|c|c|c|c|}
\hline \\
\hline CHEMBL1991188 & 809202 & 4.5 & 4.3725 & TRN & \\
\hline CHEMBL1972849 & 809202 & 4.5 & 4.332 & TRN & \\
\hline CHEMBL377408 & 809202 & 4.5 & 4.97199 & 99999999995 & TRN \\
\hline CHEMBL1986855 & 809202 & 7.2 & 7.7696 & TRN & \\
\hline CHEMBL231209 & 809202 & 4.5 & 5.2605 & TRN & \\
\hline CHEMBL1976220 & 809202 & 4.5 & 5.0656 & TRN & \\
\hline CHEMBL1989136 & 809202 & 4.5 & 5.3894 & TRN & \\
\hline CHEMBL259922 & 809202 & 4.5 & 4.3801 & TST & \\
\hline CHEMBL1997617 & 809202 & 4.5 & 5.0509 & TRN & \\
\hline CHEMBL1982383 & 809202 & 4.5 & 4.4662 & TRN & \\
\hline CHEMBL1969301 & 809202 & 4.5 & 5.2736 & TST & \\
\hline CHEMBL17370 & 809202 & 4.5 & 4.3551 & TRN & \\
\hline CHEMBL1987910 & 809202 & 4.5 & 5.117 & TRN & \\
\hline CHEMBL1983932 & 809202 & 8.2 & 6.9406 & TRN & \\
\hline CHEMBL1991285 & 809202 & 4.5 & 4.2133 & TRN & \\
\hline CHEMBL1997822 & 809202 & 4.5 & 4.1386 & TRN & \\
\hline CHEMBL 243088 & 809202 & 7.2 & 6.9519 & TRN & \\
\hline CHEMBL1984038 & 809202 & 4.5 & 4.5144 & TRN & \\
\hline CHEMBL1974416 & 809202 & 4.5 & 4.436 & TRN & \\
\hline CHEMBL1993661 & 809202 & 6.5 & 5.7049 & TRN & \\
\hline CHEMBL 2004615 & 809202 & 5.8 & 5.4979 & TST & \\
\hline CHEMBL1984039 & 809202 & 5.8 & 4.6877 & TST & \\
\hline CHEMBL1997872 & 809202 & 4.5 & 4.5496 & TRN & \\
\hline CHEMBL1964290 & 809202 & 7.1 & 6.6393 & TRN & \\
\hline CHEMBL 213505 & 809202 & 6.5 & 5.6827 & TRN & \\
\hline CHEMBL1987034 & 809202 & 7.3 & 6.5889 & TRN & \\
\hline CHEMBL1993941 & 809202 & 4.5 & 5.4375 & TRN & \\
\hline CHEMBL1980435 & 809202 & 7.5 & 7.4545 & TRN & \\
\hline CHEMBL1989293 & 809202 & 6.2 & 5.756 & TRN & \\
\hline CHEMBL377383 & 809202 & 4.5 & 4.42899 & 9999999999 & TRN \\
\hline CHEMBL 2005886 & 809202 & 4.5 & 5.3615 & TRN & \\
\hline CHEMBL481491 & 809202 & 4.5 & 4.5946 & TST & \\
\hline CHEMBL1973142 & 809202 & 6.6 & 5.7871 & TST & \\
\hline CHEMBL1973145 & 809202 & 4.5 & 4.57600 & 00000000005 & TRN \\
\hline CHEMBL1982924 & 809202 & 4.5 & 4.8971 & TRN & \\
\hline CHEMBL2005936 & 809202 & 4.5 & 5.2171 & TRN & \\
\hline CHEMBL1807515 & 809202 & 7.8 & 7.9439 & TRN & \\
\hline CHEMBL1971141 & 809202 & 4.5 & 4.3469 & TRN & \\
\hline CHEMBL1995813 & 809202 & 7.6 & 7.7977 & TRN & \\
\hline CHEMBL 206236 & 809202 & 4.5 & 4.2715 & TRN & \\
\hline CHEMBL1964288 & 809202 & 7.8 & 6.8487 & TRN & \\
\hline CHEMBL 244378 & 809202 & 7.6 & 7.3679 & TRN & \\
\hline CHEMBL 2001957 & 809202 & 4.5 & 4.7331 & TRN & \\
\hline CHEMBL1969372 & 809202 & 4.5 & 4.1626 & TRN & \\
\hline CHEMBL1993413 & 809202 & 4.4 & 5.0485 & TRN & \\
\hline CHEMBL1986943 & 809202 & 7.5 & 7.4954 & TRN & \\
\hline CHEMBL 2006263 & 809202 & 4.5 & 5.1683 & TST & \\
\hline CHEMBL1988662 & 809202 & 4.5 & 6.1478 & TRN & \\
\hline
\end{tabular}




\begin{tabular}{|c|c|c|c|c|c|}
\hline \\
\hline CHEMBL 2001646 & 809202 & 5.9 & 5.2201 & TST & \\
\hline CHEMBL1993584 & 809202 & 4.5 & 4.1199 & TRN & \\
\hline CHEMBL1986263 & 809202 & 7.4 & \multicolumn{2}{|c|}{6.5120000000000005} & TRN \\
\hline CHEMBL 2000114 & 809202 & 4.5 & 5.2458 & TRN & \\
\hline CHEMBL210618 & 809202 & 4.5 & 4.8617 & TRN & \\
\hline CHEMBL1971172 & 809202 & 6.9 & 6.6471 & TRN & \\
\hline CHEMBL1975647 & 809202 & 5.6 & 5.724 & TRN & \\
\hline CHEMBL1968380 & 809202 & 4.5 & 4.3935 & TRN & \\
\hline CHEMBL1997643 & 809202 & 7.7 & 7.2968 & TRN & \\
\hline CHEMBL1964644 & 809202 & 4.5 & 4.6671 & TRN & \\
\hline CHEMBL1981782 & 809202 & 4.5 & 4.6279 & TRN & \\
\hline CHEMBL1977681 & 809202 & 6.3 & 5.6807 & TRN & \\
\hline CHEMBL1970142 & 809202 & 4.5 & 5.5138 & TRN & \\
\hline CHEMBL1990912 & 809202 & 4.5 & 5.0125 & TRN & \\
\hline CHEMBL1988163 & 809202 & 6.7 & 6.5181 & TRN & \\
\hline CHEMBL 2006493 & 809202 & 4.5 & 5.2023 & TST & \\
\hline CHEMBL1983449 & 809202 & 4.5 & 4.5391 & TRN & \\
\hline CHEMBL1992323 & 809202 & 4.5 & 5.4215 & TST & \\
\hline CHEMBL1969735 & 809202 & 4.5 & 4.4967 & TRN & \\
\hline CHEMBL 2002649 & 809202 & 6.0 & 6.745 & TRN & \\
\hline CHEMBL1983589 & 809202 & 7.3 & 7.1135 & TRN & \\
\hline CHEMBL 2005718 & 809202 & 7.4 & 7.1637 & TRN & \\
\hline CHEMBL1995172 & 809202 & 4.5 & 4.8369 & TST & \\
\hline CHEMBL1994321 & 809202 & 4.5 & 5.3136 & TRN & \\
\hline CHEMBL1997129 & 809202 & 6.6 & 6.4365 & TRN & \\
\hline CHEMBL1984788 & 809202 & 5.7 & 5.3594 & TRN & \\
\hline CHEMBL 2000508 & 809202 & 4.5 & 4.7822 & TRN & \\
\hline CHEMBL1971694 & 809202 & 4.5 & 5.4782 & TST & \\
\hline CHEMBL 2001547 & 809202 & 4.5 & 4.3695 & TRN & \\
\hline CHEMBL210928 & 809202 & 4.5 & 4.18 & TRN & \\
\hline CHEMBL1986603 & 809202 & 4.5 & 4.7827 & TST & \\
\hline CHEMBL1977148 & 809202 & 4.5 & \multicolumn{2}{|c|}{5.3260000000000005} & TRN \\
\hline CHEMBL 2004443 & 809202 & 6.7 & 5.9792 & TST & \\
\hline CHEMBL 2003286 & 809202 & 6.2 & 6.5874 & TRN & \\
\hline CHEMBL1992306 & 809202 & 5.7 & 5.3122 & TRN & \\
\hline CHEMBL 2002165 & 809202 & 5.5 & 5.4933 & TRN & \\
\hline CHEMBL1979318 & 809202 & 4.5 & 4.3932 & TST & \\
\hline CHEMBL206382 & 809202 & 4.5 & 4.7467 & TRN & \\
\hline CHEMBL1998585 & 809202 & 6.4 & 6.1562 & TRN & \\
\hline CHEMBL127898 & 809202 & 4.5 & 4.8489 & TST & \\
\hline CHEMBL519697 & 809202 & 4.5 & 4.944 & TST & \\
\hline CHEMBL 2004934 & 809202 & 4.5 & 4.8805 & TRN & \\
\hline CHEMBL1987261 & 809202 & 7.4 & 7.3006 & TRN & \\
\hline CHEMBL1968459 & 809202 & 6.7 & 6.9926 & TRN & \\
\hline CHEMBL1975128 & 809202 & 5.8 & 5.9542 & TRN & \\
\hline CHEMBL1970369 & 809202 & 4.5 & 4.6508 & TRN & \\
\hline CHEMBL 2001485 & 809202 & 4.5 & 5.4504 & TRN & \\
\hline CHEMBL1966425 & 809202 & 4.5 & 5.3976 & TRN & \\
\hline
\end{tabular}




\begin{tabular}{|c|c|c|c|c|}
\hline & & & ient & al Ta \\
\hline CHEMBL1984363 & 809202 & 4.5 & 4.7885 & TRN \\
\hline CHEMBL1978099 & 809202 & 5.9 & 5.3155 & TRN \\
\hline CHEMBL1988608 & 809202 & 4.5 & 4.5495 & TRN \\
\hline CHEMBL184847 & 809202 & 7.2 & 5.8792 & TRN \\
\hline CHEMBL1984367 & 809202 & 4.5 & 4.1054 & TRN \\
\hline CHEMBL1985723 & 809202 & 6.8 & 7.0037 & TRN \\
\hline CHEMBL178737 & 809202 & 4.5 & 4.9606 & TST \\
\hline CHEMBL1982563 & 809202 & 4.5 & 4.6692 & TRN \\
\hline CHEMBL539474 & 809202 & 6.4 & 4.7348 & TST \\
\hline CHEMBL575824 & 809202 & 4.6 & 5.3228 & TRN \\
\hline CHEMBL1988387 & 809202 & 6.9 & 6.1231 & TRN \\
\hline CHEMBL1977128 & 809202 & 7.3 & 7.4999 & TRN \\
\hline CHEMBL1990288 & 809202 & 4.5 & 4.2577 & TRN \\
\hline CHEMBL1974803 & 809202 & 5.9 & 5.5578 & TST \\
\hline CHEMBL1970074 & 809202 & 5.5 & 5.1858 & TRN \\
\hline CHEMBL1965702 & 809202 & 7.0 & 7.0364 & TRN \\
\hline CHEMBL1986970 & 809202 & 4.5 & 3.9946 & TRN \\
\hline CHEMBL 2002456 & 809202 & 6.4 & 6.4026 & TRN \\
\hline CHEMBL1958401 & 809202 & 7.1 & 6.8908 & TRN \\
\hline CHEMBL2003456 & 809202 & 4.5 & 4.4509 & TRN \\
\hline CHEMBL1966816 & 809202 & 7.4 & 6.31 & TRN \\
\hline CHEMBL1972584 & 809202 & 4.5 & 4.8162 & TRN \\
\hline CHEMBL 2002992 & 809202 & 4.5 & 4.4019 & TRN \\
\hline CHEMBL560813 & 809202 & 4.5 & 4.6565 & TRN \\
\hline CHEMBL1968791 & 809202 & 4.5 & 4.109 & TRN \\
\hline CHEMBL 2002682 & 809202 & 5.5 & 4.5059 & TST \\
\hline CHEMBL1971186 & 809202 & 5.5 & 4.7277 & TRN \\
\hline CHEMBL 2003482 & 809202 & 4.5 & 4.6104 & TRN \\
\hline CHEMBL 2006456 & 809202 & 7.0 & 7.3179 & TRN \\
\hline CHEMBL1973211 & 809202 & 5.9 & 5.6081 & TRN \\
\hline CHEMBL1984700 & 809202 & 4.5 & 4.6058 & TRN \\
\hline CHEMBL1964340 & 809202 & 7.2 & 7.1638 & TRN \\
\hline CHEMBL1972125 & 809202 & 4.6 & 4.0938 & TRN \\
\hline CHEMBL1461728 & 809202 & 4.5 & 4.5302 & TRN \\
\hline CHEMBL1976134 & 809202 & 5.9 & 5.5774 & TRN \\
\hline CHEMBL1965131 & 809202 & 6.7 & 6.1788 & TST \\
\hline CHEMBL1999279 & 809202 & 6.5 & 7.1849 & TRN \\
\hline CHEMBL1972158 & 809202 & 5.8 & 5.4483 & TRN \\
\hline CHEMBL1967662 & 809202 & 8.1 & 7.3495 & TRN \\
\hline CHEMBL 2006580 & 809202 & 4.5 & 4.5709 & TRN \\
\hline CHEMBL1999414 & 809202 & 7.0 & 6.1613 & TRN \\
\hline CHEMBL1979855 & 809202 & 4.5 & 4.4083 & TRN \\
\hline CHEMBL1978645 & 809202 & 5.5 & 5.1736 & TST \\
\hline CHEMBL1970340 & 809202 & 4.5 & 4.3738 & TRN \\
\hline CHEMBL 2005186 & 809202 & 4.5 & 4.1884 & TRN \\
\hline CHEMBL 2006450 & 809202 & 4.4 & 5.2585 & TRN \\
\hline CHEMBL1975534 & 809202 & 4.5 & 4.801 & TRN \\
\hline CHEMBL1993424 & 809202 & 4.5 & 5.0579 & TRN \\
\hline
\end{tabular}




\begin{tabular}{|c|c|c|c|c|c|}
\hline \multicolumn{6}{|c|}{ Supplemental Table S2.txt } \\
\hline CHEMBL1966703 & 809202 & 4.5 & 4.5827 & TST & \\
\hline CHEMBL243518 & 809202 & 8.2 & 7.0783 & TRN & \\
\hline CHEMBL1969561 & 809202 & 4.5 & 4.1555 & TRN & \\
\hline CHEMBL1975121 & 809202 & 4.5 & 4.4772 & TRN & \\
\hline CHEMBL1997554 & 809202 & 8.4 & 7.5204 & TRN & \\
\hline CHEMBL1997023 & 809202 & 4.5 & 5.2391 & TST & \\
\hline CHEMBL1964687 & 809202 & 4.5 & 4.9769 & TRN & \\
\hline CHEMBL1971943 & 809202 & 4.5 & 4.6789 & TST & \\
\hline CHEMBL1974254 & 809202 & 4.5 & 5.6597 & TRN & \\
\hline CHEMBL1988537 & 809202 & 4.5 & \multicolumn{2}{|c|}{4.7410000000000005} & TST \\
\hline CHEMBL1969049 & 809202 & 4.5 & 4.9708 & TRN & \\
\hline CHEMBL 2005828 & 809202 & 7.3 & 6.2352 & TRN & \\
\hline CHEMBL1980178 & 809202 & 7.0 & 7.044 & TRN & \\
\hline CHEMBL1998611 & 809202 & 4.5 & 5.4896 & TST & \\
\hline CHEMBL1975900 & 809202 & 4.5 & 4.7093 & TRN & \\
\hline CHEMBL255822 & 809202 & 7.0 & \multicolumn{2}{|c|}{7.002000000000001} & TRN \\
\hline CHEMBL1972221 & 809202 & 4.5 & 5.1061 & TRN & \\
\hline CHEMBL 2006778 & 809202 & 4.5 & 4.4585 & TRN & \\
\hline CHEMBL1981511 & 809202 & 4.5 & 5.4347 & TRN & \\
\hline CHEMBL378627 & 809202 & 4.5 & 4.0952 & TRN & \\
\hline CHEMBL1996979 & 809202 & 5.8 & 4.8835 & TRN & \\
\hline CHEMBL1997025 & 809202 & 4.5 & 5.2712 & TRN & \\
\hline CHEMBL1968406 & 809202 & 4.5 & 5.0764 & TRN & \\
\hline CHEMBL1998545 & 809202 & 4.5 & 4.2613 & TRN & \\
\hline CHEMBL1986869 & 809202 & 4.5 & 4.42 & TRN & \\
\hline CHEMBL 2006010 & 809202 & 4.5 & 4.6543 & TRN & \\
\hline CHEMBL1682558 & 809202 & 4.5 & 4.3293 & TRN & \\
\hline CHEMBL1990496 & 809202 & 4.5 & 3.6444 & TST & \\
\hline CHEMBL1998068 & 809202 & 7.2 & 7.0226 & TRN & \\
\hline CHEMBL 2002479 & 809202 & 5.5 & 5.6878 & TRN & \\
\hline CHEMBL1967094 & 809202 & 4.5 & 4.7164 & TRN & \\
\hline CHEMBL1966035 & 809202 & 4.5 & 4.2266 & TRN & \\
\hline CHEMBL 2003341 & 809202 & 4.5 & 4.5755 & TRN & \\
\hline CHEMBL1990708 & 809202 & 7.3 & 5.8024 & TRN & \\
\hline CHEMBL1982992 & 809202 & 4.5 & 4.7471 & TRN & \\
\hline CHEMBL1999590 & 809202 & 4.5 & 4.6926 & TST & \\
\hline CHEMBL1981079 & 809202 & 7.2 & 6.9579 & TRN & \\
\hline CHEMBL1972276 & 809202 & 4.5 & 4.7859 & TRN & \\
\hline CHEMBL1980489 & 809202 & 4.5 & 4.1349 & TRN & \\
\hline CHEMBL 2000832 & 809202 & 4.5 & 4.9498 & TRN & \\
\hline CHEMBL1967116 & 809202 & 6.1 & 6.0019 & TRN & \\
\hline CHEMBL513846 & 809202 & 6.0 & 5.3444 & TRN & \\
\hline CHEMBL1970709 & 809202 & 4.5 & 4.2779 & TRN & \\
\hline CHEMBL1965660 & 809202 & 7.6 & 7.1384 & TRN & \\
\hline CHEMBL1998112 & 809202 & 4.5 & 4.3784 & TRN & \\
\hline CHEMBL1972290 & 809202 & 7.6 & 7.2971 & TRN & \\
\hline CHEMBL1969126 & 809202 & 4.5 & 4.4042 & TRN & \\
\hline CHEMBL1980896 & 809202 & 4.5 & 4.513 & TRN & \\
\hline
\end{tabular}




\begin{tabular}{|c|c|c|c|c|c|}
\hline & & & & & \\
\hline CHEMBL1975208 & 809202 & 4.5 & 4.7454 & TST & \\
\hline CHEMBL1970104 & 809202 & 5.9 & 5.2324 & TRN & \\
\hline CHEMBL1991429 & 809202 & 4.5 & 4.2294 & TRN & \\
\hline CHEMBL1964777 & 809202 & 6.1 & 5.6791 & TST & \\
\hline CHEMBL1971149 & 809202 & 4.5 & 4.3586 & TRN & \\
\hline CHEMBL1999714 & 809202 & 4.5 & 4.6622 & TRN & \\
\hline CHEMBL1987533 & 809202 & 4.5 & 4.2384 & TRN & \\
\hline CHEMBL1994040 & 809202 & 4.5 & 4.4278 & TRN & \\
\hline CHEMBL388978 & 809202 & 6.9 & 5.9492 & TST & \\
\hline CHEMBL579246 & 809202 & 4.5 & 5.004 & TRN & \\
\hline CHEMBL398951 & 809202 & 4.5 & 4.1622 & TST & \\
\hline CHEMBL1982506 & 809202 & 4.5 & 5.2468 & TST & \\
\hline CHEMBL 2004716 & 809202 & 6.8 & 6.147 & TRN & \\
\hline CHEMBL1968127 & 809202 & 4.5 & 4.3977 & TRN & \\
\hline CHEMBL1975233 & 809202 & 4.5 & 4.2094 & TRN & \\
\hline CHEMBL1985406 & 809202 & 4.5 & 5.5776 & TRN & \\
\hline CHEMBL207400 & 809202 & 4.5 & 4.81800 & 00000000005 & TST \\
\hline CHEMBL 2000894 & 809202 & 4.5 & 3.90100 & 00000000002 & TRN \\
\hline CHEMBL1982135 & 809202 & 4.5 & 4.7302 & TRN & \\
\hline CHEMBL1976090 & 809202 & 6.0 & 6.1578 & TRN & \\
\hline CHEMBL1993243 & 809202 & 4.5 & 4.2978 & TRN & \\
\hline CHEMBL 2004771 & 809202 & 4.5 & 5.1205 & TRN & \\
\hline CHEMBL1992922 & 809202 & 4.5 & 5.1307 & TRN & \\
\hline CHEMBL1997597 & 809202 & 4.5 & 4.4895 & TRN & \\
\hline CHEMBL1969537 & 809202 & 6.5 & 6.2638 & TST & \\
\hline CHEMBL1976093 & 809202 & 4.5 & 4.2847 & TRN & \\
\hline CHEMBL1975256 & 809202 & 4.5 & 3.8122 & TST & \\
\hline CHEMBL508928 & 809202 & 6.6 & 5.4847 & TRN & \\
\hline CHEMBL1991356 & 809202 & 4.5 & 5.0892 & TST & \\
\hline CHEMBL 2004892 & 809202 & 4.5 & 4.2501 & TRN & \\
\hline CHEMBL1999126 & 809202 & 5.8 & 5.5529 & TST & \\
\hline CHEMBL1997503 & 809202 & 4.5 & 4.9556 & TST & \\
\hline CHEMBL1972339 & 809202 & 6.2 & 6.2461 & TRN & \\
\hline CHEMBL116070 & 809202 & 5.5 & 5.6536 & TST & \\
\hline CHEMBL1990821 & 809202 & 6.1 & 4.7939 & TST & \\
\hline CHEMBL1970314 & 809202 & 5.5 & 4.7464 & TRN & \\
\hline CHEMBL 2004871 & 809202 & 4.5 & 4.6703 & TRN & \\
\hline CHEMBL 2004872 & 809202 & 4.5 & 4.2952 & TRN & \\
\hline CHEMBL1969879 & 809202 & 4.5 & 4.2089 & TRN & \\
\hline CHEMBL1995932 & 809202 & 6.8 & 7.0729 & TRN & \\
\hline CHEMBL1981720 & 809202 & 5.6 & 5.692 & TRN & \\
\hline CHEMBL1967704 & 809202 & 6.0 & 5.7673 & TRN & \\
\hline CHEMBL419932 & 809202 & 4.5 & 4.6011 & TRN & \\
\hline CHEMBL262433 & 809202 & 4.5 & 5.1097 & TRN & \\
\hline CHEMBL 306380 & 809202 & 4.5 & 4.4633 & TRN & \\
\hline CHEMBL1966722 & 809202 & 4.5 & 5.3495 & TST & \\
\hline CHEMBL1983595 & 809202 & 6.9 & 7.2577 & TRN & \\
\hline CHEMBL1975500 & 809202 & 4.5 & 5.0579 & TRN & \\
\hline
\end{tabular}




\begin{tabular}{|c|c|c|c|c|}
\hline & & & & al Table \\
\hline CHEMBL394619 & 809202 & 4.5 & 5.2423 & TRN \\
\hline CHEMBL1996831 & 809202 & 4.5 & 4.881 & TST \\
\hline CHEMBL411903 & 809202 & 6.4 & 6.1201 & TRN \\
\hline CHEMBL1980253 & 809202 & 6.9 & 7.2541 & TRN \\
\hline CHEMBL1965988 & 809202 & 6.0 & 5.9364 & TRN \\
\hline CHEMBL1969221 & 809202 & 4.5 & 5.2995 & TRN \\
\hline CHEMBL418203 & 809202 & 4.4 & 4.6527 & TST \\
\hline CHEMBL1989646 & 809202 & 5.7 & 5.1745 & TRN \\
\hline CHEMBL225519 & 809202 & 6.7 & 5.9639 & TRN \\
\hline CHEMBL1978200 & 809202 & 4.5 & 4.548 & TRN \\
\hline CHEMBL1970522 & 809202 & 5.8 & 6.375 & TRN \\
\hline CHEMBL402846 & 809202 & 4.5 & 4.9492 & TRN \\
\hline CHEMBL1990415 & 809202 & 4.5 & 4.6696 & TRN \\
\hline CHEMBL1966087 & 809202 & 4.5 & 4.8982 & TRN \\
\hline CHEMBL1986767 & 809202 & 7.0 & 5.7096 & TRN \\
\hline CHEMBL1996931 & 809202 & 4.5 & 4.5663 & TRN \\
\hline CHEMBL1964692 & 809202 & 6.4 & 5.5609 & TRN \\
\hline CHEMBL1964413 & 809202 & 4.5 & 4.6182 & TRN \\
\hline CHEMBL1973483 & 809202 & 4.5 & 5.2066 & TRN \\
\hline CHEMBL1998470 & 809202 & 7.0 & 5.7353 & TRN \\
\hline CHEMBL1996980 & 809202 & 8.0 & 8.0166 & TRN \\
\hline CHEMBL1970735 & 809202 & 4.5 & 4.3779 & TRN \\
\hline CHEMBL1969920 & 809202 & 6.8 & 7.04200 & 0000000001 \\
\hline CHEMBL1997340 & 809202 & 4.5 & 4.6246 & TRN \\
\hline CHEMBL2004365 & 809202 & 4.5 & 5.4784 & TST \\
\hline CHEMBL1522508 & 809202 & 4.5 & 4.3216 & TRN \\
\hline CHEMBL1989474 & 809202 & 4.5 & 4.5369 & TRN \\
\hline CHEMBL1090360 & 809202 & 4.5 & 4.3362 & TRN \\
\hline CHEMBL 226232 & 809202 & 5.8 & 6.1067 & TRN \\
\hline CHEMBL 210887 & 809202 & 4.5 & 5.0141 & TST \\
\hline CHEMBL458997 & 809202 & 6.5 & 6.3383 & TRN \\
\hline CHEMBL1971021 & 809202 & 4.5 & 4.9023 & TRN \\
\hline CHEMBL227271 & 809202 & 7.4 & 7.2893 & TRN \\
\hline CHEMBL583144 & 809202 & 6.7 & 5.7865 & TST \\
\hline CHEMBL1974310 & 809202 & 6.4 & 6.0788 & TST \\
\hline CHEMBL1982660 & 809202 & 7.3 & 6.52 & TRN \\
\hline CHEMBL1994693 & 809202 & 4.5 & 5.2202 & TRN \\
\hline CHEMBL1982957 & 809202 & 4.5 & 4.8329 & TRN \\
\hline CHEMBL1725279 & 809202 & 6.7 & 6.3933 & TST \\
\hline CHEMBL 2002346 & 809202 & 7.0 & 7.2121 & TRN \\
\hline CHEMBL1975138 & 809202 & 4.5 & 5.5677 & TST \\
\hline CHEMBL424872 & 809202 & 4.5 & 4.6522 & TRN \\
\hline CHEMBL 2006836 & 809202 & 4.5 & 5.0722 & TST \\
\hline CHEMBL412142 & 809202 & 4.5 & 4.3763 & TST \\
\hline CHEMBL1985153 & 809202 & 4.5 & 5.9307 & TRN \\
\hline CHEMBL1980704 & 809202 & 4.5 & 4.8269 & TST \\
\hline CHEMBL 2003271 & 809202 & 6.3 & 6.2895 & TST \\
\hline CHEMBL1966808 & 809202 & 6.3 & 6.4707 & TST \\
\hline
\end{tabular}




\begin{tabular}{|c|c|c|c|c|}
\hline & & & & al T \\
\hline CHEMBL 2004447 & 809202 & 4.5 & 4.1274 & TST \\
\hline CHEMBL1992231 & 809202 & 6.3 & 7.0203 & TRN \\
\hline CHEMBL1983111 & 809202 & 6.3 & 6.2512 & TRN \\
\hline CHEMBL1973860 & 809202 & 4.5 & 4.7396 & TRN \\
\hline CHEMBL 260135 & 809202 & 4.5 & 4.4012 & TRN \\
\hline CHEMBL220241 & 809202 & 6.1 & 5.0785 & TST \\
\hline CHEMBL 2004544 & 809202 & 5.5 & 4.2832 & TST \\
\hline CHEMBL1983157 & 809202 & 6.4 & 6.3391 & TRN \\
\hline CHEMBL1982610 & 809202 & 5.6 & 5.3026 & TST \\
\hline CHEMBL1989569 & 809202 & 5.7 & 5.1388 & TRN \\
\hline CHEMBL1966040 & 809202 & 5.9 & 6.7775 & TRN \\
\hline CHEMBL1999496 & 809202 & 4.5 & 4.2991 & TRN \\
\hline CHEMBL1988300 & 809202 & 4.5 & 4.1543 & TRN \\
\hline CHEMBL1991078 & 809202 & 7.6 & 7.4172 & TRN \\
\hline CHEMBL1987359 & 809202 & 4.5 & 4.6088 & TST \\
\hline CHEMBL1994438 & 809202 & 6.9 & 7.181 & TRN \\
\hline CHEMBL1989265 & 809202 & 4.5 & 4.8558 & TST \\
\hline CHEMBL1969502 & 809202 & 4.5 & 5.2108 & TRN \\
\hline CHEMBL1996447 & 809202 & 6.1 & 6.3461 & TRN \\
\hline CHEMBL1682553 & 809202 & 6.4 & 5.9344 & TRN \\
\hline CHEMBL1971430 & 809202 & 4.5 & $4.0710 e$ & 0000000001 \\
\hline CHEMBL1983963 & 809202 & 4.5 & 5.5498 & TRN \\
\hline CHEMBL1997764 & 809202 & 4.5 & 4.8814 & TRN \\
\hline CHEMBL1985092 & 809202 & 4.5 & 5.4672 & TST \\
\hline CHEMBL 2004692 & 809202 & 4.5 & 3.7347 & TST \\
\hline CHEMBL1981410 & 809202 & 5.7 & 5.4445 & TRN \\
\hline CHEMBL1996234 & 809202 & 4.5 & 3.9433 & TRN \\
\hline CHEMBL1991434 & 809202 & 4.5 & 5.6436 & TST \\
\hline CHEMBL1967544 & 809202 & 4.5 & 4.8586 & TRN \\
\hline CHEMBL223367 & 809202 & 4.5 & 5.2897 & TST \\
\hline CHEMBL340384 & 809202 & 4.5 & 4.9477 & TRN \\
\hline CHEMBL1969151 & 809202 & 7.2 & 7.5296 & TRN \\
\hline CHEMBL1996587 & 809202 & 4.5 & 4.1424 & TRN \\
\hline CHEMBL1964804 & 809202 & 5.5 & 5.1124 & TRN \\
\hline CHEMBL443962 & 809202 & 4.5 & 5.1983 & TST \\
\hline CHEMBL 2000354 & 809202 & 6.8 & 6.9235 & TRN \\
\hline CHEMBL1965507 & 809202 & 4.4 & 4.8909 & TRN \\
\hline CHEMBL274064 & 809202 & 4.5 & 5.3149 & TRN \\
\hline CHEMBL1967564 & 809202 & 4.5 & 4.3656 & TRN \\
\hline CHEMBL592030 & 809202 & 6.2 & 6.4889 & TST \\
\hline CHEMBL 2000071 & 809202 & 5.5 & 5.0452 & TRN \\
\hline CHEMBL1979176 & 809202 & 4.5 & 5.5104 & TRN \\
\hline CHEMBL1970317 & 809202 & 5.6 & 5.7866 & TRN \\
\hline CHEMBL 2002613 & 809202 & 7.0 & 6.9069 & TRN \\
\hline CHEMBL 2000408 & 809202 & 4.5 & 4.7373 & TRN \\
\hline CHEMBL 248757 & 809202 & 4.5 & 4.4735 & TST \\
\hline CHEMBL1978014 & 809202 & 4.5 & 4.6708 & TRN \\
\hline CHEMBL1974250 & 809202 & 7.7 & 6.4375 & TRN \\
\hline
\end{tabular}




\begin{tabular}{|c|c|c|c|c|c|}
\hline \multicolumn{6}{|c|}{ Supplemental Table S2.txt } \\
\hline CHEMBL1994538 & 809202 & 4.6 & 4.6435 & TRN & \\
\hline CHEMBL1983195 & 809202 & 4.5 & 4.647 & TST & \\
\hline CHEMBL1975490 & 809202 & 6.1 & 5.4659 & TRN & \\
\hline CHEMBL1964444 & 809202 & 6.1 & 5.817 & TRN & \\
\hline CHEMBL1986139 & 809202 & 4.5 & 5.0246 & TRN & \\
\hline CHEMBL1980540 & 809202 & 4.5 & 5.0653 & TRN & \\
\hline CHEMBL 2003229 & 809202 & 5.7 & 6.0654 & TRN & \\
\hline CHEMBL1979883 & 809202 & 6.0 & 5.6032 & TRN & \\
\hline CHEMBL1984162 & 809202 & 7.3 & 6.0139 & TRN & \\
\hline CHEMBL1988331 & 809202 & 6.4 & 6.9189 & TRN & \\
\hline CHEMBL1998432 & 809202 & 7.2 & 7.62299 & 9999999999 & TRN \\
\hline CHEMBL491758 & 809202 & 4.5 & 5.1955 & TRN & \\
\hline CHEMBL549730 & 809202 & 4.5 & 4.7023 & TRN & \\
\hline CHEMBL1998826 & 809202 & 4.5 & 5.9554 & TRN & \\
\hline CHEMBL1970189 & 809202 & 4.5 & 4.2705 & TST & \\
\hline CHEMBL1996791 & 809202 & 5.9 & 5.3448 & TRN & \\
\hline CHEMBL371206 & 809202 & 6.7 & 5.9182 & TRN & \\
\hline CHEMBL1974664 & 809202 & 4.5 & 4.5785 & TST & \\
\hline CHEMBL1974288 & 809202 & 4.5 & 4.4078 & TRN & \\
\hline CHEMBL 213207 & 809202 & 7.8 & 7.1462 & TRN & \\
\hline CHEMBL196363 & 809202 & 4.5 & 4.9486 & TRN & \\
\hline CHEMBL1190711 & 809202 & 6.3 & 5.4615 & TRN & \\
\hline CHEMBL1968705 & 809202 & 4.5 & 4.6266 & TRN & \\
\hline CHEMBL1991410 & 809202 & 4.4 & 5.0551 & TRN & \\
\hline CHEMBL404367 & 809202 & 4.5 & 5.2391 & TRN & \\
\hline CHEMBL1966343 & 809202 & 5.7 & 5.5383 & TRN & \\
\hline CHEMBL1967887 & 809202 & 5.5 & 5.9231 & TRN & \\
\hline CHEMBL 2000568 & 809202 & 4.5 & 4.842 & TRN & \\
\hline CHEMBL2000335 & 809202 & 6.9 & 5.8047 & TRN & \\
\hline CHEMBL1993648 & 809202 & 6.0 & 6.2172 & TRN & \\
\hline CHEMBL1988717 & 809202 & 6.5 & 5.6934 & TRN & \\
\hline CHEMBL1974328 & 809202 & 6.1 & 6.4157 & TRN & \\
\hline CHEMBL509032 & 809202 & 4.5 & 5.1192 & TRN & \\
\hline CHEMBL243298 & 809202 & 8.2 & 6.8495 & TRN & \\
\hline CHEMBL573339 & 809202 & 5.6 & 4.935 & TST & \\
\hline CHEMBL1971951 & 809202 & 4.5 & 5.8065 & TRN & \\
\hline CHEMBL1973808 & 809202 & 4.5 & 4.4106 & TRN & \\
\hline CHEMBL 2000429 & 809202 & 4.5 & 4.7757 & TRN & \\
\hline CHEMBL1972576 & 809202 & 4.5 & 4.4543 & TRN & \\
\hline CHEMBL1992555 & 809202 & 4.5 & 4.2511 & TST & \\
\hline CHEMBL1990254 & 809202 & 4.5 & 4.3376 & TRN & \\
\hline CHEMBL1992342 & 809202 & 4.5 & 4.4111 & TRN & \\
\hline CHEMBL 2003682 & 809202 & 6.2 & 6.1188 & TRN & \\
\hline CHEMBL1988173 & 809202 & 6.2 & 5.7924 & TST & \\
\hline CHEMBL1989805 & 809202 & 4.5 & 5.0988 & TST & \\
\hline CHEMBL1966204 & 809202 & 7.6 & 8.0419 & TRN & \\
\hline CHEMBL1982980 & 809202 & 6.2 & 4.9155 & TST & \\
\hline CHEMBL1965423 & 809202 & 4.5 & 4.5597 & TRN & \\
\hline
\end{tabular}




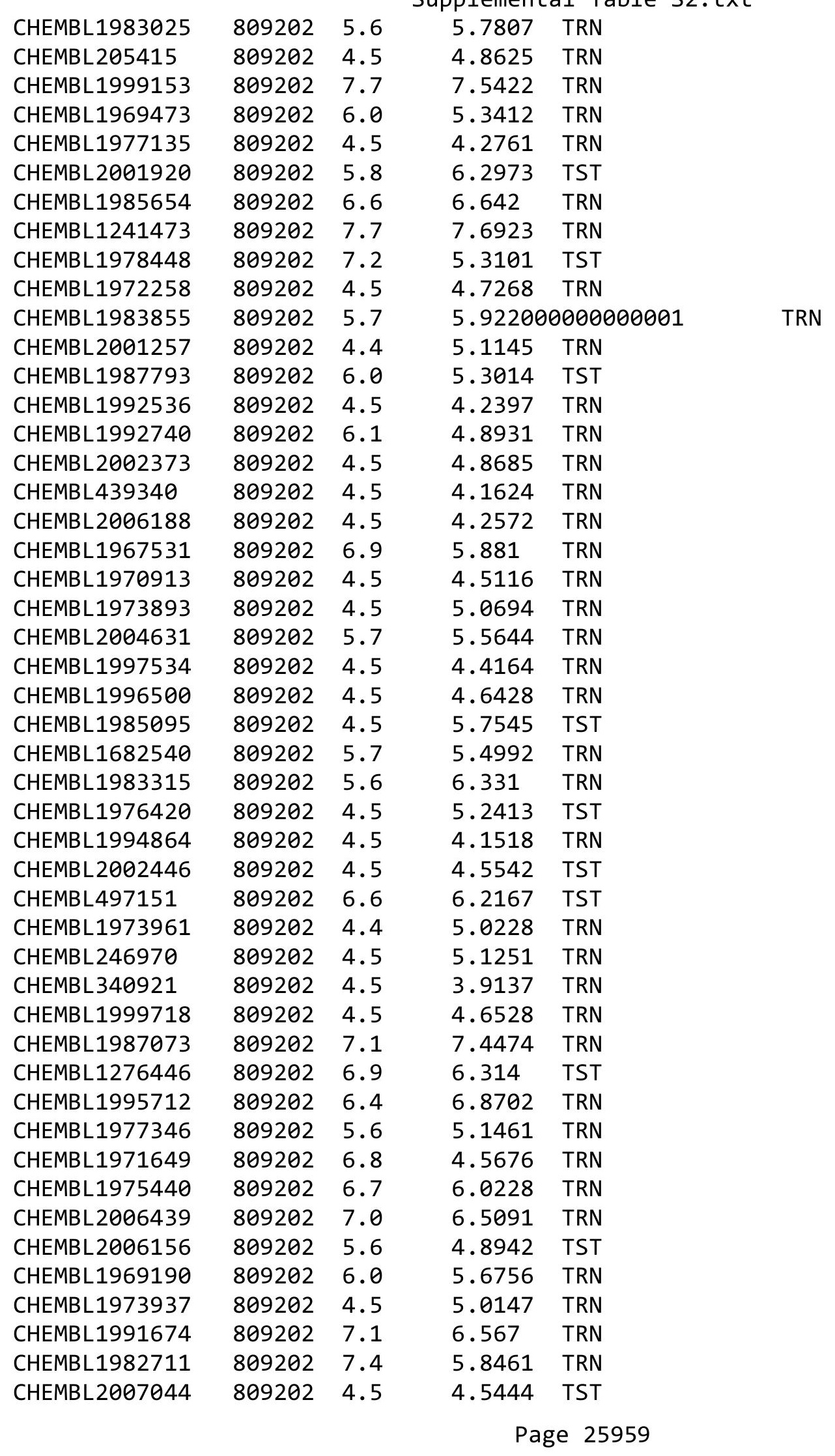




\begin{tabular}{|c|c|c|c|c|c|}
\hline & & & 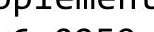 & 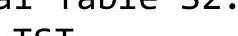 & \\
\hline CHEMBL1994241 & 809202 & 7.0 & 6.0259 & TST & \\
\hline CHEMBL223460 & 809202 & 4.5 & 4.6671 & TST & \\
\hline CHEMBL1998829 & 809202 & 4.5 & 4.0816 & TRN & \\
\hline CHEMBL50894 & 809202 & 4.5 & 5.3248 & TST & \\
\hline CHEMBL1988838 & 809202 & 5.7 & 5.892 & TRN & \\
\hline CHEMBL1981725 & 809202 & 6.0 & 5.2264 & TRN & \\
\hline CHEMBL1980562 & 809202 & 7.1 & 6.9934 & TRN & \\
\hline CHEMBL1982866 & 809202 & 4.5 & 4.2101 & TRN & \\
\hline CHEMBL2004156 & 809202 & 6.3 & 5.8274 & TST & \\
\hline CHEMBL1968926 & 809202 & 4.5 & 4.5433 & TRN & \\
\hline CHEMBL462120 & 809202 & 4.5 & 4.721 & TST & \\
\hline CHEMBL1979933 & 809202 & 7.4 & 7.115 & TRN & \\
\hline CHEMBL1965570 & 809202 & 6.6 & 5.7044 & TRN & \\
\hline CHEMBL2007592 & 809202 & 5.7 & 5.3291 & TST & \\
\hline CHEMBL1976936 & 809202 & 6.8 & 6.8266 & TRN & \\
\hline CHEMBL210963 & 809202 & 4.5 & 4.1716 & TRN & \\
\hline CHEMBL2005387 & 809202 & 6.9 & 6.9941 & TRN & \\
\hline CHEMBL1082440 & 809202 & 4.5 & 4.5602 & TST & \\
\hline CHEMBL1614705 & 809202 & 4.5 & 4.6158 & TRN & \\
\hline CHEMBL1982400 & 809202 & 7.5 & 7.0146 & TRN & \\
\hline CHEMBL1984633 & 809202 & 4.5 & 4.5474 & TRN & \\
\hline CHEMBL1972988 & 809202 & 6.3 & 6.0264 & TRN & \\
\hline CHEMBL 2007372 & 809202 & 4.5 & 4.3566 & TRN & \\
\hline CHEMBL1965845 & 809202 & 6.9 & 5.3731 & TRN & \\
\hline CHEMBL2006715 & 809202 & 4.5 & 4.5011 & TRN & \\
\hline CHEMBL1986597 & 809202 & 5.5 & 4.9537 & TRN & \\
\hline CHEMBL1990482 & 809202 & 4.5 & 4.9304 & TRN & \\
\hline CHEMBL1990904 & 809202 & 4.5 & 4.2821 & TRN & \\
\hline CHEMBL1987448 & 809202 & 8.2 & 7.4563 & TRN & \\
\hline CHEMBL2005475 & 809202 & 5.8 & 5.6648 & TRN & \\
\hline CHEMBL1997349 & 809202 & 5.7 & 5.6076 & TST & \\
\hline CHEMBL183844 & 809202 & 4.5 & 4.2835 & TRN & \\
\hline CHEMBL220057 & 809202 & 4.5 & 4.9337 & TRN & \\
\hline CHEMBL1682545 & 809202 & 4.5 & 4.5047 & TRN & \\
\hline CHEMBL383541 & 809202 & 4.5 & 4.6109 & TRN & \\
\hline CHEMBL2001224 & 809202 & 4.5 & 3.9798 & TRN & \\
\hline CHEMBL10 & 809202 & 4.5 & 4.6301 & TRN & \\
\hline CHEMBL1982982 & 809202 & 4.5 & 5.0251 & TRN & \\
\hline CHEMBL1976732 & 809202 & 4.5 & 4.5738 & TRN & \\
\hline CHEMBL2005216 & 809202 & 6.8 & 6.8056 & TRN & \\
\hline CHEMBL1969506 & 809202 & 4.5 & 4.3051 & TRN & \\
\hline CHEMBL1964937 & 809202 & 5.5 & 5.3464 & TRN & \\
\hline CHEMBL1980163 & 809202 & 4.5 & 4.4481 & TRN & \\
\hline CHEMBL2005899 & 809202 & 4.5 & 4.5551 & TRN & \\
\hline CHEMBL1682552 & 809202 & 6.6 & 6.1305 & TRN & \\
\hline CHEMBL1986851 & 809202 & 6.6 & 5.46399 & 99999999995 & TRN \\
\hline CHEMBL1987745 & 809202 & 5.9 & 5.52 & TRN & \\
\hline \multirow[t]{2}{*}{ CHEMBL229799 } & 809202 & 7.1 & 7.6141 & TRN & \\
\hline & & \multicolumn{4}{|c|}{ Page 25960} \\
\hline
\end{tabular}




\begin{tabular}{|c|c|c|c|c|c|}
\hline & & \multicolumn{4}{|c|}{ Supplemental Table S2.txt } \\
\hline CHEMBL105739 & 809202 & 4.5 & \multicolumn{2}{|c|}{4.8469999999999995} & TRN \\
\hline CHEMBL379300 & 809202 & 7.1 & 7.3179 & TRN & \\
\hline CHEMBL1973720 & 809202 & 7.4 & 7.8483 & TRN & \\
\hline CHEMBL1969523 & 809202 & 4.5 & \multicolumn{2}{|c|}{5.4670000000000005} & TRN \\
\hline CHEMBL1986781 & 809202 & 4.5 & 4.6433 & TRN & \\
\hline CHEMBL526133 & 809202 & 6.8 & 6.2223 & TRN & \\
\hline CHEMBL1979057 & 809202 & 5.6 & 5.75 & TRN & \\
\hline CHEMBL387971 & 809202 & 4.5 & 4.4324 & TST & \\
\hline CHEMBL1164180 & 809202 & 4.4 & 4.4899 & TST & \\
\hline CHEMBL1999428 & 809202 & 4.5 & 4.0441 & TRN & \\
\hline CHEMBL1967560 & 809202 & 4.5 & 4.5186 & TRN & \\
\hline CHEMBL1516890 & 809202 & 5.6 & \multicolumn{2}{|c|}{6.2139999999999995} & TST \\
\hline CHEMBL 211378 & 809202 & 4.5 & 4.8478 & TRN & \\
\hline CHEMBL1682358 & 809202 & 5.8 & 5.5378 & TRN & \\
\hline CHEMBL1982465 & 809202 & 4.5 & 5.1202 & TRN & \\
\hline CHEMBL 2001751 & 809202 & 7.4 & 6.9109 & TRN & \\
\hline CHEMBL 2003420 & 809202 & 4.5 & 4.5513 & TRN & \\
\hline CHEMBL1984586 & 809202 & 6.5 & 5.6759 & TRN & \\
\hline CHEMBL1972659 & 809202 & 4.5 & 4.4117 & TST & \\
\hline CHEMBL 272453 & 809202 & 6.5 & 5.7356 & TRN & \\
\hline CHEMBL1970217 & 809202 & 4.5 & 4.8436 & TRN & \\
\hline CHEMBL 2005528 & 809202 & 4.5 & 5.4775 & TST & \\
\hline CHEMBL185569 & 809202 & 4.5 & 5.2906 & TRN & \\
\hline CHEMBL1969843 & 809202 & 4.5 & 5.2393 & TRN & \\
\hline CHEMBL 2007002 & 809202 & 4.5 & 4.6354 & TRN & \\
\hline CHEMBL1987007 & 809202 & 4.5 & 4.7165 & TRN & \\
\hline CHEMBL1969588 & 809202 & 7.2 & 7.4718 & TRN & \\
\hline CHEMBL1984711 & 809202 & 4.5 & 4.7481 & TRN & \\
\hline CHEMBL484390 & 809202 & 4.5 & 4.9814 & TST & \\
\hline CHEMBL1979252 & 809202 & 4.5 & 4.6587 & TRN & \\
\hline CHEMBL 2004290 & 809202 & 4.5 & 5.4331 & TRN & \\
\hline CHEMBL1986499 & 809202 & 4.5 & 4.8608 & TRN & \\
\hline CHEMBL1972937 & 809202 & 5.8 & 5.6998 & TRN & \\
\hline CHEMBL 2000393 & 809202 & 4.5 & 4.6342 & TST & \\
\hline CHEMBL 2001477 & 809202 & 4.5 & 4.5819 & TRN & \\
\hline CHEMBL 2004311 & 809202 & 4.5 & 4.9566 & TRN & \\
\hline CHEMBL1992634 & 809202 & 6.0 & 5.3793 & TRN & \\
\hline CHEMBL1242373 & 809202 & 4.5 & 5.1835 & TRN & \\
\hline CHEMBL316264 & 809202 & 4.5 & 4.6265 & TRN & \\
\hline CHEMBL1988075 & 809202 & 6.8 & 5.4703 & TRN & \\
\hline CHEMBL1991678 & 809202 & 4.5 & 4.5266 & TRN & \\
\hline CHEMBL 2001239 & 809202 & 4.5 & 5.1266 & TST & \\
\hline CHEMBL1988594 & 809202 & 6.0 & 5.1579 & TRN & \\
\hline CHEMBL 2001288 & 809202 & 4.5 & 5.4751 & TRN & \\
\hline CHEMBL1992363 & 809202 & 7.9 & 8.1102 & TRN & \\
\hline CHEMBL1999811 & 809202 & 6.6 & 5.2459 & TST & \\
\hline CHEMBL1985074 & 809202 & 5.8 & 5.6282 & TST & \\
\hline CHEMBL1982874 & 809202 & 4.5 & 4.5749 & TRN & \\
\hline
\end{tabular}




\begin{tabular}{|c|c|c|c|c|c|}
\hline \\
\hline CHEMBL 2000481 & 809202 & 4.5 & 5.3707 & TRN & \\
\hline CHEMBL1991725 & 809202 & 4.5 & 4.5971 & TRN & \\
\hline CHEMBL1992242 & 809202 & 4.5 & 4.6946 & TRN & \\
\hline CHEMBL1982271 & 809202 & 7.5 & 7.5684 & TRN & \\
\hline CHEMBL 2007296 & 809202 & 4.5 & 4.9067 & TRN & \\
\hline CHEMBL208637 & 809202 & 4.5 & 4.3324 & TRN & \\
\hline CHEMBL396523 & 809202 & 7.9 & 7.6099 & TRN & \\
\hline CHEMBL1970203 & 809202 & 4.5 & 5.1542 & TRN & \\
\hline CHEMBL1986530 & 809202 & 4.5 & 4.6897 & TST & \\
\hline CHEMBL1999321 & 809202 & 4.5 & 4.0863 & TRN & \\
\hline CHEMBL 385478 & 809202 & 8.2 & 7.6923 & TRN & \\
\hline CHEMBL1968590 & 809202 & 4.5 & 4.2054 & TRN & \\
\hline CHEMBL2005375 & 809202 & 4.5 & 4.4372 & TRN & \\
\hline CHEMBL1984191 & 809202 & 4.5 & 4.2854 & TRN & \\
\hline CHEMBL1971029 & 809202 & 5.7 & 5.8299 & TRN & \\
\hline CHEMBL 394790 & 809202 & 5.7 & 5.2582 & TRN & \\
\hline CHEMBL1980592 & 809202 & 5.7 & 6.0732 & TST & \\
\hline CHEMBL226471 & 809202 & 4.5 & 5.4002 & TRN & \\
\hline CHEMBL1974702 & 809202 & 7.0 & 5.2878 & TST & \\
\hline CHEMBL1996111 & 809202 & 4.5 & 3.9731 & TRN & \\
\hline CHEMBL1965589 & 809202 & 4.5 & 4.5043 & TRN & \\
\hline CHEMBL1998193 & 809202 & 4.5 & 4.5057 & TRN & \\
\hline CHEMBL379975 & 809202 & 7.5 & 6.314 & TST & \\
\hline CHEMBL474432 & 809202 & 4.5 & 6.0199 & TST & \\
\hline CHEMBL1988153 & 809202 & 5.6 & 5.8762 & TST & \\
\hline CHEMBL2003637 & 809202 & 7.9 & 6.426 & TST & \\
\hline CHEMBL1986666 & 809202 & 6.8 & 7.4392 & TRN & \\
\hline CHEMBL1988437 & 809202 & 4.5 & 4.4231 & TST & \\
\hline CHEMBL1979577 & 809202 & 6.1 & 5.9719 & TRN & \\
\hline CHEMBL1998121 & 809202 & 6.2 & 5.6796 & TRN & \\
\hline CHEMBL1991800 & 809202 & 4.5 & 4.5936 & TRN & \\
\hline CHEMBL52387 & 809202 & 4.5 & 5.4029 & TST & \\
\hline CHEMBL379835 & 809202 & 4.5 & 4.2384 & TST & \\
\hline CHEMBL1979357 & 809202 & 4.5 & 4.5893 & TRN & \\
\hline CHEMBL1996649 & 809202 & 7.1 & 5.7787 & TRN & \\
\hline CHEMBL1989006 & 809202 & 7.1 & 7.1405 & TRN & \\
\hline CHEMBL1996817 & 809202 & 7.0 & 6.4066 & TRN & \\
\hline CHEMBL3197315 & 809202 & 4.5 & 3.7924 & TST & \\
\hline CHEMBL468280 & 809202 & 4.5 & 5.2661 & TST & \\
\hline CHEMBL1990884 & 809202 & 4.5 & 4.3801 & TRN & \\
\hline CHEMBL1996339 & 809202 & 7.3 & 7.28299 & 99999999995 & TRN \\
\hline CHEMBL3109278 & 809202 & 6.6 & 6.3357 & TRN & \\
\hline CHEMBL256835 & 809202 & 4.5 & 4.8336 & TRN & \\
\hline CHEMBL1980142 & 809202 & 4.5 & 4.7 & TRN & \\
\hline CHEMBL41783 & 809202 & 5.6 & 4.6411 & TRN & \\
\hline CHEMBL2006276 & 809202 & 4.5 & 4.7374 & TRN & \\
\hline CHEMBL271381 & 809202 & 4.5 & 5.6733 & TRN & \\
\hline CHEMBL2006785 & 809202 & 5.8 & 5.1002 & TST & \\
\hline & & & & 25962 & \\
\hline
\end{tabular}




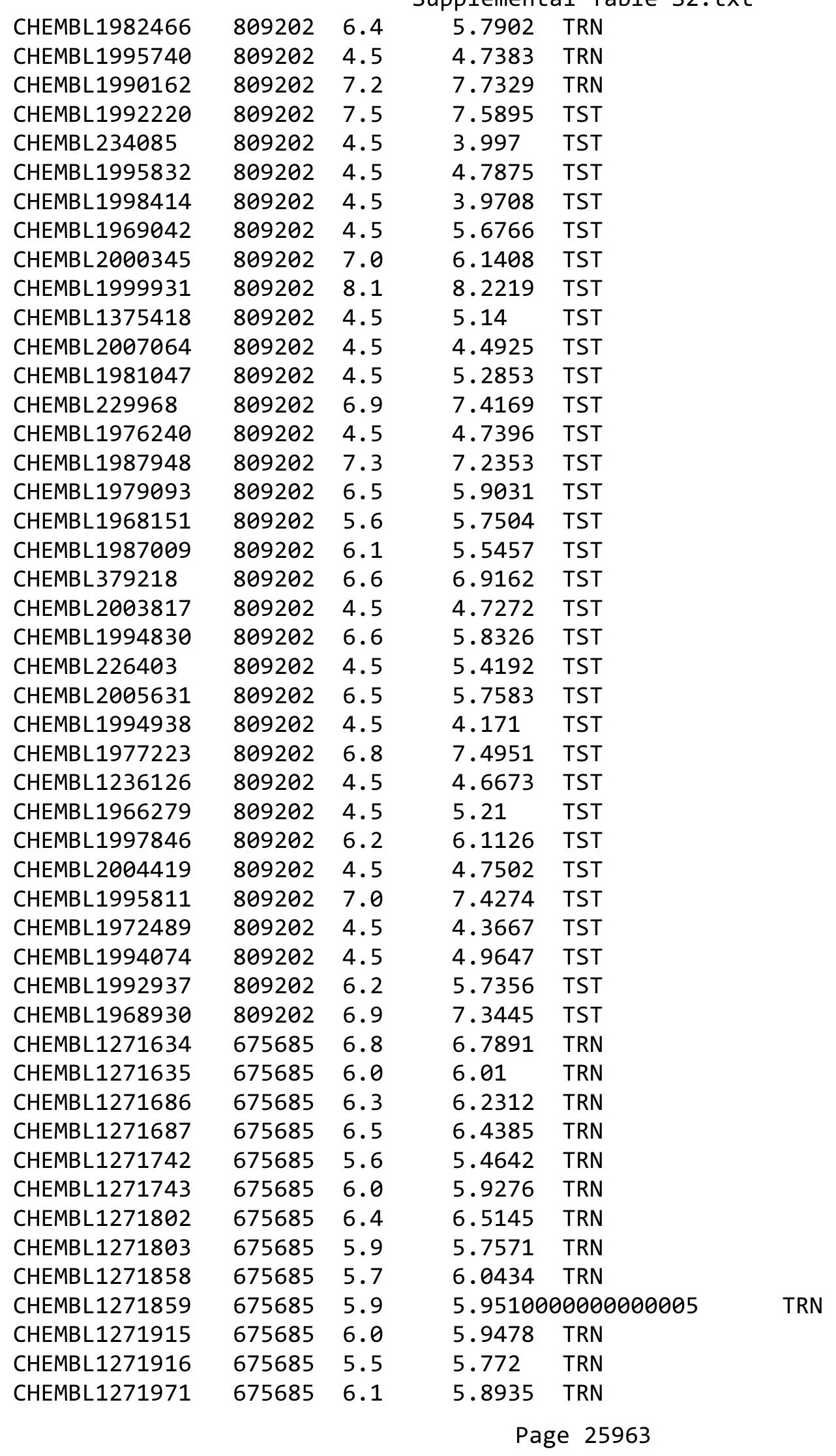




\begin{tabular}{|c|c|c|c|c|}
\hline \multicolumn{5}{|c|}{ Supplemental Table S2.txt } \\
\hline CHEMBL1271972 & 675685 & 6.4 & 6.3775 & TRN \\
\hline CHEMBL1272028 & 675685 & 6.1 & 6.0687 & TRN \\
\hline CHEMBL1272029 & 675685 & 6.8 & 6.7614 & TRN \\
\hline CHEMBL1272083 & 675685 & 6.9 & 6.8954 & TRN \\
\hline CHEMBL1272084 & 675685 & 5.3 & 5.2587 & TRN \\
\hline CHEMBL1272133 & 675685 & 6.1 & 6.2235 & TRN \\
\hline CHEMBL1272134 & 675685 & 5.4 & 5.4418 & TRN \\
\hline CHEMBL1272185 & 675685 & 6.2 & 6.1795 & TRN \\
\hline CHEMBL1272186 & 675685 & 5.8 & 5.8771 & TRN \\
\hline CHEMBL1272240 & 675685 & 6.0 & 5.8603 & TRN \\
\hline CHEMBL1272241 & 675685 & 6.0 & 6.1014 & TRN \\
\hline CHEMBL1272295 & 675685 & 6.4 & 6.4973 & TRN \\
\hline CHEMBL1272296 & 675685 & 3.6 & 3.6943 & TRN \\
\hline CHEMBL1271475 & 675685 & 6.6 & 6.6405 & TRN \\
\hline CHEMBL1271476 & 675685 & 7.3 & 7.2297 & TRN \\
\hline CHEMBL1271527 & 675685 & 7.2 & 7.1719 & TRN \\
\hline CHEMBL1271528 & 675685 & 3.6 & 3.5267 & TRN \\
\hline CHEMBL1271583 & 675685 & 3.6 & 3.5135 & TRN \\
\hline CHEMBL1271584 & 675685 & 3.6 & 3.4992 & TRN \\
\hline CHEMBL1271636 & 675685 & 3.6 & 3.7041 & TRN \\
\hline CHEMBL1271637 & 675685 & 3.6 & 3.7322 & TRN \\
\hline CHEMBL1271688 & 675685 & 5.5 & 5.2409 & TRN \\
\hline CHEMBL1271689 & 675685 & 3.6 & 3.622 & TRN \\
\hline CHEMBL1271744 & 675685 & 3.6 & 3.5711 & TRN \\
\hline CHEMBL1269038 & 675685 & 3.6 & 3.6818 & TRN \\
\hline CHEMBL1271804 & 675685 & 3.6 & 5.2308 & TST \\
\hline CHEMBL1271805 & 675685 & 3.6 & 3.5895 & TRN \\
\hline CHEMBL1271860 & 675685 & 3.6 & 5.5319 & TST \\
\hline CHEMBL1271861 & 675685 & 3.6 & 6.9195 & TST \\
\hline CHEMBL1271917 & 675685 & 5.9 & 6.8263 & TST \\
\hline CHEMBL1271918 & 675685 & 6.7 & 7.4397 & TST \\
\hline CHEMBL1271973 & 675685 & 6.3 & 6.603 & TST \\
\hline CHEMBL1271974 & 675685 & 5.9 & 6.3643 & TST \\
\hline CHEMBL1272030 & 675685 & 6.9 & 6.9136 & TST \\
\hline CHEMBL1272031 & 675685 & 6.7 & 6.4439 & TST \\
\hline CHEMBL1272085 & 675685 & 6.9 & 7.1256 & TST \\
\hline CHEMBL1272086 & 675685 & 7.0 & 6.6162 & TST \\
\hline CHEMBL1272135 & 675685 & 7.6 & 6.8529 & TST \\
\hline CHEMBL1272136 & 675685 & 8.2 & 7.3472 & TST \\
\hline CHEMBL3261508 & 1350155 & 2.9031 & 3.0442 & TRN \\
\hline CHEMBL3261494 & 1350155 & 5.7721 & 5.7467 & TRN \\
\hline CHEMBL3261490 & 1350155 & 5.0467 & 5.026 & TRN \\
\hline CHEMBL3261241 & 1350155 & 6.0119 & 5.8157 & TRN \\
\hline CHEMBL3261514 & 1350155 & 8.4237 & 8.4608 & TRN \\
\hline CHEMBL 3261230 & 1350155 & 5.3768 & 5.4872 & TRN \\
\hline CHEMBL65312 & 1350155 & 4.3307 & 3.9029 & TRN \\
\hline CHEMBL3261488 & 1350155 & 6.9393 & 6.8248 & TRN \\
\hline CHEMBL3261240 & 1350155 & 6.3458 & 6.5415 & TRN \\
\hline
\end{tabular}


Supplemental Table S2.txt

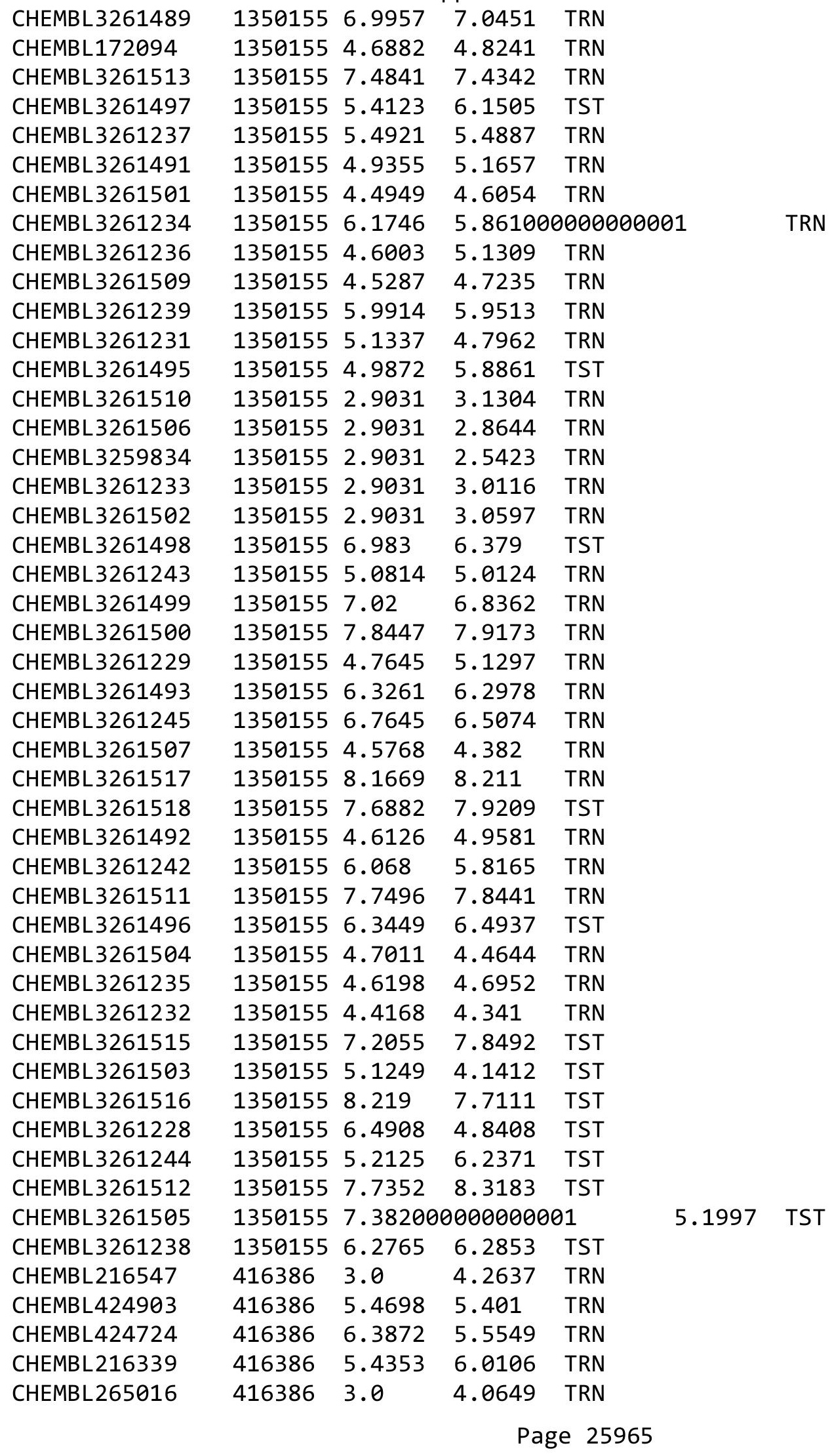




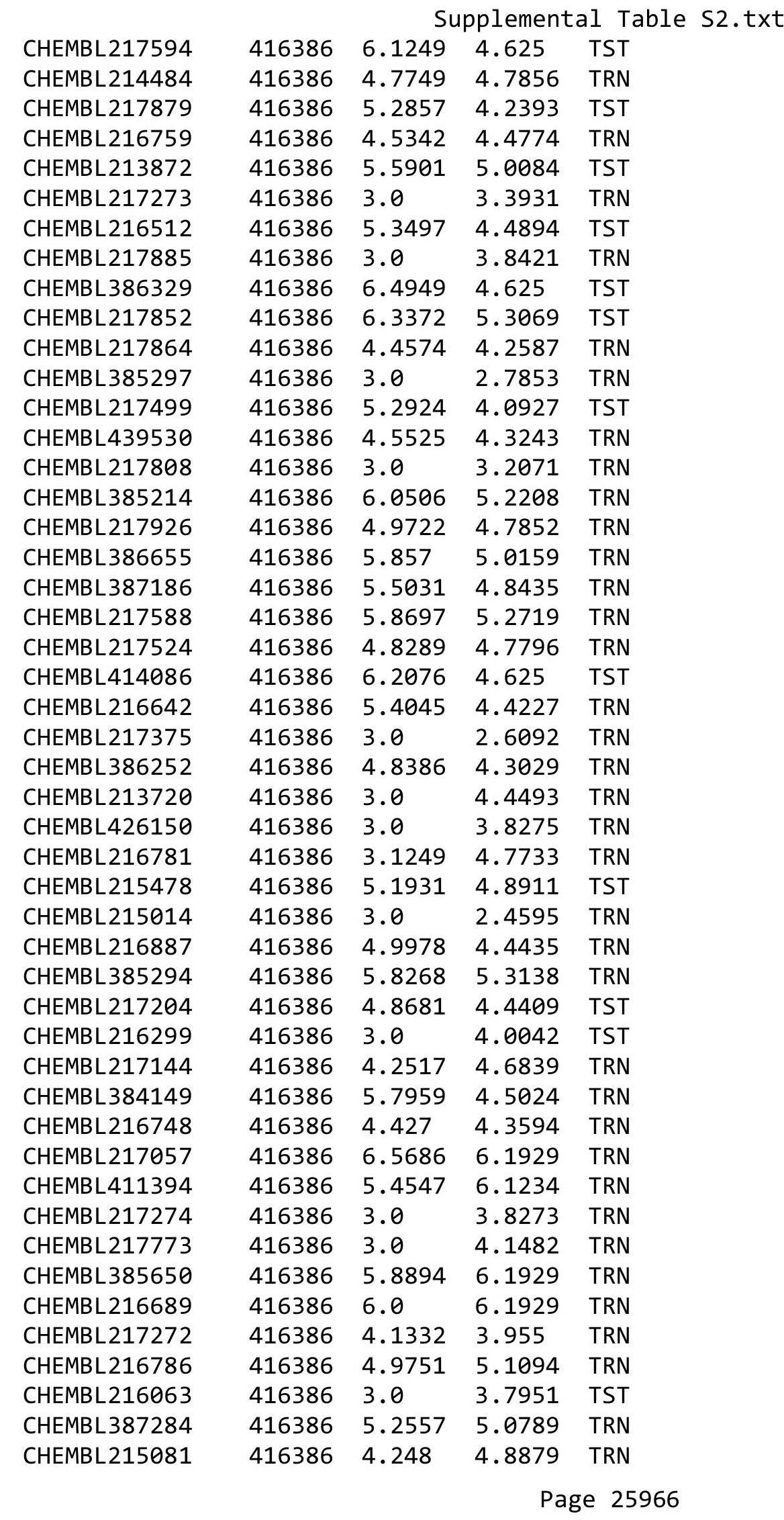


Supplemental Table S2.txt

\begin{tabular}{|c|c|c|c|c|}
\hline CHEMBL426702 & 416386 & 6.0706 & 4.4686 & TST \\
\hline CHEMBL425259 & 416386 & 6.0132 & 4.5376 & TRN \\
\hline CHEMBL386324 & 416386 & 6.0706 & 6.3146 & TRN \\
\hline CHEMBL274325 & 416386 & 3.0 & \multicolumn{2}{|c|}{2.7680000000000002} \\
\hline CHEMBL444361 & 416386 & 4.636 & 3.6353 & TRN \\
\hline CHEMBL216704 & 416386 & 5.8861 & 5.8614 & TRN \\
\hline CHEMBL415226 & 416386 & 3.0 & 3.8499 & TST \\
\hline CHEMBL217617 & 416386 & 4.5035 & 4.5038 & TRN \\
\hline CHEMBL262471 & 416386 & 5.2588 & 4.4266 & TST \\
\hline CHEMBL3674685 & 1527803 & 6.0 & 5.8919 & TRN \\
\hline CHEMBL3674724 & 1527803 & 6.0 & 7.2674 & TRN \\
\hline CHEMBL3674722 & 1527803 & 7.2233 & 7.3281 & TRN \\
\hline CHEMBL 2392828 & 1527803 & 6.0 & 6.0359 & TRN \\
\hline CHEMBL 3674725 & 1527803 & 7.6615 & 7.3678 & TRN \\
\hline CHEMBL3674723 & 1527803 & 7.8069 & 7.3426 & TRN \\
\hline CHEMBL3674716 & 1527803 & 6.3647 & 6.1037 & TRN \\
\hline CHEMBL3674687 & 1527803 & 6.0 & 6.0539 & TRN \\
\hline CHEMBL 3674711 & 1527803 & 6.0 & 6.0368 & TRN \\
\hline CHEMBL 2392840 & 1527803 & 7.9318 & 7.3098 & TRN \\
\hline CHEMBL3674712 & 1527803 & 6.392 & 6.2306 & TRN \\
\hline CHEMBL 2392837 & 1527803 & 6.0 & 6.5305 & TRN \\
\hline CHEMBL 3674715 & 1527803 & 6.0 & 6.0707 & TRN \\
\hline CHEMBL 3674713 & 1527803 & 7.4559 & 6.2808 & TRN \\
\hline CHEMBL3674695 & 1527803 & 6.0 & 6.1236 & TRN \\
\hline CHEMBL 2392833 & 1527803 & 6.0 & 6.1576 & TRN \\
\hline CHEMBL3674683 & 1527803 & 6.0 & 5.9873 & TRN \\
\hline CHEMBL3674696 & 1527803 & 6.0 & 6.0195 & TRN \\
\hline CHEMBL3674703 & 1527803 & 7.0825 & 7.0952 & TRN \\
\hline CHEMBL 3674702 & 1527803 & 6.2798 & 6.1203 & TRN \\
\hline CHEMBL3674697 & 1527803 & 6.0 & 6.0145 & TRN \\
\hline CHEMBL 3674720 & 1527803 & 7.5287 & 7.28 & TRN \\
\hline CHEMBL3674728 & 1527803 & 6.0 & 6.9288 & TST \\
\hline CHEMBL 3674714 & 1527803 & 6.0 & 6.0105 & TRN \\
\hline CHEMBL3674688 & 1527803 & 6.0 & 5.9391 & TRN \\
\hline CHEMBL3674727 & 1527803 & 6.0 & 6.0193 & TRN \\
\hline CHEMBL3674693 & 1527803 & 6.0 & 6.5455 & TRN \\
\hline CHEMBL3674707 & 1527803 & 6.0 & 6.0811 & TRN \\
\hline CHEMBL 2392832 & 1527803 & 6.0 & 6.4581 & TST \\
\hline CHEMBL 3674684 & 1527803 & 6.0 & 6.0201 & TST \\
\hline CHEMBL3674699 & 1527803 & 6.0 & 6.2412 & TRN \\
\hline CHEMBL 2392834 & 1527803 & 6.0 & 6.3147 & TRN \\
\hline CHEMBL3674730 & 1527803 & 6.0 & 6.0651 & TRN \\
\hline CHEMBL3674718 & 1527803 & 7.4763 & 6.1549 & TRN \\
\hline CHEMBL3674686 & 1527803 & 6.0 & 6.1965 & TRN \\
\hline CHEMBL 3674690 & 1527803 & 6.0 & 6.2587 & TRN \\
\hline CHEMBL3674698 & 1527803 & 6.0 & 6.1596 & TRN \\
\hline CHEMBL 3674719 & 1527803 & 7.4437 & 7.1331 & TRN \\
\hline CHEMBL3674692 & 1527803 & 6.0 & 6.2273 & TRN \\
\hline
\end{tabular}


Supplemental Table S2.txt

\begin{tabular}{|c|c|c|c|c|}
\hline CHEMBL3674726 & 1527803 & 7.8182 & 7.2943 & TRN \\
\hline CHEMBL3674694 & 1527803 & 6.0 & 6.8555 & TST \\
\hline CHEMBL3674706 & 1527803 & 6.0 & 6.1388 & TRN \\
\hline CHEMBL 2392838 & 1527803 & 6.0 & 7.015 & TRN \\
\hline CHEMBL3674710 & 1527803 & 6.0 & 6.0222 & TRN \\
\hline CHEMBL3674721 & 1527803 & 7.2636 & 7.0644 & TST \\
\hline CHEMBL2392826 & 1527803 & 6.0 & 6.0005 & TST \\
\hline CHEMBL3674689 & 1527803 & 6.0 & 6.1373 & TST \\
\hline CHEMBL2392836 & 1527803 & 7.5719 & 6.8309 & TST \\
\hline CHEMBL3674736 & 1527803 & 7.857 & 6.1568 & TST \\
\hline CHEMBL 3674704 & 1527803 & 6.0 & 7.0982 & TST \\
\hline CHEMBL3674691 & 1527803 & 6.0 & 6.184 & TST \\
\hline CHEMBL2392827 & 1527803 & 6.0 & 6.0862 & TST \\
\hline CHEMBL 3674735 & 1527803 & 6.0 & 6.1581 & TST \\
\hline CHEMBL3674717 & 1527803 & 7.7167 & 6.3343 & TST \\
\hline CHEMBL477176 & 535400 & 3.0 & 3.0303 & TRN \\
\hline CHEMBL476974 & 535400 & 5.0969 & 3.6467 & TRN \\
\hline CHEMBL448250 & 535400 & 3.0 & 3.5523 & TRN \\
\hline CHEMBL490061 & 535400 & 3.0969 & 3.3883 & TRN \\
\hline CHEMBL491005 & 535400 & 3.9586 & 4.0309 & TRN \\
\hline CHEMBL498976 & 535400 & 3.5229 & 3.4454 & TRN \\
\hline CHEMBL564201 & 535400 & 3.699 & 2.4178 & TST \\
\hline CHEMBL517807 & 535400 & 3.0605 & 3.0124 & TST \\
\hline CHEMBL442570 & 535400 & 4.5686 & 4.1677 & TST \\
\hline CHEMBL491006 & 535400 & 3.3468 & 3.929 & TRN \\
\hline CHEMBL446474 & 535400 & 4.2757 & 3.706006 & 00000000004 \\
\hline CHEMBL442892 & 535400 & 3.0 & 2.8907 & TRN \\
\hline CHEMBL476358 & 535400 & 3.0 & 3.0659 & TRN \\
\hline CHEMBL1203972 & 535400 & 3.0 & 3.1633 & TRN \\
\hline CHEMBL476973 & 535400 & 3.1249 & 3.0645 & TRN \\
\hline CHEMBL446919 & 535400 & 3.5229 & 3.9779 & TST \\
\hline CHEMBL448665 & 535400 & 3.0 & 3.2228 & TRN \\
\hline CHEMBL518440 & 535400 & 3.0458 & 3.378 & TRN \\
\hline CHEMBL477606 & 535400 & 3.0458 & 3.7652 & TRN \\
\hline CHEMBL490784 & 535400 & 3.8239 & 3.4051 & TRN \\
\hline CHEMBL477177 & 535400 & 3.0 & 2.968 & TRN \\
\hline CHEMBL508059 & 535400 & 3.0969 & 3.5249 & TRN \\
\hline CHEMBL491207 & 535400 & 3.3468 & 3.5491 & TRN \\
\hline CHEMBL489373 & 535400 & 3.4202 & 3.2687 & TRN \\
\hline CHEMBL491007 & 535400 & 3.9586 & 4.1126 & TRN \\
\hline CHEMBL470505 & 535400 & 3.0362 & 3.5705 & TRN \\
\hline CHEMBL477187 & 535400 & 3.0862 & 3.1241 & TST \\
\hline CHEMBL490999 & 535400 & 3.301 & 3.6488 & TRN \\
\hline CHEMBL502905 & 535400 & 3.0 & 3.0331 & TRN \\
\hline CHEMBL489779 & 535400 & 3.0 & 3.0827 & TRN \\
\hline CHEMBL470987 & 535400 & 3.0 & 3.6697 & TRN \\
\hline CHEMBL477550 & 535400 & 3.1549 & 3.2806 & TRN \\
\hline CHEMBL489564 & 535400 & 3.4559 & 3.1872 & TRN \\
\hline
\end{tabular}




CHEMBL452676
CHEMBL448063
CHEMBL418899
CHEMBL502222
CHEMBL478881
CHEMBL490761
CHEMBL515944
CHEMBL478882
CHEMBL476984
CHEMBL492036
CHEMBL476918
CHEMBL448446
CHEMBL510108
CHEMBL522753
CHEMBL476992
CHEMBL477596
CHEMBL489981
CHEMBL1162372
CHEMBL489169
CHEMBL489982
CHEMBL464086
CHEMBL478860
CHEMBL478859
CHEMBL504564
CHEMBL477823
CHEMBL450720
CHEMBL501654
CHEMBL476148
CHEMBL478880
CHEMBL490997
CHEMBL475475
CHEMBL522098
CHEMBL451317
CHEMBL523441
CHEMBL476983
CHEMBL477607
CHEMBL518286
CHEMBL522585
CHEMBL450704
CHEMBL490998
CHEMBL476147
CHEMBL505701
CHEMBL499938
CHEMBL489776
CHEMBL476784 489168
CHEMBL452739

Supplemental Table S2.txt

\begin{tabular}{|c|c|c|c|}
\hline 535400 & 3.1249 & 2.752 & TST \\
\hline 535400 & 4.6021 & 3.5998 & TRN \\
\hline 535400 & 3.0 & 3.2293 & TST \\
\hline 535400 & 3.0 & 2.7676 & TRN \\
\hline 535400 & 3.0 & 4.9036 & TST \\
\hline 535400 & 3.0 & 3.5308 & TRN \\
\hline 535400 & 3.0969 & 3.5568 & TST \\
\hline 535400 & 3.0315 & 3.09800 & 00000000003 \\
\hline 535400 & 3.3188 & 3.53 & TRN \\
\hline 535400 & 3.0 & 4.0038 & TST \\
\hline 535400 & 3.0 & 3.0754 & TRN \\
\hline 535400 & 3.0 & 3.4702 & TRN \\
\hline 535400 & 3.0362 & 2.884 & TRN \\
\hline 535400 & 4.2218 & 4.2812 & TRN \\
\hline 535400 & 3.0 & 3.0792 & TST \\
\hline 535400 & 3.1135 & 2.8262 & TRN \\
\hline 535400 & 4.699 & 3.6854 & TRN \\
\hline 535400 & 3.1367 & 3.612 & TST \\
\hline 535400 & 4.699 & 4.091 & TRN \\
\hline 535400 & 3.0 & 3.0187 & TRN \\
\hline 535400 & 4.6021 & 4.8508 & TRN \\
\hline 535400 & 4.9208 & 4.3461 & TRN \\
\hline 535400 & 4.3468 & 4.1426 & TRN \\
\hline 535400 & 3.6576 & 3.8309 & TRN \\
\hline 535400 & 4.2218 & 3.5521 & TST \\
\hline 535400 & 3.0 & 2.9875 & TRN \\
\hline 535400 & 3.5229 & 3.4261 & TRN \\
\hline 535400 & 3.0 & 2.9596 & TST \\
\hline 535400 & 3.0 & 3.5756 & TST \\
\hline 535400 & 3.6576 & 3.5714 & TRN \\
\hline 535400 & 3.1549 & 3.4023 & TRN \\
\hline 535400 & 3.0 & 3.6797 & TRN \\
\hline 535400 & 3.8539 & 4.0878 & TRN \\
\hline 535400 & 3.4685 & 3.4144 & TRN \\
\hline 535400 & 3.0 & 3.0273 & TRN \\
\hline 535400 & 3.0 & 2.9898 & TRN \\
\hline 535400 & 3.0 & 3.1806 & TST \\
\hline 535400 & 3.0458 & 2.7603 & TRN \\
\hline 535400 & 5.0969 & 3.9526 & TRN \\
\hline 535400 & 3.2596 & 3.3234 & TRN \\
\hline 535400 & 3.0969 & 2.9979 & TST \\
\hline 535400 & 3.0 & 3.0417 & TRN \\
\hline 535400 & 3.0 & 3.0954 & TRN \\
\hline 535400 & 3.0 & 3.0837 & TRN \\
\hline 535400 & 3.301 & 4.6388 & TST \\
\hline 535400 & 3.0706 & 3.1322 & TST \\
\hline 535400 & 3.2218 & 2.915 & TRN \\
\hline 535400 & 3.0 & 3.0841 & TRN \\
\hline
\end{tabular}




\begin{tabular}{|c|c|c|c|c|c|}
\hline & & \multicolumn{4}{|c|}{ Supplemental Table S2.txt } \\
\hline CHEMBL476783 & 535400 & 3.1549 & 3.3423 & TST & \\
\hline CHEMBL489777 & 535400 & 3.0 & 3.201 & TRN & \\
\hline CHEMBL490396 & 535400 & 3.9586 & 4.0123 & TRN & \\
\hline CHEMBL492037 & 535400 & 3.0 & 4.1314 & TST & \\
\hline CHEMBL440480 & 3819 & 7.0 & 6.9887 & TRN & \\
\hline CHEMBL55680 & 3819 & 7.0 & 6.9969 & TRN & \\
\hline CHEMBL55880 & 3819 & 5.0 & 5.4906 & TST & \\
\hline CHEMBL301304 & 3819 & 7.0 & 5.8408 & TST & \\
\hline CHEMBL414824 & 3819 & 5.7696 & 5.6864 & TRN & \\
\hline CHEMBL56576 & 3819 & 6.6198 & 6.6925 & TRN & \\
\hline CHEMBL417378 & 3819 & 5.0 & 4.9895 & TRN & \\
\hline CHEMBL55217 & 3819 & 6.4318 & 6.744 & TRN & \\
\hline CHEMBL59198 & 3819 & 7.0 & 7.1342 & TRN & \\
\hline CHEMBL56283 & 3819 & 7.0 & 6.9966 & TRN & \\
\hline CHEMBL58929 & 3819 & 5.0 & 4.4466 & TST & \\
\hline CHEMBL58987 & 3819 & 7.0 & 6.7605 & TRN & \\
\hline CHEMBL292136 & 3819 & 7.0 & 6.7229 & TST & \\
\hline CHEMBL56833 & 3819 & 7.1871 & 7.3112 & TRN & \\
\hline CHEMBL55293 & 3819 & 5.0 & 4.9787 & TRN & \\
\hline CHEMBL294003 & 3819 & 7.0 & 7.0412 & TRN & \\
\hline CHEMBL56039 & 3819 & 7.0 & 7.0329 & TRN & \\
\hline CHEMBL301017 & 3819 & 5.0 & 4.9645 & TRN & \\
\hline CHEMBL54169 & 3819 & 7.0 & 6.9951 & TRN & \\
\hline CHEMBL56460 & 3819 & 7.0 & 7.1228 & TRN & \\
\hline CHEMBL57016 & 3819 & 7.0 & 7.0156 & TRN & \\
\hline CHEMBL56551 & 3819 & 6.2291 & 6.1772 & TRN & \\
\hline CHEMBL 8842 & 3819 & 6.699 & 6.4942 & TRN & \\
\hline CHEMBL55737 & 3819 & 7.0 & 6.9869 & TRN & \\
\hline CHEMBL293821 & 3819 & 6.0 & 5.9037 & TRN & \\
\hline CHEMBL56798 & 3819 & 7.2676 & 7.1895 & TRN & \\
\hline CHEMBL413324 & 3819 & 7.0655 & 6.9244 & TRN & \\
\hline CHEMBL 8813 & 3819 & 5.0 & 4.7552 & TRN & \\
\hline CHEMBL8959 & 3819 & 5.0 & 5.2043 & TRN & \\
\hline CHEMBL55448 & 3819 & 7.0 & 7.0562 & TRN & \\
\hline CHEMBL55435 & 3819 & 7.0 & 6.7912 & TRN & \\
\hline CHEMBL58979 & 3819 & 7.3468 & 7.4119 & TRN & \\
\hline CHEMBL56563 & 3819 & 5.0 & 5.8234 & TST & \\
\hline CHEMBL56196 & 3819 & 7.0 & 6.9622 & TRN & \\
\hline CHEMBL442167 & 3819 & 5.0 & 5.0317 & TRN & \\
\hline CHEMBL55976 & 3819 & 5.0 & 4.425 & TST & \\
\hline CHEMBL291710 & 3819 & 6.5376 & 6.7087 & TRN & \\
\hline CHEMBL417379 & 3819 & 6.7696 & 6.8569 & TRN & \\
\hline CHEMBL57298 & 3819 & 5.0 & 5.3694 & TRN & \\
\hline CHEMBL 293150 & 3819 & 7.0 & 6.91106 & 00000000005 & TRN \\
\hline CHEMBL55960 & 3819 & 7.0 & 6.944 & TRN & \\
\hline CHEMBL299048 & 3819 & 7.0 & 7.0573 & TRN & \\
\hline CHEMBL58990 & 3819 & 7.0 & 6.9774 & TRN & \\
\hline CHEMBL55389 & 3819 & 5.0 & 4.9913 & TRN & \\
\hline
\end{tabular}




\begin{tabular}{|c|c|c|c|c|c|}
\hline \multirow[b]{2}{*}{ CHEMBL293825 } & \multirow[b]{2}{*}{3819} & \multicolumn{4}{|c|}{ Supplemental Table S2.txt } \\
\hline & & 7.0458 & 7.07799 & 9999999999 & TRN \\
\hline CHEMBL266100 & 3819 & 5.9208 & 6.0619 & TRN & \\
\hline CHEMBL56461 & 3819 & 6.8861 & 6.9267 & TRN & \\
\hline CHEMBL300159 & 3819 & 7.0 & 6.8936 & TRN & \\
\hline CHEMBL56422 & 3819 & 7.0 & 6.6676 & TRN & \\
\hline CHEMBL56365 & 3819 & 5.0 & 5.0396 & TRN & \\
\hline CHEMBL8595 & 3819 & 7.0 & 6.9526 & TRN & \\
\hline CHEMBL54221 & 3819 & 7.041 & 6.3807 & TST & \\
\hline CHEMBL56531 & 3819 & 7.0 & 6.0551 & TST & \\
\hline CHEMBL434783 & 3819 & 7.0655 & 7.0127 & TST & \\
\hline CHEMBL293755 & 3819 & 7.0 & 7.0851 & TST & \\
\hline CHEMBL56009 & 3819 & 6.3665 & 5.4334 & TST & \\
\hline CHEMBL54227 & 3819 & 5.0 & 5.4334 & TST & \\
\hline CHEMBL54226 & 3819 & 5.0 & 6.2278 & TST & \\
\hline CHEMBL8636 & 3819 & 5.0 & 5.5798 & TST & \\
\hline CHEMBL 8562 & 3819 & 5.9586 & 4.4786 & TST & \\
\hline CHEMBL123 & 688751 & 5.55 & 5.1799 & TRN & \\
\hline CHEMBL47814 & 688751 & 7.7496 & 5.9877 & TRN & \\
\hline CHEMBL323356 & 688751 & 4.65 & 5.1626 & TRN & \\
\hline CHEMBL604119 & 688751 & 4.3 & 5.3171 & TST & \\
\hline CHEMBL1316314 & 688751 & 4.95 & 5.3019 & TRN & \\
\hline CHEMBL310798 & 688751 & 4.5 & 4.3758 & TRN & \\
\hline CHEMBL1256484 & 688751 & 4.7 & 4.6638 & TRN & \\
\hline CHEMBL1256390 & 688751 & 6.2 & 5.26399 & 9999999999 & TRN \\
\hline CHEMBL1256659 & 688751 & 4.6 & 4.7698 & TRN & \\
\hline CHEMBL 274438 & 688751 & 4.9 & 5.5806 & TRN & \\
\hline CHEMBL 279998 & 688751 & 5.0 & 5.4362 & TST & \\
\hline CHEMBL1626274 & 688751 & 5.25 & 5.1413 & TRN & \\
\hline CHEMBL1396782 & 688751 & 4.95 & 4.9242 & TRN & \\
\hline CHEMBL1440857 & 688751 & 6.0 & 5.1359 & TRN & \\
\hline CHEMBL1256746 & 688751 & 4.85 & 4.8572 & TRN & \\
\hline CHEMBL351042 & 688751 & 4.65 & 4.6024 & TRN & \\
\hline CHEMBL1372997 & 688751 & 4.25 & 5.308 & TRN & \\
\hline CHEMBL328710 & 688751 & 4.85 & 5.011 & TRN & \\
\hline CHEMBL1256719 & 688751 & 5.45 & 5.1828 & TRN & \\
\hline CHEMBL397209 & 688751 & 7.7496 & 5.3331 & TST & \\
\hline CHEMBL60718 & 688751 & 5.15 & 5.2185 & TRN & \\
\hline CHEMBL18840 & 688751 & 4.25 & 4.9894 & TRN & \\
\hline CHEMBL1603820 & 688751 & 5.25 & 5.9158 & TRN & \\
\hline CHEMBL28626 & 688751 & 5.45 & 4.5087 & TRN & \\
\hline CHEMBL1255867 & 688751 & 5.0 & 5.2001 & TRN & \\
\hline CHEMBL68534 & 688751 & 4.9 & 4.3244 & TRN & \\
\hline CHEMBL66 & 688751 & 4.6 & 4.4423 & TRN & \\
\hline CHEMBL 77971 & 688751 & 4.45 & 5.364 & TRN & \\
\hline CHEMBL1257012 & 688751 & 3.75 & 5.2925 & TST & \\
\hline CHEMBL1593765 & 688751 & 5.1 & 5.9947 & TRN & \\
\hline CHEMBL1597692 & 688751 & 5.5 & 5.2763 & TRN & \\
\hline CHEMBL1257106 & 688751 & 5.1 & 5.6564 & TRN & \\
\hline
\end{tabular}




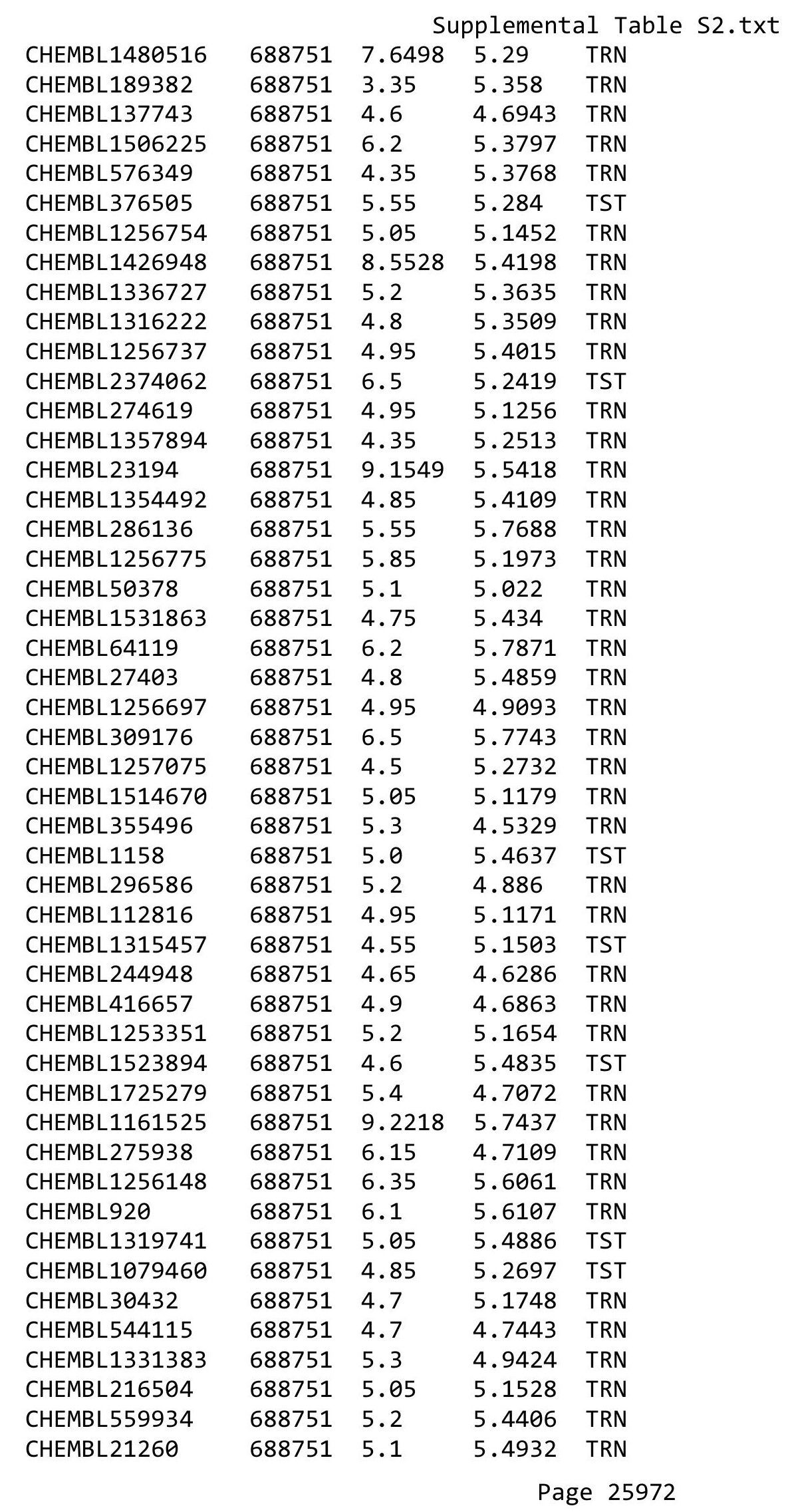




\begin{tabular}{|c|c|c|c|c|c|}
\hline \multicolumn{6}{|c|}{ Supplemental Table S2.txt } \\
\hline CHEMBL18238 & 688751 & 5.0 & 5.1818 & TRN & \\
\hline CHEMBL1256359 & 688751 & 4.95 & 5.0644 & TRN & \\
\hline CHEMBL21241 & 688751 & 4.45 & 5.4213 & TRN & \\
\hline CHEMBL 26915 & 688751 & 4.6 & 5.169 & TRN & \\
\hline CHEMBL1257076 & 688751 & 4.6 & 5.5211 & TRN & \\
\hline CHEMBL1257078 & 688751 & 4.55 & 5.6147 & TRN & \\
\hline CHEMBL1284 & 688751 & 4.65 & 4.5426 & TRN & \\
\hline CHEMBL70880 & 688751 & 7.3497 & 5.6864 & TRN & \\
\hline CHEMBL441282 & 688751 & 4.3 & 4.9074 & TRN & \\
\hline CHEMBL1256914 & 688751 & 7.9508 & 5.5166 & TRN & \\
\hline CHEMBL1257080 & 688751 & 5.2 & 4.9927 & TRN & \\
\hline CHEMBL288174 & 688751 & 4.85 & 5.0723 & TRN & \\
\hline CHEMBL1595524 & 688751 & 4.65 & 4.8617 & TRN & \\
\hline CHEMBL1450525 & 688751 & 5.55 & 5.5593 & TRN & \\
\hline CHEMBL1256776 & 688751 & 5.0 & 5.1706 & TRN & \\
\hline CHEMBL1256693 & 688751 & 6.5501 & 5.4444 & TRN & \\
\hline CHEMBL168279 & 688751 & 4.35 & 5.5154 & TRN & \\
\hline CHEMBL 278041 & 688751 & 4.6 & 4.7494 & TRN & \\
\hline CHEMBL1255649 & 688751 & 5.2 & 5.5871 & TRN & \\
\hline CHEMBL1522486 & 688751 & 4.55 & 5.1668 & TRN & \\
\hline CHEMBL 384903 & 688751 & 4.6 & 4.6278 & TRN & \\
\hline CHEMBL1224512 & 688751 & 4.6 & 4.1918 & TRN & \\
\hline CHEMBL1256661 & 688751 & 4.65 & 5.346 & TRN & \\
\hline CHEMBL 1255758 & 688751 & 4.4 & 5.1156 & TST & \\
\hline CHEMBL93403 & 688751 & 5.1 & 5.7819 & TRN & \\
\hline CHEMBL 250711 & 688751 & 4.45 & 4.5062 & TRN & \\
\hline CHEMBL539507 & 688751 & 5.25 & 5.2457 & TRN & \\
\hline CHEMBL1256667 & 688751 & 4.3 & 5.16200 & 0000000001 & TST \\
\hline CHEMBL 1255650 & 688751 & 4.4 & 5.3887 & TST & \\
\hline CHEMBL433461 & 688751 & 4.45 & 5.1877 & TST & \\
\hline CHEMBL24983 & 688751 & 4.8 & 5.1649 & TRN & \\
\hline CHEMBL1255866 & 688751 & 5.3 & 5.331 & TST & \\
\hline CHEMBL410873 & 688751 & 5.4 & 5.0072 & TRN & \\
\hline CHEMBL1608159 & 688751 & 4.25 & 4.8609 & TRN & \\
\hline CHEMBL1256716 & 688751 & 7.0 & 6.3073 & TRN & \\
\hline CHEMBL153057 & 688751 & 5.3 & 5.0545 & TRN & \\
\hline CHEMBL1255647 & 688751 & 4.95 & 4.8595 & TRN & \\
\hline CHEMBL1490919 & 688751 & 4.8 & 4.7284 & TRN & \\
\hline CHEMBL124267 & 688751 & 5.5 & 5.1437 & TRN & \\
\hline CHEMBL 303579 & 688751 & 4.35 & 5.19600 & 0000000001 & TRN \\
\hline CHEMBL3186408 & 688751 & 4.9 & 5.2615 & TST & \\
\hline CHEMBL77030 & 688751 & 4.75 & 4.2027 & TRN & \\
\hline CHEMBL1336166 & 688751 & 5.5 & 5.5616 & TRN & \\
\hline CHEMBL76904 & 688751 & 4.75 & 4.1525 & TRN & \\
\hline CHEMBL1256995 & 688751 & 4.8 & 5.1727 & TRN & \\
\hline CHEMBL1528565 & 688751 & 4.35 & 5.2625 & TRN & \\
\hline CHEMBL34155 & 688751 & 5.1 & 5.4621 & TST & \\
\hline CHEMBL62 & 688751 & 4.3 & 5.0374 & TRN & \\
\hline
\end{tabular}




\begin{tabular}{|c|c|c|c|c|c|}
\hline \multicolumn{6}{|c|}{ Supplemental Table S2.txt } \\
\hline CHEMBL513116 & 688751 & 5.5 & 5.1868 & TRN & \\
\hline CHEMBL102714 & 688751 & 4.8 & 4.8402 & TRN & \\
\hline CHEMBL391997 & 688751 & 4.6 & 4.73600 & 0000000001 & TRN \\
\hline CHEMBL420060 & 688751 & 7.8013 & 6.3339 & TRN & \\
\hline CHEMBL1529009 & 688751 & 6.5 & 5.6767 & TRN & \\
\hline CHEMBL286077 & 688751 & 5.1 & 5.2994 & TRN & \\
\hline CHEMBL1257041 & 688751 & 4.7 & 4.6977 & TRN & \\
\hline CHEMBL288096 & 688751 & 4.7 & 4.6674 & TRN & \\
\hline CHEMBL93655 & 688751 & 4.9 & 5.29899 & 99999999995 & TRN \\
\hline CHEMBL1372588 & 688751 & 4.5 & 5.0263 & TRN & \\
\hline CHEMBL 305881 & 688751 & 5.05 & 5.871 & TRN & \\
\hline CHEMBL1255966 & 688751 & 5.0 & 5.0967 & TRN & \\
\hline CHEMBL1256654 & 688751 & 5.3 & 5.5075 & TRN & \\
\hline CHEMBL1314260 & 688751 & 4.9 & 5.3625 & TST & \\
\hline CHEMBL1319469 & 688751 & 6.2 & 5.5421 & TRN & \\
\hline CHEMBL143324 & 688751 & 4.7 & 5.5378 & TRN & \\
\hline CHEMBL545050 & 688751 & 3.4 & 5.5948 & TRN & \\
\hline CHEMBL578741 & 688751 & 4.65 & 4.8812 & TRN & \\
\hline CHEMBL903 & 688751 & 5.35 & 5.4475 & TRN & \\
\hline CHEMBL188 & 688751 & 3.85 & 5.4349 & TRN & \\
\hline CHEMBL1354914 & 688751 & 5.35 & 5.5349 & TST & \\
\hline CHEMBL1257003 & 688751 & 4.8 & 4.6963 & TRN & \\
\hline CHEMBL247378 & 688751 & 5.9 & 5.3012 & TRN & \\
\hline CHEMBL1208858 & 688751 & 4.5 & 4.7204 & TST & \\
\hline CHEMBL182461 & 688751 & 6.2 & 5.5116 & TRN & \\
\hline CHEMBL1255746 & 688751 & 3.75 & 5.1482 & TST & \\
\hline CHEMBL302783 & 688751 & 4.9 & 5.4231 & TRN & \\
\hline CHEMBL1256851 & 688751 & 4.95 & 5.2197 & TRN & \\
\hline CHEMBL1323529 & 688751 & 4.95 & 5.1082 & TRN & \\
\hline CHEMBL1414452 & 688751 & 6.35 & 4.5208 & TST & \\
\hline CHEMBL22870 & 688751 & 4.65 & 4.9235 & TRN & \\
\hline CHEMBL260374 & 688751 & 4.45 & 5.6946 & TST & \\
\hline CHEMBL1256751 & 688751 & 4.75 & 5.5471 & TRN & \\
\hline CHEMBL310310 & 688751 & 5.0 & 5.3093 & TRN & \\
\hline CHEMBL 275311 & 688751 & 5.0 & 5.0966 & TRN & \\
\hline CHEMBL1255778 & 688751 & 4.35 & 4.6616 & TRN & \\
\hline CHEMBL1407852 & 688751 & 4.9 & 5.2714 & TRN & \\
\hline CHEMBL121915 & 688751 & 5.1 & 5.4081 & TRN & \\
\hline CHEMBL319244 & 688751 & 4.6 & 4.5197 & TRN & \\
\hline CHEMBL1096400 & 688751 & 4.65 & 5.3155 & TRN & \\
\hline CHEMBL126077 & 688751 & 4.95 & 4.7269 & TRN & \\
\hline CHEMBL280998 & 688751 & 4.7 & 4.8614 & TRN & \\
\hline CHEMBL1256885 & 688751 & 4.55 & 4.9456 & TRN & \\
\hline CHEMBL534084 & 688751 & 4.45 & 5.3999 & TRN & \\
\hline CHEMBL1414236 & 688751 & 4.95 & 5.4023 & TST & \\
\hline CHEMBL1256839 & 688751 & 6.9 & 5.8264 & TRN & \\
\hline CHEMBL1255657 & 688751 & 4.75 & 5.3854 & TRN & \\
\hline CHEMBL1590980 & 688751 & 4.85 & 5.8189 & TRN & \\
\hline
\end{tabular}




\begin{tabular}{|c|c|c|c|c|c|}
\hline \multicolumn{6}{|c|}{ Supplemental Table S2.txt } \\
\hline CHEMBL49247 & 688751 & 5.25 & 5.6673 & TRN & \\
\hline CHEMBL28 & 688751 & 5.25 & 4.5746 & TRN & \\
\hline CHEMBL544713 & 688751 & 4.95 & 5.7686 & TRN & \\
\hline CHEMBL481537 & 688751 & 4.8 & 5.03100 & 0000000001 & TRN \\
\hline CHEMBL1596271 & 688751 & 6.7501 & 5.1813 & TRN & \\
\hline CHEMBL 2374058 & 688751 & 4.45 & 4.9646 & TST & \\
\hline CHEMBL122270 & 688751 & 5.95 & 5.5672 & TRN & \\
\hline CHEMBL1397766 & 688751 & 4.2 & 5.1728 & TRN & \\
\hline CHEMBL1256761 & 688751 & 4.45 & 5.1868 & TRN & \\
\hline CHEMBL1556000 & 688751 & 8.5528 & 6.0022 & TRN & \\
\hline CHEMBL26320 & 688751 & 4.35 & 5.6733 & TRN & \\
\hline CHEMBL536950 & 688751 & 5.85 & 5.5071 & TRN & \\
\hline CHEMBL1256740 & 688751 & 4.6 & 5.3461 & TRN & \\
\hline CHEMBL1378659 & 688751 & 4.55 & 4.7825 & TRN & \\
\hline CHEMBL1563352 & 688751 & 5.2 & 5.148 & TST & \\
\hline CHEMBL1461491 & 688751 & 4.55 & 4.9341 & TRN & \\
\hline CHEMBL 8618 & 688751 & 7.0501 & 6.2223 & TRN & \\
\hline CHEMBL541585 & 688751 & 4.45 & 4.7859 & TRN & \\
\hline CHEMBL 1256647 & 688751 & 7.4498 & 5.7768 & TRN & \\
\hline CHEMBL1256797 & 688751 & 5.55 & 5.1965 & TRN & \\
\hline CHEMBL1255747 & 688751 & 4.7 & 4.5573 & TRN & \\
\hline CHEMBL58033 & 688751 & 7.0501 & 5.3879 & TRN & \\
\hline CHEMBL299683 & 688751 & 5.0 & 5.3744 & TRN & \\
\hline CHEMBL 1256660 & 688751 & 5.05 & 5.2724 & TRN & \\
\hline CHEMBL1256191 & 688751 & 4.5 & 4.6824 & TRN & \\
\hline CHEMBL1365553 & 688751 & 5.4 & 4.9732 & TRN & \\
\hline CHEMBL56543 & 688751 & 4.6 & 4.4303 & TRN & \\
\hline CHEMBL399043 & 688751 & 5.5 & 4.8525 & TST & \\
\hline CHEMBL 1437846 & 688751 & 5.95 & 5.2679 & TST & \\
\hline CHEMBL129795 & 688751 & 6.2 & 4.5825 & TRN & \\
\hline CHEMBL448741 & 688751 & 4.5 & 5.0711 & TRN & \\
\hline CHEMBL250447 & 688751 & 4.95 & 5.1017 & TRN & \\
\hline CHEMBL1456417 & 688751 & 3.35 & 5.2 & TRN & \\
\hline CHEMBL1476762 & 688751 & 4.65 & 5.1868 & TRN & \\
\hline CHEMBL1256759 & 688751 & 5.25 & 5.3205 & TRN & \\
\hline CHEMBL24510 & 688751 & 5.0 & 5.4518 & TRN & \\
\hline CHEMBL 74300 & 688751 & 4.95 & 5.045 & TRN & \\
\hline CHEMBL1499 & 688751 & 6.2 & 5.2358 & TST & \\
\hline CHEMBL 280065 & 688751 & 4.75 & 5.1914 & TRN & \\
\hline CHEMBL1256655 & 688751 & 4.65 & 5.5465 & TRN & \\
\hline CHEMBL 77387 & 688751 & 3.95 & 4.3125 & TRN & \\
\hline CHEMBL47940 & 688751 & 6.05 & 5.3308 & TST & \\
\hline CHEMBL1201091 & 688751 & 6.5 & 5.8493 & TRN & \\
\hline CHEMBL1097940 & 688751 & 6.3 & 5.2875 & TRN & \\
\hline CHEMBL1554717 & 688751 & 4.65 & 6.1011 & TRN & \\
\hline CHEMBL365809 & 688751 & 5.35 & 5.5543 & TRN & \\
\hline CHEMBL1374843 & 688751 & 5.3 & 5.1915 & TRN & \\
\hline CHEMBL336467 & 688751 & 5.2 & 5.1495 & TST & \\
\hline
\end{tabular}




\begin{tabular}{|c|c|c|c|c|c|}
\hline \multicolumn{6}{|c|}{ Supplemental Table S2.txt } \\
\hline CHEMBL1338358 & 688751 & 4.8 & 5.1321 & TRN & \\
\hline CHEMBL501701 & 688751 & 4.95 & 5.5023 & TRN & \\
\hline CHEMBL1396658 & 688751 & 6.6499 & 5.4636 & TRN & \\
\hline CHEMBL1376723 & 688751 & 4.75 & 4.51399 & 9999999999 & TRN \\
\hline CHEMBL1256646 & 688751 & 4.7 & 4.4114 & TRN & \\
\hline CHEMBL1491340 & 688751 & 6.35 & 5.4502 & TST & \\
\hline CHEMBL1256686 & 688751 & 5.4 & 5.1292 & TST & \\
\hline CHEMBL1255936 & 688751 & 4.9 & 5.197 & TRN & \\
\hline CHEMBL 9843 & 688751 & 5.25 & 5.2171 & TRN & \\
\hline CHEMBL157351 & 688751 & 4.55 & 5.0345 & TST & \\
\hline CHEMBL1256020 & 688751 & 5.0 & 5.1523 & TRN & \\
\hline CHEMBL1434513 & 688751 & 4.55 & 4.6594 & TRN & \\
\hline CHEMBL1453208 & 688751 & 4.8 & 5.0037 & TRN & \\
\hline CHEMBL161343 & 688751 & 5.3 & 5.1469 & TRN & \\
\hline CHEMBL34730 & 688751 & 5.35 & 5.5106 & TRN & \\
\hline CHEMBL570383 & 688751 & 4.85 & 5.3934 & TRN & \\
\hline CHEMBL1357247 & 688751 & 5.15 & 4.8955 & TRN & \\
\hline CHEMBL543 & 688751 & 5.9 & 5.6787 & TRN & \\
\hline CHEMBL 1255648 & 688751 & 5.6 & 5.5205 & TRN & \\
\hline CHEMBL559612 & 688751 & 4.5 & 4.6989 & TRN & \\
\hline CHEMBL113180 & 688751 & 4.3 & 5.3555 & TRN & \\
\hline CHEMBL333985 & 688751 & 6.8499 & 5.2268 & TRN & \\
\hline CHEMBL1257002 & 688751 & 7.6003 & 5.303 & TST & \\
\hline CHEMBL1395737 & 688751 & 4.85 & 5.0956 & TRN & \\
\hline CHEMBL1551643 & 688751 & 5.5 & 5.4927 & TRN & \\
\hline CHEMBL1255941 & 688751 & 4.95 & 4.9777 & TRN & \\
\hline CHEMBL23957 & 688751 & 6.1 & 5.5002 & TRN & \\
\hline CHEMBL573214 & 688751 & 4.4 & 5.00899 & 99999999995 & TRN \\
\hline CHEMBL 8747 & 688751 & 4.9 & 5.0834 & TRN & \\
\hline CHEMBL285843 & 688751 & 5.35 & 5.4296 & TRN & \\
\hline CHEMBL1256131 & 688751 & 6.2 & 5.2523 & TRN & \\
\hline CHEMBL1436121 & 688751 & 6.9 & 5.001 & TST & \\
\hline CHEMBL1256180 & 688751 & 5.2 & 5.0517 & TRN & \\
\hline CHEMBL1256623 & 688751 & 5.05 & 4.5229 & TRN & \\
\hline CHEMBL39 & 688751 & 5.55 & 4.8695 & TRN & \\
\hline CHEMBL1256813 & 688751 & 5.05 & 5.0587 & TST & \\
\hline CHEMBL344127 & 688751 & 4.9 & 5.1904 & TST & \\
\hline CHEMBL405358 & 688751 & 5.1 & 4.8956 & TST & \\
\hline CHEMBL 1600780 & 688751 & 4.55 & 5.2189 & TST & \\
\hline CHEMBL67535 & 688751 & 4.9 & 4.3355 & TST & \\
\hline CHEMBL445102 & 688751 & 5.95 & 5.0152 & TST & \\
\hline CHEMBL1062 & 688751 & 4.2 & 5.1979 & TST & \\
\hline CHEMBL1256186 & 688751 & 6.05 & 5.4651 & TST & \\
\hline CHEMBL587714 & 688751 & 4.95 & 4.8591 & TST & \\
\hline CHEMBL1406513 & 688751 & 2.35 & 4.8767 & TST & \\
\hline CHEMBL1367076 & 688751 & 4.65 & 5.1397 & TST & \\
\hline CHEMBL33884 & 688751 & 5.05 & 5.5847 & TST & \\
\hline CHEMBL109037 & 688751 & 4.5 & 4.9013 & TST & \\
\hline
\end{tabular}




\begin{tabular}{|c|c|c|c|c|}
\hline \multicolumn{5}{|c|}{ le s2.txt } \\
\hline CHEMBL395915 & 688751 & 5.65 & 4.9411 & TST \\
\hline CHEMBL1255755 & 688751 & 5.3 & 5.1076 & TST \\
\hline CHEMBL1256181 & 688751 & 5.25 & 5.4469 & TST \\
\hline CHEMBL273094 & 688751 & 8.5528 & 5.2523 & TST \\
\hline CHEMBL1256924 & 688751 & 6.0 & 6.1878 & TST \\
\hline CHEMBL543876 & 688751 & 4.85 & 5.6247 & TST \\
\hline CHEMBL 299613 & 688751 & 4.3 & 5.2749 & TST \\
\hline CHEMBL1371781 & 688751 & 4.65 & 5.0875 & TST \\
\hline CHEMBL17468 & 688751 & 5.0 & 5.3493 & TST \\
\hline CHEMBL546257 & 688751 & 4.9 & 5.3135 & TST \\
\hline CHEMBL602375 & 688751 & 5.0 & 5.0734 & TST \\
\hline CHEMBL 362863 & 688751 & 4.4 & 5.3767 & TST \\
\hline CHEMBL1256663 & 688751 & 5.3 & 5.7111 & TST \\
\hline CHEMBL 268868 & 688751 & 5.1 & 5.2787 & TST \\
\hline CHEMBL145 & 688751 & 4.6 & 4.4189 & TST \\
\hline CHEMBL 277525 & 688751 & 4.95 & 5.5309 & TST \\
\hline CHEMBL1710 & 688751 & 4.4 & 5.5366 & TST \\
\hline CHEMBL 267373 & 688751 & 5.9 & 5.4573 & TST \\
\hline CHEMBL428496 & 688751 & 4.45 & 5.2684 & TST \\
\hline CHEMBL1256325 & 688751 & 4.3 & 5.4542 & TST \\
\hline CHEMBL1256772 & 688751 & 5.05 & 5.7326 & TST \\
\hline CHEMBL63329 & 688751 & 4.85 & 5.4538 & TST \\
\hline CHEMBL 330129 & 688751 & 5.15 & 5.4396 & TST \\
\hline CHEMBL1315073 & 688751 & 4.5 & 5.4387 & TST \\
\hline CHEMBL62291 & 3925 & 4.8539 & 4.7711 & TST \\
\hline CHEMBL62101 & 3925 & 5.7959 & 6.1199 & TRN \\
\hline CHEMBL293617 & 3925 & 5.8861 & 6.1429 & TRN \\
\hline CHEMBL417557 & 3925 & 5.5686 & 5.386 & TRN \\
\hline CHEMBL64396 & 3925 & 5.9586 & 6.2242 & TRN \\
\hline CHEMBL 304663 & 3925 & 5.5229 & 5.9189 & TST \\
\hline CHEMBL60499 & 3925 & 5.8539 & 6.1679 & TRN \\
\hline CHEMBL64422 & 3925 & 6.301 & 6.1179 & TRN \\
\hline CHEMBL 304690 & 3925 & 5.3565 & 5.1147 & TRN \\
\hline CHEMBL302879 & 3925 & 6.5229 & 5.8696 & TRN \\
\hline CHEMBL62817 & 3925 & 4.7696 & 5.7269 & TST \\
\hline CHEMBL64076 & 3925 & 3.0 & 4.5494 & TRN \\
\hline CHEMBL64051 & 3925 & 6.3979 & 5.8724 & TRN \\
\hline CHEMBL 302414 & 3925 & 5.3979 & 5.8094 & TRN \\
\hline CHEMBL64342 & 3925 & 4.585 & 5.1983 & TST \\
\hline CHEMBL62916 & 3925 & 5.585 & 5.9967 & TRN \\
\hline CHEMBL62616 & 3925 & 5.8861 & 5.7793 & TRN \\
\hline CHEMBL60165 & 3925 & 4.699 & 4.7184 & TRN \\
\hline CHEMBL436352 & 3925 & 3.0 & 3.1559 & TRN \\
\hline CHEMBL 302208 & 3925 & 4.8477 & 5.2737 & TST \\
\hline CHEMBL 293910 & 3925 & 5.1427 & 5.7402 & TST \\
\hline CHEMBL64458 & 3925 & 5.5229 & 5.2196 & TRN \\
\hline CHEMBL64822 & 3925 & 3.0 & 3.3533 & TRN \\
\hline CHEMBL64763 & 3925 & 6.5229 & 6.3079 & TRN \\
\hline
\end{tabular}




\begin{tabular}{|c|c|c|c|c|c|}
\hline \multirow[b]{2}{*}{ CHEMBL293858 } & \multicolumn{5}{|c|}{ Supplemental Table S2.txt } \\
\hline & 3925 & 5.0458 & 5.2101 & TRN & \\
\hline CHEMBL62617 & 3925 & 5.9208 & 5.82100 & 0000000001 & TRN \\
\hline CHEMBL63546 & 3925 & 6.301 & 6.0909 & TRN & \\
\hline CHEMBL61065 & 3925 & 5.6383 & 5.4418 & TRN & \\
\hline CHEMBL59748 & 3925 & 5.5528 & 5.9683 & TRN & \\
\hline CHEMBL61952 & 3925 & 6.2218 & 6.138 & TRN & \\
\hline CHEMBL64738 & 3925 & 5.7212 & 5.3813 & TRN & \\
\hline CHEMBL60949 & 3925 & 4.3979 & 5.407 & TST & \\
\hline CHEMBL60993 & 3925 & 5.0315 & 5.4492 & TST & \\
\hline CHEMBL62693 & 3925 & 6.0 & 5.9724 & TRN & \\
\hline CHEMBL60498 & 3925 & 4.6198 & 4.0913 & TRN & \\
\hline CHEMBL292118 & 3925 & 4.6383 & 5.5064 & TST & \\
\hline CHEMBL 292324 & 3925 & 5.8539 & 5.7852 & TRN & \\
\hline CHEMBL 302838 & 3925 & 4.6778 & 5.2641 & TRN & \\
\hline CHEMBL60994 & 3925 & 6.3979 & 5.8601 & TRN & \\
\hline CHEMBL59756 & 3925 & 4.7696 & 5.1207 & TST & \\
\hline CHEMBL64064 & 3925 & 6.1549 & 5.7583 & TRN & \\
\hline CHEMBL418514 & 3925 & 4.8386 & 5.5854 & TST & \\
\hline CHEMBL 303303 & 3925 & 4.7447 & 4.9667 & TST & \\
\hline CHEMBL 276850 & 3925 & 6.4949 & 7.7328 & TST & \\
\hline CHEMBL64490 & 3925 & 6.2218 & 4.9511 & TRN & \\
\hline CHEMBL64858 & 3925 & 6.1549 & 6.2353 & TRN & \\
\hline CHEMBL60136 & 3925 & 6.0969 & 6.5253 & TRN & \\
\hline CHEMBL61422 & 3925 & 5.8239 & 5.8315 & TRN & \\
\hline CHEMBL 304647 & 3925 & 5.7212 & 5.8835 & TRN & \\
\hline CHEMBL302394 & 3925 & 5.2291 & 5.0195 & TRN & \\
\hline CHEMBL60790 & 3925 & 5.7959 & 5.8021 & TRN & \\
\hline CHEMBL 304698 & 3925 & 6.1549 & 6.0386 & TRN & \\
\hline CHEMBL 292884 & 3925 & 6.0969 & 6.2267 & TRN & \\
\hline CHEMBL64404 & 3925 & 7.699 & 5.7045 & TST & \\
\hline CHEMBL64435 & 3925 & 5.6778 & 6.1285 & TRN & \\
\hline CHEMBL 304205 & 3925 & 5.7959 & 7.6648 & TST & \\
\hline CHEMBL444828 & 3925 & 5.9208 & 5.7632 & TRN & \\
\hline CHEMBL418665 & 3925 & 5.7212 & 6.0172 & TRN & \\
\hline CHEMBL64370 & 3925 & 6.0458 & 6.2889 & TRN & \\
\hline CHEMBL62772 & 3925 & 7.0 & 6.2708 & TRN & \\
\hline CHEMBL 62572 & 3925 & 6.0458 & 6.4534 & TRN & \\
\hline CHEMBL64403 & 3925 & 5.6021 & 5.9326 & TRN & \\
\hline CHEMBL63054 & 3925 & 4.7696 & 6.9333 & TST & \\
\hline CHEMBL64337 & 3925 & 6.5229 & 5.6137 & TRN & \\
\hline CHEMBL64304 & 3925 & 4.8861 & 5.4092 & TRN & \\
\hline CHEMBL64399 & 3925 & 5.5528 & 6.6165 & TST & \\
\hline CHEMBL3403098 & 1465792 & 7.0706 & 7.5247 & TRN & \\
\hline CHEMBL3403093 & 1465792 & 8.3188 & 8.1033 & TRN & \\
\hline CHEMBL3403099 & 1465792 & 8.0506 & 8.2114 & TRN & \\
\hline CHEMBL3403144 & 1465792 & 7.699 & 7.8322 & TRN & \\
\hline CHEMBL3403103 & 1465792 & 8.0315 & 8.1571 & TRN & \\
\hline CHEMBL3401579 & 1465792 & 7.4437 & 7.824 & TRN & \\
\hline
\end{tabular}


Supplemental Table S2.txt

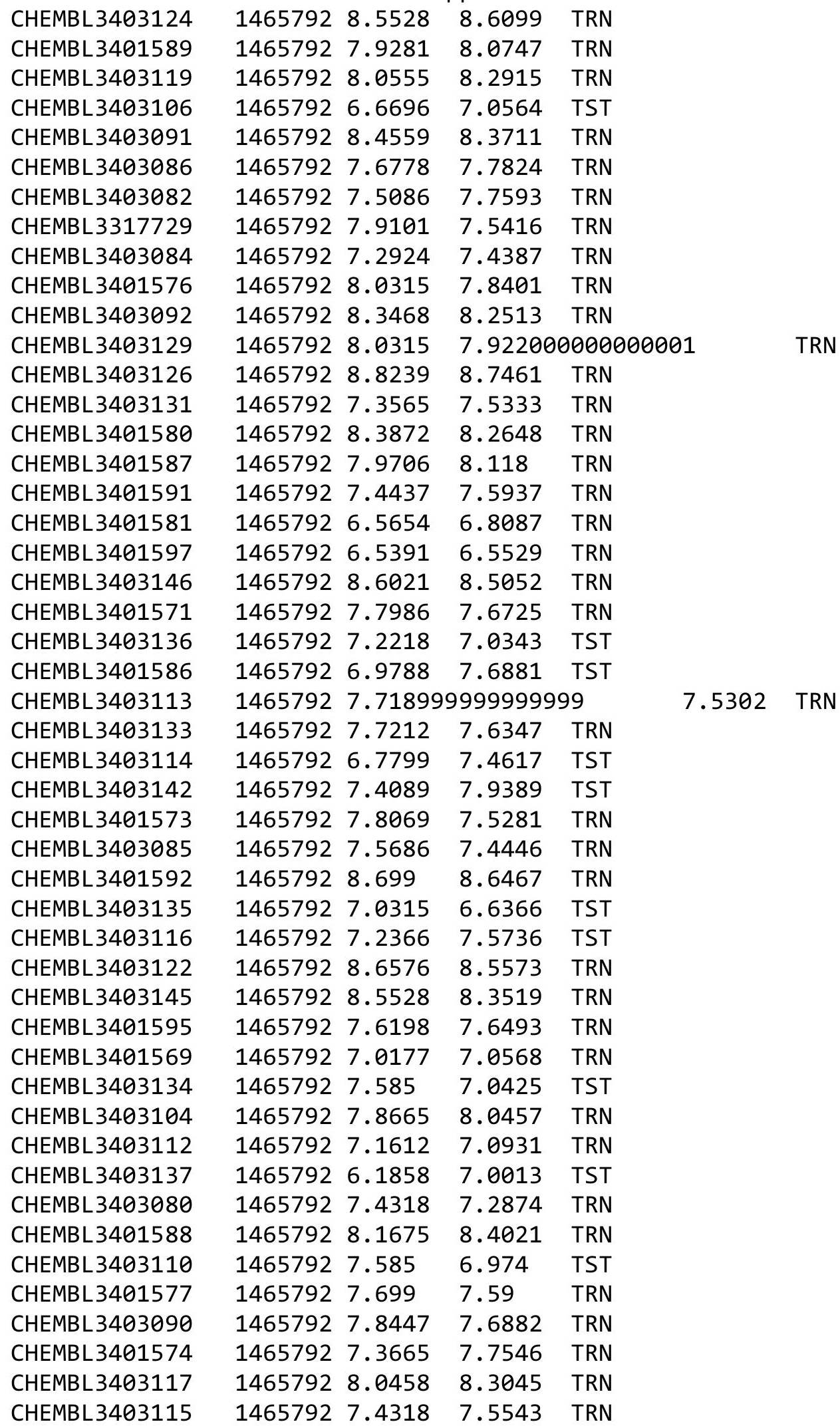

Page 25979 
Supplemental Table S2.txt

\begin{tabular}{|c|c|c|c|c|}
\hline CHEMBL3403120 & 1465792 & 8.3768 & 8.1752 & TRN \\
\hline CHEMBL3403095 & 1465792 & 7.8477 & 7.7313 & TRN \\
\hline CHEMBL3401578 & 1465792 & 8.0223 & 7.9372 & TRN \\
\hline CHEMBL3401568 & 1465792 & 8.041 & 6.7189 & TST \\
\hline CHEMBL3403123 & 1465792 & 8.1427 & 8.2555 & TRN \\
\hline CHEMBL3403094 & 1465792 & 8.5229 & 8.2745 & TRN \\
\hline CHEMBL3401585 & 1465792 & 7.284 & 7.2504 & TRN \\
\hline CHEMBL3401594 & 1465792 & 8.4815 & 8.4057 & TRN \\
\hline CHEMBL1082329 & 1465792 & 7.3098 & 6.7519 & TST \\
\hline CHEMBL3403101 & 1465792 & 8.6576 & 8.6436 & TRN \\
\hline CHEMBL3403088 & 1465792 & 7.2147 & 6.9116 & TRN \\
\hline CHEMBL3403132 & 1465792 & 7.3565 & 7.3658 & TRN \\
\hline CHEMBL3401575 & 1465792 & 7.8125 & 7.7824 & TRN \\
\hline CHEMBL 3403138 & 1465792 & 7.0809 & 7.0754 & TST \\
\hline CHEMBL3403096 & 1465792 & 7.6383 & 7.9126 & TRN \\
\hline CHEMBL3403109 & 1465792 & 7.8297 & 7.5036 & TST \\
\hline CHEMBL3403125 & 1465792 & 8.7212 & 8.7404 & TRN \\
\hline CHEMBL3401583 & 1465792 & 7.1805 & 7.1485 & TRN \\
\hline CHEMBL3401590 & 1465792 & 8.1024 & 8.083 & TRN \\
\hline CHEMBL3403083 & 1465792 & 7.4202 & 7.5095 & TRN \\
\hline CHEMBL3403102 & 1465792 & 8.9586 & 8.6979 & TRN \\
\hline CHEMBL3403128 & 1465792 & 8.6198 & 8.6558 & TRN \\
\hline CHEMBL3401593 & 1465792 & 7.3872 & 7.2906 & TRN \\
\hline CHEMBL3403111 & 1465792 & 6.9066 & 6.8163 & TRN \\
\hline CHEMBL3403130 & 1465792 & 7.8182 & 7.8389 & TRN \\
\hline CHEMBL3403118 & 1465792 & 7.8447 & 7.7096 & TRN \\
\hline CHEMBL3403121 & 1465792 & 8.7447 & 8.2387 & TST \\
\hline CHEMBL3403127 & 1465792 & 8.5686 & 8.3571 & TST \\
\hline CHEMBL3403081 & 1465792 & 7.1938 & 7.7038 & TST \\
\hline CHEMBL3403105 & 1465792 & 7.8861 & 8.26 & TST \\
\hline CHEMBL3400179 & 1465792 & 7.6576 & 7.5281 & TST \\
\hline CHEMBL3403100 & 1465792 & 8.6198 & 8.684 & TST \\
\hline CHEMBL3403140 & 1465792 & 8.0809 & 7.9763 & TST \\
\hline CHEMBL3401582 & 1465792 & 7.2676 & 7.1427 & TST \\
\hline CHEMBL3909876 & 1640603 & 5.1675 & 4.7267 & TST \\
\hline CHEMBL3909195 & 1640603 & 4.585 & 4.5169 & TRN \\
\hline CHEMBL3953726 & 1640603 & 5.0177 & 4.6424 & TRN \\
\hline CHEMBL3954732 & 1640603 & 4.4437 & 4.5927 & TRN \\
\hline CHEMBL3972999 & 1640603 & 4.4437 & 4.5502 & TRN \\
\hline CHEMBL3938386 & 1640603 & 4.7212 & 4.9855 & TRN \\
\hline CHEMBL3901849 & 1640603 & 4.7696 & 4.5848 & TRN \\
\hline CHEMBL3950474 & 1640603 & 4.7696 & 4.8145 & TRN \\
\hline CHEMBL3943141 & 1640603 & 4.9586 & 4.7833 & TRN \\
\hline CHEMBL3905303 & 1640603 & 5.2147 & 4.5926 & TST \\
\hline CHEMBL3937551 & 1640603 & 3.301 & 3.8955 & TRN \\
\hline CHEMBL3912376 & 1640603 & 5.4949 & 3.8954 & TST \\
\hline CHEMBL3922707 & 1640603 & 4.3372 & 4.0856 & TRN \\
\hline CHEMBL3930115 & 1640603 & 3.301 & 3.50699 & 79999999997 \\
\hline
\end{tabular}


Supplemental Table S2.txt

\begin{tabular}{|c|c|c|c|c|}
\hline 6 & & & & \\
\hline & 640603 & & & \\
\hline EM & 603 & & & \\
\hline HEMBL & 603 & 29 & & \\
\hline AEMBL3939249 & 640603 & 7212 & 168 & \\
\hline HEMBL3 & 603 & 5.2924 & 942 & \\
\hline 369 & 603 & & 852 & \\
\hline AEMBL & 603 & & 556 & \\
\hline HEMBL3959904 & 640603 & 4.3768 & 4.09 & \\
\hline HEMBL3945071 & 640603 & 3.301 & 3849 & \\
\hline HEMBL3977023 & 603 & & $\partial 397$ & \\
\hline 19 & 503 & & 405 & \\
\hline AEMBL3 & & & & \\
\hline HEMBL3901878 & 603 & 4.8861 & 8271 & \\
\hline AEMBL3971116 & 603 & & & \\
\hline AEMBL3 & 64 & 4. & 742 & \\
\hline HEMBL3 & 03 & & & RN \\
\hline HEMBL3 & 503 & & & \\
\hline HEMBI 3 & 503 & & & \\
\hline AEMBL3 & & & & I KIV \\
\hline HEMBL & 62 & & 81 & RN \\
\hline HEM & 3 & & 812 & ST \\
\hline AEMBL & 03 & & 302 & RN \\
\hline HEMPI & 03 & & 706 & \\
\hline AEMBL3 & & & 318 & I RN \\
\hline HEMBL3 & 23 & & 316 & RN \\
\hline HEME & 13 & & 88 & KIV \\
\hline 70 & 23 & & 024 & \\
\hline HEMBL 394 & & & 84 & $\mid$ \\
\hline HEMBL3968480 & 03 & 4. & 543 & TRN \\
\hline HEMBL; & & & & RN \\
\hline HFM & & & & 「RN \\
\hline נ & & & 48 & TST \\
\hline HEMBL 394 & & & 352 & 「RN \\
\hline HEMBL3931654 & 03 & & 556 & RN \\
\hline $15 \mathrm{MPI}$ & $\partial 3$ & & 24 & ГST \\
\hline 6 & & & 86 & TRN \\
\hline HEMBL 390 & & & 7175 & TRN \\
\hline HEMBL3980766 & 503 & & 784 & Th \\
\hline 2 & & & & IST \\
\hline HEMBL390 & & & 527 & TRN \\
\hline HEMBL3 & & & 154 & 「RN \\
\hline HEMBL3 & 603 & 49 & & RN \\
\hline HEMBL3 & 503 & 3. & & TS \\
\hline CHEMBL3927349 & & & & \\
\hline HEMBL3932799 & & & & \\
\hline CHEMBL3913644 & & 3.301 & 2924 & RN \\
\hline CHEMBL3952970 & 1640603 & 4.3565 & 4.3013 & TST \\
\hline
\end{tabular}

Page 25981 
Supplemental Table S2.txt

\begin{tabular}{|c|c|c|c|c|c|}
\hline CHEMBL 3925326 & 1640603 & 4.8239 & 4.6772 & TRN & \\
\hline CHEMBL 3967125 & 1640603 & 4.6576 & 4.7102 & TRN & \\
\hline CHEMBL 3909224 & 1640603 & 4.699 & 4.8382 & TRN & \\
\hline CHEMBL 3917550 & 1640603 & 5.4815 & 4.765 & TST & \\
\hline CHEMBL3936154 & 1640603 & 4.699 & 4.3401 & TRN & \\
\hline CHEMBL3965827 & 1640603 & 4.6576 & 4.9114 & TRN & \\
\hline CHEMBL3936519 & 1640603 & 4.7212 & 4.8797 & TRN & \\
\hline CHEMBL3982996 & 1640603 & 4.8539 & 4.705 & TST & \\
\hline CHEMBL3949919 & 1640603 & 3.301 & 3.702 & TRN & \\
\hline CHEMBL3901915 & 1640603 & 3.301 & 4.0756 & TST & \\
\hline CHEMBL3932552 & 1640603 & 4.3665 & 4.3241 & TRN & \\
\hline CHEMBL3923760 & 1640603 & 4.7696 & 4.3599 & TRN & \\
\hline CHEMBL3910117 & 1640603 & 5.0132 & 5.0921 & TRN & \\
\hline CHEMBL 3909223 & 1640603 & 4.5528 & 4.5122 & TRN & \\
\hline CHEMBL 3960556 & 1640603 & 4.4437 & 4.5504 & TRN & \\
\hline CHEMBL3969984 & 1640603 & 4.6198 & 4.6984 & TRN & \\
\hline CHEMBL 3938872 & 1640603 & 4.8539 & 4.9429 & TRN & \\
\hline CHEMBL3895759 & 1640603 & 4.4815 & 4.3289 & TRN & \\
\hline CHEMBL 3916665 & 1640603 & 4.6576 & 4.489 & TRN & \\
\hline CHEMBL 3947667 & 1640603 & 4.7696 & 4.6476 & TRN & \\
\hline CHEMBL 3937108 & 1640603 & 3.301 & 4.1514 & TRN & \\
\hline CHEMBL 3907310 & 1640603 & 4.7212 & 4.6341 & TST & \\
\hline CHEMBL3946411 & 1640603 & 5.0757 & 3.7811 & TST & \\
\hline CHEMBL 3909380 & 1640603 & 5.041 & 4.8961 & TRN & \\
\hline CHEMBL3981412 & 1640603 & 4.4089 & 4.6898 & TST & \\
\hline CHEMBL 3936920 & 1640603 & 4.7212 & 4.668 & TRN & \\
\hline CHEMBL 3946888 & 1640603 & 4.7959 & 4.63399 & 99999999995 & TRN \\
\hline CHEMBL3932131 & 1640603 & 4.6021 & 4.2879 & TRN & \\
\hline CHEMBL 3985846 & 1640603 & 4.5376 & 4.6551 & TRN & \\
\hline CHEMBL 3957620 & 1640603 & 4.4559 & 4.0984 & TRN & \\
\hline CHEMBL 3941085 & 1640603 & 5.9208 & 4.6422 & TST & \\
\hline CHEMBL 3967251 & 1640603 & 5.699 & 4.4056 & TST & \\
\hline CHEMBL3943170 & 1640603 & 4.6383 & 4.7919 & TRN & \\
\hline CHEMBL 3910286 & 1640603 & 4.699 & 4.9191 & TST & \\
\hline CHEMBL3932544 & 1640603 & 4.6576 & 4.6407 & TRN & \\
\hline CHEMBL 3946045 & 1640603 & 4.6198 & 4.6168 & TRN & \\
\hline CHEMBL3907374 & 1640603 & 6.2218 & 4.3885 & TST & \\
\hline CHEMBL3950355 & 1640603 & 5.2218 & 4.7837 & TRN & \\
\hline CHEMBL 3941635 & 1640603 & 4.6778 & 4.2729 & TST & \\
\hline CHEMBL3954973 & 1640603 & 3.301 & 4.6394 & TST & \\
\hline CHEMBL 3974582 & 1640603 & 4.4318 & 4.3966 & TST & \\
\hline CHEMBL3975507 & 1640603 & 4.4949 & 3.7973 & TST & \\
\hline CHEMBL3943785 & 1640603 & 4.6021 & 4.6529 & TRN & \\
\hline CHEMBL 3940721 & 1640603 & 4.6383 & 4.8637 & TRN & \\
\hline CHEMBL3936592 & 1640603 & 4.6778 & 4.3918 & TST & \\
\hline CHEMBL 3944222 & 1640603 & 4.5229 & 4.3939 & TRN & \\
\hline CHEMBL3939766 & 1640603 & 3.301 & 3.9896 & TRN & \\
\hline CHEMBL 3929240 & 1640603 & 4.3665 & 4.4405 & TRN & \\
\hline
\end{tabular}


Supplemental Table S2.txt

\begin{tabular}{|c|c|c|c|c|c|}
\hline CHEMBL3954756 & 1640603 & 4.7447 & 4.8519 & TRN & \\
\hline CHEMBL3906541 & 1640603 & 4.6778 & 3.0957 & TST & \\
\hline CHEMBL3962710 & 1640603 & 4.3872 & 4.284 & TRN & \\
\hline CHEMBL3978573 & 1640603 & 4.7447 & 4.7701 & TRN & \\
\hline CHEMBL3939510 & 1640603 & 4.6576 & 4.7054 & TRN & \\
\hline CHEMBL3949593 & 1640603 & 4.7447 & 4.5787 & TRN & \\
\hline CHEMBL3938981 & 1640603 & 4.5376 & 4.3803 & TRN & \\
\hline CHEMBL3970504 & 1640603 & 4.5229 & 4.2571 & TRN & \\
\hline CHEMBL3948499 & 1640603 & 4.301 & 4.5307 & TRN & \\
\hline CHEMBL3981385 & 1640603 & 5.1135 & 4.7832 & TST & \\
\hline CHEMBL3917412 & 1640603 & 3.301 & 4.1367 & TRN & \\
\hline CHEMBL3962902 & 1640603 & 4.5086 & 4.2555 & TRN & \\
\hline CHEMBL3968942 & 1640603 & 4.6576 & 4.3801 & TRN & \\
\hline CHEMBL 3942007 & 1640603 & 5.0088 & 4.9287 & TRN & \\
\hline CHEMBL3924228 & 1640603 & 4.8539 & 4.4546 & TST & \\
\hline CHEMBL3957752 & 1640603 & 3.301 & 3.8175 & TRN & \\
\hline CHEMBL3984705 & 1640603 & 4.6383 & 4.6665 & TRN & \\
\hline CHEMBL3931693 & 1640603 & 4.8539 & 4.959 & TST & \\
\hline CHEMBL3932708 & 1640603 & 4.3979 & 4.0775 & TST & \\
\hline CHEMBL3910447 & 1640603 & 4.8539 & 4.9399 & TRN & \\
\hline CHEMBL3968141 & 1640603 & 4.585 & 4.7867 & TRN & \\
\hline CHEMBL3921658 & 1640603 & 4.6198 & 4.8619 & TRN & \\
\hline CHEMBL3964719 & 1640603 & 3.301 & 4.1995 & TRN & \\
\hline CHEMBL3920320 & 1640603 & 5.9208 & 4.9071 & TST & \\
\hline CHEMBL3967139 & 1640603 & 6.5229 & 6.675 & TRN & \\
\hline CHEMBL3905808 & 1640603 & 5.2596 & 4.5547 & TST & \\
\hline CHEMBL3942262 & 1640603 & 4.7696 & 4.5434 & TRN & \\
\hline CHEMBL3938822 & 1640603 & 4.8239 & 4.9918 & TRN & \\
\hline CHEMBL3912674 & 1640603 & 4.699 & 4.7244 & TRN & \\
\hline CHEMBL3961204 & 1640603 & 5.1308 & 5.255 & TRN & \\
\hline CHEMBL3924060 & 1640603 & 4.5229 & 4.697 & TRN & \\
\hline CHEMBL3914896 & 1640603 & 4.6778 & 4.7026 & TRN & \\
\hline CHEMBL3915231 & 1640603 & 4.8239 & 4.4685 & TST & \\
\hline CHEMBL3907193 & 1640603 & 4.7212 & 4.7296 & TST & \\
\hline CHEMBL3921296 & 1640603 & 4.699 & 4.6947 & TST & \\
\hline CHEMBL3964366 & 1640603 & 3.301 & 4.765 & TST & \\
\hline CHEMBL3940958 & 1640603 & 4.6198 & 4.5469 & TRN & \\
\hline CHEMBL 3897210 & 1640603 & 4.8861 & 4.76399 & 9999999999 & TRN \\
\hline CHEMBL3930630 & 1640603 & 4.4437 & 4.3291 & TST & \\
\hline CHEMBL 3977273 & 1640603 & 5.0362 & 5.1484 & TRN & \\
\hline CHEMBL 3894723 & 1640603 & 4.3665 & 4.3772 & TRN & \\
\hline CHEMBL3910932 & 1640603 & 4.585 & 4.6548 & TRN & \\
\hline CHEMBL3963023 & 1640603 & 4.5686 & 4.6175 & TRN & \\
\hline CHEMBL3968722 & 1640603 & 4.699 & 4.4848 & TRN & \\
\hline CHEMBL3922611 & 1640603 & 4.4815 & 4.1027 & TRN & \\
\hline CHEMBL3901346 & 1640603 & 4.5229 & 4.3597 & TRN & \\
\hline CHEMBL 3947571 & 1640603 & 4.7447 & 4.5841 & TRN & \\
\hline CHEMBL3942815 & 1640603 & 4.4815 & 4.5957 & TRN & \\
\hline
\end{tabular}

Page 25983 
Supplemental Table S2.txt

\begin{tabular}{|c|c|c|c|c|}
\hline & 603 & 4.7696 & & \\
\hline HEMBL & 640603 & 4.7696 & 7647 & \\
\hline & 2108 & 229 & 542 & \\
\hline 970 & 642108 & 6.0 & 396 & \\
\hline IEMBL 3951213 & 642108 & 6.0 & 3614 & \\
\hline AEMBL 3946171 & 642108 & 6.5935 & 1225 & \\
\hline IEMBL 3975775 & 642108 & & 115 & \\
\hline 37167 & 642108 & & 938 & \\
\hline 24824 & 108 & 5.7235 & 6.2389 & \\
\hline IEMBL 3937593 & 642108 & & 6.2521 & \\
\hline IEMBL 3928190 & 642108 & & 6.2776 & \\
\hline 07138 & 642108 & & 404 & \\
\hline 69636 & 108 & & & \\
\hline IEMBL 3966922 & 1642108 & & & \\
\hline IEMBL 3943962 & 1642108 & & 934 & \\
\hline 34183 & 108 & & & \\
\hline 5335 & 108 & 39 & 202 & \\
\hline 50085 & 108 & & & \\
\hline 59941 & 108 & 38 & 93 & \\
\hline 32117 & 108 & & & \\
\hline 59501 & 108 & 844 & 65 & \\
\hline 0782 & 108 & 8 & 24 & \\
\hline 5824 & 108 & & & \\
\hline 29120 & 108 & & & \\
\hline 9835 & 08 & & & \\
\hline 82674 & 164 & & 99 & \\
\hline 864 & 108 & & 04 & \\
\hline 879 & 16 & & & \\
\hline 65425 & 108 & & & \\
\hline & 08 & & & \\
\hline 8651 & 08 & & 372 & \\
\hline 387 & 08 & & 29 & \\
\hline 240 & 164 & & 15 & \\
\hline 43372 & 164 & & & \\
\hline L3896402 & 164 & & 277 & \\
\hline 9376 & 16 & J & & \\
\hline 976 & 164 & & $\partial 6$ & \\
\hline & 164 & 6 . & 521 & \\
\hline HEMBL3945501 & 1642108 & 6.25 & 236 & \\
\hline L3977883 & 164 & & & \\
\hline 691 & 164 & & 659 & \\
\hline 9625 & 164 & 6 . & 6.3988 & \\
\hline L3906866 & 1642108 & 6.0 & 6.1029 & \\
\hline MBL3916201 & 1642108 & 6.8097 & 6.8989 & $\mathbf{n}$ \\
\hline 1206 & 1642108 & 6.5935 & 726 & \\
\hline 3943194 & 164 & & 663 & \\
\hline CHEMBL3967435 & 1642108 & 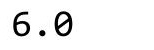 & 6.357 & \\
\hline CHEMBL3893777 & 1642108 & 5.9547 & 5.8448 & \\
\hline
\end{tabular}

Page 25984 


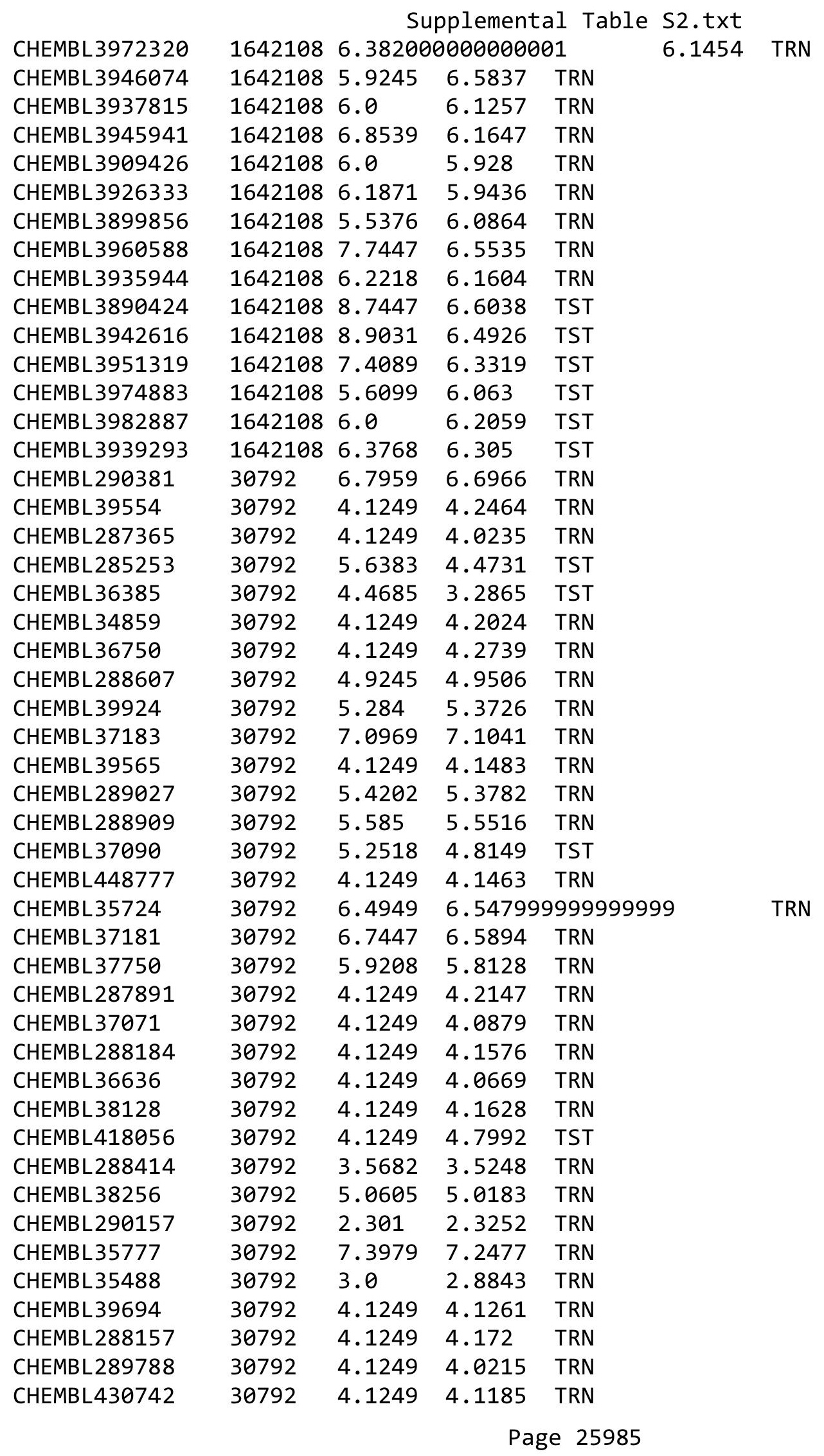




\begin{tabular}{|c|c|c|c|c|c|}
\hline \multicolumn{6}{|c|}{ Supplemental Table S2.txt } \\
\hline CHEMBL287602 & 30792 & 5.6383 & 5.7208 & TRN & \\
\hline CHEMBL36860 & 30792 & 4.1249 & 4.0335 & TRN & \\
\hline CHEMBL288819 & 30792 & 4.1249 & 4.2511 & TRN & \\
\hline CHEMBL37027 & 30792 & 4.1249 & 4.4849 & TRN & \\
\hline CHEMBL39391 & 30792 & 2.301 & 2.2273 & TRN & \\
\hline CHEMBL37910 & 30792 & 5.8539 & 5.1919 & TST & \\
\hline CHEMBL36790 & 30792 & 5.0506 & 4.9647 & TRN & \\
\hline CHEMBL40107 & 30792 & 4.0915 & 4.1302 & TRN & \\
\hline CHEMBL290619 & 30792 & 4.1249 & 3.7909 & TST & \\
\hline CHEMBL35524 & 30792 & 4.1249 & 4.1481 & TRN & \\
\hline CHEMBL39456 & 30792 & 2.301 & 2.1484 & TRN & \\
\hline CHEMBL36699 & 30792 & 5.1739 & 5.2229 & TRN & \\
\hline CHEMBL35730 & 30792 & 4.1249 & 4.158 & TRN & \\
\hline CHEMBL284779 & 30792 & 4.1249 & 4.2031 & TRN & \\
\hline CHEMBL38038 & 30792 & 4.1249 & 4.3139 & TRN & \\
\hline CHEMBL288017 & 30792 & 4.1249 & 3.8662 & TRN & \\
\hline CHEMBL37494 & 30792 & 4.1249 & 2.6664 & TST & \\
\hline CHEMBL37296 & 30792 & 4.1249 & 4.0456 & TRN & \\
\hline CHEMBL39389 & 30792 & 5.7447 & 5.78700 & 0000000001 & TRN \\
\hline CHEMBL290030 & 30792 & 6.7959 & 6.811 & TRN & \\
\hline CHEMBL288013 & 30792 & 4.1249 & 3.0589 & TST & \\
\hline CHEMBL 37074 & 30792 & 4.1249 & 4.0579 & TST & \\
\hline CHEMBL290111 & 30792 & 7.2218 & 7.4618 & TST & \\
\hline CHEMBL431512 & 30792 & 5.6198 & 5.7149 & TST & \\
\hline CHEMBL39430 & 30792 & 5.2147 & 4.2123 & TST & \\
\hline CHEMBL37559 & 30792 & 5.2518 & 6.4311 & TST & \\
\hline CHEMBL37408 & 30792 & 4.1249 & 4.0441 & TST & \\
\hline CHEMBL37305 & 30792 & 4.1249 & 3.7818 & TST & \\
\hline CHEMBL 290770 & 30792 & 6.8861 & 6.7886 & TST & \\
\hline CHEMBL3675992 & 1528480 & 7.6478 & 6.9601 & TRN & \\
\hline CHEMBL3675925 & 1528480 & 8.8239 & 9.0181 & TRN & \\
\hline CHEMBL3675966 & 1528480 & 8.4949 & 7.5022 & TRN & \\
\hline CHEMBL3676031 & 1528480 & 7.5918 & 7.6344 & TRN & \\
\hline CHEMBL3676046 & 1528480 & 8.6021 & 8.0488 & TRN & \\
\hline CHEMBL3675929 & 1528480 & 8.1308 & 8.1624 & TRN & \\
\hline CHEMBL3675908 & 1528480 & 8.71 & 8.7607 & TRN & \\
\hline CHEMBL3671155 & 1528480 & 6.6686 & 8.0597 & TRN & \\
\hline CHEMBL3676067 & 1528480 & 7.8962 & 8.2808 & TRN & \\
\hline CHEMBL 3676045 & 1528480 & 8.7447 & 7.835 & TRN & \\
\hline CHEMBL3937419 & 1528480 & 8.7212 & 7.1289 & TST & \\
\hline CHEMBL3676063 & 1528480 & 8.1675 & 8.2047 & TRN & \\
\hline CHEMBL3676047 & 1528480 & 8.0706 & 7.6756 & TRN & \\
\hline CHEMBL3676050 & 1528480 & 7.9469 & 8.5021 & TRN & \\
\hline CHEMBL 3676057 & 1528480 & 7.1169 & 6.7295 & TRN & \\
\hline CHEMBL3676029 & 1528480 & 8.0044 & 8.2121 & TRN & \\
\hline CHEMBL 3676023 & 1528480 & 7.7423 & 8.0864 & TRN & \\
\hline CHEMBL3676052 & 1528480 & 8.1308 & 7.3916 & TRN & \\
\hline CHEMBL3676105 & 1528480 & 8.0458 & 7.6735 & TST & \\
\hline
\end{tabular}


Supplemental Table S2.txt

\begin{tabular}{|c|c|c|c|c|c|}
\hline CHEMBL3675915 & 1528480 & 8.7825 & 8.6641 & TRN & \\
\hline CHEMBL3676012 & 1528480 & 7.4584 & 7.9985 & TRN & \\
\hline CHEMBL3671144 & 1528480 & 9.0458 & 8.8334 & TRN & \\
\hline CHEMBL3916880 & 1528480 & 6.0 & 8.132 & TST & \\
\hline CHEMBL3676048 & 1528480 & 7.9101 & 8.1894 & TRN & \\
\hline CHEMBL3671154 & 1528480 & 6.0 & 7.5751 & TRN & \\
\hline CHEMBL3676085 & 1528480 & 6.959 & 6.7236 & TST & \\
\hline CHEMBL3675991 & 1528480 & 7.3468 & 7.5479 & TRN & \\
\hline CHEMBL3675999 & 1528480 & 7.8928 & 7.7488 & TRN & \\
\hline CHEMBL3675912 & 1528480 & 8.9586 & 8.4683 & TRN & \\
\hline CHEMBL3675937 & 1528480 & 8.71 & 8.5205 & TST & \\
\hline CHEMBL3675926 & 1528480 & 9.2218 & 8.6924 & TRN & \\
\hline CHEMBL3676019 & 1528480 & 8.9586 & 8.4842 & TRN & \\
\hline CHEMBL 3676088 & 1528480 & 7.9788 & 7.7683 & TRN & \\
\hline CHEMBL3676090 & 1528480 & 7.8861 & 8.2761 & TRN & \\
\hline CHEMBL3676064 & 1528480 & 8.3188 & 7.8116 & TRN & \\
\hline CHEMBL3675918 & 1528480 & 9.0969 & 9.0076 & TRN & \\
\hline CHEMBL3671131 & 1528480 & 8.6383 & 8.7123 & TST & \\
\hline CHEMBL3675961 & 1528480 & 7.5735 & 8.1962 & TST & \\
\hline CHEMBL3675967 & 1528480 & 5.9943 & 6.3063 & TRN & \\
\hline CHEMBL3671134 & 1528480 & 8.8097 & 8.4883 & TRN & \\
\hline CHEMBL3675932 & 1528480 & 6.0 & 6.9966 & TRN & \\
\hline CHEMBL3675924 & 1528480 & 8.4815 & 8.6071 & TRN & \\
\hline CHEMBL3676106 & 1528480 & 7.4179 & 7.5511 & TRN & \\
\hline CHEMBL3671151 & 1528480 & 8.9586 & 8.664 & TST & \\
\hline CHEMBL3675989 & 1528480 & 6.0 & 6.6553 & TRN & \\
\hline CHEMBL3676059 & 1528480 & 7.15799 & 999999999 & 995 & 8.2086 \\
\hline CHEMBL3676058 & 1528480 & 8.6198 & 7.8742 & TRN & \\
\hline CHEMBL 3675941 & 1528480 & 9.2218 & 9.0054 & TRN & \\
\hline CHEMBL3675973 & 1528480 & 8.0458 & 7.6707 & TRN & \\
\hline CHEMBL3676087 & 1528480 & 7.2807 & 8.5253 & TST & \\
\hline CHEMBL3675942 & 1528480 & 9.2441 & 8.7934 & TRN & \\
\hline CHEMBL3675920 & 1528480 & 7.3161 & 7.9229 & TST & \\
\hline CHEMBL 3676080 & 1528480 & 7.8153 & 7.0285 & TST & \\
\hline CHEMBL 3676027 & 1528480 & 6.0 & 7.1228 & TRN & \\
\hline CHEMBL3676025 & 1528480 & 8.8861 & 8.6229 & TRN & \\
\hline CHEMBL3675911 & 1528480 & 8.8239 & 8.8445 & TRN & \\
\hline CHEMBL3675985 & 1528480 & 7.4225 & 7.6118 & TRN & \\
\hline CHEMBL3676079 & 1528480 & 8.0655 & 7.4946 & TST & \\
\hline CHEMBL 3676024 & 1528480 & 8.6778 & 8.3633 & TRN & \\
\hline CHEMBL3676086 & 1528480 & 7.3072 & 6.6933 & TST & \\
\hline CHEMBL3676033 & 1528480 & 8.6576 & 8.2888 & TRN & \\
\hline CHEMBL3675950 & 1528480 & 8.158 & 8.2967 & TRN & \\
\hline CHEMBL3676081 & 1528480 & 8.5086 & 7.4663 & TST & \\
\hline CHEMBL3671129 & 1528480 & 9.1549 & 8.7726 & TRN & \\
\hline CHEMBL3676104 & 1528480 & 8.0506 & 8.0229 & TST & \\
\hline CHEMBL3676075 & 1528480 & 7.767 & 6.4338 & TST & \\
\hline CHEMBL3671146 & 1528480 & 6.0 & 6.6457 & TRN & \\
\hline
\end{tabular}


Supplemental Table S2.txt

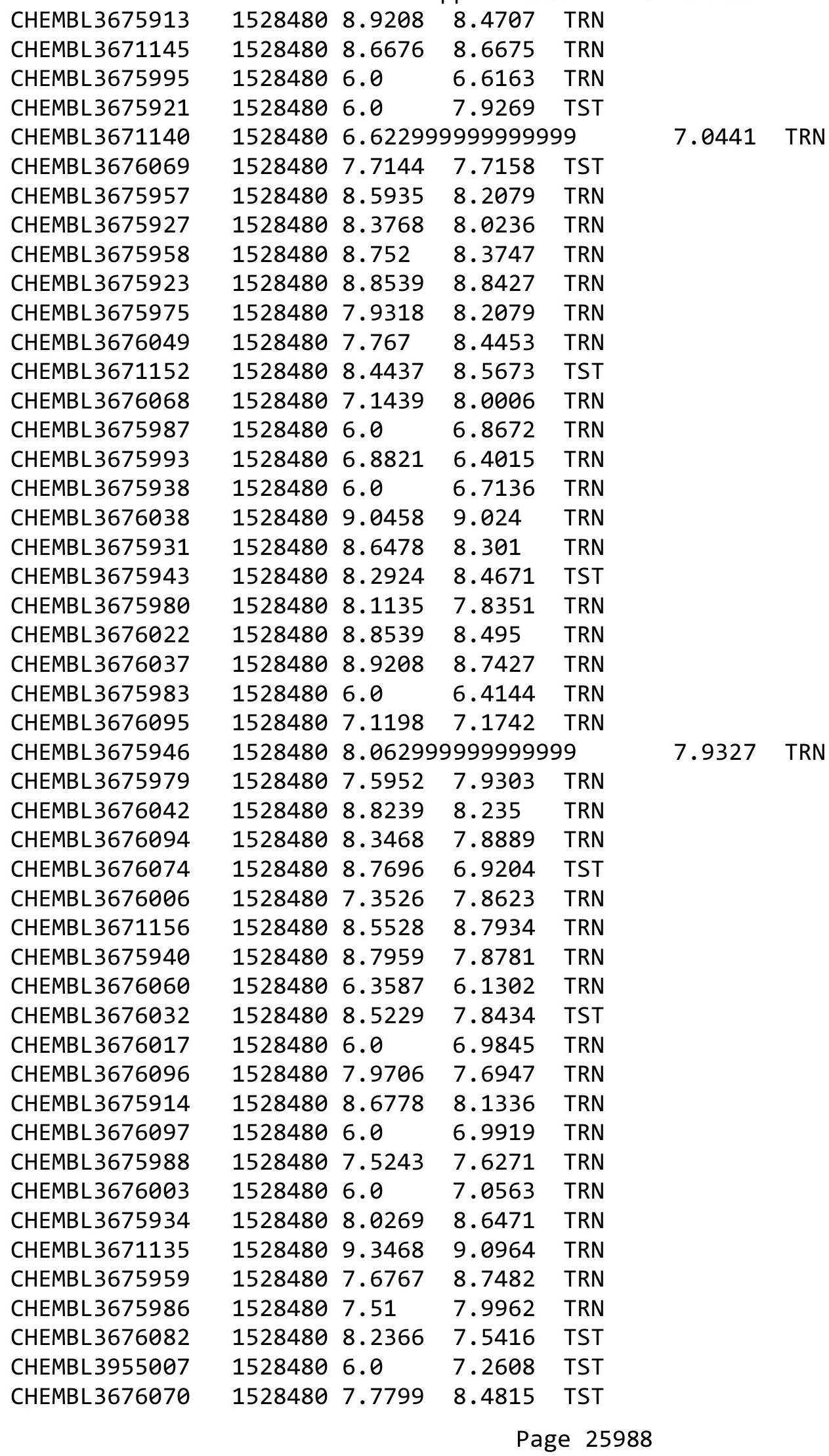


Supplemental Table S2.txt

\begin{tabular}{|c|c|c|c|c|c|}
\hline CHEMBL 3675977 & 1528480 & 6.0 & 7.4778 & TRN & \\
\hline CHEMBL 3671133 & 1528480 & 9.0223 & 8.8843 & TST & \\
\hline CHEMBL3676034 & 1528480 & 8.9586 & 9.1179 & TRN & \\
\hline CHEMBL 3675962 & 1528480 & 7.7932 & 8.6908 & TST & \\
\hline CHEMBL 3676099 & 1528480 & 8.6778 & 7.6945 & TRN & \\
\hline CHEMBL3676002 & 1528480 & 5.5859 & 5.511 & TRN & \\
\hline CHEMBL 3676018 & 1528480 & 7.5114 & 7.1129 & TRN & \\
\hline CHEMBL3671130 & 1528480 & 9.1549 & 8.8567 & TST & \\
\hline CHEMBL 3676103 & 1528480 & 7.6615 & 7.9219 & TRN & \\
\hline CHEMBL 3676015 & 1528480 & 8.0269 & 8.2245 & TRN & \\
\hline CHEMBL 3676053 & 1528480 & 8.0655 & 8.4605 & TRN & \\
\hline CHEMBL3904952 & 1528480 & 9.0458 & 7.6165 & TST & \\
\hline CHEMBL3675933 & 1528480 & 8.4056 & 8.4237 & TRN & \\
\hline CHEMBL 3675976 & 1528480 & 8.28399 & 99999999 & 99 & 7.5177 \\
\hline CHEMBL 3675910 & 1528480 & 8.2757 & 7.3487 & TRN & \\
\hline CHEMBL 3675951 & 1528480 & 7.0455 & 7.9363 & TST & \\
\hline CHEMBL 3676073 & 1528480 & 7.4776 & 7.5774 & TST & \\
\hline CHEMBL 3671142 & 1528480 & 9.2596 & 9.3224 & TRN & \\
\hline CHEMBL 3676077 & 1528480 & 8.3768 & 6.7816 & TST & \\
\hline CHEMBL 3675948 & 1528480 & 7.3138 & 7.8215 & TRN & \\
\hline CHEMBL3639748 & 1528480 & 8.1805 & 9.0259 & TST & \\
\hline CHEMBL 3676076 & 1528480 & 8.4815 & 7.3132 & TST & \\
\hline CHEMBL 3676039 & 1528480 & 7.9355 & 8.7898 & TRN & \\
\hline CHEMBL 3676102 & 1528480 & 7.9469 & 8.008 & TST & \\
\hline CHEMBL3676092 & 1528480 & 8.5229 & 8.2769 & TRN & \\
\hline CHEMBL 3675970 & 1528480 & 8.2676 & 7.9586 & TRN & \\
\hline CHEMBL 3676041 & 1528480 & 8.6021 & 9.0579 & TRN & \\
\hline CHEMBL 3671132 & 1528480 & 9.0223 & 8.8126 & TRN & \\
\hline CHEMBL 3676040 & 1528480 & 8.3279 & 8.8063 & TRN & \\
\hline CHEMBL3676065 & 1528480 & 6.6148 & 7.6268 & TRN & \\
\hline CHEMBL3676008 & 1528480 & 8.1308 & 6.9515 & TRN & \\
\hline CHEMBL 3671138 & 1528480 & 8.9788 & 8.8604 & TRN & \\
\hline CHEMBL 3675936 & 1528480 & 8.6478 & 8.7717 & TRN & \\
\hline CHEMBL 3671143 & 1528480 & 9.2218 & 8.7992 & TST & \\
\hline CHEMBL 3671150 & 1528480 & 8.6778 & 8.4982 & TST & \\
\hline CHEMBL3671148 & 1528480 & 9.2218 & 9.2017 & TRN & \\
\hline CHEMBL 3676001 & 1528480 & 6.3281 & 6.1933 & TRN & \\
\hline CHEMBL 3676013 & 1528480 & 7.4855 & 6.6442 & TRN & \\
\hline CHEMBL 3676101 & 1528480 & 7.9957 & 7.9038 & TRN & \\
\hline CHEMBL 3675935 & 1528480 & 7.7708 & 7.7881 & TST & \\
\hline CHEMBL 3675981 & 1528480 & 7.7852 & 7.6425 & TRN & \\
\hline CHEMBL 3675964 & 1528480 & 8.4437 & 8.5128 & TST & \\
\hline CHEMBL 3675944 & 1528480 & 7.2197 & 7.7402 & TRN & \\
\hline CHEMBL 3675969 & 1528480 & 6.2455 & 5.9997 & TRN & \\
\hline CHEMBL 3671149 & 1528480 & 8.5302 & 8.1936 & TST & \\
\hline CHEMBL 3639749 & 1528480 & 6.0 & 7.4355 & TRN & \\
\hline CHEMBL 3676030 & 1528480 & 8.3665 & 8.7129 & TRN & \\
\hline CHEMBL 3676054 & 1528480 & 7.2434 & 7.9528 & TRN & \\
\hline
\end{tabular}

Page 25989 
Supplemental Table S2.txt

\begin{tabular}{|c|c|c|c|c|c|}
\hline CHEMBL3675965 & 1528480 & 9.0223 & 8.8865 & TST & \\
\hline CHEMBL3675917 & 1528480 & 9.1549 & 8.8093 & TRN & \\
\hline CHEMBL3676061 & 1528480 & 7.8069 & 7.9683 & TRN & \\
\hline CHEMBL 3671139 & 1528480 & 6.1095 & 6.7324 & TRN & \\
\hline CHEMBL3675963 & 1528480 & 8.2125 & 7.5494 & TRN & \\
\hline CHEMBL 3676000 & 1528480 & 6.6605 & 6.1232 & TRN & \\
\hline CHEMBL3676089 & 1528480 & 7.9101 & 7.2456 & TRN & \\
\hline CHEMBL3676005 & 1528480 & 8.301 & 7.6183 & TRN & \\
\hline CHEMBL 3676056 & 1528480 & 7.0809 & 8.2476 & TRN & \\
\hline CHEMBL3675909 & 1528480 & 7.9747 & 6.9364 & TRN & \\
\hline CHEMBL 3676091 & 1528480 & 7.7986 & 7.9616 & TRN & \\
\hline CHEMBL 3675945 & 1528480 & 7.6207 & 7.5241 & TRN & \\
\hline CHEMBL 3676011 & 1528480 & 6.1003 & 5.9258 & TRN & \\
\hline CHEMBL 3676072 & 1528480 & 8.4089 & 8.0653 & TST & \\
\hline CHEMBL 3675971 & 1528480 & 6.4653 & 6.1653 & TRN & \\
\hline CHEMBL 3675954 & 1528480 & 8.8861 & 8.7988 & TRN & \\
\hline CHEMBL3675930 & 1528480 & 7.983 & 7.6343 & TRN & \\
\hline CHEMBL 3675968 & 1528480 & 8.2924 & 7.0962 & TRN & \\
\hline CHEMBL 3671136 & 1528480 & 8.9586 & 8.969 & TRN & \\
\hline CHEMBL3676051 & 1528480 & 8.1612 & 7.9398 & TRN & \\
\hline CHEMBL3675953 & 1528480 & 7.4578 & 8.3182 & TST & \\
\hline CHEMBL3676010 & 1528480 & 7.58 & 7.5093 & TRN & \\
\hline CHEMBL3676071 & 1528480 & 7.8447 & 7.8841 & TST & \\
\hline CHEMBL3675972 & 1528480 & 8.2076 & 7.2597 & TRN & \\
\hline CHEMBL3902802 & 1528480 & 6.0 & 7.0632 & TST & \\
\hline CHEMBL3675919 & 1528480 & 7.5391 & 8.4986 & TST & \\
\hline CHEMBL 3676093 & 1528480 & 8.0605 & 7.744 & TRN & \\
\hline CHEMBL3675982 & 1528480 & 5.9239 & 5.8133 & TRN & \\
\hline CHEMBL 3675955 & 1528480 & 8.7447 & 8.294 & TRN & \\
\hline CHEMBL 3671141 & 1528480 & 9.301 & 9.2852 & TRN & \\
\hline CHEMBL 3971680 & 1528480 & 8.4437 & 7.4509 & TST & \\
\hline CHEMBL3675947 & 1528480 & 7.3531 & 8.0799 & TRN & \\
\hline CHEMBL3675960 & 1528480 & 8.0278 & 8.3466 & TST & \\
\hline CHEMBL3675956 & 1528480 & 8.9393 & 8.5513 & TRN & \\
\hline CHEMBL3671137 & 1528480 & 8.4622 & 8.5469 & TRN & \\
\hline CHEMBL3671153 & 1528480 & 9.3979 & 8.5968 & TRN & \\
\hline CHEMBL3675922 & 1528480 & 8.8239 & 8.6422 & TRN & \\
\hline CHEMBL 3676084 & 1528480 & 6.7265 & \multicolumn{2}{|c|}{6.7139999999999995} & TST \\
\hline CHEMBL 3676026 & 1528480 & 9.699 & 8.5932 & TRN & \\
\hline CHEMBL3675916 & 1528480 & 8.8861 & 8.798 & TRN & \\
\hline CHEMBL3675949 & 1528480 & 7.8996 & 8.0736 & TRN & \\
\hline CHEMBL3676055 & 1528480 & 7.2104 & 7.7467 & TST & \\
\hline CHEMBL3675952 & 1528480 & 8.27 & 8.6068 & TST & \\
\hline CHEMBL3676016 & 1528480 & 7.8962 & 7.8993 & TST & \\
\hline CHEMBL1214720 & 650215 & 3.767 & 3.4858 & TRN & \\
\hline CHEMBL1212961 & 650215 & 2.5229 & 2.4985 & TRN & \\
\hline CHEMBL1214793 & 650215 & 3.7747 & \multicolumn{2}{|c|}{3.2680000000000002} & TRN \\
\hline CHEMBL1214719 & 650215 & 5.2218 & 4.7561 & TRN & \\
\hline
\end{tabular}




\begin{tabular}{|c|c|c|c|c|c|}
\hline \multicolumn{6}{|c|}{ Supplemental Table S2.txt } \\
\hline CHEMBL1215581 & 650215 & 4.284 & 4.5959 & TRN & \\
\hline CHEMBL1214794 & 650215 & 4.7959 & 3.9456 & TST & \\
\hline CHEMBL1215293 & 650215 & 4.0458 & 4.5476 & TRN & \\
\hline CHEMBL1215648 & 650215 & 4.6576 & 4.4253 & TRN & \\
\hline CHEMBL1215716 & 650215 & 4.5229 & 4.2958 & TRN & \\
\hline CHEMBL1214796 & 650215 & 3.9666 & 3.0955 & TRN & \\
\hline CHEMBL1215156 & 650215 & 4.8239 & 5.1907 & TRN & \\
\hline CHEMBL1215365 & 650215 & 5.699 & 5.7964 & TRN & \\
\hline CHEMBL1215227 & 650215 & 6.0 & 5.9966 & TRN & \\
\hline CHEMBL1214939 & 650215 & 5.301 & 4.2113 & TST & \\
\hline CHEMBL1214792 & 650215 & 3.5376 & 2.7055 & TST & \\
\hline CHEMBL1214795 & 650215 & 4.4559 & 3.6145 & TST & \\
\hline CHEMBL1215798 & 650215 & 3.556 & 3.2391 & TST & \\
\hline CHEMBL1214646 & 650215 & 2.5229 & 3.6011 & TST & \\
\hline CHEMBL1214862 & 650215 & 2.5229 & 2.4698 & TST & \\
\hline CHEMBL1214936 & 650215 & 5.0458 & 5.3855 & TRN & \\
\hline CHEMBL1215439 & 650215 & 4.4437 & 3.948 & TRN & \\
\hline CHEMBL1214717 & 650215 & 5.2218 & 5.0518 & TRN & \\
\hline CHEMBL1215005 & 650215 & 4.5528 & 4.4503 & TRN & \\
\hline CHEMBL1215802 & 650215 & 5.1549 & 5.4263 & TRN & \\
\hline CHEMBL1214937 & 650215 & 4.7959 & 4.8338 & TRN & \\
\hline CHEMBL1214869 & 650215 & 3.6615 & 3.4792 & TRN & \\
\hline CHEMBL1214861 & 650215 & 3.7305 & 3.1617 & TRN & \\
\hline CHEMBL1215512 & 650215 & 2.5229 & 3.2233 & TRN & \\
\hline CHEMBL1215650 & 650215 & 4.2757 & 3.9774 & TRN & \\
\hline CHEMBL1215366 & 650215 & 5.699 & 5.84200 & 00000000005 & TRN \\
\hline CHEMBL1215801 & 650215 & 6.0 & 5.8057 & TRN & \\
\hline CHEMBL1215080 & 650215 & 4.7696 & 4.6048 & TRN & \\
\hline CHEMBL1215292 & 650215 & 5.5229 & 5.0348 & TRN & \\
\hline CHEMBL1215718 & 650215 & 2.5229 & 3.4524 & TRN & \\
\hline CHEMBL1214790 & 650215 & 3.6556 & 3.6583 & TRN & \\
\hline CHEMBL1215157 & 650215 & 5.0458 & 5.0183 & TRN & \\
\hline CHEMBL1215004 & 650215 & 4.9208 & 5.1992 & TRN & \\
\hline CHEMBL1215003 & 650215 & 4.8239 & 4.8414 & TRN & \\
\hline CHEMBL1215580 & 650215 & 5.2218 & 4.9483 & TRN & \\
\hline CHEMBL1215007 & 650215 & 5.301 & 4.2935 & TST & \\
\hline CHEMBL400566 & 650215 & 4.7447 & 4.8473 & TRN & \\
\hline CHEMBL1214648 & 650215 & 4.585 & 4.8432 & TRN & \\
\hline CHEMBL1214938 & 650215 & 2.5229 & 2.81399 & 99999999996 & TRN \\
\hline CHEMBL1214798 & 650215 & 2.5229 & 2.8978 & TRN & \\
\hline CHEMBL1215510 & 650215 & 5.3979 & 5.4676 & TRN & \\
\hline CHEMBL1215800 & 650215 & 5.0969 & 5.2893 & TRN & \\
\hline CHEMBL1214791 & 650215 & 2.5229 & 2.9244 & TRN & \\
\hline CHEMBL1215155 & 650215 & 6.0 & 5.7389 & TRN & \\
\hline CHEMBL1215291 & 650215 & 5.699 & 5.1397 & TRN & \\
\hline CHEMBL1215803 & 650215 & 4.7959 & 4.997 & TRN & \\
\hline CHEMBL1215006 & 650215 & 4.4437 & 4.3021 & TRN & \\
\hline CHEMBL1214797 & 650215 & 2.5229 & 2.9037 & TRN & \\
\hline
\end{tabular}

Page 25991 
Supplemental Table S2.txt

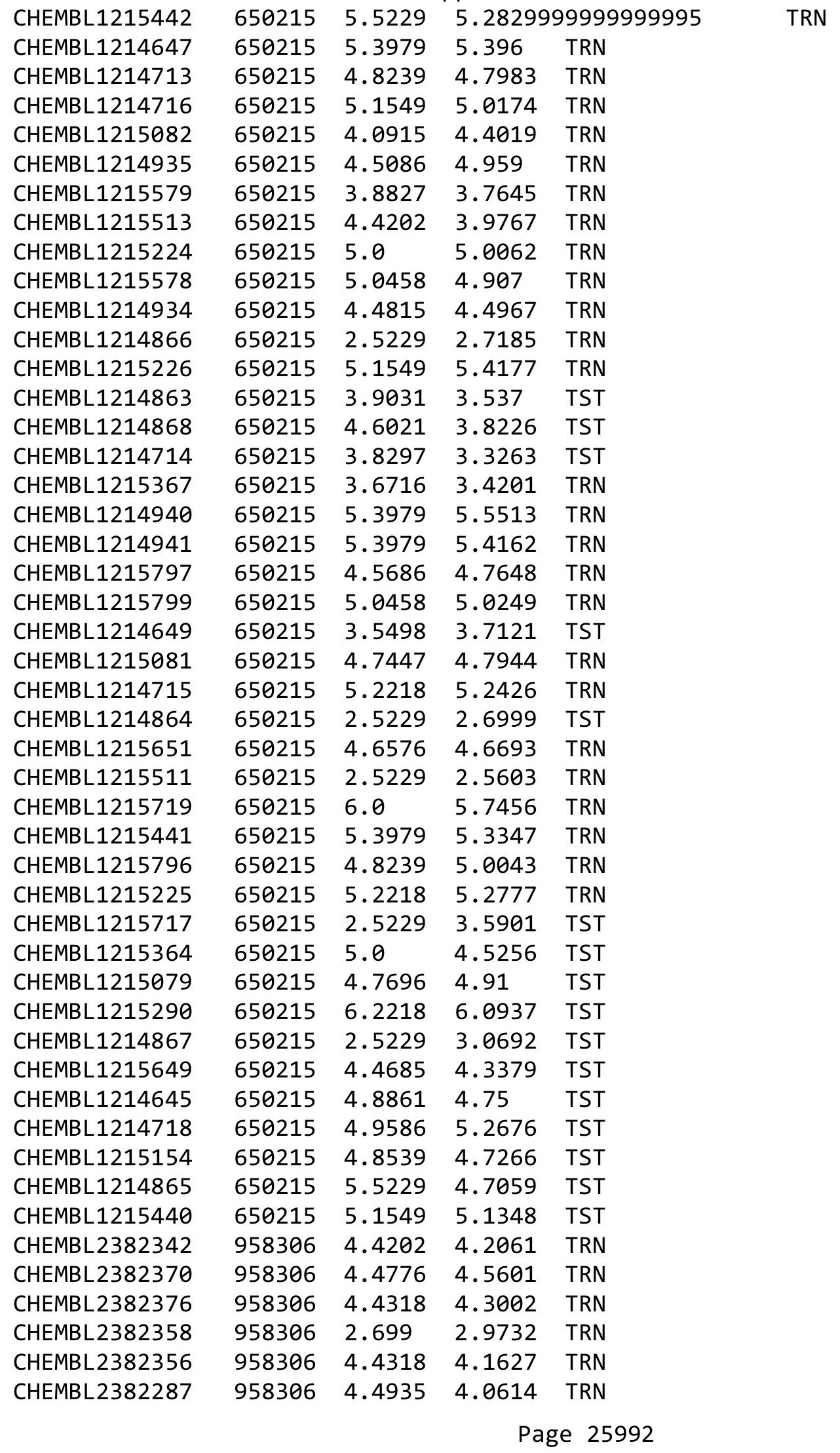




\begin{tabular}{|c|c|c|c|c|c|}
\hline & & \multicolumn{4}{|c|}{ Supplemental Table S2.txt } \\
\hline CHEMBL2382360 & 958306 & 2.699 & 3.6719 & TRN & \\
\hline CHEMBL 2382344 & 958306 & 3.9208 & 3.0973 & TRN & \\
\hline CHEMBL2382349 & 958306 & 4.2218 & 4.1268 & TRN & \\
\hline CHEMBL2382350 & 958306 & 3.0 & 3.1356 & TRN & \\
\hline CHEMBL2382365 & 958306 & 2.6198 & 3.3458 & TRN & \\
\hline CHEMBL 2382283 & 958306 & 2.9208 & 3.3202 & TRN & \\
\hline CHEMBL 2382385 & 958306 & 3.8239 & 3.7289 & TRN & \\
\hline CHEMBL 2159976 & 958306 & 4.0726 & 3.8231 & TST & \\
\hline CHEMBL 2382357 & 958306 & 3.699 & 3.4592 & TRN & \\
\hline CHEMBL2382285 & 958306 & 5.0535 & 4.3691 & TST & \\
\hline CHEMBL 2382380 & 958306 & 4.3468 & 4.3499 & TRN & \\
\hline CHEMBL2382366 & 958306 & 2.699 & 2.9179 & TRN & \\
\hline CHEMBL 2380332 & 958306 & 3.9208 & 3.4509 & TRN & \\
\hline CHEMBL 2382346 & 958306 & 4.2218 & 4.0753 & TRN & \\
\hline CHEMBL2382351 & 958306 & 4.6021 & 4.6028 & TRN & \\
\hline CHEMBL 2382375 & 958306 & 3.0 & 3.3068 & TRN & \\
\hline CHEMBL2382355 & 958306 & 4.1249 & 4.3497 & TRN & \\
\hline CHEMBL 2382368 & 958306 & 3.9208 & 4.3399 & TRN & \\
\hline CHEMBL 2382353 & 958306 & 3.9208 & 4.1346 & TRN & \\
\hline CHEMBL2382378 & 958306 & 4.2218 & 3.9155 & TRN & \\
\hline CHEMBL 2382284 & 958306 & 2.9208 & 3.1563 & TST & \\
\hline CHEMBL2382341 & 958306 & 4.4318 & 3.8948 & TRN & \\
\hline CHEMBL 2382363 & 958306 & 2.699 & 3.4464 & TRN & \\
\hline CHEMBL 2382343 & 958306 & 3.0 & 3.8671 & TRN & \\
\hline CHEMBL2382383 & 958306 & 3.9208 & 3.3835 & TRN & \\
\hline CHEMBL 2380334 & 958306 & 4.2218 & 3.9503 & TST & \\
\hline CHEMBL2380333 & 958306 & 4.2218 & 3.9948 & TRN & \\
\hline CHEMBL 2382345 & 958306 & 5.0168 & 4.5385 & TRN & \\
\hline CHEMBL2382386 & 958306 & 4.301 & 4.1867 & TRN & \\
\hline CHEMBL 2382347 & 958306 & 2.9208 & 3.4416 & TRN & \\
\hline CHEMBL2382354 & 958306 & 4.1249 & 4.1104 & TRN & \\
\hline CHEMBL2382361 & 958306 & 3.9586 & 4.0576 & TRN & \\
\hline CHEMBL2382373 & 958306 & 4.5229 & 3.9551 & TRN & \\
\hline CHEMBL 2158050 & 958306 & 4.5171 & 4.0663 & TST & \\
\hline CHEMBL2382379 & 958306 & 4.3468 & 4.5018 & TRN & \\
\hline CHEMBL2382348 & 958306 & 2.9208 & 3.7108 & TRN & \\
\hline CHEMBL 2382367 & 958306 & 3.6198 & 2.5647 & TRN & \\
\hline CHEMBL2382377 & 958306 & 4.301 & 4.1292 & TRN & \\
\hline CHEMBL 2382374 & 958306 & 4.0 & 3.8726 & TRN & \\
\hline CHEMBL2382359 & 958306 & 4.4486 & 4.3502 & TRN & \\
\hline CHEMBL2382369 & 958306 & 3.6198 & 3.68899 & 99999999996 & TRN \\
\hline CHEMBL 2382388 & 958306 & 3.0 & 3.8676 & TST & \\
\hline CHEMBL2382382 & 958306 & 4.2218 & 4.1479 & TRN & \\
\hline CHEMBL 2382362 & 958306 & 2.699 & 3.7282 & TST & \\
\hline CHEMBL 2382384 & 958306 & 4.301 & 4.151 & TST & \\
\hline CHEMBL 2382282 & 958306 & 2.9208 & 3.38199 & 99999999997 & TST \\
\hline CHEMBL 2382371 & 958306 & 2.6198 & 4.1296 & TST & \\
\hline CHEMBL2382364 & 958306 & 4.8239 & 4.2173 & TST & \\
\hline
\end{tabular}


Supplemental Table S2.txt

\begin{tabular}{|c|c|c|c|c|c|}
\hline CHEMBL 2382381 & 958306 & 4.6021 & 4.1731 & TST & \\
\hline CHEMBL 2382372 & 958306 & 5.0757 & 4.3321 & TST & \\
\hline CHEMBL 2382352 & 958306 & 3.0 & 4.064 & TST & \\
\hline CHEMBL 2382387 & 958306 & 2.699 & 4.0338 & TST & \\
\hline CHEMBL549020 & 1479003 & 6.2 & 5.9893 & TRN & \\
\hline CHEMBL526199 & 1479003 & 5.1 & 4.9569 & TRN & \\
\hline CHEMBL3430919 & 1479003 & 3.3 & \multicolumn{2}{|c|}{ 3.2239999999999998 } & TRN \\
\hline CHEMBL528583 & 1479003 & 8.1 & 7.6781 & TRN & \\
\hline CHEMBL530358 & 1479003 & 5.9 & 5.6226 & TRN & \\
\hline CHEMBL534517 & 1479003 & 5.8 & 5.7771 & TRN & \\
\hline CHEMBL 3430921 & 1479003 & 6.5 & 6.4121 & TST & \\
\hline CHEMBL3430922 & 1479003 & 6.0 & 6.0144 & TST & \\
\hline CHEMBL 2098124 & 1479003 & 6.2 & 6.2729 & TRN & \\
\hline CHEMBL2098408 & 1479003 & 5.6 & 5.6765 & TRN & \\
\hline CHEMBL1578482 & 1479003 & 5.8 & \multicolumn{2}{|c|}{5.781000000000001} & TRN \\
\hline CHEMBL2098276 & 1479003 & 5.8 & 5.6762 & TRN & \\
\hline CHEMBL3430923 & 1479003 & 6.5 & 6.1584 & TST & \\
\hline CHEMBL3430924 & 1479003 & 5.8 & 5.6464 & TRN & \\
\hline CHEMBL3430925 & 1479003 & 3.3 & 6.6795 & TST & \\
\hline CHEMBL3430926 & 1479003 & 6.1 & 6.3421 & TST & \\
\hline CHEMBL 2165401 & 1479003 & 3.3 & 4.5305 & TST & \\
\hline CHEMBL3430928 & 1479003 & 5.3 & 5.0313 & TRN & \\
\hline CHEMBL3430929 & 1479003 & 4.6 & 4.7473 & TRN & \\
\hline CHEMBL3430930 & 1479003 & 4.4 & 4.0829 & TRN & \\
\hline CHEMBL305686 & 1479003 & 5.7 & 5.4577 & TST & \\
\hline CHEMBL3430931 & 1479003 & 6.6 & 6.2807 & TST & \\
\hline CHEMBL3430932 & 1479003 & 5.9 & 5.9121 & TST & \\
\hline CHEMBL1232777 & 1479003 & 6.3 & 6.09 & TST & \\
\hline CHEMBL3430933 & 1479003 & 6.2 & 6.2882 & TRN & \\
\hline CHEMBL3430913 & 1479003 & 5.3 & 5.4633 & TRN & \\
\hline CHEMBL3430934 & 1479003 & 4.5 & 4.6173 & TRN & \\
\hline CHEMBL 3430935 & 1479003 & 6.1 & 6.2454 & TST & \\
\hline CHEMBL3430936 & 1479003 & 4.9 & \multicolumn{2}{|c|}{5.617000000000001} & TRN \\
\hline CHEMBL3430937 & 1479003 & 4.6 & 4.5761 & TST & \\
\hline CHEMBL3430938 & 1479003 & 4.8 & 5.0028 & TRN & \\
\hline CHEMBL3430939 & 1479003 & 4.9 & 4.9271 & TRN & \\
\hline CHEMBL3430940 & 1479003 & 5.0 & 5.1308 & TRN & \\
\hline CHEMBL3430941 & 1479003 & 4.9 & 4.9988 & TRN & \\
\hline CHEMBL3430942 & 1479003 & 5.2 & 5.1218 & TRN & \\
\hline CHEMBL3430943 & 1479003 & 5.0 & 5.0556 & TRN & \\
\hline CHEMBL3430944 & 1479003 & 4.2 & 4.8115 & TRN & \\
\hline CHEMBL3430945 & 1479003 & 5.6 & 5.5367 & TRN & \\
\hline CHEMBL3430946 & 1479003 & 5.5 & \multicolumn{2}{|c|}{5.577000000000001} & TRN \\
\hline CHEMBL3430947 & 1479003 & 6.0 & 5.8803 & TRN & \\
\hline CHEMBL3430948 & 1479003 & 4.6 & 4.4639 & TRN & \\
\hline CHEMBL3430949 & 1479003 & 6.1 & 5.9406 & TRN & \\
\hline CHEMBL1388922 & 1479003 & 5.5 & 5.4381 & TRN & \\
\hline CHEMBL3430950 & 1479003 & 5.6 & 5.3948 & TRN & \\
\hline
\end{tabular}




\begin{tabular}{|c|c|c|c|c|c|}
\hline & & & & & \\
\hline CHEMBL3430951 & 1479003 & 6.7 & 6.521 & TST & \\
\hline CHEMBL1321334 & 1479003 & 6.4 & 6.4234 & TRN & \\
\hline CHEMBL3430953 & 1479003 & 3.3 & 3.2351 & TRN & \\
\hline CHEMBL 3430954 & 1479003 & 6.3 & 5.7285 & TRN & \\
\hline CHEMBL3430955 & 1479003 & 6.1 & 6.107 & TST & \\
\hline CHEMBL3430956 & 1479003 & 5.9 & 5.7721 & TRN & \\
\hline CHEMBL3430957 & 1479003 & 4.8 & 4.5951 & TRN & \\
\hline CHEMBL3430958 & 1479003 & 4.9 & 4.7559 & TRN & \\
\hline CHEMBL3430959 & 1479003 & 5.6 & 5.5377 & TRN & \\
\hline CHEMBL3430960 & 1479003 & 6.6 & 6.6073 & TRN & \\
\hline CHEMBL3430961 & 1479003 & 5.3 & 5.3082 & TRN & \\
\hline CHEMBL3430962 & 1479003 & 4.5 & 4.0427 & TRN & \\
\hline CHEMBL 3430963 & 1479003 & 5.7 & 5.3666 & TRN & \\
\hline CHEMBL 3430964 & 1479003 & 5.6 & 5.3318 & TRN & \\
\hline CHEMBL3430965 & 1479003 & 4.8 & 4.4817 & TRN & \\
\hline CHEMBL 3430966 & 1479003 & 6.4 & 6.2468 & TRN & \\
\hline CHEMBL3430967 & 1479003 & 5.1 & 4.8762 & TRN & \\
\hline CHEMBL3430968 & 1479003 & 6.3 & 6.2099 & TRN & \\
\hline CHEMBL3430969 & 1479003 & 5.8 & 5.8277 & TRN & \\
\hline CHEMBL 3430970 & 1479003 & 4.6 & 4.7935 & TRN & \\
\hline CHEMBL1482137 & 1479003 & 6.4 & 6.0419 & TRN & \\
\hline CHEMBL3430971 & 1479003 & 6.5 & 6.3135 & TRN & \\
\hline CHEMBL3430972 & 1479003 & 6.0 & 5.6818 & TRN & \\
\hline CHEMBL 3430973 & 1479003 & 5.4 & 5.3359 & TRN & \\
\hline CHEMBL 3430974 & 1479003 & 3.3 & 3.1935 & TRN & \\
\hline CHEMBL 3430975 & 1479003 & 5.8 & 5.68 & TRN & \\
\hline CHEMBL3430976 & 1479003 & 5.5 & 5.5354 & TRN & \\
\hline CHEMBL3430977 & 1479003 & 4.5 & 4.3836 & TST & \\
\hline CHEMBL164422 & 1479003 & 6.0 & 5.8115 & TRN & \\
\hline CHEMBL3430978 & 1479003 & 3.3 & 3.2811 & TRN & \\
\hline CHEMBL 3430979 & 1479003 & 5.8 & 5.46299 & 9999999999 & TRN \\
\hline CHEMBL 3430980 & 1479003 & 7.1 & 7.7911 & TRN & \\
\hline CHEMBL1487481 & 1479003 & 5.6 & 5.4634 & TRN & \\
\hline CHEMBL1487467 & 1479003 & 5.8 & 5.6349 & TRN & \\
\hline CHEMBL3430981 & 1479003 & 4.5 & 4.1464 & TRN & \\
\hline CHEMBL3430982 & 1479003 & 3.3 & 3.0444 & TRN & \\
\hline CHEMBL3430983 & 1479003 & 3.3 & 3.155 & TRN & \\
\hline CHEMBL592827 & 1479003 & 6.7 & 6.7027 & TRN & \\
\hline CHEMBL 3430984 & 1479003 & 5.7 & 5.4133 & TRN & \\
\hline CHEMBL 3430985 & 1479003 & 5.3 & 5.0066 & TRN & \\
\hline CHEMBL1466712 & 1479003 & 5.5 & 4.8428 & TRN & \\
\hline CHEMBL3430986 & 1479003 & 4.6 & 4.6333 & TRN & \\
\hline CHEMBL3430987 & 1479003 & 4.7 & 5.3178 & TST & \\
\hline CHEMBL 3430988 & 1479003 & 6.5 & 6.1289 & TRN & \\
\hline CHEMBL 3430989 & 1479003 & 5.9 & 6.0028 & TRN & \\
\hline CHEMBL 3430990 & 1479003 & 6.3 & 6.0718 & TRN & \\
\hline CHEMBL3430991 & 1479003 & 6.6 & 6.2006 & TRN & \\
\hline CHEMBL 3430992 & 1479003 & 7.0 & 6.7984 & TRN & \\
\hline
\end{tabular}




\begin{tabular}{|c|c|c|c|c|c|}
\hline CHEMBL3430993 & 1479003 & 5.8 & 5.4732 & TRN & \\
\hline CHEMBL3430994 & 1479003 & 4.6 & 4.7024 & TRN & \\
\hline CHEMBL3430995 & 1479003 & 5.6 & 5.2952 & TST & \\
\hline CHEMBL3430996 & 1479003 & 6.9 & 6.2662 & TRN & \\
\hline CHEMBL3430997 & 1479003 & 5.2 & 5.409 & TRN & \\
\hline CHEMBL3430998 & 1479003 & 6.2 & 5.9779 & TRN & \\
\hline CHEMBL3430999 & 1479003 & 6.9 & 6.7448 & TRN & \\
\hline CHEMBL3431000 & 1479003 & 4.6 & 4.2293 & TRN & \\
\hline CHEMBL3431001 & 1479003 & 6.6 & 6.6535 & TRN & \\
\hline CHEMBL3431002 & 1479003 & 5.8 & 5.8434 & TST & \\
\hline CHEMBL 3431003 & 1479003 & 7.0 & 6.9512 & TRN & \\
\hline CHEMBL 3431004 & 1479003 & 6.9 & 6.9181 & TRN & \\
\hline CHEMBL3431005 & 1479003 & 6.2 & 6.2442 & TRN & \\
\hline CHEMBL3431006 & 1479003 & 6.4 & 6.4723 & TRN & \\
\hline CHEMBL3431007 & 1479003 & 3.3 & 4.66 & TRN & \\
\hline CHEMBL3431008 & 1479003 & 5.1 & 5.5008 & TST & \\
\hline CHEMBL3431009 & 1479003 & 6.7 & 6.41299 & 9999999999 & TRN \\
\hline CHEMBL 2355685 & 1479003 & 5.8 & 5.7089 & TST & \\
\hline CHEMBL3431010 & 1479003 & 5.0 & 4.8315 & TRN & \\
\hline CHEMBL3431011 & 1479003 & 6.1 & 5.7839 & TRN & \\
\hline CHEMBL3431012 & 1479003 & 4.4 & 4.3946 & TST & \\
\hline CHEMBL1731664 & 1479003 & 3.3 & 4.9729 & TRN & \\
\hline CHEMBL3431013 & 1479003 & 5.7 & 5.50799 & 9999999999 & TRN \\
\hline CHEMBL3431014 & 1479003 & 3.3 & 4.6047 & TRN & \\
\hline CHEMBL3431015 & 1479003 & 5.0 & 5.1092 & TRN & \\
\hline CHEMBL3431016 & 1479003 & 6.4 & 6.3127 & TRN & \\
\hline CHEMBL3431017 & 1479003 & 5.7 & 5.3305 & TRN & \\
\hline CHEMBL3431018 & 1479003 & 6.1 & 5.426 & TRN & \\
\hline CHEMBL3431019 & 1479003 & 3.3 & 3.1882 & TRN & \\
\hline CHEMBL3431020 & 1479003 & 6.4 & 6.2813 & TRN & \\
\hline CHEMBL3431021 & 1479003 & 4.9 & 4.7375 & TRN & \\
\hline CHEMBL 3431022 & 1479003 & 6.1 & 6.0376 & TRN & \\
\hline CHEMBL 3431023 & 1479003 & 6.4 & 6.2433 & TST & \\
\hline CHEMBL3431024 & 1479003 & 6.3 & 6.211 & TRN & \\
\hline CHEMBL3431025 & 1479003 & 7.7 & 7.4251 & TRN & \\
\hline CHEMBL3431026 & 1479003 & 5.0 & 5.2832 & TST & \\
\hline CHEMBL3431027 & 1479003 & 4.9 & 4.8086 & TRN & \\
\hline CHEMBL3431028 & 1479003 & 6.7 & 6.6048 & TRN & \\
\hline CHEMBL3431029 & 1479003 & 6.9 & 6.8908 & TRN & \\
\hline CHEMBL3431030 & 1479003 & 5.2 & 5.3406 & TRN & \\
\hline CHEMBL3431031 & 1479003 & 5.5 & 5.0162 & TRN & \\
\hline CHEMBL3431032 & 1479003 & 5.7 & 5.6943 & TRN & \\
\hline CHEMBL1527364 & 1479003 & 4.5 & 4.5248 & TRN & \\
\hline CHEMBL3430914 & 1479003 & 5.8 & 5.7146 & TRN & \\
\hline CHEMBL3431033 & 1479003 & 7.0 & 7.2204 & TRN & \\
\hline CHEMBL 3431034 & 1479003 & 6.0 & 6.0333 & TRN & \\
\hline CHEMBL3431035 & 1479003 & 5.7 & 5.5082 & TRN & \\
\hline CHEMBL3431036 & 1479003 & 6.1 & 5.8861 & TRN & \\
\hline
\end{tabular}




\begin{tabular}{|c|c|c|c|c|c|}
\hline \multirow{3}{*}{ CHEMBL 3431037} & \multirow{2}{*}{1479003} & \multirow[b]{2}{*}{5.6} & \multirow{2}{*}{\multicolumn{3}{|c|}{5.7656 TRN }} \\
\hline & & & & & \\
\hline & 1479003 & 6.2 & 6.1367 & TRN & \\
\hline CHEMBL3431039 & 1479003 & 6.3 & 6.4816 & TRN & \\
\hline CHEMBL3431040 & 1479003 & 5.5 & 5.5343 & TRN & \\
\hline CHEMBL1354075 & 1479003 & 5.0 & 5.3529 & TRN & \\
\hline CHEMBL3431041 & 1479003 & 3.3 & 4.3186 & TRN & \\
\hline CHEMBL3431042 & 1479003 & 6.7 & 6.5471 & TRN & \\
\hline CHEMBL3431043 & 1479003 & 4.7 & 4.692 & TST & \\
\hline CHEMBL3431044 & 1479003 & 6.7 & 6.3963 & TST & \\
\hline CHEMBL3431045 & 1479003 & 4.4 & 4.5984 & TRN & \\
\hline CHEMBL3431046 & 1479003 & 3.3 & 4.4967 & TRN & \\
\hline CHEMBL3431047 & 1479003 & 5.5 & 5.2528 & TRN & \\
\hline CHEMBL3431048 & 1479003 & 5.5 & 5.3058 & TRN & \\
\hline CHEMBL3431049 & 1479003 & 5.4 & 5.4315 & TRN & \\
\hline CHEMBL3431050 & 1479003 & 5.2 & 5.3769 & TRN & \\
\hline CHEMBL3431051 & 1479003 & 5.3 & 4.997 & TRN & \\
\hline CHEMBL3431052 & 1479003 & 5.3 & 5.5762 & TRN & \\
\hline CHEMBL3431053 & 1479003 & 5.6 & 6.1794 & TRN & \\
\hline CHEMBL2356808 & 1479003 & 5.8 & 5.6375 & TRN & \\
\hline CHEMBL3431054 & 1479003 & 5.5 & 5.4988 & TRN & \\
\hline CHEMBL3431055 & 1479003 & 7.0 & \multicolumn{2}{|c|}{6.3870000000000005} & TST \\
\hline CHEMBL3431056 & 1479003 & 7.0 & 6.9365 & TRN & \\
\hline CHEMBL3431057 & 1479003 & 5.4 & 5.1905 & TST & \\
\hline CHEMBL2093320 & 1479003 & 6.5 & 5.9119 & TRN & \\
\hline CHEMBL 3431058 & 1479003 & 3.3 & \multicolumn{2}{|c|}{2.9539999999999997} & TRN \\
\hline CHEMBL3431059 & 1479003 & 3.3 & 2.7182 & TRN & \\
\hline CHEMBL3431060 & 1479003 & 3.3 & 2.6573 & TRN & \\
\hline CHEMBL3431061 & 1479003 & 3.3 & 2.6855 & TRN & \\
\hline CHEMBL3431062 & 1479003 & 3.3 & 2.5161 & TRN & \\
\hline CHEMBL3431063 & 1479003 & 3.3 & 2.8767 & TRN & \\
\hline CHEMBL3431064 & 1479003 & 5.7 & 5.629 & TRN & \\
\hline CHEMBL3431065 & 1479003 & 5.5 & 6.0763 & TST & \\
\hline CHEMBL3431066 & 1479003 & 6.0 & 5.8524 & TRN & \\
\hline CHEMBL3431067 & 1479003 & 4.8 & 4.8336 & TRN & \\
\hline CHEMBL3431068 & 1479003 & 6.7 & 6.6432 & TRN & \\
\hline CHEMBL3431069 & 1479003 & 5.7 & \multicolumn{2}{|c|}{5.468999999999999} & TRN \\
\hline CHEMBL3431070 & 1479003 & 7.0 & 7.1211 & TRN & \\
\hline CHEMBL3431071 & 1479003 & 5.4 & 5.1384 & TST & \\
\hline CHEMBL3431072 & 1479003 & 6.1 & 5.7912 & TRN & \\
\hline CHEMBL3431073 & 1479003 & 3.3 & 4.8342 & TST & \\
\hline CHEMBL3431074 & 1479003 & 3.3 & 5.4287 & TRN & \\
\hline CHEMBL3431075 & 1479003 & 3.3 & 3.4873 & TST & \\
\hline CHEMBL3431076 & 1479003 & 5.9 & 5.7847 & TRN & \\
\hline CHEMBL3431077 & 1479003 & 5.9 & 5.6146 & TRN & \\
\hline CHEMBL3431078 & 1479003 & 6.0 & 5.7132 & TRN & \\
\hline CHEMBL3431079 & 1479003 & 3.3 & 4.3578 & TRN & \\
\hline CHEMBL3431080 & 1479003 & 5.8 & 5.6898 & TRN & \\
\hline \multirow[t]{2}{*}{ CHEMBL 3431081} & 1479003 & 6.4 & 6.0947 & TRN & \\
\hline & & & \multicolumn{2}{|c|}{ Page 25997} & \\
\hline
\end{tabular}




\begin{tabular}{|c|c|c|c|c|c|}
\hline \multirow{3}{*}{ CHEMBL 3431082} & \multirow{2}{*}{1479003} & \multirow[b]{2}{*}{5.1} & \\
\hline & & & & TRN & \\
\hline & 1479003 & 4.9 & 5.0126 & TRN & \\
\hline CHEMBL3431084 & 1479003 & 6.0 & 5.9856 & TST & \\
\hline CHEMBL1585368 & 1479003 & 3.3 & 4.5966 & TRN & \\
\hline CHEMBL3431085 & 1479003 & 6.3 & 6.1975 & TRN & \\
\hline CHEMBL3431086 & 1479003 & 5.0 & 4.8135 & TRN & \\
\hline CHEMBL3431087 & 1479003 & 5.9 & 5.7835 & TRN & \\
\hline CHEMBL3431088 & 1479003 & 5.9 & 5.8027 & TRN & \\
\hline CHEMBL3431089 & 1479003 & 6.4 & 6.7648 & TRN & \\
\hline CHEMBL3431090 & 1479003 & 6.3 & 6.2896 & TRN & \\
\hline CHEMBL3431091 & 1479003 & 5.1 & 5.1337 & TRN & \\
\hline CHEMBL3431092 & 1479003 & 5.1 & 5.1249 & TRN & \\
\hline CHEMBL3431093 & 1479003 & 5.3 & 5.0215 & TRN & \\
\hline CHEMBL3431094 & 1479003 & 5.6 & 5.7801 & TRN & \\
\hline CHEMBL3431095 & 1479003 & 5.8 & 5.5502 & TRN & \\
\hline CHEMBL3431096 & 1479003 & 3.3 & 3.1119 & TRN & \\
\hline CHEMBL3431097 & 1479003 & 5.7 & 5.6282 & TRN & \\
\hline CHEMBL3431098 & 1479003 & 5.8 & 5.6421 & TRN & \\
\hline CHEMBL3431099 & 1479003 & 4.3 & 4.3367 & TST & \\
\hline CHEMBL3431100 & 1479003 & 5.9 & 5.8463 & TRN & \\
\hline CHEMBL3431101 & 1479003 & 5.2 & 5.0965 & TST & \\
\hline CHEMBL3431102 & 1479003 & 4.7 & 4.96 & TST & \\
\hline CHEMBL3431103 & 1479003 & 4.3 & 4.4921 & TST & \\
\hline CHEMBL3431104 & 1479003 & 6.5 & 6.3112 & TRN & \\
\hline CHEMBL3431105 & 1479003 & 5.8 & 5.9376 & TRN & \\
\hline CHEMBL3431106 & 1479003 & 6.3 & 6.5439 & TST & \\
\hline CHEMBL3431107 & 1479003 & 6.7 & 6.7726 & TRN & \\
\hline CHEMBL3431108 & 1479003 & 6.0 & 5.9415 & TRN & \\
\hline CHEMBL3431109 & 1479003 & 5.2 & 5.3798 & TRN & \\
\hline CHEMBL3431110 & 1479003 & 5.1 & 5.3184 & TRN & \\
\hline CHEMBL3431111 & 1479003 & 5.7 & 5.513 & TRN & \\
\hline CHEMBL3431112 & 1479003 & 4.5 & 4.7485 & TRN & \\
\hline CHEMBL3431113 & 1479003 & 5.0 & 5.4366 & TRN & \\
\hline CHEMBL3431114 & 1479003 & 5.8 & 5.8734 & TRN & \\
\hline CHEMBL3431115 & 1479003 & 4.4 & 4.0179 & TST & \\
\hline CHEMBL3431116 & 1479003 & 5.4 & 5.9475 & TRN & \\
\hline CHEMBL3431117 & 1479003 & 7.7 & 7.8229 & TRN & \\
\hline CHEMBL3431118 & 1479003 & 6.3 & 5.9994 & TRN & \\
\hline CHEMBL3431119 & 1479003 & 6.6 & 6.3044 & TRN & \\
\hline CHEMBL3431120 & 1479003 & 6.4 & 6.1351 & TRN & \\
\hline CHEMBL3431121 & 1479003 & 5.8 & 5.8138 & TST & \\
\hline CHEMBL3431122 & 1479003 & 6.2 & 6.3918 & TRN & \\
\hline CHEMBL3431123 & 1479003 & 4.7 & $5.8370 e$ & 0000000001 & TRN \\
\hline CHEMBL3431124 & 1479003 & 5.8 & $5.4860 e$ & 0000000001 & TRN \\
\hline CHEMBL3431125 & 1479003 & 6.3 & 6.3414 & TST & \\
\hline CHEMBL3431126 & 1479003 & 3.3 & 3.6048 & TRN & \\
\hline CHEMBL 3431128 & 1479003 & 7.5 & 7.8249 & TST & \\
\hline CHEMBL3431129 & 1479003 & 8.7 & 8.4835 & TST & \\
\hline & & & & 25998 & \\
\hline
\end{tabular}




\begin{tabular}{|c|c|c|c|c|}
\hline \\
\hline CHEMBL3431130 & 1479003 & 6.7 & 7.5621 & TST \\
\hline CHEMBL 3431131 & 1479003 & 7.2 & 6.7312 & TRN \\
\hline CHEMBL3430915 & 1479003 & 7.1 & 6.9395 & TRN \\
\hline CHEMBL3431132 & 1479003 & 6.7 & 6.6069 & TRN \\
\hline CHEMBL3431133 & 1479003 & 6.8 & 6.7216 & TRN \\
\hline CHEMBL3431134 & 1479003 & 4.7 & 4.9142 & TRN \\
\hline CHEMBL3431135 & 1479003 & 6.3 & 6.3443 & TRN \\
\hline CHEMBL3431136 & 1479003 & 5.3 & 5.246 & TRN \\
\hline CHEMBL3431137 & 1479003 & 5.4 & 5.3471 & TRN \\
\hline CHEMBL3431138 & 1479003 & 4.3 & 4.8487 & TST \\
\hline CHEMBL3431139 & 1479003 & 6.7 & 6.6352 & TST \\
\hline CHEMBL 3431140 & 1479003 & 7.4 & 7.2837 & TST \\
\hline CHEMBL3431141 & 1479003 & 6.1 & 6.1703 & TRN \\
\hline CHEMBL3431142 & 1479003 & 5.0 & 5.2557 & TST \\
\hline CHEMBL3431143 & 1479003 & 4.4 & 4.7058 & TRN \\
\hline CHEMBL3431144 & 1479003 & 5.3 & 5.1761 & TRN \\
\hline CHEMBL3431145 & 1479003 & 6.0 & 5.8605 & TRN \\
\hline CHEMBL3431146 & 1479003 & 6.7 & 6.647 & TRN \\
\hline CHEMBL3431147 & 1479003 & 4.6 & 4.8228 & TST \\
\hline CHEMBL3431148 & 1479003 & 6.3 & 6.3391 & TRN \\
\hline CHEMBL3431149 & 1479003 & 4.9 & 5.1146 & TRN \\
\hline CHEMBL3431150 & 1479003 & 7.0 & 6.4235 & TRN \\
\hline CHEMBL3431151 & 1479003 & 6.6 & 7.0517 & TRN \\
\hline CHEMBL3431152 & 1479003 & 6.5 & 6.4978 & TRN \\
\hline CHEMBL3431153 & 1479003 & 6.5 & 6.5802 & TRN \\
\hline CHEMBL3431154 & 1479003 & 5.0 & 4.6394 & TST \\
\hline CHEMBL3431155 & 1479003 & 7.3 & 7.2311 & TRN \\
\hline CHEMBL3431156 & 1479003 & 6.5 & 6.2109 & TRN \\
\hline CHEMBL3431157 & 1479003 & 3.3 & 3.2894 & TST \\
\hline CHEMBL3431158 & 1479003 & 3.3 & 3.1338 & TST \\
\hline CHEMBL3431159 & 1479003 & 5.5 & 5.4032 & TST \\
\hline CHEMBL1593679 & 1479003 & 7.1 & 6.7678 & TRN \\
\hline CHEMBL3431160 & 1479003 & 5.2 & 5.1714 & TRN \\
\hline CHEMBL3431161 & 1479003 & 5.7 & 5.8516 & TST \\
\hline CHEMBL3431162 & 1479003 & 6.6 & 6.3575 & TST \\
\hline CHEMBL3431163 & 1479003 & 6.5 & 5.914 & TRN \\
\hline CHEMBL3431164 & 1479003 & 6.4 & 6.4966 & TRN \\
\hline CHEMBL3431165 & 1479003 & 4.5 & 4.448 & TST \\
\hline CHEMBL1458931 & 1479003 & 7.0 & 6.9519 & TRN \\
\hline CHEMBL3431166 & 1479003 & 3.3 & 3.4221 & TRN \\
\hline CHEMBL3431167 & 1479003 & 5.2 & 5.1961 & TRN \\
\hline CHEMBL3431168 & 1479003 & 5.6 & 5.1679 & TRN \\
\hline CHEMBL3431169 & 1479003 & 5.4 & 5.5124 & TRN \\
\hline CHEMBL3431170 & 1479003 & 5.4 & $6.1320 e$ & 0000000001 \\
\hline CHEMBL3431171 & 1479003 & 4.4 & 4.5221 & TRN \\
\hline CHEMBL3431172 & 1479003 & 5.1 & 5.4016 & TRN \\
\hline CHEMBL3431173 & 1479003 & 5.1 & 5.059 & TRN \\
\hline CHEMBL3431174 & 1479003 & 5.5 & 5.2485 & TRN \\
\hline
\end{tabular}

TRN 


\begin{tabular}{|c|c|c|c|c|}
\hline & & & & \\
\hline CHEMBL 3431175 & 1479003 & 6.9 & 6.5551 & TST \\
\hline CHEMBL3431176 & 1479003 & 3.3 & 3.1799 & TRN \\
\hline CHEMBL3431177 & 1479003 & 5.9 & 6.0949 & TRN \\
\hline CHEMBL 3431178 & 1479003 & 6.1 & 6.1224 & TRN \\
\hline CHEMBL3431179 & 1479003 & 3.3 & 4.0612 & TRN \\
\hline CHEMBL3431180 & 1479003 & 4.9 & 4.5215 & TRN \\
\hline CHEMBL3431181 & 1479003 & 5.2 & 5.4251 & TRN \\
\hline CHEMBL3431182 & 1479003 & 4.6 & 4.7961 & TST \\
\hline CHEMBL3431183 & 1479003 & 6.1 & 6.0667 & TRN \\
\hline CHEMBL3431184 & 1479003 & 3.3 & 3.273 & TRN \\
\hline CHEMBL3431185 & 1479003 & 4.6 & 4.5059 & TRN \\
\hline CHEMBL3431186 & 1479003 & 5.5 & 5.8863 & TRN \\
\hline CHEMBL3431187 & 1479003 & 3.3 & 4.1637 & TRN \\
\hline CHEMBL3431188 & 1479003 & 5.8 & 6.2706 & TRN \\
\hline CHEMBL3431189 & 1479003 & 4.8 & 4.5143 & TST \\
\hline CHEMBL3431190 & 1479003 & 4.4 & 4.7626 & TRN \\
\hline CHEMBL3431191 & 1479003 & 5.7 & 5.5978 & TRN \\
\hline CHEMBL3431192 & 1479003 & 7.0 & 6.944 & TRN \\
\hline CHEMBL3431193 & 1479003 & 7.2 & 7.3018 & TRN \\
\hline CHEMBL3431194 & 1479003 & 6.0 & 6.0613 & TRN \\
\hline CHEMBL3431195 & 1479003 & 5.7 & 5.8031 & TRN \\
\hline CHEMBL3431196 & 1479003 & 6.6 & 6.4197 & TRN \\
\hline CHEMBL3431197 & 1479003 & 5.3 & 5.6671 & TRN \\
\hline CHEMBL3431198 & 1479003 & 5.5 & 5.513 & TRN \\
\hline CHEMBL3431199 & 1479003 & 4.9 & 5.0297 & TST \\
\hline CHEMBL 3431200 & 1479003 & 6.0 & 5.5554 & TRN \\
\hline CHEMBL3431201 & 1479003 & 5.7 & 5.6868 & TRN \\
\hline CHEMBL3431202 & 1479003 & 5.5 & 5.5369 & TRN \\
\hline CHEMBL3431203 & 1479003 & 5.7 & 5.8559 & TRN \\
\hline CHEMBL3431204 & 1479003 & 5.3 & 5.1654 & TRN \\
\hline CHEMBL3431205 & 1479003 & 4.6 & 4.6568 & TRN \\
\hline CHEMBL3431206 & 1479003 & 7.1 & 7.3053 & TRN \\
\hline CHEMBL3431207 & 1479003 & 5.3 & 5.499 & TRN \\
\hline CHEMBL3431208 & 1479003 & 6.5 & 6.2488 & TRN \\
\hline CHEMBL3431209 & 1479003 & 6.0 & 6.0919 & TRN \\
\hline CHEMBL3431210 & 1479003 & 6.1 & 5.9889 & TRN \\
\hline CHEMBL3431211 & 1479003 & 7.3 & 6.9668 & TRN \\
\hline CHEMBL3431212 & 1479003 & 5.8 & 6.3628 & TRN \\
\hline CHEMBL3431213 & 1479003 & 5.8 & 6.0616 & TRN \\
\hline CHEMBL3431214 & 1479003 & 6.4 & 6.3703 & TRN \\
\hline CHEMBL3431215 & 1479003 & 4.7 & 5.3533 & TRN \\
\hline CHEMBL3431216 & 1479003 & 6.5 & 6.5282 & TRN \\
\hline CHEMBL3431217 & 1479003 & 5.1 & 5.2452 & TRN \\
\hline CHEMBL3431218 & 1479003 & 6.5 & 6.3658 & TRN \\
\hline CHEMBL3431219 & 1479003 & 3.3 & 2.7678 & TRN \\
\hline CHEMBL 3431220 & 1479003 & 6.9 & 6.8038 & TRN \\
\hline CHEMBL 3431221 & 1479003 & 6.4 & 6.3597 & TRN \\
\hline CHEMBL3431222 & 1479003 & 3.3 & 3.9143 & TRN \\
\hline
\end{tabular}




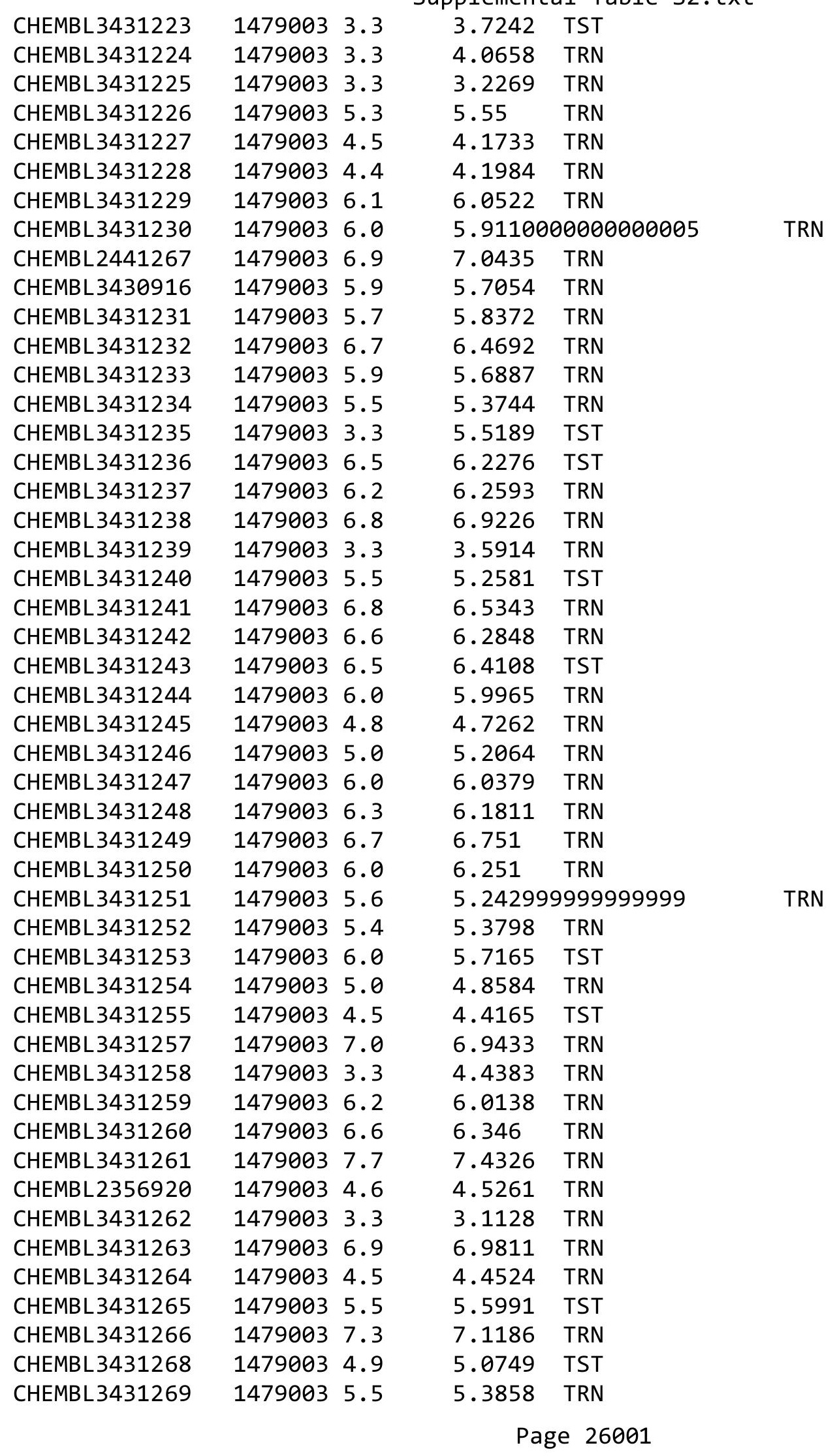




\begin{tabular}{|c|c|c|c|c|}
\hline & & & & \\
\hline CHEMBL3431270 & 1479003 & 4.7 & 4.9772 & TST \\
\hline CHEMBL3431271 & 1479003 & 5.7 & 5.5896 & TRN \\
\hline CHEMBL3431272 & 1479003 & 5.8 & 5.7509 & TRN \\
\hline CHEMBL3431273 & 1479003 & 5.6 & 5.2299 & TRN \\
\hline CHEMBL3431274 & 1479003 & 3.3 & 3.825 & TRN \\
\hline CHEMBL3431275 & 1479003 & 4.9 & 4.8448 & TRN \\
\hline CHEMBL 3431277 & 1479003 & 6.2 & 6.1518 & TRN \\
\hline CHEMBL3431278 & 1479003 & 5.9 & 5.626 & TRN \\
\hline CHEMBL3431279 & 1479003 & 3.3 & 4.2729 & TST \\
\hline CHEMBL 3431280 & 1479003 & 4.6 & 4.5777 & TST \\
\hline CHEMBL3431281 & 1479003 & 6.7 & 6.5602 & TST \\
\hline CHEMBL 3431282 & 1479003 & 3.3 & 3.4835 & TST \\
\hline CHEMBL3431283 & 1479003 & 4.4 & 4.6009 & TST \\
\hline CHEMBL3431284 & 1479003 & 4.5 & 5.1491 & TRN \\
\hline CHEMBL 3431285 & 1479003 & 6.0 & 5.6928 & TRN \\
\hline CHEMBL3431286 & 1479003 & 3.3 & 3.6104 & TST \\
\hline CHEMBL3431287 & 1479003 & 6.6 & 6.2278 & TST \\
\hline CHEMBL3431288 & 1479003 & 4.6 & 4.775 & TRN \\
\hline CHEMBL3431289 & 1479003 & 6.6 & 6.2748 & TST \\
\hline CHEMBL 3431290 & 1479003 & 6.7 & 6.9013 & TRN \\
\hline CHEMBL3431291 & 1479003 & 6.8 & 6.915 & TRN \\
\hline CHEMBL3431292 & 1479003 & 5.6 & 5.6176 & TRN \\
\hline CHEMBL3431293 & 1479003 & 6.1 & 6.3628 & TRN \\
\hline CHEMBL3431294 & 1479003 & 6.0 & 5.7035 & TRN \\
\hline CHEMBL3431295 & 1479003 & 6.3 & 6.75299 & 9999999999 \\
\hline CHEMBL3431296 & 1479003 & 6.3 & 6.749 & TRN \\
\hline CHEMBL3431297 & 1479003 & 6.3 & 6.6214 & TRN \\
\hline CHEMBL 3431298 & 1479003 & 6.5 & 6.8183 & TRN \\
\hline CHEMBL3431299 & 1479003 & 5.1 & 4.965 & TRN \\
\hline CHEMBL 3431300 & 1479003 & 6.1 & 6.2406 & TRN \\
\hline CHEMBL3431301 & 1479003 & 3.3 & 3.3062 & TST \\
\hline CHEMBL3431302 & 1479003 & 5.9 & 6.2298 & TRN \\
\hline CHEMBL3431303 & 1479003 & 6.5 & 6.3743 & TRN \\
\hline CHEMBL3431304 & 1479003 & 4.7 & 4.9577 & TRN \\
\hline CHEMBL3431305 & 1479003 & 6.3 & 6.2973 & TRN \\
\hline CHEMBL3431306 & 1479003 & 3.3 & 4.5328 & TRN \\
\hline CHEMBL3431307 & 1479003 & 6.4 & 6.766 & TRN \\
\hline CHEMBL3431308 & 1479003 & 5.0 & 4.7199 & TRN \\
\hline CHEMBL3431309 & 1479003 & 5.4 & 5.5072 & TRN \\
\hline CHEMBL3431310 & 1479003 & 6.6 & 6.1938 & TRN \\
\hline CHEMBL3431311 & 1479003 & 6.1 & 6.0219 & TRN \\
\hline CHEMBL3431312 & 1479003 & 6.1 & 5.9564 & TRN \\
\hline CHEMBL3431313 & 1479003 & 6.1 & 6.1911 & TRN \\
\hline CHEMBL3431314 & 1479003 & 6.1 & 6.0576 & TRN \\
\hline CHEMBL3431315 & 1479003 & 5.1 & 5.0196 & TRN \\
\hline CHEMBL3431316 & 1479003 & 5.5 & 5.869 & TST \\
\hline CHEMBL3431317 & 1479003 & 4.7 & 4.3866 & TRN \\
\hline CHEMBL3431318 & 1479003 & 7.1 & 7.12 & TST \\
\hline
\end{tabular}

TRN 



\begin{tabular}{|c|c|c|c|c|}
\hline \\
\hline CHEMBL3431363 & 1479003 & 4.5 & 4.6142 & TRN \\
\hline CHEMBL3431364 & 1479003 & 5.6 & 5.2258 & TRN \\
\hline CHEMBL3431365 & 1479003 & 5.7 & 5.608 & TRN \\
\hline CHEMBL3431366 & 1479003 & 3.3 & 4.3344 & TST \\
\hline CHEMBL3431367 & 1479003 & 6.1 & 6.0225 & TST \\
\hline CHEMBL3431368 & 1479003 & 5.6 & 5.7015 & TRN \\
\hline CHEMBL3431369 & 1479003 & 6.1 & 5.8506 & TRN \\
\hline CHEMBL1447267 & 1479003 & 5.7 & 5.6976 & TRN \\
\hline CHEMBL3431370 & 1479003 & 5.6 & 5.4178 & TRN \\
\hline CHEMBL1325144 & 1479003 & 7.4 & 7.3782 & TRN \\
\hline CHEMBL1429841 & 1479003 & 4.6 & 4.8229 & TRN \\
\hline CHEMBL3431371 & 1479003 & 6.2 & 6.2795 & TRN \\
\hline CHEMBL1308225 & 1479003 & 5.7 & \multicolumn{2}{|c|}{5.8020000000000005} \\
\hline CHEMBL2441359 & 1479003 & 5.1 & 5.0869 & TRN \\
\hline CHEMBL1517284 & 1479003 & 6.0 & 5.7417 & TRN \\
\hline CHEMBL3431372 & 1479003 & 6.4 & 6.2702 & TRN \\
\hline CHEMBL3431373 & 1479003 & 5.1 & 5.0724 & TRN \\
\hline CHEMBL3431374 & 1479003 & 6.2 & 5.9764 & TRN \\
\hline CHEMBL3431375 & 1479003 & 6.8 & 6.4476 & TST \\
\hline CHEMBL3431376 & 1479003 & 6.9 & 6.9154 & TRN \\
\hline CHEMBL1365653 & 1479003 & 6.0 & 5.754 & TRN \\
\hline CHEMBL3431377 & 1479003 & 4.5 & 4.6235 & TRN \\
\hline CHEMBL3431378 & 1479003 & 5.9 & 5.6881 & TRN \\
\hline CHEMBL3431379 & 1479003 & 5.3 & 5.4197 & TRN \\
\hline CHEMBL1478826 & 1479003 & 5.7 & 5.4987 & TRN \\
\hline CHEMBL1872842 & 1479003 & 6.3 & 6.03 & TRN \\
\hline CHEMBL3431380 & 1479003 & 6.3 & 6.3711 & TRN \\
\hline CHEMBL3431381 & 1479003 & 6.9 & 6.7001 & TRN \\
\hline CHEMBL3431382 & 1479003 & 4.9 & 4.8301 & TRN \\
\hline CHEMBL3431383 & 1479003 & 4.7 & 5.0578 & TRN \\
\hline CHEMBL3431384 & 1479003 & 4.8 & 4.9021 & TRN \\
\hline CHEMBL3431385 & 1479003 & 3.3 & 3.1524 & TRN \\
\hline CHEMBL3431386 & 1479003 & 5.2 & 5.227 & TRN \\
\hline CHEMBL1730515 & 1479003 & 6.4 & 6.4881 & TRN \\
\hline CHEMBL3431387 & 1479003 & 6.8 & 6.5729 & TRN \\
\hline CHEMBL3431388 & 1479003 & 5.3 & 5.8966 & TRN \\
\hline CHEMBL1566898 & 1479003 & 4.8 & 4.6727 & TRN \\
\hline CHEMBL3431389 & 1479003 & 4.5 & 4.4746 & TRN \\
\hline CHEMBL3431390 & 1479003 & 4.7 & 4.5808 & TST \\
\hline CHEMBL3431391 & 1479003 & 3.3 & 3.775 & TRN \\
\hline CHEMBL1489081 & 1479003 & 6.2 & 6.2154 & TRN \\
\hline CHEMBL3431392 & 1479003 & 3.3 & 3.272 & TRN \\
\hline CHEMBL3431393 & 1479003 & 5.9 & 5.7929 & TRN \\
\hline CHEMBL3431394 & 1479003 & 4.6 & 4.3025 & TST \\
\hline CHEMBL3431395 & 1479003 & 5.3 & 5.3541 & TRN \\
\hline CHEMBL3431396 & 1479003 & 3.3 & 3.6689 & TRN \\
\hline CHEMBL3431397 & 1479003 & 6.6 & 6.3939 & TRN \\
\hline CHEMBL3431398 & 1479003 & 3.3 & 5.0029 & TRN \\
\hline
\end{tabular}




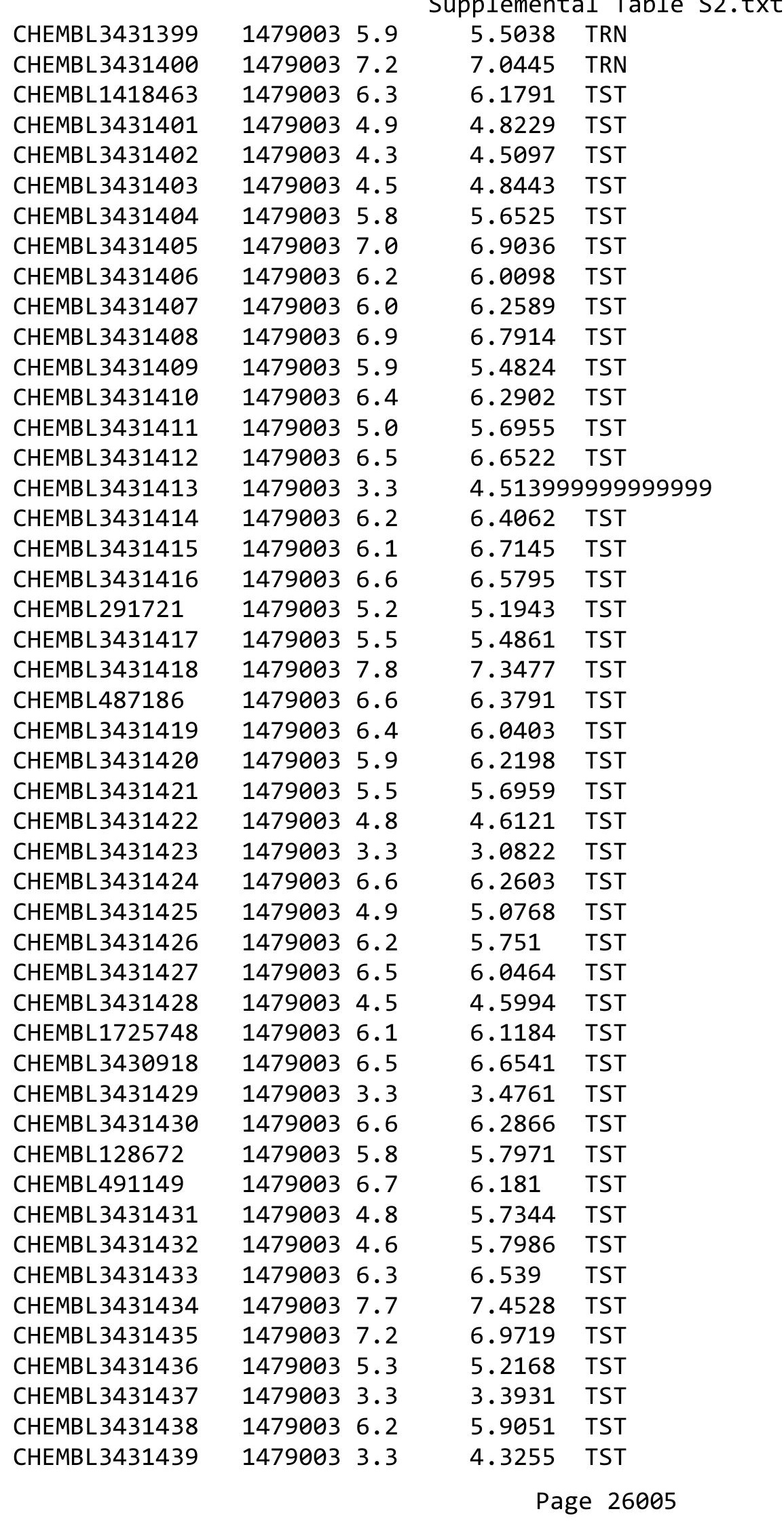




\begin{tabular}{|c|c|c|c|c|c|c|}
\hline \\
\hline CHEMBL 3431440 & 1479003 & 6.1 & 5.9585 & TST & & \\
\hline CHEMBL3431441 & 1479003 & 5.3 & 5.2215 & TST & & \\
\hline CHEMBL3431442 & 1479003 & 3.3 & 5.1633 & TST & & \\
\hline CHEMBL 3431443 & 1479003 & 6.5 & 6.6202 & TST & & \\
\hline CHEMBL 3431444 & 1479003 & 5.7 & 5.5376 & TST & & \\
\hline CHEMBL3431445 & 1479003 & 4.3 & 4.2715 & TST & & \\
\hline CHEMBL1571034 & 688119 & 4.9031 & 4.5842 & TST & & \\
\hline CHEMBL1424694 & 688119 & 5.0066 & 4.8332 & TRN & & \\
\hline CHEMBL1507308 & 688119 & 4.4737 & 4.8836 & TRN & & \\
\hline CHEMBL1390710 & 688119 & 4.9469 & 4.5971 & TRN & & \\
\hline CHEMBL1984894 & 688119 & 4.9393 & 4.9357 & TRN & & \\
\hline CHEMBL1549607 & 688119 & 5.4271 & 5.0548 & TRN & & \\
\hline CHEMBL1310699 & 688119 & 4.585 & 5.0439 & TRN & & \\
\hline CHEMBL3213007 & 688119 & 3.2457 & 4.5975 & TRN & & \\
\hline CHEMBL1566536 & 688119 & 4.8416 & 4.8722 & TRN & & \\
\hline CHEMBL1500997 & 688119 & 4.9066 & 4.6386 & TRN & & \\
\hline CHEMBL1600114 & 688119 & 5.8539 & 5.1735 & TST & & \\
\hline CHEMBL1342469 & 688119 & 4.9469 & 4.958 & TRN & & \\
\hline CHEMBL1358059 & 688119 & 3.2457 & 4.6518 & TST & & \\
\hline CHEMBL1424199 & 688119 & 4.5376 & 4.5331 & TRN & & \\
\hline CHEMBL1503620 & 688119 & 5.1024 & 5.1944 & TRN & & \\
\hline CHEMBL1591125 & 688119 & 4.9172 & 4.7888 & TST & & \\
\hline CHEMBL1374398 & 688119 & 5.0048 & 4.6482 & TRN & & \\
\hline CHEMBL1541779 & 688119 & 4.6596 & 4.8446 & TST & & \\
\hline CHEMBL1466605 & 688119 & 4.7545 & 4.6059 & TRN & & \\
\hline CHEMBL1968355 & 688119 & 4.9747 & 5.052 & TRN & & \\
\hline CHEMBL466930 & 688119 & 5.0521 & 4.9557 & TRN & & \\
\hline CHEMBL1368867 & 688119 & 4.5513 & 4.4276 & TRN & & \\
\hline CHEMBL1452774 & 688119 & 4.7721 & 5.1563 & TRN & & \\
\hline CHEMBL1531512 & 688119 & 5.0306 & 4.5984 & TRN & & \\
\hline CHEMBL1302528 & 688119 & 3.2457 & 4.3934 & TRN & & \\
\hline CHEMBL1313195 & 688119 & 5.2343 & 5.0769 & TST & & \\
\hline CHEMBL1706577 & 688119 & 5.4976 & 4.9075 & TRN & & \\
\hline CHEMBL3192879 & 688119 & 3.2457 & 4.4404 & TRN & & \\
\hline CHEMBL 3856090 & 688119 & 5.3979 & 4.8748 & TST & & \\
\hline CHEMBL1529080 & 688119 & 4.8069 & 4.9066 & TST & & \\
\hline CHEMBL1321933 & 688119 & 4.6757 & 4.8729 & TRN & & \\
\hline CHEMBL1419339 & 688119 & 3.2457 & 4.6228 & TRN & & \\
\hline CHEMBL1471788 & 688119 & 4.9355 & 5.0443 & TST & & \\
\hline CHEMBL1429145 & 688119 & 5.1694 & 4.6793 & TRN & & \\
\hline CHEMBL3189251 & 688119 & 5.3449 & 5.0669 & TRN & & \\
\hline CHEMBL1406990 & 688119 & 4.98300 & 30000000 & 005 & 4.4677 & TST \\
\hline CHEMBL1529201 & 688119 & 4.6556 & 5.0904 & TRN & & \\
\hline CHEMBL1398964 & 688119 & 4.6091 & 4.8477 & TRN & & \\
\hline CHEMBL1359410 & 688119 & 4.8827 & 4.7416 & TRN & & \\
\hline CHEMBL 75913 & 688119 & 4.9666 & 4.8013 & TRN & & \\
\hline CHEMBL1525242 & 688119 & 5.0969 & 4.5415 & TRN & & \\
\hline CHEMBL1521635 & 688119 & 3.2457 & 4.3512 & TRN & & \\
\hline
\end{tabular}


Supplemental Table S2.txt

\begin{tabular}{|c|c|c|c|c|c|c|}
\hline CHEMBL1454848 & 688119 & 5.1373 & 4.7226 & TRN & & \\
\hline CHEMBL1491300 & 688119 & 4.6345 & 4.846 & TRN & & \\
\hline CHEMBL1350622 & 688119 & 5.3224 & 4.9772 & TRN & & \\
\hline CHEMBL1393902 & 688119 & 5.1029 & 4.6456 & TRN & & \\
\hline CHEMBL1605845 & 688119 & 4.6882 & 5.0133 & TRN & & \\
\hline CHEMBL1966746 & 688119 & 5.8477 & 4.9538 & TRN & & \\
\hline CHEMBL1323590 & 688119 & 5.2083 & 4.6207 & TRN & & \\
\hline CHEMBL1448381 & 688119 & 4.8827 & 4.8795 & TRN & & \\
\hline CHEMBL1584061 & 688119 & 4.9393 & 5.0598 & TST & & \\
\hline CHEMBL1536223 & 688119 & 5.0155 & 4.7548 & TRN & & \\
\hline CHEMBL1318757 & 688119 & 5.0013 & 4.7105 & TRN & & \\
\hline CHEMBL1421400 & 688119 & 4.9469 & 4.9803 & TRN & & \\
\hline CHEMBL1704267 & 688119 & 5.05399 & & 99 & 4.8515 & TRN \\
\hline CHEMBL1731995 & 688119 & 5.04 & 4.7502 & TRN & & \\
\hline CHEMBL1509082 & 688119 & 5.0645 & 4.8265 & TRN & & \\
\hline CHEMBL1992702 & 688119 & 4.8013 & 4.0911 & TRN & & \\
\hline CHEMBL1433257 & 688119 & 4.2899 & 5.1386 & TST & & \\
\hline CHEMBL1527793 & 688119 & 3.2457 & 4.3963 & TRN & & \\
\hline CHEMBL1361443 & 688119 & 4.7959 & 4.7851 & TRN & & \\
\hline CHEMBL1497651 & 688119 & 3.2457 & 4.8655 & TRN & & \\
\hline CHEMBL1330161 & 688119 & 5.1891 & 4.9932 & TRN & & \\
\hline CHEMBL1346321 & 688119 & 6.6556 & 4.6872 & TST & & \\
\hline CHEMBL1381419 & 688119 & 5.0462 & 4.8276 & TRN & & \\
\hline CHEMBL1302524 & 688119 & 5.475 & 5.0322 & TRN & & \\
\hline CHEMBL1515088 & 688119 & 4.6253 & 4.6611 & TRN & & \\
\hline CHEMBL1722566 & 688119 & 5.1979 & 4.694 & TRN & & \\
\hline CHEMBL1326167 & 688119 & 3.2457 & 4.6004 & TRN & & \\
\hline CHEMBL1398763 & 688119 & 3.2457 & 5.0052 & TST & & \\
\hline CHEMBL1519298 & 688119 & 5.2182 & 5.1075 & TRN & & \\
\hline CHEMBL3198439 & 688119 & 4.3788 & 4.6777 & TRN & & \\
\hline CHEMBL1609392 & 688119 & 5.2269 & 4.6875 & TRN & & \\
\hline CHEMBL1369433 & 688119 & 4.4449 & 5.0443 & TRN & & \\
\hline CHEMBL1443268 & 688119 & 4.8633 & 4.712 & TRN & & \\
\hline CHEMBL 3213047 & 688119 & 5.1226 & 4.8255 & TRN & & \\
\hline CHEMBL 3189343 & 688119 & 4.6861 & 4.5243 & TST & & \\
\hline CHEMBL578742 & 688119 & 3.2457 & 4.6228 & TRN & & \\
\hline CHEMBL1441874 & 688119 & 3.2457 & 4.4457 & TRN & & \\
\hline CHEMBL1528890 & 688119 & 5.8239 & 4.6202 & TST & & \\
\hline CHEMBL1367163 & 688119 & 4.8097 & 4.7607 & TRN & & \\
\hline CHEMBL1555556 & 688119 & 4.7305 & 5.0192 & TRN & & \\
\hline CHEMBL2006639 & 688119 & 3.2457 & 4.6562 & TRN & & \\
\hline CHEMBL1469916 & 688119 & 4.9957 & 4.8617 & TRN & & \\
\hline CHEMBL1502860 & 688119 & 4.5361 & 4.9872 & TRN & & \\
\hline CHEMBL1465224 & 688119 & 5.4248 & 5.2637 & TST & & \\
\hline CHEMBL1351412 & 688119 & 5.4168 & 5.2049 & TRN & & \\
\hline CHEMBL1517799 & 688119 & 4.9914 & 4.569 & TRN & & \\
\hline CHEMBL1486680 & 688119 & 4.9957 & 4.9375 & TRN & & \\
\hline CHEMBL1535216 & 688119 & 4.8386 & 4.9612 & TRN & & \\
\hline
\end{tabular}

Page 26007 


\begin{tabular}{|c|c|c|c|c|c|c|}
\hline & & \multicolumn{5}{|c|}{ Supplemental Table S2.txt } \\
\hline CHEMBL1569711 & 688119 & 4.5452 & 5.1835 & TRN & & \\
\hline CHEMBL3190350 & 688119 & 3.2457 & 4.53 & TRN & & \\
\hline CHEMBL1543134 & 688119 & 3.2457 & 4.8426 & TRN & & \\
\hline CHEMBL1688693 & 688119 & 4.7328 & 5.0694 & TST & & \\
\hline CHEMBL1346055 & 688119 & 5.4841 & 4.8614 & TRN & & \\
\hline CHEMBL1391075 & 688119 & 5.2899 & 4.7915 & TST & & \\
\hline CHEMBL1550366 & 688119 & 4.8962 & 5.184 & TRN & & \\
\hline CHEMBL1501987 & 688119 & \multicolumn{3}{|c|}{ 4.718999999999999 } & 4.7699 & TRN \\
\hline CHEMBL 1548870 & 688119 & 5.1612 & 4.9985 & TRN & & \\
\hline CHEMBL74497 & 688119 & 5.0737 & 5.2163 & TRN & & \\
\hline CHEMBL1379677 & 688119 & 5.4976 & 4.7333 & TST & & \\
\hline CHEMBL1548107 & 688119 & 3.2457 & 4.6885 & TRN & & \\
\hline CHEMBL1504286 & 688119 & 4.7496 & 4.7576 & TRN & & \\
\hline CHEMBL1331178 & 688119 & 5.4225 & 4.6833 & TRN & & \\
\hline CHEMBL1376711 & 688119 & 5.4776 & 5.0273 & TRN & & \\
\hline CHEMBL1486729 & 688119 & 5.2967 & 5.0214 & TST & & \\
\hline CHEMBL1603005 & 688119 & 5.2218 & 4.9782 & TRN & & \\
\hline CHEMBL1527520 & 688119 & 5.065 & 5.026 & TRN & & \\
\hline CHEMBL1560954 & 688119 & 4.9586 & 5.0259 & TRN & & \\
\hline CHEMBL1305162 & 688119 & 5.3072 & 4.9542 & TRN & & \\
\hline CHEMBL1488925 & 688119 & 5.3851 & 4.8762 & TRN & & \\
\hline CHEMBL1431531 & 688119 & 5.5421 & 4.8784 & TRN & & \\
\hline CHEMBL1443090 & 688119 & 5.1811 & 4.6872 & TRN & & \\
\hline CHEMBL1501645 & 688119 & \multicolumn{3}{|c|}{5.3420000000000005} & 5.2064 & TRN \\
\hline CHEMBL1586267 & 688119 & 4.9172 & 5.1295 & TRN & & \\
\hline CHEMBL3196114 & 688119 & 5.1385 & 4.5862 & TRN & & \\
\hline CHEMBL3193786 & 688119 & \multicolumn{3}{|c|}{4.9830000000000005} & 4.7366 & TRN \\
\hline CHEMBL1978327 & 688119 & 4.7235 & 5.1476 & TRN & & \\
\hline CHEMBL1451059 & 688119 & 3.2457 & 4.9799 & TST & & \\
\hline CHEMBL1611910 & 688119 & 4.71 & 4.6198 & TRN & & \\
\hline CHEMBL1520245 & 688119 & 5.4828 & 5.0243 & TRN & & \\
\hline CHEMBL1708334 & 688119 & 4.9355 & 5.1467 & TRN & & \\
\hline CHEMBL1562523 & 688119 & 4.7545 & 5.0529 & TRN & & \\
\hline CHEMBL1610801 & 688119 & 4.857 & 4.9759 & TST & & \\
\hline CHEMBL1547049 & 688119 & 4.8097 & 5.1335 & TRN & & \\
\hline CHEMBL1513792 & 688119 & 5.3401 & 4.6883 & TST & & \\
\hline CHEMBL1672292 & 688119 & 4.4724 & 4.6418 & TRN & & \\
\hline CHEMBL1346724 & 688119 & 5.1367 & 4.768 & TRN & & \\
\hline CHEMBL1481546 & 688119 & 4.7773 & 4.7585 & TRN & & \\
\hline CHEMBL1572325 & 688119 & 4.3799 & 5.159 & TST & & \\
\hline CHEMBL1309456 & 688119 & 5.1586 & 5.1925 & TRN & & \\
\hline CHEMBL1494713 & 688119 & 5.0168 & 4.7224 & TST & & \\
\hline CHEMBL1320181 & 688119 & 4.3536 & 4.5743 & TRN & & \\
\hline CHEMBL1555566 & 688119 & 4.8729 & 4.8602 & TRN & & \\
\hline CHEMBL1464280 & 688119 & 5.7352 & 4.8653 & TRN & & \\
\hline CHEMBL1404231 & 688119 & 5.0186 & 4.8046 & TRN & & \\
\hline CHEMBL1571835 & 688119 & 5.0297 & 5.2467 & TRN & & \\
\hline CHEMBL467373 & 688119 & 4.3883 & 4.9658 & TRN & & \\
\hline
\end{tabular}




\begin{tabular}{|c|c|c|c|c|c|}
\hline \multicolumn{6}{|c|}{ Supplemental Table S2.txt } \\
\hline CHEMBL484640 & 688119 & 4.8827 & 4.8479 & TST & \\
\hline CHEMBL1504634 & 688119 & 4.8996 & 4.6685 & TRN & \\
\hline CHEMBL1561089 & 688119 & 4.644 & 5.2134 & TST & \\
\hline CHEMBL1407368 & 688119 & 5.1605 & 4.3232 & TRN & \\
\hline CHEMBL1576530 & 688119 & 5.3536 & 4.963 & TRN & \\
\hline CHEMBL1427539 & 688119 & 5.5638 & 4.86600 & 00000000005 & TRN \\
\hline CHEMBL1380889 & 688119 & 5.2503 & 5.1787 & TRN & \\
\hline CHEMBL1340633 & 688119 & 5.1192 & 4.8017 & TRN & \\
\hline CHEMBL1571238 & 688119 & 5.0516 & 4.8759 & TRN & \\
\hline CHEMBL1382305 & 688119 & 4.757 & 4.5343 & TRN & \\
\hline CHEMBL1510664 & 688119 & 5.3585 & 5.2406 & TRN & \\
\hline CHEMBL1362221 & 688119 & 4.9318 & 4.6118 & TRN & \\
\hline CHEMBL1528814 & 688119 & 4.8794 & 4.8078 & TRN & \\
\hline CHEMBL1580263 & 688119 & 4.8386 & 4.5974 & TRN & \\
\hline CHEMBL1517673 & 688119 & 5.1726 & 4.8949 & TRN & \\
\hline CHEMBL1508121 & 688119 & 4.6904 & 5.2688 & TRN & \\
\hline CHEMBL1427249 & 688119 & 5.3958 & 4.5954 & TRN & \\
\hline CHEMBL1373132 & 688119 & 5.0083 & 4.7368 & TRN & \\
\hline CHEMBL1427447 & 688119 & 5.0615 & 4.7927 & TRN & \\
\hline CHEMBL1319009 & 688119 & 4.9508 & 4.6319 & TRN & \\
\hline CHEMBL1338442 & 688119 & 5.6655 & 4.9776 & TRN & \\
\hline CHEMBL1321103 & 688119 & 4.8827 & 4.9415 & TRN & \\
\hline CHEMBL1387961 & 688119 & 5.6234 & 5.3405 & TRN & \\
\hline CHEMBL1459808 & 688119 & 5.2798 & 5.1824 & TRN & \\
\hline CHEMBL1336733 & 688119 & 5.0414 & 5.0278 & TRN & \\
\hline CHEMBL3196265 & 688119 & 5.1403 & 4.9536 & TST & \\
\hline CHEMBL1608043 & 688119 & 5.0846 & 4.9583 & TRN & \\
\hline CHEMBL1326648 & 688119 & 5.3028 & 4.7211 & TRN & \\
\hline CHEMBL1414465 & 688119 & 4.7471 & 4.7195 & TRN & \\
\hline CHEMBL3212539 & 688119 & 5.5045 & 4.5138 & TRN & \\
\hline CHEMBL1489711 & 688119 & 4.8477 & 4.7233 & TRN & \\
\hline CHEMBL1387563 & 688119 & 4.9788 & 4.8912 & TRN & \\
\hline CHEMBL1445030 & 688119 & 3.2457 & 4.6572 & TRN & \\
\hline CHEMBL1446932 & 688119 & 4.5467 & 4.6877 & TRN & \\
\hline CHEMBL513150 & 688119 & 5.0 & 4.8204 & TRN & \\
\hline CHEMBL1523209 & 688119 & 5.2541 & 5.0804 & TRN & \\
\hline CHEMBL1608789 & 688119 & 4.5528 & 4.8973 & TRN & \\
\hline CHEMBL1342736 & 688119 & 4.8327 & 4.6343 & TRN & \\
\hline CHEMBL1462267 & 688119 & 3.2457 & 4.9827 & TRN & \\
\hline CHEMBL1447158 & 688119 & 4.9281 & 4.6623 & TRN & \\
\hline CHEMBL1443570 & 688119 & 3.2457 & 4.7682 & TRN & \\
\hline CHEMBL1519229 & 688119 & 4.5867 & 4.4358 & TST & \\
\hline CHEMBL1343751 & 688119 & 3.2457 & 4.6873 & TRN & \\
\hline CHEMBL1579632 & 688119 & 3.2457 & 4.8479 & TRN & \\
\hline CHEMBL1612116 & 688119 & 3.2457 & 4.2844 & TRN & \\
\hline CHEMBL1305930 & 688119 & 4.7932 & 4.5785 & TRN & \\
\hline CHEMBL3209374 & 688119 & 5.4449 & 4.8153 & TRN & \\
\hline CHEMBL1342429 & 688119 & 4.6655 & 4.8267 & TRN & \\
\hline
\end{tabular}


Supplemental Table S2.txt

\begin{tabular}{|c|c|c|c|c|c|c|}
\hline CHEMBL1389260 & 688119 & 5.1656 & 5.0082 & TRN & & \\
\hline CHEMBL1536896 & 688119 & 5.0888 & 4.3451 & TRN & & \\
\hline CHEMBL1547938 & 688119 & 5.0376 & 4.9757 & TRN & & \\
\hline CHEMBL1584379 & 688119 & 3.2457 & 4.8722 & TRN & & \\
\hline CHEMBL1580684 & 688119 & 5.0182 & 4.6749 & TRN & & \\
\hline CHEMBL3194601 & 688119 & 4.8125 & 5.0403 & TRN & & \\
\hline CHEMBL1585333 & 688119 & \multicolumn{3}{|c|}{5.327000000000001} & 5.1011 & TRN \\
\hline CHEMBL1417064 & 688119 & 4.9031 & 4.9675 & TRN & & \\
\hline CHEMBL1387693 & 688119 & 4.8508 & 4.5899 & TRN & & \\
\hline CHEMBL1510394 & 688119 & 5.2472 & 4.3952 & TRN & & \\
\hline CHEMBL1425837 & 688119 & 3.2457 & 4.7753 & TRN & & \\
\hline CHEMBL1334484 & 688119 & 5.4179 & 5.3327 & TRN & & \\
\hline CHEMBL1537405 & 688119 & 5.0306 & 4.9992 & TRN & & \\
\hline CHEMBL1427775 & 688119 & 4.9788 & 4.8903 & TRN & & \\
\hline CHEMBL1510455 & 688119 & 4.7399 & 4.7584 & TRN & & \\
\hline CHEMBL1302139 & 688119 & 4.9066 & 4.5459 & TRN & & \\
\hline CHEMBL1501678 & 688119 & 5.0645 & 4.8006 & TRN & & \\
\hline CHEMBL1526855 & 688119 & 5.4377 & 4.9465 & TRN & & \\
\hline CHEMBL1340587 & 688119 & \multicolumn{3}{|c|}{5.382999999999999} & 4.9487 & TRN \\
\hline CHEMBL1483095 & 688119 & 5.3625 & 4.7079 & TRN & & \\
\hline CHEMBL1433088 & 688119 & 4.6003 & 4.6438 & TRN & & \\
\hline CHEMBL3192596 & 688119 & 4.9431 & 4.9086 & TST & & \\
\hline CHEMBL 1487750 & 688119 & 4.8827 & 4.4814 & TRN & & \\
\hline CHEMBL1583534 & 688119 & 4.9957 & 4.8308 & TRN & & \\
\hline CHEMBL1399979 & 688119 & 4.5406 & 4.7038 & TRN & & \\
\hline CHEMBL 3213108 & 688119 & 4.9872 & 4.74 & TRN & & \\
\hline CHEMBL1381676 & 688119 & 3.2457 & 4.1644 & TRN & & \\
\hline CHEMBL297304 & 688119 & 4.9136 & 5.2462 & TST & & \\
\hline CHEMBL1983083 & 688119 & 5.0128 & 4.6689 & TRN & & \\
\hline CHEMBL1481413 & 688119 & 5.0773 & 4.9112 & TRN & & \\
\hline CHEMBL 3197242 & 688119 & 6.1319 & 4.8971 & TRN & & \\
\hline CHEMBL1364395 & 688119 & 5.7747 & 5.149 & TRN & & \\
\hline CHEMBL1506159 & 688119 & 5.209 & 5.1685 & TST & & \\
\hline CHEMBL3194609 & 688119 & 4.9469 & 5.0497 & TRN & & \\
\hline CHEMBL1301315 & 688119 & 5.4486 & 4.9705 & TRN & & \\
\hline CHEMBL1601009 & 688119 & 5.699 & 4.9925 & TRN & & \\
\hline CHEMBL1512159 & 688119 & 4.8508 & 4.8189 & TRN & & \\
\hline CHEMBL1728993 & 688119 & 5.0329 & 5.2134 & TRN & & \\
\hline CHEMBL1099177 & 688119 & 3.2457 & 4.8006 & TRN & & \\
\hline CHEMBL1599593 & 688119 & 5.1844 & 4.6662 & TRN & & \\
\hline CHEMBL 3191831 & 688119 & 4.9626 & 4.78 & TRN & & \\
\hline CHEMBL1442893 & 688119 & 4.8697 & 4.7848 & TRN & & \\
\hline CHEMBL1582771 & 688119 & 4.752 & 5.3993 & TRN & & \\
\hline CHEMBL3715797 & 688119 & 5.3565 & 4.4344 & TRN & & \\
\hline CHEMBL1511284 & 688119 & 4.9245 & 4.7426 & TRN & & \\
\hline CHEMBL1381817 & 688119 & \multicolumn{3}{|c|}{4.4510000000000005} & 4.6472 & RI \\
\hline CHEMBL1508086 & 688119 & 5.3391 & 4.7442 & TRN & & \\
\hline CHEMBL1406195 & 688119 & 5.0269 & 4.7441 & TRN & & \\
\hline
\end{tabular}


Supplemental Table S2.txt

\begin{tabular}{|c|c|c|c|c|c|}
\hline CHEMBL399293 & 688119 & 5.3696 & 4.5235 & TST & \\
\hline CHEMBL1422097 & 688119 & 4.4486 & 4.9676 & TRN & \\
\hline CHEMBL1576392 & 688119 & 4.8601 & 4.9572 & TRN & \\
\hline CHEMBL1600270 & 688119 & 5.2741 & 5.0041 & TRN & \\
\hline CHEMBL1348629 & 688119 & 4.5768 & 5.1658 & TRN & \\
\hline CHEMBL1538966 & 688119 & 4.4622 & 5.0658 & TRN & \\
\hline CHEMBL1300876 & 688119 & 5.1662 & 4.9091 & TRN & \\
\hline CHEMBL1406727 & 688119 & 5.0088 & 4.9004 & TST & \\
\hline CHEMBL1465496 & 688119 & 4.8268 & 4.8717 & TRN & \\
\hline CHEMBL1427185 & 688119 & 4.9208 & 4.8661 & TST & \\
\hline CHEMBL1383746 & 688119 & 5.6108 & 5.0323 & TRN & \\
\hline CHEMBL1598722 & 688119 & 4.8928 & 4.9979 & TRN & \\
\hline CHEMBL1438182 & 688119 & 4.76699 & 799999999 & 995 & 5.085 \\
\hline CHEMBL1988133 & 688119 & 4.6946 & 4.4772 & TRN & \\
\hline CHEMBL1364723 & 688119 & 4.51 & 4.9514 & TST & \\
\hline CHEMBL1391622 & 688119 & 4.8665 & 5.1389 & TRN & \\
\hline CHEMBL1453822 & 688119 & 5.1192 & 4.855 & TRN & \\
\hline CHEMBL1467719 & 688119 & 4.5129 & 4.7007 & TRN & \\
\hline CHEMBL1605268 & 688119 & 5.3716 & 5.0457 & TRN & \\
\hline CHEMBL1518503 & 688119 & 5.2211 & 4.6776 & TRN & \\
\hline CHEMBL1438038 & 688119 & 4.9586 & 4.7292 & TRN & \\
\hline CHEMBL1471715 & 688119 & 5.2596 & 4.8228 & TRN & \\
\hline CHEMBL1349417 & 688119 & 5.4685 & 5.0373 & TST & \\
\hline CHEMBL1504284 & 688119 & 5.1198 & 4.7795 & TRN & \\
\hline CHEMBL1509547 & 688119 & 3.2457 & 4.8184 & TST & \\
\hline CHEMBL1362015 & 688119 & 5.0778 & 4.9891 & TRN & \\
\hline CHEMBL1419255 & 688119 & 5.0186 & 5.1801 & TRN & \\
\hline CHEMBL1610393 & 688119 & 5.0357 & 4.9842 & TRN & \\
\hline CHEMBL1424041 & 688119 & 4.9281 & 5.2079 & TRN & \\
\hline CHEMBL1520131 & 688119 & 3.2457 & 4.2342 & TRN & \\
\hline CHEMBL1494895 & 688119 & 5.2823 & 4.7674 & TRN & \\
\hline CHEMBL1441794 & 688119 & 5.4559 & 4.319 & TRN & \\
\hline CHEMBL1440977 & 688119 & 4.9872 & 4.7987 & TST & \\
\hline CHEMBL1573044 & 688119 & 4.7235 & 4.9401 & TRN & \\
\hline CHEMBL546649 & 688119 & 4.9136 & 4.6525 & TRN & \\
\hline CHEMBL1565164 & 688119 & 4.6326 & 5.0972 & TRN & \\
\hline CHEMBL1511181 & 688119 & 4.9172 & 5.1156 & TRN & \\
\hline CHEMBL1585746 & 688119 & 5.1451 & 5.0587 & TRN & \\
\hline CHEMBL1600748 & 688119 & 5.1244 & 4.7141 & TRN & \\
\hline CHEMBL1974032 & 688119 & 5.1186 & 5.151 & TST & \\
\hline CHEMBL1528194 & 688119 & 4.8633 & 4.9615 & TRN & \\
\hline CHEMBL1468575 & 688119 & 5.8962 & 5.0611 & TRN & \\
\hline CHEMBL1372046 & 688119 & 5.02 & 4.6168 & TRN & \\
\hline CHEMBL1541862 & 688119 & 5.3686 & 4.6826 & TRN & \\
\hline CHEMBL249301 & 688119 & 3.2457 & 4.3296 & TRN & \\
\hline CHEMBL1522413 & 688119 & 4.8297 & 4.9227 & TRN & \\
\hline CHEMBL1460896 & 688119 & 5.3161 & 5.2519 & TRN & \\
\hline CHEMBL1558585 & 688119 & 3.2457 & 4.9247 & TRN & \\
\hline
\end{tabular}

Page 26011 
Supplemental Table S2.txt

\begin{tabular}{|c|c|c|c|c|c|}
\hline CHEMBL1530167 & 688119 & 4.7496 & 4.6782 & TRN & \\
\hline CHEMBL1610008 & 688119 & 5.2549 & 4.7347 & TRN & \\
\hline CHEMBL1509832 & 688119 & 5.0052 & 4.8287 & TRN & \\
\hline CHEMBL1497568 & 688119 & 4.7986 & 4.5979 & TRN & \\
\hline CHEMBL274921 & 688119 & 5.0061 & 5.3307 & TRN & \\
\hline CHEMBL305469 & 688119 & 5.3372 & \multicolumn{2}{|c|}{5.1160000000000005} & TRN \\
\hline CHEMBL1347985 & 688119 & 3.2457 & 4.4212 & TRN & \\
\hline CHEMBL1367314 & 688119 & 4.3363 & 4.564 & TRN & \\
\hline CHEMBL1492565 & 688119 & 4.8761 & 4.7776 & TRN & \\
\hline CHEMBL1546396 & 688119 & 4.8827 & 4.8484 & TRN & \\
\hline CHEMBL1301673 & 688119 & 5.0 & 4.8322 & TRN & \\
\hline CHEMBL1579841 & 688119 & 5.5346 & 4.7948 & TRN & \\
\hline CHEMBL1388892 & 688119 & 4.7959 & 4.9245 & TRN & \\
\hline CHEMBL1349296 & 688119 & 5.2668 & 4.824 & TRN & \\
\hline CHEMBL1386349 & 688119 & 5.06 & 4.8121 & TRN & \\
\hline CHEMBL1497791 & 688119 & 5.1113 & 4.8616 & TRN & \\
\hline CHEMBL1468919 & 688119 & 5.2168 & 4.9333 & TRN & \\
\hline CHEMBL1310730 & 688119 & 4.6289 & 4.7253 & TRN & \\
\hline CHEMBL1533279 & 688119 & 4.6757 & 5.0651 & TRN & \\
\hline CHEMBL1594012 & 688119 & 5.3325 & 4.4469 & TRN & \\
\hline CHEMBL1388509 & 688119 & 5.3215 & 4.8862 & TST & \\
\hline CHEMBL131037 & 688119 & 5.0209 & 4.8853 & TST & \\
\hline CHEMBL574779 & 688119 & 5.4134 & 5.0916 & TRN & \\
\hline CHEMBL602213 & 688119 & 5.0186 & 4.9183 & TRN & \\
\hline CHEMBL1572375 & 688119 & 5.3458 & 4.8861 & TRN & \\
\hline CHEMBL1505757 & 688119 & 4.9136 & 4.649 & TRN & \\
\hline CHEMBL1529285 & 688119 & 3.2457 & 4.7286 & TRN & \\
\hline CHEMBL1449746 & 688119 & 5.2495 & 5.01699 & 99999999995 & TRN \\
\hline CHEMBL1302483 & 688119 & 5.0066 & 4.7303 & TRN & \\
\hline CHEMBL1530652 & 688119 & 5.0128 & 4.9888 & TRN & \\
\hline CHEMBL 3190104 & 688119 & 5.0367 & 5.1438 & TRN & \\
\hline CHEMBL1569090 & 688119 & 4.8761 & 4.9422 & TRN & \\
\hline CHEMBL1506195 & 688119 & 5.2716 & 5.1534 & TRN & \\
\hline CHEMBL1543232 & 688119 & 4.9788 & 4.827 & TST & \\
\hline CHEMBL1432336 & 688119 & 4.6716 & 5.1835 & TST & \\
\hline CHEMBL2000633 & 688119 & 4.8182 & 4.7319 & TST & \\
\hline CHEMBL1530437 & 688119 & 4.8962 & 4.8383 & TST & \\
\hline CHEMBL1471841 & 688119 & 4.7905 & 4.7431 & TST & \\
\hline CHEMBL211481 & 688119 & 5.1226 & 4.9517 & TST & \\
\hline CHEMBL1412731 & 688119 & 5.9393 & 4.7582 & TST & \\
\hline CHEMBL1530272 & 688119 & 5.7122 & 5.0195 & TST & \\
\hline CHEMBL1402286 & 688119 & 5.5867 & 4.5045 & TST & \\
\hline CHEMBL172439 & 688119 & 4.8297 & 4.7129 & TST & \\
\hline CHEMBL1457149 & 688119 & 5.5607 & 4.7549 & TST & \\
\hline CHEMBL 3198930 & 688119 & 5.6326 & 4.4909 & TST & \\
\hline CHEMBL1447467 & 688119 & 6.2321 & 4.7205 & TST & \\
\hline CHEMBL1534730 & 688119 & 5.0964 & 4.7959 & TST & \\
\hline CHEMBL1999908 & 688119 & 5.3915 & 4.6853 & TST & \\
\hline
\end{tabular}


Supplemental Table S2.txt

\begin{tabular}{|c|c|c|c|c|}
\hline CHEMBL 2002223 & 688119 & 4.3872 & 4.7323 & TST \\
\hline CHEMBL1560128 & 688119 & 5.2233 & 4.7401 & TST \\
\hline CHEMBL1533561 & 688119 & 5.5214 & 4.7463 & TST \\
\hline CHEMBL3145364 & 688119 & 4.7878 & 4.9395 & TST \\
\hline CHEMBL1481947 & 688119 & 5.0381 & 4.9093 & TST \\
\hline CHEMBL1360585 & 688119 & 4.752 & 4.851 & TST \\
\hline CHEMBL1373360 & 688119 & 5.2644 & 5.0265 & TST \\
\hline CHEMBL1405717 & 688119 & 4.5935 & 5.1682 & TST \\
\hline CHEMBL1460107 & 688119 & 5.2899 & 5.0005 & TST \\
\hline CHEMBL1507888 & 688119 & 4.9706 & 5.0313 & TST \\
\hline CHEMBL1534359 & 688119 & 3.2457 & 5.0663 & TST \\
\hline CHEMBL1499996 & 688119 & 4.9666 & 4.7148 & TST \\
\hline CHEMBL1374242 & 688119 & 4.699 & 4.8723 & TST \\
\hline CHEMBL1526690 & 688119 & 4.7496 & 4.6441 & TST \\
\hline CHEMBL1501151 & 688119 & 5.7986 & 4.8933 & TST \\
\hline CHEMBL1405161 & 688119 & 4.9431 & 4.9036 & TST \\
\hline CHEMBL1584651 & 688119 & 4.6383 & 4.9539 & TST \\
\hline CHEMBL1966224 & 688119 & 4.9666 & 5.0385 & TST \\
\hline CHEMBL1352760 & 688119 & 4.8794 & 5.2081 & TST \\
\hline CHEMBL 2000167 & 688119 & 4.9547 & 4.535 & TST \\
\hline CHEMBL1440962 & 688119 & 6.1255 & 4.9179 & TST \\
\hline CHEMBL1579066 & 688119 & 4.7011 & 5.1538 & TST \\
\hline CHEMBL1563317 & 688119 & 5.4145 & 4.944 & TST \\
\hline CHEMBL1375867 & 688119 & 6.6737 & 4.4554 & TST \\
\hline CHEMBL1516563 & 688119 & 5.1871 & 5.3853 & TST \\
\hline CHEMBL1581797 & 688119 & 5.2832 & 4.6372 & TST \\
\hline CHEMBL1978449 & 688119 & 3.2457 & 4.8973 & TST \\
\hline CHEMBL1387248 & 688119 & 4.9355 & 4.7448 & TST \\
\hline CHEMBL1701224 & 688119 & 4.9957 & 4.6343 & TST \\
\hline CHEMBL1584440 & 688119 & 3.2457 & 4.9101 & TST \\
\hline CHEMBL1597055 & 688119 & 5.0731 & 4.77800 & 30000000005 \\
\hline CHEMBL1462469 & 688119 & 3.2457 & 4.6468 & TST \\
\hline CHEMBL1438889 & 688119 & 5.1029 & 4.4786 & TST \\
\hline CHEMBL53633 & 432102 & 9.62 & 8.1405 & TST \\
\hline CHEMBL376804 & 432102 & 7.8 & 7.5746 & TRN \\
\hline CHEMBL21950 & 432102 & 7.8 & 8.3381 & TRN \\
\hline CHEMBL225095 & 432102 & 7.81 & 7.5084 & TRN \\
\hline CHEMBL21335 & 432102 & 7.85 & 7.2269 & TST \\
\hline CHEMBL282886 & 432102 & 7.86 & 7.8678 & TRN \\
\hline CHEMBL375245 & 432102 & 7.86 & 7.4775 & TRN \\
\hline CHEMBL225256 & 432102 & 7.87 & 7.6638 & TRN \\
\hline CHEMBL225395 & 432102 & 7.88 & 7.4562 & TRN \\
\hline CHEMBL 22087 & 432102 & 7.88 & 7.4445 & TRN \\
\hline CHEMBL 21810 & 432102 & 7.88 & 7.2509 & TST \\
\hline CHEMBL 21808 & 432102 & 7.91 & 7.7365 & TRN \\
\hline CHEMBL225061 & 432102 & 7.92 & 6.7382 & TRN \\
\hline CHEMBL 22086 & 432102 & 7.94 & 7.8278 & TRN \\
\hline CHEMBL297479 & 432102 & 7.96 & 8.0991 & TRN \\
\hline
\end{tabular}




\begin{tabular}{|c|c|c|c|c|c|}
\hline & & \multicolumn{4}{|c|}{ Supplemental Table s2.txt } \\
\hline CHEMBL53034 & 432102 & 8.04 & 8.0203 & TRN & \\
\hline CHEMBL278530 & 432102 & 8.04 & 8.2851 & TRN & \\
\hline CHEMBL22118 & 432102 & 8.11 & 7.6501 & TST & \\
\hline CHEMBL 21352 & 432102 & 8.15 & 8.2041 & TRN & \\
\hline CHEMBL21781 & 432102 & 8.17 & 7.9838 & TRN & \\
\hline CHEMBL224131 & 432102 & 8.19 & 8.0336 & TRN & \\
\hline CHEMBL224522 & 432102 & 8.19 & 7.4249 & TRN & \\
\hline CHEMBL54239 & 432102 & 8.23 & 8.1577 & TRN & \\
\hline CHEMBL224432 & 432102 & 8.23 & 7.5591 & TRN & \\
\hline CHEMBL25707 & 432102 & 8.26 & 8.5087 & TRN & \\
\hline CHEMBL225215 & 432102 & 8.27 & 7.8312 & TST & \\
\hline CHEMBL21945 & 432102 & 8.27 & 8.2666 & TRN & \\
\hline CHEMBL225281 & 432102 & 8.31 & 8.6805 & TRN & \\
\hline CHEMBL53369 & 432102 & 8.43 & 8.1259 & TRN & \\
\hline CHEMBL387890 & 432102 & 8.4 & 7.9292 & TRN & \\
\hline CHEMBL 224130 & 432102 & 8.45 & 7.4362 & TRN & \\
\hline CHEMBL224129 & 432102 & 8.48 & 8.2226 & TRN & \\
\hline CHEMBL281569 & 432102 & 8.49 & 7.8667 & TRN & \\
\hline CHEMBL390107 & 432102 & 8.57 & 8.7797 & TST & \\
\hline CHEMBL225144 & 432102 & 8.62 & 7.7651 & TST & \\
\hline CHEMBL21756 & 432102 & 8.66 & 8.2031 & TRN & \\
\hline CHEMBL224983 & 432102 & 8.69 & 7.8851 & TST & \\
\hline CHEMBL21835 & 432102 & 8.7 & 8.6073 & TST & \\
\hline CHEMBL225339 & 432102 & 8.72 & 8.9765 & TRN & \\
\hline CHEMBL224982 & 432102 & 8.75 & 7.4184 & TST & \\
\hline CHEMBL282439 & 432102 & 8.76 & 7.519 & TST & \\
\hline CHEMBL 21965 & 432102 & 8.82 & 8.6273 & TRN & \\
\hline CHEMBL225338 & 432102 & 8.84 & 8.4426 & TRN & \\
\hline CHEMBL 25325 & 432102 & 8.84 & 7.8784 & TST & \\
\hline CHEMBL282277 & 432102 & 8.84 & 8.9765 & TRN & \\
\hline CHEMBL22993 & 432102 & 8.91 & 8.9521 & TRN & \\
\hline CHEMBL 300500 & 432102 & 8.94 & 7.67299 & & TST \\
\hline CHEMBL21459 & 432102 & 9.0 & 8.9255 & TRN & \\
\hline CHEMBL 280148 & 432102 & 9.12 & 8.8597 & TRN & \\
\hline CHEMBL21538 & 432102 & 7.77 & 7.1987 & TST & \\
\hline CHEMBL223548 & 432102 & 6.13 & 8.4778 & TST & \\
\hline CHEMBL223764 & 432102 & 6.19 & 6.8427 & TRN & \\
\hline CHEMBL224470 & 432102 & 6.19 & 6.8172 & TRN & \\
\hline CHEMBL223995 & 432102 & 6.26 & 6.2957 & TRN & \\
\hline CHEMBL223763 & 432102 & 6.27 & 6.6704 & TRN & \\
\hline CHEMBL375336 & 432102 & 6.28 & 7.6712 & TRN & \\
\hline CHEMBL376812 & 432102 & 6.31 & 6.5324 & TRN & \\
\hline CHEMBL224685 & 432102 & 6.31 & 7.1901 & TRN & \\
\hline CHEMBL225038 & 432102 & 6.33 & 7.0672 & TRN & \\
\hline CHEMBL223762 & 432102 & 6.38 & 6.7714 & TST & \\
\hline CHEMBL223930 & 432102 & 6.38 & 6.8084 & TRN & \\
\hline CHEMBL224684 & 432102 & 6.39 & 6.6785 & TRN & \\
\hline CHEMBL223712 & 432102 & 6.39 & 6.6778 & TRN & \\
\hline
\end{tabular}




\begin{tabular}{|c|c|c|c|c|c|}
\hline \multicolumn{6}{|c|}{ Supplemental Table S2.txt } \\
\hline CHEMBL53093 & 432102 & 6.5 & 7.7779 & TST & \\
\hline CHEMBL389177 & 432102 & 6.55 & 6.8085 & TRN & \\
\hline CHEMBL374162 & 432102 & 6.69 & 6.9037 & TST & \\
\hline CHEMBL426179 & 432102 & 6.71 & 7.01399 & 9999999999 & TRN \\
\hline CHEMBL388589 & 432102 & 6.72 & 7.0262 & TRN & \\
\hline CHEMBL376805 & 432102 & 6.73 & 7.4879 & TRN & \\
\hline CHEMBL224598 & 432102 & 6.79 & 7.2421 & TRN & \\
\hline CHEMBL438480 & 432102 & 6.81 & 7.0668 & TRN & \\
\hline CHEMBL50752 & 432102 & 6.81 & 7.2185 & TRN & \\
\hline CHEMBL224597 & 432102 & 6.82 & 7.5072 & TST & \\
\hline CHEMBL389276 & 432102 & 6.85 & 6.6563 & TST & \\
\hline CHEMBL375935 & 432102 & 6.88 & 7.869 & TST & \\
\hline CHEMBL426175 & 432102 & 6.92 & 7.4929 & TRN & \\
\hline CHEMBL373441 & 432102 & 6.97 & 7.1365 & TRN & \\
\hline CHEMBL224859 & 432102 & 6.97 & 7.1029 & TRN & \\
\hline CHEMBL224418 & 432102 & 6.98 & 7.398 & TRN & \\
\hline CHEMBL266286 & 432102 & 7.0 & 7.9459 & TST & \\
\hline CHEMBL389623 & 432102 & 7.1 & 7.0439 & TRN & \\
\hline CHEMBL21568 & 432102 & 7.14 & 7.3428 & TRN & \\
\hline CHEMBL 21635 & 432102 & 7.17 & 6.80200 & 00000000005 & TRN \\
\hline CHEMBL389067 & 432102 & 7.23 & 8.2955 & TST & \\
\hline CHEMBL225367 & 432102 & 7.28 & 6.9972 & TRN & \\
\hline CHEMBL225062 & 432102 & 7.28 & 7.0342 & TRN & \\
\hline CHEMBL300659 & 432102 & 7.29 & 7.3449 & TRN & \\
\hline CHEMBL21542 & 432102 & 7.3 & 6.7988 & TRN & \\
\hline CHEMBL22020 & 432102 & 7.33 & 8.3684 & TRN & \\
\hline CHEMBL224631 & 432102 & 7.41 & 7.99100 & 00000000005 & TRN \\
\hline CHEMBL223653 & 432102 & 7.45 & 7.4284 & TRN & \\
\hline CHEMBL21933 & 432102 & 7.56 & 7.4644 & TRN & \\
\hline CHEMBL279496 & 432102 & 7.57 & 7.1744 & TRN & \\
\hline CHEMBL21754 & 432102 & 7.62 & 7.0379 & TRN & \\
\hline CHEMBL 22615 & 432102 & 7.65 & 7.2854 & TRN & \\
\hline CHEMBL21617 & 432102 & 7.66 & 7.561 & TST & \\
\hline CHEMBL282714 & 432102 & 7.66 & 7.1758 & TST & \\
\hline CHEMBL21664 & 432102 & 7.68 & 7.1144 & TRN & \\
\hline CHEMBL387880 & 432102 & 7.69 & 7.5084 & TRN & \\
\hline CHEMBL225337 & 432102 & 7.69 & 7.0951 & TRN & \\
\hline CHEMBL278552 & 432102 & 7.73 & 7.685 & TRN & \\
\hline CHEMBL21630 & 432102 & 7.73 & 7.4968 & TRN & \\
\hline CHEMBL224578 & 432102 & 7.74 & 6.9912 & TST & \\
\hline CHEMBL327919 & 688437 & 4.6 & 4.6152 & TRN & \\
\hline CHEMBL1451833 & 688437 & 4.8 & 4.5514 & TRN & \\
\hline CHEMBL280998 & 688437 & 4.8 & 4.5936 & TRN & \\
\hline CHEMBL1333512 & 688437 & 4.5 & 4.6228 & TRN & \\
\hline CHEMBL1325964 & 688437 & 4.2 & 4.3767 & TRN & \\
\hline CHEMBL36296 & 688437 & 4.3 & 4.3014 & TRN & \\
\hline CHEMBL1489064 & 688437 & 4.4 & 4.4589 & TRN & \\
\hline CHEMBL1569493 & 688437 & 6.2 & 6.2265 & TRN & \\
\hline
\end{tabular}




\begin{tabular}{|c|c|c|c|c|}
\hline \multicolumn{5}{|c|}{ Supplemental Table S2.txt } \\
\hline CHEMBL 28 & 688437 & 4.3 & 4.2852 & TRN \\
\hline CHEMBL1496957 & 688437 & 4.9 & 4.8926 & TRN \\
\hline CHEMBL85728 & 688437 & 4.1 & 4.4463 & TRN \\
\hline CHEMBL1309179 & 688437 & 4.9 & 4.9381 & TRN \\
\hline CHEMBL8739 & 688437 & 4.3 & 4.2477 & TRN \\
\hline CHEMBL1200471 & 688437 & 6.7001 & 6.7448 & TRN \\
\hline CHEMBL1344952 & 688437 & 4.3 & 4.0958 & TRN \\
\hline CHEMBL1492729 & 688437 & 4.9 & 4.8926 & TRN \\
\hline CHEMBL195953 & 688437 & 4.3 & 4.2507 & TRN \\
\hline CHEMBL1303139 & 688437 & 5.5 & 5.5644 & TRN \\
\hline CHEMBL1569226 & 688437 & 5.7 & 5.681 & TRN \\
\hline CHEMBL1510786 & 688437 & 4.6 & 4.3479 & TST \\
\hline CHEMBL1562104 & 688437 & 5.6 & 5.6169 & TRN \\
\hline CHEMBL1485974 & 688437 & 4.5 & 4.4118 & TRN \\
\hline CHEMBL1371285 & 688437 & 4.1 & 4.3679 & TRN \\
\hline CHEMBL1545634 & 688437 & 6.9 & 6.8642 & TRN \\
\hline CHEMBL462576 & 688437 & 4.3 & 4.2173 & TRN \\
\hline CHEMBL1421613 & 688437 & 4.1 & 4.1797 & TRN \\
\hline CHEMBL1529759 & 688437 & 4.1 & 4.3329 & TRN \\
\hline CHEMBL1492884 & 688437 & 4.4 & 4.578 & TRN \\
\hline CHEMBL1535689 & 688437 & 4.4 & 4.4808 & TRN \\
\hline CHEMBL1514512 & 688437 & 4.4 & 4.2255 & TRN \\
\hline CHEMBL70582 & 688437 & 4.9 & 4.5514 & TRN \\
\hline CHEMBL1602127 & 688437 & 4.3 & 4.5159 & TRN \\
\hline CHEMBL1580759 & 688437 & 4.4 & 4.4159 & TRN \\
\hline CHEMBL449362 & 688437 & 4.6 & 4.6824 & TRN \\
\hline CHEMBL1565705 & 688437 & 4.3 & 4.2266 & TRN \\
\hline CHEMBL1522486 & 688437 & 4.9 & 4.8276 & TRN \\
\hline CHEMBL1418603 & 688437 & 4.3 & 4.1706 & TRN \\
\hline CHEMBL1609459 & 688437 & 5.5 & 5.4202 & TRN \\
\hline CHEMBL192627 & 688437 & 4.8 & 4.8449 & TRN \\
\hline CHEMBL84685 & 688437 & 4.4 & 4.3991 & TRN \\
\hline CHEMBL105712 & 688437 & 5.2 & 5.1644 & TRN \\
\hline CHEMBL1499545 & 688437 & 5.5 & 5.5023 & TRN \\
\hline CHEMBL1456906 & 688437 & 4.3 & 4.4 & TST \\
\hline CHEMBL1366408 & 688437 & 4.4 & 4.6765 & TST \\
\hline CHEMBL509531 & 688437 & 4.8 & 4.7438 & TST \\
\hline CHEMBL1338613 & 688437 & 4.5 & 4.3169 & TRN \\
\hline CHEMBL1558796 & 688437 & 4.5 & 4.5896 & TRN \\
\hline CHEMBL486193 & 688437 & 4.3 & 4.4552 & TRN \\
\hline CHEMBL1600998 & 688437 & 5.7 & 5.6241 & TRN \\
\hline CHEMBL1484480 & 688437 & 4.1 & 4.1564 & TRN \\
\hline CHEMBL 28319 & 688437 & 4.6 & 4.5595 & TRN \\
\hline CHEMBL3391990 & 688437 & 4.3 & 4.3334 & TST \\
\hline CHEMBL8320 & 688437 & 4.4 & 4.3588 & TRN \\
\hline CHEMBL1319452 & 688437 & 4.9 & 4.647 & TRN \\
\hline CHEMBL1391326 & 688437 & 4.4 & 4.3908 & TRN \\
\hline CHEMBL334255 & 688437 & 4.9 & 4.918 & TRN \\
\hline
\end{tabular}




\begin{tabular}{|c|c|c|c|c|}
\hline & & & pplement & al $\mathrm{Ta}$ \\
\hline CHEMBL1579130 & 688437 & 6.0 & 5.5449 & TRN \\
\hline CHEMBL85811 & 688437 & 4.3 & 4.4171 & TRN \\
\hline CHEMBL935 & 688437 & 4.4 & 4.4568 & TRN \\
\hline CHEMBL1585396 & 688437 & 4.3 & 4.3467 & TRN \\
\hline CHEMBL443949 & 688437 & 4.3 & 4.3779 & TRN \\
\hline CHEMBL57394 & 688437 & 4.3 & 4.4061 & TRN \\
\hline CHEMBL1524617 & 688437 & 5.3 & 5.3 & TRN \\
\hline CHEMBL285235 & 688437 & 4.1 & 4.3166 & TRN \\
\hline CHEMBL1518369 & 688437 & 4.4 & 4.3758 & TRN \\
\hline CHEMBL1612246 & 688437 & 4.6 & 4.5304 & TRN \\
\hline CHEMBL440287 & 688437 & 4.7 & 4.4777 & TRN \\
\hline CHEMBL1602699 & 688437 & 5.7 & 5.5429 & TRN \\
\hline CHEMBL538146 & 688437 & 4.4 & 4.5893 & TRN \\
\hline CHEMBL1462419 & 688437 & 4.4 & 4.4183 & TRN \\
\hline CHEMBL1526721 & 688437 & 5.2 & 5.285 & TRN \\
\hline CHEMBL402063 & 688437 & 6.0 & 5.9558 & TST \\
\hline CHEMBL1308088 & 688437 & 4.9 & 4.9461 & TRN \\
\hline CHEMBL1364985 & 688437 & 4.4 & 4.4683 & TRN \\
\hline CHEMBL1566504 & 688437 & 4.4 & 4.3899 & TST \\
\hline CHEMBL167423 & 688437 & 4.3 & 4.3781 & TRN \\
\hline CHEMBL196537 & 688437 & 4.3 & 4.2282 & TRN \\
\hline CHEMBL1549844 & 688437 & 4.9 & 4.7335 & TST \\
\hline CHEMBL1324314 & 688437 & 4.3 & 4.4107 & TRN \\
\hline CHEMBL1517425 & 688437 & 4.3 & 4.0986 & TRN \\
\hline CHEMBL1530684 & 688437 & 4.4 & 4.5196 & TRN \\
\hline CHEMBL 251389 & 688437 & 5.1 & 4.8412 & TRN \\
\hline CHEMBL 296021 & 688437 & 4.1 & 4.325 & TRN \\
\hline CHEMBL1304981 & 688437 & 4.4 & 4.1093 & TRN \\
\hline CHEMBL172064 & 688437 & 4.3 & 4.2838 & TST \\
\hline CHEMBL1330518 & 688437 & 4.3 & 4.3416 & TRN \\
\hline CHEMBL1452158 & 688437 & 4.4 & 4.2672 & TRN \\
\hline CHEMBL1489568 & 688437 & 4.3 & 4.3636 & TRN \\
\hline CHEMBL1450123 & 688437 & 4.3 & 4.3268 & TRN \\
\hline CHEMBL175193 & 688437 & 4.3 & 4.0453 & TRN \\
\hline CHEMBL162598 & 688437 & 4.4 & 4.2983 & TST \\
\hline CHEMBL1448387 & 688437 & 4.5 & 4.7217 & TRN \\
\hline CHEMBL552741 & 688437 & 4.3 & 4.7763 & TRN \\
\hline CHEMBL1527567 & 688437 & 4.6 & 4.4835 & TRN \\
\hline CHEMBL1526319 & 688437 & 4.5 & 4.6084 & TRN \\
\hline CHEMBL220845 & 688437 & 4.4 & 4.5346 & TRN \\
\hline CHEMBL1430204 & 688437 & 4.5 & 4.6609 & TRN \\
\hline CHEMBL1611235 & 688437 & 4.6 & 4.3843 & TRN \\
\hline CHEMBL140 & 688437 & 4.6 & 4.4968 & TRN \\
\hline CHEMBL1408847 & 688437 & 5.4 & 5.5331 & TRN \\
\hline CHEMBL1449018 & 688437 & 4.8 & 4.6727 & TRN \\
\hline CHEMBL1331245 & 688437 & 4.3 & 4.2779 & TRN \\
\hline CHEMBL1450607 & 688437 & 4.8 & 4.7492 & TRN \\
\hline CHEMBL1407826 & 688437 & 5.0 & 4.8296 & TST \\
\hline
\end{tabular}




\begin{tabular}{|c|c|c|c|c|c|}
\hline \multicolumn{6}{|c|}{ oplemental Iable S2 } \\
\hline CHEMBL1393325 & 688437 & 4.4 & 4.3706 & TRN & \\
\hline CHEMBL1559341 & 688437 & 4.5 & 4.5136 & TRN & \\
\hline CHEMBL44072 & 688437 & 4.4 & 4.3387 & TRN & \\
\hline CHEMBL445957 & 688437 & 4.4 & 4.4245 & TRN & \\
\hline CHEMBL91732 & 688437 & 4.1 & 4.5805 & TST & \\
\hline CHEMBL1492104 & 688437 & 5.1 & 4.7798 & TST & \\
\hline CHEMBL230156 & 688437 & 4.4 & 4.3016 & TST & \\
\hline CHEMBL389950 & 688437 & 4.1 & 4.1368 & TST & \\
\hline CHEMBL491 & 688437 & 4.3 & 4.7679 & TST & \\
\hline CHEMBL1414154 & 688437 & 4.3 & 4.0896 & TST & \\
\hline CHEMBL1564920 & 688437 & 4.3 & 4.3262 & TST & \\
\hline CHEMBL194399 & 688437 & 4.3 & 4.2887 & TST & \\
\hline CHEMBL31425 & 688437 & 4.1 & 4.3945 & TST & \\
\hline CHEMBL1409985 & 688437 & 5.6 & 5.5722 & TST & \\
\hline CHEMBL1142 & 688437 & 4.6 & 4.6189 & TST & \\
\hline CHEMBL1519327 & 688437 & 6.5 & 6.6683 & TST & \\
\hline CHEMBL194400 & 688437 & 4.2 & 4.3039 & TST & \\
\hline CHEMBL 224282 & 688437 & 4.4 & 4.5254 & TST & \\
\hline CHEMBL1221925 & 688437 & 4.4 & 4.3705 & TST & \\
\hline CHEMBL454173 & 688437 & 4.4 & 4.8709 & TST & \\
\hline CHEMBL1447588 & 688437 & 4.9 & 5.0857 & TST & \\
\hline CHEMBL144530 & 688437 & 4.5 & 4.3562 & TST & \\
\hline CHEMBL1236200 & 688437 & 4.1 & 4.3422 & TST & \\
\hline CHEMBL1428964 & 688437 & 4.1 & 4.2845 & TST & \\
\hline CHEMBL1576086 & 688437 & 4.6 & 4.41100 & 00000000005 & TST \\
\hline CHEMBL1485360 & 688437 & 4.3 & 4.7261 & TST & \\
\hline CHEMBL10 & 852265 & 7.3979 & 8.129 & TST & \\
\hline CHEMBL2152939 & 852265 & 7.5229 & 8.0535 & TST & \\
\hline CHEMBL2152963 & 852265 & 7.0969 & 7.4012 & TST & \\
\hline CHEMBL 2152949 & 852265 & 8.0 & 7.694 & TRN & \\
\hline CHEMBL 2152793 & 852265 & 7.699 & 7.3908 & TRN & \\
\hline CHEMBL 2152940 & 852265 & 8.0 & 7.9574 & TRN & \\
\hline CHEMBL 2152797 & 852265 & 6.5229 & 7.5716 & TST & \\
\hline CHEMBL 2152798 & 852265 & 6.0 & 7.37799 & 9999999999 & TST \\
\hline CHEMBL 2152962 & 852265 & 7.1549 & 7.4275 & TRN & \\
\hline CHEMBL2152789 & 852265 & 7.301 & 7.1581 & TRN & \\
\hline CHEMBL 2152955 & 852265 & 7.699 & 7.9613 & TRN & \\
\hline CHEMBL2152969 & 852265 & 7.699 & 7.4637 & TRN & \\
\hline CHEMBL 2152968 & 852265 & 6.3565 & 7.9496 & TST & \\
\hline CHEMBL 2152971 & 852265 & 7.0969 & 6.9794 & TRN & \\
\hline CHEMBL 2152973 & 852265 & 7.3979 & 7.66200 & 0000000001 & TRN \\
\hline CHEMBL 2152790 & 852265 & 5.4522 & 5.4489 & TRN & \\
\hline CHEMBL 2152786 & 852265 & 7.2218 & 7.2224 & TRN & \\
\hline CHEMBL 2152784 & 852265 & 7.1549 & 7.1475 & TRN & \\
\hline CHEMBL2152779 & 852265 & 7.3979 & 7.5186 & TRN & \\
\hline CHEMBL 2152972 & 852265 & 5.983 & 7.8095 & TST & \\
\hline CHEMBL 2152794 & 852265 & 6.8539 & 6.6029 & TRN & \\
\hline CHEMBL 2152782 & 852265 & 6.3979 & 6.2951 & TRN & \\
\hline
\end{tabular}




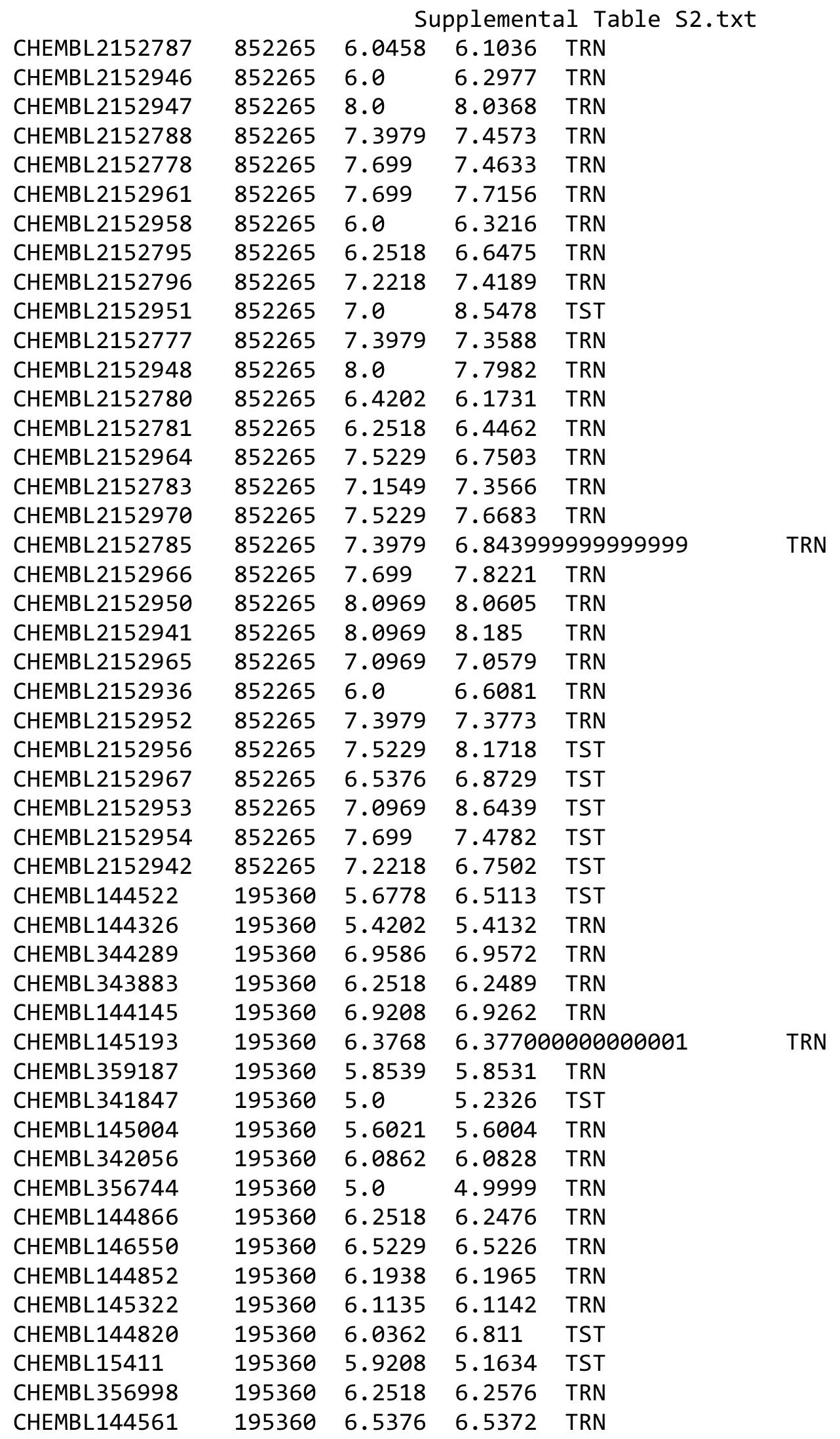

Page 26019 


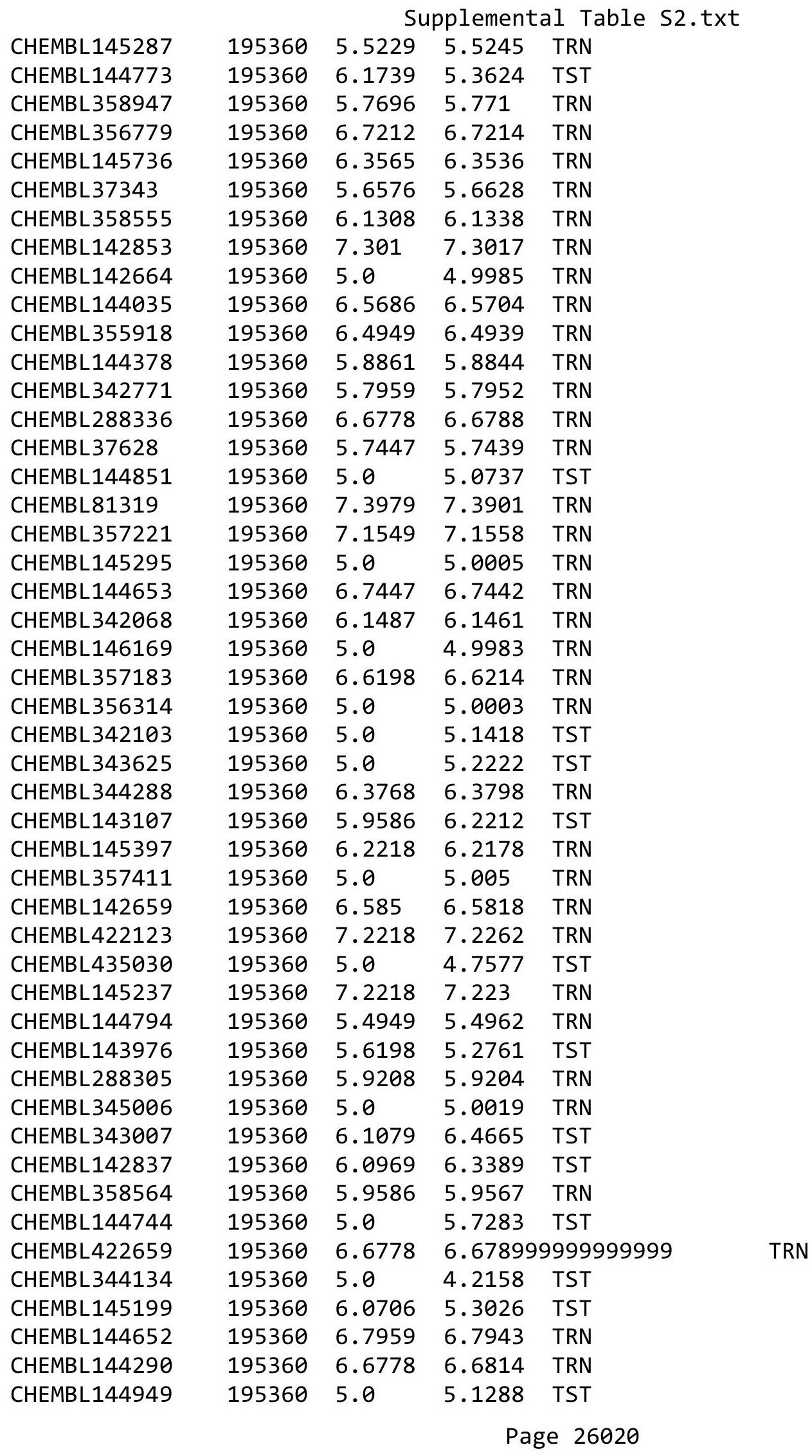




\begin{tabular}{|c|c|c|c|c|c|c|}
\hline \multirow[b]{2}{*}{ CHEMBL393929 } & \multicolumn{6}{|c|}{ Supplemental Table S2.txt } \\
\hline & 954442 & 4.1119 & 4.1095 & TRN & & \\
\hline CHEMBL 9470 & 954442 & 5.579 & 5.4229 & 9999 & 99 & TST \\
\hline CHEMBL188678 & 954442 & 6.5466 & 6.5468 & TRN & & \\
\hline CHEMBL558642 & 954442 & 5.21899 & 7999999 & 99 & 5.2172 & TRN \\
\hline CHEMBL3186408 & 954442 & 4.0474 & 3.946 & TST & & \\
\hline CHEMBL209148 & 954442 & 4.3857 & 4.3807 & TRN & & \\
\hline CHEMBL514499 & 954442 & 7.0542 & 7.057 & TRN & & \\
\hline CHEMBL3199475 & 954442 & 4.4945 & 4.4969 & TRN & & \\
\hline CHEMBL1970879 & 954442 & 2.9343 & 2.9323 & TRN & & \\
\hline CHEMBL573107 & 954442 & 4.4286 & 4.4255 & TRN & & \\
\hline CHEMBL220241 & 954442 & 4.7318 & 4.7319 & TRN & & \\
\hline CHEMBL 3392440 & 954442 & 4.1252 & 4.1266 & TRN & & \\
\hline CHEMBL449158 & 954442 & 6.1188 & 6.4469 & TST & & \\
\hline CHEMBL1404918 & 954442 & 3.0077 & 3.0098 & TRN & & \\
\hline CHEMBL412142 & 954442 & 4.9533 & 4.9499 & TRN & & \\
\hline CHEMBL 240954 & 954442 & 4.745 & 4.5381 & TST & & \\
\hline CHEMBL512504 & 954442 & 6.3293 & 6.3313 & TRN & & \\
\hline CHEMBL1643959 & 954442 & 3.6141 & 3.6138 & TRN & & \\
\hline CHEMBL1242367 & 954442 & 4.2493 & 4.255 & TRN & & \\
\hline CHEMBL1230020 & 954442 & 4.602 & 4.6043 & TRN & & \\
\hline CHEMBL392695 & 954442 & 5.3513 & 5.3472 & TRN & & \\
\hline CHEMBL483847 & 954442 & 4.1426 & 4.1431 & TRN & & \\
\hline CHEMBL2363137 & 954442 & 4.5492 & 4.5511 & TRN & & \\
\hline CHEMBL509032 & 954442 & 5.6593 & 5.6593 & TRN & & \\
\hline CHEMBL 379975 & 954442 & 4.4661 & 4.4683 & TRN & & \\
\hline CHEMBL259181 & 954442 & 4.9288 & 4.9319 & TRN & & \\
\hline CHEMBL1516890 & 954442 & 3.9487 & 3.9577 & TRN & & \\
\hline CHEMBL192566 & 954442 & 7.4686 & 8.1157 & TST & & \\
\hline CHEMBL1788116 & 954442 & 4.456 & 4.4523 & TRN & & \\
\hline CHEMBL102714 & 954442 & 7.3105 & 7.3083 & TRN & & \\
\hline CHEMBL 2005886 & 954442 & 4.1884 & 4.1893 & TRN & & \\
\hline CHEMBL65 & 954442 & 8.988 & 8.9914 & TRN & & \\
\hline CHEMBL 213100 & 954442 & 3.1453 & 3.1448 & TRN & & \\
\hline CHEMBL472940 & 954442 & 2.8878 & 2.8853 & TRN & & \\
\hline CHEMBL1909414 & 954442 & 5.099 & 5.099 & TRN & & \\
\hline CHEMBL1357247 & 954442 & 3.5688 & 3.5712 & TRN & & \\
\hline CHEMBL1190711 & 954442 & 5.2777 & 5.2759 & TRN & & \\
\hline CHEMBL92309 & 954442 & 3.2711 & 2.6733 & TST & & \\
\hline CHEMBL1256459 & 954442 & 6.0412 & 6.046 & TRN & & \\
\hline CHEMBL 379300 & 954442 & 5.7804 & 5.7744 & TRN & & \\
\hline CHEMBL 210618 & 954442 & 3.8208 & 3.8174 & TRN & & \\
\hline CHEMBL221137 & 954442 & 4.4017 & 4.3158 & TST & & \\
\hline CHEMBL483849 & 954442 & 3.9377 & 3.9404 & TRN & & \\
\hline CHEMBL 202721 & 954442 & 4.38899 & 7999999 & 99 & 4.3927 & TRN \\
\hline CHEMBL1673039 & 954442 & 5.0094 & 5.0137 & TRN & & \\
\hline CHEMBL 258844 & 954442 & 4.6404 & 4.6434 & TRN & & \\
\hline CHEMBL189584 & 954442 & 4.9437 & 4.938 & TRN & & \\
\hline CHEMBL 222102 & 954442 & 4.3026 & 4.2993 & TRN & & \\
\hline
\end{tabular}

Page 26021 
Supplemental Table S2.txt

\begin{tabular}{|c|c|c|c|c|c|}
\hline CHEMBL180127 & 954442 & 2.9739 & 2.9732 & TRN & \\
\hline CHEMBL3349342 & 954442 & 5.1532 & 5.1537 & TRN & \\
\hline CHEMBL585951 & 954442 & 6.0192 & 6.0099 & TRN & \\
\hline CHEMBL135561 & 954442 & 4.0194 & 4.4841 & TST & \\
\hline CHEMBL577784 & 954442 & 4.2391 & 5.6099 & TST & \\
\hline CHEMBL373751 & 954442 & 3.2497 & 3.4541 & TST & \\
\hline CHEMBL 2144069 & 954442 & 3.3218 & 4.5279 & TST & \\
\hline CHEMBL1590308 & 954442 & 2.5702 & 3.2578 & TST & \\
\hline CHEMBL515416 & 954442 & 3.6868 & 3.5773 & TST & \\
\hline CHEMBL 300389 & 954442 & 5.9151 & 6.2662 & TST & \\
\hline CHEMBL191334 & 954442 & 3.7733 & 4.6387 & TST & \\
\hline CHEMBL3693412 & 1528185 & 6.5376 & 6.4995 & TRN & \\
\hline CHEMBL3689019 & 1528185 & 6.6576 & 6.4557 & TRN & \\
\hline CHEMBL3693417 & 1528185 & 6.8861 & 7.4556 & TST & \\
\hline CHEMBL3693492 & 1528185 & 7.1024 & 6.9462 & TRN & \\
\hline CHEMBL3689011 & 1528185 & 6.8861 & 6.7637 & TRN & \\
\hline CHEMBL3693388 & 1528185 & 7.2291 & 6.7287 & TRN & \\
\hline CHEMBL3688903 & 1528185 & 8.1938 & 6.8179 & TRN & \\
\hline CHEMBL3688914 & 1528185 & 6.0 & 6.3543 & TRN & \\
\hline CHEMBL3688969 & 1528185 & 7.3565 & 6.92200 & 0000000001 & TRN \\
\hline CHEMBL3689007 & 1528185 & 6.8539 & 6.5941 & TRN & \\
\hline CHEMBL3693530 & 1528185 & 7.1675 & 7.4843 & TRN & \\
\hline CHEMBL3693471 & 1528185 & 6.6021 & 6.3273 & TRN & \\
\hline CHEMBL3693573 & 1528185 & 6.3872 & 6.5698 & TRN & \\
\hline CHEMBL 3693456 & 1528185 & 7.5086 & 7.261 & TRN & \\
\hline CHEMBL3693379 & 1528185 & 6.9586 & 6.9636 & TRN & \\
\hline CHEMBL3688987 & 1528185 & 7.6021 & 7.9313 & TRN & \\
\hline CHEMBL3693413 & 1528185 & 6.3565 & 6.6332 & TRN & \\
\hline CHEMBL3688904 & 1528185 & 6.3372 & 6.449 & TRN & \\
\hline CHEMBL3693402 & 1528185 & 6.1938 & 6.6894 & TST & \\
\hline CHEMBL3688842 & 1528185 & 7.4202 & 6.7103 & TST & \\
\hline CHEMBL3688968 & 1528185 & 6.6383 & 6.3534 & TRN & \\
\hline CHEMBL3693449 & 1528185 & 6.284 & 6.9575 & TST & \\
\hline CHEMBL3693382 & 1528185 & 7.4202 & 7.3741 & TRN & \\
\hline CHEMBL3693590 & 1528185 & 7.8539 & 7.3322 & TRN & \\
\hline CHEMBL3688955 & 1528185 & 6.5376 & 6.9172 & TRN & \\
\hline CHEMBL3693571 & 1528185 & 7.1135 & 6.7878 & TRN & \\
\hline CHEMBL3688954 & 1528185 & 7.1938 & 6.9192 & TST & \\
\hline CHEMBL3693447 & 1528185 & 6.4815 & 6.8485 & TST & \\
\hline CHEMBL3693393 & 1528185 & 6.9208 & 7.1797 & TRN & \\
\hline CHEMBL3688911 & 1528185 & 7.1871 & 7.9576 & TRN & \\
\hline CHEMBL3693546 & 1528185 & 6.9208 & 6.8298 & TRN & \\
\hline CHEMBL3693470 & 1528185 & 7.8539 & 7.169 & TRN & \\
\hline CHEMBL3689029 & 1528185 & 7.041 & 7.4841 & TRN & \\
\hline CHEMBL3688898 & 1528185 & 7.4202 & 7.7124 & TRN & \\
\hline CHEMBL3693527 & 1528185 & 6.4318 & \multicolumn{2}{|c|}{6.997999999999999} & TRN \\
\hline CHEMBL3693499 & 1528185 & 6.7959 & 6.9276 & TST & \\
\hline CHEMBL3916652 & 1528185 & 8.1739 & 7.9133 & TRN & \\
\hline
\end{tabular}

Page 26022 
Supplemental Table S2.txt

\begin{tabular}{|c|c|c|c|c|c|}
\hline CHEMBL3900748 & 1528185 & 7.5086 & 7.608 & TST & \\
\hline CHEMBL3693385 & 1528185 & 7.1192 & 7.0731 & TRN & \\
\hline CHEMBL3688873 & 1528185 & 8.0362 & 7.0776 & TRN & \\
\hline CHEMBL3693430 & 1528185 & 7.0555 & 6.6315 & TRN & \\
\hline CHEMBL3693560 & 1528185 & 7.2218 & 6.5523 & TST & \\
\hline CHEMBL3693455 & 1528185 & 7.4202 & 7.4477 & TRN & \\
\hline CHEMBL3693384 & 1528185 & 7.4949 & 7.6556 & TRN & \\
\hline CHEMBL3693415 & 1528185 & 7.8861 & 7.7793 & TST & \\
\hline CHEMBL 3688871 & 1528185 & 7.0458 & 6.8354 & TRN & \\
\hline CHEMBL3688921 & 1528185 & 6.3098 & \multicolumn{2}{|c|}{7.3420000000000005} & TRN \\
\hline CHEMBL3688963 & 1528185 & 6.5528 & 6.8316 & TRN & \\
\hline CHEMBL3688951 & 1528185 & 6.5686 & 6.7256 & TRN & \\
\hline CHEMBL3688991 & 1528185 & 9.5686 & 8.5771 & TRN & \\
\hline CHEMBL 3693514 & 1528185 & 7.5229 & 7.4127 & TRN & \\
\hline CHEMBL 3688832 & 1528185 & 8.3565 & 8.432 & TRN & \\
\hline CHEMBL3688997 & 1528185 & 8.041 & 7.6943 & TRN & \\
\hline CHEMBL3693579 & 1528185 & 5.699 & \multicolumn{2}{|c|}{6.5489999999999995} & TRN \\
\hline CHEMBL3693459 & 1528185 & 7.0555 & 7.0713 & TRN & \\
\hline CHEMBL 3688884 & 1528185 & 7.4559 & 6.5096 & TST & \\
\hline CHEMBL 3693422 & 1528185 & 6.7696 & 7.541 & TST & \\
\hline CHEMBL3688833 & 1528185 & 8.301 & 7.7214 & TRN & \\
\hline CHEMBL3688973 & 1528185 & 6.2518 & 6.4107 & TRN & \\
\hline CHEMBL3693509 & 1528185 & 6.2147 & 7.105 & TRN & \\
\hline CHEMBL3688930 & 1528185 & 7.699 & 7.7111 & TRN & \\
\hline CHEMBL 2336321 & 1528185 & 7.1805 & 7.5273 & TRN & \\
\hline CHEMBL 3688864 & 1528185 & 6.6778 & 7.5655 & TRN & \\
\hline CHEMBL3693533 & 1528185 & 6.0 & 7.0951 & TRN & \\
\hline CHEMBL3688928 & 1528185 & 6.6383 & 7.2858 & TRN & \\
\hline CHEMBL3986415 & 1528185 & 7.5229 & 7.7127 & TRN & \\
\hline CHEMBL 3688924 & 1528185 & 7.1805 & 7.2056 & TRN & \\
\hline CHEMBL 3688848 & 1528185 & 6.585 & 6.7417 & TRN & \\
\hline CHEMBL 3693424 & 1528185 & 7.1024 & 7.482 & TST & \\
\hline CHEMBL3693531 & 1528185 & 7.2596 & 7.3213 & TRN & \\
\hline CHEMBL3693493 & 1528185 & 7.0969 & 6.7544 & TRN & \\
\hline CHEMBL 2336320 & 1528185 & 8.4949 & 7.4149 & TRN & \\
\hline CHEMBL3688929 & 1528185 & 6.6021 & 7.4289 & TRN & \\
\hline CHEMBL 3693467 & 1528185 & 7.4318 & 7.3208 & TRN & \\
\hline CHEMBL3693439 & 1528185 & 6.8539 & 7.5274 & TST & \\
\hline CHEMBL3693391 & 1528185 & 6.9208 & 7.3049 & TRN & \\
\hline CHEMBL3693522 & 1528185 & 8.0 & 7.2969 & TRN & \\
\hline CHEMBL3688838 & 1528185 & 8.2441 & 7.7225 & TRN & \\
\hline CHEMBL3693537 & 1528185 & 6.0 & 7.3222 & TRN & \\
\hline CHEMBL3688948 & 1528185 & 6.1549 & 6.8952 & TRN & \\
\hline CHEMBL3693387 & 1528185 & 7.3098 & 7.2149 & TRN & \\
\hline CHEMBL3693399 & 1528185 & 6.0506 & 6.8849 & TST & \\
\hline CHEMBL3693414 & 1528185 & 5.8539 & 6.574 & TRN & \\
\hline CHEMBL 3689024 & 1528185 & 7.0223 & 6.769 & TRN & \\
\hline CHEMBL 3688927 & 1528185 & 7.1367 & 6.8029 & TRN & \\
\hline
\end{tabular}


Supplemental Table S2.txt

\begin{tabular}{|c|c|c|c|c|c|}
\hline CHEMBL 3688858 & 1528185 & 7.5376 & 7.2477 & TRN & \\
\hline CHEMBL 3688988 & 1528185 & 6.0 & 7.4612 & TST & \\
\hline CHEMBL3689000 & 1528185 & 7.6778 & 7.5918 & TRN & \\
\hline CHEMBL 3639878 & 1528185 & 6.6778 & 6.7657 & TRN & \\
\hline CHEMBL 3693498 & 1528185 & 7.0362 & 6.9736 & TST & \\
\hline CHEMBL3693516 & 1528185 & 7.2076 & 7.4182 & TRN & \\
\hline CHEMBL3688971 & 1528185 & 6.6383 & 6.5832 & TRN & \\
\hline CHEMBL3693549 & 1528185 & 8.5086 & 7.2525 & TRN & \\
\hline CHEMBL3693458 & 1528185 & 7.5229 & 7.195 & TRN & \\
\hline CHEMBL 3688860 & 1528185 & 5.9586 & 6.7483 & TRN & \\
\hline CHEMBL3693497 & 1528185 & 7.2366 & 6.8364 & TRN & \\
\hline CHEMBL 3689014 & 1528185 & 6.0 & 6.5337 & TST & \\
\hline CHEMBL 3688837 & 1528185 & 7.8239 & 7.6986 & TRN & \\
\hline CHEMBL3688907 & 1528185 & 9.585 & 8.2768 & TRN & \\
\hline CHEMBL3984149 & 1528185 & 6.0 & 7.0624 & TRN & \\
\hline CHEMBL 2336323 & 1528185 & 7.3979 & 7.4547 & TRN & \\
\hline CHEMBL3689001 & 1528185 & 6.7696 & 7.4435 & TRN & \\
\hline CHEMBL 3689010 & 1528185 & 6.8861 & 6.7424 & TRN & \\
\hline CHEMBL3693468 & 1528185 & 7.2676 & 7.3233 & TRN & \\
\hline CHEMBL 3688976 & 1528185 & 6.4202 & 6.6209 & TRN & \\
\hline CHEMBL3693536 & 1528185 & 8.28399 & 99999999 & 7.3384 & TRN \\
\hline CHEMBL 3693510 & 1528185 & 7.6021 & 6.9444 & TRN & \\
\hline CHEMBL 3688940 & 1528185 & 7.4559 & 7.0663 & TST & \\
\hline CHEMBL3688875 & 1528185 & 6.3565 & 6.7301 & TRN & \\
\hline CHEMBL3693473 & 1528185 & 7.6383 & 7.1631 & TRN & \\
\hline CHEMBL 3688870 & 1528185 & 7.4685 & 7.4362 & TRN & \\
\hline CHEMBL 3693441 & 1528185 & 6.7212 & 7.0609 & TRN & \\
\hline CHEMBL3693392 & 1528185 & 6.9208 & 7.3329 & TRN & \\
\hline CHEMBL3688981 & 1528185 & 6.1308 & 6.2385 & TRN & \\
\hline CHEMBL3688900 & 1528185 & 7.7447 & 7.8918 & TRN & \\
\hline CHEMBL3693440 & 1528185 & 6.3188 & 6.6433 & TRN & \\
\hline CHEMBL 3693454 & 1528185 & 7.4089 & 7.0545 & TRN & \\
\hline CHEMBL 3689027 & 1528185 & 7.9208 & 7.2963 & TRN & \\
\hline CHEMBL3693408 & 1528185 & 7.2441 & 6.8642 & TRN & \\
\hline CHEMBL3693386 & 1528185 & 6.9208 & 7.1771 & TRN & \\
\hline CHEMBL3693521 & 1528185 & 7.4089 & 7.6254 & TRN & \\
\hline CHEMBL 3688985 & 1528185 & 5.7959 & 7.0262 & TRN & \\
\hline CHEMBL3693517 & 1528185 & 7.3279 & 7.3438 & TRN & \\
\hline CHEMBL3688966 & 1528185 & 6.8539 & 7.0925 & TRN & \\
\hline CHEMBL3688996 & 1528185 & 7.7959 & 7.6045 & TRN & \\
\hline CHEMBL3693506 & 1528185 & 6.4949 & 6.9918 & TRN & \\
\hline CHEMBL3693489 & 1528185 & 7.1367 & 6.9982 & TRN & \\
\hline CHEMBL3693433 & 1528185 & 6.6682 & 6.9434 & TST & \\
\hline CHEMBL3693437 & 1528185 & 6.6198 & 6.6682 & TRN & \\
\hline CHEMBL 3693394 & 1528185 & 6.4318 & 7.4675 & TRN & \\
\hline CHEMBL 3688956 & 1528185 & 6.1938 & 6.73600 & 0000000001 & TRN \\
\hline CHEMBL3689006 & 1528185 & 7.5686 & 6.8512 & TRN & \\
\hline CHEMBL3689013 & 1528185 & 7.0605 & 7.2605 & TRN & \\
\hline
\end{tabular}

Page 26024 
Supplemental Table S2.txt

\begin{tabular}{|c|c|c|c|c|}
\hline CHEMBL3693434 & 1528185 & 7.3123 & 7.0662 & TST \\
\hline CHEMBL3688845 & 1528185 & 7.5528 & 7.5451 & TST \\
\hline CHEMBL3693419 & 1528185 & 7.0132 & 7.7289 & TST \\
\hline CHEMBL3688982 & 1528185 & 6.4685 & 6.3172 & TRN \\
\hline CHEMBL 3688878 & 1528185 & 7.8539 & 7.2065 & TRN \\
\hline CHEMBL3693524 & 1528185 & 6.6021 & 7.2406 & TRN \\
\hline CHEMBL3693513 & 1528185 & 7.1427 & 7.4202 & TRN \\
\hline CHEMBL3693580 & 1528185 & 7.0132 & 6.6556 & TRN \\
\hline CHEMBL3688970 & 1528185 & 6.4949 & 6.4737 & TRN \\
\hline CHEMBL3693401 & 1528185 & 5.8539 & 6.8821 & TST \\
\hline CHEMBL3688899 & 1528185 & 8.3372 & 8.1174 & TRN \\
\hline CHEMBL3693572 & 1528185 & 6.9208 & 7.1458 & TRN \\
\hline CHEMBL3693488 & 1528185 & 6.8539 & 7.0356 & TRN \\
\hline CHEMBL 3693570 & 1528185 & 7.2441 & 6.7085 & TRN \\
\hline CHEMBL 3693532 & 1528185 & 8.0223 & 7.4251 & TRN \\
\hline CHEMBL 2336333 & 1528185 & 7.1739 & 7.4103 & TRN \\
\hline CHEMBL3693503 & 1528185 & 6.1024 & 7.1755 & TRN \\
\hline CHEMBL3693487 & 1528185 & 7.1135 & 7.3407 & TRN \\
\hline CHEMBL3693432 & 1528185 & 6.4318 & 6.8298 & TST \\
\hline CHEMBL3688938 & 1528185 & 6.1427 & 6.9419 & TRN \\
\hline CHEMBL3693541 & 1528185 & 7.0132 & 7.0425 & TRN \\
\hline CHEMBL3693587 & 1528185 & 7.6198 & 7.4819 & TST \\
\hline CHEMBL3693380 & 1528185 & 7.0 & 7.4727 & TRN \\
\hline CHEMBL3693575 & 1528185 & 6.0 & 6.5725 & TRN \\
\hline CHEMBL 3688835 & 1528185 & 8.6778 & 8.0429 & TRN \\
\hline CHEMBL3688876 & 1528185 & 6.8539 & 7.28700 & 0000000001 \\
\hline CHEMBL3693404 & 1528185 & 6.301 & 6.8158 & TRN \\
\hline CHEMBL3688937 & 1528185 & 9.4089 & 8.0157 & TRN \\
\hline CHEMBL3688957 & 1528185 & 6.699 & 7.2232 & TST \\
\hline CHEMBL 3688913 & 1528185 & 5.6021 & 6.8731 & TRN \\
\hline CHEMBL3688859 & 1528185 & 6.0 & 6.92299 & 9999999999 \\
\hline CHEMBL3688946 & 1528185 & 7.7959 & 7.1577 & TST \\
\hline CHEMBL3693425 & 1528185 & 6.9066 & 7.6617 & TST \\
\hline CHEMBL 3688847 & 1528185 & 7.8239 & 7.2796 & TRN \\
\hline CHEMBL3693552 & 1528185 & 6.0 & 6.3679 & TRN \\
\hline CHEMBL3693406 & 1528185 & 6.2518 & 7.5388 & TST \\
\hline CHEMBL 3693463 & 1528185 & 6.5086 & 6.7937 & TRN \\
\hline CHEMBL3689015 & 1528185 & 6.7959 & 6.8579 & TST \\
\hline CHEMBL 3688974 & 1528185 & 6.9208 & 6.3235 & TRN \\
\hline CHEMBL3693548 & 1528185 & 6.1487 & 7.0442 & TRN \\
\hline CHEMBL3693550 & 1528185 & 6.6778 & 6.8333 & TRN \\
\hline CHEMBL3693398 & 1528185 & 6.5086 & 6.7345 & TST \\
\hline CHEMBL 3688888 & 1528185 & 7.3979 & 7.3517 & TRN \\
\hline CHEMBL3693480 & 1528185 & 6.6383 & 6.9685 & TRN \\
\hline CHEMBL3688941 & 1528185 & 8.4559 & 7.4476 & TST \\
\hline CHEMBL3688953 & 1528185 & 6.7696 & 6.5341 & TRN \\
\hline CHEMBL3693482 & 1528185 & 7.5229 & 7.1232 & TRN \\
\hline CHEMBL 3689028 & 1528185 & 7.2218 & 7.0738 & TST \\
\hline
\end{tabular}


Supplemental Table S2.txt

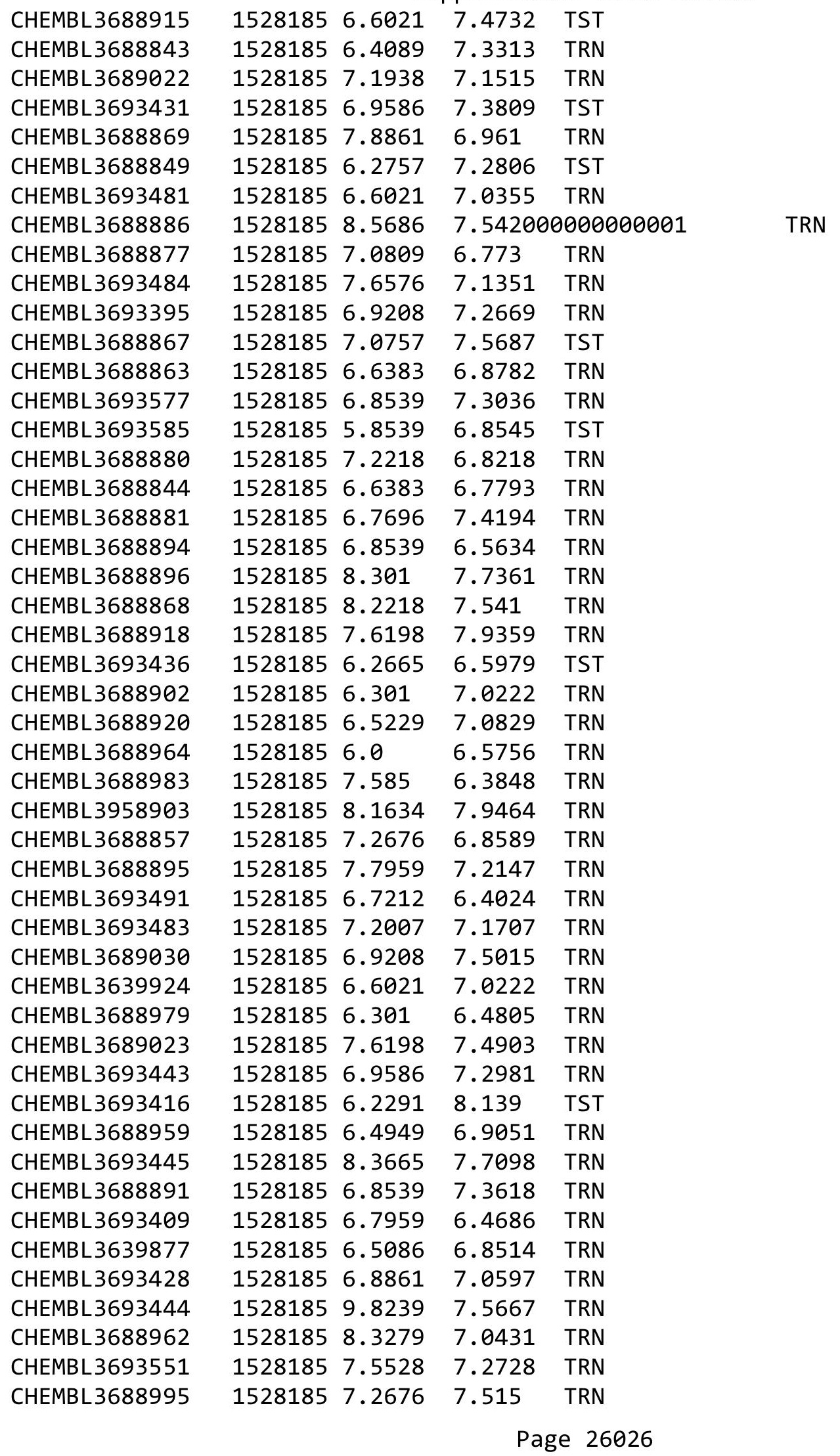


Supplemental Table S2.txt

\begin{tabular}{|c|c|c|c|c|}
\hline CHEMBL 3688851 & 1528185 & 6.4318 & 7.391 & TST \\
\hline CHEMBL3688925 & 1528185 & 5.7447 & 6.9387 & TRN \\
\hline CHEMBL3689018 & 1528185 & 6.699 & 6.5144 & TST \\
\hline CHEMBL 3693474 & 1528185 & 7.0555 & 7.1256 & TRN \\
\hline CHEMBL 3693567 & 1528185 & 8.0605 & 6.9115 & TRN \\
\hline CHEMBL3688893 & 1528185 & 7.4089 & 6.9228 & TRN \\
\hline CHEMBL3693411 & 1528185 & 6.7959 & 6.5666 & TRN \\
\hline CHEMBL3688836 & 1528185 & 8.2518 & 7.8578 & TRN \\
\hline CHEMBL3693500 & 1528185 & 6.1871 & 7.0782 & TRN \\
\hline CHEMBL3688853 & 1528185 & 7.5376 & 6.8303 & TRN \\
\hline CHEMBL 3693476 & 1528185 & 6.0 & 7.1723 & TRN \\
\hline CHEMBL3693418 & 1528185 & 7.0269 & 7.7171 & TST \\
\hline CHEMBL 3688882 & 1528185 & 7.8539 & 7.1469 & TST \\
\hline CHEMBL3693544 & 1528185 & 7.4685 & 7.2741 & TRN \\
\hline CHEMBL 3693494 & 1528185 & 6.1079 & 6.0688 & TRN \\
\hline CHEMBL 3688975 & 1528185 & 6.301 & 6.5398 & TRN \\
\hline CHEMBL3693479 & 1528185 & 7.4685 & 7.4183 & TRN \\
\hline CHEMBL2336318 & 1528185 & 7.0605 & 7.2825 & TRN \\
\hline CHEMBL3693512 & 1528185 & 7.3098 & 7.4751 & TRN \\
\hline CHEMBL 3688980 & 1528185 & 6.6198 & 6.3552 & TRN \\
\hline CHEMBL 3693465 & 1528185 & 6.6021 & 6.9 & TRN \\
\hline CHEMBL3693427 & 1528185 & 7.1024 & 7.7475 & TRN \\
\hline CHEMBL 3937461 & 1528185 & 7.5086 & 7.3866 & TST \\
\hline CHEMBL3693389 & 1528185 & 7.6383 & 7.7059 & TRN \\
\hline CHEMBL3693563 & 1528185 & 7.3188 & 6.8142 & TRN \\
\hline CHEMBL 3693381 & 1528185 & 6.8539 & 7.4204 & TRN \\
\hline CHEMBL 3689005 & 1528185 & 7.0458 & 7.4267 & TRN \\
\hline CHEMBL 3689012 & 1528185 & 5.9586 & 6.8935 & TRN \\
\hline CHEMBL3693523 & 1528185 & 8.585 & 7.6961 & TRN \\
\hline CHEMBL3693478 & 1528185 & 7.1079 & 7.3113 & TRN \\
\hline CHEMBL3693397 & 1528185 & 6.699 & 6.7374 & TST \\
\hline CHEMBL3693464 & 1528185 & 6.2924 & 6.9467 & TRN \\
\hline CHEMBL 3693582 & 1528185 & 7.1549 & 7.3236 & TRN \\
\hline CHEMBL3693539 & 1528185 & 8.2007 & 7.266 & TRN \\
\hline CHEMBL3693403 & 1528185 & 6.9208 & 7.0178 & TRN \\
\hline CHEMBL3688939 & 1528185 & 7.699 & 7.1425 & TST \\
\hline CHEMBL 3693528 & 1528185 & 7.8861 & 7.3611 & TRN \\
\hline CHEMBL3693569 & 1528185 & 6.5528 & 6.7346 & TRN \\
\hline CHEMBL3689025 & 1528185 & 7.1938 & 6.7287 & TRN \\
\hline CHEMBL3693515 & 1528185 & 7.3768 & 7.718999 & 9999999999 \\
\hline CHEMBL 3693462 & 1528185 & 7.3768 & 7.3449 & TRN \\
\hline CHEMBL 3693461 & 1528185 & 7.0132 & 7.0571 & TRN \\
\hline CHEMBL3688897 & 1528185 & 7.4437 & 7.428 & TRN \\
\hline CHEMBL3688926 & 1528185 & 7.699 & 7.3743 & TRN \\
\hline CHEMBL 2336322 & 1528185 & 7.3768 & 7.0466 & TRN \\
\hline CHEMBL 3688908 & 1528185 & 6.6576 & 7.4918 & TST \\
\hline CHEMBL 3688861 & 1528185 & 6.3098 & 6.4061 & TST \\
\hline CHEMBL3688879 & 1528185 & 6.7447 & 6.9645 & TRN \\
\hline
\end{tabular}


Supplemental Table S2.txt

\begin{tabular}{|c|c|c|c|c|}
\hline CHEMBL3693518 & 1528185 & 6.9586 & 7.4864 & TRN \\
\hline CHEMBL3693586 & 1528185 & 6.1739 & 6.9279 & TRN \\
\hline CHEMBL 3688916 & 1528185 & 6.1612 & 7.4016 & TST \\
\hline CHEMBL 3688854 & 1528185 & 6.8539 & 6.8398 & TRN \\
\hline CHEMBL 3688952 & 1528185 & 6.4559 & 6.6939 & TST \\
\hline CHEMBL 3693475 & 1528185 & 7.7212 & 7.3427 & TRN \\
\hline CHEMBL 3693535 & 1528185 & 7.8861 & 7.0166 & TRN \\
\hline CHEMBL 3898783 & 1528185 & 7.2366 & 7.5706 & TST \\
\hline CHEMBL3688892 & 1528185 & 7.2518 & 7.1478 & TRN \\
\hline CHEMBL 3688912 & 1528185 & 6.7959 & 7.4446 & TST \\
\hline CHEMBL 3688944 & 1528185 & 6.7696 & 7.2742 & TST \\
\hline CHEMBL 3688972 & 1528185 & 6.4318 & 6.356 & TRN \\
\hline CHEMBL 3693396 & 1528185 & 6.7212 & 7.1085 & TST \\
\hline CHEMBL 3688942 & 1528185 & 7.0044 & 7.8522 & TRN \\
\hline CHEMBL 3688866 & 1528185 & 8.0809 & 7.4323 & TRN \\
\hline CHEMBL3688998 & 1528185 & 7.8239 & 7.6602 & TRN \\
\hline CHEMBL3689032 & 1528185 & 8.4202 & 7.41200 & 000000001 \\
\hline CHEMBL 3693496 & 1528185 & 6.5686 & 7.2436 & TRN \\
\hline CHEMBL 3688943 & 1528185 & 7.2441 & 7.5018 & TRN \\
\hline CHEMBL 3693574 & 1528185 & 6.6576 & 6.816 & TRN \\
\hline CHEMBL3688933 & 1528185 & 7.4318 & 7.3374 & TST \\
\hline CHEMBL 3689002 & 1528185 & 6.8861 & 7.0867 & TST \\
\hline CHEMBL 3688834 & 1528185 & 7.9586 & 8.2642 & TRN \\
\hline CHEMBL3693520 & 1528185 & 7.4559 & 7.3625 & TRN \\
\hline CHEMBL 3890706 & 1528185 & 8.2596 & 7.7579 & TRN \\
\hline CHEMBL3693553 & 1528185 & 6.3979 & 6.2099 & TRN \\
\hline CHEMBL 3689020 & 1528185 & 6.3372 & 6.1896 & TRN \\
\hline CHEMBL 3693581 & 1528185 & 7.2596 & 6.6809 & TRN \\
\hline CHEMBL3688999 & 1528185 & 8.1487 & 7.4994 & TRN \\
\hline CHEMBL 3693442 & 1528185 & 6.7959 & 6.7839 & TRN \\
\hline CHEMBL3693543 & 1528185 & 7.3665 & 6.99 & TRN \\
\hline CHEMBL 3688931 & 1528185 & 7.7447 & 6.4868 & TST \\
\hline CHEMBL 3688887 & 1528185 & 7.2596 & 7.6249 & TST \\
\hline CHEMBL 3688883 & 1528185 & 7.4949 & 7.502006 & 000000001 \\
\hline CHEMBL 3688852 & 1528185 & 7.6021 & 7.5563 & TRN \\
\hline CHEMBL3693451 & 1528185 & 7.0 & 7.3335 & TRN \\
\hline CHEMBL 3688978 & 1528185 & 6.7959 & 6.4396 & TRN \\
\hline CHEMBL3688950 & 1528185 & 6.2218 & 6.7864 & TRN \\
\hline CHEMBL3693390 & 1528185 & 7.2676 & 7.284 & TRN \\
\hline CHEMBL 3688839 & 1528185 & 6.5086 & 6.7028 & TRN \\
\hline CHEMBL3693583 & 1528185 & 7.0655 & 7.3351 & TST \\
\hline CHEMBL 3688961 & 1528185 & 6.5528 & 6.5504 & TRN \\
\hline CHEMBL 3688932 & 1528185 & 8.1249 & 7.3055 & TRN \\
\hline CHEMBL3693545 & 1528185 & 7.6198 & 7.0977 & TRN \\
\hline CHEMBL3693502 & 1528185 & 6.7212 & 7.07 & TRN \\
\hline CHEMBL3693426 & 1528185 & 6.8539 & 7.6383 & TST \\
\hline CHEMBL 3689009 & 1528185 & 6.9208 & 6.8577 & TRN \\
\hline CHEMBL 3693526 & 1528185 & 7.6021 & 7.5181 & TRN \\
\hline
\end{tabular}


Supplemental Table S2.txt

\begin{tabular}{|c|c|c|c|c|c|}
\hline CHEMBL3693421 & 1528185 & 6.9066 & 7.607 & TST & \\
\hline CHEMBL3693429 & 1528185 & 5.699 & 6.6902 & TRN & \\
\hline CHEMBL3688909 & 1528185 & 6.8239 & 7.2244 & TRN & \\
\hline CHEMBL3693505 & 1528185 & 7.3279 & 7.2498 & TRN & \\
\hline CHEMBL3693435 & 1528185 & 7.58 & 7.1938 & TST & \\
\hline CHEMBL3693457 & 1528185 & 6.6383 & 6.7443 & TRN & \\
\hline CHEMBL3688862 & 1528185 & 7.7696 & 7.6115 & TRN & \\
\hline CHEMBL3688872 & 1528185 & 7.2076 & 7.1422 & TRN & \\
\hline CHEMBL3689016 & 1528185 & 6.2366 & 6.4704 & TRN & \\
\hline CHEMBL 2336326 & 1528185 & 7.5528 & 7.4332 & TRN & \\
\hline CHEMBL3693589 & 1528185 & 8.3098 & 7.2703 & TST & \\
\hline CHEMBL 3693540 & 1528185 & 8.3279 & 7.3127 & TRN & \\
\hline CHEMBL3688850 & 1528185 & 6.0 & 6.8175 & TST & \\
\hline CHEMBL3693542 & 1528185 & 7.0969 & 7.4997 & TRN & \\
\hline CHEMBL3693407 & 1528185 & 6.1739 & 7.1351 & TST & \\
\hline CHEMBL 2331605 & 1528185 & 7.5737 & 7.0638 & TST & \\
\hline CHEMBL3693562 & 1528185 & 6.0 & 7.5273 & TRN & \\
\hline CHEMBL3693565 & 1528185 & 7.284 & 7.2382 & TRN & \\
\hline CHEMBL3693584 & 1528185 & 6.0915 & 6.0869 & TST & \\
\hline CHEMBL3693438 & 1528185 & 6.4815 & 6.6164 & TST & \\
\hline CHEMBL3639923 & 1528185 & 6.7447 & 6.6547 & TRN & \\
\hline CHEMBL3693568 & 1528185 & 6.1135 & 6.7855 & TRN & \\
\hline CHEMBL3693472 & 1528185 & 7.8539 & 7.3279 & TRN & \\
\hline CHEMBL3693557 & 1528185 & 7.284 & 6.5623 & TRN & \\
\hline CHEMBL 2336324 & 1528185 & 6.699 & 6.9613 & TST & \\
\hline CHEMBL3693564 & 1528185 & 7.7447 & 6.9855 & TRN & \\
\hline CHEMBL 3693400 & 1528185 & 7.3098 & 6.6067 & TST & \\
\hline CHEMBL3688905 & 1528185 & 7.041 & 7.4183 & TRN & \\
\hline CHEMBL3688992 & 1528185 & 6.8861 & 7.231 & TRN & \\
\hline CHEMBL3693504 & 1528185 & 7.1135 & 7.39 & TRN & \\
\hline CHEMBL3688910 & 1528185 & 7.041 & 6.9495 & TRN & \\
\hline CHEMBL3689008 & 1528185 & 7.5528 & 6.8121 & TRN & \\
\hline CHEMBL3688855 & 1528185 & 8.1612 & 6.88700 & 00000000005 & TRN \\
\hline CHEMBL3688919 & 1528185 & 7.3768 & 7.4209 & TST & \\
\hline CHEMBL3693495 & 1528185 & 6.9586 & 7.2103 & TRN & \\
\hline CHEMBL3688906 & 1528185 & 7.1367 & 7.5972 & TRN & \\
\hline CHEMBL3693477 & 1528185 & 7.8539 & 7.4709 & TRN & \\
\hline CHEMBL3693453 & 1528185 & 6.8239 & 7.3238 & TRN & \\
\hline CHEMBL3688984 & 1528185 & 6.8539 & 6.2428 & TRN & \\
\hline CHEMBL3688922 & 1528185 & 6.9208 & 7.8565 & TRN & \\
\hline CHEMBL3688856 & 1528185 & 6.4202 & 6.9872 & TRN & \\
\hline CHEMBL3693566 & 1528185 & 6.9586 & 7.1796 & TRN & \\
\hline CHEMBL 2336334 & 1528185 & 7.585 & 7.291 & TRN & \\
\hline CHEMBL3693383 & 1528185 & 7.8861 & 7.9276 & TRN & \\
\hline CHEMBL3688841 & 1528185 & 6.8539 & 6.6588 & TST & \\
\hline CHEMBL 3688977 & 1528185 & 6.8861 & 6.9556 & TRN & \\
\hline CHEMBL3693525 & 1528185 & 7.7447 & 7.4508 & TRN & \\
\hline CHEMBL3693578 & 1528185 & 7.9208 & 7.1234 & TRN & \\
\hline
\end{tabular}


Supplemental Table S2.txt

\begin{tabular}{|c|c|c|c|c|}
\hline CHEMBL3693556 & 1528185 & 6.8239 & 7.0372 & TRN \\
\hline CHEMBL 3693423 & 1528185 & 6.4815 & 7.6347 & TST \\
\hline CHEMBL3693490 & 1528185 & 7.8861 & 7.2185 & TRN \\
\hline CHEMBL 3693448 & 1528185 & 7.4685 & 7.3648 & TRN \\
\hline CHEMBL3688936 & 1528185 & 8.585 & 7.2722 & TST \\
\hline CHEMBL3693529 & 1528185 & 7.1079 & 7.4455 & TRN \\
\hline CHEMBL 3693452 & 1528185 & 7.1805 & 7.3238 & TRN \\
\hline CHEMBL3688993 & 1528185 & 7.5086 & 8.1247 & TRN \\
\hline CHEMBL3688889 & 1528185 & 7.7447 & 7.0762 & TRN \\
\hline CHEMBL3688967 & 1528185 & 6.7696 & 6.4825 & TRN \\
\hline CHEMBL3693420 & 1528185 & 6.8239 & 7.4845 & TST \\
\hline CHEMBL 3693576 & 1528185 & 6.6198 & 6.6217 & TST \\
\hline CHEMBL3693485 & 1528185 & 6.3768 & 5.9103 & TRN \\
\hline CHEMBL3688960 & 1528185 & 7.0458 & 6.5487 & TRN \\
\hline CHEMBL 3689031 & 1528185 & 7.0177 & 7.3567 & TRN \\
\hline CHEMBL 3688947 & 1528185 & 8.3188 & 7.6349 & TRN \\
\hline CHEMBL 2336331 & 1528185 & 7.4559 & 7.7004 & TRN \\
\hline CHEMBL 3693588 & 1528185 & 6.699 & 7.1116 & TST \\
\hline CHEMBL3693501 & 1528185 & 7.3665 & 7.3253 & TST \\
\hline CHEMBL 3688923 & 1528185 & 6.1427 & 7.09399 & 9999999999 \\
\hline CHEMBL 3688901 & 1528185 & 6.4559 & 7.2231 & TST \\
\hline CHEMBL3689026 & 1528185 & 6.9586 & 7.2587 & TST \\
\hline CHEMBL 3688840 & 1528185 & 7.0706 & 6.7925 & TST \\
\hline CHEMBL 3693405 & 1528185 & 7.041 & 8.1556 & TST \\
\hline CHEMBL 3688874 & 1528185 & 6.0 & 7.3034 & TST \\
\hline CHEMBL 3688958 & 1528185 & 7.3188 & 6.8471 & TST \\
\hline CHEMBL3693469 & 1528185 & 7.1367 & 6.7862 & TST \\
\hline CHEMBL3688949 & 1528185 & 6.2518 & 6.7811 & TST \\
\hline CHEMBL3693486 & 1528185 & 6.4437 & 7.3149 & TST \\
\hline CHEMBL3688986 & 1528185 & 8.7959 & 8.151 & TST \\
\hline CHEMBL3693555 & 1528185 & 6.8239 & 6.727 & TST \\
\hline CHEMBL 3688885 & 1528185 & 7.4089 & 7.0038 & TST \\
\hline CHEMBL3688994 & 1528185 & 7.5686 & 7.5775 & TST \\
\hline CHEMBL3688846 & 1528185 & 6.4685 & 6.8212 & TST \\
\hline CHEMBL 3688890 & 1528185 & 6.8539 & 6.8435 & TST \\
\hline CHEMBL3689017 & 1528185 & 6.2676 & 6.7199 & TST \\
\hline CHEMBL3693410 & 1528185 & 6.8539 & 6.6161 & TST \\
\hline CHEMBL3688917 & 1528185 & 5.1249 & 6.8018 & TST \\
\hline CHEMBL3693547 & 1528185 & 7.1024 & 6.9388 & TST \\
\hline CHEMBL 3688865 & 1528185 & 6.8539 & 7.2355 & TST \\
\hline CHEMBL3693466 & 1528185 & 6.9586 & 7.37 & TST \\
\hline CHEMBL3688990 & 1528185 & 8.7212 & 8.0929 & TST \\
\hline CHEMBL3695244 & 1640308 & 4.5834 & 5.0865 & TRN \\
\hline CHEMBL3698890 & 1640308 & 3.699 & 3.6905 & TRN \\
\hline CHEMBL 3698901 & 1640308 & 5.6694 & 4.4522 & TRN \\
\hline CHEMBL3695252 & 1640308 & 5.7282 & 5.107 & TRN \\
\hline CHEMBL3698821 & 1640308 & 5.9359 & 4.7642 & TRN \\
\hline CHEMBL 3698794 & 1640308 & 4.8386 & 5.2571 & TRN \\
\hline
\end{tabular}


Supplemental Table S2.txt

\begin{tabular}{|c|c|c|c|c|}
\hline CHEMBL3698788 & 1640308 & 4.6511 & 4.7231 & TRN \\
\hline CHEMBL3695224 & 1640308 & 4.89 & 4.6927 & TRN \\
\hline CHEMBL3698799 & 1640308 & 5.1118 & 4.6459 & TRN \\
\hline CHEMBL3695243 & 1640308 & 4.7536 & 4.8118 & TST \\
\hline CHEMBL3695277 & 1640308 & 4.4106 & 4.6251 & TRN \\
\hline CHEMBL3698877 & 1640308 & 4.3852 & 5.1222 & TRN \\
\hline CHEMBL3698751 & 1640308 & 4.7179 & 4.2899 & TRN \\
\hline CHEMBL3939135 & 1640308 & 3.699 & 4.7685 & TRN \\
\hline CHEMBL3647963 & 1640308 & 4.7404 & 4.9032 & TRN \\
\hline CHEMBL3695254 & 1640308 & 4.942 & 4.796 & TST \\
\hline CHEMBL3984664 & 1640308 & 6.4134 & 5.1566 & TST \\
\hline CHEMBL3695278 & 1640308 & 4.3464 & 4.8824 & TRN \\
\hline CHEMBL3695280 & 1640308 & 3.2849 & 4.5424 & TRN \\
\hline CHEMBL3698899 & 1640308 & 3.699 & 4.8364 & TRN \\
\hline CHEMBL3698773 & 1640308 & 4.8022 & 4.4945 & TRN \\
\hline CHEMBL3695276 & 1640308 & 4.0898 & 4.4774 & TRN \\
\hline CHEMBL3698790 & 1640308 & 4.9151 & 5.5281 & TRN \\
\hline CHEMBL3698755 & 1640308 & 4.4148 & 4.2212 & TRN \\
\hline CHEMBL3698776 & 1640308 & 4.8073 & 4.5619 & TRN \\
\hline CHEMBL 3698756 & 1640308 & 4.5508 & 4.2978 & TST \\
\hline CHEMBL3698765 & 1640308 & 4.3243 & 4.9032 & TRN \\
\hline CHEMBL3698898 & 1640308 & 3.699 & 3.3733 & TST \\
\hline CHEMBL3909917 & 1640308 & 3.2715 & 3.985 & TST \\
\hline CHEMBL3698850 & 1640308 & 4.2158 & 4.2842 & TRN \\
\hline CHEMBL3695261 & 1640308 & 4.2832 & 4.3609 & TRN \\
\hline CHEMBL3698816 & 1640308 & 6.9747 & 5.1493 & TRN \\
\hline CHEMBL3698853 & 1640308 & 4.4986 & 4.1952 & TRN \\
\hline CHEMBL3698753 & 1640308 & 4.3383 & 4.8885 & TRN \\
\hline CHEMBL3695268 & 1640308 & 3.2606 & 4.2657 & TRN \\
\hline CHEMBL 3698846 & 1640308 & 4.6098 & 4.666 & TRN \\
\hline CHEMBL3698764 & 1640308 & 4.883 & 5.17399 & 99999999995 \\
\hline CHEMBL3695235 & 1640308 & 5.767 & 5.1192 & TST \\
\hline CHEMBL3695251 & 1640308 & 3.699 & 4.7612 & TRN \\
\hline CHEMBL 3698809 & 1640308 & 4.7254 & 4.3048 & TRN \\
\hline CHEMBL3695257 & 1640308 & 4.4682 & 4.4241 & TRN \\
\hline CHEMBL3698814 & 1640308 & 5.2646 & 4.771 & TRN \\
\hline CHEMBL3695279 & 1640308 & 4.3305 & 4.3367 & TRN \\
\hline CHEMBL3698834 & 1640308 & 4.5519 & 4.4844 & TRN \\
\hline CHEMBL3695222 & 1640308 & 4.5261 & 4.1124 & TRN \\
\hline CHEMBL3698884 & 1640308 & 3.275 & 5.1135 & TRN \\
\hline CHEMBL 3698804 & 1640308 & 3.699 & 4.4055 & TST \\
\hline CHEMBL3985983 & 1640308 & 4.1784 & 4.2723 & TRN \\
\hline CHEMBL3698798 & 1640308 & 3.699 & 4.836 & TST \\
\hline CHEMBL3698879 & 1640308 & 4.1627 & 4.3695 & TRN \\
\hline CHEMBL3698789 & 1640308 & 4.6366 & 4.7206 & TRN \\
\hline CHEMBL3698900 & 1640308 & 5.501 & 4.8364 & TRN \\
\hline CHEMBL3698769 & 1640308 & 4.7739 & 4.5535 & TRN \\
\hline CHEMBL210665 & 1640308 & 4.1173 & 3.9742 & TST \\
\hline
\end{tabular}


Supplemental Table S2.txt

\begin{tabular}{|c|c|c|c|c|}
\hline HEM & & & & \\
\hline HEMPI 2600051 & 640308 & 6.0 & 4.6501 & \\
\hline 45 & 308 & & & \\
\hline AEMBL & 3308 & 4.8834 & 73 & Ne \\
\hline AEMBL & 640308 & 4.7075 & 569 & \\
\hline HEMBL3698781 & 640308 & 4.2713 & 3236 & \\
\hline 54 & 308 & 6.0 & 681 & \\
\hline IFMBI: & & 32 & & \\
\hline HEMBL3695218 & 308 & 4.5977 & & \\
\hline HEMBL3695272 & 640308 & 5.1757 & 5924 & \\
\hline HEMBL3698849 & 308 & 3.263 & & \\
\hline IEMBL369 & 08 & 3 . & & \\
\hline AEMBL & & & & \\
\hline HEMBL 369 & 308 & & 995 & \\
\hline HEMBL369 & 308 & 4 . & & \\
\hline AEMBL369 & 08 & 3. & 83 & \\
\hline AEMBL39 & 08 & 3. & & \\
\hline HEMBL 36 & & & & \\
\hline HEMBL369 & 08 & 76 & & \\
\hline AEMBL36 & 08 & & & \\
\hline IEMBL 36 & 98 & & & MT \\
\hline AEMBL & & & & ודת \\
\hline HEMBL; & & & & \\
\hline HFMRI 369 & 308 & & & \\
\hline HEMBL369 & 08 & & & $\Gamma \mathrm{RN}$ \\
\hline HEMBL & 64 & & & $\cdots$ \\
\hline HEMBL & 8 & & & RN \\
\hline HFMBI : & $\partial 8$ & & & \\
\hline HEMBL369 & & & & ונI \\
\hline HEMBL 3698 & 64 & & & I RIV \\
\hline HEMBL 388 & 62 & & & RN \\
\hline HEMBL & 8 & & & RN \\
\hline HEMBL & & & & RN \\
\hline HEMBL369 & & & & IRN \\
\hline HEMBL3695253 & 08 & 4. & & TRN \\
\hline HEMBL 369 & $\partial 8$ & & & RN \\
\hline HᄃMP = & 8 & 3. & & $\Gamma \mathrm{RN}$ \\
\hline HEMBL & & & & RN \\
\hline HEMBL3698774 & 308 & 4 & & TRN \\
\hline HEMBL 369 & 08 & & & ГRN \\
\hline HEMBL369 & 64 & & & CDN \\
\hline CHEMBL3698 & 88 & & & TRN \\
\hline HEMBL3695 & 308 & 4.46 & 593 & $\Gamma \mathrm{RN}$ \\
\hline HEMBL3698839 & 640308 & 5.1217 & 5682 & TRN \\
\hline HEMBL 369 & 640308 & & & \\
\hline LHEMBL3 & 308 & & & \\
\hline LHEMBL3698792 & 640308 & & .0219 & \\
\hline HEMBL 369876 & 164030 & 4.0644 & 4.3816 & \\
\hline
\end{tabular}

Page 26032 
Supplemental Table S2.txt

\begin{tabular}{|c|c|c|c|c|c|}
\hline CHEMBL 3698791 & 1640308 & 5.6893 & 4.9352 & TRN & \\
\hline CHEMBL 3698786 & 1640308 & 5.0535 & 4.827 & TRN & \\
\hline CHEMBL3698907 & 1640308 & 5.7587 & 5.2427 & TRN & \\
\hline CHEMBL3698869 & 1640308 & 3.699 & 4.5625 & TRN & \\
\hline CHEMBL3698770 & 1640308 & 4.6784 & 4.4644 & TRN & \\
\hline CHEMBL3698826 & 1640308 & 5.1487 & 4.0173 & TRN & \\
\hline CHEMBL 3695286 & 1640308 & 4.3644 & 4.3815 & TRN & \\
\hline CHEMBL 3944932 & 1640308 & 4.5496 & 4.6193 & TRN & \\
\hline CHEMBL 3698857 & 1640308 & 5.0146 & 4.195 & TST & \\
\hline CHEMBL3695242 & 1640308 & 3.0 & 5.2702 & TRN & \\
\hline CHEMBL3698864 & 1640308 & 5.0516 & 4.3033 & TRN & \\
\hline CHEMBL 3639941 & 1640308 & 3.0 & 4.4469 & TRN & \\
\hline CHEMBL 3698837 & 1640308 & 4.9538 & 4.6844 & TRN & \\
\hline CHEMBL 3698763 & 1640308 & 6.0 & 4.664 & TRN & \\
\hline CHEMBL 3698861 & 1640308 & 3.699 & 4.7519 & TRN & \\
\hline CHEMBL3698906 & 1640308 & 4.9479 & 5.19799 & 99999999995 & TRN \\
\hline CHEMBL3695240 & 1640308 & 4.3768 & 5.1089 & TRN & \\
\hline CHEMBL3698817 & 1640308 & 5.8551 & 5.1997 & TRN & \\
\hline CHEMBL 3695256 & 1640308 & 3.699 & 4.2178 & TRN & \\
\hline CHEMBL 3698778 & 1640308 & 6.0 & 4.6731 & TRN & \\
\hline CHEMBL 3698795 & 1640308 & 5.6536 & 5.1144 & TRN & \\
\hline CHEMBL 3698889 & 1640308 & 3.699 & 4.5374 & TST & \\
\hline CHEMBL3698896 & 1640308 & 4.492 & 4.608006 & 20000000005 & TST \\
\hline CHEMBL 3698862 & 1640308 & 3.699 & 4.5602 & TRN & \\
\hline CHEMBL 3695281 & 1640308 & 3.0 & 4.4731 & TRN & \\
\hline CHEMBL 3898898 & 1640308 & 4.5855 & 4.8604 & TST & \\
\hline CHEMBL3695269 & 1640308 & 4.0177 & 4.3333 & TRN & \\
\hline CHEMBL3695219 & 1640308 & 5.3497 & 4.6293 & TRN & \\
\hline CHEMBL 3698895 & 1640308 & 3.699 & 4.0036 & TRN & \\
\hline CHEMBL 3698827 & 1640308 & 6.1203 & 4.8207 & TST & \\
\hline CHEMBL 3698835 & 1640308 & 3.0 & 4.0058 & TRN & \\
\hline CHEMBL 3695229 & 1640308 & 4.6185 & 4.4519 & TRN & \\
\hline CHEMBL3698813 & 1640308 & 3.699 & 3.3281 & TRN & \\
\hline CHEMBL3695263 & 1640308 & 4.5561 & 4.3929 & TRN & \\
\hline CHEMBL 3695283 & 1640308 & 3.2746 & 4.6817 & TRN & \\
\hline CHEMBL 3695234 & 1640308 & 3.0 & 4.4467 & TST & \\
\hline CHEMBL3698823 & 1640308 & 3.699 & 4.1573 & TRN & \\
\hline CHEMBL3698882 & 1640308 & 3.2732 & 3.7772 & TRN & \\
\hline CHEMBL3647959 & 1640308 & 3.699 & 4.8145 & TRN & \\
\hline CHEMBL 3698868 & 1640308 & 5.5622 & 4.6072 & TRN & \\
\hline CHEMBL 3647960 & 1640308 & 5.0506 & 4.9032 & TRN & \\
\hline CHEMBL 3695228 & 1640308 & 4.4484 & 4.0941 & TRN & \\
\hline CHEMBL3698787 & 1640308 & 3.699 & 4.4151 & TRN & \\
\hline CHEMBL 3698863 & 1640308 & 3.699 & 4.2726 & TRN & \\
\hline CHEMBL3698819 & 1640308 & 5.9578 & 4.9689 & TRN & \\
\hline CHEMBL 3695284 & 1640308 & 4.2275 & 4.8541 & TST & \\
\hline CHEMBL 3698760 & 1640308 & 4.0676 & 4.3452 & TST & \\
\hline CHEMBL3695259 & 1640308 & 4.646 & 4.3082 & TST & \\
\hline
\end{tabular}


Supplemental Table S2.txt

\begin{tabular}{|c|c|c|c|c|c|}
\hline CHEMBL3698841 & 1640308 & 4.5579 & 4.575 & TST & \\
\hline CHEMBL3695238 & 1640308 & 4.8619 & 4.6555 & TST & \\
\hline CHEMBL3698775 & 1640308 & 5.5667 & 4.5367 & TST & \\
\hline CHEMBL3698902 & 1640308 & 5.7943 & 4.9032 & TST & \\
\hline CHEMBL3695260 & 1640308 & 4.712 & 4.4559 & TST & \\
\hline CHEMBL3695270 & 1640308 & 4.5833 & 4.8781 & TST & \\
\hline CHEMBL3698836 & 1640308 & 4.6341 & 4.4112 & TST & \\
\hline CHEMBL3698772 & 1640308 & 4.6881 & 4.4328 & TST & \\
\hline CHEMBL3698768 & 1640308 & 4.6748 & 4.6135 & TST & \\
\hline CHEMBL3695262 & 1640308 & 4.4454 & 4.8216 & TST & \\
\hline CHEMBL3695255 & 1640308 & 4.427 & 4.5821 & TST & \\
\hline CHEMBL3698796 & 1640308 & 5.3076 & 4.6769 & TST & \\
\hline CHEMBL3698894 & 1640308 & 3.2694 & 3.4308 & TST & \\
\hline CHEMBL3698866 & 1640308 & 3.699 & 4.2458 & TST & \\
\hline CHEMBL3695216 & 1640308 & 5.0497 & 4.3783 & TST & \\
\hline CHEMBL3698876 & 1640308 & 3.2615 & 4.0793 & TST & \\
\hline CHEMBL3695221 & 1640308 & 4.8548 & 4.8955 & TST & \\
\hline CHEMBL3695266 & 1640308 & 4.2097 & 4.5605 & TST & \\
\hline CHEMBL3698785 & 1640308 & 4.6017 & 4.7917 & TST & \\
\hline CHEMBL3698874 & 1640308 & 3.699 & 4.3368 & TST & \\
\hline CHEMBL10027 & 193661 & 5.8477 & 5.849 & TRN & \\
\hline CHEMBL268749 & 193661 & 6.3288 & 6.3277 & TRN & \\
\hline CHEMBL10187 & 193661 & 6.8013 & 7.1624 & TST & \\
\hline CHEMBL10451 & 193661 & 5.9626 & 6.444 & TST & \\
\hline CHEMBL 9844 & 193661 & 5.9066 & 6.9061 & TST & \\
\hline CHEMBL 9860 & 193661 & 6.9318 & 6.4138 & TST & \\
\hline CHEMBL 9894 & 193661 & 6.7033 & 7.0602 & TST & \\
\hline CHEMBL10102 & 193661 & 7.7545 & 7.755 & TRN & \\
\hline CHEMBL269452 & 193661 & 7.1656 & 7.1696 & TRN & \\
\hline CHEMBL10369 & 193661 & 7.6144 & 7.615 & TRN & \\
\hline CHEMBL10152 & 193661 & 7.2924 & 7.2927 & TRN & \\
\hline CHEMBL10411 & 193661 & 7.3307 & 7.3284 & TRN & \\
\hline CHEMBL10068 & 193661 & 6.9957 & 6.8066 & TST & \\
\hline CHEMBL400421 & 193661 & 7.2774 & 7.28100 & 0000000001 & TRN \\
\hline CHEMBL418337 & 193661 & 7.4179 & 7.4158 & TRN & \\
\hline CHEMBL10170 & 193661 & 7.4559 & 7.4745 & TRN & \\
\hline CHEMBL10052 & 193661 & 7.5735 & 6.6337 & TST & \\
\hline CHEMBL10304 & 193661 & 7.062 & 7.0621 & TRN & \\
\hline CHEMBL274391 & 193661 & 7.7423 & 7.7434 & TRN & \\
\hline CHEMBL9886 & 193661 & 7.7878 & 7.7862 & TRN & \\
\hline CHEMBL 9924 & 193661 & 7.3526 & 7.356 & TRN & \\
\hline CHEMBL9925 & 193661 & 7.7773 & 7.7732 & TRN & \\
\hline CHEMBL269402 & 193661 & 7.4101 & 7.3847 & TRN & \\
\hline CHEMBL269171 & 193661 & 6.6402 & 6.6382 & TRN & \\
\hline CHEMBL10115 & 193661 & 7.7122 & 7.7081 & TRN & \\
\hline CHEMBL268463 & 193661 & 7.2684 & 7.2669 & TRN & \\
\hline CHEMBL10066 & 193661 & 7.4724 & 7.4706 & TRN & \\
\hline CHEMBL418336 & 193661 & 7.2233 & 7.2237 & TRN & \\
\hline
\end{tabular}

Page 26034 


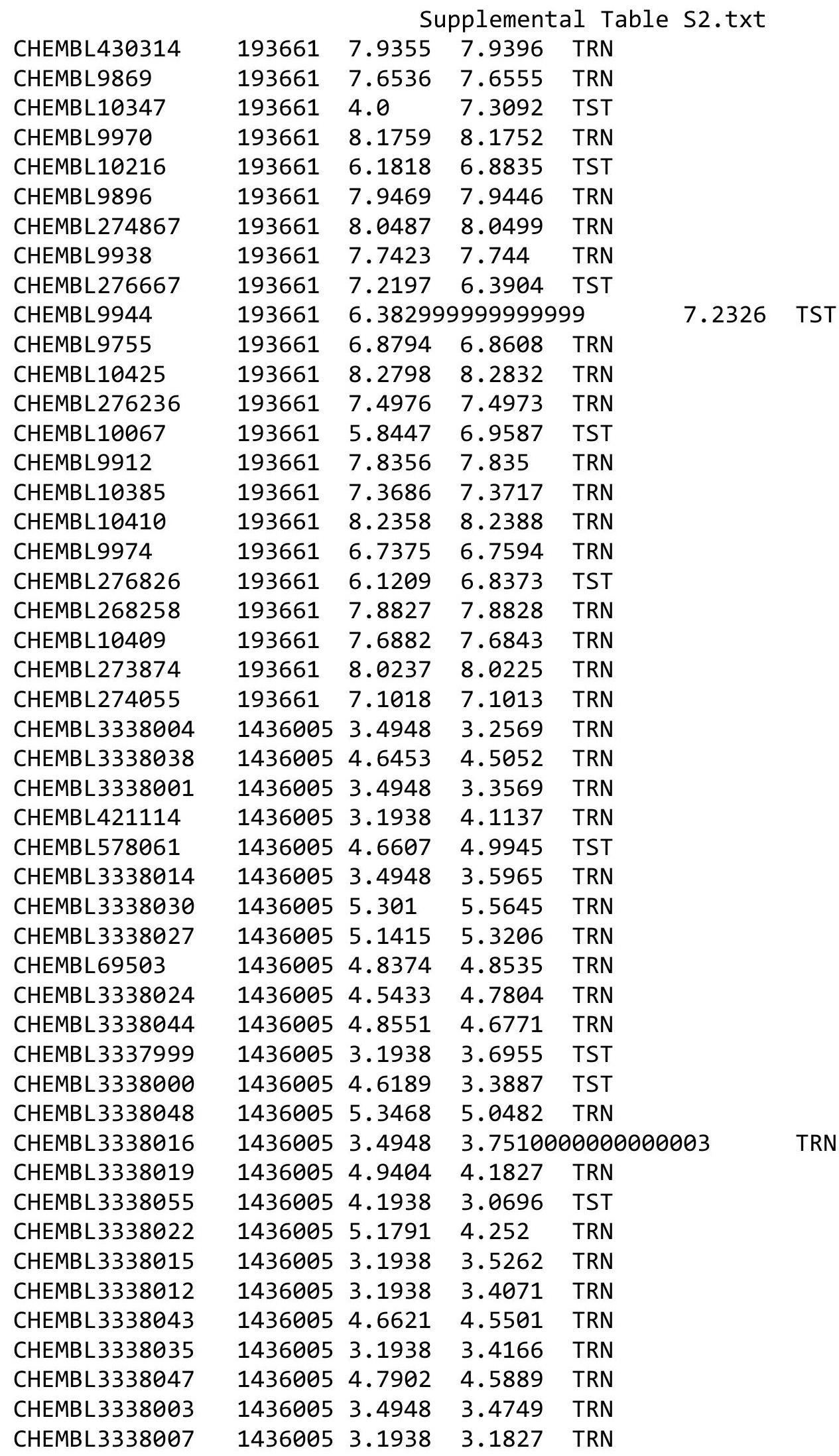

Page 26035 
Supplemental Table S2.txt

\begin{tabular}{|c|c|c|c|c|}
\hline TLI & & 791 & 5.2046 & \\
\hline & & 4.5296 & 3.7385 & \\
\hline EN & 105 & & & \\
\hline IEMBL & 6005 & 692 & & \\
\hline AEMBL3338039 & 436005 & 1938 & 3519 & \\
\hline HEMBL4 & 436005 & 523 & 3328 & \\
\hline 3046 & 5005 & & 3558 & \\
\hline AEMBL: & 5005 & & 3056 & \\
\hline HEMBL3338052 & 436005 & 4.7796 & .4325 & \\
\hline HEMBL3338028 & 436005 & 4.9147 & .9303 & \\
\hline HEMBL & 6005 & & .7622 & \\
\hline AEMBL & 005 & & .4421 & \\
\hline HEMBL. & 005 & & 3.1657 & \\
\hline HEMBL3 & 6005 & 38 & 4.0623 & \\
\hline AEMBL3338011 & 6005 & & 1237 & \\
\hline HEMBL; & 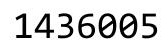 & & 481 & \\
\hline HEMBL & & & 806 & 等 \\
\hline HEMBL & 05 & & 694 & \\
\hline HEMBL - & 5005 & & .4014 & \\
\hline AEMBL3 & & & & I nIV \\
\hline HEMBL & ל & 4. & 598 & RN \\
\hline HEME & & & 359 & Norv \\
\hline HEMBL & 05 & & 3.3256 & \\
\hline AEMPI & 05 & & 064 & \\
\hline AEMBL3 & & 5 . & 581 & I RN \\
\hline HEMBL3 & 005 & & 188 & RN \\
\hline HEME & & & 59 & KIN \\
\hline HEM & & 884 & 954 & CRN \\
\hline HEMBL 7 & & & 3943 & IR \\
\hline AEMBL3338017 & 5005 & 3. & 1995 & TRN \\
\hline AEMBL & 005 & & & RN \\
\hline 25 & & & & 「RN \\
\hline יחני & & & & $\pi$ \\
\hline HEMBL3 & & & 398 & TST \\
\hline HEMBL3338006 & 10 & & 7854 & ГST \\
\hline 009 & & & 135 & TST \\
\hline ל & & & 731 & IST \\
\hline HEMBL5 & & & 2.9403 & TST \\
\hline HEMBL3 & 005 & & 5442 & TST \\
\hline AEMBL. & & & 412 & ГST \\
\hline 054 & & & 777 & IST \\
\hline HEMBL3 & & & 4.1353 & TST \\
\hline HEMBL3338020 & 6005 & 4.7786 & 4.4079 & TST \\
\hline HEMBL1 & 69 & & 782 & TR \\
\hline CHEMBL 2 & & & & \\
\hline HEMBL1 & & & .6227 & \\
\hline CHEMBL240954 & 969 & 4.6 & 3.8427 & ST \\
\hline CHEMBL512504 & 954969 & 3.6095 & 4.5761 & ГRN \\
\hline
\end{tabular}

Page 26036 


\begin{tabular}{|c|c|c|c|c|c|c|}
\hline \multirow[b]{2}{*}{ CHEMBL509032 } & \multicolumn{6}{|c|}{ Supplemental Table S2.txt } \\
\hline & 954969 & 4.9126 & 5.0158 & TRN & & \\
\hline CHEMBL65 & 954969 & 6.13299 & 79999999 & 99 & 6.6217 & TRN \\
\hline CHEMBL210618 & 954969 & 4.5596 & 3.6813 & TRN & & \\
\hline CHEMBL3186408 & 954969 & 3.8051 & 3.8988 & TST & & \\
\hline CHEMBL483849 & 954969 & 2.5573 & 2.8941 & TRN & & \\
\hline CHEMBL1970879 & 954969 & 4.6071 & 4.4574 & TRN & & \\
\hline CHEMBL3349342 & 954969 & 3.9492 & 4.6645 & TRN & & \\
\hline CHEMBL449158 & 954969 & 6.0838 & 5.7762 & TST & & \\
\hline CHEMBL209148 & 954969 & 2.9731 & 4.3375 & TRN & & \\
\hline CHEMBL1404918 & 954969 & 3.2025 & 3.3234 & TRN & & \\
\hline CHEMBL1230020 & 954969 & 4.4868 & 4.0348 & TRN & & \\
\hline CHEMBL1516890 & 954969 & 3.9473 & 4.0314 & TRN & & \\
\hline CHEMBL573107 & 954969 & 6.1661 & 4.7477 & TRN & & \\
\hline CHEMBL379300 & 954969 & 5.3131 & 5.5198 & TRN & & \\
\hline CHEMBL585951 & 954969 & 6.1583 & 5.3946 & TRN & & \\
\hline CHEMBL1788116 & 954969 & 3.5692 & 4.2389 & TRN & & \\
\hline CHEMBL 258844 & 954969 & 4.0104 & 4.2472 & TRN & & \\
\hline CHEMBL2363137 & 954969 & 4.7994 & 4.4995 & TRN & & \\
\hline CHEMBL220241 & 954969 & 4.0199 & 4.48 & TRN & & \\
\hline CHEMBL222102 & 954969 & 4.8984 & 3.9195 & TRN & & \\
\hline CHEMBL92309 & 954969 & 2.7738 & 3.3841 & TST & & \\
\hline CHEMBL191334 & 954969 & 3.3748 & 4.1479 & TRN & & \\
\hline CHEMBL202721 & 954969 & 4.9882 & 4.6426 & TRN & & \\
\hline CHEMBL1909414 & 954969 & 4.1592 & 4.0041 & TRN & & \\
\hline CHEMBL1673039 & 954969 & 4.564 & 4.5158 & TRN & & \\
\hline CHEMBL1256459 & 954969 & 5.7132 & 5.9518 & TRN & & \\
\hline CHEMBL577784 & 954969 & 5.0481 & 4.8024 & TRN & & \\
\hline CHEMBL9470 & 954969 & 6.4538 & 5.1674 & TST & & \\
\hline CHEMBL189584 & 954969 & 3.8665 & 4.4099 & TRN & & \\
\hline CHEMBL515416 & 954969 & 4.9482 & 4.3658 & TRN & & \\
\hline CHEMBL192566 & 954969 & 8.0939 & 6.6348 & TST & & \\
\hline CHEMBL3392440 & 954969 & 3.8447 & 3.9266 & TRN & & \\
\hline CHEMBL373751 & 954969 & 3.0078 & 3.8155 & TRN & & \\
\hline CHEMBL392695 & 954969 & 5.0536 & 4.7365 & TRN & & \\
\hline CHEMBL2144069 & 954969 & 3.9564 & 4.5441 & TRN & & \\
\hline CHEMBL393929 & 954969 & 4.5817 & 3.9932 & TRN & & \\
\hline CHEMBL1190711 & 954969 & 5.155 & 4.7195 & TRN & & \\
\hline CHEMBL379975 & 954969 & 4.0668 & 4.6608 & TRN & & \\
\hline CHEMBL472940 & 954969 & 4.3946 & 3.8412 & TRN & & \\
\hline CHEMBL221137 & 954969 & 3.2835 & 4.4715 & TST & & \\
\hline CHEMBL300389 & 954969 & 5.8038 & 5.8185 & TRN & & \\
\hline CHEMBL 213100 & 954969 & 5.308 & 4.6342 & TRN & & \\
\hline CHEMBL1242367 & 954969 & 3.1592 & 4.1342 & TRN & & \\
\hline CHEMBL3199475 & 954969 & 4.827 & 4.3097 & TRN & & \\
\hline CHEMBL188678 & 954969 & 5.9422 & 4.3272 & TRN & & \\
\hline CHEMBL1643959 & 954969 & 2.8419 & 3.8072 & TRN & & \\
\hline CHEMBL180127 & 954969 & 3.8103 & 4.1424 & TRN & & \\
\hline CHEMBL102714 & 954969 & 3.1033 & 3.7482 & TST & & \\
\hline
\end{tabular}




\begin{tabular}{|c|c|c|c|c|c|}
\hline & & \multicolumn{4}{|c|}{ Supplemental Table S2.txt } \\
\hline CHEMBL483847 & 954969 & 3.6269 & 4.1732 & TST & \\
\hline CHEMBL412142 & 954969 & 4.1046 & 4.016 & TST & \\
\hline CHEMBL 2005886 & 954969 & 3.0674 & 4.8655 & TST & \\
\hline CHEMBL558642 & 954969 & 5.3574 & 4.1128 & TST & \\
\hline CHEMBL135561 & 954969 & 4.0484 & 4.2948 & TST & \\
\hline CHEMBL514499 & 954969 & 7.5659 & 5.8948 & TST & \\
\hline CHEMBL 2165042 & 860331 & 4.0 & 4.9453 & TRN & \\
\hline CHEMBL 2165271 & 860331 & 4.0 & 3.7013 & TRN & \\
\hline CHEMBL 2165022 & 860331 & 4.0 & 4.058 & TRN & \\
\hline CHEMBL 2165009 & 860331 & 4.0 & 4.1685 & TRN & \\
\hline CHEMBL 2165039 & 860331 & 6.5376 & 5.2483 & TST & \\
\hline CHEMBL 2165003 & 860331 & 4.0 & 4.4446 & TRN & \\
\hline CHEMBL 2165005 & 860331 & 4.0 & 4.5029 & TRN & \\
\hline CHEMBL 2165047 & 860331 & 4.0 & 3.85399 & 99999999996 & TRN \\
\hline CHEMBL1762782 & 860331 & 8.0969 & 4.3333 & TST & \\
\hline CHEMBL 2165020 & 860331 & 4.0 & 4.3217 & TRN & \\
\hline CHEMBL 2165052 & 860331 & 6.699 & 4.4259 & TST & \\
\hline CHEMBL 2165037 & 860331 & 6.2757 & 5.1264 & TRN & \\
\hline CHEMBL 2165051 & 860331 & 8.1549 & 4.542 & TST & \\
\hline CHEMBL 2165006 & 860331 & 4.0 & 4.0823 & TRN & \\
\hline CHEMBL 2165269 & 860331 & 5.1079 & 4.283 & TRN & \\
\hline CHEMBL 2165023 & 860331 & 4.0 & 4.0691 & TRN & \\
\hline CHEMBL 2165019 & 860331 & 4.0 & 4.5323 & TRN & \\
\hline CHEMBL 2165030 & 860331 & 4.0 & 3.9674 & TRN & \\
\hline CHEMBL 2165048 & 860331 & 4.0 & 3.8355 & TRN & \\
\hline CHEMBL 2165014 & 860331 & 4.0 & 4.5823 & TRN & \\
\hline CHEMBL 2165004 & 860331 & 5.4437 & 4.5098 & TRN & \\
\hline CHEMBL 2165024 & 860331 & 4.0 & 4.0077 & TRN & \\
\hline CHEMBL 2165025 & 860331 & 4.0 & 3.9389 & TRN & \\
\hline CHEMBL 2165012 & 860331 & 4.0 & 4.4635 & TRN & \\
\hline CHEMBL 2165041 & 860331 & 5.2924 & 4.4508 & TST & \\
\hline CHEMBL 2165044 & 860331 & 4.0 & 3.1782 & TST & \\
\hline CHEMBL 2165017 & 860331 & 5.3188 & 4.5151 & TRN & \\
\hline CHEMBL 2165007 & 860331 & 4.0 & 4.0429 & TRN & \\
\hline CHEMBL 2165040 & 860331 & 4.0 & 4.2547 & TRN & \\
\hline CHEMBL 2165018 & 860331 & 4.0 & 4.659 & TRN & \\
\hline CHEMBL1615182 & 860331 & 7.0315 & 4.1807 & TST & \\
\hline CHEMBL 2165033 & 860331 & 4.0 & 4.1593 & TRN & \\
\hline CHEMBL 2165016 & 860331 & 5.8539 & 5.7528 & TRN & \\
\hline CHEMBL 2165011 & 860331 & 4.0 & 4.4822 & TRN & \\
\hline CHEMBL 2165270 & 860331 & 6.4437 & 4.1794 & TST & \\
\hline CHEMBL 2165029 & 860331 & 4.0 & 4.2701 & TRN & \\
\hline CHEMBL 2165015 & 860331 & 5.4318 & 5.7086 & TRN & \\
\hline CHEMBL 2165021 & 860331 & 4.0 & 4.0642 & TRN & \\
\hline CHEMBL 2165013 & 860331 & 4.0 & 4.3152 & TRN & \\
\hline CHEMBL 2165038 & 860331 & 6.2518 & 4.9673 & TST & \\
\hline CHEMBL 2165008 & 860331 & 4.0 & 4.1268 & TRN & \\
\hline CHEMBL 2165035 & 860331 & 4.0 & 4.0362 & TST & \\
\hline
\end{tabular}




\begin{tabular}{|c|c|c|c|c|c|}
\hline \multicolumn{6}{|c|}{ Supplemental Table S2.txt } \\
\hline CHEMBL 2165034 & 860331 & 4.0 & 4.0786 & TRN & \\
\hline CHEMBL 2165053 & 860331 & 4.0 & 4.0452 & TST & \\
\hline CHEMBL2165049 & 860331 & 4.0 & 3.803 & TRN & \\
\hline CHEMBL2165031 & 860331 & 5.8539 & 4.79899 & 99999999995 & TRN \\
\hline CHEMBL 2165045 & 860331 & 4.0 & 4.1613 & TST & \\
\hline CHEMBL 2165046 & 860331 & 4.0 & 3.7787 & TRN & \\
\hline CHEMBL 2165010 & 860331 & 4.0 & 4.0195 & TRN & \\
\hline CHEMBL 2165043 & 860331 & 4.0 & 3.0017 & TST & \\
\hline CHEMBL2165032 & 860331 & 4.0 & 3.9934 & TRN & \\
\hline CHEMBL2165050 & 860331 & 4.0 & 4.1555 & TRN & \\
\hline CHEMBL2165028 & 860331 & 4.0 & 3.9953 & TRN & \\
\hline CHEMBL2165268 & 860331 & 5.1427 & 3.9059 & TST & \\
\hline CHEMBL 2165027 & 860331 & 4.0 & 3.9748 & TRN & \\
\hline CHEMBL 2165026 & 860331 & 5.6021 & 4.5447 & TRN & \\
\hline CHEMBL2165036 & 860331 & 4.0 & 3.3126 & TST & \\
\hline CHEMBL1470122 & 688427 & 4.1599 & 4.1739 & TRN & \\
\hline CHEMBL1494345 & 688427 & 4.425 & 4.7515 & TRN & \\
\hline CHEMBL1349023 & 688427 & 4.3481 & 3.9666 & TST & \\
\hline CHEMBL1529808 & 688427 & 4.2378 & 4.6832 & TRN & \\
\hline CHEMBL1429706 & 688427 & 4.9462 & 4.6544 & TST & \\
\hline CHEMBL1528299 & 688427 & 4.8088 & 4.1335 & TST & \\
\hline CHEMBL1583874 & 688427 & 4.9041 & 4.5133 & TST & \\
\hline CHEMBL1325006 & 688427 & 3.031 & 4.1025 & TRN & \\
\hline CHEMBL1421074 & 688427 & 3.5081 & 4.3658 & TRN & \\
\hline CHEMBL1486831 & 688427 & 4.7352 & 4.4605 & TRN & \\
\hline CHEMBL1545025 & 688427 & 4.4522 & 4.1672 & TRN & \\
\hline CHEMBL1455269 & 688427 & 4.5308 & 4.3783 & TRN & \\
\hline CHEMBL 3189751 & 688427 & 3.031 & 3.7622 & TRN & \\
\hline CHEMBL1488035 & 688427 & 4.4399 & 4.6545 & TRN & \\
\hline CHEMBL356169 & 688427 & 4.4574 & 4.3019 & TST & \\
\hline CHEMBL1607973 & 688427 & 3.5081 & 4.0558 & TRN & \\
\hline CHEMBL1522425 & 688427 & 4.8072 & 4.8226 & TRN & \\
\hline CHEMBL1604166 & 688427 & 4.5113 & 4.6438 & TRN & \\
\hline CHEMBL1374352 & 688427 & 4.3286 & 4.1834 & TRN & \\
\hline CHEMBL1310505 & 688427 & 4.1797 & 4.3801 & TRN & \\
\hline CHEMBL1305371 & 688427 & 3.031 & 4.5084 & TRN & \\
\hline CHEMBL1610872 & 688427 & 3.5081 & 4.38 & TRN & \\
\hline CHEMBL1586152 & 688427 & 3.031 & 4.0474 & TST & \\
\hline CHEMBL1547674 & 688427 & 4.4577 & 4.3362 & TRN & \\
\hline CHEMBL1464354 & 688427 & 3.5081 & 4.2851 & TRN & \\
\hline CHEMBL1490070 & 688427 & 4.7392 & 4.5535 & TRN & \\
\hline CHEMBL1415432 & 688427 & 3.5081 & 4.2243 & TST & \\
\hline CHEMBL1422363 & 688427 & 3.031 & 4.0929 & TRN & \\
\hline CHEMBL1362814 & 688427 & 4.0784 & 3.8598 & TRN & \\
\hline CHEMBL492267 & 688427 & 5.0549 & 5.0653 & TRN & \\
\hline CHEMBL1416028 & 688427 & 5.3705 & 4.3402 & TRN & \\
\hline CHEMBL1545746 & 688427 & 4.6216 & 4.9066 & TRN & \\
\hline CHEMBL1565318 & 688427 & 5.0045 & 4.5009 & TRN & \\
\hline
\end{tabular}


Supplemental Table S2.txt

\begin{tabular}{|c|c|c|c|c|}
\hline CHEMBL1572342 & 688427 & 4.7951 & 4.3556 & TRN \\
\hline CHEMBL1566655 & 688427 & 4.2527 & 4.1173 & TRN \\
\hline CHEMBL1425549 & 688427 & 3.031 & 3.8189 & TST \\
\hline CHEMBL1382723 & 688427 & 4.8579 & 4.2936 & TRN \\
\hline CHEMBL1345922 & 688427 & 4.5865 & 4.9345 & TRN \\
\hline CHEMBL1345273 & 688427 & 5.3434 & 4.5954 & TRN \\
\hline CHEMBL1341058 & 688427 & 3.5081 & 4.8724 & TRN \\
\hline CHEMBL1333047 & 688427 & 4.7445 & 4.8295 & TRN \\
\hline CHEMBL512649 & 688427 & 4.6859 & 4.4752 & TRN \\
\hline CHEMBL597035 & 688427 & 3.031 & 3.2341 & TRN \\
\hline CHEMBL3195180 & 688427 & 4.2849 & 3.9262 & TST \\
\hline CHEMBL1486228 & 688427 & 4.9112 & 4.0857 & TRN \\
\hline CHEMBL3192913 & 688427 & 3.031 & 3.2344 & TRN \\
\hline CHEMBL1342633 & 688427 & \multicolumn{2}{|c|}{4.3180000000000005} & 4.7345 \\
\hline CHEMBL1501724 & 688427 & 4.6402 & 4.5245 & TRN \\
\hline CHEMBL1480110 & 688427 & 4.1917 & 4.5264 & TRN \\
\hline CHEMBL1561325 & 688427 & 4.7049 & 3.6653 & TRN \\
\hline CHEMBL1399107 & 688427 & 4.1249 & 4.1155 & TRN \\
\hline CHEMBL1570276 & 688427 & 4.3023 & 3.8659 & TST \\
\hline CHEMBL1307032 & 688427 & 5.7231 & 4.86100 & $\partial 000000001$ \\
\hline CHEMBL1613269 & 688427 & 5.3007 & 4.3217 & TST \\
\hline CHEMBL1370293 & 688427 & 4.5445 & 4.791 & TRN \\
\hline CHEMBL1520065 & 688427 & 4.6998 & 4.4275 & TRN \\
\hline CHEMBL1309595 & 688427 & 3.5081 & 4.1705 & TST \\
\hline CHEMBL1492655 & 688427 & 4.2545 & 4.0792 & TRN \\
\hline CHEMBL1391112 & 688427 & 4.4504 & 4.3501 & TST \\
\hline CHEMBL1336564 & 688427 & 3.031 & 3.7623 & TRN \\
\hline CHEMBL1454779 & 688427 & 4.4099 & 4.0547 & TRN \\
\hline CHEMBL1548066 & 688427 & 3.031 & 4.3689 & TST \\
\hline CHEMBL1584083 & 688427 & 3.031 & 3.7273 & TRN \\
\hline CHEMBL1967431 & 688427 & 4.3904 & 4.2164 & TST \\
\hline CHEMBL1330616 & 688427 & 3.031 & 4.081 & TRN \\
\hline CHEMBL1582724 & 688427 & 4.4778 & 4.3577 & TRN \\
\hline CHEMBL1577147 & 688427 & 4.6538 & 4.229 & TRN \\
\hline CHEMBL1403868 & 688427 & 4.2642 & 4.0524 & TRN \\
\hline CHEMBL1377449 & 688427 & 4.4256 & 3.8472 & TRN \\
\hline CHEMBL1461987 & 688427 & 4.6702 & 3.8521 & TRN \\
\hline CHEMBL1522377 & 688427 & 4.4277 & 4.622 & TRN \\
\hline CHEMBL1349875 & 688427 & 4.9045 & 5.052 & TRN \\
\hline CHEMBL1600077 & 688427 & 4.2545 & 4.4842 & TRN \\
\hline CHEMBL1457783 & 688427 & 4.3005 & 4.1923 & TST \\
\hline CHEMBL1417364 & 688427 & 4.4214 & 4.5315 & TRN \\
\hline CHEMBL1477887 & 688427 & 4.9784 & 4.3448 & TRN \\
\hline CHEMBL1401485 & 688427 & 4.2014 & 4.4186 & TRN \\
\hline CHEMBL1454264 & 688427 & 4.2506 & 4.8674 & TRN \\
\hline CHEMBL1445111 & 688427 & 6.2993 & 5.2982 & TRN \\
\hline CHEMBL1418336 & 688427 & 4.9314 & 4.4151 & TRN \\
\hline CHEMBL1570672 & 688427 & 4.364 & 3.9609 & TRN \\
\hline
\end{tabular}




\begin{tabular}{|c|c|c|c|c|c|}
\hline & & \multicolumn{4}{|c|}{ Supplemental Table S2.txt } \\
\hline CHEMBL1449871 & 688427 & 3.031 & 4.2177 & TRN & \\
\hline CHEMBL1358988 & 688427 & 4.3071 & 4.4427 & TRN & \\
\hline CHEMBL1540020 & 688427 & 4.3663 & 4.2487 & TRN & \\
\hline CHEMBL 3190626 & 688427 & 3.031 & 4.2794 & TST & \\
\hline CHEMBL1426468 & 688427 & 4.5719 & 4.4401 & TRN & \\
\hline CHEMBL1494965 & 688427 & 4.046 & 3.7467 & TRN & \\
\hline CHEMBL1325688 & 688427 & 4.4917 & 4.2979 & TRN & \\
\hline CHEMBL1303401 & 688427 & 5.0748 & 5.1359 & TRN & \\
\hline CHEMBL1535363 & 688427 & 3.5081 & 4.6029 & TRN & \\
\hline CHEMBL1477311 & 688427 & 5.0986 & 5.0898 & TRN & \\
\hline CHEMBL1309187 & 688427 & 4.8935 & 5.0308 & TRN & \\
\hline CHEMBL1452914 & 688427 & 4.6231 & 4.3705 & TRN & \\
\hline CHEMBL1372889 & 688427 & 5.007 & 4.6741 & TRN & \\
\hline CHEMBL1375423 & 688427 & 4.4447 & 4.0299 & TRN & \\
\hline CHEMBL1336927 & 688427 & 4.2363 & 3.8672 & TST & \\
\hline CHEMBL1525627 & 688427 & 3.5081 & 3.972 & TRN & \\
\hline CHEMBL1414543 & 688427 & 4.5176 & 4.2356 & TRN & \\
\hline CHEMBL1425417 & 688427 & 4.3 & 4.4703 & TRN & \\
\hline CHEMBL1451996 & 688427 & 4.7809 & 4.8925 & TRN & \\
\hline CHEMBL1405110 & 688427 & 3.5081 & 4.0548 & TRN & \\
\hline CHEMBL1366600 & 688427 & 3.031 & 3.801 & TRN & \\
\hline CHEMBL1537195 & 688427 & 5.2248 & 4.3598 & TRN & \\
\hline CHEMBL1455993 & 688427 & 3.031 & 3.4778 & TRN & \\
\hline CHEMBL 3189853 & 688427 & 3.031 & 4.1773 & TRN & \\
\hline CHEMBL1362013 & 688427 & 3.5081 & 3.9248 & TRN & \\
\hline CHEMBL1384896 & 688427 & 4.3793 & 4.1692 & TRN & \\
\hline CHEMBL1350944 & 688427 & 3.5081 & 4.3622 & TRN & \\
\hline CHEMBL1505364 & 688427 & 4.395 & 3.54399 & 99999999996 & TRN \\
\hline CHEMBL1346846 & 688427 & 3.031 & 4.0815 & TRN & \\
\hline CHEMBL1462110 & 688427 & 5.0357 & 5.2304 & TRN & \\
\hline CHEMBL1429028 & 688427 & 3.031 & 3.8416 & TRN & \\
\hline CHEMBL1458559 & 688427 & 4.4556 & 3.6227 & TRN & \\
\hline CHEMBL1420829 & 688427 & 4.2049 & 3.73 & TRN & \\
\hline CHEMBL1599435 & 688427 & 4.6354 & 4.0923 & TRN & \\
\hline CHEMBL1439904 & 688427 & 4.5278 & 4.2755 & TST & \\
\hline CHEMBL1337355 & 688427 & 4.3084 & 4.3385 & TRN & \\
\hline CHEMBL1329408 & 688427 & 4.391 & 4.4888 & TRN & \\
\hline CHEMBL1574263 & 688427 & 4.1706 & 4.5845 & TRN & \\
\hline CHEMBL1349019 & 688427 & 3.5081 & 4.1108 & TRN & \\
\hline CHEMBL1307610 & 688427 & 4.4697 & 4.9061 & TRN & \\
\hline CHEMBL1563647 & 688427 & 4.2208 & 4.2188 & TST & \\
\hline CHEMBL1448047 & 688427 & 3.031 & 3.9308 & TRN & \\
\hline CHEMBL1446875 & 688427 & 4.3758 & 4.8253 & TRN & \\
\hline CHEMBL1568650 & 688427 & 3.031 & 4.202 & TRN & \\
\hline CHEMBL 3194854 & 688427 & 4.3802 & 4.0721 & TRN & \\
\hline CHEMBL1385852 & 688427 & 3.031 & 3.889 & TRN & \\
\hline CHEMBL1463060 & 688427 & 5.3369 & 5.1238 & TRN & \\
\hline CHEMBL1520998 & 688427 & 5.1592 & 5.1213 & TRN & \\
\hline
\end{tabular}




\begin{tabular}{|c|c|c|c|c|c|c|}
\hline & & \multicolumn{5}{|c|}{ Supplemental Table S2.txt } \\
\hline CHEMBL1388164 & 688427 & 3.031 & 3.6696 & TRN & & \\
\hline CHEMBL1449655 & 688427 & 4.3667 & 4.238 & TST & & \\
\hline CHEMBL1432163 & 688427 & 4.2091 & 4.2196 & TRN & & \\
\hline CHEMBL1558177 & 688427 & 4.4708 & 4.1042 & TRN & & \\
\hline CHEMBL1455874 & 688427 & 4.2002 & 4.3057 & TRN & & \\
\hline CHEMBL1391385 & 688427 & 5.2032 & 4.9995 & TRN & & \\
\hline CHEMBL1606230 & 688427 & 4.8595 & 4.0447 & TST & & \\
\hline CHEMBL1307136 & 688427 & 4.6066 & 3.928 & TRN & & \\
\hline CHEMBL1392612 & 688427 & 4.4154 & 4.0732 & TRN & & \\
\hline CHEMBL1497316 & 688427 & 3.5081 & 4.0265 & TRN & & \\
\hline CHEMBL1549692 & 688427 & 4.164 & 4.0356 & TST & & \\
\hline CHEMBL1542195 & 688427 & 4.2025 & 3.8996 & TRN & & \\
\hline CHEMBL1611866 & 688427 & 3.031 & 3.8262 & TRN & & \\
\hline CHEMBL1527654 & 688427 & 4.1636 & 4.6259 & TRN & & \\
\hline CHEMBL1606939 & 688427 & 4.4035 & 4.5495 & TST & & \\
\hline CHEMBL1577894 & 688427 & 3.5081 & 4.0326 & TRN & & \\
\hline CHEMBL1461003 & 688427 & 4.2589 & 4.621 & TRN & & \\
\hline CHEMBL1343750 & 688427 & 4.7235 & 4.3513 & TRN & & \\
\hline CHEMBL576353 & 688427 & 4.5519 & 3.8524 & TRN & & \\
\hline CHEMBL1555880 & 688427 & 4.5505 & 3.9682 & TRN & & \\
\hline CHEMBL1483570 & 688427 & 4.5459 & 4.7077 & TRN & & \\
\hline CHEMBL1525418 & 688427 & $4.6110 €$ & 30000000 & 01 & 5.0259 & TRN \\
\hline CHEMBL1365941 & 688427 & 4.9739 & 4.0326 & TRN & & \\
\hline CHEMBL1349172 & 688427 & 4.2615 & 4.3001 & TST & & \\
\hline CHEMBL1519409 & 688427 & 4.2463 & 4.4322 & TRN & & \\
\hline CHEMBL1527065 & 688427 & 5.1328 & 4.9431 & TRN & & \\
\hline CHEMBL1301287 & 688427 & 5.1745 & 4.6975 & TRN & & \\
\hline CHEMBL1975622 & 688427 & 4.5102 & 4.2762 & TRN & & \\
\hline CHEMBL1525187 & 688427 & 5.4021 & 4.3489 & TRN & & \\
\hline CHEMBL1319281 & 688427 & 4.5532 & 3.8206 & TRN & & \\
\hline CHEMBL1372854 & 688427 & 4.5717 & 4.2356 & TRN & & \\
\hline CHEMBL1382822 & 688427 & 3.5081 & 3.6103 & TRN & & \\
\hline CHEMBL1524448 & 688427 & 4.4582 & 4.3177 & TRN & & \\
\hline CHEMBL1414492 & 688427 & 4.2566 & 4.6938 & TRN & & \\
\hline CHEMBL1465291 & 688427 & 5.1754 & 4.5413 & TRN & & \\
\hline CHEMBL1359999 & 688427 & 4.1914 & 4.5538 & TRN & & \\
\hline CHEMBL1401280 & 688427 & 4.1203 & 4.3325 & TRN & & \\
\hline CHEMBL1374204 & 688427 & 4.4276 & 3.8149 & TRN & & \\
\hline CHEMBL1498547 & 688427 & 4.2452 & 4.1434 & TRN & & \\
\hline CHEMBL1563389 & 688427 & 3.5081 & 4.2267 & TST & & \\
\hline CHEMBL1607473 & 688427 & 4.4041 & 4.115 & TRN & & \\
\hline CHEMBL1351746 & 688427 & 4.4881 & 3.67 & TRN & & \\
\hline CHEMBL1439313 & 688427 & 4.3773 & 4.3398 & TRN & & \\
\hline CHEMBL1368020 & 688427 & 3.031 & 4.2702 & TRN & & \\
\hline CHEMBL1606045 & 688427 & 5.2628 & 4.9307 & TRN & & \\
\hline CHEMBL1352869 & 688427 & 5.7402 & 4.8854 & TRN & & \\
\hline CHEMBL1589110 & 688427 & 4.2627 & 4.0614 & TRN & & \\
\hline CHEMBL1360631 & 688427 & 4.9427 & 4.2862 & TRN & & \\
\hline
\end{tabular}


Supplemental Table S2.txt

\begin{tabular}{|c|c|c|c|c|}
\hline 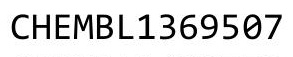 & & 776 & & \\
\hline HEMBL1423779 & 88427 & 4.8969 & 3778 & \\
\hline HEMBL1472407 & 8427 & 3419 & 3516 & \\
\hline 773 & & 81 & & \\
\hline AEMBL31 & & 319 & 576 & \\
\hline AEMBL1304910 & 88427 & 4613 & .673 & \\
\hline HEMBL1347258 & 88427 & 4.3376 & 3.9484 & \\
\hline HEMBL1367073 & 27 & 3779 & & \\
\hline AEMBL1 14 & & 172 & & \\
\hline AEMBL13 & & 772 & & \\
\hline HEMBL1416641 & 88427 & .4605 & 3.9802 & \\
\hline HEMBL1386265 & 27 & .1985 & 4.6026 & \\
\hline HEMBL1324614 & 27 & 5081 & 4.6442 & \\
\hline AEMBL14 & & 781 & 3.9744 & \\
\hline HEMBL15 & & & & \\
\hline HEMBL1522364 & 27 & 31 & 2468 & \\
\hline HEMBL15. & & 5081 & & \\
\hline HEMBL 14 & 27 & 51 & 85 & \\
\hline L13 & & 977 & & \\
\hline HEMBL15 & & 081 & & \\
\hline HEMBL13 & & 2746 & & \\
\hline JEMBL14 & & & & 1 \\
\hline HEMBL14 & & & 15 & \\
\hline L14 & & 652 & & \\
\hline 83 & & & & $\mathrm{RN}$ \\
\hline L14 & & 533 & & RN \\
\hline IEMBL13 & & 42 & & $\mathrm{R}$ \\
\hline HEMBL14 & & 843 & & RN \\
\hline L15 & & & & RN \\
\hline AEMBL13 & & 427 & & RN \\
\hline AEMBL14 & & & & RN \\
\hline HEMBL142 & & 577 & & RN \\
\hline AEMBL13 & & 009 & & RN \\
\hline 0 & & 96 & & RN \\
\hline 59 & & 72 & & RN \\
\hline IEMBL14: & & 656 & & RN \\
\hline JEMBL13 & & 3612 & & RN \\
\hline & & & & RN \\
\hline רי וסגזי & & 49 & & RN \\
\hline EMMBL13 & & 16 & & ST \\
\hline AEMBL1577637 & & 838 & 991 & RN \\
\hline HEMBL13 & & & & RN \\
\hline & & 521 & & \\
\hline HEMBL13 & & & 9961 & RN \\
\hline HEMBL 13 & & & & RN \\
\hline IEMBL69 & 27 & 689 & & \\
\hline & & & & \\
\hline & 688427 & & & \\
\hline
\end{tabular}

Page 26043 


\begin{tabular}{|c|c|c|c|c|c|c|}
\hline & & \multicolumn{5}{|c|}{ Supplemental Table S2.txt } \\
\hline CHEMBL1498218 & 688427 & 3.031 & 4.3855 & TRN & & \\
\hline CHEMBL1343539 & 688427 & 5.7402 & 4.8439 & TRN & & \\
\hline CHEMBL1536681 & 688427 & 4.2935 & 4.4492 & TRN & & \\
\hline CHEMBL1428357 & 688427 & 4.4921 & 4.8358 & TRN & & \\
\hline CHEMBL1565546 & 688427 & 3.031 & 4.1628 & TRN & & \\
\hline CHEMBL1579427 & 688427 & 5.1658 & 4.0838 & TRN & & \\
\hline CHEMBL 3189642 & 688427 & 4.2114 & 4.0535 & TRN & & \\
\hline CHEMBL1540912 & 688427 & 4.7535 & 4.0979 & TST & & \\
\hline CHEMBL1561555 & 688427 & 3.031 & 4.1262 & TST & & \\
\hline CHEMBL1568840 & 688427 & 6.0921 & 4.6111 & TRN & & \\
\hline CHEMBL315708 & 688427 & 5.6306 & 4.4805 & TRN & & \\
\hline CHEMBL1502894 & 688427 & 5.3917 & 4.2014 & TRN & & \\
\hline CHEMBL1306899 & 688427 & 4.5025 & 3.5366 & TRN & & \\
\hline CHEMBL1996902 & 688427 & 4.9401 & 4.8381 & TRN & & \\
\hline CHEMBL1313961 & 688427 & 4.3205 & 4.2884 & TST & & \\
\hline CHEMBL1340251 & 688427 & 3.031 & 4.2599 & TRN & & \\
\hline CHEMBL1595580 & 688427 & 5.0107 & 4.8666 & TRN & & \\
\hline CHEMBL1495244 & 688427 & 4.5536 & 4.1493 & TRN & & \\
\hline CHEMBL1496523 & 688427 & 4.13899 & 99999999 & 99 & 3.9571 & TRN \\
\hline CHEMBL1321356 & 688427 & 3.031 & 4.2772 & TRN & & \\
\hline CHEMBL1385937 & 688427 & 3.031 & 4.6201 & TST & & \\
\hline CHEMBL 3193799 & 688427 & 4.4942 & 4.5109 & TRN & & \\
\hline CHEMBL1586967 & 688427 & 4.4658 & 4.0939 & TRN & & \\
\hline CHEMBL1480223 & 688427 & 4.494 & 4.7286 & TRN & & \\
\hline CHEMBL1562951 & 688427 & 5.5819 & 5.0063 & TRN & & \\
\hline CHEMBL1588030 & 688427 & 4.497 & 4.121 & TRN & & \\
\hline CHEMBL1491318 & 688427 & 5.034 & 4.4281 & TRN & & \\
\hline CHEMBL1536771 & 688427 & 4.4769 & 4.372 & TRN & & \\
\hline CHEMBL1567258 & 688427 & 4.4162 & 5.0129 & TST & & \\
\hline CHEMBL1573861 & 688427 & 3.031 & 3.52 & TRN & & \\
\hline CHEMBL1559474 & 688427 & 5.1786 & 4.3078 & TRN & & \\
\hline CHEMBL 3197413 & 688427 & 4.4473 & 4.2005 & TRN & & \\
\hline CHEMBL1517409 & 688427 & 4.1145 & 4.0825 & TRN & & \\
\hline CHEMBL1367188 & 688427 & 4.5869 & 4.1495 & TRN & & \\
\hline CHEMBL1372916 & 688427 & 4.4174 & 4.3738 & TST & & \\
\hline CHEMBL1412924 & 688427 & 3.5081 & 4.1425 & TRN & & \\
\hline CHEMBL1329293 & 688427 & 5.2529 & 4.2818 & TRN & & \\
\hline CHEMBL1607477 & 688427 & 4.6402 & 5.0099 & TRN & & \\
\hline CHEMBL1486096 & 688427 & 5.2074 & 4.7895 & TRN & & \\
\hline CHEMBL1337188 & 688427 & 4.5432 & 4.544 & TRN & & \\
\hline CHEMBL1518163 & 688427 & 5.1693 & 4.2543 & TRN & & \\
\hline CHEMBL1420552 & 688427 & 5.8225 & 4.7869 & TRN & & \\
\hline CHEMBL1548293 & 688427 & 4.7525 & 3.8519 & TST & & \\
\hline CHEMBL1572205 & 688427 & 4.2607 & 4.129 & TRN & & \\
\hline CHEMBL3199093 & 688427 & 4.6362 & 4.5748 & TRN & & \\
\hline CHEMBL1527476 & 688427 & 4.4816 & 4.5166 & TRN & & \\
\hline CHEMBL1525902 & 688427 & 4.2557 & 4.4892 & TRN & & \\
\hline CHEMBL1432472 & 688427 & 4.5153 & 4.0067 & TRN & & \\
\hline
\end{tabular}




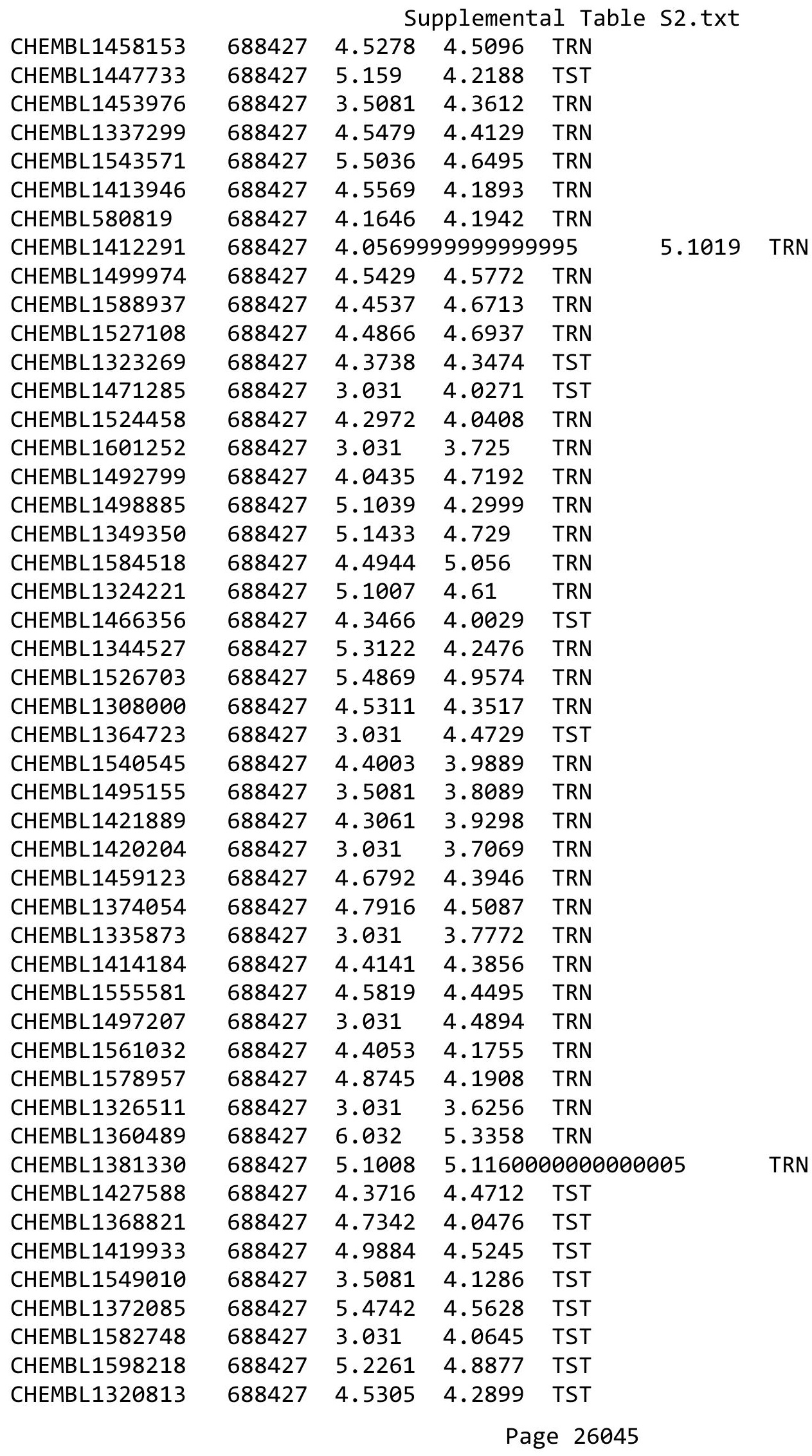


Supplemental Table S2.txt

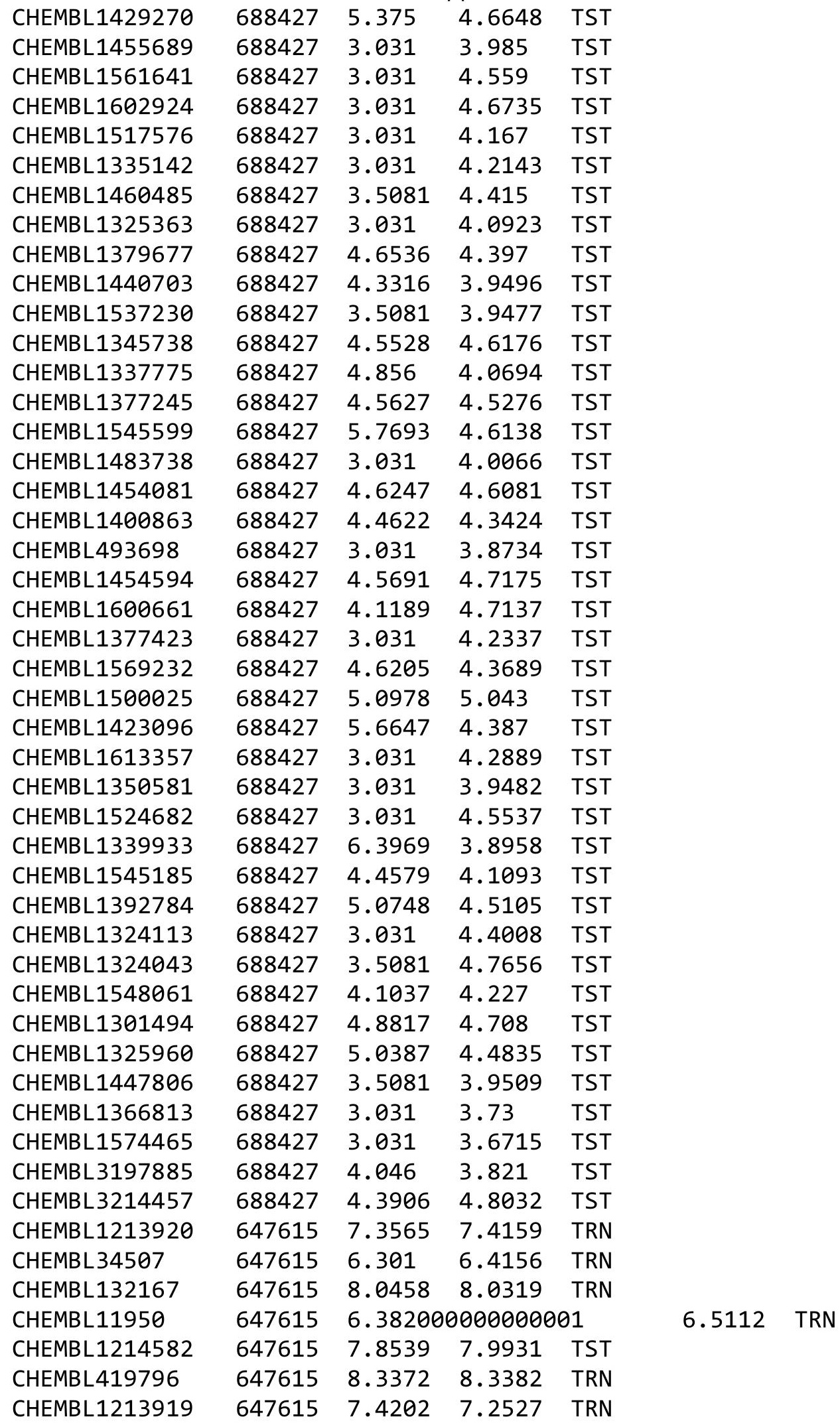

Page 26046 


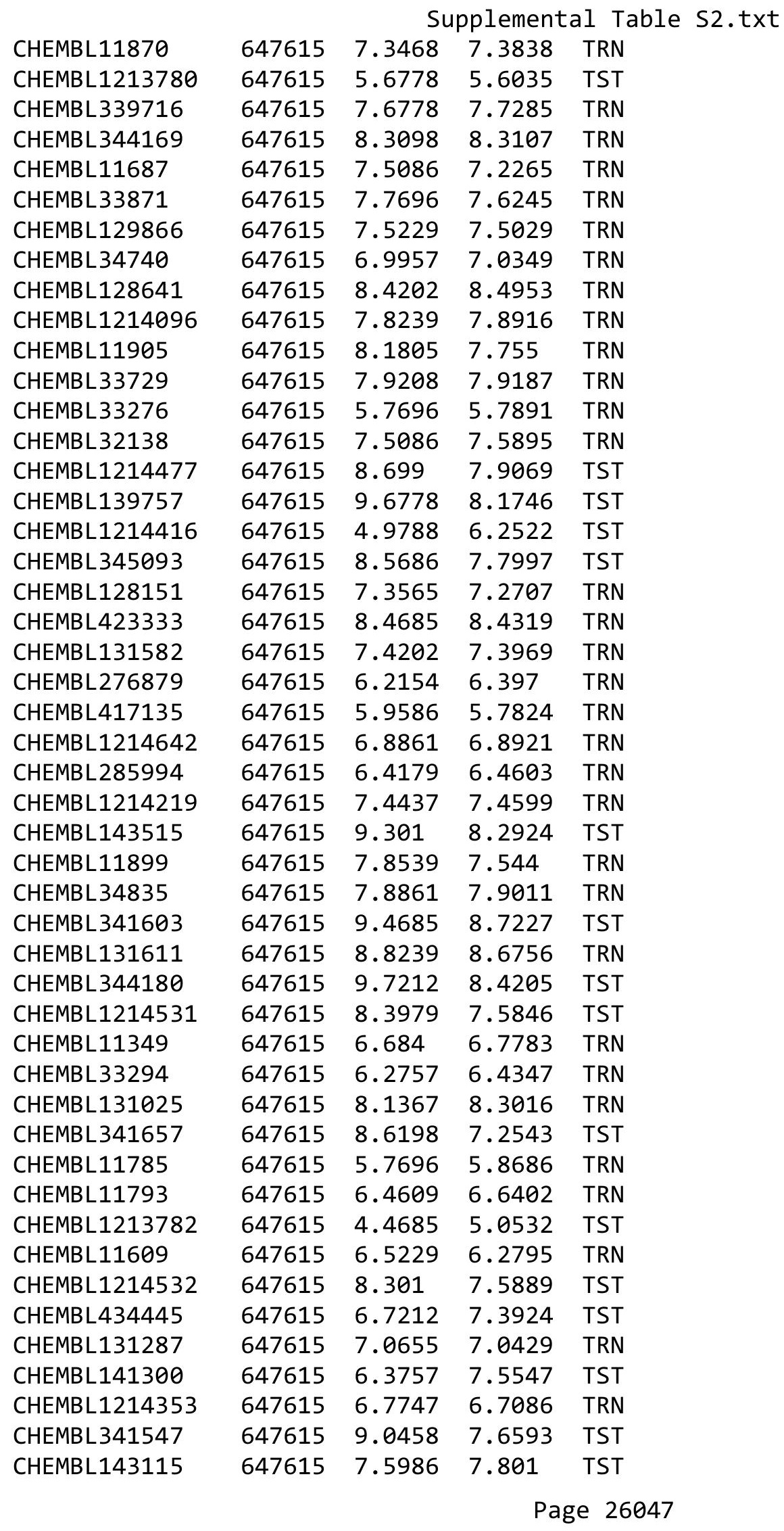




\begin{tabular}{|c|c|c|c|c|}
\hline & & & oplement & al $\mathrm{Tc}$ \\
\hline CHEMBL416769 & 647615 & 7.9586 & 8.2527 & TRN \\
\hline CHEMBL127842 & 647615 & 8.1367 & 8.0526 & TRN \\
\hline CHEMBL422609 & 647615 & 8.0362 & 8.212 & TRN \\
\hline CHEMBL 335000 & 647615 & 8.3872 & 8.4116 & TRN \\
\hline CHEMBL342705 & 647615 & 9.2924 & 8.3107 & TST \\
\hline CHEMBL337195 & 647615 & 8.0757 & 8.2219 & TRN \\
\hline CHEMBL1213844 & 647615 & 4.2596 & 4.2151 & TRN \\
\hline CHEMBL11509 & 647615 & 6.8447 & 7.0471 & TRN \\
\hline CHEMBL130846 & 647615 & 8.5686 & 8.4112 & TRN \\
\hline CHEMBL1214415 & 647615 & 6.2782 & 5.6232 & TST \\
\hline CHEMBL11921 & 647615 & 6.983 & 7.0959 & TRN \\
\hline CHEMBL1213720 & 647615 & 6.0915 & 6.0165 & TRN \\
\hline CHEMBL1213781 & 647615 & 5.3979 & 5.4629 & TRN \\
\hline CHEMBL32136 & 647615 & 7.7696 & 7.5541 & TRN \\
\hline CHEMBL1213921 & 647615 & 7.2007 & 7.3072 & TRN \\
\hline CHEMBL341172 & 647615 & 7.8861 & 7.901 & TRN \\
\hline CHEMBL11791 & 647615 & 6.3468 & 6.1768 & TRN \\
\hline CHEMBL32764 & 647615 & 6.5686 & 6.6701 & TRN \\
\hline CHEMBL11625 & 647615 & 6.9788 & 7.0699 & TRN \\
\hline CHEMBL33329 & 647615 & 6.3893 & 6.3366 & TRN \\
\hline CHEMBL 2372704 & 207952 & 3.3391 & 3.4044 & TRN \\
\hline CHEMBL 2372754 & 207952 & 2.6087 & 2.4454 & TRN \\
\hline CHEMBL2372697 & 207952 & 4.8861 & 4.8263 & TRN \\
\hline CHEMBL 2372663 & 207952 & 5.1938 & 4.9913 & TRN \\
\hline CHEMBL2372666 & 207952 & 4.9586 & 4.8876 & TRN \\
\hline CHEMBL2372679 & 207952 & 6.0 & 5.5807 & TRN \\
\hline CHEMBL 2372731 & 207952 & 4.2676 & 3.4044 & TRN \\
\hline CHEMBL 2372692 & 207952 & 3.5258 & 4.8902 & TST \\
\hline CHEMBL2372661 & 207952 & 2.7662 & 3.1157 & TST \\
\hline CHEMBL 2372718 & 207952 & 2.5943 & 2.5662 & TRN \\
\hline CHEMBL 2372749 & 207952 & 2.5245 & 2.449 & TST \\
\hline CHEMBL2372722 & 207952 & 6.0 & 4.2621 & TST \\
\hline CHEMBL 2372676 & 207952 & 2.8989 & 3.0813 & TRN \\
\hline CHEMBL 2372740 & 207952 & 3.7747 & 3.67 & TRN \\
\hline CHEMBL2372657 & 207952 & 5.1549 & 5.1029 & TRN \\
\hline CHEMBL2372696 & 207952 & 6.0 & 6.2627 & TRN \\
\hline CHEMBL2372655 & 207952 & 3.71 & 4.8252 & TRN \\
\hline CHEMBL2372726 & 207952 & 4.7696 & 4.4801 & TRN \\
\hline CHEMBL2372654 & 207952 & 6.0 & 6.0096 & TRN \\
\hline CHEMBL 2372728 & 207952 & 2.5013 & 2.494 & TRN \\
\hline CHEMBL2372694 & 207952 & 3.1261 & 4.3183 & TRN \\
\hline CHEMBL2372732 & 207952 & 5.7212 & 5.4485 & TRN \\
\hline CHEMBL2372706 & 207952 & 2.58 & 2.7605 & TRN \\
\hline CHEMBL 2372689 & 207952 & 3.9626 & 3.7448 & TRN \\
\hline CHEMBL2372742 & 207952 & 3.5317 & 3.9629 & TRN \\
\hline CHEMBL 2372734 & 207952 & 3.4045 & 3.4925 & TRN \\
\hline CHEMBL 2372743 & 207952 & 3.7122 & 3.4868 & TRN \\
\hline CHEMBL2372686 & 207952 & 4.8861 & 4.6149 & TRN \\
\hline
\end{tabular}




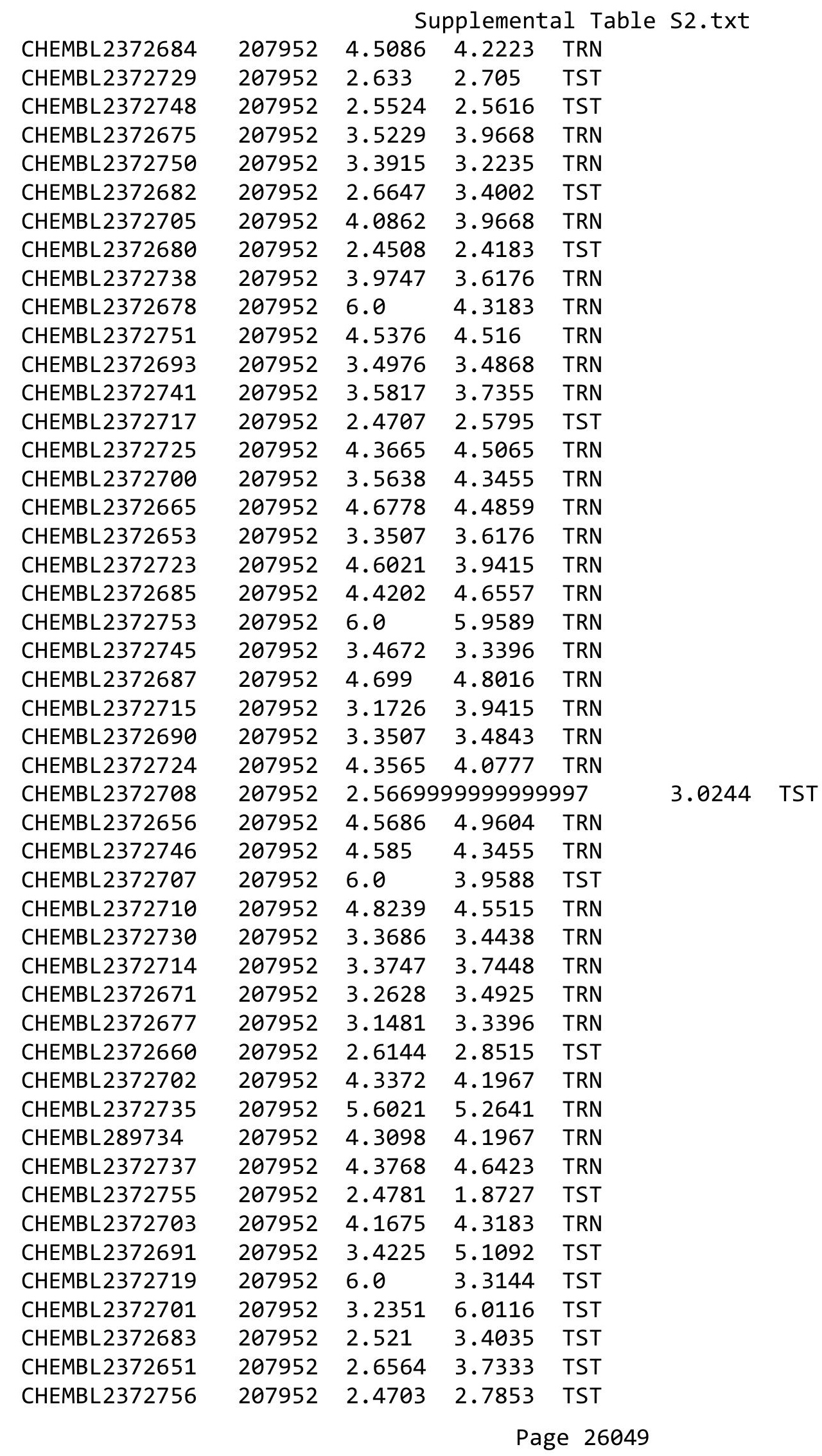


Supplemental Table S2.txt

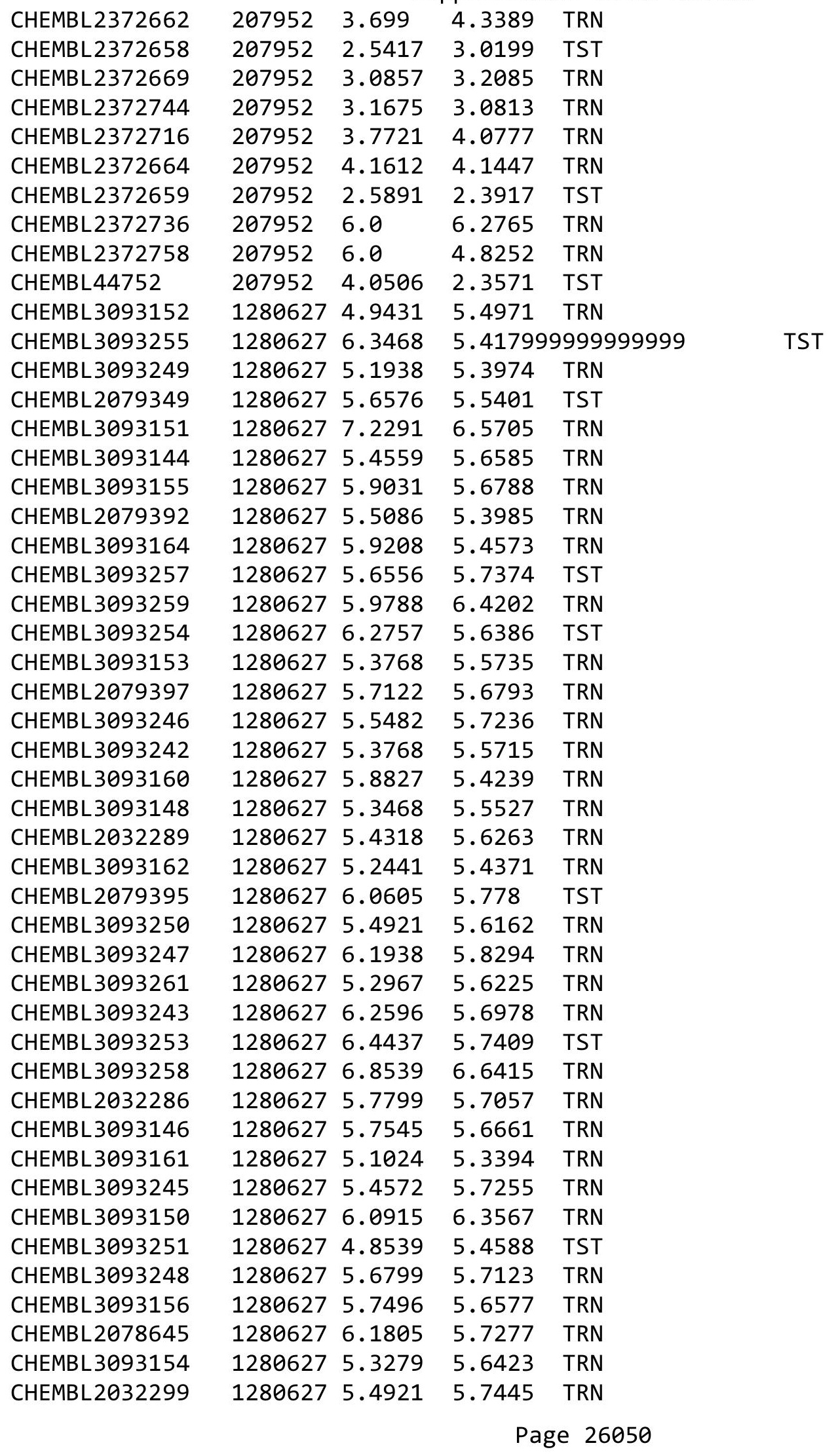


Supplemental Table S2.txt

\begin{tabular}{|c|c|c|c|c|c|}
\hline CHEMBL 3093244 & 1280627 & 6.0555 & 5.7552 & TRN & \\
\hline CHEMBL3093163 & 1280627 & 5.4437 & 5.4382 & TRN & \\
\hline CHEMBL3093147 & 1280627 & 6.1549 & 5.7658 & TRN & \\
\hline CHEMBL 2032290 & 1280627 & 6.0555 & 5.7004 & TRN & \\
\hline CHEMBL3093157 & 1280627 & 5.1612 & 5.3007 & TRN & \\
\hline CHEMBL3093260 & 1280627 & 6.9208 & 6.6236 & TRN & \\
\hline CHEMBL3093149 & 1280627 & 5.3665 & 6.5003 & TRN & \\
\hline CHEMBL3093252 & 1280627 & 5.2924 & 5.4232 & TST & \\
\hline CHEMBL 2079522 & 1280627 & 6.284 & 5.7708 & TRN & \\
\hline CHEMBL3093158 & 1280627 & 5.3979 & 5.2898 & TST & \\
\hline CHEMBL3093145 & 1280627 & 6.301 & 5.7419 & TST & \\
\hline CHEMBL3093256 & 1280627 & 5.4685 & 5.5319 & TST & \\
\hline CHEMBL 2079205 & 1280627 & 6.6778 & 5.5148 & TST & \\
\hline CHEMBL3093159 & 1280627 & 5.9431 & 5.7412 & TST & \\
\hline CHEMBL231699 & 454117 & 6.18 & 6.3405 & TRN & \\
\hline CHEMBL240029 & 454117 & 7.14 & 7.3066 & TST & \\
\hline CHEMBL240028 & 454117 & 6.23 & 7.3828 & TST & \\
\hline CHEMBL241287 & 454117 & 6.84 & 7.1052 & TST & \\
\hline CHEMBL238761 & 454117 & 6.84 & 6.8734 & TST & \\
\hline CHEMBL241077 & 454117 & 6.84 & 6.7399 & TST & \\
\hline CHEMBL241076 & 454117 & 6.84 & 7.4224 & TST & \\
\hline CHEMBL240866 & 454117 & 6.17 & 7.6209 & TST & \\
\hline CHEMBL393780 & 454117 & 6.84 & 6.9018 & TST & \\
\hline CHEMBL240667 & 454117 & 6.84 & 7.4519 & TST & \\
\hline CHEMBL393595 & 454117 & 5.97 & 5.8196 & TRN & \\
\hline CHEMBL401042 & 454117 & 6.87 & 6.8326 & TRN & \\
\hline CHEMBL240457 & 454117 & 6.68 & 6.8905 & TRN & \\
\hline CHEMBL240844 & 454117 & 7.64 & 7.504 & TRN & \\
\hline CHEMBL240436 & 454117 & 7.94 & 7.5576 & TRN & \\
\hline CHEMBL234398 & 454117 & 7.45 & 7.4052 & TRN & \\
\hline CHEMBL393178 & 454117 & 5.85 & 5.8237 & TRN & \\
\hline CHEMBL240248 & 454117 & 6.37 & 6.3328 & TRN & \\
\hline CHEMBL240247 & 454117 & 6.86 & 6.8703 & TRN & \\
\hline CHEMBL410957 & 454117 & 6.65 & 6.9475 & TRN & \\
\hline CHEMBL238754 & 454117 & 6.55 & 6.7169 & TRN & \\
\hline CHEMBL391296 & 454117 & 6.5 & 6.4963 & TRN & \\
\hline CHEMBL238752 & 454117 & 5.7 & 5.5709 & TRN & \\
\hline CHEMBL239365 & 454117 & 5.78 & 5.7437 & TRN & \\
\hline CHEMBL239363 & 454117 & 6.15 & \multicolumn{2}{|c|}{6.257999999999999} & TRN \\
\hline CHEMBL392795 & 454117 & 6.62 & 6.5237 & TRN & \\
\hline CHEMBL239137 & 454117 & 6.77 & 7.2593 & TRN & \\
\hline CHEMBL238931 & 454117 & 6.78 & 6.8152 & TRN & \\
\hline CHEMBL238930 & 454117 & 7.16 & 7.3097 & TRN & \\
\hline CHEMBL 238929 & 454117 & 7.5 & 7.6924 & TRN & \\
\hline CHEMBL392794 & 454117 & 7.54 & 7.4946 & TRN & \\
\hline CHEMBL238727 & 454117 & 7.72 & 7.25799 & 9999999999 & TRN \\
\hline CHEMBL238726 & 454117 & 6.13 & 6.0226 & TRN & \\
\hline CHEMBL392793 & 454117 & 7.89 & 8.0635 & TRN & \\
\hline
\end{tabular}




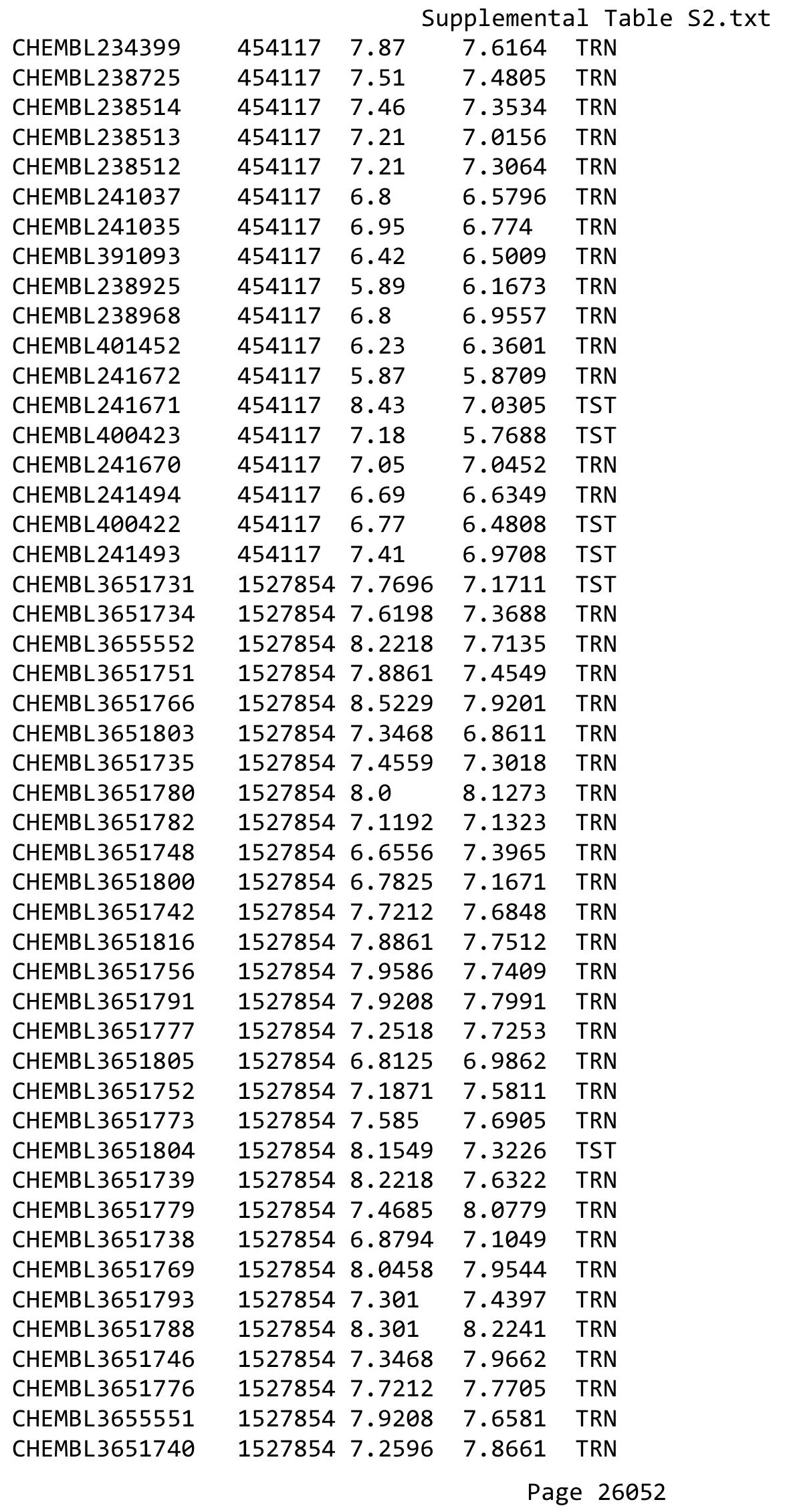


Supplemental Table S2.txt

\begin{tabular}{|c|c|c|c|c|c|}
\hline CHEMBL3651764 & 1527854 & 7.1249 & 7.5579 & TRN & \\
\hline CHEMBL3651730 & 1527854 & 7.8539 & 7.5273 & TST & \\
\hline CHEMBL3655541 & 1527854 & 7.3372 & 7.4051 & TRN & \\
\hline CHEMBL 3651760 & 1527854 & 7.6576 & 7.4815 & TRN & \\
\hline CHEMBL3651757 & 1527854 & 8.2218 & 7.8707 & TRN & \\
\hline CHEMBL3655543 & 1527854 & 7.6021 & 6.9048 & TRN & \\
\hline CHEMBL3651817 & 1527854 & 6.8861 & 7.1117 & TST & \\
\hline CHEMBL3639506 & 1527854 & 7.4437 & 7.5942 & TRN & \\
\hline CHEMBL3651754 & 1527854 & 7.6021 & 7.6166 & TRN & \\
\hline CHEMBL3655556 & 1527854 & 8.1549 & 7.5363 & TRN & \\
\hline CHEMBL 3651785 & 1527854 & 7.8539 & 7.7081 & TRN & \\
\hline CHEMBL3651736 & 1527854 & 7.1079 & 7.5304 & TST & \\
\hline CHEMBL3651802 & 1527854 & 7.5376 & 7.2187 & TRN & \\
\hline CHEMBL3651813 & 1527854 & 6.4908 & 6.8849 & TRN & \\
\hline CHEMBL3651767 & 1527854 & 8.2218 & 7.9793 & TRN & \\
\hline CHEMBL3956834 & 1527854 & 7.7212 & 6.9586 & TST & \\
\hline CHEMBL3893151 & 1527854 & 6.3054 & 7.3156 & TST & \\
\hline CHEMBL3655549 & 1527854 & 7.9586 & 7.4899 & TRN & \\
\hline CHEMBL 3655548 & 1527854 & 8.0 & 7.5975 & TRN & \\
\hline CHEMBL3651755 & 1527854 & 6.9666 & 7.2375 & TRN & \\
\hline CHEMBL3655554 & 1527854 & 6.4157 & 7.5966 & TST & \\
\hline CHEMBL3651790 & 1527854 & 6.567 & 7.5026 & TST & \\
\hline CHEMBL3651809 & 1527854 & 8.1549 & 7.0798 & TST & \\
\hline CHEMBL3655546 & 1527854 & 7.1805 & 7.4421 & TRN & \\
\hline CHEMBL3655553 & 1527854 & 8.0969 & 7.7768 & TRN & \\
\hline CHEMBL3651747 & 1527854 & 8.5229 & 8.1705 & TRN & \\
\hline CHEMBL3651749 & 1527854 & 7.5086 & 7.9151 & TRN & \\
\hline CHEMBL3651732 & 1527854 & 7.5686 & 7.6217 & TRN & \\
\hline CHEMBL 3651772 & 1527854 & 7.2924 & 7.4429 & TRN & \\
\hline CHEMBL3655555 & 1527854 & 6.1209 & 7.5163 & TRN & \\
\hline CHEMBL3651763 & 1527854 & 7.5376 & 7.4905 & TRN & \\
\hline CHEMBL 3651784 & 1527854 & 7.8861 & 7.6306 & TRN & \\
\hline CHEMBL 2152708 & 1527854 & 8.6198 & 8.2037 & TRN & \\
\hline CHEMBL 3651807 & 1527854 & 7.0458 & 6.7424 & TRN & \\
\hline CHEMBL3651814 & 1527854 & 7.4815 & 7.5753 & TRN & \\
\hline CHEMBL3651812 & 1527854 & 6.45100 & 000000000 & 305 & 7.0659 \\
\hline CHEMBL3651733 & 1527854 & 8.2218 & 7.853 & TRN & \\
\hline CHEMBL3651799 & 1527854 & 7.3979 & 7.2118 & TRN & \\
\hline CHEMBL 3651771 & 1527854 & 7.0969 & 7.4874 & TRN & \\
\hline CHEMBL3651806 & 1527854 & 7.4559 & 7.6892 & TRN & \\
\hline CHEMBL3655550 & 1527854 & 8.0458 & 7.6767 & TRN & \\
\hline CHEMBL3651783 & 1527854 & 6.983 & 7.3854 & TRN & \\
\hline CHEMBL3651795 & 1527854 & 7.5686 & 7.555 & TRN & \\
\hline CHEMBL3651786 & 1527854 & 7.8861 & 7.8923 & TRN & \\
\hline CHEMBL3651810 & 1527854 & 7.7959 & 7.9135 & TRN & \\
\hline CHEMBL3655558 & 1527854 & 6.7011 & 6.6745 & TRN & \\
\hline CHEMBL3651744 & 1527854 & 7.8539 & 8.0233 & TRN & \\
\hline CHEMBL3639544 & 1527854 & 7.8239 & 7.4704 & TRN & \\
\hline
\end{tabular}


Supplemental Table S2.txt

\begin{tabular}{|c|c|c|c|c|}
\hline HEMB & 27854 & & & \\
\hline HEMBL3651818 & 527854 & 7.8861 & .0873 & \\
\hline 70 & 854 & 8.0 & & \\
\hline AEMBL & & 7 & & \\
\hline AEMBL & 261834 & 6383 & & \\
\hline HEMBL3651796 & 527854 & 6.7645 & .8173 & \\
\hline 11 & & .6383 & 963 & \\
\hline 59 & & 8.301 & & \\
\hline AEMBL36 & 854 & 7.699 & 7.7822 & \\
\hline HEMBL3933869 & 854 & 7.6021 & .1619 & \\
\hline AEMBL365 & 54 & 7.5086 & 7.4262 & \\
\hline IEMBL36 & & 768 & 39 & \\
\hline AEMBL & & 57 & & \\
\hline HEMBL36 & 54 & 7.4089 & 7.6673 & \\
\hline AEMBL36 & 54 & 6.8861 & & \\
\hline AEMBL365 & 34 & 3372 & 7.5726 & \\
\hline AEMBL3 & & 85 & & \\
\hline HEMBL3 & & 447 & & \\
\hline HEMBL21 & & 665 & & \\
\hline IEMBL36 & & 35 & & IST \\
\hline HEMBLS & 34 & 8 & 97 & I RIV \\
\hline AEMBL & & 8 & & RN \\
\hline HEMBL; & & 7. & & \\
\hline 47 & & 7. & & TST \\
\hline AEMBL36 & & & & 1د \\
\hline AEMBL3 & 24 & 1 & & SI \\
\hline AEMBL & & 3 & & ST \\
\hline AFMRI : & & 36 & & $C T$ \\
\hline HEMBL3S & & 229 & & TS \\
\hline HEMBL 365 & & 59 & & is \\
\hline HEMBL36 & & 37 & & TST \\
\hline AFMB : & & 9 & & ST \\
\hline AEMBL3 & & 96 & & TST \\
\hline HEMBL365 & & 7.5229 & & TST \\
\hline HEMBL3651781 & 54 & 8.301 & 58 & TST \\
\hline HEMBL36 & & 665 & & TST \\
\hline HCMDI & & & & \\
\hline HEMBL3 & & 7.1135 & & TST \\
\hline HEMBL 365 & 354 & & & TST \\
\hline IEMBL2 & & & & TST \\
\hline HEMBL $20 \angle$ & & & & 80 \\
\hline CHEMBL 204 & & & & NIV \\
\hline HEMBL 204 & & 402 & 4.275 & RN \\
\hline HEMBL 204 & 18 & 7959 & 149 & TR \\
\hline MBL2 & & & & RN \\
\hline HEMBL2e & & 327 & & \\
\hline CHEMBL 204 & & 4.317 & 4.2638 & \\
\hline CHEMBL 23479 & 823518 & 6.4202 & 5.9597 & ГRN \\
\hline
\end{tabular}

Page 26054 
Supplemental Table S2.txt

\begin{tabular}{|c|c|c|c|c|c|c|}
\hline CHEMBL 2043307 & 823518 & 6.0362 & 6.4577 & TST & & \\
\hline CHEMBL1682199 & 823518 & 5.5229 & 4.4909 & TRN & & \\
\hline CHEMBL2043305 & 823518 & 5.9706 & 6.2625 & TRN & & \\
\hline CHEMBL 2043321 & 823518 & 6.2676 & 6.2292 & TRN & & \\
\hline CHEMBL2043304 & 823518 & 5.8356 & 5.9046 & TRN & & \\
\hline CHEMBL 2041772 & 823518 & 3.5229 & 4.4204 & TRN & & \\
\hline CHEMBL 2043300 & 823518 & 6.2924 & 6.7459 & TST & & \\
\hline CHEMBL 2040885 & 823518 & 5.1688 & 5.5785 & TRN & & \\
\hline CHEMBL2043316 & 823518 & 6.0605 & 6.1205 & TRN & & \\
\hline CHEMBL2041156 & 823518 & \multicolumn{3}{|c|}{4.821000000000001} & 5.1105 & TST \\
\hline CHEMBL 2043306 & 823518 & 5.4868 & 5.525 & TRN & & \\
\hline CHEMBL 2041006 & 823518 & 5.4056 & 5.6406 & TST & & \\
\hline CHEMBL 2041002 & 823518 & 6.041 & 5.3704 & TRN & & \\
\hline CHEMBL 2040993 & 823518 & 5.7258 & 5.1103 & TRN & & \\
\hline CHEMBL2040893 & 823518 & 5.4989 & 5.8274 & TRN & & \\
\hline CHEMBL 2041001 & 823518 & 6.3098 & 5.279 & TRN & & \\
\hline CHEMBL2043303 & 823518 & 6.3872 & 6.5024 & TRN & & \\
\hline CHEMBL 2041568 & 823518 & 4.9547 & 5.0285 & TST & & \\
\hline CHEMBL1682201 & 823518 & 4.71 & 4.7011 & TRN & & \\
\hline CHEMBL2043308 & 823518 & 5.4685 & 5.5957 & TRN & & \\
\hline CHEMBL1596993 & 823518 & 6.1549 & 6.2486 & TRN & & \\
\hline CHEMBL 2041560 & 823518 & 4.3507 & 4.2126 & TRN & & \\
\hline CHEMBL 2041771 & 823518 & 4.699 & 4.8274 & TRN & & \\
\hline CHEMBL2041155 & 823518 & 4.4868 & 4.9883 & TRN & & \\
\hline CHEMBL 2041553 & 823518 & 4.9872 & 4.4055 & TST & & \\
\hline CHEMBL2041159 & 823518 & 4.4365 & 4.3166 & TRN & & \\
\hline CHEMBL 2041778 & 823518 & 4.1555 & 4.252 & TRN & & \\
\hline CHEMBL 2041161 & 823518 & 4.8182 & 4.4127 & TRN & & \\
\hline CHEMBL1682206 & 823518 & 4.9393 & 4.7717 & TRN & & \\
\hline CHEMBL2041005 & 823518 & 4.7235 & 4.9275 & TRN & & \\
\hline CHEMBL2040995 & 823518 & 5.4461 & 5.27 & TRN & & \\
\hline CHEMBL2041163 & 823518 & 3.0 & 4.045 & TRN & & \\
\hline CHEMBL 2040884 & 823518 & 6.1549 & 6.334 & TRN & & \\
\hline CHEMBL 2040887 & 823518 & 5.5735 & 5.6025 & TRN & & \\
\hline CHEMBL2041559 & 823518 & 4.2503 & 4.3056 & TRN & & \\
\hline CHEMBL348522 & 823518 & 5.3809 & 5.4625 & TRN & & \\
\hline CHEMBL2041321 & 823518 & 4.7011 & 4.3055 & TRN & & \\
\hline CHEMBL 2041563 & 823518 & 4.5331 & 4.5723 & TST & & \\
\hline CHEMBL2041569 & 823518 & 4.6108 & 4.3405 & TRN & & \\
\hline CHEMBL 2043320 & 823518 & 6.5376 & 6.5019 & TRN & & \\
\hline CHEMBL2043323 & 823518 & 5.9547 & 6.0004 & TRN & & \\
\hline CHEMBL2041555 & 823518 & 5.3615 & 5.6725 & TST & & \\
\hline CHEMBL1682203 & 823518 & 4.71899 & 99999999 & 99 & 5.0588 & T TRT \\
\hline CHEMBL 2040851 & 823518 & 6.0088 & 5.6954 & TRN & & \\
\hline CHEMBL 2041160 & 823518 & 5.1445 & 4.9 & TRN & & \\
\hline CHEMBL 23832 & 823518 & 6.3565 & 5.8837 & TRN & & \\
\hline CHEMBL2040999 & 823518 & 5.5638 & 5.4763 & TRN & & \\
\hline CHEMBL2041562 & 823518 & 4.9547 & 5.1566 & TRN & & \\
\hline
\end{tabular}

Page 26055 
Supplemental Table S2.txt

\begin{tabular}{|c|c|c|c|c|}
\hline CHEMBL1682205 & 823518 & 4.5072 & 4.813 & TRN \\
\hline CHEMBL 2040998 & 823518 & 4.7282 & 5.1158 & TRN \\
\hline CHEMBL 2043302 & 823518 & 6.3979 & 5.8901 & TRN \\
\hline CHEMBL 2041008 & 823518 & 4.5719 & 4.8677 & TRN \\
\hline CHEMBL 2043311 & 823518 & 5.8268 & 6.1092 & TRN \\
\hline CHEMBL 2041152 & 823518 & 4.5003 & 4.7377 & TRN \\
\hline CHEMBL 2043312 & 823518 & 5.6198 & 5.8124 & TRN \\
\hline CHEMBL1682202 & 823518 & 4.8125 & 5.0306 & TRN \\
\hline CHEMBL1328677 & 823518 & 5.9547 & 6.0274 & TRN \\
\hline CHEMBL 2040892 & 823518 & 5.0472 & 4.9293 & TRN \\
\hline CHEMBL2041158 & 823518 & 4.7144 & 5.0762 & TST \\
\hline CHEMBL1682198 & 823518 & 4.8894 & 4.3691 & TRN \\
\hline CHEMBL 2043318 & 823518 & 6.7212 & 6.6434 & TRN \\
\hline CHEMBL2041009 & 823518 & 4.9747 & 4.7892 & TRN \\
\hline CHEMBL 2043317 & 823518 & 5.0768 & 5.6015 & TRN \\
\hline CHEMBL 2040997 & 823518 & 5.8761 & 5.7595 & TRN \\
\hline CHEMBL 2043309 & 823518 & 5.6271 & 5.5783 & TRN \\
\hline CHEMBL1574420 & 823518 & 6.5528 & 6.6968 & TST \\
\hline CHEMBL 2041154 & 823518 & 5.3215 & 5.2071 & TST \\
\hline CHEMBL 2041776 & 823518 & 4.2277 & 5.29 & TST \\
\hline CHEMBL 2041557 & 823518 & 5.7496 & 5.7736 & TST \\
\hline CHEMBL1682204 & 823518 & 4.7423 & 4.7034 & TRN \\
\hline CHEMBL 2040889 & 823518 & 5.4012 & 5.4658 & TST \\
\hline CHEMBL 2041000 & 823518 & 5.6517 & 5.575 & TRN \\
\hline CHEMBL 2040890 & 823518 & 4.8962 & 5.0823 & TRN \\
\hline CHEMBL 2041558 & 823518 & 4.7167 & 4.7408 & TRN \\
\hline CHEMBL 2043322 & 823518 & 6.041 & 6.1373 & TRN \\
\hline CHEMBL 2040891 & 823518 & 5.684 & 5.4788 & TRN \\
\hline CHEMBL2041556 & 823518 & 5.2549 & 5.4533 & TST \\
\hline CHEMBL 2043310 & 823518 & 6.6576 & 6.6173 & TRN \\
\hline CHEMBL2041775 & 823518 & 4.9872 & 4.5809 & TRN \\
\hline CHEMBL 2043301 & 823518 & 5.8097 & 5.7603 & TRN \\
\hline CHEMBL 2043319 & 823518 & 6.5686 & 5.9476 & TRN \\
\hline CHEMBL1682200 & 823518 & 5.4711 & 5.3631 & TST \\
\hline CHEMBL 2041561 & 823518 & 3.0 & 3.7196 & TRN \\
\hline CHEMBL2041007 & 823518 & 4.7959 & 5.1565 & TRN \\
\hline CHEMBL 2041554 & 823518 & 5.1931 & 5.0873 & TRN \\
\hline CHEMBL 2041777 & 823518 & 4.3072 & 4.266 & TRN \\
\hline CHEMBL 2040886 & 823518 & 5.4895 & 5.71899 & 9999999999 \\
\hline CHEMBL 22815 & 823518 & 6.8239 & 6.5597 & TST \\
\hline CHEMBL2040994 & 823518 & 5.5935 & 5.7252 & TRN \\
\hline CHEMBL 2043314 & 823518 & 6.5528 & 6.6578 & TRN \\
\hline CHEMBL 2041564 & 823518 & 3.0 & 5.2248 & TST \\
\hline CHEMBL 2040888 & 823518 & 5.4191 & 5.1791 & TST \\
\hline CHEMBL 2041566 & 823518 & 4.0737 & 4.6929 & TST \\
\hline CHEMBL2040996 & 823518 & 5.5467 & 5.16700 & 0000000001 \\
\hline CHEMBL 2041567 & 823518 & 4.6676 & 4.6187 & TST \\
\hline CHEMBL2040860 & 823518 & 5.2007 & 4.1671 & TST \\
\hline
\end{tabular}




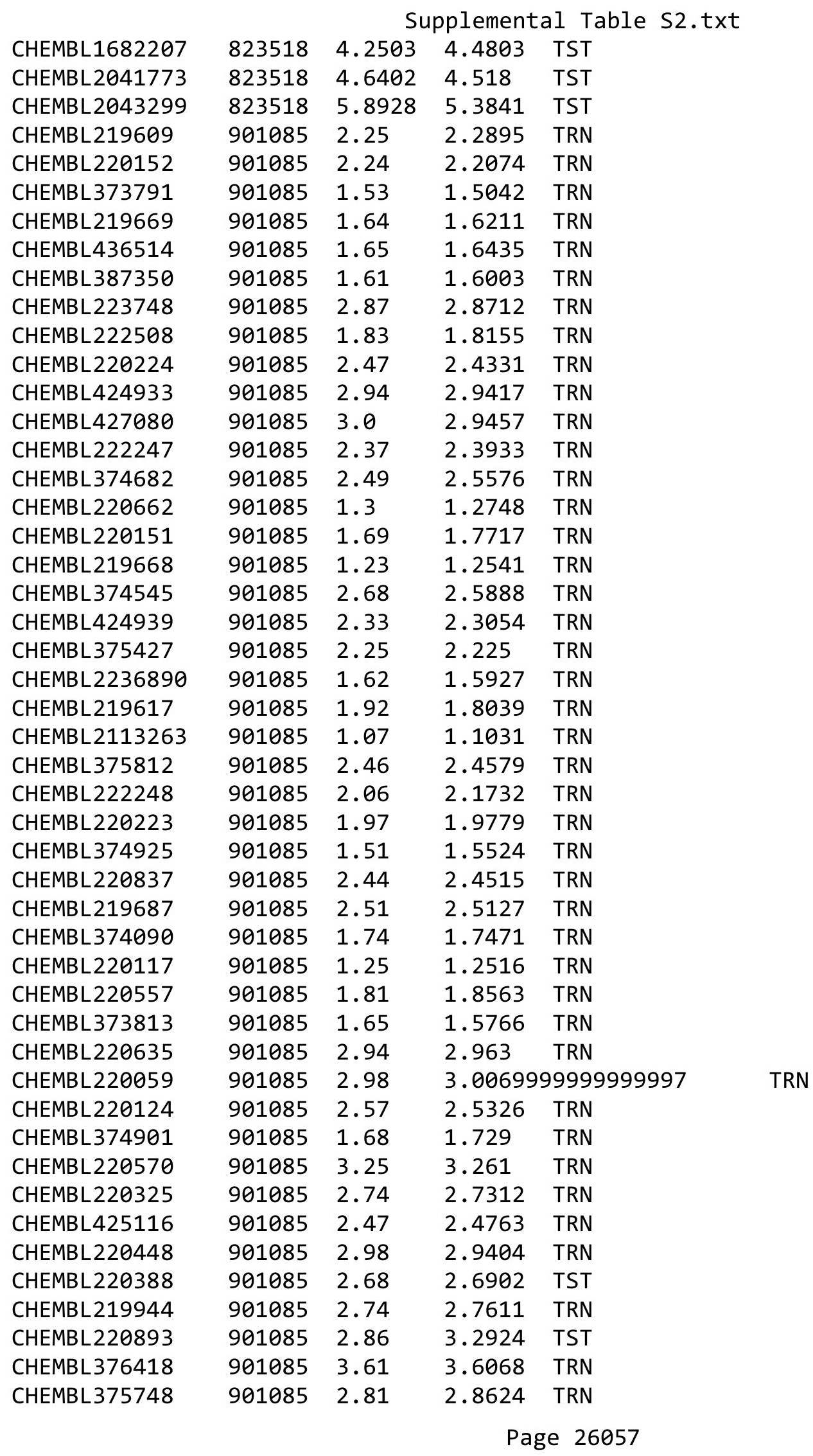




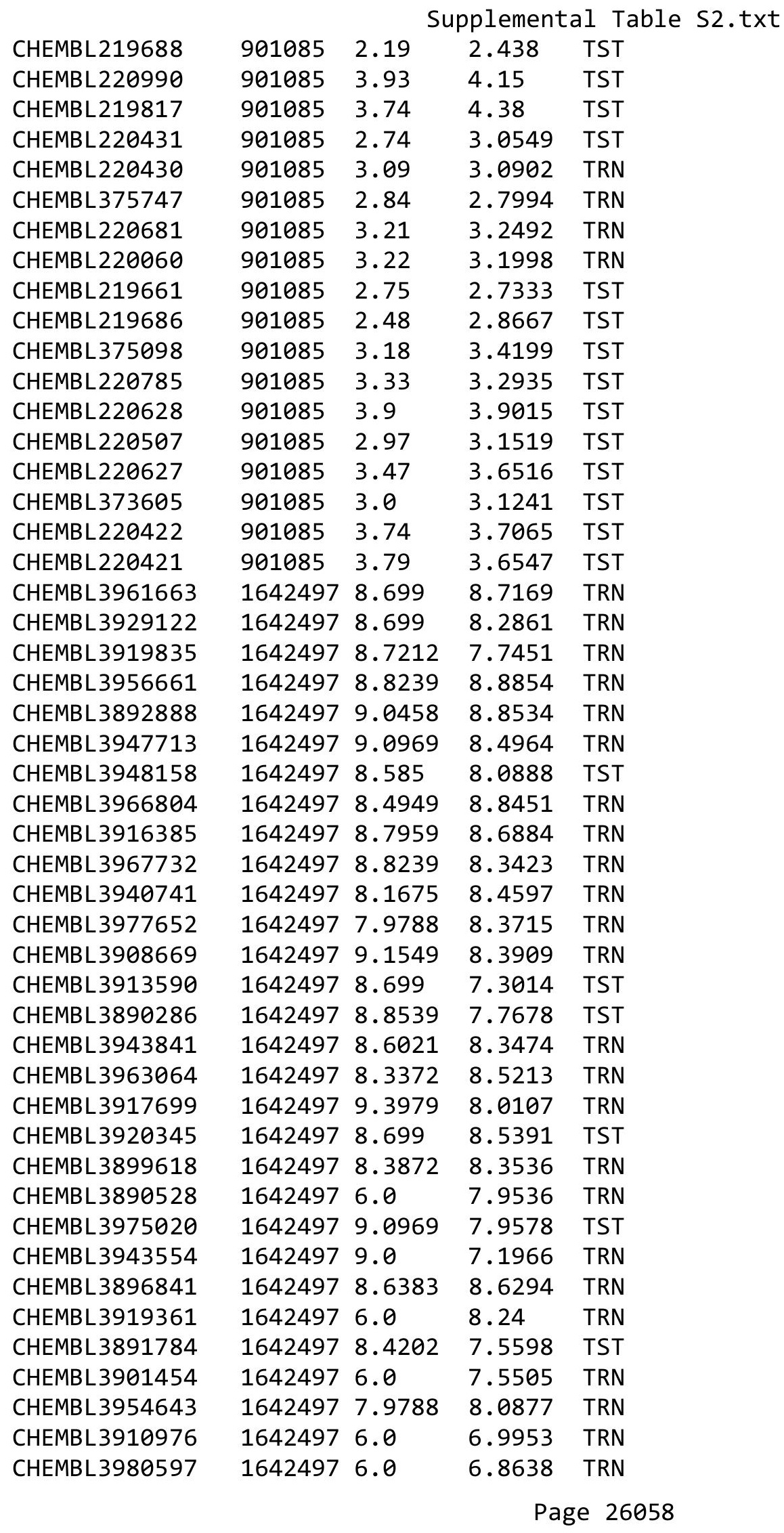




\begin{tabular}{|c|c|c|c|c|c|}
\hline \multirow{3}{*}{$\begin{array}{l}\text { CHEMBL3920205 } \\
\text { CHEMBL3942483 }\end{array}$} & \multicolumn{5}{|c|}{ Supplemental Table S2.txt } \\
\hline & 1642497 & 9.0 & 8.27700 & 0000000001 & TRN \\
\hline & 1642497 & 8.6198 & 8.221 & TST & \\
\hline CHEMBL3915889 & 1642497 & 9.0 & 8.4597 & TRN & \\
\hline CHEMBL3984435 & 1642497 & 8.4949 & 7.3212 & TRN & \\
\hline CHEMBL3929399 & 1642497 & 6.0 & 5.369 & TRN & \\
\hline CHEMBL3925377 & 1642497 & 8.5686 & 8.0993 & TRN & \\
\hline CHEMBL3961115 & 1642497 & 8.4949 & 8.5892 & TRN & \\
\hline CHEMBL3967592 & 1642497 & 8.6021 & 7.5786 & TST & \\
\hline CHEMBL 3894204 & 1642497 & 9.0969 & 8.4872 & TST & \\
\hline CHEMBL 3980145 & 1642497 & 9.0969 & 8.2857 & TRN & \\
\hline CHEMBL3972676 & 1642497 & 8.5528 & 8.0069 & TST & \\
\hline CHEMBL3975426 & 1642497 & 8.9208 & 8.718 & TRN & \\
\hline CHEMBL 3895782 & 1642497 & 8.699 & 8.0155 & TST & \\
\hline CHEMBL3985649 & 1642497 & 7.8633 & 7.1563 & TRN & \\
\hline CHEMBL3955818 & 1642497 & 8.8861 & 8.3708 & TRN & \\
\hline CHEMBL3971523 & 1642497 & 8.0223 & 8.4025 & TRN & \\
\hline CHEMBL3890659 & 1642497 & 8.9208 & 8.4951 & TRN & \\
\hline CHEMBL3986691 & 1642497 & 8.1308 & 7.7879 & TST & \\
\hline CHEMBL3923984 & 1642497 & 7.7447 & 7.1901 & TST & \\
\hline CHEMBL3897870 & 1642497 & 7.9431 & 7.6478 & TST & \\
\hline CHEMBL3972093 & 1642497 & 8.8539 & 8.1734 & TRN & \\
\hline CHEMBL 3896827 & 1642497 & 8.0458 & 8.4372 & TRN & \\
\hline CHEMBL3973664 & 1642497 & 8.2218 & 7.6868 & TRN & \\
\hline CHEMBL3934575 & 1642497 & 6.0 & 7.5803 & TRN & \\
\hline CHEMBL3949088 & 1642497 & 8.1367 & 8.4983 & TRN & \\
\hline CHEMBL3918318 & 1642497 & 6.0 & 8.0199 & TRN & \\
\hline CHEMBL3950849 & 1642497 & 8.4685 & 8.6431 & TST & \\
\hline CHEMBL3906916 & 1642497 & 8.4815 & 8.2486 & TRN & \\
\hline CHEMBL3920462 & 1642497 & 7.7328 & 7.348 & TST & \\
\hline CHEMBL3973056 & 1642497 & 9.0458 & 8.7964 & TRN & \\
\hline CHEMBL3938919 & 1642497 & 6.0 & 5.8262 & TRN & \\
\hline CHEMBL3986852 & 1642497 & 8.7696 & 8.5044 & TRN & \\
\hline CHEMBL3904602 & 1642497 & 6.0 & 7.5199 & TRN & \\
\hline CHEMBL3683865 & 1528878 & 3.3979 & 6.2828 & TRN & \\
\hline CHEMBL3693235 & 1528878 & 7.4789 & 7.4399 & TRN & \\
\hline CHEMBL3683918 & 1528878 & 7.0841 & 6.6895 & TRN & \\
\hline CHEMBL 3688638 & 1528878 & 7.2381 & 6.5171 & TRN & \\
\hline CHEMBL3688656 & 1528878 & 6.0 & 7.526 & TRN & \\
\hline CHEMBL 3683860 & 1528878 & 6.0 & 6.3731 & TRN & \\
\hline CHEMBL3688665 & 1528878 & 7.4237 & 7.2412 & TRN & \\
\hline CHEMBL3688626 & 1528878 & 6.9062 & 6.8297 & TRN & \\
\hline CHEMBL3683866 & 1528878 & 6.0 & 6.7686 & TRN & \\
\hline CHEMBL3906496 & 1528878 & 5.6003 & 5.9377 & TST & \\
\hline CHEMBL 3693249 & 1528878 & 5.9172 & 6.4151 & TST & \\
\hline CHEMBL 3688725 & 1528878 & 6.4528 & 6.8814 & TRN & \\
\hline CHEMBL3683856 & 1528878 & 7.4486 & 6.8031 & TRN & \\
\hline CHEMBL3688663 & 1528878 & 6.9014 & 6.2827 & TRN & \\
\hline CHEMBL3683799 & 1528878 & 6.0 & 6.3696 & TRN & \\
\hline
\end{tabular}


Supplemental Table S2.txt

\begin{tabular}{|c|c|c|c|c|}
\hline 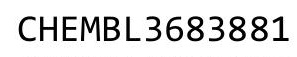 & & 731 & & \\
\hline HEMBL 3693230 & 528878 & 7.3188 & 1521 & \\
\hline 97 & & & & \\
\hline 3228 & 28878 & 11 & 98 & \\
\hline AEMBL3693255 & 528878 & 5.2688 & 364 & \\
\hline AEMBL3693229 & 528878 & 6.8386 & 0759 & \\
\hline HEMBL 3688629 & 528878 & 711 & .8983 & \\
\hline 3849 & 28878 & 6.0 & 24 & \\
\hline 88759 & 528878 & 6 & .3628 & \\
\hline HEMBL3688726 & 528878 & 7. & 892 & \\
\hline AEMBL3688693 & 528878 & 78 & 8186 & \\
\hline AEMBL3683912 & 528878 & 25 & 5812 & \\
\hline AEMBL & & & 86 & \\
\hline HEMBL & 528878 & 979 & 5208 & \\
\hline AEMBL3683916 & 528878 & 62 & 3522 & \\
\hline AEMBL3683846 & 528878 & 665 & L27 & \\
\hline AEMBL3 & 528878 & 22 & 329 & \\
\hline HEMBL; & 78 & & & \\
\hline HEMBL & 528878 & & 168 & \\
\hline 583880 & 528878 & & 4041 & RN \\
\hline HEMBL3688690 & 528878 & 99 & 8682 & I \\
\hline HEMBL3 & 28878 & 52 & 3235 & RN \\
\hline HEMBL & 528878 & & 65 & \\
\hline 82 & 78 & & 53 & RN \\
\hline AEMBL3688679 & 878 & & & RN \\
\hline HEML 3688801 & 528878 & 7. & 978 & RN \\
\hline HEMBL3683905 & 528878 & 6 & כ & RN \\
\hline HEMBL 3 & 528878 & & 001 & $\mathrm{RN}$ \\
\hline 78 & & & & RN \\
\hline IEMBL3688806 & 8878 & & & I \\
\hline AEMBL3683883 & 8878 & 96 & 872 & RN \\
\hline HEMBL3688652 & 528878 & 352 & 746 & 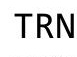 \\
\hline HEMBL36 & 878 & & & RN \\
\hline 57 & & & & RN \\
\hline AEMBL3688735 & 528878 & & 135 & RN \\
\hline AEMBL3688796 & 28878 & & 106 & ST \\
\hline HEMBL3683908 & 528878 & $\partial 6$ & 72 & RIN \\
\hline & & & & RN \\
\hline HEMBL3688747 & 528878 & & 311 & $\mathrm{RN}$ \\
\hline HEMBL3932092 & 528878 & & 694 & ST \\
\hline HEMBL3971300 & 528878 & & 631 & ST \\
\hline HEMBL3688795 & 1528878 & & 3686 & וכ \\
\hline HEMBL3688659 & & & & RN \\
\hline HEMBL3688727 & 528878 & 9 & 7047 & RN \\
\hline HEMBL3688691 & 528878 & & 672 & F \\
\hline$M D \mid 2600$ & 528878 & & 389 & \\
\hline 8625 & 528878 & .8462 & 6.9432 & \\
\hline 368868 & $15<0$ & 397 & 5.4338 & \\
\hline
\end{tabular}

Page 26060 
Supplemental Table S2.txt

\begin{tabular}{|c|c|c|c|c|c|c|}
\hline CHEMBL 3683885 & 1528878 & 6.8844 & 6.7202 & TRN & & \\
\hline CHEMBL 3688688 & 1528878 & 5.2865 & 4.7661 & TRN & & \\
\hline CHEMBL 3693247 & 1528878 & 4.4797 & 6.3502 & TST & & \\
\hline CHEMBL 3688822 & 1528878 & 7.475 & 6.9328 & TRN & & \\
\hline CHEMBL 3688661 & 1528878 & 8.2441 & 7.9557 & TRN & & \\
\hline CHEMBL 3683917 & 1528878 & 7.091 & 7.5508 & TRN & & \\
\hline CHEMBL 3683803 & 1528878 & 7.6478 & 6.9311 & TRN & & \\
\hline CHEMBL 3683922 & 1528878 & 6.7201 & 5.8436 & TRN & & \\
\hline CHEMBL 3688671 & 1528878 & 4.6122 & 5.506 & TST & & \\
\hline CHEMBL3688819 & 1528878 & 7.8416 & 7.4188 & TRN & & \\
\hline CHEMBL 3688823 & 1528878 & 7.1512 & 6.6147 & TRN & & \\
\hline CHEMBL 3683910 & 1528878 & 7.6345 & 5.9814 & TRN & & \\
\hline CHEMBL 3683816 & 1528878 & 6.0 & 7.6604 & TST & & \\
\hline CHEMBL 3688654 & 1528878 & 7.0482 & 6.7714 & TRN & & \\
\hline CHEMBL 3683804 & 1528878 & 7.8477 & 7.2061 & TRN & & \\
\hline CHEMBL 3688637 & 1528878 & 8.0269 & 6.7247 & TRN & & \\
\hline CHEMBL 3688647 & 1528878 & 7.821006 & 300000006 & 1 & 6.6248 & TRN \\
\hline CHEMBL 3683891 & 1528878 & 3.3979 & 6.3918 & TRN & & \\
\hline CHEMBL 3683823 & 1528878 & 6.0 & 7.625 & TRN & & \\
\hline CHEMBL 3683876 & 1528878 & 7.0937 & 6.7361 & TRN & & \\
\hline CHEMBL 3688731 & 1528878 & 6.383999 & 79999999 & 995 & 6.6403 & TRN \\
\hline CHEMBL 3683843 & 1528878 & 7.4908 & 6.7034 & TRN & & \\
\hline CHEMBL 3683877 & 1528878 & 7.0783 & 7.1249 & TRN & & \\
\hline CHEMBL 3688668 & 1528878 & 6.0857 & 5.5145 & TRN & & \\
\hline CHEMBL 3683878 & 1528878 & 7.4034 & 7.353 & TRN & & \\
\hline CHEMBL 3688803 & 1528878 & 5.6778 & 5.2972 & TST & & \\
\hline CHEMBL 3683793 & 1528878 & 6.0 & 6.8291 & TRN & & \\
\hline CHEMBL 3683871 & 1528878 & 7.2526 & 7.0949 & TRN & & \\
\hline CHEMBL 3688696 & 1528878 & 6.0 & 6.8998 & TRN & & \\
\hline CHEMBL 3688707 & 1528878 & 6.7089 & 6.8491 & TRN & & \\
\hline CHEMBL 3688624 & 1528878 & 7.3478 & 7.3074 & TRN & & \\
\hline CHEMBL 3688812 & 1528878 & 7.6003 & 7.2677 & TRN & & \\
\hline CHEMBL 3683805 & 1528878 & 7.2557 & 7.2295 & TRN & & \\
\hline CHEMBL 3688698 & 1528878 & 6.0 & 6.8135 & TRN & & \\
\hline CHEMBL 3688619 & 1528878 & 7.3979 & 6.6028 & TRN & & \\
\hline CHEMBL 3688676 & 1528878 & 4.3927 & 5.7258 & TST & & \\
\hline CHEMBL3919121 & 1528878 & 3.4437 & 4.8102 & TST & & \\
\hline CHEMBL 3683808 & 1528878 & 6.0 & 6.3326 & TRN & & \\
\hline CHEMBL 3683889 & 1528878 & 6.0 & 6.7628 & TRN & & \\
\hline CHEMBL 3693226 & 1528878 & 6.4855 & 7.3111 & TRN & & \\
\hline CHEMBL 3683899 & 1528878 & 7.4921 & 5.8262 & TRN & & \\
\hline CHEMBL 3688628 & 1528878 & 8.1805 & 7.7629 & TRN & & \\
\hline CHEMBL 3693259 & 1528878 & 3.3979 & 4.6806 & TST & & \\
\hline CHEMBL 3683826 & 1528878 & 7.2457 & 7.1178 & TRN & & \\
\hline CHEMBL 3688677 & 1528878 & 3.3979 & 5.7289 & TST & & \\
\hline CHEMBL 3683840 & 1528878 & 6.3058 & 6.9499 & TRN & & \\
\hline CHEMBL 3688618 & 1528878 & 5.4634 & 5.9824 & TRN & & \\
\hline CHEMBL 3688630 & 1528878 & 8.6576 & 8.3226 & TRN & & \\
\hline
\end{tabular}

Page 26061 


\begin{tabular}{|c|c|c|c|c|c|c|}
\hline & & \multicolumn{5}{|c|}{ Supplemental Table S2.txt } \\
\hline CHEMBL3683879 & 1528878 & 7.2941 & 7.2038 & TRN & & \\
\hline CHEMBL3969436 & 1528878 & 6.36100 & 30000000 & 01 & 5.9484 & TST \\
\hline CHEMBL3688686 & 1528878 & 4.6978 & 4.8831 & TRN & & \\
\hline CHEMBL 3683797 & 1528878 & 6.0 & 6.664 & TRN & & \\
\hline CHEMBL 3683809 & 1528878 & 6.0 & 6.6587 & TRN & & \\
\hline CHEMBL 3688615 & 1528878 & 7.0009 & 6.6863 & TRN & & \\
\hline CHEMBL 3683854 & 1528878 & 7.21399 & 99999999 & 995 & 6.8329 & TRN \\
\hline CHEMBL 3683833 & 1528878 & 6.0 & 7.5216 & TRN & & \\
\hline CHEMBL 3693240 & 1528878 & 5.9851 & 6.3402 & TRN & & \\
\hline CHEMBL3688666 & 1528878 & 7.6696 & 7.1585 & TRN & & \\
\hline CHEMBL 3688674 & 1528878 & 3.3979 & 5.3365 & TST & & \\
\hline CHEMBL 3683903 & 1528878 & 6.6198 & 5.6043 & TST & & \\
\hline CHEMBL 3688743 & 1528878 & 7.4283 & 7.1102 & TRN & & \\
\hline CHEMBL 3693256 & 1528878 & 6.0 & 6.8437 & TRN & & \\
\hline CHEMBL3688664 & 1528878 & 6.983 & 6.7108 & TRN & & \\
\hline CHEMBL 3688640 & 1528878 & 6.0 & 7.0348 & TRN & & \\
\hline CHEMBL 3688745 & 1528878 & 6.5369 & 6.6739 & TRN & & \\
\hline CHEMBL 3688620 & 1528878 & 6.9226 & 6.7485 & TRN & & \\
\hline CHEMBL 3688670 & 1528878 & 3.3979 & 4.5983 & TRN & & \\
\hline CHEMBL3693254 & 1528878 & 6.3251 & 7.1666 & TRN & & \\
\hline CHEMBL 3688741 & 1528878 & 7.5986 & 7.3523 & TRN & & \\
\hline CHEMBL 3688742 & 1528878 & 7.2644 & 7.3816 & TRN & & \\
\hline CHEMBL 3683884 & 1528878 & 7.6383 & 6.8831 & TRN & & \\
\hline CHEMBL 3683795 & 1528878 & 6.0 & 7.4386 & TRN & & \\
\hline CHEMBL3693250 & 1528878 & 5.0642 & 6.1649 & TST & & \\
\hline CHEMBL 3688695 & 1528878 & 7.0287 & 7.2479 & TRN & & \\
\hline CHEMBL 3639875 & 1528878 & 7.8508 & 7.1292 & TRN & & \\
\hline CHEMBL 3688721 & 1528878 & 6.7364 & 7.20200 & 0000000001 & & TRN \\
\hline CHEMBL 3688704 & 1528878 & 6.0 & 7.3808 & TRN & & \\
\hline CHEMBL3693237 & 1528878 & 4.8492 & 6.6036 & TST & & \\
\hline CHEMBL 3688736 & 1528878 & 7.6055 & 7.301 & TRN & & \\
\hline CHEMBL3693224 & 1528878 & 7.5287 & 7.1263 & TRN & & \\
\hline CHEMBL 3688614 & 1528878 & 4.8827 & 6.6349 & TRN & & \\
\hline CHEMBL3919977 & 1528878 & 6.9226 & 6.6474 & TST & & \\
\hline CHEMBL3688673 & 1528878 & 3.3979 & 5.4188 & TST & & \\
\hline CHEMBL 3683853 & 1528878 & 6.0 & 6.8234 & TRN & & \\
\hline CHEMBL3683919 & 1528878 & 7.4365 & 7.1083 & TRN & & \\
\hline CHEMBL3688669 & 1528878 & 3.3979 & 5.3374 & TRN & & \\
\hline CHEMBL3683845 & 1528878 & 7.1361 & 6.4973 & TRN & & \\
\hline CHEMBL3688675 & 1528878 & 4.5927 & 5.5418 & TRN & & \\
\hline CHEMBL 3688814 & 1528878 & 7.0386 & 7.407 & TRN & & \\
\hline CHEMBL3688729 & 1528878 & 6.93 & 6.334 & TRN & & \\
\hline CHEMBL3688609 & 1528878 & 6.7328 & 6.1233 & TRN & & \\
\hline CHEMBL3683873 & 1528878 & 7.0794 & 6.3162 & TRN & & \\
\hline CHEMBL3688715 & 1528878 & 5.9412 & 6.6985 & TRN & & \\
\hline CHEMBL 3683847 & 1528878 & 7.2958 & 6.8494 & TRN & & \\
\hline CHEMBL 3688714 & 1528878 & 6.5157 & 7.1313 & TRN & & \\
\hline CHEMBL3688813 & 1528878 & 7.4078 & 7.4105 & TRN & & \\
\hline
\end{tabular}


Supplemental Table S2.txt

\begin{tabular}{|c|c|c|c|c|}
\hline CHEMBL3688635 & 1528878 & 6.8371 & 6.6376 & TRN \\
\hline CHEMBL3688713 & 1528878 & 5.4756 & 5.9625 & TRN \\
\hline CHEMBL3688802 & 1528878 & 5.2222 & 5.1583 & TST \\
\hline CHEMBL3688611 & 1528878 & 6.0602 & 6.0462 & TRN \\
\hline CHEMBL3688798 & 1528878 & 4.9523 & 5.1206 & TST \\
\hline CHEMBL 3688820 & 1528878 & 7.7696 & 7.4795 & TRN \\
\hline CHEMBL3688616 & 1528878 & 6.9722 & 6.7925 & TRN \\
\hline CHEMBL3683857 & 1528878 & 6.9154 & 7.0572 & TRN \\
\hline CHEMBL3688815 & 1528878 & 7.6021 & 6.8381 & TRN \\
\hline CHEMBL3693233 & 1528878 & 6.9378 & 7.1911 & TRN \\
\hline CHEMBL3960008 & 1528878 & 6.8239 & 6.3595 & TST \\
\hline CHEMBL3688716 & 1528878 & 6.5222 & 5.8809 & TRN \\
\hline CHEMBL3688800 & 1528878 & 6.7986 & 5.2268 & TRN \\
\hline CHEMBL3683911 & 1528878 & 7.7167 & 6.9044 & TRN \\
\hline CHEMBL3688728 & 1528878 & 7.2823 & 6.3615 & TRN \\
\hline CHEMBL3934320 & 1528878 & 8.2218 & 6.5231 & TST \\
\hline CHEMBL3688694 & 1528878 & 7.38200 & 00000000 & 7.2139999999999995 \\
\hline CHEMBL3693236 & 1528878 & 7.2882 & 7.3772 & TRN \\
\hline CHEMBL3688722 & 1528878 & 7.0044 & 6.7467 & TRN \\
\hline CHEMBL3688702 & 1528878 & 6.0 & 7.2115 & TRN \\
\hline CHEMBL3683882 & 1528878 & 6.7328 & 6.9049 & TRN \\
\hline CHEMBL3683864 & 1528878 & 6.0 & 6.8992 & TRN \\
\hline CHEMBL3688739 & 1528878 & 6.0 & 6.8623 & TRN \\
\hline CHEMBL3904318 & 1528878 & 6.1808 & 6.8848 & TST \\
\hline CHEMBL3688756 & 1528878 & 6.0 & 6.07600 & 30000000005 \\
\hline CHEMBL3693253 & 1528878 & 6.301 & 5.8682 & TRN \\
\hline CHEMBL3688680 & 1528878 & 3.3979 & 5.5105 & TST \\
\hline CHEMBL 3688642 & 1528878 & 7.8996 & 7.2466 & TRN \\
\hline CHEMBL 3683915 & 1528878 & 7.4365 & 7.1171 & TRN \\
\hline CHEMBL3688660 & 1528878 & 7.7852 & 7.5138 & TRN \\
\hline CHEMBL3688816 & 1528878 & 7.9355 & 7.3423 & TRN \\
\hline CHEMBL3688706 & 1528878 & 7.3556 & 7.3344 & TRN \\
\hline CHEMBL3683869 & 1528878 & 6.0 & 6.6382 & TRN \\
\hline CHEMBL 3688818 & 1528878 & 6.8729 & 7.2243 & TRN \\
\hline CHEMBL3683855 & 1528878 & 7.0128 & 6.8794 & TRN \\
\hline CHEMBL3688730 & 1528878 & 7.3778 & 6.8534 & TRN \\
\hline CHEMBL3688613 & 1528878 & 5.8539 & 5.5617 & TRN \\
\hline CHEMBL 3688646 & 1528878 & 6.0 & 7.7905 & TRN \\
\hline CHEMBL 3688612 & 1528878 & 7.0372 & 6.9951 & TRN \\
\hline CHEMBL3683789 & 1528878 & 6.93 & 7.183 & TRN \\
\hline CHEMBL3683898 & 1528878 & 6.7111 & 5.9864 & TRN \\
\hline CHEMBL3639876 & 1528878 & 7.4535 & 7.602 & TRN \\
\hline CHEMBL3896093 & 1528878 & 6.065 & 6.8814 & TST \\
\hline CHEMBL 3688757 & 1528878 & 3.3979 & 6.2773 & TST \\
\hline CHEMBL3693232 & 1528878 & 7.9172 & 7.0768 & TRN \\
\hline CHEMBL3903848 & 1528878 & 6.9412 & 6.4824 & TST \\
\hline CHEMBL3683868 & 1528878 & 7.7328 & 6.2536 & TRN \\
\hline CHEMBL3898003 & 1528878 & 4.4647 & 4.1473 & TST \\
\hline
\end{tabular}


Supplemental Table S2.txt

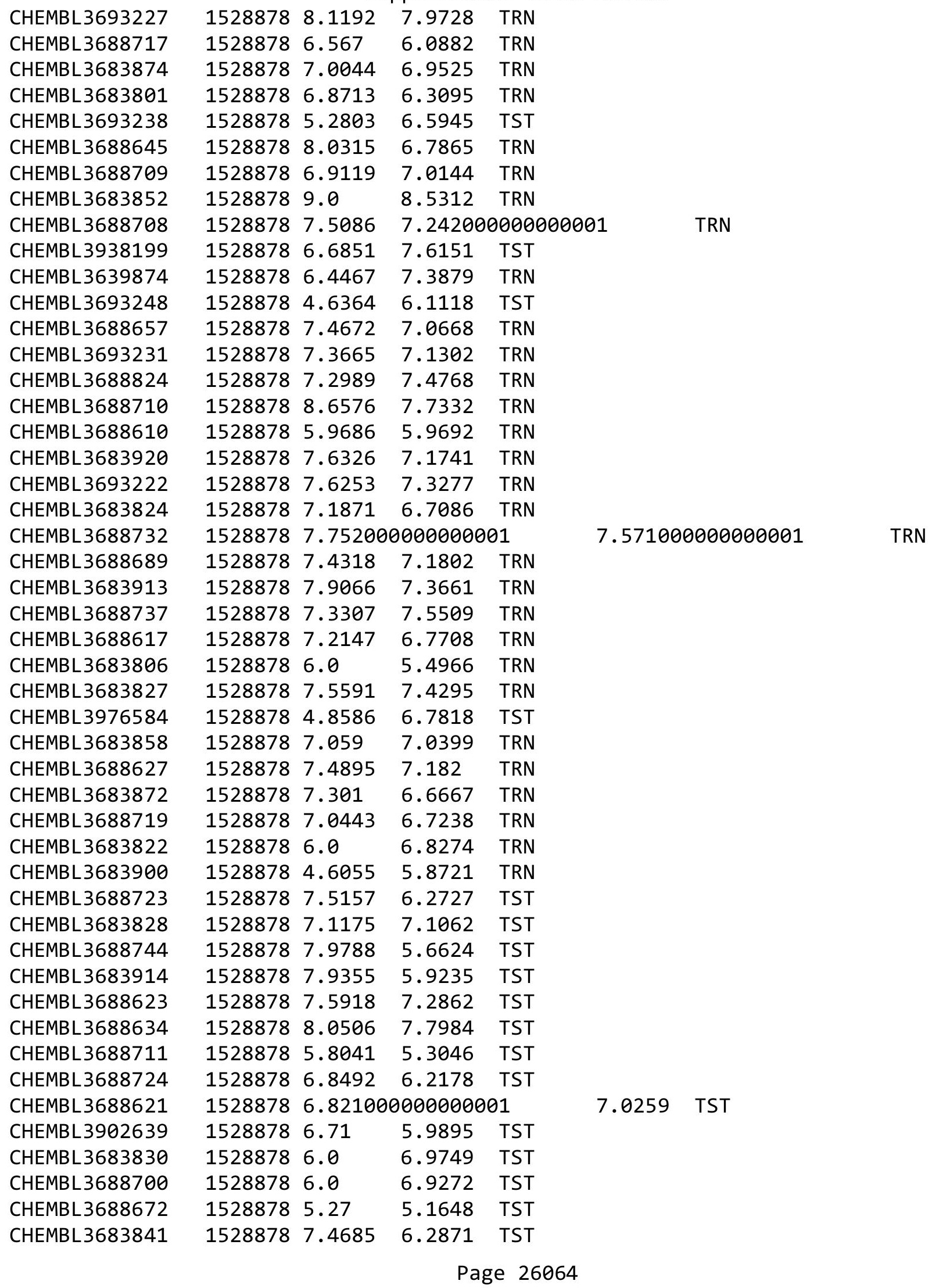


Supplemental Table S2.txt

\begin{tabular}{|c|c|c|c|c|c|}
\hline CHEMBL3683909 & 1528878 & 7.8633 & 6.0955 & TST & \\
\hline CHEMBL3683896 & 1528878 & 6.1358 & 6.9476 & TST & \\
\hline CHEMBL 3683844 & 1528878 & 7.5317 & 6.6954 & TST & \\
\hline CHEMBL3688662 & 1528878 & 6.5482 & 6.2904 & TST & \\
\hline CHEMBL3683802 & 1528878 & 7.5575 & 7.2211 & TST & \\
\hline CHEMBL 3936217 & 1528878 & 7.2104 & 6.0957 & TST & \\
\hline CHEMBL3955470 & 1528878 & 5.7352 & 4.3162 & TST & \\
\hline CHEMBL 3688752 & 1528878 & 6.0 & 6.2717 & TST & \\
\hline CHEMBL3688804 & 1528878 & 5.5459 & 6.4089 & TST & \\
\hline CHEMBL3688653 & 1528878 & 6.0 & 5.8817 & TST & \\
\hline CHEMBL 3688622 & 1528878 & 6.3825 & 6.9212 & TST & \\
\hline CHEMBL3688821 & 1528878 & 7.0915 & 7.2219 & TST & \\
\hline CHEMBL3895393 & 1528878 & 6.7825 & 6.8898 & TST & \\
\hline CHEMBL3683861 & 1528878 & 6.0 & 6.3467 & TST & \\
\hline CHEMBL 3683921 & 1528878 & 5.5406 & 5.78799 & 999999999 & TST \\
\hline CHEMBL 3683886 & 1528878 & 7.5918 & 6.8424 & TST & \\
\hline CHEMBL3973354 & 1642075 & 6.0 & 5.8839 & TRN & \\
\hline CHEMBL3934975 & 1642075 & 7.8697 & 8.1122 & TST & \\
\hline CHEMBL3973448 & 1642075 & 6.0419 & 6.7573 & TST & \\
\hline CHEMBL3906206 & 1642075 & 8.1135 & 8.5315 & TRN & \\
\hline CHEMBL3963838 & 1642075 & 8.5528 & 8.288 & TRN & \\
\hline CHEMBL3903003 & 1642075 & 8.2218 & 8.5895 & TRN & \\
\hline CHEMBL3983324 & 1642075 & 7.8327 & 7.8899 & TRN & \\
\hline CHEMBL3898719 & 1642075 & 7.8996 & 7.5246 & TRN & \\
\hline CHEMBL 3974903 & 1642075 & 7.2426 & 7.8569 & TRN & \\
\hline CHEMBL3953144 & 1642075 & 7.9872 & 7.9215 & TRN & \\
\hline CHEMBL3980526 & 1642075 & 8.0605 & 7.1751 & TRN & \\
\hline CHEMBL3889720 & 1642075 & 7.2765 & 7.1869 & TRN & \\
\hline CHEMBL3810085 & 1642075 & 8.7959 & 8.1196 & TST & \\
\hline CHEMBL 3937054 & 1642075 & 9.1549 & 8.9059 & TRN & \\
\hline CHEMBL3966805 & 1642075 & 7.857 & 7.8308 & TRN & \\
\hline CHEMBL3935691 & 1642075 & 6.0 & 6.322 & TRN & \\
\hline CHEMBL3937510 & 1642075 & 7.7423 & 7.7247 & TRN & \\
\hline CHEMBL3942200 & 1642075 & 6.0 & \multicolumn{2}{|c|}{6.287999999999999} & TRN \\
\hline CHEMBL3958651 & 1642075 & 7.7212 & 8.015 & TRN & \\
\hline CHEMBL3958307 & 1642075 & 6.0 & 5.7568 & TRN & \\
\hline CHEMBL3959074 & 1642075 & 7.3206 & 7.5108 & TRN & \\
\hline CHEMBL3897474 & 1642075 & 6.8447 & 7.1059 & TRN & \\
\hline CHEMBL3913032 & 1642075 & 8.0458 & \multicolumn{2}{|c|}{7.718999999999999} & TRN \\
\hline CHEMBL 3898587 & 1642075 & 6.0 & 6.1701 & TRN & \\
\hline CHEMBL3949181 & 1642075 & 8.3279 & 7.8506 & TRN & \\
\hline CHEMBL3936246 & 1642075 & 7.8697 & 7.8051 & TRN & \\
\hline CHEMBL3966499 & 1642075 & 7.0367 & 7.6901 & TRN & \\
\hline CHEMBL3961180 & 1642075 & 7.5214 & 6.9565 & TRN & \\
\hline CHEMBL3944428 & 1642075 & 8.0655 & 8.0796 & TRN & \\
\hline CHEMBL3930282 & 1642075 & 5.0 & 7.2821 & TRN & \\
\hline CHEMBL3905357 & 1642075 & 7.2147 & 7.4523 & TRN & \\
\hline CHEMBL3975214 & 1642075 & 7.1439 & 7.5029 & TST & \\
\hline
\end{tabular}


Supplemental Table S2.txt

\begin{tabular}{|c|c|c|c|c|c|}
\hline CHEMBL 3915285 & 1642075 & 7.4921 & 8.1411 & TST & \\
\hline CHEMBL 3983065 & 1642075 & 8.3665 & 8.3664 & TRN & \\
\hline CHEMBL 3985018 & 1642075 & 7.7352 & 7.6808 & TRN & \\
\hline CHEMBL 3898550 & 1642075 & 6.6904 & 7.1239 & TRN & \\
\hline CHEMBL 3966072 & 1642075 & 6.0 & 5.351 & TRN & \\
\hline CHEMBL3971351 & 1642075 & 9.2218 & 8.9888 & TRN & \\
\hline CHEMBL 3981435 & 1642075 & 7.2708 & 7.2 & TRN & \\
\hline CHEMBL 3966407 & 1642075 & 7.5157 & 7.6957 & TRN & \\
\hline CHEMBL 3927624 & 1642075 & 7.7852 & 7.1006 & TST & \\
\hline CHEMBL 3978196 & 1642075 & 9.0458 & 8.581 & TRN & \\
\hline CHEMBL 3918521 & 1642075 & 7.4191 & 7.3224 & TRN & \\
\hline CHEMBL 3986310 & 1642075 & 6.9393 & 7.4301 & TRN & \\
\hline CHEMBL 3966443 & 1642075 & 8.0506 & 8.0941 & TRN & \\
\hline CHEMBL 3970144 & 1642075 & 7.6655 & 8.142000 & 0000000001 & TRN \\
\hline CHEMBL 3904282 & 1642075 & 8.7959 & 8.5922 & TRN & \\
\hline CHEMBL 3916900 & 1642075 & 8.4949 & 8.6787 & TRN & \\
\hline CHEMBL 3950494 & 1642075 & 8.041 & 7.9552 & TRN & \\
\hline CHEMBL 3973961 & 1642075 & 7.6904 & 7.9582 & TST & \\
\hline CHEMBL 3890648 & 1642075 & 8.3098 & 7.5145 & TRN & \\
\hline CHEMBL 3933170 & 1642075 & 7.8239 & 8.1289 & TRN & \\
\hline CHEMBL 3981885 & 1642075 & 7.6757 & 7.7231 & TRN & \\
\hline CHEMBL 3906819 & 1642075 & 7.301 & 7.2117 & TRN & \\
\hline CHEMBL 3937446 & 1642075 & 7.1675 & 7.5792 & TRN & \\
\hline CHEMBL 3808459 & 1642075 & 8.1805 & 7.7517 & TST & \\
\hline CHEMBL 3925905 & 1642075 & 8.2596 & 7.9761 & TRN & \\
\hline CHEMBL 3927283 & 1642075 & 6.6861 & 6.9714 & TST & \\
\hline CHEMBL 3967572 & 1642075 & 8.5528 & 8.7922 & TRN & \\
\hline CHEMBL 3897814 & 1642075 & 8.2441 & 8.1133 & TRN & \\
\hline CHEMBL 3976162 & 1642075 & 8.699 & 7.9559 & TRN & \\
\hline CHEMBL 3949372 & 1642075 & 7.8447 & 8.469 & TST & \\
\hline CHEMBL 3903663 & 1642075 & 8.0506 & 7.6716 & TRN & \\
\hline CHEMBL 3904349 & 1642075 & 8.3565 & 8.3125 & TRN & \\
\hline CHEMBL3986516 & 1642075 & 8.3098 & 7.9272 & TRN & \\
\hline CHEMBL 3970213 & 1642075 & 7.3363 & 7.572999 & 99999999995 & TRN \\
\hline CHEMBL 3931277 & 1642075 & 6.1759 & 6.045 & TST & \\
\hline CHEMBL 3902209 & 1642075 & 6.0 & 6.1473 & TRN & \\
\hline CHEMBL 3897895 & 1642075 & 7.7471 & 7.8478 & TST & \\
\hline CHEMBL 3972504 & 1642075 & 7.8013 & 7.9277 & TRN & \\
\hline CHEMBL 3964527 & 1642075 & 8.4089 & 8.6542 & TST & \\
\hline CHEMBL 3939032 & 1642075 & 8.28399 & 99999999 & 8.6537 & TRN \\
\hline CHEMBL 3895191 & 1642075 & 7.0362 & 7.0799 & TST & \\
\hline CHEMBL 3964505 & 1642075 & 8.0915 & 7.7227 & TRN & \\
\hline CHEMBL 3891519 & 1642075 & 7.5346 & 7.9137 & TST & \\
\hline CHEMBL 3913060 & 1642075 & 6.0 & 6.3275 & TST & \\
\hline CHEMBL 3916316 & 1642075 & 8.1024 & 7.9663 & TRN & \\
\hline CHEMBL 3960320 & 1642075 & 8.585 & 8.1489 & TRN & \\
\hline CHEMBL 3906821 & 1642075 & 8.6576 & 8.401 & TST & \\
\hline CHEMBL 3981805 & 1642075 & 7.8729 & 8.4278 & TST & \\
\hline
\end{tabular}


Supplemental Table S2.txt

\begin{tabular}{|c|c|c|c|c|c|c|}
\hline CHEMBL 3908049 & 1642075 & 8.3279 & 8.2121 & TRN & & \\
\hline CHEMBL3904025 & 1642075 & 7.0195 & 7.614 & TRN & & \\
\hline CHEMBL 3975293 & 1642075 & 8.3372 & 7.9447 & TRN & & \\
\hline CHEMBL3928492 & 1642075 & 8.9208 & 8.3351 & TST & & \\
\hline CHEMBL 3900533 & 1642075 & 7.9788 & 7.9237 & TST & & \\
\hline CHEMBL3940639 & 1642075 & 6.0 & 6.0991 & TRN & & \\
\hline CHEMBL3976993 & 1642075 & 7.9393 & 7.9604 & TRN & & \\
\hline CHEMBL 3942347 & 1642075 & 6.4365 & 6.5231 & TRN & & \\
\hline CHEMBL 3913508 & 1642075 & 6.7799 & 7.0589 & TRN & & \\
\hline CHEMBL3929257 & 1642075 & 6.9031 & 7.2895 & TRN & & \\
\hline CHEMBL3921045 & 1642075 & \multicolumn{3}{|c|}{6.752000000000001} & 6.8117 & TRN \\
\hline CHEMBL3892866 & 1642075 & 7.9586 & 8.5119 & TRN & & \\
\hline CHEMBL 3920246 & 1642075 & 6.0 & 6.1055 & TST & & \\
\hline CHEMBL 3986342 & 1642075 & 8.5376 & 8.5196 & TST & & \\
\hline CHEMBL 3942833 & 1642075 & 8.0969 & 8.5283 & TST & & \\
\hline CHEMBL3981339 & 1642075 & 7.857 & 7.9272 & TRN & & \\
\hline CHEMBL3968103 & 1642075 & 7.0958 & 7.2663 & TST & & \\
\hline CHEMBL 3929510 & 1642075 & 7.3478 & 7.5999 & TRN & & \\
\hline CHEMBL3959725 & 1642075 & 8.8861 & 8.3752 & TRN & & \\
\hline CHEMBL3899619 & 1642075 & 7.7545 & 7.169 & TRN & & \\
\hline CHEMBL3902525 & 1642075 & 6.0 & 6.1279 & TST & & \\
\hline CHEMBL3952715 & 1642075 & 7.067 & 6.9087 & TRN & & \\
\hline CHEMBL 3922211 & 1642075 & 7.3958 & 7.4494 & TRN & & \\
\hline CHEMBL 3977073 & 1642075 & 7.8962 & 8.2544 & TST & & \\
\hline CHEMBL 3938933 & 1642075 & 6.1965 & 6.644 & TRN & & \\
\hline CHEMBL 3889660 & 1642075 & 6.0 & 5.9914 & TST & & \\
\hline CHEMBL 3957810 & 1642075 & 7.0009 & 6.6718 & TRN & & \\
\hline CHEMBL 3940808 & 1642075 & 8.8539 & 8.411 & TRN & & \\
\hline CHEMBL3947727 & 1642075 & 8.1675 & 8.2816 & TRN & & \\
\hline CHEMBL3899005 & 1642075 & 8.5528 & 8.4683 & TRN & & \\
\hline CHEMBL 3925557 & 1642075 & 7.6459 & 7.8752 & TST & & \\
\hline CHEMBL 3937248 & 1642075 & 7.7959 & 7.0919 & TRN & & \\
\hline CHEMBL3969001 & 1642075 & 7.9431 & 7.3585 & TRN & & \\
\hline CHEMBL3980066 & 1642075 & 8.3665 & 8.0978 & TRN & & \\
\hline CHEMBL 3957082 & 1642075 & \multicolumn{3}{|c|}{7.007000000000001} & 7.3484 & TRN \\
\hline CHEMBL3945081 & 1642075 & 7.7471 & 8.0015 & TRN & & \\
\hline CHEMBL3915073 & 1642075 & 7.3595 & 7.6185 & TST & & \\
\hline CHEMBL 3943939 & 1642075 & 7.4318 & 7.4862 & TRN & & \\
\hline CHEMBL 3968570 & 1642075 & 8.3372 & 8.3997 & TST & & \\
\hline CHEMBL 3956063 & 1642075 & 6.6055 & 6.6668 & TRN & & \\
\hline CHEMBL 3682240 & 1528212 & 6.7696 & 7.2274 & TRN & & \\
\hline CHEMBL 3682304 & 1528212 & 6.6576 & 7.0188 & TRN & & \\
\hline CHEMBL3677379 & 1528212 & 7.2757 & 7.4936 & TRN & & \\
\hline CHEMBL 3682252 & 1528212 & 6.0 & 6.7773 & TRN & & \\
\hline CHEMBL 3639812 & 1528212 & 7.585 & 6.197 & TRN & & \\
\hline CHEMBL3677417 & 1528212 & 6.7696 & 5.8374 & TST & & \\
\hline CHEMBL 3682408 & 1528212 & 6.0 & 6.0574 & TRN & & \\
\hline CHEMBL 3682277 & 1528212 & 6.0 & 5.9516 & TRN & & \\
\hline
\end{tabular}




\begin{tabular}{|c|c|c|c|c|}
\hline \multicolumn{5}{|c|}{ Supplemental Table S2.txt } \\
\hline CHEMBL3682376 & 1528212 & 5.0 & 5.9543 & TRN \\
\hline CHEMBL 3677340 & 1528212 & 6.2924 & 6.7631 & TRN \\
\hline CHEMBL3682271 & 1528212 & 6.4202 & 6.8372 & TRN \\
\hline CHEMBL 3682219 & 1528212 & 6.9208 & 6.2868 & TRN \\
\hline CHEMBL3682237 & 1528212 & 7.0 & 7.0657 & TRN \\
\hline CHEMBL 3677354 & 1528212 & 6.1549 & 5.9376 & TRN \\
\hline CHEMBL 3682224 & 1528212 & 8.0969 & 7.1125 & TST \\
\hline CHEMBL 3682232 & 1528212 & 7.6198 & 7.5223 & TRN \\
\hline CHEMBL3677371 & 1528212 & 6.0 & 6.8149 & TRN \\
\hline CHEMBL 3682338 & 1528212 & 7.2757 & 6.9438 & TRN \\
\hline CHEMBL 3677322 & 1528212 & 7.7959 & 7.2267 & TRN \\
\hline CHEMBL3677316 & 1528212 & 7.1549 & 5.9274 & TST \\
\hline CHEMBL 3677332 & 1528212 & 6.0 & 6.4622 & TST \\
\hline CHEMBL 3682352 & 1528212 & 6.7696 & 6.8351 & TRN \\
\hline CHEMBL 3682384 & 1528212 & 6.8861 & 6.7071 & TRN \\
\hline CHEMBL 3682236 & 1528212 & 6.2218 & 7.3954 & TRN \\
\hline CHEMBL3677376 & 1528212 & 6.0 & 6.2536 & TST \\
\hline CHEMBL3682296 & 1528212 & 5.8861 & 6.3582 & TRN \\
\hline CHEMBL 3682289 & 1528212 & 6.8861 & 5.9013 & TRN \\
\hline CHEMBL 3677323 & 1528212 & 6.0 & 7.2034 & TRN \\
\hline CHEMBL 3682320 & 1528212 & 6.0 & 6.7711 & TRN \\
\hline CHEMBL3682316 & 1528212 & 6.0 & 6.2476 & TRN \\
\hline CHEMBL3677377 & 1528212 & 6.585 & 7.1281 & TRN \\
\hline CHEMBL 3682342 & 1528212 & 6.8861 & 6.9391 & TRN \\
\hline CHEMBL 3682335 & 1528212 & 7.4202 & 6.7895 & TRN \\
\hline CHEMBL 3682251 & 1528212 & 6.8861 & 7.1405 & TRN \\
\hline CHEMBL3677363 & 1528212 & 7.5528 & 6.8226 & TRN \\
\hline CHEMBL 3677344 & 1528212 & 6.4353 & 6.9258 & TRN \\
\hline CHEMBL 3682383 & 1528212 & 6.8861 & 6.6189 & TRN \\
\hline CHEMBL 3682410 & 1528212 & 8.3468 & 6.9919 & TST \\
\hline CHEMBL 3682241 & 1528212 & 6.3279 & 7.0009 & TRN \\
\hline CHEMBL3682323 & 1528212 & 5.8861 & 6.8333 & TRN \\
\hline CHEMBL3682279 & 1528212 & 6.3468 & 6.8953 & TRN \\
\hline CHEMBL 3677328 & 1528212 & 7.0 & 6.4238 & TRN \\
\hline CHEMBL3682229 & 1528212 & 7.9586 & 7.4012 & TRN \\
\hline CHEMBL 3682235 & 1528212 & 7.4202 & 7.1346 & TRN \\
\hline CHEMBL3682396 & 1528212 & 4.7447 & 6.4592 & TRN \\
\hline CHEMBL3682353 & 1528212 & 6.1805 & 6.5764 & TRN \\
\hline CHEMBL3682386 & 1528212 & 7.2676 & 6.686 & TRN \\
\hline CHEMBL3677413 & 1528212 & 3.4202 & 5.4592 & TRN \\
\hline CHEMBL 3682358 & 1528212 & 6.6576 & 6.7294 & TRN \\
\hline CHEMBL 3677314 & 1528212 & 7.6778 & 6.6067 & TRN \\
\hline CHEMBL3677335 & 1528212 & 7.301 & 5.888 & TST \\
\hline CHEMBL 3677352 & 1528212 & 6.585 & 5.9392 & TRN \\
\hline CHEMBL 3682223 & 1528212 & 5.6021 & 6.0691 & TST \\
\hline CHEMBL 3682310 & 1528212 & 7.4949 & 7.4923 & TRN \\
\hline CHEMBL 3682259 & 1528212 & 6.8861 & 6.4223 & TRN \\
\hline CHEMBL 3682360 & 1528212 & 6.7447 & 6.557 & TRN \\
\hline
\end{tabular}


Supplemental Table S2.txt

\begin{tabular}{|c|c|c|c|c|}
\hline 365 & 528212 & & & \\
\hline & 528212 & 6.8861 & & \\
\hline 65 & 28212 & & & \\
\hline IEMBL & 528212 & & & \\
\hline 32258 & 528212 & 202 & & \\
\hline AEMBL3682249 & 528212 & .3768 & 704 & \\
\hline IEMBL & 212 & & 618 & \\
\hline EMBI & 212 & & & \\
\hline IEMBL 3682344 & 528212 & 6.4089 & 151 & \\
\hline AEMBL3677358 & 528212 & 6.0 & 318 & \\
\hline AEMBL367 & 528212 & 96 & & \\
\hline IEMBL & 212 & & 972 & \\
\hline EMBL & 212 & & & \\
\hline AEMBL. & 212 & 202 & $\partial 71$ & \\
\hline IEMBL367 & 212 & 086 & 214 & \\
\hline IEMBL368 & 12 & & $\partial 97$ & \\
\hline AEMBL & 212 & & 27 & \\
\hline AEMBL & 212 & & & \\
\hline IEMBL & 212 & & & \\
\hline IEMBL & 12 & & & \\
\hline IEMBL & 2 & & & \\
\hline EMB & 2 & & & \\
\hline EMB & 12 & & & H \\
\hline 23 & 212 & & & \\
\hline IEMBL368 & & & & RI \\
\hline IEMBL & 12 & & & וכ \\
\hline EMBL & 2 & & & \\
\hline EMB & 12 & 78 & & RN \\
\hline IEMBL: & 12 & 959 & & RN \\
\hline HEMBL367 & 12 & & 72 & RN \\
\hline AEMBL: & 12 & & 44 & RI \\
\hline 73 & 2 & & & 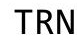 \\
\hline & 2 & 18 & & 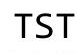 \\
\hline AEMBL 368 & 12 & & & RN \\
\hline AEMBL3682367 & 12 & 924 & & RIV \\
\hline EMBL: & 12 & 37 & & RI \\
\hline 26 & & 2 & & 促 \\
\hline & & & & RN \\
\hline AEMBL 3682329 & 528212 & & & $\mathrm{RI}$ \\
\hline EMBL. & 12 & & & RIV \\
\hline HEMBL368 & 212 & 61 & & - \\
\hline 577303 & & & & RN \\
\hline HEMBL 368 & & & & RN \\
\hline IEMBL3682340 & 528212 & 7.8861 & 578 & TS \\
\hline 54 & 12 & & & TRN \\
\hline CHEMBL 3682270 & 528212 & & & \\
\hline CHEMBL3682389 & 528212 & & 6.1803 & \\
\hline CHEMBL3677299 & 1528212 & 7.4559 & 6.7173 & IS \\
\hline
\end{tabular}

Page 26069 
Supplemental Table S2.txt

\begin{tabular}{|c|c|c|c|c|}
\hline HEN & 528212 & 6.7447 & 6.8088 & \\
\hline נכריראי וסוLM & 528212 & 7.4685 & 6.0529 & \\
\hline & 28212 & 6.0 & & \\
\hline AEMBL & 528212 & 8.0 & & \\
\hline AEMBL3682349 & 528212 & 6.6576 & 9496 & \\
\hline HEMBL523605 & 528212 & 7.0 & 1612 & \\
\hline 2406 & 212 & & 232 & \\
\hline 307 & 212 & 518 & & \\
\hline AEMBL3677409 & 212 & 6.7212 & 6227 & \\
\hline HEMBL3682315 & 528212 & 6.6576 & 0311 & \\
\hline HEMBL3682220 & 528212 & 6.0 & 39 & \\
\hline IEMBL & 212 & 41 & 265 & \\
\hline IEMBL: & & & & \\
\hline HEMBL3677351 & 212 & 5.7447 & & \\
\hline AEMBL36 & 212 & 6.0 & & \\
\hline AEMBL367 & 12 & 269 & 22 & \\
\hline AEMBL & 12 & 59 & 94 & \\
\hline HEMBL & 12 & 71 & & \\
\hline HEMBL3E & 12 & 7.7212 & 21 & \\
\hline AEMBL3 & 12 & 383 & & \\
\hline HEMBL & 2 & 6 & 57 & RIN \\
\hline HEMBL: & 12 & 427 & & RN \\
\hline HEMBL; & 12 & & & \\
\hline HEMBL & & 596 & & \\
\hline AEMBL36 & & 79 & & I RIN \\
\hline HEMBL; & L2 & 7.6021 & 81 & I RN \\
\hline HEMBL; & 12 & & 53 & Niv \\
\hline HFMBI : & 12 & 212 & & \\
\hline HEMBL3 & & 7.7696 & & $\ln$ \\
\hline HEMBL3682357 & 12 & & 91 & IRIN \\
\hline HEMBL36 & 12 & & 146 & RN \\
\hline $\mathrm{AFMBI}:$ & 12 & 59 & 88 & Niv \\
\hline HEMBL & & 12 & 29 & ST \\
\hline HEMBL3682368 & 12 & 177 & & IRN \\
\hline HEMBL3682231 & 12 & 6.9586 & 191 & TST \\
\hline HEMBL3 & 12 & 229 & & RN \\
\hline HEMRI & 12 & 76 & & RIV \\
\hline HEMBL; & & 5 . & 569 & ST \\
\hline HEMBL3677375 & 12 & 7.3872 & 312 & $\Gamma \mathrm{RN}$ \\
\hline IEMBL3 & 12 & 539 & 046 & IRN \\
\hline HEMBL36 & 12 & 7.585 & 564 & \\
\hline HEMBL3 & & 7.1871 & & RN \\
\hline HEMBL36 & 12 & 7.0044 & 3719 & TST \\
\hline HEMBL3682362 & 212 & 6 & & TST \\
\hline$M B L 3$ & 12 & 0 & & 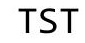 \\
\hline HEMBL36 & & .2010 & & \\
\hline CHEMBL 3677393 & & 7.2007 & & \\
\hline HEMBL3677326 & 1528212 & 7.6778 & 7.3903 & ГRN \\
\hline
\end{tabular}

Page 26070 
Supplemental Table S2.txt

\begin{tabular}{|c|c|c|c|c|}
\hline די & & 7.0 & & \\
\hline CHEMBL3682325 & .528212 & 6.8239 & 6.7475 & \\
\hline HEMBL 36 & 528212 & 7.5376 & 8202 & \\
\hline 65 & 212 & & & \\
\hline EMBL: & 528212 & & & \\
\hline AEMBL3682347 & 528212 & 3279 & 2301 & \\
\hline AEMBL3677356 & 528212 & 7.2007 & 5.402 & \\
\hline HEMBL 367 & 528212 & & & \\
\hline EMBI & 528212 & 5.7212 & & \\
\hline IEMBL: & 528212 & 5.3872 & & \\
\hline AEMBL3677357 & 528212 & 5.8239 & 1903 & \\
\hline HEMBL3677381 & 528212 & 7.7212 & 6.857 & \\
\hline HEMBL 368 & .528212 & 28 & 6573 & \\
\hline IEMBL & 212 & 4202 & & \\
\hline AEMBL. & 212 & 2596 & 474 & \\
\hline AEMBL 368 & 212 & 6.2218 & 6.4864 & \\
\hline HEMBL3682260 & 212 & 6.0 & & \\
\hline HEMBL367 & 12 & 9 & 646 & \\
\hline AEMBL. & 12 & & 371 & \\
\hline HEMB & 12 & & 502 & \\
\hline IEMBL 368 & 12 & 3279 & & \\
\hline IEMBL 367 & 2 & & & \\
\hline JEMBL368 & 52 & & & \\
\hline IEMBL & 12 & 7. & 41 & \\
\hline IEMB & 12 & 6.0 & 386 & \\
\hline IEMBL 368 & 12 & & & \\
\hline IEMBL 368 & 2 & & & \\
\hline IEMBL 364 & 12 & & & \\
\hline IEMB & 12 & & & \\
\hline 76 & 12 & & 58 & RN \\
\hline IEMBL 368 & 2 & & & \\
\hline AEMBL 368 & 12 & & & $\mathrm{RI}$ \\
\hline IEMBL & 12 & & & RI \\
\hline 1 & 12 & & & \\
\hline רת ניתו & 12 & & & $-\operatorname{mos} 2$ \\
\hline AEMBL 368 & 12 & & & S \\
\hline HEMBL 367 & 12 & 7.6 & 919 & $S$ \\
\hline 43 & 2 & 5 & 98 & RI \\
\hline 9 & 12 & & - & \\
\hline HEMBL 367 & & & 7.3792 & RN \\
\hline IEMBL 3682392 & 12 & & 6.7746 & $S$ \\
\hline IEMBL3 & 52 & 7. & & $\mathrm{RI}$ \\
\hline HEMBL368 & & & 5.6747 & \\
\hline CHEMBL 368 & & & 5.7033 & \\
\hline HEMBL3677333 & & 3.3979 & 6.376 & $S T_{1}$ \\
\hline HEMBL 368 & 12 & 7.3279 & 6.1925 & $\mathrm{R}$ \\
\hline CHEME & & & & \\
\hline CHEMBL368235 & & & & \\
\hline
\end{tabular}

Page 26071 
Supplemental Table S2.txt

\begin{tabular}{|c|c|c|c|c|c|}
\hline CHEMBL3682321 & 1528212 & 6.4559 & 7.0087 & TRN & \\
\hline CHEMBL3677414 & 1528212 & 5.699 & 6.6314 & TRN & \\
\hline CHEMBL3677425 & 1528212 & 6.0 & 6.4654 & TRN & \\
\hline CHEMBL3682345 & 1528212 & 7.6778 & 6.6786 & TST & \\
\hline CHEMBL3677350 & 1528212 & 6.0223 & 5.7082 & TRN & \\
\hline CHEMBL3682398 & 1528212 & 6.8239 & 6.8353 & TRN & \\
\hline CHEMBL3682256 & 1528212 & 8.301 & 7.0618 & TRN & \\
\hline CHEMBL 3677378 & 1528212 & 7.2007 & 7.2406 & TRN & \\
\hline CHEMBL3682309 & 1528212 & 5.7959 & 7.032 & TRN & \\
\hline CHEMBL3682297 & 1528212 & 6.5376 & 6.6092 & TRN & \\
\hline CHEMBL3682411 & 1528212 & 7.7212 & 6.596 & TRN & \\
\hline CHEMBL3677402 & 1528212 & 6.699 & 6.8786 & TRN & \\
\hline CHEMBL3682294 & 1528212 & 6.6198 & 6.37299 & 9999999999 & TRN \\
\hline CHEMBL3677397 & 1528212 & 7.041 & 7.24299 & 9999999999 & TST \\
\hline CHEMBL 3677410 & 1528212 & 6.3565 & 6.4275 & TRN & \\
\hline CHEMBL 3677300 & 1528212 & 8.0 & 7.1561 & TRN & \\
\hline CHEMBL3682275 & 1528212 & 5.8239 & 6.3394 & TRN & \\
\hline CHEMBL 3682292 & 1528212 & 5.7959 & 6.3297 & TRN & \\
\hline CHEMBL3682269 & 1528212 & 6.6383 & 6.9614 & TRN & \\
\hline CHEMBL 3682377 & 1528212 & 6.0 & 6.3665 & TST & \\
\hline CHEMBL3682285 & 1528212 & 5.9586 & 6.3884 & TRN & \\
\hline CHEMBL 3677391 & 1528212 & 7.4089 & 7.1948 & TRN & \\
\hline CHEMBL3682379 & 1528212 & 6.0 & 5.8955 & TST & \\
\hline CHEMBL3682400 & 1528212 & 7.1192 & 6.5012 & TRN & \\
\hline CHEMBL 3682401 & 1528212 & 7.2441 & 6.2167 & TRN & \\
\hline CHEMBL 3677380 & 1528212 & 6.6021 & 6.5652 & TST & \\
\hline CHEMBL 3682262 & 1528212 & 7.0 & 6.6105 & TRN & \\
\hline CHEMBL3677400 & 1528212 & 7.3565 & 6.8547 & TRN & \\
\hline CHEMBL3677353 & 1528212 & 5.1367 & 6.063 & TST & \\
\hline CHEMBL3682326 & 1528212 & 6.2924 & 6.1228 & TST & \\
\hline CHEMBL3682346 & 1528212 & 6.7696 & 5.7015 & TST & \\
\hline CHEMBL 3682263 & 1528212 & 6.8861 & 6.0837 & TST & \\
\hline CHEMBL3677330 & 1528212 & 7.4437 & 7.0184 & TRN & \\
\hline CHEMBL3682381 & 1528212 & 6.9208 & 6.6649 & TST & \\
\hline CHEMBL3682303 & 1528212 & 7.2218 & 6.7313 & TRN & \\
\hline CHEMBL3682308 & 1528212 & 6.7212 & 6.0019 & TRN & \\
\hline CHEMBL3677315 & 1528212 & 7.0 & 6.397 & TRN & \\
\hline CHEMBL3677361 & 1528212 & 7.0132 & 6.8109 & TRN & \\
\hline CHEMBL 3677325 & 1528212 & 6.0 & 6.7496 & TRN & \\
\hline CHEMBL3677336 & 1528212 & 7.2518 & \multicolumn{2}{|c|}{6.6739999999999995} & TRN \\
\hline CHEMBL 3677348 & 1528212 & 7.3468 & 6.6632 & TRN & \\
\hline CHEMBL3682351 & 1528212 & 6.301 & 6.6044 & TST & \\
\hline CHEMBL3682390 & 1528212 & 6.2147 & 6.4392 & TST & \\
\hline CHEMBL3682393 & 1528212 & 6.3565 & 6.5167 & TST & \\
\hline CHEMBL 3682287 & 1528212 & 5.1739 & 5.6927 & TRN & \\
\hline CHEMBL 3677345 & 1528212 & 6.7721 & 6.7141 & TRN & \\
\hline CHEMBL 3682245 & 1528212 & 6.7212 & 7.4441 & TRN & \\
\hline CHEMBL 3682372 & 1528212 & 7.0269 & 5.8226 & TST & \\
\hline
\end{tabular}


Supplemental Table S2.txt

\begin{tabular}{|c|c|c|c|c|}
\hline CHEMBL3682355 & 1528212 & 6.4202 & 6.3632 & TST \\
\hline CHEMBL3682225 & 1528212 & 7.5086 & 7.2643 & TRN \\
\hline CHEMBL 3682407 & 1528212 & 7.9208 & 6.9413 & TRN \\
\hline CHEMBL 3677394 & 1528212 & 8.0969 & 6.7434 & TST \\
\hline CHEMBL 3682363 & 1528212 & 6.0362 & 6.5727 & TST \\
\hline CHEMBL3677419 & 1528212 & 3.4202 & 5.8797 & TRN \\
\hline CHEMBL3682299 & 1528212 & 7.699 & 6.5328 & TRN \\
\hline CHEMBL 3677398 & 1528212 & 6.5086 & 6.7408 & TRN \\
\hline CHEMBL 3682281 & 1528212 & 6.5686 & 6.3561 & TRN \\
\hline CHEMBL 3677415 & 1528212 & 6.9208 & 6.7432 & TRN \\
\hline CHEMBL 3677390 & 1528212 & 7.7212 & 7.3924 & TRN \\
\hline CHEMBL3682272 & 1528212 & 6.9208 & 6.2029 & TRN \\
\hline CHEMBL 3677331 & 1528212 & 7.699 & 7.1216 & TRN \\
\hline CHEMBL3682339 & 1528212 & 7.1079 & 6.2254 & TST \\
\hline CHEMBL 3682348 & 1528212 & 6.8861 & 6.7579 & TST \\
\hline CHEMBL 3677347 & 1528212 & 5.2147 & 6.1623 & TRN \\
\hline CHEMBL 3677360 & 1528212 & 5.8239 & 6.4624 & TRN \\
\hline CHEMBL3677362 & 1528212 & 7.8539 & 6.689 & TST \\
\hline CHEMBL 3677317 & 1528212 & 7.3188 & 6.0182 & TRN \\
\hline CHEMBL 3677374 & 1528212 & 7.4949 & 7.2847 & TRN \\
\hline CHEMBL 3677305 & 1528212 & 7.3768 & 6.9744 & TRN \\
\hline CHEMBL 3677368 & 1528212 & 7.5376 & 7.5861 & TRN \\
\hline CHEMBL 3682341 & 1528212 & 6.9586 & 6.5941 & TST \\
\hline CHEMBL 3682261 & 1528212 & 6.6778 & 6.5594 & TRN \\
\hline CHEMBL 3677382 & 1528212 & 7.6383 & 7.15 & TRN \\
\hline CHEMBL 3677321 & 1528212 & 7.8239 & 7.2954 & TRN \\
\hline CHEMBL 3677408 & 1528212 & 6.8239 & 6.9758 & TRN \\
\hline CHEMBL 3677301 & 1528212 & 7.4437 & 6.9665 & TRN \\
\hline CHEMBL3677359 & 1528212 & 5.9208 & 6.7433 & TRN \\
\hline CHEMBL3682242 & 1528212 & 6.7696 & 7.0894 & TRN \\
\hline CHEMBL 3682286 & 1528212 & 6.4559 & 6.6626 & TRN \\
\hline CHEMBL 3682317 & 1528212 & 7.1308 & 7.1738 & TRN \\
\hline CHEMBL 3682394 & 1528212 & 5.8861 & 6.5029 & TRN \\
\hline CHEMBL 3682364 & 1528212 & 6.0 & 5.5165 & TST \\
\hline CHEMBL 3682288 & 1528212 & 7.0458 & 5.8121 & TRN \\
\hline CHEMBL 3682284 & 1528212 & 5.5686 & 6.3045 & TRN \\
\hline CHEMBL 3682243 & 1528212 & 7.8239 & 6.63299 & 999999999 \\
\hline CHEMBL3682239 & 1528212 & 7.7959 & 7.13399 & 9999999995 \\
\hline CHEMBL 3677319 & 1528212 & 7.2366 & 7.2284 & TRN \\
\hline CHEMBL3677309 & 1528212 & 6.0 & 6.5054 & TRN \\
\hline CHEMBL 3682250 & 1528212 & 7.0223 & 6.4305 & TST \\
\hline CHEMBL1940030 & 799337 & 3.6021 & 5.9651 & TST \\
\hline CHEMBL1940233 & 799337 & 5.1938 & 5.3822 & TRN \\
\hline CHEMBL1940222 & 799337 & 6.2218 & 5.2854 & TRN \\
\hline CHEMBL1940231 & 799337 & 3.6021 & 5.1192 & TRN \\
\hline CHEMBL1940237 & 799337 & 6.0458 & 5.3858 & TRN \\
\hline CHEMBL1940034 & 799337 & 5.585 & 5.7883 & TST \\
\hline CHEMBL1940041 & 799337 & 5.8239 & 5.6999 & TRN \\
\hline
\end{tabular}

Page 26073 


\begin{tabular}{|c|c|c|c|c|c|}
\hline & & & & & \\
\hline CHEMBL1940047 & 799337 & 5.041 & 5.845 & TRN & \\
\hline CHEMBL1823903 & 799337 & 5.6778 & 5.9931 & TRN & \\
\hline CHEMBL1940048 & 799337 & 5.8239 & 5.9387 & TRN & \\
\hline CHEMBL1940028 & 799337 & 3.6021 & 5.7971 & TST & \\
\hline CHEMBL1940217 & 799337 & 5.6021 & 5.5258 & TRN & \\
\hline CHEMBL1940230 & 799337 & 4.8729 & 5.348 & TRN & \\
\hline CHEMBL1940033 & 799337 & 5.0757 & 5.7414 & TST & \\
\hline CHEMBL1940049 & 799337 & 6.3206 & 6.0905 & TRN & \\
\hline CHEMBL1824123 & 799337 & 5.3979 & 5.6979 & TRN & \\
\hline CHEMBL1940240 & 799337 & 5.7447 & 5.5966 & TRN & \\
\hline CHEMBL1940042 & 799337 & 6.2218 & 6.1106 & TRN & \\
\hline CHEMBL1940241 & 799337 & 5.2366 & 5.2607 & TRN & \\
\hline CHEMBL1940235 & 799337 & 5.4685 & 5.4606 & TRN & \\
\hline CHEMBL1940027 & 799337 & 5.0706 & 5.6922 & TST & \\
\hline CHEMBL1940032 & 799337 & 5.301 & 5.6934 & TST & \\
\hline CHEMBL1940238 & 799337 & 6.0458 & 5.4564 & TRN & \\
\hline CHEMBL1940232 & 799337 & 5.301 & 5.4167 & TRN & \\
\hline CHEMBL1938413 & 799337 & 5.0862 & 5.845 & TRN & \\
\hline CHEMBL1940221 & 799337 & 3.6021 & 5.1368 & TRN & \\
\hline CHEMBL1940045 & 799337 & 5.6576 & 5.7148 & TRN & \\
\hline CHEMBL1940040 & 799337 & 6.301 & 5.7126 & TRN & \\
\hline CHEMBL1940226 & 799337 & 6.1549 & 5.2727 & TRN & \\
\hline CHEMBL1940220 & 799337 & 6.0458 & 5.4812 & TRN & \\
\hline CHEMBL1940031 & 799337 & 3.6021 & 5.8244 & TST & \\
\hline CHEMBL1940225 & 799337 & 5.1805 & 5.2727 & TRN & \\
\hline CHEMBL1940223 & 799337 & 6.0969 & 5.2727 & TRN & \\
\hline CHEMBL1940242 & 799337 & 5.9586 & 5.3064 & TRN & \\
\hline CHEMBL1940038 & 799337 & 5.4685 & 5.8329 & TRN & \\
\hline CHEMBL1940037 & 799337 & 5.4559 & 5.7738 & TRN & \\
\hline CHEMBL1940036 & 799337 & 5.4815 & 5.9596 & TRN & \\
\hline CHEMBL1940050 & 799337 & 6.4225 & 5.8621 & TRN & \\
\hline CHEMBL1940236 & 799337 & 5.1871 & 5.42899 & 9999999999 & TRN \\
\hline CHEMBL1940029 & 799337 & 3.6021 & 5.635 & TST & \\
\hline CHEMBL1940239 & 799337 & 5.8539 & 5.5182 & TRN & \\
\hline CHEMBL1940039 & 799337 & 5.7959 & 5.9469 & TRN & \\
\hline CHEMBL1940229 & 799337 & 6.3979 & 5.1685 & TRN & \\
\hline CHEMBL1940046 & 799337 & 6.5143 & 6.2462 & TRN & \\
\hline CHEMBL1823911 & 799337 & 5.5086 & 5.805 & TRN & \\
\hline CHEMBL1940026 & 799337 & 5.5229 & 5.8178 & TST & \\
\hline CHEMBL1940218 & 799337 & 3.6021 & 5.1094 & TRN & \\
\hline CHEMBL1824112 & 799337 & 3.6021 & 5.891 & TST & \\
\hline CHEMBL1940224 & 799337 & 5.2076 & 5.2988 & TRN & \\
\hline CHEMBL1940043 & 799337 & 6.301 & 6.1515 & TRN & \\
\hline CHEMBL1940228 & 799337 & 5.2441 & 5.0556 & TRN & \\
\hline CHEMBL1940234 & 799337 & 6.0458 & 5.4267 & TRN & \\
\hline CHEMBL1940227 & 799337 & 6.5528 & 5.2702 & TST & \\
\hline CHEMBL1940035 & 799337 & 5.8861 & 5.8348 & TST & \\
\hline CHEMBL1940044 & 799337 & 5.6576 & 6.1166 & TST & \\
\hline & & & & 26074 & \\
\hline
\end{tabular}




\begin{tabular}{|c|c|c|c|c|c|}
\hline \multirow[b]{2}{*}{ CHEMBL1940219 } & \multicolumn{5}{|c|}{ Supplemental Table S2.txt } \\
\hline & 799337 & 5.8861 & 5.4415 & TST & \\
\hline CHEMBL318927 & 149237 & 7.9031 & 7.86700 & 0000000001 & TRN \\
\hline CHEMBL95138 & 149237 & 8.2596 & 8.3965 & TRN & \\
\hline CHEMBL 264750 & 149237 & 6.7825 & 7.3004 & TRN & \\
\hline CHEMBL316654 & 149237 & 7.9245 & 7.88299 & 9999999999 & TRN \\
\hline CHEMBL94992 & 149237 & 7.8761 & 7.9335 & TRN & \\
\hline CHEMBL94855 & 149237 & 6.5546 & 5.4881 & TST & \\
\hline CHEMBL94554 & 149237 & 8.1249 & 8.1096 & TRN & \\
\hline CHEMBL95179 & 149237 & 6.0934 & 4.9243 & TST & \\
\hline CHEMBL97611 & 149237 & 8.0706 & 8.1062 & TRN & \\
\hline CHEMBL329816 & 149237 & 8.4318 & 8.4837 & TRN & \\
\hline CHEMBL96064 & 149237 & 8.041 & 8.0777 & TRN & \\
\hline CHEMBL97471 & 149237 & 7.2933 & 5.5284 & TST & \\
\hline CHEMBL96248 & 149237 & 7.2676 & 7.25200 & 3000000001 & TRN \\
\hline CHEMBL94521 & 149237 & 8.0223 & 7.8337 & TRN & \\
\hline CHEMBL319756 & 149237 & 7.8097 & 7.6551 & TRN & \\
\hline CHEMBL447526 & 149237 & 7.9914 & 8.0325 & TRN & \\
\hline CHEMBL 328172 & 149237 & 8.1612 & 8.0325 & TRN & \\
\hline CHEMBL330684 & 149237 & 5.0 & 5.4773 & TRN & \\
\hline CHEMBL72865 & 149237 & 7.1864 & 7.4898 & TRN & \\
\hline CHEMBL 317760 & 149237 & 7.0862 & 7.0254 & TRN & \\
\hline CHEMBL94429 & 149237 & 6.8207 & 6.8436 & TRN & \\
\hline CHEMBL 30020 & 149237 & 7.8097 & 7.5811 & TRN & \\
\hline CHEMBL 98566 & 149237 & 7.3516 & 7.4584 & TRN & \\
\hline CHEMBL262298 & 149237 & 7.8794 & 8.0045 & TRN & \\
\hline CHEMBL419698 & 149237 & 5.0 & 4.9868 & TST & \\
\hline CHEMBL 317348 & 149237 & 7.9393 & 7.9625 & TRN & \\
\hline CHEMBL97277 & 149237 & 8.2596 & 8.3729 & TRN & \\
\hline CHEMBL96675 & 149237 & 7.3565 & 7.2999 & TRN & \\
\hline CHEMBL319141 & 149237 & 7.8861 & 7.7571 & TRN & \\
\hline CHEMBL97062 & 149237 & 7.6737 & 7.6524 & TRN & \\
\hline CHEMBL94441 & 149237 & 5.8386 & 5.8622 & TRN & \\
\hline CHEMBL317958 & 149237 & 7.0655 & 6.7741 & TRN & \\
\hline CHEMBL94517 & 149237 & 6.0329 & 5.1242 & TST & \\
\hline CHEMBL94662 & 149237 & 6.7151 & 5.3383 & TST & \\
\hline CHEMBL329354 & 149237 & 7.5622 & 7.3004 & TRN & \\
\hline CHEMBL95061 & 149237 & 5.9788 & 6.0047 & TRN & \\
\hline CHEMBL98343 & 149237 & 6.8681 & 6.9486 & TRN & \\
\hline CHEMBL319162 & 149237 & 7.9393 & 7.8138 & TRN & \\
\hline CHEMBL96676 & 149237 & 8.3372 & 8.3559 & TRN & \\
\hline CHEMBL95041 & 149237 & 7.1062 & 7.2036 & TRN & \\
\hline CHEMBL95901 & 149237 & 5.0 & 4.6273 & TST & \\
\hline CHEMBL97290 & 149237 & 6.5164 & 6.7741 & TRN & \\
\hline CHEMBL329809 & 149237 & 8.1612 & 8.2513 & TRN & \\
\hline CHEMBL97247 & 149237 & 8.301 & 8.3733 & TRN & \\
\hline CHEMBL447527 & 149237 & 7.1096 & 7.04799 & 9999999999 & TRN \\
\hline CHEMBL94832 & 149237 & 7.9586 & 7.96 & TRN & \\
\hline CHEMBL97472 & 149237 & 6.2306 & 6.2354 & TRN & \\
\hline
\end{tabular}




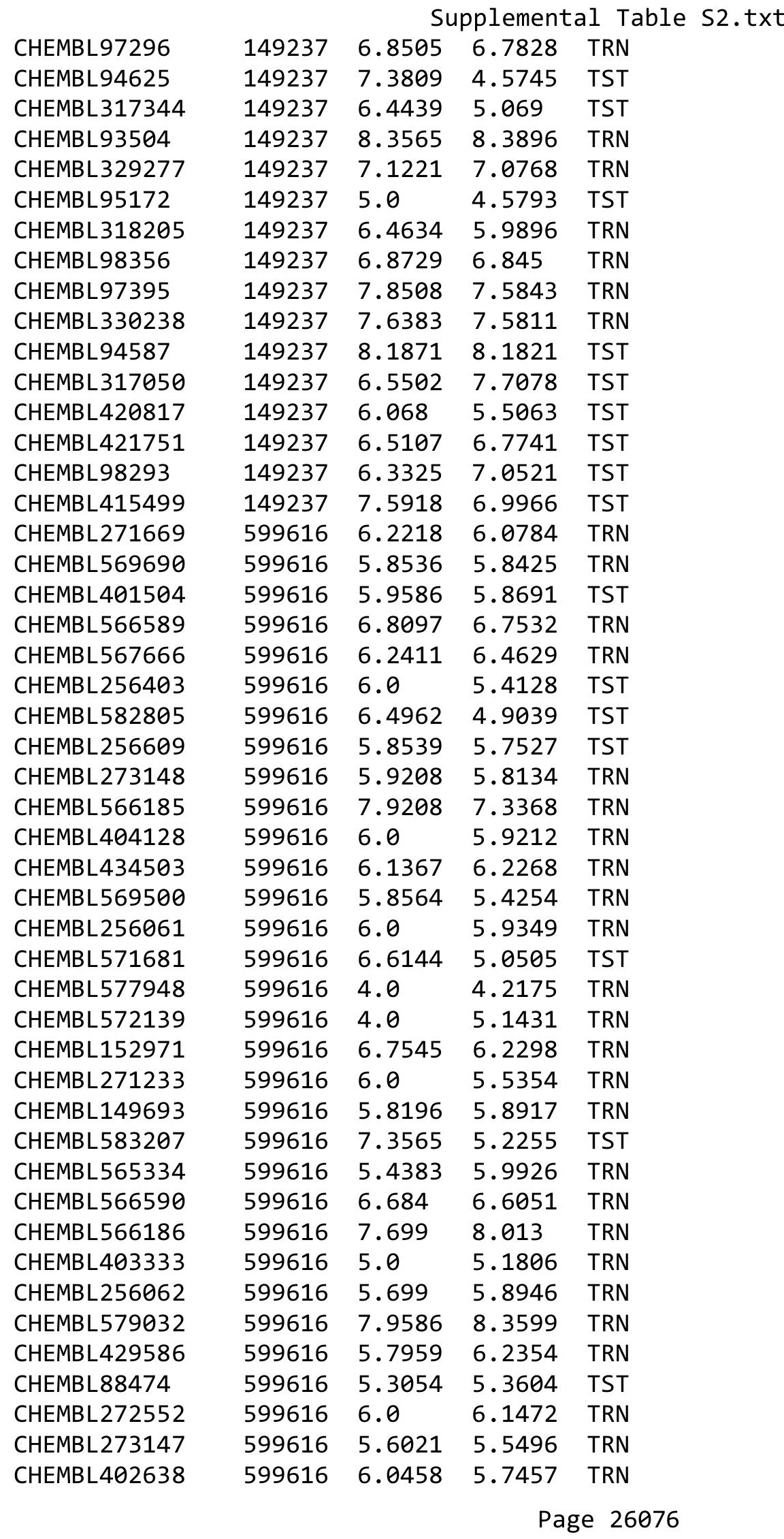




\begin{tabular}{|c|c|c|c|c|c|}
\hline \multirow[b]{2}{*}{ CHEMBL571920 } & \multicolumn{5}{|c|}{ Supplemental Table S2.txt } \\
\hline & 599616 & 5.1343 & 6.2654 & TRN & \\
\hline CHEMBL567020 & 599616 & 8.3979 & 8.6924 & TRN & \\
\hline CHEMBL572137 & 599616 & 6.3675 & 6.0104 & TRN & \\
\hline CHEMBL566561 & 599616 & 8.699 & 8.6348 & TRN & \\
\hline CHEMBL155045 & 599616 & 5.0429 & 5.228 & TRN & \\
\hline CHEMBL256204 & 599616 & 5.4202 & 5.3449 & TRN & \\
\hline CHEMBL568992 & 599616 & 7.0458 & 6.7737 & TRN & \\
\hline CHEMBL566558 & 599616 & 4.0 & 5.0032 & TRN & \\
\hline CHEMBL428064 & 599616 & 6.0 & 5.8533 & TRN & \\
\hline CHEMBL257446 & 599616 & 5.8861 & 5.5242 & TST & \\
\hline CHEMBL567665 & 599616 & 6.4101 & 6.6597 & TRN & \\
\hline CHEMBL429599 & 599616 & 5.9586 & 5.6651 & TRN & \\
\hline CHEMBL566146 & 599616 & 7.6778 & 7.6361 & TRN & \\
\hline CHEMBL540966 & 599616 & 5.8239 & 5.8168 & TRN & \\
\hline CHEMBL468454 & 599616 & 6.3019 & 5.6073 & TST & \\
\hline CHEMBL569058 & 599616 & 5.3408 & 4.5929 & TRN & \\
\hline CHEMBL153733 & 599616 & 6.0701 & 6.1179 & TRN & \\
\hline CHEMBL522502 & 599616 & 7.9586 & 6.9395 & TRN & \\
\hline CHEMBL269942 & 599616 & 5.6778 & 5.5891 & TRN & \\
\hline CHEMBL404588 & 599616 & 5.4318 & 5.8544 & TRN & \\
\hline CHEMBL153483 & 599616 & 6.2007 & 5.5978 & TRN & \\
\hline CHEMBL273149 & 599616 & 6.0458 & 5.5171 & TRN & \\
\hline CHEMBL257234 & 599616 & 5.4437 & 5.4144 & TST & \\
\hline CHEMBL579038 & 599616 & 6.5952 & 6.6328 & TRN & \\
\hline CHEMBL571921 & 599616 & 6.5072 & 6.237 & TRN & \\
\hline CHEMBL566392 & 599616 & 4.0 & 6.4125 & TST & \\
\hline CHEMBL272553 & 599616 & 5.9208 & 5.8871 & TST & \\
\hline CHEMBL565294 & 599616 & 5.0824 & 5.545 & TRN & \\
\hline CHEMBL584470 & 599616 & 7.4202 & 4.8198 & TST & \\
\hline CHEMBL151176 & 599616 & 6.1457 & 5.37799 & 9999999999 & TST \\
\hline CHEMBL42565 & 599616 & 5.6232 & 5.8944 & TRN & \\
\hline CHEMBL269941 & 599616 & 5.9586 & 5.8102 & TRN & \\
\hline CHEMBL566394 & 599616 & 6.1643 & 6.6595 & TST & \\
\hline CHEMBL256042 & 599616 & 5.6778 & 5.7563 & TRN & \\
\hline CHEMBL569060 & 599616 & 4.0 & 6.5515 & TST & \\
\hline CHEMBL249211 & 599616 & 6.3665 & 4.7746 & TST & \\
\hline CHEMBL270605 & 599616 & 5.4949 & 5.4326 & TRN & \\
\hline CHEMBL270799 & 599616 & 5.7696 & 5.941 & TST & \\
\hline CHEMBL313952 & 599616 & 6.2757 & 5.2889 & TST & \\
\hline CHEMBL569243 & 599616 & 5.1347 & 5.0793 & TRN & \\
\hline CHEMBL117554 & 599616 & 5.7371 & 5.614 & TRN & \\
\hline CHEMBL150520 & 599616 & 5.7533 & 5.5662 & TRN & \\
\hline CHEMBL571919 & 599616 & 5.2234 & 5.0379 & TRN & \\
\hline CHEMBL149553 & 599616 & 6.5045 & 5.6559 & TRN & \\
\hline CHEMBL90558 & 599616 & 4.5302 & 5.9169 & TST & \\
\hline CHEMBL565346 & 599616 & 7.3979 & 7.2723 & TRN & \\
\hline CHEMBL149800 & 599616 & 6.4634 & 6.0276 & TRN & \\
\hline CHEMBL571909 & 599616 & 7.0315 & 7.2682 & TRN & \\
\hline
\end{tabular}


Supplemental Table S2.txt

\begin{tabular}{|c|c|c|c|c|}
\hline CHEMBL569777 & 599616 & 6.6778 & 6.5424 & TRN \\
\hline CHEMBL153233 & 599616 & 5.6572 & 5.9479 & TRN \\
\hline CHEMBL566358 & 599616 & 7.3979 & 7.466 & TRN \\
\hline CHEMBL566591 & 599616 & 4.0 & 4.8182 & TRN \\
\hline CHEMBL579395 & 599616 & 5.586 & 5.3855 & TRN \\
\hline CHEMBL258314 & 599616 & 5.5528 & 5.8234 & TRN \\
\hline CHEMBL583849 & 599616 & 6.7055 & 5.0107 & TST \\
\hline CHEMBL566395 & 599616 & 6.6778 & 6.7534 & TRN \\
\hline CHEMBL 270584 & 599616 & 5.6021 & \multicolumn{2}{|c|}{ 5.343999999999999 } \\
\hline CHEMBL578787 & 599616 & 5.4325 & 6.4807 & TST \\
\hline CHEMBL3716567 & 1536566 & 6.301 & 6.471 & TRN \\
\hline CHEMBL3715362 & 1536566 & 7.301 & 7.086 & TST \\
\hline CHEMBL 3717117 & 1536566 & 4.301 & 5.5233 & TRN \\
\hline CHEMBL3717236 & 1536566 & 8.301 & 7.9481 & TRN \\
\hline CHEMBL3718473 & 1536566 & 7.301 & 7.3711 & TRN \\
\hline CHEMBL3716575 & 1536566 & 4.301 & 4.7905 & TRN \\
\hline CHEMBL3718523 & 1536566 & 8.301 & 7.6393 & TRN \\
\hline CHEMBL 3718538 & 1536566 & 4.301 & 5.3501 & TST \\
\hline CHEMBL3718863 & 1536566 & 4.301 & 4.6611 & TRN \\
\hline CHEMBL 3718766 & 1536566 & 4.301 & 4.6386 & TRN \\
\hline CHEMBL3718891 & 1536566 & 7.301 & 6.7595 & TRN \\
\hline CHEMBL3718965 & 1536566 & 7.301 & 6.9751 & TRN \\
\hline CHEMBL 3717287 & 1536566 & 7.301 & 7.7351 & TRN \\
\hline CHEMBL3715806 & 1536566 & 7.301 & 7.6886 & TRN \\
\hline CHEMBL 3718940 & 1536566 & 7.301 & 6.3308 & TRN \\
\hline CHEMBL3715956 & 1536566 & 7.301 & 6.9975 & TRN \\
\hline CHEMBL3715942 & 1536566 & 7.301 & 6.4 & TRN \\
\hline CHEMBL 3719326 & 1536566 & 7.301 & 7.2896 & TST \\
\hline CHEMBL3715546 & 1536566 & 8.301 & 7.9136 & TRN \\
\hline CHEMBL 3718453 & 1536566 & 8.301 & 7.1943 & TST \\
\hline CHEMBL 3717761 & 1536566 & 6.301 & 5.5451 & TRN \\
\hline CHEMBL3717424 & 1536566 & 8.301 & 7.8342 & TRN \\
\hline CHEMBL3717643 & 1536566 & 6.301 & 5.0702 & TRN \\
\hline CHEMBL3717998 & 1536566 & 8.301 & 9.0103 & TRN \\
\hline CHEMBL 3717276 & 1536566 & 4.301 & 5.8813 & TST \\
\hline CHEMBL3716358 & 1536566 & 4.301 & 4.6362 & TRN \\
\hline CHEMBL3715050 & 1536566 & 6.301 & 6.7864 & TRN \\
\hline CHEMBL3717846 & 1536566 & 8.301 & 8.5123 & TST \\
\hline CHEMBL 3717111 & 1536566 & 7.301 & 6.2317 & TRN \\
\hline CHEMBL 3717452 & 1536566 & 7.301 & 7.8812 & TRN \\
\hline CHEMBL3715887 & 1536566 & 8.301 & 7.6278 & TRN \\
\hline CHEMBL3716641 & 1536566 & 4.301 & 4.7172 & TRN \\
\hline CHEMBL3716318 & 1536566 & 7.301 & 6.0128 & TRN \\
\hline CHEMBL3718397 & 1536566 & 8.301 & 7.2516 & TST \\
\hline CHEMBL 3718166 & 1536566 & 7.301 & 7.4888 & TST \\
\hline CHEMBL 3719051 & 1536566 & 7.301 & 6.7958 & TRN \\
\hline CHEMBL3719165 & 1536566 & 6.301 & 6.5756 & TRN \\
\hline CHEMBL3715150 & 1536566 & 4.301 & 4.6218 & TRN \\
\hline
\end{tabular}


Supplemental Table S2.txt

\begin{tabular}{|c|c|c|c|c|}
\hline CHEMBL3717552 & 1536566 & 6.301 & 5.1917 & TRN \\
\hline CHEMBL3717227 & 1536566 & 4.301 & 4.669 & TRN \\
\hline CHEMBL3715041 & 1536566 & 6.301 & 6.4178 & TRN \\
\hline CHEMBL3718164 & 1536566 & 7.301 & 6.8963 & TRN \\
\hline CHEMBL3717713 & 1536566 & 7.301 & 6.4097 & TRN \\
\hline CHEMBL3719243 & 1536566 & 4.301 & 6.1616 & TST \\
\hline CHEMBL3718736 & 1536566 & 7.301 & 7.4942 & TRN \\
\hline CHEMBL3716968 & 1536566 & 7.301 & 8.1015 & TRN \\
\hline CHEMBL3718847 & 1536566 & 4.301 & 5.303 & TST \\
\hline CHEMBL3717468 & 1536566 & 7.301 & 7.86 & TRN \\
\hline CHEMBL3715821 & 1536566 & 8.301 & 8.4106 & TRN \\
\hline CHEMBL3719151 & 1536566 & 4.301 & 4.7382 & TRN \\
\hline CHEMBL3716597 & 1536566 & 7.301 & 7.7351 & TRN \\
\hline CHEMBL3716753 & 1536566 & 8.301 & 7.5227 & TRN \\
\hline CHEMBL3717022 & 1536566 & 8.301 & 8.6232 & TST \\
\hline CHEMBL3718499 & 1536566 & 6.301 & 5.2525 & TRN \\
\hline CHEMBL3714861 & 1536566 & 8.301 & 8.1103 & TST \\
\hline CHEMBL 3716744 & 1536566 & 7.301 & 7.7229 & TRN \\
\hline CHEMBL3715987 & 1536566 & 7.301 & 7.8145 & TST \\
\hline CHEMBL 3716741 & 1536566 & 8.301 & 8.1587 & TRN \\
\hline CHEMBL3716774 & 1536566 & 7.301 & 6.4664 & TRN \\
\hline CHEMBL3716321 & 1536566 & 4.301 & 4.8329 & TRN \\
\hline CHEMBL3717150 & 1536566 & 4.301 & 4.6444 & TRN \\
\hline CHEMBL 3716788 & 1536566 & 7.301 & 7.4999 & TRN \\
\hline CHEMBL3715380 & 1536566 & 8.301 & 7.2804 & TST \\
\hline CHEMBL3716888 & 1536566 & 4.301 & 5.0487 & TRN \\
\hline CHEMBL 3715872 & 1536566 & 7.301 & 8.4106 & TRN \\
\hline CHEMBL3715338 & 1536566 & 4.301 & 5.6109 & TST \\
\hline CHEMBL3718459 & 1536566 & 4.301 & 4.6575 & TRN \\
\hline CHEMBL3718066 & 1536566 & 7.301 & 7.7027 & TRN \\
\hline CHEMBL3715005 & 1536566 & 7.301 & 7.3843 & TST \\
\hline CHEMBL3717759 & 1536566 & 8.301 & 8.5166 & TRN \\
\hline CHEMBL3715570 & 1536566 & 4.301 & 4.7547 & TRN \\
\hline CHEMBL3715292 & 1536566 & 8.301 & 8.0611 & TST \\
\hline CHEMBL3717373 & 1536566 & 7.301 & 4.8839 & TRN \\
\hline CHEMBL3715470 & 1536566 & 4.301 & 5.1048 & TRN \\
\hline CHEMBL 3719083 & 1536566 & 4.301 & 6.2446 & TST \\
\hline CHEMBL3717193 & 1536566 & 7.301 & 7.3658 & TST \\
\hline CHEMBL3715148 & 1536566 & 8.301 & 7.3632 & TRN \\
\hline CHEMBL3718622 & 1536566 & 4.301 & 5.1951 & TRN \\
\hline CHEMBL3718578 & 1536566 & 4.301 & 4.8306 & TRN \\
\hline CHEMBL3716742 & 1536566 & 7.301 & 6.9515 & TST \\
\hline CHEMBL3715969 & 1536566 & 4.301 & 4.7176 & TRN \\
\hline CHEMBL3714849 & 1536566 & 6.301 & 6.6963 & TRN \\
\hline CHEMBL3717017 & 1536566 & 8.301 & 8.4725 & TRN \\
\hline CHEMBL3719286 & 1536566 & 7.301 & 7.5547 & TRN \\
\hline CHEMBL3717391 & 1536566 & 7.301 & 7.70299 & 9999999999 \\
\hline CHEMBL3716033 & 1536566 & 4.301 & 5.4162 & TST \\
\hline
\end{tabular}


Supplemental Table S2.txt

\begin{tabular}{|c|c|c|c|c|c|}
\hline CHEMBL 3717484 & 1536566 & 7.301 & \multicolumn{2}{|c|}{7.2410000000000005} & TST \\
\hline CHEMBL3717933 & 1536566 & 8.301 & 8.0497 & TRN & \\
\hline CHEMBL3716666 & 1536566 & 4.301 & 5.0804 & TRN & \\
\hline CHEMBL 3715589 & 1536566 & 7.301 & 7.0619 & TST & \\
\hline CHEMBL3717335 & 1536566 & 6.301 & 6.341 & TRN & \\
\hline CHEMBL 3718595 & 1536566 & 4.301 & 4.5597 & TRN & \\
\hline CHEMBL 3717584 & 1536566 & 7.301 & 7.0942 & TST & \\
\hline CHEMBL3716416 & 1536566 & 7.301 & 6.7783 & TRN & \\
\hline CHEMBL3716849 & 1536566 & 7.301 & 7.7378 & TRN & \\
\hline CHEMBL 3672860 & 1528161 & 9.2757 & 9.2697 & TRN & \\
\hline CHEMBL 3672871 & 1528161 & 9.1487 & 9.1522 & TRN & \\
\hline CHEMBL 3672872 & 1528161 & 9.5086 & 9.54 & TRN & \\
\hline CHEMBL 3667887 & 1528161 & 9.1024 & 9.2142 & TRN & \\
\hline CHEMBL3667895 & 1528161 & 6.0 & 6.1478 & TST & \\
\hline CHEMBL 3667883 & 1528161 & 9.6198 & 9.5979 & TRN & \\
\hline CHEMBL3667908 & 1528161 & 9.0269 & 9.0524 & TRN & \\
\hline CHEMBL3672873 & 1528161 & 8.9136 & 8.8953 & TRN & \\
\hline CHEMBL 3672853 & 1528161 & 8.1765 & 8.1917 & TRN & \\
\hline CHEMBL 3672891 & 1528161 & 8.9508 & 8.9959 & TRN & \\
\hline CHEMBL 3672857 & 1528161 & 9.1739 & 9.1802 & TRN & \\
\hline CHEMBL3672864 & 1528161 & 8.426 & 8.2913 & TST & \\
\hline CHEMBL 3672893 & 1528161 & 8.9208 & 8.9183 & TRN & \\
\hline CHEMBL 3672888 & 1528161 & 9.1739 & 9.1878 & TRN & \\
\hline CHEMBL 3672863 & 1528161 & 8.4609 & 8.7735 & TST & \\
\hline CHEMBL 3672858 & 1528161 & 8.3841 & 8.3723 & TRN & \\
\hline CHEMBL3903777 & 1528161 & 9.1427 & 8.8873 & TST & \\
\hline CHEMBL3667899 & 1528161 & 9.0555 & 9.068 & TRN & \\
\hline CHEMBL 3672852 & 1528161 & 8.1215 & 8.1264 & TRN & \\
\hline CHEMBL 3639717 & 1528161 & 9.0088 & 8.9893 & TRN & \\
\hline CHEMBL3667906 & 1528161 & 9.1871 & 9.1902 & TRN & \\
\hline CHEMBL3667884 & 1528161 & 9.1612 & 9.175 & TRN & \\
\hline CHEMBL 3672883 & 1528161 & 8.3036 & 8.325 & TRN & \\
\hline CHEMBL 3667888 & 1528161 & 9.3098 & 9.304 & TRN & \\
\hline CHEMBL 3672866 & 1528161 & 8.5702 & 8.554 & TRN & \\
\hline CHEMBL3672859 & 1528161 & 8.2782 & 8.8745 & TST & \\
\hline CHEMBL3672885 & 1528161 & 8.618 & 8.6006 & TRN & \\
\hline CHEMBL3667902 & 1528161 & 6.0 & 6.0183 & TRN & \\
\hline CHEMBL3672869 & 1528161 & 9.2924 & 9.2665 & TRN & \\
\hline CHEMBL 3672880 & 1528161 & 9.6198 & 9.6277 & TRN & \\
\hline CHEMBL 3667892 & 1528161 & 9.0044 & 8.9743 & TRN & \\
\hline CHEMBL 3672882 & 1528161 & 6.0 & 5.4333 & TST & \\
\hline CHEMBL3957967 & 1528161 & 8.4868 & 9.335 & TST & \\
\hline CHEMBL3667880 & 1528161 & 9.1367 & 9.6357 & TST & \\
\hline CHEMBL 3672855 & 1528161 & 8.7721 & 8.7535 & TRN & \\
\hline CHEMBL 3667910 & 1528161 & 8.8447 & 8.8339 & TRN & \\
\hline CHEMBL 3667904 & 1528161 & 8.8761 & 8.8776 & TST & \\
\hline CHEMBL3667893 & 1528161 & 9.0757 & 9.1112 & TRN & \\
\hline CHEMBL3667894 & 1528161 & 8.9586 & 8.9748 & TRN & \\
\hline
\end{tabular}


Supplemental Table S2.txt

\begin{tabular}{|c|c|c|c|c|}
\hline 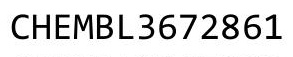 & & & & TRN \\
\hline HEMBL3667889 & 528161 & 6.0 & 0221 & \\
\hline HEMBL3 & & 9.1612 & .185 & \\
\hline 392 & & & & \\
\hline EMB & & 76 & & \\
\hline HEMBL3667912 & 528161 & 8.5918 & 8942 & \\
\hline HEMBL3667879 & 528161 & 9.8539 & .3376 & \\
\hline HEMBL & 61 & 8.2573 & 2741 & \\
\hline 396 & 51 & 66 & .9211 & \\
\hline AEMBL & 51 & 13 & & \\
\hline HEMBL3672887 & 528161 & 9.4089 & 3761 & \\
\hline AEMBL3672884 & $52 \varepsilon$ & 9.2007 & & \\
\hline HEMBL; & 51 & .5376 & & \\
\hline HEMBL; & & 72 & & \\
\hline HEMBL & 51 & 05 & & \\
\hline AEMBL3 & 51 & 9.3872 & & \\
\hline HEMBL3667898 & 51 & 8. & 75 & \\
\hline HEMBL: & 1 & 67 & 01 & \\
\hline HEMBL & & & & \\
\hline HEMBL & 51 & 069 & & \\
\hline HEMBL36 & 51 & 6.0 & & \\
\hline HEMBL 367 & 51 & 9.2757 & & IRIN \\
\hline HEMBL3 & 61 & 33 & & RN \\
\hline HEMBL & & & & RN \\
\hline HEM & & & & RN \\
\hline AEMBL3 & & & & $\mathrm{RN}$ \\
\hline HEMBL 367 & 51 & 9.1487 & & RN \\
\hline HEMBL36 & 1 & 6 & & RN \\
\hline 1 & & & & ST \\
\hline HEME & & & & ST \\
\hline HEMBL 366 & & & & S \\
\hline HEMBL1504592 & 4 & 5 . & & RN \\
\hline HEMBL42 & & 6 & 86 & RN \\
\hline 74 & & & & TRN \\
\hline HEMBL132 & & & & RN \\
\hline HEMBL161 & & 6. & & IRN \\
\hline HEMBL132 & 4 & 6 . & & RN \\
\hline AFMRI 15 & & 31 & & RN \\
\hline 1 & & & & RIN \\
\hline HEMBL15 & & & & RN \\
\hline HEMBL408 & 14 & 5 . & & RN \\
\hline HEMBL15 & & & & ST \\
\hline HEMBL15 & & 5 . & & RN \\
\hline CHEMBL149 & & & & RIN \\
\hline HEMBL156 & & 5.05 & & RN \\
\hline HEMBL547§ & 4 & 68 & 23 & $\mathrm{~N}$ \\
\hline-1 & & & & \\
\hline & & 217 & & \\
\hline
\end{tabular}

Page 26081 


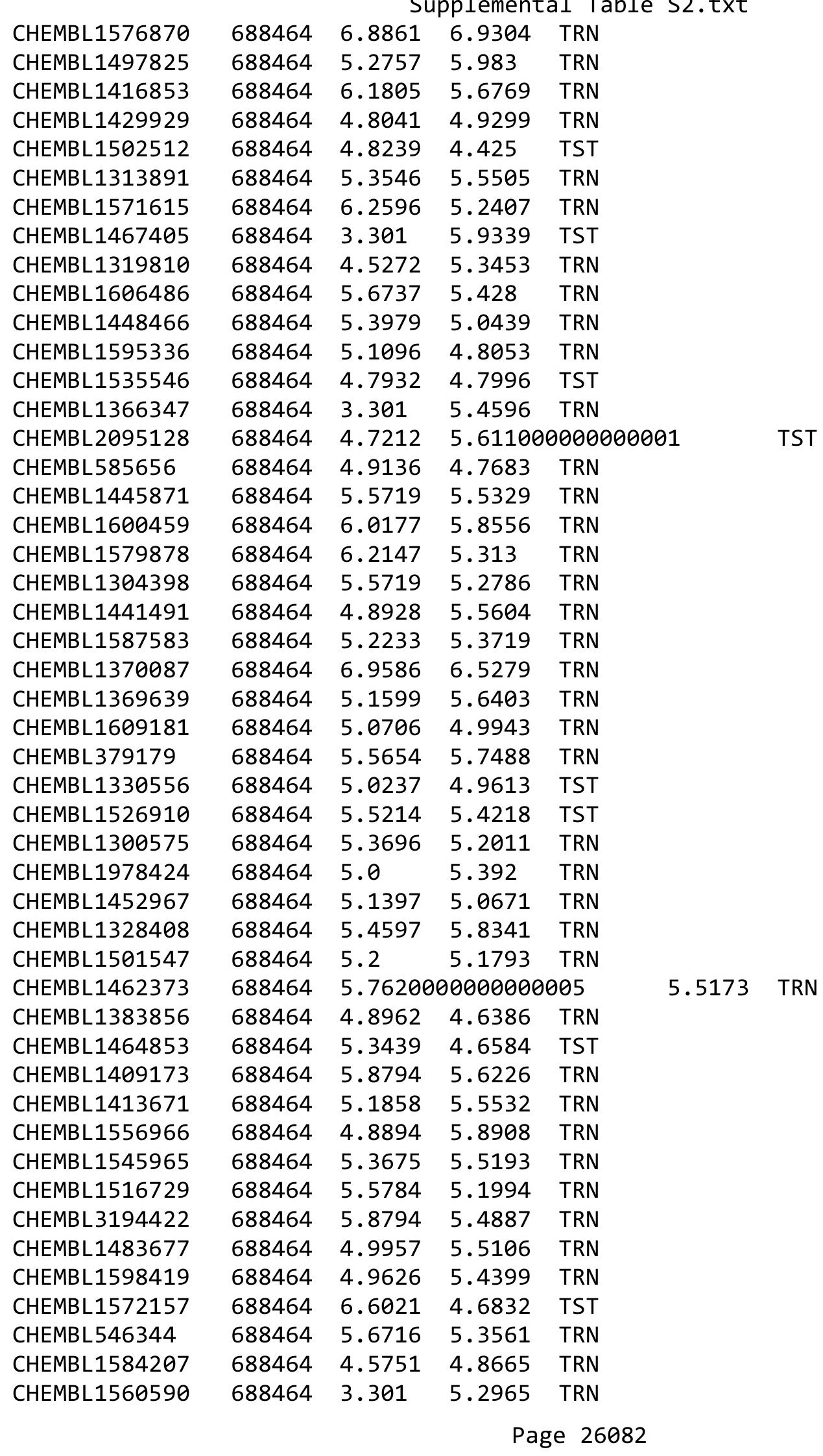




\begin{tabular}{|c|c|c|c|c|c|}
\hline CHEMBL3213419 & 688464 & \multicolumn{4}{|c|}{ Supplemental Table s2.txt } \\
\hline CHEMBL 1306522 & 688464 & 5.1463 & 5.4246 & TRN & \\
\hline CHEMBL1605879 & 688464 & 5.0565 & 5.2659 & TRN & \\
\hline CHEMBL 1487967 & 688464 & 6.1805 & 5.8852 & TRN & \\
\hline CHEMBL1320504 & 688464 & 5.6536 & 5.4246 & TRN & \\
\hline CHEMBL1544823 & 688464 & 5.1574 & 4.5965 & TRN & \\
\hline CHEMBL1332688 & 688464 & 5.2161 & 5.6748 & TRN & \\
\hline CHEMBL1460126 & 688464 & 5.1844 & 5.3396 & TRN & \\
\hline CHEMBL1408236 & 688464 & 5.4559 & 5.7783 & TRN & \\
\hline CHEMBL1428003 & 688464 & 4.8861 & 4.3809 & TRN & \\
\hline CHEMBL1467876 & 688464 & 5.0595 & 5.2216 & TRN & \\
\hline CHEMBL1497939 & 688464 & 8.0088 & 6.3845 & TRN & \\
\hline CHEMBL1412137 & 688464 & 5.1192 & 5.3303 & TRN & \\
\hline CHEMBL1498591 & 688464 & 5.2503 & 5.525 & TRN & \\
\hline CHEMBL1518946 & 688464 & 5.51 & 5.6489 & TRN & \\
\hline CHEMBL1482541 & 688464 & 6.8539 & 5.5873 & TRN & \\
\hline CHEMBL3199298 & 688464 & 5.9101 & 6.0365 & TRN & \\
\hline CHEMBL1606813 & 688464 & 5.0799 & 5.6705 & TRN & \\
\hline CHEMBL1328426 & 688464 & 5.4498 & 5.2953 & TRN & \\
\hline CHEMBL1501014 & 688464 & 5.8665 & 5.3188 & TRN & \\
\hline CHEMBL1373664 & 688464 & 5.5918 & 5.4916 & TRN & \\
\hline CHEMBL1389449 & 688464 & 5.1124 & 4.7925 & TRN & \\
\hline CHEMBL1427801 & 688464 & 5.9914 & 5.61799 & 9999999999 & TST \\
\hline CHEMBL1490887 & 688464 & 4.9208 & 4.7968 & TST & \\
\hline CHEMBL3196469 & 688464 & 6.2441 & 5.8996 & TRN & \\
\hline CHEMBL1546426 & 688464 & 3.301 & 4.4544 & TRN & \\
\hline CHEMBL191750 & 688464 & 4.8125 & 5.0645 & TRN & \\
\hline CHEMBL1379970 & 688464 & 6.699 & 7.2151 & TST & \\
\hline CHEMBL1594867 & 688464 & 5.6968 & 5.8165 & TRN & \\
\hline CHEMBL1568892 & 688464 & 5.6946 & 5.9581 & TRN & \\
\hline CHEMBL1412795 & 688464 & 5.1884 & 5.4496 & TRN & \\
\hline CHEMBL234583 & 688464 & 5.6345 & 5.3724 & TRN & \\
\hline CHEMBL1380028 & 688464 & 4.8794 & 4.8144 & TRN & \\
\hline CHEMBL1427979 & 688464 & 4.8665 & 5.4074 & TRN & \\
\hline CHEMBL1502133 & 688464 & 6.1805 & 5.7764 & TRN & \\
\hline CHEMBL1446827 & 688464 & 5.9136 & 5.8894 & TRN & \\
\hline CHEMBL1577938 & 688464 & 6.1135 & 6.4355 & TRN & \\
\hline CHEMBL1393129 & 688464 & 6.3979 & 6.0957 & TRN & \\
\hline CHEMBL475627 & 688464 & 6.0655 & 5.7621 & TRN & \\
\hline CHEMBL1491705 & 688464 & 6.2366 & 5.653 & TRN & \\
\hline CHEMBL3190812 & 688464 & 6.7447 & 5.9671 & TRN & \\
\hline CHEMBL3191594 & 688464 & 6.1024 & 5.9074 & TRN & \\
\hline CHEMBL1603691 & 688464 & 5.4425 & 5.3677 & TRN & \\
\hline CHEMBL3190131 & 688464 & 6.7212 & 5.8934 & TRN & \\
\hline CHEMBL1480522 & 688464 & 6.5528 & 5.7461 & TRN & \\
\hline CHEMBL1320514 & 688464 & 6.3768 & 6.0831 & TRN & \\
\hline CHEMBL1608261 & 688464 & 4.7721 & 5.3433 & TST & \\
\hline CHEMBL3197506 & 688464 & 5.5528 & 5.7029 & TRN & \\
\hline
\end{tabular}




\begin{tabular}{|c|c|c|c|c|c|}
\hline & & \multicolumn{4}{|c|}{ Supplemental Table S2.txt } \\
\hline CHEMBL1516803 & 688464 & 4.399 & 4.8299 & TRN & \\
\hline CHEMBL1610429 & 688464 & 5.5317 & 5.3494 & TRN & \\
\hline CHEMBL1331514 & 688464 & 6.2218 & 6.0601 & TRN & \\
\hline CHEMBL1471717 & 688464 & 5.5157 & 5.2376 & TRN & \\
\hline CHEMBL1492738 & 688464 & 5.8477 & \multicolumn{2}{|c|}{5.257999999999999} & TRN \\
\hline CHEMBL1601133 & 688464 & 4.5591 & 5.3933 & TRN & \\
\hline CHEMBL1579258 & 688464 & 5.5171 & 6.2195 & TRN & \\
\hline CHEMBL1374746 & 688464 & 5.2924 & 5.3882 & TRN & \\
\hline CHEMBL1314042 & 688464 & 4.6576 & 4.4055 & TRN & \\
\hline CHEMBL1389366 & 688464 & 5.4711 & 5.3251 & TRN & \\
\hline CHEMBL1362898 & 688464 & 3.301 & 4.5817 & TRN & \\
\hline CHEMBL1605336 & 688464 & 3.301 & 4.5697 & TRN & \\
\hline CHEMBL1988310 & 688464 & 5.4522 & 5.7345 & TST & \\
\hline CHEMBL1504575 & 688464 & 5.0453 & 5.7112 & TRN & \\
\hline CHEMBL1527929 & 688464 & 4.3768 & 4.8559 & TST & \\
\hline CHEMBL1374135 & 688464 & 4.6968 & 4.8025 & TRN & \\
\hline CHEMBL1598510 & 688464 & 5.4089 & 5.1121 & TRN & \\
\hline CHEMBL149322 & 688464 & 5.5243 & 5.3304 & TRN & \\
\hline CHEMBL1495417 & 688464 & 6.2291 & 5.8505 & TRN & \\
\hline CHEMBL1596406 & 688464 & 5.8996 & 6.0268 & TRN & \\
\hline CHEMBL1352955 & 688464 & 5.3585 & 5.0986 & TRN & \\
\hline CHEMBL1307028 & 688464 & 5.1772 & 5.1904 & TRN & \\
\hline CHEMBL1423060 & 688464 & 5.9431 & 5.5326 & TRN & \\
\hline CHEMBL1510646 & 688464 & 6.5686 & 6.0331 & TRN & \\
\hline CHEMBL1385588 & 688464 & 4.9172 & 4.7847 & TRN & \\
\hline CHEMBL1967857 & 688464 & 5.6882 & 5.7854 & TRN & \\
\hline CHEMBL1493263 & 688464 & 3.301 & 4.7355 & TRN & \\
\hline CHEMBL1527186 & 688464 & 5.5528 & 5.6309 & TRN & \\
\hline CHEMBL1462991 & 688464 & 5.6253 & 5.34399 & 9999999999 & TRN \\
\hline CHEMBL1386649 & 688464 & 4.7328 & 4.9323 & TST & \\
\hline CHEMBL1518774 & 688464 & 3.301 & 5.5912 & TRN & \\
\hline CHEMBL1459767 & 688464 & 6.2147 & 5.57100 & 0000000001 & TRN \\
\hline CHEMBL1403048 & 688464 & 5.3925 & 5.42700 & 00000000005 & TRN \\
\hline CHEMBL1502354 & 688464 & 4.7447 & 5.4272 & TRN & \\
\hline CHEMBL1471225 & 688464 & 5.0867 & 5.325 & TRN & \\
\hline CHEMBL1993627 & 688464 & 6.0915 & 5.8076 & TRN & \\
\hline CHEMBL1425919 & 688464 & 5.475 & 4.58899 & 99999999995 & TRN \\
\hline CHEMBL1312582 & 688464 & 5.2027 & 5.1099 & TRN & \\
\hline CHEMBL1319492 & 688464 & 5.7773 & 5.2514 & TRN & \\
\hline CHEMBL1494181 & 688464 & 5.4271 & 5.5774 & TRN & \\
\hline CHEMBL1363955 & 688464 & 5.9508 & 5.0758 & TRN & \\
\hline CHEMBL1308451 & 688464 & 5.7696 & 5.0603 & TRN & \\
\hline CHEMBL1347687 & 688464 & 5.7799 & 5.5042 & TRN & \\
\hline CHEMBL1369691 & 688464 & 5.3645 & 5.0426 & TST & \\
\hline CHEMBL1541834 & 688464 & 5.2358 & 5.8636 & TST & \\
\hline CHEMBL1382028 & 688464 & 5.5258 & 5.6981 & TRN & \\
\hline CHEMBL1332602 & 688464 & 4.9208 & 5.5152 & TRN & \\
\hline CHEMBL1418032 & 688464 & 4.8729 & 5.1241 & TRN & \\
\hline
\end{tabular}


Supplemental Table S2.txt

\begin{tabular}{|c|c|c|c|c|c|}
\hline CHEMBL374632 & 688464 & 5.9747 & 6.5339 & TRN & \\
\hline CHEMBL1456099 & 688464 & 5.4401 & 5.2746 & TRN & \\
\hline CHEMBL1419519 & 688464 & 5.5654 & 5.0879 & TRN & \\
\hline CHEMBL1457060 & 688464 & \multicolumn{2}{|c|}{5.7620000000000005} & 5.6188 & TRN \\
\hline CHEMBL1543238 & 688464 & 6.6383 & 6.5844 & TRN & \\
\hline CHEMBL1331520 & 688464 & 5.5143 & 5.5146 & TRN & \\
\hline CHEMBL1496640 & 688464 & 6.2441 & 5.3147 & TRN & \\
\hline CHEMBL1418018 & 688464 & 5.5361 & 5.9539 & TRN & \\
\hline CHEMBL1304009 & 688464 & 5.4056 & 5.2383 & TRN & \\
\hline CHEMBL1582048 & 688464 & 5.3595 & 5.1449 & TRN & \\
\hline CHEMBL1904348 & 688464 & 5.7055 & 5.4217 & TST & \\
\hline CHEMBL1580774 & 688464 & 5.7696 & 5.3889 & TRN & \\
\hline CHEMBL1521476 & 688464 & 5.52 & 4.9757 & TRN & \\
\hline CHEMBL1319679 & 688464 & 5.7852 & 5.3555 & TRN & \\
\hline CHEMBL1406630 & 688464 & 5.1972 & 4.93199 & 99999999995 & TRN \\
\hline CHEMBL1543742 & 688464 & 5.5406 & 4.8865 & TRN & \\
\hline CHEMBL1454247 & 688464 & 5.6635 & 5.5544 & TRN & \\
\hline CHEMBL 210730 & 688464 & 5.4522 & 5.8702 & TRN & \\
\hline CHEMBL1305233 & 688464 & 5.767 & 5.6213 & TRN & \\
\hline CHEMBL1453291 & 688464 & 5.3768 & 5.3328 & TRN & \\
\hline CHEMBL1451037 & 688464 & 5.7033 & 5.4787 & TRN & \\
\hline CHEMBL1338533 & 688464 & 4.9172 & 5.2125 & TST & \\
\hline CHEMBL1369231 & 688464 & 6.1739 & 6.2597 & TRN & \\
\hline CHEMBL1986151 & 688464 & 4.5935 & 5.7852 & TRN & \\
\hline CHEMBL1365191 & 688464 & 3.301 & 4.6027 & TRN & \\
\hline CHEMBL1453505 & 688464 & 4.8239 & 5.0856 & TST & \\
\hline CHEMBL1521023 & 688464 & 6.5086 & 6.434 & TRN & \\
\hline CHEMBL1549430 & 688464 & 5.153 & 5.1667 & TRN & \\
\hline CHEMBL1327079 & 688464 & 5.2351 & 5.2189 & TST & \\
\hline CHEMBL1386804 & 688464 & 6.1367 & 6.6686 & TRN & \\
\hline CHEMBL1413032 & 688464 & 5.7399 & 4.8641 & TRN & \\
\hline CHEMBL1329446 & 688464 & 5.983 & 6.2695 & TRN & \\
\hline CHEMBL1467411 & 688464 & 4.9101 & 5.6303 & TRN & \\
\hline CHEMBL1373194 & 688464 & 4.8861 & 5.3036 & TST & \\
\hline CHEMBL1303835 & 688464 & 6.6383 & 5.3163 & TRN & \\
\hline CHEMBL1345388 & 688464 & 4.8182 & 5.1576 & TRN & \\
\hline CHEMBL1460296 & 688464 & 4.4634 & 5.1576 & TRN & \\
\hline CHEMBL1493429 & 688464 & 6.0969 & 6.1172 & TRN & \\
\hline CHEMBL1438451 & 688464 & 4.8962 & 5.371 & TRN & \\
\hline CHEMBL1307919 & 688464 & 6.6778 & 6.0728 & TRN & \\
\hline CHEMBL1440954 & 688464 & 6.9586 & 6.6619 & TRN & \\
\hline CHEMBL1445486 & 688464 & 5.2708 & 5.273 & TRN & \\
\hline CHEMBL1441350 & 688464 & 5.2684 & 5.5303 & TRN & \\
\hline CHEMBL1424109 & 688464 & 5.8041 & 5.3746 & TRN & \\
\hline CHEMBL1451791 & 688464 & 5.5421 & 5.6314 & TRN & \\
\hline CHEMBL600572 & 688464 & 5.2125 & 5.8226 & TRN & \\
\hline CHEMBL532504 & 688464 & 4.4647 & 4.7931 & TST & \\
\hline CHEMBL1519352 & 688464 & 4.7305 & 5.1374 & TRN & \\
\hline
\end{tabular}




\begin{tabular}{|c|c|c|c|c|c|}
\hline & & \multicolumn{4}{|c|}{ Supplemental Table s2.txt } \\
\hline CHEMBL1327749 & 688464 & 5.9393 & 5.5872 & TRN & \\
\hline CHEMBL1541182 & 688464 & 5.1421 & 5.4768 & TRN & \\
\hline CHEMBL3208365 & 688464 & 5.2118 & 5.4387 & TST & \\
\hline CHEMBL1570371 & 688464 & 6.0 & 5.69799 & 99999999995 & TRN \\
\hline CHEMBL1537098 & 688464 & 6.6383 & 6.8918 & TRN & \\
\hline CHEMBL1378863 & 688464 & 5.7905 & 5.6767 & TST & \\
\hline CHEMBL1323968 & 688464 & 5.8268 & 5.7738 & TRN & \\
\hline CHEMBL1343248 & 688464 & 5.6716 & 6.0429 & TRN & \\
\hline CHEMBL1581468 & 688464 & 5.4306 & 5.4909 & TRN & \\
\hline CHEMBL1372039 & 688464 & 5.4145 & 5.1302 & TRN & \\
\hline CHEMBL1309232 & 688464 & 4.8386 & 5.5031 & TRN & \\
\hline CHEMBL1530797 & 688464 & 4.9208 & 4.5243 & TST & \\
\hline CHEMBL1491676 & 688464 & 3.301 & 4.5935 & TST & \\
\hline CHEMBL1568558 & 688464 & 5.2182 & 5.3234 & TRN & \\
\hline CHEMBL1445776 & 688464 & 4.9788 & 4.6679 & TST & \\
\hline CHEMBL1399952 & 688464 & 5.2366 & 5.3236 & TRN & \\
\hline CHEMBL1352348 & 688464 & 5.4134 & 5.2621 & TRN & \\
\hline CHEMBL482116 & 688464 & 6.5229 & 5.9666 & TRN & \\
\hline CHEMBL1579104 & 688464 & 5.7852 & 5.3997 & TRN & \\
\hline CHEMBL1323978 & 688464 & 5.9508 & 5.61 & TRN & \\
\hline CHEMBL1386466 & 688464 & 5.4522 & 5.7952 & TRN & \\
\hline CHEMBL1342109 & 688464 & 5.8447 & 4.6909 & TRN & \\
\hline CHEMBL1415517 & 688464 & 3.301 & 4.5535 & TRN & \\
\hline CHEMBL1603662 & 688464 & 5.8894 & 5.4001 & TST & \\
\hline CHEMBL1417974 & 688464 & 5.4306 & 5.4279 & TST & \\
\hline CHEMBL1427279 & 688464 & 6.699 & 5.6145 & TST & \\
\hline CHEMBL1545169 & 688464 & 5.1952 & 5.0521 & TST & \\
\hline CHEMBL1341192 & 688464 & 3.301 & 5.74100 & 00000000005 & TST \\
\hline CHEMBL1453801 & 688464 & 5.8297 & 4.9955 & TST & \\
\hline CHEMBL428064 & 688464 & 4.6091 & 5.6004 & TST & \\
\hline CHEMBL1450119 & 688464 & 6.0862 & 5.7559 & TST & \\
\hline CHEMBL1486922 & 688464 & 4.9066 & 5.4257 & TST & \\
\hline CHEMBL1426911 & 688464 & 4.4191 & 5.3641 & TST & \\
\hline CHEMBL1540894 & 688464 & 5.51 & 5.3011 & TST & \\
\hline CHEMBL1516879 & 688464 & 5.4473 & 5.032 & TST & \\
\hline CHEMBL1403830 & 688464 & 5.0958 & 4.95 & TST & \\
\hline CHEMBL1329235 & 688464 & 5.1586 & 6.4417 & TST & \\
\hline CHEMBL1527400 & 688464 & 5.0867 & 5.944 & TST & \\
\hline CHEMBL512749 & 688464 & 5.7399 & 5.5661 & TST & \\
\hline CHEMBL1372889 & 688464 & 8.0088 & 7.3016 & TST & \\
\hline CHEMBL1517703 & 688464 & 5.0448 & 5.5623 & TST & \\
\hline CHEMBL260342 & 688464 & 6.0132 & 6.0214 & TST & \\
\hline CHEMBL1384654 & 688464 & 5.6198 & 5.5084 & TST & \\
\hline CHEMBL1326967 & 688464 & 5.71899 & 99999999 & 5.8899 & TST \\
\hline CHEMBL1378118 & 688464 & 4.8794 & 4.6977 & TST & \\
\hline CHEMBL1370991 & 688464 & 8.0088 & 6.6732 & TST & \\
\hline CHEMBL1492533 & 688464 & 5.4584 & 5.2323 & TST & \\
\hline CHEMBL1406859 & 688464 & 5.0685 & 5.3332 & TST & \\
\hline
\end{tabular}




\begin{tabular}{|c|c|c|c|c|c|c|}
\hline & & \multicolumn{5}{|c|}{ Supplemental Table S2.txt } \\
\hline CHEMBL1585105 & 688464 & 5.3556 & 5.2753 & TST & & \\
\hline CHEMBL1386322 & 688464 & 5.51 & 5.4421 & TST & & \\
\hline CHEMBL146525 & 688464 & 4.6596 & 5.0464 & TST & & \\
\hline CHEMBL1485577 & 688464 & 4.8539 & 5.5774 & TST & & \\
\hline CHEMBL1521960 & 688464 & 5.32700 & 000000006 & 01 & 5.5933 & TST \\
\hline CHEMBL1567593 & 688464 & 5.7375 & 5.9229 & TST & & \\
\hline CHEMBL1301573 & 688464 & 4.9706 & 5.4461 & TST & & \\
\hline CHEMBL1450780 & 688464 & 3.301 & 5.8682 & TST & & \\
\hline CHEMBL1558159 & 688464 & 4.8827 & 5.0286 & TST & & \\
\hline CHEMBL1564077 & 688464 & 4.5528 & 4.6171 & TST & & \\
\hline CHEMBL1498959 & 688464 & 4.6271 & 5.1223 & TST & & \\
\hline CHEMBL1583650 & 688464 & 4.8794 & 6.3575 & TST & & \\
\hline CHEMBL3677143 & 1528099 & 6.0 & 6.3417 & TST & & \\
\hline CHEMBL3984256 & 1528099 & 3.301 & 5.5588 & TST & & \\
\hline CHEMBL3672185 & 1528099 & 6.4231 & 5.5763 & TRN & & \\
\hline CHEMBL 3677003 & 1528099 & 6.4145 & 5.733 & TRN & & \\
\hline CHEMBL3976438 & 1528099 & 6.0 & 6.7699 & TST & & \\
\hline CHEMBL3677062 & 1528099 & 6.8327 & 7.2434 & TRN & & \\
\hline CHEMBL3945030 & 1528099 & 3.301 & 5.8339 & TST & & \\
\hline CHEMBL3672176 & 1528099 & 6.7212 & 6.2077 & TRN & & \\
\hline CHEMBL 3898664 & 1528099 & 6.0 & 5.6373 & TST & & \\
\hline CHEMBL 3925569 & 1528099 & 5.9948 & 5.4497 & TRN & & \\
\hline CHEMBL3677077 & 1528099 & 6.16299 & 99999999 & 99 & 6.1301 & TST \\
\hline CHEMBL3915554 & 1528099 & 6.0 & 6.3239 & TST & & \\
\hline CHEMBL3677031 & 1528099 & 6.0 & 5.8945 & TRN & & \\
\hline CHEMBL3955966 & 1528099 & 5.45799 & 99999999 & 99 & 5.3761 & TRN \\
\hline CHEMBL3682136 & 1528099 & 6.6126 & 6.6169 & TRN & & \\
\hline CHEMBL 3682016 & 1528099 & 7.1249 & 7.0782 & TRN & & \\
\hline CHEMBL 3682067 & 1528099 & 7.1135 & 7.4013 & TRN & & \\
\hline CHEMBL3672189 & 1528099 & 3.301 & 5.4071 & TST & & \\
\hline CHEMBL 3909387 & 1528099 & 6.0 & 7.1501 & TRN & & \\
\hline CHEMBL3964269 & 1528099 & 3.301 & 5.398 & TRN & & \\
\hline CHEMBL 3677014 & 1528099 & 6.8268 & 6.0594 & TRN & & \\
\hline CHEMBL3914183 & 1528099 & 5.3831 & 6.7556 & TRN & & \\
\hline CHEMBL3677207 & 1528099 & 6.0 & 6.5166 & TRN & & \\
\hline CHEMBL3682006 & 1528099 & 8.6576 & 7.4651 & TRN & & \\
\hline CHEMBL3677013 & 1528099 & 7.6576 & 7.5384 & TRN & & \\
\hline CHEMBL 3677010 & 1528099 & 6.5421 & 5.9197 & TRN & & \\
\hline CHEMBL3949499 & 1528099 & 5.694 & 5.352 & TRN & & \\
\hline CHEMBL3913515 & 1528099 & 8.6576 & 7.6176 & TRN & & \\
\hline CHEMBL 3948460 & 1528099 & 6.0 & 6.1058 & TRN & & \\
\hline CHEMBL3682076 & 1528099 & 6.3979 & 6.2988 & TRN & & \\
\hline CHEMBL 3906448 & 1528099 & 7.5376 & $6.62200 t$ & 0000000001 & & TRN \\
\hline CHEMBL3677126 & 1528099 & 6.7258 & 5.6016 & TST & & \\
\hline CHEMBL 3677075 & 1528099 & 6.2652 & 6.3477 & TRN & & \\
\hline CHEMBL 3672136 & 1528099 & 6.2336 & 6.2989 & TRN & & \\
\hline CHEMBL3682113 & 1528099 & 6.0405 & 5.9875 & TRN & & \\
\hline CHEMBL3672168 & 1528099 & 6.0 & 5.9499 & TRN & & \\
\hline
\end{tabular}




\begin{tabular}{|c|c|c|c|c|c|c|}
\hline \multirow[b]{2}{*}{ CHEMBL3984142 } & \multicolumn{5}{|c|}{ Supplemental Table S2.txt } & \\
\hline & 1528099 & 6.585 & 6.3713 & TRN & & \\
\hline CHEMBL3677037 & 1528099 & 7.0706 & 6.92700 & 00000000005 & TRN & \\
\hline CHEMBL3933761 & 1528099 & 6.0 & 6.4756 & TST & & \\
\hline CHEMBL3677098 & 1528099 & 6.3344 & 6.7342 & TRN & & \\
\hline CHEMBL3677039 & 1528099 & 6.2396 & 6.4877 & TRN & & \\
\hline CHEMBL3908964 & 1528099 & 6.0 & 6.38700 & 00000000005 & TRN & \\
\hline CHEMBL3677050 & 1528099 & 7.0088 & 7.3283 & TRN & & \\
\hline CHEMBL3677052 & 1528099 & 6.5331 & 6.7824 & TRN & & \\
\hline CHEMBL 3677064 & 1528099 & 7.4089 & 8.2016 & TRN & & \\
\hline CHEMBL3677012 & 1528099 & 5.187 & 4.9003 & TRN & & \\
\hline CHEMBL3677104 & 1528099 & 6.5258 & 6.1401 & TRN & & \\
\hline CHEMBL3682125 & 1528099 & 6.8601 & 7.4457 & TRN & & \\
\hline CHEMBL 3672227 & 1528099 & 5.5031 & 5.468 & TRN & & \\
\hline CHEMBL3672148 & 1528099 & 6.0 & 6.4359 & TRN & & \\
\hline CHEMBL3982011 & 1528099 & 3.301 & 4.6665 & TRN & & \\
\hline CHEMBL3918203 & 1528099 & 6.7721 & 6.1319 & TRN & & \\
\hline CHEMBL3677083 & 1528099 & 6.1831 & 6.3311 & TST & & \\
\hline CHEMBL3904820 & 1528099 & 6.0 & 6.4264 & TRN & & \\
\hline CHEMBL3926617 & 1528099 & 5.3933 & 4.8353 & TRN & & \\
\hline CHEMBL3677103 & 1528099 & 6.5834 & 6.4303 & TST & & \\
\hline CHEMBL3672230 & 1528099 & 7.0506 & 6.9544 & TST & & \\
\hline CHEMBL3924848 & 1528099 & 6.5361 & 6.0869 & TRN & & \\
\hline CHEMBL3682119 & 1528099 & 5.5533 & 5.2755 & TST & & \\
\hline CHEMBL3677036 & 1528099 & 7.1612 & 7.6895 & TRN & & \\
\hline CHEMBL3956178 & 1528099 & 6.466 & 6.8352 & TRN & & \\
\hline CHEMBL3682084 & 1528099 & 7.2291 & 7.2826 & TRN & & \\
\hline CHEMBL 3672217 & 1528099 & 6.9281 & 6.3779 & TRN & & \\
\hline CHEMBL 3677047 & 1528099 & 5.8623 & 6.3032 & TRN & & \\
\hline CHEMBL 3672142 & 1528099 & 6.0 & 5.9942 & TST & & \\
\hline CHEMBL 3672110 & 1528099 & 3.301 & 5.0722 & TST & & \\
\hline CHEMBL3914754 & 1528099 & 5.1097 & 5.9871 & TRN & & \\
\hline CHEMBL3677128 & 1528099 & 5.7854 & 5.5035 & TST & & \\
\hline CHEMBL3976566 & 1528099 & 4.9843 & 5.8508 & TRN & & \\
\hline CHEMBL3677017 & 1528099 & 6.1959 & 5.8055 & TRN & & \\
\hline CHEMBL3914966 & 1528099 & 6.0 & 6.2092 & TRN & & \\
\hline CHEMBL3672219 & 1528099 & 6.0 & 6.20799 & 9999999999 & TST & \\
\hline CHEMBL3928354 & 1528099 & 5.1199 & 5.5052 & TRN & & \\
\hline CHEMBL3682036 & 1528099 & 5.7828 & 5.87 & TST & & \\
\hline CHEMBL3914229 & 1528099 & 7.1675 & 6.1162 & TST & & \\
\hline CHEMBL3677106 & 1528099 & 6.61799 & 99999999 & 7.0829 & 9999999999 & TRN \\
\hline CHEMBL3682130 & 1528099 & 6.3401 & 6.3241 & TRN & & \\
\hline CHEMBL3672147 & 1528099 & 6.0 & 5.5964 & TRN & & \\
\hline CHEMBL3903440 & 1528099 & 6.0 & 5.9392 & TRN & & \\
\hline CHEMBL3682133 & 1528099 & 6.3116 & 6.21 & TRN & & \\
\hline CHEMBL 3682017 & 1528099 & 6.0339 & 6.5891 & TRN & & \\
\hline CHEMBL3677081 & 1528099 & 7.4815 & 7.21700 & 00000000005 & TST & \\
\hline CHEMBL3677130 & 1528099 & 6.8827 & 5.9625 & TRN & & \\
\hline CHEMBL3672191 & 1528099 & 6.20200 & 00000000 & 6.0056 & TRN & \\
\hline
\end{tabular}




\begin{tabular}{|c|c|c|c|c|c|c|}
\hline \multirow[b]{2}{*}{ CHEMBL3677091 } & \multicolumn{6}{|c|}{ Supplemental Table S2.txt } \\
\hline & 1528099 & 7.2366 & 7.2739 & TRN & & \\
\hline CHEMBL3967026 & 1528099 & 6.0 & 5.8614 & TST & & \\
\hline CHEMBL3978043 & 1528099 & 4.8441 & 5.2375 & TRN & & \\
\hline CHEMBL3911703 & 1528099 & 5.49700 & 000000006 & $\partial 1$ & 5.8404 & TST \\
\hline CHEMBL3677054 & 1528099 & 7.585 & 8.211 & TRN & & \\
\hline CHEMBL3672173 & 1528099 & 6.0 & 6.3134 & TST & & \\
\hline CHEMBL3672205 & 1528099 & 5.7156 & 5.8278 & TRN & & \\
\hline CHEMBL3920125 & 1528099 & 6.9031 & 6.3653 & TRN & & \\
\hline CHEMBL3677016 & 1528099 & 6.7375 & 5.7459 & TRN & & \\
\hline CHEMBL3682059 & 1528099 & 6.9101 & 6.9529 & TRN & & \\
\hline CHEMBL3677100 & 1528099 & 5.7652 & 5.7007 & TST & & \\
\hline CHEMBL3682030 & 1528099 & 6.5072 & 5.8376 & TST & & \\
\hline CHEMBL3677139 & 1528099 & 7.2924 & 6.9547 & TST & & \\
\hline CHEMBL3976787 & 1528099 & 6.0 & 6.0713 & TRN & & \\
\hline CHEMBL3964052 & 1528099 & 5.0965 & 6.2301 & TRN & & \\
\hline CHEMBL3677057 & 1528099 & 7.1739 & 7.0677 & TRN & & \\
\hline CHEMBL3965893 & 1528099 & 3.301 & 5.7435 & TST & & \\
\hline CHEMBL3682022 & 1528099 & 3.301 & 4.9366 & TRN & & \\
\hline CHEMBL3923961 & 1528099 & 6.0 & 6.4809 & TRN & & \\
\hline CHEMBL3682065 & 1528099 & 7.0555 & 7.1524 & TRN & & \\
\hline CHEMBL3891015 & 1528099 & 4.8857 & 5.3633 & TST & & \\
\hline CHEMBL3672122 & 1528099 & 6.0 & 5.8014 & TST & & \\
\hline CHEMBL3939901 & 1528099 & 6.4559 & 6.1419 & TRN & & \\
\hline CHEMBL3682121 & 1528099 & 6.1169 & 6.0961 & TRN & & \\
\hline CHEMBL3672156 & 1528099 & 6.0 & 6.0629 & TRN & & \\
\hline CHEMBL3677099 & 1528099 & 7.0 & 6.8417 & TST & & \\
\hline CHEMBL3980857 & 1528099 & 6.0 & 7.2289 & TRN & & \\
\hline CHEMBL3682035 & 1528099 & 7.1739 & 6.7628 & TST & & \\
\hline CHEMBL3677044 & 1528099 & 6.4089 & 6.6867 & TRN & & \\
\hline CHEMBL3682135 & 1528099 & 7.3098 & 6.9937 & TRN & & \\
\hline CHEMBL3677101 & 1528099 & 6.0 & 5.9951 & TRN & & \\
\hline CHEMBL3682088 & 1528099 & 6.1018 & 6.5367 & TRN & & \\
\hline CHEMBL3677105 & 1528099 & 7.0269 & 7.291 & TRN & & \\
\hline CHEMBL3672188 & 1528099 & 6.1838 & 5.6811 & TRN & & \\
\hline CHEMBL3893725 & 1528099 & 6.0 & 6.6931 & TRN & & \\
\hline CHEMBL3672157 & 1528099 & 6.0 & 5.9722 & TRN & & \\
\hline CHEMBL3677108 & 1528099 & 5.1066 & 5.7348 & TRN & & \\
\hline CHEMBL3971372 & 1528099 & 5.9104 & 5.6353 & TRN & & \\
\hline CHEMBL3967122 & 1528099 & 6.4225 & 6.0185 & TST & & \\
\hline CHEMBL3677060 & 1528099 & 6.4855 & 6.4049 & TRN & & \\
\hline CHEMBL3677063 & 1528099 & 3.301 & 3.9656 & TRN & & \\
\hline CHEMBL3672215 & 1528099 & 6.0 & 6.034 & TRN & & \\
\hline CHEMBL3677015 & 1528099 & 7.1739 & 6.9193 & TRN & & \\
\hline CHEMBL3677066 & 1528099 & 6.057 & 6.4007 & TRN & & \\
\hline CHEMBL3672169 & 1528099 & 6.0 & 5.4034 & TRN & & \\
\hline CHEMBL3682060 & 1528099 & 7.0969 & 6.7022 & TRN & & \\
\hline CHEMBL3922988 & 1528099 & 6.2692 & 6.1543 & TRN & & \\
\hline CHEMBL3682090 & 1528099 & 6.2832 & 6.7316 & TRN & & \\
\hline
\end{tabular}


Supplemental Table S2.txt

\begin{tabular}{|c|c|c|c|c|c|}
\hline CHEMBL 3677120 & 1528099 & 7.3098 & 7.234 & TST & \\
\hline CHEMBL 3984418 & 1528099 & 6.4413 & 6.1673 & TRN & \\
\hline CHEMBL 3913641 & 1528099 & 6.7235 & 6.334 & TRN & \\
\hline CHEMBL 3677086 & 1528099 & 6.5817 & 6.3531 & TRN & \\
\hline CHEMBL3682105 & 1528099 & 6.945 & 7.3284 & TRN & \\
\hline CHEMBL3677070 & 1528099 & 6.8097 & \multicolumn{2}{|c|}{7.0729999999999995} & TRN \\
\hline CHEMBL 3672154 & 1528099 & 7.284 & 6.4221 & TRN & \\
\hline CHEMBL 3677135 & 1528099 & 6.5867 & 5.6555 & TRN & \\
\hline CHEMBL 3682129 & 1528099 & 6.7932 & 6.6836 & TRN & \\
\hline CHEMBL 3677080 & 1528099 & 7.1938 & 7.2351 & TST & \\
\hline CHEMBL3889647 & 1528099 & 6.0615 & 5.9909 & TRN & \\
\hline CHEMBL 3672178 & 1528099 & 7.1249 & 6.5072 & TRN & \\
\hline CHEMBL 3682087 & 1528099 & 5.7352 & 6.4469 & TRN & \\
\hline CHEMBL 3672158 & 1528099 & 5.1681 & 5.6416 & TST & \\
\hline CHEMBL 3899804 & 1528099 & 6.1586 & 6.0404 & TRN & \\
\hline CHEMBL3682137 & 1528099 & 6.9508 & 6.976 & TRN & \\
\hline CHEMBL3672095 & 1528099 & 6.0 & 5.936 & TRN & \\
\hline CHEMBL 3677109 & 1528099 & 8.6576 & 6.9298 & TRN & \\
\hline CHEMBL 3677127 & 1528099 & 5.3923 & 5.5668 & TST & \\
\hline CHEMBL3682038 & 1528099 & 6.1244 & 5.7916 & TST & \\
\hline CHEMBL 3677122 & 1528099 & 7.0223 & 6.1746 & TST & \\
\hline CHEMBL 3682064 & 1528099 & 7.585 & 7.4204 & TST & \\
\hline CHEMBL 3672207 & 1528099 & 7.0362 & \multicolumn{2}{|c|}{6.087999999999999} & TRN \\
\hline CHEMBL 3682073 & 1528099 & 6.7258 & 6.2407 & TRN & \\
\hline CHEMBL3682050 & 1528099 & 6.2573 & 5.9146 & TST & \\
\hline CHEMBL 3682092 & 1528099 & 8.6576 & 7.4435 & TRN & \\
\hline CHEMBL 3919550 & 1528099 & 5.5693 & 5.0617 & TST & \\
\hline CHEMBL3672212 & 1528099 & 6.5776 & 5.9642 & TRN & \\
\hline CHEMBL 3977046 & 1528099 & 6.0 & 7.1915 & TRN & \\
\hline CHEMBL3677008 & 1528099 & 3.301 & 5.2617 & TRN & \\
\hline CHEMBL 3672140 & 1528099 & 6.0 & 5.8758 & TST & \\
\hline CHEMBL3677055 & 1528099 & 6.9431 & 7.6868 & TRN & \\
\hline CHEMBL3941630 & 1528099 & 6.5719 & 6.6462 & TRN & \\
\hline CHEMBL 3897334 & 1528099 & 6.0 & 6.4369 & TRN & \\
\hline CHEMBL3677117 & 1528099 & 6.5003 & 6.4292 & TRN & \\
\hline CHEMBL 3682127 & 1528099 & 6.5901 & 7.2433 & TRN & \\
\hline CHEMBL3672187 & 1528099 & 5.348 & 5.4919 & TRN & \\
\hline CHEMBL 3672223 & 1528099 & 6.0 & 5.8339 & TST & \\
\hline CHEMBL3677132 & 1528099 & 7.1871 & 6.9121 & TRN & \\
\hline CHEMBL3682008 & 1528099 & 6.0039 & 6.0665 & TRN & \\
\hline CHEMBL 3672149 & 1528099 & 6.0 & 5.4304 & TST & \\
\hline CHEMBL 3677020 & 1528099 & 6.71 & 6.6741 & TRN & \\
\hline CHEMBL3672213 & 1528099 & 6.5719 & 5.985 & TRN & \\
\hline CHEMBL 3677072 & 1528099 & 6.2314 & 5.8464 & TRN & \\
\hline CHEMBL3677061 & 1528099 & 6.6003 & 6.3097 & TRN & \\
\hline CHEMBL 3672192 & 1528099 & 6.7352 & 5.9844 & TRN & \\
\hline CHEMBL 3672218 & 1528099 & 6.8013 & 6.1484 & TST & \\
\hline CHEMBL3970266 & 1528099 & 6.6253 & 6.5649 & TRN & \\
\hline
\end{tabular}


Supplemental Table S2.txt

\begin{tabular}{|c|c|c|c|c|c|}
\hline CHEMBL 3677051 & 1528099 & 6.2967 & 6.4666 & TRN & \\
\hline CHEMBL3899408 & 1528099 & 5.643 & 6.0129 & TRN & \\
\hline CHEMBL 3677011 & 1528099 & 5.2162 & 5.3141 & TRN & \\
\hline CHEMBL3917076 & 1528099 & 6.0 & 6.3369 & TRN & \\
\hline CHEMBL3677076 & 1528099 & 5.8623 & 6.3456 & TST & \\
\hline CHEMBL3677068 & 1528099 & 7.4202 & 7.3743 & TRN & \\
\hline CHEMBL 3962114 & 1528099 & 6.0 & 6.22 & TRN & \\
\hline CHEMBL 3948928 & 1528099 & 6.8761 & 7.0077 & TRN & \\
\hline CHEMBL 3682081 & 1528099 & 7.0458 & 6.9635 & TRN & \\
\hline CHEMBL3677002 & 1528099 & 5.8655 & 5.5994 & TRN & \\
\hline CHEMBL 3672214 & 1528099 & 6.9508 & 6.8057 & TRN & \\
\hline CHEMBL 3682080 & 1528099 & 6.5751 & 6.8992 & TRN & \\
\hline CHEMBL 3672183 & 1528099 & 6.5654 & 6.3802 & TRN & \\
\hline CHEMBL3672228 & 1528099 & 5.9743 & 5.1998 & TRN & \\
\hline CHEMBL3901515 & 1528099 & 6.0 & 6.61799 & 9999999999 & TST \\
\hline CHEMBL3677007 & 1528099 & 6.6345 & 6.3053 & TST & \\
\hline CHEMBL3913720 & 1528099 & 6.0 & 6.3778 & TRN & \\
\hline CHEMBL3953121 & 1528099 & 7.1612 & 7.2285 & TRN & \\
\hline CHEMBL3919546 & 1528099 & 3.301 & 5.6062 & TST & \\
\hline CHEMBL3953211 & 1528099 & 6.0 & 5.82100 & 0000000001 & TRN \\
\hline CHEMBL3677049 & 1528099 & 6.2765 & 6.5934 & TRN & \\
\hline CHEMBL3677118 & 1528099 & 5.6533 & 5.9532 & TRN & \\
\hline CHEMBL 3889664 & 1528099 & 6.4672 & 6.6067 & TRN & \\
\hline CHEMBL3682089 & 1528099 & 8.6576 & 8.0324 & TRN & \\
\hline CHEMBL 3672195 & 1528099 & 6.3969 & 6.0596 & TST & \\
\hline CHEMBL3677004 & 1528099 & 6.1198 & 5.6875 & TRN & \\
\hline CHEMBL3902890 & 1528099 & 7.0862 & 7.2789 & TRN & \\
\hline CHEMBL 3677046 & 1528099 & 6.7178 & 6.9488 & TRN & \\
\hline CHEMBL3677090 & 1528099 & 7.3979 & 7.1855 & TRN & \\
\hline CHEMBL 3677069 & 1528099 & 7.5229 & 8.0825 & TRN & \\
\hline CHEMBL 3895624 & 1528099 & 6.0 & 6.5781 & TRN & \\
\hline CHEMBL 3682077 & 1528099 & 6.3809 & 6.4267 & TRN & \\
\hline CHEMBL3915347 & 1528099 & 7.4685 & 6.2795 & TRN & \\
\hline CHEMBL3677074 & 1528099 & 6.7352 & 6.6064 & TRN & \\
\hline CHEMBL 3677110 & 1528099 & 6.7447 & 6.8243 & TRN & \\
\hline CHEMBL 3672202 & 1528099 & 6.266 & 6.1398 & TRN & \\
\hline CHEMBL3672198 & 1528099 & 6.4535 & 5.8065 & TRN & \\
\hline CHEMBL 3682068 & 1528099 & 6.9318 & 7.6727 & TRN & \\
\hline CHEMBL3925382 & 1528099 & 6.0 & 5.7226 & TRN & \\
\hline CHEMBL3932310 & 1528099 & 5.6434 & 5.3243 & TRN & \\
\hline CHEMBL3682111 & 1528099 & 6.6904 & 6.5034 & TRN & \\
\hline CHEMBL3677107 & 1528099 & 6.5058 & 5.7908 & TRN & \\
\hline CHEMBL3915330 & 1528099 & 6.0 & 6.2133 & TST & \\
\hline CHEMBL3971085 & 1528099 & 6.0 & 5.7122 & TST & \\
\hline CHEMBL3677065 & 1528099 & 6.4295 & 6.6413 & TRN & \\
\hline CHEMBL3672175 & 1528099 & 6.0 & 6.3194 & TST & \\
\hline CHEMBL3905453 & 1528099 & 6.0 & 5.8768 & TRN & \\
\hline CHEMBL3682069 & 1528099 & 8.6576 & 8.0012 & TRN & \\
\hline
\end{tabular}

Page 26091 
Supplemental Table S2.txt

\begin{tabular}{|c|c|c|c|c|c|}
\hline CHEMBL3944556 & 1528099 & 3.301 & 4.515 & TRN & \\
\hline CHEMBL 3672197 & 1528099 & 6.0 & 6.2847 & TRN & \\
\hline CHEMBL3672096 & 1528099 & 3.301 & 5.7143 & TST & \\
\hline CHEMBL3941584 & 1528099 & 6.0 & 6.0677 & TRN & \\
\hline CHEMBL 3677009 & 1528099 & 6.059 & 5.4752 & TRN & \\
\hline CHEMBL3911319 & 1528099 & 6.0 & 6.5055 & TRN & \\
\hline CHEMBL 3889619 & 1528099 & 6.4089 & 5.9253 & TRN & \\
\hline CHEMBL3911608 & 1528099 & 5.1901 & 5.6672 & TST & \\
\hline CHEMBL 3893404 & 1528099 & 6.0 & 5.9015 & TRN & \\
\hline CHEMBL 3894813 & 1528099 & 6.1328 & 5.5585 & TRN & \\
\hline CHEMBL3677059 & 1528099 & 7.1427 & \multicolumn{2}{|c|}{7.5520000000000005} & TRN \\
\hline CHEMBL3924306 & 1528099 & 6.8539 & 6.2078 & TRN & \\
\hline CHEMBL 3961384 & 1528099 & 6.0 & 5.6621 & TRN & \\
\hline CHEMBL3672159 & 1528099 & 6.0 & 5.9874 & TRN & \\
\hline CHEMBL 3672181 & 1528099 & 6.0 & 5.9334 & TST & \\
\hline CHEMBL 3889462 & 1528099 & 6.8097 & \multicolumn{2}{|c|}{6.787000000000001} & TRN \\
\hline CHEMBL 3672165 & 1528099 & 6.0 & 6.1356 & TRN & \\
\hline CHEMBL3955866 & 1528099 & 6.0 & 5.6004 & TRN & \\
\hline CHEMBL 3672210 & 1528099 & 6.9318 & 6.2884 & TST & \\
\hline CHEMBL3677053 & 1528099 & 8.6576 & 7.773 & TRN & \\
\hline CHEMBL 3682020 & 1528099 & 3.301 & 4.8633 & TRN & \\
\hline CHEMBL3945687 & 1528099 & 6.6925 & 6.5372 & TRN & \\
\hline CHEMBL 3677071 & 1528099 & 7.3188 & 6.8555 & TRN & \\
\hline CHEMBL 3682015 & 1528099 & 7.1135 & 5.8791 & TRN & \\
\hline CHEMBL 3984485 & 1528099 & 4.6014 & 5.5156 & TRN & \\
\hline CHEMBL3672229 & 1528099 & 5.9024 & 5.7141 & TST & \\
\hline CHEMBL 3672153 & 1528099 & 6.2403 & 6.2479 & TRN & \\
\hline CHEMBL 3677113 & 1528099 & 6.4089 & \multicolumn{2}{|c|}{6.207999999999999} & TRN \\
\hline CHEMBL3677000 & 1528099 & 6.1891 & \multicolumn{2}{|c|}{6.303999999999999} & TRN \\
\hline CHEMBL 3677041 & 1528099 & 6.8794 & 7.6892 & TST & \\
\hline CHEMBL3639759 & 1528099 & 5.6763 & 5.4157 & TRN & \\
\hline CHEMBL3672099 & 1528099 & 6.0 & 5.8922 & TRN & \\
\hline CHEMBL 3939273 & 1528099 & 7.1549 & 7.0885 & TRN & \\
\hline CHEMBL3682094 & 1528099 & 6.6091 & 6.4936 & TRN & \\
\hline CHEMBL 3677006 & 1528099 & 7.3979 & 6.4383 & TST & \\
\hline CHEMBL 3677038 & 1528099 & 7.0555 & 7.4068 & TST & \\
\hline CHEMBL3901680 & 1528099 & 6.0 & 6.4797 & TRN & \\
\hline CHEMBL 3677124 & 1528099 & 7.0706 & 6.0391 & TRN & \\
\hline CHEMBL 3672174 & 1528099 & 6.1681 & 5.5736 & TRN & \\
\hline CHEMBL 3682012 & 1528099 & 6.1772 & 5.5105 & TRN & \\
\hline CHEMBL 3682123 & 1528099 & 8.6576 & 8.3606 & TRN & \\
\hline CHEMBL3672106 & 1528099 & 6.0 & 5.1684 & TRN & \\
\hline CHEMBL 3682124 & 1528099 & 8.6576 & 8.275 & TRN & \\
\hline CHEMBL 3677073 & 1528099 & 6.064 & 6.6189 & TRN & \\
\hline CHEMBL 3682053 & 1528099 & 6.3468 & 6.1011 & TST & \\
\hline CHEMBL3947846 & 1528099 & 6.0 & 5.6514 & TRN & \\
\hline CHEMBL 3682091 & 1528099 & 7.1249 & 6.5723 & TRN & \\
\hline CHEMBL 3920649 & 1528099 & 6.0 & 6.4916 & TRN & \\
\hline
\end{tabular}




\begin{tabular}{|c|c|c|c|c|c|c|}
\hline \multirow[b]{2}{*}{ CHEMBL3979480 } & \multicolumn{6}{|c|}{ Supplemental Table S2.txt } \\
\hline & 1528099 & 6.9646 & 6.6832 & TRN & & \\
\hline CHEMBL3682021 & 1528099 & 3.301 & 5.2451 & TRN & & \\
\hline CHEMBL3682134 & 1528099 & 7.3768 & 7.149 & TRN & & \\
\hline CHEMBL 3672138 & 1528099 & 6.9031 & 6.4147 & TRN & & \\
\hline CHEMBL3682082 & 1528099 & 7.1249 & 7.3901 & TST & & \\
\hline CHEMBL3898041 & 1528099 & 6.0 & 6.1531 & TRN & & \\
\hline CHEMBL3893907 & 1528099 & 6.0 & 6.353 & TRN & & \\
\hline CHEMBL3902313 & 1528099 & 6.0 & 6.2896 & TRN & & \\
\hline CHEMBL3672186 & 1528099 & 6.1838 & 6.2283 & TRN & & \\
\hline CHEMBL3911714 & 1528099 & 6.0 & 6.0796 & TRN & & \\
\hline CHEMBL 3677079 & 1528099 & 7.5086 & 7.3147 & TST & & \\
\hline CHEMBL3962897 & 1528099 & 6.0 & 6.2654 & TST & & \\
\hline CHEMBL3945628 & 1528099 & 4.4403 & 4.1927 & TRN & & \\
\hline CHEMBL3682114 & 1528099 & 6.8153 & 6.0734 & TRN & & \\
\hline CHEMBL 3672184 & 1528099 & 5.5414 & 5.6981 & TST & & \\
\hline CHEMBL 3682045 & 1528099 & 6.2628 & 5.7341 & TST & & \\
\hline CHEMBL3682072 & 1528099 & 6.5129 & 6.6521 & TRN & & \\
\hline CHEMBL3672129 & 1528099 & 6.0 & 6.194 & TRN & & \\
\hline CHEMBL3682052 & 1528099 & 7.2076 & 6.3258 & TST & & \\
\hline CHEMBL3951990 & 1528099 & 6.0 & 6.0359 & TRN & & \\
\hline CHEMBL3677045 & 1528099 & 7.5086 & 7.807 & TRN & & \\
\hline CHEMBL3973735 & 1528099 & 5.5357 & 5.8186 & TST & & \\
\hline CHEMBL3677140 & 1528099 & 6.0 & 6.3344 & TRN & & \\
\hline CHEMBL3911367 & 1528099 & 6.0 & 6.5994 & TRN & & \\
\hline CHEMBL3676999 & 1528099 & 6.0 & 6.0184 & TRN & & \\
\hline CHEMBL3682085 & 1528099 & 6.8013 & 7.0072 & TRN & & \\
\hline CHEMBL 3897455 & 1528099 & 6.8297 & 6.2003 & TRN & & \\
\hline CHEMBL3672201 & 1528099 & 3.301 & 5.308 & TRN & & \\
\hline CHEMBL3677034 & 1528099 & 6.7011 & 6.8176 & TRN & & \\
\hline CHEMBL3979478 & 1528099 & 5.7172 & 5.8219 & TRN & & \\
\hline CHEMBL3677058 & 1528099 & 6.9469 & 7.2287 & TRN & & \\
\hline CHEMBL 3677085 & 1528099 & 6.7055 & 6.2075 & TRN & & \\
\hline CHEMBL3677115 & 1528099 & 4.4585 & 4.4849 & TST & & \\
\hline CHEMBL3677094 & 1528099 & 8.6576 & 7.6996 & TRN & & \\
\hline CHEMBL3677114 & 1528099 & 5.74299 & 99999999 & 99 & 5.5828 & I KIV \\
\hline CHEMBL3672097 & 1528099 & 6.0 & 6.3549 & TRN & & \\
\hline CHEMBL 3919074 & 1528099 & 5.5974 & 5.6987 & TST & & \\
\hline CHEMBL 3677048 & 1528099 & 6.2125 & 6.5507 & TRN & & \\
\hline CHEMBL3918606 & 1528099 & 6.0 & 5.9246 & TRN & & \\
\hline CHEMBL3677116 & 1528099 & 7.2757 & 6.4646 & TRN & & \\
\hline CHEMBL3672211 & 1528099 & 6.0 & 5.8058 & TRN & & \\
\hline CHEMBL3682037 & 1528099 & 6.1475 & 5.9212 & TST & & \\
\hline CHEMBL3913584 & 1528099 & 5.1908 & 5.9475 & TST & & \\
\hline CHEMBL3677030 & 1528099 & 6.0 & 6.8423 & TRN & & \\
\hline CHEMBL3682126 & 1528099 & 6.0 & 6.6966 & TRN & & \\
\hline CHEMBL 3677078 & 1528099 & 6.2328 & 7.1583 & TST & & \\
\hline CHEMBL 3672167 & 1528099 & 6.0 & 6.0238 & TRN & & \\
\hline CHEMBL3682079 & 1528099 & 6.0565 & 6.2177 & TRN & & \\
\hline
\end{tabular}

Page 26093 
Supplemental Table S2.txt

\begin{tabular}{|c|c|c|c|c|}
\hline CHEMBL3962702 & 1528099 & 6.0 & 6.6299 & TRN \\
\hline CHEMBL 3682093 & 1528099 & 8.1427 & 6.7048 & TRN \\
\hline CHEMBL 3672203 & 1528099 & 6.7258 & 6.1504 & TST \\
\hline CHEMBL3682086 & 1528099 & 6.7352 & 6.5317 & TRN \\
\hline CHEMBL 3682103 & 1528099 & 6.8697 & 6.6304 & TRN \\
\hline CHEMBL 3682131 & 1528099 & 6.2848 & 6.2764 & TRN \\
\hline CHEMBL 3672117 & 1528099 & 6.0 & 5.8646 & TST \\
\hline CHEMBL3682046 & 1528099 & 6.5719 & 6.0928 & TST \\
\hline CHEMBL3682056 & 1528099 & 7.0862 & 6.6654 & TST \\
\hline CHEMBL3677056 & 1528099 & 7.1871 & 7.5653 & TST \\
\hline CHEMBL 3672206 & 1528099 & 6.1568 & 5.6055 & TST \\
\hline CHEMBL 3677001 & 1528099 & 6.2757 & 6.2748 & TST \\
\hline CHEMBL 3672208 & 1528099 & 5.6908 & 5.737 & TST \\
\hline CHEMBL3939172 & 1528099 & 6.0 & 5.6849 & TST \\
\hline CHEMBL 3677035 & 1528099 & 5.8362 & 6.0409 & TST \\
\hline CHEMBL 2338524 & 944116 & 4.0 & 4.4891 & TST \\
\hline CHEMBL2338501 & 944116 & 5.301 & 5.3173 & TRN \\
\hline CHEMBL2338519 & 944116 & 4.0 & 3.9756 & TRN \\
\hline CHEMBL 2338497 & 944116 & 4.0 & 4.006 & TRN \\
\hline CHEMBL2338512 & 944116 & 5.3098 & 5.3217 & TRN \\
\hline CHEMBL 2338542 & 944116 & 5.1938 & 5.195 & TRN \\
\hline CHEMBL2338530 & 944116 & 4.0 & 5.3555 & TST \\
\hline CHEMBL 2338518 & 944116 & 4.0 & 4.0192 & TRN \\
\hline CHEMBL2338496 & 944116 & 4.0 & 4.0062 & TRN \\
\hline CHEMBL2338523 & 944116 & 4.0 & 4.4775 & TST \\
\hline CHEMBL2338535 & 944116 & 4.0 & 3.9969 & TRN \\
\hline CHEMBL2338493 & 944116 & 4.0 & 3.9859 & TRN \\
\hline CHEMBL 2338541 & 944116 & 4.0 & 3.9676 & TRN \\
\hline CHEMBL2338507 & 944116 & 4.0 & 4.0863 & TRN \\
\hline CHEMBL2338494 & 944116 & 4.0 & 4.0062 & TRN \\
\hline CHEMBL2338526 & 944116 & 4.0 & 4.7255 & TST \\
\hline CHEMBL2338531 & 944116 & 5.2441 & 4.2221 & TST \\
\hline CHEMBL 2338538 & 944116 & 4.0 & 3.9978 & TRN \\
\hline CHEMBL2338528 & 944116 & 4.0 & 4.1218 & TST \\
\hline CHEMBL 2338540 & 944116 & 5.0809 & 5.13399 & 99999999995 \\
\hline CHEMBL2338506 & 944116 & 4.0 & 3.9994 & TRN \\
\hline CHEMBL2338503 & 944116 & 4.0 & 3.9924 & TRN \\
\hline CHEMBL2338520 & 944116 & 4.0 & 3.9773 & TRN \\
\hline CHEMBL2338529 & 944116 & 4.0 & 4.077 & TST \\
\hline CHEMBL2338539 & 944116 & 4.0 & 3.9728 & TRN \\
\hline CHEMBL2338545 & 944116 & 4.0 & 3.9145 & TRN \\
\hline CHEMBL2338491 & 944116 & 4.0 & 4.0215 & TRN \\
\hline CHEMBL2338537 & 944116 & 4.0 & 3.9946 & TRN \\
\hline CHEMBL2338517 & 944116 & 4.0 & 3.9679 & TRN \\
\hline CHEMBL 2338544 & 944116 & 4.0 & 4.0108 & TRN \\
\hline CHEMBL2338533 & 944116 & 5.3665 & 4.2516 & TST \\
\hline CHEMBL2338508 & 944116 & 5.3098 & 5.3731 & TRN \\
\hline CHEMBL 2338498 & 944116 & 4.0 & 3.98100 & 00000000003 \\
\hline
\end{tabular}




\begin{tabular}{|c|c|c|c|c|c|}
\hline \multirow[b]{2}{*}{ CHEMBL2338504 } & \multicolumn{5}{|c|}{ Supplemental Table S2.txt } \\
\hline & 944116 & 5.7959 & 5.7631 & TRN & \\
\hline CHEMBL2338509 & 944116 & 5.6778 & 5.5944 & TRN & \\
\hline CHEMBL2338534 & 944116 & 5.2076 & 4.199 & TST & \\
\hline CHEMBL2338543 & 944116 & 5.1938 & 5.1198 & TRN & \\
\hline CHEMBL2338510 & 944116 & 5.2596 & 5.2636 & TRN & \\
\hline CHEMBL2338532 & 944116 & 4.0 & 4.2111 & TST & \\
\hline CHEMBL2338502 & 944116 & 5.6021 & 5.6165 & TRN & \\
\hline CHEMBL2338514 & 944116 & 5.6383 & 5.6459 & TRN & \\
\hline CHEMBL2338536 & 944116 & 4.0 & 4.0357 & TRN & \\
\hline CHEMBL2338527 & 944116 & 4.0 & 5.7004 & TST & \\
\hline CHEMBL2338513 & 944116 & 4.0 & 4.0147 & TRN & \\
\hline CHEMBL 2338492 & 944116 & 4.0 & 4.0319 & TRN & \\
\hline CHEMBL2338490 & 944116 & 4.0 & 4.0241 & TRN & \\
\hline CHEMBL2338546 & 944116 & 5.0088 & 5.099 & TRN & \\
\hline CHEMBL2338499 & 944116 & 4.0 & 4.0073 & TRN & \\
\hline CHEMBL2338511 & 944116 & 5.4089 & 5.3845 & TRN & \\
\hline CHEMBL2338516 & 944116 & 5.4685 & 5.4612 & TRN & \\
\hline CHEMBL2331627 & 944116 & 4.0 & 4.0273 & TRN & \\
\hline CHEMBL2338505 & 944116 & 4.0 & 3.9755 & TRN & \\
\hline CHEMBL2338500 & 944116 & 4.0 & 4.2547 & TST & \\
\hline CHEMBL2338515 & 944116 & 5.2757 & 5.2497 & TRN & \\
\hline CHEMBL2338521 & 944116 & 4.0 & 3.9896 & TRN & \\
\hline CHEMBL2338525 & 944116 & 4.0 & 4.6269 & TST & \\
\hline CHEMBL2338495 & 944116 & 4.0 & 3.673 & TST & \\
\hline CHEMBL2338522 & 944116 & 4.0 & 4.6176 & TST & \\
\hline CHEMBL3983298 & 1641350 & 9.1385 & 8.9566 & TRN & \\
\hline CHEMBL3923389 & 1641350 & 8.5068 & 8.9546 & TRN & \\
\hline CHEMBL3917617 & 1641350 & 8.2555 & 7.9917 & TRN & \\
\hline CHEMBL3974548 & 1641350 & 8.8063 & 7.9674 & TRN & \\
\hline CHEMBL3894467 & 1641350 & 9.3883 & 9.3421 & TRN & \\
\hline CHEMBL3890067 & 1641350 & 9.3045 & 8.3513 & TRN & \\
\hline CHEMBL3966205 & 1641350 & 9.8207 & 9.3024 & TRN & \\
\hline CHEMBL3954221 & 1641350 & 8.5474 & 8.2178 & TRN & \\
\hline CHEMBL3941681 & 1641350 & 6.0 & 7.7324 & TRN & \\
\hline CHEMBL3921455 & 1641350 & 9.5467 & 8.7204 & TRN & \\
\hline CHEMBL3974204 & 1641350 & 9.2941 & 9.5239 & TRN & \\
\hline CHEMBL3901238 & 1641350 & 8.8105 & 8.8027 & TRN & \\
\hline CHEMBL3928807 & 1641350 & 9.0074 & 9.197006 & 2000000001 & TRN \\
\hline CHEMBL3982874 & 1641350 & 8.997 & 9.1312 & TST & \\
\hline CHEMBL3938233 & 1641350 & 8.721 & 8.5136 & TRN & \\
\hline CHEMBL3906361 & 1641350 & 8.6319 & 8.7978 & TRN & \\
\hline CHEMBL3897539 & 1641350 & 10.284 & 10.0655 & TRN & \\
\hline CHEMBL3947920 & 1641350 & 8.7095 & 8.9265 & TST & \\
\hline CHEMBL3906395 & 1641350 & 6.0 & 7.0968 & TRN & \\
\hline CHEMBL3926890 & 1641350 & 9.1938 & 8.7728 & TRN & \\
\hline CHEMBL3924520 & 1641350 & 8.8881 & 8.4926 & TRN & \\
\hline CHEMBL3953938 & 1641350 & 10.6198 & 11.0354 & TRN & \\
\hline CHEMBL3959874 & 1641350 & 10.3872 & 10.7928 & TST & \\
\hline
\end{tabular}

Page 26095 
Supplemental Table S2.txt

\begin{tabular}{|c|c|c|c|c|c|}
\hline CHEMBL3899295 & 1641350 & 9.2573 & 8.4433 & TRN & \\
\hline CHEMBL3915674 & 1641350 & 9.0825 & 8.4617 & TRN & \\
\hline CHEMBL3943633 & 1641350 & 8.9169 & 8.1991 & TRN & \\
\hline CHEMBL3967564 & 1641350 & 11.2218 & 10.1978 & TST & \\
\hline CHEMBL3966508 & 1641350 & 9.3179 & 9.2053 & TST & \\
\hline CHEMBL3892857 & 1641350 & 9.4191 & 9.5479 & TRN & \\
\hline CHEMBL3968702 & 1641350 & 6.0 & 8.1181 & TRN & \\
\hline CHEMBL3948179 & 1641350 & 9.3391 & 9.3319 & TRN & \\
\hline CHEMBL3942688 & 1641350 & 10.8539 & 10.7041 & TRN & \\
\hline CHEMBL3916113 & 1641350 & 10.6778 & 10.9518 & TRN & \\
\hline CHEMBL3986221 & 1641350 & 8.9566 & 9.3435 & TRN & \\
\hline CHEMBL3957943 & 1641350 & 8.1312 & 7.9338 & TRN & \\
\hline CHEMBL3908481 & 1641350 & 8.2002 & 8.4127 & TRN & \\
\hline CHEMBL3978905 & 1641350 & 7.7768 & 8.2255 & TRN & \\
\hline CHEMBL3951111 & 1641350 & 9.4237 & 9.0806 & TRN & \\
\hline CHEMBL3921559 & 1641350 & 9.4225 & 8.5983 & TST & \\
\hline CHEMBL3921026 & 1641350 & 8.76100 & 000000000 & 1 & 7.6264 \\
\hline CHEMBL3977058 & 1641350 & 10.3979 & 10.5104 & TRN & \\
\hline CHEMBL3945481 & 1641350 & 10.4559 & 10.3718 & TRN & \\
\hline CHEMBL3957902 & 1641350 & 9.4045 & 9.1676 & TRN & \\
\hline CHEMBL3967457 & 1641350 & 9.4572 & 9.7934 & TRN & \\
\hline CHEMBL3912060 & 1641350 & 8.7488 & 8.8613 & TST & \\
\hline CHEMBL3950402 & 1641350 & 10.9586 & 10.9299 & TST & \\
\hline CHEMBL3893938 & 1641350 & 9.6655 & 10.2017 & TRN & \\
\hline CHEMBL3937837 & 1641350 & 11.3979 & 11.6236 & TST & \\
\hline CHEMBL3916064 & 1641350 & 9.025 & 8.3969 & TRN & \\
\hline CHEMBL3949259 & 1641350 & 8.997 & 8.9743 & TRN & \\
\hline CHEMBL3893386 & 1641350 & 8.4377 & 8.5537 & TRN & \\
\hline CHEMBL3958573 & 1641350 & 8.5136 & 8.3087 & TST & \\
\hline CHEMBL3979427 & 1641350 & 7.9666 & 7.2062 & TRN & \\
\hline CHEMBL3975969 & 1641350 & 9.4597 & 9.6413 & TRN & \\
\hline CHEMBL3944068 & 1641350 & 10.3872 & 9.9717 & TRN & \\
\hline CHEMBL3969705 & 1641350 & 8.0767 & 8.7626 & TST & \\
\hline CHEMBL 3913897 & 1641350 & 9.0292 & 8.9746 & TRN & \\
\hline CHEMBL3920437 & 1641350 & 8.2192 & 7.8937 & TRN & \\
\hline CHEMBL3906544 & 1641350 & 10.3468 & 10.27 & TST & \\
\hline CHEMBL3952817 & 1641350 & 9.1249 & 9.0224 & TRN & \\
\hline CHEMBL3971057 & 1641350 & 8.5913 & 8.9445 & TRN & \\
\hline CHEMBL3966043 & 1641350 & 6.0 & 6.6234 & TRN & \\
\hline CHEMBL3935311 & 1641350 & 9.1379 & 8.7925 & TST & \\
\hline CHEMBL3930513 & 1641350 & 8.7366 & 8.6997 & TRN & \\
\hline CHEMBL3927337 & 1641350 & 9.2132 & 8.9744 & TST & \\
\hline CHEMBL3938056 & 1641350 & 8.3576 & 9.0072 & TRN & \\
\hline CHEMBL3940152 & 1641350 & 7.7794 & 8.1109 & TRN & \\
\hline CHEMBL3942147 & 1641350 & 8.845 & 9.2009 & TRN & \\
\hline CHEMBL3969102 & 1641350 & 8.9197 & 8.8894 & TRN & \\
\hline CHEMBL3905287 & 1641350 & 8.3693 & 8.6176 & TST & \\
\hline CHEMBL3941352 & 1641350 & 9.4089 & 9.1341 & TST & \\
\hline
\end{tabular}




$$
\text { Supplemental Table S2.txt }
$$

\begin{tabular}{|c|c|c|c|c|c|}
\hline CHEMBL3959980 & 1641350 & 9.2733 & 9.856 & TRN & \\
\hline CHEMBL3948830 & 1641350 & 10.5229 & 9.5442 & TRN & \\
\hline CHEMBL3973998 & 1641350 & 8.355 & 9.2171 & TST & \\
\hline CHEMBL3907623 & 1641350 & 6.0 & 7.3814 & TRN & \\
\hline CHEMBL3940182 & 1641350 & 9.9318 & 8.6994 & TST & \\
\hline CHEMBL3892852 & 1641350 & 8.7423 & 9.2144 & TRN & \\
\hline CHEMBL3974985 & 1641350 & 7.0 & 7.7896 & TRN & \\
\hline CHEMBL3977700 & 1641350 & 9.3556 & 8.5698 & TRN & \\
\hline CHEMBL3945319 & 1641350 & 9.2343 & 8.3771 & TRN & \\
\hline CHEMBL3959836 & 1641350 & 8.4588 & 8.7937 & TRN & \\
\hline CHEMBL3955688 & 1641350 & 10.4815 & 9.478 & TST & \\
\hline CHEMBL3973997 & 1641350 & 8.8354 & 8.1458 & TST & \\
\hline CHEMBL3889817 & 1641350 & 8.8614 & 8.6904 & TRN & \\
\hline CHEMBL3908447 & 1641350 & 8.6381 & 8.7648 & TRN & \\
\hline CHEMBL3972251 & 1641350 & 10.3188 & 10.4089 & TRN & \\
\hline CHEMBL3929766 & 1641350 & 9.1308 & 9.2984 & TRN & \\
\hline CHEMBL3905281 & 1641350 & 8.0882 & 7.9204 & TST & \\
\hline CHEMBL3893987 & 1641350 & 8.9477 & 8.1837 & TRN & \\
\hline CHEMBL3899886 & 1641350 & 9.2749 & 9.0961 & TST & \\
\hline CHEMBL3981873 & 1641350 & 10.9208 & 10.5585 & TRN & \\
\hline CHEMBL3900005 & 1641350 & 8.3295 & 7.8168 & TRN & \\
\hline CHEMBL3893543 & 1641350 & 7.7438 & 7.6944 & TST & \\
\hline CHEMBL3906684 & 1641350 & 9.2848 & 9.1069 & TRN & \\
\hline CHEMBL3970479 & 1641350 & 8.8 & 8.562000 & 0000000001 & TRN \\
\hline CHEMBL3954202 & 1641350 & 6.0 & 7.4806 & TRN & \\
\hline CHEMBL3984893 & 1641350 & 9.9469 & 8.0916 & TST & \\
\hline CHEMBL3935822 & 1641350 & 8.9747 & 8.7715 & TRN & \\
\hline CHEMBL3929189 & 1641350 & 8.9694 & 9.1905 & TRN & \\
\hline CHEMBL3982359 & 1641350 & 8.7503 & 8.3005 & TRN & \\
\hline CHEMBL3976404 & 1641350 & 8.9531 & 8.3279 & TRN & \\
\hline CHEMBL3948733 & 1641350 & 8.9594 & 8.3493 & TRN & \\
\hline CHEMBL3928067 & 1641350 & 9.4134 & 9.0005 & TRN & \\
\hline CHEMBL3930552 & 1641350 & 7.9034 & 7.9079 & TRN & \\
\hline CHEMBL3952908 & 1641350 & 9.6421 & 10.1483 & TRN & \\
\hline CHEMBL3936201 & 1641350 & 6.0 & 8.7755 & TRN & \\
\hline CHEMBL3954677 & 1641350 & 9.0857 & 8.3435 & TRN & \\
\hline CHEMBL3964968 & 1641350 & 10.2757 & 10.6563 & TRN & \\
\hline CHEMBL3976072 & 1641350 & 10.3468 & 10.9227 & TST & \\
\hline CHEMBL3977903 & 1641350 & 8.3133 & 8.0356 & TRN & \\
\hline CHEMBL3974987 & 1641350 & 8.014 & 8.2139 & TRN & \\
\hline CHEMBL3945504 & 1641350 & 8.9108 & 8.5452 & TRN & \\
\hline CHEMBL3968583 & 1641350 & 8.6659 & 8.5792 & TRN & \\
\hline CHEMBL3926821 & 1641350 & 9.3706 & 8.8346 & TST & \\
\hline CHEMBL3949613 & 1641350 & 8.2626 & 8.0064 & TRN & \\
\hline CHEMBL3905972 & 1641350 & 8.7149 & 8.5011 & TRN & \\
\hline CHEMBL3921398 & 1641350 & 8.6674 & 8.4833 & TRN & \\
\hline CHEMBL3936429 & 1641350 & 8.0065 & 8.3092 & TRN & \\
\hline CHEMBL3981066 & 1641350 & 9.6635 & 8.2575 & TST & \\
\hline
\end{tabular}


Supplemental Table S2.txt

\begin{tabular}{|c|c|c|c|c|c|}
\hline CHEMBL3953401 & 1641350 & 9.0846 & 8.7124 & TRN & \\
\hline CHEMBL 3922880 & 1641350 & 7.6737 & 8.0256 & TRN & \\
\hline CHEMBL 3950076 & 1641350 & 10.3468 & 10.6609 & TST & \\
\hline CHEMBL 3950613 & 1641350 & 8.6649 & 8.0593 & TRN & \\
\hline CHEMBL 3958047 & 1641350 & 8.5206 & 8.4337 & TRN & \\
\hline CHEMBL 3950528 & 1641350 & 7.1706 & 7.7894 & TRN & \\
\hline CHEMBL3959312 & 1641350 & 8.2409 & 8.1982 & TST & \\
\hline CHEMBL 3930066 & 1641350 & 8.738 & 8.6975 & TST & \\
\hline CHEMBL 3899476 & 1641350 & 9.7326 & 9.3117 & TST & \\
\hline CHEMBL 3903035 & 1641350 & 7.8887 & 8.4498 & TST & \\
\hline CHEMBL 3965727 & 1641350 & 9.5243 & 9.1637 & TST & \\
\hline CHEMBL 3963998 & 1528720 & 7.9694 & 7.6436 & TRN & \\
\hline CHEMBL 3912197 & 1528720 & 6.7225 & 6.5611 & TRN & \\
\hline CHEMBL 3654464 & 1528720 & 7.6383 & 6.8226 & TST & \\
\hline CHEMBL 3917811 & 1528720 & 7.6615 & 7.3327 & TRN & \\
\hline CHEMBL 3941387 & 1528720 & 7.0609 & $6.82700 e$ & 3000000001 & TRN \\
\hline CHEMBL 3971508 & 1528720 & 7.2832 & 7.4679 & TST & \\
\hline CHEMBL 3955424 & 1528720 & 6.8919 & 7.1696 & TST & \\
\hline CHEMBL 3933627 & 1528720 & 7.8213 & 7.3839 & TRN & \\
\hline CHEMBL 3654618 & 1528720 & 6.8935 & 7.2289 & TRN & \\
\hline CHEMBL 3904527 & 1528720 & 6.0 & 6.343 & TST & \\
\hline CHEMBL 3909457 & 1528720 & 7.1052 & 7.4836 & TRN & \\
\hline CHEMBL 3654554 & 1528720 & 6.6185 & 6.7059 & TRN & \\
\hline CHEMBL3941699 & 1528720 & 6.6364 & 7.1698 & TST & \\
\hline CHEMBL 3979218 & 1528720 & 7.9136 & 8.0035 & TRN & \\
\hline CHEMBL 3654476 & 1528720 & 6.8499 & 6.5138 & TST & \\
\hline CHEMBL 3654527 & 1528720 & 6.0037 & 6.7564 & TRN & \\
\hline CHEMBL 3654472 & 1528720 & 6.5229 & 6.5609 & TST & \\
\hline CHEMBL 3909643 & 1528720 & 7.1615 & 7.3555 & TRN & \\
\hline CHEMBL 3658449 & 1528720 & 8.0788 & 6.4071 & TST & \\
\hline CHEMBL 3654536 & 1528720 & 6.8544 & 7.0139 & TRN & \\
\hline CHEMBL 3654569 & 1528720 & 7.1744 & 7.6401 & TRN & \\
\hline CHEMBL 3980329 & 1528720 & 8.8386 & 7.5526 & TST & \\
\hline CHEMBL 3654555 & 1528720 & 6.0781 & 6.9326 & TST & \\
\hline CHEMBL 3947872 & 1528720 & 7.8567 & 7.2619 & TRN & \\
\hline CHEMBL3938672 & 1528720 & 7.7399 & 8.0207 & TRN & \\
\hline CHEMBL 3911167 & 1528720 & 7.1844 & 7.195 & TST & \\
\hline CHEMBL 3907943 & 1528720 & 7.4881 & 7.8207 & TRN & \\
\hline CHEMBL 3654523 & 1528720 & 8.2147 & 7.2308 & TRN & \\
\hline CHEMBL 3914032 & 1528720 & 7.5516 & 7.2364 & TRN & \\
\hline CHEMBL 3977193 & 1528720 & 7.4559 & 7.2601 & TRN & \\
\hline CHEMBL 3890532 & 1528720 & 6.085 & 6.4415 & TRN & \\
\hline CHEMBL 3957971 & 1528720 & 7.718999 & 99999999 & 7.2717 & TRN \\
\hline CHEMBL 3896834 & 1528720 & 7.1085 & 7.1849 & TST & \\
\hline CHEMBL 3890668 & 1528720 & 6.6299 & 7.052006 & 00000000005 & $1 \mathrm{nt}$ \\
\hline CHEMBL 3654471 & 1528720 & 7.0711 & 6.5524 & TST & \\
\hline CHEMBL 3891637 & 1528720 & 7.6882 & 7.718999 & 7999999999 & RN \\
\hline CHEMBL 3944934 & 1528720 & 7.7708 & 7.1828 & TRN & \\
\hline
\end{tabular}




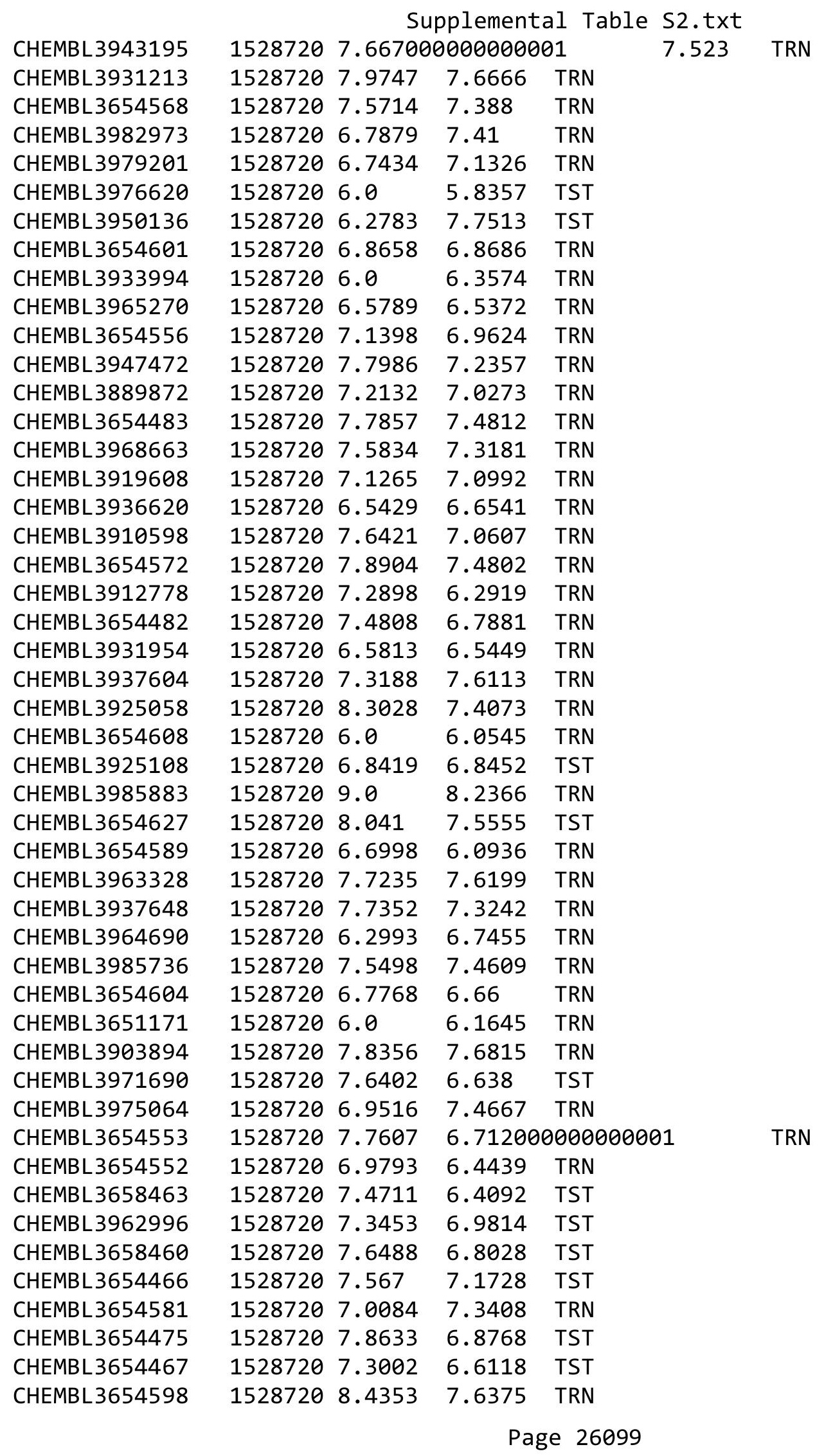


Supplemental Table S2.txt

\begin{tabular}{|c|c|c|c|c|c|}
\hline CHEMBL3947480 & 1528720 & 7.2464 & 8.0616 & TRN & \\
\hline CHEMBL 3898267 & 1528720 & 8.4461 & 7.8974 & TRN & \\
\hline CHEMBL3654533 & 1528720 & 7.189 & \multicolumn{2}{|c|}{7.0760000000000005} & TRN \\
\hline CHEMBL 3654605 & 1528720 & 6.3402 & 6.3894 & TRN & \\
\hline CHEMBL3654545 & 1528720 & 6.6367 & 7.0708 & TRN & \\
\hline CHEMBL3969025 & 1528720 & 7.9508 & 7.3873 & TRN & \\
\hline CHEMBL3906630 & 1528720 & 7.1492 & 7.1291 & TRN & \\
\hline CHEMBL3654626 & 1528720 & 7.2104 & 7.5804 & TRN & \\
\hline CHEMBL3966161 & 1528720 & 7.3325 & \multicolumn{2}{|c|}{7.5360000000000005} & TRN \\
\hline CHEMBL3980744 & 1528720 & 7.1876 & \multicolumn{2}{|c|}{6.787000000000001} & TRN \\
\hline CHEMBL3924097 & 1528720 & 6.9442 & 6.7397 & TRN & \\
\hline CHEMBL3897009 & 1528720 & 6.8537 & 7.2779 & TRN & \\
\hline CHEMBL 3654583 & 1528720 & 7.4579 & 6.9265 & TRN & \\
\hline CHEMBL 3924712 & 1528720 & 7.0453 & 7.5404 & TRN & \\
\hline CHEMBL 3945706 & 1528720 & 7.4786 & 7.4937 & TRN & \\
\hline CHEMBL3900980 & 1528720 & 8.4437 & 8.3356 & TRN & \\
\hline CHEMBL 3654474 & 1528720 & 6.5229 & 6.5769 & TST & \\
\hline CHEMBL3910705 & 1528720 & 7.6542 & 7.3819 & TRN & \\
\hline CHEMBL3913325 & 1528720 & 7.7286 & 7.445 & TRN & \\
\hline CHEMBL 3980991 & 1528720 & 6.2948 & 6.9485 & TRN & \\
\hline CHEMBL3654560 & 1528720 & 7.3754 & 7.3141 & TRN & \\
\hline CHEMBL3964635 & 1528720 & 6.0 & 6.8148 & TRN & \\
\hline CHEMBL3935556 & 1528720 & 6.0549 & 7.513 & TST & \\
\hline CHEMBL3639533 & 1528720 & 6.114 & 6.7533 & TST & \\
\hline CHEMBL3959610 & 1528720 & 6.3052 & 7.3648 & TRN & \\
\hline CHEMBL3658452 & 1528720 & 8.3183 & 7.1426 & TST & \\
\hline CHEMBL3947930 & 1528720 & 7.4225 & 7.4741 & TRN & \\
\hline CHEMBL3902755 & 1528720 & 6.6306 & 7.2158 & TRN & \\
\hline CHEMBL 3974322 & 1528720 & 6.7433 & 6.7667 & TRN & \\
\hline CHEMBL3923049 & 1528720 & 6.0 & 7.3278 & TST & \\
\hline CHEMBL3917730 & 1528720 & 7.3161 & 7.4608 & TRN & \\
\hline CHEMBL3963015 & 1528720 & 7.7905 & 7.4642 & TRN & \\
\hline CHEMBL3658451 & 1528720 & 8.51 & 6.812 & TST & \\
\hline CHEMBL 3985260 & 1528720 & 7.2226 & 7.495 & TRN & \\
\hline CHEMBL3654625 & 1528720 & 8.007 & 8.0551 & TRN & \\
\hline CHEMBL3654591 & 1528720 & 7.5077 & 7.3518 & TRN & \\
\hline CHEMBL3898915 & 1528720 & 7.9788 & 7.7578 & TRN & \\
\hline CHEMBL3902144 & 1528720 & 7.3406 & 7.4836 & TRN & \\
\hline CHEMBL3651172 & 1528720 & 6.0 & 7.2319 & TRN & \\
\hline CHEMBL3939122 & 1528720 & 6.6906 & 7.7633 & TRN & \\
\hline CHEMBL3953975 & 1528720 & 7.7852 & 7.7353 & TRN & \\
\hline CHEMBL 3658454 & 1528720 & 7.3224 & 7.2454 & TST & \\
\hline CHEMBL3970666 & 1528720 & 6.8088 & 6.6001 & TRN & \\
\hline CHEMBL 3897504 & 1528720 & 6.5605 & 7.2853 & TST & \\
\hline CHEMBL3954539 & 1528720 & 7.0931 & 7.3169 & TRN & \\
\hline CHEMBL3898065 & 1528720 & 6.6099 & 6.9499 & TRN & \\
\hline CHEMBL 3654549 & 1528720 & 8.0592 & 7.0328 & TRN & \\
\hline CHEMBL3651175 & 1528720 & 8.585 & 6.7978 & TST & \\
\hline
\end{tabular}


Supplemental Table S2.txt

\begin{tabular}{|c|c|c|c|c|}
\hline CHEMBL3654535 & 1528720 & 6.0348 & 6.8066 & TST \\
\hline CHEMBL3654547 & 1528720 & 7.101 & 7.3056 & TRN \\
\hline CHEMBL3976757 & 1528720 & 7.3325 & 7.7637 & TRN \\
\hline CHEMBL3967268 & 1528720 & 6.5215 & 7.2397 & TRN \\
\hline CHEMBL3967112 & 1528720 & 7.6765 & 7.3243 & TST \\
\hline CHEMBL3895285 & 1528720 & 7.1308 & 7.3011 & TRN \\
\hline CHEMBL3654616 & 1528720 & 6.0916 & 6.2773 & TST \\
\hline CHEMBL3979512 & 1528720 & 8.5686 & 8.1437 & TRN \\
\hline CHEMBL3932334 & 1528720 & 7.4045 & 7.4218 & TRN \\
\hline CHEMBL3901540 & 1528720 & 6.3164 & 6.40799 & 99999999995 \\
\hline CHEMBL3926598 & 1528720 & 6.7111 & 6.7288 & TRN \\
\hline CHEMBL3903326 & 1528720 & 6.2284 & 6.8753 & TST \\
\hline CHEMBL3980122 & 1528720 & 7.8416 & 7.4349 & TRN \\
\hline CHEMBL3925130 & 1528720 & 6.8817 & 6.8996 & TRN \\
\hline CHEMBL3913407 & 1528720 & 7.0053 & 8.0881 & TRN \\
\hline CHEMBL3985803 & 1528720 & 7.5272 & 7.1976 & TRN \\
\hline CHEMBL3654628 & 1528720 & 7.6904 & 7.5403 & TST \\
\hline CHEMBL3946760 & 1528720 & 9.0 & 8.1213 & TRN \\
\hline CHEMBL3952776 & 1528720 & 8.0545 & 7.4153 & TST \\
\hline CHEMBL3964914 & 1528720 & 7.5086 & 7.7371 & TRN \\
\hline CHEMBL3914691 & 1528720 & 7.0443 & 6.9313 & TRN \\
\hline CHEMBL3984829 & 1528720 & 8.2518 & 7.9666 & TRN \\
\hline CHEMBL3654595 & 1528720 & 7.0684 & 6.6592 & TST \\
\hline CHEMBL3969224 & 1528720 & 7.4823 & 7.0666 & TRN \\
\hline CHEMBL3892977 & 1528720 & 8.7696 & 8.085 & TRN \\
\hline CHEMBL3959020 & 1528720 & 7.7721 & 7.6778 & TRN \\
\hline CHEMBL3920907 & 1528720 & 7.0504 & 6.9538 & TRN \\
\hline CHEMBL3980774 & 1528720 & 8.1898 & 7.4436 & TRN \\
\hline CHEMBL3939147 & 1528720 & 6.0 & 7.3052 & TRN \\
\hline CHEMBL3959835 & 1528720 & 7.0155 & 7.1546 & TRN \\
\hline CHEMBL3906174 & 1528720 & 6.4557 & 7.0903 & TST \\
\hline CHEMBL3971394 & 1528720 & 7.5229 & 7.6734 & TRN \\
\hline CHEMBL3903939 & 1528720 & 6.6629 & 7.535 & TRN \\
\hline CHEMBL3910658 & 1528720 & 6.6503 & 6.6428 & TRN \\
\hline CHEMBL3899493 & 1528720 & 6.2156 & 6.348 & TRN \\
\hline CHEMBL3654551 & 1528720 & 6.6031 & 6.2637 & TRN \\
\hline CHEMBL3939750 & 1528720 & 6.0581 & 6.8042 & TRN \\
\hline CHEMBL3654470 & 1528720 & 6.5229 & 6.6507 & TST \\
\hline CHEMBL3654623 & 1528720 & 6.7182 & 6.2928 & TST \\
\hline CHEMBL3935399 & 1528720 & 7.6214 & 7.1726 & TRN \\
\hline CHEMBL3929933 & 1528720 & 6.0 & 6.82100 & 0000000001 \\
\hline CHEMBL3658450 & 1528720 & 8.8554 & 6.8641 & TST \\
\hline CHEMBL3654602 & 1528720 & 7.0653 & 6.9799 & TRN \\
\hline CHEMBL3954300 & 1528720 & 6.4444 & 6.6459 & TRN \\
\hline CHEMBL3658459 & 1528720 & 6.0 & 6.989 & TST \\
\hline CHEMBL3921822 & 1528720 & 7.7849 & 7.4194 & TRN \\
\hline CHEMBL3982484 & 1528720 & 7.7471 & 7.6593 & TRN \\
\hline HEMBL3970107 & 1528720 & 8.0177 & 7.7353 & TRN \\
\hline
\end{tabular}

Page 26101 
Supplemental Table S2.txt

\begin{tabular}{|c|c|c|c|c|c|c|}
\hline CHEMBL 3654612 & 1528720 & 7.3636 & 7.5166 & TRN & & \\
\hline CHEMBL3920511 & 1528720 & 7.3922 & 7.2263 & TRN & & \\
\hline CHEMBL3974278 & 1528720 & 6.0 & 6.2835 & TST & & \\
\hline CHEMBL3917153 & 1528720 & 6.8496 & 7.0546 & TRN & & \\
\hline CHEMBL3923558 & 1528720 & 7.1329 & 7.6347 & TRN & & \\
\hline CHEMBL 3654548 & 1528720 & 6.4328 & 6.6776 & TRN & & \\
\hline CHEMBL3920734 & 1528720 & 7.3798 & 7.3972 & TRN & & \\
\hline CHEMBL3977699 & 1528720 & 7.7399 & 7.3276 & TRN & & \\
\hline CHEMBL3896016 & 1528720 & 6.7559 & 7.2441 & TRN & & \\
\hline CHEMBL3972703 & 1528720 & 6.5958 & 6.8565 & TRN & & \\
\hline CHEMBL3927235 & 1528720 & 6.8645 & 7.226 & TRN & & \\
\hline CHEMBL3938533 & 1528720 & 6.8132 & 6.6019 & TRN & & \\
\hline CHEMBL3987065 & 1528720 & 7.1163 & 6.7979 & TRN & & \\
\hline CHEMBL3889808 & 1528720 & 7.2441 & 7.1139 & TRN & & \\
\hline CHEMBL3971776 & 1528720 & 6.9187 & 7.4412 & TRN & & \\
\hline CHEMBL3981485 & 1528720 & 7.71899 & 79999999 & 99 & 7.5001 & TRN \\
\hline CHEMBL3944790 & 1528720 & 7.2472 & 7.2672 & TRN & & \\
\hline CHEMBL3960651 & 1528720 & 7.4572 & 7.598 & TRN & & \\
\hline CHEMBL3658462 & 1528720 & 8.4908 & 7.1189 & TST & & \\
\hline CHEMBL3951194 & 1528720 & 7.5884 & 7.2938 & TRN & & \\
\hline CHEMBL3902280 & 1528720 & 6.2034 & 6.485 & TST & & \\
\hline CHEMBL3939212 & 1528720 & 6.3411 & 7.7334 & TRN & & \\
\hline CHEMBL3658461 & 1528720 & 8.5662 & 6.8261 & TST & & \\
\hline CHEMBL3654619 & 1528720 & 7.2123 & 7.04 & TRN & & \\
\hline CHEMBL3932479 & 1528720 & 7.6556 & 7.3171 & TRN & & \\
\hline CHEMBL3654561 & 1528720 & 7.7889 & 7.5161 & TRN & & \\
\hline CHEMBL3654546 & 1528720 & 6.8296 & 6.9694 & TRN & & \\
\hline CHEMBL3658457 & 1528720 & 8.4168 & 7.1197 & TST & & \\
\hline CHEMBL 3892518 & 1528720 & 7.8173 & 7.4007 & TRN & & \\
\hline CHEMBL3933842 & 1528720 & 7.2055 & 7.9087 & TST & & \\
\hline CHEMBL 3654624 & 1528720 & 7.6828 & 7.7499 & TRN & & \\
\hline CHEMBL3959620 & 1528720 & 6.9788 & 7.9159 & TRN & & \\
\hline CHEMBL3961514 & 1528720 & 6.9481 & 7.7502 & TRN & & \\
\hline CHEMBL3658455 & 1528720 & 8.7986 & 7.0541 & TST & & \\
\hline CHEMBL3896571 & 1528720 & 7.3002 & 7.1806 & TST & & \\
\hline CHEMBL3654563 & 1528720 & 8.301 & 7.815 & TRN & & \\
\hline CHEMBL3919116 & 1528720 & 6.8241 & 7.4092 & TST & & \\
\hline CHEMBL3654577 & 1528720 & 7.307 & 7.4393 & TRN & & \\
\hline CHEMBL3963692 & 1528720 & 7.7258 & 7.9907 & TRN & & \\
\hline CHEMBL3911771 & 1528720 & 6.8636 & 6.8086 & TRN & & \\
\hline CHEMBL3956168 & 1528720 & 6.528 & 6.9314 & TRN & & \\
\hline CHEMBL3896664 & 1528720 & 6.1805 & 6.7001 & TRN & & \\
\hline CHEMBL3941809 & 1528720 & 7.6946 & 7.8055 & TRN & & \\
\hline CHEMBL3954166 & 1528720 & 6.3235 & 7.0187 & TST & & \\
\hline CHEMBL3654573 & 1528720 & 7.8726 & 7.3581 & TRN & & \\
\hline CHEMBL3964711 & 1528720 & 7.4498 & 7.4577 & TRN & & \\
\hline CHEMBL3974073 & 1528720 & \multicolumn{3}{|c|}{7.5489999999999995} & 7.0822 & TRN \\
\hline CHEMBL3917336 & 1528720 & 6.7704 & 6.91 & TRN & & \\
\hline
\end{tabular}


Supplemental Table S2.txt

\begin{tabular}{|c|c|c|c|c|}
\hline CHEMBL 3654525 & 1528720 & 7.4083 & 7.1931 & TRN \\
\hline CHEMBL3969456 & 1528720 & 7.4417 & 7.1556 & TRN \\
\hline CHEMBL3654576 & 1528720 & 6.4037 & 6.9834 & TST \\
\hline CHEMBL 3894104 & 1528720 & 6.0931 & 7.1406 & TRN \\
\hline CHEMBL 3654579 & 1528720 & 6.8977 & 7.0398 & TRN \\
\hline CHEMBL3893828 & 1528720 & 8.3958 & 7.3611 & TRN \\
\hline CHEMBL3952830 & 1528720 & 6.8019 & 6.9298 & TRN \\
\hline CHEMBL3654528 & 1528720 & 6.0 & 6.664 & TRN \\
\hline CHEMBL 3654473 & 1528720 & 6.5229 & 6.3447 & TST \\
\hline CHEMBL3654462 & 1528720 & 6.5471 & 7.0251 & TST \\
\hline CHEMBL 3925540 & 1528720 & 6.2952 & 6.7756 & TRN \\
\hline CHEMBL3917781 & 1528720 & 6.0004 & 5.9796 & TST \\
\hline CHEMBL 3941420 & 1528720 & 7.5817 & 7.5327 & TRN \\
\hline CHEMBL3899201 & 1528720 & 9.0 & 7.9753 & TRN \\
\hline CHEMBL 3654468 & 1528720 & 7.3019 & 6.6491 & TST \\
\hline CHEMBL3654469 & 1528720 & 6.1871 & 6.4208 & TST \\
\hline CHEMBL3654617 & 1528720 & 7.8199 & 7.3992 & TRN \\
\hline CHEMBL 3970889 & 1528720 & 7.6968 & 7.4228 & TRN \\
\hline CHEMBL3904696 & 1528720 & 8.0458 & 8.1043 & TRN \\
\hline CHEMBL 3651169 & 1528720 & 6.9076 & 6.4217 & TST \\
\hline CHEMBL3949488 & 1528720 & 6.6341 & 6.8833 & TRN \\
\hline CHEMBL3980687 & 1528720 & 7.4045 & 7.1743 & TRN \\
\hline CHEMBL3654521 & 1528720 & 8.2336 & 7.3875 & TRN \\
\hline CHEMBL3976472 & 1528720 & 6.8642 & 7.1937 & TRN \\
\hline CHEMBL3972159 & 1528720 & \multicolumn{3}{|c|}{6.7620000000000005} \\
\hline CHEMBL 3981653 & 1528720 & 6.8771 & 7.4838 & TRN \\
\hline CHEMBL 3654461 & 1528720 & 6.8735 & 5.9781 & TST \\
\hline CHEMBL3639534 & 1528720 & 6.4977 & 6.638 & TRN \\
\hline CHEMBL3914782 & 1528720 & 7.4828 & 7.6198 & TRN \\
\hline CHEMBL3966005 & 1528720 & 8.1549 & 7.4049 & TRN \\
\hline CHEMBL3933955 & 1528720 & 6.8001 & 7.2911 & TST \\
\hline CHEMBL 3942814 & 1528720 & 7.2057 & 6.8365 & TRN \\
\hline CHEMBL 3654580 & 1528720 & 6.8429 & 6.0093 & TST \\
\hline CHEMBL3919999 & 1528720 & 6.6566 & 7.1633 & TRN \\
\hline CHEMBL3983054 & 1528720 & 7.7031 & 7.3483 & TRN \\
\hline CHEMBL3654529 & 1528720 & 6.8351 & 6.8492 & TRN \\
\hline CHEMBL3889777 & 1528720 & 6.6003 & 7.0071 & TST \\
\hline CHEMBL3654465 & 1528720 & 6.9263 & 6.8314 & TST \\
\hline CHEMBL3948368 & 1528720 & 7.3242 & 7.4374 & TRN \\
\hline CHEMBL3910190 & 1528720 & 7.9281 & 7.7146 & TRN \\
\hline CHEMBL3654558 & 1528720 & 6.0 & 6.3393 & TRN \\
\hline CHEMBL3731953 & 1537647 & 6.0 & 6.6377 & TST \\
\hline CHEMBL 3730110 & 1537647 & 7.0 & 7.1997 & TRN \\
\hline CHEMBL3729659 & 1537647 & 7.0 & 6.9343 & TRN \\
\hline CHEMBL3730103 & 1537647 & 7.0 & 6.8974 & TRN \\
\hline CHEMBL3730756 & 1537647 & 8.0 & 7.7478 & TRN \\
\hline CHEMBL3731969 & 1537647 & 7.0 & 6.762000 & 20000000005 \\
\hline CHEMBL3727455 & 1537647 & 5.0 & 4.9707 & TRN \\
\hline
\end{tabular}




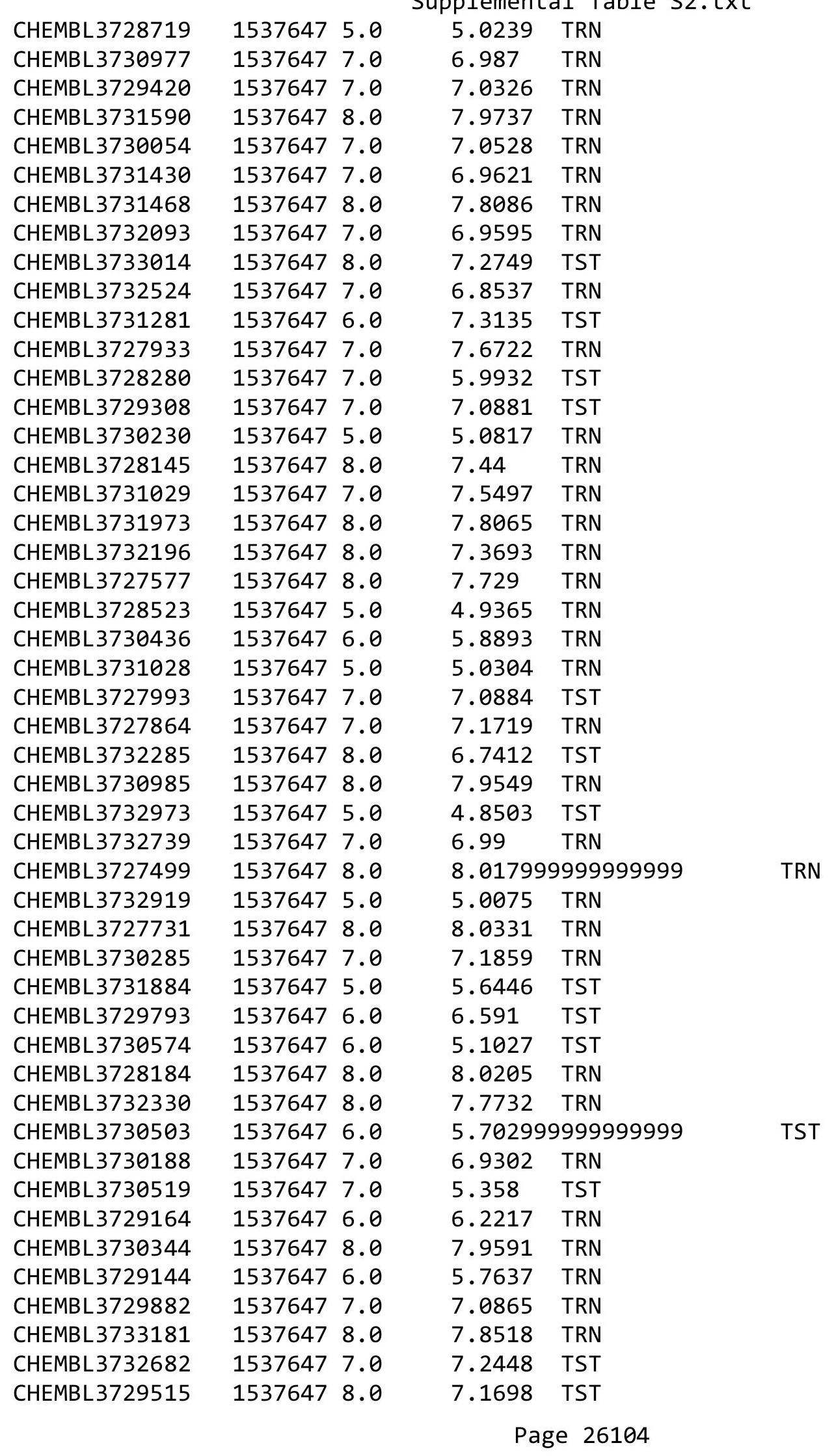




\begin{tabular}{|c|c|c|c|c|}
\hline \\
\hline CHEMBL 3730075 & 1537647 & 7.0 & 7.44 & TRN \\
\hline CHEMBL 3727595 & 1537647 & 8.0 & 7.6097 & TRN \\
\hline CHEMBL3732329 & 1537647 & 8.0 & 7.9351 & TRN \\
\hline CHEMBL3728796 & 1537647 & 7.0 & 6.1666 & TST \\
\hline CHEMBL3730761 & 1537647 & 7.0 & 6.5178 & TRN \\
\hline CHEMBL3732766 & 1537647 & 7.0 & 6.6411 & TST \\
\hline CHEMBL 3727832 & 1537647 & 7.0 & 7.0567 & TRN \\
\hline CHEMBL 3727473 & 1537647 & 7.0 & 7.2937 & TRN \\
\hline CHEMBL3731777 & 1537647 & 6.0 & 6.3546 & TRN \\
\hline CHEMBL 3728220 & 1537647 & 7.0 & 6.3209 & TST \\
\hline CHEMBL 3731445 & 1537647 & 7.0 & 7.3561 & TRN \\
\hline CHEMBL 3730414 & 1537647 & 7.0 & 7.1811 & TRN \\
\hline CHEMBL3731846 & 1537647 & 7.0 & 7.5694 & TST \\
\hline CHEMBL 3728005 & 1537647 & 6.0 & 5.8968 & TRN \\
\hline CHEMBL3731043 & 1537647 & 6.0 & 7.3818 & TST \\
\hline CHEMBL 3728236 & 1537647 & 7.0 & 6.9734 & TRN \\
\hline CHEMBL3729400 & 1537647 & 8.0 & 7.9893 & TRN \\
\hline CHEMBL 3727487 & 1537647 & 8.0 & 7.975 & TRN \\
\hline CHEMBL3732826 & 1537647 & 7.0 & 6.8295 & TRN \\
\hline CHEMBL3730185 & 1537647 & 7.0 & 7.1681 & TRN \\
\hline CHEMBL3729114 & 1537647 & 7.0 & 6.68 & TST \\
\hline CHEMBL3730663 & 1537647 & 6.0 & 5.4351 & TST \\
\hline CHEMBL3727617 & 1537647 & 7.0 & 6.4237 & TST \\
\hline CHEMBL 3732144 & 1537647 & 8.0 & 8.0044 & TRN \\
\hline CHEMBL3731994 & 1537647 & 6.0 & 6.206 & TRN \\
\hline CHEMBL3728192 & 1537647 & 5.0 & 5.7747 & TST \\
\hline CHEMBL3732781 & 1537647 & 7.0 & 7.2124 & TRN \\
\hline CHEMBL3732302 & 1537647 & 8.0 & 8.1342 & TRN \\
\hline CHEMBL3732052 & 1537647 & 6.0 & 6.858 & TST \\
\hline CHEMBL3730002 & 1537647 & 7.0 & 6.2527 & TST \\
\hline CHEMBL 3732374 & 1537647 & 7.0 & 6.8439 & TRN \\
\hline CHEMBL3732532 & 1537647 & 8.0 & 7.8945 & TRN \\
\hline CHEMBL3731733 & 1537647 & 6.0 & 5.9839 & TRN \\
\hline CHEMBL3730869 & 1537647 & 7.0 & 6.8673 & TRN \\
\hline CHEMBL3729957 & 1537647 & 8.0 & 7.8235 & TRN \\
\hline CHEMBL3731057 & 1537647 & 7.0 & 7.3168 & TRN \\
\hline CHEMBL 3731065 & 1537647 & 7.0 & 7.3604 & TRN \\
\hline CHEMBL3727925 & 1537647 & 7.0 & 7.1111 & TRN \\
\hline CHEMBL3729356 & 1537647 & 6.0 & 6.0196 & TRN \\
\hline CHEMBL 3730487 & 1537647 & 6.0 & 5.94799 & 99999999995 \\
\hline CHEMBL3730908 & 1537647 & 8.0 & 7.9966 & TRN \\
\hline CHEMBL 3727964 & 1537647 & 7.0 & 7.0803 & TRN \\
\hline CHEMBL3731455 & 1537647 & 7.0 & 7.0583 & TRN \\
\hline CHEMBL 3733286 & 1537647 & 7.0 & 7.1066 & TRN \\
\hline CHEMBL3727594 & 1537647 & 7.0 & 7.1876 & TRN \\
\hline CHEMBL3729508 & 1537647 & 7.0 & 7.2119 & TRN \\
\hline CHEMBL 3729380 & 1537647 & 8.0 & 7.7003 & TRN \\
\hline CHEMBL3730601 & 1537647 & 7.0 & 6.7171 & TRN \\
\hline
\end{tabular}




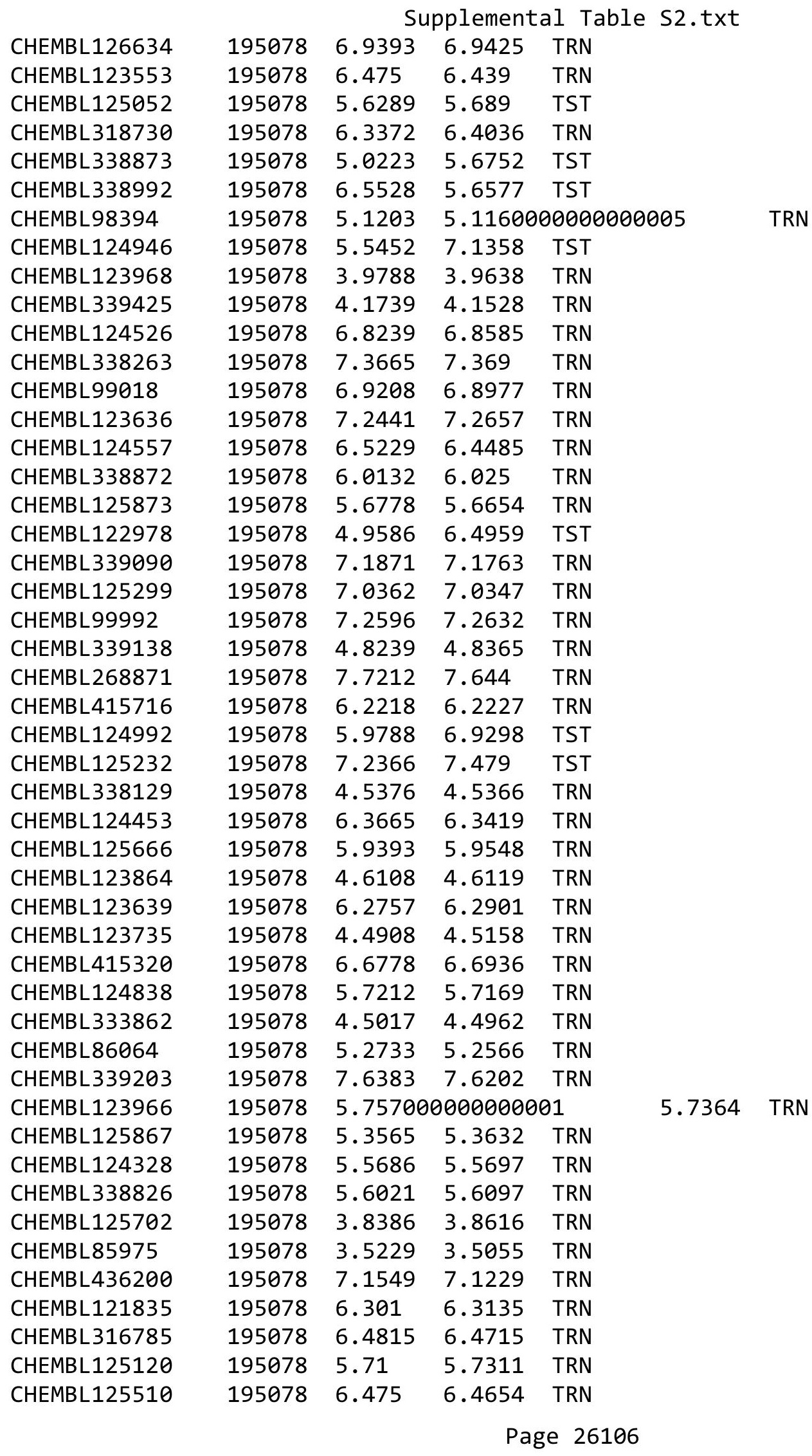




\begin{tabular}{|c|c|c|c|c|c|}
\hline & & & & & \\
\hline CHEMBL124556 & 195078 & 5.9788 & 5.9875 & TRN & \\
\hline CHEMBL124430 & 195078 & 6.9872 & 7.1485 & TST & \\
\hline CHEMBL123729 & 195078 & 2.5229 & 6.2636 & TST & \\
\hline CHEMBL431274 & 195078 & 6.4559 & 6.4577 & TRN & \\
\hline CHEMBL123778 & 195078 & 6.3565 & 6.36100 & 0000000001 & TRN \\
\hline CHEMBL124149 & 195078 & 6.5229 & 6.5518 & TRN & \\
\hline CHEMBL340658 & 195078 & 5.0 & 4.9773 & TRN & \\
\hline CHEMBL124594 & 195078 & 6.7212 & 6.7209 & TRN & \\
\hline CHEMBL122293 & 195078 & 6.9788 & 6.96899 & 9999999999 & TRN \\
\hline CHEMBL125397 & 195078 & 6.3279 & 6.2906 & TRN & \\
\hline CHEMBL125336 & 195078 & 7.3768 & 7.4486 & TRN & \\
\hline CHEMBL124726 & 195078 & 6.585 & 6.6222 & TRN & \\
\hline CHEMBL125504 & 195078 & 5.7825 & 5.7726 & TRN & \\
\hline CHEMBL126214 & 195078 & 6.1844 & 7.4743 & TST & \\
\hline CHEMBL124186 & 195078 & 5.9031 & 5.9387 & TRN & \\
\hline CHEMBL420519 & 195078 & 6.9469 & 6.566 & TST & \\
\hline CHEMBL83825 & 195078 & 7.5229 & 5.5705 & TST & \\
\hline CHEMBL338658 & 195078 & 5.9031 & 5.93 & TRN & \\
\hline CHEMBL124786 & 195078 & 6.9586 & 6.2549 & TST & \\
\hline CHEMBL127564 & 195078 & 6.7447 & 6.0157 & TST & \\
\hline CHEMBL121834 & 195078 & 5.9586 & 5.2856 & TST & \\
\hline CHEMBL 340255 & 195078 & 4.6478 & 5.1346 & TST & \\
\hline CHEMBL124991 & 195078 & 5.9469 & 5.3683 & TST & \\
\hline CHEMBL37803 & 195078 & 7.699 & 7.3227 & TST & \\
\hline CHEMBL 3685618 & 1527688 & 8.4202 & 8.0447 & TRN & \\
\hline CHEMBL 3689959 & 1527688 & 7.1931 & 7.3265 & TRN & \\
\hline CHEMBL 3685518 & 1527688 & 8.7447 & 8.5604 & TRN & \\
\hline CHEMBL 3690041 & 1527688 & 7.284 & 7.4849 & TRN & \\
\hline CHEMBL 3685457 & 1527688 & 8.5086 & 8.2786 & TRN & \\
\hline CHEMBL 3685582 & 1527688 & 8.6576 & 8.4309 & TRN & \\
\hline CHEMBL 3690040 & 1527688 & 9.0969 & 9.1353 & TRN & \\
\hline CHEMBL 3690038 & 1527688 & 8.0088 & 8.9123 & TRN & \\
\hline CHEMBL 3685585 & 1527688 & 7.4828 & 7.5265 & TRN & \\
\hline CHEMBL3690068 & 1527688 & 6.6014 & 6.7552 & TST & \\
\hline CHEMBL 3685430 & 1527688 & 8.3372 & 8.0225 & TRN & \\
\hline CHEMBL 3685492 & 1527688 & 6.0 & 7.4633 & TST & \\
\hline CHEMBL 3690016 & 1527688 & 9.0969 & 8.8466 & TRN & \\
\hline CHEMBL 3685484 & 1527688 & 8.9586 & 8.6026 & TRN & \\
\hline CHEMBL3690057 & 1527688 & 8.5376 & 8.1142 & TST & \\
\hline CHEMBL 3685530 & 1527688 & 6.9303 & 6.7938 & TRN & \\
\hline CHEMBL3689974 & 1527688 & 7.1593 & 7.3065 & TRN & \\
\hline CHEMBL 3685572 & 1527688 & 8.6021 & 7.2966 & TST & \\
\hline CHEMBL 3685485 & 1527688 & 7.0737 & 7.3438 & TST & \\
\hline CHEMBL 3690027 & 1527688 & 9.5229 & 8.7488 & TRN & \\
\hline CHEMBL 3690005 & 1527688 & 9.3979 & 9.2121 & TRN & \\
\hline CHEMBL 2180404 & 1527688 & 7.9136 & 7.8754 & TRN & \\
\hline CHEMBL 3689969 & 1527688 & 7.0297 & 7.131 & TRN & \\
\hline CHEMBL3690061 & 1527688 & 6.1606 & 6.6085 & TST & \\
\hline
\end{tabular}


Supplemental Table S2.txt

\begin{tabular}{|c|c|c|c|c|c|c|}
\hline CHEMBL 3690065 & 1527688 & 6.8989 & 6.7795 & TST & & \\
\hline CHEMBL 3685507 & 1527688 & 8.7212 & 7.4204 & TST & & \\
\hline CHEMBL 3685500 & 1527688 & 8.0555 & 6.9426 & TST & & \\
\hline CHEMBL 3685588 & 1527688 & 8.5528 & 8.3435 & TRN & & \\
\hline CHEMBL3685450 & 1527688 & 7.0565 & 6.7868 & TRN & & \\
\hline CHEMBL 3685474 & 1527688 & 8.0809 & 8.2176 & TRN & & \\
\hline CHEMBL 3685563 & 1527688 & 7.6326 & 7.8253 & TRN & & \\
\hline CHEMBL 2180403 & 1527688 & 7.8633 & 8.3187 & TRN & & \\
\hline CHEMBL 3685584 & 1527688 & 8.3565 & 7.6491 & TRN & & \\
\hline CHEMBL3689955 & 1527688 & 7.7352 & 7.4746 & TRN & & \\
\hline CHEMBL 3685480 & 1527688 & 7.6021 & 8.0228 & TST & & \\
\hline CHEMBL3690052 & 1527688 & 8.9586 & 9.1048 & TRN & & \\
\hline CHEMBL 3685497 & 1527688 & 8.3768 & 7.8493 & TST & & \\
\hline CHEMBL3689950 & 1527688 & \multicolumn{3}{|c|}{ 8. 283999999999999} & 7.6328 & TRN \\
\hline CHEMBL3685542 & 1527688 & 8.3468 & 8.3851 & TRN & & \\
\hline CHEMBL3689953 & 1527688 & 8.3098 & 8.7706 & TRN & & \\
\hline CHEMBL3685601 & 1527688 & 6.791 & 7.2161 & TST & & \\
\hline CHEMBL 3689971 & 1527688 & 7.3215 & 7.6686 & TRN & & \\
\hline CHEMBL 3685466 & 1527688 & 8.1249 & 7.8828 & TRN & & \\
\hline CHEMBL3685527 & 1527688 & 7.9469 & 7.1951 & TST & & \\
\hline CHEMBL3685586 & 1527688 & 7.6517 & 7.3197 & TRN & & \\
\hline CHEMBL 3685587 & 1527688 & 7.0511 & 7.3225 & TRN & & \\
\hline CHEMBL 3685451 & 1527688 & 5.7294 & 6.3253 & TST & & \\
\hline CHEMBL 3685600 & 1527688 & 9.5229 & 9.19 & TRN & & \\
\hline CHEMBL 3685496 & 1527688 & 7.2487 & 7.515 & TRN & & \\
\hline CHEMBL3685558 & 1527688 & 7.6038 & 8.0796 & TRN & & \\
\hline CHEMBL3689991 & 1527688 & 8.7959 & 8.4751 & TRN & & \\
\hline CHEMBL 3685523 & 1527688 & 8.6021 & 7.772 & TST & & \\
\hline CHEMBL 3685610 & 1527688 & 8.2596 & 8.0488 & TRN & & \\
\hline CHEMBL 3689982 & 1527688 & 7.7986 & 7.4822 & TRN & & \\
\hline CHEMBL 3689967 & 1527688 & 7.4685 & 7.5356 & TRN & & \\
\hline CHEMBL 3685435 & 1527688 & 6.4742 & 5.9837 & TRN & & \\
\hline CHEMBL 3690055 & 1527688 & 8.7447 & 8.0649 & TRN & & \\
\hline CHEMBL3685499 & 1527688 & 8.1367 & 6.8754 & TST & & \\
\hline CHEMBL 3689978 & 1527688 & 6.3714 & 7.3501 & TRN & & \\
\hline CHEMBL 3685433 & 1527688 & \multicolumn{3}{|c|}{ 8. 283999999999999} & 7.9735 & TRN \\
\hline CHEMBL 3685513 & 1527688 & 9.3979 & 6.9127 & TST & & \\
\hline CHEMBL 3685599 & 1527688 & 8.4559 & 8.5897 & TRN & & \\
\hline CHEMBL 3690022 & 1527688 & 7.7144 & 7.9879 & TRN & & \\
\hline CHEMBL 3685540 & 1527688 & 7.5719 & 7.7664 & TRN & & \\
\hline CHEMBL3689946 & 1527688 & 9.0 & 8.7047 & TRN & & \\
\hline CHEMBL 3685481 & 1527688 & 6.9393 & 7.457000 & 0000000001 & & TST \\
\hline CHEMBL 3690018 & 1527688 & 8.5528 & 8.1531 & TRN & & \\
\hline CHEMBL 3685568 & 1527688 & 8.0706 & 8.5058 & TRN & & \\
\hline CHEMBL 3685520 & 1527688 & 8.9586 & 8.2862 & TRN & & \\
\hline CHEMBL3685511 & 1527688 & 6.2431 & 7.3426 & TST & & \\
\hline CHEMBL3685517 & 1527688 & 6.4073 & 7.346 & TST & & \\
\hline CHEMBL 3639844 & 1527688 & 8.2518 & 8.9402 & TRN & & \\
\hline
\end{tabular}

Page 26108 
Supplemental Table S2.txt

\begin{tabular}{|c|c|c|c|c|c|}
\hline CHEMBL3685579 & 1527688 & 6.9055 & 8.1317 & TST & \\
\hline CHEMBL3690047 & 1527688 & 7.8097 & 8.0444 & TRN & \\
\hline CHEMBL 3685502 & 1527688 & 8.4685 & 7.2737 & TST & \\
\hline CHEMBL3685574 & 1527688 & 7.9508 & 7.5679 & TRN & \\
\hline CHEMBL 3685567 & 1527688 & 8.8239 & 8.4341 & TRN & \\
\hline CHEMBL3689951 & 1527688 & 7.2815 & 7.1206 & TRN & \\
\hline CHEMBL 3685576 & 1527688 & 9.0969 & 9.0424 & TRN & \\
\hline CHEMBL 3685463 & 1527688 & 7.7423 & 7.1427 & TRN & \\
\hline CHEMBL 3685545 & 1527688 & 6.0 & 7.521 & TRN & \\
\hline CHEMBL 3685562 & 1527688 & 8.9586 & 8.6615 & TRN & \\
\hline CHEMBL 3690031 & 1527688 & 6.4342 & 7.0066 & TRN & \\
\hline CHEMBL 3685620 & 1527688 & 7.2798 & 6.6168 & TRN & \\
\hline CHEMBL 3685531 & 1527688 & 7.4012 & 6.7882 & TRN & \\
\hline CHEMBL3685489 & 1527688 & 7.0605 & 7.2407 & TST & \\
\hline CHEMBL 3685501 & 1527688 & 8.1024 & 7.3877 & TST & \\
\hline CHEMBL 3685541 & 1527688 & 7.0472 & 7.0545 & TRN & \\
\hline CHEMBL3690000 & 1527688 & 7.8962 & 7.9863 & TRN & \\
\hline CHEMBL 3689960 & 1527688 & 6.0 & 6.888 & TRN & \\
\hline CHEMBL 3685472 & 1527688 & 7.7144 & 7.3434 & TRN & \\
\hline CHEMBL 3685522 & 1527688 & 8.585 & 8.38600 & 0000000001 & TST \\
\hline CHEMBL3685459 & 1527688 & 8.5086 & 8.4696 & TRN & \\
\hline CHEMBL 3685561 & 1527688 & 6.0 & 7.1697 & TRN & \\
\hline CHEMBL3690069 & 1527688 & 7.5528 & 7.1964 & TST & \\
\hline CHEMBL 3689961 & 1527688 & 7.8996 & 7.3838 & TRN & \\
\hline CHEMBL 3690020 & 1527688 & 9.1549 & 9.5303 & TRN & \\
\hline CHEMBL 3685604 & 1527688 & 7.2865 & 7.0975 & TST & \\
\hline CHEMBL3689965 & 1527688 & 7.6038 & 7.9967 & TRN & \\
\hline CHEMBL 3685473 & 1527688 & 7.8794 & 7.9883 & TRN & \\
\hline CHEMBL 3685515 & 1527688 & 8.1938 & 7.5103 & TST & \\
\hline CHEMBL3689949 & 1527688 & 7.9469 & 7.3631 & TRN & \\
\hline CHEMBL 3685544 & 1527688 & 8.2366 & 8.543 & TRN & \\
\hline CHEMBL3685532 & 1527688 & 7.7235 & 7.7174 & TRN & \\
\hline CHEMBL 3685508 & 1527688 & 7.6108 & 7.8666 & TST & \\
\hline CHEMBL 3689948 & 1527688 & 9.0969 & 8.9853 & TRN & \\
\hline CHEMBL 3685627 & 1527688 & 7.0904 & 7.0907 & TRN & \\
\hline CHEMBL3685438 & 1527688 & 6.6938 & 7.8139 & TRN & \\
\hline CHEMBL3689983 & 1527688 & 8.2366 & 8.0578 & TRN & \\
\hline CHEMBL 3685570 & 1527688 & 8.4685 & 8.4986 & TRN & \\
\hline CHEMBL 3685493 & 1527688 & 8.4815 & 8.8435 & TRN & \\
\hline CHEMBL3685592 & 1527688 & 7.6021 & 8.2041 & TRN & \\
\hline CHEMBL3690046 & 1527688 & 8.3372 & 8.7903 & TRN & \\
\hline CHEMBL 3685564 & 1527688 & 8.6778 & 8.2759 & TRN & \\
\hline CHEMBL3690014 & 1527688 & 7.7144 & 7.8818 & TRN & \\
\hline CHEMBL 3689980 & 1527688 & 8.0915 & 7.3798 & TRN & \\
\hline CHEMBL 3690007 & 1527688 & 8.7212 & 8.085 & TRN & \\
\hline CHEMBL 3689968 & 1527688 & 8.1675 & 7.5642 & TST & \\
\hline CHEMBL3685536 & 1527688 & 8.7959 & 8.8998 & TRN & \\
\hline CHEMBL 3685468 & 1527688 & 8.0915 & 8.0335 & TRN & \\
\hline
\end{tabular}


Supplemental Table S2.txt

\begin{tabular}{|c|c|c|c|c|c|}
\hline CHEMBL3685539 & 1527688 & 6.0 & 7.7259 & TRN & \\
\hline CHEMBL 3689963 & 1527688 & 7.3799 & \multicolumn{2}{|c|}{6.7989999999999995} & TRN \\
\hline CHEMBL 3685475 & 1527688 & 8.4089 & 8.338 & TRN & \\
\hline CHEMBL 3685602 & 1527688 & 5.5708 & 7.2013 & TST & \\
\hline CHEMBL 3685597 & 1527688 & 8.2596 & 8.6981 & TRN & \\
\hline CHEMBL 3690011 & 1527688 & 8.699 & 8.2981 & TRN & \\
\hline CHEMBL 3685525 & 1527688 & 7.7878 & 7.3977 & TRN & \\
\hline CHEMBL3685593 & 1527688 & 7.5686 & 7.6269 & TRN & \\
\hline CHEMBL 3690050 & 1527688 & 8.7696 & 8.7474 & TRN & \\
\hline CHEMBL 3689956 & 1527688 & 7.7423 & 7.6853 & TRN & \\
\hline CHEMBL 3685580 & 1527688 & 8.2076 & 8.5167 & TST & \\
\hline CHEMBL 3689993 & 1527688 & 9.1549 & 8.6798 & TRN & \\
\hline CHEMBL 3685446 & 1527688 & 7.041 & 7.2537 & TRN & \\
\hline CHEMBL 3685613 & 1527688 & 8.4089 & 8.168 & TRN & \\
\hline CHEMBL 3690066 & 1527688 & 8.6778 & 8.6372 & TRN & \\
\hline CHEMBL 3685619 & 1527688 & 7.4711 & 7.1758 & TRN & \\
\hline CHEMBL 3689989 & 1527688 & 6.755 & \multicolumn{2}{|c|}{7.2620000000000005} & TST \\
\hline CHEMBL 3685477 & 1527688 & 7.2366 & 7.8701 & TRN & \\
\hline CHEMBL 3690010 & 1527688 & 9.2218 & 8.5167 & TRN & \\
\hline CHEMBL 3685573 & 1527688 & 7.8962 & 7.6053 & TRN & \\
\hline CHEMBL3685566 & 1527688 & 8.9208 & 8.6215 & TRN & \\
\hline CHEMBL3689976 & 1527688 & 9.699 & 9.0219 & TRN & \\
\hline CHEMBL 3689977 & 1527688 & 7.4449 & 7.3794 & TRN & \\
\hline CHEMBL 3685510 & 1527688 & 6.7457 & 6.8706 & TST & \\
\hline CHEMBL 3685434 & 1527688 & 7.8996 & 7.8328 & TRN & \\
\hline CHEMBL3685609 & 1527688 & 7.9318 & 7.1907 & TST & \\
\hline CHEMBL3690013 & 1527688 & 7.5528 & 7.5935 & TRN & \\
\hline CHEMBL 3689966 & 1527688 & 7.1118 & 7.2551 & TRN & \\
\hline CHEMBL 3685616 & 1527688 & 6.371 & 6.7286 & TRN & \\
\hline CHEMBL 3685458 & 1527688 & 8.1367 & 7.8199 & TRN & \\
\hline CHEMBL3685482 & 1527688 & 7.1824 & 7.1372 & TST & \\
\hline CHEMBL 3685483 & 1527688 & 8.6778 & 8.3983 & TRN & \\
\hline CHEMBL 3685470 & 1527688 & 7.5622 & 7.4109 & TRN & \\
\hline CHEMBL 3685461 & 1527688 & 7.3401 & 7.8461 & TRN & \\
\hline CHEMBL 3689957 & 1527688 & 9.301 & 8.8229 & TRN & \\
\hline CHEMBL3690021 & 1527688 & 8.2218 & 8.3291 & TRN & \\
\hline CHEMBL3690004 & 1527688 & 9.3979 & 9.2032 & TRN & \\
\hline CHEMBL 3685453 & 1527688 & 7.9431 & \multicolumn{2}{|c|}{8.062000000000001} & TRN \\
\hline CHEMBL 3690001 & 1527688 & 7.2733 & 7.7616 & TRN & \\
\hline CHEMBL 3690019 & 1527688 & 7.5058 & 8.1023 & TRN & \\
\hline CHEMBL 3685442 & 1527688 & 7.9431 & 7.3255 & TRN & \\
\hline CHEMBL 3685611 & 1527688 & 7.7852 & 7.9943 & TRN & \\
\hline CHEMBL3685571 & 1527688 & 7.7932 & 7.2794 & TRN & \\
\hline CHEMBL 3685505 & 1527688 & 9.3979 & 7.1546 & TST & \\
\hline CHEMBL 3690051 & 1527688 & 7.4449 & 8.4124 & TRN & \\
\hline CHEMBL 3685615 & 1527688 & 8.2076 & 7.4519 & TRN & \\
\hline CHEMBL 3685498 & 1527688 & 7.7235 & 7.4194 & TRN & \\
\hline CHEMBL 3685623 & 1527688 & 8.8861 & 8.6586 & TRN & \\
\hline
\end{tabular}


Supplemental Table S2.txt

\begin{tabular}{|c|c|c|c|c|}
\hline HEM & 527688 & 6.3052 & & \\
\hline & 527688 & 7.0453 & & \\
\hline & 27688 & & & \\
\hline AEMBL & 7688 & 2862 & & \\
\hline AEMBL & 527688 & 314 & & \\
\hline HEMBL3690002 & 527688 & 8.0706 & 5163 & \\
\hline 5595 & 588 & & 17 & \\
\hline 5614 & 688 & 021 & & \\
\hline AEMBL3685432 & 688 & 9048 & 6247 & \\
\hline HEMBL3689979 & 527688 & 376 & 2944 & \\
\hline HEMBL3689999 & 688 & 6.0 & 3977 & \\
\hline IEMBL368 & 588 & 652 & 7839 & \\
\hline IEMBL: & & & & \\
\hline HEMBL3685495 & 588 & 78 & 5097 & \\
\hline IEMBL36 & 88 & & 3466 & \\
\hline AEMBL3685460 & 88 & 8 & 1485 & \\
\hline AEMBL36 & $8 \mathrm{~d}$ & 82 & 138 & . \\
\hline HEMBL 36 & & & 287 & \\
\hline HEMBL3690035 & & 37 & 5456 & \\
\hline IEMBL36 & & 7 & 45 & \\
\hline AEMBL3 & 88 & 6 & 091 & וב \\
\hline AEMBL: & & & 012 & RN \\
\hline HEMBL & & & 589 & \\
\hline 575 & & & 886 & \\
\hline HEMBL368 & & & & TRN \\
\hline HEMBL3 & 88 & & 081 & KIV \\
\hline HEMBL; & & & 306 & RN \\
\hline$H F M B I=$ & 88 & & & \\
\hline HEMBL3685598 & & 9. & & in \\
\hline HEMBL3685486 & & 6 . & 862 & ISI \\
\hline HEMBL 36854 & & & 648 & RN \\
\hline HEMBL & & & 772 & RN \\
\hline HEMBL. & 38 & 6 & 923 & ST \\
\hline HEMBL3689973 & & & 2771 & IRN \\
\hline HEMBL3690063 & & 9.0969 & 917 & Th \\
\hline HEMBL & & 9 & & IRN \\
\hline HFMRI & & & 421 & $\Gamma \mathrm{RN}$ \\
\hline HEMBL3 & & & 665 & TST \\
\hline HEMBL 3690029 & 38 & 9.3979 & 622 & TRN \\
\hline AEMBL 3639 & 88 & & 989 & TRN \\
\hline HEMBL3690039 & & 382 & 602 & 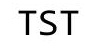 \\
\hline HEMBL3685625 & & & 9.0761 & TRN \\
\hline HEMBL3685594 & 88 & & 3809 & TRN \\
\hline AEMBL3690028 & 688 & 7.7773 & 8779 & TR \\
\hline HEMBL3 & 57 & 576 & 8282 & $\mathrm{~N}$ \\
\hline HEMBL 3685528 & & 586 & & \\
\hline HEMBL3690036 & & 9.0458 & .6953 & \\
\hline CHEMBL3685503 & 1527688 & 8.699 & 8.5135 & \\
\hline
\end{tabular}

Page 26111 
Supplemental Table S2.txt

\begin{tabular}{|c|c|c|c|c|c|c|}
\hline CHEMBL3685436 & 1527688 & 6.8551 & 6.6299 & TRN & & \\
\hline CHEMBL3690015 & 1527688 & 6.0 & 6.8763 & TRN & & \\
\hline CHEMBL3690037 & 1527688 & 8.9586 & 8.3097 & TRN & & \\
\hline CHEMBL 3690044 & 1527688 & 7.61799 & 99999999 & 99 & 7.559 & TRN \\
\hline CHEMBL3685569 & 1527688 & 8.5686 & 8.7938 & TRN & & \\
\hline CHEMBL3690060 & 1527688 & 7.8928 & 6.6024 & TST & & \\
\hline CHEMBL3690067 & 1527688 & 7.3072 & 6.9981 & TST & & \\
\hline CHEMBL 3685556 & 1527688 & 8.4437 & 8.4534 & TRN & & \\
\hline CHEMBL 3689972 & 1527688 & 6.7194 & 6.8232 & TRN & & \\
\hline CHEMBL3690023 & 1527688 & 8.6383 & 8.5416 & TRN & & \\
\hline CHEMBL3685560 & 1527688 & 8.5229 & 8.2804 & TRN & & \\
\hline CHEMBL3690048 & 1527688 & 7.064 & 7.4024 & TRN & & \\
\hline CHEMBL3689975 & 1527688 & 8.8539 & 8.3899 & TRN & & \\
\hline CHEMBL3690012 & 1527688 & 8.9586 & 8.9229 & TRN & & \\
\hline CHEMBL3685448 & 1527688 & 8.1549 & 7.9356 & TRN & & \\
\hline CHEMBL3685469 & 1527688 & 8.5086 & 8.55299 & 9999999999 & & TRN \\
\hline CHEMBL3685596 & 1527688 & 6.8286 & 7.0193 & TRN & & \\
\hline CHEMBL3685546 & 1527688 & 8.6778 & 8.3596 & TRN & & \\
\hline CHEMBL3685509 & 1527688 & 6.66700 & 30000000 & & 6.8694 & TRN \\
\hline CHEMBL3685537 & 1527688 & 8.9586 & 8.5588 & TRN & & \\
\hline CHEMBL3685626 & 1527688 & 5.57600 & 00000000 & 305 & 7.1484 & TRN \\
\hline CHEMBL3689984 & 1527688 & 7.7986 & 7.9605 & TRN & & \\
\hline CHEMBL3685555 & 1527688 & 8.1805 & 7.3917 & TRN & & \\
\hline CHEMBL 3685441 & 1527688 & 6.5923 & 7.3319 & TRN & & \\
\hline CHEMBL3690049 & 1527688 & 9.2218 & 8.2056 & TST & & \\
\hline CHEMBL3685524 & 1527688 & 8.8239 & 7.8122 & TST & & \\
\hline CHEMBL 2180801 & 1527688 & 7.5017 & 7.3902 & TRN & & \\
\hline CHEMBL3689985 & 1527688 & 7.4989 & 7.3596 & TRN & & \\
\hline CHEMBL 3685431 & 1527688 & 8.1249 & 8.6979 & TRN & & \\
\hline CHEMBL3689958 & 1527688 & 7.2652 & 7.7296 & TRN & & \\
\hline CHEMBL3685622 & 1527688 & 8.9586 & 8.6509 & TRN & & \\
\hline CHEMBL 3685548 & 1527688 & 8.0706 & 7.4616 & TRN & & \\
\hline CHEMBL3685603 & 1527688 & 7.1952 & 7.095 & TST & & \\
\hline CHEMBL 3685607 & 1527688 & 6.3278 & 7.4557 & TST & & \\
\hline CHEMBL3685476 & 1527688 & 7.4989 & 7.6788 & TRN & & \\
\hline CHEMBL3685464 & 1527688 & 8.1427 & 7.9628 & TRN & & \\
\hline CHEMBL3685521 & 1527688 & 9.3979 & 9.1388 & TRN & & \\
\hline CHEMBL 3685444 & 1527688 & 8.1192 & 7.8976 & TRN & & \\
\hline CHEMBL 3690033 & 1527688 & 8.3468 & 8.3948 & TRN & & \\
\hline CHEMBL 3685494 & 1527688 & 8.3872 & 8.0751 & TRN & & \\
\hline CHEMBL3685437 & 1527688 & 6.8268 & 6.559 & TRN & & \\
\hline CHEMBL3690056 & 1527688 & 9.3979 & 8.7933 & TST & & \\
\hline CHEMBL3690003 & 1527688 & 9.5229 & 9.3062 & TRN & & \\
\hline CHEMBL3685465 & 1527688 & 8.0862 & 8.7566 & TRN & & \\
\hline CHEMBL 3685590 & 1527688 & 7.71 & 7.8437 & TRN & & \\
\hline CHEMBL3690026 & 1527688 & 8.1079 & 7.8928 & TRN & & \\
\hline CHEMBL3689947 & 1527688 & 9.301 & 9.1564 & TRN & & \\
\hline CHEMBL3690006 & 1527688 & 8.5686 & 8.4309 & TST & & \\
\hline
\end{tabular}


Supplemental Table S2.txt

\begin{tabular}{|c|c|c|c|c|c|}
\hline CHEMBL 3689964 & 1527688 & 6.0 & 7.5901 & TRN & \\
\hline CHEMBL3685591 & 1527688 & 7.8297 & 7.6207 & TRN & \\
\hline CHEMBL3685554 & 1527688 & 7.6676 & 8.1128 & TRN & \\
\hline CHEMBL 3685559 & 1527688 & 7.9355 & 7.4924 & TRN & \\
\hline CHEMBL 3685443 & 1527688 & 7.9706 & 7.6576 & TRN & \\
\hline CHEMBL 3685577 & 1527688 & 9.3979 & 9.5975 & TRN & \\
\hline CHEMBL 3685608 & 1527688 & 8.5086 & 8.7393 & TRN & \\
\hline CHEMBL 3685605 & 1527688 & 6.8422 & 6.8373 & TRN & \\
\hline CHEMBL 3685490 & 1527688 & 5.9564 & 8.0875 & TST & \\
\hline CHEMBL 3685553 & 1527688 & 8.1739 & 8.1123 & TRN & \\
\hline CHEMBL 3685547 & 1527688 & 6.9136 & 7.7143 & TST & \\
\hline CHEMBL 3689992 & 1527688 & 8.4559 & 8.5928 & TRN & \\
\hline CHEMBL 3690054 & 1527688 & 8.5686 & 8.2443 & TRN & \\
\hline CHEMBL 3685471 & 1527688 & 7.767 & 7.98799 & 99999999995 & TRN \\
\hline CHEMBL 3685455 & 1527688 & 8.8861 & 9.0217 & TRN & \\
\hline CHEMBL 3685612 & 1527688 & 7.6576 & 7.9433 & TRN & \\
\hline CHEMBL 3689952 & 1527688 & 8.6383 & 8.8765 & TRN & \\
\hline CHEMBL 3685514 & 1527688 & 7.5607 & 6.9557 & TST & \\
\hline CHEMBL 3685488 & 1527688 & 7.0273 & 7.6286 & TST & \\
\hline CHEMBL 3685535 & 1527688 & 7.0991 & 7.5354 & TST & \\
\hline CHEMBL 3689988 & 1527688 & 7.1733 & 7.375 & TRN & \\
\hline CHEMBL3685519 & 1527688 & 7.0177 & 7.8006 & TRN & \\
\hline CHEMBL 3690059 & 1527688 & 8.5086 & 8.07200 & 0000000001 & TST \\
\hline CHEMBL 3685624 & 1527688 & 8.4318 & 8.5315 & TRN & \\
\hline CHEMBL3685439 & 1527688 & 8.9208 & 8.5804 & TRN & \\
\hline CHEMBL 3685487 & 1527688 & 8.8861 & 8.5803 & TRN & \\
\hline CHEMBL3685454 & 1527688 & 8.2218 & 8.4041 & TRN & \\
\hline CHEMBL 3685516 & 1527688 & 8.3665 & 7.7768 & TST & \\
\hline CHEMBL3685552 & 1527688 & 7.7721 & 8.7567 & TRN & \\
\hline CHEMBL 3685534 & 1527688 & 7.8239 & 7.3436 & TRN & \\
\hline CHEMBL 3685533 & 1527688 & 9.2218 & 8.98 & TRN & \\
\hline CHEMBL 3690043 & 1527688 & 7.9547 & 7.4446 & TRN & \\
\hline CHEMBL 3690058 & 1527688 & 8.9586 & 8.3794 & TST & \\
\hline CHEMBL 3689981 & 1527688 & 7.5719 & 7.7378 & TRN & \\
\hline CHEMBL 3685449 & 1527688 & 7.7282 & 7.4205 & TST & \\
\hline CHEMBL3690025 & 1527688 & 8.3872 & 6.2868 & TST & \\
\hline CHEMBL3639888 & 1527688 & 9.3979 & 9.3271 & TRN & \\
\hline CHEMBL3689996 & 1527688 & 7.6861 & 7.8066 & TRN & \\
\hline CHEMBL 3689962 & 1527688 & 6.9285 & 7.1147 & TRN & \\
\hline CHEMBL 3685445 & 1527688 & 7.8996 & 7.7746 & TRN & \\
\hline CHEMBL 3685462 & 1527688 & 8.4949 & 7.6894 & TST & \\
\hline CHEMBL 3685543 & 1527688 & 9.3979 & 8.5245 & TST & \\
\hline CHEMBL3689970 & 1527688 & 7.2815 & 7.1885 & TST & \\
\hline CHEMBL3685479 & 1527688 & 7.1325 & 6.5522 & TST & \\
\hline CHEMBL3689995 & 1527688 & 8.4949 & 8.381 & TST & \\
\hline CHEMBL 3685617 & 1527688 & 7.9393 & 8.6229 & TST & \\
\hline CHEMBL3690064 & 1527688 & 8.2757 & 7.6825 & TST & \\
\hline CHEMBL3685589 & 1527688 & 7.8894 & 8.4256 & TST & \\
\hline
\end{tabular}




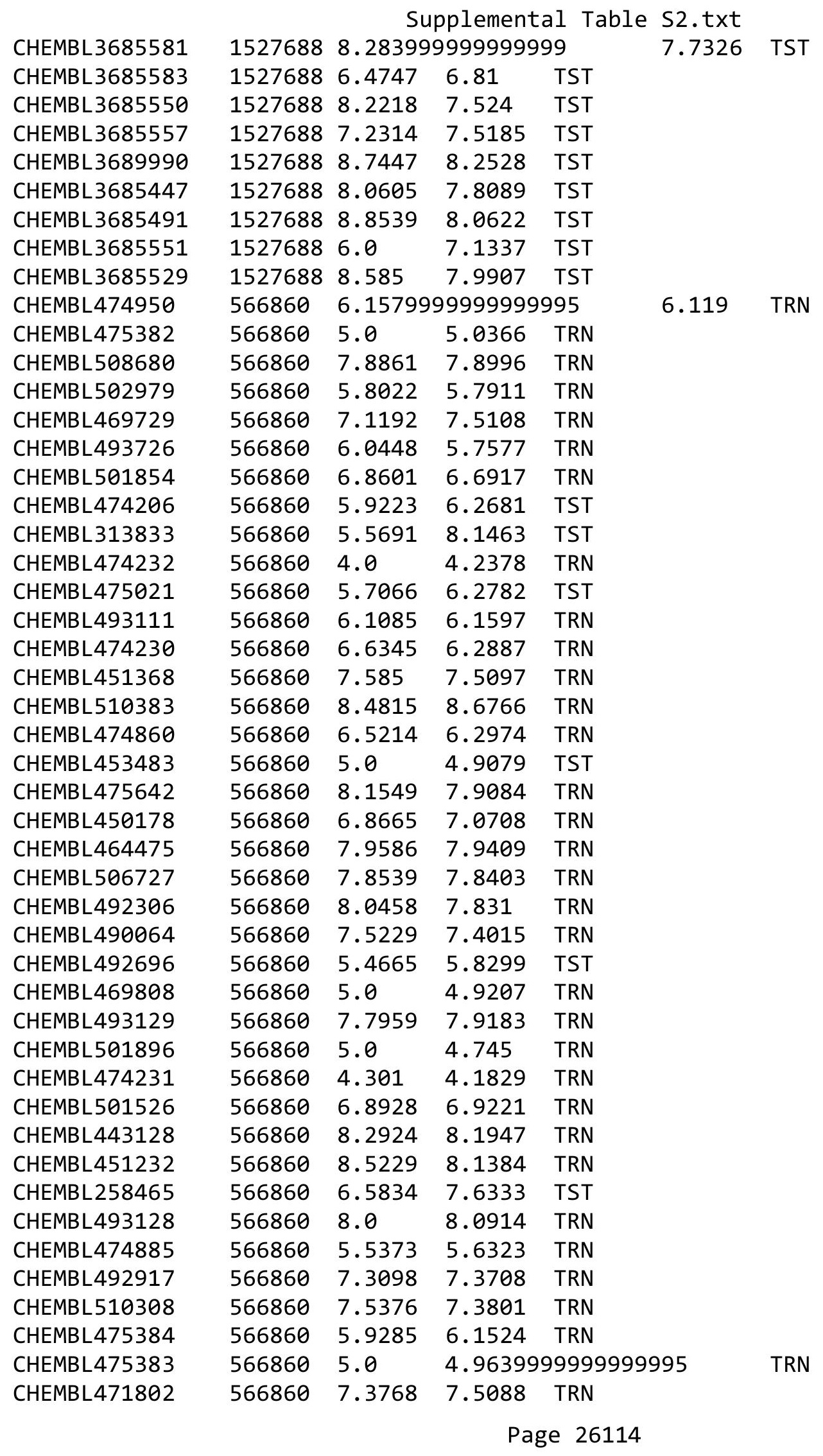




\begin{tabular}{|c|c|c|c|c|c|}
\hline \multirow[b]{2}{*}{ CHEMBL493130 } & \\
\hline & 566860 & 8.2676 & 7.8971 & TRN & \\
\hline CHEMBL449732 & 566860 & 5.0 & 4.8879 & TRN & \\
\hline CHEMBL445747 & 566860 & 8.3188 & 8.5387 & TRN & \\
\hline CHEMBL492305 & 566860 & 7.0044 & 7.2202 & TRN & \\
\hline CHEMBL474634 & 566860 & 8.4559 & 8.5889 & TRN & \\
\hline CHEMBL471202 & 566860 & 6.8697 & 6.943 & TRN & \\
\hline CHEMBL492700 & 566860 & 6.1979 & 6.7827 & TST & \\
\hline CHEMBL474205 & 566860 & 5.0 & 5.7725 & TRN & \\
\hline CHEMBL492698 & 566860 & 5.2444 & 6.6306 & TST & \\
\hline CHEMBL474229 & 566860 & 5.0 & 5.0406 & TRN & \\
\hline CHEMBL474633 & 566860 & 8.2218 & 8.0024 & TRN & \\
\hline CHEMBL475641 & 566860 & 7.0132 & 7.1195 & TRN & \\
\hline CHEMBL492926 & 566860 & 8.4815 & 8.5919 & TRN & \\
\hline CHEMBL472585 & 566860 & 5.0 & 5.0375 & TRN & \\
\hline CHEMBL498863 & 566860 & 7.0605 & 7.96399 & 99999999995 & TST \\
\hline CHEMBL452458 & 566860 & 7.7447 & 7.7703 & TST & \\
\hline CHEMBL450599 & 566860 & 7.6383 & 8.0682 & TST & \\
\hline CHEMBL501117 & 566860 & 6.7932 & 7.9834 & TST & \\
\hline CHEMBL472678 & 566860 & 6.4789 & 5.0974 & TST & \\
\hline CHEMBL475643 & 566860 & 7.4559 & 7.5442 & TST & \\
\hline CHEMBL39 & 566860 & 10.0458 & 7.6439 & TST & \\
\hline CHEMBL92309 & 954992 & 3.1487 & 3.1564 & TST & \\
\hline CHEMBL180127 & 954992 & 3.0718 & 3.6383 & TRN & \\
\hline CHEMBL515416 & 954992 & 4.4783 & 4.5406 & TRN & \\
\hline CHEMBL 2134202 & 954992 & 4.5818 & 4.056 & TRN & \\
\hline CHEMBL 213100 & 954992 & 4.5271 & 4.7649 & TRN & \\
\hline CHEMBL585951 & 954992 & 5.6599 & 5.4167 & TRN & \\
\hline CHEMBL3199475 & 954992 & 3.8282 & 3.7245 & TRN & \\
\hline CHEMBL 2137530 & 954992 & 4.0727 & 4.5655 & TRN & \\
\hline CHEMBL 258844 & 954992 & 3.6264 & 3.6494 & TRN & \\
\hline CHEMBL3186408 & 954992 & 3.5261 & 3.6664 & TST & \\
\hline CHEMBL1970879 & 954992 & 4.4379 & 4.4776 & TRN & \\
\hline CHEMBL392695 & 954992 & 5.5468 & 5.4041 & TRN & \\
\hline CHEMBL 259181 & 954992 & 3.8669 & 3.8642 & TRN & \\
\hline CHEMBL 2005886 & 954992 & 4.556 & 4.7851 & TRN & \\
\hline CHEMBL65 & 954992 & 7.0401 & 6.8795 & TRN & \\
\hline CHEMBL 399530 & 954992 & 3.4635 & 3.76 & TRN & \\
\hline CHEMBL 217354 & 954992 & 6.3656 & 6.401 & TRN & \\
\hline CHEMBL 9470 & 954992 & 6.4081 & 5.4263 & TST & \\
\hline CHEMBL 255342 & 954992 & 3.5085 & 3.5296 & TST & \\
\hline CHEMBL2363137 & 954992 & 5.5432 & 5.6069 & TRN & \\
\hline CHEMBL373751 & 954992 & 3.3781 & 3.784 & TRN & \\
\hline CHEMBL558642 & 954992 & 2.8985 & 3.1 & TRN & \\
\hline CHEMBL412142 & 954992 & 4.5086 & 4.499 & TRN & \\
\hline CHEMBL1242367 & 954992 & 4.2184 & 4.0114 & TRN & \\
\hline CHEMBL449158 & 954992 & 6.7136 & 6.3875 & TST & \\
\hline CHEMBL1186585 & 954992 & 3.9615 & 3.956006 & 00000000004 & TRN \\
\hline CHEMBL221137 & 954992 & 4.6161 & 4.5996 & TST & \\
\hline & & & & 26115 & \\
\hline
\end{tabular}




\begin{tabular}{|c|c|c|c|c|c|c|}
\hline \multirow[b]{2}{*}{ CHEMBL188678 } & & \multicolumn{5}{|c|}{ Supplemental Table S2.txt } \\
\hline & 954992 & 4.5666 & 4.1132 & TRN & & \\
\hline CHEMBL102714 & 954992 & 4.0277 & 4.24 & TRN & & \\
\hline CHEMBL512504 & 954992 & 3.947 & 3.7399 & TRN & & \\
\hline CHEMBL1256459 & 954992 & 6.8086 & 6.854 & TRN & & \\
\hline CHEMBL1404918 & 954992 & 2.7372 & 2.7868 & TRN & & \\
\hline CHEMBL1590308 & 954992 & 3.2383 & 3.214 & TST & & \\
\hline CHEMBL1190711 & 954992 & 4.695 & 4.5075 & TRN & & \\
\hline CHEMBL514499 & 954992 & 6.8258 & 6.9626 & TRN & & \\
\hline CHEMBL240954 & 954992 & 3.4174 & 3.0708 & TRN & & \\
\hline CHEMBL1643959 & 954992 & 3.6251 & 3.3342 & TRN & & \\
\hline CHEMBL1357247 & 954992 & 2.8363 & 3.1064 & TRN & & \\
\hline CHEMBL135561 & 954992 & 5.0412 & 4.7894 & TRN & & \\
\hline CHEMBL573107 & 954992 & \multicolumn{3}{|c|}{3.6830000000000003} & 4.2108 & TRN \\
\hline CHEMBL379300 & 954992 & 6.2748 & 6.2186 & TRN & & \\
\hline CHEMBL483849 & 954992 & 2.249 & 2.1999 & TRN & & \\
\hline CHEMBL472940 & 954992 & 3.8096 & 3.4522 & TRN & & \\
\hline CHEMBL1673039 & 954992 & 3.9198 & 3.987 & TRN & & \\
\hline CHEMBL509032 & 954992 & 4.8081 & 4.7098 & TRN & & \\
\hline CHEMBL1516890 & 954992 & 4.4246 & 4.0229 & TRN & & \\
\hline CHEMBL3392440 & 954992 & 3.7732 & 3.8591 & TRN & & \\
\hline CHEMBL192566 & 954992 & 7.5366 & 7.5847 & TST & & \\
\hline CHEMBL209148 & 954992 & 4.4901 & 4.5547 & TRN & & \\
\hline CHEMBL300389 & 954992 & \multicolumn{3}{|c|}{6.678999999999999} & 6.6655 & TRN \\
\hline CHEMBL 2144069 & 954992 & 5.7786 & 5.1159 & TST & & \\
\hline CHEMBL483847 & 954992 & 4.4779 & 4.3889 & TST & & \\
\hline CHEMBL1230020 & 954992 & 3.9423 & 4.0805 & TST & & \\
\hline CHEMBL222102 & 954992 & 3.3231 & 3.5196 & TST & & \\
\hline CHEMBL220241 & 954992 & 3.7742 & 4.5776 & TST & & \\
\hline CHEMBL1788116 & 954992 & 4.9347 & 4.1188 & TST & & \\
\hline CHEMBL210618 & 954992 & 3.3517 & 3.5402 & TST & & \\
\hline CHEMBL 3704360 & 1528727 & 7.3958 & 6.3637 & TST & & \\
\hline CHEMBL3704337 & 1528727 & 7.3872 & 7.3624 & TRN & & \\
\hline CHEMBL3659271 & 1528727 & 7.6271 & 7.4028 & TRN & & \\
\hline CHEMBL3704200 & 1528727 & 5.699 & 6.0457 & TRN & & \\
\hline CHEMBL3704313 & 1528727 & 7.2541 & 6.8144 & TRN & & \\
\hline CHEMBL3659285 & 1528727 & 6.0685 & 5.9518 & TRN & & \\
\hline CHEMBL3659316 & 1528727 & 6.6398 & 6.5359 & TRN & & \\
\hline CHEMBL3704317 & 1528727 & 8.1427 & 8.0316 & TRN & & \\
\hline CHEMBL3704289 & 1528727 & 8.8861 & 8.872 & TRN & & \\
\hline CHEMBL3640030 & 1528727 & \multicolumn{3}{|c|}{6.4510000000000005} & 6.5102 & TRN \\
\hline CHEMBL3704333 & 1528727 & 7.0315 & 7.1901 & TST & & \\
\hline CHEMBL3659251 & 1528727 & 7.6615 & 7.3642 & TST & & \\
\hline CHEMBL3659286 & 1528727 & 6.0034 & 5.5131 & TRN & & \\
\hline CHEMBL3704184 & 1528727 & 7.699 & 7.6104 & TRN & & \\
\hline CHEMBL3704175 & 1528727 & 7.7959 & 7.7978 & TRN & & \\
\hline CHEMBL3704276 & 1528727 & 8.3979 & 8.4367 & TRN & & \\
\hline CHEMBL3659313 & 1528727 & 4.0 & 6.3518 & TST & & \\
\hline CHEMBL3659327 & 1528727 & 4.0 & 3.6371 & TRN & & \\
\hline
\end{tabular}


Supplemental Table S2.txt

\begin{tabular}{|c|c|c|c|c|}
\hline 然 & 8727 & & 5706 & \\
\hline HEMBL3704310 & 528727 & 5.6505 & 5.6588 & \\
\hline 261 & 28727 & & & \\
\hline 345 & 28727 & 2358 & 1995 & \\
\hline IEMBL3704255 & 528727 & 2218 & 2983 & \\
\hline AEMBL3659309 & 528727 & 1707 & 0021 & \\
\hline HEMBL3659310 & 528727 & 4.0 & 0489 & \\
\hline 245 & 28727 & 114 & 7481 & \\
\hline EMBL3 & 528727 & & .7285 & \\
\hline AEMBL3586209 & 528727 & 788 & .9854 & \\
\hline HEMBL3659287 & 528727 & 434 & 2725 & \\
\hline AEMBL37 & 528727 & 272 & .1613 & \\
\hline AEMBL & & & 5351 & \\
\hline HEMBL & 528727 & 021 & .8723 & \\
\hline AEMBL 364 & 528727 & 8.699 & 3769 & \\
\hline AEMBL365 & 528727 & 391 & .7045 & \\
\hline AEMBL3 & 528727 & 924 & 058 & \\
\hline HEMBL3 & 27 & & 887 & \\
\hline HEMBL; & 727 & & 2865 & MIV \\
\hline HEMBL37 & 528727 & 549 & 5673 & \\
\hline HEMBLS & 528727 & 97 & .584 & KIV \\
\hline HEMBL3 & 27 & 7 & 2826 & \\
\hline HEMBL; & 27 & & 2826 & \\
\hline 20 & 727 & & 5667 & \\
\hline AEMBL36 & 727 & 4 & 612 & I RIV \\
\hline AEMBL36 & 27 & 7. & .0328 & I \\
\hline HEMBL37 & 27 & 7. & .7842 & RN \\
\hline HEMBL3 & 27 & 24 & .0179 & \\
\hline 357 & 27 & & 285 & ST \\
\hline AEMBL36 & 27 & 4 & 069 & ST \\
\hline AEMBL36 & .7 & & 16 & TRN \\
\hline HEMBL37 & 27 & & 1204 & RN \\
\hline HEMBL3 & 27 & & 7.4211 & RN \\
\hline HEMBL37 & & & 503 & $\mathrm{RN}$ \\
\hline HEMBL37 & 528727 & 8 . & 912 & $\mathrm{RN}$ \\
\hline EMBL36 & 3727 & 4 & 3951 & $\mathrm{RN}$ \\
\hline HEMBL 37 & 727 & & 5996 & RN \\
\hline & & & & ST \\
\hline HEMBL3704234 & 528727 & 6.6021 & 433 & $\mathrm{RN}$ \\
\hline HEMBL 37 & 528727 & 8.7696 & 495 & RN \\
\hline IEMBL36 & 28727 & 834 & 218 & \\
\hline HEMBL3659318 & & & 257 & ST \\
\hline S & & & 8.2393 & $\mathrm{RN}$ \\
\hline HEMBL3704243 & 528727 & 7.5528 & . 9952 & RN \\
\hline IEMBL365 & 528727 & $\partial 3$ & 5.1585 & RI \\
\hline & & & .9138 & \\
\hline HEM & 1528727 & 5.7131 & 6.5201 & \\
\hline ( & & & & \\
\hline
\end{tabular}

6.2741 TRN

Page 26117 
Supplemental Table S2.txt

\begin{tabular}{|c|c|c|c|c|c|c|}
\hline CHEMBL 3704216 & 1528727 & 7.5229 & 7.3865 & TRN & & \\
\hline CHEMBL 3704287 & 1528727 & 7.9914 & 7.6002 & TRN & & \\
\hline CHEMBL3659299 & 1528727 & 4.0 & 3.9462 & TRN & & \\
\hline CHEMBL 3704274 & 1528727 & 6.5171 & 6.2748 & TRN & & \\
\hline CHEMBL3704286 & 1528727 & 7.7696 & 7.8136 & TRN & & \\
\hline CHEMBL3704236 & 1528727 & \multicolumn{3}{|c|}{6.7620000000000005} & 6.4834 & TRN \\
\hline CHEMBL 3659258 & 1528727 & 8.0706 & 7.9597 & TRN & & \\
\hline CHEMBL 3659343 & 1528727 & 6.5387 & 5.9209 & TST & & \\
\hline CHEMBL 3704319 & 1528727 & 7.4342 & 7.7946 & TRN & & \\
\hline CHEMBL3659252 & 1528727 & 6.2268 & 5.1988 & TST & & \\
\hline CHEMBL 3704227 & 1528727 & 7.5229 & 7.6498 & TRN & & \\
\hline CHEMBL 3704202 & 1528727 & 5.8239 & 5.9631 & TRN & & \\
\hline CHEMBL 3704263 & 1528727 & 7.6091 & 7.6577 & TRN & & \\
\hline CHEMBL 3704182 & 1528727 & 7.0 & 6.9861 & TRN & & \\
\hline CHEMBL3704303 & 1528727 & 8.8861 & 8.3831 & TST & & \\
\hline CHEMBL3704231 & 1528727 & 6.5607 & 6.2118 & TRN & & \\
\hline CHEMBL3659350 & 1528727 & 6.6765 & 6.7016 & TST & & \\
\hline CHEMBL 3704359 & 1528727 & 7.0888 & 6.9974 & TST & & \\
\hline CHEMBL3704302 & 1528727 & \multicolumn{3}{|c|}{6.997000000000001} & 7.4831 & TST \\
\hline CHEMBL3704327 & 1528727 & 6.4045 & 6.8703 & TST & & \\
\hline CHEMBL3704198 & 1528727 & 6.2132 & 6.3294 & TRN & & \\
\hline CHEMBL 3659337 & 1528727 & 4.0 & 4.5286 & TRN & & \\
\hline CHEMBL 3704318 & 1528727 & 7.1524 & 7.2162 & TRN & & \\
\hline CHEMBL 3704178 & 1528727 & 8.301 & 8.0404 & TRN & & \\
\hline CHEMBL 3659348 & 1528727 & 6.9337 & 6.5963 & TRN & & \\
\hline CHEMBL3704189 & 1528727 & 6.7696 & 6.4222 & TRN & & \\
\hline CHEMBL 3704364 & 1528727 & 7.3325 & 6.376 & TST & & \\
\hline CHEMBL 3659289 & 1528727 & 7.5072 & 7.57 & TRN & & \\
\hline CHEMBL3704347 & 1528727 & 6.6021 & 6.6225 & TRN & & \\
\hline CHEMBL 3659355 & 1528727 & 6.9481 & 6.7474 & TST & & \\
\hline CHEMBL 3659291 & 1528727 & 8.1549 & 8.0362 & TRN & & \\
\hline CHEMBL 3659277 & 1528727 & 7.2062 & 7.1556 & TRN & & \\
\hline CHEMBL 3659270 & 1528727 & 8.0809 & 8.1972 & TRN & & \\
\hline CHEMBL3659300 & 1528727 & 4.0 & 4.1887 & TRN & & \\
\hline CHEMBL 3704260 & 1528727 & 6.6021 & 6.6107 & TRN & & \\
\hline CHEMBL3704330 & 1528727 & 7.0 & 7.0619 & TST & & \\
\hline CHEMBL3659341 & 1528727 & 4.0 & 6.1613 & TST & & \\
\hline CHEMBL 3704196 & 1528727 & 6.6021 & 6.6845 & TRN & & \\
\hline CHEMBL 3704211 & 1528727 & 6.8601 & 6.901 & TRN & & \\
\hline CHEMBL 3704226 & 1528727 & 6.1249 & 6.7964 & TRN & & \\
\hline CHEMBL3704367 & 1528727 & 6.2782 & 6.7362 & TRN & & \\
\hline CHEMBL3704334 & 1528727 & \multicolumn{3}{|c|}{6.4510000000000005} & 6.2552 & TRN \\
\hline CHEMBL3704206 & 1528727 & 7.9208 & 7.1705 & TST & & \\
\hline CHEMBL 3704223 & 1528727 & 7.7447 & 7.5776 & TRN & & \\
\hline CHEMBL 3659311 & 1528727 & 6.9974 & 6.49 & TST & & \\
\hline CHEMBL3659325 & 1528727 & 4.0 & 4.1774 & TRN & & \\
\hline CHEMBL3659265 & 1528727 & 5.886 & 6.4595 & TRN & & \\
\hline CHEMBL3704262 & 1528727 & 8.1612 & 8.0489 & TRN & & \\
\hline
\end{tabular}

Page 26118 
Supplemental Table S2.txt

\begin{tabular}{|c|c|c|c|c|c|c|}
\hline CHEMBL3704159 & 1528727 & 6.5436 & 6.5671 & TRN & & \\
\hline CHEMBL 3704242 & 1528727 & 7.1549 & 7.3642 & TRN & & \\
\hline CHEMBL 3704275 & 1528727 & 6.6021 & 6.6859 & TRN & & \\
\hline CHEMBL 3659319 & 1528727 & 7.4295 & 7.4286 & TRN & & \\
\hline CHEMBL3659330 & 1528727 & 4.0 & 3.9965 & TRN & & \\
\hline CHEMBL 3704158 & 1528727 & 7.1938 & 7.107 & TRN & & \\
\hline CHEMBL 3704192 & 1528727 & 6.5171 & 6.692 & TRN & & \\
\hline CHEMBL 3704288 & 1528727 & 8.2076 & 8.2596 & TRN & & \\
\hline CHEMBL 3659256 & 1528727 & 8.6021 & 8.3339 & TRN & & \\
\hline CHEMBL3704271 & 1528727 & 7.8356 & 7.8937 & TRN & & \\
\hline CHEMBL 3704293 & 1528727 & 8.4089 & 8.6593 & TRN & & \\
\hline CHEMBL 3704354 & 1528727 & 7.6162 & 7.4564 & TRN & & \\
\hline CHEMBL 3704235 & 1528727 & 6.699 & 6.2777 & TRN & & \\
\hline CHEMBL 3704247 & 1528727 & 8.3979 & 8.2551 & TRN & & \\
\hline CHEMBL3704326 & 1528727 & 7.4001 & 7.4499 & TRN & & \\
\hline CHEMBL 3659339 & 1528727 & 6.0112 & 5.8617 & TRN & & \\
\hline CHEMBL3659312 & 1528727 & 7.0106 & 8.2636 & TST & & \\
\hline CHEMBL 3659351 & 1528727 & 7.1319 & 6.2779 & TST & & \\
\hline CHEMBL 3659275 & 1528727 & 6.62799 & 999999999 & 99 & 7.0929 & TST \\
\hline CHEMBL 3704232 & 1528727 & 6.1249 & 6.4466 & TRN & & \\
\hline CHEMBL3704219 & 1528727 & 6.5817 & 6.4843 & TRN & & \\
\hline CHEMBL 3704248 & 1528727 & 9.0 & 9.099 & TRN & & \\
\hline CHEMBL 3704237 & 1528727 & 6.6021 & 6.6988 & TRN & & \\
\hline CHEMBL 3704215 & 1528727 & 7.4437 & 7.1002 & TRN & & \\
\hline CHEMBL 3659260 & 1528727 & 8.1135 & 7.5663 & TST & & \\
\hline CHEMBL 3704266 & 1528727 & 8.7212 & 8.7843 & TRN & & \\
\hline CHEMBL 3659276 & 1528727 & 6.3352 & 6.4836 & TRN & & \\
\hline CHEMBL 3659283 & 1528727 & 5.9226 & 6.4388 & TRN & & \\
\hline CHEMBL 3659342 & 1528727 & 5.8649 & 6.1674 & TST & & \\
\hline CHEMBL 3704306 & 1528727 & 7.2041 & 7.6616 & TRN & & \\
\hline CHEMBL 3704239 & 1528727 & 6.4045 & 6.4679 & TRN & & \\
\hline CHEMBL 3659338 & 1528727 & 8.0915 & 6.4084 & TST & & \\
\hline CHEMBL 3659307 & 1528727 & \multicolumn{3}{|c|}{7.752000000000001} & 7.3967 & TRN \\
\hline CHEMBL 3704283 & 1528727 & 6.9245 & 7.7024 & TRN & & \\
\hline CHEMBL 3704163 & 1528727 & 7.9586 & 8.1042 & TRN & & \\
\hline CHEMBL3704299 & 1528727 & 8.2676 & 8.3843 & TRN & & \\
\hline CHEMBL 3659290 & 1528727 & 8.4202 & 8.3941 & TRN & & \\
\hline CHEMBL 3659304 & 1528727 & 9.301 & 8.4834 & TST & & \\
\hline CHEMBL 3659346 & 1528727 & 6.4728 & 5.7561 & TST & & \\
\hline CHEMBL 3704180 & 1528727 & 8.2218 & 7.9534 & TRN & & \\
\hline CHEMBL3704169 & 1528727 & 6.1249 & 6.7969 & TRN & & \\
\hline CHEMBL 3659308 & 1528727 & 7.0 & 6.989 & TRN & & \\
\hline CHEMBL 3704308 & 1528727 & 7.9031 & 8.1224 & TRN & & \\
\hline CHEMBL 3640032 & 1528727 & 8.0706 & 6.5457 & TST & & \\
\hline CHEMBL 3704254 & 1528727 & 8.0969 & 7.9256 & TRN & & \\
\hline CHEMBL 3704300 & 1528727 & 9.3979 & 8.625 & TST & & \\
\hline CHEMBL 3704307 & 1528727 & 8.6383 & 8.4223 & TRN & & \\
\hline CHEMBL 3659248 & 1528727 & 5.9031 & 6.879 & TST & & \\
\hline
\end{tabular}


Supplemental Table S2.txt

\begin{tabular}{|c|c|c|c|c|}
\hline CHEMBL3659296 & 1528727 & 4.0 & 4.9778 & TRN \\
\hline CHEMBL3704209 & 1528727 & 6.4895 & 6.1407 & TRN \\
\hline CHEMBL3659255 & 1528727 & 7.6345 & 8.3449 & TRN \\
\hline CHEMBL3704336 & 1528727 & 6.4318 & 6.4242 & TRN \\
\hline CHEMBL3659279 & 1528727 & 6.586 & 6.4069 & TRN \\
\hline CHEMBL3704233 & 1528727 & 6.4318 & 6.7597 & TST \\
\hline CHEMBL3659328 & 1528727 & 4.0 & 4.4518 & TRN \\
\hline CHEMBL 3704356 & 1528727 & 6.8094 & 5.939 & TST \\
\hline CHEMBL 3704322 & 1528727 & 7.8327 & 7.8421 & TRN \\
\hline CHEMBL3704358 & 1528727 & 8.1612 & 6.6385 & TST \\
\hline CHEMBL3659323 & 1528727 & 8.1675 & 8.4246 & TRN \\
\hline CHEMBL3704339 & 1528727 & 6.4841 & 7.4467 & TST \\
\hline CHEMBL 3704172 & 1528727 & 6.9136 & 6.7464 & TRN \\
\hline CHEMBL3659259 & 1528727 & 7.6126 & 8.0824 & TST \\
\hline CHEMBL3704187 & 1528727 & 6.6498 & 6.7208 & TRN \\
\hline CHEMBL3704290 & 1528727 & 8.4559 & 8.0877 & TRN \\
\hline CHEMBL3659302 & 1528727 & 6.0972 & 6.0749 & TST \\
\hline CHEMBL3659250 & 1528727 & 4.0 & 4.162 & TRN \\
\hline CHEMBL3659268 & 1528727 & 8.4815 & 8.2466 & TRN \\
\hline CHEMBL3704278 & 1528727 & 8.5229 & 8.5862 & TRN \\
\hline CHEMBL3704199 & 1528727 & 6.6021 & 6.6617 & TRN \\
\hline CHEMBL3659329 & 1528727 & 4.0 & 3.9961 & TRN \\
\hline CHEMBL3704348 & 1528727 & 8.2757 & 7.7164 & TRN \\
\hline CHEMBL 3659244 & 1528727 & 7.0357 & 6.7411 & TRN \\
\hline CHEMBL3659293 & 1528727 & 8.8861 & 8.8072 & TRN \\
\hline CHEMBL3659273 & 1528727 & 8.4437 & 8.5167 & TRN \\
\hline CHEMBL3659332 & 1528727 & 4.0 & 4.3347 & TRN \\
\hline CHEMBL3704217 & 1528727 & 6.4855 & 6.7416 & TRN \\
\hline CHEMBL 3704363 & 1528727 & 7.3242 & 5.8473 & TST \\
\hline CHEMBL3704201 & 1528727 & 6.3665 & 5.9297 & TRN \\
\hline CHEMBL3704240 & 1528727 & 6.5171 & 6.4335 & TRN \\
\hline CHEMBL 3659320 & 1528727 & 7.7825 & 7.7636 & TST \\
\hline CHEMBL3704161 & 1528727 & 6.6021 & 6.3501 & TRN \\
\hline CHEMBL 3704205 & 1528727 & 7.3768 & 6.2463 & TST \\
\hline CHEMBL 3639581 & 1528727 & 7.5317 & 6.9766 & TST \\
\hline CHEMBL3704355 & 1528727 & 7.1085 & 5.20200 & 0000000001 \\
\hline CHEMBL3704332 & 1528727 & 7.0 & 6.159 & TST \\
\hline CHEMBL3704294 & 1528727 & 8.8861 & 8.6818 & TRN \\
\hline CHEMBL 3659254 & 1528727 & 4.0 & 4.2224 & TRN \\
\hline CHEMBL 3704204 & 1528727 & 8.0969 & 8.0289 & TRN \\
\hline CHEMBL3704170 & 1528727 & 7.0458 & 7.3829 & TRN \\
\hline CHEMBL 3659344 & 1528727 & 6.7038 & 5.9501 & TST \\
\hline CHEMBL3704246 & 1528727 & 8.3979 & 8.385 & TRN \\
\hline CHEMBL 3704281 & 1528727 & 5.6576 & 5.9475 & TRN \\
\hline CHEMBL3704245 & 1528727 & 9.0 & 8.7431 & TRN \\
\hline CHEMBL3704186 & 1528727 & 6.5171 & 6.3642 & TRN \\
\hline CHEMBL3704212 & 1528727 & 6.5287 & 6.5813 & TRN \\
\hline CHEMBL3704316 & 1528727 & 7.6536 & 7.6822 & TRN \\
\hline
\end{tabular}

Page 26120 
Supplemental Table S2.txt

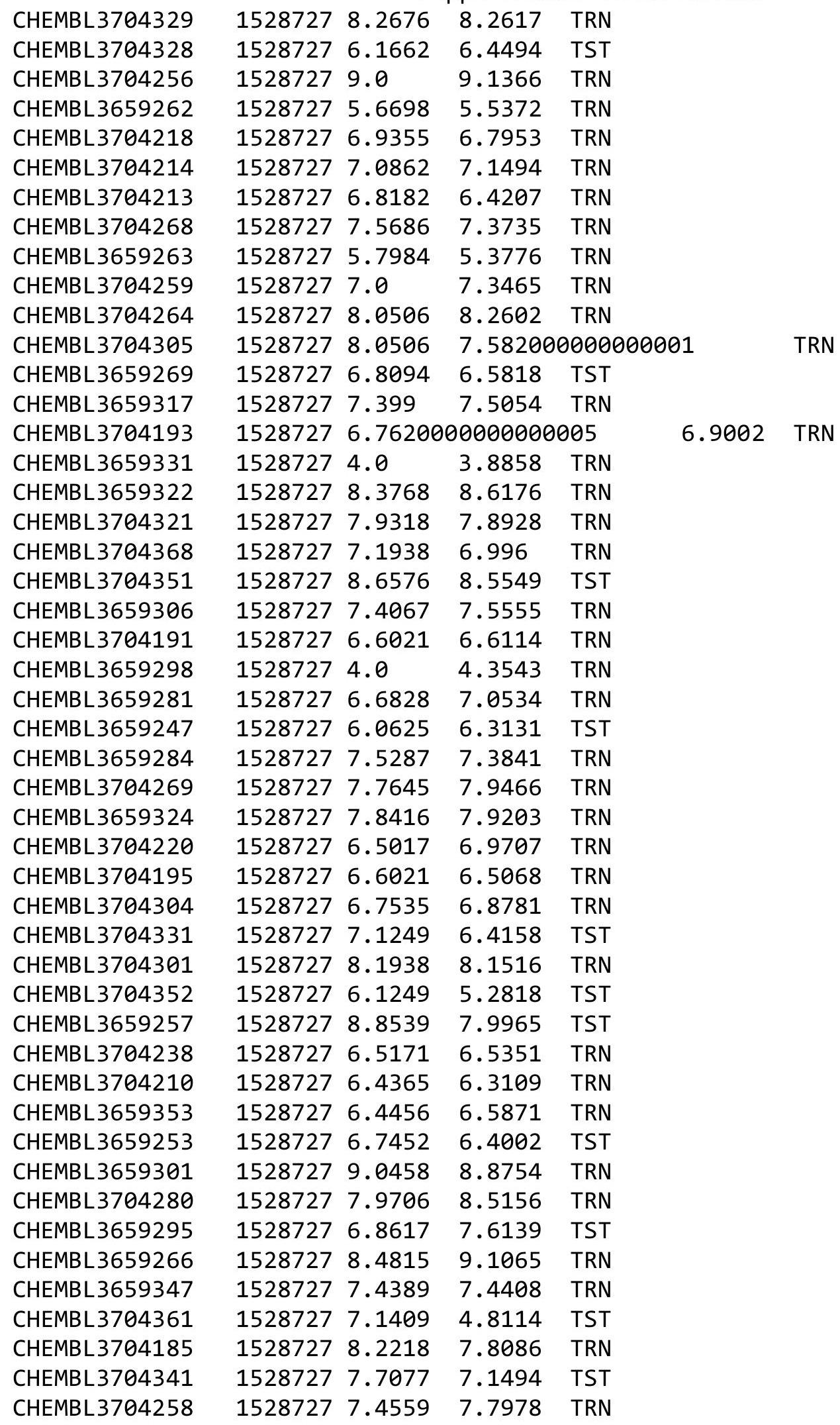

Page 26121 
Supplemental Table S2.txt

\begin{tabular}{|c|c|c|c|c|c|}
\hline CHEMBL3704297 & 1528727 & 8.5376 & 8.8389 & TRN & \\
\hline CHEMBL3659354 & 1528727 & 6.2775 & 6.0947 & TST & \\
\hline CHEMBL3659349 & 1528727 & 6.2418 & 5.9433 & TST & \\
\hline CHEMBL3704188 & 1528727 & 6.45100 & 000000006 & 6.4189 & TRN \\
\hline CHEMBL3704251 & 1528727 & 8.301 & 8.2814 & TRN & \\
\hline CHEMBL3704229 & 1528727 & 6.2076 & 6.3309 & TRN & \\
\hline CHEMBL 3704203 & 1528727 & 6.7144 & 7.1571 & TRN & \\
\hline CHEMBL 3704284 & 1528727 & 8.4318 & 8.236 & TRN & \\
\hline CHEMBL3704273 & 1528727 & 8.2218 & 7.9664 & TRN & \\
\hline CHEMBL3704173 & 1528727 & 6.7144 & 7.1427 & TRN & \\
\hline CHEMBL3704343 & 1528727 & 7.9208 & 7.8861 & TST & \\
\hline CHEMBL3659282 & 1528727 & 7.0035 & 7.2299 & TRN & \\
\hline CHEMBL3704208 & 1528727 & 5.8239 & 6.1609 & TRN & \\
\hline CHEMBL3659272 & 1528727 & 8.9208 & 7.7821 & TST & \\
\hline CHEMBL3704177 & 1528727 & 7.0 & 7.4414 & TRN & \\
\hline CHEMBL3704335 & 1528727 & 6.1249 & 6.107 & TRN & \\
\hline CHEMBL3704277 & 1528727 & 8.1549 & 7.2894 & TRN & \\
\hline CHEMBL3704222 & 1528727 & 7.0655 & 6.8334 & TRN & \\
\hline CHEMBL3704207 & 1528727 & 6.8794 & 7.0428 & TRN & \\
\hline CHEMBL3704340 & 1528727 & 7.8539 & 7.6516 & TST & \\
\hline CHEMBL3704311 & 1528727 & 7.6861 & 7.1765 & TRN & \\
\hline CHEMBL3704162 & 1528727 & 8.3979 & 8.4581 & TRN & \\
\hline CHEMBL3704230 & 1528727 & 7.7447 & 6.8203 & TRN & \\
\hline CHEMBL3704164 & 1528727 & 7.8539 & 7.7189 & TRN & \\
\hline CHEMBL3704349 & 1528727 & 8.4318 & 8.4342 & TST & \\
\hline CHEMBL3704346 & 1528727 & 7.3261 & 7.7109 & TST & \\
\hline CHEMBL3704314 & 1528727 & 7.0022 & 6.3068 & TRN & \\
\hline CHEMBL3659249 & 1528727 & 7.1118 & 6.8636 & TST & \\
\hline CHEMBL3704323 & 1528727 & 8.5528 & 8.3 & TST & \\
\hline CHEMBL3704224 & 1528727 & 6.3747 & 6.2305 & TRN & \\
\hline CHEMBL3704174 & 1528727 & 7.0088 & 7.327006 & 0000000001 & TRN \\
\hline CHEMBL3704176 & 1528727 & 6.9208 & 7.4474 & TRN & \\
\hline CHEMBL3704298 & 1528727 & 8.9586 & 8.9674 & TRN & \\
\hline CHEMBL3659358 & 1528727 & 8.4318 & 8.7307 & TST & \\
\hline CHEMBL3704345 & 1528727 & 8.0088 & 7.3001 & TST & \\
\hline CHEMBL3659356 & 1528727 & 8.0132 & 7.8527 & TRN & \\
\hline CHEMBL3704261 & 1528727 & 7.0757 & 7.1363 & TRN & \\
\hline CHEMBL3704194 & 1528727 & 6.6576 & 7.0773 & TRN & \\
\hline CHEMBL3659264 & 1528727 & 5.7749 & 5.6345 & TRN & \\
\hline CHEMBL3704160 & 1528727 & 6.8013 & 6.6437 & TRN & \\
\hline CHEMBL3704324 & 1528727 & 6.6876 & 6.6363 & TRN & \\
\hline CHEMBL3704309 & 1528727 & 8.3872 & 8.0201 & TRN & \\
\hline CHEMBL3659294 & 1528727 & 7.7077 & 8.1391 & TST & \\
\hline CHEMBL3659297 & 1528727 & 4.0 & 7.2396 & TST & \\
\hline CHEMBL3704257 & 1528727 & 7.6383 & 7.6183 & TRN & \\
\hline CHEMBL3704241 & 1528727 & 7.4318 & 7.4574 & TRN & \\
\hline CHEMBL3704353 & 1528727 & 7.7282 & 7.9255 & TST & \\
\hline CHEMBL3659333 & 1528727 & 4.0 & 4.2149 & TRN & \\
\hline
\end{tabular}


Supplemental Table S2.txt

\begin{tabular}{|c|c|c|c|c|c|}
\hline CHEMBL3704362 & 1528727 & 6.1141 & 5.4328 & TST & \\
\hline CHEMBL 3704183 & 1528727 & 7.9208 & 7.6929 & TRN & \\
\hline CHEMBL3704249 & 1528727 & 8.5229 & 8.6431 & TRN & \\
\hline CHEMBL 3704365 & 1528727 & 7.6326 & 6.0273 & TST & \\
\hline CHEMBL 3704279 & 1528727 & 6.6021 & 6.9229 & TRN & \\
\hline CHEMBL 3704285 & 1528727 & 8.2518 & 7.8303 & TRN & \\
\hline CHEMBL 3659278 & 1528727 & 7.0061 & 7.1019 & TRN & \\
\hline CHEMBL3659336 & 1528727 & 4.0 & 3.8865 & TRN & \\
\hline CHEMBL 3704225 & 1528727 & 6.7545 & 6.7131 & TRN & \\
\hline CHEMBL 3704252 & 1528727 & 8.1549 & 7.9308 & TRN & \\
\hline CHEMBL 3704166 & 1528727 & 6.1249 & 6.0595 & TRN & \\
\hline CHEMBL 3704265 & 1528727 & 8.6198 & 8.7599 & TRN & \\
\hline CHEMBL 3704168 & 1528727 & 6.0625 & 6.3428 & TRN & \\
\hline CHEMBL 3704181 & 1528727 & 8.699 & 8.1772 & TRN & \\
\hline CHEMBL 3704179 & 1528727 & 8.0969 & 7.7722 & TRN & \\
\hline CHEMBL 3704292 & 1528727 & 8.2596 & 8.184 & TRN & \\
\hline CHEMBL 3704295 & 1528727 & 8.301 & 8.174 & TRN & \\
\hline CHEMBL 3659288 & 1528727 & 6.36299 & 99999999 & 6.4206 & TRN \\
\hline CHEMBL 3704197 & 1528727 & 6.1249 & 5.9212 & TRN & \\
\hline CHEMBL 3704272 & 1528727 & 5.6021 & 7.6185 & TST & \\
\hline CHEMBL 3704250 & 1528727 & 7.5686 & 8.003 & TRN & \\
\hline CHEMBL3704167 & 1528727 & 6.0926 & 6.2567 & TRN & \\
\hline CHEMBL 3659340 & 1528727 & 8.6198 & 8.2229 & TRN & \\
\hline CHEMBL3659305 & 1528727 & 4.0 & \multicolumn{2}{|c|}{4.3660000000000005} & TRN \\
\hline CHEMBL 3704282 & 1528727 & 6.5272 & 6.7561 & TRN & \\
\hline CHEMBL 3914108 & 1639981 & 4.301 & 5.8035 & TRN & \\
\hline CHEMBL 3909989 & 1639981 & 5.1487 & \multicolumn{2}{|c|}{5.0280000000000005} & 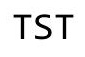 \\
\hline CHEMBL3956391 & 1639981 & 6.3925 & 5.3136 & TST & \\
\hline CHEMBL 3973644 & 1639981 & 4.6825 & 5.3297 & TRN & \\
\hline CHEMBL 3958410 & 1639981 & 6.5784 & 5.3862 & TRN & \\
\hline CHEMBL 3903611 & 1639981 & 8.699 & 6.7303 & TST & \\
\hline CHEMBL 3934163 & 1639981 & 4.0 & 5.2049 & TST & \\
\hline CHEMBL 3924987 & 1639981 & 4.0 & 6.4428 & TRN & \\
\hline CHEMBL3976452 & 1639981 & 5.5756 & 5.4901 & TRN & \\
\hline CHEMBL 3892847 & 1639981 & 8.0969 & 7.3218 & TRN & \\
\hline CHEMBL3947785 & 1639981 & 4.301 & 4.8671 & TST & \\
\hline CHEMBL 3959769 & 1639981 & 6.6459 & 7.296 & TRN & \\
\hline CHEMBL 3977724 & 1639981 & 8.7959 & 7.3028 & TRN & \\
\hline CHEMBL3897181 & 1639981 & 5.3015 & 4.283 & TRN & \\
\hline CHEMBL 3946946 & 1639981 & 4.0 & 3.9649 & TRN & \\
\hline CHEMBL 3986829 & 1639981 & 6.5751 & 5.3052 & TRN & \\
\hline CHEMBL 3963968 & 1639981 & 5.644 & 5.6233 & TRN & \\
\hline CHEMBL 3906280 & 1639981 & 6.4067 & 5.5765 & TRN & \\
\hline CHEMBL 3890808 & 1639981 & 5.7673 & 5.3659 & TRN & \\
\hline CHEMBL 3918349 & 1639981 & 5.7418 & 6.9463 & TRN & \\
\hline CHEMBL 3901088 & 1639981 & 6.3036 & 5.6112 & TRN & \\
\hline CHEMBL 3986923 & 1639981 & 4.0 & 5.3755 & TRN & \\
\hline CHEMBL 3918084 & 1639981 & 4.8239 & 4.7882 & TRN & \\
\hline
\end{tabular}

Page 26123 


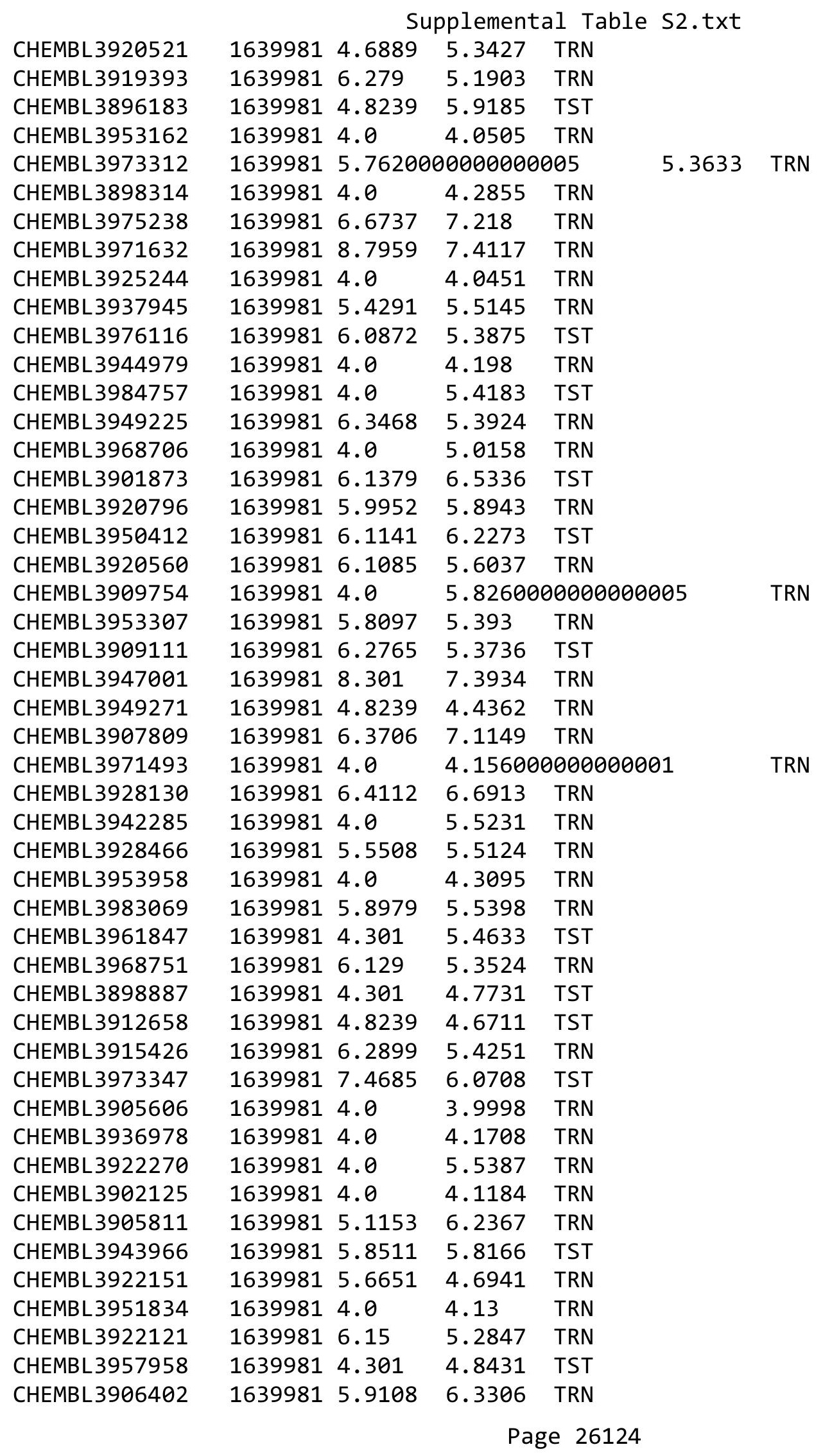


Supplemental Table S2.txt

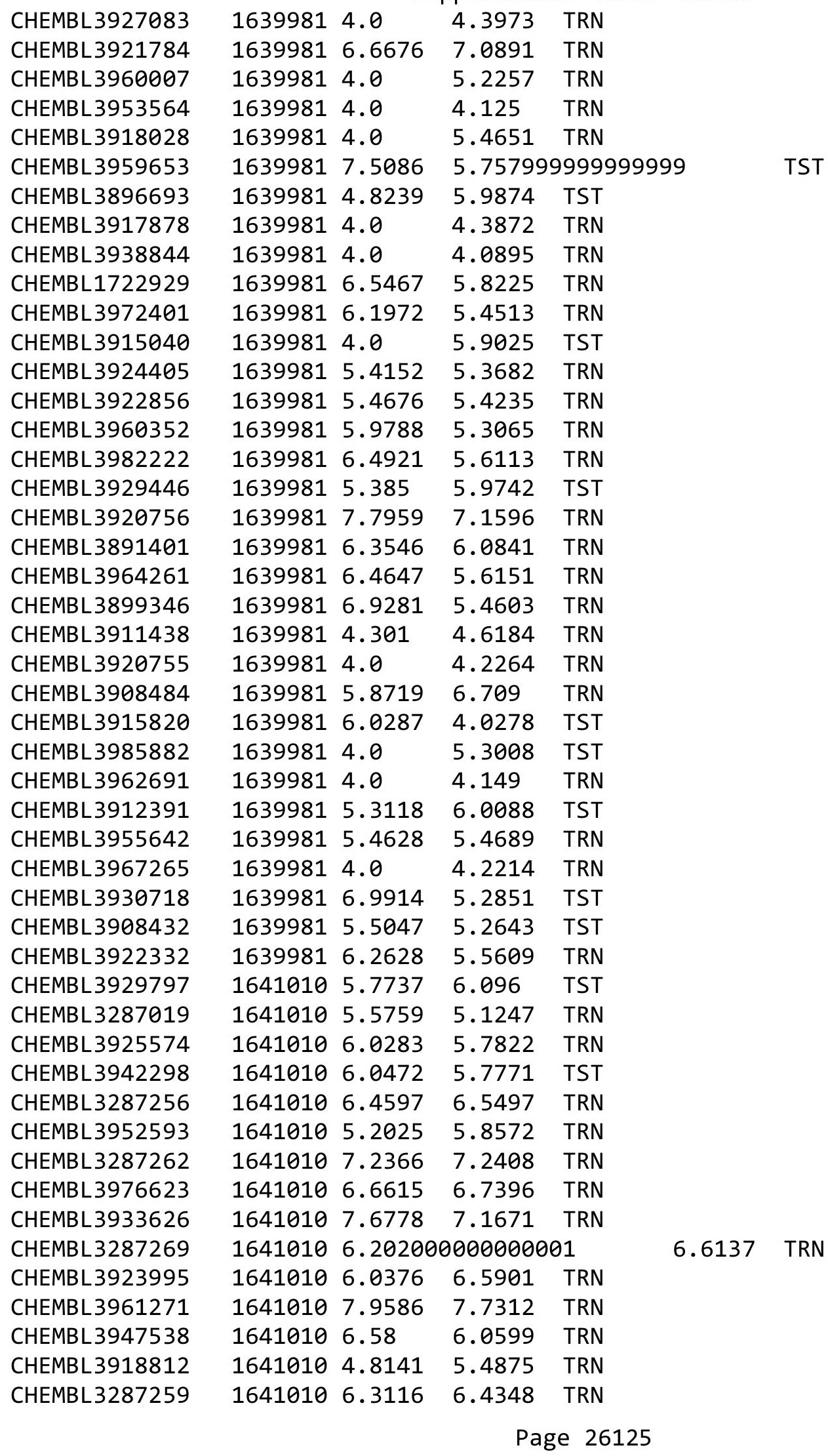


Supplemental Table S2.txt

\begin{tabular}{|c|c|c|c|c|c|}
\hline CHEMBL 3903212 & 1641010 & 7.284 & 7.8172 & TRN & \\
\hline CHEMBL 3287023 & 1641010 & 6.6737 & 6.9452 & TRN & \\
\hline CHEMBL3956299 & 1641010 & 5.2283 & 5.3517 & TRN & \\
\hline CHEMBL 3906734 & 1641010 & 6.9747 & 7.2354 & TRN & \\
\hline CHEMBL 3287021 & 1641010 & 6.0883 & 6.5272 & TRN & \\
\hline CHEMBL 3287266 & 1641010 & 7.6576 & \multicolumn{2}{|c|}{7.047999999999999} & TRN \\
\hline CHEMBL 3911545 & 1641010 & 7.699 & 7.8172 & TRN & \\
\hline CHEMBL 3925099 & 1641010 & 7.301 & 6.9866 & TRN & \\
\hline CHEMBL 3947397 & 1641010 & 5.9578 & 6.4082 & TRN & \\
\hline CHEMBL 3897044 & 1641010 & 7.1938 & 7.0554 & TRN & \\
\hline CHEMBL 3919167 & 1641010 & 5.978 & 6.0599 & TRN & \\
\hline CHEMBL 3937977 & 1641010 & 4.6853 & 5.0731 & TRN & \\
\hline CHEMBL 3960364 & 1641010 & 6.8327 & 6.7396 & TRN & \\
\hline CHEMBL 3915628 & 1641010 & 6.5686 & 6.5286 & TST & \\
\hline CHEMBL3971832 & 1641010 & 5.3461 & 5.5416 & TRN & \\
\hline CHEMBL 3935445 & 1641010 & 5.9914 & 6.0938 & TRN & \\
\hline CHEMBL 3287022 & 1641010 & 6.2716 & 6.2452 & TRN & \\
\hline CHEMBL 3959685 & 1641010 & \multicolumn{2}{|c|}{5.7379999999999995} & 5.2865 & TRN \\
\hline CHEMBL 3918869 & 1641010 & \multicolumn{3}{|c|}{6.007000000000001} & TRN \\
\hline CHEMBL 3891112 & 1641010 & 7.3279 & 6.7229 & TST & \\
\hline CHEMBL 3287258 & 1641010 & 6.6904 & 6.6592 & TRN & \\
\hline CHEMBL 3939120 & 1641010 & 7.4559 & 7.1671 & TRN & \\
\hline CHEMBL 3287257 & 1641010 & 6.9431 & 6.6994 & TRN & \\
\hline CHEMBL 3287261 & 1641010 & 6.9788 & 6.8206 & TRN & \\
\hline CHEMBL 3934705 & 1641010 & 4.8379 & 5.9114 & TRN & \\
\hline CHEMBL 3287254 & 1641010 & 7.5086 & \multicolumn{2}{|c|}{6.8839999999999995} & $\pi$ \\
\hline CHEMBL 3287255 & 1641010 & 7.1871 & 6.7119 & TRN & \\
\hline CHEMBL 3968356 & 1641010 & 6.9172 & 6.096 & TST & \\
\hline CHEMBL 3287263 & 1641010 & 7.301 & 7.0822 & TRN & \\
\hline CHEMBL 3948298 & 1641010 & 7.301 & 7.1961 & TRN & \\
\hline CHEMBL 3943359 & 1641010 & 6.3585 & 6.6238 & TRN & \\
\hline CHEMBL 3939518 & 1641010 & 7.0655 & 7.8172 & TRN & \\
\hline CHEMBL 3919448 & 1641010 & 7.1024 & 6.9198 & TST & \\
\hline CHEMBL 3287007 & 1641010 & 5.7217 & 5.8764 & TST & \\
\hline CHEMBL 3287020 & 1641010 & 5.6103 & 5.4564 & TRN & \\
\hline CHEMBL 3287008 & 1641010 & 7.0605 & 6.6067 & TST & \\
\hline CHEMBL 3968861 & 1641010 & 7.2518 & 7.1056 & TRN & \\
\hline CHEMBL 3287265 & 1641010 & 5.803 & \multicolumn{2}{|c|}{5.9639999999999995} & 10 \\
\hline CHEMBL 3287252 & 1641010 & 7.5086 & 6.7699 & TRN & \\
\hline CHEMBL 3961083 & 1641010 & 6.7496 & 7.1671 & TRN & \\
\hline CHEMBL 3984885 & 1641010 & 5.9129 & 5.9122 & TRN & \\
\hline CHEMBL 3287253 & 1641010 & 6.4672 & \multicolumn{2}{|c|}{6.577999999999999} & N \\
\hline CHEMBL 3930328 & 1641010 & 7.4949 & 7.7645 & TRN & \\
\hline CHEMBL 3977346 & 1641010 & 7.3768 & 7.0581 & TST & \\
\hline CHEMBL 3287010 & 1641010 & 6.9318 & 6.6064 & TST & \\
\hline CHEMBL 3287016 & 1641010 & 5.018 & 4.9803 & TST & \\
\hline CHEMBL 3287260 & 1641010 & 6.7825 & \multicolumn{2}{|c|}{6.617000000000001} & ST \\
\hline CHEMBL 3902539 & 1641010 & 7.6021 & 7.1529 & TRN & \\
\hline
\end{tabular}

Page 26126 
Supplemental Table S2.txt

\begin{tabular}{|c|c|c|c|c|c|}
\hline CHEMBL3933987 & 1641010 & 7.0655 & 6.8767 & TRN & \\
\hline CHEMBL3968415 & 1641010 & 6.7423 & 6.0475 & TRN & \\
\hline CHEMBL3287251 & 1641010 & 6.2175 & 6.4061 & TST & \\
\hline CHEMBL3287250 & 1641010 & 7.3279 & 7.0618 & TST & \\
\hline CHEMBL3287017 & 1641010 & 5.5872 & 5.3963 & TST & \\
\hline CHEMBL3953198 & 1641010 & 6.0195 & 6.0451 & TRN & \\
\hline CHEMBL3891163 & 1641010 & 6.1824 & 6.2789 & TST & \\
\hline CHEMBL3287268 & 1641010 & 7.8861 & 6.9757 & TST & \\
\hline CHEMBL3963714 & 1641010 & 6.8729 & 6.5959 & TST & \\
\hline CHEMBL3287009 & 1641010 & 5.585 & 5.7487 & TST & \\
\hline CHEMBL127880 & 123919 & 4.0283 & 4.2331 & TST & \\
\hline CHEMBL126886 & 123919 & 3.6021 & 3.5968 & TRN & \\
\hline CHEMBL125094 & 123919 & 5.7959 & 5.2807 & TRN & \\
\hline CHEMBL339470 & 123919 & 5.2924 & 5.3805 & TRN & \\
\hline CHEMBL126133 & 123919 & 4.0 & 4.3577 & TRN & \\
\hline CHEMBL341240 & 123919 & 4.6073 & 5.0691 & TRN & \\
\hline CHEMBL338094 & 123919 & 5.8761 & 5.9666 & TRN & \\
\hline CHEMBL127567 & 123919 & 4.301 & 4.4086 & TST & \\
\hline CHEMBL125044 & 123919 & 5.4921 & 5.86700 & 0000000001 & TRN \\
\hline CHEMBL129270 & 123919 & 4.0 & 3.8872 & TRN & \\
\hline CHEMBL125843 & 123919 & 5.8239 & 4.3107 & TST & \\
\hline CHEMBL124935 & 123919 & 6.301 & 5.6522 & TRN & \\
\hline CHEMBL125921 & 123919 & 6.0362 & 6.2781 & TRN & \\
\hline CHEMBL127758 & 123919 & 5.0 & 4.5627 & TRN & \\
\hline CHEMBL339739 & 123919 & 6.0 & 5.5006 & TRN & \\
\hline CHEMBL341071 & 123919 & 4.1284 & 3.9459 & TRN & \\
\hline CHEMBL339794 & 123919 & 4.4908 & 4.7253 & TRN & \\
\hline CHEMBL127966 & 123919 & 4.7423 & 4.6424 & TRN & \\
\hline CHEMBL127982 & 123919 & 5.6615 & 5.8504 & TRN & \\
\hline CHEMBL339429 & 123919 & 5.6576 & 5.8077 & TRN & \\
\hline CHEMBL126547 & 123919 & 4.7932 & 3.8517 & TRN & \\
\hline CHEMBL126681 & 123919 & 4.0 & 4.0436 & TRN & \\
\hline CHEMBL125520 & 123919 & 5.8827 & 5.687 & TRN & \\
\hline CHEMBL127751 & 123919 & 5.3768 & 5.6472 & TRN & \\
\hline CHEMBL127077 & 123919 & 6.0 & 5.3483 & TRN & \\
\hline CHEMBL123894 & 123919 & 3.0 & 4.0926 & TST & \\
\hline CHEMBL126027 & 123919 & 5.1135 & 3.9706 & TST & \\
\hline CHEMBL125540 & 123919 & 3.301 & 3.9437 & TRN & \\
\hline CHEMBL341073 & 123919 & 4.699 & 5.3865 & TRN & \\
\hline CHEMBL128029 & 123919 & 5.0223 & 4.2755 & TST & \\
\hline CHEMBL126419 & 123919 & 5.0 & 4.8664 & TRN & \\
\hline CHEMBL421088 & 123919 & 4.6778 & 5.1868 & TRN & \\
\hline CHEMBL123895 & 123919 & 4.0964 & 4.5213 & TRN & \\
\hline CHEMBL340028 & 123919 & 4.301 & 4.0431 & TST & \\
\hline CHEMBL420523 & 123919 & 4.4881 & 4.4658 & TRN & \\
\hline CHEMBL127717 & 123919 & 6.0 & 4.6163 & TST & \\
\hline CHEMBL340130 & 123919 & 4.301 & 4.3346 & TST & \\
\hline CHEMBL338035 & 123919 & 4.5143 & 4.4351 & TRN & \\
\hline
\end{tabular}




\begin{tabular}{|c|c|c|c|c|c|}
\hline \multicolumn{6}{|c|}{ Supplemental Table S2.txt } \\
\hline CHEMBL126504 & 123919 & 4.684 & 4.3364 & TST & \\
\hline CHEMBL126561 & 123919 & 5.0 & 5.3055 & TRN & \\
\hline CHEMBL127347 & 123919 & 5.0 & 5.3243 & TRN & \\
\hline CHEMBL126505 & 123919 & 4.6498 & 4.5606 & TRN & \\
\hline CHEMBL126830 & 123919 & 3.6021 & 3.5419 & TRN & \\
\hline CHEMBL123803 & 123919 & 5.301 & 5.5668 & TRN & \\
\hline CHEMBL126799 & 123919 & 4.0783 & 3.9608 & TST & \\
\hline CHEMBL129769 & 123919 & 4.6308 & 5.1394 & TST & \\
\hline CHEMBL339535 & 123919 & 6.0 & 5.8822 & TRN & \\
\hline CHEMBL126891 & 123919 & 5.0 & 3.9936 & TST & \\
\hline CHEMBL127622 & 123919 & 6.1805 & 5.8933 & TRN & \\
\hline CHEMBL339445 & 123919 & 3.6021 & 4.3591 & TRN & \\
\hline CHEMBL339561 & 123919 & 4.51 & 4.4816 & TRN & \\
\hline CHEMBL127774 & 123919 & 6.5528 & 5.4753 & TRN & \\
\hline CHEMBL340701 & 123919 & 6.0362 & 5.7247 & TRN & \\
\hline CHEMBL339626 & 123919 & 6.0458 & 6.1237 & TRN & \\
\hline CHEMBL127182 & 123919 & 6.1487 & 6.0822 & TRN & \\
\hline CHEMBL127518 & 123919 & 4.7986 & 5.0327 & TRN & \\
\hline CHEMBL127517 & 123919 & 6.0362 & 6.5941 & TRN & \\
\hline CHEMBL339107 & 123919 & 4.0 & 4.1795 & TST & \\
\hline CHEMBL124461 & 123919 & 5.0 & 4.5895 & TRN & \\
\hline CHEMBL340239 & 123919 & 4.301 & 4.8125 & TRN & \\
\hline CHEMBL127757 & 123919 & 5.0044 & 4.7742 & TRN & \\
\hline CHEMBL339027 & 123919 & 5.4318 & 5.4203 & TRN & \\
\hline CHEMBL124867 & 123919 & 4.5607 & 3.8961 & TST & \\
\hline CHEMBL127983 & 123919 & 7.0458 & 6.4606 & TRN & \\
\hline CHEMBL419614 & 123919 & 5.2757 & 3.4925 & TST & \\
\hline CHEMBL339565 & 123919 & 5.7496 & 4.5103 & TST & \\
\hline CHEMBL145774 & 64661 & 9.72 & 9.5181 & TRN & \\
\hline CHEMBL145055 & 64661 & 7.42 & 7.5211 & TRN & \\
\hline CHEMBL146327 & 64661 & 7.36 & 7.3008 & TRN & \\
\hline CHEMBL145035 & 64661 & 8.57 & 5.4545 & TST & \\
\hline CHEMBL2370942 & 64661 & 6.63 & 6.9078 & TST & \\
\hline CHEMBL24449 & 64661 & 5.02 & 6.5858 & TST & \\
\hline CHEMBL430432 & 64661 & 7.28 & 7.7324 & TRN & \\
\hline CHEMBL356825 & 64661 & 6.23 & 6.6513 & TRN & \\
\hline CHEMBL141663 & 64661 & 6.15 & 6.5586 & TST & \\
\hline CHEMBL356241 & 64661 & 6.26 & 6.3714 & TST & \\
\hline CHEMBL143333 & 64661 & 7.64 & 7.5688 & TRN & \\
\hline CHEMBL144995 & 64661 & 5.59 & 6.3739 & TST & \\
\hline CHEMBL358088 & 64661 & 7.04 & 6.6317 & TST & \\
\hline CHEMBL145153 & 64661 & 6.96 & 6.9716 & TRN & \\
\hline CHEMBL443745 & 64661 & 6.18 & 6.3394 & TRN & \\
\hline CHEMBL357379 & 64661 & 5.81 & 5.92200 & 3000000001 & TRN \\
\hline CHEMBL142529 & 64661 & 4.26 & 4.6992 & TRN & \\
\hline CHEMBL145618 & 64661 & 6.77 & 6.9312 & TST & \\
\hline CHEMBL146003 & 64661 & 8.18 & 8.2274 & TRN & \\
\hline CHEMBL145765 & 64661 & 6.75 & 6.82600 & 00000000005 & TRN \\
\hline & & & & 26128 & \\
\hline
\end{tabular}




\begin{tabular}{|c|c|c|c|c|c|}
\hline & & \multicolumn{4}{|c|}{ Supplemental Table S2.txt } \\
\hline CHEMBL356120 & 64661 & 10.15 & 10.2401 & TRN & \\
\hline CHEMBL142622 & 64661 & 6.16 & 6.3373 & TRN & \\
\hline CHEMBL143004 & 64661 & 6.15 & 6.5423 & TRN & \\
\hline CHEMBL145149 & 64661 & 6.96 & 6.2516 & TRN & \\
\hline CHEMBL145107 & 64661 & 6.98 & 6.473 & TST & \\
\hline CHEMBL141377 & 64661 & 5.59 & 6.0074 & TRN & \\
\hline CHEMBL146330 & 64661 & 5.67 & 6.8775 & TST & \\
\hline CHEMBL343004 & 64661 & 5.1 & 4.5697 & TRN & \\
\hline CHEMBL145678 & 64661 & 6.77 & 6.4411 & TRN & \\
\hline CHEMBL10625 & 64661 & 5.16 & 4.6187 & TRN & \\
\hline CHEMBL142156 & 64661 & 5.72 & 7.4413 & TST & \\
\hline CHEMBL450273 & 64661 & 8.19 & 9.1644 & TRN & \\
\hline CHEMBL357464 & 64661 & 9.64 & 9.8513 & TRN & \\
\hline CHEMBL145448 & 64661 & 6.03 & 5.9563 & TRN & \\
\hline CHEMBL268763 & 64661 & 4.2 & 4.565 & TST & \\
\hline CHEMBL309522 & 64661 & 6.11 & 6.532 & TRN & \\
\hline CHEMBL145505 & 64661 & 4.73 & 4.2463 & TRN & \\
\hline CHEMBL334936 & 64661 & 5.44 & 4.7273 & TRN & \\
\hline CHEMBL145694 & 64661 & 7.67 & 6.7417 & TST & \\
\hline CHEMBL356573 & 64661 & 3.08 & 3.3454 & TST & \\
\hline CHEMBL342325 & 64661 & 6.12 & 5.9088 & TST & \\
\hline CHEMBL145565 & 64661 & 7.54 & 7.5968 & TRN & \\
\hline CHEMBL145020 & 64661 & 7.14 & 7.0885 & TRN & \\
\hline CHEMBL146010 & 64661 & 7.96 & 8.0144 & TRN & \\
\hline CHEMBL145718 & 64661 & 7.68 & 6.5974 & TST & \\
\hline CHEMBL142970 & 64661 & 7.94 & 7.8729 & TRN & \\
\hline CHEMBL144906 & 64661 & 9.03 & 8.8656 & TRN & \\
\hline CHEMBL145550 & 64661 & 9.03 & 8.969 & TRN & \\
\hline CHEMBL79973 & 64661 & 7.08 & 7.0159 & TRN & \\
\hline CHEMBL343479 & 64661 & 6.13 & 6.5148 & TRN & \\
\hline CHEMBL145777 & 64661 & 5.34 & 5.8587 & TRN & \\
\hline CHEMBL144986 & 64661 & 6.06 & 5.9063 & TRN & \\
\hline CHEMBL145583 & 64661 & 7.92 & 7.5299 & TRN & \\
\hline CHEMBL344769 & 64661 & 6.94 & 6.5991 & TST & \\
\hline CHEMBL143922 & 64661 & 7.68 & 8.0756 & TRN & \\
\hline CHEMBL144919 & 64661 & 4.01 & $3.62600 t$ & 00000000003 & TRN \\
\hline CHEMBL143858 & 64661 & 6.83 & 6.3335 & TRN & \\
\hline CHEMBL143065 & 64661 & 5.87 & 6.0491 & TRN & \\
\hline CHEMBL347760 & 64661 & 9.4 & 9.1825 & TST & \\
\hline CHEMBL145012 & 64661 & 7.25 & 7.4216 & TRN & \\
\hline CHEMBL146004 & 64661 & 8.23 & 7.525 & TRN & \\
\hline CHEMBL335798 & 64661 & 6.4 & 6.5254 & TRN & \\
\hline CHEMBL358737 & 64661 & 6.35 & 6.2464 & TRN & \\
\hline CHEMBL145285 & 64661 & 5.12 & 6.336 & TST & \\
\hline CHEMBL356316 & 64661 & 5.95 & 6.6806 & TST & \\
\hline CHEMBL145729 & 64661 & 8.8 & 8.7058 & TRN & \\
\hline CHEMBL143792 & 64661 & 8.09 & 8.3274 & TRN & \\
\hline CHEMBL142623 & 64661 & 6.74 & 6.9595 & TRN & \\
\hline
\end{tabular}




\begin{tabular}{|c|c|c|c|c|c|}
\hline \multicolumn{6}{|c|}{ Supplemental Table S2.txt } \\
\hline CHEMBL141930 & 64661 & 6.6 & 6.7811 & TRN & \\
\hline CHEMBL356337 & 64661 & 6.29 & 5.3047 & TST & \\
\hline CHEMBL145214 & 64661 & 7.67 & 7.5568 & TRN & \\
\hline CHEMBL145366 & 64661 & 3.8 & 4.739 & TRN & \\
\hline CHEMBL344690 & 64661 & 6.43 & 5.8857 & TRN & \\
\hline CHEMBL444081 & 64661 & 7.15 & 7.1708 & TRN & \\
\hline CHEMBL358787 & 64661 & 4.19 & 4.2514 & TRN & \\
\hline CHEMBL141707 & 64661 & 8.24 & 8.0401 & TRN & \\
\hline CHEMBL358949 & 64661 & 7.4 & 7.4074 & TRN & \\
\hline CHEMBL142781 & 64661 & 7.47 & 7.5441 & TRN & \\
\hline CHEMBL357201 & 64661 & 6.14 & 6.3262 & TRN & \\
\hline CHEMBL145738 & 64661 & 5.54 & 6.2462 & TST & \\
\hline CHEMBL145724 & 64661 & 5.47 & 5.9354 & TRN & \\
\hline CHEMBL145581 & 64661 & 6.19 & 7.8386 & TST & \\
\hline CHEMBL145695 & 64661 & 6.67 & 6.8128 & TRN & \\
\hline CHEMBL145754 & 64661 & 6.92 & 6.7685 & TRN & \\
\hline CHEMBL343478 & 64661 & 7.04 & 7.1477 & TRN & \\
\hline CHEMBL145471 & 64661 & 7.77 & 7.0709 & TRN & \\
\hline CHEMBL145097 & 64661 & 6.19 & 6.0371 & TRN & \\
\hline CHEMBL144900 & 64661 & 7.43 & 6.688 & TST & \\
\hline CHEMBL81249 & 64661 & 9.94 & 10.0463 & TRN & \\
\hline CHEMBL142399 & 64661 & 4.5 & 4.7273 & TRN & \\
\hline CHEMBL145750 & 64661 & 6.02 & 6.1721 & TRN & \\
\hline CHEMBL145387 & 64661 & 5.7 & 5.8842 & TRN & \\
\hline CHEMBL142779 & 64661 & 5.77 & 5.7893 & TRN & \\
\hline CHEMBL142397 & 64661 & 5.19 & 5.1887 & TRN & \\
\hline CHEMBL141553 & 64661 & 8.24 & 7.2781 & TST & \\
\hline CHEMBL145600 & 64661 & 5.92 & 5.693 & TRN & \\
\hline CHEMBL356586 & 64661 & 6.5 & 6.2546 & TRN & \\
\hline CHEMBL145782 & 64661 & 6.66 & 7.0133 & TST & \\
\hline CHEMBL433932 & 64661 & 5.05 & 5.9009 & TST & \\
\hline CHEMBL422484 & 64661 & 5.36 & 6.07100 & 0000000001 & TST \\
\hline CHEMBL145348 & 64661 & 6.38 & 6.0292 & TRN & \\
\hline CHEMBL143431 & 64661 & 8.38 & 8.1226 & TRN & \\
\hline CHEMBL145185 & 64661 & 6.7 & 6.5899 & TRN & \\
\hline CHEMBL 9945 & 64661 & 4.96 & 5.1098 & TRN & \\
\hline CHEMBL356307 & 64661 & 8.0 & 8.1438 & TRN & \\
\hline CHEMBL422472 & 64661 & 6.74 & 6.9112 & TRN & \\
\hline CHEMBL341889 & 64661 & 6.96 & 6.5015 & TST & \\
\hline CHEMBL 79428 & 64661 & 10.37 & 10.3731 & TRN & \\
\hline CHEMBL145057 & 64661 & 5.84 & 6.2279 & TRN & \\
\hline CHEMBL145342 & 64661 & 4.46 & 4.2074 & TST & \\
\hline CHEMBL145021 & 64661 & 5.44 & 4.7638 & TST & \\
\hline CHEMBL145019 & 64661 & 6.82 & 6.9224 & TRN & \\
\hline CHEMBL341627 & 64661 & 6.59 & 6.4665 & TRN & \\
\hline CHEMBL142534 & 64661 & 5.96 & 6.0604 & TRN & \\
\hline CHEMBL142101 & 64661 & 6.55 & 6.5961 & TRN & \\
\hline CHEMBL444082 & 64661 & 6.62 & 6.3199 & TRN & \\
\hline
\end{tabular}




\begin{tabular}{|c|c|c|c|c|c|}
\hline \multirow[b]{2}{*}{ CHEMBL24450 } & & \multicolumn{4}{|c|}{ Supplemental Table S2.txt } \\
\hline & 64661 & 5.75 & 5.9097 & TST & \\
\hline CHEMBL143793 & 64661 & 8.85 & 8.6418 & TRN & \\
\hline CHEMBL357688 & 64661 & 5.92 & 6.0237 & TRN & \\
\hline CHEMBL357238 & 64661 & 5.9 & 5.9544 & TRN & \\
\hline CHEMBL343202 & 64661 & 5.32 & 5.437 & TST & \\
\hline CHEMBL145540 & 64661 & 6.27 & 5.9216 & TRN & \\
\hline CHEMBL145002 & 64661 & 10.02 & 9.7092 & TRN & \\
\hline CHEMBL145465 & 64661 & 6.96 & 7.181 & TRN & \\
\hline CHEMBL145365 & 64661 & 5.16 & 5.3031 & TRN & \\
\hline CHEMBL145152 & 64661 & 7.11 & 7.0525 & TRN & \\
\hline CHEMBL145749 & 64661 & 5.91 & 5.7549 & TRN & \\
\hline CHEMBL146329 & 64661 & 5.55 & 5.7506 & TRN & \\
\hline CHEMBL144955 & 64661 & 5.13 & 5.1999 & TRN & \\
\hline CHEMBL145351 & 64661 & 4.84 & 4.6185 & TRN & \\
\hline CHEMBL145492 & 64661 & 8.0 & 8.2169 & TRN & \\
\hline CHEMBL144915 & 64661 & 7.55 & 7.3593 & TRN & \\
\hline CHEMBL358987 & 64661 & 7.14 & 6.5794 & TRN & \\
\hline CHEMBL145309 & 64661 & 4.89 & 4.7688 & TRN & \\
\hline CHEMBL141877 & 64661 & 4.51 & 5.1456 & TRN & \\
\hline CHEMBL436267 & 64661 & 6.39 & 6.2259 & TRN & \\
\hline CHEMBL439625 & 64661 & 6.02 & 6.2836 & TST & \\
\hline CHEMBL146381 & 64661 & 7.51 & 7.308 & TRN & \\
\hline CHEMBL145252 & 64661 & 8.0 & 8.1688 & TRN & \\
\hline CHEMBL343643 & 64661 & 6.81 & 6.7282 & TRN & \\
\hline CHEMBL344066 & 64661 & 10.17 & 10.2958 & TRN & \\
\hline CHEMBL145592 & 64661 & 9.33 & 9.0945 & TRN & \\
\hline CHEMBL145791 & 64661 & 5.67 & 5.7942 & TRN & \\
\hline CHEMBL10756 & 64661 & 8.82 & 8.2166 & TRN & \\
\hline CHEMBL142294 & 64661 & 6.47 & 6.5581 & TRN & \\
\hline CHEMBL343003 & 64661 & 7.68 & 7.3434 & TRN & \\
\hline CHEMBL142640 & 64661 & 6.95 & 6.1896 & TST & \\
\hline CHEMBL145690 & 64661 & 6.44 & 6.4096 & TRN & \\
\hline CHEMBL145762 & 64661 & 5.09 & 5.63299 & 9999999999 & TST \\
\hline CHEMBL343250 & 64661 & 8.22 & 7.6959 & TRN & \\
\hline CHEMBL344567 & 64661 & 5.8 & 5.794 & TRN & \\
\hline CHEMBL145157 & 64661 & 5.14 & 4.18199 & 99999999995 & TST \\
\hline CHEMBL342522 & 64661 & 8.31 & 7.8298 & TRN & \\
\hline CHEMBL358112 & 64661 & 8.11 & 7.8455 & TRN & \\
\hline CHEMBL146219 & 64661 & 5.29 & 5.8022 & TRN & \\
\hline CHEMBL145207 & 64661 & 6.33 & 7.0915 & TST & \\
\hline CHEMBL145271 & 64661 & 6.0 & 6.5665 & TRN & \\
\hline CHEMBL343675 & 64661 & 7.75 & 5.5396 & TST & \\
\hline CHEMBL144918 & 64661 & 7.28 & 7.0254 & TRN & \\
\hline CHEMBL344969 & 64661 & 5.9 & 6.7112 & TRN & \\
\hline CHEMBL358083 & 64661 & 6.32 & 6.1608 & TRN & \\
\hline CHEMBL346156 & 64661 & 5.26 & 5.8287 & TRN & \\
\hline CHEMBL145096 & 64661 & 6.0 & 7.9281 & TST & \\
\hline CHEMBL145018 & 64661 & 5.7 & 5.7502 & TST & \\
\hline & & & & 26131 & \\
\hline
\end{tabular}




\begin{tabular}{|c|c|c|c|c|c|c|}
\hline & & \multicolumn{5}{|c|}{ Supplemental Table S2.txt } \\
\hline CHEMBL2402627 & 971800 & 3.301 & 3.2873 & TRN & & \\
\hline CHEMBL2402669 & 971800 & 3.301 & 3.3005 & TRN & & \\
\hline CHEMBL518707 & 971800 & 3.301 & 3.2878 & TRN & & \\
\hline CHEMBL 2402635 & 971800 & 3.301 & 2.8328 & TST & & \\
\hline CHEMBL 2402667 & 971800 & 3.301 & 3.2885 & TRN & & \\
\hline CHEMBL 2402640 & 971800 & 3.301 & 3.2695 & TRN & & \\
\hline CHEMBL 2402630 & 971800 & 4.4683 & 4.4669 & TRN & & \\
\hline CHEMBL 2402672 & 971800 & 4.7282 & 4.7497 & TRN & & \\
\hline CHEMBL2402663 & 971800 & 4.5467 & 4.5486 & TRN & & \\
\hline CHEMBL2402674 & 971800 & 5.0376 & 5.0284 & TRN & & \\
\hline CHEMBL2402632 & 971800 & 3.301 & 3.8482 & TST & & \\
\hline CHEMBL 2402797 & 971800 & 3.301 & 3.2431 & TRN & & \\
\hline CHEMBL 2402665 & 971800 & 3.301 & 3.2795 & TRN & & \\
\hline CHEMBL 2402675 & 971800 & 4.4195 & 4.3918 & TRN & & \\
\hline CHEMBL2402629 & 971800 & 4.5318 & 4.5111 & TRN & & \\
\hline CHEMBL 2402661 & 971800 & 3.301 & 3.2918 & TRN & & \\
\hline CHEMBL 2402658 & 971800 & 4.8681 & 4.82 & TRN & & \\
\hline CHEMBL 2402631 & 971800 & 3.301 & 3.2997 & TRN & & \\
\hline CHEMBL 2402794 & 971800 & 3.301 & 3.2787 & TRN & & \\
\hline CHEMBL 2402655 & 971800 & 4.4569 & 4.4723 & TRN & & \\
\hline CHEMBL 2402642 & 971800 & 4.5453 & 4.163 & TST & & \\
\hline CHEMBL2402673 & 971800 & 4.482 & 4.4718 & TRN & & \\
\hline CHEMBL 2402633 & 971800 & 3.301 & 3.8483 & TST & & \\
\hline CHEMBL2338066 & 971800 & 5.0155 & 4.1359 & TST & & \\
\hline CHEMBL 2402636 & 971800 & 3.301 & 3.8137 & TST & & \\
\hline CHEMBL 2402800 & 971800 & 3.301 & 3.3058 & TRN & & \\
\hline CHEMBL2402651 & 971800 & 4.5948 & 4.6073 & TRN & & \\
\hline CHEMBL 2402666 & 971800 & 5.567 & 5.5679 & TRN & & \\
\hline CHEMBL2402671 & 971800 & 4.7138 & 4.7318 & TRN & & \\
\hline CHEMBL 2402660 & 971800 & 4.806 & 3.5149 & TST & & \\
\hline CHEMBL 2402652 & 971800 & 4.5797 & 4.5754 & TRN & & \\
\hline CHEMBL2402798 & 971800 & 3.301 & 3.3792 & TRN & & \\
\hline CHEMBL 2402802 & 971800 & 3.301 & 3.2933 & TRN & & \\
\hline CHEMBL 2402637 & 971800 & 3.301 & 2.9297 & TST & & \\
\hline CHEMBL 2402796 & 971800 & 4.46 & 3.6694 & TST & & \\
\hline CHEMBL2402638 & 971800 & 3.301 & 3.6099 & TST & & \\
\hline CHEMBL 2402628 & 971800 & 3.301 & 3.3502 & TRN & & \\
\hline CHEMBL2402664 & 971800 & 3.301 & 3.301 & TRN & & \\
\hline CHEMBL 2402641 & 971800 & 4.4969 & 3.5807 & TST & & \\
\hline CHEMBL 2402659 & 971800 & 4.4571 & 4.4753 & TRN & & \\
\hline CHEMBL 2402649 & 971800 & 4.44600 & 00000000 & 01 & 4.5081 & TRN \\
\hline CHEMBL 2402646 & 971800 & 3.301 & 3.3084 & TRN & & \\
\hline CHEMBL2402653 & 971800 & 5.0737 & 5.0396 & TRN & & \\
\hline CHEMBL 2402639 & 971800 & 3.301 & 3.3211 & TRN & & \\
\hline CHEMBL 2402634 & 971800 & 3.301 & 3.7521 & TST & & \\
\hline CHEMBL 2402645 & 971800 & 4.4883 & 4.5088 & TRN & & \\
\hline CHEMBL 2402644 & 971800 & 4.7796 & 4.3957 & TST & & \\
\hline CHEMBL2402643 & 971800 & 4.647 & 4.0503 & TST & & \\
\hline
\end{tabular}




\begin{tabular}{|c|c|c|c|c|c|c|}
\hline & & \multicolumn{5}{|c|}{ Supplemental Table S2.txt } \\
\hline CHEMBL2402668 & 971800 & 4.5669 & 4.5735 & TRN & & \\
\hline CHEMBL1590966 & 971800 & 3.301 & 2.6156 & TST & & \\
\hline CHEMBL 2402626 & 971800 & 3.301 & 3.2503 & TRN & & \\
\hline CHEMBL2402799 & 971800 & 3.301 & 2.7692 & TST & & \\
\hline CHEMBL2402654 & 971800 & 4.5183 & 4.5174 & TRN & & \\
\hline CHEMBL2402662 & 971800 & 3.301 & 3.3291 & TRN & & \\
\hline CHEMBL 2402647 & 971800 & 4.7545 & 4.7666 & TRN & & \\
\hline CHEMBL 2402648 & 971800 & 4.4481 & 4.4434 & TRN & & \\
\hline CHEMBL 2402670 & 971800 & 3.301 & 3.338 & TRN & & \\
\hline CHEMBL2402650 & 971800 & 4.5923 & 4.515 & TRN & & \\
\hline CHEMBL 2402795 & 971800 & 3.301 & 3.2908 & TRN & & \\
\hline CHEMBL2402656 & 971800 & 4.5281 & 4.5693 & TRN & & \\
\hline CHEMBL 2402801 & 971800 & 3.301 & 3.3306 & TRN & & \\
\hline CHEMBL 2402657 & 971800 & 4.4517 & 4.4574 & TRN & & \\
\hline CHEMBL1364782 & 688115 & 4.548 & 4.9123 & TRN & & \\
\hline CHEMBL1495939 & 688115 & 4.798 & 4.6479 & TRN & & \\
\hline CHEMBL1582463 & 688115 & 4.698 & 4.6542 & TRN & & \\
\hline CHEMBL1483382 & 688115 & 4.598 & 4.6381 & TRN & & \\
\hline CHEMBL1324890 & 688115 & 4.598 & 4.4084 & TRN & & \\
\hline CHEMBL1415528 & 688115 & 4.648 & 4.9122 & TRN & & \\
\hline CHEMBL1583060 & 688115 & 4.798 & 5.178 & TRN & & \\
\hline CHEMBL1308451 & 688115 & 6.49799 & 999999999 & 99 & 4.8427 & Tाт \\
\hline CHEMBL1613499 & 688115 & 4.998 & 5.2688 & TRN & & \\
\hline CHEMBL1488009 & 688115 & 4.748 & 4.7445 & TRN & & \\
\hline CHEMBL1462202 & 688115 & 5.19799 & 999999999 & 995 & 4.7448 & TRN \\
\hline CHEMBL1402510 & 688115 & 7.4976 & 7.2447 & TRN & & \\
\hline CHEMBL1572330 & 688115 & 4.998 & 5.0108 & TST & & \\
\hline CHEMBL1584829 & 688115 & 5.048 & 4.962 & TRN & & \\
\hline CHEMBL1562076 & 688115 & 4.598 & 4.8442 & TRN & & \\
\hline CHEMBL1544956 & 688115 & 4.748 & 4.8593 & TST & & \\
\hline CHEMBL1411111 & 688115 & 4.848 & 4.6881 & TRN & & \\
\hline CHEMBL1367260 & 688115 & 4.648 & 4.9424 & TRN & & \\
\hline CHEMBL1405039 & 688115 & 5.24799 & 999999999 & 99 & 5.0643 & $1 \mathrm{~K}$ \\
\hline CHEMBL1587587 & 688115 & 4.648 & 4.5139 & TRN & & \\
\hline CHEMBL1309096 & 688115 & 5.048 & 5.0285 & TRN & & \\
\hline CHEMBL1518566 & 688115 & 4.898 & 5.2671 & TRN & & \\
\hline CHEMBL1576675 & 688115 & 4.648 & 4.6012 & TRN & & \\
\hline CHEMBL1336660 & 688115 & 4.598 & 5.1575 & TRN & & \\
\hline CHEMBL1585506 & 688115 & 4.848 & 4.8973 & TST & & \\
\hline CHEMBL1583076 & 688115 & 4.648 & 4.7904 & TST & & \\
\hline CHEMBL1500986 & 688115 & 5.79799 & 999999999 & 99 & 5.4588 & IN \\
\hline CHEMBL1548635 & 688115 & 4.698 & 4.8735 & TRN & & \\
\hline CHEMBL1460600 & 688115 & 4.698 & 4.6353 & TST & & \\
\hline CHEMBL1368803 & 688115 & 4.898 & 4.869 & TRN & & \\
\hline CHEMBL1492862 & 688115 & 4.648 & 4.7601 & TRN & & \\
\hline CHEMBL1612684 & 688115 & 4.598 & 4.4384 & TRN & & \\
\hline CHEMBL14120 & 688115 & 4.798 & 5.1411 & TRN & & \\
\hline CHEMBL1581632 & 688115 & 4.698 & 4.625 & TRN & & \\
\hline
\end{tabular}




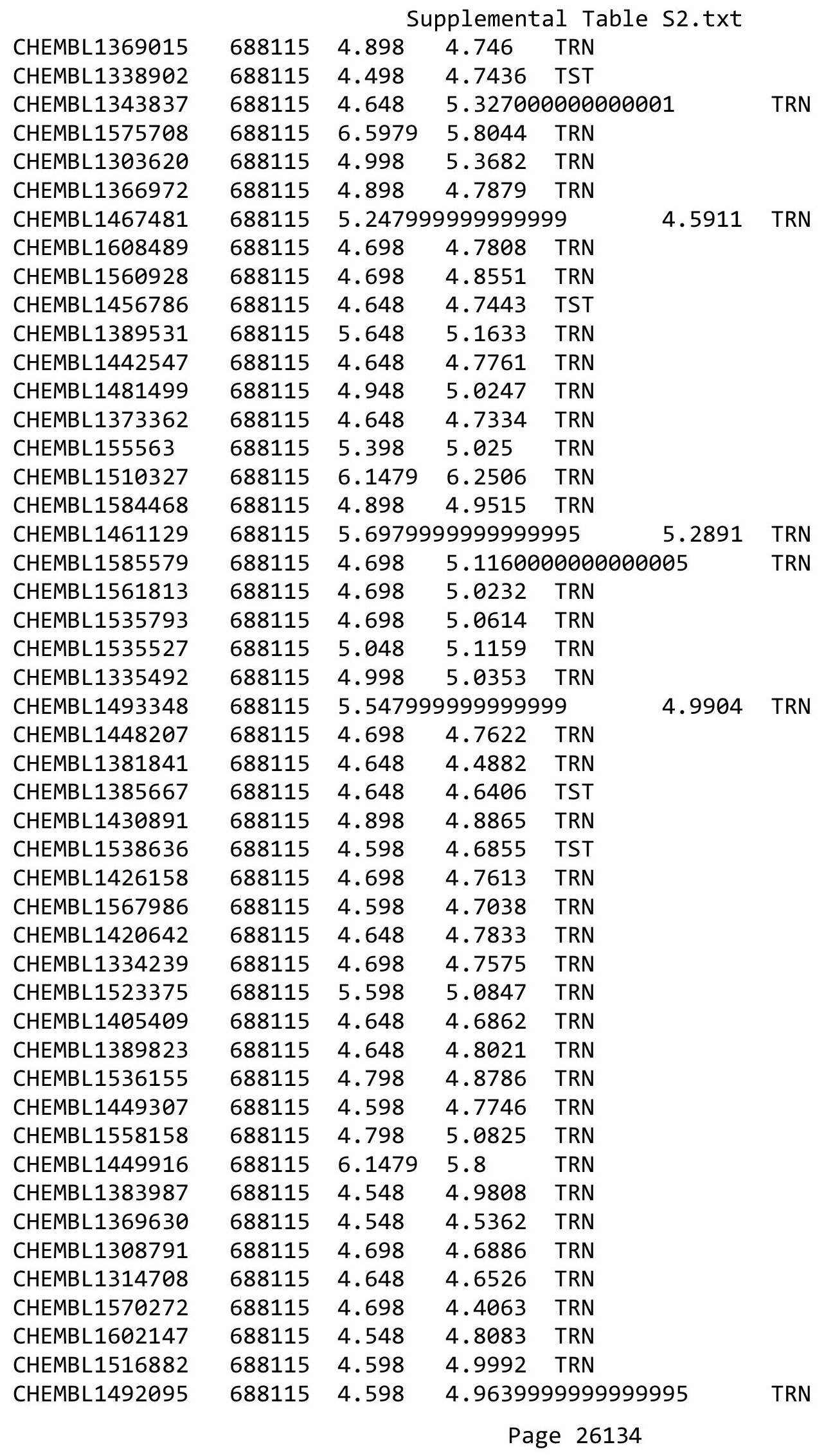




\begin{tabular}{|c|c|c|c|c|c|c|}
\hline & & \multicolumn{5}{|c|}{ Supplemental Table S2.txt } \\
\hline CHEMBL1359489 & 688115 & 4.748 & 4.6139 & TRN & & \\
\hline CHEMBL1340442 & 688115 & 7.2976 & 5.5827 & TST & & \\
\hline CHEMBL1569648 & 688115 & 4.548 & 5.0061 & TST & & \\
\hline CHEMBL586628 & 688115 & 4.648 & 4.9676 & TST & & \\
\hline CHEMBL1377884 & 688115 & 4.498 & 4.7704 & TST & & \\
\hline CHEMBL1419877 & 688115 & 4.998 & 4.7002 & TST & & \\
\hline CHEMBL1596633 & 688115 & 4.498 & 4.439 & TST & & \\
\hline CHEMBL1381933 & 688115 & 4.898 & 4.9107 & TST & & \\
\hline CHEMBL1582855 & 688115 & \multicolumn{3}{|c|}{5.1979999999999995} & 4.9245 & TST \\
\hline CHEMBL1504676 & 688115 & 4.948 & 4.8741 & TST & & \\
\hline CHEMBL1560775 & 688115 & 4.798 & 5.1149 & TST & & \\
\hline CHEMBL1378761 & 688115 & 4.648 & 4.8349 & TST & & \\
\hline CHEMBL1371252 & 688115 & 4.548 & 4.7451 & TST & & \\
\hline CHEMBL1372051 & 688115 & 4.648 & 4.5055 & TST & & \\
\hline CHEMBL1366178 & 688115 & 4.748 & 4.369 & TST & & \\
\hline CHEMBL1412451 & 688115 & 4.748 & 4.9179 & TST & & \\
\hline CHEMBL1348386 & 688115 & 4.898 & 4.6918 & TST & & \\
\hline CHEMBL3972616 & 1622851 & 7.4815 & 7.8127 & TRN & & \\
\hline CHEMBL 3917185 & 1622851 & 6.4437 & 6.0502 & TRN & & \\
\hline CHEMBL3969267 & 1622851 & 6.5918 & 6.5696 & TRN & & \\
\hline CHEMBL3931239 & 1622851 & 8.3979 & 8.2278 & TRN & & \\
\hline CHEMBL 3923097 & 1622851 & 4.1391 & 4.1467 & TRN & & \\
\hline CHEMBL3912958 & 1622851 & 7.3279 & 7.4507 & TRN & & \\
\hline CHEMBL 3925393 & 1622851 & 6.4089 & 6.2336 & TRN & & \\
\hline CHEMBL 3926201 & 1622851 & 7.3979 & \multicolumn{3}{|c|}{7.4079999999999995} & TRN \\
\hline CHEMBL 3899835 & 1622851 & 6.4318 & 6.3378 & TRN & & \\
\hline CHEMBL 3921765 & 1622851 & 7.5686 & 7.5537 & TRN & & \\
\hline CHEMBL3910085 & 1622851 & 7.1192 & 7.4844 & TRN & & \\
\hline CHEMBL 3969822 & 1622851 & 8.1549 & 8.1616 & TRN & & \\
\hline CHEMBL3915799 & 1622851 & 7.7959 & 7.737 & TRN & & \\
\hline CHEMBL 3917820 & 1622851 & 6.7258 & 6.6129 & TRN & & \\
\hline CHEMBL3930700 & 1622851 & 5.2168 & 4.4714 & TRN & & \\
\hline CHEMBL 3984489 & 1622851 & 7.4437 & 7.3011 & TST & & \\
\hline CHEMBL3979902 & 1622851 & 7.6198 & 7.1456 & TST & & \\
\hline CHEMBL3950065 & 1622851 & 6.1226 & 6.2561 & TRN & & \\
\hline CHEMBL3936568 & 1622851 & 6.3768 & 6.3072 & TRN & & \\
\hline CHEMBL3943761 & 1622851 & 7.8239 & 7.4222 & TRN & & \\
\hline CHEMBL 3944657 & 1622851 & 6.2351 & 6.144 & TRN & & \\
\hline CHEMBL3934795 & 1622851 & 7.1079 & 7.0797 & TRN & & \\
\hline CHEMBL3956823 & 1622851 & 7.1024 & 7.2098 & TRN & & \\
\hline CHEMBL 3952497 & 1622851 & \multicolumn{3}{|c|}{5.202000000000001} & 4.4106 & TRN \\
\hline CHEMBL 3985310 & 1622851 & 7.6383 & 7.1387 & TRN & & \\
\hline CHEMBL 3941448 & 1622851 & 7.5086 & 7.4998 & TRN & & \\
\hline CHEMBL3984761 & 1622851 & 7.699 & 7.3207 & TRN & & \\
\hline CHEMBL 3927837 & 1622851 & 4.2757 & 4.6047 & TRN & & \\
\hline CHEMBL 3908881 & 1622851 & 6.7496 & 6.3976 & TRN & & \\
\hline CHEMBL3950196 & 1622851 & 7.4685 & 7.1999 & TRN & & \\
\hline CHEMBL3963167 & 1622851 & 6.224 & 6.4177 & TRN & & \\
\hline
\end{tabular}


Supplemental Table S2.txt

\begin{tabular}{|c|c|c|c|c|c|}
\hline CHEMBL 3936835 & 1622851 & 8.2218 & 7.9623 & TRN & \\
\hline CHEMBL 3977114 & 1622851 & 7.585 & 7.2082 & TST & \\
\hline CHEMBL 3916048 & 1622851 & 7.5376 & 7.4492 & TRN & \\
\hline CHEMBL 3934860 & 1622851 & 8.0969 & 7.6406 & TRN & \\
\hline CHEMBL 3925915 & 1622851 & 7.1871 & 7.2409 & TRN & \\
\hline CHEMBL 3903942 & 1622851 & 6.644 & 6.715 & TRN & \\
\hline CHEMBL 3921940 & 1622851 & 7.3468 & 7.4914 & TRN & \\
\hline CHEMBL 3914936 & 1622851 & 7.1675 & 7.2171 & TRN & \\
\hline CHEMBL 3918060 & 1622851 & 7.8861 & 8.0461 & TRN & \\
\hline CHEMBL 3961356 & 1622851 & 5.9435 & 6.3157 & TRN & \\
\hline CHEMBL 3915547 & 1622851 & 7.6383 & 7.237 & TRN & \\
\hline CHEMBL 3940280 & 1622851 & 7.3468 & 7.4469 & TRN & \\
\hline CHEMBL 3976890 & 1622851 & 6.2182 & 6.4023 & TRN & \\
\hline CHEMBL 3902886 & 1622851 & 7.3979 & 7.8398 & TRN & \\
\hline CHEMBL 3923527 & 1622851 & 6.2396 & 5.8145 & TST & \\
\hline CHEMBL 3948466 & 1622851 & 6.058 & 5.9635 & TRN & \\
\hline CHEMBL 3906825 & 1622851 & 8.1549 & 8.3418 & TRN & \\
\hline CHEMBL 3950824 & 1622851 & 6.3224 & 6.4099 & TRN & \\
\hline CHEMBL 3933865 & 1622851 & 6.8539 & 7.0583 & TRN & \\
\hline CHEMBL 3951240 & 1622851 & 6.3401 & 6.4852 & TRN & \\
\hline CHEMBL 3952664 & 1622851 & 4.0269 & 4.5124 & TRN & \\
\hline CHEMBL 3972450 & 1622851 & 7.3279 & 7.2842 & TRN & \\
\hline CHEMBL 3974827 & 1622851 & 6.7282 & 6.4978 & TRN & \\
\hline CHEMBL 3924174 & 1622851 & 8.3979 & 8.1393 & TRN & \\
\hline CHEMBL 3890307 & 1622851 & 6.7144 & 6.7005 & TST & \\
\hline CHEMBL 3970445 & 1622851 & 6.1701 & 6.2626 & TST & \\
\hline CHEMBL 3939715 & 1622851 & 7.4559 & 7.1872 & TRN & \\
\hline CHEMBL 3986638 & 1622851 & 6.6576 & 6.664 & TRN & \\
\hline CHEMBL 3945715 & 1622851 & 7.9208 & 7.8159 & TRN & \\
\hline CHEMBL 3942836 & 1622851 & 7.4202 & 7.3506 & TRN & \\
\hline CHEMBL 3906199 & 1622851 & 8.301 & 8.0183 & TRN & \\
\hline CHEMBL 3958186 & 1622851 & 4.0 & 5.5312 & TRN & \\
\hline CHEMBL 3924956 & 1622851 & 4.0706 & 4.2004 & TRN & \\
\hline CHEMBL 3978193 & 1622851 & 7.2757 & 7.4307 & TRN & \\
\hline CHEMBL 3889862 & 1622851 & 7.3768 & 7.5537 & TRN & \\
\hline CHEMBL 3926060 & 1622851 & 7.4318 & 7.6984 & TRN & \\
\hline CHEMBL 3947185 & 1622851 & 6.2027 & 5.9621 & TRN & \\
\hline CHEMBL 3897240 & 1622851 & 7.6021 & 7.7249 & TRN & \\
\hline CHEMBL 3899264 & 1622851 & 6.5171 & 6.2071 & TST & \\
\hline CHEMBL 3930876 & 1622851 & 6.9393 & 7.3229 & TRN & \\
\hline CHEMBL 3974744 & 1622851 & 5.21399 & 999999999 & 5.7127 & TST \\
\hline CHEMBL 3898062 & 1622851 & 6.9706 & 6.8741 & TRN & \\
\hline CHEMBL 3977684 & 1622851 & 6.9666 & 7.252999 & 9999999999 & TRN \\
\hline CHEMBL 3959377 & 1622851 & 6.9914 & 6.6964 & TST & \\
\hline CHEMBL 3951580 & 1622851 & 6.7077 & 6.9273 & TRN & \\
\hline CHEMBL 3980491 & 1622851 & 6.585 & 6.2419 & TST & \\
\hline CHEMBL 3982832 & 1622851 & 4.0 & 4.5997 & TST & \\
\hline CHEMBL 3919009 & 1622851 & 6.3556 & 6.0502 & TST & \\
\hline
\end{tabular}


Supplemental Table S2.txt

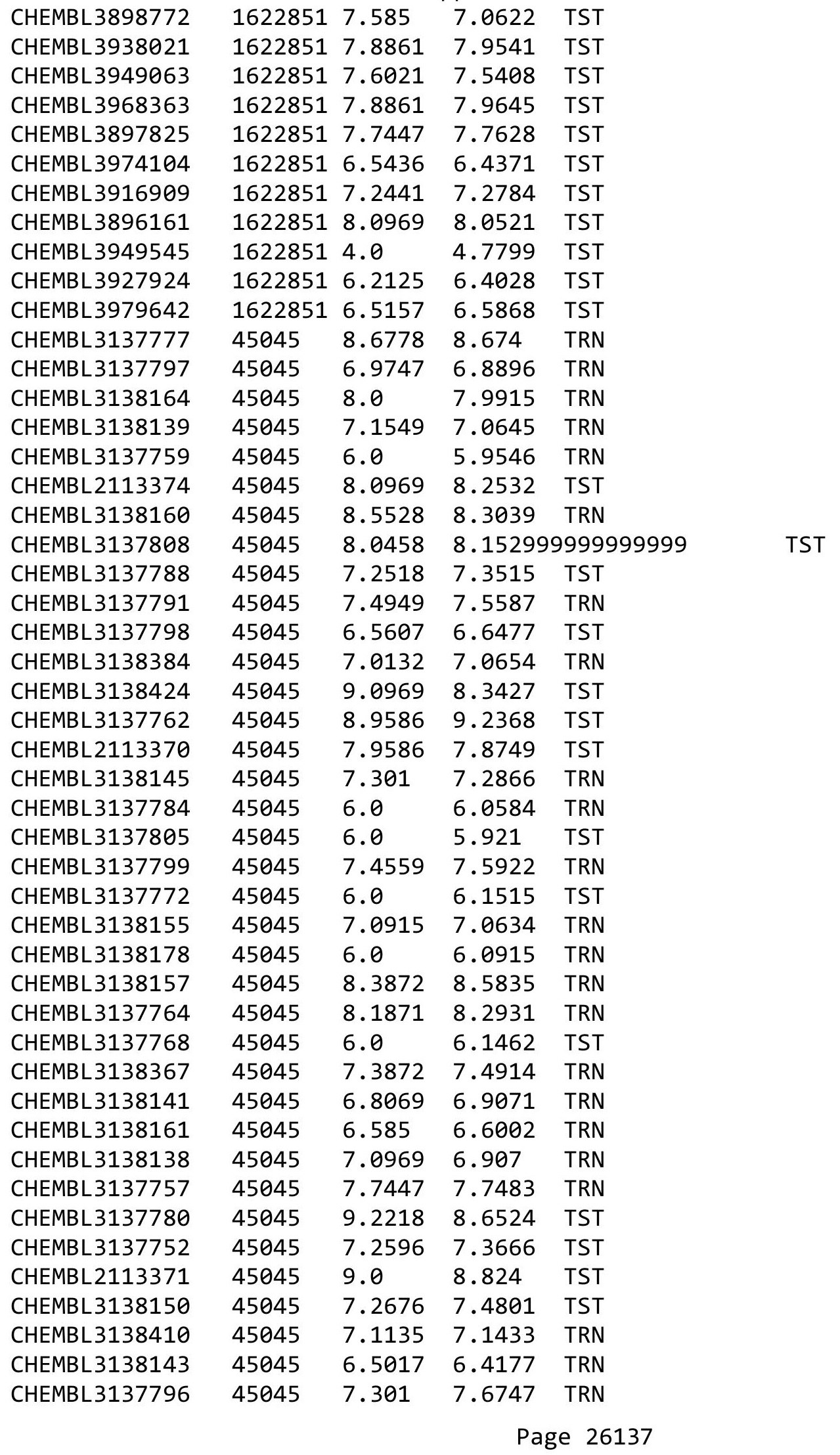




\begin{tabular}{|c|c|c|c|c|c|}
\hline & & \multicolumn{4}{|c|}{ Supplemental Table S2.txt } \\
\hline CHEMBL3137751 & 45045 & 7.2757 & 7.3927 & TRN & \\
\hline CHEMBL3138182 & 45045 & 7.9208 & 7.5429 & TST & \\
\hline CHEMBL 3137782 & 45045 & 7.1487 & 7.1571 & TRN & \\
\hline CHEMBL 3138151 & 45045 & 7.6778 & 7.6319 & TST & \\
\hline CHEMBL 2113375 & 45045 & 6.0 & 6.2602 & TST & \\
\hline CHEMBL3137786 & 45045 & 7.699 & 7.5771 & TST & \\
\hline CHEMBL3138427 & 45045 & 6.0 & 6.0709 & TRN & \\
\hline CHEMBL3138163 & 45045 & 7.0362 & 7.1056 & TRN & \\
\hline CHEMBL 3138154 & 45045 & 7.8861 & 7.7923 & TRN & \\
\hline CHEMBL3137755 & 45045 & 7.585 & 7.5871 & TRN & \\
\hline CHEMBL3137756 & 45045 & 6.5686 & 6.7172 & TST & \\
\hline CHEMBL3138179 & 45045 & 8.0458 & 7.9785 & TRN & \\
\hline CHEMBL3137766 & 45045 & 6.6615 & 6.5944 & TRN & \\
\hline CHEMBL 3138498 & 45045 & 6.0 & 5.9862 & TRN & \\
\hline CHEMBL3138146 & 45045 & 8.3188 & 8.5673 & TRN & \\
\hline CHEMBL3138166 & 45045 & 8.301 & 8.26700 & 0000000001 & TRN \\
\hline CHEMBL3138419 & 45045 & 8.3979 & 8.5759 & TRN & \\
\hline CHEMBL 3138165 & 45045 & 7.0862 & 7.2087 & TRN & \\
\hline CHEMBL3138168 & 45045 & 7.3279 & 7.5163 & TRN & \\
\hline CHEMBL3137811 & 45045 & 6.0 & 6.1278 & TRN & \\
\hline CHEMBL3138176 & 45045 & 6.6778 & 6.7326 & TRN & \\
\hline CHEMBL3138373 & 45045 & 7.0655 & 7.0475 & TRN & \\
\hline CHEMBL 3137793 & 45045 & 9.301 & 8.8782 & TST & \\
\hline CHEMBL3138171 & 45045 & 8.699 & 8.5206 & TRN & \\
\hline CHEMBL 3138180 & 45045 & 6.7696 & 6.9203 & TST & \\
\hline CHEMBL3138153 & 45045 & 6.9208 & 6.9387 & TRN & \\
\hline CHEMBL3137770 & 45045 & 6.6778 & 6.7139 & TRN & \\
\hline CHEMBL3138149 & 45045 & 6.0 & 5.9585 & TRN & \\
\hline CHEMBL 3137806 & 45045 & 6.5528 & 6.6213 & TRN & \\
\hline CHEMBL3137795 & 45045 & 8.5229 & 8.4536 & TRN & \\
\hline CHEMBL 3138169 & 45045 & 7.301 & 7.2595 & TRN & \\
\hline CHEMBL3138158 & 45045 & 7.7696 & 7.69799 & 99999999995 & TST \\
\hline CHEMBL 3137802 & 45045 & 8.9208 & 8.3012 & TRN & \\
\hline CHEMBL3137789 & 45045 & 8.6778 & 8.3911 & TRN & \\
\hline CHEMBL3138172 & 45045 & 7.3768 & 7.3654 & TRN & \\
\hline CHEMBL 3138148 & 45045 & 7.3279 & 7.305 & TRN & \\
\hline CHEMBL3138183 & 45045 & 6.0 & 5.7904 & TRN & \\
\hline CHEMBL 3137781 & 45045 & 6.9747 & 6.9229 & TRN & \\
\hline CHEMBL3138167 & 45045 & 6.0 & 5.7619 & TRN & \\
\hline CHEMBL3137787 & 45045 & 7.1135 & 6.9713 & TRN & \\
\hline CHEMBL 3137767 & 45045 & 6.0 & 5.8913 & TRN & \\
\hline CHEMBL3138159 & 45045 & 6.5086 & 6.3921 & TRN & \\
\hline CHEMBL3138364 & 45045 & 6.5528 & 6.4523 & TST & \\
\hline CHEMBL3138487 & 45045 & 6.6778 & 6.7214 & TRN & \\
\hline CHEMBL3137785 & 45045 & 6.0 & 5.8521 & TRN & \\
\hline CHEMBL 3138174 & 45045 & 9.0969 & 8.5336 & TST & \\
\hline CHEMBL3137765 & 45045 & 6.0 & 5.9969 & TRN & \\
\hline CHEMBL 3138142 & 45045 & 7.8239 & 7.8462 & TRN & \\
\hline
\end{tabular}




\begin{tabular}{|c|c|c|c|c|c|}
\hline & & \multicolumn{4}{|c|}{ Supplemental Table S2.txt } \\
\hline CHEMBL3137754 & 45045 & 6.6383 & 6.5209 & TRN & \\
\hline CHEMBL3137792 & 45045 & 7.5086 & 7.6421 & TRN & \\
\hline CHEMBL3137761 & 45045 & 7.301 & 7.4548 & TRN & \\
\hline CHEMBL3137775 & 45045 & 7.5376 & 7.76 & TRN & \\
\hline CHEMBL 3137771 & 45045 & 8.0 & 8.1631 & TRN & \\
\hline CHEMBL3137750 & 45045 & 6.0 & 6.1828 & TRN & \\
\hline CHEMBL3137807 & 45045 & 7.9586 & 7.7599 & TST & \\
\hline CHEMBL3137814 & 45045 & 8.8539 & 8.4667 & TRN & \\
\hline CHEMBL3138162 & 45045 & 7.6778 & 7.7298 & TRN & \\
\hline CHEMBL3137753 & 45045 & 7.1079 & 6.983 & TRN & \\
\hline CHEMBL3138434 & 45045 & 7.3188 & 7.314 & TRN & \\
\hline CHEMBL3137779 & 45045 & 7.0969 & 7.1081 & TRN & \\
\hline CHEMBL3138147 & 45045 & 6.0 & 6.39 & TRN & \\
\hline CHEMBL585951 & 954566 & 6.1744 & 6.1699 & TRN & \\
\hline CHEMBL1909414 & 954566 & 3.6066 & 3.6379 & TRN & \\
\hline CHEMBL1590308 & 954566 & 3.7106 & 3.4094 & TST & \\
\hline CHEMBL412142 & 954566 & 3.4591 & 3.4615 & TRN & \\
\hline CHEMBL1404918 & 954566 & 4.1045 & 4.0918 & TRN & \\
\hline CHEMBL 210618 & 954566 & 4.746 & 4.7474 & TRN & \\
\hline CHEMBL220241 & 954566 & 4.6025 & 4.5625 & TRN & \\
\hline CHEMBL1242367 & 954566 & 3.3456 & 3.3292 & TRN & \\
\hline CHEMBL509032 & 954566 & 5.8984 & 5.8814 & TRN & \\
\hline CHEMBL393929 & 954566 & 4.2183 & 4.2117 & TRN & \\
\hline CHEMBL483849 & 954566 & 3.1303 & 3.0987 & TRN & \\
\hline CHEMBL1516890 & 954566 & 5.303 & 5.28700 & 0000000001 & TRN \\
\hline CHEMBL373751 & 954566 & 3.8337 & 3.8425 & TRN & \\
\hline CHEMBL 221137 & 954566 & 4.5138 & 4.7178 & TST & \\
\hline CHEMBL1788116 & 954566 & 4.7418 & 4.7387 & TRN & \\
\hline CHEMBL472940 & 954566 & 4.55399 & 99999999 & 4.5525 & TRN \\
\hline CHEMBL222102 & 954566 & 4.4929 & 4.493 & TRN & \\
\hline CHEMBL1673039 & 954566 & 4.6468 & 4.6343 & TRN & \\
\hline CHEMBL135561 & 954566 & 5.0296 & 5.0322 & TRN & \\
\hline CHEMBL449158 & 954566 & 5.9838 & 6.9142 & TST & \\
\hline CHEMBL577784 & 954566 & 5.2951 & 5.2652 & TRN & \\
\hline CHEMBL379975 & 954566 & 4.9269 & 4.9194 & TRN & \\
\hline CHEMBL300389 & 954566 & 7.0446 & 7.0698 & TRN & \\
\hline CHEMBL188678 & 954566 & 4.914 & 4.8876 & TRN & \\
\hline CHEMBL9470 & 954566 & 7.4371 & 5.6387 & TST & \\
\hline CHEMBL1230020 & 954566 & 4.0155 & 4.0155 & TRN & \\
\hline CHEMBL3392440 & 954566 & 3.8086 & 3.8142 & TRN & \\
\hline CHEMBL3349342 & 954566 & 3.6119 & 3.6022 & TRN & \\
\hline CHEMBL92309 & 954566 & 3.6679 & 3.2244 & TST & \\
\hline CHEMBL 2005886 & 954566 & 5.4644 & 5.4658 & TRN & \\
\hline CHEMBL 2144069 & 954566 & 4.5624 & 4.5755 & TRN & \\
\hline CHEMBL515416 & 954566 & 4.2245 & 4.2083 & TRN & \\
\hline CHEMBL65 & 954566 & 8.9355 & 8.9367 & TRN & \\
\hline CHEMBL392695 & 954566 & 5.8697 & 5.892 & TRN & \\
\hline CHEMBL209148 & 954566 & 4.9907 & 5.0005 & TRN & \\
\hline
\end{tabular}




\begin{tabular}{|c|c|c|c|c|c|}
\hline \multicolumn{6}{|c|}{ Supplemental Table S2.txt } \\
\hline CHEMBL 258844 & 954566 & 4.9408 & 4.9389 & TRN & \\
\hline CHEMBL483847 & 954566 & 3.6429 & 3.6505 & TRN & \\
\hline CHEMBL192566 & 954566 & 9.3805 & 8.0247 & TST & \\
\hline CHEMBL1256459 & 954566 & 7.3055 & 7.3255 & TRN & \\
\hline CHEMBL1190711 & 954566 & 5.2699 & 5.2489 & TRN & \\
\hline CHEMBL558642 & 954566 & 4.8475 & 4.8806 & TRN & \\
\hline CHEMBL191334 & 954566 & 3.8106 & 3.8128 & TRN & \\
\hline CHEMBL573107 & 954566 & 5.2647 & 5.29299 & 9999999999 & TRN \\
\hline CHEMBL 3186408 & 954566 & 4.1809 & 3.6161 & TST & \\
\hline CHEMBL 259181 & 954566 & 5.2612 & 5.2795 & TRN & \\
\hline CHEMBL180127 & 954566 & 4.2221 & 4.2208 & TRN & \\
\hline CHEMBL 3199475 & 954566 & 4.3157 & 4.3503 & TRN & \\
\hline CHEMBL1357247 & 954566 & 4.081 & 4.0897 & TRN & \\
\hline CHEMBL189584 & 954566 & 4.1516 & 4.1565 & TRN & \\
\hline CHEMBL514499 & 954566 & 7.4121 & 7.3742 & TRN & \\
\hline CHEMBL102714 & 954566 & 3.4338 & 3.4647 & TRN & \\
\hline CHEMBL 379300 & 954566 & 6.6546 & 6.7843 & TST & \\
\hline CHEMBL512504 & 954566 & 3.8562 & 4.6222 & TST & \\
\hline CHEMBL 240954 & 954566 & 4.6869 & 4.4131 & TST & \\
\hline CHEMBL1970879 & 954566 & 3.1338 & 4.1063 & TST & \\
\hline CHEMBL 213100 & 954566 & 3.8866 & 3.9446 & TST & \\
\hline CHEMBL1643959 & 954566 & 3.4073 & 3.7558 & TST & \\
\hline CHEMBL202721 & 954566 & 4.9184 & 5.1647 & TST & \\
\hline CHEMBL 2363137 & 954566 & 4.9368 & 4.5397 & TST & \\
\hline CHEMBL 3640907 & 1528012 & 9.0 & 7.4458 & TRN & \\
\hline CHEMBL 3640871 & 1528012 & 9.0 & 8.3454 & TRN & \\
\hline CHEMBL 3640844 & 1528012 & 6.0 & 7.8147 & TST & \\
\hline CHEMBL 3640889 & 1528012 & 6.1079 & 6.9219 & TRN & \\
\hline CHEMBL 3640898 & 1528012 & 7.699 & 6.3995 & TRN & \\
\hline CHEMBL3640899 & 1528012 & 7.6021 & 6.8064 & TRN & \\
\hline CHEMBL 3640885 & 1528012 & 7.9208 & 8.3038 & TRN & \\
\hline CHEMBL 3640857 & 1528012 & 10.0 & 8.6283 & TRN & \\
\hline CHEMBL3639397 & 1528012 & 7.9208 & 6.9958 & TRN & \\
\hline CHEMBL 3640884 & 1528012 & 6.6091 & 7.2683 & TRN & \\
\hline CHEMBL 3640866 & 1528012 & 5.0 & 5.6607 & TST & \\
\hline CHEMBL 3640904 & 1528012 & 7.699 & 6.55399 & 9999999999 & TRN \\
\hline CHEMBL 3640823 & 1528012 & 6.0 & 8.0826 & TRN & \\
\hline CHEMBL 3640849 & 1528012 & 6.0 & 7.1058 & TST & \\
\hline CHEMBL 3640909 & 1528012 & 7.2218 & 7.3815 & TRN & \\
\hline CHEMBL 3640833 & 1528012 & 7.7696 & 7.6701 & TRN & \\
\hline CHEMBL 3640820 & 1528012 & 6.0 & 7.2341 & TRN & \\
\hline CHEMBL3640895 & 1528012 & 8.699 & 8.3272 & TRN & \\
\hline CHEMBL3640835 & 1528012 & 7.4559 & 6.715 & TST & \\
\hline CHEMBL 3640900 & 1528012 & 8.0 & 6.9575 & TRN & \\
\hline CHEMBL3640897 & 1528012 & 8.699 & 8.1925 & TRN & \\
\hline CHEMBL 3640876 & 1528012 & 5.0 & 6.0595 & TST & \\
\hline CHEMBL 3640873 & 1528012 & 8.0 & 7.9742 & TRN & \\
\hline CHEMBL3640905 & 1528012 & 7.6021 & 6.7324 & TRN & \\
\hline
\end{tabular}


Supplemental Table S2.txt

$\begin{array}{lllll}\text { CHEMBL3640896 } & 1528012 & 9.0 & 7.865 & \text { TRN } \\ \text { CHEMBL3640903 } & 1528012 & 6.9586 & 6.7863 & \text { TRN } \\ \text { CHEMBL3640852 } & 1528012 & 8.3979 & 7.7116 & \text { TST } \\ \text { CHEMBL3640839 } & 1528012 & 8.5229 & 8.1095 & \text { TRN } \\ \text { CHEMBL3640850 } & 1528012 & 6.0 & 7.7113 & \text { TRN } \\ \text { CHEMBL3640851 } & 1528012 & 7.8239 & 6.888 & \text { TST } \\ \text { CHEMBL3640877 } & 1528012 & 6.0 & 6.4574 & \text { TRN } \\ \text { CHEMBL3640856 } & 1528012 & 7.2218 & 7.2624 & \text { TRN } \\ \text { CHEMBL3640854 } & 1528012 & 7.9208 & 7.0835 & \text { TST } \\ \text { CHEMBL3640910 } & 1528012 & 8.699 & 8.0037 & \text { TRN } \\ \text { CHEMBL3640906 } & 1528012 & 5.0 & 6.5702 & \text { TRN } \\ \text { CHEMBL3640834 } & 1528012 & 9.301 & 8.5288 & \text { TRN } \\ \text { CHEMBL3640892 } & 1528012 & 5.0 & 6.2112 & \text { TRN } \\ \text { CHEMBL3640868 } & 1528012 & 6.2218 & 6.1683 & \text { TST } \\ \text { CHEMBL3640827 } & 1528012 & 6.0 & 7.4956 & \text { TRN } \\ \text { CHEMBL3640890 } & 1528012 & 7.5229 & 7.0205 & \text { TRN } \\ \text { CHEMBL3640883 } & 1528012 & 6.3665 & 7.9773 & \text { TRN } \\ \text { CHEMBL3640861 } & 1528012 & 8.5229 & 8.1339 & \text { TRN } \\ \text { CHEMBL3640831 } & 1528012 & 6.5229 & 6.6576 & \text { TRN } \\ \text { CHEMBL3640858 } & 1528012 & 6.0 & 8.3826 & \text { TRN } \\ \text { CHEMBL3640826 } & 1528012 & 6.0 & 7.4743 & \text { TRN } \\ \text { CHEMBL3640840 } & 1528012 & 6.0 & 7.2412 & \text { TRN } \\ \text { CHEMBL3640901 } & 1528012 & 6.9208 & 6.7702 & \text { TRN } \\ \text { CHEMBL3640888 } & 1528012 & 6.5528 & 6.9763 & \text { TRN } \\ \text { CHEMBL3640891 } & 1528012 & 8.0 & 7.1307 & \text { TRN } \\ \text { CHEMBL3640864 } & 1528012 & 6.0 & 6.6387 & \text { TST } \\ \text { CHEMBL3640836 } & 1528012 & 8.0 & 7.5049 & \text { TRN } \\ \text { CHEMBL3640846 } & 1528012 & 7.7959 & 8.6595 & \text { TST } \\ \text { CHEMBL3640832 } & 1528012 & 6.0 & 6.49 & \text { TRN } \\ \text { CHEMBL3640874 } & 1528012 & 7.9586 & 7.7332 & \text { TRN } \\ \text { CHEMBL3640911 } & 1528012 & 7.8239 & 6.8197 & \text { TRN } \\ \text { CHEMBL3640902 } & 1528012 & 6.8861 & 6.0403 & \text { TRN } \\ \text { CHEMBL3640875 } & 1528012 & 8.0 & 8.1786 & \text { TRN } \\ \text { CHEMBMB } 36342555 & 307263 & 4.7328 & 5.2072 & \text { TRN } \\ \text { CHEMBL68673 } & 307263 & 3.5544 & 3.3918 & \text { TST } \\ \text { CHEMB } & & & \end{array}$

Page 26141 


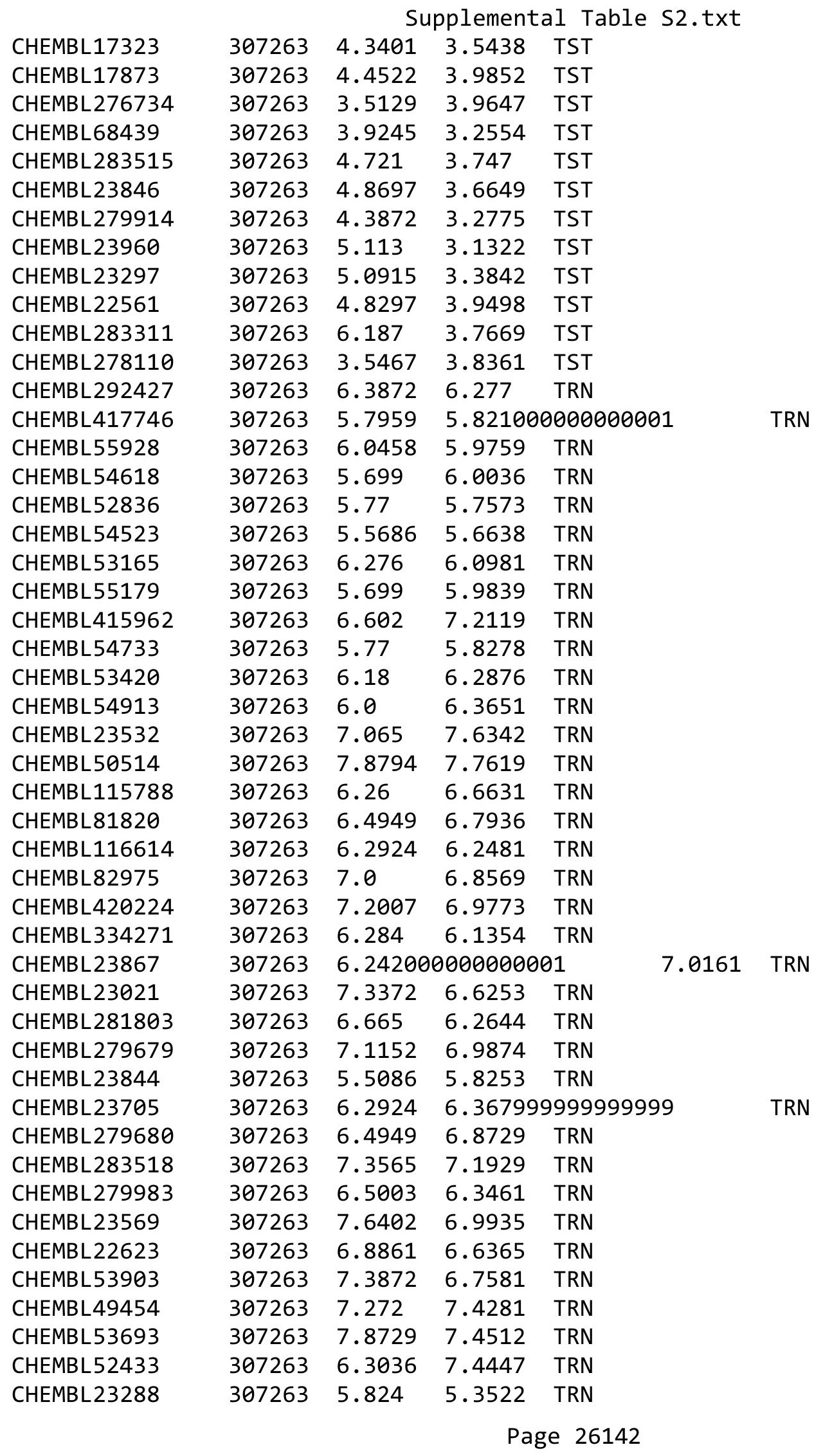




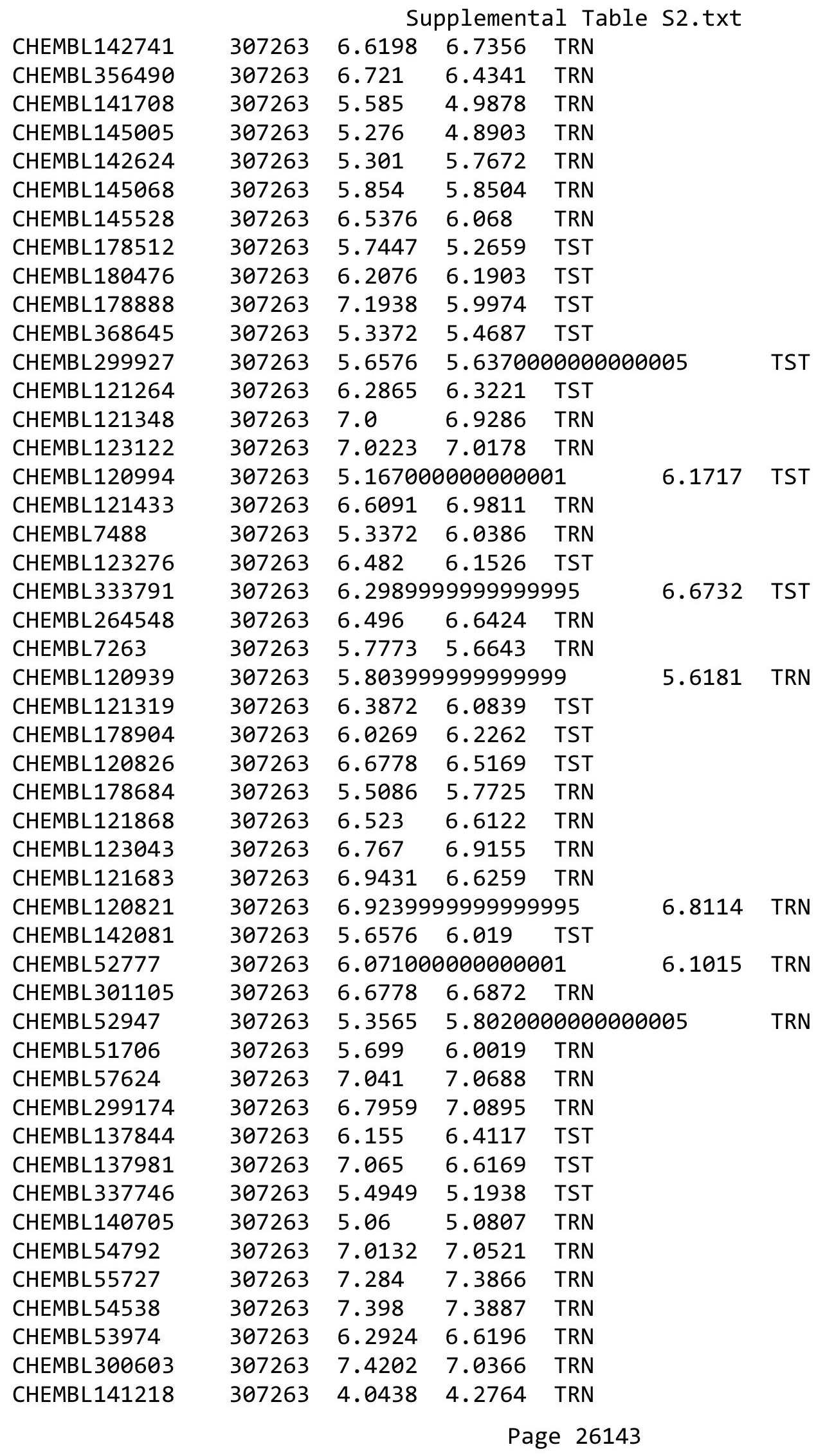




\begin{tabular}{|c|c|c|c|c|c|c|}
\hline \multirow[b]{2}{*}{ CHEMBL141585 } & \multicolumn{6}{|c|}{ Supplemental Table S2.txt } \\
\hline & 307263 & 4.3936 & 4.5027 & TRN & & \\
\hline CHEMBL141260 & 307263 & 4.793 & 4.6357 & TRN & & \\
\hline CHEMBL138452 & 307263 & 4.5867 & 4.2819 & TRN & & \\
\hline CHEMBL139188 & 307263 & 5.0809 & 4.9775 & TRN & & \\
\hline CHEMBL138252 & 307263 & 4.8356 & 4.8394 & TRN & & \\
\hline CHEMBL55063 & 307263 & 6.5376 & 7.3635 & TRN & & \\
\hline CHEMBL52698 & 307263 & 6.602 & 6.5679 & TRN & & \\
\hline CHEMBL54732 & 307263 & 6.301 & 6.7281 & TRN & & \\
\hline CHEMBL292212 & 307263 & 5.7959 & 6.0906 & TRN & & \\
\hline CHEMBL55191 & 307263 & 6.824 & 6.858 & TRN & & \\
\hline CHEMBL53318 & 307263 & 6.6778 & 6.7801 & TRN & & \\
\hline CHEMBL33038 & 307263 & 7.16700 & 00000000 & 01 & 6.8545 & TRN \\
\hline CHEMBL34337 & 307263 & 5.7447 & 5.9315 & TRN & & \\
\hline CHEMBL32113 & 307263 & 7.0757 & 7.1142 & TRN & & \\
\hline CHEMBL35569 & 307263 & 4.8508 & 5.0591 & TRN & & \\
\hline CHEMBL284849 & 307263 & 5.26 & 5.0795 & TRN & & \\
\hline CHEMBL445359 & 307263 & 6.77 & 6.8247 & TRN & & \\
\hline CHEMBL52688 & 307263 & 6.9208 & 6.7048 & TRN & & \\
\hline CHEMBL300886 & 307263 & 5.699 & 5.9712 & TST & & \\
\hline CHEMBL292634 & 307263 & 6.1367 & 6.1461 & TRN & & \\
\hline CHEMBL55656 & 307263 & 6.32799 & 99999999 & 99 & 6.284 & TST \\
\hline CHEMBL33208 & 307263 & 4.8508 & 5.0522 & TRN & & \\
\hline CHEMBL32190 & 307263 & 7.2147 & 7.1661 & TRN & & \\
\hline CHEMBL32708 & 307263 & 5.4202 & 5.4856 & TRN & & \\
\hline CHEMBL32754 & 307263 & 4.684 & 5.0219 & TRN & & \\
\hline CHEMBL33187 & 307263 & 4.614 & 4.7811 & TRN & & \\
\hline CHEMBL35222 & 307263 & 7.102 & 7.1128 & TRN & & \\
\hline CHEMBL292143 & 307263 & 6.4202 & 6.3422 & TST & & \\
\hline CHEMBL299140 & 307263 & 6.6383 & 6.5696 & TRN & & \\
\hline CHEMBL296382 & 307263 & 5.26 & 5.7479 & TRN & & \\
\hline CHEMBL278013 & 307263 & 4.548 & 4.7331 & TST & & \\
\hline CHEMBL278261 & 307263 & 3.6799 & 4.6496 & TST & & \\
\hline CHEMBL32769 & 307263 & 5.3188 & 5.0319 & TRN & & \\
\hline CHEMBL36245 & 307263 & 7.1192 & 6.995 & TRN & & \\
\hline CHEMBL32266 & 307263 & 5.2441 & 4.9045 & TRN & & \\
\hline CHEMBL32635 & 307263 & 5.4089 & 5.49 & TRN & & \\
\hline CHEMBL32220 & 307263 & 5.086 & 5.3966 & TRN & & \\
\hline CHEMBL17430 & 307263 & 4.2328 & 4.0326 & TST & & \\
\hline CHEMBL17431 & 307263 & 4.9547 & 3.7994 & TST & & \\
\hline CHEMBL17479 & 307263 & 4.9747 & 4.4778 & TST & & \\
\hline CHEMBL275893 & 307263 & 3.032 & 3.5643 & TST & & \\
\hline CHEMBL113999 & 307263 & 5.16700 & 00000000 & & 5.3471 & TRN \\
\hline CHEMBL116816 & 307263 & 5.3372 & 5.2732 & TRN & & \\
\hline CHEMBL 286700 & 307263 & 5.5686 & 5.0927 & TRN & & \\
\hline CHEMBL32583 & 307263 & 5.03600 & 20000000 & 005 & 5.176 & TRN \\
\hline CHEMBL33136 & 307263 & 5.7122 & 5.2768 & TRN & & \\
\hline CHEMBL116815 & 307263 & 5.6576 & 5.3741 & TRN & & \\
\hline CHEMBL115474 & 307263 & 5.06 & 5.4014 & TRN & & \\
\hline
\end{tabular}




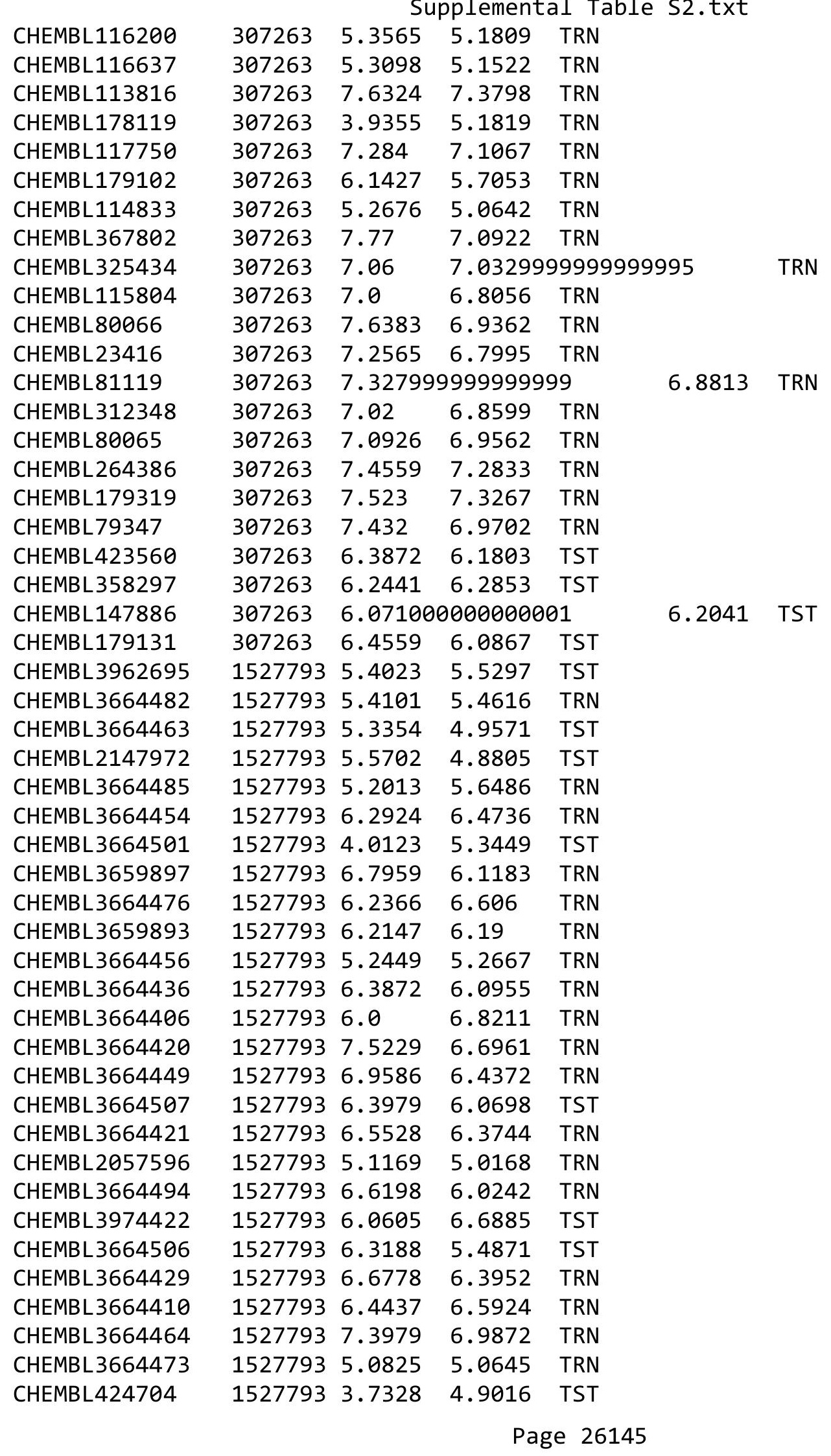


Supplemental Table S2.txt

\begin{tabular}{|c|c|c|c|c|c|}
\hline CHEMBL 3664440 & 1527793 & 6.1427 & 6.2586 & TRN & \\
\hline CHEMBL 3664470 & 1527793 & 5.7645 & 6.1439 & TRN & \\
\hline CHEMBL2057598 & 1527793 & 5.4045 & 5.4125 & TRN & \\
\hline CHEMBL 3664426 & 1527793 & 6.7959 & \multicolumn{2}{|c|}{6.5329999999999995} & TRN \\
\hline CHEMBL1234485 & 1527793 & 5.0232 & 4.8292 & TRN & \\
\hline CHEMBL3664474 & 1527793 & 5.6517 & 6.1343 & TRN & \\
\hline CHEMBL 3664400 & 1527793 & 6.2218 & 5.7829 & TRN & \\
\hline CHEMBL 3664446 & 1527793 & 6.0 & 6.6241 & TRN & \\
\hline CHEMBL3664428 & 1527793 & 5.6289 & 6.1584 & TRN & \\
\hline CHEMBL 3664430 & 1527793 & 6.8539 & 6.6713 & TRN & \\
\hline CHEMBL 3664415 & 1527793 & 5.9469 & 6.154 & TRN & \\
\hline CHEMBL3664434 & 1527793 & 6.6383 & 6.2016 & TRN & \\
\hline CHEMBL 3664457 & 1527793 & 5.5884 & 5.7964 & TRN & \\
\hline CHEMBL3664460 & 1527793 & 5.3206 & 5.2874 & TRN & \\
\hline CHEMBL3664439 & 1527793 & 6.5086 & 6.1592 & TRN & \\
\hline CHEMBL 2147974 & 1527793 & 5.5901 & 5.6578 & TST & \\
\hline CHEMBL3664503 & 1527793 & 6.0 & 6.3823 & TRN & \\
\hline CHEMBL 3659899 & 1527793 & 6.4815 & 6.4019 & TRN & \\
\hline CHEMBL3639633 & 1527793 & 5.025 & 5.2338 & TRN & \\
\hline CHEMBL3664409 & 1527793 & 7.3979 & 6.567 & TRN & \\
\hline CHEMBL 3664404 & 1527793 & 6.7212 & 6.6743 & TRN & \\
\hline CHEMBL3664425 & 1527793 & 7.0458 & 6.4115 & TRN & \\
\hline CHEMBL3664461 & 1527793 & 5.1469 & 5.982 & TRN & \\
\hline CHEMBL3664431 & 1527793 & 5.6925 & 5.8417 & TRN & \\
\hline CHEMBL 3664445 & 1527793 & 6.3872 & 6.1625 & TRN & \\
\hline CHEMBL 3664462 & 1527793 & 5.3344 & 5.5035 & TRN & \\
\hline CHEMBL3664491 & 1527793 & 5.0545 & 5.3755 & TRN & \\
\hline CHEMBL3664442 & 1527793 & 6.8539 & 6.2417 & TRN & \\
\hline CHEMBL3664487 & 1527793 & 5.0223 & 5.306 & TRN & \\
\hline CHEMBL3664407 & 1527793 & 7.3979 & 6.7741 & TRN & \\
\hline CHEMBL3664500 & 1527793 & 6.9586 & 6.2835 & TST & \\
\hline CHEMBL3664486 & 1527793 & 5.0615 & 5.1713 & TRN & \\
\hline CHEMBL 3664424 & 1527793 & 6.4815 & 6.4174 & TRN & \\
\hline CHEMBL3664480 & 1527793 & 6.5686 & 6.4153 & TST & \\
\hline CHEMBL3664423 & 1527793 & 7.3979 & 6.4911 & TRN & \\
\hline CHEMBL3905506 & 1527793 & 5.7423 & 6.6058 & TST & \\
\hline CHEMBL3664490 & 1527793 & 5.2441 & 5.0415 & TRN & \\
\hline CHEMBL3664510 & 1527793 & 5.3429 & 6.3143 & TST & \\
\hline CHEMBL2147986 & 1527793 & 6.7696 & 6.6586 & TRN & \\
\hline CHEMBL3664475 & 1527793 & 6.3872 & 6.4214 & TRN & \\
\hline CHEMBL2147985 & 1527793 & 7.301 & 6.7297 & TRN & \\
\hline CHEMBL3664450 & 1527793 & 6.1308 & 6.1293 & TRN & \\
\hline CHEMBL 3664441 & 1527793 & 6.3098 & 6.273 & TRN & \\
\hline CHEMBL3664438 & 1527793 & 5.9281 & 6.1787 & TRN & \\
\hline CHEMBL3664433 & 1527793 & 6.2924 & 6.0847 & TRN & \\
\hline CHEMBL2057601 & 1527793 & 6.0 & 6.5566 & TRN & \\
\hline CHEMBL3664467 & 1527793 & 6.284 & 6.327006 & 0000000001 & TRN \\
\hline CHEMBL3659894 & 1527793 & 6.0 & 6.4863 & TRN & \\
\hline
\end{tabular}


Supplemental Table S2.txt

\begin{tabular}{|c|c|c|c|c|}
\hline CHEMBL 2057594 & 1527793 & 5.9508 & 5.614 & TRN \\
\hline CHEMBL 3664402 & 1527793 & 5.7825 & 5.8852 & TRN \\
\hline CHEMBL 3664511 & 1527793 & 6.0 & 6.2521 & TST \\
\hline CHEMBL 3664493 & 1527793 & 6.8539 & 5.8383 & TST \\
\hline CHEMBL 3664413 & 1527793 & 6.4815 & 6.5115 & TRN \\
\hline CHEMBL 3659895 & 1527793 & 6.1938 & 6.5284 & TRN \\
\hline CHEMBL 3664422 & 1527793 & 7.0 & 6.7266 & TRN \\
\hline CHEMBL 3664437 & 1527793 & 6.0706 & 6.0341 & TRN \\
\hline CHEMBL 3659891 & 1527793 & 5.7282 & 6.1599 & TRN \\
\hline CHEMBL3664502 & 1527793 & 6.4815 & 6.2551 & TRN \\
\hline CHEMBL 3664465 & 1527793 & 7.1549 & 6.8995 & TRN \\
\hline CHEMBL 3659900 & 1527793 & 6.6778 & 6.4358 & TRN \\
\hline CHEMBL 3664479 & 1527793 & 5.0088 & 5.1706 & TRN \\
\hline CHEMBL 3664403 & 1527793 & 6.0 & 6.6868 & TRN \\
\hline CHEMBL 3664447 & 1527793 & 6.0 & 6.0511 & TRN \\
\hline CHEMBL 3664505 & 1527793 & 6.1805 & 6.8513 & TRN \\
\hline CHEMBL 3664455 & 1527793 & 5.6778 & 5.1793 & TRN \\
\hline CHEMBL 3664509 & 1527793 & 5.1831 & 5.1479 & TST \\
\hline CHEMBL 3664466 & 1527793 & 6.2147 & 6.6408 & TRN \\
\hline CHEMBL 3664492 & 1527793 & 5.0487 & 5.0637 & TST \\
\hline CHEMBL 2057599 & 1527793 & 6.585 & 6.08700 & 0000000001 \\
\hline CHEMBL3664412 & 1527793 & 6.4437 & 6.4942 & TRN \\
\hline CHEMBL 3664472 & 1527793 & 6.9208 & 6.6264 & TRN \\
\hline CHEMBL3664411 & 1527793 & 6.0506 & 6.1778 & TRN \\
\hline CHEMBL 3664478 & 1527793 & 6.4559 & 6.7173 & TRN \\
\hline CHEMBL 3664405 & 1527793 & 6.5686 & 6.2345 & TRN \\
\hline CHEMBL 3664484 & 1527793 & 5.3615 & 5.4222 & TST \\
\hline CHEMBL 3664435 & 1527793 & 6.6383 & 6.4063 & TRN \\
\hline CHEMBL3664488 & 1527793 & 5.1163 & 5.5628 & TST \\
\hline CHEMBL3664399 & 1527793 & 6.0269 & 5.6691 & TRN \\
\hline CHEMBL 3664481 & 1527793 & 5.6882 & 5.4515 & TST \\
\hline CHEMBL3664496 & 1527793 & 5.2204 & 5.0932 & TST \\
\hline CHEMBL 3664468 & 1527793 & 5.8356 & 6.5027 & TRN \\
\hline CHEMBL 3664458 & 1527793 & 5.7825 & 5.5232 & TST \\
\hline CHEMBL 2147975 & 1527793 & 6.6198 & 6.2233 & TST \\
\hline CHEMBL 3664508 & 1527793 & 6.4202 & 6.0926 & TST \\
\hline CHEMBL 3664432 & 1527793 & 6.0809 & 6.1008 & TRN \\
\hline CHEMBL3659898 & 1527793 & 5.5482 & 5.9954 & TRN \\
\hline CHEMBL 3664499 & 1527793 & 6.8861 & 6.2565 & TST \\
\hline CHEMBL3664483 & 1527793 & 5.3019 & 5.47 & TST \\
\hline CHEMBL3664459 & 1527793 & 5.8861 & 5.33799 & 9999999999 \\
\hline CHEMBL2057597 & 1527793 & 5.5575 & 5.4098 & TST \\
\hline CHEMBL3664469 & 1527793 & 6.9208 & 6.5059 & TRN \\
\hline CHEMBL 3664504 & 1527793 & 6.2366 & 6.683 & TST \\
\hline CHEMBL 3664497 & 1527793 & 5.7305 & 5.8945 & TST \\
\hline CHEMBL 3664477 & 1527793 & 6.6021 & 6.8457 & TRN \\
\hline CHEMBL3664489 & 1527793 & 5.2464 & 5.5012 & TST \\
\hline CHEMBL3664401 & 1527793 & 6.6778 & 6.4949 & TRN \\
\hline
\end{tabular}


Supplemental Table S2.txt

\begin{tabular}{|c|c|c|c|c|}
\hline CHEMBL 3664427 & 1527793 & 5.6968 & 6.2372 & TRN \\
\hline CHEMBL3664498 & 1527793 & 6.1938 & 6.2188 & TST \\
\hline CHEMBL 3664453 & 1527793 & 6.1805 & 6.2073 & TRN \\
\hline CHEMBL3664451 & 1527793 & 6.0 & 6.0775 & TRN \\
\hline CHEMBL 2057600 & 1527793 & 6.284 & 6.3399 & TRN \\
\hline CHEMBL 3664471 & 1527793 & 5.767 & \multicolumn{2}{|c|}{6.577999999999999} \\
\hline CHEMBL 3664443 & 1527793 & 6.0 & 6.0147 & TRN \\
\hline CHEMBL346691 & 219471 & 7.7959 & 7.6602 & TRN \\
\hline CHEMBL34852 & 219471 & 7.5229 & 7.6602 & TRN \\
\hline CHEMBL32096 & 219471 & 6.5376 & 6.54 & TRN \\
\hline CHEMBL35385 & 219471 & 6.5376 & 6.4895 & TRN \\
\hline CHEMBL34974 & 219471 & 6.2924 & 6.3886 & TRN \\
\hline CHEMBL35118 & 219471 & 7.1549 & 7.154 & TRN \\
\hline CHEMBL408856 & 219471 & 7.6778 & 7.5863 & TRN \\
\hline CHEMBL32732 & 219471 & 6.7447 & 6.8078 & TRN \\
\hline CHEMBL6852 & 219471 & 4.6021 & 5.2632 & TST \\
\hline CHEMBL 287316 & 219471 & 7.1024 & 7.0609 & TRN \\
\hline CHEMBL 285516 & 219471 & 6.9914 & 6.9724 & TRN \\
\hline CHEMBL 286586 & 219471 & 7.6021 & 7.5222 & TRN \\
\hline CHEMBL408857 & 219471 & 6.4881 & 6.3886 & TRN \\
\hline CHEMBL36525 & 219471 & 5.1427 & 5.1668 & TRN \\
\hline CHEMBL6853 & 219471 & 5.0809 & 5.7722 & TST \\
\hline CHEMBL35338 & 219471 & 6.8697 & 6.8078 & TRN \\
\hline CHEMBL 7087 & 219471 & 4.6778 & 5.5107 & TST \\
\hline CHEMBL 290348 & 219471 & 7.0605 & 7.1305 & TRN \\
\hline CHEMBL32982 & 219471 & 7.1024 & 7.1295 & TRN \\
\hline CHEMBL 284694 & 219471 & 5.426 & 5.4497 & TRN \\
\hline CHEMBL2112276 & 219471 & 7.4089 & 7.4288 & TRN \\
\hline CHEMBL35528 & 219471 & 5.2676 & 5.1662 & TRN \\
\hline CHEMBL 262389 & 219471 & 5.0088 & 5.0117 & TRN \\
\hline CHEMBL 289672 & 219471 & 5.0655 & 5.1662 & TRN \\
\hline CHEMBL 284831 & 219471 & 7.2007 & 7.1305 & TRN \\
\hline CHEMBL2112274 & 219471 & 7.3979 & 7.4085 & TRN \\
\hline CHEMBL 268177 & 219471 & 5.2218 & 5.8979 & TST \\
\hline CHEMBL 265674 & 219471 & 5.0655 & 6.1242 & TST \\
\hline CHEMBL34317 & 219471 & 7.4949 & 7.5863 & TRN \\
\hline CHEMBL 286449 & 219471 & 6.4202 & 6.3303 & TRN \\
\hline CHEMBL 32160 & 219471 & 6.699 & 6.7529 & TRN \\
\hline CHEMBL 284398 & 219471 & 6.8097 & 6.7529 & TRN \\
\hline CHEMBL415466 & 219471 & 7.4437 & 7.5222 & TRN \\
\hline CHEMBL7204 & 219471 & 4.1051 & 4.9227 & TST \\
\hline CHEMBL416410 & 219471 & 6.9586 & 6.9724 & TRN \\
\hline CHEMBL2112275 & 219471 & 6.4559 & 6.4335 & TRN \\
\hline CHEMBL 289888 & 219471 & 7.2076 & 7.2412 & TRN \\
\hline CHEMBL6724 & 219471 & 5.1871 & 5.8114 & TST \\
\hline CHEMBL6705 & 219471 & 4.3429 & 4.9808 & TST \\
\hline CHEMBL432083 & 219471 & 7.301 & 7.2765 & TRN \\
\hline CHEMBL 284617 & 219471 & 7.2366 & 7.3014 & TRN \\
\hline
\end{tabular}




\begin{tabular}{|c|c|c|c|c|c|c|}
\hline & & \multicolumn{5}{|c|}{ Supplemental Table S2.txt } \\
\hline CHEMBL6919 & 219471 & 4.6198 & 5.4071 & TST & & \\
\hline CHEMBL6685 & 219471 & 7.2596 & 7.2588 & TRN & & \\
\hline CHEMBL6784 & 219471 & 4.7447 & 5.4264 & TST & & \\
\hline CHEMBL 2111218 & 219471 & 7.3665 & 7.3593 & TRN & & \\
\hline CHEMBL154106 & 219471 & 7.2676 & 7.2412 & TRN & & \\
\hline CHEMBL266240 & 219471 & 5.0757 & 5.8784 & TST & & \\
\hline CHEMBL30168 & 219471 & 7.1549 & 7.1295 & TRN & & \\
\hline CHEMBL13646 & 219471 & \multicolumn{3}{|c|}{6.3420000000000005} & .3456 & TRN \\
\hline CHEMBL287117 & 219471 & 7.301 & 7.3019 & TRN & & \\
\hline CHEMBL269628 & 219471 & 5.2147 & 6.1966 & TST & & \\
\hline CHEMBL32208 & 219471 & 7.3665 & 7.3014 & TRN & & \\
\hline CHEMBL32606 & 219471 & 7.2596 & 7.2765 & TRN & & \\
\hline CHEMBL34768 & 219471 & 7.0177 & 7.0609 & TRN & & \\
\hline CHEMBL35043 & 219471 & 6.4437 & 6.4895 & TRN & & \\
\hline CHEMBL287145 & 219471 & 5.1938 & 5.1668 & TRN & & \\
\hline CHEMBL286297 & 219471 & 6.2596 & 6.3303 & TRN & & \\
\hline CHEMBL6753 & 219471 & 5.0315 & 6.2611 & TST & & \\
\hline CHEMBL 7092 & 219471 & 5.0088 & 5.6765 & TST & & \\
\hline CHEMBL32836 & 219471 & 5.3872 & 5.4497 & TST & & \\
\hline CHEMBL286549 & 219471 & 4.9208 & 5.0117 & TST & & \\
\hline CHEMBL3700592 & 1528684 & 5.9747 & 5.9235 & TRN & & \\
\hline CHEMBL 3697074 & 1528684 & 7.1192 & 6.6798 & TST & & \\
\hline CHEMBL3697060 & 1528684 & 6.9355 & 6.7638 & TRN & & \\
\hline CHEMBL3697117 & 1528684 & 6.3655 & 6.6789 & TRN & & \\
\hline CHEMBL3895135 & 1528684 & 6.6126 & 6.5199 & TST & & \\
\hline CHEMBL3697065 & 1528684 & 7.0915 & 7.3438 & TRN & & \\
\hline CHEMBL3697097 & 1528684 & 6.4622 & 6.7069 & TRN & & \\
\hline CHEMBL3697121 & 1528684 & 6.9706 & 6.9939 & TRN & & \\
\hline CHEMBL 3697129 & 1528684 & 6.6576 & 6.3627 & TRN & & \\
\hline CHEMBL3700590 & 1528684 & 7.1024 & 6.75700 & 0000000001 & & TRN \\
\hline CHEMBL3697131 & 1528684 & 5.3936 & 5.8579 & TRN & & \\
\hline CHEMBL3697071 & 1528684 & 7.6576 & 7.3321 & TRN & & \\
\hline CHEMBL3697098 & 1528684 & 6.9914 & 6.8441 & TRN & & \\
\hline CHEMBL3697079 & 1528684 & 7.0605 & 6.681 & TRN & & \\
\hline CHEMBL3697118 & 1528684 & 6.6108 & 7.0196 & TRN & & \\
\hline CHEMBL3697116 & 1528684 & 6.8125 & 6.6648 & TRN & & \\
\hline CHEMBL3697153 & 1528684 & 7.1487 & 6.5605 & TST & & \\
\hline CHEMBL3697101 & 1528684 & 6.3125 & 6.7592 & TST & & \\
\hline CHEMBL3697066 & 1528684 & 6.0 & 6.1331 & TRN & & \\
\hline CHEMBL3697162 & 1528684 & 5.9626 & 5.8474 & TRN & & \\
\hline CHEMBL3697114 & 1528684 & 6.7399 & 6.7549 & TRN & & \\
\hline CHEMBL3955242 & 1528684 & 6.8447 & 6.9257 & TST & & \\
\hline CHEMBL3697084 & 1528684 & 6.0969 & 6.3841 & TRN & & \\
\hline CHEMBL3697099 & 1528684 & 6.699 & 6.9077 & TST & & \\
\hline CHEMBL 3697124 & 1528684 & 7.7212 & 6.8171 & TRN & & \\
\hline CHEMBL3697042 & 1528684 & 6.0 & 6.7757 & TRN & & \\
\hline CHEMBL3697155 & 1528684 & 5.4949 & 5.7592 & TST & & \\
\hline CHEMBL3697100 & 1528684 & 7.2076 & 7.025 & TRN & & \\
\hline
\end{tabular}


Supplemental Table S2.txt

\begin{tabular}{|c|c|c|c|c|c|c|}
\hline CHEMBL3697069 & 1528684 & 6.9101 & 6.671 & TRN & & \\
\hline CHEMBL3639959 & 1528684 & 7.0757 & 7.2377 & TRN & & \\
\hline CHEMBL3697056 & 1528684 & 7.2596 & 7.2433 & TRN & & \\
\hline CHEMBL3700582 & 1528684 & 7.585 & 7.395 & TRN & & \\
\hline CHEMBL3928891 & 1528684 & 6.5317 & 6.2466 & TST & & \\
\hline CHEMBL 3700578 & 1528684 & 6.7773 & 6.6738 & TRN & & \\
\hline CHEMBL3697090 & 1528684 & 6.1029 & 6.8676 & TRN & & \\
\hline CHEMBL3697059 & 1528684 & 6.9508 & 6.8957 & TRN & & \\
\hline CHEMBL 3697148 & 1528684 & 6.0 & 6.3006 & TRN & & \\
\hline CHEMBL3697104 & 1528684 & 7.1135 & 7.1102 & TRN & & \\
\hline CHEMBL3697080 & 1528684 & 7.1675 & 7.4703 & TRN & & \\
\hline CHEMBL3697125 & 1528684 & 7.6383 & 6.349 & TST & & \\
\hline CHEMBL3697081 & 1528684 & 6.0 & 6.0862 & TRN & & \\
\hline CHEMBL3697109 & 1528684 & 6.0835 & 5.8685 & TRN & & \\
\hline CHEMBL3700573 & 1528684 & 5.9208 & 6.1297 & TST & & \\
\hline CHEMBL3697161 & 1528684 & 7.2366 & 6.5166 & TST & & \\
\hline CHEMBL3697087 & 1528684 & 5.9066 & 6.2085 & TRN & & \\
\hline CHEMBL3697108 & 1528684 & 6.7545 & 6.0998 & TRN & & \\
\hline CHEMBL3697133 & 1528684 & 5.3335 & 5.7626 & TRN & & \\
\hline CHEMBL3697073 & 1528684 & 7.5528 & 7.1576 & TRN & & \\
\hline CHEMBL3697113 & 1528684 & 7.3468 & 6.8839 & TRN & & \\
\hline CHEMBL3697122 & 1528684 & 7.1487 & 6.682 & TRN & & \\
\hline CHEMBL3700579 & 1528684 & 6.8356 & 6.7765 & TRN & & \\
\hline CHEMBL 3925439 & 1528684 & 6.7212 & 6.4169 & TST & & \\
\hline CHEMBL3697058 & 1528684 & 6.1986 & 6.1236 & TRN & & \\
\hline CHEMBL3700589 & 1528684 & 5.5421 & 6.3094 & TRN & & \\
\hline CHEMBL3697051 & 1528684 & 7.6021 & 7.5729 & TRN & & \\
\hline CHEMBL3895545 & 1528684 & 6.7447 & 6.9449 & TRN & & \\
\hline CHEMBL3697102 & 1528684 & 6.9172 & 6.8531 & TRN & & \\
\hline CHEMBL3697072 & 1528684 & 5.8447 & 7.1875 & TST & & \\
\hline CHEMBL3697095 & 1528684 & 6.7721 & 6.4948 & TST & & \\
\hline CHEMBL 3700574 & 1528684 & 6.0 & 5.9716 & TST & & \\
\hline CHEMBL3697086 & 1528684 & 6.1273 & 6.8919 & TST & & \\
\hline CHEMBL3700575 & 1528684 & 6.699 & 6.4343 & TST & & \\
\hline CHEMBL3697160 & 1528684 & 6.3325 & 5.9563 & TST & & \\
\hline CHEMBL3980265 & 1528684 & 6.0 & 7.0065 & TRN & & \\
\hline CHEMBL3697119 & 1528684 & 7.3372 & 6.6039 & TRN & & \\
\hline CHEMBL3700571 & 1528684 & 6.0 & 6.2865 & TST & & \\
\hline CHEMBL3697106 & 1528684 & 7.2518 & 7.1205 & TRN & & \\
\hline CHEMBL3697123 & 1528684 & 7.0706 & 7.3176 & TRN & & \\
\hline CHEMBL3956593 & 1528684 & 6.75200 & 000000000 & $\partial 1$ & 6.7459 & TRN \\
\hline CHEMBL3697062 & 1528684 & 6.0 & 6.8013 & TRN & & \\
\hline CHEMBL3700581 & 1528684 & 5.1549 & 5.9388 & TRN & & \\
\hline CHEMBL 3697077 & 1528684 & 7.0915 & 6.8156 & TRN & & \\
\hline CHEMBL3697091 & 1528684 & 6.317 & 6.1802 & TRN & & \\
\hline CHEMBL3700583 & 1528684 & 6.7825 & 7.1359 & TRN & & \\
\hline CHEMBL3697132 & 1528684 & 6.3536 & 7.0014 & TRN & & \\
\hline CHEMBL3697096 & 1528684 & 6.71 & 6.8534 & TRN & & \\
\hline
\end{tabular}


Supplemental Table S2.txt

\begin{tabular}{|c|c|c|c|c|}
\hline CHEMBL 3697070 & 1528684 & 7.3768 & 7.3566 & TRN \\
\hline CHEMBL3697120 & 1528684 & 6.8356 & 6.8366 & TRN \\
\hline CHEMBL 3697054 & 1528684 & 7.3565 & 6.8583 & TRN \\
\hline CHEMBL 3934324 & 1528684 & 6.4597 & 6.0524 & TST \\
\hline CHEMBL3697135 & 1528684 & 6.0 & 6.4684 & TRN \\
\hline CHEMBL 3700580 & 1528684 & 6.5952 & 6.3037 & TRN \\
\hline CHEMBL3697089 & 1528684 & 6.75200 & 00000000 & 6.4197 \\
\hline CHEMBL 3697130 & 1528684 & 6.2007 & 6.0868 & TRN \\
\hline CHEMBL 3697156 & 1528684 & 6.0 & 6.3901 & TST \\
\hline CHEMBL3697165 & 1528684 & 6.0 & 6.1623 & TST \\
\hline CHEMBL3697055 & 1528684 & 7.1938 & 7.2633 & TRN \\
\hline CHEMBL3697052 & 1528684 & 7.4318 & 7.5022 & TRN \\
\hline CHEMBL 3697134 & 1528684 & 6.8097 & 6.3223 & TRN \\
\hline CHEMBL 3697053 & 1528684 & 7.4559 & 6.7978 & TRN \\
\hline CHEMBL 3697093 & 1528684 & 6.6676 & 6.5633 & TRN \\
\hline CHEMBL3700591 & 1528684 & 7.1487 & 7.24299 & 9999999999 \\
\hline CHEMBL3697088 & 1528684 & 6.8041 & 6.6636 & TRN \\
\hline CHEMBL3697085 & 1528684 & 6.3883 & 6.224 & TST \\
\hline CHEMBL 3697112 & 1528684 & 7.3468 & 6.6113 & TRN \\
\hline CHEMBL 3700588 & 1528684 & 7.1549 & 7.0077 & TRN \\
\hline CHEMBL3700569 & 1528684 & 6.6198 & 6.2415 & TST \\
\hline CHEMBL3697076 & 1528684 & 7.0044 & 6.6929 & TRN \\
\hline CHEMBL 3697078 & 1528684 & 6.8827 & 6.5506 & TRN \\
\hline CHEMBL 3700572 & 1528684 & 6.1739 & 6.1073 & TST \\
\hline CHEMBL 3697110 & 1528684 & 6.8125 & 6.4195 & TRN \\
\hline CHEMBL3697152 & 1528684 & 6.7959 & 6.6591 & TST \\
\hline CHEMBL 3697147 & 1528684 & 6.0 & 6.1338 & TRN \\
\hline CHEMBL 3697057 & 1528684 & 5.9208 & 6.2846 & TRN \\
\hline CHEMBL 3697094 & 1528684 & 6.699 & 6.2676 & TRN \\
\hline CHEMBL3697111 & 1528684 & 6.4559 & 6.4878 & TRN \\
\hline CHEMBL 3697092 & 1528684 & 5.1805 & 6.718 & TST \\
\hline CHEMBL 3891443 & 1528684 & 6.2644 & 6.0915 & TST \\
\hline CHEMBL 3697103 & 1528684 & 7.0706 & 7.057 & TRN \\
\hline CHEMBL 3697061 & 1528684 & 7.2366 & 6.7881 & TRN \\
\hline CHEMBL 3920683 & 1528684 & 6.7696 & 6.1229 & TST \\
\hline CHEMBL3936523 & 1528684 & 5.5229 & 5.7236 & TST \\
\hline CHEMBL 3700568 & 1528684 & 5.7852 & 5.6538 & TRN \\
\hline CHEMBL 3697044 & 1528684 & 6.0 & 6.5866 & TRN \\
\hline CHEMBL 3697075 & 1528684 & 6.7878 & 7.0051 & TRN \\
\hline CHEMBL 3697126 & 1528684 & 6.0 & 6.4265 & TRN \\
\hline CHEMBL3697115 & 1528684 & 6.5686 & 6.5637 & TRN \\
\hline CHEMBL 3697047 & 1528684 & 6.0 & 6.2944 & TRN \\
\hline CHEMBL3667599 & 1535127 & 7.0862 & 7.5936 & TRN \\
\hline CHEMBL 3667579 & 1535127 & 7.4202 & 7.604 & TRN \\
\hline CHEMBL 3667576 & 1535127 & 6.8928 & 7.1656 & TRN \\
\hline CHEMBL 3667572 & 1535127 & 6.767 & 7.3795 & TST \\
\hline CHEMBL3667573 & 1535127 & 7.0088 & 7.5359 & TRN \\
\hline CHEMBL 3667587 & 1535127 & 7.2366 & 7.3249 & TRN \\
\hline
\end{tabular}

Page 26151 
Supplemental Table S2.txt

\begin{tabular}{|c|c|c|c|c|}
\hline - & 535127 & 6.8665 & & \\
\hline & 535127 & & .6035 & \\
\hline & & & & \\
\hline AEMBL & & & & \\
\hline AEMBL3 & 35127 & 9959 & 642 & \\
\hline HEMBL3667561 & 535127 & 8.0 & .262 & \\
\hline HEMBL & & 969 & 846 & \\
\hline |FMRI & & & & \\
\hline HEMBL3 & 27 & 7447 & . 3011 & \\
\hline HEMBL366 & 535127 & 7.585 & .7823 & \\
\hline HEMBL366 & 535127 & 8.5229 & 8.275 & \\
\hline IEMBL & & 99 & 3209 & \\
\hline HEMBL; & & & & \\
\hline HEMBL & 27 & 3098 & 5797 & \\
\hline AEMBL3 & & 979 & 5299 & \\
\hline AEMBL366 & 27 & 8.0 & .3311 & \\
\hline HEMBL3 & & 576 & 63 & KIV \\
\hline HEMBL & & & & \\
\hline HEMBL3 & & 852 & 9565 & \\
\hline AEMBL3 & & & & \\
\hline HEMBL & 27 & & 72 & Niv \\
\hline AEMBL & & 36 & 54 & וזנה \\
\hline AEMBL & & & 22 & \\
\hline 52 & & & & \\
\hline AEMBL3 & & & & I RIV \\
\hline HEMBL; & & & 899 & RN \\
\hline HEMBL & & & 99 & (1) \\
\hline HFMRI & & & 335 & \\
\hline HEMBL3 & & & 3866 & I \\
\hline HEMBL 366 & & & 589 & IK \\
\hline HEMBL3 & & & 056 & RN \\
\hline HEMBL & & 9 & 519 & RN \\
\hline 35 & & & 636 & TRN \\
\hline HEMBL3E & & & 923 & R \\
\hline HEMBL3667565 & 35 & 8. & 7.6948 & TRN \\
\hline HEMBL & & 76 & 7.2902 & RN \\
\hline HCMPI & & 7 & 365 & $\Gamma \mathrm{RN}$ \\
\hline HEMBL & & 7. & 7.5335 & RN \\
\hline HEMBL3667591 & 5351 & 6.5 & 7.5372 & TS \\
\hline AEMBL3 & 51 & 6 . & 7.4955 & TST \\
\hline HEMBL3 & 1 & 386 & 7.6387 & DN \\
\hline CHEMBL3 & & & 7.2768 & TRN \\
\hline HEMBL3 & 27 & 7.1675 & 7.3523 & TRN \\
\hline HEMBL3667605 & 535127 & 6.9747 & .6296 & TS \\
\hline SOP & & & 8.1753 & $\mathrm{~N}$ \\
\hline HEMBL3 & & & 7.1066 & \\
\hline CHEMBL 3667601 & & .8013 & 7.6418 & \\
\hline LHEMBL3667598 & 1535127 & 7.8539 & 7.7289 & ГST \\
\hline
\end{tabular}

Page 26152 
Supplemental Table S2.txt

\begin{tabular}{|c|c|c|c|c|c|}
\hline CHEMBL3667594 & 1535127 & 7.0362 & 7.6524 & TST & \\
\hline CHEMBL3667597 & 1535127 & 7.4437 & 7.6929 & TST & \\
\hline CHEMBL 3667590 & 1535127 & 7.6021 & 7.6163 & TST & \\
\hline CHEMBL 3582190 & 1500168 & 7.8697 & 7.3759 & TRN & \\
\hline CHEMBL3582205 & 1500168 & 8.3565 & 8.3075 & TRN & \\
\hline CHEMBL3582221 & 1500168 & 7.7375 & 8.3459 & TRN & \\
\hline CHEMBL3582211 & 1500168 & 7.857 & 8.2276 & TRN & \\
\hline CHEMBL3582192 & 1500168 & 7.567 & 7.4375 & TRN & \\
\hline CHEMBL 3582188 & 1500168 & 7.104 & 7.9231 & TRN & \\
\hline CHEMBL3582218 & 1500168 & 8.3665 & 8.3268 & TRN & \\
\hline CHEMBL3582231 & 1500168 & 8.5376 & 8.4351 & TRN & \\
\hline CHEMBL3582199 & 1500168 & 7.3696 & 7.3012 & TRN & \\
\hline CHEMBL3582184 & 1500168 & 6.38299 & 99999999 & 99 & 6.9398 \\
\hline CHEMBL3582191 & 1500168 & 7.9431 & 7.5892 & TRN & \\
\hline CHEMBL3582194 & 1500168 & 7.6946 & 7.308 & TRN & \\
\hline CHEMBL3582224 & 1500168 & 8.8861 & 8.5023 & TRN & \\
\hline CHEMBL3582200 & 1500168 & 8.7212 & 8.0232 & TRN & \\
\hline CHEMBL3582219 & 1500168 & 6.9914 & 8.3341 & TRN & \\
\hline CHEMBL3582207 & 1500168 & 8.7447 & 8.3151 & TRN & \\
\hline CHEMBL3582208 & 1500168 & 8.7212 & 8.37 & TRN & \\
\hline CHEMBL3582209 & 1500168 & 8.301 & 8.3196 & TRN & \\
\hline CHEMBL3582206 & 1500168 & 7.9914 & 8.0133 & TRN & \\
\hline CHEMBL3582187 & 1500168 & 7.2472 & 7.3179 & TST & \\
\hline CHEMBL3582216 & 1500168 & 9.1079 & 7.905 & TST & \\
\hline CHEMBL 3582226 & 1500168 & 8.9586 & 8.5607 & TRN & \\
\hline CHEMBL3582223 & 1500168 & 9.3372 & 8.58 & TRN & \\
\hline CHEMBL 3582232 & 1500168 & 8.2924 & 8.4771 & TRN & \\
\hline CHEMBL3582189 & 1500168 & 7.3799 & 7.1168 & TRN & \\
\hline CHEMBL3582196 & 1500168 & 7.8327 & 7.2625 & TST & \\
\hline CHEMBL3582215 & 1500168 & 8.6383 & 8.0277 & TST & \\
\hline CHEMBL 3582217 & 1500168 & 7.7305 & 8.3097 & TRN & \\
\hline CHEMBL3582204 & 1500168 & 8.0269 & 8.299 & TRN & \\
\hline CHEMBL3582227 & 1500168 & 9.5086 & 8.6299 & TRN & \\
\hline CHEMBL3582222 & 1500168 & 6.064 & 8.2815 & TRN & \\
\hline CHEMBL3359895 & 1500168 & 8.8861 & 8.1465 & TRN & \\
\hline CHEMBL3582210 & 1500168 & 7.9355 & 8.3006 & TRN & \\
\hline CHEMBL3582213 & 1500168 & 8.2757 & 8.1565 & TRN & \\
\hline CHEMBL 3582214 & 1500168 & 7.8665 & 8.0005 & TRN & \\
\hline CHEMBL3582198 & 1500168 & 7.1163 & 7.183 & TRN & \\
\hline CHEMBL3582201 & 1500168 & 9.0 & 8.3423 & TRN & \\
\hline CHEMBL3582229 & 1500168 & 8.041 & 8.4035 & TRN & \\
\hline CHEMBL3582193 & 1500168 & 7.7799 & 7.489 & TRN & \\
\hline CHEMBL3582195 & 1500168 & 7.4711 & 7.5305 & TST & \\
\hline CHEMBL3582186 & 1500168 & 7.4191 & 7.0929 & TST & \\
\hline CHEMBL3582197 & 1500168 & 6.8962 & 7.0196 & TRN & \\
\hline CHEMBL 3582225 & 1500168 & 9.0223 & 8.5695 & TRN & \\
\hline CHEMBL3582220 & 1500168 & 7.7033 & 8.4483 & TST & \\
\hline CHEMBL3582228 & 1500168 & 9.0223 & 8.3071 & TST & \\
\hline
\end{tabular}


Supplemental Table S2.txt

\begin{tabular}{|c|c|c|c|c|}
\hline CHEMBL3582185 & 1500168 & 6.8539 & 7.1534 & TST \\
\hline CHEMBL 3582230 & 1500168 & 8.6383 & 8.387 & TST \\
\hline CHEMBL3582203 & 1500168 & 8.3768 & 8.2166 & TST \\
\hline CHEMBL3582202 & 1500168 & 8.6778 & 8.1659 & TST \\
\hline CHEMBL3582212 & 1500168 & 8.6021 & 8.2591 & TST \\
\hline CHEMBL62374 & 63865 & 5.1427 & 5.1691 & TRN \\
\hline CHEMBL292041 & 63865 & 5.4559 & 5.483 & TRN \\
\hline CHEMBL64536 & 63865 & 6.7696 & 6.7561 & TRN \\
\hline CHEMBL435773 & 63865 & 5.4685 & 6.1724 & TST \\
\hline CHEMBL291841 & 63865 & 6.699 & 6.6884 & TRN \\
\hline CHEMBL62719 & 63865 & 7.3665 & 7.3228 & TRN \\
\hline CHEMBL63099 & 63865 & 4.8239 & 4.8038 & TRN \\
\hline CHEMBL63057 & 63865 & 6.1487 & 6.1389 & TRN \\
\hline CHEMBL305577 & 63865 & 6.2218 & 6.1983 & TRN \\
\hline CHEMBL65353 & 63865 & 6.4559 & 5.6415 & TST \\
\hline CHEMBL418473 & 63865 & 6.3979 & 6.3936 & TRN \\
\hline CHEMBL62465 & 63865 & 6.3279 & 6.3938 & TRN \\
\hline CHEMBL61211 & 63865 & 6.0 & 5.9199 & TRN \\
\hline CHEMBL64282 & 63865 & 7.1612 & 7.0099 & TRN \\
\hline CHEMBL294127 & 63865 & 5.6576 & 5.6781 & TRN \\
\hline CHEMBL62951 & 63865 & 6.7959 & 6.7625 & TRN \\
\hline CHEMBL63067 & 63865 & 6.1367 & 6.0978 & TRN \\
\hline CHEMBL64726 & 63865 & 6.6576 & 6.7107 & TRN \\
\hline CHEMBL61460 & 63865 & 4.5086 & 4.5031 & TRN \\
\hline CHEMBL294787 & 63865 & 5.5528 & 5.5411 & TRN \\
\hline CHEMBL63267 & 63865 & 6.8239 & 6.9631 & TRN \\
\hline CHEMBL418667 & 63865 & 5.3098 & 5.2606 & TRN \\
\hline CHEMBL62962 & 63865 & 5.7959 & 5.8084 & TRN \\
\hline CHEMBL66264 & 63865 & 6.3979 & 6.3871 & TRN \\
\hline CHEMBL293012 & 63865 & 5.7447 & 5.7426 & TRN \\
\hline CHEMBL302659 & 63865 & 6.1487 & 6.2245 & TRN \\
\hline CHEMBL293702 & 63865 & 5.9586 & 5.9884 & TRN \\
\hline CHEMBL62814 & 63865 & 6.1192 & 6.1052 & TRN \\
\hline CHEMBL64398 & 63865 & 6.1135 & 6.0814 & TRN \\
\hline CHEMBL294123 & 63865 & 5.2218 & 5.1646 & TST \\
\hline CHEMBL65619 & 63865 & 7.0706 & 6.7883 & TST \\
\hline CHEMBL417413 & 63865 & 6.1079 & 6.2218 & TRN \\
\hline CHEMBL66426 & 63865 & 7.3372 & 5.6925 & TST \\
\hline CHEMBL62759 & 63865 & 5.2366 & 5.2342 & TRN \\
\hline CHEMBL417050 & 63865 & 5.8539 & 5.8305 & TRN \\
\hline CHEMBL62669 & 63865 & 5.8861 & 5.8732 & TRN \\
\hline CHEMBL62348 & 63865 & 5.7959 & 5.8133 & TRN \\
\hline CHEMBL62586 & 63865 & 5.7447 & 5.91200 & 0000000001 \\
\hline CHEMBL65201 & 63865 & 6.1249 & 6.1375 & TRN \\
\hline CHEMBL64039 & 63865 & 6.284 & 6.2598 & TRN \\
\hline CHEMBL64340 & 63865 & 5.0 & 4.9939 & TRN \\
\hline CHEMBL65599 & 63865 & 7.1079 & 6.2376 & TRN \\
\hline CHEMBL62659 & 63865 & 3.0 & 2.9332 & TRN \\
\hline
\end{tabular}




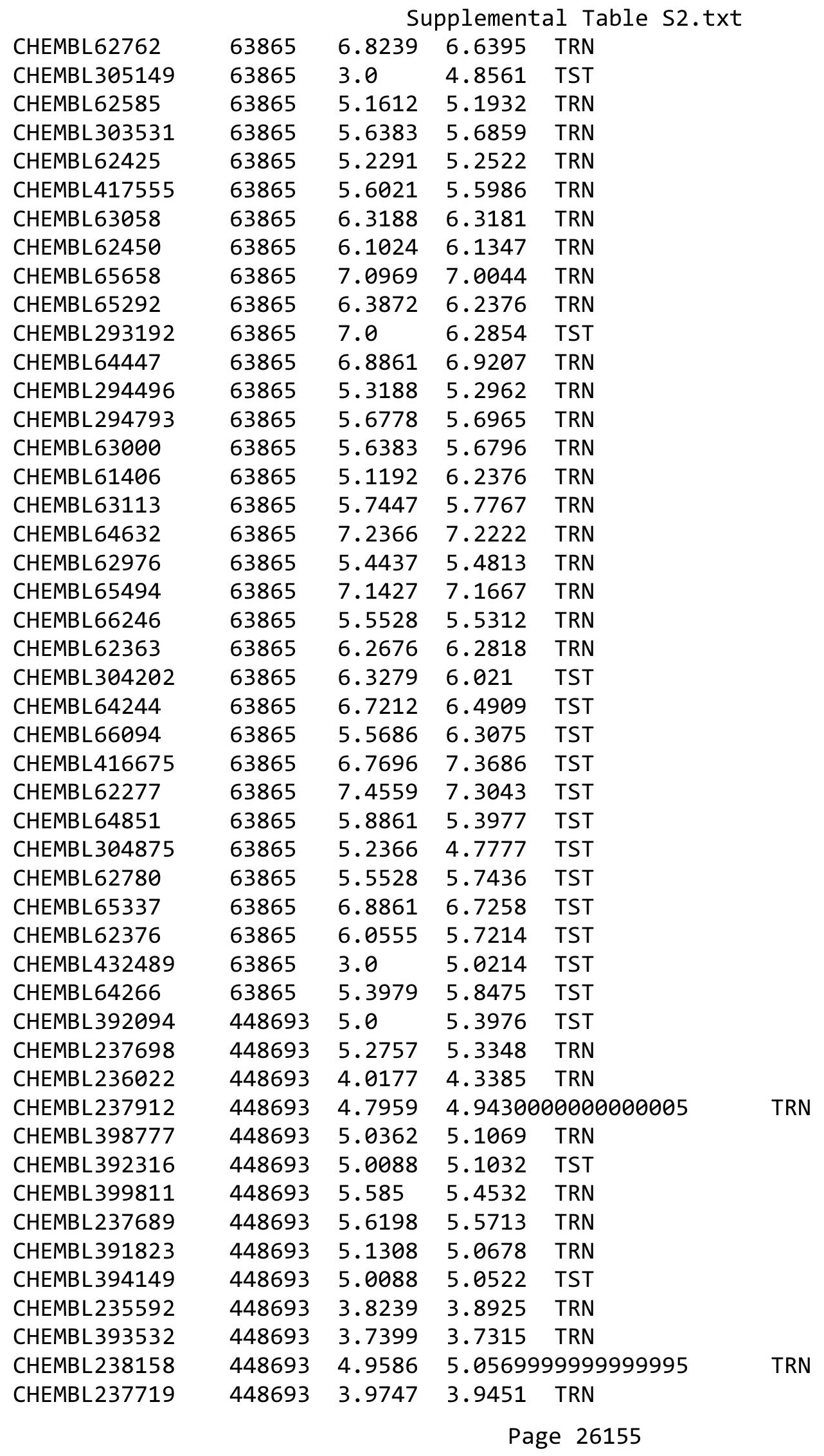




\begin{tabular}{|c|c|c|c|c|c|}
\hline \multirow[b]{2}{*}{ CHEMBL238369 } & \multicolumn{5}{|c|}{ Supplemental Table S2.txt } \\
\hline & 448693 & 5.1367 & 5.0064 & TRN & \\
\hline CHEMBL399810 & 448693 & 6.0 & 5.9472 & TRN & \\
\hline CHEMBL428903 & 448693 & 5.0 & 5.2292 & TST & \\
\hline CHEMBL235138 & 448693 & 5.301 & 5.3713 & TST & \\
\hline CHEMBL237743 & 448693 & 4.4949 & 4.2082 & TRN & \\
\hline CHEMBL237911 & 448693 & 5.1487 & 4.8972 & TST & \\
\hline CHEMBL429269 & 448693 & 4.6021 & 4.8234 & TRN & \\
\hline CHEMBL393994 & 448693 & 5.6576 & 5.682 & TRN & \\
\hline CHEMBL 236443 & 448693 & 5.1135 & 4.8278 & TRN & \\
\hline CHEMBL238135 & 448693 & 5.3279 & 5.1075 & TRN & \\
\hline CHEMBL237314 & 448693 & 3.7932 & 4.2277 & TRN & \\
\hline CHEMBL393125 & 448693 & 5.1938 & 5.1292 & TRN & \\
\hline CHEMBL 236840 & 448693 & 5.1487 & 5.2627 & TST & \\
\hline CHEMBL 237070 & 448693 & 5.4318 & 5.7646 & TRN & \\
\hline CHEMBL235139 & 448693 & 6.0 & 5.9489 & TRN & \\
\hline CHEMBL393558 & 448693 & 5.0269 & 4.7889 & TRN & \\
\hline CHEMBL236645 & 448693 & 4.9586 & 4.8264 & TRN & \\
\hline CHEMBL235589 & 448693 & 5.6778 & 5.6689 & TRN & \\
\hline CHEMBL429451 & 448693 & 5.6778 & 5.62799 & 9999999999 & TRN \\
\hline CHEMBL394073 & 448693 & 5.5229 & 5.7266 & TRN & \\
\hline CHEMBL 236626 & 448693 & 4.8539 & 5.1212 & TRN & \\
\hline CHEMBL235798 & 448693 & 4.7959 & 4.3537 & TRN & \\
\hline CHEMBL 237052 & 448693 & 4.1135 & 4.2786 & TRN & \\
\hline CHEMBL 235356 & 448693 & 5.2291 & 5.9258 & TST & \\
\hline CHEMBL394075 & 448693 & 5.1308 & 5.4789 & TRN & \\
\hline CHEMBL438672 & 448693 & 4.585 & 4.4481 & TRN & \\
\hline CHEMBL393382 & 448693 & 4.0177 & 3.8993 & TRN & \\
\hline CHEMBL236803 & 448693 & 5.3188 & 5.2237 & TST & \\
\hline CHEMBL393552 & 448693 & 5.3565 & 5.3006 & TRN & \\
\hline CHEMBL236003 & 448693 & 3.8013 & 4.6946 & TST & \\
\hline CHEMBL236630 & 448693 & 5.2676 & 5.3014 & TRN & \\
\hline CHEMBL235137 & 448693 & 5.1938 & 5.2254 & TRN & \\
\hline CHEMBL396179 & 448693 & 3.6536 & 4.7991 & TST & \\
\hline CHEMBL399624 & 448693 & 5.301 & 5.183 & TRN & \\
\hline CHEMBL237478 & 448693 & 4.1079 & 4.0536 & TRN & \\
\hline CHEMBL413982 & 448693 & 5.7212 & 5.6694 & TRN & \\
\hline CHEMBL237299 & 448693 & 4.5686 & 4.9008 & TST & \\
\hline CHEMBL235162 & 448693 & 5.2757 & 5.0958 & TRN & \\
\hline CHEMBL 237694 & 448693 & 4.9208 & 4.901 & TRN & \\
\hline CHEMBL394646 & 448693 & 5.4685 & 5.41799 & 9999999999 & TRN \\
\hline CHEMBL394074 & 448693 & 5.1079 & 5.3318 & TRN & \\
\hline CHEMBL394669 & 448693 & 5.1871 & 5.3111 & TRN & \\
\hline CHEMBL393350 & 448693 & 5.4685 & 5.2867 & TRN & \\
\hline CHEMBL236447 & 448693 & 3.8539 & 3.7769 & TRN & \\
\hline CHEMBL235382 & 448693 & 5.2441 & 5.5018 & TRN & \\
\hline CHEMBL393387 & 448693 & 5.1549 & 4.7391 & TST & \\
\hline CHEMBL237702 & 448693 & 6.0 & 6.0006 & TST & \\
\hline CHEMBL429983 & 448693 & 5.3188 & 5.2048 & TRN & \\
\hline
\end{tabular}




\begin{tabular}{|c|c|c|c|c|c|}
\hline \multirow[b]{2}{*}{ CHEMBL393919 } & \multicolumn{5}{|c|}{ Supplemental Table S2.txt } \\
\hline & 448693 & 5.4202 & 5.3014 & TRN & \\
\hline CHEMBL235358 & 448693 & 5.6383 & 5.7119 & TRN & \\
\hline CHEMBL235590 & 448693 & 3.7471 & 3.9146 & TRN & \\
\hline CHEMBL236629 & 448693 & 3.7825 & 4.5497 & TST & \\
\hline CHEMBL236649 & 448693 & 4.7696 & 4.5667 & TRN & \\
\hline CHEMBL394647 & 448693 & 4.8539 & 4.6761 & TST & \\
\hline CHEMBL235359 & 448693 & 5.5229 & 5.6103 & TRN & \\
\hline CHEMBL392096 & 448693 & 4.7447 & 4.5667 & TRN & \\
\hline CHEMBL397324 & 448693 & 5.4949 & 5.3873 & TRN & \\
\hline CHEMBL237937 & 448693 & 5.1675 & 5.5718 & TRN & \\
\hline CHEMBL428022 & 448693 & 5.2366 & 4.8334 & TRN & \\
\hline CHEMBL235140 & 448693 & 5.5528 & 5.3739 & TRN & \\
\hline CHEMBL236841 & 448693 & 5.2076 & 5.3713 & TST & \\
\hline CHEMBL396638 & 448693 & 5.3098 & 5.3934 & TST & \\
\hline CHEMBL236442 & 448693 & 4.4202 & 4.5598 & TRN & \\
\hline CHEMBL391707 & 448693 & 4.6021 & 4.7899 & TRN & \\
\hline CHEMBL237483 & 448693 & 4.8539 & 5.0575 & TST & \\
\hline CHEMBL393359 & 448693 & 4.2076 & 4.7198 & TRN & \\
\hline CHEMBL393918 & 448693 & 4.0915 & 4.3924 & TRN & \\
\hline CHEMBL410179 & 448693 & 5.1308 & 5.3014 & TRN & \\
\hline CHEMBL237094 & 448693 & 5.6198 & 5.0657 & TST & \\
\hline CHEMBL396303 & 448693 & 4.1739 & 4.3073 & TRN & \\
\hline CHEMBL235815 & 448693 & 5.2076 & 5.0839 & TRN & \\
\hline CHEMBL237688 & 448693 & 5.6021 & 5.2317 & TRN & \\
\hline CHEMBL393753 & 448693 & 5.2518 & 5.222 & TRN & \\
\hline CHEMBL237290 & 448693 & 5.3665 & 5.3073 & TRN & \\
\hline CHEMBL237504 & 448693 & 5.6778 & 5.6167 & TRN & \\
\hline CHEMBL236638 & 448693 & 5.4318 & 5.3713 & TST & \\
\hline CHEMBL438334 & 448693 & 4.7696 & 5.2254 & TRN & \\
\hline CHEMBL237920 & 448693 & 6.0 & 5.9607 & TRN & \\
\hline CHEMBL445669 & 448693 & 5.5686 & 5.6731 & TRN & \\
\hline CHEMBL238345 & 448693 & 6.0 & 6.0926 & TRN & \\
\hline CHEMBL237051 & 448693 & 4.9208 & 4.9317 & TRN & \\
\hline CHEMBL238149 & 448693 & 5.2218 & 4.7601 & TRN & \\
\hline CHEMBL391706 & 448693 & 5.6383 & 5.3014 & TRN & \\
\hline CHEMBL393383 & 448693 & 6.0 & 5.8154 & TRN & \\
\hline CHEMBL 236847 & 448693 & 4.9586 & 4.9495 & TST & \\
\hline CHEMBL235147 & 448693 & 3.8268 & 3.5406 & TRN & \\
\hline CHEMBL398980 & 448693 & 4.7959 & 4.7952 & TRN & \\
\hline CHEMBL396598 & 448693 & 4.6778 & 4.637 & TRN & \\
\hline CHEMBL236226 & 448693 & 4.7447 & 4.9328 & TRN & \\
\hline CHEMBL396111 & 448693 & 5.7212 & 5.7014 & TRN & \\
\hline CHEMBL238153 & 448693 & 6.0 & 5.8902 & TRN & \\
\hline CHEMBL236640 & 448693 & 5.4202 & 5.2254 & TRN & \\
\hline CHEMBL391944 & 448693 & 5.6383 & 5.50200 & 0000000001 & TRN \\
\hline CHEMBL392521 & 448693 & 4.4815 & 4.6373 & TRN & \\
\hline CHEMBL238136 & 448693 & 4.0044 & 4.2932 & TRN & \\
\hline CHEMBL268395 & 448693 & 3.9355 & 3.7902 & TRN & \\
\hline
\end{tabular}

Page 26157 


\begin{tabular}{|c|c|c|c|c|c|}
\hline & & \multicolumn{4}{|c|}{ Supplemental Table S2.txt } \\
\hline CHEMBL238144 & 448693 & 5.0362 & 5.1873 & TRN & \\
\hline CHEMBL392315 & 448693 & 5.4685 & 5.2254 & TRN & \\
\hline CHEMBL236639 & 448693 & 5.3872 & 5.4969 & TRN & \\
\hline CHEMBL392223 & 448693 & 5.1938 & 5.0877 & TRN & \\
\hline CHEMBL396341 & 448693 & 4.7959 & 4.8858 & TRN & \\
\hline CHEMBL236842 & 448693 & 4.8861 & 4.4188 & TRN & \\
\hline CHEMBL237479 & 448693 & 4.6778 & 4.4465 & TST & \\
\hline CHEMBL238180 & 448693 & 4.1308 & 4.9982 & TST & \\
\hline CHEMBL235582 & 448693 & 6.0 & 6.0313 & TRN & \\
\hline CHEMBL237935 & 448693 & 5.1549 & 5.1796 & TRN & \\
\hline CHEMBL393553 & 448693 & 5.6778 & 5.32 & TRN & \\
\hline CHEMBL238159 & 448693 & 5.4949 & 5.4413 & TRN & \\
\hline CHEMBL237502 & 448693 & 6.0 & 6.0993 & TRN & \\
\hline CHEMBL394645 & 448693 & 5.3468 & 5.5126 & TRN & \\
\hline CHEMBL237919 & 448693 & 6.0 & 6.0459 & TRN & \\
\hline CHEMBL235627 & 448693 & 4.9586 & 4.3627 & TST & \\
\hline CHEMBL237530 & 448693 & 3.7852 & 4.5047 & TRN & \\
\hline CHEMBL238342 & 448693 & 6.0 & 6.1065 & TRN & \\
\hline CHEMBL394394 & 448693 & 5.8239 & 5.6518 & TRN & \\
\hline CHEMBL237079 & 448693 & 4.3768 & 4.3795 & TST & \\
\hline CHEMBL237714 & 448693 & 5.3565 & 5.2585 & TRN & \\
\hline CHEMBL393568 & 448693 & 4.9208 & 4.8344 & TRN & \\
\hline CHEMBL235802 & 448693 & 3.9355 & 4.0891 & TRN & \\
\hline CHEMBL236450 & 448693 & 4.9586 & 4.3778 & TST & \\
\hline CHEMBL235797 & 448693 & 4.1805 & 4.4106 & TRN & \\
\hline CHEMBL238368 & 448693 & 5.6021 & 5.3209 & TRN & \\
\hline CHEMBL237693 & 448693 & 4.7959 & 4.4822 & TST & \\
\hline CHEMBL237687 & 448693 & 3.9547 & 4.4188 & TRN & \\
\hline CHEMBL235136 & 448693 & 4.8539 & 5.0312 & TRN & \\
\hline CHEMBL237069 & 448693 & 5.4318 & 5.5656 & TRN & \\
\hline CHEMBL394667 & 448693 & 5.7212 & 5.6974 & TRN & \\
\hline CHEMBL235616 & 448693 & 5.4318 & 5.3312 & TRN & \\
\hline CHEMBL238154 & 448693 & 6.0 & 6.1313 & TRN & \\
\hline CHEMBL235176 & 448693 & 5.6198 & 5.6027 & TRN & \\
\hline CHEMBL237528 & 448693 & 4.7959 & 4.6132 & TRN & \\
\hline CHEMBL236002 & 448693 & 5.8861 & 5.5279 & TRN & \\
\hline CHEMBL237910 & 448693 & 5.0915 & 4.5667 & TST & \\
\hline CHEMBL238353 & 448693 & 3.7471 & 3.2488 & TST & \\
\hline CHEMBL237957 & 448693 & 4.6383 & 4.9459 & TST & \\
\hline CHEMBL237930 & 448693 & 5.1367 & 4.6417 & TST & \\
\hline CHEMBL238367 & 448693 & 5.0757 & 5.3212 & TST & \\
\hline CHEMBL391705 & 448693 & 5.0757 & 5.0482 & TST & \\
\hline CHEMBL393755 & 448693 & 4.4815 & 4.4851 & TST & \\
\hline CHEMBL238134 & 448693 & 4.2291 & 4.7276 & TST & \\
\hline CHEMBL237315 & 448693 & 4.7212 & 4.7731 & TST & \\
\hline CHEMBL237291 & 448693 & 5.5229 & 5.5561 & TST & \\
\hline CHEMBL235617 & 448693 & 5.4437 & 5.50799 & 9999999999 & TST \\
\hline CHEMBL237692 & 448693 & 4.7959 & 5.311 & TST & \\
\hline
\end{tabular}




\begin{tabular}{|c|c|c|c|c|c|}
\hline \multirow[b]{2}{*}{ CHEMBL1270219 } & \multicolumn{5}{|c|}{ Supplemental Table S2.txt } \\
\hline & 675412 & 7.5686 & 7.91200 & 0000000001 & TRN \\
\hline CHEMBL1270707 & 675412 & 7.0862 & 7.4971 & TRN & \\
\hline CHEMBL1271116 & 675412 & 9.0 & 8.8315 & TRN & \\
\hline CHEMBL1269897 & 675412 & 7.8239 & 8.1949 & TRN & \\
\hline CHEMBL1270505 & 675412 & 9.0 & 7.5492 & TRN & \\
\hline CHEMBL1270507 & 675412 & 9.0 & 8.6131 & TRN & \\
\hline CHEMBL1270504 & 675412 & 7.0706 & 7.585 & TRN & \\
\hline CHEMBL1270311 & 675412 & 9.0 & 8.9979 & TRN & \\
\hline CHEMBL1271221 & 675412 & 3.1549 & 7.8801 & TST & \\
\hline CHEMBL1270913 & 675412 & 7.5086 & 8.1904 & TRN & \\
\hline CHEMBL1270113 & 675412 & 9.0 & 8.9759 & TRN & \\
\hline CHEMBL1270912 & 675412 & 9.0 & 9.0861 & TRN & \\
\hline CHEMBL1271322 & 675412 & 9.0 & 9.044 & TRN & \\
\hline CHEMBL1271012 & 675412 & 9.0 & 8.9058 & TRN & \\
\hline CHEMBL1270607 & 675412 & 7.2441 & 7.5294 & TRN & \\
\hline CHEMBL1270217 & 675412 & 7.7212 & 8.2312 & TRN & \\
\hline CHEMBL1270810 & 675412 & 9.0 & 8.4104 & TRN & \\
\hline CHEMBL1270220 & 675412 & 9.0 & 8.4943 & TRN & \\
\hline CHEMBL1271324 & 675412 & 3.0 & 7.6406 & TST & \\
\hline CHEMBL1270915 & 675412 & 6.8539 & 6.9862 & TRN & \\
\hline CHEMBL1271011 & 675412 & 9.0 & 8.9416 & TRN & \\
\hline CHEMBL1271219 & 675412 & 9.0 & 8.8969 & TRN & \\
\hline CHEMBL1270313 & 675412 & 7.0 & 7.0764 & TRN & \\
\hline CHEMBL1270004 & 675412 & 9.0 & 9.0096 & TRN & \\
\hline CHEMBL1270314 & 675412 & 9.0 & 8.9458 & TRN & \\
\hline CHEMBL1270606 & 675412 & 9.0 & 9.0347 & TRN & \\
\hline CHEMBL1271220 & 675412 & 9.0 & 8.7064 & TRN & \\
\hline CHEMBL1271118 & 675412 & 5.8861 & 8.2289 & TST & \\
\hline CHEMBL1271323 & 675412 & 5.4559 & 7.8007 & TST & \\
\hline CHEMBL1270506 & 675412 & 9.0 & 9.084 & TRN & \\
\hline CHEMBL1271321 & 675412 & 7.7959 & 8.2079 & TRN & \\
\hline CHEMBL1270218 & 675412 & 9.0 & 8.317 & TRN & \\
\hline CHEMBL1270811 & 675412 & 7.0915 & 7.74 & TRN & \\
\hline CHEMBL1270706 & 675412 & 6.0 & 6.0323 & TRN & \\
\hline CHEMBL1271013 & 675412 & 5.699 & 5.0005 & TRN & \\
\hline CHEMBL1271117 & 675412 & 9.0 & 8.3899 & TRN & \\
\hline CHEMBL1271222 & 675412 & 7.585 & 7.6488 & TRN & \\
\hline CHEMBL1270312 & 675412 & 9.0 & 8.7257 & TRN & \\
\hline CHEMBL1271119 & 675412 & 6.2218 & 8.2105 & TST & \\
\hline CHEMBL1270705 & 675412 & 7.8239 & 8.0256 & TRN & \\
\hline CHEMBL1270003 & 675412 & 7.4815 & 7.2045 & TRN & \\
\hline CHEMBL1270411 & 675412 & 6.5686 & 7.0077 & TRN & \\
\hline CHEMBL1270809 & 675412 & 7.1192 & 7.5619 & TRN & \\
\hline CHEMBL1270704 & 675412 & 7.6576 & 8.0897 & TRN & \\
\hline CHEMBL1270608 & 675412 & 9.0 & 9.0181 & TRN & \\
\hline CHEMBL1271429 & 675412 & 9.0 & 8.5166 & TST & \\
\hline CHEMBL1270412 & 675412 & 7.585 & 9.4091 & TST & \\
\hline CHEMBL1270410 & 675412 & 6.7696 & 7.3159 & TST & \\
\hline
\end{tabular}




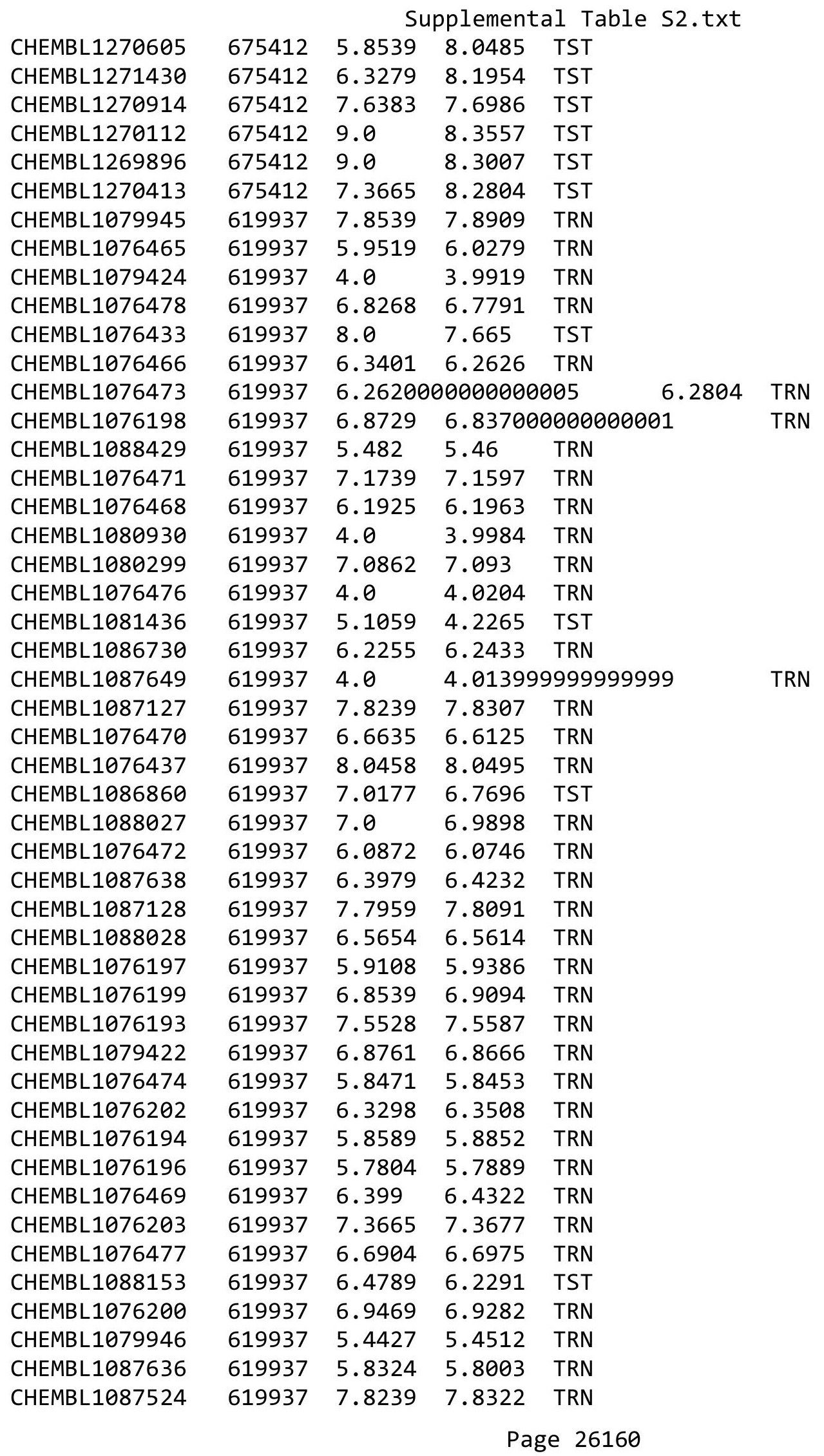




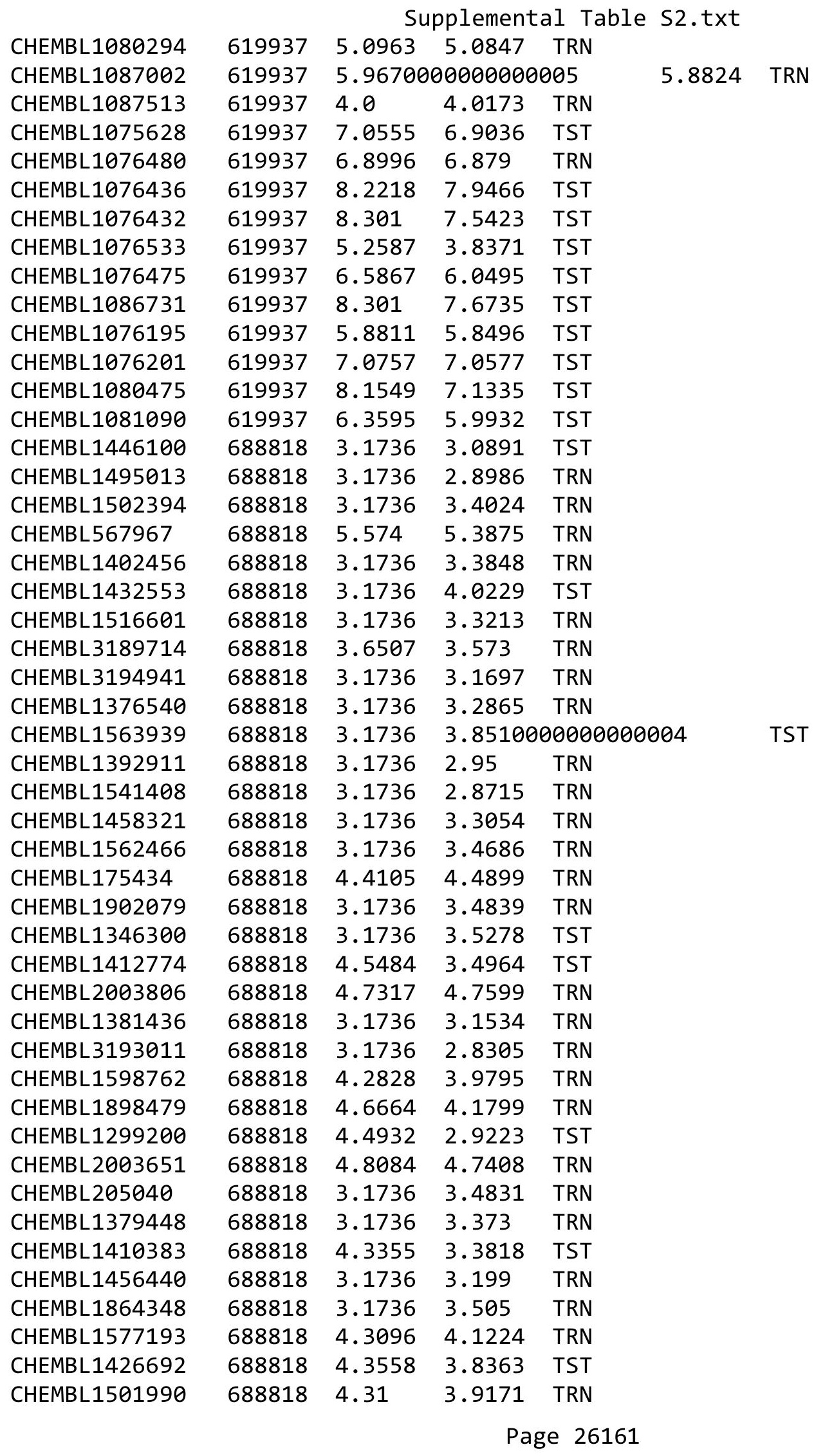


Supplemental Table S2.txt

\begin{tabular}{|c|c|c|c|c|}
\hline CHEMBL1432243 & 688818 & 3.1736 & 3.0751 & TRN \\
\hline CHEMBL1530147 & 688818 & 4.3603 & 4.3867 & TRN \\
\hline CHEMBL1453503 & 688818 & 4.3286 & 3.8982 & TRN \\
\hline CHEMBL 3187596 & 688818 & 3.1736 & 3.0251 & TRN \\
\hline CHEMBL1477061 & 688818 & 4.1935 & 4.1593 & TRN \\
\hline CHEMBL1969046 & 688818 & 4.5674 & 4.6698 & TRN \\
\hline CHEMBL578905 & 688818 & 3.1736 & 3.5553 & TRN \\
\hline CHEMBL1536273 & 688818 & 4.2481 & 4.1684 & TRN \\
\hline CHEMBL1361173 & 688818 & 3.1736 & 3.3206 & TRN \\
\hline CHEMBL1387843 & 688818 & 3.1736 & 3.2589 & TRN \\
\hline CHEMBL1996724 & 688818 & 3.1736 & 2.8892 & TRN \\
\hline CHEMBL1362561 & 688818 & 4.1967 & 2.9052 & TST \\
\hline CHEMBL1334040 & 688818 & 3.1736 & 3.1608 & TRN \\
\hline CHEMBL 3190880 & 688818 & 4.6448 & 4.8212 & TRN \\
\hline CHEMBL1303854 & 688818 & 3.1736 & 4.4257 & TST \\
\hline CHEMBL1463829 & 688818 & 4.2044 & 4.4769 & TRN \\
\hline CHEMBL1516738 & 688818 & 3.1736 & 2.9764 & TST \\
\hline CHEMBL1450505 & 688818 & 4.2396 & 2.9685 & TST \\
\hline CHEMBL3196591 & 688818 & 4.4639 & 4.3352 & TRN \\
\hline CHEMBL1585740 & 688818 & 3.1736 & 3.1359 & TRN \\
\hline CHEMBL1888528 & 688818 & 3.1736 & 3.3176 & TRN \\
\hline CHEMBL1397706 & 688818 & 4.2811 & 2.6535 & TST \\
\hline CHEMBL1378634 & 688818 & 3.1736 & 3.2 & TRN \\
\hline CHEMBL1405287 & 688818 & 3.1736 & 3.5256 & TRN \\
\hline CHEMBL 3144999 & 688818 & 4.5244 & 3.5147 & TST \\
\hline CHEMBL 2006503 & 688818 & 4.4099 & 3.5447 & TST \\
\hline CHEMBL 213475 & 510887 & 6.2076 & 6.26399 & 9999999999 \\
\hline CHEMBL1163003 & 510887 & 7.6383 & 7.399 & TRN \\
\hline CHEMBL213233 & 510887 & 4.699 & 4.9684 & TST \\
\hline CHEMBL 384089 & 510887 & 7.7212 & 7.6153 & TRN \\
\hline CHEMBL413579 & 510887 & 6.7447 & 6.6759 & TRN \\
\hline CHEMBL 211140 & 510887 & 7.699 & 7.5465 & TRN \\
\hline CHEMBL 215506 & 510887 & 7.4815 & 7.6355 & TRN \\
\hline CHEMBL 212594 & 510887 & 7.2218 & 7.3868 & TRN \\
\hline CHEMBL 211878 & 510887 & 6.1938 & 6.0483 & TRN \\
\hline CHEMBL212659 & 510887 & 6.2366 & 6.2155 & TRN \\
\hline CHEMBL 380048 & 510887 & 6.6383 & 6.8286 & TRN \\
\hline CHEMBL 212494 & 510887 & 6.6576 & 6.3637 & TRN \\
\hline CHEMBL 378067 & 510887 & 7.4559 & 7.4841 & TRN \\
\hline CHEMBL 377867 & 510887 & 4.5376 & 4.5131 & TRN \\
\hline CHEMBL 212945 & 510887 & 6.5686 & 6.7302 & TRN \\
\hline CHEMBL 379149 & 510887 & 6.7447 & 6.885 & TRN \\
\hline CHEMBL 211626 & 510887 & 6.5086 & 6.3626 & TRN \\
\hline CHEMBL 378472 & 510887 & 6.6778 & 6.8615 & TRN \\
\hline CHEMBL 209448 & 510887 & 6.7212 & 6.6793 & TRN \\
\hline CHEMBL 213422 & 510887 & 7.4202 & 7.5608 & TRN \\
\hline CHEMBL 214208 & 510887 & 7.3768 & 7.2605 & TRN \\
\hline CHEMBL212798 & 510887 & 4.7959 & 4.8148 & TRN \\
\hline
\end{tabular}




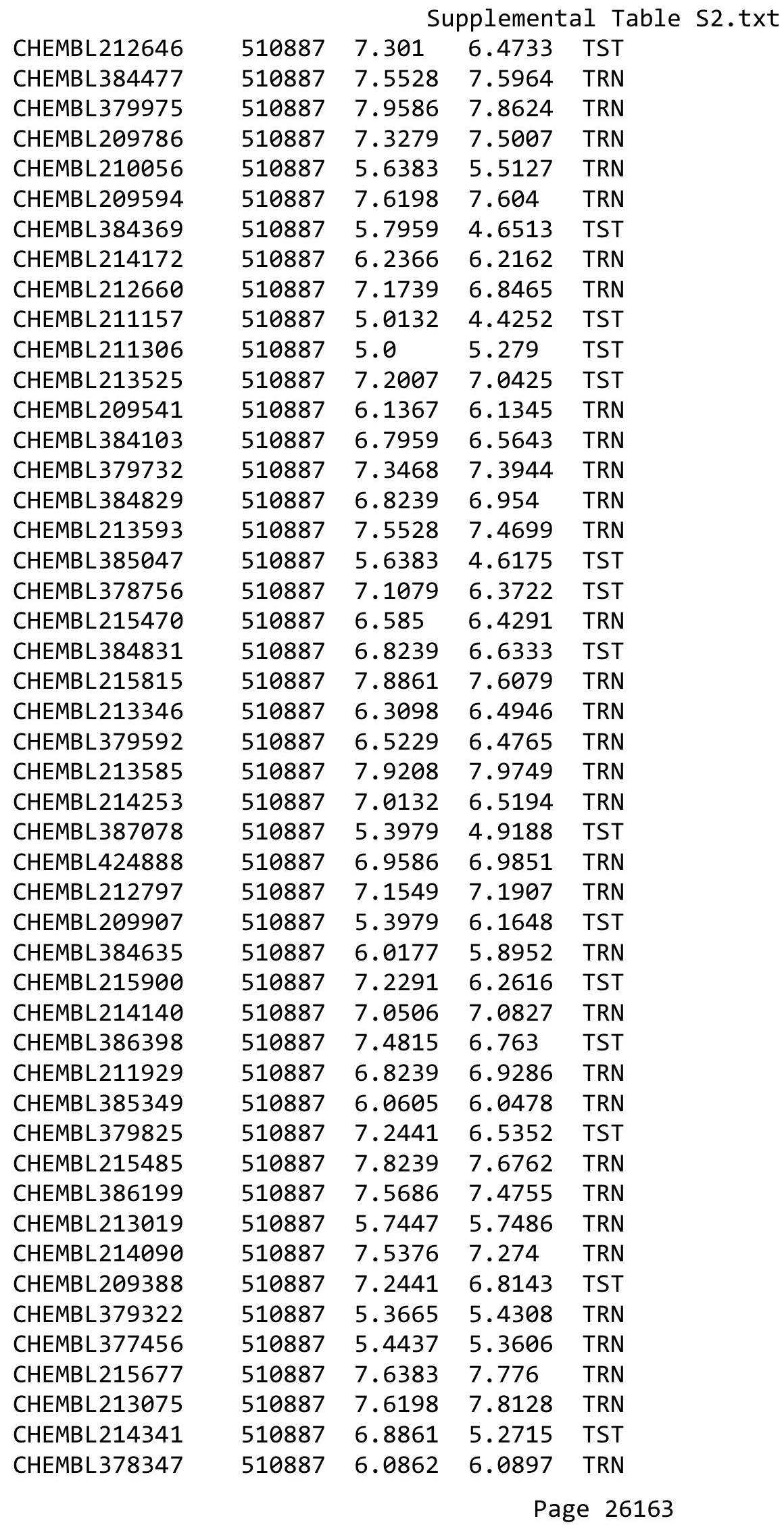




\begin{tabular}{|c|c|c|c|c|c|}
\hline \multirow{2}{*}{ CHEMBL385194 } & \multirow[b]{2}{*}{510887} & \\
\hline & & 7.1249 & \multicolumn{2}{|c|}{6.922000000000001} & \multirow[t]{2}{*}{ TRN } \\
\hline CHEMBL209785 & 510887 & 6.6576 & 6.777 & TRN & \\
\hline CHEMBL379392 & 510887 & 7.3098 & 7.3292 & TRN & \\
\hline CHEMBL 384293 & 510887 & 4.3979 & 5.0419 & TRN & \\
\hline CHEMBL209486 & 510887 & 6.8539 & 7.1003 & TST & \\
\hline CHEMBL385828 & 510887 & 5.3565 & 5.3656 & TRN & \\
\hline CHEMBL 212495 & 510887 & 7.2596 & 7.3825 & TRN & \\
\hline CHEMBL 386809 & 510887 & 6.4815 & 6.5985 & TRN & \\
\hline CHEMBL 213117 & 510887 & 4.9208 & 4.7298 & TRN & \\
\hline CHEMBL377204 & 510887 & 4.8861 & 5.5291 & TST & \\
\hline CHEMBL 214137 & 510887 & 6.7696 & \multicolumn{2}{|c|}{5.962999999999999} & TST \\
\hline CHEMBL 215764 & 510887 & 6.0809 & 6.2329 & TRN & \\
\hline CHEMBL 378066 & 510887 & 7.699 & 7.7454 & TRN & \\
\hline CHEMBL 215762 & 510887 & 5.9208 & \multicolumn{2}{|c|}{5.922000000000001} & TRN \\
\hline CHEMBL 214005 & 510887 & 6.585 & 6.0142 & TST & \\
\hline CHEMBL212933 & 510887 & 5.4089 & 4.997 & TST & \\
\hline CHEMBL 213313 & 510887 & 7.6198 & 7.7923 & TRN & \\
\hline CHEMBL526721 & 510887 & 5.9586 & 6.0112 & TRN & \\
\hline CHEMBL441695 & 510887 & 6.3665 & 5.5925 & TST & \\
\hline CHEMBL 377839 & 510887 & 7.3768 & 7.5599 & TRN & \\
\hline CHEMBL386979 & 510887 & 4.4318 & 4.2382 & TST & \\
\hline CHEMBL 386048 & 510887 & 7.7447 & 7.6833 & TRN & \\
\hline CHEMBL 212846 & 510887 & 5.4815 & 5.5609 & TRN & \\
\hline CHEMBL379346 & 510887 & 6.2441 & 6.4335 & TRN & \\
\hline CHEMBL 383926 & 510887 & 6.2924 & \multicolumn{2}{|c|}{6.321000000000001} & TRN \\
\hline CHEMBL378171 & 510887 & 6.3468 & 6.6022 & TST & \\
\hline CHEMBL378766 & 510887 & 5.5528 & 5.4246 & TST & \\
\hline CHEMBL 3127052 & 1294966 & 3.699 & 4.1044 & TRN & \\
\hline CHEMBL 3127045 & 1294966 & 3.699 & 4.2071 & TRN & \\
\hline CHEMBL3127044 & 1294966 & 4.7077 & 5.211 & TST & \\
\hline CHEMBL3126880 & 1294966 & 4.8297 & 4.8841 & TRN & \\
\hline CHEMBL3126878 & 1294966 & 3.0 & 3.3679 & TRN & \\
\hline CHEMBL3126915 & 1294966 & 5.1209 & 5.3515 & TST & \\
\hline CHEMBL3126897 & 1294966 & 3.699 & \multicolumn{2}{|c|}{3.9010000000000002} & TST \\
\hline CHEMBL 3126881 & 1294966 & 3.699 & 3.6307 & TRN & \\
\hline CHEMBL3127068 & 1294966 & 6.8539 & 6.7219 & TRN & \\
\hline CHEMBL3126901 & 1294966 & 3.699 & 3.7898 & TRN & \\
\hline CHEMBL 3127065 & 1294966 & 7.3979 & 7.4485 & TRN & \\
\hline CHEMBL 3127056 & 1294966 & 3.699 & 5.1457 & TST & \\
\hline CHEMBL 3127057 & 1294966 & 3.699 & 4.2263 & TST & \\
\hline CHEMBL1814768 & 1294966 & 7.2218 & 7.0392 & TRN & \\
\hline CHEMBL 3127053 & 1294966 & 3.699 & 3.8653 & TRN & \\
\hline CHEMBL3126911 & 1294966 & 5.8447 & 5.6488 & TRN & \\
\hline CHEMBL3126889 & 1294966 & 4.8539 & 4.5307 & TRN & \\
\hline CHEMBL 3126883 & 1294966 & 3.699 & 3.6764 & TRN & \\
\hline CHEMBL3126905 & 1294966 & 6.5376 & 7.3452 & TST & \\
\hline CHEMBL3126899 & 1294966 & 6.4949 & 6.7484 & TRN & \\
\hline CHEMBL 3126888 & 1294966 & 3.699 & 3.8621 & TRN & \\
\hline
\end{tabular}


Supplemental Table S2.txt

\begin{tabular}{|c|c|c|c|c|c|}
\hline CHEMBL1269812 & 1294966 & 7.2218 & 7.7974 & TST & \\
\hline CHEMBL3126893 & 1294966 & 3.699 & 3.9943 & TRN & \\
\hline CHEMBL3126891 & 1294966 & 3.699 & 3.839 & TRN & \\
\hline CHEMBL 3126890 & 1294966 & 3.699 & 3.4836 & TRN & \\
\hline CHEMBL 3126885 & 1294966 & 3.699 & 3.8705 & TRN & \\
\hline CHEMBL3126914 & 1294966 & 3.699 & 5.2018 & TST & \\
\hline CHEMBL3126909 & 1294966 & 3.699 & 4.0407 & TRN & \\
\hline CHEMBL 3126870 & 1294966 & 3.699 & 3.6329 & TRN & \\
\hline CHEMBL 3126874 & 1294966 & 4.7545 & 4.6457 & TRN & \\
\hline CHEMBL3126877 & 1294966 & 3.699 & 3.9271 & TRN & \\
\hline CHEMBL3126904 & 1294966 & 3.699 & 3.6759 & TRN & \\
\hline CHEMBL319177 & 1294966 & 3.0 & 2.9737 & TST & \\
\hline CHEMBL3126873 & 1294966 & 3.699 & 3.3547 & TRN & \\
\hline CHEMBL 3127049 & 1294966 & 8.0 & 7.6225 & TRN & \\
\hline CHEMBL3126892 & 1294966 & 3.699 & 3.8046 & TRN & \\
\hline CHEMBL3124960 & 1294966 & 3.699 & 3.716 & TRN & \\
\hline CHEMBL 3126872 & 1294966 & 3.699 & 3.7886 & TST & \\
\hline CHEMBL3126902 & 1294966 & 3.699 & 3.6111 & TRN & \\
\hline CHEMBL 3126879 & 1294966 & 3.699 & 4.2604 & TRN & \\
\hline CHEMBL3127060 & 1294966 & 3.699 & 3.5056 & TRN & \\
\hline CHEMBL3126906 & 1294966 & 5.2933 & 5.204 & TST & \\
\hline CHEMBL 3127050 & 1294966 & 7.0 & 6.8412 & TRN & \\
\hline CHEMBL3126912 & 1294966 & 4.0209 & 3.5304 & TRN & \\
\hline CHEMBL 3126907 & 1294966 & 6.9208 & 7.2367 & TST & \\
\hline CHEMBL3127062 & 1294966 & 3.0 & 3.4183 & TRN & \\
\hline CHEMBL1814767 & 1294966 & 6.7696 & 7.00799 & 9999999999 & TRN \\
\hline CHEMBL3126868 & 1294966 & 3.699 & 3.6167 & TRN & \\
\hline CHEMBL 3127047 & 1294966 & 5.289 & 6.5354 & TST & \\
\hline CHEMBL3126898 & 1294966 & 3.699 & 4.7894 & TST & \\
\hline CHEMBL3126886 & 1294966 & 3.699 & 4.0098 & TRN & \\
\hline CHEMBL 3127064 & 1294966 & 3.699 & 5.0945 & TST & \\
\hline CHEMBL3126894 & 1294966 & 3.699 & 3.5604 & TRN & \\
\hline CHEMBL3127066 & 1294966 & 6.8861 & 6.6965 & TRN & \\
\hline CHEMBL 3126884 & 1294966 & 3.699 & 3.5353 & TRN & \\
\hline CHEMBL403715 & 1294966 & 3.699 & 3.8701 & TST & \\
\hline CHEMBL3127059 & 1294966 & 3.699 & 3.5181 & TRN & \\
\hline CHEMBL3127054 & 1294966 & 3.699 & 3.5674 & TRN & \\
\hline CHEMBL3126903 & 1294966 & 3.699 & 3.468 & TRN & \\
\hline CHEMBL3126910 & 1294966 & 3.699 & 3.9131 & TRN & \\
\hline CHEMBL3126865 & 1294966 & 3.699 & 4.6668 & TST & \\
\hline CHEMBL3126900 & 1294966 & 3.699 & 3.7293 & TRN & \\
\hline CHEMBL3127046 & 1294966 & 4.8386 & 4.5126 & TRN & \\
\hline CHEMBL 3127048 & 1294966 & 3.699 & 3.3381 & TST & \\
\hline CHEMBL 3127067 & 1294966 & 6.3565 & 6.3203 & TRN & \\
\hline CHEMBL3126913 & 1294966 & 3.699 & 3.7565 & TRN & \\
\hline CHEMBL3126869 & 1294966 & 3.699 & 3.5847 & TRN & \\
\hline CHEMBL3126866 & 1294966 & 3.699 & 3.6697 & TRN & \\
\hline CHEMBL 3126882 & 1294966 & 3.699 & 3.1517 & TRN & \\
\hline
\end{tabular}


Supplemental Table S2.txt

\begin{tabular}{|c|c|c|c|c|c|}
\hline CHEMBL3126867 & 1294966 & 3.699 & 3.6773 & TRN & \\
\hline CHEMBL3127063 & 1294966 & 3.699 & 3.7936 & TRN & \\
\hline CHEMBL3127061 & 1294966 & 3.699 & 3.5642 & TRN & \\
\hline CHEMBL3127058 & 1294966 & 6.3565 & 6.4618 & TRN & \\
\hline CHEMBL3126887 & 1294966 & 3.699 & 3.4569 & TRN & \\
\hline CHEMBL3126875 & 1294966 & 4.7033 & 4.5759 & TRN & \\
\hline CHEMBL 3127051 & 1294966 & 3.699 & 3.6006 & TRN & \\
\hline CHEMBL3126895 & 1294966 & 4.8827 & 4.8591 & TRN & \\
\hline CHEMBL3126876 & 1294966 & 3.699 & 4.2086 & TST & \\
\hline CHEMBL3127055 & 1294966 & 7.0458 & 8.5839 & TST & \\
\hline CHEMBL3126896 & 1294966 & 3.699 & 4.7705 & TST & \\
\hline CHEMBL3126908 & 1294966 & 7.3979 & 7.5935 & TRN & \\
\hline CHEMBL3126871 & 1294966 & 3.699 & 3.9215 & TRN & \\
\hline CHEMBL153706 & 67203 & 7.3979 & 7.3767 & TRN & \\
\hline CHEMBL356852 & 67203 & 6.3098 & 6.0476 & TRN & \\
\hline CHEMBL150466 & 67203 & 7.0458 & 7.0624 & TRN & \\
\hline CHEMBL358468 & 67203 & 4.0 & 5.1553 & TST & \\
\hline CHEMBL358890 & 67203 & 6.0 & 5.9961 & TRN & \\
\hline CHEMBL153471 & 67203 & 7.4559 & 7.3935 & TRN & \\
\hline CHEMBL153765 & 67203 & 6.0862 & 6.0158 & TRN & \\
\hline CHEMBL153245 & 67203 & 6.3716 & 6.29899 & 99999999995 & TRN \\
\hline CHEMBL347560 & 67203 & 7.8239 & 7.9154 & TRN & \\
\hline CHEMBL152970 & 67203 & 6.3979 & 6.3374 & TRN & \\
\hline CHEMBL2112892 & 67203 & 6.9788 & 7.3831 & TST & \\
\hline CHEMBL356668 & 67203 & 8.0969 & 7.9694 & TRN & \\
\hline CHEMBL153289 & 67203 & 6.6778 & 6.6289 & TRN & \\
\hline CHEMBL155044 & 67203 & 6.9393 & 7.0212 & TRN & \\
\hline CHEMBL150879 & 67203 & 6.5686 & 6.5636 & TRN & \\
\hline CHEMBL150356 & 67203 & \multicolumn{3}{|c|}{5.757000000000001} & TRN \\
\hline CHEMBL150721 & 67203 & 7.3979 & 7.3462 & TRN & \\
\hline CHEMBL150593 & 67203 & 6.2218 & 6.1868 & TRN & \\
\hline CHEMBL150503 & 67203 & 5.3768 & 5.4863 & TRN & \\
\hline CHEMBL154988 & 67203 & 7.8239 & 7.8463 & TRN & \\
\hline CHEMBL434502 & 67203 & 7.6021 & 7.5928 & TRN & \\
\hline CHEMBL155510 & 67203 & 7.5229 & 7.4757 & TRN & \\
\hline CHEMBL348343 & 67203 & 7.0 & 6.9705 & TRN & \\
\hline CHEMBL153405 & 67203 & 7.8239 & 7.6835 & TRN & \\
\hline CHEMBL346215 & 67203 & 7.3979 & 7.4779 & TRN & \\
\hline CHEMBL153303 & 67203 & 6.7696 & 5.7047 & TST & \\
\hline CHEMBL356893 & 67203 & 7.301 & 7.3685 & TRN & \\
\hline CHEMBL153211 & 67203 & 5.433 & 5.4656 & TRN & \\
\hline CHEMBL152993 & 67203 & 7.301 & 7.3307 & TRN & \\
\hline CHEMBL153359 & 67203 & 7.0458 & 7.1057 & TRN & \\
\hline CHEMBL 358009 & 67203 & 4.0 & 5.6042 & TST & \\
\hline CHEMBL153115 & 67203 & 7.699 & 7.7206 & TRN & \\
\hline CHEMBL356635 & 67203 & 6.1024 & 6.1383 & TRN & \\
\hline CHEMBL150290 & 67203 & 6.9586 & 7.0216 & TRN & \\
\hline CHEMBL152913 & 67203 & 7.0 & 7.096 & TRN & \\
\hline
\end{tabular}




\begin{tabular}{|c|c|c|c|c|}
\hline & & pplement & al $\mathrm{T}$ \\
\hline CHEMBL346401 & 67203 & 6.3098 & 6.3317 & TRN \\
\hline CHEMBL346455 & 67203 & 7.8239 & 7.7991 & TRN \\
\hline CHEMBL152916 & 67203 & 6.7696 & 6.7001 & TRN \\
\hline CHEMBL150554 & 67203 & 4.0 & 5.1283 & TST \\
\hline CHEMBL152972 & 67203 & 6.6478 & 6.6469 & TRN \\
\hline CHEMBL149803 & 67203 & 7.0 & 7.0647 & TRN \\
\hline CHEMBL356874 & 67203 & 7.6021 & 7.5375 & TRN \\
\hline CHEMBL153653 & 67203 & 4.0 & 5.2596 & TST \\
\hline CHEMBL149806 & 67203 & 7.5229 & 7.6182 & TRN \\
\hline CHEMBL355980 & 67203 & 6.3098 & 6.5053 & TRN \\
\hline CHEMBL347063 & 67203 & 6.9586 & 6.9399 & TRN \\
\hline CHEMBL150279 & 67203 & 7.8239 & 7.1611 & TST \\
\hline CHEMBL153407 & 67203 & 7.1249 & 6.7048 & TST \\
\hline CHEMBL153100 & 67203 & 5.3721 & 5.5697 & TST \\
\hline CHEMBL358938 & 67203 & 6.699 & 6.723 & TST \\
\hline CHEMBL153113 & 67203 & 6.0506 & 7.0218 & TST \\
\hline CHEMBL150594 & 67203 & 7.8239 & 7.8544 & TST \\
\hline CHEMBL150704 & 67203 & 6.699 & 6.1167 & TST \\
\hline CHEMBL153709 & 67203 & 7.2596 & 6.8685 & TST \\
\hline CHEMBL 2408810 & 972683 & 4.1487 & 4.4437 & TRN \\
\hline CHEMBL 2408794 & 972683 & 5.0506 & 5.3656 & TRN \\
\hline CHEMBL 2408797 & 972683 & 5.699 & 5.2607 & TST \\
\hline CHEMBL 2408811 & 972683 & 4.3188 & 4.6538 & TRN \\
\hline CHEMBL 2409000 & 972683 & 5.1938 & 4.6303 & TRN \\
\hline CHEMBL447943 & 972683 & 3.7399 & 3.5863 & TRN \\
\hline CHEMBL452459 & 972683 & 3.7011 & 3.1893 & TRN \\
\hline CHEMBL 2408987 & 972683 & 4.8861 & 5.2678 & TRN \\
\hline CHEMBL 2408988 & 972683 & 4.9586 & 5.3119 & TRN \\
\hline CHEMBL 2409005 & 972683 & 3.9136 & 4.6261 & TRN \\
\hline CHEMBL2408976 & 972683 & 2.699 & 3.2547 & TRN \\
\hline CHEMBL 2407110 & 972683 & 2.699 & 2.4467 & TRN \\
\hline CHEMBL 2409004 & 972683 & 5.4685 & 4.7594 & TRN \\
\hline CHEMBL 2408990 & 972683 & 5.0969 & 5.3204 & TRN \\
\hline CHEMBL2408992 & 972683 & 4.9586 & 5.3808 & TRN \\
\hline CHEMBL2408989 & 972683 & 5.4089 & 5.261 & TRN \\
\hline CHEMBL2408981 & 972683 & 2.699 & 2.4805 & TRN \\
\hline CHEMBL 2408799 & 972683 & 5.6778 & 5.3607 & TRN \\
\hline CHEMBL 2408809 & 972683 & 4.2757 & 4.484 & TST \\
\hline CHEMBL2408994 & 972683 & 5.2757 & 5.06 & TRN \\
\hline CHEMBL2408996 & 972683 & 5.3279 & 5.044 & TRN \\
\hline CHEMBL 2408998 & 972683 & 4.7447 & 4.8206 & TRN \\
\hline CHEMBL 2408812 & 972683 & 4.0506 & 4.329 & TRN \\
\hline CHEMBL 2408999 & 972683 & 4.9208 & 4.7429 & TRN \\
\hline CHEMBL 2408814 & 972683 & 2.699 & 3.614 & TRN \\
\hline CHEMBL 2408995 & 972683 & 5.1549 & 5.0165 & TRN \\
\hline CHEMBL 2408997 & 972683 & 4.3372 & 5.044 & TRN \\
\hline CHEMBL 2408980 & 972683 & 2.699 & 3.1287 & TRN \\
\hline CHEMBL 2408985 & 972683 & 2.699 & 2.9592 & TRN \\
\hline
\end{tabular}


Supplemental Table S2.txt

\begin{tabular}{|c|c|c|c|c|}
\hline CHEMBL 2408796 & 972683 & 5.6778 & 5.1644 & TRN \\
\hline CHEMBL 2408983 & 972683 & 2.699 & 3.017 & TRN \\
\hline CHEMBL 2408974 & 972683 & 2.699 & 3.2988 & TRN \\
\hline CHEMBL 2408808 & 972683 & 2.699 & 3.7683 & TRN \\
\hline CHEMBL 2408993 & 972683 & 4.8861 & 4.6658 & TRN \\
\hline CHEMBL 2408806 & 972683 & 5.3979 & 4.8749 & TRN \\
\hline CHEMBL 2408795 & 972683 & 4.9208 & 5.1181 & TST \\
\hline CHEMBL2408979 & 972683 & 4.2757 & 3.3389 & TRN \\
\hline CHEMBL 2408803 & 972683 & 5.6198 & 5.0307 & TST \\
\hline CHEMBL 2408802 & 972683 & 4.6778 & 4.3459 & TRN \\
\hline CHEMBL 2409001 & 972683 & 3.7852 & 4.6734 & TST \\
\hline CHEMBL 2408805 & 972683 & 5.4559 & 5.1943 & TRN \\
\hline CHEMBL 2408982 & 972683 & 3.8416 & 3.10399 & 99999999996 \\
\hline CHEMBL 2408798 & 972683 & 5.1135 & 5.2753 & TST \\
\hline CHEMBL 2409002 & 972683 & 5.0 & 4.6895 & TST \\
\hline CHEMBL 2408978 & 972683 & 3.8447 & 3.6476 & TST \\
\hline CHEMBL2408816 & 972683 & 2.699 & 3.6421 & TRN \\
\hline CHEMBL 2408984 & 972683 & 3.9706 & 3.181 & TRN \\
\hline CHEMBL 2408804 & 972683 & 5.2007 & 4.8165 & TRN \\
\hline CHEMBL2408815 & 972683 & 3.8729 & 3.6421 & TRN \\
\hline CHEMBL 2408807 & 972683 & 5.9586 & 5.1341 & TST \\
\hline CHEMBL 2408800 & 972683 & 5.2147 & 5.1772 & TRN \\
\hline CHEMBL 2408986 & 972683 & 2.699 & 3.5905 & TST \\
\hline CHEMBL 2409003 & 972683 & 4.4202 & 5.0659 & TST \\
\hline CHEMBL2408975 & 972683 & 3.8268 & 3.1491 & TST \\
\hline CHEMBL2408813 & 972683 & 3.8097 & 4.8945 & TST \\
\hline CHEMBL 2409006 & 972683 & 4.585 & 3.9164 & TRN \\
\hline CHEMBL 2408817 & 972683 & 3.699 & 3.322 & TRN \\
\hline CHEMBL 2408801 & 972683 & 5.0223 & 4.4346 & TRN \\
\hline CHEMBL2408991 & 972683 & 4.9586 & 5.3204 & TRN \\
\hline CHEMBL2408977 & 972683 & 4.0605 & 3.2636 & TST \\
\hline CHEMBL1086626 & 647227 & 6.2226 & 6.4238 & TRN \\
\hline CHEMBL1214546 & 647227 & 6.4634 & 6.6798 & TRN \\
\hline CHEMBL1214046 & 647227 & 6.1986 & 6.1479 & TRN \\
\hline CHEMBL3216259 & 647227 & 6.5735 & 6.647 & TRN \\
\hline CHEMBL1214488 & 647227 & 7.6576 & 7.4488 & TRN \\
\hline CHEMBL1214178 & 647227 & 7.6778 & 7.6067 & TRN \\
\hline CHEMBL1213985 & 647227 & 6.1851 & 6.4786 & TST \\
\hline CHEMBL1214114 & 647227 & 6.0101 & 6.001 & TRN \\
\hline CHEMBL1213676 & 647227 & 7.0647 & 6.5959 & TST \\
\hline CHEMBL1080726 & 647227 & 6.7959 & 6.7867 & TRN \\
\hline CHEMBL1081468 & 647227 & 6.2111 & 6.3216 & TRN \\
\hline CHEMBL1080728 & 647227 & 6.5638 & 6.5773 & TRN \\
\hline CHEMBL1214366 & 647227 & 6.7235 & 7.0225 & TRN \\
\hline CHEMBL1214425 & 647227 & 7.4089 & 7.5311 & TRN \\
\hline CHEMBL1214116 & 647227 & 6.2083 & 6.1588 & TRN \\
\hline CHEMBL1080522 & 647227 & 7.4318 & 6.7094 & TRN \\
\hline CHEMBL1214595 & 647227 & 5.6523 & 6.4629 & TST \\
\hline
\end{tabular}


Supplemental Table S2.txt

\begin{tabular}{|c|c|c|c|c|c|c|}
\hline CHEMBL1212957 & 647227 & 7.0362 & 6.9113 & TRN & & \\
\hline CHEMBL3216702 & 647227 & 6.1945 & 6.4329 & TRN & & \\
\hline CHEMBL 3217141 & 647227 & 6.6556 & 6.3256 & TRN & & \\
\hline CHEMBL1214047 & 647227 & 5.8514 & 5.9165 & TRN & & \\
\hline CHEMBL1213932 & 647227 & 6.1068 & 6.1629 & TRN & & \\
\hline CHEMBL1214594 & 647227 & 6.3768 & 6.3898 & TRN & & \\
\hline CHEMBL1214304 & 647227 & 7.1249 & 6.8991 & TST & & \\
\hline CHEMBL1213673 & 647227 & 5.8564 & 5.8826 & TRN & & \\
\hline CHEMBL1214596 & 647227 & 5.9412 & 6.2236 & TST & & \\
\hline CHEMBL1086613 & 647227 & 6.857 & 6.8455 & TRN & & \\
\hline CHEMBL 3216707 & 647227 & 5.2793 & 5.5629 & TRN & & \\
\hline CHEMBL1214177 & 647227 & 7.4559 & 7.9063 & TRN & & \\
\hline CHEMBL1213933 & 647227 & 6.3072 & 6.3382 & TRN & & \\
\hline CHEMBL1214426 & 647227 & 7.585 & 7.3148 & TRN & & \\
\hline CHEMBL1214045 & 647227 & 6.4895 & 6.2637 & TRN & & \\
\hline CHEMBL1214302 & 647227 & 7.8861 & 6.8642 & TST & & \\
\hline CHEMBL1086756 & 647227 & 6.20200 & 0000000 & 1 & 6.6665 & TRN \\
\hline CHEMBL1214367 & 647227 & 6.8894 & 7.4666 & TRN & & \\
\hline CHEMBL1081035 & 647227 & 6.5086 & 6.8695 & TRN & & \\
\hline CHEMBL1213934 & 647227 & 6.6326 & 6.4134 & TST & & \\
\hline CHEMBL1086754 & 647227 & 7.9208 & 6.8955 & TRN & & \\
\hline CHEMBL1214489 & 647227 & 7.3872 & 7.2085 & TRN & & \\
\hline CHEMBL1214305 & 647227 & 7.7959 & 6.6271 & TST & & \\
\hline CHEMBL1214303 & 647227 & 7.7959 & 7.0299 & TST & & \\
\hline CHEMBL1214427 & 647227 & 6.9747 & 6.9806 & TST & & \\
\hline CHEMBL 1214428 & 647227 & 7.4089 & 7.3941 & TRN & & \\
\hline CHEMBL1213931 & 647227 & 6.1986 & 6.1316 & TRN & & \\
\hline CHEMBL1214113 & 647227 & 6.3449 & 6.4272 & TRN & & \\
\hline CHEMBL1213675 & 647227 & 7.1938 & 7.0277 & TRN & & \\
\hline CHEMBL1088163 & 647227 & 6.6478 & 6.6105 & TRN & & \\
\hline CHEMBL1214547 & 647227 & \multicolumn{3}{|c|}{6.757000000000001} & 6.5644 & TRN \\
\hline CHEMBL1213674 & 647227 & \multicolumn{3}{|c|}{5.9910000000000005} & 6.3497 & TST \\
\hline CHEMBL1214175 & 647227 & 6.3768 & 6.2295 & TST & & \\
\hline CHEMBL1214115 & 647227 & 5.9974 & 6.4832 & TST & & \\
\hline CHEMBL1214176 & 647227 & 7.9208 & 7.5583 & TRN & & \\
\hline CHEMBL1081644 & 647227 & 6.8761 & 6.8134 & TRN & & \\
\hline CHEMBL 2447969 & 647227 & 6.8069 & 7.1628 & TRN & & \\
\hline CHEMBL1214597 & 647227 & 6.9626 & 6.654 & TST & & \\
\hline CHEMBL1213856 & 647227 & 6.4572 & 6.6063 & TRN & & \\
\hline CHEMBL3895968 & 1641795 & 9.0969 & 9.1437 & TRN & & \\
\hline CHEMBL3985905 & 1641795 & 8.4815 & 8.6258 & TRN & & \\
\hline CHEMBL3902998 & 1641795 & 9.0969 & 9.066 & TRN & & \\
\hline CHEMBL3955673 & 1641795 & 8.6778 & 8.6281 & TRN & & \\
\hline CHEMBL3950819 & 1641795 & 9.1549 & 9.29 & TRN & & \\
\hline CHEMBL3920077 & 1641795 & 7.4868 & 8.6519 & TST & & \\
\hline CHEMBL 3967237 & 1641795 & 8.3979 & 8.2332 & TRN & & \\
\hline CHEMBL3904926 & 1641795 & 9.301 & 9.2838 & TRN & & \\
\hline CHEMBL 3970478 & 1641795 & 8.0969 & 8.0578 & TRN & & \\
\hline
\end{tabular}

Page 26169 
Supplemental Table S2.txt

\begin{tabular}{|c|c|c|c|c|}
\hline CHEMBL3932960 & 1641795 & 7.8239 & 7.8119 & TRN \\
\hline CHEMBL3969252 & 1641795 & 7.284 & 7.2391 & TRN \\
\hline CHEMBL3956685 & 1641795 & 8.699 & 8.8759 & TRN \\
\hline CHEMBL3912486 & 1641795 & 8.699 & 8.5923 & TRN \\
\hline CHEMBL3974945 & 1641795 & 8.3979 & 8.3818 & TRN \\
\hline CHEMBL3928681 & 1641795 & 6.0 & 5.7205 & TST \\
\hline CHEMBL3927694 & 1641795 & 6.0 & 6.1352 & TRN \\
\hline CHEMBL3959922 & 1641795 & 9.301 & 9.1352 & TRN \\
\hline CHEMBL3893276 & 1641795 & 7.7545 & 8.6151 & TST \\
\hline CHEMBL3976147 & 1641795 & 8.301 & 8.414 & TRN \\
\hline CHEMBL3966518 & 1641795 & 8.0862 & 8.1754 & TRN \\
\hline CHEMBL3956386 & 1641795 & 8.5229 & 8.6396 & TRN \\
\hline CHEMBL3921770 & 1641795 & 6.0 & 5.9725 & TRN \\
\hline CHEMBL3954483 & 1641795 & 7.7959 & 7.8274 & TRN \\
\hline CHEMBL3944374 & 1641795 & 8.0 & 8.0084 & TRN \\
\hline CHEMBL3908670 & 1641795 & 8.3279 & 8.3377 & TRN \\
\hline CHEMBL3903836 & 1641795 & 8.5229 & 8.416 & TRN \\
\hline CHEMBL3952617 & 1641795 & 7.2441 & 7.279 & TRN \\
\hline CHEMBL3903457 & 1641795 & 8.699 & 8.6988 & TRN \\
\hline CHEMBL3897339 & 1641795 & 8.0458 & 7.9593 & TRN \\
\hline CHEMBL3986148 & 1641795 & 8.2218 & 8.1595 & TRN \\
\hline CHEMBL3928874 & 1641795 & 6.0 & 6.0425 & TRN \\
\hline CHEMBL3944417 & 1641795 & 6.5591 & 9.7198 & TST \\
\hline CHEMBL3905215 & 1641795 & 8.4437 & 8.3731 & TRN \\
\hline CHEMBL3946816 & 1641795 & 8.3565 & 8.2683 & TRN \\
\hline CHEMBL3904868 & 1641795 & 6.0 & 6.42299 & 9999999999 \\
\hline CHEMBL3944874 & 1641795 & 9.0458 & 9.3296 & TRN \\
\hline CHEMBL3985128 & 1641795 & 7.3188 & 7.1495 & TRN \\
\hline CHEMBL3933229 & 1641795 & 7.3716 & 7.3754 & TRN \\
\hline CHEMBL3981375 & 1641795 & 7.4559 & 7.4693 & TRN \\
\hline CHEMBL3942210 & 1641795 & 8.3279 & 8.9114 & TST \\
\hline CHEMBL3923464 & 1641795 & 6.9508 & 6.9411 & TST \\
\hline CHEMBL3968022 & 1641795 & 7.3372 & 6.572 & TST \\
\hline CHEMBL3945552 & 1641795 & 8.1549 & 8.10799 & 9999999999 \\
\hline CHEMBL3980824 & 1641795 & 7.5376 & 7.5724 & TRN \\
\hline CHEMBL3939920 & 1641795 & 7.3372 & 9.3709 & TST \\
\hline CHEMBL3966669 & 1641795 & 8.2518 & 8.3337 & TRN \\
\hline CHEMBL3914369 & 1641795 & 8.0458 & 7.9563 & TRN \\
\hline CHEMBL3927793 & 1641795 & 8.2147 & 8.2766 & TRN \\
\hline CHEMBL3937691 & 1641795 & 8.699 & 8.7734 & TRN \\
\hline CHEMBL3961600 & 1641795 & 8.1308 & 7.8493 & TRN \\
\hline CHEMBL3918999 & 1641795 & 8.4685 & 8.4716 & TRN \\
\hline CHEMBL3956132 & 1641795 & 8.2218 & 8.3336 & TRN \\
\hline CHEMBL3963412 & 1641795 & 8.1549 & 8.3779 & TRN \\
\hline CHEMBL3919899 & 1641795 & 8.699 & 8.5834 & TRN \\
\hline CHEMBL3912790 & 1641795 & 6.0 & 6.1273 & TRN \\
\hline CHEMBL3944288 & 1641795 & 7.1805 & 7.2274 & TRN \\
\hline CHEMBL3982917 & 1641795 & 9.2218 & 9.2274 & TRN \\
\hline
\end{tabular}


Supplemental Table S2.txt

\begin{tabular}{|c|c|c|c|c|}
\hline CHEMBL3904320 & 1641795 & 8.699 & 8.6864 & TRN \\
\hline CHEMBL3946054 & 1641795 & 7.7721 & 7.8432 & TRN \\
\hline CHEMBL3930976 & 1641795 & 9.301 & 9.1665 & TRN \\
\hline CHEMBL 3955374 & 1641795 & 8.699 & 8.6498 & TRN \\
\hline CHEMBL3914687 & 1641795 & 8.1487 & 6.9582 & TST \\
\hline CHEMBL3943234 & 1641795 & 8.301 & 8.3513 & TRN \\
\hline CHEMBL3890471 & 1641795 & 8.3979 & 8.4386 & TRN \\
\hline CHEMBL3954617 & 1641795 & 8.7447 & 8.7369 & TRN \\
\hline CHEMBL3961085 & 1641795 & 7.1574 & 7.2141 & TRN \\
\hline CHEMBL3972535 & 1641795 & 8.301 & 8.1594 & TRN \\
\hline CHEMBL3924432 & 1641795 & 8.1079 & 8.0493 & TRN \\
\hline CHEMBL3975390 & 1641795 & 8.7696 & 8.6653 & TRN \\
\hline CHEMBL3961077 & 1641795 & 8.3279 & 8.3426 & TRN \\
\hline CHEMBL 3947546 & 1641795 & 6.8821 & 8.2962 & TST \\
\hline CHEMBL3980572 & 1641795 & 6.5735 & 6.5184 & TRN \\
\hline CHEMBL3950885 & 1641795 & 9.1549 & 9.1815 & TRN \\
\hline CHEMBL3922783 & 1641795 & 6.0 & 6.1393 & TRN \\
\hline CHEMBL 3938471 & 1641795 & 7.3279 & 6.4894 & TST \\
\hline CHEMBL 3924945 & 1641795 & 8.5229 & 8.4338 & TRN \\
\hline CHEMBL3972805 & 1641795 & 8.0969 & 8.0931 & TRN \\
\hline CHEMBL3912773 & 1641795 & 6.0 & 5.6465 & TRN \\
\hline CHEMBL 3975174 & 1641795 & 8.6198 & 8.6911 & TRN \\
\hline CHEMBL 3935853 & 1641795 & 8.699 & 8.7202 & TRN \\
\hline CHEMBL3958938 & 1641795 & 7.1506 & 7.1015 & TRN \\
\hline CHEMBL3949250 & 1641795 & 8.301 & 8.2246 & TRN \\
\hline CHEMBL3932428 & 1641795 & 8.4815 & 8.5617 & TRN \\
\hline CHEMBL3910204 & 1641795 & 8.5229 & 8.5262 & TRN \\
\hline CHEMBL3970996 & 1641795 & 8.7959 & 8.7243 & TRN \\
\hline CHEMBL3898211 & 1641795 & 9.5229 & 9.452 & TRN \\
\hline CHEMBL3981870 & 1641795 & 8.0862 & 7.9011 & TRN \\
\hline CHEMBL3905385 & 1641795 & 8.699 & 8.7582 & TRN \\
\hline CHEMBL3951326 & 1641795 & 8.4318 & 8.3973 & TRN \\
\hline CHEMBL 3942941 & 1641795 & 7.2076 & 6.9842 & TST \\
\hline CHEMBL3940476 & 1641795 & 9.0 & 8.933 & TRN \\
\hline CHEMBL3895212 & 1641795 & 8.4202 & 8.5639 & TRN \\
\hline CHEMBL3952910 & 1641795 & 8.7696 & 9.3929 & TST \\
\hline CHEMBL3949252 & 1641795 & 8.1871 & 8.6353 & TST \\
\hline CHEMBL3937693 & 1641795 & 8.3188 & 6.939 & TST \\
\hline CHEMBL 3943287 & 1641795 & 6.0 & 6.7164 & TST \\
\hline CHEMBL3967469 & 1641795 & 8.3979 & 8.5001 & TST \\
\hline CHEMBL3941956 & 1641795 & 8.0 & 9.7349 & TST \\
\hline CHEMBL3926047 & 1641795 & 8.3979 & 8.6257 & TST \\
\hline CHEMBL3934266 & 1641795 & 7.7696 & \multicolumn{2}{|c|}{8.392000000000001} \\
\hline CHEMBL3979381 & 1641795 & 7.5258 & 7.9191 & TST \\
\hline CHEMBL3910487 & 1641795 & 9.1549 & 8.7279 & TST \\
\hline CHEMBL3963808 & 1641795 & 7.6326 & 7.7966 & TST \\
\hline CHEMBL3963081 & 1641795 & 7.5058 & 8.46 & TST \\
\hline CHEMBL3930679 & 1641795 & 7.9208 & 8.1442 & TST \\
\hline
\end{tabular}


Supplemental Table S2.txt

\begin{tabular}{|c|c|c|c|c|c|}
\hline CHEMBL3928796 & 1641795 & 9.0 & 9.1502 & TST & \\
\hline CHEMBL3897973 & 1641795 & 8.3979 & 8.6567 & TST & \\
\hline CHEMBL3691291 & 1528759 & 6.0 & 5.86100 & 000000001 & TRN \\
\hline CHEMBL3691287 & 1528759 & 7.6162 & 7.5158 & TRN & \\
\hline CHEMBL3691301 & 1528759 & 6.0 & 5.8937 & TRN & \\
\hline CHEMBL3691311 & 1528759 & 6.0 & 6.0106 & TRN & \\
\hline CHEMBL3691328 & 1528759 & 8.301 & 8.0643 & TRN & \\
\hline CHEMBL3691303 & 1528759 & 7.6162 & 7.6435 & TRN & \\
\hline CHEMBL3691283 & 1528759 & 7.8928 & 7.8845 & TRN & \\
\hline CHEMBL3691309 & 1528759 & 8.0706 & 8.0906 & TRN & \\
\hline CHEMBL 3691340 & 1528759 & 7.9393 & 8.133 & TRN & \\
\hline CHEMBL3691308 & 1528759 & 7.6946 & 7.7104 & TRN & \\
\hline CHEMBL3691295 & 1528759 & 7.4711 & 7.5019 & TRN & \\
\hline CHEMBL3691299 & 1528759 & 7.9066 & 7.79 & TRN & \\
\hline CHEMBL3691355 & 1528759 & 8.1487 & 8.2921 & TRN & \\
\hline CHEMBL3686865 & 1528759 & 8.1024 & 8.0718 & TRN & \\
\hline CHEMBL3686864 & 1528759 & 7.9957 & 8.0519 & TRN & \\
\hline CHEMBL3691284 & 1528759 & 7.9172 & 7.8903 & TRN & \\
\hline CHEMBL 3686888 & 1528759 & 8.2007 & 8.0192 & TRN & \\
\hline CHEMBL3691268 & 1528759 & 7.9626 & 7.9982 & TST & \\
\hline CHEMBL3686873 & 1528759 & 7.7447 & 7.626 & TRN & \\
\hline CHEMBL3691352 & 1528759 & 8.0706 & 7.9263 & TRN & \\
\hline CHEMBL3691280 & 1528759 & 8.1024 & 8.1409 & TRN & \\
\hline CHEMBL 3686872 & 1528759 & 7.4237 & 7.1599 & TRN & \\
\hline CHEMBL3691289 & 1528759 & 8.0605 & 8.0858 & TRN & \\
\hline CHEMBL3691339 & 1528759 & 7.7932 & 7.9165 & TRN & \\
\hline CHEMBL 3691263 & 1528759 & 6.0 & 7.6503 & TRN & \\
\hline CHEMBL3691264 & 1528759 & 8.0706 & 8.0666 & TRN & \\
\hline CHEMBL3691270 & 1528759 & 6.0 & \multicolumn{2}{|c|}{5.928999999999999} & TRN \\
\hline CHEMBL 3686869 & 1528759 & 7.9355 & 7.7219 & TST & \\
\hline CHEMBL3691327 & 1528759 & 6.0 & 6.0558 & TRN & \\
\hline CHEMBL 3691267 & 1528759 & 7.9508 & 7.4604 & TST & \\
\hline CHEMBL3691354 & 1528759 & 6.0 & 6.1157 & TRN & \\
\hline CHEMBL3691323 & 1528759 & 7.8268 & 7.8757 & TRN & \\
\hline CHEMBL 3691343 & 1528759 & 7.9872 & 7.8317 & TRN & \\
\hline CHEMBL3691331 & 1528759 & 8.2676 & 8.3855 & TRN & \\
\hline CHEMBL3691322 & 1528759 & 8.2676 & 8.2997 & TRN & \\
\hline CHEMBL3691276 & 1528759 & 6.0 & 7.4468 & TST & \\
\hline CHEMBL3691258 & 1528759 & 8.0969 & 8.0266 & TRN & \\
\hline CHEMBL3691325 & 1528759 & 8.2441 & 8.0823 & TRN & \\
\hline CHEMBL3691313 & 1528759 & 6.0 & 7.8306 & TST & \\
\hline CHEMBL3691259 & 1528759 & 7.9508 & 7.7593 & TRN & \\
\hline CHEMBL3691316 & 1528759 & 8.1871 & 8.0689 & TST & \\
\hline CHEMBL3686881 & 1528759 & 7.8697 & 7.9229 & TRN & \\
\hline CHEMBL3691271 & 1528759 & 7.9031 & 7.9732 & TRN & \\
\hline CHEMBL3691266 & 1528759 & 6.0 & 7.6228 & TST & \\
\hline CHEMBL3691273 & 1528759 & 6.0 & 5.8176 & TST & \\
\hline CHEMBL3691348 & 1528759 & 6.0 & 6.0321 & TRN & \\
\hline
\end{tabular}


Supplemental Table S2.txt

\begin{tabular}{|c|c|c|c|c|c|c|}
\hline CHEMBL 3691350 & 1528759 & 7.7471 & 7.8012 & TRN & & \\
\hline CHEMBL 3691269 & 1528759 & 7.9788 & 7.8819 & TST & & \\
\hline CHEMBL3691300 & 1528759 & 7.4949 & 7.5556 & TRN & & \\
\hline CHEMBL 3691345 & 1528759 & 6.0 & 7.6245 & TST & & \\
\hline CHEMBL 3691294 & 1528759 & 7.9281 & 7.7783 & TRN & & \\
\hline CHEMBL 3691324 & 1528759 & 7.9747 & 7.7881 & TRN & & \\
\hline CHEMBL3691317 & 1528759 & 8.1487 & 7.6976 & TRN & & \\
\hline CHEMBL 3691298 & 1528759 & 7.9318 & 8.0124 & TRN & & \\
\hline CHEMBL 3691347 & 1528759 & 6.0 & 5.9684 & TRN & & \\
\hline CHEMBL 3686883 & 1528759 & 8.2441 & 8.1533 & TRN & & \\
\hline CHEMBL 3691274 & 1528759 & 7.61799 & 999999999 & & 8.0232 & TST \\
\hline CHEMBL3691336 & 1528759 & 6.0 & 7.819 & TST & & \\
\hline CHEMBL 3691296 & 1528759 & 6.0 & 6.0038 & TRN & & \\
\hline CHEMBL 3691307 & 1528759 & 7.71899 & 999999999 & & 7.7778 & TRN \\
\hline CHEMBL 3691351 & 1528759 & 8.0506 & \multicolumn{3}{|c|}{7.992000000000001} & TRN \\
\hline CHEMBL 3691281 & 1528759 & 8.0506 & 8.1595 & TRN & & \\
\hline CHEMBL 3691285 & 1528759 & 7.9318 & 7.7713 & TRN & & \\
\hline CHEMBL 3686879 & 1528759 & 7.8356 & 8.0458 & TRN & & \\
\hline CHEMBL 3686863 & 1528759 & 8.0088 & 7.8003 & TST & & \\
\hline CHEMBL 3942438 & 1528759 & 6.0 & 6.4836 & TST & & \\
\hline CHEMBL 3691286 & 1528759 & 7.4672 & 7.5788 & TRN & & \\
\hline CHEMBL 3691293 & 1528759 & 8.0 & 7.9421 & TRN & & \\
\hline CHEMBL 3686878 & 1528759 & 7.9393 & 8.0124 & TRN & & \\
\hline CHEMBL 3686874 & 1528759 & 7.7011 & 7.474 & TRN & & \\
\hline CHEMBL 3691342 & 1528759 & 8.4318 & 8.1149 & TRN & & \\
\hline CHEMBL 3691334 & 1528759 & 8.3768 & 8.3555 & TRN & & \\
\hline CHEMBL3691306 & 1528759 & 7.983 & 7.921 & TRN & & \\
\hline CHEMBL 3691297 & 1528759 & 7.9508 & 7.9292 & TRN & & \\
\hline CHEMBL3691305 & 1528759 & 6.0 & 6.0191 & TRN & & \\
\hline CHEMBL 3691321 & 1528759 & 6.0 & 6.1733 & TRN & & \\
\hline CHEMBL 3686871 & 1528759 & 7.5229 & 7.6493 & TRN & & \\
\hline CHEMBL 3686870 & 1528759 & 7.8794 & 7.4305 & TST & & \\
\hline CHEMBL 3691288 & 1528759 & 8.0 & 7.8907 & TRN & & \\
\hline CHEMBL 3691341 & 1528759 & 8.4089 & 8.3746 & TRN & & \\
\hline CHEMBL 3686887 & 1528759 & 8.28399 & 999999999 & 99 & 8.2807 & $1 \mathrm{~N}$ \\
\hline CHEMBL 3639901 & 1528759 & 8.0088 & 8.0306 & TRN & & \\
\hline CHEMBL 3691337 & 1528759 & 8.2518 & 8.0486 & TST & & \\
\hline CHEMBL 3691318 & 1528759 & 8.1739 & 8.0491 & TRN & & \\
\hline CHEMBL 3686884 & 1528759 & 8.2366 & 8.3203 & TRN & & \\
\hline CHEMBL 3686867 & 1528759 & 7.9208 & 7.8406 & TRN & & \\
\hline CHEMBL 3691261 & 1528759 & 7.8386 & 7.4835 & TST & & \\
\hline CHEMBL 3686875 & 1528759 & 7.5058 & 7.8792 & TST & & \\
\hline CHEMBL 3686868 & 1528759 & 7.9586 & 8.0235 & TST & & \\
\hline CHEMBL 3691358 & 1528759 & 8.2076 & 8.1084 & TRN & & \\
\hline CHEMBL 3686886 & 1528759 & 8.3565 & 8.3667 & TRN & & \\
\hline CHEMBL 3691330 & 1528759 & 6.0 & 6.064 & TRN & & \\
\hline CHEMBL 3691314 & 1528759 & 6.0 & 6.3608 & TST & & \\
\hline CHEMBL 3686876 & 1528759 & 7.9626 & 7.9787 & TRN & & \\
\hline
\end{tabular}

Page 26173 
Supplemental Table S2.txt

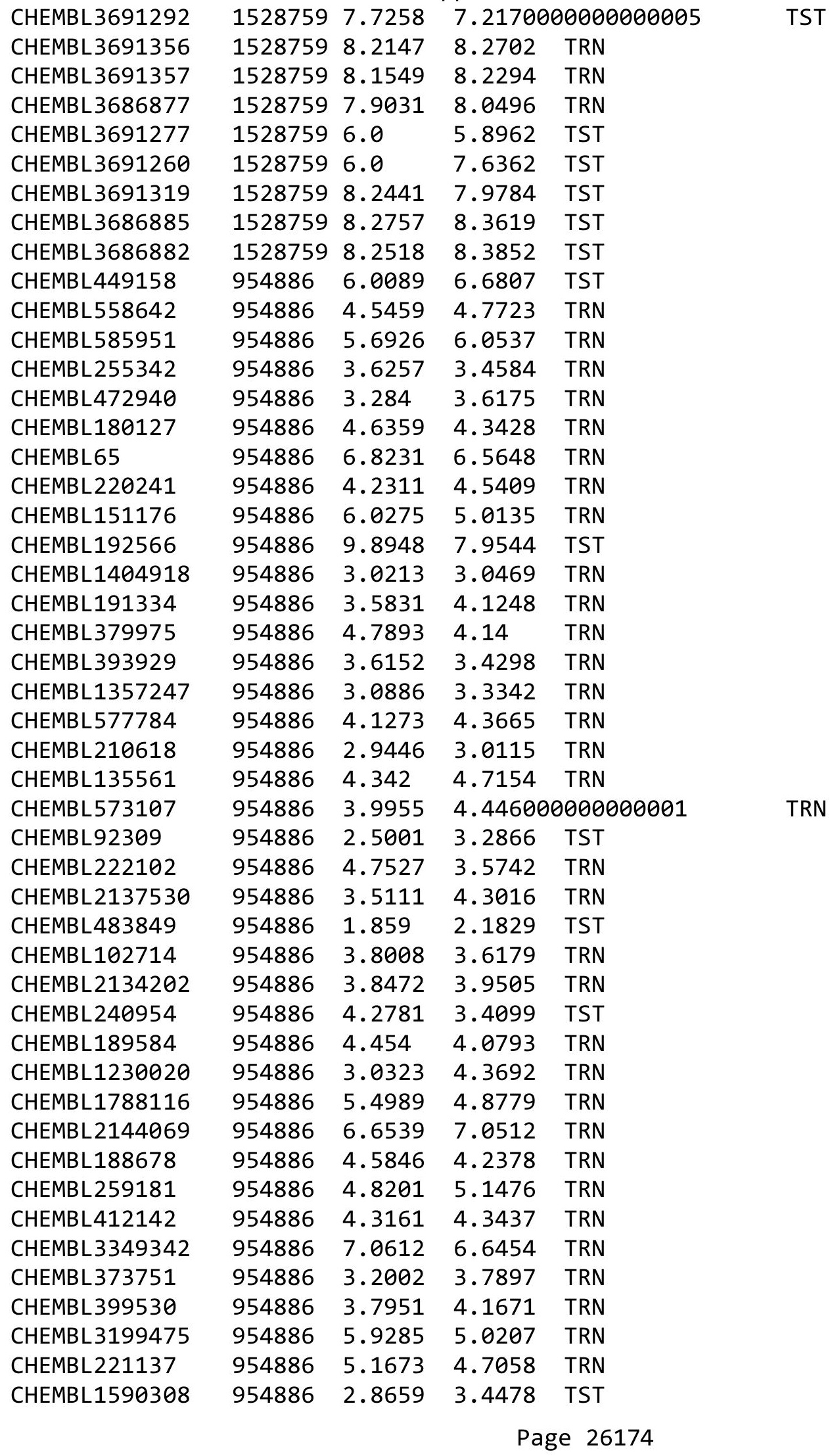


Supplemental Table S2.txt

\begin{tabular}{|c|c|c|c|c|}
\hline AFMBI 3186408 & 954886 & 9009 & 4.0155 & TST \\
\hline CHEMBL512504 & 54886 & 4.2602 & 4.0468 & TR \\
\hline HEMBL217354 & 954886 & 5.2298 & 5.7073 & \\
\hline CHEMBL1186585 & 54886 & 3.8034 & 3.8201 & TPN \\
\hline CHEMBL1190711 & 954886 & 5.2554 & 5.0276 & \\
\hline CHEMBL202721 & 54886 & 4.4033 & 4.2881 & \\
\hline CHEMBL1673039 & 54886 & 5.0676 & 5.0892 & \\
\hline CHEMBL258844 & 54886 & 3.9577 & 4.6231 & \\
\hline CHEMBL9470 & 54886 & 4.3369 & 5.8259 & \\
\hline CHEMBL1909414 & 54886 & 3.6456 & 4.2912 & \\
\hline HEMBL2363137 & 54886 & 5.5017 & 569 & \\
\hline CHEMBL1516890 & 954886 & 3.9942 & 4.0835 & $-e_{-}$ \\
\hline CHEMBL 362231 & 302709 & 5.5528 & 5.5802 & TRN \\
\hline CHEMBL179544 & 02709 & & 4.0183 & \\
\hline CHEMBL178516 & 02709 & 6.6021 & 6.2918 & $\mathrm{RN}$ \\
\hline HEMBL359736 & 2709 & 5.2924 & 306 & \\
\hline CHEMBL179618 & 2709 & 5.9208 & 6.8426 & RN \\
\hline 8781 & 02709 & 6.7696 & 5.7162 & TST \\
\hline CHEME & & 35 & & \\
\hline CHEMB & 09 & 5.1805 & 4.5032 & TRN \\
\hline HEME & 2709 & 6.6198 & 6.1671 & \\
\hline CHFMBI 180524 & & & & \\
\hline 50779 & 09 & 5.2076 & 5.2675 & TRN \\
\hline CHEMI & 09 & 5.0088 & 785 & TRN \\
\hline CHEMI & 09 & 5.9586 & 5.8626 & TRN \\
\hline CHEMB & 2709 & 5.3468 & 4.7117 & TRN \\
\hline CHEMBL179200 & 2709 & 4.3595 & 395 & \\
\hline CHEM & 2709 & 6.0132 & 5.9945 & TRN \\
\hline 179566 & 2709 & 5.8239 & 5.7221 & IRN \\
\hline CHEM & 92709 & 6.1024 & 5.9083 & TRN \\
\hline CHEMI & g9 & 6.8861 & 6.9179 & TRN \\
\hline CHEM & & & & TST \\
\hline CHEME & g9 & 3.1 & 3.5752 & TRN \\
\hline CHEMB & 2709 & 6.0506 & 6.2042 & TST \\
\hline CHEM & 2709 & 4.3261 & 5.2458 & TRN \\
\hline CHEME & g9 & 6.6383 & 6.4724 & TRN \\
\hline CHEM & & & 5.6701 & TST \\
\hline CHEME & פ9 & 6.6576 & 6.5823 & TRN \\
\hline CHEMBL362062 & 2709 & 6.7696 & 5.8503 & TRN \\
\hline CHEMI & & & & \\
\hline CHEMBL361364 & 02709 & 6.284 & 6.4469 & TRN \\
\hline HEME & & 7.0 & & TF \\
\hline CHEM & & 6 & 536 & \\
\hline CHEMBL178938 & 2709 & 6.5528 & 6.4901 & TRN \\
\hline CUFM & & & & \\
\hline (mLT & 9 & 4.1884 & 4.3176 & \\
\hline CHEMBL360068 & & & 4.672 & \\
\hline & ברת & & & \\
\hline
\end{tabular}

Page 26175 


CHEMBL179762
CHEMBL179589
CHEMBL359657
CHEMBL178090
CHEMBL179962
CHEMBL362702
CHEMBL179366
CHEMBL359672
CHEMBL178878
CHEMBL179610
CHEMBL368434
CHEMBL178453
CHEMBL425519
CHEMBL179477
CHEMBL180270
CHEMBL179529
CHEMBL156679
CHEMBL368883
CHEMBL178196
CHEMBL369285
CHEMBL178711
CHEMBL232477
CHEMBL234543
CHEMBL395838
CHEMBL228690
CHEMBL397761
CHEMBL233721
CHEMBL233536
CHEMBL400036
CHEMBL233750
CHEMBL398794
CHEMBL231664
CHEMBL232273
CHEMBL234773
CHEMBL233502
CHEMBL393985
CHEMBL232066
CHEMBL232286
CHEMBL232075
CHEMBL233327
CHEMBL232285
CHEMBL394222
CHEMBL232074
CHEMBL233493 332067
CHEMB 3937380
CHE

Supplemental Table S2.txt

\begin{tabular}{|c|c|c|c|c|c|}
\hline & & & & & \\
\hline 302709 & 4.5622 & 4.8392 & TRN & & \\
\hline 302709 & 5.5686 & 5.5136 & TRN & & \\
\hline 302709 & 7.699 & 6.8261 & TST & & \\
\hline 302709 & 7.3979 & 6.5021 & TST & & \\
\hline 302709 & 4.9586 & 5.4532 & TRN & & \\
\hline 302709 & 5.8539 & 5.9439 & TST & & \\
\hline 302709 & 3.1739 & 4.5333 & TST & & \\
\hline 302709 & 3.1739 & 3.5511 & TRN & & \\
\hline 302709 & 5.7447 & 5.6219 & TRN & & \\
\hline 302709 & 4.7055 & 4.916 & TST & & \\
\hline 302709 & 5.4949 & 5.8033 & TRN & & \\
\hline 302709 & 4.3516 & 4.4388 & TRN & & \\
\hline 302709 & 5.585 & 5.7642 & TRN & & \\
\hline 302709 & 6.2076 & 5.7262 & TST & & \\
\hline 302709 & 4.644 & 4.9026 & TST & & \\
\hline 302709 & 6.2291 & 6.1091 & TST & & \\
\hline 302709 & 5.2007 & 5.1772 & TRN & & \\
\hline 302709 & 6.6021 & 6.5728 & TST & & \\
\hline 302709 & 5.8239 & 5.7469 & TRN & & \\
\hline 302709 & 6.7447 & 6.8328 & TST & & \\
\hline 302709 & 5.9208 & 6.2288 & TST & & \\
\hline 443967 & 6.7773 & 6.7887 & TRN & & \\
\hline 443967 & 5.4643 & 5.4693 & TRN & & \\
\hline 443967 & 6.1518 & 6.1598 & TRN & & \\
\hline 443967 & 6.684 & 6.6952 & TRN & & \\
\hline 443967 & 6.5654 & 6.0632 & TST & & \\
\hline 443967 & 4.8784 & 5.2531 & TST & & \\
\hline 443967 & 7.1427 & 7.0867 & TRN & & \\
\hline 443967 & 6.2104 & 6.21 & TRN & & \\
\hline 443967 & 6.6038 & 6.5265 & TRN & & \\
\hline 443967 & 7.1427 & 7.2265 & TRN & & \\
\hline 443967 & 5.4731 & 5.3621 & TST & & \\
\hline 443967 & 7.1308 & 7.1375 & TRN & & \\
\hline 443967 & 5.0507 & 5.6743 & TST & & \\
\hline 443967 & 6.7305 & 6.7209 & TRN & & \\
\hline 443967 & 6.0269 & 6.0612 & TRN & & \\
\hline 443967 & 6.1129 & 6.1063 & TRN & & \\
\hline 443967 & 6.4522 & 6.4569 & TRN & & \\
\hline 443967 & 6.8386 & 6.8473 & TRN & & \\
\hline 443967 & 7.5528 & 7.5457 & TRN & & \\
\hline 443967 & 6.4547 & 6.4491 & TRN & & \\
\hline 443967 & 6.9208 & 6.9241 & TRN & & \\
\hline 443967 & 6.5171 & 6.505 & TRN & & \\
\hline 443967 & 6.0074 & 6.0093 & TRN & & \\
\hline 443967 & 5.9759 & 5.9578 & TRN & & \\
\hline 443967 & 4.73600 & 30000000 & & 5.6370000000000005 & TST \\
\hline 443967 & 6.7423 & 5.8072 & TST & & \\
\hline 443967 & 6.5638 & 6.5663 & TRN & & \\
\hline
\end{tabular}

Page 26176 


\begin{tabular}{|c|c|c|c|c|c|}
\hline \multicolumn{6}{|c|}{ Supplemental Table s2.txt } \\
\hline CHEMBL394695 & 443967 & 6.3904 & 6.2903 & TST & \\
\hline CHEMBL233748 & 443967 & 6.2993 & 6.2652 & TRN & \\
\hline CHEMBL393971 & 443967 & 4.9378 & 4.9374 & TRN & \\
\hline CHEMBL233955 & 443967 & 7.4318 & 7.4289 & TRN & \\
\hline CHEMBL231661 & 443967 & 4.9834 & 5.3104 & TST & \\
\hline CHEMBL234771 & 443967 & 5.4438 & 6.1126 & TST & \\
\hline CHEMBL393675 & 443967 & 4.942 & 4.9423 & TRN & \\
\hline CHEMBL232476 & 443967 & 6.2299 & 6.2142 & TRN & \\
\hline CHEMBL437177 & 443967 & 6.7878 & 6.7846 & TRN & \\
\hline CHEMBL233956 & 443967 & 6.2104 & 6.2781 & TRN & \\
\hline CHEMBL233326 & 443967 & 8.699 & 8.6953 & TRN & \\
\hline CHEMBL393356 & 443967 & 6.1215 & 6.523 & TST & \\
\hline CHEMBL233749 & 443967 & 5.5107 & 5.5366 & TRN & \\
\hline CHEMBL231874 & 443967 & 5.3416 & 5.336 & TRN & \\
\hline CHEMBL232478 & 443967 & 6.567 & 6.572 & TRN & \\
\hline CHEMBL233503 & 443967 & 6.9031 & 6.9146 & TRN & \\
\hline CHEMBL233501 & 443967 & 5.0767 & 5.0764 & TRN & \\
\hline CHEMBL233494 & 443967 & 5.5246 & 5.5338 & TRN & \\
\hline CHEMBL232076 & 443967 & 6.7212 & 6.7236 & TRN & \\
\hline CHEMBL231866 & 443967 & 6.7033 & 6.6912 & TRN & \\
\hline CHEMBL233323 & 443967 & 5.761 & 5.7531 & TRN & \\
\hline CHEMBL392753 & 443967 & 6.0287 & 6.0039 & TRN & \\
\hline CHEMBL441914 & 443967 & 8.699 & 8.7934 & TST & \\
\hline CHEMBL233535 & 443967 & 6.3449 & 6.1143 & TST & \\
\hline CHEMBL400035 & 443967 & 6.7212 & 6.95299 & 99999 & TST \\
\hline CHEMBL401234 & 443967 & 4.9566 & 5.1446 & TST & \\
\hline CHEMBL428104 & 500129 & 8.7447 & 9.0275 & TST & \\
\hline CHEMBL511806 & 500129 & 7.7423 & 7.7029 & TRN & \\
\hline CHEMBL158438 & 500129 & 7.3372 & 8.1862 & TST & \\
\hline CHEMBL500631 & 500129 & 9.2441 & 9.1441 & TRN & \\
\hline CHEMBL474838 & 500129 & 7.9208 & 8.7 & TST & \\
\hline CHEMBL161594 & 500129 & 7.5229 & 8.4738 & TST & \\
\hline CHEMBL471542 & 500129 & 8.9208 & 8.8259 & TRN & \\
\hline CHEMBL102674 & 500129 & 8.2218 & 8.3695 & TRN & \\
\hline CHEMBL520755 & 500129 & 9.1739 & 8.6266 & TRN & \\
\hline CHEMBL323370 & 500129 & 8.1549 & 8.0891 & TRN & \\
\hline CHEMBL175327 & 500129 & 8.9208 & 8.8107 & TRN & \\
\hline CHEMBL511154 & 500129 & 8.2076 & 8.4135 & TRN & \\
\hline CHEMBL157983 & 500129 & 7.8539 & 7.4465 & TST & \\
\hline CHEMBL480503 & 500129 & 9.5376 & 9.3095 & TRN & \\
\hline CHEMBL432596 & 500129 & 8.2218 & 7.9336 & TRN & \\
\hline CHEMBL475777 & 500129 & 7.1871 & 8.7267 & TST & \\
\hline CHEMBL352514 & 500129 & 8.7959 & 8.676 & TRN & \\
\hline CHEMBL511634 & 500129 & 9.0969 & 8.8651 & TRN & \\
\hline CHEMBL471766 & 500129 & 8.4202 & 8.67 & TRN & \\
\hline CHEMBL137206 & 500129 & 7.6383 & 8.033 & TST & \\
\hline CHEMBL417825 & 500129 & 8.3188 & 8.5532 & TRN & \\
\hline CHEMBL 364070 & 500129 & 8.6021 & 8.6875 & TST & \\
\hline
\end{tabular}




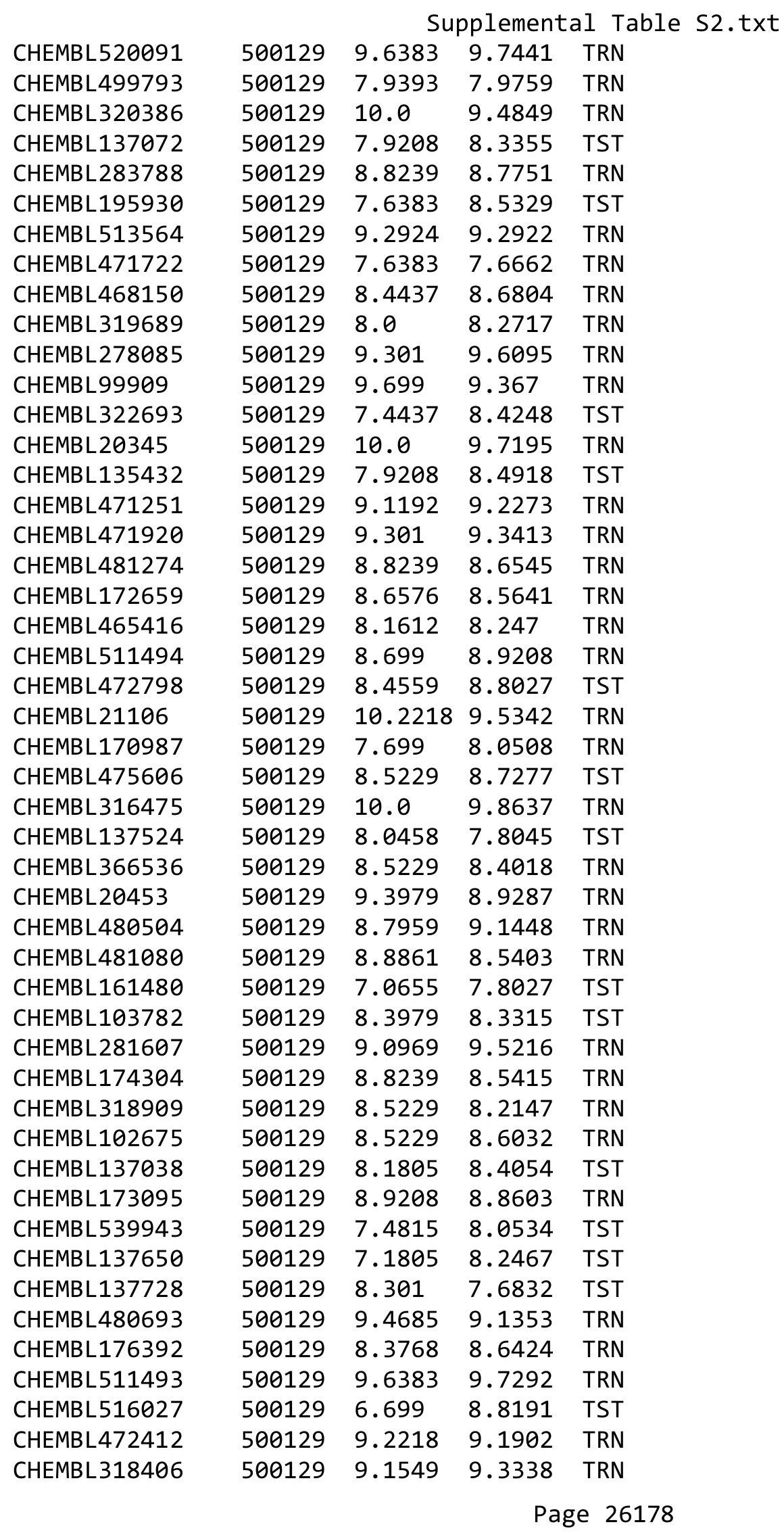




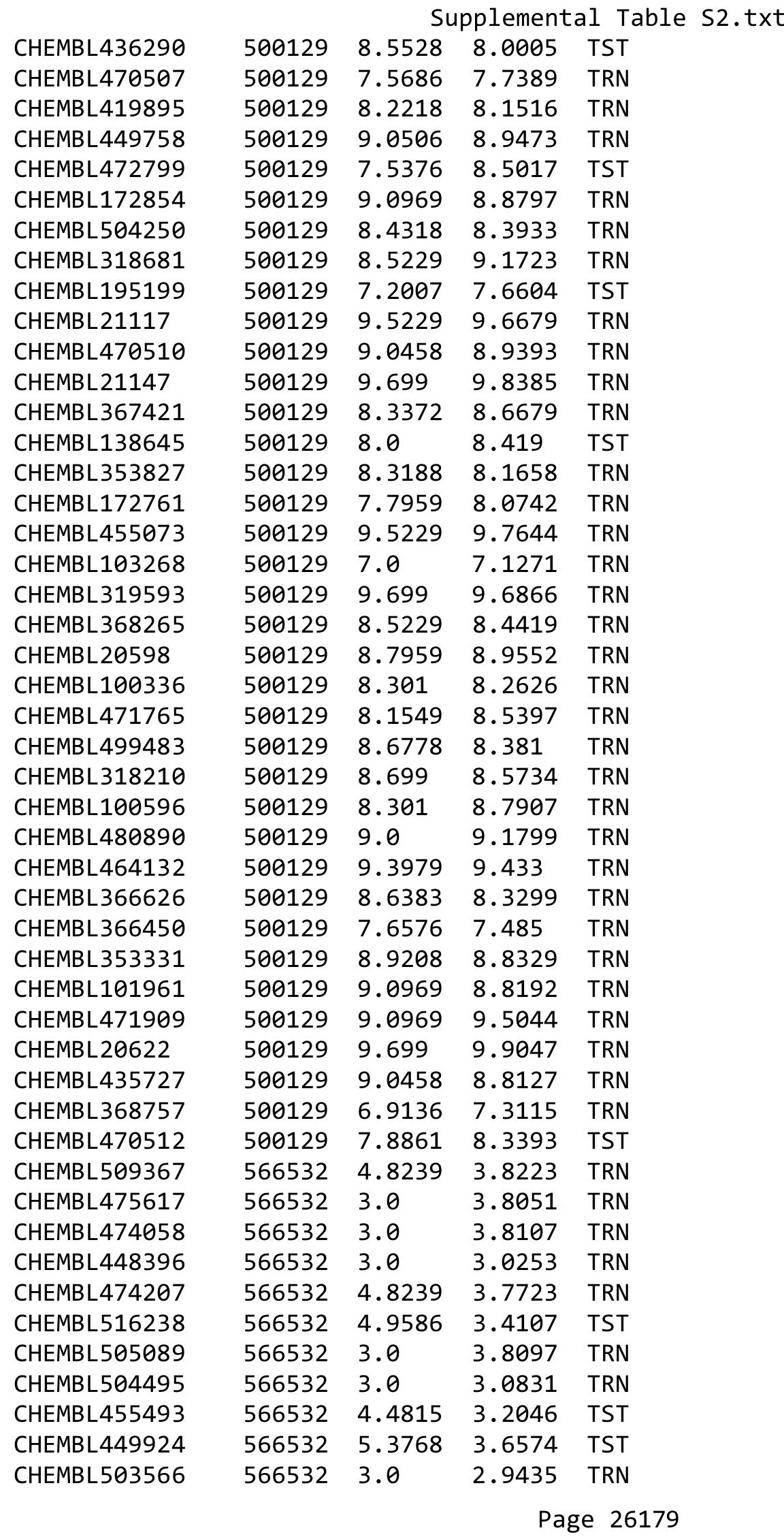




\begin{tabular}{|c|c|c|c|c|c|}
\hline \multicolumn{6}{|c|}{ Supplemental Table s2.txt } \\
\hline CHEMBL475030 & 566532 & 3.0 & 2.9312 & TRN & \\
\hline CHEMBL510907 & 566532 & 3.0 & 3.0711 & TRN & \\
\hline CHEMBL65747 & 566532 & 4.0 & 3.4561 & TST & \\
\hline CHEMBL151071 & 566532 & 3.0 & 3.5626 & TRN & \\
\hline CHEMBL468633 & 566532 & 4.5528 & 3.9298 & TRN & \\
\hline CHEMBL65976 & 566532 & 3.0 & 3.1367 & TRN & \\
\hline CHEMBL266094 & 566532 & 3.0 & 2.9653 & TRN & \\
\hline CHEMBL475023 & 566532 & 3.0 & 3.1804 & TRN & \\
\hline CHEMBL515419 & 566532 & 5.2076 & 3.7054 & TST & \\
\hline CHEMBL 304009 & 566532 & 3.0 & 3.1438 & TRN & \\
\hline CHEMBL508561 & 566532 & 3.0 & 3.7352 & TRN & \\
\hline CHEMBL505633 & 566532 & 3.0 & 3.7215 & TRN & \\
\hline CHEMBL466850 & 566532 & 3.0 & 2.8402 & TRN & \\
\hline CHEMBL95897 & 566532 & 3.0 & 3.0592 & TRN & \\
\hline CHEMBL506888 & 566532 & 4.699 & 3.8169 & TRN & \\
\hline CHEMBL475455 & 566532 & 5.4949 & 3.8584 & TRN & \\
\hline CHEMBL449628 & 566532 & 3.0 & 3.0488 & TRN & \\
\hline CHEMBL445974 & 566532 & 3.0 & 3.0533 & TRN & \\
\hline CHEMBL 294590 & 566532 & 4.8861 & 3.1507 & TST & \\
\hline CHEMBL466044 & 566532 & 3.0 & 3.2037 & TRN & \\
\hline CHEMBL183 & 566532 & 5.3979 & 3.627 & TST & \\
\hline CHEMBL510288 & 566532 & 3.0 & 3.8037 & TRN & \\
\hline CHEMBL503376 & 566532 & 3.5229 & 3.5213 & TRN & \\
\hline CHEMBL474396 & 566532 & 3.0 & 3.4107 & TST & \\
\hline CHEMBL445696 & 566532 & 3.0 & 2.9334 & TRN & \\
\hline CHEMBL449346 & 566532 & 3.0 & 2.8746 & TRN & \\
\hline CHEMBL475456 & 566532 & 3.0 & 2.8419 & TRN & \\
\hline CHEMBL447623 & 566532 & 3.0 & 2.8704 & TRN & \\
\hline CHEMBL446264 & 566532 & 4.8239 & 3.8561 & TST & \\
\hline CHEMBL472147 & 566532 & 3.0 & 2.8368 & TRN & \\
\hline CHEMBL469409 & 566532 & 3.0 & 3.0844 & TST & \\
\hline CHEMBL451363 & 566532 & 3.0 & 2.9123 & TRN & \\
\hline CHEMBL474623 & 566532 & 3.0 & 2.8309 & TRN & \\
\hline CHEMBL67199 & 566532 & 3.0 & 3.2369 & TRN & \\
\hline CHEMBL62835 & 566532 & 3.0 & 2.9842 & TST & \\
\hline CHEMBL494759 & 566532 & 3.0 & 3.0037 & TRN & \\
\hline CHEMBL449108 & 566532 & 3.0 & 2.9215 & TRN & \\
\hline CHEMBL63783 & 566532 & 3.0 & 2.9842 & TST & \\
\hline CHEMBL506450 & 566532 & 3.0 & 3.8771 & TST & \\
\hline CHEMBL164576 & 164909 & 5.3188 & 5.3069 & TRN & \\
\hline CHEMBL436056 & 164909 & 5.9031 & 5.9024 & TRN & \\
\hline CHEMBL164997 & 164909 & 6.2218 & 5.1864 & TST & \\
\hline CHEMBL445383 & 164909 & 3.2708 & 3.7002 & TST & \\
\hline CHEMBL164598 & 164909 & 5.8861 & 5.8888 & TRN & \\
\hline CHEMBL165082 & 164909 & 2.8539 & 2.8334 & TRN & \\
\hline CHEMBL350181 & 164909 & 3.5834 & $3.4930 e$ & 00000000003 & TRN \\
\hline CHEMBL167571 & 164909 & 3.1986 & 3.1859 & TRN & \\
\hline CHEMBL350779 & 164909 & 3.3206 & 3.30899 & 99999999997 & TRN \\
\hline & & & & 2618 & \\
\hline
\end{tabular}




\begin{tabular}{|c|c|c|c|c|c|c|}
\hline & & & & & & \\
\hline CHEMBL352193 & 164909 & 5.0969 & 4.305 & TST & & \\
\hline CHEMBL349758 & 164909 & 5.7447 & 5.7303 & TRN & & \\
\hline CHEMBL168163 & 164909 & 3.2865 & 3.3092 & TRN & & \\
\hline CHEMBL349399 & 164909 & 3.4225 & 3.4235 & TRN & & \\
\hline CHEMBL350349 & 164909 & 4.7212 & 4.7201 & TRN & & \\
\hline CHEMBL164589 & 164909 & 3.699 & 3.5168 & TRN & & \\
\hline CHEMBL351894 & 164909 & 6.0458 & 5.3633 & TST & & \\
\hline CHEMBL165027 & 164909 & 3.1707 & 3.1583 & TRN & & \\
\hline CHEMBL164591 & 164909 & 3.1494 & 3.2065 & TRN & & \\
\hline CHEMBL163902 & 164909 & 4.585 & 4.5983 & TRN & & \\
\hline CHEMBL164712 & 164909 & 5.3098 & 5.3007 & TRN & & \\
\hline CHEMBL164707 & 164909 & 3.68399 & 99999999 & 997 & 3.7008 & TRN \\
\hline CHEMBL164839 & 164909 & 5.9208 & 5.2056 & TST & & \\
\hline CHEMBL355604 & 164909 & 5.0315 & 5.0562 & TRN & & \\
\hline CHEMBL164379 & 164909 & 5.0177 & 5.0515 & TRN & & \\
\hline CHEMBL351005 & 164909 & 3.5986 & 3.6178 & TRN & & \\
\hline CHEMBL353759 & 164909 & 3.5171 & 3.3965 & TRN & & \\
\hline CHEMBL349607 & 164909 & 5.1591 & 5.1643 & TRN & & \\
\hline CHEMBL165091 & 164909 & 5.1427 & 5.1175 & TRN & & \\
\hline CHEMBL165157 & 164909 & 3.6144 & 3.6041 & TRN & & \\
\hline CHEMBL349705 & 164909 & 3.25100 & 30000000 & 003 & .2089 & TRN \\
\hline CHEMBL352684 & 164909 & 5.0269 & 4.9922 & TRN & & \\
\hline CHEMBL350866 & 164909 & 5.0088 & 5.2072 & TST & & \\
\hline CHEMBL349166 & 164909 & 3.1871 & 3.18899 & 99999999996 & & TRN \\
\hline CHEMBL353853 & 164909 & 5.0 & 4.7723 & TST & & \\
\hline CHEMBL349176 & 164909 & 3.6615 & 3.6733 & TRN & & \\
\hline CHEMBL349760 & 164909 & 2.8881 & 2.8406 & TRN & & \\
\hline CHEMBL164835 & 164909 & 3.383 & 3.3496 & TRN & & \\
\hline CHEMBL163969 & 164909 & 3.0438 & 3.2095 & TRN & & \\
\hline CHEMBL164172 & 164909 & 5.4949 & 4.9798 & TST & & \\
\hline CHEMBL167754 & 164909 & 5.4949 & 5.5321 & TRN & & \\
\hline CHEMBL168043 & 164909 & 3.5654 & 3.5598 & TRN & & \\
\hline CHEMBL348964 & 164909 & 5.7696 & 5.3607 & TST & & \\
\hline CHEMBL164245 & 164909 & 5.8239 & 5.41299 & 9999999999 & & TST \\
\hline CHEMBL353567 & 164909 & 3.0778 & 3.0226 & TRN & & \\
\hline CHEMBL354006 & 164909 & 3.6326 & 3.6913 & TRN & & \\
\hline CHEMBL165313 & 164909 & 5.0655 & 5.04899 & 99999999995 & & TRN \\
\hline CHEMBL333985 & 164909 & 5.0 & 5.2219 & TST & & \\
\hline CHEMBL166744 & 164909 & 3.4647 & 3.4621 & TRN & & \\
\hline CHEMBL349828 & 164909 & 3.5143 & 3.5114 & TRN & & \\
\hline CHEMBL351661 & 164909 & 3.2941 & 3.2867 & TRN & & \\
\hline CHEMBL434085 & 164909 & 4.8239 & 5.1015 & TST & & \\
\hline CHEMBL350533 & 164909 & 3.2306 & 3.2124 & TRN & & \\
\hline CHEMBL164590 & 164909 & 5.0605 & 5.1919 & TST & & \\
\hline CHEMBL165899 & 164909 & 3.4078 & 3.4566 & TRN & & \\
\hline CHEMBL353510 & 164909 & 2.9825 & 3.1838 & TRN & & \\
\hline CHEMBL167292 & 164909 & 4.6904 & 5.4997 & TST & & \\
\hline CHEMBL164448 & 164909 & 4.7959 & 5.1125 & TST & & \\
\hline
\end{tabular}




\begin{tabular}{|c|c|c|c|c|c|}
\hline \multicolumn{6}{|c|}{ Supplemental Table S2.txt } \\
\hline CHEMBL164648 & 164909 & 3.3851 & 3.4524 & TRN & \\
\hline CHEMBL3349128 & 36310 & 3.0 & 3.1446 & TRN & \\
\hline CHEMBL3349099 & 36310 & 4.0 & 4.0154 & TRN & \\
\hline CHEMBL574897 & 36310 & 5.0 & 4.0495 & TST & \\
\hline CHEMBL 3085570 & 36310 & 6.2518 & 6.4035 & TRN & \\
\hline CHEMBL590709 & 36310 & 3.0 & 3.742 & TRN & \\
\hline CHEMBL3349154 & 36310 & 3.0 & 3.1696 & TRN & \\
\hline CHEMBL1790284 & 36310 & 5.7212 & 6.5096 & TRN & \\
\hline CHEMBL3349100 & 36310 & 7.0506 & 5.5198 & TST & \\
\hline CHEMBL3349210 & 36310 & 7.6383 & 5.1252 & TST & \\
\hline CHEMBL3349072 & 36310 & 6.0315 & 6.0319 & TRN & \\
\hline CHEMBL3349293 & 36310 & 6.8539 & 6.9299 & TST & \\
\hline CHEMBL1563246 & 36310 & 6.4815 & 5.1169 & TST & \\
\hline CHEMBL3349073 & 36310 & 6.0177 & 5.6311 & TRN & \\
\hline CHEMBL3349149 & 36310 & 5.0969 & 4.9897 & TRN & \\
\hline CHEMBL3349077 & 36310 & 8.8239 & 7.2539 & TST & \\
\hline CHEMBL3349130 & 36310 & 6.6778 & 6.0529 & TRN & \\
\hline CHEMBL3349095 & 36310 & 7.0 & 6.6186 & TRN & \\
\hline CHEMBL572724 & 36310 & 6.3468 & 6.3512 & TRN & \\
\hline CHEMBL3349076 & 36310 & 4.0 & 4.1991 & TRN & \\
\hline CHEMBL3349084 & 36310 & 6.2366 & 6.3193 & TRN & \\
\hline CHEMBL3349153 & 36310 & 3.0 & 5.5174 & TRN & \\
\hline CHEMBL3349127 & 36310 & 3.0 & 2.6202 & TRN & \\
\hline CHEMBL1790293 & 36310 & 4.6778 & 4.5679 & TRN & \\
\hline CHEMBL3349104 & 36310 & 6.3565 & 5.7486 & TRN & \\
\hline CHEMBL3349113 & 36310 & 6.7696 & 6.9468 & TRN & \\
\hline CHEMBL1230438 & 36310 & 7.699 & 6.3787 & TST & \\
\hline CHEMBL3349122 & 36310 & 7.9208 & 4.77800 & 00000000005 & TST \\
\hline CHEMBL3349137 & 36310 & 3.0 & 3.0467 & TRN & \\
\hline CHEMBL2298401 & 36310 & 4.7959 & 4.7284 & TRN & \\
\hline CHEMBL583743 & 36310 & 6.7696 & 6.1835 & TRN & \\
\hline CHEMBL 3349290 & 36310 & 5.6021 & 5.1556 & TST & \\
\hline CHEMBL3349090 & 36310 & 5.7696 & 5.968 & TRN & \\
\hline CHEMBL3349138 & 36310 & 4.3372 & 4.9698 & TRN & \\
\hline CHEMBL3349129 & 36310 & 6.4685 & 7.0844 & TRN & \\
\hline CHEMBL3349160 & 36310 & 6.8239 & 6.3776 & TRN & \\
\hline CHEMBL3349141 & 36310 & 6.5376 & 6.6128 & TRN & \\
\hline CHEMBL3349105 & 36310 & 6.8861 & 6.1184 & TRN & \\
\hline CHEMBL1790288 & 36310 & 4.3188 & 5.0285 & TRN & \\
\hline CHEMBL3349111 & 36310 & 5.9586 & 6.1401 & TRN & \\
\hline CHEMBL3185181 & 36310 & 5.0506 & 3.9901 & TST & \\
\hline CHEMBL 575767 & 36310 & 6.3979 & 4.9288 & TST & \\
\hline CHEMBL3349088 & 36310 & 4.7696 & 6.1184 & TRN & \\
\hline CHEMBL3349126 & 36310 & 6.4685 & 3.8513 & TST & \\
\hline CHEMBL3349147 & 36310 & 6.301 & 7.1081 & TST & \\
\hline CHEMBL3349075 & 36310 & 3.0 & 3.7406 & TRN & \\
\hline CHEMBL3349078 & 36310 & 6.8539 & 4.949 & TST & \\
\hline CHEMBL3349170 & 36310 & 6.1675 & 5.3736 & TRN & \\
\hline
\end{tabular}




\begin{tabular}{|c|c|c|c|c|}
\hline & & & pplement & al $\mathrm{Tc}$ \\
\hline CHEMBL3349166 & 36310 & 5.4318 & 5.4022 & TRN \\
\hline CHEMBL 2298402 & 36310 & 5.5686 & 4.9412 & TRN \\
\hline CHEMBL574911 & 36310 & 5.4949 & 4.7306 & TRN \\
\hline CHEMBL3349151 & 36310 & 3.0 & 3.8216 & TRN \\
\hline CHEMBL3349168 & 36310 & 3.0 & 3.4114 & TRN \\
\hline CHEMBL572946 & 36310 & 4.0 & 3.8783 & TRN \\
\hline CHEMBL3349143 & 36310 & 4.8239 & 4.8771 & TRN \\
\hline CHEMBL1790294 & 36310 & 4.3372 & 4.596 & TRN \\
\hline CHEMBL 3349288 & 36310 & 6.0315 & 6.3097 & TRN \\
\hline CHEMBL1790279 & 36310 & 6.0655 & 6.3867 & TRN \\
\hline CHEMBL3349093 & 36310 & 4.301 & 5.1132 & TRN \\
\hline CHEMBL3349150 & 36310 & 7.1938 & 6.5696 & TRN \\
\hline CHEMBL3349144 & 36310 & 6.3768 & 5.5982 & TRN \\
\hline CHEMBL 2298404 & 36310 & 5.7447 & 5.3109 & TRN \\
\hline CHEMBL3349289 & 36310 & 4.8861 & 5.9835 & TST \\
\hline CHEMBL1790287 & 36310 & 6.3665 & 5.445 & TRN \\
\hline CHEMBL567823 & 36310 & 4.0 & 4.2902 & TRN \\
\hline CHEMBL3349101 & 36310 & 5.8861 & 3.3681 & TST \\
\hline CHEMBL3349114 & 36310 & 7.0506 & 6.9566 & TST \\
\hline CHEMBL 2298410 & 36310 & 7.1805 & 7.1302 & TRN \\
\hline CHEMBL3349118 & 36310 & 5.284 & 4.1559 & TRN \\
\hline CHEMBL3349510 & 36310 & 5.2676 & 4.0621 & TST \\
\hline CHEMBL3349108 & 36310 & 6.2218 & 5.3851 & TRN \\
\hline CHEMBL 2298403 & 36310 & 6.1487 & 5.1864 & TRN \\
\hline CHEMBL3349159 & 36310 & 5.0 & 5.9116 & TRN \\
\hline CHEMBL 3349087 & 36310 & 6.9586 & 7.8906 & TST \\
\hline CHEMBL3349158 & 36310 & 4.7447 & 3.2106 & TRN \\
\hline CHEMBL3349083 & 36310 & 4.6021 & 3.6152 & TST \\
\hline CHEMBL3349512 & 36310 & 6.7212 & 4.1941 & TST \\
\hline CHEMBL3349156 & 36310 & 3.0 & 3.1197 & TRN \\
\hline CHEMBL3349152 & 36310 & 4.0 & 4.5164 & TRN \\
\hline CHEMBL3349148 & 36310 & 7.8239 & 7.8448 & TRN \\
\hline CHEMBL3349094 & 36310 & 6.5686 & 6.5721 & TRN \\
\hline CHEMBL 2295868 & 36310 & 5.2147 & 5.2505 & TRN \\
\hline CHEMBL3349086 & 36310 & 8.1308 & 6.9258 & TST \\
\hline CHEMBL3349134 & 36310 & 7.8861 & 7.7086 & TRN \\
\hline CHEMBL3349132 & 36310 & 4.4949 & 4.4637 & TRN \\
\hline CHEMBL3349089 & 36310 & 3.0 & 3.6662 & TRN \\
\hline CHEMBL3349106 & 36310 & 5.1487 & 5.6623 & TRN \\
\hline CHEMBL3349112 & 36310 & 5.9586 & 5.9892 & TRN \\
\hline CHEMBL584295 & 36310 & 7.0809 & 7.0473 & TRN \\
\hline CHEMBL559246 & 36310 & 8.6198 & 8.9482 & TRN \\
\hline CHEMBL3349070 & 36310 & 3.0 & 3.7664 & TRN \\
\hline CHEMBL3349096 & 36310 & 4.0 & 4.1382 & TRN \\
\hline CHEMBL572678 & 36310 & 5.1938 & 4.5234 & TST \\
\hline CHEMBL3349180 & 36310 & 6.0 & 5.7699 & TST \\
\hline CHEMBL3349125 & 36310 & 5.0315 & 4.7278 & TRN \\
\hline CHEMBL3349119 & 36310 & 6.6021 & 6.2412 & TRN \\
\hline
\end{tabular}




\begin{tabular}{|c|c|c|c|c|c|}
\hline \multirow[b]{2}{*}{ CHEMBL3349135 } & \multicolumn{5}{|c|}{ Supplemental Table S2.txt } \\
\hline & 36310 & 5.8239 & 5.2268 & TST & \\
\hline CHEMBL3349167 & 36310 & 6.1024 & 5.8821 & TRN & \\
\hline CHEMBL3349103 & 36310 & 6.0269 & 5.1912 & TRN & \\
\hline CHEMBL 2311174 & 36310 & 7.7212 & 7.9616 & TRN & \\
\hline CHEMBL3349071 & 36310 & 4.1675 & 4.0519 & TRN & \\
\hline CHEMBL3349145 & 36310 & 5.0 & 5.7395 & TRN & \\
\hline CHEMBL3349109 & 36310 & 4.0 & 3.5495 & TRN & \\
\hline CHEMBL 3085568 & 36310 & 5.041 & 5.1791 & TRN & \\
\hline CHEMBL3349165 & 36310 & 6.8239 & 6.7449 & TRN & \\
\hline CHEMBL573180 & 36310 & 4.8539 & 3.5869 & TST & \\
\hline CHEMBL3349169 & 36310 & 5.7959 & 5.3253 & TRN & \\
\hline CHEMBL3349116 & 36310 & 6.9208 & 6.6871 & TRN & \\
\hline CHEMBL3349097 & 36310 & 5.699 & 6.2805 & TST & \\
\hline CHEMBL3349162 & 36310 & 3.0 & 3.6703 & TRN & \\
\hline CHEMBL3349139 & 36310 & 3.0 & 3.0678 & TRN & \\
\hline CHEMBL3349146 & 36310 & 7.0506 & 7.0362 & TRN & \\
\hline CHEMBL2298601 & 36310 & 5.5528 & 5.3727 & TRN & \\
\hline CHEMBL 3349157 & 36310 & 3.0 & 2.7909 & TRN & \\
\hline CHEMBL3349098 & 36310 & 6.2676 & 5.359 & TRN & \\
\hline CHEMBL1790280 & 36310 & 7.1308 & 6.7075 & TST & \\
\hline CHEMBL3349121 & 36310 & 5.4949 & 5.3404 & TST & \\
\hline CHEMBL3349120 & 36310 & 7.5229 & 5.3359 & TST & \\
\hline CHEMBL 3622633 & 1520607 & 6.2414 & 5.8091 & TRN & \\
\hline CHEMBL 3622673 & 1520607 & 8.2147 & 8.3496 & TRN & \\
\hline CHEMBL 3622623 & 1520607 & 6.87 & 6.8232 & TRN & \\
\hline CHEMBL 3622646 & 1520607 & 5.0 & 5.6214 & TRN & \\
\hline CHEMBL 3622674 & 1520607 & 8.4815 & 8.2687 & TRN & \\
\hline CHEMBL 3622655 & 1520607 & 8.2596 & 8.3007 & TRN & \\
\hline CHEMBL 3622650 & 1520607 & 8.2757 & 8.612 & TRN & \\
\hline CHEMBL 3622670 & 1520607 & 8.1549 & 8.0636 & TRN & \\
\hline CHEMBL 3621220 & 1520607 & 6.9905 & 7.1876 & TST & \\
\hline CHEMBL 3622635 & 1520607 & 5.0 & 6.3714 & TRN & \\
\hline CHEMBL 3622619 & 1520607 & 6.9389 & 6.5259 & TRN & \\
\hline CHEMBL3622638 & 1520607 & 8.0 & 7.9592 & TST & \\
\hline CHEMBL 3622645 & 1520607 & 8.9208 & 8.4055 & TRN & \\
\hline CHEMBL 3622656 & 1520607 & 5.0 & 5.34399 & 9999999999 & TRN \\
\hline CHEMBL 3622666 & 1520607 & 8.1871 & 8.4229 & TRN & \\
\hline CHEMBL 3622661 & 1520607 & 5.0 & 4.6784 & TRN & \\
\hline CHEMBL 3622668 & 1520607 & 8.1612 & 7.9738 & TRN & \\
\hline CHEMBL 3622639 & 1520607 & 8.9208 & 8.3338 & TRN & \\
\hline CHEMBL 3622620 & 1520607 & 6.7082 & 6.3902 & TRN & \\
\hline CHEMBL 3622637 & 1520607 & 8.2676 & 7.2452 & TST & \\
\hline CHEMBL3622641 & 1520607 & 6.2923 & 7.2016 & TST & \\
\hline CHEMBL 3622675 & 1520607 & 8.6198 & 8.5341 & TRN & \\
\hline CHEMBL 3622667 & 1520607 & 8.0177 & 8.1451 & TRN & \\
\hline CHEMBL 3622664 & 1520607 & 9.0458 & 8.883 & TRN & \\
\hline CHEMBL 3622678 & 1520607 & 8.3768 & 8.5973 & TRN & \\
\hline CHEMBL 3622629 & 1520607 & 8.2366 & 8.3252 & TRN & \\
\hline
\end{tabular}

Page 26184 
Supplemental Table S2.txt

\begin{tabular}{|c|c|c|c|c|c|}
\hline CHEMBL 3622658 & 1520607 & 6.961 & 6.3576 & TRN & \\
\hline CHEMBL 3622679 & 1520607 & 8.1938 & 7.9673 & TRN & \\
\hline CHEMBL 3622625 & 1520607 & 7.4921 & 8.1034 & TRN & \\
\hline CHEMBL 3622622 & 1520607 & 7.1415 & 7.7457 & TST & \\
\hline CHEMBL 3622636 & 1520607 & 7.041 & 8.1235 & TST & \\
\hline CHEMBL 3622677 & 1520607 & 8.1024 & 8.3652 & TRN & \\
\hline CHEMBL3622669 & 1520607 & 6.8508 & 6.5914 & TRN & \\
\hline CHEMBL 3622644 & 1520607 & 8.0458 & 7.6739 & TST & \\
\hline CHEMBL 3622671 & 1520607 & 8.2757 & 8.1522 & TRN & \\
\hline CHEMBL 3622627 & 1520607 & 5.0 & 6.2694 & TRN & \\
\hline CHEMBL 3622649 & 1520607 & 8.0915 & 8.0776 & TRN & \\
\hline CHEMBL 3622643 & 1520607 & 8.0915 & 7.0182 & TST & \\
\hline CHEMBL 3622654 & 1520607 & 8.0506 & 8.1993 & TRN & \\
\hline CHEMBL 3622652 & 1520607 & 6.2838 & 6.3167 & TRN & \\
\hline CHEMBL 3622660 & 1520607 & 5.0 & 4.585 & TRN & \\
\hline CHEMBL 3622624 & 1520607 & 6.9996 & 7.4749 & TST & \\
\hline CHEMBL 3622648 & 1520607 & 8.2218 & 8.3521 & TRN & \\
\hline CHEMBL 3622676 & 1520607 & 8.2518 & 8.1095 & TRN & \\
\hline CHEMBL 3622634 & 1520607 & 6.9901 & 6.7069 & TRN & \\
\hline CHEMBL 3622657 & 1520607 & 5.0 & 5.987 & TRN & \\
\hline CHEMBL 3622665 & 1520607 & 8.6778 & 8.4575 & TRN & \\
\hline CHEMBL3622630 & 1520607 & 6.9169 & 7.6896 & TST & \\
\hline CHEMBL3622617 & 1520607 & 8.7447 & 8.1717 & TST & \\
\hline CHEMBL 3622632 & 1520607 & 8.9208 & 8.5309 & TST & \\
\hline CHEMBL 3622653 & 1520607 & 7.5702 & 7.8387 & TRN & \\
\hline CHEMBL 3622662 & 1520607 & 5.0 & 4.9671 & TRN & \\
\hline CHEMBL3622631 & 1520607 & 5.0 & 7.3265 & TST & \\
\hline CHEMBL 3622647 & 1520607 & 6.8315 & 6.461 & TRN & \\
\hline CHEMBL 3622651 & 1520607 & 8.6778 & 8.7683 & TRN & \\
\hline CHEMBL 3622640 & 1520607 & 8.5229 & 7.7296 & TST & \\
\hline CHEMBL 3622621 & 1520607 & 6.2515 & 7.0714 & TST & \\
\hline CHEMBL 3622618 & 1520607 & 5.0 & 5.5992 & TRN & \\
\hline CHEMBL3622626 & 1520607 & 6.9801 & 5.63200 & 0000000001 & TRN \\
\hline CHEMBL 3622663 & 1520607 & 5.0 & 5.0334 & TRN & \\
\hline CHEMBL 3622672 & 1520607 & 8.5686 & 8.2115 & TRN & \\
\hline CHEMBL 3622628 & 1520607 & 6.7765 & 6.6051 & TRN & \\
\hline CHEMBL3622659 & 1520607 & 6.4478 & 6.4339 & TRN & \\
\hline CHEMBL 3622642 & 1520607 & 6.8732 & 7.9511 & TST & \\
\hline CHEMBL 3925687 & 1640465 & 6.3768 & 6.8225 & TRN & \\
\hline CHEMBL 3933748 & 1640465 & 6.2076 & 5.6892 & TRN & \\
\hline CHEMBL 3962534 & 1640465 & 6.5528 & 6.1764 & TRN & \\
\hline CHEMBL 3982994 & 1640465 & 4.1739 & 5.6457 & TRN & \\
\hline CHEMBL3932609 & 1640465 & 5.8861 & 4.8055 & TRN & \\
\hline CHEMBL 3891722 & 1640465 & 8.0 & 7.0792 & TRN & \\
\hline CHEMBL 3915424 & 1640465 & 4.1759 & 6.0722 & TRN & \\
\hline CHEMBL1290144 & 1640465 & 6.9586 & 6.4742 & TRN & \\
\hline CHEMBL 3907261 & 1640465 & 8.699 & 8.1713 & TRN & \\
\hline CHEMBL 3973014 & 1640465 & 6.8539 & 7.2118 & TRN & \\
\hline
\end{tabular}

Page 26185 
Supplemental Table S2.txt

\begin{tabular}{|c|c|c|c|c|}
\hline - & & 5.7212 & & \\
\hline HEMBL3911305 & & 4.1759 & 5.8593 & \\
\hline 577 & & 49 & & \\
\hline HEMBL3934700 & 640465 & 6.0 & 5376 & \\
\hline AEMBL3917165 & 640465 & 458 & & \\
\hline HEMBL3920198 & 640465 & 7.0969 & 0759 & \\
\hline 186 & & 372 & 7759 & \\
\hline IEMBL396 & & & 199 & \\
\hline AEMBL3930858 & $64 €$ & 6.8861 & 5712 & \\
\hline HEMBL3986293 & 640 & 6.284 & 176 & \\
\hline HEMBL3972081 & 64 & 7.3979 & 7618 & \\
\hline IEMBL393 & 64 & 291 & 937 & \\
\hline AEMBL39 & & & 278 & \\
\hline HEMBL 390 & $61+2-1$ & 6.0757 & 5689 & \\
\hline AEMBL 389 & 64 & 376 & 666 & \\
\hline AEMBL391 & 64 & 665 & 2975 & \\
\hline HEMBL12 & 64 & 447 & 543 & \\
\hline HEMBL 12 & & & 3534 & \\
\hline HEMBL 12 & $61+2+3$ & 99 & 5163 & \\
\hline AEMBL39 & 5 & 759 & & \\
\hline HEIMBLSS & 64 & 7 & 85 & KIV \\
\hline AEMBL39 & & 51 & 163 & RN \\
\hline AEMBL39 & & 528 & 202 & \\
\hline HFMRI 380 & & 7. & 014 & \\
\hline AEMBL391 & & & & $1=2+3$ \\
\hline HEMBL39 & 64 & & 578 & RN \\
\hline HEMBL3S & P & 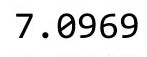 & 804 & Niv \\
\hline HFMBI $3 c$ & & 7. & 159 & CT \\
\hline AEMBL3S & & 239 & 5326 & TS \\
\hline HEMBL 394 & 64 & & 599 & IK \\
\hline HEMBL396 & 64 & 6 & 054 & SI \\
\hline HEMBL3 & 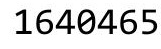 & 59 & 651 & RN \\
\hline ALMP & & & 375 & RN \\
\hline HEMBL 393 & & 7. & 859 & IRN \\
\hline HEMBL 3892154 & $a_{1}+2$ & & 719 & TR \\
\hline HEMBL 389 & 64 & 0 & 105 & RIN \\
\hline HFMRI 3 & J & 8. & 361 & $\Gamma \mathrm{RN}$ \\
\hline HEMBL39 & & 7. & 704 & 「RN \\
\hline HEMBL3983523 & 64 & 5.9586 & 2061 & TST \\
\hline HEMBL 395 & 64 & 979 & 5695 & TRN \\
\hline HEMBL 395 & 64 & 6 & 128 & ГRN \\
\hline HEMBL 392 & & 6 & 5.9623 & ו \\
\hline HEMBL3894299 & 164 & 7.1367 & 7694 & TRN \\
\hline AEMBL3974334 & 64 & 4.6576 & 1335 & rS \\
\hline HEMBL39 & & 979 & & $\mathrm{~N}$ \\
\hline LHEMBL 397 & & 861 & 4889 & \\
\hline LHEMBL 3894440 & 164 & 6.8861 & .9879 & \\
\hline HEMBL3962929 & 1640465 & 6.2007 & 6.3725 & ГRN \\
\hline
\end{tabular}

Page 26186 
Supplemental Table S2.txt

\begin{tabular}{|c|c|c|c|c|}
\hline HEMBL & נטדרטי & 5229 & .7537 & \\
\hline HEMBL3894322 & 640465 & 7.1549 & 6.1353 & \\
\hline 713 & & & & \\
\hline HEMBL39 & & & & \\
\hline AEMBL1289500 & 640465 & 2676 & 5566 & \\
\hline HEMBL3978268 & 640465 & 6.3279 & 7335 & \\
\hline HEMBL397 & 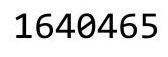 & & 5213 & \\
\hline HEMBL394 & & & & קח \\
\hline AEMBL3938772 & 640 & & 2257 & \\
\hline HEMBL3945467 & 640 & & 5431 & \\
\hline HEMBL3971194 & 64 & & $\partial 427$ & \\
\hline IEMBL392 & 64 & & 759 & \\
\hline HEMBL 391 & & & & \\
\hline HEMBL1289266 & 64 & & 5956 & \\
\hline AEMBL128 & $64 e$ & 6 & 4271 & \\
\hline HEMBL397 & 64 & 7. & 361 & \\
\hline HEMBL398 & 64 & & 896 & \\
\hline HEMBL 390 & & & & \\
\hline HEMBL396 & 61 & & 2929 & \\
\hline HEMBL39e & 64 & & & \\
\hline AEMBL39 & 64 & & 38 & ונד \\
\hline HEMBL12 & 62 & & 18 & I \\
\hline HEMBL39 & & & 83 & \\
\hline HEMBL 392 & & & & \\
\hline AEMBL391 & & & & $\Gamma \mathrm{RN}$ \\
\hline HEMBL39 & 64 & & & SI \\
\hline HEMBL39 & 64 & & & RN \\
\hline HFMBI 12 & 5 & & 63 & \\
\hline HEMBL 39 & & & 234 & 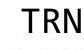 \\
\hline HEMBL3942656 & 64 & & & s \\
\hline HEMBL 389 & 64 & & 183 & RN \\
\hline HEMBL3S & 64 & 8 & 45 & RN \\
\hline HEMBL3 & & 7 & 772 & R \\
\hline HEMBL 398 & 64 & & 1835 & IRN \\
\hline HEMBL3894994 & 640 & & 368 & TRN \\
\hline HEMBL 394 & 6 & & 048 & TRN \\
\hline HEMRI 3 & & & 717 & ST \\
\hline HEMBL393 & & & 864 & $\Gamma \mathrm{RN}$ \\
\hline HEMBL3946236 & 646 & & 829 & TST \\
\hline HEMBL 391 & 61 & & 147 & TRN \\
\hline HEMBL396 & 64 & & 766 & \\
\hline CHEMBL163 & 161 & & 5.8544 & RN \\
\hline HEMBL3910272 & 164 & & 6439 & RN \\
\hline HEMBL3959645 & $64 t$ & & 5712 & TRN \\
\hline MBL39 & & & & \\
\hline HEMBL 392 & 64 & & 3491 & \\
\hline CHEMBL3986482 & 1640 & 5.74 & .186 & \\
\hline CHEMBL3973746 & 1640465 & 6.4318 & 6.0535 & ГRN \\
\hline
\end{tabular}

Page 26187 
Supplemental Table S2.txt

\begin{tabular}{|c|c|c|c|c|}
\hline CHEMBL 3921782 & 1640465 & 6.0 & 6.4681 & TRN \\
\hline CHEMBL1290705 & 1640465 & 7.699 & 7.3343 & TRN \\
\hline CHEMBL3986669 & 1640465 & 7.1549 & 7.4501 & TRN \\
\hline CHEMBL3967074 & 1640465 & 5.3546 & 5.7214 & TRN \\
\hline CHEMBL3961136 & 1640465 & 6.8861 & 7.1474 & TRN \\
\hline CHEMBL3973472 & 1640465 & 6.0 & 6.3178 & TRN \\
\hline CHEMBL3954599 & 1640465 & 4.1759 & 4.525 & TRN \\
\hline CHEMBL1630619 & 1640465 & 6.0 & 6.3865 & TRN \\
\hline CHEMBL 3938880 & 1640465 & 6.7447 & 7.3808 & TRN \\
\hline CHEMBL3954474 & 1640465 & 6.3188 & 6.0688 & TRN \\
\hline CHEMBL3956462 & 1640465 & 7.5229 & 7.0381 & TRN \\
\hline CHEMBL 3899524 & 1640465 & 3.699 & 5.5074 & TRN \\
\hline CHEMBL3910339 & 1640465 & 6.9586 & 6.58899 & 99999999995 \\
\hline CHEMBL 3912852 & 1640465 & 5.7959 & 5.6398 & TST \\
\hline CHEMBL3928234 & 1640465 & 6.2596 & 6.4006 & TRN \\
\hline CHEMBL1289607 & 1640465 & 6.0 & 6.7716 & TRN \\
\hline CHEMBL3929543 & 1640465 & 7.7212 & 7.2442 & TRN \\
\hline CHEMBL1290036 & 1640465 & 5.5243 & 5.0498 & TRN \\
\hline CHEMBL 3894388 & 1640465 & 7.3979 & 7.5078 & TRN \\
\hline CHEMBL1290372 & 1640465 & 5.7122 & 5.7008 & TST \\
\hline CHEMBL3945933 & 1640465 & 8.301 & 7.6448 & TRN \\
\hline CHEMBL 3898430 & 1640465 & 4.1759 & 5.7714 & TRN \\
\hline CHEMBL 3938521 & 1640465 & 6.0915 & 7.2228 & TST \\
\hline CHEMBL 3945761 & 1640465 & 7.699 & 7.0243 & TRN \\
\hline CHEMBL3923408 & 1640465 & 7.0458 & 7.6382 & TRN \\
\hline CHEMBL 3982151 & 1640465 & 5.767 & 6.1163 & TRN \\
\hline CHEMBL 3889561 & 1640465 & 5.4815 & 5.8048 & TRN \\
\hline CHEMBL 3923415 & 1640465 & 5.5467 & 6.9329 & TRN \\
\hline CHEMBL 3950920 & 1640465 & 6.5528 & 7.1607 & TRN \\
\hline CHEMBL 3954464 & 1640465 & 7.0458 & 6.5146 & TRN \\
\hline CHEMBL3960122 & 1640465 & 5.0297 & 5.4116 & TRN \\
\hline CHEMBL 3892896 & 1640465 & 6.3768 & 6.5388 & TRN \\
\hline CHEMBL 3953429 & 1640465 & 8.0 & 7.7102 & TRN \\
\hline CHEMBL3959968 & 1640465 & 6.4089 & 6.263 & TRN \\
\hline CHEMBL1289933 & 1640465 & 6.0 & 6.1102 & TRN \\
\hline CHEMBL3957371 & 1640465 & 6.2147 & 5.7656 & TST \\
\hline CHEMBL 3917868 & 1640465 & 7.699 & 8.173 & TRN \\
\hline CHEMBL3972105 & 1640465 & 6.8861 & 7.2687 & TRN \\
\hline CHEMBL1289608 & 1640465 & 6.9208 & 6.4183 & TRN \\
\hline CHEMBL 3942472 & 1640465 & 7.5229 & 7.3328 & TRN \\
\hline CHEMBL 3982572 & 1640465 & 5.7595 & 7.7552 & TST \\
\hline CHEMBL 3891783 & 1640465 & 6.0 & 6.3931 & TST \\
\hline CHEMBL3897716 & 1640465 & 8.0 & 6.5413 & TRN \\
\hline CHEMBL 3977828 & 1640465 & 6.5086 & 6.7308 & TRN \\
\hline CHEMBL 3934522 & 1640465 & 6.7212 & 8.2289 & TST \\
\hline CHEMBL 3985130 & 1640465 & 7.5229 & 6.3167 & TRN \\
\hline CHEMBL1290145 & 1640465 & 6.0757 & 4.9795 & TRN \\
\hline CHEMBL3978435 & 1640465 & 7.3979 & 7.7102 & TRN \\
\hline
\end{tabular}

Page 26188 
Supplemental Table S2.txt

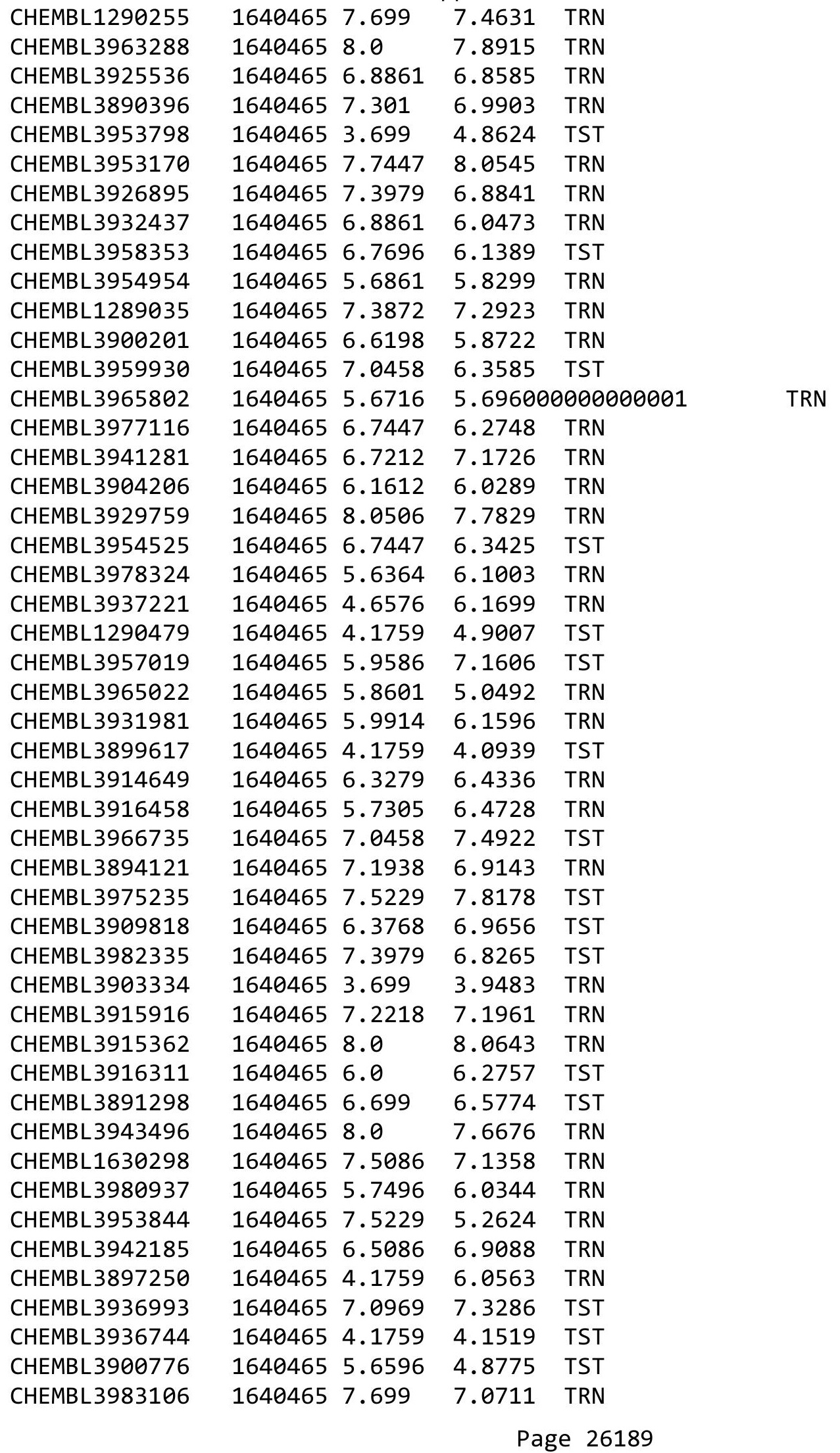


Supplemental Table S2.txt

\begin{tabular}{|c|c|c|c|c|}
\hline CHEMBL1289712 & 1640465 & 7.6576 & 7.5149 & TRN \\
\hline CHEMBL3911794 & 1640465 & 4.1739 & 4.0987 & TRN \\
\hline CHEMBL3968373 & 1640465 & 6.4685 & 6.7247 & TRN \\
\hline CHEMBL3931928 & 1640465 & 7.0969 & 7.0897 & TRN \\
\hline CHEMBL3978165 & 1640465 & 6.7959 & 8.0381 & TRN \\
\hline CHEMBL3928469 & 1640465 & 8.0 & 6.7387 & TST \\
\hline CHEMBL3970608 & 1640465 & 4.1759 & 6.2974 & TRN \\
\hline CHEMBL3961217 & 1640465 & 8.5229 & 6.7078 & TRN \\
\hline CHEMBL3954625 & 1640465 & 7.5229 & 4.9134 & TRN \\
\hline CHEMBL1290256 & 1640465 & 6.7696 & 6.4478 & TRN \\
\hline CHEMBL 3924788 & 1640465 & 7.2218 & 7.1622 & TRN \\
\hline CHEMBL1289934 & 1640465 & 7.3979 & 7.3057 & TRN \\
\hline CHEMBL3928676 & 1640465 & 6.585 & 6.2489 & TRN \\
\hline CHEMBL3936281 & 1640465 & 3.699 & 4.3624 & TST \\
\hline CHEMBL3948000 & 1640465 & 5.7799 & 5.9156 & TRN \\
\hline CHEMBL3901792 & 1640465 & 7.699 & 7.6084 & TRN \\
\hline CHEMBL3928587 & 1640465 & 4.1739 & 6.3392 & TRN \\
\hline CHEMBL3971599 & 1640465 & 7.301 & 6.5898 & TRN \\
\hline CHEMBL3961842 & 1640465 & 7.5229 & 7.5876 & TRN \\
\hline CHEMBL1290035 & 1640465 & 6.2924 & 5.7851 & TRN \\
\hline CHEMBL3907452 & 1640465 & 3.699 & 4.1254 & TST \\
\hline CHEMBL3929305 & 1640465 & 6.9208 & 6.6367 & TRN \\
\hline CHEMBL3956653 & 1640465 & 7.0 & 6.7908 & TRN \\
\hline CHEMBL3925809 & 1640465 & 7.5229 & 7.3525 & TRN \\
\hline CHEMBL3938061 & 1640465 & 7.0458 & 6.9533 & TRN \\
\hline CHEMBL3899860 & 1640465 & 6.7696 & 6.8954 & TRN \\
\hline CHEMBL3892895 & 1640465 & 7.3768 & 6.9784 & TRN \\
\hline CHEMBL3924126 & 1640465 & 6.2007 & 5.9191 & TRN \\
\hline CHEMBL3929597 & 1640465 & 7.0458 & 6.6825 & TRN \\
\hline CHEMBL3985029 & 1640465 & 4.1739 & 4.577 & TST \\
\hline CHEMBL3949850 & 1640465 & 4.1759 & 6.5013 & TRN \\
\hline CHEMBL3977078 & 1640465 & 5.5331 & 5.6621 & TRN \\
\hline CHEMBL3968598 & 1640465 & 8.1675 & 7.8203 & TRN \\
\hline CHEMBL3981968 & 1640465 & 6.301 & 6.1265 & TRN \\
\hline CHEMBL3985031 & 1640465 & 4.1739 & 4.7243 & TRN \\
\hline CHEMBL3923475 & 1640465 & 7.5229 & 6.8813 & TRN \\
\hline CHEMBL3975868 & 1640465 & 5.7773 & 6.5924 & TRN \\
\hline CHEMBL1289265 & 1640465 & 6.0315 & 6.2369 & TRN \\
\hline CHEMBL1289383 & 1640465 & 7.5686 & 6.8049 & TRN \\
\hline CHEMBL3931987 & 1640465 & 4.1739 & 4.348 & TRN \\
\hline CHEMBL3956609 & 1640465 & 5.5702 & 6.1355 & TRN \\
\hline CHEMBL3932917 & 1640465 & 6.2518 & 6.1331 & TRN \\
\hline CHEMBL1289935 & 1640465 & 5.284 & 4.9245 & TRN \\
\hline CHEMBL3899439 & 1640465 & 7.2218 & 7.4389 & TRN \\
\hline CHEMBL1289932 & 1640465 & 5.4815 & 5.7323 & TRN \\
\hline CHEMBL3897854 & 1640465 & 6.699 & 6.5942 & TRN \\
\hline CHEMBL3933769 & 1640465 & 6.3468 & 6.4941 & TRN \\
\hline CHEMBL3980089 & 1640465 & 8.3979 & 7.52 & TRN \\
\hline
\end{tabular}


Supplemental Table S2.txt

\begin{tabular}{|c|c|c|c|c|}
\hline 政 & 640465 & 8.0 & 7.1915 & \\
\hline HEMBL3945067 & 640465 & 4.1759 & 5.3331 & \\
\hline & & & & \\
\hline IEMBL1290034 & 465 & & 4153 & \\
\hline AEMBL3985157 & 540465 & 7.5229 & 4172 & \\
\hline AEMBL3932316 & 640465 & 6.4202 & 3904 & \\
\hline HEMBL3899510 & 640465 & 6.9208 & 2824 & \\
\hline IEMBL38 & 65 & & 3763 & \\
\hline EMBL1290587 & 65 & & 6.9172 & \\
\hline AEMBL3956088 & 640465 & 6.2757 & . 1707 & \\
\hline HEMBL3916834 & 65 & 5.8125 & 1961 & \\
\hline HEMBL3960981 & $54 e$ & 58 & 2238 & \\
\hline AEMBL3 & & & 64 & \\
\hline HEMBL39 & & & 2952 & \\
\hline AEMBL3938193 & 65 & 79 & 9757 & \\
\hline AEMBL3942372 & & 29 & .46 & \\
\hline AEMBL3S & 64 & 79 & 99 & \\
\hline HEMBL3S & & & & \\
\hline HEMBL3C & 55 & & 19 & \\
\hline HEMBL 39 & 55 & & & \\
\hline AEMBL3893009 & 04 & 3. & 5.0223 & I \\
\hline HEMBL39 & 62 & 7. & 001 & \\
\hline HEMBL3S & & & 778 & \\
\hline AEMBL 30 & 55 & & 872 & RN \\
\hline HEMBL $39 e$ & 5 & & & RN \\
\hline AEMBL393 & $0<$ & & 14 & I RN \\
\hline HEMBL 39 & 64 & 5 & 202 & \\
\hline HEMBL39 & & & 15 & ST \\
\hline HEM & & & & RN \\
\hline HEMBL393 & 5 & & 85 & I \\
\hline HEMBL 392 & 55 & 29 & 527 & RN \\
\hline HEMBL 392 & 64 & 22 & 307 & I \\
\hline HEMBL12 & & & 425 & RN \\
\hline 99 & & 8 & & RN \\
\hline HEMBL3917392 & 64 & 7. & 574 & RN \\
\hline IEMBL393 & 640 & 6 & 311 & \\
\hline HEMBL395 & 619 & 8 & 565 & I \\
\hline & & & & RN \\
\hline HEMBL3949949 & 64 & 6.8 & 08 & ST \\
\hline HEMBL3936874 & 64 & 6 . & 817 & ST \\
\hline HEMBL391 & $c$ & 71 & 433 & \\
\hline HEMBL3973310 & & & 6.5421 & \\
\hline HEMBL39 & & & & ST \\
\hline HEMBL3956727 & $64 t$ & & 6149 & TST \\
\hline AEMBL3940442 & 64 & 76 & 097 & $\mathrm{R}$ \\
\hline HEMBL389 & & & 0779 & \\
\hline CHEMBL390 & & 5.2441 & 6.3904 & \\
\hline 398538 & -0404 & .4647 & 5.0983 & \\
\hline
\end{tabular}

Page 26191 
Supplemental Table S2.txt

\begin{tabular}{|c|c|c|c|c|}
\hline HEMBL & & & 385 & \\
\hline & & 7.0915 & & \\
\hline IFM & 65 & & & \\
\hline IEMBL39e & & 021 & 63 & \\
\hline AEMBL1290143 & 640465 & 7.4202 & 4534 & \\
\hline HEMBL 3894471 & 64 & 6.2676 & 2496 & \\
\hline HEMBL396 & 55 & & 8794 & \\
\hline AEMBL3920308 & & & 3018 & $\mathrm{M}$ \\
\hline HEMBL3983573 & 640465 & 6.0605 & 3197 & \\
\hline HEMBL3964103 & 640465 & 6.5686 & 9822 & \\
\hline HEMBL3927232 & 465 & & 4151 & \\
\hline 755 & 55 & 528 & 027 & \\
\hline HEMBL389 & 55 & 8 . & & \\
\hline HEMBL3931231 & 165 & 3.69 & 5893 & 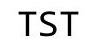 \\
\hline HEMBL1290704 & 65 & 6.0 & 2722 & \\
\hline HEMBL3S & 64 & 5 & 5762 & RIV \\
\hline HEMBL3 & 5 & & 1644 & r \\
\hline HEMBL3 & 55 & & 3311 & RN \\
\hline HEMBL 396 & 65 & & 2133 & 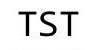 \\
\hline HEMBL396 & 55 & & 34 & I KIV \\
\hline HEMBL3 & 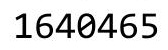 & 17 & 156 & ГRN \\
\hline HEM & 5 & 43 & 59 & ST \\
\hline HEMBL & 55 & 979 & 919 & $\mathrm{RN}$ \\
\hline HEMBL3 & 55 & & 195 & RIV \\
\hline HEMBL392 & 5 & 957 & 383 & |SI \\
\hline HEMBL 396 & 64 & & 936 & $\mathrm{RN}$ \\
\hline HEM & 5 & & 57 & RN \\
\hline 34 & 55 & 6. & 115 & RN \\
\hline HEMBL 398 & & & & IRIN \\
\hline HEMBL394 & 54 & 7. & 664 & TRN \\
\hline AEMBL & & 8 & 631 & RN \\
\hline HFN & & 5 & & 「RN \\
\hline ح & & & & RN \\
\hline HEMBL128 & & & 158 & 「RN \\
\hline HEMBL3891989 & 62 & 7. & 3872 & RN \\
\hline 3 & 5 & & 783 & TRN \\
\hline 8 & & 59 & 39 & ГRN \\
\hline HEMBL 128 & & & 541 & 「RN \\
\hline HEMBL 395 & & & 495 & Th \\
\hline 52 & 5 & & & RN \\
\hline HEMBL3 & & 447 & 198 & ГST \\
\hline HEMBL3 & & 5.7496 & 328 & TRN \\
\hline HEMBL 392 & 64 & 3.699 & 2345 & TST \\
\hline HEMBL3 & 64 & 508 & 436 & TST \\
\hline 0 & & & & $\mathrm{~N}$ \\
\hline HEMBL3 & & 7.2218 & 3993 & \\
\hline HEMBL 398 & 161 & 7.301 & 5.3167 & RN \\
\hline CHEMBL3969429 & 1640465 & 8.0 & 8.1772 & TRN \\
\hline
\end{tabular}

Page 26192 
Supplemental Table S2.txt

\begin{tabular}{|c|c|c|c|c|}
\hline CHEMBL3939734 & 1640465 & 6.2924 & 5.7415 & TRN \\
\hline CHEMBL3941057 & 1640465 & 4.1759 & 5.9131 & TST \\
\hline CHEMBL3980220 & 1640465 & 6.2076 & 6.1527 & TRN \\
\hline CHEMBL3916996 & 1640465 & 7.2147 & 6.7049 & TRN \\
\hline CHEMBL3917198 & 1640465 & 7.0655 & 6.6882 & TRN \\
\hline CHEMBL3970805 & 1640465 & 8.0 & 7.7001 & TRN \\
\hline CHEMBL3959471 & 1640465 & 5.6055 & 5.9839 & TRN \\
\hline CHEMBL3904702 & 1640465 & 5.52 & 5.3704 & TST \\
\hline CHEMBL3986546 & 1640465 & 6.1871 & 6.7905 & TRN \\
\hline CHEMBL3981487 & 1640465 & 6.2218 & 6.2566 & TST \\
\hline CHEMBL3935389 & 1640465 & 5.7077 & 6.7109 & TST \\
\hline CHEMBL3907323 & 1640465 & 8.0 & 7.3827 & TRN \\
\hline CHEMBL3925517 & 1640465 & 6.2007 & 6.4679 & TST \\
\hline CHEMBL3891662 & 1640465 & 6.301 & 4.6577 & TRN \\
\hline CHEMBL3967680 & 1640465 & 7.1549 & 4.7845 & TRN \\
\hline CHEMBL3970771 & 1640465 & 4.1759 & 4.6173 & TST \\
\hline CHEMBL1290373 & 1640465 & 6.3468 & 6.5045 & TST \\
\hline CHEMBL3927160 & 1640465 & 3.699 & 4.1978 & TRN \\
\hline CHEMBL3900270 & 1640465 & 4.1739 & 4.2951 & TST \\
\hline CHEMBL1449923 & 1640701 & 4.301 & 4.2898 & TRN \\
\hline CHEMBL1369215 & 1640701 & 5.7144 & 5.8495 & TRN \\
\hline CHEMBL3967196 & 1640701 & 4.301 & 4.4042 & TRN \\
\hline CHEMBL3978318 & 1640701 & 6.1713 & 6.3414 & TRN \\
\hline CHEMBL1488035 & 1640701 & 8.3979 & 8.4513 & TRN \\
\hline CHEMBL3937380 & 1640701 & 8.3979 & 8.387 & TRN \\
\hline CHEMBL 1602578 & 1640701 & 8.3979 & 8.2809 & TRN \\
\hline CHEMBL1527391 & 1640701 & 8.3979 & 8.3473 & TRN \\
\hline CHEMBL51858 & 1640701 & 8.3979 & 8.2703 & TRN \\
\hline CHEMBL601757 & 1640701 & 8.3979 & 8.2775 & TRN \\
\hline CHEMBL1376622 & 1640701 & 4.301 & 4.1516 & TRN \\
\hline CHEMBL1451931 & 1640701 & 5.3687 & 5.2231 & TRN \\
\hline CHEMBL3977238 & 1640701 & 5.4795 & 5.36299 & 99999999995 \\
\hline CHEMBL3957925 & 1640701 & 4.301 & 4.3817 & TRN \\
\hline CHEMBL3983553 & 1640701 & 4.301 & 4.1573 & TRN \\
\hline CHEMBL1325945 & 1640701 & 8.3979 & 8.4884 & TRN \\
\hline CHEMBL1517074 & 1640701 & 8.3979 & 8.4628 & TRN \\
\hline CHEMBL3933880 & 1640701 & 5.7721 & 7.1735 & TST \\
\hline CHEMBL 2151190 & 1640701 & 6.3575 & 6.3629 & TRN \\
\hline CHEMBL3908323 & 1640701 & 4.301 & 4.3316 & TRN \\
\hline CHEMBL1450796 & 1640701 & 8.3979 & 8.2617 & TRN \\
\hline CHEMBL3915561 & 1640701 & 8.3979 & 8.5281 & TRN \\
\hline CHEMBL3134043 & 1640701 & 8.3979 & 8.2421 & TRN \\
\hline CHEMBL433282 & 1640701 & 6.1605 & 6.1639 & TRN \\
\hline CHEMBL3970460 & 1640701 & 4.301 & 4.7507 & TRN \\
\hline CHEMBL 2094386 & 1640701 & 4.301 & 4.3058 & TRN \\
\hline CHEMBL 2086889 & 1640701 & 8.3979 & 8.731 & TRN \\
\hline CHEMBL 3896702 & 1640701 & 5.7817 & 6.13899 & 9999999999 \\
\hline CHEMBL3975566 & 1640701 & 4.301 & 4.6413 & TRN \\
\hline
\end{tabular}


Supplemental Table S2.txt

\begin{tabular}{|c|c|c|c|c|}
\hline CHEMBL3891183 & 1640701 & 8.3979 & 8.4721 & TRN \\
\hline CHEMBL 2028043 & 1640701 & 8.3979 & 8.1648 & TRN \\
\hline CHEMBL3899280 & 1640701 & 4.301 & 4.313 & TRN \\
\hline CHEMBL3589013 & 1640701 & 8.3979 & 8.4156 & TRN \\
\hline CHEMBL1555938 & 1640701 & 4.301 & 4.4385 & TRN \\
\hline CHEMBL3911255 & 1640701 & 5.505 & 5.6729 & TST \\
\hline CHEMBL1334062 & 1640701 & 8.3979 & 8.4768 & TRN \\
\hline CHEMBL3184493 & 1640701 & 8.3979 & \multicolumn{2}{|c|}{8.347000000000001} \\
\hline CHEMBL3951719 & 1640701 & 5.9469 & 6.0375 & TRN \\
\hline CHEMBL1438218 & 1640701 & 8.3979 & 8.452 & TRN \\
\hline CHEMBL3980446 & 1640701 & 8.3979 & 8.397 & TRN \\
\hline CHEMBL3893028 & 1640701 & 5.9329 & 5.9333 & TRN \\
\hline CHEMBL3924071 & 1640701 & 6.0205 & 5.1305 & TRN \\
\hline CHEMBL1098317 & 1640701 & 8.3979 & 7.9542 & TST \\
\hline CHEMBL3917323 & 1640701 & 6.3468 & 5.5164 & TST \\
\hline CHEMBL3933712 & 1640701 & 6.8539 & 6.7993 & TST \\
\hline CHEMBL 2094689 & 1640701 & 5.8425 & 7.5413 & TST \\
\hline CHEMBL3905781 & 1640701 & 6.1192 & 6.5443 & TST \\
\hline CHEMBL3902439 & 1640701 & 5.4353 & 6.5351 & TST \\
\hline CHEMBL1605094 & 1640701 & 4.301 & 4.0981 & TST \\
\hline CHEMBL417727 & 1640701 & 6.1035 & 6.4291 & TST \\
\hline CHEMBL555689 & 1640701 & 8.3979 & 8.0313 & TST \\
\hline CHEMBL599924 & 1640701 & 8.3979 & 8.2386 & TST \\
\hline CHEMBL1096283 & 1640701 & 8.3979 & 7.4018 & TST \\
\hline CHEMBL1270082 & 1495325 & 4.556 & 4.5561 & TRN \\
\hline CHEMBL3560194 & 1495325 & 3.301 & 3.301 & TRN \\
\hline CHEMBL3560971 & 1495325 & 3.301 & 3.3007 & TRN \\
\hline CHEMBL3560810 & 1495325 & 3.301 & 3.3011 & TRN \\
\hline CHEMBL1325958 & 1495325 & 3.301 & 3.3012 & TRN \\
\hline CHEMBL3560697 & 1495325 & 3.301 & 3.3012 & TRN \\
\hline CHEMBL1531170 & 1495325 & 3.301 & 3.3008 & TRN \\
\hline CHEMBL1495454 & 1495325 & 4.9586 & 4.9587 & TRN \\
\hline CHEMBL1466455 & 1495325 & 3.301 & 3.8931 & TST \\
\hline CHEMBL1440177 & 1495325 & 3.301 & 3.1118 & TST \\
\hline CHEMBL1443753 & 1495325 & 3.301 & 3.3014 & TRN \\
\hline CHEMBL3560933 & 1495325 & 3.301 & 3.3006 & TRN \\
\hline CHEMBL1580420 & 1495325 & 3.301 & 3.301 & TRN \\
\hline CHEMBL1512293 & 1495325 & 3.301 & 3.3012 & TRN \\
\hline CHEMBL3559846 & 1495325 & 3.301 & 3.3004 & TRN \\
\hline CHEMBL1546216 & 1495325 & 3.301 & 3.3013 & TRN \\
\hline CHEMBL1353293 & 1495325 & 3.301 & 3.3012 & TRN \\
\hline CHEMBL1721523 & 1495325 & 3.301 & 3.3012 & TRN \\
\hline CHEMBL1516418 & 1495325 & 3.301 & 3.3006 & TRN \\
\hline CHEMBL3560119 & 1495325 & 3.301 & 3.3011 & TRN \\
\hline CHEMBL1365447 & 1495325 & 3.301 & 3.3016 & TRN \\
\hline CHEMBL1461552 & 1495325 & 3.301 & 3.3255 & TST \\
\hline CHEMBL3561477 & 1495325 & 3.301 & 3.3007 & TRN \\
\hline CHEMBL3561064 & 1495325 & 3.301 & 3.3006 & TRN \\
\hline
\end{tabular}




$$
\text { Supplemental Table S2.txt }
$$

\begin{tabular}{|c|c|c|c|c|}
\hline CHEMBL1384489 & 1495325 & 5.0915 & 5.0911 & TRN \\
\hline CHEMBL1338820 & 1495325 & 3.301 & 3.3007 & TRN \\
\hline CHEMBL 3560948 & 1495325 & 3.301 & 3.301 & TRN \\
\hline CHEMBL 3560615 & 1495325 & 3.301 & 3.301 & TRN \\
\hline CHEMBL 3560406 & 1495325 & 3.301 & 3.3024 & TRN \\
\hline CHEMBL 3559956 & 1495325 & 3.301 & 3.3013 & TRN \\
\hline CHEMBL1462792 & 1495325 & 3.301 & 3.3008 & TRN \\
\hline CHEMBL 3560022 & 1495325 & 3.301 & 3.3003 & TRN \\
\hline CHEMBL 3561421 & 1495325 & 3.301 & 3.3014 & TRN \\
\hline CHEMBL 3560564 & 1495325 & 3.301 & 3.3014 & TRN \\
\hline CHEMBL1337517 & 1495325 & 4.8697 & 3.6014 & TST \\
\hline CHEMBL1473337 & 1495325 & 3.301 & 3.3014 & TRN \\
\hline CHEMBL1510761 & 1495325 & 4.567 & 4.567 & TRN \\
\hline CHEMBL1313574 & 1495325 & 3.301 & 3.3007 & TRN \\
\hline CHEMBL1575439 & 1495325 & 3.301 & 3.3007 & TRN \\
\hline CHEMBL1572525 & 1495325 & 3.301 & 3.3008 & TRN \\
\hline CHEMBL1457228 & 1495325 & 4.6345 & 4.6348 & TRN \\
\hline CHEMBL1733791 & 1495325 & 3.301 & 3.5583 & TST \\
\hline CHEMBL1463019 & 1495325 & 3.301 & 3.301 & TRN \\
\hline CHEMBL1414059 & 1495325 & 4.6271 & 3.8295 & TST \\
\hline CHEMBL1270286 & 1495325 & 4.3979 & 3.5692 & TST \\
\hline CHEMBL 3559920 & 1495325 & 3.301 & 3.5858 & TST \\
\hline CHEMBL 3560957 & 1495325 & 3.301 & 3.1131 & TST \\
\hline CHEMBL 3561672 & 1495325 & 3.301 & 3.2602 & TST \\
\hline CHEMBL 3561440 & 1495325 & 3.301 & 3.6148 & TST \\
\hline CHEMBL3559935 & 1495325 & 3.301 & 3.0085 & TST \\
\hline CHEMBL1308377 & 1495325 & 5.1141 & 3.5875 & TST \\
\hline CHEMBL 3398069 & 1463309 & 4.5229 & 4.6521 & TRN \\
\hline CHEMBL 3398034 & 1463309 & 4.5528 & 3.4683 & TST \\
\hline CHEMBL 3398055 & 1463309 & 4.0223 & 4.2031 & TRN \\
\hline CHEMBL 3398076 & 1463309 & 4.6778 & 4.3946 & TRN \\
\hline CHEMBL 3398017 & 1463309 & 3.0 & 4.2473 & TST \\
\hline CHEMBL 3398065 & 1463309 & 3.0 & 3.4235 & TRN \\
\hline CHEMBL3398062 & 1463309 & 4.3468 & 4.2095 & TRN \\
\hline CHEMBL 3398078 & 1463309 & 3.0 & 3.4047 & TRN \\
\hline CHEMBL 3398067 & 1463309 & 4.4437 & 3.9748 & TRN \\
\hline CHEMBL3397056 & 1463309 & 4.6198 & 4.2066 & TRN \\
\hline CHEMBL 3398060 & 1463309 & 3.0 & 3.4857 & TRN \\
\hline CHEMBL 3398061 & 1463309 & 4.6021 & 4.4165 & TRN \\
\hline CHEMBL 3398072 & 1463309 & 3.0 & 4.7455 & TRN \\
\hline CHEMBL 3398007 & 1463309 & 4.1739 & 4.4541 & TST \\
\hline CHEMBL 3398033 & 1463309 & 3.0 & 3.3364 & TRN \\
\hline CHEMBL 3398075 & 1463309 & 5.2007 & 4.8464 & TRN \\
\hline CHEMBL 3398046 & 1463309 & 4.7696 & 4.5425 & TRN \\
\hline CHEMBL 3398026 & 1463309 & 3.0 & 4.4488 & TST \\
\hline CHEMBL3398079 & 1463309 & 3.0 & 4.4659 & TST \\
\hline CHEMBL 3398063 & 1463309 & 3.0 & \multicolumn{2}{|c|}{ 3. 2439999999999998} \\
\hline CHEMBL 3398042 & 1463309 & 3.0 & 3.2435 & TRN \\
\hline
\end{tabular}




\begin{tabular}{|c|c|c|c|c|c|}
\hline \multicolumn{6}{|c|}{ Supplemental Table S2.txt } \\
\hline CHEMBL 3398020 & 1463309 & 3.0 & 4.2387 & TST & \\
\hline CHEMBL 3398068 & 1463309 & 3.0 & 2.6872 & TRN & \\
\hline CHEMBL 3398053 & 1463309 & 4.2291 & 4.5433 & TRN & \\
\hline CHEMBL 3398035 & 1463309 & 3.0 & 3.2958 & TRN & \\
\hline CHEMBL 3398073 & 1463309 & 5.0269 & 4.8769 & TRN & \\
\hline CHEMBL3398059 & 1463309 & 4.7212 & 4.3292 & TRN & \\
\hline CHEMBL 3398014 & 1463309 & 3.0 & 4.3119 & TST & \\
\hline CHEMBL 3398071 & 1463309 & 4.2076 & 4.5412 & TRN & \\
\hline CHEMBL 3398052 & 1463309 & 4.5086 & 4.5168 & TRN & \\
\hline CHEMBL3398057 & 1463309 & 4.3279 & 3.6672 & TRN & \\
\hline CHEMBL 3398037 & 1463309 & 3.0 & 3.245 & TRN & \\
\hline CHEMBL 3398080 & 1463309 & 3.0 & 4.4162 & TST & \\
\hline CHEMBL3398039 & 1463309 & 3.0 & 3.1358 & TRN & \\
\hline CHEMBL 3398027 & 1463309 & 3.0 & 4.6283 & TST & \\
\hline CHEMBL3398041 & 1463309 & 4.7447 & 3.5032 & TRN & \\
\hline CHEMBL3398077 & 1463309 & 3.0 & 3.9977 & TRN & \\
\hline CHEMBL 3398038 & 1463309 & 3.0 & 3.053 & TRN & \\
\hline CHEMBL3398056 & 1463309 & 4.5686 & 4.2651 & TRN & \\
\hline CHEMBL 3398036 & 1463309 & 3.0 & 3.14899 & 99999999996 & TRN \\
\hline CHEMBL 3398040 & 1463309 & 3.0 & 2.9628 & TRN & \\
\hline CHEMBL3398043 & 1463309 & 3.0 & 2.951 & TRN & \\
\hline CHEMBL 3398058 & 1463309 & 4.4089 & 4.4391 & TRN & \\
\hline CHEMBL3398074 & 1463309 & 4.9208 & 4.1728 & TRN & \\
\hline CHEMBL 3398081 & 1463309 & 4.1249 & 3.4697 & TST & \\
\hline CHEMBL 3398064 & 1463309 & 4.1487 & 3.8229 & TRN & \\
\hline CHEMBL3398070 & 1463309 & 4.9586 & 4.7205 & TRN & \\
\hline CHEMBL 3398022 & 1463309 & 3.0 & 4.4215 & TST & \\
\hline CHEMBL3398023 & 1463309 & 3.0 & 4.511 & TST & \\
\hline CHEMBL 3398012 & 1463309 & 3.0 & 4.109 & TST & \\
\hline CHEMBL3398051 & 1463309 & 4.4559 & 3.935 & TRN & \\
\hline CHEMBL 3398021 & 1463309 & 4.2291 & 4.5224 & TRN & \\
\hline CHEMBL 3398013 & 1463309 & 4.1871 & 4.2518 & TST & \\
\hline CHEMBL1379761 & 688561 & 5.4518 & 5.1062 & TST & \\
\hline CHEMBL1485734 & 688561 & 4.8518 & 4.7254 & TRN & \\
\hline CHEMBL1443793 & 688561 & 4.4518 & 4.6418 & TRN & \\
\hline CHEMBL1326212 & 688561 & 5.0018 & 5.6507 & TRN & \\
\hline CHEMBL1596709 & 688561 & 9.5229 & 5.9472 & TRN & \\
\hline CHEMBL1328353 & 688561 & 4.4518 & 4.6921 & TST & \\
\hline CHEMBL1597241 & 688561 & 4.7018 & 4.9354 & TRN & \\
\hline CHEMBL1423968 & 688561 & 4.8518 & 4.9161 & TRN & \\
\hline CHEMBL1495977 & 688561 & 5.2517 & 5.7935 & TRN & \\
\hline CHEMBL1520671 & 688561 & 5.1018 & 5.3372 & TST & \\
\hline CHEMBL578512 & 688561 & 6.3517 & 5.7011 & TRN & \\
\hline CHEMBL1403535 & 688561 & 4.7018 & 4.9093 & TST & \\
\hline CHEMBL3194266 & 688561 & 7.2518 & 4.9779 & TST & \\
\hline CHEMBL1493769 & 688561 & 4.6018 & 4.5771 & TRN & \\
\hline CHEMBL 1478282 & 688561 & 5.5518 & 5.6106 & TRN & \\
\hline CHEMBL1330575 & 688561 & 4.9518 & 5.0069 & TRN & \\
\hline
\end{tabular}




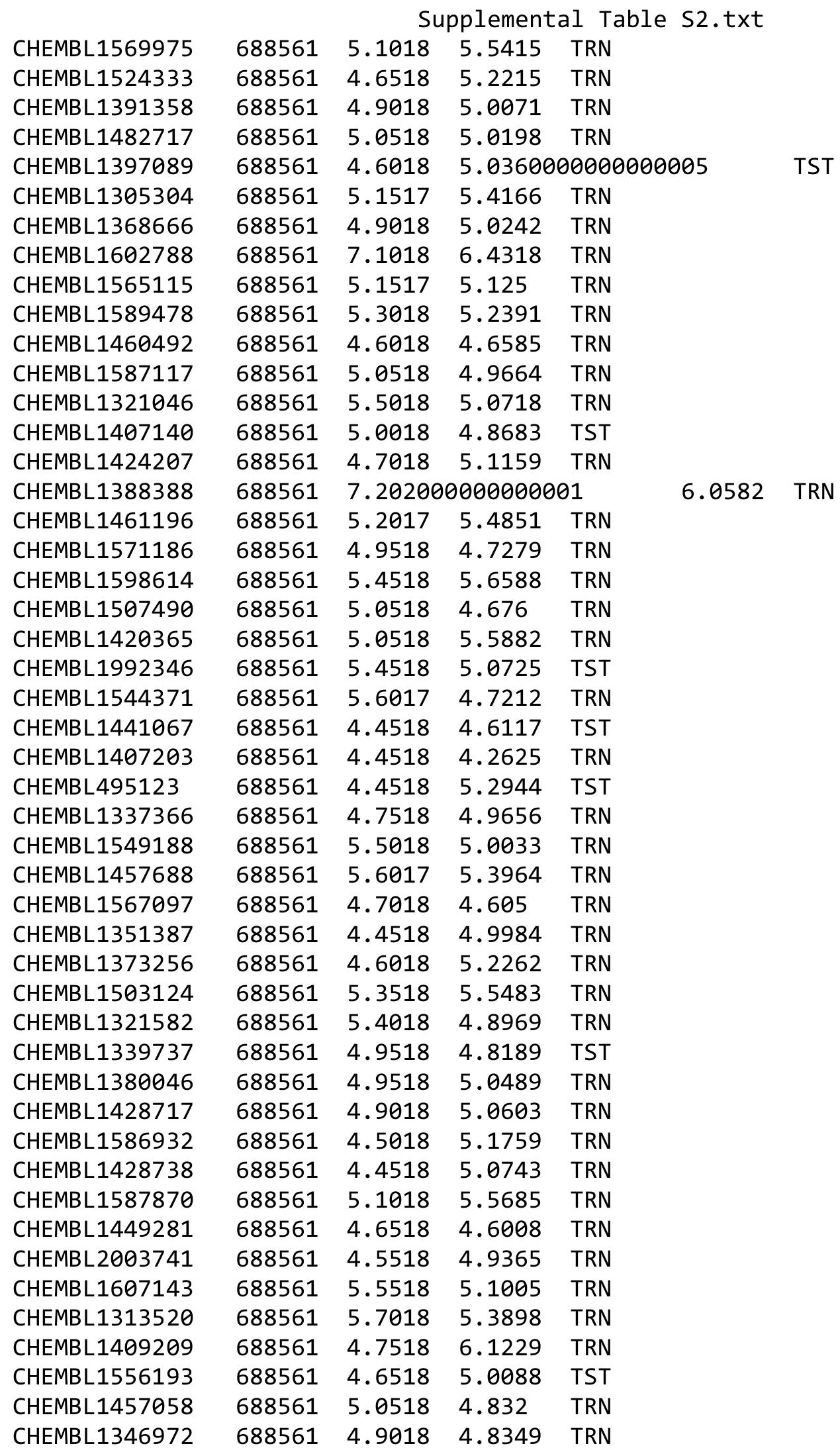

Page 26197 


\begin{tabular}{|c|c|c|c|c|c|}
\hline \multicolumn{6}{|c|}{ Supplemental Table S2.txt } \\
\hline CHEMBL3212254 & 688561 & 5.5518 & 5.4517 & TST & \\
\hline CHEMBL1311543 & 688561 & 4.5018 & 4.6621 & TRN & \\
\hline CHEMBL1469561 & 688561 & 4.6518 & 5.1685 & TRN & \\
\hline CHEMBL504977 & 688561 & 6.4018 & 5.4147 & TST & \\
\hline CHEMBL1302596 & 688561 & 5.8018 & 5.5147 & TRN & \\
\hline CHEMBL1561348 & 688561 & 4.7018 & 4.8362 & TRN & \\
\hline CHEMBL1546713 & 688561 & 5.3018 & 4.8406 & TRN & \\
\hline CHEMBL1367761 & 688561 & 4.6018 & 4.6654 & TRN & \\
\hline CHEMBL1501056 & 688561 & 4.5018 & 4.7236 & TRN & \\
\hline CHEMBL1568012 & 688561 & 4.9518 & 4.8105 & TST & \\
\hline CHEMBL1303266 & 688561 & 4.6518 & 4.9634 & TRN & \\
\hline CHEMBL1340626 & 688561 & 5.7018 & 5.3965 & TRN & \\
\hline CHEMBL1486324 & 688561 & 4.9518 & 4.8795 & TST & \\
\hline CHEMBL1507537 & 688561 & 4.7018 & 5.0299 & TRN & \\
\hline CHEMBL1391684 & 688561 & 6.0017 & 5.6914 & TRN & \\
\hline CHEMBL1444259 & 688561 & 5.2017 & 5.0514 & TRN & \\
\hline CHEMBL1432583 & 688561 & 5.1018 & 5.5261 & TRN & \\
\hline CHEMBL1310884 & 688561 & 4.6018 & 4.9855 & TRN & \\
\hline CHEMBL1611258 & 688561 & 4.5518 & 5.2073 & TRN & \\
\hline CHEMBL1529310 & 688561 & 6.6517 & 6.1634 & TRN & \\
\hline CHEMBL1449083 & 688561 & 4.6018 & 4.5309 & TRN & \\
\hline CHEMBL1480457 & 688561 & 4.6018 & 4.6963 & TRN & \\
\hline CHEMBL1348037 & 688561 & 4.7018 & 4.8521 & TRN & \\
\hline CHEMBL1300319 & 688561 & 5.9017 & 5.311 & TRN & \\
\hline CHEMBL1492752 & 688561 & 5.8018 & 5.2736 & TRN & \\
\hline CHEMBL1325413 & 688561 & 4.8518 & 5.7093 & TRN & \\
\hline CHEMBL1547784 & 688561 & 4.6018 & 4.7078 & TRN & \\
\hline CHEMBL590706 & 688561 & 4.9518 & 4.8189 & TST & \\
\hline CHEMBL1300968 & 688561 & 5.2017 & 5.17700 & 00000000005 & TRN \\
\hline CHEMBL1445134 & 688561 & 4.8518 & 5.2196 & TRN & \\
\hline CHEMBL1426505 & 688561 & 7.8508 & 5.0558 & TRN & \\
\hline CHEMBL1510524 & 688561 & 4.7018 & 4.2557 & TRN & \\
\hline CHEMBL1317220 & 688561 & 5.3018 & 5.0397 & TST & \\
\hline CHEMBL1303623 & 688561 & 4.6018 & 5.5889 & TRN & \\
\hline CHEMBL1465899 & 688561 & 5.0018 & 4.9335 & TRN & \\
\hline CHEMBL1311158 & 688561 & 5.2517 & 4.7656 & TRN & \\
\hline CHEMBL1584921 & 688561 & 4.6518 & 4.9395 & TRN & \\
\hline CHEMBL1342290 & 688561 & 4.4518 & 4.7625 & TRN & \\
\hline CHEMBL1605875 & 688561 & 4.6018 & 4.8938 & TRN & \\
\hline CHEMBL1428580 & 688561 & 4.7018 & 4.9268 & TST & \\
\hline CHEMBL1463050 & 688561 & 5.3518 & 4.9439 & TRN & \\
\hline CHEMBL1303619 & 688561 & 4.4518 & 4.9686 & TRN & \\
\hline CHEMBL1504153 & 688561 & 5.0018 & 4.8149 & TRN & \\
\hline CHEMBL1608301 & 688561 & 5.6017 & 5.9043 & TRN & \\
\hline CHEMBL1439668 & 688561 & 4.4518 & 4.9249 & TRN & \\
\hline CHEMBL1555516 & 688561 & 4.8018 & 4.9545 & TRN & \\
\hline CHEMBL1429861 & 688561 & 5.4518 & 5.5308 & TRN & \\
\hline CHEMBL1597878 & 688561 & 4.9018 & 4.9533 & TRN & \\
\hline
\end{tabular}

Page 26198 
Supplemental Table S2.txt

\begin{tabular}{|c|c|c|c|c|}
\hline HEMBL & 38561 & .6017 & 5.0336 & $\mathrm{TR}$ \\
\hline HEMBL1597726 & 88561 & .5518 & & \\
\hline 2681 & 61 & & & \\
\hline HEMBL1538160 & 3561 & & & \\
\hline HEMBL165 & 3561 & & & \\
\hline HEMBL1579509 & 88561 & 5.0518 & 0675 & \\
\hline HEMBL1 & 38561 & & 65 & \\
\hline AEMBL152 & 88561 & & & RN \\
\hline HEMBL582073 & 88561 & & 312 & \\
\hline HEMBL136 & 88561 & 18 & 92 & \\
\hline HEMBL146 & 88561 & .7018 & & \\
\hline AEMBL1 & 88561 & 17 & 12 & \\
\hline HEMBL1 & 88561 & & & RN \\
\hline HEMBL1. & 88561 & 518 & & \\
\hline AEMBL1 & 88561 & & & \\
\hline AEMBL1 & $\$ 88561$ & 18 & 81 & \\
\hline HEMBL3 & 88561 & & 49 & 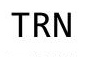 \\
\hline HEMBL1 & 88561 & & & \\
\hline HEMBL1 & 88561 & & & \\
\hline HEMBL1 & 88561 & & & \\
\hline JEMBL1 & 88561 & & 5 & NIV \\
\hline HEMBL1 & 1 & & & RN \\
\hline HEMBL1 & 88561 & & & \\
\hline HEMBL1 & 88561 & & & \\
\hline HEMBL31 & 3561 & & & $1=2$. \\
\hline HEMBL1 & 61 & & & SI \\
\hline HEMBL1 & 561 & 2 & & ST \\
\hline HEMBL 1 & 88561 & 8 & & \\
\hline HEMBL1 & 88561 & & & TS \\
\hline HEMBL149 & 88561 & & & TS \\
\hline HEMBL1 & 88561 & & & TST \\
\hline HEMBLI & 561 & & & ST \\
\hline HEMBLI & 561 & & & TST \\
\hline HEMBL1524122 & 88561 & & & TS \\
\hline HEMBL1347001 & 88561 & & & TS \\
\hline HEMBL1 & 88561 & & & ГST \\
\hline HFMRI 1 & 1 & & & TST \\
\hline HEMBL14 & 88561 & & & TST \\
\hline HEMBL1472925 & 88561 & 4. & & TST \\
\hline HEMBL1 & 88561 & re & & TST \\
\hline HEMBL 3 & 05108 & & 02 & ST \\
\hline CHEMBL 2 & 05108 & 0 & 26 & TRN \\
\hline HEMBL 320 & 105108 & & 32 & TRN \\
\hline HEMBL109235 & 105108 & 8 & 7065 & $R$ \\
\hline CHEMBL139 & 05108 & & 76 & TRN \\
\hline CHEMBL1 & 105108 & & & ST \\
\hline CHEMBL344268 & 105108 & 8.1 & 7.8769 & RN \\
\hline CHEMBL139855 & 105108 & 10.9 & 10.0813 & ST \\
\hline
\end{tabular}

Page 26199 


\begin{tabular}{|c|c|c|c|c|c|}
\hline & & & & & \\
\hline CHEMBL336225 & 105108 & 7.9 & 7.8747 & TRN & \\
\hline CHEMBL139014 & 105108 & 8.2 & 7.9799 & TRN & \\
\hline CHEMBL141796 & 105108 & 6.3 & 6.5881 & TRN & \\
\hline CHEMBL138581 & 105108 & 7.4 & 6.5552 & TST & \\
\hline CHEMBL140826 & 105108 & 6.9 & 7.2831 & TRN & \\
\hline CHEMBL138201 & 105108 & 7.8 & 8.019 & TRN & \\
\hline CHEMBL138440 & 105108 & 8.3 & 8.5056 & TRN & \\
\hline CHEMBL335116 & 105108 & 8.4 & 8.2018 & TRN & \\
\hline CHEMBL138037 & 105108 & 7.8 & 7.4374 & TRN & \\
\hline CHEMBL141694 & 105108 & 5.2 & 6.0658 & TRN & \\
\hline CHEMBL138496 & 105108 & 7.7 & 5.6618 & TST & \\
\hline CHEMBL417151 & 105108 & 8.9 & 8.3727 & TRN & \\
\hline CHEMBL137948 & 105108 & 6.9 & 6.3847 & TRN & \\
\hline CHEMBL344488 & 105108 & 6.9 & 7.4011 & TRN & \\
\hline CHEMBL342949 & 105108 & 7.0 & 7.0238 & TRN & \\
\hline CHEMBL341761 & 105108 & 8.0 & 7.7972 & TRN & \\
\hline CHEMBL140549 & 105108 & 8.5 & 8.2705 & TRN & \\
\hline CHEMBL342592 & 105108 & 7.9 & 8.0545 & TRN & \\
\hline CHEMBL138549 & 105108 & 8.1 & 8.3902 & TRN & \\
\hline CHEMBL138468 & 105108 & 5.0 & 5.0606 & TRN & \\
\hline CHEMBL11356 & 105108 & 9.8 & 9.6735 & TRN & \\
\hline CHEMBL343575 & 105108 & 5.0 & 5.0105 & TRN & \\
\hline CHEMBL139627 & 105108 & 7.4 & 7.3609 & TRN & \\
\hline CHEMBL 38728 & 105108 & 9.0 & 6.449 & TST & \\
\hline CHEMBL137823 & 105108 & 7.0 & 7.1196 & TRN & \\
\hline CHEMBL137949 & 105108 & 7.7 & 6.8285 & TRN & \\
\hline CHEMBL138355 & 105108 & 5.7 & 6.4689 & TST & \\
\hline CHEMBL136346 & 105108 & 5.9 & 5.6114 & TRN & \\
\hline CHEMBL342836 & 105108 & 5.8 & 5.557 & TRN & \\
\hline CHEMBL110980 & 105108 & 8.3 & 8.099 & TRN & \\
\hline CHEMBL337764 & 105108 & 9.5 & 9.4988 & TRN & \\
\hline CHEMBL337767 & 105108 & 6.2 & 7.2087 & TRN & \\
\hline CHEMBL139516 & 105108 & 7.9 & 7.7975 & TST & \\
\hline CHEMBL423011 & 105108 & 6.9 & 7.2633 & TRN & \\
\hline CHEMBL 37703 & 105108 & 8.6 & 8.6112 & TRN & \\
\hline CHEMBL141430 & 105108 & 4.8 & 4.3255 & TST & \\
\hline CHEMBL140244 & 105108 & 6.5 & 6.00299 & 9999999999 & TRN \\
\hline CHEMBL138321 & 105108 & 9.0 & 8.7768 & TRN & \\
\hline CHEMBL141115 & 105108 & 8.5 & 8.497 & TRN & \\
\hline CHEMBL138807 & 105108 & 7.7 & 7.74299 & 9999999999 & TRN \\
\hline CHEMBL441664 & 105108 & 8.4 & 8.0972 & TRN & \\
\hline CHEMBL109086 & 105108 & 8.7 & 8.411 & TRN & \\
\hline CHEMBL138180 & 105108 & 4.8 & $6.4670 e$ & 00000000005 & TST \\
\hline CHEMBL342855 & 105108 & 7.2 & 7.2726 & TRN & \\
\hline CHEMBL137969 & 105108 & 6.9 & 7.7418 & TST & \\
\hline CHEMBL288300 & 105108 & 4.0 & 4.703 & TRN & \\
\hline CHEMBL137998 & 105108 & 9.1 & 8.5707 & TRN & \\
\hline CHEMBL343819 & 105108 & 7.3 & 6.9453 & TRN & \\
\hline & & & & 26200 & \\
\hline
\end{tabular}




\begin{tabular}{|c|c|c|c|c|c|}
\hline \\
\hline CHEMBL137983 & 105108 & 7.8 & 8.2702 & TRN & \\
\hline CHEMBL 344632 & 105108 & 5.8 & 6.1919 & TST & \\
\hline CHEMBL138387 & 105108 & 6.0 & 8.0176 & TST & \\
\hline CHEMBL 344880 & 105108 & 7.9 & 7.8271 & TRN & \\
\hline CHEMBL141208 & 105108 & 6.2 & 6.6705 & TRN & \\
\hline CHEMBL139087 & 105108 & 5.1 & 5.0969 & TRN & \\
\hline CHEMBL136816 & 105108 & 6.7 & 7.6794 & TRN & \\
\hline CHEMBL422636 & 105108 & 6.0 & 7.1121 & TST & \\
\hline CHEMBL11416 & 105108 & 7.8 & 7.691 & TRN & \\
\hline CHEMBL111718 & 105108 & 8.2 & 7.3738 & TRN & \\
\hline CHEMBL140433 & 105108 & 7.4 & 8.8076 & TRN & \\
\hline CHEMBL138508 & 105108 & 5.0 & 6.41799 & 9999999999 & TST \\
\hline CHEMBL139744 & 105108 & 6.1 & 5.97 & TRN & \\
\hline CHEMBL109361 & 105108 & 7.4 & 7.38299 & 9999999999 & TRN \\
\hline CHEMBL139016 & 105108 & 4.8 & 4.8709 & TRN & \\
\hline CHEMBL 337580 & 105108 & 8.4 & 8.5232 & TST & \\
\hline CHEMBL140611 & 105108 & 6.2 & 6.4966 & TRN & \\
\hline CHEMBL138774 & 105108 & 5.8 & 6.6849 & TST & \\
\hline CHEMBL139510 & 105108 & 6.5 & 6.8134 & TRN & \\
\hline CHEMBL413121 & 105108 & 7.8 & 7.8642 & TRN & \\
\hline CHEMBL137910 & 105108 & 8.3 & 8.5733 & TRN & \\
\hline CHEMBL 289233 & 105108 & 9.0 & 9.0044 & TRN & \\
\hline CHEMBL138938 & 105108 & 6.3 & 6.1957 & TRN & \\
\hline CHEMBL 321612 & 105108 & 8.4 & 8.0447 & TRN & \\
\hline CHEMBL139133 & 105108 & 5.5 & 6.8637 & TST & \\
\hline CHEMBL136214 & 105108 & 6.8 & 5.9929 & TST & \\
\hline CHEMBL141507 & 105108 & 7.1 & 7.1043 & TRN & \\
\hline CHEMBL140896 & 105108 & 6.3 & 6.4658 & TRN & \\
\hline CHEMBL 337802 & 105108 & 7.4 & 5.7148 & TST & \\
\hline CHEMBL138752 & 105108 & 8.3 & 7.1605 & TST & \\
\hline CHEMBL 323332 & 105108 & 8.8 & 8.7857 & TRN & \\
\hline CHEMBL137970 & 105108 & 5.0 & 5.2007 & TST & \\
\hline CHEMBL138924 & 105108 & 7.7 & 7.3267 & TRN & \\
\hline CHEMBL436006 & 105108 & 8.5 & 8.4505 & TRN & \\
\hline CHEMBL138817 & 105108 & 8.6 & 8.6703 & TRN & \\
\hline CHEMBL138766 & 105108 & 8.7 & 8.6276 & TRN & \\
\hline CHEMBL11328 & 105108 & 8.0 & 6.574 & TST & \\
\hline CHEMBL11404 & 105108 & 8.9 & 8.5552 & TST & \\
\hline CHEMBL136815 & 105108 & 6.8 & 6.7647 & TRN & \\
\hline CHEMBL138929 & 105108 & 7.1 & 7.2862 & TRN & \\
\hline CHEMBL111558 & 105108 & 7.0 & 7.062 & TRN & \\
\hline CHEMBL138182 & 105108 & 7.2 & 7.3761 & TST & \\
\hline CHEMBL35017 & 105108 & 5.7 & 5.4908 & TRN & \\
\hline CHEMBL139428 & 105108 & 6.6 & 6.9568 & TRN & \\
\hline CHEMBL138301 & 105108 & 5.0 & 6.5757 & TST & \\
\hline CHEMBL342649 & 105108 & 7.3 & 5.0976 & TST & \\
\hline CHEMBL141785 & 105108 & 5.8 & 5.652 & TRN & \\
\hline CHEMBL138808 & 105108 & 7.7 & 7.0668 & TRN & \\
\hline
\end{tabular}




\begin{tabular}{|c|c|c|c|c|c|}
\hline & & \\
\hline CHEMBL140427 & 105108 & 7.6 & 7.8129 & TRN & \\
\hline CHEMBL138631 & 105108 & 4.9 & 6.5821 & TST & \\
\hline CHEMBL342432 & 105108 & 8.1 & 8.1015 & TRN & \\
\hline CHEMBL140548 & 105108 & 5.0 & 5.6659 & TST & \\
\hline CHEMBL329263 & 105108 & 10.8 & 9.7052 & TRN & \\
\hline CHEMBL344454 & 105108 & 7.3 & 7.3232 & TRN & \\
\hline CHEMBL138288 & 105108 & 8.0 & \multicolumn{2}{|c|}{8.181000000000001} & TRN \\
\hline CHEMBL138841 & 105108 & 7.3 & \multicolumn{2}{|c|}{7.212999999999999} & TRN \\
\hline CHEMBL139410 & 105108 & 8.2 & 8.1573 & TRN & \\
\hline CHEMBL341989 & 105108 & 7.1 & 7.515 & TRN & \\
\hline CHEMBL113441 & 105108 & 8.9 & 8.2734 & TRN & \\
\hline CHEMBL444857 & 105108 & 6.8 & 7.849 & TST & \\
\hline CHEMBL140551 & 105108 & 7.1 & 8.0459 & TST & \\
\hline CHEMBL139021 & 105108 & 7.6 & 7.5 & TRN & \\
\hline CHEMBL37771 & 105108 & 8.7 & 8.4703 & TRN & \\
\hline CHEMBL37341 & 105108 & 5.6 & 5.3815 & TRN & \\
\hline CHEMBL111667 & 105108 & 7.6 & 6.9466 & TST & \\
\hline CHEMBL342162 & 105108 & 7.3 & 7.1894 & TRN & \\
\hline CHEMBL138475 & 105108 & 6.3 & \multicolumn{2}{|c|}{7.1160000000000005} & TRN \\
\hline CHEMBL139228 & 105108 & 7.9 & 7.796 & TRN & \\
\hline CHEMBL342655 & 105108 & 8.1 & 8.3943 & TRN & \\
\hline CHEMBL138675 & 105108 & 6.3 & 5.9727 & TRN & \\
\hline CHEMBL345029 & 105108 & 7.7 & 7.7568 & TRN & \\
\hline CHEMBL344179 & 105108 & 5.6 & 5.7089 & TRN & \\
\hline CHEMBL336010 & 105108 & 8.1 & 7.9879 & TRN & \\
\hline CHEMBL137878 & 105108 & 9.1 & 8.3869 & TRN & \\
\hline CHEMBL344242 & 105108 & 6.1 & 8.3853 & TST & \\
\hline CHEMBL140835 & 105108 & 5.2 & 5.3721 & TRN & \\
\hline CHEMBL342207 & 105108 & 6.0 & 6.4032 & TRN & \\
\hline CHEMBL322762 & 105108 & 9.1 & 9.201 & TRN & \\
\hline CHEMBL138053 & 105108 & 7.8 & 6.2902 & TST & \\
\hline CHEMBL344866 & 105108 & 4.5 & 5.3115 & TST & \\
\hline CHEMBL139418 & 105108 & 5.0 & 7.7265 & TST & \\
\hline CHEMBL341802 & 105108 & 7.4 & 8.0488 & TRN & \\
\hline CHEMBL435032 & 105108 & 5.8 & 6.2153 & TRN & \\
\hline CHEMBL 287310 & 105108 & 5.4 & 5.2519 & TRN & \\
\hline CHEMBL141522 & 105108 & 5.7 & 4.5615 & TRN & \\
\hline CHEMBL1203037 & 67039 & 6.0706 & 6.0749 & TRN & \\
\hline CHEMBL109428 & 67039 & 6.7447 & 6.7588 & TRN & \\
\hline CHEMBL1203059 & 67039 & 3.04 & 3.0961 & TRN & \\
\hline CHEMBL324045 & 67039 & 6.0088 & 6.0393 & TRN & \\
\hline CHEMBL439596 & 67039 & 2.9905 & 4.75899 & 99999999995 & TST \\
\hline CHEMBL111664 & 67039 & 4.8586 & 4.8089 & TRN & \\
\hline CHEMBL110055 & 67039 & 6.2076 & 6.2693 & TRN & \\
\hline CHEMBL110065 & 67039 & 4.6739 & 4.572 & TRN & \\
\hline CHEMBL 323424 & 67039 & 6.6383 & 6.6674 & TRN & \\
\hline CHEMBL109355 & 67039 & 5.8297 & 5.8166 & TRN & \\
\hline \multirow[t]{2}{*}{ CHEMBL109332 } & 67039 & 5.4724 & 5.4824 & TST & \\
\hline & & \multicolumn{4}{|c|}{ Page 26202} \\
\hline
\end{tabular}




\begin{tabular}{|c|c|c|c|c|c|}
\hline \multicolumn{6}{|c|}{ Supplemental Table S2.txt } \\
\hline CHEMBL1203047 & 67039 & 4.1497 & 4.1434 & TRN & \\
\hline CHEMBL109575 & 67039 & 5.3788 & 4.4932 & TST & \\
\hline CHEMBL113535 & 67039 & 5.6556 & 5.6654 & TRN & \\
\hline CHEMBL114446 & 67039 & 4.819 & 4.5729 & TST & \\
\hline CHEMBL111222 & 67039 & 5.1707 & 5.1678 & TRN & \\
\hline CHEMBL109503 & 67039 & 5.8386 & 5.8661 & TRN & \\
\hline CHEMBL320479 & 67039 & 6.1308 & 6.1501 & TRN & \\
\hline CHEMBL110577 & 67039 & 5.1965 & 5.1858 & TRN & \\
\hline CHEMBL111520 & 67039 & 6.0605 & 6.0383 & TRN & \\
\hline CHEMBL325981 & 67039 & 5.2882 & 5.6468 & TST & \\
\hline CHEMBL111307 & 67039 & 5.7471 & 5.78299 & 99999999995 & TRN \\
\hline CHEMBL111443 & 67039 & 4.4812 & 4.572 & TRN & \\
\hline CHEMBL432396 & 67039 & 4.3193 & 4.3646 & TRN & \\
\hline CHEMBL1203088 & 67039 & 6.7959 & 6.7969 & TRN & \\
\hline CHEMBL419185 & 67039 & 5.5017 & 5.4899 & TRN & \\
\hline CHEMBL323970 & 67039 & 5.1141 & 5.1226 & TRN & \\
\hline CHEMBL325760 & 67039 & 5.1319 & 5.1596 & TRN & \\
\hline CHEMBL109212 & 67039 & 6.3768 & 6.3018 & TRN & \\
\hline CHEMBL326445 & 67039 & 4.769 & 4.7823 & TRN & \\
\hline CHEMBL110062 & 67039 & 5.1681 & 5.4426 & TST & \\
\hline CHEMBL541988 & 67039 & 4.4657 & 4.4025 & TST & \\
\hline CHEMBL29197 & 67039 & 7.1549 & 7.0802 & TST & \\
\hline CHEMBL111586 & 67039 & 6.4559 & 6.4891 & TRN & \\
\hline CHEMBL 323900 & 67039 & 5.1772 & 5.1034 & TRN & \\
\hline CHEMBL111442 & 67039 & 2.9801 & 5.7146 & TST & \\
\hline CHEMBL112096 & 67039 & 6.4437 & 4.9423 & TST & \\
\hline CHEMBL109625 & 67039 & 4.2054 & 4.1369 & TRN & \\
\hline CHEMBL443277 & 67039 & 3.0899 & 4.5227 & TST & \\
\hline CHEMBL324399 & 67039 & 4.1586 & 4.1772 & TRN & \\
\hline CHEMBL 83228 & 67039 & 4.2968 & 4.322 & TRN & \\
\hline CHEMBL109372 & 67039 & 6.2676 & 6.2302 & TRN & \\
\hline CHEMBL1203026 & 67039 & 6.1192 & 6.0981 & TRN & \\
\hline CHEMBL110036 & 67039 & 6.0862 & 6.0514 & TRN & \\
\hline CHEMBL110945 & 67039 & 5.0438 & 5.0136 & TRN & \\
\hline CHEMBL109259 & 67039 & 4.0541 & 4.0443 & TRN & \\
\hline CHEMBL112225 & 67039 & 6.0757 & 5.06800 & 00000000005 & TST \\
\hline CHEMBL109515 & 67039 & 5.9586 & 5.9751 & TRN & \\
\hline CHEMBL111033 & 67039 & 4.8483 & 4.8565 & TRN & \\
\hline CHEMBL109476 & 67039 & 5.5638 & 5.5562 & TRN & \\
\hline CHEMBL111038 & 67039 & 6.7212 & 6.3233 & TST & \\
\hline CHEMBL3985390 & 1641035 & 7.2218 & 7.1079 & TRN & \\
\hline CHEMBL3954819 & 1641035 & 6.0 & 5.77 & TRN & \\
\hline CHEMBL3978366 & 1641035 & 7.5086 & 7.2091 & TRN & \\
\hline CHEMBL 3897131 & 1641035 & 6.0862 & 6.0548 & TST & \\
\hline CHEMBL3963443 & 1641035 & 6.0 & 6.1185 & TRN & \\
\hline CHEMBL3967682 & 1641035 & 6.0 & 5.7988 & TRN & \\
\hline CHEMBL3915844 & 1641035 & 6.6576 & 6.8711 & TST & \\
\hline CHEMBL3927682 & 1641035 & 6.7447 & 6.6958 & TST & \\
\hline
\end{tabular}


Supplemental Table S2.txt

\begin{tabular}{|c|c|c|c|c|}
\hline CHEMBL3936565 & 1641035 & 7.4949 & 7.2792 & TRN \\
\hline CHEMBL3985243 & 1641035 & 7.9208 & 8.1898 & TRN \\
\hline CHEMBL3949040 & 1641035 & 8.3565 & 8.3224 & TRN \\
\hline CHEMBL3913228 & 1641035 & 6.0 & 6.3023 & TRN \\
\hline CHEMBL3931293 & 1641035 & 6.4685 & 6.2462 & TST \\
\hline CHEMBL3972962 & 1641035 & 6.8539 & 6.5952 & TRN \\
\hline CHEMBL3897648 & 1641035 & 6.6778 & 6.6699 & TRN \\
\hline CHEMBL3892562 & 1641035 & 6.5376 & 6.1682 & TRN \\
\hline CHEMBL3933397 & 1641035 & 7.5376 & 7.2998 & TST \\
\hline CHEMBL3983231 & 1641035 & 6.0 & 5.8461 & TRN \\
\hline CHEMBL3906776 & 1641035 & 7.3468 & 6.9693 & TRN \\
\hline CHEMBL3986618 & 1641035 & 7.8239 & 8.1332 & TRN \\
\hline CHEMBL3922488 & 1641035 & 6.699 & 6.6167 & TRN \\
\hline CHEMBL3971373 & 1641035 & 7.5086 & 7.4217 & TRN \\
\hline CHEMBL3958508 & 1641035 & 6.4089 & 6.7083 & TRN \\
\hline CHEMBL3927252 & 1641035 & 8.6576 & 8.4117 & TRN \\
\hline CHEMBL3963319 & 1641035 & 6.4685 & 6.2059 & TST \\
\hline CHEMBL3973102 & 1641035 & 6.0 & 6.2473 & TRN \\
\hline CHEMBL3975090 & 1641035 & 6.7696 & 6.7908 & TRN \\
\hline CHEMBL3956966 & 1641035 & 7.0132 & 6.9698 & TST \\
\hline CHEMBL3939325 & 1641035 & 7.301 & 7.2788 & TRN \\
\hline CHEMBL3905617 & 1641035 & 6.5376 & 6.4127 & TST \\
\hline CHEMBL3918854 & 1641035 & 7.3872 & 7.4615 & TRN \\
\hline CHEMBL3900738 & 1641035 & 6.5376 & 6.7647 & TRN \\
\hline CHEMBL3981338 & 1641035 & 7.4685 & 7.50200 & 0000000001 \\
\hline CHEMBL3917774 & 1641035 & 7.8861 & 7.7598 & TRN \\
\hline CHEMBL3908624 & 1641035 & 7.3768 & 7.6103 & TRN \\
\hline CHEMBL3967735 & 1641035 & 6.0 & 6.2793 & TRN \\
\hline CHEMBL3978189 & 1641035 & 7.0 & 7.0588 & TRN \\
\hline CHEMBL3951230 & 1641035 & 8.0 & 7.6925 & TRN \\
\hline CHEMBL3935532 & 1641035 & 7.2076 & 7.2908 & TRN \\
\hline CHEMBL3912503 & 1641035 & 6.0 & 6.1078 & TRN \\
\hline CHEMBL3981393 & 1641035 & 7.7959 & 7.5887 & TRN \\
\hline CHEMBL3942459 & 1641035 & 6.8861 & 7.1125 & TRN \\
\hline CHEMBL3965307 & 1641035 & 7.4437 & 7.2955 & TRN \\
\hline CHEMBL3914847 & 1641035 & 7.2924 & 7.1492 & TRN \\
\hline CHEMBL3967749 & 1641035 & 8.3372 & 8.2963 & TRN \\
\hline CHEMBL3969811 & 1641035 & 6.699 & 7.0447 & TRN \\
\hline CHEMBL3947422 & 1641035 & 6.0 & 5.4029 & TRN \\
\hline CHEMBL3906210 & 1641035 & 7.2676 & 7.138 & TRN \\
\hline CHEMBL3896215 & 1641035 & 7.4949 & 7.0374 & TST \\
\hline CHEMBL3910680 & 1641035 & 6.699 & 6.6125 & TRN \\
\hline CHEMBL3896784 & 1641035 & 6.0 & 6.1546 & TRN \\
\hline CHEMBL3931368 & 1641035 & 6.9586 & 6.6541 & TRN \\
\hline CHEMBL3928338 & 1641035 & 7.9586 & 7.3386 & TST \\
\hline CHEMBL3896566 & 1641035 & 8.0 & 7.9525 & TRN \\
\hline CHEMBL3923184 & 1641035 & 7.4559 & 7.6746 & TRN \\
\hline CHEMBL3942120 & 1641035 & 7.0 & 6.9478 & TRN \\
\hline
\end{tabular}


Supplemental Table S2.txt

\begin{tabular}{|c|c|c|c|c|}
\hline CHEMBL3919034 & 1641035 & 7.0088 & 6.7623 & TST \\
\hline CHEMBL3949257 & 1641035 & 7.9208 & 7.7843 & TRN \\
\hline CHEMBL3962138 & 1641035 & 7.5686 & 7.895 & TRN \\
\hline CHEMBL3934116 & 1641035 & 8.3665 & 8.2195 & TRN \\
\hline CHEMBL3935174 & 1641035 & 6.6021 & 6.3946 & TRN \\
\hline CHEMBL3926894 & 1641035 & 7.5086 & 7.6314 & TRN \\
\hline CHEMBL3984960 & 1641035 & 7.3372 & 7.9573 & TRN \\
\hline CHEMBL3922303 & 1641035 & 6.8539 & 6.8098 & TRN \\
\hline CHEMBL3901676 & 1641035 & 6.4815 & 6.1419 & TRN \\
\hline CHEMBL3967880 & 1641035 & 7.4685 & 7.3305 & TRN \\
\hline CHEMBL3985119 & 1641035 & 7.585 & 7.312 & TRN \\
\hline CHEMBL3932581 & 1641035 & 6.7696 & 7.1982 & TST \\
\hline CHEMBL3954792 & 1641035 & 6.4685 & 6.3421 & TST \\
\hline CHEMBL 3975088 & 1641035 & 7.7959 & 7.5256 & TRN \\
\hline CHEMBL3922520 & 1641035 & 7.5086 & 7.4141 & TRN \\
\hline CHEMBL3943768 & 1641035 & 6.6778 & 6.5247 & TST \\
\hline CHEMBL3940267 & 1641035 & 7.9586 & 7.7372 & TRN \\
\hline CHEMBL3912419 & 1641035 & 7.1427 & 7.4574 & TRN \\
\hline CHEMBL 3934440 & 1641035 & 7.2518 & 7.0765 & TRN \\
\hline CHEMBL 3936877 & 1641035 & 7.6383 & 7.7429 & TRN \\
\hline CHEMBL3909793 & 1641035 & 6.2076 & 5.9548 & TRN \\
\hline CHEMBL3945740 & 1641035 & 7.4089 & 7.0879 & TST \\
\hline CHEMBL3974989 & 1641035 & 7.699 & 7.8899 & TRN \\
\hline CHEMBL 3930389 & 1641035 & 8.0555 & 7.8375 & TRN \\
\hline CHEMBL3926766 & 1641035 & 7.8861 & 7.67299 & و999999999 \\
\hline CHEMBL3957937 & 1641035 & 7.5229 & 7.6147 & TRN \\
\hline CHEMBL3947711 & 1641035 & 7.3279 & 7.2567 & TRN \\
\hline CHEMBL3973429 & 1641035 & 6.7447 & 6.8803 & TRN \\
\hline CHEMBL3933612 & 1641035 & 6.6778 & 6.4391 & TST \\
\hline CHEMBL 3949242 & 1641035 & 7.2007 & 7.2966 & TRN \\
\hline CHEMBL3928091 & 1641035 & 7.3188 & 6.6732 & TRN \\
\hline CHEMBL3936616 & 1641035 & 7.5528 & 7.2567 & TRN \\
\hline CHEMBL3923711 & 1641035 & 7.3279 & 7.1723 & TRN \\
\hline CHEMBL3973276 & 1641035 & 6.041 & 5.6311 & TRN \\
\hline CHEMBL3952151 & 1641035 & 6.0 & 5.9057 & TRN \\
\hline CHEMBL3896766 & 1641035 & 7.3468 & 6.9487 & TRN \\
\hline CHEMBL3903941 & 1641035 & 6.0 & 5.4821 & TRN \\
\hline CHEMBL3892138 & 1641035 & 7.7696 & 7.5402 & TRN \\
\hline CHEMBL3897798 & 1641035 & 7.7447 & 8.0119 & TRN \\
\hline CHEMBL 3892296 & 1641035 & 8.1135 & 8.0117 & TRN \\
\hline CHEMBL3896324 & 1641035 & 8.2147 & 7.8758 & TRN \\
\hline CHEMBL3894535 & 1641035 & 7.4202 & 7.1826 & TST \\
\hline CHEMBL3972067 & 1641035 & 7.5086 & 6.8254 & TRN \\
\hline CHEMBL3906986 & 1641035 & 7.5376 & 7.1872 & TRN \\
\hline CHEMBL 3953550 & 1641035 & 8.0 & 7.8817 & TRN \\
\hline CHEMBL3959692 & 1641035 & 7.4685 & 7.5726 & TST \\
\hline CHEMBL 3958797 & 1641035 & 7.3979 & 7.2833 & TRN \\
\hline CHEMBL 3925854 & 1641035 & 7.699 & 7.8511 & TRN \\
\hline
\end{tabular}


Supplemental Table S2.txt

\begin{tabular}{|c|c|c|c|c|c|}
\hline CHEMBL 3975123 & 1641035 & 6.0555 & \multicolumn{2}{|c|}{6.537999999999999} & TRN \\
\hline CHEMBL 3959556 & 1641035 & 7.3565 & 7.0804 & TRN & \\
\hline CHEMBL 3937326 & 1641035 & 6.7447 & 6.7207 & TRN & \\
\hline CHEMBL 3906460 & 1641035 & 6.7696 & 6.7715 & TRN & \\
\hline CHEMBL 3930431 & 1641035 & 7.4559 & 7.2642 & TRN & \\
\hline CHEMBL 3963555 & 1641035 & 6.9586 & 6.8894 & TST & \\
\hline CHEMBL 3913693 & 1641035 & 7.4949 & 6.8625 & TRN & \\
\hline CHEMBL3900724 & 1641035 & 5.0 & 6.0534 & TRN & \\
\hline CHEMBL 3949195 & 1641035 & 6.0269 & 6.1521 & TRN & \\
\hline CHEMBL 3894474 & 1641035 & 7.585 & 7.7857 & TRN & \\
\hline CHEMBL 3907944 & 1641035 & 7.6198 & 6.85 & TRN & \\
\hline CHEMBL 3891204 & 1641035 & 6.699 & 6.9891 & TRN & \\
\hline CHEMBL3983856 & 1641035 & 6.6576 & 6.5685 & TRN & \\
\hline CHEMBL 3981121 & 1641035 & 6.0 & 6.2313 & TRN & \\
\hline CHEMBL 3904453 & 1641035 & 6.7212 & 6.1185 & TRN & \\
\hline CHEMBL 3978202 & 1641035 & 8.0757 & 8.1113 & TRN & \\
\hline CHEMBL 3934664 & 1641035 & 6.9586 & 7.2579 & TRN & \\
\hline CHEMBL 3918875 & 1641035 & 6.8861 & 6.4619 & TST & \\
\hline CHEMBL 3986443 & 1641035 & 7.2441 & 6.9965 & TRN & \\
\hline CHEMBL 3985220 & 1641035 & 7.8539 & 7.5925 & TST & \\
\hline CHEMBL 3917783 & 1641035 & 6.4318 & 6.4073 & TST & \\
\hline CHEMBL 3934580 & 1641035 & 8.2676 & 8.1191 & TRN & \\
\hline CHEMBL3907770 & 1641035 & 7.5229 & 7.7602 & TRN & \\
\hline CHEMBL 3906687 & 1641035 & 7.284 & 7.3643 & TRN & \\
\hline CHEMBL 3979988 & 1641035 & 8.3565 & 8.0754 & TRN & \\
\hline CHEMBL3916915 & 1641035 & 7.7212 & 7.6876 & TRN & \\
\hline CHEMBL 3941680 & 1641035 & 6.6576 & 6.6949 & TRN & \\
\hline CHEMBL 3907648 & 1641035 & 6.9208 & 6.9628 & TRN & \\
\hline CHEMBL 3972353 & 1641035 & 7.4685 & 7.7831 & TRN & \\
\hline CHEMBL 3973060 & 1641035 & 7.0506 & 6.858 & TST & \\
\hline CHEMBL3959789 & 1641035 & 5.0 & 6.2085 & TST & \\
\hline CHEMBL 3923030 & 1641035 & 6.0 & 5.9434 & TRN & \\
\hline CHEMBL 3942424 & 1641035 & 6.0 & 5.7836 & TRN & \\
\hline CHEMBL3907076 & 1641035 & 6.0 & 5.7575 & TRN & \\
\hline CHEMBL 3934192 & 1641035 & 7.2676 & 6.8285 & TRN & \\
\hline CHEMBL3951710 & 1641035 & 6.7959 & 6.5985 & TRN & \\
\hline CHEMBL 3946824 & 1641035 & 7.0458 & 6.9231 & TRN & \\
\hline CHEMBL 3898786 & 1641035 & 7.585 & 7.2067 & TST & \\
\hline CHEMBL3962689 & 1641035 & 6.3979 & 6.1871 & TRN & \\
\hline CHEMBL 3902428 & 1641035 & 6.699 & 6.7801 & TRN & \\
\hline CHEMBL3971717 & 1641035 & 6.9586 & 6.8239 & TRN & \\
\hline CHEMBL 3956450 & 1641035 & 8.0757 & 7.6236 & TRN & \\
\hline CHEMBL 3949461 & 1641035 & 6.9586 & 6.9244 & TRN & \\
\hline CHEMBL 3916687 & 1641035 & 7.2291 & 7.2342 & TRN & \\
\hline CHEMBL 3924572 & 1641035 & 7.8239 & 7.7158 & TRN & \\
\hline CHEMBL3913397 & 1641035 & 7.4685 & 6.9504 & TRN & \\
\hline CHEMBL 3902447 & 1641035 & 6.2518 & 6.2426 & TRN & \\
\hline CHEMBL3947782 & 1641035 & 7.3279 & 6.8994 & TRN & \\
\hline
\end{tabular}


Supplemental Table S2.txt

\begin{tabular}{|c|c|c|c|c|}
\hline HEMBL & 年 & 7.4815 & & \\
\hline & & & 5583 & \\
\hline 89 & & & & \\
\hline HEMBL394 & & & & $\mathrm{MI}$ \\
\hline HEMBL3898916 & 035 & 5.0 & 9211 & \\
\hline HEMBL3980369 & 641035 & 6.7696 & 609 & \\
\hline HEMBL39 & & & 54 & \\
\hline AFMBI 39 & & & 383 & \\
\hline HEMBL 398 & & 2076 & 1442 & \\
\hline HEMBL395 & 335 & 7.5086 & 9548 & \\
\hline HEMBL390 & בט & 7.2757 & 6298 & \\
\hline AEMBL395 & 35 & 79 & 655 & \\
\hline AEMBL39 & & & & \\
\hline HEMBL397 & $c$ & 28 & $\partial 889$ & \\
\hline AEMBL393 & 35 & & 308 & \\
\hline AEMBL394 & 0 & 7.6 & 7851 & \\
\hline HEMBL39 & 6 & 5 & 233 & m \\
\hline HEMBL39 & & & 5732 & \\
\hline HEMBL392 & & & 6.5981 & \\
\hline HEMBL398 & & & 29 & \\
\hline HEIMBLSS & 64 & & 137 & 1 \\
\hline HEMBL3S & & & & RN \\
\hline HEMBL39 & & 8 . & 219 & \\
\hline HFMBI 397 & & 5.6021 & 2355 & \\
\hline HEMBL390 & & & & TST \\
\hline HEMBL39 & 6 & & 83 & RN \\
\hline HEMBL3S & & & 18 & RN \\
\hline HFMBI $3 c$ & & 7. & 11 & $\mathrm{RN}$ \\
\hline HEMBL 39 & & & 5844 & 15 \\
\hline HEMBL 388 & & & 513 & ISI \\
\hline HEMBL 396 & 6 & & 962 & $\mathrm{RN}$ \\
\hline HEMBL3S & & 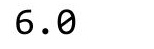 & 43 & RN \\
\hline HEMBL3 & & 6 & 284 & RN \\
\hline HEMBL3907503 & & 7.5686 & 35 & IRN \\
\hline HEMBL 392731 & & 5.0 & 2097 & TRN \\
\hline HEMBL396 & 6 & 0. & 5994 & TST \\
\hline HFMRI 3 & & & & TRN \\
\hline HEMBL 397 & & & 887 & IRN \\
\hline HEMBL3962232 & 5 & 6 . & 5022 & TRN \\
\hline AEMBL395 & & & 9093 & TRN \\
\hline HEMBL 391 & 6 & 7. & 6394 & TRN \\
\hline CHEMBL394 & & & 8.0755 & RN \\
\hline HEMBL3956550 & & & 6.7607 & TRN \\
\hline HEMBL3973343 & 035 & 559 & 9266 & $T R$ \\
\hline$M B \mid 3$ & & & & RN \\
\hline HEMBL 39 & & & 2251 & \\
\hline CHEMBL397 & & 7.4559 & 7.8081 & \\
\hline CHEMBL3965485 & 1641035 & 6.6021 & 5.9783 & ГRN \\
\hline
\end{tabular}

Page 26207 
Supplemental Table S2.txt

\begin{tabular}{|c|c|c|c|c|}
\hline CHEMBL3894516 & 1641035 & 7.585 & 7.6086 & TRN \\
\hline CHEMBL3900189 & 1641035 & 5.0 & 6.2567 & TRN \\
\hline CHEMBL3900224 & 1641035 & 7.585 & 7.0026 & TRN \\
\hline CHEMBL3956611 & 1641035 & 6.0 & 5.8575 & TRN \\
\hline CHEMBL3955720 & 1641035 & 8.0915 & 7.8408 & TRN \\
\hline CHEMBL 3952261 & 1641035 & 8.2518 & 7.9649 & TRN \\
\hline CHEMBL3970198 & 1641035 & 6.6778 & 6.715 & TRN \\
\hline CHEMBL3958601 & 1641035 & 6.5086 & 6.4483 & TST \\
\hline CHEMBL3951107 & 1641035 & 8.7212 & 8.0221 & TRN \\
\hline CHEMBL3962364 & 1641035 & 6.1427 & 6.1503 & TRN \\
\hline CHEMBL3956911 & 1641035 & 6.0 & 6.0108 & TRN \\
\hline CHEMBL3947889 & 1641035 & 7.6198 & 7.3163 & TRN \\
\hline CHEMBL 3940483 & 1641035 & 6.8539 & 6.7658 & TRN \\
\hline CHEMBL3917860 & 1641035 & 7.0315 & 7.0193 & TRN \\
\hline CHEMBL 3912553 & 1641035 & 7.6576 & 8.4505 & TRN \\
\hline CHEMBL 3898818 & 1641035 & 7.8861 & 7.4348 & TRN \\
\hline CHEMBL 3899570 & 1641035 & 7.6198 & 7.4439 & TRN \\
\hline CHEMBL3931093 & 1641035 & 8.6383 & 8.4724 & TRN \\
\hline CHEMBL3937067 & 1641035 & 8.3979 & 8.3319 & TRN \\
\hline CHEMBL3893196 & 1641035 & 6.699 & 6.635 & TRN \\
\hline CHEMBL3919766 & 1641035 & 7.4949 & 7.3956 & TRN \\
\hline CHEMBL3975439 & 1641035 & 7.0757 & 7.3093 & TST \\
\hline CHEMBL3981130 & 1641035 & 7.284 & 7.23799 & 99999999995 \\
\hline CHEMBL 3890951 & 1641035 & 6.1308 & 6.1423 & TST \\
\hline CHEMBL 3937827 & 1641035 & 6.7212 & 6.6911 & TRN \\
\hline CHEMBL 3890660 & 1641035 & 6.3872 & 6.3296 & TRN \\
\hline CHEMBL3945787 & 1641035 & 6.8239 & 7.0958 & TRN \\
\hline CHEMBL 3929124 & 1641035 & 7.699 & 7.5922 & TRN \\
\hline CHEMBL3940316 & 1641035 & 6.4815 & 6.49299 & 9999999999 \\
\hline CHEMBL3945378 & 1641035 & 7.3279 & 6.9809 & TRN \\
\hline CHEMBL 3946758 & 1641035 & 7.5376 & 6.936 & TRN \\
\hline CHEMBL3985597 & 1641035 & 6.2924 & 6.0235 & TST \\
\hline CHEMBL3973453 & 1641035 & 5.0 & 6.8017 & TRN \\
\hline CHEMBL 3923513 & 1641035 & 8.3098 & 7.9539 & TRN \\
\hline CHEMBL3975255 & 1641035 & 5.0 & 6.3033 & TST \\
\hline CHEMBL3983303 & 1641035 & 5.0 & 6.938 & TRN \\
\hline CHEMBL3935688 & 1641035 & 7.1871 & 7.3379 & TRN \\
\hline CHEMBL3948921 & 1641035 & 7.5376 & 7.4707 & TRN \\
\hline CHEMBL3964008 & 1641035 & 7.6778 & 7.7184 & TRN \\
\hline CHEMBL 3983344 & 1641035 & 7.2924 & 7.1906 & TRN \\
\hline CHEMBL3960109 & 1641035 & 7.3565 & 7.4429 & TST \\
\hline CHEMBL3894366 & 1641035 & 7.0605 & 6.8222 & TST \\
\hline CHEMBL3955124 & 1641035 & 6.5376 & 6.3943 & TRN \\
\hline CHEMBL 3897849 & 1641035 & 7.6198 & 7.3941 & TRN \\
\hline CHEMBL 3956418 & 1641035 & 7.4202 & 7.7039 & TRN \\
\hline CHEMBL3936356 & 1641035 & 7.9208 & 7.7679 & TST \\
\hline CHEMBL3936927 & 1641035 & 5.0 & 5.9252 & TRN \\
\hline CHEMBL3915165 & 1641035 & 6.8239 & 6.8563 & TRN \\
\hline
\end{tabular}

Page 26208 
Supplemental Table S2.txt

\begin{tabular}{|c|c|c|c|c|}
\hline HEMB & 541035 & 249 & & 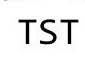 \\
\hline & & 8.2518 & & \\
\hline HFMRI & 335 & 6.0 & & \\
\hline AEMBL & & 147 & & \\
\hline AEMBL3917030 & 641035 & 7.0269 & 9595 & \\
\hline HEMBL3983447 & 35 & 7.1805 & 43 & \\
\hline HEMBL3 & 35 & 5.0 & & \\
\hline AEMBL3 & & 1 & & \\
\hline HEMBL3954894 & 641035 & 9.0 & 6189 & \\
\hline HEMBL3981443 & 235 & 7.2676 & 2212 & \\
\hline HEMBL3 & 35 & 7.0132 & & \\
\hline HEMBL3 & 35 & 686 & & \\
\hline HEMBL3 & & 38 & & \\
\hline HEMBL 392 & 335 & 6.6383 & 6.4071 & \\
\hline HEMBL 389 & 335 & 8.4318 & & \\
\hline HEMBL3 & 6 & 7. & & \\
\hline HEMBL3 & & & & r \\
\hline HEMBL3 & & 506 & & \\
\hline HEMBL3 & 35 & 815 & & \\
\hline AEMBL3 & & 5 . & & niv \\
\hline HEMBL & 64 & 7 & $\partial 8$ & RN \\
\hline HEME & & & & RN \\
\hline HEMBL & 35 & 6 . & & \\
\hline HEMBL3 & & 5. & & IST \\
\hline HEMBL3S & & 7. & & IRN \\
\hline HEMBL3 & & 72 & & RN \\
\hline HEM & & 39 & 77 & RN \\
\hline 23 & & 686 & 94 & RN \\
\hline HEMBL3 & & & & $\Gamma \mathrm{RN}$ \\
\hline HEMBL39 & & 7.9208 & 598 & RN \\
\hline HEMBL; & & 7 & 472 & RN \\
\hline HFM & & 59 & 53 & RN \\
\hline (15MP & & & & 「RN \\
\hline HEMBL3 & & & & 「RN \\
\hline HEMBL398 & & 949 & 91 & RN \\
\hline HEMRI $=$ & & 949 & 08 & . \\
\hline 6 & & & & RN \\
\hline HEMBL3 & & 7.85 & & TRN \\
\hline HEMBL3 & & 7.8239 & & $\Gamma R$ \\
\hline IEMBL & & 12 & & RN \\
\hline HEMBL3 & & 6 . & & \\
\hline HEMBL3 & & 7.1024 & 74 & $\mathrm{RN}$ \\
\hline HEMBL3 & 235 & 6 & 113 & {$\left[R_{2}>>\right.$} \\
\hline HEMBL3 & 35 & 7. & & TR \\
\hline CHEMPI 38 & & & & \\
\hline HEMBL 3921442 & & 7.44 & & \\
\hline CHEMBL3899587 & 235 & 6.0 & 5.8061 & \\
\hline CHEMBL3976885 & 1641035 & 6.3768 & 6.4162 & \\
\hline
\end{tabular}

Page 26209 
Supplemental Table S2.txt

\begin{tabular}{|c|c|c|c|c|c|}
\hline CHEMBL3933671 & 1641035 & 6.3188 & 6.3642 & TRN & \\
\hline CHEMBL3920091 & 1641035 & 8.1805 & 8.01100 & 0000000001 & TST \\
\hline CHEMBL3972475 & 1641035 & 8.8239 & 8.5042 & TRN & \\
\hline CHEMBL3948605 & 1641035 & 7.7696 & 7.4891 & TST & \\
\hline CHEMBL3974289 & 1641035 & 6.0 & 6.0617 & TRN & \\
\hline CHEMBL3926516 & 1641035 & 8.1487 & 7.92 & TST & \\
\hline CHEMBL3975399 & 1641035 & 8.1367 & 7.6977 & TRN & \\
\hline CHEMBL3922180 & 1641035 & 7.1427 & 6.8545 & TRN & \\
\hline CHEMBL 3940782 & 1641035 & 7.4318 & 7.4874 & TRN & \\
\hline CHEMBL3978777 & 1641035 & 6.3279 & 6.7205 & TRN & \\
\hline CHEMBL3904571 & 1641035 & 7.8861 & 7.657 & TRN & \\
\hline CHEMBL3908073 & 1641035 & 7.3188 & 7.1156 & TST & \\
\hline CHEMBL3973072 & 1641035 & 6.7212 & 6.8586 & TRN & \\
\hline CHEMBL3976356 & 1641035 & 6.4318 & 6.4319 & TRN & \\
\hline CHEMBL 3902287 & 1641035 & 6.0 & 6.1228 & TRN & \\
\hline CHEMBL3964133 & 1641035 & 7.284 & 7.2942 & TRN & \\
\hline CHEMBL3968423 & 1641035 & 6.0 & 5.6635 & TRN & \\
\hline CHEMBL 3917954 & 1641035 & 7.1871 & 7.2885 & TRN & \\
\hline CHEMBL3972033 & 1641035 & 7.4815 & 7.5228 & TRN & \\
\hline CHEMBL 3902333 & 1641035 & 7.3098 & 7.0052 & TRN & \\
\hline CHEMBL3986660 & 1641035 & 7.041 & 7.6317 & TRN & \\
\hline CHEMBL3949285 & 1641035 & 8.5686 & 8.4509 & TRN & \\
\hline CHEMBL3954249 & 1641035 & 7.7696 & 7.7406 & TST & \\
\hline CHEMBL3939232 & 1641035 & 7.2676 & 7.3141 & TRN & \\
\hline CHEMBL3931226 & 1641035 & 7.5229 & 7.7825 & TRN & \\
\hline CHEMBL3941598 & 1641035 & 7.0969 & 6.9604 & TRN & \\
\hline CHEMBL3953486 & 1641035 & 7.6383 & 7.6874 & TRN & \\
\hline CHEMBL3902431 & 1641035 & 6.8861 & 6.8988 & TST & \\
\hline CHEMBL3921202 & 1641035 & 7.2218 & 7.0639 & TRN & \\
\hline CHEMBL3962300 & 1641035 & 7.0 & 6.735 & TRN & \\
\hline CHEMBL3910017 & 1641035 & 7.0458 & 6.8053 & TRN & \\
\hline CHEMBL3908040 & 1641035 & 7.2147 & 7.6477 & TRN & \\
\hline CHEMBL3934943 & 1641035 & 7.0655 & 7.2294 & TRN & \\
\hline CHEMBL 3916457 & 1641035 & 7.7959 & 7.8269 & TRN & \\
\hline CHEMBL3942304 & 1641035 & 7.1487 & 7.0888 & TRN & \\
\hline CHEMBL3918308 & 1641035 & 8.5229 & 8.4227 & TRN & \\
\hline CHEMBL3940421 & 1641035 & 6.585 & 6.6138 & TRN & \\
\hline CHEMBL3986377 & 1641035 & 7.9586 & 8.0748 & TRN & \\
\hline CHEMBL3986588 & 1641035 & 7.0458 & 6.782 & TRN & \\
\hline CHEMBL3937822 & 1641035 & 6.7696 & 6.6258 & TST & \\
\hline CHEMBL3973302 & 1641035 & 7.2596 & 7.5359 & TRN & \\
\hline CHEMBL3970109 & 1641035 & 6.7212 & 6.563 & TRN & \\
\hline CHEMBL3902205 & 1641035 & 6.8239 & 7.0501 & TRN & \\
\hline CHEMBL3907394 & 1641035 & 6.5086 & 6.5373 & TRN & \\
\hline CHEMBL3963532 & 1641035 & 6.5086 & 6.5841 & TST & \\
\hline CHEMBL3967397 & 1641035 & 7.3872 & 7.655 & TRN & \\
\hline CHEMBL 3900746 & 1641035 & 7.1549 & 7.7395 & TRN & \\
\hline CHEMBL3971898 & 1641035 & 7.0 & 6.9792 & TRN & \\
\hline
\end{tabular}


Supplemental Table S2.txt

\begin{tabular}{|c|c|c|c|c|}
\hline CHEMBL3957659 & 1641035 & 7.6778 & 7.5792 & TRN \\
\hline CHEMBL 3923802 & 1641035 & 6.8239 & 6.778 & TRN \\
\hline CHEMBL 3960910 & 1641035 & 7.7212 & 7.8197 & TRN \\
\hline CHEMBL 3962451 & 1641035 & 7.0915 & 7.0198 & TRN \\
\hline CHEMBL 3919050 & 1641035 & 7.0 & 7.4864 & TRN \\
\hline CHEMBL 3941925 & 1641035 & 7.9208 & 7.8022 & TST \\
\hline CHEMBL 3973486 & 1641035 & 6.3665 & 6.3187 & TRN \\
\hline CHEMBL 3899650 & 1641035 & 6.7696 & 6.8143 & TRN \\
\hline CHEMBL 3977017 & 1641035 & 7.8861 & 8.0567 & TRN \\
\hline CHEMBL 3941241 & 1641035 & 6.0 & 5.5253 & TRN \\
\hline CHEMBL 3904186 & 1641035 & 7.1938 & 7.4126 & TRN \\
\hline CHEMBL 3913565 & 1641035 & 7.3979 & 7.2879 & TRN \\
\hline CHEMBL 3955496 & 1641035 & 7.3372 & 7.0828 & TST \\
\hline CHEMBL 3935408 & 1641035 & 7.2596 & 7.1546 & TST \\
\hline CHEMBL 3935714 & 1641035 & 7.5229 & 7.1867 & TST \\
\hline CHEMBL 3938593 & 1641035 & 7.3565 & 7.2203 & TRN \\
\hline CHEMBL 3903353 & 1641035 & 6.7447 & 6.3814 & TRN \\
\hline CHEMBL 3896777 & 1641035 & 7.585 & 7.3757 & TRN \\
\hline CHEMBL 3920329 & 1641035 & 7.9586 & 7.9558 & TRN \\
\hline CHEMBL 3966840 & 1641035 & 6.0 & 5.9066 & TRN \\
\hline CHEMBL 3957421 & 1641035 & 6.0 & 5.6583 & TRN \\
\hline CHEMBL 3945964 & 1641035 & 7.8539 & 7.5238 & TRN \\
\hline CHEMBL 3924171 & 1641035 & 5.0 & 6.1659 & TRN \\
\hline CHEMBL 3965217 & 1641035 & 7.4202 & 7.3744 & TST \\
\hline CHEMBL 3889789 & 1641035 & 6.0 & 6.0043 & TST \\
\hline CHEMBL 3980992 & 1641035 & 7.2366 & 6.8543 & TST \\
\hline CHEMBL 3902770 & 1641035 & 6.699 & 6.7295 & TST \\
\hline CHEMBL 3916636 & 1641035 & 7.7696 & 7.7116 & TST \\
\hline CHEMBL 3929398 & 1641035 & 6.4202 & 6.3931 & TST \\
\hline CHEMBL 3965520 & 1641035 & 7.0269 & 6.6976 & TST \\
\hline CHEMBL 3984562 & 1641035 & 8.9208 & 8.6526 & TST \\
\hline CHEMBL 3899634 & 1641035 & 8.1938 & 8.1706 & TST \\
\hline CHEMBL 3965670 & 1641035 & 8.1308 & 7.2871 & TST \\
\hline CHEMBL 3938956 & 1641035 & 7.2596 & 7.0465 & TST \\
\hline CHEMBL 3917056 & 1641035 & 6.9586 & 7.3205 & TST \\
\hline CHEMBL 3911874 & 1641035 & 6.8861 & 7.1433 & TST \\
\hline CHEMBL 3941431 & 1641035 & 7.5229 & 7.2576 & TST \\
\hline CHEMBL 3980120 & 1641035 & 7.0223 & 6.7685 & TST \\
\hline CHEMBL 3977129 & 1641035 & 7.2924 & 7.1605 & TST \\
\hline CHEMBL 3943994 & 1641035 & 7.0506 & 7.6524 & TST \\
\hline CHEMBL 3909814 & 1641035 & 7.3468 & 7.2215 & TST \\
\hline CHEMBL 3983127 & 1641035 & 6.9208 & 6.9605 & TST \\
\hline CHEMBL 3963994 & 1641035 & 6.7212 & 6.5609 & TST \\
\hline CHEMBL 3911186 & 1641035 & 6.5229 & 6.6889 & TST \\
\hline CHEMBL 3907774 & 1641035 & 7.5528 & 7.5372 & TST \\
\hline CHEMBL 3945676 & 1641035 & 7.284 & 7.6098 & TST \\
\hline CHEMBL 3953229 & 1641035 & 8.6021 & 7.7587 & TST \\
\hline \multirow[t]{2}{*}{ CHEMBL3891947 } & 1641035 & 7.3872 & 7.92899 & 7999999999 \\
\hline & & & \multicolumn{2}{|c|}{ Page 26211} \\
\hline
\end{tabular}


Supplemental Table S2.txt

\begin{tabular}{|c|c|c|c|c|}
\hline CHEMBL3969516 & 1641035 & 7.3468 & 7.2993 & TST \\
\hline CHEMBL 3984424 & 1641035 & 6.0 & 5.9683 & TST \\
\hline CHEMBL 3975250 & 1641035 & 7.1079 & 7.0352 & TST \\
\hline CHEMBL 3892159 & 1641035 & 7.0 & 7.4154 & TST \\
\hline CHEMBL 3896712 & 1641035 & 6.2441 & 5.9306 & TST \\
\hline CHEMBL 3973017 & 1641035 & 6.4437 & 6.5281 & TST \\
\hline CHEMBL3950399 & 1641035 & 7.041 & 6.6628 & TST \\
\hline CHEMBL 3896461 & 1641035 & 7.2007 & 6.5222 & TST \\
\hline CHEMBL 3975158 & 1641035 & 7.5086 & 7.4329 & TST \\
\hline CHEMBL 3939331 & 1641035 & 6.7212 & 6.6143 & TST \\
\hline CHEMBL 3983078 & 1641035 & 7.8861 & 7.8508 & TST \\
\hline CHEMBL 3943501 & 1641035 & 7.4559 & 6.7289 & TST \\
\hline CHEMBL 3905358 & 1641035 & 6.6021 & 6.7116 & TST \\
\hline CHEMBL 3902992 & 1641035 & 6.0 & 6.3711 & TST \\
\hline CHEMBL 3927827 & 1641035 & 7.4949 & 6.9816 & TST \\
\hline CHEMBL 3929096 & 1641035 & 7.3279 & 7.177006 & 30000000005 \\
\hline CHEMBL67363 & 50979 & 4.0 & 4.0742 & TRN \\
\hline CHEMBL68340 & 50979 & 6.1858 & 5.9042 & TRN \\
\hline CHEMBL69686 & 50979 & 5.8359 & 5.6575 & TRN \\
\hline CHEMBL67660 & 50979 & 4.0 & 5.2948 & TST \\
\hline CHEMBL63172 & 50979 & 4.0 & 3.9797 & TRN \\
\hline CHEMBL68238 & 50979 & 6.5243 & 6.53 & TRN \\
\hline CHEMBL68118 & 50979 & 6.6655 & 6.6569 & TRN \\
\hline CHEMBL67364 & 50979 & 4.0 & 4.0545 & TRN \\
\hline CHEMBL63180 & 50979 & 4.0 & 4.6829 & TST \\
\hline CHEMBL66698 & 50979 & 5.2055 & 4.9688 & TRN \\
\hline CHEMBL66815 & 50979 & 4.0 & 4.193006 & 30000000005 \\
\hline CHEMBL67469 & 50979 & 4.0 & 3.9302 & TRN \\
\hline CHEMBL 70142 & 50979 & 5.1095 & 4.8386 & TST \\
\hline CHEMBL67958 & 50979 & 4.0 & 4.1769 & TRN \\
\hline CHEMBL307795 & 50979 & 7.3665 & 7.5331 & TRN \\
\hline CHEMBL69374 & 50979 & 5.8471 & 5.8512 & TRN \\
\hline CHEMBL 308442 & 50979 & 4.0 & 4.479 & TRN \\
\hline CHEMBL65937 & 50979 & 4.0 & 3.9848 & TST \\
\hline CHEMBL 66330 & 50979 & 4.0 & 3.8885 & TRN \\
\hline CHEMBL67891 & 50979 & 4.0 & 5.2884 & TST \\
\hline CHEMBL420178 & 50979 & 4.0 & 3.8481 & TST \\
\hline CHEMBL67394 & 50979 & 6.279 & 6.1963 & TRN \\
\hline CHEMBL63664 & 50979 & 5.5654 & 5.457006 & 0000000001 \\
\hline CHEMBL 67438 & 50979 & 7.1805 & 7.117006 & 0000000001 \\
\hline CHEMBL417037 & 50979 & 6.5361 & 6.6056 & TRN \\
\hline CHEMBL66157 & 50979 & 7.2076 & 7.5509 & TRN \\
\hline CHEMBL66602 & 50979 & 5.0655 & 3.1974 & TST \\
\hline CHEMBL67486 & 50979 & 4.0 & 5.4837 & TST \\
\hline CHEMBL 70143 & 50979 & 6.1871 & 5.1204 & TST \\
\hline CHEMBL 70196 & 50979 & 4.0 & 4.3197 & TRN \\
\hline CHEMBL67785 & 50979 & 5.1578 & 5.2954 & TRN \\
\hline CHEMBL67482 & 50979 & 4.0 & 4.1205 & TRN \\
\hline
\end{tabular}




\begin{tabular}{|c|c|c|c|c|c|}
\hline \multicolumn{6}{|c|}{ Supplemental Table S2.txt } \\
\hline CHEMBL305796 & 50979 & 4.0 & 5.7687 & TST & \\
\hline CHEMBL67784 & 50979 & 4.0 & 3.8045 & TRN & \\
\hline CHEMBL68119 & 50979 & 4.0 & 4.4659 & TRN & \\
\hline CHEMBL67477 & 50979 & 4.0 & 4.7625 & TST & \\
\hline CHEMBL67448 & 50979 & \multicolumn{3}{|c|}{6.382000000000001} & 6 \\
\hline CHEMBL416693 & 50979 & 7.4559 & 7.4314 & TRN & \\
\hline CHEMBL66722 & 50979 & 4.0 & 3.8694 & TRN & \\
\hline CHEMBL65721 & 50979 & 5.6457 & 5.526 & TRN & \\
\hline CHEMBL 307751 & 50979 & 6.2692 & 6.2295 & TRN & \\
\hline CHEMBL66572 & 50979 & 4.0 & 3.6869 & TRN & \\
\hline CHEMBL67570 & 50979 & 5.4126 & 5.256 & TRN & \\
\hline CHEMBL433505 & 50979 & 6.7055 & 6.4251 & TRN & \\
\hline CHEMBL65767 & 50979 & 4.0 & 3.8529 & TRN & \\
\hline CHEMBL63140 & 50979 & \multicolumn{3}{|c|}{5.9670000000000005} & 5. \\
\hline CHEMBL69165 & 50979 & 4.0 & 4.032 & TRN & \\
\hline CHEMBL67121 & 50979 & 7.2924 & 5.5736 & TST & \\
\hline CHEMBL442559 & 50979 & 5.6562 & 4.6675 & TST & \\
\hline CHEMBL418688 & 50979 & 4.0 & 3.8854 & TST & \\
\hline CHEMBL66160 & 50979 & 4.0 & 4.3383 & TRN & \\
\hline CHEMBL420361 & 50979 & 5.7371 & 5.2813 & TRN & \\
\hline CHEMBL 303931 & 50979 & 6.3799 & 6.4865 & TRN & \\
\hline CHEMBL 70195 & 50979 & 5.3272 & 5.5172 & TRN & \\
\hline CHEMBL66950 & 50979 & 6.9393 & 6.8758 & TRN & \\
\hline CHEMBL 304072 & 50979 & 5.8529 & 5.7064 & TRN & \\
\hline CHEMBL65708 & 50979 & 6.279 & 6.3286 & TRN & \\
\hline CHEMBL68182 & 50979 & 4.0 & 3.8094 & TRN & \\
\hline CHEMBL67342 & 50979 & 4.0 & 4.9005 & TST & \\
\hline CHEMBL67343 & 50979 & 4.0 & 5.4801 & TST & \\
\hline CHEMBL69431 & 50979 & 5.6411 & 5.4855 & TRN & \\
\hline CHEMBL67603 & 50979 & 7.3665 & 7.3781 & TRN & \\
\hline CHEMBL 304130 & 50979 & 4.0 & 4.2042 & TRN & \\
\hline CHEMBL1386623 & 688474 & 4.6477 & 4.6732 & TRN & \\
\hline CHEMBL1524365 & 688474 & 5.3323 & 4.7722 & TRN & \\
\hline CHEMBL1396145 & 688474 & 3.301 & 3.4242 & TRN & \\
\hline CHEMBL1381571 & 688474 & 4.9241 & 4.5073 & TRN & \\
\hline CHEMBL495285 & 688474 & 5.8069 & 5.0525 & TRN & \\
\hline CHEMBL1464468 & 688474 & 3.301 & 3.7375 & TRN & \\
\hline CHEMBL489372 & 688474 & 3.301 & 3.6688 & TRN & \\
\hline CHEMBL1586936 & 688474 & 3.301 & 3.86800 & 00000 & 003 \\
\hline CHEMBL3216654 & 688474 & 3.301 & 4.7629 & TRN & \\
\hline CHEMBL1583199 & 688474 & 5.6178 & 3.968 & TST & \\
\hline CHEMBL1503638 & 688474 & 3.301 & 3.0535 & TRN & \\
\hline CHEMBL1515699 & 688474 & 3.301 & 2.7386 & TRN & \\
\hline CHEMBL1426787 & 688474 & 3.301 & 3.3767 & TRN & \\
\hline CHEMBL1581554 & 688474 & 3.301 & 4.1427 & TRN & \\
\hline CHEMBL1602711 & 688474 & 3.301 & 3.2871 & TRN & \\
\hline CHEMBL52 & 688474 & 5.5812 & 4.8851 & TRN & \\
\hline CHEMBL1412538 & 688474 & 5.7061 & 4.8498 & TRN & \\
\hline
\end{tabular}

Page 26213 


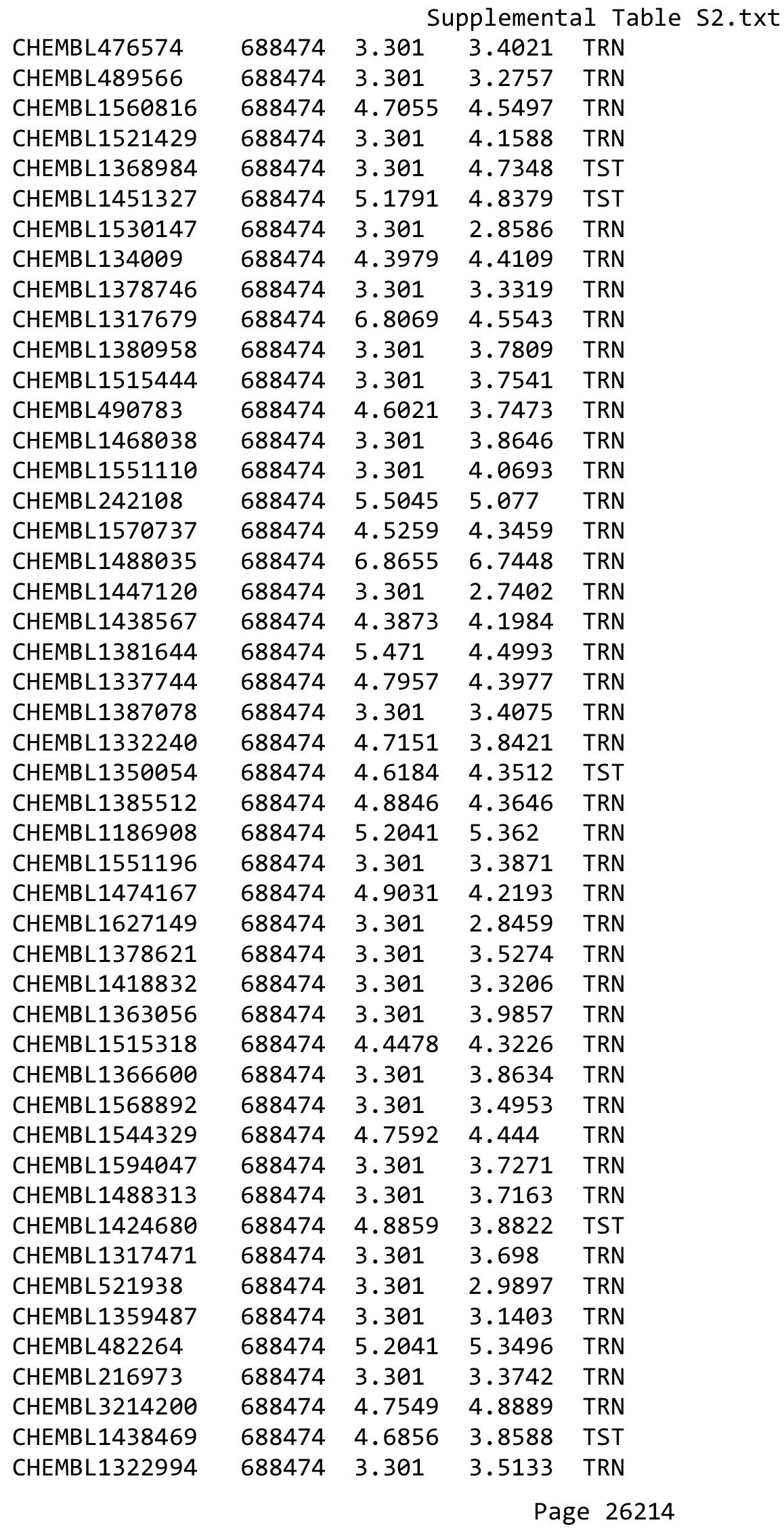




\begin{tabular}{|c|c|c|c|c|c|c|}
\hline \multirow[b]{2}{*}{ CHEMBL1601286 } & & \multicolumn{5}{|c|}{ Supplemental Table S2.txt } \\
\hline & 688474 & 3.301 & 3.3932 & TRN & & \\
\hline CHEMBL1315272 & 688474 & 3.301 & 4.284 & TST & & \\
\hline CHEMBL1317901 & 688474 & 3.301 & 3.9367 & TRN & & \\
\hline CHEMBL1307875 & 688474 & 3.301 & 3.2315 & TRN & & \\
\hline CHEMBL1393480 & 688474 & 4.9718 & 4.7907 & TRN & & \\
\hline CHEMBL1502839 & 688474 & 5.95299 & 99999999 & 99 & 5.0914 & TRN \\
\hline CHEMBL1423479 & 688474 & 4.832 & 4.2694 & TRN & & \\
\hline CHEMBL1564386 & 688474 & 3.301 & 3.2608 & TRN & & \\
\hline CHEMBL1404609 & 688474 & 3.301 & 3.6948 & TRN & & \\
\hline CHEMBL1461276 & 688474 & 3.301 & 3.5079 & TRN & & \\
\hline CHEMBL1970662 & 688474 & 4.699 & 4.6544 & TRN & & \\
\hline CHEMBL1501990 & 688474 & 4.7093 & 5.5082 & TRN & & \\
\hline CHEMBL1447501 & 688474 & 3.301 & 3.2984 & TRN & & \\
\hline CHEMBL1437896 & 688474 & 3.301 & 3.8694 & TRN & & \\
\hline CHEMBL1531620 & 688474 & 4.5652 & 4.3108 & TST & & \\
\hline CHEMBL358546 & 688474 & 5.1122 & 4.9195 & TRN & & \\
\hline CHEMBL3196377 & 688474 & 4.8759 & 4.7821 & TRN & & \\
\hline CHEMBL1573700 & 688474 & 4.476 & 3.8678 & TRN & & \\
\hline CHEMBL1416417 & 688474 & 5.237 & 4.4398 & TST & & \\
\hline CHEMBL489767 & 688474 & 4.6021 & 4.5117 & TRN & & \\
\hline CHEMBL1627146 & 688474 & 3.301 & 2.6187 & TRN & & \\
\hline CHEMBL482117 & 688474 & 4.9031 & 4.7039 & TRN & & \\
\hline CHEMBL1341789 & 688474 & 3.301 & 3.5222 & TRN & & \\
\hline CHEMBL1317797 & 688474 & 3.301 & 3.2256 & TRN & & \\
\hline CHEMBL1555938 & 688474 & 4.5667 & 4.7306 & TRN & & \\
\hline CHEMBL1712181 & 688474 & 3.301 & 4.7049 & TST & & \\
\hline CHEMBL1477720 & 688474 & 3.301 & 4.4593 & TST & & \\
\hline CHEMBL1534307 & 688474 & 3.301 & 3.3182 & TRN & & \\
\hline CHEMBL1330631 & 688474 & 3.301 & 4.4417 & TST & & \\
\hline CHEMBL1516834 & 688474 & 4.4706 & 4.7144 & TRN & & \\
\hline CHEMBL1526851 & 688474 & 6.1305 & 4.8432 & TRN & & \\
\hline CHEMBL1550356 & 688474 & 3.301 & 3.5075 & TST & & \\
\hline CHEMBL454173 & 688474 & 5.6194 & 4.65 & TST & & \\
\hline CHEMBL1462093 & 688474 & 3.301 & 3.4119 & TRN & & \\
\hline CHEMBL1601490 & 688474 & 3.301 & 3.2784 & TRN & & \\
\hline CHEMBL521966 & 688474 & 3.301 & 3.0884 & TRN & & \\
\hline CHEMBL1486907 & 688474 & 3.301 & 3.0288 & TRN & & \\
\hline CHEMBL53898 & 688474 & 4.7185 & 4.7946 & TRN & & \\
\hline CHEMBL489772 & 688474 & 3.301 & 2.9407 & TRN & & \\
\hline CHEMBL325916 & 688474 & 3.301 & 3.3816 & TRN & & \\
\hline CHEMBL1447712 & 688474 & 3.301 & 3.5847 & TRN & & \\
\hline CHEMBL1360810 & 688474 & 3.301 & 3.6224 & TRN & & \\
\hline CHEMBL1479881 & 688474 & 3.301 & 4.7705 & TST & & \\
\hline CHEMBL1335945 & 688474 & 4.9503 & 3.2636 & TST & & \\
\hline CHEMBL1453910 & 688474 & 3.301 & 3.5193 & TRN & & \\
\hline CHEMBL1564253 & 688474 & 3.301 & 4.7302 & TST & & \\
\hline CHEMBL1394289 & 688474 & 3.301 & 3.1577 & TRN & & \\
\hline CHEMBL1436777 & 688474 & 5.8069 & 4.3603 & TRN & & \\
\hline
\end{tabular}

Page 26215 


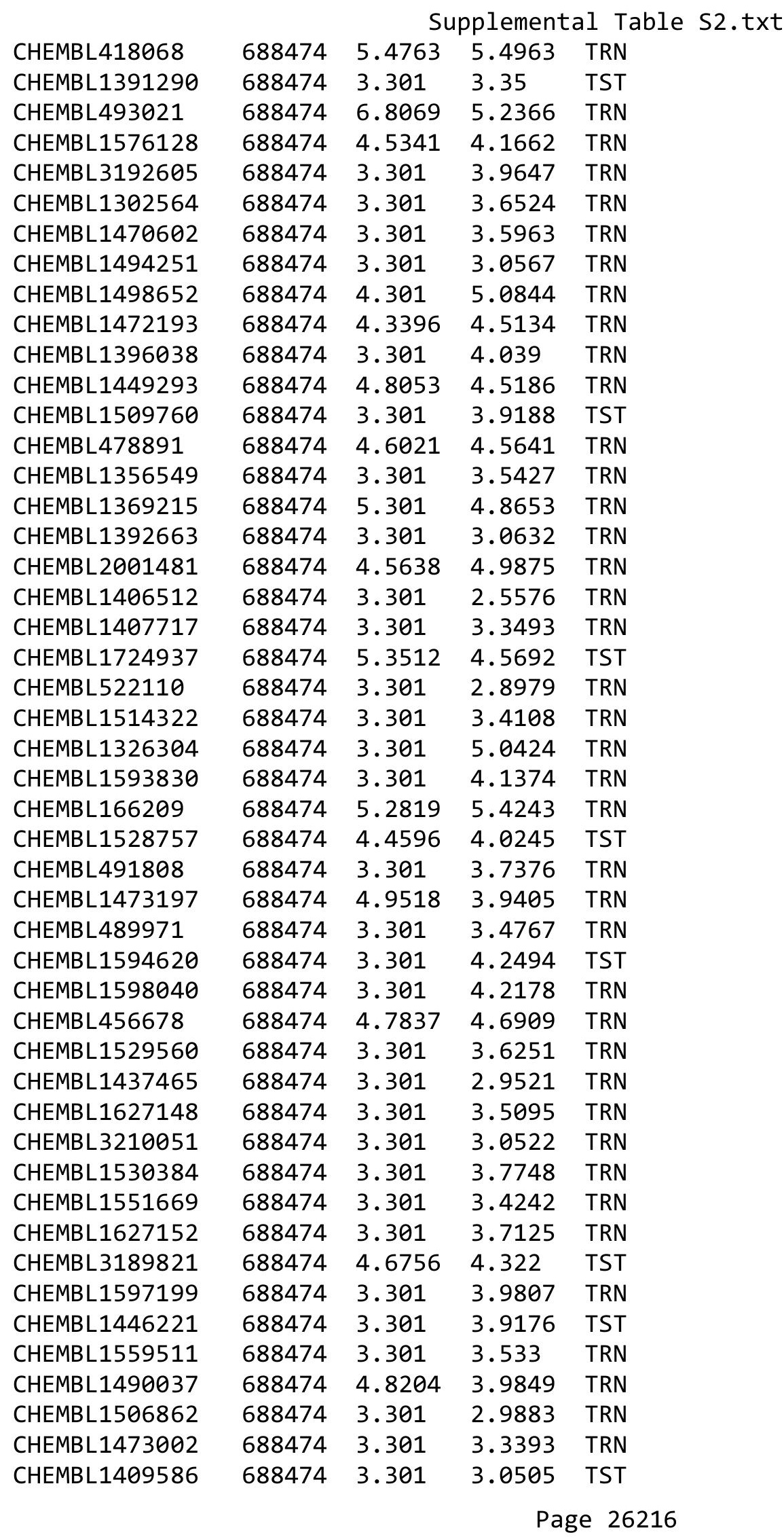




\begin{tabular}{|c|c|c|c|c|c|}
\hline & & \multicolumn{4}{|c|}{ Supplemental Table S2.txt } \\
\hline CHEMBL1483290 & 688474 & 3.301 & 2.6196 & TRN & \\
\hline CHEMBL1520982 & 688474 & 3.301 & 3.6177 & TRN & \\
\hline CHEMBL1575084 & 688474 & 4.8736 & 4.9875 & TRN & \\
\hline CHEMBL1578064 & 688474 & 4.9126 & 4.958 & TRN & \\
\hline CHEMBL1337685 & 688474 & 4.9629 & 4.3644 & TST & \\
\hline CHEMBL480967 & 688474 & 5.5051 & 4.79 & TRN & \\
\hline CHEMBL1601990 & 688474 & 5.1048 & 4.5869 & TRN & \\
\hline CHEMBL1360323 & 688474 & 3.301 & 3.3727 & TRN & \\
\hline CHEMBL1379677 & 688474 & 6.5527 & 6.6277 & TRN & \\
\hline CHEMBL1588197 & 688474 & 3.301 & 4.0025 & TST & \\
\hline CHEMBL1451927 & 688474 & 3.301 & 3.0645 & TRN & \\
\hline CHEMBL1332170 & 688474 & 3.301 & 3.3918 & TRN & \\
\hline CHEMBL1438081 & 688474 & 4.4906 & 4.1509 & TRN & \\
\hline CHEMBL1521422 & 688474 & 3.301 & 3.4166 & TRN & \\
\hline CHEMBL1358332 & 688474 & 3.301 & 4.1969 & TRN & \\
\hline CHEMBL1396499 & 688474 & 3.301 & 4.6127 & TRN & \\
\hline CHEMBL1474345 & 688474 & 3.301 & 3.6641 & TRN & \\
\hline CHEMBL491499 & 688474 & 5.6581 & 4.2335 & TST & \\
\hline CHEMBL209511 & 688474 & 3.301 & 3.1491 & TRN & \\
\hline CHEMBL1440703 & 688474 & 5.2445 & 5.2419 & TRN & \\
\hline CHEMBL578512 & 688474 & 6.6232 & 6.9106 & TRN & \\
\hline CHEMBL1336718 & 688474 & 4.5957 & 4.2815 & TRN & \\
\hline CHEMBL1589657 & 688474 & 3.301 & 3.5907 & TRN & \\
\hline CHEMBL1436635 & 688474 & 3.301 & 3.5998 & TRN & \\
\hline CHEMBL361845 & 688474 & 3.301 & 3.0223 & TRN & \\
\hline CHEMBL1563133 & 688474 & 3.301 & 4.1397 & TRN & \\
\hline CHEMBL1306951 & 688474 & 3.301 & 3.7188 & TRN & \\
\hline CHEMBL1485365 & 688474 & 3.301 & 3.1769 & TRN & \\
\hline CHEMBL1093246 & 688474 & 4.686 & 4.6674 & TRN & \\
\hline CHEMBL1480770 & 688474 & 3.301 & 3.7271 & TRN & \\
\hline CHEMBL1536235 & 688474 & 3.301 & 2.9837 & TST & \\
\hline CHEMBL1569232 & 688474 & 6.8062 & 6.504 & TRN & \\
\hline CHEMBL1409118 & 688474 & 3.301 & 3.213 & TRN & \\
\hline CHEMBL1353231 & 688474 & 3.301 & 3.2203 & TRN & \\
\hline CHEMBL1421089 & 688474 & 3.301 & 3.7546 & TRN & \\
\hline CHEMBL1339642 & 688474 & 3.301 & 3.5636 & TST & \\
\hline CHEMBL3190629 & 688474 & 5.1933 & 4.5753 & TRN & \\
\hline CHEMBL1313900 & 688474 & 5.6087 & 4.6475 & TST & \\
\hline CHEMBL1597467 & 688474 & 4.5273 & 4.03600 & 00000000005 & TRN \\
\hline CHEMBL1448100 & 688474 & 3.301 & 4.7458 & TRN & \\
\hline CHEMBL490602 & 688474 & 3.301 & 2.7519 & TRN & \\
\hline CHEMBL1350227 & 688474 & 4.3258 & 4.4098 & TRN & \\
\hline CHEMBL174025 & 688474 & 6.8069 & 4.8853 & TRN & \\
\hline CHEMBL1355948 & 688474 & 3.301 & 4.2484 & TRN & \\
\hline CHEMBL404923 & 688474 & 3.301 & 3.7728 & TRN & \\
\hline CHEMBL1593720 & 688474 & 3.301 & 3.4847 & TRN & \\
\hline CHEMBL1412717 & 688474 & 3.301 & 3.2533 & TRN & \\
\hline CHEMBL1318208 & 688474 & 3.301 & 3.3873 & TRN & \\
\hline
\end{tabular}




\begin{tabular}{|c|c|c|c|c|c|}
\hline & & \multicolumn{4}{|c|}{ Supplemental Table S2.txt } \\
\hline CHEMBL1465135 & 688474 & 4.811 & 5.0699 & TRN & \\
\hline CHEMBL3207650 & 688474 & 4.8719 & 4.0928 & TST & \\
\hline CHEMBL1475213 & 688474 & 3.301 & 4.0894 & TRN & \\
\hline CHEMBL1463829 & 688474 & 3.301 & 3.7352 & TRN & \\
\hline CHEMBL1526405 & 688474 & 5.0776 & 3.4966 & TST & \\
\hline CHEMBL1603087 & 688474 & 3.301 & 3.8653 & TRN & \\
\hline CHEMBL1495074 & 688474 & 3.301 & 4.2133 & TRN & \\
\hline CHEMBL1529951 & 688474 & 3.301 & 3.1437 & TRN & \\
\hline CHEMBL1597036 & 688474 & 4.4427 & 3.3774 & TRN & \\
\hline CHEMBL1436129 & 688474 & 6.8069 & 5.54899 & 99999999995 & TRN \\
\hline CHEMBL1505489 & 688474 & 3.301 & 3.3489 & TRN & \\
\hline CHEMBL1592362 & 688474 & 3.301 & 3.4798 & TRN & \\
\hline CHEMBL490596 & 688474 & 3.301 & 3.1762 & TRN & \\
\hline CHEMBL1598223 & 688474 & 5.1318 & 4.2214 & TST & \\
\hline CHEMBL1437912 & 688474 & 3.301 & 4.7346 & TST & \\
\hline CHEMBL 145 & 688474 & 3.301 & 4.8811 & TST & \\
\hline CHEMBL1500220 & 688474 & 3.301 & 3.3379 & TST & \\
\hline CHEMBL1408033 & 688474 & 4.4201 & 2.8831 & TST & \\
\hline CHEMBL1321811 & 688474 & 4.301 & 4.9936 & TST & \\
\hline CHEMBL1306960 & 688474 & 6.1678 & 4.8566 & TST & \\
\hline CHEMBL210638 & 688474 & 3.301 & 3.6258 & TST & \\
\hline CHEMBL1530090 & 688474 & 3.301 & 3.81600 & 00000000003 & TST \\
\hline CHEMBL1605701 & 688474 & 4.6315 & 3.7918 & TST & \\
\hline CHEMBL99932 & 688474 & 3.301 & 4.2471 & TST & \\
\hline CHEMBL1489106 & 688474 & 3.301 & 3.4073 & TST & \\
\hline CHEMBL1398211 & 688474 & 3.301 & 4.6451 & TST & \\
\hline CHEMBL1528924 & 688474 & 3.301 & 4.7225 & TST & \\
\hline CHEMBL1530229 & 688474 & 3.301 & 3.2001 & TST & \\
\hline CHEMBL1478881 & 688474 & 4.7456 & 4.5324 & TST & \\
\hline CHEMBL1610341 & 688474 & 3.301 & 4.2534 & TST & \\
\hline CHEMBL1510784 & 688474 & 4.8682 & 5.1658 & TST & \\
\hline CHEMBL444355 & 688474 & 4.8861 & 3.9995 & TST & \\
\hline CHEMBL1398487 & 688474 & 3.301 & 2.9417 & TST & \\
\hline CHEMBL1413772 & 688474 & 3.301 & 3.7611 & TST & \\
\hline CHEMBL1594124 & 688474 & 3.301 & 4.612 & TST & \\
\hline CHEMBL489970 & 688474 & 3.301 & 4.1749 & TST & \\
\hline CHEMBL555689 & 688474 & 5.301 & 5.9069 & TST & \\
\hline CHEMBL1467240 & 688474 & 3.301 & 3.565 & TST & \\
\hline CHEMBL1608331 & 688474 & 3.301 & 3.5173 & TST & \\
\hline CHEMBL1467677 & 688474 & 3.301 & 3.3549 & TST & \\
\hline CHEMBL1376197 & 688474 & 3.301 & 3.9158 & TST & \\
\hline CHEMBL1492984 & 688474 & 3.301 & 3.3451 & TST & \\
\hline CHEMBL1370010 & 688474 & 3.301 & 4.6404 & TST & \\
\hline CHEMBL494825 & 688474 & 5.8069 & 4.5946 & TST & \\
\hline CHEMBL3189329 & 688524 & 4.6 & 4.8946 & TRN & \\
\hline CHEMBL1464442 & 688524 & 5.4 & 4.9562 & TRN & \\
\hline CHEMBL1531709 & 688524 & 5.3 & 5.0608 & TRN & \\
\hline CHEMBL1311989 & 688524 & 4.9 & 5.0919 & TST & \\
\hline
\end{tabular}




\begin{tabular}{|c|c|c|c|c|}
\hline \multicolumn{5}{|c|}{ plemental } \\
\hline CHEMBL1438768 & 688524 & 4.9 & 4.8445 & TRN \\
\hline CHEMBL1538505 & 688524 & 4.6 & 5.0249 & TRN \\
\hline CHEMBL1545556 & 688524 & 5.4 & 5.0215 & TRN \\
\hline CHEMBL1410359 & 688524 & 5.4 & 5.0067 & TRN \\
\hline CHEMBL1517718 & 688524 & 5.4 & 5.0256 & TRN \\
\hline CHEMBL1310299 & 688524 & 5.0 & 4.9666 & TRN \\
\hline CHEMBL1510628 & 688524 & 5.0 & 4.8756 & TRN \\
\hline CHEMBL1474475 & 688524 & 4.5 & 4.9656 & TRN \\
\hline CHEMBL1583702 & 688524 & 5.0 & 4.8797 & TRN \\
\hline CHEMBL1486555 & 688524 & 6.5 & 5.254 & TST \\
\hline CHEMBL1432420 & 688524 & 5.6 & 4.8779 & TRN \\
\hline CHEMBL1612274 & 688524 & 4.9 & 4.8871 & TRN \\
\hline CHEMBL3192249 & 688524 & 4.7 & 4.9508 & TRN \\
\hline CHEMBL1322233 & 688524 & 4.6 & 4.9564 & TRN \\
\hline CHEMBL1312465 & 688524 & 4.9 & 4.9113 & TRN \\
\hline CHEMBL3196412 & 688524 & 4.9 & 5.0664 & TRN \\
\hline CHEMBL374632 & 688524 & 5.4 & 5.0753 & TRN \\
\hline CHEMBL1528905 & 688524 & 5.1 & 4.9399 & TRN \\
\hline CHEMBL1443124 & 688524 & 5.9 & 4.8091 & TRN \\
\hline CHEMBL1555189 & 688524 & 5.9 & 5.2583 & TRN \\
\hline CHEMBL1579773 & 688524 & 4.9 & 4.9727 & TRN \\
\hline CHEMBL1303345 & 688524 & 4.9 & 4.9562 & TRN \\
\hline CHEMBL577887 & 688524 & 4.5 & 5.0151 & TST \\
\hline CHEMBL1329235 & 688524 & 5.8 & 5.2559 & TRN \\
\hline CHEMBL1449491 & 688524 & 4.5 & 5.0216 & TRN \\
\hline CHEMBL1376242 & 688524 & 4.9 & 5.2077 & TRN \\
\hline CHEMBL1330344 & 688524 & 6.1 & 4.834 & TRN \\
\hline CHEMBL1303003 & 688524 & 5.0 & 4.8098 & TRN \\
\hline CHEMBL1339237 & 688524 & 4.6 & 5.1077 & TRN \\
\hline CHEMBL1545060 & 688524 & 4.5 & 4.8237 & TRN \\
\hline CHEMBL1316158 & 688524 & 4.7 & 5.3299 & TRN \\
\hline CHEMBL1588196 & 688524 & 5.0 & 4.9782 & TRN \\
\hline CHEMBL194594 & 688524 & 4.7 & 4.9403 & TRN \\
\hline CHEMBL1610286 & 688524 & 4.8 & 4.9849 & TRN \\
\hline CHEMBL1433343 & 688524 & 5.0 & 5.0349 & TRN \\
\hline CHEMBL1583650 & 688524 & 4.9 & 4.9174 & TRN \\
\hline CHEMBL1450185 & 688524 & 4.8 & 4.8675 & TRN \\
\hline CHEMBL502057 & 688524 & 4.5 & 5.1069 & TST \\
\hline CHEMBL1440131 & 688524 & 5.3 & 5.152 & TST \\
\hline CHEMBL1510738 & 688524 & 4.9 & 5.1188 & TRN \\
\hline CHEMBL1372237 & 688524 & 4.9 & 5.1654 & TRN \\
\hline CHEMBL1543497 & 688524 & 4.9 & 5.0145 & TST \\
\hline CHEMBL1613411 & 688524 & 4.9 & 4.8649 & TRN \\
\hline CHEMBL1611449 & 688524 & 5.5 & 5.0598 & TRN \\
\hline CHEMBL 258893 & 688524 & 6.0 & 5.0656 & TST \\
\hline CHEMBL1354678 & 688524 & 4.5 & 5.21 & TRN \\
\hline CHEMBL1386525 & 688524 & 4.8 & 4.9948 & TRN \\
\hline CHEMBL1356949 & 688524 & 4.6 & 5.0153 & TST \\
\hline
\end{tabular}




\begin{tabular}{|c|c|c|c|c|}
\hline & & & & \\
\hline CHEMBL1447383 & 688524 & 5.4 & 5.1291 & TST \\
\hline CHEMBL1557474 & 688524 & 5.7 & 4.8648 & TRN \\
\hline CHEMBL1407509 & 688524 & 4.9 & 4.8303 & TRN \\
\hline CHEMBL1352987 & 688524 & 5.0 & 5.1152 & TRN \\
\hline CHEMBL1340178 & 688524 & 4.5 & 5.0445 & TRN \\
\hline CHEMBL1529687 & 688524 & 5.2 & 5.0588 & TRN \\
\hline CHEMBL1327326 & 688524 & 5.0 & 4.9934 & TRN \\
\hline CHEMBL1608194 & 688524 & 5.0 & 4.9737 & TRN \\
\hline CHEMBL1502512 & 688524 & 4.7 & 4.9248 & TST \\
\hline CHEMBL1389540 & 688524 & 4.9 & 5.1231 & TRN \\
\hline CHEMBL1406155 & 688524 & 5.0 & 4.8461 & TRN \\
\hline CHEMBL1468227 & 688524 & 5.3 & 5.044 & TRN \\
\hline CHEMBL1559987 & 688524 & 4.7 & 4.8273 & TRN \\
\hline CHEMBL1591258 & 688524 & 4.5 & 5.0507 & TST \\
\hline CHEMBL1456564 & 688524 & 4.9 & 5.0902 & TST \\
\hline CHEMBL1534227 & 688524 & 4.7 & 4.7968 & TRN \\
\hline CHEMBL1389857 & 688524 & 5.0 & 5.072 & TRN \\
\hline CHEMBL1366539 & 688524 & 5.2 & 5.0277 & TST \\
\hline CHEMBL1473123 & 688524 & 4.5 & 5.2092 & TRN \\
\hline CHEMBL1449655 & 688524 & 5.0 & 5.1166 & TST \\
\hline CHEMBL1431131 & 688524 & 4.9 & 4.8282 & TRN \\
\hline CHEMBL1464645 & 688524 & 5.5 & 5.0588 & TRN \\
\hline CHEMBL1303616 & 688524 & 4.9 & 4.8827 & TRN \\
\hline CHEMBL1432058 & 688524 & 4.9 & 4.9932 & TRN \\
\hline CHEMBL15594 & 688524 & 5.4 & 5.1299 & TRN \\
\hline CHEMBL1568497 & 688524 & 4.7 & 4.7257 & TRN \\
\hline CHEMBL1467411 & 688524 & 5.4 & 5.0114 & TRN \\
\hline CHEMBL452477 & 688524 & 5.9 & 5.1824 & TST \\
\hline CHEMBL1395219 & 688524 & 4.6 & 5.0447 & TRN \\
\hline CHEMBL1381999 & 688524 & 5.3 & 5.2059 & TST \\
\hline CHEMBL1326322 & 688524 & 5.9 & 5.5616 & TRN \\
\hline CHEMBL1495694 & 688524 & 5.3 & 5.1945 & TRN \\
\hline CHEMBL1369152 & 688524 & 4.5 & 5.0474 & TST \\
\hline CHEMBL1429054 & 688524 & 4.9 & 4.9369 & TRN \\
\hline CHEMBL1566730 & 688524 & 5.4 & 5.0496 & TRN \\
\hline CHEMBL1331627 & 688524 & 6.9 & 5.1397 & TRN \\
\hline CHEMBL1480526 & 688524 & 5.6 & 4.8971 & TRN \\
\hline CHEMBL1569027 & 688524 & 4.9 & 5.1145 & TST \\
\hline CHEMBL1333578 & 688524 & 5.5 & 4.8877 & TRN \\
\hline CHEMBL1455735 & 688524 & 4.5 & 5.053 & TRN \\
\hline CHEMBL395808 & 688524 & 4.8 & 4.9195 & TRN \\
\hline CHEMBL1521602 & 688524 & 5.0 & 4.9692 & TRN \\
\hline CHEMBL1382702 & 688524 & 4.9 & 4.9586 & TST \\
\hline CHEMBL1499366 & 688524 & 5.1 & 5.1086 & TRN \\
\hline CHEMBL1547784 & 688524 & 4.8 & 4.9705 & TRN \\
\hline CHEMBL1361777 & 688524 & 4.8 & 5.0457 & TRN \\
\hline CHEMBL1255940 & 688524 & 5.0 & 5.0556 & TST \\
\hline CHEMBL1415245 & 688524 & 4.9 & 4.9843 & TRN \\
\hline
\end{tabular}




\begin{tabular}{|c|c|c|c|c|c|}
\hline \multicolumn{6}{|c|}{ Supplemental Table S2.txt } \\
\hline CHEMBL1340569 & 688524 & 4.9 & 5.2353 & TRN & \\
\hline CHEMBL1412678 & 688524 & 5.5 & 5.038 & TRN & \\
\hline CHEMBL1595142 & 688524 & 7.2 & 5.3275 & TRN & \\
\hline CHEMBL1468355 & 688524 & 5.6 & 5.0632 & TRN & \\
\hline CHEMBL1456811 & 688524 & 4.9 & 5.2277 & TRN & \\
\hline CHEMBL346516 & 688524 & 5.5 & 5.12299 & 9999999999 & TST \\
\hline CHEMBL1538034 & 688524 & 7.4001 & 5.1743 & TRN & \\
\hline CHEMBL3198047 & 688524 & 5.6 & 5.0745 & TST & \\
\hline CHEMBL1309051 & 688524 & 4.7 & 4.9126 & TRN & \\
\hline CHEMBL388931 & 688524 & 6.7001 & 5.5459 & TRN & \\
\hline CHEMBL 3198038 & 688524 & 4.9 & 5.1628 & TRN & \\
\hline CHEMBL1545634 & 688524 & 6.0 & 5.2108 & TRN & \\
\hline CHEMBL1363228 & 688524 & 4.9 & 4.922 & TRN & \\
\hline CHEMBL1404301 & 688524 & 5.2 & 4.8785 & TRN & \\
\hline CHEMBL1390468 & 688524 & 4.5 & 4.8538 & TRN & \\
\hline CHEMBL1561383 & 688524 & 5.5 & 4.8802 & TRN & \\
\hline CHEMBL1474468 & 688524 & 4.5 & 5.515 & TRN & \\
\hline CHEMBL1518739 & 688524 & 5.1 & 4.8845 & TRN & \\
\hline CHEMBL1438928 & 688524 & 5.0 & 5.0848 & TRN & \\
\hline CHEMBL1393129 & 688524 & 5.2 & 5.2217 & TRN & \\
\hline CHEMBL123 & 688524 & 5.1 & 5.1498 & TRN & \\
\hline CHEMBL1388976 & 688524 & 5.4 & 5.0446 & TRN & \\
\hline CHEMBL1363615 & 688524 & 4.7 & 5.2207 & TRN & \\
\hline CHEMBL1503485 & 688524 & 5.3 & 5.0004 & TRN & \\
\hline CHEMBL1442326 & 688524 & 5.1 & 4.9246 & TRN & \\
\hline CHEMBL1426763 & 688524 & 5.0 & 4.9577 & TRN & \\
\hline CHEMBL1373113 & 688524 & 4.7 & 4.7885 & TRN & \\
\hline CHEMBL1609605 & 688524 & 4.5 & 5.0305 & TRN & \\
\hline CHEMBL1451802 & 688524 & 4.8 & 4.8731 & TRN & \\
\hline CHEMBL1423851 & 688524 & 4.5 & 5.0599 & TRN & \\
\hline CHEMBL1563034 & 688524 & 5.8 & 4.956 & TRN & \\
\hline CHEMBL1581147 & 688524 & 4.9 & 4.93199 & 99999999995 & TRN \\
\hline CHEMBL1569989 & 688524 & 5.5 & 5.2386 & TRN & \\
\hline CHEMBL1528565 & 688524 & 5.0 & 4.9523 & TST & \\
\hline CHEMBL1550861 & 688524 & 5.0 & 5.0473 & TRN & \\
\hline CHEMBL1321356 & 688524 & 4.9 & 5.0157 & TRN & \\
\hline CHEMBL1432657 & 688524 & 4.9 & 4.9413 & TRN & \\
\hline CHEMBL1573511 & 688524 & 5.0 & 5.065 & TRN & \\
\hline CHEMBL3348955 & 688524 & 8.1487 & 5.2065 & TST & \\
\hline CHEMBL1502126 & 688524 & 5.8 & 5.0531 & TRN & \\
\hline CHEMBL1335169 & 688524 & 4.9 & 4.9436 & TRN & \\
\hline CHEMBL1438256 & 688524 & 4.9 & 5.0995 & TRN & \\
\hline CHEMBL1587568 & 688524 & 4.5 & 5.0744 & TRN & \\
\hline CHEMBL1412669 & 688524 & 5.1 & 5.0583 & TRN & \\
\hline CHEMBL1547380 & 688524 & 4.8 & 4.8722 & TRN & \\
\hline CHEMBL1313027 & 688524 & 4.6 & 5.0907 & TRN & \\
\hline CHEMBL1330870 & 688524 & 6.1 & 5.1342 & TRN & \\
\hline CHEMBL1506639 & 688524 & 4.5 & 4.9696 & TRN & \\
\hline
\end{tabular}




\begin{tabular}{|c|c|c|c|c|}
\hline & & & ipplement & $d \perp$ \\
\hline CHEMBL1201091 & 688524 & 6.0 & 4.8847 & TST \\
\hline CHEMBL457504 & 688524 & 4.8 & 5.1111 & TRN \\
\hline CHEMBL1373232 & 688524 & 4.9 & 5.1553 & TRN \\
\hline CHEMBL1595583 & 688524 & 4.7 & 4.9449 & TRN \\
\hline CHEMBL546170 & 688524 & 5.0 & 5.019 & TRN \\
\hline CHEMBL1583283 & 688524 & 4.8 & 4.9858 & TRN \\
\hline CHEMBL1402928 & 688524 & 4.8 & 4.9955 & TST \\
\hline CHEMBL1510625 & 688524 & 5.1 & 4.9575 & TRN \\
\hline CHEMBL1343571 & 688524 & 4.8 & 4.9697 & TRN \\
\hline CHEMBL1408864 & 688524 & 5.3 & 5.0417 & TRN \\
\hline CHEMBL1435261 & 688524 & 5.1 & 5.2572 & TST \\
\hline CHEMBL1605613 & 688524 & 4.9 & 4.9882 & TRN \\
\hline CHEMBL1365104 & 688524 & 4.9 & 4.9556 & TRN \\
\hline CHEMBL1413233 & 688524 & 5.4 & 4.8387 & TRN \\
\hline CHEMBL 300460 & 688524 & 4.45 & 5.0631 & TRN \\
\hline CHEMBL 1600340 & 688524 & 4.9 & 5.1885 & TRN \\
\hline CHEMBL1312582 & 688524 & 5.1 & 5.0679 & TRN \\
\hline CHEMBL1516735 & 688524 & 4.5 & 4.9853 & TRN \\
\hline CHEMBL1301670 & 688524 & 4.9 & 4.9774 & TRN \\
\hline CHEMBL1498547 & 688524 & 5.0 & 4.8787 & TRN \\
\hline CHEMBL1522355 & 688524 & 4.5 & 5.2371 & TRN \\
\hline CHEMBL1571474 & 688524 & 4.8 & 5.0986 & TRN \\
\hline CHEMBL1532928 & 688524 & 5.0 & 5.1401 & TRN \\
\hline CHEMBL1517986 & 688524 & 4.9 & 5.1688 & TRN \\
\hline CHEMBL1407492 & 688524 & 4.8 & 4.8497 & TRN \\
\hline CHEMBL1307618 & 688524 & 4.9 & 4.9052 & TRN \\
\hline CHEMBL1311378 & 688524 & 4.9 & 4.9476 & TRN \\
\hline CHEMBL3191155 & 688524 & 4.9 & 5.0892 & TST \\
\hline CHEMBL1305131 & 688524 & 5.0 & 5.1471 & TST \\
\hline CHEMBL1544324 & 688524 & 4.5 & 4.8589 & TRN \\
\hline CHEMBL1475487 & 688524 & 5.2 & 5.504 & TRN \\
\hline CHEMBL1350287 & 688524 & 5.4 & 4.7375 & TRN \\
\hline CHEMBL1322844 & 688524 & 5.2 & 4.959 & TRN \\
\hline CHEMBL1359387 & 688524 & 6.4 & 5.0172 & TRN \\
\hline CHEMBL1393189 & 688524 & 4.5 & 5.0068 & TRN \\
\hline CHEMBL1488782 & 688524 & 5.0 & 4.854 & TRN \\
\hline CHEMBL1359529 & 688524 & 5.0 & 4.8345 & TRN \\
\hline CHEMBL1572908 & 688524 & 4.9 & 5.0046 & TRN \\
\hline CHEMBL1552922 & 688524 & 4.5 & 5.1355 & TRN \\
\hline CHEMBL1493178 & 688524 & 5.3 & 5.0495 & TRN \\
\hline CHEMBL1222385 & 688524 & 4.5 & 4.8838 & TRN \\
\hline CHEMBL579104 & 688524 & 5.0 & 5.0899 & TRN \\
\hline CHEMBL1319476 & 688524 & 4.5 & 4.9375 & TST \\
\hline CHEMBL1500421 & 688524 & 5.5 & 4.9805 & TRN \\
\hline CHEMBL1508615 & 688524 & 5.0 & 4.8456 & TRN \\
\hline CHEMBL1312101 & 688524 & 4.9 & 5.0029 & TRN \\
\hline CHEMBL1399969 & 688524 & 4.9 & 4.9188 & TRN \\
\hline CHEMBL1303593 & 688524 & 4.5 & 5.1274 & TST \\
\hline
\end{tabular}




\begin{tabular}{|c|c|c|c|c|}
\hline \multicolumn{5}{|c|}{ Supplemental Table S2.txt } \\
\hline CHEMBL1508435 & 688524 & 5.0 & 5.0585 & TRN \\
\hline CHEMBL1366926 & 688524 & 4.9 & 5.2197 & TRN \\
\hline CHEMBL1393762 & 688524 & 4.5 & 4.971 & TST \\
\hline CHEMBL1371785 & 688524 & 5.0 & 4.9443 & TRN \\
\hline CHEMBL1600927 & 688524 & 4.9 & 4.9332 & TRN \\
\hline CHEMBL1520559 & 688524 & 5.5 & 4.777 & TRN \\
\hline CHEMBL1556566 & 688524 & 4.9 & 5.0137 & TST \\
\hline CHEMBL1429951 & 688524 & 4.9 & 5.0429 & TST \\
\hline CHEMBL1433668 & 688524 & 4.5 & 4.9446 & TRN \\
\hline CHEMBL3210051 & 688524 & 4.6 & 5.1486 & TST \\
\hline CHEMBL1566939 & 688524 & 5.0 & 4.9678 & TRN \\
\hline CHEMBL1492041 & 688524 & 4.8 & 4.9256 & TRN \\
\hline CHEMBL1339724 & 688524 & 4.9 & 4.9838 & TRN \\
\hline CHEMBL1531073 & 688524 & 6.5 & 4.9724 & TRN \\
\hline CHEMBL1481772 & 688524 & 4.5 & 4.8334 & TRN \\
\hline CHEMBL1319980 & 688524 & 4.9 & 4.8074 & TRN \\
\hline CHEMBL228078 & 688524 & 6.8 & 5.0157 & TST \\
\hline CHEMBL1430362 & 688524 & 4.7 & 5.0692 & TRN \\
\hline CHEMBL1574614 & 688524 & 5.0 & 5.0437 & TST \\
\hline CHEMBL510698 & 688524 & 4.9 & 5.1449 & TRN \\
\hline CHEMBL1605478 & 688524 & 5.0 & 4.9985 & TRN \\
\hline CHEMBL1570911 & 688524 & 5.3 & 5.2355 & TRN \\
\hline CHEMBL1551915 & 688524 & 4.7 & 5.0427 & TST \\
\hline CHEMBL1365197 & 688524 & 4.5 & 4.9141 & TST \\
\hline CHEMBL1546299 & 688524 & 8.1024 & 5.192 & TRN \\
\hline CHEMBL1364263 & 688524 & 5.0 & 4.953 & TRN \\
\hline CHEMBL1495025 & 688524 & 5.6 & 5.0394 & TRN \\
\hline CHEMBL1515012 & 688524 & 5.1 & 5.1772 & TST \\
\hline CHEMBL448741 & 688524 & 6.0 & 5.0918 & TST \\
\hline CHEMBL1474771 & 688524 & 4.5 & 5.2845 & TRN \\
\hline CHEMBL1448413 & 688524 & 4.7 & 4.8834 & TRN \\
\hline CHEMBL1359781 & 688524 & 5.0 & 4.95 & TRN \\
\hline CHEMBL1441920 & 688524 & 5.0 & 5.1345 & TST \\
\hline CHEMBL1589562 & 688524 & 4.5 & 5.0987 & TRN \\
\hline CHEMBL1506228 & 688524 & 4.5 & 5.1964 & TST \\
\hline CHEMBL1548798 & 688524 & 4.5 & 4.9829 & TRN \\
\hline CHEMBL1543789 & 688524 & 5.0 & 5.1022 & TST \\
\hline CHEMBL1428659 & 688524 & 5.3 & 4.9125 & TRN \\
\hline CHEMBL1486944 & 688524 & 5.6 & 5.1461 & TRN \\
\hline CHEMBL1384533 & 688524 & 4.9 & 4.855 & TRN \\
\hline CHEMBL1445822 & 688524 & 4.6 & 5.146 & TRN \\
\hline CHEMBL1558739 & 688524 & 4.7 & 5.0255 & TRN \\
\hline CHEMBL1375018 & 688524 & 5.0 & 5.0698 & TST \\
\hline CHEMBL1423704 & 688524 & 5.0 & 5.1502 & TRN \\
\hline CHEMBL1467184 & 688524 & 4.8 & 4.9968 & TRN \\
\hline CHEMBL1420628 & 688524 & 4.9 & 4.829 & TRN \\
\hline CHEMBL1468267 & 688524 & 5.0 & 4.9172 & TRN \\
\hline CHEMBL1580543 & 688524 & 4.6 & 4.919 & TRN \\
\hline
\end{tabular}




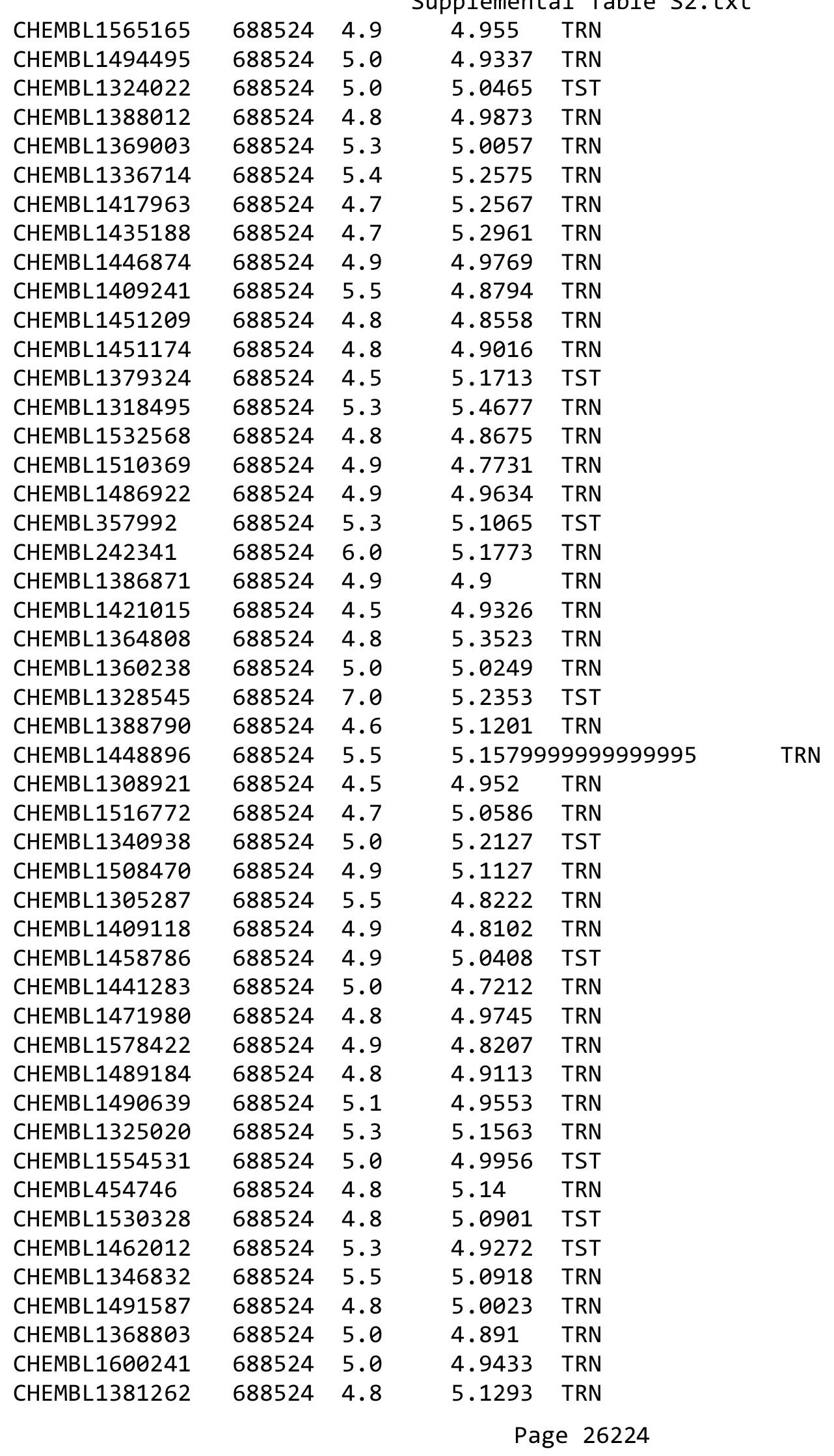




\begin{tabular}{|c|c|c|c|c|c|}
\hline \multirow{2}{*}{ CHEMBL1457311 } & \multirow{2}{*}{688524} & \\
\hline & & 5.0 & 4.9451 & \multirow{2}{*}{\multicolumn{2}{|c|}{$\begin{array}{l}\text { TRN } \\
\text { TRN }\end{array}$}} \\
\hline CHEMBL1440891 & 688524 & 4.8 & 5.1119 & & \\
\hline CHEMBL1472193 & 688524 & 5.0 & 5.0174 & \multicolumn{2}{|l|}{ TST } \\
\hline CHEMBL1400406 & 688524 & 4.9 & 4.879 & \multicolumn{2}{|l|}{ TRN } \\
\hline CHEMBL1394731 & 688524 & 5.2 & 5.0538 & \multicolumn{2}{|l|}{ TST } \\
\hline CHEMBL1518304 & 688524 & 4.9 & 5.0207 & \multicolumn{2}{|l|}{ TRN } \\
\hline CHEMBL1450147 & 688524 & 4.5 & 5.0769 & \multicolumn{2}{|l|}{ TRN } \\
\hline CHEMBL1394738 & 688524 & 4.7 & 5.074 & \multicolumn{2}{|l|}{ TRN } \\
\hline CHEMBL1338958 & 688524 & 5.2 & 5.0272 & \multicolumn{2}{|l|}{ TRN } \\
\hline CHEMBL1449750 & 688524 & 4.8 & 5.0181 & \multicolumn{2}{|l|}{ TRN } \\
\hline CHEMBL1399912 & 688524 & 5.5 & 4.8752 & \multicolumn{2}{|l|}{ TRN } \\
\hline CHEMBL1610124 & 688524 & 5.6 & 5.0163 & \multicolumn{2}{|l|}{ TRN } \\
\hline CHEMBL1587018 & 688524 & 5.4 & 5.0124 & \multicolumn{2}{|l|}{ TRN } \\
\hline CHEMBL490742 & 688524 & 6.3 & 5.5529 & \multicolumn{2}{|l|}{ TRN } \\
\hline CHEMBL1317335 & 688524 & 4.5 & 5.4431 & \multicolumn{2}{|l|}{ TRN } \\
\hline CHEMBL490749 & 688524 & 5.4 & 5.3115 & \multicolumn{2}{|l|}{ TRN } \\
\hline CHEMBL1566105 & 688524 & 5.5 & 5.1626 & \multicolumn{2}{|l|}{ TST } \\
\hline CHEMBL1399951 & 688524 & 4.8 & 5.0381 & \multicolumn{2}{|l|}{ TRN } \\
\hline CHEMBL1323422 & 688524 & 4.5 & 4.9195 & TRN & \\
\hline CHEMBL1375544 & 688524 & 4.5 & 4.9477 & TRN & \\
\hline CHEMBL1431789 & 688524 & 4.8 & 4.8033 & TRN & \\
\hline CHEMBL1438593 & 688524 & 5.2 & 5.0355 & TRN & \\
\hline CHEMBL1470059 & 688524 & 4.7 & 4.9631 & TST & \\
\hline CHEMBL1502721 & 688524 & 5.3 & 4.9853 & TRN & \\
\hline CHEMBL1567818 & 688524 & 4.5 & 5.1241 & TRN & \\
\hline CHEMBL521971 & 688524 & 7.6003 & 5.4352 & TRN & \\
\hline CHEMBL1534193 & 688524 & 4.8 & 4.9784 & TRN & \\
\hline CHEMBL1085765 & 688524 & 4.7 & 4.7935 & TRN & \\
\hline CHEMBL1426223 & 688524 & 5.3 & 5.244 & TST & \\
\hline CHEMBL1471563 & 688524 & 5.3 & 5.0644 & TRN & \\
\hline CHEMBL1419696 & 688524 & 4.7 & 4.9259 & TRN & \\
\hline CHEMBL1462290 & 688524 & 4.9 & 4.7943 & TRN & \\
\hline CHEMBL1450034 & 688524 & 5.3 & 4.7651 & TRN & \\
\hline CHEMBL1376469 & 688524 & 5.4 & 5.1055 & TRN & \\
\hline CHEMBL1345505 & 688524 & 5.0 & 4.9148 & TRN & \\
\hline CHEMBL1377290 & 688524 & 4.9 & 4.8904 & TRN & \\
\hline CHEMBL1586590 & 688524 & 4.9 & 4.96899 & 9999999999 & TRN \\
\hline CHEMBL1341973 & 688524 & 4.9 & 4.7939 & TRN & \\
\hline CHEMBL1712082 & 688524 & 5.9 & 5.2208 & TST & \\
\hline CHEMBL1418548 & 688524 & 4.8 & 5.0347 & TRN & \\
\hline CHEMBL1564780 & 688524 & 4.9 & 5.1003 & TRN & \\
\hline CHEMBL1568022 & 688524 & 4.8 & 5.0561 & TRN & \\
\hline CHEMBL334255 & 688524 & 5.7 & 5.1536 & TST & \\
\hline CHEMBL1397270 & 688524 & 5.0 & 5.04899 & 99999999995 & TST \\
\hline CHEMBL1463848 & 688524 & 4.9 & 4.9047 & TRN & \\
\hline CHEMBL1399791 & 688524 & 4.7 & 4.9752 & TRN & \\
\hline CHEMBL1544241 & 688524 & 5.2 & 4.7649 & TRN & \\
\hline CHEMBL1414522 & 688524 & 4.6 & 4.9495 & TRN & \\
\hline & & & & 26225 & \\
\hline
\end{tabular}




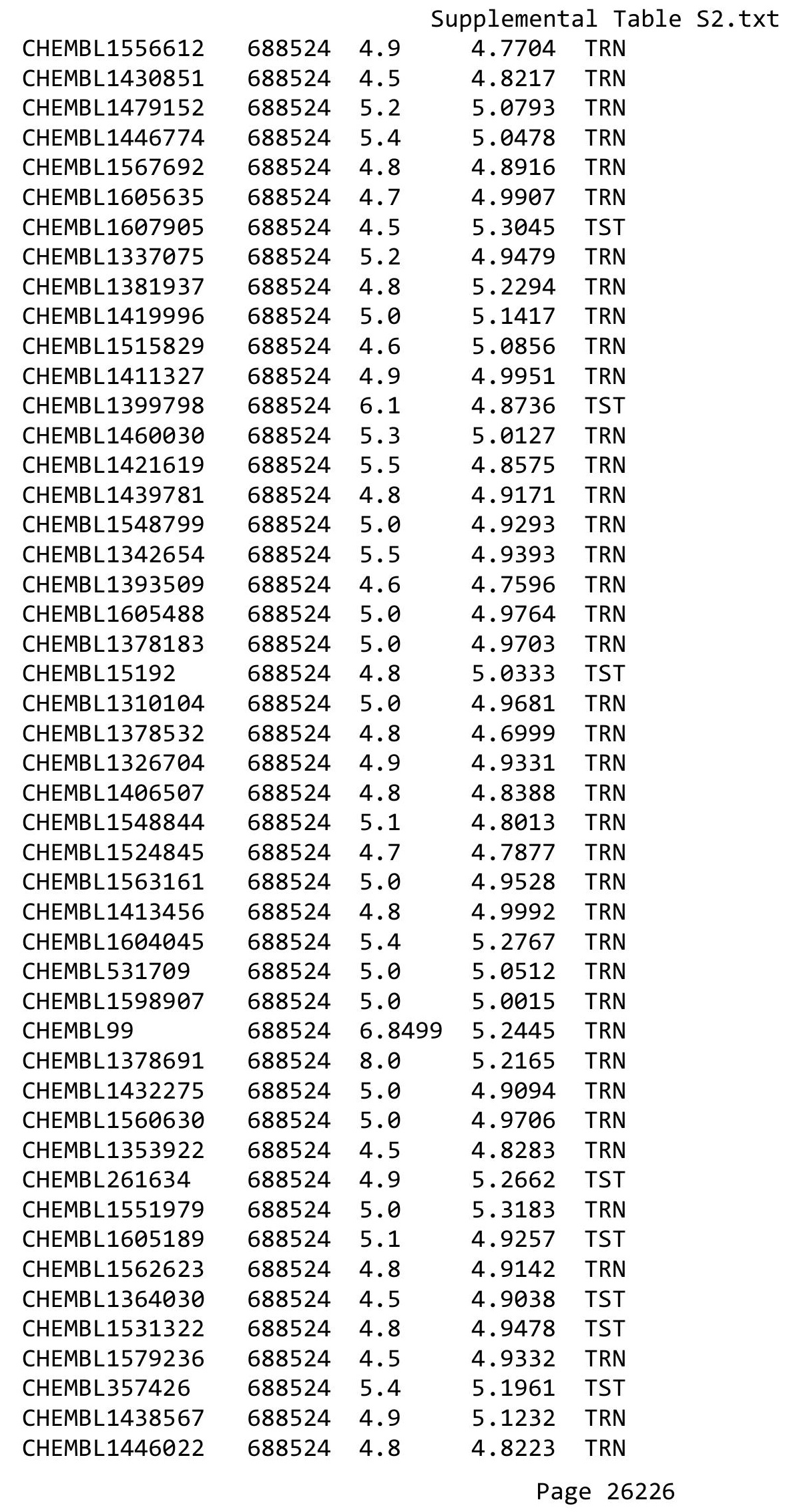




\begin{tabular}{|c|c|c|c|c|}
\hline & & & & $a \perp 1 a$ \\
\hline CHEMBL1389307 & 688524 & 4.9 & 5.0148 & TRN \\
\hline CHEMBL3190620 & 688524 & 4.9 & 5.0872 & TST \\
\hline CHEMBL1506407 & 688524 & 4.9 & 4.9178 & TRN \\
\hline CHEMBL1404123 & 688524 & 5.0 & 4.7412 & TRN \\
\hline CHEMBL1429007 & 688524 & 5.7 & 5.1479 & TRN \\
\hline CHEMBL1523094 & 688524 & 4.6 & 4.8016 & TRN \\
\hline CHEMBL1421517 & 688524 & 4.5 & 4.9579 & TRN \\
\hline CHEMBL1573636 & 688524 & 5.6 & 5.30399 & 9999999999 \\
\hline CHEMBL1538954 & 688524 & 5.0 & 5.0934 & TRN \\
\hline CHEMBL1527814 & 688524 & 5.0 & 5.15 & TRN \\
\hline CHEMBL1371377 & 688524 & 5.0 & 4.8006 & TRN \\
\hline CHEMBL1574926 & 688524 & 4.5 & 4.894 & TRN \\
\hline CHEMBL1529147 & 688524 & 4.8 & 5.1024 & TST \\
\hline CHEMBL1313955 & 688524 & 4.8 & 4.8715 & TRN \\
\hline CHEMBL1411128 & 688524 & 6.2 & 5.0214 & TST \\
\hline CHEMBL1557820 & 688524 & 5.1 & 4.9552 & TRN \\
\hline CHEMBL1576291 & 688524 & 4.8 & 4.9457 & TRN \\
\hline CHEMBL1577314 & 688524 & 4.6 & 5.008 & TRN \\
\hline CHEMBL1594961 & 688524 & 5.3 & 5.1494 & TRN \\
\hline CHEMBL1534343 & 688524 & 4.8 & 5.004 & TRN \\
\hline CHEMBL1382247 & 688524 & 4.9 & 4.9679 & TRN \\
\hline CHEMBL1483004 & 688524 & 4.9 & 4.909 & TRN \\
\hline CHEMBL1349449 & 688524 & 4.8 & 4.838 & TRN \\
\hline CHEMBL1366321 & 688524 & 4.8 & 5.0565 & TRN \\
\hline CHEMBL1432957 & 688524 & 5.0 & 5.0671 & TST \\
\hline CHEMBL1564471 & 688524 & 4.8 & 4.9718 & TRN \\
\hline CHEMBL1359565 & 688524 & 5.0 & 4.8007 & TRN \\
\hline CHEMBL1596486 & 688524 & 4.7 & 4.856 & TRN \\
\hline CHEMBL1906077 & 688524 & 4.5 & 4.9596 & TST \\
\hline CHEMBL1440954 & 688524 & 5.0 & 4.9396 & TRN \\
\hline CHEMBL1373914 & 688524 & 5.0 & 5.0161 & TRN \\
\hline CHEMBL1340722 & 688524 & 4.8 & 4.9951 & TRN \\
\hline CHEMBL1567793 & 688524 & 4.9 & 4.8866 & TRN \\
\hline CHEMBL1435666 & 688524 & 4.8 & 5.0999 & TRN \\
\hline CHEMBL1357598 & 688524 & 6.1 & 5.1537 & TRN \\
\hline CHEMBL1471326 & 688524 & 4.6 & 4.9015 & TRN \\
\hline CHEMBL1318114 & 688524 & 4.5 & 5.12 & TRN \\
\hline CHEMBL1542359 & 688524 & 5.0 & 4.8666 & TRN \\
\hline CHEMBL1417952 & 688524 & 4.7 & 4.9858 & TST \\
\hline CHEMBL1352912 & 688524 & 5.2 & 4.9991 & TRN \\
\hline CHEMBL1351338 & 688524 & 4.5 & 4.898 & TRN \\
\hline CHEMBL1352023 & 688524 & 4.9 & 5.0988 & TRN \\
\hline CHEMBL1454050 & 688524 & 4.8 & 5.0368 & TRN \\
\hline CHEMBL1388273 & 688524 & 4.9 & 5.008 & TRN \\
\hline CHEMBL1608009 & 688524 & 5.0 & 4.8348 & TRN \\
\hline CHEMBL1580679 & 688524 & 5.0 & 4.9522 & TRN \\
\hline CHEMBL1590397 & 688524 & 4.5 & 5.1067 & TRN \\
\hline CHEMBL1253382 & 688524 & 4.9 & 4.8169 & TRN \\
\hline
\end{tabular}

TRN 


\begin{tabular}{|c|c|c|c|c|}
\hline & & & ent & al Ta \\
\hline CHEMBL1389819 & 688524 & 4.6 & 4.9769 & TRN \\
\hline CHEMBL1398806 & 688524 & 4.7 & 4.8611 & TRN \\
\hline CHEMBL1382565 & 688524 & 4.9 & 5.0246 & TST \\
\hline CHEMBL1541577 & 688524 & 4.9 & 4.8637 & TRN \\
\hline CHEMBL1595927 & 688524 & 4.8 & 4.9002 & TRN \\
\hline CHEMBL1394477 & 688524 & 5.3 & 5.2858 & TRN \\
\hline CHEMBL1447991 & 688524 & 4.9 & 4.9894 & TRN \\
\hline CHEMBL1450119 & 688524 & 5.5 & 5.0526 & TRN \\
\hline CHEMBL1449204 & 688524 & 4.8 & 5.1155 & TRN \\
\hline CHEMBL1490337 & 688524 & 4.5 & 4.8577 & TRN \\
\hline CHEMBL486626 & 688524 & 4.9 & 5.3776 & TRN \\
\hline CHEMBL1451926 & 688524 & 5.0 & 4.9566 & TRN \\
\hline CHEMBL1447909 & 688524 & 6.2 & 5.2751 & TRN \\
\hline CHEMBL1429958 & 688524 & 4.9 & 4.9001 & TRN \\
\hline CHEMBL1379920 & 688524 & 4.9 & 4.7502 & TRN \\
\hline CHEMBL1496439 & 688524 & 4.8 & 4.8861 & TRN \\
\hline CHEMBL1342111 & 688524 & 4.5 & 5.1672 & TST \\
\hline CHEMBL3198964 & 688524 & 4.9 & 4.9319 & TRN \\
\hline CHEMBL12998 & 688524 & 4.9 & 5.1075 & TST \\
\hline CHEMBL1412940 & 688524 & 4.5 & 4.7414 & TRN \\
\hline CHEMBL1489036 & 688524 & 5.6 & 4.8851 & TRN \\
\hline CHEMBL1450455 & 688524 & 5.7 & 5.0679 & TRN \\
\hline CHEMBL1338533 & 688524 & 4.5 & 4.9002 & TRN \\
\hline CHEMBL1443205 & 688524 & 5.2 & 5.3367 & TRN \\
\hline CHEMBL1541865 & 688524 & 5.0 & 4.9198 & TRN \\
\hline CHEMBL1505569 & 688524 & 4.9 & 5.1045 & TRN \\
\hline CHEMBL1327089 & 688524 & 5.9 & 5.0425 & TRN \\
\hline CHEMBL1159655 & 688524 & 4.6 & 5.0524 & TST \\
\hline CHEMBL1411257 & 688524 & 5.4 & 4.8565 & TRN \\
\hline CHEMBL1459963 & 688524 & 4.5 & 5.1112 & TRN \\
\hline CHEMBL1523196 & 688524 & 4.7 & 5.1243 & TRN \\
\hline CHEMBL1466151 & 688524 & 4.8 & 4.9205 & TRN \\
\hline CHEMBL1413682 & 688524 & 4.9 & 4.8626 & TRN \\
\hline CHEMBL1508535 & 688524 & 5.2 & 5.0154 & TRN \\
\hline CHEMBL1450614 & 688524 & 4.5 & 4.9101 & TRN \\
\hline CHEMBL1511045 & 688524 & 5.0 & 4.6782 & TRN \\
\hline CHEMBL1508370 & 688524 & 5.0 & 4.8621 & TST \\
\hline CHEMBL1563604 & 688524 & 5.3 & 5.0396 & TRN \\
\hline CHEMBL1480350 & 688524 & 7.699 & 5.4265 & TRN \\
\hline CHEMBL1583582 & 688524 & 5.3 & 5.0651 & TRN \\
\hline CHEMBL1459601 & 688524 & 4.9 & 4.9541 & TRN \\
\hline CHEMBL1412478 & 688524 & 4.9 & 5.0263 & TRN \\
\hline CHEMBL1377820 & 688524 & 5.4 & 4.9699 & TRN \\
\hline CHEMBL1392188 & 688524 & 5.4 & 5.047 & TRN \\
\hline CHEMBL1429292 & 688524 & 4.8 & 4.9559 & TRN \\
\hline CHEMBL1367710 & 688524 & 5.4 & 5.0966 & TRN \\
\hline CHEMBL1568981 & 688524 & 5.6 & 4.9435 & TRN \\
\hline CHEMBL1482823 & 688524 & 5.5 & 5.0875 & TRN \\
\hline
\end{tabular}




\begin{tabular}{|c|c|c|c|c|}
\hline & & & pमeme & al Ta \\
\hline CHEMBL1573190 & 688524 & 4.9 & 5.0158 & TRN \\
\hline CHEMBL604119 & 688524 & 5.0 & 4.9547 & TST \\
\hline CHEMBL1577977 & 688524 & 4.8 & 4.8615 & TRN \\
\hline CHEMBL1443559 & 688524 & 4.9 & 4.8701 & TRN \\
\hline CHEMBL1451402 & 688524 & 5.0 & 5.0881 & TRN \\
\hline CHEMBL1369871 & 688524 & 4.6 & 5.4079 & TRN \\
\hline CHEMBL1587527 & 688524 & 4.9 & 4.8679 & TRN \\
\hline CHEMBL1431336 & 688524 & 5.0 & 4.9212 & TRN \\
\hline CHEMBL 3198423 & 688524 & 5.2 & 4.9222 & TST \\
\hline CHEMBL1428456 & 688524 & 5.3 & 4.9933 & TRN \\
\hline CHEMBL1584401 & 688524 & 5.0 & 4.8885 & TRN \\
\hline CHEMBL1512027 & 688524 & 5.0 & 5.1985 & TRN \\
\hline CHEMBL1498130 & 688524 & 4.5 & 4.9533 & TRN \\
\hline CHEMBL1394854 & 688524 & 5.2 & 5.519 & TRN \\
\hline CHEMBL1527316 & 688524 & 5.5 & 4.9748 & TRN \\
\hline CHEMBL1542161 & 688524 & 4.9 & 4.9545 & TRN \\
\hline CHEMBL1419342 & 688524 & 4.9 & 4.9431 & TRN \\
\hline CHEMBL1410331 & 688524 & 4.5 & 5.0342 & TST \\
\hline CHEMBL1454839 & 688524 & 5.1 & 4.9661 & TST \\
\hline CHEMBL1353168 & 688524 & 5.4 & 5.2369 & TRN \\
\hline CHEMBL1452426 & 688524 & 5.0 & 5.2119 & TRN \\
\hline CHEMBL 234583 & 688524 & 4.7 & 4.9113 & TRN \\
\hline CHEMBL1513359 & 688524 & 5.3 & 5.2962 & TRN \\
\hline CHEMBL1529239 & 688524 & 5.3 & 5.0622 & TRN \\
\hline CHEMBL595227 & 688524 & 6.1 & 5.0177 & TST \\
\hline CHEMBL406557 & 688524 & 5.0 & 4.9187 & TRN \\
\hline CHEMBL1391673 & 688524 & 4.5 & 5.0884 & TRN \\
\hline CHEMBL1453713 & 688524 & 4.5 & 5.2756 & TRN \\
\hline CHEMBL3193023 & 688524 & 4.9 & 4.9241 & TRN \\
\hline CHEMBL1299531 & 688524 & 5.3 & 4.9248 & TRN \\
\hline CHEMBL1365553 & 688524 & 4.8 & 5.2143 & TST \\
\hline CHEMBL546257 & 688524 & 6.0 & 4.9815 & TST \\
\hline CHEMBL1313986 & 688524 & 4.7 & 4.8481 & TRN \\
\hline CHEMBL1536841 & 688524 & 4.7 & 5.1577 & TRN \\
\hline CHEMBL1299268 & 688524 & 5.0 & 4.9416 & TRN \\
\hline CHEMBL1513669 & 688524 & 5.2 & 5.2752 & TRN \\
\hline CHEMBL1536135 & 688524 & 5.5 & 4.8326 & TRN \\
\hline CHEMBL1585520 & 688524 & 4.6 & 4.9603 & TRN \\
\hline CHEMBL1552727 & 688524 & 6.3 & 5.2459 & TRN \\
\hline CHEMBL1569493 & 688524 & 6.3 & 5.265 & TRN \\
\hline CHEMBL1429805 & 688524 & 4.9 & 4.9358 & TRN \\
\hline CHEMBL1596701 & 688524 & 5.4 & 4.7854 & TRN \\
\hline CHEMBL1485168 & 688524 & 4.8 & 5.3755 & TRN \\
\hline CHEMBL1367789 & 688524 & 5.4 & 5.0211 & TRN \\
\hline CHEMBL1487981 & 688524 & 5.9 & 5.1613 & TST \\
\hline CHEMBL1369812 & 688524 & 5.3 & 5.0867 & TST \\
\hline CHEMBL1522136 & 688524 & 5.1 & 4.9618 & TRN \\
\hline CHEMBL1381205 & 688524 & 4.9 & 4.8888 & TRN \\
\hline
\end{tabular}




\begin{tabular}{|c|c|c|c|c|c|}
\hline \multicolumn{6}{|c|}{ Supplemental Table S2.txt } \\
\hline CHEMBL310396 & 688524 & 5.0 & 5.1249 & TRN & \\
\hline CHEMBL1377927 & 688524 & 4.5 & 5.0899 & TRN & \\
\hline CHEMBL1308051 & 688524 & 5.3 & 5.1056 & TRN & \\
\hline CHEMBL465339 & 688524 & 5.5 & 5.09699 & 99999999995 & TST \\
\hline CHEMBL288096 & 688524 & 4.7 & 5.0602 & TST & \\
\hline CHEMBL1352058 & 688524 & 4.9 & 5.1707 & TRN & \\
\hline CHEMBL1443170 & 688524 & 4.6 & 4.8713 & TRN & \\
\hline CHEMBL1417837 & 688524 & 4.5 & 4.9766 & TRN & \\
\hline CHEMBL1599993 & 688524 & 4.6 & 4.9918 & TRN & \\
\hline CHEMBL1342302 & 688524 & 5.4 & 4.9559 & TRN & \\
\hline CHEMBL1489223 & 688524 & 5.0 & 5.0229 & TRN & \\
\hline CHEMBL1565217 & 688524 & 4.7 & 5.0786 & TST & \\
\hline CHEMBL13791 & 688524 & 4.7 & 5.0078 & TRN & \\
\hline CHEMBL1400688 & 688524 & 4.5 & 4.9734 & TST & \\
\hline CHEMBL1369177 & 688524 & 5.0 & 5.1298 & TRN & \\
\hline CHEMBL1332004 & 688524 & 4.8 & 4.8986 & TRN & \\
\hline CHEMBL1324952 & 688524 & 4.9 & 4.8778 & TRN & \\
\hline CHEMBL1338965 & 688524 & 4.9 & 4.9436 & TRN & \\
\hline CHEMBL393136 & 688524 & 6.0 & 5.1708 & TST & \\
\hline CHEMBL1509065 & 688524 & 4.9 & 5.1239 & TRN & \\
\hline CHEMBL1540822 & 688524 & 4.5 & 4.9837 & TRN & \\
\hline CHEMBL1492293 & 688524 & 4.5 & 4.7464 & TRN & \\
\hline CHEMBL1385529 & 688524 & 4.7 & 4.7902 & TRN & \\
\hline CHEMBL1558777 & 688524 & 5.3 & $5.1370 e$ & 00000000005 & TRN \\
\hline CHEMBL1408002 & 688524 & 4.9 & 5.16799 & 9999999999 & TRN \\
\hline CHEMBL1405259 & 688524 & 4.7 & 4.8313 & TRN & \\
\hline CHEMBL1567481 & 688524 & 5.1 & 4.9194 & TRN & \\
\hline CHEMBL1507540 & 688524 & 4.9 & 5.01699 & 99999999995 & TRN \\
\hline CHEMBL1584466 & 688524 & 4.9 & 5.0916 & TRN & \\
\hline CHEMBL1380684 & 688524 & 6.0 & $5.1160 e$ & 00000000005 & TST \\
\hline CHEMBL1423060 & 688524 & 4.8 & 4.9179 & TRN & \\
\hline CHEMBL1409629 & 688524 & 4.9 & 4.8844 & TRN & \\
\hline CHEMBL523283 & 688524 & 6.5 & 5.3422 & TRN & \\
\hline CHEMBL1565329 & 688524 & 4.9 & 4.8886 & TST & \\
\hline CHEMBL1549175 & 688524 & 5.2 & 5.2255 & TRN & \\
\hline CHEMBL9352 & 688524 & 6.0 & 5.1788 & TST & \\
\hline CHEMBL1559596 & 688524 & 4.6 & 4.9227 & TRN & \\
\hline CHEMBL1569541 & 688524 & 4.5 & 4.9872 & TRN & \\
\hline CHEMBL1433152 & 688524 & 4.9 & 5.2122 & TRN & \\
\hline CHEMBL 3197885 & 688524 & 5.0 & 5.1149 & TRN & \\
\hline CHEMBL1397218 & 688524 & 5.8 & 5.1941 & TST & \\
\hline CHEMBL1507162 & 688524 & 4.5 & 5.1272 & TRN & \\
\hline CHEMBL1360378 & 688524 & 4.9 & 4.82 & TRN & \\
\hline CHEMBL320159 & 688524 & 5.5 & 5.1606 & TST & \\
\hline CHEMBL1316265 & 688524 & 4.7 & 5.1024 & TRN & \\
\hline CHEMBL1600906 & 688524 & 4.7 & 5.0461 & TRN & \\
\hline CHEMBL1596888 & 688524 & 4.9 & 4.92899 & 9999999999 & TRN \\
\hline CHEMBL35482 & 688524 & 4.9 & 4.8727 & TRN & \\
\hline
\end{tabular}




\begin{tabular}{|c|c|c|c|c|}
\hline \multicolumn{5}{|c|}{ semental } \\
\hline CHEMBL1393735 & 688524 & 4.8 & 4.9525 & TRN \\
\hline CHEMBL1373774 & 688524 & 4.9 & 4.9433 & TRN \\
\hline CHEMBL1566650 & 688524 & 4.5 & 4.9245 & TRN \\
\hline CHEMBL60718 & 688524 & 4.5 & 5.2166 & TRN \\
\hline CHEMBL1569294 & 688524 & 4.7 & 5.0839 & TRN \\
\hline CHEMBL3211367 & 688524 & 4.5 & \multicolumn{2}{|c|}{5.093999999999999} \\
\hline CHEMBL1308088 & 688524 & 4.9 & 5.1279 & TRN \\
\hline CHEMBL1489348 & 688524 & 5.4 & 4.9895 & TRN \\
\hline CHEMBL1439137 & 688524 & 4.9 & 4.9423 & TRN \\
\hline CHEMBL1326968 & 688524 & 4.9 & 5.0605 & TRN \\
\hline CHEMBL1325549 & 688524 & 4.8 & 5.1424 & TRN \\
\hline CHEMBL1313357 & 688524 & 4.9 & 4.9694 & TRN \\
\hline CHEMBL1376443 & 688524 & 4.7 & 4.8561 & TRN \\
\hline CHEMBL1348548 & 688524 & 4.9 & 5.0439 & TRN \\
\hline CHEMBL1383057 & 688524 & 4.5 & 4.9698 & TRN \\
\hline CHEMBL1609626 & 688524 & 4.5 & 5.0941 & TRN \\
\hline CHEMBL1333282 & 688524 & 4.8 & 4.975 & TRN \\
\hline CHEMBL1331649 & 688524 & 5.4 & 5.1037 & TRN \\
\hline CHEMBL1490765 & 688524 & 4.5 & 5.1928 & TRN \\
\hline CHEMBL1481361 & 688524 & 4.9 & 5.0878 & TST \\
\hline CHEMBL1594432 & 688524 & 4.8 & 4.9325 & TST \\
\hline CHEMBL1360959 & 688524 & 4.8 & 5.0753 & TST \\
\hline CHEMBL1427595 & 688524 & 4.7 & 4.8155 & TRN \\
\hline CHEMBL1497341 & 688524 & 5.5 & 4.9888 & TRN \\
\hline CHEMBL1417290 & 688524 & 4.8 & 5.0291 & TRN \\
\hline CHEMBL1561442 & 688524 & 5.2 & 4.9823 & TRN \\
\hline CHEMBL1353777 & 688524 & 4.8 & 5.0371 & TRN \\
\hline CHEMBL1596621 & 688524 & 4.9 & 4.7242 & TRN \\
\hline CHEMBL1526686 & 688524 & 4.8 & 5.1123 & TRN \\
\hline CHEMBL1306522 & 688524 & 4.9 & 4.9762 & TRN \\
\hline CHEMBL1330058 & 688524 & 5.6 & 5.2281 & TRN \\
\hline CHEMBL1484925 & 688524 & 5.0 & 5.0949 & TST \\
\hline CHEMBL1310191 & 688524 & 5.0 & 4.9053 & TRN \\
\hline CHEMBL1497436 & 688524 & 4.8 & 5.0321 & TRN \\
\hline CHEMBL1477857 & 688524 & 5.3 & 5.2165 & TRN \\
\hline CHEMBL129795 & 688524 & 6.0 & 5.2623 & TRN \\
\hline CHEMBL1492648 & 688524 & 5.0 & 5.3377 & TRN \\
\hline CHEMBL1568191 & 688524 & 4.6 & 4.9537 & TRN \\
\hline CHEMBL1495119 & 688524 & 4.9 & 4.8812 & TRN \\
\hline CHEMBL1611200 & 688524 & 4.9 & 4.9393 & TRN \\
\hline CHEMBL1542969 & 688524 & 4.8 & 4.7684 & TRN \\
\hline CHEMBL1477253 & 688524 & 5.0 & 4.8473 & TRN \\
\hline CHEMBL1407052 & 688524 & 5.0 & 5.0779 & TRN \\
\hline CHEMBL1495849 & 688524 & 5.0 & 4.9603 & TRN \\
\hline CHEMBL1374179 & 688524 & 4.9 & 4.9068 & TRN \\
\hline CHEMBL1377385 & 688524 & 6.4 & 5.2872 & TRN \\
\hline CHEMBL 1541182 & 688524 & 5.0 & 4.9898 & TRN \\
\hline CHEMBL1365850 & 688524 & 5.0 & 5.2779 & TRN \\
\hline
\end{tabular}




\begin{tabular}{|c|c|c|c|c|c|}
\hline & & & & & \\
\hline CHEMBL1358983 & 688524 & 5.4 & 5.3009 & TRN & \\
\hline CHEMBL186872 & 688524 & 6.0 & 5.1884 & TST & \\
\hline CHEMBL1316656 & 688524 & 4.5 & 5.1819 & TRN & \\
\hline CHEMBL1358818 & 688524 & 4.5 & 5.1437 & TRN & \\
\hline CHEMBL1569585 & 688524 & 6.0 & 5.1433 & TST & \\
\hline CHEMBL1374573 & 688524 & 4.7 & 4.8188 & TRN & \\
\hline CHEMBL453974 & 688524 & 5.35 & 5.1804 & TST & \\
\hline CHEMBL131921 & 688524 & 4.6 & 5.1517 & TRN & \\
\hline CHEMBL1543808 & 688524 & 4.8 & 4.9976 & TRN & \\
\hline CHEMBL1566193 & 688524 & 4.5 & 4.8975 & TRN & \\
\hline CHEMBL1368261 & 688524 & 4.8 & 5.2702 & TST & \\
\hline CHEMBL1350487 & 688524 & 4.7 & 4.9906 & TST & \\
\hline CHEMBL1608047 & 688524 & 4.9 & 4.8523 & TRN & \\
\hline CHEMBL1369639 & 688524 & 5.0 & 5.0507 & TRN & \\
\hline CHEMBL1464418 & 688524 & 4.6 & 4.9273 & TRN & \\
\hline CHEMBL154762 & 688524 & 4.9 & 5.0015 & TRN & \\
\hline CHEMBL1371774 & 688524 & 5.1 & 5.1936 & TRN & \\
\hline CHEMBL1587996 & 688524 & 4.7 & 4.90606 & 2000000001 & TRN \\
\hline CHEMBL1375164 & 688524 & 5.0 & 4.9705 & TRN & \\
\hline CHEMBL1603881 & 688524 & 5.6 & 5.04 & TRN & \\
\hline CHEMBL447876 & 688524 & 5.7 & 5.3009 & TST & \\
\hline CHEMBL1300339 & 688524 & 4.8 & 5.0085 & TRN & \\
\hline CHEMBL3194157 & 688524 & 4.8 & 4.8862 & TRN & \\
\hline CHEMBL1445590 & 688524 & 4.9 & 4.9655 & TRN & \\
\hline CHEMBL1400508 & 688524 & 5.2 & 5.0415 & TRN & \\
\hline CHEMBL1465031 & 688524 & 4.9 & 5.0149 & TRN & \\
\hline CHEMBL1308738 & 688524 & 4.8 & 5.0614 & TRN & \\
\hline CHEMBL1524365 & 688524 & 4.9 & 4.8975 & TRN & \\
\hline CHEMBL1579284 & 688524 & 4.9 & $5.2360 e$ & 0000000001 & TRN \\
\hline CHEMBL1340321 & 688524 & 4.7 & 4.9022 & TRN & \\
\hline CHEMBL1405922 & 688524 & 4.7 & 5.0075 & TST & \\
\hline CHEMBL484662 & 688524 & 4.9 & 5.13899 & 9999999999 & TRN \\
\hline CHEMBL1523675 & 688524 & 4.7 & 5.1628 & TRN & \\
\hline CHEMBL1431242 & 688524 & 5.0 & 4.8099 & TRN & \\
\hline CHEMBL1413371 & 688524 & 4.9 & 5.062 & TST & \\
\hline CHEMBL1418018 & 688524 & 5.0 & 4.9313 & TRN & \\
\hline CHEMBL1518014 & 688524 & 5.5 & 4.961 & TRN & \\
\hline CHEMBL1349829 & 688524 & 4.5 & 4.9196 & TRN & \\
\hline CHEMBL1501676 & 688524 & 5.8 & 5.0852 & TRN & \\
\hline CHEMBL1337035 & 688524 & 4.8 & 4.9611 & TRN & \\
\hline CHEMBL1558816 & 688524 & 4.9 & 4.9858 & TRN & \\
\hline CHEMBL 3212441 & 688524 & 5.2 & 5.1332 & TRN & \\
\hline CHEMBL1346933 & 688524 & 4.8 & 5.016 & TRN & \\
\hline CHEMBL1344216 & 688524 & 4.7 & 4.8601 & TRN & \\
\hline CHEMBL1512562 & 688524 & 6.8 & 5.1314 & TRN & \\
\hline CHEMBL1449478 & 688524 & 6.8 & 5.0075 & TRN & \\
\hline CHEMBL1565478 & 688524 & 5.0 & 5.1798 & TRN & \\
\hline CHEMBL198159 & 688524 & 4.4 & 5.2079 & TST & \\
\hline & & & & 26232 & \\
\hline
\end{tabular}




\begin{tabular}{|c|c|c|c|c|c|}
\hline & & & & & \\
\hline CHEMBL323197 & 688524 & 4.6 & 5.1161 & TST & \\
\hline CHEMBL1596099 & 688524 & 6.0 & 5.1065 & TST & \\
\hline CHEMBL1414269 & 688524 & 4.8 & 5.2964 & TRN & \\
\hline CHEMBL1493644 & 688524 & 5.5 & 5.0734 & TRN & \\
\hline CHEMBL1487088 & 688524 & 5.0 & 4.9019 & TST & \\
\hline CHEMBL1463906 & 688524 & 4.5 & 5.0241 & TRN & \\
\hline CHEMBL1376193 & 688524 & 4.9 & 4.9208 & TRN & \\
\hline CHEMBL 3211340 & 688524 & 4.7 & 5.1482 & TST & \\
\hline CHEMBL1374135 & 688524 & 5.1 & 5.1736 & TRN & \\
\hline CHEMBL1367076 & 688524 & 5.0 & 4.8254 & TRN & \\
\hline CHEMBL1497245 & 688524 & 5.1 & 4.8905 & TRN & \\
\hline CHEMBL1530209 & 688524 & 4.8 & 4.8799 & TRN & \\
\hline CHEMBL1490133 & 688524 & 4.9 & 5.1361 & TRN & \\
\hline CHEMBL1485869 & 688524 & 4.7 & 4.9259 & TRN & \\
\hline CHEMBL1439088 & 688524 & 5.1 & 4.9624 & TST & \\
\hline CHEMBL1584891 & 688524 & 4.8 & 4.8684 & TRN & \\
\hline CHEMBL1319214 & 688524 & 4.9 & 5.2248 & TST & \\
\hline CHEMBL1393205 & 688524 & 5.0 & 4.927 & TRN & \\
\hline CHEMBL1981833 & 688524 & 4.9 & 4.9005 & TRN & \\
\hline CHEMBL1489960 & 688524 & 5.3 & 5.0285 & TRN & \\
\hline CHEMBL1256484 & 688524 & 4.9 & 5.072 & TRN & \\
\hline CHEMBL1362964 & 688524 & 4.7 & 4.917 & TRN & \\
\hline CHEMBL1463025 & 688524 & 4.9 & 5.0614 & TRN & \\
\hline CHEMBL1472728 & 688524 & 5.9 & 5.2255 & TST & \\
\hline CHEMBL1300881 & 688524 & 4.7 & 5.0003 & TRN & \\
\hline CHEMBL1606230 & 688524 & 5.0 & 5.1886 & TRN & \\
\hline CHEMBL1342182 & 688524 & 5.0 & 4.9603 & TRN & \\
\hline CHEMBL1323290 & 688524 & 5.9 & 5.3018 & TST & \\
\hline CHEMBL1591503 & 688524 & 4.5 & 5.0718 & TRN & \\
\hline CHEMBL1535431 & 688524 & 4.5 & 5.09399 & 9999999999 & TRN \\
\hline CHEMBL1320983 & 688524 & 5.5 & 4.9573 & TRN & \\
\hline CHEMBL1324032 & 688524 & 5.3 & 5.0844 & TST & \\
\hline CHEMBL1342109 & 688524 & 5.0 & 4.8838 & TRN & \\
\hline CHEMBL1302701 & 688524 & 4.9 & 5.0122 & TRN & \\
\hline CHEMBL1402732 & 688524 & 5.2 & 5.1029 & TRN & \\
\hline CHEMBL3190499 & 688524 & 4.9 & 5.1036 & TRN & \\
\hline CHEMBL1256913 & 688524 & 5.1 & 5.2369 & TRN & \\
\hline CHEMBL1479917 & 688524 & 4.9 & 4.9582 & TRN & \\
\hline CHEMBL1448387 & 688524 & 6.0 & 5.1548 & TST & \\
\hline CHEMBL1411051 & 688524 & 5.3 & 5.0446 & TRN & \\
\hline CHEMBL1436980 & 688524 & 4.5 & 4.9698 & TST & \\
\hline CHEMBL10347 & 688524 & 5.2 & 5.0557 & TST & \\
\hline CHEMBL1436042 & 688524 & 4.8 & 5.1488 & TRN & \\
\hline CHEMBL1488608 & 688524 & 4.9 & 4.9228 & TRN & \\
\hline CHEMBL1342647 & 688524 & 4.8 & 5.2234 & TST & \\
\hline CHEMBL1332602 & 688524 & 4.9 & 4.9209 & TRN & \\
\hline CHEMBL48310 & 688524 & 5.0 & 5.0415 & TST & \\
\hline CHEMBL1347687 & 688524 & 4.9 & 4.9589 & TRN & \\
\hline & & & & 26233 & \\
\hline
\end{tabular}




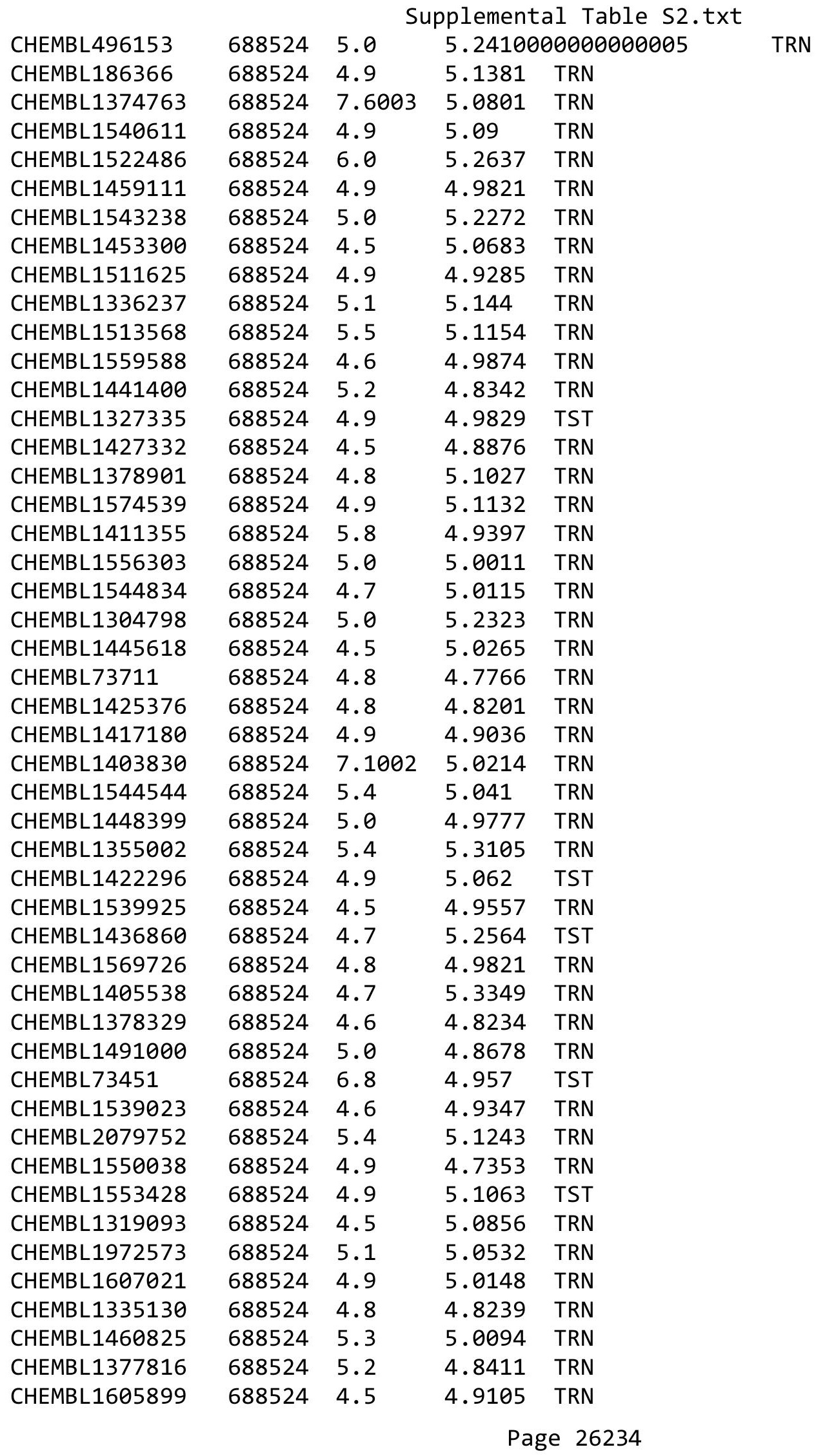




\begin{tabular}{|c|c|c|c|c|c|}
\hline & & & & & \\
\hline CHEMBL1382977 & 688524 & 4.5 & 4.9301 & TRN & \\
\hline CHEMBL1608110 & 688524 & 5.2 & 5.0564 & TRN & \\
\hline CHEMBL1371504 & 688524 & 4.8 & 4.9949 & TRN & \\
\hline CHEMBL1315318 & 688524 & 5.3 & 5.2096 & TRN & \\
\hline CHEMBL1408051 & 688524 & 5.1 & 4.9086 & TRN & \\
\hline CHEMBL1441140 & 688524 & 5.3 & 5.0855 & TST & \\
\hline CHEMBL1481374 & 688524 & 4.7 & 4.8599 & TRN & \\
\hline CHEMBL1381002 & 688524 & 4.9 & 5.0728 & TRN & \\
\hline CHEMBL 260148 & 688524 & 5.1 & 5.118 & TRN & \\
\hline CHEMBL1522275 & 688524 & 5.0 & 5.084 & TRN & \\
\hline CHEMBL137648 & 688524 & 4.8 & 4.959 & TST & \\
\hline CHEMBL1330965 & 688524 & 5.2 & 5.0688 & TRN & \\
\hline CHEMBL1440713 & 688524 & 5.4 & 5.197 & TST & \\
\hline CHEMBL 3213585 & 688524 & 4.5 & 5.1346 & TRN & \\
\hline CHEMBL1517047 & 688524 & 5.0 & 4.8391 & TRN & \\
\hline CHEMBL1516925 & 688524 & 5.0 & 4.9336 & TRN & \\
\hline CHEMBL1334323 & 688524 & 5.5 & 4.9087 & TRN & \\
\hline CHEMBL1306308 & 688524 & 4.6 & 5.0276 & TRN & \\
\hline CHEMBL1462616 & 688524 & 5.0 & 4.8806 & TRN & \\
\hline CHEMBL1407140 & 688524 & 4.7 & 5.0134 & TRN & \\
\hline CHEMBL448515 & 688524 & 5.1 & 5.1038 & TST & \\
\hline CHEMBL1546147 & 688524 & 5.2 & 5.0131 & TRN & \\
\hline CHEMBL1529860 & 688524 & 5.0 & 4.9615 & TRN & \\
\hline CHEMBL279564 & 688524 & 4.9 & 5.1035 & TST & \\
\hline CHEMBL1401717 & 688524 & 4.6 & 5.1879 & TST & \\
\hline CHEMBL1469736 & 688524 & 4.9 & 4.8558 & TRN & \\
\hline CHEMBL1331578 & 688524 & 4.9 & 5.0244 & TRN & \\
\hline CHEMBL1400681 & 688524 & 5.0 & $4.7810 e$ & 0000000001 & TRN \\
\hline CHEMBL1448695 & 688524 & 4.5 & 5.0404 & TRN & \\
\hline CHEMBL1460357 & 688524 & 4.9 & 4.8926 & TRN & \\
\hline CHEMBL1338509 & 688524 & 5.3 & 4.9542 & TST & \\
\hline CHEMBL1494309 & 688524 & 4.5 & 4.8494 & TRN & \\
\hline CHEMBL1398925 & 688524 & 5.1 & 4.9346 & TRN & \\
\hline CHEMBL1375580 & 688524 & 4.7 & 4.9568 & TRN & \\
\hline CHEMBL3213723 & 688524 & 5.4 & 5.1276 & TST & \\
\hline CHEMBL1510906 & 688524 & 4.9 & 5.1577 & TRN & \\
\hline CHEMBL1495908 & 688524 & 4.9 & 4.9401 & TRN & \\
\hline CHEMBL1478676 & 688524 & 4.9 & 5.1355 & TRN & \\
\hline CHEMBL1611267 & 688524 & 4.9 & 4.9654 & TST & \\
\hline CHEMBL1501726 & 688524 & 7.0 & 5.0706 & TRN & \\
\hline CHEMBL1361710 & 688524 & 5.2 & 4.9547 & TST & \\
\hline CHEMBL1581403 & 688524 & 4.5 & 5.0729 & TRN & \\
\hline CHEMBL1519535 & 688524 & 5.5 & 4.9738 & TST & \\
\hline CHEMBL1423690 & 688524 & 4.9 & 5.1044 & TRN & \\
\hline CHEMBL1324842 & 688524 & 5.3 & 5.0608 & TST & \\
\hline CHEMBL1577975 & 688524 & 5.0 & 4.8754 & TRN & \\
\hline CHEMBL1602424 & 688524 & 5.0 & 5.0612 & TRN & \\
\hline CHEMBL1603509 & 688524 & 5.7 & 4.9712 & TRN & \\
\hline & & & & 26235 & \\
\hline
\end{tabular}




\begin{tabular}{|c|c|c|c|c|}
\hline & & & & al lable \\
\hline CHEMBL1330858 & 688524 & 4.7 & 5.0922 & TRN \\
\hline CHEMBL1576290 & 688524 & 4.5 & 4.9602 & TRN \\
\hline CHEMBL1509933 & 688524 & 5.0 & 4.836 & TRN \\
\hline CHEMBL1438559 & 688524 & 5.3 & 5.0479 & TRN \\
\hline CHEMBL1387781 & 688524 & 4.6 & 4.9766 & TRN \\
\hline CHEMBL1577562 & 688524 & 4.9 & 4.9503 & TRN \\
\hline CHEMBL1335042 & 688524 & 5.0 & 5.0543 & TRN \\
\hline CHEMBL1482981 & 688524 & 5.7 & 5.0385 & TST \\
\hline CHEMBL1542165 & 688524 & 4.5 & 4.9516 & TRN \\
\hline CHEMBL1410437 & 688524 & 4.9 & 4.8639 & TRN \\
\hline CHEMBL1384832 & 688524 & 5.0 & 5.1707 & TRN \\
\hline CHEMBL1495497 & 688524 & 4.9 & 4.9195 & TRN \\
\hline CHEMBL1475428 & 688524 & 5.4 & 5.2156 & TRN \\
\hline CHEMBL290914 & 688524 & 5.0 & 5.2782 & TST \\
\hline CHEMBL1330018 & 688524 & 5.0 & 5.0079 & TRN \\
\hline CHEMBL1530084 & 688524 & 4.9 & 4.9014 & TRN \\
\hline CHEMBL1517112 & 688524 & 4.8 & 4.8208 & TRN \\
\hline CHEMBL1481546 & 688524 & 4.7 & 4.8955 & TRN \\
\hline CHEMBL1456771 & 688524 & 5.1 & 4.7438 & TRN \\
\hline CHEMBL1596170 & 688524 & 5.3 & 5.21200 & 0000000001 \\
\hline CHEMBL1548444 & 688524 & 5.0 & 5.0696 & TRN \\
\hline CHEMBL1299397 & 688524 & 5.3 & 5.0319 & TRN \\
\hline CHEMBL512908 & 688524 & 5.3 & 5.2891 & TRN \\
\hline CHEMBL1329528 & 688524 & 4.5 & 4.7827 & TRN \\
\hline CHEMBL1552663 & 688524 & 5.15 & 4.8812 & TRN \\
\hline CHEMBL1577952 & 688524 & 4.8 & 4.9946 & TRN \\
\hline CHEMBL1529460 & 688524 & 5.0 & 5.1021 & TST \\
\hline CHEMBL1353113 & 688524 & 4.9 & 4.9962 & TRN \\
\hline CHEMBL1304951 & 688524 & 5.3 & 4.9929 & TRN \\
\hline CHEMBL1374041 & 688524 & 4.7 & 4.8175 & TRN \\
\hline CHEMBL1381446 & 688524 & 4.9 & 5.1621 & TRN \\
\hline CHEMBL500351 & 688524 & 4.9 & 4.8559 & TRN \\
\hline CHEMBL1528250 & 688524 & 4.7 & 4.8831 & TRN \\
\hline CHEMBL1463869 & 688524 & 5.0 & 5.1668 & TRN \\
\hline CHEMBL1583597 & 688524 & 5.2 & 5.044 & TRN \\
\hline CHEMBL260342 & 688524 & 5.7 & 5.1045 & TRN \\
\hline CHEMBL1438452 & 688524 & 4.7 & 4.9454 & TRN \\
\hline CHEMBL1309176 & 688524 & 5.1 & 5.1274 & TRN \\
\hline CHEMBL1545554 & 688524 & 5.2 & 5.0619 & TRN \\
\hline CHEMBL1360146 & 688524 & 4.8 & 5.0086 & TRN \\
\hline CHEMBL1504889 & 688524 & 4.8 & 4.81 & TRN \\
\hline CHEMBL423081 & 688524 & 4.5 & 5.2847 & TST \\
\hline CHEMBL1561615 & 688524 & 5.2 & 5.1762 & TRN \\
\hline CHEMBL1546068 & 688524 & 4.7 & 5.2303 & TST \\
\hline CHEMBL1290347 & 688524 & 4.9 & 5.0366 & TRN \\
\hline CHEMBL1310217 & 688524 & 4.9 & 4.8872 & TRN \\
\hline CHEMBL1416472 & 688524 & 5.0 & 4.865 & TRN \\
\hline CHEMBL1572280 & 688524 & 4.7 & 5.1309 & TST \\
\hline
\end{tabular}




\begin{tabular}{|c|c|c|c|c|c|}
\hline \multirow[b]{2}{*}{ CHEMBL1550703 } & \multirow[b]{2}{*}{688524} & \\
\hline & & 5.0 & 5.2873 & TRN & \\
\hline CHEMBL484663 & 688524 & 6.9 & 5.1917 & TRN & \\
\hline CHEMBL1304919 & 688524 & 5.0 & 4.8343 & TRN & \\
\hline CHEMBL1428337 & 688524 & 5.4 & 4.9307 & TST & \\
\hline CHEMBL1326100 & 688524 & 7.0 & 5.2508 & TRN & \\
\hline CHEMBL1506153 & 688524 & 4.5 & 4.9923 & TRN & \\
\hline CHEMBL1451172 & 688524 & 4.9 & 5.1894 & TRN & \\
\hline CHEMBL1367968 & 688524 & 4.5 & 5.0307 & TST & \\
\hline CHEMBL1309056 & 688524 & 4.9 & 4.9293 & TRN & \\
\hline CHEMBL1531414 & 688524 & 4.6 & 4.8771 & TRN & \\
\hline CHEMBL1422128 & 688524 & 4.8 & 4.8529 & TRN & \\
\hline CHEMBL1492217 & 688524 & 5.5 & 5.0621 & TRN & \\
\hline CHEMBL1608663 & 688524 & 5.4 & 4.9847 & TRN & \\
\hline CHEMBL1504585 & 688524 & 4.9 & 5.0605 & TST & \\
\hline CHEMBL1328533 & 688524 & 4.7 & 5.1608 & TST & \\
\hline CHEMBL1603187 & 688524 & 4.9 & 4.9292 & TRN & \\
\hline CHEMBL1575943 & 688524 & 5.0 & 5.0121 & TRN & \\
\hline CHEMBL1496737 & 688524 & 4.9 & 4.85 & TRN & \\
\hline CHEMBL1301465 & 688524 & 4.5 & 4.7678 & TRN & \\
\hline CHEMBL1575782 & 688524 & 5.0 & 4.9552 & TRN & \\
\hline CHEMBL1557662 & 688524 & 5.0 & 5.0971 & TRN & \\
\hline CHEMBL1406066 & 688524 & 5.3 & 4.9476 & TRN & \\
\hline CHEMBL1555153 & 688524 & 4.8 & 5.0845 & TST & \\
\hline CHEMBL24983 & 688524 & 5.1 & 5.0486 & TRN & \\
\hline CHEMBL1581071 & 688524 & 4.5 & 5.1043 & TST & \\
\hline CHEMBL243652 & 688524 & 4.9 & 5.0192 & TST & \\
\hline CHEMBL1586500 & 688524 & 4.5 & 5.0628 & TRN & \\
\hline CHEMBL1490793 & 688524 & 4.8 & 5.0146 & TST & \\
\hline CHEMBL1436821 & 688524 & 5.5 & 5.0676 & TST & \\
\hline CHEMBL1534248 & 688524 & 6.0 & 5.03600 & 00000000005 & TST \\
\hline CHEMBL1506602 & 688524 & 4.5 & 5.0105 & TRN & \\
\hline CHEMBL1607973 & 688524 & 4.9 & 4.9344 & TRN & \\
\hline CHEMBL1333212 & 688524 & 5.0 & 5.0311 & TRN & \\
\hline CHEMBL1370573 & 688524 & 4.9 & 5.1351 & TRN & \\
\hline CHEMBL1602710 & 688524 & 7.2 & 5.4264 & TRN & \\
\hline CHEMBL1398810 & 688524 & 4.5 & 5.3266 & TRN & \\
\hline CHEMBL3212239 & 688524 & 4.9 & 5.1604 & TRN & \\
\hline CHEMBL1536319 & 688524 & 4.9 & 4.86100 & 0000000001 & TRN \\
\hline CHEMBL1497555 & 688524 & 5.0 & 4.9928 & TRN & \\
\hline CHEMBL1368562 & 688524 & 4.6 & 4.9222 & TRN & \\
\hline CHEMBL1534894 & 688524 & 5.2 & 4.8696 & TRN & \\
\hline CHEMBL1466155 & 688524 & 4.5 & 4.8273 & TRN & \\
\hline CHEMBL1572894 & 688524 & 5.0 & 4.8904 & TRN & \\
\hline CHEMBL1592679 & 688524 & 4.8 & 5.002 & TRN & \\
\hline CHEMBL1405295 & 688524 & 4.9 & 5.1584 & TRN & \\
\hline CHEMBL1391290 & 688524 & 4.5 & 5.2508 & TST & \\
\hline CHEMBL1326231 & 688524 & 4.9 & 5.1729 & TRN & \\
\hline CHEMBL1442190 & 688524 & 5.4 & 5.0338 & TRN & \\
\hline & & & & 2623 & \\
\hline
\end{tabular}




\begin{tabular}{|c|c|c|c|c|}
\hline \multicolumn{5}{|c|}{ lemental T } \\
\hline CHEMBL1399634 & 688524 & 7.0 & 5.4726 & TRN \\
\hline CHEMBL1470598 & 688524 & 5.0 & 4.6615 & TRN \\
\hline CHEMBL1349299 & 688524 & 4.6 & 5.1013 & TRN \\
\hline CHEMBL1560842 & 688524 & 4.9 & 5.0274 & TRN \\
\hline CHEMBL1569543 & 688524 & 4.9 & 4.7857 & TRN \\
\hline CHEMBL1438690 & 688524 & 6.1 & 5.3056 & TRN \\
\hline CHEMBL1365070 & 688524 & 4.8 & 5.0918 & TRN \\
\hline CHEMBL1521974 & 688524 & 4.9 & 5.0386 & TRN \\
\hline CHEMBL1347369 & 688524 & 4.8 & 4.8436 & TRN \\
\hline CHEMBL1500193 & 688524 & 5.5 & 5.1133 & TRN \\
\hline CHEMBL1597257 & 688524 & 5.4 & 4.8802 & TRN \\
\hline CHEMBL1449072 & 688524 & 5.0 & 4.9219 & TRN \\
\hline CHEMBL1564551 & 688524 & 7.0 & 5.0635 & TRN \\
\hline CHEMBL1386099 & 688524 & 5.0 & 5.0914 & TRN \\
\hline CHEMBL1390525 & 688524 & 4.5 & 5.0096 & TRN \\
\hline CHEMBL1424284 & 688524 & 4.5 & 4.9967 & TST \\
\hline CHEMBL1542001 & 688524 & 4.5 & 5.0948 & TST \\
\hline CHEMBL1338988 & 688524 & 4.5 & 4.9494 & TRN \\
\hline CHEMBL1380505 & 688524 & 4.5 & 5.0128 & TST \\
\hline CHEMBL1483446 & 688524 & 4.9 & 5.1827 & TRN \\
\hline CHEMBL1479996 & 688524 & 4.6 & 5.0576 & TRN \\
\hline CHEMBL1613672 & 688524 & 5.0 & 4.853 & TRN \\
\hline CHEMBL1326664 & 688524 & 4.9 & 4.8482 & TRN \\
\hline CHEMBL1441246 & 688524 & 4.9 & 4.7617 & TRN \\
\hline CHEMBL1526738 & 688524 & 5.0 & 4.8677 & TRN \\
\hline CHEMBL1349964 & 688524 & 4.9 & 4.9482 & TST \\
\hline CHEMBL1537293 & 688524 & 5.0 & 4.9211 & TRN \\
\hline CHEMBL1530043 & 688524 & 4.9 & 4.8562 & TRN \\
\hline CHEMBL1603051 & 688524 & 4.5 & 5.0466 & TRN \\
\hline CHEMBL1565346 & 688524 & 4.5 & 4.8575 & TRN \\
\hline CHEMBL1603884 & 688524 & 5.5 & 5.0043 & TRN \\
\hline CHEMBL1343768 & 688524 & 5.0 & 5.1158 & TRN \\
\hline CHEMBL1332221 & 688524 & 4.5 & 5.3091 & TRN \\
\hline CHEMBL1400609 & 688524 & 4.8 & 4.8433 & TRN \\
\hline CHEMBL1603402 & 688524 & 5.3 & 4.9854 & TRN \\
\hline CHEMBL1427012 & 688524 & 4.5 & 5.0356 & TRN \\
\hline CHEMBL1578302 & 688524 & 4.5 & 4.8406 & TRN \\
\hline CHEMBL1563855 & 688524 & 4.8 & 4.9855 & TRN \\
\hline CHEMBL1327032 & 688524 & 4.5 & 5.0051 & TRN \\
\hline CHEMBL1552814 & 688524 & 4.5 & 5.0148 & TRN \\
\hline CHEMBL1611800 & 688524 & 4.6 & 5.1205 & TRN \\
\hline CHEMBL428496 & 688524 & 4.8 & 5.1832 & TST \\
\hline CHEMBL1485269 & 688524 & 4.7 & 5.0788 & TRN \\
\hline CHEMBL1375780 & 688524 & 4.9 & 5.0303 & TST \\
\hline CHEMBL1324947 & 688524 & 4.7 & 4.8561 & TRN \\
\hline CHEMBL1432550 & 688524 & 4.9 & 4.9373 & TRN \\
\hline CHEMBL1477015 & 688524 & 6.0 & 5.2997 & TRN \\
\hline CHEMBL1374426 & 688524 & 5.2 & 4.9787 & TST \\
\hline
\end{tabular}




\begin{tabular}{|c|c|c|c|c|}
\hline \multicolumn{5}{|c|}{ plemental T } \\
\hline CHEMBL1326041 & 688524 & 5.1 & 4.9106 & TRN \\
\hline CHEMBL1586619 & 688524 & 4.5 & 4.9456 & TRN \\
\hline CHEMBL1535438 & 688524 & 4.5 & 5.165 & TRN \\
\hline CHEMBL1563858 & 688524 & 4.9 & 5.1318 & TRN \\
\hline CHEMBL1437718 & 688524 & 4.5 & 5.0672 & TRN \\
\hline CHEMBL1577808 & 688524 & 4.9 & 5.1208 & TRN \\
\hline CHEMBL1478330 & 688524 & 4.9 & 4.7825 & TRN \\
\hline CHEMBL580381 & 688524 & 5.4 & 4.9662 & TRN \\
\hline CHEMBL1548833 & 688524 & 4.8 & 4.9077 & TRN \\
\hline CHEMBL1395107 & 688524 & 4.9 & 5.1165 & TRN \\
\hline CHEMBL1393805 & 688524 & 4.5 & 4.9715 & TRN \\
\hline CHEMBL1592549 & 688524 & 4.5 & 4.9924 & TRN \\
\hline CHEMBL1556820 & 688524 & 5.1 & 4.8431 & TRN \\
\hline CHEMBL1542288 & 688524 & 4.7 & 5.2539 & TRN \\
\hline CHEMBL1461809 & 688524 & 4.6 & 4.9028 & TRN \\
\hline CHEMBL 1974818 & 688524 & 4.5 & 4.7533 & TRN \\
\hline CHEMBL1577264 & 688524 & 4.8 & 5.1985 & TRN \\
\hline CHEMBL1340349 & 688524 & 6.9 & 5.02 & TRN \\
\hline CHEMBL1307804 & 688524 & 4.9 & 4.9119 & TRN \\
\hline CHEMBL1432063 & 688524 & 4.9 & 4.9678 & TRN \\
\hline CHEMBL1256816 & 688524 & 4.8 & 4.9862 & TST \\
\hline CHEMBL1521872 & 688524 & 4.9 & 5.0649 & TST \\
\hline CHEMBL1605161 & 688524 & 4.5 & 4.8977 & TRN \\
\hline CHEMBL1972346 & 688524 & 6.0 & 5.2268 & TRN \\
\hline CHEMBL1326619 & 688524 & 5.3 & 5.2807 & TRN \\
\hline CHEMBL1426299 & 688524 & 4.9 & 4.9074 & TST \\
\hline CHEMBL1456099 & 688524 & 5.7 & 4.8426 & TRN \\
\hline CHEMBL1323938 & 688524 & 4.5 & 4.8414 & TRN \\
\hline CHEMBL1426739 & 688524 & 4.5 & 4.8925 & TRN \\
\hline CHEMBL1497932 & 688524 & 5.0 & 4.9955 & TRN \\
\hline CHEMBL1423062 & 688524 & 4.7 & 4.8386 & TRN \\
\hline CHEMBL1483048 & 688524 & 4.9 & 4.97 & TRN \\
\hline CHEMBL1328164 & 688524 & 5.3 & 4.8008 & TRN \\
\hline CHEMBL1455814 & 688524 & 5.5 & 4.9857 & TRN \\
\hline CHEMBL1531911 & 688524 & 4.9 & 4.8997 & TRN \\
\hline CHEMBL1560215 & 688524 & 4.9 & 5.0015 & TRN \\
\hline CHEMBL1488499 & 688524 & 4.5 & 4.7726 & TRN \\
\hline CHEMBL1475902 & 688524 & 5.0 & 5.4131 & TRN \\
\hline CHEMBL1381595 & 688524 & 5.0 & 5.0458 & TRN \\
\hline CHEMBL1328887 & 688524 & 5.0 & 5.1567 & TRN \\
\hline CHEMBL1519261 & 688524 & 4.7 & 5.1976 & TRN \\
\hline CHEMBL1439183 & 688524 & 5.4 & 5.1245 & TRN \\
\hline CHEMBL1426947 & 688524 & 4.7 & 4.9803 & TRN \\
\hline CHEMBL1548453 & 688524 & 4.8 & 4.8742 & TRN \\
\hline CHEMBL1440316 & 688524 & 4.8 & 5.0014 & TRN \\
\hline CHEMBL1578861 & 688524 & 4.9 & 4.6992 & TRN \\
\hline CHEMBL1596425 & 688524 & 5.3 & 4.9811 & TST \\
\hline CHEMBL1476043 & 688524 & 5.3 & 5.064 & TRN \\
\hline
\end{tabular}




\begin{tabular}{|c|c|c|c|c|c|}
\hline \multirow[b]{2}{*}{ CHEMBL1610565 } & \multirow[b]{2}{*}{688524} & \\
\hline & & 5.0 & 4.8133 & TRN & \\
\hline CHEMBL1383829 & 688524 & 4.9 & 4.8977 & TRN & \\
\hline CHEMBL225230 & 688524 & 4.6 & 5.1049 & TST & \\
\hline CHEMBL1548635 & 688524 & 5.0 & 5.0662 & TRN & \\
\hline CHEMBL242171 & 688524 & 4.8 & 5.0536 & TRN & \\
\hline CHEMBL1591380 & 688524 & 4.9 & 5.0652 & TRN & \\
\hline CHEMBL406835 & 688524 & 5.5 & 5.0652 & TRN & \\
\hline CHEMBL1471515 & 688524 & 4.6 & 4.9748 & TRN & \\
\hline CHEMBL1419839 & 688524 & 4.8 & 4.8958 & TRN & \\
\hline CHEMBL1325105 & 688524 & 4.9 & 4.998 & TRN & \\
\hline CHEMBL1320306 & 688524 & 4.8 & 5.0605 & TRN & \\
\hline CHEMBL1524752 & 688524 & 4.6 & 4.9571 & TRN & \\
\hline CHEMBL1437006 & 688524 & 4.6 & 4.8753 & TRN & \\
\hline CHEMBL1462781 & 688524 & 4.9 & 4.9441 & TRN & \\
\hline CHEMBL1418235 & 688524 & 4.8 & 4.8629 & TRN & \\
\hline CHEMBL1515738 & 688524 & 4.45 & 4.9144 & TRN & \\
\hline CHEMBL1449954 & 688524 & 4.8 & 5.0444 & TRN & \\
\hline CHEMBL1465180 & 688524 & 4.8 & 4.9764 & TRN & \\
\hline CHEMBL1546705 & 688524 & 5.0 & 4.8938 & TRN & \\
\hline CHEMBL1493396 & 688524 & 4.9 & 5.1501 & TST & \\
\hline CHEMBL1393953 & 688524 & 5.5 & 4.9641 & TRN & \\
\hline CHEMBL1491542 & 688524 & 4.8 & 4.83 & TRN & \\
\hline CHEMBL1566759 & 688524 & 5.0 & 4.9939 & TRN & \\
\hline CHEMBL1498594 & 688524 & 5.1 & 5.0258 & TRN & \\
\hline CHEMBL276473 & 688524 & 4.8 & 5.2107 & TRN & \\
\hline CHEMBL1320882 & 688524 & 4.9 & 5.1643 & TRN & \\
\hline CHEMBL1458471 & 688524 & 4.9 & 4.7625 & TRN & \\
\hline CHEMBL1491818 & 688524 & 5.5 & 5.21899 & 9999999999 & TRN \\
\hline CHEMBL3145108 & 688524 & 4.8 & 5.0157 & TRN & \\
\hline CHEMBL543467 & 688524 & 4.8 & 5.0722 & TRN & \\
\hline CHEMBL1481621 & 688524 & 5.0 & 5.2806 & TRN & \\
\hline CHEMBL1364404 & 688524 & 5.5 & 5.0009 & TRN & \\
\hline CHEMBL1592435 & 688524 & 5.5 & 5.1345 & TST & \\
\hline CHEMBL1557782 & 688524 & 4.6 & 4.8624 & TRN & \\
\hline CHEMBL1572452 & 688524 & 4.9 & 5.0476 & TRN & \\
\hline CHEMBL1529046 & 688524 & 4.9 & 4.8622 & TRN & \\
\hline CHEMBL1323125 & 688524 & 5.0 & 5.1399 & TST & \\
\hline CHEMBL1497224 & 688524 & 4.7 & 4.8175 & TRN & \\
\hline CHEMBL1483509 & 688524 & 4.7 & 5.0294 & TST & \\
\hline CHEMBL1539681 & 688524 & 4.8 & 4.8217 & TRN & \\
\hline CHEMBL1597273 & 688524 & 5.0 & 5.1569 & TST & \\
\hline CHEMBL228792 & 688524 & 6.0 & 5.2532 & TRN & \\
\hline CHEMBL1391630 & 688524 & 4.6 & 4.9608 & TRN & \\
\hline CHEMBL1526606 & 688524 & 4.8 & 5.0223 & TST & \\
\hline CHEMBL1446875 & 688524 & 4.9 & 5.0613 & TST & \\
\hline CHEMBL1447359 & 688524 & 4.8 & 5.1782 & TRN & \\
\hline CHEMBL1593867 & 688524 & 4.5 & 5.1002 & TRN & \\
\hline CHEMBL3195761 & 688524 & 5.7 & 4.8732 & TRN & \\
\hline & & & & 26240 & \\
\hline
\end{tabular}




\begin{tabular}{|c|c|c|c|c|c|}
\hline & & & & & \\
\hline CHEMBL1563483 & 688524 & 5.6 & 5.2478 & TST & \\
\hline CHEMBL1301914 & 688524 & 4.9 & 5.0078 & TRN & \\
\hline CHEMBL1401412 & 688524 & 4.5 & 4.8134 & TRN & \\
\hline CHEMBL1504945 & 688524 & 5.3 & 4.9921 & TRN & \\
\hline CHEMBL1372085 & 688524 & 5.0 & 5.157 & TRN & \\
\hline CHEMBL1426830 & 688524 & 4.9 & 5.0737 & TRN & \\
\hline CHEMBL1536120 & 688524 & 4.5 & 4.8398 & TRN & \\
\hline CHEMBL1560487 & 688524 & 5.0 & 5.0426 & TRN & \\
\hline CHEMBL1511197 & 688524 & 4.7 & 5.2413 & TRN & \\
\hline CHEMBL1527686 & 688524 & 4.9 & 4.9213 & TRN & \\
\hline CHEMBL580819 & 688524 & 4.5 & 4.9685 & TRN & \\
\hline CHEMBL18686 & 688524 & 5.2 & 5.0825 & TST & \\
\hline CHEMBL1321156 & 688524 & 4.6 & 4.9211 & TRN & \\
\hline CHEMBL1460021 & 688524 & 4.7 & 5.1157 & TRN & \\
\hline CHEMBL1451434 & 688524 & 4.7 & 5.226 & TRN & \\
\hline CHEMBL1363210 & 688524 & 5.0 & 5.0315 & TRN & \\
\hline CHEMBL1583096 & 688524 & 4.9 & 4.8919 & TST & \\
\hline CHEMBL1509985 & 688524 & 5.2 & 5.1795 & TRN & \\
\hline CHEMBL1522934 & 688524 & 4.7 & 4.8667 & TRN & \\
\hline CHEMBL1422597 & 688524 & 4.9 & 5.091 & TRN & \\
\hline CHEMBL1329108 & 688524 & 4.6 & 5.1519 & TRN & \\
\hline CHEMBL1255650 & 688524 & 5.3 & 5.0669 & TST & \\
\hline CHEMBL1390313 & 688524 & 4.9 & 5.0257 & TRN & \\
\hline CHEMBL1519770 & 688524 & 5.3 & 5.3248 & TRN & \\
\hline CHEMBL8918 & 688524 & 4.9 & 5.0455 & TRN & \\
\hline CHEMBL1301814 & 688524 & 4.9 & 4.9592 & TRN & \\
\hline CHEMBL1453607 & 688524 & 4.9 & 4.8898 & TRN & \\
\hline CHEMBL1356107 & 688524 & 4.9 & 5.195 & TRN & \\
\hline CHEMBL1306271 & 688524 & 4.5 & 4.9452 & TRN & \\
\hline CHEMBL1519740 & 688524 & 5.0 & 4.8807 & TRN & \\
\hline CHEMBL116438 & 688524 & 4.8 & 5.0679 & TRN & \\
\hline CHEMBL1563333 & 688524 & 5.0 & 5.0559 & TRN & \\
\hline CHEMBL1487027 & 688524 & 5.2 & 5.0698 & TRN & \\
\hline CHEMBL1596602 & 688524 & 4.6 & 4.96399 & 99999999995 & TRN \\
\hline CHEMBL1362403 & 688524 & 5.0 & 4.8583 & TRN & \\
\hline CHEMBL1501697 & 688524 & 5.0 & 4.9864 & TRN & \\
\hline CHEMBL1488445 & 688524 & 4.6 & 5.1282 & TRN & \\
\hline CHEMBL1492738 & 688524 & 5.0 & 5.0323 & TRN & \\
\hline CHEMBL1407417 & 688524 & 4.5 & 5.2412 & TST & \\
\hline CHEMBL3196464 & 688524 & 4.6 & 4.8582 & TRN & \\
\hline CHEMBL1537051 & 688524 & 5.0 & 5.0094 & TRN & \\
\hline CHEMBL1402832 & 688524 & 4.6 & 4.793 & TRN & \\
\hline CHEMBL1556284 & 688524 & 4.8 & 5.0005 & TRN & \\
\hline CHEMBL1403333 & 688524 & 5.0 & 5.4778 & TRN & \\
\hline CHEMBL1325702 & 688524 & 4.5 & 4.9506 & TRN & \\
\hline CHEMBL1463808 & 688524 & 5.1 & 5.0412 & TRN & \\
\hline CHEMBL1516542 & 688524 & 4.9 & 4.8649 & TRN & \\
\hline CHEMBL1338853 & 688524 & 4.9 & 5.1399 & TRN & \\
\hline & & & & 26241 & \\
\hline
\end{tabular}




\begin{tabular}{|c|c|c|c|c|}
\hline & & & ient & al Ta \\
\hline CHEMBL1320319 & 688524 & 4.8 & 5.0576 & TRN \\
\hline CHEMBL1490567 & 688524 & 4.6 & 5.0604 & TRN \\
\hline CHEMBL1381044 & 688524 & 4.7 & 4.9701 & TRN \\
\hline CHEMBL1502701 & 688524 & 4.9 & 4.8475 & TRN \\
\hline CHEMBL1318310 & 688524 & 4.5 & 5.1477 & TRN \\
\hline CHEMBL1358614 & 688524 & 5.9 & 5.1953 & TRN \\
\hline CHEMBL543876 & 688524 & 5.1 & 4.8799 & TRN \\
\hline CHEMBL1441782 & 688524 & 5.2 & 5.1925 & TRN \\
\hline CHEMBL1200471 & 688524 & 7.2 & 5.2006 & TST \\
\hline CHEMBL1360592 & 688524 & 4.9 & 4.9623 & TRN \\
\hline CHEMBL1462788 & 688524 & 5.0 & 4.9778 & TRN \\
\hline CHEMBL1606004 & 688524 & 5.5 & 4.9396 & TST \\
\hline CHEMBL1369506 & 688524 & 4.8 & 5.2915 & TRN \\
\hline CHEMBL1575411 & 688524 & 5.0 & 4.8763 & TRN \\
\hline CHEMBL1449651 & 688524 & 5.8 & 5.1199 & TST \\
\hline CHEMBL1477337 & 688524 & 5.3 & 4.979 & TRN \\
\hline CHEMBL1462804 & 688524 & 4.9 & 4.8034 & TRN \\
\hline CHEMBL1402362 & 688524 & 5.0 & 5.0326 & TRN \\
\hline CHEMBL1584777 & 688524 & 5.0 & 4.7978 & TRN \\
\hline CHEMBL1499069 & 688524 & 5.3 & 4.9822 & TRN \\
\hline CHEMBL1357167 & 688524 & 4.5 & 5.3063 & TRN \\
\hline CHEMBL1393763 & 688524 & 4.8 & 4.9347 & TRN \\
\hline CHEMBL1583496 & 688524 & 4.7 & 4.7982 & TRN \\
\hline CHEMBL1453440 & 688524 & 4.5 & 5.1962 & TST \\
\hline CHEMBL577546 & 688524 & 4.9 & 4.7695 & TRN \\
\hline CHEMBL1599897 & 688524 & 5.4 & 5.0193 & TRN \\
\hline CHEMBL1347936 & 688524 & 4.5 & 5.1145 & TRN \\
\hline CHEMBL1454322 & 688524 & 5.0 & 4.9263 & TRN \\
\hline CHEMBL1332437 & 688524 & 5.0 & 5.0881 & TST \\
\hline CHEMBL1359317 & 688524 & 5.2 & 4.8676 & TRN \\
\hline CHEMBL1439292 & 688524 & 4.8 & 4.9727 & TST \\
\hline CHEMBL1374617 & 688524 & 4.8 & 5.0649 & TRN \\
\hline CHEMBL1351402 & 688524 & 4.9 & 4.7753 & TRN \\
\hline CHEMBL1452763 & 688524 & 4.9 & 5.1193 & TRN \\
\hline CHEMBL 255073 & 688524 & 5.0 & 5.1938 & TRN \\
\hline CHEMBL575073 & 688524 & 5.2 & 5.0392 & TRN \\
\hline CHEMBL1532203 & 688524 & 4.9 & 4.9568 & TRN \\
\hline CHEMBL1412163 & 688524 & 4.5 & 4.9415 & TST \\
\hline CHEMBL1561523 & 688524 & 4.7 & 4.845 & TRN \\
\hline CHEMBL1449018 & 688524 & 4.6 & 5.0511 & TRN \\
\hline CHEMBL 1459382 & 688524 & 5.4 & 4.8806 & TRN \\
\hline CHEMBL424581 & 688524 & 5.0 & 5.0935 & TRN \\
\hline CHEMBL1333664 & 688524 & 4.7 & 4.9756 & TRN \\
\hline CHEMBL1519146 & 688524 & 4.6 & 5.2731 & TRN \\
\hline CHEMBL1367508 & 688524 & 5.0 & 5.0516 & TRN \\
\hline CHEMBL1511986 & 688524 & 6.1 & 5.1718 & TRN \\
\hline CHEMBL483325 & 688524 & 4.5 & 5.0029 & TRN \\
\hline CHEMBL1312401 & 688524 & 4.7 & 5.0272 & TST \\
\hline
\end{tabular}




\begin{tabular}{|c|c|c|c|c|c|}
\hline \multicolumn{6}{|c|}{ Supplemental Table S2.txt } \\
\hline CHEMBL1489253 & 688524 & 4.9 & 5.1314 & TRN & \\
\hline CHEMBL1371234 & 688524 & 5.1 & 5.1159 & TRN & \\
\hline CHEMBL1584791 & 688524 & 7.1002 & 4.92899 & 9999999999 & TRN \\
\hline CHEMBL1319919 & 688524 & 4.9 & 5.0171 & TRN & \\
\hline CHEMBL1545478 & 688524 & 4.9 & 5.0287 & TRN & \\
\hline CHEMBL1313505 & 688524 & 5.3 & 5.0383 & TST & \\
\hline CHEMBL1513800 & 688524 & 4.8 & 5.0368 & TRN & \\
\hline CHEMBL6291 & 688524 & 4.9 & 5.0993 & TST & \\
\hline CHEMBL1596474 & 688524 & 5.6 & 5.0115 & TRN & \\
\hline CHEMBL1442458 & 688524 & 4.9 & 5.3029 & TRN & \\
\hline CHEMBL1530314 & 688524 & 7.5003 & 4.9899 & TST & \\
\hline CHEMBL1310534 & 688524 & 4.6 & 5.015 & TRN & \\
\hline CHEMBL1495785 & 688524 & 4.7 & 5.1021 & TST & \\
\hline CHEMBL3197417 & 688524 & 4.9 & 5.0996 & TRN & \\
\hline CHEMBL1374813 & 688524 & 4.9 & 5.0016 & TRN & \\
\hline CHEMBL1514455 & 688524 & 5.4 & 5.0097 & TRN & \\
\hline CHEMBL1480124 & 688524 & 4.9 & 5.0299 & TRN & \\
\hline CHEMBL1364432 & 688524 & 4.9 & 5.0163 & TRN & \\
\hline CHEMBL1601246 & 688524 & 5.5 & 5.1728 & TRN & \\
\hline CHEMBL1451609 & 688524 & 4.9 & 5.008 & TRN & \\
\hline CHEMBL1430921 & 688524 & 4.9 & 4.941 & TRN & \\
\hline CHEMBL1361232 & 688524 & 4.7 & 4.9477 & TRN & \\
\hline CHEMBL1306528 & 688524 & 4.5 & 5.0301 & TRN & \\
\hline CHEMBL1391548 & 688524 & 4.9 & 4.8163 & TRN & \\
\hline CHEMBL1505916 & 688524 & 5.1 & 4.9014 & TRN & \\
\hline CHEMBL102970 & 688524 & 4.9 & 5.2746 & TST & \\
\hline CHEMBL1433752 & 688524 & 6.0 & 5.3885 & TRN & \\
\hline CHEMBL1612493 & 688524 & 4.8 & 4.8088 & TRN & \\
\hline CHEMBL1323124 & 688524 & 4.7 & 5.0381 & TRN & \\
\hline CHEMBL1500452 & 688524 & 4.7 & 5.2562 & TRN & \\
\hline CHEMBL1545383 & 688524 & 5.6 & 5.0388 & TRN & \\
\hline CHEMBL1400212 & 688524 & 4.5 & 4.894 & TST & \\
\hline CHEMBL1562193 & 688524 & 4.6 & 5.0187 & TRN & \\
\hline CHEMBL1329375 & 688524 & 4.6 & 4.8278 & TRN & \\
\hline CHEMBL1533107 & 688524 & 4.5 & 5.0442 & TRN & \\
\hline CHEMBL1518629 & 688524 & 4.9 & 4.7998 & TRN & \\
\hline CHEMBL1457783 & 688524 & 4.9 & 5.1499 & TST & \\
\hline CHEMBL1337500 & 688524 & 5.6 & 5.0686 & TST & \\
\hline CHEMBL1444884 & 688524 & 4.9 & 4.9535 & TRN & \\
\hline CHEMBL1568666 & 688524 & 5.0 & 5.0878 & TRN & \\
\hline CHEMBL24450 & 688524 & 4.8 & 5.0553 & TRN & \\
\hline CHEMBL3194970 & 688524 & 4.9 & 5.0876 & TRN & \\
\hline CHEMBL1466669 & 688524 & 4.5 & 4.8789 & TRN & \\
\hline CHEMBL1538015 & 688524 & 4.6 & 4.7862 & TRN & \\
\hline CHEMBL1542404 & 688524 & 4.9 & 4.8458 & TRN & \\
\hline CHEMBL1569407 & 688524 & 4.9 & 5.1823 & TRN & \\
\hline CHEMBL1516276 & 688524 & 6.0 & 4.9981 & TRN & \\
\hline CHEMBL1370674 & 688524 & 6.5 & 5.1293 & TRN & \\
\hline
\end{tabular}




\begin{tabular}{|c|c|c|c|c|}
\hline \multicolumn{5}{|c|}{ Supplemental Table } \\
\hline CHEMBL1371236 & 688524 & 5.0 & 4.8604 & TRN \\
\hline CHEMBL1519872 & 688524 & 4.5 & 4.9932 & TRN \\
\hline CHEMBL1440038 & 688524 & 4.7 & 5.1046 & TRN \\
\hline CHEMBL1368561 & 688524 & 5.2 & 4.9814 & TRN \\
\hline CHEMBL1386446 & 688524 & 4.8 & 5.0578 & TRN \\
\hline CHEMBL1341981 & 688524 & 5.4 & 5.0715 & TRN \\
\hline CHEMBL1346468 & 688524 & 4.9 & 5.1005 & TRN \\
\hline CHEMBL1361552 & 688524 & 4.9 & 5.3935 & TRN \\
\hline CHEMBL1412927 & 688524 & 5.5 & 5.0518 & TRN \\
\hline CHEMBL16807 & 688524 & 6.5 & 5.0638 & TRN \\
\hline CHEMBL1469246 & 688524 & 4.8 & 5.0109 & TRN \\
\hline CHEMBL1367176 & 688524 & 5.0 & 4.9753 & TRN \\
\hline CHEMBL1329027 & 688524 & 4.8 & 5.4121 & TRN \\
\hline CHEMBL1599150 & 688524 & 4.9 & 4.9561 & TRN \\
\hline CHEMBL598263 & 688524 & 6.0 & 5.1618 & TST \\
\hline CHEMBL1319097 & 688524 & 5.0 & 5.0027 & TRN \\
\hline CHEMBL1450778 & 688524 & 5.0 & 4.9396 & TRN \\
\hline CHEMBL1478381 & 688524 & 5.3 & 5.0997 & TRN \\
\hline CHEMBL1452240 & 688524 & 5.0 & 4.9065 & TRN \\
\hline CHEMBL1513990 & 688524 & 7.699 & 5.6271 & TRN \\
\hline CHEMBL1545025 & 688524 & 4.7 & 5.0588 & TRN \\
\hline CHEMBL1543505 & 688524 & 5.4 & 4.9711 & TRN \\
\hline CHEMBL1532349 & 688524 & 4.6 & 5.1556 & TRN \\
\hline CHEMBL1302512 & 688524 & 4.5 & 5.0352 & TRN \\
\hline CHEMBL1570230 & 688524 & 5.0 & 4.9412 & TST \\
\hline CHEMBL1323112 & 688524 & 5.6 & 5.1303 & TST \\
\hline CHEMBL1422210 & 688524 & 5.0 & 4.9682 & TRN \\
\hline CHEMBL1570216 & 688524 & 5.9 & 5.3196 & TRN \\
\hline CHEMBL1324347 & 688524 & 4.5 & 4.8081 & TRN \\
\hline CHEMBL1473252 & 688524 & 7.699 & 5.1677 & TST \\
\hline CHEMBL1592975 & 688524 & 4.5 & 5.09 & TST \\
\hline CHEMBL1492724 & 688524 & 6.1 & 5.0596 & TRN \\
\hline CHEMBL1562777 & 688524 & 5.6 & 5.1399 & TRN \\
\hline CHEMBL1489099 & 688524 & 4.9 & 5.0612 & TRN \\
\hline CHEMBL1539721 & 688524 & 4.9 & 4.9714 & TRN \\
\hline CHEMBL1526425 & 688524 & 4.5 & 4.9146 & TRN \\
\hline CHEMBL1531697 & 688524 & 4.5 & 4.9023 & TST \\
\hline CHEMBL1549273 & 688524 & 5.5 & 4.9411 & TST \\
\hline CHEMBL1388206 & 688524 & 5.3 & 5.0833 & TRN \\
\hline CHEMBL1484454 & 688524 & 6.1 & 5.0891 & TRN \\
\hline CHEMBL1470269 & 688524 & 5.0 & 4.8026 & TRN \\
\hline CHEMBL1485219 & 688524 & 5.1 & 5.3088 & TRN \\
\hline CHEMBL1343623 & 688524 & 4.7 & 5.0949 & TRN \\
\hline CHEMBL1490146 & 688524 & 4.9 & 5.0295 & TRN \\
\hline CHEMBL1449222 & 688524 & 4.4 & 4.9991 & TST \\
\hline CHEMBL1519327 & 688524 & 6.0 & 5.2393 & TST \\
\hline CHEMBL1363938 & 688524 & 4.9 & 4.9414 & TRN \\
\hline CHEMBL1532186 & 688524 & 4.5 & 4.947 & TST \\
\hline
\end{tabular}




\begin{tabular}{|c|c|c|c|c|c|}
\hline \multicolumn{6}{|c|}{ Supplemental Table S2.txt } \\
\hline CHEMBL1359803 & 688524 & 4.8 & 4.9238 & TRN & \\
\hline CHEMBL1547349 & 688524 & 4.7 & 5.0749 & TRN & \\
\hline CHEMBL393287 & 688524 & 4.9 & 5.0395 & TRN & \\
\hline CHEMBL1486042 & 688524 & 5.3 & 5.1718 & TST & \\
\hline CHEMBL1321618 & 688524 & 6.3 & 5.0952 & TRN & \\
\hline CHEMBL1608535 & 688524 & 5.2 & 5.1359 & TST & \\
\hline CHEMBL1413556 & 688524 & 5.0 & 4.9944 & TST & \\
\hline CHEMBL1255659 & 688524 & 5.1 & 5.0753 & TST & \\
\hline CHEMBL1351643 & 688524 & 4.9 & 5.0062 & TRN & \\
\hline CHEMBL1370627 & 688524 & 4.9 & 4.9894 & TRN & \\
\hline CHEMBL1384800 & 688524 & 4.9 & 4.8849 & TRN & \\
\hline CHEMBL1542660 & 688524 & 5.0 & 4.876 & TRN & \\
\hline CHEMBL1333305 & 688524 & 5.5 & 5.2952 & TRN & \\
\hline CHEMBL1606052 & 688524 & 4.5 & 5.0473 & TRN & \\
\hline CHEMBL1566877 & 688524 & 5.7 & 5.1222 & TRN & \\
\hline CHEMBL1368274 & 688524 & 4.9 & 4.9014 & TRN & \\
\hline CHEMBL1590106 & 688524 & 5.0 & 5.4113 & TRN & \\
\hline CHEMBL1416772 & 688524 & 5.3 & 4.9592 & TRN & \\
\hline CHEMBL1574261 & 688524 & 4.9 & 5.0697 & TRN & \\
\hline CHEMBL1360260 & 688524 & 5.0 & 5.0221 & TRN & \\
\hline CHEMBL69086 & 688524 & 4.9 & 4.9547 & TRN & \\
\hline CHEMBL1604278 & 688524 & 4.8 & 4.9682 & TRN & \\
\hline CHEMBL1440672 & 688524 & 4.6 & 5.1485 & TRN & \\
\hline CHEMBL1455018 & 688524 & 7.5003 & 5.3617 & TRN & \\
\hline CHEMBL1556013 & 688524 & 4.8 & 4.9277 & TRN & \\
\hline CHEMBL 212242 & 688524 & 4.5 & 5.0153 & TRN & \\
\hline CHEMBL1098658 & 688524 & 4.6 & 4.9081 & TRN & \\
\hline CHEMBL1597847 & 688524 & 4.9 & 4.9418 & TST & \\
\hline CHEMBL1382924 & 688524 & 4.5 & 4.9783 & TRN & \\
\hline CHEMBL1378566 & 688524 & 5.1 & 5.026 & TRN & \\
\hline CHEMBL1331573 & 688524 & 5.6 & 4.9626 & TRN & \\
\hline CHEMBL1332957 & 688524 & 4.6 & 5.129 & TRN & \\
\hline CHEMBL1532607 & 688524 & 4.8 & 4.8579 & TRN & \\
\hline CHEMBL1560836 & 688524 & 5.3 & 5.0397 & TST & \\
\hline CHEMBL1256759 & 688524 & 6.0 & 5.4133 & TRN & \\
\hline CHEMBL1384525 & 688524 & 4.9 & 4.8484 & TRN & \\
\hline CHEMBL1558388 & 688524 & 5.0 & 5.1789 & TRN & \\
\hline CHEMBL1461844 & 688524 & 5.8 & 5.0054 & TRN & \\
\hline CHEMBL1538541 & 688524 & 4.6 & 5.0571 & TRN & \\
\hline CHEMBL1604441 & 688524 & 5.0 & 4.9589 & TRN & \\
\hline CHEMBL454761 & 688524 & 5.0 & 5.1567 & TST & \\
\hline CHEMBL1594460 & 688524 & 4.7 & 4.9213 & TRN & \\
\hline CHEMBL1491327 & 688524 & 5.0 & 4.9405 & TRN & \\
\hline CHEMBL1535689 & 688524 & 4.6 & 5.3151 & TRN & \\
\hline CHEMBL1528201 & 688524 & 4.9 & 4.926 & TRN & \\
\hline CHEMBL3198719 & 688524 & 4.5 & 5.0738 & TRN & \\
\hline CHEMBL1172822 & 688524 & 5.3 & 5.15600 & 0000000001 & TRN \\
\hline CHEMBL1537206 & 688524 & 4.8 & 5.0038 & TST & \\
\hline
\end{tabular}




\begin{tabular}{|c|c|c|c|c|c|}
\hline \\
\hline CHEMBL1565595 & 688524 & 5.5 & 5.1623 & TRN & \\
\hline CHEMBL1335571 & 688524 & 5.9 & 5.0202 & TRN & \\
\hline CHEMBL1328973 & 688524 & 4.7 & 4.9625 & TRN & \\
\hline CHEMBL1331095 & 688524 & 4.9 & 4.8982 & TST & \\
\hline CHEMBL1544907 & 688524 & 5.1 & 4.9435 & TRN & \\
\hline CHEMBL1573480 & 688524 & 5.6 & 5.1763 & TRN & \\
\hline CHEMBL1368212 & 688524 & 5.1 & 5.0496 & TRN & \\
\hline CHEMBL1497815 & 688524 & 4.9 & 4.8409 & TRN & \\
\hline CHEMBL1350737 & 688524 & 4.5 & 5.2594 & TRN & \\
\hline CHEMBL530115 & 688524 & 5.1 & 5.0147 & TRN & \\
\hline CHEMBL1530074 & 688524 & 4.5 & 5.0204 & TST & \\
\hline CHEMBL1310481 & 688524 & 5.0 & 5.0068 & TRN & \\
\hline CHEMBL582068 & 688524 & 7.3002 & 5.0771 & TRN & \\
\hline CHEMBL400478 & 688524 & 4.65 & 5.1231 & TST & \\
\hline CHEMBL1484882 & 688524 & 5.0 & 4.8862 & TRN & \\
\hline CHEMBL1415130 & 688524 & 4.9 & 5.1994 & TRN & \\
\hline CHEMBL1406806 & 688524 & 5.0 & 4.9091 & TRN & \\
\hline CHEMBL1565736 & 688524 & 4.9 & 4.9389 & TRN & \\
\hline CHEMBL1384900 & 688524 & 4.6 & 5.1228 & TRN & \\
\hline CHEMBL1419183 & 688524 & 4.6 & 5.0417 & TST & \\
\hline CHEMBL33618 & 688524 & 4.45 & 4.9548 & TRN & \\
\hline CHEMBL1455190 & 688524 & 4.5 & 4.9299 & TRN & \\
\hline CHEMBL1515001 & 688524 & 5.0 & 4.9848 & TST & \\
\hline CHEMBL1338657 & 688524 & 4.8 & 4.8729 & TRN & \\
\hline CHEMBL1416865 & 688524 & 4.5 & 5.1455 & TRN & \\
\hline CHEMBL1432396 & 688524 & 4.6 & 4.9614 & TRN & \\
\hline CHEMBL3214065 & 688524 & 4.9 & 4.9703 & TST & \\
\hline CHEMBL1429699 & 688524 & 4.7 & 4.8809 & TRN & \\
\hline CHEMBL1311267 & 688524 & 4.9 & 4.8959 & TRN & \\
\hline CHEMBL1365203 & 688524 & 4.9 & 5.0477 & TRN & \\
\hline CHEMBL 77456 & 688524 & 4.8 & 4.9856 & TRN & \\
\hline CHEMBL59030 & 688524 & 4.55 & 5.0427 & TST & \\
\hline CHEMBL1501418 & 688524 & 4.8 & 5.1671 & TRN & \\
\hline CHEMBL1424915 & 688524 & 5.2 & 5.0917 & TRN & \\
\hline CHEMBL1563631 & 688524 & 5.2 & 4.9397 & TRN & \\
\hline CHEMBL507026 & 688524 & 6.15 & 5.2259 & TST & \\
\hline CHEMBL1387542 & 688524 & 5.5 & 4.8261 & TRN & \\
\hline CHEMBL1393260 & 688524 & 4.9 & 5.0669 & TRN & \\
\hline CHEMBL1300237 & 688524 & 5.5 & 5.0142 & TRN & \\
\hline CHEMBL1608644 & 688524 & 4.7 & 5.05699 & 99999999995 & TRN \\
\hline CHEMBL1472148 & 688524 & 5.5 & 5.2734 & TST & \\
\hline CHEMBL1589657 & 688524 & 4.9 & 4.9 & TRN & \\
\hline CHEMBL1542576 & 688524 & 5.2 & 4.90300 & 00000000005 & TRN \\
\hline CHEMBL1521937 & 688524 & 4.8 & 5.0441 & TRN & \\
\hline CHEMBL1560035 & 688524 & 4.8 & 5.0953 & TRN & \\
\hline CHEMBL1416548 & 688524 & 4.9 & 4.88 & TRN & \\
\hline CHEMBL1530735 & 688524 & 4.8 & 4.9042 & TRN & \\
\hline CHEMBL1471016 & 688524 & 5.3 & 4.8622 & TRN & \\
\hline
\end{tabular}




\begin{tabular}{|c|c|c|c|c|c|}
\hline & & & & & \\
\hline CHEMBL1537488 & 688524 & 4.5 & 4.9782 & TRN & \\
\hline CHEMBL1529665 & 688524 & 5.9 & 5.0721 & TST & \\
\hline CHEMBL289277 & 688524 & 6.0 & 5.1358 & TST & \\
\hline CHEMBL1530762 & 688524 & 4.8 & 5.1407 & TRN & \\
\hline CHEMBL1367151 & 688524 & 4.8 & 4.9048 & TRN & \\
\hline CHEMBL1328073 & 688524 & 4.9 & 5.021 & TRN & \\
\hline CHEMBL1535518 & 688524 & 4.9 & 4.9221 & TRN & \\
\hline CHEMBL1442642 & 688524 & 4.5 & 4.8996 & TRN & \\
\hline CHEMBL1382072 & 688524 & 4.5 & 4.9434 & TRN & \\
\hline CHEMBL1454247 & 688524 & 4.9 & 5.0726 & TRN & \\
\hline CHEMBL1429644 & 688524 & 5.0 & 4.9724 & TRN & \\
\hline CHEMBL1496608 & 688524 & 4.9 & 4.8177 & TRN & \\
\hline CHEMBL1487010 & 688524 & 5.2 & 4.8431 & TRN & \\
\hline CHEMBL1351020 & 688524 & 4.8 & 4.993 & TRN & \\
\hline CHEMBL1447530 & 688524 & 5.4 & 4.9688 & TRN & \\
\hline CHEMBL1594554 & 688524 & 4.9 & 5.1068 & TRN & \\
\hline CHEMBL1580805 & 688524 & 4.8 & 4.9837 & TRN & \\
\hline CHEMBL1521629 & 688524 & 5.0 & 4.9743 & TRN & \\
\hline CHEMBL1490139 & 688524 & 7.2 & 5.1997 & TRN & \\
\hline CHEMBL600060 & 688524 & 5.3 & 5.0805 & TRN & \\
\hline CHEMBL1509699 & 688524 & 5.3 & 5.0216 & TST & \\
\hline CHEMBL1500773 & 688524 & 4.9 & 5.1397 & TRN & \\
\hline CHEMBL1528814 & 688524 & 4.5 & 4.9415 & TST & \\
\hline CHEMBL1467014 & 688524 & 4.6 & 5.0207 & TRN & \\
\hline CHEMBL1351765 & 688524 & 5.0 & 5.0227 & TRN & \\
\hline CHEMBL1346382 & 688524 & 5.2 & 5.015 & TRN & \\
\hline CHEMBL1415598 & 688524 & 4.9 & 4.8055 & TRN & \\
\hline CHEMBL1410426 & 688524 & 4.7 & 4.9915 & TRN & \\
\hline CHEMBL1580627 & 688524 & 4.9 & 5.14 & TRN & \\
\hline CHEMBL 8145 & 688524 & 6.0 & 5.3867 & TRN & \\
\hline CHEMBL1429775 & 688524 & 4.9 & 4.976 & TRN & \\
\hline CHEMBL576317 & 688524 & 4.7 & 4.9853 & TRN & \\
\hline CHEMBL1510135 & 688524 & 4.8 & 4.9983 & TRN & \\
\hline CHEMBL1496089 & 688524 & 5.5 & 4.9628 & TRN & \\
\hline CHEMBL3199152 & 688524 & 5.0 & 4.997 & TRN & \\
\hline CHEMBL1450349 & 688524 & 5.3 & 5.1287 & TRN & \\
\hline CHEMBL1515764 & 688524 & 4.8 & 5.1483 & TRN & \\
\hline CHEMBL1353081 & 688524 & 4.7 & 4.9838 & TRN & \\
\hline CHEMBL1418209 & 688524 & 4.9 & 4.6543 & TRN & \\
\hline CHEMBL1441891 & 688524 & 4.5 & 5.1125 & TRN & \\
\hline CHEMBL1389061 & 688524 & 5.6 & 5.0941 & TRN & \\
\hline CHEMBL191015 & 688524 & 4.5 & 4.7951 & TRN & \\
\hline CHEMBL137498 & 688524 & 4.8 & 4.9362 & TRN & \\
\hline CHEMBL1450760 & 688524 & 4.8 & 4.9254 & TRN & \\
\hline CHEMBL1348430 & 688524 & 4.9 & 4.882 & TRN & \\
\hline CHEMBL1313750 & 688524 & 4.9 & 5.0907 & TRN & \\
\hline CHEMBL1309807 & 688524 & 4.9 & 5.1327 & TRN & \\
\hline CHEMBL1234696 & 688524 & 7.699 & $5.4120 e$ & 2000000001 & TRN \\
\hline & & & & 26247 & \\
\hline
\end{tabular}




\begin{tabular}{|c|c|c|c|c|}
\hline \\
\hline CHEMBL1534683 & 688524 & 5.0 & 4.9873 & TRN \\
\hline CHEMBL1438469 & 688524 & 4.5 & 5.0386 & TRN \\
\hline CHEMBL1412416 & 688524 & 5.0 & 4.97 & TRN \\
\hline CHEMBL1568237 & 688524 & 4.9 & 4.8617 & TRN \\
\hline CHEMBL1300468 & 688524 & 4.9 & 5.0022 & TRN \\
\hline CHEMBL1595564 & 688524 & 4.6 & 5.0958 & TST \\
\hline CHEMBL1400884 & 688524 & 5.3 & 5.1623 & TST \\
\hline CHEMBL1372624 & 688524 & 5.9 & 4.9018 & TRN \\
\hline CHEMBL1374854 & 688524 & 4.8 & 5.0426 & TRN \\
\hline CHEMBL1451398 & 688524 & 4.45 & 5.0029 & TST \\
\hline CHEMBL2003973 & 688524 & 5.2 & 5.1454 & TST \\
\hline CHEMBL1466652 & 688524 & 5.0 & 4.8991 & TRN \\
\hline CHEMBL1388289 & 688524 & 5.5 & 5.1602 & TRN \\
\hline CHEMBL1611300 & 688524 & 4.9 & 4.836 & TRN \\
\hline CHEMBL1358252 & 688524 & 5.2 & 5.2302 & TRN \\
\hline CHEMBL1369358 & 688524 & 5.4 & 5.1191 & TST \\
\hline CHEMBL1329230 & 688524 & 4.5 & 4.9004 & TRN \\
\hline CHEMBL1429633 & 688524 & 4.9 & 4.982 & TRN \\
\hline CHEMBL1567773 & 688524 & 4.8 & 4.8091 & TRN \\
\hline CHEMBL1444124 & 688524 & 5.6 & 4.968 & TRN \\
\hline CHEMBL1334840 & 688524 & 5.1 & 4.9826 & TRN \\
\hline CHEMBL1555859 & 688524 & 5.0 & 5.2994 & TST \\
\hline CHEMBL1534136 & 688524 & 6.9 & 5.2132 & TRN \\
\hline CHEMBL1479249 & 688524 & 4.9 & 5.1414 & TRN \\
\hline CHEMBL1431561 & 688524 & 4.8 & 5.0192 & TRN \\
\hline CHEMBL1536864 & 688524 & 4.9 & 5.0767 & TRN \\
\hline CHEMBL1488204 & 688524 & 5.5 & 5.0861 & TRN \\
\hline CHEMBL1303046 & 688524 & 4.9 & 4.9241 & TRN \\
\hline CHEMBL1314115 & 688524 & 5.0 & 5.145 & TRN \\
\hline CHEMBL1528874 & 688524 & 4.9 & 5.1162 & TRN \\
\hline CHEMBL1359927 & 688524 & 5.0 & 4.9345 & TRN \\
\hline CHEMBL1478614 & 688524 & 5.9 & 5.2797 & TST \\
\hline CHEMBL1316980 & 688524 & 5.4 & 5.5611 & TRN \\
\hline CHEMBL1387465 & 688524 & 4.8 & 4.9394 & TRN \\
\hline CHEMBL1360011 & 688524 & 4.6 & 5.0434 & TRN \\
\hline CHEMBL1312427 & 688524 & 5.0 & 5.0449 & TRN \\
\hline CHEMBL1494650 & 688524 & 4.6 & 4.6836 & TRN \\
\hline CHEMBL1345910 & 688524 & 4.8 & 4.9384 & TRN \\
\hline CHEMBL1478852 & 688524 & 4.6 & 4.9276 & TST \\
\hline CHEMBL1545628 & 688524 & 5.3 & 5.067 & TRN \\
\hline CHEMBL1453291 & 688524 & 5.5 & 5.2503 & TRN \\
\hline CHEMBL1325178 & 688524 & 4.8 & 4.8626 & TRN \\
\hline CHEMBL1362849 & 688524 & 4.5 & 4.8179 & TRN \\
\hline CHEMBL1434022 & 688524 & 4.7 & $5.2020 e$ & 0000000001 \\
\hline CHEMBL1333047 & 688524 & 5.7 & 5.0968 & TRN \\
\hline CHEMBL1526488 & 688524 & 4.9 & 5.0175 & TRN \\
\hline CHEMBL1604836 & 688524 & 5.0 & 5.0105 & TRN \\
\hline CHEMBL2374259 & 688524 & 4.9 & 5.0661 & TST \\
\hline
\end{tabular}

TRN 


\begin{tabular}{|c|c|c|c|c|}
\hline & & & & \\
\hline CHEMBL1528253 & 688524 & 4.8 & 4.9926 & TRN \\
\hline CHEMBL1521739 & 688524 & 5.2 & 5.1136 & TST \\
\hline CHEMBL1587270 & 688524 & 4.9 & 4.9267 & TRN \\
\hline CHEMBL1370448 & 688524 & 4.8 & 4.9001 & TRN \\
\hline CHEMBL 271023 & 688524 & 4.9 & 5.1053 & TST \\
\hline CHEMBL1328156 & 688524 & 4.8 & 5.124 & TRN \\
\hline CHEMBL1406088 & 688524 & 4.9 & 5.1185 & TRN \\
\hline CHEMBL1542533 & 688524 & 4.9 & 4.8537 & TRN \\
\hline CHEMBL407501 & 688524 & 4.9 & 4.9077 & TRN \\
\hline CHEMBL1422751 & 688524 & 5.5 & 4.9867 & TRN \\
\hline CHEMBL935 & 688524 & 6.0 & 5.0877 & TRN \\
\hline CHEMBL1597278 & 688524 & 7.1002 & 4.8503 & TRN \\
\hline CHEMBL1466712 & 688524 & 4.9 & 5.4183 & TRN \\
\hline CHEMBL1571341 & 688524 & 4.8 & 5.3147 & TRN \\
\hline CHEMBL1528170 & 688524 & 5.2 & 5.1555 & TRN \\
\hline CHEMBL1450499 & 688524 & 4.5 & 5.1551 & TRN \\
\hline CHEMBL1517172 & 688524 & 4.9 & 4.8847 & TRN \\
\hline CHEMBL1605879 & 688524 & 5.0 & 4.9487 & TRN \\
\hline CHEMBL1531257 & 688524 & 4.8 & 5.0824 & TRN \\
\hline CHEMBL1548222 & 688524 & 4.5 & 4.9403 & TRN \\
\hline CHEMBL1518154 & 688524 & 6.6 & 5.0284 & TST \\
\hline CHEMBL1568343 & 688524 & 5.0 & 4.9071 & TRN \\
\hline CHEMBL1383846 & 688524 & 4.7 & 5.078 & TRN \\
\hline CHEMBL1449129 & 688524 & 5.0 & 4.94 & TRN \\
\hline CHEMBL1449772 & 688524 & 5.9 & 5.3182 & TRN \\
\hline CHEMBL1363190 & 688524 & 4.5 & 4.9559 & TST \\
\hline CHEMBL1551012 & 688524 & 4.7 & 4.8823 & TRN \\
\hline CHEMBL1527675 & 688524 & 4.9 & 5.0806 & TST \\
\hline CHEMBL1462948 & 688524 & 4.6 & 4.9429 & TRN \\
\hline CHEMBL1588181 & 688524 & 4.5 & 4.9077 & TRN \\
\hline CHEMBL1330229 & 688524 & 5.2 & 4.8547 & TRN \\
\hline CHEMBL1565801 & 688524 & 4.9 & 4.9351 & TRN \\
\hline CHEMBL1419997 & 688524 & 5.0 & 4.9591 & TRN \\
\hline CHEMBL16312 & 688524 & 4.9 & 4.92 & TRN \\
\hline CHEMBL1458629 & 688524 & 5.3 & 5.0654 & TRN \\
\hline CHEMBL1386609 & 688524 & 4.5 & 4.7448 & TRN \\
\hline CHEMBL216504 & 688524 & 4.7 & 5.2823 & TRN \\
\hline CHEMBL1606399 & 688524 & 5.0 & 4.8499 & TRN \\
\hline CHEMBL1395247 & 688524 & 6.1 & 5.0986 & TRN \\
\hline CHEMBL1518205 & 688524 & 4.8 & 4.9519 & TRN \\
\hline CHEMBL1404128 & 688524 & 5.0 & 4.9445 & TRN \\
\hline CHEMBL1394348 & 688524 & 4.8 & 5.2534 & TRN \\
\hline CHEMBL1549188 & 688524 & 4.5 & 4.9137 & TRN \\
\hline CHEMBL1547321 & 688524 & 4.6 & 4.9288 & TRN \\
\hline CHEMBL1976446 & 688524 & 4.5 & 5.0072 & TST \\
\hline CHEMBL1561497 & 688524 & 4.5 & 4.8667 & TRN \\
\hline CHEMBL1412825 & 688524 & 5.1 & 5.0781 & TRN \\
\hline CHEMBL1406859 & 688524 & 4.9 & 4.8709 & TRN \\
\hline
\end{tabular}




\begin{tabular}{|c|c|c|c|c|}
\hline & & & plement & al Table S \\
\hline CHEMBL1491332 & 688524 & 4.5 & 5.2706 & TRN \\
\hline CHEMBL1610968 & 688524 & 5.0 & $4.9860 e$ & 0000000001 \\
\hline CHEMBL1551503 & 688524 & 5.3 & 5.2215 & TRN \\
\hline CHEMBL1360059 & 688524 & 4.5 & 5.0452 & TRN \\
\hline CHEMBL1411635 & 688524 & 4.8 & 4.9802 & TRN \\
\hline CHEMBL1566182 & 688524 & 5.5 & 5.021 & TRN \\
\hline CHEMBL 2374050 & 688524 & 6.0 & 5.2711 & TST \\
\hline CHEMBL1315091 & 688524 & 5.3 & 5.0393 & TRN \\
\hline CHEMBL1407352 & 688524 & 4.8 & 4.9583 & TRN \\
\hline CHEMBL1508817 & 688524 & 4.9 & 4.9221 & TRN \\
\hline CHEMBL1594720 & 688524 & 4.9 & 4.9316 & TRN \\
\hline CHEMBL51085 & 688524 & 6.0 & 5.21 & TST \\
\hline CHEMBL3199093 & 688524 & 4.9 & 5.1869 & TRN \\
\hline CHEMBL1304203 & 688524 & 4.5 & 5.2122 & TRN \\
\hline CHEMBL 1395253 & 688524 & 4.35 & 4.9299 & TST \\
\hline CHEMBL1396142 & 688524 & 4.7 & 5.1258 & TRN \\
\hline CHEMBL1527037 & 688524 & 5.0 & 5.0154 & TRN \\
\hline CHEMBL1347426 & 688524 & 4.7 & 4.9803 & TRN \\
\hline CHEMBL1317415 & 688524 & 5.5 & 5.1373 & TST \\
\hline CHEMBL1255832 & 688524 & 5.3 & 5.1416 & TRN \\
\hline CHEMBL 1551597 & 688524 & 4.45 & 5.0597 & TST \\
\hline CHEMBL1613209 & 688524 & 4.5 & 5.0306 & TRN \\
\hline CHEMBL1604705 & 688524 & 5.0 & 4.9614 & TRN \\
\hline CHEMBL1424280 & 688524 & 4.9 & 5.0131 & TRN \\
\hline CHEMBL 421215 & 688524 & 5.2 & 5.2213 & TRN \\
\hline CHEMBL1306949 & 688524 & 4.9 & 4.8879 & TRN \\
\hline CHEMBL 1480378 & 688524 & 4.9 & 5.0657 & TRN \\
\hline CHEMBL1452131 & 688524 & 4.7 & 5.1268 & TRN \\
\hline CHEMBL1519624 & 688524 & 5.5 & 4.8565 & TRN \\
\hline CHEMBL1302741 & 688524 & 4.5 & 4.8583 & TRN \\
\hline CHEMBL1527008 & 688524 & 5.2 & 4.9881 & TRN \\
\hline CHEMBL1573797 & 688524 & 5.6 & 4.9119 & TRN \\
\hline CHEMBL1347531 & 688524 & 5.0 & 5.0441 & TST \\
\hline CHEMBL1328759 & 688524 & 5.5 & 4.9079 & TRN \\
\hline CHEMBL 38832 & 688524 & 4.9 & 5.0703 & TRN \\
\hline CHEMBL1528699 & 688524 & 4.8 & 5.0989 & TRN \\
\hline CHEMBL1372267 & 688524 & 4.7 & 4.9621 & TRN \\
\hline CHEMBL1340679 & 688524 & 4.9 & 5.078 & TRN \\
\hline CHEMBL1403976 & 688524 & 4.9 & 5.0422 & TST \\
\hline CHEMBL1602353 & 688524 & 4.5 & 5.157 & TRN \\
\hline CHEMBL1608782 & 688524 & 4.9 & 5.0196 & TRN \\
\hline CHEMBL1369023 & 688524 & 4.9 & 5.0535 & TRN \\
\hline CHEMBL1496701 & 688524 & 4.7 & 4.862 & TRN \\
\hline CHEMBL1326434 & 688524 & 5.0 & 4.9355 & TRN \\
\hline CHEMBL1483293 & 688524 & 4.9 & 4.9552 & TRN \\
\hline CHEMBL1452263 & 688524 & 4.9 & 4.9437 & TRN \\
\hline CHEMBL1401453 & 688524 & 4.9 & 5.0002 & TRN \\
\hline CHEMBL1506052 & 688524 & 4.9 & 5.1241 & TRN \\
\hline
\end{tabular}

TRN 


\begin{tabular}{|c|c|c|c|c|c|}
\hline \\
\hline CHEMBL1314291 & 688524 & 6.0 & 5.0594 & TRN & \\
\hline CHEMBL1602943 & 688524 & 4.5 & 5.2125 & TRN & \\
\hline CHEMBL1603287 & 688524 & 4.5 & 4.953 & TRN & \\
\hline CHEMBL1304004 & 688524 & 4.9 & 4.9336 & TRN & \\
\hline CHEMBL1543924 & 688524 & 4.9 & 4.9389 & TRN & \\
\hline CHEMBL1317921 & 688524 & 7.6003 & 5.2464 & TST & \\
\hline CHEMBL1570956 & 688524 & 5.2 & 5.2466 & TRN & \\
\hline CHEMBL1491767 & 688524 & 4.9 & 4.8798 & TRN & \\
\hline CHEMBL1447108 & 688524 & 4.8 & 5.0427 & TRN & \\
\hline CHEMBL1300962 & 688524 & 4.9 & 5.0472 & TST & \\
\hline CHEMBL1537469 & 688524 & 4.6 & 4.8397 & TRN & \\
\hline CHEMBL1379011 & 688524 & 4.9 & 5.2149 & TRN & \\
\hline CHEMBL1306966 & 688524 & 5.0 & 4.9575 & TRN & \\
\hline CHEMBL1339873 & 688524 & 5.5 & 5.0056 & TRN & \\
\hline CHEMBL1541000 & 688524 & 4.9 & 5.1484 & TRN & \\
\hline CHEMBL1346385 & 688524 & 5.8 & 4.8093 & TRN & \\
\hline CHEMBL1393994 & 688524 & 4.7 & 4.8824 & TRN & \\
\hline CHEMBL1587456 & 688524 & 4.5 & 4.9161 & TRN & \\
\hline CHEMBL1446802 & 688524 & 5.2 & 5.1236 & TRN & \\
\hline CHEMBL1428563 & 688524 & 5.8 & 4.9547 & TST & \\
\hline CHEMBL1564777 & 688524 & 4.7 & 4.7659 & TRN & \\
\hline CHEMBL1581801 & 688524 & 5.3 & 5.0367 & TRN & \\
\hline CHEMBL1331247 & 688524 & 6.9 & 5.1949 & TRN & \\
\hline CHEMBL1313315 & 688524 & 5.1 & 5.0597 & TRN & \\
\hline CHEMBL1443923 & 688524 & 6.1 & 5.2076 & TST & \\
\hline CHEMBL539313 & 688524 & 4.7 & 4.9781 & TST & \\
\hline CHEMBL1472989 & 688524 & 4.5 & 5.1251 & TRN & \\
\hline CHEMBL1542047 & 688524 & 4.9 & 4.9886 & TRN & \\
\hline CHEMBL1502260 & 688524 & 4.5 & 4.8358 & TRN & \\
\hline CHEMBL1325877 & 688524 & 4.9 & 4.9486 & TRN & \\
\hline CHEMBL1459318 & 688524 & 4.9 & 5.0051 & TRN & \\
\hline CHEMBL1352943 & 688524 & 4.5 & 5.0914 & TST & \\
\hline CHEMBL1488591 & 688524 & 6.1 & 4.9916 & TST & \\
\hline CHEMBL1359648 & 688524 & 4.9 & 4.8967 & TRN & \\
\hline CHEMBL408653 & 688524 & 5.5 & 5.16200 & 2000000001 & TRN \\
\hline CHEMBL1383401 & 688524 & 4.9 & 5.0864 & TRN & \\
\hline CHEMBL1519387 & 688524 & 5.5 & 4.9554 & TRN & \\
\hline CHEMBL1323978 & 688524 & 5.1 & 4.8192 & TRN & \\
\hline CHEMBL1323768 & 688524 & 4.5 & 5.0479 & TST & \\
\hline CHEMBL1465357 & 688524 & 5.1 & 4.9685 & TRN & \\
\hline CHEMBL1321138 & 688524 & 4.9 & 5.0122 & TRN & \\
\hline CHEMBL1331786 & 688524 & 6.0 & 5.0187 & TST & \\
\hline CHEMBL1439602 & 688524 & 5.1 & 4.9636 & TRN & \\
\hline CHEMBL3199731 & 688524 & 4.85 & 5.0712 & TST & \\
\hline CHEMBL1369384 & 688524 & 4.9 & 5.1846 & TST & \\
\hline CHEMBL1525230 & 688524 & 5.3 & 4.838 & TRN & \\
\hline CHEMBL1374258 & 688524 & 4.6 & 4.8225 & TRN & \\
\hline CHEMBL1558621 & 688524 & 4.7 & 5.1948 & TST & \\
\hline
\end{tabular}




\begin{tabular}{|c|c|c|c|c|}
\hline \multicolumn{5}{|c|}{ Supplemental Table S2.txt } \\
\hline CHEMBL1399252 & 688524 & 5.1 & 5.2357 & TRN \\
\hline CHEMBL1550891 & 688524 & 4.7 & 4.9196 & TRN \\
\hline CHEMBL1546699 & 688524 & 5.3 & 4.9842 & TRN \\
\hline CHEMBL1488251 & 688524 & 5.0 & 5.2365 & TST \\
\hline CHEMBL1583526 & 688524 & 4.8 & 5.1713 & TRN \\
\hline CHEMBL1311349 & 688524 & 5.1 & 4.8551 & TRN \\
\hline CHEMBL1576725 & 688524 & 4.6 & 5.0908 & TRN \\
\hline CHEMBL571700 & 688524 & 5.2 & 5.2349 & TST \\
\hline CHEMBL1374097 & 688524 & 4.8 & 4.8722 & TRN \\
\hline CHEMBL1401202 & 688524 & 6.5 & 5.1798 & TRN \\
\hline CHEMBL1462693 & 688524 & 4.6 & 4.8308 & TRN \\
\hline CHEMBL1477172 & 688524 & 5.0 & 4.9509 & TRN \\
\hline CHEMBL85139 & 688524 & 6.0 & 5.0919 & TRN \\
\hline CHEMBL1594311 & 688524 & 4.5 & 4.9126 & TRN \\
\hline CHEMBL1399516 & 688524 & 4.5 & 5.003 & TRN \\
\hline CHEMBL1401707 & 688524 & 4.9 & 4.8977 & TRN \\
\hline CHEMBL1471717 & 688524 & 5.6 & 5.0578 & TRN \\
\hline CHEMBL1455699 & 688524 & 5.9 & 5.1273 & TRN \\
\hline CHEMBL1385471 & 688524 & 5.0 & 4.9406 & TST \\
\hline CHEMBL1256940 & 688524 & 5.4 & 5.157 & TST \\
\hline CHEMBL1369612 & 688524 & 4.45 & 4.927 & TRN \\
\hline CHEMBL1516388 & 688524 & 4.9 & 5.2269 & TST \\
\hline CHEMBL1440291 & 688524 & 4.8 & 5.1168 & TRN \\
\hline CHEMBL1536252 & 688524 & 4.9 & 5.11 & TST \\
\hline CHEMBL1305404 & 688524 & 4.9 & 4.9283 & TRN \\
\hline CHEMBL1403488 & 688524 & 4.5 & 5.0078 & TRN \\
\hline CHEMBL1345494 & 688524 & 5.1 & 4.8916 & TRN \\
\hline CHEMBL1373308 & 688524 & 5.0 & 4.8568 & TRN \\
\hline CHEMBL1605356 & 688524 & 5.0 & 4.9986 & TST \\
\hline CHEMBL1548142 & 688524 & 4.9 & 4.958 & TST \\
\hline CHEMBL1473317 & 688524 & 4.8 & 5.0742 & TRN \\
\hline CHEMBL1426002 & 688524 & 4.8 & 4.8453 & TRN \\
\hline CHEMBL1492497 & 688524 & 4.5 & 4.9793 & TRN \\
\hline CHEMBL1451023 & 688524 & 5.0 & 4.947 & TRN \\
\hline CHEMBL1421202 & 688524 & 4.8 & 5.0202 & TRN \\
\hline CHEMBL1612406 & 688524 & 5.5 & 5.1025 & TST \\
\hline CHEMBL1587224 & 688524 & 5.0 & 4.8703 & TRN \\
\hline CHEMBL 3199576 & 688524 & 4.7 & 5.1138 & TRN \\
\hline CHEMBL1598587 & 688524 & 4.9 & 5.0044 & TST \\
\hline CHEMBL1350771 & 688524 & 4.9 & 4.9758 & TRN \\
\hline CHEMBL1395275 & 688524 & 5.3 & 5.1864 & TRN \\
\hline CHEMBL1301055 & 688524 & 4.8 & 4.9842 & TRN \\
\hline CHEMBL1338892 & 688524 & 6.6 & 5.0251 & TRN \\
\hline CHEMBL 8165 & 688524 & 5.2 & 4.9739 & TRN \\
\hline CHEMBL23236 & 688524 & 4.7 & 5.2676 & TST \\
\hline CHEMBL580421 & 688524 & 4.8 & 5.1913 & TST \\
\hline CHEMBL1352430 & 688524 & 6.3 & 4.8602 & TRN \\
\hline CHEMBL355496 & 688524 & 4.5 & 5.1014 & TRN \\
\hline
\end{tabular}




\begin{tabular}{|c|c|c|c|c|}
\hline & & & & \\
\hline CHEMBL1453347 & 688524 & 6.9 & 5.0719 & TST \\
\hline CHEMBL1302688 & 688524 & 4.8 & 5.1705 & TRN \\
\hline CHEMBL1569176 & 688524 & 4.7 & 4.8837 & TRN \\
\hline CHEMBL19612 & 688524 & 6.0 & 5.1694 & TST \\
\hline CHEMBL994 & 688524 & 5.1 & 5.0658 & TRN \\
\hline CHEMBL1373061 & 688524 & 5.0 & 5.1786 & TRN \\
\hline CHEMBL512749 & 688524 & 6.0 & 5.0877 & TRN \\
\hline CHEMBL1556777 & 688524 & 5.5 & 5.0833 & TRN \\
\hline CHEMBL117 & 688524 & 6.0 & 5.176 & TRN \\
\hline CHEMBL1403134 & 688524 & 7.699 & 5.3384 & TRN \\
\hline CHEMBL1470485 & 688524 & 6.6 & 5.1277 & TST \\
\hline CHEMBL1508382 & 688524 & 5.7 & 5.0447 & TRN \\
\hline CHEMBL1331514 & 688524 & 5.5 & 4.8917 & TRN \\
\hline CHEMBL1438323 & 688524 & 5.4 & 5.4105 & TRN \\
\hline CHEMBL1480310 & 688524 & 5.3 & 5.0155 & TRN \\
\hline CHEMBL3208365 & 688524 & 5.5 & 4.9654 & TRN \\
\hline CHEMBL1569012 & 688524 & 4.5 & 4.9396 & TRN \\
\hline CHEMBL1581337 & 688524 & 4.6 & 4.8365 & TRN \\
\hline CHEMBL1462538 & 688524 & 5.0 & 4.9215 & TRN \\
\hline CHEMBL88961 & 688524 & 4.8 & 5.0249 & TRN \\
\hline CHEMBL1460356 & 688524 & 4.7 & 4.8284 & TRN \\
\hline CHEMBL1301175 & 688524 & 4.5 & 5.021 & TRN \\
\hline CHEMBL1396230 & 688524 & 4.5 & 5.0875 & TRN \\
\hline CHEMBL1407066 & 688524 & 5.0 & 4.9722 & TRN \\
\hline CHEMBL1496345 & 688524 & 5.7 & 4.8893 & TRN \\
\hline CHEMBL1397552 & 688524 & 4.5 & 5.0541 & TRN \\
\hline CHEMBL1356882 & 688524 & 5.1 & 5.4124 & TRN \\
\hline CHEMBL1449120 & 688524 & 4.5 & 4.9102 & TRN \\
\hline CHEMBL149322 & 688524 & 4.9 & 5.0707 & TRN \\
\hline CHEMBL1424426 & 688524 & 4.7 & 4.9393 & TRN \\
\hline CHEMBL1340268 & 688524 & 5.0 & 4.8662 & TRN \\
\hline CHEMBL1478086 & 688524 & 4.6 & 5.0081 & TRN \\
\hline CHEMBL1369972 & 688524 & 4.9 & 4.8712 & TRN \\
\hline CHEMBL1533452 & 688524 & 4.9 & 5.0698 & TRN \\
\hline CHEMBL1305368 & 688524 & 4.5 & 5.1289 & TRN \\
\hline CHEMBL1510242 & 688524 & 4.9 & 4.8367 & TRN \\
\hline CHEMBL1401763 & 688524 & 4.9 & 5.0021 & TRN \\
\hline CHEMBL1551418 & 688524 & 4.9 & 4.9304 & TRN \\
\hline CHEMBL1424952 & 688524 & 5.3 & 4.93 & TRN \\
\hline CHEMBL1542060 & 688524 & 4.9 & 4.9707 & TRN \\
\hline CHEMBL1566950 & 688524 & 4.6 & 4.8847 & TRN \\
\hline CHEMBL1338826 & 688524 & 5.0 & 5.0452 & TRN \\
\hline CHEMBL1311969 & 688524 & 5.0 & 4.7888 & TRN \\
\hline CHEMBL1572266 & 688524 & 4.8 & 5.0846 & TST \\
\hline CHEMBL1426646 & 688524 & 5.3 & 5.1848 & TRN \\
\hline CHEMBL1408218 & 688524 & 5.0 & 5.018 & TRN \\
\hline CHEMBL1546857 & 688524 & 4.5 & 4.9383 & TRN \\
\hline CHEMBL1566453 & 688524 & 4.5 & 4.9671 & TRN \\
\hline
\end{tabular}




\begin{tabular}{|c|c|c|c|c|c|}
\hline & & & & & \\
\hline CHEMBL1557599 & 688524 & 5.2 & 5.0336 & TRN & \\
\hline CHEMBL1517241 & 688524 & 6.9 & 5.1173 & TRN & \\
\hline CHEMBL584759 & 688524 & 6.0 & 5.1626 & TST & \\
\hline CHEMBL1611208 & 688524 & 4.6 & 5.0896 & TRN & \\
\hline CHEMBL1503016 & 688524 & 4.8 & 4.9877 & TRN & \\
\hline CHEMBL1480147 & 688524 & 4.9 & 4.94300 & 00000000005 & TRN \\
\hline CHEMBL1389728 & 688524 & 4.9 & 4.8539 & TRN & \\
\hline CHEMBL1529777 & 688524 & 5.2 & 4.9852 & TRN & \\
\hline CHEMBL1407035 & 688524 & 5.4 & 5.0771 & TRN & \\
\hline CHEMBL1492825 & 688524 & 5.0 & 4.9536 & TRN & \\
\hline CHEMBL1436075 & 688524 & 5.4 & 4.9477 & TRN & \\
\hline CHEMBL1477878 & 688524 & 4.9 & 4.8867 & TRN & \\
\hline CHEMBL1376975 & 688524 & 4.9 & 4.8657 & TRN & \\
\hline CHEMBL1366017 & 688524 & 4.6 & 5.0211 & TRN & \\
\hline CHEMBL1400336 & 688524 & 4.7 & 5.1127 & TRN & \\
\hline CHEMBL1401682 & 688524 & 5.4 & 5.2515 & TRN & \\
\hline CHEMBL1511557 & 688524 & 4.9 & 4.8389 & TRN & \\
\hline CHEMBL1530272 & 688524 & 4.9 & 5.0395 & TRN & \\
\hline CHEMBL1508182 & 688524 & 5.4 & 5.2695 & TRN & \\
\hline CHEMBL1580050 & 688524 & 4.8 & 4.9616 & TRN & \\
\hline CHEMBL1476051 & 688524 & 5.7 & 5.2383 & TRN & \\
\hline CHEMBL1478448 & 688524 & 4.5 & 5.0271 & TRN & \\
\hline CHEMBL1535017 & 688524 & 5.0 & 5.0912 & TRN & \\
\hline CHEMBL1519838 & 688524 & 4.8 & 5.0221 & TRN & \\
\hline CHEMBL1500739 & 688524 & 4.6 & 5.1558 & TST & \\
\hline CHEMBL1424131 & 688524 & 4.7 & 4.9998 & TRN & \\
\hline CHEMBL1360916 & 688524 & 5.4 & 5.2818 & TST & \\
\hline CHEMBL1316831 & 688524 & 6.2 & 5.1428 & TST & \\
\hline CHEMBL1422386 & 688524 & 5.5 & 5.0997 & TRN & \\
\hline CHEMBL 277120 & 688524 & 4.9 & 5.0644 & TRN & \\
\hline CHEMBL 330320 & 688524 & 7.5003 & 5.1221 & TST & \\
\hline CHEMBL460518 & 688524 & 5.8 & 5.2044 & TRN & \\
\hline CHEMBL1589567 & 688524 & 4.9 & 4.9924 & TRN & \\
\hline CHEMBL1518453 & 688524 & 5.4 & 5.0296 & TRN & \\
\hline CHEMBL1306666 & 688524 & 5.0 & 5.0237 & TRN & \\
\hline CHEMBL1387912 & 688524 & 4.8 & 4.9491 & TRN & \\
\hline CHEMBL1613220 & 688524 & 4.8 & 5.0293 & TST & \\
\hline CHEMBL1506239 & 688524 & 4.6 & 4.9551 & TRN & \\
\hline CHEMBL1407267 & 688524 & 4.5 & 4.8995 & TRN & \\
\hline CHEMBL1389609 & 688524 & 6.9 & 5.0931 & TRN & \\
\hline CHEMBL1321646 & 688524 & 4.5 & 5.0215 & TRN & \\
\hline CHEMBL3197622 & 688524 & 4.9 & 5.2864 & TRN & \\
\hline CHEMBL1504601 & 688524 & 4.6 & 5.176 & TRN & \\
\hline CHEMBL1310372 & 688524 & 4.5 & 4.9808 & TRN & \\
\hline CHEMBL1536547 & 688524 & 4.9 & 4.7493 & TRN & \\
\hline CHEMBL1483253 & 688524 & 4.9 & 5.0427 & TRN & \\
\hline CHEMBL1476199 & 688524 & 5.5 & 5.0507 & TST & \\
\hline CHEMBL1505622 & 688524 & 5.3 & 4.9836 & TRN & \\
\hline & & & & 26254 & \\
\hline
\end{tabular}




\begin{tabular}{|c|c|c|c|c|}
\hline & & & Supplement & \\
\hline CHEMBL1453691 & 688524 & 4.8 & 4.6684 & TRN \\
\hline CHEMBL1373043 & 688524 & 5.5 & 4.9951 & TRN \\
\hline CHEMBL237253 & 688524 & 4.8 & 5.0119 & TRN \\
\hline CHEMBL1610977 & 688524 & 5.3 & 5.0403 & TRN \\
\hline CHEMBL405358 & 688524 & 6.0 & 5.0089 & TST \\
\hline CHEMBL1502184 & 688524 & 4.5 & 5.0153 & TRN \\
\hline CHEMBL1555008 & 688524 & 5.5 & 5.1478 & TRN \\
\hline CHEMBL1484247 & 688524 & 6.8 & 5.1217 & TRN \\
\hline CHEMBL1373587 & 688524 & 5.3 & 5.3848 & TRN \\
\hline CHEMBL1330095 & 688524 & 4.8 & 5.1798 & TRN \\
\hline CHEMBL1607866 & 688524 & 4.5 & 4.8961 & TRN \\
\hline CHEMBL1398581 & 688524 & 4.7 & 5.1296 & TRN \\
\hline CHEMBL 2136498 & 688524 & 5.0 & 5.0215 & TRN \\
\hline CHEMBL1468497 & 688524 & 5.0 & 4.9674 & TRN \\
\hline CHEMBL1392200 & 688524 & 4.9 & 5.0258 & TRN \\
\hline CHEMBL1990300 & 688524 & 5.4 & 5.2676 & TST \\
\hline CHEMBL601578 & 688524 & 5.5 & 4.9633 & TRN \\
\hline CHEMBL1529766 & 688524 & 4.8 & 5.1303 & TRN \\
\hline CHEMBL465843 & 688524 & 6.0 & 5.1531 & TRN \\
\hline CHEMBL1411318 & 688524 & 4.5 & 4.8693 & TRN \\
\hline CHEMBL1349450 & 688524 & 4.6 & 4.9073 & TRN \\
\hline CHEMBL119171 & 688524 & 5.5 & 5.4775 & TRN \\
\hline CHEMBL1439048 & 688524 & 5.0 & 5.2146 & TRN \\
\hline CHEMBL1363905 & 688524 & 4.9 & 4.9934 & TRN \\
\hline CHEMBL1410356 & 688524 & 4.9 & 4.9694 & TRN \\
\hline CHEMBL1525127 & 688524 & 4.9 & 4.8853 & TRN \\
\hline CHEMBL1505338 & 688524 & 5.1 & 5.0272 & TRN \\
\hline CHEMBL73930 & 688524 & 6.0 & 5.0015 & TRN \\
\hline CHEMBL1500106 & 688524 & 5.6 & 4.9458 & TRN \\
\hline CHEMBL1335397 & 688524 & 5.8 & 5.0684 & TRN \\
\hline CHEMBL1432336 & 688524 & 5.0 & 4.9531 & TRN \\
\hline CHEMBL104264 & 688524 & 4.9 & 5.3384 & TST \\
\hline CHEMBL1585402 & 688524 & 4.9 & 5.1788 & TRN \\
\hline CHEMBL1549823 & 688524 & 5.1 & 4.9146 & TRN \\
\hline CHEMBL1485078 & 688524 & 4.9 & 5.0533 & TRN \\
\hline CHEMBL1406161 & 688524 & 4.5 & 4.7746 & TRN \\
\hline CHEMBL1315845 & 688524 & 4.9 & 5.3613 & TRN \\
\hline CHEMBL 277525 & 688524 & 4.6 & 5.0614 & TRN \\
\hline CHEMBL1409985 & 688524 & 5.2 & 5.079 & TRN \\
\hline CHEMBL1490654 & 688524 & 4.5 & 5.1405 & TST \\
\hline CHEMBL1507127 & 688524 & 5.0 & 5.2376 & TRN \\
\hline CHEMBL1517703 & 688524 & 5.5 & 5.0871 & TRN \\
\hline CHEMBL1471476 & 688524 & 4.7 & 4.8803 & TRN \\
\hline CHEMBL1506848 & 688524 & 4.9 & 5.1271 & TST \\
\hline CHEMBL1509104 & 688524 & 5.7 & 4.9164 & TRN \\
\hline CHEMBL1492194 & 688524 & 5.0 & 4.938 & TRN \\
\hline CHEMBL1410147 & 688524 & 5.5 & 5.0686 & TST \\
\hline CHEMBL1386036 & 688524 & 4.9 & 5.2064 & TRN \\
\hline
\end{tabular}




\begin{tabular}{|c|c|c|c|c|}
\hline & & & pplement & at \\
\hline CHEMBL1521215 & 688524 & 5.6 & 4.9043 & TRN \\
\hline CHEMBL1380736 & 688524 & 5.1 & 5.0516 & TST \\
\hline CHEMBL1256869 & 688524 & 4.9 & 4.9823 & TRN \\
\hline CHEMBL1357724 & 688524 & 4.5 & 5.3842 & TRN \\
\hline CHEMBL1328413 & 688524 & 4.9 & 4.8407 & TRN \\
\hline CHEMBL1526223 & 688524 & 5.2 & 4.9832 & TRN \\
\hline CHEMBL1497744 & 688524 & 5.3 & 4.8433 & TRN \\
\hline CHEMBL 3189194 & 688524 & 4.7 & 4.9684 & TRN \\
\hline CHEMBL1555898 & 688524 & 4.9 & 5.0598 & TRN \\
\hline CHEMBL1322828 & 688524 & 4.7 & 4.9268 & TRN \\
\hline CHEMBL1356094 & 688524 & 5.1 & 5.0215 & TST \\
\hline CHEMBL1370456 & 688524 & 4.6 & 5.2034 & TST \\
\hline CHEMBL1600434 & 688524 & 5.0 & 4.8364 & TRN \\
\hline CHEMBL1455387 & 688524 & 4.9 & 5.0308 & TRN \\
\hline CHEMBL581886 & 688524 & 7.5003 & 5.1941 & TST \\
\hline CHEMBL1493388 & 688524 & 5.7 & 4.953 & TST \\
\hline CHEMBL1322922 & 688524 & 5.0 & 4.9702 & TRN \\
\hline CHEMBL1604166 & 688524 & 4.5 & 4.8426 & TRN \\
\hline CHEMBL1491946 & 688524 & 4.8 & 4.9008 & TRN \\
\hline CHEMBL3196498 & 688524 & 4.8 & 5.1654 & TRN \\
\hline CHEMBL1415327 & 688524 & 5.0 & 4.9618 & TST \\
\hline CHEMBL182653 & 688524 & 7.699 & 5.0817 & TRN \\
\hline CHEMBL1613522 & 688524 & 4.5 & 4.809 & TRN \\
\hline CHEMBL1500546 & 688524 & 4.9 & 4.8668 & TRN \\
\hline CHEMBL1378818 & 688524 & 4.5 & 5.0824 & TRN \\
\hline CHEMBL1546809 & 688524 & 4.5 & 4.99 & TRN \\
\hline CHEMBL1483180 & 688524 & 5.0 & 4.9641 & TRN \\
\hline CHEMBL1559404 & 688524 & 5.4 & 5.0238 & TRN \\
\hline CHEMBL1256751 & 688524 & 5.1 & 4.9078 & TST \\
\hline CHEMBL1328694 & 688524 & 4.8 & 4.7995 & TRN \\
\hline CHEMBL1447828 & 688524 & 4.8 & 4.9429 & TRN \\
\hline CHEMBL1595820 & 688524 & 4.9 & 5.044 & TRN \\
\hline CHEMBL1533940 & 688524 & 5.5 & 5.0873 & TRN \\
\hline CHEMBL1541619 & 688524 & 4.8 & 4.8787 & TRN \\
\hline CHEMBL1386396 & 688524 & 4.8 & 5.0984 & TRN \\
\hline CHEMBL1518450 & 688524 & 5.0 & 5.0359 & TRN \\
\hline CHEMBL1530070 & 688524 & 5.0 & 4.9744 & TRN \\
\hline CHEMBL1404810 & 688524 & 7.699 & 4.8764 & TST \\
\hline CHEMBL389162 & 688524 & 4.9 & 5.1243 & TRN \\
\hline CHEMBL1576748 & 688524 & 4.9 & 4.8272 & TRN \\
\hline CHEMBL1501406 & 688524 & 4.9 & 4.7954 & TRN \\
\hline CHEMBL1533068 & 688524 & 4.9 & 4.9873 & TRN \\
\hline CHEMBL1480918 & 688524 & 5.5 & 5.058 & TRN \\
\hline CHEMBL365356 & 688524 & 4.8 & 5.2871 & TRN \\
\hline CHEMBL1312271 & 688524 & 4.8 & 4.9617 & TRN \\
\hline CHEMBL1493117 & 688524 & 4.5 & 5.1774 & TST \\
\hline CHEMBL1355840 & 688524 & 5.5 & 5.4413 & TRN \\
\hline CHEMBL1568086 & 688524 & 7.5003 & 5.1132 & TRN \\
\hline
\end{tabular}




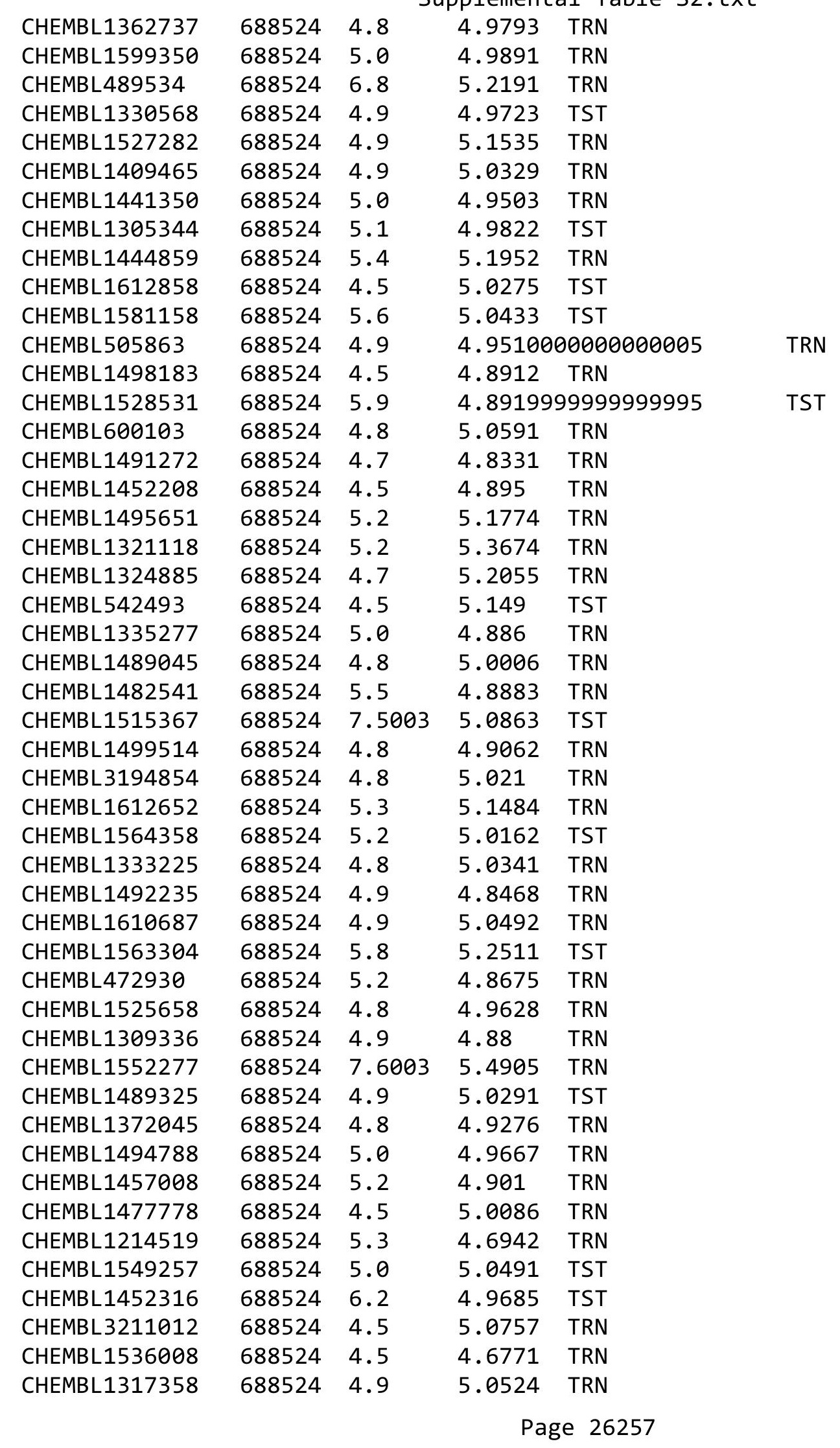




\begin{tabular}{|c|c|c|c|c|}
\hline \multicolumn{5}{|c|}{ lemental T } \\
\hline CHEMBL1313548 & 688524 & 5.5 & 5.3046 & TRN \\
\hline CHEMBL1367111 & 688524 & 5.0 & 5.0531 & TST \\
\hline CHEMBL1446742 & 688524 & 4.4 & 4.8575 & TRN \\
\hline CHEMBL1332169 & 688524 & 4.8 & 5.0631 & TRN \\
\hline CHEMBL1392033 & 688524 & 4.9 & 5.0355 & TST \\
\hline CHEMBL1372850 & 688524 & 5.3 & 5.2088 & TRN \\
\hline CHEMBL1473205 & 688524 & 6.0 & 5.1319 & TRN \\
\hline CHEMBL1386434 & 688524 & 5.0 & 4.769 & TRN \\
\hline CHEMBL1601822 & 688524 & 5.0 & 4.9734 & TRN \\
\hline CHEMBL1500379 & 688524 & 4.5 & 5.0261 & TRN \\
\hline CHEMBL1562961 & 688524 & 4.5 & 4.8723 & TRN \\
\hline CHEMBL3197234 & 688524 & 4.9 & 4.9209 & TRN \\
\hline CHEMBL1479966 & 688524 & 5.4 & 5.0279 & TRN \\
\hline CHEMBL1410766 & 688524 & 4.9 & 5.0085 & TRN \\
\hline CHEMBL1433341 & 688524 & 6.9 & 4.9538 & TRN \\
\hline CHEMBL 3208047 & 688524 & 5.0 & 5.0587 & TRN \\
\hline CHEMBL1541706 & 688524 & 4.5 & 4.9823 & TRN \\
\hline CHEMBL1449933 & 688524 & 4.9 & 5.2325 & TST \\
\hline CHEMBL1568911 & 688524 & 4.8 & 4.9608 & TRN \\
\hline CHEMBL1583174 & 688524 & 4.9 & 4.8516 & TRN \\
\hline CHEMBL1532174 & 688524 & 4.5 & 5.14 & TST \\
\hline CHEMBL1409084 & 688524 & 5.4 & 4.8929 & TRN \\
\hline CHEMBL1595818 & 688524 & 4.8 & 5.0025 & TST \\
\hline CHEMBL1537173 & 688524 & 5.5 & 4.8514 & TRN \\
\hline CHEMBL1541009 & 688524 & 4.9 & 4.9475 & TRN \\
\hline CHEMBL1341712 & 688524 & 4.7 & 4.9016 & TRN \\
\hline CHEMBL1469033 & 688524 & 4.9 & 4.9856 & TRN \\
\hline CHEMBL1404401 & 688524 & 4.7 & 4.9589 & TRN \\
\hline CHEMBL1581228 & 688524 & 4.8 & 5.0402 & TRN \\
\hline CHEMBL1352755 & 688524 & 5.2 & 4.9479 & TST \\
\hline CHEMBL1493328 & 688524 & 5.4 & 4.8832 & TRN \\
\hline CHEMBL1322327 & 688524 & 4.9 & 4.8651 & TRN \\
\hline CHEMBL1603775 & 688524 & 4.7 & 5.0254 & TRN \\
\hline CHEMBL1426455 & 688524 & 4.8 & 4.9842 & TRN \\
\hline CHEMBL1315335 & 688524 & 4.8 & 5.149 & TRN \\
\hline CHEMBL1430319 & 688524 & 4.6 & 5.0686 & TRN \\
\hline CHEMBL1501377 & 688524 & 4.8 & 5.181 & TRN \\
\hline CHEMBL1327059 & 688524 & 4.5 & 5.0892 & TRN \\
\hline CHEMBL1512567 & 688524 & 5.1 & 5.2766 & TRN \\
\hline CHEMBL1603418 & 688524 & 5.3 & 5.3964 & TRN \\
\hline CHEMBL1549879 & 688524 & 4.5 & 4.9627 & TRN \\
\hline CHEMBL1382685 & 688524 & 5.3 & 5.0216 & TST \\
\hline CHEMBL1417306 & 688524 & 7.0 & 5.2803 & TRN \\
\hline CHEMBL1567983 & 688524 & 4.9 & 4.9986 & TRN \\
\hline CHEMBL1591600 & 688524 & 5.8 & 5.3292 & TRN \\
\hline CHEMBL1542724 & 688524 & 7.1002 & 4.9213 & TST \\
\hline CHEMBL1256364 & 688524 & 4.9 & 5.0561 & TRN \\
\hline CHEMBL1255755 & 688524 & 4.9 & 5.1361 & TRN \\
\hline
\end{tabular}




\begin{tabular}{|c|c|c|c|c|c|}
\hline & & & & & \\
\hline CHEMBL1347123 & 688524 & 5.5 & 5.1138 & TRN & \\
\hline CHEMBL1490373 & 688524 & 4.9 & 5.0555 & TRN & \\
\hline CHEMBL1411570 & 688524 & 5.0 & 4.9845 & TRN & \\
\hline CHEMBL546597 & 688524 & 4.9 & 5.2349 & TRN & \\
\hline CHEMBL1585637 & 688524 & 4.7 & 4.7976 & TRN & \\
\hline CHEMBL192627 & 688524 & 4.7 & 5.1267 & TST & \\
\hline CHEMBL1412168 & 688524 & 5.0 & 4.6884 & TRN & \\
\hline CHEMBL1458559 & 688524 & 4.8 & 5.0392 & TRN & \\
\hline CHEMBL 3194664 & 688524 & 4.5 & 4.9264 & TRN & \\
\hline CHEMBL1576300 & 688524 & 4.9 & 5.0901 & TRN & \\
\hline CHEMBL1555354 & 688524 & 4.6 & 5.001 & TST & \\
\hline CHEMBL1443741 & 688524 & 5.3 & 5.088 & TRN & \\
\hline CHEMBL1370512 & 688524 & 4.9 & 4.8163 & TRN & \\
\hline CHEMBL 294009 & 688524 & 4.5 & 5.1413 & TRN & \\
\hline CHEMBL1321900 & 688524 & 5.3 & $5.1960 e$ & 0000000001 & TRN \\
\hline CHEMBL1518080 & 688524 & 4.9 & 5.0492 & TST & \\
\hline CHEMBL1443554 & 688524 & 5.0 & 4.8687 & TRN & \\
\hline CHEMBL1434513 & 688524 & 4.7 & 5.0489 & TST & \\
\hline CHEMBL1455021 & 688524 & 4.9 & 4.9457 & TRN & \\
\hline CHEMBL1407366 & 688524 & 4.5 & 5.1307 & TRN & \\
\hline CHEMBL1570931 & 688524 & 4.9 & 4.9238 & TRN & \\
\hline CHEMBL1585127 & 688524 & 5.1 & 5.0116 & TRN & \\
\hline CHEMBL1419870 & 688524 & 4.9 & 5.0854 & TRN & \\
\hline CHEMBL1471841 & 688524 & 4.7 & 4.9782 & TRN & \\
\hline CHEMBL 273103 & 688524 & 4.5 & 5.0196 & TRN & \\
\hline CHEMBL1556666 & 688524 & 4.5 & 4.6947 & TRN & \\
\hline CHEMBL1610219 & 688524 & 5.9 & 5.1784 & TST & \\
\hline CHEMBL1475472 & 688524 & 4.5 & 5.2774 & TRN & \\
\hline CHEMBL1442927 & 688524 & 4.7 & 5.1405 & TRN & \\
\hline CHEMBL493698 & 688524 & 5.2 & 5.007 & TRN & \\
\hline CHEMBL1365239 & 688524 & 4.9 & 4.8719 & TRN & \\
\hline CHEMBL1342772 & 688524 & 4.8 & 4.8955 & TRN & \\
\hline CHEMBL1512614 & 688524 & 4.7 & 5.01399 & 9999999999 & TRN \\
\hline CHEMBL1586817 & 688524 & 4.7 & 4.9513 & TRN & \\
\hline CHEMBL1481585 & 688524 & 5.5 & 5.0408 & TRN & \\
\hline CHEMBL1568748 & 688524 & 4.9 & 5.1386 & TST & \\
\hline CHEMBL1430700 & 688524 & 4.9 & 4.9774 & TRN & \\
\hline CHEMBL1425704 & 688524 & 4.8 & 4.7666 & TRN & \\
\hline CHEMBL1331875 & 688524 & 4.8 & 5.2382 & TRN & \\
\hline CHEMBL1484097 & 688524 & 4.6 & 5.0239 & TRN & \\
\hline CHEMBL1407962 & 688524 & 6.0 & 5.1513 & TST & \\
\hline CHEMBL 233302 & 688524 & 4.5 & 5.0714 & TRN & \\
\hline CHEMBL1352427 & 688524 & 4.5 & 4.9239 & TRN & \\
\hline CHEMBL1173475 & 688524 & 6.6 & 5.295 & TRN & \\
\hline CHEMBL1588938 & 688524 & 5.3 & 5.1622 & TST & \\
\hline CHEMBL1386457 & 688524 & 4.8 & 4.9844 & TRN & \\
\hline CHEMBL1505658 & 688524 & 4.9 & 4.9255 & TRN & \\
\hline CHEMBL1376740 & 688524 & 4.8 & 4.9223 & TST & \\
\hline & & & & 26259 & \\
\hline
\end{tabular}




\begin{tabular}{|c|c|c|c|c|}
\hline \multicolumn{5}{|c|}{ lemental T } \\
\hline CHEMBL1540310 & 688524 & 4.7 & 4.9094 & TRN \\
\hline CHEMBL1453505 & 688524 & 4.9 & 4.9757 & TRN \\
\hline CHEMBL1541425 & 688524 & 4.9 & 5.0497 & TRN \\
\hline CHEMBL1557823 & 688524 & 4.8 & 4.9143 & TRN \\
\hline CHEMBL1488035 & 688524 & 5.6 & 5.0525 & TRN \\
\hline CHEMBL1352955 & 688524 & 5.2 & 4.7963 & TRN \\
\hline CHEMBL1608788 & 688524 & 4.5 & 5.0598 & TRN \\
\hline CHEMBL1425419 & 688524 & 4.5 & 4.9387 & TRN \\
\hline CHEMBL1458840 & 688524 & 5.3 & 5.0341 & TRN \\
\hline CHEMBL1487762 & 688524 & 4.8 & 5.0815 & TST \\
\hline CHEMBL1407826 & 688524 & 5.1 & 5.0381 & TST \\
\hline CHEMBL1514719 & 688524 & 4.9 & 5.1597 & TRN \\
\hline CHEMBL1401211 & 688524 & 4.6 & 5.0984 & TRN \\
\hline CHEMBL1388457 & 688524 & 4.6 & 5.096 & TST \\
\hline CHEMBL1360816 & 688524 & 4.6 & 4.8472 & TRN \\
\hline CHEMBL1332712 & 688524 & 4.7 & 4.8073 & TRN \\
\hline CHEMBL1409101 & 688524 & 6.9 & 5.0155 & TRN \\
\hline CHEMBL598663 & 688524 & 5.5 & 4.8857 & TRN \\
\hline CHEMBL3196681 & 688524 & 5.6 & 5.1258 & TRN \\
\hline CHEMBL1514639 & 688524 & 4.8 & 4.8848 & TRN \\
\hline CHEMBL1417043 & 688524 & 5.0 & 4.8926 & TRN \\
\hline CHEMBL1488071 & 688524 & 4.8 & 4.8821 & TRN \\
\hline CHEMBL3213759 & 688524 & 5.0 & 5.1629 & TST \\
\hline CHEMBL1331602 & 688524 & 5.5 & 5.0402 & TRN \\
\hline CHEMBL1510117 & 688524 & 5.1 & 4.9923 & TRN \\
\hline CHEMBL1400251 & 688524 & 5.0 & 4.9802 & TRN \\
\hline CHEMBL1330067 & 688524 & 4.5 & 4.8876 & TRN \\
\hline CHEMBL1407257 & 688524 & 4.7 & 5.1811 & TRN \\
\hline CHEMBL1301849 & 688524 & 4.9 & 4.9776 & TRN \\
\hline CHEMBL1584661 & 688524 & 4.9 & 4.9858 & TRN \\
\hline CHEMBL1479700 & 688524 & 4.5 & 4.9643 & TRN \\
\hline CHEMBL1401648 & 688524 & 4.9 & 5.0527 & TRN \\
\hline CHEMBL1531320 & 688524 & 5.8 & 5.0469 & TRN \\
\hline CHEMBL1497370 & 688524 & 4.9 & 4.8628 & TRN \\
\hline CHEMBL1510039 & 688524 & 4.6 & 4.9607 & TRN \\
\hline CHEMBL1509975 & 688524 & 4.6 & 5.0544 & TRN \\
\hline CHEMBL1523920 & 688524 & 4.9 & 5.0614 & TRN \\
\hline CHEMBL294018 & 688524 & 6.5 & 5.1594 & TST \\
\hline CHEMBL1507324 & 688524 & 5.2 & 4.6668 & TRN \\
\hline CHEMBL1598674 & 688524 & 4.9 & 4.9104 & TRN \\
\hline CHEMBL265686 & 688524 & 5.3 & 5.34 & TRN \\
\hline CHEMBL1585854 & 688524 & 4.9 & 5.107 & TRN \\
\hline CHEMBL285480 & 688524 & 4.5 & 5.2598 & TRN \\
\hline CHEMBL1444626 & 688524 & 4.8 & 4.9394 & TRN \\
\hline CHEMBL1553352 & 688524 & 5.5 & 5.3204 & TRN \\
\hline CHEMBL1505683 & 688524 & 4.9 & 4.8708 & TRN \\
\hline CHEMBL1373648 & 688524 & 5.0 & 5.0961 & TRN \\
\hline CHEMBL 3304020 & 688524 & 5.5 & 5.1229 & TST \\
\hline
\end{tabular}




\begin{tabular}{|c|c|c|c|c|c|}
\hline \multicolumn{6}{|c|}{ Supplemental Table S2.txt } \\
\hline CHEMBL1334203 & 688524 & 4.9 & 5.1632 & TRN & \\
\hline CHEMBL 6567 & 688524 & 5.5 & 5.2199 & TST & \\
\hline CHEMBL375126 & 688524 & 5.5 & 5.019 & TST & \\
\hline CHEMBL1468774 & 688524 & 4.9 & 5.0211 & TRN & \\
\hline CHEMBL1450337 & 688524 & 4.9 & 4.8898 & TRN & \\
\hline CHEMBL1563323 & 688524 & 5.0 & 4.9281 & TRN & \\
\hline CHEMBL1321213 & 688524 & 4.5 & 5.0326 & TRN & \\
\hline CHEMBL1447750 & 688524 & 4.8 & 4.8917 & TRN & \\
\hline CHEMBL3198293 & 688524 & 5.3 & 4.9305 & TST & \\
\hline CHEMBL1581943 & 688524 & 5.0 & 4.8718 & TRN & \\
\hline CHEMBL253786 & 688524 & 4.8 & 5.1341 & TRN & \\
\hline CHEMBL1577086 & 688524 & 4.5 & 4.9913 & TRN & \\
\hline CHEMBL1309323 & 688524 & 4.9 & 4.8556 & TRN & \\
\hline CHEMBL1394579 & 688524 & 4.5 & 5.0608 & TRN & \\
\hline CHEMBL308688 & 688524 & 5.3 & 5.0144 & TRN & \\
\hline CHEMBL1367138 & 688524 & 4.9 & 4.806 & TRN & \\
\hline CHEMBL1316562 & 688524 & 4.9 & 5.0678 & TRN & \\
\hline CHEMBL1518405 & 688524 & 4.9 & 4.8063 & TRN & \\
\hline CHEMBL197027 & 688524 & 5.1 & 5.1406 & TST & \\
\hline CHEMBL1400272 & 688524 & 4.5 & 4.9991 & TRN & \\
\hline CHEMBL1607122 & 688524 & 5.0 & 5.041 & TST & \\
\hline CHEMBL310310 & 688524 & 6.0 & 4.8499 & TST & \\
\hline CHEMBL260028 & 688524 & 5.5 & 5.2225 & TRN & \\
\hline CHEMBL3196123 & 688524 & 4.9 & 5.0386 & TST & \\
\hline CHEMBL1481616 & 688524 & 5.5 & 4.9817 & TRN & \\
\hline CHEMBL1514740 & 688524 & 5.5 & $5.2520 e$ & 0000000001 & TRN \\
\hline CHEMBL238188 & 688524 & 4.5 & 5.2719 & TST & \\
\hline CHEMBL3196538 & 688524 & 4.9 & 4.9365 & TRN & \\
\hline CHEMBL1308677 & 688524 & 4.8 & 4.9099 & TRN & \\
\hline CHEMBL1536462 & 688524 & 4.7 & 4.9981 & TRN & \\
\hline CHEMBL1319452 & 688524 & 4.6 & 4.9089 & TRN & \\
\hline CHEMBL1528482 & 688524 & 7.699 & 4.9761 & TST & \\
\hline CHEMBL1524085 & 688524 & 4.6 & 5.0522 & TST & \\
\hline CHEMBL1610040 & 688524 & 4.6 & 4.8583 & TRN & \\
\hline CHEMBL1528876 & 688524 & 5.0 & 5.1215 & TST & \\
\hline CHEMBL1610636 & 688524 & 5.0 & 4.9224 & TRN & \\
\hline CHEMBL1539178 & 688524 & 7.0 & 5.0893 & TRN & \\
\hline CHEMBL1455586 & 688524 & 5.3 & 4.8 & TRN & \\
\hline CHEMBL1402604 & 688524 & 4.6 & 4.8576 & TRN & \\
\hline CHEMBL99203 & 688524 & 5.3 & 5.5579 & TRN & \\
\hline CHEMBL1567472 & 688524 & 5.3 & 5.1367 & TRN & \\
\hline CHEMBL8260 & 688524 & 4.8 & 5.1014 & TRN & \\
\hline CHEMBL1533214 & 688524 & 8.3979 & 5.4303 & TRN & \\
\hline CHEMBL1338747 & 688524 & 4.9 & 5.088 & TST & \\
\hline CHEMBL1378744 & 688524 & 4.5 & 4.7539 & TRN & \\
\hline CHEMBL1456775 & 688524 & 5.2 & 5.0383 & TRN & \\
\hline CHEMBL1526643 & 688524 & 4.9 & 4.9263 & TRN & \\
\hline CHEMBL1521005 & 688524 & 4.7 & 4.9402 & TRN & \\
\hline
\end{tabular}




\begin{tabular}{|c|c|c|c|c|}
\hline & & & ient & al Ta \\
\hline CHEMBL1360082 & 688524 & 5.3 & 4.9788 & TST \\
\hline CHEMBL1442681 & 688524 & 4.9 & 5.0446 & TRN \\
\hline CHEMBL1388079 & 688524 & 4.7 & 4.7376 & TRN \\
\hline CHEMBL1507697 & 688524 & 5.4 & 5.0028 & TRN \\
\hline CHEMBL1531063 & 688524 & 5.1 & 4.955 & TRN \\
\hline CHEMBL1327592 & 688524 & 4.9 & 4.8754 & TRN \\
\hline CHEMBL1529639 & 688524 & 4.8 & 5.0063 & TRN \\
\hline CHEMBL1375660 & 688524 & 4.5 & 4.9033 & TRN \\
\hline CHEMBL1505212 & 688524 & 4.9 & 5.0232 & TRN \\
\hline CHEMBL1440238 & 688524 & 4.5 & 4.7902 & TRN \\
\hline CHEMBL1363540 & 688524 & 4.9 & 4.9826 & TRN \\
\hline CHEMBL1343695 & 688524 & 4.5 & 5.1636 & TST \\
\hline CHEMBL1321297 & 688524 & 5.0 & 4.8158 & TRN \\
\hline CHEMBL1370119 & 688524 & 6.0 & 5.0431 & TRN \\
\hline CHEMBL1535690 & 688524 & 6.9 & 5.0982 & TRN \\
\hline CHEMBL1502892 & 688524 & 5.0 & 5.0549 & TRN \\
\hline CHEMBL428064 & 688524 & 5.2 & 5.1685 & TRN \\
\hline CHEMBL1427979 & 688524 & 4.9 & 5.0166 & TRN \\
\hline CHEMBL1513511 & 688524 & 4.5 & 5.2237 & TRN \\
\hline CHEMBL1405199 & 688524 & 4.5 & 5.1805 & TRN \\
\hline CHEMBL1432348 & 688524 & 5.3 & 5.0509 & TRN \\
\hline CHEMBL1542791 & 688524 & 4.9 & 5.1463 & TRN \\
\hline CHEMBL3192913 & 688524 & 5.0 & 4.984 & TRN \\
\hline CHEMBL1538462 & 688524 & 5.5 & 5.0263 & TRN \\
\hline CHEMBL1531761 & 688524 & 5.5 & 5.0492 & TST \\
\hline CHEMBL1389606 & 688524 & 5.0 & 4.9353 & TRN \\
\hline CHEMBL1327810 & 688524 & 5.7 & 5.0038 & TRN \\
\hline CHEMBL1487466 & 688524 & 4.8 & 4.9185 & TRN \\
\hline CHEMBL1389753 & 688524 & 5.0 & 4.9467 & TRN \\
\hline CHEMBL1577389 & 688524 & 4.9 & 4.8487 & TRN \\
\hline CHEMBL1401519 & 688524 & 5.2 & 5.1997 & TST \\
\hline CHEMBL1517685 & 688524 & 4.7 & 4.9137 & TRN \\
\hline CHEMBL1592568 & 688524 & 4.8 & 5.2274 & TRN \\
\hline CHEMBL1370721 & 688524 & 6.9 & 5.175 & TRN \\
\hline CHEMBL1993627 & 688524 & 5.0 & 5.0673 & TRN \\
\hline CHEMBL1486291 & 688524 & 4.7 & 5.0554 & TRN \\
\hline CHEMBL1438117 & 688524 & 4.6 & 5.1234 & TRN \\
\hline CHEMBL1456417 & 688524 & 4.7 & 5.0459 & TST \\
\hline CHEMBL1321934 & 688524 & 5.4 & 5.1229 & TRN \\
\hline CHEMBL1528446 & 688524 & 5.2 & 5.0867 & TST \\
\hline CHEMBL1532720 & 688524 & 5.7 & 5.0912 & TRN \\
\hline CHEMBL 3192871 & 688524 & 5.2 & 5.1946 & TRN \\
\hline CHEMBL1439172 & 688524 & 5.0 & 5.1774 & TST \\
\hline CHEMBL1435520 & 688524 & 4.5 & 5.1784 & TRN \\
\hline CHEMBL1324524 & 688524 & 4.5 & 4.9305 & TRN \\
\hline CHEMBL1572391 & 688524 & 5.0 & 4.88 & TRN \\
\hline CHEMBL452409 & 688524 & 4.8 & 5.1532 & TRN \\
\hline CHEMBL1431880 & 688524 & 4.9 & 4.9433 & TRN \\
\hline
\end{tabular}




\begin{tabular}{|c|c|c|c|c|}
\hline & & & 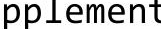 & al Ta \\
\hline CHEMBL1474479 & 688524 & 4.7 & 5.0604 & TRN \\
\hline CHEMBL1346516 & 688524 & 4.6 & 5.0085 & TRN \\
\hline CHEMBL1384293 & 688524 & 4.9 & 4.8568 & TRN \\
\hline CHEMBL1503388 & 688524 & 5.3 & 5.0111 & TRN \\
\hline CHEMBL1590682 & 688524 & 5.0 & 5.0569 & TST \\
\hline CHEMBL1591357 & 688524 & 4.6 & 5.1612 & TST \\
\hline CHEMBL1573063 & 688524 & 5.5 & 5.3941 & TRN \\
\hline CHEMBL1363955 & 688524 & 4.5 & 4.9492 & TRN \\
\hline CHEMBL 200238 & 688524 & 6.0 & 4.9381 & TRN \\
\hline CHEMBL1437285 & 688524 & 5.9 & 5.2264 & TST \\
\hline CHEMBL1333766 & 688524 & 5.4 & 5.056 & TRN \\
\hline CHEMBL1420994 & 688524 & 5.0 & 4.9515 & TRN \\
\hline CHEMBL1432565 & 688524 & 4.9 & 4.899 & TST \\
\hline CHEMBL1561369 & 688524 & 4.5 & 4.9505 & TRN \\
\hline CHEMBL1405692 & 688524 & 5.3 & 4.9412 & TRN \\
\hline CHEMBL1510137 & 688524 & 4.8 & 4.8926 & TRN \\
\hline CHEMBL1478857 & 688524 & 4.9 & 5.0217 & TST \\
\hline CHEMBL153036 & 688524 & 6.0 & 5.0451 & TST \\
\hline CHEMBL1438393 & 688524 & 4.7 & 5.3014 & TST \\
\hline CHEMBL1606939 & 688524 & 5.9 & 5.0068 & TST \\
\hline CHEMBL16098 & 688524 & 5.4 & 5.1755 & TRN \\
\hline CHEMBL1314422 & 688524 & 5.2 & 5.1928 & TRN \\
\hline CHEMBL1309006 & 688524 & 4.9 & 4.8439 & TRN \\
\hline CHEMBL1494491 & 688524 & 5.5 & 4.9984 & TRN \\
\hline CHEMBL1407398 & 688524 & 5.5 & 5.0558 & TRN \\
\hline CHEMBL1346587 & 688524 & 5.1 & 5.0369 & TRN \\
\hline CHEMBL1413787 & 688524 & 5.1 & 4.9967 & TRN \\
\hline CHEMBL1316402 & 688524 & 5.3 & 5.5134 & TRN \\
\hline CHEMBL1341130 & 688524 & 4.7 & 5.1162 & TRN \\
\hline CHEMBL3193472 & 688524 & 4.5 & 5.1037 & TRN \\
\hline CHEMBL1413649 & 688524 & 5.9 & 5.1748 & TST \\
\hline CHEMBL1488946 & 688524 & 5.3 & 5.0687 & TRN \\
\hline CHEMBL1458155 & 688524 & 4.9 & 5.1311 & TRN \\
\hline CHEMBL1589227 & 688524 & 4.8 & 5.0467 & TRN \\
\hline CHEMBL1612277 & 688524 & 5.0 & 4.6232 & TRN \\
\hline CHEMBL295316 & 688524 & 6.0 & 5.1576 & TRN \\
\hline CHEMBL1549476 & 688524 & 4.6 & 4.8772 & TRN \\
\hline CHEMBL 3212690 & 688524 & 4.9 & 4.947 & TST \\
\hline CHEMBL1488813 & 688524 & 4.8 & 5.2293 & TRN \\
\hline CHEMBL1389630 & 688524 & 5.3 & 4.9574 & TRN \\
\hline CHEMBL1528312 & 688524 & 4.9 & 5.2799 & TRN \\
\hline CHEMBL1299689 & 688524 & 5.0 & 5.0498 & TST \\
\hline CHEMBL1558310 & 688524 & 4.9 & 5.1091 & TRN \\
\hline CHEMBL173530 & 688524 & 4.7 & 5.0558 & TST \\
\hline CHEMBL1491745 & 688524 & 5.0 & 5.2276 & TST \\
\hline CHEMBL327919 & 688524 & 4.8 & 4.9495 & TRN \\
\hline CHEMBL1537700 & 688524 & 4.6 & 5.2645 & TRN \\
\hline CHEMBL1353882 & 688524 & 4.9 & 5.0654 & TRN \\
\hline
\end{tabular}




\begin{tabular}{|c|c|c|c|c|c|}
\hline CHEMBL1400517 & 688524 & 5.3 & 4.8541 & TRN & \\
\hline CHEMBL1573634 & 688524 & 4.9 & 5.0355 & TRN & \\
\hline CHEMBL1300493 & 688524 & 5.0 & 5.0883 & TRN & \\
\hline CHEMBL1368067 & 688524 & 4.8 & 4.7949 & TRN & \\
\hline CHEMBL1449755 & 688524 & 6.1 & 4.97 & TST & \\
\hline CHEMBL3211877 & 688524 & 5.0 & 5.1353 & TRN & \\
\hline CHEMBL1488720 & 688524 & 4.7 & \multicolumn{2}{|c|}{4.906000000000001} & TRN \\
\hline CHEMBL1368695 & 688524 & 5.0 & 4.8872 & TRN & \\
\hline CHEMBL1508043 & 688524 & 4.7 & 5.1353 & TRN & \\
\hline CHEMBL1358867 & 688524 & 5.3 & 5.0275 & TRN & \\
\hline CHEMBL1399303 & 688524 & 4.9 & 4.9764 & TRN & \\
\hline CHEMBL1567227 & 688524 & 4.9 & 4.9468 & TRN & \\
\hline CHEMBL1313167 & 688524 & 4.9 & 5.1728 & TRN & \\
\hline CHEMBL1603950 & 688524 & 4.5 & 5.1296 & TRN & \\
\hline CHEMBL1568641 & 688524 & 5.2 & 4.7848 & TST & \\
\hline CHEMBL1357520 & 688524 & 4.5 & 5.0609 & TRN & \\
\hline CHEMBL1386546 & 688524 & 4.9 & 5.0083 & TRN & \\
\hline CHEMBL1366219 & 688524 & 4.9 & 5.0811 & TRN & \\
\hline CHEMBL1449490 & 688524 & 4.6 & 5.0343 & TRN & \\
\hline CHEMBL1423438 & 688524 & 4.9 & 4.9239 & TRN & \\
\hline CHEMBL1522726 & 688524 & 5.0 & 5.1418 & TRN & \\
\hline CHEMBL1390641 & 688524 & 6.0 & 5.0117 & TRN & \\
\hline CHEMBL15845 & 688524 & 5.6 & \multicolumn{2}{|c|}{5.093999999999999} & TRN \\
\hline CHEMBL1489483 & 688524 & 5.0 & 4.9459 & TRN & \\
\hline CHEMBL1457846 & 688524 & 5.2 & 5.0161 & TRN & \\
\hline CHEMBL1341119 & 688524 & 4.8 & 4.9143 & TRN & \\
\hline CHEMBL1368138 & 688524 & 4.5 & 4.9546 & TRN & \\
\hline CHEMBL1309229 & 688524 & 5.0 & 5.0454 & TRN & \\
\hline CHEMBL140220 & 688524 & 5.2 & 5.0113 & TRN & \\
\hline CHEMBL1322746 & 688524 & 4.5 & 5.0113 & TRN & \\
\hline CHEMBL1439989 & 688524 & 4.8 & 5.0994 & TST & \\
\hline CHEMBL1301630 & 688524 & 4.8 & 4.8355 & TRN & \\
\hline CHEMBL1368697 & 688524 & 4.6 & 4.8021 & TRN & \\
\hline CHEMBL1328193 & 688524 & 4.5 & 5.0124 & TST & \\
\hline CHEMBL1322635 & 688524 & 4.9 & 4.8813 & TRN & \\
\hline CHEMBL1541840 & 688524 & 4.7 & 5.0394 & TRN & \\
\hline CHEMBL1358105 & 688524 & 4.9 & 5.0818 & TST & \\
\hline CHEMBL1598791 & 688524 & 5.1 & 5.0297 & TST & \\
\hline CHEMBL1558321 & 688524 & 4.9 & 4.8461 & TRN & \\
\hline CHEMBL43612 & 688524 & 4.6 & 5.1936 & TRN & \\
\hline CHEMBL1537683 & 688524 & 4.6 & 5.079 & TRN & \\
\hline CHEMBL1570093 & 688524 & 4.5 & 4.9479 & TRN & \\
\hline CHEMBL1373244 & 688524 & 5.0 & 4.9272 & TRN & \\
\hline CHEMBL1340328 & 688524 & 4.7 & 5.2082 & TRN & \\
\hline CHEMBL1313301 & 688524 & 4.9 & 5.3009 & TRN & \\
\hline CHEMBL1517045 & 688524 & 4.5 & 4.9172 & TRN & \\
\hline CHEMBL 388676 & 688524 & 5.6 & 5.1567 & TST & \\
\hline CHEMBL1338333 & 688524 & 5.0 & 5.0916 & TRN & \\
\hline
\end{tabular}




\begin{tabular}{|c|c|c|c|c|c|}
\hline \multicolumn{6}{|c|}{ Supplemental Table S2.txt } \\
\hline CHEMBL602409 & 688524 & 4.6 & 4.9873 & TRN & \\
\hline CHEMBL1339508 & 688524 & 5.3 & 4.9465 & TRN & \\
\hline CHEMBL1316222 & 688524 & 4.9 & 5.0433 & TST & \\
\hline CHEMBL1316828 & 688524 & 5.1 & 5.0324 & TST & \\
\hline CHEMBL1414129 & 688524 & 4.6 & 4.945 & TRN & \\
\hline CHEMBL1317931 & 688524 & 4.6 & 5.1667 & TST & \\
\hline CHEMBL1326644 & 688524 & 4.8 & 4.9062 & TRN & \\
\hline CHEMBL1546062 & 688524 & 4.9 & 4.7935 & TRN & \\
\hline CHEMBL1330161 & 688524 & 5.0 & 4.8501 & TST & \\
\hline CHEMBL1331809 & 688524 & 4.9 & 4.9821 & TST & \\
\hline CHEMBL1375672 & 688524 & 5.5 & 5.0172 & TRN & \\
\hline CHEMBL1426968 & 688524 & 4.9 & 4.816 & TRN & \\
\hline CHEMBL1335654 & 688524 & 5.0 & 5.20100 & 00000000005 & TRN \\
\hline CHEMBL1537285 & 688524 & 4.9 & 4.9853 & TRN & \\
\hline CHEMBL1423751 & 688524 & 5.0 & 4.9413 & TRN & \\
\hline CHEMBL1557216 & 688524 & 6.0 & 5.2197 & TRN & \\
\hline CHEMBL1336166 & 688524 & 4.5 & 4.9075 & TRN & \\
\hline CHEMBL1530439 & 688524 & 5.6 & 5.1982 & TRN & \\
\hline CHEMBL1511800 & 688524 & 4.6 & 5.0451 & TRN & \\
\hline CHEMBL1510440 & 688524 & 4.9 & 5.2576 & TRN & \\
\hline CHEMBL1412046 & 688524 & 4.9 & 5.0521 & TRN & \\
\hline CHEMBL1451939 & 688524 & 4.9 & 4.9236 & TRN & \\
\hline CHEMBL1366471 & 688524 & 4.5 & 4.9724 & TRN & \\
\hline CHEMBL1539867 & 688524 & 4.9 & 4.925 & TRN & \\
\hline CHEMBL1560644 & 688524 & 7.8996 & 4.9065 & TRN & \\
\hline CHEMBL1383093 & 688524 & 4.7 & 4.998 & TRN & \\
\hline CHEMBL1355463 & 688524 & 6.0 & 5.4469 & TRN & \\
\hline CHEMBL1507042 & 688524 & 4.9 & 5.0242 & TRN & \\
\hline CHEMBL275311 & 688524 & 4.5 & 5.2054 & TST & \\
\hline CHEMBL1534496 & 688524 & 4.8 & 4.9766 & TRN & \\
\hline CHEMBL1549065 & 688524 & 4.8 & 5.2897 & TRN & \\
\hline CHEMBL 297784 & 688524 & 4.9 & 4.9941 & TRN & \\
\hline CHEMBL1455316 & 688524 & 4.9 & 4.8686 & TRN & \\
\hline CHEMBL1312255 & 688524 & 4.6 & 4.9346 & TRN & \\
\hline CHEMBL1467824 & 688524 & 5.5 & 5.1535 & TST & \\
\hline CHEMBL1318220 & 688524 & 4.5 & 5.1697 & TST & \\
\hline CHEMBL1331733 & 688524 & 6.2 & 5.0464 & TRN & \\
\hline CHEMBL1450603 & 688524 & 4.8 & 4.7287 & TRN & \\
\hline CHEMBL1317178 & 688524 & 4.5 & 5.0953 & TRN & \\
\hline CHEMBL1335523 & 688524 & 4.5 & 5.0053 & TRN & \\
\hline CHEMBL1356780 & 688524 & 4.8 & 5.26200 & 00000000005 & TST \\
\hline CHEMBL1526910 & 688524 & 5.1 & 5.0721 & TRN & \\
\hline CHEMBL464157 & 688524 & 5.3 & 4.9669 & TRN & \\
\hline CHEMBL1548458 & 688524 & 4.9 & 5.0628 & TRN & \\
\hline CHEMBL1573915 & 688524 & 4.9 & 4.9398 & TRN & \\
\hline CHEMBL1452498 & 688524 & 4.9 & 4.9848 & TRN & \\
\hline CHEMBL1490005 & 688524 & 4.9 & 4.9591 & TRN & \\
\hline CHEMBL1544153 & 688524 & 4.5 & 4.9769 & TRN & \\
\hline
\end{tabular}




\begin{tabular}{|c|c|c|c|c|}
\hline & & & ient & al Ta \\
\hline CHEMBL1599168 & 688524 & 5.3 & 4.8229 & TRN \\
\hline CHEMBL1453801 & 688524 & 5.0 & 5.0854 & TRN \\
\hline CHEMBL1481930 & 688524 & 5.0 & 5.0144 & TST \\
\hline CHEMBL1600876 & 688524 & 4.5 & 5.1409 & TRN \\
\hline CHEMBL 70582 & 688524 & 4.6 & 4.987 & TRN \\
\hline CHEMBL1473996 & 688524 & 5.2 & 5.2302 & TRN \\
\hline CHEMBL1582803 & 688524 & 5.2 & 5.004 & TRN \\
\hline CHEMBL1321310 & 688524 & 5.1 & 5.0174 & TRN \\
\hline CHEMBL1424468 & 688524 & 6.6 & 4.9749 & TRN \\
\hline CHEMBL1518120 & 688524 & 4.5 & 5.0858 & TRN \\
\hline CHEMBL1390339 & 688524 & 4.9 & 4.9211 & TRN \\
\hline CHEMBL1590450 & 688524 & 5.0 & 5.0091 & TRN \\
\hline CHEMBL1417994 & 688524 & 4.5 & 4.9428 & TRN \\
\hline CHEMBL1370884 & 688524 & 6.2 & 5.0457 & TRN \\
\hline CHEMBL1509691 & 688524 & 4.8 & 5.0248 & TRN \\
\hline CHEMBL1308850 & 688524 & 4.9 & 4.963 & TST \\
\hline CHEMBL1394002 & 688524 & 4.9 & 4.8544 & TRN \\
\hline CHEMBL1585075 & 688524 & 4.7 & 5.1059 & TRN \\
\hline CHEMBL608699 & 688524 & 4.8 & 5.0701 & TRN \\
\hline CHEMBL1564386 & 688524 & 4.9 & 4.9326 & TRN \\
\hline CHEMBL1557696 & 688524 & 5.3 & 5.0923 & TRN \\
\hline CHEMBL1424024 & 688524 & 4.9 & 5.0868 & TRN \\
\hline CHEMBL1332688 & 688524 & 4.7 & 4.8518 & TRN \\
\hline CHEMBL1200462 & 688524 & 4.8 & 5.0457 & TST \\
\hline CHEMBL1461196 & 688524 & 4.9 & 4.9624 & TRN \\
\hline CHEMBL1580224 & 688524 & 4.7 & 5.0917 & TRN \\
\hline CHEMBL1564728 & 688524 & 4.9 & 4.9626 & TRN \\
\hline CHEMBL303579 & 688524 & 5.2 & 5.1572 & TRN \\
\hline CHEMBL1557658 & 688524 & 4.9 & 5.1332 & TRN \\
\hline CHEMBL1331469 & 688524 & 4.9 & 5.0335 & TRN \\
\hline CHEMBL1314749 & 688524 & 5.3 & 5.2195 & TST \\
\hline CHEMBL1586376 & 688524 & 4.8 & 4.9505 & TRN \\
\hline CHEMBL1371789 & 688524 & 5.0 & 5.0611 & TRN \\
\hline CHEMBL1533634 & 688524 & 5.0 & 4.9446 & TRN \\
\hline CHEMBL 2078862 & 688524 & 5.8 & 5.229 & TST \\
\hline CHEMBL1493165 & 688524 & 5.1 & 5.1931 & TRN \\
\hline CHEMBL1556882 & 688524 & 4.9 & 5.0257 & TRN \\
\hline CHEMBL1451375 & 688524 & 5.0 & 4.9575 & TRN \\
\hline CHEMBL1479264 & 688524 & 5.5 & 5.051 & TRN \\
\hline CHEMBL1402137 & 688524 & 5.2 & 5.0911 & TST \\
\hline CHEMBL1368256 & 688524 & 5.0 & 4.9213 & TRN \\
\hline CHEMBL1366732 & 688524 & 5.4 & 5.1948 & TRN \\
\hline CHEMBL1413451 & 688524 & 7.0 & 5.176 & TST \\
\hline CHEMBL1339466 & 688524 & 5.5 & 4.9987 & TRN \\
\hline CHEMBL1256911 & 688524 & 4.9 & 4.9953 & TST \\
\hline CHEMBL1304955 & 688524 & 4.9 & 5.067 & TRN \\
\hline CHEMBL1404296 & 688524 & 5.5 & 5.0876 & TST \\
\hline CHEMBL1482057 & 688524 & 4.5 & 4.8479 & TRN \\
\hline
\end{tabular}




\begin{tabular}{|c|c|c|c|c|}
\hline \multicolumn{5}{|c|}{ emental T } \\
\hline CHEMBL1413419 & 688524 & 4.9 & 4.9689 & TRN \\
\hline CHEMBL1500474 & 688524 & 4.7 & 5.0132 & TRN \\
\hline CHEMBL1322575 & 688524 & 5.0 & 4.9344 & TRN \\
\hline CHEMBL1484657 & 688524 & 4.8 & 4.9894 & TRN \\
\hline CHEMBL1459095 & 688524 & 4.9 & 5.0556 & TRN \\
\hline CHEMBL1470647 & 688524 & 5.1 & 4.9619 & TRN \\
\hline CHEMBL1547793 & 688524 & 4.9 & 5.23 & TRN \\
\hline CHEMBL473736 & 688524 & 4.5 & 5.0251 & TRN \\
\hline CHEMBL1571784 & 688524 & 4.5 & 4.8518 & TRN \\
\hline CHEMBL1393250 & 688524 & 5.4 & 5.0161 & TRN \\
\hline CHEMBL1449686 & 688524 & 4.5 & 5.2105 & TRN \\
\hline CHEMBL1467999 & 688524 & 4.7 & 4.7437 & TRN \\
\hline CHEMBL1568566 & 688524 & 5.5 & 4.9715 & TRN \\
\hline CHEMBL1343980 & 688524 & 5.2 & 4.9928 & TRN \\
\hline CHEMBL1352174 & 688524 & 5.0 & 5.0346 & TRN \\
\hline CHEMBL1330197 & 688524 & 4.7 & 4.8749 & TRN \\
\hline CHEMBL1354355 & 688524 & 5.4 & 5.0162 & TRN \\
\hline CHEMBL1430893 & 688524 & 4.9 & 5.0358 & TRN \\
\hline CHEMBL1594704 & 688524 & 5.3 & 5.2378 & TRN \\
\hline CHEMBL1496009 & 688524 & 5.0 & 5.0627 & TST \\
\hline CHEMBL1583377 & 688524 & 5.0 & 4.9303 & TRN \\
\hline CHEMBL1358722 & 688524 & 6.0 & 5.2114 & TST \\
\hline CHEMBL1557386 & 688524 & 5.0 & 4.8475 & TRN \\
\hline CHEMBL1486886 & 688524 & 4.7 & 4.9853 & TRN \\
\hline CHEMBL1499393 & 688524 & 4.6 & 4.9248 & TRN \\
\hline CHEMBL1321935 & 688524 & 4.8 & 4.9669 & TRN \\
\hline CHEMBL1334482 & 688524 & 5.7 & 5.2182 & TRN \\
\hline CHEMBL1431252 & 688524 & 4.8 & 5.1159 & TRN \\
\hline CHEMBL1398994 & 688524 & 5.3 & 4.8486 & TRN \\
\hline CHEMBL1380984 & 688524 & 4.9 & 5.0921 & TRN \\
\hline CHEMBL1322195 & 688524 & 5.3 & 4.9624 & TRN \\
\hline CHEMBL1594948 & 688524 & 4.5 & 5.0988 & TST \\
\hline CHEMBL1582439 & 688524 & 5.2 & 4.8774 & TRN \\
\hline CHEMBL1464144 & 688524 & 4.9 & 4.8703 & TRN \\
\hline CHEMBL1328299 & 688524 & 4.9 & 4.7675 & TRN \\
\hline CHEMBL85826 & 688524 & 6.2 & 5.0037 & TRN \\
\hline CHEMBL1504575 & 688524 & 5.3 & 5.1184 & TRN \\
\hline CHEMBL1356652 & 688524 & 5.2 & 5.4521 & TRN \\
\hline CHEMBL1506343 & 688524 & 4.9 & 4.8925 & TRN \\
\hline CHEMBL1606608 & 688524 & 5.0 & 4.8584 & TRN \\
\hline CHEMBL1413555 & 688524 & 4.9 & 4.8242 & TRN \\
\hline CHEMBL1423479 & 688524 & 5.3 & 5.1223 & TST \\
\hline CHEMBL1529392 & 688524 & 4.9 & 4.9057 & TRN \\
\hline CHEMBL1460247 & 688524 & 4.5 & 4.8624 & TRN \\
\hline CHEMBL1409173 & 688524 & 4.9 & 4.9433 & TRN \\
\hline CHEMBL1485204 & 688524 & 4.7 & 5.059 & TST \\
\hline CHEMBL1523560 & 688524 & 5.0 & 5.0266 & TRN \\
\hline CHEMBL1558324 & 688524 & 5.0 & 5.0018 & TRN \\
\hline
\end{tabular}




\begin{tabular}{|c|c|c|c|c|}
\hline & & & & al labıe s \\
\hline CHEMBL1339340 & 688524 & 4.6 & 5.0869 & TRN \\
\hline CHEMBL1546623 & 688524 & 4.8 & 4.8566 & TRN \\
\hline CHEMBL1570559 & 688524 & 5.3 & 5.0021 & TRN \\
\hline CHEMBL1388442 & 688524 & 4.6 & 4.8612 & TRN \\
\hline CHEMBL 74675 & 688524 & 4.7 & 4.9898 & TRN \\
\hline CHEMBL1499489 & 688524 & 5.3 & 4.8538 & TRN \\
\hline CHEMBL1488689 & 688524 & 5.4 & 4.912 & TRN \\
\hline CHEMBL1417665 & 688524 & 5.0 & 4.9248 & TRN \\
\hline CHEMBL1453521 & 688524 & 4.6 & 5.1322 & TRN \\
\hline CHEMBL1362012 & 688524 & 5.3 & 5.0956 & TRN \\
\hline CHEMBL1318259 & 688524 & 4.8 & 5.1369 & TST \\
\hline CHEMBL1449856 & 688524 & 4.8 & 5.3717 & TRN \\
\hline CHEMBL1431620 & 688524 & 4.5 & 4.9795 & TRN \\
\hline CHEMBL1367325 & 688524 & 5.4 & 5.0286 & TRN \\
\hline CHEMBL1487525 & 688524 & 4.9 & 4.997 & TRN \\
\hline CHEMBL1464644 & 688524 & 4.5 & 4.9297 & TRN \\
\hline CHEMBL1575028 & 688524 & 4.9 & 4.9786 & TRN \\
\hline CHEMBL1213771 & 688524 & 4.8 & 4.8086 & TRN \\
\hline CHEMBL1386171 & 688524 & 5.8 & 4.8964 & TRN \\
\hline CHEMBL1382164 & 688524 & 4.9 & 4.9934 & TRN \\
\hline CHEMBL1496758 & 688524 & 4.9 & 5.0829 & TRN \\
\hline CHEMBL1428964 & 688524 & 6.0 & 5.3781 & TST \\
\hline CHEMBL1510394 & 688524 & 4.9 & 4.8402 & TRN \\
\hline CHEMBL1366544 & 688524 & 5.5 & 4.9281 & TRN \\
\hline CHEMBL1350429 & 688524 & 4.5 & 5.2158 & TRN \\
\hline CHEMBL1362630 & 688524 & 5.4 & 5.1079 & TRN \\
\hline CHEMBL1343178 & 688524 & 4.8 & 5.0384 & TRN \\
\hline CHEMBL1348020 & 688524 & 4.7 & 5.046 & TRN \\
\hline CHEMBL1306076 & 688524 & 4.8 & 4.9719 & TRN \\
\hline CHEMBL 259422 & 688524 & 5.5 & 5.1922 & TRN \\
\hline CHEMBL528256 & 688524 & 4.9 & 4.9761 & TRN \\
\hline CHEMBL1538545 & 688524 & 4.8 & 4.9586 & TST \\
\hline CHEMBL1445061 & 688524 & 5.0 & 5.1021 & TST \\
\hline CHEMBL1495008 & 688524 & 4.8 & 4.7914 & TRN \\
\hline CHEMBL1527281 & 688524 & 4.5 & 4.8656 & TRN \\
\hline CHEMBL1531693 & 688524 & 4.8 & 4.7134 & TRN \\
\hline CHEMBL1255656 & 688524 & 5.0 & 5.1163 & TST \\
\hline CHEMBL1406753 & 688524 & 4.5 & 5.0275 & TRN \\
\hline CHEMBL1423913 & 688524 & 4.6 & 4.937 & TRN \\
\hline CHEMBL1554637 & 688524 & 5.3 & 5.1991 & TRN \\
\hline CHEMBL1544460 & 688524 & 4.9 & 5.0586 & TRN \\
\hline CHEMBL276727 & 688524 & 5.2 & 5.1813 & TST \\
\hline CHEMBL1409978 & 688524 & 5.3 & $5.2810 e$ & 0000000001 \\
\hline CHEMBL1570089 & 688524 & 5.1 & 5.2773 & TST \\
\hline CHEMBL1567220 & 688524 & 5.0 & 4.966 & TRN \\
\hline CHEMBL 3199241 & 688524 & 4.9 & 4.8112 & TRN \\
\hline CHEMBL1479061 & 688524 & 4.7 & 4.9334 & TRN \\
\hline CHEMBL1500059 & 688524 & 4.8 & 4.9735 & TST \\
\hline
\end{tabular}




\begin{tabular}{|c|c|c|c|c|}
\hline & & & ient & al Ta \\
\hline CHEMBL179024 & 688524 & 4.9 & 4.9646 & TRN \\
\hline CHEMBL404505 & 688524 & 4.8 & 4.9765 & TRN \\
\hline CHEMBL1449547 & 688524 & 5.3 & 4.9573 & TRN \\
\hline CHEMBL1612655 & 688524 & 5.3 & 4.8526 & TRN \\
\hline CHEMBL1496838 & 688524 & 4.8 & 5.1133 & TRN \\
\hline CHEMBL1391746 & 688524 & 5.0 & 4.8605 & TRN \\
\hline CHEMBL78150 & 688524 & 5.2 & 5.2704 & TRN \\
\hline CHEMBL1571058 & 688524 & 4.9 & 5.1682 & TRN \\
\hline CHEMBL1431130 & 688524 & 5.0 & 5.0204 & TRN \\
\hline CHEMBL1567815 & 688524 & 5.3 & 5.1763 & TRN \\
\hline CHEMBL566933 & 688524 & 4.5 & 4.7834 & TRN \\
\hline CHEMBL1526216 & 688524 & 4.5 & 4.9019 & TRN \\
\hline CHEMBL1584634 & 688524 & 5.5 & 4.8518 & TRN \\
\hline CHEMBL1385176 & 688524 & 4.8 & 4.9304 & TRN \\
\hline CHEMBL1569816 & 688524 & 4.9 & 5.0815 & TRN \\
\hline CHEMBL1439954 & 688524 & 5.0 & 5.0293 & TRN \\
\hline CHEMBL601952 & 688524 & 4.5 & 4.9731 & TRN \\
\hline CHEMBL1346091 & 688524 & 4.8 & 4.9661 & TRN \\
\hline CHEMBL3192857 & 688524 & 5.0 & 5.0823 & TST \\
\hline CHEMBL1391178 & 688524 & 4.9 & 4.9612 & TRN \\
\hline CHEMBL1376079 & 688524 & 4.9 & 4.8549 & TRN \\
\hline CHEMBL399121 & 688524 & 6.0 & 5.0492 & TST \\
\hline CHEMBL1610601 & 688524 & 4.8 & 5.2062 & TRN \\
\hline CHEMBL1561833 & 688524 & 4.9 & 5.0786 & TRN \\
\hline CHEMBL 225196 & 688524 & 4.7 & 4.9189 & TRN \\
\hline CHEMBL1494362 & 688524 & 4.5 & 4.9163 & TRN \\
\hline CHEMBL1546387 & 688524 & 4.5 & 4.955 & TRN \\
\hline CHEMBL1377448 & 688524 & 5.0 & 4.9374 & TRN \\
\hline CHEMBL1718952 & 688524 & 5.4 & 5.0038 & TST \\
\hline CHEMBL1555873 & 688524 & 4.9 & 5.0232 & TRN \\
\hline CHEMBL1350251 & 688524 & 4.8 & 4.9463 & TRN \\
\hline CHEMBL376426 & 688524 & 4.9 & 5.069 & TRN \\
\hline CHEMBL1332882 & 688524 & 4.8 & 4.9949 & TRN \\
\hline CHEMBL1526316 & 688524 & 4.8 & 4.8321 & TRN \\
\hline CHEMBL597744 & 688524 & 5.5 & 5.1035 & TRN \\
\hline CHEMBL1320441 & 688524 & 4.8 & 4.9551 & TRN \\
\hline CHEMBL1545613 & 688524 & 4.8 & 4.8563 & TRN \\
\hline CHEMBL1559418 & 688524 & 5.2 & 5.0126 & TRN \\
\hline CHEMBL1405342 & 688524 & 4.6 & 4.9719 & TRN \\
\hline CHEMBL1509555 & 688524 & 4.9 & 4.9939 & TRN \\
\hline CHEMBL 361845 & 688524 & 5.3 & 5.1039 & TRN \\
\hline CHEMBL75913 & 688524 & 5.0 & 4.9577 & TST \\
\hline CHEMBL1467929 & 688524 & 4.9 & 5.0695 & TRN \\
\hline CHEMBL1964282 & 688524 & 5.3 & 5.0779 & TRN \\
\hline CHEMBL1540503 & 688524 & 4.9 & 4.9731 & TRN \\
\hline CHEMBL1457966 & 688524 & 4.8 & 5.0619 & TST \\
\hline CHEMBL1408982 & 688524 & 4.7 & 4.9639 & TRN \\
\hline CHEMBL1401895 & 688524 & 4.6 & 4.9482 & TRN \\
\hline
\end{tabular}




\begin{tabular}{|c|c|c|c|c|c|}
\hline & & & & & \\
\hline CHEMBL1380975 & 688524 & 4.8 & 4.8592 & TRN & \\
\hline CHEMBL1455689 & 688524 & 4.9 & 5.0724 & TRN & \\
\hline CHEMBL1331768 & 688524 & 4.5 & 4.9385 & TRN & \\
\hline CHEMBL1319083 & 688524 & 4.8 & 5.0107 & TRN & \\
\hline CHEMBL1468652 & 688524 & 4.7 & 4.8503 & TRN & \\
\hline CHEMBL3194135 & 688524 & 4.5 & 5.12700 & 0000000001 & TRN \\
\hline CHEMBL1308000 & 688524 & 4.5 & 5.1407 & TRN & \\
\hline CHEMBL1464103 & 688524 & 4.9 & 4.9543 & TST & \\
\hline CHEMBL1486519 & 688524 & 4.9 & 4.9466 & TRN & \\
\hline CHEMBL1320489 & 688524 & 5.0 & 4.9189 & TRN & \\
\hline CHEMBL1543940 & 688524 & 5.0 & 4.8703 & TST & \\
\hline CHEMBL1545566 & 688524 & 4.8 & 5.0172 & TRN & \\
\hline CHEMBL1393152 & 688524 & 4.7 & 4.8121 & TRN & \\
\hline CHEMBL222556 & 688524 & 4.7 & 5.0774 & TRN & \\
\hline CHEMBL1397636 & 688524 & 5.6 & 5.0941 & TRN & \\
\hline CHEMBL1521232 & 688524 & 4.5 & 4.9709 & TRN & \\
\hline CHEMBL1308592 & 688524 & 5.0 & 4.9826 & TRN & \\
\hline CHEMBL1371413 & 688524 & 7.8013 & 5.05699 & 99999999995 & TRN \\
\hline CHEMBL1594218 & 688524 & 5.0 & 5.0922 & TRN & \\
\hline CHEMBL1305911 & 688524 & 4.5 & 4.8361 & TRN & \\
\hline CHEMBL1444700 & 688524 & 4.9 & 4.732 & TRN & \\
\hline CHEMBL1311290 & 688524 & 4.9 & 5.0077 & TST & \\
\hline CHEMBL260311 & 688524 & 5.4 & 5.2131 & TRN & \\
\hline CHEMBL1504619 & 688524 & 4.7 & 4.9055 & TRN & \\
\hline CHEMBL1429218 & 688524 & 5.8 & 5.0934 & TRN & \\
\hline CHEMBL1405026 & 688524 & 4.6 & 5.2564 & TRN & \\
\hline CHEMBL1466997 & 688524 & 5.5 & 5.0147 & TRN & \\
\hline CHEMBL1368342 & 688524 & 4.9 & 5.1181 & TRN & \\
\hline CHEMBL1305429 & 688524 & 4.7 & 4.9309 & TRN & \\
\hline CHEMBL1574518 & 688524 & 5.2 & 5.055 & TRN & \\
\hline CHEMBL1353378 & 688524 & 4.5 & 4.7489 & TRN & \\
\hline CHEMBL1543167 & 688524 & 4.5 & 5.0971 & TRN & \\
\hline CHEMBL1361655 & 688524 & 5.3 & 5.1109 & TST & \\
\hline CHEMBL1332490 & 688524 & 4.7 & 5.0717 & TST & \\
\hline CHEMBL1424677 & 688524 & 4.9 & 5.0282 & TRN & \\
\hline CHEMBL1560685 & 688524 & 4.9 & 5.1164 & TST & \\
\hline CHEMBL1551729 & 688524 & 6.1 & 5.1684 & TRN & \\
\hline CHEMBL1542587 & 688524 & 5.4 & 5.0612 & TRN & \\
\hline CHEMBL1444812 & 688524 & 5.5 & 4.9576 & TRN & \\
\hline CHEMBL1413391 & 688524 & 4.9 & 4.8138 & TRN & \\
\hline CHEMBL1313565 & 688524 & 5.0 & 4.8661 & TRN & \\
\hline CHEMBL1559014 & 688524 & 5.1 & 4.7394 & TRN & \\
\hline CHEMBL1539053 & 688524 & 4.9 & 4.8212 & TRN & \\
\hline CHEMBL1417543 & 688524 & 5.9 & 5.1262 & TST & \\
\hline CHEMBL1566664 & 688524 & 5.1 & 4.8505 & TRN & \\
\hline CHEMBL1570590 & 688524 & 5.2 & 4.9457 & TRN & \\
\hline CHEMBL1333464 & 688524 & 4.9 & 4.8954 & TRN & \\
\hline CHEMBL1330157 & 688524 & 4.6 & 4.9492 & TRN & \\
\hline & & & & 26270 & \\
\hline
\end{tabular}




\begin{tabular}{|c|c|c|c|c|}
\hline \multicolumn{5}{|c|}{ Supplemental Table S2.txt } \\
\hline CHEMBL1383345 & 688524 & 4.9 & 5.0072 & TRN \\
\hline CHEMBL1256876 & 688524 & 4.9 & 5.0923 & TST \\
\hline CHEMBL1539690 & 688524 & 4.8 & 4.9824 & TST \\
\hline CHEMBL 3198962 & 688524 & 4.9 & 5.1704 & TRN \\
\hline CHEMBL1323781 & 688524 & 5.7 & 5.2589 & TRN \\
\hline CHEMBL1469487 & 688524 & 4.7 & 4.8938 & TST \\
\hline CHEMBL1440703 & 688524 & 4.9 & 5.1054 & TRN \\
\hline CHEMBL1461491 & 688524 & 6.0 & 5.2232 & TST \\
\hline CHEMBL1605454 & 688524 & 5.0 & 5.1627 & TRN \\
\hline CHEMBL1404372 & 688524 & 4.9 & 5.0578 & TRN \\
\hline CHEMBL1475131 & 688524 & 6.9 & 5.2896 & TRN \\
\hline CHEMBL1407150 & 688524 & 5.2 & 5.0308 & TRN \\
\hline CHEMBL1518415 & 688524 & 7.1002 & 5.4384 & TRN \\
\hline CHEMBL1433897 & 688524 & 5.0 & 5.1018 & TST \\
\hline CHEMBL1405815 & 688524 & 5.0 & 4.9091 & TRN \\
\hline CHEMBL1413055 & 688524 & 4.9 & 4.8625 & TRN \\
\hline CHEMBL1391217 & 688524 & 4.9 & 5.0872 & TST \\
\hline CHEMBL1363917 & 688524 & 4.9 & 5.0303 & TRN \\
\hline CHEMBL 3194325 & 688524 & 5.1 & 5.0143 & TRN \\
\hline CHEMBL1594951 & 688524 & 4.9 & 4.8749 & TRN \\
\hline CHEMBL1337912 & 688524 & 4.7 & 4.8927 & TRN \\
\hline CHEMBL1337634 & 688524 & 4.9 & 5.0202 & TRN \\
\hline CHEMBL1349859 & 688524 & 4.9 & 4.9181 & TRN \\
\hline CHEMBL1414263 & 688524 & 4.6 & 4.9681 & TST \\
\hline CHEMBL1513485 & 688524 & 4.5 & 5.0427 & TRN \\
\hline CHEMBL1533037 & 688524 & 5.5 & 4.9791 & TRN \\
\hline CHEMBL1256749 & 688524 & 6.0 & 4.9835 & TST \\
\hline CHEMBL1569079 & 688524 & 4.8 & 5.0144 & TRN \\
\hline CHEMBL 83456 & 688524 & 5.1 & 5.1409 & TRN \\
\hline CHEMBL1424060 & 688524 & 4.8 & 4.952 & TRN \\
\hline CHEMBL1515132 & 688524 & 5.5 & 5.0711 & TST \\
\hline CHEMBL1474701 & 688524 & 4.7 & 5.0943 & TST \\
\hline CHEMBL1314989 & 688524 & 4.5 & 5.3076 & TST \\
\hline CHEMBL 201325 & 688524 & 5.1 & 5.0357 & TRN \\
\hline CHEMBL1597558 & 688524 & 4.8 & 5.1543 & TRN \\
\hline CHEMBL1526028 & 688524 & 4.7 & 5.0438 & TRN \\
\hline CHEMBL1331060 & 688524 & 4.5 & 5.1809 & TRN \\
\hline CHEMBL1372465 & 688524 & 6.0 & 5.0273 & TRN \\
\hline CHEMBL1469084 & 688524 & 5.0 & 5.0384 & TRN \\
\hline CHEMBL1599409 & 688524 & 4.5 & 4.896 & TRN \\
\hline CHEMBL1396203 & 688524 & 4.5 & 5.2332 & TRN \\
\hline CHEMBL1313788 & 688524 & 4.9 & 5.0543 & TRN \\
\hline CHEMBL1357674 & 688524 & 4.7 & 5.045 & TST \\
\hline CHEMBL1495004 & 688524 & 6.3 & 5.2734 & TRN \\
\hline CHEMBL1362984 & 688524 & 4.7 & 4.953 & TRN \\
\hline CHEMBL1440311 & 688524 & 4.9 & 4.7407 & TRN \\
\hline CHEMBL1415784 & 688524 & 4.9 & 4.8426 & TRN \\
\hline CHEMBL1569043 & 688524 & 4.9 & 4.8316 & TRN \\
\hline
\end{tabular}




\begin{tabular}{|c|c|c|c|c|}
\hline & & & & al \\
\hline CHEMBL1478993 & 688524 & 4.9 & 5.0619 & TST \\
\hline CHEMBL1596675 & 688524 & 4.7 & 5.1538 & TST \\
\hline CHEMBL1370238 & 688524 & 5.4 & 5.1996 & TRN \\
\hline CHEMBL1604539 & 688524 & 4.6 & 4.9383 & TRN \\
\hline CHEMBL95606 & 688524 & 6.5 & 5.3334 & TRN \\
\hline CHEMBL1524276 & 688524 & 5.1 & 4.8711 & TRN \\
\hline CHEMBL1380514 & 688524 & 4.9 & 4.9391 & TRN \\
\hline CHEMBL1436488 & 688524 & 5.9 & 5.0617 & TRN \\
\hline CHEMBL1454681 & 688524 & 4.8 & 4.9358 & TRN \\
\hline CHEMBL1403653 & 688524 & 4.5 & 4.9763 & TRN \\
\hline CHEMBL1425916 & 688524 & 6.1 & 4.973 & TRN \\
\hline CHEMBL1368007 & 688524 & 5.0 & 4.8565 & TRN \\
\hline CHEMBL1329707 & 688524 & 5.4 & 5.1141 & TRN \\
\hline CHEMBL1582677 & 688524 & 4.6 & 4.9991 & TRN \\
\hline CHEMBL1461880 & 688524 & 4.6 & 5.1351 & TST \\
\hline CHEMBL1532037 & 688524 & 4.9 & 5.0754 & TRN \\
\hline CHEMBL1338950 & 688524 & 7.0 & 5.4802 & TRN \\
\hline CHEMBL1504540 & 688524 & 4.9 & 4.9425 & TRN \\
\hline CHEMBL1441843 & 688524 & 5.5 & 5.2438 & TRN \\
\hline CHEMBL1540207 & 688524 & 4.9 & 4.9855 & TRN \\
\hline CHEMBL1408900 & 688524 & 5.0 & 4.9761 & TRN \\
\hline CHEMBL1393097 & 688524 & 4.5 & 5.0145 & TST \\
\hline CHEMBL497781 & 688524 & 4.9 & 4.956 & TRN \\
\hline CHEMBL1537477 & 688524 & 5.6 & 4.9613 & TRN \\
\hline CHEMBL1534049 & 688524 & 4.9 & 5.046 & TST \\
\hline CHEMBL1537558 & 688524 & 4.9 & 5.0535 & TRN \\
\hline CHEMBL1303910 & 688524 & 5.3 & 5.0746 & TRN \\
\hline CHEMBL3213381 & 688524 & 4.7 & 4.9366 & TST \\
\hline CHEMBL1305537 & 688524 & 4.9 & 5.0006 & TRN \\
\hline CHEMBL1350624 & 688524 & 4.9 & 5.0021 & TRN \\
\hline CHEMBL1484225 & 688524 & 4.5 & 4.9802 & TRN \\
\hline CHEMBL1521099 & 688524 & 4.5 & 5.1466 & TRN \\
\hline CHEMBL1438451 & 688524 & 4.9 & 4.9743 & TRN \\
\hline CHEMBL1461863 & 688524 & 5.0 & 5.0852 & TRN \\
\hline CHEMBL3208307 & 688524 & 4.8 & 5.0648 & TRN \\
\hline CHEMBL1501051 & 688524 & 4.7 & 4.9888 & TRN \\
\hline CHEMBL1433083 & 688524 & 4.8 & 4.9965 & TST \\
\hline CHEMBL1502783 & 688524 & 4.9 & 5.0025 & TRN \\
\hline CHEMBL1499632 & 688524 & 5.3 & 5.1064 & TRN \\
\hline CHEMBL201221 & 688524 & 5.1 & 4.9457 & TRN \\
\hline CHEMBL16671 & 688524 & 7.2 & 5.221 & TST \\
\hline CHEMBL1404438 & 688524 & 5.0 & 4.9939 & TRN \\
\hline CHEMBL1366916 & 688524 & 4.8 & 4.9134 & TRN \\
\hline CHEMBL1319432 & 688524 & 4.5 & 5.0322 & TST \\
\hline CHEMBL1309434 & 688524 & 5.5 & 4.9303 & TRN \\
\hline CHEMBL513116 & 688524 & 4.8 & 5.1862 & TST \\
\hline CHEMBL1309690 & 688524 & 4.9 & 4.872 & TRN \\
\hline CHEMBL140979 & 688524 & 5.45 & 5.0098 & TRN \\
\hline
\end{tabular}




\begin{tabular}{|c|c|c|c|c|c|}
\hline \multicolumn{6}{|c|}{ Supplemental Table S2.txt } \\
\hline CHEMBL1304631 & 688524 & 4.8 & 4.6725 & TRN & \\
\hline CHEMBL1362234 & 688524 & 4.6 & 4.8621 & TRN & \\
\hline CHEMBL1500401 & 688524 & 6.9 & 5.1126 & TRN & \\
\hline CHEMBL1574805 & 688524 & 5.5 & 4.6941 & TRN & \\
\hline CHEMBL1463366 & 688524 & 5.0 & 4.9937 & TRN & \\
\hline CHEMBL3209674 & 688524 & 4.8 & 4.8038 & TRN & \\
\hline CHEMBL1341789 & 688524 & 5.2 & 5.1196 & TST & \\
\hline CHEMBL1540272 & 688524 & 4.9 & 4.8389 & TRN & \\
\hline CHEMBL1472108 & 688524 & 4.5 & 5.0 & TRN & \\
\hline CHEMBL1400667 & 688524 & 4.5 & 5.1147 & TST & \\
\hline CHEMBL1404255 & 688524 & 4.7 & 5.0251 & TST & \\
\hline CHEMBL1410454 & 688524 & 5.1 & 5.0717 & TRN & \\
\hline CHEMBL1304856 & 688524 & 4.7 & 4.9969 & TRN & \\
\hline CHEMBL1324690 & 688524 & 5.3 & 4.9909 & TRN & \\
\hline CHEMBL596674 & 688524 & 5.1 & 5.1153 & TRN & \\
\hline CHEMBL1441771 & 688524 & 4.9 & 4.9597 & TRN & \\
\hline CHEMBL1490377 & 688524 & 4.6 & 5.072 & TRN & \\
\hline CHEMBL1384956 & 688524 & 5.3 & 4.9544 & TRN & \\
\hline CHEMBL1431829 & 688524 & 4.9 & 4.9735 & TRN & \\
\hline CHEMBL1606751 & 688524 & 4.5 & 5.1651 & TRN & \\
\hline CHEMBL1479246 & 688524 & 5.4 & 5.2803 & TRN & \\
\hline CHEMBL1382363 & 688524 & 5.3 & 4.9577 & TRN & \\
\hline CHEMBL1466662 & 688524 & 5.0 & 4.9606 & TRN & \\
\hline CHEMBL1419668 & 688524 & 7.8996 & 5.1063 & TST & \\
\hline CHEMBL1607497 & 688524 & 4.8 & 5.0322 & TRN & \\
\hline CHEMBL1307890 & 688524 & 5.0 & 4.9812 & TRN & \\
\hline CHEMBL1373876 & 688524 & 4.5 & 5.0967 & TRN & \\
\hline CHEMBL1341087 & 688524 & 5.5 & 4.9843 & TRN & \\
\hline CHEMBL472931 & 688524 & 5.2 & 5.0022 & TRN & \\
\hline CHEMBL1407127 & 688524 & 4.25 & $4.9830 e$ & 00000000005 & TRN \\
\hline CHEMBL1475255 & 688524 & 5.0 & 5.2885 & TRN & \\
\hline CHEMBL481577 & 688524 & 4.5 & 4.9245 & TRN & \\
\hline CHEMBL1350956 & 688524 & 5.8 & 4.8928 & TRN & \\
\hline CHEMBL3212499 & 688524 & 4.5 & 5.067 & TST & \\
\hline CHEMBL1533175 & 688524 & 4.9 & 4.9903 & TRN & \\
\hline CHEMBL1373092 & 688524 & 4.8 & 5.1577 & TRN & \\
\hline CHEMBL1311783 & 688524 & 4.6 & 4.854 & TRN & \\
\hline CHEMBL1605700 & 688524 & 4.8 & 5.1874 & TST & \\
\hline CHEMBL1553136 & 688524 & 5.3 & 5.0205 & TRN & \\
\hline CHEMBL1493362 & 688524 & 4.9 & 5.1455 & TRN & \\
\hline CHEMBL1560213 & 688524 & 5.0 & 5.1435 & TRN & \\
\hline CHEMBL1410792 & 688524 & 5.1 & 4.8933 & TRN & \\
\hline CHEMBL1570765 & 688524 & 5.8 & 5.279 & TRN & \\
\hline CHEMBL1492178 & 688524 & 4.9 & 4.9789 & TRN & \\
\hline CHEMBL1326914 & 688524 & 4.9 & 4.958 & TRN & \\
\hline CHEMBL1445057 & 688524 & 5.9 & 5.1586 & TST & \\
\hline CHEMBL1372514 & 688524 & 5.4 & 4.9401 & TRN & \\
\hline CHEMBL1387610 & 688524 & 6.0 & 5.2971 & TRN & \\
\hline
\end{tabular}




CHEMBL1504634
CHEMBL1393060
CHEMBL1407918
CHEMBL1452098
CHEMBL1329878
CHEMBL1427447
CHEMBL1567097
CHEMBL1533288
CHEMBL1472532
CHEMBL26915
CHEMBL1325690
CHEMBL1549430
CHEMBL1333653
CHEMBL1312708
CHEMBL1424065
CHEMBL1428417
CHEMBL1369297
CHEMBL1437158
CHEMBL1566838
CHEMBL1341784
CHEMBL1483677
CHEMBL1482872
CHEMBL1424675
CHEMBL1398185
CHEMBL1505809
CHEMBL1440188
CHEMBL1610972
CHEMBL1588219
CHEMBL1333823
CHEMBL1448488
CHEMBL232202
CHEMBL1415516
CHEMBL1504346
CHEMBL845
CHEMBL1494345
CHEMBL1390889
CHEMBL1366133
CHEMBL14925
CHEMBL1426905
CHEMBL1511024
CHEMBL1605520
CHEMBL1516265
CHEMBL1429640
CHEMBL1325260
CHE

$\begin{array}{llll} & & \text { Supplemental Table S2.txt } \\ 688524 & 5.0 & 4.8971 & \text { TRN } \\ 688524 & 4.8 & 4.9356 & \text { TST } \\ 688524 & 4.9 & 4.9504 & \text { TRN } \\ 688524 & 5.3 & 5.1824 & \text { TRN } \\ 688524 & 5.0 & 4.8673 & \text { TRN } \\ 688524 & 4.5 & 4.8565 & \text { TST } \\ 688524 & 5.2 & 5.0583 & \text { TRN } \\ 688524 & 4.9 & 5.0014 & \text { TST } \\ 688524 & 4.9 & 4.9805 & \text { TRN } \\ 688524 & 5.2 & 4.8901 & \text { TST } \\ 688524 & 5.4 & 5.0116 & \text { TRN } \\ 688524 & 5.1 & 4.9172 & \text { TRN } \\ 688524 & 4.5 & 5.0481 & \text { TRN } \\ 688524 & 4.7 & 4.9208 & \text { TRN } \\ 688524 & 5.1 & 4.9913 & \text { TRN } \\ 688524 & 4.7 & 4.9427 & \text { TRN } \\ 688524 & 4.6 & 5.1391 & \text { TST } \\ 688524 & 6.4 & 5.101 & \text { TRN } \\ 688524 & 5.2 & 5.0676 & \text { TRN } \\ 688524 & 4.7 & 4.9034 & \text { TRN } \\ 688524 & 5.5 & 5.0478 & \text { TRN } \\ 688524 & 4.7 & 4.8722 & \text { TRN } \\ 688524 & 4.8 & 5.0571 & \text { TRN } \\ 688524 & 4.7 & 5.079 & \text { TRN } \\ 688524 & 5.0 & 4.9832 & \text { TRN } \\ 688524 & 5.0 & 5.0275 & \text { TRN } \\ 688524 & 4.8 & 5.1457 & \text { TST } \\ 688524 & 4.8 & 4.822 & \text { TRN } \\ 688524 & 6.1 & 5.0541 & \text { TST } \\ 688524 & 5.9 & 5.1366 & \text { TRN } \\ 688524 & 4.7 & 5.3007 & \text { TRN } \\ 688524 & 4.9 & 4.8152 & \text { TRN } \\ 688524 & 5.3 & 5.2138 & \text { TRN } \\ 688524 & 4.9 & 4.9202 & \text { TRN } \\ 688524 & 4.9 & 4.9977 & \text { TRN } \\ 688524 & 4.5 & 4.9407 & \text { TRN } \\ 688524 & 5.0 & 4.9043 & \text { TRN } \\ 688524 & 4.9 & 4.9552 & \text { TRN } \\ 688524 & 5.0 & 4.8779 & \text { TRN } \\ 688524 & 4.7 & 4.696000000000001 \\ 688524 & 4.6 & 5.0983 & \text { TRN } \\ 688524 & 5.5 & 4.9609 & \text { TRN } \\ 688524 & 4.7 & 5.0103 & \text { TRN } \\ 688524 & 5.5 & 5.1486 & \text { TRN } \\ 688524 & 5.1 & 4.8255 & \text { TRN } \\ 688524 & 4.9 & 4.9155 & \text { TRN } \\ 688524 & 4.9 & 4.8646 & \text { TRN } \\ 688524 & 7.3002 & 5.2691 & \text { TRN }\end{array}$




\begin{tabular}{|c|c|c|c|c|c|}
\hline \multicolumn{6}{|c|}{ Supplemental Table S2.txt } \\
\hline CHEMBL1425330 & 688524 & 4.8 & 4.8838 & TRN & \\
\hline CHEMBL1445691 & 688524 & 5.3 & 5.0691 & TST & \\
\hline CHEMBL1346656 & 688524 & 4.5 & 4.8378 & TRN & \\
\hline CHEMBL1318810 & 688524 & 4.6 & 5.1041 & TST & \\
\hline CHEMBL1335413 & 688524 & 4.7 & 4.7758 & TRN & \\
\hline CHEMBL1541834 & 688524 & 4.9 & 5.1605 & TRN & \\
\hline CHEMBL1329798 & 688524 & 5.7 & 5.432 & TRN & \\
\hline CHEMBL1544968 & 688524 & 4.5 & 5.1473 & TRN & \\
\hline CHEMBL1353747 & 688524 & 4.7 & 5.0318 & TRN & \\
\hline CHEMBL1374182 & 688524 & 5.9 & 4.8377 & TRN & \\
\hline CHEMBL1308733 & 688524 & 4.5 & 4.9324 & TRN & \\
\hline CHEMBL1492801 & 688524 & 6.2 & 5.148 & TRN & \\
\hline CHEMBL1369217 & 688524 & 4.9 & 5.0387 & TRN & \\
\hline CHEMBL 3189853 & 688524 & 4.9 & 4.9608 & TRN & \\
\hline CHEMBL1514272 & 688524 & 7.5003 & 5.3897 & TRN & \\
\hline CHEMBL1434460 & 688524 & 4.8 & 5.2316 & TRN & \\
\hline CHEMBL1438761 & 688524 & 4.9 & 4.8807 & TRN & \\
\hline CHEMBL1450863 & 688524 & 4.9 & 5.0241 & TST & \\
\hline CHEMBL1568575 & 688524 & 5.4 & 5.2609 & TRN & \\
\hline CHEMBL1348405 & 688524 & 4.5 & 4.9902 & TRN & \\
\hline CHEMBL1576107 & 688524 & 4.7 & 4.7772 & TRN & \\
\hline CHEMBL1605290 & 688524 & 8.0 & 4.9814 & TRN & \\
\hline CHEMBL1515354 & 688524 & 5.9 & 5.1324 & TST & \\
\hline CHEMBL1321135 & 688524 & 4.9 & 4.9764 & TRN & \\
\hline CHEMBL1331047 & 688524 & 4.9 & 5.0845 & TRN & \\
\hline CHEMBL1370437 & 688524 & 5.0 & 5.11100 & 0000000001 & TRN \\
\hline CHEMBL340807 & 688524 & 5.8 & 4.9844 & TRN & \\
\hline CHEMBL1389037 & 688524 & 4.9 & 4.8569 & TRN & \\
\hline CHEMBL1409828 & 688524 & 5.4 & 4.8717 & TRN & \\
\hline CHEMBL1426379 & 688524 & 4.9 & 4.891 & TRN & \\
\hline CHEMBL1359715 & 688524 & 4.9 & 4.9474 & TRN & \\
\hline CHEMBL536950 & 688524 & 5.0 & 4.9803 & TST & \\
\hline CHEMBL1604106 & 688524 & 5.1 & 4.9614 & TST & \\
\hline CHEMBL1580372 & 688524 & 4.5 & 4.9005 & TRN & \\
\hline CHEMBL1404704 & 688524 & 4.8 & 4.9188 & TRN & \\
\hline CHEMBL1411785 & 688524 & 5.3 & 4.9628 & TRN & \\
\hline CHEMBL1466083 & 688524 & 5.0 & 5.1295 & TRN & \\
\hline CHEMBL1363731 & 688524 & 4.8 & 4.9137 & TRN & \\
\hline CHEMBL1364378 & 688524 & 4.6 & 5.0915 & TRN & \\
\hline CHEMBL1561385 & 688524 & 5.0 & 5.0509 & TRN & \\
\hline CHEMBL1339504 & 688524 & 4.5 & 4.8682 & TRN & \\
\hline CHEMBL1257080 & 688524 & 4.9 & 5.1562 & TST & \\
\hline CHEMBL1439347 & 688524 & 4.8 & 5.1227 & TRN & \\
\hline CHEMBL1536129 & 688524 & 4.8 & 4.9183 & TRN & \\
\hline CHEMBL1432507 & 688524 & 6.4 & 5.1561 & TRN & \\
\hline CHEMBL1501554 & 688524 & 4.5 & 4.9107 & TRN & \\
\hline CHEMBL3214595 & 688524 & 5.0 & 4.9536 & TRN & \\
\hline CHEMBL 277127 & 688524 & 4.8 & 5.1837 & TRN & \\
\hline
\end{tabular}




\begin{tabular}{|c|c|c|c|c|}
\hline \multicolumn{5}{|c|}{ Supplemental T } \\
\hline CHEMBL1501825 & 688524 & 4.8 & 4.9162 & TRN \\
\hline CHEMBL1430804 & 688524 & 4.9 & 4.8919 & TRN \\
\hline CHEMBL1462286 & 688524 & 4.9 & 4.9676 & TRN \\
\hline CHEMBL1370010 & 688524 & 5.0 & 4.9735 & TRN \\
\hline CHEMBL1324042 & 688524 & 4.8 & 5.0193 & TRN \\
\hline CHEMBL1489232 & 688524 & 4.9 & 5.0837 & TRN \\
\hline CHEMBL1571545 & 688524 & 4.9 & 5.0688 & TRN \\
\hline CHEMBL1360942 & 688524 & 5.9 & 5.3921 & TRN \\
\hline CHEMBL1539423 & 688524 & 4.5 & 4.9132 & TRN \\
\hline CHEMBL1573013 & 688524 & 4.5 & 4.8157 & TRN \\
\hline CHEMBL1522803 & 688524 & 4.7 & 5.1484 & TRN \\
\hline CHEMBL1499631 & 688524 & 4.9 & 4.9483 & TRN \\
\hline CHEMBL1591934 & 688524 & 6.1 & 5.1026 & TST \\
\hline CHEMBL1346410 & 688524 & 5.2 & 5.1139 & TRN \\
\hline CHEMBL1391039 & 688524 & 5.3 & 5.0284 & TRN \\
\hline CHEMBL1596499 & 688524 & 4.9 & 5.3035 & TRN \\
\hline CHEMBL1367402 & 688524 & 4.5 & 5.0127 & TRN \\
\hline CHEMBL1573957 & 688524 & 5.1 & 5.046 & TST \\
\hline CHEMBL1497405 & 688524 & 4.8 & 5.1727 & TRN \\
\hline CHEMBL1527859 & 688524 & 4.9 & 4.9272 & TRN \\
\hline CHEMBL1592110 & 688524 & 5.2 & 4.9162 & TRN \\
\hline CHEMBL1558273 & 688524 & 4.9 & 5.03 & TRN \\
\hline CHEMBL1307312 & 688524 & 4.9 & 4.7496 & TRN \\
\hline CHEMBL1454920 & 688524 & 5.5 & 5.3 & TRN \\
\hline CHEMBL444376 & 688524 & 5.5 & 5.2513 & TRN \\
\hline CHEMBL 3208847 & 688524 & 5.7 & 5.085 & TRN \\
\hline CHEMBL1425746 & 688524 & 4.5 & 4.8958 & TRN \\
\hline CHEMBL1352879 & 688524 & 4.7 & 4.9836 & TRN \\
\hline CHEMBL1606727 & 688524 & 4.5 & 5.3998 & TRN \\
\hline CHEMBL1406851 & 688524 & 5.5 & 5.4038 & TRN \\
\hline CHEMBL1439371 & 688524 & 4.7 & 4.8558 & TRN \\
\hline CHEMBL3209178 & 688524 & 4.5 & 5.0329 & TST \\
\hline CHEMBL1312100 & 688524 & 4.9 & 4.9702 & TRN \\
\hline CHEMBL1451492 & 688524 & 4.5 & 4.9581 & TRN \\
\hline CHEMBL1490334 & 688524 & 5.1 & 4.7455 & TRN \\
\hline CHEMBL329872 & 688524 & 5.0 & 4.8405 & TRN \\
\hline CHEMBL1613688 & 688524 & 7.7496 & 5.2275 & TST \\
\hline CHEMBL1529779 & 688524 & 4.6 & 5.2339 & TRN \\
\hline CHEMBL1373256 & 688524 & 5.0 & 4.7497 & TRN \\
\hline CHEMBL 2094573 & 688524 & 4.5 & 5.0172 & TRN \\
\hline CHEMBL 210298 & 688524 & 4.5 & 4.8476 & TRN \\
\hline CHEMBL1603268 & 688524 & 4.9 & 4.9285 & TRN \\
\hline CHEMBL1388722 & 688524 & 4.35 & 5.0952 & TRN \\
\hline CHEMBL1405230 & 688524 & 4.9 & 5.1848 & TST \\
\hline CHEMBL1431659 & 688524 & 4.9 & 4.8326 & TRN \\
\hline CHEMBL1608718 & 688524 & 4.9 & 5.0428 & TRN \\
\hline CHEMBL1370293 & 688524 & 4.9 & 5.1225 & TST \\
\hline CHEMBL1603890 & 688524 & 4.9 & 5.1033 & TST \\
\hline
\end{tabular}




\begin{tabular}{|c|c|c|c|c|c|}
\hline \\
\hline CHEMBL1483329 & 688524 & 4.5 & 4.9033 & TRN & \\
\hline CHEMBL1564004 & 688524 & 5.0 & 4.9391 & TRN & \\
\hline CHEMBL1495233 & 688524 & 7.0 & 5.0188 & TRN & \\
\hline CHEMBL1564375 & 688524 & 4.9 & 4.8882 & TRN & \\
\hline CHEMBL252744 & 688524 & 4.8 & 5.023 & TST & \\
\hline CHEMBL1389878 & 688524 & 4.6 & 5.0497 & TST & \\
\hline CHEMBL1601711 & 688524 & 4.8 & 4.8323 & TRN & \\
\hline CHEMBL1499996 & 688524 & 5.0 & 4.9088 & TRN & \\
\hline CHEMBL1305681 & 688524 & 5.2 & 5.0053 & TRN & \\
\hline CHEMBL138921 & 688524 & 5.2 & 5.0708 & TRN & \\
\hline CHEMBL1416951 & 688524 & 4.9 & 4.9041 & TRN & \\
\hline CHEMBL472929 & 688524 & 5.0 & 4.8528 & TRN & \\
\hline CHEMBL1382167 & 688524 & 4.9 & 4.8777 & TRN & \\
\hline CHEMBL1588503 & 688524 & 5.1 & 4.8386 & TRN & \\
\hline CHEMBL1352614 & 688524 & 5.5 & 5.147 & TRN & \\
\hline CHEMBL1363622 & 688524 & 4.5 & 5.1035 & TRN & \\
\hline CHEMBL1413671 & 688524 & 4.9 & 4.9308 & TRN & \\
\hline CHEMBL1301117 & 688524 & 4.5 & 4.9141 & TST & \\
\hline CHEMBL1329715 & 688524 & 4.5 & 5.1023 & TRN & \\
\hline CHEMBL1503644 & 688524 & 4.9 & 4.9872 & TRN & \\
\hline CHEMBL1484990 & 688524 & 4.5 & 4.9547 & TRN & \\
\hline CHEMBL1603776 & 688524 & 5.6 & 4.9431 & TRN & \\
\hline CHEMBL1349788 & 688524 & 4.5 & 5.0384 & TRN & \\
\hline CHEMBL1393266 & 688524 & 4.9 & 4.8843 & TRN & \\
\hline CHEMBL1432760 & 688524 & 4.9 & 4.837 & TRN & \\
\hline CHEMBL1328894 & 688524 & 5.0 & 5.0361 & TRN & \\
\hline CHEMBL1385790 & 688524 & 5.3 & 4.8901 & TRN & \\
\hline CHEMBL1302570 & 688524 & 5.3 & 4.9067 & TRN & \\
\hline CHEMBL1409406 & 688524 & 4.8 & 4.9328 & TRN & \\
\hline CHEMBL1391159 & 688524 & 5.4 & 5.1667 & TRN & \\
\hline CHEMBL1399208 & 688524 & 4.9 & 4.9518 & TRN & \\
\hline CHEMBL1415155 & 688524 & 4.9 & 4.9212 & TRN & \\
\hline CHEMBL112597 & 688524 & 5.1 & 5.2309 & TRN & \\
\hline CHEMBL1463200 & 688524 & 4.7 & 5.0858 & TRN & \\
\hline CHEMBL1398528 & 688524 & 6.9 & 5.28299 & 99999999995 & TRN \\
\hline CHEMBL1362013 & 688524 & 5.7 & 5.2026 & TRN & \\
\hline CHEMBL1510883 & 688524 & 5.0 & 4.6954 & TRN & \\
\hline CHEMBL1307495 & 688524 & 4.9 & 4.7352 & TRN & \\
\hline CHEMBL1444917 & 688524 & 4.8 & 4.9109 & TRN & \\
\hline CHEMBL1449719 & 688524 & 4.6 & 4.9693 & TRN & \\
\hline CHEMBL1426732 & 688524 & 4.8 & 4.9135 & TRN & \\
\hline CHEMBL1539876 & 688524 & 5.0 & 5.0463 & TST & \\
\hline CHEMBL1469830 & 688524 & 4.9 & 4.8616 & TST & \\
\hline CHEMBL1602663 & 688524 & 4.8 & 5.0446 & TRN & \\
\hline CHEMBL1483032 & 688524 & 5.7 & 5.1838 & TRN & \\
\hline CHEMBL1316709 & 688524 & 7.0 & 5.3093 & TRN & \\
\hline CHEMBL1543995 & 688524 & 5.0 & 4.9771 & TRN & \\
\hline CHEMBL2374058 & 688524 & 6.0 & 5.1481 & TST & \\
\hline & & & & 2627 & \\
\hline
\end{tabular}




\begin{tabular}{|c|c|c|c|c|}
\hline & & & ient & al Ta \\
\hline CHEMBL1315891 & 688524 & 5.2 & 5.1628 & TST \\
\hline CHEMBL1604690 & 688524 & 5.3 & 4.9658 & TRN \\
\hline CHEMBL1503025 & 688524 & 4.9 & 4.8857 & TRN \\
\hline CHEMBL1482179 & 688524 & 4.9 & 4.9587 & TRN \\
\hline CHEMBL1430943 & 688524 & 4.6 & 5.2295 & TRN \\
\hline CHEMBL1506771 & 688524 & 5.3 & 5.0655 & TRN \\
\hline CHEMBL1538480 & 688524 & 5.0 & 4.9883 & TRN \\
\hline CHEMBL3191413 & 688524 & 4.5 & 4.9479 & TST \\
\hline CHEMBL69151 & 688524 & 4.7 & 5.0194 & TRN \\
\hline CHEMBL1480452 & 688524 & 4.5 & 4.9721 & TST \\
\hline CHEMBL1486729 & 688524 & 5.3 & 5.042 & TRN \\
\hline CHEMBL1610991 & 688524 & 6.1 & 5.0857 & TRN \\
\hline CHEMBL1523894 & 688524 & 4.7 & 5.0644 & TST \\
\hline CHEMBL1360134 & 688524 & 5.3 & 5.0452 & TRN \\
\hline CHEMBL1342971 & 688524 & 4.6 & 5.3211 & TRN \\
\hline CHEMBL1433559 & 688524 & 5.4 & 5.3704 & TRN \\
\hline CHEMBL608998 & 688524 & 5.3 & 5.1572 & TRN \\
\hline CHEMBL1421057 & 688524 & 4.9 & 4.7306 & TRN \\
\hline CHEMBL1366431 & 688524 & 5.4 & 5.0359 & TRN \\
\hline CHEMBL1478115 & 688524 & 5.2 & 4.9945 & TRN \\
\hline CHEMBL1422046 & 688524 & 4.9 & 4.9903 & TRN \\
\hline CHEMBL1511705 & 688524 & 5.1 & 5.0296 & TRN \\
\hline CHEMBL1991908 & 688524 & 4.6 & 4.8377 & TRN \\
\hline CHEMBL1392315 & 688524 & 5.5 & 5.2169 & TRN \\
\hline CHEMBL1536590 & 688524 & 4.9 & 4.9025 & TRN \\
\hline CHEMBL1319513 & 688524 & 4.5 & 5.1821 & TRN \\
\hline CHEMBL18115 & 688524 & 7.0 & 5.6046 & TRN \\
\hline CHEMBL1400807 & 688524 & 4.5 & 4.9111 & TRN \\
\hline CHEMBL1365701 & 688524 & 6.2 & 5.0593 & TRN \\
\hline CHEMBL1496655 & 688524 & 4.9 & 4.982 & TRN \\
\hline CHEMBL1367506 & 688524 & 5.3 & 5.1645 & TST \\
\hline CHEMBL1488459 & 688524 & 5.0 & 5.0244 & TRN \\
\hline CHEMBL1545040 & 688524 & 5.3 & 4.7526 & TRN \\
\hline CHEMBL1461767 & 688524 & 4.9 & 5.0899 & TRN \\
\hline CHEMBL1458119 & 688524 & 4.9 & 4.8823 & TRN \\
\hline CHEMBL1316178 & 688524 & 4.5 & 5.1025 & TST \\
\hline CHEMBL1550068 & 688524 & 4.6 & 4.9759 & TRN \\
\hline CHEMBL1399361 & 688524 & 4.7 & 4.8642 & TRN \\
\hline CHEMBL405317 & 688524 & 5.5 & 5.385 & TRN \\
\hline CHEMBL1582826 & 688524 & 5.0 & 4.9369 & TRN \\
\hline CHEMBL21260 & 688524 & 6.0 & 5.1657 & TST \\
\hline CHEMBL1580340 & 688524 & 4.9 & 5.004 & TRN \\
\hline CHEMBL1322062 & 688524 & 5.9 & 5.272 & TRN \\
\hline CHEMBL1412074 & 688524 & 5.4 & 4.9381 & TRN \\
\hline CHEMBL3199262 & 688524 & 4.8 & 5.1328 & TRN \\
\hline CHEMBL1438621 & 688524 & 4.8 & 4.945 & TST \\
\hline CHEMBL1610082 & 688524 & 4.8 & 5.2155 & TRN \\
\hline CHEMBL1521681 & 688524 & 6.3 & 4.9949 & TST \\
\hline
\end{tabular}




\begin{tabular}{|c|c|c|c|c|c|}
\hline & & & & & \\
\hline CHEMBL1590378 & 688524 & 4.7 & 5.0904 & TST & \\
\hline CHEMBL1372076 & 688524 & 4.7 & 5.0659 & TST & \\
\hline CHEMBL1524385 & 688524 & 4.9 & 4.9096 & TRN & \\
\hline CHEMBL1427956 & 688524 & 5.7 & 4.9701 & TRN & \\
\hline CHEMBL1584930 & 688524 & 4.7 & 4.9857 & TRN & \\
\hline CHEMBL1565369 & 688524 & 4.9 & 5.1677 & TRN & \\
\hline CHEMBL1531260 & 688524 & 4.5 & 4.9518 & TRN & \\
\hline CHEMBL1453208 & 688524 & 4.8 & 5.1019 & TST & \\
\hline CHEMBL1439775 & 688524 & 4.6 & 4.8396 & TRN & \\
\hline CHEMBL1493650 & 688524 & 5.1 & 4.9165 & TRN & \\
\hline CHEMBL1448856 & 688524 & 5.1 & 5.03600 & 20000000005 & TRN \\
\hline CHEMBL1583436 & 688524 & 6.1 & 5.0509 & TRN & \\
\hline CHEMBL1352855 & 688524 & 4.9 & 5.1704 & TRN & \\
\hline CHEMBL526034 & 688524 & 5.1 & $5.1160 e$ & 00000000005 & TST \\
\hline CHEMBL1469134 & 688524 & 4.7 & 5.1401 & TRN & \\
\hline CHEMBL1565294 & 688524 & 4.9 & 4.8889 & TRN & \\
\hline CHEMBL1590360 & 688524 & 4.8 & 4.9942 & TRN & \\
\hline CHEMBL1321006 & 688524 & 4.5 & 4.9339 & TST & \\
\hline CHEMBL1382030 & 688524 & 4.9 & 4.9266 & TRN & \\
\hline CHEMBL1328390 & 688524 & 5.9 & 5.0989 & TRN & \\
\hline CHEMBL1332664 & 688524 & 4.7 & 5.1027 & TRN & \\
\hline CHEMBL1578437 & 688524 & 4.9 & 4.9329 & TRN & \\
\hline CHEMBL1450369 & 688524 & 4.5 & 4.9868 & TRN & \\
\hline CHEMBL466933 & 688524 & 4.9 & 4.9253 & TRN & \\
\hline CHEMBL1458755 & 688524 & 5.0 & 4.9018 & TRN & \\
\hline CHEMBL1319905 & 688524 & 5.0 & 5.0989 & TRN & \\
\hline CHEMBL1438371 & 688524 & 4.9 & 5.2713 & TRN & \\
\hline CHEMBL1585453 & 688524 & 5.5 & 5.1159 & TRN & \\
\hline CHEMBL1330642 & 688524 & 4.5 & 4.936 & TRN & \\
\hline CHEMBL1604894 & 688524 & 4.7 & 5.0292 & TRN & \\
\hline CHEMBL1306561 & 688524 & 4.8 & 4.9612 & TRN & \\
\hline CHEMBL1596996 & 688524 & 4.9 & 4.9471 & TST & \\
\hline CHEMBL1325934 & 688524 & 4.9 & 5.0331 & TRN & \\
\hline CHEMBL1305414 & 688524 & 4.7 & 4.9612 & TST & \\
\hline CHEMBL1366812 & 688524 & 5.9 & 5.1309 & TST & \\
\hline CHEMBL1484049 & 688524 & 4.9 & 5.0235 & TRN & \\
\hline CHEMBL1503655 & 688524 & 4.5 & 5.1542 & TRN & \\
\hline CHEMBL1493226 & 688524 & 5.1 & 4.9758 & TRN & \\
\hline CHEMBL1416270 & 688524 & 4.9 & 4.7291 & TRN & \\
\hline CHEMBL1451765 & 688524 & 5.9 & 5.1783 & TRN & \\
\hline CHEMBL 277040 & 688524 & 5.5 & 5.2361 & TST & \\
\hline CHEMBL1359371 & 688524 & 4.8 & 4.8502 & TRN & \\
\hline CHEMBL1390348 & 688524 & 5.6 & 4.9349 & TRN & \\
\hline CHEMBL1450476 & 688524 & 4.7 & 4.8818 & TST & \\
\hline CHEMBL1585105 & 688524 & 4.9 & 4.7767 & TRN & \\
\hline CHEMBL1459932 & 688524 & 6.0 & 4.9956 & TRN & \\
\hline CHEMBL1351018 & 688524 & 5.6 & 4.9108 & TRN & \\
\hline CHEMBL1423466 & 688524 & 5.3 & 5.0447 & TRN & \\
\hline & & & & 26279 & \\
\hline
\end{tabular}




\begin{tabular}{|c|c|c|c|c|c|}
\hline \multicolumn{6}{|c|}{ Supplemental Table S2.txt } \\
\hline CHEMBL254255 & 688524 & 4.7 & 4.774 & TRN & \\
\hline CHEMBL1379941 & 688524 & 5.2 & 4.7947 & TRN & \\
\hline CHEMBL1348895 & 688524 & 4.7 & 5.00899 & 99999999995 & TRN \\
\hline CHEMBL1586370 & 688524 & 4.8 & 4.9614 & TRN & \\
\hline CHEMBL1557648 & 688524 & 4.9 & 4.8831 & TRN & \\
\hline CHEMBL1427779 & 688524 & 4.5 & 4.9521 & TRN & \\
\hline CHEMBL1490477 & 688524 & 5.3 & 5.35 & TRN & \\
\hline CHEMBL1409297 & 688524 & 4.9 & 5.0611 & TRN & \\
\hline CHEMBL1334254 & 688524 & 4.9 & 5.0176 & TRN & \\
\hline CHEMBL1444654 & 688524 & 4.8 & 5.0642 & TRN & \\
\hline CHEMBL1611261 & 688524 & 5.3 & 5.234 & TRN & \\
\hline CHEMBL242384 & 688524 & 5.1 & 4.9655 & TRN & \\
\hline CHEMBL1584578 & 688524 & 5.5 & 5.0902 & TST & \\
\hline CHEMBL1574483 & 688524 & 5.2 & 5.0649 & TRN & \\
\hline CHEMBL1595747 & 688524 & 5.2 & 5.0948 & TRN & \\
\hline CHEMBL1452716 & 688524 & 4.6 & 5.0853 & TST & \\
\hline CHEMBL1475737 & 688524 & 5.5 & 5.3806 & TRN & \\
\hline CHEMBL1578404 & 688524 & 5.0 & 4.7652 & TRN & \\
\hline CHEMBL1409318 & 688524 & 4.9 & 4.9897 & TRN & \\
\hline CHEMBL1521672 & 688524 & 4.9 & 4.9499 & TRN & \\
\hline CHEMBL1411410 & 688524 & 4.5 & 4.9405 & TRN & \\
\hline CHEMBL1552542 & 688524 & 4.7 & 4.9506 & TRN & \\
\hline CHEMBL1477081 & 688524 & 6.1 & 5.3091 & TST & \\
\hline CHEMBL1600947 & 688524 & 5.1 & 5.1235 & TRN & \\
\hline CHEMBL1580034 & 688524 & 4.9 & 5.1344 & TRN & \\
\hline CHEMBL1489424 & 688524 & 5.4 & 5.5106 & TRN & \\
\hline CHEMBL1329600 & 688524 & 4.5 & 5.0827 & TRN & \\
\hline CHEMBL1495242 & 688524 & 5.4 & 5.1837 & TRN & \\
\hline CHEMBL1360670 & 688524 & 4.5 & 4.9473 & TST & \\
\hline CHEMBL570345 & 688524 & 4.5 & 5.0495 & TRN & \\
\hline CHEMBL1706619 & 688524 & 4.5 & 4.8224 & TST & \\
\hline CHEMBL1587117 & 688524 & 5.9 & 5.4589 & TRN & \\
\hline CHEMBL1365362 & 688524 & 4.6 & 5.0036 & TRN & \\
\hline CHEMBL1407390 & 688524 & 4.5 & 4.9688 & TRN & \\
\hline CHEMBL1482624 & 688524 & 4.9 & 4.801 & TRN & \\
\hline CHEMBL1477837 & 688524 & 4.5 & 4.927 & TRN & \\
\hline CHEMBL1490744 & 688524 & 4.9 & 4.8141 & TRN & \\
\hline CHEMBL1401837 & 688524 & 4.9 & 4.9624 & TRN & \\
\hline CHEMBL1575235 & 688524 & 4.9 & 5.0022 & TST & \\
\hline CHEMBL1364271 & 688524 & 5.5 & 5.0818 & TRN & \\
\hline CHEMBL447111 & 688524 & 7.3002 & 5.1085 & TRN & \\
\hline CHEMBL1312996 & 688524 & 5.6 & 4.9312 & TRN & \\
\hline CHEMBL1311339 & 688524 & 4.7 & 5.0952 & TRN & \\
\hline CHEMBL1406241 & 688524 & 4.8 & 4.7627 & TRN & \\
\hline CHEMBL1330459 & 688524 & 6.0 & 5.398 & TRN & \\
\hline CHEMBL1390531 & 688524 & 4.6 & 4.9616 & TRN & \\
\hline CHEMBL1325350 & 688524 & 5.2 & 4.931 & TST & \\
\hline CHEMBL582005 & 688524 & 4.5 & 5.2377 & TRN & \\
\hline
\end{tabular}




\begin{tabular}{|c|c|c|c|c|}
\hline & & & & \\
\hline CHEMBL1317135 & 688524 & 6.6 & 5.2904 & TST \\
\hline CHEMBL572994 & 688524 & 4.9 & 5.0537 & TST \\
\hline CHEMBL1524798 & 688524 & 5.5 & 4.9757 & TRN \\
\hline CHEMBL428789 & 688524 & 4.5 & 4.9861 & TRN \\
\hline CHEMBL1497019 & 688524 & 5.4 & 5.0028 & TRN \\
\hline CHEMBL1606091 & 688524 & 5.1 & 4.9759 & TRN \\
\hline CHEMBL1374501 & 688524 & 6.1 & 5.1659 & TRN \\
\hline CHEMBL1303037 & 688524 & 4.9 & 5.062 & TRN \\
\hline CHEMBL44 & 688524 & 6.0 & 5.3992 & TRN \\
\hline CHEMBL1534317 & 688524 & 4.6 & 5.0601 & TRN \\
\hline CHEMBL1305665 & 688524 & 4.5 & 4.8785 & TRN \\
\hline CHEMBL1424457 & 688524 & 5.0 & 4.9025 & TRN \\
\hline CHEMBL3198373 & 688524 & 4.7 & 4.9138 & TRN \\
\hline CHEMBL1580491 & 688524 & 4.9 & 4.9976 & TRN \\
\hline CHEMBL1422720 & 688524 & 5.2 & 4.9113 & TRN \\
\hline CHEMBL16685 & 688524 & 5.4 & 4.8994 & TRN \\
\hline CHEMBL1406070 & 688524 & 4.9 & 4.9663 & TRN \\
\hline CHEMBL1308522 & 688524 & 4.8 & 4.9613 & TRN \\
\hline CHEMBL1364407 & 688524 & 4.9 & 5.0069 & TRN \\
\hline CHEMBL263116 & 688524 & 4.6 & 5.1478 & TRN \\
\hline CHEMBL1502986 & 688524 & 4.7 & 4.9597 & TST \\
\hline CHEMBL1565890 & 688524 & 5.6 & 5.0183 & TST \\
\hline CHEMBL1603191 & 688524 & 4.8 & 5.0872 & TRN \\
\hline CHEMBL1368118 & 688524 & 4.9 & 4.9362 & TRN \\
\hline CHEMBL1569366 & 688524 & 4.9 & 4.9654 & TRN \\
\hline CHEMBL1373818 & 688524 & 4.6 & 4.9881 & TST \\
\hline CHEMBL1550507 & 688524 & 5.5 & 4.9425 & TRN \\
\hline CHEMBL1327079 & 688524 & 4.9 & 4.8284 & TRN \\
\hline CHEMBL1348218 & 688524 & 5.5 & 4.7726 & TRN \\
\hline CHEMBL1443752 & 688524 & 4.9 & 5.0305 & TRN \\
\hline CHEMBL1441589 & 688524 & 5.4 & 5.0105 & TRN \\
\hline CHEMBL1611313 & 688524 & 4.7 & 5.0774 & TRN \\
\hline CHEMBL1535546 & 688524 & 4.9 & 5.1572 & TRN \\
\hline CHEMBL1441059 & 688524 & 5.2 & 5.1915 & TST \\
\hline CHEMBL1611453 & 688524 & 4.7 & 4.9346 & TRN \\
\hline CHEMBL1316314 & 688524 & 4.9 & 5.0299 & TST \\
\hline CHEMBL1402065 & 688524 & 4.7 & 4.9399 & TRN \\
\hline CHEMBL1414737 & 688524 & 4.9 & 5.0294 & TRN \\
\hline CHEMBL1559379 & 688524 & 5.0 & 4.9671 & TRN \\
\hline CHEMBL220845 & 688524 & 4.5 & 5.2108 & TRN \\
\hline CHEMBL1319873 & 688524 & 4.9 & 4.9864 & TRN \\
\hline CHEMBL1435994 & 688524 & 6.0 & 5.3207 & TRN \\
\hline CHEMBL1518422 & 688524 & 4.7 & 5.0461 & TRN \\
\hline CHEMBL1568558 & 688524 & 5.0 & 5.0856 & TRN \\
\hline CHEMBL1543818 & 688524 & 5.4 & 4.9857 & TRN \\
\hline CHEMBL1512222 & 688524 & 4.9 & 5.1114 & TRN \\
\hline CHEMBL1396742 & 688524 & 5.4 & 5.1431 & TRN \\
\hline CHEMBL1497953 & 688524 & 5.0 & 5.003 & TRN \\
\hline
\end{tabular}




\begin{tabular}{|c|c|c|c|c|}
\hline \multicolumn{5}{|c|}{ ipplemental T } \\
\hline CHEMBL1568835 & 688524 & 4.7 & 4.9746 & TRN \\
\hline CHEMBL1567235 & 688524 & 4.8 & 4.7653 & TRN \\
\hline CHEMBL1438429 & 688524 & 5.0 & 4.9339 & TRN \\
\hline CHEMBL1601910 & 688524 & 4.8 & 4.9598 & TRN \\
\hline CHEMBL1351706 & 688524 & 4.6 & 4.8972 & TRN \\
\hline CHEMBL1330028 & 688524 & 6.4 & 5.1458 & TRN \\
\hline CHEMBL1476642 & 688524 & 4.9 & 5.1472 & TST \\
\hline CHEMBL1386201 & 688524 & 4.5 & 5.0508 & TRN \\
\hline CHEMBL1346515 & 688524 & 5.1 & 4.8285 & TRN \\
\hline CHEMBL1496569 & 688524 & 5.8 & 4.9926 & TRN \\
\hline CHEMBL1594960 & 688524 & 4.9 & 4.8184 & TRN \\
\hline CHEMBL1418522 & 688524 & 4.7 & 5.0253 & TST \\
\hline CHEMBL1376290 & 688524 & 5.0 & 5.3832 & TRN \\
\hline CHEMBL1613188 & 688524 & 4.6 & 4.8023 & TRN \\
\hline CHEMBL1605491 & 688524 & 4.5 & 4.9243 & TRN \\
\hline CHEMBL155265 & 688524 & 5.3 & 5.2968 & TRN \\
\hline CHEMBL1487311 & 688524 & 4.7 & 5.1841 & TRN \\
\hline CHEMBL1362206 & 688524 & 4.5 & 4.89 & TRN \\
\hline CHEMBL1542091 & 688524 & 4.9 & 5.0733 & TRN \\
\hline CHEMBL1342444 & 688524 & 5.0 & 4.954 & TRN \\
\hline CHEMBL1418023 & 688524 & 4.6 & 5.1845 & TST \\
\hline CHEMBL1571874 & 688524 & 4.8 & 4.9208 & TST \\
\hline CHEMBL1565441 & 688524 & 4.9 & 5.2511 & TRN \\
\hline CHEMBL1431510 & 688524 & 5.5 & 5.0449 & TRN \\
\hline CHEMBL16223 & 688524 & 5.1 & 5.0792 & TRN \\
\hline CHEMBL1527380 & 688524 & 5.3 & 5.1941 & TRN \\
\hline CHEMBL3195995 & 688524 & 5.3 & 4.9395 & TRN \\
\hline CHEMBL1524169 & 688524 & 4.8 & 5.2456 & TRN \\
\hline CHEMBL1342148 & 688524 & 4.5 & 4.8803 & TRN \\
\hline CHEMBL1450465 & 688524 & 4.6 & 5.0025 & TRN \\
\hline CHEMBL3198180 & 688524 & 4.7 & 4.868 & TRN \\
\hline CHEMBL1587239 & 688524 & 4.9 & 5.0543 & TRN \\
\hline CHEMBL1576757 & 688524 & 4.5 & 4.8937 & TRN \\
\hline CHEMBL1493135 & 688524 & 5.0 & 5.0619 & TRN \\
\hline CHEMBL1576328 & 688524 & 4.8 & 4.894 & TRN \\
\hline CHEMBL1507997 & 688524 & 4.7 & 4.8862 & TRN \\
\hline CHEMBL1468285 & 688524 & 4.8 & 4.8782 & TRN \\
\hline CHEMBL3196267 & 688524 & 4.8 & 5.0912 & TST \\
\hline CHEMBL1497593 & 688524 & 5.3 & 5.2423 & TRN \\
\hline CHEMBL1591336 & 688524 & 4.5 & 5.2322 & TRN \\
\hline CHEMBL1308126 & 688524 & 4.5 & 5.0705 & TRN \\
\hline CHEMBL1368619 & 688524 & 4.7 & 4.9163 & TST \\
\hline CHEMBL1526043 & 688524 & 4.7 & 5.1864 & TRN \\
\hline CHEMBL1606813 & 688524 & 4.6 & 4.934 & TRN \\
\hline CHEMBL 3195747 & 688524 & 4.9 & 5.1101 & TST \\
\hline CHEMBL1314386 & 688524 & 4.9 & 5.2473 & TRN \\
\hline CHEMBL1516331 & 688524 & 4.8 & 5.1055 & TRN \\
\hline CHEMBL1400218 & 688524 & 4.9 & 5.1046 & TRN \\
\hline
\end{tabular}




\begin{tabular}{|c|c|c|c|c|c|}
\hline \multicolumn{6}{|c|}{ Supplemental Table S2.txt } \\
\hline CHEMBL274866 & 688524 & 5.5 & 5.0152 & TRN & \\
\hline CHEMBL1386241 & 688524 & 5.3 & 4.9293 & TRN & \\
\hline CHEMBL1343161 & 688524 & 4.9 & 4.9635 & TRN & \\
\hline CHEMBL1095566 & 688524 & 5.1 & 5.1188 & TRN & \\
\hline CHEMBL1302191 & 688524 & 4.8 & 5.0886 & TRN & \\
\hline CHEMBL1514607 & 688524 & 5.3 & 5.5938 & TRN & \\
\hline CHEMBL3193298 & 688524 & 4.9 & 5.0896 & TRN & \\
\hline CHEMBL1213073 & 688524 & 4.9 & 5.044 & TRN & \\
\hline CHEMBL1417435 & 688524 & 4.9 & 4.7945 & TRN & \\
\hline CHEMBL1401087 & 688524 & 5.1 & 5.083 & TRN & \\
\hline CHEMBL1321992 & 688524 & 5.2 & 5.0295 & TRN & \\
\hline CHEMBL1314376 & 688524 & 4.6 & 5.0278 & TRN & \\
\hline CHEMBL3208247 & 688524 & 5.0 & 5.2133 & TRN & \\
\hline CHEMBL1465074 & 688524 & 4.8 & 4.8792 & TRN & \\
\hline CHEMBL1453214 & 688524 & 4.6 & 5.0253 & TRN & \\
\hline CHEMBL1470303 & 688524 & 4.7 & 5.0394 & TRN & \\
\hline CHEMBL1326624 & 688524 & 4.5 & 4.992 & TST & \\
\hline CHEMBL1562190 & 688524 & 5.0 & 5.1137 & TRN & \\
\hline CHEMBL1478324 & 688524 & 5.3 & 5.1129 & TST & \\
\hline CHEMBL1554360 & 688524 & 4.5 & 5.1428 & TRN & \\
\hline CHEMBL1345146 & 688524 & 4.9 & 4.9157 & TRN & \\
\hline CHEMBL1490528 & 688524 & 5.1 & 4.9064 & TRN & \\
\hline CHEMBL1558822 & 688524 & 4.8 & 5.2027 & TRN & \\
\hline CHEMBL1442201 & 688524 & 4.9 & 5.1074 & TRN & \\
\hline CHEMBL1459355 & 688524 & 4.7 & 4.8497 & TRN & \\
\hline CHEMBL1469870 & 688524 & 4.9 & 5.08 & TRN & \\
\hline CHEMBL3190400 & 688524 & 4.9 & 5.1616 & TRN & \\
\hline CHEMBL1518572 & 688524 & 5.55 & 5.13 & TRN & \\
\hline CHEMBL1471225 & 688524 & 4.8 & 4.9229 & TRN & \\
\hline CHEMBL1498728 & 688524 & 5.7 & 5.0363 & TRN & \\
\hline CHEMBL1608078 & 688524 & 5.2 & 5.1968 & TRN & \\
\hline CHEMBL1416426 & 688524 & 6.9 & 5.3342 & TRN & \\
\hline CHEMBL1521130 & 688524 & 5.0 & 5.0517 & TRN & \\
\hline CHEMBL1400834 & 688524 & 5.5 & 5.267 & TRN & \\
\hline CHEMBL1526246 & 688524 & 5.8 & 5.1372 & TST & \\
\hline CHEMBL1610769 & 688524 & 4.8 & 4.99100 & 00000000005 & TRN \\
\hline CHEMBL1478082 & 688524 & 4.5 & 4.9341 & TRN & \\
\hline CHEMBL259103 & 688524 & 5.5 & 5.1131 & TRN & \\
\hline CHEMBL1413342 & 688524 & 6.3 & 5.2933 & TST & \\
\hline CHEMBL1374843 & 688524 & 5.1 & 5.1547 & TST & \\
\hline CHEMBL1385107 & 688524 & 4.8 & 5.0084 & TRN & \\
\hline CHEMBL1523699 & 688524 & 4.9 & 5.2387 & TRN & \\
\hline CHEMBL1357750 & 688524 & 4.5 & 5.2418 & TST & \\
\hline CHEMBL1350257 & 688524 & 5.0 & 4.8164 & TRN & \\
\hline CHEMBL540848 & 688524 & 5.2 & 5.1958 & TST & \\
\hline CHEMBL1470577 & 688524 & 4.9 & 5.2201 & TST & \\
\hline CHEMBL1488420 & 688524 & 5.3 & 5.0509 & TST & \\
\hline CHEMBL1453762 & 688524 & 5.0 & 5.0108 & TRN & \\
\hline
\end{tabular}




\begin{tabular}{|c|c|c|c|c|c|}
\hline & & & & & \\
\hline CHEMBL1495665 & 688524 & 5.2 & 5.1182 & TRN & \\
\hline CHEMBL1501180 & 688524 & 4.8 & 4.7523 & TRN & \\
\hline CHEMBL192566 & 688524 & 6.0 & 4.9156 & TST & \\
\hline CHEMBL1425987 & 688524 & 5.0 & 4.8062 & TRN & \\
\hline CHEMBL1309655 & 688524 & 5.0 & 4.926 & TRN & \\
\hline CHEMBL1411158 & 688524 & 4.9 & 5.0056 & TRN & \\
\hline CHEMBL1301573 & 688524 & 4.9 & 5.0167 & TRN & \\
\hline CHEMBL1426084 & 688524 & 5.7 & 4.9058 & TRN & \\
\hline CHEMBL77098 & 688524 & 4.5 & 4.96399 & & TRN \\
\hline CHEMBL438909 & 688524 & 4.9 & 5.1783 & TST & \\
\hline CHEMBL1580789 & 688524 & 5.7 & 4.916 & TRN & \\
\hline CHEMBL1311351 & 688524 & 4.9 & 5.0705 & TRN & \\
\hline CHEMBL1337092 & 688524 & 4.8 & 5.2621 & TRN & \\
\hline CHEMBL460517 & 688524 & 6.1 & 5.2558 & TRN & \\
\hline CHEMBL48449 & 688524 & 6.0 & 5.2374 & TST & \\
\hline CHEMBL1488667 & 688524 & 4.8 & 5.0871 & TRN & \\
\hline CHEMBL1302596 & 688524 & 4.9 & 5.1043 & TRN & \\
\hline CHEMBL1603399 & 688524 & 4.6 & 5.1305 & TRN & \\
\hline CHEMBL1607713 & 688524 & 6.0 & 5.1542 & TRN & \\
\hline CHEMBL1446967 & 688524 & 5.1 & 4.8576 & TRN & \\
\hline CHEMBL1451814 & 688524 & 4.5 & 5.0879 & TRN & \\
\hline CHEMBL1599463 & 688524 & 4.9 & 4.9726 & TRN & \\
\hline CHEMBL1371455 & 688524 & 5.3 & 4.9774 & TRN & \\
\hline CHEMBL1320147 & 688524 & 4.7 & 5.1031 & TRN & \\
\hline CHEMBL1401242 & 688524 & 4.6 & 5.0424 & TRN & \\
\hline CHEMBL1993164 & 688524 & 4.9 & 4.8449 & TRN & \\
\hline CHEMBL1347477 & 688524 & 5.5 & 4.9715 & TRN & \\
\hline CHEMBL578636 & 688524 & 4.8 & 4.9187 & TRN & \\
\hline CHEMBL1559674 & 688524 & 4.5 & 5.3023 & TST & \\
\hline CHEMBL514612 & 688524 & 4.9 & 4.8972 & TRN & \\
\hline CHEMBL1601133 & 688524 & 5.6 & 5.1376 & TRN & \\
\hline CHEMBL1582285 & 688524 & 4.9 & 5.0747 & TRN & \\
\hline CHEMBL1547207 & 688524 & 4.9 & 5.1001 & TRN & \\
\hline CHEMBL1371792 & 688524 & 5.0 & 5.13 & TRN & \\
\hline CHEMBL1412410 & 688524 & 4.9 & 4.6868 & TRN & \\
\hline CHEMBL1587375 & 688524 & 4.5 & 4.7929 & TRN & \\
\hline CHEMBL1470632 & 688524 & 4.5 & 5.0536 & TRN & \\
\hline CHEMBL1558613 & 688524 & 4.5 & 4.9287 & TRN & \\
\hline CHEMBL1343389 & 688524 & 5.5 & 5.0289 & TRN & \\
\hline CHEMBL1213769 & 688524 & 5.6 & 4.7423 & TRN & \\
\hline CHEMBL428909 & 688524 & 4.5 & 5.0631 & TRN & \\
\hline CHEMBL1477459 & 688524 & 4.5 & 4.8685 & TRN & \\
\hline CHEMBL1444259 & 688524 & 4.9 & 4.9804 & TRN & \\
\hline CHEMBL1356395 & 688524 & 5.5 & 5.3426 & TRN & \\
\hline CHEMBL1572855 & 688524 & 4.5 & 5.3186 & TRN & \\
\hline CHEMBL1568234 & 688524 & 4.5 & 5.0814 & TRN & \\
\hline CHEMBL1535794 & 688524 & 5.6 & 4.918 & TRN & \\
\hline CHEMBL1594328 & 688524 & 4.5 & 5.0581 & TRN & \\
\hline
\end{tabular}




\begin{tabular}{|c|c|c|c|c|}
\hline & & & & \\
\hline CHEMBL1488771 & 688524 & 5.6 & 5.0245 & TST \\
\hline CHEMBL1336277 & 688524 & 5.2 & 5.3576 & TRN \\
\hline CHEMBL1408427 & 688524 & 4.6 & 5.6263 & TRN \\
\hline CHEMBL1257041 & 688524 & 4.9 & 5.0834 & TST \\
\hline CHEMBL1383072 & 688524 & 5.5 & 4.9147 & TRN \\
\hline CHEMBL1364598 & 688524 & 4.9 & 4.919 & TRN \\
\hline CHEMBL250711 & 688524 & 6.0 & 5.0423 & TRN \\
\hline CHEMBL1429769 & 688524 & 5.0 & 5.0157 & TRN \\
\hline CHEMBL1556134 & 688524 & 4.7 & 4.9135 & TRN \\
\hline CHEMBL269550 & 688524 & 5.1 & 4.8782 & TRN \\
\hline CHEMBL1436272 & 688524 & 5.3 & 5.6365 & TRN \\
\hline CHEMBL509256 & 688524 & 4.5 & 5.0984 & TRN \\
\hline CHEMBL1339709 & 688524 & 5.2 & 4.8442 & TRN \\
\hline CHEMBL1450042 & 688524 & 4.7 & 5.0148 & TRN \\
\hline CHEMBL1482341 & 688524 & 4.9 & 4.8931 & TRN \\
\hline CHEMBL1429330 & 688524 & 4.8 & 5.0151 & TRN \\
\hline CHEMBL1370622 & 688524 & 4.5 & 5.0497 & TRN \\
\hline CHEMBL3190751 & 688524 & 4.9 & 4.9684 & TST \\
\hline CHEMBL1428790 & 688524 & 5.3 & 5.1513 & TRN \\
\hline CHEMBL1408742 & 688524 & 5.0 & 5.0643 & TRN \\
\hline CHEMBL1371765 & 688524 & 4.9 & 4.9596 & TRN \\
\hline CHEMBL1455992 & 688524 & 4.7 & 4.9614 & TRN \\
\hline CHEMBL1550430 & 688524 & 5.0 & 4.9788 & TRN \\
\hline CHEMBL1504368 & 688524 & 4.9 & 5.073 & TRN \\
\hline CHEMBL1543399 & 688524 & 5.3 & 4.9482 & TST \\
\hline CHEMBL1608208 & 688524 & 4.8 & 4.7818 & TRN \\
\hline CHEMBL1569844 & 688524 & 4.8 & 5.3265 & TRN \\
\hline CHEMBL1576026 & 688524 & 4.9 & 4.8856 & TRN \\
\hline CHEMBL1611005 & 688524 & 4.9 & 4.9841 & TRN \\
\hline CHEMBL1483459 & 688524 & 5.9 & 5.1973 & TRN \\
\hline CHEMBL1579020 & 688524 & 4.9 & 5.1982 & TST \\
\hline CHEMBL1453501 & 688524 & 4.9 & 5.0878 & TRN \\
\hline CHEMBL1385395 & 688524 & 4.7 & 4.9135 & TRN \\
\hline CHEMBL84685 & 688524 & 4.9 & 5.1167 & TRN \\
\hline CHEMBL1332463 & 688524 & 5.6 & 5.5529 & TRN \\
\hline CHEMBL1344041 & 688524 & 4.9 & 5.085 & TRN \\
\hline CHEMBL1612462 & 688524 & 5.5 & 5.0662 & TRN \\
\hline CHEMBL1563047 & 688524 & 4.8 & 5.154 & TRN \\
\hline CHEMBL1347850 & 688524 & 4.5 & 4.9169 & TRN \\
\hline CHEMBL1517581 & 688524 & 4.8 & 5.1093 & TRN \\
\hline CHEMBL1412093 & 688524 & 4.9 & 5.0583 & TRN \\
\hline CHEMBL1540492 & 688524 & 4.7 & 5.2852 & TRN \\
\hline CHEMBL1178 & 688524 & 5.0 & 5.1905 & TST \\
\hline CHEMBL1453168 & 688524 & 4.6 & 4.9903 & TST \\
\hline CHEMBL1450770 & 688524 & 4.8 & 5.1289 & TRN \\
\hline CHEMBL1551618 & 688524 & 5.5 & 5.1845 & TRN \\
\hline CHEMBL1319047 & 688524 & 4.8 & 5.0728 & TRN \\
\hline CHEMBL1336727 & 688524 & 5.8 & 5.1576 & TST \\
\hline
\end{tabular}




\begin{tabular}{|c|c|c|c|c|}
\hline & & & Supplement & \\
\hline CHEMBL1457356 & 688524 & 4.8 & 5.0402 & TRN \\
\hline CHEMBL1525780 & 688524 & 4.8 & 5.0241 & TRN \\
\hline CHEMBL1583165 & 688524 & 5.4 & 4.9144 & TRN \\
\hline CHEMBL1478602 & 688524 & 4.7 & 4.9168 & TRN \\
\hline CHEMBL1522231 & 688524 & 4.7 & 4.9775 & TST \\
\hline CHEMBL486817 & 688524 & 5.0 & 5.0981 & TRN \\
\hline CHEMBL1441355 & 688524 & 5.0 & 4.8017 & TRN \\
\hline CHEMBL1561456 & 688524 & 4.9 & 4.9159 & TRN \\
\hline CHEMBL1350528 & 688524 & 4.7 & 5.015 & TST \\
\hline CHEMBL1331486 & 688524 & 4.8 & 5.1504 & TRN \\
\hline CHEMBL1469826 & 688524 & 5.0 & 4.9424 & TRN \\
\hline CHEMBL1319379 & 688524 & 4.8 & 5.1013 & TRN \\
\hline CHEMBL1581922 & 688524 & 4.8 & 4.8848 & TST \\
\hline CHEMBL1368062 & 688524 & 6.0 & 5.1584 & TRN \\
\hline CHEMBL1332840 & 688524 & 4.9 & 5.0488 & TRN \\
\hline CHEMBL1570012 & 688524 & 4.5 & 4.9101 & TRN \\
\hline CHEMBL1351040 & 688524 & 4.5 & 4.8554 & TRN \\
\hline CHEMBL1384654 & 688524 & 4.9 & 4.981 & TRN \\
\hline CHEMBL1566549 & 688524 & 5.0 & 4.8154 & TRN \\
\hline CHEMBL1438160 & 688524 & 4.9 & 5.0623 & TRN \\
\hline CHEMBL1366020 & 688524 & 4.9 & 5.0854 & TRN \\
\hline CHEMBL1327046 & 688524 & 5.1 & 4.8627 & TRN \\
\hline CHEMBL3214002 & 688524 & 4.5 & 5.0169 & TRN \\
\hline CHEMBL1536517 & 688524 & 4.9 & 5.0456 & TRN \\
\hline CHEMBL429335 & 688524 & 5.6 & 5.1629 & TRN \\
\hline CHEMBL1371175 & 688524 & 4.9 & 5.0237 & TRN \\
\hline CHEMBL1373326 & 688524 & 5.5 & 5.1237 & TRN \\
\hline CHEMBL1363142 & 688524 & 5.2 & 5.1447 & TST \\
\hline CHEMBL1504089 & 688524 & 4.6 & 4.766 & TRN \\
\hline CHEMBL1421163 & 688524 & 5.3 & 4.9041 & TRN \\
\hline CHEMBL1445150 & 688524 & 4.8 & 4.8979 & TRN \\
\hline CHEMBL1373428 & 688524 & 4.5 & 5.0451 & TRN \\
\hline CHEMBL1431928 & 688524 & 4.9 & 4.9399 & TRN \\
\hline CHEMBL1558550 & 688524 & 4.8 & 4.7037 & TRN \\
\hline CHEMBL1550109 & 688524 & 5.0 & 4.9759 & TRN \\
\hline CHEMBL1490031 & 688524 & 4.9 & 4.8138 & TRN \\
\hline CHEMBL1373194 & 688524 & 5.8 & 5.0422 & TRN \\
\hline CHEMBL1387029 & 688524 & 5.0 & 4.7983 & TST \\
\hline CHEMBL1405627 & 688524 & 4.5 & 5.2392 & TRN \\
\hline CHEMBL1347099 & 688524 & 5.1 & 5.0818 & TRN \\
\hline CHEMBL1382724 & 688524 & 4.5 & 4.9794 & TRN \\
\hline CHEMBL1415816 & 688524 & 4.9 & 4.9136 & TRN \\
\hline CHEMBL1484981 & 688524 & 5.8 & 4.9607 & TRN \\
\hline CHEMBL1603853 & 688524 & 4.9 & 5.0187 & TRN \\
\hline CHEMBL1577023 & 688524 & 5.5 & 4.9916 & TRN \\
\hline CHEMBL1573961 & 688524 & 4.6 & 5.0256 & TRN \\
\hline CHEMBL1558562 & 688524 & 4.7 & 4.9182 & TST \\
\hline CHEMBL1535478 & 688524 & 5.0 & 5.0366 & TRN \\
\hline
\end{tabular}




\begin{tabular}{|c|c|c|c|c|}
\hline \multicolumn{5}{|c|}{ Supplemental Table S2.txt } \\
\hline CHEMBL1392056 & 688524 & 4.5 & 4.9619 & TRN \\
\hline CHEMBL1346729 & 688524 & 4.8 & 5.1365 & TRN \\
\hline CHEMBL1498669 & 688524 & 4.9 & 4.809 & TRN \\
\hline CHEMBL1352443 & 688524 & 4.7 & 4.7467 & TRN \\
\hline CHEMBL1451317 & 688524 & 4.6 & 4.9425 & TRN \\
\hline CHEMBL1449701 & 688524 & 5.0 & 5.4631 & TRN \\
\hline CHEMBL1575073 & 688524 & 5.0 & 4.9776 & TRN \\
\hline CHEMBL1580655 & 688524 & 4.8 & 4.9306 & TRN \\
\hline CHEMBL473735 & 688524 & 5.4 & 4.9087 & TRN \\
\hline CHEMBL1505268 & 688524 & 4.9 & 4.8326 & TST \\
\hline CHEMBL1612606 & 688524 & 4.5 & 4.9021 & TRN \\
\hline CHEMBL1438626 & 688524 & 5.0 & 4.9159 & TRN \\
\hline CHEMBL1601416 & 688524 & 4.7 & 5.24 & TRN \\
\hline CHEMBL1564688 & 688524 & 5.0 & 5.0838 & TRN \\
\hline CHEMBL1452128 & 688524 & 5.1 & 4.8676 & TRN \\
\hline CHEMBL1358788 & 688524 & 5.0 & 4.897 & TRN \\
\hline CHEMBL1447073 & 688524 & 5.0 & 5.1321 & TRN \\
\hline CHEMBL1529092 & 688524 & 4.9 & 5.0218 & TRN \\
\hline CHEMBL1580704 & 688524 & 4.5 & 4.7692 & TRN \\
\hline CHEMBL1403448 & 688524 & 4.8 & 5.0045 & TST \\
\hline CHEMBL1369119 & 688524 & 4.7 & 4.9657 & TST \\
\hline CHEMBL1488723 & 688524 & 4.5 & 4.8705 & TRN \\
\hline CHEMBL1417970 & 688524 & 5.6 & 5.0928 & TRN \\
\hline CHEMBL1582494 & 688524 & 4.6 & 4.8978 & TRN \\
\hline CHEMBL1565686 & 688524 & 5.3 & 5.0948 & TRN \\
\hline CHEMBL1531593 & 688524 & 4.7 & 4.8676 & TST \\
\hline CHEMBL1492432 & 688524 & 5.0 & 5.0079 & TRN \\
\hline CHEMBL1471358 & 688524 & 4.8 & 4.8381 & TRN \\
\hline CHEMBL1613241 & 688524 & 5.2 & 5.0966 & TRN \\
\hline CHEMBL456446 & 688524 & 4.9 & 5.1986 & TRN \\
\hline CHEMBL1595178 & 688524 & 4.9 & 4.9096 & TRN \\
\hline CHEMBL1409152 & 688524 & 4.9 & 4.9691 & TRN \\
\hline CHEMBL1394140 & 688524 & 4.5 & 5.0141 & TRN \\
\hline CHEMBL1320149 & 688524 & 4.8 & 4.9912 & TRN \\
\hline CHEMBL1302108 & 688524 & 5.3 & 5.1329 & TRN \\
\hline CHEMBL1524475 & 688524 & 5.0 & 5.1112 & TRN \\
\hline CHEMBL1371093 & 688524 & 5.0 & 5.0707 & TRN \\
\hline CHEMBL1413999 & 688524 & 4.8 & 4.7722 & TRN \\
\hline CHEMBL1332732 & 688524 & 5.5 & 4.9543 & TRN \\
\hline CHEMBL478 & 688524 & 6.0 & 4.9435 & TRN \\
\hline CHEMBL1336047 & 688524 & 4.9 & 4.96899 & 9999999999 \\
\hline CHEMBL1358485 & 688524 & 4.45 & 5.1066 & TST \\
\hline CHEMBL1397821 & 688524 & 5.4 & 5.2338 & TRN \\
\hline CHEMBL1511858 & 688524 & 5.1 & 4.9148 & TRN \\
\hline CHEMBL1305554 & 688524 & 4.5 & 4.7881 & TRN \\
\hline CHEMBL3214237 & 688524 & 4.6 & 5.0405 & TST \\
\hline CHEMBL 236685 & 688524 & 4.5 & 4.9087 & TRN \\
\hline CHEMBL1348890 & 688524 & 5.3 & 4.8465 & TRN \\
\hline
\end{tabular}




\begin{tabular}{|c|c|c|c|c|c|}
\hline CHEMBL1572265 & 688524 & 4.9 & 4.9164 & TRN & \\
\hline CHEMBL3192583 & 688524 & 5.3 & 4.9357 & TST & \\
\hline CHEMBL1320502 & 688524 & 5.2 & 5.0372 & TRN & \\
\hline CHEMBL1539637 & 688524 & 5.0 & 5.155 & TST & \\
\hline CHEMBL1309585 & 688524 & 6.4 & 5.0467 & TST & \\
\hline CHEMBL1588726 & 688524 & 5.2 & 4.8294 & TRN & \\
\hline CHEMBL1598419 & 688524 & 5.0 & 4.9106 & TRN & \\
\hline CHEMBL1559104 & 688524 & 4.5 & 4.8242 & TRN & \\
\hline CHEMBL1545166 & 688524 & 4.6 & 4.8158 & TRN & \\
\hline CHEMBL1607304 & 688524 & 5.5 & 5.1299 & TRN & \\
\hline CHEMBL1572964 & 688524 & 4.7 & 5.0674 & TST & \\
\hline CHEMBL1589415 & 688524 & 4.9 & 4.8403 & TRN & \\
\hline CHEMBL1492655 & 688524 & 4.8 & 4.9981 & TRN & \\
\hline CHEMBL1319897 & 688524 & 4.9 & 4.9453 & TRN & \\
\hline CHEMBL1572363 & 688524 & 4.8 & 5.1494 & TRN & \\
\hline CHEMBL1474724 & 688524 & 4.35 & \multicolumn{2}{|c|}{5.0280000000000005} & TRN \\
\hline CHEMBL1409939 & 688524 & 5.8 & 5.3225 & TRN & \\
\hline CHEMBL1549097 & 688524 & 4.9 & 5.2278 & TRN & \\
\hline CHEMBL1453474 & 688524 & 5.2 & 5.1462 & TRN & \\
\hline CHEMBL276618 & 688524 & 4.7 & 5.0023 & TRN & \\
\hline CHEMBL1337449 & 688524 & 5.4 & 4.8896 & TRN & \\
\hline CHEMBL1337085 & 688524 & 4.6 & 5.2721 & TST & \\
\hline CHEMBL1526240 & 688524 & 5.8 & 5.3059 & TST & \\
\hline CHEMBL1468134 & 688524 & 5.1 & 4.953 & TRN & \\
\hline CHEMBL1360460 & 688524 & 4.9 & 4.9607 & TRN & \\
\hline CHEMBL1514765 & 688524 & 5.9 & 5.3464 & TST & \\
\hline CHEMBL1392208 & 688524 & 4.8 & 4.9631 & TRN & \\
\hline CHEMBL1408476 & 688524 & 7.0 & 4.966 & TRN & \\
\hline CHEMBL1501652 & 688524 & 5.5 & 5.0269 & TRN & \\
\hline CHEMBL1519055 & 688524 & 4.9 & 5.1409 & TST & \\
\hline CHEMBL1418898 & 688524 & 4.9 & 4.7926 & TRN & \\
\hline CHEMBL1433705 & 688524 & 4.9 & 5.1046 & TRN & \\
\hline CHEMBL1448625 & 688524 & 5.1 & 5.0212 & TRN & \\
\hline CHEMBL1478853 & 688524 & 5.4 & 4.931 & TST & \\
\hline CHEMBL1523556 & 688524 & 5.0 & 4.9641 & TRN & \\
\hline CHEMBL1592209 & 688524 & 5.3 & 5.3671 & TRN & \\
\hline CHEMBL259389 & 688524 & 4.8 & 5.0591 & TRN & \\
\hline CHEMBL1535988 & 688524 & 4.8 & 5.0962 & TRN & \\
\hline CHEMBL1304659 & 688524 & 5.0 & 5.0966 & TST & \\
\hline CHEMBL1570641 & 688524 & 5.0 & 5.0014 & TRN & \\
\hline CHEMBL1429464 & 688524 & 5.1 & 4.9317 & TRN & \\
\hline CHEMBL1474684 & 688524 & 5.3 & 5.069 & TST & \\
\hline CHEMBL564664 & 688524 & 4.6 & 4.9257 & TRN & \\
\hline CHEMBL1485101 & 688524 & 5.0 & 5.0759 & TRN & \\
\hline CHEMBL23194 & 688524 & 4.6 & 5.1373 & TST & \\
\hline CHEMBL1565416 & 688524 & 4.9 & 4.9353 & TRN & \\
\hline CHEMBL1407077 & 688524 & 5.0 & 4.9101 & TRN & \\
\hline CHEMBL1517556 & 688524 & 4.45 & 4.9528 & TST & \\
\hline
\end{tabular}




\begin{tabular}{|c|c|c|c|c|c|}
\hline \\
\hline CHEMBL1410495 & 688524 & 4.7 & 4.9067 & & \\
\hline CHEMBL1375862 & 688524 & 5.5 & 5.0546 & TST & \\
\hline CHEMBL1302494 & 688524 & 4.9 & 4.8516 & TRN & \\
\hline CHEMBL1534715 & 688524 & 5.2 & 4.8873 & TRN & \\
\hline CHEMBL1346584 & 688524 & 4.5 & 5.07600 & 00000000005 & TRN \\
\hline CHEMBL1395807 & 688524 & 5.3 & 5.0881 & TST & \\
\hline CHEMBL1602548 & 688524 & 4.5 & 4.9171 & TRN & \\
\hline CHEMBL1546037 & 688524 & 4.7 & 4.9762 & TRN & \\
\hline CHEMBL1602564 & 688524 & 5.0 & 5.0223 & TRN & \\
\hline CHEMBL1363077 & 688524 & 5.4 & 5.4127 & TRN & \\
\hline CHEMBL1378087 & 688524 & 4.7 & 4.803 & TRN & \\
\hline CHEMBL1604241 & 688524 & 4.9 & 5.1439 & TRN & \\
\hline CHEMBL1445274 & 688524 & 4.5 & 5.1391 & TRN & \\
\hline CHEMBL1450805 & 688524 & 5.4 & 5.2018 & TRN & \\
\hline CHEMBL1609339 & 688524 & 5.0 & 4.9628 & TRN & \\
\hline CHEMBL1414251 & 688524 & 5.8 & 5.456 & TRN & \\
\hline CHEMBL1588513 & 688524 & 5.4 & 5.1773 & TRN & \\
\hline CHEMBL1572780 & 688524 & 4.7 & 5.0672 & TRN & \\
\hline CHEMBL1521414 & 688524 & 5.0 & 4.8808 & TRN & \\
\hline CHEMBL1468779 & 688524 & 4.7 & 4.83899 & 99999999995 & TRN \\
\hline CHEMBL1315073 & 688524 & 5.0 & 5.0374 & TRN & \\
\hline CHEMBL1478141 & 688524 & 4.5 & 4.7635 & TRN & \\
\hline CHEMBL26318 & 688524 & 6.0 & 5.1835 & TST & \\
\hline CHEMBL1455570 & 688524 & 5.3 & 5.157 & TRN & \\
\hline CHEMBL1507389 & 688524 & 5.5 & 4.7862 & TRN & \\
\hline CHEMBL1343219 & 688524 & 4.6 & 4.9854 & TRN & \\
\hline CHEMBL1357444 & 688524 & 5.5 & 5.1472 & TRN & \\
\hline CHEMBL1494038 & 688524 & 5.1 & 5.004 & TRN & \\
\hline CHEMBL1417385 & 688524 & 4.6 & 5.0445 & TRN & \\
\hline CHEMBL224214 & 688524 & 4.9 & 4.9756 & TRN & \\
\hline CHEMBL1372504 & 688524 & 5.5 & 5.2222 & TRN & \\
\hline CHEMBL1452967 & 688524 & 5.5 & 5.0899 & TRN & \\
\hline CHEMBL399491 & 688524 & 4.8 & 5.1342 & TST & \\
\hline CHEMBL1550642 & 688524 & 4.8 & 5.1209 & TRN & \\
\hline CHEMBL1351715 & 688524 & 4.8 & 5.119 & TRN & \\
\hline CHEMBL1423013 & 688524 & 4.5 & 4.9887 & TRN & \\
\hline CHEMBL554041 & 688524 & 4.8 & 5.0637 & TST & \\
\hline CHEMBL1554158 & 688524 & 5.8 & 5.4347 & TRN & \\
\hline CHEMBL1556579 & 688524 & 4.9 & 4.7903 & TRN & \\
\hline CHEMBL1312116 & 688524 & 5.5 & 4.9903 & TRN & \\
\hline CHEMBL1516916 & 688524 & 5.0 & 5.112 & TRN & \\
\hline CHEMBL1537626 & 688524 & 6.0 & 5.1996 & TRN & \\
\hline CHEMBL1493554 & 688524 & 4.65 & 4.8975 & TRN & \\
\hline CHEMBL1329017 & 688524 & 4.5 & 5.0191 & TRN & \\
\hline CHEMBL1493290 & 688524 & 4.8 & 4.997 & TRN & \\
\hline CHEMBL468719 & 688524 & 4.6 & 5.1942 & TST & \\
\hline CHEMBL1596248 & 688524 & 4.9 & 4.9955 & TRN & \\
\hline CHEMBL1438073 & 688524 & 4.5 & 4.8392 & TRN & \\
\hline
\end{tabular}




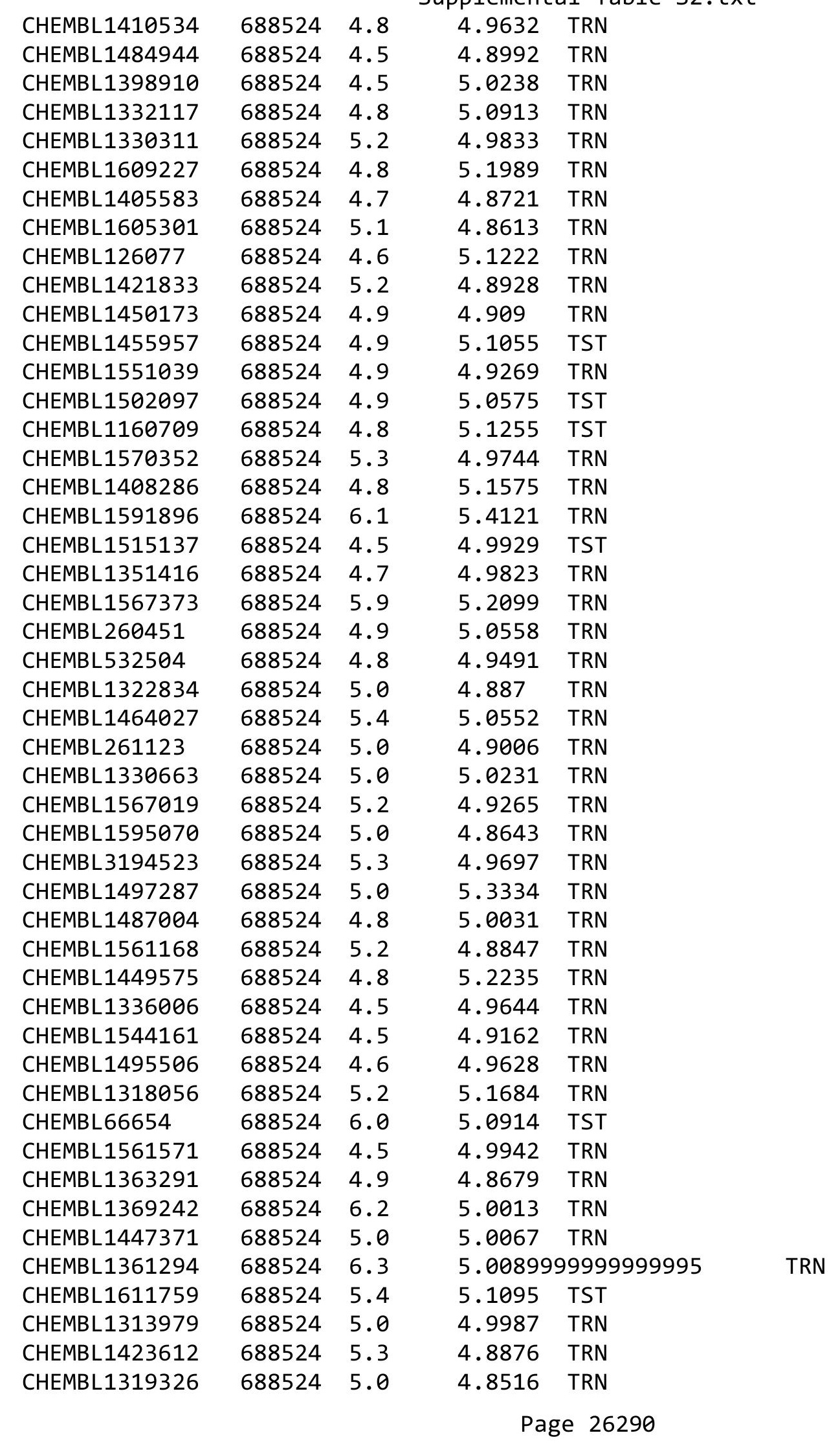




\begin{tabular}{|c|c|c|c|c|c|}
\hline \\
\hline CHEMBL1583952 & 688524 & 5.0 & 5.0245 & TRN & \\
\hline CHEMBL 2146209 & 688524 & 5.9 & 5.0651 & TST & \\
\hline CHEMBL1541213 & 688524 & 5.2 & 4.9527 & TRN & \\
\hline CHEMBL1310041 & 688524 & 5.0 & 5.0631 & TRN & \\
\hline CHEMBL1313273 & 688524 & 5.3 & 4.936 & TRN & \\
\hline CHEMBL75267 & 688524 & 4.5 & 5.0999 & TRN & \\
\hline CHEMBL264931 & 688524 & 5.3 & 5.0711 & TRN & \\
\hline CHEMBL1603580 & 688524 & 4.8 & 4.7271 & TRN & \\
\hline CHEMBL1577029 & 688524 & 4.7 & 5.0229 & TRN & \\
\hline CHEMBL1519997 & 688524 & 5.3 & 5.1042 & TST & \\
\hline CHEMBL468590 & 688524 & 4.8 & 5.0662 & TRN & \\
\hline CHEMBL1516883 & 688524 & 4.9 & 4.7703 & TRN & \\
\hline CHEMBL1344681 & 688524 & 4.9 & 4.9014 & TRN & \\
\hline CHEMBL1547096 & 688524 & 4.5 & 5.0294 & TST & \\
\hline CHEMBL589207 & 688524 & 4.8 & 4.8784 & TRN & \\
\hline CHEMBL1546669 & 688524 & 4.9 & 4.9256 & TRN & \\
\hline CHEMBL1410552 & 688524 & 4.55 & 4.9221 & TRN & \\
\hline CHEMBL229012 & 688524 & 4.9 & 4.9492 & TRN & \\
\hline CHEMBL1377449 & 688524 & 4.5 & 5.0412 & TRN & \\
\hline CHEMBL1456751 & 688524 & 4.9 & 4.8656 & TRN & \\
\hline CHEMBL1464657 & 688524 & 4.8 & 4.8235 & TRN & \\
\hline CHEMBL1466104 & 688524 & 4.9 & 4.8939 & TRN & \\
\hline CHEMBL1492918 & 688524 & 4.9 & 5.1364 & TRN & \\
\hline CHEMBL1562990 & 688524 & 5.3 & 4.8128 & TRN & \\
\hline CHEMBL1400666 & 688524 & 4.6 & 5.0799 & TRN & \\
\hline CHEMBL1313627 & 688524 & 4.9 & 4.9681 & TRN & \\
\hline CHEMBL1364871 & 688524 & 7.3002 & 5.5261 & TRN & \\
\hline CHEMBL1548335 & 688524 & 5.5 & $4.9910 e$ & 30000000005 & TRN \\
\hline CHEMBL1399952 & 688524 & 6.2 & 5.1418 & TRN & \\
\hline CHEMBL1358961 & 688524 & 5.2 & 4.852 & TST & \\
\hline CHEMBL1499043 & 688524 & 4.6 & 5.0104 & TRN & \\
\hline CHEMBL1603946 & 688524 & 4.7 & 5.0442 & TST & \\
\hline CHEMBL1583063 & 688524 & 5.4 & 5.1249 & TRN & \\
\hline CHEMBL1315716 & 688524 & 4.5 & 5.1513 & TRN & \\
\hline CHEMBL1510945 & 688524 & 4.9 & 4.9108 & TRN & \\
\hline CHEMBL1438585 & 688524 & 4.5 & 5.1202 & TRN & \\
\hline CHEMBL1256656 & 688524 & 4.8 & 4.6879 & TRN & \\
\hline CHEMBL1423940 & 688524 & 5.0 & 4.8512 & TRN & \\
\hline CHEMBL131199 & 688524 & 5.2 & 5.2308 & TRN & \\
\hline CHEMBL1439295 & 688524 & 4.6 & 4.8296 & TRN & \\
\hline CHEMBL1499028 & 688524 & 4.9 & 4.7908 & TRN & \\
\hline CHEMBL1355010 & 688524 & 4.5 & 5.1064 & TRN & \\
\hline CHEMBL1420306 & 688524 & 5.0 & 5.0071 & TRN & \\
\hline CHEMBL1487784 & 688524 & 4.9 & 5.0476 & TRN & \\
\hline CHEMBL1372701 & 688524 & 4.8 & 5.0435 & TRN & \\
\hline CHEMBL1475257 & 688524 & 5.4 & 5.1138 & TRN & \\
\hline CHEMBL1609075 & 688524 & 4.5 & 4.9321 & TST & \\
\hline CHEMBL1395564 & 688524 & 5.3 & 5.1018 & TRN & \\
\hline & & & & 62 & \\
\hline
\end{tabular}




\begin{tabular}{|c|c|c|c|c|}
\hline & & & & al lable s \\
\hline CHEMBL515505 & 688524 & 5.3 & 5.2292 & TST \\
\hline CHEMBL1381328 & 688524 & 5.0 & 5.1047 & TRN \\
\hline CHEMBL1593199 & 688524 & 5.2 & 5.1519 & TRN \\
\hline CHEMBL1362096 & 688524 & 4.5 & 4.8527 & TST \\
\hline CHEMBL1571461 & 688524 & 5.0 & 5.0513 & TRN \\
\hline CHEMBL1611496 & 688524 & 6.0 & 5.2336 & TRN \\
\hline CHEMBL1300505 & 688524 & 4.9 & 4.9453 & TRN \\
\hline CHEMBL1327137 & 688524 & 4.5 & 4.9364 & TRN \\
\hline CHEMBL1499433 & 688524 & 4.8 & 4.79 & TRN \\
\hline CHEMBL1482184 & 688524 & 4.8 & 5.0758 & TST \\
\hline CHEMBL1607987 & 688524 & 5.9 & 4.8496 & TRN \\
\hline CHEMBL1373816 & 688524 & 4.9 & 4.9634 & TRN \\
\hline CHEMBL1556431 & 688524 & 4.7 & 4.9768 & TRN \\
\hline CHEMBL1330911 & 688524 & 4.8 & 5.0366 & TRN \\
\hline CHEMBL1535040 & 688524 & 5.4 & 5.1226 & TRN \\
\hline CHEMBL1319080 & 688524 & 5.2 & 4.8363 & TRN \\
\hline CHEMBL1576586 & 688524 & 5.4 & 5.284 & TRN \\
\hline CHEMBL1487152 & 688524 & 4.8 & 4.7902 & TRN \\
\hline CHEMBL 221300 & 688524 & 4.8 & 5.0906 & TRN \\
\hline CHEMBL1375233 & 688524 & 4.5 & 5.0208 & TRN \\
\hline CHEMBL1565133 & 688524 & 5.4 & 5.1399 & TST \\
\hline CHEMBL1452380 & 688524 & 4.5 & 4.9278 & TRN \\
\hline CHEMBL1392454 & 688524 & 5.0 & 4.938 & TST \\
\hline CHEMBL1371762 & 688524 & 5.9 & 5.2059 & TRN \\
\hline CHEMBL3192631 & 688524 & 5.0 & 5.0014 & TRN \\
\hline CHEMBL1524484 & 688524 & 5.6 & 5.1569 & TRN \\
\hline CHEMBL1395567 & 688524 & 5.3 & 5.1979 & TRN \\
\hline CHEMBL1395128 & 688524 & 5.4 & 5.3147 & TST \\
\hline CHEMBL1312502 & 688524 & 5.4 & 4.7787 & TRN \\
\hline CHEMBL1590645 & 688524 & 5.5 & 5.0133 & TRN \\
\hline CHEMBL1487166 & 688524 & 5.3 & 5.0512 & TST \\
\hline CHEMBL1487859 & 688524 & 4.9 & 5.0013 & TRN \\
\hline CHEMBL1256291 & 688524 & 4.5 & 5.2002 & TRN \\
\hline CHEMBL1564246 & 688524 & 5.0 & 4.8662 & TRN \\
\hline CHEMBL1370428 & 688524 & 5.0 & 4.9877 & TRN \\
\hline CHEMBL1605430 & 688524 & 5.3 & 5.0804 & TRN \\
\hline CHEMBL1315457 & 688524 & 4.8 & 5.0538 & TST \\
\hline CHEMBL1559822 & 688524 & 5.3 & 5.0559 & TRN \\
\hline CHEMBL1383970 & 688524 & 5.4 & 4.8276 & TRN \\
\hline CHEMBL1495155 & 688524 & 5.0 & 4.9255 & TRN \\
\hline CHEMBL1425919 & 688524 & 5.3 & 4.8816 & TRN \\
\hline CHEMBL1366946 & 688524 & 7.4001 & 4.8955 & TST \\
\hline CHEMBL1317823 & 688524 & 4.9 & 5.0569 & TRN \\
\hline CHEMBL1488131 & 688524 & 5.2 & 5.0574 & TST \\
\hline CHEMBL1550178 & 688524 & 4.8 & 5.00899 & 99999999995 \\
\hline CHEMBL1515194 & 688524 & 4.9 & 5.1 & TRN \\
\hline CHEMBL1492520 & 688524 & 5.0 & 4.8634 & TRN \\
\hline CHEMBL1555702 & 688524 & 4.9 & 4.9139 & TRN \\
\hline
\end{tabular}




\begin{tabular}{|c|c|c|c|c|}
\hline \multicolumn{5}{|c|}{ Supplemental Table S2.txt } \\
\hline CHEMBL1554659 & 688524 & 4.7 & 5.1566 & TRN \\
\hline CHEMBL1455438 & 688524 & 4.5 & 5.0398 & TRN \\
\hline CHEMBL1349500 & 688524 & 4.9 & 5.0749 & TRN \\
\hline CHEMBL1336496 & 688524 & 4.9 & 4.9394 & TRN \\
\hline CHEMBL1474402 & 688524 & 4.5 & 5.5481 & TRN \\
\hline CHEMBL1300587 & 688524 & 5.4 & 4.9654 & TST \\
\hline CHEMBL1302106 & 688524 & 4.9 & 4.8463 & TRN \\
\hline CHEMBL1304015 & 688524 & 4.9 & 5.0379 & TRN \\
\hline CHEMBL1329268 & 688524 & 4.9 & 4.9804 & TRN \\
\hline CHEMBL1547051 & 688524 & 5.0 & 5.0153 & TRN \\
\hline CHEMBL1398171 & 688524 & 4.9 & 5.1228 & TRN \\
\hline CHEMBL1453313 & 688524 & 5.0 & 4.9128 & TRN \\
\hline CHEMBL1375166 & 688524 & 4.9 & 5.1304 & TRN \\
\hline CHEMBL1349215 & 688524 & 4.9 & 4.894 & TRN \\
\hline CHEMBL1329340 & 688524 & 5.3 & 4.9234 & TRN \\
\hline CHEMBL1329091 & 688524 & 4.9 & 4.9404 & TRN \\
\hline CHEMBL1360151 & 688524 & 5.5 & 5.2195 & TRN \\
\hline CHEMBL468167 & 688524 & 6.2 & 5.12 & TST \\
\hline CHEMBL1472246 & 688524 & 5.0 & 5.1772 & TRN \\
\hline CHEMBL175858 & 688524 & 7.4001 & 5.1903 & TST \\
\hline CHEMBL1518745 & 688524 & 5.0 & 5.1102 & TRN \\
\hline CHEMBL1509119 & 688524 & 4.5 & 5.0677 & TRN \\
\hline CHEMBL1606645 & 688524 & 4.9 & 5.0267 & TST \\
\hline CHEMBL1395431 & 688524 & 5.3 & 5.2211 & TRN \\
\hline CHEMBL1462568 & 688524 & 4.5 & 5.0274 & TST \\
\hline CHEMBL1529661 & 688524 & 5.3 & 4.9498 & TST \\
\hline CHEMBL1378830 & 688524 & 4.9 & 5.0235 & TRN \\
\hline CHEMBL1511639 & 688524 & 5.0 & 4.87 & TRN \\
\hline CHEMBL1321751 & 688524 & 4.9 & 4.9962 & TRN \\
\hline CHEMBL1342602 & 688524 & 5.3 & 4.9763 & TRN \\
\hline CHEMBL1304816 & 688524 & 5.2 & 5.0494 & TRN \\
\hline CHEMBL1451690 & 688524 & 5.3 & 5.0438 & TRN \\
\hline CHEMBL1208858 & 688524 & 4.9 & 4.8862 & TST \\
\hline CHEMBL1450653 & 688524 & 5.0 & 5.0494 & TRN \\
\hline CHEMBL1357894 & 688524 & 5.2 & 5.1039 & TST \\
\hline CHEMBL1591080 & 688524 & 4.5 & 4.8929 & TRN \\
\hline CHEMBL3192253 & 688524 & 4.9 & 5.0673 & TRN \\
\hline CHEMBL1534844 & 688524 & 5.2 & 4.9264 & TST \\
\hline CHEMBL1318988 & 688524 & 5.0 & 4.8716 & TRN \\
\hline CHEMBL1506743 & 688524 & 5.0 & 4.9666 & TRN \\
\hline CHEMBL1336808 & 688524 & 5.3 & 4.9726 & TRN \\
\hline CHEMBL1351257 & 688524 & 4.7 & 5.0004 & TRN \\
\hline CHEMBL1349067 & 688524 & 6.0 & 4.9944 & TRN \\
\hline CHEMBL1391304 & 688524 & 4.9 & 5.0206 & TRN \\
\hline CHEMBL54804 & 688524 & 6.0 & 5.1671 & TST \\
\hline CHEMBL1235001 & 688524 & 5.3 & 5.1002 & TRN \\
\hline CHEMBL1487735 & 688524 & 4.8 & 5.0718 & TRN \\
\hline CHEMBL1449642 & 688524 & 4.7 & 4.8442 & TRN \\
\hline
\end{tabular}




\begin{tabular}{|c|c|c|c|c|}
\hline & & & & al lable \\
\hline CHEMBL1372129 & 688524 & 4.5 & 4.8469 & TRN \\
\hline CHEMBL1534466 & 688524 & 5.0 & 5.2979 & TRN \\
\hline CHEMBL1370787 & 688524 & 4.8 & 4.8566 & TRN \\
\hline CHEMBL1350860 & 688524 & 4.9 & 4.888 & TRN \\
\hline CHEMBL1467557 & 688524 & 4.9 & 5.0486 & TRN \\
\hline CHEMBL1214345 & 688524 & 4.9 & 4.823 & TRN \\
\hline CHEMBL1541384 & 688524 & 5.5 & 5.2695 & TRN \\
\hline CHEMBL1429106 & 688524 & 4.8 & 4.9616 & TRN \\
\hline CHEMBL1727680 & 688524 & 5.3 & 5.1156 & TRN \\
\hline CHEMBL1506412 & 688524 & 5.5 & 5.0962 & TRN \\
\hline CHEMBL1536089 & 688524 & 5.0 & 4.9033 & TRN \\
\hline CHEMBL1417492 & 688524 & 4.6 & 4.9345 & TRN \\
\hline CHEMBL1442269 & 688524 & 5.3 & 4.9792 & TRN \\
\hline CHEMBL1560928 & 688524 & 4.6 & 4.8345 & TRN \\
\hline CHEMBL1527221 & 688524 & 4.7 & 5.3733 & TRN \\
\hline CHEMBL3209065 & 688524 & 5.0 & 4.9895 & TRN \\
\hline CHEMBL1473752 & 688524 & 5.2 & 5.0616 & TRN \\
\hline CHEMBL1602759 & 688524 & 5.0 & 5.0644 & TRN \\
\hline CHEMBL1527750 & 688524 & 5.2 & $5.0310 e$ & 0000000001 \\
\hline CHEMBL1386855 & 688524 & 4.7 & 5.2384 & TRN \\
\hline CHEMBL 3197801 & 688524 & 4.6 & 4.938 & TRN \\
\hline CHEMBL1537937 & 688524 & 4.8 & 5.0985 & TRN \\
\hline CHEMBL1452382 & 688524 & 5.0 & 4.7543 & TRN \\
\hline CHEMBL1531998 & 688524 & 5.0 & 4.953 & TRN \\
\hline CHEMBL1609140 & 688524 & 5.2 & 4.8918 & TRN \\
\hline CHEMBL1308694 & 688524 & 4.7 & 4.8789 & TRN \\
\hline CHEMBL1413924 & 688524 & 4.9 & 4.8362 & TRN \\
\hline CHEMBL1384306 & 688524 & 4.8 & 4.9973 & TRN \\
\hline CHEMBL1484854 & 688524 & 4.8 & 4.8478 & TRN \\
\hline CHEMBL1325865 & 688524 & 4.9 & 5.0812 & TRN \\
\hline CHEMBL1464447 & 688524 & 4.9 & 5.0143 & TRN \\
\hline CHEMBL1451013 & 688524 & 4.7 & 5.0552 & TST \\
\hline CHEMBL1496640 & 688524 & 4.9 & 4.9291 & TRN \\
\hline CHEMBL1558529 & 688524 & 4.5 & 4.9236 & TRN \\
\hline CHEMBL1158 & 688524 & 4.9 & 5.1412 & TST \\
\hline CHEMBL1489281 & 688524 & 4.9 & 4.8657 & TRN \\
\hline CHEMBL1460256 & 688524 & 4.6 & 4.9069 & TRN \\
\hline CHEMBL1302822 & 688524 & 5.0 & 4.8286 & TRN \\
\hline CHEMBL492010 & 688524 & 4.9 & 5.2022 & TRN \\
\hline CHEMBL1439313 & 688524 & 4.9 & 5.0195 & TRN \\
\hline CHEMBL1399096 & 688524 & 5.1 & 5.1912 & TST \\
\hline CHEMBL1489064 & 688524 & 4.9 & 5.1091 & TST \\
\hline CHEMBL1364205 & 688524 & 4.5 & 4.8366 & TRN \\
\hline CHEMBL1571950 & 688524 & 4.7 & 5.215 & TRN \\
\hline CHEMBL1531056 & 688524 & 5.3 & 5.2393 & TRN \\
\hline CHEMBL1324157 & 688524 & 5.0 & 4.8254 & TRN \\
\hline CHEMBL1568071 & 688524 & 5.3 & 5.0357 & TST \\
\hline CHEMBL1558607 & 688524 & 4.7 & 5.164 & TRN \\
\hline
\end{tabular}




\begin{tabular}{|c|c|c|c|c|}
\hline \\
\hline CHEMBL1611487 & 688524 & 5.3 & 5.1288 & TRN \\
\hline CHEMBL1488592 & 688524 & 4.9 & 4.8905 & TRN \\
\hline CHEMBL1604333 & 688524 & 5.3 & 5.02 & TRN \\
\hline CHEMBL1407095 & 688524 & 5.0 & 4.867 & TRN \\
\hline CHEMBL1319037 & 688524 & 4.9 & 4.9072 & TRN \\
\hline CHEMBL1352008 & 688524 & 4.7 & 5.0211 & TRN \\
\hline CHEMBL1595371 & 688524 & 5.4 & 5.0843 & TRN \\
\hline CHEMBL1384101 & 688524 & 4.5 & 5.0593 & TRN \\
\hline CHEMBL1307790 & 688524 & 4.6 & 4.9248 & TRN \\
\hline CHEMBL34450 & 688524 & 5.1 & 5.1034 & TST \\
\hline CHEMBL445969 & 688524 & 5.4 & 5.1385 & TST \\
\hline CHEMBL1390802 & 688524 & 4.9 & 5.0941 & TRN \\
\hline CHEMBL1467362 & 688524 & 5.0 & 5.0985 & TST \\
\hline CHEMBL1498759 & 688524 & 4.6 & 5.1603 & TRN \\
\hline CHEMBL1423455 & 688524 & 4.6 & 4.9025 & TRN \\
\hline CHEMBL1324794 & 688524 & 4.9 & 4.9445 & TRN \\
\hline CHEMBL1579670 & 688524 & 4.8 & 4.816 & TRN \\
\hline CHEMBL1474151 & 688524 & 4.5 & 5.2976 & TRN \\
\hline CHEMBL1569916 & 688524 & 5.4 & 4.9143 & TST \\
\hline CHEMBL1413699 & 688524 & 6.0 & 5.011 & TRN \\
\hline CHEMBL1442562 & 688524 & 4.8 & 4.8527 & TRN \\
\hline CHEMBL1323791 & 688524 & 5.0 & 5.1476 & TRN \\
\hline CHEMBL1564824 & 688524 & 4.5 & 4.9604 & TRN \\
\hline CHEMBL1339860 & 688524 & 4.9 & 4.9526 & TRN \\
\hline CHEMBL1340747 & 688524 & 4.7 & 4.9596 & TRN \\
\hline CHEMBL1375740 & 688524 & 5.9 & 5.0622 & TRN \\
\hline CHEMBL1332948 & 688524 & 5.3 & 5.0274 & TST \\
\hline CHEMBL3214589 & 688524 & 4.5 & 4.9024 & TST \\
\hline CHEMBL1608049 & 688524 & 5.0 & 5.0178 & TRN \\
\hline CHEMBL1420358 & 688524 & 5.0 & 4.783 & TRN \\
\hline CHEMBL1368418 & 688524 & 4.8 & 4.7728 & TRN \\
\hline CHEMBL408563 & 688524 & 5.0 & 5.1372 & TRN \\
\hline CHEMBL1334277 & 688524 & 5.9 & 5.0233 & TRN \\
\hline CHEMBL3197611 & 688524 & 4.5 & 5.0441 & TST \\
\hline CHEMBL443954 & 688524 & 5.5 & 5.3458 & TST \\
\hline CHEMBL1401735 & 688524 & 4.9 & 5.086 & TRN \\
\hline CHEMBL1363246 & 688524 & 4.8 & 5.0592 & TRN \\
\hline CHEMBL1383856 & 688524 & 4.9 & 4.8595 & TRN \\
\hline CHEMBL1507425 & 688524 & 5.2 & 5.048 & TRN \\
\hline CHEMBL1605749 & 688524 & 4.9 & 4.8616 & TRN \\
\hline CHEMBL1304870 & 688524 & 4.5 & 4.8566 & TRN \\
\hline CHEMBL65 & 688524 & 6.5 & $5.0360 e$ & 00000000005 \\
\hline CHEMBL1540711 & 688524 & 4.9 & 4.9885 & TRN \\
\hline CHEMBL193888 & 688524 & 5.0 & 5.1214 & TRN \\
\hline CHEMBL1345546 & 688524 & 5.3 & 5.0233 & TRN \\
\hline CHEMBL1538689 & 688524 & 4.6 & 5.0122 & TRN \\
\hline CHEMBL 280822 & 688524 & 6.0 & 4.9439 & TST \\
\hline CHEMBL1384001 & 688524 & 5.3 & 5.0128 & TST \\
\hline
\end{tabular}




\begin{tabular}{|c|c|c|c|c|}
\hline \multicolumn{5}{|c|}{ Supplemental Table s2.txt } \\
\hline CHEMBL198759 & 688524 & 4.9 & 4.9155 & TST \\
\hline CHEMBL1382277 & 688524 & 4.9 & 4.9836 & TRN \\
\hline CHEMBL1353493 & 688524 & 4.6 & 5.2306 & TST \\
\hline CHEMBL1348502 & 688524 & 5.0 & 5.1044 & TRN \\
\hline CHEMBL1506442 & 688524 & 4.9 & 4.9373 & TRN \\
\hline CHEMBL1449918 & 688524 & 6.1 & 5.0861 & TST \\
\hline CHEMBL1568028 & 688524 & 4.6 & 4.8888 & TRN \\
\hline CHEMBL1470984 & 688524 & 4.7 & 4.9257 & TRN \\
\hline CHEMBL1316156 & 688524 & 4.8 & 5.1129 & TRN \\
\hline CHEMBL1341122 & 688524 & 4.6 & 4.9326 & TST \\
\hline CHEMBL1612125 & 688524 & 5.0 & 5.0423 & TRN \\
\hline CHEMBL1359723 & 688524 & 4.9 & 5.056 & TRN \\
\hline CHEMBL1595629 & 688524 & 5.5 & 5.0115 & TRN \\
\hline CHEMBL601968 & 688524 & 4.9 & 5.0875 & TRN \\
\hline CHEMBL1477856 & 688524 & 4.8 & 4.7683 & TRN \\
\hline CHEMBL1388106 & 688524 & 5.4 & 4.8845 & TRN \\
\hline CHEMBL1466452 & 688524 & 4.5 & 4.9904 & TRN \\
\hline CHEMBL1308955 & 688524 & 5.0 & 5.0105 & TRN \\
\hline CHEMBL1409150 & 688524 & 5.5 & 5.0722 & TRN \\
\hline CHEMBL1969353 & 688524 & 4.8 & 4.971 & TST \\
\hline CHEMBL1527656 & 688524 & 5.1 & 4.9094 & TRN \\
\hline CHEMBL1430634 & 688524 & 5.3 & 5.0617 & TRN \\
\hline CHEMBL 2001481 & 688524 & 5.0 & 5.1506 & TRN \\
\hline CHEMBL1390831 & 688524 & 5.0 & 4.9958 & TRN \\
\hline CHEMBL1490792 & 688524 & 4.9 & 5.013 & TRN \\
\hline CHEMBL1444429 & 688524 & 4.9 & 4.9554 & TST \\
\hline CHEMBL1518866 & 688524 & 5.2 & 5.2224 & TRN \\
\hline CHEMBL1505651 & 688524 & 4.9 & 5.0979 & TRN \\
\hline CHEMBL1344731 & 688524 & 5.1 & 5.029 & TRN \\
\hline CHEMBL1330278 & 688524 & 4.5 & 4.8974 & TRN \\
\hline CHEMBL1518159 & 688524 & 5.0 & 4.9413 & TRN \\
\hline CHEMBL1319881 & 688524 & 4.5 & 5.1679 & TST \\
\hline CHEMBL1973226 & 688524 & 4.6 & 5.1073 & TRN \\
\hline CHEMBL1364791 & 688524 & 5.8 & 5.0846 & TRN \\
\hline CHEMBL1416282 & 688524 & 5.4 & 4.9486 & TRN \\
\hline CHEMBL1515858 & 688524 & 4.5 & 5.0993 & TRN \\
\hline CHEMBL1439893 & 688524 & 5.3 & 5.2279 & TRN \\
\hline CHEMBL1445157 & 688524 & 4.7 & 4.8536 & TRN \\
\hline CHEMBL1436507 & 688524 & 5.3 & 5.0621 & TRN \\
\hline CHEMBL430266 & 688524 & 9.0969 & 5.2615 & TST \\
\hline CHEMBL1565272 & 688524 & 4.7 & 4.8987 & TRN \\
\hline CHEMBL1601364 & 688524 & 5.0 & 4.8318 & TRN \\
\hline CHEMBL1605564 & 688524 & 4.8 & 4.8763 & TRN \\
\hline CHEMBL1486831 & 688524 & 5.0 & 5.1397 & TRN \\
\hline CHEMBL1599378 & 688524 & 6.8 & 5.2236 & TRN \\
\hline CHEMBL1435032 & 688524 & 4.5 & 5.4647 & TRN \\
\hline CHEMBL1561564 & 688524 & 4.9 & 5.0494 & TRN \\
\hline CHEMBL1531277 & 688524 & 5.0 & 5.046 & TRN \\
\hline
\end{tabular}




\begin{tabular}{|c|c|c|c|c|}
\hline & & & & al \\
\hline CHEMBL1335633 & 688524 & 4.9 & 5.0599 & TRN \\
\hline CHEMBL1426586 & 688524 & 4.5 & 4.9228 & TRN \\
\hline CHEMBL1379677 & 688524 & 4.5 & 5.1794 & TRN \\
\hline CHEMBL1310986 & 688524 & 4.9 & 4.9063 & TRN \\
\hline CHEMBL1441052 & 688524 & 5.5 & 5.3043 & TRN \\
\hline CHEMBL1356744 & 688524 & 4.8 & 5.145 & TRN \\
\hline CHEMBL1465252 & 688524 & 5.5 & 5.038 & TRN \\
\hline CHEMBL1357850 & 688524 & 5.2 & 5.3691 & TRN \\
\hline CHEMBL1502359 & 688524 & 4.8 & 4.8267 & TRN \\
\hline CHEMBL1991885 & 688524 & 5.0 & 5.0488 & TRN \\
\hline CHEMBL1435409 & 688524 & 5.1 & 5.2895 & TRN \\
\hline CHEMBL1332808 & 688524 & 4.5 & 5.1685 & TRN \\
\hline CHEMBL1414021 & 688524 & 5.3 & 4.9386 & TRN \\
\hline CHEMBL1584663 & 688524 & 4.9 & 4.9323 & TRN \\
\hline CHEMBL1433228 & 688524 & 4.7 & 4.9511 & TRN \\
\hline CHEMBL3197626 & 688524 & 5.5 & 5.0937 & TRN \\
\hline CHEMBL1535025 & 688524 & 4.5 & 4.8711 & TRN \\
\hline CHEMBL1605926 & 688524 & 5.0 & 4.9523 & TRN \\
\hline CHEMBL1476939 & 688524 & 5.4 & 5.1061 & TST \\
\hline CHEMBL1327950 & 688524 & 4.9 & 5.011 & TRN \\
\hline CHEMBL1377923 & 688524 & 5.0 & 5.0543 & TST \\
\hline CHEMBL1491330 & 688524 & 5.6 & 5.1406 & TRN \\
\hline CHEMBL1333617 & 688524 & 4.9 & 4.9495 & TRN \\
\hline CHEMBL1346702 & 688524 & 5.0 & 5.0309 & TRN \\
\hline CHEMBL1411867 & 688524 & 4.5 & 5.2272 & TST \\
\hline CHEMBL1505732 & 688524 & 4.5 & 5.0963 & TST \\
\hline CHEMBL1500317 & 688524 & 4.5 & 4.9559 & TRN \\
\hline CHEMBL1490320 & 688524 & 5.6 & 5.0818 & TRN \\
\hline CHEMBL3198492 & 688524 & 4.8 & 4.9345 & TRN \\
\hline CHEMBL77030 & 688524 & 4.5 & 5.1093 & TRN \\
\hline CHEMBL1408676 & 688524 & 4.9 & 4.8811 & TRN \\
\hline CHEMBL1481378 & 688524 & 7.0 & 5.0303 & TST \\
\hline CHEMBL1320722 & 688524 & 5.3 & 5.1489 & TRN \\
\hline CHEMBL1592793 & 688524 & 4.9 & 5.0362 & TST \\
\hline CHEMBL1514276 & 688524 & 4.9 & 4.9705 & TST \\
\hline CHEMBL1592160 & 688524 & 5.1 & 4.7559 & TRN \\
\hline CHEMBL1320219 & 688524 & 5.4 & 4.8138 & TRN \\
\hline CHEMBL1347065 & 688524 & 4.9 & 4.9406 & TRN \\
\hline CHEMBL1398425 & 688524 & 4.5 & 5.1532 & TRN \\
\hline CHEMBL1517237 & 688524 & 5.3 & 4.9033 & TRN \\
\hline CHEMBL1421605 & 688524 & 4.5 & 5.1547 & TRN \\
\hline CHEMBL1375911 & 688524 & 5.0 & 4.8815 & TST \\
\hline CHEMBL1574559 & 688524 & 5.1 & 4.9089 & TRN \\
\hline CHEMBL1426233 & 688524 & 4.7 & 4.8798 & TST \\
\hline CHEMBL1304063 & 688524 & 5.5 & 4.9991 & TRN \\
\hline CHEMBL1531413 & 688524 & 4.5 & 4.8804 & TRN \\
\hline CHEMBL 328710 & 688524 & 6.0 & 5.1406 & TST \\
\hline CHEMBL1551841 & 688524 & 5.4 & 5.0784 & TRN \\
\hline
\end{tabular}




\begin{tabular}{|c|c|c|c|c|c|}
\hline \multicolumn{6}{|c|}{ Supplemental Table S2.txt } \\
\hline CHEMBL134291 & 688524 & 4.8 & 4.9475 & TRN & \\
\hline CHEMBL1408170 & 688524 & 5.0 & 5.05 & TRN & \\
\hline CHEMBL1570245 & 688524 & 4.5 & 4.9193 & TST & \\
\hline CHEMBL1427986 & 688524 & 4.5 & 4.9081 & TRN & \\
\hline CHEMBL1352498 & 688524 & 5.2 & 5.1181 & TRN & \\
\hline CHEMBL1417025 & 688524 & 5.4 & 5.081 & TRN & \\
\hline CHEMBL1533296 & 688524 & 5.3 & 5.0471 & TRN & \\
\hline CHEMBL1427972 & 688524 & 5.2 & 5.2205 & TRN & \\
\hline CHEMBL267160 & 688524 & 4.9 & 5.0561 & TRN & \\
\hline CHEMBL1578190 & 688524 & 4.9 & 4.8813 & TRN & \\
\hline CHEMBL1568060 & 688524 & 4.9 & 5.039 & TRN & \\
\hline CHEMBL243677 & 688524 & 4.7 & 5.069 & TRN & \\
\hline CHEMBL1314906 & 688524 & 5.2 & 5.1516 & TRN & \\
\hline CHEMBL3197924 & 688524 & 4.8 & 4.8714 & TRN & \\
\hline CHEMBL3194052 & 688524 & 5.1 & 4.9228 & TST & \\
\hline CHEMBL143703 & 688524 & 4.9 & 5.1364 & TRN & \\
\hline CHEMBL1525805 & 688524 & 4.5 & 5.0805 & TRN & \\
\hline CHEMBL1444479 & 688524 & 4.5 & 4.9826 & TST & \\
\hline CHEMBL1604474 & 688524 & 5.3 & 4.8186 & TRN & \\
\hline CHEMBL1351433 & 688524 & 5.4 & 5.0665 & TRN & \\
\hline CHEMBL1584108 & 688524 & 4.6 & 4.9573 & TRN & \\
\hline CHEMBL530361 & 688524 & 4.7 & 5.1552 & TST & \\
\hline CHEMBL1448066 & 688524 & 4.9 & 4.7624 & TRN & \\
\hline CHEMBL1597692 & 688524 & 5.4 & 4.9744 & TST & \\
\hline CHEMBL1332515 & 688524 & 5.5 & 5.0504 & TRN & \\
\hline CHEMBL1306412 & 688524 & 4.9 & 4.8754 & TRN & \\
\hline CHEMBL1558102 & 688524 & 4.5 & 4.9873 & TRN & \\
\hline CHEMBL429095 & 688524 & 6.0 & 5.1634 & TST & \\
\hline CHEMBL1496611 & 688524 & 4.7 & 4.9447 & TRN & \\
\hline CHEMBL1530839 & 688524 & 4.9 & 5.0237 & TRN & \\
\hline CHEMBL1540570 & 688524 & 4.7 & 5.0917 & TRN & \\
\hline CHEMBL1544224 & 688524 & 4.5 & 4.9423 & TST & \\
\hline CHEMBL1362370 & 688524 & 4.9 & 4.8959 & TRN & \\
\hline CHEMBL472839 & 688524 & 4.7 & 4.8621 & TRN & \\
\hline CHEMBL1479729 & 688524 & 4.7 & 4.8062 & TRN & \\
\hline CHEMBL1315373 & 688524 & 4.5 & 5.1809 & TRN & \\
\hline CHEMBL1337753 & 688524 & 4.6 & 5.0431 & TRN & \\
\hline CHEMBL1415858 & 688524 & 4.5 & 4.8864 & TRN & \\
\hline CHEMBL1562104 & 688524 & 4.9 & 4.9325 & TST & \\
\hline CHEMBL1494040 & 688524 & 5.5 & 5.1619 & TRN & \\
\hline CHEMBL1552187 & 688524 & 5.3 & 5.3013 & TRN & \\
\hline CHEMBL1522344 & 688524 & 5.0 & 4.9227 & TRN & \\
\hline CHEMBL1549591 & 688524 & 4.6 & 5.1348 & TRN & \\
\hline CHEMBL354676 & 688524 & 4.9 & 5.0266 & TRN & \\
\hline CHEMBL1477057 & 688524 & 5.0 & $5.0360 e$ & 00000000005 & TRN \\
\hline CHEMBL1547623 & 688524 & 4.8 & 4.9919 & TRN & \\
\hline CHEMBL1495693 & 688524 & 4.5 & 4.9727 & TRN & \\
\hline CHEMBL579503 & 688524 & 4.9 & 4.9193 & TRN & \\
\hline
\end{tabular}


Supplemental Table S2.txt

\begin{tabular}{|c|c|c|c|c|c|}
\hline CHEMBL1256655 & 688524 & 6.7001 & 5.2747 & TRN & \\
\hline CHEMBL1490135 & 688524 & 5.5 & 5.4263 & TRN & \\
\hline CHEMBL1453083 & 688524 & 5.7 & 5.2125 & TRN & \\
\hline CHEMBL1604523 & 688524 & 4.8 & 5.1118 & TST & \\
\hline CHEMBL1534413 & 688524 & 5.0 & 4.9924 & TRN & \\
\hline CHEMBL1324569 & 688524 & 5.9 & 5.0677 & TRN & \\
\hline CHEMBL1381824 & 688524 & 5.5 & 4.917 & TRN & \\
\hline CHEMBL1353364 & 688524 & 4.6 & 5.0396 & TST & \\
\hline CHEMBL1500986 & 688524 & 5.7 & 5.1095 & TRN & \\
\hline CHEMBL1548388 & 688524 & 5.4 & 4.9445 & TRN & \\
\hline CHEMBL1431951 & 688524 & 4.9 & 5.126 & TST & \\
\hline CHEMBL1511217 & 688524 & 5.2 & 4.8708 & TRN & \\
\hline CHEMBL1428727 & 688524 & 4.7 & 5.1032 & TST & \\
\hline CHEMBL1535024 & 688524 & 4.7 & 5.0447 & TRN & \\
\hline CHEMBL1472216 & 688524 & 4.5 & 5.1012 & TRN & \\
\hline CHEMBL1331418 & 688524 & 4.9 & 4.9745 & TRN & \\
\hline CHEMBL1356824 & 688524 & 4.8 & 4.963 & TRN & \\
\hline CHEMBL1445456 & 688524 & 5.0 & 5.0893 & TRN & \\
\hline CHEMBL1583361 & 688524 & 5.0 & 4.8233 & TRN & \\
\hline CHEMBL1581560 & 688524 & 4.9 & 4.9181 & TRN & \\
\hline CHEMBL1350152 & 688524 & 5.0 & 5.2578 & TRN & \\
\hline CHEMBL1601992 & 688524 & 4.9 & 4.8838 & TRN & \\
\hline CHEMBL 20963 & 688524 & 4.9 & 4.8174 & TRN & \\
\hline CHEMBL1374335 & 688524 & 5.9 & 4.9266 & TRN & \\
\hline CHEMBL1301225 & 688524 & 4.9 & 4.925 & TRN & \\
\hline CHEMBL1529677 & 688524 & 4.6 & 5.0413 & TST & \\
\hline CHEMBL1519059 & 688524 & 4.9 & 5.0012 & TRN & \\
\hline CHEMBL1453678 & 688524 & 5.5 & 5.3019 & TRN & \\
\hline CHEMBL1301287 & 688524 & 5.2 & 5.1707 & TRN & \\
\hline CHEMBL1408922 & 688524 & 5.9 & 5.1303 & TST & \\
\hline CHEMBL1387988 & 688524 & 5.2 & 4.9206 & TRN & \\
\hline CHEMBL1324529 & 688524 & 5.3 & 5.12299 & 9999999999 & TRN \\
\hline CHEMBL1536801 & 688524 & 4.9 & 4.9342 & TRN & \\
\hline CHEMBL1606330 & 688524 & 5.5 & 4.9071 & TST & \\
\hline CHEMBL1366055 & 688524 & 4.7 & 4.9858 & TRN & \\
\hline CHEMBL1353522 & 688524 & 5.4 & 5.2538 & TRN & \\
\hline CHEMBL1505050 & 688524 & 5.0 & 5.0585 & TRN & \\
\hline CHEMBL1551271 & 688524 & 4.9 & 5.3211 & TST & \\
\hline CHEMBL1534577 & 688524 & 4.9 & 4.7727 & TRN & \\
\hline CHEMBL1214407 & 688524 & 5.2 & 4.8244 & TRN & \\
\hline CHEMBL592712 & 688524 & 4.9 & 5.0228 & TRN & \\
\hline CHEMBL1594644 & 688524 & 4.5 & 4.9898 & TRN & \\
\hline CHEMBL1324629 & 688524 & 4.6 & 4.9416 & TRN & \\
\hline CHEMBL1570219 & 688524 & 5.0 & 4.9757 & TRN & \\
\hline CHEMBL1600520 & 688524 & 4.9 & 5.0243 & TRN & \\
\hline CHEMBL1471052 & 688524 & 4.8 & 5.0349 & TRN & \\
\hline CHEMBL1497878 & 688524 & 5.3 & 4.9087 & TRN & \\
\hline CHEMBL1419438 & 688524 & 4.5 & 4.9223 & TRN & \\
\hline
\end{tabular}




\begin{tabular}{|c|c|c|c|c|c|}
\hline & & & & & \\
\hline CHEMBL1414043 & 688524 & 5.0 & 4.9101 & TRN & \\
\hline CHEMBL1520705 & 688524 & 5.4 & 4.9477 & TRN & \\
\hline CHEMBL1448181 & 688524 & 4.9 & 5.0643 & TRN & \\
\hline CHEMBL1420361 & 688524 & 4.9 & 4.9449 & TRN & \\
\hline CHEMBL1390941 & 688524 & 4.5 & 5.106 & TRN & \\
\hline CHEMBL1580990 & 688524 & 5.0 & 4.7178 & TRN & \\
\hline CHEMBL1477224 & 688524 & 5.0 & 5.0547 & TRN & \\
\hline CHEMBL239276 & 688524 & 6.5 & 5.1541 & TRN & \\
\hline CHEMBL1563166 & 688524 & 5.0 & 4.9373 & TRN & \\
\hline CHEMBL1564546 & 688524 & 4.6 & 4.8013 & TRN & \\
\hline CHEMBL1520624 & 688524 & 4.5 & 5.0289 & TRN & \\
\hline CHEMBL1306935 & 688524 & 4.5 & 5.0155 & TRN & \\
\hline CHEMBL1493956 & 688524 & 5.0 & 4.9596 & TRN & \\
\hline CHEMBL1477649 & 688524 & 4.7 & 5.0008 & TRN & \\
\hline CHEMBL1610429 & 688524 & 6.1 & 5.1225 & TRN & \\
\hline CHEMBL1305371 & 688524 & 5.9 & 5.1741 & TRN & \\
\hline CHEMBL1328448 & 688524 & 4.8 & 5.0553 & TRN & \\
\hline CHEMBL1370320 & 688524 & 4.6 & 5.1197 & TST & \\
\hline CHEMBL1460920 & 688524 & 4.9 & 5.2449 & TST & \\
\hline CHEMBL1534202 & 688524 & 4.5 & 4.9247 & TRN & \\
\hline CHEMBL1534376 & 688524 & 5.5 & 5.2483 & TRN & \\
\hline CHEMBL1320183 & 688524 & 4.6 & 4.9117 & TRN & \\
\hline CHEMBL1404858 & 688524 & 5.0 & 5.04899 & 99999999995 & TRN \\
\hline CHEMBL1468773 & 688524 & 4.5 & 4.9798 & TRN & \\
\hline CHEMBL1384330 & 688524 & 4.7 & 5.041 & TRN & \\
\hline CHEMBL1421444 & 688524 & 4.9 & 5.0535 & TRN & \\
\hline CHEMBL1440011 & 688524 & 4.7 & 4.9305 & TRN & \\
\hline CHEMBL535307 & 688524 & 7.2 & 5.2064 & TST & \\
\hline CHEMBL1395850 & 688524 & 5.3 & 5.4312 & TRN & \\
\hline CHEMBL1569671 & 688524 & 5.0 & 5.0977 & TRN & \\
\hline CHEMBL1444938 & 688524 & 5.1 & 4.9337 & TRN & \\
\hline CHEMBL1348377 & 688524 & 4.6 & 4.887 & TRN & \\
\hline CHEMBL1364249 & 688524 & 4.5 & 4.937 & TRN & \\
\hline CHEMBL1347221 & 688524 & 5.0 & 5.1543 & TRN & \\
\hline CHEMBL1594867 & 688524 & 5.0 & 5.3584 & TRN & \\
\hline CHEMBL3192897 & 688524 & 5.5 & 4.9118 & TST & \\
\hline CHEMBL1570213 & 688524 & 4.5 & 5.0384 & TRN & \\
\hline CHEMBL1321276 & 688524 & 4.8 & 4.9411 & TRN & \\
\hline CHEMBL1346510 & 688524 & 4.9 & 4.8704 & TRN & \\
\hline CHEMBL600765 & 688524 & 4.6 & 5.1378 & TST & \\
\hline CHEMBL1536546 & 688524 & 5.0 & 4.9055 & TRN & \\
\hline CHEMBL1358724 & 688524 & 4.5 & 5.1405 & TST & \\
\hline CHEMBL1437478 & 688524 & 5.4 & 5.1671 & TST & \\
\hline CHEMBL3195980 & 688524 & 4.9 & 4.8364 & TRN & \\
\hline CHEMBL1538696 & 688524 & 4.5 & 4.9274 & TRN & \\
\hline CHEMBL1569535 & 688524 & 4.7 & 5.029 & TRN & \\
\hline CHEMBL1473331 & 688524 & 4.5 & 5.1988 & TRN & \\
\hline CHEMBL1524331 & 688524 & 7.1002 & 5.1007 & TST & \\
\hline & & & & 26300 & \\
\hline
\end{tabular}




\begin{tabular}{|c|c|c|c|c|c|}
\hline & & \multicolumn{4}{|c|}{ Supplemental Table S2.txt } \\
\hline CHEMBL1363191 & 688524 & 7.5003 & 5.1438 & TST & \\
\hline CHEMBL1449262 & 688524 & 4.7 & 4.9528 & TRN & \\
\hline CHEMBL1307769 & 688524 & 4.8 & 4.8868 & TRN & \\
\hline CHEMBL1612481 & 688524 & 4.6 & 4.9793 & TRN & \\
\hline CHEMBL1389304 & 688524 & 4.6 & 4.9236 & TRN & \\
\hline CHEMBL1547706 & 688524 & 4.9 & 4.9655 & TRN & \\
\hline CHEMBL1606022 & 688524 & 4.9 & 4.9486 & TRN & \\
\hline CHEMBL 8151 & 688524 & 5.7 & 5.1246 & TST & \\
\hline CHEMBL1601256 & 688524 & 6.0 & \multicolumn{2}{|c|}{5.212999999999999} & TRN \\
\hline CHEMBL1368270 & 688524 & 5.2 & 5.2057 & TRN & \\
\hline CHEMBL186784 & 688524 & 4.9 & 5.0423 & TRN & \\
\hline CHEMBL3190739 & 688524 & 4.5 & 5.0839 & TST & \\
\hline CHEMBL508779 & 688524 & 5.4 & 5.1901 & TST & \\
\hline CHEMBL1333547 & 688524 & 4.5 & 4.9478 & TST & \\
\hline CHEMBL1588968 & 688524 & 4.9 & 4.8498 & TRN & \\
\hline CHEMBL1600851 & 688524 & 5.3 & 4.8072 & TRN & \\
\hline CHEMBL1369259 & 688524 & 5.0 & 4.6993 & TRN & \\
\hline CHEMBL1347057 & 688524 & 5.1 & \multicolumn{2}{|c|}{5.0889999999999995} & TRN \\
\hline CHEMBL1447797 & 688524 & 4.9 & 4.8954 & TST & \\
\hline CHEMBL1413161 & 688524 & 6.9 & 5.2581 & TRN & \\
\hline CHEMBL1338051 & 688524 & 5.5 & 5.118 & TRN & \\
\hline CHEMBL1427266 & 688524 & 4.9 & 5.0208 & TRN & \\
\hline CHEMBL1318461 & 688524 & 5.9 & 5.0792 & TST & \\
\hline CHEMBL1521688 & 688524 & 5.1 & 5.0586 & TRN & \\
\hline CHEMBL1412886 & 688524 & 4.7 & 5.0604 & TRN & \\
\hline CHEMBL1573665 & 688524 & 4.9 & 4.8724 & TRN & \\
\hline CHEMBL1452079 & 688524 & 5.0 & 5.0026 & TRN & \\
\hline CHEMBL1349818 & 688524 & 5.0 & 4.9761 & TRN & \\
\hline CHEMBL1483438 & 688524 & 5.9 & 5.1588 & TRN & \\
\hline CHEMBL1499488 & 688524 & 5.4 & 5.1808 & TRN & \\
\hline CHEMBL3211670 & 688524 & 5.0 & 5.0003 & TST & \\
\hline CHEMBL1431301 & 688524 & 4.8 & 4.9285 & TRN & \\
\hline CHEMBL1308582 & 688524 & 4.8 & 5.0866 & TRN & \\
\hline CHEMBL1346720 & 688524 & 5.0 & 4.9099 & TRN & \\
\hline CHEMBL1300635 & 688524 & 5.0 & 4.9446 & TRN & \\
\hline CHEMBL1302139 & 688524 & 5.0 & 4.848 & TRN & \\
\hline CHEMBL1388233 & 688524 & 4.9 & 4.9202 & TRN & \\
\hline CHEMBL1564002 & 688524 & 4.9 & 4.9423 & TRN & \\
\hline CHEMBL1316286 & 688524 & 5.85 & 4.9163 & TRN & \\
\hline CHEMBL1347879 & 688524 & 4.5 & 4.8423 & TRN & \\
\hline CHEMBL1521239 & 688524 & 4.8 & 5.0281 & TRN & \\
\hline CHEMBL1321042 & 688524 & 5.0 & 5.2337 & TRN & \\
\hline CHEMBL1544498 & 688524 & 5.3 & 5.2253 & TRN & \\
\hline CHEMBL1311534 & 688524 & 4.9 & 5.1463 & TRN & \\
\hline CHEMBL1553919 & 688524 & 5.3 & 5.0368 & TST & \\
\hline CHEMBL1450522 & 688524 & 4.5 & 5.0255 & TRN & \\
\hline CHEMBL396994 & 688524 & 4.5 & 5.0405 & TRN & \\
\hline CHEMBL1378808 & 688524 & 5.5 & 5.2055 & TST & \\
\hline
\end{tabular}




\begin{tabular}{|c|c|c|c|c|}
\hline & & & & al lable \\
\hline CHEMBL1436763 & 688524 & 4.5 & 5.1612 & TRN \\
\hline CHEMBL1428673 & 688524 & 4.8 & 5.0106 & TRN \\
\hline CHEMBL1372535 & 688524 & 4.9 & 4.878 & TRN \\
\hline CHEMBL1582610 & 688524 & 4.9 & 4.9816 & TRN \\
\hline CHEMBL1455722 & 688524 & 4.6 & 4.8769 & TRN \\
\hline CHEMBL1498069 & 688524 & 4.9 & 4.9726 & TRN \\
\hline CHEMBL1546004 & 688524 & 4.8 & 4.9892 & TRN \\
\hline CHEMBL1369907 & 688524 & 5.0 & 4.8983 & TRN \\
\hline CHEMBL1422858 & 688524 & 4.7 & 5.0563 & TRN \\
\hline CHEMBL1337484 & 688524 & 4.8 & 4.8782 & TRN \\
\hline CHEMBL1550083 & 688524 & 4.9 & 4.8246 & TRN \\
\hline CHEMBL1576438 & 688524 & 4.9 & 4.901 & TRN \\
\hline CHEMBL1320504 & 688524 & 4.9 & 5.0508 & TRN \\
\hline CHEMBL1438512 & 688524 & 4.8 & 4.8828 & TRN \\
\hline CHEMBL1371553 & 688524 & 5.3 & 4.9577 & TRN \\
\hline CHEMBL1550457 & 688524 & 4.9 & 5.0864 & TST \\
\hline CHEMBL1333254 & 688524 & 5.6 & 4.9265 & TRN \\
\hline CHEMBL1416650 & 688524 & 4.9 & 4.7655 & TRN \\
\hline CHEMBL1608875 & 688524 & 5.0 & 4.9405 & TRN \\
\hline CHEMBL1316979 & 688524 & 5.3 & 5.16700 & 0000000001 \\
\hline CHEMBL1522104 & 688524 & 6.0 & 5.2026 & TST \\
\hline CHEMBL1340073 & 688524 & 4.5 & 4.9774 & TRN \\
\hline CHEMBL1352200 & 688524 & 4.7 & 4.7987 & TRN \\
\hline CHEMBL1545278 & 688524 & 4.9 & 5.2874 & TRN \\
\hline CHEMBL1323935 & 688524 & 4.5 & 4.9846 & TRN \\
\hline CHEMBL1371090 & 688524 & 5.3 & 4.8911 & TRN \\
\hline CHEMBL1382723 & 688524 & 4.8 & 5.1963 & TRN \\
\hline CHEMBL1369392 & 688524 & 4.7 & 4.8601 & TRN \\
\hline CHEMBL1361737 & 688524 & 4.9 & 4.9016 & TRN \\
\hline CHEMBL1556993 & 688524 & 5.0 & 4.8676 & TRN \\
\hline CHEMBL1398540 & 688524 & 5.5 & 5.1839 & TRN \\
\hline CHEMBL1365810 & 688524 & 4.9 & 4.8755 & TRN \\
\hline CHEMBL1483850 & 688524 & 4.9 & 4.9604 & TRN \\
\hline CHEMBL1379264 & 688524 & 4.9 & 4.9329 & TRN \\
\hline CHEMBL1527652 & 688524 & 5.0 & 5.0736 & TRN \\
\hline CHEMBL1537166 & 688524 & 4.7 & 4.9347 & TRN \\
\hline CHEMBL1538018 & 688524 & 4.8 & 5.1135 & TRN \\
\hline CHEMBL1452644 & 688524 & 4.5 & 4.9171 & TRN \\
\hline CHEMBL1414671 & 688524 & 4.9 & 4.8282 & TRN \\
\hline CHEMBL1353373 & 688524 & 5.5 & 4.9411 & TST \\
\hline CHEMBL1495277 & 688524 & 4.8 & 5.0472 & TRN \\
\hline CHEMBL1401953 & 688524 & 4.5 & 4.8579 & TRN \\
\hline CHEMBL 259784 & 688524 & 5.6 & 4.9876 & TRN \\
\hline CHEMBL1562420 & 688524 & 4.8 & 5.2592 & TST \\
\hline CHEMBL1394520 & 688524 & 4.8 & 5.1418 & TRN \\
\hline CHEMBL1578674 & 688524 & 4.9 & 4.8657 & TRN \\
\hline CHEMBL1324618 & 688524 & 5.0 & 5.0791 & TRN \\
\hline CHEMBL1462713 & 688524 & 5.6 & 5.0185 & TRN \\
\hline
\end{tabular}

TRN 


\begin{tabular}{|c|c|c|c|c|c|}
\hline \multirow{2}{*}{ CHEMBL1333976 } & \multirow[b]{2}{*}{688524} & \\
\hline & & 5.5 & 4.9286 & TRN & \\
\hline CHEMBL1458514 & 688524 & 4.9 & 4.9405 & TRN & \\
\hline CHEMBL1454544 & 688524 & 4.7 & 5.2147 & TRN & \\
\hline CHEMBL1349014 & 688524 & 4.9 & 4.9355 & TRN & \\
\hline CHEMBL3193799 & 688524 & 5.0 & 5.2577 & TRN & \\
\hline CHEMBL1462511 & 688524 & 5.5 & 4.9152 & TRN & \\
\hline CHEMBL1588293 & 688524 & 4.9 & 4.9779 & TRN & \\
\hline CHEMBL1562638 & 688524 & 4.8 & 4.9393 & TRN & \\
\hline CHEMBL1214274 & 688524 & 5.2 & 5.3193 & TST & \\
\hline CHEMBL1392831 & 688524 & 6.5 & 5.0554 & TST & \\
\hline CHEMBL1416355 & 688524 & 5.0 & 4.9272 & TRN & \\
\hline CHEMBL1580311 & 688524 & 4.6 & 4.9564 & TRN & \\
\hline CHEMBL13790 & 688524 & 6.0 & 4.8414 & TRN & \\
\hline CHEMBL1521538 & 688524 & 5.3 & 4.9221 & TRN & \\
\hline CHEMBL1551610 & 688524 & 6.0 & 5.0967 & TST & \\
\hline CHEMBL1331520 & 688524 & 4.9 & 5.0017 & TRN & \\
\hline CHEMBL1442111 & 688524 & 4.8 & 4.8412 & TRN & \\
\hline CHEMBL1321291 & 688524 & 5.6 & 4.9563 & TRN & \\
\hline CHEMBL319244 & 688524 & 6.0 & 5.1711 & TRN & \\
\hline CHEMBL1312186 & 688524 & 4.7 & 4.8633 & TRN & \\
\hline CHEMBL1397532 & 688524 & 5.2 & 4.9933 & TRN & \\
\hline CHEMBL1605650 & 688524 & 5.3 & 5.1776 & TST & \\
\hline CHEMBL1594740 & 688524 & 4.5 & 4.7281 & TRN & \\
\hline CHEMBL1470754 & 688524 & 4.9 & 4.6691 & TRN & \\
\hline CHEMBL1413793 & 688524 & 4.5 & 4.8273 & TRN & \\
\hline CHEMBL1596959 & 688524 & 4.9 & 5.1664 & TRN & \\
\hline CHEMBL1182777 & 688524 & 5.4 & 5.2859 & TRN & \\
\hline CHEMBL1575796 & 688524 & 5.3 & 5.0255 & TRN & \\
\hline CHEMBL1335678 & 688524 & 5.2 & 4.9046 & TRN & \\
\hline CHEMBL1420281 & 688524 & 5.3 & 5.0281 & TRN & \\
\hline CHEMBL1558796 & 688524 & 4.5 & 5.0663 & TRN & \\
\hline CHEMBL 1487675 & 688524 & 5.9 & 5.1909 & TST & \\
\hline CHEMBL1543857 & 688524 & 5.1 & 4.9336 & TRN & \\
\hline CHEMBL1609759 & 688524 & 4.5 & 5.1734 & TRN & \\
\hline CHEMBL1527016 & 688524 & 5.5 & 4.859 & TRN & \\
\hline CHEMBL1271764 & 688524 & 4.8 & $4.9460 €$ & 0000000001 & TRN \\
\hline CHEMBL1606369 & 688524 & 4.5 & 5.0113 & TRN & \\
\hline CHEMBL1341395 & 688524 & 5.8 & 4.84 & TRN & \\
\hline CHEMBL1455566 & 688524 & 4.6 & 4.9967 & TRN & \\
\hline CHEMBL1320092 & 688524 & 4.9 & 4.9547 & TRN & \\
\hline CHEMBL1317302 & 688524 & 4.5 & 5.2607 & TRN & \\
\hline CHEMBL1582463 & 688524 & 4.5 & 4.9066 & TRN & \\
\hline CHEMBL1364763 & 688524 & 4.7 & 4.8992 & TRN & \\
\hline CHEMBL1521011 & 688524 & 5.3 & 5.0116 & TRN & \\
\hline CHEMBL1370549 & 688524 & 5.4 & 4.8609 & TRN & \\
\hline CHEMBL1566571 & 688524 & 4.5 & 4.9879 & TRN & \\
\hline CHEMBL1360383 & 688524 & 5.3 & 4.9808 & TST & \\
\hline CHEMBL1563581 & 688524 & 5.5 & 4.8529 & TRN & \\
\hline & & & & 26303 & \\
\hline
\end{tabular}




\begin{tabular}{|c|c|c|c|c|}
\hline \multicolumn{5}{|c|}{ Supplemental Table S2.txt } \\
\hline CHEMBL1443354 & 688524 & 4.7 & 4.9417 & TST \\
\hline CHEMBL1356834 & 688524 & 6.2 & 5.0143 & TRN \\
\hline CHEMBL1360872 & 688524 & 4.9 & 5.0629 & TRN \\
\hline CHEMBL1478871 & 688524 & 5.4 & 5.023 & TRN \\
\hline CHEMBL1483066 & 688524 & 5.3 & 5.2321 & TST \\
\hline CHEMBL1588303 & 688524 & 4.6 & 4.9059 & TRN \\
\hline CHEMBL1596124 & 688524 & 5.4 & 4.9221 & TRN \\
\hline CHEMBL242385 & 688524 & 4.9 & 5.0955 & TRN \\
\hline CHEMBL1327001 & 688524 & 5.1 & 4.9093 & TRN \\
\hline CHEMBL585443 & 688524 & 5.0 & 4.9654 & TRN \\
\hline CHEMBL1451062 & 688524 & 5.0 & 4.7897 & TRN \\
\hline CHEMBL1303139 & 688524 & 4.6 & 5.1314 & TRN \\
\hline CHEMBL1510399 & 688524 & 5.1 & 5.0366 & TRN \\
\hline CHEMBL1543352 & 688524 & 4.9 & 4.8489 & TRN \\
\hline CHEMBL275516 & 688524 & 5.5 & 5.1849 & TST \\
\hline CHEMBL225012 & 688524 & 4.8 & 4.8805 & TRN \\
\hline CHEMBL1592556 & 688524 & 4.5 & 5.2216 & TRN \\
\hline CHEMBL1548014 & 688524 & 4.5 & 4.9184 & TRN \\
\hline CHEMBL1430895 & 688524 & 5.2 & 5.1293 & TRN \\
\hline CHEMBL1336564 & 688524 & 4.5 & 4.9599 & TRN \\
\hline CHEMBL1465792 & 688524 & 4.6 & 4.9383 & TRN \\
\hline CHEMBL1439115 & 688524 & 4.9 & 5.2739 & TRN \\
\hline CHEMBL1336025 & 688524 & 6.0 & 5.1121 & TRN \\
\hline CHEMBL1978564 & 688524 & 4.8 & 5.0674 & TRN \\
\hline CHEMBL1574769 & 688524 & 5.2 & 5.1583 & TRN \\
\hline CHEMBL1324079 & 688524 & 5.4 & 4.7827 & TRN \\
\hline CHEMBL1256686 & 688524 & 6.0 & 5.1913 & TST \\
\hline CHEMBL1492524 & 688524 & 5.0 & 4.9763 & TRN \\
\hline CHEMBL1606513 & 688524 & 4.7 & 4.912 & TRN \\
\hline CHEMBL1623028 & 688524 & 4.9 & 5.1749 & TRN \\
\hline CHEMBL1490042 & 688524 & 5.0 & 4.9778 & TRN \\
\hline CHEMBL1353589 & 688524 & 4.5 & 5.0049 & TRN \\
\hline CHEMBL1581549 & 688524 & 4.9 & 5.0618 & TST \\
\hline CHEMBL1585843 & 688524 & 4.9 & 5.1156 & TRN \\
\hline CHEMBL1421232 & 688524 & 5.1 & 4.9 & TRN \\
\hline CHEMBL1589173 & 688524 & 4.9 & 4.9377 & TRN \\
\hline CHEMBL1420684 & 688524 & 4.6 & 4.971 & TST \\
\hline CHEMBL1316492 & 688524 & 5.2 & 5.0817 & TRN \\
\hline CHEMBL110739 & 688524 & 4.9 & 5.2885 & TST \\
\hline CHEMBL1613090 & 688524 & 4.5 & 4.9864 & TRN \\
\hline CHEMBL1406630 & 688524 & 5.2 & 4.9769 & TRN \\
\hline CHEMBL1541721 & 688524 & 4.9 & 4.9828 & TRN \\
\hline CHEMBL1484237 & 688524 & 4.5 & 4.9616 & TRN \\
\hline CHEMBL1423847 & 688524 & 5.5 & 5.0483 & TRN \\
\hline CHEMBL1426818 & 688524 & 4.5 & 5.1054 & TST \\
\hline CHEMBL23970 & 688524 & 5.1 & 5.1335 & TST \\
\hline CHEMBL1300689 & 688524 & 5.1 & 4.7118 & TRN \\
\hline CHEMBL 20730 & 688524 & 5.3 & 5.1128 & TRN \\
\hline
\end{tabular}




\begin{tabular}{|c|c|c|c|c|}
\hline \multicolumn{5}{|c|}{ Supplemental Table S2.txt } \\
\hline CHEMBL86931 & 688524 & 4.8 & 5.1125 & TST \\
\hline CHEMBL1414943 & 688524 & 5.2 & 5.4733 & TRN \\
\hline CHEMBL3199915 & 688524 & 5.0 & 5.0181 & TST \\
\hline CHEMBL1445111 & 688524 & 5.4 & 5.1135 & TRN \\
\hline CHEMBL1602568 & 688524 & 5.5 & 5.2529 & TRN \\
\hline CHEMBL1482011 & 688524 & 6.0 & 5.0339 & TRN \\
\hline CHEMBL1500866 & 688524 & 5.0 & 5.1764 & TRN \\
\hline CHEMBL1476139 & 688524 & 4.8 & 5.1621 & TRN \\
\hline CHEMBL1415756 & 688524 & 4.8 & 4.9668 & TRN \\
\hline CHEMBL3191307 & 688524 & 5.0 & 5.0523 & TST \\
\hline CHEMBL1567436 & 688524 & 5.4 & 5.28100 & 0000000001 \\
\hline CHEMBL1332128 & 688524 & 6.95 & 5.0482 & TRN \\
\hline CHEMBL1338673 & 688524 & 4.7 & 5.0616 & TST \\
\hline CHEMBL1501982 & 688524 & 4.8 & 5.1545 & TRN \\
\hline CHEMBL1461857 & 688524 & 4.9 & 5.2357 & TRN \\
\hline CHEMBL1607965 & 688524 & 4.5 & 4.9311 & TRN \\
\hline CHEMBL30432 & 688524 & 5.0 & 5.3489 & TST \\
\hline CHEMBL1545411 & 688524 & 4.8 & 5.2192 & TRN \\
\hline CHEMBL1549860 & 688524 & 4.5 & 4.8767 & TRN \\
\hline CHEMBL16751 & 688524 & 4.9 & 4.9967 & TRN \\
\hline CHEMBL1519919 & 688524 & 4.9 & 4.8959 & TRN \\
\hline CHEMBL1479792 & 688524 & 5.5 & 4.9906 & TRN \\
\hline CHEMBL1414530 & 688524 & 4.5 & 4.9698 & TRN \\
\hline CHEMBL1467033 & 688524 & 4.9 & 5.0696 & TRN \\
\hline CHEMBL1464530 & 688524 & 4.6 & 4.9756 & TRN \\
\hline CHEMBL1417337 & 688524 & 4.9 & 5.061 & TRN \\
\hline CHEMBL1442250 & 688524 & 5.4 & 5.1069 & TRN \\
\hline CHEMBL1603852 & 688524 & 7.3002 & 5.7421 & TRN \\
\hline CHEMBL3213515 & 688524 & 4.8 & 4.9452 & TRN \\
\hline CHEMBL1378375 & 688524 & 4.9 & 4.8861 & TRN \\
\hline CHEMBL1516882 & 688524 & 5.0 & 4.9465 & TRN \\
\hline CHEMBL1547795 & 688524 & 4.5 & 5.0229 & TRN \\
\hline CHEMBL1462547 & 688524 & 4.6 & 4.9174 & TRN \\
\hline CHEMBL1438276 & 688524 & 4.8 & 5.0006 & TRN \\
\hline CHEMBL1310038 & 688524 & 5.5 & 5.0428 & TRN \\
\hline CHEMBL1490804 & 688524 & 4.9 & 4.8995 & TRN \\
\hline CHEMBL1596661 & 688524 & 4.7 & 4.9588 & TRN \\
\hline CHEMBL1562041 & 688524 & 5.3 & 4.7341 & TRN \\
\hline CHEMBL1403374 & 688524 & 4.5 & 5.0561 & TRN \\
\hline CHEMBL1384329 & 688524 & 4.9 & 5.1561 & TRN \\
\hline CHEMBL473106 & 688524 & 4.9 & 4.9172 & TST \\
\hline CHEMBL1302667 & 688524 & 4.8 & 4.9583 & TRN \\
\hline CHEMBL1361325 & 688524 & 4.8 & 4.7198 & TRN \\
\hline CHEMBL1555952 & 688524 & 5.0 & 5.0115 & TRN \\
\hline CHEMBL1572041 & 688524 & 4.9 & 5.0939 & TRN \\
\hline CHEMBL1370720 & 688524 & 4.7 & 5.0778 & TRN \\
\hline CHEMBL1564849 & 688524 & 4.9 & 4.8498 & TRN \\
\hline CHEMBL1566790 & 688524 & 4.9 & 4.8992 & TST \\
\hline
\end{tabular}




\begin{tabular}{|c|c|c|c|c|c|}
\hline \multicolumn{6}{|c|}{ Supplemental Table S2.txt } \\
\hline CHEMBL1333327 & 688524 & 4.9 & 4.9787 & TRN & \\
\hline CHEMBL1612551 & 688524 & 4.45 & 4.9855 & TST & \\
\hline CHEMBL1368460 & 688524 & 4.7 & 4.9827 & TRN & \\
\hline CHEMBL1529932 & 688524 & 4.9 & 4.8641 & TRN & \\
\hline CHEMBL1311577 & 688524 & 5.2 & 5.199 & TRN & \\
\hline CHEMBL1525659 & 688524 & 4.5 & 5.0232 & TST & \\
\hline CHEMBL1602127 & 688524 & 4.5 & 5.2823 & TST & \\
\hline CHEMBL1424222 & 688524 & 6.2 & 5.0808 & TRN & \\
\hline CHEMBL1416853 & 688524 & 5.3 & 5.1312 & TRN & \\
\hline CHEMBL1359157 & 688524 & 4.7 & 4.9189 & TST & \\
\hline CHEMBL563919 & 688524 & 5.6 & 5.0953 & TRN & \\
\hline CHEMBL1501614 & 688524 & 5.4 & 5.0158 & TST & \\
\hline CHEMBL1537967 & 688524 & 4.8 & 4.9617 & TRN & \\
\hline CHEMBL1495375 & 688524 & 5.0 & 5.0103 & TRN & \\
\hline CHEMBL1441858 & 688524 & 5.0 & 5.0259 & TRN & \\
\hline CHEMBL34704 & 688524 & 4.5 & 5.0428 & TST & \\
\hline CHEMBL1439324 & 688524 & 4.5 & 5.2259 & TST & \\
\hline CHEMBL1369350 & 688524 & 5.5 & 5.0576 & TRN & \\
\hline CHEMBL1363415 & 688524 & 4.9 & 5.2619 & TRN & \\
\hline CHEMBL1367094 & 688524 & 4.5 & 4.9952 & TRN & \\
\hline CHEMBL1415565 & 688524 & 4.9 & 4.7575 & TRN & \\
\hline CHEMBL1375309 & 688524 & 4.5 & 5.0896 & TRN & \\
\hline CHEMBL1530068 & 688524 & 4.5 & 4.936 & TRN & \\
\hline CHEMBL578512 & 688524 & 5.4 & 5.221 & TRN & \\
\hline CHEMBL 288174 & 688524 & 4.6 & 4.9015 & TST & \\
\hline CHEMBL1399546 & 688524 & 4.7 & 4.8826 & TST & \\
\hline CHEMBL1453944 & 688524 & 6.0 & 5.1091 & TST & \\
\hline CHEMBL398095 & 688524 & 4.9 & 4.7994 & TRN & \\
\hline CHEMBL1318064 & 688524 & 5.3 & 5.2871 & TRN & \\
\hline CHEMBL55814 & 688524 & 4.7 & 5.1614 & TRN & \\
\hline CHEMBL1601908 & 688524 & 4.7 & 5.2215 & TRN & \\
\hline CHEMBL1305756 & 688524 & 5.8 & 5.07600 & 00000000005 & TRN \\
\hline CHEMBL1473842 & 688524 & 4.5 & 4.9987 & TST & \\
\hline CHEMBL270299 & 688524 & 6.0 & 5.4544 & TST & \\
\hline CHEMBL1602722 & 688524 & 4.7 & 4.9724 & TRN & \\
\hline CHEMBL1538140 & 688524 & 4.5 & 4.8674 & TRN & \\
\hline CHEMBL1302998 & 688524 & 4.9 & 5.1003 & TRN & \\
\hline CHEMBL1371531 & 688524 & 5.1 & 5.0364 & TRN & \\
\hline CHEMBL229887 & 688524 & 4.9 & 4.9751 & TRN & \\
\hline CHEMBL1349095 & 688524 & 4.5 & 4.9002 & TST & \\
\hline CHEMBL1356085 & 688524 & 5.5 & 5.1364 & TRN & \\
\hline CHEMBL1595153 & 688524 & 5.0 & 5.1349 & TRN & \\
\hline CHEMBL1608727 & 688524 & 6.4 & 5.0545 & TST & \\
\hline CHEMBL1471674 & 688524 & 4.9 & 4.8565 & TRN & \\
\hline CHEMBL1540894 & 688524 & 5.4 & 4.9863 & TRN & \\
\hline CHEMBL1418201 & 688524 & 5.1 & 4.8986 & TRN & \\
\hline CHEMBL311158 & 688524 & 6.0 & 5.0242 & TRN & \\
\hline CHEMBL1324999 & 688524 & 4.8 & 4.9518 & TRN & \\
\hline
\end{tabular}




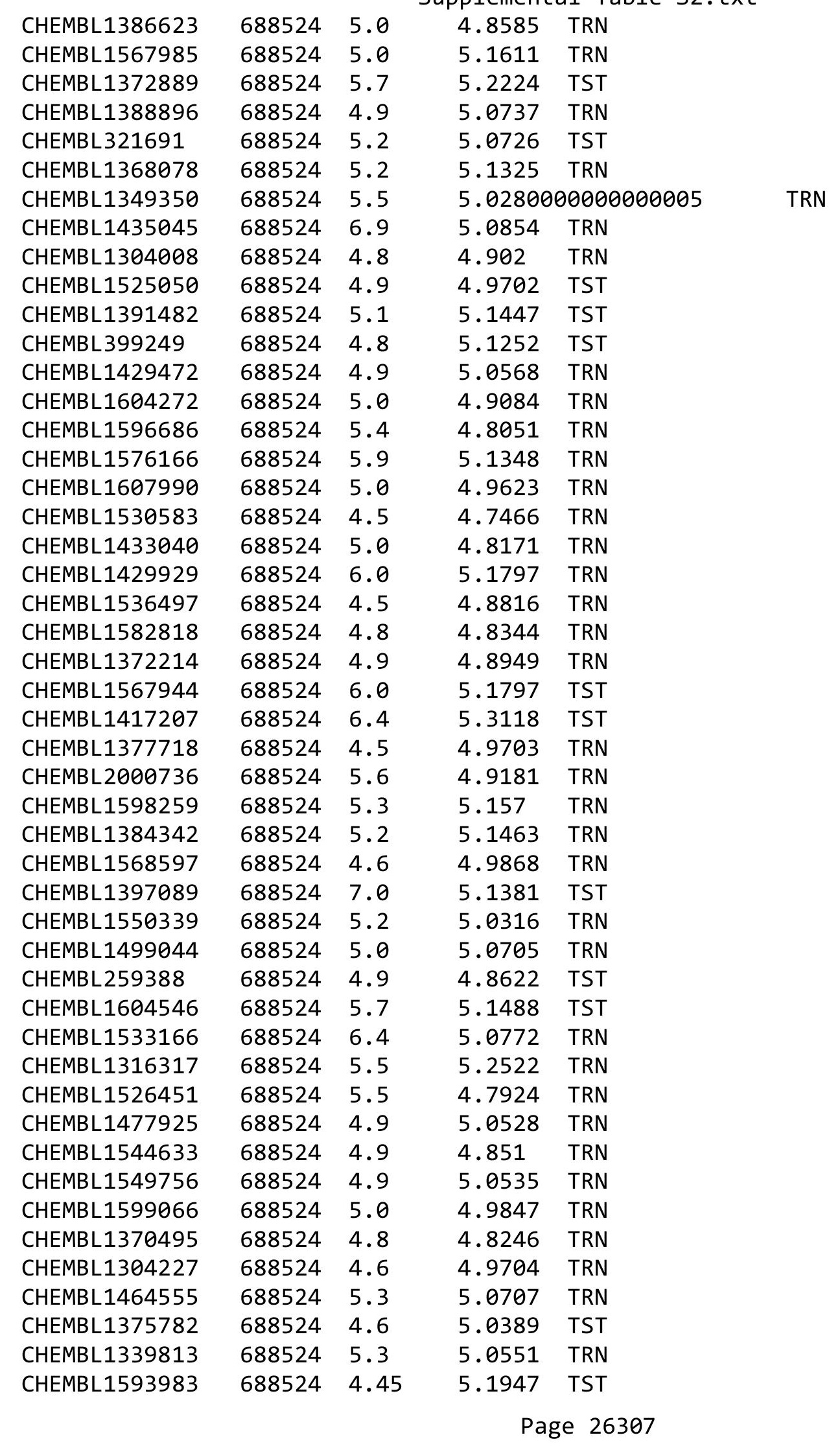




\begin{tabular}{|c|c|c|c|c|c|}
\hline \\
\hline CHEMBL1413178 & 688524 & 5.2 & 5.1297 & TST & \\
\hline CHEMBL259805 & 688524 & 5.5 & 5.1309 & TRN & \\
\hline CHEMBL1332802 & 688524 & 4.6 & 4.8634 & TRN & \\
\hline CHEMBL1585842 & 688524 & 4.5 & 4.9813 & TRN & \\
\hline CHEMBL1386286 & 688524 & 4.8 & 4.9961 & TRN & \\
\hline CHEMBL1600092 & 688524 & 4.9 & 5.1859 & TST & \\
\hline CHEMBL1390047 & 688524 & 4.9 & 4.7678 & TRN & \\
\hline CHEMBL1473472 & 688524 & 5.5 & 5.2938 & TRN & \\
\hline CHEMBL1603003 & 688524 & 4.5 & 5.051 & TST & \\
\hline CHEMBL1396595 & 688524 & 4.9 & 5.4711 & TRN & \\
\hline CHEMBL1540546 & 688524 & 4.9 & 5.0005 & TRN & \\
\hline CHEMBL1518161 & 688524 & 4.9 & 4.8345 & TRN & \\
\hline CHEMBL1421398 & 688524 & 5.1 & 4.7719 & TRN & \\
\hline CHEMBL1349995 & 688524 & 4.7 & 4.9798 & TRN & \\
\hline CHEMBL1594518 & 688524 & 5.2 & 4.8501 & TRN & \\
\hline CHEMBL1318340 & 688524 & 5.6 & 5.3134 & TRN & \\
\hline CHEMBL1447983 & 688524 & 6.1 & 5.2339 & TST & \\
\hline CHEMBL1429841 & 688524 & 4.9 & 5.2383 & TRN & \\
\hline CHEMBL1382622 & 688524 & 6.4 & 4.8973 & TRN & \\
\hline CHEMBL1556942 & 688524 & 5.5 & 5.1643 & TRN & \\
\hline CHEMBL1412548 & 688524 & 4.9 & 5.0651 & TRN & \\
\hline CHEMBL1380186 & 688524 & 5.0 & 4.9514 & TRN & \\
\hline CHEMBL1506570 & 688524 & 4.5 & 4.9198 & TRN & \\
\hline CHEMBL1463660 & 688524 & 5.0 & 5.3815 & TRN & \\
\hline CHEMBL1597563 & 688524 & 4.5 & 5.0067 & TRN & \\
\hline CHEMBL1500220 & 688524 & 4.9 & 4.9861 & TRN & \\
\hline CHEMBL1304419 & 688524 & 4.7 & 4.9763 & TRN & \\
\hline CHEMBL259018 & 688524 & 4.9 & 5.0127 & TRN & \\
\hline CHEMBL1492062 & 688524 & 4.8 & 5.09399 & 9999999999 & TRN \\
\hline CHEMBL1405306 & 688524 & 4.9 & 4.9151 & TRN & \\
\hline CHEMBL1312797 & 688524 & 5.0 & 5.2456 & TRN & \\
\hline CHEMBL1422053 & 688524 & 5.4 & 4.9337 & TRN & \\
\hline CHEMBL405914 & 688524 & 5.2 & 5.0071 & TRN & \\
\hline CHEMBL1416418 & 688524 & 4.5 & 4.896 & TRN & \\
\hline CHEMBL1531105 & 688524 & 5.2 & 5.033 & TRN & \\
\hline CHEMBL1552084 & 688524 & 4.65 & 4.8642 & TRN & \\
\hline CHEMBL1591677 & 688524 & 5.2 & 5.3342 & TRN & \\
\hline CHEMBL1387380 & 688524 & 5.4 & 5.0209 & TRN & \\
\hline CHEMBL1371479 & 688524 & 5.2 & 4.8289 & TRN & \\
\hline CHEMBL1498591 & 688524 & 5.0 & 4.8869 & TRN & \\
\hline CHEMBL1452574 & 688524 & 5.0 & 5.1211 & TRN & \\
\hline CHEMBL1489209 & 688524 & 5.1 & 4.9823 & TRN & \\
\hline CHEMBL1422359 & 688524 & 5.0 & 5.1073 & TRN & \\
\hline CHEMBL1520496 & 688524 & 4.5 & 4.8937 & TRN & \\
\hline CHEMBL1323080 & 688524 & 5.0 & 5.0239 & TRN & \\
\hline CHEMBL1459588 & 688524 & 5.0 & 5.0577 & TRN & \\
\hline CHEMBL1600364 & 688524 & 5.0 & 4.8879 & TRN & \\
\hline CHEMBL1502876 & 688524 & 5.0 & 4.8917 & TRN & \\
\hline & & & & 530 & \\
\hline
\end{tabular}




\begin{tabular}{|c|c|c|c|c|}
\hline \multicolumn{5}{|c|}{ oplemental lable s2.tx } \\
\hline CHEMBL1322920 & 688524 & 4.8 & 4.8106 & TRN \\
\hline CHEMBL1439258 & 688524 & 4.9 & 5.0034 & TST \\
\hline CHEMBL1594793 & 688524 & 4.6 & 4.7576 & TRN \\
\hline CHEMBL1348318 & 688524 & 4.9 & 4.9464 & TRN \\
\hline CHEMBL1610341 & 688524 & 4.8 & 5.0543 & TST \\
\hline CHEMBL1443281 & 688524 & 5.2 & 4.9862 & TRN \\
\hline CHEMBL1511868 & 688524 & 4.5 & 5.1181 & TRN \\
\hline CHEMBL1349955 & 688524 & 5.3 & 4.9948 & TRN \\
\hline CHEMBL1488007 & 688524 & 5.5 & 4.8858 & TRN \\
\hline CHEMBL1607194 & 688524 & 4.9 & 4.9183 & TRN \\
\hline CHEMBL1513300 & 688524 & 5.4 & 4.9773 & TRN \\
\hline CHEMBL1359238 & 688524 & 4.9 & 4.9318 & TRN \\
\hline CHEMBL1406433 & 688524 & 4.9 & 5.2947 & TST \\
\hline CHEMBL1585829 & 688524 & 4.7 & 4.9091 & TRN \\
\hline CHEMBL1301842 & 688524 & 4.6 & 4.9356 & TST \\
\hline CHEMBL1427103 & 688524 & 4.8 & 4.9287 & TRN \\
\hline CHEMBL 3189442 & 688524 & 5.0 & 4.8926 & TRN \\
\hline CHEMBL1408971 & 688524 & 4.9 & 4.851 & TRN \\
\hline CHEMBL 24850 & 688524 & 5.0 & 5.1963 & TRN \\
\hline CHEMBL1364935 & 688524 & 5.0 & 4.8933 & TRN \\
\hline CHEMBL1579518 & 688524 & 4.7 & 5.0577 & TRN \\
\hline CHEMBL1424830 & 688524 & 6.8 & 5.1656 & TST \\
\hline CHEMBL14276 & 688524 & 4.5 & 4.9972 & TRN \\
\hline CHEMBL1373487 & 688524 & 4.9 & 4.9947 & TRN \\
\hline CHEMBL1374845 & 688524 & 5.0 & 4.9153 & TRN \\
\hline CHEMBL1341822 & 688524 & 4.9 & 4.7786 & TRN \\
\hline CHEMBL1572026 & 688524 & 4.9 & 4.9389 & TRN \\
\hline CHEMBL1338135 & 688524 & 4.9 & 5.0549 & TST \\
\hline CHEMBL111951 & 688524 & 5.1 & 5.0882 & TST \\
\hline CHEMBL1412695 & 688524 & 4.9 & 5.0313 & TST \\
\hline CHEMBL1611998 & 688524 & 4.9 & 4.8738 & TST \\
\hline CHEMBL1517041 & 688524 & 5.0 & 4.9874 & TST \\
\hline CHEMBL1420550 & 688524 & 4.8 & 4.9114 & TST \\
\hline CHEMBL1344206 & 688524 & 4.9 & 4.8966 & TST \\
\hline CHEMBL1378617 & 688524 & 5.2 & 4.9816 & TST \\
\hline CHEMBL1515867 & 688524 & 5.5 & 5.0189 & TST \\
\hline CHEMBL1472687 & 688524 & 5.4 & 5.1259 & TST \\
\hline CHEMBL1484711 & 688524 & 4.9 & 4.9171 & TST \\
\hline CHEMBL1551919 & 688524 & 5.9 & 5.2647 & TST \\
\hline CHEMBL41040 & 688524 & 5.0 & 4.9134 & TST \\
\hline CHEMBL1361406 & 688524 & 4.5 & 5.0794 & TST \\
\hline CHEMBL1476146 & 688524 & 4.5 & 5.1386 & TST \\
\hline CHEMBL1331926 & 688524 & 4.7 & 4.9 & TST \\
\hline CHEMBL1402437 & 688524 & 5.0 & 4.9482 & TST \\
\hline CHEMBL1367163 & 688524 & 4.9 & 5.0068 & TST \\
\hline CHEMBL1542053 & 688524 & 5.3 & 5.24100 & 00000000005 \\
\hline CHEMBL1406081 & 688524 & 4.8 & 4.8431 & TST \\
\hline CHEMBL1411953 & 688524 & 5.5 & 4.9025 & TST \\
\hline
\end{tabular}




\begin{tabular}{|c|c|c|c|c|}
\hline & & & CII & al Table S \\
\hline CHEMBL1315183 & 688524 & 4.45 & 4.927 & TST \\
\hline CHEMBL1472513 & 688524 & 4.8 & 4.917 & TST \\
\hline CHEMBL1490048 & 688524 & 5.5 & 4.9861 & TST \\
\hline CHEMBL 28 & 688524 & 6.0 & 5.2442 & TST \\
\hline CHEMBL1603540 & 688524 & 4.5 & 4.7821 & TST \\
\hline CHEMBL1300280 & 688524 & 4.9 & 5.0629 & TST \\
\hline CHEMBL1508175 & 688524 & 5.0 & 5.0377 & TST \\
\hline CHEMBL1354135 & 688524 & 4.5 & 5.1323 & TST \\
\hline CHEMBL1440081 & 688524 & 4.9 & 5.1493 & TST \\
\hline CHEMBL243664 & 688524 & 6.0 & 5.0207 & TST \\
\hline CHEMBL1360475 & 688524 & 4.9 & \multicolumn{2}{|c|}{4.8660000000000005} \\
\hline CHEMBL1328353 & 688524 & 4.6 & 4.9217 & TST \\
\hline CHEMBL1532659 & 688524 & 4.8 & 5.1871 & TST \\
\hline CHEMBL1560138 & 688524 & 4.9 & 4.9345 & TST \\
\hline CHEMBL1505465 & 688524 & 4.5 & 4.9259 & TST \\
\hline CHEMBL1391326 & 688524 & 4.5 & 5.0214 & TST \\
\hline CHEMBL1516006 & 688524 & 5.5 & 5.0588 & TST \\
\hline CHEMBL 278755 & 688524 & 4.9 & 4.9711 & TST \\
\hline CHEMBL1328322 & 688524 & 4.6 & 4.9726 & TST \\
\hline CHEMBL1531943 & 688524 & 5.0 & 5.0398 & TST \\
\hline CHEMBL1428468 & 688524 & 4.9 & 5.042 & TST \\
\hline CHEMBL1562926 & 688524 & 5.9 & 4.923 & TST \\
\hline CHEMBL1604762 & 688524 & 5.3 & 4.9776 & TST \\
\hline CHEMBL1603373 & 688524 & 5.6 & 5.0964 & TST \\
\hline CHEMBL1423259 & 688524 & 5.2 & 5.1433 & TST \\
\hline CHEMBL1526507 & 688524 & 5.0 & 5.08 & TST \\
\hline CHEMBL3214451 & 688524 & 4.5 & 5.0737 & TST \\
\hline CHEMBL343732 & 688524 & 4.5 & 5.0534 & TST \\
\hline CHEMBL1361659 & 688524 & 4.4 & 5.1034 & TST \\
\hline CHEMBL1256995 & 688524 & 4.8 & 4.9772 & TST \\
\hline CHEMBL1213834 & 688524 & 5.0 & 4.851 & TST \\
\hline CHEMBL1485627 & 688524 & 5.6 & 5.0089 & TST \\
\hline CHEMBL1547813 & 688524 & 5.0 & 4.7774 & TST \\
\hline CHEMBL1429287 & 688524 & 5.3 & 5.1068 & TST \\
\hline CHEMBL1395137 & 688524 & 4.8 & 5.2379 & TST \\
\hline CHEMBL1393407 & 688524 & 5.6 & 5.095 & TST \\
\hline CHEMBL1531919 & 688524 & 4.8 & 5.0121 & TST \\
\hline CHEMBL1457336 & 688524 & 5.0 & 4.862 & TST \\
\hline CHEMBL1412731 & 688524 & 4.8 & 4.8766 & TST \\
\hline CHEMBL67450 & 688524 & 4.9 & 5.1264 & TST \\
\hline CHEMBL1466554 & 688524 & 4.9 & 5.1572 & TST \\
\hline CHEMBL1375986 & 688524 & 4.7 & 4.8081 & TST \\
\hline CHEMBL1393919 & 688524 & 4.9 & 4.8609 & TST \\
\hline CHEMBL1453909 & 688524 & 4.9 & 5.1932 & TST \\
\hline CHEMBL1566148 & 688524 & 4.9 & 4.9115 & TST \\
\hline CHEMBL 3213303 & 688524 & 4.9 & 5.1537 & TST \\
\hline CHEMBL1342056 & 688524 & 4.9 & 4.9401 & TST \\
\hline CHEMBL 3190834 & 688524 & 5.0 & 5.1309 & TST \\
\hline
\end{tabular}




\begin{tabular}{|c|c|c|c|c|}
\hline & & & pplement & al $\mathrm{Ta}$ \\
\hline CHEMBL1598482 & 688524 & 4.9 & 5.1591 & TST \\
\hline CHEMBL1532132 & 688524 & 4.6 & 4.9653 & TST \\
\hline CHEMBL1333339 & 688524 & 4.7 & 5.1452 & TST \\
\hline CHEMBL1540821 & 688524 & 4.9 & 4.8966 & TST \\
\hline CHEMBL1528455 & 688524 & 5.0 & 4.8615 & TST \\
\hline CHEMBL1414048 & 688524 & 5.3 & 4.729 & TST \\
\hline CHEMBL374308 & 688524 & 5.5 & 5.2761 & TST \\
\hline CHEMBL1379362 & 688524 & 4.9 & 5.1193 & TST \\
\hline CHEMBL1502741 & 688524 & 4.9 & 4.8839 & TST \\
\hline CHEMBL1481391 & 688524 & 5.0 & 4.9587 & TST \\
\hline CHEMBL1370676 & 688524 & 4.9 & 4.8516 & TST \\
\hline CHEMBL1334083 & 688524 & 4.8 & 4.9536 & TST \\
\hline CHEMBL1546185 & 688524 & 5.0 & 5.11 & TST \\
\hline CHEMBL1339717 & 688524 & 5.0 & 4.9342 & TST \\
\hline CHEMBL449690 & 688524 & 6.0 & 5.0402 & TST \\
\hline CHEMBL1545998 & 688524 & 4.8 & 4.8944 & TST \\
\hline CHEMBL202721 & 688524 & 4.45 & 4.9287 & TST \\
\hline CHEMBL1523485 & 688524 & 4.9 & 5.0066 & TST \\
\hline CHEMBL1515004 & 688524 & 5.3 & 5.1004 & TST \\
\hline CHEMBL1608430 & 688524 & 5.6 & 5.0384 & TST \\
\hline CHEMBL1611143 & 688524 & 4.7 & 4.8779 & TST \\
\hline CHEMBL1588326 & 688524 & 5.0 & 4.9743 & TST \\
\hline CHEMBL1412795 & 688524 & 4.9 & 5.0189 & TST \\
\hline CHEMBL1256740 & 688524 & 4.9 & 5.1752 & TST \\
\hline CHEMBL1448839 & 688524 & 5.4 & 5.1364 & TST \\
\hline CHEMBL1321398 & 688524 & 5.2 & 5.1914 & TST \\
\hline CHEMBL1541291 & 688524 & 7.4001 & 4.9089 & TST \\
\hline CHEMBL 3186408 & 688524 & 6.0 & 5.1026 & TST \\
\hline CHEMBL1334764 & 688524 & 4.6 & 5.1746 & TST \\
\hline CHEMBL313244 & 688524 & 4.5 & 4.9843 & TST \\
\hline CHEMBL1412775 & 688524 & 6.5 & 5.0914 & TST \\
\hline CHEMBL1533853 & 688524 & 4.5 & 5.3745 & TST \\
\hline CHEMBL1349869 & 688524 & 4.9 & 4.9908 & TST \\
\hline CHEMBL1583131 & 688524 & 5.0 & 5.0077 & TST \\
\hline CHEMBL1524034 & 688524 & 5.5 & 5.0021 & TST \\
\hline CHEMBL1413610 & 688524 & 5.5 & 5.0655 & TST \\
\hline CHEMBL1523461 & 688524 & 5.4 & 4.9771 & TST \\
\hline CHEMBL1412657 & 688524 & 4.6 & 4.9469 & TST \\
\hline CHEMBL1484174 & 688524 & 4.9 & 4.9429 & TST \\
\hline CHEMBL1605575 & 688524 & 4.8 & 5.0538 & TST \\
\hline CHEMBL1610783 & 688524 & 5.1 & 4.9092 & TST \\
\hline CHEMBL1214410 & 688524 & 4.7 & 4.8879 & TST \\
\hline CHEMBL1314387 & 688524 & 4.6 & 5.1486 & TST \\
\hline CHEMBL1407794 & 688524 & 5.5 & 5.0715 & TST \\
\hline CHEMBL1091971 & 688524 & 5.8 & 5.1303 & TST \\
\hline CHEMBL1609048 & 688524 & 4.9 & 4.8929 & TST \\
\hline CHEMBL1560367 & 688524 & 4.7 & 5.273 & TST \\
\hline CHEMBL1386257 & 688524 & 4.7 & 5.0061 & TST \\
\hline
\end{tabular}




\begin{tabular}{|c|c|c|c|c|c|}
\hline \multicolumn{6}{|c|}{ Supplemental Table S2.txt } \\
\hline CHEMBL1479805 & 688524 & 5.6 & 5.1494 & TST & \\
\hline CHEMBL1416417 & 688524 & 4.7 & 5.0398 & TST & \\
\hline CHEMBL1463435 & 688524 & 5.0 & 4.8521 & TST & \\
\hline CHEMBL404613 & 688524 & 7.5003 & 4.9085 & TST & \\
\hline CHEMBL1466507 & 688524 & 5.2 & 4.9548 & TST & \\
\hline CHEMBL34730 & 688524 & 5.3 & 5.065 & TST & \\
\hline CHEMBL1419093 & 688524 & 4.9 & 4.9816 & TST & \\
\hline CHEMBL1437747 & 688524 & 4.5 & 5.2006 & TST & \\
\hline CHEMBL1475284 & 688524 & 5.4 & 5.154 & TST & \\
\hline CHEMBL1584295 & 688524 & 4.6 & 5.0801 & TST & \\
\hline CHEMBL1402510 & 688524 & 6.0 & 5.3746 & TST & \\
\hline CHEMBL1441854 & 688524 & 4.6 & 4.7351 & TST & \\
\hline CHEMBL 3194422 & 688524 & 4.9 & 5.215 & TST & \\
\hline CHEMBL1337274 & 688524 & 5.1 & 5.0631 & TST & \\
\hline CHEMBL1300301 & 688524 & 5.0 & 4.8754 & TST & \\
\hline CHEMBL1320414 & 688524 & 5.5 & 4.966 & TST & \\
\hline CHEMBL1574368 & 688524 & 4.8 & 4.9483 & TST & \\
\hline CHEMBL1433489 & 688524 & 4.9 & 5.3361 & TST & \\
\hline CHEMBL1577745 & 688524 & 5.0 & 4.9946 & TST & \\
\hline CHEMBL1517447 & 688524 & 4.9 & 4.8379 & TST & \\
\hline CHEMBL1593337 & 688524 & 4.5 & 5.0848 & TST & \\
\hline CHEMBL1350119 & 688524 & 5.4 & 5.0514 & TST & \\
\hline CHEMBL1450655 & 688524 & 4.5 & 4.9023 & TST & \\
\hline CHEMBL1378442 & 688524 & 4.8 & 4.8316 & TST & \\
\hline CHEMBL1591971 & 688524 & 5.0 & 5.1462 & TST & \\
\hline CHEMBL1422099 & 688524 & 5.5 & 4.9597 & TST & \\
\hline CHEMBL1568286 & 688524 & 5.4 & 4.9113 & TST & \\
\hline CHEMBL1610894 & 688524 & 5.0 & 4.869 & TST & \\
\hline CHEMBL1402390 & 688524 & 6.0 & 4.9818 & TST & \\
\hline CHEMBL1404408 & 688524 & 4.9 & 5.084 & TST & \\
\hline CHEMBL1328426 & 688524 & 5.9 & 4.9855 & TST & \\
\hline CHEMBL1448756 & 688524 & 4.5 & 4.9057 & TST & \\
\hline CHEMBL1494058 & 688524 & 4.8 & 5.0775 & TST & \\
\hline CHEMBL1333386 & 688524 & 5.2 & 4.7822 & TST & \\
\hline CHEMBL1544015 & 688524 & 4.7 & $4.8580 e$ & 00000000005 & TST \\
\hline CHEMBL1975289 & 688524 & 5.1 & 5.0006 & TST & \\
\hline CHEMBL1359181 & 688524 & 4.9 & 5.0241 & TST & \\
\hline CHEMBL595250 & 688524 & 4.9 & 4.8681 & TST & \\
\hline CHEMBL1507095 & 688524 & 5.4 & 4.9959 & TST & \\
\hline CHEMBL1360842 & 688524 & 4.8 & 5.0669 & TST & \\
\hline CHEMBL1336245 & 688524 & 4.5 & 5.0574 & TST & \\
\hline CHEMBL1308291 & 688524 & 5.4 & 4.7011 & TST & \\
\hline CHEMBL1507642 & 688524 & 4.7 & 5.0613 & TST & \\
\hline CHEMBL1573495 & 688524 & 5.4 & 4.9907 & TST & \\
\hline CHEMBL1458004 & 688524 & 4.8 & 4.9334 & TST & \\
\hline CHEMBL1360037 & 688524 & 5.3 & 5.187 & TST & \\
\hline CHEMBL1451096 & 688524 & 4.9 & 5.0178 & TST & \\
\hline CHEMBL3191772 & 688524 & 5.1 & 5.165 & TST & \\
\hline
\end{tabular}




\begin{tabular}{|c|c|c|c|c|c|}
\hline \multirow[b]{2}{*}{ CHEMBL1508988 } & \multirow[b]{2}{*}{688524} & \\
\hline & & 4.8 & 5.0327 & TST & \\
\hline CHEMBL1537418 & 688524 & 4.7 & 4.9472 & TST & \\
\hline CHEMBL1356808 & 688524 & 5.5 & 5.2669 & TST & \\
\hline CHEMBL1594251 & 688524 & 5.6 & 4.9479 & TST & \\
\hline CHEMBL1445396 & 688524 & 5.1 & 5.1584 & TST & \\
\hline CHEMBL1414183 & 688524 & 5.1 & 4.8422 & TST & \\
\hline CHEMBL1350199 & 688524 & 4.9 & 4.9636 & TST & \\
\hline CHEMBL1518305 & 688524 & 5.3 & 4.9919 & TST & \\
\hline CHEMBL1370087 & 688524 & 5.3 & 4.9706 & TST & \\
\hline CHEMBL1487441 & 688524 & 4.8 & 5.05 & TST & \\
\hline CHEMBL1321146 & 688524 & 5.0 & 5.0858 & TST & \\
\hline CHEMBL1350915 & 688524 & 4.9 & 4.8234 & TST & \\
\hline CHEMBL1427003 & 688524 & 5.0 & 5.1115 & TST & \\
\hline CHEMBL1465576 & 688524 & 6.2 & 4.9996 & TST & \\
\hline CHEMBL1374544 & 688524 & 5.5 & 5.3401 & TST & \\
\hline CHEMBL1736254 & 688524 & 5.4 & $5.3020 e$ & 00000000005 & TST \\
\hline CHEMBL1181366 & 688524 & 5.8 & 5.0978 & TST & \\
\hline CHEMBL1541535 & 688524 & 4.9 & 5.0294 & TST & \\
\hline CHEMBL1544277 & 688524 & 5.6 & 5.1535 & TST & \\
\hline CHEMBL1309064 & 688524 & 5.5 & 4.7886 & TST & \\
\hline CHEMBL1606432 & 688524 & 4.9 & 4.8651 & TST & \\
\hline CHEMBL1562028 & 688524 & 5.2 & 4.9782 & TST & \\
\hline CHEMBL1404788 & 688524 & 4.9 & 4.8344 & TST & \\
\hline CHEMBL1453964 & 688524 & 4.5 & 4.8798 & TST & \\
\hline CHEMBL1435216 & 688524 & 4.7 & 5.3362 & TST & \\
\hline CHEMBL1321786 & 688524 & 4.5 & 4.8238 & TST & \\
\hline CHEMBL1373889 & 688524 & 5.1 & 4.9358 & TST & \\
\hline CHEMBL1508532 & 688524 & 4.5 & $4.8660 e$ & 00000000005 & TST \\
\hline CHEMBL577635 & 688524 & 6.0 & 5.1838 & TST & \\
\hline CHEMBL429023 & 688524 & 4.9 & 5.1236 & TST & \\
\hline CHEMBL1332033 & 688524 & 5.0 & 5.3407 & TST & \\
\hline CHEMBL1557676 & 688524 & 4.8 & 5.1038 & TST & \\
\hline CHEMBL3207541 & 688524 & 4.8 & 4.9555 & TST & \\
\hline CHEMBL1432515 & 688524 & 4.9 & 5.0888 & TST & \\
\hline CHEMBL1336216 & 688524 & 4.7 & 4.9529 & TST & \\
\hline CHEMBL1608077 & 688524 & 4.8 & 5.0401 & TST & \\
\hline CHEMBL194458 & 688524 & 6.1 & 5.1059 & TST & \\
\hline CHEMBL1503636 & 688524 & 4.7 & 4.9821 & TST & \\
\hline CHEMBL1256775 & 688524 & 4.8 & 4.9683 & TST & \\
\hline CHEMBL1529007 & 688524 & 5.3 & 4.8288 & TST & \\
\hline CHEMBL1450386 & 688524 & 4.9 & 5.0152 & TST & \\
\hline CHEMBL1376094 & 688524 & 5.0 & 5.0602 & TST & \\
\hline CHEMBL1403884 & 688524 & 5.2 & 4.956 & TST & \\
\hline CHEMBL1431872 & 688524 & 4.5 & 4.8957 & TST & \\
\hline CHEMBL288591 & 688524 & 4.5 & 4.9761 & TST & \\
\hline CHEMBL1507474 & 688524 & 4.7 & 4.8782 & TST & \\
\hline CHEMBL1560223 & 688524 & 5.5 & 5.2025 & TST & \\
\hline CHEMBL1550059 & 688524 & 5.4 & 4.9991 & TST & \\
\hline & & & & 26313 & \\
\hline
\end{tabular}




\begin{tabular}{|c|c|c|c|c|}
\hline & & & plement & al lable s \\
\hline CHEMBL1490497 & 688524 & 5.4 & 5.0779 & TST \\
\hline CHEMBL1513063 & 688524 & 5.2 & 5.1402 & TST \\
\hline CHEMBL1531944 & 688524 & 5.2 & 5.0946 & TST \\
\hline CHEMBL1522852 & 688524 & 5.7 & 5.1382 & TST \\
\hline CHEMBL1361750 & 688524 & 4.7 & 5.2707 & TST \\
\hline CHEMBL1562057 & 688524 & 4.8 & 4.9029 & TST \\
\hline CHEMBL1501480 & 688524 & 5.3 & 4.948 & TST \\
\hline CHEMBL363332 & 688524 & 5.2 & 5.0198 & TST \\
\hline CHEMBL1472079 & 688524 & 4.9 & 5.0789 & TST \\
\hline CHEMBL1492090 & 688524 & 4.8 & 5.1381 & TST \\
\hline CHEMBL1568922 & 688524 & 4.6 & 5.12299 & 9999999999 \\
\hline CHEMBL1521574 & 688524 & 4.8 & 4.871 & TST \\
\hline CHEMBL1523375 & 688524 & 4.9 & 4.8668 & TST \\
\hline CHEMBL332122 & 688524 & 5.5 & 5.12299 & 9999999999 \\
\hline CHEMBL1315725 & 688524 & 5.9 & 4.9981 & TST \\
\hline CHEMBL1367976 & 688524 & 5.4 & 5.1921 & TST \\
\hline CHEMBL1372987 & 688524 & 5.0 & 4.8375 & TST \\
\hline CHEMBL1338413 & 688524 & 4.5 & 4.9282 & TST \\
\hline CHEMBL1377511 & 688524 & 4.9 & 4.7632 & TST \\
\hline CHEMBL1377687 & 688524 & 5.3 & 4.918 & TST \\
\hline CHEMBL1578693 & 688524 & 5.5 & 5.0548 & TST \\
\hline CHEMBL14120 & 688524 & 4.95 & 5.0814 & TST \\
\hline CHEMBL1574263 & 688524 & 5.0 & 4.8772 & TST \\
\hline CHEMBL272005 & 688524 & 4.5 & 4.984 & TST \\
\hline CHEMBL1453911 & 688524 & 4.5 & 5.2768 & TST \\
\hline CHEMBL1470391 & 688524 & 4.5 & 4.9289 & TST \\
\hline CHEMBL1423482 & 688524 & 4.8 & 5.0513 & TST \\
\hline CHEMBL1593707 & 688524 & 4.8 & 5.2136 & TST \\
\hline CHEMBL1607059 & 688524 & 4.9 & 4.9545 & TST \\
\hline CHEMBL1501238 & 688524 & 5.8 & 5.1727 & TST \\
\hline CHEMBL1563228 & 688524 & 8.0 & 5.015 & TST \\
\hline CHEMBL1979527 & 688524 & 5.4 & 4.9699 & TST \\
\hline CHEMBL1355881 & 688524 & 5.5 & 5.2519 & TST \\
\hline CHEMBL1300796 & 688524 & 4.5 & 4.9564 & TST \\
\hline CHEMBL1338768 & 688524 & 5.5 & 4.9848 & TST \\
\hline CHEMBL1567490 & 688524 & 5.2 & 4.8556 & TST \\
\hline CHEMBL1368993 & 688524 & 4.7 & 4.871 & TST \\
\hline CHEMBL1407945 & 688524 & 4.8 & 4.9328 & TST \\
\hline CHEMBL1400242 & 688524 & 4.8 & 4.8716 & TST \\
\hline CHEMBL1490895 & 688524 & 5.0 & 5.1158 & TST \\
\hline CHEMBL1569960 & 688524 & 5.9 & 5.0604 & TST \\
\hline CHEMBL1440339 & 688524 & 4.9 & 4.9457 & TST \\
\hline CHEMBL1565247 & 688524 & 6.4 & 5.091 & TST \\
\hline CHEMBL1331076 & 688524 & 4.9 & 4.987 & TST \\
\hline CHEMBL1492722 & 688524 & 5.5 & 5.175 & TST \\
\hline CHEMBL1592493 & 688524 & 5.5 & 5.1041 & TST \\
\hline CHEMBL1481651 & 688524 & 5.5 & 4.9896 & TST \\
\hline CHEMBL1393320 & 688524 & 4.6 & 4.8454 & TST \\
\hline
\end{tabular}

TST

TST 


\begin{tabular}{|c|c|c|c|c|}
\hline \multicolumn{5}{|c|}{ Supplemental Table S2.txt } \\
\hline CHEMBL1487173 & 688524 & 4.7 & 5.0294 & TST \\
\hline CHEMBL1359848 & 688524 & 4.8 & 5.1122 & TST \\
\hline CHEMBL1501506 & 688524 & 5.0 & 5.1214 & TST \\
\hline CHEMBL1488229 & 688524 & 4.9 & 5.1321 & TST \\
\hline CHEMBL1571899 & 688524 & 5.0 & 4.9435 & TST \\
\hline CHEMBL1348624 & 688524 & 5.4 & 4.8349 & TST \\
\hline CHEMBL1394923 & 688524 & 5.4 & 5.1008 & TST \\
\hline CHEMBL1332023 & 688524 & 4.7 & 5.1643 & TST \\
\hline CHEMBL1443913 & 688524 & 4.8 & 5.0541 & TST \\
\hline CHEMBL1411450 & 688524 & 5.2 & 4.8407 & TST \\
\hline CHEMBL1606199 & 688524 & 5.4 & 5.385 & TST \\
\hline CHEMBL1373449 & 688524 & 4.9 & 5.004 & TST \\
\hline CHEMBL1214525 & 688524 & 4.9 & 4.7994 & TST \\
\hline CHEMBL1465179 & 688524 & 4.9 & 4.9285 & TST \\
\hline CHEMBL1492780 & 688524 & 4.9 & 5.0499 & TST \\
\hline CHEMBL1460155 & 688524 & 5.5 & 5.0647 & TST \\
\hline CHEMBL1328119 & 688524 & 5.9 & 5.0156 & TST \\
\hline CHEMBL1307028 & 688524 & 4.9 & 5.0896 & TST \\
\hline CHEMBL1318509 & 688524 & 7.4001 & 5.4274 & TST \\
\hline CHEMBL1318105 & 688524 & 6.0 & 5.1879 & TST \\
\hline CHEMBL1525273 & 688524 & 4.8 & 5.0779 & TST \\
\hline CHEMBL1473874 & 688524 & 6.0 & 5.0277 & TST \\
\hline CHEMBL1365696 & 688524 & 5.0 & 5.1081 & TST \\
\hline CHEMBL1374828 & 688524 & 4.9 & 4.9251 & TST \\
\hline CHEMBL165 & 688524 & 6.0 & 5.2881 & TST \\
\hline CHEMBL1520875 & 688524 & 4.5 & 4.7954 & TST \\
\hline CHEMBL1399653 & 688524 & 5.0 & 4.7906 & TST \\
\hline CHEMBL1344611 & 688524 & 5.0 & 5.1417 & TST \\
\hline CHEMBL1255936 & 688524 & 5.5 & 5.1412 & TST \\
\hline CHEMBL1312990 & 688524 & 4.7 & 4.8274 & TST \\
\hline CHEMBL1381896 & 688524 & 4.8 & 4.9068 & TST \\
\hline CHEMBL1480093 & 688524 & 5.4 & 5.0737 & TST \\
\hline CHEMBL1446788 & 688524 & 5.7 & 5.008 & TST \\
\hline CHEMBL1380574 & 688524 & 4.9 & 5.0282 & TST \\
\hline CHEMBL1321836 & 688524 & 4.9 & 5.0108 & TST \\
\hline CHEMBL1437007 & 688524 & 4.6 & 4.9432 & TST \\
\hline CHEMBL1534598 & 688524 & 4.9 & 4.7912 & TST \\
\hline CHEMBL1591107 & 688524 & 6.4 & 5.1528 & TST \\
\hline CHEMBL1332728 & 688524 & 6.1 & 5.0708 & TST \\
\hline CHEMBL1577226 & 688524 & 5.0 & 5.0244 & TST \\
\hline CHEMBL1519960 & 688524 & 4.9 & 4.7901 & TST \\
\hline CHEMBL261693 & 688524 & 5.5 & 5.0589 & TST \\
\hline CHEMBL1560445 & 688524 & 5.4 & 5.256 & TST \\
\hline CHEMBL1422795 & 688524 & 4.5 & 4.9533 & TST \\
\hline CHEMBL1325006 & 688524 & 5.0 & 4.8842 & TST \\
\hline CHEMBL1595236 & 688524 & 4.9 & 4.8243 & TST \\
\hline CHEMBL1521854 & 688524 & 4.5 & 5.1094 & TST \\
\hline CHEMBL1416101 & 688524 & 5.6 & 4.9996 & TST \\
\hline
\end{tabular}




\begin{tabular}{|c|c|c|c|c|c|}
\hline \\
\hline CHEMBL1443764 & 688524 & 4.5 & 5.073 & TST & \\
\hline CHEMBL1484264 & 688524 & 5.0 & 5.0233 & TST & \\
\hline CHEMBL1466697 & 688524 & 5.5 & 4.9131 & TST & \\
\hline CHEMBL1397257 & 688524 & 5.7 & 5.1034 & TST & \\
\hline CHEMBL1416369 & 688524 & 4.9 & 5.025 & TST & \\
\hline CHEMBL1417671 & 688524 & 4.9 & 4.9078 & TST & \\
\hline CHEMBL1404605 & 688524 & 4.9 & 5.0518 & TST & \\
\hline CHEMBL1597445 & 688524 & 5.0 & 5.1023 & TST & \\
\hline CHEMBL1531681 & 688524 & 4.7 & 4.8398 & TST & \\
\hline CHEMBL1503124 & 688524 & 4.9 & 5.2034 & TST & \\
\hline CHEMBL1395226 & 688524 & 4.8 & 5.1803 & TST & \\
\hline CHEMBL1411341 & 688524 & 4.5 & 5.3315 & TST & \\
\hline CHEMBL1463494 & 688524 & 4.9 & 4.9539 & TST & \\
\hline CHEMBL1385434 & 688524 & 4.9 & 5.0647 & TST & \\
\hline CHEMBL1499803 & 688524 & 4.8 & 4.8991 & TST & \\
\hline CHEMBL1370669 & 688524 & 5.0 & 5.1144 & TST & \\
\hline CHEMBL1546252 & 688524 & 4.6 & 5.1469 & TST & \\
\hline CHEMBL1454850 & 688524 & 4.8 & 4.9231 & TST & \\
\hline CHEMBL 210868 & 688524 & 4.5 & 5.1556 & TST & \\
\hline CHEMBL1399667 & 688524 & 4.8 & 5.02800 & 00000000005 & TST \\
\hline CHEMBL1367737 & 688524 & 4.6 & 5.0508 & TST & \\
\hline CHEMBL1425542 & 688524 & 4.8 & 4.9811 & TST & \\
\hline CHEMBL1374355 & 688524 & 4.9 & 5.4718 & TST & \\
\hline CHEMBL1509357 & 688524 & 4.9 & 5.0593 & TST & \\
\hline CHEMBL1577902 & 688524 & 5.0 & 5.1111 & TST & \\
\hline CHEMBL1361718 & 688524 & 4.6 & 5.088 & TST & \\
\hline CHEMBL1504651 & 688524 & 4.9 & 5.0562 & TST & \\
\hline CHEMBL1491493 & 688524 & 4.5 & 5.193 & TST & \\
\hline CHEMBL337173 & 688524 & 5.0 & 5.1396 & TST & \\
\hline CHEMBL1449118 & 688524 & 4.8 & 4.9436 & TST & \\
\hline CHEMBL317757 & 688524 & 4.8 & 4.9071 & TST & \\
\hline CHEMBL1328519 & 688524 & 4.9 & 4.8701 & TST & \\
\hline CHEMBL1537368 & 688524 & 5.0 & 4.8799 & TST & \\
\hline CHEMBL122360 & 688524 & 4.7 & 5.0835 & TST & \\
\hline CHEMBL1345993 & 688524 & 4.7 & 4.9611 & TST & \\
\hline CHEMBL1548328 & 688524 & 5.3 & 5.05699 & 99999999995 & TST \\
\hline CHEMBL1313351 & 688524 & 4.5 & 5.0005 & TST & \\
\hline CHEMBL1483638 & 688524 & 4.8 & 4.9907 & TST & \\
\hline CHEMBL1415341 & 688524 & 4.9 & 4.8954 & TST & \\
\hline CHEMBL 260213 & 688524 & 5.4 & 5.2264 & TST & \\
\hline CHEMBL1550366 & 688524 & 4.5 & 5.1304 & TST & \\
\hline CHEMBL1532281 & 688524 & 4.5 & 5.121 & TST & \\
\hline CHEMBL1586450 & 688524 & 4.7 & 4.8376 & TST & \\
\hline CHEMBL1601947 & 688524 & 6.9 & 4.9652 & TST & \\
\hline CHEMBL1303653 & 688524 & 5.2 & 4.8764 & TST & \\
\hline CHEMBL1526600 & 688524 & 4.8 & 4.9094 & TST & \\
\hline CHEMBL1375823 & 688524 & 4.9 & 4.9231 & TST & \\
\hline CHEMBL1533059 & 688524 & 6.1 & 5.0116 & TST & \\
\hline
\end{tabular}




\begin{tabular}{|c|c|c|c|c|}
\hline \multicolumn{5}{|c|}{ olemental Table s } \\
\hline CHEMBL1331097 & 688524 & 5.0 & 4.9579 & TST \\
\hline CHEMBL1568298 & 688524 & 5.0 & 4.8369 & TST \\
\hline CHEMBL1356135 & 688524 & 5.0 & 5.2208 & TST \\
\hline CHEMBL1487637 & 688524 & 4.5 & 4.7844 & TST \\
\hline CHEMBL1469912 & 688524 & 4.5 & 4.9222 & TST \\
\hline CHEMBL 1459538 & 688524 & 5.1 & 4.9829 & TST \\
\hline CHEMBL1546987 & 688524 & 5.1 & 4.7719 & TST \\
\hline CHEMBL1562214 & 688524 & 4.7 & 4.9735 & TST \\
\hline CHEMBL1526810 & 688524 & 4.5 & 4.8292 & TST \\
\hline CHEMBL1316387 & 688524 & 4.6 & 5.1614 & TST \\
\hline CHEMBL 1317250 & 688524 & 5.3 & \multicolumn{2}{|c|}{5.111000000000001} \\
\hline CHEMBL1597718 & 688524 & 5.0 & 4.9739 & TST \\
\hline CHEMBL1376804 & 688524 & 4.9 & 4.9512 & TST \\
\hline CHEMBL1318710 & 688524 & 5.3 & 5.0061 & TST \\
\hline CHEMBL1599005 & 688524 & 5.05 & 4.8609 & TST \\
\hline CHEMBL 2261512 & 688524 & 4.9 & 5.1324 & TST \\
\hline CHEMBL1518182 & 688524 & 4.9 & 5.1515 & TST \\
\hline CHEMBL1591815 & 688524 & 4.8 & 5.1194 & TST \\
\hline CHEMBL1379970 & 688524 & 6.0 & 5.2335 & TST \\
\hline CHEMBL1582770 & 688524 & 5.0 & 4.9985 & TST \\
\hline CHEMBL 1398246 & 688524 & 5.9 & 5.0853 & TST \\
\hline CHEMBL1510729 & 688524 & 4.8 & 4.8014 & TST \\
\hline CHEMBL1496243 & 688524 & 4.6 & 5.011 & TST \\
\hline CHEMBL1401535 & 688524 & 4.9 & 4.837 & TST \\
\hline CHEMBL1317494 & 688524 & 4.6 & 5.4538 & TST \\
\hline CHEMBL1332436 & 688524 & 4.6 & 4.9584 & TST \\
\hline CHEMBL1452645 & 688524 & 4.9 & 4.9167 & TST \\
\hline CHEMBL1514027 & 688524 & 5.5 & 5.3646 & TST \\
\hline CHEMBL1581616 & 688524 & 4.9 & 4.8627 & TST \\
\hline CHEMBL1433725 & 688524 & 4.5 & 5.1025 & TST \\
\hline CHEMBL1520873 & 688524 & 4.9 & 5.1613 & TST \\
\hline CHEMBL56731 & 688524 & 6.0 & 5.0656 & TST \\
\hline CHEMBL1516211 & 688524 & 5.5 & 5.3141 & TST \\
\hline CHEMBL408850 & 688524 & 5.4 & 5.0126 & TST \\
\hline CHEMBL3196340 & 688524 & 5.0 & 5.2402 & TST \\
\hline CHEMBL1415970 & 688524 & 4.6 & 4.9243 & TST \\
\hline CHEMBL1550809 & 688524 & 5.0 & 4.8856 & TST \\
\hline CHEMBL1470714 & 688524 & 4.9 & 5.0607 & TST \\
\hline CHEMBL1588780 & 688524 & 4.9 & 4.9516 & TST \\
\hline CHEMBL199194 & 688524 & 5.2 & 5.0569 & TST \\
\hline CHEMBL1560403 & 688524 & 5.55 & 5.2826 & TST \\
\hline CHEMBL1567689 & 688524 & 5.2 & 4.9208 & TST \\
\hline CHEMBL1567296 & 688524 & 5.2 & 5.0051 & TST \\
\hline CHEMBL1520216 & 688524 & 4.9 & 5.3446 & TST \\
\hline CHEMBL1547504 & 688524 & 4.9 & 5.0641 & TST \\
\hline CHEMBL1505359 & 688524 & 4.9 & 5.1199 & TST \\
\hline CHEMBL1489717 & 688524 & 5.7 & 4.8266 & TST \\
\hline CHEMBL1493606 & 688524 & 4.9 & 4.9885 & TST \\
\hline
\end{tabular}




\begin{tabular}{|c|}
\hline \\
\hline CHEMBL: \\
\hline CHEMBL14 \\
\hline CHEMBL1345478 \\
\hline CHEMBL1567531 \\
\hline CHEMBL1733652 \\
\hline CHEMBL1564477 \\
\hline CHEMBL1533766 \\
\hline CHEMBL1498680 \\
\hline CHEMBL1443720 \\
\hline CHEMBL1449976 \\
\hline CHEMBL1370540 \\
\hline CHEMBL1311280 \\
\hline CHEMBL1389242 \\
\hline CHEMBL1407552 \\
\hline CHEMBL1538469 \\
\hline CHEMBL1591384 \\
\hline CHEMBL1337235 \\
\hline CHEMBL 70971 \\
\hline CHEMBL571087 \\
\hline CHEMBL1563063 \\
\hline CHEMBL1358743 \\
\hline CHEMBL12014 \\
\hline CHEMBL1442969 \\
\hline CHEMBL1336039 \\
\hline CHEMBL1586893 \\
\hline CHEMBL1361251 \\
\hline CHEMBL1315292 \\
\hline CHEMBL1373079 \\
\hline CHEMBL1384374 \\
\hline CHEMBL1423830 \\
\hline CHEMBL 1376000 \\
\hline CHEMBL1508377 \\
\hline CHEMBL1400308 \\
\hline CHEMBL1454201 \\
\hline CHEMBL1559756 \\
\hline CHEMBL1606951 \\
\hline CHEMBL1524617 \\
\hline CHEMBL1507523 \\
\hline CHEMBL1528815 \\
\hline CHEMBL1329823 \\
\hline CHEMBL1495515 \\
\hline CHEMBL1514431 \\
\hline CHEMBL1498971 \\
\hline CHEMBL1419759 \\
\hline CHEMBL1374189 \\
\hline CHEMBL1313666 \\
\hline CHEMBL555689 \\
\hline
\end{tabular}

Supplemental Table S2.txt

$\begin{array}{llll}688524 & 6.8 & 5.0877 & \text { TST } \\ 688524 & 4.9 & 4.9793 & \text { TST } \\ 688524 & 5.9 & 5.0852 & \text { TST } \\ 688524 & 5.3 & 4.9809 & \text { TST } \\ 688524 & 4.5 & 4.9931 & \text { TST } \\ 688524 & 5.1 & 5.1167 & \text { TST } \\ 688524 & 4.8 & 5.1426 & \text { TST } \\ 688524 & 4.5 & 5.0979 & \text { TST } \\ 688524 & 4.5 & 4.9814 & \text { TST } \\ 688524 & 5.2 & 4.9148 & \text { TST } \\ 688524 & 6.8 & 4.8063 & \text { TST } \\ 688524 & 5.7 & 4.978 & \text { TST } \\ 688524 & 5.3 & 4.8226 & \text { TST } \\ 688524 & 5.0 & 5.0037 & \text { TST } \\ 688524 & 4.9 & 5.1378 & \text { TST } \\ 688524 & 5.6 & 4.9895 & \text { TST } \\ 688524 & 4.8 & 4.9977 & \text { TST } \\ 688524 & 4.8 & 5.0904 & \text { TST } \\ 688524 & 4.6 & 4.98 & \text { TST } \\ 688524 & 4.7 & 5.0556 & \text { TST } \\ 688524 & 5.0 & 4.8582 & \text { TST } \\ 688524 & 5.9 & 5.0818 & \text { TST } \\ 688524 & 6.0 & 5.1318 & \text { TST } \\ 688524 & 5.0 & 5.0569999999999995 \\ 688524 & 5.0 & 4.976 & \text { TST } \\ 688524 & 5.5 & 4.7782 & \text { TST } \\ 688524 & 4.8 & 4.9192 & \text { TST } \\ 688524 & 4.7 & 5.2558 & \text { TST } \\ 688524 & 4.5 & 5.0289 & \text { TST } \\ 688524 & 4.7 & 4.9348 & \text { TST } \\ 688524 & 5.5 & 5.1394 & \text { TST } \\ 688524 & 6.1 & 5.1836 & \text { TST } \\ 688524 & 4.9 & 4.9519 & \text { TST } \\ 688524 & 5.0 & 4.8286 & \text { TST } \\ 688524 & 4.9 & 5.0305 & \text { TST } \\ 688524 & 5.4 & 5.0475 & \text { TST } \\ 688524 & 4.9 & 4.8597 & \text { TST } \\ 688524 & 5.1 & 5.1729 & \text { TST } \\ 688524 & 4.8 & 4.9575 & \text { TST } \\ 688524 & 4.9 & 4.8518 & \text { TST } \\ 688524 & 5.3 & 5.3955 & \text { TST } \\ 688524 & 4.5 & 4.9171 & \text { TST } \\ 688524 & 5.5 & 5.1833 & \text { TST } \\ 688524 & 4.9 & 4.8537 & \text { TST } \\ 688524 & 4.9 & 4.9107 & \text { TST } \\ 688524 & 4.7 & 5.1057 & \text { TST } \\ 688524 & 5.9 & 4.7596 & \text { TST } \\ & & 4.9021 & \text { TST } \\ 6 & & \text { Page } 26318 \\ 6 & & \end{array}$




\begin{tabular}{|c|c|c|c|c|c|}
\hline \\
\hline CHEMBL3199263 & 688524 & 5.3 & 4.9786 & TST & \\
\hline CHEMBL 1600780 & 688524 & 4.8 & 4.9491 & TST & \\
\hline CHEMBL1386323 & 688524 & 5.0 & 5.016 & TST & \\
\hline CHEMBL1451972 & 688524 & 5.2 & 5.0009 & TST & \\
\hline CHEMBL1256139 & 688524 & 5.3 & 5.2223 & TST & \\
\hline CHEMBL1374103 & 688524 & 6.5 & 4.8774 & TST & \\
\hline CHEMBL1401515 & 688524 & 4.5 & 5.1042 & TST & \\
\hline CHEMBL1609319 & 688524 & 4.7 & 4.9112 & TST & \\
\hline CHEMBL1319810 & 688524 & 5.1 & 5.063 & TST & \\
\hline CHEMBL1604833 & 688524 & 4.9 & 5.0402 & TST & \\
\hline CHEMBL1466749 & 688524 & 4.9 & 4.9172 & TST & \\
\hline CHEMBL1411687 & 688524 & 5.2 & 4.8428 & TST & \\
\hline CHEMBL1589925 & 688524 & 4.8 & 5.1657 & TST & \\
\hline CHEMBL1522523 & 688524 & 4.9 & 4.9875 & TST & \\
\hline CHEMBL1342873 & 688524 & 6.7001 & 4.8045 & TST & \\
\hline CHEMBL1500964 & 688524 & 4.7 & 5.1514 & TST & \\
\hline CHEMBL1495505 & 688524 & 5.6 & 5.2261 & TST & \\
\hline CHEMBL1424033 & 688524 & 5.6 & 4.7988 & TST & \\
\hline CHEMBL1970879 & 954894 & 4.6795 & 4.4029 & TRN & \\
\hline CHEMBL65 & 954894 & 6.3133 & 6.3134 & TRN & \\
\hline CHEMBL259181 & 954894 & 3.1933 & 3.5111 & TRN & \\
\hline CHEMBL213100 & 954894 & 3.122 & 3.33699 & 99999999997 & TRN \\
\hline CHEMBL1242367 & 954894 & 4.3917 & 4.357 & TRN & \\
\hline CHEMBL180127 & 954894 & 3.6718 & 3.9037 & TRN & \\
\hline CHEMBL1673039 & 954894 & 4.0821 & 4.1093 & TRN & \\
\hline CHEMBL240954 & 954894 & 3.9773 & 4.3658 & TST & \\
\hline CHEMBL92309 & 954894 & 2.7246 & 2.5621 & TST & \\
\hline CHEMBL1516890 & 954894 & 3.9841 & 4.0393 & TRN & \\
\hline CHEMBL220241 & 954894 & 4.0725 & 4.0574 & TRN & \\
\hline CHEMBL3349342 & 954894 & 3.5653 & 3.4495 & TRN & \\
\hline CHEMBL449158 & 954894 & 6.0365 & 6.2056 & TST & \\
\hline CHEMBL1788116 & 954894 & 4.2367 & 4.2287 & TRN & \\
\hline CHEMBL 2363137 & 954894 & 5.1733 & 4.88399 & 99999999995 & TRN \\
\hline CHEMBL1643959 & 954894 & 3.136 & 3.2307 & TRN & \\
\hline CHEMBL373751 & 954894 & 2.9918 & 3.3221 & TRN & \\
\hline CHEMBL1230020 & 954894 & 3.9072 & 3.9403 & TRN & \\
\hline CHEMBL202721 & 954894 & 4.3682 & 4.4776 & TRN & \\
\hline CHEMBL3392440 & 954894 & 3.5715 & 3.2563 & TRN & \\
\hline CHEMBL393929 & 954894 & 3.8993 & 3.9013 & TRN & \\
\hline CHEMBL188678 & 954894 & 6.4902 & 6.3608 & TRN & \\
\hline CHEMBL258844 & 954894 & 4.6094 & 4.7024 & TRN & \\
\hline CHEMBL483849 & 954894 & 2.7492 & 2.6239 & TRN & \\
\hline CHEMBL512504 & 954894 & $6.8660 e$ & 00000000 & 6.6886 & TRN \\
\hline CHEMBL1256459 & 954894 & 5.0018 & 5.1399 & TRN & \\
\hline CHEMBL210618 & 954894 & 3.9335 & 3.6147 & TRN & \\
\hline CHEMBL1357247 & 954894 & 3.33 & 3.154 & TRN & \\
\hline CHEMBL472940 & 954894 & 4.1886 & 4.4375 & TRN & \\
\hline CHEMBL189584 & 954894 & 4.8202 & 4.8131 & TRN & \\
\hline
\end{tabular}


Supplemental Table S2.txt

\begin{tabular}{|c|c|c|c|c|}
\hline HEMBL & & 656 & 4.507 & TR \\
\hline HFMBI 509032 & 54894 & 4.4703 & 4.4921 & \\
\hline HEMBL 392695 & & 8233 & 7327 & \\
\hline HEMBL 300389 & 54894 & 1521 & .12 & \\
\hline HEMBL 2144069 & 54894 & 3.4586 & 3.5173 & \\
\hline HEMBL192566 & 54894 & .6678 & 548 & \\
\hline HEMBL 2 & & 675 & & . \\
\hline HEMBL 379300 & 94 & 994 & 3086 & PN \\
\hline HEMBL514499 & 54894 & 7.1578 & .001 & \\
\hline HEMBL483847 & 54894 & 3.6038 & 3.8407 & \\
\hline HEMBL2 & 394 & 7646 & 5492 & \\
\hline HEMBL1 & & & 3.1044 & RN \\
\hline HEMBL3 & 94 & 18 & 5.8726 & \\
\hline HEMBL2 & 394 & 662 & 8863 & \\
\hline HEMBL135561 & 94 & 4.1381 & 4.1135 & \\
\hline HEMBL 5 & 94 & 838 & 401 & \\
\hline HEMBL & & & 199 & RN \\
\hline HEMBLI & 94 & 399 & 4713 & RN \\
\hline HEMBL 5 & 94 & 19 & 3743 & \\
\hline HEMBL5 & 94 & 73 & 721 & וכ \\
\hline HEMBL1 & 94 & 72 & 366 & SI \\
\hline HEMBL: & & & & ST \\
\hline HEMBL3 & 94 & 63 & 46 & TST \\
\hline HEMBL3 & & & & TST \\
\hline HEMBL9 & 94 & 79 & 515 & |S| \\
\hline AEMBL & & & 37 & ST \\
\hline HEME & & & 43 & ST \\
\hline 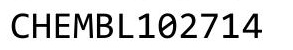 & & & & ICT \\
\hline AEMBL5 & & & & $|S|$ \\
\hline HEMBL1 & 92 & 4 & 696 & 「RN \\
\hline AEMBL] & 92 & 98 & 747 & 「RN \\
\hline HEME & & & 77 & ST \\
\hline & & & & TST \\
\hline HEMBL1 & 92 & & 595 & TST \\
\hline HEMBL1 & 92 & 067 & 4326 & 「RN \\
\hline HEMBL1 & 92 & & 992 & 「RN \\
\hline III & & & & RN \\
\hline HEMBL1 & & & 581 & TRN \\
\hline HEMBL1 & 92 & 5.7077 & 007 & 「RN \\
\hline EMBL] & 92 & 55 & 575 & 「RN \\
\hline HEMBL1 & & & 974 & TRN \\
\hline HEMBL1 & & & 5.0394 & 「RN \\
\hline HEMBL17 & 92 & 5.5017 & & TRN \\
\hline AEMBL1 & 92 & 249 & & TST \\
\hline EMBL1 & & & 752 & IST \\
\hline CHEMBL1797357 & 753892 & 5.5834 & 5.6867 & \\
\hline CHEMBL1797471 & 753892 & 5.6198 & 5.2537 & \\
\hline CHEMBL1797474 & 753892 & 5.4908 & 4.867 & RN \\
\hline
\end{tabular}

Page 26320 


\begin{tabular}{|c|c|c|c|c|c|}
\hline \multirow[b]{2}{*}{ CHEMBL1797492 } & \multicolumn{5}{|c|}{ Supplemental Table S2.txt } \\
\hline & 753892 & 5.5884 & 6.239 & TST & \\
\hline CHEMBL1797486 & 753892 & 3.0 & 2.7771 & TRN & \\
\hline CHEMBL1797369 & 753892 & 5.4437 & 5.3616 & TRN & \\
\hline CHEMBL1797366 & 753892 & 6.0132 & 6.11700 & 0000000001 & TRN \\
\hline CHEMBL1797599 & 753892 & 6.2441 & 6.3823 & TST & \\
\hline CHEMBL1797355 & 753892 & 5.5575 & 5.5885 & TRN & \\
\hline CHEMBL1797457 & 753892 & $5.7520 e$ & 00000000 & 5.8253 & TRN \\
\hline CHEMBL1797487 & 753892 & 4.1145 & 4.9716 & TRN & \\
\hline CHEMBL1797485 & 753892 & 3.0 & 3.3037 & TRN & \\
\hline CHEMBL1797602 & 753892 & 6.1135 & 5.8162 & TST & \\
\hline CHEMBL1797190 & 753892 & 6.0 & 5.5187 & TRN & \\
\hline CHEMBL1797462 & 753892 & 3.301 & 3.5798 & TRN & \\
\hline CHEMBL1797483 & 753892 & 4.6882 & 4.9921 & TRN & \\
\hline CHEMBL1797494 & 753892 & 5.9706 & 6.1875 & TST & \\
\hline CHEMBL1797345 & 753892 & 5.5346 & 5.38700 & 00000000005 & TRN \\
\hline CHEMBL1797336 & 753892 & 3.0 & 3.4135 & TRN & \\
\hline CHEMBL1797351 & 753892 & 3.301 & 4.1222 & TRN & \\
\hline CHEMBL1797456 & 753892 & 5.9914 & 5.96899 & 9999999999 & TRN \\
\hline CHEMBL1797354 & 753892 & 5.1778 & 5.2961 & TRN & \\
\hline CHEMBL1797479 & 753892 & 5.8153 & 5.037 & TRN & \\
\hline CHEMBL1797335 & 753892 & 3.0 & 3.4189 & TRN & \\
\hline CHEMBL1797460 & 753892 & 6.041 & 6.0252 & TRN & \\
\hline CHEMBL1797365 & 753892 & 5.8729 & 5.9855 & TRN & \\
\hline CHEMBL1797337 & 753892 & 5.1952 & 4.4306 & TRN & \\
\hline CHEMBL1797463 & 753892 & 3.301 & 3.6712 & TRN & \\
\hline CHEMBL1797476 & 753892 & 3.0 & 3.3899 & TRN & \\
\hline CHEMBL1652176 & 753892 & 5.2426 & 5.4781 & TRN & \\
\hline CHEMBL1797493 & 753892 & 6.9586 & 6.58299 & 9999999999 & TST \\
\hline CHEMBL1797186 & 753892 & 5.1249 & 5.1693 & TST & \\
\hline CHEMBL1797343 & 753892 & 5.9172 & 5.7046 & TRN & \\
\hline CHEMBL1797327 & 753892 & 5.0246 & 5.2069 & TRN & \\
\hline CHEMBL1797475 & 753892 & 4.2306 & 3.5846 & TST & \\
\hline CHEMBL1797465 & 753892 & 5.0516 & 4.9053 & TRN & \\
\hline CHEMBL1797334 & 753892 & 5.4622 & 4.8169 & TRN & \\
\hline CHEMBL1797340 & 753892 & 5.1284 & 5.0957 & TRN & \\
\hline CHEMBL1797363 & 753892 & 5.8539 & 6.0706 & TRN & \\
\hline CHEMBL1797360 & 753892 & 5.7471 & 5.7772 & TRN & \\
\hline CHEMBL1797495 & 753892 & 6.3768 & 6.5056 & TST & \\
\hline CHEMBL1797468 & 753892 & 5.1349 & 4.2012 & TRN & \\
\hline CHEMBL1773232 & 753892 & 6.2366 & 6.2439 & TST & \\
\hline CHEMBL1797346 & 753892 & 5.466 & 5.7748 & TRN & \\
\hline CHEMBL1797350 & 753892 & 5.4377 & 5.2333 & TRN & \\
\hline CHEMBL1797349 & 753892 & 5.0467 & 5.1114 & TRN & \\
\hline CHEMBL1797322 & 753892 & 5.0182 & 4.8619 & TRN & \\
\hline CHEMBL1797458 & 753892 & 5.8477 & 6.0997 & TRN & \\
\hline CHEMBL1773239 & 753892 & 6.1192 & 6.2292 & TST & \\
\hline CHEMBL1773235 & 753892 & 6.3372 & 6.1262 & TST & \\
\hline CHEMBL1797362 & 753892 & 5.6861 & 5.636 & TRN & \\
\hline
\end{tabular}




\begin{tabular}{|c|c|c|c|c|c|}
\hline & & \multicolumn{4}{|c|}{ Supplemental Table S2.txt } \\
\hline CHEMBL1795365 & 753892 & 5.7932 & 5.651 & TRN & \\
\hline CHEMBL1797498 & 753892 & 5.9469 & 5.8844 & TST & \\
\hline CHEMBL1797604 & 753892 & 6.4318 & 5.2685 & TST & \\
\hline CHEMBL1797477 & 753892 & 3.0 & 2.8645 & TRN & \\
\hline CHEMBL1797497 & 753892 & 6.3768 & 6.479 & TST & \\
\hline CHEMBL1797491 & 753892 & 6.3188 & 6.4336 & TST & \\
\hline CHEMBL1797598 & 753892 & 5.8239 & 6.0965 & TST & \\
\hline CHEMBL1797364 & 753892 & 5.8268 & 6.0757 & TRN & \\
\hline CHEMBL1797198 & 753892 & 5.058 & 4.6468 & TRN & \\
\hline CHEMBL1797326 & 753892 & 5.1209 & 5.0482 & TRN & \\
\hline CHEMBL1797333 & 753892 & 3.0 & 3.3781 & TRN & \\
\hline CHEMBL1797344 & 753892 & 3.301 & 3.9978 & TRN & \\
\hline CHEMBL1797339 & 753892 & 3.0 & 3.6478 & TRN & \\
\hline CHEMBL1797482 & 753892 & 3.0 & 4.9104 & TRN & \\
\hline CHEMBL1797478 & 753892 & 5.1656 & 5.1312 & TRN & \\
\hline CHEMBL1797342 & 753892 & 5.5129 & 5.7952 & TRN & \\
\hline CHEMBL1797368 & 753892 & 5.2708 & 5.1026 & TRN & \\
\hline CHEMBL461055 & 753892 & 5.0 & 5.1186 & TST & \\
\hline CHEMBL1797469 & 753892 & 3.0 & 2.8681 & TRN & \\
\hline CHEMBL1797601 & 753892 & 6.4437 & 6.3047 & TST & \\
\hline CHEMBL1797466 & 753892 & 6.0088 & 5.4039 & TRN & \\
\hline CHEMBL1797341 & 753892 & 5.0872 & 4.7392 & TRN & \\
\hline CHEMBL1797603 & 753892 & 6.4089 & 6.2239 & TST & \\
\hline CHEMBL1797472 & 753892 & 4.3996 & 4.2802 & TRN & \\
\hline CHEMBL1797488 & 753892 & 3.0 & 5.0159 & TRN & \\
\hline CHEMBL1773231 & 753892 & 6.301 & 5.1482 & TST & \\
\hline CHEMBL1797464 & 753892 & 4.7131 & 4.4672 & TRN & \\
\hline CHEMBL1797473 & 753892 & 3.0 & 3.3204 & TRN & \\
\hline CHEMBL1797470 & 753892 & 5.52 & 5.3743 & TRN & \\
\hline CHEMBL1797332 & 753892 & 5.6234 & 3.7008 & TRN & \\
\hline CHEMBL1797359 & 753892 & 5.9245 & 5.8399 & TRN & \\
\hline CHEMBL1797338 & 753892 & 3.0 & 3.6438 & TRN & \\
\hline CHEMBL1797325 & 753892 & 4.9045 & 4.4805 & TRN & \\
\hline CHEMBL389471 & 753892 & 4.1549 & 5.2084 & TST & \\
\hline CHEMBL1797352 & 753892 & 4.967 & 4.7366 & TRN & \\
\hline CHEMBL1797480 & 753892 & 5.2097 & 4.5611 & TRN & \\
\hline CHEMBL1797481 & 753892 & 4.5771 & 4.27800 & 00000000005 & TRN \\
\hline CHEMBL1797187 & 753892 & 5.699 & 5.2452 & TST & \\
\hline CHEMBL1797324 & 753892 & 5.0246 & 5.2759 & TRN & \\
\hline CHEMBL1797361 & 753892 & 5.9208 & 5.801 & TRN & \\
\hline CHEMBL1797367 & 753892 & 5.9245 & 6.0762 & TRN & \\
\hline CHEMBL1427058 & 954299 & 3.0264 & 3.09 & TRN & \\
\hline CHEMBL1497680 & 954299 & 3.0263 & 2.841 & TRN & \\
\hline CHEMBL1333208 & 954299 & 3.0263 & 2.9344 & TRN & \\
\hline CHEMBL 2137175 & 954299 & 3.02600 & 00000000 & 3.0628 & TRN \\
\hline CHEMBL1407282 & 954299 & 3.0263 & 3.094 & TRN & \\
\hline CHEMBL1463851 & 954299 & 3.0264 & 3.0438 & TRN & \\
\hline CHEMBL1426378 & 954299 & 3.0265 & 3.1724 & TRN & \\
\hline
\end{tabular}




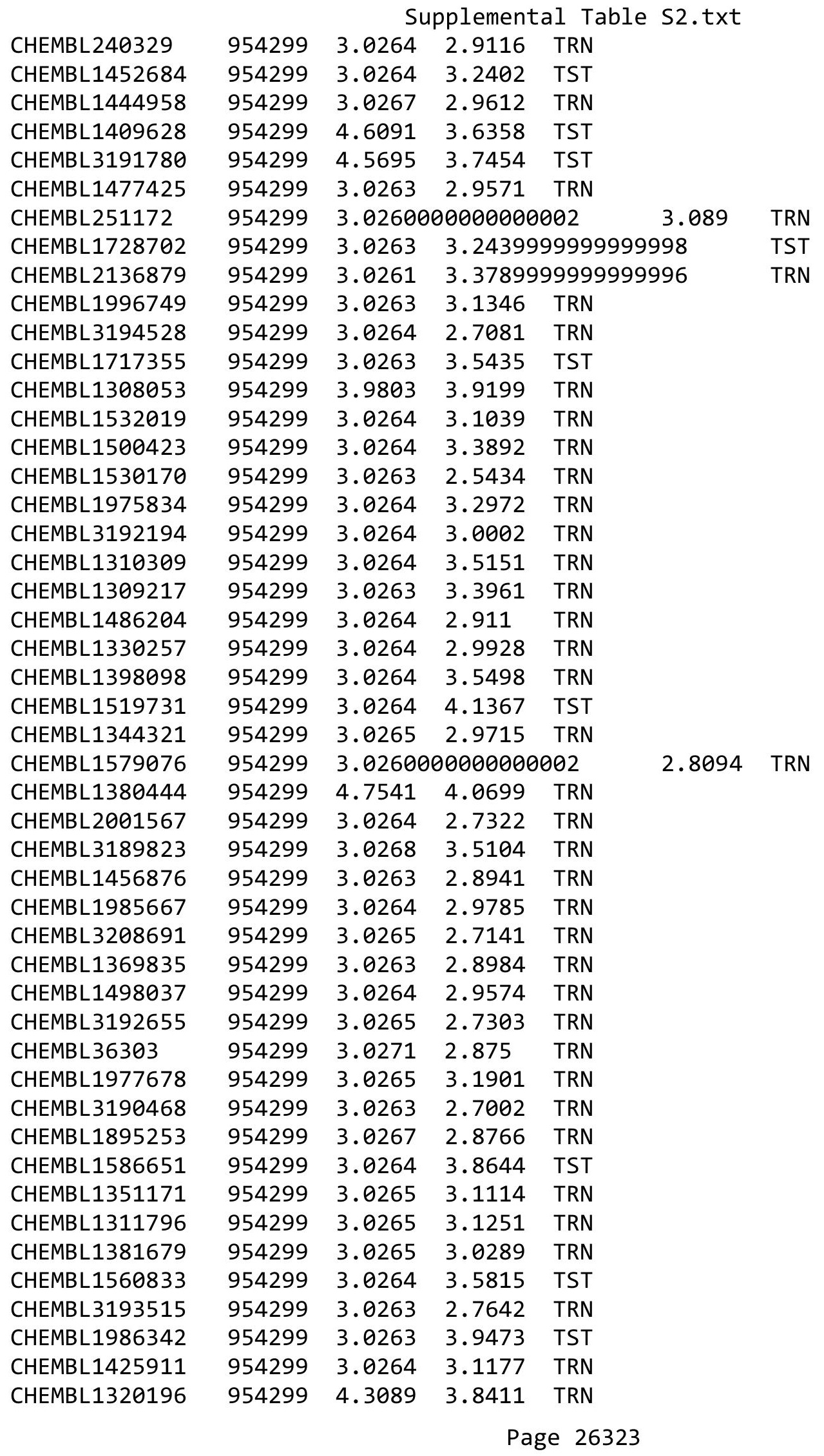


Supplemental Table S2.txt

\begin{tabular}{|c|c|c|c|c|c|c|}
\hline CHEMBL1305787 & 954299 & 3.0263 & 3.6785 & TST & & \\
\hline CHEMBL1409822 & 954299 & 3.0264 & 3.0532 & TRN & & \\
\hline CHEMBL1560921 & 954299 & 3.0263 & 2.9903 & TRN & & \\
\hline CHEMBL1537113 & 954299 & 3.0264 & 3.088 & TRN & & \\
\hline CHEMBL1426155 & 954299 & 3.0264 & 3.0361 & TRN & & \\
\hline CHEMBL1964442 & 954299 & 3.0268 & 3.1406 & TRN & & \\
\hline CHEMBL 3190021 & 954299 & 4.9764 & 4.0326 & TRN & & \\
\hline CHEMBL1594376 & 954299 & 4.246 & 3.7493 & TRN & & \\
\hline CHEMBL 3199820 & 954299 & 3.0264 & 3.3571 & TRN & & \\
\hline CHEMBL1518452 & 954299 & 3.0267 & 2.7209 & TRN & & \\
\hline CHEMBL1332075 & 954299 & 3.0264 & 3.0673 & TRN & & \\
\hline CHEMBL1995252 & 954299 & 3.0264 & 2.8396 & TRN & & \\
\hline CHEMBL1505420 & 954299 & 3.0265 & 2.8583 & TRN & & \\
\hline CHEMBL1975961 & 954299 & 3.0267 & 3.122 & TRN & & \\
\hline CHEMBL3196642 & 954299 & 3.0264 & 3.0083 & TRN & & \\
\hline CHEMBL1488474 & 954299 & 5.0532 & 3.818 & TST & & \\
\hline CHEMBL1967046 & 954299 & 4.4076 & 3.8325 & TST & & \\
\hline CHEMBL69612 & 954299 & 3.0264 & 3.6536 & TST & & \\
\hline CHEMBL1704223 & 954299 & 3.0263 & 3.8273 & TRN & & \\
\hline CHEMBL 2006909 & 954299 & 3.0265 & 3.0393 & TRN & & \\
\hline CHEMBL1985664 & 954299 & 5.4159 & 3.7338 & TRN & & \\
\hline CHEMBL1878187 & 954299 & 3.0262 & 3.4353 & TST & & \\
\hline CHEMBL1479083 & 954299 & 3.0264 & 2.7455 & TRN & & \\
\hline CHEMBL1464852 & 954299 & 3.0264 & 3.2182 & TRN & & \\
\hline CHEMBL66953 & 954299 & 5.3577 & 3.7242 & TST & & \\
\hline CHEMBL1904459 & 954299 & 3.0264 & 2.742 & TRN & & \\
\hline CHEMBL1724080 & 954299 & 3.0265 & 3.4761 & TRN & & \\
\hline CHEMBL1605524 & 954299 & 3.0263 & 3.2749 & TRN & & \\
\hline CHEMBL1315592 & 954299 & 3.0263 & 3.2745 & TRN & & \\
\hline CHEMBL607979 & 954299 & 3.0262 & 3.6554 & TRN & & \\
\hline CHEMBL1423611 & 954299 & 3.0265 & 3.7982 & TRN & & \\
\hline CHEMBL1376200 & 954299 & \multicolumn{3}{|c|}{3.0260000000000002} & 3.5718 & TRN \\
\hline CHEMBL1344137 & 954299 & 3.0267 & 3.0641 & TRN & & \\
\hline CHEMBL1373095 & 954299 & 3.0263 & 3.7578 & TRN & & \\
\hline CHEMBL1403216 & 954299 & 3.0264 & 3.3202 & TRN & & \\
\hline CHEMBL3193676 & 954299 & 4.7346 & 3.6955 & TRN & & \\
\hline CHEMBL1461351 & 954299 & 4.8313 & 3.9533 & TRN & & \\
\hline CHEMBL 3197790 & 954299 & 3.0263 & 2.8752 & TRN & & \\
\hline CHEMBL1573966 & 954299 & 3.0268 & 3.0226 & TRN & & \\
\hline CHEMBL 3194441 & 954299 & 3.0263 & 3.0378 & TRN & & \\
\hline CHEMBL1600086 & 954299 & 3.0264 & 3.168 & TRN & & \\
\hline CHEMBL3213606 & 954299 & 3.0262 & 3.0985 & TRN & & \\
\hline CHEMBL1557939 & 954299 & 3.0265 & 2.8759 & TRN & & \\
\hline CHEMBL1704267 & 954299 & 3.0264 & 2.9977 & TRN & & \\
\hline CHEMBL3192179 & 954299 & 3.0265 & 3.8731 & TRN & & \\
\hline CHEMBL323554 & 954299 & 3.0263 & 2.9368 & TRN & & \\
\hline CHEMBL1378131 & 954299 & 3.0264 & 3.1613 & TRN & & \\
\hline CHEMBL1538082 & 954299 & 3.0263 & 3.0329 & TRN & & \\
\hline
\end{tabular}

Page 26324 


\begin{tabular}{|c|c|c|c|c|c|c|}
\hline & & \multicolumn{5}{|c|}{ Supplemental Table S2.txt } \\
\hline CHEMBL234338 & 954299 & 3.0258 & 3.6306 & TRN & & \\
\hline CHEMBL1441430 & 954299 & 3.0264 & 3.2652 & TRN & & \\
\hline CHEMBL1343371 & 954299 & 3.0263 & 4.0524 & TST & & \\
\hline CHEMBL1722566 & 954299 & 3.0264 & 3.5585 & TRN & & \\
\hline CHEMBL1335838 & 954299 & 4.5418 & 4.1286 & TRN & & \\
\hline CHEMBL1609276 & 954299 & 3.0263 & 3.6631 & TST & & \\
\hline CHEMBL1581048 & 954299 & 3.0267 & 2.8214 & TRN & & \\
\hline CHEMBL1981122 & 954299 & 4.4877 & 3.8256 & TRN & & \\
\hline CHEMBL1442460 & 954299 & 3.0259 & 3.2253 & TST & & \\
\hline CHEMBL1465741 & 954299 & \multicolumn{3}{|c|}{3.0260000000000002} & 3.0284 & TRN \\
\hline CHEMBL 3214310 & 954299 & 3.0264 & 3.0618 & TRN & & \\
\hline CHEMBL176599 & 954299 & 3.5042 & 3.4636 & TRN & & \\
\hline CHEMBL1453409 & 954299 & 4.2546 & 3.6421 & TST & & \\
\hline CHEMBL1367050 & 954299 & 3.0264 & 3.3418 & TRN & & \\
\hline CHEMBL1494506 & 954299 & 3.0265 & 3.0713 & TRN & & \\
\hline CHEMBL599013 & 954299 & 3.0263 & 2.9605 & TRN & & \\
\hline CHEMBL1397916 & 954299 & 3.0267 & 2.8735 & TRN & & \\
\hline CHEMBL1482959 & 954299 & 5.2041 & 3.9744 & TRN & & \\
\hline CHEMBL1504777 & 954299 & 3.0268 & 3.1126 & TRN & & \\
\hline CHEMBL1983351 & 954299 & 3.0264 & 3.1672 & TRN & & \\
\hline CHEMBL95615 & 954299 & 3.0265 & 2.9319 & TRN & & \\
\hline CHEMBL1385451 & 954299 & 3.0264 & 2.9585 & TRN & & \\
\hline CHEMBL1501132 & 954299 & 3.0264 & 3.2975 & TRN & & \\
\hline CHEMBL3198823 & 954299 & 3.0263 & 2.9927 & TRN & & \\
\hline CHEMBL1592276 & 954299 & 3.0265 & 3.5212 & TST & & \\
\hline CHEMBL3197991 & 954299 & 3.0265 & 2.9031 & TRN & & \\
\hline CHEMBL1329747 & 954299 & 4.1166 & 4.2137 & TRN & & \\
\hline CHEMBL1970872 & 954299 & 3.0265 & 2.7732 & TRN & & \\
\hline CHEMBL1430405 & 954299 & 3.0265 & 3.0359 & TRN & & \\
\hline CHEMBL1528395 & 954299 & \multicolumn{3}{|c|}{3.0260000000000002} & 2.9983 & TRN \\
\hline CHEMBL65675 & 954299 & 3.0256 & 3.5028 & TRN & & \\
\hline CHEMBL1500850 & 954299 & 3.0261 & 3.5322 & TST & & \\
\hline CHEMBL1343658 & 954299 & 3.0264 & 3.0745 & TRN & & \\
\hline CHEMBL1300836 & 954299 & 3.0264 & 4.1521 & TST & & \\
\hline CHEMBL3194876 & 954299 & 4.8704 & 3.8735 & TRN & & \\
\hline CHEMBL1379810 & 954299 & 3.0266 & 3.0094 & TRN & & \\
\hline CHEMBL 250574 & 954299 & 3.0265 & 3.0664 & TRN & & \\
\hline CHEMBL1310594 & 954299 & 3.0264 & 2.9276 & TRN & & \\
\hline CHEMBL3197346 & 954299 & 3.0263 & 3.3604 & TRN & & \\
\hline CHEMBL1594616 & 954299 & 3.0268 & 3.05 & TRN & & \\
\hline CHEMBL1463926 & 954299 & 4.2779 & 3.8569 & TRN & & \\
\hline CHEMBL3198301 & 954299 & 3.0263 & 3.2992 & TRN & & \\
\hline CHEMBL1450570 & 954299 & 3.0265 & 3.6888 & TRN & & \\
\hline CHEMBL1412999 & 954299 & 3.0267 & 3.5502 & TRN & & \\
\hline CHEMBL1601394 & 954299 & 3.0263 & 3.6726 & TRN & & \\
\hline CHEMBL1348579 & 954299 & 3.0265 & 2.97 & TRN & & \\
\hline CHEMBL1515809 & 954299 & 3.0259 & 3.9106 & TRN & & \\
\hline CHEMBL1447307 & 954299 & 3.0265 & 2.9912 & TRN & & \\
\hline
\end{tabular}




\begin{tabular}{|c|c|c|c|c|c|c|}
\hline & & \multicolumn{5}{|c|}{ Supplemental Table S2.txt } \\
\hline CHEMBL1981446 & 954299 & 3.0265 & 2.8605 & TRN & & \\
\hline CHEMBL1906282 & 954299 & 3.0261 & 2.7447 & TRN & & \\
\hline CHEMBL3195985 & 954299 & 3.0263 & 3.5 & TST & & \\
\hline CHEMBL1606197 & 954299 & 3.0264 & 2.9103 & TRN & & \\
\hline CHEMBL1398682 & 954299 & 3.0265 & 3.4276 & TRN & & \\
\hline CHEMBL1388365 & 954299 & 3.0263 & 3.4231 & TRN & & \\
\hline CHEMBL1897711 & 954299 & 3.0264 & 3.5306 & TRN & & \\
\hline CHEMBL241598 & 954299 & 3.0265 & 2.8057 & TRN & & \\
\hline CHEMBL1399979 & 954299 & 4.3472 & 3.8233 & TRN & & \\
\hline CHEMBL3192855 & 954299 & 3.0263 & 2.9909 & TRN & & \\
\hline CHEMBL1546110 & 954299 & 3.0263 & 2.8006 & TRN & & \\
\hline CHEMBL1516401 & 954299 & 3.0263 & 3.3871 & TRN & & \\
\hline CHEMBL 2311878 & 954299 & \multicolumn{3}{|c|}{3.0260000000000002} & 2.7517 & TRN \\
\hline CHEMBL1561775 & 954299 & 3.0265 & 2.9228 & TRN & & \\
\hline CHEMBL3207619 & 954299 & 3.0263 & 3.145 & TRN & & \\
\hline CHEMBL 2007390 & 954299 & 3.0264 & 3.7421 & TRN & & \\
\hline CHEMBL1469656 & 954299 & 3.0267 & 2.7757 & TRN & & \\
\hline CHEMBL1968928 & 954299 & 5.6494 & 4.1237 & TRN & & \\
\hline CHEMBL3197902 & 954299 & 3.0264 & 3.0861 & TRN & & \\
\hline CHEMBL1404987 & 954299 & 3.0261 & 3.2725 & TRN & & \\
\hline CHEMBL1994094 & 954299 & 3.0263 & 3.2622 & TRN & & \\
\hline CHEMBL3144976 & 954299 & 3.0263 & 3.2273 & TST & & \\
\hline CHEMBL3196810 & 954299 & 3.0265 & 2.9871 & TRN & & \\
\hline CHEMBL1500597 & 954299 & 3.0263 & 3.3259 & TRN & & \\
\hline CHEMBL3190900 & 954299 & 3.0265 & 3.1422 & TRN & & \\
\hline CHEMBL1429070 & 954299 & 5.4276 & 4.1446 & TRN & & \\
\hline CHEMBL3193326 & 954299 & 3.0261 & 3.4923 & TRN & & \\
\hline CHEMBL1736254 & 954299 & 4.7256 & 3.6053 & TST & & \\
\hline CHEMBL1334484 & 954299 & 4.947 & 3.8009 & TST & & \\
\hline CHEMBL1425487 & 954299 & 3.0267 & 2.7618 & TRN & & \\
\hline CHEMBL1524511 & 954299 & 3.0264 & 3.0661 & TRN & & \\
\hline CHEMBL 3212364 & 954299 & 3.0263 & 3.0104 & TRN & & \\
\hline CHEMBL1602055 & 954299 & 3.0264 & 3.373 & TRN & & \\
\hline CHEMBL1312820 & 954299 & 3.0259 & 3.3317 & TST & & \\
\hline CHEMBL1980197 & 954299 & 3.0264 & 2.9984 & TRN & & \\
\hline CHEMBL3209849 & 954299 & 3.0264 & 3.4453 & TRN & & \\
\hline CHEMBL1486457 & 954299 & 3.0262 & 3.1391 & TRN & & \\
\hline CHEMBL1424208 & 954299 & 3.0265 & 3.3841 & TST & & \\
\hline CHEMBL1996360 & 954299 & 3.9807 & 3.5097 & TST & & \\
\hline CHEMBL1484185 & 954299 & 3.0264 & 3.0549 & TRN & & \\
\hline CHEMBL1706454 & 954299 & 4.7801 & 3.9603 & TST & & \\
\hline CHEMBL3195531 & 954299 & 3.0263 & 3.0435 & TRN & & \\
\hline CHEMBL1540637 & 954299 & 3.0263 & 3.5424 & TRN & & \\
\hline CHEMBL3192648 & 954299 & 3.0265 & 2.9815 & TRN & & \\
\hline CHEMBL1973722 & 954299 & 3.0263 & 3.6184 & TST & & \\
\hline CHEMBL3193134 & 954299 & 3.0263 & 3.2197 & TRN & & \\
\hline CHEMBL1407474 & 954299 & 3.0263 & 3.4058 & TST & & \\
\hline CHEMBL1613004 & 954299 & 4.6655 & 4.263 & TST & & \\
\hline
\end{tabular}


Supplemental Table S2.txt

\begin{tabular}{|c|c|c|c|c|}
\hline CHEMBL1869804 & 954299 & 3.0263 & 3.0758 & TRN \\
\hline CHEMBL3192777 & 954299 & 3.0263 & 2.8284 & TRN \\
\hline CHEMBL1501392 & 954299 & 5.2196 & 4.1965 & TRN \\
\hline CHEMBL3195767 & 954299 & 3.0264 & 3.392 & TRN \\
\hline CHEMBL3192879 & 954299 & 3.0264 & 3.1097 & TRN \\
\hline CHEMBL1500363 & 954299 & 3.0263 & 2.9659 & TRN \\
\hline CHEMBL398969 & 954299 & 3.0264 & 2.9616 & TRN \\
\hline CHEMBL1326997 & 954299 & 3.0264 & 3.5614 & TRN \\
\hline CHEMBL 224916 & 954299 & 3.0265 & 3.2443 & TST \\
\hline CHEMBL1574551 & 954299 & 3.0263 & 3.1695 & TST \\
\hline CHEMBL 2136441 & 954299 & 3.0268 & 3.0634 & TST \\
\hline CHEMBL1592387 & 954299 & 3.0264 & 3.3488 & TST \\
\hline CHEMBL1705092 & 954299 & 3.0263 & 3.2378 & TST \\
\hline CHEMBL1992109 & 954299 & 3.0264 & 3.0106 & TST \\
\hline CHEMBL1997990 & 954299 & 5.9884 & 3.7896 & TST \\
\hline CHEMBL1593571 & 954299 & 3.0264 & 2.7479 & TST \\
\hline CHEMBL1502723 & 954299 & 4.9692 & 3.43300 & 00000000003 \\
\hline CHEMBL1994988 & 954299 & 3.0263 & 3.7364 & TST \\
\hline CHEMBL1457092 & 954299 & 3.0263 & 2.9009 & TST \\
\hline CHEMBL1502397 & 954299 & 3.0263 & 3.3594 & TST \\
\hline CHEMBL1975615 & 954299 & 3.0264 & 3.6028 & TST \\
\hline CHEMBL1874620 & 954299 & 3.0264 & 3.2406 & TST \\
\hline CHEMBL3192715 & 954299 & 3.0266 & 4.2843 & TST \\
\hline CHEMBL3193886 & 954299 & 3.0263 & 3.6319 & TST \\
\hline CHEMBL3198930 & 954299 & 3.0263 & 2.9957 & TST \\
\hline CHEMBL1609550 & 954299 & 3.0264 & 3.8042 & TST \\
\hline CHEMBL1972774 & 954299 & 3.0265 & 3.2202 & TST \\
\hline CHEMBL1405691 & 954299 & 3.0264 & 3.0319 & TST \\
\hline CHEMBL3196548 & 954299 & 3.0264 & 3.2984 & TST \\
\hline CHEMBL1449718 & 954299 & 3.0264 & 2.9776 & TST \\
\hline CHEMBL156383 & 954299 & 3.0264 & 4.0217 & TST \\
\hline CHEMBL 2359560 & 954299 & 3.0268 & 2.8318 & TST \\
\hline CHEMBL1494426 & 954299 & 3.0264 & 2.9488 & TST \\
\hline CHEMBL1343812 & 737367 & 3.0 & 3.4584 & TRN \\
\hline CHEMBL594957 & 737367 & 4.7011 & 3.7607 & TST \\
\hline CHEMBL1338394 & 737367 & 3.0 & 4.1162 & TST \\
\hline CHEMBL1529919 & 737367 & 3.0 & 2.6162 & TRN \\
\hline CHEMBL1731432 & 737367 & 5.4763 & 5.6463 & TRN \\
\hline CHEMBL1569953 & 737367 & 4.2652 & 4.4362 & TRN \\
\hline CHEMBL512931 & 737367 & 7.4559 & 7.6412 & TRN \\
\hline CHEMBL466808 & 737367 & 7.4622 & 7.9147 & TRN \\
\hline CHEMBL1334710 & 737367 & 4.4461 & 3.5309 & TRN \\
\hline CHEMBL1331685 & 737367 & 3.0 & 3.0857 & TRN \\
\hline CHEMBL 200238 & 737367 & 3.0 & 3.79 & TST \\
\hline CHEMBL1624209 & 737367 & 3.0 & 2.4083 & TST \\
\hline CHEMBL1726777 & 737367 & 3.0 & 3.1822 & TRN \\
\hline CHEMBL1409723 & 737367 & 4.0 & 4.0303 & TRN \\
\hline CHEMBL1334685 & 737367 & 3.0 & 2.8796 & TRN \\
\hline
\end{tabular}




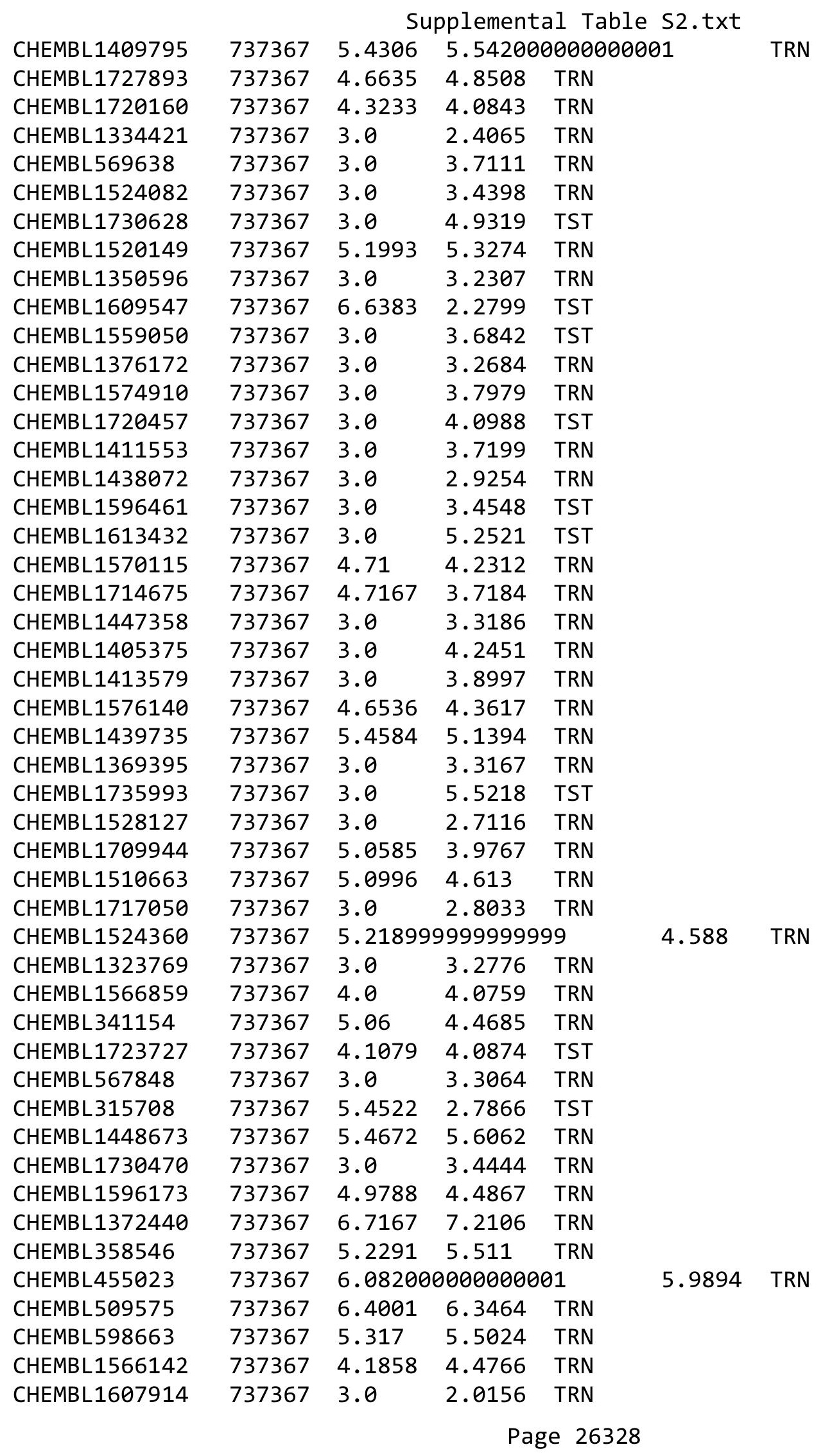




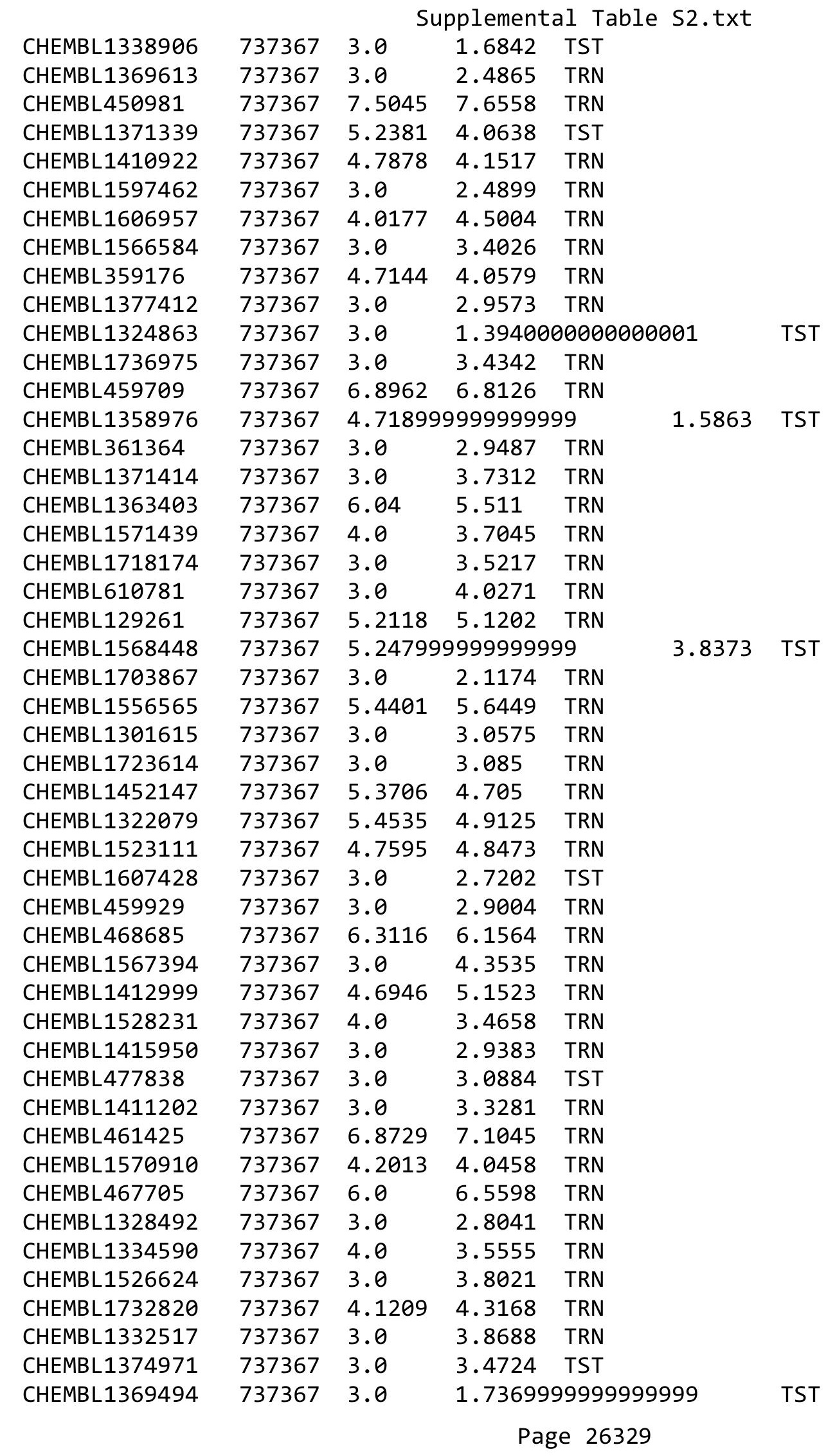




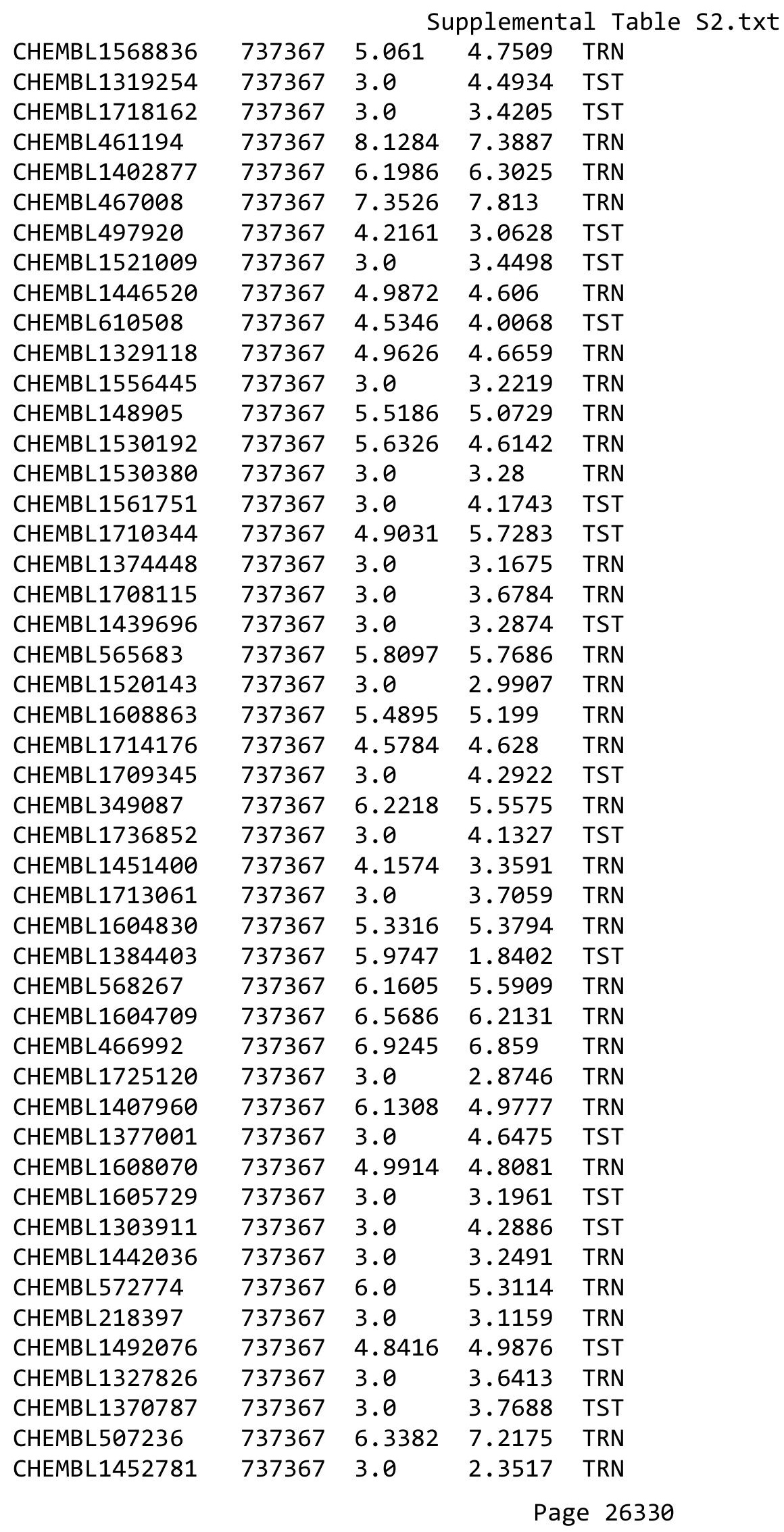




\begin{tabular}{|c|c|c|c|c|}
\hline \multicolumn{5}{|c|}{ Supplement } \\
\hline CHEMBL1407614 & 737367 & 3.0 & 2.1283 & TST \\
\hline CHEMBL1406130 & 737367 & 3.0 & 3.1804 & TRN \\
\hline CHEMBL560074 & 737367 & 3.0 & 2.8582 & TRN \\
\hline CHEMBL1369256 & 737367 & 6.0405 & 6.619 & TRN \\
\hline CHEMBL1359487 & 737367 & 3.0 & 3.6442 & TRN \\
\hline CHEMBL1715095 & 737367 & 4.8539 & 4.405 & TRN \\
\hline CHEMBL1408562 & 737367 & 3.0 & 3.2953 & TRN \\
\hline CHEMBL1712030 & 737367 & 3.0 & 3.8854 & TRN \\
\hline CHEMBL178453 & 737367 & 3.0 & 2.7156 & TRN \\
\hline CHEMBL1532279 & 737367 & 5.4763 & 4.6427 & TRN \\
\hline CHEMBL1596188 & 737367 & 4.71 & 4.6004 & TRN \\
\hline CHEMBL1609416 & 737367 & 3.0 & 3.7836 & TRN \\
\hline CHEMBL1409393 & 737367 & 3.0 & 4.138 & TRN \\
\hline CHEMBL597421 & 737367 & 3.0 & 3.6038 & TRN \\
\hline CHEMBL1605831 & 737367 & 3.0 & 3.7525 & TRN \\
\hline CHEMBL1735198 & 737367 & 4.5421 & 4.5227 & TST \\
\hline CHEMBL1716238 & 737367 & 4.1409 & 4.56 & TST \\
\hline CHEMBL1450046 & 737367 & 4.0 & 4.3781 & TST \\
\hline CHEMBL1535958 & 737367 & 5.6055 & 5.9025 & TRN \\
\hline CHEMBL1713178 & 737367 & 3.0 & 2.5999 & TRN \\
\hline CHEMBL1555745 & 737367 & 3.0 & 3.1764 & TRN \\
\hline CHEMBL467854 & 737367 & 7.1649 & 6.4075 & TRN \\
\hline CHEMBL1375393 & 737367 & 5.2233 & 5.67299 & 9999999999 \\
\hline CHEMBL1334987 & 737367 & 3.0 & 3.7871 & TRN \\
\hline CHEMBL1603738 & 737367 & 3.0 & 3.3991 & TRN \\
\hline CHEMBL1527949 & 737367 & 3.0 & 3.4516 & TRN \\
\hline CHEMBL571720 & 737367 & 6.1878 & 5.2697 & TRN \\
\hline CHEMBL1449531 & 737367 & 3.0 & 3.6779 & TRN \\
\hline CHEMBL599678 & 737367 & 4.2418 & 5.3995 & TST \\
\hline CHEMBL511689 & 737367 & 7.2534 & 6.891 & TRN \\
\hline CHEMBL1408462 & 737367 & 4.3325 & 4.1775 & TRN \\
\hline CHEMBL1725074 & 737367 & 5.3958 & 3.9627 & TST \\
\hline CHEMBL1450582 & 737367 & 3.0 & 3.6907 & TRN \\
\hline CHEMBL1442092 & 737367 & 3.0 & 2.6981 & TRN \\
\hline CHEMBL1526424 & 737367 & 3.0 & 3.2589 & TRN \\
\hline CHEMBL466809 & 737367 & 7.3335 & 7.3953 & TRN \\
\hline CHEMBL1702844 & 737367 & 3.0 & 3.181 & TST \\
\hline CHEMBL1717729 & 737367 & 3.0 & 4.1087 & TRN \\
\hline CHEMBL467382 & 737367 & 5.8827 & 3.9832 & TST \\
\hline CHEMBL1439678 & 737367 & 3.0 & 2.9991 & TRN \\
\hline CHEMBL1460778 & 737367 & 3.0 & 3.7142 & TST \\
\hline CHEMBL1408722 & 737367 & 4.7852 & 4.8087 & TRN \\
\hline CHEMBL1521484 & 737367 & 3.0 & 3.7172 & TRN \\
\hline CHEMBL1604601 & 737367 & 3.0 & 3.0142 & TST \\
\hline CHEMBL1705410 & 737367 & 3.0 & 3.7999 & TST \\
\hline CHEMBL1334243 & 737367 & 3.0 & 3.4608 & TRN \\
\hline CHEMBL 1608620 & 737367 & 4.7905 & 5.0061 & TST \\
\hline CHEMBL1408130 & 737367 & 3.0 & 3.9698 & TRN \\
\hline
\end{tabular}

TRN 


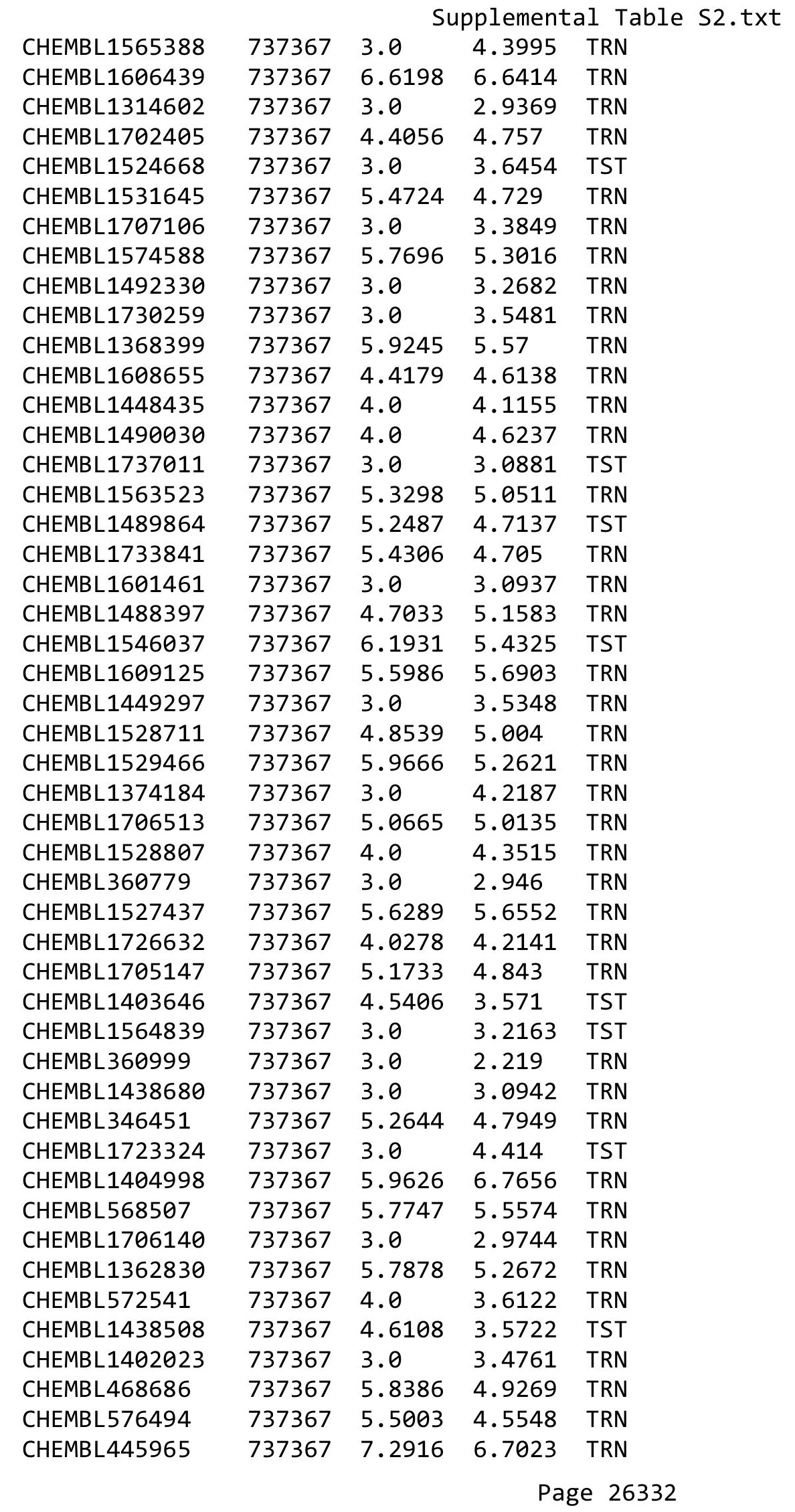




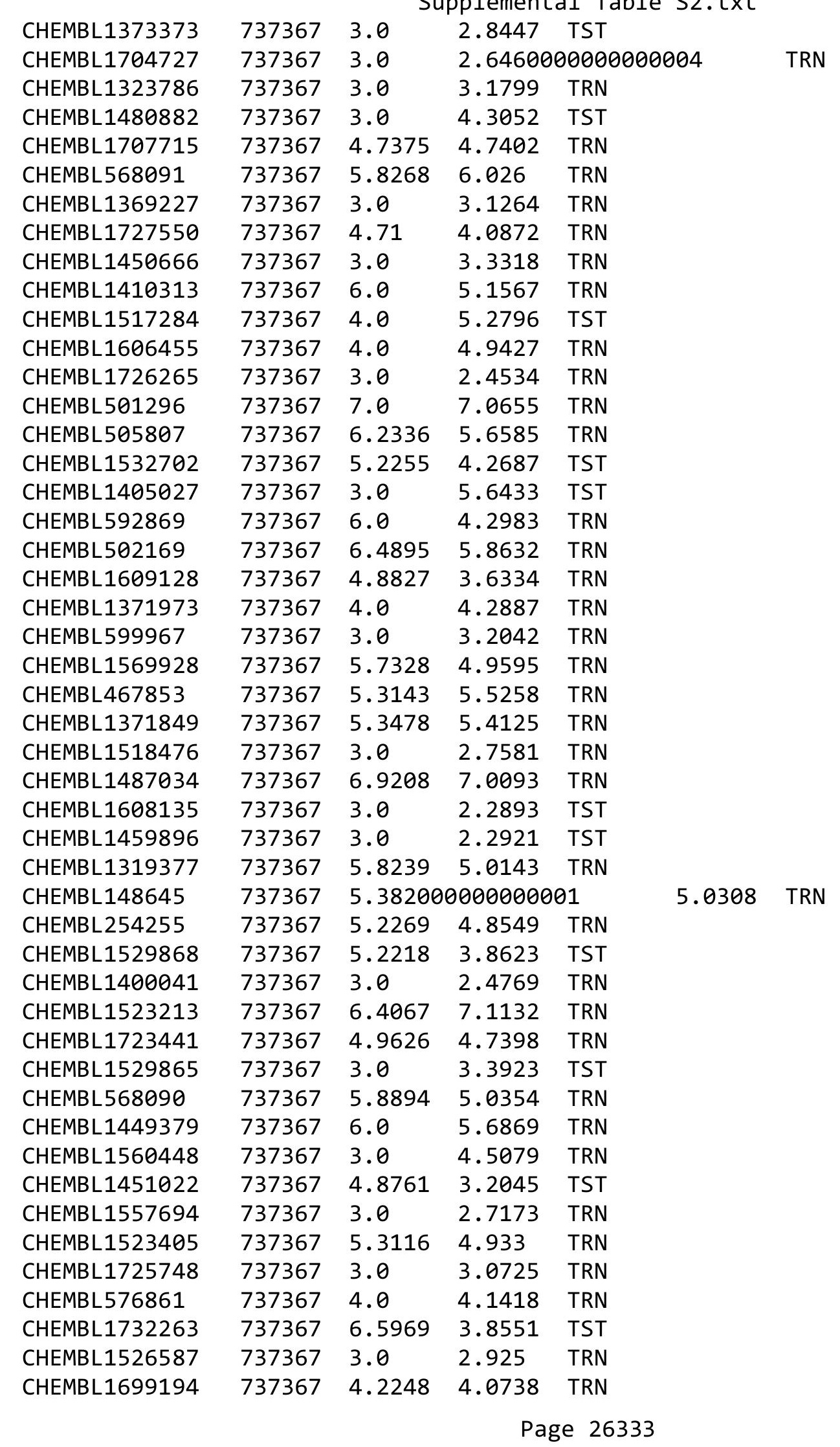




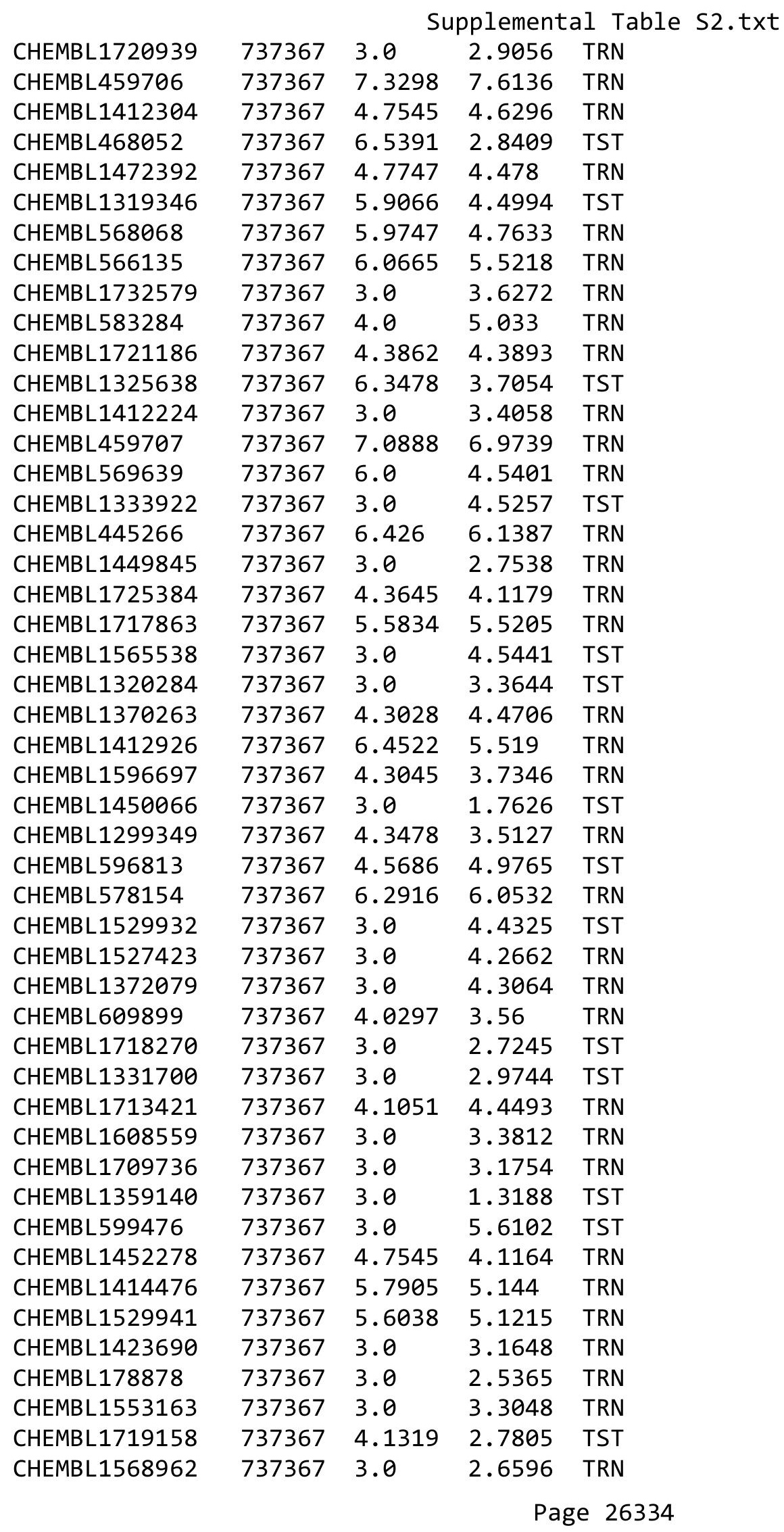




\begin{tabular}{|c|c|c|c|c|c|}
\hline \multirow[b]{2}{*}{ CHEMBL217125 } & \multicolumn{5}{|c|}{ Supplemental Table s2.txt } \\
\hline & 737367 & 3.0 & 2.4106 & TRN & \\
\hline CHEMBL1348184 & 737367 & 4.5143 & 4.0314 & TRN & \\
\hline CHEMBL1487206 & 737367 & 3.0 & 3.0668 & TRN & \\
\hline CHEMBL1332679 & 737367 & 4.1772 & 4.2177 & TRN & \\
\hline CHEMBL1420033 & 737367 & 3.0 & 3.4429 & TRN & \\
\hline CHEMBL1532040 & 737367 & 5.1726 & 4.5979 & TRN & \\
\hline CHEMBL1595707 & 737367 & 3.0 & 4.6281 & TRN & \\
\hline CHEMBL1716509 & 737367 & 5.1851 & 6.0018 & TRN & \\
\hline CHEMBL1609040 & 737367 & 5.7645 & 5.9776 & TRN & \\
\hline CHEMBL179366 & 737367 & 3.0 & 2.0762 & TST & \\
\hline CHEMBL1328778 & 737367 & 3.0 & 3.3446 & TRN & \\
\hline CHEMBL565461 & 737367 & 4.5884 & 4.1134 & TRN & \\
\hline CHEMBL1734721 & 737367 & 5.5952 & 4.8322 & TST & \\
\hline CHEMBL1333250 & 737367 & 3.0 & 3.2746 & TRN & \\
\hline CHEMBL 1480750 & 737367 & 3.0 & 1.8375 & TST & \\
\hline CHEMBL1451467 & 737367 & 3.0 & 0.4872 & TST & \\
\hline CHEMBL1378328 & 737367 & 3.0 & 3.21100 & 00000000003 & TRN \\
\hline CHEMBL1601716 & 737367 & 3.0 & 3.2078 & TRN & \\
\hline CHEMBL1699317 & 737367 & 4.2041 & 3.4848 & TRN & \\
\hline CHEMBL1569163 & 737367 & 3.0 & 3.7175 & TRN & \\
\hline CHEMBL1604946 & 737367 & 5.3242 & 5.0873 & TRN & \\
\hline CHEMBL1734685 & 737367 & 4.7235 & 4.8608 & TRN & \\
\hline CHEMBL1415745 & 737367 & 6.5003 & 6.1138 & TRN & \\
\hline CHEMBL1368903 & 737367 & 3.0 & 3.5746 & TST & \\
\hline CHEMBL1588306 & 737367 & 3.0 & 1.9978 & TST & \\
\hline CHEMBL1354431 & 737367 & 3.0 & 1.9505 & TRN & \\
\hline CHEMBL1559579 & 737367 & 3.0 & 2.8343 & TRN & \\
\hline CHEMBL587759 & 737367 & 3.0 & 3.0815 & TRN & \\
\hline CHEMBL459708 & 737367 & 6.5452 & 6.3437 & TRN & \\
\hline CHEMBL1606304 & 737367 & 3.0 & 2.0213 & TST & \\
\hline CHEMBL1400401 & 737367 & 5.2993 & 3.9831 & TST & \\
\hline CHEMBL1523497 & 737367 & 4.0 & 3.9912 & TRN & \\
\hline CHEMBL1529535 & 737367 & 3.0 & 2.85 & TRN & \\
\hline CHEMBL1531945 & 737367 & 5.4473 & 3.3367 & TST & \\
\hline CHEMBL1322971 & 737367 & 3.0 & 2.94199 & 99999999997 & TRN \\
\hline CHEMBL1414254 & 737367 & 3.0 & 4.085 & TST & \\
\hline CHEMBL1718423 & 737367 & 3.0 & 1.7993 & TST & \\
\hline CHEMBL1705696 & 737367 & 3.0 & 5.541 & TST & \\
\hline CHEMBL1530617 & 737367 & 5.9706 & 6.5208 & TRN & \\
\hline CHEMBL1712819 & 737367 & 4.9031 & 4.9782 & TRN & \\
\hline CHEMBL1330574 & 737367 & 5.8665 & 6.3927 & TRN & \\
\hline CHEMBL1486493 & 737367 & 6.1739 & 5.3689 & TRN & \\
\hline CHEMBL1518041 & 737367 & 3.0 & 2.8973 & TST & \\
\hline CHEMBL1419980 & 737367 & 4.4672 & 3.9363 & TST & \\
\hline CHEMBL1529171 & 737367 & 4.0 & 3.9553 & TRN & \\
\hline CHEMBL179365 & 737367 & 3.0 & 2.9508 & TRN & \\
\hline CHEMBL549785 & 737367 & 3.0 & 2.5747 & TRN & \\
\hline CHEMBL1487722 & 737367 & 4.7496 & 4.8106 & TRN & \\
\hline
\end{tabular}




\begin{tabular}{|c|c|c|c|c|}
\hline \multicolumn{5}{|c|}{ Supplemental Table S2.txt } \\
\hline CHEMBL1591163 & 737367 & 3.0 & 3.5589 & TRN \\
\hline CHEMBL1328625 & 737367 & 3.0 & 3.6808 & TRN \\
\hline CHEMBL1411030 & 737367 & 5.8041 & 5.1259 & TRN \\
\hline CHEMBL1392606 & 737367 & 3.0 & 3.2747 & TRN \\
\hline CHEMBL1369998 & 737367 & 3.0 & 1.3683 & TST \\
\hline CHEMBL1705728 & 737367 & 3.0 & 3.9763 & TRN \\
\hline CHEMBL1523437 & 737367 & 5.3526 & 4.8187 & TRN \\
\hline CHEMBL1604362 & 737367 & 5.3279 & 5.904 & TRN \\
\hline CHEMBL1334400 & 737367 & 3.0 & 4.1458 & TRN \\
\hline CHEMBL1368487 & 737367 & 3.0 & 3.272 & TRN \\
\hline CHEMBL1528241 & 737367 & 3.0 & 3.9549 & TST \\
\hline CHEMBL1735286 & 737367 & 3.0 & 3.6118 & TST \\
\hline CHEMBL1736776 & 737367 & 4.4123 & 3.9918 & TRN \\
\hline CHEMBL1571983 & 737367 & 3.0 & 3.7558 & TRN \\
\hline CHEMBL455954 & 737367 & 3.0 & 3.9071 & TRN \\
\hline CHEMBL596812 & 737367 & 3.0 & 3.0985 & TRN \\
\hline CHEMBL579010 & 737367 & 5.9469 & 5.86 & TRN \\
\hline CHEMBL1608691 & 737367 & 3.0 & 3.4812 & TST \\
\hline CHEMBL1487179 & 737367 & 6.4921 & 5.2994 & TRN \\
\hline CHEMBL1717953 & 737367 & 3.0 & 3.9994 & TRN \\
\hline CHEMBL1412376 & 737367 & 3.0 & 2.5286 & TRN \\
\hline CHEMBL1570045 & 737367 & 3.0 & 2.9446 & TST \\
\hline CHEMBL368883 & 737367 & 3.0 & 3.6695 & TST \\
\hline CHEMBL1488215 & 737367 & 4.5544 & 4.9049 & TRN \\
\hline CHEMBL1325487 & 737367 & 4.2495 & 4.7981 & TST \\
\hline CHEMBL556847 & 737367 & 3.0 & 2.6825 & TRN \\
\hline CHEMBL1533512 & 737367 & 3.0 & 2.1391 & TST \\
\hline CHEMBL1606904 & 737367 & 3.0 & 2.8348 & TST \\
\hline CHEMBL565468 & 737367 & 6.27 & 5.289 & TRN \\
\hline CHEMBL599359 & 737367 & 3.0 & 2.7132 & TRN \\
\hline CHEMBL1491489 & 737367 & 3.0 & 4.0408 & TRN \\
\hline CHEMBL1449951 & 737367 & 5.1824 & 5.3399 & TRN \\
\hline CHEMBL1709543 & 737367 & 3.0 & 2.7285 & TRN \\
\hline CHEMBL1413771 & 737367 & 3.0 & 3.2043 & TRN \\
\hline CHEMBL1440486 & 737367 & 3.0 & 2.7787 & TRN \\
\hline CHEMBL1528166 & 737367 & 3.0 & 4.3179 & TST \\
\hline CHEMBL468676 & 737367 & 6.2411 & 5.9632 & TRN \\
\hline CHEMBL1408336 & 737367 & 3.0 & 4.3265 & TST \\
\hline CHEMBL1362833 & 737367 & 3.0 & 5.5377 & TST \\
\hline CHEMBL1731166 & 737367 & 3.0 & 4.3016 & TRN \\
\hline CHEMBL400144 & 737367 & 4.684 & 4.2882 & TRN \\
\hline CHEMBL312097 & 737367 & 3.0 & 3.676 & TST \\
\hline CHEMBL368434 & 737367 & 3.0 & 3.2197 & TRN \\
\hline CHEMBL1734946 & 737367 & 5.0665 & 4.613 & TRN \\
\hline CHEMBL1330839 & 737367 & 3.0 & 2.9957 & TRN \\
\hline CHEMBL1568379 & 737367 & 3.0 & 3.9686 & TST \\
\hline CHEMBL1728453 & 737367 & 3.0 & 3.9002 & TST \\
\hline CHEMBL179762 & 737367 & 3.0 & 2.6838 & TRN \\
\hline
\end{tabular}




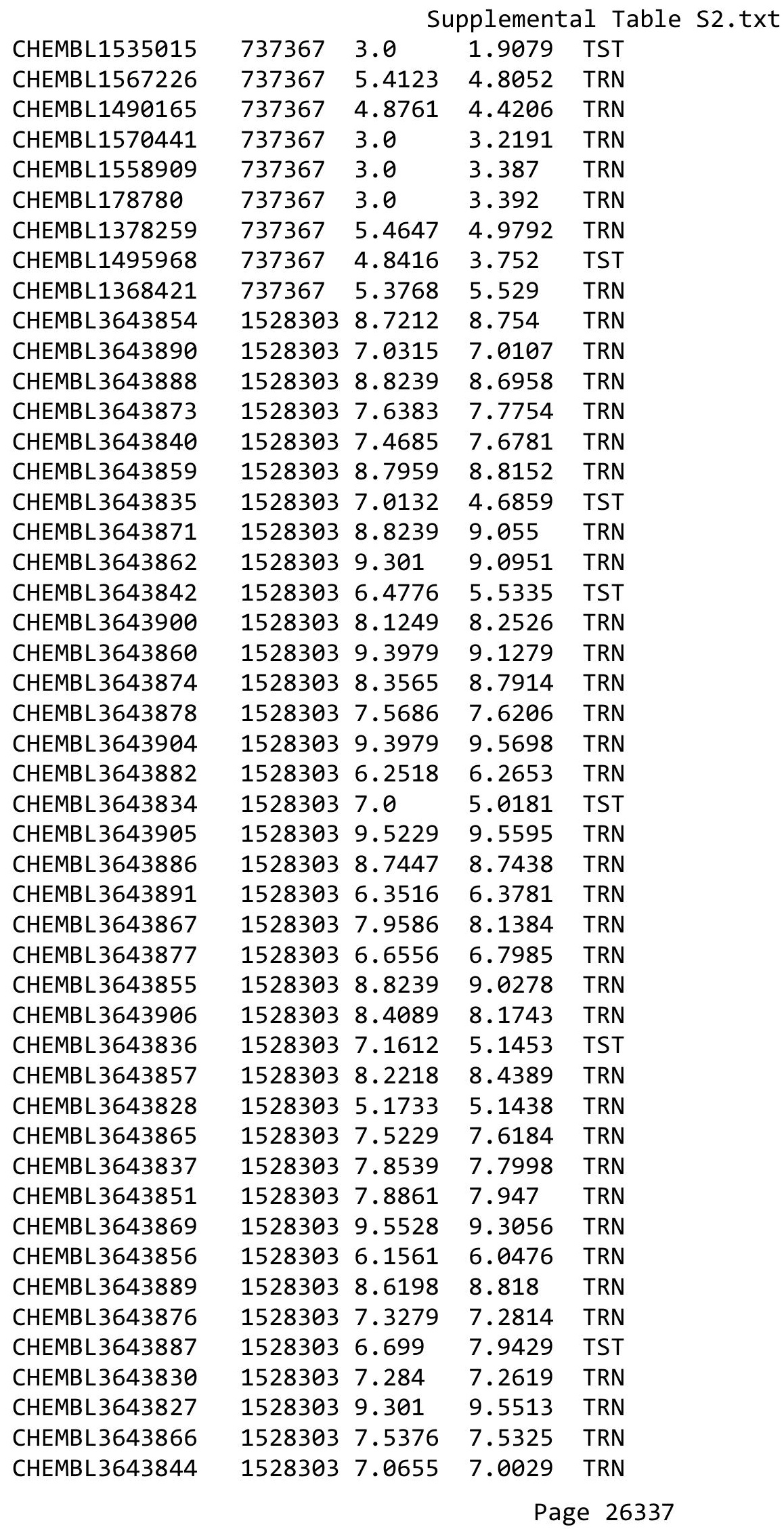


Supplemental Table S2.txt

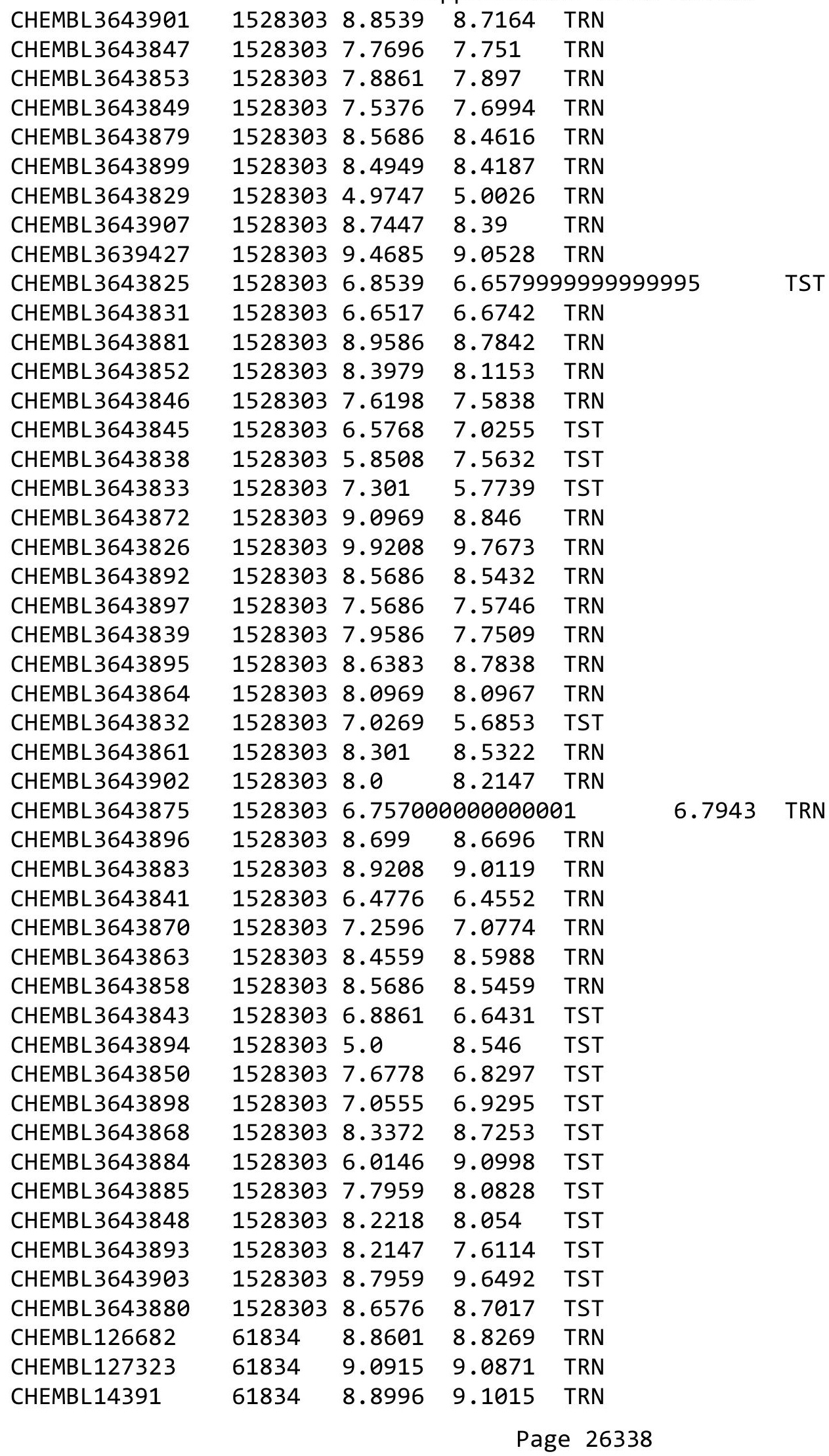


Supplemental Table S2.txt

\begin{tabular}{|c|c|c|c|c|c|c|}
\hline CHEMBL340760 & 61834 & 7.9706 & \multicolumn{3}{|c|}{7.968999999999999} & TRN \\
\hline CHEMBL126229 & 61834 & 8.2612 & 8.331 & TRN & & \\
\hline CHEMBL127040 & 61834 & 8.8539 & 8.8933 & TRN & & \\
\hline CHEMBL340761 & 61834 & 8.8239 & 8.7724 & TRN & & \\
\hline CHEMBL126660 & 61834 & 7.0904 & 7.1361 & TRN & & \\
\hline CHEMBL421651 & 61834 & 7.5622 & 7.1736 & TRN & & \\
\hline CHEMBL127546 & 61834 & 9.3665 & 9.112 & TRN & & \\
\hline CHEMBL339130 & 61834 & 7.9066 & 7.9132 & TRN & & \\
\hline CHEMBL82027 & 61834 & \multicolumn{3}{|c|}{8.767000000000001} & 8.7335 & \\
\hline CHEMBL126887 & 61834 & 7.0195 & 7.0402 & TRN & & \\
\hline CHEMBL339809 & 61834 & 6.7423 & 6.7667 & TRN & & \\
\hline CHEMBL126538 & 61834 & 9.0706 & 9.2034 & TST & & \\
\hline CHEMBL126503 & 61834 & 8.0867 & 8.101 & TRN & & \\
\hline CHEMBL126848 & 61834 & 7.6073 & 7.9129 & TST & & \\
\hline CHEMBL126261 & 61834 & 8.8697 & 8.3584 & TST & & \\
\hline CHEMBL126751 & 61834 & 7.1487 & 7.0996 & TRN & & \\
\hline CHEMBL3085512 & 61834 & 8.8601 & 7.8669 & TST & & \\
\hline CHEMBL340912 & 61834 & 8.4868 & 8.4092 & TRN & & \\
\hline CHEMBL340763 & 61834 & 6.9318 & 7.1736 & TRN & & \\
\hline CHEMBL127260 & 61834 & 8.8327 & 8.1093 & TST & & \\
\hline CHEMBL87031 & 61834 & 9.1024 & 9.0589 & TRN & & \\
\hline CHEMBL340138 & 61834 & 8.158 & 7.7275 & TST & & \\
\hline CHEMBL306208 & 61834 & 8.9508 & 9.077 & TRN & & \\
\hline CHEMBL126610 & 61834 & 8.5935 & 8.9183 & TST & & \\
\hline CHEMBL127457 & 61834 & 6.71 & 6.7375 & TRN & & \\
\hline CHEMBL338995 & 61834 & 6.6596 & 6.5707 & TST & & \\
\hline CHEMBL126410 & 61834 & 8.4271 & 8.3942 & TRN & & \\
\hline CHEMBL420343 & 61834 & 7.2596 & 7.204 & TRN & & \\
\hline CHEMBL127472 & 61834 & 8.4078 & 8.3134 & TRN & & \\
\hline CHEMBL125400 & 61834 & 7.0701 & 7.1504 & TRN & & \\
\hline CHEMBL14144 & 61834 & 8.7033 & 8.7339 & TRN & & \\
\hline CHEMBL126772 & 61834 & 8.7747 & 8.6247 & TRN & & \\
\hline CHEMBL340372 & 61834 & 6.1232 & 6.1314 & TRN & & \\
\hline CHEMBL127533 & 61834 & 7.9393 & 7.8819 & TRN & & \\
\hline CHEMBL127561 & 61834 & 7.7496 & 7.7465 & TRN & & \\
\hline CHEMBL338093 & 61834 & 6.8327 & 6.8229 & TRN & & \\
\hline CHEMBL127026 & 61834 & 6.9508 & 6.7349 & TST & & \\
\hline CHEMBL127981 & 61834 & 6.5901 & 6.6142 & TRN & & \\
\hline CHEMBL127146 & 61834 & 7.9318 & 7.2477 & TST & & \\
\hline CHEMBL125524 & 61834 & \multicolumn{3}{|c|}{7.3420000000000005} & 8.8287 & \\
\hline CHEMBL339763 & 61834 & 9.1249 & 8.2058 & TST & & \\
\hline CHEMBL127700 & 61834 & 5.6155 & 5.6357 & TRN & & \\
\hline CHEMBL341336 & 61834 & 9.2147 & 9.2516 & TRN & & \\
\hline CHEMBL446357 & 61834 & 7.4868 & 7.5779 & TRN & & \\
\hline CHEMBL1790051 & 61834 & 7.6383 & 7.4656 & TRN & & \\
\hline CHEMBL127011 & 61834 & 9.0177 & 9.0784 & TRN & & \\
\hline CHEMBL338220 & 61834 & 8.1824 & 8.1414 & TST & & \\
\hline CHEMBL126271 & 61834 & 8.5376 & 7.6952 & TST & & \\
\hline
\end{tabular}

Page 26339 


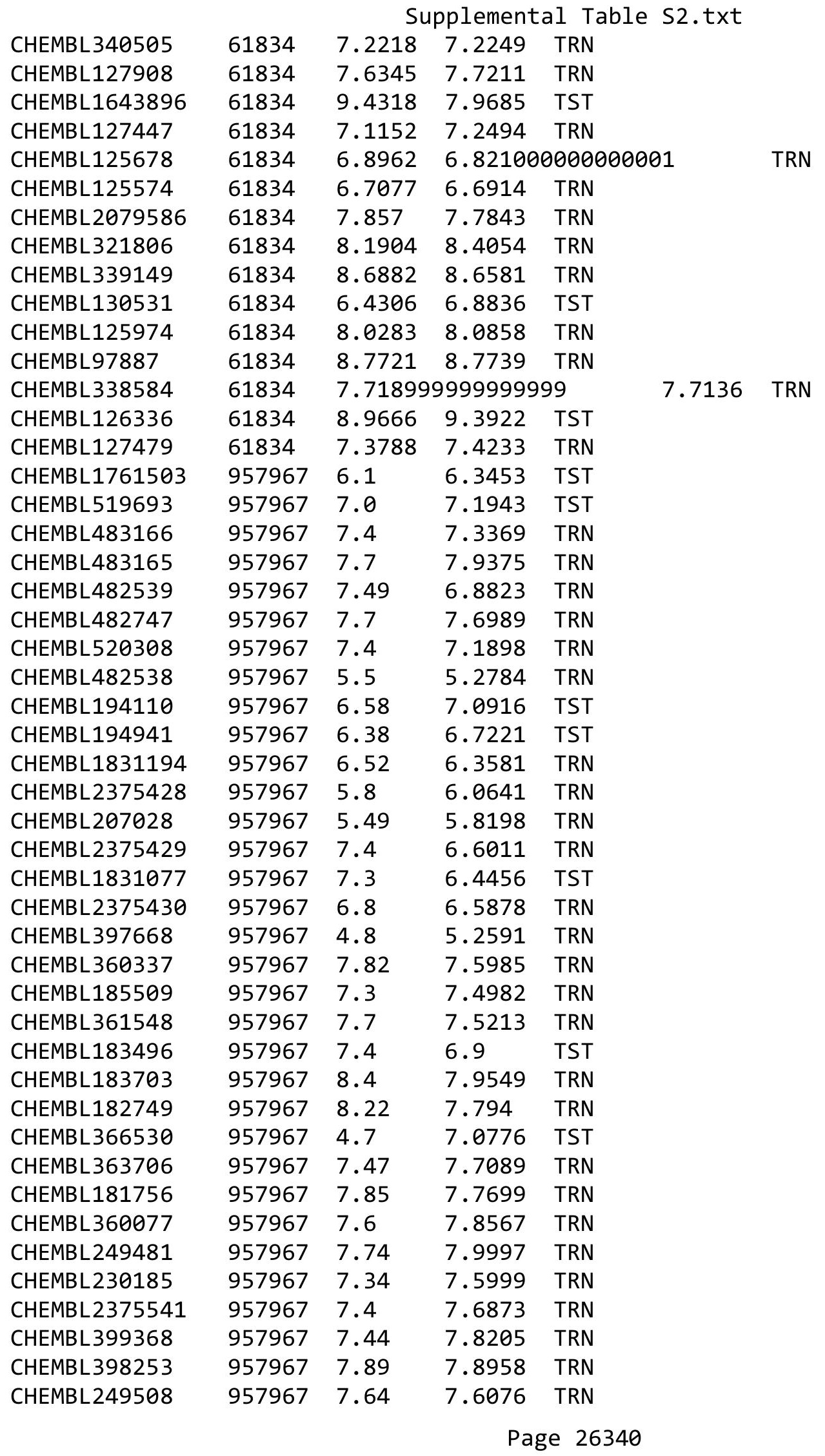




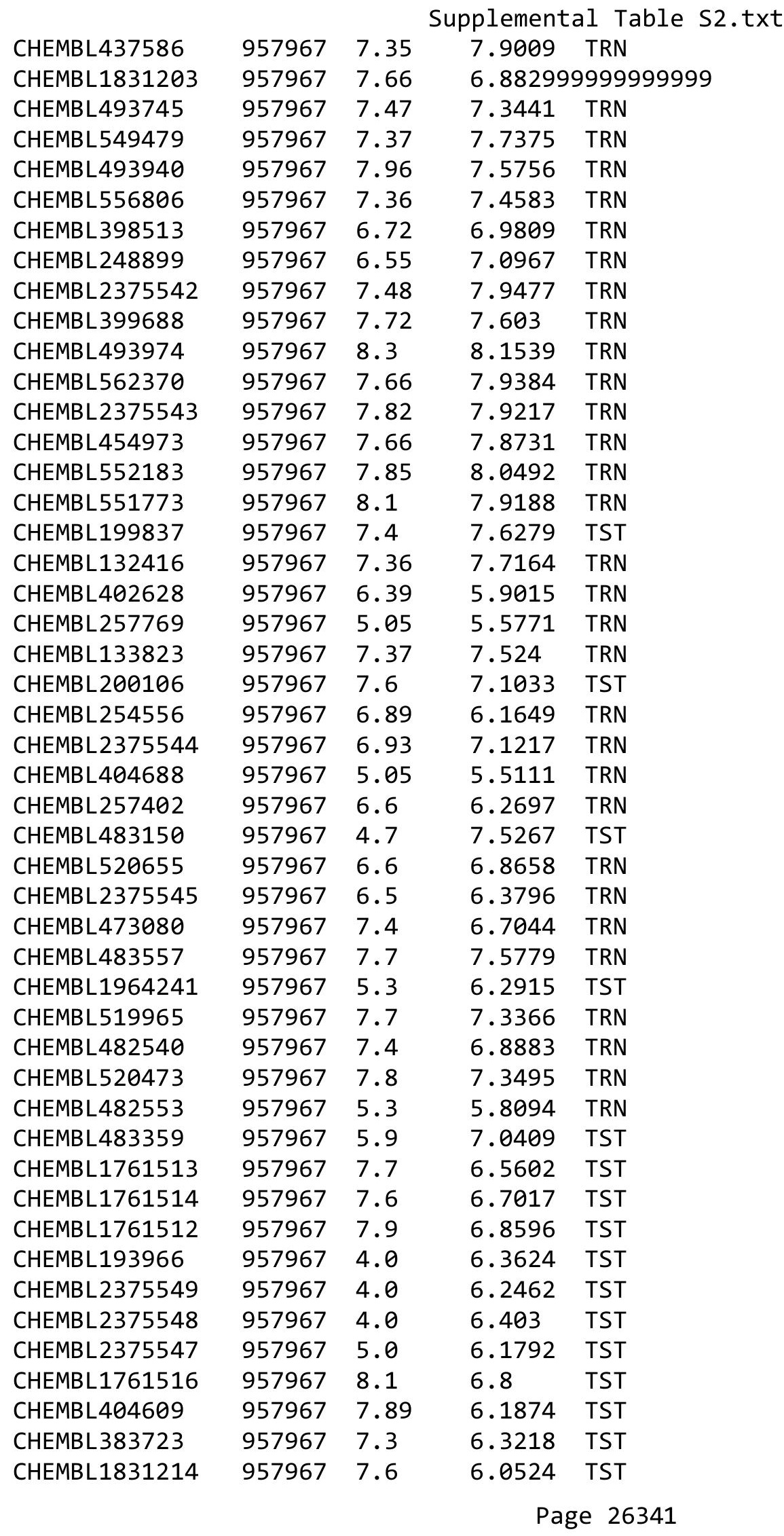




\begin{tabular}{|c|c|c|c|c|c|}
\hline \\
\hline CHEMBL207940 & 957967 & 4.8 & 5.5276 & TRN & \\
\hline CHEMBL 2375546 & 957967 & 4.8 & 6.7532 & TST & \\
\hline CHEMBL388033 & 957967 & 4.8 & 6.4496 & TST & \\
\hline CHEMBL230911 & 957967 & 5.4 & 5.2488 & TRN & \\
\hline CHEMBL230809 & 957967 & 5.4 & 5.7962 & TRN & \\
\hline CHEMBL361841 & 957967 & 7.92 & 7.7558 & TRN & \\
\hline CHEMBL1187917 & 957967 & 4.82 & 7.0932 & TST & \\
\hline CHEMBL361233 & 957967 & 8.04 & 7.5969 & TRN & \\
\hline CHEMBL181495 & 957967 & 8.3 & 8.0195 & TRN & \\
\hline CHEMBL181334 & 957967 & 8.3 & 7.9508 & TRN & \\
\hline CHEMBL174140 & 957967 & 5.74 & 6.8643 & TST & \\
\hline CHEMBL360691 & 957967 & 7.6 & 7.4982 & TRN & \\
\hline CHEMBL2375673 & 957967 & 8.07 & 7.943 & TRN & \\
\hline CHEMBL181434 & 957967 & 7.82 & 7.8203 & TRN & \\
\hline CHEMBL352957 & 957967 & 4.7 & 6.8286 & TST & \\
\hline CHEMBL425346 & 957967 & 7.58 & 7.9506 & TRN & \\
\hline CHEMBL182173 & 957967 & 7.85 & 8.0011 & TRN & \\
\hline CHEMBL182407 & 957967 & 8.52 & 8.0303 & TRN & \\
\hline CHEMBL182358 & 957967 & 7.82 & 7.8199 & TRN & \\
\hline CHEMBL249102 & 957967 & 7.36 & 7.5189 & TRN & \\
\hline CHEMBL249681 & 957967 & 7.29 & 7.7545 & TRN & \\
\hline CHEMBL428754 & 957967 & 7.64 & 7.638 & TRN & \\
\hline CHEMBL400078 & 957967 & 7.37 & 7.5649 & TRN & \\
\hline CHEMBL522171 & 957967 & 5.82 & 7.1279 & TRN & \\
\hline CHEMBL230186 & 957967 & 7.46 & 7.2256 & TST & \\
\hline CHEMBL230184 & 957967 & 7.74 & 7.4614 & TRN & \\
\hline CHEMBL 249280 & 957967 & 8.52 & 7.8792 & TRN & \\
\hline CHEMBL 2375675 & 957967 & 6.35 & 7.4255 & TRN & \\
\hline CHEMBL562720 & 957967 & 7.96 & 8.2094 & TRN & \\
\hline CHEMBL390201 & 957967 & 7.96 & 6.9992 & TST & \\
\hline CHEMBL249515 & 957967 & 7.68 & 7.8007 & TRN & \\
\hline CHEMBL249482 & 957967 & 8.15 & 8.1796 & TRN & \\
\hline CHEMBL249886 & 957967 & 7.89 & 7.6646 & TRN & \\
\hline CHEMBL249279 & 957967 & 7.42 & 7.6631 & TRN & \\
\hline CHEMBL561447 & 957967 & 7.6 & 7.7947 & TRN & \\
\hline CHEMBL231530 & 957967 & 7.74 & 7.5537 & TRN & \\
\hline CHEMBL 2375674 & 957967 & 7.55 & 7.8547 & TRN & \\
\hline CHEMBL249103 & 957967 & 7.02 & 7.5093 & TRN & \\
\hline CHEMBL249899 & 957967 & 7.64 & 7.7527 & TRN & \\
\hline CHEMBL400077 & 957967 & 8.07 & 7.8254 & TRN & \\
\hline CHEMBL565076 & 957967 & 7.4 & 7.6736 & TRN & \\
\hline CHEMBL249901 & 957967 & 7.66 & 7.3214 & TRN & \\
\hline CHEMBL249104 & 957967 & 8.1 & $7.6160 e$ & 00000000005 & TRN \\
\hline CHEMBL 2375678 & 957967 & 6.64 & $7.3210 e$ & 0000000001 & TST \\
\hline CHEMBL249929 & 957967 & 6.44 & 7.1086 & TRN & \\
\hline CHEMBL2375677 & 957967 & 7.82 & 7.6044 & TRN & \\
\hline CHEMBL 249902 & 957967 & 7.54 & 7.7579 & TRN & \\
\hline CHEMBL522014 & 957967 & 7.8 & 7.4422 & TRN & \\
\hline
\end{tabular}




\begin{tabular}{|c|c|c|c|c|c|}
\hline \multicolumn{6}{|c|}{ Supplemental Table S2.txt } \\
\hline CHEMBL538910 & 957967 & 7.58 & 7.3766 & TRN & \\
\hline CHEMBL250105 & 957967 & 8.6 & 7.5051 & TRN & \\
\hline CHEMBL494162 & 957967 & 7.6 & 7.4963 & TRN & \\
\hline CHEMBL1831202 & 957967 & 8.04 & 7.0895 & TST & \\
\hline CHEMBL523692 & 957967 & 7.48 & 7.3857 & TRN & \\
\hline CHEMBL1831200 & 957967 & 8.1 & 7.4845 & TST & \\
\hline CHEMBL 249480 & 957967 & 7.68 & 8.0527 & TRN & \\
\hline CHEMBL 2375676 & 957967 & 7.82 & 7.8595 & TRN & \\
\hline CHEMBL560708 & 957967 & 7.41 & 7.6293 & TRN & \\
\hline CHEMBL562971 & 957967 & 7.92 & 7.7084 & TRN & \\
\hline CHEMBL1831209 & 957967 & 6.43 & 6.8514 & TST & \\
\hline CHEMBL493161 & 957967 & 7.41 & 7.0678 & TRN & \\
\hline CHEMBL549478 & 957967 & 8.15 & 7.78 & TRN & \\
\hline CHEMBL558491 & 957967 & 8.15 & 8.3131 & TRN & \\
\hline CHEMBL521643 & 957967 & 8.22 & 7.4141 & TRN & \\
\hline CHEMBL 2375686 & 957967 & 3.0 & 6.5311 & TST & \\
\hline CHEMBL200027 & 957967 & 7.4 & 7.063 & TST & \\
\hline CHEMBL372736 & 957967 & 7.3 & 7.1102 & TST & \\
\hline CHEMBL133548 & 957967 & 7.51 & 7.515 & TRN & \\
\hline CHEMBL131693 & 957967 & 7.96 & 7.2638 & TRN & \\
\hline CHEMBL130631 & 957967 & 7.32 & 7.3396 & TRN & \\
\hline CHEMBL371543 & 957967 & 7.3 & 7.5035 & TST & \\
\hline CHEMBL133941 & 957967 & 6.29 & 7.2017 & TRN & \\
\hline CHEMBL403615 & 957967 & 6.4 & 6.1693 & TRN & \\
\hline CHEMBL2375685 & 957967 & 7.59 & 7.5197 & TRN & \\
\hline CHEMBL440404 & 957967 & 5.22 & 5.0365 & TRN & \\
\hline CHEMBL2375684 & 957967 & 5.6 & 5.3 & TRN & \\
\hline CHEMBL 2041970 & 823821 & 5.7645 & 5.6395 & TRN & \\
\hline CHEMBL2041809 & 823821 & 5.2 & 5.3736 & TRN & \\
\hline CHEMBL590266 & 823821 & 6.6576 & 6.9325 & TRN & \\
\hline CHEMBL2041622 & 823821 & 6.3468 & 6.3714 & TRN & \\
\hline CHEMBL 2041820 & 823821 & 7.5686 & 7.5843 & TRN & \\
\hline CHEMBL 2041618 & 823821 & 6.6799 & 6.6807 & TRN & \\
\hline CHEMBL596746 & 823821 & 3.8962 & 3.7719 & TRN & \\
\hline CHEMBL 2041843 & 823821 & 8.699 & 8.0398 & TRN & \\
\hline CHEMBL2041803 & 823821 & 5.4171 & 5.2509 & TRN & \\
\hline CHEMBL 2041829 & 823821 & 6.6364 & 6.5297 & TRN & \\
\hline CHEMBL 2041839 & 823821 & 6.4157 & 6.4576 & TRN & \\
\hline CHEMBL605979 & 823821 & 5.0706 & 5.2016 & TRN & \\
\hline CHEMBL2041621 & 823821 & 6.5376 & 6.8022 & TRN & \\
\hline CHEMBL601066 & 823821 & 6.585 & 6.7422 & TRN & \\
\hline CHEMBL 2041818 & 823821 & 6.9872 & 6.99299 & 9999999999 & TRN \\
\hline CHEMBL 2041832 & 823821 & 6.3188 & 6.38399 & 99999999995 & TRN \\
\hline CHEMBL 2041830 & 823821 & 6.3116 & 6.8221 & TRN & \\
\hline CHEMBL601707 & 823821 & 5.8356 & 5.6892 & TRN & \\
\hline CHEMBL2041805 & 823821 & 6.9626 & 6.5963 & TRN & \\
\hline CHEMBL 2041836 & 823821 & 3.0362 & 3.3448 & TST & \\
\hline CHEMBL 2041624 & 823821 & 6.8477 & 7.0747 & TRN & \\
\hline
\end{tabular}

Page 26343 


\begin{tabular}{|c|c|c|c|c|c|c|}
\hline \multirow[b]{2}{*}{ CHEMBL2041616 } & & \multicolumn{5}{|c|}{ Supplemental Table S2.txt } \\
\hline & 823821 & 7.8539 & 7.7376 & TRN & & \\
\hline CHEMBL 2041808 & 823821 & 4.9416 & 6.0025 & TST & & \\
\hline CHEMBL601067 & 823821 & 6.2168 & 6.2503 & TRN & & \\
\hline CHEMBL2041971 & 823821 & 5.279 & 5.5593 & TRN & & \\
\hline CHEMBL601708 & 823821 & 6.7055 & 6.9335 & TST & & \\
\hline CHEMBL590505 & 823821 & 6.585 & 6.7453 & TRN & & \\
\hline CHEMBL 2041816 & 823821 & 2.5952 & 3.1696 & TRN & & \\
\hline CHEMBL605561 & 823821 & 5.0555 & 4.9522 & TRN & & \\
\hline CHEMBL 2041807 & 823821 & 6.9508 & 6.9325 & TRN & & \\
\hline CHEMBL601069 & 823821 & 4.8598 & 5.0154 & TST & & \\
\hline CHEMBL2041826 & 823821 & 6.7696 & 7.2586 & TRN & & \\
\hline CHEMBL 2041828 & 823821 & 6.7986 & 6.8594 & TST & & \\
\hline CHEMBL2041813 & 823821 & 4.7282 & 4.6862 & TRN & & \\
\hline CHEMBL 2041810 & 823821 & 5.7905 & 5.8247 & TRN & & \\
\hline CHEMBL 2041802 & 823821 & 5.9208 & 5.9691 & TRN & & \\
\hline CHEMBL601706 & 823821 & 6.4498 & 6.1356 & TRN & & \\
\hline CHEMBL2041812 & 823821 & 4.4962 & 4.4826 & TRN & & \\
\hline CHEMBL 2041827 & 823821 & \multicolumn{3}{|c|}{6.7620000000000005} & 6.5387 & TRN \\
\hline CHEMBL 2041846 & 823821 & 4.7852 & 4.7708 & TRN & & \\
\hline CHEMBL 2041804 & 823821 & 5.5874 & 5.6789 & TRN & & \\
\hline CHEMBL 2041799 & 823821 & 6.2464 & 6.3106 & TST & & \\
\hline CHEMBL 2041831 & 823821 & 6.5376 & 5.9317 & TST & & \\
\hline CHEMBL2041815 & 823821 & 6.5735 & 6.6041 & TRN & & \\
\hline CHEMBL 2041795 & 823821 & 6.699 & 6.6141 & TRN & & \\
\hline CHEMBL 2041817 & 823821 & 6.4248 & 6.2988 & TRN & & \\
\hline CHEMBL 2041837 & 823821 & 6.3979 & 6.4438 & TRN & & \\
\hline CHEMBL 2041797 & 823821 & 6.2328 & 6.3157 & TRN & & \\
\hline CHEMBL 2041619 & 823821 & 6.699 & 6.7681 & TRN & & \\
\hline CHEMBL 2041800 & 823821 & 6.0975 & 6.2943 & TST & & \\
\hline CHEMBL598801 & 823821 & 5.0177 & 5.1274 & TRN & & \\
\hline CHEMBL 2041840 & 823821 & 6.0 & 5.9744 & TRN & & \\
\hline CHEMBL590385 & 823821 & 6.4949 & 7.1588 & TST & & \\
\hline CHEMBL 2041845 & 823821 & 6.8153 & 6.7132 & TRN & & \\
\hline CHEMBL2041824 & 823821 & 6.0 & 6.0897 & TRN & & \\
\hline CHEMBL 2041811 & 823821 & 6.4868 & 6.0222 & TRN & & \\
\hline CHEMBL2041801 & 823821 & 5.9136 & 5.9021 & TRN & & \\
\hline CHEMBL 2041623 & 823821 & 6.3872 & 6.4407 & TRN & & \\
\hline CHEMBL601065 & 823821 & 6.2565 & 6.3987 & TRN & & \\
\hline CHEMBL539632 & 823821 & 6.5391 & 6.5418 & TRN & & \\
\hline CHEMBL598176 & 823821 & 5.5376 & 5.5995 & TRN & & \\
\hline CHEMBL 2041838 & 823821 & 6.5243 & 6.5977 & TRN & & \\
\hline CHEMBL 2041620 & 823821 & 6.6383 & 6.4666 & TRN & & \\
\hline CHEMBL 2041842 & 823821 & 7.0915 & 6.9457 & TRN & & \\
\hline CHEMBL 2041796 & 823821 & 6.3665 & 7.2248 & TST & & \\
\hline CHEMBL596744 & 823821 & 4.109 & 3.55 & TRN & & \\
\hline CHEMBL2041833 & 823821 & 4.7959 & 5.6147 & TST & & \\
\hline CHEMBL 2041844 & 823821 & 6.5622 & 6.23 & TRN & & \\
\hline CHEMBL601068 & 823821 & 6.7959 & 6.9925 & TRN & & \\
\hline
\end{tabular}




\begin{tabular}{|c|c|c|c|c|c|c|}
\hline & & \multicolumn{5}{|c|}{ Supplemental Table S2.txt } \\
\hline CHEMBL 2041806 & 823821 & 6.7447 & 6.8322 & TST & & \\
\hline CHEMBL590504 & 823821 & 6.1831 & 5.8879 & TST & & \\
\hline CHEMBL2041821 & 823821 & 7.1367 & 7.3439 & TST & & \\
\hline CHEMBL2041617 & 823821 & 7.0044 & 6.9666 & TST & & \\
\hline CHEMBL2041834 & 823821 & 4.8928 & 5.1227 & TST & & \\
\hline CHEMBL 2041814 & 823821 & 5.3487 & 5.3761 & TST & & \\
\hline CHEMBL 2041798 & 823821 & 6.2725 & 6.2865 & TST & & \\
\hline CHEMBL 2041819 & 823821 & 4.7711 & 4.4638 & TST & & \\
\hline CHEMBL 2041835 & 823821 & 3.0362 & 3.5531 & TST & & \\
\hline CHEMBL99779 & 71150 & 5.0 & 5.0585 & TST & & \\
\hline CHEMBL121543 & 71150 & 6.699 & 6.7564 & TRN & & \\
\hline CHEMBL316485 & 71150 & 5.678 & 5.3174 & TST & & \\
\hline CHEMBL318208 & 71150 & 6.398 & 5.7753 & TRN & & \\
\hline CHEMBL430574 & 71150 & \multicolumn{3}{|c|}{6.207999999999999} & 5.6595 & TRN \\
\hline CHEMBL317964 & 71150 & 6.886 & 6.1622 & TRN & & \\
\hline CHEMBL120030 & 71150 & 6.301 & 5.1795 & TST & & \\
\hline CHEMBL331722 & 71150 & 3.301 & 3.9103 & TRN & & \\
\hline CHEMBL331120 & 71150 & 3.0 & 5.439 & TST & & \\
\hline CHEMBL95477 & 71150 & \multicolumn{3}{|c|}{5.367000000000001} & 5.0337 & TRN \\
\hline CHEMBL545053 & 71150 & 7.523 & 6.8397 & TRN & & \\
\hline CHEMBL97844 & 71150 & 4.62 & 4.8002 & TST & & \\
\hline CHEMBL121958 & 71150 & 6.456 & 5.9904 & TRN & & \\
\hline CHEMBL 325403 & 71150 & \multicolumn{3}{|c|}{7.6579999999999995} & 7.4788 & $1 \mathrm{n}$ \\
\hline CHEMBL 98360 & 71150 & 6.097 & 6.6095 & TRN & & \\
\hline CHEMBL332678 & 71150 & 7.125 & 5.6114 & TST & & \\
\hline CHEMBL121957 & 71150 & \multicolumn{3}{|c|}{5.6579999999999995} & 6.3671 & TRN \\
\hline CHEMBL99037 & 71150 & 7.097 & 6.1709 & TRN & & \\
\hline CHEMBL328194 & 71150 & 7.125 & 7.085 & TRN & & \\
\hline CHEMBL 324064 & 71150 & 5.398 & 5.2999 & TST & & \\
\hline CHEMBL319373 & 71150 & 7.0 & 7.1563 & TRN & & \\
\hline CHEMBL116545 & 71150 & 7.155 & 7.4076 & TRN & & \\
\hline CHEMBL331000 & 71150 & 7.745 & 7.1914 & TRN & & \\
\hline CHEMBL331190 & 71150 & 7.886 & 7.7789 & TRN & & \\
\hline CHEMBL 334084 & 71150 & 6.62 & 6.9733 & TRN & & \\
\hline CHEMBL121492 & 71150 & 7.481 & 7.3395 & TRN & & \\
\hline CHEMBL329063 & 71150 & 6.921 & 6.5671 & TRN & & \\
\hline CHEMBL431634 & 71150 & 6.046 & 6.2902 & TRN & & \\
\hline CHEMBL 99803 & 71150 & 6.523 & 5.6655 & TST & & \\
\hline CHEMBL116832 & 71150 & 6.602 & 5.7433 & TRN & & \\
\hline CHEMBL120355 & 71150 & 4.921 & 5.7392 & TRN & & \\
\hline CHEMBL331783 & 71150 & 5.26 & 5.0344 & TRN & & \\
\hline CHEMBL334031 & 71150 & 6.398 & 6.1225 & TRN & & \\
\hline CHEMBL100309 & 71150 & 5.699 & 6.74700 & 0000000001 & & W \\
\hline CHEMBL 317150 & 71150 & 6.155 & 5.8251 & TRN & & \\
\hline CHEMBL120941 & 71150 & 4.387 & 5.6735 & TRN & & \\
\hline CHEMBL120078 & 71150 & 5.276 & 4.4804 & TRN & & \\
\hline CHEMBL329505 & 71150 & 7.523 & 6.3637 & TRN & & \\
\hline CHEMBL316512 & 71150 & 5.301 & 5.5888 & TST & & \\
\hline
\end{tabular}




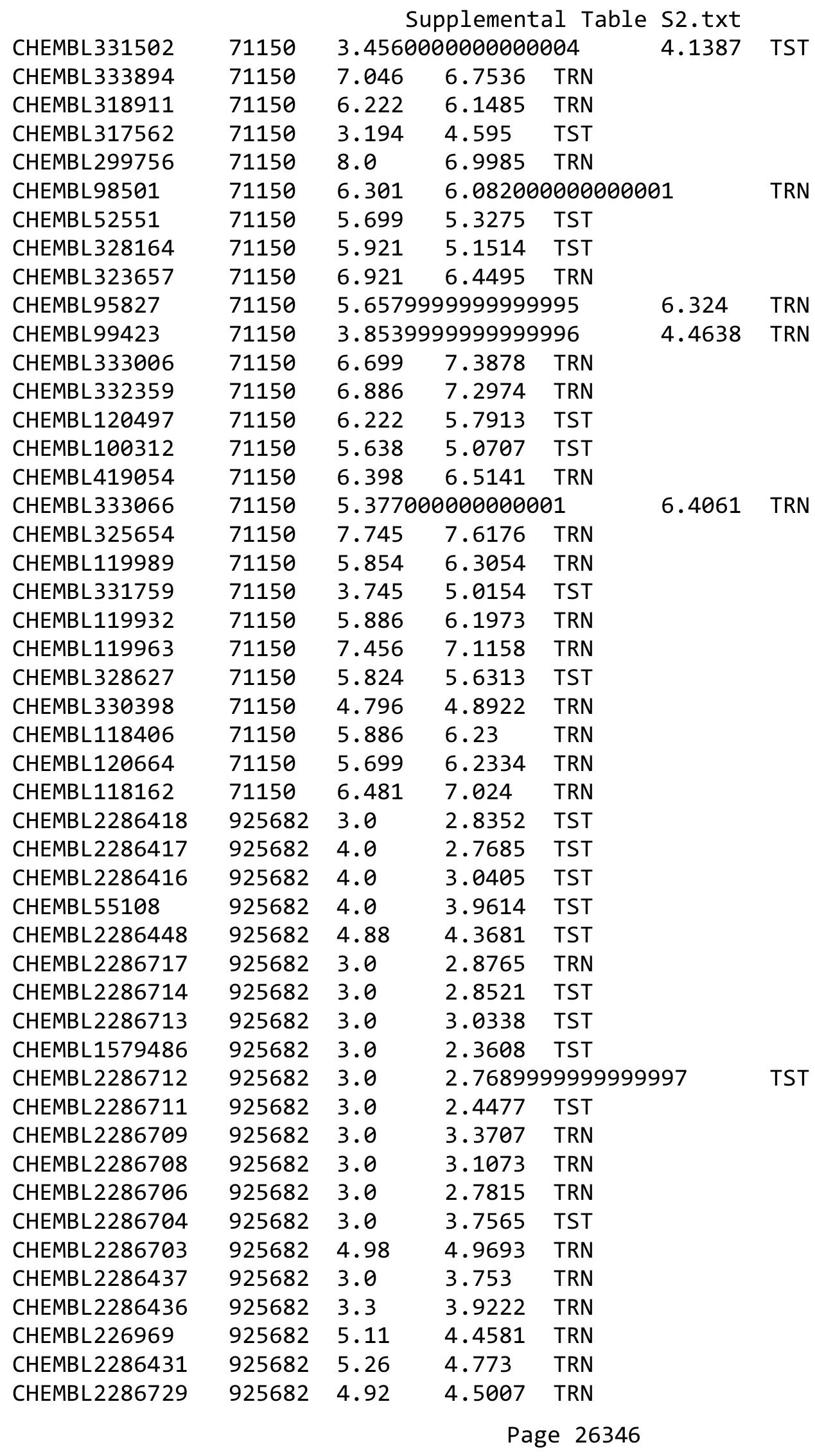




\begin{tabular}{|c|c|c|c|c|c|}
\hline \multicolumn{6}{|c|}{ Supplemental Table s2.txt } \\
\hline CHEMBL55772 & 925682 & 4.78 & 5.0169 & TRN & \\
\hline CHEMBL 2228859 & 925682 & 4.78 & 4.9635 & TRN & \\
\hline CHEMBL226968 & 925682 & 5.18 & 5.3364 & TRN & \\
\hline CHEMBL 2286728 & 925682 & 4.95 & 4.9393 & TRN & \\
\hline CHEMBL 2286727 & 925682 & 4.34 & 4.4867 & TRN & \\
\hline CHEMBL 2286726 & 925682 & 4.18 & 4.54899 & 99999999995 & TRN \\
\hline CHEMBL 2286725 & 925682 & 3.97 & 3.8158 & TRN & \\
\hline CHEMBL 2286724 & 925682 & 3.89 & 4.3433 & TRN & \\
\hline CHEMBL 2286723 & 925682 & 4.78 & 5.058 & TRN & \\
\hline CHEMBL 2286722 & 925682 & 4.94 & 4.8954 & TRN & \\
\hline CHEMBL 2286721 & 925682 & 5.11 & 4.9095 & TRN & \\
\hline CHEMBL 2286429 & 925682 & 4.95 & 4.7961 & TRN & \\
\hline CHEMBL 2286428 & 925682 & 4.92 & 4.7333 & TRN & \\
\hline CHEMBL 2286427 & 925682 & 5.01 & 5.0989 & TRN & \\
\hline CHEMBL 2286720 & 925682 & 4.81 & 5.275 & TRN & \\
\hline CHEMBL 2286719 & 925682 & 5.49 & 4.9786 & TRN & \\
\hline CHEMBL 2286718 & 925682 & 4.03 & 4.114 & TRN & \\
\hline CHEMBL 2286946 & 925682 & 5.15 & 5.1559 & TRN & \\
\hline CHEMBL 2286426 & 925682 & 5.55 & 4.9103 & TRN & \\
\hline CHEMBL 2286752 & 925682 & 4.09 & 4.7016 & TRN & \\
\hline CHEMBL 2286751 & 925682 & 4.43 & 4.2534 & TRN & \\
\hline CHEMBL 2286750 & 925682 & 4.14 & 4.6111 & TRN & \\
\hline CHEMBL 2286749 & 925682 & 3.97 & 4.2035 & TRN & \\
\hline CHEMBL 2286748 & 925682 & 4.44 & 3.8385 & TRN & \\
\hline CHEMBL 2286747 & 925682 & 4.88 & 4.493 & TRN & \\
\hline CHEMBL 2286425 & 925682 & 4.78 & 4.3163 & TRN & \\
\hline CHEMBL 2286746 & 925682 & 4.59 & 4.506 & TRN & \\
\hline CHEMBL 2286423 & 925682 & 4.59 & 4.4446 & TRN & \\
\hline CHEMBL 2286745 & 925682 & 4.06 & 3.9244 & TRN & \\
\hline CHEMBL 2286744 & 925682 & 4.22 & 4.2817 & TRN & \\
\hline CHEMBL 2286743 & 925682 & 3.98 & 4.2015 & TRN & \\
\hline CHEMBL 2286422 & 925682 & 4.47 & 4.59 & TRN & \\
\hline CHEMBL 2228438 & 925682 & 4.18 & 4.2997 & TRN & \\
\hline CHEMBL 2286742 & 925682 & 3.83 & 4.197 & TRN & \\
\hline CHEMBL 2228437 & 925682 & 3.92 & 3.9611 & TRN & \\
\hline CHEMBL 2286741 & 925682 & 4.01 & 3.8051 & TRN & \\
\hline CHEMBL 2286740 & 925682 & 3.92 & 3.98199 & 99999999998 & TRN \\
\hline CHEMBL 2286739 & 925682 & 4.81 & 4.1912 & TRN & \\
\hline CHEMBL 2286420 & 925682 & 4.47 & 3.6928 & TST & \\
\hline CHEMBL 2286738 & 925682 & 4.04 & 4.1097 & TST & \\
\hline CHEMBL 2286737 & 925682 & 4.09 & 4.1341 & TST & \\
\hline CHEMBL 2228435 & 925682 & 5.07 & 4.4615 & TST & \\
\hline CHEMBL 2286736 & 925682 & 4.14 & 4.0369 & TST & \\
\hline CHEMBL 387744 & 925682 & 4.43 & 3.908 & TST & \\
\hline CHEMBL3884678 & 1632526 & 4.7535 & 4.7053 & TRN & \\
\hline CHEMBL3883348 & 1632526 & 4.3134 & 2.6541 & TST & \\
\hline CHEMBL3885269 & 1632526 & 4.9169 & 4.8127 & TRN & \\
\hline CHEMBL3884752 & 1632526 & 6.0809 & 5.9359 & TRN & \\
\hline
\end{tabular}

Page 26347 
Supplemental Table S2.txt

\begin{tabular}{|c|c|c|c|c|c|}
\hline CHEMBL 3884935 & 1632526 & 6.1135 & 6.1869 & TRN & \\
\hline CHEMBL 3883797 & 1632526 & 6.2924 & 5.7582 & TRN & \\
\hline CHEMBL 3885169 & 1632526 & 5.4437 & 5.4586 & TRN & \\
\hline CHEMBL 3884147 & 1632526 & 4.301 & 4.4324 & TRN & \\
\hline CHEMBL 3884530 & 1632526 & 4.7567 & 4.6927 & TRN & \\
\hline CHEMBL 3883395 & 1632526 & 4.6251 & 5.048 & TRN & \\
\hline CHEMBL 3884660 & 1632526 & 3.301 & 3.3593 & TRN & \\
\hline CHEMBL 3884595 & 1632526 & 5.2055 & 5.4763 & TRN & \\
\hline CHEMBL 3884702 & 1632526 & 5.3768 & 5.4489 & TRN & \\
\hline CHEMBL 3885381 & 1632526 & 4.6021 & 4.5354 & TRN & \\
\hline CHEMBL 3884854 & 1632526 & 3.301 & 3.2014 & TST & \\
\hline CHEMBL 3884730 & 1632526 & 5.279 & 5.1681 & TRN & \\
\hline CHEMBL 3884962 & 1632526 & 5.3458 & 5.4533 & TRN & \\
\hline CHEMBL 3884309 & 1632526 & 4.301 & 3.9015 & TRN & \\
\hline CHEMBL 3885263 & 1632526 & 5.3363 & 4.9622 & TRN & \\
\hline CHEMBL 3884761 & 1632526 & 5.4935 & 5.4098 & TRN & \\
\hline CHEMBL 3884787 & 1632526 & 5.0 & 4.9383 & TRN & \\
\hline CHEMBL 3883383 & 1632526 & 6.0862 & 5.9334 & TRN & \\
\hline CHEMBL 3884055 & 1632526 & 4.6162 & 3.7567 & TST & \\
\hline CHEMBL 3883464 & 1632526 & 3.301 & 2.7949 & TST & \\
\hline CHEMBL 3884553 & 1632526 & 4.937 & 5.2058 & TRN & \\
\hline CHEMBL 3884556 & 1632526 & 3.301 & 3.1262 & TRN & \\
\hline CHEMBL 3883490 & 1632526 & 5.5817 & 5.5042 & TRN & \\
\hline CHEMBL3884925 & 1632526 & 5.3757 & \multicolumn{2}{|c|}{5.327000000000001} & TRN \\
\hline CHEMBL 3885023 & 1632526 & 5.0168 & \multicolumn{2}{|c|}{5.212000000000001} & TRN \\
\hline CHEMBL 3884207 & 1632526 & 4.9614 & 5.0195 & TRN & \\
\hline CHEMBL 3884806 & 1632526 & 4.9805 & 5.0068 & TRN & \\
\hline CHEMBL 3884024 & 1632526 & 5.3098 & 5.1656 & TRN & \\
\hline CHEMBL3883809 & 1632526 & 3.301 & 3.4967 & TRN & \\
\hline CHEMBL 3885052 & 1632526 & 4.3134 & 4.2568 & TRN & \\
\hline CHEMBL 3885251 & 1632526 & 5.4202 & 5.5846 & TRN & \\
\hline CHEMBL 3884284 & 1632526 & 4.4078 & 4.3621 & TRN & \\
\hline CHEMBL 3884510 & 1632526 & 4.3737 & 4.3987 & TRN & \\
\hline CHEMBL 3884153 & 1632526 & 5.3872 & 3.0672 & TST & \\
\hline CHEMBL 3884900 & 1632526 & 4.3605 & 4.4231 & TRN & \\
\hline CHEMBL 3884646 & 1632526 & 4.9385 & 4.9632 & TRN & \\
\hline CHEMBL 3885104 & 1632526 & 3.301 & \multicolumn{2}{|c|}{ 3.2889999999999997 } & TST \\
\hline CHEMBL 3883607 & 1632526 & 4.3947 & 3.318 & TST & \\
\hline CHEMBL3885427 & 1632526 & 5.34200 & $20000000 t$ & 5.4812 & TRN \\
\hline CHEMBL 3884003 & 1632526 & 4.3655 & 2.8481 & TST & \\
\hline CHEMBL 3885185 & 1632526 & 3.301 & 3.0226 & TST & \\
\hline CHEMBL 3883568 & 1632526 & 3.301 & 3.3639 & TRN & \\
\hline CHEMBL 3884913 & 1632526 & 4.5918 & 3.9646 & TST & \\
\hline CHEMBL 3885446 & 1632526 & 4.317 & 2.6148 & TST & \\
\hline CHEMBL 3885298 & 1632526 & 5.301 & 5.3091 & TRN & \\
\hline CHEMBL 3884331 & 1632526 & 4.978 & 5.0111 & TRN & \\
\hline CHEMBL 3883577 & 1632526 & 4.3107 & 3.3795 & TST & \\
\hline CHEMBL 3885192 & 1632526 & 3.301 & 2.8192 & TST & \\
\hline
\end{tabular}


Supplemental Table S2.txt

\begin{tabular}{|c|c|c|c|c|}
\hline CHEMBL3883968 & 1632526 & 5.0405 & 4.88 & TRN \\
\hline CHEMBL 3884879 & 1632526 & 4.9344 & 4.9831 & TRN \\
\hline CHEMBL 3885136 & 1632526 & 4.7737 & 4.9133 & TRN \\
\hline CHEMBL 3883228 & 1632526 & 5.5867 & 5.8818 & TRN \\
\hline CHEMBL 3884186 & 1632526 & 4.5776 & 4.4862 & TRN \\
\hline CHEMBL3885216 & 1632526 & 5.4342 & 5.4639 & TRN \\
\hline CHEMBL 3884205 & 1632526 & 3.301 & 3.7685 & TST \\
\hline CHEMBL 3884648 & 1632526 & 5.4134 & 5.5101 & TRN \\
\hline CHEMBL 3883475 & 1632526 & 4.301 & 3.91600 & 30000000004 \\
\hline CHEMBL 3883815 & 1632526 & 5.3372 & 3.4712 & TST \\
\hline CHEMBL3885226 & 1632526 & 3.301 & 3.3987 & TRN \\
\hline CHEMBL 3884085 & 1632526 & 4.6668 & 4.6431 & TRN \\
\hline CHEMBL 3884259 & 1632526 & 5.6655 & 5.5645 & TRN \\
\hline CHEMBL 3885289 & 1632526 & 5.0 & 4.9745 & TRN \\
\hline CHEMBL 3885470 & 1632526 & 5.0491 & 5.0083 & TRN \\
\hline CHEMBL 3885295 & 1632526 & 5.1637 & 5.0196 & TRN \\
\hline CHEMBL3883656 & 1632526 & 5.3737 & 5.3352 & TRN \\
\hline CHEMBL 3883371 & 1632526 & 4.9606 & 5.0283 & TRN \\
\hline CHEMBL 3885407 & 1632526 & 3.301 & 3.4584 & TST \\
\hline CHEMBL 3884713 & 1632526 & 4.4377 & 4.3053 & TRN \\
\hline CHEMBL 3884175 & 1632526 & 5.1349 & 5.1569 & TRN \\
\hline CHEMBL 3884125 & 1632526 & 3.301 & 3.5388 & TRN \\
\hline CHEMBL 3884288 & 1632526 & 4.6223 & 3.7312 & TST \\
\hline CHEMBL 3884677 & 1632526 & 5.3188 & 3.0367 & TST \\
\hline CHEMBL1332111 & 736911 & 3.4948 & 3.2965 & TRN \\
\hline CHEMBL428064 & 736911 & 3.4948 & 3.528 & TRN \\
\hline CHEMBL1981951 & 736911 & 3.4948 & 3.2204 & TST \\
\hline CHEMBL 3190827 & 736911 & 5.9523 & 4.9986 & TRN \\
\hline CHEMBL1307050 & 736911 & 5.1376 & 5.0462 & TRN \\
\hline CHEMBL1979800 & 736911 & 3.4948 & 3.3347 & TRN \\
\hline CHEMBL1572001 & 736911 & 5.3957 & 5.1193 & TRN \\
\hline CHEMBL1447284 & 736911 & 3.4948 & 3.7597 & TRN \\
\hline CHEMBL1383376 & 736911 & 3.4948 & 3.5646 & TRN \\
\hline CHEMBL3210072 & 736911 & 3.4948 & 3.8367 & TRN \\
\hline CHEMBL1336535 & 736911 & 3.4948 & 3.4569 & TRN \\
\hline CHEMBL1588411 & 736911 & 3.4948 & 4.1628 & TRN \\
\hline CHEMBL1303426 & 736911 & 4.523 & 4.493 & TRN \\
\hline CHEMBL1491626 & 736911 & 5.079 & 5.1261 & TRN \\
\hline CHEMBL1585390 & 736911 & 5.0718 & 4.8722 & TRN \\
\hline CHEMBL 3198868 & 736911 & 3.4948 & 3.38 & TRN \\
\hline CHEMBL1990174 & 736911 & 3.4948 & 3.3225 & TRN \\
\hline CHEMBL1510156 & 736911 & 5.58 & 4.6903 & TST \\
\hline CHEMBL 3192432 & 736911 & 3.4948 & 3.5589 & TRN \\
\hline CHEMBL1372698 & 736911 & 3.4948 & 3.6286 & TRN \\
\hline CHEMBL 3197021 & 736911 & 3.4948 & 3.2715 & TRN \\
\hline CHEMBL1579152 & 736911 & 3.4948 & 4.2466 & TST \\
\hline CHEMBL1426792 & 736911 & 4.7452 & 4.3753 & TST \\
\hline CHEMBL1460705 & 736911 & 3.4948 & 3.285 & TRN \\
\hline
\end{tabular}




\begin{tabular}{|c|c|c|c|c|c|}
\hline \multirow[b]{2}{*}{ CHEMBL1530899 } & \multicolumn{5}{|c|}{ Supplemental Table S2.txt } \\
\hline & 736911 & 5.6844 & 5.67899 & 9999999999 & TRN \\
\hline CHEMBL131037 & 736911 & 3.4948 & 3.8592 & TST & \\
\hline CHEMBL1539624 & 736911 & 3.4948 & 3.8722 & TRN & \\
\hline CHEMBL1421427 & 736911 & 3.4948 & 3.6535 & TRN & \\
\hline CHEMBL1384246 & 736911 & 3.4948 & 3.28 & TRN & \\
\hline CHEMBL1411665 & 736911 & 3.4948 & 3.6219 & TRN & \\
\hline CHEMBL1302391 & 736911 & 3.4948 & 3.3886 & TRN & \\
\hline CHEMBL1578607 & 736911 & 3.4948 & 3.3741 & TRN & \\
\hline CHEMBL140425 & 736911 & 3.4948 & 3.7367 & TRN & \\
\hline CHEMBL1529511 & 736911 & 3.4948 & 4.3802 & TST & \\
\hline CHEMBL1353124 & 736911 & 3.4948 & 3.8232 & TRN & \\
\hline CHEMBL1520214 & 736911 & 4.7182 & 4.5665 & TRN & \\
\hline CHEMBL3192010 & 736911 & 3.4948 & 3.5011 & TRN & \\
\hline CHEMBL1574879 & 736911 & 5.1178 & 4.9848 & TRN & \\
\hline CHEMBL1548770 & 736911 & 3.4948 & 3.3943 & TRN & \\
\hline CHEMBL1578482 & 736911 & 3.4948 & 3.1454 & TRN & \\
\hline CHEMBL3199851 & 736911 & 3.4948 & 3.4265 & TRN & \\
\hline CHEMBL270605 & 736911 & 3.4948 & 3.4907 & TRN & \\
\hline CHEMBL1461585 & 736911 & 5.0599 & 4.82100 & 0000000001 & TRN \\
\hline CHEMBL1553074 & 736911 & 4.5538 & 4.4842 & TRN & \\
\hline CHEMBL1560839 & 736911 & 3.4948 & 3.3315 & TRN & \\
\hline CHEMBL1463088 & 736911 & 3.4948 & 3.3957 & TRN & \\
\hline CHEMBL1442120 & 736911 & 3.4948 & 4.2271 & TST & \\
\hline CHEMBL1302178 & 736911 & 3.4948 & 3.49899 & 99999999997 & TRN \\
\hline CHEMBL1455766 & 736911 & 6.0872 & 6.1768 & TRN & \\
\hline CHEMBL3195898 & 736911 & 3.4948 & 3.4713 & TRN & \\
\hline CHEMBL1485010 & 736911 & 5.1658 & 4.3594 & TST & \\
\hline CHEMBL1377278 & 736911 & 4.6637 & 4.68199 & 99999999995 & TRN \\
\hline CHEMBL528694 & 736911 & 3.4948 & 3.4025 & TRN & \\
\hline CHEMBL1984876 & 736911 & 3.4948 & 3.7145 & TRN & \\
\hline CHEMBL3199403 & 736911 & 3.4948 & 3.5538 & TRN & \\
\hline CHEMBL2005961 & 736911 & 3.4948 & 3.597 & TRN & \\
\hline CHEMBL1324005 & 736911 & 3.4948 & 3.3188 & TRN & \\
\hline CHEMBL1976308 & 736911 & 3.4948 & 3.761 & TRN & \\
\hline CHEMBL1554920 & 736911 & 5.2924 & 4.1498 & TST & \\
\hline CHEMBL3193639 & 736911 & 3.4948 & 3.6248 & TRN & \\
\hline CHEMBL1586491 & 736911 & 3.4948 & 3.6702 & TRN & \\
\hline CHEMBL1973773 & 736911 & 3.4948 & 3.8563 & TRN & \\
\hline CHEMBL1490336 & 736911 & 3.4948 & 3.5556 & TRN & \\
\hline CHEMBL3190555 & 736911 & 5.6084 & 4.9497 & TRN & \\
\hline CHEMBL1341190 & 736911 & 6.2874 & 4.1115 & TST & \\
\hline CHEMBL1350432 & 736911 & 5.4495 & 3.6778 & TST & \\
\hline CHEMBL1522851 & 736911 & 3.4948 & 3.6265 & TRN & \\
\hline CHEMBL1585944 & 736911 & 7.301 & 3.4053 & TST & \\
\hline CHEMBL1486214 & 736911 & 3.4948 & 3.5009 & TRN & \\
\hline CHEMBL1606916 & 736911 & 3.4948 & 3.4461 & TRN & \\
\hline CHEMBL3193629 & 736911 & 3.4948 & 3.5681 & TRN & \\
\hline CHEMBL3199421 & 736911 & 3.4948 & 3.7325 & TRN & \\
\hline
\end{tabular}




\begin{tabular}{|c|c|c|c|c|c|}
\hline \multirow[b]{2}{*}{ CHEMBL1311826 } & \multicolumn{5}{|c|}{ Supplemental Table S2.txt } \\
\hline & 736911 & 3.4948 & 3.2158 & TRN & \\
\hline CHEMBL1557816 & 736911 & 3.4948 & 3.3452 & TRN & \\
\hline CHEMBL1384726 & 736911 & 6.0841 & 5.1589 & TRN & \\
\hline CHEMBL1310782 & 736911 & 5.2912 & 4.8804 & TRN & \\
\hline CHEMBL1309573 & 736911 & 3.4948 & 3.4888 & TRN & \\
\hline CHEMBL1427431 & 736911 & 3.4948 & 3.0504 & TRN & \\
\hline CHEMBL 256042 & 736911 & 3.4948 & 3.6608 & TRN & \\
\hline CHEMBL1610025 & 736911 & 3.4948 & 4.1856 & TRN & \\
\hline CHEMBL1422078 & 736911 & 3.4948 & 3.5841 & TRN & \\
\hline CHEMBL1492017 & 736911 & 3.4948 & 3.4512 & TRN & \\
\hline CHEMBL1390716 & 736911 & 4.7419 & 4.4482 & TRN & \\
\hline CHEMBL1456130 & 736911 & 3.4948 & 4.0456 & TST & \\
\hline CHEMBL1565646 & 736911 & 3.4948 & 3.6794 & TRN & \\
\hline CHEMBL255067 & 736911 & 3.4948 & 3.7276 & TRN & \\
\hline CHEMBL1455427 & 736911 & 3.4948 & 3.1308 & TRN & \\
\hline CHEMBL1433128 & 736911 & 3.4948 & 3.6854 & TRN & \\
\hline CHEMBL1999049 & 736911 & 5.3143 & 4.5079 & TST & \\
\hline CHEMBL1505604 & 736911 & 3.4948 & 3.64600 & 00000000004 & TRN \\
\hline CHEMBL1420325 & 736911 & 5.4901 & 4.45100 & 00000000005 & TST \\
\hline CHEMBL3189245 & 736911 & 3.4948 & 3.4553 & TRN & \\
\hline CHEMBL1405968 & 736911 & 6.2007 & 6.1691 & TRN & \\
\hline CHEMBL1500450 & 736911 & 3.4948 & 3.4096 & TRN & \\
\hline CHEMBL1300269 & 736911 & 3.4948 & 3.3935 & TRN & \\
\hline CHEMBL1599708 & 736911 & 3.4948 & 3.4731 & TRN & \\
\hline CHEMBL1546739 & 736911 & 3.4948 & 3.4322 & TRN & \\
\hline CHEMBL1987579 & 736911 & 3.4948 & 3.4699 & TRN & \\
\hline CHEMBL1572356 & 736911 & 3.4948 & 3.8001 & TRN & \\
\hline CHEMBL1545369 & 736911 & 3.4948 & 3.7194 & TRN & \\
\hline CHEMBL1384550 & 736911 & 3.4948 & 3.3162 & TRN & \\
\hline CHEMBL1471101 & 736911 & 3.4948 & 3.4256 & TRN & \\
\hline CHEMBL1477640 & 736911 & 3.4948 & 3.5164 & TRN & \\
\hline CHEMBL1391094 & 736911 & 4.6246 & 4.5902 & TST & \\
\hline CHEMBL3192235 & 736911 & 3.4948 & 3.4367 & TRN & \\
\hline CHEMBL1351467 & 736911 & 5.2101 & 5.2795 & TRN & \\
\hline CHEMBL3190274 & 736911 & 3.4948 & 3.6465 & TST & \\
\hline CHEMBL3195226 & 736911 & 3.4948 & 3.5925 & TRN & \\
\hline CHEMBL1311831 & 736911 & 5.841 & 5.9981 & TRN & \\
\hline CHEMBL1965132 & 736911 & 3.4948 & 3.7267 & TRN & \\
\hline CHEMBL1323553 & 736911 & 3.4948 & 3.397 & TRN & \\
\hline CHEMBL1301723 & 736911 & 4.7227 & 4.3953 & TST & \\
\hline CHEMBL1439246 & 736911 & 4.7002 & 4.7014 & TRN & \\
\hline CHEMBL1343705 & 736911 & 3.4948 & 3.5935 & TRN & \\
\hline CHEMBL1306723 & 736911 & 3.4948 & 3.3161 & TRN & \\
\hline CHEMBL1976317 & 736911 & 3.4948 & 3.7825 & TRN & \\
\hline CHEMBL1432227 & 736911 & 3.4948 & 3.1261 & TRN & \\
\hline CHEMBL1304363 & 736911 & 3.4948 & 3.655 & TRN & \\
\hline CHEMBL1562926 & 736911 & 3.4948 & 3.5512 & TRN & \\
\hline CHEMBL1557648 & 736911 & 3.4948 & 3.4437 & TRN & \\
\hline
\end{tabular}

Page 26351 


\begin{tabular}{|c|c|c|c|c|c|}
\hline \multirow[b]{2}{*}{ CHEMBL1460585 } & \multicolumn{5}{|c|}{ Supplemental Table S2.txt } \\
\hline & 736911 & 3.4948 & 3.513 & TRN & \\
\hline CHEMBL3145316 & 736911 & 3.4948 & 4.3358 & TST & \\
\hline CHEMBL534353 & 736911 & 3.4948 & 3.1118 & TRN & \\
\hline CHEMBL1337227 & 736911 & 5.5459 & 3.9902 & TST & \\
\hline CHEMBL1493936 & 736911 & 3.4948 & 3.8367 & TRN & \\
\hline CHEMBL1605583 & 736911 & 3.4948 & 3.5156 & TRN & \\
\hline CHEMBL1417204 & 736911 & 3.4948 & 4.0007 & TRN & \\
\hline CHEMBL3189289 & 736911 & 3.4948 & 3.1418 & TRN & \\
\hline CHEMBL1400298 & 736911 & 3.4948 & 3.2554 & TRN & \\
\hline CHEMBL1416089 & 736911 & 5.3768 & 5.5986 & TRN & \\
\hline CHEMBL1383537 & 736911 & 3.4948 & 3.6317 & TRN & \\
\hline CHEMBL1998521 & 736911 & 3.4948 & 3.6029 & TRN & \\
\hline CHEMBL1299526 & 736911 & 4.8574 & 4.2507 & TST & \\
\hline CHEMBL1442698 & 736911 & 3.4948 & 3.8326 & TST & \\
\hline CHEMBL1375133 & 736911 & 5.3829 & 4.2669 & TST & \\
\hline CHEMBL1385690 & 736911 & 4.5153 & 4.4626 & TRN & \\
\hline CHEMBL1597655 & 736911 & 3.4948 & 3.5926 & TRN & \\
\hline CHEMBL3196139 & 736911 & 3.4948 & 3.5655 & TRN & \\
\hline CHEMBL1558590 & 736911 & 3.4948 & 4.1529 & TST & \\
\hline CHEMBL1964464 & 736911 & 3.4948 & 3.7516 & TRN & \\
\hline CHEMBL1539016 & 736911 & 3.4948 & 3.6107 & TRN & \\
\hline CHEMBL 2373602 & 736911 & 7.301 & 3.784 & TST & \\
\hline CHEMBL3193056 & 736911 & 3.4948 & 3.5034 & TRN & \\
\hline CHEMBL1464745 & 736911 & 5.4314 & 5.2863 & TRN & \\
\hline CHEMBL3145108 & 736911 & 3.4948 & 3.7214 & TRN & \\
\hline CHEMBL1609419 & 736911 & 4.7675 & 4.55 & TRN & \\
\hline CHEMBL1319867 & 736911 & 4.939 & 4.7556 & TRN & \\
\hline CHEMBL3195760 & 736911 & 3.4948 & 3.4478 & TRN & \\
\hline CHEMBL1458833 & 736911 & 3.4948 & 3.6442 & TRN & \\
\hline CHEMBL3194040 & 736911 & 3.4948 & 3.4658 & TRN & \\
\hline CHEMBL1363376 & 736911 & 3.4948 & 3.8214 & TRN & \\
\hline CHEMBL3199359 & 736911 & 5.4139 & 3.5058 & TST & \\
\hline CHEMBL1576301 & 736911 & 3.4948 & 3.4125 & TRN & \\
\hline CHEMBL1964873 & 736911 & 3.4948 & 3.62100 & 00000000004 & TRN \\
\hline CHEMBL1542886 & 736911 & 3.4948 & 3.4167 & TRN & \\
\hline CHEMBL1504142 & 736911 & 5.1556 & 3.8289 & TST & \\
\hline CHEMBL1311879 & 736911 & 3.4948 & 3.4288 & TRN & \\
\hline CHEMBL1344225 & 736911 & 5.3273 & 5.4455 & TRN & \\
\hline CHEMBL1455045 & 736911 & 5.8784 & 6.1308 & TRN & \\
\hline CHEMBL1608776 & 736911 & 4.788 & 4.3355 & TRN & \\
\hline CHEMBL1431014 & 736911 & 3.4948 & 3.5902 & TRN & \\
\hline CHEMBL1570958 & 736911 & 4.6443 & 4.6019 & TRN & \\
\hline CHEMBL1602250 & 736911 & 4.8353 & 4.8858 & TRN & \\
\hline CHEMBL1495714 & 736911 & 3.4948 & 3.4495 & TRN & \\
\hline CHEMBL1497139 & 736911 & 4.8126 & 4.2982 & TST & \\
\hline CHEMBL1566610 & 736911 & 5.0391 & 4.1117 & TST & \\
\hline CHEMBL455284 & 736911 & 3.4948 & 3.5131 & TRN & \\
\hline CHEMBL1597627 & 736911 & 3.4948 & 3.5795 & TRN & \\
\hline
\end{tabular}




\begin{tabular}{|c|c|c|c|c|}
\hline \multicolumn{5}{|c|}{ Supplemental Table S2.txt } \\
\hline CHEMBL1359415 & 736911 & 4.8303 & 4.5314 & TRN \\
\hline CHEMBL1370719 & 736911 & 3.4948 & 3.2238 & TRN \\
\hline CHEMBL1445491 & 736911 & 5.3932 & 5.0011 & TRN \\
\hline CHEMBL 1421770 & 736911 & 4.7424 & 3.2364 & TST \\
\hline CHEMBL1542074 & 736911 & 3.4948 & 3.3769 & TRN \\
\hline CHEMBL1979954 & 736911 & 3.4948 & 4.0951 & TST \\
\hline CHEMBL1544221 & 736911 & 3.4948 & 3.3745 & TRN \\
\hline CHEMBL1598011 & 736911 & 3.4948 & 4.4967 & TST \\
\hline CHEMBL1596609 & 736911 & 4.5593 & 4.2182 & TRN \\
\hline CHEMBL 2094567 & 736911 & 3.4948 & 3.7671 & TRN \\
\hline CHEMBL1462003 & 736911 & 3.4948 & 4.0176 & TRN \\
\hline CHEMBL1471189 & 736911 & 4.7827 & 3.4933 & TST \\
\hline CHEMBL1522211 & 736911 & 3.4948 & 3.45 & TRN \\
\hline CHEMBL1456232 & 736911 & 3.4948 & 3.8672 & TRN \\
\hline CHEMBL1580946 & 736911 & 3.4948 & 3.5309 & TRN \\
\hline CHEMBL1310734 & 736911 & 5.0258 & 3.7207 & TST \\
\hline CHEMBL1387605 & 736911 & 3.4948 & 3.3961 & TRN \\
\hline CHEMBL1448582 & 736911 & 5.0135 & 4.8959 & TRN \\
\hline CHEMBL1387060 & 736911 & 3.4948 & 4.7261 & TRN \\
\hline CHEMBL1472570 & 736911 & 3.4948 & 3.5129 & TST \\
\hline CHEMBL1978355 & 736911 & 3.4948 & 3.9237 & TST \\
\hline CHEMBL1428935 & 736911 & 4.7838 & 4.6055 & TST \\
\hline CHEMBL1423597 & 736911 & 4.8532 & 4.9987 & TST \\
\hline CHEMBL1368060 & 736911 & 5.341 & 5.1857 & TST \\
\hline CHEMBL586135 & 736911 & 3.4948 & 3.4214 & TST \\
\hline CHEMBL1358924 & 736911 & 5.5899 & 4.8677 & TST \\
\hline CHEMBL1350780 & 736911 & 3.4948 & 3.5578 & TST \\
\hline CHEMBL3212029 & 736911 & 3.4948 & 4.0001 & TST \\
\hline CHEMBL1377737 & 736911 & 5.0829 & 5.275 & TST \\
\hline CHEMBL1334809 & 736911 & 3.4948 & 3.8225 & TST \\
\hline CHEMBL1477197 & 736911 & 4.7933 & 5.0214 & TST \\
\hline CHEMBL546170 & 736911 & 3.4948 & 3.3413 & TST \\
\hline CHEMBL3193535 & 736911 & 3.4948 & 3.8705 & TST \\
\hline CHEMBL1461661 & 736911 & 5.6893 & 5.8617 & TST \\
\hline CHEMBL1368523 & 736911 & 3.4948 & 3.5323 & TST \\
\hline CHEMBL1557615 & 736911 & 3.4948 & 4.1786 & TST \\
\hline CHEMBL108231 & 29233 & 5.9626 & 5.9233 & TRN \\
\hline CHEMBL75110 & 29233 & 7.699 & 7.599 & TRN \\
\hline CHEMBL107263 & 29233 & 6.6576 & 7.0123 & TRN \\
\hline CHEMBL110723 & 29233 & 6.2168 & 6.6794 & TRN \\
\hline CHEMBL107149 & 29233 & 5.9706 & 6.0348 & TRN \\
\hline CHEMBL105825 & 29233 & 6.5986 & 6.4547 & TRN \\
\hline CHEMBL310467 & 29233 & 6.4248 & 6.3113 & TRN \\
\hline CHEMBL418807 & 29233 & 7.0 & 6.6758 & TST \\
\hline CHEMBL110298 & 29233 & 5.4724 & 5.5113 & TRN \\
\hline CHEMBL108369 & 29233 & 7.3468 & 7.3765 & TRN \\
\hline CHEMBL74962 & 29233 & 5.5031 & 5.4938 & TRN \\
\hline CHEMBL307513 & 29233 & 5.8761 & 5.8714 & TRN \\
\hline
\end{tabular}




\begin{tabular}{|c|c|c|c|c|c|}
\hline \multirow[b]{2}{*}{ CHEMBL106574 } & \multicolumn{5}{|c|}{ Supplemental Table S2.txt } \\
\hline & 29233 & 6.5157 & 6.6932 & TRN & \\
\hline CHEMBL311017 & 29233 & 8.0 & 8.2135 & TRN & \\
\hline CHEMBL73637 & 29233 & 7.1675 & 7.185 & TRN & \\
\hline CHEMBL326868 & 29233 & 5.5229 & 5.2291 & TST & \\
\hline CHEMBL74747 & 29233 & 7.0915 & 7.2183 & TRN & \\
\hline CHEMBL322392 & 29233 & 8.0 & 7.8849 & TRN & \\
\hline CHEMBL106891 & 29233 & 7.5229 & 5.99299 & 9999999999 & TST \\
\hline CHEMBL110627 & 29233 & 7.5528 & 6.9742 & TRN & \\
\hline CHEMBL105932 & 29233 & 6.2684 & 6.6949 & TST & \\
\hline CHEMBL108171 & 29233 & 5.5229 & 6.6897 & TST & \\
\hline CHEMBL 323420 & 29233 & 4.7212 & 4.6472 & TRN & \\
\hline CHEMBL106528 & 29233 & 5.7212 & 5.8477 & TRN & \\
\hline CHEMBL322393 & 29233 & 6.82100 & 00000000 & 6.6794 & TRN \\
\hline CHEMBL104005 & 29233 & 5.8665 & 5.8107 & TRN & \\
\hline CHEMBL419184 & 29233 & 4.5686 & 4.9221 & TST & \\
\hline CHEMBL108632 & 29233 & 7.284 & 7.2845 & TRN & \\
\hline CHEMBL110554 & 29233 & 7.301 & 7.3075 & TRN & \\
\hline CHEMBL110281 & 29233 & 6.1135 & 6.2423 & TRN & \\
\hline CHEMBL105874 & 29233 & 7.8861 & 7.0535 & TST & \\
\hline CHEMBL106678 & 29233 & 5.0846 & 5.5284 & TRN & \\
\hline CHEMBL322328 & 29233 & 6.5702 & 6.5623 & TRN & \\
\hline CHEMBL320636 & 29233 & 7.6198 & 7.5512 & TRN & \\
\hline CHEMBL108356 & 29233 & 6.0362 & 6.0793 & TRN & \\
\hline CHEMBL110437 & 29233 & 4.7328 & 4.86100 & 0000000001 & TRN \\
\hline CHEMBL432023 & 29233 & 5.5768 & 5.5722 & TRN & \\
\hline CHEMBL110244 & 29233 & 6.7932 & 6.5644 & TRN & \\
\hline CHEMBL107572 & 29233 & 7.699 & 6.4019 & TST & \\
\hline CHEMBL 308793 & 29233 & 7.9586 & 8.0729 & TRN & \\
\hline CHEMBL110268 & 29233 & 8.2218 & 6.6758 & TST & \\
\hline CHEMBL 74560 & 29233 & 7.6576 & 7.5798 & TRN & \\
\hline CHEMBL108525 & 29233 & 5.6383 & 5.7721 & TST & \\
\hline CHEMBL 320730 & 29233 & 6.3242 & 5.8107 & TRN & \\
\hline CHEMBL106582 & 29233 & 5.2741 & 5.1246 & TRN & \\
\hline CHEMBL316737 & 29233 & 4.52 & 4.5894 & TRN & \\
\hline CHEMBL319003 & 29233 & 7.6198 & 7.8849 & TST & \\
\hline CHEMBL107110 & 29233 & 6.5622 & 6.4658 & TRN & \\
\hline CHEMBL107208 & 29233 & 7.1192 & 5.7936 & TST & \\
\hline CHEMBL106739 & 29233 & 9.4202 & 9.3966 & TRN & \\
\hline CHEMBL106766 & 29233 & 4.9281 & 5.8001 & TST & \\
\hline CHEMBL 3675228 & 1527988 & 4.4685 & 5.2697 & TST & \\
\hline CHEMBL1834373 & 1527988 & 6.5622 & 6.6072 & TRN & \\
\hline CHEMBL1834376 & 1527988 & 6.1349 & 6.2609 & TRN & \\
\hline CHEMBL1834288 & 1527988 & 6.7328 & 6.3768 & TRN & \\
\hline CHEMBL1688280 & 1527988 & 5.9208 & 5.9835 & TRN & \\
\hline CHEMBL1688267 & 1527988 & 6.0074 & 6.0165 & TRN & \\
\hline CHEMBL1688258 & 1527988 & 6.0 & 5.9202 & TRN & \\
\hline CHEMBL1834377 & 1527988 & 6.0448 & 5.8244 & TRN & \\
\hline CHEMBL 3675223 & 1527988 & 7.7212 & 7.3264 & TRN & \\
\hline
\end{tabular}


Supplemental Table S2.txt

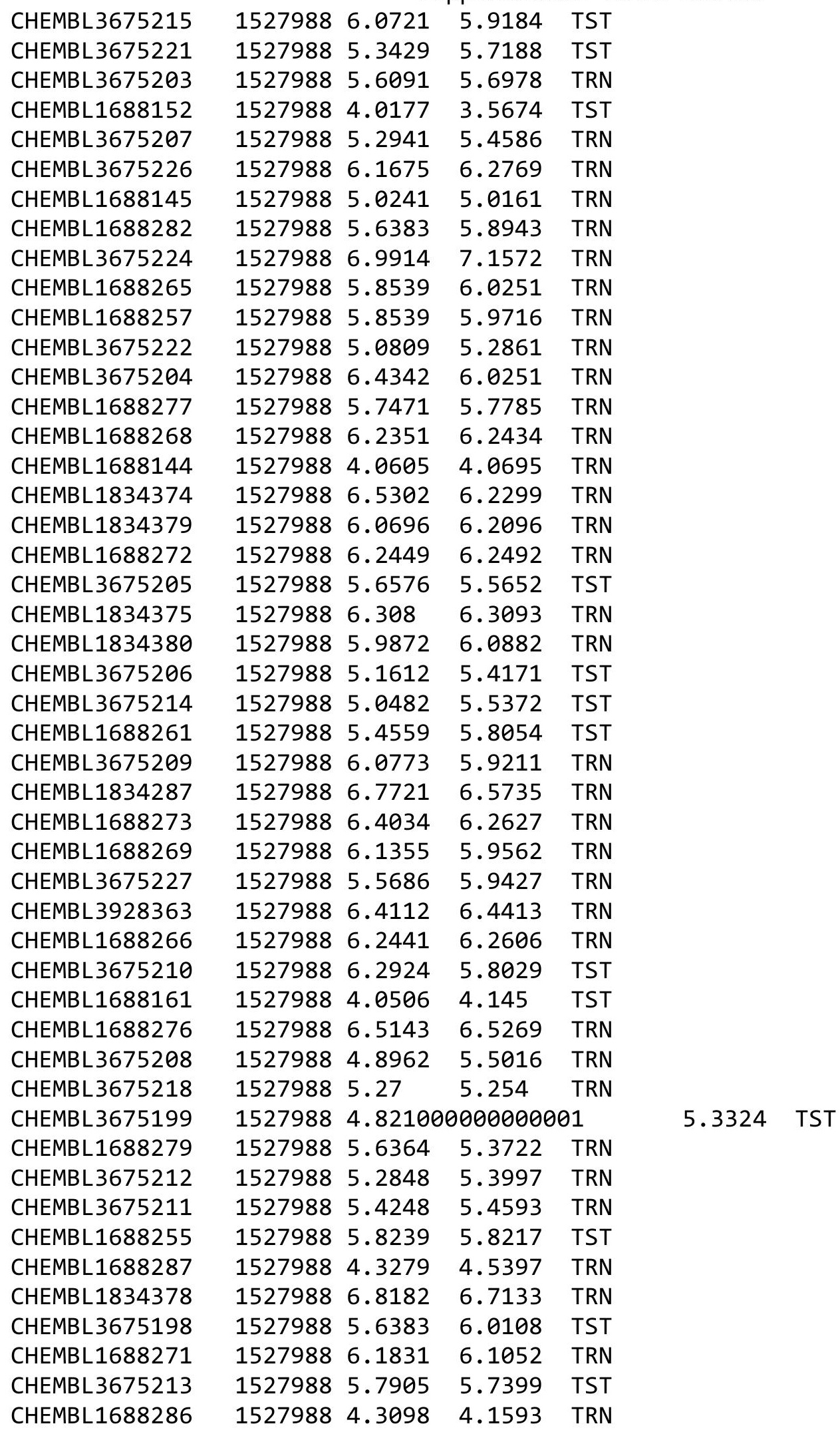

Page 26355 
Supplemental Table S2.txt

\begin{tabular}{|c|c|c|c|c|}
\hline CHEMBL1688293 & 1527988 & 4.7696 & 4.8751 & TRN \\
\hline CHEMBL1688281 & 1527988 & 5.8239 & 5.6413 & TRN \\
\hline CHEMBL1688297 & 1527988 & 4.9747 & 4.8068 & TRN \\
\hline CHEMBL3675201 & 1527988 & 6.426 & 6.4351 & TST \\
\hline CHEMBL1688264 & 1527988 & 5.4949 & 5.5201 & TRN \\
\hline CHEMBL1688283 & 1527988 & 5.5528 & 5.4309 & TRN \\
\hline CHEMBL3675216 & 1527988 & 5.5513 & 5.5095 & TST \\
\hline CHEMBL1688254 & 1527988 & 5.6383 & 5.4481 & TST \\
\hline CHEMBL 3675225 & 1527988 & 6.9914 & 7.2803 & TRN \\
\hline CHEMBL1688274 & 1527988 & 6.5258 & 5.8819 & TRN \\
\hline CHEMBL1688256 & 1527988 & 5.8539 & 6.3029 & TST \\
\hline CHEMBL 3675217 & 1527988 & 5.8356 & 5.8244 & TRN \\
\hline CHEMBL1834286 & 1527988 & 6.0 & 6.5076 & TRN \\
\hline CHEMBL1834381 & 1527988 & 5.4353 & 5.7607 & TRN \\
\hline CHEMBL3675219 & 1527988 & 5.2457 & 4.9607 & TRN \\
\hline CHEMBL3953424 & 1528395 & 4.0 & 3.7132 & TST \\
\hline CHEMBL3650822 & 1528395 & 4.0 & 3.9141 & TRN \\
\hline CHEMBL 3650829 & 1528395 & 5.0 & 4.9519 & TRN \\
\hline CHEMBL3703310 & 1528395 & 4.0 & 4.2661 & TRN \\
\hline CHEMBL3650848 & 1528395 & 5.4881 & 5.4491 & TRN \\
\hline CHEMBL3703265 & 1528395 & 5.7773 & 5.7792 & TRN \\
\hline CHEMBL3703281 & 1528395 & 4.0 & 3.7142 & TRN \\
\hline CHEMBL3703302 & 1528395 & 5.0 & 5.0233 & TRN \\
\hline CHEMBL3703239 & 1528395 & 4.0 & 4.3788 & TRN \\
\hline CHEMBL3703271 & 1528395 & 5.0851 & 4.6108 & TRN \\
\hline CHEMBL3703208 & 1528395 & 4.0 & 4.6104 & TST \\
\hline CHEMBL3703257 & 1528395 & 4.0 & 4.6296 & TST \\
\hline CHEMBL3650849 & 1528395 & 4.0 & 4.3479 & TRN \\
\hline CHEMBL 3703286 & 1528395 & 4.0 & 3.8445 & TRN \\
\hline CHEMBL3703221 & 1528395 & 4.0 & 4.082 & TRN \\
\hline CHEMBL3703309 & 1528395 & 4.0 & 4.1029 & TRN \\
\hline CHEMBL 3650843 & 1528395 & 4.0 & 3.9798 & TRN \\
\hline CHEMBL3703266 & 1528395 & 5.0101 & 4.8654 & TRN \\
\hline CHEMBL 3650774 & 1528395 & 5.0 & 4.8392 & TRN \\
\hline CHEMBL3703283 & 1528395 & 4.0 & 4.0624 & TRN \\
\hline CHEMBL3703249 & 1528395 & 4.0 & 4.3371 & TST \\
\hline CHEMBL3703290 & 1528395 & 4.0 & 4.2248 & TRN \\
\hline CHEMBL3954909 & 1528395 & 4.0 & 3.7545 & TST \\
\hline CHEMBL3703215 & 1528395 & 4.0 & 4.0606 & TRN \\
\hline CHEMBL3640021 & 1528395 & 4.0 & 4.0294 & TRN \\
\hline CHEMBL3703253 & 1528395 & 4.0 & 3.6005 & TRN \\
\hline CHEMBL3650840 & 1528395 & 4.0 & 3.9927 & TRN \\
\hline CHEMBL3703307 & 1528395 & 4.0 & 4.0412 & TRN \\
\hline CHEMBL 3703250 & 1528395 & 4.0 & 4.7716 & TST \\
\hline CHEMBL3650823 & 1528395 & 4.0 & 4.1058 & TRN \\
\hline CHEMBL 3703222 & 1528395 & 4.0 & 4.22199 & 99999999995 \\
\hline CHEMBL3650826 & 1528395 & 4.0 & 4.4406 & TRN \\
\hline CHEMBL3650837 & 1528395 & 4.0 & 3.9829 & TRN \\
\hline
\end{tabular}




\begin{tabular}{|c|c|c|c|c|c|c|}
\hline \multicolumn{7}{|c|}{ Supplemental Table S2.txt } \\
\hline CHEMBL3703274 & 1528395 & 4.0 & 4.0884 & TRN & & \\
\hline CHEMBL3703289 & 1528395 & 5.2725 & 5.2155 & TRN & & \\
\hline CHEMBL3650821 & 1528395 & 4.0 & 3.8875 & TRN & & \\
\hline CHEMBL3703262 & 1528395 & 5.0353 & 4.9298 & TST & & \\
\hline CHEMBL3650850 & 1528395 & 4.6826 & 4.5978 & TRN & & \\
\hline CHEMBL3703269 & 1528395 & 4.0 & 3.8611 & TRN & & \\
\hline CHEMBL3703300 & 1528395 & 5.2403 & 5.3804 & TRN & & \\
\hline CHEMBL3703301 & 1528395 & 5.5361 & 5.4304 & TRN & & \\
\hline CHEMBL3703298 & 1528395 & 5.4881 & 5.0839 & TRN & & \\
\hline CHEMBL3650833 & 1528395 & 4.0 & 4.0285 & TRN & & \\
\hline CHEMBL 3951464 & 1528395 & 4.0 & 4.4656 & TST & & \\
\hline CHEMBL3703299 & 1528395 & 5.1024 & 5.0654 & TRN & & \\
\hline CHEMBL3650819 & 1528395 & 4.0 & 3.9585 & TRN & & \\
\hline CHEMBL3650824 & 1528395 & 4.0 & 4.2459 & TRN & & \\
\hline CHEMBL3703247 & 1528395 & 4.0 & 4.2444 & TST & & \\
\hline CHEMBL3703297 & 1528395 & 4.0 & 4.2487 & TRN & & \\
\hline CHEMBL3703291 & 1528395 & 5.0 & 5.0416 & TRN & & \\
\hline CHEMBL 3650841 & 1528395 & 4.0 & 4.4471 & TST & & \\
\hline CHEMBL3703210 & 1528395 & 4.0 & 3.853 & TRN & & \\
\hline CHEMBL3703304 & 1528395 & 5.3645 & 5.2514 & TRN & & \\
\hline CHEMBL3703209 & 1528395 & 4.0 & 3.7741 & TRN & & \\
\hline CHEMBL3703236 & 1528395 & 4.0 & 3.9865 & TRN & & \\
\hline CHEMBL3703263 & 1528395 & 5.3536 & 5.2846 & TST & & \\
\hline CHEMBL3703296 & 1528395 & 4.0 & 4.0867 & TRN & & \\
\hline CHEMBL3703256 & 1528395 & 4.0 & 4.0645 & TRN & & \\
\hline CHEMBL3703234 & 1528395 & 4.0 & 4.0646 & TRN & & \\
\hline CHEMBL3703260 & 1528395 & 5.1612 & 5.2763 & TRN & & \\
\hline CHEMBL 3703284 & 1528395 & 4.0 & 3.8214 & TRN & & \\
\hline CHEMBL3650825 & 1528395 & 5.3089 & 4.755 & TRN & & \\
\hline CHEMBL3703270 & 1528395 & 4.0 & 3.8183 & TRN & & \\
\hline CHEMBL3703264 & 1528395 & 5.3487 & 5.2544 & TRN & & \\
\hline CHEMBL3703303 & 1528395 & 5.0 & 4.8315 & TRN & & \\
\hline CHEMBL3703235 & 1528395 & 4.0 & 3.8362 & TRN & & \\
\hline CHEMBL3703259 & 1528395 & 5.2358 & 5.2028 & TRN & & \\
\hline CHEMBL3703287 & 1528395 & 4.0 & 4.0812 & TRN & & \\
\hline CHEMBL3703282 & 1528395 & 4.0 & 4.4089 & TRN & & \\
\hline CHEMBL3703258 & 1528395 & 5.4584 & 5.4419 & TRN & & \\
\hline CHEMBL3703233 & 1528395 & 4.0 & 3.7582 & TRN & & \\
\hline CHEMBL3650851 & 1528395 & 4.82100 & 00000000 & $\partial 1$ & 4.8694 & TRN \\
\hline CHEMBL3703278 & 1528395 & 4.0 & 3.9333 & TRN & & \\
\hline CHEMBL 3650838 & 1528395 & 5.4318 & 5.5921 & TRN & & \\
\hline CHEMBL3703292 & 1528395 & 4.0 & 4.04 & TRN & & \\
\hline CHEMBL3650835 & 1528395 & 4.0 & 4.2959 & TRN & & \\
\hline CHEMBL3703293 & 1528395 & 4.0 & 4.0412 & TRN & & \\
\hline CHEMBL3703267 & 1528395 & 4.0 & 4.1239 & TRN & & \\
\hline CHEMBL 3650830 & 1528395 & 5.3716 & 4.1482 & TST & & \\
\hline CHEMBL 3650820 & 1528395 & 4.0 & 4.0563 & TRN & & \\
\hline CHEMBL3703294 & 1528395 & 4.0 & 4.2281 & TRN & & \\
\hline
\end{tabular}




\begin{tabular}{|c|c|c|c|c|}
\hline \multicolumn{5}{|c|}{ Supplemental Table S2.txt } \\
\hline CHEMBL 3703288 & 1528395 & 4.0 & 4.0532 & TRN \\
\hline CHEMBL3703285 & 1528395 & 5.1002 & 5.1591 & TRN \\
\hline CHEMBL3703261 & 1528395 & 5.556 & 5.4279 & TRN \\
\hline CHEMBL3703308 & 1528395 & 4.0 & 4.0359 & TRN \\
\hline CHEMBL 3650828 & 1528395 & 4.0 & 4.0281 & TST \\
\hline CHEMBL3650836 & 1528395 & 4.0 & 3.9985 & TST \\
\hline CHEMBL 3650827 & 1528395 & 5.4377 & 4.2197 & TST \\
\hline CHEMBL3703268 & 1528395 & 5.2182 & 5.2838 & TST \\
\hline CHEMBL3650786 & 1528395 & 5.0 & 4.4898 & TST \\
\hline CHEMBL3703279 & 1528395 & 4.0 & 3.8217 & TST \\
\hline CHEMBL 3650834 & 1528395 & 5.2823 & 5.2055 & TST \\
\hline CHEMBL 3703237 & 1528395 & 5.6635 & 5.0697 & TST \\
\hline CHEMBL3703295 & 1528395 & 5.2774 & 4.052 & TST \\
\hline CHEMBL3703246 & 1528395 & 4.0 & 4.0633 & TST \\
\hline CHEMBL3703214 & 1528395 & 4.0 & 4.1517 & TST \\
\hline CHEMBL 3650846 & 1528395 & 4.0 & 4.1859 & TST \\
\hline CHEMBL3703275 & 1528395 & 4.0 & 4.1908 & TST \\
\hline CHEMBL189007 & 304987 & 4.0 & 4.4939 & TRN \\
\hline CHEMBL361476 & 304987 & 4.0 & 5.1099 & TST \\
\hline CHEMBL362512 & 304987 & 7.3665 & 6.7447 & TRN \\
\hline CHEMBL360645 & 304987 & 4.0 & 4.5782 & TRN \\
\hline CHEMBL190263 & 304987 & 4.0 & 4.5725 & TRN \\
\hline CHEMBL366287 & 304987 & 5.3487 & 4.7171 & TRN \\
\hline CHEMBL 370238 & 304987 & 4.0 & 4.5685 & TRN \\
\hline CHEMBL187548 & 304987 & 4.0 & 4.7479 & TRN \\
\hline CHEMBL366212 & 304987 & 5.7645 & 4.925 & TRN \\
\hline CHEMBL188292 & 304987 & 5.699 & 6.3532 & TRN \\
\hline CHEMBL364482 & 304987 & 4.0 & 4.2312 & TRN \\
\hline CHEMBL189656 & 304987 & 5.7645 & 4.5843 & TRN \\
\hline CHEMBL188677 & 304987 & 5.4123 & 4.8389 & TRN \\
\hline CHEMBL362580 & 304987 & 5.4045 & 5.0719 & TRN \\
\hline CHEMBL190906 & 304987 & 4.0 & 4.7055 & TRN \\
\hline CHEMBL188334 & 304987 & 5.4089 & 5.0986 & TRN \\
\hline CHEMBL185798 & 304987 & 6.699 & 5.3159 & TRN \\
\hline CHEMBL191335 & 304987 & 4.0 & 4.7979 & TRN \\
\hline CHEMBL188108 & 304987 & 4.0 & 4.6858 & TRN \\
\hline CHEMBL190948 & 304987 & 6.4202 & 4.51399 & 9999999999 \\
\hline CHEMBL188233 & 304987 & 4.0 & 4.4584 & TRN \\
\hline CHEMBL363668 & 304987 & 5.9586 & 6.7447 & TRN \\
\hline CHEMBL188241 & 304987 & 4.0 & 4.2637 & TRN \\
\hline CHEMBL187442 & 304987 & 4.0 & 4.3427 & TRN \\
\hline CHEMBL365857 & 304987 & 4.0 & 4.827 & TRN \\
\hline CHEMBL191041 & 304987 & 6.4089 & 6.33799 & 9999999999 \\
\hline CHEMBL361691 & 304987 & 4.0 & 4.331 & TRN \\
\hline CHEMBL188333 & 304987 & 5.0969 & 4.7101 & TRN \\
\hline CHEMBL365694 & 304987 & 5.5735 & 4.8995 & TST \\
\hline CHEMBL 362370 & 304987 & 5.5528 & 5.19 & TST \\
\hline CHEMBL189520 & 304987 & 5.8665 & 4.9874 & TRN \\
\hline
\end{tabular}




\begin{tabular}{|c|c|c|c|c|c|c|}
\hline \multicolumn{7}{|c|}{ Supplemental Table S2.txt } \\
\hline CHEMBL191443 & 304987 & 4.0 & 4.7494 & TRN & & \\
\hline CHEMBL366118 & 304987 & 7.0605 & 6.4602 & TRN & & \\
\hline CHEMBL188211 & 304987 & 5.61799 & 99999995 & 99 & 5.0996 & TRN \\
\hline CHEMBL365214 & 304987 & 4.0 & 4.7739 & TRN & & \\
\hline CHEMBL188628 & 304987 & 6.2007 & 4.8355 & TRN & & \\
\hline CHEMBL190376 & 304987 & 4.0 & 4.7504 & TRN & & \\
\hline CHEMBL363301 & 304987 & 5.5331 & 4.805 & TRN & & \\
\hline CHEMBL361448 & 304987 & 4.0 & 5.1816 & TST & & \\
\hline CHEMBL189519 & 304987 & 4.0 & 4.672 & TRN & & \\
\hline CHEMBL190849 & 304987 & 5.3449 & 5.0522 & TRN & & \\
\hline CHEMBL187382 & 304987 & 5.1972 & 6.0914 & TRN & & \\
\hline CHEMBL188162 & 304987 & 4.0 & 4.8443 & TST & & \\
\hline CHEMBL188332 & 304987 & 4.0 & 4.4893 & TRN & & \\
\hline CHEMBL371587 & 304987 & 4.0 & 4.4593 & TRN & & \\
\hline CHEMBL188647 & 304987 & 5.7423 & 4.6051 & TRN & & \\
\hline CHEMBL365618 & 304987 & 5.3468 & 4.4718 & TRN & & \\
\hline CHEMBL188461 & 304987 & 5.5686 & 6.3532 & TRN & & \\
\hline CHEMBL187341 & 304987 & 4.0 & 4.591 & TRN & & \\
\hline CHEMBL190787 & 304987 & 6.0362 & 4.8827 & TRN & & \\
\hline CHEMBL365147 & 304987 & 6.0 & 4.6712 & TRN & & \\
\hline CHEMBL189566 & 304987 & 4.0 & 4.8169 & TST & & \\
\hline CHEMBL439667 & 304987 & 5.2441 & 5.3836 & TST & & \\
\hline CHEMBL189182 & 304987 & 5.1487 & 4.4439 & TST & & \\
\hline CHEMBL364888 & 304987 & 4.0 & 4.7874 & TST & & \\
\hline CHEMBL361481 & 304987 & 6.1739 & 4.8878 & TST & & \\
\hline CHEMBL187632 & 304987 & 4.0 & 5.114 & TST & & \\
\hline CHEMBL189772 & 304987 & 4.0 & 4.6527 & TST & & \\
\hline CHEMBL188397 & 304987 & 4.0 & 5.0515 & TST & & \\
\hline CHEMBL188960 & 304987 & 4.0 & 5.0058 & TST & & \\
\hline CHEMBL189008 & 304987 & 4.0 & 4.9809 & TST & & \\
\hline CHEMBL 82925 & 49312 & 8.5229 & 7.0364 & TRN & & \\
\hline CHEMBL312134 & 49312 & 5.6198 & 5.3301 & TRN & & \\
\hline CHEMBL310878 & 49312 & 4.301 & 5.1541 & TRN & & \\
\hline CHEMBL84502 & 49312 & 6.301 & 6.6196 & TRN & & \\
\hline CHEMBL 79950 & 49312 & 5.5686 & 5.3112 & TRN & & \\
\hline CHEMBL 81632 & 49312 & 4.301 & 5.4126 & TRN & & \\
\hline CHEMBL 82739 & 49312 & 6.1427 & 6.0791 & TRN & & \\
\hline CHEMBL79929 & 49312 & 4.301 & 4.9835 & TRN & & \\
\hline CHEMBL 83324 & 49312 & 5.6576 & 5.8496 & TRN & & \\
\hline CHEMBL 79501 & 49312 & 6.1612 & 5.9423 & TRN & & \\
\hline CHEMBL440311 & 49312 & 6.1549 & 5.7669 & TRN & & \\
\hline CHEMBL79735 & 49312 & 5.9208 & 5.4511 & TRN & & \\
\hline CHEMBL 79828 & 49312 & 7.8861 & 6.1926 & TST & & \\
\hline CHEMBL 84410 & 49312 & 5.7447 & 6.0062 & TRN & & \\
\hline CHEMBL 82873 & 49312 & 5.2596 & 5.3627 & TRN & & \\
\hline CHEMBL310857 & 49312 & 4.301 & 4.19 & TRN & & \\
\hline CHEMBL79529 & 49312 & 8.0757 & 5.9496 & TST & & \\
\hline CHEMBL 79715 & 49312 & 4.301 & 5.646 & TST & & \\
\hline
\end{tabular}




\begin{tabular}{|c|c|c|c|c|c|}
\hline & & \multicolumn{4}{|c|}{ Supplemental Table S2.txt } \\
\hline CHEMBL314591 & 49312 & 6.3979 & 6.5359 & TRN & \\
\hline CHEMBL83903 & 49312 & 5.699 & 5.9365 & TRN & \\
\hline CHEMBL81852 & 49312 & 4.301 & 5.7557 & TRN & \\
\hline CHEMBL311788 & 49312 & 4.301 & \multicolumn{2}{|c|}{4.553999999999999} & TRN \\
\hline CHEMBL420963 & 49312 & 4.301 & 5.8072 & TRN & \\
\hline CHEMBL315796 & 49312 & 5.8539 & 6.0863 & TRN & \\
\hline CHEMBL312378 & 49312 & 6.1938 & 6.3586 & TRN & \\
\hline CHEMBL79344 & 49312 & 4.301 & 5.5138 & TRN & \\
\hline CHEMBL81579 & 49312 & 6.5528 & 5.7249 & TRN & \\
\hline CHEMBL82175 & 49312 & 6.3372 & 5.8914 & TRN & \\
\hline CHEMBL82339 & 49312 & 6.0915 & 5.9617 & TST & \\
\hline CHEMBL84419 & 49312 & 6.4949 & \multicolumn{2}{|c|}{6.242000000000001} & TRN \\
\hline CHEMBL309717 & 49312 & 6.7447 & 5.085 & TRN & \\
\hline CHEMBL 79647 & 49312 & 4.301 & 5.6068 & TRN & \\
\hline CHEMBL80119 & 49312 & 6.0915 & 5.7539 & TRN & \\
\hline CHEMBL81007 & 49312 & 5.6778 & 5.9897 & TRN & \\
\hline CHEMBL83798 & 49312 & 6.0862 & 6.0111 & TRN & \\
\hline CHEMBL432939 & 49312 & 7.1079 & 5.6669 & TST & \\
\hline CHEMBL81301 & 49312 & 4.301 & 5.7673 & TRN & \\
\hline CHEMBL419651 & 49312 & 8.7447 & 6.1242 & TRN & \\
\hline CHEMBL312592 & 49312 & 6.58 & 5.6384 & TST & \\
\hline CHEMBL82058 & 49312 & 5.6198 & 5.0716 & TRN & \\
\hline CHEMBL310373 & 49312 & 7.585 & 6.2669 & TST & \\
\hline CHEMBL84065 & 49312 & 8.6198 & 6.1142 & TST & \\
\hline CHEMBL81932 & 49312 & 6.5528 & 5.7427 & TRN & \\
\hline CHEMBL48604 & 49312 & 7.2291 & 5.8755 & TST & \\
\hline CHEMBL83925 & 49312 & 4.301 & 5.2693 & TRN & \\
\hline CHEMBL309541 & 49312 & 8.0458 & 5.9856 & TST & \\
\hline CHEMBL 83175 & 49312 & 6.7959 & 5.3837 & TRN & \\
\hline CHEMBL312275 & 49312 & 5.301 & 5.3765 & TRN & \\
\hline CHEMBL 84030 & 49312 & 5.7696 & 6.6069 & TRN & \\
\hline CHEMBL 83648 & 49312 & 5.4815 & 6.4776 & TRN & \\
\hline CHEMBL419661 & 49312 & 6.2076 & \multicolumn{2}{|c|}{6.2379999999999995} & TRN \\
\hline CHEMBL84437 & 49312 & 7.9208 & 6.3008 & TST & \\
\hline CHEMBL83978 & 49312 & 5.6198 & 5.1364 & TRN & \\
\hline CHEMBL83054 & 49312 & 6.2757 & 5.8998 & TRN & \\
\hline CHEMBL82149 & 49312 & 5.2366 & 5.0033 & TRN & \\
\hline CHEMBL79395 & 49312 & 4.301 & 4.8932 & TRN & \\
\hline CHEMBL83431 & 49312 & 5.284 & 5.6965 & TRN & \\
\hline CHEMBL314645 & 49312 & 6.4318 & 5.8966 & TRN & \\
\hline CHEMBL 309879 & 49312 & 8.0969 & 6.1573 & TST & \\
\hline CHEMBL 83370 & 49312 & 5.301 & 6.4134 & TRN & \\
\hline CHEMBL310575 & 49312 & 5.8697 & 5.8727 & TRN & \\
\hline CHEMBL82127 & 49312 & 5.8539 & 5.8751 & TRN & \\
\hline CHEMBL81893 & 49312 & 6.6576 & 5.9722 & TRN & \\
\hline CHEMBL 79986 & 49312 & 7.8539 & 6.1829 & TRN & \\
\hline CHEMBL70730 & 49312 & 7.0969 & 5.9098 & TRN & \\
\hline CHEMBL79258 & 49312 & 6.7959 & 5.9195 & TRN & \\
\hline
\end{tabular}




\begin{tabular}{|c|c|c|c|c|}
\hline & & & pplement & al $\mathrm{T}$ \\
\hline CHEMBL83675 & 49312 & 6.7959 & 6.5473 & TRN \\
\hline CHEMBL83106 & 49312 & 5.8539 & 5.2334 & TRN \\
\hline CHEMBL79996 & 49312 & 5.8539 & 5.7164 & TRN \\
\hline CHEMBL 83873 & 49312 & 5.4949 & 6.4903 & TRN \\
\hline CHEMBL82040 & 49312 & 5.6021 & 5.8451 & TRN \\
\hline CHEMBL315014 & 49312 & 7.0706 & 5.8934 & TST \\
\hline CHEMBL83367 & 49312 & 5.8861 & 6.3874 & TRN \\
\hline CHEMBL83392 & 49312 & 4.301 & 6.1242 & TRN \\
\hline CHEMBL 81086 & 49312 & 4.301 & 5.3753 & TRN \\
\hline CHEMBL419116 & 49312 & 5.3468 & 5.3259 & TRN \\
\hline CHEMBL82006 & 49312 & 8.2218 & 6.1127 & TST \\
\hline CHEMBL49636 & 49312 & 7.8861 & 6.555 & TRN \\
\hline CHEMBL311608 & 49312 & 6.1427 & 5.2693 & TRN \\
\hline CHEMBL 82355 & 49312 & 4.301 & 5.3487 & TRN \\
\hline CHEMBL441450 & 49312 & 5.4198 & 5.2361 & TRN \\
\hline CHEMBL82831 & 49312 & 5.7447 & 5.0669 & TRN \\
\hline CHEMBL 79303 & 49312 & 8.5086 & 5.9281 & TST \\
\hline CHEMBL 309617 & 49312 & 6.9031 & 6.4368 & TST \\
\hline CHEMBL 84482 & 49312 & 5.3979 & 4.9272 & TRN \\
\hline CHEMBL 79447 & 49312 & 6.1871 & 6.5338 & TRN \\
\hline CHEMBL 80017 & 49312 & 5.9208 & 6.1798 & TST \\
\hline CHEMBL 82456 & 49312 & 7.6383 & 5.8338 & TST \\
\hline CHEMBL 83003 & 49312 & 5.7959 & 6.1987 & TST \\
\hline CHEMBL314047 & 49312 & 6.8539 & 5.3697 & TST \\
\hline CHEMBL84379 & 49312 & 5.8861 & 5.9099 & TST \\
\hline CHEMBL83779 & 49312 & 4.301 & 5.2353 & TST \\
\hline CHEMBL 84275 & 49312 & 7.1938 & 7.0325 & TST \\
\hline CHEMBL 83743 & 49312 & 5.8539 & 6.3612 & TST \\
\hline CHEMBL3922875 & 1528496 & 8.0 & 7.7213 & TRN \\
\hline CHEMBL 3644714 & 1528496 & 7.7959 & 7.2578 & TRN \\
\hline CHEMBL 3644704 & 1528496 & 8.699 & 8.1817 & TRN \\
\hline CHEMBL3644697 & 1528496 & 8.699 & 7.9534 & TRN \\
\hline CHEMBL 3944324 & 1528496 & 5.6975 & 7.0121 & TST \\
\hline CHEMBL3644686 & 1528496 & 6.0 & 7.9059 & TRN \\
\hline CHEMBL3647292 & 1528496 & 7.1024 & 8.0681 & TRN \\
\hline CHEMBL3644743 & 1528496 & 7.9586 & 7.9604 & TRN \\
\hline CHEMBL3644731 & 1528496 & 7.6778 & 7.9173 & TRN \\
\hline CHEMBL 3644751 & 1528496 & 6.0 & 7.459 & TST \\
\hline CHEMBL3644758 & 1528496 & 9.0 & 8.2472 & TRN \\
\hline CHEMBL3953327 & 1528496 & 7.8239 & 6.9989 & TRN \\
\hline CHEMBL 3644690 & 1528496 & 7.9586 & 8.0683 & TRN \\
\hline CHEMBL 3644741 & 1528496 & 9.0 & 8.0323 & TRN \\
\hline CHEMBL3644761 & 1528496 & 8.301 & 8.2926 & TRN \\
\hline CHEMBL3947622 & 1528496 & 7.699 & 7.7133 & TRN \\
\hline CHEMBL 3644708 & 1528496 & 8.301 & 7.9159 & TST \\
\hline CHEMBL 3644725 & 1528496 & 7.8861 & 7.9522 & TST \\
\hline CHEMBL3644733 & 1528496 & 8.699 & 7.6706 & TRN \\
\hline CHEMBL3899851 & 1528496 & 9.0 & 7.6794 & TRN \\
\hline
\end{tabular}


Supplemental Table S2.txt

\begin{tabular}{|c|c|c|c|c|}
\hline CHEMBL 3647293 & 1528496 & 7.8539 & 8.2039 & TRN \\
\hline CHEMBL 3644737 & 1528496 & 6.5575 & 7.0976 & TRN \\
\hline CHEMBL 3644722 & 1528496 & 8.699 & 7.9112 & TRN \\
\hline CHEMBL 3644710 & 1528496 & 6.0 & 7.8526 & TRN \\
\hline CHEMBL 3644729 & 1528496 & 8.699 & 7.8139 & TRN \\
\hline CHEMBL3647295 & 1528496 & 8.0969 & 8.1873 & TRN \\
\hline CHEMBL 3644723 & 1528496 & 8.0969 & 7.7966 & TRN \\
\hline CHEMBL 3644748 & 1528496 & 8.301 & 7.7757 & TST \\
\hline CHEMBL 3647296 & 1528496 & 7.7447 & 8.1649 & TRN \\
\hline CHEMBL 3644740 & 1528496 & 7.2757 & 8.0203 & TRN \\
\hline CHEMBL 3644734 & 1528496 & 8.1549 & 8.001 & TRN \\
\hline CHEMBL 3644706 & 1528496 & 8.301 & 8.1183 & TST \\
\hline CHEMBL 3644719 & 1528496 & 5.9602 & 6.9797 & TRN \\
\hline CHEMBL 3644707 & 1528496 & 6.0 & 6.8452 & TRN \\
\hline CHEMBL 3647299 & 1528496 & 7.6576 & 8.0723 & TRN \\
\hline CHEMBL 3647291 & 1528496 & 7.7212 & 8.1601 & TRN \\
\hline CHEMBL 3644711 & 1528496 & 7.8539 & 6.7553 & TRN \\
\hline CHEMBL 3644698 & 1528496 & 8.301 & 8.2345 & TRN \\
\hline CHEMBL 3644726 & 1528496 & 8.2218 & 7.7098 & TRN \\
\hline CHEMBL 3644746 & 1528496 & 7.3468 & 7.9867 & TST \\
\hline CHEMBL 3644747 & 1528496 & 7.4949 & 7.9518 & TST \\
\hline CHEMBL 3956006 & 1528496 & 6.104 & 7.761 & TRN \\
\hline CHEMBL 3644680 & 1528496 & 9.0 & 8.1651 & TST \\
\hline CHEMBL 3644709 & 1528496 & 8.301 & 8.0909 & TST \\
\hline CHEMBL 3644717 & 1528496 & 5.9935 & 6.7593 & TRN \\
\hline CHEMBL 3644739 & 1528496 & 7.1675 & 7.2454 & TRN \\
\hline CHEMBL 3644696 & 1528496 & 8.0969 & 7.2065 & TRN \\
\hline CHEMBL 3644693 & 1528496 & 8.0969 & 7.9093 & TRN \\
\hline CHEMBL 3644682 & 1528496 & 8.3979 & 7.9363 & TRN \\
\hline CHEMBL 3644683 & 1528496 & 8.699 & 8.2137 & TRN \\
\hline CHEMBL 3644689 & 1528496 & 8.699 & 7.9781 & TRN \\
\hline CHEMBL 3644716 & 1528496 & 6.2291 & 6.8631 & TRN \\
\hline CHEMBL 3644760 & 1528496 & 8.0969 & 8.1712 & TRN \\
\hline CHEMBL 3644736 & 1528496 & 8.3979 & 7.9791 & TST \\
\hline CHEMBL 3639436 & 1528496 & 8.699 & 8.2792 & TRN \\
\hline CHEMBL 3644755 & 1528496 & 8.699 & 7.7513 & TST \\
\hline CHEMBL 3953254 & 1528496 & 8.699 & 7.8759 & TRN \\
\hline CHEMBL 3644744 & 1528496 & 6.9547 & 7.7949 & TRN \\
\hline CHEMBL 3644724 & 1528496 & 8.5229 & 7.7382 & TRN \\
\hline CHEMBL 3644712 & 1528496 & 9.0 & 8.1627 & TRN \\
\hline CHEMBL 3647297 & 1528496 & 7.3872 & 8.155 & TRN \\
\hline CHEMBL 3644721 & 1528496 & 6.6946 & 6.7579 & TRN \\
\hline CHEMBL 3644738 & 1528496 & 7.7447 & 8.0021 & TRN \\
\hline CHEMBL 3644692 & 1528496 & 6.0 & \multicolumn{2}{|c|}{7.882999999999999} \\
\hline CHEMBL 3644757 & 1528496 & 8.301 & 8.2324 & TRN \\
\hline CHEMBL 3644718 & 1528496 & 7.5686 & 6.8062 & TRN \\
\hline CHEMBL 3647294 & 1528496 & 7.1427 & 7.9218 & TRN \\
\hline CHEMBL 3644684 & 1528496 & 7.301 & 8.0526 & TRN \\
\hline
\end{tabular}


Supplemental Table S2.txt

\begin{tabular}{|c|c|c|c|c|c|}
\hline CHEMBL3644759 & 1528496 & 8.699 & 8.2106 & TRN & \\
\hline CHEMBL 3644681 & 1528496 & 8.3979 & 8.2165 & TRN & \\
\hline CHEMBL3644699 & 1528496 & 8.3979 & 8.2002 & TRN & \\
\hline CHEMBL3644753 & 1528496 & 6.0 & 7.5284 & TST & \\
\hline CHEMBL3928957 & 1528496 & 7.7447 & 6.9934 & TST & \\
\hline CHEMBL3644727 & 1528496 & 8.1549 & 7.8709 & TRN & \\
\hline CHEMBL3644687 & 1528496 & 7.7959 & 8.0885 & TRN & \\
\hline CHEMBL3644691 & 1528496 & 8.0458 & 7.7918 & TRN & \\
\hline CHEMBL3647298 & 1528496 & 8.2218 & 8.0588 & TRN & \\
\hline CHEMBL3644730 & 1528496 & 7.8239 & 7.9347 & TST & \\
\hline CHEMBL3644756 & 1528496 & 6.1669 & 7.0698 & TST & \\
\hline CHEMBL3644762 & 1528496 & 7.4815 & 8.2103 & TST & \\
\hline CHEMBL3644749 & 1528496 & 8.1549 & 7.4752 & TST & \\
\hline CHEMBL3902030 & 1528496 & 6.6556 & 6.86799 & 9999999999 & TST \\
\hline CHEMBL 3647290 & 1528496 & 7.6198 & 8.179 & TST & \\
\hline CHEMBL3644713 & 1528496 & 8.699 & 7.2145 & TST & \\
\hline CHEMBL3928370 & 1641783 & 8.8356 & 8.8235 & TRN & \\
\hline CHEMBL 3915865 & 1641783 & 9.1427 & 8.9648 & TRN & \\
\hline CHEMBL3941118 & 1641783 & 9.0969 & 9.0944 & TRN & \\
\hline CHEMBL3958066 & 1641783 & 9.2676 & 8.9527 & TST & \\
\hline CHEMBL3978749 & 1641783 & 9.1367 & 9.25 & TRN & \\
\hline CHEMBL 3950200 & 1641783 & 8.9872 & 8.8522 & TRN & \\
\hline CHEMBL3914377 & 1641783 & 9.2291 & 9.5212 & TRN & \\
\hline CHEMBL3899509 & 1641783 & 8.8633 & 8.5949 & TST & \\
\hline CHEMBL3972830 & 1641783 & 9.0269 & 9.1184 & TRN & \\
\hline CHEMBL3915304 & 1641783 & 9.3372 & 8.9051 & TST & \\
\hline CHEMBL3920178 & 1641783 & 9.2596 & 9.2161 & TRN & \\
\hline CHEMBL3918497 & 1641783 & 9.0177 & 8.3206 & TST & \\
\hline CHEMBL3905546 & 1641783 & 8.684 & 8.7838 & TRN & \\
\hline CHEMBL3913141 & 1641783 & 9.5376 & 9.4666 & TRN & \\
\hline CHEMBL3892396 & 1641783 & 8.6925 & 8.9731 & TRN & \\
\hline CHEMBL3949479 & 1641783 & 8.1524 & 8.0199 & TRN & \\
\hline CHEMBL3980959 & 1641783 & 9.7447 & 9.9848 & TRN & \\
\hline CHEMBL3940918 & 1641783 & 8.9066 & 8.8514 & TRN & \\
\hline CHEMBL3949681 & 1641783 & 8.9245 & 8.9405 & TST & \\
\hline CHEMBL3910888 & 1641783 & 8.4855 & 8.4818 & TST & \\
\hline CHEMBL 3928573 & 1641783 & 8.9031 & 8.7746 & TRN & \\
\hline CHEMBL3909300 & 1641783 & 8.8894 & 9.0522 & TRN & \\
\hline CHEMBL3906087 & 1641783 & 9.0132 & 8.9232 & TRN & \\
\hline CHEMBL3948591 & 1641783 & 9.1249 & 9.1422 & TRN & \\
\hline CHEMBL3943816 & 1641783 & 8.7986 & 8.9733 & TRN & \\
\hline CHEMBL3931538 & 1641783 & 8.762 & 8.9027 & TRN & \\
\hline CHEMBL3926009 & 1641783 & 9.4437 & 9.4239 & TRN & \\
\hline CHEMBL3970778 & 1641783 & 8.8327 & \multicolumn{2}{|c|}{8.982999999999999} & TRN \\
\hline CHEMBL3896393 & 1641783 & 6.0 & 5.7363 & TRN & \\
\hline CHEMBL3972271 & 1641783 & 9.6778 & 9.6402 & TRN & \\
\hline CHEMBL3937898 & 1641783 & 9.2596 & 9.1618 & TRN & \\
\hline CHEMBL3916925 & 1641783 & 9.0088 & 9.0116 & TRN & \\
\hline
\end{tabular}


Supplemental Table S2.txt

\begin{tabular}{|c|c|c|c|c|}
\hline CHEMBL3905318 & 1641783 & 6.0 & 5.4587 & TST \\
\hline CHEMBL3922554 & 1641783 & 8.9788 & 8.956 & TRN \\
\hline CHEMBL3952022 & 1641783 & 9.2366 & 9.3016 & TRN \\
\hline CHEMBL3957547 & 1641783 & 9.3098 & 9.0285 & TRN \\
\hline CHEMBL3955984 & 1641783 & 8.8447 & 8.8514 & TRN \\
\hline CHEMBL3909091 & 1641783 & 6.0 & 6.2173 & TST \\
\hline CHEMBL3968299 & 1641783 & 9.2076 & 8.9733 & TRN \\
\hline CHEMBL3976520 & 1641783 & 9.0177 & 9.074 & TRN \\
\hline CHEMBL3926601 & 1641783 & 9.2924 & 9.4178 & TST \\
\hline CHEMBL3924016 & 1641783 & 9.699 & 9.8273 & TST \\
\hline CHEMBL3961154 & 1641783 & 8.9872 & 8.8802 & TRN \\
\hline CHEMBL3952559 & 1641783 & 8.567 & 8.692 & TRN \\
\hline CHEMBL3962087 & 1641783 & 8.7212 & 8.9791 & TRN \\
\hline CHEMBL3969424 & 1641783 & 8.8894 & 8.8024 & TRN \\
\hline CHEMBL 3956283 & 1641783 & 8.8962 & 9.0327 & TRN \\
\hline CHEMBL3970779 & 1641783 & 9.1612 & 9.1988 & TRN \\
\hline CHEMBL3959266 & 1641783 & 9.0315 & 9.1579 & TRN \\
\hline CHEMBL3934963 & 1641783 & 9.5376 & 9.1914 & TST \\
\hline CHEMBL3947977 & 1641783 & 9.1675 & 9.1764 & TRN \\
\hline CHEMBL 3983983 & 1641783 & 9.1135 & 9.1794 & TRN \\
\hline CHEMBL3920777 & 1641783 & 9.4559 & 9.5885 & TRN \\
\hline CHEMBL3896759 & 1641783 & 9.0555 & 9.031 & TRN \\
\hline CHEMBL3967093 & 1641783 & 8.9281 & 9.0082 & TRN \\
\hline CHEMBL3894039 & 1641783 & 8.4634 & \multicolumn{2}{|c|}{8.761000000000001} \\
\hline CHEMBL3908233 & 1641783 & 9.0506 & 9.0806 & TRN \\
\hline CHEMBL3934335 & 1641783 & 6.0 & 6.1457 & TRN \\
\hline CHEMBL3970998 & 1641783 & 9.1427 & 9.535 & TRN \\
\hline CHEMBL3946179 & 1641783 & 8.6925 & 8.9288 & TST \\
\hline CHEMBL 3905858 & 1641783 & 8.8297 & 9.0055 & TRN \\
\hline CHEMBL3961634 & 1641783 & 8.4365 & 8.2998 & TRN \\
\hline CHEMBL3929711 & 1641783 & 8.6038 & 8.7452 & TRN \\
\hline CHEMBL3890657 & 1641783 & 9.0506 & 9.2865 & TRN \\
\hline CHEMBL3926308 & 1641783 & 9.2596 & 9.4685 & TRN \\
\hline CHEMBL3962975 & 1641783 & 8.7852 & 8.8297 & TST \\
\hline CHEMBL 3968315 & 1641783 & 9.1871 & 9.1556 & TRN \\
\hline CHEMBL3907313 & 1641783 & 8.4989 & 8.5748 & TRN \\
\hline CHEMBL 3971083 & 1641783 & 9.3979 & 9.585 & TST \\
\hline CHEMBL 3932229 & 1641783 & 8.0794 & 8.1754 & TRN \\
\hline CHEMBL3914169 & 1641783 & 8.51 & 8.4097 & TRN \\
\hline CHEMBL 3941620 & 1641783 & 8.7932 & 8.4387 & TRN \\
\hline CHEMBL3894548 & 1641783 & 9.585 & 9.3217 & TRN \\
\hline CHEMBL3944331 & 1641783 & 9.2441 & 9.1264 & TRN \\
\hline CHEMBL3922831 & 1641783 & 9.0757 & 9.1407 & TRN \\
\hline CHEMBL3935396 & 1641783 & 9.301 & 9.2975 & TST \\
\hline CHEMBL3971137 & 1641783 & 9.8861 & 9.5608 & TRN \\
\hline CHEMBL3966652 & 1641783 & 8.6308 & 8.6096 & TRN \\
\hline CHEMBL3963191 & 1641783 & 9.1367 & 9.14 & TRN \\
\hline CHEMBL3923151 & 1641783 & 8.9355 & 9.0039 & TRN \\
\hline
\end{tabular}


Supplemental Table S2.txt

\begin{tabular}{|c|c|c|c|c|}
\hline CHEMBL3922979 & 1641783 & 9.0655 & 8.9929 & TST \\
\hline CHEMBL 3950178 & 1641783 & 9.0757 & 9.0445 & TRN \\
\hline CHEMBL3935850 & 1641783 & 9.7959 & 9.8181 & TRN \\
\hline CHEMBL3909519 & 1641783 & 9.1135 & 9.1174 & TRN \\
\hline CHEMBL3932570 & 1641783 & 9.6576 & 9.6936 & TRN \\
\hline CHEMBL3968155 & 1641783 & 8.7825 & 8.9338 & TRN \\
\hline CHEMBL 3968827 & 1641783 & 8.7399 & 8.7677 & TRN \\
\hline CHEMBL3898224 & 1641783 & 8.8996 & 8.3065 & TST \\
\hline CHEMBL3957787 & 1641783 & 8.5114 & 8.6342 & TRN \\
\hline CHEMBL3894603 & 1641783 & 9.1487 & 8.8075 & TST \\
\hline CHEMBL 3946275 & 1641783 & 10.0 & 10.0219 & TST \\
\hline CHEMBL3981242 & 1641783 & 6.0 & 6.446000 & 3000000001 \\
\hline CHEMBL3952029 & 1641783 & 9.2147 & 9.0877 & TRN \\
\hline CHEMBL3923526 & 1641783 & 8.6635 & 8.8145 & TRN \\
\hline CHEMBL3909533 & 1641783 & 9.8539 & 9.8192 & TRN \\
\hline CHEMBL 3921926 & 1641783 & 9.0757 & 9.0431 & TRN \\
\hline CHEMBL3913483 & 1641783 & 8.9031 & 8.8624 & TRN \\
\hline CHEMBL3929573 & 1641783 & 9.3372 & 9.1733 & TST \\
\hline CHEMBL 3970070 & 1641783 & 9.1192 & 9.061 & TRN \\
\hline CHEMBL3956898 & 1641783 & 9.1487 & 8.8663 & TRN \\
\hline CHEMBL3979546 & 1641783 & 9.1549 & 9.2203 & TRN \\
\hline CHEMBL3896379 & 1641783 & 6.0 & 5.2826 & TST \\
\hline CHEMBL3979772 & 1641783 & 6.9226 & 6.9809 & TRN \\
\hline CHEMBL3896994 & 1641783 & 8.6234 & 8.7041 & TRN \\
\hline CHEMBL3981144 & 1641783 & 9.1487 & 9.2618 & TRN \\
\hline CHEMBL3960123 & 1641783 & 8.9547 & 8.6486 & TRN \\
\hline CHEMBL3974475 & 1641783 & 8.98299 & 999999999 & 8.7063 \\
\hline CHEMBL 3897207 & 1641783 & 8.6055 & 8.3971 & TRN \\
\hline CHEMBL 3937195 & 1641783 & 9.5086 & 9.3069 & TRN \\
\hline CHEMBL3902522 & 1641783 & 8.5719 & 8.8593 & TRN \\
\hline CHEMBL3983381 & 1641783 & 9.7212 & 9.3941 & TRN \\
\hline CHEMBL3920538 & 1641783 & 8.9706 & 8.9117 & TRN \\
\hline CHEMBL3899968 & 1641783 & 9.4089 & 9.0408 & TRN \\
\hline CHEMBL3892543 & 1641783 & 8.4248 & 8.595 & TRN \\
\hline CHEMBL3917854 & 1641783 & 9.7696 & 9.3337 & TRN \\
\hline CHEMBL3922782 & 1641783 & 9.0969 & 9.2336 & TRN \\
\hline CHEMBL3890535 & 1641783 & 9.2676 & 9.2917 & TRN \\
\hline CHEMBL3957933 & 1641783 & 8.5884 & 8.6771 & TRN \\
\hline CHEMBL3941221 & 1641783 & 8.9393 & 9.0791 & TRN \\
\hline CHEMBL3890537 & 1641783 & 9.1192 & 9.1148 & TRN \\
\hline CHEMBL3908409 & 1641783 & 9.1739 & 9.2013 & TRN \\
\hline CHEMBL3906961 & 1641783 & 9.0655 & 9.0093 & TST \\
\hline CHEMBL3980799 & 1641783 & 9.1739 & 9.27 & TST \\
\hline CHEMBL3961393 & 1641783 & 9.301 & 9.2397 & TRN \\
\hline CHEMBL 3944383 & 1641783 & 8.5346 & 8.7467 & TST \\
\hline CHEMBL3949394 & 1641783 & 10.2218 & 10.2426 & TRN \\
\hline CHEMBL3915326 & 1641783 & 9.1549 & 9.1908 & TRN \\
\hline CHEMBL3896662 & 1641783 & 9.1549 & 9.1778 & TRN \\
\hline
\end{tabular}


Supplemental Table S2.txt

\begin{tabular}{|c|c|c|c|c|}
\hline CHEMBL3965809 & 1641783 & 9.0458 & 9.0675 & TRN \\
\hline CHEMBL3970360 & 1641783 & 9.1192 & 8.8394 & TRN \\
\hline CHEMBL3894756 & 1641783 & 9.2291 & 9.2627 & TST \\
\hline CHEMBL 3944446 & 1641783 & 8.8539 & 8.8031 & TRN \\
\hline CHEMBL3937016 & 1641783 & 8.8386 & 8.8936 & TRN \\
\hline CHEMBL3982408 & 1641783 & 9.0555 & 9.0816 & TRN \\
\hline CHEMBL3985698 & 1641783 & 9.6021 & 9.5261 & TRN \\
\hline CHEMBL3896005 & 1641783 & 9.3279 & 9.31200 & 0000000001 \\
\hline CHEMBL3904335 & 1641783 & 9.7696 & 9.5105 & TRN \\
\hline CHEMBL3932430 & 1641783 & 9.585 & 9.5502 & TRN \\
\hline CHEMBL3915071 & 1641783 & 9.1871 & 9.4601 & TST \\
\hline CHEMBL3920072 & 1641783 & 8.9172 & 8.7053 & TST \\
\hline CHEMBL3932644 & 1641783 & 9.0915 & 8.7618 & TRN \\
\hline CHEMBL3974690 & 1641783 & 8.8508 & 8.6336 & TST \\
\hline CHEMBL3943256 & 1641783 & 8.8477 & 8.9383 & TRN \\
\hline CHEMBL3962664 & 1641783 & 9.0757 & 9.1303 & TST \\
\hline CHEMBL3982069 & 1641783 & 8.6576 & 8.7893 & TRN \\
\hline CHEMBL3967830 & 1641783 & 9.0655 & 8.9545 & TRN \\
\hline CHEMBL3953947 & 1641783 & 9.4202 & 9.4296 & TRN \\
\hline CHEMBL3935428 & 1641783 & 8.8356 & 9.1337 & TST \\
\hline CHEMBL3957195 & 1641783 & 9.0555 & 9.206 & TRN \\
\hline CHEMBL3915972 & 1641783 & 9.1249 & 9.1528 & TRN \\
\hline CHEMBL3965438 & 1641783 & 8.752 & 8.8107 & TRN \\
\hline CHEMBL3983975 & 1641783 & 8.9788 & 8.7243 & TST \\
\hline CHEMBL 3893713 & 1641783 & 9.585 & 9.6525 & TST \\
\hline CHEMBL3977237 & 1641783 & 9.7447 & 9.6178 & TRN \\
\hline CHEMBL3912919 & 1641783 & 9.2924 & 9.2418 & TRN \\
\hline CHEMBL3964990 & 1641783 & 9.0757 & 9.1199 & TRN \\
\hline CHEMBL3951483 & 1641783 & 8.8386 & 8.9608 & TRN \\
\hline CHEMBL 3919476 & 1641783 & 8.9706 & 9.2975 & TST \\
\hline CHEMBL3954749 & 1641783 & 9.1249 & 9.2819 & TRN \\
\hline CHEMBL3924451 & 1641783 & 9.4949 & 9.5389 & TST \\
\hline CHEMBL3897795 & 1641783 & 8.7959 & 8.798 & TRN \\
\hline CHEMBL3934709 & 1641783 & 9.4318 & 9.6655 & TRN \\
\hline CHEMBL3938720 & 1641783 & 9.0506 & 9.0025 & TRN \\
\hline CHEMBL3924554 & 1641783 & 8.4841 & 8.68700 & 0000000001 \\
\hline CHEMBL 3890200 & 1641783 & 6.0 & 8.6696 & TRN \\
\hline CHEMBL3910787 & 1641783 & 8.7496 & 8.904 & TRN \\
\hline CHEMBL3970566 & 1641783 & 9.3188 & 9.4087 & TRN \\
\hline CHEMBL3937878 & 1641783 & 9.7447 & 9.3236 & TRN \\
\hline CHEMBL3924255 & 1641783 & 9.1079 & 9.1896 & TRN \\
\hline CHEMBL3900004 & 1641783 & 9.0605 & 8.9768 & TRN \\
\hline CHEMBL3935981 & 1641783 & 9.2596 & 9.022 & TRN \\
\hline CHEMBL3915926 & 1641783 & 9.041 & 8.8816 & TRN \\
\hline CHEMBL3981187 & 1641783 & 9.0458 & 8.9118 & TRN \\
\hline CHEMBL3960068 & 1641783 & 9.6198 & 9.3257 & TRN \\
\hline CHEMBL3929734 & 1641783 & 9.0605 & 9.0428 & TRN \\
\hline CHEMBL3908154 & 1641783 & 9.1308 & 9.1626 & TRN \\
\hline
\end{tabular}


Supplemental Table S2.txt

\begin{tabular}{|c|c|c|c|c|}
\hline CHEMBL3931819 & 1641783 & 9.7696 & 9.3976 & TRN \\
\hline CHEMBL 3946308 & 1641783 & 9.3979 & 9.6115 & TST \\
\hline CHEMBL3914779 & 1641783 & 9.3665 & 9.05 & TST \\
\hline CHEMBL 3907485 & 1641783 & 8.4295 & 8.5082 & TST \\
\hline CHEMBL 3898708 & 1641783 & 8.7878 & 8.5342 & TRN \\
\hline CHEMBL3927656 & 1641783 & 8.8125 & 8.7537 & TRN \\
\hline CHEMBL 3931278 & 1641783 & 9.0969 & \multicolumn{2}{|c|}{9.177999999999999} \\
\hline CHEMBL3933766 & 1641783 & 9.0915 & 9.2235 & TST \\
\hline CHEMBL 3898459 & 1641783 & 8.8416 & 8.6494 & TST \\
\hline CHEMBL 3927535 & 1641783 & 9.7696 & 9.4982 & TST \\
\hline CHEMBL3950981 & 1641783 & 9.2676 & 9.3523 & TRN \\
\hline CHEMBL 3925455 & 1641783 & 8.1367 & 8.0006 & TRN \\
\hline CHEMBL3945615 & 1641783 & 8.9586 & 8.786 & TRN \\
\hline CHEMBL3942739 & 1641783 & 8.8633 & 8.8312 & TRN \\
\hline CHEMBL 3979963 & 1641783 & 9.6383 & 9.4762 & TRN \\
\hline CHEMBL3918206 & 1641783 & 8.3675 & 8.6209 & TST \\
\hline CHEMBL3938660 & 1641783 & 6.0 & 6.3139 & TRN \\
\hline CHEMBL 3891254 & 1641783 & 8.9547 & 8.8858 & TRN \\
\hline CHEMBL 3951444 & 1641783 & 8.6778 & 9.1456 & TST \\
\hline CHEMBL 3889937 & 1641783 & 9.4089 & 9.5207 & TRN \\
\hline CHEMBL3895560 & 1641783 & 8.6536 & 8.5277 & TRN \\
\hline CHEMBL 3944568 & 1641783 & 8.9747 & 8.7749 & TRN \\
\hline CHEMBL 3924226 & 1641783 & 9.2076 & 9.2031 & TST \\
\hline CHEMBL 3929567 & 1641783 & 9.0506 & 9.23 & TST \\
\hline CHEMBL 3976064 & 1641783 & 9.6576 & 9.3219 & TRN \\
\hline CHEMBL 3890487 & 1641783 & 9.3372 & 9.1756 & TRN \\
\hline CHEMBL3958970 & 1641783 & 8.9957 & 8.8796 & TRN \\
\hline CHEMBL3957132 & 1641783 & 9.1192 & 9.2404 & TRN \\
\hline CHEMBL3959924 & 1641783 & 9.4437 & 9.3112 & TRN \\
\hline CHEMBL 3904982 & 1641783 & 9.2757 & 9.329 & TRN \\
\hline CHEMBL3934132 & 1641783 & 8.9957 & 9.0654 & TRN \\
\hline CHEMBL 3959085 & 1641783 & 8.8508 & 9.0204 & TRN \\
\hline CHEMBL 3898868 & 1641783 & 9.1308 & 9.1763 & TRN \\
\hline CHEMBL3915738 & 1641783 & 9.2147 & 8.9673 & TST \\
\hline CHEMBL3912892 & 1641783 & 9.5229 & 9.4141 & TRN \\
\hline CHEMBL3933199 & 1641783 & 9.6778 & 9.9294 & TST \\
\hline CHEMBL 3946737 & 1641783 & 9.4202 & 9.318 & TRN \\
\hline CHEMBL 3920894 & 1641783 & 9.2147 & 9.2076 & TST \\
\hline CHEMBL3980794 & 1641783 & 8.4776 & 8.5162 & TRN \\
\hline CHEMBL 3950143 & 1641783 & 9.8861 & 9.5617 & TRN \\
\hline CHEMBL3923446 & 1641783 & 6.0 & 5.3877 & TST \\
\hline CHEMBL 3914707 & 1641783 & 8.762 & 8.202 & TST \\
\hline CHEMBL3975592 & 1641783 & 8.8601 & 8.7337 & TRN \\
\hline CHEMBL 3923734 & 1641783 & 9.0223 & 9.2429 & TST \\
\hline CHEMBL3907006 & 1641783 & 8.7167 & 8.7222 & TRN \\
\hline CHEMBL3918941 & 1641783 & 8.6925 & 8.5614 & TRN \\
\hline CHEMBL 3975201 & 1641783 & 9.2757 & 8.3735 & TRN \\
\hline CHEMBL 3934458 & 1641783 & 8.7399 & 9.0143 & TST \\
\hline
\end{tabular}


Supplemental Table S2.txt

\begin{tabular}{|c|c|c|c|c|}
\hline IE & 33 & 32 & & \\
\hline & 641783 & 8.9355 & 9.1645 & \\
\hline 22 & & & & \\
\hline AEMBL3929644 & 783 & 09 & & \\
\hline AEMBL3910212 & 783 & & 3966 & \\
\hline HEMBL3948702 & 641783 & 9.0177 & 9932 & \\
\hline HEMBL3911700 & & & & \\
\hline IEMBL 3891220 & & & & \\
\hline AEMBL3901982 & & & 1361 & \\
\hline HEMBL3895921 & 83 & 18 & 9036 & \\
\hline AEMBL3906556 & 33 & 8.7 & 8051 & \\
\hline IEMBL 3950713 & 33 & 59 & 821 & \\
\hline AEMBL3900819 & & & & \\
\hline AEMBL3945218 & & 9.2596 & 3922 & \\
\hline AEMBL3915871 & 33 & & 5661 & \\
\hline AEMBL3970487 & 53 & 9. & $\$ 32$ & \\
\hline AEMBL3972612 & 33 & 9. & 15 & \\
\hline HEMBL3942241 & & & & \\
\hline HEMBL3914221 & & 35 & 0777 & \\
\hline AEMBL3921546 & & & 26 & \\
\hline HEMIBL35 & 33 & & 79 & \\
\hline HEMBL 3928 & & & 37 & \\
\hline AEMBL 3914 & & & & \\
\hline AEMBL3903629 & & & 263 & \\
\hline AEMBL3906168 & & & & I RIV \\
\hline HEMBL 3951 & 6 & & 52 & \\
\hline AEMBL3 & & & 91 & \\
\hline AEMBL3898055 & & & & RN \\
\hline AEMBL3964224 & & & & ST \\
\hline HEMBL39844 & & & 771 & RIN \\
\hline HEMBL3945907 & 6 & & 7642 & ST \\
\hline 231 & & & 55 & RN \\
\hline 77 & & & 65 & RN \\
\hline HEMBL3894688 & & & & RN \\
\hline HEMBL3939892 & 6 & & 7951 & IST \\
\hline HEMBL3974801 & & & 5132 & RN \\
\hline 4 & & & & RN \\
\hline HEMBL3 & & & 3298 & RN \\
\hline HEMBL3964279 & 3 & 10.0 & 7077 & $\Gamma \mathrm{RN}$ \\
\hline IEMBL39 & 6 & 6 & 933 & IST \\
\hline HEMBL3984681 & 6 & & 504 & \\
\hline LHEMBL 3977209 & & & & RN \\
\hline HEMBL392. & & & .086 & $\mathrm{RN}$ \\
\hline HEMBL3924292 & 83 & 8.6655 & 4926 & TRN \\
\hline EMBL390 & & 6 & & \\
\hline HEMBL 3956651 & & & 8.8541 & \\
\hline CHEMBL 3984319 & & 9.2518 & 9.1787 & \\
\hline CHEMBL3932881 & 1641783 & 9.0044 & 8.9547 & ГRN \\
\hline
\end{tabular}

Page 26368 
Supplemental Table S2.txt

\begin{tabular}{|c|c|c|c|c|c|c|}
\hline CHEMBL3937927 & 1641783 & 9.6021 & 9.5445 & TRN & & \\
\hline CHEMBL3940217 & 1641783 & 8.9747 & 8.9536 & TRN & & \\
\hline CHEMBL3931929 & 1641783 & 8.06200 & 000000000 & 01 & 8.3666 & TST \\
\hline CHEMBL 3897993 & 1641783 & 9.7447 & 9.6654 & TRN & & \\
\hline CHEMBL3959615 & 1641783 & 8.7423 & 8.9048 & TRN & & \\
\hline CHEMBL3915560 & 1641783 & 9.4437 & 9.6565 & TST & & \\
\hline CHEMBL3903218 & 1641783 & 9.7212 & 9.2021 & TRN & & \\
\hline CHEMBL 3916637 & 1641783 & 9.1079 & 9.245 & TRN & & \\
\hline CHEMBL 3911942 & 1641783 & 9.0506 & 9.0794 & TRN & & \\
\hline CHEMBL3950272 & 1641783 & 8.5986 & 8.4554 & TRN & & \\
\hline CHEMBL 3909510 & 1641783 & 9.0044 & 9.0504 & TRN & & \\
\hline CHEMBL 3962342 & 1641783 & 9.0809 & 9.1373 & TRN & & \\
\hline CHEMBL3968781 & 1641783 & 9.041 & 9.2049 & TRN & & \\
\hline CHEMBL3948039 & 1641783 & 9.585 & 9.707 & TST & & \\
\hline CHEMBL3937284 & 1641783 & 7.9897 & 8.2059 & TST & & \\
\hline CHEMBL 3958770 & 1641783 & 8.7932 & 8.7217 & TST & & \\
\hline CHEMBL3901746 & 1641783 & 8.7747 & 8.9587 & TRN & & \\
\hline CHEMBL3981440 & 1641783 & 8.8827 & 8.7983 & TRN & & \\
\hline CHEMBL 3939335 & 1641783 & 8.6326 & 8.6936 & TRN & & \\
\hline CHEMBL3963271 & 1641783 & 9.2007 & 8.9624 & TRN & & \\
\hline CHEMBL3979961 & 1641783 & 8.76700 & 000000000 & 31 & 8.9833 & TRN \\
\hline CHEMBL3966147 & 1641783 & 9.1427 & 9.3976 & TST & & \\
\hline CHEMBL 3925958 & 1641783 & 9.6198 & 9.5043 & TRN & & \\
\hline CHEMBL 3908328 & 1641783 & 9.2291 & 9.1497 & TRN & & \\
\hline CHEMBL 3958243 & 1641783 & 9.4949 & 9.5432 & TST & & \\
\hline CHEMBL3971672 & 1641783 & 9.2076 & 9.1937 & TRN & & \\
\hline CHEMBL 3978448 & 1641783 & 8.7471 & 8.8388 & TRN & & \\
\hline CHEMBL 3975210 & 1641783 & 8.6234 & 8.5764 & TRN & & \\
\hline CHEMBL 3958691 & 1641783 & 9.6383 & 9.2234 & TRN & & \\
\hline CHEMBL3970958 & 1641783 & 8.7959 & 8.7919 & TRN & & \\
\hline CHEMBL3910933 & 1641783 & 8.5768 & 8.3261 & TST & & \\
\hline CHEMBL 3921728 & 1641783 & 8.8729 & 9.0198 & TRN & & \\
\hline CHEMBL3892526 & 1641783 & 9.585 & 8.7746 & TRN & & \\
\hline CHEMBL3901497 & 1641783 & 9.6383 & 9.9592 & TST & & \\
\hline CHEMBL 3960474 & 1641783 & 9.5229 & 9.4347 & TRN & & \\
\hline CHEMBL3936541 & 1641783 & 9.4949 & 9.6003 & TRN & & \\
\hline CHEMBL 3934286 & 1641783 & 9.3372 & 9.2219 & TRN & & \\
\hline CHEMBL3923871 & 1641783 & 8.9469 & 8.6928 & TRN & & \\
\hline CHEMBL 3912732 & 1641783 & 6.0 & 5.9381 & TRN & & \\
\hline CHEMBL3965157 & 1641783 & 9.4089 & 9.4902 & TST & & \\
\hline CHEMBL3940032 & 1641783 & 9.6576 & 9.5936 & TST & & \\
\hline CHEMBL3974166 & 1641783 & 9.0915 & 8.7972 & TRN & & \\
\hline CHEMBL3913842 & 1641783 & 9.0757 & 9.2298 & TRN & & \\
\hline CHEMBL 3981362 & 1641783 & 8.9031 & 9.0106 & TRN & & \\
\hline CHEMBL 3892717 & 1641783 & 8.6108 & 8.8839 & TRN & & \\
\hline CHEMBL3953340 & 1641783 & 8.5376 & 8.5911 & TRN & & \\
\hline CHEMBL 3907971 & 1641783 & 8.5817 & 8.8558 & TRN & & \\
\hline CHEMBL3984720 & 1641783 & 9.1249 & 9.1241 & TRN & & \\
\hline
\end{tabular}


Supplemental Table S2.txt

\begin{tabular}{|c|c|c|c|c|c|}
\hline CHEMBL3921881 & 1641783 & 9.3872 & 9.4682 & TST & \\
\hline CHEMBL 3942542 & 1641783 & 6.0 & 5.8202 & TRN & \\
\hline CHEMBL3981690 & 1641783 & 9.1938 & 9.0612 & TRN & \\
\hline CHEMBL 3984741 & 1641783 & 9.2147 & 9.2978 & TRN & \\
\hline CHEMBL 3985077 & 1641783 & 9.2518 & 9.2777 & TST & \\
\hline CHEMBL3974692 & 1641783 & 9.0458 & 9.3757 & TRN & \\
\hline CHEMBL 3909090 & 1641783 & 9.4089 & 9.3766 & TST & \\
\hline CHEMBL3921889 & 1641783 & 6.0 & 5.1353 & TST & \\
\hline CHEMBL3941957 & 1641783 & 9.6383 & 9.5726 & TRN & \\
\hline CHEMBL 3947456 & 1641783 & 9.0915 & 9.0655 & TRN & \\
\hline CHEMBL3933501 & 1641783 & 8.9872 & 8.8295 & TRN & \\
\hline CHEMBL3918506 & 1641783 & 8.6162 & 8.6989 & TRN & \\
\hline CHEMBL3951397 & 1641783 & 9.2218 & 9.2596 & TRN & \\
\hline CHEMBL3976701 & 1641783 & 9.7447 & 9.6043 & TST & \\
\hline CHEMBL 3970542 & 1641783 & 8.7055 & 8.6328 & TRN & \\
\hline CHEMBL3921334 & 1641783 & 8.7747 & 8.7302 & TRN & \\
\hline CHEMBL 3897920 & 1641783 & 6.0 & 6.8013 & TST & \\
\hline CHEMBL3907431 & 1641783 & 9.3565 & 9.4239 & TRN & \\
\hline CHEMBL3911166 & 1641783 & 9.1427 & 9.0797 & TRN & \\
\hline CHEMBL 3982869 & 1641783 & 8.6003 & 8.6507 & TRN & \\
\hline CHEMBL3975506 & 1641783 & 9.0605 & 9.1937 & TRN & \\
\hline CHEMBL 3956075 & 1641783 & 9.1612 & 9.1598 & TRN & \\
\hline CHEMBL3956219 & 1641783 & 6.0 & 6.2272 & TST & \\
\hline CHEMBL3950688 & 1641783 & 9.0315 & 8.9485 & TRN & \\
\hline CHEMBL 3900096 & 1641783 & 8.3516 & 8.3057 & TRN & \\
\hline CHEMBL3940929 & 1641783 & 9.1487 & 9.0888 & TRN & \\
\hline CHEMBL 3899109 & 1641783 & 9.0362 & 8.9974 & TRN & \\
\hline CHEMBL 3980934 & 1641783 & 8.9172 & 8.7638 & TST & \\
\hline CHEMBL 3956628 & 1641783 & 9.1249 & \multicolumn{2}{|c|}{9.097000000000001} & TRN \\
\hline CHEMBL 3966370 & 1641783 & 8.585 & 8.8164 & TRN & \\
\hline CHEMBL3935161 & 1641783 & 9.5086 & 9.9439 & TST & \\
\hline CHEMBL 3929116 & 1641783 & 9.1308 & 8.9389 & TRN & \\
\hline CHEMBL3909987 & 1641783 & 9.3279 & 8.8882 & TST & \\
\hline CHEMBL3900033 & 1641783 & 8.6925 & 8.8252 & TRN & \\
\hline CHEMBL3914541 & 1641783 & 9.2518 & 9.4062 & TRN & \\
\hline CHEMBL3966418 & 1641783 & 9.0969 & 9.0827 & TRN & \\
\hline CHEMBL 3969253 & 1641783 & 10.0458 & 9.7107 & TRN & \\
\hline CHEMBL3946998 & 1641783 & 8.6757 & 8.8829 & TRN & \\
\hline CHEMBL3969204 & 1641783 & 8.9355 & 9.0684 & TRN & \\
\hline CHEMBL3910553 & 1641783 & 9.5528 & 9.7221 & TST & \\
\hline CHEMBL3959420 & 1641783 & 9.1612 & 9.2214 & TST & \\
\hline CHEMBL 3930303 & 1641783 & 8.8928 & 8.9792 & TRN & \\
\hline CHEMBL 3890546 & 1641783 & 8.5544 & 8.7587 & TST & \\
\hline CHEMBL3954699 & 1641783 & 6.0 & 6.914 & TST & \\
\hline CHEMBL 3933811 & 1641783 & 8.8861 & 9.052 & TRN & \\
\hline CHEMBL3983256 & 1641783 & 9.699 & 9.5042 & TRN & \\
\hline CHEMBL 3932031 & 1641783 & 9.0044 & 9.1585 & TRN & \\
\hline CHEMBL 3900032 & 1641783 & 8.9547 & 8.8701 & TST & \\
\hline
\end{tabular}


Supplemental Table S2.txt

CHEMBL 3979537

CHEMBL 3926957

CHEMBL3976610

CHEMBL3941450

CHEMBL3892798

CHEMBL3957231

CHEMBL3901134

CHEMBL3964801

CHEMBL 3900499

CHEMBL3956152

CHEMBL3921497

CHEMBL3912946

CHEMBL3978806

CHEMBL3981642

CHEMBL3912643

CHEMBL3984799

CHEMBL3901102

CHEMBL 3919674

CHEMBL3958362

CHEMBL 3983445

CHEMBL3963779

CHEMBL3891057

CHEMBL 3910000

CHEMBL 3920142

CHEMBL 3893449

CHEMBL 3899762

CHEMBL 3909568

CHEMBL3976050

CHEMBL3899912

CHEMBL3958363

CHEMBL3973547

CHEMBL 3950892

CHEMBL 3897112

CHEMBL3942659

CHEMBL3925409

CHEMBL3912167

CHEMBL3977319

CHEMBL 3925466

CHEMBL3927987

CHEMBL3900031

CHEMBL 3914623

CHEMBL 3913096

CHEMBL3952689

CHEMBL 3903720

CHEMBL 3920585

CHEMBL3892587

CHEMBL 3897943

CHEMBL 3932623 $\begin{array}{lll}1641783 & 10.0458 & 10.051 \\ \text { TRN }\end{array}$

$\begin{array}{llll}1641783 & 8.6799 & 8.8025 & \text { TST }\end{array}$

$\begin{array}{llll}1641783 & 9.8861 & 10.353 & \text { TRN }\end{array}$

$\begin{array}{lllll}1641783 & 8.7747 & 8.8218 & \text { TRN }\end{array}$

$\begin{array}{llll}1641783 & 8.6162 & 8.6563 & \text { TRN }\end{array}$

$\begin{array}{llll}1641783 & 9.2441 & 9.3534 & \text { TST }\end{array}$

$\begin{array}{lll}1641783 & 10.1549 & 9.6802 \\ \text { TRN }\end{array}$

$\begin{array}{llll}1641783 & 9.1549 & 9.1189 & \text { TRN }\end{array}$

$\begin{array}{llll}1641783 & 9.699 & 9.9861 & \text { TRN }\end{array}$

$\begin{array}{llll}1641783 & 9.8239 & 9.6371 & \text { TST }\end{array}$

$\begin{array}{llll}1641783 & 9.6778 & 9.8649 & \text { TST }\end{array}$

$\begin{array}{llll}1641783 & 8.6946 & 8.7607 & \text { TST }\end{array}$

$\begin{array}{llll}1641783 & 9.1135 & 9.2911 & \text { TST }\end{array}$

$\begin{array}{llll}1641783 & 8.8861 & 8.8183 & \text { TRN }\end{array}$

$\begin{array}{llll}1641783 & 9.7212 & 9.8722 & \text { TRN }\end{array}$

$\begin{array}{llll}1641783 & 9.6383 & 9.4863 & \text { TST }\end{array}$

$\begin{array}{llll}1641783 & 9.1805 & 9.1196 & \text { TRN }\end{array}$

$\begin{array}{llll}1641783 & 8.5361 & 8.7648 & \text { TRN }\end{array}$

$\begin{array}{llll}1641783 & 8.0443 & 8.202 & \text { TST }\end{array}$

$\begin{array}{llll}1641783 & 9.1675 & 8.8492 & \text { TST }\end{array}$

$\begin{array}{llll}1641783 & 9.4815 & 9.4966 & \text { TRN }\end{array}$

$\begin{array}{llll}1641783 & 9.0655 & 9.0095 & \text { TRN }\end{array}$

$\begin{array}{llll}1641783 & 8.0996 & 7.9802 & \text { TRN }\end{array}$

$\begin{array}{llll}1641783 & 9.2596 & 9.4766 & \text { TRN }\end{array}$

$\begin{array}{llll}1641783 & 9.2007 & 9.3344 & \text { TRN }\end{array}$

$\begin{array}{llll}1641783 & 9.1079 & 9.0669 & \text { TRN }\end{array}$

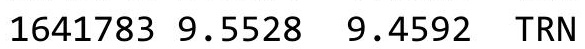

$\begin{array}{llll}1641783 & 9.7447 & 9.8418 & \text { TRN }\end{array}$

$\begin{array}{llll}1641783 & 8.9547 & 9.0214 & \text { TRN }\end{array}$

$\begin{array}{llll}1641783 & 8.7144 & 8.8089 & \text { TRN }\end{array}$

$\begin{array}{lllll}1641783 & 9.3468 & 8.8748 & \text { TRN }\end{array}$

$\begin{array}{llll}1641783 & 8.6968 & 8.6902 & \text { TRN }\end{array}$

$\begin{array}{llll}1641783 & 9.9208 & 9.6716 & \text { TST }\end{array}$

$\begin{array}{llll}1641783 & 8.7959 & 8.874 & \text { TRN }\end{array}$

$\begin{array}{lllll}1641783 & 8.8633 & 9.1283 & \text { TST }\end{array}$

$\begin{array}{llll}1641783 & 9.9586 & 9.7933 & \text { TRN }\end{array}$

$\begin{array}{llll}1641783 & 8.719 & 8.6428 & \text { TRN }\end{array}$

$\begin{array}{lllll}1641783 & 8.7282 & 8.8325 & \text { TRN }\end{array}$

$\begin{array}{lllll}1641783 & 8.4895 & 8.2559 & \text { TST }\end{array}$

$\begin{array}{llll}1641783 & 8.9355 & 8.8286 & \text { TRN }\end{array}$

$\begin{array}{lllll}1641783 & 9.4089 & 9.689 & \text { TST }\end{array}$

$\begin{array}{llll}1641783 & 8.6038 & 8.6275 & \text { TRN }\end{array}$

$\begin{array}{llll}1641783 & 8.9393 & 8.9993 & \text { TRN }\end{array}$

$\begin{array}{llll}1641783 & 9.0757 & 9.0654 & \text { TRN }\end{array}$

$\begin{array}{lllll}1641783 & 8.8861 & 8.8957 & \text { TRN }\end{array}$

$\begin{array}{llll}1641783 & 8.9031 & 8.7754 & \text { TRN }\end{array}$

$\begin{array}{llll}1641783 & 8.382 & 8.4087 & \text { TST }\end{array}$

$\begin{array}{llll}1641783 & 9.1805 & 9.1451 & \text { TRN }\end{array}$ 
Supplemental Table S2.txt

\begin{tabular}{|c|c|c|c|c|c|}
\hline CHEMBL3985468 & 1641783 & 9.3372 & 8.6068 & TST & \\
\hline CHEMBL 3905788 & 1641783 & 9.1308 & 9.1657 & TRN & \\
\hline CHEMBL3892301 & 1641783 & 8.6402 & 8.8983 & TRN & \\
\hline CHEMBL3914162 & 1641783 & 9.1308 & 9.1445 & TRN & \\
\hline CHEMBL3951860 & 1641783 & 6.0 & 6.4045 & TRN & \\
\hline CHEMBL3896141 & 1641783 & 9.0555 & 8.9871 & TRN & \\
\hline CHEMBL3912800 & 1641783 & 9.9208 & 9.9443 & TRN & \\
\hline CHEMBL3903778 & 1641783 & 9.3665 & 9.5419 & TRN & \\
\hline CHEMBL3976307 & 1641783 & 9.0706 & 8.8929 & TRN & \\
\hline CHEMBL3942091 & 1641783 & 8.9914 & 9.0087 & TRN & \\
\hline CHEMBL3951947 & 1641783 & 9.1427 & 9.0534 & TRN & \\
\hline CHEMBL3950547 & 1641783 & 8.9666 & 9.1082 & TST & \\
\hline CHEMBL3937077 & 1641783 & 9.7447 & 10.1643 & TRN & \\
\hline CHEMBL3918538 & 1641783 & 9.1367 & 9.0199 & TRN & \\
\hline CHEMBL3975956 & 1641783 & 8.6126 & 8.9287 & TRN & \\
\hline CHEMBL3971636 & 1641783 & 10.0 & 10.0689 & TRN & \\
\hline CHEMBL3905167 & 1641783 & 8.7447 & 9.027999 & 9999999999 & TRN \\
\hline CHEMBL3954236 & 1641783 & 8.9031 & 9.128 & TST & \\
\hline CHEMBL3973184 & 1641783 & 8.9586 & 9.1332 & TRN & \\
\hline CHEMBL3933698 & 1641783 & 8.8327 & 8.884 & TRN & \\
\hline CHEMBL3961979 & 1641783 & 8.6402 & 8.6283 & TRN & \\
\hline CHEMBL3890152 & 1641783 & 8.6234 & 8.5881 & TST & \\
\hline CHEMBL3918255 & 1641783 & 8.7423 & 8.764 & TRN & \\
\hline CHEMBL2011035 & 809462 & 6.2676 & 4.9512 & TRN & \\
\hline CHEMBL2011039 & 809462 & 5.699 & 3.9077 & TRN & \\
\hline CHEMBL2011004 & 809462 & 4.301 & 5.7608 & TST & \\
\hline CHEMBL2011052 & 809462 & 6.301 & 5.5764 & TRN & \\
\hline CHEMBL 2011050 & 809462 & 5.1367 & 4.7343 & TRN & \\
\hline CHEMBL2011056 & 809462 & 5.8239 & 5.9975 & TRN & \\
\hline CHEMBL2011017 & 809462 & 3.699 & 3.1827 & TRN & \\
\hline CHEMBL2011034 & 809462 & 5.2518 & 4.829 & TRN & \\
\hline CHEMBL2011030 & 809462 & 2.699 & 4.2659 & TRN & \\
\hline CHEMBL 2011049 & 809462 & 5.4089 & 6.3706 & TRN & \\
\hline CHEMBL2011058 & 809462 & 7.4949 & 5.5947 & TST & \\
\hline CHEMBL2011027 & 809462 & 4.8861 & 4.6591 & TRN & \\
\hline CHEMBL2011022 & 809462 & 2.699 & 3.36 & TST & \\
\hline CHEMBL2011044 & 809462 & 3.0 & 3.3018 & TRN & \\
\hline CHEMBL2011012 & 809462 & 3.699 & 3.0731 & TRN & \\
\hline CHEMBL2011045 & 809462 & 2.699 & 3.6042 & TRN & \\
\hline CHEMBL2011015 & 809462 & 2.699 & 2.8712 & TRN & \\
\hline CHEMBL2011031 & 809462 & 3.699 & 4.915 & TRN & \\
\hline CHEMBL2011047 & 809462 & 4.8239 & 5.6162 & TRN & \\
\hline CHEMBL2011016 & 809462 & 3.699 & 3.5148 & TRN & \\
\hline CHEMBL2011043 & 809462 & 2.699 & 3.2864 & TRN & \\
\hline CHEMBL2011028 & 809462 & 4.8539 & 5.2512 & TRN & \\
\hline CHEMBL2011006 & 809462 & 2.699 & 3.3135 & TRN & \\
\hline CHEMBL2011007 & 809462 & 3.699 & 3.4639 & TRN & \\
\hline CHEMBL2011032 & 809462 & 2.699 & 4.4072 & TRN & \\
\hline
\end{tabular}




\begin{tabular}{|c|c|c|c|c|c|}
\hline \multicolumn{6}{|c|}{ Supplemental Table S2.txt } \\
\hline CHEMBL2011042 & 809462 & 2.699 & 3.3782 & TRN & \\
\hline CHEMBL 2011033 & 809462 & 4.2676 & 4.6487 & TRN & \\
\hline CHEMBL2011025 & 809462 & 5.1549 & 4.1427 & TRN & \\
\hline CHEMBL 2011036 & 809462 & 6.2366 & 6.2012 & TRN & \\
\hline CHEMBL2011059 & 809462 & 7.5686 & 6.36299 & 99999999995 & TST \\
\hline CHEMBL 2011001 & 809462 & 6.284 & 5.4154 & TRN & \\
\hline CHEMBL 2010806 & 809462 & 5.6383 & 5.0461 & TRN & \\
\hline CHEMBL 2011041 & 809462 & 2.699 & 2.9275 & TRN & \\
\hline CHEMBL 2011009 & 809462 & 5.6576 & 3.7965 & TRN & \\
\hline CHEMBL2011060 & 809462 & 7.8539 & 6.5757 & TST & \\
\hline CHEMBL 2011024 & 809462 & 5.5229 & 5.5908 & TRN & \\
\hline CHEMBL2011019 & 809462 & 3.699 & 4.1091 & TRN & \\
\hline CHEMBL 2011054 & 809462 & 6.2518 & 5.4874 & TRN & \\
\hline CHEMBL 2011026 & 809462 & 5.0 & 5.6821 & TRN & \\
\hline CHEMBL2011023 & 809462 & 4.699 & 2.6767 & TST & \\
\hline CHEMBL 2011055 & 809462 & 6.7959 & 6.5793 & TRN & \\
\hline CHEMBL 2011051 & 809462 & 4.7696 & 4.5759 & TRN & \\
\hline CHEMBL 2011020 & 809462 & 3.699 & 4.191 & TRN & \\
\hline CHEMBL 2011048 & 809462 & 5.301 & 4.6414 & TRN & \\
\hline CHEMBL1092582 & 809462 & 8.5229 & 3.0593 & TST & \\
\hline CHEMBL 2011057 & 809462 & 7.0 & 6.8502 & TRN & \\
\hline CHEMBL2011046 & 809462 & 5.6021 & 5.7549 & TRN & \\
\hline CHEMBL 2011005 & 809462 & 3.699 & 3.9905 & TRN & \\
\hline CHEMBL 2011003 & 809462 & 4.9208 & 4.3271 & TRN & \\
\hline CHEMBL2011013 & 809462 & 3.699 & 3.1322 & TRN & \\
\hline CHEMBL 2011018 & 809462 & 3.699 & 4.1641 & TRN & \\
\hline CHEMBL2011029 & 809462 & 4.8239 & 4.6492 & TRN & \\
\hline CHEMBL 2011014 & 809462 & 2.699 & 3.5855 & TRN & \\
\hline CHEMBL2011038 & 809462 & 4.8539 & 4.6878 & TST & \\
\hline CHEMBL 2011053 & 809462 & 6.0 & 4.9861 & TST & \\
\hline CHEMBL 2011010 & 809462 & 6.0 & 3.8182 & TST & \\
\hline CHEMBL2011040 & 809462 & 5.1739 & 4.0979 & TST & \\
\hline CHEMBL2011008 & 809462 & 4.3372 & 4.4486 & TST & \\
\hline CHEMBL 2011037 & 809462 & 5.6383 & 4.9147 & TST & \\
\hline CHEMBL 2011002 & 809462 & 5.5229 & 4.4471 & TST & \\
\hline CHEMBL 2011021 & 809462 & 3.699 & 3.0782 & TST & \\
\hline CHEMBL 2011011 & 809462 & 5.6383 & 2.5952 & TST & \\
\hline CHEMBL 3718544 & 1536680 & 6.0 & 5.8973 & TRN & \\
\hline CHEMBL3715363 & 1536680 & 6.0 & 6.2098 & TRN & \\
\hline CHEMBL3716633 & 1536680 & 6.0 & 6.0213 & TRN & \\
\hline CHEMBL3715119 & 1536680 & 6.0 & 5.9793 & TRN & \\
\hline CHEMBL3718450 & 1536680 & 6.0 & 5.6292 & TRN & \\
\hline CHEMBL 3718487 & 1536680 & 6.0 & 6.24100 & 00000000005 & TRN \\
\hline CHEMBL3718533 & 1536680 & 6.0 & 5.87299 & 9999999999 & TRN \\
\hline CHEMBL3718212 & 1536680 & 6.0 & 6.07600 & 00000000005 & TRN \\
\hline CHEMBL3715350 & 1536680 & 6.0 & 5.9858 & TRN & \\
\hline CHEMBL 3715282 & 1536680 & 6.0 & 4.579 & TST & \\
\hline CHEMBL3719121 & 1536680 & 6.0 & 5.9382 & TST & \\
\hline
\end{tabular}




\begin{tabular}{|c|c|c|c|c|c|}
\hline \\
\hline CHEMBL3714784 & 1536680 & 4.0 & 4.8366 & TRN & \\
\hline CHEMBL3717288 & 1536680 & 6.0 & 5.9375 & TRN & \\
\hline CHEMBL3716509 & 1536680 & 6.0 & 5.8246 & TRN & \\
\hline CHEMBL3718137 & 1536680 & 6.0 & 5.7919 & TRN & \\
\hline CHEMBL3719138 & 1536680 & 6.0 & 5.683 & TRN & \\
\hline CHEMBL3715877 & 1536680 & 6.0 & 6.2009 & TST & \\
\hline CHEMBL3719337 & 1536680 & 4.0 & 3.9742 & TRN & \\
\hline CHEMBL3717672 & 1536680 & 6.0 & 6.4685 & TST & \\
\hline CHEMBL3716108 & 1536680 & 6.0 & 5.7643 & TRN & \\
\hline CHEMBL3715426 & 1536680 & 6.0 & 6.1266 & TRN & \\
\hline CHEMBL 3717322 & 1536680 & 6.0 & 5.2663 & TRN & \\
\hline CHEMBL 3715564 & 1536680 & 6.0 & 5.9006 & TRN & \\
\hline CHEMBL3716764 & 1536680 & 6.0 & 6.148 & TRN & \\
\hline CHEMBL3718046 & 1536680 & 6.0 & 5.8043 & TRN & \\
\hline CHEMBL 3718820 & 1536680 & 6.0 & 5.9855 & TRN & \\
\hline CHEMBL 3718457 & 1536680 & 4.0 & 4.0705 & TRN & \\
\hline CHEMBL3715657 & 1536680 & 6.0 & 5.8183 & TRN & \\
\hline CHEMBL3716286 & 1536680 & 6.0 & 5.8963 & TRN & \\
\hline CHEMBL3717508 & 1536680 & 6.0 & 6.0269 & TRN & \\
\hline CHEMBL 3716745 & 1536680 & 6.0 & 6.6328 & TST & \\
\hline CHEMBL3718708 & 1536680 & 6.0 & 5.8339 & TST & \\
\hline CHEMBL 3719095 & 1536680 & 6.0 & 6.49700 & 0000000001 & TST \\
\hline CHEMBL3715899 & 1536680 & 6.0 & 6.4053 & TRN & \\
\hline CHEMBL3715034 & 1536680 & 4.0 & 5.0001 & TRN & \\
\hline CHEMBL 3716684 & 1536680 & 6.0 & 5.6221 & TRN & \\
\hline CHEMBL3715059 & 1536680 & 6.0 & 6.0891 & TRN & \\
\hline CHEMBL3716769 & 1536680 & 6.0 & 6.4334 & TRN & \\
\hline CHEMBL3716209 & 1536680 & 6.0 & 6.09399 & 9999999999 & TRN \\
\hline CHEMBL3719214 & 1536680 & 6.0 & 5.6128 & TRN & \\
\hline CHEMBL 3716887 & 1536680 & 6.0 & 6.0568 & TST & \\
\hline CHEMBL 3717856 & 1536680 & 6.0 & 6.6602 & TST & \\
\hline CHEMBL 3718930 & 1536680 & 6.0 & 5.7348 & TRN & \\
\hline CHEMBL 3714787 & 1536680 & 6.0 & 7.251 & TST & \\
\hline CHEMBL3718633 & 1536680 & 6.0 & 5.9437 & TRN & \\
\hline CHEMBL 3716803 & 1536680 & 6.0 & 6.5711 & TST & \\
\hline CHEMBL3716307 & 1536680 & 6.0 & 6.03299 & 99999999995 & TST \\
\hline CHEMBL3716168 & 1536680 & 6.0 & 5.8963 & TRN & \\
\hline CHEMBL3716476 & 1536680 & 6.0 & 6.2501 & TRN & \\
\hline CHEMBL3715782 & 1536680 & 6.0 & 6.5584 & TST & \\
\hline CHEMBL 3716926 & 1536680 & 6.0 & 6.2501 & TRN & \\
\hline CHEMBL 3717264 & 1536680 & 6.0 & 6.2263 & TST & \\
\hline CHEMBL 3718734 & 1536680 & 6.0 & 5.9002 & TRN & \\
\hline CHEMBL1388113 & 737212 & 4.7034 & 4.2105 & TRN & \\
\hline CHEMBL1994623 & 737212 & 3.699 & 3.6111 & TRN & \\
\hline CHEMBL1302109 & 737212 & 3.699 & 4.1514 & TRN & \\
\hline CHEMBL585502 & 737212 & 5.0295 & 4.3476 & TRN & \\
\hline CHEMBL1514917 & 737212 & 4.9449 & 4.2067 & TST & \\
\hline CHEMBL1385296 & 737212 & 4.7154 & 4.1059 & TRN & \\
\hline
\end{tabular}




\begin{tabular}{|c|c|c|c|c|c|}
\hline & & \multicolumn{4}{|c|}{ Supplemental Table S2.txt } \\
\hline CHEMBL1337226 & 737212 & 4.9903 & 4.3736 & TRN & \\
\hline CHEMBL1367597 & 737212 & 3.699 & 4.1671 & TRN & \\
\hline CHEMBL1440314 & 737212 & 3.699 & 4.0565 & TRN & \\
\hline CHEMBL1409423 & 737212 & 4.9523 & 4.2069 & TRN & \\
\hline CHEMBL1434502 & 737212 & 3.699 & 3.8057 & TRN & \\
\hline CHEMBL1502883 & 737212 & 3.699 & 4.3697 & TRN & \\
\hline CHEMBL1332060 & 737212 & 3.699 & 4.0367 & TRN & \\
\hline CHEMBL1481778 & 737212 & 4.9202 & 4.1741 & TRN & \\
\hline CHEMBL1478815 & 737212 & 3.699 & 4.0445 & TRN & \\
\hline CHEMBL1449912 & 737212 & 3.699 & 4.1847 & TST & \\
\hline CHEMBL1537124 & 737212 & 3.699 & 4.1105 & TRN & \\
\hline CHEMBL1437979 & 737212 & 5.0694 & 4.215 & TRN & \\
\hline CHEMBL1415844 & 737212 & 4.7347 & 4.1425 & TRN & \\
\hline CHEMBL1504170 & 737212 & 4.7562 & 4.1163 & TRN & \\
\hline CHEMBL1571360 & 737212 & 3.699 & 3.7638 & TRN & \\
\hline CHEMBL1501527 & 737212 & 3.699 & 4.0874 & TRN & \\
\hline CHEMBL1455507 & 737212 & 3.699 & 4.2536 & TRN & \\
\hline CHEMBL1322356 & 737212 & 3.699 & 3.85399 & 99999999996 & TRN \\
\hline CHEMBL1982381 & 737212 & 3.699 & 4.1533 & TRN & \\
\hline CHEMBL1968085 & 737212 & 3.699 & 3.7697 & TRN & \\
\hline CHEMBL1323622 & 737212 & 3.699 & 4.0815 & TRN & \\
\hline CHEMBL1321987 & 737212 & 4.9328 & 4.1667 & TRN & \\
\hline CHEMBL1333593 & 737212 & 3.699 & 3.802 & TRN & \\
\hline CHEMBL1542558 & 737212 & 3.699 & 3.6387 & TRN & \\
\hline CHEMBL1525940 & 737212 & 3.699 & 3.5571 & TRN & \\
\hline CHEMBL1569724 & 737212 & 4.7002 & 4.19600 & 0000000001 & TRN \\
\hline CHEMBL1379291 & 737212 & 3.699 & 4.3009 & TRN & \\
\hline CHEMBL1369425 & 737212 & 3.699 & 4.173 & TRN & \\
\hline CHEMBL1500227 & 737212 & 4.9378 & 4.2128 & TST & \\
\hline CHEMBL1607172 & 737212 & 5.008 & 4.2392 & TRN & \\
\hline CHEMBL1470676 & 737212 & 3.699 & 4.124 & TRN & \\
\hline CHEMBL1478256 & 737212 & 3.699 & 3.8322 & TRN & \\
\hline CHEMBL1407627 & 737212 & 4.8313 & 4.2243 & TRN & \\
\hline CHEMBL1416848 & 737212 & 3.699 & 4.2912 & TRN & \\
\hline CHEMBL1523659 & 737212 & 3.699 & 4.1247 & TRN & \\
\hline CHEMBL1462451 & 737212 & 4.8669 & 4.1179 & TST & \\
\hline CHEMBL1599782 & 737212 & 4.8726 & 3.9269 & TRN & \\
\hline CHEMBL1575051 & 737212 & 5.0244 & 4.2425 & TRN & \\
\hline CHEMBL1574961 & 737212 & 3.699 & 3.7289 & TRN & \\
\hline CHEMBL1339310 & 737212 & 3.699 & 4.0536 & TRN & \\
\hline CHEMBL1444785 & 737212 & 4.7707 & 4.1962 & TRN & \\
\hline CHEMBL1565083 & 737212 & 4.8298 & 4.1669 & TRN & \\
\hline CHEMBL1378118 & 737212 & 3.699 & 4.224 & TRN & \\
\hline CHEMBL1504069 & 737212 & 3.699 & 4.4324 & TRN & \\
\hline CHEMBL1388356 & 737212 & 3.699 & 3.639 & TRN & \\
\hline CHEMBL1426966 & 737212 & 3.699 & 3.855 & TRN & \\
\hline CHEMBL1570135 & 737212 & 5.0535 & 4.173 & TRN & \\
\hline CHEMBL1536767 & 737212 & 3.699 & 4.1895 & TRN & \\
\hline
\end{tabular}


Supplemental Table S2.txt

\begin{tabular}{|c|c|c|c|c|}
\hline CHEMBL1509029 & 737212 & 3.699 & 4.0922 & TRN \\
\hline CHEMBL1465119 & 737212 & 3.699 & 4.2092 & TRN \\
\hline CHEMBL1313090 & 737212 & 3.699 & 4.043 & TRN \\
\hline CHEMBL1362734 & 737212 & 4.9579 & 4.2787 & TST \\
\hline CHEMBL1498038 & 737212 & 5.0827 & 4.2153 & TRN \\
\hline CHEMBL1427059 & 737212 & 4.9681 & 4.3073 & TRN \\
\hline CHEMBL1486619 & 737212 & 5.1655 & 4.3488 & TRN \\
\hline CHEMBL1572157 & 737212 & 3.699 & 3.833 & TRN \\
\hline CHEMBL1503006 & 737212 & 3.699 & 3.8285 & TRN \\
\hline CHEMBL1509707 & 737212 & 4.7682 & 4.0797 & TRN \\
\hline CHEMBL1461392 & 737212 & 4.8639 & 4.1871 & TRN \\
\hline CHEMBL1446753 & 737212 & 3.699 & 4.1257 & TRN \\
\hline CHEMBL1991112 & 737212 & 3.699 & 3.7972 & TST \\
\hline CHEMBL1503962 & 737212 & 3.699 & 4.0999 & TST \\
\hline CHEMBL1569954 & 737212 & 3.699 & 4.1096 & TRN \\
\hline CHEMBL1323512 & 737212 & 3.699 & 3.8913 & TRN \\
\hline CHEMBL1407401 & 737212 & 5.0084 & 4.1993 & TRN \\
\hline CHEMBL1361883 & 737212 & 5.1725 & 4.3509 & TRN \\
\hline CHEMBL1370183 & 737212 & 3.699 & 3.7058 & TRN \\
\hline CHEMBL1604797 & 737212 & 3.699 & 4.0878 & TRN \\
\hline CHEMBL1346232 & 737212 & 4.8071 & 4.046 & TRN \\
\hline CHEMBL1445206 & 737212 & 3.699 & 3.9024 & TRN \\
\hline CHEMBL1369879 & 737212 & 4.7891 & 4.2088 & TRN \\
\hline CHEMBL1318742 & 737212 & 3.699 & 4.0856 & TRN \\
\hline CHEMBL3189997 & 737212 & 3.699 & 3.7958 & TST \\
\hline CHEMBL1376195 & 737212 & 3.699 & 4.0868 & TRN \\
\hline CHEMBL1415786 & 737212 & 3.699 & 3.6835 & TST \\
\hline CHEMBL1412853 & 737212 & 3.699 & 3.7564 & TRN \\
\hline CHEMBL1351159 & 737212 & 3.699 & 4.0835 & TRN \\
\hline CHEMBL1400385 & 737212 & 3.699 & 4.0996 & TRN \\
\hline CHEMBL1496313 & 737212 & 3.699 & 4.1201 & TST \\
\hline CHEMBL1444690 & 737212 & 3.699 & 4.2327 & TST \\
\hline CHEMBL1436964 & 737212 & 4.8443 & 3.9833 & TRN \\
\hline CHEMBL1413363 & 737212 & 3.699 & 4.1447 & TRN \\
\hline CHEMBL1565526 & 737212 & 3.699 & 4.2763 & TRN \\
\hline CHEMBL3197607 & 737212 & 4.7325 & 3.6956 & TST \\
\hline CHEMBL1349532 & 737212 & 3.699 & 3.9429 & TRN \\
\hline CHEMBL1520276 & 737212 & 4.9361 & 4.3042 & TRN \\
\hline CHEMBL1309210 & 737212 & 3.699 & 4.2209 & TRN \\
\hline CHEMBL1507128 & 737212 & 3.699 & 3.5601 & TRN \\
\hline CHEMBL1595790 & 737212 & 3.699 & 4.5653 & TST \\
\hline CHEMBL3197098 & 737212 & 3.699 & 4.01399 & 9999999999 \\
\hline CHEMBL1541329 & 737212 & 5.011 & 4.2201 & TRN \\
\hline CHEMBL1519375 & 737212 & 3.699 & 3.8519 & TST \\
\hline CHEMBL1402502 & 737212 & 5.0974 & 4.2688 & TST \\
\hline CHEMBL1489361 & 737212 & 3.699 & 4.1565 & TST \\
\hline CHEMBL1542713 & 737212 & 4.7288 & 4.1699 & TRN \\
\hline CHEMBL1374703 & 737212 & 3.699 & 3.6571 & TRN \\
\hline
\end{tabular}




\begin{tabular}{|c|c|c|c|c|c|c|}
\hline & & \multicolumn{5}{|c|}{ Supplemental Table S2.txt } \\
\hline CHEMBL1417054 & 737212 & 5.1405 & 4.1898 & TRN & & \\
\hline CHEMBL3195658 & 737212 & 4.9645 & 4.0914 & TRN & & \\
\hline CHEMBL1406480 & 737212 & 3.699 & 4.2113 & TRN & & \\
\hline CHEMBL1393375 & 737212 & 3.699 & 3.8729 & TRN & & \\
\hline CHEMBL 272945 & 737212 & 3.699 & 4.165 & TRN & & \\
\hline CHEMBL1418614 & 737212 & 3.699 & 4.165 & TRN & & \\
\hline CHEMBL1369671 & 737212 & 3.699 & 4.1687 & TRN & & \\
\hline CHEMBL1310479 & 737212 & 3.699 & 4.0485 & TRN & & \\
\hline CHEMBL1332013 & 737212 & 4.7335 & 4.0584 & TRN & & \\
\hline CHEMBL1525854 & 737212 & 3.699 & 3.7458 & TRN & & \\
\hline CHEMBL1306769 & 737212 & 3.699 & 3.6716 & TRN & & \\
\hline CHEMBL588028 & 737212 & 5.1281 & 4.1755 & TRN & & \\
\hline CHEMBL1445071 & 737212 & 3.699 & 3.6819 & TRN & & \\
\hline CHEMBL1439435 & 737212 & 3.699 & 3.9003 & TRN & & \\
\hline CHEMBL1570792 & 737212 & 3.699 & 4.1938 & TRN & & \\
\hline CHEMBL1599462 & 737212 & 3.699 & 4.158 & TRN & & \\
\hline CHEMBL1598561 & 737212 & 4.9736 & 4.0758 & TRN & & \\
\hline CHEMBL1491541 & 737212 & 5.0622 & 3.8984 & TRN & & \\
\hline CHEMBL1612423 & 737212 & 3.699 & 4.3311 & TRN & & \\
\hline CHEMBL1334593 & 737212 & 3.699 & 3.8069 & TST & & \\
\hline CHEMBL1581425 & 737212 & \multicolumn{3}{|c|}{4.8260000000000005} & 4.1639 & TRN \\
\hline CHEMBL1586575 & 737212 & 4.775 & 4.1844 & TRN & & \\
\hline CHEMBL1425921 & 737212 & 4.7523 & 4.2682 & TRN & & \\
\hline CHEMBL1380813 & 737212 & 3.699 & 4.0718 & TRN & & \\
\hline CHEMBL1345481 & 737212 & 3.699 & 4.1199 & TRN & & \\
\hline CHEMBL1427335 & 737212 & 3.699 & 4.1081 & TST & & \\
\hline CHEMBL3210725 & 737212 & 3.699 & 4.5223 & TRN & & \\
\hline CHEMBL1495687 & 737212 & 4.9777 & 4.261 & TST & & \\
\hline CHEMBL1581233 & 737212 & 3.699 & 4.0743 & TRN & & \\
\hline CHEMBL1493793 & 737212 & 3.699 & 4.1214 & TRN & & \\
\hline CHEMBL1308674 & 737212 & 3.699 & 4.1245 & TRN & & \\
\hline CHEMBL1550862 & 737212 & 4.8732 & 4.2924 & TRN & & \\
\hline CHEMBL1534959 & 737212 & 3.699 & 3.8099 & TST & & \\
\hline CHEMBL1525315 & 737212 & 4.7451 & 4.1086 & TRN & & \\
\hline CHEMBL1299634 & 737212 & 3.699 & 4.2123 & TRN & & \\
\hline CHEMBL1424118 & 737212 & 3.699 & 4.1652 & TST & & \\
\hline CHEMBL1449663 & 737212 & 3.699 & 3.6818 & TRN & & \\
\hline CHEMBL1582794 & 737212 & 3.699 & 4.2179 & TRN & & \\
\hline CHEMBL1613298 & 737212 & 3.699 & 4.2448 & TRN & & \\
\hline CHEMBL1333987 & 737212 & 3.699 & 3.9775 & TRN & & \\
\hline CHEMBL1313978 & 737212 & 5.059 & 4.2862 & TRN & & \\
\hline CHEMBL1555482 & 737212 & 3.699 & 4.2691 & TRN & & \\
\hline CHEMBL1421574 & 737212 & 3.699 & 4.114 & TRN & & \\
\hline CHEMBL1996376 & 737212 & 3.699 & 3.6928 & TST & & \\
\hline CHEMBL1444822 & 737212 & 3.699 & 4.0298 & TST & & \\
\hline CHEMBL1478220 & 737212 & 3.699 & 4.0537 & TRN & & \\
\hline CHEMBL1504685 & 737212 & 5.0392 & 4.2081 & TST & & \\
\hline CHEMBL3194040 & 737212 & 3.699 & 3.8911 & TRN & & \\
\hline
\end{tabular}


Supplemental Table S2.txt

\begin{tabular}{|c|c|c|c|c|c|}
\hline CHEMBL1547420 & 737212 & 3.699 & 4.2093 & TRN & \\
\hline CHEMBL1400275 & 737212 & 5.0789 & 4.2277 & TRN & \\
\hline CHEMBL583558 & 737212 & 3.699 & 4.0708 & TST & \\
\hline CHEMBL1380946 & 737212 & 3.699 & 3.9218 & TRN & \\
\hline CHEMBL1301855 & 737212 & 3.699 & 3.9336 & TRN & \\
\hline CHEMBL1482357 & 737212 & 3.699 & 3.8658 & TRN & \\
\hline CHEMBL1346518 & 737212 & 4.9469 & 4.2733 & TRN & \\
\hline CHEMBL1543473 & 737212 & 3.699 & 4.0992 & TRN & \\
\hline CHEMBL1568614 & 737212 & 3.699 & 3.6871 & TRN & \\
\hline CHEMBL1986274 & 737212 & 4.9099 & \multicolumn{2}{|c|}{4.1080000000000005} & TRN \\
\hline CHEMBL1543504 & 737212 & 4.7841 & 3.8585 & TST & \\
\hline CHEMBL1571150 & 737212 & 3.699 & 4.1144 & TST & \\
\hline CHEMBL590706 & 737212 & 4.7417 & 4.2003 & TST & \\
\hline CHEMBL1547436 & 737212 & 4.8441 & 4.2065 & TST & \\
\hline CHEMBL1330503 & 737212 & 3.699 & \multicolumn{2}{|c|}{3.9330000000000003} & TRN \\
\hline CHEMBL1493896 & 737212 & 3.699 & 4.1527 & TRN & \\
\hline CHEMBL1372398 & 737212 & 4.9847 & 4.3863 & TRN & \\
\hline CHEMBL1344677 & 737212 & 3.699 & 4.1904 & TST & \\
\hline CHEMBL3189344 & 737212 & 3.699 & 3.6331 & TRN & \\
\hline CHEMBL1299319 & 737212 & 4.9252 & 4.1952 & TRN & \\
\hline CHEMBL1426245 & 737212 & 4.7254 & 4.0428 & TRN & \\
\hline CHEMBL1497669 & 737212 & 3.699 & 4.173 & TRN & \\
\hline CHEMBL1423286 & 737212 & 3.699 & 4.1402 & TRN & \\
\hline CHEMBL1576555 & 737212 & 4.7513 & 4.2039 & TRN & \\
\hline CHEMBL1501375 & 737212 & 3.699 & 4.1636 & TRN & \\
\hline CHEMBL1490092 & 737212 & 4.7287 & 4.123 & TRN & \\
\hline CHEMBL1510940 & 737212 & 4.8024 & 4.1632 & TRN & \\
\hline CHEMBL1361509 & 737212 & 3.699 & 4.2155 & TRN & \\
\hline CHEMBL1516853 & 737212 & 5.0156 & 4.1947 & TRN & \\
\hline CHEMBL1361922 & 737212 & 3.699 & 4.3167 & TST & \\
\hline CHEMBL1612381 & 737212 & 4.9467 & 4.199 & TRN & \\
\hline CHEMBL1611106 & 737212 & 3.699 & 4.2041 & TST & \\
\hline CHEMBL1568646 & 737212 & 4.8924 & 4.2924 & TRN & \\
\hline CHEMBL1377693 & 737212 & 3.699 & 4.1745 & TRN & \\
\hline CHEMBL1544103 & 737212 & 3.699 & 4.0822 & TST & \\
\hline CHEMBL1405985 & 737212 & 3.699 & 3.8694 & TRN & \\
\hline CHEMBL1454614 & 737212 & 4.8677 & 4.0814 & TST & \\
\hline CHEMBL1467115 & 737212 & 3.699 & 4.1866 & TRN & \\
\hline CHEMBL1612227 & 737212 & 4.8045 & 4.1991 & TRN & \\
\hline CHEMBL1483308 & 737212 & 4.8394 & 4.1532 & TRN & \\
\hline CHEMBL1360862 & 737212 & 4.7893 & 4.1947 & TRN & \\
\hline CHEMBL1479888 & 737212 & 4.7473 & 4.1679 & TST & \\
\hline CHEMBL1446570 & 737212 & 3.699 & 3.7444 & TRN & \\
\hline CHEMBL1401029 & 737212 & 3.699 & 3.5599 & TRN & \\
\hline CHEMBL1306839 & 737212 & 3.699 & 4.0386 & TRN & \\
\hline CHEMBL1446827 & 737212 & 3.699 & 3.7383 & TRN & \\
\hline CHEMBL1588455 & 737212 & 4.7666 & 4.1485 & TRN & \\
\hline CHEMBL1567973 & 737212 & 3.699 & 4.1453 & TST & \\
\hline
\end{tabular}


Supplemental Table S2.txt

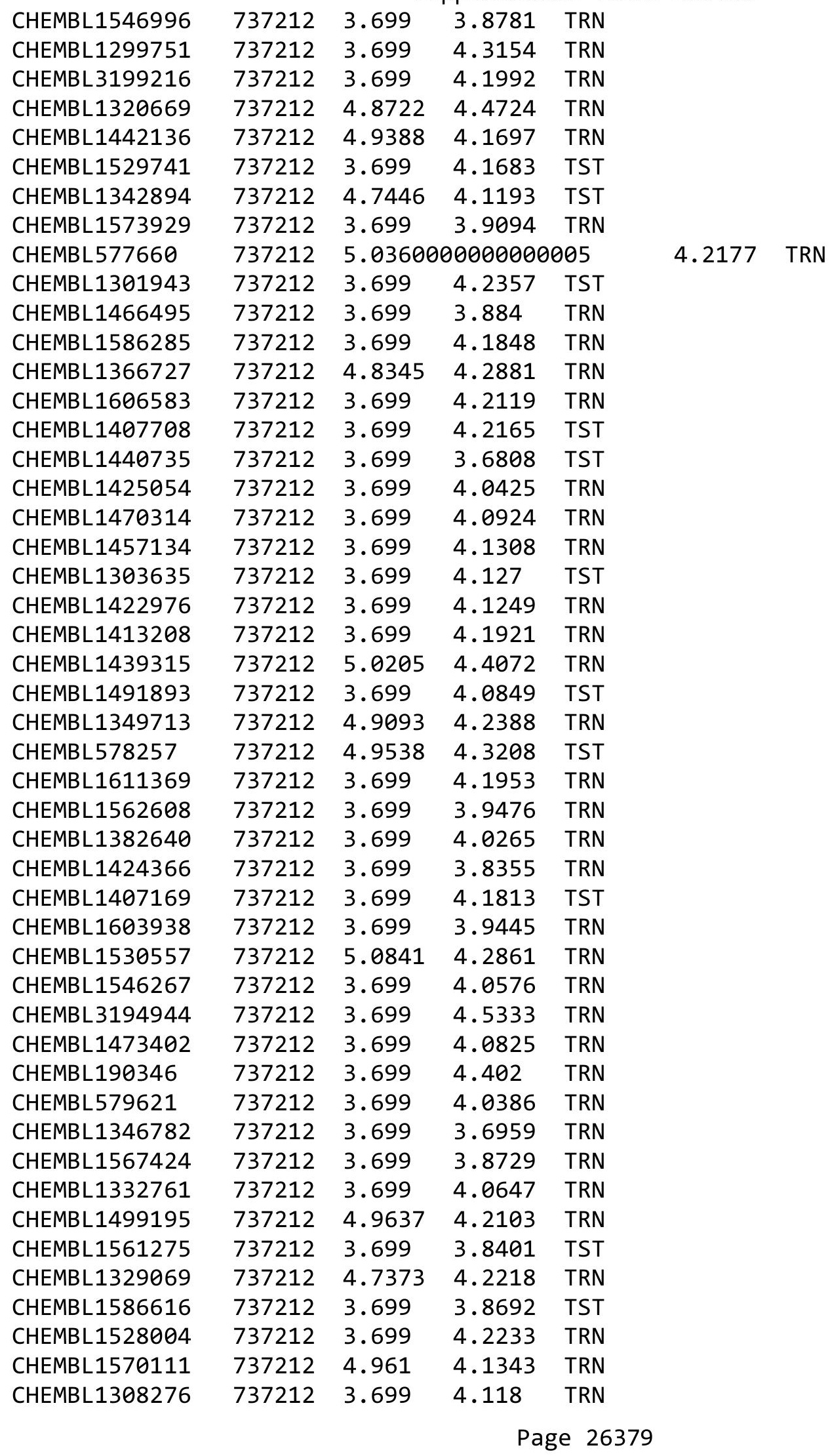


Supplemental Table S2.txt

\begin{tabular}{|c|c|c|c|c|}
\hline HEMBL15e & 212 & & & TF \\
\hline HEMBL1351908 & 37212 & .699 & & \\
\hline 886 & 12 & 831 & & \\
\hline AEMBL1497803 & 7212 & 699 & & $3 \mathrm{~N}$ \\
\hline HEMBL3145330 & 37212 & 599 & & \\
\hline HEMBL1299281 & 37212 & 699 & 1306 & \\
\hline HEMBL1431014 & 7212 & 599 & 545 & \\
\hline AEMBL 318 & 7212 & & & \\
\hline HEMBL1374160 & 37212 & 599 & 2394 & \\
\hline HEMBL1483105 & 37212 & 599 & 9909 & \\
\hline HEMBL3195322 & 37212 & 599 & $\partial 59$ & \\
\hline IEMBL14 & 37212 & 99 & 006 & \\
\hline AEMBL13 & & & & RN \\
\hline HEMBL 144 & 37212 & 99 & 9305 & \\
\hline AEMBL13: & 12 & & 169 & \\
\hline AEMBL13 & 2 & & 91 & \\
\hline HEMBL15 & 12 & 079 & 398 & \\
\hline HEMBL15 & 12 & & 951 & \\
\hline HEMBL15\& & 37212 & 284 & 2329 & \\
\hline AEMBL13 & & & 66 & \\
\hline AEMBL15 & 2 & & & SI \\
\hline AEMBL15 & 2 & - & 563 & RN \\
\hline HEMBL14 & 2 & 06 & 34 & \\
\hline 776 & & 504 & 1811 & \\
\hline AEMBL15 & & & & N \\
\hline HEMBL14 & 2 & & 3794 & KIV \\
\hline HEMBL13 & 12 & 227 & 295 & RN \\
\hline HFMBI 15 & 12 & 13 & 505 & RN \\
\hline HEMBL1C & & & 1943 & I KIV \\
\hline HEMBL134 & & & 029 & iv \\
\hline HEMBL15 & 2 & & 386 & RN \\
\hline HEMBL1: & 2 & & 115 & RN \\
\hline HEMR 1 & 2 & 396 & 612 & RN \\
\hline HEMBL1586359 & 37 & & 1824 & ISI \\
\hline HEMBL1386754 & 37 & & 579 & TRN \\
\hline HEMBL1 & 2 & & 23 & RN \\
\hline HFMBI 1 & 2 & & 785 & $\Gamma \mathrm{RN}$ \\
\hline HEMBL3: & & & 647 & TRN \\
\hline HEMBL1386337 & 37 & 654 & 2581 & TST \\
\hline AEMBL31 & 2 & & 5211 & $\Gamma \mathrm{RN}$ \\
\hline HEMBL59 & 2 & 99 & 5559 & \\
\hline HEMBL139 & 12 & 527 & 1.1079 & Niv \\
\hline HEMBL148 & 372 & & 4.2328 & $\Gamma \mathrm{RN}$ \\
\hline AEMBL1531328 & 372 & 4.8597 & .3235 & -s \\
\hline MBL13 & 2 & 588 & 539 & $\mathrm{~K}$ \\
\hline HEMBL13 & 37 & 99 & .0903 & \\
\hline CHEMBL14ع & 37212 & 3.699 & .3925 & \\
\hline HEMBL157870e & 737212 & 4.7541 & 4.2192 & ГRN \\
\hline
\end{tabular}

Page 26380 


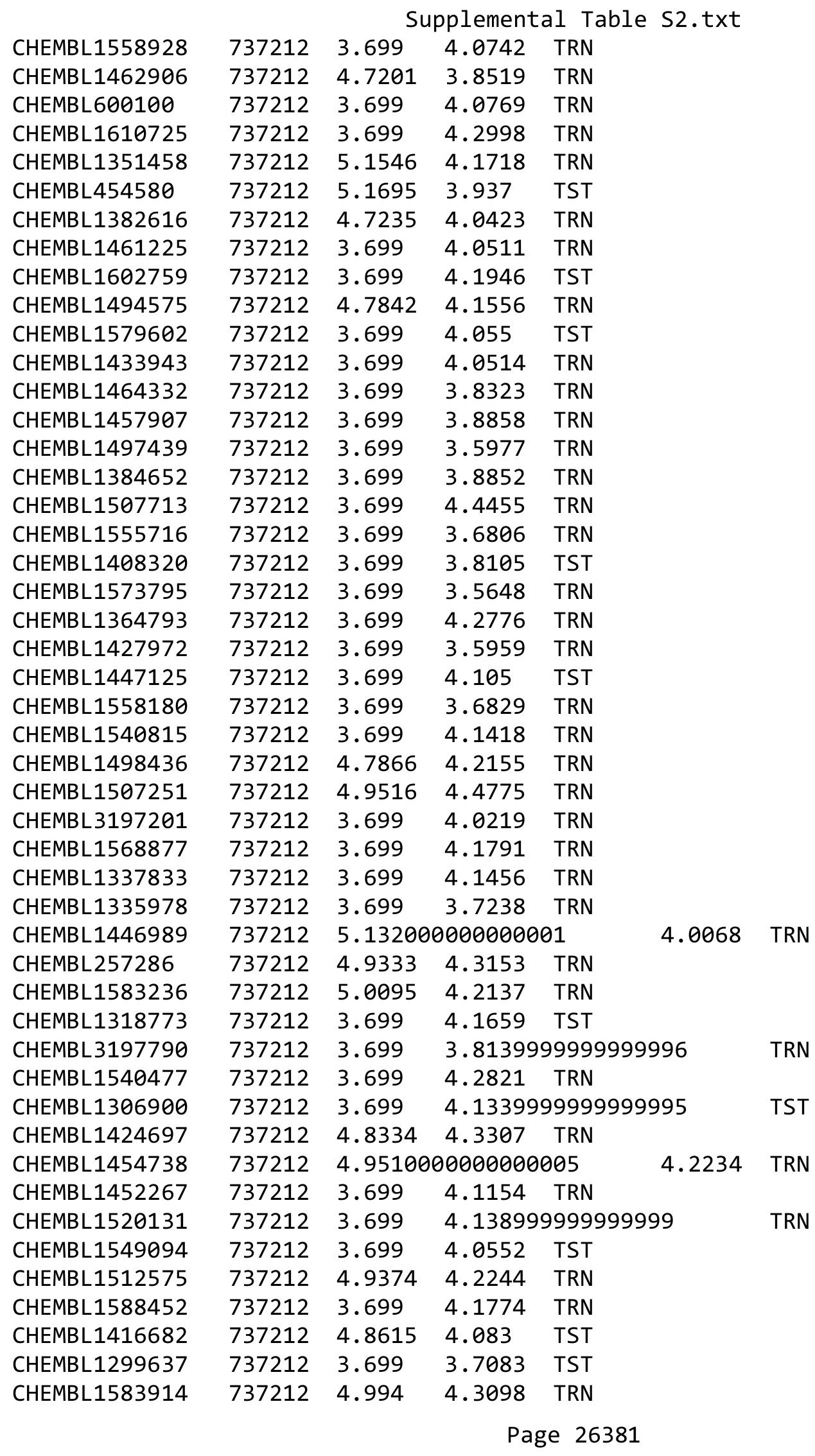


Supplemental Table S2.txt

\begin{tabular}{|c|c|c|c|c|c|}
\hline CHEMBL1468750 & 737212 & 3.699 & 4.1907 & TRN & \\
\hline CHEMBL1477528 & 737212 & 3.699 & 4.1252 & TRN & \\
\hline CHEMBL1550032 & 737212 & 3.699 & 3.8961 & TRN & \\
\hline CHEMBL1468075 & 737212 & 3.699 & 4.0645 & TRN & \\
\hline CHEMBL1466636 & 737212 & 3.699 & \multicolumn{2}{|c|}{ 4. 343999999999999} & TST \\
\hline CHEMBL1336374 & 737212 & 3.699 & 4.0488 & TRN & \\
\hline CHEMBL1372308 & 737212 & 3.699 & 4.16 & TRN & \\
\hline CHEMBL1437053 & 737212 & 4.7813 & 4.1682 & TRN & \\
\hline CHEMBL1324011 & 737212 & 3.699 & 4.3297 & TRN & \\
\hline CHEMBL1456373 & 737212 & 4.9412 & 4.1133 & TRN & \\
\hline CHEMBL1457068 & 737212 & 3.699 & 3.6581 & TRN & \\
\hline CHEMBL1374797 & 737212 & 3.699 & 4.09 & TRN & \\
\hline CHEMBL1577792 & 737212 & 3.699 & 3.931 & TST & \\
\hline CHEMBL1544114 & 737212 & 3.699 & 4.3056 & TRN & \\
\hline CHEMBL1544150 & 737212 & 3.699 & 3.7989 & TRN & \\
\hline CHEMBL1344875 & 737212 & 5.2097 & 4.2519 & TRN & \\
\hline CHEMBL1598294 & 737212 & 3.699 & 3.8966 & TRN & \\
\hline CHEMBL1333821 & 737212 & 4.7955 & 4.2667 & TRN & \\
\hline CHEMBL1606309 & 737212 & 4.8677 & 4.1983 & TRN & \\
\hline CHEMBL1608077 & 737212 & 4.9779 & 4.2148 & TRN & \\
\hline CHEMBL1997659 & 737212 & 3.699 & 3.9656 & TRN & \\
\hline CHEMBL321747 & 737212 & 3.699 & 4.117 & TRN & \\
\hline CHEMBL1573242 & 737212 & 3.699 & 4.2186 & TRN & \\
\hline CHEMBL1431769 & 737212 & 3.699 & 4.0848 & TRN & \\
\hline CHEMBL1308936 & 737212 & 4.8731 & 4.2292 & TRN & \\
\hline CHEMBL1309874 & 737212 & 4.8801 & 4.238 & TRN & \\
\hline CHEMBL1415184 & 737212 & 3.699 & 4.4756 & TST & \\
\hline CHEMBL1556615 & 737212 & 4.8699 & 4.152 & TRN & \\
\hline CHEMBL1486981 & 737212 & 3.699 & 4.2867 & TRN & \\
\hline CHEMBL1431608 & 737212 & 3.699 & 4.2218 & TRN & \\
\hline CHEMBL1464490 & 737212 & 3.699 & 3.6537 & TRN & \\
\hline CHEMBL1325644 & 737212 & 3.699 & 3.96100 & 00000000003 & TRN \\
\hline CHEMBL1382232 & 737212 & 3.699 & 4.0732 & TRN & \\
\hline CHEMBL1506308 & 737212 & 4.7561 & 4.1938 & TRN & \\
\hline CHEMBL1597716 & 737212 & 3.699 & 4.1889 & TRN & \\
\hline CHEMBL1521877 & 737212 & 3.699 & 3.9247 & TRN & \\
\hline CHEMBL 2006780 & 737212 & 4.75 & 4.2511 & TRN & \\
\hline CHEMBL1444020 & 737212 & 4.7569 & 4.1921 & TRN & \\
\hline CHEMBL1325227 & 737212 & 5.1783 & 4.2493 & TRN & \\
\hline CHEMBL1426978 & 737212 & 3.699 & 4.0889 & TRN & \\
\hline CHEMBL472646 & 737212 & 4.8034 & 4.0973 & TST & \\
\hline CHEMBL1414053 & 737212 & 3.699 & 4.2841 & TRN & \\
\hline CHEMBL1418948 & 737212 & 4.8911 & 4.1591 & TST & \\
\hline CHEMBL1387990 & 737212 & 3.699 & 3.8775 & TST & \\
\hline CHEMBL1458660 & 737212 & 3.699 & 4.0944 & TRN & \\
\hline CHEMBL1383777 & 737212 & 3.699 & 4.0704 & TRN & \\
\hline CHEMBL1380661 & 737212 & 3.699 & 3.8245 & TRN & \\
\hline CHEMBL1366153 & 737212 & 3.699 & 3.883 & TRN & \\
\hline
\end{tabular}


Supplemental Table S2.txt

\begin{tabular}{|c|c|c|c|c|}
\hline CHEMBL169272 & 737212 & 3.699 & 4.1517 & TRN \\
\hline CHEMBL1411209 & 737212 & 4.7858 & 4.1205 & TRN \\
\hline CHEMBL1422567 & 737212 & 3.699 & 4.2139 & TRN \\
\hline CHEMBL1332684 & 737212 & 3.699 & 4.3368 & TST \\
\hline CHEMBL1347256 & 737212 & 3.699 & 3.9068 & TRN \\
\hline CHEMBL1555568 & 737212 & 3.699 & 3.8748 & TRN \\
\hline CHEMBL1556239 & 737212 & 3.699 & 3.8507 & TST \\
\hline CHEMBL3190198 & 737212 & 3.699 & 4.1423 & TRN \\
\hline CHEMBL3199186 & 737212 & 3.699 & 3.9483 & TRN \\
\hline CHEMBL1421605 & 737212 & 3.699 & 4.1451 & TST \\
\hline CHEMBL1347270 & 737212 & 5.0729 & 4.2475 & TRN \\
\hline CHEMBL1538154 & 737212 & 5.0121 & 4.2454 & TRN \\
\hline CHEMBL1344292 & 737212 & 5.0146 & 4.163 & TRN \\
\hline CHEMBL1400601 & 737212 & 3.699 & 3.8413 & TRN \\
\hline CHEMBL1451181 & 737212 & 3.699 & 4.1121 & TRN \\
\hline CHEMBL1550184 & 737212 & 3.699 & 4.1063 & TST \\
\hline CHEMBL1542483 & 737212 & 3.699 & 3.6516 & TRN \\
\hline CHEMBL1426152 & 737212 & 3.699 & 4.0841 & TRN \\
\hline CHEMBL1588806 & 737212 & 3.699 & 4.1365 & TRN \\
\hline CHEMBL1323456 & 737212 & 3.699 & 4.1124 & TRN \\
\hline CHEMBL3197890 & 737212 & 3.699 & 3.925 & TRN \\
\hline CHEMBL1354394 & 737212 & 3.699 & 3.8781 & TRN \\
\hline CHEMBL1447831 & 737212 & 4.8128 & 4.228 & TRN \\
\hline CHEMBL3213107 & 737212 & 3.699 & 3.9745 & TRN \\
\hline CHEMBL1377340 & 737212 & 3.699 & 3.8534 & TST \\
\hline CHEMBL1338804 & 737212 & 4.8748 & 4.114 & TRN \\
\hline CHEMBL1384893 & 737212 & 4.829 & 4.1197 & TRN \\
\hline CHEMBL1556086 & 737212 & 3.699 & 3.9043 & TRN \\
\hline CHEMBL1311887 & 737212 & 4.918 & 4.1425 & TRN \\
\hline CHEMBL1428415 & 737212 & 3.699 & 4.1364 & TRN \\
\hline CHEMBL1549092 & 737212 & 3.699 & 3.68 & TRN \\
\hline CHEMBL3195189 & 737212 & 3.699 & 4.3248 & TRN \\
\hline CHEMBL1560679 & 737212 & 3.699 & 4.0335 & TRN \\
\hline CHEMBL1984298 & 737212 & 4.7625 & 4.0445 & TRN \\
\hline CHEMBL1608707 & 737212 & 3.699 & 3.9002 & TRN \\
\hline CHEMBL1462357 & 737212 & 3.699 & 4.1894 & TRN \\
\hline CHEMBL3198251 & 737212 & 3.699 & 3.8002 & TRN \\
\hline CHEMBL1351584 & 737212 & 3.699 & 4.2963 & TRN \\
\hline CHEMBL1531428 & 737212 & 3.699 & 4.1516 & TST \\
\hline CHEMBL3195226 & 737212 & 3.699 & 4.0885 & TRN \\
\hline CHEMBL1456848 & 737212 & 4.8552 & 3.9445 & TRN \\
\hline CHEMBL1351128 & 737212 & 4.9312 & 4.3325 & TRN \\
\hline CHEMBL1349185 & 737212 & 3.699 & 3.5634 & TRN \\
\hline CHEMBL1465720 & 737212 & 3.699 & 4.3511 & TRN \\
\hline CHEMBL1602150 & 737212 & 3.699 & 4.1927 & TRN \\
\hline CHEMBL1502127 & 737212 & 5.1421 & 4.1957 & TRN \\
\hline CHEMBL1611774 & 737212 & 3.699 & 4.098 & TST \\
\hline CHEMBL1477197 & 737212 & 3.699 & 3.8423 & TRN \\
\hline
\end{tabular}


Supplemental Table S2.txt

\begin{tabular}{|c|c|c|c|c|c|}
\hline CHEMBL1597042 & 737212 & 3.699 & 3.8018 & TST & \\
\hline CHEMBL1560539 & 737212 & 4.713 & 4.0244 & TRN & \\
\hline CHEMBL1327276 & 737212 & 3.699 & 4.1086 & TRN & \\
\hline CHEMBL1526479 & 737212 & 3.699 & 4.1525 & TST & \\
\hline CHEMBL1306524 & 737212 & 4.8617 & 4.2642 & TRN & \\
\hline CHEMBL1379347 & 737212 & 4.7096 & 4.2156 & TRN & \\
\hline CHEMBL1391279 & 737212 & 3.699 & 4.1168 & TST & \\
\hline CHEMBL3189325 & 737212 & 3.699 & 3.6542 & TRN & \\
\hline CHEMBL1586263 & 737212 & 4.7176 & 4.2133 & TRN & \\
\hline CHEMBL1580660 & 737212 & 4.7518 & 4.0973 & TRN & \\
\hline CHEMBL1349428 & 737212 & 3.699 & 3.7957 & TRN & \\
\hline CHEMBL1472304 & 737212 & 4.7626 & 4.1554 & TRN & \\
\hline CHEMBL1329385 & 737212 & 3.699 & 3.6502 & TRN & \\
\hline CHEMBL1413565 & 737212 & 3.699 & 4.0118 & TRN & \\
\hline CHEMBL1414898 & 737212 & 4.8094 & 4.2086 & TRN & \\
\hline CHEMBL1544947 & 737212 & 3.699 & 4.2362 & TRN & \\
\hline CHEMBL1467187 & 737212 & 3.699 & 3.87399 & 99999999997 & TRN \\
\hline CHEMBL1375966 & 737212 & 3.699 & 4.3075 & TRN & \\
\hline CHEMBL1304065 & 737212 & 3.699 & 4.1971 & TRN & \\
\hline CHEMBL1967099 & 737212 & 3.699 & 3.6035 & TRN & \\
\hline CHEMBL1562819 & 737212 & 3.699 & 4.0854 & TRN & \\
\hline CHEMBL1567684 & 737212 & 3.699 & 3.9647 & TRN & \\
\hline CHEMBL3195760 & 737212 & 3.699 & 4.126 & TRN & \\
\hline CHEMBL1525546 & 737212 & 3.699 & 3.9229 & TST & \\
\hline CHEMBL1409963 & 737212 & 3.699 & 4.1112 & TST & \\
\hline CHEMBL1571872 & 737212 & 3.699 & 3.8353 & TRN & \\
\hline CHEMBL1421446 & 737212 & 3.699 & 4.2773 & TRN & \\
\hline CHEMBL1347274 & 737212 & 5.1911 & 4.2829 & TRN & \\
\hline CHEMBL1529494 & 737212 & 3.699 & 3.82899 & 99999999997 & TRN \\
\hline CHEMBL1450208 & 737212 & 3.699 & 4.1135 & TRN & \\
\hline CHEMBL1466929 & 737212 & 3.699 & 3.6242 & TST & \\
\hline CHEMBL1301733 & 737212 & 3.699 & 4.1649 & TRN & \\
\hline CHEMBL1481689 & 737212 & 3.699 & 4.1387 & TRN & \\
\hline CHEMBL1457427 & 737212 & 3.699 & 4.0472 & TRN & \\
\hline CHEMBL3193234 & 737212 & 3.699 & 3.8897 & TRN & \\
\hline CHEMBL1543588 & 737212 & 3.699 & 4.063 & TST & \\
\hline CHEMBL1420606 & 737212 & 3.699 & 3.7578 & TRN & \\
\hline CHEMBL1411639 & 737212 & 3.699 & 4.271 & TRN & \\
\hline CHEMBL1349146 & 737212 & 4.8806 & 4.1573 & TRN & \\
\hline CHEMBL1375884 & 737212 & 3.699 & 4.0596 & TRN & \\
\hline CHEMBL1302130 & 737212 & 4.8688 & 4.2723 & TRN & \\
\hline CHEMBL1460585 & 737212 & 3.699 & 3.9407 & TRN & \\
\hline CHEMBL1580556 & 737212 & 3.699 & 4.57 & TRN & \\
\hline CHEMBL1484482 & 737212 & 3.699 & 4.1464 & TRN & \\
\hline CHEMBL3192230 & 737212 & 3.699 & 3.6395 & TRN & \\
\hline CHEMBL1364018 & 737212 & 3.699 & 4.2732 & TST & \\
\hline CHEMBL1597561 & 737212 & 3.699 & 4.9222 & TRN & \\
\hline CHEMBL1611733 & 737212 & 3.699 & 3.8107 & TST & \\
\hline
\end{tabular}


Supplemental Table S2.txt

\begin{tabular}{|c|c|c|c|c|}
\hline CHEMBL1468181 & 737212 & 3.699 & 4.5798 & TRN \\
\hline CHEMBL1300239 & 737212 & 3.699 & 4.2735 & TRN \\
\hline CHEMBL1451348 & 737212 & 5.0395 & 4.313 & TRN \\
\hline CHEMBL1328478 & 737212 & 3.699 & 3.6686 & TRN \\
\hline CHEMBL1376861 & 737212 & 4.7366 & 4.2976 & TRN \\
\hline CHEMBL1475198 & 737212 & 4.7229 & \multicolumn{2}{|c|}{4.1930000000000005} \\
\hline CHEMBL1332003 & 737212 & 3.699 & 3.9531 & TRN \\
\hline CHEMBL1595779 & 737212 & 5.0482 & 4.2232 & TST \\
\hline CHEMBL1887153 & 737212 & 3.699 & 4.0194 & TST \\
\hline CHEMBL1495890 & 737212 & 4.8818 & 4.1333 & TST \\
\hline CHEMBL1520241 & 737212 & 3.699 & 4.4545 & TST \\
\hline CHEMBL1347586 & 737212 & 3.699 & 3.8625 & TST \\
\hline CHEMBL1489105 & 737212 & 3.699 & 3.8769 & TST \\
\hline CHEMBL578944 & 737212 & 5.1957 & 4.2959 & TST \\
\hline CHEMBL1455542 & 737212 & 5.1786 & 4.3733 & TST \\
\hline CHEMBL1472748 & 737212 & 3.699 & 4.0196 & TST \\
\hline CHEMBL1468596 & 737212 & 4.9001 & 4.2081 & TST \\
\hline CHEMBL1583186 & 737212 & 5.0097 & 4.315 & TST \\
\hline CHEMBL1310435 & 737212 & 3.699 & 4.2191 & TST \\
\hline CHEMBL1545677 & 737212 & 3.699 & 3.6819 & TST \\
\hline CHEMBL1495358 & 737212 & 3.699 & 4.1371 & TST \\
\hline CHEMBL600778 & 737212 & 3.699 & 3.7889 & TST \\
\hline CHEMBL1525735 & 737212 & 5.3721 & 4.3026 & TST \\
\hline CHEMBL1379081 & 737212 & 3.699 & 3.6861 & TST \\
\hline CHEMBL 1370276 & 737212 & 3.699 & 4.2258 & TST \\
\hline CHEMBL1385087 & 737212 & 3.699 & 3.89 & TST \\
\hline CHEMBL1593484 & 737212 & 3.699 & 3.6181 & TST \\
\hline CHEMBL1993613 & 737212 & 3.699 & 3.8492 & TST \\
\hline CHEMBL1604919 & 737212 & 4.8198 & 4.1265 & TST \\
\hline CHEMBL1459111 & 737212 & 4.957 & 4.2417 & TST \\
\hline CHEMBL1305930 & 737212 & 3.699 & 4.3526 & TST \\
\hline CHEMBL1490563 & 737212 & 3.699 & 3.8844 & TST \\
\hline CHEMBL1320494 & 737212 & 3.699 & 4.1575 & TST \\
\hline CHEMBL1375155 & 737212 & 5.0634 & 4.1925 & TST \\
\hline CHEMBL495005 & 737212 & 3.699 & 4.2069 & TST \\
\hline CHEMBL1342784 & 737212 & 3.699 & 4.0753 & TST \\
\hline CHEMBL1509539 & 737212 & 4.7428 & 4.2002 & TST \\
\hline CHEMBL1522043 & 737212 & 3.699 & 4.1664 & TST \\
\hline CHEMBL1483975 & 737212 & 3.699 & 4.3445 & TST \\
\hline CHEMBL1560379 & 737212 & 5.1482 & 4.2749 & TST \\
\hline CHEMBL1490169 & 737212 & 4.9599 & 4.1565 & TST \\
\hline CHEMBL1319304 & 737212 & 5.0607 & 4.4027 & TST \\
\hline CHEMBL1350780 & 737212 & 3.699 & 4.2663 & TST \\
\hline CHEMBL1484741 & 737212 & 5.1975 & 4.215 & TST \\
\hline CHEMBL1401026 & 737212 & 3.699 & 4.2527 & TST \\
\hline CHEMBL1508723 & 737212 & 3.699 & 3.8654 & TST \\
\hline CHEMBL1348555 & 737212 & 3.699 & 4.0828 & TST \\
\hline CHEMBL1528265 & 737212 & 3.699 & 4.1215 & TST \\
\hline
\end{tabular}


Supplemental Table S2.txt

\begin{tabular}{|c|c|c|c|c|c|}
\hline CHEMBL1359986 & 737212 & 3.699 & 4.2211 & TST & \\
\hline CHEMBL1569174 & 737212 & 3.699 & 4.6995 & TST & \\
\hline CHEMBL1304363 & 737212 & 3.699 & 4.1932 & TST & \\
\hline CHEMBL1320446 & 737212 & 3.699 & 4.1678 & TST & \\
\hline CHEMBL1312200 & 737212 & 3.699 & 3.8678 & TST & \\
\hline CHEMBL1332756 & 737212 & 3.699 & 3.7658 & TST & \\
\hline CHEMBL1506728 & 737212 & 3.699 & 4.1001 & TST & \\
\hline CHEMBL1398541 & 737212 & 3.699 & 4.0884 & TST & \\
\hline CHEMBL1605213 & 737212 & 3.699 & 4.2126 & TST & \\
\hline CHEMBL1536849 & 737212 & 3.699 & 4.0424 & TST & \\
\hline CHEMBL1407286 & 737212 & 4.8768 & 4.2108 & TST & \\
\hline CHEMBL165445 & 165068 & 5.6576 & 5.7816 & TRN & \\
\hline CHEMBL165086 & 165068 & 7.0706 & 6.5419 & TST & \\
\hline CHEMBL164346 & 165068 & 4.6778 & 4.6789 & TRN & \\
\hline CHEMBL 98189 & 165068 & 5.9586 & 6.7726 & TST & \\
\hline CHEMBL348940 & 165068 & 4.7959 & 5.8931 & TST & \\
\hline CHEMBL165049 & 165068 & 5.6198 & 6.1204 & TRN & \\
\hline CHEMBL414459 & 165068 & 6.3565 & 6.1055 & TRN & \\
\hline CHEMBL353566 & 165068 & 6.0915 & 6.6163 & TRN & \\
\hline CHEMBL 89902 & 165068 & 5.7212 & 6.1367 & TRN & \\
\hline CHEMBL164404 & 165068 & 6.0177 & 6.1527 & TRN & \\
\hline CHEMBL164717 & 165068 & 3.5229 & 4.5262 & TRN & \\
\hline CHEMBL349193 & 165068 & 7.9208 & 6.8672 & TRN & \\
\hline CHEMBL164922 & 165068 & 6.1612 & 5.9959 & TRN & \\
\hline CHEMBL 352750 & 165068 & 5.2076 & 6.272 & TRN & \\
\hline CHEMBL354450 & 165068 & 5.9586 & 6.7846 & TST & \\
\hline CHEMBL350296 & 165068 & 6.0223 & 6.2274 & TST & \\
\hline CHEMBL167384 & 165068 & 6.1367 & 6.239 & TRN & \\
\hline CHEMBL165217 & 165068 & 5.6198 & 5.63299 & э999999999 & TRN \\
\hline CHEMBL 354353 & 165068 & 4.7447 & 5.4946 & TRN & \\
\hline CHEMBL354088 & 165068 & 5.0458 & 5.865 & TRN & \\
\hline CHEMBL349752 & 165068 & 5.6021 & 5.4657 & TRN & \\
\hline CHEMBL163740 & 165068 & 6.7212 & 7.08899 & 99999999995 & TST \\
\hline CHEMBL353757 & 165068 & 6.2366 & 5.6657 & TST & \\
\hline CHEMBL164917 & 165068 & 5.4559 & 4.7933 & TRN & \\
\hline CHEMBL165444 & 165068 & 6.7212 & 5.7633 & TRN & \\
\hline CHEMBL167147 & 165068 & 5.4815 & 5.5995 & TRN & \\
\hline CHEMBL350406 & 165068 & 3.5229 & 4.5656 & TRN & \\
\hline CHEMBL354268 & 165068 & 6.9208 & 5.921 & TRN & \\
\hline CHEMBL163839 & 165068 & 6.1024 & 6.7051 & TRN & \\
\hline CHEMBL164247 & 165068 & 5.9586 & 6.2419 & TRN & \\
\hline CHEMBL355684 & 165068 & 6.4815 & 6.0573 & TRN & \\
\hline CHEMBL451239 & 165068 & 6.0223 & 6.7582 & TRN & \\
\hline CHEMBL423085 & 165068 & 6.2218 & 6.0956 & TRN & \\
\hline CHEMBL164760 & 165068 & 4.4089 & 4.5418 & TRN & \\
\hline CHEMBL164399 & 165068 & 6.7447 & 5.2549 & TRN & \\
\hline CHEMBL349254 & 165068 & 7.1675 & 6.5951 & TRN & \\
\hline CHEMBL351235 & 165068 & 6.5229 & 6.322 & TRN & \\
\hline
\end{tabular}


Supplemental Table S2.txt

\begin{tabular}{|c|c|c|c|c|}
\hline CHEMBL167746 & 165068 & 5.0362 & 6.0735 & TRN \\
\hline CHEMBL349140 & 165068 & 6.5086 & 5.9832 & TRN \\
\hline CHEMBL315809 & 165068 & 5.8239 & 5.9121 & TRN \\
\hline CHEMBL167935 & 165068 & 7.1192 & 6.7058 & TRN \\
\hline CHEMBL168066 & 165068 & 6.8239 & 5.4304 & TRN \\
\hline CHEMBL350321 & 165068 & 6.4685 & 6.87799 & \\
\hline CHEMBL348931 & 165068 & 5.7959 & 5.5121 & TRN \\
\hline CHEMBL163719 & 165068 & 4.8861 & 4.7139 & TRN \\
\hline CHEMBL354143 & 165068 & 6.3188 & 6.5361 & TRN \\
\hline CHEMBL163673 & 165068 & 7.0 & 6.9327 & TRN \\
\hline CHEMBL168099 & 165068 & 6.3768 & 6.6225 & TRN \\
\hline CHEMBL423093 & 165068 & 5.284 & 5.6161 & TRN \\
\hline CHEMBL352922 & 165068 & 6.1367 & 5.9312 & TRN \\
\hline CHEMBL166631 & 165068 & 5.3468 & 5.5392 & TRN \\
\hline CHEMBL89099 & 165068 & 5.3279 & 5.8635 & TRN \\
\hline CHEMBL164134 & 165068 & 6.7696 & 5.8533 & TRN \\
\hline CHEMBL348843 & 165068 & 6.4318 & 5.6182 & TST \\
\hline CHEMBL164948 & 165068 & 5.9586 & 6.5756 & TST \\
\hline CHEMBL163771 & 165068 & 7.1367 & 5.5284 & TST \\
\hline CHEMBL167512 & 165068 & 6.7959 & 5.9858 & TST \\
\hline CHEMBL354933 & 165068 & 5.7212 & 6.0743 & TST \\
\hline CHEMBL410539 & 165068 & 5.4202 & 6.2952 & TST \\
\hline CHEMBL351402 & 165068 & 5.2076 & 5.3368 & TST \\
\hline CHEMBL168013 & 165068 & 5.3768 & 6.5928 & TST \\
\hline CHEMBL 387253 & 424574 & 6.5686 & 6.5689 & TRN \\
\hline CHEMBL219112 & 424574 & 7.0915 & 7.0908 & TRN \\
\hline CHEMBL374193 & 424574 & 7.3665 & 7.2687 & TST \\
\hline CHEMBL220810 & 424574 & 7.0315 & 7.0332 & TRN \\
\hline CHEMBL218419 & 424574 & 6.3768 & 6.3772 & TRN \\
\hline CHEMBL221229 & 424574 & 7.0706 & 7.0739 & TRN \\
\hline CHEMBL218139 & 424574 & 5.7959 & 5.7955 & TRN \\
\hline CHEMBL 220749 & 424574 & 6.0862 & 6.0871 & TRN \\
\hline CHEMBL221179 & 424574 & 6.4976 & 6.4965 & TRN \\
\hline CHEMBL385177 & 424574 & 5.8386 & 5.4803 & TST \\
\hline CHEMBL434560 & 424574 & 7.2676 & 7.2671 & TRN \\
\hline CHEMBL221075 & 424574 & 6.2076 & 6.4476 & TST \\
\hline CHEMBL 374447 & 424574 & 6.2757 & 6.5669 & TST \\
\hline CHEMBL220758 & 424574 & 6.585 & 6.5858 & TRN \\
\hline CHEMBL 374855 & 424574 & 5.4647 & 5.4633 & TRN \\
\hline CHEMBL 221963 & 424574 & 5.9626 & 5.965 & TRN \\
\hline CHEMBL 221128 & 424574 & 7.1024 & 7.1011 & TRN \\
\hline CHEMBL220812 & 424574 & 6.3665 & 6.3657 & TRN \\
\hline CHEMBL 222008 & 424574 & 5.9281 & 5.855 & TST \\
\hline CHEMBL 218367 & 424574 & 6.6021 & 6.1778 & TST \\
\hline CHEMBL 220811 & 424574 & 6.4949 & \multicolumn{2}{|c|}{6.582000000000001} \\
\hline CHEMBL 220864 & 424574 & 5.5331 & 5.5345 & TRN \\
\hline CHEMBL375795 & 424574 & 7.0177 & 7.0139 & TRN \\
\hline CHEMBL221916 & 424574 & 5.9281 & 5.9278 & TRN \\
\hline
\end{tabular}


Supplemental Table S2.txt

\begin{tabular}{|c|c|c|c|c|c|}
\hline CHEMBL218658 & 424574 & 7.0555 & 7.0558 & TRN & \\
\hline CHEMBL 221252 & 424574 & 6.3665 & 6.29899 & 99999999995 & TST \\
\hline CHEMBL 373740 & 424574 & 5.8097 & 5.8107 & TRN & \\
\hline CHEMBL 374431 & 424574 & 6.4089 & 6.4096 & TRN & \\
\hline CHEMBL383994 & 424574 & 6.4559 & 6.4558 & TRN & \\
\hline CHEMBL218219 & 424574 & 7.0315 & 7.0316 & TRN & \\
\hline CHEMBL 220865 & 424574 & 6.3872 & 6.3871 & TRN & \\
\hline CHEMBL 386010 & 424574 & 7.2291 & 7.2277 & TRN & \\
\hline CHEMBL434368 & 424574 & 6.5229 & 5.9098 & TST & \\
\hline CHEMBL384951 & 424574 & 6.9208 & 6.9213 & TRN & \\
\hline CHEMBL222011 & 424574 & 5.7852 & 5.7852 & TRN & \\
\hline CHEMBL220504 & 424574 & 7.8239 & 7.8244 & TRN & \\
\hline CHEMBL220547 & 424574 & 6.2441 & 6.4413 & TST & \\
\hline CHEMBL221315 & 424574 & 7.1805 & 7.1791 & TRN & \\
\hline CHEMBL274389 & 424574 & 5.8239 & 5.82299 & 99999999995 & TRN \\
\hline CHEMBL221958 & 424574 & 5.2798 & 5.2804 & TRN & \\
\hline CHEMBL384219 & 424574 & 7.1192 & 7.1206 & TRN & \\
\hline CHEMBL218194 & 424574 & 7.1739 & 7.1735 & TRN & \\
\hline CHEMBL220658 & 424574 & 7.4949 & 7.4961 & TRN & \\
\hline CHEMBL374795 & 424574 & 5.6144 & 5.6141 & TRN & \\
\hline CHEMBL218141 & 424574 & 6.7696 & 6.5448 & TST & \\
\hline CHEMBL220607 & 424574 & 5.7011 & 5.7011 & TST & \\
\hline CHEMBL376096 & 424574 & 5.6498 & 5.6492 & TRN & \\
\hline CHEMBL374269 & 424574 & 7.6383 & 7.6372 & TRN & \\
\hline CHEMBL 221175 & 424574 & 5.1367 & 5.1361 & TRN & \\
\hline CHEMBL218734 & 424574 & 4.0 & 3.9994 & TRN & \\
\hline CHEMBL 221745 & 424574 & 6.699 & 6.7582 & TST & \\
\hline CHEMBL324399 & 4992 & 5.5817 & 5.5549 & TRN & \\
\hline CHEMBL109476 & 4992 & 6.0177 & 5.9623 & TRN & \\
\hline CHEMBL110055 & 4992 & 6.1367 & 6.0447 & TRN & \\
\hline CHEMBL109332 & 4992 & 5.71 & 5.5314 & TST & \\
\hline CHEMBL111442 & 4992 & 6.3768 & 6.1867 & TRN & \\
\hline CHEMBL320479 & 4992 & 5.5129 & 5.5485 & TRN & \\
\hline CHEMBL111033 & 4992 & 5.4547 & 5.1577 & TRN & \\
\hline CHEMBL325981 & 4992 & 5.6819 & 5.6511 & TRN & \\
\hline CHEMBL1203088 & 4992 & 5.1124 & 5.3816 & TRN & \\
\hline CHEMBL1203047 & 4992 & 4.7268 & 5.3881 & TST & \\
\hline CHEMBL323424 & 4992 & 5.52 & 5.5685 & TRN & \\
\hline CHEMBL114446 & 4992 & 5.3325 & 5.1384 & TST & \\
\hline CHEMBL109372 & 4992 & 6.1549 & 6.1316 & TRN & \\
\hline CHEMBL 323900 & 4992 & 6.1192 & 5.9756 & TRN & \\
\hline CHEMBL111664 & 4992 & 6.0872 & 6.1707 & TRN & \\
\hline CHEMBL1203026 & 4992 & 5.8383 & 5.7602 & TRN & \\
\hline CHEMBL541988 & 4992 & 4.7392 & 5.0736 & TST & \\
\hline CHEMBL110065 & 4992 & 6.2441 & 6.6686 & TRN & \\
\hline CHEMBL 325760 & 4992 & 5.1325 & 5.3365 & TRN & \\
\hline CHEMBL1203059 & 4992 & 6.0506 & 5.8608 & TRN & \\
\hline CHEMBL443277 & 4992 & 5.5214 & 5.5604 & TST & \\
\hline
\end{tabular}




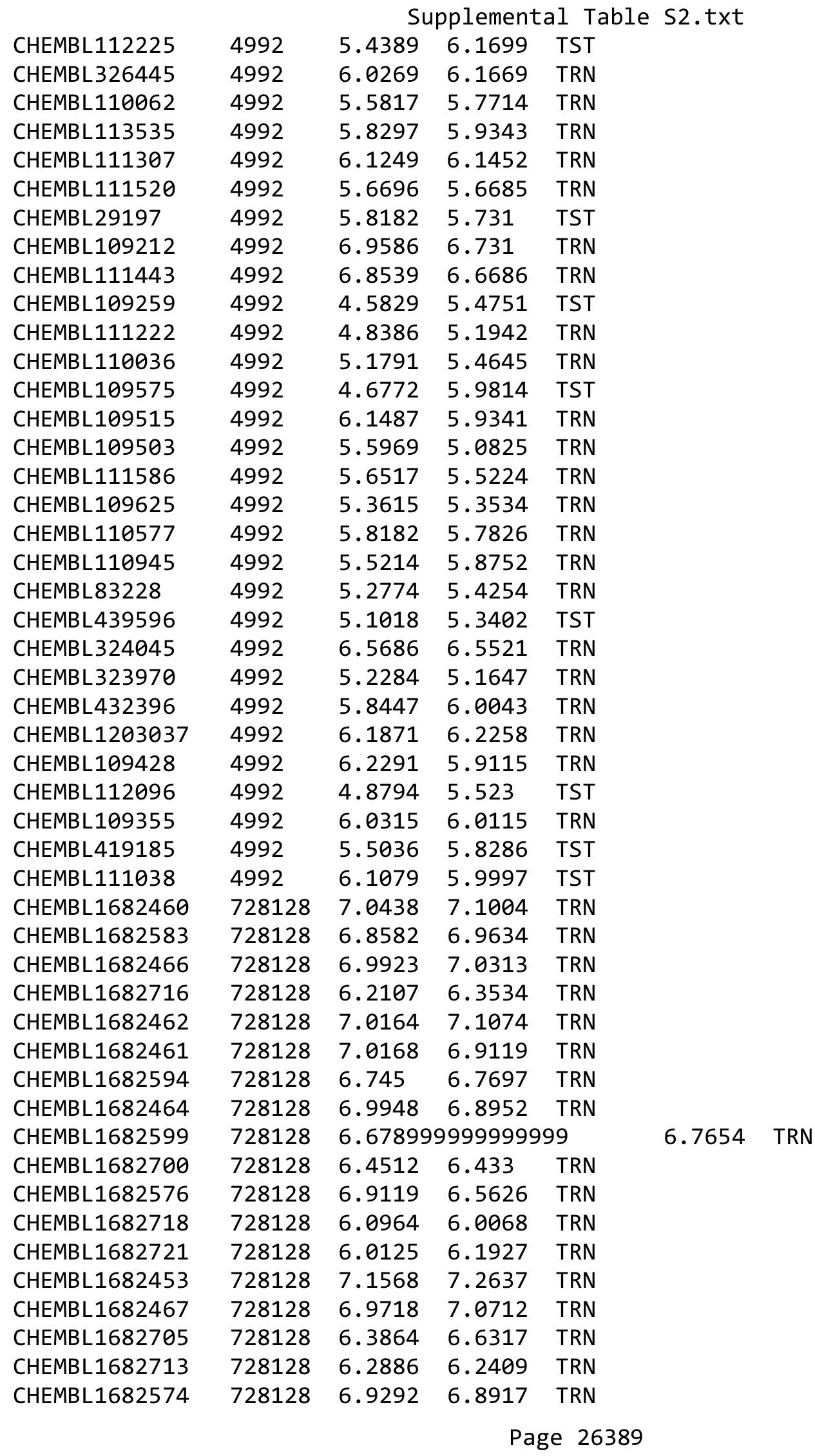




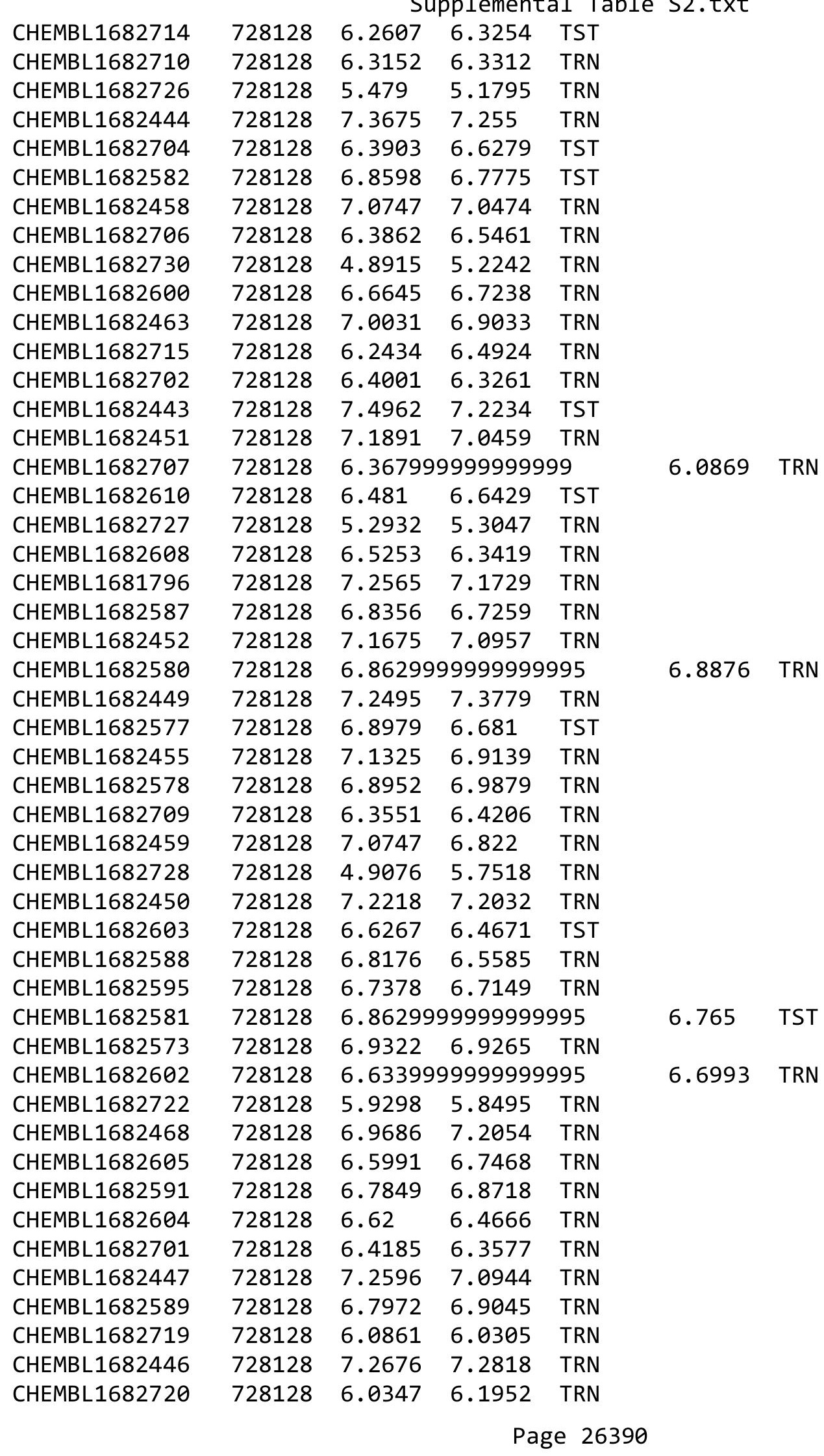




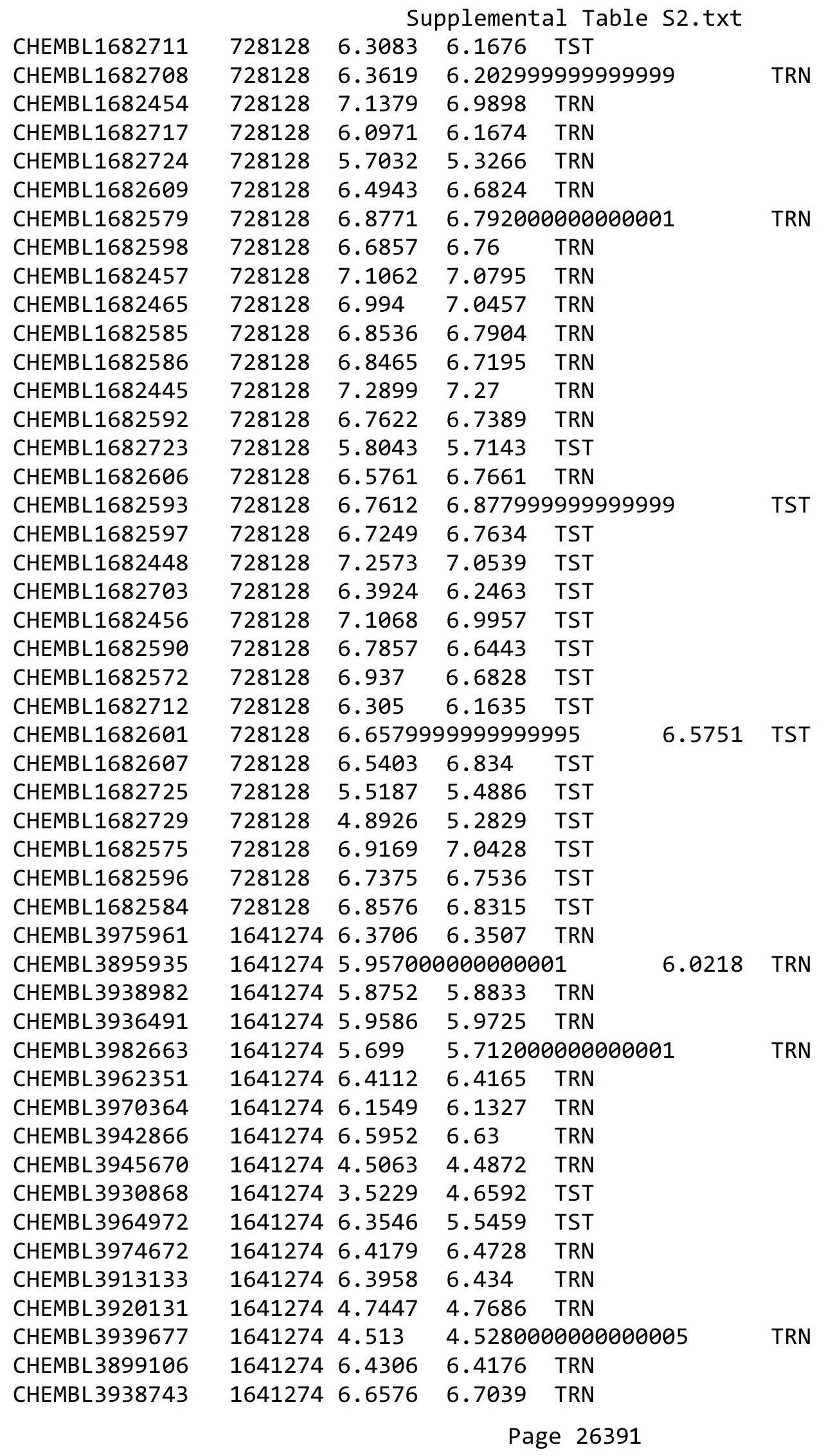


Supplemental Table S2.txt

\begin{tabular}{|c|c|c|c|c|}
\hline 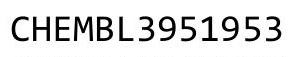 & 1274 & & & \\
\hline HEMBL3967028 & 641274 & 7.2147 & 2289 & \\
\hline 12 & 1274 & 017 & 787 & \\
\hline 596 & 274 & 351 & 844 & \\
\hline AEMBL3899528 & 641274 & 5.83 & 9524 & \\
\hline HEMBL3953107 & 641274 & 4.5229 & 0328 & \\
\hline HEMBL3908924 & 274 & 3358 & 1666 & \\
\hline 889 & 274 & & & \\
\hline EMBL3939372 & 274 & 282 & 5672 & \\
\hline AEMBL3924039 & 274 & 4.5769 & .5203 & \\
\hline HEMBL3938470 & 274 & 5.3519 & 3709 & \\
\hline HEMBL3905310 & 274 & 6.9706 & 9553 & \\
\hline AEMBL3 & & & & \\
\hline HEMBL3 & & 233 & & \\
\hline AEMBL3895328 & 274 & 435 & 0397 & \\
\hline AEMBL3893715 & 274 & 192 & 42 & \\
\hline AEMBL3S & 274 & $c_{1}+$ & 7761 & \\
\hline HEMBL3 & & & 13 & \\
\hline 933 & & & & \\
\hline HEMBL3947446 & 74 & & 9557 & RN \\
\hline AEMBL39, & 74 & 6.2097 & 2035 & NIV \\
\hline HEMBL99 & 74 & 739 & 186 & \\
\hline HEM & & $\partial 8$ & 89 & RN \\
\hline 379 & & 884 & 714 & RN \\
\hline HEMBL $39 e$ & & 777 & 899 & r \\
\hline AEMBL394 & 74 & 47 & .7615 & KIN \\
\hline HEMBL394 & 74 & 067 & 3673 & 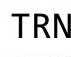 \\
\hline HEMBL39 & & 97 & 1251 & \\
\hline 015 & & & 276 & RN \\
\hline 502 & & & 92 & RIN \\
\hline AEMBL3955625 & 74 & 4.6351 & 5.3821 & ST \\
\hline HEMBL3966661 & 74 & 32 & .7302 & ST \\
\hline HEMBL3 & & & 764 & RN \\
\hline 441 & & & 315 & ST \\
\hline AEMBL3957512 & 274 & 66 & 758 & RN \\
\hline EMBL3897806 & 74 & 212 & 141 & \\
\hline HEMBL3956300 & 74 & 306 & 1062 & Niv \\
\hline & & & & RN \\
\hline HEMBL3940906 & & 6.3605 & 6.3488 & $\mathrm{RN}$ \\
\hline HEMBL3909885 & 74 & 549 & 5.9797 & ST \\
\hline AEMBL3898697 & & 197 & 38 & \\
\hline HEMBL3907792 & & & 4.8943 & SI \\
\hline HEMBL3977389 & & & & RN \\
\hline HEMBL3973971 & 274 & 6.5243 & 6.4758 & RN \\
\hline AEMBL3934399 & 274 & .399 & 6.3966 & $N$ \\
\hline & & & & \\
\hline L3907690 & & .5909 & 5.626 & \\
\hline L3932247 & 64127 & & 6.0041 & \\
\hline
\end{tabular}

Page 26392 
Supplemental Table S2.txt

\begin{tabular}{|c|c|c|c|c|c|}
\hline CHEMBL3974241 & 1641274 & 4.7447 & 4.9351 & TST & \\
\hline CHEMBL3949676 & 1641274 & 6.0 & 6.0317 & TRN & \\
\hline CHEMBL3909801 & 1641274 & 6.3947 & 6.3724 & TRN & \\
\hline CHEMBL3978733 & 1641274 & 6.6925 & 6.736000 & 000000001 & TRN \\
\hline CHEMBL3935015 & 1641274 & 6.1124 & 6.0423 & TRN & \\
\hline CHEMBL 3925137 & 1641274 & 4.4095 & 4.6364 & TRN & \\
\hline CHEMBL3968223 & 1641274 & 6.7595 & 6.7442 & TRN & \\
\hline CHEMBL3925220 & 1641274 & 6.5229 & 6.6365 & TRN & \\
\hline CHEMBL3987199 & 1641274 & 6.58 & 6.5364 & TRN & \\
\hline CHEMBL3961745 & 1641274 & 6.5243 & 6.6167 & TRN & \\
\hline CHEMBL 3973671 & 1641274 & 6.6615 & 6.6942 & TRN & \\
\hline CHEMBL3911708 & 1641274 & 6.2807 & 6.2169 & TRN & \\
\hline CHEMBL3921050 & 1641274 & 6.1713 & 6.0875 & TRN & \\
\hline CHEMBL3903543 & 1641274 & 6.6968 & 6.7172 & TRN & \\
\hline CHEMBL 3958558 & 1641274 & 5.6914 & 5.6851 & TRN & \\
\hline CHEMBL3918218 & 1641274 & 5.4253 & 5.3971 & TRN & \\
\hline CHEMBL 3979241 & 1641274 & 4.4835 & 4.5239 & TRN & \\
\hline CHEMBL 3940561 & 1641274 & 6.3516 & 6.372000 & 000000001 & \\
\hline CHEMBL3946098 & 1641274 & 6.2328 & 6.2417 & TRN & \\
\hline CHEMBL3929959 & 1641274 & 6.7055 & 6.7439 & TRN & \\
\hline CHEMBL 3955258 & 1641274 & 5.669 & 5.6881 & TRN & \\
\hline CHEMBL 3946574 & 1641274 & 6.5686 & 6.661000 & 0000000005 & \\
\hline CHEMBL3956097 & 1641274 & 6.0883 & 5.8569 & TRN & \\
\hline CHEMBL3956667 & 1641274 & 6.3635 & 6.2735 & TRN & \\
\hline CHEMBL 3898287 & 1641274 & 7.6778 & 5.2581 & TST & \\
\hline CHEMBL 3948150 & 1641274 & 6.3788 & 6.4265 & TRN & \\
\hline CHEMBL3978857 & 1641274 & 6.2441 & 6.3056 & TRN & \\
\hline CHEMBL3953948 & 1641274 & 6.3344 & 6.2679 & TRN & \\
\hline CHEMBL3900516 & 1641274 & 5.44600 & 00000000 & 5.4242 & \\
\hline CHEMBL3895086 & 1641274 & 6.2782 & 6.24 & TRN & \\
\hline CHEMBL 3908578 & 1641274 & 5.4481 & 5.4735 & TRN & \\
\hline CHEMBL3962891 & 1641274 & 6.1549 & 6.1252 & TRN & \\
\hline CHEMBL 3986857 & 1641274 & 6.6055 & 6.5642 & TRN & \\
\hline CHEMBL3970532 & 1641274 & 5.6198 & 6.2141 & TRN & \\
\hline CHEMBL3948651 & 1641274 & 5.8626 & 5.7394 & TRN & \\
\hline CHEMBL 3983762 & 1641274 & 6.6234 & 6.0022 & TST & \\
\hline CHEMBL3923213 & 1641274 & 6.5784 & 6.5911 & TRN & \\
\hline CHEMBL3986003 & 1641274 & 5.5704 & 5.5192 & TRN & \\
\hline CHEMBL3975513 & 1641274 & 6.71 & 6.6749 & TRN & \\
\hline CHEMBL3931528 & 1641274 & 6.4855 & 6.7145 & TRN & \\
\hline CHEMBL 3918737 & 1641274 & 6.7645 & 6.7618 & TRN & \\
\hline CHEMBL3930488 & 1641274 & 6.7144 & 6.7849 & TRN & \\
\hline CHEMBL3947603 & 1641274 & 6.3152 & 6.1928 & TST & \\
\hline CHEMBL3945418 & 1641274 & 5.5656 & 5.4963 & TRN & \\
\hline CHEMBL 3909922 & 1641274 & 5.5391 & 5.2561 & TST & \\
\hline CHEMBL 3923298 & 1641274 & 5.4307 & 6.0714 & TRN & \\
\hline CHEMBL3926116 & 1641274 & 6.6615 & 6.6118 & TRN & \\
\hline CHEMBL 3912702 & 1641274 & 4.6008 & 4.6552 & TRN & \\
\hline
\end{tabular}

Page 26393 
Supplemental Table S2.txt

\begin{tabular}{|c|c|c|c|c|}
\hline CHEMBL3984252 & 1641274 & 6.0119 & 6.0134 & TRN \\
\hline CHEMBL3960543 & 1641274 & 6.6498 & 6.6405 & TRN \\
\hline CHEMBL3932658 & 1641274 & 6.1079 & 5.7509 & TST \\
\hline CHEMBL3964140 & 1641274 & 7.0915 & 7.0284 & TRN \\
\hline CHEMBL3961801 & 1641274 & 6.4157 & 6.4519 & TRN \\
\hline CHEMBL 3916454 & 1641274 & 6.0 & 6.2039 & TST \\
\hline CHEMBL3927558 & 1641274 & 6.4763 & 6.5071 & TRN \\
\hline CHEMBL3936525 & 1641274 & 5.945 & 5.9459 & TRN \\
\hline CHEMBL3901649 & 1641274 & 5.6893 & 5.7307 & TRN \\
\hline CHEMBL3957946 & 1641274 & 5.0284 & 4.1448 & TST \\
\hline CHEMBL3910629 & 1641274 & 6.6091 & 6.661000 & 00000000005 \\
\hline CHEMBL3897087 & 1641274 & 6.3002 & 6.3372 & TRN \\
\hline CHEMBL3919822 & 1641274 & 7.0223 & 7.0095 & TRN \\
\hline CHEMBL3937638 & 1641274 & 6.5654 & 6.5455 & TRN \\
\hline CHEMBL 3904894 & 1641274 & 5.644 & 5.6544 & TRN \\
\hline CHEMBL3980389 & 1641274 & 7.3872 & 7.2892 & TRN \\
\hline CHEMBL3956946 & 1641274 & 5.5578 & 5.902 & TST \\
\hline CHEMBL 3909083 & 1641274 & 6.75200 & 000000000 & 7.0401 \\
\hline CHEMBL3934285 & 1641274 & 6.4449 & 6.2416 & TRN \\
\hline CHEMBL3921382 & 1641274 & 6.8697 & 6.9293 & TRN \\
\hline CHEMBL3907742 & 1641274 & 5.569 & 5.5666 & TRN \\
\hline CHEMBL3964239 & 1641274 & 6.5229 & 5.6127 & TST \\
\hline CHEMBL3986625 & 1641274 & 6.1192 & 6.0775 & TRN \\
\hline CHEMBL3969468 & 1641274 & 5.7447 & 5.9316 & TST \\
\hline CHEMBL3971652 & 1641274 & 6.4377 & 6.4473 & TRN \\
\hline CHEMBL3967206 & 1641274 & 5.8996 & 5.6273 & TST \\
\hline CHEMBL3912782 & 1641274 & 5.7696 & 6.0604 & TST \\
\hline CHEMBL3957219 & 1641274 & 6.3298 & 6.3507 & TRN \\
\hline CHEMBL3934304 & 1641274 & 5.9208 & 6.3711 & TST \\
\hline CHEMBL3958365 & 1641274 & 5.0862 & 5.0777 & TST \\
\hline CHEMBL3920640 & 1641274 & 5.4844 & 5.5184 & TRN \\
\hline CHEMBL3900619 & 1641274 & 6.3161 & 6.6679 & TST \\
\hline CHEMBL3945898 & 1641274 & 6.3478 & 6.3504 & TST \\
\hline CHEMBL3933843 & 1641274 & 5.9884 & 5.9884 & TRN \\
\hline CHEMBL3907307 & 1641274 & 6.1549 & 6.312 & TST \\
\hline CHEMBL3975640 & 1641274 & 7.1024 & 6.8389 & TST \\
\hline CHEMBL3969656 & 1641274 & 7.0223 & 6.8031 & TRN \\
\hline CHEMBL3973794 & 1641274 & 6.5817 & 6.9787 & TST \\
\hline CHEMBL3977839 & 1641274 & 5.9834 & 5.9668 & TRN \\
\hline CHEMBL3980806 & 1641274 & 6.7077 & 6.6949 & TRN \\
\hline CHEMBL3894753 & 1641274 & 5.3653 & 5.9222 & TST \\
\hline CHEMBL3981124 & 1641274 & 4.0757 & 4.9513 & TST \\
\hline CHEMBL3925407 & 1641274 & 6.2218 & 6.222 & TST \\
\hline CHEMBL3985895 & 1641274 & 6.5884 & 6.2205 & TST \\
\hline CHEMBL3919200 & 1641274 & 6.4535 & 6.2346 & TST \\
\hline CHEMBL3908408 & 1641274 & 7.2291 & 7.2529 & TRN \\
\hline CHEMBL3955671 & 1641274 & 6.3316 & 6.2987 & TRN \\
\hline CHEMBL3917862 & 1641274 & 5.6934 & 4.6181 & TST \\
\hline
\end{tabular}


Supplemental Table S2.txt

\begin{tabular}{|c|c|c|c|c|c|}
\hline CHEMBL 3904771 & 1641274 & 6.0969 & 6.0448 & TRN & \\
\hline CHEMBL3933316 & 1641274 & 6.17200 & 000000006 & 1 & 6.3334 \\
\hline CHEMBL3961016 & 1641274 & 6.2604 & 6.2816 & TRN & \\
\hline CHEMBL3915917 & 1641274 & 6.0 & 5.8262 & TST & \\
\hline CHEMBL3961324 & 1641274 & 5.9073 & 5.9515 & TRN & \\
\hline CHEMBL 3891630 & 1641274 & 6.684 & 6.7435 & TRN & \\
\hline CHEMBL 3942719 & 1641274 & 7.0315 & 6.8862 & TST & \\
\hline CHEMBL 3935380 & 1641274 & 6.2596 & 6.2901 & TRN & \\
\hline CHEMBL 3917305 & 1641274 & 5.5654 & 5.5508 & TRN & \\
\hline CHEMBL3905120 & 1641274 & 6.3979 & 6.4163 & TRN & \\
\hline CHEMBL 3963124 & 1641274 & 5.2417 & 5.2921 & TRN & \\
\hline CHEMBL 3984113 & 1641274 & 5.1382 & 4.7825 & TST & \\
\hline CHEMBL 3943942 & 1641274 & 5.6205 & 5.6412 & TRN & \\
\hline CHEMBL 3987006 & 1641274 & 6.3706 & 6.6111 & TST & \\
\hline CHEMBL3932246 & 1641274 & 5.5581 & 5.4938 & TRN & \\
\hline CHEMBL188695 & 1454785 & 0.57 & 0.621 & TRN & \\
\hline CHEMBL3321996 & 1454785 & 2.38 & 2.0669 & TRN & \\
\hline CHEMBL1807676 & 1454785 & 0.6 & 0.4408 & TRN & \\
\hline CHEMBL 3321995 & 1454785 & 1.08 & 0.9792 & TRN & \\
\hline CHEMBL3321994 & 1454785 & 1.45 & 1.537 & TRN & \\
\hline CHEMBL8486 & 1454785 & 0.96 & 1.3603 & TRN & \\
\hline CHEMBL57338 & 1454785 & 1.88 & 1.9945 & TRN & \\
\hline CHEMBL 3321993 & 1454785 & 1.95 & 1.9627 & TRN & \\
\hline CHEMBL 54572 & 1454785 & 1.4 & 1.5323 & TRN & \\
\hline CHEMBL53400 & 1454785 & 2.32 & 3.0945 & TST & \\
\hline CHEMBL56099 & 1454785 & 1.51 & 1.056 & TRN & \\
\hline CHEMBL91090 & 1454785 & 0.79 & 0.8409 & TRN & \\
\hline CHEMBL414828 & 1454785 & 2.43 & 2.3777 & TRN & \\
\hline CHEMBL56923 & 1454785 & 0.67 & 0.3493 & TRN & \\
\hline CHEMBL91160 & 1454785 & 1.2 & 0.8824 & TRN & \\
\hline CHEMBL3321992 & 1454785 & 1.0 & 1.0741 & TRN & \\
\hline CHEMBL91777 & 1454785 & 0.2 & 0.4438 & TRN & \\
\hline CHEMBL299759 & 1454785 & 1.4 & 2.4655 & TST & \\
\hline CHEMBL56154 & 1454785 & 1.24 & 0.5223 & TST & \\
\hline CHEMBL91792 & 1454785 & 1.08 & 1.0506 & TST & \\
\hline CHEMBL170376 & 1454785 & 2.56 & 1.7451 & TST & \\
\hline CHEMBL3321991 & 1454785 & 1.67 & 2.1159 & TST & \\
\hline CHEMBL299889 & 1454785 & 2.44 & 3.5215 & TST & \\
\hline CHEMBL 3321990 & 1454785 & 2.11 & 1.6833 & TST & \\
\hline CHEMBL92255 & 1454785 & 1.97 & 1.7782 & TST & \\
\hline CHEMBL3321989 & 1454785 & 1.65 & 2.0366 & TST & \\
\hline CHEMBL 2370596 & 1454785 & 0.89 & 1.3205 & TST & \\
\hline CHEMBL90069 & 1454785 & 1.2 & 1.1307 & TST & \\
\hline CHEMBL 3321988 & 1454785 & 1.51 & 1.9178 & TST & \\
\hline CHEMBL1221898 & 1454785 & 1.82 & 1.4707 & TST & \\
\hline CHEMBL3321987 & 1454785 & 1.42 & 1.7892 & TST & \\
\hline CHEMBL94016 & 1454785 & 1.28 & 1.6683 & TST & \\
\hline CHEMBL3321986 & 1454785 & 1.71 & 0.9065 & TST & \\
\hline
\end{tabular}




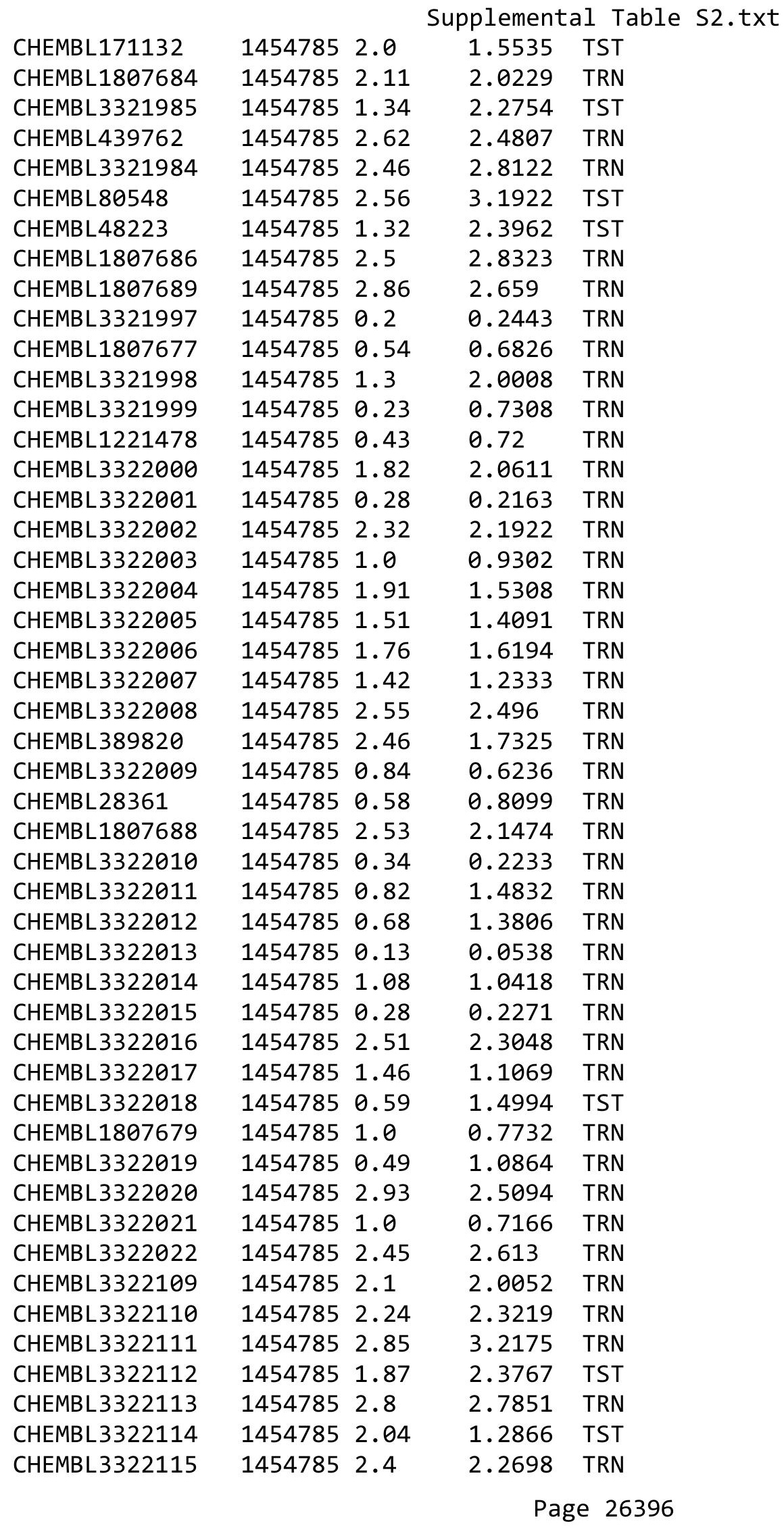


Supplemental Table S2.txt

\begin{tabular}{|c|c|c|c|c|}
\hline CHEMBL3322116 & 1454785 & 2.53 & 1.7027 & TST \\
\hline HEMBL3322117 & 1454785 & 2.6 & 2.5472 & TPN \\
\hline HEMBL3322118 & 454785 & 1.26 & .4668 & \\
\hline HEMBL3322119 & 454785 & 0.65 & .6705 & \\
\hline HEMBL3322120 & 454785 & 0.34 & .7404 & \\
\hline HEMBL3322121 & 454785 & 2.9 & .5112 & \\
\hline HEMBL3322106 & 785 & 1.56 & .7199 & RN \\
\hline HEMBL3322107 & 785 & 2.04 & .3372 & DN \\
\hline HEMBL3322108 & 785 & 2.23 & 1.9754 & \\
\hline HEMBL3322122 & 785 & 1.61 & L. 1864 & \\
\hline HEMBL3322123 & 785 & 0.78 & .7922 & \\
\hline HEMBL 332 & & 1.9 & 9898 & RN \\
\hline HEMBL3322125 & & 1.49 & 1.6256 & RN \\
\hline HEMBL3322126 & & 2.05 & .2802 & \\
\hline HEMBL3322127 & & 1.79 & 1.5602 & \\
\hline HEMBL 332 & & 2.77 & 2506 & RIV \\
\hline HEMBL 33 & & 2.24 & & RN \\
\hline HEMBL3322130 & & 0.7 & 0.7412 & RN \\
\hline HEMBL3322131 & & 2.07 & .2417 & \\
\hline HEMBL3322132 & & 1.66 & .229 & SI \\
\hline HEMBL332 & & 1.18 & 3887 & ST \\
\hline HEMBL33 & & 0.57 & 218 & RN \\
\hline HEMBL 332 & & 0.78 & 0.488 & RN \\
\hline HEMBL 332 & & 0.36 & 898 & 「RN \\
\hline HEMBL3322137 & 35 & 0.28 & 09 & RN \\
\hline HEMBL332 & & 1.28 & 926 & RN \\
\hline HEMBL3: & & 0.95 & 22 & RN \\
\hline HEMBL3: & & 1.81 & 844 & TRN \\
\hline HEMBL22 & & 3.56 & 29 & TRN \\
\hline HEMBL 392695 & & 6.262 & 6.2621 & TRN \\
\hline HEMBL47. & & 3.97 & 701 & 「RN \\
\hline HEMBL5 & & 3. & 19 & 「RN \\
\hline HEMBL16 & & & 3277 & TRN \\
\hline HEMBL483 & & 1.6578 & 579 & TRN \\
\hline HEMBL1242367 & & 5.0808 & 5 & TRN \\
\hline HEMBL19 & & 9.1823 & 702 & IST \\
\hline CHEMBL3 & & 4. & & ST \\
\hline HEMBL399 & & 4.8324 & 4.8326 & TRN \\
\hline HEMBL188678 & & 4.2481 & 483 & TRN \\
\hline HEMBL 209 & & 4. & 887 & TRN \\
\hline HEMBL 210 & & 3.02 & 238 & nIV \\
\hline CHEMBL1190711 & & 5.7419 & 5.7419 & RN \\
\hline CHEMBL2137530 & & 5.2334 & 5.2341 & TRN \\
\hline HEMBL 255342 & & 3.2369 & 3.5047 & TST \\
\hline HEMBL33 & & 3.78 & 3.7885 & $\mathrm{~K}$ \\
\hline CHEMBL412142 & & 3.7669 & 3.7669 & \\
\hline CHEMBL 213100 & & 6.7562 & 6.7563 & \\
\hline CHEMBL1186585 & 954920 & 5.0877 & 5.0873 & $\mathrm{RN}$ \\
\hline
\end{tabular}

Page 26397 
Supplemental Table S2.txt

\begin{tabular}{|c|c|c|c|c|}
\hline CHEMBL 2134202 & 954920 & 4.7353 & 4.7356 & TRN \\
\hline CHEMBL573107 & 954920 & 5.4358 & 5.4356 & TRN \\
\hline CHEMBL221137 & 954920 & 5.6281 & 4.7804 & TST \\
\hline CHEMBL259181 & 954920 & 5.8839 & 5.8839 & TRN \\
\hline CHEMBL 2005886 & 954920 & 6.3315 & 6.3315 & TRN \\
\hline CHEMBL1788116 & 954920 & 5.0179 & 5.0182 & TRN \\
\hline CHEMBL1404918 & 954920 & 2.9043 & 2.9042 & TRN \\
\hline CHEMBL65 & 954920 & 8.4708 & 8.4709 & TRN \\
\hline CHEMBL558642 & 954920 & 5.8855 & 5.8853 & TRN \\
\hline CHEMBL515416 & 954920 & \multicolumn{3}{|c|}{4.486000000000001} \\
\hline CHEMBL1673039 & 954920 & 4.8085 & 4.8084 & TRN \\
\hline CHEMBL 373751 & 954920 & 4.1027 & 4.1026 & TRN \\
\hline CHEMBL449158 & 954920 & 7.1258 & 6.7269 & TST \\
\hline CHEMBL1357247 & 954920 & 3.3335 & 3.3335 & TRN \\
\hline CHEMBL135561 & 954920 & 4.5707 & 4.5706 & TRN \\
\hline CHEMBL1516890 & 954920 & 3.7745 & 3.7748 & TRN \\
\hline CHEMBL92309 & 954920 & 2.9001 & 2.95600 & 00000000004 \\
\hline CHEMBL1590308 & 954920 & 3.3776 & 3.4473 & TST \\
\hline CHEMBL1230020 & 954920 & 3.2354 & 3.2353 & TRN \\
\hline CHEMBL1256459 & 954920 & 8.032 & 8.032 & TRN \\
\hline CHEMBL514499 & 954920 & 7.6511 & 7.6513 & TRN \\
\hline CHEMBL483847 & 954920 & 4.0873 & 4.0871 & TRN \\
\hline CHEMBL 379300 & 954920 & 6.9442 & 6.9442 & TRN \\
\hline CHEMBL 2144069 & 954920 & 6.0073 & 6.0073 & TRN \\
\hline CHEMBL585951 & 954920 & 5.3736 & 5.3733 & TRN \\
\hline CHEMBL102714 & 954920 & 2.9637 & 2.964 & TRN \\
\hline CHEMBL9470 & 954920 & 6.4316 & 5.206 & TST \\
\hline CHEMBL 217354 & 954920 & 7.0604 & 7.0603 & TRN \\
\hline CHEMBL 220241 & 954920 & 5.4214 & 5.4214 & TRN \\
\hline CHEMBL509032 & 954920 & 6.3245 & 6.3245 & TRN \\
\hline CHEMBL3199475 & 954920 & 4.0888 & 4.5433 & TST \\
\hline CHEMBL 2363137 & 954920 & 5.9394 & 5.09 & TST \\
\hline CHEMBL 258844 & 954920 & 5.1167 & 4.677 & TST \\
\hline CHEMBL1970879 & 954920 & 5.8225 & 6.1242 & TST \\
\hline CHEMBL180127 & 954920 & 4.9329 & 4.6284 & TST \\
\hline CHEMBL240954 & 954920 & 3.1405 & 3.3161 & TST \\
\hline CHEMBL300389 & 954920 & 7.694 & 6.6825 & TST \\
\hline CHEMBL189705 & 311931 & 4.5229 & 4.809 & TRN \\
\hline CHEMBL362891 & 311931 & 4.5229 & 4.7812 & TRN \\
\hline CHEMBL186044 & 311931 & 5.7064 & 5.5699 & TRN \\
\hline CHEMBL364788 & 311931 & 5.5743 & 5.3449 & TST \\
\hline CHEMBL187638 & 311931 & 4.5229 & 4.8286 & TRN \\
\hline CHEMBL361685 & 311931 & 6.5406 & 6.1766 & TRN \\
\hline CHEMBL186323 & 311931 & 5.9248 & 6.0449 & TRN \\
\hline CHEMBL188372 & 311931 & 6.8447 & 6.544 & TRN \\
\hline CHEMBL184739 & 311931 & 4.5229 & 5.087 & TRN \\
\hline CHEMBL364121 & 311931 & 6.8097 & 6.6011 & TRN \\
\hline CHEMBL189702 & 311931 & 6.2403 & 6.0529 & TRN \\
\hline
\end{tabular}


Supplemental Table S2.txt

\begin{tabular}{|c|c|c|c|c|}
\hline CHEMBL188682 & 311931 & 6.2899 & 6.5005 & TRN \\
\hline CHEMBL186567 & 311931 & 4.5229 & 4.8514 & TRN \\
\hline CHEMBL188891 & 311931 & 4.5229 & 4.5899 & TRN \\
\hline CHEMBL186983 & 311931 & 5.6295 & 5.6162 & TRN \\
\hline CHEMBL181650 & 311931 & 6.5186 & 6.7097 & TRN \\
\hline CHEMBL189227 & 311931 & 4.5229 & 4.1441 & TRN \\
\hline CHEMBL188724 & 311931 & 4.5229 & 4.863 & TRN \\
\hline CHEMBL186875 & 311931 & 5.7986 & 5.5054 & TRN \\
\hline CHEMBL185767 & 311931 & 4.5229 & 4.7242 & TRN \\
\hline CHEMBL364159 & 311931 & 6.9355 & 6.6757 & TRN \\
\hline CHEMBL365487 & 311931 & 4.5229 & 5.0751 & TRN \\
\hline CHEMBL186081 & 311931 & 7.1192 & 6.5945 & TST \\
\hline CHEMBL188356 & 311931 & 5.7788 & 5.6183 & TST \\
\hline CHEMBL362883 & 311931 & 5.7525 & 5.3448 & TRN \\
\hline CHEMBL185704 & 311931 & 5.7282 & 5.4862 & TRN \\
\hline CHEMBL185985 & 311931 & 4.5229 & 4.5397 & TRN \\
\hline CHEMBL186187 & 311931 & 4.5229 & 4.8939 & TST \\
\hline CHEMBL426627 & 311931 & 4.5229 & 4.3632 & TRN \\
\hline CHEMBL185957 & 311931 & 4.5229 & 4.9699 & TRN \\
\hline CHEMBL427525 & 311931 & 4.5229 & 4.8924 & TRN \\
\hline CHEMBL187298 & 311931 & 4.5229 & 4.2026 & TRN \\
\hline CHEMBL187316 & 311931 & 4.5229 & 4.0595 & TRN \\
\hline CHEMBL362118 & 311931 & 4.5229 & 5.8519 & TST \\
\hline CHEMBL363114 & 311931 & 4.5229 & 5.4768 & TST \\
\hline CHEMBL186238 & 311931 & 6.75200 & 00000006 & 6.939 \\
\hline CHEMBL189817 & 311931 & 6.6596 & 6.6564 & TRN \\
\hline CHEMBL362289 & 311931 & 5.63299 & 999999995 & 5.73 \\
\hline CHEMBL186997 & 311931 & 4.5229 & 5.1734 & TST \\
\hline CHEMBL361294 & 311931 & 4.5229 & 4.488 & TRN \\
\hline CHEMBL189092 & 311931 & 6.9431 & 6.927006 & 00000000005 \\
\hline CHEMBL188321 & 311931 & 4.5229 & 4.2008 & TRN \\
\hline CHEMBL189406 & 311931 & 4.5229 & 4.2737 & TRN \\
\hline CHEMBL189648 & 311931 & 6.4365 & 6.4851 & TRN \\
\hline CHEMBL186143 & 311931 & 5.9739 & 5.7146 & TRN \\
\hline CHEMBL189042 & 311931 & 6.3197 & 6.348 & TRN \\
\hline CHEMBL364107 & 311931 & 6.2899 & 5.6166 & TST \\
\hline CHEMBL189034 & 311931 & 4.5229 & 5.1787 & TST \\
\hline CHEMBL189131 & 311931 & 4.5229 & 3.9549 & TST \\
\hline CHEMBL188632 & 311931 & 4.5229 & 5.3926 & TST \\
\hline CHEMBL362764 & 311931 & 4.5229 & 5.0782 & TST \\
\hline CHEMBL425183 & 311931 & 4.5229 & 5.065 & TST \\
\hline CHEMBL14144 & 142944 & 5.5294 & 5.5071 & TRN \\
\hline CHEMBL127011 & 142944 & 6.6289 & 6.6167 & TRN \\
\hline CHEMBL338584 & 142944 & 5.4629 & 5.4799 & TRN \\
\hline CHEMBL340372 & 142944 & 5.4 & 5.4374 & TRN \\
\hline CHEMBL340138 & 142944 & 5.7565 & 5.0388 & TST \\
\hline CHEMBL339149 & 142944 & 6.8416 & 6.8679 & TRN \\
\hline CHEMBL127561 & 142944 & 5.5804 & 5.5786 & TRN \\
\hline
\end{tabular}




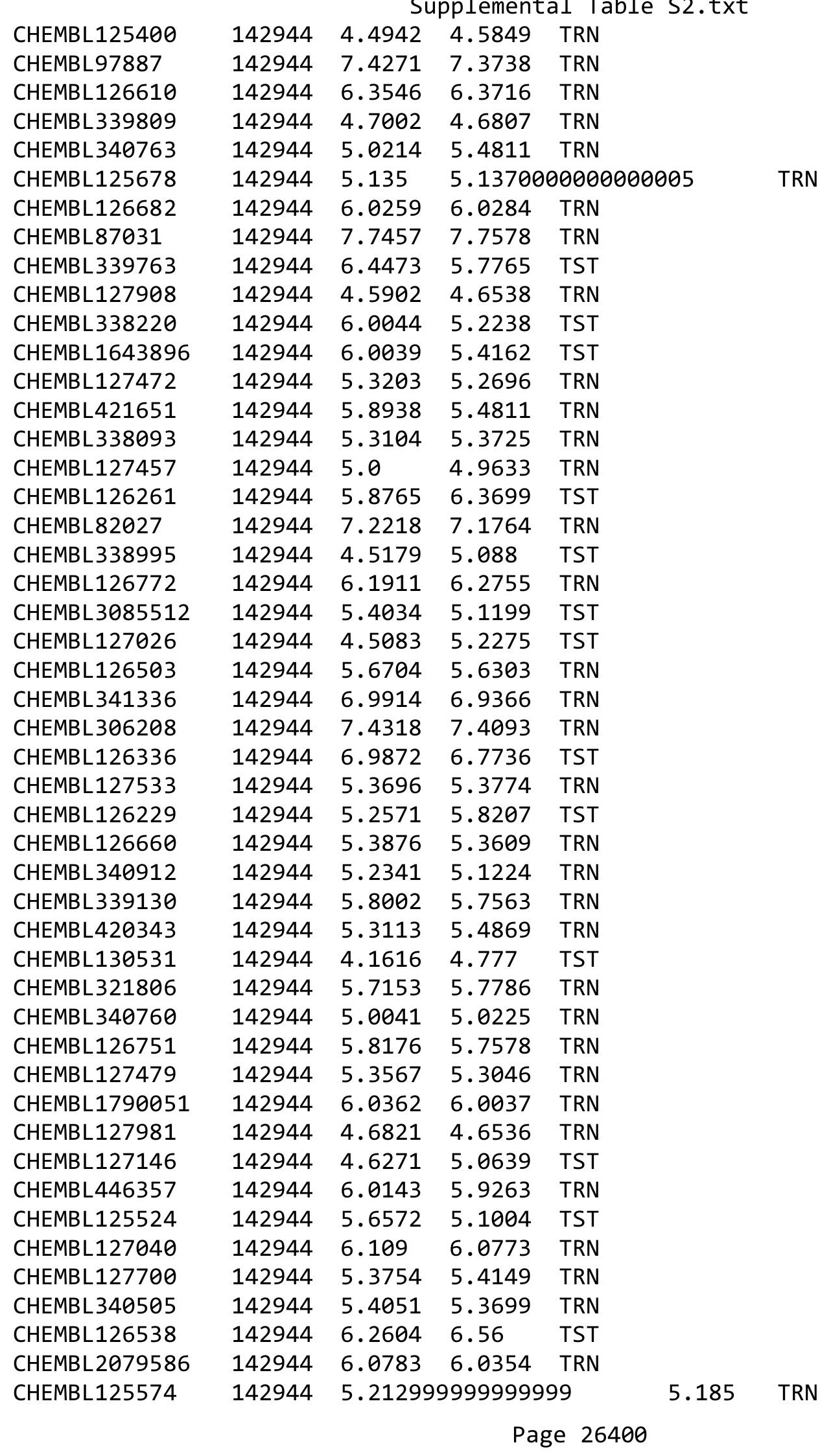




\begin{tabular}{|c|c|c|c|c|c|}
\hline \multicolumn{6}{|c|}{ Supplemental Table S2 } \\
\hline CHEMBL340761 & 142944 & 5.4212 & 5.5051 & TRN & \\
\hline CHEMBL126410 & 142944 & 5.3244 & 5.2958 & TRN & \\
\hline CHEMBL127447 & 142944 & 4.7153 & 4.6939 & TRN & \\
\hline CHEMBL126848 & 142944 & 5.2061 & 5.6264 & TST & \\
\hline CHEMBL127260 & 142944 & 5.9654 & 5.4484 & TST & \\
\hline CHEMBL127546 & 142944 & 6.5452 & 6.4673 & TRN & \\
\hline CHEMBL125974 & 142944 & 5.5616 & 5.5916 & TRN & \\
\hline CHEMBL126271 & 142944 & 5.0683 & 5.2845 & TST & \\
\hline CHEMBL14391 & 142944 & 7.4437 & 7.5781 & TRN & \\
\hline CHEMBL127323 & 142944 & 7.4413 & 7.4764 & TRN & \\
\hline CHEMBL126887 & 142944 & 5.5016 & 5.5198 & TRN & \\
\hline CHEMBL568846 & 599573 & 3.0 & 3.0022 & TRN & \\
\hline CHEMBL574694 & 599573 & 5.6778 & 5.6786 & TRN & \\
\hline CHEMBL566190 & 599573 & 4.5686 & 4.5686 & TRN & \\
\hline CHEMBL577515 & 599573 & 4.4437 & 4.44300 & 20000000005 & TRN \\
\hline CHEMBL579036 & 599573 & 3.301 & 3.2933 & TRN & \\
\hline CHEMBL569260 & 599573 & 5.2007 & 5.2001 & TRN & \\
\hline CHEMBL569498 & 599573 & 6.2924 & 6.2879 & TRN & \\
\hline CHEMBL565340 & 599573 & 3.0 & 3.0094 & TRN & \\
\hline CHEMBL566584 & 599573 & 3.0 & 3.0046 & TRN & \\
\hline CHEMBL576872 & 599573 & 3.0 & 3.0001 & TRN & \\
\hline CHEMBL577298 & 599573 & 3.699 & 3.6937 & TRN & \\
\hline CHEMBL569219 & 599573 & 3.0 & 2.9987 & TRN & \\
\hline CHEMBL568844 & 599573 & 3.3979 & 3.4025 & TRN & \\
\hline CHEMBL569453 & 599573 & 4.2676 & 4.2647 & TRN & \\
\hline CHEMBL569055 & 599573 & 3.301 & 3.2957 & TRN & \\
\hline CHEMBL569497 & 599573 & 5.9208 & 5.9205 & TRN & \\
\hline CHEMBL566567 & 599573 & 6.0915 & 6.0951 & TRN & \\
\hline CHEMBL568993 & 599573 & 3.0458 & 3.0425 & TRN & \\
\hline CHEMBL569022 & 599573 & 5.9586 & 5.966 & TRN & \\
\hline CHEMBL577293 & 599573 & 4.8239 & 4.9676 & TST & \\
\hline CHEMBL579030 & 599573 & 5.2147 & 5.2227 & TRN & \\
\hline CHEMBL569514 & 599573 & 5.585 & 5.5743 & TRN & \\
\hline CHEMBL569511 & 599573 & 5.3768 & 5.3873 & TRN & \\
\hline CHEMBL566801 & 599573 & 5.0088 & 5.0009 & TRN & \\
\hline CHEMBL569274 & 599573 & 3.0 & 3.0009 & TRN & \\
\hline CHEMBL569041 & 599573 & 5.5229 & 6.1157 & TST & \\
\hline CHEMBL579037 & 599573 & 4.6198 & 4.6246 & TRN & \\
\hline CHEMBL576425 & 599573 & 5.4949 & 5.4835 & TRN & \\
\hline CHEMBL566568 & 599573 & 6.0177 & 6.0122 & TRN & \\
\hline CHEMBL584723 & 599573 & 4.0 & 4.0045 & TRN & \\
\hline CHEMBL569021 & 599573 & 5.699 & 4.7943 & TST & \\
\hline CHEMBL565339 & 599573 & 3.301 & 3.3006 & TRN & \\
\hline CHEMBL568320 & 599573 & 3.0 & 2.9964 & TRN & \\
\hline CHEMBL566802 & 599573 & 3.0 & 3.0016 & TRN & \\
\hline CHEMBL585942 & 599573 & 4.1135 & 4.1141 & TRN & \\
\hline CHEMBL583718 & 599573 & 5.7212 & 5.7225 & TRN & \\
\hline CHEMBL584677 & 599573 & 4.2596 & 4.2604 & TRN & \\
\hline
\end{tabular}




\begin{tabular}{|c|c|c|c|c|c|}
\hline \multirow[b]{2}{*}{ CHEMBL569216 } & \multicolumn{5}{|c|}{ Supplemental Table S2.txt } \\
\hline & 599573 & 7.1871 & 5.5091 & TST & \\
\hline CHEMBL568537 & 599573 & 3.0 & 3.2204 & TST & \\
\hline CHEMBL566583 & 599573 & 4.5086 & 4.5012 & TRN & \\
\hline CHEMBL576217 & 599573 & 4.0 & 4.8465 & TST & \\
\hline CHEMBL577517 & 599573 & 5.4202 & 5.4043 & TRN & \\
\hline CHEMBL565317 & 599573 & 6.9208 & 6.9288 & TRN & \\
\hline CHEMBL569512 & 599573 & 4.0 & 4.9629 & TST & \\
\hline CHEMBL569293 & 599573 & 6.2218 & 6.2069 & TRN & \\
\hline CHEMBL571918 & 599573 & 5.9208 & 5.9275 & TRN & \\
\hline CHEMBL569452 & 599573 & 4.5086 & 4.5215 & TRN & \\
\hline CHEMBL577514 & 599573 & 3.0 & 2.9968 & TRN & \\
\hline CHEMBL579185 & 599573 & 3.0 & 3.8007 & TST & \\
\hline CHEMBL577947 & 599573 & 3.0 & 2.9999 & TRN & \\
\hline CHEMBL565349 & 599573 & 3.0 & 2.9984 & TRN & \\
\hline CHEMBL566803 & 599573 & 4.0 & 4.9169 & TST & \\
\hline CHEMBL569283 & 599573 & 6.4437 & 5.1859 & TST & \\
\hline CHEMBL579031 & 599573 & 6.4559 & 6.45700 & 0000000001 & TRN \\
\hline CHEMBL577930 & 599573 & 4.0 & 4.8363 & TST & \\
\hline CHEMBL569287 & 599573 & 3.0 & 3.0013 & TRN & \\
\hline CHEMBL576221 & 599573 & 4.0 & 3.5709 & TST & \\
\hline CHEMBL568319 & 599573 & 3.0 & 5.7988 & TST & \\
\hline CHEMBL578791 & 599573 & 6.1805 & 5.5514 & TST & \\
\hline CHEMBL579235 & 599573 & 3.0 & 4.0825 & TST & \\
\hline CHEMBL576418 & 599573 & 3.301 & 4.4949 & TST & \\
\hline CHEMBL577295 & 599573 & 4.0 & 4.6418 & TST & \\
\hline CHEMBL566397 & 599573 & 6.2518 & 6.2487 & TRN & \\
\hline CHEMBL569218 & 599573 & 5.4815 & 5.5008 & TRN & \\
\hline CHEMBL571911 & 599573 & 5.3665 & 5.36799 & 9999999999 & TRN \\
\hline CHEMBL577728 & 599573 & 4.4559 & 4.4572 & TRN & \\
\hline CHEMBL1090777 & 688772 & 6.5501 & 5.8197 & TRN & \\
\hline CHEMBL1083166 & 688772 & 10.5003 & 7.0999 & TRN & \\
\hline CHEMBL1600060 & 688772 & 4.5 & 5.8806 & TRN & \\
\hline CHEMBL1093687 & 688772 & 6.1 & 5.8086 & TRN & \\
\hline CHEMBL1319524 & 688772 & 4.75 & 6.569 & TRN & \\
\hline CHEMBL1084899 & 688772 & 6.1 & 6.5579 & TRN & \\
\hline CHEMBL1082454 & 688772 & 7.5498 & 8.7833 & TRN & \\
\hline CHEMBL1318844 & 688772 & 4.35 & 7.3787 & TST & \\
\hline CHEMBL1084058 & 688772 & 6.5501 & 8.8951 & TST & \\
\hline CHEMBL1371719 & 688772 & 5.1 & 3.6832 & TRN & \\
\hline CHEMBL1092480 & 688772 & 7.4498 & 5.0005 & TRN & \\
\hline CHEMBL1083136 & 688772 & 10.5003 & 9.7784 & TRN & \\
\hline CHEMBL1521954 & 688772 & 5.3 & 6.1389 & TRN & \\
\hline CHEMBL1083882 & 688772 & 5.6 & 7.476 & TRN & \\
\hline CHEMBL1088748 & 688772 & 9.3979 & 6.4755 & TRN & \\
\hline CHEMBL1086565 & 688772 & 9.3979 & 6.9609 & TRN & \\
\hline CHEMBL1086566 & 688772 & 5.5 & 6.3395 & TRN & \\
\hline CHEMBL1091794 & 688772 & 5.3 & 5.3556 & TRN & \\
\hline CHEMBL1091503 & 688772 & 7.2503 & 6.2715 & TRN & \\
\hline
\end{tabular}




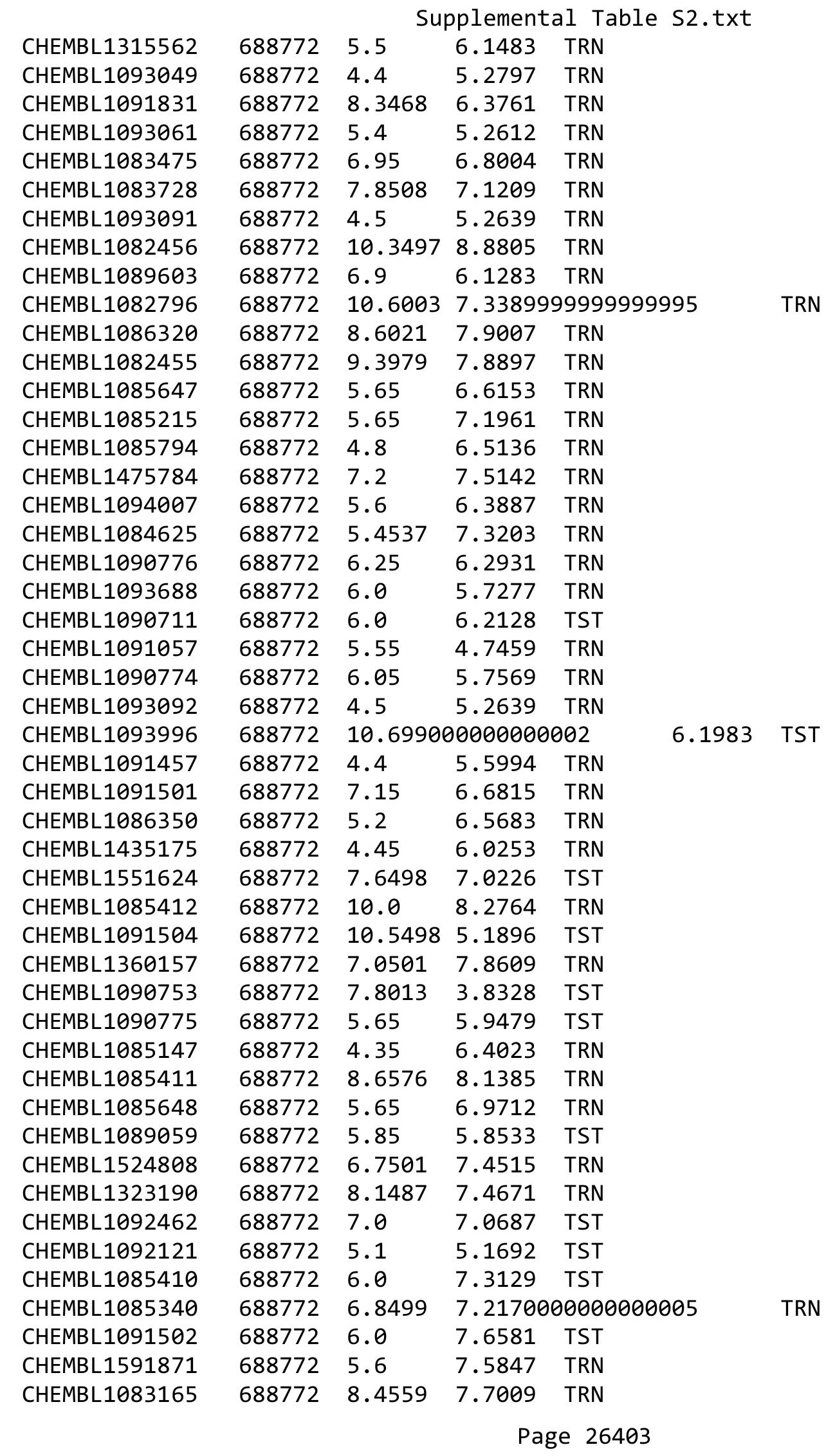




\begin{tabular}{|c|c|c|c|c|c|}
\hline & & \multicolumn{4}{|c|}{ Supplemental Table S2.txt } \\
\hline CHEMBL1086539 & 688772 & 7.6003 & 6.3268 & TRN & \\
\hline CHEMBL1086349 & 688772 & 5.45 & 6.3484 & TRN & \\
\hline CHEMBL1093369 & 688772 & 6.0 & 6.53799 & 9999999999 & TST \\
\hline CHEMBL1089366 & 688772 & 6.0 & 6.9382 & TST & \\
\hline CHEMBL1515029 & 688772 & 5.6 & 5.7368 & TRN & \\
\hline CHEMBL1092297 & 688772 & 6.15 & 6.3845 & TST & \\
\hline CHEMBL1094006 & 688772 & 7.0 & 6.7622 & TST & \\
\hline CHEMBL1091458 & 688772 & 6.5501 & 5.1244 & TST & \\
\hline CHEMBL1084057 & 688772 & 10.4498 & 7.2372 & TST & \\
\hline CHEMBL1396401 & 688772 & 7.1002 & 8.7296 & TRN & \\
\hline CHEMBL1091078 & 688772 & 7.6498 & 6.8955 & TST & \\
\hline CHEMBL1242202 & 654931 & 6.1986 & 5.8896 & TRN & \\
\hline CHEMBL1241950 & 654931 & 4.0 & 4.63399 & 99999999995 & TRN \\
\hline CHEMBL1242034 & 654931 & 4.0 & 4.1516 & TRN & \\
\hline CHEMBL1241949 & 654931 & 4.0 & 4.9644 & TRN & \\
\hline CHEMBL1242119 & 654931 & 4.0 & 4.2456 & TRN & \\
\hline CHEMBL1242845 & 654931 & 4.0 & 4.5799 & TST & \\
\hline CHEMBL1242033 & 654931 & 4.0 & 4.5649 & TRN & \\
\hline CHEMBL1242748 & 654931 & 6.0 & 4.8921 & TRN & \\
\hline CHEMBL1242377 & 654931 & 6.063 & 6.0942 & TRN & \\
\hline CHEMBL1242379 & 654931 & 4.0 & 4.3756 & TRN & \\
\hline CHEMBL1241771 & 654931 & 4.0 & 4.0929 & TRN & \\
\hline CHEMBL1242201 & 654931 & 6.3655 & 5.7101 & TRN & \\
\hline CHEMBL1241482 & 654931 & 4.0 & 4.2234 & TST & \\
\hline CHEMBL1242574 & 654931 & 5.9208 & 6.3198 & TRN & \\
\hline CHEMBL1242470 & 654931 & 4.0 & 4.6806 & TST & \\
\hline CHEMBL1241582 & 654931 & 4.9208 & 4.7069 & TRN & \\
\hline CHEMBL1242112 & 654931 & 5.4437 & 5.4047 & TRN & \\
\hline CHEMBL1241948 & 654931 & 5.0 & 4.4404 & TRN & \\
\hline CHEMBL1242662 & 654931 & 7.2596 & 6.7175 & TRN & \\
\hline CHEMBL1242117 & 654931 & 4.0 & 3.7554 & TRN & \\
\hline CHEMBL1242572 & 654931 & 6.0315 & 5.5989 & TRN & \\
\hline CHEMBL1242376 & 654931 & 5.7721 & 5.9153 & TRN & \\
\hline CHEMBL1242032 & 654931 & 4.301 & 4.3412 & TRN & \\
\hline CHEMBL1241677 & 654931 & 4.5686 & 4.6372 & TRN & \\
\hline CHEMBL1241947 & 654931 & 5.1549 & 4.8816 & TST & \\
\hline CHEMBL1242750 & 654931 & 4.0 & 5.3849 & TRN & \\
\hline CHEMBL1241945 & 654931 & 6.3726 & 5.8652 & TRN & \\
\hline CHEMBL1241775 & 654931 & 4.0 & 4.0894 & TRN & \\
\hline CHEMBL1241241 & 654931 & 5.4949 & 5.7247 & TRN & \\
\hline CHEMBL1242754 & 654931 & 5.2366 & 5.4697 & TRN & \\
\hline CHEMBL1241581 & 654931 & 5.8794 & 5.4715 & TRN & \\
\hline CHEMBL1241770 & 654931 & 4.7305 & 4.3359 & TRN & \\
\hline CHEMBL1242469 & 654931 & 4.0 & 4.553 & TST & \\
\hline CHEMBL1241861 & 654931 & 5.6198 & 4.8081 & TRN & \\
\hline CHEMBL1240565 & 654931 & 5.1675 & 5.326006 & 00000000005 & TRN \\
\hline CHEMBL1241578 & 654931 & 5.7212 & 6.3475 & TRN & \\
\hline CHEMBL1242666 & 654931 & 4.9318 & 5.2289 & TRN & \\
\hline
\end{tabular}


Supplemental Table S2.txt

\begin{tabular}{|c|c|c|c|c|c|}
\hline CHEMBL1241682 & 654931 & 5.0177 & 4.7883 & TRN & \\
\hline CHEMBL1241675 & 654931 & 3.301 & 4.1041 & TST & \\
\hline CHEMBL1242385 & 654931 & 5.8861 & 5.5441 & TRN & \\
\hline CHEMBL1242286 & 654931 & 5.1284 & 5.2209 & TRN & \\
\hline CHEMBL1242757 & 654931 & 6.0 & 5.4024 & TST & \\
\hline CHEMBL1242844 & 654931 & 4.0 & 3.7827 & TRN & \\
\hline CHEMBL1242113 & 654931 & 5.1481 & 5.3336 & TRN & \\
\hline CHEMBL1242756 & 654931 & 5.5229 & 4.3324 & TRN & \\
\hline CHEMBL1242285 & 654931 & 6.1373 & 6.2936 & TRN & \\
\hline CHEMBL1241860 & 654931 & 4.2291 & 4.6138 & TRN & \\
\hline CHEMBL1241487 & 654931 & 5.6925 & 5.8098 & TRN & \\
\hline CHEMBL1242753 & 654931 & 4.8013 & 4.1524 & TRN & \\
\hline CHEMBL1242027 & 654931 & 4.7645 & 5.034 & TRN & \\
\hline CHEMBL1241492 & 654931 & 4.301 & 4.1442 & TRN & \\
\hline CHEMBL1242476 & 654931 & 5.6576 & $5.55200 t$ & 00000000005 & TRN \\
\hline CHEMBL1242031 & 654931 & 5.7959 & 4.6084 & TRN & \\
\hline CHEMBL1241588 & 654931 & 5.1612 & 4.6592 & TST & \\
\hline CHEMBL1242665 & 654931 & 4.0 & 4.1928 & TST & \\
\hline CHEMBL1242110 & 654931 & 5.3179 & 5.5352 & TRN & \\
\hline CHEMBL1241946 & 654931 & 4.0 & 4.7202 & TRN & \\
\hline CHEMBL1242659 & 654931 & 4.0 & 4.4152 & TRN & \\
\hline CHEMBL1242847 & 654931 & 4.7959 & 5.1162 & TRN & \\
\hline CHEMBL1242664 & 654931 & 6.6021 & 6.0754 & TRN & \\
\hline CHEMBL1242209 & 654931 & 4.0 & 4.5533 & TRN & \\
\hline CHEMBL1240545 & 654931 & 4.9208 & 4.5697 & TRN & \\
\hline CHEMBL1241864 & 654931 & 4.0 & 4.4664 & TRN & \\
\hline CHEMBL1242755 & 654931 & 4.7696 & 5.2732 & TRN & \\
\hline CHEMBL1242567 & 654931 & 4.0 & 4.7887 & TRN & \\
\hline CHEMBL1240554 & 654931 & 5.0381 & 4.6718 & TRN & \\
\hline CHEMBL1241679 & 654931 & 4.301 & 4.0377 & TRN & \\
\hline CHEMBL1241680 & 654931 & 4.0 & 4.0878 & TRN & \\
\hline CHEMBL1242114 & 654931 & \multicolumn{3}{|c|}{5.752000000000001} & TRN \\
\hline CHEMBL1242198 & 654931 & 5.6778 & 6.0633 & TRN & \\
\hline CHEMBL1241587 & 654931 & 4.0 & 4.6457 & TST & \\
\hline CHEMBL1242752 & 654931 & 4.8996 & 4.434 & TRN & \\
\hline CHEMBL1241774 & 654931 & 4.0 & 4.3788 & TRN & \\
\hline CHEMBL1242029 & 654931 & 4.8861 & 4.9704 & TRN & \\
\hline CHEMBL 1241486 & 654931 & 4.5528 & 5.3209 & TRN & \\
\hline CHEMBL1241683 & 654931 & 5.2441 & 4.7539 & TRN & \\
\hline CHEMBL1242475 & 654931 & 6.5834 & 5.4631 & TRN & \\
\hline CHEMBL1242853 & 654931 & 6.3565 & 5.9574 & TRN & \\
\hline CHEMBL1241858 & 654931 & 4.0 & 3.9297 & TRN & \\
\hline CHEMBL1241481 & 654931 & 7.6021 & 6.0207 & TRN & \\
\hline CHEMBL1242381 & 654931 & 6.0 & 5.2317 & TRN & \\
\hline CHEMBL1081312 & 654931 & 6.6576 & 6.0054 & TRN & \\
\hline CHEMBL1241684 & 654931 & 4.301 & 4.8252 & TST & \\
\hline CHEMBL1242115 & 654931 & 5.4815 & 5.1766 & TST & \\
\hline CHEMBL1241586 & 654931 & 4.284 & 5.1501 & TRN & \\
\hline
\end{tabular}


Supplemental Table S2.txt

\begin{tabular}{|c|c|c|c|c|}
\hline 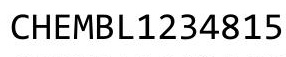 & & & & \\
\hline HEMBL1242566 & 54931 & 4.0 & 2582 & \\
\hline HEMBL1241769 & 54931 & 3635 & 2211 & \\
\hline EMBL1 & & & 5747 & \\
\hline IEMBL1241484 & & 39 & 9832 & PN \\
\hline HEMBL1241270 & 54931 & 747 & 4807 & \\
\hline HEMBL1241674 & 54931 & .2924 & 9302 & \\
\hline HEMBL1242384 & & & 6959 & \\
\hline EMBL12 & & & 4228 & \\
\hline IEMBL124 & 31 & 8 & .4293 & \\
\hline HEMBL1233882 & 54931 & & 5221 & \\
\hline HEMBL1241485 & 31 & & .0718 & \\
\hline HEMBL1241772 & 31 & & 9384 & \\
\hline HEMBL12 & & 1 & .09 & \\
\hline HEMBL124 & & & .2264 & \\
\hline HEMBL1242118 & 31 & $\partial 5$ & 3653 & \\
\hline HEMBL1241944 & 31 & 51 & & \\
\hline HEMBL124 & 1 & 32 & .9938 & \\
\hline HEMBL 124 & & & 13 & RN \\
\hline HEMBL 124 & & & 4.5713 & \\
\hline HEMBL124 & 31 & & 8949 & \\
\hline HEMBL1241483 & 31 & & 83 & $\mathrm{~N}$ \\
\hline HEMBL124 & 1 & & 6.3112 & RIV \\
\hline HEMBL12 2 & & & 2698 & RN \\
\hline HEME & & & 4.8162 & $\mathrm{RN}$ \\
\hline HEMBL 124 & & & 5.4657 & N \\
\hline HEMBL 124 & & & 4.8712 & Iv \\
\hline HEMBL12 & & & 504 & RN \\
\hline HEMBL12 & & & 714 & RN \\
\hline HEMBL124 & 1 & 10 & 4.6745 & RN \\
\hline HEMBL1241491 & & & & v \\
\hline HEMBL1241439 & & 76 & 4.8364 & ST \\
\hline HEMBL 12 & & & 406 & RN \\
\hline HEM & & 4. & 53 & RN \\
\hline HEMBL124 & & & 5.7103 & RN \\
\hline HEMBL1242472 & & & 5967 & IRN \\
\hline HEMBL1242200 & & & 1549 & RN \\
\hline 852 & & & 913 & RN \\
\hline 1219 & & & & RN \\
\hline HEMBL1241681 & & & & RN \\
\hline HEMBL1241271 & & & 635 & IRN \\
\hline HEMBL 124 & & & & ST \\
\hline HEMBL1241863 & & & 4.8631 & \\
\hline CHEMBL1242287 & & & 5.9026 & RN \\
\hline HEMBL1242111 & & 5.3969 & 5.2537 & ST \\
\hline HEMBL124 & 31 & 15 & 5.4187 & RN \\
\hline 12 & & & & \\
\hline ריבים & & 5.3098 & & \\
\hline
\end{tabular}

Page 26406 


\begin{tabular}{|c|c|c|c|c|c|}
\hline \multicolumn{6}{|c|}{ Supplemental Table S2.txt } \\
\hline CHEMBL1241773 & 654931 & 4.0 & 4.5903 & TRN & \\
\hline CHEMBL1241391 & 654931 & 4.0 & 3.9389 & TRN & \\
\hline CHEMBL1242471 & 654931 & 4.0 & 4.1061 & TST & \\
\hline CHEMBL1242758 & 654931 & 5.8861 & 5.2049 & TST & \\
\hline CHEMBL1242203 & 654931 & 4.0 & 4.7692 & TST & \\
\hline CHEMBL1241676 & 654931 & 5.8239 & 5.9245 & TST & \\
\hline CHEMBL1240566 & 654931 & 4.9586 & 5.3859 & TST & \\
\hline CHEMBL1241862 & 654931 & 4.0 & 4.1968 & TST & \\
\hline CHEMBL1242028 & 654931 & 5.6778 & 5.3868 & TST & \\
\hline CHEMBL1242025 & 654931 & 4.6925 & 4.6089 & TST & \\
\hline CHEMBL1242569 & 654931 & 4.0 & 4.2007 & TST & \\
\hline CHEMBL1241390 & 654931 & 4.0 & 3.9926 & TST & \\
\hline CHEMBL1242848 & 654931 & 5.1073 & 5.7886 & TST & \\
\hline CHEMBL1242663 & 654931 & 5.4685 & 4.6526 & TST & \\
\hline CHEMBL1241300 & 654931 & 4.8962 & 5.1132 & TST & \\
\hline CHEMBL1241859 & 654931 & 4.0 & 3.8038 & TST & \\
\hline CHEMBL1242657 & 654931 & 6.0 & 4.6772 & TST & \\
\hline CHEMBL1242656 & 654931 & 6.2007 & 5.7279 & TST & \\
\hline CHEMBL1230790 & 654931 & 5.5086 & 6.0422 & TST & \\
\hline CHEMBL1242386 & 654931 & 6.4056 & 5.8792 & TST & \\
\hline CHEMBL1241583 & 654931 & 4.0 & 4.4759 & TST & \\
\hline CHEMBL1240553 & 654931 & 5.585 & 4.8494 & TST & \\
\hline CHEMBL1241299 & 654931 & 4.0 & 5.199 & TST & \\
\hline CHEMBL1242751 & 654931 & 5.2211 & 4.8438 & TST & \\
\hline CHEMBL1964290 & 809266 & 6.2 & 5.9712 & TRN & \\
\hline CHEMBL 2003768 & 809266 & 4.1 & 4.9984 & TRN & \\
\hline CHEMBL213505 & 809266 & 7.9 & 8.0449 & TRN & \\
\hline CHEMBL1987034 & 809266 & 7.0 & 7.79899 & 99999999995 & TRN \\
\hline CHEMBL1993941 & 809266 & 6.4 & 6.69600 & 0000000001 & TRN \\
\hline CHEMBL 377383 & 809266 & 4.1 & 4.2642 & TRN & \\
\hline CHEMBL 2005886 & 809266 & 5.2 & 4.479 & TRN & \\
\hline CHEMBL481491 & 809266 & 5.3 & 4.4678 & TST & \\
\hline CHEMBL1973142 & 809266 & 4.1 & 5.6673 & TRN & \\
\hline CHEMBL1973145 & 809266 & 6.2 & 5.4638 & TRN & \\
\hline CHEMBL1982924 & 809266 & 5.5 & 4.3219 & TRN & \\
\hline CHEMBL 2005936 & 809266 & 5.5 & 5.269 & TRN & \\
\hline CHEMBL1807515 & 809266 & 5.6 & 6.4706 & TRN & \\
\hline CHEMBL1971141 & 809266 & 4.1 & 5.2078 & TRN & \\
\hline CHEMBL1995813 & 809266 & 5.8 & 6.4137 & TRN & \\
\hline CHEMBL206236 & 809266 & 4.1 & 4.4962 & TRN & \\
\hline CHEMBL 244378 & 809266 & 7.2 & 7.572 & TRN & \\
\hline CHEMBL 2001957 & 809266 & 4.1 & 4.3549 & TRN & \\
\hline CHEMBL1969372 & 809266 & 4.1 & 3.8318 & TRN & \\
\hline CHEMBL1986943 & 809266 & 6.4 & 6.2888 & TRN & \\
\hline CHEMBL 2006263 & 809266 & 4.1 & 4.5712 & TRN & \\
\hline CHEMBL 2001646 & 809266 & 5.5 & 5.8256 & TST & \\
\hline CHEMBL1993584 & 809266 & 5.3 & 5.0667 & TRN & \\
\hline CHEMBL1986263 & 809266 & 7.1 & 6.5314 & TRN & \\
\hline
\end{tabular}




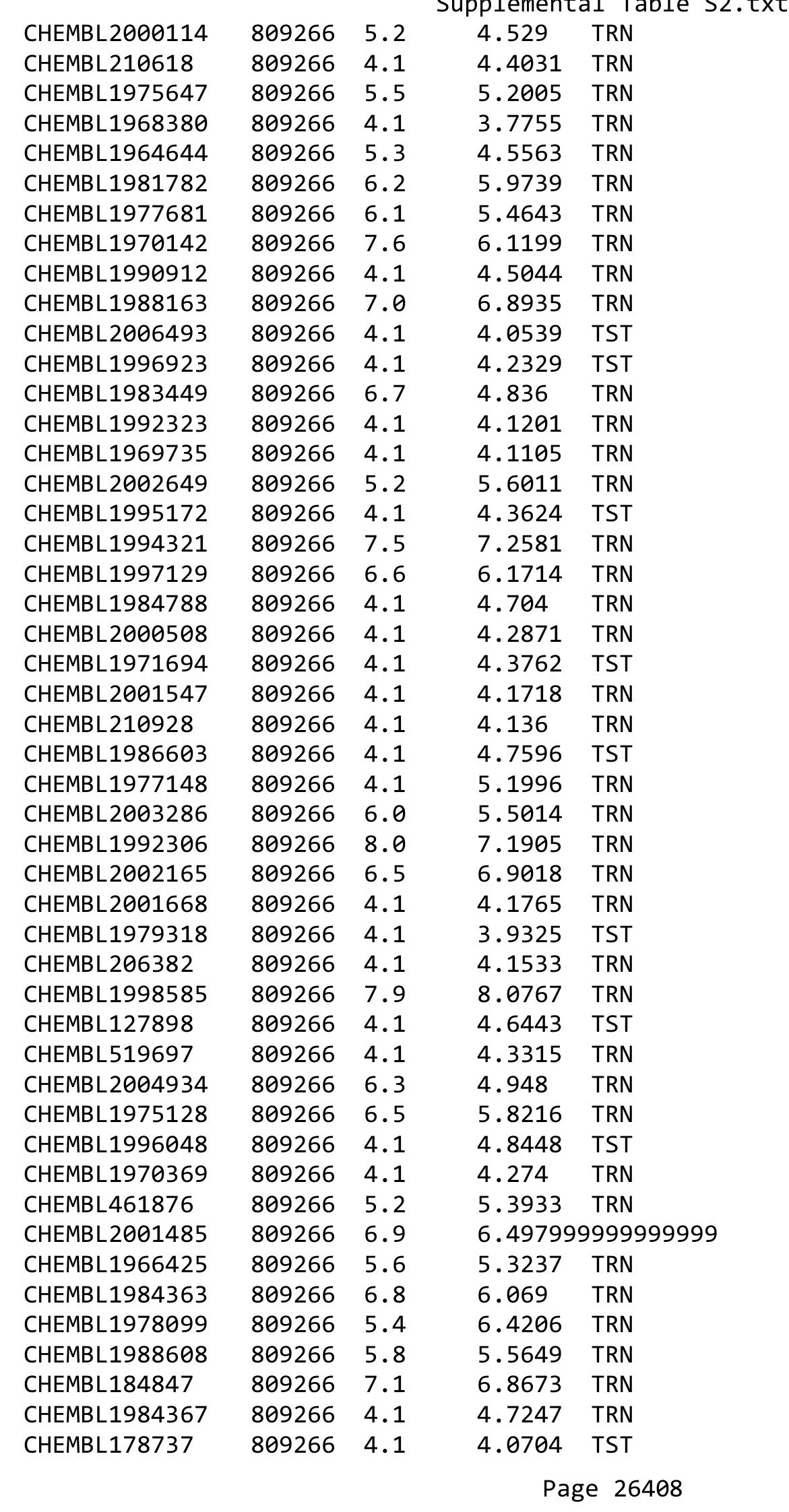




\begin{tabular}{|c|c|c|c|c|}
\hline & & & ipplemen & \\
\hline CHEMBL 226898 & 809266 & 7.6 & 6.09 & TRN \\
\hline CHEMBL1982563 & 809266 & 4.1 & 4.1793 & TRN \\
\hline CHEMBL539474 & 809266 & 4.1 & 5.2136 & TST \\
\hline CHEMBL575824 & 809266 & 5.7 & 4.7106 & TRN \\
\hline CHEMBL1988387 & 809266 & 8.0 & 7.7546 & TRN \\
\hline CHEMBL1974803 & 809266 & 5.9 & 4.9838 & TRN \\
\hline CHEMBL1970074 & 809266 & 7.8 & 7.0774 & TRN \\
\hline CHEMBL1825138 & 809266 & 4.1 & 4.8148 & TST \\
\hline CHEMBL1986970 & 809266 & 4.1 & 4.8176 & TRN \\
\hline CHEMBL2005112 & 809266 & 4.1 & 4.8136 & TST \\
\hline CHEMBL1958401 & 809266 & 6.1 & 5.3772 & TRN \\
\hline CHEMBL1984044 & 809266 & 4.1 & 4.3525 & TRN \\
\hline CHEMBL 2003456 & 809266 & 4.1 & 4.4577 & TRN \\
\hline CHEMBL1966816 & 809266 & 7.5 & 5.9827 & TRN \\
\hline CHEMBL1972584 & 809266 & 5.3 & 4.9079 & TRN \\
\hline CHEMBL2002992 & 809266 & 4.1 & 5.0308 & TRN \\
\hline CHEMBL560813 & 809266 & 4.1 & 5.3197 & TRN \\
\hline CHEMBL 207253 & 809266 & 4.1 & 3.8268 & TST \\
\hline CHEMBL1990635 & 809266 & 5.3 & 4.5682 & TST \\
\hline CHEMBL1968791 & 809266 & 4.1 & 5.0913 & TRN \\
\hline CHEMBL2002682 & 809266 & 5.5 & 4.5526 & TST \\
\hline CHEMBL1971186 & 809266 & 4.1 & 4.0937 & TRN \\
\hline CHEMBL 2003482 & 809266 & 4.1 & 4.2964 & TRN \\
\hline CHEMBL1973211 & 809266 & 7.7 & 7.7784 & TRN \\
\hline CHEMBL1984700 & 809266 & 4.1 & 4.2765 & TRN \\
\hline CHEMBL1972125 & 809266 & 4.1 & 4.0842 & TRN \\
\hline CHEMBL1461728 & 809266 & 4.1 & 4.6981 & TRN \\
\hline CHEMBL1976134 & 809266 & 6.2 & 4.7456 & TRN \\
\hline CHEMBL1965131 & 809266 & 5.3 & 5.312 & TRN \\
\hline CHEMBL1972158 & 809266 & 5.8 & 5.4276 & TRN \\
\hline CHEMBL2006580 & 809266 & 4.1 & 4.913 & TRN \\
\hline CHEMBL 2006481 & 809266 & 4.1 & 4.1734 & TRN \\
\hline CHEMBL1979855 & 809266 & 4.1 & 4.1043 & TRN \\
\hline CHEMBL1970340 & 809266 & 4.1 & 4.5377 & TRN \\
\hline CHEMBL 2005186 & 809266 & 4.1 & 4.3379 & TRN \\
\hline CHEMBL1995927 & 809266 & 4.1 & 3.9269 & TST \\
\hline CHEMBL1975534 & 809266 & 4.1 & 4.3678 & TRN \\
\hline CHEMBL1993424 & 809266 & 5.9 & 5.9574 & TRN \\
\hline CHEMBL1966703 & 809266 & 4.1 & 4.1039 & TST \\
\hline CHEMBL1969561 & 809266 & 4.1 & 5.0059 & TRN \\
\hline CHEMBL1997023 & 809266 & 4.1 & 4.4019 & TST \\
\hline CHEMBL1964687 & 809266 & 6.5 & 6.6084 & TRN \\
\hline CHEMBL1971943 & 809266 & 4.1 & 5.1383 & TST \\
\hline CHEMBL1974254 & 809266 & 6.6 & 6.2959 & TRN \\
\hline CHEMBL1988537 & 809266 & 4.1 & 4.6818 & TST \\
\hline CHEMBL1969049 & 809266 & 6.4 & 4.8171 & TRN \\
\hline CHEMBL 2005828 & 809266 & 7.3 & 6.5722 & TRN \\
\hline CHEMBL 2002240 & 809266 & 4.1 & 3.9395 & TRN \\
\hline
\end{tabular}




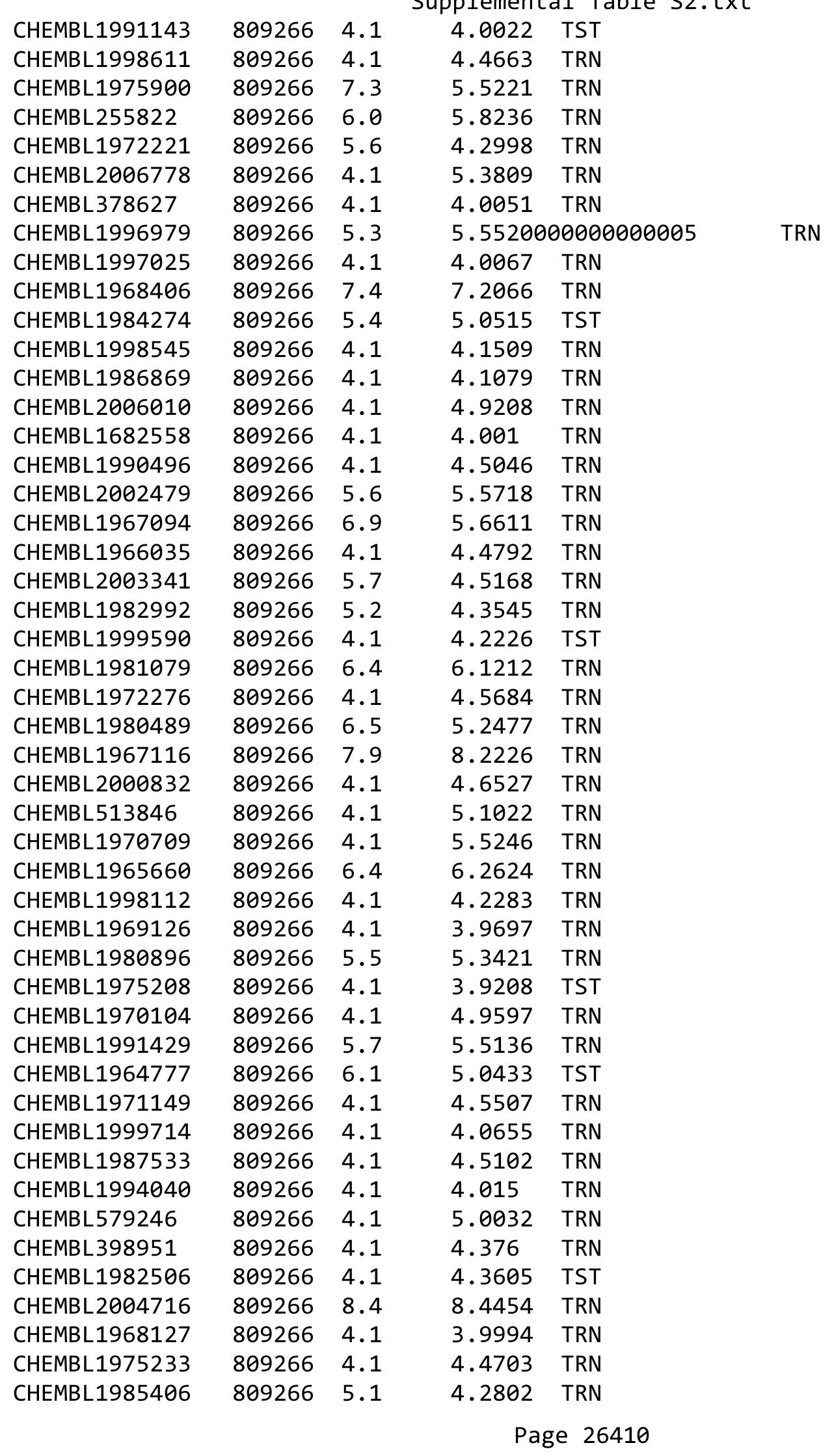




\begin{tabular}{|c|c|c|c|c|}
\hline & & & ipplement & al Table S2. \\
\hline CHEMBL 207400 & 809266 & 4.1 & 3.7297 & TST \\
\hline CHEMBL 2000894 & 809266 & 4.1 & 4.0763 & TST \\
\hline CHEMBL1982135 & 809266 & 5.5 & 5.2148 & TRN \\
\hline CHEMBL1976090 & 809266 & 5.2 & 5.28299 & 99999999995 \\
\hline CHEMBL1993243 & 809266 & 4.1 & 4.7198 & TRN \\
\hline CHEMBL1992922 & 809266 & 4.1 & 4.5895 & TRN \\
\hline CHEMBL 2004771 & 809266 & 4.1 & 5.3211 & TRN \\
\hline CHEMBL1997597 & 809266 & 5.3 & 4.3768 & TRN \\
\hline CHEMBL1969537 & 809266 & 6.0 & 5.1474 & TST \\
\hline CHEMBL1976093 & 809266 & 4.1 & 3.9439 & TRN \\
\hline CHEMBL 210032 & 809266 & 4.1 & 3.8789 & TRN \\
\hline CHEMBL1975256 & 809266 & 4.1 & 4.1519 & TST \\
\hline CHEMBL508928 & 809266 & 6.3 & 7.1729 & TRN \\
\hline CHEMBL1991356 & 809266 & 4.1 & 4.4358 & TRN \\
\hline CHEMBL1983309 & 809266 & 5.8 & 4.6248 & TRN \\
\hline CHEMBL 2004892 & 809266 & 4.1 & 4.178 & TRN \\
\hline CHEMBL1999126 & 809266 & 5.4 & 4.5428 & TST \\
\hline CHEMBL1997503 & 809266 & 4.1 & 4.2102 & TST \\
\hline CHEMBL116070 & 809266 & 6.7 & 4.5648 & TST \\
\hline CHEMBL1990821 & 809266 & 5.6 & 5.0815 & TST \\
\hline CHEMBL1970314 & 809266 & 4.1 & 4.8117 & TRN \\
\hline CHEMBL 2004871 & 809266 & 4.1 & 4.1986 & TRN \\
\hline CHEMBL 2004872 & 809266 & 4.1 & 4.706 & TRN \\
\hline CHEMBL1727312 & 809266 & 4.1 & 3.9048 & TRN \\
\hline CHEMBL1969879 & 809266 & 4.1 & 4.1293 & TRN \\
\hline CHEMBL1981720 & 809266 & 5.6 & 5.4146 & TRN \\
\hline CHEMBL419932 & 809266 & 4.1 & 4.7572 & TRN \\
\hline CHEMBL 262433 & 809266 & 7.0 & 7.2105 & TRN \\
\hline CHEMBL 306380 & 809266 & 4.1 & 4.4012 & TRN \\
\hline CHEMBL1966722 & 809266 & 4.1 & 5.0125 & TRN \\
\hline CHEMBL1975500 & 809266 & 4.1 & 4.3867 & TRN \\
\hline CHEMBL394619 & 809266 & 6.9 & 6.8551 & TRN \\
\hline CHEMBL1996831 & 809266 & 4.1 & 4.1384 & TST \\
\hline CHEMBL411903 & 809266 & 8.3 & 8.3471 & TRN \\
\hline CHEMBL1965988 & 809266 & 7.8 & 7.8757 & TRN \\
\hline CHEMBL418203 & 809266 & 4.1 & 3.9288 & TST \\
\hline CHEMBL1989646 & 809266 & 5.7 & 5.3152 & TRN \\
\hline CHEMBL225519 & 809266 & 6.2 & 5.6441 & TRN \\
\hline CHEMBL1978200 & 809266 & 4.1 & 4.2476 & TRN \\
\hline CHEMBL 2006631 & 809266 & 4.1 & 4.2125 & TRN \\
\hline CHEMBL1970522 & 809266 & 5.3 & 5.6002 & TRN \\
\hline CHEMBL402846 & 809266 & 6.7 & 7.4069 & TRN \\
\hline CHEMBL1990415 & 809266 & 4.1 & 4.1725 & TRN \\
\hline CHEMBL1966087 & 809266 & 4.1 & 3.929 & TRN \\
\hline CHEMBL1996931 & 809266 & 5.1 & 4.4041 & TRN \\
\hline CHEMBL1964413 & 809266 & 4.1 & 4.6983 & TRN \\
\hline CHEMBL1973483 & 809266 & 5.7 & 4.9623 & TRN \\
\hline CHEMBL1970735 & 809266 & 4.1 & 3.8289 & TRN \\
\hline
\end{tabular}




\begin{tabular}{|c|c|c|c|c|c|}
\hline \multirow[b]{2}{*}{ CHEMBL1997340 } & \multirow[b]{2}{*}{809266} & \multirow[b]{2}{*}{4.1} & \\
\hline & & & 4.3657 & TRN & \\
\hline CHEMBL 2004365 & 809266 & 5.2 & 4.1792 & TST & \\
\hline CHEMBL1522508 & 809266 & 4.1 & 3.9873 & TRN & \\
\hline CHEMBL1989474 & 809266 & 4.1 & 4.0208 & TRN & \\
\hline CHEMBL1090360 & 809266 & 6.5 & 5.013 & TRN & \\
\hline CHEMBL210887 & 809266 & 4.1 & 4.0013 & TRN & \\
\hline CHEMBL458997 & 809266 & 7.0 & 6.6974 & TRN & \\
\hline CHEMBL 227271 & 809266 & 5.8 & 6.5326 & TRN & \\
\hline CHEMBL1971021 & 809266 & 5.9 & 6.1417 & TRN & \\
\hline CHEMBL583144 & 809266 & 5.3 & 5.2937 & TRN & \\
\hline CHEMBL1974310 & 809266 & 6.5 & 5.2369 & TST & \\
\hline CHEMBL1982660 & 809266 & 7.3 & 6.3019 & TRN & \\
\hline CHEMBL1994693 & 809266 & 6.3 & 6.0362 & TRN & \\
\hline CHEMBL1982957 & 809266 & 4.1 & 4.7919 & TRN & \\
\hline CHEMBL1725279 & 809266 & 5.7 & 5.5195 & TST & \\
\hline CHEMBL1975138 & 809266 & 4.1 & 4.7369 & TRN & \\
\hline CHEMBL424872 & 809266 & 4.1 & 4.1611 & TRN & \\
\hline CHEMBL 2006836 & 809266 & 4.1 & $3.8960 e$ & 00000000004 & TST \\
\hline CHEMBL412142 & 809266 & 4.1 & 4.1133 & TST & \\
\hline CHEMBL1980704 & 809266 & 4.1 & 4.5247 & TST & \\
\hline CHEMBL 2003271 & 809266 & 5.6 & 5.5856 & TRN & \\
\hline CHEMBL1966808 & 809266 & 5.9 & 4.6748 & TST & \\
\hline CHEMBL 2004447 & 809266 & 4.1 & 3.9155 & TST & \\
\hline CHEMBL1983111 & 809266 & 5.2 & 6.278 & TST & \\
\hline CHEMBL1973860 & 809266 & 4.1 & 4.329 & TRN & \\
\hline CHEMBL1977713 & 809266 & 4.1 & 4.7572 & TRN & \\
\hline CHEMBL260135 & 809266 & 4.1 & 3.92199 & 99999999997 & TRN \\
\hline CHEMBL 220241 & 809266 & 5.3 & 6.0137 & TRN & \\
\hline CHEMBL 2004544 & 809266 & 4.1 & 4.7397 & TST & \\
\hline CHEMBL1982610 & 809266 & 4.1 & 4.2826 & TRN & \\
\hline CHEMBL1999496 & 809266 & 4.1 & 4.4381 & TRN & \\
\hline CHEMBL1988300 & 809266 & 4.1 & 4.1592 & TRN & \\
\hline CHEMBL1991078 & 809266 & 6.0 & 6.5242 & TRN & \\
\hline CHEMBL1987359 & 809266 & 4.1 & 4.4891 & TST & \\
\hline CHEMBL1989265 & 809266 & 4.1 & 3.5668 & TST & \\
\hline CHEMBL 2004647 & 809266 & 4.1 & 4.3552 & TST & \\
\hline CHEMBL1969502 & 809266 & 6.0 & 5.2263 & TRN & \\
\hline CHEMBL1682553 & 809266 & 5.5 & 5.1794 & TRN & \\
\hline CHEMBL1971430 & 809266 & 4.1 & 4.4748 & TRN & \\
\hline CHEMBL1997764 & 809266 & 5.4 & 4.1716 & TRN & \\
\hline CHEMBL1983963 & 809266 & 7.1 & 6.8337 & TRN & \\
\hline CHEMBL1985092 & 809266 & 5.7 & 5.2664 & TST & \\
\hline CHEMBL2004692 & 809266 & 4.1 & 4.0666 & TST & \\
\hline CHEMBL1981410 & 809266 & 6.3 & $6.6320 e$ & 0000000001 & TRN \\
\hline CHEMBL1996234 & 809266 & 4.1 & 3.8332 & TRN & \\
\hline CHEMBL1991434 & 809266 & 4.1 & 4.1511 & TRN & \\
\hline CHEMBL1967544 & 809266 & 4.1 & 4.6441 & TRN & \\
\hline CHEMBL223367 & 809266 & 4.1 & 4.4603 & TST & \\
\hline & & & & 26412 & \\
\hline
\end{tabular}




\begin{tabular}{|c|c|c|c|c|}
\hline & & & Supplement & \\
\hline CHEMBL340384 & 809266 & 5.6 & 4.6856 & TST \\
\hline CHEMBL1996587 & 809266 & 4.1 & 3.6972 & TRN \\
\hline CHEMBL1964804 & 809266 & 5.6 & 5.4081 & TRN \\
\hline CHEMBL443962 & 809266 & 4.1 & 4.5367 & TST \\
\hline CHEMBL 2000354 & 809266 & 5.9 & 5.9741 & TRN \\
\hline CHEMBL1965507 & 809266 & 6.3 & 6.1781 & TRN \\
\hline CHEMBL274064 & 809266 & 4.1 & 3.9694 & TRN \\
\hline CHEMBL1967564 & 809266 & 4.1 & 4.2733 & TRN \\
\hline CHEMBL592030 & 809266 & 6.3 & 5.6074 & TST \\
\hline CHEMBL 2000071 & 809266 & 4.1 & 5.0847 & TRN \\
\hline CHEMBL1979176 & 809266 & 5.7 & 5.4918 & TRN \\
\hline CHEMBL 2000408 & 809266 & 4.1 & 4.2246 & TRN \\
\hline CHEMBL248757 & 809266 & 4.1 & 3.8431 & TST \\
\hline CHEMBL1978014 & 809266 & 4.1 & 4.3226 & TRN \\
\hline CHEMBL1994538 & 809266 & 4.1 & 4.619 & TRN \\
\hline CHEMBL1983195 & 809266 & 4.1 & 4.6486 & TST \\
\hline CHEMBL1975490 & 809266 & 5.6 & 5.5453 & TRN \\
\hline CHEMBL1964444 & 809266 & 6.6 & 5.2842 & TRN \\
\hline CHEMBL1989957 & 809266 & 4.1 & 4.2635 & TRN \\
\hline CHEMBL1986139 & 809266 & 5.2 & 4.5981 & TRN \\
\hline CHEMBL1980540 & 809266 & 7.1 & 4.8415 & TRN \\
\hline CHEMBL1979883 & 809266 & 7.7 & 7.972 & TRN \\
\hline CHEMBL1984162 & 809266 & 8.0 & 6.8699 & TRN \\
\hline CHEMBL491758 & 809266 & 5.2 & 5.4852 & TRN \\
\hline CHEMBL86066 & 809266 & 5.7 & 4.3297 & TST \\
\hline CHEMBL549730 & 809266 & 4.1 & 4.6629 & TRN \\
\hline CHEMBL1970189 & 809266 & 4.1 & 3.7844 & TST \\
\hline CHEMBL1996791 & 809266 & 4.1 & 3.7771 & TRN \\
\hline CHEMBL371206 & 809266 & 8.0 & 7.8426 & TRN \\
\hline CHEMBL1974664 & 809266 & 4.1 & 4.356 & TRN \\
\hline CHEMBL1974288 & 809266 & 4.1 & 4.5216 & TRN \\
\hline CHEMBL196363 & 809266 & 7.2 & 6.9594 & TRN \\
\hline CHEMBL1190711 & 809266 & 5.2 & 5.5033 & TRN \\
\hline CHEMBL205526 & 809266 & 5.1 & 4.713 & TST \\
\hline CHEMBL1968705 & 809266 & 5.3 & 5.0789 & TRN \\
\hline CHEMBL404367 & 809266 & 7.0 & 7.2889 & TRN \\
\hline CHEMBL1966343 & 809266 & 5.2 & 4.9524 & TRN \\
\hline CHEMBL1967887 & 809266 & 4.1 & 4.4058 & TRN \\
\hline CHEMBL2000568 & 809266 & 4.1 & 4.2323 & TRN \\
\hline CHEMBL 2000335 & 809266 & 8.4 & 7.9517 & TRN \\
\hline CHEMBL1977604 & 809266 & 4.1 & 3.7186 & TST \\
\hline CHEMBL1988717 & 809266 & 7.9 & 7.0582 & TRN \\
\hline CHEMBL1974328 & 809266 & 5.3 & 5.3053 & TRN \\
\hline CHEMBL509032 & 809266 & 5.0 & 5.6481 & TRN \\
\hline CHEMBL573339 & 809266 & 4.1 & 4.5304 & TRN \\
\hline CHEMBL1973808 & 809266 & 4.1 & 4.4414 & TRN \\
\hline CHEMBL 2000429 & 809266 & 4.1 & 4.2228 & TRN \\
\hline CHEMBL1972576 & 809266 & 4.1 & 5.8142 & TRN \\
\hline
\end{tabular}




\begin{tabular}{|c|c|c|c|c|}
\hline & & & - EIIIC & \\
\hline CHEMBL1992555 & 809266 & 4.1 & 3.9217 & TRN \\
\hline CHEMBL1992342 & 809266 & 5.2 & 4.4169 & TRN \\
\hline CHEMBL1988173 & 809266 & 6.1 & 5.6488 & TRN \\
\hline CHEMBL1164265 & 809266 & 4.1 & 4.7353 & TST \\
\hline CHEMBL535331 & 809266 & 4.1 & 4.3321 & TRN \\
\hline CHEMBL1989805 & 809266 & 4.1 & 3.6619 & TST \\
\hline CHEMBL1965423 & 809266 & 4.1 & 4.1792 & TRN \\
\hline CHEMBL1982980 & 809266 & 5.8 & 4.993 & TST \\
\hline CHEMBL1983025 & 809266 & 7.1 & 7.6002 & TRN \\
\hline CHEMBL205415 & 809266 & 5.4 & 5.5657 & TRN \\
\hline CHEMBL1977135 & 809266 & 4.1 & 4.5293 & TRN \\
\hline CHEMBL 2001920 & 809266 & 6.2 & 5.2809 & TRN \\
\hline CHEMBL1241473 & 809266 & 6.1 & 6.8104 & TRN \\
\hline CHEMBL1978448 & 809266 & 6.3 & 5.4213 & TST \\
\hline CHEMBL 2004513 & 809266 & 4.1 & 4.6475 & TRN \\
\hline CHEMBL1972258 & 809266 & 4.1 & 4.2579 & TRN \\
\hline CHEMBL 2001257 & 809266 & 7.4 & 7.7853 & TRN \\
\hline CHEMBL1992536 & 809266 & 4.1 & 4.4847 & TRN \\
\hline CHEMBL1987793 & 809266 & 5.8 & 5.4113 & TST \\
\hline CHEMBL1992740 & 809266 & 4.1 & 5.0864 & TRN \\
\hline CHEMBL439340 & 809266 & 4.1 & 4.08 & TRN \\
\hline CHEMBL 2002373 & 809266 & 4.1 & 4.1402 & TRN \\
\hline CHEMBL 2006188 & 809266 & 4.1 & 4.8044 & TRN \\
\hline CHEMBL1967531 & 809266 & 6.9 & 7.0586 & TRN \\
\hline CHEMBL1970913 & 809266 & 4.1 & 4.0467 & TRN \\
\hline CHEMBL1973893 & 809266 & 5.6 & 4.2066 & TRN \\
\hline CHEMBL1995736 & 809266 & 4.1 & 4.14 & TRN \\
\hline CHEMBL1997534 & 809266 & 4.1 & 4.8056 & TRN \\
\hline CHEMBL1996500 & 809266 & 4.1 & 4.2973 & TRN \\
\hline CHEMBL1985095 & 809266 & 4.1 & 5.3622 & TST \\
\hline CHEMBL1998551 & 809266 & 4.1 & 3.7661 & TRN \\
\hline CHEMBL1977374 & 809266 & 4.1 & 3.7695 & TRN \\
\hline CHEMBL1682540 & 809266 & 4.1 & 4.8774 & TRN \\
\hline CHEMBL1976420 & 809266 & 4.1 & 3.6229 & TST \\
\hline CHEMBL1994864 & 809266 & 6.2 & 5.1078 & TRN \\
\hline CHEMBL 2002446 & 809266 & 5.2 & 4.8596 & TRN \\
\hline CHEMBL497151 & 809266 & 7.9 & 5.5039 & TST \\
\hline CHEMBL1973961 & 809266 & 4.1 & 4.5382 & TRN \\
\hline CHEMBL246970 & 809266 & 4.1 & 4.6989 & TRN \\
\hline CHEMBL340921 & 809266 & 4.1 & 3.9286 & TST \\
\hline CHEMBL1999718 & 809266 & 4.1 & 4.6408 & TRN \\
\hline CHEMBL1276446 & 809266 & 5.7 & 6.8078 & TST \\
\hline CHEMBL1977346 & 809266 & 4.1 & 4.5673 & TRN \\
\hline CHEMBL1971649 & 809266 & 4.1 & 5.7004 & TRN \\
\hline CHEMBL1998435 & 809266 & 4.1 & 4.4361 & TRN \\
\hline CHEMBL 2006439 & 809266 & 5.9 & 5.9276 & TRN \\
\hline CHEMBL 2006156 & 809266 & 5.6 & 5.0208 & TST \\
\hline CHEMBL1969190 & 809266 & 6.8 & 7.5211 & TRN \\
\hline
\end{tabular}




\begin{tabular}{|c|c|c|c|c|c|}
\hline & & & & & \\
\hline CHEMBL1973937 & 809266 & 7.5 & 6.7883 & TRN & \\
\hline CHEMBL1991674 & 809266 & 6.0 & 6.1156 & TRN & \\
\hline CHEMBL1982711 & 809266 & 6.2 & 6.2744 & TRN & \\
\hline CHEMBL1987982 & 809266 & 4.1 & 4.5134 & TST & \\
\hline CHEMBL 2007044 & 809266 & 4.1 & 4.4642 & TRN & \\
\hline CHEMBL1994241 & 809266 & 5.9 & 5.3508 & TST & \\
\hline CHEMBL 223460 & 809266 & 4.1 & 3.9791 & TST & \\
\hline CHEMBL1998829 & 809266 & 4.1 & 4.0515 & TRN & \\
\hline CHEMBL50894 & 809266 & 4.1 & 3.5946 & TST & \\
\hline CHEMBL1988838 & 809266 & 6.0 & 6.7331 & TRN & \\
\hline CHEMBL1981725 & 809266 & 7.6 & 6.2571 & TRN & \\
\hline CHEMBL1982866 & 809266 & 4.1 & 4.0672 & TRN & \\
\hline CHEMBL1968926 & 809266 & 4.1 & 4.2107 & TRN & \\
\hline CHEMBL462120 & 809266 & 4.1 & 4.101 & TRN & \\
\hline CHEMBL1965570 & 809266 & 6.5 & 6.8371 & TRN & \\
\hline CHEMBL 2007592 & 809266 & 4.1 & 4.5492 & TST & \\
\hline CHEMBL 210963 & 809266 & 4.1 & 4.01399 & 9999999999 & TRN \\
\hline CHEMBL1082440 & 809266 & 4.1 & 4.4382 & TST & \\
\hline CHEMBL1614705 & 809266 & 4.1 & 4.2506 & TRN & \\
\hline CHEMBL1984633 & 809266 & 4.1 & 5.0792 & TRN & \\
\hline CHEMBL 2007372 & 809266 & 4.1 & 4.0087 & TRN & \\
\hline CHEMBL1965845 & 809266 & 6.0 & 6.6848 & TRN & \\
\hline CHEMBL 2006715 & 809266 & 5.7 & 5.1236 & TRN & \\
\hline CHEMBL1986597 & 809266 & 4.1 & 4.9193 & TRN & \\
\hline CHEMBL1990482 & 809266 & 4.1 & 4.7601 & TRN & \\
\hline CHEMBL1990904 & 809266 & 4.1 & 3.9382 & TRN & \\
\hline CHEMBL 2005475 & 809266 & 6.6 & 5.2886 & TRN & \\
\hline CHEMBL183844 & 809266 & 4.1 & 5.4335 & TRN & \\
\hline CHEMBL1997349 & 809266 & 5.6 & 4.7507 & TST & \\
\hline CHEMBL 220057 & 809266 & 7.0 & 6.8378 & TRN & \\
\hline CHEMBL1682545 & 809266 & 4.1 & 5.0074 & TRN & \\
\hline CHEMBL 383541 & 809266 & 5.4 & 4.9028 & TRN & \\
\hline CHEMBL 2001224 & 809266 & 4.1 & 4.4401 & TRN & \\
\hline CHEMBL10 & 809266 & 4.1 & 4.1407 & TRN & \\
\hline CHEMBL1976732 & 809266 & 4.1 & 3.7321 & TRN & \\
\hline CHEMBL1964937 & 809266 & 5.4 & 5.8665 & TRN & \\
\hline CHEMBL1969506 & 809266 & 4.1 & 4.4115 & TRN & \\
\hline CHEMBL1980163 & 809266 & 4.1 & 4.6025 & TRN & \\
\hline CHEMBL2005899 & 809266 & 4.1 & 4.794 & TRN & \\
\hline CHEMBL1682552 & 809266 & 5.6 & 5.1337 & TRN & \\
\hline CHEMBL1972568 & 809266 & 4.1 & 4.3799 & TRN & \\
\hline CHEMBL229799 & 809266 & 5.8 & 6.5069 & TRN & \\
\hline CHEMBL105739 & 809266 & 4.1 & 4.3569 & TRN & \\
\hline CHEMBL 379300 & 809266 & 6.3 & 6.1889 & TRN & \\
\hline CHEMBL1969523 & 809266 & 6.3 & 5.9035 & TRN & \\
\hline CHEMBL1988995 & 809266 & 4.1 & 3.7165 & TRN & \\
\hline CHEMBL1986781 & 809266 & 4.1 & 3.9137 & TRN & \\
\hline CHEMBL526133 & 809266 & 5.8 & $5.9110 e$ & 00000000005 & TRN \\
\hline & & & & 26415 & \\
\hline
\end{tabular}




\begin{tabular}{|c|c|c|c|c|c|}
\hline \multicolumn{6}{|c|}{ Supplemental Table s2.txt } \\
\hline CHEMBL387971 & 809266 & 4.1 & 4.1943 & TRN & \\
\hline CHEMBL1979057 & 809266 & 6.8 & 5.2951 & TRN & \\
\hline CHEMBL1999428 & 809266 & 4.1 & 4.6937 & TRN & \\
\hline CHEMBL1967560 & 809266 & 4.1 & 3.9202 & TRN & \\
\hline CHEMBL 211378 & 809266 & 6.6 & 5.9834 & TRN & \\
\hline CHEMBL1516890 & 809266 & 5.6 & 4.933 & TRN & \\
\hline CHEMBL1982465 & 809266 & 7.1 & 7.1316 & TRN & \\
\hline CHEMBL 2001751 & 809266 & 7.2 & 6.2166 & TRN & \\
\hline CHEMBL 2003420 & 809266 & 4.1 & 4.5714 & TRN & \\
\hline CHEMBL1984586 & 809266 & 6.2 & 6.45299 & 9999999999 & TRN \\
\hline CHEMBL1972659 & 809266 & 4.1 & 4.2633 & TST & \\
\hline CHEMBL 272453 & 809266 & 7.9 & 7.7099 & TRN & \\
\hline CHEMBL1970217 & 809266 & 5.9 & 5.0593 & TRN & \\
\hline CHEMBL 2005528 & 809266 & 4.1 & 4.2757 & TST & \\
\hline CHEMBL185569 & 809266 & 5.4 & 5.7189 & TRN & \\
\hline CHEMBL1969843 & 809266 & 4.1 & 4.1355 & TRN & \\
\hline CHEMBL 2007002 & 809266 & 4.1 & 4.7863 & TRN & \\
\hline CHEMBL1987007 & 809266 & 4.1 & 4.4362 & TRN & \\
\hline CHEMBL1969588 & 809266 & 6.4 & 6.0554 & TRN & \\
\hline CHEMBL1984711 & 809266 & 4.1 & 4.7427 & TRN & \\
\hline CHEMBL484390 & 809266 & 4.1 & 4.3259 & TRN & \\
\hline CHEMBL1979252 & 809266 & 6.8 & 5.8118 & TRN & \\
\hline CHEMBL1986499 & 809266 & 4.1 & 4.7639 & TRN & \\
\hline CHEMBL 2004290 & 809266 & 6.5 & 5.6668 & TRN & \\
\hline CHEMBL1972937 & 809266 & 4.1 & 4.9858 & TRN & \\
\hline CHEMBL 2000393 & 809266 & 4.1 & 4.7067 & TST & \\
\hline CHEMBL 2004311 & 809266 & 6.0 & 6.5215 & TRN & \\
\hline CHEMBL1992634 & 809266 & 6.4 & 5.603 & TRN & \\
\hline CHEMBL1242373 & 809266 & 7.1 & 6.7365 & TRN & \\
\hline CHEMBL56543 & 809266 & 5.6 & 4.5195 & TRN & \\
\hline CHEMBL1988075 & 809266 & 6.6 & 7.1828 & TRN & \\
\hline CHEMBL316264 & 809266 & 4.1 & 4.1877 & TRN & \\
\hline CHEMBL1991678 & 809266 & 4.1 & 4.285 & TRN & \\
\hline CHEMBL 2001239 & 809266 & 5.2 & 4.4039 & TST & \\
\hline CHEMBL1988594 & 809266 & 6.1 & 6.0722 & TRN & \\
\hline CHEMBL 2001288 & 809266 & 5.4 & 3.9725 & TRN & \\
\hline CHEMBL1999811 & 809266 & 5.7 & 5.6402 & TST & \\
\hline CHEMBL1985074 & 809266 & 4.1 & 4.5192 & TST & \\
\hline CHEMBL1982874 & 809266 & 4.1 & 4.1571 & TRN & \\
\hline CHEMBL 2000481 & 809266 & 4.1 & 4.8278 & TRN & \\
\hline CHEMBL1991725 & 809266 & 5.3 & 4.7441 & TRN & \\
\hline CHEMBL1992242 & 809266 & 6.0 & 5.2704 & TRN & \\
\hline CHEMBL 2007296 & 809266 & 5.3 & 4.6676 & TRN & \\
\hline CHEMBL396523 & 809266 & 7.7 & 7.3203 & TRN & \\
\hline CHEMBL 208637 & 809266 & 4.1 & 3.7983 & TRN & \\
\hline CHEMBL1970203 & 809266 & 6.3 & 5.6035 & TRN & \\
\hline CHEMBL1986530 & 809266 & 4.1 & 4.1336 & TST & \\
\hline CHEMBL1999321 & 809266 & 4.1 & 4.6613 & TRN & \\
\hline
\end{tabular}




\begin{tabular}{|c|c|c|c|c|c|}
\hline \multirow[b]{2}{*}{ CHEMBL1968590 } & \multirow[b]{2}{*}{809266} & \\
\hline & & 4.1 & 4.3804 & TRN & \\
\hline CHEMBL 2005375 & 809266 & 4.1 & 3.8141 & TRN & \\
\hline CHEMBL1984191 & 809266 & 4.1 & 4.3513 & TRN & \\
\hline CHEMBL1972183 & 809266 & 4.1 & 4.1896 & TST & \\
\hline CHEMBL1971029 & 809266 & 6.1 & 6.0061 & TRN & \\
\hline CHEMBL394790 & 809266 & 6.9 & 7.65799 & 99999999995 & TRN \\
\hline CHEMBL226471 & 809266 & 4.1 & 4.8609 & TRN & \\
\hline CHEMBL1996111 & 809266 & 4.1 & 4.9532 & TRN & \\
\hline CHEMBL1974702 & 809266 & 4.1 & 5.082 & TRN & \\
\hline CHEMBL1965589 & 809266 & 4.1 & 4.1571 & TRN & \\
\hline CHEMBL1998193 & 809266 & 4.1 & 4.8722 & TRN & \\
\hline CHEMBL474432 & 809266 & 6.0 & 4.8485 & TST & \\
\hline CHEMBL1988153 & 809266 & 6.4 & 4.5478 & TST & \\
\hline CHEMBL1988437 & 809266 & 4.1 & 5.4799 & TST & \\
\hline CHEMBL1998121 & 809266 & 7.0 & 6.5629 & TRN & \\
\hline CHEMBL1979577 & 809266 & 7.9 & 7.9536 & TRN & \\
\hline CHEMBL1991800 & 809266 & 4.1 & 4.0549 & TRN & \\
\hline CHEMBL52387 & 809266 & 5.8 & 4.1701 & TST & \\
\hline CHEMBL379835 & 809266 & 4.1 & 3.753 & TST & \\
\hline CHEMBL1979357 & 809266 & 5.2 & 4.3042 & TRN & \\
\hline CHEMBL1996817 & 809266 & 6.4 & 5.3751 & TRN & \\
\hline CHEMBL3197315 & 809266 & 4.1 & 4.2543 & TST & \\
\hline CHEMBL468280 & 809266 & 4.1 & 4.0489 & TST & \\
\hline CHEMBL1990884 & 809266 & 5.4 & 5.1223 & TRN & \\
\hline CHEMBL 3109278 & 809266 & 5.8 & 5.4695 & TRN & \\
\hline CHEMBL 256835 & 809266 & 4.1 & 4.0061 & TRN & \\
\hline CHEMBL1980142 & 809266 & 4.1 & 4.8242 & TRN & \\
\hline CHEMBL41783 & 809266 & 4.1 & 4.8589 & TRN & \\
\hline CHEMBL 2006276 & 809266 & 4.1 & 5.1738 & TRN & \\
\hline CHEMBL 271381 & 809266 & 7.8 & 7.1535 & TRN & \\
\hline CHEMBL 2006785 & 809266 & 4.1 & 4.513 & TRN & \\
\hline CHEMBL1982466 & 809266 & 8.0 & 7.268 & TRN & \\
\hline CHEMBL1995740 & 809266 & 4.1 & 4.3789 & TRN & \\
\hline CHEMBL234085 & 809266 & 4.1 & 4.1217 & TRN & \\
\hline CHEMBL1995832 & 809266 & 4.1 & 4.379 & TRN & \\
\hline CHEMBL1998414 & 809266 & 4.1 & 4.599 & TRN & \\
\hline CHEMBL1969042 & 809266 & 5.6 & 5.3406 & TST & \\
\hline CHEMBL 2000345 & 809266 & 5.9 & 5.5331 & TST & \\
\hline CHEMBL1999931 & 809266 & 6.9 & 6.7427 & TRN & \\
\hline CHEMBL1375418 & 809266 & 4.1 & 3.7815 & TRN & \\
\hline CHEMBL 2007064 & 809266 & 4.1 & 4.5763 & TRN & \\
\hline CHEMBL1981047 & 809266 & 4.1 & 4.7191 & TRN & \\
\hline CHEMBL229968 & 809266 & 5.6 & 6.1307 & TRN & \\
\hline CHEMBL1976240 & 809266 & 5.5 & 5.2444 & TRN & \\
\hline CHEMBL1979093 & 809266 & 7.4 & 7.99 & TRN & \\
\hline CHEMBL1968151 & 809266 & 4.1 & 4.4858 & TST & \\
\hline CHEMBL1987009 & 809266 & 6.9 & 6.2726 & TRN & \\
\hline CHEMBL379218 & 809266 & 5.9 & 5.8712 & TRN & \\
\hline & & & & 26417 & \\
\hline
\end{tabular}




\begin{tabular}{|c|c|c|c|c|c|}
\hline \multirow{2}{*}{ CHEMBL 2003817} & \multirow{2}{*}{809266} & \\
\hline & & 4.1 & 4.9643 & TRN & \\
\hline CHEMBL1994830 & 809266 & 7.2 & 4.4652 & TST & \\
\hline CHEMBL226403 & 809266 & 4.4 & \multicolumn{2}{|c|}{4.6610000000000005} & TRN \\
\hline CHEMBL 2005631 & 809266 & 7.9 & 7.8174 & TRN & \\
\hline CHEMBL1994938 & 809266 & 4.1 & 4.8353 & TRN & \\
\hline CHEMBL1977223 & 809266 & 6.5 & 5.7031 & TRN & \\
\hline CHEMBL1236126 & 809266 & 4.1 & 4.0076 & TRN & \\
\hline CHEMBL1966279 & 809266 & 4.1 & 4.6414 & TRN & \\
\hline CHEMBL1997846 & 809266 & 5.9 & 5.7361 & TRN & \\
\hline CHEMBL 2004419 & 809266 & 4.1 & 4.1953 & TRN & \\
\hline CHEMBL1972489 & 809266 & 4.1 & 4.1533 & TRN & \\
\hline CHEMBL1994074 & 809266 & 5.2 & 4.6983 & TRN & \\
\hline CHEMBL1992937 & 809266 & 5.5 & 5.4126 & TRN & \\
\hline CHEMBL1972119 & 809266 & 6.7 & 4.5508 & TRN & \\
\hline CHEMBL1090356 & 809266 & 5.4 & 5.1324 & TRN & \\
\hline CHEMBL95692 & 809266 & 4.1 & 3.8913 & TRN & \\
\hline CHEMBL1986328 & 809266 & 4.1 & 4.4988 & TST & \\
\hline CHEMBL1976455 & 809266 & 6.5 & 6.2042 & TRN & \\
\hline CHEMBL1983923 & 809266 & 5.4 & 4.9224 & TST & \\
\hline CHEMBL1982361 & 809266 & 6.4 & 5.3354 & TRN & \\
\hline CHEMBL1983534 & 809266 & 5.8 & 5.2108 & TRN & \\
\hline CHEMBL1982122 & 809266 & 6.4 & 5.465 & TRN & \\
\hline CHEMBL 2000801 & 809266 & 7.2 & 5.4231 & TRN & \\
\hline CHEMBL1999112 & 809266 & 5.5 & 3.8698 & TST & \\
\hline CHEMBL1682546 & 809266 & 4.1 & 4.8521 & TRN & \\
\hline CHEMBL1991395 & 809266 & 4.1 & 3.978 & TRN & \\
\hline CHEMBL1971245 & 809266 & 4.1 & 4.9433 & TRN & \\
\hline CHEMBL1972142 & 809266 & 6.6 & 4.6524 & TRN & \\
\hline CHEMBL1966514 & 809266 & 6.6 & 6.5387 & TRN & \\
\hline CHEMBL 2003638 & 809266 & 6.3 & 6.5904 & TRN & \\
\hline CHEMBL1996066 & 809266 & 4.1 & 5.1218 & TST & \\
\hline CHEMBL1993722 & 809266 & 5.7 & 5.4795 & TRN & \\
\hline CHEMBL1970806 & 809266 & 4.1 & 4.0021 & TST & \\
\hline CHEMBL1375640 & 809266 & 6.4 & 5.0285 & TST & \\
\hline CHEMBL1979970 & 809266 & 4.1 & 4.6202 & TST & \\
\hline CHEMBL 249282 & 809266 & 4.1 & 4.4551 & TST & \\
\hline CHEMBL 2006237 & 809266 & 4.1 & 4.2518 & TST & \\
\hline CHEMBL1967720 & 809266 & 6.3 & 6.9429 & TST & \\
\hline CHEMBL1572266 & 809266 & 4.1 & 4.0871 & TST & \\
\hline CHEMBL1991138 & 809266 & 4.1 & 4.4219 & TST & \\
\hline CHEMBL1969755 & 809266 & 4.1 & 4.2904 & TST & \\
\hline CHEMBL1979516 & 809266 & 6.4 & 7.1546 & TST & \\
\hline CHEMBL1605605 & 809266 & 4.1 & 4.4671 & TST & \\
\hline CHEMBL1972820 & 809266 & 5.2 & 4.0418 & TST & \\
\hline CHEMBL1996208 & 809266 & 4.1 & 4.2409 & TST & \\
\hline CHEMBL1989029 & 809266 & 5.6 & 4.7887 & TST & \\
\hline CHEMBL392642 & 809266 & 4.1 & 4.5585 & TST & \\
\hline CHEMBL514499 & 809266 & 4.1 & 4.55699 & 99999999995 & TST \\
\hline & & & & 26418 & \\
\hline
\end{tabular}




\begin{tabular}{|c|c|c|c|c|}
\hline & & & pplement & al $\mathrm{Ta}$ \\
\hline CHEMBL1965631 & 809266 & 5.5 & 5.2571 & TST \\
\hline CHEMBL1980144 & 809266 & 4.1 & 5.2062 & TST \\
\hline CHEMBL1991188 & 809266 & 4.1 & 4.9249 & TST \\
\hline CHEMBL1972849 & 809266 & 4.1 & 3.7086 & TST \\
\hline CHEMBL377408 & 809266 & 4.1 & 4.2558 & TST \\
\hline CHEMBL231209 & 809266 & 6.4 & 6.6707 & TST \\
\hline CHEMBL1975357 & 809266 & 4.1 & 4.0986 & TST \\
\hline CHEMBL1976220 & 809266 & 7.4 & 7.2414 & TST \\
\hline CHEMBL259922 & 809266 & 4.1 & 4.7418 & TST \\
\hline CHEMBL1997617 & 809266 & 4.1 & 5.1812 & TST \\
\hline CHEMBL1982383 & 809266 & 4.1 & 4.2794 & TST \\
\hline CHEMBL1969301 & 809266 & 4.1 & 4.3544 & TST \\
\hline CHEMBL17370 & 809266 & 4.1 & 4.2331 & TST \\
\hline CHEMBL1987910 & 809266 & 5.2 & 5.5383 & TST \\
\hline CHEMBL1983932 & 809266 & 8.1 & 7.1142 & TST \\
\hline CHEMBL1997822 & 809266 & 4.1 & 4.7 & TST \\
\hline CHEMBL1991285 & 809266 & 4.1 & 4.1329 & TST \\
\hline CHEMBL1984038 & 809266 & 4.1 & 4.3383 & TST \\
\hline CHEMBL243088 & 809266 & 6.8 & 6.9778 & TST \\
\hline CHEMBL1993661 & 809266 & 5.6 & 6.0676 & TST \\
\hline CHEMBL1974416 & 809266 & 4.1 & 4.7189 & TST \\
\hline CHEMBL2004615 & 809266 & 6.0 & 4.9953 & TST \\
\hline CHEMBL1984039 & 809266 & 4.1 & 5.0707 & TST \\
\hline CHEMBL1997872 & 809266 & 4.1 & 3.8688 & TST \\
\hline CHEMBL180127 & 955065 & 4.6317 & 4.6325 & TRN \\
\hline CHEMBL213100 & 955065 & 4.2331 & 4.2345 & TRN \\
\hline CHEMBL 3392440 & 955065 & 5.8878 & 5.8866 & TRN \\
\hline CHEMBL1404918 & 955065 & 3.2128 & 3.213 & TRN \\
\hline CHEMBL2363137 & 955065 & 5.2815 & 5.2826 & TRN \\
\hline CHEMBL1256459 & 955065 & 7.1552 & 7.1545 & TRN \\
\hline CHEMBL379300 & 955065 & 7.2385 & 7.2348 & TRN \\
\hline CHEMBL472940 & 955065 & 5.0379 & 5.0359 & TRN \\
\hline CHEMBL300389 & 955065 & 7.3655 & 7.3658 & TRN \\
\hline CHEMBL222102 & 955065 & 4.544 & 4.5497 & TRN \\
\hline CHEMBL258844 & 955065 & 4.8408 & 4.8427 & TRN \\
\hline CHEMBL1357247 & 955065 & 3.5464 & 3.5475 & TRN \\
\hline CHEMBL202721 & 955065 & 6.0989 & 6.0978 & TRN \\
\hline CHEMBL1230020 & 955065 & 4.1213 & 4.1178 & TRN \\
\hline CHEMBL3349342 & 955065 & 6.0903 & 6.0913 & TRN \\
\hline CHEMBL2005886 & 955065 & 6.6854 & 6.6862 & TRN \\
\hline CHEMBL577784 & 955065 & 7.4342 & 7.4363 & TRN \\
\hline CHEMBL483849 & 955065 & 3.9667 & 3.9654 & TRN \\
\hline CHEMBL558642 & 955065 & 6.7828 & 6.7814 & TRN \\
\hline CHEMBL1673039 & 955065 & 5.7924 & 5.7917 & TRN \\
\hline CHEMBL189584 & 955065 & 5.1697 & 5.1679 & TRN \\
\hline CHEMBL392695 & 955065 & 6.4195 & 6.4188 & TRN \\
\hline CHEMBL373751 & 955065 & 4.2161 & 4.2253 & TRN \\
\hline CHEMBL1909414 & 955065 & 5.02 & 5.0193 & TRN \\
\hline
\end{tabular}


Supplemental Table S2.txt

\begin{tabular}{|c|c|c|c|c|}
\hline CHEMBL 240954 & 955065 & 4.9307 & 4.6234 & TST \\
\hline CHEMBL 3186408 & 955065 & 4.4977 & 5.0144 & TST \\
\hline CHEMBL514499 & 955065 & 7.5869 & 7.588999 & 99999999995 \\
\hline CHEMBL92309 & 955065 & 3.5584 & 3.7433 & TST \\
\hline CHEMBL449158 & 955065 & 6.7888 & 7.6623 & TST \\
\hline CHEMBL573107 & 955065 & 6.0092 & 6.0108 & TRN \\
\hline CHEMBL1190711 & 955065 & 8.1311 & 8.1315 & TRN \\
\hline CHEMBL1643959 & 955065 & 5.6211 & 5.6185 & TRN \\
\hline CHEMBL379975 & 955065 & 6.0921 & 6.0953 & TRN \\
\hline CHEMBL 2144069 & 955065 & 5.8467 & 5.8453 & TRN \\
\hline CHEMBL 259181 & 955065 & 5.2586 & 5.2567 & TRN \\
\hline CHEMBL1970879 & 955065 & 4.9277 & 4.9248 & TRN \\
\hline CHEMBL65 & 955065 & 9.1513 & 9.1512 & TRN \\
\hline CHEMBL 221137 & 955065 & 3.8662 & 5.8227 & TST \\
\hline CHEMBL512504 & 955065 & 7.6432 & 7.6426 & TRN \\
\hline CHEMBL191334 & 955065 & 6.21299 & 999999999 & 6.2118 \\
\hline CHEMBL412142 & 955065 & 5.0684 & 5.0659 & TRN \\
\hline CHEMBL9470 & 955065 & 6.5628 & 7.0502 & TST \\
\hline CHEMBL192566 & 955065 & 7.9594 & 9.3769 & TST \\
\hline CHEMBL1516890 & 955065 & 6.53 & 6.5298 & TRN \\
\hline CHEMBL188678 & 955065 & 5.6245 & 5.6202 & TRN \\
\hline CHEMBL209148 & 955065 & 5.2305 & 5.2322 & TRN \\
\hline CHEMBL509032 & 955065 & 6.404 & 6.4062 & TRN \\
\hline CHEMBL515416 & 955065 & 5.2821 & 5.2837 & TRN \\
\hline CHEMBL1590308 & 955065 & 4.2171 & 4.4233 & TST \\
\hline CHEMBL102714 & 955065 & 5.5691 & 5.5736 & TRN \\
\hline CHEMBL393929 & 955065 & 4.0677 & 4.0649 & TRN \\
\hline CHEMBL483847 & 955065 & 3.5549 & 3.5514 & TRN \\
\hline CHEMBL 3199475 & 955065 & 3.5433 & 5.9338 & TST \\
\hline CHEMBL1788116 & 955065 & 5.8445 & 5.9698 & TST \\
\hline CHEMBL 210618 & 955065 & 2.9858 & 3.4919 & TST \\
\hline CHEMBL 220241 & 955065 & 6.8565 & 5.1945 & TST \\
\hline CHEMBL1242367 & 955065 & 5.2799 & 5.0107 & TST \\
\hline CHEMBL135561 & 955065 & 4.1511 & 5.6371 & TST \\
\hline CHEMBL585951 & 955065 & 6.2638 & 7.1892 & TST \\
\hline CHEMBL505814 & 493369 & 8.6556 & 8.8233 & TRN \\
\hline CHEMBL509751 & 493369 & 8.8729 & 8.9629 & TRN \\
\hline CHEMBL487378 & 493369 & 6.8697 & 6.8363 & TRN \\
\hline CHEMBL488595 & 493369 & 7.6021 & 7.1331 & TST \\
\hline CHEMBL487377 & 493369 & 7.5391 & 7.5193 & TRN \\
\hline CHEMBL485733 & 493369 & 7.9208 & 7.5403 & TST \\
\hline CHEMBL485754 & 493369 & 7.8069 & 7.834 & TRN \\
\hline CHEMBL519720 & 493369 & 7.2027 & 7.1815 & TRN \\
\hline CHEMBL519214 & 493369 & 7.8125 & 7.7854 & TRN \\
\hline CHEMBL521205 & 493369 & 7.4425 & 7.4688 & TRN \\
\hline CHEMBL520551 & 493369 & 8.6271 & 8.5683 & TRN \\
\hline CHEMBL487178 & 493369 & 8.5607 & 8.6334 & TRN \\
\hline CHEMBL485744 & 493369 & 8.065 & 8.1358 & TST \\
\hline
\end{tabular}




\begin{tabular}{|c|c|c|c|c|c|c|}
\hline & & \multicolumn{5}{|l|}{3} \\
\hline CHEMBL487162 & 493369 & 8.0458 & 8.066 & TRN & & \\
\hline CHEMBL520884 & 493369 & 7.8827 & 7.3658 & TST & & \\
\hline CHEMBL487158 & 493369 & 8.1198 & 8.0662 & TRN & & \\
\hline CHEMBL519400 & 493369 & 7.7167 & 7.7254 & TRN & & \\
\hline CHEMBL487163 & 493369 & 7.7447 & 7.7599 & TRN & & \\
\hline CHEMBL485732 & 493369 & 8.0747 & 8.0686 & TRN & & \\
\hline CHEMBL486154 & 493369 & 8.3161 & 8.3235 & TRN & & \\
\hline CHEMBL487161 & 493369 & 7.9957 & 7.9645 & TRN & & \\
\hline CHEMBL487384 & 493369 & 9.0177 & 9.0228 & TRN & & \\
\hline CHEMBL521513 & 493369 & 8.3206 & 8.3721 & TRN & & \\
\hline CHEMBL487974 & 493369 & 7.983 & 7.2236 & TST & & \\
\hline CHEMBL487170 & 493369 & 7.6498 & 7.6471 & TRN & & \\
\hline CHEMBL521216 & 493369 & 7.7721 & 7.7635 & TRN & & \\
\hline CHEMBL486555 & 493369 & 7.2848 & 7.3011 & TRN & & \\
\hline CHEMBL486972 & 493369 & 7.3401 & 7.3586 & TRN & & \\
\hline CHEMBL486956 & 493369 & 7.9626 & 6.9603 & TST & & \\
\hline CHEMBL487171 & 493369 & 7.684 & 7.6667 & TRN & & \\
\hline CHEMBL520729 & 493369 & 7.7282 & 7.7139 & TRN & & \\
\hline CHEMBL487585 & 493369 & 7.8928 & 7.9062 & TRN & & \\
\hline CHEMBL487773 & 493369 & 8.0691 & 8.2802 & TST & & \\
\hline CHEMBL520392 & 493369 & 7.38200 & 30000000 & $\partial 1$ & 7.3763 & TRN \\
\hline CHEMBL486752 & 493369 & 6.5513 & 6.5435 & TRN & & \\
\hline CHEMBL487583 & 493369 & 7.0273 & 7.0195 & TRN & & \\
\hline CHEMBL520542 & 493369 & 7.475 & 7.4911 & TRN & & \\
\hline CHEMBL488794 & 493369 & 7.1439 & 6.9585 & TST & & \\
\hline CHEMBL487172 & 493369 & 8.2132 & 8.2083 & TRN & & \\
\hline CHEMBL519875 & 493369 & 7.6459 & 7.6289 & TRN & & \\
\hline CHEMBL501851 & 493369 & 9.2441 & 9.0781 & TRN & & \\
\hline CHEMBL486562 & 493369 & 7.8508 & 7.8229 & TRN & & \\
\hline CHEMBL525936 & 493369 & 6.7959 & 7.169 & TST & & \\
\hline CHEMBL486957 & 493369 & 7.82100 & 30000000 & & 6.9415 & TST \\
\hline CHEMBL486343 & 493369 & 6.7077 & 7.4237 & TST & & \\
\hline CHEMBL521382 & 493369 & 7.6882 & 7.6961 & TRN & & \\
\hline CHEMBL486548 & 493369 & 7.8356 & 7.8097 & TRN & & \\
\hline CHEMBL518895 & 493369 & 7.3063 & 7.3214 & TRN & & \\
\hline CHEMBL486958 & 493369 & 7.4989 & 7.3266 & TST & & \\
\hline CHEMBL486549 & 493369 & 7.9586 & 8.0103 & TST & & \\
\hline CHEMBL488786 & 493369 & 8.7033 & 8.5821 & TRN & & \\
\hline CHEMBL485734 & 493369 & 7.5768 & 7.5403 & TST & & \\
\hline CHEMBL487586 & 493369 & 8.4724 & 8.4825 & TRN & & \\
\hline CHEMBL486356 & 493369 & 7.4413 & 7.4694 & TRN & & \\
\hline CHEMBL468425 & 493369 & 8.9626 & 8.8806 & TRN & & \\
\hline CHEMBL485930 & 493369 & 7.015 & 8.0186 & TST & & \\
\hline CHEMBL486973 & 493369 & 6.644 & 6.6596 & TRN & & \\
\hline CHEMBL487381 & 493369 & 9.0315 & 8.9673 & TRN & & \\
\hline CHEMBL485931 & 493369 & 6.2495 & 7.3538 & TST & & \\
\hline CHEMBL485735 & 493369 & 7.644 & 7.8397 & TST & & \\
\hline CHEMBL486756 & 493369 & 8.1824 & 8.1829 & TRN & & \\
\hline
\end{tabular}




\begin{tabular}{|c|c|c|c|c|c|c|}
\hline \multicolumn{7}{|c|}{ Supplemental Table S2.txt } \\
\hline CHEMBL487772 & 493369 & 7.8327 & 7.8341 & TRN & & \\
\hline CHEMBL519731 & 493369 & 7.6126 & 7.6059 & TRN & & \\
\hline CHEMBL487174 & 493369 & 7.4157 & 7.4014 & TRN & & \\
\hline CHEMBL521042 & 493369 & 7.5186 & 7.5368 & TRN & & \\
\hline CHEMBL521054 & 493369 & 4.0 & 3.9998 & TRN & & \\
\hline CHEMBL519078 & 493369 & 6.5421 & 6.511 & TRN & & \\
\hline CHEMBL485753 & 493369 & 7.8327 & 7.8443 & TRN & & \\
\hline CHEMBL519553 & 493369 & 6.9469 & 6.9654 & TRN & & \\
\hline CHEMBL487582 & 493369 & 8.1169 & 8.147 & TRN & & \\
\hline CHEMBL530557 & 493369 & 7.4559 & 6.9688 & TST & & \\
\hline CHEMBL486554 & 493369 & 6.9508 & 8.0089 & TST & & \\
\hline CHEMBL487173 & 493369 & 6.9031 & 6.9345 & TRN & & \\
\hline CHEMBL520401 & 493369 & 7.983 & 7.9749 & TRN & & \\
\hline CHEMBL530339 & 493369 & 8.821 & 8.8628 & TRN & & \\
\hline CHEMBL487380 & 493369 & 8.5513 & 8.6494 & TRN & & \\
\hline CHEMBL549839 & 579304 & 6.6383 & 6.9819 & TRN & & \\
\hline CHEMBL562602 & 579304 & 8.0 & 7.0253 & TRN & & \\
\hline CHEMBL553470 & 579304 & 8.2218 & 8.588 & TRN & & \\
\hline CHEMBL563010 & 579304 & 8.699 & 7.6769 & TRN & & \\
\hline CHEMBL562787 & 579304 & 7.6778 & 8.0446 & TRN & & \\
\hline CHEMBL550918 & 579304 & 7.8539 & 8.1047 & TRN & & \\
\hline CHEMBL550163 & 579304 & 7.5686 & 8.8689 & TST & & \\
\hline CHEMBL551459 & 579304 & 7.8239 & 7.7274 & TRN & & \\
\hline CHEMBL550916 & 579304 & 9.5229 & 9.1692 & TRN & & \\
\hline CHEMBL561784 & 579304 & 7.8239 & 7.8946 & TRN & & \\
\hline CHEMBL556417 & 579304 & 9.301 & 8.9935 & TRN & & \\
\hline CHEMBL551518 & 579304 & 7.7212 & 8.2665 & TRN & & \\
\hline CHEMBL557439 & 579304 & 8.4559 & 8.4545 & TRN & & \\
\hline CHEMBL554520 & 579304 & 8.4685 & 7.7727 & TRN & & \\
\hline CHEMBL550386 & 579304 & 7.699 & 7.9606 & TRN & & \\
\hline CHEMBL540494 & 579304 & 7.301 & 7.4116 & TRN & & \\
\hline CHEMBL564188 & 579304 & 7.9586 & 7.6971 & TRN & & \\
\hline CHEMBL557710 & 579304 & 7.2596 & 7.0291 & TST & & \\
\hline CHEMBL562570 & 579304 & 7.8539 & 8.5758 & TST & & \\
\hline CHEMBL563562 & 579304 & 6.7212 & 7.4463 & TST & & \\
\hline CHEMBL552192 & 579304 & 7.7959 & 8.1802 & TST & & \\
\hline CHEMBL539429 & 579304 & 7.9101 & 8.0163 & TRN & & \\
\hline CHEMBL551661 & 579304 & 6.7447 & 6.7889 & TRN & & \\
\hline CHEMBL565097 & 579304 & 7.7959 & 7.7138 & TST & & \\
\hline CHEMBL558404 & 579304 & 9.0 & 8.2735 & TST & & \\
\hline CHEMBL564061 & 579304 & 7.61799 & 99999999 & 99 & 7.4639999999999995 & TRN \\
\hline CHEMBL549360 & 579304 & 8.1805 & 7.7019 & TRN & & \\
\hline CHEMBL563690 & 579304 & 5.2284 & 5.4092 & TRN & & \\
\hline CHEMBL558116 & 579304 & 8.7212 & 7.7422 & TRN & & \\
\hline CHEMBL558947 & 579304 & 7.699 & 7.227 & TRN & & \\
\hline CHEMBL549428 & 579304 & 7.2676 & 8.1708 & TRN & & \\
\hline CHEMBL557643 & 579304 & 8.2291 & 7.9649 & TRN & & \\
\hline CHEMBL560180 & 579304 & 8.585 & 8.7036 & TRN & & \\
\hline
\end{tabular}




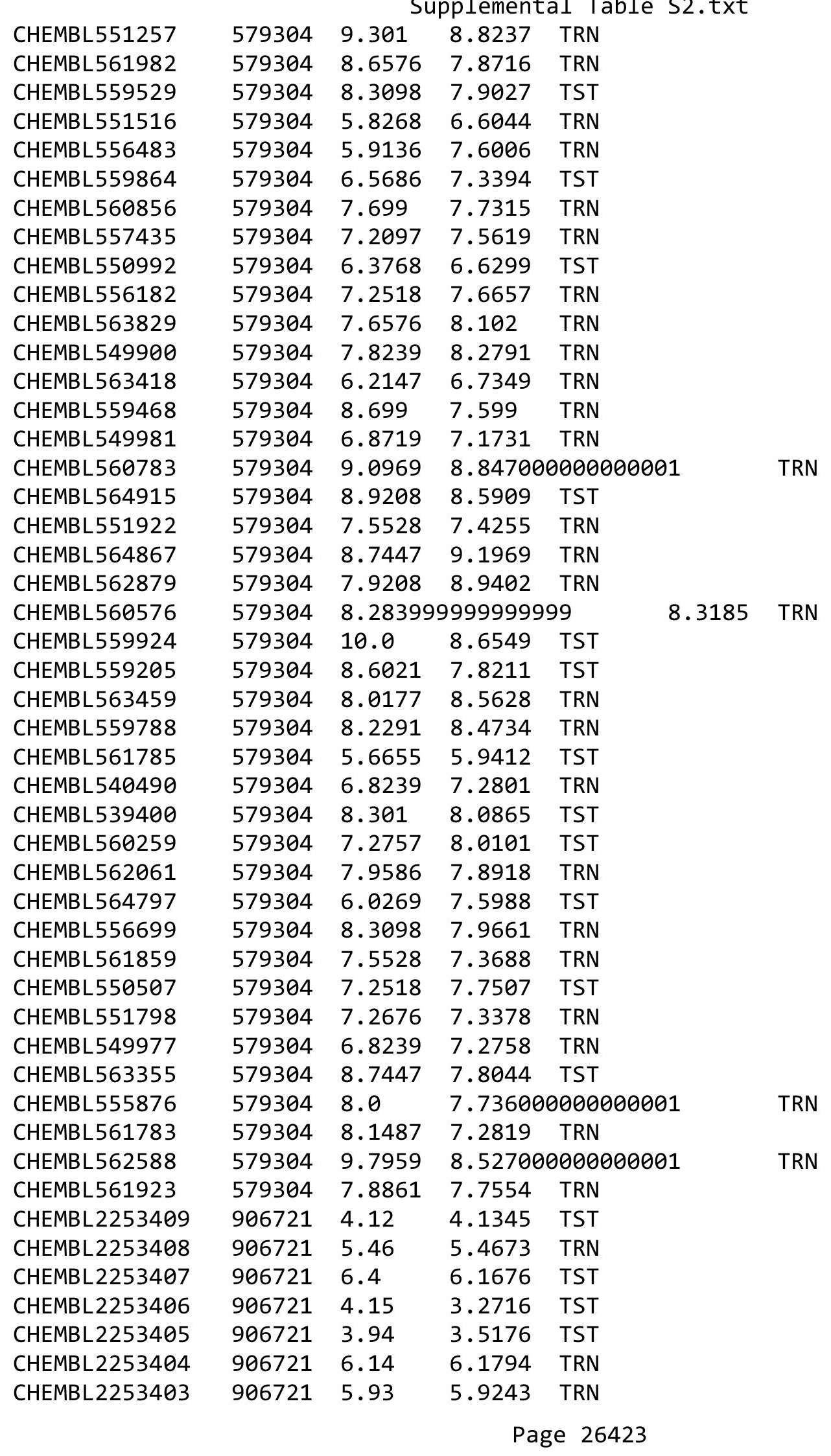




\begin{tabular}{|c|c|c|c|c|}
\hline \multicolumn{5}{|c|}{ Supplemental Table S2.txt } \\
\hline CHEMBL 2253402 & 906721 & 4.08 & 4.0904 & TRN \\
\hline CHEMBL 2227921 & 906721 & 4.31 & 4.2084 & TST \\
\hline CHEMBL 2227920 & 906721 & 5.53 & 5.5804 & TRN \\
\hline CHEMBL 2227919 & 906721 & 6.36 & 6.2481 & TST \\
\hline CHEMBL 2227922 & 906721 & 3.68 & 3.292 & TST \\
\hline CHEMBL 2253424 & 906721 & 4.0 & 3.5499 & TST \\
\hline CHEMBL 2227918 & 906721 & 6.37 & 6.3339 & TRN \\
\hline CHEMBL 2227924 & 906721 & 5.82 & 5.8753 & TRN \\
\hline CHEMBL 2227923 & 906721 & 3.95 & 3.969 & TRN \\
\hline CHEMBL 2253423 & 906721 & 5.87 & 6.0056 & TRN \\
\hline CHEMBL 2253422 & 906721 & 5.91 & 5.8784 & TRN \\
\hline CHEMBL 2253421 & 906721 & 6.11 & 5.9986 & TRN \\
\hline CHEMBL 2253420 & 906721 & 6.02 & 6.0066 & TRN \\
\hline CHEMBL 2253419 & 906721 & 6.05 & 6.1137 & TRN \\
\hline CHEMBL 2253418 & 906721 & 5.99 & 5.9407 & TRN \\
\hline CHEMBL 2253417 & 906721 & 5.88 & 5.8319 & TRN \\
\hline CHEMBL 2253416 & 906721 & 6.04 & 6.0617 & TRN \\
\hline CHEMBL 2253415 & 906721 & 6.02 & 5.9975 & TRN \\
\hline CHEMBL 2253414 & 906721 & 6.24 & 6.314 & TRN \\
\hline CHEMBL 2253413 & 906721 & 6.35 & 6.2781 & TRN \\
\hline CHEMBL 2253412 & 906721 & 5.13 & 4.2868 & TST \\
\hline CHEMBL 2253411 & 906721 & 5.08 & 4.7497 & TST \\
\hline CHEMBL 2253410 & 906721 & 4.84 & 5.5337 & TST \\
\hline CHEMBL 2253443 & 906721 & 5.16 & 5.3372 & TST \\
\hline CHEMBL 2253442 & 906721 & 5.1 & 4.5501 & TST \\
\hline CHEMBL 2253441 & 906721 & 4.14 & 4.1918 & TRN \\
\hline CHEMBL 2253440 & 906721 & 5.59 & 5.5972 & TRN \\
\hline CHEMBL 2253439 & 906721 & 6.45 & 6.3102 & TRN \\
\hline CHEMBL 2253438 & 906721 & 3.64 & 3.4146 & TST \\
\hline CHEMBL 2253437 & 906721 & 4.07 & 3.6896 & TST \\
\hline CHEMBL 2253436 & 906721 & 6.37 & 6.3281 & TRN \\
\hline CHEMBL 2253435 & 906721 & 5.82 & 5.7885 & TRN \\
\hline CHEMBL 2253434 & 906721 & 3.95 & 3.9925 & TRN \\
\hline CHEMBL 2253433 & 906721 & 4.29 & 4.2445 & TRN \\
\hline CHEMBL 2253432 & 906721 & 5.63 & 5.6078 & TRN \\
\hline CHEMBL 2253431 & 906721 & 6.33 & 6.2634 & TRN \\
\hline CHEMBL 2253430 & 906721 & 3.23 & 3.3334 & TRN \\
\hline CHEMBL 2253429 & 906721 & 3.75 & 3.6429 & TRN \\
\hline CHEMBL 2253428 & 906721 & 6.24 & 6.2385 & TRN \\
\hline CHEMBL 2253427 & 906721 & 6.55 & 6.6637 & TRN \\
\hline CHEMBL 2253426 & 906721 & 5.58 & 5.6031 & TRN \\
\hline CHEMBL 2253425 & 906721 & 3.9 & 3.92 & TRN \\
\hline CHEMBL 2253452 & 906721 & 4.06 & 4.0115 & TRN \\
\hline CHEMBL 2253451 & 906721 & 5.44 & 5.4151 & TRN \\
\hline CHEMBL 2253450 & 906721 & 5.42 & 5.67 & TRN \\
\hline CHEMBL 2253449 & 906721 & 3.35 & 3.2767 & TRN \\
\hline CHEMBL 2253448 & 906721 & 3.49 & 3.5466 & TRN \\
\hline CHEMBL 2253447 & 906721 & 6.47 & 6.4198 & TRN \\
\hline
\end{tabular}




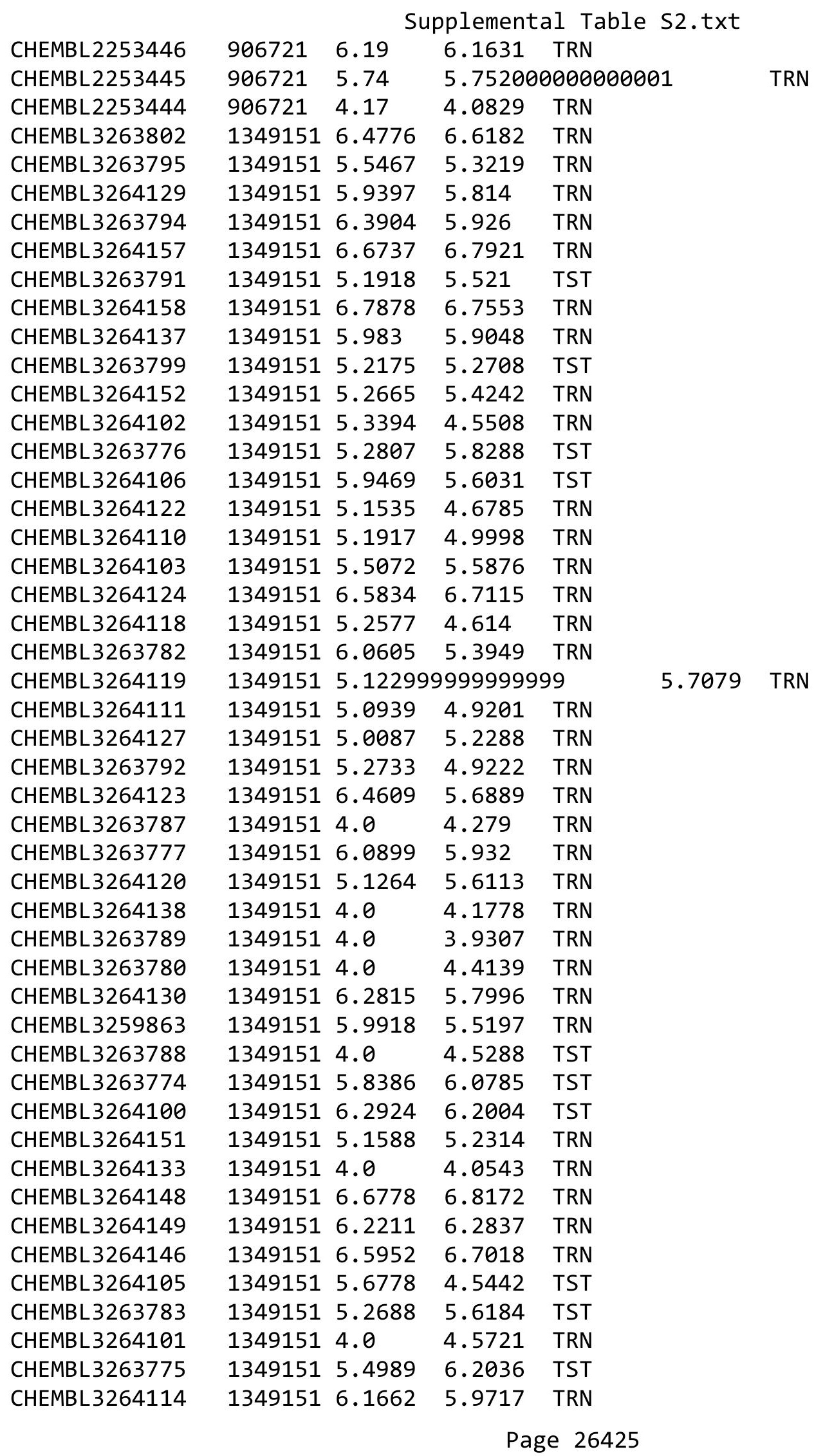


Supplemental Table S2.txt

\begin{tabular}{|c|c|c|c|c|c|}
\hline CHEMBL3263804 & 1349151 & 4.0 & 4.7095 & TRN & \\
\hline CHEMBL3263807 & 1349151 & 6.3098 & 6.2604 & TRN & \\
\hline CHEMBL 3264144 & 1349151 & 6.2366 & 5.7399 & TST & \\
\hline CHEMBL 3264153 & 1349151 & 5.6221 & 6.4081 & TRN & \\
\hline CHEMBL 3263803 & 1349151 & 5.0057 & 4.8881 & TRN & \\
\hline CHEMBL3264109 & 1349151 & 6.2865 & \multicolumn{2}{|c|}{6.2139999999999995} & TRN \\
\hline CHEMBL 3263801 & 1349151 & 5.8365 & 6.0737 & TRN & \\
\hline CHEMBL 3264113 & 1349151 & 6.4855 & 6.0697 & TRN & \\
\hline CHEMBL 3263798 & 1349151 & 5.4157 & 5.0176 & TRN & \\
\hline CHEMBL3263784 & 1349151 & 6.3979 & 5.8551 & TRN & \\
\hline CHEMBL 3264150 & 1349151 & 6.8447 & 6.6972 & TRN & \\
\hline CHEMBL3263779 & 1349151 & 5.3833 & 5.5615 & TRN & \\
\hline CHEMBL 3264107 & 1349151 & 6.7055 & 6.7152 & TRN & \\
\hline CHEMBL 3264104 & 1349151 & 5.2823 & 6.0418 & TRN & \\
\hline CHEMBL 3263781 & 1349151 & 4.0 & 4.658 & TST & \\
\hline CHEMBL 3264142 & 1349151 & 6.3675 & 5.8919 & TST & \\
\hline CHEMBL3263796 & 1349151 & 4.0 & 4.0411 & TRN & \\
\hline CHEMBL 3263797 & 1349151 & 4.0 & 4.317 & TST & \\
\hline CHEMBL 3263790 & 1349151 & 5.7447 & 5.2916 & TRN & \\
\hline CHEMBL 3264121 & 1349151 & 6.4365 & 6.2933 & TRN & \\
\hline CHEMBL 3264108 & 1349151 & 6.5287 & \multicolumn{2}{|c|}{6.617999999999999} & TRN \\
\hline CHEMBL3264115 & 1349151 & 6.129 & 6.3671 & TRN & \\
\hline CHEMBL 3263778 & 1349151 & 5.5147 & 6.1387 & TRN & \\
\hline CHEMBL 3264132 & 1349151 & 4.0 & 4.117 & TRN & \\
\hline CHEMBL 3264155 & 1349151 & 4.0 & 5.3571 & TRN & \\
\hline CHEMBL 3263786 & 1349151 & 5.5086 & \multicolumn{2}{|c|}{5.5120000000000005} & TRN \\
\hline CHEMBL3263806 & 1349151 & 5.8536 & 5.7507 & TST & \\
\hline CHEMBL 3264112 & 1349151 & 4.0 & 4.5003 & TRN & \\
\hline CHEMBL 3264134 & 1349151 & 4.0 & 5.0614 & TRN & \\
\hline CHEMBL3264159 & 1349151 & 6.8477 & 6.7889 & TRN & \\
\hline CHEMBL 3264136 & 1349151 & 5.187 & 5.0663 & TRN & \\
\hline CHEMBL3263805 & 1349151 & 6.4789 & 5.9548 & TRN & \\
\hline CHEMBL3263785 & 1349151 & 5.9281 & 6.0616 & TRN & \\
\hline CHEMBL 3264117 & 1349151 & 5.1094 & 4.6896 & TRN & \\
\hline CHEMBL 3264126 & 1349151 & 4.0 & 4.2011 & TRN & \\
\hline CHEMBL3264128 & 1349151 & 6.3788 & 5.7608 & TRN & \\
\hline CHEMBL3264125 & 1349151 & 6.0747 & 5.9227 & TRN & \\
\hline CHEMBL 3264154 & 1349151 & 6.7305 & 6.6544 & TRN & \\
\hline CHEMBL 3264143 & 1349151 & 5.3872 & 4.2148 & TST & \\
\hline CHEMBL3264116 & 1349151 & 6.1858 & 6.2688 & TRN & \\
\hline CHEMBL3264145 & 1349151 & 5.4789 & 5.0646 & TST & \\
\hline CHEMBL 3264140 & 1349151 & 4.0 & 4.0135 & TRN & \\
\hline CHEMBL3264139 & 1349151 & 5.9914 & 5.7279 & TRN & \\
\hline CHEMBL 3263793 & 1349151 & 6.4437 & 5.6984 & TST & \\
\hline CHEMBL 3264131 & 1349151 & 4.0 & 4.0518 & TST & \\
\hline CHEMBL 3264141 & 1349151 & 4.0 & 5.0443 & TST & \\
\hline CHEMBL3263800 & 1349151 & 5.8268 & 6.0538 & TST & \\
\hline CHEMBL 3264147 & 1349151 & 6.6055 & 6.6788 & TST & \\
\hline
\end{tabular}




\begin{tabular}{|c|c|c|c|c|c|}
\hline \multicolumn{6}{|c|}{ serter } \\
\hline CHEMBL3264156 & 1349151 & 4.0 & 6.4642 & TST & \\
\hline CHEMBL3264135 & 1349151 & 4.0 & 5.1166 & TST & \\
\hline CHEMBL122925 & 105195 & 6.0 & 5.2318 & TST & \\
\hline CHEMBL331308 & 105195 & 3.0 & 3.9125 & TST & \\
\hline CHEMBL333248 & 105195 & 6.9547 & 6.7116 & TST & \\
\hline CHEMBL122868 & 105195 & 4.7959 & 4.7645 & TRN & \\
\hline CHEMBL331342 & 105195 & 8.0458 & 7.9886 & TRN & \\
\hline CHEMBL122109 & 105195 & 4.6383 & 4.75899 & 99999999995 & TST \\
\hline CHEMBL330950 & 105195 & 3.0 & 3.5295 & TST & \\
\hline CHEMBL121501 & 105195 & 4.6198 & 5.1652 & TST & \\
\hline CHEMBL332439 & 105195 & 4.6021 & 4.6838 & TST & \\
\hline CHEMBL332429 & 105195 & 6.9281 & 6.6387 & TST & \\
\hline CHEMBL121559 & 105195 & 4.1938 & 4.1706 & TRN & \\
\hline CHEMBL450327 & 105195 & 7.699 & 7.5857 & TRN & \\
\hline CHEMBL332406 & 105195 & 6.983 & 6.9729 & TRN & \\
\hline CHEMBL 293503 & 105195 & 10.0 & 9.7231 & TRN & \\
\hline CHEMBL333532 & 105195 & 6.9208 & 6.8873 & TRN & \\
\hline CHEMBL122711 & 105195 & 9.0 & 9.1656 & TRN & \\
\hline CHEMBL55110 & 105195 & 8.6198 & 8.7038 & TRN & \\
\hline CHEMBL333122 & 105195 & 4.1192 & 5.2205 & TST & \\
\hline CHEMBL123404 & 105195 & 4.1612 & 4.1723 & TRN & \\
\hline CHEMBL122831 & 105195 & 8.1938 & 8.168 & TRN & \\
\hline CHEMBL332362 & 105195 & 5.8239 & 5.7826 & TRN & \\
\hline CHEMBL332755 & 105195 & 9.0 & 9.085 & TRN & \\
\hline CHEMBL316169 & 105195 & 7.7212 & 7.62299 & 9999999999 & TRN \\
\hline CHEMBL304281 & 105195 & 8.2924 & 8.3133 & TRN & \\
\hline CHEMBL 123775 & 105195 & 9.5229 & 9.4088 & TRN & \\
\hline CHEMBL262676 & 105195 & 8.9586 & 9.0685 & TRN & \\
\hline CHEMBL122836 & 105195 & 8.6383 & 8.5941 & TRN & \\
\hline CHEMBL98328 & 105195 & 6.0 & 4.0507 & TST & \\
\hline CHEMBL332145 & 105195 & 4.1249 & 4.0918 & TRN & \\
\hline CHEMBL440714 & 105195 & 7.5686 & 7.5568 & TRN & \\
\hline CHEMBL332120 & 105195 & 7.7447 & 7.9162 & TRN & \\
\hline CHEMBL331114 & 105195 & 4.7959 & 4.8218 & TRN & \\
\hline CHEMBL 83508 & 105195 & 6.8097 & 6.8478 & TRN & \\
\hline CHEMBL331311 & 105195 & 8.4815 & 8.5945 & TRN & \\
\hline CHEMBL441084 & 105195 & 8.2757 & 8.2538 & TRN & \\
\hline CHEMBL123443 & 105195 & 6.9666 & 6.7974 & TST & \\
\hline CHEMBL 293774 & 105195 & 7.6778 & 7.83899 & 99999999995 & TRN \\
\hline CHEMBL123463 & 105195 & 8.9586 & 8.9289 & TRN & \\
\hline CHEMBL124237 & 105195 & 3.0 & 3.6559 & TST & \\
\hline CHEMBL55310 & 105195 & 4.1308 & 4.1199 & TRN & \\
\hline CHEMBL120934 & 105195 & 4.1487 & 4.2128 & TRN & \\
\hline CHEMBL432223 & 105195 & 8.8861 & 8.8495 & TRN & \\
\hline CHEMBL121729 & 105195 & 4.8239 & 4.797 & TRN & \\
\hline CHEMBL121916 & 105195 & 6.8996 & 6.947 & TRN & \\
\hline CHEMBL331669 & 105195 & 6.9355 & 6.92299 & 9999999999 & TRN \\
\hline CHEMBL82868 & 105195 & 7.5086 & 7.4458 & TRN & \\
\hline
\end{tabular}




\begin{tabular}{|c|c|c|c|c|c|}
\hline \multicolumn{6}{|c|}{ Supplemental Table S2.txt } \\
\hline CHEMBL123064 & 105195 & 4.4437 & 4.7221 & TST & \\
\hline CHEMBL 306726 & 105195 & 8.9586 & 8.9612 & TRN & \\
\hline CHEMBL123041 & 105195 & 8.3098 & 8.293 & TRN & \\
\hline CHEMBL 301469 & 105195 & 4.1549 & 4.1737 & TRN & \\
\hline CHEMBL122719 & 105195 & 8.2596 & 8.3238 & TRN & \\
\hline CHEMBL311336 & 105195 & 7.8861 & 7.82299 & 99999999995 & TRN \\
\hline CHEMBL123105 & 105195 & 4.6778 & 4.7117 & TRN & \\
\hline CHEMBL 333896 & 105195 & 6.9031 & 6.8898 & TRN & \\
\hline CHEMBL330857 & 105195 & 8.3768 & 8.415 & TRN & \\
\hline CHEMBL122950 & 105195 & 5.0 & 5.0099 & TRN & \\
\hline CHEMBL120049 & 105195 & 6.9957 & 6.9574 & TRN & \\
\hline CHEMBL123167 & 105195 & 6.9031 & 7.0627 & TST & \\
\hline CHEMBL 340461 & 105195 & 9.2218 & 9.26700 & 0000000001 & TRN \\
\hline CHEMBL122651 & 105195 & 7.5686 & 7.4507 & TRN & \\
\hline CHEMBL123382 & 105195 & 6.9101 & 6.9737 & TRN & \\
\hline CHEMBL121592 & 105195 & 4.7959 & 4.7867 & TRN & \\
\hline CHEMBL332858 & 105195 & 6.8861 & 6.6264 & TST & \\
\hline CHEMBL123233 & 105195 & 4.9208 & 5.2212 & TST & \\
\hline CHEMBL565703 & 591251 & 8.9031 & 8.8602 & TRN & \\
\hline CHEMBL573699 & 591251 & 7.8013 & 7.8077 & TRN & \\
\hline CHEMBL575885 & 591251 & 8.9031 & 8.6935 & TST & \\
\hline CHEMBL577247 & 591251 & 8.8539 & 8.9073 & TRN & \\
\hline CHEMBL575886 & 591251 & 8.9031 & 8.9257 & TRN & \\
\hline CHEMBL583934 & 591251 & 9.0 & 9.0446 & TRN & \\
\hline CHEMBL584137 & 591251 & 8.3002 & 8.1634 & TRN & \\
\hline CHEMBL576961 & 591251 & 7.3001 & 8.6075 & TST & \\
\hline CHEMBL567838 & 591251 & 8.0 & 8.0528 & TRN & \\
\hline CHEMBL572798 & 591251 & 7.5003 & 7.4508 & TRN & \\
\hline CHEMBL565903 & 591251 & 8.7011 & 8.7027 & TRN & \\
\hline CHEMBL565713 & 591251 & 8.1002 & 8.1012 & TRN & \\
\hline CHEMBL578558 & 591251 & 7.9031 & 7.79799 & 9999999999 & TRN \\
\hline CHEMBL565890 & 591251 & 7.6003 & 7.7416 & TRN & \\
\hline CHEMBL572507 & 591251 & 9.1024 & 9.0775 & TRN & \\
\hline CHEMBL565680 & 591251 & 8.1002 & 8.1136 & TRN & \\
\hline CHEMBL567214 & 591251 & 7.5003 & 7.51399 & 9999999999 & TRN \\
\hline CHEMBL583836 & 591251 & 8.1002 & 8.1081 & TRN & \\
\hline CHEMBL577277 & 591251 & 8.4001 & 8.3808 & TRN & \\
\hline CHEMBL 233664 & 591251 & 8.5003 & 8.5545 & TRN & \\
\hline CHEMBL583425 & 591251 & 7.6003 & 8.6287 & TST & \\
\hline CHEMBL567623 & 591251 & 9.0 & 8.9936 & TRN & \\
\hline CHEMBL573700 & 591251 & 8.0 & 7.9988 & TRN & \\
\hline CHEMBL578764 & 591251 & 8.2007 & 8.1722 & TRN & \\
\hline CHEMBL566555 & 591251 & 7.6003 & 7.5542 & TRN & \\
\hline CHEMBL572509 & 591251 & 8.0 & 8.1316 & TRN & \\
\hline CHEMBL574141 & 591251 & 8.9031 & 8.8983 & TRN & \\
\hline CHEMBL574163 & 591251 & 8.9031 & 8.8873 & TRN & \\
\hline CHEMBL 338047 & 591251 & 7.5003 & 8.1235 & TST & \\
\hline CHEMBL568526 & 591251 & 8.6003 & 8.5867 & TRN & \\
\hline
\end{tabular}


Supplemental Table S2.txt

\begin{tabular}{|c|c|c|c|c|}
\hline CHEMBL567215 & 591251 & 7.5003 & 7.4897 & TRN \\
\hline CHEMBL574185 & 591251 & 7.5003 & 7.6088 & TRN \\
\hline CHEMBL573020 & 591251 & 8.1002 & 7.4218 & TST \\
\hline CHEMBL575047 & 591251 & 7.6002 & 7.6044 & TRN \\
\hline CHEMBL568278 & 591251 & 8.1002 & 8.0942 & TRN \\
\hline CHEMBL565690 & 591251 & 8.2007 & 8.2477 & TRN \\
\hline CHEMBL573960 & 591251 & 8.0 & 7.8744 & TRN \\
\hline CHEMBL366692 & 591251 & 8.0 & 8.1908 & TST \\
\hline CHEMBL574164 & 591251 & 9.0 & 8.963 & TRN \\
\hline CHEMBL574374 & 591251 & 7.9031 & 7.9249 & TRN \\
\hline CHEMBL566546 & 591251 & 7.4001 & 7.4264 & TRN \\
\hline CHEMBL565689 & 591251 & 7.9031 & 8.2931 & TST \\
\hline CHEMBL578979 & 591251 & 6.8013 & 6.7985 & TRN \\
\hline CHEMBL574840 & 591251 & 8.3002 & 8.1924 & TST \\
\hline CHEMBL575246 & 591251 & 9.0 & 8.9758 & TRN \\
\hline CHEMBL573732 & 591251 & 8.2007 & 7.7828 & TST \\
\hline CHEMBL575040 & 591251 & 6.8013 & 7.45700 & 0000000001 \\
\hline CHEMBL584409 & 591251 & 9.5086 & 9.546 & TRN \\
\hline CHEMBL575458 & 591251 & 8.8013 & 8.8453 & TRN \\
\hline CHEMBL583428 & 591251 & 7.5003 & 7.4891 & TRN \\
\hline CHEMBL576627 & 591251 & 7.5918 & 7.6239 & TRN \\
\hline CHEMBL575464 & 591251 & 9.301 & 9.3108 & TRN \\
\hline CHEMBL573185 & 591251 & 8.7011 & 8.6331 & TRN \\
\hline CHEMBL573467 & 591251 & 8.3002 & 8.3988 & TRN \\
\hline CHEMBL574834 & 591251 & 8.5003 & 8.4741 & TRN \\
\hline CHEMBL573021 & 591251 & 7.8002 & 7.7967 & TRN \\
\hline CHEMBL566761 & 591251 & 9.0 & 8.8118 & TRN \\
\hline CHEMBL577276 & 591251 & 7.8013 & 7.8367 & TRN \\
\hline CHEMBL584571 & 591251 & 8.3002 & 8.2397 & TRN \\
\hline CHEMBL566750 & 591251 & 8.2007 & 8.2465 & TRN \\
\hline CHEMBL582967 & 591251 & 7.9031 & 7.8934 & TRN \\
\hline CHEMBL565691 & 591251 & 7.6003 & 7.5652 & TRN \\
\hline CHEMBL583614 & 591251 & 8.1002 & 8.0506 & TRN \\
\hline CHEMBL573489 & 591251 & 8.4001 & 8.4119 & TRN \\
\hline CHEMBL575884 & 591251 & 8.3002 & 8.3637 & TRN \\
\hline CHEMBL576592 & 591251 & 7.8013 & 7.8029 & TRN \\
\hline CHEMBL565477 & 591251 & 8.8013 & 8.8209 & TRN \\
\hline CHEMBL566547 & 591251 & 7.5003 & 7.4745 & TRN \\
\hline CHEMBL568496 & 591251 & 7.4001 & 7.3942 & TRN \\
\hline CHEMBL574592 & 591251 & 7.7011 & 7.6689 & TRN \\
\hline CHEMBL565891 & 591251 & 8.2007 & 8.2482 & TRN \\
\hline CHEMBL565902 & 591251 & 7.4001 & 7.3859 & TRN \\
\hline CHEMBL565702 & 591251 & 8.1002 & 8.1556 & TRN \\
\hline CHEMBL567204 & 591251 & 9.0 & 8.9539 & TRN \\
\hline CHEMBL578802 & 591251 & 8.4001 & 8.3421 & TRN \\
\hline CHEMBL568065 & 591251 & 8.7011 & 8.6448 & TRN \\
\hline CHEMBL578367 & 591251 & 8.2007 & 8.2935 & TRN \\
\hline CHEMBL573720 & 591251 & 9.2076 & 9.2517 & TRN \\
\hline
\end{tabular}


Supplemental Table S2.txt

\begin{tabular}{|c|c|c|c|c|c|}
\hline CHEMBL567205 & 591251 & 8.1002 & 8.0214 & TST & \\
\hline CHEMBL578797 & 591251 & 7.5003 & 7.529 & TST & \\
\hline CHEMBL572579 & 591251 & 8.1002 & 8.4959 & TST & \\
\hline CHEMBL567837 & 591251 & 8.8013 & 7.9589 & TST & \\
\hline CHEMBL566751 & 591251 & 7.3002 & 7.6281 & TST & \\
\hline CHEMBL584160 & 591251 & 9.0 & 8.9509 & TST & \\
\hline CHEMBL583839 & 591251 & 6.7011 & 8.1611 & TST & \\
\hline CHEMBL576184 & 591251 & 9.0 & 8.8229 & TST & \\
\hline CHEMBL575683 & 591251 & 7.9031 & 8.1493 & TST & \\
\hline CHEMBL566556 & 591251 & 8.2007 & 8.0393 & TST & \\
\hline CHEMBL578376 & 591251 & 8.2007 & 8.4006 & TST & \\
\hline CHEMBL583493 & 591251 & 7.5003 & 7.5781 & TST & \\
\hline CHEMBL565712 & 591251 & 6.8013 & 7.1471 & TST & \\
\hline CHEMBL53977 & 69792 & 5.0 & 5.2114 & TRN & \\
\hline CHEMBL273680 & 69792 & 5.0 & 5.4774 & TRN & \\
\hline CHEMBL273456 & 69792 & 7.3872 & 7.5932 & TRN & \\
\hline CHEMBL298386 & 69792 & 9.0 & 8.8387 & TRN & \\
\hline CHEMBL53729 & 69792 & 7.0915 & 6.4418 & TRN & \\
\hline CHEMBL299736 & 69792 & 7.2757 & 6.8542 & TRN & \\
\hline CHEMBL53642 & 69792 & 6.7696 & 6.5951 & TRN & \\
\hline CHEMBL300615 & 69792 & 9.4318 & 9.3161 & TRN & \\
\hline CHEMBL300497 & 69792 & 8.3665 & 8.9649 & TRN & \\
\hline CHEMBL50581 & 69792 & 7.3872 & 7.3633 & TRN & \\
\hline CHEMBL53238 & 69792 & 9.0706 & 8.9886 & TRN & \\
\hline CHEMBL441978 & 69792 & 7.284 & 6.8797 & TRN & \\
\hline CHEMBL298730 & 69792 & 5.0 & 5.421 & TRN & \\
\hline CHEMBL299802 & 69792 & 7.9586 & 7.6666 & TRN & \\
\hline CHEMBL299642 & 69792 & 7.4559 & 7.8747 & TRN & \\
\hline CHEMBL55081 & 69792 & 6.585 & \multicolumn{2}{|c|}{5.877999999999999} & TRN \\
\hline CHEMBL52310 & 69792 & 7.6778 & 7.8071 & TRN & \\
\hline CHEMBL299995 & 69792 & 5.0 & 5.2364 & TST & \\
\hline CHEMBL52962 & 69792 & 5.0 & 4.8986 & TST & \\
\hline CHEMBL292380 & 69792 & 8.8861 & 9.1762 & TRN & \\
\hline CHEMBL297958 & 69792 & 5.0 & 5.7054 & TST & \\
\hline CHEMBL299437 & 69792 & 7.7212 & 7.8228 & TRN & \\
\hline CHEMBL53528 & 69792 & 5.0 & 5.347 & TRN & \\
\hline CHEMBL299882 & 69792 & 5.0 & 5.5328 & TRN & \\
\hline CHEMBL299210 & 69792 & 9.6576 & 9.5846 & TRN & \\
\hline CHEMBL52640 & 69792 & 7.1805 & 6.5875 & TRN & \\
\hline CHEMBL292462 & 69792 & 8.6198 & 8.917 & TRN & \\
\hline CHEMBL298501 & 69792 & 6.7447 & 6.9075 & TRN & \\
\hline CHEMBL52014 & 69792 & 5.0 & 5.3918 & TRN & \\
\hline CHEMBL300862 & 69792 & 9.1487 & 9.11 & TRN & \\
\hline CHEMBL300951 & 69792 & 9.4318 & 9.1631 & TRN & \\
\hline CHEMBL55450 & 69792 & 7.4318 & 7.0666 & TRN & \\
\hline CHEMBL299611 & 69792 & 9.1487 & 9.1428 & TRN & \\
\hline CHEMBL52696 & 69792 & 6.6021 & 6.7403 & TRN & \\
\hline CHEMBL300018 & 69792 & 6.9208 & 6.9465 & TRN & \\
\hline
\end{tabular}

Page 26430 


\begin{tabular}{|c|c|c|c|c|c|}
\hline \multicolumn{6}{|c|}{ Supplemental Table S2.txt } \\
\hline CHEMBL53587 & 69792 & 7.9208 & 8.1564 & TRN & \\
\hline CHEMBL50320 & 69792 & 7.7696 & 7.9262 & TRN & \\
\hline CHEMBL52030 & 69792 & 7.9586 & 8.2858 & TST & \\
\hline CHEMBL416659 & 69792 & 8.9208 & 8.7979 & TRN & \\
\hline CHEMBL 298760 & 69792 & 7.6383 & 7.9813 & TRN & \\
\hline CHEMBL13662 & 69792 & 5.9208 & 6.7731 & TST & \\
\hline CHEMBL301336 & 69792 & 6.7212 & 6.6686 & TRN & \\
\hline CHEMBL301063 & 69792 & 8.585 & 8.4054 & TRN & \\
\hline CHEMBL297481 & 69792 & 6.3768 & 5.5985 & TRN & \\
\hline CHEMBL441612 & 69792 & 7.9586 & 8.1838 & TRN & \\
\hline CHEMBL52672 & 69792 & 9.1487 & 8.63 & TRN & \\
\hline CHEMBL52818 & 69792 & 6.4949 & 6.5259 & TRN & \\
\hline CHEMBL297717 & 69792 & 6.7696 & 6.648 & TRN & \\
\hline CHEMBL51911 & 69792 & 6.0757 & 6.301 & TRN & \\
\hline CHEMBL54859 & 69792 & 5.8539 & 5.4234 & TST & \\
\hline CHEMBL296383 & 69792 & 8.5086 & 8.6929 & TRN & \\
\hline CHEMBL 301104 & 69792 & 5.0 & 5.4073 & TST & \\
\hline CHEMBL 300690 & 69792 & 6.6198 & 6.5986 & TST & \\
\hline CHEMBL445358 & 69792 & 6.6198 & 6.7143 & TST & \\
\hline CHEMBL300867 & 69792 & 6.7212 & 7.00200 & 0000000001 & TST \\
\hline CHEMBL53529 & 69792 & 7.4089 & 7.2296 & TST & \\
\hline CHEMBL301181 & 69792 & 7.7696 & 8.315 & TST & \\
\hline CHEMBL296607 & 69792 & 8.9208 & 8.40899 & 9999999999 & TST \\
\hline CHEMBL54211 & 69792 & 6.1427 & 5.6482 & TST & \\
\hline CHEMBL50402 & 69792 & 8.0 & 8.2101 & TST & \\
\hline CHEMBL1092985 & 623656 & 3.0 & 3.7031 & TST & \\
\hline CHEMBL1093988 & 623656 & 3.0 & 3.6578 & TRN & \\
\hline CHEMBL1093875 & 623656 & 3.5229 & 3.0782 & TRN & \\
\hline CHEMBL1089893 & 623656 & 3.0 & 3.2591 & TRN & \\
\hline CHEMBL1093507 & 623656 & 3.0 & 3.3654 & TRN & \\
\hline CHEMBL1093853 & 623656 & 3.0 & 3.1692 & TRN & \\
\hline CHEMBL1093874 & 623656 & 3.0 & 3.1732 & TRN & \\
\hline CHEMBL1090902 & 623656 & 4.2924 & 3.168 & TRN & \\
\hline CHEMBL1091953 & 623656 & 3.0 & 3.0853 & TRN & \\
\hline CHEMBL1092935 & 623656 & 3.1249 & 3.8534 & TRN & \\
\hline CHEMBL341112 & 623656 & 3.0 & 3.6557 & TRN & \\
\hline CHEMBL1093492 & 623656 & 3.0 & 3.3642 & TRN & \\
\hline CHEMBL1092674 & 623656 & 3.0969 & 3.8168 & TRN & \\
\hline CHEMBL1093827 & 623656 & 3.4559 & 3.509 & TRN & \\
\hline CHEMBL1092967 & 623656 & 3.0 & 3.7374 & TST & \\
\hline CHEMBL1092703 & 623656 & 3.2218 & 3.2704 & TRN & \\
\hline CHEMBL1094254 & 623656 & 3.0 & 3.2469 & TRN & \\
\hline CHEMBL1093233 & 623656 & 4.6198 & 3.4542 & TRN & \\
\hline CHEMBL1093876 & 623656 & 3.0 & 3.28 & TRN & \\
\hline CHEMBL1093511 & 623656 & 3.0 & 3.7633 & TRN & \\
\hline CHEMBL1093553 & 623656 & 4.5528 & 3.8691 & TRN & \\
\hline CHEMBL209918 & 623656 & 3.0 & 3.6787 & TRN & \\
\hline CHEMBL1093520 & 623656 & 3.0 & 3.1332 & TRN & \\
\hline
\end{tabular}




\begin{tabular}{|c|c|c|c|c|c|}
\hline \multicolumn{6}{|c|}{ Supplemental Table S2.txt } \\
\hline CHEMBL1091652 & 623656 & 3.0 & 3.6929 & TRN & \\
\hline CHEMBL1092673 & 623656 & 4.699 & 3.9394 & TRN & \\
\hline CHEMBL418899 & 623656 & 3.0 & 3.554 & TST & \\
\hline CHEMBL1092095 & 623656 & 3.699 & 3.6334 & TRN & \\
\hline CHEMBL1093906 & 623656 & 3.0 & 3.47899 & 99999999996 & TRN \\
\hline CHEMBL1092614 & 623656 & 3.0 & 3.4416 & TRN & \\
\hline CHEMBL1095561 & 623656 & 3.0 & 3.2265 & TRN & \\
\hline CHEMBL1091037 & 623656 & 4.3098 & 3.3123 & TRN & \\
\hline CHEMBL 98778 & 623656 & 3.0 & 3.4943 & TST & \\
\hline CHEMBL1092937 & 623656 & 3.0 & 3.818 & TST & \\
\hline CHEMBL1093920 & 623656 & 4.9208 & 3.7045 & TRN & \\
\hline CHEMBL1090903 & 623656 & 3.0 & 3.154 & TRN & \\
\hline CHEMBL1093493 & 623656 & 3.5086 & 3.3591 & TRN & \\
\hline CHEMBL1090566 & 623656 & 3.0 & 3.3367 & TRN & \\
\hline CHEMBL1092701 & 623656 & 3.5229 & 3.2165 & TRN & \\
\hline CHEMBL1091257 & 623656 & 3.301 & 3.6718 & TRN & \\
\hline CHEMBL1093220 & 623656 & 4.3979 & 3.6776 & TST & \\
\hline CHEMBL1091653 & 623656 & 3.1549 & 3.6309 & TRN & \\
\hline CHEMBL1093919 & 623656 & 3.8239 & 3.7487 & TRN & \\
\hline CHEMBL111951 & 623656 & 3.0 & 3.7509 & TST & \\
\hline CHEMBL1095562 & 623656 & 3.0458 & 3.2118 & TRN & \\
\hline CHEMBL1093508 & 623656 & 5.1549 & 3.5764 & TRN & \\
\hline CHEMBL1089907 & 623656 & 3.0 & 3.2264 & TRN & \\
\hline CHEMBL1090678 & 623656 & 3.0 & 2.97399 & 99999999998 & TRN \\
\hline CHEMBL1094255 & 623656 & 3.0 & 3.4367 & TRN & \\
\hline CHEMBL1089235 & 623656 & 4.6021 & 3.66300 & 00000000003 & TRN \\
\hline CHEMBL1093907 & 623656 & 4.2924 & 3.5486 & TRN & \\
\hline CHEMBL1093513 & 623656 & 4.4202 & 3.5442 & TRN & \\
\hline CHEMBL1092702 & 623656 & 3.0 & 3.155 & TRN & \\
\hline CHEMBL1092966 & 623656 & 3.6021 & 3.6275 & TRN & \\
\hline CHEMBL1092979 & 623656 & 3.2218 & 3.66399 & 99999999997 & TRN \\
\hline CHEMBL159895 & 623656 & 3.0 & 3.7413 & TST & \\
\hline CHEMBL1089234 & 623656 & 3.0 & 3.3982 & TRN & \\
\hline CHEMBL1090936 & 623656 & 3.5376 & 3.6661 & TRN & \\
\hline CHEMBL1092936 & 623656 & 3.0 & 3.8037 & TST & \\
\hline CHEMBL564201 & 623656 & 3.699 & 3.5518 & TST & \\
\hline CHEMBL1092938 & 623656 & 3.0 & 3.352 & TRN & \\
\hline CHEMBL1090901 & 623656 & 3.0 & 3.2801 & TRN & \\
\hline CHEMBL1092978 & 623656 & 3.6021 & 3.562 & TRN & \\
\hline CHEMBL1091651 & 623656 & 3.0 & 3.6557 & TRN & \\
\hline CHEMBL1093873 & 623656 & 3.0 & 3.1548 & TRN & \\
\hline CHEMBL1090567 & 623656 & 3.0 & 3.1048 & TRN & \\
\hline CHEMBL1092947 & 623656 & 4.3468 & 3.3711 & TRN & \\
\hline CHEMBL1091736 & 623656 & 4.6021 & 3.6845 & TRN & \\
\hline CHEMBL1093512 & 623656 & 3.0 & 3.5667 & TST & \\
\hline CHEMBL1088991 & 623656 & 3.0 & 3.6649 & TST & \\
\hline CHEMBL1093263 & 623656 & 3.0 & 3.5785 & TST & \\
\hline CHEMBL1092984 & 623656 & 3.0 & 3.7131 & TST & \\
\hline
\end{tabular}




\begin{tabular}{|c|c|c|c|c|c|}
\hline \multicolumn{6}{|c|}{ Supplemental Table s2.txt } \\
\hline CHEMBL1090692 & 623656 & 3.0 & 3.5212 & TST & \\
\hline CHEMBL1092746 & 623656 & 3.7447 & 3.8827 & TST & \\
\hline CHEMBL1092613 & 623656 & 3.0 & 3.457 & TST & \\
\hline CHEMBL1093826 & 623656 & 3.0 & 3.4867 & TST & \\
\hline CHEMBL1091258 & 623656 & 3.3468 & 3.6186 & TST & \\
\hline CHEMBL 3235538 & 1334961 & 7.6383 & 7.5171 & TRN & \\
\hline CHEMBL 3235547 & 1334961 & 5.9547 & 5.7874 & TRN & \\
\hline CHEMBL 3235573 & 1334961 & 6.3665 & 6.4062 & TST & \\
\hline CHEMBL 3235184 & 1334961 & 4.9952 & 6.4243 & TST & \\
\hline CHEMBL3235546 & 1334961 & 6.1249 & 6.1237 & TRN & \\
\hline CHEMBL 3235567 & 1334961 & 6.2291 & 6.2421 & TRN & \\
\hline CHEMBL3235559 & 1334961 & 7.0605 & 7.0833 & TRN & \\
\hline CHEMBL3235180 & 1334961 & 5.3595 & 5.4173 & TRN & \\
\hline CHEMBL3235533 & 1334961 & 5.6021 & 5.6151 & TRN & \\
\hline CHEMBL3235563 & 1334961 & 7.3279 & 7.4811 & TRN & \\
\hline CHEMBL3235560 & 1334961 & 7.4815 & 7.5685 & TRN & \\
\hline CHEMBL3235532 & 1334961 & 5.4461 & 5.4329 & TRN & \\
\hline CHEMBL3235552 & 1334961 & 8.0 & 7.697 & TRN & \\
\hline CHEMBL3235561 & 1334961 & 6.2441 & 6.21299 & 9999999999 & TRN \\
\hline CHEMBL3235557 & 1334961 & 6.3768 & 6.1392 & TRN & \\
\hline CHEMBL3235562 & 1334961 & 5.9626 & 6.0249 & TRN & \\
\hline CHEMBL 3235550 & 1334961 & 5.9318 & 5.7501 & TRN & \\
\hline CHEMBL3235554 & 1334961 & 6.2076 & 6.4328 & TRN & \\
\hline CHEMBL 3235541 & 1334961 & 5.9172 & 5.9288 & TRN & \\
\hline CHEMBL3235535 & 1334961 & 7.0809 & 7.0235 & TRN & \\
\hline CHEMBL3235181 & 1334961 & 5.4214 & 6.1011 & TST & \\
\hline CHEMBL 3233034 & 1334961 & 5.0311 & 5.5393 & TST & \\
\hline CHEMBL1405979 & 1334961 & 6.4815 & 6.4242 & TRN & \\
\hline CHEMBL3235558 & 1334961 & 6.0044 & 5.8825 & TRN & \\
\hline CHEMBL3235571 & 1334961 & 5.8447 & 5.9834 & TRN & \\
\hline CHEMBL3235551 & 1334961 & 6.5376 & 6.6301 & TRN & \\
\hline CHEMBL3235539 & 1334961 & 6.2757 & 6.2769 & TRN & \\
\hline CHEMBL3235556 & 1334961 & 7.3768 & 7.5488 & TRN & \\
\hline CHEMBL3235564 & 1334961 & 7.2518 & 7.3237 & TRN & \\
\hline CHEMBL3235565 & 1334961 & 5.9066 & 5.9397 & TRN & \\
\hline CHEMBL3235570 & 1334961 & 5.9508 & 6.1029 & TRN & \\
\hline CHEMBL3235549 & 1334961 & 6.4949 & 6.5039 & TRN & \\
\hline CHEMBL3235542 & 1334961 & 7.1675 & 6.8919 & TRN & \\
\hline CHEMBL3235569 & 1334961 & 7.1024 & 6.9149 & TRN & \\
\hline CHEMBL3235185 & 1334961 & 5.5702 & 5.7613 & TST & \\
\hline CHEMBL3235186 & 1334961 & 5.7144 & 5.7329 & TRN & \\
\hline CHEMBL3235187 & 1334961 & 5.1319 & 5.9162 & TST & \\
\hline CHEMBL3235193 & 1334961 & 5.3862 & 6.2016 & TST & \\
\hline CHEMBL3235545 & 1334961 & 7.1871 & 7.3703 & TRN & \\
\hline CHEMBL3235179 & 1334961 & 5.1278 & 5.66700 & 0000000001 & TST \\
\hline CHEMBL3235198 & 1334961 & 5.7077 & 5.74 & TRN & \\
\hline CHEMBL3235568 & 1334961 & 6.7212 & 6.7598 & TRN & \\
\hline CHEMBL3235574 & 1334961 & 6.3372 & 6.334 & TRN & \\
\hline
\end{tabular}


Supplemental Table S2.txt

\begin{tabular}{|c|c|c|c|c|c|c|}
\hline CHEMBL 3235548 & 1334961 & 6.585 & 6.6581 & TRN & & \\
\hline CHEMBL 3235531 & 1334961 & 5.5498 & 5.37 & TRN & & \\
\hline CHEMBL 3235183 & 1334961 & 6.0706 & 6.1783 & TRN & & \\
\hline CHEMBL 3235534 & 1334961 & 5.2596 & 5.2589 & TRN & & \\
\hline CHEMBL 3235543 & 1334961 & 5.0128 & 5.1173 & TRN & & \\
\hline CHEMBL 3235544 & 1334961 & 4.7587 & 4.8424 & TRN & & \\
\hline CHEMBL576349 & 1334961 & 6.0 & 5.5057 & TST & & \\
\hline CHEMBL 3235178 & 1334961 & 5.1373 & 5.1773 & TRN & & \\
\hline CHEMBL 3235553 & 1334961 & 5.6536 & 5.5953 & TRN & & \\
\hline CHEMBL 3235182 & 1334961 & 5.1986 & 5.997000 & 3000000001 & & TST \\
\hline CHEMBL 3235540 & 1334961 & 6.2676 & 6.5074 & TST & & \\
\hline CHEMBL 3235188 & 1334961 & 5.9508 & 6.61 & TST & & \\
\hline CHEMBL 3235572 & 1334961 & 7.8239 & 8.0346 & TST & & \\
\hline CHEMBL 3235555 & 1334961 & 5.2396 & 5.5337 & TST & & \\
\hline CHEMBL 3235566 & 1334961 & 5.4647 & 5.595 & TST & & \\
\hline CHEMBL1080131 & 620935 & 6.8861 & 6.8167 & TRN & & \\
\hline CHEMBL1081710 & 620935 & 7.0 & 6.8528 & TRN & & \\
\hline CHEMBL1082093 & 620935 & 7.699 & 6.9426 & TRN & & \\
\hline CHEMBL1080992 & 620935 & 4.3979 & 4.141 & TRN & & \\
\hline CHEMBL1082167 & 620935 & 4.8013 & 4.0156 & TRN & & \\
\hline CHEMBL1081828 & 620935 & 6.3979 & 5.5838 & TRN & & \\
\hline CHEMBL1080120 & 620935 & 8.0 & 7.2588 & TRN & & \\
\hline CHEMBL1080133 & 620935 & 6.585 & 6.9691 & TRN & & \\
\hline CHEMBL1076320 & 620935 & 5.6778 & 6.4469 & TRN & & \\
\hline CHEMBL1080450 & 620935 & 4.3872 & 4.1619 & TRN & & \\
\hline CHEMBL1079755 & 620935 & 7.699 & 6.6939 & TRN & & \\
\hline CHEMBL1080621 & 620935 & 6.1549 & 6.8756 & TRN & & \\
\hline CHEMBL1087409 & 620935 & 5.0506 & 5.4061 & TRN & & \\
\hline CHEMBL1080804 & 620935 & 6.4202 & 6.8364 & TRN & & \\
\hline CHEMBL 1086880 & 620935 & 5.301 & 5.2596 & TRN & & \\
\hline CHEMBL1081553 & 620935 & 5.5467 & 5.8005 & TRN & & \\
\hline CHEMBL1079914 & 620935 & 6.8861 & 6.752999 & 999999999 & & TRI \\
\hline CHEMBL1079550 & 620935 & 3.8447 & 4.4022 & TRN & & \\
\hline CHEMBL1076542 & 620935 & 6.1549 & 5.7967 & TRN & & \\
\hline CHEMBL1079744 & 620935 & 6.7959 & 6.2163 & TRN & & \\
\hline CHEMBL1080130 & 620935 & 6.0969 & 6.7092 & TRN & & \\
\hline CHEMBL1079916 & 620935 & 6.7696 & 6.3575 & TRN & & \\
\hline CHEMBL1080825 & 620935 & 6.4559 & 6.4202 & TRN & & \\
\hline CHEMBL1080466 & 620935 & 5.5607 & 6.0615 & TRN & & \\
\hline CHEMBL1079764 & 620935 & 5.4559 & 6.7245 & TST & & \\
\hline CHEMBL1081531 & 620935 & 7.2218 & 6.9899 & TRN & & \\
\hline CHEMBL1079763 & 620935 & 7.0458 & 7.0337 & TST & & \\
\hline CHEMBL1079549 & 620935 & 4.7721 & 4.3386 & TRN & & \\
\hline CHEMBL1080993 & 620935 & 4.2007 & 4.0659 & TRN & & \\
\hline CHEMBL1081716 & 620935 & \multicolumn{3}{|c|}{3.8569999999999998} & 3.7649 & $\mathrm{~K}$ \\
\hline CHEMBL1079915 & 620935 & 5.6861 & 6.3709 & TRN & & \\
\hline CHEMBL1080991 & 620935 & 3.61800 & 000000000 & 303 & 4.6474 & 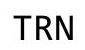 \\
\hline CHEMBL1087407 & 620935 & 5.8861 & 6.0675 & TST & & \\
\hline
\end{tabular}




\begin{tabular}{|c|c|c|c|c|}
\hline & & & olement & \\
\hline CHEMBL1081988 & 620935 & 6.301 & 5.9955 & TRN \\
\hline CHEMBL1079756 & 620935 & 6.7212 & 6.5455 & TRN \\
\hline CHEMBL1087410 & 620935 & 5.6778 & 5.9816 & TST \\
\hline CHEMBL1079728 & 620935 & 3.8416 & 4.1396 & TRN \\
\hline CHEMBL1080465 & 620935 & 5.5214 & 6.1716 & TRN \\
\hline CHEMBL1079762 & 620935 & 5.7959 & 6.0729 & TRN \\
\hline CHEMBL1081554 & 620935 & 6.5229 & 6.3235 & TST \\
\hline CHEMBL1079754 & 620935 & 6.5686 & 6.4183 & TRN \\
\hline CHEMBL1087408 & 620935 & 5.0223 & 5.3979 & TRN \\
\hline CHEMBL1076321 & 620935 & 3.699 & 5.5532 & TST \\
\hline CHEMBL1081178 & 620935 & 3.767 & 4.2979 & TST \\
\hline CHEMBL1080119 & 620935 & 4.301 & 6.1677 & TST \\
\hline CHEMBL1080132 & 620935 & 6.7696 & 6.7382 & TST \\
\hline CHEMBL1079954 & 620935 & 5.301 & 6.7188 & TST \\
\hline CHEMBL1080824 & 620935 & 4.3979 & 5.897 & TST \\
\hline CHEMBL1076205 & 620935 & 4.5528 & 4.4826 & TST \\
\hline CHEMBL1081989 & 620935 & 5.699 & 5.6548 & TST \\
\hline CHEMBL1956475 & 808184 & 5.3098 & 4.9685 & TRN \\
\hline CHEMBL1956287 & 808184 & 7.5229 & 7.3729 & TRN \\
\hline CHEMBL1956487 & 808184 & 4.0 & 5.5268 & TST \\
\hline CHEMBL1956277 & 808184 & 6.0862 & 5.7666 & TST \\
\hline CHEMBL1956270 & 808184 & 5.699 & 5.1392 & TRN \\
\hline CHEMBL1956285 & 808184 & 7.4815 & 7.1638 & TRN \\
\hline CHEMBL1956295 & 808184 & 6.4089 & 6.3391 & TRN \\
\hline CHEMBL1956483 & 808184 & 4.0 & 3.4738 & TRN \\
\hline CHEMBL1956471 & 808184 & 6.5686 & 6.5713 & TRN \\
\hline CHEMBL1956286 & 808184 & 7.4685 & 7.4118 & TRN \\
\hline CHEMBL1956482 & 808184 & 4.0 & 3.9171 & TRN \\
\hline CHEMBL1956281 & 808184 & 5.7696 & 5.6839 & TRN \\
\hline CHEMBL1956492 & 808184 & 4.0 & 3.7859 & TRN \\
\hline CHEMBL1956468 & 808184 & 6.301 & 6.5124 & TRN \\
\hline CHEMBL1956302 & 808184 & 7.4437 & 6.7023 & TST \\
\hline CHEMBL1956273 & 808184 & 6.2596 & 6.4543 & TRN \\
\hline CHEMBL1956300 & 808184 & 7.5229 & 5.7967 & TST \\
\hline CHEMBL1956473 & 808184 & 7.2441 & 7.0931 & TRN \\
\hline CHEMBL1956267 & 808184 & 6.9208 & 5.101 & TST \\
\hline CHEMBL1956305 & 808184 & 6.7959 & 4.9583 & TST \\
\hline CHEMBL1956276 & 808184 & 6.0555 & 5.7585 & TST \\
\hline CHEMBL1956264 & 808184 & 7.0605 & 7.2023 & TRN \\
\hline CHEMBL1956498 & 808184 & 5.2147 & 5.3188 & TRN \\
\hline CHEMBL1956466 & 808184 & 7.0458 & 5.8688 & TST \\
\hline CHEMBL1956301 & 808184 & 7.585 & 5.8078 & TST \\
\hline CHEMBL1956261 & 808184 & 4.0 & 4.05 & TRN \\
\hline CHEMBL1956291 & 808184 & 7.5229 & 7.2862 & TRN \\
\hline CHEMBL1956467 & 808184 & 6.9586 & 5.3951 & TST \\
\hline CHEMBL1956480 & 808184 & 4.0 & 3.4407 & TRN \\
\hline CHEMBL1956262 & 808184 & 6.5528 & 6.2051 & TRN \\
\hline CHEMBL1956290 & 808184 & 7.4559 & 7.2488 & TRN \\
\hline
\end{tabular}


Supplemental Table S2.txt

\begin{tabular}{|c|c|c|c|c|c|}
\hline CHEMBL1956280 & 808184 & 4.9208 & 4.7435 & TRN & \\
\hline CHEMBL1956499 & 808184 & 6.0315 & 5.9146 & TRN & \\
\hline CHEMBL1956282 & 808184 & 5.2441 & 5.2846 & TRN & \\
\hline CHEMBL1956271 & 808184 & 4.0 & 4.6479 & TRN & \\
\hline CHEMBL1956493 & 808184 & 4.0 & 3.9463 & TRN & \\
\hline CHEMBL1956297 & 808184 & 4.0 & 4.4212 & TRN & \\
\hline CHEMBL1956272 & 808184 & 6.3372 & \multicolumn{2}{|c|}{6.752000000000001} & TRN \\
\hline CHEMBL1956484 & 808184 & 4.0 & 4.3582 & TRN & \\
\hline CHEMBL1956477 & 808184 & 4.0 & 3.6441 & TRN & \\
\hline CHEMBL1956472 & 808184 & 7.2518 & 7.3401 & TRN & \\
\hline CHEMBL1956497 & 808184 & 5.2757 & \multicolumn{2}{|c|}{5.3629999999999995} & TRN \\
\hline CHEMBL1956488 & 808184 & 4.0 & 3.7692 & TRN & \\
\hline CHEMBL1956288 & 808184 & 7.7212 & 7.7508 & TRN & \\
\hline CHEMBL1956283 & 808184 & 7.4202 & \multicolumn{2}{|c|}{7.002000000000001} & TRN \\
\hline CHEMBL1956296 & 808184 & 4.0 & 4.4064 & TRN & \\
\hline CHEMBL1956496 & 808184 & 4.0 & 4.0158 & TRN & \\
\hline CHEMBL1956292 & 808184 & 5.6576 & 5.8099 & TRN & \\
\hline CHEMBL1956298 & 808184 & 5.6021 & 5.2288 & TRN & \\
\hline CHEMBL1956289 & 808184 & 7.1249 & 7.6126 & TRN & \\
\hline CHEMBL1738786 & 808184 & 7.4202 & 7.2555 & TRN & \\
\hline CHEMBL1956260 & 808184 & 4.0 & 4.0798 & TRN & \\
\hline CHEMBL1956485 & 808184 & 4.0 & 3.7507 & TRN & \\
\hline CHEMBL1956266 & 808184 & 6.4815 & 5.0918 & TST & \\
\hline CHEMBL1956278 & 808184 & 6.8539 & 6.5532 & TST & \\
\hline CHEMBL1956486 & 808184 & 4.0 & 5.4665 & TST & \\
\hline CHEMBL1956274 & 808184 & 6.4202 & 5.6143 & TST & \\
\hline CHEMBL1956294 & 808184 & 6.3872 & 6.6449 & TRN & \\
\hline CHEMBL1956489 & 808184 & 4.0 & 4.1537 & TRN & \\
\hline CHEMBL1956470 & 808184 & 6.3979 & 6.5196 & TRN & \\
\hline CHEMBL1956275 & 808184 & 6.4815 & 5.2038 & TST & \\
\hline CHEMBL1956495 & 808184 & 4.0 & 4.2449 & TRN & \\
\hline CHEMBL1956279 & 808184 & 7.0315 & 6.1751 & TST & \\
\hline CHEMBL1956491 & 808184 & 4.0 & 3.9115 & TRN & \\
\hline CHEMBL1956478 & 808184 & 4.0 & 4.4819 & TRN & \\
\hline CHEMBL1956303 & 808184 & 7.5229 & 6.3276 & TST & \\
\hline CHEMBL1956265 & 808184 & 6.8239 & 6.8456 & TRN & \\
\hline CHEMBL1956268 & 808184 & 6.9586 & 5.9002 & TST & \\
\hline CHEMBL1956490 & 808184 & 4.0 & 4.1762 & TRN & \\
\hline CHEMBL1956481 & 808184 & 4.0 & 4.2223 & TRN & \\
\hline CHEMBL1956469 & 808184 & 6.3372 & 6.4899 & TRN & \\
\hline CHEMBL1956299 & 808184 & 5.6021 & 5.0283 & TRN & \\
\hline CHEMBL1956263 & 808184 & 6.6198 & 6.1237 & TRN & \\
\hline CHEMBL1956284 & 808184 & 7.2676 & \multicolumn{2}{|c|}{7.0489999999999995} & TRN \\
\hline CHEMBL1955872 & 808184 & 4.0 & 4.1537 & TRN & \\
\hline CHEMBL1956474 & 808184 & 4.0 & 4.8827 & TRN & \\
\hline CHEMBL1955870 & 808184 & 4.0 & 4.788 & TRN & \\
\hline CHEMBL1956304 & 808184 & 7.3468 & 4.9569 & TST & \\
\hline CHEMBL1956293 & 808184 & 5.7696 & 5.7709 & TRN & \\
\hline
\end{tabular}




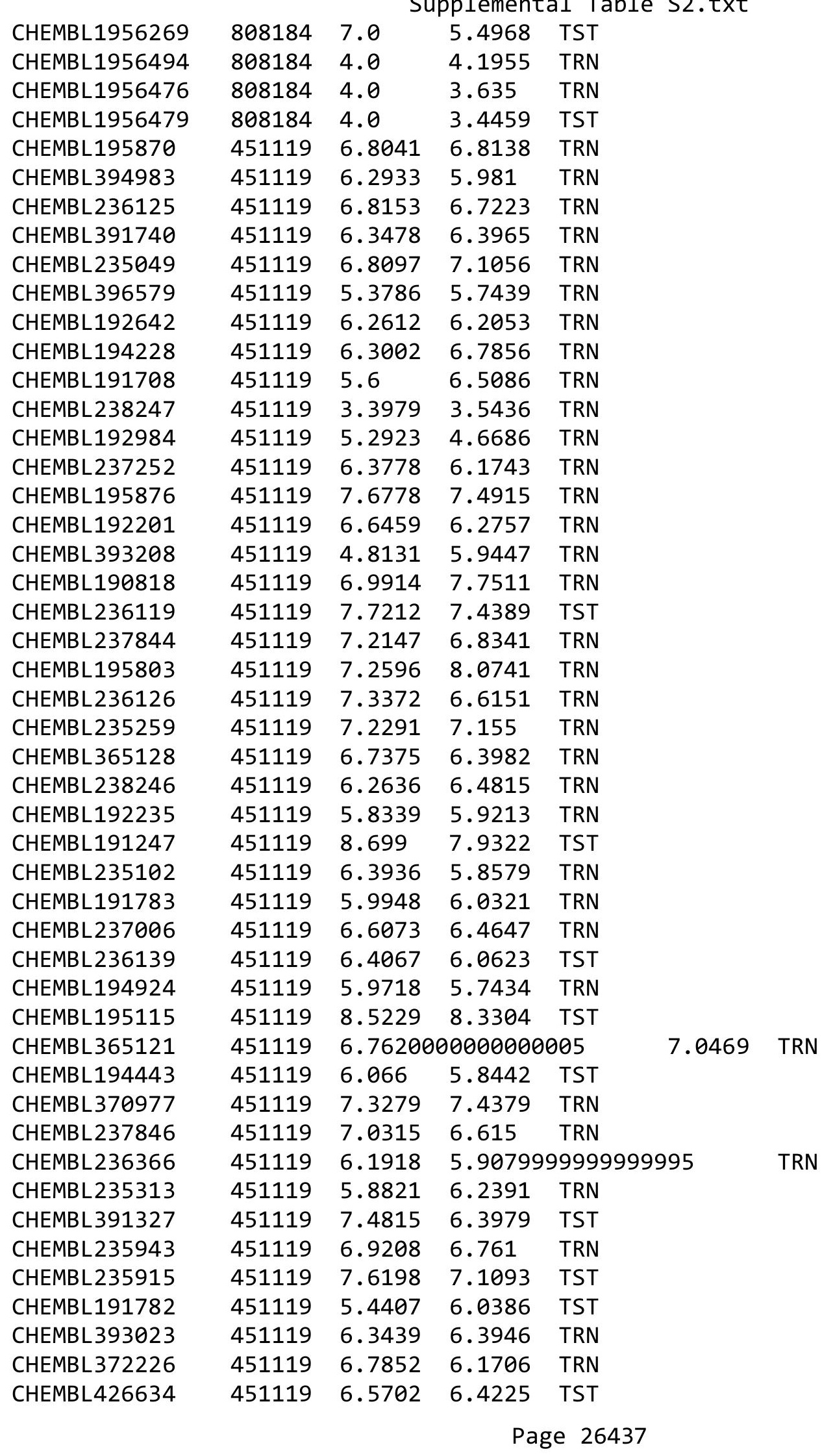




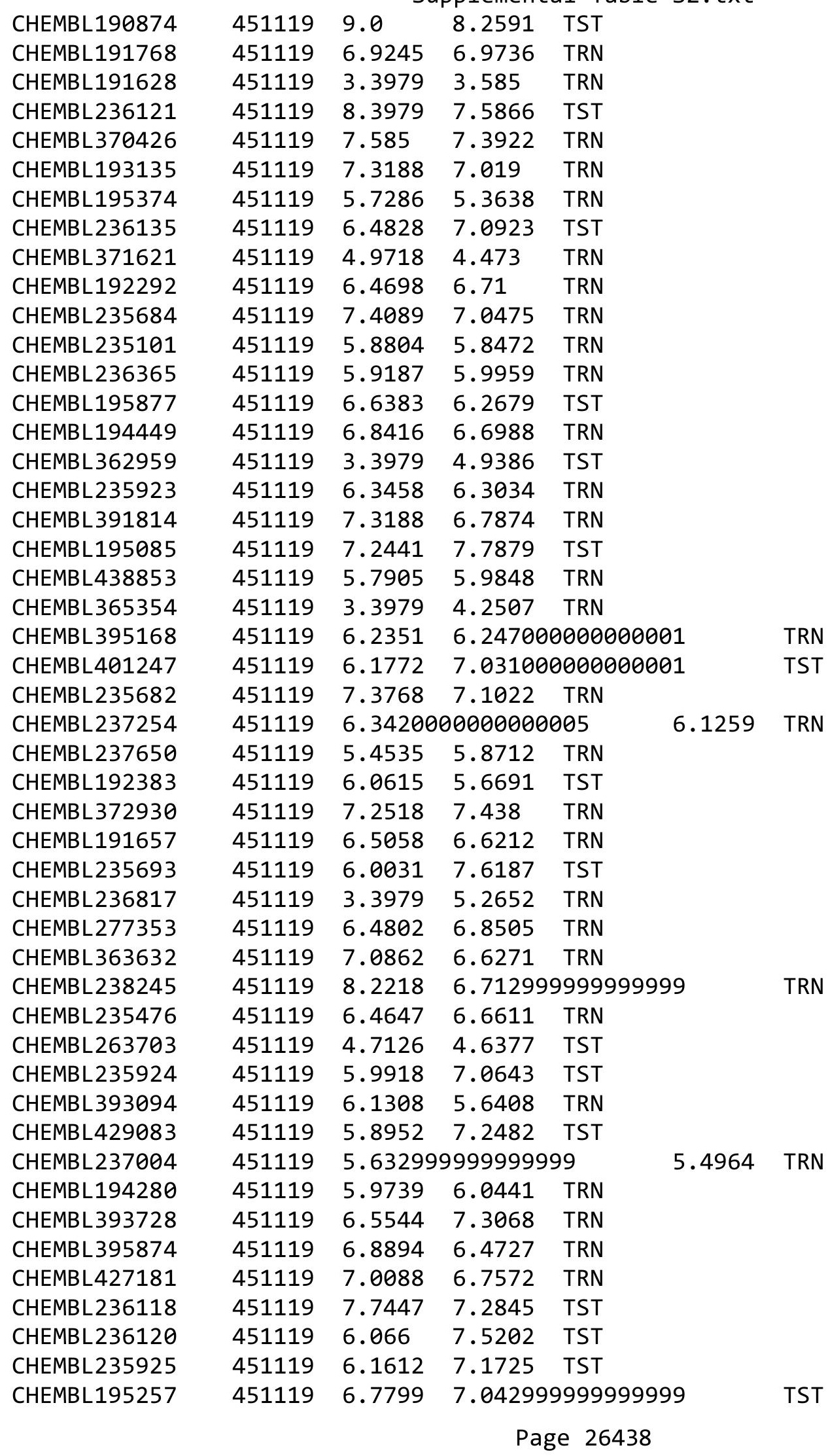




\begin{tabular}{|c|c|c|c|c|c|c|}
\hline & & \multicolumn{5}{|c|}{ Supplemental Table S2.txt } \\
\hline CHEMBL 370078 & 451119 & 6.9208 & 6.6888 & TRN & & \\
\hline CHEMBL192079 & 451119 & 6.6655 & 6.8373 & TRN & & \\
\hline CHEMBL 236368 & 451119 & 5.4432 & 5.7583 & TRN & & \\
\hline CHEMBL191940 & 451119 & 6.6073 & 6.2676 & TRN & & \\
\hline CHEMBL191939 & 451119 & 6.5331 & 6.2131 & TRN & & \\
\hline CHEMBL191807 & 451119 & 5.9543 & 6.0599 & TRN & & \\
\hline CHEMBL195880 & 451119 & 7.585 & 7.6123 & TRN & & \\
\hline CHEMBL192205 & 451119 & 7.3872 & 7.5844 & TRN & & \\
\hline CHEMBL191756 & 451119 & 6.4078 & 6.7472 & TRN & & \\
\hline CHEMBL191031 & 451119 & 6.2343 & 6.1283 & TST & & \\
\hline CHEMBL 209148 & 954889 & 4.4492 & 4.5017 & TRN & & \\
\hline CHEMBL1516890 & 954889 & 4.149 & 4.2318 & TRN & & \\
\hline CHEMBL1242367 & 954889 & 5.034 & 5.0445 & TRN & & \\
\hline CHEMBL3199475 & 954889 & 4.0764 & 4.1434 & TRN & & \\
\hline CHEMBL1909414 & 954889 & 3.4065 & 3.0682 & TRN & & \\
\hline CHEMBL 255342 & 954889 & 3.225 & 3.2054 & TRN & & \\
\hline CHEMBL 3349342 & 954889 & 3.6805 & 3.9267 & TRN & & \\
\hline CHEMBL483847 & 954889 & 3.9591 & 4.2914 & TRN & & \\
\hline CHEMBL1970879 & 954889 & 5.6308 & 5.7153 & TRN & & \\
\hline CHEMBL483849 & 954889 & 2.7679 & 2.6976 & TST & & \\
\hline CHEMBL1357247 & 954889 & 3.35600 & 00000000 & 203 & 3.492 & TRN \\
\hline CHEMBL515416 & 954889 & 3.7451 & 3.739 & TRN & & \\
\hline CHEMBL 399530 & 954889 & 2.7807 & 2.8692 & TRN & & \\
\hline CHEMBL191334 & 954889 & 3.3575 & 3.1595 & TRN & & \\
\hline CHEMBL 379300 & 954889 & 6.9811 & 7.0052 & TRN & & \\
\hline CHEMBL412142 & 954889 & 3.719 & 3.5797 & TRN & & \\
\hline CHEMBL 3392440 & 954889 & 4.2628 & 3.6706 & TST & & \\
\hline CHEMBL135561 & 954889 & 4.2476 & 4.5823 & TRN & & \\
\hline CHEMBL102714 & 954889 & 3.2626 & 3.1692 & TRN & & \\
\hline CHEMBL 2134202 & 954889 & 3.2509 & 3.3684 & TRN & & \\
\hline CHEMBL300389 & 954889 & 6.3905 & 6.3188 & TRN & & \\
\hline CHEMBL573107 & 954889 & 4.9112 & 4.4301 & TRN & & \\
\hline CHEMBL92309 & 954889 & 3.2629 & 3.0692 & TST & & \\
\hline CHEMBL1230020 & 954889 & 4.0336 & 3.8194 & TRN & & \\
\hline CHEMBL 2137530 & 954889 & 5.4 & 5.0902 & TRN & & \\
\hline CHEMBL509032 & 954889 & 5.7936 & 6.0792 & TRN & & \\
\hline CHEMBL514499 & 954889 & 7.8567 & 7.6287 & TRN & & \\
\hline CHEMBL392695 & 954889 & 6.3285 & 5.9258 & TRN & & \\
\hline CHEMBL 213100 & 954889 & 4.6397 & 4.9966 & TRN & & \\
\hline CHEMBL449158 & 954889 & 6.0216 & 5.8192 & TST & & \\
\hline CHEMBL1643959 & 954889 & 3.6298 & 3.8721 & TRN & & \\
\hline CHEMBL1186585 & 954889 & 4.119 & 3.6328 & TRN & & \\
\hline CHEMBL1404918 & 954889 & 4.7577 & 4.2469 & TRN & & \\
\hline CHEMBL 210618 & 954889 & 3.2169 & 3.2584 & TRN & & \\
\hline CHEMBL 202721 & 954889 & 4.6785 & 4.5897 & TRN & & \\
\hline CHEMBL577784 & 954889 & 5.2756 & 5.0169 & TRN & & \\
\hline CHEMBL1788116 & 954889 & 4.8924 & 5.1772 & TRN & & \\
\hline CHEMBL558642 & 954889 & 5.1196 & 5.2692 & TRN & & \\
\hline
\end{tabular}




\begin{tabular}{|c|c|c|c|c|c|c|}
\hline & & \multicolumn{5}{|c|}{ Supplemental Table S2.txt } \\
\hline CHEMBL189584 & 954889 & 3.8197 & 4.032 & TRN & & \\
\hline CHEMBL217354 & 954889 & 6.3288 & 6.4895 & TRN & & \\
\hline CHEMBL393929 & 954889 & 3.6301 & 3.8509 & TRN & & \\
\hline CHEMBL 2363137 & 954889 & 5.2639 & 4.967 & TRN & & \\
\hline CHEMBL259181 & 954889 & 5.1266 & 5.146 & TRN & & \\
\hline CHEMBL258844 & 954889 & 4.3808 & 4.4021 & TRN & & \\
\hline CHEMBL1256459 & 954889 & 7.414 & 7.3595 & TRN & & \\
\hline CHEMBL240954 & 954889 & 4.0677 & 3.2907 & TST & & \\
\hline CHEMBL1190711 & 954889 & 5.29899 & 99999999 & 995 & 5.3843 & TRN \\
\hline CHEMBL472940 & 954889 & 3.7173 & 4.1039 & TRN & & \\
\hline CHEMBL221137 & 954889 & 5.0675 & 4.2739 & TST & & \\
\hline CHEMBL 2005886 & 954889 & 4.3868 & 4.5412 & TRN & & \\
\hline CHEMBL188678 & 954889 & 4.5246 & 3.8751 & TST & & \\
\hline CHEMBL585951 & 954889 & 6.0445 & 4.9943 & TST & & \\
\hline CHEMBL151176 & 954889 & 5.8853 & 4.9667 & TST & & \\
\hline CHEMBL192566 & 954889 & 8.3721 & 6.9725 & TST & & \\
\hline CHEMBL379975 & 954889 & 4.92399 & 99999999 & 995 & 4.3798 & ST \\
\hline CHEMBL512504 & 954889 & 4.8942 & 4.1261 & TST & & \\
\hline CHEMBL222102 & 954889 & 4.078 & 3.3482 & TST & & \\
\hline CHEMBL65 & 954889 & 8.7414 & 6.5491 & TST & & \\
\hline CHEMBL 9470 & 954889 & 6.4102 & 5.0552 & TST & & \\
\hline CHEMBL102714 & 954737 & 2.9906 & 3.1832 & TRN & & \\
\hline CHEMBL222102 & 954737 & 3.2965 & 3.4316 & TRN & & \\
\hline CHEMBL240954 & 954737 & 4.0932 & 3.6509 & TST & & \\
\hline CHEMBL180127 & 954737 & 3.9571 & 4.2154 & TRN & & \\
\hline CHEMBL412142 & 954737 & 4.4187 & 4.5839 & TRN & & \\
\hline CHEMBL 220241 & 954737 & 6.1749 & 6.0994 & TRN & & \\
\hline CHEMBL558642 & 954737 & 3.7011 & 3.6424 & TRN & & \\
\hline CHEMBL1404918 & 954737 & 2.727 & 2.8093 & TRN & & \\
\hline CHEMBL191334 & 954737 & 3.99 & 3.7531 & TRN & & \\
\hline CHEMBL3392440 & 954737 & 3.8508 & 3.8188 & TRN & & \\
\hline CHEMBL1242367 & 954737 & 4.9839 & 4.8185 & TRN & & \\
\hline CHEMBL1516890 & 954737 & 4.0287 & 4.1007 & TRN & & \\
\hline CHEMBL 9470 & 954737 & 6.5373 & 5.2276 & TST & & \\
\hline CHEMBL1256459 & 954737 & 7.8002 & 7.8258 & TRN & & \\
\hline CHEMBL393929 & 954737 & 4.0509 & 4.2117 & TRN & & \\
\hline CHEMBL1909414 & 954737 & 3.89399 & 99999999 & 997 & 3.542 & 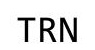 \\
\hline CHEMBL1643959 & 954737 & 4.3628 & 4.4263 & TRN & & \\
\hline CHEMBL 209148 & 954737 & 4.2532 & 4.4085 & TRN & & \\
\hline CHEMBL221137 & 954737 & 4.8573 & 4.5516 & TST & & \\
\hline CHEMBL202721 & 954737 & 4.4952 & 4.3689 & TRN & & \\
\hline CHEMBL3186408 & 954737 & 5.8743 & 4.0259 & TST & & \\
\hline CHEMBL 2144069 & 954737 & 4.6476 & 4.5139 & TRN & & \\
\hline CHEMBL135561 & 954737 & 4.766 & 4.8431 & TRN & & \\
\hline CHEMBL217354 & 954737 & 6.5575 & 6.5707 & TRN & & \\
\hline CHEMBL1230020 & 954737 & 3.1453 & 3.109 & TRN & & \\
\hline CHEMBL509032 & 954737 & 4.5831 & 4.7699 & TRN & & \\
\hline CHEMBL373751 & 954737 & 4.6483 & 4.5568 & TRN & & \\
\hline
\end{tabular}


Supplemental Table S2.txt

\begin{tabular}{|c|c|c|c|c|}
\hline CHEMBL 2005886 & 954737 & 5.176 & 5.0975 & TRN \\
\hline CHEMBL1190711 & 954737 & 3.7096 & 3.6713 & TRN \\
\hline CHEMBL1673039 & 954737 & 5.0155 & 4.9039 & TRN \\
\hline CHEMBL 3349342 & 954737 & 4.0007 & 3.9042 & TRN \\
\hline CHEMBL512504 & 954737 & 4.1098 & 4.3639 & TRN \\
\hline CHEMBL 2134202 & 954737 & 3.3235 & 3.6686 & TRN \\
\hline CHEMBL3199475 & 954737 & 3.7657 & 3.6166 & TRN \\
\hline CHEMBL188678 & 954737 & 3.8257 & 3.9032 & TRN \\
\hline CHEMBL 2363137 & 954737 & 4.4653 & 4.6731 & TRN \\
\hline CHEMBL92309 & 954737 & 3.002 & 3.1082 & TST \\
\hline CHEMBL1590308 & 954737 & 5.0042 & 3.9652 & TST \\
\hline CHEMBL189584 & 954737 & 4.7296 & 4.6742 & TRN \\
\hline CHEMBL573107 & 954737 & 4.6478 & 4.5394 & TRN \\
\hline CHEMBL65 & 954737 & 6.7594 & 6.6613 & TRN \\
\hline CHEMBL483847 & 954737 & 5.0158 & 4.8111 & TRN \\
\hline CHEMBL483849 & 954737 & 1.6445 & 2.0833 & TST \\
\hline CHEMBL 2137530 & 954737 & 4.9158 & 4.9297 & TRN \\
\hline CHEMBL192566 & 954737 & 6.1094 & 6.9343 & TST \\
\hline CHEMBL259181 & 954737 & 3.5198 & 3.5106 & TRN \\
\hline CHEMBL 379300 & 954737 & 6.8893 & 6.8618 & TRN \\
\hline CHEMBL 213100 & 954737 & 4.8813 & 4.9974 & TRN \\
\hline CHEMBL585951 & 954737 & 5.7343 & 5.8542 & TRN \\
\hline CHEMBL379975 & 954737 & 4.2133 & 4.2759 & TRN \\
\hline CHEMBL472940 & 954737 & 2.9243 & 2.9282 & TRN \\
\hline CHEMBL449158 & 954737 & 6.4498 & 6.5824 & TST \\
\hline CHEMBL1186585 & 954737 & 3.8293 & 3.702 & TRN \\
\hline CHEMBL 258844 & 954737 & 4.0838 & 4.197 & TRN \\
\hline CHEMBL 255342 & 954737 & 4.3653 & 3.8645 & TRN \\
\hline CHEMBL 210618 & 954737 & 3.7853 & 3.7815 & TRN \\
\hline CHEMBL1357247 & 954737 & 3.3581 & 3.3734 & TRN \\
\hline CHEMBL1788116 & 954737 & 4.3422 & 4.5157 & TST \\
\hline CHEMBL 300389 & 954737 & 7.8303 & 6.6805 & TST \\
\hline CHEMBL515416 & 954737 & 5.209 & 4.591 & TST \\
\hline CHEMBL392695 & 954737 & 5.7069 & 5.1191 & TST \\
\hline CHEMBL1970879 & 954737 & 5.6618 & 5.0146 & TST \\
\hline CHEMBL399530 & 954737 & 3.3416 & 4.4893 & TST \\
\hline CHEMBL577784 & 954737 & 4.5886 & 5.0783 & TST \\
\hline CHEMBL514499 & 954737 & 7.6849 & 7.2184 & TST \\
\hline CHEMBL 209082 & 363242 & 5.0757 & 5.0773 & TRN \\
\hline CHEMBL210804 & 363242 & 4.0 & 3.9984 & TRN \\
\hline CHEMBL426134 & 363242 & 6.5622 & 6.5676 & TRN \\
\hline CHEMBL210586 & 363242 & 6.0458 & 6.0442 & TRN \\
\hline CHEMBL211009 & 363242 & 6.5686 & 6.5714 & TRN \\
\hline CHEMBL 210737 & 363242 & 5.2924 & 4.7782 & TST \\
\hline CHEMBL209669 & 363242 & 6.7447 & 6.7413 & TRN \\
\hline CHEMBL 210552 & 363242 & 4.0 & 4.3537 & TST \\
\hline CHEMBL208447 & 363242 & 6.1024 & 6.0953 & TRN \\
\hline CHEMBL 210256 & 363242 & 4.0 & 4.5686 & TST \\
\hline
\end{tabular}




\begin{tabular}{|c|c|c|c|c|c|}
\hline \multicolumn{6}{|c|}{ Supplemental Table S2.txt } \\
\hline CHEMBL425413 & 363242 & 5.4685 & 5.4744 & TRN & \\
\hline CHEMBL209291 & 363242 & 6.5086 & 6.5024 & TRN & \\
\hline CHEMBL377201 & 363242 & 5.3098 & 5.3152 & TRN & \\
\hline CHEMBL380152 & 363242 & 6.1308 & 6.13299 & 9999999999 & TRN \\
\hline CHEMBL 208448 & 363242 & 4.0 & 3.997 & TRN & \\
\hline CHEMBL210861 & 363242 & 6.1135 & 6.1184 & TRN & \\
\hline CHEMBL 210222 & 363242 & 5.4559 & 5.4504 & TRN & \\
\hline CHEMBL209505 & 363242 & 7.0 & 7.0011 & TRN & \\
\hline CHEMBL 210462 & 363242 & 6.6198 & 6.6193 & TRN & \\
\hline CHEMBL209770 & 363242 & 6.1938 & 6.1897 & TRN & \\
\hline CHEMBL210728 & 363242 & 4.0 & 4.0033 & TRN & \\
\hline CHEMBL 378627 & 363242 & 7.1938 & 7.1716 & TRN & \\
\hline CHEMBL210963 & 363242 & 6.8239 & 6.8534 & TRN & \\
\hline CHEMBL210826 & 363242 & 4.0 & 4.0002 & TRN & \\
\hline CHEMBL382639 & 363242 & 6.7959 & 6.79200 & 0000000001 & TRN \\
\hline CHEMBL 380044 & 363242 & 4.0 & 3.9917 & TRN & \\
\hline CHEMBL383308 & 363242 & 6.1308 & 6.1252 & TRN & \\
\hline CHEMBL210618 & 363242 & 6.7959 & 6.7932 & TRN & \\
\hline CHEMBL 377838 & 363242 & 4.0 & 4.0038 & TRN & \\
\hline CHEMBL 377348 & 363242 & 5.5376 & 5.5302 & TST & \\
\hline CHEMBL209136 & 363242 & 5.5229 & 5.5172 & TRN & \\
\hline CHEMBL379414 & 363242 & 4.0 & 3.9968 & TRN & \\
\hline CHEMBL210363 & 363242 & 5.3468 & 5.3462 & TRN & \\
\hline CHEMBL208637 & 363242 & 5.9586 & 5.9501 & TRN & \\
\hline CHEMBL209299 & 363242 & 5.2007 & 5.2013 & TRN & \\
\hline CHEMBL378931 & 363242 & 6.3279 & 6.3496 & TRN & \\
\hline CHEMBL 377578 & 363242 & 6.8861 & 6.8895 & TRN & \\
\hline CHEMBL210670 & 363242 & 4.0 & 4.0044 & TRN & \\
\hline CHEMBL 378500 & 363242 & 4.0 & 3.9982 & TRN & \\
\hline CHEMBL 210553 & 363242 & 4.0 & 3.6413 & TST & \\
\hline CHEMBL210655 & 363242 & 6.585 & 6.5756 & TRN & \\
\hline CHEMBL 208668 & 363242 & 4.0 & 3.9988 & TRN & \\
\hline CHEMBL 378980 & 363242 & 5.3313 & 5.3295 & TRN & \\
\hline CHEMBL 209192 & 363242 & 6.4437 & 6.4435 & TRN & \\
\hline CHEMBL 210928 & 363242 & 7.1549 & 7.1538 & TRN & \\
\hline CHEMBL210033 & 363242 & 4.0 & 4.0058 & TRN & \\
\hline CHEMBL 209292 & 363242 & 6.2147 & 6.2217 & TRN & \\
\hline CHEMBL210307 & 363242 & 5.3098 & 4.7719 & TST & \\
\hline CHEMBL209769 & 363242 & 7.585 & 8.0839 & TST & \\
\hline CHEMBL378499 & 363242 & 6.1612 & 5.0317 & TST & \\
\hline CHEMBL209182 & 363242 & 4.0 & 5.0784 & TST & \\
\hline CHEMBL 210752 & 363242 & 4.0 & 5.6278 & TST & \\
\hline CHEMBL 380279 & 363242 & 4.0 & 5.3813 & TST & \\
\hline CHEMBL208877 & 363242 & 5.9208 & 5.6853 & TST & \\
\hline CHEMBL208558 & 363242 & 6.1308 & 4.5574 & TST & \\
\hline CHEMBL210032 & 363242 & 5.1135 & 5.2114 & TST & \\
\hline CHEMBL315484 & 89839 & 3.0 & 4.9621 & TST & \\
\hline CHEMBL326678 & 89839 & 4.7352 & 4.7328 & TRN & \\
\hline
\end{tabular}




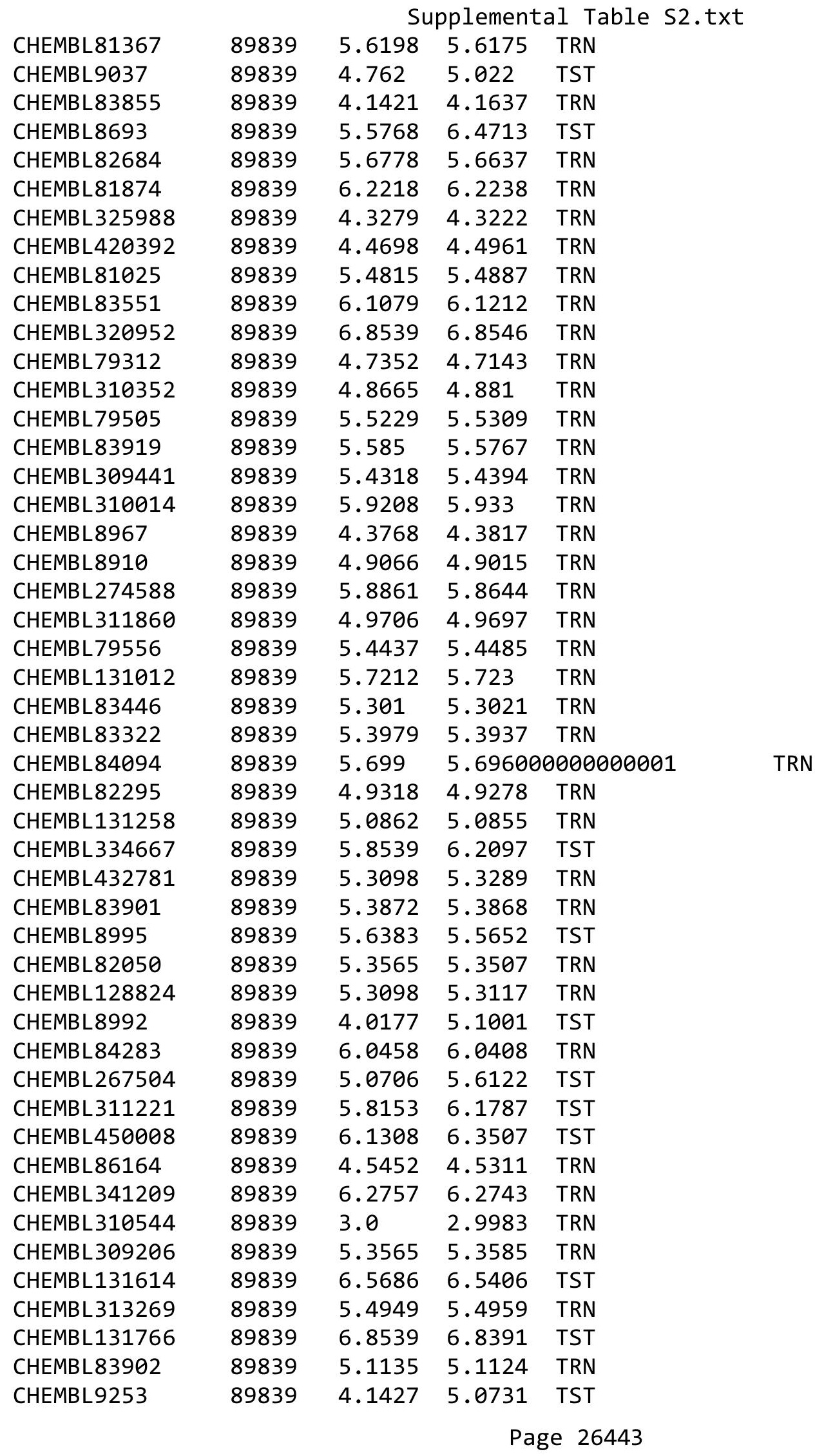




\begin{tabular}{|c|c|c|c|c|c|c|}
\hline & & \multicolumn{5}{|c|}{ Supplemental Table s2.txt } \\
\hline CHEMBL131309 & 89839 & 5.6198 & 6.365 & TST & & \\
\hline CHEMBL 275106 & 89839 & 5.1427 & 5.7287 & TST & & \\
\hline CHEMBL106088 & 89839 & 4.6904 & 4.6631 & TRN & & \\
\hline CHEMBL1596578 & 688733 & 4.5021 & 4.7695 & TRN & & \\
\hline CHEMBL1369691 & 688733 & 6.1192 & 6.2033 & TST & & \\
\hline CHEMBL1501717 & 688733 & 6.0701 & 5.691 & TRN & & \\
\hline CHEMBL1519770 & 688733 & \multicolumn{3}{|c|}{5.162999999999999} & 5.6588 & TST \\
\hline CHEMBL1607497 & 688733 & 3.2543 & 4.4233 & TRN & & \\
\hline CHEMBL1582181 & 688733 & 5.4117 & 6.0228 & TRN & & \\
\hline CHEMBL1409658 & 688733 & 6.1192 & 6.0682 & TRN & & \\
\hline CHEMBL1578302 & 688733 & 5.8874 & 5.7177 & TRN & & \\
\hline CHEMBL1403922 & 688733 & 5.7825 & 5.4868 & TRN & & \\
\hline CHEMBL1400807 & 688733 & \multicolumn{3}{|c|}{5.162999999999999} & 5.4326 & TRN \\
\hline CHEMBL131921 & 688733 & 4.6861 & 5.1908 & TRN & & \\
\hline CHEMBL1330655 & 688733 & 5.7342 & 6.0425 & TRN & & \\
\hline CHEMBL1449208 & 688733 & 6.1192 & 5.4133 & TST & & \\
\hline CHEMBL1393635 & 688733 & 6.1192 & 6.1447 & TRN & & \\
\hline CHEMBL1500421 & 688733 & \multicolumn{3}{|c|}{5.162999999999999} & 5.4275 & TRN \\
\hline CHEMBL1532459 & 688733 & 4.7298 & 5.0133 & TRN & & \\
\hline CHEMBL3196521 & 688733 & 5.8592 & 5.9096 & TRN & & \\
\hline CHEMBL1528861 & 688733 & 5.5173 & 4.9347 & TRN & & \\
\hline CHEMBL1335678 & 688733 & 5.6402 & 5.6236 & TRN & & \\
\hline CHEMBL1333621 & 688733 & 7.0605 & 6.4173 & TRN & & \\
\hline CHEMBL1458453 & 688733 & 6.1302 & 5.4255 & TRN & & \\
\hline CHEMBL1480310 & 688733 & 5.7951 & 5.5387 & TRN & & \\
\hline CHEMBL85826 & 688733 & 6.1192 & 6.2511 & TRN & & \\
\hline CHEMBL1427219 & 688733 & 4.8755 & 4.9294 & TRN & & \\
\hline CHEMBL1459547 & 688733 & 5.8645 & 5.1744 & TST & & \\
\hline CHEMBL1381396 & 688733 & 6.0799 & 5.8884 & TRN & & \\
\hline CHEMBL1345128 & 688733 & 5.8233 & 5.8267 & TST & & \\
\hline CHEMBL1598743 & 688733 & 5.6402 & 5.9155 & TRN & & \\
\hline CHEMBL1535921 & 688733 & 6.8996 & 6.8761 & TRN & & \\
\hline CHEMBL1420610 & 688733 & \multicolumn{3}{|c|}{5.162999999999999} & 5.7633 & TRN \\
\hline CHEMBL1519868 & 688733 & 5.9076 & 6.0698 & TRN & & \\
\hline CHEMBL1465006 & 688733 & 6.4802 & 6.5082 & TRN & & \\
\hline CHEMBL1543182 & 688733 & 6.3768 & 5.5343 & TST & & \\
\hline CHEMBL1471728 & 688733 & 5.7053 & 5.7137 & TST & & \\
\hline CHEMBL1430765 & 688733 & 6.2798 & 6.484 & TRN & & \\
\hline CHEMBL1496911 & 688733 & 6.1244 & 5.2587 & TST & & \\
\hline CHEMBL1490730 & 688733 & \multicolumn{3}{|c|}{5.542999999999999} & 5.6271 & TRN \\
\hline CHEMBL1309377 & 688733 & \multicolumn{3}{|c|}{5.162999999999999} & 5.624 & TRN \\
\hline CHEMBL1351997 & 688733 & \multicolumn{3}{|c|}{5.162999999999999} & 5.5085 & TRN \\
\hline CHEMBL1309162 & 688733 & 3.2541 & 5.7708 & TST & & \\
\hline CHEMBL1366272 & 688733 & 6.1746 & 5.7283 & TRN & & \\
\hline CHEMBL1371289 & 688733 & 6.1192 & 6.2214 & TRN & & \\
\hline CHEMBL1424170 & 688733 & 5.5232 & 5.8233 & TRN & & \\
\hline CHEMBL1324408 & 688733 & 5.1584 & 5.1554 & TRN & & \\
\hline CHEMBL1584661 & 688733 & 5.4642 & 5.4648 & TRN & & \\
\hline
\end{tabular}




\begin{tabular}{|c|c|c|c|c|c|c|}
\hline & & & & & & \\
\hline CHEMBL1453960 & 688733 & 6.3605 & 5.5504 & TST & & \\
\hline CHEMBL1587583 & 688733 & 5.6402 & 5.4438 & TRN & & \\
\hline CHEMBL1417225 & 688733 & 5.63899 & 999999999 & 99 & 4.931 & TRN \\
\hline CHEMBL1353400 & 688733 & 5.1061 & 5.2712 & TST & & \\
\hline CHEMBL1343819 & 688733 & 5.1624 & 5.2572 & TRN & & \\
\hline CHEMBL1571018 & 688733 & 6.4672 & 6.1347 & TRN & & \\
\hline CHEMBL1603839 & 688733 & 5.1604 & 5.0821 & TRN & & \\
\hline CHEMBL1565523 & 688733 & 5.7242 & 5.5061 & TRN & & \\
\hline CHEMBL1383541 & 688733 & 5.5948 & 5.2918 & TRN & & \\
\hline CHEMBL1508190 & 688733 & 5.5661 & 5.7213 & TST & & \\
\hline CHEMBL1423409 & 688733 & 6.0362 & 6.6177 & TRN & & \\
\hline CHEMBL1321017 & 688733 & 5.9151 & 6.3158 & TRN & & \\
\hline CHEMBL1408441 & 688733 & 6.0835 & 5.5163 & TRN & & \\
\hline CHEMBL 1438256 & 688733 & 5.4135 & 5.685 & TRN & & \\
\hline CHEMBL1383569 & 688733 & 5.16299 & 999999999 & & 5.5409 & TRN \\
\hline CHEMBL1422976 & 688733 & 5.6745 & 5.3255 & TRN & & \\
\hline CHEMBL 1456683 & 688733 & 5.16299 & 999999999 & 99 & 5.3315 & this \\
\hline CHEMBL1497574 & 688733 & 6.1192 & 5.6944 & TRN & & \\
\hline CHEMBL1543167 & 688733 & 6.3883 & 5.3954 & TST & & \\
\hline CHEMBL1500499 & 688733 & 5.5203 & 5.3112 & TRN & & \\
\hline CHEMBL1584144 & 688733 & 5.5131 & 5.3021 & TRN & & \\
\hline CHEMBL 1450536 & 688733 & 5.7833 & 5.7797 & TRN & & \\
\hline CHEMBL1334083 & 688733 & 5.6402 & 5.2342 & TRN & & \\
\hline CHEMBL 1406726 & 688733 & 6.3344 & 5.6896 & TRN & & \\
\hline CHEMBL1387008 & 688733 & 5.5043 & 5.8923 & TRN & & \\
\hline CHEMBL1503742 & 688733 & 5.16299 & 999999999 & 99 & 5.3499 & TRN \\
\hline CHEMBL1565955 & 688733 & 5.1643 & 5.4316 & TRN & & \\
\hline CHEMBL1531634 & 688733 & 6.3655 & 6.3115 & TRN & & \\
\hline CHEMBL1507757 & 688733 & 5.16299 & 999999999 & 99 & 5.5024 & 110 \\
\hline CHEMBL1450911 & 688733 & 6.6778 & 6.0906 & TRN & & \\
\hline CHEMBL1334210 & 688733 & 6.4486 & 6.3095 & TRN & & \\
\hline CHEMBL1384103 & 688733 & 5.5514 & 5.4493 & TRN & & \\
\hline CHEMBL1478089 & 688733 & 5.0946 & 5.6562 & TST & & \\
\hline CHEMBL1577902 & 688733 & 6.6402 & 5.8714 & TRN & & \\
\hline CHEMBL1080171 & 688733 & 5.2897 & 5.4411 & TRN & & \\
\hline CHEMBL1563821 & 688733 & 6.2874 & 5.8965 & TRN & & \\
\hline CHEMBL 1347686 & 688733 & 5.8908 & 5.7823 & TRN & & \\
\hline CHEMBL1559414 & 688733 & 6.6326 & 5.779 & TRN & & \\
\hline CHEMBL1349067 & 688733 & 5.5727 & 5.662000 & 00000000 & & \\
\hline CHEMBL1585055 & 688733 & 5.9172 & 5.9038 & TRN & & \\
\hline CHEMBL1330046 & 688733 & 5.9208 & 5.7553 & TST & & \\
\hline CHEMBL 1403635 & 688733 & 5.16299 & 999999999 & & 5.9976 & N \\
\hline CHEMBL1502956 & 688733 & 5.585 & 6.032 & TRN & & \\
\hline CHEMBL 1374200 & 688733 & 5.1169 & 5.4303 & TRN & & \\
\hline CHEMBL1548992 & 688733 & 5.4919 & 5.3637 & TRN & & \\
\hline CHEMBL1499327 & 688733 & 5.3449 & 5.6495 & TRN & & \\
\hline CHEMBL 1600023 & 688733 & 5.6535 & 5.6578 & TRN & & \\
\hline CHEMBL1413624 & 688733 & 5.6402 & 5.4819 & TRN & & \\
\hline
\end{tabular}




\begin{tabular}{|c|c|c|c|c|c|}
\hline & & \multicolumn{4}{|c|}{ Supplemental Table S2.txt } \\
\hline CHEMBL1518405 & 688733 & 6.091 & 5.8802 & TST & \\
\hline CHEMBL1426300 & 688733 & 5.6794 & 5.6749 & TRN & \\
\hline CHEMBL1497162 & 688733 & 7.1612 & 5.4292 & TST & \\
\hline CHEMBL1523697 & 688733 & 6.9431 & 5.8458 & TST & \\
\hline CHEMBL1604696 & 688733 & 6.7471 & 5.3389 & TST & \\
\hline CHEMBL1505212 & 688733 & 5.9165 & 5.625 & TST & \\
\hline CHEMBL1410357 & 688733 & 5.8706 & 5.6859 & TST & \\
\hline CHEMBL1328302 & 688733 & 7.0315 & 5.7671 & TST & \\
\hline CHEMBL1499823 & 688733 & 5.3691 & 5.2224 & TST & \\
\hline CHEMBL1519311 & 688733 & 5.4811 & 5.777 & TST & \\
\hline CHEMBL1610388 & 688733 & 5.9991 & 6.1291 & TST & \\
\hline CHEMBL1413986 & 688733 & 5.7053 & 5.7094 & TST & \\
\hline CHEMBL1539768 & 688733 & 4.9602 & 5.5827 & TST & \\
\hline CHEMBL85811 & 688829 & 4.3 & 4.2975 & TRN & \\
\hline CHEMBL46730 & 688829 & 8.7959 & 5.4204 & TRN & \\
\hline CHEMBL288998 & 688829 & 5.7 & 5.0598 & TRN & \\
\hline CHEMBL1579130 & 688829 & 6.0 & 4.8144 & TRN & \\
\hline CHEMBL 263116 & 688829 & 4.3 & 5.5719 & TRN & \\
\hline CHEMBL44072 & 688829 & 4.7 & 4.6578 & TST & \\
\hline CHEMBL486193 & 688829 & 4.3 & 4.692 & TRN & \\
\hline CHEMBL26215 & 688829 & 5.2 & 4.4674 & TRN & \\
\hline CHEMBL1562104 & 688829 & 5.4 & 5.125 & TRN & \\
\hline CHEMBL553181 & 688829 & 4.5 & 4.4497 & TRN & \\
\hline CHEMBL353971 & 688829 & 4.8 & 4.2178 & TRN & \\
\hline CHEMBL1526319 & 688829 & 4.4 & 4.4367 & TRN & \\
\hline CHEMBL1451833 & 688829 & 4.6 & 4.561 & TST & \\
\hline CHEMBL1489064 & 688829 & 4.4 & 4.8222 & TRN & \\
\hline CHEMBL1304981 & 688829 & 4.4 & 5.2966 & TRN & \\
\hline CHEMBL453797 & 688829 & 4.1 & 4.2765 & TRN & \\
\hline CHEMBL1338909 & 688829 & 4.2 & 5.4848 & TRN & \\
\hline CHEMBL105712 & 688829 & 5.0 & 6.4986 & TRN & \\
\hline CHEMBL449362 & 688829 & 6.7001 & 5.6497 & TRN & \\
\hline CHEMBL1412431 & 688829 & 4.3 & 4.2957 & TRN & \\
\hline CHEMBL1527567 & 688829 & 4.5 & 4.4323 & TRN & \\
\hline CHEMBL1450607 & 688829 & 4.8 & 5.1359 & TST & \\
\hline CHEMBL1366925 & 688829 & 7.4001 & 5.74100 & 00000000005 & TRN \\
\hline CHEMBL1320187 & 688829 & 4.1 & 4.6167 & TRN & \\
\hline CHEMBL1351619 & 688829 & 4.1 & 5.0552 & TRN & \\
\hline CHEMBL1489206 & 688829 & 4.5 & 4.4465 & TRN & \\
\hline CHEMBL194400 & 688829 & 4.4 & 4.57600 & 00000000005 & TST \\
\hline CHEMBL325415 & 688829 & 4.1 & 4.7104 & TRN & \\
\hline CHEMBL1499545 & 688829 & 5.1 & 4.4456 & TRN & \\
\hline CHEMBL1608558 & 688829 & 4.1 & 4.7456 & TRN & \\
\hline CHEMBL14173 & 688829 & 7.8013 & 6.6273 & TRN & \\
\hline CHEMBL443436 & 688829 & 5.0 & 5.0138 & TRN & \\
\hline CHEMBL1409985 & 688829 & 5.2 & 5.0572 & TRN & \\
\hline CHEMBL319398 & 688829 & 5.4 & 3.8804 & TRN & \\
\hline CHEMBL1522486 & 688829 & 4.8 & 4.8325 & TRN & \\
\hline
\end{tabular}




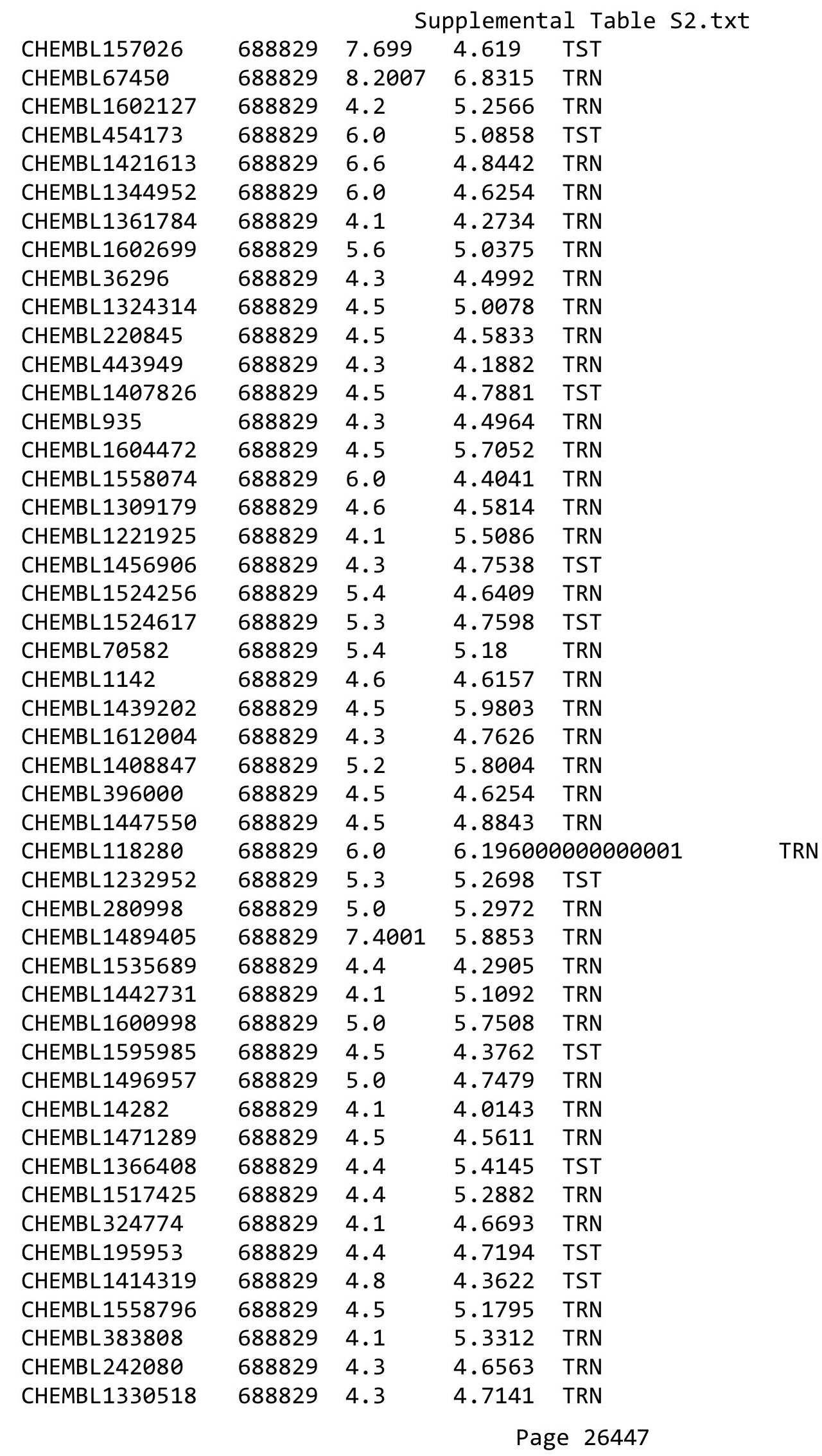




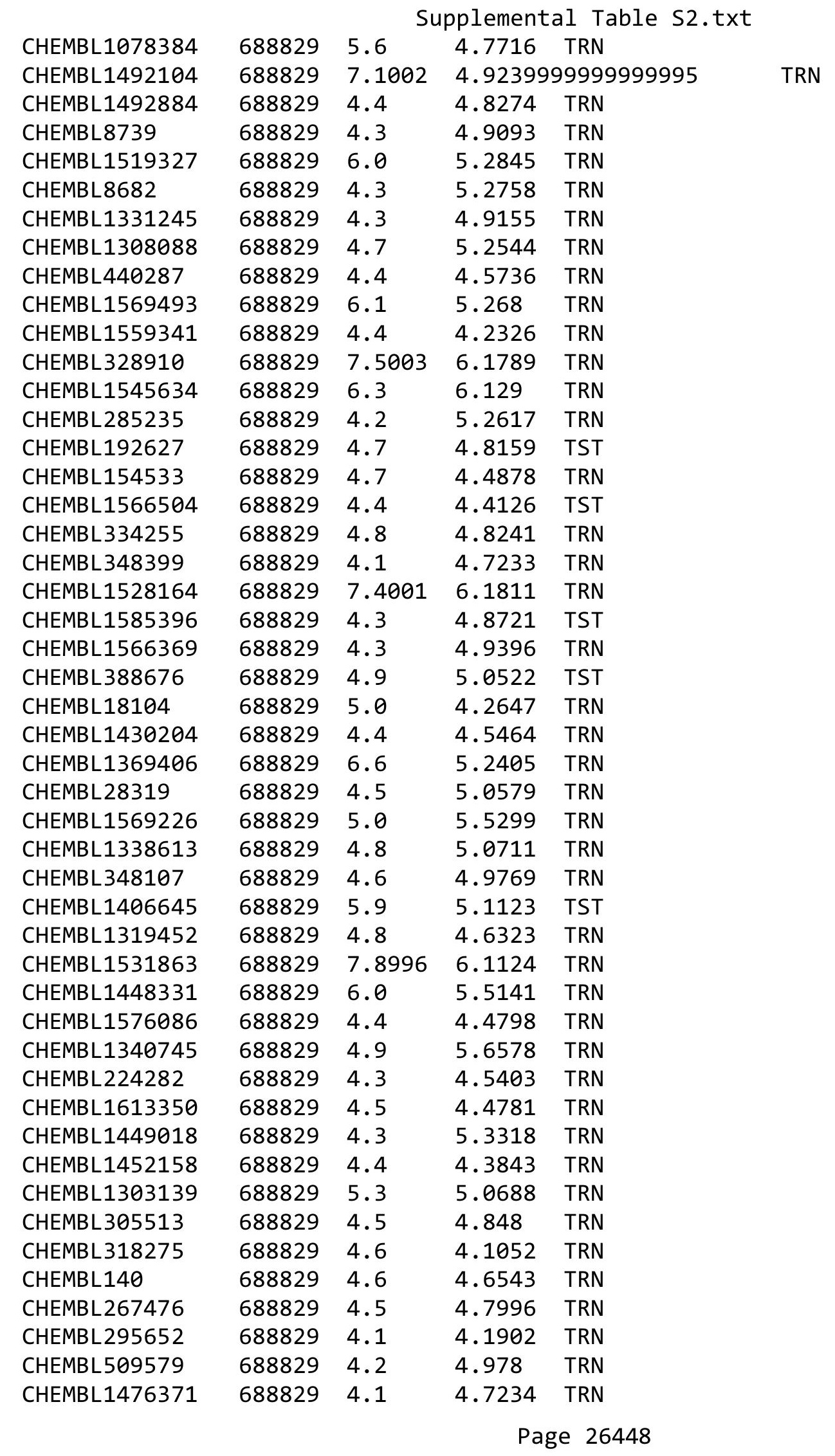




\begin{tabular}{|c|c|c|c|c|c|}
\hline \\
\hline CHEMBL1530684 & 688829 & 4.4 & 4.7087 & TRN & \\
\hline CHEMBL1549844 & 688829 & 4.3 & 4.7784 & TST & \\
\hline CHEMBL1393325 & 688829 & 4.4 & 4.9377 & TRN & \\
\hline CHEMBL1325985 & 688829 & 4.1 & 4.4478 & TST & \\
\hline CHEMBL1609459 & 688829 & 4.9 & 4.8035 & TST & \\
\hline CHEMBL333298 & 688829 & 6.8 & 4.5663 & TST & \\
\hline CHEMBL165 & 688829 & 4.1 & 4.6828 & TST & \\
\hline CHEMBL89295 & 688829 & 5.6 & 4.6699 & TST & \\
\hline CHEMBL194399 & 688829 & 4.5 & 4.7278 & TST & \\
\hline CHEMBL362919 & 688829 & 4.1 & 4.6278 & TST & \\
\hline CHEMBL1531235 & 688829 & 6.2 & 4.8531 & TST & \\
\hline CHEMBL1448387 & 688829 & 4.5 & 4.65 & TST & \\
\hline CHEMBL1514512 & 688829 & 4.4 & 4.6355 & TST & \\
\hline CHEMBL1200471 & 688829 & 6.7001 & 5.5674 & TST & \\
\hline CHEMBL1518369 & 688829 & 4.4 & 5.45100 & 00000000005 & TST \\
\hline CHEMBL164921 & 688829 & 4.1 & 4.0479 & TST & \\
\hline CHEMBL1365278 & 688829 & 4.9 & 4.4885 & TST & \\
\hline CHEMBL117311 & 688829 & 4.1 & 4.9209 & TST & \\
\hline CHEMBL267373 & 688829 & 4.9 & 6.4683 & TST & \\
\hline CHEMBL509531 & 688829 & 4.8 & 4.3094 & TST & \\
\hline CHEMBL1414154 & 688829 & 4.3 & 5.25 & TST & \\
\hline CHEMBL1447588 & 688829 & 4.9 & 4.6056 & TST & \\
\hline CHEMBL3919299 & 1641031 & 6.0 & 6.6452 & TRN & \\
\hline CHEMBL3940119 & 1641031 & 7.5086 & 7.9862 & TRN & \\
\hline CHEMBL 3924789 & 1641031 & 7.0223 & 8.2851 & TRN & \\
\hline CHEMBL3909674 & 1641031 & 6.0 & 5.8798 & TRN & \\
\hline CHEMBL3909686 & 1641031 & 6.0 & 5.7864 & TRN & \\
\hline CHEMBL3928407 & 1641031 & 6.0 & 8.0184 & TRN & \\
\hline CHEMBL3952478 & 1641031 & 7.3768 & 7.6495 & TRN & \\
\hline CHEMBL3920883 & 1641031 & 8.2218 & 7.6617 & TRN & \\
\hline CHEMBL3962159 & 1641031 & 9.0969 & 8.7355 & TRN & \\
\hline CHEMBL 3938347 & 1641031 & 7.8539 & 8.5498 & TRN & \\
\hline CHEMBL3908784 & 1641031 & 7.6778 & 7.7572 & TRN & \\
\hline CHEMBL3927360 & 1641031 & 8.699 & 7.3928 & TRN & \\
\hline CHEMBL3943844 & 1641031 & 8.3979 & 8.4018 & TRN & \\
\hline CHEMBL3982635 & 1641031 & 8.699 & 8.2288 & TRN & \\
\hline CHEMBL 3971257 & 1641031 & 8.3979 & 8.4952 & TRN & \\
\hline CHEMBL3943088 & 1641031 & 6.0 & 5.9493 & TST & \\
\hline CHEMBL3890147 & 1641031 & 8.0458 & 8.4787 & TRN & \\
\hline CHEMBL3938252 & 1641031 & 7.8239 & 8.5656 & TRN & \\
\hline CHEMBL3970845 & 1641031 & 8.5229 & 8.6143 & TRN & \\
\hline CHEMBL3957355 & 1641031 & 9.2218 & 8.6314 & TRN & \\
\hline CHEMBL3947434 & 1641031 & 8.0458 & 8.4095 & TRN & \\
\hline CHEMBL3908006 & 1641031 & 9.3979 & 8.4338 & TRN & \\
\hline CHEMBL3933760 & 1641031 & 8.0969 & 7.8124 & TRN & \\
\hline CHEMBL3901860 & 1641031 & 8.1549 & 8.1347 & TRN & \\
\hline CHEMBL3917562 & 1641031 & 6.0 & 7.5729 & TRN & \\
\hline CHEMBL3914170 & 1641031 & 8.301 & 8.7253 & TRN & \\
\hline
\end{tabular}


Supplemental Table S2.txt

\begin{tabular}{|c|c|c|c|c|c|}
\hline CHEMBL3948693 & 1641031 & 8.0458 & 8.9606 & TRN & \\
\hline CHEMBL3909179 & 1641031 & 6.0 & 5.7057 & TRN & \\
\hline CHEMBL3909181 & 1641031 & 9.0 & 8.0172 & TRN & \\
\hline CHEMBL3905829 & 1641031 & 9.2218 & 8.7167 & TRN & \\
\hline CHEMBL3947710 & 1641031 & 7.1739 & 8.2094 & TRN & \\
\hline CHEMBL3908617 & 1641031 & 9.0 & 8.1022 & TST & \\
\hline CHEMBL3976101 & 1641031 & 8.699 & 8.5695 & TRN & \\
\hline CHEMBL3905431 & 1641031 & 7.3188 & 7.8343 & TST & \\
\hline CHEMBL3956754 & 1641031 & 9.0 & 8.6815 & TST & \\
\hline CHEMBL3912748 & 1641031 & 8.0969 & 8.4291 & TRN & \\
\hline CHEMBL3920988 & 1641031 & 7.2218 & 7.9152 & TST & \\
\hline CHEMBL3927128 & 1641031 & 8.301 & 8.2207 & TRN & \\
\hline CHEMBL3933314 & 1641031 & 8.0458 & 8.5131 & TST & \\
\hline CHEMBL3898636 & 1641031 & 8.0458 & 7.9307 & TST & \\
\hline CHEMBL3966390 & 1641031 & 6.0 & 5.8188 & TRN & \\
\hline CHEMBL3948071 & 1641031 & 6.0 & 5.8851 & TRN & \\
\hline CHEMBL3970492 & 1641031 & 8.0969 & 7.9424 & TST & \\
\hline CHEMBL3921732 & 1641031 & 9.0969 & 8.0488 & TRN & \\
\hline CHEMBL3958629 & 1641031 & 9.0 & 7.9967 & TRN & \\
\hline CHEMBL3911944 & 1641031 & 9.2218 & 9.0609 & TST & \\
\hline CHEMBL 3892884 & 1641031 & 8.3979 & 8.4654 & TRN & \\
\hline CHEMBL3921336 & 1641031 & 7.0757 & 8.1254 & TST & \\
\hline CHEMBL3934385 & 1641031 & 6.0 & 6.8812 & TST & \\
\hline CHEMBL3915848 & 1641031 & 6.0 & 7.6891 & TRN & \\
\hline CHEMBL3935702 & 1641031 & 6.0 & 6.2942 & TRN & \\
\hline CHEMBL3943356 & 1641031 & 6.0 & 6.8494 & TST & \\
\hline CHEMBL 3919440 & 1641031 & 8.3979 & 8.3972 & TRN & \\
\hline CHEMBL3931089 & 1641031 & 9.2218 & 8.5075 & TRN & \\
\hline CHEMBL3923554 & 1641031 & 6.0 & 5.7375 & TRN & \\
\hline CHEMBL3914829 & 1641031 & 9.0 & 8.0028 & TRN & \\
\hline CHEMBL3900134 & 1641031 & 6.0 & 6.3855 & TRN & \\
\hline CHEMBL3903107 & 1641031 & 8.699 & 8.6137 & TST & \\
\hline CHEMBL3924661 & 1641031 & 6.0 & 6.9686 & TST & \\
\hline CHEMBL3957788 & 1641031 & 8.301 & 8.2436 & TST & \\
\hline CHEMBL3980395 & 1641031 & 8.5229 & 8.1417 & TRN & \\
\hline CHEMBL3981564 & 1641031 & 7.8539 & 8.2858 & TST & \\
\hline CHEMBL 3926774 & 1641031 & 7.9208 & 8.3412 & TST & \\
\hline CHEMBL3985378 & 1641031 & 7.7447 & 7.9553 & TRN & \\
\hline CHEMBL3937412 & 1641031 & 8.0969 & 7.8694 & TRN & \\
\hline CHEMBL3927130 & 1641031 & 8.699 & 8.0412 & TRN & \\
\hline CHEMBL3964528 & 1641031 & 6.0 & 5.5072 & TRN & \\
\hline CHEMBL3961903 & 1641031 & 7.2007 & 7.88200 & 0000000001 & TRN \\
\hline CHEMBL3948051 & 1641031 & 8.699 & 8.5132 & TRN & \\
\hline CHEMBL3915789 & 1641031 & 7.8539 & 8.2294 & TRN & \\
\hline CHEMBL3942165 & 1641031 & 9.2218 & 8.9041 & TRN & \\
\hline CHEMBL3910412 & 1641031 & 6.4202 & 7.893 & TST & \\
\hline CHEMBL3972344 & 1641031 & 8.2218 & 8.3585 & TRN & \\
\hline CHEMBL3899696 & 1641031 & 9.301 & 8.4879 & TST & \\
\hline
\end{tabular}


Supplemental Table S2.txt

\begin{tabular}{|c|c|c|c|c|c|}
\hline CHEMBL3920698 & 1641031 & 7.4559 & 7.7065 & TRN & \\
\hline CHEMBL3896596 & 1641031 & 9.0 & 8.255 & TRN & \\
\hline CHEMBL3897420 & 1641031 & 8.699 & 8.4965 & TRN & \\
\hline CHEMBL3894708 & 1641031 & 6.0 & 6.8979 & TRN & \\
\hline CHEMBL3942725 & 1641031 & 9.1549 & 8.3917 & TRN & \\
\hline CHEMBL3956715 & 1641031 & 8.301 & 8.5622 & TRN & \\
\hline CHEMBL3931616 & 1641031 & 8.0 & 8.122 & TST & \\
\hline CHEMBL3954692 & 1641031 & 9.2218 & 8.0837 & TRN & \\
\hline CHEMBL3954776 & 1641031 & 8.3979 & 7.8364 & TRN & \\
\hline CHEMBL3969816 & 1641031 & 7.0269 & 7.8209 & TST & \\
\hline CHEMBL3951571 & 1641031 & 8.699 & 7.8689 & TRN & \\
\hline CHEMBL3900451 & 1641031 & 6.0 & 7.6257 & TRN & \\
\hline CHEMBL3943752 & 1641031 & 7.5229 & 8.3409 & TST & \\
\hline CHEMBL3928926 & 1641031 & 9.2218 & 8.5921 & TRN & \\
\hline CHEMBL572236 & 787656 & 3.0 & 3.4241 & TRN & \\
\hline CHEMBL1917836 & 787656 & 3.0 & 3.7703 & TST & \\
\hline CHEMBL1917656 & 787656 & 4.8502 & 4.8309 & TRN & \\
\hline CHEMBL1917839 & 787656 & 3.0 & 3.52399 & 99999999996 & TST \\
\hline CHEMBL572026 & 787656 & 4.1462 & 3.7063 & TRN & \\
\hline CHEMBL571359 & 787656 & 5.0867 & 3.9464 & TRN & \\
\hline CHEMBL571146 & 787656 & 4.6724 & 4.7459 & TRN & \\
\hline CHEMBL1914493 & 787656 & 4.8486 & 4.4895 & TST & \\
\hline CHEMBL570466 & 787656 & 4.4438 & 4.4728 & TRN & \\
\hline CHEMBL569558 & 787656 & 3.0 & 3.9464 & TRN & \\
\hline CHEMBL578814 & 787656 & 5.2125 & 5.5468 & TRN & \\
\hline CHEMBL1917662 & 787656 & 3.0 & 3.3069 & TRN & \\
\hline CHEMBL1917827 & 787656 & 3.0 & 3.1507 & TRN & \\
\hline CHEMBL1917664 & 787656 & 3.0 & 3.3851 & TRN & \\
\hline CHEMBL1917832 & 787656 & 4.6148 & 4.1843 & TST & \\
\hline CHEMBL1917665 & 787656 & 4.5911 & 3.2706 & TRN & \\
\hline CHEMBL1917829 & 787656 & 3.0 & 3.4748 & TST & \\
\hline CHEMBL1917659 & 787656 & 4.7442 & 5.0828 & TRN & \\
\hline CHEMBL1917654 & 787656 & 5.5834 & 5.137006 & 00000000005 & TRN \\
\hline CHEMBL569557 & 787656 & 3.0 & 3.824 & TRN & \\
\hline CHEMBL1917666 & 787656 & 5.2083 & 4.5047 & TRN & \\
\hline CHEMBL576070 & 787656 & 4.9112 & 4.5091 & TRN & \\
\hline CHEMBL570510 & 787656 & 4.957 & 4.1722 & TRN & \\
\hline CHEMBL572024 & 787656 & 5.1543 & 5.6181 & TRN & \\
\hline CHEMBL1917670 & 787656 & 4.1071 & 3.6277 & TRN & \\
\hline CHEMBL570511 & 787656 & 4.1197 & 3.7171 & TRN & \\
\hline CHEMBL583335 & 787656 & 4.6014 & 4.6665 & TRN & \\
\hline CHEMBL569115 & 787656 & 6.2007 & 5.2964 & TRN & \\
\hline CHEMBL1917657 & 787656 & 4.9838 & 5.3119 & TRN & \\
\hline CHEMBL584953 & 787656 & 2.8047 & 4.4646 & TRN & \\
\hline CHEMBL569338 & 787656 & 3.0 & 4.3814 & TRN & \\
\hline CHEMBL1917663 & 787656 & 5.0794 & 4.4166 & TRN & \\
\hline CHEMBL1917831 & 787656 & 3.0 & 3.3557 & TST & \\
\hline CHEMBL1917658 & 787656 & 3.0 & 3.6255 & TRN & \\
\hline
\end{tabular}




\begin{tabular}{|c|c|c|c|c|c|c|}
\hline \multicolumn{7}{|c|}{ Supplemental Table S2.txt } \\
\hline CHEMBL1917668 & 787656 & 3.0 & 3.2384 & TRN & & \\
\hline CHEMBL1917669 & 787656 & 3.0 & 3.2417 & TRN & & \\
\hline CHEMBL1917837 & 787656 & 3.0 & 3.5686 & TST & & \\
\hline CHEMBL1917828 & 787656 & 5.1325 & 4.5672 & TRN & & \\
\hline CHEMBL1917667 & 787656 & 3.0 & 3.5719 & TRN & & \\
\hline CHEMBL1917661 & 787656 & 4.4881 & 4.1153 & TRN & & \\
\hline CHEMBL1917835 & 787656 & 4.5732 & 4.4042 & TST & & \\
\hline CHEMBL1917838 & 787656 & 4.8526 & 3.4516 & TST & & \\
\hline CHEMBL1917834 & 787656 & 3.0 & 3.3463 & TST & & \\
\hline CHEMBL1917655 & 787656 & 4.8914 & 4.7615 & TRN & & \\
\hline CHEMBL570059 & 787656 & 5.0487 & 5.0858 & TRN & & \\
\hline CHEMBL1917833 & 787656 & 4.7757 & 4.2919 & TST & & \\
\hline CHEMBL1917671 & 787656 & 4.6459 & 3.7657 & TRN & & \\
\hline CHEMBL1917660 & 787656 & 5.0391 & 4.2659 & TST & & \\
\hline CHEMBL1917830 & 787656 & 3.0 & 3.4894 & TST & & \\
\hline CHEMBL570465 & 787656 & 3.0 & 3.2284 & TRN & & \\
\hline CHEMBL3943631 & 1642435 & 9.0044 & 8.7857 & TRN & & \\
\hline CHEMBL 3957149 & 1642435 & 9.699 & 9.1208 & TRN & & \\
\hline CHEMBL3975977 & 1642435 & 9.5376 & 9.0425 & TRN & & \\
\hline CHEMBL3933598 & 1642435 & 6.0 & 8.6179 & TRN & & \\
\hline CHEMBL3926882 & 1642435 & 7.7212 & 8.9356 & TRN & & \\
\hline CHEMBL3963597 & 1642435 & 9.0 & 8.1976 & TRN & & \\
\hline CHEMBL 3977690 & 1642435 & 9.3188 & 8.9458 & TRN & & \\
\hline CHEMBL3939304 & 1642435 & 9.2924 & 8.8466 & TRN & & \\
\hline CHEMBL3935812 & 1642435 & 8.3098 & 8.6959 & TRN & & \\
\hline CHEMBL3984070 & 1642435 & 9.8861 & 9.5763 & TRN & & \\
\hline CHEMBL3970381 & 1642435 & 9.1675 & 9.0395 & TRN & & \\
\hline CHEMBL 3932525 & 1642435 & 8.4685 & 8.4934 & TRN & & \\
\hline CHEMBL3984009 & 1642435 & 9.8861 & 9.1227 & TRN & & \\
\hline CHEMBL3892736 & 1642435 & 9.1549 & 9.25 & TRN & & \\
\hline CHEMBL3933646 & 1642435 & 8.2839 & 99999999 & 99 & 8.2269 & TRN \\
\hline CHEMBL3967601 & 1642435 & 8.8861 & 9.4122 & TRN & & \\
\hline CHEMBL3967547 & 1642435 & 9.5686 & 8.979 & TST & & \\
\hline CHEMBL3966643 & 1642435 & 9.8861 & 9.5024 & TRN & & \\
\hline CHEMBL 3904204 & 1642435 & 9.4815 & 8.9566 & TST & & \\
\hline CHEMBL3927615 & 1642435 & 8.4437 & 8.2621 & TRN & & \\
\hline CHEMBL3971305 & 1642435 & 7.9586 & 8.7186 & TRN & & \\
\hline CHEMBL3933423 & 1642435 & 9.0555 & 8.7221 & TRN & & \\
\hline CHEMBL3981979 & 1642435 & 8.3768 & 8.3856 & TRN & & \\
\hline CHEMBL3949162 & 1642435 & 7.301 & 7.6186 & TST & & \\
\hline CHEMBL3968031 & 1642435 & 8.7447 & 9.117 & TRN & & \\
\hline CHEMBL3943813 & 1642435 & 9.8239 & 9.4328 & TST & & \\
\hline CHEMBL3916984 & 1642435 & 8.8239 & 8.8555 & TRN & & \\
\hline CHEMBL3901073 & 1642435 & 9.6576 & 8.8001 & TRN & & \\
\hline CHEMBL 3908251 & 1642435 & 9.3979 & 8.9483 & TRN & & \\
\hline CHEMBL3958917 & 1642435 & 9.8861 & 9.4133 & TST & & \\
\hline CHEMBL3976541 & 1642435 & 9.7212 & 9.1637 & TRN & & \\
\hline CHEMBL 3907088 & 1642435 & 9.4559 & 9.5295 & TRN & & \\
\hline
\end{tabular}


Supplemental Table S2.txt

\begin{tabular}{|c|c|c|c|c|}
\hline HEM & 642435 & 7.6383 & 7.8268 & \\
\hline & & & 7.95 & \\
\hline HFMBI & 35 & & & \\
\hline HEMBL & & 3861 & & \\
\hline AEMBL3951893 & 642435 & 9.8861 & 3324 & \\
\hline HEMBL3920517 & 64 & 9.8861 & 544 & \\
\hline HEMBL392 & & 9.2757 & .5665 & \\
\hline HEMBL394 & & & & PM > \\
\hline HEMBL3903385 & 64 & 8.3098 & 8.1604 & \\
\hline HEMBL3942619 & 64 & 9.7212 & 9463 & \\
\hline HEMBL 392 & 6 & & .5716 & \\
\hline AEMBL3S & & 021 & 9353 & ST \\
\hline AEMBL3 & & & & \\
\hline HEMBL3889877 & 35 & 9.0969 & 9.2643 & $m$ \\
\hline HEMBL 398 & & & & \\
\hline HEMBL3S & 6 & 9. & 184 & \\
\hline HEMBL3S & & 9. & 121 & RN \\
\hline HEMBL3 & 6 & 6. & 2591 & RN \\
\hline HEMBL3 & & 9 . & 2554 & \\
\hline AEMBL3 & & 7. & & I KIV \\
\hline HEMBL; & 64 & 9 . & 58 & ST \\
\hline HEM & & & & RN \\
\hline HEMBL & 5 & & 559 & RN \\
\hline HEMBL3 & & & & I RIV \\
\hline HEMBL396 & & 9. & 784 & | \\
\hline HEMBL3 & & & 569 & 「RN \\
\hline HEM & & & 77 & $\mathrm{RN}$ \\
\hline 95 & & 9. & 98 & 「RN \\
\hline AEMBL3 & & & & IRIN \\
\hline HEMBL 392 & 6 & 8. & 276 & RN \\
\hline HEMBL & & 33 & 198 & RN \\
\hline HFN & & 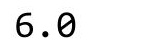 & & 「RN \\
\hline - - נסבז & & & & $\mathrm{RN}$ \\
\hline HEMBL 395 & & & & 「RN \\
\hline HEMBL3968875 & & 9.2441 & 9447 & ГRN \\
\hline HEMRI 2 & 6 & 9. & 23 & TRN \\
\hline 4 & & 9. & 85 & ГRN \\
\hline HEMBL 396 & & & & TRN \\
\hline HEMBL 390 & & 9. & & TST \\
\hline 8 & & & & IST \\
\hline HEMBL3 & & 8 . & 3974 & TRN \\
\hline & & 9.3979 & 9.4386 & 「RN \\
\hline HEMBL3 & & 8.7212 & .7829 & TRN \\
\hline HEMBL3 & 16 & & 81 & TR \\
\hline CHEMPI 307 & & & & \\
\hline HEMBL 3970090 & & 9.8861 & & \\
\hline CHEMBL3896642 & 164 & 8.7696 & 3.8192 & \\
\hline CHEMBL3909775 & 1642435 & 9.3372 & 8.9368 & \\
\hline
\end{tabular}

Page 26453 
Supplemental Table S2.txt

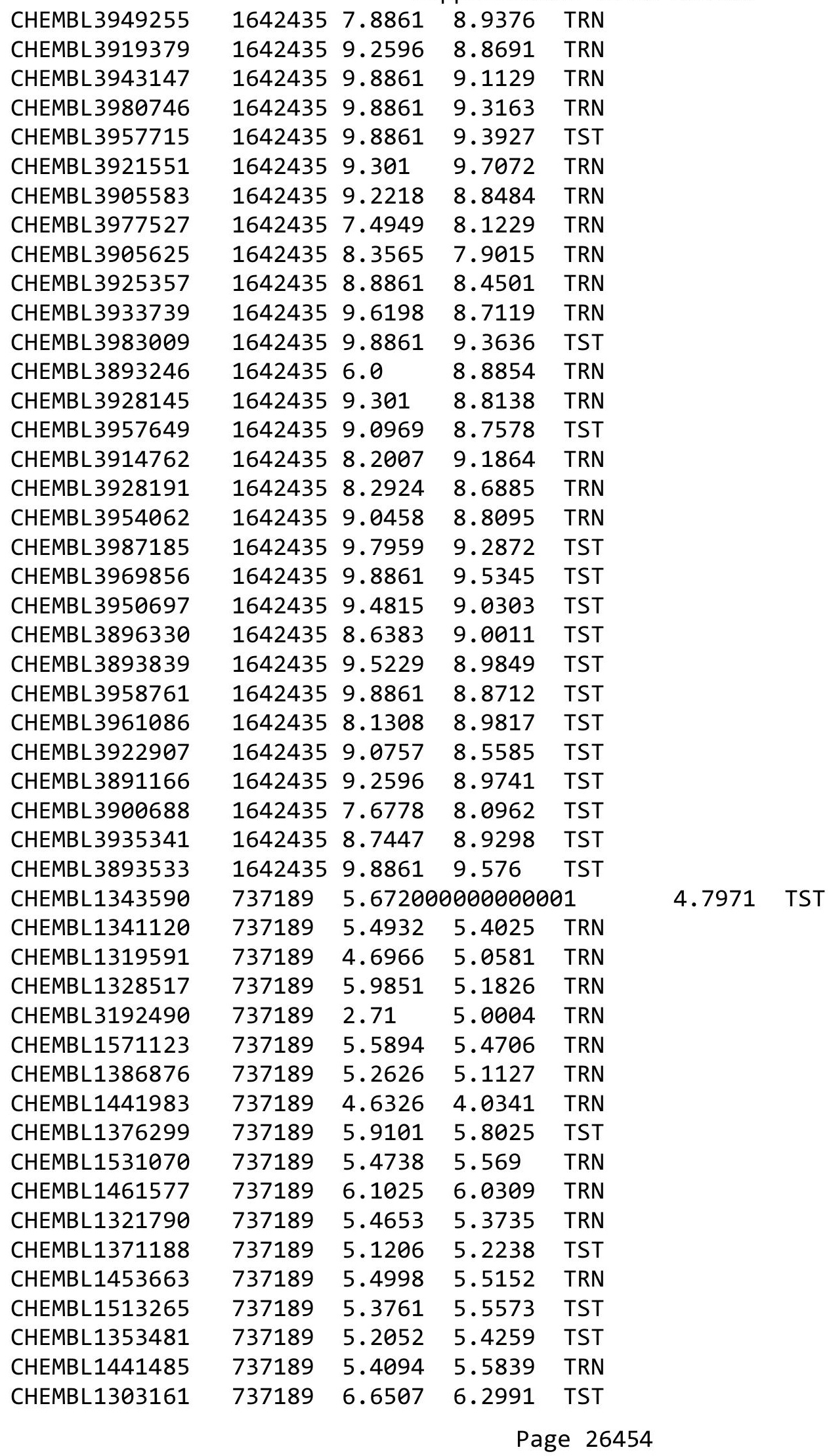




\begin{tabular}{|c|c|c|c|c|c|c|}
\hline & & \multicolumn{5}{|c|}{ Supplemental Table S2.txt } \\
\hline CHEMBL1596003 & 737189 & 5.6469 & 5.5677 & TRN & & \\
\hline CHEMBL1360793 & 737189 & 5.765 & 5.8006 & TRN & & \\
\hline CHEMBL1599654 & 737189 & 5.5411 & 5.5586 & TRN & & \\
\hline CHEMBL1309874 & 737189 & 5.8069 & 5.7434 & TRN & & \\
\hline CHEMBL1520507 & 737189 & 5.088 & 5.2602 & TRN & & \\
\hline CHEMBL1583997 & 737189 & 5.4185 & 5.4178 & TRN & & \\
\hline CHEMBL1708441 & 737189 & 5.6474 & 5.5528 & TRN & & \\
\hline CHEMBL1521259 & 737189 & \multicolumn{3}{|c|}{5.361000000000001} & 5.6299 & TRN \\
\hline CHEMBL1339537 & 737189 & 6.2089 & 5.6399 & TRN & & \\
\hline CHEMBL1339232 & 737189 & 6.307 & 5.9403 & TRN & & \\
\hline CHEMBL1501495 & 737189 & 5.278 & 5.5616 & TRN & & \\
\hline CHEMBL486541 & 737189 & 5.3112 & 5.4792 & TRN & & \\
\hline CHEMBL1584128 & 737189 & 4.2115 & 4.6692 & TRN & & \\
\hline CHEMBL1732074 & 737189 & 7.7959 & 7.2021 & TST & & \\
\hline CHEMBL1582505 & 737189 & 5.8989 & 5.782 & TRN & & \\
\hline CHEMBL1384349 & 737189 & 5.5701 & 5.6641 & TRN & & \\
\hline CHEMBL1608786 & 737189 & 5.6919 & 5.7355 & TRN & & \\
\hline CHEMBL1406019 & 737189 & 5.487 & 5.5831 & TRN & & \\
\hline CHEMBL1302460 & 737189 & 5.7217 & 5.7055 & TRN & & \\
\hline CHEMBL1475973 & 737189 & 5.3881 & 5.435 & TRN & & \\
\hline CHEMBL1551880 & 737189 & 5.4062 & 5.6657 & TST & & \\
\hline CHEMBL3196721 & 737189 & 6.1558 & 6.5129 & TRN & & \\
\hline CHEMBL 374350 & 737189 & 5.5036 & 5.6215 & TST & & \\
\hline CHEMBL1604983 & 737189 & 5.5891 & 6.1747 & TST & & \\
\hline CHEMBL1490225 & 737189 & 5.5099 & 5.6734 & TRN & & \\
\hline CHEMBL1540688 & 737189 & 5.6164 & 5.7428 & TST & & \\
\hline CHEMBL2007313 & 737189 & 5.5984 & 5.6777 & TRN & & \\
\hline CHEMBL1447682 & 737189 & 5.3155 & 5.4824 & TRN & & \\
\hline CHEMBL3191568 & 737189 & 5.3675 & 5.5044 & TRN & & \\
\hline CHEMBL1609651 & 737189 & 5.0908 & \multicolumn{3}{|c|}{5.406000000000001} & TRN \\
\hline CHEMBL1710307 & 737189 & 5.3294 & 5.4413 & TRN & & \\
\hline CHEMBL1352441 & 737189 & 5.5462 & 5.4235 & TRN & & \\
\hline CHEMBL1583716 & 737189 & 5.1744 & 5.431 & TST & & \\
\hline CHEMBL1433995 & 737189 & 5.5789 & 5.6668 & TST & & \\
\hline CHEMBL1538692 & 737189 & 4.8598 & 5.3625 & TRN & & \\
\hline CHEMBL1435286 & 737189 & 5.8438 & 5.6398 & TRN & & \\
\hline CHEMBL 2007601 & 737189 & 6.153 & 6.0528 & TRN & & \\
\hline CHEMBL1479114 & 737189 & 5.511 & 5.5211 & TRN & & \\
\hline CHEMBL1382944 & 737189 & \multicolumn{3}{|c|}{5.167000000000001} & 5.3578 & TRN \\
\hline CHEMBL1996343 & 737189 & 6.0018 & 5.7135 & TST & & \\
\hline CHEMBL1599453 & 737189 & 5.5919 & 5.7182 & TRN & & \\
\hline CHEMBL1568267 & 737189 & 6.0838 & 6.2863 & TRN & & \\
\hline CHEMBL1401888 & 737189 & 5.2822 & 5.4019 & TRN & & \\
\hline CHEMBL1381408 & 737189 & 5.1547 & 5.3327 & TRN & & \\
\hline CHEMBL1323821 & 737189 & 5.5248 & 5.5913 & TRN & & \\
\hline CHEMBL1564038 & 737189 & 5.2609 & 5.4184 & TRN & & \\
\hline CHEMBL1375844 & 737189 & 5.3104 & 5.07 & TRN & & \\
\hline CHEMBL1342173 & 737189 & 5.8386 & 5.7248 & TRN & & \\
\hline
\end{tabular}




\begin{tabular}{|c|c|c|c|c|c|c|}
\hline \multirow[b]{2}{*}{ CHEMBL1393568 } & \multirow[b]{2}{*}{737189} & \multicolumn{5}{|c|}{ Supplemental Table S2.txt } \\
\hline & & 5.6694 & 5.6383 & TRN & & \\
\hline CHEMBL1305815 & 737189 & 2.71 & 3.9213 & TRN & & \\
\hline CHEMBL1432917 & 737189 & 2.71 & 3.8403 & TST & & \\
\hline CHEMBL576208 & 737189 & 5.1586 & 5.4216 & TRN & & \\
\hline CHEMBL1368429 & 737189 & 5.5996 & 5.8778 & TRN & & \\
\hline CHEMBL1582302 & 737189 & 5.2907 & 5.4798 & TRN & & \\
\hline CHEMBL1416769 & 737189 & 5.8162 & 5.5639 & TRN & & \\
\hline CHEMBL3145301 & 737189 & 5.3366 & 5.4221 & TST & & \\
\hline CHEMBL283078 & 737189 & 6.5219 & 6.0845 & TST & & \\
\hline CHEMBL1338723 & 737189 & 6.6792 & 4.9775 & TRN & & \\
\hline CHEMBL1544265 & 737189 & 6.5444 & 6.0885 & TST & & \\
\hline CHEMBL1391272 & 737189 & \multicolumn{3}{|c|}{5.542000000000001} & 5.6294 & TRN \\
\hline CHEMBL1423440 & 737189 & 4.5859 & 4.9314 & TRN & & \\
\hline CHEMBL1320465 & 737189 & 5.1997 & 5.3439 & TRN & & \\
\hline CHEMBL1562454 & 737189 & 5.8798 & 5.6987 & TRN & & \\
\hline CHEMBL1714457 & 737189 & 5.4955 & 5.6604 & TRN & & \\
\hline CHEMBL1506932 & 737189 & 6.4817 & 5.5532 & TST & & \\
\hline CHEMBL1420908 & 737189 & 5.2031 & 5.5678 & TRN & & \\
\hline CHEMBL1315789 & 737189 & 5.5981 & 5.7523 & TRN & & \\
\hline CHEMBL393244 & 737189 & 5.7607 & 5.5523 & TRN & & \\
\hline CHEMBL1434681 & 737189 & 5.4769 & 5.4822 & TRN & & \\
\hline CHEMBL1549935 & 737189 & 5.2456 & 5.4845 & TRN & & \\
\hline CHEMBL1324082 & 737189 & 6.0691 & 5.7038 & TRN & & \\
\hline CHEMBL3196392 & 737189 & 5.2152 & 5.4316 & TRN & & \\
\hline CHEMBL1360615 & 737189 & 5.0365 & 5.3561 & TRN & & \\
\hline CHEMBL1701759 & 737189 & 5.4959 & 5.6736 & TST & & \\
\hline CHEMBL1730110 & 737189 & 5.3739 & 5.4442 & TRN & & \\
\hline CHEMBL1308346 & 737189 & \multicolumn{3}{|c|}{5.0680000000000005} & 5.3109 & TRN \\
\hline CHEMBL1556321 & 737189 & 5.3979 & 5.4011 & TRN & & \\
\hline CHEMBL1342029 & 737189 & 5.5494 & 5.5037 & TRN & & \\
\hline CHEMBL496633 & 737189 & 5.2695 & 5.4719 & TST & & \\
\hline CHEMBL1427962 & 737189 & 5.1208 & 5.92 & TRN & & \\
\hline CHEMBL1363275 & 737189 & 5.3254 & 5.5259 & TRN & & \\
\hline CHEMBL1735477 & 737189 & 5.9838 & 5.9029 & TRN & & \\
\hline CHEMBL1705324 & 737189 & 2.71 & 3.8823 & TRN & & \\
\hline CHEMBL1549140 & 737189 & 5.4291 & 5.3511 & TRN & & \\
\hline CHEMBL1320794 & 737189 & 5.6953 & 5.6637 & TRN & & \\
\hline CHEMBL1496917 & 737189 & 4.965 & 5.3691 & TRN & & \\
\hline CHEMBL1609090 & 737189 & 5.188 & 5.2987 & TRN & & \\
\hline CHEMBL1604690 & 737189 & 5.1476 & 5.2585 & TRN & & \\
\hline CHEMBL1523019 & 737189 & 5.1651 & 5.4127 & TRN & & \\
\hline CHEMBL1384414 & 737189 & 5.6212 & 5.6606 & TRN & & \\
\hline CHEMBL1405850 & 737189 & 5.263 & 3.9019 & TRN & & \\
\hline CHEMBL1992154 & 737189 & 5.3173 & 5.5463 & TRN & & \\
\hline CHEMBL1360873 & 737189 & 5.6119 & 5.5257 & TST & & \\
\hline CHEMBL1565888 & 737189 & 5.4609 & 5.4399 & TRN & & \\
\hline CHEMBL1547342 & 737189 & 5.2878 & 5.4083 & TRN & & \\
\hline \multirow[t]{2}{*}{ CHEMBL591178 } & 737189 & \multicolumn{3}{|c|}{5.4079999999999995} & 5.5411 & TRN \\
\hline & & \multicolumn{5}{|c|}{ Page 26456} \\
\hline
\end{tabular}




\begin{tabular}{|c|c|c|c|c|c|}
\hline & & & & & \\
\hline CHEMBL259018 & 737189 & 5.4045 & 5.4488 & TST & \\
\hline CHEMBL1428003 & 737189 & 5.2912 & 5.511 & TRN & \\
\hline CHEMBL3197921 & 737189 & 5.4111 & 5.5314 & TRN & \\
\hline CHEMBL1333191 & 737189 & 5.1878 & 5.4418 & TRN & \\
\hline CHEMBL1705498 & 737189 & 5.5827 & 5.7693 & TRN & \\
\hline CHEMBL1495621 & 737189 & 6.1268 & 6.1576 & TRN & \\
\hline CHEMBL1347339 & 737189 & 5.4803 & 5.6469 & TRN & \\
\hline CHEMBL1464497 & 737189 & 5.7245 & 5.6213 & TRN & \\
\hline CHEMBL1437950 & 737189 & 5.7082 & 5.5454 & TRN & \\
\hline CHEMBL1982808 & 737189 & 5.4849 & 5.5491 & TRN & \\
\hline CHEMBL1390112 & 737189 & 5.4276 & 5.6008 & TRN & \\
\hline CHEMBL3190837 & 737189 & 5.4817 & 5.4309 & TRN & \\
\hline CHEMBL1703770 & 737189 & 6.1616 & 5.9959 & TST & \\
\hline CHEMBL1311109 & 737189 & 5.3856 & 5.4012 & TST & \\
\hline CHEMBL1467329 & 737189 & 5.2477 & 4.4604 & TST & \\
\hline CHEMBL1421900 & 737189 & 4.8419 & 5.1474 & TRN & \\
\hline CHEMBL63883 & 737189 & 5.2193 & 5.4352 & TRN & \\
\hline CHEMBL1453708 & 737189 & 5.7994 & 5.5711 & TST & \\
\hline CHEMBL1480659 & 737189 & 5.8176 & 5.6935 & TRN & \\
\hline CHEMBL1493120 & 737189 & 4.8697 & 5.1537 & TST & \\
\hline CHEMBL1360535 & 737189 & 6.0 & 5.9605 & TST & \\
\hline CHEMBL1571290 & 737189 & 6.0 & 5.8187 & TRN & \\
\hline CHEMBL1366115 & 737189 & 5.4181 & 5.5861 & TRN & \\
\hline CHEMBL1431776 & 737189 & 5.1666 & 5.4278 & TRN & \\
\hline CHEMBL1596462 & 737189 & 4.6123 & 4.037 & TRN & \\
\hline CHEMBL1589098 & 737189 & 6.1414 & 3.8052 & TST & \\
\hline CHEMBL1402122 & 737189 & 6.2 & 6.102 & TRN & \\
\hline CHEMBL1733950 & 737189 & 5.4699 & 5.6325 & TRN & \\
\hline CHEMBL1579805 & 737189 & 4.9767 & 5.17899 & 9999999999 & TRN \\
\hline CHEMBL1093074 & 737189 & 5.5417 & 5.6551 & TRN & \\
\hline CHEMBL1566586 & 737189 & 4.9578 & 5.1815 & TRN & \\
\hline CHEMBL3145321 & 737189 & 5.8502 & 5.5631 & TST & \\
\hline CHEMBL1441884 & 737189 & 5.527 & 5.6921 & TRN & \\
\hline CHEMBL1732073 & 737189 & 5.4748 & 5.5598 & TRN & \\
\hline CHEMBL1359154 & 737189 & 5.5544 & 5.4968 & TRN & \\
\hline CHEMBL578716 & 737189 & 6.0079 & 5.8774 & TST & \\
\hline CHEMBL1498873 & 737189 & 5.5844 & 5.7618 & TRN & \\
\hline CHEMBL1584795 & 737189 & 5.8368 & 5.67 & TST & \\
\hline CHEMBL1518479 & 737189 & 5.4267 & 5.4679 & TRN & \\
\hline CHEMBL1499929 & 737189 & 4.7889 & 5.1626 & TRN & \\
\hline CHEMBL1474098 & 737189 & 5.1185 & 5.5083 & TST & \\
\hline CHEMBL1469659 & 737189 & 5.2703 & 5.5457 & TRN & \\
\hline CHEMBL3194892 & 737189 & 6.3629 & 5.5049 & TRN & \\
\hline CHEMBL 1385727 & 737189 & 5.2779 & 5.3822 & TRN & \\
\hline CHEMBL1326053 & 737189 & 5.2293 & 5.5303 & TRN & \\
\hline CHEMBL1344600 & 737189 & 5.9772 & 5.8571 & TRN & \\
\hline CHEMBL1443898 & 737189 & 4.6043 & 4.61 & TST & \\
\hline CHEMBL1576593 & 737189 & 5.0397 & 5.0272 & TRN & \\
\hline
\end{tabular}


Supplemental Table S2.txt

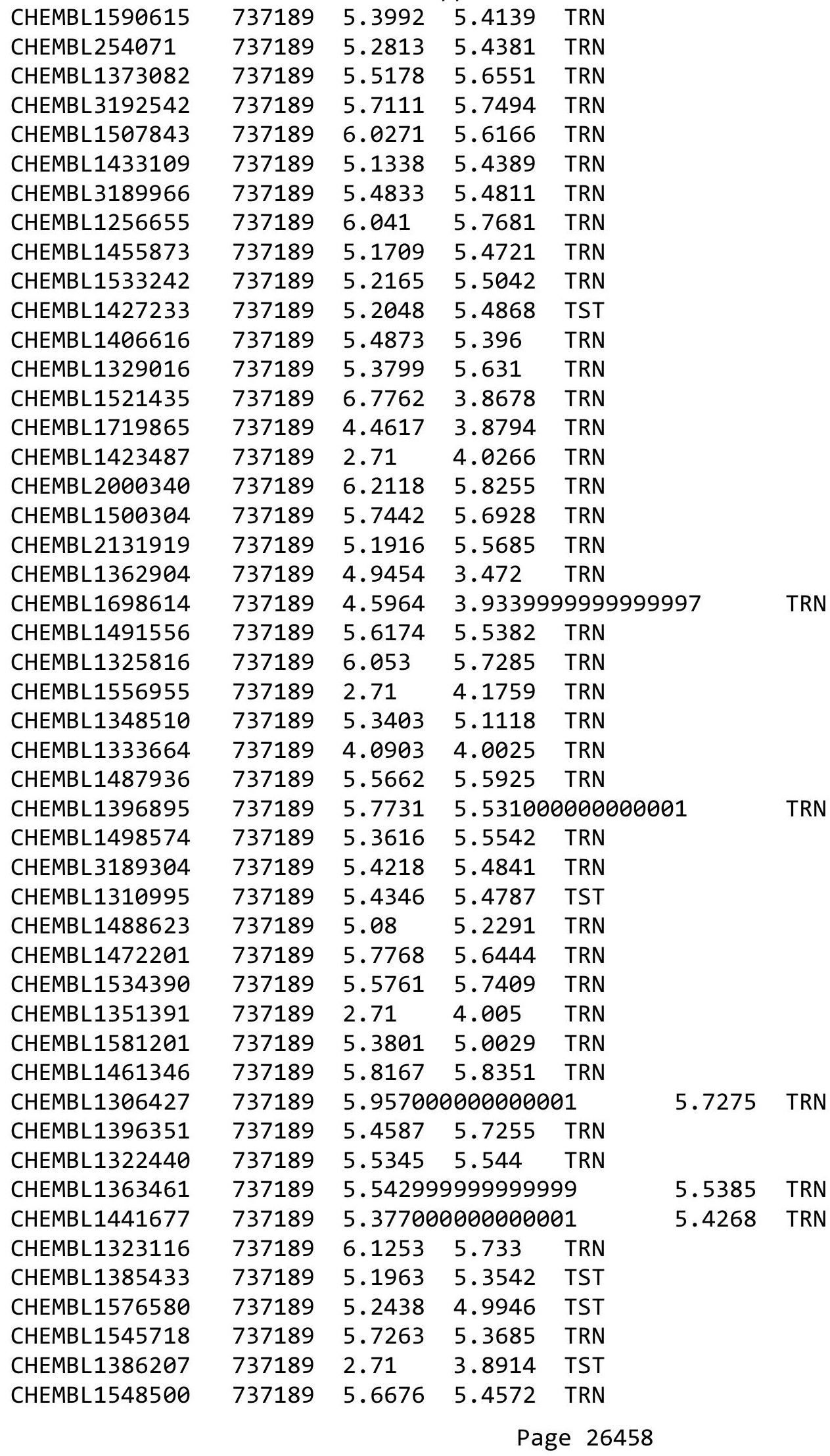


Supplemental Table S2.txt

\begin{tabular}{|c|c|c|c|c|}
\hline CHEMBL3195975 & 737189 & 5.3913 & 5.3769 & TRN \\
\hline CHEMBL1454195 & 737189 & 5.6085 & 5.7326 & TRN \\
\hline CHEMBL1535991 & 737189 & 6.6996 & 6.2549 & TRN \\
\hline CHEMBL1364395 & 737189 & 2.71 & 3.9004 & TST \\
\hline CHEMBL1373985 & 737189 & 5.388 & 5.5701 & TRN \\
\hline CHEMBL1579223 & 737189 & 6.1321 & 5.8057 & TRN \\
\hline CHEMBL1494659 & 737189 & 6.7265 & 6.2247 & TRN \\
\hline CHEMBL1381152 & 737189 & 5.3102 & 4.9371 & TRN \\
\hline CHEMBL1428014 & 737189 & 5.6415 & 3.925 & TRN \\
\hline CHEMBL1593757 & 737189 & 5.3493 & 5.4386 & TRN \\
\hline CHEMBL1454819 & 737189 & 5.2748 & 5.6355 & TRN \\
\hline CHEMBL1566675 & 737189 & 5.8671 & 5.779 & TRN \\
\hline CHEMBL3194039 & 737189 & 5.0881 & 5.4655 & TRN \\
\hline CHEMBL1414806 & 737189 & 5.8834 & 5.7491 & TRN \\
\hline CHEMBL1533963 & 737189 & 5.1462 & 5.6506 & TRN \\
\hline CHEMBL269277 & 737189 & 6.0 & 6.0059 & TST \\
\hline CHEMBL1440979 & 737189 & 4.7235 & 4.9969 & TRN \\
\hline CHEMBL1379817 & 737189 & 6.0678 & 5.7761 & TRN \\
\hline CHEMBL1417320 & 737189 & 5.3138 & 5.3459 & TRN \\
\hline CHEMBL1569222 & 737189 & 6.6108 & 6.2135 & TRN \\
\hline CHEMBL1299463 & 737189 & 5.2411 & 5.4788 & TRN \\
\hline CHEMBL1379561 & 737189 & 5.3514 & 5.32 & TRN \\
\hline CHEMBL1309297 & 737189 & 5.5772 & 5.0161 & TRN \\
\hline CHEMBL3196472 & 737189 & 6.263 & 5.4983 & TRN \\
\hline CHEMBL1431684 & 737189 & 5.3523 & 5.5052 & TRN \\
\hline CHEMBL1313978 & 737189 & 5.6716 & 5.6587 & TRN \\
\hline CHEMBL539027 & 737189 & 5.3065 & 5.4636 & TRN \\
\hline CHEMBL1569094 & 737189 & 5.1882 & 5.419 & TRN \\
\hline CHEMBL1450690 & 737189 & 6.1789 & 5.7905 & TRN \\
\hline CHEMBL1559883 & 737189 & 5.6022 & 5.5321 & TST \\
\hline CHEMBL3189613 & 737189 & 5.3481 & 5.5918 & TRN \\
\hline CHEMBL1324397 & 737189 & 5.1575 & 5.472 & TRN \\
\hline CHEMBL1483522 & 737189 & 5.5787 & 5.6775 & TRN \\
\hline CHEMBL1393990 & 737189 & 5.0465 & 5.3841 & TRN \\
\hline CHEMBL 2006122 & 737189 & 5.2904 & 5.4663 & TRN \\
\hline CHEMBL2355735 & 737189 & 5.2952 & 5.6526 & TRN \\
\hline CHEMBL1433155 & 737189 & 5.414 & 5.2747 & TRN \\
\hline CHEMBL1456324 & 737189 & 5.4347 & 5.4453 & TST \\
\hline CHEMBL1716610 & 737189 & 4.9805 & 5.225 & TRN \\
\hline CHEMBL1428600 & 737189 & 5.6876 & 5.9542 & TRN \\
\hline CHEMBL1377059 & 737189 & 5.3239 & 5.1809 & TST \\
\hline CHEMBL1393611 & 737189 & 4.4806 & 3.5802 & TRN \\
\hline CHEMBL1464042 & 737189 & 5.4029 & 5.54899 & 99999999995 \\
\hline CHEMBL1554818 & 737189 & 5.9531 & 5.7534 & TRN \\
\hline CHEMBL1385588 & 737189 & 7.7959 & 5.5505 & TRN \\
\hline CHEMBL581860 & 737189 & 5.6146 & 5.4487 & TRN \\
\hline CHEMBL1535252 & 737189 & 5.8142 & 5.7774 & TRN \\
\hline CHEMBL599943 & 737189 & 5.4195 & 5.4917 & TRN \\
\hline
\end{tabular}




\begin{tabular}{|c|c|c|c|c|c|c|}
\hline & & \multicolumn{5}{|c|}{ Supplemental Table S2.txt } \\
\hline CHEMBL1306481 & 737189 & 5.6586 & 5.4427 & TST & & \\
\hline CHEMBL1365516 & 737189 & 5.9763 & 5.6416 & TST & & \\
\hline CHEMBL1612163 & 737189 & 6.435 & 4.523 & TRN & & \\
\hline CHEMBL1406251 & 737189 & 5.8233 & 5.8188 & TRN & & \\
\hline CHEMBL1404138 & 737189 & 5.1975 & 5.4355 & TST & & \\
\hline CHEMBL1597772 & 737189 & 5.6209 & 5.5395 & TRN & & \\
\hline CHEMBL1495748 & 737189 & 5.8359 & 4.9508 & TRN & & \\
\hline CHEMBL1392564 & 737189 & 5.0632 & 5.4315 & TRN & & \\
\hline CHEMBL1329537 & 737189 & 5.4646 & 4.9308 & TRN & & \\
\hline CHEMBL1612633 & 737189 & 5.3502 & 5.505 & TRN & & \\
\hline CHEMBL 3193493 & 737189 & 5.1904 & 5.4246 & TRN & & \\
\hline CHEMBL1496769 & 737189 & 5.7368 & 4.9418 & TRN & & \\
\hline CHEMBL3210362 & 737189 & 5.7683 & 5.7349 & TRN & & \\
\hline CHEMBL1993058 & 737189 & 5.8286 & 5.7528 & TRN & & \\
\hline CHEMBL1411465 & 737189 & $5.2120 e$ & 00000000 & $\partial 1$ & 5.4575 & TRN \\
\hline CHEMBL1312320 & 737189 & 5.3517 & 5.568 & TRN & & \\
\hline CHEMBL1369071 & 737189 & 2.71 & 4.0719 & TST & & \\
\hline CHEMBL1969475 & 737189 & 5.9893 & 5.7507 & TRN & & \\
\hline CHEMBL1594604 & 737189 & 5.4597 & 5.6572 & TRN & & \\
\hline CHEMBL 3192891 & 737189 & 4.0804 & 5.1377 & TRN & & \\
\hline CHEMBL1352995 & 737189 & 5.2588 & 5.3945 & TRN & & \\
\hline CHEMBL1453837 & 737189 & 5.5177 & 4.8829 & TRN & & \\
\hline CHEMBL1593654 & 737189 & 5.4443 & 5.3513 & TRN & & \\
\hline CHEMBL1508769 & 737189 & 6.6851 & 5.9717 & TRN & & \\
\hline CHEMBL1444854 & 737189 & 5.8904 & 5.8923 & TRN & & \\
\hline CHEMBL1311835 & 737189 & 5.4864 & 5.1372 & TRN & & \\
\hline CHEMBL1376799 & 737189 & 5.191 & 5.4538 & TRN & & \\
\hline CHEMBL1719501 & 737189 & 5.2756 & 5.351 & TST & & \\
\hline CHEMBL1467492 & 737189 & 5.6187 & 5.7068 & TRN & & \\
\hline CHEMBL1304990 & 737189 & 5.4399 & 5.5298 & TRN & & \\
\hline CHEMBL1605111 & 737189 & 4.6423 & 3.915 & TRN & & \\
\hline CHEMBL1983745 & 737189 & 5.6737 & 5.8066 & TST & & \\
\hline CHEMBL2139687 & 737189 & 5.5079 & 5.6334 & TRN & & \\
\hline CHEMBL1405919 & 737189 & 5.5872 & 5.6807 & TRN & & \\
\hline CHEMBL1386918 & 737189 & 5.3624 & 5.5229 & TRN & & \\
\hline CHEMBL1326359 & 737189 & 4.7084 & 5.0463 & TRN & & \\
\hline CHEMBL1335734 & 737189 & 5.4589 & 3.9364 & TRN & & \\
\hline CHEMBL1445219 & 737189 & 5.0542 & 5.3863 & TRN & & \\
\hline CHEMBL1600599 & 737189 & 2.71 & 4.0214 & TST & & \\
\hline CHEMBL3193922 & 737189 & 5.7133 & 5.1139 & TRN & & \\
\hline CHEMBL1479320 & 737189 & 5.6992 & 5.6173 & TRN & & \\
\hline CHEMBL1589637 & 737189 & 5.273 & 5.454 & TRN & & \\
\hline CHEMBL1481113 & 737189 & 5.3104 & 5.3947 & TRN & & \\
\hline CHEMBL1256667 & 737189 & 5.3279 & 5.6202 & TST & & \\
\hline CHEMBL1311992 & 737189 & 6.2584 & 5.6032 & TST & & \\
\hline CHEMBL1367459 & 737189 & 2.71 & 3.9817 & TRN & & \\
\hline CHEMBL1542931 & 737189 & 5.8545 & 5.8314 & TRN & & \\
\hline CHEMBL1968992 & 737189 & 5.6291 & 5.5895 & TRN & & \\
\hline
\end{tabular}


Supplemental Table S2.txt

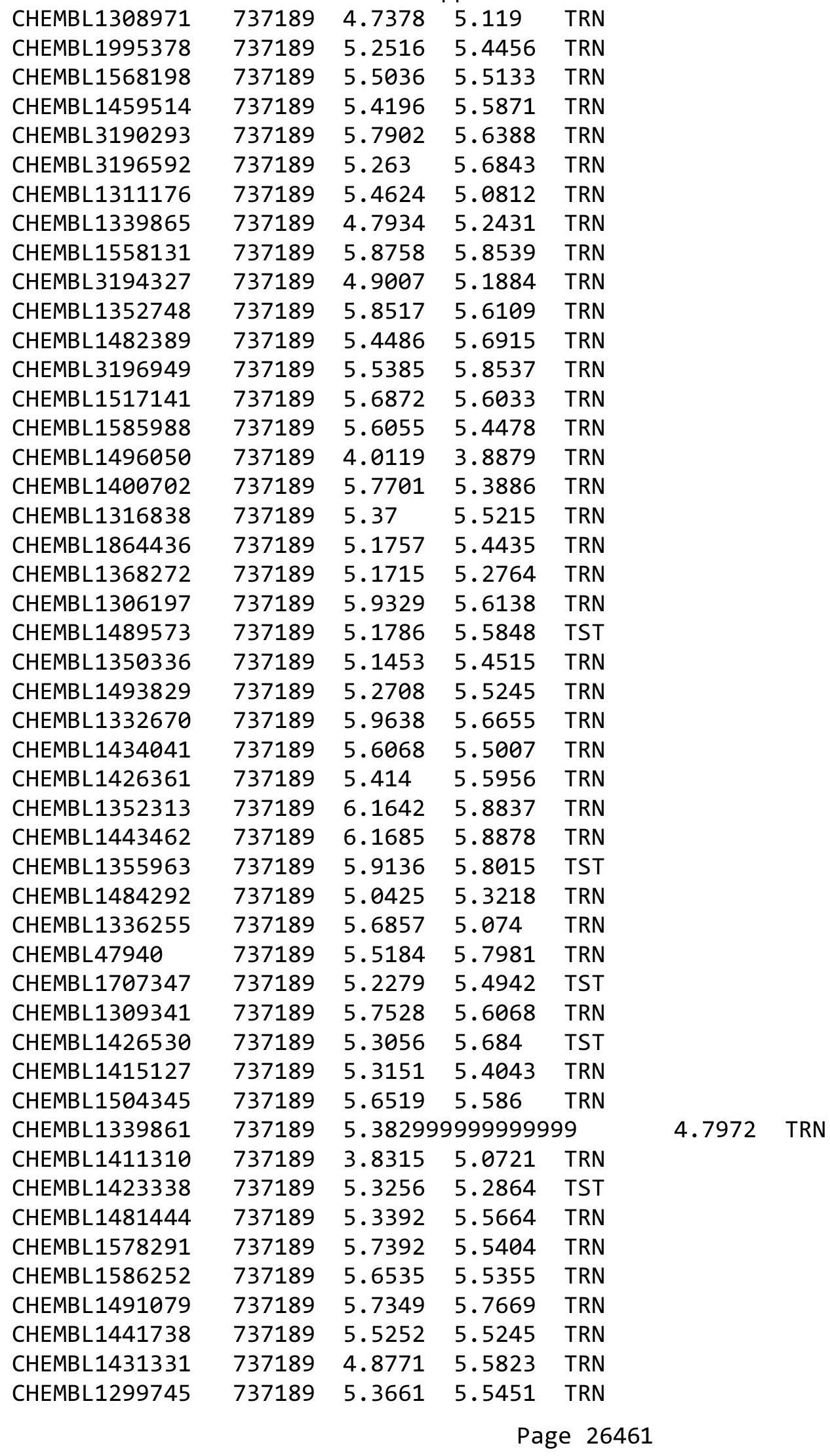


Supplemental Table S2.txt

\begin{tabular}{|c|c|c|c|c|c|}
\hline CHEMBL1463654 & 737189 & 5.159 & 5.4706 & TRN & \\
\hline CHEMBL3213728 & 737189 & 5.7625 & 5.4954 & TRN & \\
\hline CHEMBL1726132 & 737189 & 5.6498 & 5.6665 & TST & \\
\hline CHEMBL1575766 & 737189 & 5.2874 & 5.396 & TST & \\
\hline CHEMBL1713977 & 737189 & 5.6423 & 5.8224 & TRN & \\
\hline CHEMBL1430795 & 737189 & 5.6381 & 5.6176 & TRN & \\
\hline CHEMBL1492729 & 737189 & 4.7174 & 4.7875 & TST & \\
\hline CHEMBL1529482 & 737189 & 5.1881 & 5.3597 & TST & \\
\hline CHEMBL1539522 & 737189 & 5.6959 & 5.4371 & TRN & \\
\hline CHEMBL1594949 & 737189 & 5.3507 & 4.0756 & TRN & \\
\hline CHEMBL1591082 & 737189 & 5.5605 & 5.7069 & TRN & \\
\hline CHEMBL1484874 & 737189 & 2.71 & 4.0107 & TST & \\
\hline CHEMBL1580134 & 737189 & 5.2315 & 5.4139 & TRN & \\
\hline CHEMBL3197483 & 737189 & 5.5417 & 5.6498 & TRN & \\
\hline CHEMBL1559928 & 737189 & \multicolumn{2}{|c|}{6.202000000000001} & 5.6818 & TRN \\
\hline CHEMBL1496362 & 737189 & 5.3691 & 5.4469 & TRN & \\
\hline CHEMBL1538205 & 737189 & 5.8904 & 5.8152 & TRN & \\
\hline CHEMBL1543548 & 737189 & 4.9194 & 5.1722 & TRN & \\
\hline CHEMBL1580804 & 737189 & \multicolumn{2}{|c|}{5.422999999999999} & 5.5757 & TRN \\
\hline CHEMBL1717542 & 737189 & 2.71 & 4.0123 & TRN & \\
\hline CHEMBL1391399 & 737189 & 5.6139 & 5.5894 & TRN & \\
\hline CHEMBL1532238 & 737189 & 5.5514 & 5.4576 & TRN & \\
\hline CHEMBL1576099 & 737189 & 2.71 & 4.147 & TST & \\
\hline CHEMBL1316573 & 737189 & 5.2134 & 5.4864 & TRN & \\
\hline CHEMBL1504204 & 737189 & 5.4015 & 5.441 & TRN & \\
\hline CHEMBL1480264 & 737189 & 5.1319 & 5.2062 & TRN & \\
\hline CHEMBL1429000 & 737189 & 5.2607 & 5.3836 & TST & \\
\hline CHEMBL1480273 & 737189 & 5.4029 & 5.3428 & TRN & \\
\hline CHEMBL1512327 & 737189 & 5.2687 & \multicolumn{2}{|c|}{5.4270000000000005} & TRN \\
\hline CHEMBL1549566 & 737189 & 5.5106 & 5.5921 & TRN & \\
\hline CHEMBL1541391 & 737189 & 5.5226 & 5.6648 & TRN & \\
\hline CHEMBL1443328 & 737189 & 5.6107 & 5.3352 & TRN & \\
\hline CHEMBL1508295 & 737189 & 5.6866 & 5.6062 & TRN & \\
\hline CHEMBL543876 & 737189 & 5.5151 & 5.6883 & TRN & \\
\hline CHEMBL1508932 & 737189 & 5.8722 & 5.9256 & TRN & \\
\hline CHEMBL1503568 & 737189 & 5.3195 & 5.5118 & TRN & \\
\hline CHEMBL1481139 & 737189 & 5.8661 & 5.689 & TRN & \\
\hline CHEMBL1530518 & 737189 & 4.9504 & 5.7441 & TST & \\
\hline CHEMBL1567321 & 737189 & 5.2185 & 5.3551 & TRN & \\
\hline CHEMBL1375424 & 737189 & 5.3063 & 5.4344 & TRN & \\
\hline CHEMBL1702433 & 737189 & 5.4085 & 5.7783 & TRN & \\
\hline CHEMBL1421071 & 737189 & 5.4806 & 5.5237 & TST & \\
\hline CHEMBL1438655 & 737189 & 5.9393 & 5.8632 & TRN & \\
\hline CHEMBL1511276 & 737189 & 6.0 & 5.8652 & TRN & \\
\hline CHEMBL1474208 & 737189 & 5.2984 & 5.5445 & TST & \\
\hline CHEMBL1362799 & 737189 & \multicolumn{3}{|c|}{5.542999999999999} & TRN \\
\hline CHEMBL1382562 & 737189 & 5.2938 & 5.5056 & TRN & \\
\hline CHEMBL1563110 & 737189 & 5.6951 & 5.4609 & TRN & \\
\hline
\end{tabular}




\begin{tabular}{|c|c|c|c|c|c|c|}
\hline & & \multicolumn{5}{|c|}{ Supplemental Table S2.txt } \\
\hline CHEMBL1299925 & 737189 & 5.45 & 5.6416 & TRN & & \\
\hline CHEMBL1321386 & 737189 & 5.026 & 5.3541 & TRN & & \\
\hline CHEMBL1990959 & 737189 & 5.4866 & 5.6802 & TRN & & \\
\hline CHEMBL2001316 & 737189 & \multicolumn{3}{|c|}{5.242999999999999} & 5.4996 & TRN \\
\hline CHEMBL1522198 & 737189 & 4.6415 & 5.1038 & TRN & & \\
\hline CHEMBL1373688 & 737189 & 5.8921 & 5.3509 & TRN & & \\
\hline CHEMBL1417651 & 737189 & 6.0293 & 5.2491 & TRN & & \\
\hline CHEMBL1366770 & 737189 & 4.6643 & 4.0093 & TRN & & \\
\hline CHEMBL3198729 & 737189 & 5.5002 & 5.6436 & TRN & & \\
\hline CHEMBL1382617 & 737189 & 5.3836 & 5.518 & TRN & & \\
\hline CHEMBL3212034 & 737189 & 4.7582 & 5.2672 & TRN & & \\
\hline CHEMBL3195531 & 737189 & 4.9927 & 3.8624 & TRN & & \\
\hline CHEMBL1404661 & 737189 & 4.4728 & 5.12 & TST & & \\
\hline CHEMBL1578975 & 737189 & 5.3398 & 5.5713 & TRN & & \\
\hline CHEMBL1569849 & 737189 & 4.613 & 3.9093 & TRN & & \\
\hline CHEMBL1408368 & 737189 & 5.3406 & 5.6605 & TRN & & \\
\hline CHEMBL1336284 & 737189 & \multicolumn{3}{|c|}{ 4. 388999999999999} & 4.0017 & TST \\
\hline CHEMBL1329413 & 737189 & 5.1407 & 5.209 & TRN & & \\
\hline CHEMBL1427339 & 737189 & 5.8483 & 5.8899 & TRN & & \\
\hline CHEMBL1414465 & 737189 & 6.6084 & 5.6845 & TRN & & \\
\hline CHEMBL1409554 & 737189 & 5.2596 & 5.4832 & TRN & & \\
\hline CHEMBL1724733 & 737189 & \multicolumn{3}{|c|}{5.957000000000001} & 5.7032 & TRN \\
\hline CHEMBL1531686 & 737189 & 5.4972 & 5.4184 & TRN & & \\
\hline CHEMBL1339433 & 737189 & 5.4735 & 5.6639 & TRN & & \\
\hline CHEMBL1577934 & 737189 & 2.71 & 3.877 & TST & & \\
\hline CHEMBL1359462 & 737189 & 5.4869 & 5.4165 & TRN & & \\
\hline CHEMBL1359790 & 737189 & 6.0591 & 5.9323 & TRN & & \\
\hline CHEMBL1542378 & 737189 & 5.1761 & 5.3411 & TRN & & \\
\hline CHEMBL1309733 & 737189 & 5.4759 & 5.5607 & TRN & & \\
\hline CHEMBL1384843 & 737189 & 5.2504 & 5.4459 & TRN & & \\
\hline CHEMBL1969593 & 737189 & 5.4418 & 5.5985 & TRN & & \\
\hline CHEMBL1343265 & 737189 & 6.3551 & 6.0626 & TRN & & \\
\hline CHEMBL1509716 & 737189 & 5.3828 & 5.3808 & TST & & \\
\hline CHEMBL1321948 & 737189 & 5.7258 & 4.9309 & TRN & & \\
\hline CHEMBL1596084 & 737189 & 5.7844 & 5.7511 & TRN & & \\
\hline CHEMBL1594827 & 737189 & 5.3172 & 5.5222 & TST & & \\
\hline CHEMBL1549975 & 737189 & 5.4302 & 5.4396 & TRN & & \\
\hline CHEMBL1996281 & 737189 & 5.4167 & 5.6227 & TRN & & \\
\hline CHEMBL1301926 & 737189 & 4.9126 & 5.2029 & TRN & & \\
\hline CHEMBL1568184 & 737189 & 5.2464 & 5.3214 & TRN & & \\
\hline CHEMBL 2002945 & 737189 & 6.1089 & 5.2876 & TRN & & \\
\hline CHEMBL1500937 & 737189 & 6.1347 & 5.6213 & TRN & & \\
\hline CHEMBL1504675 & 737189 & 5.3653 & 5.4798 & TRN & & \\
\hline CHEMBL1426274 & 737189 & 5.7317 & 5.7492 & TRN & & \\
\hline CHEMBL1597007 & 737189 & 4.8159 & 5.2477 & TRN & & \\
\hline CHEMBL1521599 & 737189 & 5.8471 & 5.66200 & 0000000001 & & TST \\
\hline CHEMBL1545873 & 737189 & 4.5685 & 5.0489 & TRN & & \\
\hline CHEMBL1400404 & 737189 & 5.6087 & 5.5562 & TRN & & \\
\hline
\end{tabular}


Supplemental Table S2.txt

\begin{tabular}{|c|c|c|c|c|c|c|}
\hline CHEMBL1418095 & 737189 & 7.7959 & 6.2252 & TRN & & \\
\hline CHEMBL1581848 & 737189 & 5.7178 & 4.878 & TRN & & \\
\hline CHEMBL3199824 & 737189 & 5.6817 & 5.5852 & TRN & & \\
\hline CHEMBL1587928 & 737189 & 5.4803 & 5.7472 & TRN & & \\
\hline CHEMBL 3196847 & 737189 & 7.7959 & 6.3722 & TRN & & \\
\hline CHEMBL1385701 & 737189 & 5.4761 & 5.5697 & TRN & & \\
\hline CHEMBL1372201 & 737189 & 5.3288 & 5.5984 & TRN & & \\
\hline CHEMBL1353919 & 737189 & \multicolumn{3}{|c|}{5.542000000000001} & 5.5908 & TRN \\
\hline CHEMBL1573796 & 737189 & 5.1256 & 5.3072 & TRN & & \\
\hline CHEMBL1559129 & 737189 & 5.1539 & 5.3212 & TRN & & \\
\hline CHEMBL1381353 & 737189 & \multicolumn{3}{|c|}{5.111000000000001} & 5.4147 & TRN \\
\hline CHEMBL1498457 & 737189 & 6.1985 & 5.9781 & TRN & & \\
\hline CHEMBL1713814 & 737189 & 5.0618 & 5.1628 & TRN & & \\
\hline CHEMBL1329311 & 737189 & 5.9359 & 5.6544 & TRN & & \\
\hline CHEMBL1596357 & 737189 & 5.5521 & 5.6282 & TRN & & \\
\hline CHEMBL1513694 & 737189 & 5.3786 & 5.5231 & TRN & & \\
\hline CHEMBL1544703 & 737189 & 5.4841 & 5.7518 & TRN & & \\
\hline CHEMBL1465144 & 737189 & 5.6205 & 5.7594 & TRN & & \\
\hline CHEMBL1318749 & 737189 & 5.2986 & 5.5532 & TRN & & \\
\hline CHEMBL1457787 & 737189 & 5.1495 & 5.2815 & TRN & & \\
\hline CHEMBL1319378 & 737189 & 5.4292 & 5.4813 & TRN & & \\
\hline CHEMBL1369287 & 737189 & 5.4958 & 5.70700 & 0000000001 & & TRN \\
\hline CHEMBL1476181 & 737189 & 5.0965 & 5.3572 & TRN & & \\
\hline CHEMBL1557704 & 737189 & 6.0987 & 5.4682 & TRN & & \\
\hline CHEMBL 3197425 & 737189 & 5.255 & 5.4 & TRN & & \\
\hline CHEMBL1336324 & 737189 & 6.1139 & 5.8437 & TRN & & \\
\hline CHEMBL1413208 & 737189 & 5.4602 & 5.4948 & TRN & & \\
\hline CHEMBL1584568 & 737189 & 5.8894 & 5.50200 & 0000000001 & & TRN \\
\hline CHEMBL1341395 & 737189 & 5.7719 & 6.0461 & TRN & & \\
\hline CHEMBL 3195091 & 737189 & 5.436 & 5.644 & TRN & & \\
\hline CHEMBL1404113 & 737189 & 5.3809 & 4.9959 & TRN & & \\
\hline CHEMBL1403470 & 737189 & 5.218 & 5.2553 & TRN & & \\
\hline CHEMBL1579186 & 737189 & 4.7411 & 5.2181 & TRN & & \\
\hline CHEMBL1548535 & 737189 & 5.1806 & 5.4269 & TRN & & \\
\hline CHEMBL 3198185 & 737189 & 4.6202 & 5.3087 & TRN & & \\
\hline CHEMBL1566671 & 737189 & 4.7637 & 5.0535 & TRN & & \\
\hline CHEMBL1473052 & 737189 & 5.528 & 5.5234 & TRN & & \\
\hline CHEMBL 3207852 & 737189 & 7.7959 & 6.5755 & TRN & & \\
\hline CHEMBL1707745 & 737189 & 5.9041 & 5.641 & TST & & \\
\hline CHEMBL 292687 & 737189 & 5.3213 & 5.5267 & TRN & & \\
\hline CHEMBL1399957 & 737189 & 5.4403 & 5.6786 & TRN & & \\
\hline CHEMBL1320366 & 737189 & 5.0347 & 3.9274 & TRN & & \\
\hline CHEMBL248847 & 737189 & 5.8339 & 5.4671 & TRN & & \\
\hline CHEMBL1591556 & 737189 & 7.7959 & 7.1507 & TST & & \\
\hline CHEMBL1367284 & 737189 & 5.8775 & 5.8892 & TRN & & \\
\hline CHEMBL 3190181 & 737189 & 6.0783 & 5.9452 & TRN & & \\
\hline CHEMBL1555532 & 737189 & 5.7924 & 5.5464 & TRN & & \\
\hline CHEMBL 3197243 & 737189 & 5.3658 & 5.4399 & TRN & & \\
\hline
\end{tabular}


Supplemental Table S2.txt

\begin{tabular}{|c|c|c|c|c|c|c|}
\hline CHEMBL1552589 & 737189 & 5.2062 & 5.4351 & TRN & & \\
\hline CHEMBL 3195824 & 737189 & 4.6474 & 5.0516 & TRN & & \\
\hline CHEMBL 3208712 & 737189 & 4.9389 & 5.2775 & TRN & & \\
\hline CHEMBL1439236 & 737189 & 5.3786 & 5.5242 & TRN & & \\
\hline CHEMBL1537680 & 737189 & 6.2156 & 5.6214 & TRN & & \\
\hline CHEMBL1484893 & 737189 & 5.5067 & 5.4555 & TRN & & \\
\hline CHEMBL1986381 & 737189 & 4.626 & 5.0732 & TST & & \\
\hline CHEMBL3191812 & 737189 & 5.7113 & 5.3059 & TRN & & \\
\hline CHEMBL3198116 & 737189 & 5.9666 & 5.8777 & TST & & \\
\hline CHEMBL1346881 & 737189 & 5.1782 & 5.3952 & TRN & & \\
\hline CHEMBL1543340 & 737189 & 5.7972 & 5.4741 & TRN & & \\
\hline CHEMBL1736608 & 737189 & 2.71 & 3.8416 & TRN & & \\
\hline CHEMBL1532147 & 737189 & 5.4739 & 5.5725 & TRN & & \\
\hline CHEMBL1372698 & 737189 & 5.4544 & 5.5397 & TRN & & \\
\hline CHEMBL1395171 & 737189 & 5.8336 & 5.8703 & TRN & & \\
\hline CHEMBL1558527 & 737189 & 5.6297 & 5.2118 & TRN & & \\
\hline CHEMBL1461508 & 737189 & 5.5153 & 5.6187 & TST & & \\
\hline CHEMBL1577064 & 737189 & 5.3785 & 5.4786 & TST & & \\
\hline CHEMBL1483730 & 737189 & 5.0181 & 5.2722 & TST & & \\
\hline CHEMBL1343076 & 737189 & 5.2437 & 5.1262 & TRN & & \\
\hline CHEMBL1343758 & 737189 & 4.501 & 5.4747 & TRN & & \\
\hline CHEMBL17201 & 737189 & 5.8492 & 5.6836 & TRN & & \\
\hline CHEMBL1445504 & 737189 & \multicolumn{3}{|c|}{5.582000000000001} & 5.0163 & TRN \\
\hline CHEMBL1480024 & 737189 & 5.4438 & 5.6415 & TRN & & \\
\hline CHEMBL1344982 & 737189 & 5.37 & 5.6751 & TRN & & \\
\hline CHEMBL1338406 & 737189 & 4.8834 & 5.2707 & TRN & & \\
\hline CHEMBL1462451 & 737189 & 5.1981 & 5.2995 & TST & & \\
\hline CHEMBL 236897 & 737189 & 4.9087 & 5.2356 & TRN & & \\
\hline CHEMBL1346716 & 737189 & 5.3004 & 5.4241 & TRN & & \\
\hline CHEMBL1386049 & 737189 & 5.5134 & 5.6686 & TRN & & \\
\hline CHEMBL1337280 & 737189 & 5.5311 & 5.5517 & TRN & & \\
\hline CHEMBL1610842 & 737189 & 6.2243 & 5.0636 & TST & & \\
\hline CHEMBL1568095 & 737189 & 5.8119 & 5.8315 & TRN & & \\
\hline CHEMBL1606412 & 737189 & \multicolumn{3}{|c|}{5.3870000000000005} & 4.9978 & TRN \\
\hline CHEMBL1463693 & 737189 & 5.4461 & 3.9823 & TST & & \\
\hline CHEMBL1580286 & 737189 & 5.9059 & 5.4163 & TRN & & \\
\hline CHEMBL1449768 & 737189 & 5.9983 & 5.8518 & TST & & \\
\hline CHEMBL1492617 & 737189 & 4.4085 & 3.951 & TRN & & \\
\hline CHEMBL1448901 & 737189 & 4.3451 & 3.9928 & TRN & & \\
\hline CHEMBL1600941 & 737189 & 4.9825 & 5.4314 & TRN & & \\
\hline CHEMBL1334707 & 737189 & 4.62 & 3.8902 & TRN & & \\
\hline CHEMBL1364796 & 737189 & 2.71 & 3.8735 & TST & & \\
\hline CHEMBL523375 & 737189 & 5.7312 & 5.6254 & TRN & & \\
\hline CHEMBL1500686 & 737189 & 5.5664 & 5.5812 & TRN & & \\
\hline CHEMBL1702810 & 737189 & 5.601 & 5.7913 & TRN & & \\
\hline CHEMBL1468912 & 737189 & 2.71 & 4.1162 & TRN & & \\
\hline CHEMBL1556485 & 737189 & 5.4699 & 5.6389 & TRN & & \\
\hline CHEMBL548458 & 737189 & 5.7421 & 5.6467 & TRN & & \\
\hline
\end{tabular}


Supplemental Table S2.txt

\begin{tabular}{|c|c|c|c|c|}
\hline CHEMBL1702298 & 737189 & 5.6566 & 5.869 & TRN \\
\hline CHEMBL1568695 & 737189 & 5.9551 & 5.8227 & TST \\
\hline CHEMBL579082 & 737189 & 5.4778 & 5.6394 & TST \\
\hline CHEMBL1413669 & 737189 & 6.0063 & 5.5939 & TRN \\
\hline CHEMBL1423674 & 737189 & 5.1127 & 5.2418 & TRN \\
\hline CHEMBL1400410 & 737189 & 6.5794 & 6.1293 & TRN \\
\hline CHEMBL1498599 & 737189 & 5.3482 & 5.5881 & TRN \\
\hline CHEMBL1347706 & 737189 & 6.0395 & 5.8803 & TRN \\
\hline CHEMBL1971151 & 737189 & 5.5161 & 5.6505 & TRN \\
\hline CHEMBL1385983 & 737189 & 5.3457 & 5.6624 & TRN \\
\hline CHEMBL1390303 & 737189 & 5.4138 & 5.425 & TRN \\
\hline CHEMBL1468192 & 737189 & 5.3736 & 5.5325 & TRN \\
\hline CHEMBL1465176 & 737189 & 5.6194 & 5.6977 & TST \\
\hline CHEMBL1530090 & 737189 & 5.1327 & 5.1652 & TRN \\
\hline CHEMBL1734250 & 737189 & 5.2099 & 5.4276 & TRN \\
\hline CHEMBL1536646 & 737189 & 5.3226 & 5.3863 & TRN \\
\hline CHEMBL1570857 & 737189 & 5.4462 & 5.7159 & TRN \\
\hline CHEMBL1500051 & 737189 & 5.4908 & 5.4245 & TRN \\
\hline CHEMBL1585894 & 737189 & 5.6178 & 5.3477 & TRN \\
\hline CHEMBL1495140 & 737189 & 5.7948 & 5.7136 & TRN \\
\hline CHEMBL1496663 & 737189 & 5.3564 & 5.6207 & TRN \\
\hline CHEMBL1540944 & 737189 & 5.7428 & 5.6921 & TRN \\
\hline CHEMBL1720579 & 737189 & 5.1888 & 5.4445 & TRN \\
\hline CHEMBL1543298 & 737189 & 5.2969 & 5.4585 & TRN \\
\hline CHEMBL3190609 & 737189 & 5.4133 & 5.4236 & TST \\
\hline CHEMBL1387668 & 737189 & 5.8353 & 5.655 & TRN \\
\hline CHEMBL1311726 & 737189 & 5.7428 & 5.5493 & TST \\
\hline CHEMBL1487171 & 737189 & 5.9851 & 5.7884 & TRN \\
\hline CHEMBL1495254 & 737189 & 4.8928 & 5.2451 & TRN \\
\hline CHEMBL3214447 & 737189 & 5.6232 & 5.5873 & TRN \\
\hline CHEMBL1416316 & 737189 & 5.3048 & 5.23 & TRN \\
\hline CHEMBL3194407 & 737189 & 5.1351 & 4.938 & TRN \\
\hline CHEMBL1427793 & 737189 & 5.4496 & 5.5536 & TRN \\
\hline CHEMBL1352450 & 737189 & 5.7734 & 5.7127 & TRN \\
\hline CHEMBL3198705 & 737189 & 5.6531 & 5.4751 & TRN \\
\hline CHEMBL1539706 & 737189 & 6.2084 & 5.6243 & TRN \\
\hline CHEMBL1497731 & 737189 & 4.388 & 4.9642 & TRN \\
\hline CHEMBL1588298 & 737189 & 5.8063 & 5.5192 & TRN \\
\hline CHEMBL1348853 & 737189 & 5.6286 & 5.6352 & TRN \\
\hline CHEMBL3193507 & 737189 & 5.6815 & 5.5267 & TRN \\
\hline CHEMBL1580604 & 737189 & 5.4319 & 5.5852 & TRN \\
\hline CHEMBL1589111 & 737189 & 6.2503 & 5.9954 & TRN \\
\hline CHEMBL1408593 & 737189 & 6.3016 & 5.6363 & TST \\
\hline CHEMBL 3208834 & 737189 & 5.5107 & 5.50700 & 0000000001 \\
\hline CHEMBL1612379 & 737189 & 6.0465 & 5.7424 & TRN \\
\hline CHEMBL1591413 & 737189 & 7.7959 & 5.2699 & TRN \\
\hline CHEMBL3197720 & 737189 & 5.1643 & 5.2328 & TRN \\
\hline CHEMBL1573661 & 737189 & 5.6082 & 5.7632 & TRN \\
\hline
\end{tabular}

Page 26466 
Supplemental Table S2.txt

\begin{tabular}{|c|c|c|c|c|c|}
\hline CHEMBL1974230 & 737189 & 5.3171 & 5.5214 & TRN & \\
\hline CHEMBL1502104 & 737189 & 5.3645 & \multicolumn{2}{|c|}{5.361000000000001} & TRN \\
\hline CHEMBL1405281 & 737189 & 5.1786 & 5.5886 & TRN & \\
\hline CHEMBL1722313 & 737189 & 5.4804 & 5.6063 & TRN & \\
\hline CHEMBL1314665 & 737189 & 5.4669 & 5.6245 & TRN & \\
\hline CHEMBL1557089 & 737189 & 5.2965 & 5.4364 & TRN & \\
\hline CHEMBL1371902 & 737189 & 5.4365 & 5.3937 & TST & \\
\hline CHEMBL1348954 & 737189 & 5.1292 & \multicolumn{2}{|c|}{5.297000000000001} & TST \\
\hline CHEMBL1441096 & 737189 & 5.1359 & 5.3953 & TRN & \\
\hline CHEMBL1513846 & 737189 & 5.4812 & 3.925 & TRN & \\
\hline CHEMBL1344346 & 737189 & 5.4577 & 5.7877 & TST & \\
\hline CHEMBL1348336 & 737189 & 5.2389 & 5.4964 & TRN & \\
\hline CHEMBL1476017 & 737189 & 5.8511 & 5.8773 & TRN & \\
\hline CHEMBL1372052 & 737189 & 4.8668 & 3.7649 & TST & \\
\hline CHEMBL1995377 & 737189 & 6.1527 & 5.8484 & TRN & \\
\hline CHEMBL1585703 & 737189 & 2.71 & 3.89 & TRN & \\
\hline CHEMBL1700254 & 737189 & 5.1343 & 5.5297 & TST & \\
\hline CHEMBL1429230 & 737189 & 5.6929 & 4.0067 & TRN & \\
\hline CHEMBL1612814 & 737189 & 5.3005 & 5.2415 & TST & \\
\hline CHEMBL1543977 & 737189 & 5.87 & 5.9984 & TRN & \\
\hline CHEMBL1580116 & 737189 & 5.6319 & 5.5628 & TRN & \\
\hline CHEMBL1541593 & 737189 & 5.7873 & 5.6081 & TRN & \\
\hline CHEMBL1725546 & 737189 & 5.1868 & 5.4583 & TRN & \\
\hline CHEMBL1410068 & 737189 & 5.1799 & 5.3719 & TRN & \\
\hline CHEMBL1544622 & 737189 & 5.4528 & 5.5281 & TRN & \\
\hline CHEMBL1443383 & 737189 & 5.2036 & \multicolumn{2}{|c|}{5.382000000000001} & TRN \\
\hline CHEMBL1735848 & 737189 & 5.8962 & 5.8589 & TRN & \\
\hline CHEMBL1727734 & 737189 & 6.0213 & 5.926 & TRN & \\
\hline CHEMBL1352907 & 737189 & 4.794 & 5.2457 & TRN & \\
\hline CHEMBL1398061 & 737189 & 5.1047 & 5.3239 & TRN & \\
\hline CHEMBL582444 & 737189 & 5.6757 & 5.6277 & TST & \\
\hline CHEMBL1338462 & 737189 & 5.6089 & 5.6402 & TST & \\
\hline CHEMBL1467073 & 737189 & 4.7595 & 5.2736 & TRN & \\
\hline CHEMBL3190726 & 737189 & 5.3577 & 5.4728 & TRN & \\
\hline CHEMBL1510676 & 737189 & 6.0587 & 5.9085 & TST & \\
\hline CHEMBL1928483 & 737189 & 5.0966 & 5.4425 & TRN & \\
\hline CHEMBL1448356 & 737189 & 5.8159 & 5.5817 & TRN & \\
\hline CHEMBL1398209 & 737189 & 5.3567 & 5.4842 & TRN & \\
\hline CHEMBL441282 & 737189 & 5.4224 & 5.4983 & TST & \\
\hline CHEMBL1385055 & 737189 & 5.6334 & 5.8011 & TST & \\
\hline CHEMBL1369478 & 737189 & 5.3626 & 5.5517 & TRN & \\
\hline CHEMBL1346822 & 737189 & 5.5607 & 5.6378 & TRN & \\
\hline CHEMBL1587837 & 737189 & 5.6751 & 5.69 & TRN & \\
\hline CHEMBL1310680 & 737189 & 5.3499 & 5.3204 & TRN & \\
\hline CHEMBL3211803 & 737189 & 5.4241 & 5.3772 & TRN & \\
\hline CHEMBL1591271 & 737189 & 5.5441 & 5.6391 & TST & \\
\hline CHEMBL1733922 & 737189 & 5.6807 & 5.7419 & TRN & \\
\hline CHEMBL1385598 & 737189 & 5.2828 & 5.5128 & TRN & \\
\hline
\end{tabular}




\begin{tabular}{|c|c|c|c|c|c|c|}
\hline & & \multicolumn{5}{|c|}{ Supplemental Table S2.txt } \\
\hline CHEMBL1446610 & 737189 & 5.4026 & 5.5452 & TRN & & \\
\hline CHEMBL1421466 & 737189 & 5.586 & 5.3887 & TRN & & \\
\hline CHEMBL1333929 & 737189 & 6.0 & 5.7739 & TRN & & \\
\hline CHEMBL1543907 & 737189 & \multicolumn{3}{|c|}{5.2989999999999995} & 5.4973 & TRN \\
\hline CHEMBL1359270 & 737189 & 5.1133 & 5.4468 & TST & & \\
\hline CHEMBL1406161 & 737189 & 5.6548 & 5.1522 & TRN & & \\
\hline CHEMBL1322527 & 737189 & 6.7592 & 5.6675 & TST & & \\
\hline CHEMBL3189662 & 737189 & 5.8945 & 5.7719 & TRN & & \\
\hline CHEMBL570400 & 737189 & 5.421 & 5.4723 & TRN & & \\
\hline CHEMBL3188935 & 737189 & 5.5075 & 5.7556 & TRN & & \\
\hline CHEMBL1343743 & 737189 & 5.6282 & 5.7334 & TRN & & \\
\hline CHEMBL3195477 & 737189 & 6.434 & 6.2303 & TRN & & \\
\hline CHEMBL1597580 & 737189 & 6.0628 & 5.9714 & TRN & & \\
\hline CHEMBL1529352 & 737189 & 5.1191 & 5.2311 & TRN & & \\
\hline CHEMBL1573697 & 737189 & 5.2899 & 5.5476 & TRN & & \\
\hline CHEMBL1321445 & 737189 & 4.9809 & 5.2956 & TST & & \\
\hline CHEMBL1470935 & 737189 & \multicolumn{3}{|c|}{5.172999999999999} & 5.4315 & TST \\
\hline CHEMBL1365132 & 737189 & 5.607 & 5.6938 & TRN & & \\
\hline CHEMBL 1353750 & 737189 & 5.4385 & 5.409 & TST & & \\
\hline CHEMBL1502302 & 737189 & 5.7106 & 5.6398 & TRN & & \\
\hline CHEMBL1429241 & 737189 & 5.3768 & 5.1696 & TRN & & \\
\hline CHEMBL1530807 & 737189 & 5.5996 & 5.5206 & TRN & & \\
\hline CHEMBL1492961 & 737189 & 5.9504 & 5.8269 & TRN & & \\
\hline CHEMBL 1440277 & 737189 & 5.5418 & 5.5997 & TRN & & \\
\hline CHEMBL1971604 & 737189 & 5.5405 & 5.2912 & TRN & & \\
\hline CHEMBL1363609 & 737189 & 4.8368 & 5.0838 & TST & & \\
\hline CHEMBL1300905 & 737189 & 4.9504 & 5.2863 & TRN & & \\
\hline CHEMBL282489 & 737189 & 5.6269 & 5.597 & TST & & \\
\hline CHEMBL 1373636 & 737189 & 5.1819 & 5.3913 & TRN & & \\
\hline CHEMBL1392673 & 737189 & 5.5148 & 5.4265 & TRN & & \\
\hline CHEMBL1998651 & 737189 & 5.4194 & 5.6395 & TRN & & \\
\hline CHEMBL1299780 & 737189 & 4.8847 & 5.1926 & TRN & & \\
\hline CHEMBL1382827 & 737189 & 5.4331 & 5.49200 & 0000000001 & & TRN \\
\hline CHEMBL1500263 & 737189 & 5.1749 & 4.0779 & TRN & & \\
\hline CHEMBL1556273 & 737189 & 5.1746 & 5.4544 & TRN & & \\
\hline CHEMBL1583099 & 737189 & 5.1867 & 5.1978 & TRN & & \\
\hline CHEMBL1463434 & 737189 & 5.9859 & 5.9098 & TRN & & \\
\hline CHEMBL1583617 & 737189 & 4.7284 & 5.1656 & TRN & & \\
\hline CHEMBL1325908 & 737189 & 5.0687 & 5.4757 & TRN & & \\
\hline CHEMBL1537864 & 737189 & 5.683 & 5.4779 & TRN & & \\
\hline CHEMBL1348102 & 737189 & 5.0764 & 5.4184 & TST & & \\
\hline CHEMBL1558863 & 737189 & 4.2378 & 3.863 & TRN & & \\
\hline CHEMBL1497819 & 737189 & 5.4458 & 5.1993 & TRN & & \\
\hline CHEMBL3190031 & 737189 & 5.5524 & 5.6236 & TRN & & \\
\hline CHEMBL1486387 & 737189 & 5.2599 & 5.4912 & TRN & & \\
\hline CHEMBL3194133 & 737189 & 5.0651 & 5.2364 & TRN & & \\
\hline CHEMBL1517532 & 737189 & 5.1929 & 5.2433 & TRN & & \\
\hline CHEMBL1381793 & 737189 & 4.9488 & 5.4205 & TRN & & \\
\hline
\end{tabular}




\begin{tabular}{|c|c|c|c|c|c|c|}
\hline & & \multicolumn{5}{|c|}{ Supplemental Table S2.txt } \\
\hline CHEMBL1315006 & 737189 & 5.8292 & 5.7969 & TRN & & \\
\hline CHEMBL1302406 & 737189 & 5.6611 & 5.7088 & TRN & & \\
\hline CHEMBL1446916 & 737189 & 5.4966 & 5.6756 & TRN & & \\
\hline CHEMBL1605622 & 737189 & \multicolumn{3}{|c|}{5.452000000000001} & 5.5899 & TRN \\
\hline CHEMBL1518810 & 737189 & 5.3801 & 5.9422 & TRN & & \\
\hline CHEMBL1705580 & 737189 & 5.761 & 5.8426 & TRN & & \\
\hline CHEMBL1558102 & 737189 & 6.4957 & 5.9567 & TRN & & \\
\hline CHEMBL1341442 & 737189 & 6.5259 & 6.0011 & TST & & \\
\hline CHEMBL1496539 & 737189 & 5.2935 & 5.8109 & TRN & & \\
\hline CHEMBL1404327 & 737189 & 6.466 & 6.2919 & TRN & & \\
\hline CHEMBL1200512 & 737189 & 6.6121 & 5.8439 & TST & & \\
\hline CHEMBL1974450 & 737189 & 4.6792 & 4.0447 & TRN & & \\
\hline CHEMBL1304238 & 737189 & 4.8508 & 5.0974 & TRN & & \\
\hline CHEMBL1313821 & 737189 & 4.1036 & 3.9343 & TRN & & \\
\hline CHEMBL1458981 & 737189 & 5.245 & 5.2793 & TRN & & \\
\hline CHEMBL1524733 & 737189 & 5.0186 & 5.376 & TRN & & \\
\hline CHEMBL1598561 & 737189 & 5.9017 & 5.8292 & TRN & & \\
\hline CHEMBL1511037 & 737189 & 5.6574 & 5.6747 & TRN & & \\
\hline CHEMBL1406980 & 737189 & 5.6207 & 5.7633 & TRN & & \\
\hline CHEMBL1546781 & 737189 & 5.5193 & 5.5641 & TRN & & \\
\hline CHEMBL1439067 & 737189 & \multicolumn{3}{|c|}{5.257000000000001} & 5.3978 & TRN \\
\hline CHEMBL1438538 & 737189 & 5.2703 & 5.4916 & TRN & & \\
\hline CHEMBL1413724 & 737189 & 5.272 & 5.3656 & TST & & \\
\hline CHEMBL1583396 & 737189 & 5.6696 & 5.704 & TRN & & \\
\hline CHEMBL1444767 & 737189 & 5.2425 & 5.4867 & TRN & & \\
\hline CHEMBL547483 & 737189 & 5.7498 & 5.6897 & TST & & \\
\hline CHEMBL1411142 & 737189 & 5.4214 & 5.6993 & TRN & & \\
\hline CHEMBL1484231 & 737189 & 5.2754 & 5.5068 & TRN & & \\
\hline CHEMBL1712111 & 737189 & 5.1805 & 5.3161 & TRN & & \\
\hline CHEMBL1482951 & 737189 & 6.5904 & 5.7578 & TRN & & \\
\hline CHEMBL1338690 & 737189 & 4.5754 & 4.8547 & TRN & & \\
\hline CHEMBL1418230 & 737189 & 5.2663 & 5.5096 & TRN & & \\
\hline CHEMBL1985345 & 737189 & 5.716 & 5.1604 & TRN & & \\
\hline CHEMBL1424746 & 737189 & 5.7082 & 5.774 & TRN & & \\
\hline CHEMBL1463219 & 737189 & 6.3356 & 6.1151 & TST & & \\
\hline CHEMBL1429303 & 737189 & 4.2072 & 3.9168 & TRN & & \\
\hline CHEMBL3211198 & 737189 & 5.2383 & 5.42399 & 99999 & 995 & TRN \\
\hline CHEMBL1589652 & 737189 & 5.2707 & 5.4526 & TRN & & \\
\hline CHEMBL3192254 & 737189 & 5.4077 & 5.1833 & TRN & & \\
\hline CHEMBL1501102 & 737189 & 5.2459 & 5.6264 & TRN & & \\
\hline CHEMBL1593516 & 737189 & 5.2577 & 5.4374 & TRN & & \\
\hline CHEMBL1358945 & 737189 & 2.71 & 3.9091 & TST & & \\
\hline CHEMBL1391764 & 737189 & 5.2668 & 5.5081 & TRN & & \\
\hline CHEMBL1368434 & 737189 & 5.9151 & 5.3414 & TRN & & \\
\hline CHEMBL1984130 & 737189 & 5.2919 & 5.2057 & TRN & & \\
\hline CHEMBL1549957 & 737189 & 5.4574 & 5.4968 & TRN & & \\
\hline CHEMBL1605460 & 737189 & 5.3858 & 5.5702 & TST & & \\
\hline CHEMBL1422465 & 737189 & 5.3246 & 5.4486 & TRN & & \\
\hline
\end{tabular}


Supplemental Table S2.txt

\begin{tabular}{|c|c|c|c|c|c|c|}
\hline CHEMBL1710184 & 737189 & 5.5855 & 5.7405 & TRN & & \\
\hline CHEMBL1425906 & 737189 & 5.2712 & 5.4414 & TRN & & \\
\hline CHEMBL1423285 & 737189 & 6.2938 & 5.8427 & TRN & & \\
\hline CHEMBL1319807 & 737189 & 4.9755 & 5.3161 & TRN & & \\
\hline CHEMBL1324044 & 737189 & 5.9523 & 5.9372 & TRN & & \\
\hline CHEMBL1611796 & 737189 & 5.7552 & 5.8263 & TRN & & \\
\hline CHEMBL1566678 & 737189 & 6.0835 & 5.8503 & TRN & & \\
\hline CHEMBL1347710 & 737189 & 5.3239 & 5.585 & TRN & & \\
\hline CHEMBL1536342 & 737189 & 6.3927 & 5.9551 & TRN & & \\
\hline CHEMBL1612931 & 737189 & 4.9784 & 5.3083 & TRN & & \\
\hline CHEMBL1592636 & 737189 & 5.4602 & 5.7842 & TRN & & \\
\hline CHEMBL1564550 & 737189 & 5.5366 & 5.5701 & TRN & & \\
\hline CHEMBL1588976 & 737189 & 5.3653 & 5.4537 & TRN & & \\
\hline CHEMBL1701527 & 737189 & 6.0197 & 5.7415 & TST & & \\
\hline CHEMBL1736072 & 737189 & 5.4214 & 5.3945 & TRN & & \\
\hline CHEMBL 3198079 & 737189 & 5.1699 & 5.4115 & TRN & & \\
\hline CHEMBL1373388 & 737189 & 5.6893 & 5.6241 & TRN & & \\
\hline CHEMBL1980661 & 737189 & 5.1479 & 5.447 & TST & & \\
\hline CHEMBL1728498 & 737189 & 2.71 & 5.0295 & TRN & & \\
\hline CHEMBL1382429 & 737189 & 5.9307 & 5.8513 & TRN & & \\
\hline CHEMBL1491315 & 737189 & 5.2767 & 5.267 & TRN & & \\
\hline CHEMBL1430018 & 737189 & \multicolumn{3}{|c|}{5.9910000000000005} & 5.8711 & TRN \\
\hline CHEMBL1437083 & 737189 & 5.7298 & 5.7367 & TRN & & \\
\hline CHEMBL1478145 & 737189 & 5.3522 & 5.5809 & TRN & & \\
\hline CHEMBL3189946 & 737189 & 5.082 & 5.4462 & TRN & & \\
\hline CHEMBL1423912 & 737189 & 5.237 & 5.0974 & TRN & & \\
\hline CHEMBL1491324 & 737189 & 6.0547 & 5.598 & TRN & & \\
\hline CHEMBL1405067 & 737189 & 6.0486 & 5.9643 & TRN & & \\
\hline CHEMBL1411758 & 737189 & 5.3965 & 5.3072 & TRN & & \\
\hline CHEMBL1999960 & 737189 & 5.4159 & 5.4195 & TRN & & \\
\hline CHEMBL 3145111 & 737189 & 5.3843 & 5.3591 & TRN & & \\
\hline CHEMBL1373727 & 737189 & 5.6985 & 5.5174 & TRN & & \\
\hline CHEMBL472646 & 737189 & 5.4748 & 5.6562 & TST & & \\
\hline CHEMBL1364807 & 737189 & 5.3336 & 5.4734 & TRN & & \\
\hline CHEMBL3198237 & 737189 & 5.1972 & 5.4453 & TRN & & \\
\hline CHEMBL 2003356 & 737189 & 5.4231 & 5.4783 & TRN & & \\
\hline CHEMBL 3189832 & 737189 & 5.1771 & 5.5165 & TST & & \\
\hline CHEMBL1588760 & 737189 & 5.5983 & 5.6008 & TRN & & \\
\hline CHEMBL1325313 & 737189 & 5.5654 & 5.4845 & TRN & & \\
\hline CHEMBL1998606 & 737189 & 6.329 & 6.0589 & TRN & & \\
\hline CHEMBL1966497 & 737189 & 5.3129 & 5.4858 & TRN & & \\
\hline CHEMBL1432155 & 737189 & 5.8716 & 6.0821 & TRN & & \\
\hline CHEMBL3196852 & 737189 & 5.7537 & 5.6347 & TRN & & \\
\hline CHEMBL1512775 & 737189 & 5.6666 & 5.476 & TRN & & \\
\hline CHEMBL1557552 & 737189 & 4.7036 & 3.9763 & TRN & & \\
\hline CHEMBL1330145 & 737189 & 5.8435 & 5.575 & TRN & & \\
\hline CHEMBL1537722 & 737189 & 5.21299 & 999999999 & 9 & 5.4425 & TRN \\
\hline CHEMBL1510359 & 737189 & 5.3021 & 5.4694 & TST & & \\
\hline
\end{tabular}




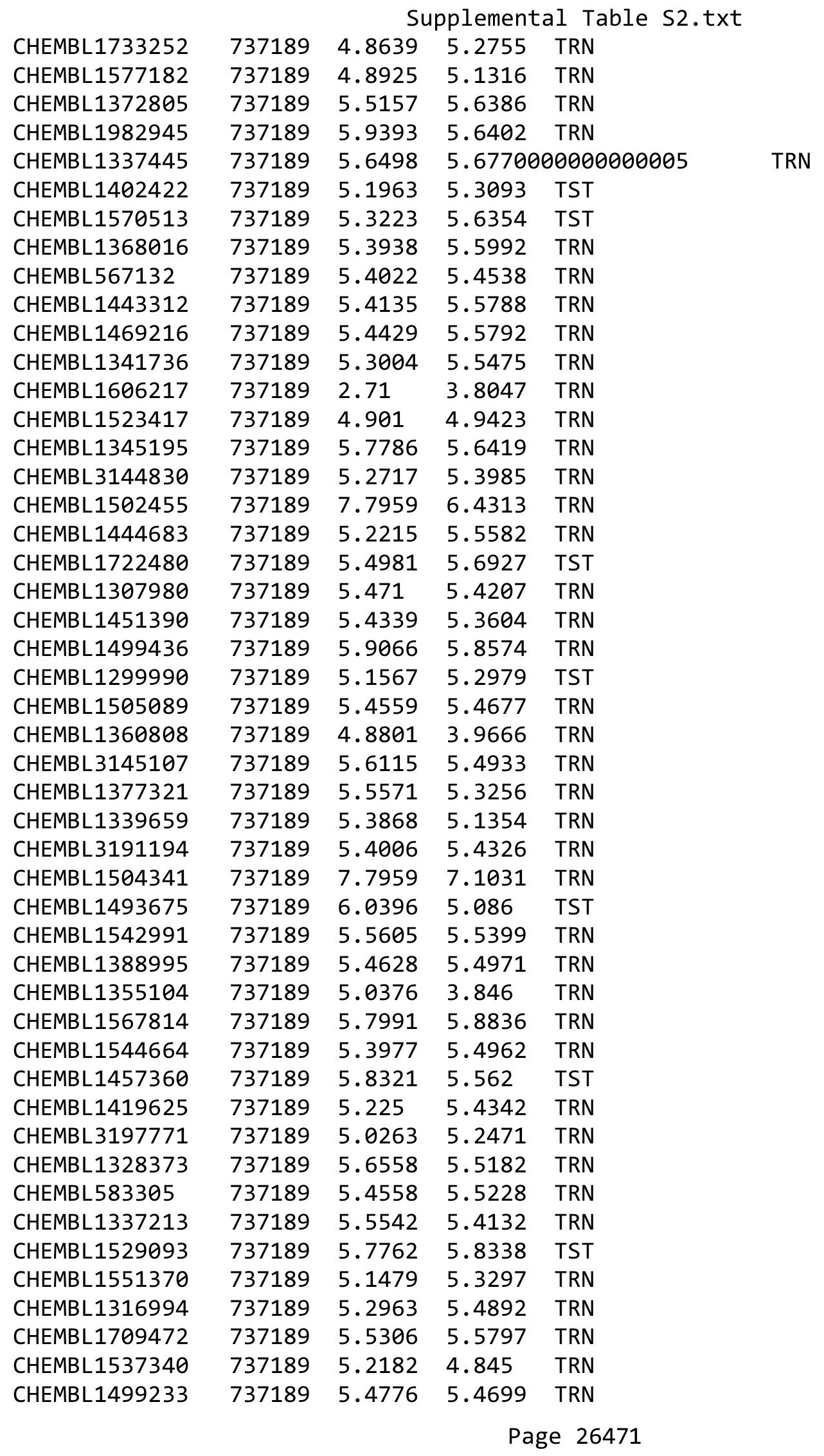




\begin{tabular}{|c|c|c|c|c|c|}
\hline & & \multicolumn{4}{|c|}{ Supplemental Table S2.txt } \\
\hline CHEMBL1608128 & 737189 & 4.9119 & 5.1339 & TRN & \\
\hline CHEMBL1494802 & 737189 & 6.5822 & 5.8454 & TRN & \\
\hline CHEMBL1425736 & 737189 & 4.0536 & 5.1451 & TRN & \\
\hline CHEMBL1459330 & 737189 & 5.6807 & 5.5584 & TRN & \\
\hline CHEMBL3193150 & 737189 & 4.6028 & 5.1222 & TRN & \\
\hline CHEMBL1575526 & 737189 & 5.7467 & 5.5117 & TRN & \\
\hline CHEMBL92824 & 737189 & 5.8456 & 5.8296 & TRN & \\
\hline CHEMBL1339368 & 737189 & 5.4014 & 5.246 & TRN & \\
\hline CHEMBL1498161 & 737189 & 6.0097 & 5.778 & TRN & \\
\hline CHEMBL1965045 & 737189 & 5.0562 & 5.1142 & TRN & \\
\hline CHEMBL1720696 & 737189 & 4.8761 & 5.3268 & TRN & \\
\hline CHEMBL1584973 & 737189 & 5.3987 & 5.2314 & TRN & \\
\hline CHEMBL1486198 & 737189 & 5.3527 & 5.6026 & TRN & \\
\hline CHEMBL1463825 & 737189 & 5.0982 & 5.4094 & TRN & \\
\hline CHEMBL1558327 & 737189 & 5.7678 & 4.0119 & TRN & \\
\hline CHEMBL1511739 & 737189 & 5.3064 & 5.4508 & TRN & \\
\hline CHEMBL1532863 & 737189 & 5.1721 & 5.4789 & TST & \\
\hline CHEMBL3190755 & 737189 & 5.0359 & 5.2123 & TRN & \\
\hline CHEMBL1583461 & 737189 & 5.2252 & 5.4944 & TRN & \\
\hline CHEMBL3198597 & 737189 & 5.7545 & 5.7519 & TRN & \\
\hline CHEMBL3195428 & 737189 & 5.5702 & 5.46899 & 9999999999 & TRN \\
\hline CHEMBL1446827 & 737189 & 5.7528 & 5.5133 & TRN & \\
\hline CHEMBL1501616 & 737189 & 5.2325 & 5.2281 & TRN & \\
\hline CHEMBL1533220 & 737189 & 6.1392 & 5.8448 & TRN & \\
\hline CHEMBL1432288 & 737189 & 4.5965 & 4.7533 & TRN & \\
\hline CHEMBL1479340 & 737189 & 5.2417 & 5.4796 & TRN & \\
\hline CHEMBL1517752 & 737189 & 5.9948 & 5.938 & TRN & \\
\hline CHEMBL1439833 & 737189 & 5.51399 & (99999999 & 5.6543 & TRN \\
\hline CHEMBL 1731400 & 737189 & 5.6087 & 5.6904 & TRN & \\
\hline CHEMBL1607546 & 737189 & 5.3141 & 4.8705 & TRN & \\
\hline CHEMBL220845 & 737189 & 5.3496 & 5.3101 & TST & \\
\hline CHEMBL1315284 & 737189 & 2.71 & 3.9283 & TRN & \\
\hline CHEMBL1702908 & 737189 & 4.9759 & 5.4781 & TRN & \\
\hline CHEMBL1383315 & 737189 & 5.9263 & 5.4971 & TRN & \\
\hline CHEMBL1503239 & 737189 & 4.9747 & 5.2891 & TRN & \\
\hline CHEMBL1407237 & 737189 & 5.7582 & 5.7087 & TRN & \\
\hline CHEMBL1592417 & 737189 & 5.318 & 5.4641 & TRN & \\
\hline CHEMBL1609900 & 737189 & 5.6794 & 4.7514 & TRN & \\
\hline CHEMBL1712620 & 737189 & 5.2738 & 5.037 & TRN & \\
\hline CHEMBL1411724 & 737189 & 6.2893 & 6.0408 & TST & \\
\hline CHEMBL1532377 & 737189 & 5.5724 & 5.7014 & TRN & \\
\hline CHEMBL1603906 & 737189 & 5.2472 & 5.4692 & TRN & \\
\hline CHEMBL1484282 & 737189 & 5.7562 & 5.3773 & TRN & \\
\hline CHEMBL1721990 & 737189 & 5.2384 & 5.5076 & TST & \\
\hline CHEMBL1563442 & 737189 & 5.6635 & 5.4444 & TRN & \\
\hline CHEMBL1393195 & 737189 & 6.3214 & 6.0334 & TRN & \\
\hline CHEMBL1498256 & 737189 & 5.4522 & 5.8038 & TRN & \\
\hline CHEMBL1543257 & 737189 & 6.1226 & 5.7768 & TRN & \\
\hline
\end{tabular}


Supplemental Table S2.txt

\begin{tabular}{|c|c|c|c|c|}
\hline CHEMBL 2144394 & 737189 & 5.5776 & 5.6494 & TRN \\
\hline CHEMBL1443802 & 737189 & 5.2361 & 5.5913 & TRN \\
\hline CHEMBL1451117 & 737189 & 5.9179 & 5.1535 & TRN \\
\hline CHEMBL1478794 & 737189 & 5.6216 & 5.5131 & TRN \\
\hline CHEMBL1256693 & 737189 & 5.8693 & 5.8339 & TRN \\
\hline CHEMBL1437208 & 737189 & 5.3027 & 5.393 & TRN \\
\hline CHEMBL1900055 & 737189 & 5.6603 & 5.449 & TRN \\
\hline CHEMBL1499306 & 737189 & 5.8851 & 5.75 & TRN \\
\hline CHEMBL1462872 & 737189 & 5.4881 & 5.4909 & TRN \\
\hline CHEMBL1458660 & 737189 & 5.1637 & 5.4334 & TRN \\
\hline CHEMBL1456632 & 737189 & 4.9359 & 5.199 & TST \\
\hline CHEMBL3199204 & 737189 & 4.6189 & 4.8277 & TRN \\
\hline CHEMBL1387654 & 737189 & 2.71 & 4.1778 & TRN \\
\hline CHEMBL1511464 & 737189 & 5.3029 & 5.1165 & TRN \\
\hline CHEMBL1315463 & 737189 & 5.2225 & 5.5913 & TRN \\
\hline CHEMBL1335068 & 737189 & 5.4642 & 5.5312 & TRN \\
\hline CHEMBL1567891 & 737189 & 5.3437 & 5.5678 & TRN \\
\hline CHEMBL1601686 & 737189 & 7.7959 & 6.2097 & TRN \\
\hline CHEMBL1360203 & 737189 & 5.2661 & 5.4633 & TRN \\
\hline CHEMBL1342053 & 737189 & 5.7331 & 5.6594 & TRN \\
\hline CHEMBL1998304 & 737189 & 5.2878 & 5.4506 & TRN \\
\hline CHEMBL1335722 & 737189 & 5.688 & 5.5535 & TST \\
\hline CHEMBL 3194489 & 737189 & 5.3912 & 5.5847 & TRN \\
\hline CHEMBL1390555 & 737189 & 5.5065 & 5.4798 & TRN \\
\hline CHEMBL1549308 & 737189 & 5.3612 & 5.5555 & TRN \\
\hline CHEMBL1569238 & 737189 & 5.0195 & 5.26399 & 9999999999 \\
\hline CHEMBL1573738 & 737189 & 5.6031 & 5.5554 & TRN \\
\hline CHEMBL1542422 & 737189 & 4.5525 & 5.0563 & TRN \\
\hline CHEMBL1387172 & 737189 & 6.0195 & 5.9021 & TRN \\
\hline CHEMBL1491729 & 737189 & 5.4094 & 5.1776 & TRN \\
\hline CHEMBL1605393 & 737189 & 5.2171 & 5.3293 & TST \\
\hline CHEMBL1387177 & 737189 & 5.9416 & 5.8932 & TRN \\
\hline CHEMBL1485593 & 737189 & 5.2699 & 5.2515 & TRN \\
\hline CHEMBL1609332 & 737189 & 5.2823 & 5.4604 & TRN \\
\hline CHEMBL1611613 & 737189 & 4.721 & 5.2502 & TRN \\
\hline CHEMBL1527120 & 737189 & 5.5408 & 5.609 & TRN \\
\hline CHEMBL1386044 & 737189 & 5.2812 & 5.6032 & TRN \\
\hline CHEMBL1391377 & 737189 & 6.0575 & 5.8915 & TRN \\
\hline CHEMBL1300899 & 737189 & 5.6103 & 5.16299 & 79999999999 \\
\hline CHEMBL1471737 & 737189 & 5.4652 & 5.5543 & TRN \\
\hline CHEMBL1570710 & 737189 & 2.71 & 3.8506 & TRN \\
\hline CHEMBL 3198765 & 737189 & 5.5872 & 5.7876 & TRN \\
\hline CHEMBL1428087 & 737189 & 7.7959 & 6.2688 & TRN \\
\hline CHEMBL3198389 & 737189 & 5.7762 & 5.6195 & TRN \\
\hline CHEMBL1718750 & 737189 & 5.2851 & 5.2301 & TST \\
\hline CHEMBL1528413 & 737189 & 5.5965 & 5.6274 & TST \\
\hline CHEMBL1533968 & 737189 & 5.1667 & 5.4285 & TRN \\
\hline CHEMBL1599847 & 737189 & 5.2684 & 5.4588 & TRN \\
\hline
\end{tabular}




\begin{tabular}{|c|c|c|c|c|c|c|}
\hline \multicolumn{7}{|c|}{ splemental Ia } \\
\hline CHEMBL416657 & 737189 & 5.8 & 5.8123 & TST & & \\
\hline CHEMBL1374714 & 737189 & 4.9307 & 5.4474 & TRN & & \\
\hline CHEMBL1470925 & 737189 & 5.4138 & 5.4849 & TRN & & \\
\hline CHEMBL1579771 & 737189 & 7.7959 & 5.5923 & TRN & & \\
\hline CHEMBL1395972 & 737189 & 5.8821 & 5.8408 & TST & & \\
\hline CHEMBL1545403 & 737189 & 5.8671 & 5.0903 & TRN & & \\
\hline CHEMBL1467244 & 737189 & 2.71 & 3.8723 & TRN & & \\
\hline CHEMBL1543478 & 737189 & 5.1733 & 5.5543 & TRN & & \\
\hline CHEMBL1442252 & 737189 & 5.3545 & 5.6288 & TRN & & \\
\hline CHEMBL1311878 & 737189 & 6.0813 & 5.7343 & TRN & & \\
\hline CHEMBL1376796 & 737189 & 5.4633 & 3.9755 & TRN & & \\
\hline CHEMBL3191590 & 737189 & 5.426 & 5.2052 & TRN & & \\
\hline CHEMBL1597768 & 737189 & 5.5769 & 5.4598 & TRN & & \\
\hline CHEMBL1457240 & 737189 & 5.2522 & 5.4187 & TRN & & \\
\hline CHEMBL1549135 & 737189 & 5.0621 & 5.2272 & TRN & & \\
\hline CHEMBL1577629 & 737189 & 6.29899 & 99999999 & 995 & 5.5071 & TRN \\
\hline CHEMBL1403645 & 737189 & 2.71 & 3.9634 & TRN & & \\
\hline CHEMBL1326634 & 737189 & 5.4157 & 5.4574 & TRN & & \\
\hline CHEMBL1367944 & 737189 & 4.9987 & 5.4058 & TRN & & \\
\hline CHEMBL1440160 & 737189 & 5.1992 & 5.2542 & TRN & & \\
\hline CHEMBL1993401 & 737189 & 5.6131 & 5.7176 & TRN & & \\
\hline CHEMBL1562493 & 737189 & 5.2685 & 5.4023 & TRN & & \\
\hline CHEMBL1504077 & 737189 & 5.7873 & 5.4786 & TRN & & \\
\hline CHEMBL1307744 & 737189 & 5.6698 & 5.5927 & TRN & & \\
\hline CHEMBL1399127 & 737189 & 5.5781 & 5.7174 & TST & & \\
\hline CHEMBL1732881 & 737189 & 5.4441 & 5.5766 & TST & & \\
\hline CHEMBL1462582 & 737189 & 5.9838 & 5.5997 & TRN & & \\
\hline CHEMBL1481361 & 737189 & 5.4916 & 5.5597 & TRN & & \\
\hline CHEMBL1999595 & 737189 & 5.6349 & 5.5965 & TRN & & \\
\hline CHEMBL1363773 & 737189 & 5.5955 & 5.6645 & TRN & & \\
\hline CHEMBL1556592 & 737189 & 5.9851 & 5.7128 & TRN & & \\
\hline CHEMBL1543714 & 737189 & 5.4288 & 5.522 & TRN & & \\
\hline CHEMBL3208752 & 737189 & 5.5607 & 5.4461 & TRN & & \\
\hline CHEMBL1326819 & 737189 & 5.586 & 5.7225 & TRN & & \\
\hline CHEMBL1376876 & 737189 & 4.9965 & 5.4201 & TST & & \\
\hline CHEMBL3196488 & 737189 & 5.0112 & 5.3431 & TRN & & \\
\hline CHEMBL1548173 & 737189 & 5.1182 & 5.5872 & TRN & & \\
\hline CHEMBL1453819 & 737189 & 6.1595 & 5.5791 & TRN & & \\
\hline CHEMBL596674 & 737189 & 5.2534 & 5.3768 & TRN & & \\
\hline CHEMBL584444 & 737189 & 5.3102 & 5.6086 & TRN & & \\
\hline CHEMBL 346258 & 737189 & 5.0009 & 5.3178 & TRN & & \\
\hline CHEMBL1720216 & 737189 & 5.3711 & 5.2186 & TRN & & \\
\hline CHEMBL1421741 & 737189 & 5.2631 & 5.295 & TRN & & \\
\hline CHEMBL1374476 & 737189 & 5.5566 & 5.1762 & TRN & & \\
\hline CHEMBL1515668 & 737189 & 5.5336 & 5.4686 & TRN & & \\
\hline CHEMBL1544097 & 737189 & 6.0029 & 99999999 & 99 & 5.4187 & TRN \\
\hline CHEMBL1500199 & 737189 & 5.6596 & 5.6358 & TRN & & \\
\hline CHEMBL1369587 & 737189 & 5.3483 & 5.5772 & TRN & & \\
\hline
\end{tabular}




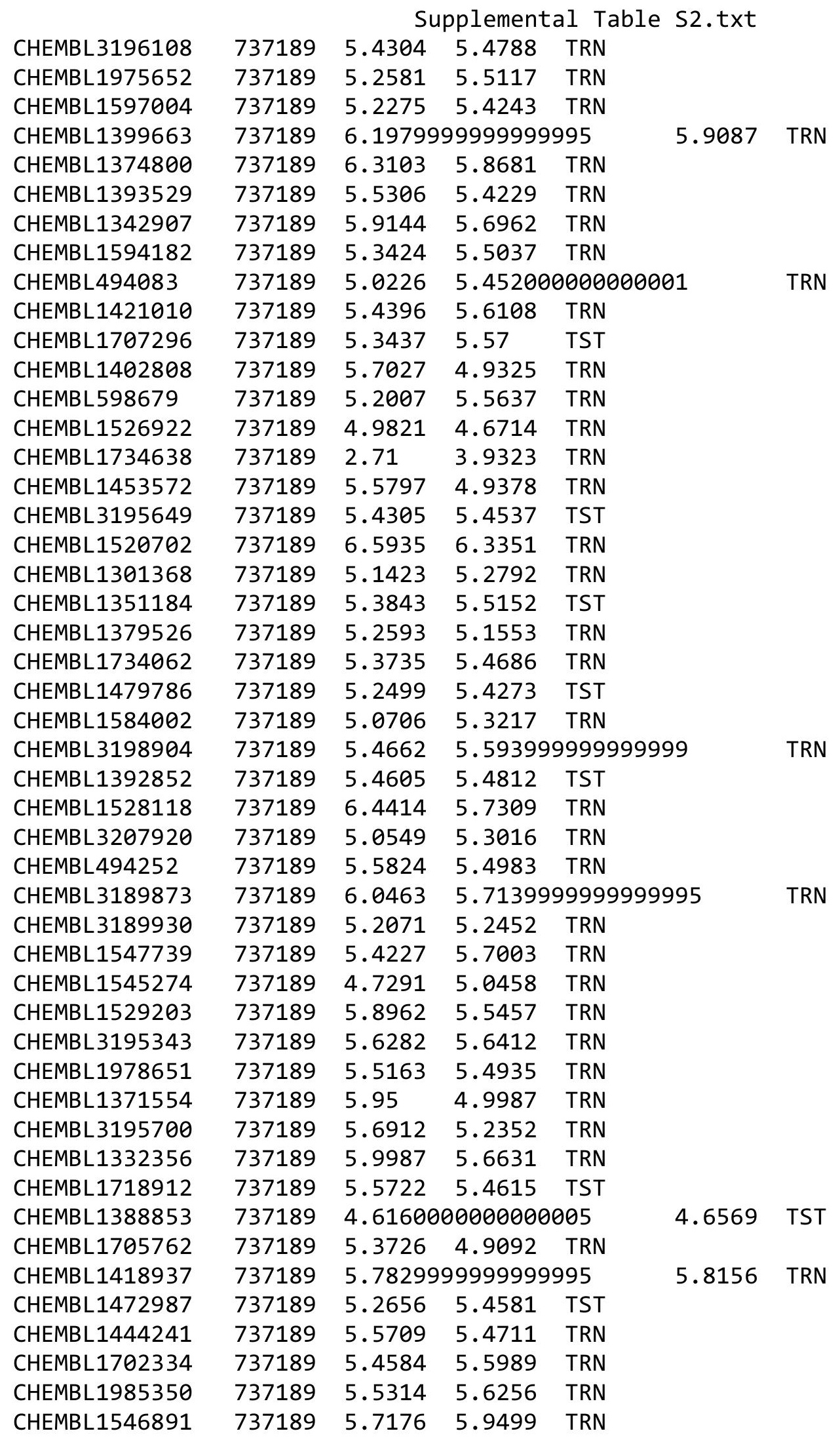

Page 26475 


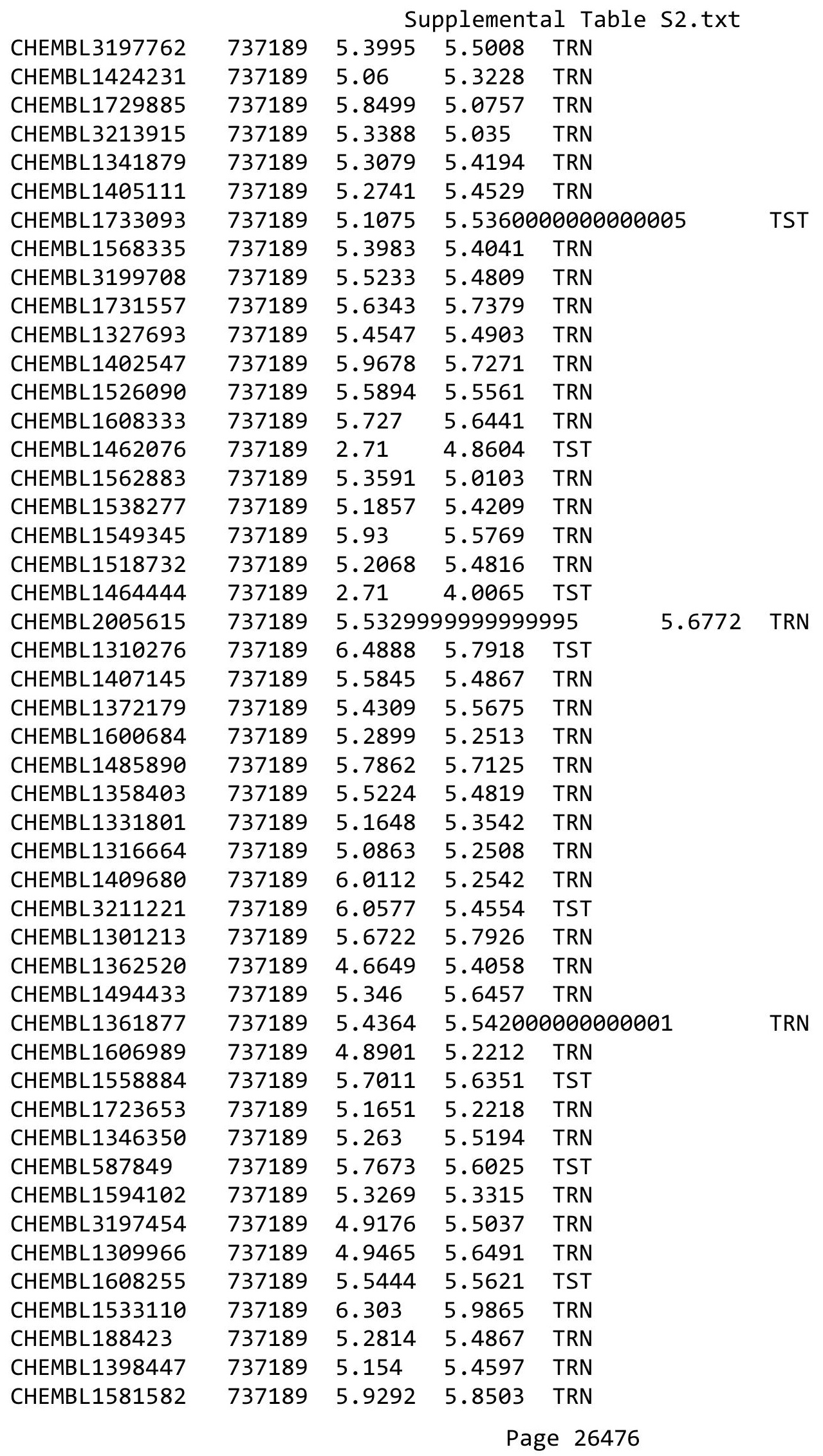




\begin{tabular}{|c|c|c|c|c|c|c|}
\hline & & \multicolumn{5}{|c|}{ Supplemental Table S2.txt } \\
\hline CHEMBL1339303 & 737189 & 5.461 & 5.5049 & TRN & & \\
\hline CHEMBL3194571 & 737189 & 5.6655 & 5.6711 & TRN & & \\
\hline CHEMBL1481229 & 737189 & 4.9488 & 5.31 & TRN & & \\
\hline CHEMBL1613096 & 737189 & 5.1725 & 5.4546 & TRN & & \\
\hline CHEMBL1713961 & 737189 & 4.6218 & 5.2774 & TRN & & \\
\hline CHEMBL1340698 & 737189 & 5.7256 & 5.6704 & TRN & & \\
\hline CHEMBL1313848 & 737189 & 5.9038 & 5.5356 & TRN & & \\
\hline CHEMBL3192903 & 737189 & 4.9539 & 5.1993 & TRN & & \\
\hline CHEMBL1308415 & 737189 & 5.1062 & 5.3072 & TRN & & \\
\hline CHEMBL3199926 & 737189 & 5.3705 & 5.4613 & TRN & & \\
\hline CHEMBL1442611 & 737189 & \multicolumn{3}{|c|}{6.1160000000000005} & 5.7671 & TRN \\
\hline CHEMBL1372667 & 737189 & 4.9255 & 5.2423 & TST & & \\
\hline CHEMBL1430058 & 737189 & 5.6934 & 5.4771 & TRN & & \\
\hline CHEMBL1421583 & 737189 & 5.1722 & 5.2252 & TRN & & \\
\hline CHEMBL1521702 & 737189 & 6.1912 & 5.9106 & TRN & & \\
\hline CHEMBL1486715 & 737189 & 5.1656 & 5.2796 & TRN & & \\
\hline CHEMBL1596702 & 737189 & 5.7194 & 5.5697 & TRN & & \\
\hline CHEMBL1543300 & 737189 & 5.2668 & 5.1549 & TRN & & \\
\hline CHEMBL1602334 & 737189 & 5.1946 & 5.3702 & TRN & & \\
\hline CHEMBL1480920 & 737189 & 5.2331 & 5.4052 & TRN & & \\
\hline CHEMBL1561063 & 737189 & 5.5776 & 5.5721 & TRN & & \\
\hline CHEMBL1480812 & 737189 & 5.516 & 5.597 & TRN & & \\
\hline CHEMBL503363 & 737189 & 5.4488 & 5.5639 & TST & & \\
\hline CHEMBL1531676 & 737189 & 5.6645 & 5.7277 & TST & & \\
\hline CHEMBL1494288 & 737189 & 4.5445 & 4.5866 & TRN & & \\
\hline CHEMBL3197633 & 737189 & 5.2232 & 5.2194 & TRN & & \\
\hline CHEMBL1573869 & 737189 & 5.7486 & 5.5392 & TRN & & \\
\hline CHEMBL1358777 & 737189 & 4.5619 & 3.9277 & TST & & \\
\hline CHEMBL1256737 & 737189 & 4.9566 & 5.2849 & TRN & & \\
\hline CHEMBL3196457 & 737189 & 5.5626 & 5.8106 & TRN & & \\
\hline CHEMBL1511080 & 737189 & 5.8784 & 5.7214 & TRN & & \\
\hline CHEMBL1701959 & 737189 & 2.71 & 3.8959 & TST & & \\
\hline CHEMBL1371897 & 737189 & 5.5792 & 5.6429 & TRN & & \\
\hline CHEMBL1308557 & 737189 & 5.1746 & 5.1365 & TRN & & \\
\hline CHEMBL1433859 & 737189 & 4.9504 & 5.3124 & TRN & & \\
\hline CHEMBL1335650 & 737189 & 4.7791 & 5.1771 & TST & & \\
\hline CHEMBL 226876 & 737189 & 5.1958 & 5.4976 & TRN & & \\
\hline CHEMBL1603029 & 737189 & 5.5777 & 5.7305 & TST & & \\
\hline CHEMBL1575373 & 737189 & 5.2123 & 5.3823 & TRN & & \\
\hline CHEMBL1728336 & 737189 & 4.3251 & 3.8282 & TRN & & \\
\hline CHEMBL1486191 & 737189 & 5.7622 & 5.6627 & TRN & & \\
\hline CHEMBL1523597 & 737189 & 5.49 & 5.6022 & TRN & & \\
\hline CHEMBL398969 & 737189 & 5.1193 & 5.591 & TRN & & \\
\hline CHEMBL1344296 & 737189 & 6.1508 & 5.8089 & TRN & & \\
\hline CHEMBL1378921 & 737189 & 5.1082 & 5.4193 & TRN & & \\
\hline CHEMBL1975756 & 737189 & 5.6282 & 4.9891 & TRN & & \\
\hline CHEMBL1330524 & 737189 & 4.6026 & 5.1481 & TRN & & \\
\hline CHEMBL1405781 & 737189 & 5.6499 & 5.6855 & TRN & & \\
\hline
\end{tabular}




\begin{tabular}{|c|c|c|c|c|c|c|}
\hline & & \multicolumn{5}{|c|}{ Supplemental Table s2.txt } \\
\hline CHEMBL1485676 & 737189 & 4.5255 & 4.9848 & TST & & \\
\hline CHEMBL1576310 & 737189 & 5.0599 & 5.4702 & TRN & & \\
\hline CHEMBL1542880 & 737189 & \multicolumn{3}{|c|}{6.082000000000001} & 5.8799 & TRN \\
\hline CHEMBL1600986 & 737189 & 5.3459 & 5.534 & TRN & & \\
\hline CHEMBL317115 & 737189 & 5.3255 & 5.6505 & TRN & & \\
\hline CHEMBL1526505 & 737189 & 5.5462 & 5.5006 & TRN & & \\
\hline CHEMBL1300242 & 737189 & 5.2808 & 5.4469 & TRN & & \\
\hline CHEMBL1590743 & 737189 & 5.1838 & 5.4278 & TST & & \\
\hline CHEMBL1332977 & 737189 & 5.5021 & 5.2949 & TRN & & \\
\hline CHEMBL1603602 & 737189 & 6.2958 & 6.1176 & TRN & & \\
\hline CHEMBL1542165 & 737189 & 4.9401 & \multicolumn{3}{|c|}{5.257000000000001} & TRN \\
\hline CHEMBL1702299 & 737189 & 5.4859 & 5.6402 & TRN & & \\
\hline CHEMBL1380592 & 737189 & 6.307 & 6.0204 & TRN & & \\
\hline CHEMBL1497889 & 737189 & 5.6792 & 5.4667 & TRN & & \\
\hline CHEMBL1425849 & 737189 & 5.9634 & \multicolumn{3}{|c|}{5.9479999999999995} & TRN \\
\hline CHEMBL1545093 & 737189 & 5.1306 & 5.3129 & TRN & & \\
\hline CHEMBL1612159 & 737189 & 5.721 & 5.7086 & TST & & \\
\hline CHEMBL 2001024 & 737189 & 5.3977 & \multicolumn{3}{|c|}{5.412000000000001} & TRN \\
\hline CHEMBL1525259 & 737189 & 5.6617 & 5.5321 & TRN & & \\
\hline CHEMBL1303489 & 737189 & 5.7645 & 5.7508 & TRN & & \\
\hline CHEMBL1576942 & 737189 & 5.3942 & 5.5664 & TRN & & \\
\hline CHEMBL1468731 & 737189 & 5.9523 & 5.8508 & TRN & & \\
\hline CHEMBL1594844 & 737189 & 5.1205 & 5.5603 & TST & & \\
\hline CHEMBL1255733 & 737189 & 6.0 & 6.2334 & TST & & \\
\hline CHEMBL1493343 & 737189 & 5.5441 & 5.7219 & TRN & & \\
\hline CHEMBL1331851 & 737189 & 5.7592 & 5.6944 & TRN & & \\
\hline CHEMBL1502550 & 737189 & 5.4517 & 5.6326 & TRN & & \\
\hline CHEMBL1430105 & 737189 & 5.4992 & 5.5993 & TRN & & \\
\hline CHEMBL1351489 & 737189 & 6.0223 & 5.9446 & TRN & & \\
\hline CHEMBL1567547 & 737189 & 4.4662 & 3.9224 & TST & & \\
\hline CHEMBL1528043 & 737189 & 5.3151 & 5.4844 & TRN & & \\
\hline CHEMBL1341114 & 737189 & 5.9442 & 5.6872 & TRN & & \\
\hline CHEMBL1383899 & 737189 & 5.3475 & 5.1695 & TST & & \\
\hline CHEMBL1514420 & 737189 & 5.0107 & 4.0738 & TRN & & \\
\hline CHEMBL1367633 & 737189 & 5.182 & 5.4258 & TRN & & \\
\hline CHEMBL1469171 & 737189 & 5.5302 & 5.2953 & TRN & & \\
\hline CHEMBL1502878 & 737189 & 2.71 & 4.7988 & TST & & \\
\hline CHEMBL1728809 & 737189 & \multicolumn{3}{|c|}{5.468999999999999} & 5.5474 & TST \\
\hline CHEMBL1595864 & 737189 & 5.2599 & 5.3868 & TRN & & \\
\hline CHEMBL1471980 & 737189 & 5.8024 & 5.694 & TRN & & \\
\hline CHEMBL1379449 & 737189 & 5.2852 & 5.3752 & TRN & & \\
\hline CHEMBL1967859 & 737189 & 5.6398 & 5.5546 & TRN & & \\
\hline CHEMBL1301717 & 737189 & 4.6885 & 5.7952 & TRN & & \\
\hline CHEMBL1307271 & 737189 & 5.9614 & 5.5608 & TRN & & \\
\hline CHEMBL1505474 & 737189 & 5.6832 & 5.6756 & TST & & \\
\hline CHEMBL1426592 & 737189 & 5.5176 & 5.4245 & TRN & & \\
\hline CHEMBL1506173 & 737189 & 5.5918 & 5.6542 & TST & & \\
\hline CHEMBL1608294 & 737189 & 6.2347 & 5.9259 & TRN & & \\
\hline
\end{tabular}




\begin{tabular}{|c|c|c|c|c|c|}
\hline \multicolumn{6}{|c|}{ Supplemental Table S2.txt } \\
\hline CHEMBL1367989 & 737189 & 4.8755 & 5.2909 & TRN & \\
\hline CHEMBL1727802 & 737189 & 5.0971 & 5.2071 & TRN & \\
\hline CHEMBL 3214487 & 737189 & 5.4511 & 5.4639 & TRN & \\
\hline CHEMBL1526149 & 737189 & 5.8248 & 5.7554 & TRN & \\
\hline CHEMBL1991277 & 737189 & 5.3519 & 5.4861 & TRN & \\
\hline CHEMBL1506512 & 737189 & 5.3486 & 5.4047 & TRN & \\
\hline CHEMBL 3208181 & 737189 & 4.5071 & 5.5903 & TRN & \\
\hline CHEMBL1585709 & 737189 & 6.221 & 5.7258 & TRN & \\
\hline CHEMBL1561338 & 737189 & 5.6778 & 5.559 & TRN & \\
\hline CHEMBL1337749 & 737189 & 6.66 & 5.3951 & TRN & \\
\hline CHEMBL 3213965 & 737189 & 5.2912 & 5.3858 & TRN & \\
\hline CHEMBL1539483 & 737189 & 5.2817 & 5.3786 & TRN & \\
\hline CHEMBL 3197948 & 737189 & 2.71 & 3.9343 & TRN & \\
\hline CHEMBL1389765 & 737189 & 5.522 & 4.723 & TRN & \\
\hline CHEMBL1561439 & 737189 & 5.869 & 5.9113 & TRN & \\
\hline CHEMBL1350167 & 737189 & 5.4546 & 5.5453 & TRN & \\
\hline CHEMBL1725605 & 737189 & 4.9901 & 5.2477 & TRN & \\
\hline CHEMBL1336508 & 737189 & 5.6017 & 5.5108 & TRN & \\
\hline CHEMBL1988268 & 737189 & 5.2763 & 5.6935 & TRN & \\
\hline CHEMBL1556958 & 737189 & 5.3034 & 5.2703 & TRN & \\
\hline CHEMBL1334887 & 737189 & 5.4722 & 5.6548 & TRN & \\
\hline CHEMBL1588813 & 737189 & 6.4044 & 5.66700 & 0000000001 & TRN \\
\hline CHEMBL1453187 & 737189 & 5.5597 & 5.6276 & TST & \\
\hline CHEMBL1490267 & 737189 & 5.3026 & 5.5949 & TRN & \\
\hline CHEMBL1527664 & 737189 & 5.2812 & 5.2694 & TST & \\
\hline CHEMBL1569705 & 737189 & 5.4237 & 5.5348 & TRN & \\
\hline CHEMBL1545902 & 737189 & 5.6794 & 5.5441 & TRN & \\
\hline CHEMBL1313265 & 737189 & 5.6792 & 5.6084 & TST & \\
\hline CHEMBL1426867 & 737189 & 5.3388 & 5.4107 & TRN & \\
\hline CHEMBL1712283 & 737189 & 6.5373 & 6.4184 & TRN & \\
\hline CHEMBL1591393 & 737189 & 5.506 & 5.4608 & TRN & \\
\hline CHEMBL1555870 & 737189 & 4.9329 & 5.2505 & TST & \\
\hline CHEMBL1540377 & 737189 & 5.4887 & 5.4278 & TRN & \\
\hline CHEMBL1384298 & 737189 & 5.4376 & 5.6306 & TRN & \\
\hline CHEMBL1553738 & 737189 & 4.8136 & 5.2508 & TRN & \\
\hline CHEMBL1606810 & 737189 & 5.147 & 5.3421 & TRN & \\
\hline CHEMBL1395408 & 737189 & 5.1351 & 5.4761 & TST & \\
\hline CHEMBL1469642 & 737189 & 4.3027 & 4.9628 & TRN & \\
\hline CHEMBL1981408 & 737189 & 5.5656 & 5.6424 & TRN & \\
\hline CHEMBL1698409 & 737189 & 5.5047 & 5.5774 & TST & \\
\hline CHEMBL 3145293 & 737189 & 5.5372 & 5.4984 & TST & \\
\hline CHEMBL1386656 & 737189 & 5.6472 & 6.0184 & TRN & \\
\hline CHEMBL1542674 & 737189 & 5.4337 & 5.4401 & TRN & \\
\hline CHEMBL1455566 & 737189 & 5.5085 & 5.5142 & TRN & \\
\hline CHEMBL1709970 & 737189 & 5.648 & 5.4946 & TRN & \\
\hline CHEMBL1391280 & 737189 & 2.71 & 3.8883 & TRN & \\
\hline CHEMBL1561237 & 737189 & 5.3966 & 5.5951 & TRN & \\
\hline CHEMBL1428368 & 737189 & 5.1932 & 5.4642 & TRN & \\
\hline
\end{tabular}


Supplemental Table S2.txt

\begin{tabular}{|c|c|c|c|c|c|}
\hline CHEMBL1501302 & 737189 & 5.1778 & 5.4754 & TRN & \\
\hline CHEMBL3197639 & 737189 & 5.2264 & 5.3013 & TRN & \\
\hline CHEMBL1599863 & 737189 & 6.189 & 6.1308 & TRN & \\
\hline CHEMBL1476358 & 737189 & 5.6803 & 5.7879 & TRN & \\
\hline CHEMBL1477528 & 737189 & 5.6578 & 5.575 & TRN & \\
\hline CHEMBL275311 & 737189 & 5.5082 & 5.6577 & TRN & \\
\hline CHEMBL3196955 & 737189 & 5.2827 & 5.4667 & TRN & \\
\hline CHEMBL1301155 & 737189 & 5.5293 & 5.6049 & TRN & \\
\hline CHEMBL1309718 & 737189 & 5.5397 & 5.2269 & TRN & \\
\hline CHEMBL1362687 & 737189 & 5.4364 & 5.4951 & TRN & \\
\hline CHEMBL1588525 & 737189 & 6.2337 & 5.9846 & TRN & \\
\hline CHEMBL1348933 & 737189 & 5.4492 & 5.6369 & TRN & \\
\hline CHEMBL1568625 & 737189 & 4.6696 & 5.0065 & TRN & \\
\hline CHEMBL1429116 & 737189 & 5.2627 & 5.401 & TRN & \\
\hline CHEMBL1382518 & 737189 & 5.5355 & 5.6997 & TRN & \\
\hline CHEMBL1332956 & 737189 & 4.9442 & 5.4952 & TST & \\
\hline CHEMBL3189694 & 737189 & 5.4567 & 5.0898 & TRN & \\
\hline CHEMBL1455530 & 737189 & 5.4728 & 5.6183 & TRN & \\
\hline CHEMBL1393630 & 737189 & 5.2495 & 5.5757 & TRN & \\
\hline CHEMBL1312689 & 737189 & 6.4652 & 6.99299 & 7999999999 & TST \\
\hline CHEMBL1526806 & 737189 & 5.3783 & 5.3974 & TRN & \\
\hline CHEMBL1457982 & 737189 & 5.4789 & 5.5163 & TST & \\
\hline CHEMBL1451736 & 737189 & 6.6929 & 6.1161 & TRN & \\
\hline CHEMBL3193229 & 737189 & 4.7104 & 3.9921 & TRN & \\
\hline CHEMBL3209007 & 737189 & 4.3595 & 4.8045 & TRN & \\
\hline CHEMBL1609818 & 737189 & 5.5071 & 5.4167 & TRN & \\
\hline CHEMBL3211808 & 737189 & 5.2695 & 5.3887 & TRN & \\
\hline CHEMBL1504685 & 737189 & 5.1991 & 5.4083 & TST & \\
\hline CHEMBL1423474 & 737189 & 5.5527 & 5.6669 & TRN & \\
\hline CHEMBL1456411 & 737189 & 4.9259 & 5.0678 & TRN & \\
\hline CHEMBL1372947 & 737189 & 5.9801 & 6.2096 & TST & \\
\hline CHEMBL3196499 & 737189 & 5.3501 & 5.6236 & TRN & \\
\hline CHEMBL1411680 & 737189 & 5.2847 & 5.2078 & TRN & \\
\hline CHEMBL1531170 & 737189 & 6.4355 & 5.7561 & TRN & \\
\hline CHEMBL1548377 & 737189 & 5.3959 & 5.5615 & TRN & \\
\hline CHEMBL1335732 & 737189 & 5.4282 & 5.5073 & TRN & \\
\hline CHEMBL1348326 & 737189 & 5.8362 & 5.6685 & TRN & \\
\hline CHEMBL1703531 & 737189 & 5.29 & 5.5084 & TST & \\
\hline CHEMBL590887 & 737189 & 5.5164 & 5.6145 & TRN & \\
\hline CHEMBL1570705 & 737189 & 5.1663 & 5.4353 & TRN & \\
\hline CHEMBL1342495 & 737189 & 5.6192 & 5.5264 & TRN & \\
\hline CHEMBL1524101 & 737189 & 5.1288 & 5.1982 & TRN & \\
\hline CHEMBL1560530 & 737189 & 5.9893 & 5.5746 & TRN & \\
\hline CHEMBL1416561 & 737189 & 5.5268 & 5.2271 & TRN & \\
\hline CHEMBL1515852 & 737189 & 6.369 & 5.7149 & TST & \\
\hline CHEMBL1470481 & 737189 & 5.4316 & 5.1924 & TRN & \\
\hline CHEMBL1446234 & 737189 & 5.1838 & 5.4158 & TRN & \\
\hline CHEMBL1561133 & 737189 & 5.5505 & 5.5704 & TRN & \\
\hline
\end{tabular}




\begin{tabular}{|c|c|c|c|c|c|c|}
\hline & & \multicolumn{5}{|c|}{ Supplemental Table S2.txt } \\
\hline CHEMBL1736729 & 737189 & 5.3984 & 5.3352 & TRN & & \\
\hline CHEMBL1973139 & 737189 & 5.4193 & 5.4451 & TRN & & \\
\hline CHEMBL1424510 & 737189 & 5.0877 & 5.4116 & TRN & & \\
\hline CHEMBL 3208258 & 737189 & \multicolumn{3}{|c|}{5.287999999999999} & 5.5946 & TRN \\
\hline CHEMBL1539411 & 737189 & 5.4045 & 5.4432 & TRN & & \\
\hline CHEMBL1411959 & 737189 & 5.3009 & 5.4235 & TRN & & \\
\hline CHEMBL1445386 & 737189 & 6.5507 & 5.7295 & TST & & \\
\hline CHEMBL3199539 & 737189 & \multicolumn{3}{|c|}{5.3420000000000005} & 5.524 & TRN \\
\hline CHEMBL3209995 & 737189 & 2.71 & 3.9121 & TRN & & \\
\hline CHEMBL1441505 & 737189 & 5.4744 & 5.6178 & TRN & & \\
\hline CHEMBL1541371 & 737189 & 5.5672 & 5.6685 & TRN & & \\
\hline CHEMBL1432314 & 737189 & 5.5153 & 5.6267 & TRN & & \\
\hline CHEMBL1419311 & 737189 & 5.8011 & 5.5356 & TRN & & \\
\hline CHEMBL1398260 & 737189 & 5.9367 & 6.3326 & TST & & \\
\hline CHEMBL1736978 & 737189 & 5.3236 & 5.3752 & TST & & \\
\hline CHEMBL1333707 & 737189 & 5.9851 & 5.4736 & TRN & & \\
\hline CHEMBL1521991 & 737189 & \multicolumn{3}{|c|}{5.638999999999999} & 5.5769 & \\
\hline CHEMBL1518036 & 737189 & 5.2761 & 5.4227 & TRN & & \\
\hline CHEMBL1712367 & 737189 & 5.5226 & 5.6109 & TRN & & \\
\hline CHEMBL1361820 & 737189 & 5.2442 & 5.5155 & TRN & & \\
\hline CHEMBL1363437 & 737189 & 7.7959 & 5.425 & TRN & & \\
\hline CHEMBL1497146 & 737189 & 5.4487 & 5.59 & TRN & & \\
\hline CHEMBL1407614 & 737189 & 6.0648 & 5.7646 & TRN & & \\
\hline CHEMBL1573331 & 737189 & 5.1838 & 5.226 & TRN & & \\
\hline CHEMBL1429298 & 737189 & 5.1563 & 5.7496 & TRN & & \\
\hline CHEMBL1465409 & 737189 & 5.2975 & 5.45100 & 0000000000 & S & \\
\hline CHEMBL1485847 & 737189 & 6.3389 & 5.1881 & TRN & & \\
\hline CHEMBL1515023 & 737189 & 6.6535 & 6.3 & TRN & & \\
\hline CHEMBL1326403 & 737189 & 5.6432 & 5.6589 & TRN & & \\
\hline CHEMBL1517861 & 737189 & 5.1366 & 5.5777 & TRN & & \\
\hline CHEMBL3192408 & 737189 & \multicolumn{3}{|c|}{5.9670000000000005} & 6.0232 & \\
\hline CHEMBL1377544 & 737189 & 5.6321 & 5.5963 & TRN & & \\
\hline CHEMBL3197271 & 737189 & 5.2801 & 4.9199 & TRN & & \\
\hline CHEMBL1709184 & 737189 & 7.7959 & 6.2299 & TRN & & \\
\hline CHEMBL1390139 & 737189 & 5.3933 & 5.5906 & TRN & & \\
\hline CHEMBL541845 & 737189 & 5.2574 & 5.4302 & TRN & & \\
\hline CHEMBL1457472 & 737189 & 6.0083 & 5.7932 & TRN & & \\
\hline CHEMBL1427949 & 737189 & \multicolumn{3}{|c|}{5.422999999999999} & 5.4668 & rRN \\
\hline CHEMBL1974180 & 737189 & 5.1666 & \multicolumn{3}{|c|}{5.457999999999999} & TR \\
\hline CHEMBL1422809 & 737189 & 5.766 & 5.6944 & TRN & & \\
\hline CHEMBL1415310 & 737189 & 5.5874 & 5.6419 & TRN & & \\
\hline CHEMBL1578411 & 737189 & 5.8894 & 5.8814 & TRN & & \\
\hline CHEMBL3212782 & 737189 & 5.0816 & 5.2661 & TST & & \\
\hline CHEMBL1500197 & 737189 & 5.7411 & 5.6639 & TRN & & \\
\hline CHEMBL1532651 & 737189 & 5.5393 & 5.6884 & TRN & & \\
\hline CHEMBL1413963 & 737189 & 5.325 & 5.4251 & TRN & & \\
\hline CHEMBL1371925 & 737189 & 5.4077 & 5.5922 & TRN & & \\
\hline CHEMBL1392717 & 737189 & 5.4553 & 5.3567 & TRN & & \\
\hline
\end{tabular}




\begin{tabular}{|c|c|c|c|c|c|}
\hline & & \multicolumn{4}{|c|}{ Supplemental Table S2.txt } \\
\hline CHEMBL1441535 & 737189 & 5.4114 & 5.5118 & TRN & \\
\hline CHEMBL1530018 & 737189 & 5.1346 & 5.2547 & TRN & \\
\hline CHEMBL1388542 & 737189 & 5.4187 & 5.5029 & TRN & \\
\hline CHEMBL1312969 & 737189 & 5.9923 & 5.6766 & TRN & \\
\hline CHEMBL1595033 & 737189 & 5.1221 & 5.364 & TRN & \\
\hline CHEMBL1329561 & 737189 & 5.734 & 5.3471 & TRN & \\
\hline CHEMBL1435818 & 737189 & 5.5042 & 5.74700 & 0000000001 & TRN \\
\hline CHEMBL1517327 & 737189 & 5.1045 & 5.442 & TRN & \\
\hline CHEMBL1602360 & 737189 & 5.4634 & 5.6298 & TRN & \\
\hline CHEMBL1384920 & 737189 & 5.2534 & 5.3467 & TRN & \\
\hline CHEMBL1412039 & 737189 & 6.0715 & 5.8497 & TRN & \\
\hline CHEMBL1309568 & 737189 & 5.4374 & 5.5477 & TRN & \\
\hline CHEMBL1967938 & 737189 & 5.4306 & 5.5092 & TRN & \\
\hline CHEMBL3190556 & 737189 & 5.8 & 5.2932 & TRN & \\
\hline CHEMBL1310893 & 737189 & 7.7959 & 6.2079 & TRN & \\
\hline CHEMBL1511091 & 737189 & 6.205 & 5.7026 & TRN & \\
\hline CHEMBL1325605 & 737189 & 5.2722 & 5.3369 & TRN & \\
\hline CHEMBL1703850 & 737189 & 5.34 & 5.4336 & TRN & \\
\hline CHEMBL1596903 & 737189 & 5.3919 & 5.354 & TRN & \\
\hline CHEMBL1971234 & 737189 & 5.0138 & 5.3033 & TRN & \\
\hline CHEMBL3191879 & 737189 & 5.4612 & 5.6328 & TRN & \\
\hline CHEMBL3189567 & 737189 & 5.6962 & 4.7735 & TRN & \\
\hline CHEMBL1441609 & 737189 & 6.1458 & 5.9679 & TRN & \\
\hline CHEMBL1535276 & 737189 & 5.6169 & 5.6335 & TRN & \\
\hline CHEMBL1414364 & 737189 & 6.7734 & 6.0173 & TRN & \\
\hline CHEMBL3190645 & 737189 & 4.7902 & 5.1386 & TRN & \\
\hline CHEMBL1426226 & 737189 & 6.317 & 5.7423 & TRN & \\
\hline CHEMBL1579341 & 737189 & 5.7585 & 5.3576 & TRN & \\
\hline CHEMBL1484169 & 737189 & 5.3532 & 5.5058 & TRN & \\
\hline CHEMBL1572294 & 737189 & 5.9133 & 5.6431 & TST & \\
\hline CHEMBL1347011 & 737189 & 5.9674 & 5.9484 & TRN & \\
\hline CHEMBL1506791 & 737189 & 5.8413 & 5.8104 & TRN & \\
\hline CHEMBL1414108 & 737189 & 5.5181 & 5.5359 & TRN & \\
\hline CHEMBL1507404 & 737189 & 5.9389 & 5.5521 & TST & \\
\hline CHEMBL1394747 & 737189 & 5.3053 & 5.4174 & TRN & \\
\hline CHEMBL1467036 & 737189 & 5.565 & 5.5831 & TRN & \\
\hline CHEMBL 2021431 & 737189 & 5.643 & 5.58 & TST & \\
\hline CHEMBL1607670 & 737189 & 5.9867 & 4.8615 & TRN & \\
\hline CHEMBL1705121 & 737189 & 5.6351 & 5.5492 & TRN & \\
\hline CHEMBL1411526 & 737189 & 7.7959 & 6.2633 & TRN & \\
\hline CHEMBL1574280 & 737189 & 6.7022 & 6.1733 & TRN & \\
\hline CHEMBL1999885 & 737189 & 4.863 & 5.1243 & TRN & \\
\hline CHEMBL1526165 & 737189 & 5.4587 & 5.612 & TRN & \\
\hline CHEMBL1457501 & 737189 & 5.5032 & 5.6846 & TRN & \\
\hline CHEMBL1307682 & 737189 & 6.2012 & 5.9911 & TRN & \\
\hline CHEMBL1710067 & 737189 & 5.5099 & 5.654 & TST & \\
\hline CHEMBL1486582 & 737189 & 4.7597 & 4.8954 & TRN & \\
\hline CHEMBL1385413 & 737189 & 6.0 & 6.0268 & TRN & \\
\hline
\end{tabular}




\begin{tabular}{|c|c|c|c|c|c|c|c|}
\hline \multicolumn{8}{|c|}{ Supplemental Table S2.txt } \\
\hline CHEMBL1406953 & 737189 & 5.6755 & 5.6385 & TRN & & & \\
\hline CHEMBL1586230 & 737189 & 6.189 & 5.8438 & TRN & & & \\
\hline CHEMBL1544136 & 737189 & 6.6082 & 5.5309 & TRN & & & \\
\hline CHEMBL1319866 & 737189 & 5.9027 & 5.8151 & TRN & & & \\
\hline CHEMBL 1444540 & 737189 & 5.7943 & 5.4401 & TRN & & & \\
\hline CHEMBL1711149 & 737189 & 6.0161 & 5.7684 & TRN & & & \\
\hline CHEMBL1517872 & 737189 & 6.3546 & 5.8639 & TRN & & & \\
\hline CHEMBL1496341 & 737189 & 5.4632 & 5.2897 & TRN & & & \\
\hline CHEMBL3197985 & 737189 & 5.6114 & 5.5257 & TST & & & \\
\hline CHEMBL1363402 & 737189 & 5.54299 & 99999999 & & 5.6226 & 0000000001 & TRN \\
\hline CHEMBL1312872 & 737189 & 5.3365 & 5.4846 & TRN & & & \\
\hline CHEMBL1301313 & 737189 & 4.8693 & 4.96 & TRN & & & \\
\hline CHEMBL1733515 & 737189 & 5.414 & 5.6186 & TRN & & & \\
\hline CHEMBL1733904 & 737189 & 5.7575 & 5.8647 & TRN & & & \\
\hline CHEMBL1340197 & 737189 & 5.1608 & 5.494 & TRN & & & \\
\hline CHEMBL1423626 & 737189 & 5.7331 & 5.631 & TRN & & & \\
\hline CHEMBL1326132 & 737189 & 5.121 & 5.1538 & TRN & & & \\
\hline CHEMBL1735413 & 737189 & 3.9003 & 3.8924 & TRN & & & \\
\hline CHEMBL3211859 & 737189 & 5.6126 & 5.5931 & TRN & & & \\
\hline CHEMBL1344000 & 737189 & 5.3058 & 5.4507 & TRN & & & \\
\hline CHEMBL1324303 & 737189 & 5.2629 & 5.4222 & TRN & & & \\
\hline CHEMBL1306258 & 737189 & 5.2484 & 5.4292 & TRN & & & \\
\hline CHEMBL1418611 & 737189 & 6.149 & 6.0663 & TRN & & & \\
\hline CHEMBL1399370 & 737189 & 5.4735 & 5.6495 & TRN & & & \\
\hline CHEMBL1728103 & 737189 & 5.3389 & 5.5747 & TST & & & \\
\hline CHEMBL1455813 & 737189 & 5.3402 & 5.6135 & TRN & & & \\
\hline CHEMBL1452712 & 737189 & 4.6047 & 3.9133 & TRN & & & \\
\hline CHEMBL188 & 737189 & 5.4592 & 5.5284 & TST & & & \\
\hline CHEMBL1389601 & 737189 & 5.0771 & 5.3862 & TRN & & & \\
\hline CHEMBL1341586 & 737189 & 5.983 & 5.6505 & TRN & & & \\
\hline CHEMBL1328132 & 737189 & 2.71 & 3.8841 & TRN & & & \\
\hline CHEMBL1474058 & 737189 & 5.761 & 5.5557 & TRN & & & \\
\hline CHEMBL1568646 & 737189 & 5.7467 & 5.7179 & TRN & & & \\
\hline CHEMBL1582319 & 737189 & 6.5867 & 5.9433 & TRN & & & \\
\hline CHEMBL3196840 & 737189 & 5.3329 & 5.434 & TRN & & & \\
\hline CHEMBL1590892 & 737189 & 5.4293 & 5.6062 & TRN & & & \\
\hline CHEMBL 2003567 & 737189 & 5.5158 & 5.5725 & TRN & & & \\
\hline CHEMBL1581361 & 737189 & 5.3729 & 5.4765 & TRN & & & \\
\hline CHEMBL1586404 & 737189 & 5.2738 & 5.5407 & TRN & & & \\
\hline CHEMBL1301107 & 737189 & 5.70799 & 99999999 & 99 & 5.864 & TRN & \\
\hline CHEMBL1456226 & 737189 & 5.7001 & 5.5788 & TRN & & & \\
\hline CHEMBL3191107 & 737189 & 6.6419 & 5.8917 & TRN & & & \\
\hline CHEMBL1308276 & 737189 & 5.8271 & 5.8433 & TRN & & & \\
\hline CHEMBL1553553 & 737189 & 5.3497 & 5.6061 & TRN & & & \\
\hline CHEMBL1502522 & 737189 & 6.1439 & 5.7881 & TRN & & & \\
\hline CHEMBL1327046 & 737189 & 6.3273 & 6.0298 & TRN & & & \\
\hline CHEMBL1598921 & 737189 & 4.2523 & 5.058 & TRN & & & \\
\hline CHEMBL3193466 & 737189 & 5.3598 & 5.525 & TRN & & & \\
\hline
\end{tabular}




\begin{tabular}{|c|c|c|c|c|c|c|}
\hline & & \multicolumn{5}{|c|}{ Supplemental Table S2.txt } \\
\hline CHEMBL1499890 & 737189 & 5.8726 & 5.8183 & TRN & & \\
\hline CHEMBL1595544 & 737189 & 5.3799 & 5.5274 & TRN & & \\
\hline CHEMBL1511042 & 737189 & 5.5129 & 5.5917 & TST & & \\
\hline CHEMBL1464265 & 737189 & 5.407 & 5.4993 & TRN & & \\
\hline CHEMBL1562359 & 737189 & 5.2612 & 5.2471 & TRN & & \\
\hline CHEMBL1420268 & 737189 & 5.0529 & 5.1853 & TRN & & \\
\hline CHEMBL1347030 & 737189 & 5.2832 & 5.355 & TRN & & \\
\hline CHEMBL1986081 & 737189 & 6.316 & 5.6705 & TRN & & \\
\hline CHEMBL1387741 & 737189 & 5.4742 & 5.2898 & TRN & & \\
\hline CHEMBL1442309 & 737189 & 5.7508 & 5.845 & TRN & & \\
\hline CHEMBL1505688 & 737189 & \multicolumn{3}{|c|}{5.4510000000000005} & 5.5566 & TRN \\
\hline CHEMBL1458403 & 737189 & 5.2116 & 5.695 & TST & & \\
\hline CHEMBL1600175 & 737189 & 5.4909 & 5.209 & TRN & & \\
\hline CHEMBL1477805 & 737189 & 5.2541 & 5.4226 & TRN & & \\
\hline CHEMBL1404620 & 737189 & 5.2261 & 5.3772 & TRN & & \\
\hline CHEMBL1363861 & 737189 & 5.5447 & 5.4547 & TRN & & \\
\hline CHEMBL1328712 & 737189 & 5.5953 & 5.6859 & TRN & & \\
\hline CHEMBL1547962 & 737189 & 5.3424 & 5.4026 & TRN & & \\
\hline CHEMBL1592251 & 737189 & 5.4669 & 5.5183 & TRN & & \\
\hline CHEMBL1326118 & 737189 & 5.8677 & 5.7844 & TRN & & \\
\hline CHEMBL1575267 & 737189 & 5.5385 & 5.6842 & TRN & & \\
\hline CHEMBL1445941 & 737189 & 4.7565 & 5.0997 & TST & & \\
\hline CHEMBL1524527 & 737189 & 5.3029 & 5.1856 & TRN & & \\
\hline CHEMBL1437139 & 737189 & 6.2348 & 6.5244 & TST & & \\
\hline CHEMBL1352912 & 737189 & 5.9416 & 5.8436 & TRN & & \\
\hline CHEMBL1344059 & 737189 & 5.6838 & 5.5169 & TRN & & \\
\hline CHEMBL1345480 & 737189 & 5.5911 & 5.5683 & TRN & & \\
\hline CHEMBL1425889 & 737189 & 5.8658 & 5.7376 & TRN & & \\
\hline CHEMBL1542491 & 737189 & 5.1921 & 5.4178 & TST & & \\
\hline CHEMBL1365262 & 737189 & 5.0124 & 5.3417 & TRN & & \\
\hline CHEMBL1602449 & 737189 & 6.4479 & 5.9026 & TRN & & \\
\hline CHEMBL1320397 & 737189 & 5.5022 & 5.5053 & TRN & & \\
\hline CHEMBL1471345 & 737189 & 6.1454 & 5.9993 & TRN & & \\
\hline CHEMBL1431769 & 737189 & 5.8419 & 5.5786 & TRN & & \\
\hline CHEMBL1309208 & 737189 & 5.7383 & 5.4076 & TRN & & \\
\hline CHEMBL1322219 & 737189 & 6.0074 & 5.6485 & TRN & & \\
\hline CHEMBL3196080 & 737189 & 5.2596 & 5.3635 & TRN & & \\
\hline CHEMBL3189224 & 737189 & 5.3407 & 5.4894 & TRN & & \\
\hline CHEMBL1386067 & 737189 & 2.71 & 4.9837 & TST & & \\
\hline CHEMBL21241 & 737189 & 5.3508 & 5.4615 & TST & & \\
\hline CHEMBL3208968 & 737189 & 5.8251 & 5.5683 & TRN & & \\
\hline CHEMBL1487501 & 737189 & 5.6733 & 5.6234 & TRN & & \\
\hline CHEMBL1513240 & 737189 & 5.3601 & 5.5435 & TRN & & \\
\hline CHEMBL1372844 & 737189 & 5.3258 & 5.4437 & TRN & & \\
\hline CHEMBL1711680 & 737189 & 4.9974 & 5.6657 & TRN & & \\
\hline CHEMBL1330058 & 737189 & 5.5802 & 5.8118 & TRN & & \\
\hline CHEMBL1299352 & 737189 & 5.6449 & 5.5272 & TST & & \\
\hline CHEMBL1602206 & 737189 & 5.1204 & 5.34 & TRN & & \\
\hline
\end{tabular}


Supplemental Table S2.txt

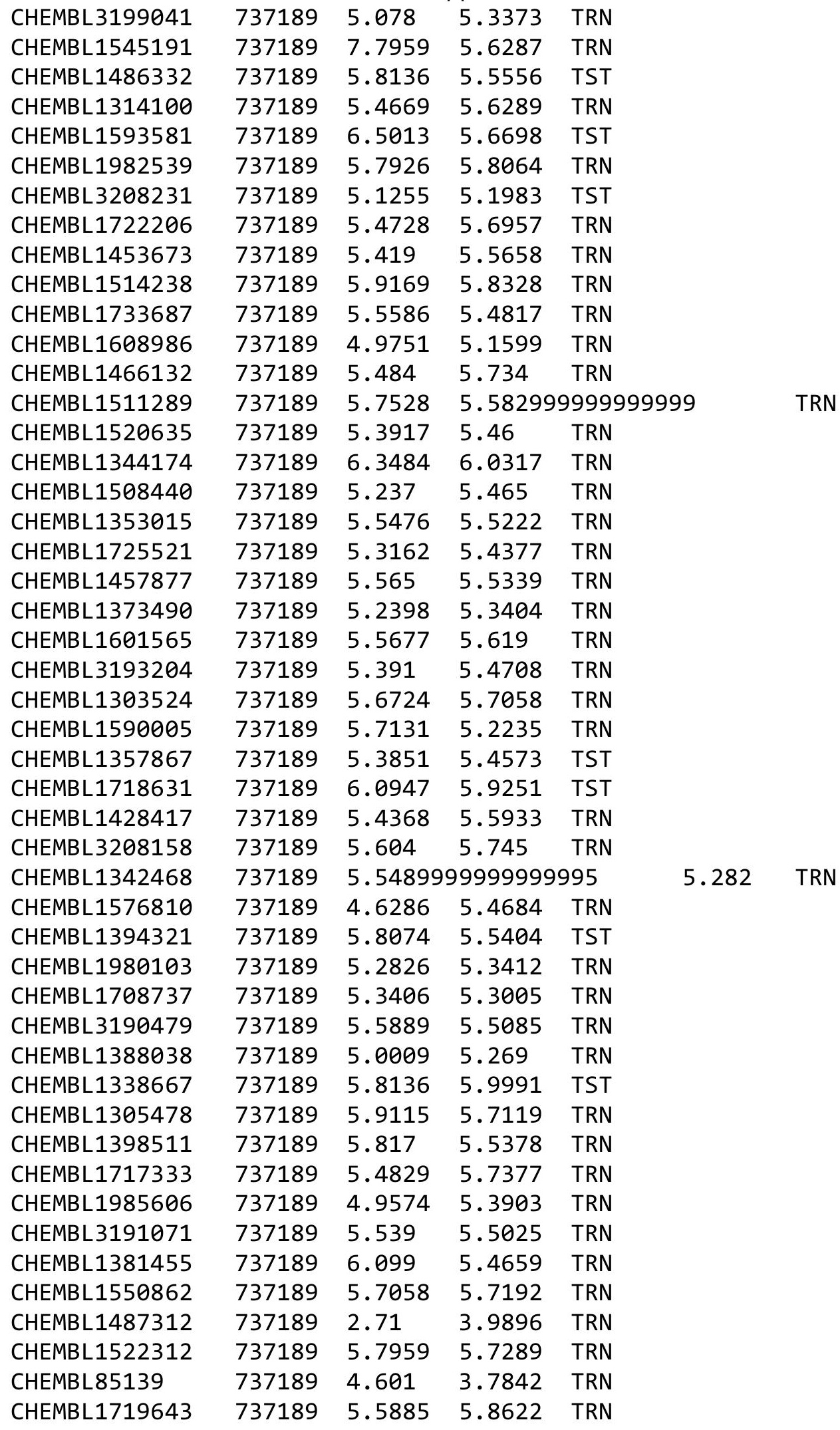

Page 26485 
Supplemental Table S2.txt

\begin{tabular}{|c|c|c|c|c|c|c|}
\hline CHEMBL1302894 & 737189 & 5.7582 & 5.6051 & TRN & & \\
\hline CHEMBL1313764 & 737189 & 5.5701 & 5.6041 & TRN & & \\
\hline CHEMBL1436936 & 737189 & 5.3854 & 5.4292 & TRN & & \\
\hline CHEMBL1468680 & 737189 & 5.3854 & 5.6024 & TRN & & \\
\hline CHEMBL1320663 & 737189 & 5.7084 & 5.7183 & TRN & & \\
\hline CHEMBL1606938 & 737189 & 4.9087 & 5.14 & TRN & & \\
\hline CHEMBL1708683 & 737189 & 2.71 & 3.8897 & TRN & & \\
\hline CHEMBL1345447 & 737189 & 5.504 & 5.5748 & TRN & & \\
\hline CHEMBL1413660 & 737189 & 5.3114 & 5.1925 & TST & & \\
\hline CHEMBL1334928 & 737189 & 5.1338 & 5.4091 & TRN & & \\
\hline CHEMBL1324730 & 737189 & 4.5358 & 4.9524 & TST & & \\
\hline CHEMBL 250711 & 737189 & 5.5867 & 5.5614 & TST & & \\
\hline CHEMBL1579658 & 737189 & 5.8604 & 4.9994 & TRN & & \\
\hline CHEMBL1493199 & 737189 & 5.3738 & 5.4598 & TRN & & \\
\hline CHEMBL1422567 & 737189 & 5.3575 & 5.6094 & TRN & & \\
\hline CHEMBL1516044 & 737189 & 5.1317 & 5.5768 & TRN & & \\
\hline CHEMBL1555884 & 737189 & 5.5376 & 5.6557 & TST & & \\
\hline CHEMBL1547809 & 737189 & 5.2235 & 5.276 & TST & & \\
\hline CHEMBL1375452 & 737189 & 5.4962 & 5.6029 & TST & & \\
\hline CHEMBL 2006762 & 737189 & 4.9722 & 5.2042 & TRN & & \\
\hline CHEMBL1379160 & 737189 & 5.2904 & 5.4003 & TST & & \\
\hline CHEMBL1457960 & 737189 & 5.461 & 5.3441 & TST & & \\
\hline CHEMBL1726040 & 737189 & 5.6313 & 5.8566 & TRN & & \\
\hline CHEMBL1440191 & 737189 & 4.2983 & 5.0986 & TRN & & \\
\hline CHEMBL1425525 & 737189 & 5.5173 & 5.7146 & TRN & & \\
\hline CHEMBL1392178 & 737189 & 5.6426 & 5.5675 & TRN & & \\
\hline CHEMBL1980369 & 737189 & 5.3741 & 5.5178 & TRN & & \\
\hline CHEMBL1591983 & 737189 & 5.0167 & 5.3625 & TRN & & \\
\hline CHEMBL1723286 & 737189 & 5.7775 & 5.6136 & TRN & & \\
\hline CHEMBL1495939 & 737189 & 5.3253 & 5.5596 & TRN & & \\
\hline CHEMBL1706262 & 737189 & 5.2991 & 5.5502 & TRN & & \\
\hline CHEMBL1979574 & 737189 & 5.5236 & 5.7698 & TRN & & \\
\hline CHEMBL1598139 & 737189 & 5.7089 & 5.5786 & TRN & & \\
\hline CHEMBL1971913 & 737189 & 5.8024 & 5.87 & TRN & & \\
\hline CHEMBL1351108 & 737189 & 5.2377 & 5.515 & TRN & & \\
\hline CHEMBL1334169 & 737189 & 5.61299 & 999999999 & 995 & 5.6032 & TRN \\
\hline CHEMBL1602590 & 737189 & 5.4473 & 5.6092 & TRN & & \\
\hline CHEMBL1455549 & 737189 & 5.4414 & 5.4655 & TRN & & \\
\hline CHEMBL1331064 & 737189 & 5.3851 & 5.52 & TRN & & \\
\hline CHEMBL1418191 & 737189 & 5.2835 & 5.3548 & TRN & & \\
\hline CHEMBL1714510 & 737189 & 5.6108 & 5.5195 & TST & & \\
\hline CHEMBL1383919 & 737189 & 5.2423 & 5.4242 & TST & & \\
\hline CHEMBL1542652 & 737189 & 5.1767 & 5.4058 & TST & & \\
\hline CHEMBL 1450025 & 737189 & 4.758 & 5.0367 & TRN & & \\
\hline CHEMBL1503209 & 737189 & 5.669 & 5.6836 & TST & & \\
\hline CHEMBL 3195351 & 737189 & 5.2279 & 5.4057 & TRN & & \\
\hline CHEMBL1709051 & 737189 & 5.2541 & 5.7837 & TRN & & \\
\hline CHEMBL46703 & 737189 & 5.4772 & 5.6471 & TST & & \\
\hline
\end{tabular}


Supplemental Table S2.txt

\begin{tabular}{|c|c|c|c|c|}
\hline CHEMBL1364506 & 737189 & 5.2772 & 5.4692 & TRN \\
\hline CHEMBL1540036 & 737189 & 5.3565 & 5.4464 & TRN \\
\hline CHEMBL1401378 & 737189 & 5.2691 & 5.4753 & TST \\
\hline CHEMBL1502289 & 737189 & 6.0993 & 5.4757 & TRN \\
\hline CHEMBL1723226 & 737189 & 5.8925 & 5.8363 & TRN \\
\hline CHEMBL1407478 & 737189 & 5.6817 & 5.3658 & TST \\
\hline CHEMBL1319018 & 737189 & 5.2611 & 5.6339 & TRN \\
\hline CHEMBL1343101 & 737189 & 5.33 & 5.4324 & TST \\
\hline CHEMBL1437106 & 737189 & 5.6455 & 5.5146 & TRN \\
\hline CHEMBL1608361 & 737189 & 4.8655 & 5.5198 & TRN \\
\hline CHEMBL 2001476 & 737189 & 6.3938 & 6.0033 & TRN \\
\hline CHEMBL1438308 & 737189 & 5.435 & 5.4072 & TRN \\
\hline CHEMBL1489779 & 737189 & 7.7959 & 6.0801 & TRN \\
\hline CHEMBL1463198 & 737189 & 5.2732 & 5.476 & TRN \\
\hline CHEMBL1497239 & 737189 & 5.4381 & 5.5372 & TRN \\
\hline CHEMBL1488371 & 737189 & 5.9303 & 5.7543 & TRN \\
\hline CHEMBL1607286 & 737189 & 5.3684 & 5.5765 & TRN \\
\hline CHEMBL 2141549 & 737189 & 5.16299 & 99999999 & 5.4949 \\
\hline CHEMBL1310713 & 737189 & 5.6934 & 5.4275 & TRN \\
\hline CHEMBL1386752 & 737189 & 6.0149 & 5.7543 & TST \\
\hline CHEMBL1334291 & 737189 & 6.0517 & 5.7871 & TRN \\
\hline CHEMBL1490308 & 737189 & 5.6824 & 5.4916 & TST \\
\hline CHEMBL3198420 & 737189 & 5.6015 & 5.6003 & TRN \\
\hline CHEMBL1584867 & 737189 & 5.4803 & 5.6235 & TRN \\
\hline CHEMBL1377699 & 737189 & 6.404 & 5.8248 & TRN \\
\hline CHEMBL1415208 & 737189 & 4.4698 & 5.4416 & TRN \\
\hline CHEMBL1408150 & 737189 & 6.0992 & 5.9152 & TST \\
\hline CHEMBL306783 & 737189 & 5.1936 & 5.4838 & TRN \\
\hline CHEMBL1513083 & 737189 & 5.9602 & 5.8115 & TRN \\
\hline CHEMBL1570920 & 737189 & 5.2484 & 5.4631 & TST \\
\hline CHEMBL1479637 & 737189 & 5.4646 & 5.631 & TRN \\
\hline CHEMBL1491124 & 737189 & 6.5281 & 5.406000 & 0000000001 \\
\hline CHEMBL1727618 & 737189 & 5.7291 & 5.6242 & TRN \\
\hline CHEMBL1368203 & 737189 & 4.9834 & 5.3008 & TST \\
\hline CHEMBL1408097 & 737189 & 5.1542 & 5.3983 & TRN \\
\hline CHEMBL1980322 & 737189 & 5.4516 & 5.4406 & TRN \\
\hline CHEMBL1213137 & 737189 & 6.0012 & 5.843 & TRN \\
\hline CHEMBL1323822 & 737189 & 5.2106 & 5.3974 & TRN \\
\hline CHEMBL1719132 & 737189 & 5.5586 & 5.3413 & TRN \\
\hline CHEMBL1984804 & 737189 & 5.4337 & 5.5545 & TRN \\
\hline CHEMBL3191688 & 737189 & 5.3825 & 5.3685 & TRN \\
\hline CHEMBL3195012 & 737189 & 5.9126 & 5.5274 & TRN \\
\hline CHEMBL1388234 & 737189 & 5.3257 & 5.6797 & TRN \\
\hline CHEMBL1311489 & 737189 & 5.4126 & 5.6422 & TRN \\
\hline CHEMBL1882689 & 737189 & 5.3332 & 5.4502 & TRN \\
\hline CHEMBL3196698 & 737189 & 6.1631 & 5.8054 & TRN \\
\hline CHEMBL1989294 & 737189 & 5.7438 & 5.7274 & TRN \\
\hline CHEMBL1392092 & 737189 & 5.1712 & 5.4249 & TST \\
\hline
\end{tabular}


Supplemental Table S2.txt

\begin{tabular}{|c|c|c|c|c|c|}
\hline CHEMBL 2139269 & 737189 & 5.3528 & 5.629 & TRN & \\
\hline CHEMBL1429432 & 737189 & 5.8011 & 5.6869 & TRN & \\
\hline CHEMBL1400523 & 737189 & 5.1609 & 5.4501 & TST & \\
\hline CHEMBL1401668 & 737189 & 5.7765 & 5.6708 & TST & \\
\hline CHEMBL1570845 & 737189 & 5.5065 & 5.3168 & TST & \\
\hline CHEMBL1430074 & 737189 & 5.6531 & 5.6541 & TST & \\
\hline CHEMBL1419585 & 737189 & 5.0356 & 5.4382 & TRN & \\
\hline CHEMBL1336630 & 737189 & 5.294 & 5.4254 & TRN & \\
\hline CHEMBL1543599 & 737189 & 5.745 & 5.5558 & TRN & \\
\hline CHEMBL1579548 & 737189 & 5.6426 & 5.678 & TRN & \\
\hline CHEMBL1531156 & 737189 & 5.1892 & 5.131 & TRN & \\
\hline CHEMBL1429887 & 737189 & 5.1481 & 5.3901 & TRN & \\
\hline CHEMBL1400514 & 737189 & 5.7022 & 3.8659 & TRN & \\
\hline CHEMBL1471486 & 737189 & 5.3904 & 5.4874 & TRN & \\
\hline CHEMBL1587580 & 737189 & 5.624 & \multicolumn{2}{|c|}{5.462000000000001} & TRN \\
\hline CHEMBL3192217 & 737189 & 5.0475 & 5.3698 & TRN & \\
\hline CHEMBL1990582 & 737189 & 5.473 & 5.1934 & TRN & \\
\hline CHEMBL3210478 & 737189 & 5.4009 & 5.8387 & TRN & \\
\hline CHEMBL1603182 & 737189 & 5.8542 & 5.8598 & TRN & \\
\hline CHEMBL1444877 & 737189 & 5.3502 & 5.5901 & TRN & \\
\hline CHEMBL1480494 & 737189 & 4.9838 & 5.3252 & TRN & \\
\hline CHEMBL1392793 & 737189 & 5.2137 & 5.4198 & TRN & \\
\hline CHEMBL1463877 & 737189 & 5.6315 & 5.6111 & TRN & \\
\hline CHEMBL1524417 & 737189 & 5.5596 & 5.142 & TRN & \\
\hline CHEMBL3196747 & 737189 & 5.6212 & 5.3739 & TST & \\
\hline CHEMBL1397158 & 737189 & 5.5412 & 5.4309 & TRN & \\
\hline CHEMBL1452409 & 737189 & 5.631 & 5.6578 & TRN & \\
\hline CHEMBL1365988 & 737189 & 5.6936 & 5.4452 & TRN & \\
\hline CHEMBL1339398 & 737189 & 6.1004 & 5.7018 & TST & \\
\hline CHEMBL1526479 & 737189 & 5.305 & 5.5262 & TRN & \\
\hline CHEMBL1412410 & 737189 & 3.9041 & 3.9567 & TRN & \\
\hline CHEMBL1323248 & 737189 & 5.6853 & 5.6822 & TRN & \\
\hline CHEMBL1433662 & 737189 & 5.3672 & 5.6218 & TRN & \\
\hline CHEMBL1482539 & 737189 & 5.4653 & 5.4693 & TRN & \\
\hline CHEMBL1395074 & 737189 & 2.71 & 3.7957 & TST & \\
\hline CHEMBL1547736 & 737189 & 5.3368 & 5.6525 & TST & \\
\hline CHEMBL1426637 & 737189 & 4.0776 & 5.9985 & TRN & \\
\hline CHEMBL1990071 & 737189 & 6.7781 & 6.3288 & TRN & \\
\hline CHEMBL1532737 & 737189 & 5.4703 & 5.4282 & TRN & \\
\hline CHEMBL1304209 & 737189 & 5.9059 & 5.7152 & TRN & \\
\hline CHEMBL1598311 & 737189 & 5.4665 & 5.6197 & TRN & \\
\hline CHEMBL1529236 & 737189 & 5.4946 & 5.5469 & TRN & \\
\hline CHEMBL1606870 & 737189 & 5.2894 & 5.5193 & TRN & \\
\hline CHEMBL1546068 & 737189 & 5.4064 & 5.6709 & TST & \\
\hline CHEMBL1378668 & 737189 & 5.0623 & 5.3436 & TST & \\
\hline CHEMBL1411991 & 737189 & 5.4552 & 5.3655 & TRN & \\
\hline CHEMBL1463521 & 737189 & 5.3294 & 5.36799 & 9999999999 & TRN \\
\hline CHEMBL1200792 & 737189 & 5.3814 & 5.5588 & TRN & \\
\hline
\end{tabular}


Supplemental Table S2.txt

\begin{tabular}{|c|c|c|c|c|}
\hline HEMBL & 189 & 782 & & \\
\hline UГMDI 1561001 & 37189 & 5.6423 & 5.4705 & \\
\hline-10 & & & & \\
\hline AEMBL1 & 189 & 2296 & 507 & $\mathrm{MI}$ \\
\hline HEMBL155 & 37189 & 574 & 5816 & \\
\hline HEMBL1734710 & 37189 & . 2987 & 4475 & \\
\hline HEMBL1 & 189 & 22 & 5637 & \\
\hline |FMRI: & & & & \\
\hline HEMBL1 & 37189 & & 5146 & \\
\hline HEMBL138 & 37189 & 2077 & 3844 & \\
\hline HEMBL139 & 37189 & .2356 & 1697 & \\
\hline AEMBL1 & 89 & 14 & 178 & \\
\hline HEMBL 1 & & & & \\
\hline HEMBL1 & 37189 & 241 & 5154 & \\
\hline AEMBL1 & & & 701 & \\
\hline HEMBL1 & 89 & 578 & 4622 & \\
\hline HEMBL1 & 89 & & 629 & . \\
\hline HEMBL1 & & & & \\
\hline HEMBL1 & 89 & 896 & 1337 & \\
\hline AEMBL1 & & 2 & & \\
\hline HEMBL: & 39 & & 561 & MIN \\
\hline HEMBL & & & 867 & IIr \\
\hline HEMBL & 39 & & 952 & \\
\hline AFMRI & & & & \\
\hline AEMBL1 & & & & I RIN \\
\hline HEMBL: & & & 002 & KIV \\
\hline HEMBL & & & 326 & ST \\
\hline AFMRI & 89 & & 112 & \\
\hline HEMBL1 & & & & IRIN \\
\hline HEMBL 319 & & & & I RN \\
\hline HEMBL1 & & & 394 & RN \\
\hline HEMBL & & & 09 & RN \\
\hline HEMPI & 39 & & 179 & $\Gamma R N$ \\
\hline HEMBL1 & & & 338 & IRN \\
\hline HEMBL1307949 & & 259 & 414 & TRN \\
\hline HEMBL1 & & & 227 & TRN \\
\hline HFMDI. & & & 269 & ST \\
\hline HEMBL1 & & & 688 & ST \\
\hline HEMBL1387695 & 89 & 31 & 385 & TRN \\
\hline AEMBL5 & & & 155 & TRN \\
\hline HEMBL1 & & & 746 & \\
\hline CHEMBL3 & & & & TRN \\
\hline HEMBL1. & 89 & & 3947 & TRN \\
\hline HEMBL155 & 89 & 75 & 7717 & $-S_{2}$ \\
\hline 1 & & & 3088 & $T$ \\
\hline HEMBL1 & & & 3604 & \\
\hline CHEMBL 78150 & 37189 & .8847 & 5.6535 & \\
\hline CHEMBL152003 & 737189 & 5.8471 & 5.6571 & RN \\
\hline
\end{tabular}

Page 26489 


\begin{tabular}{|c|c|c|c|c|c|}
\hline & & \multicolumn{4}{|c|}{ Supplemental Table s2.txt } \\
\hline CHEMBL1385815 & 737189 & 4.9187 & 3.5085 & TRN & \\
\hline CHEMBL 3195142 & 737189 & 5.4845 & 5.6202 & TRN & \\
\hline CHEMBL1495592 & 737189 & 5.9104 & 5.5921 & TRN & \\
\hline CHEMBL1342385 & 737189 & 5.313 & 5.3088 & TRN & \\
\hline CHEMBL1401059 & 737189 & 5.1314 & 5.164 & TRN & \\
\hline CHEMBL1452115 & 737189 & 5.2106 & 5.4591 & TRN & \\
\hline CHEMBL1550535 & 737189 & 5.5033 & 5.4403 & TRN & \\
\hline CHEMBL1438084 & 737189 & 5.6794 & 5.4129 & TRN & \\
\hline CHEMBL1353194 & 737189 & 5.4194 & 5.6508 & TRN & \\
\hline CHEMBL1492021 & 737189 & 5.4369 & 5.36799 & 9999999999 & TRN \\
\hline CHEMBL1393332 & 737189 & 5.5774 & 5.5318 & TST & \\
\hline CHEMBL1474042 & 737189 & 6.1193 & 5.7943 & TRN & \\
\hline CHEMBL1502607 & 737189 & 5.2573 & 5.3594 & TRN & \\
\hline CHEMBL1977487 & 737189 & 5.3303 & 5.4274 & TST & \\
\hline CHEMBL1977863 & 737189 & 5.4444 & 5.624 & TRN & \\
\hline CHEMBL1445250 & 737189 & 5.5945 & 5.5361 & TRN & \\
\hline CHEMBL1418827 & 737189 & 4.6753 & 5.1289 & TST & \\
\hline CHEMBL 2000445 & 737189 & 5.3323 & 5.3833 & TRN & \\
\hline CHEMBL1364308 & 737189 & 5.2585 & 5.2662 & TRN & \\
\hline CHEMBL1434767 & 737189 & 5.1757 & 5.3984 & TRN & \\
\hline CHEMBL1711394 & 737189 & 6.1873 & 6.1326 & TRN & \\
\hline CHEMBL1449512 & 737189 & 5.317 & 5.4925 & TRN & \\
\hline CHEMBL1602217 & 737189 & 5.6684 & 5.5609 & TRN & \\
\hline CHEMBL3145106 & 737189 & 5.3897 & 5.2327 & TRN & \\
\hline CHEMBL1328069 & 737189 & 6.7354 & 6.2046 & TRN & \\
\hline CHEMBL1349266 & 737189 & 6.0351 & 6.0218 & TRN & \\
\hline CHEMBL1499014 & 737189 & 5.471 & 5.7183 & TRN & \\
\hline CHEMBL1569918 & 737189 & 5.2725 & 5.407 & TRN & \\
\hline CHEMBL1499845 & 737189 & 5.8661 & 5.8903 & TRN & \\
\hline CHEMBL1439902 & 737189 & 5.3617 & 5.3667 & TST & \\
\hline CHEMBL1502830 & 737189 & 5.4471 & 5.6038 & TRN & \\
\hline CHEMBL1725261 & 737189 & 5.5284 & 5.6705 & TRN & \\
\hline CHEMBL3197008 & 737189 & 5.7263 & 5.6379 & TRN & \\
\hline CHEMBL1380741 & 737189 & 5.9285 & 5.82 & TRN & \\
\hline CHEMBL1985744 & 737189 & 5.0852 & 5.291 & TRN & \\
\hline CHEMBL1598222 & 737189 & 5.2027 & 5.3337 & TRN & \\
\hline CHEMBL1329925 & 737189 & 6.151 & 5.791 & TRN & \\
\hline CHEMBL1385250 & 737189 & 5.5375 & 5.5014 & TRN & \\
\hline CHEMBL493153 & 737189 & 5.8049 & 5.4087 & TRN & \\
\hline CHEMBL1381760 & 737189 & 5.3614 & 5.353 & TRN & \\
\hline CHEMBL578515 & 737189 & 5.2585 & 5.6158 & TRN & \\
\hline CHEMBL1494962 & 737189 & 5.7104 & 5.6051 & TST & \\
\hline CHEMBL1312504 & 737189 & 5.7452 & 4.8587 & TRN & \\
\hline CHEMBL1967987 & 737189 & 5.0473 & 5.4614 & TRN & \\
\hline CHEMBL1965821 & 737189 & 5.5277 & 5.305 & TRN & \\
\hline CHEMBL1586805 & 737189 & 5.8365 & 5.8135 & TST & \\
\hline CHEMBL1516914 & 737189 & 5.2151 & 5.49100 & 00000000005 & TST \\
\hline CHEMBL1525530 & 737189 & 6.1602 & 5.6821 & TRN & \\
\hline
\end{tabular}


Supplemental Table S2.txt

\begin{tabular}{|c|c|c|c|c|c|c|}
\hline CHEMBL1526349 & 737189 & 5.7924 & 3.9209 & TST & & \\
\hline CHEMBL1305960 & 737189 & 5.7411 & 5.7176 & TRN & & \\
\hline CHEMBL1490441 & 737189 & 6.0579 & 5.678 & TRN & & \\
\hline CHEMBL1569824 & 737189 & 5.6643 & 5.496 & TRN & & \\
\hline CHEMBL1345576 & 737189 & 4.8755 & 5.1536 & TST & & \\
\hline CHEMBL1445707 & 737189 & 7.7959 & 6.4531 & TST & & \\
\hline CHEMBL1347729 & 737189 & 5.2211 & 5.3846 & TRN & & \\
\hline CHEMBL1495016 & 737189 & 5.4969 & 5.4913 & TRN & & \\
\hline CHEMBL1311505 & 737189 & 5.2838 & 5.4398 & TRN & & \\
\hline CHEMBL528506 & 737189 & 5.5222 & 5.6343 & TRN & & \\
\hline CHEMBL1979756 & 737189 & 5.2985 & 5.6319 & TRN & & \\
\hline CHEMBL3190860 & 737189 & 5.9834 & 5.6972 & TST & & \\
\hline CHEMBL1325346 & 737189 & 6.04700 & 00000000 & & 5.7181 & TR \\
\hline CHEMBL1539807 & 737189 & 5.4084 & 5.6363 & TRN & & \\
\hline CHEMBL1714892 & 737189 & 5.6207 & 5.6498 & TRN & & \\
\hline CHEMBL1423282 & 737189 & 5.6162 & 5.6309 & TST & & \\
\hline CHEMBL3196163 & 737189 & 5.766 & 5.7946 & TRN & & \\
\hline CHEMBL1726094 & 737189 & 5.53 & 5.6666 & TST & & \\
\hline CHEMBL1547395 & 737189 & 5.3577 & 5.4818 & TRN & & \\
\hline CHEMBL3195449 & 737189 & 4.9234 & 5.4865 & TRN & & \\
\hline CHEMBL1606613 & 737189 & 5.2949 & 5.5104 & TRN & & \\
\hline CHEMBL3198030 & 737189 & 5.2814 & 5.479 & TRN & & \\
\hline CHEMBL1470446 & 737189 & 5.58799 & 99999999 & 9 & 5.6166 & \\
\hline CHEMBL1563874 & 737189 & 5.3348 & 5.4722 & TRN & & \\
\hline CHEMBL1993788 & 737189 & 5.7354 & 5.4325 & TRN & & \\
\hline CHEMBL1345981 & 737189 & 4.8781 & 5.2797 & TRN & & \\
\hline CHEMBL1342093 & 737189 & 5.7106 & 5.6562 & TRN & & \\
\hline CHEMBL1998863 & 737189 & 5.5283 & 5.6851 & TRN & & \\
\hline CHEMBL1307587 & 737189 & 5.0488 & 5.197 & TRN & & \\
\hline CHEMBL1719938 & 737189 & 2.71 & 4.0914 & TST & & \\
\hline CHEMBL1427851 & 737189 & 5.1528 & 5.3025 & TRN & & \\
\hline CHEMBL1401945 & 737189 & 5.2597 & 5.4663 & TRN & & \\
\hline CHEMBL1505606 & 737189 & 5.3935 & 5.2222 & TRN & & \\
\hline CHEMBL1353998 & 737189 & 5.8857 & 5.5816 & TRN & & \\
\hline CHEMBL1327509 & 737189 & 5.5303 & 5.5363 & TRN & & \\
\hline CHEMBL1337235 & 737189 & 5.289 & 5.4532 & TRN & & \\
\hline CHEMBL1567553 & 737189 & 5.2847 & 5.5756 & TST & & \\
\hline CHEMBL563585 & 737189 & 5.2177 & 5.497999 & 999999999 & & ו 3 \\
\hline CHEMBL1730631 & 737189 & 4.8011 & 5.1271 & TST & & \\
\hline CHEMBL1327791 & 737189 & 5.0458 & 5.4009 & TRN & & \\
\hline CHEMBL1306816 & 737189 & 5.3761 & 5.6271 & TRN & & \\
\hline CHEMBL1505956 & 737189 & 5.3564 & 5.1641 & TRN & & \\
\hline CHEMBL1588557 & 737189 & 5.6232 & 5.528 & TRN & & \\
\hline CHEMBL 1427576 & 737189 & 5.1905 & 5.4789 & TRN & & \\
\hline CHEMBL1504972 & 737189 & 5.2623 & 5.4622 & TRN & & \\
\hline CHEMBL1509374 & 737189 & 5.5361 & 5.4184 & TRN & & \\
\hline CHEMBL1536544 & 737189 & 5.4111 & 5.5369 & TRN & & \\
\hline CHEMBL1447262 & 737189 & 5.6957 & 5.3537 & TRN & & \\
\hline
\end{tabular}

Page 26491 


\begin{tabular}{|c|c|c|c|c|c|}
\hline \multirow[b]{2}{*}{ CHEMBL1550618 } & \multicolumn{5}{|c|}{ Supplemental Table s2.txt } \\
\hline & 737189 & 2.71 & 3.7791 & TRN & \\
\hline CHEMBL1336428 & 737189 & 5.4527 & 5.5698 & TRN & \\
\hline CHEMBL1497119 & 737189 & 5.8044 & 5.5202 & TST & \\
\hline CHEMBL1733054 & 737189 & 5.3119 & 5.4804 & TRN & \\
\hline CHEMBL3190739 & 737189 & 5.3995 & 5.4504 & TST & \\
\hline CHEMBL1509453 & 737189 & 5.8196 & 5.6173 & TRN & \\
\hline CHEMBL1986591 & 737189 & 5.9539 & 5.8523 & TRN & \\
\hline CHEMBL591370 & 737189 & 5.3057 & 5.5947 & TRN & \\
\hline CHEMBL1387773 & 737189 & 5.3248 & 5.3684 & TRN & \\
\hline CHEMBL1449204 & 737189 & 5.5577 & 5.6079 & TRN & \\
\hline CHEMBL1477416 & 737189 & $6.0120 e$ & 00000000 & 305 & TST \\
\hline CHEMBL1612398 & 737189 & 5.6672 & 5.6401 & TRN & \\
\hline CHEMBL1302054 & 737189 & 5.4439 & 5.5738 & TRN & \\
\hline CHEMBL1554332 & 737189 & 5.2972 & 5.5345 & TRN & \\
\hline CHEMBL1566829 & 737189 & 5.21 & 5.4004 & TRN & \\
\hline CHEMBL1415447 & 737189 & 5.4375 & 5.5997 & TST & \\
\hline CHEMBL1339991 & 737189 & 5.3953 & 5.5073 & TRN & \\
\hline CHEMBL3198595 & 737189 & 5.3655 & 5.7377 & TRN & \\
\hline CHEMBL1572829 & 737189 & 5.901 & 5.2046 & TRN & \\
\hline CHEMBL1495094 & 737189 & 5.1201 & 5.3355 & TRN & \\
\hline CHEMBL1445171 & 737189 & 6.1298 & 6.0326 & TRN & \\
\hline CHEMBL1368599 & 737189 & 5.7185 & 5.7787 & TRN & \\
\hline CHEMBL1363346 & 737189 & 5.6114 & 5.7026 & TRN & \\
\hline CHEMBL1712850 & 737189 & 5.7428 & 5.7117 & TRN & \\
\hline CHEMBL1558426 & 737189 & 5.5754 & 4.9172 & TRN & \\
\hline CHEMBL1613694 & 737189 & 2.71 & 3.8623 & TST & \\
\hline CHEMBL1350043 & 737189 & 5.4647 & 3.9571 & TRN & \\
\hline CHEMBL1333110 & 737189 & 5.2935 & 5.3608 & TRN & \\
\hline CHEMBL1076559 & 737189 & 5.275 & 5.41700 & 3000000001 & TRN \\
\hline CHEMBL1341919 & 737189 & 5.1719 & 5.3042 & TST & \\
\hline CHEMBL1310553 & 737189 & 5.9215 & 5.8724 & TRN & \\
\hline CHEMBL1538187 & 737189 & 5.1644 & 5.4618 & TRN & \\
\hline CHEMBL1362055 & 737189 & 6.7685 & 6.3473 & TRN & \\
\hline CHEMBL1331933 & 737189 & 5.994 & 5.74100 & 30000000005 & TST \\
\hline CHEMBL1363916 & 737189 & 5.5943 & 5.3557 & TRN & \\
\hline CHEMBL1509183 & 737189 & 5.4327 & 5.4368 & TRN & \\
\hline CHEMBL1522049 & 737189 & 5.8102 & 5.693 & TRN & \\
\hline CHEMBL1462968 & 737189 & 5.4318 & 5.6694 & TRN & \\
\hline CHEMBL1538986 & 737189 & 5.3352 & 5.4774 & TRN & \\
\hline CHEMBL1442370 & 737189 & 4.994 & 4.9128 & TRN & \\
\hline CHEMBL1386684 & 737189 & 5.7719 & 5.6139 & TRN & \\
\hline CHEMBL1731938 & 737189 & 5.1225 & 5.3946 & TRN & \\
\hline CHEMBL1549574 & 737189 & 5.2302 & 5.4325 & TRN & \\
\hline CHEMBL1449008 & 737189 & 5.8658 & 5.936 & TRN & \\
\hline CHEMBL1328614 & 737189 & 5.477 & 5.3498 & TRN & \\
\hline CHEMBL1527216 & 737189 & 6.2603 & 6.186 & TRN & \\
\hline CHEMBL1379991 & 737189 & 5.9355 & 5.8853 & TRN & \\
\hline CHEMBL1481791 & 737189 & 5.4149 & 5.6251 & TST & \\
\hline
\end{tabular}




\begin{tabular}{|c|c|c|c|c|c|c|}
\hline & & & & & & \\
\hline CHEMBL1415703 & 737189 & 5.4225 & 5.6442 & TRN & & \\
\hline CHEMBL1518799 & 737189 & 5.2313 & 5.3419 & TRN & & \\
\hline CHEMBL1478578 & 737189 & 5.5071 & 5.4766 & TRN & & \\
\hline CHEMBL1508457 & 737189 & 5.2699 & 5.4033 & TRN & & \\
\hline CHEMBL1340447 & 737189 & 5.1966 & 5.4613 & TRN & & \\
\hline CHEMBL1413988 & 737189 & 5.524 & 5.6263 & TRN & & \\
\hline CHEMBL1735851 & 737189 & 2.71 & 3.9704 & TRN & & \\
\hline CHEMBL3191789 & 737189 & 5.4658 & 5.607 & TRN & & \\
\hline CHEMBL1509590 & 737189 & 5.8969 & 5.6348 & TRN & & \\
\hline CHEMBL3214091 & 737189 & 5.9743 & 5.7901 & TST & & \\
\hline CHEMBL1466614 & 737189 & 5.5862 & 5.6701 & TRN & & \\
\hline CHEMBL1359188 & 737189 & 5.7881 & 5.631 & TRN & & \\
\hline CHEMBL1500223 & 737189 & 5.354 & 5.4984 & TRN & & \\
\hline CHEMBL1464102 & 737189 & 5.8636 & 5.9169 & TRN & & \\
\hline CHEMBL1518077 & 737189 & 5.6073 & 5.5561 & TRN & & \\
\hline CHEMBL1713440 & 737189 & 5.7151 & 5.6529 & TRN & & \\
\hline CHEMBL1308811 & 737189 & 4.6142 & 3.9253 & TRN & & \\
\hline CHEMBL1375199 & 737189 & 5.6447 & 5.7028 & TRN & & \\
\hline CHEMBL1341845 & 737189 & 5.3431 & 5.5255 & TRN & & \\
\hline CHEMBL3189161 & 737189 & 6.0287 & 5.6296 & TRN & & \\
\hline CHEMBL1971674 & 737189 & 5.9393 & 5.8343 & TRN & & \\
\hline CHEMBL3209045 & 737189 & 5.4464 & 5.3809 & TRN & & \\
\hline CHEMBL1572955 & 737189 & 5.2116 & 5.45799 & 9999999999 & & TRN \\
\hline CHEMBL3195045 & 737189 & 4.963 & 5.2242 & TRN & & \\
\hline CHEMBL1342999 & 737189 & 5.7053 & 5.5766 & TRN & & \\
\hline CHEMBL1518309 & 737189 & 5.7014 & 5.6253 & TST & & \\
\hline CHEMBL1540048 & 737189 & 6.0254 & 6.0559 & TRN & & \\
\hline CHEMBL1337990 & 737189 & 6.3281 & 5.7926 & TRN & & \\
\hline CHEMBL1420800 & 737189 & 5.41200 & 30000000 & $\partial 1$ & 5.5967 & TRN \\
\hline CHEMBL1408272 & 737189 & 5.4281 & 5.5734 & TRN & & \\
\hline CHEMBL1498231 & 737189 & 5.4769 & 5.5506 & TST & & \\
\hline CHEMBL1360884 & 737189 & 2.71 & 3.8715 & TRN & & \\
\hline CHEMBL1391387 & 737189 & 7.7959 & 5.5247 & TRN & & \\
\hline CHEMBL1328260 & 737189 & 5.75200 & 30000000 & $\partial 1$ & 4.0125 & TRN \\
\hline CHEMBL1706626 & 737189 & 6.0748 & 6.0025 & TRN & & \\
\hline CHEMBL1493953 & 737189 & 5.5177 & 5.5672 & TRN & & \\
\hline CHEMBL1735971 & 737189 & 5.8456 & 5.9779 & TRN & & \\
\hline CHEMBL1372616 & 737189 & 5.5372 & 5.4976 & TRN & & \\
\hline CHEMBL3195171 & 737189 & 5.4402 & 5.6433 & TRN & & \\
\hline CHEMBL1335220 & 737189 & 5.5399 & 5.604 & TRN & & \\
\hline CHEMBL3195663 & 737189 & 5.3808 & 5.4754 & TST & & \\
\hline CHEMBL1460151 & 737189 & 5.2801 & 5.397 & TRN & & \\
\hline CHEMBL1609366 & 737189 & 5.82100 & 00000000 & & 5.7035 & TRN \\
\hline CHEMBL1720916 & 737189 & 5.2545 & 5.5281 & TRN & & \\
\hline CHEMBL251005 & 737189 & 6.291 & 5.2604 & TRN & & \\
\hline CHEMBL1610796 & 737189 & 7.7959 & 7.1255 & TRN & & \\
\hline CHEMBL1508593 & 737189 & 5.3855 & 5.5432 & TST & & \\
\hline CHEMBL590666 & 737189 & 5.2691 & 5.5551 & TRN & & \\
\hline
\end{tabular}




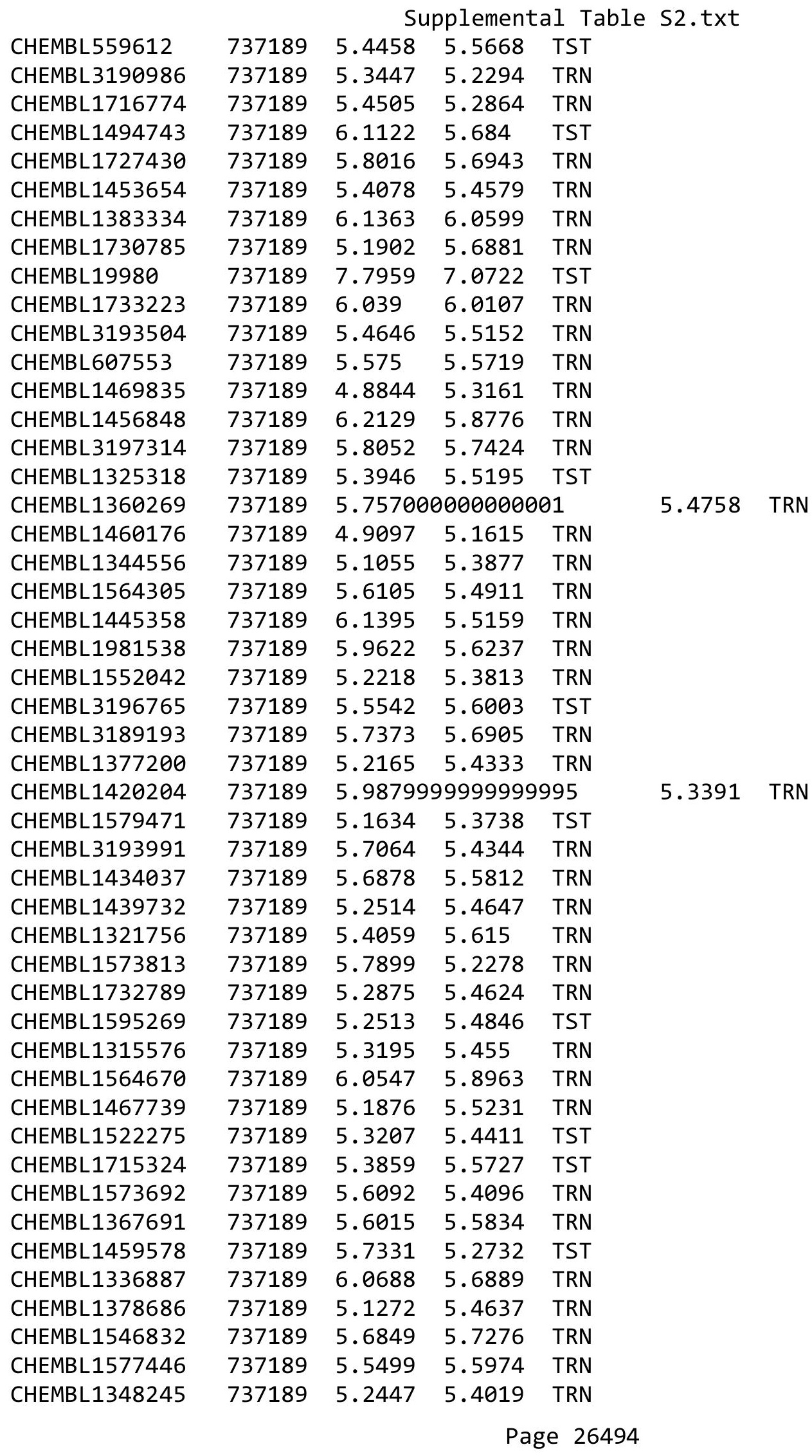




\begin{tabular}{|c|c|c|c|c|c|}
\hline \\
\hline CHEMBL3213830 & 737189 & 3.0 & 3.9952 & TST & \\
\hline CHEMBL1549706 & 737189 & 5.4448 & 5.7299 & TST & \\
\hline CHEMBL498436 & 737189 & 5.5372 & 5.6258 & TST & \\
\hline CHEMBL1546722 & 737189 & 5.7293 & 5.7795 & TST & \\
\hline CHEMBL3191127 & 737189 & 5.9412 & 5.0653 & TRN & \\
\hline CHEMBL3189686 & 737189 & 5.2054 & 5.45200 & 0000000001 & TRN \\
\hline CHEMBL1448503 & 737189 & 6.1157 & 5.9602 & TRN & \\
\hline CHEMBL1485259 & 737189 & 5.5 & 5.6453 & TRN & \\
\hline CHEMBL1545240 & 737189 & 4.2825 & 5.1572 & TST & \\
\hline CHEMBL1698474 & 737189 & 5.4024 & 5.3503 & TRN & \\
\hline CHEMBL1516308 & 737189 & 5.1956 & 5.4522 & TRN & \\
\hline CHEMBL1423708 & 737189 & 4.6203 & 4.7079 & TST & \\
\hline CHEMBL1536814 & 737189 & 5.5296 & 5.5201 & TRN & \\
\hline CHEMBL3193989 & 737189 & 5.2476 & 5.4084 & TRN & \\
\hline CHEMBL1377902 & 737189 & 4.6912 & 5.1656 & TRN & \\
\hline CHEMBL3190200 & 737189 & 5.6015 & 5.67700 & 20000000005 & TST \\
\hline CHEMBL1728642 & 737189 & 6.0 & 5.9656 & TST & \\
\hline CHEMBL1489353 & 737189 & 5.6916 & 5.7094 & TRN & \\
\hline CHEMBL1586807 & 737189 & 5.8419 & 5.8429 & TRN & \\
\hline CHEMBL1085765 & 737189 & 5.447 & 5.574 & TRN & \\
\hline CHEMBL3189663 & 737189 & 5.2142 & 5.4962 & TRN & \\
\hline CHEMBL1314190 & 737189 & 5.051 & 5.36 & TST & \\
\hline CHEMBL1326318 & 737189 & 5.3164 & 5.4436 & TST & \\
\hline CHEMBL3192616 & 737189 & 5.3237 & 5.6453 & TST & \\
\hline CHEMBL1559239 & 737189 & 5.0552 & 5.1928 & TST & \\
\hline CHEMBL1494564 & 737189 & 5.0611 & 5.2457 & TST & \\
\hline CHEMBL1730026 & 737189 & 5.0351 & 5.4015 & TST & \\
\hline CHEMBL1489294 & 737189 & 5.9594 & 5.8734 & TST & \\
\hline CHEMBL1432636 & 737189 & 5.4814 & 5.6175 & TST & \\
\hline CHEMBL1535538 & 737189 & 5.3939 & 5.4817 & TST & \\
\hline CHEMBL1522987 & 737189 & 5.0155 & 5.2691 & TST & \\
\hline CHEMBL1537261 & 737189 & 5.9352 & 5.7898 & TST & \\
\hline CHEMBL1506300 & 737189 & 5.2041 & 5.4312 & TST & \\
\hline CHEMBL1536060 & 737189 & 5.1409 & 5.3366 & TST & \\
\hline CHEMBL1354069 & 737189 & 6.1637 & 6.0185 & TST & \\
\hline CHEMBL1516581 & 737189 & 5.2228 & 5.3044 & TST & \\
\hline CHEMBL1322690 & 737189 & 5.3211 & 5.1132 & TST & \\
\hline CHEMBL1347104 & 737189 & 5.3578 & 5.4639 & TST & \\
\hline CHEMBL1573251 & 737189 & 5.3651 & 5.2821 & TST & \\
\hline CHEMBL1325640 & 737189 & 5.5327 & 5.6071 & TST & \\
\hline CHEMBL1403477 & 737189 & 6.3904 & 6.1184 & TST & \\
\hline CHEMBL1524089 & 737189 & 5.2803 & 5.5547 & TST & \\
\hline CHEMBL1475774 & 737189 & 5.7305 & 5.5999 & TST & \\
\hline CHEMBL1447526 & 737189 & 5.2992 & 5.5295 & TST & \\
\hline CHEMBL1315654 & 737189 & 5.7226 & 5.7817 & TST & \\
\hline CHEMBL1425314 & 737189 & 5.7073 & 5.3664 & TST & \\
\hline CHEMBL1403913 & 737189 & 5.6639 & 4.0435 & TST & \\
\hline CHEMBL1586169 & 737189 & 5.4571 & 5.5893 & TST & \\
\hline
\end{tabular}




\begin{tabular}{|c|c|c|c|c|c|c|}
\hline \multirow[b]{2}{*}{ CHEMBL1403664 } & \multicolumn{6}{|c|}{ Supplemental Table S2.txt } \\
\hline & 737189 & 2.71 & 4.0176 & TST & & \\
\hline CHEMBL1392952 & 737189 & 4.166 & 3.7947 & TST & & \\
\hline CHEMBL1547021 & 737189 & 5.3438 & 5.1757 & TST & & \\
\hline CHEMBL194400 & 737189 & 5.2148 & 5.4833 & TST & & \\
\hline CHEMBL1341308 & 737189 & 5.6107 & 5.6447 & TST & & \\
\hline CHEMBL1387474 & 737189 & $5.5370 e$ & 00000000 & & 5.4275 & TST \\
\hline CHEMBL155563 & 737189 & 6.1087 & 5.8217 & TST & & \\
\hline CHEMBL1585375 & 737189 & 5.6474 & 5.4088 & TST & & \\
\hline CHEMBL1304839 & 737189 & 5.6198 & 5.3942 & TST & & \\
\hline CHEMBL3210428 & 737189 & 5.8557 & 5.765 & TST & & \\
\hline CHEMBL3392059 & 737189 & 6.2513 & 6.0223 & TST & & \\
\hline CHEMBL1341399 & 737189 & 5.4105 & 5.4658 & TST & & \\
\hline CHEMBL1301082 & 737189 & 5.0564 & 5.4405 & TST & & \\
\hline CHEMBL1420454 & 737189 & 4.9359 & 5.112 & TST & & \\
\hline CHEMBL1497479 & 737189 & 5.2403 & 5.4704 & TST & & \\
\hline CHEMBL1540477 & 737189 & 5.1648 & 5.439 & TST & & \\
\hline CHEMBL1481836 & 737189 & 5.3595 & 5.4859 & TST & & \\
\hline CHEMBL1716939 & 737189 & 5.0748 & 5.2856 & TST & & \\
\hline CHEMBL1730123 & 737189 & 5.5916 & 5.5679 & TST & & \\
\hline CHEMBL1426228 & 737189 & 5.1886 & 5.5227 & TST & & \\
\hline CHEMBL 2006607 & 737189 & 5.2806 & 5.8145 & TST & & \\
\hline CHEMBL1722190 & 737189 & 5.1128 & 5.0321 & TST & & \\
\hline CHEMBL3207339 & 737189 & 5.5867 & 5.5161 & TST & & \\
\hline CHEMBL1303689 & 737189 & 5.199 & 5.4013 & TST & & \\
\hline CHEMBL1701004 & 737189 & 5.5334 & 5.8081 & TST & & \\
\hline CHEMBL1423432 & 737189 & 5.2599 & 5.3936 & TST & & \\
\hline CHEMBL1483540 & 737189 & 4.5051 & 5.2373 & TST & & \\
\hline CHEMBL1430931 & 737189 & 5.8921 & 5.801 & TST & & \\
\hline CHEMBL1495763 & 737189 & 5.5346 & 5.6236 & TST & & \\
\hline CHEMBL1518291 & 737189 & 4.8864 & 5.4606 & TST & & \\
\hline CHEMBL1731981 & 737189 & 5.1906 & 5.49299 & 9999999999 & & TST \\
\hline CHEMBL1511045 & 737189 & 6.6048 & 5.9838 & TST & & \\
\hline CHEMBL1728427 & 737189 & 5.5339 & 5.6698 & TST & & \\
\hline CHEMBL1523835 & 737189 & 5.4043 & 5.5763 & TST & & \\
\hline CHEMBL1491529 & 737189 & 5.479 & 5.5299 & TST & & \\
\hline CHEMBL1454776 & 737189 & 5.4915 & 5.5509 & TST & & \\
\hline CHEMBL1570687 & 737189 & 5.4034 & 5.3631 & TST & & \\
\hline CHEMBL1307636 & 737189 & 4.9172 & 5.4545 & TST & & \\
\hline CHEMBL1566415 & 737189 & 5.3283 & 5.5091 & TST & & \\
\hline CHEMBL1713496 & 737189 & 5.4594 & 5.5379 & TST & & \\
\hline CHEMBL550294 & 737189 & 5.1409 & 5.525 & TST & & \\
\hline CHEMBL1496647 & 737189 & 5.334 & 5.5322 & TST & & \\
\hline CHEMBL3191051 & 737189 & 5.5271 & 5.5248 & TST & & \\
\hline CHEMBL1423709 & 737189 & 5.9285 & 5.8207 & TST & & \\
\hline CHEMBL1379737 & 737189 & 5.3583 & 5.597 & TST & & \\
\hline CHEMBL1399358 & 737189 & 5.5638 & 5.2615 & TST & & \\
\hline CHEMBL1599111 & 737189 & 5.4458 & 5.6078 & TST & & \\
\hline CHEMBL1329962 & 737189 & 5.4141 & 5.5769 & TST & & \\
\hline
\end{tabular}


Supplemental Table S2.txt

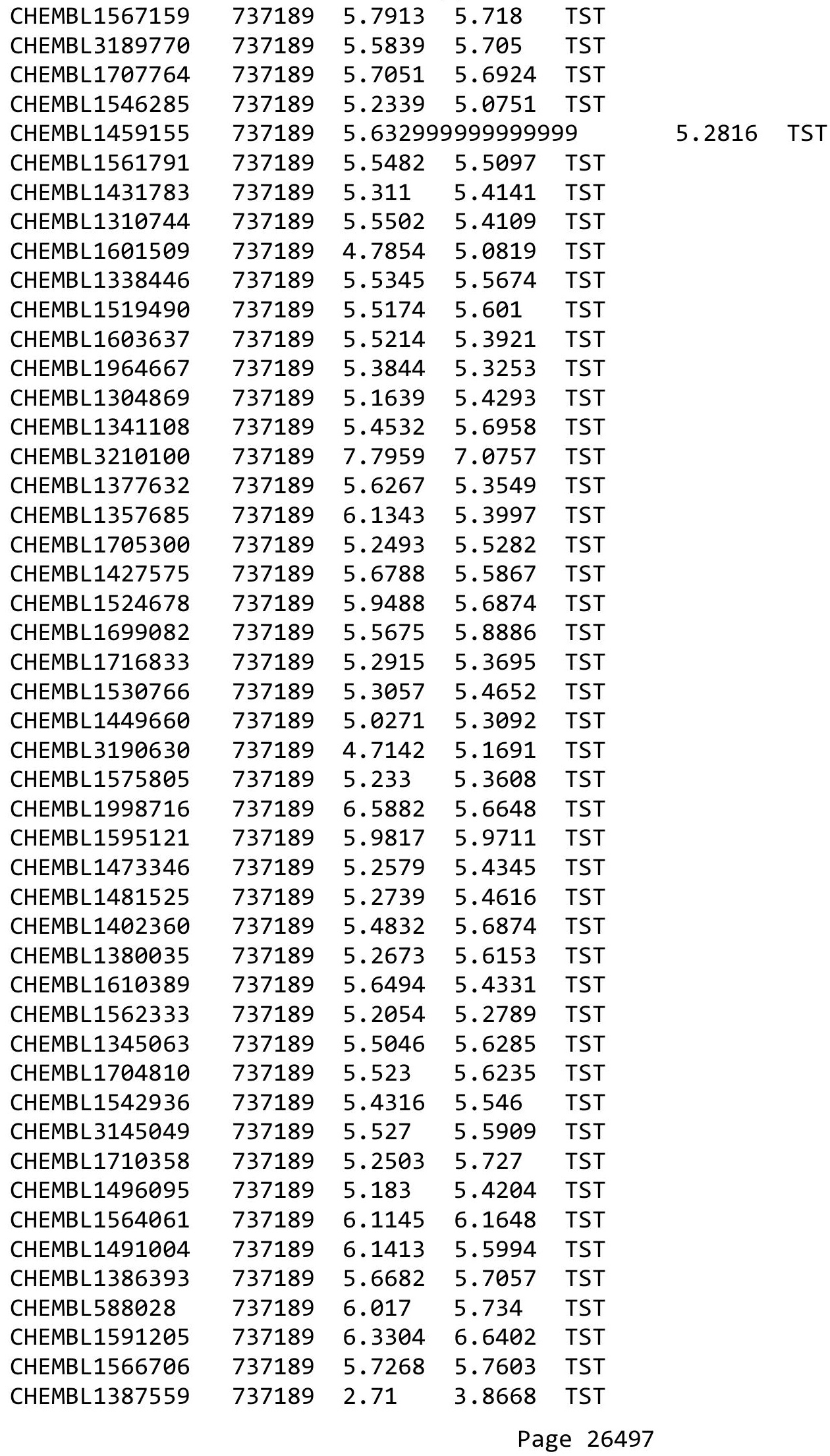


Supplemental Table S2.txt

\begin{tabular}{|c|c|c|c|c|c|c|}
\hline CHEMBL1449811 & 737189 & 5.7773 & \multicolumn{3}{|c|}{5.672999999999999} & TST \\
\hline CHEMBL3193600 & 737189 & 4.5223 & 5.0523 & TST & & \\
\hline CHEMBL1610227 & 737189 & 5.2141 & 5.4262 & TST & & \\
\hline CHEMBL1505142 & 737189 & 5.5084 & 5.3991 & TST & & \\
\hline CHEMBL1410260 & 737189 & 5.12299 & 99999999 & 99 & 5.3134 & TST \\
\hline CHEMBL1974432 & 737189 & 4.9527 & 5.3761 & TST & & \\
\hline CHEMBL1610051 & 737189 & 5.5415 & 5.6062 & TST & & \\
\hline CHEMBL1423046 & 737189 & 5.7324 & 5.7193 & TST & & \\
\hline CHEMBL1305526 & 737189 & $5.4120 e$ & 00000000 & 01 & 5.6584 & TST \\
\hline CHEMBL1986380 & 737189 & 6.3276 & 6.1196 & TST & & \\
\hline CHEMBL 3198754 & 737189 & 5.1894 & 5.5287 & TST & & \\
\hline CHEMBL1598340 & 737189 & 5.4633 & 5.7538 & TST & & \\
\hline CHEMBL1517493 & 737189 & 4.9285 & 5.3419 & TST & & \\
\hline CHEMBL1608073 & 737189 & 5.2971 & 5.4837 & TST & & \\
\hline CHEMBL1563171 & 737189 & 5.1623 & 5.4197 & TST & & \\
\hline CHEMBL1720389 & 737189 & 5.4626 & 5.7463 & TST & & \\
\hline CHEMBL1526705 & 737189 & 4.5487 & 3.9153 & TST & & \\
\hline CHEMBL1417120 & 737189 & 5.4299 & 5.447 & TST & & \\
\hline CHEMBL1975191 & 737189 & 6.3005 & 5.6213 & TST & & \\
\hline CHEMBL1329726 & 737189 & 5.6832 & 5.4945 & TST & & \\
\hline CHEMBL1342448 & 737189 & 6.086 & 5.9374 & TST & & \\
\hline CHEMBL1486416 & 737189 & 6.2455 & 5.8772 & TST & & \\
\hline CHEMBL1313030 & 737189 & 5.3935 & 5.2521 & TST & & \\
\hline CHEMBL1348593 & 737189 & 5.3403 & 5.4878 & TST & & \\
\hline CHEMBL1703524 & 737189 & 5.42299 & 99999999 & 99 & 5.5319 & TST \\
\hline CHEMBL1423656 & 737189 & 5.8044 & 5.7747 & TST & & \\
\hline CHEMBL577419 & 737189 & 5.2027 & 5.4495 & TST & & \\
\hline CHEMBL1504993 & 737189 & 5.3583 & 5.5942 & TST & & \\
\hline CHEMBL1401498 & 737189 & 4.4554 & 4.7538 & TST & & \\
\hline CHEMBL 3210067 & 737189 & 5.3516 & 5.471 & TST & & \\
\hline CHEMBL1433384 & 737189 & 5.2658 & 5.2761 & TST & & \\
\hline CHEMBL1418082 & 737189 & 5.6853 & 5.3575 & TST & & \\
\hline CHEMBL1423370 & 737189 & 5.6946 & 3.8919 & TST & & \\
\hline CHEMBL1319750 & 737189 & 5.2776 & 5.1475 & TST & & \\
\hline CHEMBL3192206 & 737189 & 5.9948 & 5.5525 & TST & & \\
\hline CHEMBL1448198 & 737189 & 6.0 & 6.0034 & TST & & \\
\hline CHEMBL1321278 & 737189 & 5.1973 & 5.4519 & TST & & \\
\hline CHEMBL1479319 & 737189 & 5.6345 & 5.4968 & TST & & \\
\hline CHEMBL1312486 & 737189 & 5.58 & 5.4184 & TST & & \\
\hline CHEMBL3391726 & 737189 & 5.7567 & 5.8257 & TST & & \\
\hline CHEMBL1738986 & 737189 & 5.4653 & 5.3276 & TST & & \\
\hline CHEMBL1718852 & 737189 & 5.4001 & 5.2151 & TST & & \\
\hline CHEMBL1493071 & 737189 & 5.2446 & 5.4122 & TST & & \\
\hline CHEMBL1402899 & 737189 & 5.4728 & 5.4228 & TST & & \\
\hline CHEMBL1577855 & 737189 & 5.7523 & 5.5338 & TST & & \\
\hline CHEMBL1340825 & 737189 & 5.2641 & 5.485 & TST & & \\
\hline CHEMBL1481657 & 737189 & 5.2117 & 5.4813 & TST & & \\
\hline CHEMBL1556095 & 737189 & 5.4547 & 5.4638 & TST & & \\
\hline
\end{tabular}


Supplemental Table S2.txt

\begin{tabular}{|c|c|c|c|c|c|}
\hline CHEMBL3189459 & 737189 & 5.5123 & 5.5237 & TST & \\
\hline CHEMBL1413508 & 737189 & 5.0362 & 5.2976 & TST & \\
\hline CHEMBL 3194032 & 737189 & 4.4421 & 3.7902 & TST & \\
\hline CHEMBL1378835 & 737189 & 5.1784 & 4.7889 & TST & \\
\hline CHEMBL517341 & 737189 & 7.7959 & 6.8728 & TST & \\
\hline CHEMBL1509245 & 737189 & 5.0438 & 5.3541 & TST & \\
\hline CHEMBL1544036 & 737189 & 5.3865 & 5.4581 & TST & \\
\hline CHEMBL1990675 & 737189 & 5.4707 & 5.3652 & TST & \\
\hline CHEMBL1550485 & 737189 & 5.9784 & 5.5825 & TST & \\
\hline CHEMBL1337117 & 737189 & 4.6968 & 4.8099 & TST & \\
\hline CHEMBL1571821 & 737189 & 5.7894 & 5.6834 & TST & \\
\hline CHEMBL1555833 & 737189 & 5.3008 & 5.6951 & TST & \\
\hline CHEMBL1403670 & 737189 & 5.3904 & 5.5286 & TST & \\
\hline CHEMBL1580409 & 737189 & 5.5098 & 5.4472 & TST & \\
\hline CHEMBL1446216 & 737189 & 5.2889 & 5.572999 & 99999999995 & TST \\
\hline CHEMBL1500335 & 737189 & 5.3425 & 5.5827 & TST & \\
\hline CHEMBL 3144828 & 737189 & 4.9996 & 5.2788 & TST & \\
\hline CHEMBL1401784 & 737189 & 4.9226 & 5.1921 & TST & \\
\hline CHEMBL1461458 & 737189 & 6.0775 & 6.004 & TST & \\
\hline CHEMBL 3190644 & 737189 & 5.2447 & 5.5383 & TST & \\
\hline CHEMBL1584391 & 737189 & 5.3516 & 5.5081 & TST & \\
\hline CHEMBL1321447 & 737189 & 4.2116 & 3.7951 & TST & \\
\hline CHEMBL1391715 & 737189 & 4.6488 & 3.9443 & TST & \\
\hline CHEMBL1438983 & 737189 & 5.6726 & 5.5781 & TST & \\
\hline CHEMBL 3190240 & 737189 & 2.71 & 3.9124 & TST & \\
\hline CHEMBL1555208 & 737189 & 5.2147 & 5.4675 & TST & \\
\hline CHEMBL1529783 & 737189 & 5.7457 & 5.5287 & TST & \\
\hline CHEMBL1347204 & 737189 & 5.4487 & 5.4771 & TST & \\
\hline CHEMBL1460871 & 737189 & 5.1736 & 5.7096 & TST & \\
\hline CHEMBL1328939 & 737189 & 5.6615 & 5.8215 & TST & \\
\hline CHEMBL581868 & 737189 & 6.1583 & 5.3859 & TST & \\
\hline CHEMBL1442438 & 737189 & 5.5696 & 5.5626 & TST & \\
\hline CHEMBL 3190965 & 737189 & 6.7744 & 6.2387 & TST & \\
\hline CHEMBL1452114 & 737189 & 5.2756 & 5.4344 & TST & \\
\hline CHEMBL1553387 & 737189 & 6.0411 & 5.4729 & TST & \\
\hline CHEMBL1403285 & 737189 & 4.668 & 4.9353 & TST & \\
\hline CHEMBL1537093 & 737189 & 5.4291 & 5.6126 & TST & \\
\hline CHEMBL1569004 & 737189 & 4.5053 & 4.0849 & TST & \\
\hline CHEMBL1563176 & 737189 & 5.3519 & 5.5044 & TST & \\
\hline CHEMBL1423839 & 737189 & 5.2843 & 5.5325 & TST & \\
\hline CHEMBL586061 & 737189 & 5.4711 & 5.5478 & TST & \\
\hline CHEMBL1320781 & 737189 & 5.8471 & 5.6145 & TST & \\
\hline CHEMBL1311812 & 737189 & 5.7823 & 5.6271 & TST & \\
\hline CHEMBL1732120 & 737189 & 2.71 & 4.0149 & TST & \\
\hline CHEMBL1447487 & 737189 & 5.9813 & 6.0788 & TST & \\
\hline CHEMBL1595152 & 737189 & 5.5581 & 5.6041 & TST & \\
\hline CHEMBL 2003688 & 737189 & \multicolumn{3}{|c|}{5.6370000000000005} & TST \\
\hline CHEMBL1515360 & 737189 & 5.516 & 5.5297 & TST & \\
\hline
\end{tabular}


Supplemental Table S2.txt

\begin{tabular}{|c|c|c|c|c|}
\hline CHEMBL1532181 & 737189 & 4.8722 & 4.9171 & TST \\
\hline CHEMBL1492763 & 737189 & 5.5022 & 5.2952 & TST \\
\hline CHEMBL1331328 & 737189 & 5.4787 & 5.4999 & TST \\
\hline CHEMBL1541195 & 737189 & 5.481 & 5.5484 & TST \\
\hline CHEMBL1466948 & 737189 & 5.7049 & 3.7807 & TST \\
\hline CHEMBL602990 & 737189 & 5.3527 & 5.6055 & TST \\
\hline CHEMBL1421592 & 737189 & 5.5569 & 4.9446 & TST \\
\hline CHEMBL1318653 & 737189 & 5.3718 & 5.5928 & TST \\
\hline CHEMBL 3195021 & 737189 & 5.9359 & 6.0974 & TST \\
\hline CHEMBL3210967 & 737189 & 5.9508 & 5.8505 & TST \\
\hline CHEMBL1716500 & 737189 & 5.6584 & 5.6569 & TST \\
\hline CHEMBL1610565 & 737189 & 6.3132 & 6.0558 & TST \\
\hline CHEMBL1706157 & 737189 & 5.5033 & 5.6024 & TST \\
\hline CHEMBL1405705 & 737189 & 5.4734 & 4.043 & TST \\
\hline CHEMBL1423533 & 737189 & 5.1958 & 5.3086 & TST \\
\hline CHEMBL1567225 & 737189 & 5.1676 & 5.4497 & TST \\
\hline CHEMBL1726492 & 737189 & 5.5667 & 5.582999 & 999999999 \\
\hline CHEMBL1336879 & 737189 & 5.3824 & 5.0238 & TST \\
\hline CHEMBL1467843 & 737189 & 5.7183 & 5.5705 & TST \\
\hline CHEMBL3947705 & 1638156 & 5.699 & 5.6868 & TRN \\
\hline CHEMBL 3938696 & 1638156 & 4.6576 & 4.6478 & TRN \\
\hline CHEMBL3915956 & 1638156 & 6.284 & 5.9678 & TST \\
\hline CHEMBL 3969800 & 1638156 & 5.301 & 5.3384 & TRN \\
\hline CHEMBL 3959030 & 1638156 & 6.5686 & 6.0111 & TST \\
\hline CHEMBL 3936430 & 1638156 & 6.6021 & 6.1847 & TST \\
\hline CHEMBL3928578 & 1638156 & 6.1308 & 6.099 & TRN \\
\hline CHEMBL 3966654 & 1638156 & 4.699 & 4.7094 & TRN \\
\hline CHEMBL 3954675 & 1638156 & 4.5229 & 6.0852 & TST \\
\hline CHEMBL3939753 & 1638156 & 4.4437 & 4.4777 & TRN \\
\hline CHEMBL 3956848 & 1638156 & 5.8539 & 5.6819 & TRN \\
\hline CHEMBL 3929181 & 1638156 & 5.0706 & 5.8367 & TST \\
\hline CHEMBL 3943711 & 1638156 & 5.585 & 5.5822 & TRN \\
\hline CHEMBL 3940951 & 1638156 & 4.7212 & 4.7582 & TRN \\
\hline CHEMBL 3947427 & 1638156 & 5.0315 & 4.9776 & TRN \\
\hline CHEMBL3891367 & 1638156 & 5.3279 & 5.7164 & TST \\
\hline CHEMBL 3905338 & 1638156 & 5.585 & 5.627006 & 000000001 \\
\hline CHEMBL 3927215 & 1638156 & 6.4815 & 6.3116 & TRN \\
\hline CHEMBL 3890925 & 1638156 & 6.2366 & 6.1489 & TRN \\
\hline CHEMBL 3905053 & 1638156 & 6.0605 & 6.1066 & TRN \\
\hline CHEMBL 3943291 & 1638156 & 5.4437 & 5.8818 & TST \\
\hline CHEMBL3952004 & 1638156 & 5.6383 & 5.6712 & TRN \\
\hline CHEMBL 3982208 & 1638156 & 5.3279 & 5.3077 & TRN \\
\hline CHEMBL3902817 & 1638156 & 5.7696 & 5.6497 & TRN \\
\hline CHEMBL3954700 & 1638156 & 4.7959 & 4.7387 & TRN \\
\hline CHEMBL 3904534 & 1638156 & 5.7696 & 5.9829 & TRN \\
\hline CHEMBL3907812 & 1638156 & 5.7959 & 5.8283 & TRN \\
\hline CHEMBL 3918994 & 1638156 & 4.8928 & 4.8984 & TRN \\
\hline CHEMBL 3975257 & 1638156 & 5.6576 & 5.659 & TRN \\
\hline
\end{tabular}


Supplemental Table S2.txt

\begin{tabular}{|c|c|c|c|c|}
\hline CHEMBL3959547 & 1638156 & 5.4202 & 5.426 & TRN \\
\hline CHEMBL3954204 & 1638156 & 6.2007 & 6.2725 & TRN \\
\hline CHEMBL3926982 & 1638156 & 6.0605 & \multicolumn{2}{|c|}{6.047999999999999} \\
\hline CHEMBL3918212 & 1638156 & 5.7696 & 5.6552 & TRN \\
\hline CHEMBL 3973247 & 1638156 & 5.7212 & 5.7852 & TRN \\
\hline CHEMBL3892146 & 1638156 & 6.3098 & 6.2548 & TRN \\
\hline CHEMBL3986455 & 1638156 & 6.4815 & 6.4764 & TRN \\
\hline CHEMBL3936481 & 1638156 & 5.8239 & 5.8765 & TRN \\
\hline CHEMBL3943626 & 1638156 & 4.8861 & 4.8986 & TRN \\
\hline CHEMBL3923338 & 1638156 & 5.0088 & 5.0101 & TRN \\
\hline CHEMBL3978260 & 1638156 & 5.9586 & 5.9944 & TRN \\
\hline CHEMBL3955068 & 1638156 & 4.7959 & 6.0381 & TST \\
\hline CHEMBL3963140 & 1638156 & 5.8539 & 5.9159 & TRN \\
\hline CHEMBL3922050 & 1638156 & 5.4318 & 5.3789 & TRN \\
\hline CHEMBL 3975700 & 1638156 & 5.5086 & 5.5007 & TRN \\
\hline CHEMBL3956785 & 1638156 & 5.7959 & 5.8972 & TRN \\
\hline CHEMBL3908130 & 1638156 & 6.6383 & 6.666 & TRN \\
\hline CHEMBL3928699 & 1638156 & 4.9586 & 5.016 & TRN \\
\hline CHEMBL3981836 & 1638156 & 6.1871 & 6.056 & TST \\
\hline CHEMBL3936228 & 1638156 & 6.0915 & 6.1656 & TST \\
\hline CHEMBL3924249 & 1638156 & 6.2441 & 5.9786 & TST \\
\hline CHEMBL3950658 & 1638156 & 6.2366 & 5.8458 & TST \\
\hline CHEMBL3954499 & 1638156 & 4.699 & 5.0426 & TST \\
\hline CHEMBL3945267 & 1636656 & 6.6861 & 6.7742 & TRN \\
\hline CHEMBL3924053 & 1636656 & 5.51 & 5.6978 & TRN \\
\hline CHEMBL3979926 & 1636656 & 6.5654 & 6.4345 & TRN \\
\hline CHEMBL3934806 & 1636656 & 5.5129 & 5.6207 & TRN \\
\hline CHEMBL3895455 & 1636656 & 6.6073 & 6.2471 & TST \\
\hline CHEMBL3926030 & 1636656 & 6.0526 & 6.1493 & TRN \\
\hline CHEMBL 3910672 & 1636656 & 5.6556 & 5.3328 & TRN \\
\hline CHEMBL3926494 & 1636656 & 5.109 & 5.2577 & TRN \\
\hline CHEMBL 3889490 & 1636656 & 6.5272 & 6.4595 & TRN \\
\hline CHEMBL3976207 & 1636656 & 6.7447 & 6.3258 & TST \\
\hline CHEMBL3905364 & 1636656 & 7.3565 & 7.2481 & TRN \\
\hline CHEMBL3980064 & 1636656 & 4.308 & 5.3376 & TST \\
\hline CHEMBL3978933 & 1636656 & 6.2358 & 6.4085 & TRN \\
\hline CHEMBL3927463 & 1636656 & 5.6021 & 6.7059 & TST \\
\hline CHEMBL3955618 & 1636656 & 6.1175 & 6.2695 & TRN \\
\hline CHEMBL3929601 & 1636656 & 6.1175 & 5.8452 & TRN \\
\hline CHEMBL3925700 & 1636656 & 6.8477 & 6.3804 & TRN \\
\hline CHEMBL3920594 & 1636656 & 5.9245 & 6.0198 & TRN \\
\hline CHEMBL3955099 & 1636656 & 6.3179 & 6.2775 & TRN \\
\hline CHEMBL3946910 & 1636656 & 6.0477 & 5.7698 & TRN \\
\hline CHEMBL3899009 & 1636656 & 6.2104 & 6.1226 & TRN \\
\hline CHEMBL3981004 & 1636656 & 6.7055 & 6.709 & TRN \\
\hline CHEMBL 3901641 & 1636656 & 5.6696 & 5.8077 & TRN \\
\hline CHEMBL3901542 & 1636656 & 6.3696 & 6.2308 & TRN \\
\hline CHEMBL 3984245 & 1636656 & 6.6536 & 6.6751 & TRN \\
\hline
\end{tabular}


Supplemental Table S2.txt

\begin{tabular}{|c|c|c|c|c|c|}
\hline CHEMBL3938116 & 1636656 & 5.6308 & 5.7193 & TRN & \\
\hline CHEMBL 3900846 & 1636656 & 5.2541 & 5.6869 & TST & \\
\hline CHEMBL 3917382 & 1636656 & 6.0545 & 6.3452 & TRN & \\
\hline CHEMBL 3898445 & 1636656 & 6.7721 & 6.3694 & TRN & \\
\hline CHEMBL3960727 & 1636656 & 6.75700 & $20000000 t$ & 6.8878 & TRN \\
\hline CHEMBL 3944370 & 1636656 & 6.8861 & 6.9088 & TRN & \\
\hline CHEMBL 3904389 & 1636656 & 6.8928 & 6.8454 & TRN & \\
\hline CHEMBL 3925433 & 1636656 & 6.1314 & 6.0718 & TRN & \\
\hline CHEMBL 3919626 & 1636656 & 6.8125 & 6.7797 & TRN & \\
\hline CHEMBL3950984 & 1636656 & 6.1035 & 6.2956 & TRN & \\
\hline CHEMBL 3936361 & 1636656 & 6.5157 & 6.4307 & TRN & \\
\hline CHEMBL 3983745 & 1636656 & 6.4237 & 6.7084 & TRN & \\
\hline CHEMBL 3984707 & 1636656 & 5.7055 & 5.8841 & TRN & \\
\hline CHEMBL 3973700 & 1636656 & 6.9747 & 7.0367 & TRN & \\
\hline CHEMBL3942246 & 1636656 & 5.4672 & 5.518 & TRN & \\
\hline CHEMBL 3909905 & 1636656 & 5.5834 & 5.4608 & TST & \\
\hline CHEMBL 3935254 & 1636656 & 6.6517 & 6.8651 & TRN & \\
\hline CHEMBL 3910083 & 1636656 & 5.7932 & 5.8438 & TRN & \\
\hline CHEMBL 3907470 & 1636656 & 6.699 & 6.8811 & TRN & \\
\hline CHEMBL3908056 & 1636656 & 5.9914 & 5.9334 & TRN & \\
\hline CHEMBL 3959702 & 1636656 & 7.4815 & 7.2276 & TRN & \\
\hline CHEMBL 3891863 & 1636656 & 5.6904 & 5.3938 & TST & \\
\hline CHEMBL 3933268 & 1636656 & 6.4989 & 6.8153 & TRN & \\
\hline CHEMBL 3908653 & 1636656 & 6.5867 & 6.5927 & TRN & \\
\hline CHEMBL 3908781 & 1636656 & 6.4295 & 6.3875 & TRN & \\
\hline CHEMBL 3966747 & 1636656 & 6.8601 & 6.9924 & TRN & \\
\hline CHEMBL 3971994 & 1636656 & 5.1707 & 6.4992 & TST & \\
\hline CHEMBL 3971851 & 1636656 & 6.0721 & 6.0183 & TRN & \\
\hline CHEMBL 3917513 & 1636656 & 5.5751 & 5.7933 & TRN & \\
\hline CHEMBL 3915927 & 1636656 & 6.1255 & 6.2083 & TRN & \\
\hline CHEMBL 3967690 & 1636656 & 5.7932 & 5.9406 & TRN & \\
\hline CHEMBL 3928909 & 1636656 & 5.7545 & 5.9556 & TRN & \\
\hline CHEMBL 3892598 & 1636656 & 5.9586 & 5.9505 & TRN & \\
\hline CHEMBL 3897952 & 1636656 & 5.9706 & 5.8953 & TRN & \\
\hline CHEMBL 3979005 & 1636656 & 6.5072 & 6.1806 & TRN & \\
\hline CHEMBL 3890631 & 1636656 & 7.6198 & \multicolumn{2}{|c|}{7.3660000000000005} & ThN \\
\hline CHEMBL 3916433 & 1636656 & 6.0872 & 5.8876 & TRN & \\
\hline CHEMBL 3986776 & 1636656 & 6.3036 & 6.1446 & TRN & \\
\hline CHEMBL 3962745 & 1636656 & 6.5361 & 6.4448 & TRN & \\
\hline CHEMBL 3908568 & 1636656 & 6.1463 & 5.8494 & TST & \\
\hline CHEMBL 3938624 & 1636656 & 5.9706 & 6.2841 & TST & \\
\hline CHEMBL 3914213 & 1636656 & 6.9586 & 7.1081 & TST & \\
\hline CHEMBL 3964957 & 1636656 & 7.3372 & 6.7751 & TST & \\
\hline CHEMBL 3960872 & 1636656 & 5.1284 & 5.4404 & TST & \\
\hline CHEMBL3935411 & 1636656 & 5.6757 & 6.3689 & TST & \\
\hline CHEMBL 3974614 & 1636656 & 6.1035 & 5.7641 & TST & \\
\hline CHEMBL 3947426 & 1636656 & 6.251 & \multicolumn{2}{|c|}{6.502999999999999} & SI \\
\hline CHEMBL 3956130 & 1636656 & 5.8539 & 4.94 & TST & \\
\hline
\end{tabular}


Supplemental Table S2.txt

\begin{tabular}{lll} 
CHEMBL3943890 & 1636656 & 5.9547 \\
CHEMBL3952177 & 1636656 & 5.5287 \\
CHEMBL3126866 & 1294947 & 5.6126 \\
CHEMBL3126885 & 1294947 & 4.6718 \\
CHEMBL3126912 & 1294947 & 4.458 \\
CHEMBL1814768 & 1294947 & 3.3565 \\
CHEMBL319177 & 1294947 & 3.3565 \\
CHEMBL3126895 & 1294947 & 5.2118 \\
CHEMBL3126889 & 1294947 & 5.2534 \\
CHEMBL3126906 & 1294947 & 6.5686 \\
CHEMBL3127054 & 1294947 & 5.0953 \\
CHEMBL1814767 & 1294947 & 3.3565 \\
CHEMBL3126869 & 1294947 & 4.8401 \\
CHEMBL3126886 & 1294947 & 4.9987 \\
CHEMBL3127049 & 1294947 & 7.1549 \\
CHEMBL3127052 & 1294947 & 4.9614 \\
CHEMBL3126910 & 1294947 & 5.1759 \\
CHEMBL3126879 & 1294947 & 3.3565 \\
CHEMBL3127067 & 1294947 & 5.9666 \\
CHEMBL3126913 & 1294947 & 5.1701 \\
CHEMBL3127058 & 1294947 & 7.2218 \\
CHEMBL3126884 & 1294947 & 4.9048 \\
CHEMBL3126877 & 1294947 & 3.3565 \\
CHEMBL3126911 & 1294947 & 5.3497 \\
CHEMBL3127050 & 1294947 & 5.3261 \\
CHEMBL1269812 & 1294947 & 7.699 \\
CHEMBL3127065 & 1294947 & 7.699 \\
CHEMBL3126876 & 1294947 & 3.3565 \\
CHEMB 3127044 & 1294947 & 4.9205 \\
CHEMBL3127060 & 1294947 & 3.3565 \\
CHEMBL3126868 & 1294947 & 5.2168 \\
CHEMBL3126874 & 1294947 & 4.5907 \\
CHEMBL403715 & 1294947 & 3.3565 \\
CHEMBL3126887 & 1294947 & 3.3565 \\
CHEMBL3126903 & 1294947 & 4.5706 \\
CHEMBL3126892 & 1294947 & 3.3565 \\
CHEMBL3126880 & 1294947 & 5.3429 \\
CHEMBL3127068 & 1294947 & 6.2596 \\
CHEMBL3126901 & 1294947 & 4.7757 \\
CHEMBL3126878 & 1294947 & 3.3565 \\
CHEMBL3127047 & 1294947 & 6.7447 \\
CHEM 3126909 & 1294947 & 5.8268 \\
& 1294947 & 5.3536 \\
\hline
\end{tabular}

$\begin{array}{ll}5.9033 & \text { TST } \\ 5.6454 & \text { TST } \\ 5.2478 & \text { TRN } \\ 4.5711 & \text { TRN } \\ 4.3421 & \text { TRN } \\ 3.2709 & \text { TRN }\end{array}$

4.1080000000000005

TST

4.5197 TRN

5.124 TRN

6.3545 TST

5.4453 TRN

3.5508 TRN

4.5083 TRN

4.5601 TRN

7.4457 TRN

4.7723 TRN

5.2668 TRN

3.9258 TRN

5.8041 TRN

5.6255 TRN

6.4589 TRN

4.2777 TRN

3.3514 TRN

5.2893 TRN

5.5466 TRN

7.5483 TST

7.666 TRN

3.5046 TRN

4.106 TRN

5.191 TRN

4.4046 TRN

5.2449 TST

4.0349 TRN

3.8806 TRN

4.0969 TRN

4.7815 TRN

5.6347 TRN

4.7549 TRN

3.8189 TRN

5.5922 TST

6.0188 TRN

5.6749 TRN

3.9748 TRN

4.6742 TST

5.3687 TST

5.0315 TRN

5.9068 TST

6.5617 TRN

Page 26503 
Supplemental Table S2.txt

\begin{tabular}{|c|c|c|c|c|}
\hline CHEMBL3126867 & 1294947 & 4.7047 & 5.0816 & TRN \\
\hline CHEMBL 3126890 & 1294947 & 3.3565 & 3.7059 & TRN \\
\hline CHEMBL3126865 & 1294947 & 5.6108 & 4.35 & TST \\
\hline CHEMBL3126883 & 1294947 & 5.1421 & 4.4356 & TRN \\
\hline CHEMBL3126902 & 1294947 & 4.4156 & 4.4228 & TRN \\
\hline CHEMBL3127063 & 1294947 & 5.6882 & 4.88 & TRN \\
\hline CHEMBL 3127056 & 1294947 & 4.5245 & 5.0034 & TST \\
\hline CHEMBL3126875 & 1294947 & 4.7258 & 4.136 & TRN \\
\hline CHEMBL3126882 & 1294947 & 3.3565 & 3.4235 & TRN \\
\hline CHEMBL3126894 & 1294947 & 3.3565 & 3.2629 & TRN \\
\hline CHEMBL3126900 & 1294947 & 5.1035 & 5.0791 & TRN \\
\hline CHEMBL3126896 & 1294947 & 5.0969 & 4.3609 & TST \\
\hline CHEMBL3127062 & 1294947 & 3.3565 & 3.3066 & TRN \\
\hline CHEMBL3126897 & 1294947 & 3.3565 & 4.2543 & TST \\
\hline CHEMBL3126870 & 1294947 & 3.3565 & 4.169 & TRN \\
\hline CHEMBL3127046 & 1294947 & 5.5784 & 5.7586 & TRN \\
\hline CHEMBL3126908 & 1294947 & 7.1549 & 7.6468 & TRN \\
\hline CHEMBL 3127057 & 1294947 & 4.7165 & 4.8455 & TST \\
\hline CHEMBL3126915 & 1294947 & 5.6655 & 5.9089 & TST \\
\hline CHEMBL3126888 & 1294947 & 3.3565 & 3.7992 & TRN \\
\hline CHEMBL 3124960 & 1294947 & 3.3565 & 4.059 & TRN \\
\hline CHEMBL3126904 & 1294947 & 4.7167 & 4.7286 & TRN \\
\hline CHEMBL3126873 & 1294947 & 3.3565 & 3.5172 & TRN \\
\hline CHEMBL3127059 & 1294947 & 4.4445 & 4.3558 & TRN \\
\hline CHEMBL 3127045 & 1294947 & 4.6782 & 4.355 & TRN \\
\hline CHEMBL3126872 & 1294947 & 3.3565 & 5.0414 & TST \\
\hline CHEMBL3126893 & 1294947 & 4.5417 & 3.5739 & TRN \\
\hline CHEMBL3126871 & 1294947 & 5.0467 & 5.495 & TRN \\
\hline CHEMBL3127053 & 1294947 & 4.6332 & 4.1916 & TRN \\
\hline CHEMBL 3127048 & 1294947 & 3.3565 & 5.2772 & TST \\
\hline CHEMBL3126914 & 1294947 & 6.6383 & 6.6943 & TST \\
\hline CHEMBL3126907 & 1294947 & 6.1612 & 5.4176 & TST \\
\hline CHEMBL3126881 & 1294947 & 4.8431 & 3.7107 & TST \\
\hline CHEMBL3127061 & 1294947 & 3.3565 & 3.6806 & TRN \\
\hline CHEMBL3126905 & 1294947 & 7.1549 & 6.8921 & TST \\
\hline CHEMBL3127064 & 1294947 & 6.4559 & 4.7645 & TST \\
\hline CHEMBL1309916 & 1301615 & 2.9118 & 2.9672 & TRN \\
\hline CHEMBL1530341 & 1301615 & 2.912 & 2.7884 & TRN \\
\hline CHEMBL3188010 & 1301615 & 4.3203 & 4.3393 & TRN \\
\hline CHEMBL1723109 & 1301615 & 2.9122 & 2.7542 & TRN \\
\hline CHEMBL1376300 & 1301615 & 2.9119 & 3.2033 & TRN \\
\hline CHEMBL1495760 & 1301615 & 2.9119 & 2.7941 & TRN \\
\hline CHEMBL1504032 & 1301615 & 2.912 & 2.3387 & TRN \\
\hline CHEMBL3186042 & 1301615 & 4.2284 & 4.2598 & TRN \\
\hline CHEMBL1300159 & 1301615 & 2.9124 & 2.9893 & TRN \\
\hline CHEMBL1503852 & 1301615 & 2.9119 & 2.7081 & TRN \\
\hline CHEMBL 3190747 & 1301615 & 2.912 & 3.18399 & 9999999999 \\
\hline CHEMBL1715748 & 1301615 & 2.912 & 3.0632 & TRN \\
\hline
\end{tabular}


Supplemental Table S2.txt

\begin{tabular}{|c|c|c|c|c|c|}
\hline CHEMBL1609285 & 1301615 & 2.9118 & 2.6402 & TRN & \\
\hline CHEMBL3185439 & 1301615 & 4.3494 & 4.3044 & TRN & \\
\hline CHEMBL210208 & 1301615 & 4.8482 & 3.9708 & TRN & \\
\hline CHEMBL1574857 & 1301615 & 2.9119 & 3.0975 & TRN & \\
\hline CHEMBL1493191 & 1301615 & 2.9116 & 2.9944 & TRN & \\
\hline CHEMBL3184030 & 1301615 & 4.1624 & 4.0802 & TRN & \\
\hline CHEMBL583969 & 1301615 & \multicolumn{3}{|c|}{5.6579999999999995} & TST \\
\hline CHEMBL1439104 & 1301615 & 2.9119 & 2.72 & TRN & \\
\hline CHEMBL3199654 & 1301615 & 2.9119 & 2.804 & TRN & \\
\hline CHEMBL1464048 & 1301615 & 2.9116 & 3.6964 & TST & \\
\hline CHEMBL1878086 & 1301615 & 5.5693 & 4.1252 & TST & \\
\hline CHEMBL1711814 & 1301615 & 2.9119 & 2.9012 & TRN & \\
\hline CHEMBL235504 & 1301615 & 4.95 & 4.9713 & TRN & \\
\hline CHEMBL417727 & 1301615 & 5.2892 & 5.1142 & TRN & \\
\hline CHEMBL3182718 & 1301615 & 4.3462 & 4.4227 & TRN & \\
\hline CHEMBL1505398 & 1301615 & 2.9118 & 2.8194 & TRN & \\
\hline CHEMBL1451668 & 1301615 & 4.8092 & 4.4913 & TRN & \\
\hline CHEMBL1300360 & 1301615 & 2.912 & 2.86 & TRN & \\
\hline CHEMBL1512150 & 1301615 & 2.9116 & 3.1954 & TRN & \\
\hline CHEMBL1432707 & 1301615 & 4.8641 & 4.663 & TRN & \\
\hline CHEMBL1376762 & 1301615 & 2.9119 & 2.89600 & 30000000004 & TRN \\
\hline CHEMBL1325945 & 1301615 & 4.8204 & 4.5493 & TRN & \\
\hline CHEMBL1459552 & 1301615 & 3.9675 & 4.1574 & TRN & \\
\hline CHEMBL1442896 & 1301615 & 2.912 & 2.8359 & TRN & \\
\hline CHEMBL1321239 & 1301615 & 4.9039 & 3.8828 & TST & \\
\hline CHEMBL1889809 & 1301615 & 2.9117 & 2.9265 & TRN & \\
\hline CHEMBL1700270 & 1301615 & 2.9123 & 3.1917 & TRN & \\
\hline CHEMBL3199700 & 1301615 & 2.9119 & 2.8511 & TRN & \\
\hline CHEMBL1425949 & 1301615 & 2.912 & 3.3382 & TRN & \\
\hline CHEMBL1380904 & 1301615 & 2.9118 & 2.5104 & TRN & \\
\hline CHEMBL1457896 & 1301615 & 2.9118 & 3.5154 & TST & \\
\hline CHEMBL1394150 & 1301615 & 2.9119 & 2.7969 & TRN & \\
\hline CHEMBL1422512 & 1301615 & 2.9116 & 3.1688 & TRN & \\
\hline CHEMBL1733012 & 1301615 & 2.9118 & 2.9265 & TRN & \\
\hline CHEMBL1407560 & 1301615 & 2.9121 & 2.995 & TRN & \\
\hline CHEMBL136344 & 1301615 & 2.9123 & 4.0317 & TST & \\
\hline CHEMBL1374016 & 1301615 & 3.9923 & 4.1064 & TRN & \\
\hline CHEMBL1438133 & 1301615 & 4.2448 & 4.0045 & TRN & \\
\hline CHEMBL1999630 & 1301615 & 4.0454 & 3.8504 & TRN & \\
\hline CHEMBL69612 & 1301615 & 2.912 & 2.97399 & 99999999998 & TRN \\
\hline CHEMBL1463659 & 1301615 & 4.3432 & 4.4448 & TRN & \\
\hline CHEMBL1601726 & 1301615 & 2.9122 & 2.9245 & TRN & \\
\hline CHEMBL1529471 & 1301615 & 2.912 & $2.61800 t$ & 00000000003 & TRN \\
\hline CHEMBL1487824 & 1301615 & 2.9118 & 2.6029 & TRN & \\
\hline CHEMBL1719888 & 1301615 & 2.9118 & 3.1555 & TRN & \\
\hline CHEMBL1487124 & 1301615 & 2.9119 & 2.9205 & TRN & \\
\hline CHEMBL1734082 & 1301615 & 2.9123 & 2.8609 & TRN & \\
\hline CHEMBL1728637 & 1301615 & 4.40600 & 30000000 & 4.5148 & TRN \\
\hline
\end{tabular}


Supplemental Table S2.txt

\begin{tabular}{|c|c|c|c|c|c|}
\hline CHEMBL1325440 & 1301615 & 2.9119 & 3.3028 & TRN & \\
\hline CHEMBL1449479 & 1301615 & 2.9119 & 3.6739 & TST & \\
\hline CHEMBL1726134 & 1301615 & 2.9119 & 3.8305 & TRN & \\
\hline CHEMBL1457879 & 1301615 & 2.9121 & 2.8642 & TRN & \\
\hline CHEMBL1901455 & 1301615 & 2.9119 & 3.1249 & TRN & \\
\hline CHEMBL 3184374 & 1301615 & 2.912 & 3.2979 & TRN & \\
\hline CHEMBL1986342 & 1301615 & 3.389 & 3.7119 & TRN & \\
\hline CHEMBL1499020 & 1301615 & 2.9119 & 2.3963 & TRN & \\
\hline CHEMBL1508847 & 1301615 & 4.8204 & 3.9558 & TRN & \\
\hline CHEMBL1563898 & 1301615 & 4.1707 & 3.9575 & TRN & \\
\hline CHEMBL1304374 & 1301615 & 4.2675 & 4.2282 & TRN & \\
\hline CHEMBL1875076 & 1301615 & 2.9123 & 3.1617 & TRN & \\
\hline CHEMBL1310172 & 1301615 & 2.9116 & 2.8778 & TRN & \\
\hline CHEMBL3186739 & 1301615 & 2.9119 & 3.2931 & TRN & \\
\hline CHEMBL1701326 & 1301615 & 2.9122 & 2.8389 & TRN & \\
\hline CHEMBL1360400 & 1301615 & 2.912 & 3.10100 & 20000000004 & TRN \\
\hline CHEMBL3183312 & 1301615 & 2.9118 & 2.6676 & TRN & \\
\hline CHEMBL1389924 & 1301615 & 2.9117 & 3.3056 & TRN & \\
\hline CHEMBL401317 & 1301615 & 2.9118 & 2.9013 & TST & \\
\hline CHEMBL1605642 & 1301615 & 2.9118 & 3.278 & TRN & \\
\hline CHEMBL1464200 & 1301615 & 5.4013 & 4.8722 & TRN & \\
\hline CHEMBL3185799 & 1301615 & 4.3432 & 3.7945 & TRN & \\
\hline CHEMBL1330614 & 1301615 & 2.9117 & 3.1227 & TRN & \\
\hline CHEMBL 2000517 & 1301615 & 4.5329 & 4.2585 & TRN & \\
\hline CHEMBL1609550 & 1301615 & 2.9121 & 2.6956 & TRN & \\
\hline CHEMBL3194876 & 1301615 & 2.9119 & 3.0611 & TST & \\
\hline CHEMBL3182202 & 1301615 & 4.5174 & 4.7664 & TRN & \\
\hline CHEMBL1450977 & 1301615 & 2.912 & 2.5737 & TST & \\
\hline CHEMBL1603333 & 1301615 & 2.9118 & 3.0041 & TRN & \\
\hline CHEMBL1556531 & 1301615 & 2.912 & 2.6035 & TRN & \\
\hline CHEMBL1876280 & 1301615 & 2.912 & 2.861 & TRN & \\
\hline CHEMBL1734083 & 1301615 & 2.9123 & 3.0321 & TRN & \\
\hline CHEMBL1336517 & 1301615 & 2.9122 & 3.1583 & TRN & \\
\hline CHEMBL1466471 & 1301615 & 2.9118 & 2.7568 & TRN & \\
\hline CHEMBL1449194 & 1301615 & 2.9118 & 3.0995 & TRN & \\
\hline CHEMBL1423005 & 1301615 & 2.912 & 3.4991 & TST & \\
\hline CHEMBL1578243 & 1301615 & 2.9118 & 4.1214 & TST & \\
\hline CHEMBL1328212 & 1301615 & 2.9119 & 3.364 & TRN & \\
\hline CHEMBL1458550 & 1301615 & 2.9123 & 2.8955 & TRN & \\
\hline CHEMBL1353371 & 1301615 & 2.912 & 3.1701 & TRN & \\
\hline CHEMBL1594896 & 1301615 & 2.9111 & 3.3288 & TRN & \\
\hline CHEMBL1439521 & 1301615 & 2.9119 & 3.655 & TST & \\
\hline CHEMBL1606907 & 1301615 & 2.9119 & 2.7833 & TRN & \\
\hline CHEMBL1529260 & 1301615 & 2.9119 & 3.1988 & TRN & \\
\hline CHEMBL402053 & 1301615 & 2.9118 & 2.9462 & TRN & \\
\hline CHEMBL1375895 & 1301615 & 2.912 & 2.8583 & TRN & \\
\hline CHEMBL1534470 & 1301615 & 4.6259 & 4.4351 & TRN & \\
\hline CHEMBL3193711 & 1301615 & 2.9118 & 2.5824 & TRN & \\
\hline
\end{tabular}

Page 26506 
Supplemental Table S2.txt

\begin{tabular}{|c|c|c|c|}
\hline CHEMBL66953 & & 4.6798 & 4.4146 \\
\hline CHEMBL1478395 & 1301615 & 4.3237 & 4.119 \\
\hline HEMBL1257003 & 301615 & 2.9119 & 2167 \\
\hline CHEMBL1892575 & L301615 & 4.4468 & 3.8357 \\
\hline CHEMBL1362935 & 301615 & 4.726 & 4.1254 \\
\hline CHEMBL1874339 & 301615 & 2.9121 & 3.0167 \\
\hline CHEMBL1453707 & 301615 & 2.9119 & 2.9725 \\
\hline CHEMBL3189868 & 1301615 & 2.9118 & 2.8985 \\
\hline CHEMBL1590201 & 1301615 & 2.912 & 3.2485 \\
\hline CHEMBL51931 & 1301615 & 5.1957 & 4.8711 \\
\hline CHEMBL13 & 1301 & 2.9119 & 3.2542 \\
\hline CHEMBL17 & 130 & 4.5482 & 4.1858 \\
\hline CHEMBL1723511 & 1301615 & 2.9119 & 3.3821 \\
\hline CHEMBL225831 & 1301615 & 4.2944 & 4.3939 \\
\hline CHEMBL1 & 1301 & 2.9118 & 9937 \\
\hline CHEMBL & 130 & 121 & 2.6145 \\
\hline CHEMBL & 130 & 123 & 2.9549 \\
\hline CHEMBL1998302 & 130 & 4.3417 & 4.1568 \\
\hline HEMBL1430175 & 130 & 2.9119 & 2.7675 \\
\hline CHEMBL: & 130 & $4.5-5+x-5$ & 4.534 \\
\hline CHEMBL & 130 & & 604 \\
\hline CHEMBL & $13 e$ & & 999 \\
\hline CHEMBL: & 130 & 2.9121 & 737 \\
\hline CHEMBL1497153 & 130 & 4.575 & 652 \\
\hline CHEMBL & 130 & 16 & 5.2922 \\
\hline CHEMBL & $13 e$ & 4. & 483 \\
\hline CHEMBL & 130 & 21 & 377 \\
\hline CHEMBL: & 130 & 2.9119 & 2.9087 \\
\hline CHEMBL1519076 & 1301 & 2.912 & 2.8603 \\
\hline CHEMBL1€ & 1301615 & 119 & 2.8665 \\
\hline CHEMB & $13 e$ & & 3.4005 \\
\hline CHEMBL & $13 e$ & 2. & 3.8178 \\
\hline CHEMBL1734853 & 1301615 & 2.9119 & 2.49 \\
\hline CHEMBL 3188921 & 1301615 & 5.6934 & 3.5455 \\
\hline CHEMBL & 130 & 117 & 182 \\
\hline CHEMBL & $13 e$ & 5 . & 4.2762 \\
\hline CHEMBL: & 130 & 2.9119 & 3.5865 \\
\hline CHEMBL1526250 & 1301615 & 2.9121 & 2.9996 \\
\hline CHEMBL1981314 & 1301615 & 2.9119 & 3.161 \\
\hline & 130 & & 178 \\
\hline CHEMBL & 130 & 2.9 & 2.7348 \\
\hline CHEMBL1741744 & 1301615 & 2.9119 & 2.9749 \\
\hline CHEMBL 3192461 & 1301615 & 2.912 & 3.0715 \\
\hline CHEMBL & 1301615 & 2.912 & 2.9498 \\
\hline CHEMBL: & 1301 & & 1.9489 \\
\hline CHEMBL 3126895 & 1294970 & 4.8041 & 4.6852 \\
\hline CHEMBL 3126874 & 1294970 & 4.7077 & 4.3526 \\
\hline CHEMBL3126909 & 1294970 & 3.699 & 4.1478 \\
\hline
\end{tabular}

Page 26507 
Supplemental Table S2.txt

\begin{tabular}{|c|c|c|c|c|}
\hline CHEMBL3126886 & 1294970 & 3.699 & 3.553 & TRN \\
\hline CHEMBL 3127048 & 1294970 & 3.699 & 5.8888 & TST \\
\hline CHEMBL3126904 & 1294970 & 3.699 & 3.7037 & TRN \\
\hline CHEMBL3126912 & 1294970 & 3.699 & 3.46199 & 99999999997 \\
\hline CHEMBL 3127054 & 1294970 & 4.7645 & 4.8196 & TRN \\
\hline CHEMBL319177 & 1294970 & 3.0 & 3.6077 & TST \\
\hline CHEMBL 3127044 & 1294970 & 3.699 & 5.7076 & TST \\
\hline CHEMBL 3126880 & 1294970 & 4.9031 & 5.0058 & TRN \\
\hline CHEMBL3126876 & 1294970 & 3.699 & 3.5374 & TRN \\
\hline CHEMBL3126901 & 1294970 & 3.699 & 4.1909 & TRN \\
\hline CHEMBL3126875 & 1294970 & 3.699 & 3.4673 & TRN \\
\hline CHEMBL 3127045 & 1294970 & 3.699 & 3.7684 & TRN \\
\hline CHEMBL3126913 & 1294970 & 4.71 & 4.1343 & TRN \\
\hline CHEMBL 3126894 & 1294970 & 3.699 & 3.7324 & TRN \\
\hline CHEMBL 3126903 & 1294970 & 3.699 & 3.7001 & TRN \\
\hline CHEMBL3126905 & 1294970 & 6.9586 & 7.0132 & TST \\
\hline CHEMBL3126868 & 1294970 & 3.699 & 3.6602 & TRN \\
\hline CHEMBL 3127060 & 1294970 & 3.699 & 3.5253 & TRN \\
\hline CHEMBL 3127050 & 1294970 & 7.2218 & 7.1374 & TRN \\
\hline CHEMBL3126900 & 1294970 & 5.8125 & 5.4032 & TRN \\
\hline CHEMBL 3126872 & 1294970 & 3.699 & 3.9959 & TST \\
\hline CHEMBL 3126887 & 1294970 & 3.699 & 3.7629 & TRN \\
\hline CHEMBL3126915 & 1294970 & 4.7496 & 5.7269 & TST \\
\hline CHEMBL1269812 & 1294970 & 8.0 & 7.8773 & TST \\
\hline CHEMBL 3126883 & 1294970 & 3.699 & 3.5492 & TRN \\
\hline CHEMBL 3124960 & 1294970 & 3.699 & 3.4853 & TRN \\
\hline CHEMBL 3126877 & 1294970 & 3.699 & 3.8738 & TRN \\
\hline CHEMBL3127055 & 1294970 & 7.5229 & 7.28299 & 99999999995 \\
\hline CHEMBL3126899 & 1294970 & 6.8239 & 6.8176 & TRN \\
\hline CHEMBL 3127058 & 1294970 & 6.6576 & 6.4145 & TRN \\
\hline CHEMBL 3127062 & 1294970 & 3.699 & 3.3519 & TRN \\
\hline CHEMBL3127059 & 1294970 & 3.699 & 3.7971 & TRN \\
\hline CHEMBL 3127049 & 1294970 & 7.3979 & 7.6661 & TRN \\
\hline CHEMBL3126885 & 1294970 & 3.699 & 3.5985 & TRN \\
\hline CHEMBL 3126890 & 1294970 & 3.699 & 3.7018 & TRN \\
\hline CHEMBL3126869 & 1294970 & 3.699 & 3.8397 & TRN \\
\hline CHEMBL 3126914 & 1294970 & 5.1599 & 5.5277 & TST \\
\hline CHEMBL 3127067 & 1294970 & 7.1549 & 7.0268 & TRN \\
\hline CHEMBL 3127057 & 1294970 & 4.9788 & 6.1671 & TST \\
\hline CHEMBL 3127047 & 1294970 & 6.5229 & 5.6473 & TST \\
\hline CHEMBL1814767 & 1294970 & 7.3979 & 7.5013 & TRN \\
\hline CHEMBL 3126866 & 1294970 & 3.699 & 3.7189 & TRN \\
\hline CHEMBL 3127056 & 1294970 & 3.699 & 5.5193 & TST \\
\hline CHEMBL3126897 & 1294970 & 3.699 & 4.5191 & TST \\
\hline CHEMBL3126910 & 1294970 & 3.699 & 4.3969 & TRN \\
\hline CHEMBL3126889 & 1294970 & 4.7305 & 4.6484 & TRN \\
\hline CHEMBL 3126893 & 1294970 & 3.699 & 3.7629 & TRN \\
\hline CHEMBL3126906 & 1294970 & 5.2774 & 6.4626 & TST \\
\hline
\end{tabular}


Supplemental Table S2.txt

\begin{tabular}{|c|c|c|c|c|}
\hline HEMBL31 & & 757 & 754 & \\
\hline HFMBI 3126878 & 294970 & 3.699 & 40257 & \\
\hline HEMBL 312 & & & & \\
\hline AEMBL3126881 & 294970 & & 1748 & \\
\hline HEMBL3126898 & 294970 & 3.699 & 5321 & \\
\hline HEMBL3126882 & 70 & 599 & 5246 & \\
\hline IEMBL: & & 799 & 5675 & \\
\hline HEMBL3127063 & & 699 & 9845 & \\
\hline HEMBL3126907 & 70 & 7.1549 & 6142 & \\
\hline HEMBL3126896 & 70 & 3.699 & 1256 & \\
\hline AEMBL1814768 & 70 & 229 & 5941 & \\
\hline AEMBL3 & & & 5766 & RN \\
\hline 26867 & & 99 & 5653 & \\
\hline AEMBL3127052 & 70 & 468 & 463 & \\
\hline AEMBL3127068 & 70 & 458 & & \\
\hline AEMBL & & 99 & 201 & \\
\hline HEMBL; & & 979 & & iv \\
\hline HEMBL3 & & 599 & 866 & RN \\
\hline AEMBL3127051 & & 355 & 613 & \\
\hline AEMBL3127065 & & 7.2218 & 065 & NIV \\
\hline IEMBL & & 99 & 871 & I \\
\hline AEME & & & & RN \\
\hline HEMBL; & & 907 & 44 & ST \\
\hline AEMBL3 & & 356 & & RN \\
\hline AEMBL3127053 & & 3. & 14 & $R N$ \\
\hline AEMBL 3 & & 99 & 78 & RN \\
\hline AEM & & & & ST \\
\hline וסMינזו & & 949 & & $\mathrm{RN}$ \\
\hline AEMBL & & & & IRN \\
\hline AEMBL3127066 & & 212 & 45 & $\mathrm{RN}$ \\
\hline AEMBL & & 097 & & ST \\
\hline 9 & & 86 & & RN \\
\hline & & & & RN \\
\hline AEMBL2 & & 044 & & 「RN \\
\hline HEMBL2171546 & & 5.7447 & 433 & RN \\
\hline AFMRI & & & 206 & RN \\
\hline & & & & RN \\
\hline HEMBL2 & & & & RN \\
\hline AEMBL 217156 & & 372 & 394 & $\Gamma R$ \\
\hline IEMBL2 & & 768 & 756 & $\mathrm{RN}$ \\
\hline HEMBL2 & & 539 & 537 & \\
\hline HEMBL2 & & 4.9208 & 3.9182 & ST \\
\hline HEMBL2171335 & & 7.3372 & 7.3387 & 「RN \\
\hline AEMBL2 & & 5 & 968 & TR \\
\hline the & & $3 / 6$ & 394 & \\
\hline HEMBL2171565 & & 5.0362 & 5.0344 & \\
\hline CHEMBL 2171551 & & 4.5686 & 4.5689 & \\
\hline CHEMBL 78464 & 862091 & 6.699 & 4.5562 & ГST \\
\hline
\end{tabular}

Page 26509 
Supplemental Table S2.txt

\begin{tabular}{|c|c|c|c|c|c|}
\hline CHEMBL 2171545 & 862091 & 5.5528 & 5.5545 & TRN & \\
\hline CHEMBL 2171528 & 862091 & 4.9586 & 4.9588 & TRN & \\
\hline CHEMBL 2171530 & 862091 & 4.8239 & 4.8273 & TRN & \\
\hline CHEMBL 2171542 & 862091 & 5.4202 & 5.4185 & TRN & \\
\hline CHEMBL 2171563 & 862091 & 4.8861 & 4.8859 & TRN & \\
\hline CHEMBL 2171532 & 862091 & 5.4685 & 5.4661 & TRN & \\
\hline CHEMBL56459 & 862091 & 6.9586 & 6.1764 & TST & \\
\hline CHEMBL 2171552 & 862091 & 4.2518 & 4.2537 & TRN & \\
\hline CHEMBL 2171529 & 862091 & 4.6778 & 4.6756 & TRN & \\
\hline CHEMBL 2171527 & 862091 & 4.5528 & 4.5525 & TRN & \\
\hline CHEMBL 2171564 & 862091 & 5.2007 & 5.2001 & TRN & \\
\hline CHEMBL1808759 & 862091 & 7.1308 & 7.1336 & TRN & \\
\hline CHEMBL 2171544 & 862091 & 4.1487 & 3.7913 & TST & \\
\hline CHEMBL 2171524 & 862091 & 6.8508 & 6.8514 & TRN & \\
\hline CHEMBL 2171547 & 862091 & 5.0969 & 5.0939 & TRN & \\
\hline CHEMBL 2171550 & 862091 & 3.9281 & 3.9262 & TRN & \\
\hline CHEMBL 2171557 & 862091 & 5.0458 & 5.0471 & TRN & \\
\hline CHEMBL 2171537 & 862091 & 5.585 & 5.5862 & TRN & \\
\hline CHEMBL 2171548 & 862091 & 5.3152 & 5.3195 & TRN & \\
\hline CHEMBL 2171540 & 862091 & 5.9208 & 5.9228 & TRN & \\
\hline CHEMBL 2171539 & 862091 & 5.8239 & 5.8221 & TRN & \\
\hline CHEMBL 2171525 & 862091 & 7.4949 & 7.4923 & TRN & \\
\hline CHEMBL 2171556 & 862091 & 5.585 & 5.5865 & TRN & \\
\hline CHEMBL 2171531 & 862091 & 4.7212 & 4.7233 & TRN & \\
\hline CHEMBL 2171566 & 862091 & 5.1549 & 5.1572 & TRN & \\
\hline CHEMBL 2171555 & 862091 & 5.0044 & 5.4179 & TST & \\
\hline CHEMBL 2171559 & 862091 & 5.6716 & 5.9917 & TST & \\
\hline CHEMBL 2171562 & 862091 & 4.8239 & 5.7934 & TST & \\
\hline CHEMBL 2171533 & 862091 & 4.8539 & 4.665 & TST & \\
\hline CHEMBL 2171567 & 862091 & 5.2154 & 5.5081 & TST & \\
\hline CHEMBL 2171568 & 862091 & 6.699 & 5.8131 & TST & \\
\hline CHEMBL 2171561 & 862091 & 5.4318 & 5.0949 & TST & \\
\hline CHEMBL 2171538 & 862091 & 5.3768 & 5.5821 & TST & \\
\hline CHEMBL54381 & 862091 & 4.1805 & 4.5719 & TST & \\
\hline CHEMBL 235224 & 448646 & 6.5622 & 6.6628 & TRN & \\
\hline CHEMBL237335 & 448646 & 7.301 & 7.5027 & TRN & \\
\hline CHEMBL236492 & 448646 & 8.0458 & 7.9778 & TST & \\
\hline CHEMBL392360 & 448646 & 6.7852 & 6.82 & TRN & \\
\hline CHEMBL236284 & 448646 & 5.6373 & 6.6458 & TST & \\
\hline CHEMBL399596 & 448646 & 6.9586 & 6.8886 & TRN & \\
\hline CHEMBL235662 & 448646 & 2.5994 & 2.6446 & TRN & \\
\hline CHEMBL236912 & 448646 & 6.1035 & 6.0334 & TRN & \\
\hline CHEMBL392563 & 448646 & 6.58 & 6.229 & TST & \\
\hline CHEMBL400439 & 448646 & $3.1630 e$ & t00000006 & 303 & 3.318 \\
\hline CHEMBL235644 & 448646 & 6.1518 & 6.1387 & TRN & \\
\hline CHEMBL236911 & 448646 & 7.0862 & 7.1946 & TRN & \\
\hline CHEMBL400821 & 448646 & 2.5628 & 5.2366 & TST & \\
\hline CHEMBL238405 & 448646 & 7.0809 & 6.5484 & TST & \\
\hline
\end{tabular}




\begin{tabular}{|c|c|c|c|c|c|c|}
\hline & & & pplement & al Table & 2.txt & \\
\hline CHEMBL236285 & 448646 & 6.6757 & 6.6762 & TST & & \\
\hline CHEMBL393610 & 448646 & 6.6383 & 6.71299 & 9999999995 & & TRN \\
\hline CHEMBL236493 & 448646 & 6.8327 & 6.527 & TST & & \\
\hline CHEMBL430176 & 448646 & 7.2596 & 6.9676 & TRN & & \\
\hline CHEMBL238214 & 448646 & 8.0458 & 7.8621 & TRN & & \\
\hline CHEMBL400437 & 448646 & 7.3565 & 7.0263 & TST & & \\
\hline CHEMBL237118 & 448646 & 6.5031 & 6.4894 & TRN & & \\
\hline CHEMBL235444 & 448646 & 5.9905 & 5.91299 & 999999999؛ & & TRN \\
\hline CHEMBL238215 & 448646 & 6.7696 & 6.7924 & TRN & & \\
\hline CHEMBL438848 & 448646 & 7.4318 & 7.4054 & TRN & & \\
\hline CHEMBL393573 & 448646 & 5.2418 & 5.1279 & TRN & & \\
\hline CHEMBL399002 & 448646 & 7.9586 & 8.0855 & TRN & & \\
\hline CHEMBL438152 & 448646 & 6.0448 & 5.6352 & TST & & \\
\hline CHEMBL237755 & 448646 & 5.7317 & 5.6813 & TRN & & \\
\hline CHEMBL236702 & 448646 & 5.9559 & 5.9884 & TRN & & \\
\hline CHEMBL238404 & 448646 & 8.5229 & 7.7842 & TST & & \\
\hline CHEMBL236701 & 448646 & 6.1035 & 5.4104 & TST & & \\
\hline CHEMBL237536 & 448646 & 8.0969 & 8.0995 & TRN & & \\
\hline CHEMBL391419 & 448646 & 5.6003 & 6.4007 & TST & & \\
\hline CHEMBL235222 & 448646 & 7.3372 & 7.3104 & TRN & & \\
\hline CHEMBL236913 & 448646 & 2.7194 & 2.7238 & TRN & & \\
\hline CHEMBL237998 & 448646 & 5.2808 & 5.1187 & TRN & & \\
\hline CHEMBL235423 & 448646 & 7.4949 & 7.5114 & TRN & & \\
\hline CHEMBL410956 & 448646 & 6.585 & 6.615 & TRN & & \\
\hline CHEMBL391855 & 448646 & 6.6402 & 6.5167 & TRN & & \\
\hline CHEMBL237153 & 448646 & 6.767 & 6.9197 & TRN & & \\
\hline CHEMBL427681 & 448646 & 7.7447 & 7.7492 & TRN & & \\
\hline CHEMBL391913 & 448646 & 8.0969 & 8.1333 & TRN & & \\
\hline CHEMBL237117 & 448646 & 2.6633 & 2.5062 & TRN & & \\
\hline CHEMBL235442 & 448646 & 7.2291 & 7.2104 & TRN & & \\
\hline CHEMBL238192 & 448646 & 6.3645 & 6.6046 & TRN & & \\
\hline CHEMBL235002 & 448646 & 6.3788 & 6.3928 & TRN & & \\
\hline CHEMBL391027 & 448646 & 7.7212 & 7.71899 & 9999999995 & & TRN \\
\hline CHEMBL236283 & 448646 & 6.4214 & 6.5187 & TRN & & \\
\hline CHEMBL 235443 & 448646 & 5.8729 & 6.1015 & TRN & & \\
\hline CHEMBL392049 & 448646 & 5.74299 & 9999999 & 99 & 5.7058 & TRN \\
\hline CHEMBL237329 & 448646 & 7.6778 & 7.6699 & TRN & & \\
\hline CHEMBL399001 & 448646 & 7.4437 & 7.2554 & TRN & & \\
\hline CHEMBL236703 & 448646 & 6.341 & 6.3239 & TRN & & \\
\hline CHEMBL 235643 & 448646 & 7.7212 & 5.2145 & TST & & \\
\hline CHEMBL400636 & 448646 & 8.0458 & 7.8987 & TRN & & \\
\hline CHEMBL235424 & 448646 & 7.0132 & 4.9518 & TST & & \\
\hline CHEMBL237784 & 448646 & 6.5406 & 6.6398 & TRN & & \\
\hline CHEMBL392362 & 448646 & 6.6882 & 6.6118 & TRN & & \\
\hline CHEMBL400820 & 448646 & 8.0969 & 7.9188 & TST & & \\
\hline CHEMBL391856 & 448646 & 5.1152 & 5.1361 & TRN & & \\
\hline CHEMBL236494 & 448646 & 4.5864 & 5.473 & TST & & \\
\hline CHEMBL393572 & 448646 & 5.9931 & 6.0547 & TRN & & \\
\hline
\end{tabular}


Supplemental Table S2.txt

\begin{tabular}{|c|c|c|c|c|c|}
\hline CHEMBL392050 & 448646 & 6.2596 & 6.4263 & TRN & \\
\hline CHEMBL391627 & 448646 & 7.6021 & 7.3991 & TRN & \\
\hline CHEMBL3918953 & 1641765 & 5.5346 & 5.5213 & TRN & \\
\hline CHEMBL3890100 & 1641765 & 7.475 & \multicolumn{2}{|c|}{6.742999999999999} & TRN \\
\hline CHEMBL3949355 & 1641765 & 7.9031 & 7.2753 & TRN & \\
\hline CHEMBL3891509 & 1641765 & 5.983 & 6.7775 & TST & \\
\hline CHEMBL3957373 & 1641765 & 6.1349 & 6.2665 & TRN & \\
\hline CHEMBL 3954510 & 1641765 & 7.7959 & 7.7712 & TST & \\
\hline CHEMBL3912701 & 1641765 & 5.7696 & 6.1417 & TRN & \\
\hline CHEMBL3973123 & 1641765 & 5.6253 & 5.6793 & TRN & \\
\hline CHEMBL3974790 & 1641765 & 6.8125 & 6.7049 & TST & \\
\hline CHEMBL3925263 & 1641765 & 6.2434 & 5.9763 & TRN & \\
\hline CHEMBL3906360 & 1641765 & 6.2487 & 6.0599 & TST & \\
\hline CHEMBL3938138 & 1641765 & 6.9706 & 6.4843 & TRN & \\
\hline CHEMBL3979461 & 1641765 & 6.6038 & 6.3058 & TRN & \\
\hline CHEMBL3945380 & 1641765 & 6.6478 & 6.4087 & TRN & \\
\hline CHEMBL3983393 & 1641765 & 5.5258 & 6.2144 & TRN & \\
\hline CHEMBL 3960217 & 1641765 & 5.3363 & 5.9332 & TST & \\
\hline CHEMBL3900187 & 1641765 & 6.6126 & 6.5966 & TRN & \\
\hline CHEMBL3902709 & 1641765 & 8.0301 & 8.1381 & TST & \\
\hline CHEMBL3908279 & 1641765 & 6.6289 & 6.1562 & TRN & \\
\hline CHEMBL3931583 & 1641765 & 6.8477 & 6.7328 & TST & \\
\hline CHEMBL3940662 & 1641765 & 7.585 & 7.376 & TRN & \\
\hline CHEMBL 3948444 & 1641765 & 7.9393 & 7.2349 & TRN & \\
\hline CHEMBL3909713 & 1641765 & 7.2924 & 7.281000 & 0000000001 & TRN \\
\hline CHEMBL3951340 & 1641765 & 5.5719 & 6.1541 & TRN & \\
\hline CHEMBL3898069 & 1641765 & 5.9957 & 5.7673 & TRN & \\
\hline CHEMBL 3946087 & 1641765 & 7.0872 & 7.6794 & TST & \\
\hline CHEMBL3909869 & 1641765 & 6.0 & 6.9064 & TST & \\
\hline CHEMBL 3895680 & 1641765 & 5.0311 & 5.9463 & TST & \\
\hline CHEMBL 3959387 & 1641765 & 7.3098 & 7.3649 & TRN & \\
\hline CHEMBL3955931 & 1641765 & 6.7496 & 6.7655 & TRN & \\
\hline CHEMBL 3895145 & 1641765 & 5.5969 & 6.268 & TST & \\
\hline CHEMBL3943111 & 1641765 & 7.8013 & 7.8634 & TST & \\
\hline CHEMBL 3967311 & 1641765 & 6.8508 & 6.2898 & TRN & \\
\hline CHEMBL3946933 & 1641765 & 6.7033 & 6.3584 & TRN & \\
\hline CHEMBL3970163 & 1641765 & 5.9031 & 5.8885 & TRN & \\
\hline CHEMBL 3954678 & 1641765 & 5.8729 & 5.7245 & TRN & \\
\hline CHEMBL3922776 & 1641765 & 6.5622 & 6.7358 & TRN & \\
\hline CHEMBL 3926715 & 1641765 & 5.4283 & 5.9498 & TRN & \\
\hline CHEMBL3913715 & 1641765 & 6.0 & 6.8724 & TST & \\
\hline CHEMBL3946486 & 1641765 & 8.2596 & 7.5951 & TRN & \\
\hline CHEMBL3924938 & 1641765 & 6.3799 & 5.9809 & TRN & \\
\hline CHEMBL3902690 & 1641765 & 6.8013 & 6.3372 & TST & \\
\hline CHEMBL3943116 & 1641765 & 7.5452 & 6.8725 & TST & \\
\hline CHEMBL3943018 & 1641765 & 6.4868 & 6.2005 & TRN & \\
\hline CHEMBL3957302 & 1641765 & 6.0635 & 5.7423 & TST & \\
\hline CHEMBL3935962 & 1641765 & 5.1203 & 5.8974 & TRN & \\
\hline
\end{tabular}


Supplemental Table S2.txt

\begin{tabular}{|c|c|c|c|c|c|}
\hline CHEMBL3889949 & 1641765 & 6.3233 & 6.3081 & TRN & \\
\hline CHEMBL3911712 & 1641765 & 7.8386 & 7.2566 & TRN & \\
\hline CHEMBL 3983724 & 1641765 & 7.1938 & 7.7692 & TRN & \\
\hline CHEMBL3929582 & 1641765 & 7.8861 & 8.1562 & TRN & \\
\hline CHEMBL3910221 & 1641765 & 7.1772 & 6.7954 & TRN & \\
\hline CHEMBL 3899549 & 1641765 & 7.6198 & 8.2781 & TRN & \\
\hline CHEMBL3969101 & 1641765 & 5.2807 & 5.9529 & TRN & \\
\hline CHEMBL3911657 & 1641765 & 5.8928 & 5.8784 & TRN & \\
\hline CHEMBL 3952945 & 1641765 & 7.9788 & 8.0013 & TST & \\
\hline CHEMBL3896276 & 1641765 & 6.0575 & 6.0158 & TRN & \\
\hline CHEMBL 3923857 & 1641765 & 6.7878 & 6.5921 & TRN & \\
\hline CHEMBL 3944898 & 1641765 & 6.6946 & 6.349 & TRN & \\
\hline CHEMBL3912959 & 1641765 & 7.9788 & 7.856 & TST & \\
\hline CHEMBL3928011 & 1641765 & 7.8539 & 8.0275 & TRN & \\
\hline CHEMBL3956199 & 1641765 & 6.6655 & 6.6737 & TRN & \\
\hline CHEMBL3928121 & 1641765 & 7.5452 & 6.9935 & TRN & \\
\hline CHEMBL3949608 & 1641765 & 5.5969 & 6.00299 & 9999999999 & TRN \\
\hline CHEMBL3980641 & 1641765 & 6.5406 & 6.3135 & TRN & \\
\hline CHEMBL 3900428 & 1641765 & 6.9318 & 7.4653 & TRN & \\
\hline CHEMBL3945942 & 1641765 & 5.6108 & 6.4603 & TST & \\
\hline CHEMBL3962721 & 1641765 & 7.9469 & 7.8979 & TST & \\
\hline CHEMBL3944229 & 1641765 & 6.0 & 7.20200 & 0000000001 & TRN \\
\hline CHEMBL3934234 & 1641765 & 6.1805 & 5.6246 & TRN & \\
\hline CHEMBL 3921824 & 1641765 & 6.0991 & 6.6209 & TRN & \\
\hline CHEMBL 3983609 & 1641765 & 6.6757 & 6.5681 & TST & \\
\hline CHEMBL 3986882 & 1641765 & 6.1733 & 5.9319 & TRN & \\
\hline CHEMBL3951692 & 1641765 & 6.0655 & 5.6791 & TRN & \\
\hline CHEMBL3906799 & 1641765 & 6.9508 & 6.9208 & TRN & \\
\hline CHEMBL 3934179 & 1641765 & 8.2076 & 7.8176 & TRN & \\
\hline CHEMBL3932638 & 1641765 & 5.5702 & 6.0404 & TRN & \\
\hline CHEMBL 3919882 & 1641765 & 7.3979 & 7.0845 & TST & \\
\hline CHEMBL3909534 & 1641765 & 7.6478 & 7.6539 & TRN & \\
\hline CHEMBL3955185 & 1641765 & 5.1325 & 6.1513 & TRN & \\
\hline CHEMBL 3972621 & 1641765 & 6.9431 & 6.7441 & TRN & \\
\hline CHEMBL 3977812 & 1641765 & 7.9393 & 7.7881 & TRN & \\
\hline CHEMBL3980561 & 1641765 & 6.1385 & 6.4446 & TRN & \\
\hline CHEMBL3889642 & 1641765 & 5.7645 & 5.9508 & TRN & \\
\hline CHEMBL3904074 & 1641765 & 7.058 & 6.9467 & TRN & \\
\hline CHEMBL3967377 & 1641765 & 6.0788 & 5.9733 & TRN & \\
\hline CHEMBL3958187 & 1641765 & 5.6556 & 6.2564 & TRN & \\
\hline CHEMBL3930852 & 1641765 & 6.0 & 6.8071 & TST & \\
\hline CHEMBL3922400 & 1641765 & 8.3565 & 8.3499 & TST & \\
\hline CHEMBL3958250 & 1641765 & 5.6696 & 5.9132 & TRN & \\
\hline CHEMBL3963432 & 1641765 & 8.1249 & 7.3455 & TRN & \\
\hline CHEMBL3939862 & 1641765 & 5.8268 & 6.2127 & TRN & \\
\hline CHEMBL3934299 & 1641765 & 6.8894 & 6.9265 & TRN & \\
\hline CHEMBL3969238 & 1641765 & 6.4949 & 7.1956 & TRN & \\
\hline CHEMBL3948638 & 1641765 & 6.7144 & 6.8274 & TRN & \\
\hline
\end{tabular}




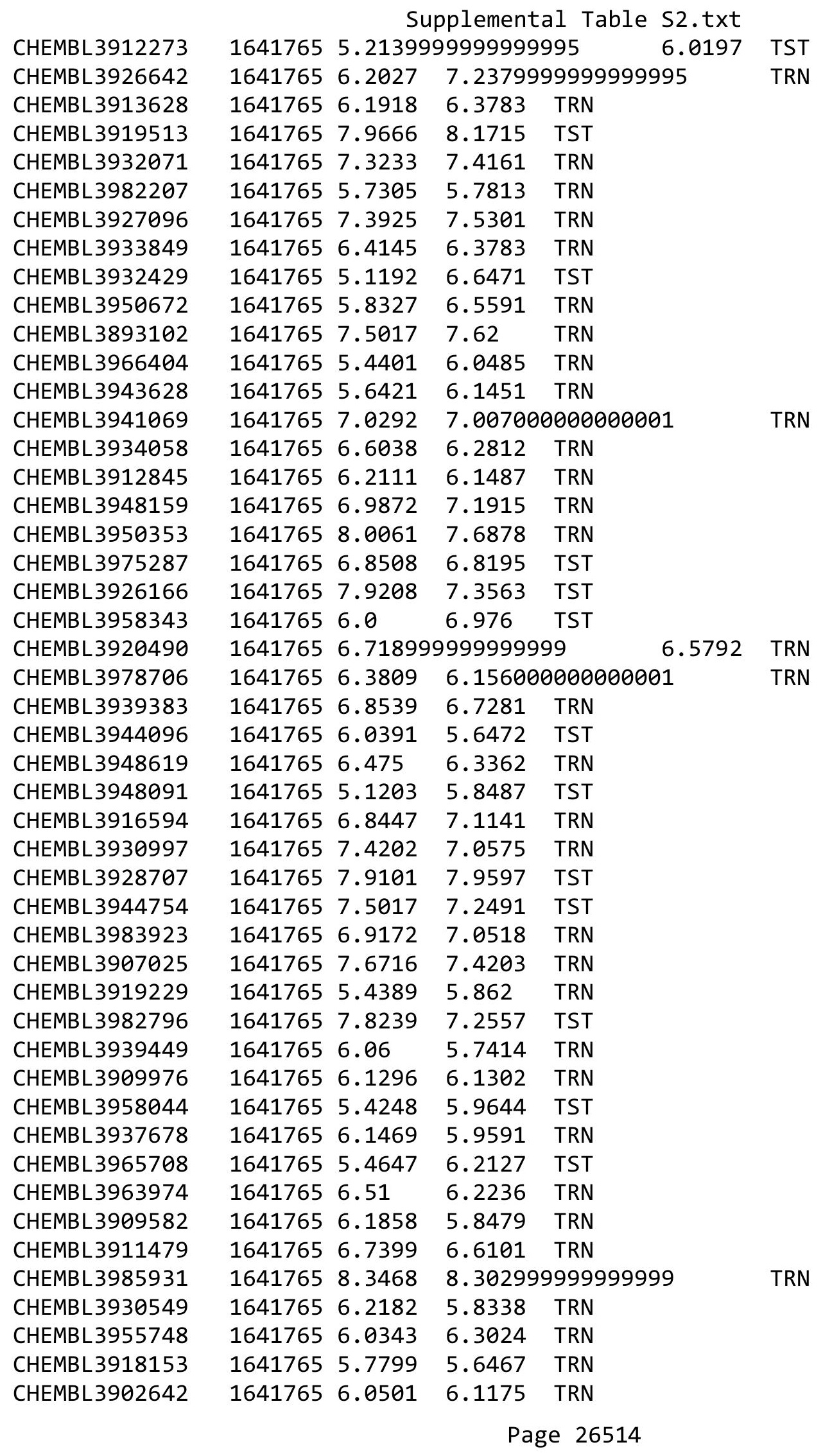


Supplemental Table S2.txt

\begin{tabular}{|c|c|c|c|c|c|c|c|}
\hline CHEMBL3937730 & 1641765 & 7.5258 & 7.4654 & TST & & & \\
\hline CHEMBL3907373 & 1641765 & 6.7959 & 6.2238 & TRN & & & \\
\hline CHEMBL3949406 & 1641765 & 7.15799 & 99999999 & 995 & 6.7769 & TRN & \\
\hline CHEMBL3975139 & 1641765 & 7.4377 & 6.6893 & TRN & & & \\
\hline CHEMBL3929996 & 1641765 & 6.1972 & 5.9798 & TRN & & & \\
\hline CHEMBL3972706 & 1641765 & 6.0487 & 5.9708 & TRN & & & \\
\hline CHEMBL3906169 & 1641765 & 7.8239 & 7.4849 & TRN & & & \\
\hline CHEMBL 3896891 & 1641765 & 7.1232 & 6.7529 & TRN & & & \\
\hline CHEMBL3922625 & 1641765 & 7.7696 & 7.4507 & TRN & & & \\
\hline CHEMBL3902869 & 1641765 & 5.8477 & 5.8975 & TRN & & & \\
\hline CHEMBL3964144 & 1641765 & 6.3788 & 6.6994 & TST & & & \\
\hline CHEMBL 3939634 & 1641765 & 6.0752 & 5.9841 & TRN & & & \\
\hline CHEMBL3985774 & 1641765 & 5.4225 & 5.9279 & TRN & & & \\
\hline CHEMBL3961669 & 1641765 & 6.7825 & 6.6634 & TRN & & & \\
\hline CHEMBL3977404 & 1641765 & 7.3615 & 7.331 & TST & & & \\
\hline CHEMBL3914297 & 1641765 & 6.7305 & 7.2929 & TRN & & & \\
\hline CHEMBL3959065 & 1641765 & 8.0223 & 8.0546 & TST & & & \\
\hline CHEMBL3935306 & 1641765 & 5.9706 & 5.9296 & TRN & & & \\
\hline CHEMBL 3900228 & 1641765 & 6.3969 & 6.5415 & TRN & & & \\
\hline CHEMBL3928626 & 1641765 & 6.8996 & 7.0082 & TRN & & & \\
\hline CHEMBL3934231 & 1641765 & 6.4855 & 6.1592 & TRN & & & \\
\hline CHEMBL3341981 & 1641765 & 8.1062 & 7.5472 & TRN & & & \\
\hline CHEMBL3921636 & 1641765 & 6.3458 & 6.6197 & TRN & & & \\
\hline CHEMBL3960584 & 1641765 & 6.9393 & 7.1203 & TRN & & & \\
\hline CHEMBL 3981707 & 1641765 & \multicolumn{3}{|c|}{7.1579999999999995} & \multirow{13}{*}{\multicolumn{2}{|c|}{7.071000000000001}} & TRN \\
\hline CHEMBL3961261 & 1641765 & 5.4935 & 5.7372 & TRN & & & \\
\hline CHEMBL3920827 & 1641765 & 8.0969 & 7.5303 & TRN & & & \\
\hline CHEMBL3912549 & 1641765 & 6.1952 & 5.7687 & TRN & & & \\
\hline CHEMBL3974650 & 1641765 & 6.6108 & 7.1456 & TRN & & & \\
\hline CHEMBL 3982445 & 1641765 & 6.58 & 6.2132 & TST & & & \\
\hline CHEMBL 3927450 & 1641765 & 7.5686 & 7.6941 & TRN & & & \\
\hline CHEMBL 3900671 & 1641765 & 6.684 & 6.2761 & TST & & & \\
\hline CHEMBL 3895556 & 1641765 & 7.8697 & 7.4704 & TRN & & & \\
\hline CHEMBL3939564 & 1641765 & 5.8827 & 5.4659 & TRN & & & \\
\hline CHEMBL3944914 & 1641765 & 6.4191 & 6.9022 & TRN & & & \\
\hline CHEMBL3978865 & 1641765 & 6.983 & 6.8591 & TRN & & & \\
\hline CHEMBL3929862 & 1641765 & 8.3468 & 7.4929 & TRN & & & \\
\hline CHEMBL3939863 & 1641765 & \multicolumn{3}{|c|}{6.752000000000001} & 6.3188 & TRN & \\
\hline CHEMBL3911405 & 1641765 & 7.2798 & 6.9919 & TRN & & & \\
\hline CHEMBL3955295 & 1641765 & 6.9547 & 6.8011 & TRN & & & \\
\hline CHEMBL3954108 & 1641765 & 5.9281 & 6.3541 & TST & & & \\
\hline CHEMBL3974688 & 1641765 & 6.1656 & 5.8199 & TST & & & \\
\hline CHEMBL3966862 & 1641765 & 6.6498 & 7.2587 & TST & & & \\
\hline CHEMBL3927048 & 1641765 & 5.7986 & 5.8115 & TRN & & & \\
\hline CHEMBL3915316 & 1641765 & 5.7799 & 6.0755 & TRN & & & \\
\hline CHEMBL3913179 & 1641765 & 6.4776 & 5.8463 & TST & & & \\
\hline CHEMBL3986073 & 1641765 & 5.5702 & 5.5672 & TRN & & & \\
\hline CHEMBL3930854 & 1641765 & 5.9586 & 6.0032 & TRN & & & \\
\hline
\end{tabular}


Supplemental Table S2.txt

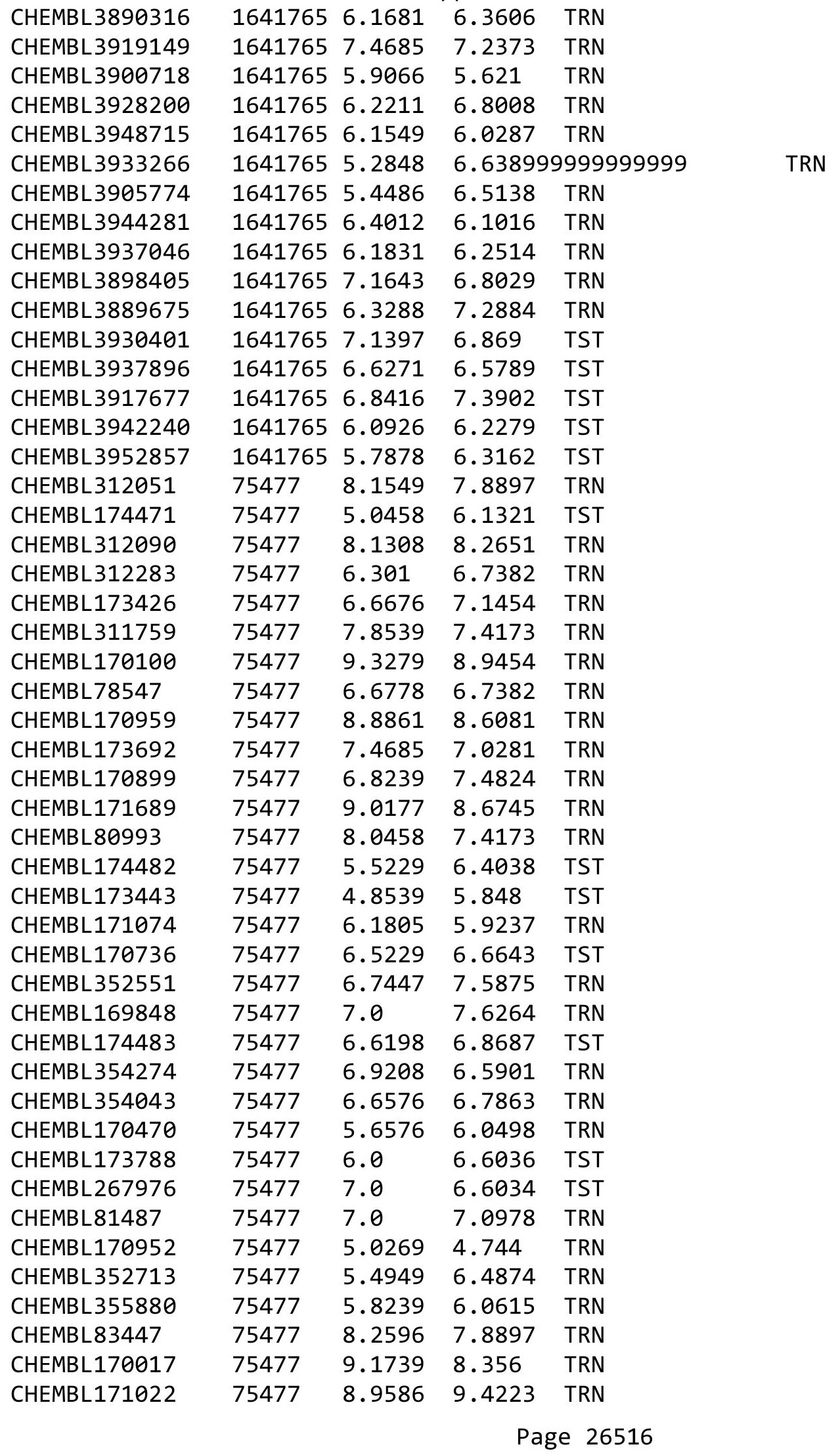




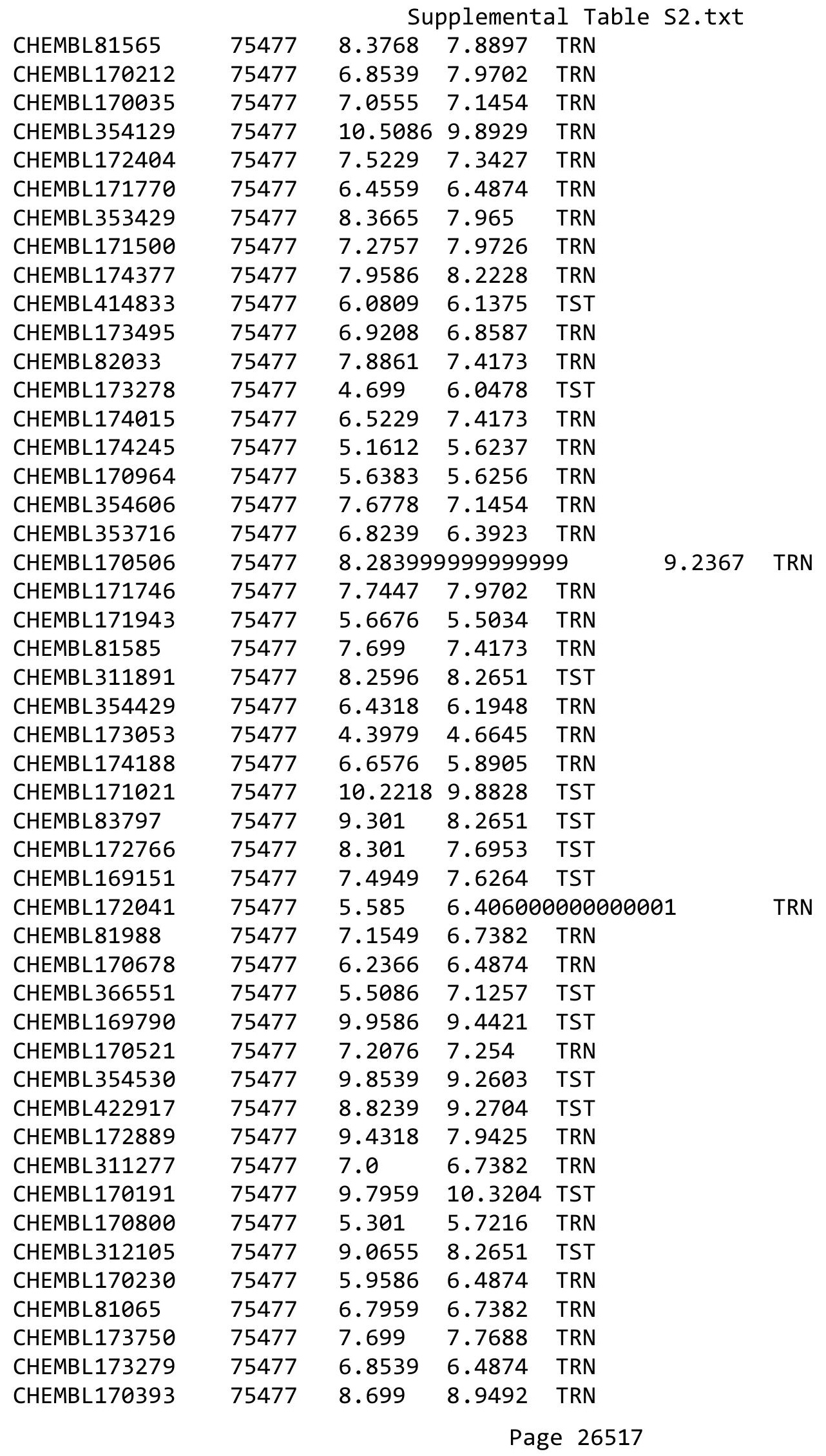




\begin{tabular}{|c|c|c|c|c|c|c|}
\hline & & & pplement & al Tabl & $2 . t$ & \\
\hline CHEMBL173330 & 75477 & 6.3098 & 5.4385 & TRN & & \\
\hline CHEMBL78974 & 75477 & 7.8239 & 7.8897 & TST & & \\
\hline CHEMBL240954 & 954654 & 3.0795 & 3.603999 & 99999999 & 996 & TST \\
\hline CHEMBL188678 & 954654 & 4.5978 & 4.3169 & TRN & & \\
\hline CHEMBL1190711 & 954654 & 5.5505 & 5.2435 & TRN & & \\
\hline CHEMBL573107 & 954654 & 5.1756 & 5.1733 & TRN & & \\
\hline CHEMBL1909414 & 954654 & 3.9502 & 3.8122 & TRN & & \\
\hline CHEMBL393929 & 954654 & 3.2388 & 3.7693 & TRN & & \\
\hline CHEMBL412142 & 954654 & 3.8725 & 4.2297 & TRN & & \\
\hline CHEMBL1242367 & 954654 & 5.3371 & 4.968 & TRN & & \\
\hline CHEMBL 3392440 & 954654 & 4.1002 & 4.1744 & TRN & & \\
\hline CHEMBL515416 & 954654 & 5.7396 & 5.0742 & TRN & & \\
\hline CHEMBL3349342 & 954654 & 5.801 & 5.7858 & TRN & & \\
\hline CHEMBL 2134202 & 954654 & 3.8667 & 3.968 & TRN & & \\
\hline CHEMBL 255342 & 954654 & 3.431 & 3.3554 & TRN & & \\
\hline CHEMBL221137 & 954654 & 5.2958 & 5.0053 & TST & & \\
\hline CHEMBL65 & 954654 & 7.6666 & 7.5518 & TRN & & \\
\hline CHEMBL1673039 & 954654 & 5.3459 & 5.2807 & TRN & & \\
\hline CHEMBL1516890 & 954654 & 3.9345 & 4.1024 & TRN & & \\
\hline CHEMBL180127 & 954654 & 4.0284 & 4.4559 & TRN & & \\
\hline CHEMBL192566 & 954654 & 9.0069 & 8.7053 & TST & & \\
\hline CHEMBL210618 & 954654 & 3.6172 & 3.4624 & TRN & & \\
\hline CHEMBL222102 & 954654 & 4.3015 & 3.7732 & TRN & & \\
\hline CHEMBL1230020 & 954654 & 4.1045 & 4.1174 & TRN & & \\
\hline CHEMBL259181 & 954654 & 5.4068 & 4.9828 & TRN & & \\
\hline CHEMBL472940 & 954654 & 3.0546 & 3.5797 & TRN & & \\
\hline CHEMBL3199475 & 954654 & 4.3229 & 4.5205 & TRN & & \\
\hline CHEMBL514499 & 954654 & 7.4666 & 7.539 & TRN & & \\
\hline CHEMBL102714 & 954654 & 3.0588 & 3.34 & TRN & & \\
\hline CHEMBL92309 & 954654 & 3.8295 & 3.2471 & TST & & \\
\hline CHEMBL1590308 & 954654 & 4.4643 & 3.6247 & TST & & \\
\hline CHEMBL209148 & 954654 & 5.0299 & 5.2395 & TRN & & \\
\hline CHEMBL202721 & 954654 & 5.5945 & 4.9404 & TRN & & \\
\hline CHEMBL1788116 & 954654 & 4.2083 & 4.9051 & TRN & & \\
\hline CHEMBL135561 & 954654 & 5.37 & 4.9135 & TRN & & \\
\hline CHEMBL220241 & 954654 & 4.6526 & 4.9911 & TRN & & \\
\hline CHEMBL191334 & 954654 & 3.2513 & 3.9928 & TRN & & \\
\hline CHEMBL 2137530 & 954654 & 5.2948 & 4.8556 & TRN & & \\
\hline CHEMBL 213100 & 954654 & 5.7317 & 6.2349 & TRN & & \\
\hline CHEMBL217354 & 954654 & 6.7912 & 6.725 & TRN & & \\
\hline CHEMBL509032 & 954654 & 5.9465 & 6.2876 & TRN & & \\
\hline CHEMBL189584 & 954654 & 3.9114 & 4.4546 & TRN & & \\
\hline CHEMBL258844 & 954654 & 5.54299 & 999999999 & 99 & 4.8729 & KI \\
\hline CHEMBL 9470 & 954654 & 6.6135 & 5.996 & TST & & \\
\hline CHEMBL1970879 & 954654 & 6.0586 & 6.0474 & TRN & & \\
\hline CHEMBL483847 & 954654 & 4.0433 & 4.7135 & TRN & & \\
\hline CHEMBL 3186408 & 954654 & 4.4031 & 4.0605 & TST & & \\
\hline CHEMBL577784 & 954654 & 4.1669 & 5.1818 & TRN & & \\
\hline
\end{tabular}




\begin{tabular}{|c|c|c|c|c|c|c|}
\hline & & \multicolumn{5}{|c|}{ Supplemental Table S2.txt } \\
\hline CHEMBL300389 & 954654 & 7.2799 & 7.3012 & TRN & & \\
\hline CHEMBL379975 & 954654 & 5.8672 & 4.7553 & TRN & & \\
\hline CHEMBL2144069 & 954654 & 5.7067 & 5.6821 & TRN & & \\
\hline CHEMBL512504 & 954654 & 4.4878 & 4.05 & TRN & & \\
\hline CHEMBL1357247 & 954654 & 3.2738 & 3.4266 & TRN & & \\
\hline CHEMBL2005886 & 954654 & 5.9492 & 6.3861 & TRN & & \\
\hline CHEMBL1643959 & 954654 & 5.4671 & 4.6058 & TRN & & \\
\hline CHEMBL449158 & 954654 & \multicolumn{3}{|c|}{6.957999999999999} & 7.1244 & TST \\
\hline CHEMBL392695 & 954654 & 5.925 & 5.5637 & TRN & & \\
\hline CHEMBL1404918 & 954654 & 3.2163 & 3.0328 & TRN & & \\
\hline CHEMBL483849 & 954654 & 3.6699 & 2.2081 & TST & & \\
\hline CHEMBL 399530 & 954654 & 5.4422 & 4.5371 & TST & & \\
\hline CHEMBL585951 & 954654 & 6.9123 & 6.3455 & TST & & \\
\hline CHEMBL1256459 & 954654 & 7.2418 & 7.7627 & TST & & \\
\hline CHEMBL558642 & 954654 & 5.6323 & 4.6586 & TST & & \\
\hline CHEMBL2363137 & 954654 & 5.5833 & 5.2471 & TST & & \\
\hline CHEMBL1186585 & 954654 & 3.887 & 4.0057 & TST & & \\
\hline CHEMBL 379300 & 954654 & 6.6583 & 6.9772 & TST & & \\
\hline CHEMBL 373751 & 954654 & \multicolumn{3}{|c|}{3.7310000000000003} & 4.1751 & TST \\
\hline CHEMBL 3416572 & 1473169 & 5.0088 & 4.65 & TST & & \\
\hline CHEMBL3416695 & 1473169 & 5.301 & 4.2221 & TRN & & \\
\hline CHEMBL3416716 & 1473169 & 4.6882 & 4.5501 & TRN & & \\
\hline CHEMBL3416724 & 1473169 & 4.4202 & 4.2598 & TRN & & \\
\hline CHEMBL3414595 & 1473169 & 4.2366 & 3.6374 & TST & & \\
\hline CHEMBL 3416700 & 1473169 & 3.0 & 3.8373 & TST & & \\
\hline CHEMBL3416692 & 1473169 & 5.7959 & 5.4262 & TRN & & \\
\hline CHEMBL3416577 & 1473169 & 5.585 & 5.0851 & TRN & & \\
\hline CHEMBL3416710 & 1473169 & 3.0 & 3.1271 & TRN & & \\
\hline CHEMBL3416731 & 1473169 & 4.9281 & 5.4869 & TRN & & \\
\hline CHEMBL3416714 & 1473169 & 4.7959 & 4.4992 & TRN & & \\
\hline CHEMBL3416725 & 1473169 & 6.1221 & 5.5468 & TRN & & \\
\hline CHEMBL3416719 & 1473169 & 4.1549 & 4.4636 & TRN & & \\
\hline CHEMBL3416585 & 1473169 & 4.7696 & 5.522 & TRN & & \\
\hline CHEMBL3416715 & 1473169 & \multicolumn{3}{|c|}{4.821000000000001} & 4.516 & TRN \\
\hline CHEMBL3416713 & 1473169 & 4.9281 & 5.1318 & TRN & & \\
\hline CHEMBL3416582 & 1473169 & 4.284 & 4.7344 & TRN & & \\
\hline CHEMBL3416690 & 1473169 & 3.0 & 4.0631 & TRN & & \\
\hline CHEMBL3416586 & 1473169 & 4.301 & 3.2457 & TRN & & \\
\hline CHEMBL3416729 & 1473169 & 5.8539 & 5.7345 & TRN & & \\
\hline CHEMBL3416705 & 1473169 & 3.0 & 4.1914 & TRN & & \\
\hline CHEMBL3416588 & 1473169 & 4.4815 & 4.3089 & TRN & & \\
\hline CHEMBL3416711 & 1473169 & 5.2596 & 4.6167 & TRN & & \\
\hline CHEMBL3416584 & 1473169 & 5.0809 & 5.3474 & TRN & & \\
\hline CHEMBL3416578 & 1473169 & 5.3468 & 5.1449 & TRN & & \\
\hline CHEMBL3416730 & 1473169 & 5.9586 & 5.9576 & TRN & & \\
\hline CHEMBL3416712 & 1473169 & 4.9586 & 4.6317 & TRN & & \\
\hline CHEMBL3416717 & 1473169 & 5.3188 & 4.782 & TRN & & \\
\hline CHEMBL3416567 & 1473169 & 5.4949 & 3.6912 & TST & & \\
\hline
\end{tabular}


Supplemental Table s2.txt

\begin{tabular}{|c|c|c|c|c|}
\hline CHEMBL3416723 & 1473169 & 5.2076 & 4.1829 & TRN \\
\hline CHEMBL3416699 & 1473169 & 4.2366 & 3.9435 & TST \\
\hline CHEMBL3416693 & 1473169 & 5.4202 & 5.5142 & TRN \\
\hline CHEMBL3416706 & 1473169 & 5.7212 & 4.2658 & TRN \\
\hline CHEMBL 3416687 & 1473169 & 3.0 & 4.2228 & TRN \\
\hline CHEMBL3416579 & 1473169 & 5.3188 & 4.6269 & TRN \\
\hline CHEMBL3416566 & 1473169 & 3.0 & 3.7594 & TST \\
\hline CHEMBL3416697 & 1473169 & 6.2299 & 5.6867 & TRN \\
\hline CHEMBL 3416580 & 1473169 & 4.8861 & 4.3547 & TRN \\
\hline CHEMBL3416686 & 1473169 & 3.0 & 4.5227 & TRN \\
\hline CHEMBL 3416688 & 1473169 & 3.0 & 4.4649 & TRN \\
\hline CHEMBL3416709 & 1473169 & 3.0 & 3.1048 & TRN \\
\hline CHEMBL 3416726 & 1473169 & 6.1494 & 5.6167 & TRN \\
\hline CHEMBL 3416720 & 1473169 & 5.0269 & 4.7208 & TST \\
\hline CHEMBL 3416574 & 1473169 & 3.0 & 4.7145 & TST \\
\hline CHEMBL 3416583 & 1473169 & 5.6778 & 4.9165 & TRN \\
\hline CHEMBL3416587 & 1473169 & 3.0 & 3.2475 & TRN \\
\hline CHEMBL 3416694 & 1473169 & 5.6021 & 5.7316 & TRN \\
\hline CHEMBL 3416728 & 1473169 & 4.5143 & 5.2995 & TRN \\
\hline CHEMBL3416691 & 1473169 & 5.1938 & 5.3543 & TRN \\
\hline CHEMBL 3416573 & 1473169 & 5.4318 & 4.8516 & TST \\
\hline CHEMBL3416702 & 1473169 & 5.6021 & 5.0638 & TST \\
\hline CHEMBL3416696 & 1473169 & 6.2857 & 5.5405 & TRN \\
\hline CHEMBL 3416733 & 1473169 & 7.9586 & 4.5723 & TST \\
\hline CHEMBL 3416727 & 1473169 & 6.6253 & 5.7579 & TST \\
\hline CHEMBL 3416721 & 1473169 & 4.6778 & 4.7699 & TST \\
\hline CHEMBL3416689 & 1473169 & 3.0 & 4.0034 & TRN \\
\hline CHEMBL3416701 & 1473169 & 5.9586 & 4.868 & TST \\
\hline CHEMBL3416589 & 1473169 & 4.4089 & 3.6568 & TRN \\
\hline CHEMBL3416718 & 1473169 & 3.0 & 4.8613 & TRN \\
\hline CHEMBL3416685 & 1473169 & 4.3979 & 4.5577 & TST \\
\hline CHEMBL196875 & 305497 & 6.3979 & 6.3946 & TRN \\
\hline CHEMBL197565 & 305497 & 5.4559 & 5.2529 & TRN \\
\hline CHEMBL193882 & 305497 & 6.1549 & 5.9015 & TRN \\
\hline CHEMBL197366 & 305497 & 6.3979 & 5.54799 & 9999999999 \\
\hline CHEMBL424835 & 305497 & 5.0706 & 5.5096 & TST \\
\hline CHEMBL196336 & 305497 & 6.2218 & 5.4144 & TST \\
\hline CHEMBL196299 & 305497 & 6.1249 & 5.675 & TRN \\
\hline CHEMBL197461 & 305497 & 5.699 & 6.2102 & TRN \\
\hline CHEMBL193906 & 305497 & 6.699 & 5.8338 & TST \\
\hline CHEMBL194271 & 305497 & 6.0969 & 6.2566 & TRN \\
\hline CHEMBL193591 & 305497 & 6.699 & 5.9142 & TST \\
\hline CHEMBL193584 & 305497 & 5.2596 & 5.8072 & TRN \\
\hline CHEMBL381848 & 305497 & 5.5229 & 5.6983 & TST \\
\hline CHEMBL195663 & 305497 & 6.3979 & 5.8232 & TRN \\
\hline CHEMBL192463 & 305497 & 5.8239 & 5.2417 & TRN \\
\hline CHEMBL364515 & 305497 & 5.0969 & 4.9776 & TRN \\
\hline CHEMBL538656 & 305497 & 6.1249 & 6.1207 & TRN \\
\hline
\end{tabular}

Page 26520 


\begin{tabular}{|c|c|c|c|c|c|}
\hline \multicolumn{6}{|c|}{ Supplemental Table S2.txt } \\
\hline CHEMBL196338 & 305497 & 6.3468 & 5.9704 & TRN & \\
\hline CHEMBL197098 & 305497 & 4.0 & 5.6508 & TST & \\
\hline CHEMBL195985 & 305497 & 6.0969 & 6.2035 & TRN & \\
\hline CHEMBL196701 & 305497 & 5.4559 & 5.4306 & TRN & \\
\hline CHEMBL196786 & 305497 & 5.5229 & 5.3822 & TRN & \\
\hline CHEMBL196825 & 305497 & 5.6021 & 5.2809 & TRN & \\
\hline CHEMBL371702 & 305497 & 6.3979 & 5.155 & TST & \\
\hline CHEMBL196662 & 305497 & 6.4559 & 5.819 & TRN & \\
\hline CHEMBL196894 & 305497 & 5.3979 & $5.7520 e$ & 0000000001 & TST \\
\hline CHEMBL195907 & 305497 & 6.1249 & 6.3107 & TRN & \\
\hline CHEMBL196746 & 305497 & 6.699 & 6.2702 & TRN & \\
\hline CHEMBL196713 & 305497 & 6.1549 & 6.2348 & TRN & \\
\hline CHEMBL371524 & 305497 & 5.6021 & 6.2874 & TRN & \\
\hline CHEMBL364476 & 305497 & 6.5229 & 5.914 & TST & \\
\hline CHEMBL195773 & 305497 & 5.6021 & 5.8762 & TRN & \\
\hline CHEMBL425734 & 305497 & 5.5229 & 6.0476 & TRN & \\
\hline CHEMBL196845 & 305497 & 5.6021 & 5.8295 & TRN & \\
\hline CHEMBL 383774 & 305497 & 6.5229 & 5.7572 & TRN & \\
\hline CHEMBL196827 & 305497 & 4.6021 & 5.5583 & TST & \\
\hline CHEMBL380999 & 305497 & 5.5229 & 6.1798 & TRN & \\
\hline CHEMBL193625 & 305497 & 6.699 & 6.027 & TST & \\
\hline CHEMBL197295 & 305497 & 5.3979 & 5.0548 & TRN & \\
\hline CHEMBL196826 & 305497 & 6.1249 & 5.7379 & TRN & \\
\hline CHEMBL195722 & 305497 & 5.5229 & 5.4743 & TRN & \\
\hline CHEMBL381461 & 305497 & 6.3468 & 4.8811 & TST & \\
\hline CHEMBL195225 & 305497 & 5.0706 & 5.8557 & TRN & \\
\hline CHEMBL197136 & 305497 & 5.5229 & 5.5105 & TRN & \\
\hline CHEMBL195806 & 305497 & 3.5229 & 5.1491 & TRN & \\
\hline CHEMBL196876 & 305497 & 5.8239 & 5.6597 & TRN & \\
\hline CHEMBL381885 & 305497 & 6.5229 & 5.5305 & TST & \\
\hline CHEMBL370434 & 305497 & 4.0 & 5.3164 & TRN & \\
\hline CHEMBL196383 & 305497 & 5.6021 & 5.8295 & TRN & \\
\hline CHEMBL196672 & 305497 & 4.0 & 5.3037 & TST & \\
\hline CHEMBL194231 & 305497 & 6.3979 & 6.1626 & TST & \\
\hline CHEMBL195672 & 305497 & 6.301 & 5.7531 & TRN & \\
\hline CHEMBL194140 & 305497 & 5.5229 & 5.4739 & TRN & \\
\hline CHEMBL197450 & 305497 & 5.6021 & 5.3711 & TRN & \\
\hline CHEMBL 373202 & 305497 & 5.5229 & 5.199 & TRN & \\
\hline CHEMBL197107 & 305497 & 6.0 & 5.1006 & TRN & \\
\hline CHEMBL196395 & 305497 & 6.5229 & 6.1885 & TRN & \\
\hline CHEMBL382948 & 305497 & 6.0969 & 6.2758 & TRN & \\
\hline CHEMBL193564 & 305497 & 5.5229 & 5.4743 & TRN & \\
\hline CHEMBL196394 & 305497 & 5.6021 & 5.341 & TRN & \\
\hline CHEMBL197566 & 305497 & 6.2218 & 5.9015 & TRN & \\
\hline CHEMBL383157 & 305497 & 6.4559 & 6.3614 & TRN & \\
\hline CHEMBL194095 & 305497 & 3.5229 & 4.6596 & TRN & \\
\hline CHEMBL371640 & 305497 & 6.3979 & 6.1183 & TRN & \\
\hline CHEMBL 3685214 & 1528048 & 7.8239 & 8.3915 & TRN & \\
\hline
\end{tabular}


Supplemental Table S2.txt

\begin{tabular}{|c|c|c|c|c|c|}
\hline CHEMBL 3675467 & 1528048 & 7.8861 & 8.077 & TRN & \\
\hline CHEMBL 3891886 & 1528048 & 8.4437 & 7.3032 & TST & \\
\hline CHEMBL3675466 & 1528048 & 9.585 & 9.3385 & TRN & \\
\hline CHEMBL3680482 & 1528048 & 7.2518 & 6.9956 & TST & \\
\hline CHEMBL3680554 & 1528048 & 9.6198 & 8.414 & TST & \\
\hline CHEMBL3670485 & 1528048 & 9.1871 & 9.3719 & TRN & \\
\hline CHEMBL 3680400 & 1528048 & 6.0 & 6.3111 & TRN & \\
\hline CHEMBL 3685264 & 1528048 & 9.041 & 9.0025 & TRN & \\
\hline CHEMBL3685273 & 1528048 & 7.9208 & 8.2641 & TRN & \\
\hline CHEMBL3670463 & 1528048 & 5.7696 & 5.7876 & TRN & \\
\hline CHEMBL3685290 & 1528048 & 9.0809 & 8.3553 & TRN & \\
\hline CHEMBL3675376 & 1528048 & 5.0 & 6.4853 & TRN & \\
\hline CHEMBL 3680485 & 1528048 & 9.3872 & 9.30299 & 9999999999 & TRN \\
\hline CHEMBL 3685301 & 1528048 & 8.4202 & 6.8609 & TST & \\
\hline CHEMBL3685298 & 1528048 & 7.9208 & 8.0907 & TRN & \\
\hline CHEMBL 3675388 & 1528048 & 6.4685 & 6.5779 & TRN & \\
\hline CHEMBL 3680578 & 1528048 & 9.0 & 8.1223 & TRN & \\
\hline CHEMBL 3675422 & 1528048 & 9.1739 & 8.968 & TRN & \\
\hline CHEMBL3680539 & 1528048 & 7.8539 & 7.4648 & TRN & \\
\hline CHEMBL3670497 & 1528048 & 9.0132 & 9.0391 & TRN & \\
\hline CHEMBL 3680515 & 1528048 & 6.0 & 6.5831 & TRN & \\
\hline CHEMBL3680594 & 1528048 & 8.6778 & 9.047 & TRN & \\
\hline CHEMBL 3675423 & 1528048 & 6.1739 & 6.5366 & TST & \\
\hline CHEMBL3675511 & 1528048 & 9.2007 & 8.6007 & TST & \\
\hline CHEMBL3685203 & 1528048 & 8.1805 & 8.4748 & TST & \\
\hline CHEMBL3675401 & 1528048 & 9.585 & 9.329 & TRN & \\
\hline CHEMBL3675358 & 1528048 & 5.1249 & 5.1753 & TRN & \\
\hline CHEMBL 3675503 & 1528048 & 8.6383 & 8.8851 & TRN & \\
\hline CHEMBL3675485 & 1528048 & 6.0 & 5.6216 & TRN & \\
\hline CHEMBL 3670427 & 1528048 & 9.0655 & 6.602 & TRN & \\
\hline CHEMBL 3675363 & 1528048 & 5.7212 & 5.8997 & TRN & \\
\hline CHEMBL3685317 & 1528048 & 6.9208 & 6.7615 & TST & \\
\hline CHEMBL 3675492 & 1528048 & 8.9208 & 9.2214 & TRN & \\
\hline CHEMBL3680486 & 1528048 & 8.8861 & 6.4726 & TST & \\
\hline CHEMBL 3670419 & 1528048 & 6.7212 & 7.2739 & TRN & \\
\hline CHEMBL3680526 & 1528048 & 7.4949 & 6.4518 & TRN & \\
\hline CHEMBL3680527 & 1528048 & 9.1427 & 8.0339 & TRN & \\
\hline CHEMBL 3680450 & 1528048 & 8.3468 & 9.0197 & TST & \\
\hline CHEMBL 3675387 & 1528048 & 5.9208 & \multicolumn{2}{|c|}{5.997000000000001} & TRN \\
\hline CHEMBL 3680545 & 1528048 & 9.7959 & 9.2991 & TRN & \\
\hline CHEMBL 3675426 & 1528048 & 6.4202 & 6.8405 & TRN & \\
\hline CHEMBL3680470 & 1528048 & 9.3565 & 8.0374 & TST & \\
\hline CHEMBL 3675505 & 1528048 & 8.4089 & 8.8764 & TRN & \\
\hline CHEMBL3680461 & 1528048 & 5.7212 & 6.5229 & TRN & \\
\hline CHEMBL 3685292 & 1528048 & 9.5229 & 8.6901 & TST & \\
\hline CHEMBL3964083 & 1528048 & 9.699 & 7.349 & TST & \\
\hline CHEMBL 3685279 & 1528048 & 8.2676 & 8.4602 & TRN & \\
\hline CHEMBL3685224 & 1528048 & 7.4559 & 7.6847 & TRN & \\
\hline
\end{tabular}

Page 26522 
Supplemental Table S2.txt

\begin{tabular}{|c|c|c|c|c|}
\hline 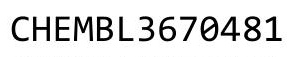 & & & & \\
\hline HEMBL3670411 & 528048 & 6.1135 & 6.7793 & \\
\hline & 28048 & & & \\
\hline 35249 & 28048 & 71 & 72 & \\
\hline AEMBL3675347 & 528048 & 949 & 2702 & \\
\hline AEMBL3680445 & 528048 & 6.284 & 7767 & \\
\hline HEMBL3685278 & 528048 & 8.9208 & .2659 & \\
\hline IEMBL & 28048 & & & \\
\hline EMBL & 528048 & & & \\
\hline HEMBL3675369 & 528048 & 768 & 3222 & \\
\hline AEMBL3675410 & 528048 & 9.2147 & $\partial 946$ & \\
\hline AEMBL36 & 528048 & 9.6383 & 56 & \\
\hline HEMBL; & 28048 & & & \\
\hline HEMBL & 528048 & & & \\
\hline AEMBL3 & 528048 & 79 & 5786 & \\
\hline HEMBL 368 & 528048 & 9. & 35 & \\
\hline AEMBL & 528048 & 88 & 06 & \\
\hline HEMBL; & 528048 & & & \\
\hline HEMBL & 528048 & & & \\
\hline HEMBL & 528048 & & & RN \\
\hline AEMBL3670492 & 528048 & 62 & ס9 & NIV \\
\hline HEMBL3 & 528048 & & 85 & RN \\
\hline HEMBL & 528048 & & & $2 \mathrm{~N}$ \\
\hline AMBL & 528048 & & & ו \\
\hline AEMBL3 & 528048 & & & RN \\
\hline EMBL3E & 528048 & 8. & 85 & RIN \\
\hline HEMBL3 & 528048 & 5 & & RN \\
\hline HEMBL & 528048 & 6. & & RN \\
\hline HEM & 48 & & & RN \\
\hline IEMBL3 & 528048 & 6 & & RN \\
\hline AEMBL 36 & 528048 & 8. & 581 & RN \\
\hline HEMBL36 & 528048 & 7. & 98 & RN \\
\hline HEMBL3 & 528048 & & & RN \\
\hline IEN & & & & RN \\
\hline HEMBL36 & 528048 & & 8 . & RN \\
\hline EMBL36 & 28048 & & 26 & \\
\hline HEMBL36 & 528048 & 98 & 12 & Niv \\
\hline & & & & ST \\
\hline HEMBL3675350 & 528048 & & 71 & $\mathrm{RN}$ \\
\hline HEMBL36 & 528048 & 5 . & 28 & RN \\
\hline HEMBL36 & 528048 & 6 & 79 & \\
\hline HEMBL3685295 & 1528048 & 6 & 3.4703 & \\
\hline HEMBL 3 & & & & RN \\
\hline HEMBL367 & 528048 & 6 & 3661 & RN \\
\hline AEMBL36 & 528048 & 6 . & 45 & \\
\hline & & & & \\
\hline HEMBL3 & .528048 & & 7.3619 & \\
\hline 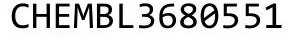 & ג) & & 9.0019 & \\
\hline
\end{tabular}

Page 26523 
Supplemental Table S2.txt

\begin{tabular}{|c|c|c|c|c|c|}
\hline CHEMBL 3670403 & 1528048 & 5.3098 & 7.2479 & TRN & \\
\hline CHEMBL 3675332 & 1528048 & 6.2291 & 7.0912 & TST & \\
\hline CHEMBL 3675352 & 1528048 & 8.0915 & 7.0026 & TRN & \\
\hline CHEMBL 3680430 & 1528048 & 9.5229 & 9.4085 & TRN & \\
\hline CHEMBL3675395 & 1528048 & 6.6576 & 6.0001 & TST & \\
\hline CHEMBL 3680424 & 1528048 & 8.301 & 8.47 & TRN & \\
\hline CHEMBL 3680583 & 1528048 & 8.8539 & 8.3323 & TST & \\
\hline CHEMBL 3685260 & 1528048 & 8.0458 & 9.0044 & TST & \\
\hline CHEMBL 3675483 & 1528048 & 6.0 & 8.2951 & TRN & \\
\hline CHEMBL3680521 & 1528048 & 6.1612 & 5.9566 & TRN & \\
\hline CHEMBL 3680525 & 1528048 & 8.1135 & 6.0305 & TRN & \\
\hline CHEMBL3685266 & 1528048 & 9.5086 & 8.9279 & TRN & \\
\hline CHEMBL 3680444 & 1528048 & 9.1805 & 9.4648 & TRN & \\
\hline CHEMBL 3675497 & 1528048 & 6.2518 & 6.6406 & TRN & \\
\hline CHEMBL3639792 & 1528048 & 9.4202 & 8.7822 & TRN & \\
\hline CHEMBL3680459 & 1528048 & 6.7959 & 6.7775 & TRN & \\
\hline CHEMBL3680466 & 1528048 & 9.4202 & 7.9789 & TST & \\
\hline CHEMBL 3675320 & 1528048 & 5.8861 & 7.0237 & TRN & \\
\hline CHEMBL 3675440 & 1528048 & 6.0 & 5.1801 & TRN & \\
\hline CHEMBL3670445 & 1528048 & 7.8861 & 6.8414 & TRN & \\
\hline CHEMBL3680534 & 1528048 & 8.2299 & 9.2368 & TST & \\
\hline CHEMBL 3680542 & 1528048 & 9.8239 & 8.7198 & TRN & \\
\hline CHEMBL3670433 & 1528048 & 6.1427 & 6.8039 & TRN & \\
\hline CHEMBL3639794 & 1528048 & 8.6383 & 8.1226 & TRN & \\
\hline CHEMBL 3680431 & 1528048 & 6.4089 & 6.5407 & TRN & \\
\hline CHEMBL 3670471 & 1528048 & 9.2924 & 9.6441 & TRN & \\
\hline CHEMBL 3680574 & 1528048 & 9.0655 & 8.1387 & TRN & \\
\hline CHEMBL 3670455 & 1528048 & 6.8539 & 5.9577 & TRN & \\
\hline CHEMBL 3675480 & 1528048 & 9.7447 & 9.6758 & TRN & \\
\hline CHEMBL 3680566 & 1528048 & 9.2518 & 9.3028 & TRN & \\
\hline CHEMBL3685213 & 1528048 & 7.9586 & 7.2191 & TST & \\
\hline CHEMBL 3680588 & 1528048 & 8.7447 & 8.4808 & TRN & \\
\hline CHEMBL 3680511 & 1528048 & 6.5229 & \multicolumn{3}{|c|}{6.047999999999999} \\
\hline CHEMBL 3670495 & 1528048 & 5.699 & \multicolumn{2}{|c|}{6.553999999999999} & TRN \\
\hline CHEMBL 3685300 & 1528048 & 8.6198 & 8.7253 & TRN & \\
\hline CHEMBL 3675540 & 1528048 & 9.3098 & 8.8934 & TRN & \\
\hline CHEMBL 3685210 & 1528048 & 8.0458 & 8.7118 & TST & \\
\hline CHEMBL 3675459 & 1528048 & 9.9208 & 9.6029 & TRN & \\
\hline CHEMBL 3670447 & 1528048 & 5.284 & 6.0349 & TRN & \\
\hline CHEMBL 3675454 & 1528048 & 7.2441 & 7.0926 & TRN & \\
\hline CHEMBL 3680581 & 1528048 & 8.8861 & 8.8124 & TRN & \\
\hline CHEMBL 3680587 & 1528048 & 8.7696 & 9.274 & TRN & \\
\hline CHEMBL 3685223 & 1528048 & 7.4685 & 8.851 & TRN & \\
\hline CHEMBL3675420 & 1528048 & 9.0757 & 8.6575 & TRN & \\
\hline CHEMBL3675536 & 1528048 & 6.1024 & 6.9379 & TRN & \\
\hline CHEMBL 3685318 & 1528048 & 6.1938 & 6.2541 & TST & \\
\hline CHEMBL 3685228 & 1528048 & 8.0177 & 7.6724 & TST & \\
\hline CHEMBL 3675333 & 1528048 & 5.3665 & 5.9621 & TRN & \\
\hline
\end{tabular}

Page 26524 
Supplemental Table S2.txt

\begin{tabular}{|c|c|c|c|c|c|}
\hline CHEMBL 3675470 & 1528048 & 9.4202 & 9.5613 & TRN & \\
\hline CHEMBL3680569 & 1528048 & 9.1427 & 9.0697 & TRN & \\
\hline CHEMBL3685305 & 1528048 & 10.0969 & 9.2808 & TRN & \\
\hline CHEMBL 3680397 & 1528048 & 6.301 & 6.2772 & TRN & \\
\hline CHEMBL3680393 & 1528048 & 7.7212 & 7.7584 & TST & \\
\hline CHEMBL3680392 & 1528048 & 8.7447 & 9.1255 & TRN & \\
\hline CHEMBL 3680467 & 1528048 & 9.3098 & 7.4337 & TST & \\
\hline CHEMBL 3680483 & 1528048 & 7.2924 & 5.7528 & TRN & \\
\hline CHEMBL 3675421 & 1528048 & 6.4202 & \multicolumn{2}{|c|}{6.8229999999999995} & TRN \\
\hline CHEMBL3670412 & 1528048 & 8.9208 & 8.3251 & TRN & \\
\hline CHEMBL3680406 & 1528048 & 9.0044 & 8.2329 & TST & \\
\hline CHEMBL 3675384 & 1528048 & 5.1675 & 5.2927 & TRN & \\
\hline CHEMBL 3670486 & 1528048 & 6.2291 & 7.2834 & TRN & \\
\hline CHEMBL 3680457 & 1528048 & 8.2924 & 8.3107 & TRN & \\
\hline CHEMBL3680599 & 1528048 & 8.6021 & 8.3796 & TRN & \\
\hline CHEMBL3670417 & 1528048 & 8.1805 & \multicolumn{2}{|c|}{6.486000000000001} & TST \\
\hline CHEMBL3680501 & 1528048 & 6.8239 & 6.7651 & TST & \\
\hline CHEMBL 3685282 & 1528048 & 9.4089 & 9.2436 & TRN & \\
\hline CHEMBL 3680388 & 1528048 & 9.041 & 8.5821 & TRN & \\
\hline CHEMBL 3675468 & 1528048 & 6.2441 & 6.4101 & TRN & \\
\hline CHEMBL 3685231 & 1528048 & 7.1612 & 7.8411 & TST & \\
\hline CHEMBL 3685261 & 1528048 & 9.2007 & 9.5944 & TRN & \\
\hline CHEMBL3680514 & 1528048 & 6.5229 & 5.8408 & TRN & \\
\hline CHEMBL 3680407 & 1528048 & 5.7959 & 5.1319 & TRN & \\
\hline CHEMBL3685245 & 1528048 & 9.9208 & 9.9017 & TRN & \\
\hline CHEMBL 3680490 & 1528048 & 8.9208 & 8.631 & TRN & \\
\hline CHEMBL 3670440 & 1528048 & 5.1612 & 5.7783 & TRN & \\
\hline CHEMBL3680565 & 1528048 & 9.2676 & 9.1174 & TRN & \\
\hline CHEMBL 3670502 & 1528048 & 5.0 & 6.5496 & TRN & \\
\hline CHEMBL3680522 & 1528048 & 9.1367 & 9.0334 & TST & \\
\hline CHEMBL3675336 & 1528048 & 5.2218 & 7.1548 & TST & \\
\hline CHEMBL 3685285 & 1528048 & 6.0 & 7.8034 & TRN & \\
\hline CHEMBL3675324 & 1528048 & 9.7447 & 7.3602 & TRN & \\
\hline CHEMBL 3680530 & 1528048 & 9.3188 & 9.493 & TRN & \\
\hline CHEMBL3680547 & 1528048 & 6.0 & 8.1877 & TRN & \\
\hline CHEMBL 3685247 & 1528048 & 9.8861 & 9.453 & TRN & \\
\hline CHEMBL3680589 & 1528048 & 8.7447 & 7.7021 & TRN & \\
\hline CHEMBL 3675408 & 1528048 & 6.6778 & 6.6067 & TRN & \\
\hline CHEMBL 3685251 & 1528048 & 9.2676 & 8.97 & TRN & \\
\hline CHEMBL 3685248 & 1528048 & 9.7959 & 8.5062 & TRN & \\
\hline CHEMBL 3680428 & 1528048 & 9.7447 & 9.2728 & TRN & \\
\hline CHEMBL 3670404 & 1528048 & 6.1805 & 7.0683 & TRN & \\
\hline CHEMBL3675375 & 1528048 & 5.0 & 4.7389 & TRN & \\
\hline CHEMBL 3675457 & 1528048 & 9.9586 & 9.5252 & TRN & \\
\hline CHEMBL3680602 & 1528048 & 8.5086 & 7.7316 & TRN & \\
\hline CHEMBL3685309 & 1528048 & 9.6576 & 9.3505 & TRN & \\
\hline CHEMBL 3670498 & 1528048 & 8.2007 & 8.5411 & TRN & \\
\hline CHEMBL 3685206 & 1528048 & 8.1549 & 8.6891 & TST & \\
\hline
\end{tabular}


Supplemental Table S2.txt

\begin{tabular}{|c|c|c|c|c|}
\hline CHEMBL 3680517 & 1528048 & 8.4685 & 8.7888 & TRN \\
\hline CHEMBL3675532 & 1528048 & 9.8239 & 9.2988 & TRN \\
\hline CHEMBL3675518 & 1528048 & 9.2366 & 9.2343 & TRN \\
\hline CHEMBL 3685208 & 1528048 & 8.1192 & 8.7237 & TRN \\
\hline CHEMBL 3675355 & 1528048 & 6.2596 & 6.345 & TRN \\
\hline CHEMBL 3675418 & 1528048 & 8.3098 & 9.0295 & TRN \\
\hline CHEMBL 3670464 & 1528048 & 6.5086 & 6.8957 & TRN \\
\hline CHEMBL 3675345 & 1528048 & 5.0555 & 6.3757 & TRN \\
\hline CHEMBL3675502 & 1528048 & 7.5686 & 6.1303 & TRN \\
\hline CHEMBL3670438 & 1528048 & 5.3372 & 6.0468 & TST \\
\hline CHEMBL3680556 & 1528048 & 9.5376 & 9.595 & TRN \\
\hline CHEMBL 3680544 & 1528048 & 9.7959 & 9.3094 & TRN \\
\hline CHEMBL3675424 & 1528048 & 5.6198 & 6.4045 & TRN \\
\hline CHEMBL3685289 & 1528048 & 8.2291 & 8.2347 & TRN \\
\hline CHEMBL3680507 & 1528048 & 9.3768 & 9.4554 & TRN \\
\hline CHEMBL 3680523 & 1528048 & 8.1487 & 9.0343 & TRN \\
\hline CHEMBL3685275 & 1528048 & 7.9586 & 8.4012 & TRN \\
\hline CHEMBL3675413 & 1528048 & 9.0 & 8.9007 & TRN \\
\hline CHEMBL3675433 & 1528048 & 6.7447 & 7.1062 & TRN \\
\hline CHEMBL3685259 & 1528048 & 9.4318 & 8.7158 & TRN \\
\hline CHEMBL3670488 & 1528048 & 7.4815 & 6.8143 & TRN \\
\hline CHEMBL3675471 & 1528048 & 7.0088 & 6.8463 & TRN \\
\hline CHEMBL3675513 & 1528048 & 7.1367 & 7.0841 & TRN \\
\hline CHEMBL3670491 & 1528048 & 7.2366 & 6.1593 & TRN \\
\hline CHEMBL3680576 & 1528048 & 9.0555 & 8.362 & TRN \\
\hline CHEMBL3675425 & 1528048 & 9.7696 & 9.3022 & TST \\
\hline CHEMBL3680580 & 1528048 & 8.9208 & 9.1232 & TRN \\
\hline CHEMBL3675412 & 1528048 & 9.1308 & 8.7836 & TRN \\
\hline CHEMBL 3675346 & 1528048 & 5.1308 & 5.0829 & TST \\
\hline CHEMBL3680498 & 1528048 & 6.0862 & 6.6728 & TST \\
\hline CHEMBL3675396 & 1528048 & 6.2676 & 6.7955 & TRN \\
\hline CHEMBL 3680414 & 1528048 & 6.0969 & 6.4952 & TRN \\
\hline CHEMBL 3670456 & 1528048 & 5.8861 & 6.5013 & TRN \\
\hline CHEMBL3670435 & 1528048 & 5.7447 & 6.8374 & TRN \\
\hline CHEMBL3680394 & 1528048 & 9.4949 & 9.6364 & TRN \\
\hline CHEMBL3685283 & 1528048 & 7.699 & 6.9066 & TRN \\
\hline CHEMBL3680404 & 1528048 & 8.9586 & 8.5819 & TRN \\
\hline CHEMBL3680604 & 1528048 & 8.4437 & 8.826 & TRN \\
\hline CHEMBL3685332 & 1528048 & 7.9586 & 8.3838 & TRN \\
\hline CHEMBL3685287 & 1528048 & 9.6576 & 8.802999 & 9999999999 \\
\hline CHEMBL3675319 & 1528048 & 5.9586 & 7.407 & TRN \\
\hline CHEMBL3680537 & 1528048 & 5.7959 & 6.7373 & TRN \\
\hline CHEMBL3680504 & 1528048 & 9.1079 & 8.9272 & TRN \\
\hline CHEMBL3675474 & 1528048 & 9.6778 & 9.6615 & TRN \\
\hline CHEMBL3680520 & 1528048 & 9.4318 & 9.0646 & TRN \\
\hline CHEMBL3675342 & 1528048 & 6.0 & 6.1953 & TRN \\
\hline CHEMBL3675325 & 1528048 & 8.2366 & 7.9476 & TRN \\
\hline CHEMBL3685205 & 1528048 & 8.1549 & 6.7294 & TST \\
\hline
\end{tabular}


Supplemental Table S2.txt

\begin{tabular}{|c|c|c|c|c|}
\hline CHEMBL3675389 & 1528048 & 6.9586 & 6.7083 & TRN \\
\hline CHEMBL3680403 & 1528048 & 9.5376 & 9.2975 & TRN \\
\hline CHEMBL3675391 & 1528048 & 5.1367 & 6.3882 & TRN \\
\hline CHEMBL3675523 & 1528048 & 6.4815 & 6.4166 & TST \\
\hline CHEMBL3680573 & 1528048 & 9.0655 & 8.9707 & TRN \\
\hline CHEMBL3675430 & 1528048 & 7.7212 & 9.0536 & TRN \\
\hline CHEMBL3680506 & 1528048 & 5.8239 & 6.3104 & TST \\
\hline CHEMBL 3670458 & 1528048 & 6.3468 & 6.4757 & TRN \\
\hline CHEMBL3675519 & 1528048 & 9.0132 & 9.0526 & TRN \\
\hline CHEMBL3685204 & 1528048 & 8.1549 & 8.2116 & TST \\
\hline CHEMBL 3670470 & 1528048 & 9.9586 & 9.337 & TRN \\
\hline CHEMBL3680489 & 1528048 & 9.6383 & 8.1151 & TST \\
\hline CHEMBL3680533 & 1528048 & 9.5086 & 9.0105 & TRN \\
\hline CHEMBL3685320 & 1528048 & 6.1308 & 6.0017 & TST \\
\hline CHEMBL 3685241 & 1528048 & 10.0 & 9.2537 & TRN \\
\hline CHEMBL 3675443 & 1528048 & 10.0458 & 9.1037 & TRN \\
\hline CHEMBL3680495 & 1528048 & 9.6576 & 9.3266 & TRN \\
\hline CHEMBL 3685272 & 1528048 & 10.0969 & 9.3709 & TRN \\
\hline CHEMBL3670466 & 1528048 & 7.5376 & 5.526 & TRN \\
\hline CHEMBL 3680600 & 1528048 & 8.6021 & 7.8392 & TRN \\
\hline CHEMBL3680455 & 1528048 & 9.6576 & 8.9469 & TRN \\
\hline CHEMBL 3680598 & 1528048 & 8.6198 & 8.1665 & TRN \\
\hline CHEMBL3685250 & 1528048 & 9.9586 & 8.7993 & TRN \\
\hline CHEMBL3680603 & 1528048 & 8.4559 & 8.5696 & TRN \\
\hline CHEMBL3680416 & 1528048 & 9.6021 & 8.7567 & TRN \\
\hline CHEMBL 3675444 & 1528048 & 6.0 & 9.186 & TRN \\
\hline CHEMBL 3685270 & 1528048 & 8.1367 & 7.9516 & TRN \\
\hline CHEMBL3680579 & 1528048 & 8.9586 & 7.7117 & TRN \\
\hline CHEMBL3675330 & 1528048 & 8.7212 & 6.659 & TRN \\
\hline CHEMBL 3680448 & 1528048 & 6.2218 & 6.7525 & TST \\
\hline CHEMBL3675382 & 1528048 & 5.4437 & 6.2173 & TRN \\
\hline CHEMBL 3680528 & 1528048 & 9.1805 & 9.3321 & TRN \\
\hline CHEMBL3685306 & 1528048 & 9.9586 & 9.1544 & TRN \\
\hline CHEMBL3680518 & 1528048 & 8.1308 & 8.2205 & TRN \\
\hline CHEMBL3675479 & 1528048 & 6.0362 & 6.0701 & TRN \\
\hline CHEMBL3670421 & 1528048 & 6.5086 & 6.8508 & TRN \\
\hline CHEMBL3685236 & 1528048 & 8.8827 & 8.7048 & TRN \\
\hline CHEMBL3670460 & 1528048 & 6.699 & 7.1277 & TRN \\
\hline CHEMBL 3670442 & 1528048 & 6.1549 & 6.1376 & TRN \\
\hline CHEMBL3675533 & 1528048 & 8.3565 & 8.2561 & TRN \\
\hline CHEMBL3680391 & 1528048 & 8.8539 & 8.1163 & TST \\
\hline CHEMBL3680474 & 1528048 & 8.7959 & 9.4684 & TRN \\
\hline CHEMBL3680519 & 1528048 & 9.2147 & 8.068 & TRN \\
\hline CHEMBL 3685234 & 1528048 & 9.4089 & 9.227 & TRN \\
\hline CHEMBL3675504 & 1528048 & 8.4089 & 7.7632 & TST \\
\hline CHEMBL3675337 & 1528048 & 6.1192 & 6.8364 & TRN \\
\hline CHEMBL3670451 & 1528048 & 5.9208 & 8.3066 & TRN \\
\hline \multirow[t]{2}{*}{ CHEMBL3680413 } & 1528048 & 7.3979 & 7.61700 & 0000 \\
\hline & & & \multicolumn{2}{|c|}{ Page 26527} \\
\hline
\end{tabular}




$$
\text { Supplemental Table S2.txt }
$$

\begin{tabular}{|c|c|c|c|c|c|}
\hline CHEMBL 3680584 & 1528048 & 8.8239 & 8.582 & TRN & \\
\hline CHEMBL 3675537 & 1528048 & 10.0969 & 9.6535 & TRN & \\
\hline CHEMBL3670496 & 1528048 & 5.585 & 6.3422 & TRN & \\
\hline CHEMBL 3680477 & 1528048 & 10.0458 & 9.0212 & TRN & \\
\hline CHEMBL3685200 & 1528048 & 8.2596 & 7.6656 & TST & \\
\hline CHEMBL3685281 & 1528048 & 9.3372 & 8.9299 & TRN & \\
\hline CHEMBL3670468 & 1528048 & 9.1871 & 9.9869 & TRN & \\
\hline CHEMBL3675491 & 1528048 & 9.699 & 9.1267 & TRN & \\
\hline CHEMBL3670489 & 1528048 & 6.4672 & 6.5925 & TRN & \\
\hline CHEMBL3670400 & 1528048 & 6.041 & 6.0133 & TRN & \\
\hline CHEMBL3680395 & 1528048 & 9.3768 & 9.3573 & TRN & \\
\hline CHEMBL3675439 & 1528048 & 6.0 & 8.6902 & TRN & \\
\hline CHEMBL3675371 & 1528048 & 8.7959 & 6.6979 & TRN & \\
\hline CHEMBL3670402 & 1528048 & 5.1192 & 7.3004 & TRN & \\
\hline CHEMBL3680575 & 1528048 & 9.0655 & 7.9333 & TRN & \\
\hline CHEMBL3680492 & 1528048 & 8.4685 & 8.8171 & TST & \\
\hline CHEMBL3680567 & 1528048 & 9.2366 & 8.9364 & TRN & \\
\hline CHEMBL 3675538 & 1528048 & 9.699 & 9.3293 & TRN & \\
\hline CHEMBL3675486 & 1528048 & 9.3372 & 9.2022 & TRN & \\
\hline CHEMBL3675397 & 1528048 & 7.3188 & 7.2166 & TRN & \\
\hline CHEMBL3675379 & 1528048 & 8.4089 & 6.5686 & TRN & \\
\hline CHEMBL3680447 & 1528048 & 9.4318 & 9.1354 & TRN & \\
\hline CHEMBL 3675428 & 1528048 & 8.9586 & 9.0344 & TRN & \\
\hline CHEMBL3670423 & 1528048 & 6.0 & 7.0753 & TRN & \\
\hline CHEMBL3670429 & 1528048 & 6.2366 & 4.8738 & TRN & \\
\hline CHEMBL3675340 & 1528048 & 6.6383 & 5.7707 & TRN & \\
\hline CHEMBL 3675527 & 1528048 & 6.6778 & 6.9783 & TRN & \\
\hline CHEMBL3675419 & 1528048 & 9.6198 & 9.2741 & TRN & \\
\hline CHEMBL3675354 & 1528048 & 6.4559 & \multicolumn{2}{|c|}{6.377000000000001} & TRN \\
\hline CHEMBL3675404 & 1528048 & 9.2366 & 9.6545 & TRN & \\
\hline CHEMBL3675445 & 1528048 & 8.6383 & 8.8003 & TRN & \\
\hline CHEMBL 3675373 & 1528048 & 5.2291 & 4.9691 & TRN & \\
\hline CHEMBL3685262 & 1528048 & 10.0969 & 9.7018 & TRN & \\
\hline CHEMBL3670454 & 1528048 & 8.6778 & 7.5504 & TRN & \\
\hline CHEMBL3675517 & 1528048 & 9.2518 & 9.0346 & TRN & \\
\hline CHEMBL3675394 & 1528048 & 6.0 & 6.8592 & TRN & \\
\hline CHEMBL3680529 & 1528048 & 9.3188 & 8.6453 & TRN & \\
\hline CHEMBL3680456 & 1528048 & 9.0 & 8.6979 & TRN & \\
\hline CHEMBL3675406 & 1528048 & 9.5686 & 8.962 & TRN & \\
\hline CHEMBL3670494 & 1528048 & 6.6576 & 6.7592 & TRN & \\
\hline CHEMBL3675328 & 1528048 & 7.1079 & 7.4457 & TRN & \\
\hline CHEMBL3670450 & 1528048 & 6.0 & 6.2142 & TST & \\
\hline CHEMBL3680491 & 1528048 & 9.2757 & 9.5442 & TRN & \\
\hline CHEMBL3685268 & 1528048 & 8.5086 & 8.4905 & TRN & \\
\hline CHEMBL3639841 & 1528048 & 10.2218 & 10.0365 & TRN & \\
\hline CHEMBL3675385 & 1528048 & 6.0223 & 7.2485 & TRN & \\
\hline CHEMBL3670436 & 1528048 & 5.1079 & 6.9029 & TRN & \\
\hline CHEMBL3685293 & 1528048 & 9.3979 & 9.2977 & TRN & \\
\hline
\end{tabular}

Page 26528 
Supplemental Table S2.txt

\begin{tabular}{|c|c|c|c|c|c|}
\hline CHEMBL 3675482 & 1528048 & 6.0 & 6.1687 & TRN & \\
\hline CHEMBL 3685257 & 1528048 & 9.5086 & 9.12 & TRN & \\
\hline CHEMBL3675359 & 1528048 & 6.2366 & 5.83700 & 000000001 & TRN \\
\hline CHEMBL 3680585 & 1528048 & 8.8239 & 9.0964 & TRN & \\
\hline CHEMBL 3675525 & 1528048 & 9.7696 & 9.2018 & TRN & \\
\hline CHEMBL 3675414 & 1528048 & 6.3188 & 6.9522 & TRN & \\
\hline CHEMBL 3639742 & 1528048 & 8.6576 & 7.1365 & TRN & \\
\hline CHEMBL 3680390 & 1528048 & 9.0 & 9.2265 & TRN & \\
\hline CHEMBL 3680437 & 1528048 & 9.0315 & 9.314 & TRN & \\
\hline CHEMBL3680593 & 1528048 & 8.6778 & 7.6965 & TRN & \\
\hline CHEMBL 3675368 & 1528048 & 6.2366 & 8.5343 & TRN & \\
\hline CHEMBL 3680479 & 1528048 & 10.3009 & 99999999 & 9.7389 & \\
\hline CHEMBL3670422 & 1528048 & 6.8861 & 6.6938 & TRN & \\
\hline CHEMBL 3670414 & 1528048 & 6.5528 & 7.0426 & TRN & \\
\hline CHEMBL3685265 & 1528048 & 8.5376 & 8.5583 & TRN & \\
\hline CHEMBL3675409 & 1528048 & 6.8539 & 6.4834 & TRN & \\
\hline CHEMBL3675499 & 1528048 & 9.4559 & 9.5195 & TRN & \\
\hline CHEMBL3680481 & 1528048 & 8.8539 & 8.1333 & TRN & \\
\hline CHEMBL3685212 & 1528048 & 7.9586 & 8.3182 & TRN & \\
\hline CHEMBL3680607 & 1528048 & 8.3768 & 8.0542 & TRN & \\
\hline CHEMBL3675458 & 1528048 & 8.7696 & 9.1525 & TRN & \\
\hline CHEMBL 3962025 & 1528048 & 8.9208 & 7.7005 & TST & \\
\hline CHEMBL3685220 & 1528048 & 7.5376 & 6.8641 & TST & \\
\hline CHEMBL3680531 & 1528048 & 7.9208 & 8.0647 & TRN & \\
\hline CHEMBL 3670505 & 1528048 & 8.4685 & 7.773 & TRN & \\
\hline CHEMBL3670477 & 1528048 & 6.699 & 7.2872 & TRN & \\
\hline CHEMBL 3675507 & 1528048 & 6.0 & 6.6904 & TRN & \\
\hline CHEMBL3680591 & 1528048 & 8.699 & 8.7728 & TRN & \\
\hline CHEMBL3680509 & 1528048 & 9.1135 & 8.7137 & TRN & \\
\hline CHEMBL3680421 & 1528048 & 8.5376 & 8.773 & TRN & \\
\hline CHEMBL3680434 & 1528048 & 6.3665 & 6.9627 & TRN & \\
\hline CHEMBL 3680582 & 1528048 & 8.8539 & 8.8898 & TRN & \\
\hline CHEMBL 3670476 & 1528048 & 9.3979 & 9.4728 & TRN & \\
\hline CHEMBL3680471 & 1528048 & 7.7696 & 8.3913 & TRN & \\
\hline CHEMBL3675510 & 1528048 & 9.4559 & 9.1924 & TST & \\
\hline CHEMBL3675367 & 1528048 & 5.284 & 6.7031 & TRN & \\
\hline CHEMBL3685284 & 1528048 & 9.7447 & 9.2486 & TRN & \\
\hline CHEMBL 3680510 & 1528048 & 6.0 & 6.1283 & TRN & \\
\hline CHEMBL3675431 & 1528048 & 8.8861 & 8.6086 & TST & \\
\hline CHEMBL 3680563 & 1528048 & 9.2924 & 8.3639 & TRN & \\
\hline CHEMBL3680410 & 1528048 & 8.5686 & 8.52700 & 000000001 & \\
\hline CHEMBL3685255 & 1528048 & 9.7447 & 8.1179 & TRN & \\
\hline CHEMBL3675453 & 1528048 & 9.4685 & 9.0431 & TRN & \\
\hline CHEMBL3675432 & 1528048 & 9.6021 & 9.6994 & TRN & \\
\hline CHEMBL3675339 & 1528048 & 6.8861 & 6.4889 & TRN & \\
\hline CHEMBL3685254 & 1528048 & 8.5229 & 7.8441 & TRN & \\
\hline CHEMBL 3675323 & 1528048 & 8.1675 & 7.3589 & TRN & \\
\hline CHEMBL 3675500 & 1528048 & 9.699 & 8.7369 & TRN & \\
\hline
\end{tabular}


Supplemental Table S2.txt

\begin{tabular}{|c|c|c|c|c|c|}
\hline CHEMBL3675411 & 1528048 & 8.8861 & 8.7513 & TRN & \\
\hline CHEMBL3675521 & 1528048 & 8.4283 & 8.1736 & TRN & \\
\hline CHEMBL3675441 & 1528048 & 9.7959 & 9.6068 & TRN & \\
\hline CHEMBL 3675520 & 1528048 & 8.9586 & 8.8769 & TRN & \\
\hline CHEMBL3670484 & 1528048 & 5.8861 & 5.2015 & TRN & \\
\hline CHEMBL3670499 & 1528048 & 9.4949 & 7.311 & TRN & \\
\hline CHEMBL3680557 & 1528048 & 9.5229 & 8.8142 & TRN & \\
\hline CHEMBL3680605 & 1528048 & 8.3768 & 8.7088 & TST & \\
\hline CHEMBL3670457 & 1528048 & 5.6021 & 6.2648 & TRN & \\
\hline CHEMBL3675481 & 1528048 & 8.6576 & 8.6272 & TRN & \\
\hline CHEMBL 3680543 & 1528048 & 9.8239 & 9.0237 & TRN & \\
\hline CHEMBL3680417 & 1528048 & 9.6383 & 9.5531 & TRN & \\
\hline CHEMBL 3675473 & 1528048 & 6.1739 & 6.6176 & TRN & \\
\hline CHEMBL 3685243 & 1528048 & 9.7696 & 9.2333 & TRN & \\
\hline CHEMBL3956997 & 1528048 & 8.5528 & 6.8265 & TST & \\
\hline CHEMBL3680451 & 1528048 & 7.699 & 7.9291 & TRN & \\
\hline CHEMBL3675365 & 1528048 & 6.1308 & 6.5764 & TRN & \\
\hline CHEMBL3670487 & 1528048 & 8.301 & 8.5048 & TRN & \\
\hline CHEMBL 3675386 & 1528048 & 5.4685 & 5.8177 & TRN & \\
\hline CHEMBL3670439 & 1528048 & 9.1805 & 7.2456 & TRN & \\
\hline CHEMBL3680387 & 1528048 & 9.1612 & 9.0556 & TRN & \\
\hline CHEMBL3685227 & 1528048 & 7.3279 & 8.3609 & TRN & \\
\hline CHEMBL 3680553 & 1528048 & 9.6576 & 6.3738 & TST & \\
\hline CHEMBL 3685310 & 1528048 & 9.585 & 8.9561 & TRN & \\
\hline CHEMBL3670472 & 1528048 & 8.585 & 7.67899 & 9999999999 & TRN \\
\hline CHEMBL3675326 & 1528048 & 6.5528 & 7.0511 & TRN & \\
\hline CHEMBL3675490 & 1528048 & 9.1367 & 9.4165 & TRN & \\
\hline CHEMBL3685302 & 1528048 & 7.6198 & 8.1151 & TRN & \\
\hline CHEMBL 3675448 & 1528048 & 9.2076 & 9.2818 & TST & \\
\hline CHEMBL3680411 & 1528048 & 8.301 & 8.9458 & TRN & \\
\hline CHEMBL3685222 & 1528048 & 7.4949 & 7.7974 & TST & \\
\hline CHEMBL 3675447 & 1528048 & 9.4815 & 9.3302 & TRN & \\
\hline CHEMBL 3675403 & 1528048 & 9.7696 & 9.9876 & TRN & \\
\hline CHEMBL 3675351 & 1528048 & 5.0 & 5.9769 & TRN & \\
\hline CHEMBL3675506 & 1528048 & 9.1367 & 8.9456 & TRN & \\
\hline CHEMBL3685256 & 1528048 & 10.0969 & 8.6293 & TST & \\
\hline CHEMBL 3680524 & 1528048 & 6.3279 & 6.8957 & TRN & \\
\hline CHEMBL 3675524 & 1528048 & 10.0458 & 9.2734 & TRN & \\
\hline CHEMBL 3675489 & 1528048 & 6.2441 & 6.9602 & TRN & \\
\hline CHEMBL 3685221 & 1528048 & 7.5376 & 8.1744 & TRN & \\
\hline CHEMBL3685217 & 1528048 & 7.699 & 8.8337 & TRN & \\
\hline CHEMBL3675374 & 1528048 & 5.9208 & 6.4669 & TRN & \\
\hline CHEMBL3670474 & 1528048 & 9.4089 & 9.3972 & TRN & \\
\hline CHEMBL 3680436 & 1528048 & 9.2757 & 8.2429 & TRN & \\
\hline CHEMBL3639693 & 1528048 & 8.8239 & 9.0159 & TRN & \\
\hline CHEMBL3675526 & 1528048 & 6.8539 & 6.2799 & TRN & \\
\hline CHEMBL3675398 & 1528048 & 9.3565 & 9.4054 & TRN & \\
\hline CHEMBL3675372 & 1528048 & 6.3872 & 5.1113 & TRN & \\
\hline
\end{tabular}


Supplemental Table S2.txt

\begin{tabular}{|c|c|c|c|c|c|}
\hline CHEMBL 3675434 & 1528048 & 6.9586 & 6.6377 & TRN & \\
\hline CHEMBL3670409 & 1528048 & 6.0 & 6.2663 & TST & \\
\hline CHEMBL 3685242 & 1528048 & 9.6576 & 8.0757 & TST & \\
\hline CHEMBL3675415 & 1528048 & 6.6383 & 6.3244 & TRN & \\
\hline CHEMBL 3685229 & 1528048 & 8.0088 & 7.8869 & TST & \\
\hline CHEMBL3670430 & 1528048 & 5.8539 & 5.8123 & TRN & \\
\hline CHEMBL3680555 & 1528048 & 9.585 & 9.1845 & TRN & \\
\hline CHEMBL 3685202 & 1528048 & 9.0 & 8.1231 & TRN & \\
\hline CHEMBL 3675512 & 1528048 & 9.0269 & 8.1498 & TRN & \\
\hline CHEMBL 3675353 & 1528048 & 9.4318 & 7.0551 & TRN & \\
\hline CHEMBL 3675417 & 1528048 & 9.6021 & 9.3771 & TRN & \\
\hline CHEMBL3675356 & 1528048 & 7.0 & 6.8009 & TRN & \\
\hline CHEMBL 3685240 & 1528048 & 9.3279 & 9.0954 & TRN & \\
\hline CHEMBL 3675390 & 1528048 & 5.0 & 6.8066 & TRN & \\
\hline CHEMBL 3685267 & 1528048 & 9.4815 & 8.247 & TRN & \\
\hline CHEMBL 3680441 & 1528048 & 6.1612 & 5.2409 & TST & \\
\hline CHEMBL 3675370 & 1528048 & 5.3098 & 6.6478 & TRN & \\
\hline CHEMBL 3680464 & 1528048 & 9.0506 & 9.2051 & TRN & \\
\hline CHEMBL 3680508 & 1528048 & 9.2441 & 7.636 & TRN & \\
\hline CHEMBL 3675334 & 1528048 & 6.0 & 8.2531 & TST & \\
\hline CHEMBL 3675362 & 1528048 & 5.7447 & 6.7097 & TRN & \\
\hline CHEMBL3685209 & 1528048 & 8.0655 & 8.4968 & TRN & \\
\hline CHEMBL 3680497 & 1528048 & 8.3565 & 9.3615 & TRN & \\
\hline CHEMBL 3680487 & 1528048 & 8.0555 & 8.2063 & TRN & \\
\hline CHEMBL 3685246 & 1528048 & 9.699 & 9.2743 & TRN & \\
\hline CHEMBL 3675463 & 1528048 & 9.6576 & \multicolumn{2}{|c|}{9.277000000000001} & TRN \\
\hline CHEMBL3680532 & 1528048 & 9.9208 & 9.3138 & TRN & \\
\hline CHEMBL 3680548 & 1528048 & 9.7212 & 8.7787 & TRN & \\
\hline CHEMBL 3675437 & 1528048 & 6.0 & 8.9097 & TRN & \\
\hline CHEMBL 3670418 & 1528048 & 5.585 & \multicolumn{2}{|c|}{6.388999999999999} & TST \\
\hline CHEMBL 3680597 & 1528048 & 8.6383 & 9.03 & TRN & \\
\hline CHEMBL 3675465 & 1528048 & 6.0 & 8.1337 & TRN & \\
\hline CHEMBL 3685225 & 1528048 & 7.4437 & 7.9543 & TRN & \\
\hline CHEMBL 3675508 & 1528048 & \multicolumn{3}{|c|}{10.300999999999998} & TRN \\
\hline CHEMBL 3670465 & 1528048 & 8.0757 & 8.0279 & TRN & \\
\hline CHEMBL 3670473 & 1528048 & 8.9586 & 9.361 & TRN & \\
\hline CHEMBL 3675516 & 1528048 & 9.7959 & 9.3748 & TRN & \\
\hline CHEMBL 3670444 & 1528048 & 5.041 & 7.5856 & TRN & \\
\hline CHEMBL 3680577 & 1528048 & 9.0 & 8.934 & TRN & \\
\hline CHEMBL 3680564 & 1528048 & 9.2757 & 9.4779 & TRN & \\
\hline CHEMBL 3670431 & 1528048 & 5.8239 & 6.3984 & TRN & \\
\hline CHEMBL3685297 & 1528048 & 8.9586 & 8.646 & TRN & \\
\hline CHEMBL 3675393 & 1528048 & 6.6383 & 6.4911 & TRN & \\
\hline CHEMBL 3675364 & 1528048 & 6.2441 & 7.2276 & TRN & \\
\hline CHEMBL 3680559 & 1528048 & 9.4815 & 8.9844 & TRN & \\
\hline CHEMBL 3675377 & 1528048 & 6.1805 & 6.9463 & TRN & \\
\hline CHEMBL3675341 & 1528048 & 6.4685 & 6.0169 & TRN & \\
\hline CHEMBL 3685331 & 1528048 & 6.1878 & 6.2083 & TRN & \\
\hline
\end{tabular}

Page 26531 
Supplemental Table S2.txt

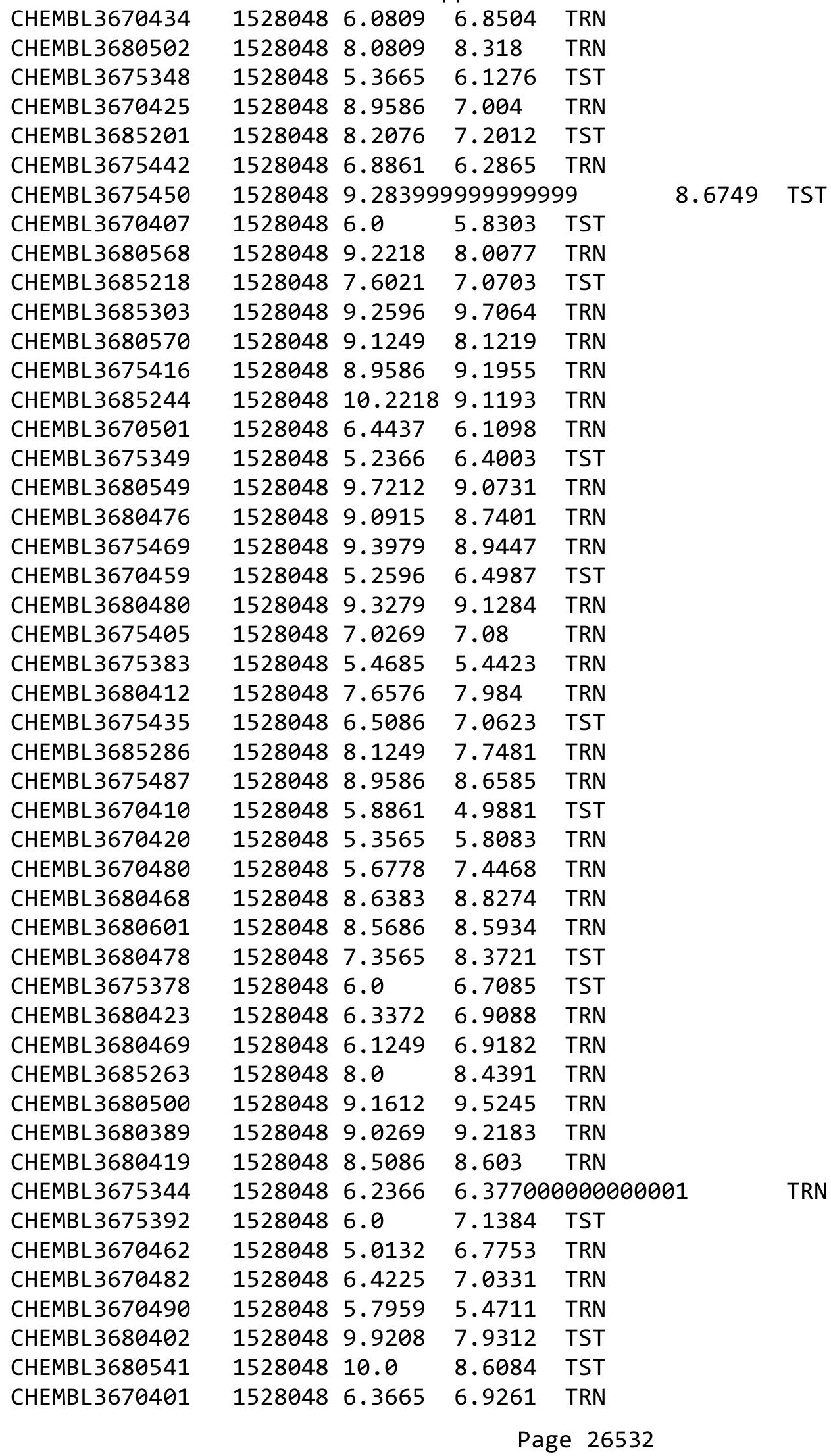


Supplemental Table S2.txt

\begin{tabular}{|c|c|c|c|c|}
\hline CHEMBL 3685253 & 1528048 & 8.4815 & 8.0427 & TRN \\
\hline CHEMBL 3670443 & 1528048 & 6.1427 & 6.6733 & TRN \\
\hline CHEMBL3675493 & 1528048 & 8.8861 & 8.7925 & TRN \\
\hline CHEMBL 3680560 & 1528048 & 9.4318 & 9.4135 & TRN \\
\hline CHEMBL3680513 & 1528048 & 7.9208 & 9.0144 & TRN \\
\hline CHEMBL3685307 & 1528048 & 9.9208 & 8.9647 & TRN \\
\hline CHEMBL3670452 & 1528048 & 6.6778 & 6.5761 & TRN \\
\hline CHEMBL3685216 & 1528048 & 7.7212 & 7.5474 & TST \\
\hline CHEMBL 3675321 & 1528048 & 8.1739 & 7.4418 & TRN \\
\hline CHEMBL3680536 & 1528048 & 6.0 & 6.9405 & TST \\
\hline CHEMBL3680425 & 1528048 & 8.0969 & 8.9786 & TRN \\
\hline CHEMBL3680438 & 1528048 & 6.0 & 8.3884 & TRN \\
\hline CHEMBL 3675446 & 1528048 & 9.9208 & 9.7758 & TRN \\
\hline CHEMBL3675327 & 1528048 & 6.3098 & 6.354 & TST \\
\hline CHEMBL 3680458 & 1528048 & 8.2596 & 8.4839 & TST \\
\hline CHEMBL 3675361 & 1528048 & 5.7696 & 6.7424 & TST \\
\hline CHEMBL3685252 & 1528048 & 9.7696 & 8.746 & TST \\
\hline CHEMBL 3675436 & 1528048 & 9.3979 & 10.1396 & TST \\
\hline CHEMBL3685235 & 1528048 & 9.3565 & 8.73200 & 0000000001 \\
\hline CHEMBL3685308 & 1528048 & 9.7447 & 9.2444 & TST \\
\hline CHEMBL3670413 & 1528048 & 6.0 & 6.0749 & TST \\
\hline CHEMBL3639743 & 1528048 & 6.0 & 8.9907 & TST \\
\hline CHEMBL3685269 & 1528048 & 8.1079 & 8.5012 & TST \\
\hline CHEMBL 3675335 & 1528048 & 5.8297 & 8.1653 & TST \\
\hline CHEMBL3685296 & 1528048 & 8.1079 & 8.1787 & TST \\
\hline CHEMBL3670493 & 1528048 & 7.5376 & 8.8287 & TST \\
\hline CHEMBL3680405 & 1528048 & 6.8539 & 6.62 & TST \\
\hline CHEMBL 3685238 & 1528048 & 8.0 & 8.2588 & TST \\
\hline CHEMBL3670453 & 1528048 & 8.3279 & 7.1684 & TST \\
\hline CHEMBL3670416 & 1528048 & 8.1427 & 6.16700 & 2000000001 \\
\hline CHEMBL 3675343 & 1528048 & 7.0362 & 5.9197 & TST \\
\hline CHEMBL3680512 & 1528048 & 8.8539 & 8.9612 & TST \\
\hline CHEMBL3670506 & 1528048 & 7.0555 & 6.4073 & TST \\
\hline CHEMBL3680488 & 1528048 & 9.9208 & 8.145 & TST \\
\hline CHEMBL3685237 & 1528048 & 9.9208 & 8.9714 & TST \\
\hline CHEMBL3675402 & 1528048 & 9.1192 & 8.8754 & TST \\
\hline CHEMBL3675329 & 1528048 & 5.8239 & 6.86299 & 99999999995 \\
\hline CHEMBL 3675449 & 1528048 & 9.0044 & 9.1714 & TST \\
\hline CHEMBL 3680546 & 1528048 & 9.7696 & 9.0242 & TST \\
\hline CHEMBL3680454 & 1528048 & 9.3979 & 8.7038 & TST \\
\hline CHEMBL 3675322 & 1528048 & 5.1249 & 7.4464 & TST \\
\hline CHEMBL3680505 & 1528048 & 8.301 & 8.5735 & TST \\
\hline CHEMBL 3675427 & 1528048 & 9.4685 & 9.23 & TST \\
\hline CHEMBL3680462 & 1528048 & 9.2518 & 8.7413 & TST \\
\hline CHEMBL3680562 & 1528048 & 9.3098 & 8.6668 & TST \\
\hline CHEMBL3670408 & 1528048 & 5.0 & 5.9942 & TST \\
\hline CHEMBL 3675338 & 1528048 & 5.0 & 5.7308 & TST \\
\hline CHEMBL 3680443 & 1528048 & 9.2147 & 8.8458 & TST \\
\hline
\end{tabular}


Supplemental Table S2.txt

\begin{tabular}{|c|c|c|c|c|}
\hline HEMBL & 528048 & 6.2596 & 6.0152 & TST \\
\hline HEMBL3685258 & 528048 & 9.1427 & 8.8541 & \\
\hline HEMBL & 28048 & 315 & & \\
\hline AEMBL3680535 & 28048 & 2147 & 4092 & \\
\hline HEMBL3680571 & 528048 & 9.0809 & .367 & \\
\hline HEMBL3670467 & 528048 & 9.5376 & 2974 & \\
\hline HEMBL3675438 & 528048 & 7.8239 & $\partial 107$ & \\
\hline HEMBL3685219 & 528048 & 7.5686 & 3012 & \\
\hline HEMBL3680432 & 528048 & 8.2147 & 9.3949 & \\
\hline HEMBL3685233 & 528048 & 9.6021 & .7522 & \\
\hline HEMBL3675455 & 528048 & 9.5686 & 2902 & \\
\hline 70415 & 528048 & 6.6383 & 5304 & \\
\hline 80484 & 528048 & 229 & 717 & \\
\hline HEMBL3675475 & 528048 & 9.4089 & 6252 & \\
\hline HEMBL3670461 & 528048 & 5.4559 & & \\
\hline HEMBL 3943 & 528048 & 8. & 98 & \\
\hline HEMBL3 & 528048 & 6 & 73 & 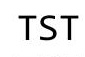 \\
\hline 75488 & 528048 & 08 & 42 & \\
\hline HEMBL3675366 & 528048 & 39 & 19 & \\
\hline HEMBL3670479 & 528048 & 9.2 & & 1. \\
\hline HEMBL3 & 528048 & 6 & 14 & | \\
\hline HEMBL & 28048 & & & \\
\hline HEMBL & 528048 & 076 & & \\
\hline HEMBL3685230 & 528048 & 924 & & IST \\
\hline HEMBL 3680422 & 528048 & 6.3979 & 8 & SI \\
\hline HEMBL36804 & 528048 & 79 & & ST \\
\hline HEMBL & 8048 & 52 & & ST \\
\hline HEMBL & 48 & 959 & & \\
\hline HEMBL3675514 & 528048 & & & IST \\
\hline HEMBL3680561 & 528048 & 9.3372 & 941 & ГST \\
\hline HEMBL3 & 528048 & 5.7212 & 56 & \\
\hline HEMBL: & $\theta 0$ & 7. & & RN \\
\hline HEMBLI & & 8 . & & TRN \\
\hline HEMBL2047258 & 300 & & & ST \\
\hline HEMBL 2047259 & 8300 & 6 & 3936 & ГST \\
\hline HEMBL 2 & 00 & 5 & 82 & ST \\
\hline 1 & $\partial 0$ & 5 & & ST \\
\hline HEMBL2047262 & & 5.7 & & TST \\
\hline HEMBL1938843 & 8300 & 5 & 51 & TST \\
\hline IEMBL2 & 300 & 7 & & 「RN \\
\hline HEMBL2047264 & 300 & 7. & 88 & \\
\hline HEMBL 2047265 & 300 & 6. & 14 & $\mathrm{RN}$ \\
\hline HEMBL2047266 & 28300 & 6.8 & 507 & TRN \\
\hline CHEMBL 20472 & 300 & 6. & & TR \\
\hline HEM & & 6 & & \\
\hline HEMBL2047269 & 28300 & 5 & 82 & \\
\hline CHEMBL436381 & 828300 & 7.8 & 7.8278 & RN \\
\hline CHEMBL128088 & 828300 & 7.3 & 7.3246 & TRN \\
\hline
\end{tabular}

Page 26534 


\begin{tabular}{|c|c|c|c|c|}
\hline & & & ET & al Ta \\
\hline CHEMBL128637 & 828300 & 6.0 & 5.8384 & TRN \\
\hline CHEMBL128958 & 828300 & 7.6 & 7.8547 & TRN \\
\hline CHEMBL 2047270 & 828300 & 7.1 & 6.0323 & TST \\
\hline CHEMBL 340740 & 828300 & 7.5 & 7.6325 & TRN \\
\hline CHEMBL 2047271 & 828300 & 4.9 & 4.7383 & TRN \\
\hline CHEMBL 2047272 & 828300 & 6.8 & 7.0486 & TRN \\
\hline CHEMBL1437043 & 828300 & 4.8 & 4.9207 & TRN \\
\hline CHEMBL 2047273 & 828300 & 7.6 & 7.176 & TRN \\
\hline CHEMBL 2047274 & 828300 & 5.7 & 5.3303 & TST \\
\hline CHEMBL 2047275 & 828300 & 7.1 & 6.9213 & TRN \\
\hline CHEMBL 2047276 & 828300 & 7.7 & 7.4597 & TRN \\
\hline CHEMBL338051 & 828300 & 7.7 & 7.6607 & TRN \\
\hline CHEMBL129488 & 828300 & 7.9 & 7.5149 & TRN \\
\hline CHEMBL 2047440 & 828300 & 5.6 & 5.7716 & TRN \\
\hline CHEMBL 2047441 & 828300 & 6.1 & 5.9547 & TRN \\
\hline CHEMBL129540 & 828300 & 7.8 & 7.4873 & TRN \\
\hline CHEMBL 2047442 & 828300 & 6.0 & 6.0647 & TRN \\
\hline CHEMBL 2047443 & 828300 & 7.4 & 7.2854 & TRN \\
\hline CHEMBL 2047444 & 828300 & 6.2 & 6.1873 & TRN \\
\hline CHEMBL 2047445 & 828300 & 6.4 & 6.4847 & TRN \\
\hline CHEMBL 2047446 & 828300 & 7.1 & 7.1007 & TRN \\
\hline CHEMBL 2047447 & 828300 & 8.2 & 8.3314 & TRN \\
\hline CHEMBL129436 & 828300 & 8.2 & 8.1209 & TRN \\
\hline CHEMBL 2047448 & 828300 & 8.2 & 8.184 & TRN \\
\hline CHEMBL2047449 & 828300 & 8.2 & 8.1143 & TRN \\
\hline CHEMBL 2047450 & 828300 & 8.3 & 8.2845 & TRN \\
\hline CHEMBL 2047451 & 828300 & 7.9 & 7.9011 & TRN \\
\hline CHEMBL 2047452 & 828300 & 6.6 & 6.8695 & TST \\
\hline CHEMBL 2047453 & 828300 & 6.7 & 7.1533 & TST \\
\hline CHEMBL 2047454 & 828300 & 7.5 & 7.6956 & TST \\
\hline CHEMBL 2047455 & 828300 & 7.4 & 7.2115 & TRN \\
\hline CHEMBL 2047456 & 828300 & 6.4 & 6.5191 & TRN \\
\hline CHEMBL 2047457 & 828300 & 5.3 & 5.1294 & TRN \\
\hline CHEMBL 2047458 & 828300 & 6.6 & 6.688 & TRN \\
\hline CHEMBL 2047459 & 828300 & 4.8 & 4.8063 & TRN \\
\hline CHEMBL 2047460 & 828300 & 6.4 & 6.4509 & TRN \\
\hline CHEMBL 2047461 & 828300 & 5.8 & 6.4858 & TRN \\
\hline CHEMBL 2047462 & 828300 & 7.4 & 6.9268 & TST \\
\hline CHEMBL 2047463 & 828300 & 7.0 & 7.0716 & TRN \\
\hline CHEMBL 2047464 & 828300 & 6.3 & 6.1386 & TST \\
\hline CHEMBL 2047465 & 828300 & 6.4 & 6.4203 & TST \\
\hline CHEMBL 2047466 & 828300 & 8.0 & 7.6521 & TST \\
\hline CHEMBL 2047467 & 828300 & 7.2 & 7.1162 & TRN \\
\hline CHEMBL 2047468 & 828300 & 7.2 & 7.2369 & TRN \\
\hline CHEMBL 2047469 & 828300 & 7.5 & 7.3822 & TRN \\
\hline CHEMBL 2047470 & 828300 & 7.8 & 7.6772 & TST \\
\hline CHEMBL 2047471 & 828300 & 7.0 & 7.1736 & TST \\
\hline CHEMBL 2047472 & 828300 & 6.6 & 6.9011 & TST \\
\hline
\end{tabular}




\begin{tabular}{|c|c|c|c|c|c|}
\hline & & \\
\hline CHEMBL 2047473 & 828300 & 7.7 & 7.8256 & TRN & \\
\hline CHEMBL 2047474 & 828300 & 6.4 & 6.5285 & TRN & \\
\hline CHEMBL 2047475 & 828300 & 7.4 & 7.4107 & TRN & \\
\hline CHEMBL 2047476 & 828300 & 7.1 & 7.1412 & TRN & \\
\hline CHEMBL503605 & 828300 & 7.9 & 7.8593 & TRN & \\
\hline CHEMBL 2426470 & 983404 & 4.0 & 4.0565 & TRN & \\
\hline CHEMBL 2426479 & 983404 & 4.0 & 4.0207 & TRN & \\
\hline CHEMBL 2426467 & 983404 & 4.0 & 3.9808 & TRN & \\
\hline CHEMBL 2426365 & 983404 & 4.0 & 3.9855 & TRN & \\
\hline CHEMBL2426477 & 983404 & 4.0 & 4.0179 & TRN & \\
\hline CHEMBL 2426480 & 983404 & 4.0 & 3.9902 & TRN & \\
\hline CHEMBL 2426496 & 983404 & 4.0 & 3.9129 & TRN & \\
\hline CHEMBL 2426476 & 983404 & 5.1079 & 5.085 & TRN & \\
\hline CHEMBL 2426483 & 983404 & 5.0915 & 5.0923 & TRN & \\
\hline CHEMBL2426361 & 983404 & 4.0 & 3.9778 & TRN & \\
\hline CHEMBL 2426486 & 983404 & 4.0 & $4.0280 e$ & 00000000005 & TRN \\
\hline CHEMBL 2426471 & 983404 & 4.0 & 3.9753 & TRN & \\
\hline CHEMBL 2426484 & 983404 & 5.0 & 5.0997 & TRN & \\
\hline CHEMBL 2426360 & 983404 & 5.2441 & 5.2297 & TRN & \\
\hline CHEMBL1235119 & 983404 & 4.0 & 4.7082 & TST & \\
\hline CHEMBL 2426494 & 983404 & 4.0 & 4.0125 & TRN & \\
\hline CHEMBL 2426474 & 983404 & 5.3098 & 5.0997 & TRN & \\
\hline CHEMBL 2424678 & 983404 & 4.0 & 4.0088 & TRN & \\
\hline CHEMBL 2426376 & 983404 & 5.4559 & 6.1031 & TST & \\
\hline CHEMBL 2426468 & 983404 & 4.0 & 4.0695 & TST & \\
\hline CHEMBL 2426469 & 983404 & 4.0 & 3.9129 & TRN & \\
\hline CHEMBL 2426375 & 983404 & 4.0 & 5.7232 & TST & \\
\hline CHEMBL 2426488 & 983404 & 4.0 & 4.0343 & TRN & \\
\hline CHEMBL 2426491 & 983404 & 4.0 & 3.9984 & TRN & \\
\hline CHEMBL 2426495 & 983404 & 4.0 & 3.9745 & TRN & \\
\hline CHEMBL 2426463 & 983404 & 4.0 & 4.7843 & TST & \\
\hline CHEMBL 2426366 & 983404 & 5.1675 & 5.1748 & TRN & \\
\hline CHEMBL 2426481 & 983404 & 5.2676 & 5.2844 & TRN & \\
\hline CHEMBL 2426473 & 983404 & 4.0 & 4.42399 & 99999999995 & TST \\
\hline CHEMBL 2426368 & 983404 & 4.0 & 4.0217 & TRN & \\
\hline CHEMBL 2426464 & 983404 & 4.0 & 4.0514 & TRN & \\
\hline CHEMBL 2426363 & 983404 & 4.0 & 4.0357 & TRN & \\
\hline CHEMBL 2424677 & 983404 & 5.2924 & 6.1674 & TST & \\
\hline CHEMBL 2426498 & 983404 & 4.0 & 4.1368 & TRN & \\
\hline CHEMBL 2426466 & 983404 & 4.0 & 3.9536 & TRN & \\
\hline CHEMBL 2426472 & 983404 & 5.3979 & 5.3836 & TRN & \\
\hline CHEMBL 2426364 & 983404 & 5.0458 & 5.0559 & TRN & \\
\hline CHEMBL 2426358 & 983404 & 4.0 & 3.9957 & TST & \\
\hline CHEMBL 2426489 & 983404 & 4.0 & 4.006 & TRN & \\
\hline CHEMBL 2426490 & 983404 & 5.2596 & 5.2645 & TRN & \\
\hline CHEMBL 2426475 & 983404 & 4.0 & 3.9841 & TRN & \\
\hline CHEMBL 2426497 & 983404 & 4.0 & 4.0095 & TRN & \\
\hline CHEMBL 2426478 & 983404 & 4.0 & 3.9417 & TRN & \\
\hline & & & & 26536 & \\
\hline
\end{tabular}




\begin{tabular}{|c|c|c|c|c|}
\hline \multicolumn{5}{|c|}{ Supplemental Table S2.txt } \\
\hline CHEMBL 2426462 & 983404 & 4.0 & 3.9743 & TRN \\
\hline CHEMBL 2426374 & 983404 & 4.0 & 4.7954 & TST \\
\hline CHEMBL2426485 & 983404 & 5.0132 & 5.0997 & TRN \\
\hline CHEMBL 2426492 & 983404 & 4.0 & 4.0574 & TRN \\
\hline CHEMBL 2426367 & 983404 & 5.0315 & 5.0221 & TRN \\
\hline CHEMBL 2426461 & 983404 & 4.0 & 4.003 & TRN \\
\hline CHEMBL 2426482 & 983404 & 5.0862 & 5.0805 & TRN \\
\hline CHEMBL2426362 & 983404 & 4.0 & 3.9887 & TRN \\
\hline CHEMBL 2426487 & 983404 & 5.0915 & 5.3731 & TST \\
\hline CHEMBL 2426465 & 983404 & 4.0 & 3.965 & TST \\
\hline CHEMBL 2426493 & 983404 & 4.0 & 3.7968 & TST \\
\hline CHEMBL 2426359 & 983404 & 4.0 & 3.9774 & TST \\
\hline CHEMBL 2426373 & 983404 & 4.0 & 4.9202 & TST \\
\hline CHEMBL1643959 & 954387 & 5.0665 & 5.099 & TRN \\
\hline CHEMBL191334 & 954387 & 3.84 & 3.8504 & TRN \\
\hline CHEMBL209148 & 954387 & 4.9531 & 4.8814 & TRN \\
\hline CHEMBL472940 & 954387 & 2.6006 & 2.667 & TRN \\
\hline CHEMBL399530 & 954387 & 3.1311 & 3.1279 & TRN \\
\hline CHEMBL 2137530 & 954387 & 4.5029 & 4.5908 & TRN \\
\hline CHEMBL512504 & 954387 & 4.3774 & 4.3912 & TRN \\
\hline CHEMBL3199475 & 954387 & 3.6078 & 3.6154 & TRN \\
\hline CHEMBL483847 & 954387 & 4.6794 & 4.7426 & TRN \\
\hline CHEMBL65 & 954387 & 7.4194 & 7.4174 & TRN \\
\hline CHEMBL259181 & 954387 & 3.8546 & 3.8336 & TRN \\
\hline CHEMBL220241 & 954387 & 3.7958 & 3.7408 & TRN \\
\hline CHEMBL 2144069 & 954387 & 6.1722 & 6.1996 & TRN \\
\hline CHEMBL1190711 & 954387 & 5.0718 & 5.0331 & TRN \\
\hline CHEMBL373751 & 954387 & 3.8072 & 3.8662 & TRN \\
\hline CHEMBL 2005886 & 954387 & 6.7221 & 6.7413 & TRN \\
\hline CHEMBL 188678 & 954387 & 4.1745 & 4.2891 & TRN \\
\hline CHEMBL379975 & 954387 & 4.096 & 4.0793 & TRN \\
\hline CHEMBL210618 & 954387 & 4.0592 & 4.0074 & TRN \\
\hline CHEMBL213100 & 954387 & 6.2875 & 6.3248 & TRN \\
\hline CHEMBL92309 & 954387 & 2.7779 & 3.0473 & TST \\
\hline CHEMBL9470 & 954387 & 4.9528 & 5.2075 & TST \\
\hline CHEMBL3349342 & 954387 & 4.4715 & 4.4741 & TRN \\
\hline CHEMBL1357247 & 954387 & 3.5948 & 3.6811 & TRN \\
\hline CHEMBL180127 & 954387 & 4.3079 & 4.2731 & TRN \\
\hline CHEMBL1970879 & 954387 & 6.4127 & 6.3839 & TRN \\
\hline CHEMBL102714 & 954387 & 3.4564 & 3.5475 & TRN \\
\hline CHEMBL217354 & 954387 & 5.9499 & 5.8947 & TRN \\
\hline CHEMBL 255342 & 954387 & 3.8439 & 3.765 & TRN \\
\hline CHEMBL202721 & 954387 & 4.8266 & 4.8791 & TRN \\
\hline CHEMBL483849 & 954387 & 2.6553 & 2.4508 & TST \\
\hline CHEMBL1242367 & 954387 & 4.3793 & 4.3412 & TRN \\
\hline CHEMBL515416 & 954387 & 4.7161 & 4.7295 & TRN \\
\hline CHEMBL 258844 & 954387 & 5.2399 & 5.1593 & TRN \\
\hline CHEMBL3186408 & 954387 & 3.5974 & 3.8609 & TST \\
\hline
\end{tabular}




\begin{tabular}{|c|c|c|c|c|c|}
\hline \multicolumn{6}{|c|}{ Supplemental Table S2.txt } \\
\hline CHEMBL585951 & 954387 & 6.3251 & 6.3405 & TRN & \\
\hline CHEMBL 2363137 & 954387 & 5.6895 & 5.7256 & TRN & \\
\hline CHEMBL558642 & 954387 & 4.6576 & 4.6031 & TRN & \\
\hline CHEMBL393929 & 954387 & 3.5557 & 3.4889 & TRN & \\
\hline CHEMBL573107 & 954387 & 4.9407 & 4.9457 & TRN & \\
\hline CHEMBL1516890 & 954387 & 4.3738 & 4.2711 & TRN & \\
\hline CHEMBL1590308 & 954387 & 3.6392 & 3.8002 & TST & \\
\hline CHEMBL135561 & 954387 & 4.2228 & 4.2182 & TRN & \\
\hline CHEMBL 222102 & 954387 & 4.4833 & 4.4261 & TRN & \\
\hline CHEMBL379300 & 954387 & 6.7368 & 6.7547 & TRN & \\
\hline CHEMBL221137 & 954387 & 5.0315 & 4.5096 & TST & \\
\hline CHEMBL 300389 & 954387 & 6.7234 & 6.7159 & TRN & \\
\hline CHEMBL412142 & 954387 & 4.4835 & 4.4116 & TRN & \\
\hline CHEMBL514499 & 954387 & 7.841 & 7.8257 & TRN & \\
\hline CHEMBL1256459 & 954387 & 7.4411 & 7.4451 & TRN & \\
\hline CHEMBL1673039 & 954387 & 3.9698 & 4.0254 & TRN & \\
\hline CHEMBL577784 & 954387 & 4.4902 & 4.4751 & TRN & \\
\hline CHEMBL192566 & 954387 & 8.8428 & 8.7332 & TST & \\
\hline CHEMBL509032 & 954387 & 6.5551 & 6.5857 & TRN & \\
\hline CHEMBL1788116 & 954387 & 4.9929 & 5.015 & TRN & \\
\hline CHEMBL1404918 & 954387 & 3.128 & 2.8349 & TST & \\
\hline CHEMBL1230020 & 954387 & 4.7491 & 4.2646 & TST & \\
\hline CHEMBL1186585 & 954387 & 3.8986 & 4.5148 & TST & \\
\hline CHEMBL392695 & 954387 & 6.2204 & 5.5439 & TST & \\
\hline CHEMBL189584 & 954387 & 4.2384 & 4.6671 & TST & \\
\hline CHEMBL449158 & 954387 & 7.495 & 6.897 & TST & \\
\hline CHEMBL3392440 & 954387 & 3.9548 & 4.3225 & TST & \\
\hline CHEMBL240954 & 954387 & 4.3086 & 3.80800 & 00000000003 & TST \\
\hline CHEMBL 2134202 & 954387 & 3.1332 & 4.3763 & TST & \\
\hline CHEMBL 222102 & 954810 & 3.9618 & 3.9618 & TRN & \\
\hline CHEMBL509032 & 954810 & 5.8361 & 5.8361 & TRN & \\
\hline CHEMBL3349342 & 954810 & 7.7366 & 7.7366 & TRN & \\
\hline CHEMBL512504 & 954810 & 4.1676 & 4.1676 & TRN & \\
\hline CHEMBL585951 & 954810 & 6.245 & 6.245 & TRN & \\
\hline CHEMBL393929 & 954810 & 4.1124 & 4.1124 & TRN & \\
\hline CHEMBL 9470 & 954810 & 6.7451 & 6.0582 & TST & \\
\hline CHEMBL188678 & 954810 & 5.0013 & 5.0013 & TRN & \\
\hline CHEMBL515416 & 954810 & 3.9628 & 3.9628 & TRN & \\
\hline CHEMBL573107 & 954810 & 6.2974 & 6.2974 & TRN & \\
\hline CHEMBL220241 & 954810 & 3.9685 & 3.9685 & TRN & \\
\hline CHEMBL1590308 & 954810 & 2.4681 & 3.0129 & TST & \\
\hline CHEMBL1357247 & 954810 & 3.7477 & 3.7477 & TRN & \\
\hline CHEMBL2363137 & 954810 & 5.1063 & 5.1063 & TRN & \\
\hline CHEMBL449158 & 954810 & 7.5056 & 6.9714 & TST & \\
\hline CHEMBL379300 & 954810 & 6.0966 & 6.0966 & TRN & \\
\hline CHEMBL 202721 & 954810 & 4.9035 & 4.9035 & TRN & \\
\hline CHEMBL65 & 954810 & 8.5133 & 8.5133 & TRN & \\
\hline CHEMBL192566 & 954810 & 8.2242 & 8.59700 & 0000000001 & ובנ \\
\hline & & & & 26538 & \\
\hline
\end{tabular}


Supplemental Table S2.txt

\begin{tabular}{|c|c|c|c|c|c|c|}
\hline CHEMBL1909414 & 954810 & 7.6282 & 7.6282 & TRN & & \\
\hline CHEMBL180127 & 954810 & 3.591 & 3.591 & TRN & & \\
\hline CHEMBL 300389 & 954810 & 6.8525 & 6.8525 & TRN & & \\
\hline CHEMBL1230020 & 954810 & 7.1274 & 7.1274 & TRN & & \\
\hline CHEMBL412142 & 954810 & 3.2915 & 3.2915 & TRN & & \\
\hline CHEMBL135561 & 954810 & 5.3585 & 5.3585 & TRN & & \\
\hline CHEMBL 209148 & 954810 & 4.598 & 4.598 & TRN & & \\
\hline CHEMBL 2005886 & 954810 & 5.2016 & 5.2016 & TRN & & \\
\hline CHEMBL221137 & 954810 & 4.878 & 5.4005 & TST & & \\
\hline CHEMBL 2144069 & 954810 & 7.9901 & 7.9901 & TRN & & \\
\hline CHEMBL1404918 & 954810 & 3.6002 & 3.6002 & TRN & & \\
\hline CHEMBL1970879 & 954810 & 4.3814 & 4.3814 & TRN & & \\
\hline CHEMBL514499 & 954810 & 7.0967 & 7.0967 & TRN & & \\
\hline CHEMBL189584 & 954810 & 4.7015 & 4.7015 & TRN & & \\
\hline CHEMBL483847 & 954810 & 3.8172 & 3.8172 & TRN & & \\
\hline CHEMBL 240954 & 954810 & 5.1164 & 4.086 & TST & & \\
\hline CHEMBL392695 & 954810 & 5.8222 & 5.8222 & TRN & & \\
\hline CHEMBL 379975 & 954810 & 5.5618 & 5.5618 & TRN & & \\
\hline CHEMBL 3186408 & 954810 & 4.0587 & 4.1758 & TST & & \\
\hline CHEMBL1190711 & 954810 & 5.6633 & 5.6633 & TRN & & \\
\hline CHEMBL3392440 & 954810 & 3.4897 & 3.4897 & TRN & & \\
\hline CHEMBL1516890 & 954810 & 3.938 & 3.938 & TRN & & \\
\hline CHEMBL472940 & 954810 & 3.6246 & 3.6246 & TRN & & \\
\hline CHEMBL92309 & 954810 & 3.0463 & 3.7973 & TST & & \\
\hline CHEMBL577784 & 954810 & 5.8886 & 5.8886 & TRN & & \\
\hline CHEMBL1242367 & 954810 & 4.7995 & 4.7995 & TRN & & \\
\hline CHEMBL3199475 & 954810 & 5.7178 & 5.7178 & TRN & & \\
\hline CHEMBL 373751 & 954810 & 3.0615 & 3.0615 & TRN & & \\
\hline CHEMBL259181 & 954810 & 5.7876 & 5.7876 & TRN & & \\
\hline CHEMBL 213100 & 954810 & 4.0253 & 4.0253 & TRN & & \\
\hline CHEMBL1643959 & 954810 & 4.1381 & 4.1381 & TRN & & \\
\hline CHEMBL558642 & 954810 & 4.2613 & 4.8768 & TST & & \\
\hline CHEMBL1673039 & 954810 & 5.0807 & 5.0263 & TST & & \\
\hline CHEMBL1788116 & 954810 & 3.8017 & 4.501 & TST & & \\
\hline CHEMBL 210618 & 954810 & 3.4922 & 3.7427 & TST & & \\
\hline CHEMBL1256459 & 954810 & 7.0379 & 7.652 & TST & & \\
\hline CHEMBL 258844 & 954810 & 4.89199 & 99999999 & 95 & 4.8909 & TST \\
\hline CHEMBL191334 & 954810 & 5.5536 & 5.4419 & TST & & \\
\hline CHEMBL 2364338 & 955103 & 9.0 & 7.7288 & TST & & \\
\hline CHEMBL 2364339 & 955103 & 7.5 & 7.7217 & TST & & \\
\hline CHEMBL 2364340 & 955103 & 7.7 & 7.3755 & TST & & \\
\hline CHEMBL 2364341 & 955103 & 7.2 & 7.4172 & TST & & \\
\hline CHEMBL 2364342 & 955103 & 8.3 & 9.2744 & TST & & \\
\hline CHEMBL 2364343 & 955103 & 8.0 & 7.7461 & TST & & \\
\hline CHEMBL 2364344 & 955103 & 7.6 & 8.4215 & TST & & \\
\hline CHEMBL2364345 & 955103 & 7.5 & 7.779 & TST & & \\
\hline CHEMBL 2364346 & 955103 & 7.8 & 8.3673 & TRN & & \\
\hline CHEMBL2364347 & 955103 & 7.5 & 7.5983 & TRN & & \\
\hline
\end{tabular}




\begin{tabular}{|c|c|c|c|c|c|}
\hline \\
\hline CHEMBL 2364348 & 955103 & 7.8 & 7.4432 & TST & \\
\hline CHEMBL 2364349 & 955103 & 6.9 & 7.2119 & TRN & \\
\hline CHEMBL 2364350 & 955103 & 6.4 & 6.8683 & TRN & \\
\hline CHEMBL 2364351 & 955103 & 7.2 & 7.2874 & TRN & \\
\hline CHEMBL2364352 & 955103 & 8.2 & 7.2348 & TST & \\
\hline CHEMBL 2364353 & 955103 & 9.0 & 8.769 & TRN & \\
\hline CHEMBL 2364354 & 955103 & 9.2 & 8.508 & TRN & \\
\hline CHEMBL 2364355 & 955103 & 7.1 & 7.4047 & TST & \\
\hline CHEMBL 2364356 & 955103 & 8.1 & 8.2137 & TRN & \\
\hline CHEMBL2364357 & 955103 & 6.9 & 6.8069 & TRN & \\
\hline CHEMBL 2364358 & 955103 & 8.0 & 8.1073 & TRN & \\
\hline CHEMBL 2364359 & 955103 & 8.0 & 8.1265 & TRN & \\
\hline CHEMBL 2364360 & 955103 & 7.8 & 7.4478 & TRN & \\
\hline CHEMBL 2364361 & 955103 & 7.3 & 6.8165 & TRN & \\
\hline CHEMBL2364362 & 955103 & 7.3 & 7.1394 & TRN & \\
\hline CHEMBL 2364363 & 955103 & 7.3 & 7.5412 & TRN & \\
\hline CHEMBL 2364364 & 955103 & 7.0 & 7.2102 & TRN & \\
\hline CHEMBL 2364365 & 955103 & 8.3 & 8.4382 & TRN & \\
\hline CHEMBL 2364366 & 955103 & 7.0 & 7.2216 & TRN & \\
\hline CHEMBL2364367 & 955103 & 8.3 & 8.2401 & TRN & \\
\hline CHEMBL 2364368 & 955103 & 7.8 & 8.273 & TRN & \\
\hline CHEMBL2364369 & 955103 & 7.6 & 7.8521 & TST & \\
\hline CHEMBL 2364370 & 955103 & 7.4 & 7.6251 & TRN & \\
\hline CHEMBL 2364371 & 955103 & 6.8 & 6.2906 & TRN & \\
\hline CHEMBL2364372 & 955103 & 8.1 & 8.3629 & TRN & \\
\hline CHEMBL 2364373 & 955103 & 7.7 & 7.2529 & TST & \\
\hline CHEMBL 2364374 & 955103 & 8.4 & 8.2673 & TRN & \\
\hline CHEMBL 2364336 & 955103 & 7.9 & 8.0777 & TRN & \\
\hline CHEMBL 2364375 & 955103 & 7.0 & 7.3064 & TRN & \\
\hline CHEMBL 2364376 & 955103 & 7.0 & 6.756 & TRN & \\
\hline CHEMBL 2364377 & 955103 & 8.0 & 7.7728 & TST & \\
\hline CHEMBL 2364378 & 955103 & 7.5 & 6.7247 & TST & \\
\hline CHEMBL2364379 & 955103 & 8.6 & 8.6241 & TRN & \\
\hline CHEMBL 2364380 & 955103 & 7.8 & 7.9716 & TRN & \\
\hline CHEMBL 2364381 & 955103 & 8.8 & 8.6318 & TRN & \\
\hline CHEMBL 2364382 & 955103 & 9.0 & 8.3944 & TRN & \\
\hline CHEMBL 2364383 & 955103 & 7.6 & 7.5984 & TRN & \\
\hline CHEMBL 2364384 & 955103 & 8.8 & 8.7272 & TRN & \\
\hline CHEMBL 2364385 & 955103 & 7.4 & 7.7829 & 99999999995 & TRN \\
\hline CHEMBL2364386 & 955103 & 7.5 & 7.0593 & TRN & \\
\hline CHEMBL 2364387 & 955103 & 7.9 & 8.0291 & TRN & \\
\hline CHEMBL 2364388 & 955103 & 7.8 & 8.0501 & TRN & \\
\hline CHEMBL 2364389 & 955103 & 7.4 & 6.8797 & TST & \\
\hline CHEMBL 2364390 & 955103 & 8.0 & 6.8486 & TST & \\
\hline CHEMBL 2364391 & 955103 & 8.2 & 8.3311 & TRN & \\
\hline CHEMBL 2364392 & 955103 & 7.8 & 7.6501 & TRN & \\
\hline CHEMBL 2364393 & 955103 & 7.7 & 6.8018 & TST & \\
\hline CHEMBL 2364394 & 955103 & 7.5 & 7.1323 & TST & \\
\hline & & & & 26540 & \\
\hline
\end{tabular}




\begin{tabular}{|c|c|c|c|c|}
\hline & & & ipplement & al lable S2 \\
\hline CHEMBL2364395 & 955103 & 8.2 & 7.9423 & TRN \\
\hline CHEMBL2364396 & 955103 & 7.6 & 7.541 & TRN \\
\hline CHEMBL2364397 & 955103 & 7.0 & 7.17700 & 00000000005 \\
\hline CHEMBL2364398 & 955103 & 8.1 & 7.9293 & TRN \\
\hline CHEMBL2364399 & 955103 & 8.7 & 8.7342 & TRN \\
\hline CHEMBL 2364400 & 955103 & 7.6 & 6.3857 & TST \\
\hline CHEMBL 2364401 & 955103 & 7.4 & 7.1274 & TRN \\
\hline CHEMBL2364402 & 955103 & 8.6 & 8.8037 & TRN \\
\hline CHEMBL 2364403 & 955103 & 9.0 & 8.7379 & TRN \\
\hline CHEMBL2364404 & 955103 & 7.7 & 7.3982 & TRN \\
\hline CHEMBL 2364405 & 955103 & 7.5 & 7.4581 & TRN \\
\hline CHEMBL2364406 & 955103 & 8.3 & 8.1403 & TRN \\
\hline CHEMBL2364407 & 955103 & 8.7 & 8.5559 & TRN \\
\hline CHEMBL 2364408 & 955103 & 9.1 & 8.9522 & TRN \\
\hline CHEMBL2364409 & 955103 & 7.1 & 7.7519 & TRN \\
\hline CHEMBL 2364410 & 955103 & 7.6 & 7.3269 & TRN \\
\hline CHEMBL2364411 & 955103 & 7.3 & 7.6132 & TRN \\
\hline CHEMBL2364412 & 955103 & 7.6 & 7.5917 & TRN \\
\hline CHEMBL2364413 & 955103 & 8.4 & 8.1863 & TRN \\
\hline CHEMBL2364414 & 955103 & 7.0 & 7.716 & TRN \\
\hline CHEMBL2364415 & 955103 & 8.6 & 8.1994 & TRN \\
\hline CHEMBL2364416 & 955103 & 7.5 & 7.4209 & TRN \\
\hline CHEMBL 2364417 & 955103 & 7.5 & 7.8252 & TRN \\
\hline CHEMBL2364418 & 955103 & 7.0 & 6.7524 & TRN \\
\hline CHEMBL2364419 & 955103 & 7.9 & 8.2764 & TRN \\
\hline CHEMBL2364420 & 955103 & 8.3 & 8.2537 & TRN \\
\hline CHEMBL 2364421 & 955103 & 7.6 & 7.9466 & TRN \\
\hline CHEMBL2364422 & 955103 & 7.7 & 7.3967 & TST \\
\hline CHEMBL2364423 & 955103 & 8.4 & 8.435 & TRN \\
\hline CHEMBL 2364424 & 955103 & 8.9 & 8.7449 & TRN \\
\hline CHEMBL2364425 & 955103 & 8.5 & 8.5509 & TRN \\
\hline CHEMBL 2364426 & 955103 & 8.8 & 8.3643 & TRN \\
\hline CHEMBL2364427 & 955103 & 9.4 & 8.8007 & TRN \\
\hline CHEMBL2364428 & 955103 & 8.6 & 8.2369 & TRN \\
\hline CHEMBL 2364429 & 955103 & 9.3 & 8.879 & TRN \\
\hline CHEMBL2364430 & 955103 & 8.8 & 8.6984 & TRN \\
\hline CHEMBL 2364431 & 955103 & 8.0 & 7.7951 & TRN \\
\hline CHEMBL 2364432 & 955103 & 8.9 & 9.0814 & TRN \\
\hline CHEMBL2364433 & 955103 & 7.9 & 8.0941 & TRN \\
\hline CHEMBL 2364434 & 955103 & 7.0 & 7.1069 & TRN \\
\hline CHEMBL2364435 & 955103 & 7.7 & 7.3927 & TRN \\
\hline CHEMBL 2364436 & 955103 & 7.5 & 7.3114 & TRN \\
\hline CHEMBL2364437 & 955103 & 8.1 & 8.1133 & TRN \\
\hline CHEMBL 2364438 & 955103 & 7.1 & 7.6155 & TRN \\
\hline CHEMBL2364439 & 955103 & 7.5 & 7.6871 & TRN \\
\hline CHEMBL2364440 & 955103 & 7.7 & 8.033 & TRN \\
\hline CHEMBL 2364441 & 955103 & 8.7 & 8.6296 & TRN \\
\hline CHEMBL 2364442 & 955103 & 8.1 & 8.3467 & TRN \\
\hline
\end{tabular}

TRN 


\begin{tabular}{|c|c|c|c|c|c|}
\hline & & & & & \\
\hline CHEMBL2364443 & 955103 & 7.7 & 7.9028 & TRN & \\
\hline CHEMBL 2364444 & 955103 & 8.0 & 7.9702 & TRN & \\
\hline CHEMBL2364445 & 955103 & 7.6 & 7.5836 & TRN & \\
\hline CHEMBL 2364446 & 955103 & 7.5 & 7.2936 & TRN & \\
\hline CHEMBL 2364447 & 955103 & 7.8 & 7.459 & TRN & \\
\hline CHEMBL 2364448 & 955103 & 7.7 & 7.7007 & TRN & \\
\hline CHEMBL 2364449 & 955103 & 8.2 & 8.0166 & TRN & \\
\hline CHEMBL 2364450 & 955103 & 7.2 & 7.0971 & TRN & \\
\hline CHEMBL 2364451 & 955103 & 7.9 & 7.5612 & TRN & \\
\hline CHEMBL 2364452 & 955103 & 7.6 & 7.5662 & TRN & \\
\hline CHEMBL2364453 & 955103 & 7.5 & 7.5009 & TST & \\
\hline CHEMBL 2364454 & 955103 & 8.1 & 8.0135 & TRN & \\
\hline CHEMBL 2364455 & 955103 & 7.1 & 7.5028 & TST & \\
\hline CHEMBL 2364456 & 955103 & 8.3 & 8.3032 & TRN & \\
\hline CHEMBL 2364457 & 955103 & 7.4 & 7.902 & TRN & \\
\hline CHEMBL 2364458 & 955103 & 7.9 & 8.0597 & TRN & \\
\hline CHEMBL2364459 & 955103 & 8.4 & 8.3654 & TRN & \\
\hline CHEMBL 2364460 & 955103 & 8.5 & 8.7376 & TRN & \\
\hline CHEMBL 2364461 & 955103 & 7.4 & 7.3395 & TRN & \\
\hline CHEMBL 2364462 & 955103 & 7.3 & 8.2619 & TRN & \\
\hline CHEMBL 2364463 & 955103 & 7.0 & 6.5303 & TST & \\
\hline CHEMBL 2364464 & 955103 & 7.2 & 6.63200 & 0000000001 & TST \\
\hline CHEMBL2364465 & 955103 & 7.7 & 7.8176 & TRN & \\
\hline CHEMBL 2364466 & 955103 & 8.2 & 8.1022 & TRN & \\
\hline CHEMBL 2364467 & 955103 & 7.5 & 7.2549 & TRN & \\
\hline CHEMBL 2364468 & 955103 & 9.5 & 8.9478 & TRN & \\
\hline CHEMBL 2364469 & 955103 & 8.2 & 8.2583 & TRN & \\
\hline CHEMBL 2364470 & 955103 & 7.7 & 8.0106 & TRN & \\
\hline CHEMBL 2364471 & 955103 & 7.7 & 7.87700 & 0000000001 & TRN \\
\hline CHEMBL 2364472 & 955103 & 9.3 & 9.0919 & TRN & \\
\hline CHEMBL 2364473 & 955103 & 8.4 & 8.2498 & TRN & \\
\hline CHEMBL 2364337 & 955103 & 7.8 & 7.6544 & TRN & \\
\hline CHEMBL 2364474 & 955103 & 7.3 & 7.6754 & TRN & \\
\hline CHEMBL 2364475 & 955103 & 8.8 & 8.9318 & TST & \\
\hline CHEMBL 2364476 & 955103 & 7.8 & 7.7971 & TRN & \\
\hline CHEMBL 2364477 & 955103 & 8.0 & 7.8255 & TRN & \\
\hline CHEMBL 2364478 & 955103 & 8.1 & 7.4962 & TST & \\
\hline CHEMBL 2364479 & 955103 & 8.0 & 8.0347 & TST & \\
\hline CHEMBL 2364480 & 955103 & 8.7 & 7.979 & TST & \\
\hline CHEMBL 2364481 & 955103 & 8.6 & 8.2107 & TST & \\
\hline CHEMBL 2364482 & 955103 & 8.4 & 8.3244 & TST & \\
\hline CHEMBL 2364483 & 955103 & 7.9 & 7.1324 & TST & \\
\hline CHEMBL 2364484 & 955103 & 7.3 & 7.5616 & TST & \\
\hline CHEMBL 2364485 & 955103 & 8.5 & 7.9868 & TST & \\
\hline CHEMBL 2364486 & 955103 & 7.9 & 8.5512 & TST & \\
\hline CHEMBL 2364487 & 955103 & 8.3 & 8.5599 & TST & \\
\hline CHEMBL 2364488 & 955103 & 7.8 & 8.7556 & TST & \\
\hline CHEMBL 2364491 & 955103 & 8.5 & 8.058 & TST & \\
\hline & & & & 26542 & \\
\hline
\end{tabular}




\begin{tabular}{|c|c|c|c|c|c|c|}
\hline & & \multicolumn{5}{|c|}{ Supplemental Table S2.txt } \\
\hline CHEMBL2364492 & 955103 & 8.2 & 7.6666 & TST & & \\
\hline CHEMBL1076194 & 619933 & 7.6576 & 7.7443 & TRN & & \\
\hline CHEMBL1076466 & 619933 & 7.8861 & 7.3275 & TRN & & \\
\hline CHEMBL1080475 & 619933 & 8.0 & 7.5814 & TRN & & \\
\hline CHEMBL1076437 & 619933 & 7.9586 & 8.1783 & TRN & & \\
\hline CHEMBL1080930 & 619933 & 4.6021 & 5.5255 & TRN & & \\
\hline CHEMBL1088027 & 619933 & 7.7696 & 7.4719 & TRN & & \\
\hline CHEMBL1076199 & 619933 & 7.7447 & 8.0684 & TRN & & \\
\hline CHEMBL1079424 & 619933 & \multicolumn{3}{|c|}{6.752000000000001} & 6.7167 & TRN \\
\hline CHEMBL1076433 & 619933 & 8.3979 & 7.9493 & TST & & \\
\hline CHEMBL1087649 & 619933 & 7.2007 & 7.0484 & TRN & & \\
\hline CHEMBL1087127 & 619933 & 7.5229 & 7.7437 & TRN & & \\
\hline CHEMBL1076472 & 619933 & 7.4202 & 7.1539 & TRN & & \\
\hline CHEMBL1076465 & 619933 & 7.6383 & 7.1986 & TRN & & \\
\hline CHEMBL1076476 & 619933 & 4.6021 & 4.8484 & TRN & & \\
\hline CHEMBL1076197 & 619933 & 7.7212 & 7.8119 & TRN & & \\
\hline CHEMBL1076475 & 619933 & 6.6904 & 7.0539 & TRN & & \\
\hline CHEMBL1079946 & 619933 & 7.2366 & 6.4681 & TRN & & \\
\hline CHEMBL1076474 & 619933 & 6.7747 & 6.4382 & TRN & & \\
\hline CHEMBL1075628 & 619933 & 8.0969 & 8.0419 & TST & & \\
\hline CHEMBL1076201 & 619933 & 7.7447 & 8.298 & TRN & & \\
\hline CHEMBL1076198 & 619933 & 7.8239 & 8.0974 & TRN & & \\
\hline CHEMBL1086731 & 619933 & 7.3665 & 8.0968 & TST & & \\
\hline CHEMBL1087002 & 619933 & 7.284 & 6.9735 & TRN & & \\
\hline CHEMBL1081436 & 619933 & 6.2104 & 6.2678 & TST & & \\
\hline CHEMBL1087128 & 619933 & 7.6576 & 7.6348 & TRN & & \\
\hline CHEMBL1076478 & 619933 & 8.2218 & 7.9337 & TRN & & \\
\hline CHEMBL1087636 & 619933 & 6.6383 & 6.9288 & TRN & & \\
\hline CHEMBL1076200 & 619933 & 7.9586 & 7.9061 & TRN & & \\
\hline CHEMBL1076432 & 619933 & 7.6198 & 7.7513 & TRN & & \\
\hline CHEMBL1086860 & 619933 & 6.9208 & 7.4578 & TST & & \\
\hline CHEMBL1079422 & 619933 & 6.8794 & 6.8404 & TRN & & \\
\hline CHEMBL1081090 & 619933 & 7.0458 & 7.0496 & TRN & & \\
\hline CHEMBL1088429 & 619933 & 5.9348 & 5.7452 & TRN & & \\
\hline CHEMBL1087638 & 619933 & 7.5686 & 7.2174 & TRN & & \\
\hline CHEMBL1080299 & 619933 & 7.1549 & 6.9466 & TRN & & \\
\hline CHEMBL1076533 & 619933 & 5.9666 & 6.2866 & TRN & & \\
\hline CHEMBL1080294 & 619933 & 5.6198 & 5.9617 & TRN & & \\
\hline CHEMBL1076477 & 619933 & 7.5376 & 7.5581 & TRN & & \\
\hline CHEMBL1076469 & 619933 & 8.301 & 7.6166 & TRN & & \\
\hline CHEMBL1076195 & 619933 & 7.699 & 7.7184 & TRN & & \\
\hline CHEMBL1088028 & 619933 & 7.3665 & 7.1009 & TRN & & \\
\hline CHEMBL1086730 & 619933 & 6.1457 & 6.7177 & TRN & & \\
\hline CHEMBL1076193 & 619933 & 6.6234 & 7.38200 & 0000000001 & & TRN \\
\hline CHEMBL1076480 & 619933 & 6.8697 & 7.1173 & TRN & & \\
\hline CHEMBL1076203 & 619933 & 7.9208 & 8.0339 & TRN & & \\
\hline CHEMBL1076196 & 619933 & 7.4202 & 7.4509 & TRN & & \\
\hline CHEMBL1087513 & 619933 & 5.6925 & 5.2268 & TRN & & \\
\hline
\end{tabular}


Supplemental Table S2.txt

\begin{tabular}{|c|c|c|c|c|c|}
\hline CHEMBL1076202 & 619933 & 5.8642 & 7.4343 & TST & \\
\hline CHEMBL1079945 & 619933 & 7.9586 & 7.2084 & TST & \\
\hline CHEMBL1087524 & 619933 & 7.2291 & 7.4294 & TST & \\
\hline CHEMBL1076468 & 619933 & 6.9547 & 7.0878 & TST & \\
\hline CHEMBL1076470 & 619933 & 7.9208 & 7.7173 & TST & \\
\hline CHEMBL1076471 & 619933 & 7.585 & 7.2855 & TST & \\
\hline CHEMBL1076436 & 619933 & 7.9586 & 7.8312 & TST & \\
\hline CHEMBL1088153 & 619933 & 6.5003 & 7.2566 & TST & \\
\hline CHEMBL1076473 & 619933 & 7.1487 & 6.481 & TST & \\
\hline CHEMBL307015 & 199311 & 5.2218 & 5.1059 & TRN & \\
\hline CHEMBL 74558 & 199311 & 4.0969 & 3.9352 & TRN & \\
\hline CHEMBL 76122 & 199311 & 4.9208 & 4.2822 & TST & \\
\hline CHEMBL 76244 & 199311 & 4.699 & 4.9443 & TRN & \\
\hline CHEMBL73228 & 199311 & 3.0 & 3.1679 & TRN & \\
\hline CHEMBL440496 & 199311 & 3.0 & 3.6598 & TRN & \\
\hline CHEMBL75556 & 199311 & 4.6021 & 4.4164 & TRN & \\
\hline CHEMBL 309822 & 199311 & 4.8239 & 4.0067 & TRN & \\
\hline CHEMBL75716 & 199311 & 4.301 & 4.6164 & TRN & \\
\hline CHEMBL75194 & 199311 & 5.3979 & 3.5779 & TST & \\
\hline CHEMBL263192 & 199311 & 4.699 & 4.444 & TRN & \\
\hline CHEMBL75592 & 199311 & 4.284 & 3.638 & TRN & \\
\hline CHEMBL73927 & 199311 & 3.0 & 2.8649 & TRN & \\
\hline CHEMBL73440 & 199311 & 4.5229 & 4.4051 & TRN & \\
\hline CHEMBL307518 & 199311 & 3.0 & 3.4751 & TRN & \\
\hline CHEMBL 75476 & 199311 & 3.0 & 3.2539 & TRN & \\
\hline CHEMBL73594 & 199311 & 4.699 & 4.7524 & TRN & \\
\hline CHEMBL 76322 & 199311 & 4.6021 & 4.1704 & TRN & \\
\hline CHEMBL311149 & 199311 & 3.0 & 3.6102 & TST & \\
\hline CHEMBL75894 & 199311 & 4.301 & 4.3069 & TRN & \\
\hline CHEMBL75376 & 199311 & 4.1549 & 3.5335 & TRN & \\
\hline CHEMBL75759 & 199311 & 5.1549 & 5.2425 & TST & \\
\hline CHEMBL307964 & 199311 & 5.0 & 4.9973 & TRN & \\
\hline CHEMBL72458 & 199311 & 4.699 & \multicolumn{2}{|c|}{5.0760000000000005} & TRN \\
\hline CHEMBL310263 & 199311 & 4.5229 & 4.3837 & TRN & \\
\hline CHEMBL 74724 & 199311 & 5.0 & 4.5414 & TRN & \\
\hline CHEMBL306775 & 199311 & 5.5229 & 4.9312 & TRN & \\
\hline CHEMBL75003 & 199311 & 4.2218 & 4.4149 & TST & \\
\hline CHEMBL305926 & 199311 & 3.0 & 3.3831 & TRN & \\
\hline CHEMBL306308 & 199311 & 4.6021 & 4.6311 & TRN & \\
\hline CHEMBL73601 & 199311 & 4.4559 & 4.416 & TRN & \\
\hline CHEMBL74702 & 199311 & 4.9208 & 4.8096 & TRN & \\
\hline CHEMBL310040 & 199311 & 3.0 & 3.4288 & TST & \\
\hline CHEMBL 307278 & 199311 & 4.0969 & 3.9991 & TRN & \\
\hline CHEMBL423859 & 199311 & 4.699 & 4.6504 & TRN & \\
\hline CHEMBL310469 & 199311 & 4.5229 & 4.4922 & TRN & \\
\hline CHEMBL73738 & 199311 & 4.0969 & 3.2535 & TST & \\
\hline CHEMBL 74985 & 199311 & 4.5229 & 4.7946 & TRN & \\
\hline CHEMBL75501 & 199311 & 4.4559 & 3.9598 & TRN & \\
\hline
\end{tabular}

Page 26544 
Supplemental Table S2.txt

\begin{tabular}{|c|c|c|c|c|}
\hline CHEMBL308081 & 199311 & 4.1871 & 4.2702 & TRN \\
\hline CHEMBL305610 & 199311 & 3.0 & 2.7787 & TRN \\
\hline CHEMBL433111 & 99311 & 4.301 & 3.8632 & \\
\hline HEMBL 75109 & 199311 & 3.0 & 3.4585 & 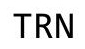 \\
\hline CHEMBL306255 & 199311 & 4.699 & 5.0684 & \\
\hline CHEMBL 75731 & 99311 & 3.0 & 3.637 & \\
\hline CHEMBL443272 & 99311 & 4.6021 & 4.6421 & \\
\hline CHEMBL 74773 & 199311 & 3.0 & 2.9321 & \\
\hline CHEMBL75213 & 199311 & 5.2218 & 4.9054 & \\
\hline CHEMBL309184 & 199311 & 4.6198 & 4.3992 & \\
\hline HEMBL 75606 & 199311 & 6.0969 & 4.1616 & \\
\hline HEMBL 74219 & 199311 & 4.301 & 4.2053 & \\
\hline HEMBL 75473 & 199311 & 3.0 & 3.3041 & \\
\hline CHEMBL 74847 & 199311 & 4.8239 & 4.1294 & \\
\hline CHEMBL 307371 & 199311 & 4.6021 & 5.0415 & \\
\hline HEMBL 312542 & 199311 & 4.5229 & 4.6696 & RN \\
\hline CHEMBL311404 & 199311 & 4.1549 & 4.3955 & \\
\hline CHEMBL 75044 & 199311 & 4.8239 & 5.0618 & RN \\
\hline CHEMBL 74311 & 199311 & 3.0 & 2.4119 & \\
\hline CHEMBL72496 & 199311 & 4.6021 & 3.5822 & ו \\
\hline CHEMBL & 199311 & 3. & 4.1619 & . \\
\hline CHEMBL & 199311 & 229 & 4.4027 & \\
\hline CHEMBL418894 & 199311 & 3.0 & 3.1789 & RN \\
\hline CHEMBL72132 & 199311 & 4. & 4.3206 & \\
\hline CHEMBL 73713 & 199311 & 3. & 3.8241 & RIV \\
\hline CHEMBL & 199311 & 979 & 4.1573 & RN \\
\hline CHEMBL & 199311 & 4. & 4.6334 & \\
\hline HEMBL 73604 & 199311 & 4.301 & 3.6832 & \\
\hline CHEMBL 76106 & 199311 & 5.6021 & 5.1842 & TF \\
\hline CHEMBL306754 & 199311 & 4. & 3.4759 & ST \\
\hline CHEMBL & 199311 & 5 . & 5.6145 & $\mathrm{RN}$ \\
\hline CHEMBL & 199311 & 871 & 4.1181 & \\
\hline CHEMBL310936 & 199311 & 5.699 & 5.3338 & TRA \\
\hline CHEMBL75136 & 199311 & 3.0 & 4.3266 & TF \\
\hline CHEMBL 73314 & 199311 & 218 & 4.6707 & TST \\
\hline CHEMBL & 199311 & 969 & 4.1149 & TRN \\
\hline CHEMBL & 199311 & 4.301 & 4.2436 & TRN \\
\hline CHEMBL 74440 & 199311 & 5.0 & 4.6883 & TRA \\
\hline CHEMBL76349 & 199311 & 4.5229 & 3.4582 & $\mathrm{~T}$ \\
\hline CHEMBL & 199311 & 4. & 609 & K \\
\hline CHEMBL 73018 & 199311 & 4.3979 & 4.1766 & TS \\
\hline CHEMBL306597 & 199311 & 5.301 & 4.8135 & TRN \\
\hline CHEMBL 72991 & 199311 & 4.2218 & 4.1281 & TS \\
\hline CHEMBL 75891 & 199311 & 3.0 & 4.3914 & 1 \\
\hline CHEMBL73591 & 199311 & 4.8239 & 4.6272 & $S$ \\
\hline CHEMBL312313 & 199311 & 5.0 & 4.632 & \\
\hline CHEMBL446665 & 199311 & 3.0 & 4.1692 & \\
\hline CHEMBL306046 & 199311 & 3.0 & 3.9422 & TS \\
\hline
\end{tabular}

Page 26545 


\begin{tabular}{|c|c|c|c|c|c|}
\hline \multicolumn{6}{|c|}{ Supplemental Table S2.txt } \\
\hline CHEMBL341473 & 144341 & 4.0 & 4.0838 & TRN & \\
\hline CHEMBL419798 & 144341 & 4.0 & 3.9129 & TRN & \\
\hline CHEMBL125357 & 144341 & 7.0458 & 5.6321 & TRN & \\
\hline CHEMBL129232 & 144341 & 6.1726 & 6.21299 & 7999999999 & TST \\
\hline CHEMBL131467 & 144341 & 7.3979 & 6.154 & TRN & \\
\hline CHEMBL128246 & 144341 & 5.6198 & 5.9865 & TRN & \\
\hline CHEMBL542222 & 144341 & 5.9208 & 5.4753 & TST & \\
\hline CHEMBL126452 & 144341 & 6.5229 & 6.8175 & TRN & \\
\hline CHEMBL126427 & 144341 & 5.7144 & 4.5456 & TRN & \\
\hline CHEMBL129645 & 144341 & 4.0 & 3.7064 & TRN & \\
\hline CHEMBL126606 & 144341 & 4.0 & 4.7334 & TRN & \\
\hline CHEMBL126517 & 144341 & 7.0458 & 4.9497 & TRN & \\
\hline CHEMBL129827 & 144341 & 8.3468 & 6.7319 & TRN & \\
\hline CHEMBL131223 & 144341 & 7.0969 & 6.7517 & TRN & \\
\hline CHEMBL126350 & 144341 & 4.0 & 4.4991 & TRN & \\
\hline CHEMBL341127 & 144341 & 4.0 & 3.7362 & TRN & \\
\hline CHEMBL128503 & 144341 & 4.0 & 3.9425 & TRN & \\
\hline CHEMBL129639 & 144341 & 4.0 & 4.4813 & TST & \\
\hline CHEMBL127023 & 144341 & 5.9872 & 5.4026 & TRN & \\
\hline CHEMBL129399 & 144341 & 6.7447 & 4.8618 & TRN & \\
\hline CHEMBL130857 & 144341 & 4.0 & 4.3682 & TRN & \\
\hline CHEMBL128196 & 144341 & 5.6216 & 6.0205 & TRN & \\
\hline CHEMBL128847 & 144341 & 6.3768 & 5.7942 & TRN & \\
\hline CHEMBL127014 & 144341 & 4.0 & 5.3172 & TRN & \\
\hline CHEMBL137134 & 144341 & 4.0 & 4.0076 & TRN & \\
\hline CHEMBL126030 & 144341 & 6.301 & 6.5676 & TRN & \\
\hline CHEMBL553292 & 144341 & 5.9208 & 5.8186 & TST & \\
\hline CHEMBL543184 & 144341 & 4.0 & 4.8065 & TRN & \\
\hline CHEMBL129291 & 144341 & 6.0458 & 6.9097 & TRN & \\
\hline CHEMBL337220 & 144341 & 6.4134 & 4.8151 & TRN & \\
\hline CHEMBL543892 & 144341 & 4.0 & 4.7472 & TST & \\
\hline CHEMBL125636 & 144341 & 6.2218 & 6.4448 & TST & \\
\hline CHEMBL127055 & 144341 & 4.0 & 4.7594 & TRN & \\
\hline CHEMBL555040 & 144341 & 4.0 & 5.3699 & TST & \\
\hline CHEMBL129679 & 144341 & 4.0 & 4.4635 & TRN & \\
\hline CHEMBL542223 & 144341 & 4.0 & 4.7796 & TST & \\
\hline CHEMBL126348 & 144341 & 6.7696 & 4.3515 & TRN & \\
\hline CHEMBL554657 & 144341 & 5.9586 & 6.3031 & TST & \\
\hline CHEMBL128809 & 144341 & 4.0 & 4.5431 & TRN & \\
\hline CHEMBL131465 & 144341 & 4.0 & 4.135 & TRN & \\
\hline CHEMBL126197 & 144341 & 7.6576 & 6.727 & TRN & \\
\hline CHEMBL129790 & 144341 & 8.1675 & 6.7959 & TRN & \\
\hline CHEMBL128610 & 144341 & 8.0969 & 6.67 & TRN & \\
\hline CHEMBL126498 & 144341 & 5.8386 & 6.4177 & TST & \\
\hline CHEMBL340365 & 144341 & 4.0 & 4.4253 & TRN & \\
\hline CHEMBL339069 & 144341 & 4.0 & 5.0318 & TRN & \\
\hline CHEMBL125353 & 144341 & 7.6576 & 6.6013 & TRN & \\
\hline CHEMBL126607 & 144341 & 5.7212 & 6.681 & TRN & \\
\hline
\end{tabular}




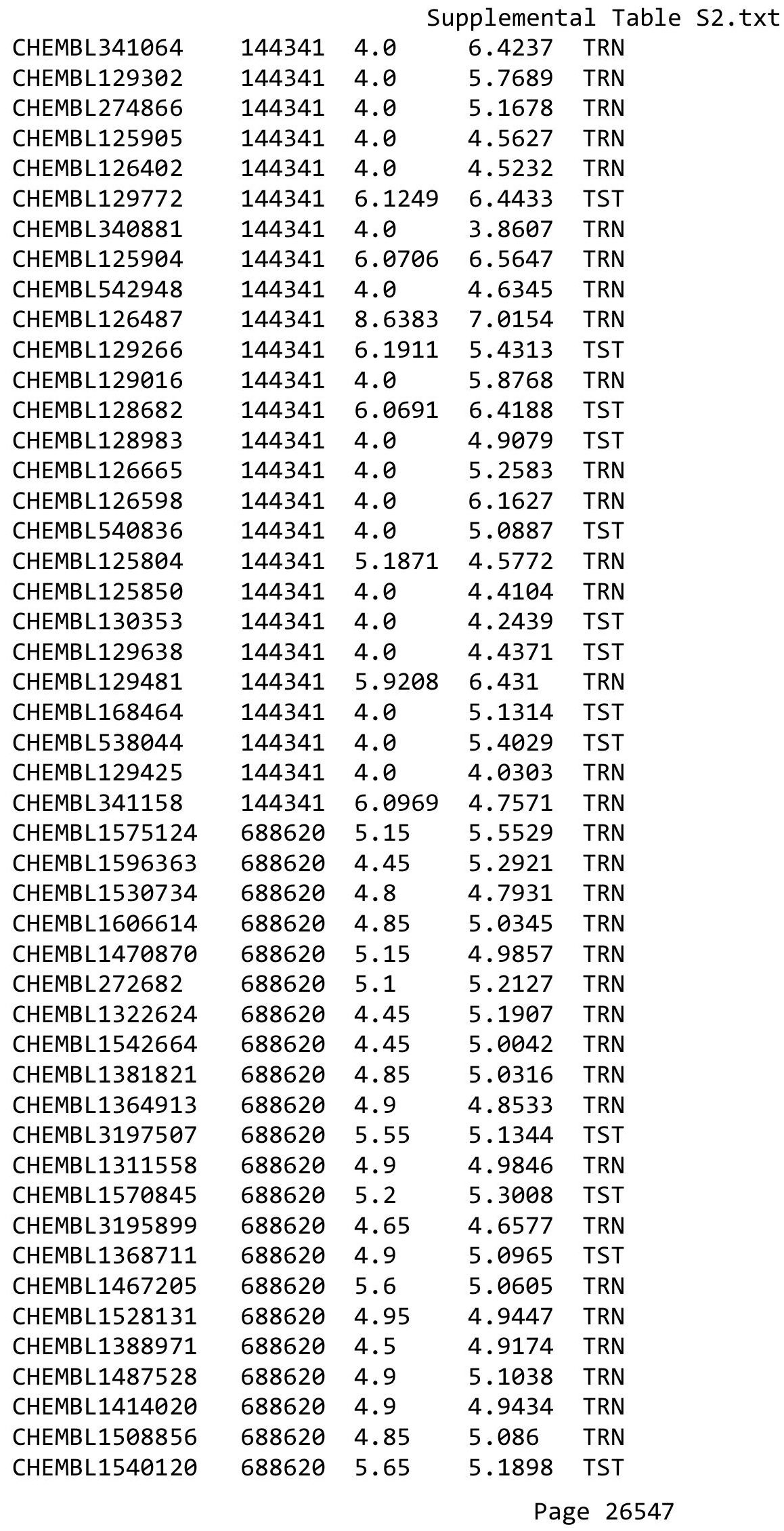




\begin{tabular}{|c|c|c|c|c|c|}
\hline \\
\hline CHEMBL1332690 & 688620 & 4.7 & 4.9333 & TRN & \\
\hline CHEMBL1364889 & 688620 & 4.95 & 5.1999 & TRN & \\
\hline CHEMBL1441032 & 688620 & 5.55 & 5.5008 & TRN & \\
\hline CHEMBL1447621 & 688620 & 5.25 & 4.9117 & TRN & \\
\hline CHEMBL3194505 & 688620 & 5.1 & 4.8228 & TRN & \\
\hline CHEMBL1480640 & 688620 & 4.9 & 5.0653 & TRN & \\
\hline CHEMBL1608066 & 688620 & 4.9 & 5.1815 & TRN & \\
\hline CHEMBL1419687 & 688620 & 5.05 & 4.7665 & TST & \\
\hline CHEMBL1544836 & 688620 & 4.45 & 4.6926 & TRN & \\
\hline CHEMBL3199018 & 688620 & 5.2 & 5.5471 & TRN & \\
\hline CHEMBL1982391 & 688620 & 6.35 & 5.7951 & TRN & \\
\hline CHEMBL1326539 & 688620 & 4.65 & 5.0057 & TRN & \\
\hline CHEMBL1489562 & 688620 & 5.5 & 5.1931 & TRN & \\
\hline CHEMBL1582404 & 688620 & 5.5 & 4.8372 & TST & \\
\hline CHEMBL1570587 & 688620 & 5.15 & 5.2145 & TRN & \\
\hline CHEMBL1343335 & 688620 & 5.65 & 5.0463 & TST & \\
\hline CHEMBL1536627 & 688620 & 4.65 & 4.9091 & TST & \\
\hline CHEMBL1356647 & 688620 & 5.25 & 5.0958 & TRN & \\
\hline CHEMBL1352604 & 688620 & 4.95 & 4.9328 & TST & \\
\hline CHEMBL3145114 & 688620 & 4.9 & 5.0456 & TRN & \\
\hline CHEMBL3191078 & 688620 & 4.45 & 5.0237 & TST & \\
\hline CHEMBL1349672 & 688620 & 4.9 & 4.8475 & TRN & \\
\hline CHEMBL1401737 & 688620 & 5.0 & 4.8537 & TRN & \\
\hline CHEMBL1976814 & 688620 & 5.45 & 5.0402 & TRN & \\
\hline CHEMBL1528584 & 688620 & 4.45 & 5.0814 & TRN & \\
\hline CHEMBL1414519 & 688620 & 6.15 & 5.7396 & TRN & \\
\hline CHEMBL1493893 & 688620 & 4.95 & 5.1162 & TRN & \\
\hline CHEMBL1520764 & 688620 & 4.8 & 4.9046 & TRN & \\
\hline CHEMBL1361933 & 688620 & 4.7 & 5.0779 & TST & \\
\hline CHEMBL1517902 & 688620 & 5.05 & 4.9106 & TRN & \\
\hline CHEMBL1451100 & 688620 & 5.95 & 5.7963 & TRN & \\
\hline CHEMBL1414150 & 688620 & 7.0 & 5.1046 & TRN & \\
\hline CHEMBL3195922 & 688620 & 5.15 & 4.9711 & TRN & \\
\hline CHEMBL1383884 & 688620 & 5.0 & 5.0076 & TRN & \\
\hline CHEMBL1549499 & 688620 & 4.8 & 4.9274 & TST & \\
\hline CHEMBL1575332 & 688620 & 5.1 & 5.0702 & TRN & \\
\hline CHEMBL1316449 & 688620 & 6.1 & 5.7253 & TRN & \\
\hline CHEMBL1312743 & 688620 & 4.8 & 5.2256 & TRN & \\
\hline CHEMBL1323726 & 688620 & 4.7 & 4.9736 & TRN & \\
\hline CHEMBL1612026 & 688620 & 4.95 & 4.7781 & TST & \\
\hline CHEMBL1971665 & 688620 & 5.15 & 5.2102 & TRN & \\
\hline CHEMBL1301260 & 688620 & 4.9 & 4.92899 & 9999999999 & TRN \\
\hline CHEMBL1570510 & 688620 & 4.45 & 4.7914 & TRN & \\
\hline CHEMBL1994540 & 688620 & 5.35 & 5.5885 & TRN & \\
\hline CHEMBL1382840 & 688620 & 4.45 & 5.0287 & TST & \\
\hline CHEMBL1470584 & 688620 & 4.8 & 5.1511 & TRN & \\
\hline CHEMBL 3195477 & 688620 & 6.1 & 6.0283 & TRN & \\
\hline CHEMBL1532801 & 688620 & 4.85 & 5.0184 & TRN & \\
\hline
\end{tabular}




\begin{tabular}{|c|c|c|c|c|c|}
\hline \multicolumn{6}{|c|}{ plemental } \\
\hline CHEMBL1336005 & 688620 & 4.9 & 5.0572 & TRN & \\
\hline CHEMBL1594058 & 688620 & 4.45 & 5.1054 & TRN & \\
\hline CHEMBL1535737 & 688620 & 5.1 & 5.0285 & TRN & \\
\hline CHEMBL1556277 & 688620 & 6.05 & 6.1188 & TRN & \\
\hline CHEMBL1473927 & 688620 & 5.25 & 5.013 & TST & \\
\hline CHEMBL1461040 & 688620 & 7.0 & 6.4693 & TRN & \\
\hline CHEMBL1508457 & 688620 & 4.75 & 5.0126 & TRN & \\
\hline CHEMBL1370467 & 688620 & 6.0 & 4.8366 & TRN & \\
\hline CHEMBL1353325 & 688620 & 4.75 & 4.9966 & TRN & \\
\hline CHEMBL1429410 & 688620 & 6.2 & 5.4503 & TRN & \\
\hline CHEMBL1466405 & 688620 & 5.25 & 5.0104 & TST & \\
\hline CHEMBL3198494 & 688620 & 5.0 & 5.1894 & TRN & \\
\hline CHEMBL3195143 & 688620 & 4.95 & 5.2899 & TST & \\
\hline CHEMBL1419361 & 688620 & 4.5 & 5.20299 & 9999999999 & TRN \\
\hline CHEMBL1556782 & 688620 & 4.75 & 4.9275 & TRN & \\
\hline CHEMBL1456888 & 688620 & 4.65 & 4.9137 & TST & \\
\hline CHEMBL1563710 & 688620 & 5.45 & 5.0031 & TRN & \\
\hline CHEMBL1587849 & 688620 & 4.95 & 5.1525 & TST & \\
\hline CHEMBL1585275 & 688620 & 5.0 & 4.8256 & TRN & \\
\hline CHEMBL1411221 & 688620 & 4.95 & 5.0405 & TST & \\
\hline CHEMBL1523580 & 688620 & 4.7 & 5.2711 & TRN & \\
\hline CHEMBL1439578 & 688620 & 4.6 & 5.2727 & TRN & \\
\hline CHEMBL1549291 & 688620 & 4.65 & 4.7768 & TRN & \\
\hline CHEMBL1524706 & 688620 & 4.85 & 5.0478 & TRN & \\
\hline CHEMBL1532152 & 688620 & 5.6 & 5.3394 & TRN & \\
\hline CHEMBL1373508 & 688620 & 4.9 & 4.8487 & TRN & \\
\hline CHEMBL1549151 & 688620 & 4.65 & 4.6694 & TST & \\
\hline CHEMBL1415475 & 688620 & 4.75 & 4.9729 & TRN & \\
\hline CHEMBL1590048 & 688620 & 6.0 & 5.0275 & TST & \\
\hline CHEMBL1346284 & 688620 & 4.45 & 4.8887 & TRN & \\
\hline CHEMBL3189421 & 688620 & 5.2 & 5.2932 & TRN & \\
\hline CHEMBL1313929 & 688620 & 4.45 & 4.8565 & TRN & \\
\hline CHEMBL1504364 & 688620 & 4.95 & 5.0282 & TRN & \\
\hline CHEMBL1578209 & 688620 & 4.9 & 5.1214 & TST & \\
\hline CHEMBL1511113 & 688620 & 5.0 & 5.2301 & TRN & \\
\hline CHEMBL1309207 & 688620 & 6.3 & 7.0917 & TRN & \\
\hline CHEMBL1351157 & 688620 & 4.6 & 4.9824 & TRN & \\
\hline CHEMBL3210042 & 688620 & 5.95 & 5.1369 & TST & \\
\hline CHEMBL 200027 & 688620 & 4.65 & 4.6728 & TST & \\
\hline CHEMBL1528420 & 688620 & 6.25 & 5.74700 & 0000000001 & TRN \\
\hline CHEMBL1557003 & 688620 & 5.35 & 5.1929 & TST & \\
\hline CHEMBL 260370 & 688620 & 4.45 & 4.8482 & TRN & \\
\hline CHEMBL1334336 & 688620 & 5.5 & 5.1188 & TST & \\
\hline CHEMBL1479709 & 688620 & 5.1 & 5.0922 & TST & \\
\hline CHEMBL1313946 & 688620 & 5.25 & 5.654 & TRN & \\
\hline CHEMBL3191570 & 688620 & 5.5 & 5.4513 & TRN & \\
\hline CHEMBL3193886 & 688620 & 4.45 & 4.9402 & TST & \\
\hline CHEMBL1584460 & 688620 & 6.5501 & 5.0434 & TRN & \\
\hline
\end{tabular}




\begin{tabular}{|c|c|c|c|c|c|}
\hline \multirow[b]{2}{*}{ CHEMBL 3211775} & \multirow[b]{2}{*}{688620} & \\
\hline & & 4.9 & 5.4708 & TRN & \\
\hline CHEMBL1399523 & 688620 & 4.55 & 5.0058 & TRN & \\
\hline CHEMBL1511257 & 688620 & 4.85 & 5.0778 & TRN & \\
\hline CHEMBL1529368 & 688620 & 4.95 & \multicolumn{2}{|c|}{4.821000000000001} & TRN \\
\hline CHEMBL1449065 & 688620 & 5.3 & 4.9873 & TST & \\
\hline CHEMBL1579217 & 688620 & 5.55 & 5.2052 & TRN & \\
\hline CHEMBL1538412 & 688620 & 4.9 & 4.8887 & TRN & \\
\hline CHEMBL1376503 & 688620 & 4.95 & 5.0943 & TST & \\
\hline CHEMBL3207660 & 688620 & 5.35 & 5.8599 & TRN & \\
\hline CHEMBL3856095 & 688620 & 6.4 & 5.5156 & TST & \\
\hline CHEMBL1571328 & 688620 & 4.9 & 5.2913 & TST & \\
\hline CHEMBL1982109 & 688620 & 4.8 & 4.8345 & TRN & \\
\hline CHEMBL1332925 & 688620 & 4.95 & 5.013 & TST & \\
\hline CHEMBL1570616 & 688620 & 5.5 & 5.2905 & TRN & \\
\hline CHEMBL1459819 & 688620 & 4.45 & 4.9059 & TRN & \\
\hline CHEMBL1462015 & 688620 & 4.75 & 5.1738 & TRN & \\
\hline CHEMBL1329486 & 688620 & 4.45 & 4.8958 & TRN & \\
\hline CHEMBL1359384 & 688620 & 4.45 & 4.7214 & TRN & \\
\hline CHEMBL1567923 & 688620 & 4.7 & 5.1947 & TST & \\
\hline CHEMBL1410102 & 688620 & 4.7 & 4.8461 & TRN & \\
\hline CHEMBL1300910 & 688620 & 5.45 & 5.0709 & TRN & \\
\hline CHEMBL1604532 & 688620 & 4.95 & 5.0217 & TST & \\
\hline CHEMBL1598069 & 688620 & 4.45 & 4.9846 & TRN & \\
\hline CHEMBL1347024 & 688620 & 5.05 & 5.0935 & TRN & \\
\hline CHEMBL1405775 & 688620 & 5.1 & 5.1025 & TST & \\
\hline CHEMBL1336483 & 688620 & 4.5 & 4.8828 & TRN & \\
\hline CHEMBL1496138 & 688620 & 4.45 & 4.7343 & TST & \\
\hline CHEMBL1380266 & 688620 & 4.95 & 5.2652 & TRN & \\
\hline CHEMBL1462243 & 688620 & 4.55 & 5.1805 & TST & \\
\hline CHEMBL3198627 & 688620 & 6.25 & 6.0141 & TRN & \\
\hline CHEMBL1464666 & 688620 & 4.5 & 4.8633 & TRN & \\
\hline CHEMBL1527312 & 688620 & 5.5 & 5.4804 & TRN & \\
\hline CHEMBL3192408 & 688620 & 4.45 & 5.1254 & TST & \\
\hline CHEMBL1362660 & 688620 & 5.65 & 5.6524 & TST & \\
\hline CHEMBL3196071 & 688620 & 4.9 & 4.6393 & TST & \\
\hline CHEMBL1583735 & 688620 & 4.7 & 4.8077 & TRN & \\
\hline CHEMBL1546347 & 688620 & 6.0 & 5.6452 & TST & \\
\hline CHEMBL1463718 & 688620 & 5.15 & 4.8808 & TRN & \\
\hline CHEMBL1323542 & 688620 & 5.25 & 5.0349 & TRN & \\
\hline CHEMBL1371641 & 688620 & 4.5 & 5.1073 & TRN & \\
\hline CHEMBL1418203 & 688620 & 5.8 & 5.3602 & TRN & \\
\hline CHEMBL1299843 & 688620 & 4.65 & 5.0092 & TRN & \\
\hline CHEMBL1483246 & 688620 & 4.9 & 5.2327 & TST & \\
\hline CHEMBL1426012 & 688620 & 4.7 & 4.8628 & TRN & \\
\hline CHEMBL1481434 & 688620 & 4.9 & 5.0463 & TST & \\
\hline CHEMBL3192696 & 688620 & 5.05 & 5.5914 & TRN & \\
\hline CHEMBL1388919 & 688620 & 4.85 & 4.8975 & TRN & \\
\hline CHEMBL1542861 & 688620 & 5.3 & 5.36799 & & TRN \\
\hline & & & & 26550 & \\
\hline
\end{tabular}




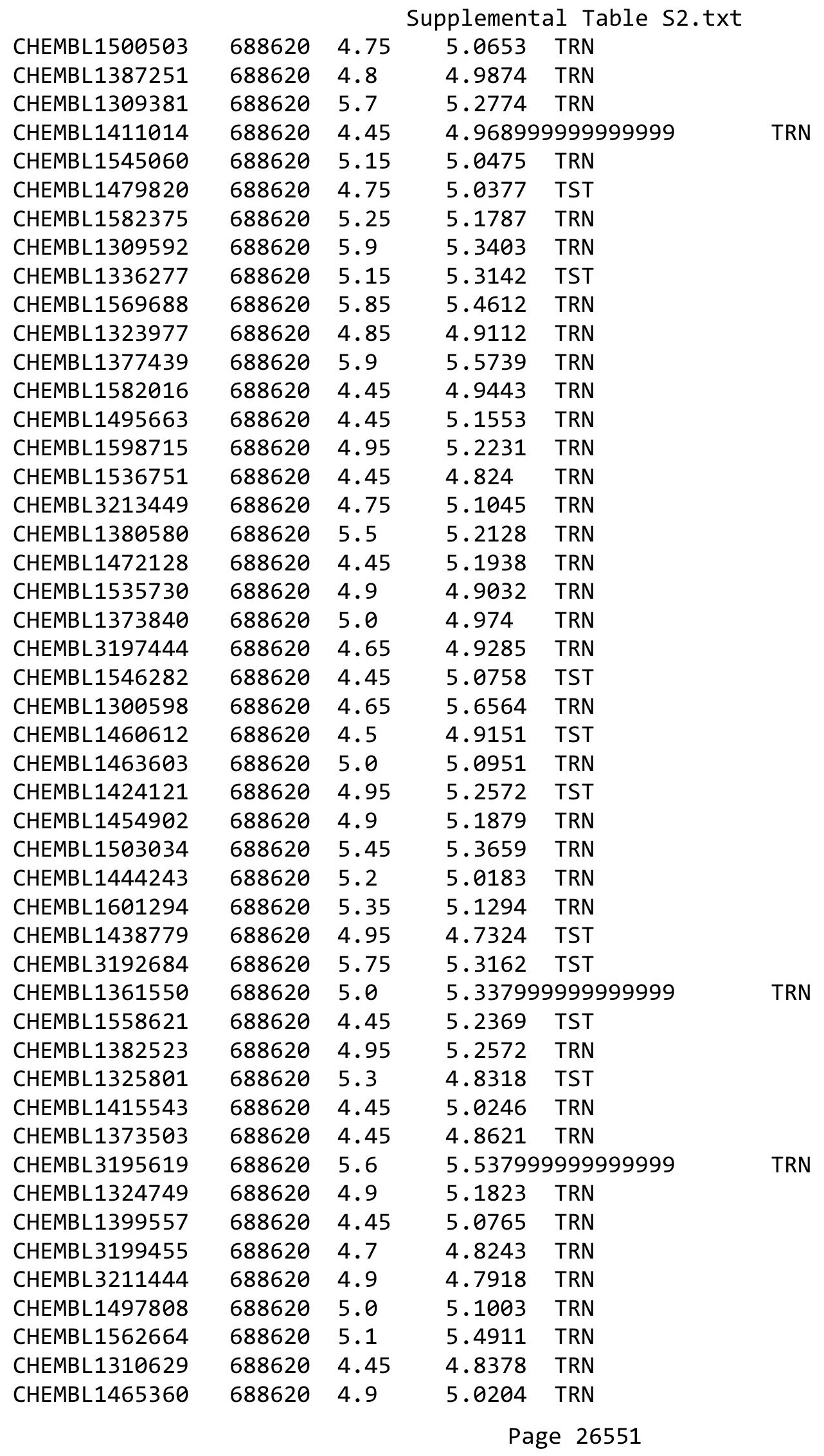




\begin{tabular}{|c|c|c|c|c|}
\hline & & & & \\
\hline CHEMBL1513410 & 688620 & 4.5 & 4.9867 & TRN \\
\hline CHEMBL1416299 & 688620 & 4.5 & 5.034 & TST \\
\hline CHEMBL1559425 & 688620 & 5.45 & 5.4039 & TST \\
\hline CHEMBL1520839 & 688620 & 4.95 & 5.0626 & TRN \\
\hline CHEMBL1345969 & 688620 & 6.1 & 5.0652 & TRN \\
\hline CHEMBL1419381 & 688620 & 6.35 & 5.3097 & TST \\
\hline CHEMBL1451834 & 688620 & 5.0 & 5.3321 & TRN \\
\hline CHEMBL1358035 & 688620 & 4.8 & 5.0583 & TRN \\
\hline CHEMBL1603001 & 688620 & 7.5003 & 5.8099 & TRN \\
\hline CHEMBL1448697 & 688620 & 5.4 & 5.1302 & TST \\
\hline CHEMBL1530736 & 688620 & 5.0 & 5.0232 & TRN \\
\hline CHEMBL1404846 & 688620 & 5.15 & 4.9496 & TRN \\
\hline CHEMBL1979662 & 688620 & 4.95 & 4.6287 & TRN \\
\hline CHEMBL1557476 & 688620 & 4.65 & 4.8734 & TRN \\
\hline CHEMBL1414555 & 688620 & 5.5 & 4.9669 & TRN \\
\hline CHEMBL1503778 & 688620 & 4.45 & 4.9058 & TST \\
\hline CHEMBL1320243 & 688620 & 4.85 & 5.3731 & TRN \\
\hline CHEMBL 2007056 & 688620 & 4.65 & 5.3122 & TST \\
\hline CHEMBL1341735 & 688620 & 5.15 & 5.222 & TRN \\
\hline CHEMBL1527720 & 688620 & 4.95 & 4.798 & TRN \\
\hline CHEMBL1416410 & 688620 & 4.95 & 5.1273 & TRN \\
\hline CHEMBL1510779 & 688620 & 4.65 & 4.8468 & TRN \\
\hline CHEMBL1310106 & 688620 & 5.55 & 5.2895 & TRN \\
\hline CHEMBL1510146 & 688620 & 5.5 & 5.4064 & TRN \\
\hline CHEMBL1395062 & 688620 & 4.65 & 4.9263 & TRN \\
\hline CHEMBL1608666 & 688620 & 5.55 & 5.2953 & TRN \\
\hline CHEMBL1445683 & 688620 & 4.75 & 4.796 & TRN \\
\hline CHEMBL1544099 & 688620 & 4.85 & 5.1697 & TRN \\
\hline CHEMBL1601425 & 688620 & 4.8 & 4.8787 & TRN \\
\hline CHEMBL 2001577 & 688620 & 5.85 & 5.6221 & TRN \\
\hline CHEMBL3208962 & 688620 & 4.85 & 4.9946 & TST \\
\hline CHEMBL1543588 & 688620 & 4.55 & 4.941 & TST \\
\hline CHEMBL1503333 & 688620 & 5.7 & 5.4099 & TRN \\
\hline CHEMBL1505485 & 688620 & 4.45 & 4.8484 & TRN \\
\hline CHEMBL3189451 & 688620 & 6.0 & 4.9767 & TRN \\
\hline CHEMBL1328419 & 688620 & 4.45 & 4.9543 & TST \\
\hline CHEMBL1321158 & 688620 & 4.9 & 5.3452 & TRN \\
\hline CHEMBL 3197231 & 688620 & 4.95 & 5.1686 & TRN \\
\hline CHEMBL1504273 & 688620 & 5.0 & 5.0575 & TRN \\
\hline CHEMBL1493594 & 688620 & 4.95 & 4.8555 & TRN \\
\hline CHEMBL1411897 & 688620 & 5.5 & 5.1699 & TST \\
\hline CHEMBL1387455 & 688620 & 5.4 & 4.7723 & TRN \\
\hline CHEMBL1403295 & 688620 & 4.65 & 4.9619 & TRN \\
\hline CHEMBL1386076 & 688620 & 5.3 & 5.2847 & TRN \\
\hline CHEMBL1545712 & 688620 & 5.7 & 5.0932 & TRN \\
\hline CHEMBL1391774 & 688620 & 4.85 & 5.0649 & TRN \\
\hline CHEMBL1489531 & 688620 & 5.7 & 5.6358 & TRN \\
\hline CHEMBL1329504 & 688620 & 4.7 & 5.0697 & TST \\
\hline
\end{tabular}




\begin{tabular}{|c|c|c|c|c|}
\hline \multicolumn{5}{|c|}{ Supplemental Table S2.txt } \\
\hline CHEMBL 2006545 & 688620 & 6.25 & 5.7781 & TRN \\
\hline CHEMBL 1479845 & 688620 & 5.6 & 5.1044 & TRN \\
\hline CHEMBL1416710 & 688620 & 4.45 & 4.919 & TRN \\
\hline CHEMBL 3196226 & 688620 & 4.95 & 4.9137 & TRN \\
\hline CHEMBL1528419 & 688620 & 5.35 & 4.7918 & TRN \\
\hline CHEMBL 1441040 & 688620 & 5.45 & 5.4084 & TRN \\
\hline CHEMBL1480651 & 688620 & 4.7 & 5.1166 & TRN \\
\hline CHEMBL282489 & 688620 & 6.0 & 5.5805 & TST \\
\hline CHEMBL1531072 & 688620 & 4.9 & 4.9746 & TRN \\
\hline CHEMBL1361072 & 688620 & 4.7 & 5.1508 & TRN \\
\hline CHEMBL1403932 & 688620 & 6.2 & 5.1124 & TRN \\
\hline CHEMBL 3197168 & 688620 & 5.45 & 5.2844 & TRN \\
\hline CHEMBL1447733 & 688620 & 4.85 & 6.9722 & TST \\
\hline CHEMBL1339518 & 688620 & 4.6 & 5.0173 & TST \\
\hline CHEMBL1497137 & 688620 & 4.45 & 5.0786 & TRN \\
\hline CHEMBL1466000 & 688620 & 5.65 & 5.2634 & TST \\
\hline CHEMBL1447294 & 688620 & 5.15 & 5.085 & TRN \\
\hline CHEMBL1426991 & 688620 & 4.95 & 4.9625 & TRN \\
\hline CHEMBL1407826 & 688620 & 6.0 & 5.7159 & TST \\
\hline CHEMBL1374957 & 688620 & 4.9 & 4.6963 & TRN \\
\hline CHEMBL600336 & 688620 & 4.9 & 5.0058 & TRN \\
\hline CHEMBL1496957 & 688620 & 4.45 & 5.5128 & TRN \\
\hline CHEMBL1600751 & 688620 & 5.3 & 5.3655 & TRN \\
\hline CHEMBL1409569 & 688620 & 4.45 & 5.225 & TRN \\
\hline CHEMBL1345703 & 688620 & 6.7501 & 5.1238 & TRN \\
\hline CHEMBL3190149 & 688620 & 5.95 & 5.4918 & TRN \\
\hline CHEMBL1969010 & 688620 & 4.45 & 5.3229 & TRN \\
\hline CHEMBL1305066 & 688620 & 4.45 & 4.787 & TST \\
\hline CHEMBL1598434 & 688620 & 4.45 & 4.993 & TST \\
\hline CHEMBL1388239 & 688620 & 5.95 & 5.0868 & TRN \\
\hline CHEMBL1584165 & 688620 & 4.95 & 5.0104 & TST \\
\hline CHEMBL 3189278 & 688620 & 4.45 & 5.0606 & TRN \\
\hline CHEMBL1505618 & 688620 & 5.8 & 4.8183 & TRN \\
\hline CHEMBL1979063 & 688620 & 4.75 & 5.024 & TST \\
\hline CHEMBL 3197854 & 688620 & 4.7 & 5.2054 & TRN \\
\hline CHEMBL1608226 & 688620 & 4.45 & 5.1685 & TRN \\
\hline CHEMBL1393954 & 688620 & 4.9 & 4.9004 & TRN \\
\hline CHEMBL600968 & 688620 & 4.85 & 4.6966 & TRN \\
\hline CHEMBL 3198963 & 688620 & 5.75 & 5.8327 & TST \\
\hline CHEMBL1578405 & 688620 & 4.65 & 4.9509 & TST \\
\hline CHEMBL1453770 & 688620 & 4.95 & 4.8943 & TRN \\
\hline CHEMBL1606150 & 688620 & 4.75 & 5.3797 & TRN \\
\hline CHEMBL1975487 & 688620 & 5.15 & 4.9341 & TRN \\
\hline CHEMBL1566842 & 688620 & 5.45 & 5.0351 & TRN \\
\hline CHEMBL1307011 & 688620 & 5.2 & 5.1763 & TRN \\
\hline CHEMBL1440565 & 688620 & 5.0 & 5.4028 & TRN \\
\hline CHEMBL1488460 & 688620 & 4.45 & 5.0658 & TRN \\
\hline CHEMBL531990 & 688620 & 6.0 & 5.249 & TST \\
\hline
\end{tabular}




\begin{tabular}{|c|c|c|c|c|}
\hline \multicolumn{5}{|c|}{ Supplemental Table S2.txt } \\
\hline CHEMBL1425497 & 688620 & 4.65 & 4.793 & TRN \\
\hline CHEMBL1438210 & 688620 & 4.45 & 4.8188 & TRN \\
\hline CHEMBL1368713 & 688620 & 4.85 & 4.9247 & TRN \\
\hline CHEMBL1510028 & 688620 & 4.45 & 4.9957 & TST \\
\hline CHEMBL1395226 & 688620 & 4.85 & 4.6547 & TRN \\
\hline CHEMBL1368746 & 688620 & 5.25 & 5.1929 & TRN \\
\hline CHEMBL1307893 & 688620 & 5.45 & 5.1526 & TRN \\
\hline CHEMBL 3213061 & 688620 & 7.0501 & 5.9246 & TRN \\
\hline CHEMBL1387913 & 688620 & 5.4 & 5.3096 & TRN \\
\hline CHEMBL1505130 & 688620 & 4.65 & 4.743 & TST \\
\hline CHEMBL1571083 & 688620 & 4.45 & 4.9477 & TRN \\
\hline CHEMBL 3193034 & 688620 & 4.45 & 4.9988 & TRN \\
\hline CHEMBL1327993 & 688620 & 4.85 & 5.0009 & TRN \\
\hline CHEMBL 3190404 & 688620 & 5.3 & 5.4448 & TRN \\
\hline CHEMBL1323000 & 688620 & 4.45 & 4.7809 & TRN \\
\hline CHEMBL3193900 & 688620 & 5.2 & 5.2956 & TRN \\
\hline CHEMBL1570754 & 688620 & 6.7501 & 4.9908 & TST \\
\hline CHEMBL1524649 & 688620 & 4.45 & 4.8407 & TRN \\
\hline CHEMBL601137 & 688620 & 5.25 & 4.9484 & TRN \\
\hline CHEMBL1454195 & 688620 & 4.45 & 4.8502 & TRN \\
\hline CHEMBL1520830 & 688620 & 5.0 & 4.9692 & TRN \\
\hline CHEMBL1385720 & 688620 & 6.95 & 4.9461 & TRN \\
\hline CHEMBL1598287 & 688620 & 4.9 & 5.1897 & TRN \\
\hline CHEMBL1312353 & 688620 & 5.2 & 4.9939 & TST \\
\hline CHEMBL1528135 & 688620 & 5.8 & 4.8066 & TST \\
\hline CHEMBL1419642 & 688620 & 4.85 & 5.2406 & TRN \\
\hline CHEMBL1555488 & 688620 & 4.9 & 4.8915 & TRN \\
\hline CHEMBL456446 & 688620 & 4.8 & 5.1285 & TRN \\
\hline CHEMBL1546532 & 688620 & 4.85 & 4.8808 & TST \\
\hline CHEMBL1459063 & 688620 & 4.8 & 4.9507 & TRN \\
\hline CHEMBL1523429 & 688620 & 5.0 & 4.9836 & TRN \\
\hline CHEMBL1321146 & 688620 & 4.45 & 5.3547 & TRN \\
\hline CHEMBL1389067 & 688620 & 4.65 & 5.1352 & TRN \\
\hline CHEMBL1366811 & 688620 & 5.2 & 5.0958 & TRN \\
\hline CHEMBL1466420 & 688620 & 5.25 & 5.1571 & TRN \\
\hline CHEMBL 2005001 & 688620 & 6.95 & 6.1216 & TRN \\
\hline CHEMBL1389877 & 688620 & 4.6 & 5.0808 & TST \\
\hline CHEMBL1556810 & 688620 & 5.0 & 5.204 & TRN \\
\hline CHEMBL1790039 & 688620 & 5.6 & 4.8795 & TRN \\
\hline CHEMBL1583258 & 688620 & 4.6 & 5.2776 & TST \\
\hline CHEMBL1419954 & 688620 & 4.8 & 4.9108 & TST \\
\hline CHEMBL1337802 & 688620 & 4.9 & 4.8022 & TRN \\
\hline CHEMBL1419585 & 688620 & 4.45 & 4.9886 & TST \\
\hline CHEMBL1494176 & 688620 & 5.3 & 5.1002 & TRN \\
\hline CHEMBL1999451 & 688620 & 4.45 & 5.9696 & TRN \\
\hline CHEMBL1369244 & 688620 & 5.05 & 4.9348 & TRN \\
\hline CHEMBL1546898 & 688620 & 5.55 & 5.2196 & TRN \\
\hline CHEMBL1332729 & 688620 & 4.95 & 4.8635 & TST \\
\hline
\end{tabular}




\begin{tabular}{|c|c|c|c|c|c|}
\hline \multicolumn{6}{|c|}{ Supplemental Table S2.txt } \\
\hline CHEMBL1589677 & 688620 & 4.45 & 4.9637 & TRN & \\
\hline CHEMBL1522071 & 688620 & 4.75 & 4.9859 & TST & \\
\hline CHEMBL1422986 & 688620 & 5.95 & 5.4283 & TRN & \\
\hline CHEMBL3191358 & 688620 & 6.1 & 5.2766 & TST & \\
\hline CHEMBL116438 & 688620 & 6.0 & 5.5052 & TRN & \\
\hline CHEMBL1418162 & 688620 & 5.05 & 5.282 & TRN & \\
\hline CHEMBL1526156 & 688620 & 4.85 & 5.1781 & TRN & \\
\hline CHEMBL1422030 & 688620 & 6.5 & 5.1911 & TRN & \\
\hline CHEMBL1384265 & 688620 & 4.7 & 5.0059 & TRN & \\
\hline CHEMBL1391551 & 688620 & 4.85 & 4.8179 & TST & \\
\hline CHEMBL1308052 & 688620 & 5.45 & 5.0188 & TST & \\
\hline CHEMBL1479023 & 688620 & 4.85 & 5.1297 & TRN & \\
\hline CHEMBL3392484 & 688620 & 5.25 & 5.9692 & TRN & \\
\hline CHEMBL1403009 & 688620 & 4.95 & 5.0699 & TRN & \\
\hline CHEMBL1460186 & 688620 & 4.7 & 5.0816 & TST & \\
\hline CHEMBL1600875 & 688620 & 4.95 & 5.356 & TRN & \\
\hline CHEMBL1417638 & 688620 & 5.0 & 5.1273 & TRN & \\
\hline CHEMBL1388662 & 688620 & 5.25 & 4.8657 & TRN & \\
\hline CHEMBL1437883 & 688620 & 4.45 & 4.9275 & TRN & \\
\hline CHEMBL1508196 & 688620 & 5.55 & 5.4596 & TRN & \\
\hline CHEMBL1603619 & 688620 & 4.95 & 5.3828 & TRN & \\
\hline CHEMBL3196261 & 688620 & 5.55 & 5.1379 & TRN & \\
\hline CHEMBL1611456 & 688620 & 4.45 & 4.89199 & 99999999995 & TRN \\
\hline CHEMBL1472503 & 688620 & 4.45 & 5.2906 & TRN & \\
\hline CHEMBL1588452 & 688620 & 6.1 & 5.6102 & TRN & \\
\hline CHEMBL1341378 & 688620 & 7.0 & 5.0071 & TRN & \\
\hline CHEMBL876 & 688620 & 4.45 & 4.9465 & TST & \\
\hline CHEMBL1604139 & 688620 & 5.4 & 5.5029 & TRN & \\
\hline CHEMBL1360064 & 688620 & 5.35 & 5.0843 & TRN & \\
\hline CHEMBL1610015 & 688620 & 4.45 & 4.8038 & TST & \\
\hline CHEMBL1426907 & 688620 & 4.7 & 5.2143 & TRN & \\
\hline CHEMBL1542201 & 688620 & 4.95 & 4.9035 & TRN & \\
\hline CHEMBL1424159 & 688620 & 4.45 & 5.2597 & TST & \\
\hline CHEMBL1531695 & 688620 & 4.9 & 4.9516 & TRN & \\
\hline CHEMBL3213419 & 688620 & 4.95 & 5.2748 & TRN & \\
\hline CHEMBL1429198 & 688620 & 5.5 & 5.1832 & TST & \\
\hline CHEMBL1422158 & 688620 & 6.1 & 5.7079 & TRN & \\
\hline CHEMBL1454609 & 688620 & 6.35 & 5.9928 & TRN & \\
\hline CHEMBL1574930 & 688620 & 4.7 & 4.8999 & TRN & \\
\hline CHEMBL1500621 & 688620 & 4.45 & 4.9086 & TRN & \\
\hline CHEMBL1549279 & 688620 & 5.5 & 5.0908 & TRN & \\
\hline CHEMBL1433047 & 688620 & 5.1 & 5.0169 & TRN & \\
\hline CHEMBL1371404 & 688620 & 4.65 & 4.7614 & TRN & \\
\hline CHEMBL1320393 & 688620 & 5.4 & 5.2658 & TRN & \\
\hline CHEMBL1972216 & 688620 & 6.15 & 5.847 & TRN & \\
\hline CHEMBL1447198 & 688620 & 4.9 & 4.875 & TRN & \\
\hline CHEMBL3193873 & 688620 & 5.6 & 5.612 & TRN & \\
\hline CHEMBL1371876 & 688620 & 4.45 & 4.9746 & TRN & \\
\hline
\end{tabular}




\begin{tabular}{|c|c|c|c|c|c|}
\hline \multicolumn{6}{|c|}{ Supplemental Table S2.txt } \\
\hline CHEMBL1450634 & 688620 & 4.65 & 5.0128 & TRN & \\
\hline CHEMBL1384803 & 688620 & 4.65 & 4.9791 & TST & \\
\hline CHEMBL1398875 & 688620 & 4.65 & 4.5928 & TRN & \\
\hline CHEMBL1369091 & 688620 & 4.9 & 5.0195 & TRN & \\
\hline CHEMBL1544550 & 688620 & 4.45 & 4.9391 & TRN & \\
\hline CHEMBL1383918 & 688620 & 4.45 & 5.0 & TRN & \\
\hline CHEMBL1448475 & 688620 & 4.9 & 4.9654 & TST & \\
\hline CHEMBL1509691 & 688620 & 6.6 & 5.7618 & TRN & \\
\hline CHEMBL1559916 & 688620 & 4.45 & 4.7408 & TRN & \\
\hline CHEMBL1327950 & 688620 & 4.85 & 4.8008 & TST & \\
\hline CHEMBL1465422 & 688620 & 5.4 & 5.7557 & TRN & \\
\hline CHEMBL1304301 & 688620 & 5.6 & 5.0595 & TRN & \\
\hline CHEMBL1563959 & 688620 & 5.3 & 4.8342 & TRN & \\
\hline CHEMBL1599863 & 688620 & 6.6499 & 5.0912 & TST & \\
\hline CHEMBL1571161 & 688620 & 4.75 & 4.90300 & 00000000005 & TST \\
\hline CHEMBL1569716 & 688620 & 4.65 & 4.8552 & TRN & \\
\hline CHEMBL3208142 & 688620 & 4.5 & 5.199 & TST & \\
\hline CHEMBL1443119 & 688620 & 4.75 & 5.0834 & TRN & \\
\hline CHEMBL1558319 & 688620 & 6.5501 & 4.9828 & TRN & \\
\hline CHEMBL1382069 & 688620 & 5.8 & 5.1657 & TST & \\
\hline CHEMBL1394710 & 688620 & 4.45 & 4.8293 & TST & \\
\hline CHEMBL1470920 & 688620 & 5.3 & 5.2784 & TRN & \\
\hline CHEMBL1578946 & 688620 & 4.95 & 4.9353 & TRN & \\
\hline CHEMBL1500997 & 688620 & 4.5 & 5.1748 & TST & \\
\hline CHEMBL1410323 & 688620 & 5.05 & 4.9756 & TRN & \\
\hline CHEMBL1371079 & 688620 & 4.5 & 5.1446 & TRN & \\
\hline CHEMBL1313081 & 688620 & 5.1 & 4.8228 & TRN & \\
\hline CHEMBL1471728 & 688620 & 6.25 & 5.0783 & TRN & \\
\hline CHEMBL1429370 & 688620 & 6.0 & 5.1092 & TRN & \\
\hline CHEMBL1375217 & 688620 & 4.65 & 4.9867 & TRN & \\
\hline CHEMBL1455128 & 688620 & 4.65 & 4.9499 & TRN & \\
\hline CHEMBL3212532 & 688620 & 4.55 & 5.1625 & TRN & \\
\hline CHEMBL1502139 & 688620 & 5.35 & 4.9002 & TRN & \\
\hline CHEMBL3195410 & 688620 & 4.95 & 4.8908 & TRN & \\
\hline CHEMBL1393775 & 688620 & 5.55 & 5.3234 & TRN & \\
\hline CHEMBL1408044 & 688620 & 4.85 & 4.8983 & TRN & \\
\hline CHEMBL3191314 & 688620 & 4.9 & 5.1768 & TST & \\
\hline CHEMBL1418243 & 688620 & 4.45 & 4.825 & TRN & \\
\hline CHEMBL1603114 & 688620 & 5.4 & 5.1194 & TRN & \\
\hline CHEMBL1350778 & 688620 & 5.3 & 5.0494 & TRN & \\
\hline CHEMBL1374384 & 688620 & 5.25 & 5.3819 & TST & \\
\hline CHEMBL3197758 & 688620 & 5.2 & 4.7255 & TRN & \\
\hline CHEMBL1373875 & 688620 & 5.75 & 5.0006 & TRN & \\
\hline CHEMBL1440391 & 688620 & 4.9 & 5.0815 & TRN & \\
\hline CHEMBL1335330 & 688620 & 4.45 & 4.7331 & TRN & \\
\hline CHEMBL1568010 & 688620 & 4.85 & 4.8553 & TRN & \\
\hline CHEMBL1595904 & 688620 & 4.9 & 4.9717 & TRN & \\
\hline CHEMBL1463626 & 688620 & 5.95 & 5.6843 & TRN & \\
\hline
\end{tabular}




\begin{tabular}{|c|c|c|c|c|}
\hline \multicolumn{5}{|c|}{ Supplemental Table S2.txt } \\
\hline CHEMBL1349223 & 688620 & 5.05 & 5.1873 & TRN \\
\hline CHEMBL1370664 & 688620 & 4.95 & 4.9305 & TST \\
\hline CHEMBL1345251 & 688620 & 5.3 & 5.0791 & TST \\
\hline CHEMBL1352272 & 688620 & 4.45 & 5.2038 & TRN \\
\hline CHEMBL3197252 & 688620 & 4.7 & 5.126 & TST \\
\hline CHEMBL1601426 & 688620 & 4.45 & 5.0279 & TRN \\
\hline CHEMBL1375459 & 688620 & 4.9 & 5.2297 & TRN \\
\hline CHEMBL1417200 & 688620 & 6.25 & 5.0417 & TRN \\
\hline CHEMBL1361709 & 688620 & 4.9 & 4.8666 & TRN \\
\hline CHEMBL1385143 & 688620 & 4.9 & 4.6944 & TRN \\
\hline CHEMBL1499698 & 688620 & 4.8 & 4.957 & TRN \\
\hline CHEMBL1404669 & 688620 & 5.0 & 5.0113 & TST \\
\hline CHEMBL1574097 & 688620 & 4.95 & 5.0673 & TRN \\
\hline CHEMBL1504026 & 688620 & 5.15 & 5.1022 & TRN \\
\hline CHEMBL1301497 & 688620 & 5.35 & 5.2971 & TRN \\
\hline CHEMBL1333985 & 688620 & 8.301 & 4.953 & TRN \\
\hline CHEMBL1451830 & 688620 & 4.95 & 4.8509 & TRN \\
\hline CHEMBL1467036 & 688620 & 5.0 & 4.9581 & TRN \\
\hline CHEMBL1546369 & 688620 & 4.9 & 4.9741 & TRN \\
\hline CHEMBL1549703 & 688620 & 4.45 & 5.1416 & TST \\
\hline CHEMBL1610393 & 688620 & 4.45 & 5.0135 & TRN \\
\hline CHEMBL1492850 & 688620 & 5.25 & 5.3999 & TRN \\
\hline CHEMBL3189622 & 688620 & 4.85 & 4.8186 & TRN \\
\hline CHEMBL3191932 & 688620 & 4.85 & 4.6835 & TRN \\
\hline CHEMBL1431912 & 688620 & 5.2 & 5.101 & TRN \\
\hline CHEMBL1299713 & 688620 & 4.75 & 4.6867 & TRN \\
\hline CHEMBL1418658 & 688620 & 4.65 & 4.7819 & TRN \\
\hline CHEMBL1415929 & 688620 & 5.95 & 5.0492 & TRN \\
\hline CHEMBL1538965 & 688620 & 4.9 & 4.9216 & TRN \\
\hline CHEMBL257856 & 688620 & 4.65 & 4.9239 & TRN \\
\hline CHEMBL1383612 & 688620 & 6.0 & 5.7239 & TRN \\
\hline CHEMBL1366478 & 688620 & 6.25 & 5.7832 & TRN \\
\hline CHEMBL1352695 & 688620 & 4.7 & 5.0886 & TRN \\
\hline CHEMBL1531328 & 688620 & 5.2 & 5.6053 & TRN \\
\hline CHEMBL1385440 & 688620 & 5.6 & 5.3153 & TRN \\
\hline CHEMBL1485005 & 688620 & 5.1 & 4.8437 & TRN \\
\hline CHEMBL3195920 & 688620 & 4.45 & 5.0432 & TST \\
\hline CHEMBL3195463 & 688620 & 4.7 & 5.4569 & TRN \\
\hline CHEMBL1548277 & 688620 & 6.7001 & 5.33200 & 2000000001 \\
\hline CHEMBL1408276 & 688620 & 5.25 & 5.228 & TRN \\
\hline CHEMBL1406447 & 688620 & 4.55 & 5.0689 & TRN \\
\hline CHEMBL491716 & 688620 & 4.45 & 5.0884 & TST \\
\hline CHEMBL1550562 & 688620 & 6.1 & 5.3144 & TRN \\
\hline CHEMBL1416950 & 688620 & 4.6 & 4.7969 & TRN \\
\hline CHEMBL1508671 & 688620 & 4.85 & 5.2375 & TRN \\
\hline CHEMBL1302182 & 688620 & 4.95 & 5.1357 & TRN \\
\hline CHEMBL1235717 & 688620 & 5.3 & 5.319 & TST \\
\hline CHEMBL1336423 & 688620 & 4.65 & 5.0013 & TRN \\
\hline
\end{tabular}




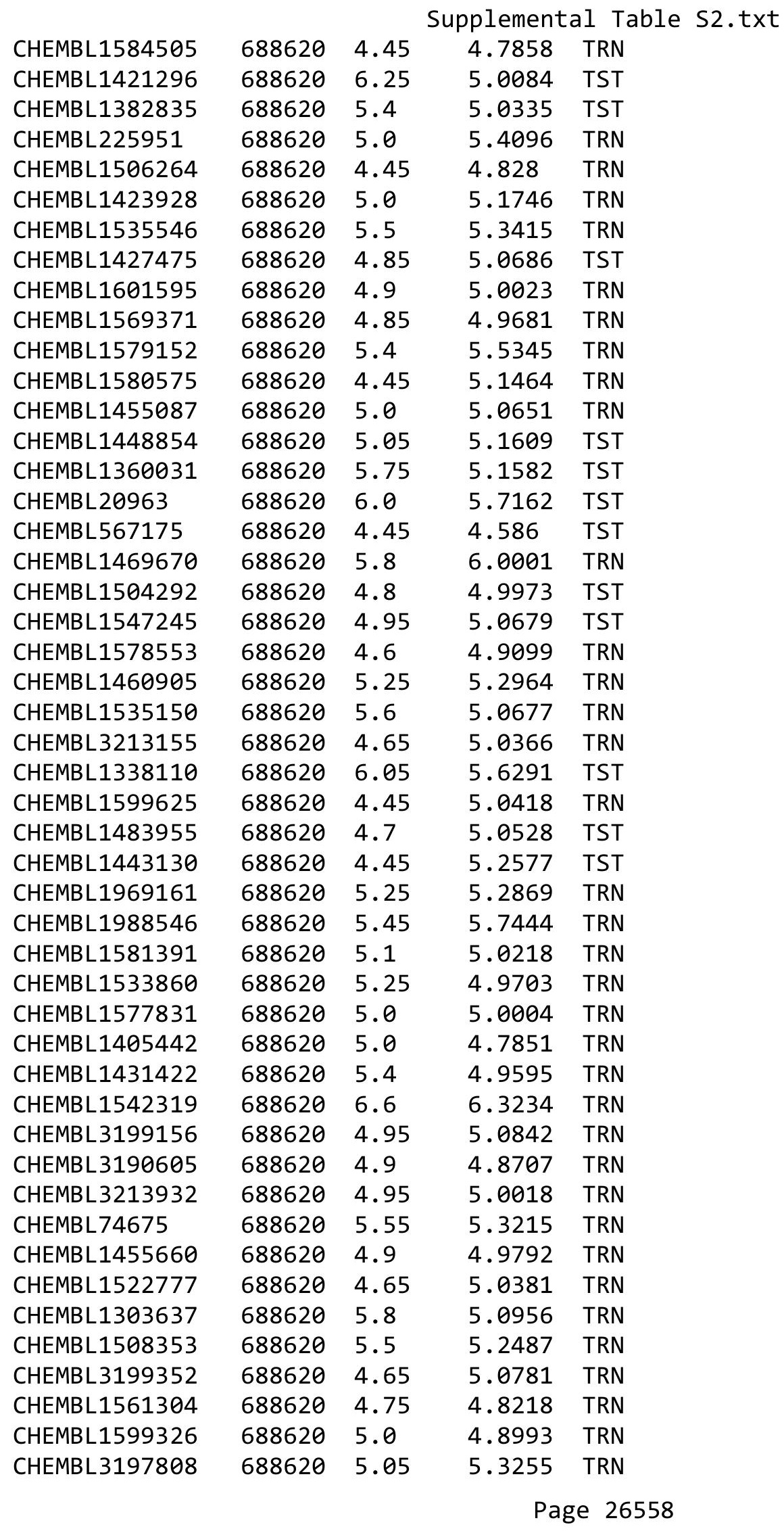




\begin{tabular}{|c|c|c|c|c|}
\hline \multicolumn{5}{|c|}{ Supplemental Table S2.txt } \\
\hline CHEMBL 2001831 & 688620 & 5.0 & 4.9905 & TRN \\
\hline CHEMBL1368775 & 688620 & 5.55 & 5.2591 & TRN \\
\hline CHEMBL1360759 & 688620 & 5.1 & 5.2735 & TRN \\
\hline CHEMBL1490584 & 688620 & 4.55 & 4.9352 & TRN \\
\hline CHEMBL3197122 & 688620 & 5.55 & 5.7523 & TRN \\
\hline CHEMBL1305511 & 688620 & 4.6 & 4.9685 & TST \\
\hline CHEMBL1338085 & 688620 & 4.9 & 5.1905 & TRN \\
\hline CHEMBL1365243 & 688620 & 4.85 & 5.1136 & TST \\
\hline CHEMBL1605758 & 688620 & 4.5 & 4.9395 & TRN \\
\hline CHEMBL1489449 & 688620 & 4.55 & 4.7653 & TRN \\
\hline CHEMBL1332715 & 688620 & 4.65 & 5.1501 & TRN \\
\hline CHEMBL1596771 & 688620 & 5.2 & 4.9944 & TST \\
\hline CHEMBL1526190 & 688620 & 4.45 & 4.9382 & TST \\
\hline CHEMBL1426854 & 688620 & 4.8 & 5.1466 & TST \\
\hline CHEMBL1324142 & 688620 & 5.55 & 4.8729 & TST \\
\hline CHEMBL1563953 & 688620 & 4.75 & 5.0646 & TRN \\
\hline CHEMBL1568622 & 688620 & 4.75 & 4.9738 & TRN \\
\hline CHEMBL1380240 & 688620 & 5.7 & 5.4218 & TRN \\
\hline CHEMBL1966295 & 688620 & 5.25 & 5.0871 & TRN \\
\hline CHEMBL1536048 & 688620 & 5.8 & 4.9348 & TRN \\
\hline CHEMBL1303140 & 688620 & 6.4 & 5.2978 & TRN \\
\hline CHEMBL1479296 & 688620 & 5.35 & 5.6426 & TRN \\
\hline CHEMBL1416838 & 688620 & 4.9 & 5.19 & TRN \\
\hline CHEMBL1970014 & 688620 & 4.8 & 4.8943 & TST \\
\hline CHEMBL1308292 & 688620 & 5.2 & 4.9718 & TRN \\
\hline CHEMBL1313622 & 688620 & 5.1 & 5.1018 & TST \\
\hline CHEMBL491748 & 688620 & 4.95 & 4.8487 & TRN \\
\hline CHEMBL1304287 & 688620 & 4.9 & 5.1893 & TRN \\
\hline CHEMBL1584472 & 688620 & 4.45 & 4.7665 & TRN \\
\hline CHEMBL565856 & 688620 & 4.8 & 5.1305 & TRN \\
\hline CHEMBL1338673 & 688620 & 4.45 & 5.0867 & TRN \\
\hline CHEMBL1328483 & 688620 & 5.4 & 5.671 & TRN \\
\hline CHEMBL1401188 & 688620 & 6.2 & 6.1841 & TRN \\
\hline CHEMBL1353467 & 688620 & 5.55 & 5.3851 & TRN \\
\hline CHEMBL1590100 & 688620 & 4.8 & 4.8518 & TRN \\
\hline CHEMBL1313410 & 688620 & 6.5501 & 5.8062 & TRN \\
\hline CHEMBL1522880 & 688620 & 4.8 & 5.1646 & TRN \\
\hline CHEMBL1491879 & 688620 & 4.45 & 5.2237 & TRN \\
\hline CHEMBL1580400 & 688620 & 5.55 & 5.1369 & TRN \\
\hline CHEMBL3193970 & 688620 & 4.95 & 5.0599 & TST \\
\hline CHEMBL1424292 & 688620 & 4.45 & 5.0185 & TRN \\
\hline CHEMBL1415645 & 688620 & 4.7 & 5.0229 & TRN \\
\hline CHEMBL3212972 & 688620 & 4.95 & 5.3242 & TRN \\
\hline CHEMBL1398373 & 688620 & 4.7 & 5.438 & TRN \\
\hline CHEMBL1975101 & 688620 & 4.7 & 5.1612 & TRN \\
\hline CHEMBL 3193272 & 688620 & 6.2 & 5.07600 & 00000000005 \\
\hline CHEMBL1540920 & 688620 & 5.35 & 5.2294 & TRN \\
\hline CHEMBL3196661 & 688620 & 5.45 & 5.0475 & TRN \\
\hline
\end{tabular}




\begin{tabular}{|c|c|c|c|c|}
\hline \multicolumn{5}{|c|}{ Supplemental Table S2.txt } \\
\hline CHEMBL1400375 & 688620 & 5.0 & 4.9463 & TRN \\
\hline CHEMBL1502163 & 688620 & 4.7 & 5.0325 & TRN \\
\hline CHEMBL1381714 & 688620 & 5.5 & 4.829 & TRN \\
\hline CHEMBL1329138 & 688620 & 6.1 & 5.693 & TST \\
\hline CHEMBL3192907 & 688620 & 4.75 & 5.245 & TRN \\
\hline CHEMBL1502796 & 688620 & 4.8 & 4.9148 & TRN \\
\hline CHEMBL1383204 & 688620 & 5.45 & 4.9818 & TRN \\
\hline CHEMBL1430213 & 688620 & 5.0 & 5.051 & TST \\
\hline CHEMBL1313307 & 688620 & 5.25 & 4.9554 & TST \\
\hline CHEMBL1532147 & 688620 & 6.0 & 4.8809 & TRN \\
\hline CHEMBL3193413 & 688620 & 5.15 & 5.4612 & TRN \\
\hline CHEMBL1487333 & 688620 & 4.6 & 4.94600 & 0000000001 \\
\hline CHEMBL1560925 & 688620 & 4.5 & 4.806 & TRN \\
\hline CHEMBL1485650 & 688620 & 4.45 & 4.9318 & TRN \\
\hline CHEMBL1326930 & 688620 & 5.4 & 5.1174 & TRN \\
\hline CHEMBL1431282 & 688620 & 4.8 & 5.0779 & TST \\
\hline CHEMBL140 & 688620 & 6.0 & 5.5411 & TRN \\
\hline CHEMBL1387245 & 688620 & 5.95 & 5.0288 & TRN \\
\hline CHEMBL3208679 & 688620 & 4.7 & 4.9598 & TRN \\
\hline CHEMBL3209413 & 688620 & 6.3 & 4.94 & TRN \\
\hline CHEMBL1425778 & 688620 & 5.0 & 5.037 & TRN \\
\hline CHEMBL1574366 & 688620 & 5.1 & 5.4603 & TRN \\
\hline CHEMBL3190063 & 688620 & 6.0 & 5.5404 & TRN \\
\hline CHEMBL 3197348 & 688620 & 5.35 & 4.9002 & TRN \\
\hline CHEMBL1501039 & 688620 & 4.45 & 4.9219 & TRN \\
\hline CHEMBL1417929 & 688620 & 4.9 & 4.9466 & TRN \\
\hline CHEMBL1348179 & 688620 & 6.1 & 5.5834 & TRN \\
\hline CHEMBL1547983 & 688620 & 5.45 & 5.1807 & TRN \\
\hline CHEMBL1524921 & 688620 & 6.25 & 5.1982 & TRN \\
\hline CHEMBL1568589 & 688620 & 5.2 & 5.0269 & TRN \\
\hline CHEMBL1605366 & 688620 & 5.2 & 4.8905 & TRN \\
\hline CHEMBL1299330 & 688620 & 5.0 & 4.7352 & TRN \\
\hline CHEMBL1538368 & 688620 & 4.5 & 4.8509 & TST \\
\hline CHEMBL1573446 & 688620 & 4.85 & 5.047 & TRN \\
\hline CHEMBL1361939 & 688620 & 4.95 & 4.7262 & TRN \\
\hline CHEMBL1307784 & 688620 & 4.95 & 5.2933 & TRN \\
\hline CHEMBL1563862 & 688620 & 4.45 & 4.5095 & TRN \\
\hline CHEMBL3198940 & 688620 & 4.4 & 5.2875 & TRN \\
\hline CHEMBL1352127 & 688620 & 5.8 & 5.0225 & TRN \\
\hline CHEMBL1545934 & 688620 & 4.85 & 5.2197 & TST \\
\hline CHEMBL1548430 & 688620 & 5.35 & 4.8181 & TRN \\
\hline CHEMBL1543080 & 688620 & 5.6 & 5.0319 & TRN \\
\hline CHEMBL1453173 & 688620 & 7.0501 & 4.9825 & TRN \\
\hline CHEMBL1464945 & 688620 & 4.45 & 5.1646 & TRN \\
\hline CHEMBL3198624 & 688620 & 5.05 & 5.2957 & TRN \\
\hline CHEMBL1520319 & 688620 & 5.2 & 5.6129 & TRN \\
\hline CHEMBL1345052 & 688620 & 5.15 & 5.1768 & TST \\
\hline CHEMBL1498574 & 688620 & 4.55 & 5.1093 & TRN \\
\hline
\end{tabular}




\begin{tabular}{|c|c|c|c|c|}
\hline \multicolumn{5}{|c|}{ Supplemental Table S2.txt } \\
\hline CHEMBL1528479 & 688620 & 4.45 & 4.8893 & TRN \\
\hline CHEMBL1587296 & 688620 & 4.45 & 4.9124 & TRN \\
\hline CHEMBL1563920 & 688620 & 5.4 & 4.9749 & TRN \\
\hline CHEMBL1459027 & 688620 & 4.45 & 5.0389 & TRN \\
\hline CHEMBL1309420 & 688620 & 4.8 & 5.1472 & TRN \\
\hline CHEMBL1440262 & 688620 & 5.15 & 5.1585 & TST \\
\hline CHEMBL1568610 & 688620 & 5.6 & 5.2242 & TST \\
\hline CHEMBL1350529 & 688620 & 6.8499 & 5.2495 & TRN \\
\hline CHEMBL1460464 & 688620 & 4.95 & 5.3723 & TRN \\
\hline CHEMBL1417204 & 688620 & 5.55 & 5.3591 & TRN \\
\hline CHEMBL1439249 & 688620 & 6.25 & 4.9518 & TRN \\
\hline CHEMBL1363042 & 688620 & 5.0 & 4.8957 & TRN \\
\hline CHEMBL1602798 & 688620 & 4.45 & 5.2605 & TST \\
\hline CHEMBL1327850 & 688620 & 4.95 & 4.9964 & TRN \\
\hline CHEMBL1988851 & 688620 & 4.95 & 5.0128 & TRN \\
\hline CHEMBL1461722 & 688620 & 4.9 & 5.099 & TRN \\
\hline CHEMBL1972031 & 688620 & 5.5 & 5.3842 & TRN \\
\hline CHEMBL1441650 & 688620 & 5.55 & 5.1963 & TRN \\
\hline CHEMBL1342423 & 688620 & 5.45 & 5.6234 & TRN \\
\hline CHEMBL1320956 & 688620 & 5.0 & 4.7711 & TRN \\
\hline CHEMBL1308975 & 688620 & 4.45 & 4.7137 & TST \\
\hline CHEMBL1544871 & 688620 & 4.45 & 4.9008 & TRN \\
\hline CHEMBL1511286 & 688620 & 4.95 & 5.1292 & TRN \\
\hline CHEMBL1529772 & 688620 & 4.7 & 5.4266 & TST \\
\hline CHEMBL1484167 & 688620 & 5.9 & 4.9238 & TST \\
\hline CHEMBL1594218 & 688620 & 4.45 & 4.9568 & TRN \\
\hline CHEMBL1320567 & 688620 & 6.2 & 5.0439 & TST \\
\hline CHEMBL1386170 & 688620 & 4.85 & 5.0552 & TRN \\
\hline CHEMBL1495224 & 688620 & 4.9 & 5.1193 & TST \\
\hline CHEMBL1578377 & 688620 & 4.5 & 4.8015 & TST \\
\hline CHEMBL1544884 & 688620 & 4.75 & 4.8866 & TRN \\
\hline CHEMBL1446312 & 688620 & 5.0 & 5.2564 & TRN \\
\hline CHEMBL1494282 & 688620 & 4.65 & 5.0071 & TST \\
\hline CHEMBL3191818 & 688620 & 5.75 & 5.1176 & TRN \\
\hline CHEMBL193627 & 688620 & 5.95 & 5.3527 & TRN \\
\hline CHEMBL1521991 & 688620 & 4.45 & 4.8169 & TST \\
\hline CHEMBL3191040 & 688620 & 5.55 & 5.3243 & TRN \\
\hline CHEMBL1424340 & 688620 & 4.75 & 4.802 & TRN \\
\hline CHEMBL1506604 & 688620 & 4.45 & 4.8893 & TRN \\
\hline CHEMBL1481222 & 688620 & 5.05 & 5.0261 & TRN \\
\hline CHEMBL1324723 & 688620 & 4.45 & 5.0758 & TRN \\
\hline CHEMBL1330453 & 688620 & 4.95 & 4.9532 & TRN \\
\hline CHEMBL1332512 & 688620 & 5.3 & 5.4226 & TRN \\
\hline CHEMBL1489256 & 688620 & 5.7 & 5.1026 & TRN \\
\hline CHEMBL1547890 & 688620 & 5.1 & 5.4098 & TRN \\
\hline CHEMBL1459263 & 688620 & 4.85 & 4.9661 & TRN \\
\hline CHEMBL1334426 & 688620 & 4.95 & 4.8122 & TRN \\
\hline CHEMBL1426949 & 688620 & 4.75 & 4.8759 & TRN \\
\hline
\end{tabular}




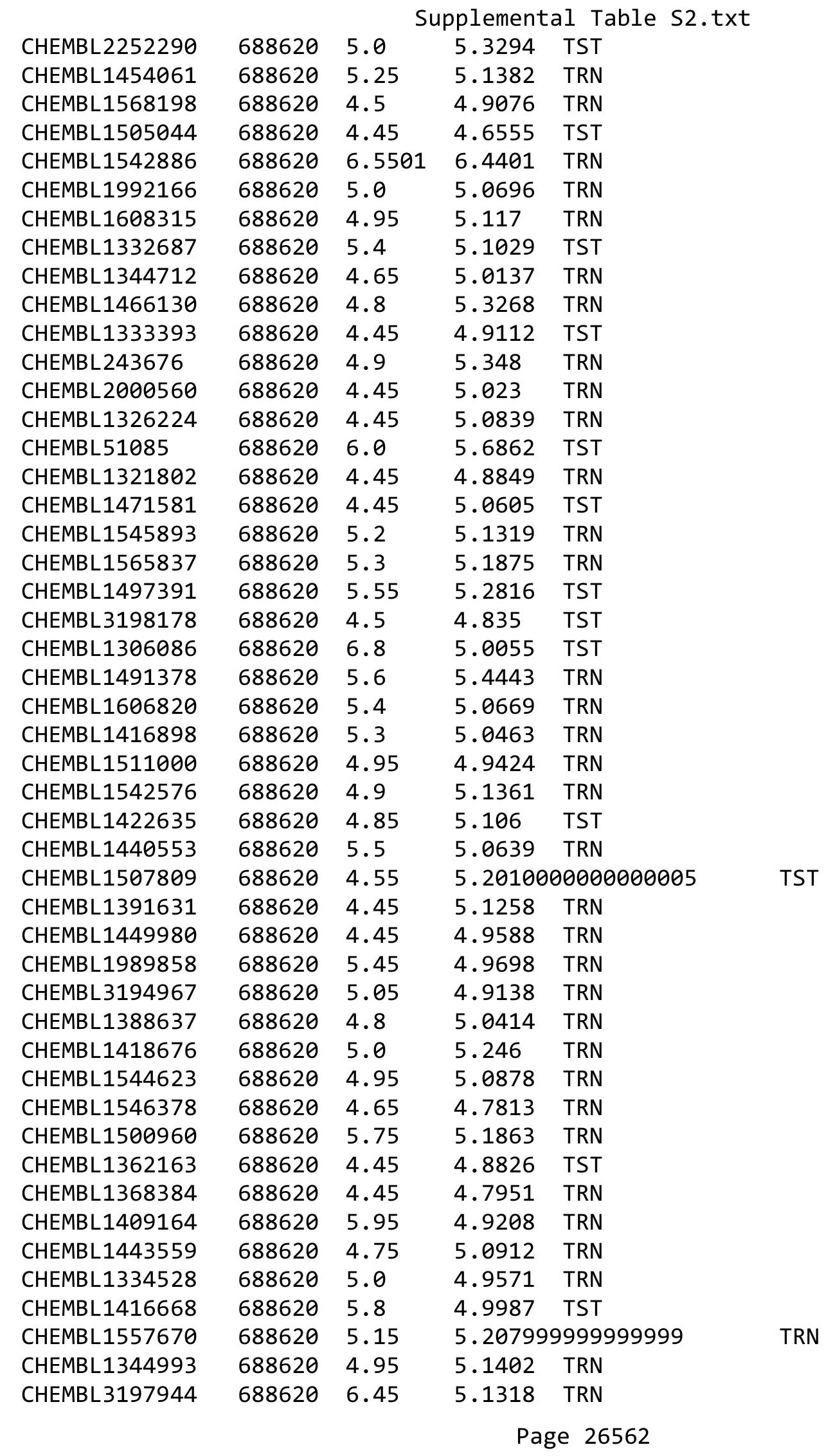




\begin{tabular}{|c|c|c|c|c|}
\hline & & \multicolumn{3}{|c|}{ Supplemental Table S2.txt } \\
\hline CHEMBL1613591 & 688620 & 6.35 & 5.0954 & TRN \\
\hline CHEMBL1519862 & 688620 & 4.75 & 5.0531 & TRN \\
\hline CHEMBL362994 & 688620 & 5.95 & 5.688 & TRN \\
\hline CHEMBL1430052 & 688620 & 5.55 & 5.3306 & TRN \\
\hline CHEMBL 2006856 & 688620 & 5.2 & 5.5673 & TRN \\
\hline CHEMBL1496539 & 688620 & 5.4 & 4.9128 & TST \\
\hline CHEMBL1313253 & 688620 & 5.1 & 5.1853 & TST \\
\hline CHEMBL1353821 & 688620 & 5.0 & 5.2661 & TRN \\
\hline CHEMBL3191466 & 688620 & 4.75 & 4.9882 & TRN \\
\hline CHEMBL1570908 & 688620 & 5.55 & 5.0216 & TST \\
\hline CHEMBL1458393 & 688620 & 4.85 & 4.9567 & TST \\
\hline CHEMBL1494382 & 688620 & 4.95 & 4.9106 & TRN \\
\hline CHEMBL1340777 & 688620 & 5.05 & 4.8663 & TST \\
\hline CHEMBL1382783 & 688620 & 5.3 & 5.1631 & TRN \\
\hline CHEMBL1403920 & 688620 & 4.95 & 5.1941 & TRN \\
\hline CHEMBL1470907 & 688620 & 5.2 & 4.9976 & TST \\
\hline CHEMBL1409974 & 688620 & 4.75 & 5.1108 & TRN \\
\hline CHEMBL1365203 & 688620 & 4.95 & 5.0823 & TRN \\
\hline CHEMBL1352335 & 688620 & 4.95 & 4.9604 & TRN \\
\hline CHEMBL1341719 & 688620 & 4.95 & 5.0756 & TRN \\
\hline CHEMBL1450292 & 688620 & 6.15 & 4.9495 & TRN \\
\hline CHEMBL1308487 & 688620 & 4.9 & 5.0868 & TST \\
\hline CHEMBL1442496 & 688620 & 4.65 & 4.9414 & TST \\
\hline CHEMBL1604514 & 688620 & 4.95 & 4.9941 & TRN \\
\hline CHEMBL1969707 & 688620 & 4.45 & 5.1882 & TRN \\
\hline CHEMBL1460489 & 688620 & 4.45 & 4.8882 & TRN \\
\hline CHEMBL1583527 & 688620 & 6.1 & 4.9597 & TST \\
\hline CHEMBL1488127 & 688620 & 4.7 & 5.0862 & TRN \\
\hline CHEMBL1331521 & 688620 & 4.9 & 5.0772 & TRN \\
\hline CHEMBL1364895 & 688620 & 4.95 & 5.5217 & TRN \\
\hline CHEMBL1355340 & 688620 & 5.1 & 5.3983 & TRN \\
\hline CHEMBL1502652 & 688620 & 5.6 & 5.2486 & TRN \\
\hline CHEMBL1970621 & 688620 & 4.75 & 4.8213 & TRN \\
\hline CHEMBL3193709 & 688620 & 4.7 & 5.1681 & TRN \\
\hline CHEMBL1384670 & 688620 & 4.6 & 4.9042 & TST \\
\hline CHEMBL1373092 & 688620 & 4.45 & 5.1087 & TRN \\
\hline CHEMBL1402730 & 688620 & 5.45 & 5.182 & TST \\
\hline CHEMBL1329012 & 688620 & 5.25 & 4.8564 & TRN \\
\hline CHEMBL1396595 & 688620 & 5.15 & 4.8768 & TST \\
\hline CHEMBL1388759 & 688620 & 6.15 & 4.9737 & TRN \\
\hline CHEMBL1443646 & 688620 & 4.9 & 5.0329 & TRN \\
\hline CHEMBL1367183 & 688620 & 5.15 & 4.8269 & TRN \\
\hline CHEMBL1565441 & 688620 & 4.6 & 5.2306 & TRN \\
\hline CHEMBL1319040 & 688620 & 4.45 & 4.9715 & TST \\
\hline CHEMBL1343063 & 688620 & 4.45 & 4.8767 & TRN \\
\hline CHEMBL1579464 & 688620 & 5.25 & 5.0871 & TRN \\
\hline CHEMBL1364747 & 688620 & 4.9 & 4.9679 & TST \\
\hline CHEMBL1451608 & 688620 & 5.2 & 5.1058 & TST \\
\hline
\end{tabular}




\begin{tabular}{|c|c|c|c|c|}
\hline \multicolumn{5}{|c|}{ Supplemental Table S2.txt } \\
\hline CHEMBL1537063 & 688620 & 4.7 & 5.038 & TRN \\
\hline CHEMBL1445607 & 688620 & 4.8 & 5.9136 & TRN \\
\hline CHEMBL1454652 & 688620 & 4.45 & 5.2215 & TRN \\
\hline CHEMBL 3195572 & 688620 & 4.75 & 5.0964 & TRN \\
\hline CHEMBL1365565 & 688620 & 4.6 & 5.2845 & TRN \\
\hline CHEMBL1446194 & 688620 & 4.55 & 4.9099 & TRN \\
\hline CHEMBL1324478 & 688620 & 5.95 & 5.2809 & TRN \\
\hline CHEMBL1449208 & 688620 & 4.95 & 5.2181 & TRN \\
\hline CHEMBL1392606 & 688620 & 5.55 & 5.0939 & TRN \\
\hline CHEMBL1429972 & 688620 & 4.95 & 5.1503 & TRN \\
\hline CHEMBL1342712 & 688620 & 4.5 & 4.9863 & TRN \\
\hline CHEMBL3191598 & 688620 & 5.4 & 5.1011 & TRN \\
\hline CHEMBL1430977 & 688620 & 4.9 & 5.1201 & TRN \\
\hline CHEMBL3208977 & 688620 & 6.05 & 4.7962 & TST \\
\hline CHEMBL1343588 & 688620 & 7.4498 & 4.9637 & TST \\
\hline CHEMBL1351283 & 688620 & 4.95 & 5.4082 & TRN \\
\hline CHEMBL1377479 & 688620 & 4.9 & 4.8501 & TRN \\
\hline CHEMBL1507026 & 688620 & 5.1 & 4.931 & TRN \\
\hline CHEMBL1384677 & 688620 & 4.75 & 4.9104 & TRN \\
\hline CHEMBL1444035 & 688620 & 6.35 & 5.2624 & TST \\
\hline CHEMBL3193151 & 688620 & 5.3 & 4.9598 & TRN \\
\hline CHEMBL1464521 & 688620 & 4.85 & 5.2733 & TRN \\
\hline CHEMBL1528450 & 688620 & 4.8 & 4.9344 & TRN \\
\hline CHEMBL1327692 & 688620 & 6.2 & 5.1617 & TST \\
\hline CHEMBL1517471 & 688620 & 4.95 & 4.9935 & TRN \\
\hline CHEMBL1541050 & 688620 & 5.5 & 5.5619 & TRN \\
\hline CHEMBL1305775 & 688620 & 5.0 & 5.0296 & TRN \\
\hline CHEMBL1538367 & 688620 & 4.8 & 4.83 & TRN \\
\hline CHEMBL1412372 & 688620 & 4.7 & 4.86 & TRN \\
\hline CHEMBL3214618 & 688620 & 4.95 & 4.9407 & TRN \\
\hline CHEMBL1548823 & 688620 & 4.5 & 4.8532 & TRN \\
\hline CHEMBL3197457 & 688620 & 4.9 & 4.7066 & TRN \\
\hline CHEMBL1485637 & 688620 & 5.15 & 5.0954 & TRN \\
\hline CHEMBL1366073 & 688620 & 4.45 & 5.1983 & TRN \\
\hline CHEMBL1345104 & 688620 & 4.45 & 4.8484 & TRN \\
\hline CHEMBL1488695 & 688620 & 5.35 & 5.1168 & TRN \\
\hline CHEMBL1541350 & 688620 & 6.4 & 5.7062 & TRN \\
\hline CHEMBL1342400 & 688620 & 4.65 & 5.0772 & TRN \\
\hline CHEMBL3196605 & 688620 & 5.4 & 5.4122 & TRN \\
\hline CHEMBL1606550 & 688620 & 4.75 & 4.9789 & TRN \\
\hline CHEMBL1470676 & 688620 & 5.4 & 5.7022 & TRN \\
\hline CHEMBL1818878 & 688620 & 6.15 & 6.6842 & TRN \\
\hline CHEMBL1362174 & 688620 & 4.95 & 5.3871 & TRN \\
\hline CHEMBL1398924 & 688620 & 4.9 & 5.0149 & TRN \\
\hline CHEMBL1526008 & 688620 & 5.05 & 4.95 & TRN \\
\hline CHEMBL1302596 & 688620 & 7.1002 & 5.8195 & TRN \\
\hline CHEMBL1450430 & 688620 & 6.1 & 5.7887 & TRN \\
\hline CHEMBL1427854 & 688620 & 4.45 & 4.8268 & TRN \\
\hline
\end{tabular}




\begin{tabular}{|c|c|c|c|c|}
\hline \multicolumn{5}{|c|}{ Supplemental Table S2.txt } \\
\hline CHEMBL1525372 & 688620 & 4.45 & 4.9341 & TST \\
\hline CHEMBL1363519 & 688620 & 4.5 & 5.1571 & TRN \\
\hline CHEMBL1537952 & 688620 & 4.45 & 5.3591 & TST \\
\hline CHEMBL1558927 & 688620 & 4.95 & 4.9798 & TRN \\
\hline CHEMBL1385788 & 688620 & 4.45 & 4.8093 & TRN \\
\hline CHEMBL1446579 & 688620 & 5.2 & 5.034 & TST \\
\hline CHEMBL1333842 & 688620 & 4.65 & 4.7824 & TRN \\
\hline CHEMBL1562541 & 688620 & 4.9 & 4.9449 & TRN \\
\hline CHEMBL1449242 & 688620 & 4.9 & 5.1478 & TRN \\
\hline CHEMBL1537472 & 688620 & 5.8 & 5.0976 & TRN \\
\hline CHEMBL1536582 & 688620 & 5.2 & 5.0635 & TST \\
\hline CHEMBL1351469 & 688620 & 4.75 & 4.9808 & TRN \\
\hline CHEMBL1540149 & 688620 & 4.45 & 4.7722 & TRN \\
\hline CHEMBL1511783 & 688620 & 5.1 & 4.988 & TST \\
\hline CHEMBL3190818 & 688620 & 5.05 & 5.3707 & TST \\
\hline CHEMBL1389605 & 688620 & 4.85 & 4.6948 & TRN \\
\hline CHEMBL3189245 & 688620 & 5.9 & 6.001 & TRN \\
\hline CHEMBL 3196249 & 688620 & 4.75 & 4.9395 & TRN \\
\hline CHEMBL1498179 & 688620 & 4.65 & 5.1606 & TRN \\
\hline CHEMBL1536374 & 688620 & 5.4 & 5.5944 & TRN \\
\hline CHEMBL1344463 & 688620 & 5.3 & 5.0925 & TRN \\
\hline CHEMBL1423968 & 688620 & 6.6499 & 5.5213 & TRN \\
\hline CHEMBL1524108 & 688620 & 5.1 & 4.8581 & TST \\
\hline CHEMBL1454726 & 688620 & 4.85 & 4.9576 & TRN \\
\hline CHEMBL1538966 & 688620 & 4.95 & 4.8907 & TST \\
\hline CHEMBL1420751 & 688620 & 6.35 & 5.2766 & TST \\
\hline CHEMBL1362310 & 688620 & 5.55 & 5.3464 & TRN \\
\hline CHEMBL1428407 & 688620 & 4.95 & 4.6136 & TRN \\
\hline CHEMBL1321145 & 688620 & 4.9 & 5.0946 & TRN \\
\hline CHEMBL1539149 & 688620 & 4.65 & 4.8052 & TST \\
\hline CHEMBL1455380 & 688620 & 4.9 & 5.1527 & TRN \\
\hline CHEMBL1461932 & 688620 & 4.75 & 4.7873 & TRN \\
\hline CHEMBL1540081 & 688620 & 5.65 & 5.1556 & TRN \\
\hline CHEMBL1352052 & 688620 & 5.5 & 5.3671 & TRN \\
\hline CHEMBL1430275 & 688620 & 4.75 & 5.0583 & TRN \\
\hline CHEMBL1601223 & 688620 & 4.9 & 5.1669 & TST \\
\hline CHEMBL1376421 & 688620 & 4.45 & 4.7494 & TRN \\
\hline CHEMBL1511392 & 688620 & 6.0 & 5.0 & TRN \\
\hline CHEMBL1390843 & 688620 & 4.95 & 4.976 & TRN \\
\hline CHEMBL1562609 & 688620 & 6.3 & 5.1861 & TRN \\
\hline CHEMBL1609660 & 688620 & 4.5 & 4.9195 & TST \\
\hline CHEMBL1580197 & 688620 & 6.0 & 5.6094 & TRN \\
\hline CHEMBL1501692 & 688620 & 4.85 & 4.9649 & TRN \\
\hline CHEMBL1576069 & 688620 & 5.35 & 5.0907 & TRN \\
\hline CHEMBL1413595 & 688620 & 4.95 & 5.0771 & TST \\
\hline CHEMBL1583098 & 688620 & 4.45 & 4.9510 & 00000000005 \\
\hline CHEMBL1479269 & 688620 & 4.5 & 4.9639 & TRN \\
\hline CHEMBL1309525 & 688620 & 4.45 & 4.8314 & TRN \\
\hline
\end{tabular}

TRN 


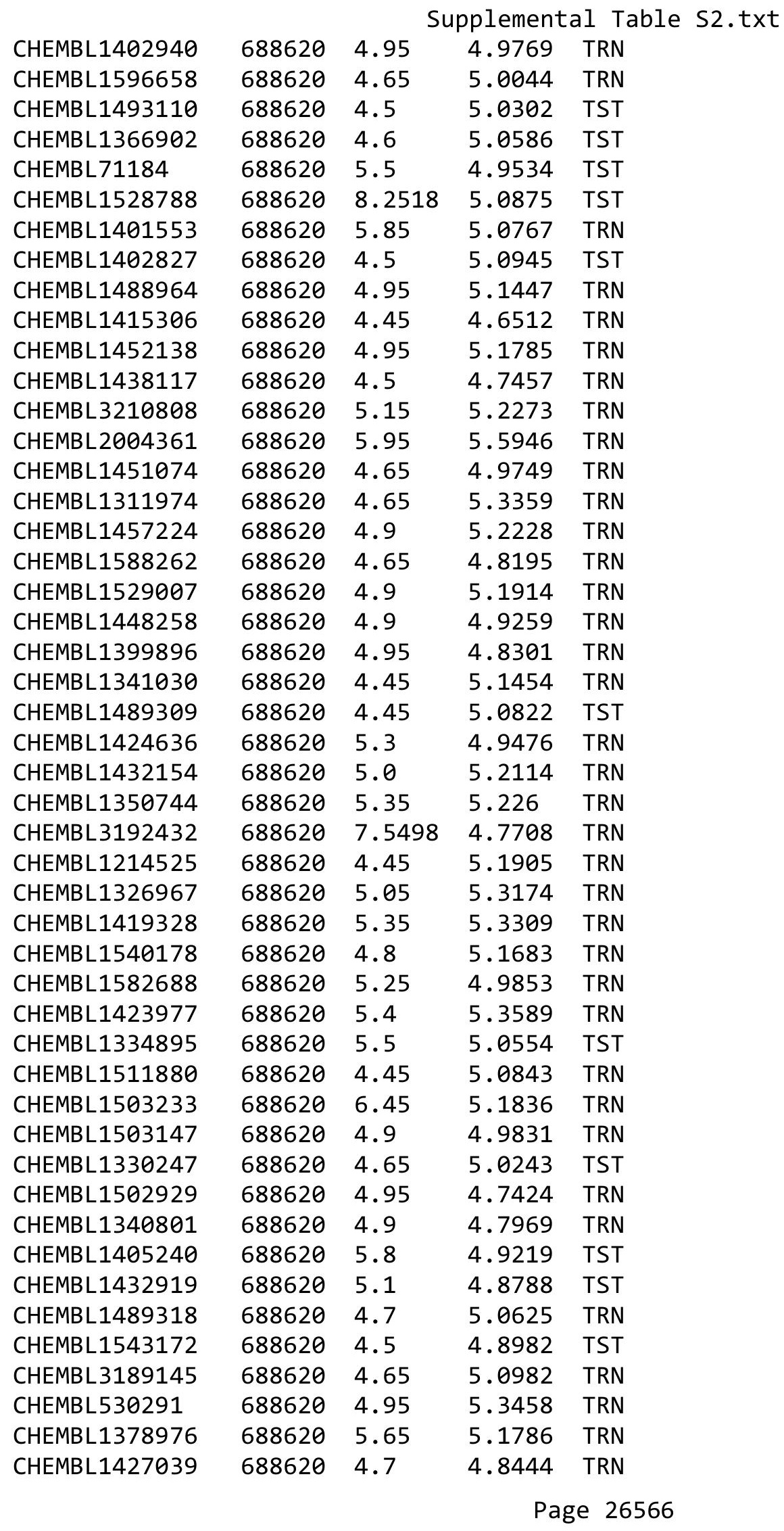




\begin{tabular}{|c|c|c|c|c|c|}
\hline \multicolumn{6}{|c|}{ Supplemental Table S2.txt } \\
\hline CHEMBL1575200 & 688620 & 4.45 & 4.9826 & TRN & \\
\hline CHEMBL1606717 & 688620 & 5.6 & 5.3133 & TRN & \\
\hline CHEMBL1347204 & 688620 & 5.35 & 5.7036 & TRN & \\
\hline CHEMBL1519293 & 688620 & 4.75 & 4.8915 & TRN & \\
\hline CHEMBL1390678 & 688620 & 5.0 & 4.6995 & TRN & \\
\hline CHEMBL1596810 & 688620 & 4.95 & 5.2446 & TRN & \\
\hline CHEMBL1433204 & 688620 & 4.85 & 4.8106 & TRN & \\
\hline CHEMBL1604970 & 688620 & 5.15 & 4.9325 & TRN & \\
\hline CHEMBL1313479 & 688620 & 5.25 & 4.9186 & TRN & \\
\hline CHEMBL1503463 & 688620 & 4.8 & 5.0899 & TST & \\
\hline CHEMBL1496880 & 688620 & 4.5 & 4.8862 & TRN & \\
\hline CHEMBL1325852 & 688620 & 4.75 & 4.8245 & TRN & \\
\hline CHEMBL2016647 & 688620 & 5.9 & 5.2436 & TRN & \\
\hline CHEMBL1313534 & 688620 & 4.6 & 5.0458 & TRN & \\
\hline CHEMBL1561800 & 688620 & 4.9 & 4.931 & TRN & \\
\hline CHEMBL1589780 & 688620 & 8.3468 & 5.0912 & TST & \\
\hline CHEMBL3210071 & 688620 & 4.7 & 5.3073 & TST & \\
\hline CHEMBL1546528 & 688620 & 4.9 & 4.9986 & TRN & \\
\hline CHEMBL1386777 & 688620 & 4.45 & 5.0056 & TRN & \\
\hline CHEMBL3199726 & 688620 & 5.55 & 4.97199 & 99999999995 & TST \\
\hline CHEMBL1413726 & 688620 & 4.75 & 4.7621 & TRN & \\
\hline CHEMBL1418001 & 688620 & 6.0 & 4.9934 & TRN & \\
\hline CHEMBL1520214 & 688620 & 5.5 & 5.1722 & TRN & \\
\hline CHEMBL1580515 & 688620 & 5.1 & 5.079 & TRN & \\
\hline CHEMBL1525438 & 688620 & 5.6 & 5.19799 & 99999999995 & TST \\
\hline CHEMBL1469984 & 688620 & 5.55 & 5.0376 & TRN & \\
\hline CHEMBL1332226 & 688620 & 5.3 & 5.3235 & TRN & \\
\hline CHEMBL1369747 & 688620 & 6.1 & 5.5334 & TRN & \\
\hline CHEMBL1571378 & 688620 & 4.9 & 5.0628 & TRN & \\
\hline CHEMBL97453 & 688620 & 4.9 & 5.0746 & TST & \\
\hline CHEMBL3195933 & 688620 & 4.7 & 5.0103 & TRN & \\
\hline CHEMBL1523410 & 688620 & 4.65 & 4.9115 & TRN & \\
\hline CHEMBL1421160 & 688620 & 4.55 & 5.1579 & TST & \\
\hline CHEMBL1431012 & 688620 & 4.5 & 4.9461 & TST & \\
\hline CHEMBL1302028 & 688620 & 4.8 & 4.7839 & TRN & \\
\hline CHEMBL1540808 & 688620 & 5.3 & 5.0653 & TST & \\
\hline CHEMBL3192117 & 688620 & 4.65 & 4.9141 & TRN & \\
\hline CHEMBL1362133 & 688620 & 4.75 & 4.9508 & TRN & \\
\hline CHEMBL1390793 & 688620 & 5.5 & 5.2856 & TRN & \\
\hline CHEMBL3190460 & 688620 & 4.95 & 4.9243 & TRN & \\
\hline CHEMBL1377608 & 688620 & 4.8 & 4.7754 & TRN & \\
\hline CHEMBL 2000321 & 688620 & 5.25 & 5.1767 & TRN & \\
\hline CHEMBL1587366 & 688620 & 5.3 & 5.1887 & TRN & \\
\hline CHEMBL1540556 & 688620 & 4.95 & 4.9669 & TST & \\
\hline CHEMBL1402398 & 688620 & 4.8 & 5.0091 & TRN & \\
\hline CHEMBL1536992 & 688620 & 4.7 & 4.8854 & TST & \\
\hline CHEMBL588327 & 688620 & 4.45 & 4.9054 & TST & \\
\hline CHEMBL1525742 & 688620 & 4.6 & 4.819 & TRN & \\
\hline
\end{tabular}




\begin{tabular}{|c|c|c|c|c|}
\hline \multicolumn{5}{|c|}{ Supplemental Table S2.txt } \\
\hline CHEMBL1585763 & 688620 & 5.55 & 4.6853 & TRN \\
\hline CHEMBL1353221 & 688620 & 4.45 & 4.8197 & TST \\
\hline CHEMBL1413488 & 688620 & 4.5 & 4.8079 & TRN \\
\hline CHEMBL1462653 & 688620 & 4.95 & 5.1887 & TRN \\
\hline CHEMBL1460786 & 688620 & 4.65 & 5.1874 & TRN \\
\hline CHEMBL1415371 & 688620 & 5.0 & 5.0468 & TST \\
\hline CHEMBL1468458 & 688620 & 4.75 & 5.1185 & TRN \\
\hline CHEMBL1365269 & 688620 & 4.6 & 5.28799 & 9999999999 \\
\hline CHEMBL1578900 & 688620 & 5.8 & 5.0054 & TST \\
\hline CHEMBL1572496 & 688620 & 4.7 & 4.925 & TRN \\
\hline CHEMBL3190039 & 688620 & 5.3 & 5.1247 & TRN \\
\hline CHEMBL1408314 & 688620 & 4.45 & 4.6992 & TRN \\
\hline CHEMBL3211930 & 688620 & 5.45 & 5.2332 & TRN \\
\hline CHEMBL1375035 & 688620 & 5.0 & 5.0179 & TRN \\
\hline CHEMBL1543427 & 688620 & 5.35 & 5.136 & TRN \\
\hline CHEMBL1369999 & 688620 & 4.85 & 5.1244 & TRN \\
\hline CHEMBL1425624 & 688620 & 5.95 & 5.9858 & TRN \\
\hline CHEMBL1448486 & 688620 & 5.0 & 5.3631 & TRN \\
\hline CHEMBL1384754 & 688620 & 4.45 & 5.1058 & TST \\
\hline CHEMBL1565338 & 688620 & 4.65 & 5.0671 & TRN \\
\hline CHEMBL1345218 & 688620 & 5.55 & 4.9453 & TRN \\
\hline CHEMBL3195627 & 688620 & 4.85 & 5.149 & TRN \\
\hline CHEMBL1506352 & 688620 & 4.95 & 4.9643 & TRN \\
\hline CHEMBL 2004449 & 688620 & 5.05 & 5.2868 & TRN \\
\hline CHEMBL1585641 & 688620 & 5.25 & 4.7456 & TRN \\
\hline CHEMBL1555566 & 688620 & 5.4 & 4.7914 & TRN \\
\hline CHEMBL1443952 & 688620 & 6.45 & 4.9156 & TRN \\
\hline CHEMBL1587341 & 688620 & 4.85 & 4.9553 & TST \\
\hline CHEMBL1337798 & 688620 & 5.0 & 5.4981 & TRN \\
\hline CHEMBL1301270 & 688620 & 5.0 & 5.0135 & TRN \\
\hline CHEMBL1380314 & 688620 & 4.7 & 5.0309 & TST \\
\hline CHEMBL1581362 & 688620 & 4.7 & 4.8958 & TRN \\
\hline CHEMBL1489859 & 688620 & 4.45 & 5.1144 & TST \\
\hline CHEMBL1300172 & 688620 & 5.3 & 5.3075 & TRN \\
\hline CHEMBL1350929 & 688620 & 5.85 & 5.3539 & TRN \\
\hline CHEMBL1300057 & 688620 & 4.75 & 4.8387 & TST \\
\hline CHEMBL1341727 & 688620 & 4.9 & 4.8226 & TRN \\
\hline CHEMBL1385763 & 688620 & 5.1 & 5.0917 & TRN \\
\hline CHEMBL1590298 & 688620 & 4.45 & 5.1491 & TRN \\
\hline CHEMBL1589389 & 688620 & 4.8 & 4.8574 & TRN \\
\hline CHEMBL1313267 & 688620 & 4.75 & 4.6849 & TRN \\
\hline CHEMBL1530521 & 688620 & 5.15 & 4.9392 & TRN \\
\hline CHEMBL1410605 & 688620 & 5.6 & 5.52 & TRN \\
\hline CHEMBL1313931 & 688620 & 4.8 & 5.0278 & TRN \\
\hline CHEMBL1306902 & 688620 & 7.3497 & 5.1147 & TRN \\
\hline CHEMBL1309461 & 688620 & 4.45 & 4.7152 & TRN \\
\hline CHEMBL1461604 & 688620 & 4.45 & 4.9688 & TRN \\
\hline CHEMBL1580615 & 688620 & 5.2 & 4.9961 & TRN \\
\hline
\end{tabular}




\begin{tabular}{|c|c|c|c|c|c|}
\hline \multicolumn{6}{|c|}{ Supplemental Table S2.txt } \\
\hline CHEMBL1406568 & 688620 & 5.85 & 5.2073 & TRN & \\
\hline CHEMBL1431073 & 688620 & 4.95 & 4.9424 & TRN & \\
\hline CHEMBL1543774 & 688620 & 5.9 & 5.0521 & TRN & \\
\hline CHEMBL1550715 & 688620 & 6.8499 & 5.1811 & TST & \\
\hline CHEMBL1422371 & 688620 & 4.8 & 5.2033 & TST & \\
\hline CHEMBL3193706 & 688620 & 4.85 & 4.9814 & TRN & \\
\hline CHEMBL1456474 & 688620 & 4.95 & 4.9393 & TRN & \\
\hline CHEMBL3192785 & 688620 & 5.8 & 5.608 & TRN & \\
\hline CHEMBL1575704 & 688620 & 5.15 & 4.7479 & TRN & \\
\hline CHEMBL1388491 & 688620 & 5.4 & 5.6949 & TRN & \\
\hline CHEMBL1402697 & 688620 & 4.95 & 4.9498 & TRN & \\
\hline CHEMBL1353706 & 688620 & 4.8 & 4.8935 & TRN & \\
\hline CHEMBL1383944 & 688620 & 4.95 & 4.9683 & TRN & \\
\hline CHEMBL1466670 & 688620 & 7.0501 & 5.3467 & TRN & \\
\hline CHEMBL1326449 & 688620 & 4.75 & 4.9387 & TRN & \\
\hline CHEMBL1326255 & 688620 & 4.9 & 4.7303 & TRN & \\
\hline CHEMBL1389151 & 688620 & 4.45 & 5.1078 & TRN & \\
\hline CHEMBL1360870 & 688620 & 4.9 & 4.8359 & TST & \\
\hline CHEMBL1453153 & 688620 & 4.9 & 5.0051 & TRN & \\
\hline CHEMBL1510513 & 688620 & 4.5 & 5.0383 & TST & \\
\hline CHEMBL1468428 & 688620 & 4.8 & 5.0668 & TRN & \\
\hline CHEMBL1605956 & 688620 & 4.5 & 5.2495 & TRN & \\
\hline CHEMBL3192924 & 688620 & 4.9 & 5.3246 & TRN & \\
\hline CHEMBL1499723 & 688620 & 5.2 & 5.0099 & TRN & \\
\hline CHEMBL1381638 & 688620 & 4.85 & 5.072 & TRN & \\
\hline CHEMBL1593707 & 688620 & 4.75 & 4.7917 & TST & \\
\hline CHEMBL1523016 & 688620 & 4.85 & 5.0721 & TRN & \\
\hline CHEMBL3191980 & 688620 & 5.95 & 5.5041 & TRN & \\
\hline CHEMBL1449454 & 688620 & 4.45 & 4.9888 & TRN & \\
\hline CHEMBL1577726 & 688620 & 4.75 & 4.9659 & TST & \\
\hline CHEMBL1352510 & 688620 & 5.3 & 4.953 & TRN & \\
\hline CHEMBL3197483 & 688620 & 4.85 & 5.104 & TRN & \\
\hline CHEMBL1457661 & 688620 & 6.5 & 5.0424 & TRN & \\
\hline CHEMBL3209267 & 688620 & 5.65 & 5.19799 & 99999999995 & TRN \\
\hline CHEMBL1447284 & 688620 & 6.9 & 6.5164 & TRN & \\
\hline CHEMBL1486138 & 688620 & 4.95 & 4.8756 & TRN & \\
\hline CHEMBL1364691 & 688620 & 4.9 & 4.9752 & TRN & \\
\hline CHEMBL1351876 & 688620 & 5.65 & 5.1212 & TRN & \\
\hline CHEMBL1594162 & 688620 & 4.45 & 4.8098 & TRN & \\
\hline CHEMBL1504337 & 688620 & 5.75 & 5.1648 & TRN & \\
\hline CHEMBL1360977 & 688620 & 5.1 & 5.2377 & TRN & \\
\hline CHEMBL1350754 & 688620 & 5.7 & 5.8095 & TRN & \\
\hline CHEMBL1482845 & 688620 & 5.8 & 5.2869 & TRN & \\
\hline CHEMBL1455570 & 688620 & 4.9 & 5.1347 & TRN & \\
\hline CHEMBL3193578 & 688620 & 4.9 & 5.186 & TRN & \\
\hline CHEMBL1599864 & 688620 & 5.1 & 4.6929 & TRN & \\
\hline CHEMBL1549321 & 688620 & 4.9 & 4.9117 & TRN & \\
\hline CHEMBL1359701 & 688620 & 5.85 & 5.0306 & TST & \\
\hline
\end{tabular}




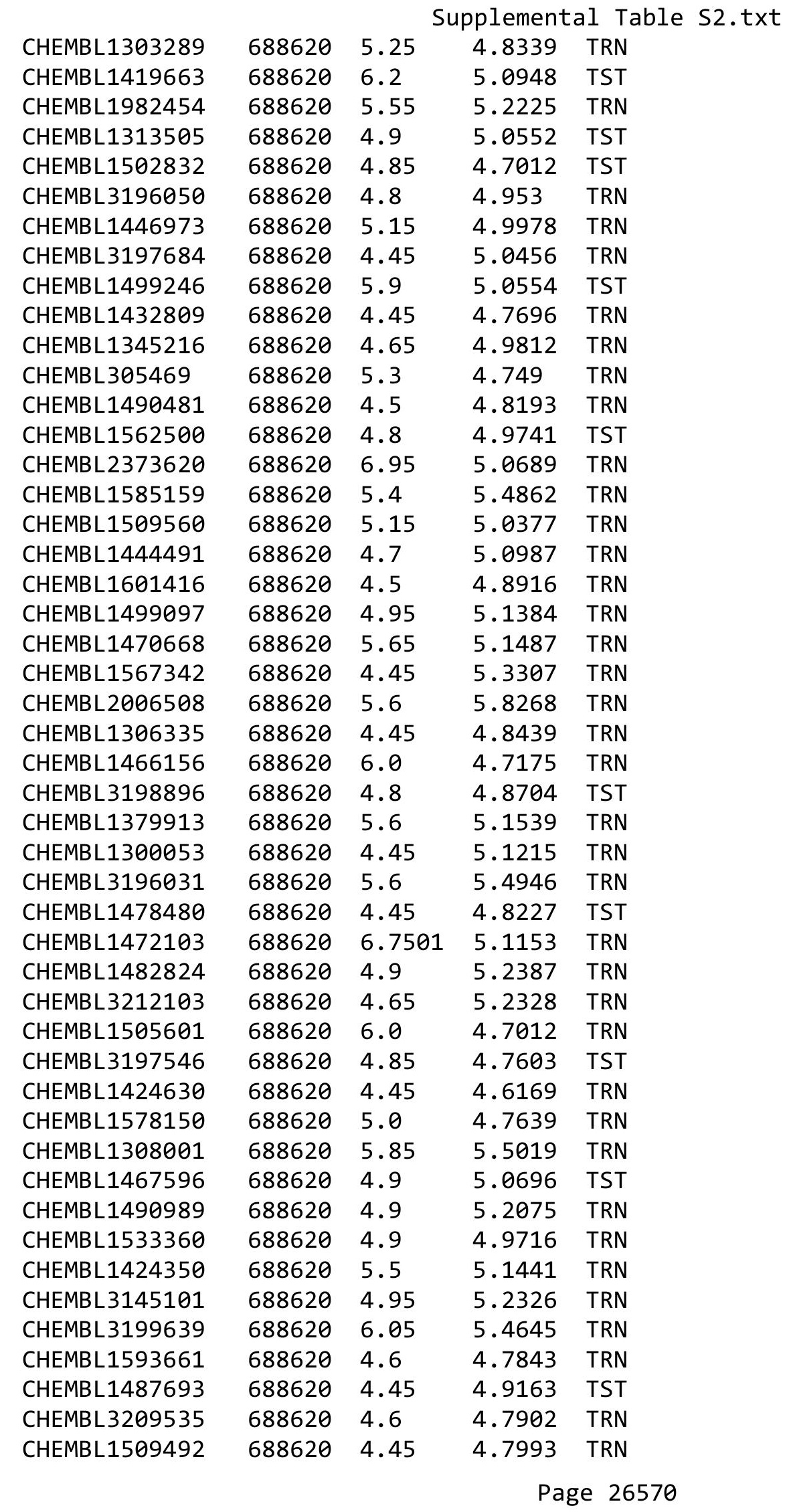




\begin{tabular}{|c|c|c|c|c|}
\hline \multicolumn{5}{|c|}{ Supplemental Table S2.txt } \\
\hline CHEMBL1547893 & 688620 & 5.3 & 5.1994 & TRN \\
\hline CHEMBL1366620 & 688620 & 5.0 & 4.9204 & TRN \\
\hline CHEMBL1562704 & 688620 & 5.2 & 4.9416 & TST \\
\hline CHEMBL1482532 & 688620 & 5.2 & 5.2439 & TRN \\
\hline CHEMBL1370710 & 688620 & 5.65 & 5.0526 & TRN \\
\hline CHEMBL1521711 & 688620 & 5.3 & 4.9767 & TRN \\
\hline CHEMBL1603110 & 688620 & 4.65 & 4.8936 & TRN \\
\hline CHEMBL1392365 & 688620 & 5.8 & 5.0249 & TST \\
\hline CHEMBL1342542 & 688620 & 4.65 & 4.8032 & TRN \\
\hline CHEMBL1608640 & 688620 & 5.0 & 4.814 & TRN \\
\hline CHEMBL1336905 & 688620 & 4.45 & 5.1283 & TRN \\
\hline CHEMBL1429260 & 688620 & 5.1 & 4.9024 & TST \\
\hline CHEMBL1330334 & 688620 & 4.95 & 4.8254 & TST \\
\hline CHEMBL254576 & 688620 & 4.7 & 4.9168 & TST \\
\hline CHEMBL1540343 & 688620 & 5.25 & 5.9588 & TST \\
\hline CHEMBL1560214 & 688620 & 4.6 & 5.0858 & TRN \\
\hline CHEMBL1603591 & 688620 & 4.9 & 5.1256 & TST \\
\hline CHEMBL1420118 & 688620 & 5.25 & 4.8964 & TST \\
\hline CHEMBL1563166 & 688620 & 4.75 & 5.3525 & TRN \\
\hline CHEMBL1555793 & 688620 & 4.9 & 5.0543 & TRN \\
\hline CHEMBL1408451 & 688620 & 5.15 & 5.0659 & TRN \\
\hline CHEMBL1532266 & 688620 & 4.45 & 5.0154 & TRN \\
\hline CHEMBL1449672 & 688620 & 4.9 & 5.1302 & TRN \\
\hline CHEMBL1517819 & 688620 & 5.35 & 5.0502 & TRN \\
\hline CHEMBL1393397 & 688620 & 6.45 & 6.0748 & TRN \\
\hline CHEMBL1430957 & 688620 & 6.8499 & 5.3223 & TRN \\
\hline CHEMBL1378666 & 688620 & 5.6 & 4.9185 & TST \\
\hline CHEMBL1340850 & 688620 & 4.75 & 5.0892 & TRN \\
\hline CHEMBL1468736 & 688620 & 4.9 & 4.8154 & TRN \\
\hline CHEMBL1597199 & 688620 & 5.5 & 5.0719 & TRN \\
\hline CHEMBL1498301 & 688620 & 4.8 & 5.1904 & TRN \\
\hline CHEMBL1571727 & 688620 & 5.75 & 5.2751 & TRN \\
\hline CHEMBL1432420 & 688620 & 4.45 & 4.8672 & TRN \\
\hline CHEMBL1386875 & 688620 & 4.45 & 4.9972 & TST \\
\hline CHEMBL1519453 & 688620 & 4.8 & 5.1862 & TST \\
\hline CHEMBL1406297 & 688620 & 4.75 & 4.7677 & TRN \\
\hline CHEMBL1387637 & 688620 & 5.25 & 5.1348 & TST \\
\hline CHEMBL1586982 & 688620 & 4.95 & 5.1204 & TST \\
\hline CHEMBL1401657 & 688620 & 4.85 & 4.7503 & TST \\
\hline CHEMBL1568373 & 688620 & 8.0 & 4.8829 & TRN \\
\hline CHEMBL1464264 & 688620 & 4.45 & 4.9265 & TRN \\
\hline CHEMBL3197924 & 688620 & 4.9 & 4.893 & TRN \\
\hline CHEMBL3195023 & 688620 & 4.95 & 5.2057 & TRN \\
\hline CHEMBL1429209 & 688620 & 4.75 & 4.9328 & TRN \\
\hline CHEMBL1335855 & 688620 & 5.05 & 5.1952 & TRN \\
\hline CHEMBL 3197023 & 688620 & 4.45 & 4.8679 & TRN \\
\hline CHEMBL1444698 & 688620 & 4.8 & 5.2005 & TRN \\
\hline CHEMBL1335914 & 688620 & 4.45 & 5.0004 & TST \\
\hline
\end{tabular}




\begin{tabular}{|c|c|c|c|c|}
\hline & & & pplement & al $\mathrm{Ta}$ \\
\hline CHEMBL1340482 & 688620 & 6.6 & 6.0782 & TRN \\
\hline CHEMBL1301428 & 688620 & 4.95 & 4.8734 & TRN \\
\hline CHEMBL1482750 & 688620 & 5.05 & 4.9814 & TST \\
\hline CHEMBL1526567 & 688620 & 5.6 & 5.2138 & TRN \\
\hline CHEMBL1463393 & 688620 & 5.0 & 4.9719 & TRN \\
\hline CHEMBL3192319 & 688620 & 4.55 & 5.0463 & TRN \\
\hline CHEMBL1599626 & 688620 & 4.65 & 5.1116 & TRN \\
\hline CHEMBL1415111 & 688620 & 4.85 & 4.9567 & TRN \\
\hline CHEMBL1391965 & 688620 & 5.55 & 5.8645 & TRN \\
\hline CHEMBL1980744 & 688620 & 5.15 & 5.1531 & TST \\
\hline CHEMBL1301812 & 688620 & 5.35 & 5.1986 & TRN \\
\hline CHEMBL 3194915 & 688620 & 4.9 & 5.1078 & TRN \\
\hline CHEMBL1366735 & 688620 & 5.95 & 5.5836 & TRN \\
\hline CHEMBL1462722 & 688620 & 4.9 & 5.0953 & TRN \\
\hline CHEMBL1606786 & 688620 & 5.25 & 5.0207 & TRN \\
\hline CHEMBL1460223 & 688620 & 5.65 & 5.4787 & TRN \\
\hline CHEMBL1502354 & 688620 & 6.8 & 5.2524 & TST \\
\hline CHEMBL1580319 & 688620 & 4.95 & 4.9959 & TRN \\
\hline CHEMBL546597 & 688620 & 4.45 & 4.8375 & TRN \\
\hline CHEMBL1539245 & 688620 & 4.8 & 4.8636 & TRN \\
\hline CHEMBL1459834 & 688620 & 5.55 & 5.1595 & TRN \\
\hline CHEMBL1320619 & 688620 & 4.85 & 4.869 & TRN \\
\hline CHEMBL1603847 & 688620 & 6.35 & 5.4555 & TRN \\
\hline CHEMBL1330854 & 688620 & 4.75 & 5.0987 & TRN \\
\hline CHEMBL1498680 & 688620 & 4.9 & 4.9954 & TRN \\
\hline CHEMBL1450881 & 688620 & 4.85 & 5.0774 & TST \\
\hline CHEMBL1534655 & 688620 & 6.4 & 5.4574 & TRN \\
\hline CHEMBL1499030 & 688620 & 5.3 & 5.5544 & TRN \\
\hline CHEMBL1431288 & 688620 & 4.9 & 4.869 & TRN \\
\hline CHEMBL1446461 & 688620 & 4.9 & 4.9858 & TST \\
\hline CHEMBL1433190 & 688620 & 4.45 & 5.0395 & TST \\
\hline CHEMBL 3209043 & 688620 & 5.85 & 5.234 & TRN \\
\hline CHEMBL1442201 & 688620 & 5.35 & 5.3144 & TRN \\
\hline CHEMBL1502510 & 688620 & 4.45 & 4.8832 & TST \\
\hline CHEMBL1550368 & 688620 & 4.45 & 4.9271 & TST \\
\hline CHEMBL1569985 & 688620 & 5.05 & 4.7662 & TRN \\
\hline CHEMBL1589993 & 688620 & 6.3 & 4.8494 & TRN \\
\hline CHEMBL1562399 & 688620 & 6.15 & 5.004 & TST \\
\hline CHEMBL1586673 & 688620 & 4.9 & 5.098 & TST \\
\hline CHEMBL1478050 & 688620 & 5.1 & 5.0272 & TRN \\
\hline CHEMBL1587062 & 688620 & 5.15 & 5.1556 & TRN \\
\hline CHEMBL1609234 & 688620 & 4.9 & 4.8771 & TST \\
\hline CHEMBL1388928 & 688620 & 5.35 & 5.4491 & TRN \\
\hline CHEMBL1603712 & 688620 & 4.95 & 4.9318 & TRN \\
\hline CHEMBL1337034 & 688620 & 5.35 & 5.1253 & TRN \\
\hline CHEMBL1462426 & 688620 & 5.45 & 5.3102 & TRN \\
\hline CHEMBL1349706 & 688620 & 4.9 & 5.0697 & TRN \\
\hline CHEMBL1559926 & 688620 & 4.45 & 4.9433 & TST \\
\hline
\end{tabular}




\begin{tabular}{|c|c|c|c|c|c|}
\hline \multicolumn{6}{|c|}{ Supplemental Table S2.txt } \\
\hline CHEMBL1583578 & 688620 & 4.45 & 5.0438 & TRN & \\
\hline CHEMBL1430724 & 688620 & 5.5 & 5.2852 & TRN & \\
\hline CHEMBL1567029 & 688620 & 5.45 & 5.5912 & TRN & \\
\hline CHEMBL1424425 & 688620 & 5.9 & 5.0303 & TRN & \\
\hline CHEMBL1606172 & 688620 & 5.1 & 5.0788 & TRN & \\
\hline CHEMBL1558716 & 688620 & 4.45 & 4.9986 & TRN & \\
\hline CHEMBL1565693 & 688620 & 5.65 & 5.2314 & TRN & \\
\hline CHEMBL1497792 & 688620 & 5.2 & $5.2070 e$ & 0000000001 & TST \\
\hline CHEMBL 2003452 & 688620 & 4.9 & 4.8144 & TRN & \\
\hline CHEMBL1305708 & 688620 & 4.45 & 4.9188 & TST & \\
\hline CHEMBL1495180 & 688620 & 4.6 & 5.2483 & TST & \\
\hline CHEMBL1426286 & 688620 & 5.95 & 5.2743 & TRN & \\
\hline CHEMBL1350551 & 688620 & 4.7 & 4.8619 & TST & \\
\hline CHEMBL1448733 & 688620 & 4.65 & 4.8291 & TRN & \\
\hline CHEMBL1545802 & 688620 & 5.2 & 4.9065 & TRN & \\
\hline CHEMBL3191619 & 688620 & 4.7 & 5.4611 & TRN & \\
\hline CHEMBL1413222 & 688620 & 4.45 & 5.1777 & TRN & \\
\hline CHEMBL1560216 & 688620 & 5.15 & 5.0214 & TRN & \\
\hline CHEMBL1968123 & 688620 & 4.65 & 4.7833 & TRN & \\
\hline CHEMBL1314500 & 688620 & 4.75 & 4.9816 & TST & \\
\hline CHEMBL1344508 & 688620 & 5.7 & 5.0162 & TRN & \\
\hline CHEMBL1350345 & 688620 & 4.45 & 5.038 & TRN & \\
\hline CHEMBL1521404 & 688620 & 5.85 & 5.1784 & TRN & \\
\hline CHEMBL584074 & 688620 & 5.35 & 5.4208 & TRN & \\
\hline CHEMBL1538739 & 688620 & 4.95 & 4.8433 & TRN & \\
\hline CHEMBL1325219 & 688620 & 4.9 & 5.5493 & TST & \\
\hline CHEMBL1521617 & 688620 & 4.9 & 4.8383 & TST & \\
\hline CHEMBL1424948 & 688620 & 4.85 & 5.1098 & TST & \\
\hline CHEMBL1557569 & 688620 & 5.55 & 5.3063 & TRN & \\
\hline CHEMBL1467316 & 688620 & 4.65 & 4.7678 & TRN & \\
\hline CHEMBL1613567 & 688620 & 4.95 & 4.9634 & TRN & \\
\hline CHEMBL1359126 & 688620 & 4.75 & $5.1220 e$ & 0000000001 & TRN \\
\hline CHEMBL1967408 & 688620 & 6.15 & 5.6489 & TRN & \\
\hline CHEMBL1544030 & 688620 & 4.95 & 5.0583 & TRN & \\
\hline CHEMBL1489280 & 688620 & 4.9 & 4.9175 & TRN & \\
\hline CHEMBL1353065 & 688620 & 4.75 & 4.96 & TST & \\
\hline CHEMBL1429971 & 688620 & 4.45 & 4.9774 & TRN & \\
\hline CHEMBL1568646 & 688620 & 4.85 & 5.148 & TRN & \\
\hline CHEMBL1383973 & 688620 & 4.9 & 5.0156 & TST & \\
\hline CHEMBL1337990 & 688620 & 5.1 & 5.0618 & TRN & \\
\hline CHEMBL1376210 & 688620 & 5.8 & 5.4321 & TRN & \\
\hline CHEMBL1390748 & 688620 & 5.15 & 4.8304 & TST & \\
\hline CHEMBL1604907 & 688620 & 5.2 & 4.9701 & TRN & \\
\hline CHEMBL1360867 & 688620 & 4.8 & 5.3456 & TRN & \\
\hline CHEMBL1417131 & 688620 & 4.45 & 5.2728 & TST & \\
\hline CHEMBL 3188031 & 688620 & 4.45 & 4.6973 & TRN & \\
\hline CHEMBL1563766 & 688620 & 6.9 & 6.4111 & TRN & \\
\hline CHEMBL1572615 & 688620 & 5.85 & 5.2875 & TRN & \\
\hline
\end{tabular}




\begin{tabular}{|c|c|c|c|c|c|}
\hline & & \multicolumn{4}{|c|}{ Supplemental Table s2.txt } \\
\hline CHEMBL1422233 & 688620 & 4.95 & 4.7858 & TST & \\
\hline CHEMBL 3214067 & 688620 & 5.25 & 4.9158 & TRN & \\
\hline CHEMBL1500788 & 688620 & 5.3 & 5.1358 & TST & \\
\hline CHEMBL1441437 & 688620 & 4.9 & 4.9738 & TRN & \\
\hline CHEMBL1431906 & 688620 & 4.95 & 5.2356 & TRN & \\
\hline CHEMBL1388841 & 688620 & 4.9 & 4.8273 & TRN & \\
\hline CHEMBL1602002 & 688620 & 5.4 & 5.1791 & TRN & \\
\hline CHEMBL1987071 & 688620 & 4.7 & 4.9283 & TRN & \\
\hline CHEMBL1488455 & 688620 & 5.25 & 5.2788 & TRN & \\
\hline CHEMBL1560117 & 688620 & 4.5 & 5.149 & TRN & \\
\hline CHEMBL1563140 & 688620 & 4.45 & 4.9248 & TST & \\
\hline CHEMBL1543868 & 688620 & 5.5 & 5.5631 & TRN & \\
\hline CHEMBL1469637 & 688620 & 5.1 & 4.8965 & TRN & \\
\hline CHEMBL 3197903 & 688620 & 5.7 & 5.1068 & TST & \\
\hline CHEMBL1492526 & 688620 & 6.1 & 4.8708 & TRN & \\
\hline CHEMBL1404375 & 688620 & 5.05 & 4.6802 & TRN & \\
\hline CHEMBL1482610 & 688620 & 5.0 & 5.0833 & TRN & \\
\hline CHEMBL3197408 & 688620 & 5.0 & 5.178 & TRN & \\
\hline CHEMBL 3212940 & 688620 & 6.0 & 5.3551 & TRN & \\
\hline CHEMBL1525187 & 688620 & 5.5 & 5.0896 & TST & \\
\hline CHEMBL1444270 & 688620 & 4.9 & 5.0265 & TRN & \\
\hline CHEMBL1503027 & 688620 & 4.75 & 4.8719 & TRN & \\
\hline CHEMBL1439672 & 688620 & 4.9 & 4.9314 & TST & \\
\hline CHEMBL1574798 & 688620 & 4.95 & 4.8662 & TRN & \\
\hline CHEMBL1373960 & 688620 & 4.7 & 5.1138 & TRN & \\
\hline CHEMBL1579139 & 688620 & 4.45 & 5.1098 & TST & \\
\hline CHEMBL1394640 & 688620 & 4.45 & 5.2111 & TRN & \\
\hline CHEMBL 3194995 & 688620 & 4.85 & 4.8412 & TRN & \\
\hline CHEMBL1561288 & 688620 & 4.95 & 4.9936 & TST & \\
\hline CHEMBL1450341 & 688620 & 4.85 & 4.966 & TRN & \\
\hline CHEMBL163316 & 688620 & 5.3 & 5.102 & TRN & \\
\hline CHEMBL 3192830 & 688620 & 5.0 & 5.0306 & TRN & \\
\hline CHEMBL1386032 & 688620 & 5.1 & 5.1469 & TRN & \\
\hline CHEMBL1519231 & 688620 & 4.45 & 5.0933 & TRN & \\
\hline CHEMBL1519446 & 688620 & 4.5 & 4.7833 & TST & \\
\hline CHEMBL1409680 & 688620 & 5.0 & 4.7209 & TRN & \\
\hline CHEMBL1432688 & 688620 & 5.8 & 5.0922 & TRN & \\
\hline CHEMBL1567154 & 688620 & 5.35 & 4.99100 & 00000000005 & TRN \\
\hline CHEMBL1337208 & 688620 & 4.9 & 5.1369 & TRN & \\
\hline CHEMBL1580723 & 688620 & 4.8 & 4.9562 & TRN & \\
\hline CHEMBL1494803 & 688620 & 5.1 & 5.0971 & TRN & \\
\hline CHEMBL1579382 & 688620 & 4.75 & 5.0476 & TRN & \\
\hline CHEMBL1548238 & 688620 & 5.55 & 5.1576 & TST & \\
\hline CHEMBL1556224 & 688620 & 4.85 & 5.0243 & TRN & \\
\hline CHEMBL1508789 & 688620 & 5.5 & 5.2192 & TRN & \\
\hline CHEMBL1975179 & 688620 & 5.1 & 5.0563 & TST & \\
\hline CHEMBL1547792 & 688620 & 6.35 & 6.0521 & TRN & \\
\hline CHEMBL 2000655 & 688620 & 5.15 & 5.3648 & TRN & \\
\hline
\end{tabular}




\begin{tabular}{|c|c|c|c|c|c|}
\hline \multicolumn{6}{|c|}{ Supplemental Table S2.txt } \\
\hline CHEMBL1423561 & 688620 & 6.95 & 5.0878 & TRN & \\
\hline CHEMBL1379149 & 688620 & 4.75 & 5.0028 & TRN & \\
\hline CHEMBL3191110 & 688620 & 4.75 & 5.0046 & TRN & \\
\hline CHEMBL1595544 & 688620 & 5.9 & 5.5988 & TRN & \\
\hline CHEMBL1383537 & 688620 & 5.4 & 4.9856 & TST & \\
\hline CHEMBL1571876 & 688620 & 4.95 & 5.0065 & TRN & \\
\hline CHEMBL1509805 & 688620 & 4.55 & 4.8227 & TRN & \\
\hline CHEMBL1564407 & 688620 & 4.85 & 4.9186 & TRN & \\
\hline CHEMBL1599621 & 688620 & 5.45 & 5.0559 & TRN & \\
\hline CHEMBL1341164 & 688620 & 5.0 & 4.996 & TRN & \\
\hline CHEMBL1593107 & 688620 & 4.55 & 5.3098 & TST & \\
\hline CHEMBL1543306 & 688620 & 4.9 & 4.7654 & TRN & \\
\hline CHEMBL 259018 & 688620 & 4.65 & 5.0991 & TRN & \\
\hline CHEMBL1345642 & 688620 & 4.45 & 4.773 & TST & \\
\hline CHEMBL1580885 & 688620 & 4.45 & 4.7971 & TRN & \\
\hline CHEMBL1394017 & 688620 & 4.75 & 4.7941 & TRN & \\
\hline CHEMBL1388226 & 688620 & 4.95 & 4.918 & TST & \\
\hline CHEMBL1545489 & 688620 & 4.65 & 4.9848 & TST & \\
\hline CHEMBL1558082 & 688620 & 5.35 & 4.8718 & TRN & \\
\hline CHEMBL1370592 & 688620 & 5.55 & 5.3794 & TRN & \\
\hline CHEMBL1488597 & 688620 & 5.8 & 5.5523 & TRN & \\
\hline CHEMBL1551329 & 688620 & 4.85 & 4.96399 & 99999999995 & TRN \\
\hline CHEMBL1563059 & 688620 & 4.5 & 5.35 & TRN & \\
\hline CHEMBL1339624 & 688620 & 4.45 & 5.1541 & TST & \\
\hline CHEMBL3192601 & 688620 & 4.95 & 5.13 & TST & \\
\hline CHEMBL1978069 & 688620 & 4.9 & 4.8069 & TRN & \\
\hline CHEMBL1582203 & 688620 & 4.95 & 5.0235 & TRN & \\
\hline CHEMBL1361538 & 688620 & 4.85 & 5.1349 & TRN & \\
\hline CHEMBL1428611 & 688620 & 4.45 & 4.9996 & TST & \\
\hline CHEMBL3197595 & 688620 & 5.2 & 5.1669 & TRN & \\
\hline CHEMBL1523635 & 688620 & 6.25 & 4.9842 & TRN & \\
\hline CHEMBL3144933 & 688620 & 5.35 & 5.4675 & TST & \\
\hline CHEMBL1459316 & 688620 & 4.9 & 4.8777 & TRN & \\
\hline CHEMBL1494386 & 688620 & 6.3 & 5.4447 & TRN & \\
\hline CHEMBL1524284 & 688620 & 5.25 & 5.2404 & TRN & \\
\hline CHEMBL1469115 & 688620 & 4.45 & 5.0465 & TST & \\
\hline CHEMBL1423286 & 688620 & 6.05 & 5.88399 & 99999999995 & TRN \\
\hline CHEMBL1421980 & 688620 & 4.9 & 4.8767 & TRN & \\
\hline CHEMBL1410177 & 688620 & 5.45 & 5.2086 & TRN & \\
\hline CHEMBL1558823 & 688620 & 5.4 & 4.9266 & TRN & \\
\hline CHEMBL1491581 & 688620 & 5.05 & 4.7807 & TRN & \\
\hline CHEMBL1563081 & 688620 & 5.35 & 5.1984 & TRN & \\
\hline CHEMBL1456339 & 688620 & 4.45 & 5.0235 & TRN & \\
\hline CHEMBL3196894 & 688620 & 5.1 & 5.063 & TRN & \\
\hline CHEMBL1308111 & 688620 & 5.55 & 4.9383 & TRN & \\
\hline CHEMBL1319328 & 688620 & 6.2 & 5.5554 & TRN & \\
\hline CHEMBL1379991 & 688620 & 4.45 & 4.9129 & TST & \\
\hline CHEMBL1371961 & 688620 & 4.65 & 4.9448 & TRN & \\
\hline
\end{tabular}




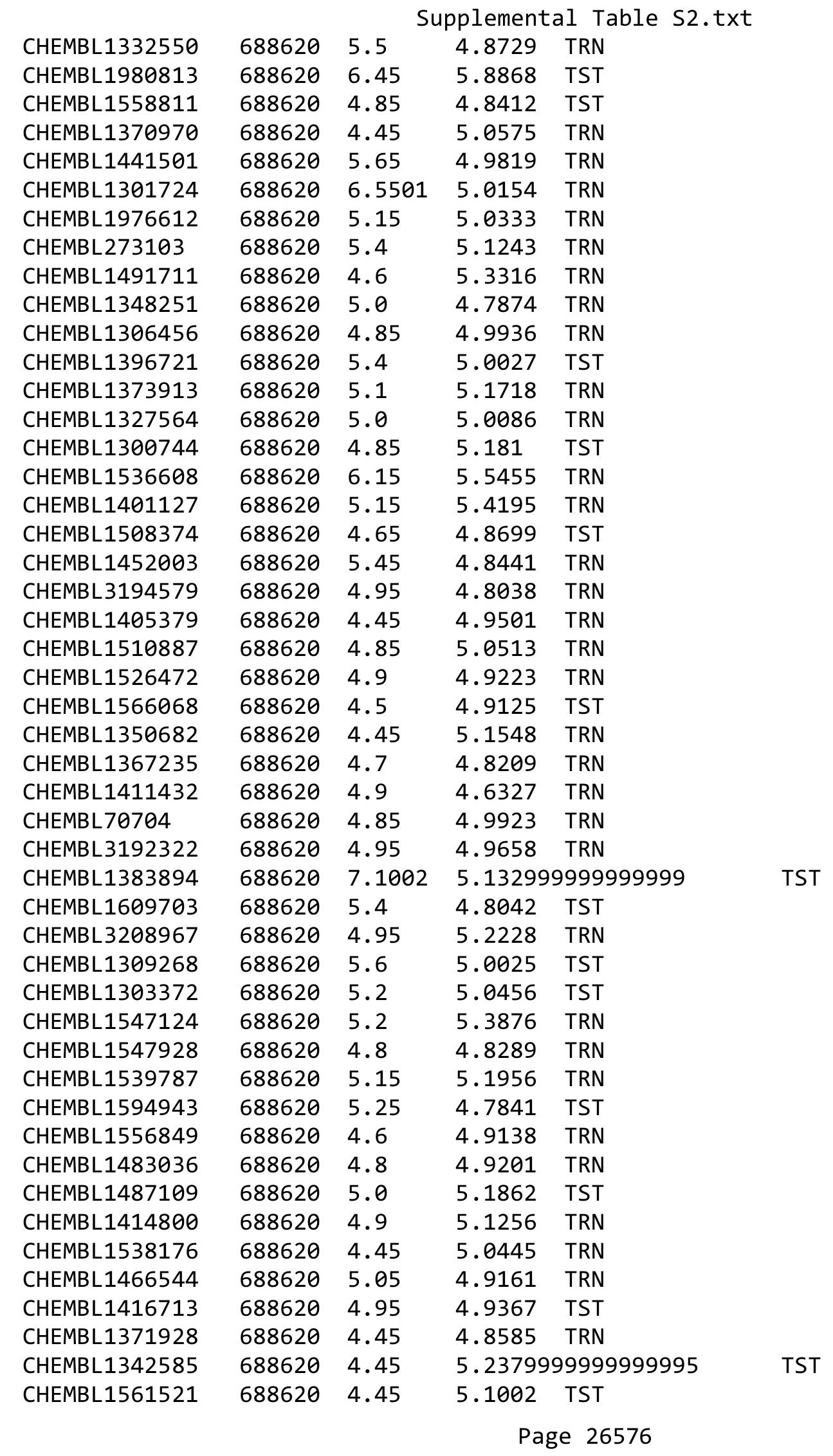




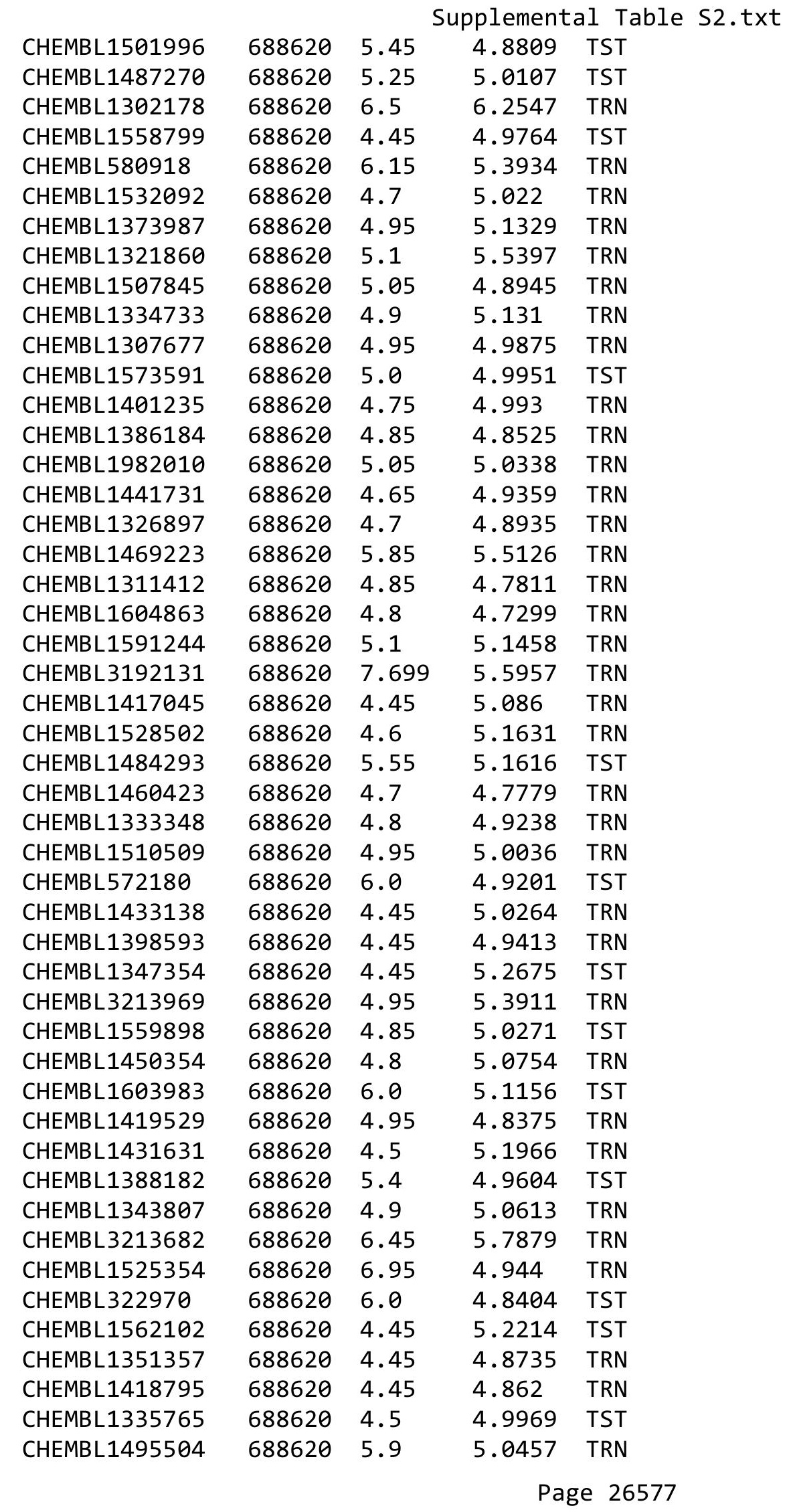




\begin{tabular}{|c|c|c|c|c|c|}
\hline \multicolumn{6}{|c|}{ Supplemental Table S2.txt } \\
\hline CHEMBL3208451 & 688620 & 5.95 & 5.9224 & TRN & \\
\hline CHEMBL1335497 & 688620 & 4.85 & 4.867 & TRN & \\
\hline CHEMBL1439156 & 688620 & 4.95 & 4.8664 & TRN & \\
\hline CHEMBL1373756 & 688620 & 4.7 & 4.9582 & TRN & \\
\hline CHEMBL1386744 & 688620 & 4.95 & 4.9417 & TST & \\
\hline CHEMBL1574046 & 688620 & 4.5 & 5.0719 & TST & \\
\hline CHEMBL1491242 & 688620 & 4.45 & 4.9087 & TRN & \\
\hline CHEMBL1372480 & 688620 & 4.75 & 5.1226 & TST & \\
\hline CHEMBL1345124 & 688620 & 4.9 & 4.7592 & TRN & \\
\hline CHEMBL1313187 & 688620 & 4.95 & 5.3918 & TRN & \\
\hline CHEMBL1382140 & 688620 & 4.8 & 5.0485 & TST & \\
\hline CHEMBL1445905 & 688620 & 5.25 & 5.0518 & TRN & \\
\hline CHEMBL1359280 & 688620 & 4.8 & 5.0077 & TRN & \\
\hline CHEMBL1580874 & 688620 & 4.7 & 4.7887 & TRN & \\
\hline CHEMBL1312905 & 688620 & 4.7 & 5.0551 & TRN & \\
\hline CHEMBL1486882 & 688620 & 4.9 & 4.8259 & TST & \\
\hline CHEMBL1408348 & 688620 & 5.4 & 5.06800 & 00000000005 & TRN \\
\hline CHEMBL1587076 & 688620 & 4.9 & 5.0758 & TRN & \\
\hline CHEMBL1601134 & 688620 & 4.65 & 4.8871 & TRN & \\
\hline CHEMBL1384671 & 688620 & 4.45 & 5.1267 & TST & \\
\hline CHEMBL1585332 & 688620 & 4.7 & 4.6692 & TRN & \\
\hline CHEMBL1418815 & 688620 & 5.2 & 5.0575 & TST & \\
\hline CHEMBL1424300 & 688620 & 5.45 & 5.10800 & 00000000005 & TRN \\
\hline CHEMBL1307154 & 688620 & 4.45 & 5.1526 & TRN & \\
\hline CHEMBL1491091 & 688620 & 6.8499 & 5.0621 & TRN & \\
\hline CHEMBL1505100 & 688620 & 6.3 & 5.7276 & TST & \\
\hline CHEMBL1312329 & 688620 & 5.1 & 5.0553 & TRN & \\
\hline CHEMBL1407542 & 688620 & 5.35 & 5.3488 & TRN & \\
\hline CHEMBL1565350 & 688620 & 4.8 & 4.9605 & TST & \\
\hline CHEMBL1410337 & 688620 & 5.2 & 4.7569 & TRN & \\
\hline CHEMBL1982575 & 688620 & 4.85 & 5.2447 & TRN & \\
\hline CHEMBL1613615 & 688620 & 4.85 & 4.8742 & TRN & \\
\hline CHEMBL1354563 & 688620 & 4.45 & 4.8777 & TST & \\
\hline CHEMBL 3212690 & 688620 & 5.45 & 5.2465 & TST & \\
\hline CHEMBL1594299 & 688620 & 4.45 & 5.1346 & TRN & \\
\hline CHEMBL1572342 & 688620 & 4.8 & 5.0008 & TRN & \\
\hline CHEMBL1581045 & 688620 & 4.8 & 4.9802 & TRN & \\
\hline CHEMBL1547527 & 688620 & 4.5 & 5.0615 & TRN & \\
\hline CHEMBL1601574 & 688620 & 4.9 & 5.1822 & TRN & \\
\hline CHEMBL1379788 & 688620 & 4.45 & 5.3204 & TST & \\
\hline CHEMBL1456469 & 688620 & 4.5 & 5.0783 & TRN & \\
\hline CHEMBL1450686 & 688620 & 5.3 & 4.8959 & TRN & \\
\hline CHEMBL3198774 & 688620 & 4.95 & 5.2156 & TRN & \\
\hline CHEMBL1546765 & 688620 & 6.5501 & 5.0155 & TRN & \\
\hline CHEMBL1605217 & 688620 & 5.55 & 5.7423 & TRN & \\
\hline CHEMBL1404523 & 688620 & 4.9 & 5.1178 & TST & \\
\hline CHEMBL1507779 & 688620 & 4.45 & 5.0536 & TRN & \\
\hline CHEMBL1303411 & 688620 & 4.65 & 4.648 & TRN & \\
\hline
\end{tabular}




\begin{tabular}{|c|c|c|c|c|}
\hline \multicolumn{5}{|c|}{ Supplemental Table S2.txt } \\
\hline CHEMBL1300154 & 688620 & 6.0 & 5.7984 & TRN \\
\hline CHEMBL3208796 & 688620 & 4.65 & 4.9307 & TRN \\
\hline CHEMBL1511494 & 688620 & 4.45 & 5.098 & TRN \\
\hline CHEMBL1387850 & 688620 & 4.45 & 4.9837 & TST \\
\hline CHEMBL1505567 & 688620 & 4.95 & 5.0948 & TRN \\
\hline CHEMBL1393656 & 688620 & 4.45 & 5.0956 & TRN \\
\hline CHEMBL1490810 & 688620 & 4.45 & 4.9751 & TRN \\
\hline CHEMBL1509181 & 688620 & 4.8 & 5.0737 & TST \\
\hline CHEMBL1336374 & 688620 & 4.45 & 4.8146 & TST \\
\hline CHEMBL1381600 & 688620 & 5.05 & 5.223 & TST \\
\hline CHEMBL1454514 & 688620 & 4.65 & 5.1228 & TRN \\
\hline CHEMBL1408215 & 688620 & 4.45 & 5.1121 & TRN \\
\hline CHEMBL1401063 & 688620 & 4.95 & 4.8163 & TST \\
\hline CHEMBL1374601 & 688620 & 5.6 & 5.9927 & TRN \\
\hline CHEMBL1603844 & 688620 & 4.45 & 4.6787 & TST \\
\hline CHEMBL1496004 & 688620 & 4.85 & 4.9314 & TRN \\
\hline CHEMBL 207881 & 688620 & 4.8 & 4.8603 & TST \\
\hline CHEMBL1526847 & 688620 & 4.8 & 4.8841 & TRN \\
\hline CHEMBL1579634 & 688620 & 8.2007 & 4.9127 & TRN \\
\hline CHEMBL1533645 & 688620 & 4.45 & 4.944 & TST \\
\hline CHEMBL1415845 & 688620 & 5.4 & 5.3151 & TRN \\
\hline CHEMBL1510117 & 688620 & 6.25 & 5.1624 & TRN \\
\hline CHEMBL1569410 & 688620 & 4.8 & 4.9833 & TST \\
\hline CHEMBL1313212 & 688620 & 4.65 & 5.21 & TRN \\
\hline CHEMBL1375741 & 688620 & 4.45 & 4.7191 & TRN \\
\hline CHEMBL1454211 & 688620 & 5.55 & 5.024 & TRN \\
\hline CHEMBL1584307 & 688620 & 4.9 & 5.0358 & TST \\
\hline CHEMBL1299526 & 688620 & 5.7 & 5.3888 & TRN \\
\hline CHEMBL1303863 & 688620 & 8.301 & 5.1815 & TRN \\
\hline CHEMBL1443090 & 688620 & 4.5 & 5.2188 & TST \\
\hline CHEMBL1507468 & 688620 & 4.95 & 5.0074 & TRN \\
\hline CHEMBL1309591 & 688620 & 5.0 & 5.1642 & TRN \\
\hline CHEMBL 76447 & 688620 & 4.95 & 5.1356 & TRN \\
\hline CHEMBL1576152 & 688620 & 4.45 & 5.0524 & TRN \\
\hline CHEMBL1415002 & 688620 & 4.8 & 4.9624 & TRN \\
\hline CHEMBL1372136 & 688620 & 4.8 & 4.8376 & TRN \\
\hline CHEMBL1459332 & 688620 & 5.35 & 5.2015 & TRN \\
\hline CHEMBL1416268 & 688620 & 5.95 & 5.8282 & TST \\
\hline CHEMBL1416892 & 688620 & 5.05 & 5.0485 & TRN \\
\hline CHEMBL1342147 & 688620 & 5.8 & 5.1473 & TRN \\
\hline CHEMBL1425889 & 688620 & 5.85 & 5.2073 & TRN \\
\hline CHEMBL1322328 & 688620 & 5.0 & 4.9184 & TRN \\
\hline CHEMBL3191706 & 688620 & 4.45 & 5.151 & TRN \\
\hline CHEMBL1549128 & 688620 & 5.3 & 5.1053 & TST \\
\hline CHEMBL1531203 & 688620 & 4.95 & 5.0187 & TST \\
\hline CHEMBL3207624 & 688620 & 5.55 & 5.06 & TRN \\
\hline CHEMBL1384216 & 688620 & 4.95 & 5.0544 & TRN \\
\hline CHEMBL1309218 & 688620 & 5.6 & 5.34 & TRN \\
\hline
\end{tabular}




\begin{tabular}{|c|c|c|c|c|c|}
\hline \multicolumn{6}{|c|}{ Supplemental Table S2.txt } \\
\hline CHEMBL1418018 & 688620 & 4.45 & 5.8955 & TRN & \\
\hline CHEMBL1422222 & 688620 & 4.55 & 4.8013 & TRN & \\
\hline CHEMBL3199661 & 688620 & 4.95 & 5.3861 & TRN & \\
\hline CHEMBL1567692 & 688620 & 4.45 & 5.0242 & TRN & \\
\hline CHEMBL3191236 & 688620 & 5.0 & 4.9561 & TRN & \\
\hline CHEMBL3189853 & 688620 & 4.85 & 4.902 & TST & \\
\hline CHEMBL1478300 & 688620 & 4.7 & 5.0253 & TRN & \\
\hline CHEMBL1418230 & 688620 & 4.85 & 4.9128 & TRN & \\
\hline CHEMBL1453914 & 688620 & 4.85 & 5.1148 & TRN & \\
\hline CHEMBL1338502 & 688620 & 5.15 & 5.38700 & 00000000005 & TRN \\
\hline CHEMBL1562123 & 688620 & 4.95 & 4.9531 & TRN & \\
\hline CHEMBL1595934 & 688620 & 4.45 & 5.0634 & TST & \\
\hline CHEMBL1452284 & 688620 & 5.2 & 5.1513 & TST & \\
\hline CHEMBL1601686 & 688620 & 5.2 & 5.0356 & TRN & \\
\hline CHEMBL3191290 & 688620 & 4.95 & 4.945 & TRN & \\
\hline CHEMBL3208884 & 688620 & 4.45 & 5.0468 & TRN & \\
\hline CHEMBL3199775 & 688620 & 5.35 & 5.0324 & TRN & \\
\hline CHEMBL3195222 & 688620 & 4.9 & 5.0207 & TRN & \\
\hline CHEMBL2369189 & 688620 & 5.6 & 5.3257 & TST & \\
\hline CHEMBL1342284 & 688620 & 4.45 & 5.0667 & TRN & \\
\hline CHEMBL1537844 & 688620 & 5.45 & 5.3348 & TRN & \\
\hline CHEMBL2369265 & 688620 & 5.2 & 5.4416 & TRN & \\
\hline CHEMBL1467234 & 688620 & 4.6 & 4.9646 & TRN & \\
\hline CHEMBL1585488 & 688620 & 4.85 & 4.8773 & TRN & \\
\hline CHEMBL1438616 & 688620 & 5.85 & 4.93199 & 99999999995 & TST \\
\hline CHEMBL3198154 & 688620 & 4.9 & 5.1073 & TRN & \\
\hline CHEMBL1443757 & 688620 & 4.95 & 4.91100 & 00000000005 & TRN \\
\hline CHEMBL1430482 & 688620 & 4.9 & 4.8362 & TRN & \\
\hline CHEMBL1380009 & 688620 & 4.85 & 5.0341 & TRN & \\
\hline CHEMBL1431406 & 688620 & 5.5 & 5.5816 & TRN & \\
\hline CHEMBL1426993 & 688620 & 4.85 & 5.2291 & TRN & \\
\hline CHEMBL1347542 & 688620 & 5.0 & 4.9449 & TST & \\
\hline CHEMBL1612805 & 688620 & 4.45 & 4.7334 & TRN & \\
\hline CHEMBL45281 & 688620 & 5.45 & 5.1299 & TST & \\
\hline CHEMBL1387817 & 688620 & 6.05 & 5.1845 & TST & \\
\hline CHEMBL1443895 & 688620 & 5.0 & 5.0899 & TST & \\
\hline CHEMBL1376710 & 688620 & 4.45 & 5.0413 & TST & \\
\hline CHEMBL1336400 & 688620 & 5.15 & 5.0062 & TRN & \\
\hline CHEMBL1521107 & 688620 & 4.8 & 4.8133 & TRN & \\
\hline CHEMBL1599624 & 688620 & 4.6 & 4.9345 & TST & \\
\hline CHEMBL1508642 & 688620 & 6.25 & 5.9758 & TRN & \\
\hline CHEMBL1523656 & 688620 & 4.65 & 5.0696 & TST & \\
\hline CHEMBL1579478 & 688620 & 4.75 & 4.9644 & TRN & \\
\hline CHEMBL3195271 & 688620 & 5.2 & 5.2509 & TRN & \\
\hline CHEMBL1385094 & 688620 & 4.45 & 4.9613 & TRN & \\
\hline CHEMBL1424446 & 688620 & 5.15 & 5.0638 & TRN & \\
\hline CHEMBL3197141 & 688620 & 4.8 & 5.3783 & TRN & \\
\hline CHEMBL1321613 & 688620 & 4.45 & 5.0248 & TRN & \\
\hline
\end{tabular}




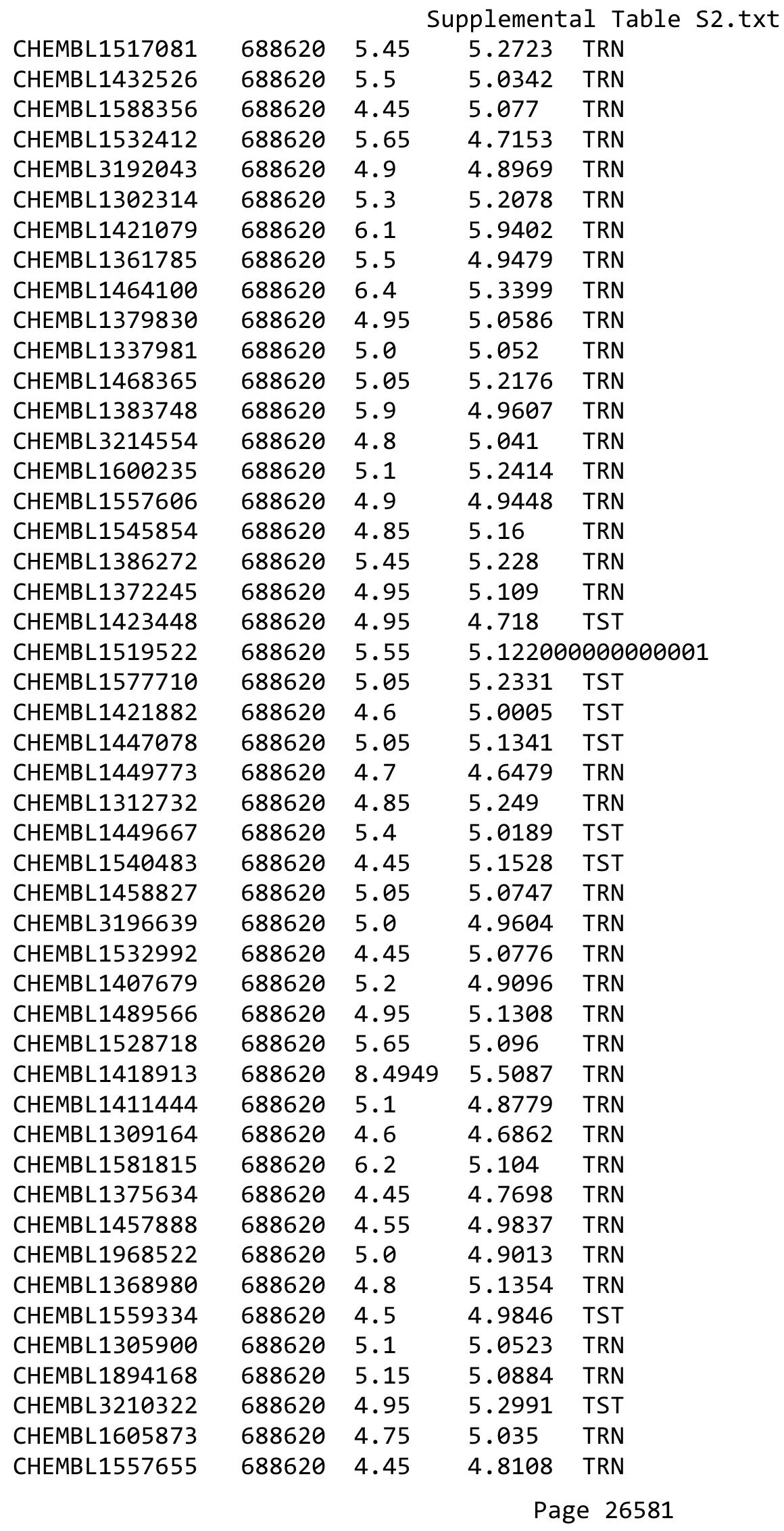




\begin{tabular}{|c|c|c|c|c|c|}
\hline & & & & & \\
\hline CHEMBL1333559 & 688620 & 5.4 & 5.0165 & TRN & \\
\hline CHEMBL1453089 & 688620 & 4.9 & 4.9786 & TST & \\
\hline CHEMBL1536896 & 688620 & 5.4 & 5.0638 & TST & \\
\hline CHEMBL1468042 & 688620 & 4.9 & 5.0353 & TST & \\
\hline CHEMBL1372371 & 688620 & 4.7 & 4.9186 & TRN & \\
\hline CHEMBL1464995 & 688620 & 4.8 & 5.13399 & 99999999995 & TRN \\
\hline CHEMBL1789998 & 688620 & 6.0 & 5.1058 & TRN & \\
\hline CHEMBL1424284 & 688620 & 4.55 & 5.3348 & TST & \\
\hline CHEMBL1313565 & 688620 & 4.9 & 5.357 & TRN & \\
\hline CHEMBL1490793 & 688620 & 4.75 & 5.1726 & TST & \\
\hline CHEMBL1521635 & 688620 & 5.25 & 5.0376 & TRN & \\
\hline CHEMBL1500586 & 688620 & 4.75 & 4.7686 & TRN & \\
\hline CHEMBL1325754 & 688620 & 5.65 & 5.05699 & 99999999995 & TRN \\
\hline CHEMBL1990586 & 688620 & 4.85 & 5.0271 & TRN & \\
\hline CHEMBL1539307 & 688620 & 5.75 & 5.239 & TRN & \\
\hline CHEMBL1464735 & 688620 & 5.0 & 5.1368 & TST & \\
\hline CHEMBL1489739 & 688620 & 4.95 & 5.0756 & TST & \\
\hline CHEMBL1327052 & 688620 & 4.9 & 5.0737 & TST & \\
\hline CHEMBL1381186 & 688620 & 4.95 & 5.1208 & TST & \\
\hline CHEMBL1377809 & 688620 & 5.05 & 5.0148 & TRN & \\
\hline CHEMBL1540330 & 688620 & 5.0 & 5.0932 & TRN & \\
\hline CHEMBL1565566 & 688620 & 5.25 & 4.9674 & TST & \\
\hline CHEMBL3209965 & 688620 & 4.8 & 4.8375 & TST & \\
\hline CHEMBL1505028 & 688620 & 6.15 & 5.6792 & TRN & \\
\hline CHEMBL1437028 & 688620 & 5.15 & 5.01399 & 9999999999 & TRN \\
\hline CHEMBL3210228 & 688620 & 5.8 & 5.7258 & TRN & \\
\hline CHEMBL1332862 & 688620 & 5.25 & 5.15600 & 0000000001 & TRN \\
\hline CHEMBL1469675 & 688620 & 4.75 & 5.0024 & TRN & \\
\hline CHEMBL1367980 & 688620 & 4.5 & 4.9629 & TRN & \\
\hline CHEMBL1560403 & 688620 & 4.8 & 4.8857 & TST & \\
\hline CHEMBL1402808 & 688620 & 4.9 & 5.0139 & TRN & \\
\hline CHEMBL1529008 & 688620 & 5.4 & 5.3263 & TRN & \\
\hline CHEMBL1555581 & 688620 & 4.45 & 5.1507 & TRN & \\
\hline CHEMBL1572494 & 688620 & 6.15 & 5.0399 & TRN & \\
\hline CHEMBL3207825 & 688620 & 4.9 & 5.2797 & TRN & \\
\hline CHEMBL1976312 & 688620 & 6.05 & 5.7094 & TRN & \\
\hline CHEMBL1569924 & 688620 & 4.75 & 4.7934 & TRN & \\
\hline CHEMBL1481748 & 688620 & 5.45 & 5.2621 & TST & \\
\hline CHEMBL1304243 & 688620 & 5.35 & 4.9339 & TRN & \\
\hline CHEMBL1421560 & 688620 & 7.0 & 5.1812 & TST & \\
\hline CHEMBL1556383 & 688620 & 4.8 & 4.8837 & TST & \\
\hline CHEMBL1561740 & 688620 & 5.2 & 5.0441 & TRN & \\
\hline CHEMBL1517238 & 688620 & 5.05 & 5.0521 & TRN & \\
\hline CHEMBL1499490 & 688620 & 4.5 & 4.7898 & TRN & \\
\hline CHEMBL1391061 & 688620 & 4.5 & 4.9038 & TRN & \\
\hline CHEMBL1547739 & 688620 & 4.45 & 5.0185 & TRN & \\
\hline CHEMBL1424268 & 688620 & 4.85 & 5.225 & TST & \\
\hline CHEMBL1374406 & 688620 & 4.5 & 4.9692 & TRN & \\
\hline & & & & 26582 & \\
\hline
\end{tabular}




\begin{tabular}{|c|c|c|c|c|}
\hline \multicolumn{5}{|c|}{ Supplemental Table S2.txt } \\
\hline CHEMBL1478323 & 688620 & 5.3 & 4.7751 & TRN \\
\hline CHEMBL1504286 & 688620 & 5.15 & 5.3916 & TRN \\
\hline CHEMBL1609942 & 688620 & 4.7 & 4.9417 & TRN \\
\hline CHEMBL1452939 & 688620 & 4.65 & 4.8041 & TST \\
\hline CHEMBL3208159 & 688620 & 4.6 & 5.1222 & TRN \\
\hline CHEMBL1490656 & 688620 & 5.45 & 5.5287 & TRN \\
\hline CHEMBL1306557 & 688620 & 4.75 & 5.0325 & TRN \\
\hline CHEMBL590186 & 688620 & 5.0 & 4.9465 & TST \\
\hline CHEMBL1320392 & 688620 & 4.95 & 5.1529 & TRN \\
\hline CHEMBL1540555 & 688620 & 6.2 & 4.8744 & TST \\
\hline CHEMBL1576074 & 688620 & 4.45 & 5.0046 & TRN \\
\hline CHEMBL1568600 & 688620 & 4.6 & 5.0608 & TST \\
\hline CHEMBL1301939 & 688620 & 4.45 & 4.6957 & TRN \\
\hline CHEMBL1325818 & 688620 & 4.45 & 4.7483 & TRN \\
\hline CHEMBL1412263 & 688620 & 4.65 & 4.7836 & TRN \\
\hline CHEMBL1544580 & 688620 & 4.7 & 4.8543 & TRN \\
\hline CHEMBL1609233 & 688620 & 5.25 & 5.0739 & TRN \\
\hline CHEMBL1460564 & 688620 & 4.45 & 5.0089 & TRN \\
\hline CHEMBL1322532 & 688620 & 5.0 & 4.8503 & TRN \\
\hline CHEMBL3197564 & 688620 & 5.15 & 5.4362 & TRN \\
\hline CHEMBL1969625 & 688620 & 5.35 & 6.0351 & TRN \\
\hline CHEMBL3195547 & 688620 & 4.45 & 5.0224 & TRN \\
\hline CHEMBL1386507 & 688620 & 4.75 & 4.9142 & TRN \\
\hline CHEMBL1366575 & 688620 & 5.9 & 4.9757 & TRN \\
\hline CHEMBL1402656 & 688620 & 5.15 & 5.2378 & TST \\
\hline CHEMBL1585107 & 688620 & 5.05 & 4.7891 & TRN \\
\hline CHEMBL1990481 & 688620 & 5.05 & 5.2011 & TRN \\
\hline CHEMBL1466202 & 688620 & 4.5 & 4.7927 & TRN \\
\hline CHEMBL1535931 & 688620 & 4.95 & 4.8864 & TRN \\
\hline CHEMBL1319682 & 688620 & 4.95 & 5.1718 & TST \\
\hline CHEMBL1473521 & 688620 & 5.0 & 5.0667 & TST \\
\hline CHEMBL1405197 & 688620 & 4.95 & 5.0247 & TRN \\
\hline CHEMBL1455441 & 688620 & 4.45 & 4.9471 & TRN \\
\hline CHEMBL1592606 & 688620 & 4.55 & 4.8426 & TST \\
\hline CHEMBL1402669 & 688620 & 4.45 & 4.8637 & TRN \\
\hline CHEMBL1482228 & 688620 & 5.35 & 5.1019 & TRN \\
\hline CHEMBL1566793 & 688620 & 5.5 & 5.0167 & TRN \\
\hline CHEMBL1301654 & 688620 & 4.75 & 5.0334 & TST \\
\hline CHEMBL1343532 & 688620 & 5.65 & 5.4082 & TRN \\
\hline CHEMBL1589116 & 688620 & 4.9 & 4.8703 & TRN \\
\hline CHEMBL1485154 & 688620 & 4.7 & 5.2189 & TST \\
\hline CHEMBL1313391 & 688620 & 4.9 & 5.0392 & TRN \\
\hline CHEMBL1462198 & 688620 & 4.45 & 5.0942 & TST \\
\hline CHEMBL1529563 & 688620 & 5.55 & 5.1467 & TRN \\
\hline CHEMBL1485228 & 688620 & 4.65 & 5.0386 & TRN \\
\hline CHEMBL3195565 & 688620 & 5.25 & 4.8436 & TRN \\
\hline CHEMBL1405143 & 688620 & 6.15 & 4.999 & TST \\
\hline CHEMBL1386293 & 688620 & 4.9 & 4.7195 & TRN \\
\hline
\end{tabular}




\begin{tabular}{|c|c|c|c|c|}
\hline \multicolumn{5}{|c|}{ Supplemental Table S2.txt } \\
\hline CHEMBL1420187 & 688620 & 4.45 & 4.8639 & TRN \\
\hline CHEMBL1300295 & 688620 & 4.55 & 5.0162 & TST \\
\hline CHEMBL1536780 & 688620 & 4.95 & 4.9498 & TST \\
\hline CHEMBL1462157 & 688620 & 5.65 & 5.2745 & TRN \\
\hline CHEMBL1385219 & 688620 & 4.95 & 4.4934 & TST \\
\hline CHEMBL3190051 & 688620 & 4.45 & 5.0914 & TST \\
\hline CHEMBL3209381 & 688620 & 4.65 & 4.8607 & TRN \\
\hline CHEMBL1402856 & 688620 & 4.6 & 4.7725 & TST \\
\hline CHEMBL1308000 & 688620 & 4.45 & 4.7045 & TRN \\
\hline CHEMBL1426270 & 688620 & 4.45 & 5.0209 & TRN \\
\hline CHEMBL1421132 & 688620 & 5.05 & 5.1563 & TRN \\
\hline CHEMBL1351755 & 688620 & 4.9 & 4.8163 & TRN \\
\hline CHEMBL1384014 & 688620 & 4.75 & 5.1443 & TST \\
\hline CHEMBL1545674 & 688620 & 6.1 & 5.0668 & TRN \\
\hline CHEMBL1521652 & 688620 & 5.2 & 5.0706 & TRN \\
\hline CHEMBL1585388 & 688620 & 4.9 & 4.9785 & TRN \\
\hline CHEMBL1537615 & 688620 & 5.45 & 5.3512 & TST \\
\hline CHEMBL1390636 & 688620 & 4.45 & 4.8633 & TRN \\
\hline CHEMBL1898074 & 688620 & 5.9 & 5.8944 & TRN \\
\hline CHEMBL1459563 & 688620 & 4.45 & 4.8288 & TST \\
\hline CHEMBL1569203 & 688620 & 4.95 & 5.0417 & TRN \\
\hline CHEMBL1311485 & 688620 & 5.8 & 5.1385 & TRN \\
\hline CHEMBL1407848 & 688620 & 5.15 & 5.0047 & TRN \\
\hline CHEMBL3195716 & 688620 & 6.95 & 6.3548 & TRN \\
\hline CHEMBL1527186 & 688620 & 5.1 & 5.1534 & TRN \\
\hline CHEMBL1534461 & 688620 & 5.05 & 5.1268 & TRN \\
\hline CHEMBL601320 & 688620 & 4.8 & 4.9954 & TST \\
\hline CHEMBL1368942 & 688620 & 4.45 & 4.962 & TRN \\
\hline CHEMBL1421040 & 688620 & 4.8 & 4.9706 & TST \\
\hline CHEMBL1458174 & 688620 & 4.95 & 4.8897 & TRN \\
\hline CHEMBL3198254 & 688620 & 4.8 & 5.0908 & TST \\
\hline CHEMBL3208118 & 688620 & 4.75 & 5.0632 & TRN \\
\hline CHEMBL1420282 & 688620 & 5.0 & 4.8757 & TRN \\
\hline CHEMBL1570693 & 688620 & 4.8 & 4.922 & TRN \\
\hline CHEMBL1534441 & 688620 & 4.55 & 5.0166 & TRN \\
\hline CHEMBL1489605 & 688620 & 5.05 & 4.808 & TRN \\
\hline CHEMBL1505231 & 688620 & 5.35 & 5.0383 & TST \\
\hline CHEMBL1570727 & 688620 & 5.0 & 5.038 & TRN \\
\hline CHEMBL1586380 & 688620 & 4.95 & 4.7803 & TRN \\
\hline CHEMBL1500610 & 688620 & 4.9 & 5.0973 & TRN \\
\hline CHEMBL1488879 & 688620 & 4.7 & 4.9804 & TRN \\
\hline CHEMBL1301060 & 688620 & 5.0 & 4.8997 & TST \\
\hline CHEMBL1339228 & 688620 & 6.35 & 5.907 & TRN \\
\hline CHEMBL1348009 & 688620 & 7.1002 & 5.2997 & TRN \\
\hline CHEMBL3349003 & 688620 & 4.9 & 4.8574 & TRN \\
\hline CHEMBL1408022 & 688620 & 4.45 & 4.9465 & TRN \\
\hline CHEMBL1585247 & 688620 & 6.2 & 4.9506 & TRN \\
\hline CHEMBL1458754 & 688620 & 4.9 & 4.9162 & TST \\
\hline
\end{tabular}




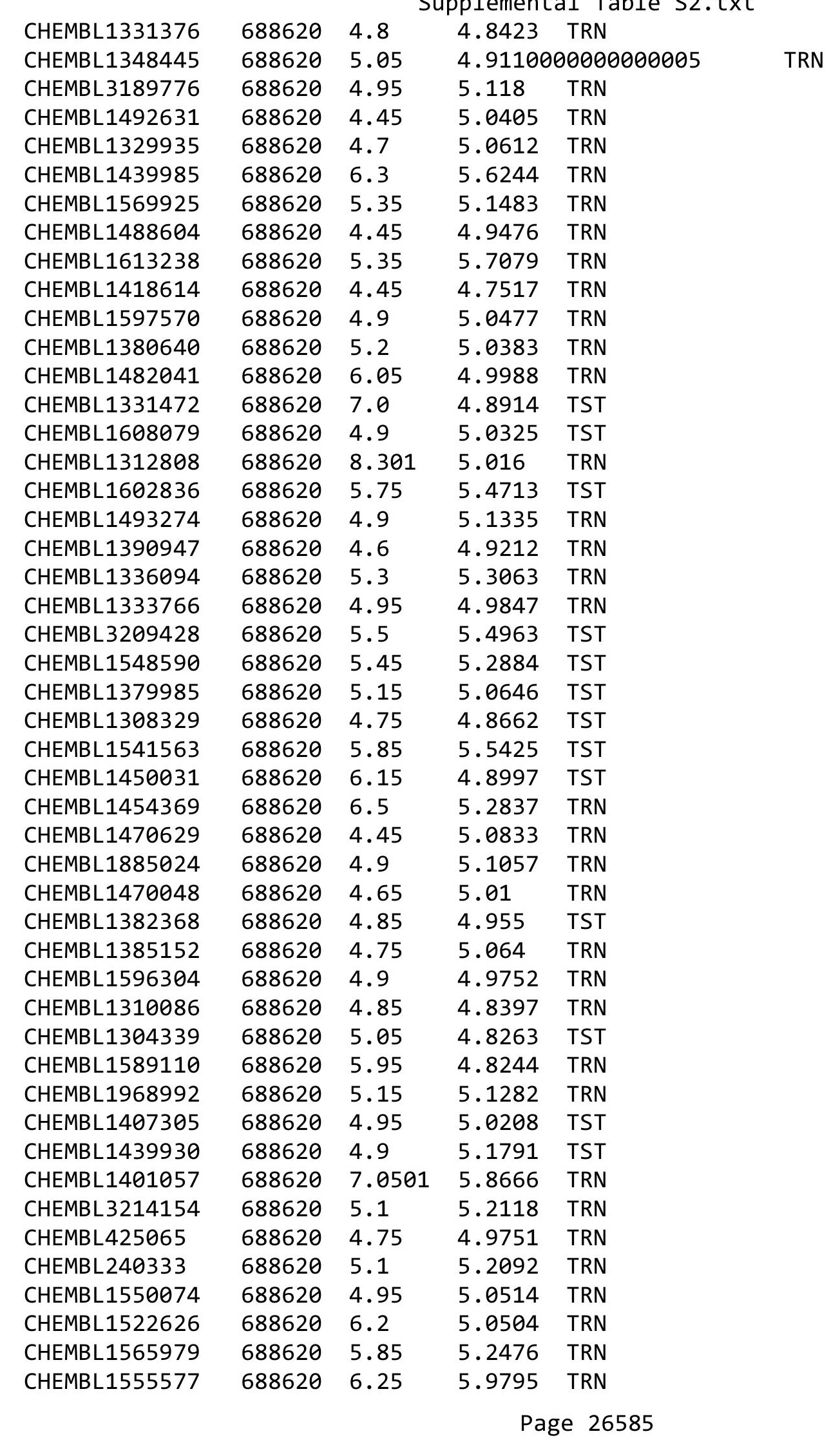




\begin{tabular}{|c|c|c|c|c|c|}
\hline \multicolumn{6}{|c|}{ Supplemental Table s2.txt } \\
\hline CHEMBL1559310 & 688620 & 5.0 & 5.2267 & TRN & \\
\hline CHEMBL1599722 & 688620 & 4.75 & 4.9383 & TST & \\
\hline CHEMBL3192961 & 688620 & 5.5 & 5.2463 & TRN & \\
\hline CHEMBL3195133 & 688620 & 4.9 & 5.8432 & TRN & \\
\hline CHEMBL1426933 & 688620 & 4.9 & 4.8823 & TRN & \\
\hline CHEMBL1302628 & 688620 & 4.5 & 4.9039 & TRN & \\
\hline CHEMBL1538279 & 688620 & 4.65 & 5.1741 & TRN & \\
\hline CHEMBL1416726 & 688620 & 4.95 & 5.4026 & TST & \\
\hline CHEMBL1473396 & 688620 & 4.9 & 4.6708 & TST & \\
\hline CHEMBL1364528 & 688620 & 4.75 & 5.1129 & TRN & \\
\hline CHEMBL1479546 & 688620 & 5.0 & 5.0322 & TRN & \\
\hline CHEMBL1384294 & 688620 & 4.65 & 5.093 & TRN & \\
\hline CHEMBL1400753 & 688620 & 5.05 & 5.3582 & TST & \\
\hline CHEMBL 319244 & 688620 & 5.05 & 5.3372 & TST & \\
\hline CHEMBL1308609 & 688620 & 4.7 & 5.0075 & TRN & \\
\hline CHEMBL3195667 & 688620 & 5.2 & 5.1574 & TRN & \\
\hline CHEMBL1365557 & 688620 & 4.8 & 4.8937 & TST & \\
\hline CHEMBL1485411 & 688620 & 5.5 & 5.1384 & TST & \\
\hline CHEMBL1525358 & 688620 & 5.1 & 5.2766 & TST & \\
\hline CHEMBL1417470 & 688620 & 4.8 & 4.9227 & TRN & \\
\hline CHEMBL1498466 & 688620 & 5.15 & 5.1931 & TRN & \\
\hline CHEMBL1302616 & 688620 & 5.9 & 4.9874 & TST & \\
\hline CHEMBL1544500 & 688620 & 4.8 & 5.30399 & 9999999999 & TRN \\
\hline CHEMBL1504554 & 688620 & 5.6 & 5.6223 & TRN & \\
\hline CHEMBL 242948 & 688620 & 5.65 & 5.2259 & TST & \\
\hline CHEMBL1459736 & 688620 & 4.45 & 4.6452 & TST & \\
\hline CHEMBL1385999 & 688620 & 4.95 & 5.1502 & TRN & \\
\hline CHEMBL1308169 & 688620 & 4.65 & 4.8223 & TRN & \\
\hline CHEMBL1327796 & 688620 & 4.85 & 4.9693 & TRN & \\
\hline CHEMBL1611133 & 688620 & 4.6 & 5.0378 & TRN & \\
\hline CHEMBL1474036 & 688620 & 5.15 & 4.9984 & TRN & \\
\hline CHEMBL1524880 & 688620 & 4.5 & 5.0233 & TST & \\
\hline CHEMBL1341241 & 688620 & 4.45 & 4.7844 & TRN & \\
\hline CHEMBL1502434 & 688620 & 5.2 & 5.0332 & TRN & \\
\hline CHEMBL1558833 & 688620 & 5.0 & 5.0874 & TRN & \\
\hline CHEMBL1391508 & 688620 & 4.75 & 5.0763 & TST & \\
\hline CHEMBL1318622 & 688620 & 5.2 & 4.8235 & TRN & \\
\hline CHEMBL1421388 & 688620 & 4.9 & 5.125 & TRN & \\
\hline CHEMBL3192413 & 688620 & 4.9 & 5.1327 & TRN & \\
\hline CHEMBL1362712 & 688620 & 4.65 & 5.0631 & TRN & \\
\hline CHEMBL3190020 & 688620 & 5.05 & 5.2195 & TRN & \\
\hline CHEMBL1378304 & 688620 & 4.95 & 4.9648 & TRN & \\
\hline CHEMBL 3213050 & 688620 & 5.5 & 5.0513 & TRN & \\
\hline CHEMBL1500878 & 688620 & 4.45 & 5.3193 & TRN & \\
\hline CHEMBL1466593 & 688620 & 5.15 & 5.0856 & TRN & \\
\hline CHEMBL1427627 & 688620 & 5.1 & 5.2529 & TRN & \\
\hline CHEMBL1489824 & 688620 & 5.0 & 4.9102 & TRN & \\
\hline CHEMBL1454827 & 688620 & 5.45 & 5.2763 & TRN & \\
\hline
\end{tabular}




\begin{tabular}{|c|c|c|c|c|}
\hline \multicolumn{5}{|c|}{ Supplemental Table S2.txt } \\
\hline CHEMBL1418920 & 688620 & 4.95 & 5.2031 & TRN \\
\hline CHEMBL3211405 & 688620 & 5.25 & 5.2279 & TRN \\
\hline CHEMBL1426163 & 688620 & 6.45 & 4.8213 & TRN \\
\hline CHEMBL 3195507 & 688620 & 4.6 & 5.1158 & TST \\
\hline CHEMBL1539603 & 688620 & 4.5 & 4.8947 & TRN \\
\hline CHEMBL1406160 & 688620 & 4.45 & 5.0256 & TST \\
\hline CHEMBL1485220 & 688620 & 4.8 & 4.9281 & TST \\
\hline CHEMBL1480610 & 688620 & 5.05 & 5.0592 & TRN \\
\hline CHEMBL1447719 & 688620 & 4.95 & 5.1516 & TRN \\
\hline CHEMBL1367991 & 688620 & 4.9 & 4.8638 & TRN \\
\hline CHEMBL1304514 & 688620 & 4.75 & 4.8261 & TST \\
\hline CHEMBL1612281 & 688620 & 4.8 & 4.8687 & TRN \\
\hline CHEMBL3192652 & 688620 & 4.45 & 4.868 & TRN \\
\hline CHEMBL1369506 & 688620 & 4.9 & 5.4081 & TRN \\
\hline CHEMBL1425477 & 688620 & 5.6 & 5.4609 & TRN \\
\hline CHEMBL1584885 & 688620 & 5.5 & 5.1397 & TRN \\
\hline CHEMBL1360959 & 688620 & 5.25 & 4.9093 & TST \\
\hline CHEMBL3195824 & 688620 & 4.65 & 4.7405 & TST \\
\hline CHEMBL 3198284 & 688620 & 5.1 & 5.2589 & TRN \\
\hline CHEMBL1269508 & 688620 & 4.45 & 5.0014 & TRN \\
\hline CHEMBL1516706 & 688620 & 5.2 & 4.9658 & TST \\
\hline CHEMBL1438570 & 688620 & 6.0 & 5.5863 & TRN \\
\hline CHEMBL3193392 & 688620 & 5.2 & 5.1502 & TRN \\
\hline CHEMBL1504403 & 688620 & 4.9 & 5.2296 & TST \\
\hline CHEMBL1329367 & 688620 & 4.9 & 5.1898 & TST \\
\hline CHEMBL538430 & 688620 & 5.8 & 5.1295 & TRN \\
\hline CHEMBL1521842 & 688620 & 5.2 & 4.9974 & TRN \\
\hline CHEMBL1335952 & 688620 & 5.55 & 4.8195 & TRN \\
\hline CHEMBL1377295 & 688620 & 4.9 & 5.1264 & TRN \\
\hline CHEMBL1352122 & 688620 & 4.8 & 4.9899 & TRN \\
\hline CHEMBL1332918 & 688620 & 5.85 & 5.1274 & TST \\
\hline CHEMBL527585 & 688620 & 4.45 & 5.2955 & TRN \\
\hline CHEMBL1400068 & 688620 & 4.95 & 5.0537 & TRN \\
\hline CHEMBL3212008 & 688620 & 7.5003 & 5.0749 & TST \\
\hline CHEMBL1306817 & 688620 & 4.45 & 4.8439 & TRN \\
\hline CHEMBL1342894 & 688620 & 5.15 & 5.6129 & TST \\
\hline CHEMBL1574971 & 688620 & 4.85 & 4.6765 & TRN \\
\hline CHEMBL1530230 & 688620 & 4.6 & 5.0298 & TRN \\
\hline CHEMBL1430804 & 688620 & 5.2 & 5.0593 & TRN \\
\hline CHEMBL1381668 & 688620 & 4.85 & 4.8941 & TRN \\
\hline CHEMBL3144967 & 688620 & 4.5 & 5.0948 & TST \\
\hline CHEMBL1605171 & 688620 & 4.8 & 5.0725 & TRN \\
\hline CHEMBL1564505 & 688620 & 5.25 & 5.062 & TRN \\
\hline CHEMBL1586168 & 688620 & 5.2 & 5.3235 & TRN \\
\hline CHEMBL1470880 & 688620 & 5.2 & 5.0357 & TRN \\
\hline CHEMBL1571263 & 688620 & 5.15 & 5.0641 & TRN \\
\hline CHEMBL1406476 & 688620 & 4.7 & 5.1277 & TST \\
\hline CHEMBL3189227 & 688620 & 4.45 & 5.2744 & TRN \\
\hline
\end{tabular}




\begin{tabular}{|c|c|c|c|c|c|}
\hline & & \multicolumn{4}{|c|}{ Supplemental Table s2.txt } \\
\hline CHEMBL1467739 & 688620 & 4.95 & 4.8336 & TRN & \\
\hline CHEMBL1611496 & 688620 & 5.0 & 4.6733 & TRN & \\
\hline CHEMBL1525771 & 688620 & 5.7 & 5.1103 & TST & \\
\hline CHEMBL1331945 & 688620 & 4.8 & 4.9056 & TRN & \\
\hline CHEMBL1576080 & 688620 & 6.25 & 4.9109 & TRN & \\
\hline CHEMBL3195759 & 688620 & 5.05 & 5.0077 & TRN & \\
\hline CHEMBL1380324 & 688620 & 5.0 & 4.8846 & TST & \\
\hline CHEMBL1562650 & 688620 & 4.9 & 5.0673 & TST & \\
\hline CHEMBL1419516 & 688620 & 4.95 & 4.9634 & TST & \\
\hline CHEMBL1319784 & 688620 & 5.25 & 4.8787 & TRN & \\
\hline CHEMBL267099 & 688620 & 6.2 & 5.7185 & TRN & \\
\hline CHEMBL1407677 & 688620 & 4.8 & 4.7116 & TRN & \\
\hline CHEMBL1484597 & 688620 & 4.85 & 4.9059 & TRN & \\
\hline CHEMBL1543767 & 688620 & 4.75 & 5.0723 & TRN & \\
\hline CHEMBL1388897 & 688620 & 4.75 & 4.9361 & TRN & \\
\hline CHEMBL1504000 & 688620 & 4.45 & 4.8606 & TST & \\
\hline CHEMBL1337405 & 688620 & 4.8 & 4.7053 & TRN & \\
\hline CHEMBL3213726 & 688620 & 4.45 & 5.1486 & TRN & \\
\hline CHEMBL1564823 & 688620 & 4.45 & 4.9564 & TST & \\
\hline CHEMBL1492391 & 688620 & 5.0 & 4.9961 & TRN & \\
\hline CHEMBL1354122 & 688620 & 4.45 & 4.9431 & TST & \\
\hline CHEMBL1561725 & 688620 & 4.75 & 5.3463 & TRN & \\
\hline CHEMBL1595173 & 688620 & 5.4 & 5.0692 & TRN & \\
\hline CHEMBL1558417 & 688620 & 5.2 & 5.1919 & TRN & \\
\hline CHEMBL1389496 & 688620 & 4.45 & 4.9893 & TST & \\
\hline CHEMBL1488521 & 688620 & 5.65 & 4.8973 & TRN & \\
\hline CHEMBL3192089 & 688620 & 5.55 & 5.3273 & TST & \\
\hline CHEMBL1567575 & 688620 & 4.95 & 5.24 & TST & \\
\hline CHEMBL1597664 & 688620 & 4.45 & 4.9863 & TRN & \\
\hline CHEMBL1451720 & 688620 & 5.8 & 5.0052 & TRN & \\
\hline CHEMBL1504677 & 688620 & 4.85 & 4.6667 & TRN & \\
\hline CHEMBL1417400 & 688620 & 4.9 & 4.9326 & TRN & \\
\hline CHEMBL1520847 & 688620 & 5.15 & 5.1203 & TRN & \\
\hline CHEMBL1382853 & 688620 & 5.7 & 5.1954 & TST & \\
\hline CHEMBL436589 & 688620 & 5.5 & 4.9268 & TST & \\
\hline CHEMBL3196672 & 688620 & 5.35 & 5.0477 & TST & \\
\hline CHEMBL1411048 & 688620 & 4.95 & 4.9699 & TRN & \\
\hline CHEMBL1336796 & 688620 & 4.95 & 5.1392 & TST & \\
\hline CHEMBL1975216 & 688620 & 5.05 & 5.2016 & TRN & \\
\hline CHEMBL1425470 & 688620 & 4.7 & 5.1253 & TST & \\
\hline CHEMBL1422255 & 688620 & 5.5 & 5.3924 & TRN & \\
\hline CHEMBL1438796 & 688620 & 5.2 & 5.092 & TRN & \\
\hline CHEMBL1607084 & 688620 & 4.45 & 5.2298 & TRN & \\
\hline CHEMBL1448642 & 688620 & 4.65 & 4.919 & TRN & \\
\hline CHEMBL1387595 & 688620 & 4.85 & 5.4627 & TRN & \\
\hline CHEMBL3198813 & 688620 & 5.0 & 4.7045 & TRN & \\
\hline CHEMBL1967070 & 688620 & 5.7 & 5.5569 & TRN & \\
\hline CHEMBL3199166 & 688620 & 4.65 & 4.82600 & 00000000005 & TRN \\
\hline & & & & 26588 & \\
\hline
\end{tabular}




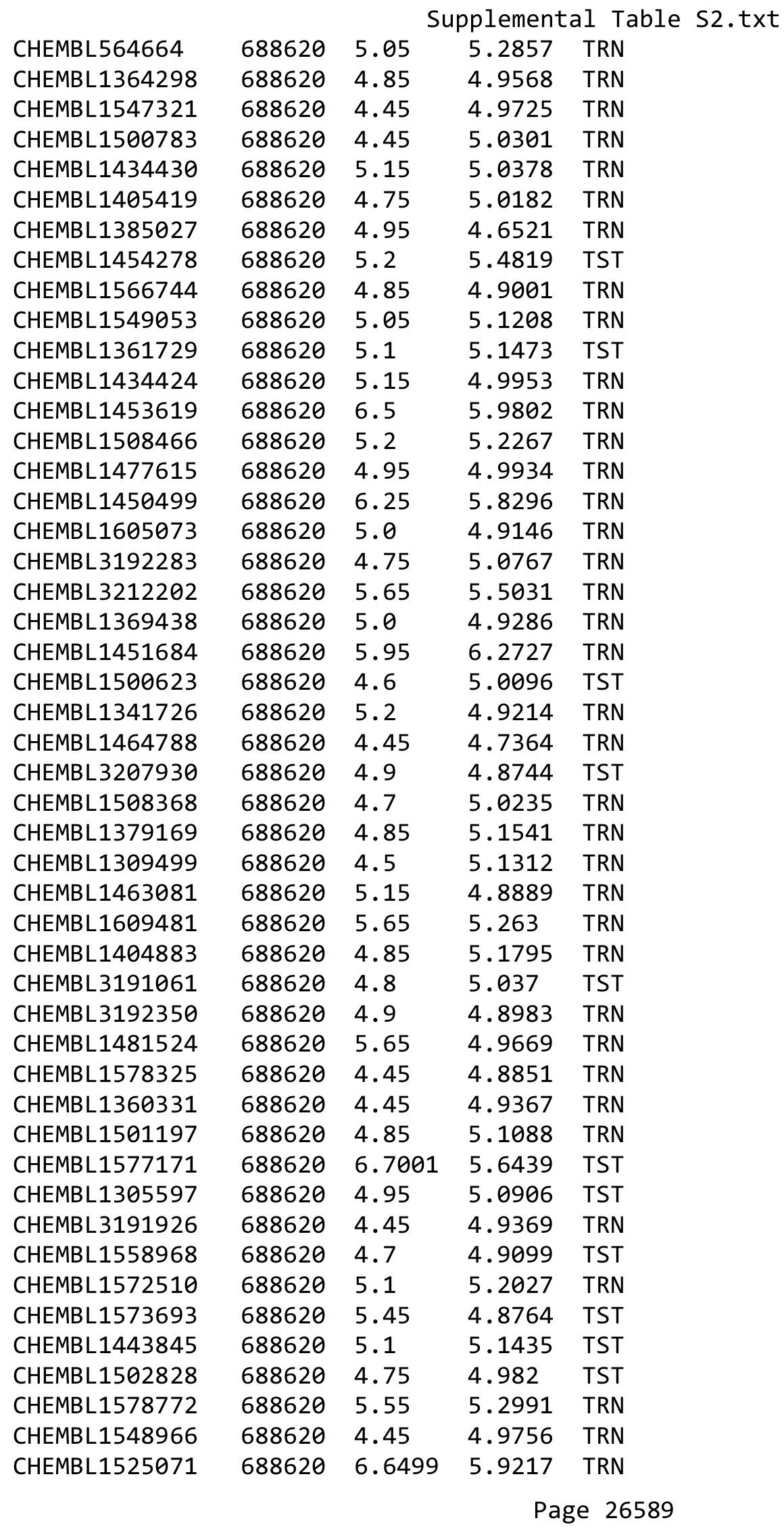




\begin{tabular}{|c|c|c|c|c|c|}
\hline \multicolumn{6}{|c|}{ Supplemental Table S2.txt } \\
\hline CHEMBL1343345 & 688620 & 5.15 & 5.2137 & TRN & \\
\hline CHEMBL1588557 & 688620 & 4.45 & 5.2887 & TST & \\
\hline CHEMBL1529143 & 688620 & 5.2 & 5.1452 & TRN & \\
\hline CHEMBL1337461 & 688620 & 6.05 & 5.9743 & TRN & \\
\hline CHEMBL1350207 & 688620 & 5.0 & 4.9233 & TRN & \\
\hline CHEMBL1469232 & 688620 & 4.45 & 5.0272 & TRN & \\
\hline CHEMBL1495350 & 688620 & 5.45 & 5.1249 & TST & \\
\hline CHEMBL1503096 & 688620 & 5.7 & 5.1862 & TRN & \\
\hline CHEMBL1421141 & 688620 & 5.25 & 5.0391 & TRN & \\
\hline CHEMBL1576788 & 688620 & 4.7 & 5.1692 & TRN & \\
\hline CHEMBL1540900 & 688620 & 4.9 & 5.3505 & TRN & \\
\hline CHEMBL1370409 & 688620 & 4.75 & 5.6424 & TRN & \\
\hline CHEMBL1411275 & 688620 & 6.8499 & 5.16700 & 0000000001 & TST \\
\hline CHEMBL1383826 & 688620 & 6.2 & 5.19799 & 99999999995 & TST \\
\hline CHEMBL1425650 & 688620 & 5.2 & 4.8606 & TST & \\
\hline CHEMBL1519067 & 688620 & 6.05 & 6.1877 & TRN & \\
\hline CHEMBL1390700 & 688620 & 4.65 & 5.7054 & TRN & \\
\hline CHEMBL1336274 & 688620 & 4.85 & 4.9833 & TRN & \\
\hline CHEMBL1988731 & 688620 & 4.45 & 4.9326 & TRN & \\
\hline CHEMBL1420386 & 688620 & 4.45 & 4.7476 & TST & \\
\hline CHEMBL1458567 & 688620 & 4.7 & 4.7627 & TRN & \\
\hline CHEMBL1375696 & 688620 & 4.5 & 4.8156 & TRN & \\
\hline CHEMBL1426235 & 688620 & 5.4 & 4.9114 & TRN & \\
\hline CHEMBL1565809 & 688620 & 5.35 & 5.2535 & TRN & \\
\hline CHEMBL1511493 & 688620 & 4.7 & 4.7743 & TRN & \\
\hline CHEMBL1525374 & 688620 & 4.6 & 5.0399 & TRN & \\
\hline CHEMBL3196218 & 688620 & 5.1 & 5.2016 & TRN & \\
\hline CHEMBL3212552 & 688620 & 4.8 & 4.8996 & TRN & \\
\hline CHEMBL1382937 & 688620 & 4.8 & 4.9487 & TRN & \\
\hline CHEMBL1541965 & 688620 & 4.45 & 5.86299 & 99999999995 & TRN \\
\hline CHEMBL1335149 & 688620 & 4.95 & 4.8129 & TST & \\
\hline CHEMBL1521791 & 688620 & 5.75 & 5.3514 & TRN & \\
\hline CHEMBL585444 & 688620 & 4.6 & 5.0994 & TST & \\
\hline CHEMBL1433041 & 688620 & 4.7 & 4.8667 & TRN & \\
\hline CHEMBL1325102 & 688620 & 4.6 & 5.4422 & TRN & \\
\hline CHEMBL1550240 & 688620 & 5.9 & 5.26200 & 00000000005 & TRN \\
\hline CHEMBL1448321 & 688620 & 4.45 & 4.7228 & TRN & \\
\hline CHEMBL3198127 & 688620 & 4.85 & 5.0961 & TST & \\
\hline CHEMBL1437183 & 688620 & 4.6 & 4.9375 & TRN & \\
\hline CHEMBL1432700 & 688620 & 6.5501 & 6.1455 & TRN & \\
\hline CHEMBL1423702 & 688620 & 5.35 & 4.7224 & TRN & \\
\hline CHEMBL1539294 & 688620 & 4.8 & 5.0423 & TRN & \\
\hline CHEMBL1332530 & 688620 & 4.45 & 5.4094 & TRN & \\
\hline CHEMBL1562313 & 688620 & 4.9 & 4.9994 & TST & \\
\hline CHEMBL1576887 & 688620 & 4.45 & 4.8864 & TRN & \\
\hline CHEMBL1465319 & 688620 & 4.9 & 4.9595 & TRN & \\
\hline CHEMBL1536789 & 688620 & 4.95 & 4.9429 & TRN & \\
\hline CHEMBL1524881 & 688620 & 5.6 & 5.2429 & TRN & \\
\hline
\end{tabular}




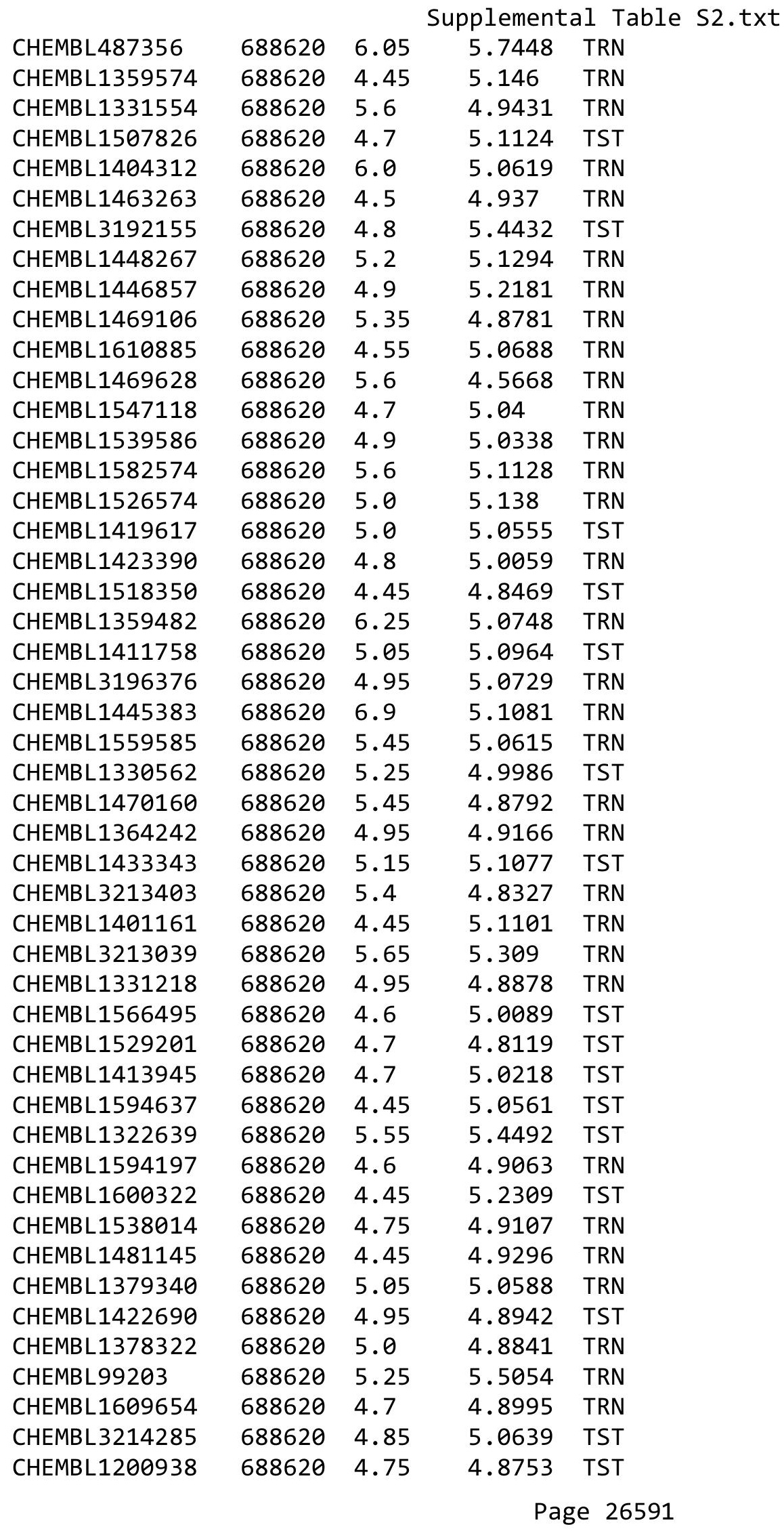




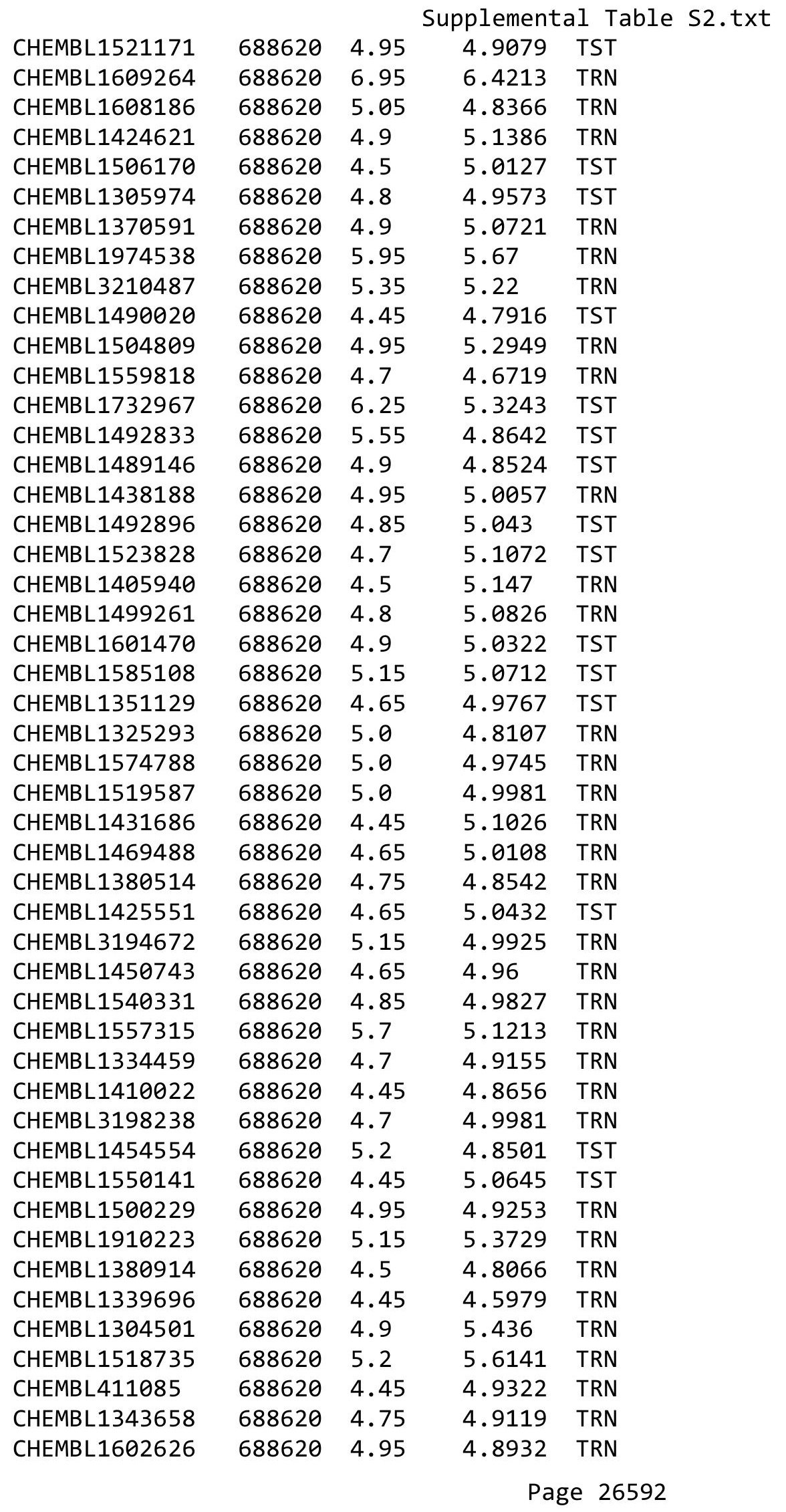




\begin{tabular}{|c|c|c|c|c|c|}
\hline & & \multicolumn{4}{|c|}{ Supplemental Table s2.txt } \\
\hline CHEMBL1407969 & 688620 & 4.45 & 4.8526 & TRN & \\
\hline CHEMBL1603643 & 688620 & 4.9 & 5.2341 & TRN & \\
\hline CHEMBL1538240 & 688620 & 4.65 & 5.0992 & TRN & \\
\hline CHEMBL1481691 & 688620 & 5.6 & 4.8856 & TST & \\
\hline CHEMBL1427529 & 688620 & 4.5 & 5.1 & TRN & \\
\hline CHEMBL1415844 & 688620 & 5.35 & 5.2243 & TRN & \\
\hline CHEMBL1413392 & 688620 & 4.45 & 5.2357 & TRN & \\
\hline CHEMBL1319817 & 688620 & 5.2 & 4.9735 & TST & \\
\hline CHEMBL1490227 & 688620 & 4.7 & 5.1527 & TRN & \\
\hline CHEMBL1604446 & 688620 & 5.45 & 5.6573 & TRN & \\
\hline CHEMBL1326445 & 688620 & 7.0 & 5.0853 & TRN & \\
\hline CHEMBL1270192 & 688620 & 5.2 & 4.9679 & TRN & \\
\hline CHEMBL1303170 & 688620 & 5.4 & 5.2685 & TRN & \\
\hline CHEMBL1371977 & 688620 & 4.8 & 5.119 & TRN & \\
\hline CHEMBL3214418 & 688620 & 4.65 & 4.8524 & TRN & \\
\hline CHEMBL1590362 & 688620 & 4.8 & 5.0523 & TST & \\
\hline CHEMBL1547855 & 688620 & 4.9 & 4.941 & TRN & \\
\hline CHEMBL1606741 & 688620 & 5.05 & \multicolumn{2}{|c|}{5.1979999999999995} & TRN \\
\hline CHEMBL1533140 & 688620 & 4.75 & 5.1382 & TRN & \\
\hline CHEMBL1541037 & 688620 & 4.5 & 5.0205 & TRN & \\
\hline CHEMBL1464941 & 688620 & 5.0 & 5.1283 & TRN & \\
\hline CHEMBL1360933 & 688620 & 4.7 & 4.9934 & TRN & \\
\hline CHEMBL1494384 & 688620 & 4.75 & 5.1761 & TRN & \\
\hline CHEMBL1487162 & 688620 & 4.45 & \multicolumn{2}{|c|}{5.122999999999999} & TRN \\
\hline CHEMBL1488315 & 688620 & 4.7 & 4.9395 & TST & \\
\hline CHEMBL1322382 & 688620 & 4.45 & 5.0423 & TRN & \\
\hline CHEMBL1585616 & 688620 & 4.75 & 5.0464 & TST & \\
\hline CHEMBL1535417 & 688620 & 6.0 & 5.0027 & TRN & \\
\hline CHEMBL1432064 & 688620 & 4.5 & 4.9818 & TRN & \\
\hline CHEMBL3196207 & 688620 & 4.45 & 5.0415 & TRN & \\
\hline CHEMBL1570122 & 688620 & 4.45 & 4.996 & TST & \\
\hline CHEMBL1349024 & 688620 & 4.5 & 4.9281 & TST & \\
\hline CHEMBL1418555 & 688620 & 4.45 & 4.9868 & TRN & \\
\hline CHEMBL1985428 & 688620 & 4.75 & 4.9901 & TRN & \\
\hline CHEMBL3195257 & 688620 & 4.65 & 5.0036 & TRN & \\
\hline CHEMBL1324773 & 688620 & 4.8 & 5.0082 & TRN & \\
\hline CHEMBL1319948 & 688620 & 5.0 & 5.1533 & TRN & \\
\hline CHEMBL1444022 & 688620 & 5.5 & 4.8992 & TRN & \\
\hline CHEMBL1347378 & 688620 & 6.15 & 6.4829 & TRN & \\
\hline CHEMBL1346796 & 688620 & 5.0 & 5.0685 & TST & \\
\hline CHEMBL1984240 & 688620 & 5.7 & 5.0657 & TRN & \\
\hline CHEMBL1561467 & 688620 & 4.75 & 4.8285 & TRN & \\
\hline CHEMBL1305879 & 688620 & 4.9 & 5.0132 & TRN & \\
\hline CHEMBL1422319 & 688620 & 4.45 & 4.8386 & TRN & \\
\hline CHEMBL1430473 & 688620 & 5.0 & 4.9604 & TST & \\
\hline CHEMBL1529445 & 688620 & 4.8 & 4.9179 & TRN & \\
\hline CHEMBL1509758 & 688620 & 4.75 & 4.6315 & TRN & \\
\hline CHEMBL1407483 & 688620 & 4.45 & 4.9099 & TST & \\
\hline
\end{tabular}




\begin{tabular}{|c|c|c|c|c|}
\hline & & & upplement & al $\mathrm{T}$ \\
\hline CHEMBL1423957 & 688620 & 4.55 & 5.0587 & TST \\
\hline CHEMBL1454716 & 688620 & 5.75 & 4.9824 & TRN \\
\hline CHEMBL1463088 & 688620 & 6.0 & 5.7018 & TRN \\
\hline CHEMBL1382648 & 688620 & 4.95 & 5.0785 & TRN \\
\hline CHEMBL1599119 & 688620 & 4.75 & 5.0584 & TRN \\
\hline CHEMBL1569492 & 688620 & 4.65 & 5.2101 & TRN \\
\hline CHEMBL 3190522 & 688620 & 5.05 & 5.2603 & TRN \\
\hline CHEMBL1299753 & 688620 & 5.45 & 5.2415 & TRN \\
\hline CHEMBL3196115 & 688620 & 4.95 & 5.3876 & TRN \\
\hline CHEMBL 1425348 & 688620 & 5.6 & 5.5753 & TRN \\
\hline CHEMBL1392292 & 688620 & 5.05 & 4.9228 & TRN \\
\hline CHEMBL1346291 & 688620 & 4.9 & 5.1245 & TST \\
\hline CHEMBL1345400 & 688620 & 5.0 & 4.9385 & TRN \\
\hline CHEMBL1344570 & 688620 & 4.9 & 5.0774 & TRN \\
\hline CHEMBL1540667 & 688620 & 4.9 & 4.8802 & TST \\
\hline CHEMBL1346539 & 688620 & 5.45 & 4.9826 & TST \\
\hline CHEMBL1484013 & 688620 & 6.95 & 5.1448 & TST \\
\hline CHEMBL1385105 & 688620 & 4.95 & 5.1718 & TRN \\
\hline CHEMBL3208158 & 688620 & 4.45 & 4.794 & TRN \\
\hline CHEMBL492010 & 688620 & 4.95 & 5.0336 & TRN \\
\hline CHEMBL1402742 & 688620 & 4.95 & 5.4201 & TST \\
\hline CHEMBL1375362 & 688620 & 5.15 & 5.2459 & TRN \\
\hline CHEMBL1327783 & 688620 & 5.95 & 5.2281 & TRN \\
\hline CHEMBL1380012 & 688620 & 4.45 & 5.1765 & TRN \\
\hline CHEMBL139935 & 688620 & 5.9 & 5.4155 & TRN \\
\hline CHEMBL 2001887 & 688620 & 5.1 & 5.1035 & TRN \\
\hline CHEMBL1340151 & 688620 & 6.45 & 5.1137 & TRN \\
\hline CHEMBL1334907 & 688620 & 5.55 & 4.9539 & TST \\
\hline CHEMBL1302154 & 688620 & 5.25 & 5.2212 & TRN \\
\hline CHEMBL1312123 & 688620 & 4.95 & 4.834 & TRN \\
\hline CHEMBL1502609 & 688620 & 4.65 & 4.8995 & TRN \\
\hline CHEMBL1454169 & 688620 & 5.55 & 5.5426 & TRN \\
\hline CHEMBL1419714 & 688620 & 4.45 & 4.8602 & TRN \\
\hline CHEMBL1373533 & 688620 & 5.0 & 4.8905 & TRN \\
\hline CHEMBL1539377 & 688620 & 4.65 & 5.0303 & TRN \\
\hline CHEMBL1577632 & 688620 & 5.1 & 5.0197 & TRN \\
\hline CHEMBL1479639 & 688620 & 4.85 & 5.0466 & TRN \\
\hline CHEMBL1545421 & 688620 & 4.95 & 5.1128 & TRN \\
\hline CHEMBL1505345 & 688620 & 4.85 & 5.32 & TRN \\
\hline CHEMBL1541693 & 688620 & 4.7 & 4.6644 & TRN \\
\hline CHEMBL1599344 & 688620 & 5.05 & 5.1356 & TRN \\
\hline CHEMBL1517333 & 688620 & 5.95 & 6.0705 & TRN \\
\hline CHEMBL1506496 & 688620 & 4.45 & 4.8164 & TRN \\
\hline CHEMBL3207804 & 688620 & 4.9 & 5.1993 & TRN \\
\hline CHEMBL1521840 & 688620 & 4.95 & 5.059 & TRN \\
\hline CHEMBL1484740 & 688620 & 5.0 & 4.9711 & TST \\
\hline CHEMBL3212029 & 688620 & 6.6 & 6.004 & TRN \\
\hline CHEMBL1496604 & 688620 & 4.8 & 5.0291 & TRN \\
\hline
\end{tabular}




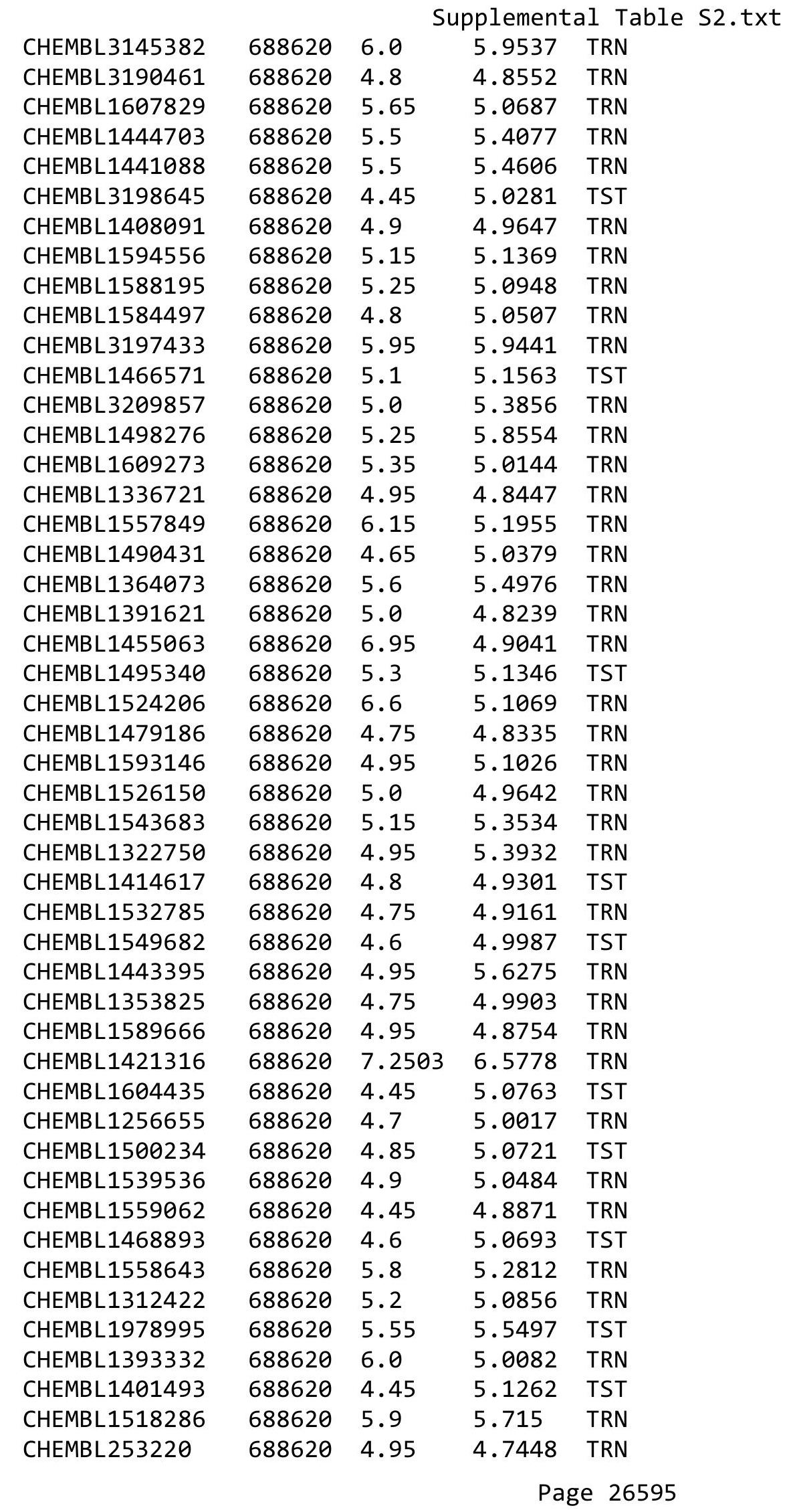




\begin{tabular}{|c|c|c|c|c|c|}
\hline \multicolumn{6}{|c|}{ Supplemental Table S2.txt } \\
\hline CHEMBL1513226 & 688620 & 4.8 & 4.9113 & TRN & \\
\hline CHEMBL1309190 & 688620 & 6.5501 & 5.6237 & TST & \\
\hline CHEMBL1548612 & 688620 & 5.45 & 4.9316 & TRN & \\
\hline CHEMBL1516900 & 688620 & 5.2 & 4.8951 & TRN & \\
\hline CHEMBL 3214342 & 688620 & 4.95 & 5.0527 & TRN & \\
\hline CHEMBL1301709 & 688620 & 4.8 & 5.0494 & TST & \\
\hline CHEMBL 3144881 & 688620 & 4.95 & 5.0261 & TST & \\
\hline CHEMBL1338423 & 688620 & 4.65 & 4.6916 & TST & \\
\hline CHEMBL1576578 & 688620 & 4.45 & 5.1822 & TST & \\
\hline CHEMBL1567897 & 688620 & 4.7 & 5.1631 & TRN & \\
\hline CHEMBL1424479 & 688620 & 4.45 & 4.8902 & TRN & \\
\hline CHEMBL1416946 & 688620 & 4.85 & 4.7898 & TRN & \\
\hline CHEMBL1368823 & 688620 & 5.2 & 4.9253 & TRN & \\
\hline CHEMBL1406639 & 688620 & 5.15 & 4.9176 & TST & \\
\hline CHEMBL1380297 & 688620 & 6.6499 & 4.9975 & TRN & \\
\hline CHEMBL3195163 & 688620 & 4.75 & 4.8572 & TST & \\
\hline CHEMBL1390761 & 688620 & 5.3 & 4.9853 & TRN & \\
\hline CHEMBL1305048 & 688620 & 4.7 & 5.0573 & TRN & \\
\hline CHEMBL1991187 & 688620 & 5.4 & 5.2541 & TRN & \\
\hline CHEMBL1573667 & 688620 & 5.45 & 4.9833 & TRN & \\
\hline CHEMBL1468537 & 688620 & 4.75 & 5.2366 & TST & \\
\hline CHEMBL1484163 & 688620 & 5.0 & 4.8573 & TRN & \\
\hline CHEMBL1520481 & 688620 & 5.5 & 5.35 & TRN & \\
\hline CHEMBL3197800 & 688620 & 4.55 & 4.8708 & TRN & \\
\hline CHEMBL1540439 & 688620 & 5.25 & 5.0657 & TRN & \\
\hline CHEMBL1480844 & 688620 & 4.9 & 5.0599 & TST & \\
\hline CHEMBL3189295 & 688620 & 5.55 & 5.206 & TRN & \\
\hline CHEMBL1549202 & 688620 & 5.3 & 5.4255 & TRN & \\
\hline CHEMBL1460502 & 688620 & 4.45 & 5.1808 & TRN & \\
\hline CHEMBL3210119 & 688620 & 4.9 & 5.064 & TRN & \\
\hline CHEMBL1579253 & 688620 & 4.65 & 4.8156 & TRN & \\
\hline CHEMBL1967082 & 688620 & 4.45 & 4.9837 & TST & \\
\hline CHEMBL1548542 & 688620 & 4.45 & 4.7077 & TRN & \\
\hline CHEMBL1462618 & 688620 & 4.45 & 5.04899 & 99999999995 & TRN \\
\hline CHEMBL1449706 & 688620 & 5.5 & 5.0176 & TRN & \\
\hline CHEMBL1467287 & 688620 & 4.95 & 4.8972 & TRN & \\
\hline CHEMBL1412855 & 688620 & 5.25 & 5.2645 & TRN & \\
\hline CHEMBL1350777 & 688620 & 4.95 & 4.7317 & TST & \\
\hline CHEMBL1461749 & 688620 & 4.8 & 5.0661 & TRN & \\
\hline CHEMBL1594138 & 688620 & 4.45 & 4.9364 & TRN & \\
\hline CHEMBL1607878 & 688620 & 5.35 & 5.2369 & TRN & \\
\hline CHEMBL1335236 & 688620 & 4.85 & 5.1098 & TRN & \\
\hline CHEMBL3193536 & 688620 & 5.15 & 5.2309 & TST & \\
\hline CHEMBL 1477889 & 688620 & 5.2 & 5.3267 & TRN & \\
\hline CHEMBL1468929 & 688620 & 6.45 & 5.7204 & TRN & \\
\hline CHEMBL 3190475 & 688620 & 4.95 & 4.84 & TST & \\
\hline CHEMBL1550252 & 688620 & 4.5 & 4.9245 & TRN & \\
\hline CHEMBL1448982 & 688620 & 5.8 & 5.4905 & TRN & \\
\hline
\end{tabular}




\begin{tabular}{|c|c|c|c|c|c|}
\hline \\
\hline CHEMBL1374258 & 688620 & 5.0 & 5.1779 & TRN & \\
\hline CHEMBL1988428 & 688620 & 5.2 & 5.1472 & TST & \\
\hline CHEMBL1541535 & 688620 & 4.9 & 5.0274 & TRN & \\
\hline CHEMBL1545559 & 688620 & 4.65 & 5.0322 & TST & \\
\hline CHEMBL1564396 & 688620 & 6.05 & 5.4301 & TRN & \\
\hline CHEMBL1416886 & 688620 & 5.25 & 5.0905 & TST & \\
\hline CHEMBL1345405 & 688620 & 4.45 & 4.8534 & TRN & \\
\hline CHEMBL1307308 & 688620 & 5.85 & 4.862 & TRN & \\
\hline CHEMBL1440549 & 688620 & 4.85 & 5.0368 & TRN & \\
\hline CHEMBL1479457 & 688620 & 5.1 & 4.8554 & TRN & \\
\hline CHEMBL1318033 & 688620 & 4.45 & 4.762 & TST & \\
\hline CHEMBL 2002046 & 688620 & 4.95 & 4.9921 & TST & \\
\hline CHEMBL1160160 & 688620 & 5.3 & 5.2293 & TST & \\
\hline CHEMBL 2262870 & 688620 & 4.75 & 4.9194 & TRN & \\
\hline CHEMBL1308812 & 688620 & 6.1 & 4.9713 & TRN & \\
\hline CHEMBL1977653 & 688620 & 6.5 & 5.5969 & TRN & \\
\hline CHEMBL1534271 & 688620 & 4.45 & 4.9173 & TST & \\
\hline CHEMBL1495714 & 688620 & 5.5 & 5.3762 & TRN & \\
\hline CHEMBL1361710 & 688620 & 4.45 & 5.0763 & TRN & \\
\hline CHEMBL1407546 & 688620 & 4.75 & 4.9806 & TRN & \\
\hline CHEMBL1343394 & 688620 & 6.2 & 5.1804 & TRN & \\
\hline CHEMBL1325550 & 688620 & 4.85 & 4.8422 & TRN & \\
\hline CHEMBL1321930 & 688620 & 4.8 & 4.8746 & TRN & \\
\hline CHEMBL1573850 & 688620 & 5.0 & 4.859 & TRN & \\
\hline CHEMBL3187596 & 688620 & 6.5 & 5.6556 & TST & \\
\hline CHEMBL 3208210 & 688620 & 6.15 & 5.6138 & TRN & \\
\hline CHEMBL1520151 & 688620 & 4.7 & 4.9624 & TRN & \\
\hline CHEMBL1429175 & 688620 & 4.85 & 5.1393 & TST & \\
\hline CHEMBL1489698 & 688620 & 4.9 & 4.8861 & TRN & \\
\hline CHEMBL1344025 & 688620 & 4.7 & 5.0363 & TRN & \\
\hline CHEMBL1532077 & 688620 & 4.85 & 5.0028 & TRN & \\
\hline CHEMBL1488172 & 688620 & 5.3 & 5.4192 & TRN & \\
\hline CHEMBL1486043 & 688620 & 4.75 & 5.1718 & TRN & \\
\hline CHEMBL 3198422 & 688620 & 4.95 & 4.79899 & 99999999995 & TST \\
\hline CHEMBL1496720 & 688620 & 5.9 & 5.0403 & TRN & \\
\hline CHEMBL1381281 & 688620 & 4.75 & 4.8467 & TRN & \\
\hline CHEMBL1603331 & 688620 & 5.0 & 4.9358 & TST & \\
\hline CHEMBL1369633 & 688620 & 5.1 & 4.9172 & TST & \\
\hline CHEMBL 3210531 & 688620 & 5.05 & 5.0489 & TRN & \\
\hline CHEMBL1310453 & 688620 & 5.2 & 5.2366 & TRN & \\
\hline CHEMBL1547249 & 688620 & 4.5 & 4.8184 & TRN & \\
\hline CHEMBL1343615 & 688620 & 4.45 & 4.7044 & TST & \\
\hline CHEMBL1360260 & 688620 & 4.45 & 5.1032 & TRN & \\
\hline CHEMBL1572550 & 688620 & 4.45 & 5.1703 & TRN & \\
\hline CHEMBL1611777 & 688620 & 4.7 & 4.8737 & TST & \\
\hline CHEMBL3190195 & 688620 & 4.7 & 4.9491 & TST & \\
\hline CHEMBL1971144 & 688620 & 5.95 & 5.7789 & TRN & \\
\hline CHEMBL1311981 & 688620 & 5.2 & 5.0158 & TRN & \\
\hline & & & & 6597 & \\
\hline
\end{tabular}




\begin{tabular}{|c|c|c|c|c|c|}
\hline \multicolumn{6}{|c|}{ Supplemental Table S2.txt } \\
\hline CHEMBL3197167 & 688620 & 4.95 & 5.4758 & TST & \\
\hline CHEMBL1524995 & 688620 & 5.35 & 5.4582 & TRN & \\
\hline CHEMBL1377826 & 688620 & 6.05 & 5.0597 & TRN & \\
\hline CHEMBL1506066 & 688620 & 4.7 & 5.1096 & TRN & \\
\hline CHEMBL1569513 & 688620 & 4.75 & 5.0341 & TRN & \\
\hline CHEMBL1566486 & 688620 & 5.7 & 4.9558 & TST & \\
\hline CHEMBL3198025 & 688620 & 4.65 & 5.3081 & TST & \\
\hline CHEMBL1531188 & 688620 & 5.2 & 4.8976 & TRN & \\
\hline CHEMBL1309939 & 688620 & 5.35 & 5.1423 & TRN & \\
\hline CHEMBL1548564 & 688620 & 4.45 & 4.9875 & TRN & \\
\hline CHEMBL1489370 & 688620 & 4.9 & 4.7526 & TRN & \\
\hline CHEMBL1429112 & 688620 & 4.75 & 4.8312 & TRN & \\
\hline CHEMBL1458745 & 688620 & 5.25 & 5.4033 & TRN & \\
\hline CHEMBL1468758 & 688620 & 4.85 & 4.9667 & TST & \\
\hline CHEMBL1305348 & 688620 & 5.0 & 4.9388 & TRN & \\
\hline CHEMBL1590550 & 688620 & 4.85 & 4.8194 & TST & \\
\hline CHEMBL1497100 & 688620 & 5.0 & 4.9487 & TRN & \\
\hline CHEMBL1482541 & 688620 & 5.85 & 5.4976 & TRN & \\
\hline CHEMBL1497602 & 688620 & 5.5 & 5.5449 & TRN & \\
\hline CHEMBL1352633 & 688620 & 5.0 & 5.0875 & TST & \\
\hline CHEMBL1502738 & 688620 & 4.45 & 4.9976 & TST & \\
\hline CHEMBL1376126 & 688620 & 5.65 & 4.9097 & TRN & \\
\hline CHEMBL 239275 & 688620 & 5.55 & 5.8491 & TRN & \\
\hline CHEMBL1524270 & 688620 & 4.65 & 5.0414 & TST & \\
\hline CHEMBL1374550 & 688620 & 4.9 & 4.8548 & TRN & \\
\hline CHEMBL1420411 & 688620 & 4.7 & 4.9353 & TRN & \\
\hline CHEMBL1327749 & 688620 & 4.75 & 4.9944 & TRN & \\
\hline CHEMBL1585840 & 688620 & 5.7 & 4.9841 & TRN & \\
\hline CHEMBL1446666 & 688620 & 4.95 & 5.1792 & TRN & \\
\hline CHEMBL1421670 & 688620 & 5.0 & 5.19799 & 99999999995 & TRN \\
\hline CHEMBL1535532 & 688620 & 6.25 & 5.4339 & TRN & \\
\hline CHEMBL1539686 & 688620 & 4.6 & 5.1439 & TRN & \\
\hline CHEMBL1338466 & 688620 & 4.95 & 4.9243 & TST & \\
\hline CHEMBL1587495 & 688620 & 4.85 & 5.13399 & 99999999995 & TST \\
\hline CHEMBL1531181 & 688620 & 5.0 & 4.8857 & TRN & \\
\hline CHEMBL3212891 & 688620 & 4.95 & 5.0022 & TST & \\
\hline CHEMBL3191707 & 688620 & 4.45 & 4.8606 & TST & \\
\hline CHEMBL1320285 & 688620 & 4.95 & 5.0492 & TRN & \\
\hline CHEMBL 3145374 & 688620 & 6.5 & 6.1826 & TRN & \\
\hline CHEMBL1507956 & 688620 & 5.0 & 4.9194 & TRN & \\
\hline CHEMBL1548205 & 688620 & 5.6 & 5.2484 & TRN & \\
\hline CHEMBL3209159 & 688620 & 6.05 & 5.7218 & TRN & \\
\hline CHEMBL1574313 & 688620 & 4.45 & 5.2009 & TST & \\
\hline CHEMBL1371147 & 688620 & 4.95 & 5.0505 & TRN & \\
\hline CHEMBL1570278 & 688620 & 4.9 & 5.026 & TRN & \\
\hline CHEMBL1410727 & 688620 & 6.1 & 5.256 & TRN & \\
\hline CHEMBL1336054 & 688620 & 5.15 & 5.0092 & TRN & \\
\hline CHEMBL1380218 & 688620 & 5.2 & 5.2255 & TRN & \\
\hline
\end{tabular}




\begin{tabular}{|c|c|c|c|c|c|}
\hline \multicolumn{6}{|c|}{ Supplemental Table S2.txt } \\
\hline CHEMBL1555650 & 688620 & 4.45 & 4.792 & TST & \\
\hline CHEMBL3144932 & 688620 & 4.45 & 4.7653 & TRN & \\
\hline CHEMBL3193315 & 688620 & 4.6 & 4.9922 & TRN & \\
\hline CHEMBL1343711 & 688620 & 4.5 & 5.2616 & TRN & \\
\hline CHEMBL1500770 & 688620 & 5.5 & 5.0655 & TST & \\
\hline CHEMBL1412789 & 688620 & 5.15 & 5.07100 & 0000000001 & TRN \\
\hline CHEMBL1479513 & 688620 & 5.5 & 4.7057 & TRN & \\
\hline CHEMBL3195315 & 688620 & 4.8 & 4.9088 & TRN & \\
\hline CHEMBL1493724 & 688620 & 5.9 & 5.3027 & TST & \\
\hline CHEMBL1608588 & 688620 & 5.1 & 5.0901 & TRN & \\
\hline CHEMBL1597512 & 688620 & 4.9 & 5.0193 & TRN & \\
\hline CHEMBL 2000342 & 688620 & 5.0 & 5.0489 & TRN & \\
\hline CHEMBL1320429 & 688620 & 4.65 & 5.4367 & TRN & \\
\hline CHEMBL1422701 & 688620 & 5.15 & 4.9683 & TRN & \\
\hline CHEMBL1501741 & 688620 & 4.45 & 4.9296 & TST & \\
\hline CHEMBL1341629 & 688620 & 4.85 & 4.8911 & TRN & \\
\hline CHEMBL1398698 & 688620 & 4.75 & 5.029 & TRN & \\
\hline CHEMBL1480827 & 688620 & 6.95 & 5.7292 & TST & \\
\hline CHEMBL1613209 & 688620 & 4.9 & 4.9781 & TRN & \\
\hline CHEMBL1414102 & 688620 & 4.95 & 5.086 & TRN & \\
\hline CHEMBL1601883 & 688620 & 4.9 & 4.9475 & TRN & \\
\hline CHEMBL1352703 & 688620 & 4.45 & 5.1489 & TRN & \\
\hline CHEMBL1541397 & 688620 & 5.2 & 5.0198 & TST & \\
\hline CHEMBL1597241 & 688620 & 5.7 & 4.9158 & TRN & \\
\hline CHEMBL1978504 & 688620 & 7.3002 & 5.6949 & TST & \\
\hline CHEMBL1607030 & 688620 & 5.0 & 5.1221 & TRN & \\
\hline CHEMBL1323252 & 688620 & 4.65 & 4.8802 & TRN & \\
\hline CHEMBL1556805 & 688620 & 5.3 & 5.6248 & TST & \\
\hline CHEMBL1356917 & 688620 & 4.85 & 4.7675 & TRN & \\
\hline CHEMBL435003 & 688620 & 5.55 & 5.3876 & TRN & \\
\hline CHEMBL1606516 & 688620 & 6.35 & 5.32799 & 9999999999 & TRN \\
\hline CHEMBL1361952 & 688620 & 5.8 & 5.0817 & TST & \\
\hline CHEMBL604321 & 688620 & 4.8 & 4.8975 & TST & \\
\hline CHEMBL1387010 & 688620 & 4.95 & 4.6739 & TRN & \\
\hline CHEMBL1500052 & 688620 & 4.85 & 4.9588 & TST & \\
\hline CHEMBL1424653 & 688620 & 4.45 & 5.115 & TRN & \\
\hline CHEMBL1418702 & 688620 & 4.45 & 4.9881 & TRN & \\
\hline CHEMBL1474312 & 688620 & 4.75 & 4.7837 & TRN & \\
\hline CHEMBL2003587 & 688620 & 5.65 & 5.4959 & TST & \\
\hline CHEMBL1443263 & 688620 & 5.35 & 5.0553 & TRN & \\
\hline CHEMBL1591263 & 688620 & 4.45 & 5.0936 & TST & \\
\hline CHEMBL3189517 & 688620 & 5.25 & 4.9477 & TST & \\
\hline CHEMBL1510200 & 688620 & 5.3 & 5.296 & TRN & \\
\hline CHEMBL1477131 & 688620 & 4.8 & 4.7881 & TRN & \\
\hline CHEMBL1336630 & 688620 & 4.6 & 5.0897 & TRN & \\
\hline CHEMBL1559872 & 688620 & 4.75 & 5.0114 & TRN & \\
\hline CHEMBL1547533 & 688620 & 4.5 & 4.9669 & TST & \\
\hline CHEMBL1364657 & 688620 & 5.05 & 4.9598 & TRN & \\
\hline
\end{tabular}




\begin{tabular}{|c|c|c|c|c|}
\hline \multicolumn{5}{|c|}{ Supplemental Table S2.txt } \\
\hline CHEMBL1595850 & 688620 & 5.5 & 5.1449 & TRN \\
\hline CHEMBL1558788 & 688620 & 5.0 & 4.8689 & TST \\
\hline CHEMBL1439435 & 688620 & 4.9 & 4.8147 & TRN \\
\hline CHEMBL1565362 & 688620 & 4.8 & 4.8195 & TRN \\
\hline CHEMBL1489960 & 688620 & 4.45 & 4.9592 & TRN \\
\hline CHEMBL1319365 & 688620 & 5.2 & 5.2503 & TRN \\
\hline CHEMBL1445230 & 688620 & 5.15 & 5.0546 & TST \\
\hline CHEMBL1562010 & 688620 & 4.45 & 5.2078 & TRN \\
\hline CHEMBL1576331 & 688620 & 4.6 & 5.3972 & TRN \\
\hline CHEMBL1452467 & 688620 & 5.7 & 5.6991 & TRN \\
\hline CHEMBL3198944 & 688620 & 4.65 & 4.8623 & TRN \\
\hline CHEMBL1587947 & 688620 & 5.1 & 5.2932 & TST \\
\hline CHEMBL1337788 & 688620 & 4.9 & 4.9383 & TRN \\
\hline CHEMBL1427785 & 688620 & 5.0 & 5.2051 & TRN \\
\hline CHEMBL1517393 & 688620 & 5.55 & 4.6827 & TST \\
\hline CHEMBL1409287 & 688620 & 4.45 & 4.9165 & TST \\
\hline CHEMBL1524076 & 688620 & 4.45 & 4.7805 & TRN \\
\hline CHEMBL1518450 & 688620 & 6.05 & 5.2239 & TRN \\
\hline CHEMBL1358525 & 688620 & 4.55 & 5.0305 & TST \\
\hline CHEMBL1510455 & 688620 & 4.65 & 4.7838 & TST \\
\hline CHEMBL1372302 & 688620 & 4.5 & 4.9471 & TST \\
\hline CHEMBL1505073 & 688620 & 6.1 & 5.2807 & TST \\
\hline CHEMBL3196808 & 688620 & 4.85 & 5.0411 & TST \\
\hline CHEMBL1549289 & 688620 & 4.9 & 5.0375 & TRN \\
\hline CHEMBL1401510 & 688620 & 5.6 & 5.5978 & TRN \\
\hline CHEMBL1440547 & 688620 & 4.45 & 4.8559 & TRN \\
\hline CHEMBL1416096 & 688620 & 4.85 & 5.1775 & TRN \\
\hline CHEMBL1499365 & 688620 & 5.0 & 5.1213 & TRN \\
\hline CHEMBL1535529 & 688620 & 5.3 & 5.0539 & TRN \\
\hline CHEMBL1461931 & 688620 & 4.85 & 4.9281 & TRN \\
\hline CHEMBL1408672 & 688620 & 4.75 & 5.1878 & TRN \\
\hline CHEMBL3195277 & 688620 & 5.1 & 5.1165 & TST \\
\hline CHEMBL1573365 & 688620 & 5.55 & 5.1358 & TST \\
\hline CHEMBL1318819 & 688620 & 4.9 & 5.0691 & TST \\
\hline CHEMBL 2003564 & 688620 & 4.95 & 5.2216 & TRN \\
\hline CHEMBL1310934 & 688620 & 4.75 & 5.1137 & TRN \\
\hline CHEMBL1409314 & 688620 & 4.75 & 4.9552 & TRN \\
\hline CHEMBL1420945 & 688620 & 4.45 & 4.6932 & TRN \\
\hline CHEMBL1486775 & 688620 & 4.75 & 4.9526 & TRN \\
\hline CHEMBL1537065 & 688620 & 4.95 & 5.1142 & TST \\
\hline CHEMBL1521297 & 688620 & 6.25 & 5.0008 & TRN \\
\hline CHEMBL1360487 & 688620 & 5.1 & 5.0756 & TST \\
\hline CHEMBL1321132 & 688620 & 5.65 & 5.3161 & TRN \\
\hline CHEMBL1346451 & 688620 & 4.55 & 5.1672 & TST \\
\hline CHEMBL1597849 & 688620 & 8.2518 & 5.1854 & TRN \\
\hline CHEMBL3190920 & 688620 & 4.9 & 4.9813 & TRN \\
\hline CHEMBL1353274 & 688620 & 5.2 & 5.4045 & TRN \\
\hline CHEMBL1481269 & 688620 & 4.65 & 5.0638 & TRN \\
\hline
\end{tabular}




\begin{tabular}{|c|c|c|c|c|c|}
\hline \multicolumn{6}{|c|}{ Supplemental Table S2.txt } \\
\hline CHEMBL1307271 & 688620 & 6.1 & 5.6402 & TRN & \\
\hline CHEMBL1528396 & 688620 & 5.1 & 4.8898 & TST & \\
\hline CHEMBL1305872 & 688620 & 5.45 & 5.5495 & TRN & \\
\hline CHEMBL 3208586 & 688620 & 4.65 & 5.0643 & TRN & \\
\hline CHEMBL1308125 & 688620 & 5.35 & 4.872 & TRN & \\
\hline CHEMBL1362552 & 688620 & 5.3 & 4.9822 & TRN & \\
\hline CHEMBL1385545 & 688620 & 4.95 & 4.9635 & TST & \\
\hline CHEMBL3189658 & 688620 & 4.7 & 5.5409 & TRN & \\
\hline CHEMBL1452708 & 688620 & 5.7 & 4.9559 & TRN & \\
\hline CHEMBL1523892 & 688620 & 5.15 & 4.9432 & TRN & \\
\hline CHEMBL1518051 & 688620 & 4.95 & 5.0135 & TST & \\
\hline CHEMBL1476229 & 688620 & 4.5 & 5.1212 & TRN & \\
\hline CHEMBL1501377 & 688620 & 5.5 & 5.1526 & TST & \\
\hline CHEMBL1339359 & 688620 & 4.75 & 5.016 & TRN & \\
\hline CHEMBL1426264 & 688620 & 4.75 & \multicolumn{2}{|c|}{5.127000000000001} & TST \\
\hline CHEMBL1470322 & 688620 & 4.45 & 5.1493 & TRN & \\
\hline CHEMBL1585412 & 688620 & 5.0 & 4.7849 & TRN & \\
\hline CHEMBL1491872 & 688620 & 4.95 & 5.0349 & TRN & \\
\hline CHEMBL1379895 & 688620 & 5.45 & 4.9243 & TST & \\
\hline CHEMBL1579335 & 688620 & 5.05 & 4.9389 & TST & \\
\hline CHEMBL1349481 & 688620 & 4.95 & 5.0511 & TRN & \\
\hline CHEMBL1514592 & 688620 & 5.05 & 5.3386 & TRN & \\
\hline CHEMBL1368619 & 688620 & 5.55 & 5.3637 & TST & \\
\hline CHEMBL1555396 & 688620 & 4.95 & 4.9055 & TST & \\
\hline CHEMBL1370564 & 688620 & 5.0 & 5.1055 & TRN & \\
\hline CHEMBL3191300 & 688620 & 5.05 & 5.1407 & TRN & \\
\hline CHEMBL3191459 & 688620 & 5.35 & 5.1305 & TRN & \\
\hline CHEMBL1997177 & 688620 & 4.95 & 4.8839 & TRN & \\
\hline CHEMBL1590123 & 688620 & 4.7 & 4.9438 & TRN & \\
\hline CHEMBL1597623 & 688620 & 4.95 & 5.0615 & TST & \\
\hline CHEMBL1374546 & 688620 & 5.1 & 5.2972 & TRN & \\
\hline CHEMBL1601712 & 688620 & 4.65 & 5.073 & TST & \\
\hline CHEMBL1478650 & 688620 & 6.6499 & 5.0884 & TRN & \\
\hline CHEMBL1459310 & 688620 & 5.8 & 4.8054 & TRN & \\
\hline CHEMBL1596765 & 688620 & 5.35 & 5.6567 & TRN & \\
\hline CHEMBL1480763 & 688620 & 4.5 & 5.0842 & TRN & \\
\hline CHEMBL 3197288 & 688620 & 5.45 & 5.6662 & TRN & \\
\hline CHEMBL1410293 & 688620 & 4.95 & 5.4788 & TST & \\
\hline CHEMBL1385481 & 688620 & 4.55 & 4.902 & TRN & \\
\hline CHEMBL3195752 & 688620 & 4.5 & 4.9789 & TRN & \\
\hline CHEMBL1597352 & 688620 & 4.45 & 4.8771 & TRN & \\
\hline CHEMBL1343603 & 688620 & 4.75 & 4.9174 & TRN & \\
\hline CHEMBL3196288 & 688620 & 5.4 & 5.21299 & 9999999999 & TRN \\
\hline CHEMBL1408307 & 688620 & 5.65 & 5.2681 & TRN & \\
\hline CHEMBL1587985 & 688620 & 5.6 & 5.3989 & TST & \\
\hline CHEMBL1559254 & 688620 & 4.9 & 5.0705 & TRN & \\
\hline CHEMBL1485022 & 688620 & 4.85 & 5.16299 & 9999999999 & TRN \\
\hline CHEMBL1330578 & 688620 & 5.3 & 5.1022 & TRN & \\
\hline
\end{tabular}




\begin{tabular}{|c|c|c|c|c|}
\hline \multicolumn{5}{|c|}{ Supplemental Table s2.txt } \\
\hline CHEMBL1475366 & 688620 & 4.9 & 4.7454 & TRN \\
\hline CHEMBL1406494 & 688620 & 4.5 & 5.0209 & TRN \\
\hline CHEMBL2436520 & 688620 & 4.75 & 5.4195 & TRN \\
\hline CHEMBL1516792 & 688620 & 5.6 & 5.0943 & TRN \\
\hline CHEMBL1465321 & 688620 & 4.9 & 4.958 & TRN \\
\hline CHEMBL1386426 & 688620 & 4.85 & 4.7883 & TRN \\
\hline CHEMBL1346313 & 688620 & 4.95 & 5.1043 & TRN \\
\hline CHEMBL1439505 & 688620 & 4.75 & 4.8536 & TRN \\
\hline CHEMBL1410274 & 688620 & 5.1 & 4.8245 & TRN \\
\hline CHEMBL1302704 & 688620 & 5.3 & 5.0263 & TST \\
\hline CHEMBL1571575 & 688620 & 4.75 & 4.9761 & TRN \\
\hline CHEMBL 3214022 & 688620 & 5.95 & 5.2748 & TRN \\
\hline CHEMBL1457669 & 688620 & 4.95 & 5.1442 & TRN \\
\hline CHEMBL 3196340 & 688620 & 5.6 & 5.2512 & TRN \\
\hline CHEMBL1423790 & 688620 & 5.45 & 5.216 & TRN \\
\hline CHEMBL1441067 & 688620 & 5.25 & 4.8447 & TRN \\
\hline CHEMBL1541079 & 688620 & 4.95 & 5.0899 & TRN \\
\hline CHEMBL1373517 & 688620 & 4.8 & 5.1523 & TST \\
\hline CHEMBL1579513 & 688620 & 5.4 & 5.07 & TRN \\
\hline CHEMBL1416591 & 688620 & 4.9 & 5.0427 & TRN \\
\hline CHEMBL1607013 & 688620 & 4.45 & 5.3463 & TST \\
\hline CHEMBL1369240 & 688620 & 5.1 & 5.2783 & TRN \\
\hline CHEMBL1424173 & 688620 & 5.8 & 5.2656 & TST \\
\hline CHEMBL1304661 & 688620 & 4.7 & 5.2247 & TST \\
\hline CHEMBL1519976 & 688620 & 5.15 & 5.2163 & TRN \\
\hline CHEMBL1359534 & 688620 & 4.45 & 5.2356 & TST \\
\hline CHEMBL1338187 & 688620 & 4.65 & 4.9908 & TST \\
\hline CHEMBL1612528 & 688620 & 5.35 & 5.0213 & TST \\
\hline CHEMBL1463976 & 688620 & 4.65 & 5.0827 & TRN \\
\hline CHEMBL3195091 & 688620 & 5.4 & 5.5101 & TRN \\
\hline CHEMBL1557066 & 688620 & 4.6 & 5.0958 & TRN \\
\hline CHEMBL1427623 & 688620 & 4.65 & 4.876 & TRN \\
\hline CHEMBL1409516 & 688620 & 5.95 & 5.095 & TST \\
\hline CHEMBL3197516 & 688620 & 4.65 & 5.0629 & TST \\
\hline CHEMBL1587250 & 688620 & 4.65 & 4.6331 & TRN \\
\hline CHEMBL1409527 & 688620 & 4.95 & 5.3123 & TRN \\
\hline CHEMBL1541611 & 688620 & 4.8 & 5.1773 & TST \\
\hline CHEMBL1499216 & 688620 & 4.45 & 5.0238 & TRN \\
\hline CHEMBL1567220 & 688620 & 4.75 & $5.1320 e$ & 0000000001 \\
\hline CHEMBL1557306 & 688620 & 5.25 & 4.8914 & TRN \\
\hline CHEMBL1493464 & 688620 & 4.7 & 5.0455 & TRN \\
\hline CHEMBL1568766 & 688620 & 5.0 & 5.0365 & TRN \\
\hline CHEMBL1405585 & 688620 & 4.85 & 5.0016 & TRN \\
\hline CHEMBL1461206 & 688620 & 4.9 & 4.8948 & TRN \\
\hline CHEMBL1486459 & 688620 & 4.85 & 4.7279 & TRN \\
\hline CHEMBL1607396 & 688620 & 4.45 & 5.0266 & TRN \\
\hline CHEMBL1388286 & 688620 & 5.0 & 5.052 & TRN \\
\hline CHEMBL584668 & 688620 & 5.6 & 4.998 & TRN \\
\hline
\end{tabular}




\begin{tabular}{|c|c|c|c|c|c|}
\hline \\
\hline CHEMBL1576727 & 688620 & 4.9 & 5.0384 & TRN & \\
\hline CHEMBL1526524 & 688620 & 4.75 & 5.0042 & TRN & \\
\hline CHEMBL1392835 & 688620 & 4.6 & 4.7849 & TRN & \\
\hline CHEMBL1596531 & 688620 & 5.45 & 5.32299 & 99999999995 & TRN \\
\hline CHEMBL1310527 & 688620 & 4.45 & 5.1737 & TRN & \\
\hline CHEMBL1378307 & 688620 & 5.05 & 5.1267 & TST & \\
\hline CHEMBL1446161 & 688620 & 5.2 & 6.1348 & TST & \\
\hline CHEMBL1335463 & 688620 & 4.95 & 4.8977 & TRN & \\
\hline CHEMBL1459884 & 688620 & 4.6 & 4.8467 & TRN & \\
\hline CHEMBL1344426 & 688620 & 4.9 & 5.1099 & TRN & \\
\hline CHEMBL1533988 & 688620 & 4.9 & 5.05399 & 9999999999 & TRN \\
\hline CHEMBL1574492 & 688620 & 5.0 & 4.8668 & TRN & \\
\hline CHEMBL1353474 & 688620 & 4.8 & 5.2862 & TRN & \\
\hline CHEMBL3214518 & 688620 & 4.9 & 5.0465 & TST & \\
\hline CHEMBL1310819 & 688620 & 4.65 & 4.7909 & TRN & \\
\hline CHEMBL3189424 & 688620 & 4.65 & 5.104 & TRN & \\
\hline CHEMBL1576955 & 688620 & 4.9 & 4.9723 & TRN & \\
\hline CHEMBL3192951 & 688620 & 4.75 & 5.0657 & TST & \\
\hline CHEMBL1302592 & 688620 & 4.7 & 5.0658 & TST & \\
\hline CHEMBL3191017 & 688620 & 4.9 & 5.1381 & TRN & \\
\hline CHEMBL1443128 & 688620 & 5.15 & 4.9921 & TRN & \\
\hline CHEMBL3198107 & 688620 & 5.15 & 5.1616 & TRN & \\
\hline CHEMBL3191540 & 688620 & 5.3 & 5.5481 & TRN & \\
\hline CHEMBL1541843 & 688620 & 6.2 & 5.0966 & TRN & \\
\hline CHEMBL1375366 & 688620 & 4.9 & 4.9505 & TRN & \\
\hline CHEMBL1530935 & 688620 & 4.45 & 4.8716 & TST & \\
\hline CHEMBL243644 & 688620 & 4.7 & 4.8346 & TRN & \\
\hline CHEMBL1443692 & 688620 & 4.9 & 5.0114 & TRN & \\
\hline CHEMBL1318220 & 688620 & 4.45 & 5.0689 & TRN & \\
\hline CHEMBL1319268 & 688620 & 4.85 & 5.0032 & TRN & \\
\hline CHEMBL1338027 & 688620 & 4.5 & 4.8417 & TST & \\
\hline CHEMBL1506495 & 688620 & 4.9 & 5.0405 & TRN & \\
\hline CHEMBL1571129 & 688620 & 4.45 & 4.8586 & TST & \\
\hline CHEMBL1558181 & 688620 & 5.6 & 5.9183 & TRN & \\
\hline CHEMBL1314125 & 688620 & 4.95 & 5.0975 & TST & \\
\hline CHEMBL3195661 & 688620 & 4.95 & 4.9829 & TRN & \\
\hline CHEMBL3190432 & 688620 & 4.95 & 5.0222 & TST & \\
\hline CHEMBL 2000577 & 688620 & 5.6 & 5.046 & TRN & \\
\hline CHEMBL 337821 & 688620 & 6.5 & 5.37299 & 9999999999 & TRN \\
\hline CHEMBL1360358 & 688620 & 5.05 & 4.9361 & TST & \\
\hline CHEMBL1488986 & 688620 & 5.85 & 4.9907 & TRN & \\
\hline CHEMBL1414388 & 688620 & 4.45 & 5.0079 & TST & \\
\hline CHEMBL1324365 & 688620 & 6.15 & 5.0351 & TRN & \\
\hline CHEMBL1536902 & 688620 & 4.75 & 5.0035 & TRN & \\
\hline CHEMBL1354712 & 688620 & 5.3 & 5.0919 & TST & \\
\hline CHEMBL1472239 & 688620 & 4.9 & 5.043 & TST & \\
\hline CHEMBL1399255 & 688620 & 4.85 & 4.8812 & TRN & \\
\hline CHEMBL1509734 & 688620 & 4.7 & 5.0394 & TRN & \\
\hline
\end{tabular}




\begin{tabular}{|c|c|c|c|c|c|}
\hline \multicolumn{6}{|c|}{ Supplemental Table S2.txt } \\
\hline CHEMBL1420219 & 688620 & 4.75 & 4.9812 & TRN & \\
\hline CHEMBL3208936 & 688620 & 5.15 & 5.4213 & TRN & \\
\hline CHEMBL1541911 & 688620 & 4.8 & 4.7335 & TRN & \\
\hline CHEMBL1568819 & 688620 & 4.95 & 5.0152 & TRN & \\
\hline CHEMBL1989723 & 688620 & 4.7 & 4.941 & TRN & \\
\hline CHEMBL1499296 & 688620 & 5.95 & 5.374 & TRN & \\
\hline CHEMBL1469323 & 688620 & 4.5 & 4.7425 & TRN & \\
\hline CHEMBL1549074 & 688620 & 4.9 & 4.9944 & TST & \\
\hline CHEMBL1465743 & 688620 & 5.15 & 4.8891 & TRN & \\
\hline CHEMBL1980667 & 688620 & 5.5 & 5.12200 & 0000000001 & TRN \\
\hline CHEMBL 3195153 & 688620 & 4.45 & 5.1383 & TRN & \\
\hline CHEMBL1534175 & 688620 & 5.05 & 5.0334 & TRN & \\
\hline CHEMBL1478730 & 688620 & 4.8 & 5.2452 & TRN & \\
\hline CHEMBL1561861 & 688620 & 4.45 & 4.9408 & TST & \\
\hline CHEMBL1399248 & 688620 & 5.0 & 4.9659 & TRN & \\
\hline CHEMBL1589670 & 688620 & 5.8 & 5.8144 & TRN & \\
\hline CHEMBL1342270 & 688620 & 5.85 & 5.1468 & TRN & \\
\hline CHEMBL1431014 & 688620 & 5.55 & 5.4322 & TRN & \\
\hline CHEMBL1384894 & 688620 & 4.45 & 5.1611 & TRN & \\
\hline CHEMBL1991908 & 688620 & 4.9 & 4.6919 & TRN & \\
\hline CHEMBL 3214632 & 688620 & 4.8 & 5.0468 & TST & \\
\hline CHEMBL3196164 & 688620 & 5.4 & 5.1864 & TRN & \\
\hline CHEMBL1372323 & 688620 & 5.75 & 5.0188 & TST & \\
\hline CHEMBL1463923 & 688620 & 4.95 & 4.8592 & TRN & \\
\hline CHEMBL1353548 & 688620 & 4.9 & 5.1743 & TRN & \\
\hline CHEMBL1299813 & 688620 & 4.45 & 5.0411 & TRN & \\
\hline CHEMBL1438081 & 688620 & 4.45 & 4.7072 & TRN & \\
\hline CHEMBL1482585 & 688620 & 5.5 & 4.975 & TRN & \\
\hline CHEMBL3195584 & 688620 & 4.6 & 4.9946 & TRN & \\
\hline CHEMBL1451042 & 688620 & 6.6499 & 5.0471 & TRN & \\
\hline CHEMBL1350286 & 688620 & 4.8 & 5.025 & TRN & \\
\hline CHEMBL1985660 & 688620 & 4.95 & 4.9631 & TST & \\
\hline CHEMBL1523684 & 688620 & 4.95 & 4.7639 & TST & \\
\hline CHEMBL1429733 & 688620 & 4.95 & 5.0258 & TST & \\
\hline CHEMBL1431394 & 688620 & 5.35 & 5.4682 & TRN & \\
\hline CHEMBL3199286 & 688620 & 5.45 & 5.2761 & TRN & \\
\hline CHEMBL1378880 & 688620 & 4.65 & 5.0271 & TRN & \\
\hline CHEMBL1392367 & 688620 & 5.0 & 4.8926 & TRN & \\
\hline CHEMBL1471485 & 688620 & 4.9 & 4.9298 & TST & \\
\hline CHEMBL1415077 & 688620 & 4.8 & 5.059 & TST & \\
\hline CHEMBL1412560 & 688620 & 4.8 & 5.02800 & 00000000005 & TRN \\
\hline CHEMBL1439789 & 688620 & 4.95 & 4.9485 & TRN & \\
\hline CHEMBL3190966 & 688620 & 5.35 & 4.9901 & TRN & \\
\hline CHEMBL3212139 & 688620 & 5.55 & 5.3012 & TRN & \\
\hline CHEMBL1480836 & 688620 & 4.65 & 4.96 & TRN & \\
\hline CHEMBL1531619 & 688620 & 5.85 & 5.1045 & TRN & \\
\hline CHEMBL1465494 & 688620 & 4.95 & 4.8996 & TRN & \\
\hline CHEMBL1504531 & 688620 & 5.65 & 5.0195 & TRN & \\
\hline
\end{tabular}




\begin{tabular}{|c|c|c|c|c|}
\hline \multicolumn{5}{|c|}{ Supplemental Table S2.txt } \\
\hline CHEMBL1430086 & 688620 & 4.65 & 5.0613 & TRN \\
\hline CHEMBL1559369 & 688620 & 4.6 & 4.8739 & TRN \\
\hline CHEMBL1573864 & 688620 & 5.9 & 4.8834 & TRN \\
\hline CHEMBL1359573 & 688620 & 5.6 & 5.1086 & TRN \\
\hline CHEMBL1534803 & 688620 & 5.1 & 5.1777 & TRN \\
\hline CHEMBL1485821 & 688620 & 4.65 & 4.9212 & TRN \\
\hline CHEMBL1510039 & 688620 & 4.65 & 5.876 & TRN \\
\hline CHEMBL1312087 & 688620 & 6.25 & 5.274 & TRN \\
\hline CHEMBL1417277 & 688620 & 5.05 & 5.2419 & TRN \\
\hline CHEMBL1410852 & 688620 & 4.75 & 5.1351 & TRN \\
\hline CHEMBL1344271 & 688620 & 4.6 & 5.0448 & TST \\
\hline CHEMBL1519734 & 688620 & 4.85 & 4.7052 & TRN \\
\hline CHEMBL1540496 & 688620 & 4.85 & 5.0093 & TRN \\
\hline CHEMBL1596270 & 688620 & 4.45 & 5.1358 & TRN \\
\hline CHEMBL3198281 & 688620 & 5.0 & 5.0285 & TRN \\
\hline CHEMBL3145282 & 688620 & 5.25 & 5.3785 & TRN \\
\hline CHEMBL1507595 & 688620 & 4.45 & 4.7456 & TRN \\
\hline CHEMBL1526319 & 688620 & 5.0 & 4.9576 & TST \\
\hline CHEMBL1323465 & 688620 & 4.7 & 4.9776 & TRN \\
\hline CHEMBL1555882 & 688620 & 5.0 & 5.2847 & TRN \\
\hline CHEMBL1417942 & 688620 & 5.0 & 5.0497 & TRN \\
\hline CHEMBL3199695 & 688620 & 4.9 & 5.1575 & TRN \\
\hline CHEMBL1375246 & 688620 & 5.5 & 5.0488 & TRN \\
\hline CHEMBL1490445 & 688620 & 4.75 & 4.9326 & TRN \\
\hline CHEMBL1454296 & 688620 & 4.45 & 5.0901 & TST \\
\hline CHEMBL1529138 & 688620 & 5.9 & 5.4857 & TRN \\
\hline CHEMBL1480241 & 688620 & 4.45 & 5.1196 & TRN \\
\hline CHEMBL1574283 & 688620 & 6.3 & 5.8513 & TRN \\
\hline CHEMBL1347833 & 688620 & 5.0 & 4.8651 & TRN \\
\hline CHEMBL1611867 & 688620 & 4.5 & 4.939 & TRN \\
\hline CHEMBL1504937 & 688620 & 6.8 & 6.1427 & TRN \\
\hline CHEMBL1446921 & 688620 & 5.55 & 5.0654 & TRN \\
\hline CHEMBL1321353 & 688620 & 5.45 & 5.1295 & TRN \\
\hline CHEMBL1609493 & 688620 & 5.1 & 4.9004 & TST \\
\hline CHEMBL1539902 & 688620 & 5.2 & 5.1998 & TST \\
\hline CHEMBL1605157 & 688620 & 4.5 & 4.8178 & TRN \\
\hline CHEMBL1328149 & 688620 & 4.45 & 4.8511 & TST \\
\hline CHEMBL3191025 & 688620 & 6.2 & 5.5704 & TRN \\
\hline CHEMBL1446209 & 688620 & 4.95 & 4.8457 & TRN \\
\hline CHEMBL1504506 & 688620 & 5.2 & 5.0394 & TST \\
\hline CHEMBL1349784 & 688620 & 4.95 & 5.0182 & TRN \\
\hline CHEMBL1422270 & 688620 & 4.45 & 5.1523 & TST \\
\hline CHEMBL3209096 & 688620 & 5.7 & 5.1984 & TRN \\
\hline CHEMBL1451981 & 688620 & 4.55 & 5.0859 & TST \\
\hline CHEMBL1556134 & 688620 & 4.45 & 4.8203 & TRN \\
\hline CHEMBL1338324 & 688620 & 7.2 & 5.3729 & TRN \\
\hline CHEMBL3194650 & 688620 & 4.95 & 5.0756 & TRN \\
\hline CHEMBL1328049 & 688620 & 5.0 & 4.9682 & TRN \\
\hline
\end{tabular}




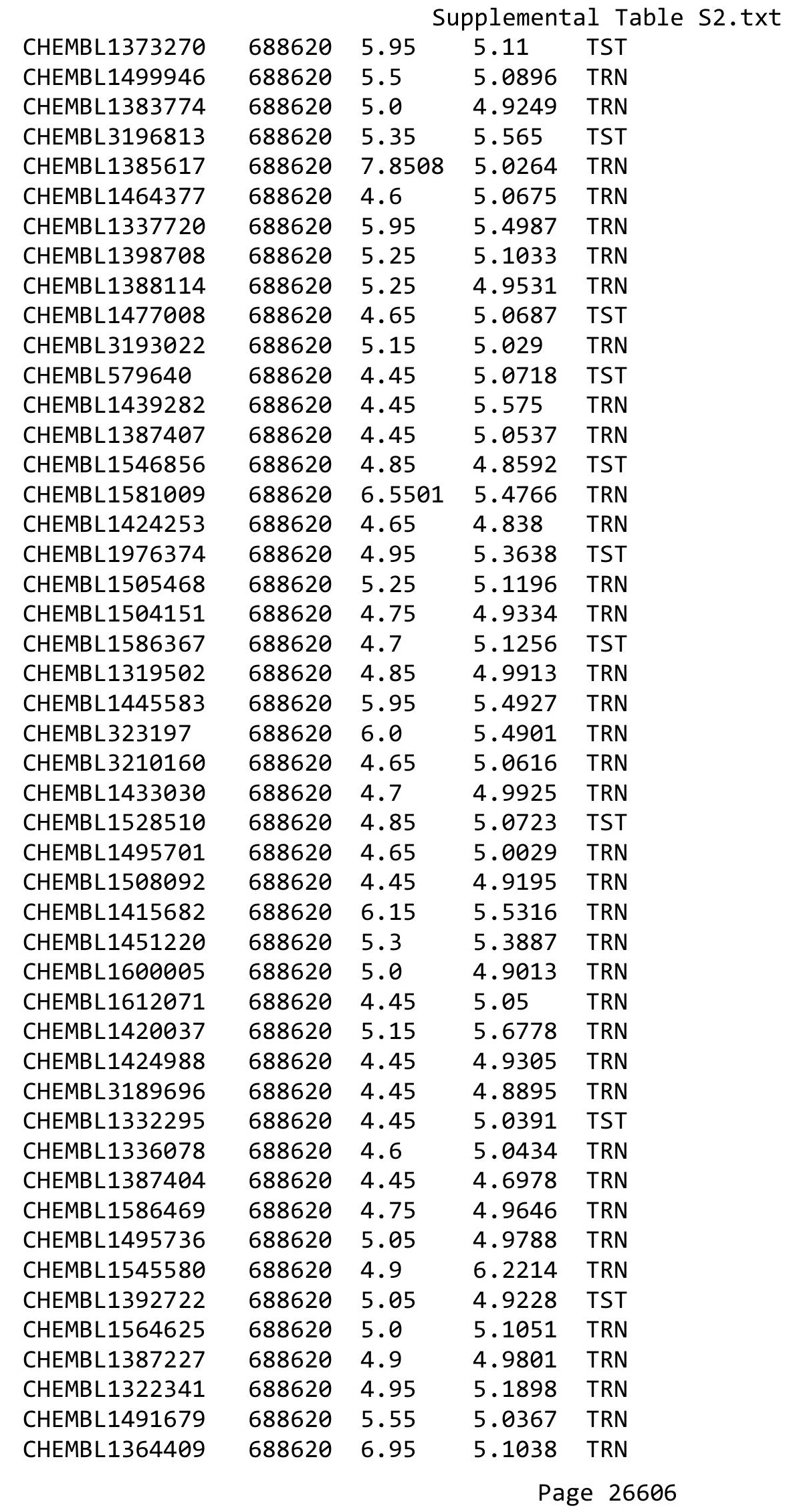




\begin{tabular}{|c|c|c|c|c|c|}
\hline \multirow{3}{*}{$\begin{array}{l}\text { CHEMBL1502397 } \\
\text { CHEMBL1350293 }\end{array}$} & \multirow{3}{*}{$\begin{array}{l}688620 \\
688620\end{array}$} & \multicolumn{4}{|c|}{ Supplemental Table S2.txt } \\
\hline & & 5.4 & 5.3270 & 0000000001 & TRN \\
\hline & & 4.75 & 4.9472 & TRN & \\
\hline CHEMBL1423507 & 688620 & 4.45 & 4.7718 & TRN & \\
\hline CHEMBL1380451 & 688620 & 4.75 & 4.9262 & TRN & \\
\hline CHEMBL1511022 & 688620 & 4.55 & 5.0221 & TST & \\
\hline CHEMBL3195265 & 688620 & 4.75 & 5.2508 & TRN & \\
\hline CHEMBL1455255 & 688620 & 4.55 & 4.9895 & TRN & \\
\hline CHEMBL1462049 & 688620 & 4.9 & 5.0459 & TRN & \\
\hline CHEMBL1450390 & 688620 & 5.05 & 5.0448 & TRN & \\
\hline CHEMBL1571769 & 688620 & 4.9 & 5.1067 & TRN & \\
\hline CHEMBL1604920 & 688620 & 4.75 & 4.8968 & TST & \\
\hline CHEMBL1534764 & 688620 & 4.9 & 4.9451 & TRN & \\
\hline CHEMBL1469831 & 688620 & 5.3 & 5.322 & TRN & \\
\hline CHEMBL1359423 & 688620 & 4.8 & 4.7822 & TRN & \\
\hline CHEMBL1576975 & 688620 & 5.3 & 5.0275 & TRN & \\
\hline CHEMBL1381066 & 688620 & 5.65 & 5.0334 & TST & \\
\hline CHEMBL1521747 & 688620 & 4.5 & 4.8231 & TRN & \\
\hline CHEMBL1558674 & 688620 & 5.0 & 5.0241 & TST & \\
\hline CHEMBL1444958 & 688620 & 4.9 & 4.9229 & TRN & \\
\hline CHEMBL1469451 & 688620 & 4.95 & 4.9782 & TRN & \\
\hline CHEMBL1345498 & 688620 & 4.5 & 5.0219 & TRN & \\
\hline CHEMBL1583775 & 688620 & 4.45 & 4.9876 & TRN & \\
\hline CHEMBL1567359 & 688620 & 5.3 & 5.0747 & TRN & \\
\hline CHEMBL1479729 & 688620 & 4.45 & 4.9231 & TRN & \\
\hline CHEMBL3198622 & 688620 & 5.15 & 5.1211 & TRN & \\
\hline CHEMBL1335363 & 688620 & 4.9 & 5.1908 & TRN & \\
\hline CHEMBL1450250 & 688620 & 6.15 & 4.9096 & TRN & \\
\hline CHEMBL1430615 & 688620 & 4.95 & 5.0405 & TRN & \\
\hline CHEMBL1579561 & 688620 & 4.65 & 4.994 & TRN & \\
\hline CHEMBL1595659 & 688620 & 5.9 & 5.0887 & TRN & \\
\hline CHEMBL3193012 & 688620 & 5.55 & 5.2511 & TRN & \\
\hline CHEMBL1422706 & 688620 & 5.85 & 5.0799 & TST & \\
\hline CHEMBL3194640 & 688620 & 5.6 & 5.0678 & TRN & \\
\hline CHEMBL1569763 & 688620 & 4.45 & 5.4183 & TRN & \\
\hline CHEMBL1456654 & 688620 & 5.95 & 5.4386 & TRN & \\
\hline CHEMBL1495958 & 688620 & 7.1002 & 5.0648 & TRN & \\
\hline CHEMBL1422985 & 688620 & 4.7 & 5.1235 & TRN & \\
\hline CHEMBL1466803 & 688620 & 4.9 & 5.0442 & TRN & \\
\hline CHEMBL171145 & 688620 & 5.2 & 4.9042 & TST & \\
\hline CHEMBL1603182 & 688620 & 4.6 & 4.9317 & TRN & \\
\hline CHEMBL1359677 & 688620 & 7.0 & 5.0529 & TST & \\
\hline CHEMBL1564483 & 688620 & 4.55 & 5.0428 & TRN & \\
\hline CHEMBL1546299 & 688620 & 6.25 & 5.9201 & TRN & \\
\hline CHEMBL1596967 & 688620 & 4.85 & 5.2681 & TRN & \\
\hline CHEMBL1407996 & 688620 & 5.0 & 5.3604 & TRN & \\
\hline CHEMBL1351676 & 688620 & 6.4 & 5.8949 & TRN & \\
\hline CHEMBL1463757 & 688620 & 5.0 & 4.9927 & TST & \\
\hline CHEMBL1529850 & 688620 & 4.95 & 4.981 & TRN & \\
\hline
\end{tabular}




\begin{tabular}{|c|c|c|c|c|}
\hline & & & pplement & al $\mathrm{T}$ \\
\hline CHEMBL1598857 & 688620 & 4.8 & 4.9976 & TRN \\
\hline CHEMBL1341577 & 688620 & 5.4 & 5.5456 & TRN \\
\hline CHEMBL1562660 & 688620 & 5.05 & 5.1777 & TST \\
\hline CHEMBL1410744 & 688620 & 4.65 & 5.0245 & TRN \\
\hline CHEMBL1431224 & 688620 & 4.45 & 5.1178 & TRN \\
\hline CHEMBL1441551 & 688620 & 4.8 & 5.1691 & TRN \\
\hline CHEMBL1349957 & 688620 & 6.05 & 5.2625 & TRN \\
\hline CHEMBL1426691 & 688620 & 4.65 & 5.103 & TRN \\
\hline CHEMBL1480422 & 688620 & 4.75 & 5.1378 & TRN \\
\hline CHEMBL1457863 & 688620 & 4.45 & 5.0338 & TRN \\
\hline CHEMBL1537660 & 688620 & 4.45 & 4.9445 & TRN \\
\hline CHEMBL1345601 & 688620 & 4.95 & 5.0866 & TST \\
\hline CHEMBL1411139 & 688620 & 4.5 & 4.8703 & TRN \\
\hline CHEMBL1364080 & 688620 & 4.45 & 4.9345 & TRN \\
\hline CHEMBL1419960 & 688620 & 4.45 & 5.0396 & TRN \\
\hline CHEMBL1372698 & 688620 & 5.5 & 5.3741 & TST \\
\hline CHEMBL1454177 & 688620 & 4.45 & 4.9413 & TRN \\
\hline CHEMBL1333191 & 688620 & 4.45 & 5.4653 & TRN \\
\hline CHEMBL1407623 & 688620 & 4.45 & 5.1781 & TRN \\
\hline CHEMBL1398985 & 688620 & 4.95 & 5.1141 & TRN \\
\hline CHEMBL1578036 & 688620 & 4.65 & 4.9856 & TRN \\
\hline CHEMBL1552270 & 688620 & 4.9 & 4.9677 & TRN \\
\hline CHEMBL1560355 & 688620 & 6.05 & 5.1281 & TST \\
\hline CHEMBL1557176 & 688620 & 5.0 & 4.8671 & TRN \\
\hline CHEMBL1598383 & 688620 & 4.9 & 4.9419 & TST \\
\hline CHEMBL1391015 & 688620 & 4.85 & 4.9971 & TRN \\
\hline CHEMBL1418742 & 688620 & 6.05 & 5.2933 & TRN \\
\hline CHEMBL1341173 & 688620 & 5.0 & 4.9027 & TRN \\
\hline CHEMBL1559742 & 688620 & 4.95 & 5.235 & TST \\
\hline CHEMBL1569984 & 688620 & 5.0 & 5.341 & TRN \\
\hline CHEMBL1383086 & 688620 & 4.95 & 4.9991 & TRN \\
\hline CHEMBL1399999 & 688620 & 4.65 & 4.9324 & TRN \\
\hline CHEMBL1310684 & 688620 & 5.0 & 4.7899 & TRN \\
\hline CHEMBL1409513 & 688620 & 5.0 & 5.3338 & TRN \\
\hline CHEMBL1430107 & 688620 & 6.6499 & 6.3327 & TRN \\
\hline CHEMBL1414078 & 688620 & 4.45 & 4.9819 & TRN \\
\hline CHEMBL 3189829 & 688620 & 4.6 & 4.7246 & TST \\
\hline CHEMBL3196889 & 688620 & 4.95 & 5.204 & TRN \\
\hline CHEMBL1406355 & 688620 & 4.85 & 4.9082 & TRN \\
\hline CHEMBL1510821 & 688620 & 4.85 & 5.2012 & TRN \\
\hline CHEMBL1351919 & 688620 & 4.45 & 4.9758 & TRN \\
\hline CHEMBL1606558 & 688620 & 4.95 & 4.957 & TRN \\
\hline CHEMBL1986025 & 688620 & 6.7501 & 5.8731 & TRN \\
\hline CHEMBL1575531 & 688620 & 5.5 & 5.0199 & TST \\
\hline CHEMBL1571488 & 688620 & 4.45 & 5.0204 & TRN \\
\hline CHEMBL1434635 & 688620 & 4.8 & 4.9886 & TRN \\
\hline CHEMBL1369831 & 688620 & 4.45 & 4.9136 & TRN \\
\hline CHEMBL1402045 & 688620 & 4.7 & 4.9832 & TRN \\
\hline
\end{tabular}




\begin{tabular}{|c|c|c|c|c|c|}
\hline \multicolumn{6}{|c|}{ Supplemental Table S2.txt } \\
\hline CHEMBL1521140 & 688620 & 4.45 & 4.9139 & TRN & \\
\hline CHEMBL1444941 & 688620 & 4.45 & 4.8931 & TRN & \\
\hline CHEMBL1423168 & 688620 & 4.65 & 5.0067 & TRN & \\
\hline CHEMBL1507032 & 688620 & 5.0 & 5.176 & TRN & \\
\hline CHEMBL1303707 & 688620 & 5.5 & 5.055 & TRN & \\
\hline CHEMBL1522671 & 688620 & 4.9 & 4.936 & TST & \\
\hline CHEMBL 1450518 & 688620 & 5.55 & 5.0454 & TST & \\
\hline CHEMBL1371414 & 688620 & 5.4 & 5.0705 & TRN & \\
\hline CHEMBL1449376 & 688620 & 5.55 & 5.4935 & TRN & \\
\hline CHEMBL1576749 & 688620 & 4.45 & 4.8797 & TRN & \\
\hline CHEMBL1546005 & 688620 & 6.0 & 5.5429 & TRN & \\
\hline CHEMBL1327172 & 688620 & 6.15 & 5.8529 & TRN & \\
\hline CHEMBL1318843 & 688620 & 4.9 & 5.0332 & TRN & \\
\hline CHEMBL1446218 & 688620 & 5.25 & 5.3671 & TRN & \\
\hline CHEMBL1492103 & 688620 & 5.6 & 5.6065 & TRN & \\
\hline CHEMBL1462884 & 688620 & 5.3 & 5.1275 & TRN & \\
\hline CHEMBL1508685 & 688620 & 4.75 & 4.9071 & TRN & \\
\hline CHEMBL1585269 & 688620 & 4.9 & 5.2287 & TRN & \\
\hline CHEMBL1611164 & 688620 & 4.7 & 5.0349 & TRN & \\
\hline CHEMBL 1431530 & 688620 & 5.0 & 5.225 & TRN & \\
\hline CHEMBL3196823 & 688620 & 5.35 & 5.4915 & TRN & \\
\hline CHEMBL1542780 & 688620 & 4.45 & 4.896 & TRN & \\
\hline CHEMBL 3209820 & 688620 & 4.7 & 5.0344 & TRN & \\
\hline CHEMBL1444715 & 688620 & 5.05 & 5.1449 & TRN & \\
\hline CHEMBL1988138 & 688620 & 6.1 & 5.7896 & TRN & \\
\hline CHEMBL1565793 & 688620 & 5.0 & 4.944 & TRN & \\
\hline CHEMBL1339989 & 688620 & 5.4 & 5.0223 & TST & \\
\hline CHEMBL1442375 & 688620 & 4.55 & 4.9991 & TRN & \\
\hline CHEMBL1409176 & 688620 & 5.2 & 4.9998 & TRN & \\
\hline CHEMBL1544670 & 688620 & 4.45 & 4.9721 & TRN & \\
\hline CHEMBL1332962 & 688620 & 4.45 & 5.1318 & TST & \\
\hline CHEMBL1414390 & 688620 & 4.9 & 4.9799 & TRN & \\
\hline CHEMBL1346752 & 688620 & 5.2 & 5.0014 & TST & \\
\hline CHEMBL1570734 & 688620 & 5.3 & 5.17899 & 9999999999 & TRN \\
\hline CHEMBL1432680 & 688620 & 5.4 & 5.0408 & TRN & \\
\hline CHEMBL1305792 & 688620 & 5.1 & 5.0424 & TST & \\
\hline CHEMBL1366997 & 688620 & 4.9 & 5.1912 & TRN & \\
\hline CHEMBL1408685 & 688620 & 4.95 & 4.9193 & TRN & \\
\hline CHEMBL1541706 & 688620 & 5.1 & 4.9973 & TRN & \\
\hline CHEMBL1610989 & 688620 & 4.8 & 5.064 & TRN & \\
\hline CHEMBL1490111 & 688620 & 5.0 & 5.2244 & TST & \\
\hline CHEMBL3198299 & 688620 & 5.35 & 5.3958 & TRN & \\
\hline CHEMBL3197306 & 688620 & 4.45 & 4.8466 & TRN & \\
\hline CHEMBL1407362 & 688620 & 5.35 & 5.0402 & TRN & \\
\hline CHEMBL1590743 & 688620 & 4.95 & 4.9407 & TST & \\
\hline CHEMBL1452264 & 688620 & 5.25 & $5.4620 e$ & 0000000001 & TRN \\
\hline CHEMBL1423918 & 688620 & 4.45 & 4.8976 & TRN & \\
\hline CHEMBL1343082 & 688620 & 5.95 & 5.1147 & TRN & \\
\hline
\end{tabular}




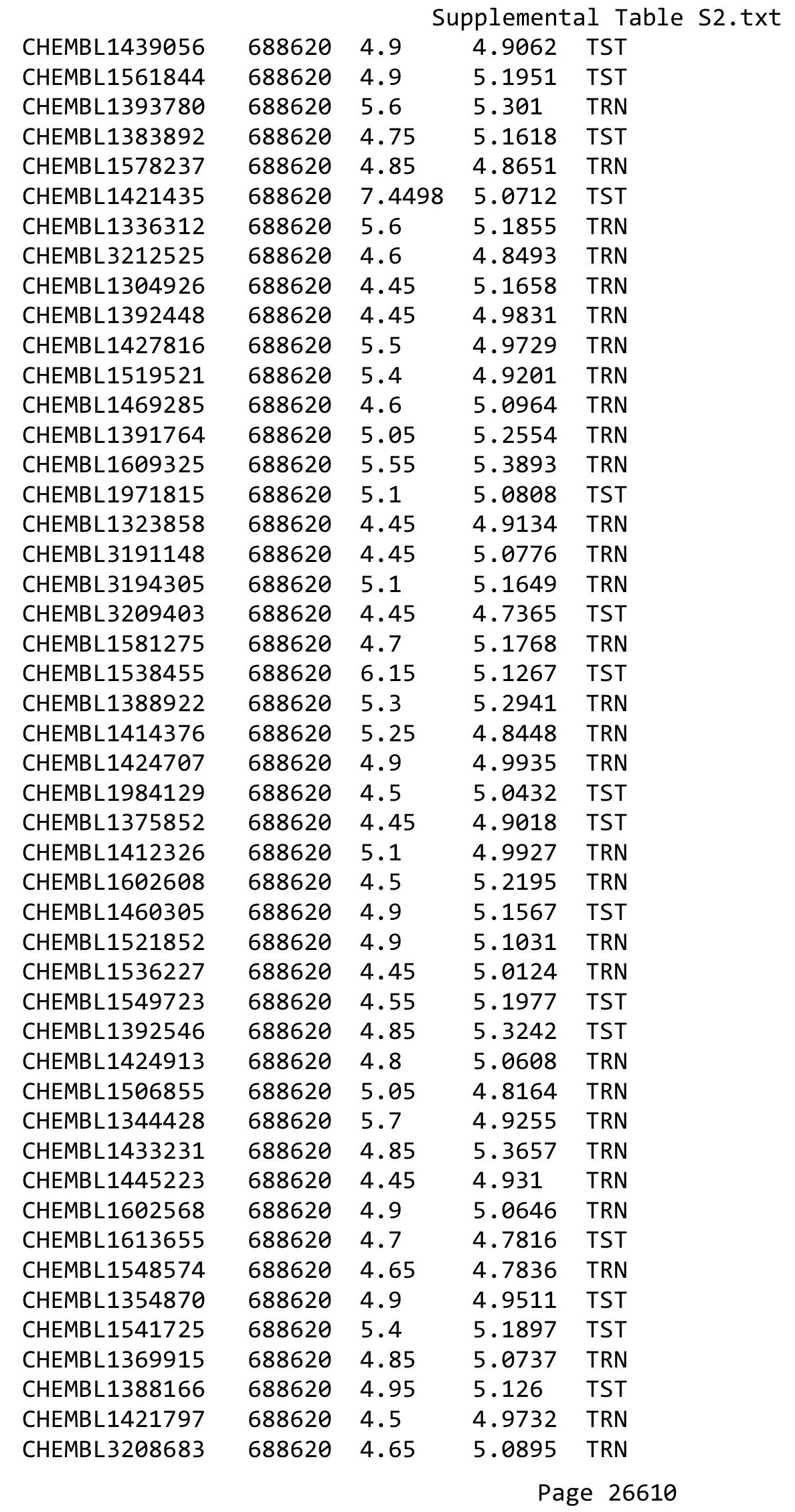




\begin{tabular}{|c|c|c|c|c|}
\hline \multicolumn{5}{|c|}{ Supplemental Table S2.txt } \\
\hline CHEMBL1329829 & 688620 & 4.95 & 5.2311 & TRN \\
\hline CHEMBL1557157 & 688620 & 4.75 & 5.2184 & TRN \\
\hline CHEMBL1613163 & 688620 & 4.65 & 4.9033 & TRN \\
\hline CHEMBL1596623 & 688620 & 4.8 & 5.3089 & TRN \\
\hline CHEMBL1482671 & 688620 & 5.9 & 5.0774 & TRN \\
\hline CHEMBL1406758 & 688620 & 4.9 & 4.9097 & TST \\
\hline CHEMBL1527256 & 688620 & 5.5 & 5.1867 & TRN \\
\hline CHEMBL1421901 & 688620 & 4.9 & 4.7816 & TST \\
\hline CHEMBL1489831 & 688620 & 5.0 & 5.0673 & TRN \\
\hline CHEMBL1382191 & 688620 & 5.2 & 5.6886 & TST \\
\hline CHEMBL1414252 & 688620 & 4.8 & 5.0886 & TRN \\
\hline CHEMBL1406688 & 688620 & 5.35 & 4.9403 & TRN \\
\hline CHEMBL1464549 & 688620 & 5.3 & 4.8193 & TRN \\
\hline CHEMBL1422818 & 688620 & 5.15 & 5.4825 & TRN \\
\hline CHEMBL119506 & 688620 & 4.5 & 5.0486 & TRN \\
\hline CHEMBL1604371 & 688620 & 4.9 & 5.1632 & TRN \\
\hline CHEMBL3192014 & 688620 & 4.9 & 4.8636 & TRN \\
\hline CHEMBL1324820 & 688620 & 5.2 & 5.3068 & TRN \\
\hline CHEMBL3197318 & 688620 & 5.45 & 5.1329 & TRN \\
\hline CHEMBL1521673 & 688620 & 4.85 & 4.9069 & TRN \\
\hline CHEMBL1334947 & 688620 & 5.0 & 5.0147 & TST \\
\hline CHEMBL1464030 & 688620 & 4.45 & 4.8082 & TRN \\
\hline CHEMBL1300752 & 688620 & 5.65 & 5.2229 & TRN \\
\hline CHEMBL1530767 & 688620 & 5.8 & 5.4639 & TRN \\
\hline CHEMBL1595691 & 688620 & 4.45 & 4.8773 & TRN \\
\hline CHEMBL1390021 & 688620 & 5.05 & 5.1485 & TRN \\
\hline CHEMBL1538737 & 688620 & 4.65 & 5.0461 & TST \\
\hline CHEMBL1384971 & 688620 & 4.45 & 4.9302 & TRN \\
\hline CHEMBL 28 & 688620 & 6.0 & 6.0627 & TRN \\
\hline CHEMBL1466547 & 688620 & 4.9 & 5.1566 & TRN \\
\hline CHEMBL1324536 & 688620 & 5.25 & 5.1602 & TST \\
\hline CHEMBL1472438 & 688620 & 4.9 & 5.0126 & TRN \\
\hline CHEMBL1422275 & 688620 & 4.7 & 4.7972 & TRN \\
\hline CHEMBL1494624 & 688620 & 5.45 & 5.4713 & TRN \\
\hline CHEMBL3194828 & 688620 & 5.5 & 5.4888 & TST \\
\hline CHEMBL1555435 & 688620 & 4.95 & 5.0089 & TST \\
\hline CHEMBL1402525 & 688620 & 5.0 & 4.9404 & TRN \\
\hline CHEMBL1486080 & 688620 & 4.45 & 5.05 & TST \\
\hline CHEMBL1428729 & 688620 & 4.7 & 4.9796 & TRN \\
\hline CHEMBL1492783 & 688620 & 4.8 & 4.9998 & TRN \\
\hline CHEMBL1420365 & 688620 & 6.3 & 5.4524 & TRN \\
\hline CHEMBL1454171 & 688620 & 5.9 & 5.4974 & TRN \\
\hline CHEMBL1586269 & 688620 & 5.0 & 4.9451 & TRN \\
\hline CHEMBL1598452 & 688620 & 4.65 & 5.1102 & TRN \\
\hline CHEMBL1498052 & 688620 & 4.95 & 5.1591 & TRN \\
\hline CHEMBL1374657 & 688620 & 4.9 & 4.9389 & TRN \\
\hline CHEMBL1491066 & 688620 & 4.45 & 4.8541 & TST \\
\hline CHEMBL1324490 & 688620 & 5.8 & 6.0143 & TRN \\
\hline
\end{tabular}




\begin{tabular}{|c|c|c|c|c|c|}
\hline \multicolumn{6}{|c|}{ Supplemental Table S2.txt } \\
\hline CHEMBL1388997 & 688620 & 5.25 & 5.7534 & TRN & \\
\hline CHEMBL1495358 & 688620 & 4.75 & 4.9108 & TRN & \\
\hline CHEMBL1513151 & 688620 & 5.35 & 4.9582 & TRN & \\
\hline CHEMBL1365357 & 688620 & 5.35 & 5.1704 & TRN & \\
\hline CHEMBL1539314 & 688620 & 4.7 & 4.9461 & TRN & \\
\hline CHEMBL1448256 & 688620 & 5.35 & 4.9537 & TRN & \\
\hline CHEMBL1414293 & 688620 & 4.9 & 5.1228 & TST & \\
\hline CHEMBL1583978 & 688620 & 4.95 & 5.0031 & TRN & \\
\hline CHEMBL1527929 & 688620 & 5.25 & 5.26399 & 9999999999 & TRN \\
\hline CHEMBL202582 & 688620 & 4.6 & 4.9723 & TRN & \\
\hline CHEMBL1418582 & 688620 & 4.45 & 5.2374 & TST & \\
\hline CHEMBL1567876 & 688620 & 4.85 & 4.8612 & TRN & \\
\hline CHEMBL3210589 & 688620 & 5.25 & 5.0331 & TRN & \\
\hline CHEMBL1450517 & 688620 & 4.45 & 5.1353 & TST & \\
\hline CHEMBL1350975 & 688620 & 4.85 & 4.8203 & TST & \\
\hline CHEMBL3198083 & 688620 & 5.2 & 5.1227 & TRN & \\
\hline CHEMBL1313515 & 688620 & 5.35 & 4.9762 & TST & \\
\hline CHEMBL1350967 & 688620 & 5.5 & 4.9064 & TRN & \\
\hline CHEMBL1461889 & 688620 & 6.9 & 5.1391 & TRN & \\
\hline CHEMBL1310496 & 688620 & 5.0 & 5.1768 & TST & \\
\hline CHEMBL1584320 & 688620 & 5.25 & 4.9748 & TRN & \\
\hline CHEMBL1518394 & 688620 & 6.1 & 5.2493 & TRN & \\
\hline CHEMBL3190131 & 688620 & 5.45 & 5.4601 & TST & \\
\hline CHEMBL1526831 & 688620 & 4.95 & 4.8777 & TRN & \\
\hline CHEMBL1428897 & 688620 & 4.85 & 4.8453 & TRN & \\
\hline CHEMBL1504520 & 688620 & 5.4 & 5.2785 & TRN & \\
\hline CHEMBL1351600 & 688620 & 5.4 & 5.4791 & TST & \\
\hline CHEMBL3193858 & 688620 & 5.6 & 5.3866 & TRN & \\
\hline CHEMBL1491800 & 688620 & 4.45 & 4.8194 & TRN & \\
\hline CHEMBL1541522 & 688620 & 5.45 & 5.1914 & TRN & \\
\hline CHEMBL1523272 & 688620 & 4.95 & 4.851 & TRN & \\
\hline CHEMBL1407346 & 688620 & 4.5 & 4.9696 & TRN & \\
\hline CHEMBL1346822 & 688620 & 4.95 & 4.8988 & TRN & \\
\hline CHEMBL1361376 & 688620 & 4.45 & 5.0037 & TRN & \\
\hline CHEMBL1372216 & 688620 & 4.85 & 4.9852 & TRN & \\
\hline CHEMBL1353819 & 688620 & 4.8 & 4.8367 & TRN & \\
\hline CHEMBL1420934 & 688620 & 4.85 & 5.1068 & TRN & \\
\hline CHEMBL1495190 & 688620 & 5.05 & 5.0115 & TST & \\
\hline CHEMBL1453704 & 688620 & 4.95 & 5.0775 & TRN & \\
\hline CHEMBL3193468 & 688620 & 4.45 & 5.3438 & TRN & \\
\hline CHEMBL1372094 & 688620 & 5.7 & 5.4872 & TRN & \\
\hline CHEMBL1331898 & 688620 & 4.95 & 4.9402 & TRN & \\
\hline CHEMBL1501649 & 688620 & 4.65 & 5.0122 & TST & \\
\hline CHEMBL3197144 & 688620 & 5.15 & 5.3107 & TRN & \\
\hline CHEMBL1583754 & 688620 & 4.45 & 5.0878 & TRN & \\
\hline CHEMBL1444118 & 688620 & 7.2503 & 5.155 & TRN & \\
\hline CHEMBL1517171 & 688620 & 4.8 & 4.7333 & TRN & \\
\hline CHEMBL1486519 & 688620 & 4.95 & 4.698 & TRN & \\
\hline
\end{tabular}




\begin{tabular}{|c|c|c|c|c|c|}
\hline \multirow[b]{2}{*}{ CHEMBL1360129 } & \multirow[b]{2}{*}{688620} & \\
\hline & & 4.8 & 4.9437 & TRN & \\
\hline CHEMBL1423566 & 688620 & 4.95 & 4.9694 & TRN & \\
\hline CHEMBL1304486 & 688620 & 6.15 & 5.1195 & TRN & \\
\hline CHEMBL1332895 & 688620 & 5.0 & 4.9606 & TRN & \\
\hline CHEMBL1544925 & 688620 & 4.65 & 4.7529 & TRN & \\
\hline CHEMBL1535553 & 688620 & 5.0 & 4.8978 & TST & \\
\hline CHEMBL1337226 & 688620 & 4.6 & 4.9029 & TRN & \\
\hline CHEMBL3196901 & 688620 & 4.6 & 4.9566 & TRN & \\
\hline CHEMBL1372904 & 688620 & 4.45 & \multicolumn{2}{|c|}{5.0089999999999995} & TRN \\
\hline CHEMBL1501129 & 688620 & 4.9 & 4.9635 & TRN & \\
\hline CHEMBL1547125 & 688620 & 5.35 & 5.1223 & TRN & \\
\hline CHEMBL1520412 & 688620 & 5.0 & 4.9317 & TST & \\
\hline CHEMBL1390681 & 688620 & 5.5 & 4.8981 & TRN & \\
\hline CHEMBL1448094 & 688620 & 4.85 & 4.7987 & TRN & \\
\hline CHEMBL3197232 & 688620 & 5.4 & \multicolumn{2}{|c|}{5.3629999999999995} & TRN \\
\hline CHEMBL1518861 & 688620 & 4.8 & 4.95 & TRN & \\
\hline CHEMBL1306962 & 688620 & 4.85 & 5.021 & TRN & \\
\hline CHEMBL3212275 & 688620 & 5.9 & 5.2031 & TST & \\
\hline CHEMBL1335957 & 688620 & 5.15 & 5.4488 & TRN & \\
\hline CHEMBL3190694 & 688620 & 5.65 & 5.3367 & TRN & \\
\hline CHEMBL1431075 & 688620 & 4.95 & 4.6646 & TRN & \\
\hline CHEMBL1416944 & 688620 & 4.45 & 5.2143 & TRN & \\
\hline CHEMBL1558928 & 688620 & 4.45 & 5.0259 & TRN & \\
\hline CHEMBL1493618 & 688620 & 4.95 & 5.2259 & TRN & \\
\hline CHEMBL1303581 & 688620 & 5.35 & 5.5757 & TRN & \\
\hline CHEMBL1332976 & 688620 & 5.0 & 4.912 & TRN & \\
\hline CHEMBL1390373 & 688620 & 4.9 & 4.8856 & TRN & \\
\hline CHEMBL1562694 & 688620 & 4.85 & 5.075 & TST & \\
\hline CHEMBL1462106 & 688620 & 4.8 & 5.5228 & TRN & \\
\hline CHEMBL1487727 & 688620 & 5.9 & 5.0771 & TST & \\
\hline CHEMBL1525496 & 688620 & 5.7 & 5.011 & TRN & \\
\hline CHEMBL3194813 & 688620 & 4.8 & 4.8373 & TRN & \\
\hline CHEMBL1498753 & 688620 & 5.65 & 5.4517 & TRN & \\
\hline CHEMBL1349639 & 688620 & 5.05 & 5.1329 & TRN & \\
\hline CHEMBL1391745 & 688620 & 4.9 & \multicolumn{2}{|c|}{ 4.96399999999999995 } & TRN \\
\hline CHEMBL1300297 & 688620 & 4.95 & 5.1689 & TRN & \\
\hline CHEMBL1411241 & 688620 & 5.4 & 4.9866 & TRN & \\
\hline CHEMBL3193807 & 688620 & 4.9 & 4.878 & TRN & \\
\hline CHEMBL1550330 & 688620 & 5.95 & 5.0563 & TST & \\
\hline CHEMBL1414667 & 688620 & 5.0 & 4.8276 & TRN & \\
\hline CHEMBL1406709 & 688620 & 7.15 & 4.9141 & TRN & \\
\hline CHEMBL1481570 & 688620 & 6.15 & 5.9513 & TRN & \\
\hline CHEMBL1437246 & 688620 & 4.55 & 5.3799 & TRN & \\
\hline CHEMBL3213495 & 688620 & 4.95 & 5.2791 & TRN & \\
\hline CHEMBL1417524 & 688620 & 4.45 & 5.0993 & TST & \\
\hline CHEMBL1604967 & 688620 & 4.45 & 4.96399 & 99999999995 & TST \\
\hline CHEMBL1503806 & 688620 & 5.2 & 5.0966 & TST & \\
\hline \multirow[t]{2}{*}{ CHEMBL89671 } & 688620 & 5.6 & 5.1917 & TRN & \\
\hline & & \multicolumn{4}{|c|}{ Page 26613} \\
\hline
\end{tabular}




\begin{tabular}{|c|c|c|c|c|}
\hline \multicolumn{5}{|c|}{ Supplemental Table S2.txt } \\
\hline CHEMBL3191231 & 688620 & 6.0 & 5.8014 & TRN \\
\hline CHEMBL1553211 & 688620 & 4.8 & 4.8527 & TRN \\
\hline CHEMBL242112 & 688620 & 5.45 & 5.5506 & TRN \\
\hline CHEMBL1420159 & 688620 & 6.6499 & 4.9733 & TRN \\
\hline CHEMBL3209116 & 688620 & 4.45 & 5.1082 & TST \\
\hline CHEMBL1985591 & 688620 & 4.75 & 4.806 & TRN \\
\hline CHEMBL1404573 & 688620 & 5.7 & 5.5278 & TST \\
\hline CHEMBL 2001111 & 688620 & 5.2 & 4.9465 & TRN \\
\hline CHEMBL1313851 & 688620 & 5.5 & 5.2333 & TST \\
\hline CHEMBL1320840 & 688620 & 4.8 & 5.0986 & TRN \\
\hline CHEMBL1452287 & 688620 & 4.85 & 5.2263 & TRN \\
\hline CHEMBL1381823 & 688620 & 5.15 & 5.2611 & TRN \\
\hline CHEMBL1582739 & 688620 & 5.2 & 5.3183 & TST \\
\hline CHEMBL1411134 & 688620 & 6.2 & 5.0332 & TRN \\
\hline CHEMBL1585320 & 688620 & 4.8 & 5.1825 & TRN \\
\hline CHEMBL1368403 & 688620 & 5.2 & 5.0639 & TRN \\
\hline CHEMBL1326326 & 688620 & 5.3 & 4.9939 & TST \\
\hline CHEMBL1307237 & 688620 & 4.55 & 4.8094 & TRN \\
\hline CHEMBL3208123 & 688620 & 4.45 & 4.7891 & TRN \\
\hline CHEMBL1429202 & 688620 & 4.45 & 4.7067 & TRN \\
\hline CHEMBL1970965 & 688620 & 4.8 & 4.955 & TRN \\
\hline CHEMBL585425 & 688620 & 5.15 & 4.9563 & TST \\
\hline CHEMBL1486651 & 688620 & 6.4 & 5.5782 & TRN \\
\hline CHEMBL1455402 & 688620 & 4.45 & 5.1913 & TRN \\
\hline CHEMBL1491446 & 688620 & 4.75 & 4.9394 & TST \\
\hline CHEMBL600490 & 688620 & 4.45 & 5.5922 & TRN \\
\hline CHEMBL1573290 & 688620 & 4.9 & 4.9265 & TRN \\
\hline CHEMBL 2003214 & 688620 & 4.45 & 4.8557 & TRN \\
\hline CHEMBL1596496 & 688620 & 4.65 & 5.0637 & TRN \\
\hline CHEMBL1612533 & 688620 & 4.95 & 5.0572 & TST \\
\hline CHEMBL3190175 & 688620 & 4.75 & 5.0649 & TRN \\
\hline CHEMBL1456026 & 688620 & 5.5 & 4.9939 & TST \\
\hline CHEMBL1392771 & 688620 & 5.45 & 5.1658 & TST \\
\hline CHEMBL3197599 & 688620 & 4.7 & 4.7255 & TRN \\
\hline CHEMBL1508220 & 688620 & 4.9 & 4.9184 & TST \\
\hline CHEMBL1345761 & 688620 & 4.75 & 5.0244 & TRN \\
\hline CHEMBL1421603 & 688620 & 5.9 & 5.4926 & TST \\
\hline CHEMBL1478280 & 688620 & 5.95 & 5.8191 & TRN \\
\hline CHEMBL1307922 & 688620 & 4.85 & 5.1844 & TRN \\
\hline CHEMBL1471896 & 688620 & 4.85 & 5.1615 & TST \\
\hline CHEMBL1396779 & 688620 & 4.9 & 4.6278 & TRN \\
\hline CHEMBL1589755 & 688620 & 5.2 & 4.9323 & TRN \\
\hline CHEMBL1406186 & 688620 & 4.65 & 5.1578 & TRN \\
\hline CHEMBL1484934 & 688620 & 4.65 & 4.8867 & TRN \\
\hline CHEMBL1583808 & 688620 & 5.15 & 5.5598 & TRN \\
\hline CHEMBL1593809 & 688620 & 4.9 & 5.2276 & TRN \\
\hline CHEMBL1349347 & 688620 & 4.45 & 4.9454 & TST \\
\hline CHEMBL1480806 & 688620 & 4.95 & 4.8379 & TRN \\
\hline
\end{tabular}




\begin{tabular}{|c|c|c|c|c|}
\hline \multicolumn{5}{|c|}{ Supplemental Tabl } \\
\hline CHEMBL1462421 & 688620 & 5.65 & 4.8644 & TRN \\
\hline CHEMBL1340014 & 688620 & 4.8 & 5.3748 & TRN \\
\hline CHEMBL1446833 & 688620 & 4.75 & 4.9792 & TRN \\
\hline CHEMBL1363778 & 688620 & 5.95 & 5.2189 & TRN \\
\hline CHEMBL1541592 & 688620 & 4.95 & 5.0703 & TRN \\
\hline CHEMBL1431146 & 688620 & 4.75 & 4.8956 & TRN \\
\hline CHEMBL1568982 & 688620 & 5.4 & 5.0552 & TRN \\
\hline CHEMBL1319709 & 688620 & 4.8 & 4.9758 & TRN \\
\hline CHEMBL1438512 & 688620 & 4.95 & 5.388 & TRN \\
\hline CHEMBL1379740 & 688620 & 5.0 & 4.9869 & TST \\
\hline CHEMBL1373491 & 688620 & 6.9 & 5.0959 & TST \\
\hline CHEMBL1407914 & 688620 & 4.9 & 5.073 & TRN \\
\hline CHEMBL1379165 & 688620 & 4.45 & 5.1173 & TRN \\
\hline CHEMBL1382356 & 688620 & 4.8 & 5.0628 & TST \\
\hline CHEMBL1428870 & 688620 & 4.45 & 5.4478 & TRN \\
\hline CHEMBL1514068 & 688620 & 4.75 & 5.1399 & TRN \\
\hline CHEMBL1498142 & 688620 & 4.5 & 5.0092 & TRN \\
\hline CHEMBL1611033 & 688620 & 5.9 & 4.9212 & TRN \\
\hline CHEMBL1459929 & 688620 & 4.85 & 4.9577 & TRN \\
\hline CHEMBL1362067 & 688620 & 5.15 & 4.9897 & TRN \\
\hline CHEMBL3198468 & 688620 & 6.1 & 5.7642 & TRN \\
\hline CHEMBL1540470 & 688620 & 4.95 & 5.0878 & TRN \\
\hline CHEMBL1483894 & 688620 & 4.7 & 5.1681 & TRN \\
\hline CHEMBL28517 & 688620 & 4.95 & 5.3198 & TST \\
\hline CHEMBL1350351 & 688620 & 4.95 & 5.3776 & TST \\
\hline CHEMBL1516586 & 688620 & 5.75 & 4.9245 & TRN \\
\hline CHEMBL1467755 & 688620 & 4.85 & 4.7216 & TRN \\
\hline CHEMBL1600298 & 688620 & 4.95 & 5.1101 & TRN \\
\hline CHEMBL1524930 & 688620 & 5.65 & 5.0579 & TRN \\
\hline CHEMBL1373606 & 688620 & 4.8 & 5.0356 & TRN \\
\hline CHEMBL1427446 & 688620 & 5.65 & 5.3177 & TRN \\
\hline CHEMBL1333751 & 688620 & 6.95 & 5.06 & TRN \\
\hline CHEMBL1384568 & 688620 & 5.6 & 5.144 & TRN \\
\hline CHEMBL3191982 & 688620 & 4.9 & 5.2277 & TRN \\
\hline CHEMBL1496986 & 688620 & 5.1 & 4.9225 & TRN \\
\hline CHEMBL3194628 & 688620 & 5.15 & 4.9781 & TRN \\
\hline CHEMBL1570277 & 688620 & 4.9 & 4.944 & TRN \\
\hline CHEMBL1500023 & 688620 & 6.0 & 5.735 & TRN \\
\hline CHEMBL3209012 & 688620 & 4.95 & 5.2369 & TRN \\
\hline CHEMBL3198666 & 688620 & 5.1 & 5.1436 & TRN \\
\hline CHEMBL1511163 & 688620 & 5.35 & 5.2193 & TST \\
\hline CHEMBL1331006 & 688620 & 4.55 & 4.9597 & TRN \\
\hline CHEMBL1407944 & 688620 & 5.3 & 5.0253 & TRN \\
\hline CHEMBL1306418 & 688620 & 5.0 & 5.1196 & TST \\
\hline CHEMBL1517823 & 688620 & 5.0 & 5.2085 & TRN \\
\hline CHEMBL1413254 & 688620 & 5.7 & 5.3558 & TRN \\
\hline CHEMBL1565508 & 688620 & 5.0 & 5.0615 & TST \\
\hline CHEMBL1349442 & 688620 & 5.0 & 5.1869 & TRN \\
\hline
\end{tabular}




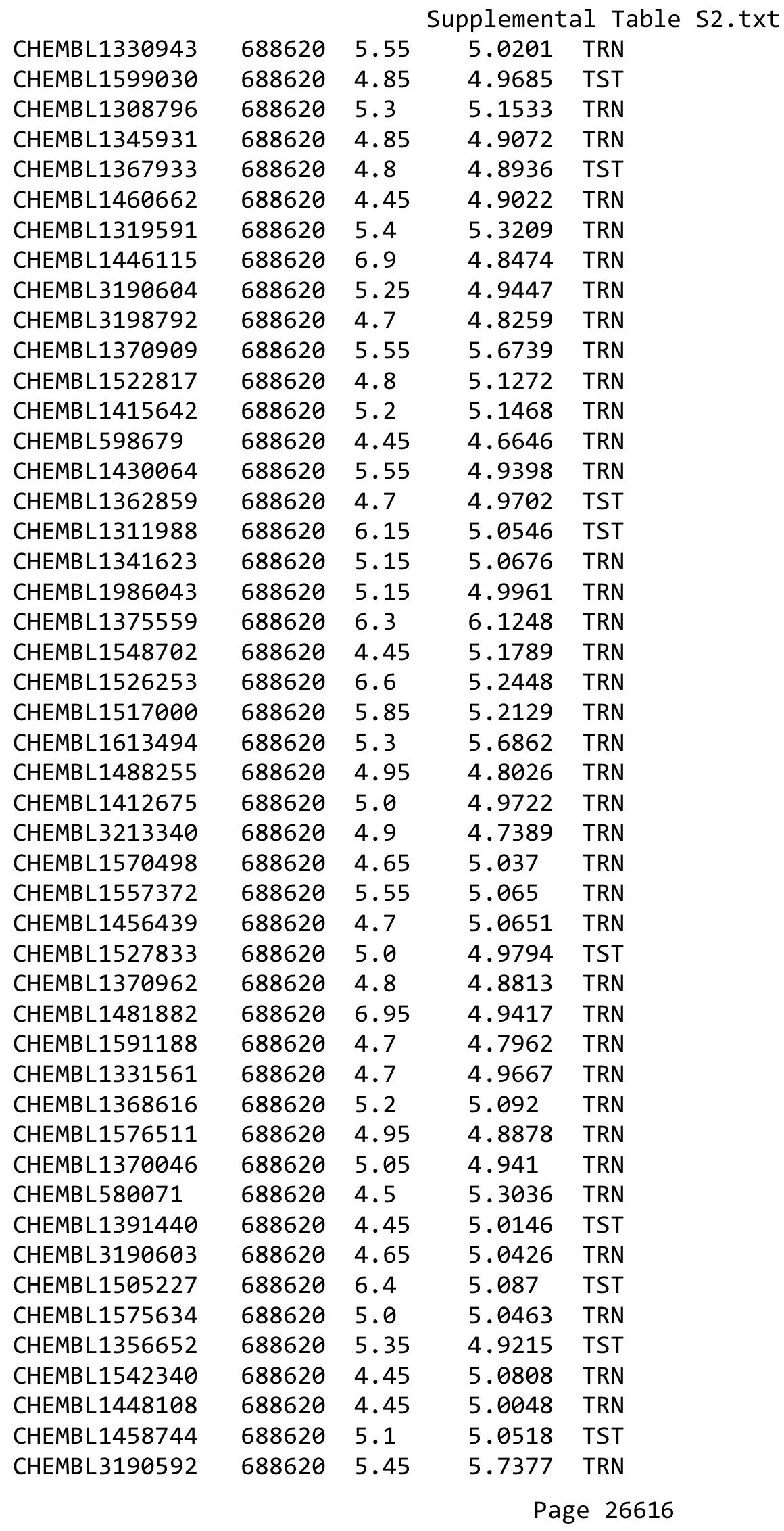




\begin{tabular}{|c|c|c|c|c|c|}
\hline \multicolumn{6}{|c|}{ Supplemental Table S2.txt } \\
\hline CHEMBL1613430 & 688620 & 4.45 & 4.9427 & TST & \\
\hline CHEMBL3191137 & 688620 & 4.9 & 5.1115 & TST & \\
\hline CHEMBL1389794 & 688620 & 4.45 & 5.0135 & TRN & \\
\hline CHEMBL1300769 & 688620 & 4.95 & 5.142 & TST & \\
\hline CHEMBL3197432 & 688620 & 5.85 & 5.0816 & TRN & \\
\hline CHEMBL1490858 & 688620 & 4.95 & 4.867 & TRN & \\
\hline CHEMBL1302142 & 688620 & 4.45 & 5.0004 & TRN & \\
\hline CHEMBL1338717 & 688620 & 5.05 & 5.1519 & TST & \\
\hline CHEMBL1313044 & 688620 & 5.0 & 5.01699 & 99999999995 & TRN \\
\hline CHEMBL1558446 & 688620 & 4.9 & 5.0562 & TRN & \\
\hline CHEMBL1360162 & 688620 & 5.5 & 5.1912 & TRN & \\
\hline CHEMBL1431862 & 688620 & 4.45 & 4.8432 & TRN & \\
\hline CHEMBL 2002349 & 688620 & 4.95 & 5.4087 & TRN & \\
\hline CHEMBL1374818 & 688620 & 5.65 & 5.3518 & TRN & \\
\hline CHEMBL1535348 & 688620 & 5.0 & 5.0748 & TRN & \\
\hline CHEMBL1532623 & 688620 & 5.0 & 5.2709 & TST & \\
\hline CHEMBL3191544 & 688620 & 5.8 & 5.6172 & TST & \\
\hline CHEMBL1313141 & 688620 & 4.45 & 4.9017 & TRN & \\
\hline CHEMBL1443795 & 688620 & 5.6 & 5.1372 & TRN & \\
\hline CHEMBL1505963 & 688620 & 4.9 & 5.0814 & TRN & \\
\hline CHEMBL1417396 & 688620 & 5.0 & 5.4211 & TRN & \\
\hline CHEMBL1392673 & 688620 & 5.2 & 5.266 & TST & \\
\hline CHEMBL1462996 & 688620 & 5.2 & 5.0536 & TRN & \\
\hline CHEMBL1539503 & 688620 & 4.9 & 5.159 & TRN & \\
\hline CHEMBL1492366 & 688620 & 5.45 & 5.141 & TST & \\
\hline CHEMBL3199475 & 688620 & 5.95 & 5.4286 & TRN & \\
\hline CHEMBL1458251 & 688620 & 4.75 & 4.9739 & TRN & \\
\hline CHEMBL1541799 & 688620 & 4.9 & 4.9557 & TRN & \\
\hline CHEMBL1467538 & 688620 & 4.7 & 5.0136 & TST & \\
\hline CHEMBL3210876 & 688620 & 4.65 & 5.1472 & TRN & \\
\hline CHEMBL1547301 & 688620 & 5.55 & 5.211 & TRN & \\
\hline CHEMBL1432276 & 688620 & 5.25 & 5.4006 & TST & \\
\hline CHEMBL1581201 & 688620 & 5.55 & 5.2815 & TST & \\
\hline CHEMBL1301776 & 688620 & 5.65 & 4.8619 & TST & \\
\hline CHEMBL1542791 & 688620 & 6.1 & 5.1911 & TRN & \\
\hline CHEMBL1364518 & 688620 & 4.75 & 5.0314 & TST & \\
\hline CHEMBL1415726 & 688620 & 4.6 & 4.8947 & TRN & \\
\hline CHEMBL1440061 & 688620 & 4.7 & 6.0335 & TRN & \\
\hline CHEMBL1503559 & 688620 & 5.2 & 5.4133 & TST & \\
\hline CHEMBL1409251 & 688620 & 4.95 & 4.9389 & TST & \\
\hline CHEMBL1381755 & 688620 & 5.3 & 5.2778 & TRN & \\
\hline CHEMBL1589101 & 688620 & 5.4 & 5.0432 & TST & \\
\hline CHEMBL1469526 & 688620 & 5.2 & 4.9985 & TRN & \\
\hline CHEMBL1995377 & 688620 & 5.6 & 5.5025 & TRN & \\
\hline CHEMBL1307592 & 688620 & 5.0 & 5.0137 & TRN & \\
\hline CHEMBL1499442 & 688620 & 4.75 & 5.3213 & TRN & \\
\hline CHEMBL1256876 & 688620 & 4.5 & 4.8948 & TST & \\
\hline CHEMBL1427637 & 688620 & 4.95 & 4.9109 & TST & \\
\hline
\end{tabular}




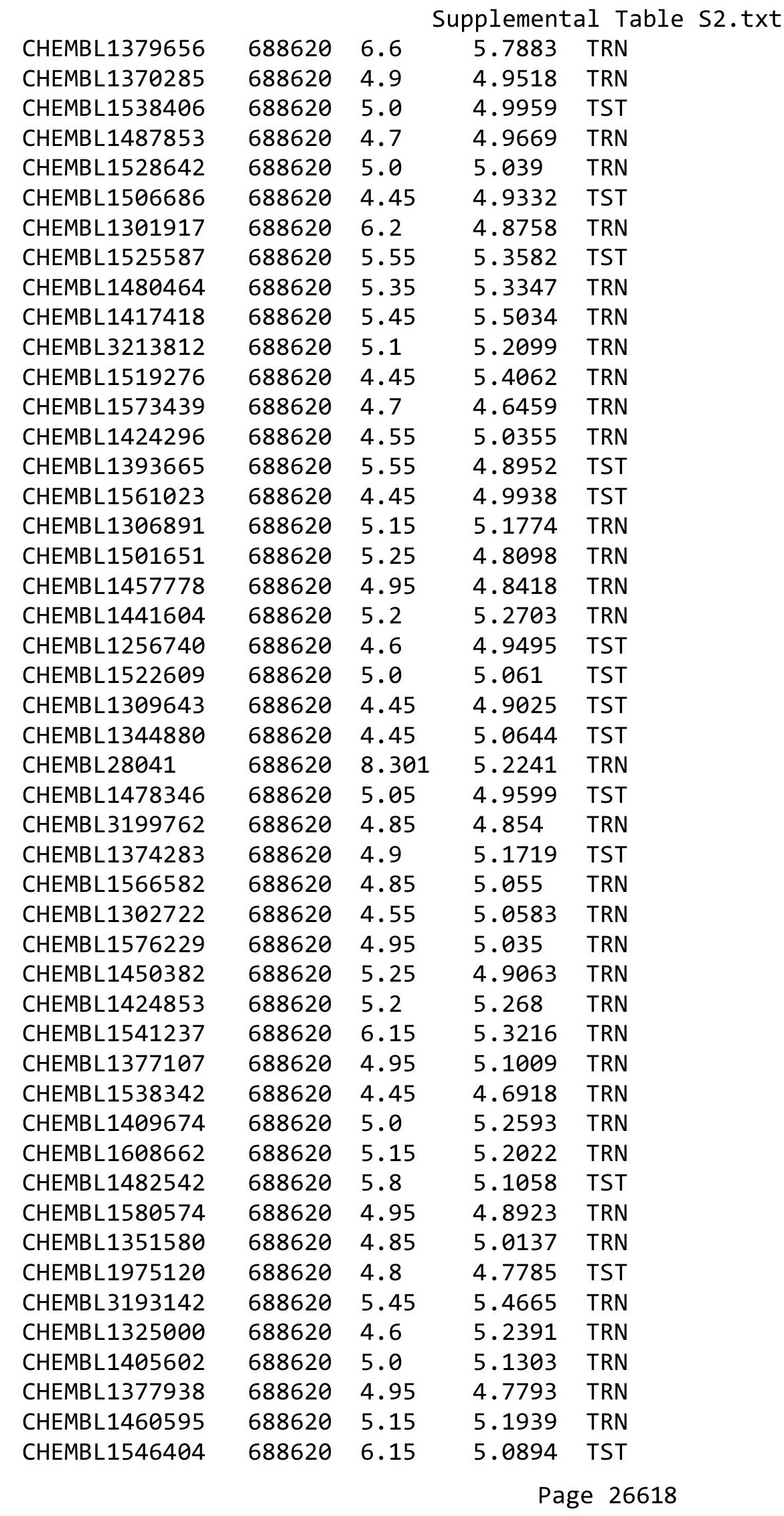




\begin{tabular}{|c|c|c|c|c|}
\hline & & & pplement & al $\mathrm{Ta}$ \\
\hline CHEMBL1464827 & 688620 & 4.85 & 5.2395 & TST \\
\hline CHEMBL1344639 & 688620 & 5.95 & 4.9438 & TRN \\
\hline CHEMBL1313052 & 688620 & 5.65 & 5.8503 & TRN \\
\hline CHEMBL1540680 & 688620 & 5.05 & 4.9975 & TST \\
\hline CHEMBL1462987 & 688620 & 5.0 & 4.9927 & TRN \\
\hline CHEMBL1478589 & 688620 & 4.85 & 4.7632 & TRN \\
\hline CHEMBL1594071 & 688620 & 4.65 & 4.8961 & TRN \\
\hline CHEMBL1372732 & 688620 & 4.95 & 4.7817 & TST \\
\hline CHEMBL1597131 & 688620 & 5.0 & 4.9251 & TRN \\
\hline CHEMBL1982569 & 688620 & 5.0 & 5.2669 & TRN \\
\hline CHEMBL1412056 & 688620 & 4.45 & 4.9615 & TRN \\
\hline CHEMBL1369231 & 688620 & 6.1 & 5.8281 & TST \\
\hline CHEMBL 3194774 & 688620 & 5.0 & 5.0872 & TRN \\
\hline CHEMBL1490196 & 688620 & 4.7 & 5.1073 & TRN \\
\hline CHEMBL3190146 & 688620 & 5.7 & 5.5773 & TRN \\
\hline CHEMBL1422383 & 688620 & 5.7 & 5.101 & TRN \\
\hline CHEMBL1381362 & 688620 & 5.35 & 4.8235 & TRN \\
\hline CHEMBL1520325 & 688620 & 5.55 & 5.3004 & TRN \\
\hline CHEMBL1569471 & 688620 & 4.85 & 4.8969 & TRN \\
\hline CHEMBL1455375 & 688620 & 4.45 & 5.0639 & TRN \\
\hline CHEMBL1586741 & 688620 & 4.65 & 4.9815 & TRN \\
\hline CHEMBL1570469 & 688620 & 5.65 & 5.3858 & TRN \\
\hline CHEMBL 2006221 & 688620 & 4.6 & 4.9856 & TRN \\
\hline CHEMBL1303983 & 688620 & 5.3 & 5.0494 & TST \\
\hline CHEMBL1381291 & 688620 & 4.45 & 4.9422 & TRN \\
\hline CHEMBL1564450 & 688620 & 5.55 & 4.9333 & TST \\
\hline CHEMBL1347216 & 688620 & 4.75 & 4.8246 & TST \\
\hline CHEMBL1508982 & 688620 & 5.25 & 5.3202 & TRN \\
\hline CHEMBL1482054 & 688620 & 4.85 & 4.7939 & TRN \\
\hline CHEMBL1384509 & 688620 & 4.45 & 4.9333 & TRN \\
\hline CHEMBL1468497 & 688620 & 5.6 & 5.2868 & TRN \\
\hline CHEMBL1583554 & 688620 & 6.9 & 5.0912 & TST \\
\hline CHEMBL1460701 & 688620 & 4.8 & 5.1004 & TRN \\
\hline CHEMBL1467386 & 688620 & 4.95 & 5.1335 & TST \\
\hline CHEMBL1349028 & 688620 & 4.8 & 5.0129 & TRN \\
\hline CHEMBL1557054 & 688620 & 4.95 & 4.7768 & TST \\
\hline CHEMBL 3144892 & 688620 & 4.7 & 5.2196 & TRN \\
\hline CHEMBL1429593 & 688620 & 4.6 & 5.0397 & TST \\
\hline CHEMBL1410575 & 688620 & 4.6 & 4.8628 & TST \\
\hline CHEMBL1572843 & 688620 & 4.7 & 5.03 & TRN \\
\hline CHEMBL3190734 & 688620 & 4.9 & 5.1782 & TRN \\
\hline CHEMBL1417650 & 688620 & 5.15 & 4.9887 & TRN \\
\hline CHEMBL1381818 & 688620 & 5.0 & 4.8544 & TRN \\
\hline CHEMBL 3208382 & 688620 & 4.45 & 4.989 & TRN \\
\hline CHEMBL1520670 & 688620 & 4.5 & 4.8168 & TRN \\
\hline CHEMBL1539065 & 688620 & 4.8 & 5.0135 & TRN \\
\hline CHEMBL1301599 & 688620 & 4.6 & 4.9216 & TRN \\
\hline CHEMBL1598125 & 688620 & 4.7 & 5.1697 & TRN \\
\hline
\end{tabular}




\begin{tabular}{|c|c|c|c|c|c|}
\hline \multicolumn{6}{|c|}{ Supplemental Table S2.txt } \\
\hline CHEMBL1421211 & 688620 & 4.8 & 4.954 & TRN & \\
\hline CHEMBL1499320 & 688620 & 6.0 & 5.9064 & TRN & \\
\hline CHEMBL3189445 & 688620 & 4.45 & 5.1242 & TRN & \\
\hline CHEMBL1470861 & 688620 & 5.6 & 5.1514 & TRN & \\
\hline CHEMBL1302738 & 688620 & 4.45 & 5.0685 & TRN & \\
\hline CHEMBL1477453 & 688620 & 4.9 & 5.0704 & TRN & \\
\hline CHEMBL1601747 & 688620 & 4.85 & 4.927 & TRN & \\
\hline CHEMBL1351128 & 688620 & 5.25 & 5.2085 & TST & \\
\hline CHEMBL1383719 & 688620 & 4.8 & 4.9488 & TRN & \\
\hline CHEMBL1452032 & 688620 & 6.1 & 5.0675 & TRN & \\
\hline CHEMBL1508072 & 688620 & 6.35 & 5.5362 & TST & \\
\hline CHEMBL1424700 & 688620 & 4.45 & 4.7449 & TRN & \\
\hline CHEMBL1416806 & 688620 & 4.45 & 4.7942 & TRN & \\
\hline CHEMBL1444264 & 688620 & 6.15 & 5.0402 & TRN & \\
\hline CHEMBL3191616 & 688620 & 4.9 & 4.9334 & TRN & \\
\hline CHEMBL1533919 & 688620 & 5.85 & 5.4825 & TRN & \\
\hline CHEMBL1427465 & 688620 & 5.05 & 5.2318 & TRN & \\
\hline CHEMBL1503380 & 688620 & 4.95 & 4.7744 & TRN & \\
\hline CHEMBL3197435 & 688620 & 5.9 & 5.0849 & TRN & \\
\hline CHEMBL1507156 & 688620 & 4.8 & 4.8205 & TRN & \\
\hline CHEMBL1332154 & 688620 & 4.7 & 4.9177 & TRN & \\
\hline CHEMBL1477304 & 688620 & 5.4 & 4.9816 & TRN & \\
\hline CHEMBL1541102 & 688620 & 4.95 & 5.0103 & TRN & \\
\hline CHEMBL1342572 & 688620 & 5.5 & 5.0579 & TRN & \\
\hline CHEMBL1524250 & 688620 & 5.35 & 5.1293 & TRN & \\
\hline CHEMBL1384468 & 688620 & 4.45 & 5.0844 & TST & \\
\hline CHEMBL1496868 & 688620 & 6.0 & 5.53799 & 9999999999 & TRN \\
\hline CHEMBL1534842 & 688620 & 4.85 & 4.9482 & TRN & \\
\hline CHEMBL1584016 & 688620 & 5.0 & 4.8007 & TRN & \\
\hline CHEMBL1300176 & 688620 & 5.15 & 4.9625 & TST & \\
\hline CHEMBL486094 & 688620 & 4.7 & 4.9505 & TST & \\
\hline CHEMBL1386304 & 688620 & 5.6 & 5.3346 & TRN & \\
\hline CHEMBL1587285 & 688620 & 6.25 & 4.9673 & TST & \\
\hline CHEMBL1418948 & 688620 & 5.35 & 4.6971 & TST & \\
\hline CHEMBL1508617 & 688620 & 4.45 & 4.7923 & TST & \\
\hline CHEMBL1584640 & 688620 & 4.9 & 5.1574 & TRN & \\
\hline CHEMBL1509452 & 688620 & 4.95 & 5.3048 & TRN & \\
\hline CHEMBL1410843 & 688620 & 5.6 & 5.2236 & TRN & \\
\hline CHEMBL3196453 & 688620 & 4.45 & 5.1347 & TST & \\
\hline CHEMBL1609313 & 688620 & 5.35 & 5.0053 & TRN & \\
\hline CHEMBL1533616 & 688620 & 5.05 & 4.8594 & TRN & \\
\hline CHEMBL1565901 & 688620 & 4.6 & 4.7908 & TRN & \\
\hline CHEMBL1448179 & 688620 & 5.55 & 5.3345 & TRN & \\
\hline CHEMBL1429833 & 688620 & 5.1 & 5.3402 & TRN & \\
\hline CHEMBL1332244 & 688620 & 5.15 & 4.777 & TRN & \\
\hline CHEMBL1389090 & 688620 & 4.45 & 4.9254 & TRN & \\
\hline CHEMBL1491327 & 688620 & 5.7 & 5.5728 & TRN & \\
\hline CHEMBL1605578 & 688620 & 4.95 & 5.1461 & TST & \\
\hline
\end{tabular}




\begin{tabular}{|c|c|c|c|c|c|}
\hline \multicolumn{6}{|c|}{ Supplemental Table S2.txt } \\
\hline CHEMBL1470964 & 688620 & 4.95 & 5.6402 & TST & \\
\hline CHEMBL1522185 & 688620 & 4.85 & 4.9236 & TRN & \\
\hline CHEMBL1373467 & 688620 & 4.45 & 5.6101 & TST & \\
\hline CHEMBL1491616 & 688620 & 5.35 & 5.4051 & TRN & \\
\hline CHEMBL3195259 & 688620 & 5.2 & 5.5531 & TRN & \\
\hline CHEMBL1328618 & 688620 & 4.45 & 5.0819 & TRN & \\
\hline CHEMBL1969992 & 688620 & 5.6 & 5.6032 & TRN & \\
\hline CHEMBL1345220 & 688620 & 4.65 & 4.9315 & TRN & \\
\hline CHEMBL3189698 & 688620 & 5.5 & 5.4297 & TRN & \\
\hline CHEMBL1518655 & 688620 & 5.2 & 5.1806 & TRN & \\
\hline CHEMBL3211285 & 688620 & 5.3 & 4.9376 & TRN & \\
\hline CHEMBL1362771 & 688620 & 4.9 & 6.0204 & TRN & \\
\hline CHEMBL1449811 & 688620 & 5.35 & 5.4256 & TRN & \\
\hline CHEMBL1456981 & 688620 & 4.5 & 4.9977 & TRN & \\
\hline CHEMBL1531291 & 688620 & 5.65 & 5.4571 & TRN & \\
\hline CHEMBL1449301 & 688620 & 7.0 & 4.98600 & 0000000001 & TRN \\
\hline CHEMBL3199707 & 688620 & 6.05 & 5.6094 & TRN & \\
\hline CHEMBL1392537 & 688620 & 5.1 & 5.28700 & 0000000001 & TRN \\
\hline CHEMBL1980031 & 688620 & 4.95 & 5.1115 & TRN & \\
\hline CHEMBL1468853 & 688620 & 4.9 & 5.0324 & TRN & \\
\hline CHEMBL3190182 & 688620 & 5.65 & 5.2515 & TRN & \\
\hline CHEMBL1320591 & 688620 & 5.2 & 5.2824 & TST & \\
\hline CHEMBL1222385 & 688620 & 4.45 & 5.0213 & TRN & \\
\hline CHEMBL1491862 & 688620 & 4.8 & 5.2282 & TRN & \\
\hline CHEMBL1326290 & 688620 & 4.95 & 5.0564 & TRN & \\
\hline CHEMBL3194506 & 688620 & 4.95 & 4.9641 & TRN & \\
\hline CHEMBL1452395 & 688620 & 4.85 & 4.9848 & TST & \\
\hline CHEMBL1301544 & 688620 & 4.45 & 4.7598 & TRN & \\
\hline CHEMBL1487365 & 688620 & 4.45 & 5.1357 & TST & \\
\hline CHEMBL1411495 & 688620 & 6.15 & 5.0782 & TRN & \\
\hline CHEMBL1572333 & 688620 & 5.05 & 5.1608 & TST & \\
\hline CHEMBL1365875 & 688620 & 4.95 & 5.0212 & TRN & \\
\hline CHEMBL1478949 & 688620 & 4.8 & 5.20299 & 9999999999 & TRN \\
\hline CHEMBL1564711 & 688620 & 4.95 & 5.6879 & TRN & \\
\hline CHEMBL1429444 & 688620 & 4.85 & 5.0152 & TRN & \\
\hline CHEMBL605708 & 688620 & 4.75 & 4.9099 & TRN & \\
\hline CHEMBL1337833 & 688620 & 5.35 & 4.758 & TRN & \\
\hline CHEMBL1343759 & 688620 & 4.8 & 5.0557 & TST & \\
\hline CHEMBL1417579 & 688620 & 4.95 & 5.5078 & TRN & \\
\hline CHEMBL1449048 & 688620 & 4.6 & 4.8163 & TRN & \\
\hline CHEMBL1322077 & 688620 & 5.05 & 5.0795 & TST & \\
\hline CHEMBL1428134 & 688620 & 5.5 & 5.1174 & TST & \\
\hline CHEMBL1360251 & 688620 & 5.1 & 5.1161 & TRN & \\
\hline CHEMBL1502226 & 688620 & 4.45 & 4.9381 & TRN & \\
\hline CHEMBL1387450 & 688620 & 6.7501 & 5.0632 & TRN & \\
\hline CHEMBL1342559 & 688620 & 4.85 & 5.1874 & TRN & \\
\hline CHEMBL1611088 & 688620 & 4.65 & 5.0672 & TST & \\
\hline CHEMBL1564332 & 688620 & 4.45 & 5.7235 & TRN & \\
\hline
\end{tabular}




\begin{tabular}{|c|c|c|c|c|}
\hline & & & upplement & al $\mathrm{T}$ \\
\hline CHEMBL1547206 & 688620 & 6.0 & 5.1441 & TRN \\
\hline CHEMBL194814 & 688620 & 5.5 & 5.0176 & TST \\
\hline CHEMBL1537269 & 688620 & 4.6 & 5.1616 & TST \\
\hline CHEMBL1418643 & 688620 & 5.4 & 5.3016 & TRN \\
\hline CHEMBL3207661 & 688620 & 4.45 & 4.9633 & TRN \\
\hline CHEMBL1333600 & 688620 & 6.0 & 5.6739 & TST \\
\hline CHEMBL1464286 & 688620 & 4.45 & 4.8146 & TRN \\
\hline CHEMBL1342821 & 688620 & 4.6 & 4.9136 & TST \\
\hline CHEMBL1509840 & 688620 & 5.2 & 5.1008 & TRN \\
\hline CHEMBL1505211 & 688620 & 5.1 & 5.1365 & TST \\
\hline CHEMBL1379815 & 688620 & 4.65 & 5.0351 & TRN \\
\hline CHEMBL1470450 & 688620 & 4.8 & 4.8814 & TRN \\
\hline CHEMBL1564660 & 688620 & 4.65 & 4.8676 & TST \\
\hline CHEMBL3199498 & 688620 & 4.85 & 4.928 & TRN \\
\hline CHEMBL1406283 & 688620 & 5.15 & 5.3128 & TRN \\
\hline CHEMBL1597616 & 688620 & 4.45 & 5.0468 & TST \\
\hline CHEMBL1571907 & 688620 & 4.55 & 5.0519 & TRN \\
\hline CHEMBL3192104 & 688620 & 4.45 & 5.1389 & TST \\
\hline CHEMBL1531082 & 688620 & 4.95 & 5.0021 & TST \\
\hline CHEMBL1326731 & 688620 & 4.95 & 5.0809 & TRN \\
\hline CHEMBL1499996 & 688620 & 5.4 & 5.4156 & TRN \\
\hline CHEMBL1387173 & 688620 & 6.1 & 5.0905 & TRN \\
\hline CHEMBL1320118 & 688620 & 4.85 & 4.9435 & TRN \\
\hline CHEMBL1392105 & 688620 & 4.8 & 4.9702 & TRN \\
\hline CHEMBL1490447 & 688620 & 5.55 & 5.2006 & TST \\
\hline CHEMBL1384068 & 688620 & 4.45 & 5.0009 & TRN \\
\hline CHEMBL1980684 & 688620 & 6.45 & 6.1296 & TRN \\
\hline CHEMBL1325631 & 688620 & 5.15 & 5.1904 & TRN \\
\hline CHEMBL1428836 & 688620 & 5.15 & 4.9475 & TRN \\
\hline CHEMBL1344775 & 688620 & 5.0 & 4.973 & TRN \\
\hline CHEMBL 2007202 & 688620 & 4.6 & 5.1301 & TST \\
\hline CHEMBL1550695 & 688620 & 5.5 & 5.4024 & TRN \\
\hline CHEMBL 3207824 & 688620 & 5.05 & 5.1489 & TRN \\
\hline CHEMBL1431332 & 688620 & 5.5 & 5.0434 & TRN \\
\hline CHEMBL1533823 & 688620 & 6.35 & 5.7207 & TST \\
\hline CHEMBL1524568 & 688620 & 5.85 & 5.2511 & TST \\
\hline CHEMBL1484490 & 688620 & 4.6 & 5.1948 & TRN \\
\hline CHEMBL3191708 & 688620 & 5.2 & 5.3147 & TRN \\
\hline CHEMBL1467498 & 688620 & 4.75 & 4.9595 & TRN \\
\hline CHEMBL1596283 & 688620 & 4.55 & 5.0551 & TRN \\
\hline CHEMBL1408866 & 688620 & 4.9 & 5.1157 & TRN \\
\hline CHEMBL1429133 & 688620 & 4.85 & 5.0294 & TRN \\
\hline CHEMBL1421029 & 688620 & 4.45 & 5.289 & TST \\
\hline CHEMBL1332898 & 688620 & 4.95 & 4.9795 & TRN \\
\hline CHEMBL1577763 & 688620 & 5.3 & 5.4229 & TRN \\
\hline CHEMBL1467246 & 688620 & 4.5 & 4.7988 & TRN \\
\hline CHEMBL1534410 & 688620 & 5.35 & 5.1131 & TST \\
\hline CHEMBL1538079 & 688620 & 4.7 & 4.8968 & TRN \\
\hline
\end{tabular}




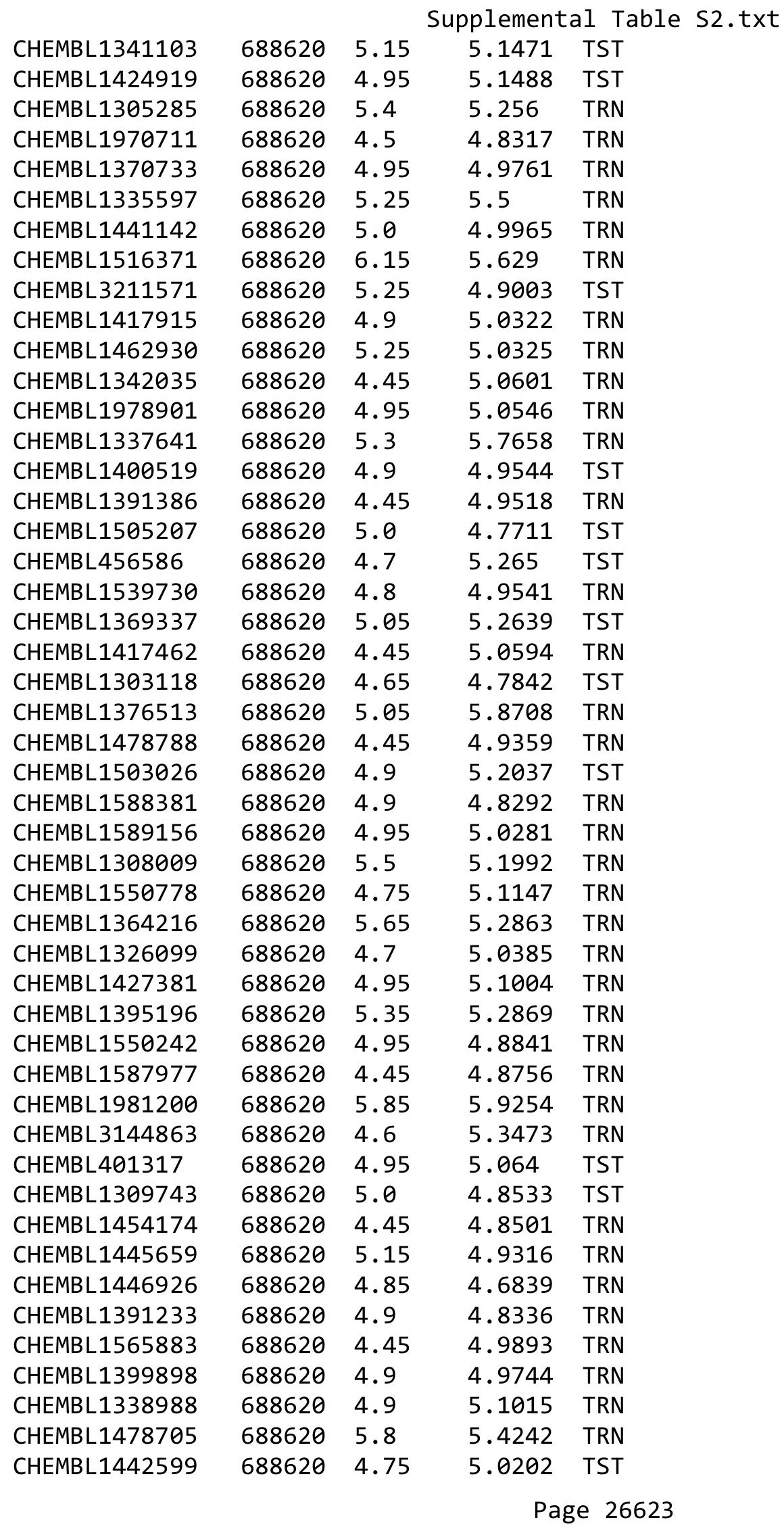




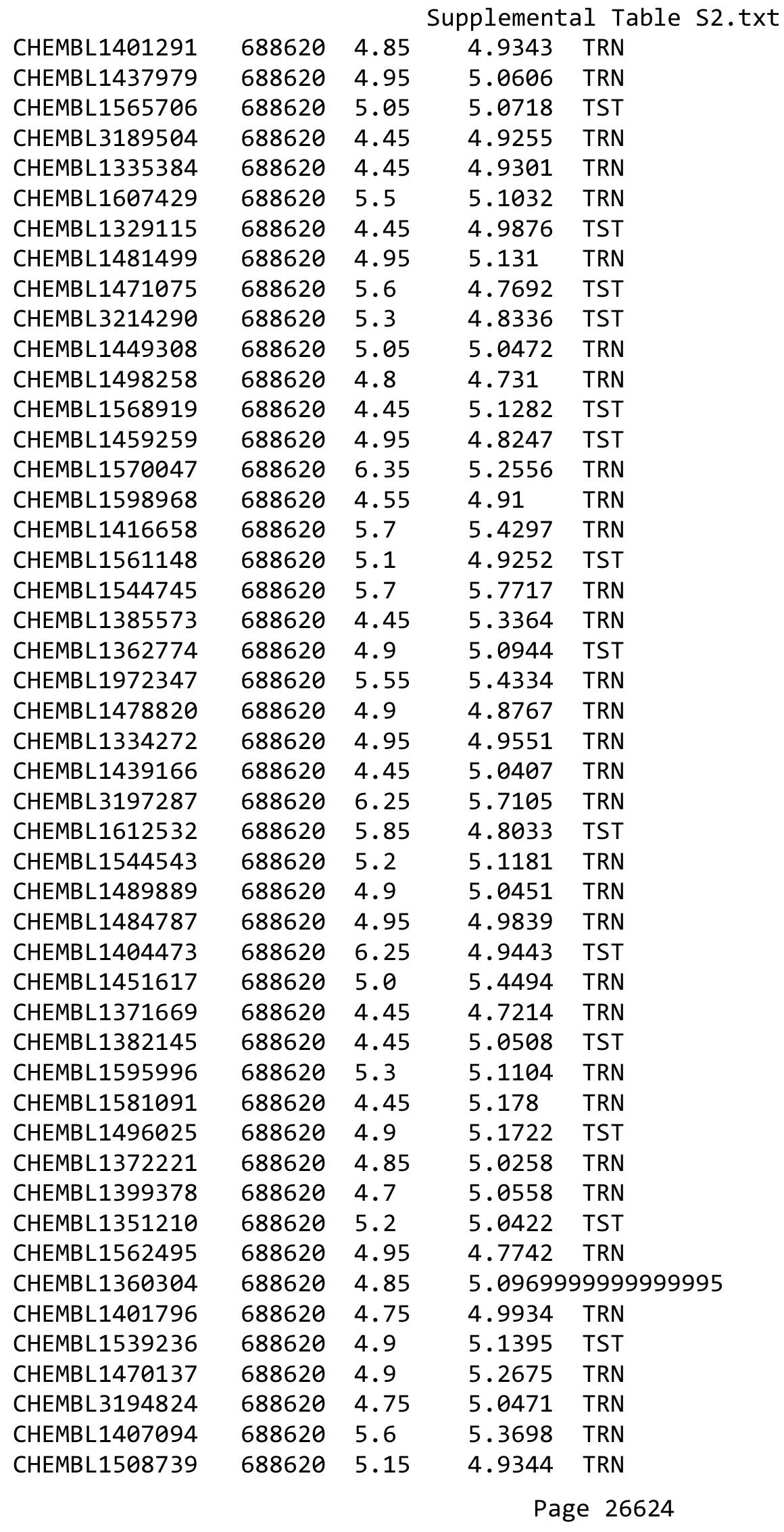




\begin{tabular}{|c|c|c|c|c|}
\hline \multicolumn{5}{|c|}{ Supplemental Table S2.txt } \\
\hline CHEMBL1344059 & 688620 & 4.45 & 4.7755 & TRN \\
\hline CHEMBL1312152 & 688620 & 4.45 & 4.8499 & TRN \\
\hline CHEMBL1374947 & 688620 & 5.35 & 5.0385 & TRN \\
\hline CHEMBL 3194877 & 688620 & 4.6 & 5.4991 & TRN \\
\hline CHEMBL1419787 & 688620 & 4.45 & 5.0467 & TRN \\
\hline CHEMBL1305035 & 688620 & 5.8 & 5.3458 & TRN \\
\hline CHEMBL1312903 & 688620 & 5.85 & 4.9307 & TST \\
\hline CHEMBL1461789 & 688620 & 5.25 & 4.897 & TRN \\
\hline CHEMBL1589353 & 688620 & 4.75 & 5.0642 & TST \\
\hline CHEMBL1447129 & 688620 & 5.3 & 5.0909 & TRN \\
\hline CHEMBL1424411 & 688620 & 5.0 & 5.3891 & TRN \\
\hline CHEMBL3196757 & 688620 & 5.65 & 5.8325 & TRN \\
\hline CHEMBL1369310 & 688620 & 5.0 & 5.1092 & TRN \\
\hline CHEMBL1373110 & 688620 & 5.6 & 5.5473 & TRN \\
\hline CHEMBL3213318 & 688620 & 4.75 & 4.9277 & TRN \\
\hline CHEMBL1519234 & 688620 & 4.75 & 5.0081 & TST \\
\hline CHEMBL1349322 & 688620 & 6.25 & 6.0794 & TRN \\
\hline CHEMBL1431540 & 688620 & 6.05 & 5.4102 & TST \\
\hline CHEMBL1413718 & 688620 & 4.5 & 5.0721 & TST \\
\hline CHEMBL1556555 & 688620 & 4.5 & 5.6657 & TRN \\
\hline CHEMBL1308814 & 688620 & 5.35 & 4.7968 & TRN \\
\hline CHEMBL393883 & 688620 & 4.95 & 5.1047 & TRN \\
\hline CHEMBL1449566 & 688620 & 8.1487 & 4.9759 & TST \\
\hline CHEMBL1547182 & 688620 & 4.75 & 4.8887 & TST \\
\hline CHEMBL1518570 & 688620 & 5.25 & 4.9621 & TST \\
\hline CHEMBL1430486 & 688620 & 5.0 & 5.2391 & TRN \\
\hline CHEMBL1405604 & 688620 & 5.45 & 5.3674 & TST \\
\hline CHEMBL1386270 & 688620 & 6.3 & 6.466 & TRN \\
\hline CHEMBL1415811 & 688620 & 4.95 & $5.2020 e$ & 0000000001 \\
\hline CHEMBL1422176 & 688620 & 5.0 & 4.9596 & TRN \\
\hline CHEMBL1303953 & 688620 & 4.6 & 4.9438 & TRN \\
\hline CHEMBL1485010 & 688620 & 4.55 & 5.8789 & TRN \\
\hline CHEMBL1508470 & 688620 & 6.05 & 5.1598 & TRN \\
\hline CHEMBL1345863 & 688620 & 5.2 & 4.989 & TST \\
\hline CHEMBL1582900 & 688620 & 6.8 & 6.0444 & TST \\
\hline CHEMBL1527254 & 688620 & 4.45 & 5.1851 & TST \\
\hline CHEMBL1494752 & 688620 & 4.7 & 4.9522 & TRN \\
\hline CHEMBL3191852 & 688620 & 6.25 & 5.1242 & TRN \\
\hline CHEMBL585267 & 688620 & 4.8 & 5.0241 & TST \\
\hline CHEMBL2354668 & 688620 & 4.85 & 4.7655 & TRN \\
\hline CHEMBL3210882 & 688620 & 4.45 & 5.2141 & TRN \\
\hline CHEMBL1310543 & 688620 & 4.9 & 5.1573 & TRN \\
\hline CHEMBL3197792 & 688620 & 5.5 & 4.8569 & TRN \\
\hline CHEMBL1422381 & 688620 & 4.5 & 5.0749 & TST \\
\hline CHEMBL1608436 & 688620 & 4.75 & 4.7879 & TRN \\
\hline CHEMBL1520238 & 688620 & 4.85 & 5.0132 & TRN \\
\hline CHEMBL510698 & 688620 & 5.05 & 4.7671 & TRN \\
\hline CHEMBL1519338 & 688620 & 5.15 & 5.3767 & TRN \\
\hline
\end{tabular}




\begin{tabular}{|c|c|c|c|c|c|}
\hline \multicolumn{6}{|c|}{ Supplemental Table S2.txt } \\
\hline CHEMBL3192217 & 688620 & 4.65 & 4.9152 & TRN & \\
\hline CHEMBL 374308 & 688620 & 6.5501 & 5.2515 & TST & \\
\hline CHEMBL3192371 & 688620 & 5.55 & 5.09399 & 9999999999 & TST \\
\hline CHEMBL3197941 & 688620 & 5.25 & 5.4226 & TRN & \\
\hline CHEMBL1323014 & 688620 & 5.1 & 5.2666 & TRN & \\
\hline CHEMBL1512141 & 688620 & 5.85 & 5.0848 & TRN & \\
\hline CHEMBL1523457 & 688620 & 5.25 & 4.8968 & TST & \\
\hline CHEMBL1400202 & 688620 & 5.45 & 5.4724 & TRN & \\
\hline CHEMBL1477528 & 688620 & 4.85 & 4.9568 & TRN & \\
\hline CHEMBL3189461 & 688620 & 5.4 & 5.0349 & TRN & \\
\hline CHEMBL 3145291 & 688620 & 5.6 & 5.6205 & TRN & \\
\hline CHEMBL1390548 & 688620 & 4.9 & 5.0404 & TST & \\
\hline CHEMBL1373026 & 688620 & 4.7 & 5.0614 & TRN & \\
\hline CHEMBL1451399 & 688620 & 4.9 & 5.1912 & TRN & \\
\hline CHEMBL1466134 & 688620 & 4.85 & 5.0626 & TRN & \\
\hline CHEMBL1348645 & 688620 & 4.95 & 5.1008 & TST & \\
\hline CHEMBL1379814 & 688620 & 4.45 & 4.9887 & TRN & \\
\hline CHEMBL1341696 & 688620 & 4.45 & 5.0607 & TRN & \\
\hline CHEMBL1488045 & 688620 & 5.15 & 5.0226 & TRN & \\
\hline CHEMBL3192121 & 688620 & 5.15 & 5.1417 & TRN & \\
\hline CHEMBL1449121 & 688620 & 4.95 & 5.2216 & TST & \\
\hline CHEMBL1581100 & 688620 & 4.7 & 4.809 & TRN & \\
\hline CHEMBL1348667 & 688620 & 6.3 & 6.2349 & TRN & \\
\hline CHEMBL1468352 & 688620 & 4.45 & 5.0731 & TRN & \\
\hline CHEMBL1378291 & 688620 & 5.15 & 5.3358 & TRN & \\
\hline CHEMBL1411162 & 688620 & 4.45 & 4.8777 & TRN & \\
\hline CHEMBL1465666 & 688620 & 5.3 & 4.827 & TRN & \\
\hline CHEMBL1518929 & 688620 & 4.75 & 5.0496 & TRN & \\
\hline CHEMBL1585843 & 688620 & 4.8 & 4.8921 & TRN & \\
\hline CHEMBL1304118 & 688620 & 5.25 & 5.2627 & TRN & \\
\hline CHEMBL579924 & 688620 & 4.95 & 5.0195 & TST & \\
\hline CHEMBL1408090 & 688620 & 5.4 & 5.5808 & TRN & \\
\hline CHEMBL1391447 & 688620 & 4.45 & 5.0665 & TST & \\
\hline CHEMBL1605368 & 688620 & 6.8 & 5.0699 & TRN & \\
\hline CHEMBL1483161 & 688620 & 4.85 & 4.80699 & 99999999995 & TRN \\
\hline CHEMBL1566403 & 688620 & 5.4 & 5.0895 & TRN & \\
\hline CHEMBL1501761 & 688620 & 5.15 & 5.2905 & TRN & \\
\hline CHEMBL1382367 & 688620 & 5.4 & 4.9321 & TRN & \\
\hline CHEMBL1421456 & 688620 & 4.6 & 5.2654 & TST & \\
\hline CHEMBL1371231 & 688620 & 4.85 & 4.7305 & TRN & \\
\hline CHEMBL1560112 & 688620 & 4.8 & 5.3291 & TST & \\
\hline CHEMBL1577546 & 688620 & 4.45 & 4.9333 & TST & \\
\hline CHEMBL1339851 & 688620 & 4.9 & 5.0405 & TRN & \\
\hline CHEMBL1352000 & 688620 & 4.75 & 4.9974 & TRN & \\
\hline CHEMBL1546810 & 688620 & 4.8 & 4.9468 & TRN & \\
\hline CHEMBL1492123 & 688620 & 5.5 & 4.9951 & TST & \\
\hline CHEMBL1299831 & 688620 & 5.0 & 4.8616 & TRN & \\
\hline CHEMBL1582467 & 688620 & 4.85 & 5.0571 & TRN & \\
\hline
\end{tabular}




\begin{tabular}{|c|c|c|c|c|c|}
\hline \multicolumn{6}{|c|}{ Supplemental Table S2.txt } \\
\hline CHEMBL1566822 & 688620 & 5.8 & 5.6075 & TRN & \\
\hline CHEMBL1352200 & 688620 & 4.65 & 5.0568 & TRN & \\
\hline CHEMBL3192156 & 688620 & 4.95 & 5.0556 & TST & \\
\hline CHEMBL1416039 & 688620 & 4.85 & 5.1454 & TRN & \\
\hline CHEMBL3211263 & 688620 & 4.95 & 5.1805 & TRN & \\
\hline CHEMBL1188078 & 688620 & 4.9 & 4.85 & TRN & \\
\hline CHEMBL1349880 & 688620 & 7.6003 & 5.1588 & TRN & \\
\hline CHEMBL1372800 & 688620 & 5.2 & 5.2716 & TRN & \\
\hline CHEMBL1301321 & 688620 & 4.7 & 4.9289 & TST & \\
\hline CHEMBL1563508 & 688620 & 4.9 & 5.2091 & TRN & \\
\hline CHEMBL1309692 & 688620 & 5.15 & 4.9513 & TST & \\
\hline CHEMBL1468969 & 688620 & 4.45 & 4.8452 & TST & \\
\hline CHEMBL1966944 & 688620 & 6.0 & 5.51399 & 9999999999 & TRN \\
\hline CHEMBL1309827 & 688620 & 4.9 & 5.045 & TST & \\
\hline CHEMBL1313101 & 688620 & 5.1 & 4.8345 & TRN & \\
\hline CHEMBL1428889 & 688620 & 4.85 & 5.3911 & TRN & \\
\hline CHEMBL1327999 & 688620 & 5.2 & 5.0426 & TRN & \\
\hline CHEMBL1587027 & 688620 & 4.65 & 5.1649 & TST & \\
\hline CHEMBL1530813 & 688620 & 4.6 & 5.0007 & TRN & \\
\hline CHEMBL1550803 & 688620 & 5.0 & 4.8928 & TRN & \\
\hline CHEMBL1557758 & 688620 & 5.15 & 4.9798 & TRN & \\
\hline CHEMBL1368587 & 688620 & 4.85 & 5.0164 & TRN & \\
\hline CHEMBL1490357 & 688620 & 4.85 & 5.0582 & TST & \\
\hline CHEMBL1386698 & 688620 & 5.6 & 4.9954 & TRN & \\
\hline CHEMBL1537379 & 688620 & 5.0 & 5.7493 & TST & \\
\hline CHEMBL1605957 & 688620 & 4.45 & 4.9051 & TRN & \\
\hline CHEMBL1348395 & 688620 & 5.8 & 5.0152 & TRN & \\
\hline CHEMBL1341544 & 688620 & 6.05 & 5.8564 & TRN & \\
\hline CHEMBL1588558 & 688620 & 4.85 & 5.1756 & TRN & \\
\hline CHEMBL1504205 & 688620 & 4.55 & 4.843 & TRN & \\
\hline CHEMBL1481915 & 688620 & 5.1 & 4.7782 & TRN & \\
\hline CHEMBL3199711 & 688620 & 4.45 & 4.971 & TRN & \\
\hline CHEMBL1403905 & 688620 & 6.0 & 4.8426 & TRN & \\
\hline CHEMBL1586627 & 688620 & 6.1 & 5.0184 & TST & \\
\hline CHEMBL3192231 & 688620 & 6.0 & 5.4075 & TRN & \\
\hline CHEMBL1505565 & 688620 & 4.75 & 4.8186 & TRN & \\
\hline CHEMBL1587219 & 688620 & 4.75 & 5.0605 & TST & \\
\hline CHEMBL1606490 & 688620 & 6.35 & 5.0163 & TST & \\
\hline CHEMBL1386510 & 688620 & 4.65 & 4.9448 & TST & \\
\hline CHEMBL1465867 & 688620 & 4.7 & 4.945 & TRN & \\
\hline CHEMBL1469191 & 688620 & 4.8 & 5.0827 & TRN & \\
\hline CHEMBL1970160 & 688620 & 5.65 & 5.4454 & TST & \\
\hline CHEMBL1598569 & 688620 & 5.4 & 5.6182 & TRN & \\
\hline CHEMBL3213896 & 688620 & 6.6499 & 4.9475 & TRN & \\
\hline CHEMBL1380986 & 688620 & 4.6 & 5.273 & TST & \\
\hline CHEMBL1349013 & 688620 & 4.6 & 5.1051 & TRN & \\
\hline CHEMBL1559795 & 688620 & 4.95 & 4.918 & TST & \\
\hline CHEMBL1312870 & 688620 & 4.9 & 4.9665 & TRN & \\
\hline
\end{tabular}




\begin{tabular}{|c|c|c|c|c|}
\hline & & \multicolumn{3}{|c|}{ Supplemental Table S2.txt } \\
\hline CHEMBL3199164 & 688620 & 7.6498 & 5.5597 & TRN \\
\hline CHEMBL1487720 & 688620 & 5.65 & 5.524 & TRN \\
\hline CHEMBL1577585 & 688620 & 4.45 & 4.7355 & TRN \\
\hline CHEMBL1535141 & 688620 & 6.45 & 5.0724 & TRN \\
\hline CHEMBL1308006 & 688620 & 4.7 & 4.8861 & TRN \\
\hline CHEMBL1431669 & 688620 & 5.2 & 4.9517 & TRN \\
\hline CHEMBL3193765 & 688620 & 5.6 & 5.4306 & TRN \\
\hline CHEMBL1583889 & 688620 & 6.25 & 5.0095 & TRN \\
\hline CHEMBL1570784 & 688620 & 5.4 & 4.9588 & TRN \\
\hline CHEMBL1466575 & 688620 & 5.2 & 4.9364 & TRN \\
\hline CHEMBL1979784 & 688620 & 5.55 & 5.2555 & TRN \\
\hline CHEMBL1337387 & 688620 & 4.45 & 4.8252 & TST \\
\hline CHEMBL1468351 & 688620 & 5.0 & 4.9679 & TRN \\
\hline CHEMBL1305555 & 688620 & 4.95 & 5.0487 & TST \\
\hline CHEMBL1461359 & 688620 & 4.9 & 5.1332 & TRN \\
\hline CHEMBL1978331 & 688620 & 5.8 & 5.5893 & TRN \\
\hline CHEMBL1335100 & 688620 & 4.95 & 5.1428 & TRN \\
\hline CHEMBL1509621 & 688620 & 4.85 & 5.1166 & TRN \\
\hline CHEMBL 202740 & 688620 & 4.95 & 5.21 & TRN \\
\hline CHEMBL 3193404 & 688620 & 5.65 & 5.4436 & TRN \\
\hline CHEMBL1350421 & 688620 & 5.5 & 4.9017 & TRN \\
\hline CHEMBL3192165 & 688620 & 5.65 & 5.64 & TRN \\
\hline CHEMBL1463540 & 688620 & 4.45 & 4.9103 & TST \\
\hline CHEMBL1410416 & 688620 & 6.0 & 5.1689 & TRN \\
\hline CHEMBL1331251 & 688620 & 4.45 & 5.03600 & 00000000005 \\
\hline CHEMBL1422848 & 688620 & 5.0 & 5.0911 & TRN \\
\hline CHEMBL1450780 & 688620 & 5.05 & 5.0453 & TRN \\
\hline CHEMBL1472200 & 688620 & 4.8 & 4.7094 & TRN \\
\hline CHEMBL1564526 & 688620 & 4.65 & 5.098 & TRN \\
\hline CHEMBL1444721 & 688620 & 4.7 & 4.8805 & TRN \\
\hline CHEMBL1330299 & 688620 & 4.8 & 5.0915 & TRN \\
\hline CHEMBL1975834 & 688620 & 5.6 & 5.1278 & TRN \\
\hline CHEMBL1602693 & 688620 & 5.2 & 5.2424 & TST \\
\hline CHEMBL1335671 & 688620 & 4.7 & 5.0134 & TRN \\
\hline CHEMBL1575720 & 688620 & 5.05 & 5.7516 & TRN \\
\hline CHEMBL1477129 & 688620 & 4.45 & 4.796 & TST \\
\hline CHEMBL3210704 & 688620 & 6.7501 & 5.915 & TRN \\
\hline CHEMBL 1426600 & 688620 & 4.6 & 4.9271 & TRN \\
\hline CHEMBL1589095 & 688620 & 5.05 & 4.9841 & TRN \\
\hline CHEMBL1508337 & 688620 & 4.45 & 4.9631 & TRN \\
\hline CHEMBL1352042 & 688620 & 5.45 & 5.0474 & TRN \\
\hline CHEMBL1468905 & 688620 & 4.45 & 5.0462 & TST \\
\hline CHEMBL1351669 & 688620 & 5.1 & 5.062 & TST \\
\hline CHEMBL1583337 & 688620 & 4.45 & 4.8749 & TST \\
\hline CHEMBL1483660 & 688620 & 4.55 & 4.5902 & TRN \\
\hline CHEMBL1542694 & 688620 & 6.05 & 6.3261 & TRN \\
\hline CHEMBL1984523 & 688620 & 4.85 & 4.9584 & TST \\
\hline CHEMBL1470569 & 688620 & 5.45 & 4.8149 & TST \\
\hline
\end{tabular}




\begin{tabular}{|c|c|c|c|c|}
\hline \multicolumn{5}{|c|}{ Supplemental Table s2.txt } \\
\hline CHEMBL1383635 & 688620 & 4.45 & 4.6489 & TRN \\
\hline CHEMBL1598670 & 688620 & 4.65 & 5.2169 & TST \\
\hline CHEMBL1385546 & 688620 & 5.0 & 5.1336 & TRN \\
\hline CHEMBL1413629 & 688620 & 5.4 & 5.4544 & TRN \\
\hline CHEMBL168276 & 688620 & 6.0 & 4.968 & TRN \\
\hline CHEMBL1391974 & 688620 & 5.75 & 5.5361 & TRN \\
\hline CHEMBL1547399 & 688620 & 4.8 & 5.0238 & TST \\
\hline CHEMBL1406323 & 688620 & 4.45 & 5.0163 & TRN \\
\hline CHEMBL1509719 & 688620 & 6.5 & 6.0276 & TRN \\
\hline CHEMBL1557778 & 688620 & 4.9 & 5.3677 & TRN \\
\hline CHEMBL3191670 & 688620 & 4.45 & 4.7214 & TRN \\
\hline CHEMBL1340876 & 688620 & 4.45 & 4.8599 & TRN \\
\hline CHEMBL1338262 & 688620 & 4.45 & 5.0841 & TST \\
\hline CHEMBL1346885 & 688620 & 4.45 & 4.8735 & TRN \\
\hline CHEMBL1578718 & 688620 & 5.6 & 5.1613 & TRN \\
\hline CHEMBL1367679 & 688620 & 4.45 & 4.9519 & TRN \\
\hline CHEMBL1579210 & 688620 & 4.55 & 4.8568 & TST \\
\hline CHEMBL1323212 & 688620 & 4.85 & 5.4521 & TRN \\
\hline CHEMBL1302626 & 688620 & 4.95 & 5.0038 & TST \\
\hline CHEMBL1535902 & 688620 & 5.55 & 5.41299 & 9999999999 \\
\hline CHEMBL1352829 & 688620 & 4.6 & 4.9344 & TRN \\
\hline CHEMBL1355405 & 688620 & 4.45 & 4.8341 & TRN \\
\hline CHEMBL1392842 & 688620 & 6.0 & 5.107 & TRN \\
\hline CHEMBL1559881 & 688620 & 4.85 & 5.1235 & TRN \\
\hline CHEMBL1580709 & 688620 & 4.9 & 4.806 & TRN \\
\hline CHEMBL1417955 & 688620 & 4.95 & 4.9321 & TRN \\
\hline CHEMBL1571503 & 688620 & 4.5 & 4.9926 & TST \\
\hline CHEMBL1567585 & 688620 & 5.45 & 5.1456 & TST \\
\hline CHEMBL1404173 & 688620 & 4.75 & 4.9512 & TST \\
\hline CHEMBL1536172 & 688620 & 5.55 & 5.2334 & TRN \\
\hline CHEMBL1425908 & 688620 & 4.85 & 4.9462 & TST \\
\hline CHEMBL1385271 & 688620 & 4.65 & 4.9841 & TRN \\
\hline CHEMBL3192075 & 688620 & 4.9 & 4.9837 & TRN \\
\hline CHEMBL1465840 & 688620 & 5.5 & 4.9383 & TRN \\
\hline CHEMBL1299352 & 688620 & 4.6 & 4.8922 & TST \\
\hline CHEMBL1341864 & 688620 & 4.8 & 5.0524 & TST \\
\hline CHEMBL1604180 & 688620 & 4.95 & 4.8629 & TRN \\
\hline CHEMBL1338838 & 688620 & 5.15 & 4.9709 & TRN \\
\hline CHEMBL3191146 & 688620 & 4.55 & 4.9649 & TST \\
\hline CHEMBL1521262 & 688620 & 6.8 & 4.9034 & TST \\
\hline CHEMBL1456081 & 688620 & 4.95 & 4.9532 & TRN \\
\hline CHEMBL1521005 & 688620 & 4.8 & 4.9686 & TRN \\
\hline CHEMBL1563340 & 688620 & 5.25 & 5.1234 & TRN \\
\hline CHEMBL1537016 & 688620 & 4.95 & 5.191 & TST \\
\hline CHEMBL3211076 & 688620 & 5.6 & 5.1777 & TRN \\
\hline CHEMBL1380531 & 688620 & 4.45 & 5.02 & TRN \\
\hline CHEMBL1409528 & 688620 & 5.15 & 5.3193 & TRN \\
\hline CHEMBL1323364 & 688620 & 4.95 & 4.7086 & TST \\
\hline
\end{tabular}

TRN 


\begin{tabular}{|c|c|c|c|c|}
\hline & & & upplement & al $\mathrm{T}$ \\
\hline CHEMBL1606105 & 688620 & 4.45 & 5.1689 & TST \\
\hline CHEMBL1363742 & 688620 & 5.0 & 5.0466 & TRN \\
\hline CHEMBL 3199322 & 688620 & 6.3 & 5.8409 & TRN \\
\hline CHEMBL1471847 & 688620 & 4.45 & 4.7853 & TRN \\
\hline CHEMBL1531419 & 688620 & 4.55 & 4.8642 & TRN \\
\hline CHEMBL1505430 & 688620 & 4.45 & 4.9662 & TRN \\
\hline CHEMBL1460947 & 688620 & 5.2 & 5.2356 & TRN \\
\hline CHEMBL1393793 & 688620 & 5.15 & 5.2224 & TRN \\
\hline CHEMBL1452214 & 688620 & 4.75 & 5.6614 & TRN \\
\hline CHEMBL1528905 & 688620 & 4.65 & 5.2844 & TRN \\
\hline CHEMBL1540237 & 688620 & 5.25 & 5.3118 & TRN \\
\hline CHEMBL1528842 & 688620 & 5.5 & 5.3399 & TRN \\
\hline CHEMBL1542067 & 688620 & 4.85 & 5.4204 & TST \\
\hline CHEMBL1590890 & 688620 & 4.55 & 5.1118 & TRN \\
\hline CHEMBL3189550 & 688620 & 4.5 & 5.1187 & TST \\
\hline CHEMBL1347238 & 688620 & 4.75 & 5.0467 & TST \\
\hline CHEMBL1560188 & 688620 & 4.45 & 4.9885 & TRN \\
\hline CHEMBL1408577 & 688620 & 4.45 & 5.0093 & TST \\
\hline CHEMBL 3192125 & 688620 & 5.15 & 4.7882 & TRN \\
\hline CHEMBL1508914 & 688620 & 4.45 & 4.6705 & TRN \\
\hline CHEMBL1569744 & 688620 & 4.45 & 4.9218 & TRN \\
\hline CHEMBL1329897 & 688620 & 4.9 & 5.0304 & TRN \\
\hline CHEMBL1568087 & 688620 & 4.75 & 4.9989 & TST \\
\hline CHEMBL1584520 & 688620 & 5.25 & 5.0267 & TRN \\
\hline CHEMBL1454113 & 688620 & 4.45 & 5.0489 & TST \\
\hline CHEMBL3192589 & 688620 & 4.45 & 5.0498 & TRN \\
\hline CHEMBL1450964 & 688620 & 5.6 & 4.99 & TRN \\
\hline CHEMBL1445725 & 688620 & 6.6 & 5.3154 & TRN \\
\hline CHEMBL 577546 & 688620 & 5.0 & 4.7714 & TRN \\
\hline CHEMBL1392664 & 688620 & 4.85 & 4.9391 & TST \\
\hline CHEMBL1327251 & 688620 & 5.1 & 4.7392 & TST \\
\hline CHEMBL1607355 & 688620 & 6.25 & 5.6259 & TST \\
\hline CHEMBL1307293 & 688620 & 5.0 & 5.0319 & TRN \\
\hline CHEMBL1493504 & 688620 & 4.9 & 4.7676 & TRN \\
\hline CHEMBL1494303 & 688620 & 4.9 & 4.8582 & TST \\
\hline CHEMBL1390685 & 688620 & 4.5 & 4.9302 & TRN \\
\hline CHEMBL1415915 & 688620 & 6.0 & 5.2734 & TRN \\
\hline CHEMBL1371207 & 688620 & 4.45 & 5.1081 & TRN \\
\hline CHEMBL1348329 & 688620 & 4.9 & 5.0046 & TST \\
\hline CHEMBL3212421 & 688620 & 5.45 & 5.4632 & TRN \\
\hline CHEMBL1309291 & 688620 & 5.65 & 5.1473 & TST \\
\hline CHEMBL 1505818 & 688620 & 4.9 & 4.9179 & TST \\
\hline CHEMBL1500354 & 688620 & 4.95 & 5.2987 & TRN \\
\hline CHEMBL1338944 & 688620 & 4.45 & 4.8864 & TRN \\
\hline CHEMBL1448066 & 688620 & 4.65 & 5.2305 & TRN \\
\hline CHEMBL1542176 & 688620 & 5.0 & 5.4054 & TRN \\
\hline CHEMBL 1341788 & 688620 & 4.9 & 4.8451 & TRN \\
\hline CHEMBL1367095 & 688620 & 5.0 & 5.0322 & TRN \\
\hline
\end{tabular}




\begin{tabular}{|c|c|c|c|c|c|}
\hline & & \multicolumn{4}{|c|}{ Supplemental Table s2.txt } \\
\hline CHEMBL1566658 & 688620 & 4.95 & 4.84 & TRN & \\
\hline CHEMBL1602142 & 688620 & 5.5 & 5.1285 & TST & \\
\hline CHEMBL1385768 & 688620 & 4.75 & 5.0751 & TRN & \\
\hline CHEMBL1390866 & 688620 & 5.8 & 4.7337 & TRN & \\
\hline CHEMBL1332089 & 688620 & 4.95 & 4.8623 & TRN & \\
\hline CHEMBL1481105 & 688620 & 4.7 & 5.0711 & TST & \\
\hline CHEMBL1574779 & 688620 & 5.0 & 5.0722 & TRN & \\
\hline CHEMBL1548292 & 688620 & 4.9 & 4.8879 & TRN & \\
\hline CHEMBL1526577 & 688620 & 4.7 & 5.1162 & TRN & \\
\hline CHEMBL1409560 & 688620 & 5.0 & 4.9355 & TST & \\
\hline CHEMBL1382022 & 688620 & 4.9 & 4.5516 & TRN & \\
\hline CHEMBL1500315 & 688620 & 4.45 & 4.7637 & TRN & \\
\hline CHEMBL1491978 & 688620 & 4.75 & 5.2006 & TST & \\
\hline CHEMBL1300514 & 688620 & 4.9 & 4.9642 & TST & \\
\hline CHEMBL1301558 & 688620 & 4.6 & 5.2507 & TRN & \\
\hline CHEMBL1484678 & 688620 & 4.45 & 4.9836 & TST & \\
\hline CHEMBL1543866 & 688620 & 4.8 & 5.1804 & TRN & \\
\hline CHEMBL1600444 & 688620 & 4.75 & 4.9794 & TRN & \\
\hline CHEMBL1576562 & 688620 & 5.05 & 5.1368 & TRN & \\
\hline CHEMBL1330735 & 688620 & 4.95 & 5.0054 & TRN & \\
\hline CHEMBL1383636 & 688620 & 6.6 & 4.9707 & TRN & \\
\hline CHEMBL1541405 & 688620 & 4.65 & 4.9006 & TRN & \\
\hline CHEMBL1430258 & 688620 & 4.75 & 4.7657 & TST & \\
\hline CHEMBL1344603 & 688620 & 6.8 & 5.9049 & TRN & \\
\hline CHEMBL1990694 & 688620 & 5.45 & 5.1469 & TST & \\
\hline CHEMBL1558285 & 688620 & 4.75 & 5.1494 & TST & \\
\hline CHEMBL1561548 & 688620 & 5.5 & 5.3891 & TRN & \\
\hline CHEMBL1507444 & 688620 & 4.65 & 5.1047 & TRN & \\
\hline CHEMBL1403214 & 688620 & 4.95 & 5.0114 & TRN & \\
\hline CHEMBL1503229 & 688620 & 4.95 & 4.647 & TST & \\
\hline CHEMBL1537804 & 688620 & 4.85 & 5.0024 & TRN & \\
\hline CHEMBL1303200 & 688620 & 4.45 & 4.9602 & TRN & \\
\hline CHEMBL1414754 & 688620 & 6.1 & 5.0710 & $\partial 000000001$ & TRN \\
\hline CHEMBL1381105 & 688620 & 4.45 & 4.6485 & TRN & \\
\hline CHEMBL1361130 & 688620 & 5.15 & 5.1266 & TRN & \\
\hline CHEMBL1568902 & 688620 & 4.9 & 5.0386 & TST & \\
\hline CHEMBL1368933 & 688620 & 4.45 & 5.0559 & TRN & \\
\hline CHEMBL3209789 & 688620 & 4.8 & 4.8351 & TRN & \\
\hline CHEMBL1547516 & 688620 & 4.85 & 5.0673 & TRN & \\
\hline CHEMBL1526936 & 688620 & 4.9 & 5.0672 & TST & \\
\hline CHEMBL1540377 & 688620 & 4.9 & 5.0166 & TRN & \\
\hline CHEMBL1446667 & 688620 & 4.95 & 4.7283 & TST & \\
\hline CHEMBL1967901 & 688620 & 6.45 & 6.2329 & TRN & \\
\hline CHEMBL1351859 & 688620 & 5.6 & 5.1338 & TRN & \\
\hline CHEMBL1453051 & 688620 & 4.6 & 4.9797 & TRN & \\
\hline CHEMBL1506090 & 688620 & 4.5 & 4.9454 & TRN & \\
\hline CHEMBL1393983 & 688620 & 6.5501 & 5.2652 & TRN & \\
\hline CHEMBL1496722 & 688620 & 4.85 & 4.875 & TRN & \\
\hline
\end{tabular}




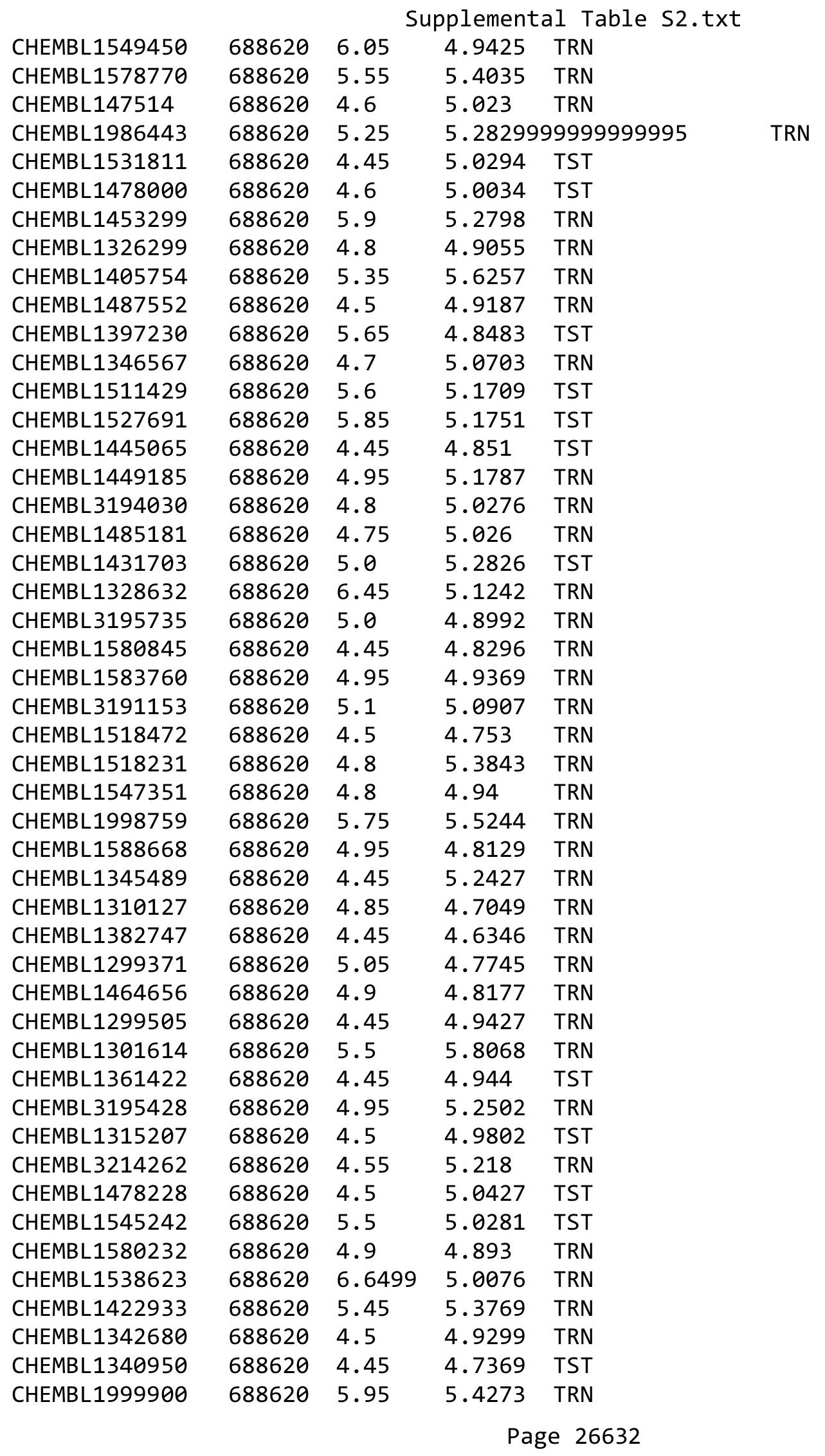




\begin{tabular}{|c|c|c|c|c|}
\hline \multicolumn{5}{|c|}{ Supplemental Table s2.txt } \\
\hline CHEMBL1551046 & 688620 & 4.45 & 5.0973 & TRN \\
\hline CHEMBL1425536 & 688620 & 5.8 & 5.0445 & TRN \\
\hline CHEMBL1601030 & 688620 & 4.45 & 5.051 & TST \\
\hline CHEMBL1460722 & 688620 & 4.55 & 4.8358 & TRN \\
\hline CHEMBL1308340 & 688620 & 4.95 & 4.8575 & TST \\
\hline CHEMBL1603823 & 688620 & 4.45 & 5.1714 & TRN \\
\hline CHEMBL1500847 & 688620 & 4.75 & 5.0607 & TRN \\
\hline CHEMBL1491389 & 688620 & 6.1 & 5.6199 & TRN \\
\hline CHEMBL1488855 & 688620 & 5.8 & 5.2278 & TRN \\
\hline CHEMBL1502527 & 688620 & 4.45 & 4.8497 & TRN \\
\hline CHEMBL1398823 & 688620 & 5.05 & 5.0894 & TRN \\
\hline CHEMBL1986921 & 688620 & 6.6499 & 5.1183 & TRN \\
\hline CHEMBL1329037 & 688620 & 5.75 & 5.1936 & TST \\
\hline CHEMBL1419973 & 688620 & 5.0 & 5.1291 & TRN \\
\hline CHEMBL1310302 & 688620 & 4.45 & 4.5625 & TRN \\
\hline CHEMBL1547598 & 688620 & 4.45 & 4.6907 & TRN \\
\hline CHEMBL1982305 & 688620 & 4.8 & 4.7988 & TRN \\
\hline CHEMBL1541983 & 688620 & 4.9 & 5.1313 & TST \\
\hline CHEMBL1419536 & 688620 & 5.55 & 5.4113 & TRN \\
\hline CHEMBL1326043 & 688620 & 5.0 & 4.7318 & TST \\
\hline CHEMBL1600669 & 688620 & 4.95 & 4.958 & TRN \\
\hline CHEMBL1312476 & 688620 & 4.7 & 5.1206 & TST \\
\hline CHEMBL1486832 & 688620 & 5.35 & 4.8955 & TRN \\
\hline CHEMBL1369723 & 688620 & 4.8 & 5.1693 & TST \\
\hline CHEMBL1306838 & 688620 & 5.3 & 4.7776 & TRN \\
\hline CHEMBL1383224 & 688620 & 4.9 & 5.0296 & TRN \\
\hline CHEMBL 3210494 & 688620 & 5.7 & 5.3002 & TRN \\
\hline CHEMBL1305233 & 688620 & 4.65 & 5.0113 & TRN \\
\hline CHEMBL1465454 & 688620 & 4.7 & 4.9582 & TRN \\
\hline CHEMBL1573858 & 688620 & 5.1 & 5.0006 & TRN \\
\hline CHEMBL1417504 & 688620 & 5.0 & 5.0047 & TRN \\
\hline CHEMBL3196339 & 688620 & 4.8 & 4.8353 & TRN \\
\hline CHEMBL1409150 & 688620 & 4.45 & 4.9356 & TRN \\
\hline CHEMBL1307473 & 688620 & 5.35 & 5.1336 & TRN \\
\hline CHEMBL1446802 & 688620 & 5.0 & 4.9647 & TRN \\
\hline CHEMBL3198914 & 688620 & 4.85 & 5.1647 & TRN \\
\hline CHEMBL1369880 & 688620 & 5.4 & 5.0165 & TST \\
\hline CHEMBL1382613 & 688620 & 4.95 & 5.0462 & TRN \\
\hline CHEMBL1482740 & 688620 & 4.8 & 5.0645 & TRN \\
\hline CHEMBL1557834 & 688620 & 6.05 & 5.354 & TRN \\
\hline CHEMBL1584295 & 688620 & 5.8 & 5.8455 & TRN \\
\hline CHEMBL3211143 & 688620 & 4.95 & 5.1095 & TRN \\
\hline CHEMBL1566908 & 688620 & 5.3 & 5.1018 & TRN \\
\hline CHEMBL1469563 & 688620 & 5.2 & $5.1320 e$ & 0000000001 \\
\hline CHEMBL1586147 & 688620 & 5.65 & 5.2562 & TRN \\
\hline CHEMBL1419435 & 688620 & 5.1 & 5.1034 & TST \\
\hline CHEMBL1431004 & 688620 & 4.65 & 4.8844 & TRN \\
\hline CHEMBL1430827 & 688620 & 4.7 & 4.8246 & TRN \\
\hline
\end{tabular}

TRN 


\begin{tabular}{|c|c|c|c|c|c|}
\hline \\
\hline CHEMBL1576216 & 688620 & 4.5 & 4.9832 & TRN & \\
\hline CHEMBL1361390 & 688620 & 5.0 & 4.9715 & TRN & \\
\hline CHEMBL1575808 & 688620 & 6.9 & 5.6162 & TRN & \\
\hline CHEMBL3145371 & 688620 & 6.4 & 6.1044 & TRN & \\
\hline CHEMBL3193098 & 688620 & 6.05 & 5.4193 & TRN & \\
\hline CHEMBL1965461 & 688620 & 4.45 & 5.0658 & TST & \\
\hline CHEMBL1442968 & 688620 & 5.3 & 4.962 & TST & \\
\hline CHEMBL1371286 & 688620 & 5.0 & 5.1 & TRN & \\
\hline CHEMBL1982152 & 688620 & 5.55 & 5.4632 & TRN & \\
\hline CHEMBL1438371 & 688620 & 5.25 & 4.9137 & TRN & \\
\hline CHEMBL1411257 & 688620 & 6.1 & 5.6502 & TRN & \\
\hline CHEMBL1308936 & 688620 & 5.05 & 4.9319 & TRN & \\
\hline CHEMBL1532875 & 688620 & 4.45 & 5.0275 & TRN & \\
\hline CHEMBL1366516 & 688620 & 4.45 & 5.17899 & 9999999999 & TST \\
\hline CHEMBL1469871 & 688620 & 5.45 & 5.8778 & TRN & \\
\hline CHEMBL1326560 & 688620 & 4.7 & 5.2112 & TRN & \\
\hline CHEMBL1464281 & 688620 & 4.65 & 4.9093 & TST & \\
\hline CHEMBL1302974 & 688620 & 5.0 & 5.1582 & TRN & \\
\hline CHEMBL1569862 & 688620 & 5.6 & 5.4435 & TST & \\
\hline CHEMBL1970597 & 688620 & 5.6 & 5.3658 & TRN & \\
\hline CHEMBL1370872 & 688620 & 4.9 & 5.0404 & TRN & \\
\hline CHEMBL1326787 & 688620 & 6.0 & 4.8588 & TRN & \\
\hline CHEMBL1596702 & 688620 & 4.5 & 4.678 & TRN & \\
\hline CHEMBL1328241 & 688620 & 6.8499 & 5.2013 & TST & \\
\hline CHEMBL1541922 & 688620 & 4.45 & 5.0369 & TRN & \\
\hline CHEMBL477139 & 688620 & 5.1 & 4.8592 & TST & \\
\hline CHEMBL1333928 & 688620 & 4.95 & 4.9357 & TRN & \\
\hline CHEMBL1299901 & 688620 & 5.1 & 4.9681 & TST & \\
\hline CHEMBL1472931 & 688620 & 4.95 & 4.9019 & TRN & \\
\hline CHEMBL1309878 & 688620 & 5.0 & 4.7833 & TST & \\
\hline CHEMBL1523004 & 688620 & 4.45 & 5.0187 & TRN & \\
\hline CHEMBL1377650 & 688620 & 5.0 & 5.1828 & TRN & \\
\hline CHEMBL1410935 & 688620 & 5.0 & 4.8883 & TST & \\
\hline CHEMBL1426144 & 688620 & 5.85 & 5.2374 & TRN & \\
\hline CHEMBL1598093 & 688620 & 4.95 & 5.1826 & TRN & \\
\hline CHEMBL1353090 & 688620 & 4.85 & 4.8729 & TRN & \\
\hline CHEMBL1379804 & 688620 & 4.7 & 4.8207 & TRN & \\
\hline CHEMBL1384843 & 688620 & 5.15 & 4.6669 & TRN & \\
\hline CHEMBL1490853 & 688620 & 4.45 & 4.8429 & TRN & \\
\hline CHEMBL1407991 & 688620 & 4.75 & 4.63399 & 99999999995 & TRN \\
\hline CHEMBL1974329 & 688620 & 4.65 & 4.8616 & TRN & \\
\hline CHEMBL1597398 & 688620 & 5.05 & 5.0853 & TST & \\
\hline CHEMBL1547211 & 688620 & 4.9 & 4.9907 & TST & \\
\hline CHEMBL1538677 & 688620 & 4.45 & 4.9719 & TST & \\
\hline CHEMBL1337689 & 688620 & 5.6 & 5.0193 & TST & \\
\hline CHEMBL1335934 & 688620 & 5.35 & 5.0647 & TRN & \\
\hline CHEMBL3197663 & 688620 & 4.95 & 5.1278 & TRN & \\
\hline CHEMBL1539359 & 688620 & 6.45 & 5.5146 & TRN & \\
\hline
\end{tabular}




\begin{tabular}{|c|c|c|c|c|c|}
\hline \\
\hline CHEMBL1440001 & 688620 & 4.9 & 4.9375 & TST & \\
\hline CHEMBL1493769 & 688620 & 5.65 & 4.9889 & TRN & \\
\hline CHEMBL3213705 & 688620 & 5.25 & 5.4428 & TRN & \\
\hline CHEMBL1412080 & 688620 & 5.25 & 5.2044 & TRN & \\
\hline CHEMBL1339981 & 688620 & 6.6499 & 5.1398 & TST & \\
\hline CHEMBL1511673 & 688620 & 4.9 & 5.0758 & TRN & \\
\hline CHEMBL1537645 & 688620 & 4.85 & 4.9039 & TRN & \\
\hline CHEMBL1596599 & 688620 & 4.45 & 4.827 & TRN & \\
\hline CHEMBL1428961 & 688620 & 5.35 & 5.1396 & TRN & \\
\hline CHEMBL1501031 & 688620 & 4.55 & 5.2984 & TRN & \\
\hline CHEMBL1548184 & 688620 & 5.05 & 5.2 & TST & \\
\hline CHEMBL1458150 & 688620 & 4.85 & 4.9577 & TRN & \\
\hline CHEMBL3213491 & 688620 & 5.65 & 5.0714 & TRN & \\
\hline CHEMBL1445617 & 688620 & 4.8 & 4.8983 & TST & \\
\hline CHEMBL1536881 & 688620 & 4.45 & 4.94300 & 20000000005 & TRN \\
\hline CHEMBL1546510 & 688620 & 4.75 & 4.9129 & TRN & \\
\hline CHEMBL1340427 & 688620 & 4.9 & 5.1259 & TRN & \\
\hline CHEMBL1533612 & 688620 & 5.1 & 5.1588 & TST & \\
\hline CHEMBL323356 & 688620 & 4.7 & 5.2497 & TST & \\
\hline CHEMBL1312858 & 688620 & 5.55 & 5.0282 & TRN & \\
\hline CHEMBL3190371 & 688620 & 4.7 & 5.0834 & TRN & \\
\hline CHEMBL1584152 & 688620 & 6.0 & 5.1103 & TST & \\
\hline CHEMBL1379293 & 688620 & 4.65 & 5.7188 & TRN & \\
\hline CHEMBL3195076 & 688620 & 4.75 & 5.0871 & TRN & \\
\hline CHEMBL1404244 & 688620 & 4.9 & 5.0513 & TRN & \\
\hline CHEMBL3198651 & 688620 & 5.55 & 5.501 & TRN & \\
\hline CHEMBL1550241 & 688620 & 4.45 & 4.8848 & TRN & \\
\hline CHEMBL1548327 & 688620 & 5.35 & 5.0168 & TST & \\
\hline CHEMBL1321898 & 688620 & 5.1 & 4.9775 & TRN & \\
\hline CHEMBL1536840 & 688620 & 5.05 & 4.6855 & TRN & \\
\hline CHEMBL1965298 & 688620 & 6.25 & 5.8468 & TRN & \\
\hline CHEMBL1576355 & 688620 & 5.2 & 5.1052 & TST & \\
\hline CHEMBL1324145 & 688620 & 5.25 & 4.9865 & TRN & \\
\hline CHEMBL1393156 & 688620 & 6.4 & 5.9124 & TRN & \\
\hline CHEMBL1532089 & 688620 & 6.0 & 5.7756 & TRN & \\
\hline CHEMBL1391151 & 688620 & 4.45 & 4.9941 & TRN & \\
\hline CHEMBL1494856 & 688620 & 4.45 & 5.0233 & TRN & \\
\hline CHEMBL1583197 & 688620 & 4.85 & 5.0186 & TRN & \\
\hline CHEMBL1540442 & 688620 & 6.1 & 5.1274 & TST & \\
\hline CHEMBL1468078 & 688620 & 5.05 & 5.1556 & TRN & \\
\hline CHEMBL1322716 & 688620 & 4.45 & 5.0816 & TRN & \\
\hline CHEMBL114544 & 688620 & 6.0 & 6.1207 & TRN & \\
\hline CHEMBL1335250 & 688620 & 5.35 & 5.3698 & TRN & \\
\hline CHEMBL1415523 & 688620 & 4.95 & 4.9903 & TRN & \\
\hline CHEMBL1443660 & 688620 & 4.9 & 5.0399 & TRN & \\
\hline CHEMBL1536140 & 688620 & 6.15 & 5.0151 & TST & \\
\hline CHEMBL1385574 & 688620 & 5.4 & 5.0846 & TRN & \\
\hline CHEMBL1550516 & 688620 & 4.95 & 5.0893 & TST & \\
\hline
\end{tabular}




\begin{tabular}{|c|c|c|c|c|c|}
\hline \multirow[b]{2}{*}{ CHEMBL1328493 } & & \multicolumn{4}{|c|}{ Supplemental Table S2.txt } \\
\hline & 688620 & 6.5501 & 6.4834 & TRN & \\
\hline CHEMBL1492455 & 688620 & 5.9 & 6.09399 & 9999999999 & TRN \\
\hline CHEMBL1412001 & 688620 & 5.55 & 5.0291 & TST & \\
\hline CHEMBL3195977 & 688620 & 4.95 & 5.0684 & TST & \\
\hline CHEMBL1460750 & 688620 & 6.1 & 5.191 & TRN & \\
\hline CHEMBL1470760 & 688620 & 5.95 & 5.5363 & TRN & \\
\hline CHEMBL1375052 & 688620 & 4.65 & 4.9145 & TST & \\
\hline CHEMBL1466994 & 688620 & 5.0 & 5.178 & TRN & \\
\hline CHEMBL1419583 & 688620 & 4.95 & 5.0852 & TRN & \\
\hline CHEMBL1392836 & 688620 & 5.0 & 4.9211 & TRN & \\
\hline CHEMBL1505417 & 688620 & 6.1 & 5.0065 & TRN & \\
\hline CHEMBL1432181 & 688620 & 4.95 & 4.8951 & TRN & \\
\hline CHEMBL1326497 & 688620 & 4.7 & 5.0637 & TRN & \\
\hline CHEMBL1499719 & 688620 & 5.0 & 4.8574 & TRN & \\
\hline CHEMBL1379706 & 688620 & 4.95 & 5.0902 & TRN & \\
\hline CHEMBL1449153 & 688620 & 4.45 & 4.9727 & TRN & \\
\hline CHEMBL1610974 & 688620 & 5.2 & 4.9342 & TRN & \\
\hline CHEMBL1568156 & 688620 & 4.85 & 4.8959 & TRN & \\
\hline CHEMBL587475 & 688620 & 4.95 & 4.8241 & TRN & \\
\hline CHEMBL1570025 & 688620 & 4.45 & 4.9085 & TRN & \\
\hline CHEMBL1341432 & 688620 & 4.8 & 5.1107 & TRN & \\
\hline CHEMBL1383401 & 688620 & 5.9 & 5.2215 & TRN & \\
\hline CHEMBL3199870 & 688620 & 5.5 & 5.1345 & TRN & \\
\hline CHEMBL1518129 & 688620 & 4.95 & 5.0924 & TST & \\
\hline CHEMBL1464402 & 688620 & 5.1 & 5.0614 & TRN & \\
\hline CHEMBL1353194 & 688620 & 4.9 & 5.4996 & TRN & \\
\hline CHEMBL600862 & 688620 & 5.65 & 5.7849 & TRN & \\
\hline CHEMBL1421466 & 688620 & 4.8 & 4.7291 & TRN & \\
\hline CHEMBL1584699 & 688620 & 4.45 & 5.0175 & TRN & \\
\hline CHEMBL3211985 & 688620 & 4.95 & 4.8485 & TST & \\
\hline CHEMBL1435188 & 688620 & 4.9 & 4.9859 & TST & \\
\hline CHEMBL1458839 & 688620 & 4.85 & 4.7364 & TRN & \\
\hline CHEMBL1543765 & 688620 & 5.1 & 4.8127 & TRN & \\
\hline CHEMBL1553123 & 688620 & 4.6 & 5.0303 & TRN & \\
\hline CHEMBL1461431 & 688620 & 4.85 & 5.0197 & TRN & \\
\hline CHEMBL1447121 & 688620 & 4.95 & 4.9828 & TRN & \\
\hline CHEMBL1517719 & 688620 & 5.05 & 4.9486 & TRN & \\
\hline CHEMBL 1374555 & 688620 & 6.5501 & 6.1707 & TRN & \\
\hline CHEMBL1416951 & 688620 & 4.45 & 5.2374 & TRN & \\
\hline CHEMBL1256656 & 688620 & 4.7 & 4.9946 & TST & \\
\hline CHEMBL1522699 & 688620 & 4.95 & 4.8674 & TRN & \\
\hline CHEMBL1451037 & 688620 & 4.95 & 4.9845 & TRN & \\
\hline CHEMBL1332619 & 688620 & 5.6 & 5.472 & TRN & \\
\hline CHEMBL1307610 & 688620 & 4.9 & 4.9708 & TRN & \\
\hline CHEMBL1585778 & 688620 & 5.0 & 4.9731 & TRN & \\
\hline CHEMBL1579695 & 688620 & 5.85 & 5.32600 & 00000000005 & TRN \\
\hline CHEMBL1566766 & 688620 & 5.15 & 4.8068 & TRN & \\
\hline CHEMBL1583650 & 688620 & 4.95 & 5.7999 & TRN & \\
\hline
\end{tabular}




\begin{tabular}{|c|c|c|c|c|c|}
\hline \multirow[b]{2}{*}{ CHEMBL1401361 } & \multirow[b]{2}{*}{688620} & \\
\hline & & 4.45 & 5.1733 & TST & \\
\hline CHEMBL1324471 & 688620 & 5.35 & 5.2527 & TRN & \\
\hline CHEMBL1542875 & 688620 & 4.85 & 5.0463 & TST & \\
\hline CHEMBL1521882 & 688620 & 4.85 & 5.2757 & TRN & \\
\hline CHEMBL512048 & 688620 & 5.15 & 5.0887 & TRN & \\
\hline CHEMBL1376887 & 688620 & 4.9 & 5.0873 & TST & \\
\hline CHEMBL1440021 & 688620 & 5.25 & 5.4079 & TRN & \\
\hline CHEMBL1404672 & 688620 & 5.85 & 5.0168 & TRN & \\
\hline CHEMBL1448789 & 688620 & 6.45 & 5.4755 & TRN & \\
\hline CHEMBL1610149 & 688620 & 4.45 & 4.8341 & TRN & \\
\hline CHEMBL1402259 & 688620 & 5.15 & \multicolumn{2}{|c|}{4.9910000000000005} & TST \\
\hline CHEMBL1506263 & 688620 & 4.45 & 4.919 & TST & \\
\hline CHEMBL3193152 & 688620 & 4.8 & 4.9769 & TRN & \\
\hline CHEMBL1321387 & 688620 & 4.8 & 4.7163 & TRN & \\
\hline CHEMBL1462524 & 688620 & 4.45 & 5.2221 & TST & \\
\hline CHEMBL1532212 & 688620 & 4.75 & 4.8698 & TRN & \\
\hline CHEMBL1380207 & 688620 & 4.45 & 5.1492 & TST & \\
\hline CHEMBL1351724 & 688620 & 4.45 & 4.8868 & TRN & \\
\hline CHEMBL1365596 & 688620 & 5.25 & 4.944 & TST & \\
\hline CHEMBL1473289 & 688620 & 5.15 & 4.9388 & TRN & \\
\hline CHEMBL1410509 & 688620 & 4.85 & 4.8551 & TRN & \\
\hline CHEMBL1352116 & 688620 & 4.75 & 4.7974 & TRN & \\
\hline CHEMBL3192169 & 688620 & 4.65 & \multicolumn{2}{|c|}{4.9719999999999995} & TST \\
\hline CHEMBL1346595 & 688620 & 5.25 & 5.1955 & TRN & \\
\hline CHEMBL1402113 & 688620 & 4.95 & 5.0218 & TST & \\
\hline CHEMBL1398953 & 688620 & 4.5 & 4.7912 & TRN & \\
\hline CHEMBL1556421 & 688620 & 4.95 & 5.5076 & TRN & \\
\hline CHEMBL 3198222 & 688620 & 4.45 & 4.8718 & TRN & \\
\hline CHEMBL1535806 & 688620 & 6.95 & 4.9971 & TRN & \\
\hline CHEMBL1327307 & 688620 & 4.85 & 5.2417 & TST & \\
\hline CHEMBL1411484 & 688620 & 4.6 & 4.9201 & TST & \\
\hline CHEMBL1538939 & 688620 & 4.9 & 4.9219 & TRN & \\
\hline CHEMBL1460128 & 688620 & 4.45 & 5.0716 & TRN & \\
\hline CHEMBL3196326 & 688620 & 6.15 & 5.5266 & TRN & \\
\hline CHEMBL 1457318 & 688620 & 4.95 & 5.0789 & TRN & \\
\hline CHEMBL3145375 & 688620 & 6.45 & 6.1124 & TRN & \\
\hline CHEMBL 3193540 & 688620 & 4.8 & 5.0577 & TRN & \\
\hline CHEMBL1527907 & 688620 & 4.5 & 4.9372 & TST & \\
\hline CHEMBL1360435 & 688620 & 5.0 & 4.7329 & TRN & \\
\hline CHEMBL1602109 & 688620 & 5.2 & 4.9108 & TST & \\
\hline CHEMBL1457481 & 688620 & 5.8 & \multicolumn{2}{|c|}{5.127000000000001} & TRN \\
\hline CHEMBL1373909 & 688620 & 5.7 & 5.0835 & TST & \\
\hline CHEMBL1303632 & 688620 & 4.9 & 5.0478 & TRN & \\
\hline CHEMBL1544715 & 688620 & 4.75 & 4.9648 & TRN & \\
\hline CHEMBL1560486 & 688620 & 4.45 & 5.2296 & TST & \\
\hline CHEMBL1446690 & 688620 & 5.2 & 5.3339 & TRN & \\
\hline CHEMBL1540435 & 688620 & 5.55 & 5.1072 & TRN & \\
\hline \multirow[t]{2}{*}{ CHEMBL1309984 } & 688620 & 4.8 & 5.2392 & TST & \\
\hline & & \multicolumn{4}{|c|}{ Page 26637} \\
\hline
\end{tabular}




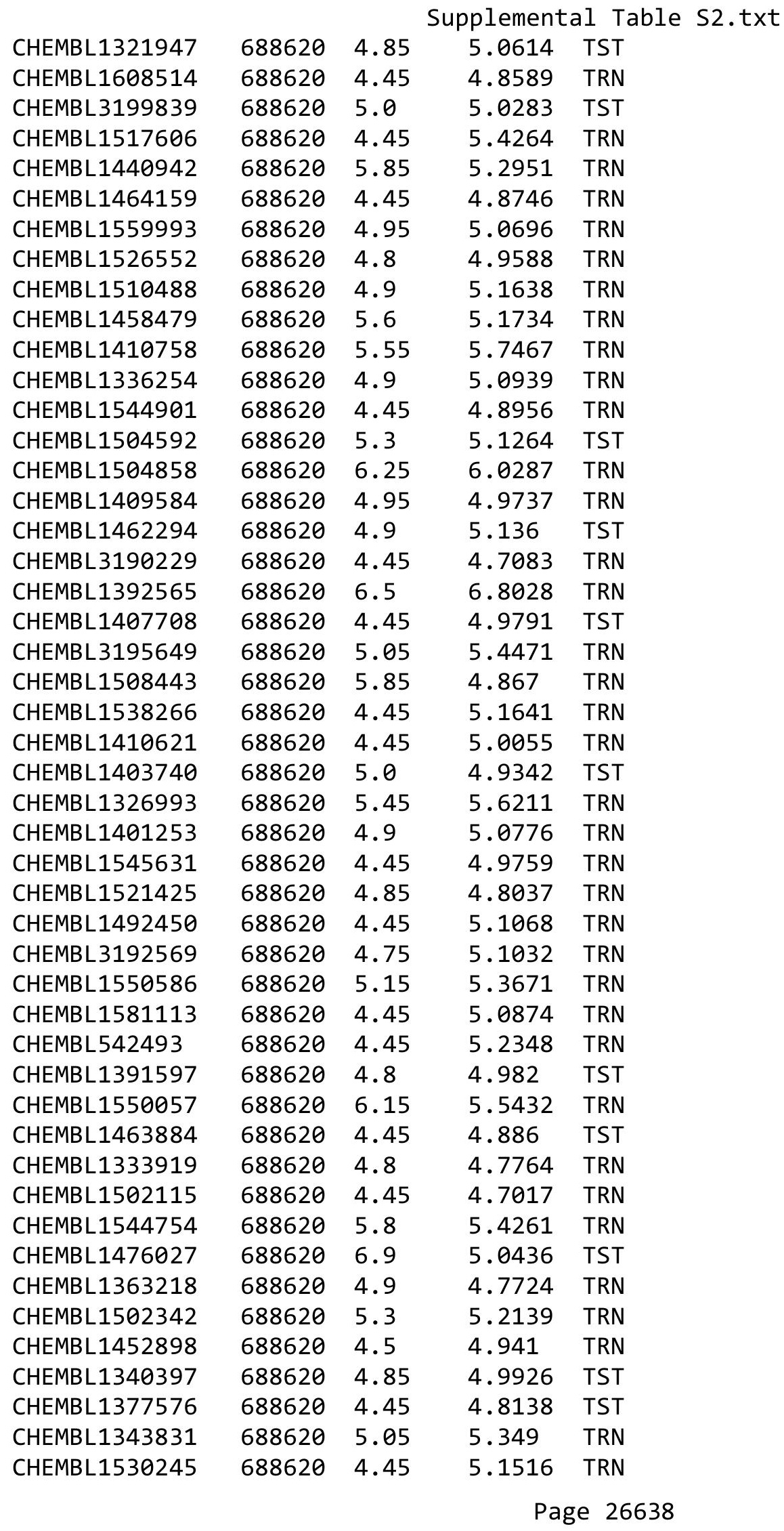




\begin{tabular}{|c|c|c|c|c|}
\hline \multicolumn{5}{|c|}{ Supplemental Table S2.txt } \\
\hline CHEMBL3196812 & 688620 & 5.05 & 4.9892 & TRN \\
\hline CHEMBL600255 & 688620 & 4.45 & 4.7912 & TRN \\
\hline CHEMBL1360916 & 688620 & 5.25 & 5.2268 & TRN \\
\hline CHEMBL1412433 & 688620 & 4.95 & 4.9894 & TRN \\
\hline CHEMBL1340858 & 688620 & 8.2007 & 5.2871 & TST \\
\hline CHEMBL1370403 & 688620 & 5.2 & 4.9458 & TST \\
\hline CHEMBL1399121 & 688620 & 4.65 & 4.7977 & TRN \\
\hline CHEMBL1530929 & 688620 & 4.8 & 4.9505 & TST \\
\hline CHEMBL 375530 & 688620 & 6.0 & 5.4974 & TRN \\
\hline CHEMBL1331257 & 688620 & 4.65 & 5.0935 & TRN \\
\hline CHEMBL1497930 & 688620 & 5.0 & 5.1829 & TRN \\
\hline CHEMBL1522791 & 688620 & 4.45 & 5.2262 & TRN \\
\hline CHEMBL1442836 & 688620 & 4.85 & 5.0486 & TRN \\
\hline CHEMBL1424624 & 688620 & 4.85 & 5.1753 & TRN \\
\hline CHEMBL1495554 & 688620 & 4.85 & 4.9992 & TRN \\
\hline CHEMBL1459024 & 688620 & 5.6 & 4.91 & TRN \\
\hline CHEMBL1300812 & 688620 & 4.65 & 5.1413 & TRN \\
\hline CHEMBL1609267 & 688620 & 4.95 & 5.0111 & TRN \\
\hline CHEMBL1582725 & 688620 & 4.45 & 5.0633 & TRN \\
\hline CHEMBL1410587 & 688620 & 6.3 & 5.0372 & TRN \\
\hline CHEMBL3207562 & 688620 & 4.95 & 4.635 & TST \\
\hline CHEMBL1610478 & 688620 & 5.8 & 5.6201 & TRN \\
\hline CHEMBL1310238 & 688620 & 4.9 & 5.2518 & TST \\
\hline CHEMBL1528114 & 688620 & 4.65 & 5.047 & TRN \\
\hline CHEMBL1337727 & 688620 & 5.15 & 5.276 & TRN \\
\hline CHEMBL1491804 & 688620 & 5.6 & 5.0176 & TRN \\
\hline CHEMBL1603720 & 688620 & 4.45 & 4.7913 & TRN \\
\hline CHEMBL1458930 & 688620 & 5.55 & 5.4524 & TRN \\
\hline CHEMBL1580139 & 688620 & 5.15 & 5.0026 & TRN \\
\hline CHEMBL1556069 & 688620 & 4.45 & 4.9348 & TRN \\
\hline CHEMBL1480370 & 688620 & 4.75 & 4.9644 & TRN \\
\hline CHEMBL3192375 & 688620 & 4.85 & 5.0624 & TRN \\
\hline CHEMBL3199312 & 688620 & 4.95 & 4.9123 & TRN \\
\hline CHEMBL1564926 & 688620 & 5.6 & 5.1892 & TRN \\
\hline CHEMBL1419309 & 688620 & 5.75 & 5.5813 & TRN \\
\hline CHEMBL1420806 & 688620 & 6.25 & 5.0467 & TRN \\
\hline CHEMBL1412475 & 688620 & 5.35 & 5.1098 & TRN \\
\hline CHEMBL1466488 & 688620 & 4.5 & 4.8919 & TRN \\
\hline CHEMBL1577348 & 688620 & 4.85 & 4.9681 & TST \\
\hline CHEMBL1495092 & 688620 & 4.7 & 5.0064 & TST \\
\hline CHEMBL1568827 & 688620 & 5.35 & 5.1197 & TRN \\
\hline CHEMBL1415541 & 688620 & 5.3 & 5.1649 & TRN \\
\hline CHEMBL3208035 & 688620 & 6.25 & 5.8021 & TRN \\
\hline CHEMBL1386461 & 688620 & 4.45 & 5.3885 & TRN \\
\hline CHEMBL1488564 & 688620 & 4.7 & 4.9352 & TST \\
\hline CHEMBL1537103 & 688620 & 4.8 & 4.8379 & TRN \\
\hline CHEMBL1479574 & 688620 & 4.45 & 5.0402 & TRN \\
\hline CHEMBL1457823 & 688620 & 4.45 & 4.9443 & TRN \\
\hline
\end{tabular}




\begin{tabular}{|c|c|c|c|c|c|}
\hline \multicolumn{6}{|c|}{ Supplemental Table S2.txt } \\
\hline CHEMBL1400323 & 688620 & 6.05 & 5.0287 & TRN & \\
\hline CHEMBL 3198824 & 688620 & 4.8 & 5.1394 & TRN & \\
\hline CHEMBL1502512 & 688620 & 5.0 & 4.6258 & TRN & \\
\hline CHEMBL1331739 & 688620 & 5.05 & 5.1366 & TRN & \\
\hline CHEMBL1481358 & 688620 & 4.9 & 5.2153 & TRN & \\
\hline CHEMBL1966684 & 688620 & 5.6 & 5.5923 & TRN & \\
\hline CHEMBL1453572 & 688620 & 7.0 & 6.145 & TRN & \\
\hline CHEMBL1306720 & 688620 & 5.55 & 5.3622 & TRN & \\
\hline CHEMBL1466798 & 688620 & 4.45 & 5.3093 & TRN & \\
\hline CHEMBL1580362 & 688620 & 4.95 & 5.1908 & TRN & \\
\hline CHEMBL1455793 & 688620 & 4.95 & 4.8272 & TRN & \\
\hline CHEMBL1452349 & 688620 & 5.45 & 5.2535 & TRN & \\
\hline CHEMBL1579471 & 688620 & 4.5 & 4.6721 & TRN & \\
\hline CHEMBL1608844 & 688620 & 5.35 & 5.0981 & TST & \\
\hline CHEMBL1383666 & 688620 & 4.85 & 5.3351 & TRN & \\
\hline CHEMBL1550538 & 688620 & 5.15 & 5.3149 & TRN & \\
\hline CHEMBL1564962 & 688620 & 5.1 & 4.81 & TRN & \\
\hline CHEMBL1330304 & 688620 & 4.45 & 4.9567 & TST & \\
\hline CHEMBL1479816 & 688620 & 4.95 & 4.89 & TRN & \\
\hline CHEMBL1550620 & 688620 & 4.9 & 5.1537 & TRN & \\
\hline CHEMBL1360884 & 688620 & 4.95 & 4.9679 & TRN & \\
\hline CHEMBL1594372 & 688620 & 4.45 & 4.9313 & TRN & \\
\hline CHEMBL1582893 & 688620 & 4.45 & 4.998 & TRN & \\
\hline CHEMBL1322755 & 688620 & 5.2 & 4.8502 & TST & \\
\hline CHEMBL3212018 & 688620 & 4.6 & 4.8894 & TST & \\
\hline CHEMBL1492365 & 688620 & 4.9 & 4.8808 & TRN & \\
\hline CHEMBL1344786 & 688620 & 4.85 & 5.2194 & TRN & \\
\hline CHEMBL1376345 & 688620 & 5.65 & 4.8911 & TRN & \\
\hline CHEMBL1426358 & 688620 & 5.7 & 5.0159 & TST & \\
\hline CHEMBL1416398 & 688620 & 4.85 & 5.1174 & TRN & \\
\hline CHEMBL547304 & 688620 & 4.7 & 5.0275 & TST & \\
\hline CHEMBL1466373 & 688620 & 7.1002 & 5.03100 & 0000000001 & TRN \\
\hline CHEMBL1399767 & 688620 & 5.25 & 5.3447 & TRN & \\
\hline CHEMBL1334038 & 688620 & 5.0 & 4.8793 & TRN & \\
\hline CHEMBL1548234 & 688620 & 4.5 & 4.7641 & TRN & \\
\hline CHEMBL1519626 & 688620 & 4.9 & 5.1413 & TRN & \\
\hline CHEMBL 3208807 & 688620 & 4.75 & 4.8159 & TRN & \\
\hline CHEMBL1492412 & 688620 & 5.9 & 5.4756 & TRN & \\
\hline CHEMBL1560485 & 688620 & 4.95 & 5.0419 & TRN & \\
\hline CHEMBL1560072 & 688620 & 6.2 & 5.7485 & TRN & \\
\hline CHEMBL1403276 & 688620 & 5.85 & 5.8483 & TRN & \\
\hline CHEMBL3190702 & 688620 & 5.65 & 5.2847 & TRN & \\
\hline CHEMBL1470538 & 688620 & 5.6 & 5.3044 & TRN & \\
\hline CHEMBL1431977 & 688620 & 4.45 & 5.314 & TRN & \\
\hline CHEMBL1463827 & 688620 & 4.7 & 5.0799 & TRN & \\
\hline CHEMBL1583414 & 688620 & 6.95 & 5.1503 & TRN & \\
\hline CHEMBL1462135 & 688620 & 6.7501 & 5.0102 & TST & \\
\hline CHEMBL1594699 & 688620 & 6.1 & 4.9641 & TRN & \\
\hline
\end{tabular}




\begin{tabular}{|c|c|c|c|c|c|}
\hline \multicolumn{6}{|c|}{ Supplemental Table S2.txt } \\
\hline CHEMBL1425043 & 688620 & 4.75 & 5.1134 & TST & \\
\hline CHEMBL1417267 & 688620 & 4.75 & 4.8737 & TRN & \\
\hline CHEMBL1327069 & 688620 & 5.0 & 6.154 & TRN & \\
\hline CHEMBL1413660 & 688620 & 5.6 & 5.2373 & TST & \\
\hline CHEMBL1548139 & 688620 & 5.4 & 4.9874 & TRN & \\
\hline CHEMBL1388402 & 688620 & 4.45 & 4.9692 & TRN & \\
\hline CHEMBL1521700 & 688620 & 5.0 & 5.069 & TST & \\
\hline CHEMBL1523317 & 688620 & 4.9 & 5.1066 & TST & \\
\hline CHEMBL1613510 & 688620 & 4.45 & 4.7767 & TRN & \\
\hline CHEMBL1510882 & 688620 & 4.45 & 4.9231 & TRN & \\
\hline CHEMBL1299911 & 688620 & 4.75 & 5.16100 & 00000000005 & TRN \\
\hline CHEMBL1428310 & 688620 & 5.8 & 5.0085 & TST & \\
\hline CHEMBL3192475 & 688620 & 5.05 & 5.0524 & TRN & \\
\hline CHEMBL1525316 & 688620 & 4.7 & 5.1585 & TRN & \\
\hline CHEMBL1486702 & 688620 & 5.5 & 5.28 & TRN & \\
\hline CHEMBL1537297 & 688620 & 4.85 & 4.9626 & TRN & \\
\hline CHEMBL1340895 & 688620 & 4.65 & 5.0446 & TRN & \\
\hline CHEMBL1393594 & 688620 & 5.0 & 5.6133 & TST & \\
\hline CHEMBL1348484 & 688620 & 4.8 & 4.9471 & TRN & \\
\hline CHEMBL1451585 & 688620 & 4.85 & 5.0124 & TRN & \\
\hline CHEMBL1468164 & 688620 & 5.1 & 5.2773 & TST & \\
\hline CHEMBL1611110 & 688620 & 4.45 & 4.9649 & TRN & \\
\hline CHEMBL3190119 & 688620 & 5.45 & 5.6271 & TRN & \\
\hline CHEMBL1433189 & 688620 & 4.45 & 5.1657 & TRN & \\
\hline CHEMBL3214237 & 688620 & 5.2 & 5.0982 & TST & \\
\hline CHEMBL1530414 & 688620 & 4.95 & 4.8618 & TRN & \\
\hline CHEMBL1493956 & 688620 & 5.5 & 5.4401 & TRN & \\
\hline CHEMBL3194373 & 688620 & 5.55 & 4.7848 & TRN & \\
\hline CHEMBL1350144 & 688620 & 4.9 & 5.0831 & TRN & \\
\hline CHEMBL1444442 & 688620 & 5.2 & 4.8202 & TRN & \\
\hline CHEMBL1580352 & 688620 & 4.5 & 5.2205 & TRN & \\
\hline CHEMBL3198512 & 688620 & 5.3 & 5.2861 & TRN & \\
\hline CHEMBL1444730 & 688620 & 4.85 & 5.0328 & TRN & \\
\hline CHEMBL1303830 & 688620 & 4.7 & 4.9243 & TRN & \\
\hline CHEMBL1580181 & 688620 & 5.1 & 5.1798 & TST & \\
\hline CHEMBL1368398 & 688620 & 5.05 & 4.9477 & TST & \\
\hline CHEMBL1432590 & 688620 & 4.45 & 5.0106 & TRN & \\
\hline CHEMBL1600654 & 688620 & 5.3 & 5.3577 & TRN & \\
\hline CHEMBL1411044 & 688620 & 5.2 & 4.86100 & 0000000001 & TST \\
\hline CHEMBL1613574 & 688620 & 4.45 & 4.81800 & 00000000005 & TRN \\
\hline CHEMBL1341179 & 688620 & 5.0 & 4.9381 & TRN & \\
\hline CHEMBL1403137 & 688620 & 4.9 & 4.914 & TRN & \\
\hline CHEMBL1489348 & 688620 & 5.0 & 4.9752 & TST & \\
\hline CHEMBL405686 & 688620 & 4.45 & 5.0392 & TRN & \\
\hline CHEMBL1594363 & 688620 & 4.9 & 5.0474 & TST & \\
\hline CHEMBL1302428 & 688620 & 4.45 & 4.9912 & TRN & \\
\hline CHEMBL1303668 & 688620 & 4.9 & 5.1034 & TST & \\
\hline CHEMBL1582654 & 688620 & 5.05 & 5.3176 & TRN & \\
\hline
\end{tabular}




\begin{tabular}{|c|c|c|c|c|c|}
\hline & & \multicolumn{4}{|c|}{ Supplemental Table s2.txt } \\
\hline CHEMBL1496611 & 688620 & 4.95 & 5.1928 & TRN & \\
\hline CHEMBL1368008 & 688620 & 5.3 & 5.08 & TRN & \\
\hline CHEMBL1980665 & 688620 & 5.75 & 5.4416 & TRN & \\
\hline CHEMBL1985045 & 688620 & 5.55 & 5.3286 & TRN & \\
\hline CHEMBL1424408 & 688620 & 4.65 & 4.7866 & TST & \\
\hline CHEMBL1556637 & 688620 & 4.95 & 5.0432 & TST & \\
\hline CHEMBL1354548 & 688620 & 5.5 & 4.9716 & TST & \\
\hline CHEMBL1404327 & 688620 & 5.6 & 5.4657 & TST & \\
\hline CHEMBL1311392 & 688620 & 5.8 & 5.574 & TRN & \\
\hline CHEMBL1561766 & 688620 & 4.45 & 4.8662 & TRN & \\
\hline CHEMBL1509175 & 688620 & 5.45 & 5.1942 & TRN & \\
\hline CHEMBL1434149 & 688620 & 4.95 & 5.4349 & TRN & \\
\hline CHEMBL1349167 & 688620 & 4.45 & 5.0194 & TRN & \\
\hline CHEMBL1417801 & 688620 & 5.05 & 5.1133 & TRN & \\
\hline CHEMBL1534330 & 688620 & 5.35 & 5.2079 & TRN & \\
\hline CHEMBL1331822 & 688620 & 4.8 & 4.9546 & TST & \\
\hline CHEMBL1306540 & 688620 & 4.85 & 5.0952 & TRN & \\
\hline CHEMBL1466104 & 688620 & 5.55 & 5.0292 & TRN & \\
\hline CHEMBL1475142 & 688620 & 4.85 & 5.09399 & 7999999999 & TRN \\
\hline CHEMBL1500654 & 688620 & 5.25 & 5.2029 & TRN & \\
\hline CHEMBL1499999 & 688620 & 4.9 & 4.9311 & TST & \\
\hline CHEMBL1474680 & 688620 & 4.45 & 4.9696 & TST & \\
\hline CHEMBL1489984 & 688620 & 5.1 & 4.9155 & TST & \\
\hline CHEMBL1431792 & 688620 & 5.15 & 5.1097 & TST & \\
\hline CHEMBL3210927 & 688620 & 5.25 & 5.0345 & TRN & \\
\hline CHEMBL3197434 & 688620 & 4.55 & 4.8324 & TRN & \\
\hline CHEMBL1379390 & 688620 & 5.2 & 5.0861 & TRN & \\
\hline CHEMBL1535326 & 688620 & 4.95 & 5.1377 & TST & \\
\hline CHEMBL1566088 & 688620 & 5.5 & 4.9793 & TST & \\
\hline CHEMBL1572330 & 688620 & 6.0 & 5.5686 & TRN & \\
\hline CHEMBL1575552 & 688620 & 4.75 & 4.8067 & TRN & \\
\hline CHEMBL1455566 & 688620 & 4.45 & 5.0206 & TST & \\
\hline CHEMBL1588586 & 688620 & 4.65 & 4.8094 & TRN & \\
\hline CHEMBL1347230 & 688620 & 4.85 & 4.9533 & TRN & \\
\hline CHEMBL1388526 & 688620 & 4.95 & 4.8183 & TRN & \\
\hline CHEMBL1595476 & 688620 & 4.95 & 4.9006 & TRN & \\
\hline CHEMBL1409629 & 688620 & 4.9 & 4.7936 & TRN & \\
\hline CHEMBL1348703 & 688620 & 5.85 & 4.8844 & TST & \\
\hline CHEMBL1410438 & 688620 & 4.8 & 4.8718 & TRN & \\
\hline CHEMBL1607529 & 688620 & 5.05 & 5.0293 & TRN & \\
\hline CHEMBL1548519 & 688620 & 4.85 & 5.1663 & TRN & \\
\hline CHEMBL1555816 & 688620 & 4.7 & 5.0212 & TRN & \\
\hline CHEMBL1525969 & 688620 & 5.6 & 5.2314 & TRN & \\
\hline CHEMBL1584371 & 688620 & 4.9 & 4.8733 & TRN & \\
\hline CHEMBL1501339 & 688620 & 4.65 & 5.0723 & TRN & \\
\hline CHEMBL1400703 & 688620 & 5.0 & 5.0397 & TRN & \\
\hline CHEMBL1519672 & 688620 & 5.0 & 5.2133 & TRN & \\
\hline CHEMBL1386429 & 688620 & 5.85 & 5.2333 & TRN & \\
\hline
\end{tabular}




\begin{tabular}{|c|c|c|c|c|c|}
\hline & & \multicolumn{4}{|c|}{ Supplemental Table s2.txt } \\
\hline CHEMBL1306051 & 688620 & 4.95 & 4.8375 & TRN & \\
\hline CHEMBL3195003 & 688620 & 4.9 & 5.365 & TST & \\
\hline CHEMBL1580472 & 688620 & 5.1 & 5.0895 & TRN & \\
\hline CHEMBL1480625 & 688620 & 5.5 & 4.7924 & TST & \\
\hline CHEMBL1452171 & 688620 & 5.05 & 4.7998 & TRN & \\
\hline CHEMBL1578645 & 688620 & 4.95 & 4.9177 & TRN & \\
\hline CHEMBL104560 & 688620 & 4.95 & 4.8508 & TRN & \\
\hline CHEMBL1479829 & 688620 & 4.5 & 5.0208 & TRN & \\
\hline CHEMBL1318808 & 688620 & 4.9 & 4.8917 & TRN & \\
\hline CHEMBL1301764 & 688620 & 5.3 & 4.8738 & TST & \\
\hline CHEMBL1387054 & 688620 & 4.95 & 5.0938 & TRN & \\
\hline CHEMBL1340120 & 688620 & 4.75 & 5.0677 & TRN & \\
\hline CHEMBL3191640 & 688620 & 4.8 & 4.9065 & TST & \\
\hline CHEMBL1489022 & 688620 & 5.9 & 4.9977 & TRN & \\
\hline CHEMBL1459476 & 688620 & 4.45 & 5.0847 & TST & \\
\hline CHEMBL1373785 & 688620 & 4.85 & 5.0206 & TRN & \\
\hline CHEMBL1331943 & 688620 & 4.5 & 5.0576 & TRN & \\
\hline CHEMBL1302527 & 688620 & 4.9 & 5.0615 & TRN & \\
\hline CHEMBL1566568 & 688620 & 4.95 & 5.1538 & TRN & \\
\hline CHEMBL1606787 & 688620 & 4.45 & 5.1178 & TRN & \\
\hline CHEMBL1568715 & 688620 & 4.9 & 4.9669 & TST & \\
\hline CHEMBL3392058 & 688620 & 4.95 & 4.9089 & TRN & \\
\hline CHEMBL1256749 & 688620 & 4.5 & 4.8399 & TST & \\
\hline CHEMBL1586205 & 688620 & 6.3 & 5.1046 & TST & \\
\hline CHEMBL3210545 & 688620 & 5.05 & 4.9552 & TST & \\
\hline CHEMBL1403800 & 688620 & 5.2 & 4.8898 & TRN & \\
\hline CHEMBL409695 & 688620 & 4.5 & 4.8711 & TRN & \\
\hline CHEMBL1471444 & 688620 & 6.9 & 5.12200 & 0000000001 & TRN \\
\hline CHEMBL1542846 & 688620 & 5.2 & 5.1188 & TST & \\
\hline CHEMBL1518566 & 688620 & 4.6 & 4.9256 & TRN & \\
\hline CHEMBL1384181 & 688620 & 4.75 & 4.8854 & TRN & \\
\hline CHEMBL1487135 & 688620 & 5.15 & 5.3473 & TRN & \\
\hline CHEMBL1299575 & 688620 & 5.3 & 5.1077 & TRN & \\
\hline CHEMBL1411389 & 688620 & 4.45 & 5.0721 & TRN & \\
\hline CHEMBL1583582 & 688620 & 5.5 & 5.2321 & TRN & \\
\hline CHEMBL1406826 & 688620 & 4.45 & 4.8179 & TRN & \\
\hline CHEMBL1416937 & 688620 & 5.35 & 5.2495 & TST & \\
\hline CHEMBL1346568 & 688620 & 6.95 & 4.9171 & TRN & \\
\hline CHEMBL1603074 & 688620 & 4.9 & 5.0302 & TRN & \\
\hline CHEMBL1548657 & 688620 & 4.95 & 5.0507 & TRN & \\
\hline CHEMBL1310577 & 688620 & 5.0 & 5.0062 & TRN & \\
\hline CHEMBL1348618 & 688620 & 5.7 & 4.8136 & TST & \\
\hline CHEMBL1542692 & 688620 & 4.95 & 4.9123 & TRN & \\
\hline CHEMBL1395840 & 688620 & 4.7 & 5.3835 & TRN & \\
\hline CHEMBL1509244 & 688620 & 4.9 & 4.9683 & TRN & \\
\hline CHEMBL1363615 & 688620 & 6.3 & 5.6755 & TRN & \\
\hline CHEMBL1550269 & 688620 & 4.8 & 5.1389 & TRN & \\
\hline CHEMBL3197010 & 688620 & 4.85 & 5.0158 & TRN & \\
\hline
\end{tabular}




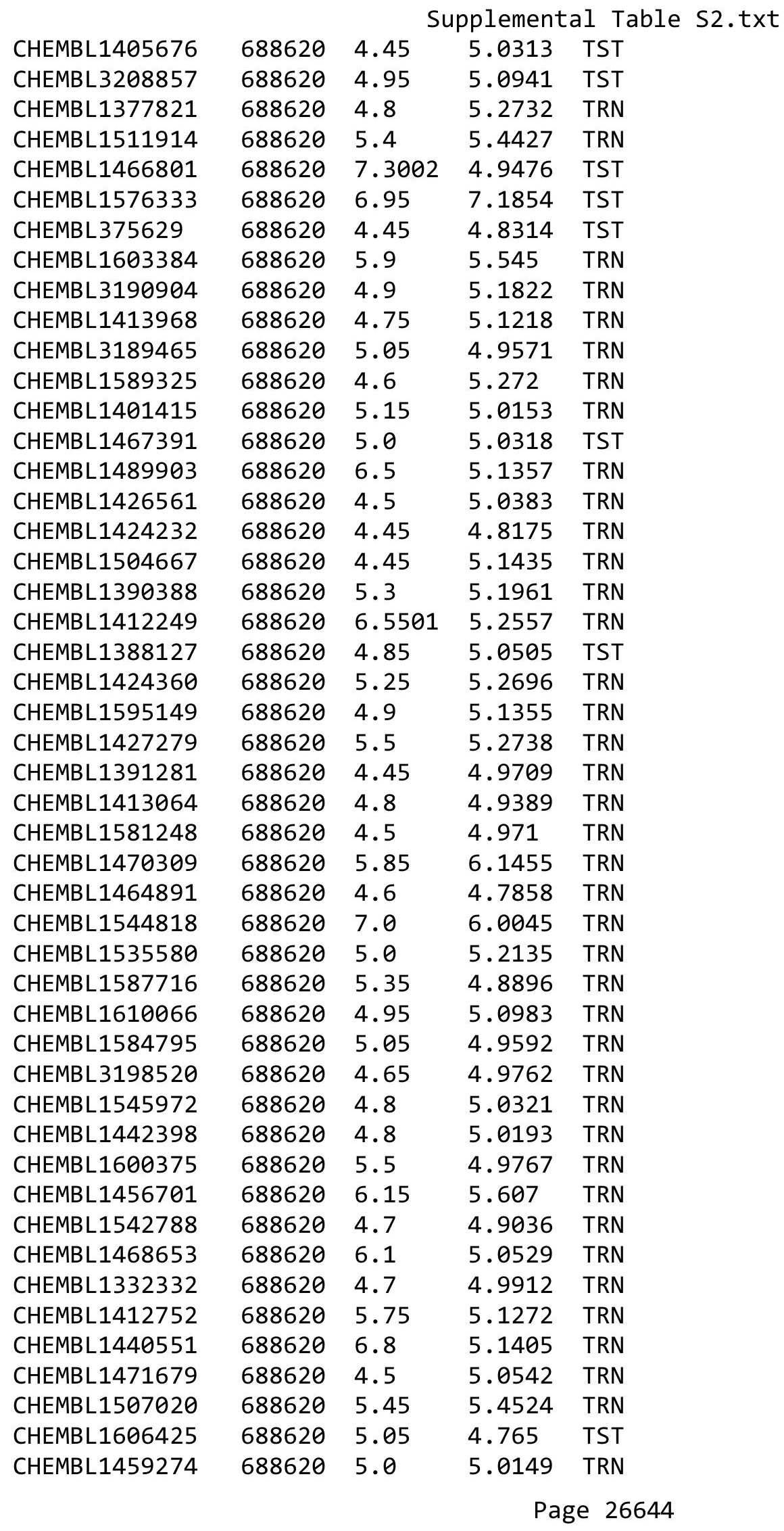




\begin{tabular}{|c|c|c|c|c|c|}
\hline & & & & & \\
\hline CHEMBL1348752 & 688620 & 4.7 & 5.2283 & TST & \\
\hline CHEMBL1524967 & 688620 & 4.55 & 5.1201 & TRN & \\
\hline CHEMBL1448780 & 688620 & 5.7 & 5.4082 & TRN & \\
\hline CHEMBL1327593 & 688620 & 5.5 & 5.1018 & TRN & \\
\hline CHEMBL1612634 & 688620 & 4.9 & 5.0752 & TRN & \\
\hline CHEMBL1466538 & 688620 & 4.45 & 4.953 & TST & \\
\hline CHEMBL1432977 & 688620 & 4.85 & 5.1193 & TST & \\
\hline CHEMBL1322588 & 688620 & 8.2518 & 5.0727 & TRN & \\
\hline CHEMBL1387834 & 688620 & 4.45 & 4.8657 & TRN & \\
\hline CHEMBL1326041 & 688620 & 4.9 & 4.97199 & 99999999995 & TRN \\
\hline CHEMBL1517604 & 688620 & 4.45 & 4.7941 & TRN & \\
\hline CHEMBL1533990 & 688620 & 5.6 & 5.0862 & TRN & \\
\hline CHEMBL1578978 & 688620 & 6.0 & 5.4495 & TST & \\
\hline CHEMBL1525888 & 688620 & 4.95 & 5.1765 & TRN & \\
\hline CHEMBL1349053 & 688620 & 5.2 & 5.0707 & TST & \\
\hline CHEMBL1581818 & 688620 & 4.45 & 4.7919 & TST & \\
\hline CHEMBL1539148 & 688620 & 5.5 & 5.4429 & TRN & \\
\hline CHEMBL1494558 & 688620 & 4.9 & 5.2009 & TRN & \\
\hline CHEMBL1361940 & 688620 & 4.9 & 5.0564 & TRN & \\
\hline CHEMBL1567269 & 688620 & 5.7 & 4.9003 & TRN & \\
\hline CHEMBL1532755 & 688620 & 5.8 & 5.6717 & TRN & \\
\hline CHEMBL1507648 & 688620 & 5.05 & 4.9198 & TST & \\
\hline CHEMBL1350066 & 688620 & 4.75 & 4.7656 & TRN & \\
\hline CHEMBL1529154 & 688620 & 4.6 & 5.0947 & TST & \\
\hline CHEMBL3192554 & 688620 & 4.45 & 5.0517 & TRN & \\
\hline CHEMBL1544404 & 688620 & 4.95 & 5.0166 & TST & \\
\hline CHEMBL1526479 & 688620 & 4.7 & 4.7531 & TRN & \\
\hline CHEMBL 3208587 & 688620 & 4.45 & 5.2499 & TRN & \\
\hline CHEMBL1996778 & 688620 & 5.0 & 5.1247 & TST & \\
\hline CHEMBL117804 & 688620 & 5.95 & 5.8249 & TRN & \\
\hline CHEMBL1368413 & 688620 & 5.45 & 5.553 & TRN & \\
\hline CHEMBL1508055 & 688620 & 5.55 & 5.4694 & TRN & \\
\hline CHEMBL1478682 & 688620 & 4.95 & 5.1557 & TRN & \\
\hline CHEMBL1534109 & 688620 & 4.5 & 4.7847 & TRN & \\
\hline CHEMBL1424762 & 688620 & 5.0 & 4.9353 & TRN & \\
\hline CHEMBL1321578 & 688620 & 4.45 & 5.268 & TRN & \\
\hline CHEMBL1348205 & 688620 & 4.8 & 5.0249 & TRN & \\
\hline CHEMBL1420502 & 688620 & 4.75 & 4.9942 & TRN & \\
\hline CHEMBL1321268 & 688620 & 4.95 & 5.0207 & TRN & \\
\hline CHEMBL1343029 & 688620 & 4.95 & 5.0777 & TRN & \\
\hline CHEMBL1330991 & 688620 & 5.0 & 5.2094 & TRN & \\
\hline CHEMBL1364654 & 688620 & 5.6 & 5.026 & TRN & \\
\hline CHEMBL 2001983 & 688620 & 6.4 & 4.9438 & TRN & \\
\hline CHEMBL1300404 & 688620 & 5.2 & 4.9576 & TRN & \\
\hline CHEMBL1509913 & 688620 & 5.4 & 5.0404 & TRN & \\
\hline CHEMBL1611978 & 688620 & 4.7 & 5.0544 & TRN & \\
\hline CHEMBL1381299 & 688620 & 4.45 & 5.0219 & TST & \\
\hline CHEMBL3192527 & 688620 & 5.0 & 5.0316 & TRN & \\
\hline
\end{tabular}




\begin{tabular}{|c|c|c|c|c|}
\hline \multicolumn{5}{|c|}{ Supplemental Table S2.txt } \\
\hline CHEMBL1405651 & 688620 & 5.0 & 5.0139 & TRN \\
\hline CHEMBL1592571 & 688620 & 5.1 & 5.2931 & TRN \\
\hline CHEMBL3195898 & 688620 & 6.2 & 5.7583 & TRN \\
\hline CHEMBL1377737 & 688620 & 5.95 & 5.4656 & TRN \\
\hline CHEMBL1301948 & 688620 & 4.95 & 4.7345 & TRN \\
\hline CHEMBL1320819 & 688620 & 5.3 & 5.0171 & TRN \\
\hline CHEMBL1426370 & 688620 & 4.45 & 4.7936 & TRN \\
\hline CHEMBL1397184 & 688620 & 4.5 & 4.9749 & TST \\
\hline CHEMBL1536183 & 688620 & 5.35 & 4.7883 & TRN \\
\hline CHEMBL1364221 & 688620 & 4.9 & 5.0398 & TRN \\
\hline CHEMBL 260283 & 688620 & 4.45 & 4.8614 & TRN \\
\hline CHEMBL1580882 & 688620 & 4.45 & 4.9994 & TRN \\
\hline CHEMBL1428960 & 688620 & 6.35 & 6.2104 & TRN \\
\hline CHEMBL1429565 & 688620 & 4.9 & 4.9673 & TRN \\
\hline CHEMBL1527082 & 688620 & 5.65 & 5.4728 & TRN \\
\hline CHEMBL1438842 & 688620 & 5.05 & 5.1971 & TRN \\
\hline CHEMBL1334538 & 688620 & 4.5 & 5.1791 & TST \\
\hline CHEMBL1423799 & 688620 & 4.45 & 4.7161 & TRN \\
\hline CHEMBL1310715 & 688620 & 4.45 & 5.0275 & TRN \\
\hline CHEMBL1361609 & 688620 & 4.55 & 5.2136 & TST \\
\hline CHEMBL1569978 & 688620 & 5.2 & 5.091 & TRN \\
\hline CHEMBL1362688 & 688620 & 5.6 & 5.0267 & TRN \\
\hline CHEMBL1300899 & 688620 & 5.9 & 5.2654 & TST \\
\hline CHEMBL1583283 & 688620 & 4.65 & 4.9219 & TRN \\
\hline CHEMBL1303619 & 688620 & 5.5 & 5.1668 & TST \\
\hline CHEMBL1359156 & 688620 & 4.45 & 5.0825 & TRN \\
\hline CHEMBL1977555 & 688620 & 4.45 & 5.1591 & TRN \\
\hline CHEMBL1368666 & 688620 & 5.45 & 5.1754 & TRN \\
\hline CHEMBL1562713 & 688620 & 5.0 & 5.2557 & TST \\
\hline CHEMBL3210113 & 688620 & 6.0 & 5.4453 & TRN \\
\hline CHEMBL1487284 & 688620 & 5.65 & 4.8617 & TST \\
\hline CHEMBL1421312 & 688620 & 5.45 & 5.0412 & TRN \\
\hline CHEMBL3197954 & 688620 & 6.8 & 5.1265 & TRN \\
\hline CHEMBL1391851 & 688620 & 4.95 & 5.1844 & TRN \\
\hline CHEMBL1534392 & 688620 & 4.85 & 4.8927 & TST \\
\hline CHEMBL541231 & 688620 & 4.55 & 5.1435 & TST \\
\hline CHEMBL 1498058 & 688620 & 4.9 & 5.0456 & TST \\
\hline CHEMBL1415031 & 688620 & 4.65 & 5.1646 & TRN \\
\hline CHEMBL1421857 & 688620 & 5.45 & 4.9134 & TST \\
\hline CHEMBL1550184 & 688620 & 5.15 & 5.2483 & TRN \\
\hline CHEMBL1535952 & 688620 & 5.7 & 5.2452 & TRN \\
\hline CHEMBL1347855 & 688620 & 4.8 & 5.0827 & TST \\
\hline CHEMBL1993711 & 688620 & 4.45 & 4.7478 & TRN \\
\hline CHEMBL1590132 & 688620 & 4.95 & 4.7388 & TRN \\
\hline CHEMBL1500966 & 688620 & 4.95 & 4.9996 & TRN \\
\hline CHEMBL3213905 & 688620 & 4.8 & 4.8686 & TRN \\
\hline CHEMBL534535 & 688620 & 4.45 & 4.7833 & TST \\
\hline CHEMBL3199217 & 688620 & 4.95 & 4.7796 & TRN \\
\hline
\end{tabular}




\begin{tabular}{|c|c|c|c|c|}
\hline \multicolumn{5}{|c|}{ Supplemental Table S2.txt } \\
\hline CHEMBL1363285 & 688620 & 5.2 & 5.0248 & TRN \\
\hline CHEMBL1311514 & 688620 & 4.45 & 4.8229 & TRN \\
\hline CHEMBL1509241 & 688620 & 8.301 & 5.3169 & TST \\
\hline CHEMBL1384209 & 688620 & 6.8499 & 4.9237 & TRN \\
\hline CHEMBL3213412 & 688620 & 4.45 & 5.1041 & TRN \\
\hline CHEMBL1526249 & 688620 & 5.4 & 6.0375 & TRN \\
\hline CHEMBL1335851 & 688620 & 5.3 & 5.4519 & TRN \\
\hline CHEMBL1528376 & 688620 & 4.85 & 4.8811 & TRN \\
\hline CHEMBL1346783 & 688620 & 4.65 & 4.8851 & TRN \\
\hline CHEMBL1422160 & 688620 & 5.05 & 5.3455 & TRN \\
\hline CHEMBL1392142 & 688620 & 5.45 & 5.3077 & TRN \\
\hline CHEMBL1549419 & 688620 & 5.0 & 5.2119 & TRN \\
\hline CHEMBL1602489 & 688620 & 4.45 & 4.8693 & TST \\
\hline CHEMBL1581116 & 688620 & 6.05 & 6.3552 & TRN \\
\hline CHEMBL2369275 & 688620 & 5.55 & 5.1603 & TRN \\
\hline CHEMBL1595274 & 688620 & 5.0 & 5.919 & TRN \\
\hline CHEMBL1504307 & 688620 & 5.0 & 4.9261 & TRN \\
\hline CHEMBL1480031 & 688620 & 5.55 & 5.3037 & TRN \\
\hline CHEMBL1342291 & 688620 & 4.65 & 4.8568 & TST \\
\hline CHEMBL1338747 & 688620 & 5.3 & 5.2839 & TST \\
\hline CHEMBL1305854 & 688620 & 5.8 & 5.4233 & TRN \\
\hline CHEMBL1496814 & 688620 & 4.65 & 5.2822 & TRN \\
\hline CHEMBL1424415 & 688620 & 5.05 & 4.9196 & TRN \\
\hline CHEMBL1503418 & 688620 & 4.8 & 5.0119 & TRN \\
\hline CHEMBL1359720 & 688620 & 4.45 & 5.1186 & TRN \\
\hline CHEMBL1470949 & 688620 & 5.0 & 5.1082 & TRN \\
\hline CHEMBL3209757 & 688620 & 5.35 & 5.1101 & TRN \\
\hline CHEMBL1343485 & 688620 & 6.0 & 5.3965 & TRN \\
\hline CHEMBL1445654 & 688620 & 4.85 & 4.7063 & TRN \\
\hline CHEMBL3190974 & 688620 & 5.55 & 5.2078 & TST \\
\hline CHEMBL1505519 & 688620 & 5.8 & 5.6244 & TRN \\
\hline CHEMBL1429738 & 688620 & 4.95 & 5.2475 & TRN \\
\hline CHEMBL1405760 & 688620 & 4.7 & 4.7497 & TRN \\
\hline CHEMBL1561860 & 688620 & 4.8 & 4.9462 & TRN \\
\hline CHEMBL3195742 & 688620 & 6.45 & 6.0602 & TRN \\
\hline CHEMBL1391917 & 688620 & 4.95 & 5.1586 & TRN \\
\hline CHEMBL3193378 & 688620 & 5.95 & 6.527 & TRN \\
\hline CHEMBL1521798 & 688620 & 4.95 & 4.8917 & TRN \\
\hline CHEMBL1448566 & 688620 & 4.5 & 4.801 & TRN \\
\hline CHEMBL1334481 & 688620 & 4.45 & 4.9695 & TRN \\
\hline CHEMBL1497972 & 688620 & 5.45 & 5.0335 & TST \\
\hline CHEMBL1422005 & 688620 & 5.75 & 5.0044 & TST \\
\hline CHEMBL1462256 & 688620 & 5.5 & 4.9395 & TST \\
\hline CHEMBL1496984 & 688620 & 5.85 & 5.1434 & TRN \\
\hline CHEMBL3195455 & 688620 & 4.9 & 4.8617 & TST \\
\hline CHEMBL1580871 & 688620 & 6.5 & 5.0188 & TRN \\
\hline CHEMBL1613477 & 688620 & 5.2 & 4.8343 & TST \\
\hline CHEMBL1373166 & 688620 & 4.8 & 5.0007 & TRN \\
\hline
\end{tabular}




\begin{tabular}{|c|c|c|c|c|c|}
\hline \multicolumn{6}{|c|}{ Supplemental Table s2.txt } \\
\hline CHEMBL1497800 & 688620 & 6.35 & 5.0622 & TRN & \\
\hline CHEMBL1431036 & 688620 & 5.05 & 4.9068 & TRN & \\
\hline CHEMBL1490169 & 688620 & 5.15 & 5.2211 & TRN & \\
\hline CHEMBL1501932 & 688620 & 5.6 & 5.3245 & TRN & \\
\hline CHEMBL1351052 & 688620 & 5.25 & 5.1105 & TRN & \\
\hline CHEMBL1426107 & 688620 & 5.4 & 5.4889 & TRN & \\
\hline CHEMBL1519696 & 688620 & 5.5 & 4.9843 & TRN & \\
\hline CHEMBL1420307 & 688620 & 5.3 & 5.09 & TRN & \\
\hline CHEMBL1553195 & 688620 & 4.9 & 5.0203 & TST & \\
\hline CHEMBL1466669 & 688620 & 4.85 & 4.9179 & TRN & \\
\hline CHEMBL1306253 & 688620 & 4.65 & 4.9994 & TRN & \\
\hline CHEMBL1327715 & 688620 & 5.1 & 5.1976 & TRN & \\
\hline CHEMBL1450603 & 688620 & 4.9 & 4.954 & TRN & \\
\hline CHEMBL1344571 & 688620 & 5.0 & 4.9367 & TRN & \\
\hline CHEMBL3190674 & 688620 & 5.45 & 5.3175 & TRN & \\
\hline CHEMBL1469476 & 688620 & 4.95 & 5.1404 & TRN & \\
\hline CHEMBL1541684 & 688620 & 4.9 & 5.103 & TRN & \\
\hline CHEMBL 3198454 & 688620 & 4.8 & 5.0419 & TRN & \\
\hline CHEMBL1603420 & 688620 & 4.8 & 4.8786 & TRN & \\
\hline CHEMBL1548748 & 688620 & 4.9 & 5.2296 & TRN & \\
\hline CHEMBL1442264 & 688620 & 5.0 & 4.9562 & TRN & \\
\hline CHEMBL1367284 & 688620 & 4.9 & 5.4571 & TST & \\
\hline CHEMBL1308367 & 688620 & 4.95 & 4.8427 & TRN & \\
\hline CHEMBL1505566 & 688620 & 4.5 & 4.8765 & TRN & \\
\hline CHEMBL1574379 & 688620 & 5.25 & 5.0322 & TRN & \\
\hline CHEMBL1308511 & 688620 & 4.95 & 5.0688 & TRN & \\
\hline CHEMBL1358862 & 688620 & 4.75 & 5.1724 & TST & \\
\hline CHEMBL1459230 & 688620 & 5.4 & 5.2925 & TRN & \\
\hline CHEMBL1996363 & 688620 & 4.8 & 4.7136 & TST & \\
\hline CHEMBL1458961 & 688620 & 4.5 & 4.7661 & TRN & \\
\hline CHEMBL1356631 & 688620 & 5.6 & 5.2509 & TST & \\
\hline CHEMBL1442515 & 688620 & 4.9 & 5.0799 & TRN & \\
\hline CHEMBL3195464 & 688620 & 5.4 & 4.9919 & TRN & \\
\hline CHEMBL1419429 & 688620 & 4.45 & 5.1346 & TRN & \\
\hline CHEMBL1500651 & 688620 & 6.9 & 5.1087 & TST & \\
\hline CHEMBL1571260 & 688620 & 5.0 & 5.1592 & TRN & \\
\hline CHEMBL1303623 & 688620 & 6.1 & 5.1029 & TRN & \\
\hline CHEMBL1412332 & 688620 & 4.45 & 5.0814 & TRN & \\
\hline CHEMBL1432065 & 688620 & 6.1 & 5.6421 & TST & \\
\hline CHEMBL1452063 & 688620 & 5.15 & 5.1876 & TRN & \\
\hline CHEMBL1531764 & 688620 & 5.6 & 5.1606 & TRN & \\
\hline CHEMBL1597103 & 688620 & 4.5 & 4.8224 & TRN & \\
\hline CHEMBL236899 & 688620 & 5.2 & 5.16299 & э999999999 & TRN \\
\hline CHEMBL3195732 & 688620 & 5.2 & 5.0951 & TRN & \\
\hline CHEMBL1369307 & 688620 & 4.45 & 4.6849 & TRN & \\
\hline CHEMBL1464122 & 688620 & 4.6 & 4.8065 & TST & \\
\hline CHEMBL1519076 & 688620 & 5.95 & 4.8706 & TRN & \\
\hline CHEMBL1593948 & 688620 & 5.85 & 5.1964 & TRN & \\
\hline
\end{tabular}




\begin{tabular}{|c|c|c|c|c|c|}
\hline \multicolumn{6}{|c|}{ Supplemental Table S2.txt } \\
\hline CHEMBL1312114 & 688620 & 5.25 & 5.0369 & TRN & \\
\hline CHEMBL1521261 & 688620 & 5.0 & 5.027 & TST & \\
\hline CHEMBL1538039 & 688620 & 5.0 & 4.9919 & TRN & \\
\hline CHEMBL1275655 & 688620 & 4.45 & 4.9627 & TST & \\
\hline CHEMBL1501506 & 688620 & 5.2 & 4.9612 & TST & \\
\hline CHEMBL1489308 & 688620 & 7.3497 & 4.872 & TST & \\
\hline CHEMBL1496143 & 688620 & 5.3 & 5.0509 & TRN & \\
\hline CHEMBL1368763 & 688620 & 4.85 & 5.0109 & TRN & \\
\hline CHEMBL1604633 & 688620 & 5.25 & 5.329 & TRN & \\
\hline CHEMBL1556395 & 688620 & 4.65 & 4.9376 & TST & \\
\hline CHEMBL1430257 & 688620 & 5.2 & 5.0324 & TRN & \\
\hline CHEMBL1588832 & 688620 & 5.2 & 5.5386 & TRN & \\
\hline CHEMBL1309265 & 688620 & 4.8 & 5.09399 & 9999999999 & TRN \\
\hline CHEMBL 3197545 & 688620 & 5.1 & 5.1911 & TST & \\
\hline CHEMBL1405668 & 688620 & 4.5 & 5.0162 & TST & \\
\hline CHEMBL1583175 & 688620 & 5.1 & 4.9796 & TRN & \\
\hline CHEMBL1449388 & 688620 & 4.65 & 5.0417 & TRN & \\
\hline CHEMBL1379491 & 688620 & 4.55 & 4.7673 & TRN & \\
\hline CHEMBL1425013 & 688620 & 5.0 & 4.9324 & TRN & \\
\hline CHEMBL1414513 & 688620 & 6.95 & 5.1369 & TRN & \\
\hline CHEMBL1595161 & 688620 & 4.65 & 4.8503 & TRN & \\
\hline CHEMBL1457634 & 688620 & 5.0 & 5.1943 & TRN & \\
\hline CHEMBL1319464 & 688620 & 4.65 & 4.9964 & TRN & \\
\hline CHEMBL1484499 & 688620 & 4.7 & 4.9595 & TRN & \\
\hline CHEMBL1576615 & 688620 & 5.0 & 4.9615 & TRN & \\
\hline CHEMBL1610782 & 688620 & 4.95 & 4.8033 & TRN & \\
\hline CHEMBL1612890 & 688620 & 4.55 & 4.8774 & TRN & \\
\hline CHEMBL1345746 & 688620 & 4.45 & 5.0617 & TRN & \\
\hline CHEMBL 3189725 & 688620 & 5.3 & 5.2718 & TRN & \\
\hline CHEMBL1455366 & 688620 & 5.6 & 5.1127 & TRN & \\
\hline CHEMBL1446069 & 688620 & 4.45 & 5.0424 & TST & \\
\hline CHEMBL1459660 & 688620 & 5.3 & 4.8997 & TRN & \\
\hline CHEMBL1418827 & 688620 & 4.65 & 4.8823 & TST & \\
\hline CHEMBL1599401 & 688620 & 5.3 & 5.3495 & TRN & \\
\hline CHEMBL3208830 & 688620 & 4.85 & 4.6751 & TRN & \\
\hline CHEMBL1430741 & 688620 & 4.95 & 4.9647 & TST & \\
\hline CHEMBL1342614 & 688620 & 5.1 & 5.4909 & TRN & \\
\hline CHEMBL1986741 & 688620 & 4.55 & 4.6667 & TRN & \\
\hline CHEMBL1613088 & 688620 & 4.8 & 4.9114 & TRN & \\
\hline CHEMBL1446387 & 688620 & 4.45 & 4.82600 & 00000000005 & TRN \\
\hline CHEMBL1463007 & 688620 & 4.45 & 4.9517 & TRN & \\
\hline CHEMBL1340866 & 688620 & 4.95 & 5.0483 & TRN & \\
\hline CHEMBL1438892 & 688620 & 5.5 & 5.6282 & TST & \\
\hline CHEMBL1302050 & 688620 & 4.6 & 4.702 & TRN & \\
\hline CHEMBL1366088 & 688620 & 6.0 & 5.1871 & TRN & \\
\hline CHEMBL1500193 & 688620 & 4.45 & 5.1594 & TRN & \\
\hline CHEMBL1411301 & 688620 & 5.2 & 4.9414 & TRN & \\
\hline CHEMBL1442305 & 688620 & 4.65 & 4.7687 & TRN & \\
\hline
\end{tabular}




\begin{tabular}{|c|c|c|c|c|}
\hline \multicolumn{5}{|c|}{ Supplemental Table S2.txt } \\
\hline CHEMBL1495936 & 688620 & 6.8 & 5.2056 & TST \\
\hline CHEMBL1481141 & 688620 & 4.45 & 4.9251 & TRN \\
\hline CHEMBL1498214 & 688620 & 4.6 & 5.0534 & TST \\
\hline CHEMBL1475254 & 688620 & 5.95 & 5.0966 & TRN \\
\hline CHEMBL1564666 & 688620 & 5.2 & 5.6358 & TRN \\
\hline CHEMBL1530841 & 688620 & 4.9 & 5.3057 & TRN \\
\hline CHEMBL1481271 & 688620 & 5.0 & 5.3895 & TRN \\
\hline CHEMBL1547630 & 688620 & 6.95 & 6.1753 & TRN \\
\hline CHEMBL1544768 & 688620 & 4.8 & 5.2651 & TRN \\
\hline CHEMBL1320352 & 688620 & 5.05 & 5.0876 & TRN \\
\hline CHEMBL1443454 & 688620 & 5.25 & 5.0847 & TRN \\
\hline CHEMBL1580695 & 688620 & 4.8 & 5.0436 & TRN \\
\hline CHEMBL1339428 & 688620 & 4.85 & 5.0495 & TRN \\
\hline CHEMBL 3195724 & 688620 & 4.5 & 4.9404 & TST \\
\hline CHEMBL1325271 & 688620 & 5.05 & 5.0868 & TST \\
\hline CHEMBL1370880 & 688620 & 5.3 & 4.9073 & TRN \\
\hline CHEMBL1428445 & 688620 & 6.35 & 6.2204 & TRN \\
\hline CHEMBL1381640 & 688620 & 4.95 & 5.2035 & TRN \\
\hline CHEMBL1303995 & 688620 & 5.3 & 5.1182 & TST \\
\hline CHEMBL1528603 & 688620 & 5.1 & 4.9026 & TRN \\
\hline CHEMBL1341114 & 688620 & 4.6 & 4.8591 & TRN \\
\hline CHEMBL1533535 & 688620 & 4.85 & 5.1531 & TRN \\
\hline CHEMBL1307148 & 688620 & 4.95 & 4.8672 & TRN \\
\hline CHEMBL1520705 & 688620 & 4.65 & 4.9399 & TRN \\
\hline CHEMBL1322597 & 688620 & 5.15 & 5.1571 & TST \\
\hline CHEMBL3192133 & 688620 & 4.8 & 5.3687 & TRN \\
\hline CHEMBL1353757 & 688620 & 4.7 & 5.0552 & TRN \\
\hline CHEMBL1461919 & 688620 & 4.95 & 5.0416 & TRN \\
\hline CHEMBL1504751 & 688620 & 4.65 & 5.0988 & TST \\
\hline CHEMBL1485968 & 688620 & 4.65 & 5.1768 & TST \\
\hline CHEMBL1563971 & 688620 & 5.05 & 4.994 & TST \\
\hline CHEMBL1575245 & 688620 & 5.2 & 4.8492 & TRN \\
\hline CHEMBL1538716 & 688620 & 4.45 & 5.0147 & TRN \\
\hline CHEMBL1533481 & 688620 & 6.0 & 4.9838 & TRN \\
\hline CHEMBL1551507 & 688620 & 4.9 & 5.0573 & TRN \\
\hline CHEMBL1346011 & 688620 & 5.0 & 5.0813 & TST \\
\hline CHEMBL1562139 & 688620 & 4.9 & 4.7382 & TRN \\
\hline CHEMBL1308219 & 688620 & 6.35 & 5.1967 & TST \\
\hline CHEMBL1581048 & 688620 & 5.3 & 4.8782 & TRN \\
\hline CHEMBL3213715 & 688620 & 4.95 & 5.0597 & TRN \\
\hline CHEMBL1327062 & 688620 & 4.45 & 4.8878 & TRN \\
\hline CHEMBL1549923 & 688620 & 6.25 & 4.8801 & TRN \\
\hline CHEMBL97643 & 688620 & 4.7 & 4.9461 & TRN \\
\hline CHEMBL1579644 & 688620 & 4.45 & 4.9124 & TRN \\
\hline CHEMBL1453986 & 688620 & 4.6 & 5.1193 & TRN \\
\hline CHEMBL1390457 & 688620 & 5.0 & 4.9615 & TRN \\
\hline CHEMBL1542457 & 688620 & 4.5 & 5.2194 & TRN \\
\hline CHEMBL1523770 & 688620 & 4.95 & 4.8113 & TST \\
\hline
\end{tabular}




\begin{tabular}{|c|c|c|c|c|c|}
\hline \multicolumn{6}{|c|}{ Supplemental Table S2.txt } \\
\hline CHEMBL1464493 & 688620 & 4.8 & 4.8926 & TRN & \\
\hline CHEMBL140979 & 688620 & 4.95 & 4.8295 & TST & \\
\hline CHEMBL1596909 & 688620 & 5.45 & 5.5902 & TRN & \\
\hline CHEMBL1343037 & 688620 & 5.55 & 5.4816 & TRN & \\
\hline CHEMBL1522747 & 688620 & 5.2 & 4.9967 & TRN & \\
\hline CHEMBL1470824 & 688620 & 4.95 & 4.9535 & TRN & \\
\hline CHEMBL1428521 & 688620 & 4.45 & 4.9198 & TRN & \\
\hline CHEMBL1306735 & 688620 & 4.65 & 5.1225 & TRN & \\
\hline CHEMBL1529149 & 688620 & 5.65 & 5.5573 & TRN & \\
\hline CHEMBL1474282 & 688620 & 4.85 & 5.0106 & TRN & \\
\hline CHEMBL1381963 & 688620 & 6.15 & 5.4591 & TRN & \\
\hline CHEMBL1345310 & 688620 & 5.85 & 5.3549 & TST & \\
\hline CHEMBL1372218 & 688620 & 4.8 & 4.7878 & TRN & \\
\hline CHEMBL1302253 & 688620 & 5.75 & 5.3278 & TRN & \\
\hline CHEMBL3193871 & 688620 & 4.8 & 5.0234 & TRN & \\
\hline CHEMBL1366199 & 688620 & 5.1 & 4.9281 & TRN & \\
\hline CHEMBL1513448 & 688620 & 4.45 & 4.931 & TST & \\
\hline CHEMBL1444424 & 688620 & 4.45 & 5.0787 & TST & \\
\hline CHEMBL1608074 & 688620 & 4.8 & 4.9714 & TRN & \\
\hline CHEMBL1360180 & 688620 & 4.45 & 4.846 & TRN & \\
\hline CHEMBL1382888 & 688620 & 4.75 & 4.7391 & TRN & \\
\hline CHEMBL1361493 & 688620 & 4.65 & 4.9602 & TRN & \\
\hline CHEMBL1556732 & 688620 & 5.55 & 5.2649 & TRN & \\
\hline CHEMBL1310248 & 688620 & 4.85 & 4.8534 & TRN & \\
\hline CHEMBL1530565 & 688620 & 7.0501 & 4.8594 & TRN & \\
\hline CHEMBL1469913 & 688620 & 5.25 & 5.4473 & TRN & \\
\hline CHEMBL1593516 & 688620 & 5.8 & 4.7311 & TST & \\
\hline CHEMBL1501171 & 688620 & 4.9 & 5.3351 & TRN & \\
\hline CHEMBL1491954 & 688620 & 4.85 & $5.1320 e$ & 2000000001 & TRN \\
\hline CHEMBL1602040 & 688620 & 4.95 & 5.0614 & TST & \\
\hline CHEMBL1487736 & 688620 & 4.9 & 5.2009 & TRN & \\
\hline CHEMBL1459783 & 688620 & 4.95 & 4.7327 & TRN & \\
\hline CHEMBL1597729 & 688620 & 5.55 & 4.927 & TRN & \\
\hline CHEMBL1470480 & 688620 & 4.75 & 5.1769 & TRN & \\
\hline CHEMBL1431574 & 688620 & 4.9 & 4.8433 & TST & \\
\hline CHEMBL1507324 & 688620 & 4.7 & 4.9561 & TRN & \\
\hline CHEMBL1544015 & 688620 & 5.2 & 5.2616 & TRN & \\
\hline CHEMBL1610087 & 688620 & 5.6 & 4.9563 & TRN & \\
\hline CHEMBL1449055 & 688620 & 4.5 & 4.9196 & TST & \\
\hline CHEMBL3196137 & 688620 & 4.75 & 4.8067 & TRN & \\
\hline CHEMBL406557 & 688620 & 4.5 & 5.3328 & TRN & \\
\hline CHEMBL1476766 & 688620 & 4.7 & 5.1271 & TST & \\
\hline CHEMBL15780 & 688620 & 4.7 & 4.8246 & TRN & \\
\hline CHEMBL3214527 & 688620 & 4.45 & 5.4294 & TRN & \\
\hline CHEMBL1367548 & 688620 & 4.85 & 5.1092 & TRN & \\
\hline CHEMBL1472088 & 688620 & 4.45 & 5.1933 & TRN & \\
\hline CHEMBL451574 & 688620 & 6.05 & 5.2971 & TST & \\
\hline CHEMBL1539445 & 688620 & 4.45 & 5.1093 & TST & \\
\hline
\end{tabular}




\begin{tabular}{|c|c|c|c|c|}
\hline \multicolumn{5}{|c|}{ Supplemental Table S2.txt } \\
\hline CHEMBL1603407 & 688620 & 5.35 & 5.1353 & TST \\
\hline CHEMBL1478808 & 688620 & 4.75 & 5.0688 & TRN \\
\hline CHEMBL 3193485 & 688620 & 4.45 & 5.2412 & TRN \\
\hline CHEMBL1537535 & 688620 & 4.95 & 5.1333 & TST \\
\hline CHEMBL1594541 & 688620 & 5.05 & 5.2636 & TRN \\
\hline CHEMBL1577117 & 688620 & 4.65 & 5.0772 & TRN \\
\hline CHEMBL1585166 & 688620 & 5.35 & 4.9877 & TRN \\
\hline CHEMBL1997288 & 688620 & 5.1 & 4.8716 & TST \\
\hline CHEMBL1426493 & 688620 & 5.0 & 4.8537 & TRN \\
\hline CHEMBL1573919 & 688620 & 5.0 & 5.1466 & TRN \\
\hline CHEMBL1555444 & 688620 & 5.0 & 4.7052 & TRN \\
\hline CHEMBL1389603 & 688620 & 5.8 & 5.1136 & TST \\
\hline CHEMBL1582791 & 688620 & 5.15 & 5.1319 & TST \\
\hline CHEMBL128427 & 688620 & 5.4 & 5.5605 & TRN \\
\hline CHEMBL1494587 & 688620 & 5.35 & 5.5464 & TRN \\
\hline CHEMBL1524632 & 688620 & 5.55 & 5.2095 & TRN \\
\hline CHEMBL1539156 & 688620 & 5.0 & 4.9811 & TRN \\
\hline CHEMBL1430765 & 688620 & 5.3 & 5.1609 & TRN \\
\hline CHEMBL1529448 & 688620 & 4.45 & 5.0912 & TRN \\
\hline CHEMBL1347956 & 688620 & 4.9 & 4.9218 & TST \\
\hline CHEMBL1340289 & 688620 & 4.75 & 5.0893 & TRN \\
\hline CHEMBL468018 & 688620 & 4.95 & 4.63 & TST \\
\hline CHEMBL1340268 & 688620 & 5.65 & 5.3819 & TRN \\
\hline CHEMBL591630 & 688620 & 4.9 & 5.0475 & TRN \\
\hline CHEMBL1417970 & 688620 & 5.25 & 5.3082 & TRN \\
\hline CHEMBL1333964 & 688620 & 4.45 & 4.8332 & TRN \\
\hline CHEMBL1466183 & 688620 & 4.8 & 5.0328 & TRN \\
\hline CHEMBL1384840 & 688620 & 6.1 & 4.9794 & TRN \\
\hline CHEMBL1256697 & 688620 & 4.85 & 4.8647 & TST \\
\hline CHEMBL1321333 & 688620 & 5.5 & 5.428 & TRN \\
\hline CHEMBL1424224 & 688620 & 4.95 & 4.9434 & TRN \\
\hline CHEMBL1465383 & 688620 & 4.5 & 4.7316 & TST \\
\hline CHEMBL1343282 & 688620 & 4.9 & 4.6767 & TRN \\
\hline CHEMBL1383545 & 688620 & 7.0 & 4.8975 & TRN \\
\hline CHEMBL3210671 & 688620 & 5.15 & 5.3026 & TRN \\
\hline CHEMBL1386659 & 688620 & 5.4 & 5.7903 & TRN \\
\hline CHEMBL1420768 & 688620 & 5.7 & 5.4021 & TRN \\
\hline CHEMBL1455706 & 688620 & 5.2 & 5.3084 & TRN \\
\hline CHEMBL1306782 & 688620 & 5.4 & 5.1455 & TST \\
\hline CHEMBL1501169 & 688620 & 4.5 & 5.0213 & TST \\
\hline CHEMBL1463538 & 688620 & 5.3 & 5.0017 & TRN \\
\hline CHEMBL 1440884 & 688620 & 4.8 & 5.0885 & TRN \\
\hline CHEMBL1360873 & 688620 & 5.9 & 5.0713 & TST \\
\hline CHEMBL1441632 & 688620 & 4.85 & 5.0909 & TRN \\
\hline CHEMBL1334514 & 688620 & 5.8 & 5.3696 & TRN \\
\hline CHEMBL1568335 & 688620 & 4.95 & 4.8332 & TRN \\
\hline CHEMBL1583471 & 688620 & 6.7001 & 5.4749 & TRN \\
\hline CHEMBL1386228 & 688620 & 4.95 & 5.3072 & TRN \\
\hline
\end{tabular}




\begin{tabular}{|c|c|c|c|c|}
\hline \multirow[b]{2}{*}{ CHEMBL1381886 } & \multicolumn{4}{|c|}{ Supplemental Table S2.txt } \\
\hline & 688620 & 5.45 & 5.03 & TRN \\
\hline CHEMBL1568406 & 688620 & 5.3 & 4.8761 & TRN \\
\hline CHEMBL1549879 & 688620 & 4.45 & 4.7071 & TRN \\
\hline CHEMBL1513050 & 688620 & 5.55 & 5.2165 & TRN \\
\hline CHEMBL 3144874 & 688620 & 4.45 & 4.8026 & TRN \\
\hline CHEMBL1300672 & 688620 & 4.75 & 4.871 & TRN \\
\hline CHEMBL1530144 & 688620 & 4.85 & 4.9434 & TST \\
\hline CHEMBL1598160 & 688620 & 5.4 & 5.1303 & TRN \\
\hline CHEMBL1443992 & 688620 & 4.9 & 4.9737 & TRN \\
\hline CHEMBL1382623 & 688620 & 4.55 & 5.0595 & TRN \\
\hline CHEMBL1385113 & 688620 & 4.65 & 4.9436 & TST \\
\hline CHEMBL1468391 & 688620 & 4.95 & 4.8884 & TRN \\
\hline CHEMBL1483545 & 688620 & 4.95 & 4.8985 & TST \\
\hline CHEMBL1612354 & 688620 & 7.0 & 4.9611 & TRN \\
\hline CHEMBL3193783 & 688620 & 4.9 & 4.9261 & TST \\
\hline CHEMBL1483851 & 688620 & 5.5 & 5.0829 & TST \\
\hline CHEMBL1473701 & 688620 & 5.0 & 5.5526 & TRN \\
\hline CHEMBL1587813 & 688620 & 5.0 & 4.9995 & TRN \\
\hline CHEMBL 3194264 & 688620 & 4.45 & 4.8451 & TRN \\
\hline CHEMBL1583985 & 688620 & 4.9 & 4.9599 & TRN \\
\hline CHEMBL1569032 & 688620 & 4.45 & 4.6664 & TRN \\
\hline CHEMBL1545428 & 688620 & 5.8 & 5.1704 & TRN \\
\hline CHEMBL1391768 & 688620 & 4.9 & 5.2947 & TRN \\
\hline CHEMBL1381871 & 688620 & 4.7 & 4.855 & TRN \\
\hline CHEMBL1594132 & 688620 & 5.45 & 4.9885 & TST \\
\hline CHEMBL1610214 & 688620 & 4.9 & 5.0774 & TRN \\
\hline CHEMBL1548952 & 688620 & 5.4 & 4.9937 & TRN \\
\hline CHEMBL1503067 & 688620 & 5.55 & 5.2266 & TRN \\
\hline CHEMBL1572790 & 688620 & 4.7 & 5.051 & TRN \\
\hline CHEMBL1455788 & 688620 & 4.65 & 4.8251 & TRN \\
\hline CHEMBL1523797 & 688620 & 5.45 & 5.3308 & TRN \\
\hline CHEMBL1426204 & 688620 & 6.5501 & 5.1012 & TST \\
\hline CHEMBL1557219 & 688620 & 4.65 & 5.0497 & TRN \\
\hline CHEMBL1381735 & 688620 & 5.5 & 4.9324 & TST \\
\hline CHEMBL1371222 & 688620 & 4.95 & 5.1582 & TST \\
\hline CHEMBL1537509 & 688620 & 6.15 & 4.6331 & TST \\
\hline CHEMBL3195056 & 688620 & 5.9 & 4.9805 & TRN \\
\hline CHEMBL1560412 & 688620 & 4.45 & 4.676 & TST \\
\hline CHEMBL1301811 & 688620 & 4.95 & 5.1838 & TRN \\
\hline CHEMBL1601907 & 688620 & 4.65 & 4.9666 & TRN \\
\hline CHEMBL1421226 & 688620 & 4.55 & 5.0788 & TRN \\
\hline CHEMBL1320855 & 688620 & 4.7 & 4.7973 & TRN \\
\hline CHEMBL1430895 & 688620 & 5.7 & 5.4429 & TRN \\
\hline CHEMBL3193650 & 688620 & 5.45 & 5.4625 & TRN \\
\hline CHEMBL1579095 & 688620 & 4.95 & 5.1266 & TRN \\
\hline CHEMBL1439952 & 688620 & 4.8 & 5.0388 & TRN \\
\hline CHEMBL1997899 & 688620 & 5.15 & 5.3105 & TST \\
\hline CHEMBL1467254 & 688620 & 4.85 & 5.1234 & TRN \\
\hline
\end{tabular}




\begin{tabular}{|c|c|c|c|c|c|}
\hline \multicolumn{6}{|c|}{ Supplemental Table S2.txt } \\
\hline CHEMBL1490569 & 688620 & 4.9 & 4.8836 & TRN & \\
\hline CHEMBL1581040 & 688620 & 4.95 & 4.9894 & TRN & \\
\hline CHEMBL1359851 & 688620 & 5.0 & 5.2456 & TRN & \\
\hline CHEMBL1486772 & 688620 & 5.15 & 4.926 & TRN & \\
\hline CHEMBL1505411 & 688620 & 5.2 & 5.0849 & TRN & \\
\hline CHEMBL1522907 & 688620 & 4.45 & 5.0633 & TST & \\
\hline CHEMBL1442326 & 688620 & 5.15 & 5.144 & TRN & \\
\hline CHEMBL1439835 & 688620 & 4.95 & 5.0515 & TRN & \\
\hline CHEMBL1412284 & 688620 & 4.45 & 4.9602 & TST & \\
\hline CHEMBL1326305 & 688620 & 4.9 & 4.9569 & TRN & \\
\hline CHEMBL1557850 & 688620 & 4.95 & 4.9168 & TST & \\
\hline CHEMBL1360416 & 688620 & 5.7 & 5.5804 & TRN & \\
\hline CHEMBL1407057 & 688620 & 5.45 & 5.118 & TRN & \\
\hline CHEMBL1540648 & 688620 & 5.05 & 5.0216 & TRN & \\
\hline CHEMBL3213162 & 688620 & 4.75 & 5.1456 & TRN & \\
\hline CHEMBL1533468 & 688620 & 5.2 & 5.0192 & TRN & \\
\hline CHEMBL1350733 & 688620 & 4.45 & 5.0357 & TST & \\
\hline CHEMBL1464622 & 688620 & 4.45 & 4.9212 & TST & \\
\hline CHEMBL1389732 & 688620 & 4.9 & $4.8180 e$ & 00000000005 & TRN \\
\hline CHEMBL1338256 & 688620 & 5.85 & $5.2020 e$ & 0000000001 & TRN \\
\hline CHEMBL1400132 & 688620 & 4.45 & 4.8537 & TRN & \\
\hline CHEMBL1504641 & 688620 & 4.8 & 5.046 & TRN & \\
\hline CHEMBL1391557 & 688620 & 5.2 & 4.8785 & TRN & \\
\hline CHEMBL1558165 & 688620 & 4.6 & 4.5862 & TST & \\
\hline CHEMBL1458261 & 688620 & 5.55 & 5.4871 & TRN & \\
\hline CHEMBL1319990 & 688620 & 4.9 & 4.9706 & TST & \\
\hline CHEMBL1402469 & 688620 & 4.65 & $5.3260 e$ & 00000000005 & TRN \\
\hline CHEMBL1472962 & 688620 & 4.8 & 4.9446 & TRN & \\
\hline CHEMBL1563019 & 688620 & 5.3 & 5.0853 & TRN & \\
\hline CHEMBL1470298 & 688620 & 5.05 & 4.7749 & TRN & \\
\hline CHEMBL533602 & 688620 & 5.3 & 5.2035 & TST & \\
\hline CHEMBL1345813 & 688620 & 4.7 & 5.0207 & TRN & \\
\hline CHEMBL1467189 & 688620 & 6.25 & 5.0066 & TST & \\
\hline CHEMBL3189202 & 688620 & 4.9 & 5.3209 & TRN & \\
\hline CHEMBL1456353 & 688620 & 5.4 & 4.9362 & TRN & \\
\hline CHEMBL1458036 & 688620 & 4.85 & 4.7598 & TRN & \\
\hline CHEMBL1342160 & 688620 & 5.0 & 4.9251 & TRN & \\
\hline CHEMBL1427212 & 688620 & 5.7 & 5.3192 & TRN & \\
\hline CHEMBL1443495 & 688620 & 5.85 & 5.3954 & TRN & \\
\hline CHEMBL1393219 & 688620 & 4.9 & $4.8210 e$ & $\partial 000000001$ & TRN \\
\hline CHEMBL1451156 & 688620 & 5.05 & 5.1504 & TST & \\
\hline CHEMBL1519021 & 688620 & 4.85 & 5.0165 & TRN & \\
\hline CHEMBL1544743 & 688620 & 5.2 & 5.392 & TRN & \\
\hline CHEMBL1375753 & 688620 & 5.3 & 5.0133 & TRN & \\
\hline CHEMBL1603150 & 688620 & 4.8 & 4.8101 & TST & \\
\hline CHEMBL1498856 & 688620 & 4.9 & 5.0489 & TRN & \\
\hline CHEMBL1313702 & 688620 & 4.75 & 4.8469 & TRN & \\
\hline CHEMBL1608161 & 688620 & 5.6 & 5.0467 & TRN & \\
\hline
\end{tabular}




\begin{tabular}{|c|c|c|c|c|}
\hline \multicolumn{5}{|c|}{ Supplemental Table S2.txt } \\
\hline CHEMBL328834 & 688620 & 4.85 & 5.7351 & TRN \\
\hline CHEMBL 3198858 & 688620 & 4.7 & 5.2915 & TRN \\
\hline CHEMBL1559440 & 688620 & 4.45 & 5.1329 & TRN \\
\hline CHEMBL1361237 & 688620 & 6.4 & 5.4225 & TRN \\
\hline CHEMBL1342183 & 688620 & 4.95 & 5.2521 & TST \\
\hline CHEMBL1982363 & 688620 & 5.05 & 5.1201 & TRN \\
\hline CHEMBL1351922 & 688620 & 4.45 & 5.0649 & TST \\
\hline CHEMBL1447614 & 688620 & 4.75 & 5.2289 & TRN \\
\hline CHEMBL1576675 & 688620 & 4.7 & 5.0205 & TST \\
\hline CHEMBL1424731 & 688620 & 6.8 & 5.0532 & TRN \\
\hline CHEMBL1497196 & 688620 & 5.05 & 4.8271 & TRN \\
\hline CHEMBL1443797 & 688620 & 5.15 & 5.0228 & TRN \\
\hline CHEMBL3212024 & 688620 & 5.6 & 5.1641 & TST \\
\hline CHEMBL1322663 & 688620 & 4.45 & 4.7717 & TRN \\
\hline CHEMBL1522883 & 688620 & 4.45 & 5.0048 & TRN \\
\hline CHEMBL1365177 & 688620 & 5.6 & 5.3349 & TRN \\
\hline CHEMBL1589065 & 688620 & 5.2 & 5.3705 & TRN \\
\hline CHEMBL233194 & 688620 & 4.85 & 5.1663 & TRN \\
\hline CHEMBL 299853 & 688620 & 5.1 & 5.082 & TRN \\
\hline CHEMBL1342235 & 688620 & 5.9 & 5.0065 & TRN \\
\hline CHEMBL1300759 & 688620 & 5.0 & 5.0912 & TST \\
\hline CHEMBL1502830 & 688620 & 4.45 & 4.7834 & TRN \\
\hline CHEMBL1582382 & 688620 & 4.7 & 4.9558 & TRN \\
\hline CHEMBL1541862 & 688620 & 4.65 & 5.0933 & TRN \\
\hline CHEMBL1329980 & 688620 & 4.85 & 4.8382 & TRN \\
\hline CHEMBL1448137 & 688620 & 5.05 & 5.0439 & TRN \\
\hline CHEMBL1511026 & 688620 & 4.55 & 5.1196 & TRN \\
\hline CHEMBL1508437 & 688620 & 4.45 & 4.8262 & TRN \\
\hline CHEMBL 2006904 & 688620 & 5.9 & 5.2586 & TRN \\
\hline CHEMBL1311597 & 688620 & 4.45 & 5.007 & TST \\
\hline CHEMBL1569849 & 688620 & 4.85 & 5.024 & TRN \\
\hline CHEMBL1368523 & 688620 & 4.95 & 5.3405 & TST \\
\hline CHEMBL1586421 & 688620 & 4.8 & 5.1831 & TST \\
\hline CHEMBL1482069 & 688620 & 4.45 & 4.8827 & TST \\
\hline CHEMBL1475787 & 688620 & 4.45 & 5.0796 & TRN \\
\hline CHEMBL1494694 & 688620 & 5.05 & 5.1249 & TRN \\
\hline CHEMBL1987272 & 688620 & 4.7 & 4.7987 & TRN \\
\hline CHEMBL1337496 & 688620 & 5.2 & 5.3203 & TRN \\
\hline CHEMBL587433 & 688620 & 4.95 & 4.9627 & TRN \\
\hline CHEMBL1446970 & 688620 & 5.35 & 5.0858 & TST \\
\hline CHEMBL1329626 & 688620 & 4.65 & 4.8429 & TRN \\
\hline CHEMBL1418615 & 688620 & 5.0 & 4.9464 & TRN \\
\hline CHEMBL1300396 & 688620 & 4.45 & 5.1209 & TRN \\
\hline CHEMBL1364030 & 688620 & 4.95 & 4.7065 & TRN \\
\hline CHEMBL1346400 & 688620 & 5.2 & 5.1764 & TST \\
\hline CHEMBL1560661 & 688620 & 5.4 & 5.2121 & TRN \\
\hline CHEMBL1990057 & 688620 & 4.45 & 4.8888 & TRN \\
\hline CHEMBL1490820 & 688620 & 4.95 & 5.1097 & TRN \\
\hline
\end{tabular}




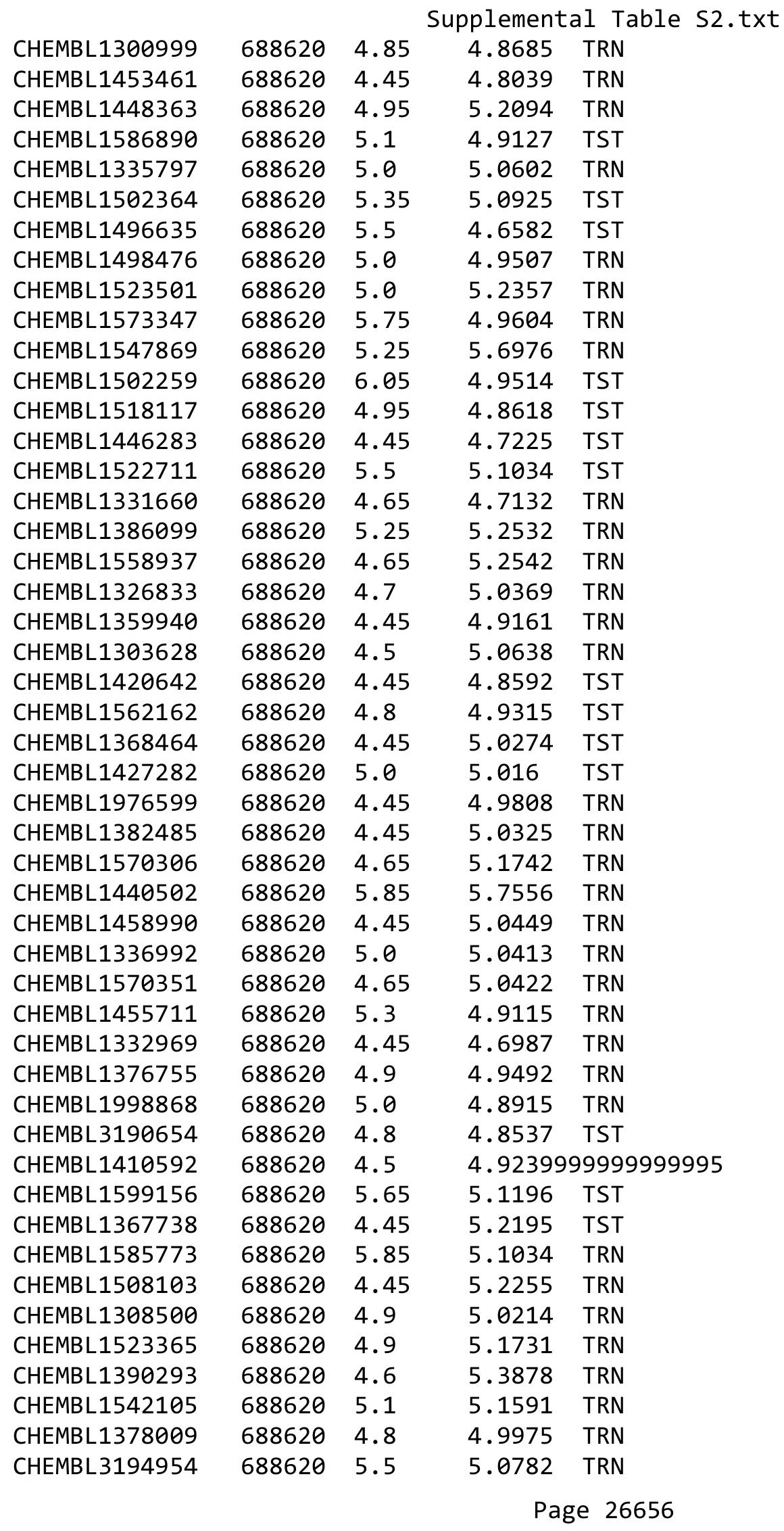




\begin{tabular}{|c|c|c|c|c|c|}
\hline & & \multicolumn{4}{|c|}{ Supplemental Table s2.txt } \\
\hline CHEMBL1969867 & 688620 & 5.25 & 5.5669 & TRN & \\
\hline CHEMBL1449312 & 688620 & 4.85 & 5.046 & TRN & \\
\hline CHEMBL1477101 & 688620 & 4.45 & 5.0904 & TRN & \\
\hline CHEMBL1486816 & 688620 & 4.9 & 5.1318 & TRN & \\
\hline CHEMBL1290347 & 688620 & 4.75 & 4.8759 & TRN & \\
\hline CHEMBL1424441 & 688620 & 4.45 & 4.9041 & TRN & \\
\hline CHEMBL1999161 & 688620 & 5.7 & 5.3061 & TRN & \\
\hline CHEMBL1301406 & 688620 & 4.45 & 4.784 & TRN & \\
\hline CHEMBL1577208 & 688620 & 5.0 & 5.0321 & TST & \\
\hline CHEMBL1379167 & 688620 & 5.0 & 5.1522 & TST & \\
\hline CHEMBL1393029 & 688620 & 5.0 & 4.9274 & TRN & \\
\hline CHEMBL3194929 & 688620 & 5.4 & 5.4211 & TRN & \\
\hline CHEMBL1409863 & 688620 & 5.05 & 5.1949 & TRN & \\
\hline CHEMBL1481019 & 688620 & 4.45 & 4.9926 & TRN & \\
\hline CHEMBL1328072 & 688620 & 6.5 & 5.5712 & TRN & \\
\hline CHEMBL1449387 & 688620 & 4.85 & 4.8986 & TRN & \\
\hline CHEMBL1540740 & 688620 & 6.4 & 5.0213 & TST & \\
\hline CHEMBL239478 & 688620 & 6.25 & 5.9182 & TRN & \\
\hline CHEMBL525889 & 688620 & 4.65 & 4.7576 & TST & \\
\hline CHEMBL1336286 & 688620 & 4.75 & 4.9784 & TRN & \\
\hline CHEMBL1346149 & 688620 & 5.5 & 5.2688 & TST & \\
\hline CHEMBL1430598 & 688620 & 4.9 & 5.0481 & TRN & \\
\hline CHEMBL1384911 & 688620 & 5.0 & 5.0182 & TRN & \\
\hline CHEMBL1612636 & 688620 & 5.95 & 5.4626 & TST & \\
\hline CHEMBL1308230 & 688620 & 5.6 & 5.4521 & TRN & \\
\hline CHEMBL1348625 & 688620 & 4.45 & 4.9189 & TRN & \\
\hline CHEMBL1386299 & 688620 & 5.5 & 5.4484 & TRN & \\
\hline CHEMBL1505860 & 688620 & 4.9 & 4.8144 & TST & \\
\hline CHEMBL1459334 & 688620 & 4.95 & 5.0174 & TRN & \\
\hline CHEMBL1385582 & 688620 & 5.0 & 5.2231 & TRN & \\
\hline CHEMBL1508922 & 688620 & 5.5 & 4.9414 & TST & \\
\hline CHEMBL1421231 & 688620 & 4.95 & 4.9569 & TRN & \\
\hline CHEMBL1444356 & 688620 & 5.35 & 5.1342 & TRN & \\
\hline CHEMBL1575763 & 688620 & 4.85 & 5.0247 & TRN & \\
\hline CHEMBL1372596 & 688620 & 5.45 & 5.006 & TRN & \\
\hline CHEMBL1569637 & 688620 & 4.6 & 4.8827 & TRN & \\
\hline CHEMBL1557782 & 688620 & 5.0 & 4.8097 & TRN & \\
\hline CHEMBL3196927 & 688620 & 4.45 & 5.0124 & TRN & \\
\hline CHEMBL1504918 & 688620 & 4.65 & 5.0758 & TST & \\
\hline CHEMBL1422741 & 688620 & 5.25 & 4.8476 & TRN & \\
\hline CHEMBL1519302 & 688620 & 6.0 & 5.7331 & TRN & \\
\hline CHEMBL3192463 & 688620 & 6.4 & 6.1748 & TRN & \\
\hline CHEMBL1490503 & 688620 & 5.7 & 5.5673 & TRN & \\
\hline CHEMBL1463331 & 688620 & 4.45 & 4.6681 & TRN & \\
\hline CHEMBL1579065 & 688620 & 4.75 & 5.0424 & TRN & \\
\hline CHEMBL1541376 & 688620 & 5.8 & 5.3976 & TRN & \\
\hline CHEMBL1391360 & 688620 & 4.5 & 4.9976 & TRN & \\
\hline CHEMBL1469661 & 688620 & 5.25 & $5.1270 e$ & 0000000001 & TRN \\
\hline & & & & 26657 & \\
\hline
\end{tabular}




\begin{tabular}{|c|c|c|c|c|}
\hline & & & pplement & al $\mathrm{Ta}$ \\
\hline CHEMBL1505170 & 688620 & 6.25 & 5.3887 & TRN \\
\hline CHEMBL3212830 & 688620 & 5.65 & 5.1898 & TRN \\
\hline CHEMBL3196798 & 688620 & 4.65 & 5.1249 & TRN \\
\hline CHEMBL1606135 & 688620 & 4.7 & 4.9407 & TRN \\
\hline CHEMBL1427682 & 688620 & 4.95 & 5.2639 & TRN \\
\hline CHEMBL1538546 & 688620 & 6.2 & 4.8547 & TRN \\
\hline CHEMBL 2373654 & 688620 & 5.7 & 5.1725 & TRN \\
\hline CHEMBL1505510 & 688620 & 6.45 & 5.6969 & TRN \\
\hline CHEMBL 3195220 & 688620 & 5.45 & 5.3638 & TRN \\
\hline CHEMBL1308147 & 688620 & 4.85 & 4.8363 & TRN \\
\hline CHEMBL 252744 & 688620 & 4.85 & 4.9278 & TST \\
\hline CHEMBL1493336 & 688620 & 5.4 & 4.8802 & TRN \\
\hline CHEMBL1601109 & 688620 & 5.95 & 4.9419 & TRN \\
\hline CHEMBL1469756 & 688620 & 4.6 & 5.0258 & TRN \\
\hline CHEMBL1339404 & 688620 & 4.9 & 5.1687 & TRN \\
\hline CHEMBL1442566 & 688620 & 6.05 & 5.1957 & TRN \\
\hline CHEMBL1458332 & 688620 & 4.45 & 4.73 & TST \\
\hline CHEMBL1983757 & 688620 & 5.0 & 4.9654 & TRN \\
\hline CHEMBL1344878 & 688620 & 5.2 & 5.0982 & TRN \\
\hline CHEMBL1534183 & 688620 & 5.2 & 4.9563 & TRN \\
\hline CHEMBL1526087 & 688620 & 5.2 & 4.9445 & TRN \\
\hline CHEMBL3198754 & 688620 & 4.9 & 5.1805 & TRN \\
\hline CHEMBL1558800 & 688620 & 5.2 & 5.0199 & TRN \\
\hline CHEMBL1503513 & 688620 & 4.5 & 5.1948 & TRN \\
\hline CHEMBL1426525 & 688620 & 4.85 & 5.0873 & TRN \\
\hline CHEMBL1506238 & 688620 & 5.15 & 4.9018 & TRN \\
\hline CHEMBL1547077 & 688620 & 4.7 & 4.9717 & TRN \\
\hline CHEMBL3208585 & 688620 & 5.5 & 4.9255 & TRN \\
\hline CHEMBL1362985 & 688620 & 4.7 & 4.7905 & TRN \\
\hline CHEMBL1431867 & 688620 & 4.75 & 4.9131 & TRN \\
\hline CHEMBL1538654 & 688620 & 4.75 & 4.9824 & TRN \\
\hline CHEMBL1543260 & 688620 & 5.0 & 5.0051 & TRN \\
\hline CHEMBL1420051 & 688620 & 6.1 & 6.2479 & TRN \\
\hline CHEMBL2373593 & 688620 & 5.35 & 5.1461 & TST \\
\hline CHEMBL1320019 & 688620 & 5.0 & 4.7697 & TST \\
\hline CHEMBL1312377 & 688620 & 5.3 & 4.9247 & TST \\
\hline CHEMBL1340852 & 688620 & 5.35 & 5.1516 & TRN \\
\hline CHEMBL1508553 & 688620 & 4.45 & 5.0552 & TST \\
\hline CHEMBL1536845 & 688620 & 5.35 & 5.0781 & TRN \\
\hline CHEMBL1505668 & 688620 & 4.75 & 5.1775 & TST \\
\hline CHEMBL1372626 & 688620 & 5.0 & 4.9477 & TRN \\
\hline CHEMBL1325658 & 688620 & 5.2 & 5.3325 & TRN \\
\hline CHEMBL1323859 & 688620 & 5.0 & 4.9274 & TRN \\
\hline CHEMBL1453121 & 688620 & 4.95 & 4.7395 & TRN \\
\hline CHEMBL3193735 & 688620 & 4.85 & 5.2056 & TRN \\
\hline CHEMBL1559290 & 688620 & 4.45 & 5.0849 & TST \\
\hline CHEMBL1509635 & 688620 & 5.05 & 4.8892 & TRN \\
\hline CHEMBL1445496 & 688620 & 5.3 & 5.0856 & TRN \\
\hline
\end{tabular}




\begin{tabular}{|c|c|c|c|c|c|}
\hline \\
\hline CHEMBL1586130 & 688620 & 4.9 & 4.8912 & TST & \\
\hline CHEMBL1333534 & 688620 & 4.95 & 5.2077 & TST & \\
\hline CHEMBL1608283 & 688620 & 5.1 & 4.9707 & TRN & \\
\hline CHEMBL1432661 & 688620 & 4.8 & 5.0135 & TRN & \\
\hline CHEMBL1429980 & 688620 & 6.0 & 5.6607 & TST & \\
\hline CHEMBL1536449 & 688620 & 4.7 & 4.9547 & TRN & \\
\hline CHEMBL1469202 & 688620 & 5.15 & 5.4334 & TRN & \\
\hline CHEMBL1451929 & 688620 & 5.05 & 5.1496 & TRN & \\
\hline CHEMBL1398762 & 688620 & 5.8 & 5.1616 & TRN & \\
\hline CHEMBL1368448 & 688620 & 5.0 & 4.9374 & TST & \\
\hline CHEMBL1559506 & 688620 & 4.45 & 4.8878 & TRN & \\
\hline CHEMBL1576593 & 688620 & 5.0 & 5.178 & TRN & \\
\hline CHEMBL1583168 & 688620 & 5.25 & 4.9442 & TST & \\
\hline CHEMBL1574831 & 688620 & 6.15 & 5.7001 & TRN & \\
\hline CHEMBL1488901 & 688620 & 4.8 & 5.0484 & TST & \\
\hline CHEMBL1404224 & 688620 & 5.55 & 4.9722 & TST & \\
\hline CHEMBL1335226 & 688620 & 4.8 & 5.0238 & TRN & \\
\hline CHEMBL1484830 & 688620 & 4.45 & 4.91 & TST & \\
\hline CHEMBL1462285 & 688620 & 4.45 & 5.1275 & TRN & \\
\hline CHEMBL1451755 & 688620 & 5.5 & 5.0711 & TRN & \\
\hline CHEMBL1316674 & 688620 & 7.2 & 5.2305 & TST & \\
\hline CHEMBL1333812 & 688620 & 4.7 & 5.1001 & TRN & \\
\hline CHEMBL1601994 & 688620 & 4.7 & 4.8815 & TRN & \\
\hline CHEMBL1535460 & 688620 & 4.45 & 5.0124 & TST & \\
\hline CHEMBL3191222 & 688620 & 4.65 & 4.9306 & TRN & \\
\hline CHEMBL3195285 & 688620 & 4.7 & 5.0833 & TRN & \\
\hline CHEMBL1376201 & 688620 & 6.5501 & 5.73799 & 99999999995 & TRN \\
\hline CHEMBL1454364 & 688620 & 4.45 & 4.9648 & TRN & \\
\hline CHEMBL1491515 & 688620 & 4.95 & 5.1292 & TRN & \\
\hline CHEMBL1470121 & 688620 & 4.65 & 4.9755 & TRN & \\
\hline CHEMBL1425864 & 688620 & 7.6003 & 5.2887 & TST & \\
\hline CHEMBL1492585 & 688620 & 5.25 & 5.7264 & TRN & \\
\hline CHEMBL1533920 & 688620 & 5.9 & 5.0242 & TST & \\
\hline CHEMBL466179 & 688620 & 4.65 & 4.7959 & TST & \\
\hline CHEMBL1456124 & 688620 & 5.0 & 5.0511 & TST & \\
\hline CHEMBL3190607 & 688620 & 4.65 & 5.0233 & TRN & \\
\hline CHEMBL1995252 & 688620 & 5.25 & 5.4602 & TRN & \\
\hline CHEMBL1352405 & 688620 & 5.55 & 5.0211 & TRN & \\
\hline CHEMBL1999636 & 688620 & 5.85 & 5.6212 & TRN & \\
\hline CHEMBL1325513 & 688620 & 4.45 & 5.0722 & TRN & \\
\hline CHEMBL1363125 & 688620 & 4.8 & 5.2862 & TST & \\
\hline CHEMBL581574 & 688620 & 4.8 & 4.9242 & TRN & \\
\hline CHEMBL1403127 & 688620 & 5.45 & 5.8767 & TST & \\
\hline CHEMBL1505091 & 688620 & 4.95 & 4.8431 & TST & \\
\hline CHEMBL1502487 & 688620 & 5.45 & 5.0847 & TRN & \\
\hline CHEMBL1307808 & 688620 & 4.85 & 4.6928 & TST & \\
\hline CHEMBL1543395 & 688620 & 4.9 & 5.2701 & TRN & \\
\hline CHEMBL1992164 & 688620 & 5.85 & 5.0577 & TRN & \\
\hline
\end{tabular}




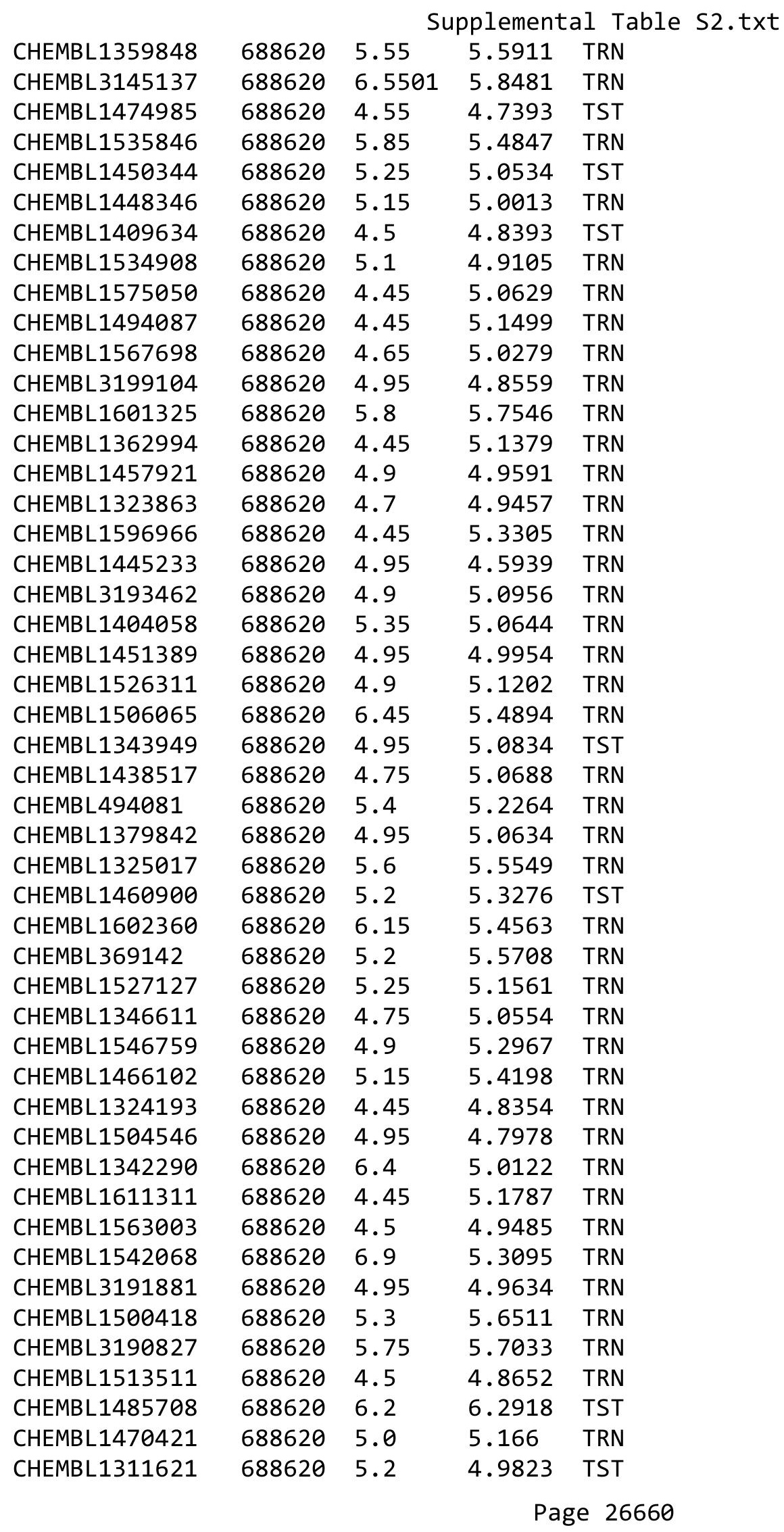




\begin{tabular}{|c|c|c|c|c|c|}
\hline & & \multicolumn{4}{|c|}{ Supplemental Table s2.txt } \\
\hline CHEMBL1527620 & 688620 & 6.25 & 5.0208 & TRN & \\
\hline CHEMBL1588034 & 688620 & 4.55 & 4.9563 & TRN & \\
\hline CHEMBL1503086 & 688620 & 4.9 & 4.8568 & TRN & \\
\hline CHEMBL1352202 & 688620 & 4.95 & 5.1777 & TST & \\
\hline CHEMBL1566358 & 688620 & 4.5 & 4.8647 & TRN & \\
\hline CHEMBL1566846 & 688620 & 5.55 & 5.48799 & 99999999995 & TRN \\
\hline CHEMBL1571532 & 688620 & 5.05 & 4.9444 & TRN & \\
\hline CHEMBL1470732 & 688620 & 5.15 & 5.2452 & TRN & \\
\hline CHEMBL1358184 & 688620 & 4.8 & 4.7129 & TRN & \\
\hline CHEMBL1425248 & 688620 & 5.4 & 5.1297 & TRN & \\
\hline CHEMBL1388603 & 688620 & 4.45 & 4.9522 & TRN & \\
\hline CHEMBL1541329 & 688620 & 5.0 & 4.7739 & TRN & \\
\hline CHEMBL3189409 & 688620 & 4.45 & 4.7032 & TRN & \\
\hline CHEMBL1574343 & 688620 & 4.45 & 5.1267 & TRN & \\
\hline CHEMBL1319986 & 688620 & 4.9 & 4.8677 & TRN & \\
\hline CHEMBL1390831 & 688620 & 5.35 & 5.5063 & TRN & \\
\hline CHEMBL1531571 & 688620 & 5.6 & 5.0957 & TRN & \\
\hline CHEMBL1309463 & 688620 & 5.0 & 4.9805 & TRN & \\
\hline CHEMBL1417569 & 688620 & 4.5 & 4.7085 & TRN & \\
\hline CHEMBL1441866 & 688620 & 6.45 & 4.9558 & TRN & \\
\hline CHEMBL1596104 & 688620 & 4.75 & 5.085 & TRN & \\
\hline CHEMBL1322938 & 688620 & 5.2 & 5.019 & TST & \\
\hline CHEMBL1497649 & 688620 & 4.5 & 4.9742 & TRN & \\
\hline CHEMBL1488020 & 688620 & 5.05 & 5.0959 & TRN & \\
\hline CHEMBL1509789 & 688620 & 5.0 & 5.2336 & TST & \\
\hline CHEMBL1602833 & 688620 & 4.75 & 4.6787 & TRN & \\
\hline CHEMBL1989225 & 688620 & 5.55 & 5.4497 & TRN & \\
\hline CHEMBL1598626 & 688620 & 5.15 & 5.0003 & TRN & \\
\hline CHEMBL1310080 & 688620 & 5.85 & 5.8085 & TRN & \\
\hline CHEMBL1360086 & 688620 & 6.9 & 5.1493 & TST & \\
\hline CHEMBL1999535 & 688620 & 5.1 & 4.9221 & TRN & \\
\hline CHEMBL1428638 & 688620 & 4.75 & 4.9013 & TST & \\
\hline CHEMBL1491916 & 688620 & 5.15 & 5.1305 & TRN & \\
\hline CHEMBL1390928 & 688620 & 5.8 & 4.7221 & TST & \\
\hline CHEMBL1390196 & 688620 & 5.25 & 4.9754 & TRN & \\
\hline CHEMBL1439350 & 688620 & 4.85 & 5.0689 & TRN & \\
\hline CHEMBL1537879 & 688620 & 5.15 & 5.0788 & TST & \\
\hline CHEMBL1371457 & 688620 & 5.55 & 5.2859 & TRN & \\
\hline CHEMBL1511377 & 688620 & 5.0 & 4.9778 & TST & \\
\hline CHEMBL1512222 & 688620 & 4.45 & 4.8182 & TRN & \\
\hline CHEMBL1319525 & 688620 & 5.95 & 5.1021 & TST & \\
\hline CHEMBL1979580 & 688620 & 5.25 & 5.1086 & TRN & \\
\hline CHEMBL1407324 & 688620 & 4.75 & 4.7971 & TST & \\
\hline CHEMBL1440016 & 688620 & 5.0 & 4.9994 & TRN & \\
\hline CHEMBL1425614 & 688620 & 4.95 & 5.0198 & TRN & \\
\hline CHEMBL1302365 & 688620 & 6.5 & 4.9631 & TRN & \\
\hline CHEMBL1431448 & 688620 & 4.45 & 4.9645 & TRN & \\
\hline CHEMBL1444690 & 688620 & 5.05 & 5.1897 & TRN & \\
\hline
\end{tabular}




\begin{tabular}{|c|c|c|c|c|c|}
\hline \multicolumn{6}{|c|}{ Supplemental Table S2.txt } \\
\hline CHEMBL1430467 & 688620 & 4.95 & 5.0851 & TRN & \\
\hline CHEMBL1392104 & 688620 & 4.75 & 4.9944 & TRN & \\
\hline CHEMBL1447667 & 688620 & 4.95 & 4.8014 & TST & \\
\hline CHEMBL1494629 & 688620 & 4.45 & 4.7936 & TRN & \\
\hline CHEMBL1386337 & 688620 & 4.95 & 4.8343 & TRN & \\
\hline CHEMBL256062 & 688620 & 6.0 & 5.9226 & TRN & \\
\hline CHEMBL1421233 & 688620 & 4.7 & 5.0315 & TST & \\
\hline CHEMBL1498530 & 688620 & 4.8 & 4.913 & TRN & \\
\hline CHEMBL1384094 & 688620 & 4.45 & 5.0885 & TST & \\
\hline CHEMBL1537937 & 688620 & 5.4 & 5.1159 & TST & \\
\hline CHEMBL1325823 & 688620 & 5.15 & 5.1484 & TST & \\
\hline CHEMBL1581364 & 688620 & 5.6 & 5.0183 & TRN & \\
\hline CHEMBL1382546 & 688620 & 4.45 & 5.3506 & TRN & \\
\hline CHEMBL1587911 & 688620 & 5.5 & 5.1014 & TRN & \\
\hline CHEMBL1440291 & 688620 & 4.45 & 4.949 & TRN & \\
\hline CHEMBL1467530 & 688620 & 4.95 & 5.1365 & TRN & \\
\hline CHEMBL1466746 & 688620 & 5.1 & 5.0528 & TRN & \\
\hline CHEMBL1452608 & 688620 & 4.7 & 4.98300 & 00000000005 & TST \\
\hline CHEMBL1488238 & 688620 & 5.0 & 5.2313 & TST & \\
\hline CHEMBL1541426 & 688620 & 6.6 & 5.4091 & TRN & \\
\hline CHEMBL1369724 & 688620 & 4.45 & 4.773 & TRN & \\
\hline CHEMBL1332102 & 688620 & 4.7 & 4.8908 & TST & \\
\hline CHEMBL1373728 & 688620 & 4.95 & 4.8129 & TST & \\
\hline CHEMBL1463077 & 688620 & 5.9 & 5.5958 & TRN & \\
\hline CHEMBL1323291 & 688620 & 4.45 & 4.8402 & TST & \\
\hline CHEMBL1608776 & 688620 & 4.95 & 5.0992 & TRN & \\
\hline CHEMBL1568778 & 688620 & 4.5 & 5.0115 & TRN & \\
\hline CHEMBL510773 & 688620 & 4.45 & 5.1947 & TRN & \\
\hline CHEMBL3193242 & 688620 & 4.5 & 4.9165 & TRN & \\
\hline CHEMBL1439790 & 688620 & 4.85 & 4.7868 & TRN & \\
\hline CHEMBL1518543 & 688620 & 6.15 & 4.7506 & TST & \\
\hline CHEMBL3196131 & 688620 & 5.1 & 4.8635 & TRN & \\
\hline CHEMBL3209099 & 688620 & 5.0 & 5.0775 & TST & \\
\hline CHEMBL1540743 & 688620 & 4.45 & 4.9915 & TST & \\
\hline CHEMBL1379467 & 688620 & 5.6 & 4.998 & TRN & \\
\hline CHEMBL1598536 & 688620 & 4.95 & 5.1824 & TRN & \\
\hline CHEMBL1353483 & 688620 & 5.6 & 5.4594 & TRN & \\
\hline CHEMBL1563106 & 688620 & 5.7 & 4.9841 & TST & \\
\hline CHEMBL1517741 & 688620 & 5.5 & 5.2504 & TRN & \\
\hline CHEMBL1547865 & 688620 & 4.45 & 4.7009 & TRN & \\
\hline CHEMBL1541082 & 688620 & 4.9 & 5.0141 & TRN & \\
\hline CHEMBL1588307 & 688620 & 4.45 & 5.0435 & TST & \\
\hline CHEMBL1502622 & 688620 & 6.25 & 5.0581 & TRN & \\
\hline CHEMBL1407754 & 688620 & 4.45 & 4.8838 & TRN & \\
\hline CHEMBL1577005 & 688620 & 4.8 & 4.7945 & TST & \\
\hline CHEMBL1506376 & 688620 & 5.05 & 4.9421 & TST & \\
\hline CHEMBL509531 & 688620 & 4.45 & 5.0498 & TST & \\
\hline CHEMBL1593789 & 688620 & 5.75 & 5.0802 & TST & \\
\hline
\end{tabular}




\begin{tabular}{|c|c|c|c|c|c|}
\hline \multicolumn{6}{|c|}{ Supplemental Table S2.txt } \\
\hline CHEMBL1604686 & 688620 & 4.45 & 5.0017 & TRN & \\
\hline CHEMBL1462076 & 688620 & 5.6 & 5.3083 & TRN & \\
\hline CHEMBL1325416 & 688620 & 4.85 & 5.0886 & TRN & \\
\hline CHEMBL1311413 & 688620 & 4.65 & 5.3831 & TST & \\
\hline CHEMBL1589415 & 688620 & 6.2 & 5.1418 & TRN & \\
\hline CHEMBL1307541 & 688620 & 5.2 & 5.1854 & TST & \\
\hline CHEMBL1588446 & 688620 & 4.85 & 4.9992 & TRN & \\
\hline CHEMBL1525053 & 688620 & 4.6 & 4.8961 & TRN & \\
\hline CHEMBL1334969 & 688620 & 4.95 & 5.1084 & TRN & \\
\hline CHEMBL1351348 & 688620 & 5.5 & 5.2367 & TRN & \\
\hline CHEMBL1422273 & 688620 & 5.1 & 4.9258 & TRN & \\
\hline CHEMBL1439180 & 688620 & 6.05 & 5.0243 & TRN & \\
\hline CHEMBL1299757 & 688620 & 5.4 & 5.3493 & TST & \\
\hline CHEMBL1599280 & 688620 & 5.0 & 5.0647 & TRN & \\
\hline CHEMBL1451680 & 688620 & 4.3 & 4.7214 & TST & \\
\hline CHEMBL1601943 & 688620 & 4.7 & 4.862 & TRN & \\
\hline CHEMBL1979843 & 688620 & 4.95 & 4.8537 & TRN & \\
\hline CHEMBL3210530 & 688620 & 4.95 & 5.0961 & TRN & \\
\hline CHEMBL1477118 & 688620 & 6.5 & 4.9359 & TST & \\
\hline CHEMBL577222 & 688620 & 4.75 & 4.7819 & TRN & \\
\hline CHEMBL1344022 & 688620 & 4.95 & 5.0192 & TRN & \\
\hline CHEMBL1364793 & 688620 & 5.05 & 4.8656 & TRN & \\
\hline CHEMBL1548185 & 688620 & 5.65 & 5.0828 & TRN & \\
\hline CHEMBL1480172 & 688620 & 6.8 & 4.9036 & TRN & \\
\hline CHEMBL1524617 & 688620 & 5.95 & 5.9228 & TST & \\
\hline CHEMBL1448545 & 688620 & 4.45 & 5.1553 & TST & \\
\hline CHEMBL1490077 & 688620 & 4.85 & 4.9735 & TRN & \\
\hline CHEMBL1422888 & 688620 & 4.65 & 5.07600 & 00000000005 & TRN \\
\hline CHEMBL1970221 & 688620 & 5.95 & 5.6427 & TRN & \\
\hline CHEMBL3190537 & 688620 & 5.4 & 5.1963 & TRN & \\
\hline CHEMBL1370681 & 688620 & 5.15 & 5.2973 & TRN & \\
\hline CHEMBL1502031 & 688620 & 5.1 & 4.873 & TRN & \\
\hline CHEMBL261131 & 688620 & 4.95 & 4.838 & TRN & \\
\hline CHEMBL1312954 & 688620 & 4.85 & 4.9698 & TRN & \\
\hline CHEMBL1336449 & 688620 & 5.5 & 4.9608 & TRN & \\
\hline CHEMBL1337804 & 688620 & 5.05 & 5.4071 & TRN & \\
\hline CHEMBL1525364 & 688620 & 5.2 & 4.8274 & TRN & \\
\hline CHEMBL1537417 & 688620 & 5.35 & 5.152 & TST & \\
\hline CHEMBL1236104 & 688620 & 6.25 & 5.12700 & $\partial 000000001$ & TRN \\
\hline CHEMBL1365654 & 688620 & 4.45 & 4.8279 & TST & \\
\hline CHEMBL1594954 & 688620 & 4.45 & 5.1887 & TRN & \\
\hline CHEMBL1605348 & 688620 & 5.1 & 5.1316 & TRN & \\
\hline CHEMBL1490905 & 688620 & 4.95 & 4.963 & TRN & \\
\hline CHEMBL1333983 & 688620 & 4.95 & 5.0193 & TST & \\
\hline CHEMBL1540678 & 688620 & 4.95 & 4.8329 & TST & \\
\hline CHEMBL1533514 & 688620 & 4.8 & 4.8072 & TRN & \\
\hline CHEMBL1541794 & 688620 & 4.45 & 5.0778 & TRN & \\
\hline CHEMBL1386591 & 688620 & 5.1 & 5.2211 & TST & \\
\hline
\end{tabular}




\begin{tabular}{|c|c|c|c|c|}
\hline \multicolumn{5}{|c|}{ Supplemental Table S2.txt } \\
\hline CHEMBL1389590 & 688620 & 5.2 & 4.9381 & TRN \\
\hline CHEMBL1413708 & 688620 & 4.45 & 5.1557 & TRN \\
\hline CHEMBL1336113 & 688620 & 5.45 & 5.187 & TST \\
\hline CHEMBL1322258 & 688620 & 5.15 & 4.9605 & TRN \\
\hline CHEMBL1522786 & 688620 & 5.0 & 5.1386 & TRN \\
\hline CHEMBL1612044 & 688620 & 6.35 & 5.7685 & TRN \\
\hline CHEMBL1459612 & 688620 & 5.0 & 4.9767 & TRN \\
\hline CHEMBL1400614 & 688620 & 4.45 & 4.9659 & TRN \\
\hline CHEMBL1537113 & 688620 & 4.45 & 5.0865 & TRN \\
\hline CHEMBL3208617 & 688620 & 4.65 & 5.3905 & TST \\
\hline CHEMBL1441307 & 688620 & 5.4 & 4.9632 & TRN \\
\hline CHEMBL1346587 & 688620 & 4.5 & 5.1376 & TRN \\
\hline CHEMBL1409559 & 688620 & 6.1 & 5.1433 & TRN \\
\hline CHEMBL1498038 & 688620 & 4.95 & 5.0364 & TRN \\
\hline CHEMBL1601214 & 688620 & 4.45 & 5.3806 & TRN \\
\hline CHEMBL1557308 & 688620 & 4.45 & 5.0165 & TRN \\
\hline CHEMBL1527898 & 688620 & 4.8 & 5.2583 & TRN \\
\hline CHEMBL1338825 & 688620 & 4.45 & 4.9027 & TRN \\
\hline CHEMBL1361913 & 688620 & 5.3 & 5.152 & TST \\
\hline CHEMBL1353329 & 688620 & 4.75 & 5.1144 & TRN \\
\hline CHEMBL1330033 & 688620 & 4.9 & 5.1237 & TRN \\
\hline CHEMBL1433076 & 688620 & 4.9 & 4.8132 & TRN \\
\hline CHEMBL1507888 & 688620 & 4.65 & 4.9815 & TST \\
\hline CHEMBL1596224 & 688620 & 5.0 & 4.8366 & TRN \\
\hline CHEMBL1347858 & 688620 & 4.65 & 5.0201 & TST \\
\hline CHEMBL1482122 & 688620 & 4.45 & 5.0246 & TRN \\
\hline CHEMBL1603669 & 688620 & 6.95 & 5.6286 & TRN \\
\hline CHEMBL1536673 & 688620 & 4.75 & 4.8093 & TRN \\
\hline CHEMBL1504283 & 688620 & 4.6 & 4.8274 & TST \\
\hline CHEMBL1550033 & 688620 & 4.85 & 5.1629 & TRN \\
\hline CHEMBL1556540 & 688620 & 4.85 & 4.9591 & TRN \\
\hline CHEMBL1379826 & 688620 & 5.15 & 4.9398 & TRN \\
\hline CHEMBL3210361 & 688620 & 8.2518 & 5.192 & TRN \\
\hline CHEMBL610198 & 688620 & 5.0 & 5.1735 & TRN \\
\hline CHEMBL1327531 & 688620 & 5.85 & 5.0199 & TRN \\
\hline CHEMBL1478400 & 688620 & 5.15 & 5.3182 & TRN \\
\hline CHEMBL1309466 & 688620 & 5.3 & 5.2192 & TRN \\
\hline CHEMBL1458376 & 688620 & 5.2 & 4.998 & TRN \\
\hline CHEMBL1364304 & 688620 & 4.85 & 5.1878 & TRN \\
\hline CHEMBL1579999 & 688620 & 4.95 & 4.9114 & TST \\
\hline CHEMBL1439957 & 688620 & 4.6 & 5.0312 & TRN \\
\hline CHEMBL1587598 & 688620 & 6.05 & 4.9021 & TRN \\
\hline CHEMBL1419764 & 688620 & 4.85 & 4.9717 & TST \\
\hline CHEMBL3214426 & 688620 & 4.45 & 4.9182 & TST \\
\hline CHEMBL1587432 & 688620 & 5.0 & 5.053 & TST \\
\hline CHEMBL1406575 & 688620 & 4.65 & 5.1742 & TRN \\
\hline CHEMBL33242 & 688620 & 5.85 & 5.5106 & TRN \\
\hline CHEMBL1430987 & 688620 & 4.5 & 5.063 & TST \\
\hline
\end{tabular}




\begin{tabular}{|c|c|c|c|c|c|}
\hline \multicolumn{6}{|c|}{ Supplemental Table S2.txt } \\
\hline CHEMBL1558796 & 688620 & 4.75 & 5.1936 & TST & \\
\hline CHEMBL1602080 & 688620 & 5.05 & 5.2357 & TRN & \\
\hline CHEMBL1561484 & 688620 & 5.25 & 5.1143 & TST & \\
\hline CHEMBL1546938 & 688620 & 4.9 & 4.907 & TST & \\
\hline CHEMBL592314 & 688620 & 5.05 & 5.2539 & TRN & \\
\hline CHEMBL1427405 & 688620 & 4.5 & 5.0908 & TST & \\
\hline CHEMBL1370377 & 688620 & 5.15 & 5.1084 & TRN & \\
\hline CHEMBL3199733 & 688620 & 4.95 & 5.1121 & TRN & \\
\hline CHEMBL1344491 & 688620 & 4.45 & 4.6826 & TRN & \\
\hline CHEMBL1445490 & 688620 & 5.0 & 4.8787 & TRN & \\
\hline CHEMBL1308722 & 688620 & 6.8499 & 5.04899 & 99999999995 & TST \\
\hline CHEMBL1577106 & 688620 & 4.85 & 5.0124 & TRN & \\
\hline CHEMBL1341270 & 688620 & 5.2 & 5.5322 & TRN & \\
\hline CHEMBL1356497 & 688620 & 4.9 & 5.1048 & TRN & \\
\hline CHEMBL535331 & 688620 & 5.45 & 5.3495 & TRN & \\
\hline CHEMBL1562746 & 688620 & 4.95 & 4.9572 & TRN & \\
\hline CHEMBL3207564 & 688620 & 4.45 & 4.9174 & TRN & \\
\hline CHEMBL1378490 & 688620 & 4.45 & 4.9146 & TRN & \\
\hline CHEMBL1380448 & 688620 & 5.2 & 5.0403 & TRN & \\
\hline CHEMBL1489628 & 688620 & 4.75 & 5.1252 & TRN & \\
\hline CHEMBL 2369162 & 688620 & 5.8 & 5.6931 & TRN & \\
\hline CHEMBL1555900 & 688620 & 4.95 & 4.7382 & TRN & \\
\hline CHEMBL1370523 & 688620 & 4.95 & 4.9077 & TRN & \\
\hline CHEMBL1507873 & 688620 & 4.75 & 5.2649 & TRN & \\
\hline CHEMBL1538598 & 688620 & 5.0 & 5.0979 & TST & \\
\hline CHEMBL1596156 & 688620 & 4.75 & 4.7831 & TRN & \\
\hline CHEMBL1380938 & 688620 & 4.95 & 5.06800 & 00000000005 & TRN \\
\hline CHEMBL1404205 & 688620 & 5.45 & 5.2001 & TRN & \\
\hline CHEMBL1427517 & 688620 & 4.9 & 4.9513 & TST & \\
\hline CHEMBL1290249 & 688620 & 5.0 & 5.0488 & TRN & \\
\hline CHEMBL1484576 & 688620 & 5.4 & 5.148 & TST & \\
\hline CHEMBL1528883 & 688620 & 5.0 & 4.9672 & TRN & \\
\hline CHEMBL1445606 & 688620 & 5.45 & 4.6934 & TST & \\
\hline CHEMBL340807 & 688620 & 4.9 & 4.9721 & TST & \\
\hline CHEMBL1347533 & 688620 & 5.1 & 5.4059 & TRN & \\
\hline CHEMBL1367811 & 688620 & 5.0 & 4.8545 & TRN & \\
\hline CHEMBL1304770 & 688620 & 5.65 & 5.2682 & TRN & \\
\hline CHEMBL1408605 & 688620 & 5.25 & 5.3762 & TRN & \\
\hline CHEMBL1419567 & 688620 & 4.45 & 4.8514 & TRN & \\
\hline CHEMBL1453663 & 688620 & 4.9 & 4.8057 & TRN & \\
\hline CHEMBL1480650 & 688620 & 4.75 & 5.1273 & TRN & \\
\hline CHEMBL1404215 & 688620 & 4.45 & 4.96399 & 99999999995 & TRN \\
\hline CHEMBL1997392 & 688620 & 4.9 & 5.0677 & TRN & \\
\hline CHEMBL3195051 & 688620 & 4.95 & 5.0851 & TRN & \\
\hline CHEMBL1603769 & 688620 & 4.65 & 5.0087 & TRN & \\
\hline CHEMBL1471779 & 688620 & 4.6 & 5.4467 & TRN & \\
\hline CHEMBL1984454 & 688620 & 5.75 & 5.0125 & TRN & \\
\hline CHEMBL1366987 & 688620 & 4.8 & 4.985 & TST & \\
\hline
\end{tabular}




\begin{tabular}{|c|c|c|c|c|}
\hline & & & upplement & al $\mathrm{T}$ \\
\hline CHEMBL1429739 & 688620 & 5.15 & 5.0417 & TST \\
\hline CHEMBL1469615 & 688620 & 4.9 & 4.7997 & TRN \\
\hline CHEMBL1325603 & 688620 & 4.45 & 4.7722 & TRN \\
\hline CHEMBL1347063 & 688620 & 4.7 & 4.9605 & TRN \\
\hline CHEMBL1386098 & 688620 & 6.35 & 5.6144 & TRN \\
\hline CHEMBL1453476 & 688620 & 4.45 & 5.1875 & TRN \\
\hline CHEMBL1383679 & 688620 & 5.55 & 5.0599 & TST \\
\hline CHEMBL1427179 & 688620 & 5.3 & 5.0333 & TST \\
\hline CHEMBL1413937 & 688620 & 5.75 & 5.0274 & TRN \\
\hline CHEMBL1331053 & 688620 & 4.9 & 4.9413 & TST \\
\hline CHEMBL1371108 & 688620 & 5.3 & 5.4272 & TRN \\
\hline CHEMBL1499411 & 688620 & 6.0 & 5.2265 & TST \\
\hline CHEMBL1424861 & 688620 & 4.95 & 5.2166 & TRN \\
\hline CHEMBL1422720 & 688620 & 5.55 & 5.2521 & TRN \\
\hline CHEMBL1439730 & 688620 & 4.75 & 5.2311 & TRN \\
\hline CHEMBL1306982 & 688620 & 4.9 & 5.2549 & TRN \\
\hline CHEMBL548708 & 688620 & 4.7 & 4.9715 & TRN \\
\hline CHEMBL1445590 & 688620 & 6.6 & 6.4656 & TRN \\
\hline CHEMBL1609187 & 688620 & 4.8 & 5.4407 & TRN \\
\hline CHEMBL3191182 & 688620 & 6.0 & 5.5361 & TRN \\
\hline CHEMBL1347416 & 688620 & 6.15 & 4.8655 & TRN \\
\hline CHEMBL1507425 & 688620 & 4.45 & 4.8626 & TRN \\
\hline CHEMBL410525 & 688620 & 6.45 & 5.0992 & TRN \\
\hline CHEMBL1324947 & 688620 & 5.65 & 5.3647 & TRN \\
\hline CHEMBL1330389 & 688620 & 4.85 & 4.8852 & TRN \\
\hline CHEMBL1595868 & 688620 & 5.15 & 4.9396 & TRN \\
\hline CHEMBL1343878 & 688620 & 5.6 & 4.952 & TRN \\
\hline CHEMBL1586625 & 688620 & 5.5 & 5.2999 & TRN \\
\hline CHEMBL1440856 & 688620 & 4.95 & 5.1586 & TRN \\
\hline CHEMBL1360820 & 688620 & 5.3 & 5.3305 & TRN \\
\hline CHEMBL1424665 & 688620 & 6.95 & 5.6051 & TRN \\
\hline CHEMBL1439891 & 688620 & 4.65 & 4.7967 & TRN \\
\hline CHEMBL1361574 & 688620 & 4.45 & 4.9834 & TRN \\
\hline CHEMBL1438316 & 688620 & 6.15 & 4.9573 & TST \\
\hline CHEMBL2002062 & 688620 & 4.9 & 4.928 & TRN \\
\hline CHEMBL1503700 & 688620 & 5.35 & 5.0587 & TRN \\
\hline CHEMBL1482809 & 688620 & 4.45 & 5.0406 & TRN \\
\hline CHEMBL1567315 & 688620 & 5.35 & 5.3949 & TRN \\
\hline CHEMBL1581664 & 688620 & 4.6 & 5.1381 & TRN \\
\hline CHEMBL1977242 & 688620 & 5.45 & 4.9737 & TRN \\
\hline CHEMBL1559853 & 688620 & 6.5 & 5.7427 & TRN \\
\hline CHEMBL1539912 & 688620 & 5.15 & 5.0713 & TRN \\
\hline CHEMBL1555495 & 688620 & 4.45 & 4.8323 & TRN \\
\hline CHEMBL1456874 & 688620 & 4.75 & 5.157 & TRN \\
\hline CHEMBL1415081 & 688620 & 4.7 & 5.029 & TRN \\
\hline CHEMBL1360298 & 688620 & 4.95 & 5.1713 & TRN \\
\hline CHEMBL1537091 & 688620 & 4.75 & 5.3735 & TST \\
\hline CHEMBL3194311 & 688620 & 4.9 & 5.0693 & TRN \\
\hline
\end{tabular}




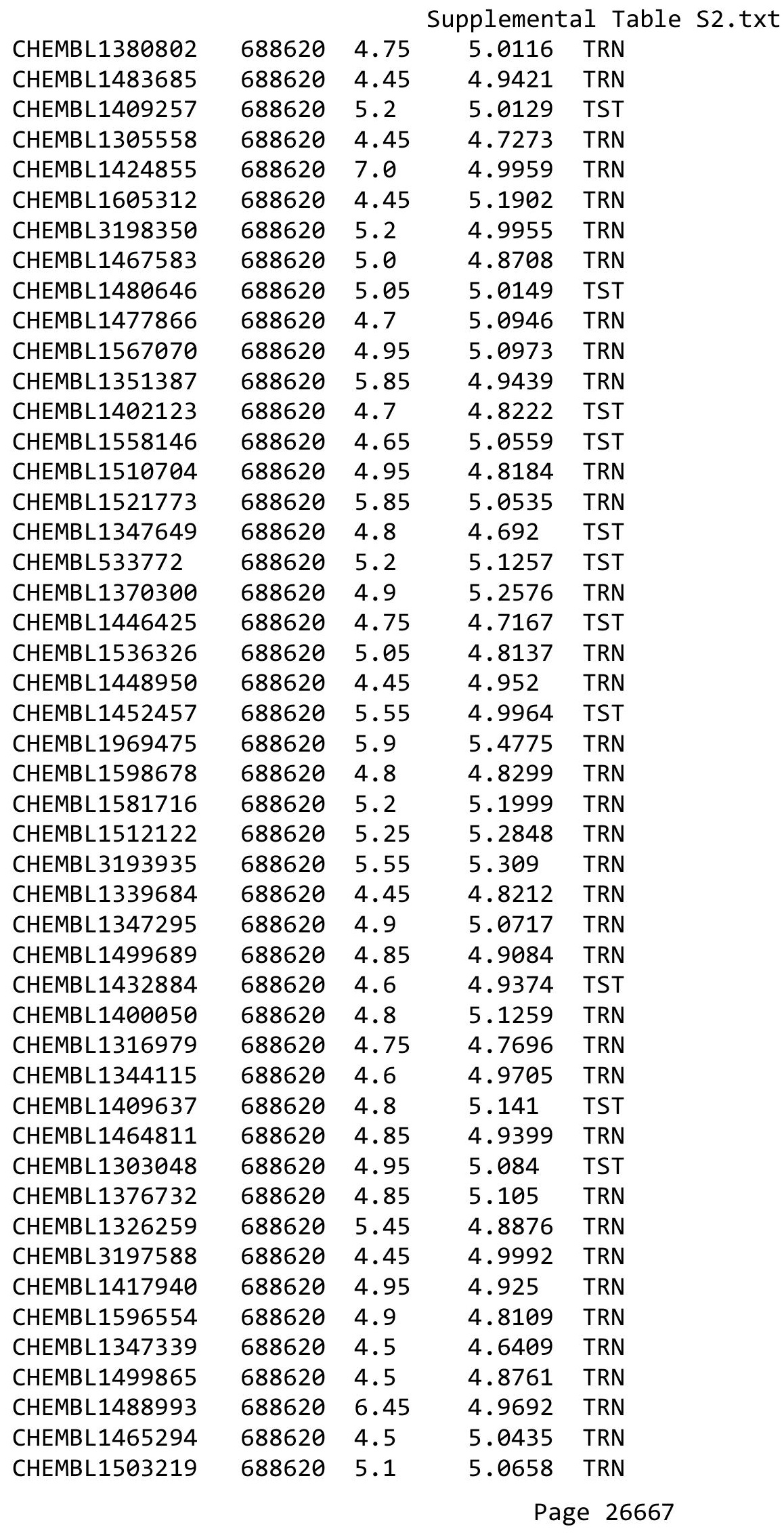




\begin{tabular}{|c|c|c|c|c|}
\hline \multicolumn{5}{|c|}{ Supplemental Table S2.txt } \\
\hline CHEMBL1503949 & 688620 & 5.0 & 4.9054 & TST \\
\hline CHEMBL1430205 & 688620 & 4.9 & 4.9906 & TRN \\
\hline CHEMBL1573497 & 688620 & 4.95 & 5.2227 & TRN \\
\hline CHEMBL 3195095 & 688620 & 4.65 & 5.4557 & TRN \\
\hline CHEMBL1518866 & 688620 & 4.8 & 6.1626 & TRN \\
\hline CHEMBL1578120 & 688620 & 5.2 & 4.9724 & TRN \\
\hline CHEMBL1256667 & 688620 & 5.15 & 5.2751 & TST \\
\hline CHEMBL1410166 & 688620 & 8.3468 & 5.0813 & TRN \\
\hline CHEMBL1487969 & 688620 & 4.45 & 5.1903 & TRN \\
\hline CHEMBL3213483 & 688620 & 4.65 & 5.0484 & TRN \\
\hline CHEMBL1428171 & 688620 & 4.95 & 5.1513 & TRN \\
\hline CHEMBL3198515 & 688620 & 6.8499 & 5.2278 & TRN \\
\hline CHEMBL1459632 & 688620 & 5.35 & 5.0323 & TRN \\
\hline CHEMBL1560212 & 688620 & 5.05 & 5.4488 & TRN \\
\hline CHEMBL1613066 & 688620 & 5.15 & 5.306 & TRN \\
\hline CHEMBL1453484 & 688620 & 5.0 & 5.2499 & TRN \\
\hline CHEMBL1580810 & 688620 & 4.45 & 5.0247 & TRN \\
\hline CHEMBL1430687 & 688620 & 5.0 & 4.7573 & TRN \\
\hline CHEMBL3212061 & 688620 & 4.95 & 4.8402 & TRN \\
\hline CHEMBL1535308 & 688620 & 5.85 & 5.0602 & TST \\
\hline CHEMBL1353228 & 688620 & 5.6 & 5.1577 & TRN \\
\hline CHEMBL1577363 & 688620 & 4.95 & 5.0153 & TRN \\
\hline CHEMBL1580404 & 688620 & 5.05 & 5.0309 & TRN \\
\hline CHEMBL1367633 & 688620 & 4.65 & 4.9942 & TRN \\
\hline CHEMBL1502571 & 688620 & 6.2 & 5.084 & TRN \\
\hline CHEMBL1308733 & 688620 & 5.25 & 4.7843 & TST \\
\hline CHEMBL521971 & 688620 & 7.6003 & 4.9921 & TRN \\
\hline CHEMBL1386766 & 688620 & 4.45 & 5.0063 & TRN \\
\hline CHEMBL1413208 & 688620 & 4.7 & 4.9475 & TRN \\
\hline CHEMBL1370669 & 688620 & 4.65 & 4.7328 & TRN \\
\hline CHEMBL1570790 & 688620 & 7.2 & 5.1049 & TRN \\
\hline CHEMBL 2002776 & 688620 & 5.0 & 5.3348 & TRN \\
\hline CHEMBL1331656 & 688620 & 5.1 & 5.6227 & TRN \\
\hline CHEMBL1448354 & 688620 & 4.8 & 4.8817 & TRN \\
\hline CHEMBL3209886 & 688620 & 5.85 & 5.6145 & TST \\
\hline CHEMBL1361054 & 688620 & 6.95 & 5.8757 & TRN \\
\hline CHEMBL1533877 & 688620 & 4.85 & 5.0984 & TRN \\
\hline CHEMBL1589518 & 688620 & 4.8 & 4.9173 & TRN \\
\hline CHEMBL1547965 & 688620 & 4.85 & 5.0993 & TRN \\
\hline CHEMBL1411760 & 688620 & 5.65 & 5.7216 & TRN \\
\hline CHEMBL1540463 & 688620 & 4.6 & 4.9031 & TST \\
\hline CHEMBL399760 & 688620 & 6.0 & 4.8238 & TRN \\
\hline CHEMBL1342925 & 688620 & 4.65 & 5.1408 & TRN \\
\hline CHEMBL1404964 & 688620 & 4.5 & 4.9362 & TST \\
\hline CHEMBL1300136 & 688620 & 4.8 & 5.1312 & TRN \\
\hline CHEMBL1505735 & 688620 & 4.85 & 4.9145 & TRN \\
\hline CHEMBL1305633 & 688620 & 5.65 & 5.2818 & TRN \\
\hline CHEMBL1369816 & 688620 & 4.95 & 5.0603 & TST \\
\hline
\end{tabular}




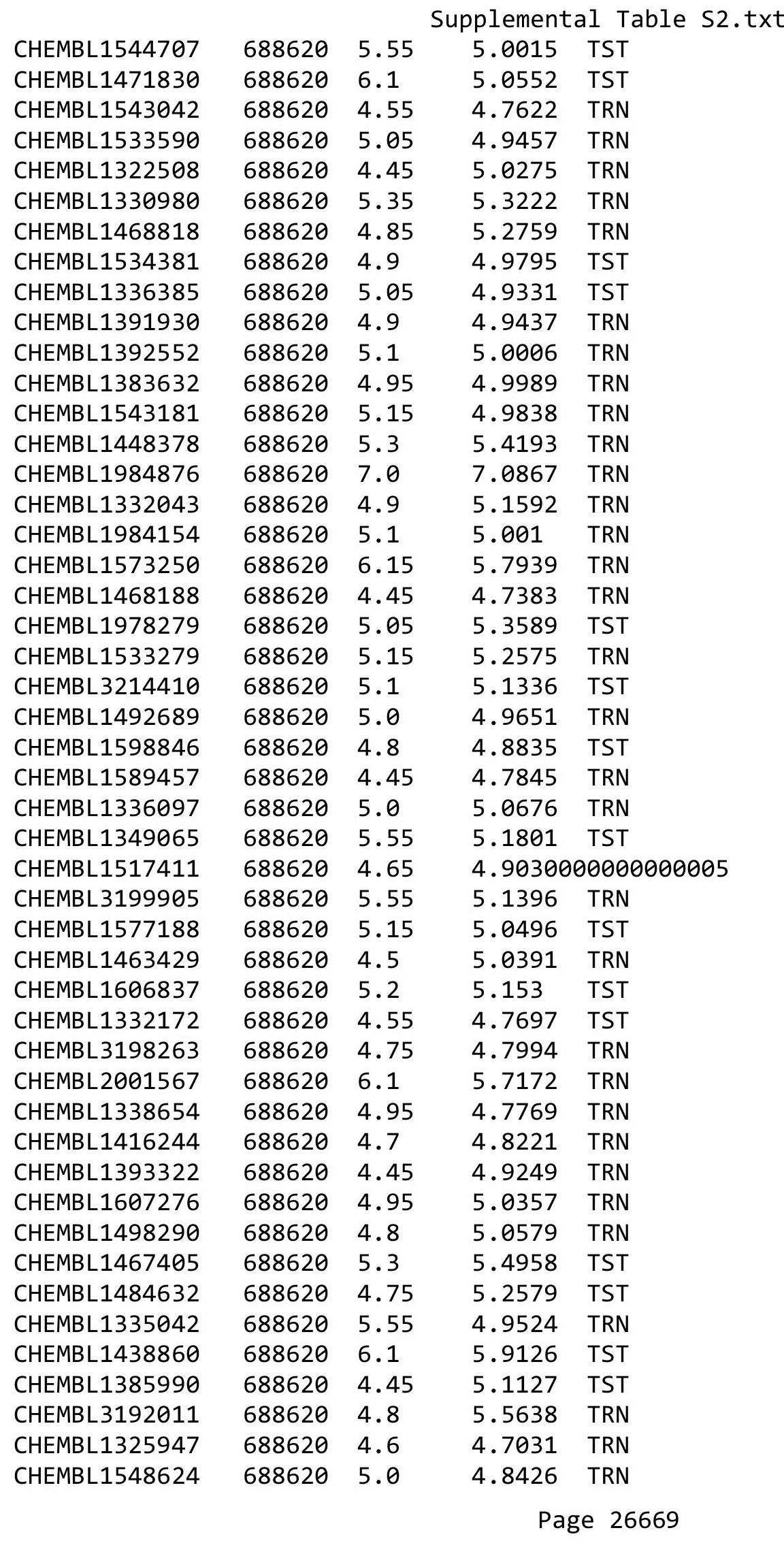




\begin{tabular}{|c|c|c|c|c|}
\hline \multicolumn{5}{|c|}{ Supplemental Table S2.txt } \\
\hline CHEMBL1320716 & 688620 & 4.7 & 4.8387 & TRN \\
\hline CHEMBL1600095 & 688620 & 4.65 & 5.3119 & TST \\
\hline CHEMBL1436697 & 688620 & 4.75 & 5.3245 & TST \\
\hline CHEMBL1882689 & 688620 & 4.5 & 4.7704 & TRN \\
\hline CHEMBL1494265 & 688620 & 4.65 & 5.1001 & TRN \\
\hline CHEMBL1542531 & 688620 & 5.45 & 5.1124 & TST \\
\hline CHEMBL1353136 & 688620 & 4.5 & 5.1583 & TST \\
\hline CHEMBL3193517 & 688620 & 5.35 & 4.8436 & TRN \\
\hline CHEMBL1544593 & 688620 & 4.7 & 4.9884 & TRN \\
\hline CHEMBL1362483 & 688620 & 4.55 & 4.9759 & TRN \\
\hline CHEMBL1597789 & 688620 & 5.25 & 5.3797 & TRN \\
\hline CHEMBL1299582 & 688620 & 6.35 & 5.7706 & TRN \\
\hline CHEMBL1605888 & 688620 & 5.0 & 4.849 & TRN \\
\hline CHEMBL1570765 & 688620 & 5.35 & 5.1301 & TST \\
\hline CHEMBL1359619 & 688620 & 5.25 & 5.1277 & TST \\
\hline CHEMBL 3212874 & 688620 & 4.45 & 5.0751 & TST \\
\hline CHEMBL1314222 & 688620 & 4.9 & 5.0821 & TRN \\
\hline CHEMBL1547559 & 688620 & 4.9 & 5.329 & TST \\
\hline CHEMBL3190565 & 688620 & 4.45 & 4.8864 & TRN \\
\hline CHEMBL1558057 & 688620 & 4.8 & 4.8155 & TST \\
\hline CHEMBL1508595 & 688620 & 4.95 & 4.9943 & TRN \\
\hline CHEMBL1345967 & 688620 & 5.7 & 4.963 & TST \\
\hline CHEMBL1595941 & 688620 & 4.95 & 4.8679 & TRN \\
\hline CHEMBL1323962 & 688620 & 5.8 & 5.1547 & TST \\
\hline CHEMBL1521051 & 688620 & 4.8 & 5.1398 & TRN \\
\hline CHEMBL1301569 & 688620 & 5.05 & 4.9392 & TRN \\
\hline CHEMBL1502166 & 688620 & 5.1 & 4.9799 & TRN \\
\hline CHEMBL1412291 & 688620 & 5.0 & 4.8324 & TRN \\
\hline CHEMBL1516412 & 688620 & 5.6 & 5.3121 & TRN \\
\hline CHEMBL3193795 & 688620 & 5.55 & 6.6741 & TRN \\
\hline CHEMBL1471269 & 688620 & 4.65 & 5.0281 & TRN \\
\hline CHEMBL1535863 & 688620 & 5.25 & 5.1462 & TST \\
\hline CHEMBL1313386 & 688620 & 4.9 & 5.1285 & TRN \\
\hline CHEMBL1477584 & 688620 & 4.8 & 5.1093 & TST \\
\hline CHEMBL 234378 & 688620 & 5.1 & 5.2949 & TRN \\
\hline CHEMBL1469436 & 688620 & 5.3 & 4.9822 & TST \\
\hline CHEMBL1442280 & 688620 & 6.15 & 6.0362 & TRN \\
\hline CHEMBL3209579 & 688620 & 5.95 & 4.7786 & TRN \\
\hline CHEMBL1407989 & 688620 & 6.05 & 5.0853 & TRN \\
\hline CHEMBL3191103 & 688620 & 5.1 & 4.9307 & TRN \\
\hline CHEMBL1386856 & 688620 & 4.45 & 4.8199 & TRN \\
\hline CHEMBL1490803 & 688620 & 5.05 & 5.1159 & TST \\
\hline CHEMBL1529905 & 688620 & 4.75 & 5.0553 & TRN \\
\hline CHEMBL1085065 & 688620 & 4.45 & 4.6722 & TRN \\
\hline CHEMBL1581005 & 688620 & 5.4 & 5.2376 & TRN \\
\hline CHEMBL1606302 & 688620 & 4.45 & 4.8682 & TRN \\
\hline CHEMBL1530743 & 688620 & 5.95 & 5.6456 & TRN \\
\hline CHEMBL1417590 & 688620 & 5.2 & 4.9218 & TST \\
\hline
\end{tabular}




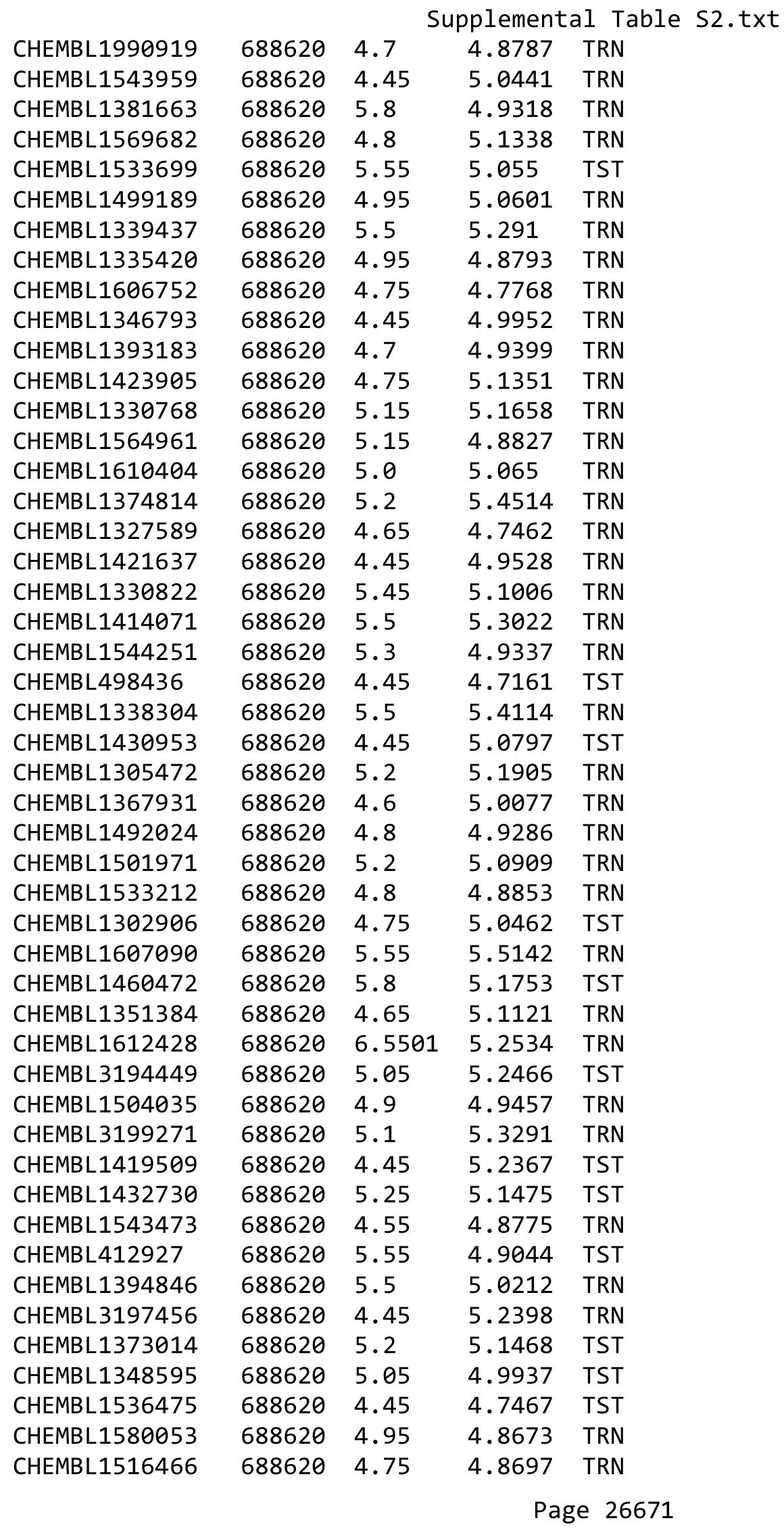




\begin{tabular}{|c|c|c|c|c|c|}
\hline & & & & & \\
\hline CHEMBL3195852 & 688620 & 5.1 & 5.0336 & TRN & \\
\hline CHEMBL1863606 & 688620 & 5.45 & 5.1412 & TRN & \\
\hline CHEMBL1559070 & 688620 & 5.0 & 4.9081 & TRN & \\
\hline CHEMBL1341096 & 688620 & 5.0 & 4.9766 & TRN & \\
\hline CHEMBL1499099 & 688620 & 5.2 & 5.1159 & TRN & \\
\hline CHEMBL1593888 & 688620 & 5.45 & 5.5881 & TRN & \\
\hline CHEMBL1987232 & 688620 & 5.3 & 4.9147 & TRN & \\
\hline CHEMBL1506369 & 688620 & 4.85 & 4.9944 & TST & \\
\hline CHEMBL1431428 & 688620 & 4.65 & 5.0659 & TRN & \\
\hline CHEMBL3198793 & 688620 & 5.0 & 5.0073 & TRN & \\
\hline CHEMBL1514916 & 688620 & 4.85 & 4.8067 & TST & \\
\hline CHEMBL3199370 & 688620 & 4.7 & 4.9709 & TRN & \\
\hline CHEMBL1366776 & 688620 & 4.85 & 4.9584 & TST & \\
\hline CHEMBL1568934 & 688620 & 4.6 & 4.6792 & TRN & \\
\hline CHEMBL1542003 & 688620 & 5.55 & 4.9515 & TRN & \\
\hline CHEMBL3197192 & 688620 & 5.9 & 5.4722 & TRN & \\
\hline CHEMBL1485836 & 688620 & 5.25 & 5.3732 & TRN & \\
\hline CHEMBL1201088 & 688620 & 5.3 & 5.4674 & TRN & \\
\hline CHEMBL1310758 & 688620 & 4.45 & 5.0037 & TRN & \\
\hline CHEMBL 3211844 & 688620 & 4.75 & 5.2429 & TRN & \\
\hline CHEMBL1559673 & 688620 & 4.9 & 4.9904 & TRN & \\
\hline CHEMBL1565221 & 688620 & 4.85 & 5.6122 & TST & \\
\hline CHEMBL1538213 & 688620 & 4.45 & 5.093 & TST & \\
\hline CHEMBL1312681 & 688620 & 6.95 & 5.5547 & TRN & \\
\hline CHEMBL1328117 & 688620 & 5.1 & 4.6934 & TRN & \\
\hline CHEMBL1378625 & 688620 & 4.45 & 4.8386 & TST & \\
\hline CHEMBL1537320 & 688620 & 4.9 & 4.9549 & TRN & \\
\hline CHEMBL1336588 & 688620 & 5.35 & 5.5376 & TRN & \\
\hline CHEMBL1523323 & 688620 & 6.1 & 4.9246 & TRN & \\
\hline CHEMBL1589529 & 688620 & 5.25 & 4.9589 & TRN & \\
\hline CHEMBL1572375 & 688620 & 4.9 & 4.8659 & TST & \\
\hline CHEMBL3193913 & 688620 & 5.25 & 4.8985 & TRN & \\
\hline CHEMBL1411236 & 688620 & 5.0 & 4.9774 & TST & \\
\hline CHEMBL1420025 & 688620 & 4.95 & 5.3486 & TST & \\
\hline CHEMBL1368450 & 688620 & 4.45 & 4.9701 & TST & \\
\hline CHEMBL1328591 & 688620 & 4.45 & 5.1269 & TST & \\
\hline CHEMBL1558506 & 688620 & 4.9 & 4.9367 & TST & \\
\hline CHEMBL1410320 & 688620 & 5.8 & 5.3111 & TRN & \\
\hline CHEMBL1333596 & 688620 & 4.95 & 4.9968 & TRN & \\
\hline CHEMBL1600439 & 688620 & 4.65 & 4.8718 & TRN & \\
\hline CHEMBL1503689 & 688620 & 4.45 & 4.7203 & TRN & \\
\hline CHEMBL 3194751 & 688620 & 4.8 & 4.9619 & TRN & \\
\hline CHEMBL3189974 & 688620 & 4.95 & $5.1670 e$ & 2000000001 & TRN \\
\hline CHEMBL3210095 & 688620 & 4.95 & 5.0829 & TST & \\
\hline CHEMBL1368371 & 688620 & 4.45 & 4.63899 & 9999999999 & TRN \\
\hline CHEMBL1352489 & 688620 & 6.05 & 5.1932 & TRN & \\
\hline CHEMBL1493528 & 688620 & 4.7 & 5.0262 & TST & \\
\hline CHEMBL1362344 & 688620 & 5.9 & 4.9718 & TRN & \\
\hline & & & & 26672 & \\
\hline
\end{tabular}




\begin{tabular}{|c|c|c|c|c|c|}
\hline \multicolumn{6}{|c|}{ Supplemental Table S2.txt } \\
\hline CHEMBL1431023 & 688620 & 4.85 & 5.1753 & TRN & \\
\hline CHEMBL1570495 & 688620 & 5.3 & 5.2572 & TRN & \\
\hline CHEMBL1431789 & 688620 & 4.95 & 4.919 & TRN & \\
\hline CHEMBL1350933 & 688620 & 4.9 & 4.9248 & TRN & \\
\hline CHEMBL1521942 & 688620 & 4.85 & 4.9874 & TRN & \\
\hline CHEMBL1347183 & 688620 & 4.9 & 4.8999 & TRN & \\
\hline CHEMBL1612195 & 688620 & 4.95 & 5.0022 & TRN & \\
\hline CHEMBL1339535 & 688620 & 4.45 & 4.9196 & TRN & \\
\hline CHEMBL1523861 & 688620 & 4.75 & 5.0728 & TRN & \\
\hline CHEMBL 235929 & 688620 & 5.35 & 4.9072 & TRN & \\
\hline CHEMBL1326536 & 688620 & 4.45 & 4.7436 & TRN & \\
\hline CHEMBL1456825 & 688620 & 4.8 & 4.8397 & TRN & \\
\hline CHEMBL1343823 & 688620 & 5.4 & 5.2548 & TRN & \\
\hline CHEMBL 2002898 & 688620 & 5.65 & 4.94300 & 00000000005 & TRN \\
\hline CHEMBL1605040 & 688620 & 5.15 & 4.9517 & TRN & \\
\hline CHEMBL3199005 & 688620 & 4.6 & 4.9592 & TRN & \\
\hline CHEMBL1464043 & 688620 & 5.5 & 5.1974 & TST & \\
\hline CHEMBL1331130 & 688620 & 5.3 & 5.0679 & TRN & \\
\hline CHEMBL1448612 & 688620 & 5.05 & 4.912 & TST & \\
\hline CHEMBL1589440 & 688620 & 4.85 & 4.841 & TST & \\
\hline CHEMBL1508182 & 688620 & 5.35 & 5.1808 & TRN & \\
\hline CHEMBL1576691 & 688620 & 4.45 & 4.8093 & TRN & \\
\hline CHEMBL1561748 & 688620 & 4.9 & 4.9975 & TRN & \\
\hline CHEMBL1338121 & 688620 & 5.05 & 5.2536 & TRN & \\
\hline CHEMBL1507279 & 688620 & 5.75 & 5.0169 & TRN & \\
\hline CHEMBL1598388 & 688620 & 4.85 & 4.9526 & TRN & \\
\hline CHEMBL1582365 & 688620 & 4.9 & 5.3072 & TRN & \\
\hline CHEMBL1325943 & 688620 & 5.8 & 5.3368 & TRN & \\
\hline CHEMBL1412071 & 688620 & 4.45 & 4.9038 & TRN & \\
\hline CHEMBL1540987 & 688620 & 5.7 & 5.1463 & TRN & \\
\hline CHEMBL1486934 & 688620 & 5.75 & 5.4725 & TRN & \\
\hline CHEMBL1319900 & 688620 & 4.5 & 4.8491 & TST & \\
\hline CHEMBL1579849 & 688620 & 4.45 & 4.8966 & TST & \\
\hline CHEMBL1402081 & 688620 & 5.0 & 5.3767 & TRN & \\
\hline CHEMBL1462447 & 688620 & 4.95 & 5.026 & TRN & \\
\hline CHEMBL1578466 & 688620 & 4.45 & 4.9141 & TRN & \\
\hline CHEMBL1502583 & 688620 & 5.6 & 5.1759 & TRN & \\
\hline CHEMBL1547751 & 688620 & 4.8 & 5.0249 & TRN & \\
\hline CHEMBL1496863 & 688620 & 5.15 & 5.103 & TST & \\
\hline CHEMBL1507655 & 688620 & 4.45 & 5.0263 & TRN & \\
\hline CHEMBL1607578 & 688620 & 5.0 & 4.9595 & TRN & \\
\hline CHEMBL1409734 & 688620 & 4.35 & 4.8825 & TRN & \\
\hline CHEMBL1361868 & 688620 & 6.5501 & 5.2928 & TRN & \\
\hline CHEMBL3197480 & 688620 & 4.9 & 5.1412 & TRN & \\
\hline CHEMBL34704 & 688620 & 4.45 & 4.8103 & TST & \\
\hline CHEMBL1369567 & 688620 & 4.9 & 4.8871 & TST & \\
\hline CHEMBL1352181 & 688620 & 5.05 & 4.7117 & TRN & \\
\hline CHEMBL1414542 & 688620 & 4.45 & 4.9647 & TRN & \\
\hline
\end{tabular}




\begin{tabular}{|c|c|c|c|c|}
\hline \multicolumn{5}{|c|}{ Supplemental Table S2.txt } \\
\hline CHEMBL1355808 & 688620 & 4.85 & 5.2627 & TRN \\
\hline CHEMBL1338657 & 688620 & 4.85 & 4.8907 & TRN \\
\hline CHEMBL1424398 & 688620 & 5.15 & 5.2587 & TRN \\
\hline CHEMBL 3196542 & 688620 & 4.45 & 4.8162 & TST \\
\hline CHEMBL1329450 & 688620 & 4.9 & 4.5549 & TRN \\
\hline CHEMBL1511631 & 688620 & 4.45 & 5.0166 & TRN \\
\hline CHEMBL1470354 & 688620 & 6.25 & 4.8977 & TST \\
\hline CHEMBL1391941 & 688620 & 5.0 & 4.9677 & TST \\
\hline CHEMBL1425552 & 688620 & 5.7 & 5.4914 & TRN \\
\hline CHEMBL1304248 & 688620 & 4.95 & 5.2756 & TRN \\
\hline CHEMBL1599120 & 688620 & 4.45 & 5.0452 & TRN \\
\hline CHEMBL1532716 & 688620 & 5.6 & 5.4413 & TRN \\
\hline CHEMBL1580096 & 688620 & 5.8 & 5.2924 & TRN \\
\hline CHEMBL1420312 & 688620 & 5.35 & 4.9216 & TRN \\
\hline CHEMBL1347084 & 688620 & 5.15 & 5.2498 & TRN \\
\hline CHEMBL3194320 & 688620 & 6.15 & 5.7631 & TRN \\
\hline CHEMBL3145205 & 688620 & 6.4 & 5.9205 & TRN \\
\hline CHEMBL1550786 & 688620 & 5.3 & 5.7344 & TRN \\
\hline CHEMBL1578249 & 688620 & 5.4 & 5.2879 & TRN \\
\hline CHEMBL3208184 & 688620 & 5.15 & 5.1096 & TRN \\
\hline CHEMBL1549165 & 688620 & 4.45 & 4.8629 & TRN \\
\hline CHEMBL1583257 & 688620 & 4.95 & 4.9285 & TRN \\
\hline CHEMBL1480991 & 688620 & 4.45 & 4.8879 & TST \\
\hline CHEMBL1604032 & 688620 & 5.5 & 5.4094 & TRN \\
\hline CHEMBL1363720 & 688620 & 4.95 & 4.8137 & TRN \\
\hline CHEMBL1487636 & 688620 & 4.95 & 4.8981 & TRN \\
\hline CHEMBL1610772 & 688620 & 4.95 & 4.73 & TST \\
\hline CHEMBL1402379 & 688620 & 6.8 & 5.081 & TST \\
\hline CHEMBL1609574 & 688620 & 4.95 & 5.046 & TRN \\
\hline CHEMBL1449850 & 688620 & 4.9 & 4.976 & TRN \\
\hline CHEMBL1387697 & 688620 & 4.95 & 4.9512 & TRN \\
\hline CHEMBL1480349 & 688620 & 4.95 & 4.9413 & TRN \\
\hline CHEMBL1438038 & 688620 & 4.95 & 4.8663 & TRN \\
\hline CHEMBL1449499 & 688620 & 4.9 & 4.6608 & TRN \\
\hline CHEMBL1302290 & 688620 & 4.65 & 4.9769 & TRN \\
\hline CHEMBL1386366 & 688620 & 4.6 & 5.1787 & TRN \\
\hline CHEMBL1579995 & 688620 & 4.65 & 5.0413 & TRN \\
\hline CHEMBL1336235 & 688620 & 4.45 & 4.7303 & TRN \\
\hline CHEMBL1412127 & 688620 & 4.85 & 4.9582 & TRN \\
\hline CHEMBL1340862 & 688620 & 7.6003 & 5.1932 & TRN \\
\hline CHEMBL1339897 & 688620 & 5.3 & 5.5281 & TRN \\
\hline CHEMBL1326890 & 688620 & 5.4 & 4.9425 & TRN \\
\hline CHEMBL1501056 & 688620 & 5.75 & 5.1238 & TRN \\
\hline CHEMBL1557826 & 688620 & 6.15 & 5.2622 & TRN \\
\hline CHEMBL1456659 & 688620 & 4.9 & 4.749 & TST \\
\hline CHEMBL1360493 & 688620 & 5.15 & 5.0195 & TRN \\
\hline CHEMBL1448496 & 688620 & 5.15 & 5.4581 & TRN \\
\hline CHEMBL1979367 & 688620 & 4.6 & 5.1268 & TRN \\
\hline
\end{tabular}




\begin{tabular}{|c|c|c|c|c|}
\hline \multicolumn{5}{|c|}{ Supplemental Table S2.txt } \\
\hline CHEMBL1399758 & 688620 & 5.4 & 5.3623 & TRN \\
\hline CHEMBL1511116 & 688620 & 5.0 & 5.1419 & TRN \\
\hline CHEMBL1422301 & 688620 & 4.6 & 5.8987 & TRN \\
\hline CHEMBL1346765 & 688620 & 4.95 & 4.9009 & TST \\
\hline CHEMBL1422824 & 688620 & 6.1 & 4.9898 & TRN \\
\hline CHEMBL1383122 & 688620 & 5.2 & 4.8177 & TRN \\
\hline CHEMBL1300736 & 688620 & 4.45 & 4.7031 & TRN \\
\hline CHEMBL1532576 & 688620 & 4.65 & 5.0278 & TRN \\
\hline CHEMBL1576316 & 688620 & 5.2 & 5.1533 & TRN \\
\hline CHEMBL1542764 & 688620 & 5.0 & 4.9503 & TRN \\
\hline CHEMBL1328606 & 688620 & 4.8 & 4.827 & TRN \\
\hline CHEMBL156360 & 688620 & 4.65 & 5.0573 & TRN \\
\hline CHEMBL1324538 & 688620 & 4.65 & 4.9504 & TST \\
\hline CHEMBL1608472 & 688620 & 4.45 & 4.8152 & TRN \\
\hline CHEMBL1322854 & 688620 & 5.65 & 5.7858 & TRN \\
\hline CHEMBL1481737 & 688620 & 5.0 & 4.8911 & TRN \\
\hline CHEMBL1539222 & 688620 & 4.8 & 4.8572 & TST \\
\hline CHEMBL1510792 & 688620 & 4.95 & 5.1393 & TRN \\
\hline CHEMBL1594395 & 688620 & 4.85 & 5.1904 & TRN \\
\hline CHEMBL1545258 & 688620 & 5.3 & 5.2002 & TRN \\
\hline CHEMBL1526494 & 688620 & 4.8 & 4.928 & TST \\
\hline CHEMBL3208263 & 688620 & 5.05 & 4.74 & TST \\
\hline CHEMBL3190447 & 688620 & 6.0 & 5.6542 & TRN \\
\hline CHEMBL1469572 & 688620 & 4.9 & 5.4615 & TRN \\
\hline CHEMBL1599291 & 688620 & 5.45 & 5.3923 & TRN \\
\hline CHEMBL1603695 & 688620 & 4.85 & 5.0039 & TRN \\
\hline CHEMBL1482162 & 688620 & 4.8 & 4.7277 & TRN \\
\hline CHEMBL1324305 & 688620 & 4.9 & 4.9916 & TRN \\
\hline CHEMBL1377920 & 688620 & 4.95 & 5.0561 & TST \\
\hline CHEMBL1427646 & 688620 & 4.9 & 4.9758 & TST \\
\hline CHEMBL1340717 & 688620 & 5.0 & 5.3 & TRN \\
\hline CHEMBL1493755 & 688620 & 4.95 & 5.2257 & TRN \\
\hline CHEMBL3197664 & 688620 & 6.05 & 5.5015 & TRN \\
\hline CHEMBL1375250 & 688620 & 4.95 & 4.8636 & TST \\
\hline CHEMBL1399784 & 688620 & 5.6 & 4.8344 & TST \\
\hline CHEMBL1344093 & 688620 & 4.6 & 4.9708 & TRN \\
\hline CHEMBL3191618 & 688620 & 4.7 & 4.9877 & TRN \\
\hline CHEMBL588234 & 688620 & 6.05 & 4.9414 & TRN \\
\hline CHEMBL1584676 & 688620 & 5.35 & 5.004 & TST \\
\hline CHEMBL1458178 & 688620 & 5.85 & 5.3516 & TST \\
\hline CHEMBL3190751 & 688620 & 4.9 & 5.3481 & TRN \\
\hline CHEMBL1347169 & 688620 & 4.75 & 4.9492 & TRN \\
\hline CHEMBL1542257 & 688620 & 5.15 & 4.9931 & TRN \\
\hline CHEMBL1467082 & 688620 & 4.85 & 4.8161 & TRN \\
\hline CHEMBL1497627 & 688620 & 4.95 & 4.8069 & TRN \\
\hline CHEMBL1417307 & 688620 & 4.8 & 4.9556 & TRN \\
\hline CHEMBL1337149 & 688620 & 4.95 & 4.9716 & TRN \\
\hline CHEMBL1441329 & 688620 & 4.45 & 4.8891 & TST \\
\hline
\end{tabular}




\begin{tabular}{|c|c|c|c|c|}
\hline \multicolumn{5}{|c|}{ Supplemental Table S2.txt } \\
\hline CHEMBL1313488 & 688620 & 5.45 & 5.1018 & TRN \\
\hline CHEMBL1448210 & 688620 & 6.1 & 5.0929 & TST \\
\hline CHEMBL1344299 & 688620 & 5.1 & 5.1464 & TRN \\
\hline CHEMBL1342437 & 688620 & 4.9 & 4.8522 & TRN \\
\hline CHEMBL1303711 & 688620 & 5.5 & 5.003 & TRN \\
\hline CHEMBL1536459 & 688620 & 4.9 & 4.9991 & TST \\
\hline CHEMBL1446040 & 688620 & 6.0 & 5.5341 & TRN \\
\hline CHEMBL1575101 & 688620 & 4.9 & 5.02 & TRN \\
\hline CHEMBL1987078 & 688620 & 4.45 & 5.0793 & TRN \\
\hline CHEMBL1398981 & 688620 & 4.6 & 4.8876 & TRN \\
\hline CHEMBL1537974 & 688620 & 5.25 & 4.9172 & TST \\
\hline CHEMBL1410474 & 688620 & 6.15 & 6.3624 & TRN \\
\hline CHEMBL1471708 & 688620 & 4.95 & 5.1896 & TRN \\
\hline CHEMBL1309384 & 688620 & 5.0 & 5.0217 & TRN \\
\hline CHEMBL3212537 & 688620 & 4.9 & 5.0222 & TRN \\
\hline CHEMBL1548363 & 688620 & 4.45 & 5.0802 & TST \\
\hline CHEMBL1426220 & 688620 & 4.8 & 4.9889 & TRN \\
\hline CHEMBL1531280 & 688620 & 4.9 & 4.8033 & TRN \\
\hline CHEMBL1587103 & 688620 & 4.45 & 4.8437 & TRN \\
\hline CHEMBL1491763 & 688620 & 5.05 & 4.843 & TST \\
\hline CHEMBL3196156 & 688620 & 5.75 & 4.8221 & TRN \\
\hline CHEMBL1484881 & 688620 & 4.45 & 4.9684 & TST \\
\hline CHEMBL1408779 & 688620 & 5.45 & 5.1609 & TST \\
\hline CHEMBL1393000 & 688620 & 4.9 & 4.9695 & TRN \\
\hline CHEMBL93109 & 688620 & 5.35 & 5.2463 & TRN \\
\hline CHEMBL1539591 & 688620 & 4.75 & 4.9817 & TRN \\
\hline CHEMBL1310992 & 688620 & 5.15 & 5.0088 & TRN \\
\hline CHEMBL1374465 & 688620 & 4.95 & 4.9384 & TST \\
\hline CHEMBL1407520 & 688620 & 5.45 & 4.9992 & TRN \\
\hline CHEMBL1324569 & 688620 & 4.95 & 4.9693 & TRN \\
\hline CHEMBL1568598 & 688620 & 4.55 & 5.0635 & TST \\
\hline CHEMBL1354014 & 688620 & 5.45 & 5.3005 & TRN \\
\hline CHEMBL493032 & 688620 & 4.95 & 4.7949 & TST \\
\hline CHEMBL1605087 & 688620 & 4.8 & 4.8887 & TRN \\
\hline CHEMBL1540469 & 688620 & 4.6 & 4.8185 & TRN \\
\hline CHEMBL1402218 & 688620 & 5.0 & 4.8964 & TRN \\
\hline CHEMBL1497597 & 688620 & 4.45 & 4.7748 & TST \\
\hline CHEMBL1418347 & 688620 & 5.55 & 5.1071 & TRN \\
\hline CHEMBL 239883 & 688620 & 6.1 & 5.6509 & TRN \\
\hline CHEMBL1588897 & 688620 & 8.4949 & 5.0972 & TRN \\
\hline CHEMBL1352454 & 688620 & 6.15 & 5.0807 & TST \\
\hline CHEMBL1402134 & 688620 & 5.45 & 5.4939 & TRN \\
\hline CHEMBL3145365 & 688620 & 6.25 & 5.9198 & TRN \\
\hline CHEMBL1515137 & 688620 & 4.65 & 4.711 & TST \\
\hline CHEMBL1570972 & 688620 & 4.8 & 4.8794 & TRN \\
\hline CHEMBL3210583 & 688620 & 5.05 & 5.2441 & TRN \\
\hline CHEMBL3211817 & 688620 & 5.0 & 5.1969 & TRN \\
\hline CHEMBL1375590 & 688620 & 4.95 & 5.0866 & TRN \\
\hline
\end{tabular}




\begin{tabular}{|c|c|c|c|c|}
\hline \multicolumn{5}{|c|}{ Supplemental Table S2.txt } \\
\hline CHEMBL1596900 & 688620 & 4.8 & 5.0479 & TRN \\
\hline CHEMBL1450269 & 688620 & 6.05 & 4.8131 & TRN \\
\hline CHEMBL1549179 & 688620 & 5.05 & 4.9399 & TST \\
\hline CHEMBL1527275 & 688620 & 4.45 & 4.8942 & TRN \\
\hline CHEMBL1495768 & 688620 & 4.45 & 5.0341 & TRN \\
\hline CHEMBL1582584 & 688620 & 5.35 & 5.3435 & TRN \\
\hline CHEMBL1326543 & 688620 & 5.5 & 5.169 & TRN \\
\hline CHEMBL1565649 & 688620 & 5.55 & 4.9811 & TRN \\
\hline CHEMBL1440960 & 688620 & 5.7 & 5.0524 & TRN \\
\hline CHEMBL3192881 & 688620 & 4.65 & 5.0587 & TST \\
\hline CHEMBL1555446 & 688620 & 4.45 & 4.9391 & TRN \\
\hline CHEMBL1575744 & 688620 & 6.3 & 5.513 & TRN \\
\hline CHEMBL1580654 & 688620 & 4.9 & 5.0631 & TRN \\
\hline CHEMBL1459539 & 688620 & 5.3 & 4.9088 & TRN \\
\hline CHEMBL1403412 & 688620 & 5.5 & 5.5626 & TRN \\
\hline CHEMBL455983 & 688620 & 6.0 & 5.1413 & TRN \\
\hline CHEMBL1319301 & 688620 & 4.9 & 4.9501 & TRN \\
\hline CHEMBL1458840 & 688620 & 4.9 & 5.0443 & TST \\
\hline CHEMBL1367860 & 688620 & 4.9 & 5.0951 & TST \\
\hline CHEMBL1470835 & 688620 & 4.9 & 4.9337 & TRN \\
\hline CHEMBL1460956 & 688620 & 5.4 & 5.3096 & TRN \\
\hline CHEMBL1349299 & 688620 & 4.45 & 5.1037 & TRN \\
\hline CHEMBL1543714 & 688620 & 5.5 & 5.118 & TRN \\
\hline CHEMBL1545064 & 688620 & 5.8 & 5.37 & TST \\
\hline CHEMBL1567206 & 688620 & 4.45 & 4.7797 & TRN \\
\hline CHEMBL1462208 & 688620 & 4.85 & 4.9216 & TRN \\
\hline CHEMBL1386134 & 688620 & 5.45 & 5.2466 & TRN \\
\hline CHEMBL1999756 & 688620 & 4.45 & 4.8228 & TRN \\
\hline CHEMBL1375566 & 688620 & 4.95 & 5.0701 & TST \\
\hline CHEMBL3193865 & 688620 & 5.5 & 4.7981 & TRN \\
\hline CHEMBL1385529 & 688620 & 4.45 & 5.3409 & TRN \\
\hline CHEMBL1367735 & 688620 & 5.65 & 4.7419 & TRN \\
\hline CHEMBL1505508 & 688620 & 5.35 & 5.0233 & TST \\
\hline CHEMBL1348315 & 688620 & 4.85 & 4.9957 & TST \\
\hline CHEMBL1495590 & 688620 & 4.5 & 5.01 & TRN \\
\hline CHEMBL1999481 & 688620 & 6.05 & 5.6928 & TRN \\
\hline CHEMBL1468229 & 688620 & 8.2518 & 4.8875 & TRN \\
\hline CHEMBL1430478 & 688620 & 4.7 & 4.9304 & TRN \\
\hline CHEMBL1366443 & 688620 & 6.45 & 5.2563 & TST \\
\hline CHEMBL278315 & 688620 & 5.35 & 5.1519 & TST \\
\hline CHEMBL1497549 & 688620 & 5.2 & 5.7259 & TRN \\
\hline CHEMBL1594350 & 688620 & 5.3 & 5.0582 & TST \\
\hline CHEMBL1413096 & 688620 & 4.45 & 4.9446 & TRN \\
\hline CHEMBL1610631 & 688620 & 5.0 & 5.0361 & TST \\
\hline CHEMBL1550564 & 688620 & 4.5 & 5.1309 & TST \\
\hline CHEMBL1604793 & 688620 & 6.0 & 4.9736 & TRN \\
\hline CHEMBL1485818 & 688620 & 5.15 & 5.6607 & TRN \\
\hline CHEMBL1560432 & 688620 & 5.1 & 5.1031 & TRN \\
\hline
\end{tabular}




\begin{tabular}{|c|c|c|c|c|}
\hline \multicolumn{5}{|c|}{ Supplemental Table S2.txt } \\
\hline CHEMBL1577767 & 688620 & 6.5 & 4.9668 & TRN \\
\hline CHEMBL1548165 & 688620 & 6.6 & 5.0485 & TST \\
\hline CHEMBL1613304 & 688620 & 4.8 & 5.0664 & TRN \\
\hline CHEMBL1479032 & 688620 & 4.9 & 4.9359 & TST \\
\hline CHEMBL1568009 & 688620 & 4.9 & 4.9937 & TRN \\
\hline CHEMBL1425172 & 688620 & 5.2 & 5.1748 & TST \\
\hline CHEMBL1492423 & 688620 & 4.9 & 5.1083 & TST \\
\hline CHEMBL3189943 & 688620 & 4.9 & 5.0343 & TRN \\
\hline CHEMBL1482855 & 688620 & 4.95 & 4.9933 & TRN \\
\hline CHEMBL3194649 & 688620 & 4.8 & 5.409 & TST \\
\hline CHEMBL1429142 & 688620 & 4.85 & 5.3305 & TRN \\
\hline CHEMBL3214029 & 688620 & 4.45 & 4.9467 & TRN \\
\hline CHEMBL1517112 & 688620 & 4.9 & 4.8944 & TRN \\
\hline CHEMBL1454374 & 688620 & 5.2 & 5.3657 & TRN \\
\hline CHEMBL1344322 & 688620 & 4.9 & 5.0359 & TRN \\
\hline CHEMBL1499309 & 688620 & 5.3 & 4.9128 & TRN \\
\hline CHEMBL1572121 & 688620 & 4.9 & 4.9048 & TRN \\
\hline CHEMBL1490944 & 688620 & 4.8 & 5.019 & TRN \\
\hline CHEMBL1329698 & 688620 & 4.95 & 5.1254 & TST \\
\hline CHEMBL1611183 & 688620 & 5.5 & 5.4099 & TRN \\
\hline CHEMBL3189847 & 688620 & 5.15 & 5.1145 & TRN \\
\hline CHEMBL1377509 & 688620 & 4.45 & 4.975 & TRN \\
\hline CHEMBL1446766 & 688620 & 5.0 & 4.9522 & TRN \\
\hline CHEMBL1509395 & 688620 & 5.3 & 5.1298 & TRN \\
\hline CHEMBL1430328 & 688620 & 5.1 & 4.8773 & TRN \\
\hline CHEMBL1517842 & 688620 & 5.7 & 4.7433 & TRN \\
\hline CHEMBL1335511 & 688620 & 5.75 & 4.9927 & TRN \\
\hline CHEMBL1448093 & 688620 & 4.45 & 4.7473 & TST \\
\hline CHEMBL1303147 & 688620 & 4.7 & 4.7531 & TRN \\
\hline CHEMBL1581163 & 688620 & 4.7 & 4.9337 & TRN \\
\hline CHEMBL1571985 & 688620 & 4.45 & 4.9012 & TRN \\
\hline CHEMBL1404610 & 688620 & 4.8 & 5.1869 & TST \\
\hline CHEMBL1428691 & 688620 & 4.95 & 5.2686 & TST \\
\hline CHEMBL1509324 & 688620 & 5.15 & 5.1056 & TRN \\
\hline CHEMBL1599992 & 688620 & 4.6 & 4.9394 & TRN \\
\hline CHEMBL 2369168 & 688620 & 4.45 & 4.7994 & TRN \\
\hline CHEMBL1507187 & 688620 & 4.45 & 4.6466 & TRN \\
\hline CHEMBL 1605448 & 688620 & 5.95 & 5.4159 & TST \\
\hline CHEMBL1362080 & 688620 & 4.45 & 4.9844 & TRN \\
\hline CHEMBL1545279 & 688620 & 5.5 & 4.9185 & TRN \\
\hline CHEMBL1377198 & 688620 & 4.8 & 5.1559 & TRN \\
\hline CHEMBL1327577 & 688620 & 5.0 & 4.8072 & TRN \\
\hline CHEMBL3199216 & 688620 & 6.2 & 6.2588 & TRN \\
\hline CHEMBL1477696 & 688620 & 5.35 & 5.932 & TRN \\
\hline CHEMBL1368514 & 688620 & 5.65 & 5.3887 & TRN \\
\hline CHEMBL1374288 & 688620 & 6.0 & 5.1868 & TST \\
\hline CHEMBL1303469 & 688620 & 4.9 & 4.8479 & TRN \\
\hline CHEMBL1438241 & 688620 & 5.55 & 5.3923 & TRN \\
\hline
\end{tabular}




\begin{tabular}{|c|c|c|c|c|}
\hline \multicolumn{5}{|c|}{ Supplemental Table S2.txt } \\
\hline CHEMBL1455024 & 688620 & 4.75 & 4.6527 & TRN \\
\hline CHEMBL3197532 & 688620 & 4.8 & 4.9195 & TRN \\
\hline CHEMBL1406536 & 688620 & 6.25 & 6.1024 & TRN \\
\hline CHEMBL1604121 & 688620 & 4.5 & 4.8753 & TRN \\
\hline CHEMBL393417 & 688620 & 6.0 & 5.8433 & TRN \\
\hline CHEMBL1574432 & 688620 & 5.55 & 5.2492 & TST \\
\hline CHEMBL1557846 & 688620 & 4.8 & 4.7212 & TST \\
\hline CHEMBL1576124 & 688620 & 4.7 & 4.8881 & TRN \\
\hline CHEMBL1483014 & 688620 & 4.75 & 5.1613 & TST \\
\hline CHEMBL1342701 & 688620 & 4.5 & 4.9279 & TRN \\
\hline CHEMBL 3212386 & 688620 & 4.45 & 4.9398 & TRN \\
\hline CHEMBL1559736 & 688620 & 4.75 & 5.1235 & TST \\
\hline CHEMBL1964909 & 688620 & 6.5 & 5.1761 & TRN \\
\hline CHEMBL1376083 & 688620 & 4.9 & 5.1203 & TST \\
\hline CHEMBL1528292 & 688620 & 4.5 & 5.0319 & TRN \\
\hline CHEMBL1337540 & 688620 & 4.45 & 4.9836 & TRN \\
\hline CHEMBL3207512 & 688620 & 4.9 & 4.8688 & TRN \\
\hline CHEMBL1410157 & 688620 & 5.45 & 5.4944 & TRN \\
\hline CHEMBL1323333 & 688620 & 5.55 & 5.0618 & TRN \\
\hline CHEMBL1397270 & 688620 & 5.0 & 5.1615 & TST \\
\hline CHEMBL1376693 & 688620 & 6.05 & 5.0797 & TRN \\
\hline CHEMBL1492003 & 688620 & 4.45 & 5.1227 & TST \\
\hline CHEMBL1984247 & 688620 & 4.75 & 5.0757 & TST \\
\hline CHEMBL1447448 & 688620 & 5.3 & 5.0926 & TRN \\
\hline CHEMBL1482096 & 688620 & 4.9 & 4.9202 & TRN \\
\hline CHEMBL1425417 & 688620 & 5.15 & 5.1422 & TRN \\
\hline CHEMBL1350460 & 688620 & 5.0 & 5.0011 & TRN \\
\hline CHEMBL1449291 & 688620 & 4.95 & 5.1226 & TRN \\
\hline CHEMBL1977867 & 688620 & 5.8 & 5.3532 & TRN \\
\hline CHEMBL1389361 & 688620 & 5.0 & 5.1101 & TRN \\
\hline CHEMBL1348532 & 688620 & 4.95 & 4.8568 & TRN \\
\hline CHEMBL1422035 & 688620 & 4.75 & 4.695 & TRN \\
\hline CHEMBL1442884 & 688620 & 5.95 & 5.5646 & TST \\
\hline CHEMBL1494311 & 688620 & 5.5 & 5.2467 & TRN \\
\hline CHEMBL1390516 & 688620 & 5.05 & 4.7869 & TRN \\
\hline CHEMBL1569071 & 688620 & 4.6 & 5.2186 & TRN \\
\hline CHEMBL1972736 & 688620 & 5.75 & 5.585 & TST \\
\hline CHEMBL1503123 & 688620 & 4.6 & 5.0245 & TRN \\
\hline CHEMBL1329262 & 688620 & 5.5 & 5.2366 & TRN \\
\hline CHEMBL1339320 & 688620 & 5.05 & 5.0284 & TRN \\
\hline CHEMBL1482944 & 688620 & 5.3 & 5.2002 & TST \\
\hline CHEMBL1306488 & 688620 & 5.55 & 5.3855 & TRN \\
\hline CHEMBL1530937 & 688620 & 5.3 & 4.9558 & TST \\
\hline CHEMBL1388197 & 688620 & 4.8 & 4.7423 & TRN \\
\hline CHEMBL3190943 & 688620 & 5.6 & 5.4246 & TRN \\
\hline CHEMBL1535486 & 688620 & 4.9 & 4.9222 & TRN \\
\hline CHEMBL1367247 & 688620 & 5.05 & 4.9821 & TST \\
\hline CHEMBL1501701 & 688620 & 4.7 & 5.1662 & TST \\
\hline
\end{tabular}




\begin{tabular}{|c|c|c|c|c|c|}
\hline & & \multicolumn{4}{|c|}{ Supplemental Table S2.txt } \\
\hline CHEMBL1308848 & 688620 & 6.6499 & 5.557 & TST & \\
\hline CHEMBL1611676 & 688620 & 5.65 & 5.2204 & TRN & \\
\hline CHEMBL1585361 & 688620 & 4.8 & 4.9395 & TRN & \\
\hline CHEMBL1517003 & 688620 & 4.8 & 4.9789 & TST & \\
\hline CHEMBL1516548 & 688620 & 4.8 & 5.2112 & TRN & \\
\hline CHEMBL1379451 & 688620 & 4.8 & 4.7946 & TRN & \\
\hline CHEMBL1467421 & 688620 & 5.5 & 5.0743 & TRN & \\
\hline CHEMBL1451448 & 688620 & 5.35 & 5.7535 & TRN & \\
\hline CHEMBL1521809 & 688620 & 4.95 & 5.0989 & TST & \\
\hline CHEMBL463175 & 688620 & 5.3 & 5.2183 & TST & \\
\hline CHEMBL1431222 & 688620 & 5.4 & 5.1093 & TRN & \\
\hline CHEMBL1379257 & 688620 & 4.45 & 4.9027 & TRN & \\
\hline CHEMBL1464503 & 688620 & 5.0 & 4.97 & TST & \\
\hline CHEMBL1570716 & 688620 & 6.0 & 4.9576 & TRN & \\
\hline CHEMBL1582675 & 688620 & 4.45 & 4.7815 & TRN & \\
\hline CHEMBL1308070 & 688620 & 4.45 & 4.8407 & TRN & \\
\hline CHEMBL1302283 & 688620 & 4.95 & 4.8531 & TRN & \\
\hline CHEMBL1582634 & 688620 & 6.15 & 5.2403 & TRN & \\
\hline CHEMBL1470273 & 688620 & 4.65 & 5.0628 & TRN & \\
\hline CHEMBL1567664 & 688620 & 4.85 & 5.0726 & TRN & \\
\hline CHEMBL1509526 & 688620 & 5.3 & 4.8969 & TRN & \\
\hline CHEMBL1337140 & 688620 & 4.7 & 5.2461 & TST & \\
\hline CHEMBL1608540 & 688620 & 4.45 & 4.8147 & TRN & \\
\hline CHEMBL1538398 & 688620 & 5.2 & 5.4262 & TRN & \\
\hline CHEMBL1319606 & 688620 & 5.4 & 5.00899 & 99999999995 & TST \\
\hline CHEMBL1381470 & 688620 & 4.8 & 4.8757 & TST & \\
\hline CHEMBL1430973 & 688620 & 5.05 & 4.9694 & TRN & \\
\hline CHEMBL1443951 & 688620 & 4.8 & 4.9021 & TST & \\
\hline CHEMBL1404163 & 688620 & 4.7 & 5.4369 & TRN & \\
\hline CHEMBL1432969 & 688620 & 4.45 & 4.8957 & TRN & \\
\hline CHEMBL1382716 & 688620 & 5.1 & 5.24700 & 0000000001 & TRN \\
\hline CHEMBL 3194052 & 688620 & 4.5 & 5.3616 & TRN & \\
\hline CHEMBL1571440 & 688620 & 5.1 & 5.228 & TST & \\
\hline CHEMBL1461143 & 688620 & 4.65 & 5.095 & TRN & \\
\hline CHEMBL1606318 & 688620 & 6.5 & 5.0349 & TST & \\
\hline CHEMBL1457747 & 688620 & 4.45 & 5.1831 & TRN & \\
\hline CHEMBL3198081 & 688620 & 4.9 & 5.204 & TRN & \\
\hline CHEMBL1606548 & 688620 & 4.85 & 5.05 & TST & \\
\hline CHEMBL1414146 & 688620 & 4.9 & 5.1057 & TRN & \\
\hline CHEMBL1422131 & 688620 & 5.3 & 4.9054 & TST & \\
\hline CHEMBL1727447 & 688620 & 5.1 & 5.1694 & TRN & \\
\hline CHEMBL1303400 & 688620 & 5.45 & 5.8454 & TRN & \\
\hline CHEMBL1581530 & 688620 & 5.0 & 5.0413 & TST & \\
\hline CHEMBL1329751 & 688620 & 4.95 & 4.7954 & TRN & \\
\hline CHEMBL1524109 & 688620 & 4.95 & 4.8147 & TRN & \\
\hline CHEMBL1378167 & 688620 & 5.1 & 5.1512 & TRN & \\
\hline CHEMBL1576288 & 688620 & 5.7 & 5.3662 & TRN & \\
\hline CHEMBL1588286 & 688620 & 4.45 & 4.7287 & TRN & \\
\hline
\end{tabular}




\begin{tabular}{|c|c|c|c|c|}
\hline \multicolumn{5}{|c|}{ Supplemental Table S2.txt } \\
\hline CHEMBL1313271 & 688620 & 5.55 & 5.1221 & TRN \\
\hline CHEMBL 3196788 & 688620 & 4.45 & 5.3506 & TRN \\
\hline CHEMBL1407008 & 688620 & 4.9 & 4.838 & TST \\
\hline CHEMBL1596325 & 688620 & 5.05 & 5.1657 & TRN \\
\hline CHEMBL3192672 & 688620 & 5.2 & 5.4862 & TRN \\
\hline CHEMBL1330558 & 688620 & 6.05 & 5.2028 & TRN \\
\hline CHEMBL1534157 & 688620 & 5.2 & 5.4627 & TRN \\
\hline CHEMBL1342711 & 688620 & 5.55 & 5.6237 & TST \\
\hline CHEMBL1479752 & 688620 & 4.45 & 4.8505 & TST \\
\hline CHEMBL1384996 & 688620 & 4.45 & 4.9315 & TRN \\
\hline CHEMBL1326356 & 688620 & 4.75 & 5.0597 & TRN \\
\hline CHEMBL1541055 & 688620 & 5.05 & 5.2349 & TRN \\
\hline CHEMBL1401845 & 688620 & 4.45 & 4.9352 & TRN \\
\hline CHEMBL1313648 & 688620 & 5.0 & 5.2356 & TRN \\
\hline CHEMBL1545839 & 688620 & 4.85 & 4.8649 & TRN \\
\hline CHEMBL1380573 & 688620 & 4.6 & 5.0658 & TST \\
\hline CHEMBL1417486 & 688620 & 6.6 & 5.1686 & TRN \\
\hline CHEMBL1429863 & 688620 & 5.8 & 5.3334 & TRN \\
\hline CHEMBL1376629 & 688620 & 5.1 & 4.7732 & TRN \\
\hline CHEMBL3211980 & 688620 & 5.95 & 5.8239 & TRN \\
\hline CHEMBL1459715 & 688620 & 4.95 & 5.1932 & TRN \\
\hline CHEMBL1349737 & 688620 & 6.5501 & 5.2028 & TRN \\
\hline CHEMBL1331392 & 688620 & 5.0 & 4.8892 & TRN \\
\hline CHEMBL1352800 & 688620 & 5.15 & 5.2509 & TST \\
\hline CHEMBL1609320 & 688620 & 4.75 & 5.0092 & TST \\
\hline CHEMBL1413336 & 688620 & 4.8 & 4.7049 & TRN \\
\hline CHEMBL1414670 & 688620 & 4.9 & 4.8681 & TST \\
\hline CHEMBL1418004 & 688620 & 5.15 & 5.6043 & TRN \\
\hline CHEMBL1342847 & 688620 & 4.65 & 5.3611 & TRN \\
\hline CHEMBL1541058 & 688620 & 4.9 & 5.042 & TRN \\
\hline CHEMBL1311571 & 688620 & 4.95 & 5.1543 & TRN \\
\hline CHEMBL1432998 & 688620 & 5.55 & 5.0942 & TRN \\
\hline CHEMBL1516663 & 688620 & 5.75 & 5.5178 & TST \\
\hline CHEMBL1327754 & 688620 & 4.65 & 5.2527 & TRN \\
\hline CHEMBL1471698 & 688620 & 5.45 & 5.8977 & TRN \\
\hline CHEMBL1518672 & 688620 & 6.05 & 5.6897 & TRN \\
\hline CHEMBL1516103 & 688620 & 4.45 & 4.9701 & TRN \\
\hline CHEMBL1451507 & 688620 & 4.95 & 5.2379 & TRN \\
\hline CHEMBL1536403 & 688620 & 5.8 & 5.2016 & TST \\
\hline CHEMBL1396798 & 688620 & 4.9 & 4.8984 & TRN \\
\hline CHEMBL1569671 & 688620 & 4.45 & 5.2961 & TST \\
\hline CHEMBL1342612 & 688620 & 4.7 & 5.0716 & TST \\
\hline CHEMBL1528830 & 688620 & 4.9 & 4.8863 & TRN \\
\hline CHEMBL1459959 & 688620 & 4.65 & 4.9615 & TST \\
\hline CHEMBL1981951 & 688620 & 5.75 & 5.5609 & TRN \\
\hline CHEMBL1526676 & 688620 & 4.45 & 5.0879 & TST \\
\hline CHEMBL 2374042 & 688620 & 5.5 & 5.1438 & TST \\
\hline CHEMBL1383439 & 688620 & 5.05 & 5.0448 & TRN \\
\hline
\end{tabular}




\begin{tabular}{|c|c|c|c|c|c|}
\hline \multicolumn{6}{|c|}{ Supplemental Table S2.txt } \\
\hline CHEMBL1374923 & 688620 & 4.65 & 4.8464 & TRN & \\
\hline CHEMBL1565345 & 688620 & 5.4 & 5.0898 & TRN & \\
\hline CHEMBL1371282 & 688620 & 4.65 & 4.9317 & TST & \\
\hline CHEMBL22870 & 688620 & 4.55 & 4.8837 & TRN & \\
\hline CHEMBL1402245 & 688620 & 4.9 & 5.1454 & TRN & \\
\hline CHEMBL1525102 & 688620 & 4.45 & 5.0784 & TST & \\
\hline CHEMBL1466463 & 688620 & 5.2 & 4.997 & TRN & \\
\hline CHEMBL1402355 & 688620 & 5.3 & 5.1668 & TST & \\
\hline CHEMBL1466135 & 688620 & 4.45 & 5.1716 & TST & \\
\hline CHEMBL1428804 & 688620 & 5.15 & 5.0925 & TRN & \\
\hline CHEMBL1481304 & 688620 & 4.6 & 5.16799 & 9999999999 & TRN \\
\hline CHEMBL1400196 & 688620 & 5.9 & 5.0875 & TST & \\
\hline CHEMBL1718568 & 688620 & 5.8 & 5.9398 & TRN & \\
\hline CHEMBL569958 & 688620 & 5.05 & 5.0023 & TRN & \\
\hline CHEMBL3197587 & 688620 & 5.8 & 5.6335 & TRN & \\
\hline CHEMBL3210929 & 688620 & 5.55 & 5.2325 & TRN & \\
\hline CHEMBL1469882 & 688620 & 4.9 & 5.0501 & TRN & \\
\hline CHEMBL1465512 & 688620 & 4.95 & 5.0026 & TRN & \\
\hline CHEMBL1301944 & 688620 & 5.65 & 5.0484 & TRN & \\
\hline CHEMBL1504748 & 688620 & 4.65 & 5.0844 & TRN & \\
\hline CHEMBL1467747 & 688620 & 4.5 & 5.181 & TST & \\
\hline CHEMBL1363514 & 688620 & 4.8 & 4.9105 & TRN & \\
\hline CHEMBL1408024 & 688620 & 4.8 & 5.0722 & TRN & \\
\hline CHEMBL1322395 & 688620 & 5.2 & 4.9049 & TST & \\
\hline CHEMBL1431414 & 688620 & 4.5 & 4.802 & TRN & \\
\hline CHEMBL1482035 & 688620 & 5.2 & 5.1072 & TRN & \\
\hline CHEMBL525103 & 688620 & 4.95 & 5.0708 & TRN & \\
\hline CHEMBL1425385 & 688620 & 6.1 & 5.2064 & TST & \\
\hline CHEMBL1450887 & 688620 & 5.6 & 5.5142 & TRN & \\
\hline CHEMBL1379604 & 688620 & 4.65 & 4.8479 & TRN & \\
\hline CHEMBL1388942 & 688620 & 5.45 & 5.0093 & TST & \\
\hline CHEMBL1597189 & 688620 & 5.25 & 5.0929 & TST & \\
\hline CHEMBL1422502 & 688620 & 6.1 & 5.5751 & TST & \\
\hline CHEMBL1983451 & 688620 & 6.25 & 5.6247 & TRN & \\
\hline CHEMBL1607277 & 688620 & 5.4 & 5.1755 & TRN & \\
\hline CHEMBL1537008 & 688620 & 5.55 & 5.3881 & TST & \\
\hline CHEMBL1736798 & 688620 & 4.65 & 4.9379 & TRN & \\
\hline CHEMBL1607210 & 688620 & 5.0 & 4.8274 & TRN & \\
\hline CHEMBL1427337 & 688620 & 4.45 & 4.8511 & TRN & \\
\hline CHEMBL1338605 & 688620 & 6.15 & 4.9712 & TRN & \\
\hline CHEMBL1545300 & 688620 & 4.65 & 5.1302 & TST & \\
\hline CHEMBL1999436 & 688620 & 6.3 & 5.0595 & TST & \\
\hline CHEMBL105310 & 688620 & 5.55 & 4.9686 & TRN & \\
\hline CHEMBL1336046 & 688620 & 4.85 & 5.1737 & TST & \\
\hline CHEMBL491555 & 688620 & 4.65 & 4.9329 & TRN & \\
\hline CHEMBL3189357 & 688620 & 5.45 & 5.3602 & TRN & \\
\hline CHEMBL 1423567 & 688620 & 5.2 & 5.1841 & TST & \\
\hline CHEMBL1381448 & 688620 & 6.1 & 5.5971 & TRN & \\
\hline
\end{tabular}




\begin{tabular}{|c|c|c|c|c|c|}
\hline & & \multicolumn{4}{|c|}{ Supplemental Table s2.txt } \\
\hline CHEMBL1559111 & 688620 & 5.35 & 5.1127 & TRN & \\
\hline CHEMBL1441338 & 688620 & 4.9 & 4.8695 & TRN & \\
\hline CHEMBL1542642 & 688620 & 4.95 & 4.9722 & TRN & \\
\hline CHEMBL1541973 & 688620 & 5.0 & 4.955 & TRN & \\
\hline CHEMBL1349944 & 688620 & 4.45 & 5.2726 & TRN & \\
\hline CHEMBL1463970 & 688620 & 5.0 & 4.9564 & TRN & \\
\hline CHEMBL1421186 & 688620 & 6.15 & 5.2711 & TST & \\
\hline CHEMBL1439498 & 688620 & 4.45 & 4.7479 & TST & \\
\hline CHEMBL1461573 & 688620 & 5.85 & 5.2865 & TST & \\
\hline CHEMBL1528330 & 688620 & 5.2 & 5.0216 & TRN & \\
\hline CHEMBL1308335 & 688620 & 4.8 & 4.8605 & TST & \\
\hline CHEMBL1419273 & 688620 & 4.45 & 5.0752 & TST & \\
\hline CHEMBL1483167 & 688620 & 5.15 & 4.9923 & TRN & \\
\hline CHEMBL1376386 & 688620 & 4.8 & 5.061 & TST & \\
\hline CHEMBL149322 & 688620 & 5.0 & 5.4323 & TRN & \\
\hline CHEMBL1343127 & 688620 & 6.6 & 5.0046 & TRN & \\
\hline CHEMBL1503729 & 688620 & 5.55 & 5.4731 & TRN & \\
\hline CHEMBL1327372 & 688620 & 4.65 & 5.0786 & TST & \\
\hline CHEMBL3196890 & 688620 & 4.75 & 5.1649 & TST & \\
\hline CHEMBL1583706 & 688620 & 4.6 & 4.59699 & 99999999995 & TRN \\
\hline CHEMBL1445393 & 688620 & 5.25 & 4.9794 & TRN & \\
\hline CHEMBL3189162 & 688620 & 4.75 & 4.8813 & TRN & \\
\hline CHEMBL1504135 & 688620 & 5.5 & 5.4509 & TRN & \\
\hline CHEMBL1348682 & 688620 & 4.65 & 5.0927 & TST & \\
\hline CHEMBL3189770 & 688620 & 4.7 & 4.7615 & TST & \\
\hline CHEMBL3193703 & 688620 & 4.9 & 4.9994 & TRN & \\
\hline CHEMBL1304154 & 688620 & 5.25 & 5.1748 & TRN & \\
\hline CHEMBL1538044 & 688620 & 4.9 & 5.16 & TST & \\
\hline CHEMBL1603120 & 688620 & 5.25 & 4.9102 & TST & \\
\hline CHEMBL1467757 & 688620 & 4.45 & 5.0186 & TST & \\
\hline CHEMBL1522373 & 688620 & 6.1 & 6.0268 & TRN & \\
\hline CHEMBL1350258 & 688620 & 6.1 & 4.9222 & TRN & \\
\hline CHEMBL1563943 & 688620 & 5.65 & 5.6843 & TRN & \\
\hline CHEMBL1600821 & 688620 & 5.85 & 4.9634 & TRN & \\
\hline CHEMBL1365404 & 688620 & 4.9 & 4.9314 & TST & \\
\hline CHEMBL1580113 & 688620 & 4.95 & 4.994 & TST & \\
\hline CHEMBL1401502 & 688620 & 4.9 & 4.9143 & TRN & \\
\hline CHEMBL1492242 & 688620 & 5.0 & 4.9499 & TRN & \\
\hline CHEMBL1520849 & 688620 & 5.1 & 5.1424 & TRN & \\
\hline CHEMBL1320224 & 688620 & 4.95 & 5.2282 & TRN & \\
\hline CHEMBL1304101 & 688620 & 4.75 & 5.1575 & TST & \\
\hline CHEMBL1477542 & 688620 & 4.45 & 4.9944 & TRN & \\
\hline CHEMBL1604224 & 688620 & 5.0 & 4.7677 & TST & \\
\hline CHEMBL3199808 & 688620 & 5.55 & 5.3701 & TRN & \\
\hline CHEMBL1463671 & 688620 & 5.3 & 5.2945 & TST & \\
\hline CHEMBL1480918 & 688620 & 5.4 & 5.1921 & TRN & \\
\hline CHEMBL1469004 & 688620 & 4.45 & 4.9571 & TRN & \\
\hline CHEMBL1412523 & 688620 & 4.5 & 4.873 & TRN & \\
\hline
\end{tabular}




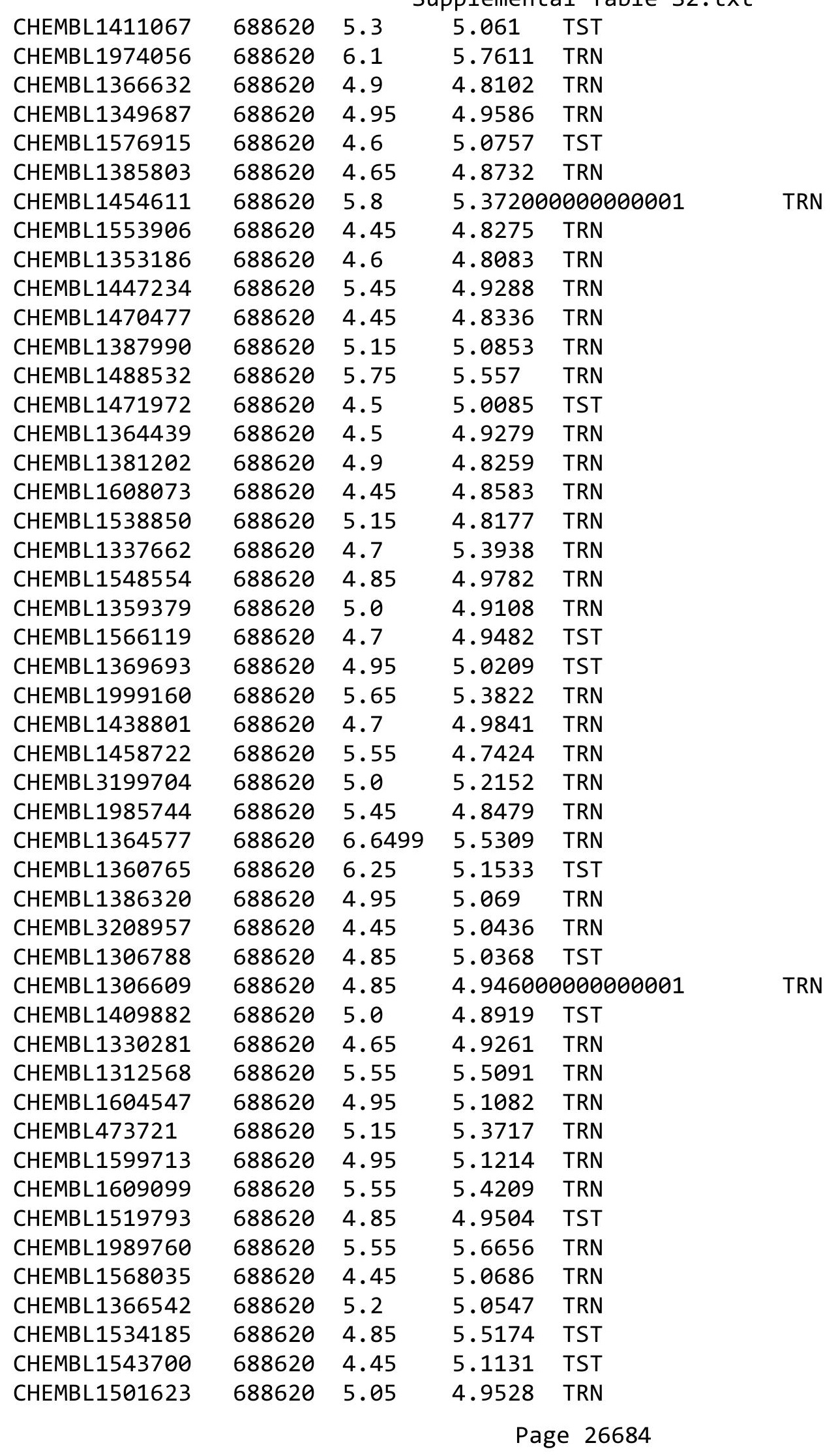




\begin{tabular}{|c|c|c|c|c|c|}
\hline & & & & & \\
\hline CHEMBL3194285 & 688620 & 5.0 & 4.8974 & TRN & \\
\hline CHEMBL1420791 & 688620 & 5.0 & 5.0424 & TRN & \\
\hline CHEMBL1991112 & 688620 & 6.5 & 5.9133 & TST & \\
\hline CHEMBL1455100 & 688620 & 7.0501 & 5.0941 & TRN & \\
\hline CHEMBL1382438 & 688620 & 6.0 & 5.4367 & TRN & \\
\hline CHEMBL1326933 & 688620 & 4.95 & 5.1067 & TRN & \\
\hline CHEMBL 3195251 & 688620 & 5.15 & 5.0307 & TST & \\
\hline CHEMBL1583082 & 688620 & 5.4 & 5.2503 & TRN & \\
\hline CHEMBL1602599 & 688620 & 5.35 & 5.0582 & TRN & \\
\hline CHEMBL581225 & 688620 & 5.05 & 5.1526 & TST & \\
\hline CHEMBL1400069 & 688620 & 6.25 & 4.9648 & TRN & \\
\hline CHEMBL1304903 & 688620 & 4.9 & 5.8767 & TST & \\
\hline CHEMBL1517558 & 688620 & 6.0 & 4.9695 & TRN & \\
\hline CHEMBL1874620 & 688620 & 5.6 & 5.7542 & TRN & \\
\hline CHEMBL1463388 & 688620 & 4.8 & 4.9449 & TRN & \\
\hline CHEMBL1304143 & 688620 & 4.95 & 5.2597 & TRN & \\
\hline CHEMBL1419065 & 688620 & 6.45 & 4.8487 & TRN & \\
\hline CHEMBL3190578 & 688620 & 4.45 & 5.28600 & 00000000005 & TRN \\
\hline CHEMBL1341097 & 688620 & 4.7 & 4.9148 & TST & \\
\hline CHEMBL1529968 & 688620 & 4.75 & 5.1326 & TRN & \\
\hline CHEMBL1411038 & 688620 & 4.45 & 5.0232 & TRN & \\
\hline CHEMBL1348393 & 688620 & 4.8 & 5.1516 & TRN & \\
\hline CHEMBL3194785 & 688620 & 5.35 & 5.1973 & TRN & \\
\hline CHEMBL1307589 & 688620 & 4.95 & 4.96399 & 99999999995 & TRN \\
\hline CHEMBL1381384 & 688620 & 5.6 & 5.0023 & TRN & \\
\hline CHEMBL1318768 & 688620 & 4.45 & 5.1148 & TST & \\
\hline CHEMBL1309644 & 688620 & 4.45 & 5.0071 & TRN & \\
\hline CHEMBL3191434 & 688620 & 5.15 & 4.8853 & TST & \\
\hline CHEMBL1366856 & 688620 & 6.05 & 5.0267 & TRN & \\
\hline CHEMBL1383497 & 688620 & 4.45 & 4.8536 & TST & \\
\hline CHEMBL1466023 & 688620 & 5.9 & 5.01699 & 99999999995 & TST \\
\hline CHEMBL1393300 & 688620 & 5.55 & 5.2738 & TST & \\
\hline CHEMBL448741 & 688620 & 4.45 & 4.9647 & TST & \\
\hline CHEMBL1423879 & 688620 & 5.1 & 5.2354 & TRN & \\
\hline CHEMBL1530766 & 688620 & 5.2 & 4.7738 & TRN & \\
\hline CHEMBL1577611 & 688620 & 4.9 & 5.0065 & TST & \\
\hline CHEMBL1361333 & 688620 & 5.55 & 5.037 & TRN & \\
\hline CHEMBL1323867 & 688620 & 4.95 & 4.9113 & TRN & \\
\hline CHEMBL1388137 & 688620 & 4.9 & 4.833 & TRN & \\
\hline CHEMBL1465128 & 688620 & 4.75 & 5.0197 & TRN & \\
\hline CHEMBL1458720 & 688620 & 5.2 & 5.0963 & TST & \\
\hline CHEMBL1406697 & 688620 & 4.45 & 4.9287 & TRN & \\
\hline CHEMBL1511549 & 688620 & 4.45 & 5.2778 & TRN & \\
\hline CHEMBL1362464 & 688620 & 4.9 & 4.9681 & TRN & \\
\hline CHEMBL1324938 & 688620 & 4.95 & 5.1217 & TRN & \\
\hline CHEMBL1387688 & 688620 & 6.15 & 5.2602 & TRN & \\
\hline CHEMBL1457755 & 688620 & 4.5 & 4.7671 & TRN & \\
\hline CHEMBL1389547 & 688620 & 4.65 & 5.002 & TRN & \\
\hline & & & & 26685 & \\
\hline
\end{tabular}




\begin{tabular}{|c|c|c|c|c|c|}
\hline \\
\hline CHEMBL1499966 & 688620 & 6.5 & 5.6749 & TST & \\
\hline CHEMBL1574256 & 688620 & 4.9 & 5.0346 & TRN & \\
\hline CHEMBL1572381 & 688620 & 4.95 & 5.0524 & TRN & \\
\hline CHEMBL1403691 & 688620 & 5.0 & 4.995 & TST & \\
\hline CHEMBL1367438 & 688620 & 5.2 & 4.7963 & TRN & \\
\hline CHEMBL1421792 & 688620 & 4.6 & 5.1409 & TRN & \\
\hline CHEMBL1503605 & 688620 & 5.0 & 4.9885 & TRN & \\
\hline CHEMBL1304919 & 688620 & 4.85 & 4.9561 & TRN & \\
\hline CHEMBL3211609 & 688620 & 4.45 & 5.0864 & TRN & \\
\hline CHEMBL1584170 & 688620 & 6.45 & 5.0718 & TST & \\
\hline CHEMBL1521318 & 688620 & 5.45 & 4.886 & TRN & \\
\hline CHEMBL1548237 & 688620 & 5.3 & 5.17200 & $\partial 000000001$ & TST \\
\hline CHEMBL1480952 & 688620 & 4.65 & 4.9882 & TRN & \\
\hline CHEMBL1538719 & 688620 & 4.95 & 4.989 & TRN & \\
\hline CHEMBL1389210 & 688620 & 4.45 & 4.8561 & TRN & \\
\hline CHEMBL1572275 & 688620 & 4.45 & 4.9603 & TRN & \\
\hline CHEMBL1428071 & 688620 & 5.8 & 4.7974 & TRN & \\
\hline CHEMBL1459198 & 688620 & 4.45 & 4.79899 & 99999999995 & TRN \\
\hline CHEMBL1501041 & 688620 & 4.7 & 4.9226 & TRN & \\
\hline CHEMBL3211718 & 688620 & 4.8 & 4.8933 & TRN & \\
\hline CHEMBL1427152 & 688620 & 4.75 & 5.0055 & TRN & \\
\hline CHEMBL1392570 & 688620 & 5.15 & 5.3812 & TRN & \\
\hline CHEMBL1469648 & 688620 & 4.8 & 5.2511 & TST & \\
\hline CHEMBL1472013 & 688620 & 4.45 & 4.9366 & TRN & \\
\hline CHEMBL3197900 & 688620 & 4.9 & 5.0674 & TRN & \\
\hline CHEMBL1446169 & 688620 & 5.65 & 5.0706 & TRN & \\
\hline CHEMBL1457385 & 688620 & 5.4 & 4.9725 & TRN & \\
\hline CHEMBL1507932 & 688620 & 4.45 & 4.9933 & TST & \\
\hline CHEMBL1967105 & 688620 & 5.15 & 5.1019 & TRN & \\
\hline CHEMBL1313129 & 688620 & 5.2 & 5.0901 & TRN & \\
\hline CHEMBL1540795 & 688620 & 4.8 & 4.7127 & TRN & \\
\hline CHEMBL1433790 & 688620 & 5.0 & 5.124 & TRN & \\
\hline CHEMBL1565537 & 688620 & 4.45 & 4.9728 & TST & \\
\hline CHEMBL1494659 & 688620 & 4.45 & 5.1308 & TRN & \\
\hline CHEMBL1570819 & 688620 & 6.3 & 5.1859 & TRN & \\
\hline CHEMBL1353013 & 688620 & 5.0 & 5.3628 & TRN & \\
\hline CHEMBL1341849 & 688620 & 4.75 & 4.859 & TRN & \\
\hline CHEMBL1461681 & 688620 & 6.2 & 5.0264 & TRN & \\
\hline CHEMBL1303288 & 688620 & 6.1 & 5.4089 & TRN & \\
\hline CHEMBL1362338 & 688620 & 4.85 & 5.1259 & TRN & \\
\hline CHEMBL1546953 & 688620 & 4.75 & 5.2651 & TRN & \\
\hline CHEMBL1557559 & 688620 & 5.95 & 5.4353 & TRN & \\
\hline CHEMBL1373849 & 688620 & 4.6 & 4.8854 & TRN & \\
\hline CHEMBL1535528 & 688620 & 5.2 & 5.1614 & TRN & \\
\hline CHEMBL3210301 & 688620 & 8.0506 & 4.9191 & TRN & \\
\hline CHEMBL1301024 & 688620 & 4.65 & 4.9016 & TRN & \\
\hline CHEMBL3208517 & 688620 & 5.1 & 4.8468 & TRN & \\
\hline CHEMBL1966570 & 688620 & 5.5 & 4.9856 & TRN & \\
\hline
\end{tabular}




\begin{tabular}{|c|c|c|c|c|c|}
\hline \multicolumn{6}{|c|}{ Supplemental Table S2.txt } \\
\hline CHEMBL1469941 & 688620 & 4.45 & 5.001 & TRN & \\
\hline CHEMBL1409857 & 688620 & 5.2 & 4.9675 & TST & \\
\hline CHEMBL1448389 & 688620 & 4.9 & 5.1556 & TRN & \\
\hline CHEMBL1560177 & 688620 & 4.95 & 5.3975 & TST & \\
\hline CHEMBL1500619 & 688620 & 4.45 & 4.9343 & TRN & \\
\hline CHEMBL1449374 & 688620 & 5.15 & 5.2355 & TST & \\
\hline CHEMBL1496422 & 688620 & 4.9 & 4.9772 & TST & \\
\hline CHEMBL1588962 & 688620 & 4.9 & 5.0962 & TST & \\
\hline CHEMBL1462424 & 688620 & 4.75 & 5.1874 & TRN & \\
\hline CHEMBL3211934 & 688620 & 4.95 & 5.7045 & TRN & \\
\hline CHEMBL568739 & 688620 & 4.6 & 5.0566 & TST & \\
\hline CHEMBL1466228 & 688620 & 5.0 & 4.9729 & TST & \\
\hline CHEMBL1585823 & 688620 & 4.45 & 4.9628 & TST & \\
\hline CHEMBL1404150 & 688620 & 5.2 & 5.2529 & TRN & \\
\hline CHEMBL1306666 & 688620 & 7.5498 & 6.8582 & TRN & \\
\hline CHEMBL3209035 & 688620 & 5.45 & 5.0072 & TRN & \\
\hline CHEMBL1579982 & 688620 & 4.6 & 5.0166 & TRN & \\
\hline CHEMBL1346824 & 688620 & 4.45 & 5.1063 & TST & \\
\hline CHEMBL3192465 & 688620 & 4.45 & 4.8649 & TRN & \\
\hline CHEMBL1526582 & 688620 & 4.9 & 4.827 & TRN & \\
\hline CHEMBL1308404 & 688620 & 5.25 & 5.1572 & TRN & \\
\hline CHEMBL1429297 & 688620 & 4.9 & 4.875 & TRN & \\
\hline CHEMBL1568213 & 688620 & 5.0 & 5.2999 & TRN & \\
\hline CHEMBL1351037 & 688620 & 5.0 & 5.1804 & TST & \\
\hline CHEMBL1575083 & 688620 & 6.0 & 5.01399 & 9999999999 & TRN \\
\hline CHEMBL1468335 & 688620 & 4.9 & 5.0052 & TRN & \\
\hline CHEMBL3192190 & 688620 & 4.85 & 5.1684 & TRN & \\
\hline CHEMBL3189512 & 688620 & 5.65 & 4.9956 & TRN & \\
\hline CHEMBL1601369 & 688620 & 4.9 & 5.2528 & TRN & \\
\hline CHEMBL1510259 & 688620 & 5.15 & 5.0323 & TRN & \\
\hline CHEMBL3189479 & 688620 & 6.45 & 5.9834 & TRN & \\
\hline CHEMBL1380606 & 688620 & 5.2 & 5.1452 & TRN & \\
\hline CHEMBL3195206 & 688620 & 4.95 & 5.0572 & TRN & \\
\hline CHEMBL1511688 & 688620 & 5.15 & 4.8158 & TST & \\
\hline CHEMBL1581324 & 688620 & 5.95 & 5.0798 & TST & \\
\hline CHEMBL1333565 & 688620 & 6.25 & 5.6728 & TRN & \\
\hline CHEMBL1462820 & 688620 & 5.6 & 5.5151 & TRN & \\
\hline CHEMBL1580601 & 688620 & 4.45 & 4.9491 & TRN & \\
\hline CHEMBL1373440 & 688620 & 5.25 & 5.2819 & TRN & \\
\hline CHEMBL1372793 & 688620 & 4.85 & 5.0568 & TRN & \\
\hline CHEMBL1522979 & 688620 & 4.45 & 5.2154 & TRN & \\
\hline CHEMBL1456222 & 688620 & 5.25 & 5.1921 & TST & \\
\hline CHEMBL1589403 & 688620 & 4.85 & 4.8293 & TRN & \\
\hline CHEMBL1306614 & 688620 & 8.301 & 5.026 & TRN & \\
\hline CHEMBL 3214461 & 688620 & 4.95 & 4.9416 & TRN & \\
\hline CHEMBL1516654 & 688620 & 4.55 & 5.0308 & TRN & \\
\hline CHEMBL1372932 & 688620 & 5.65 & 5.4152 & TRN & \\
\hline CHEMBL1562689 & 688620 & 5.1 & 5.0067 & TST & \\
\hline
\end{tabular}




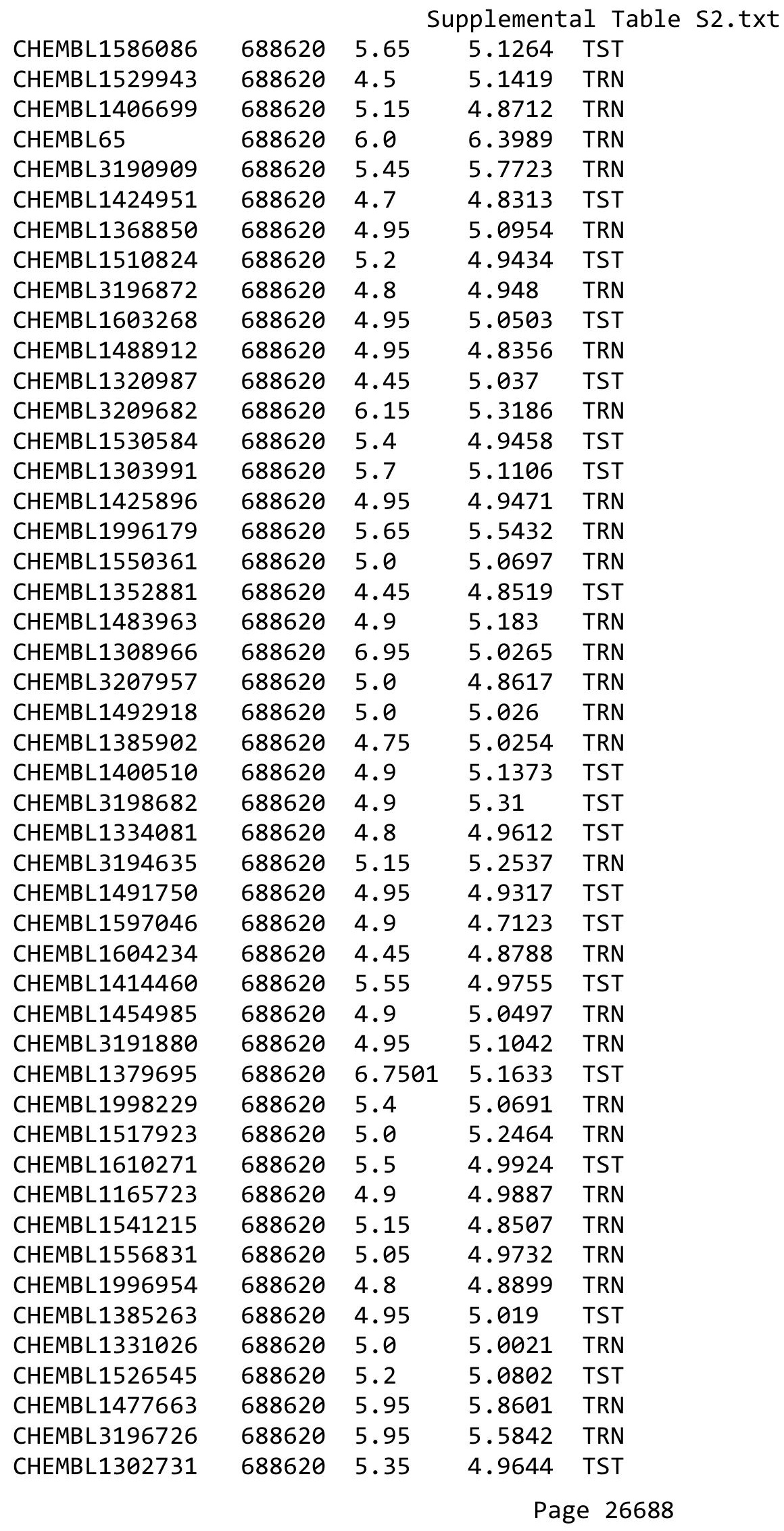




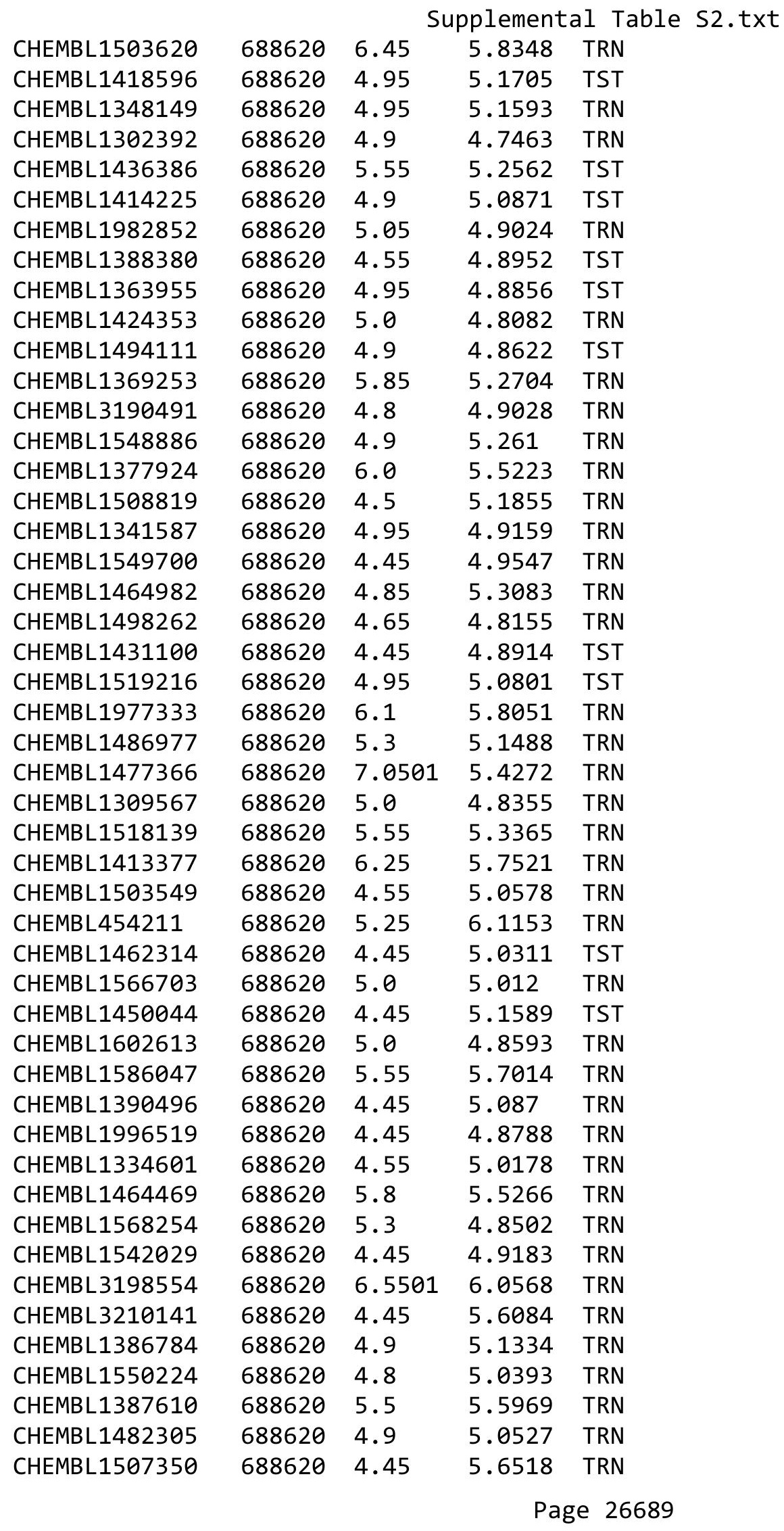




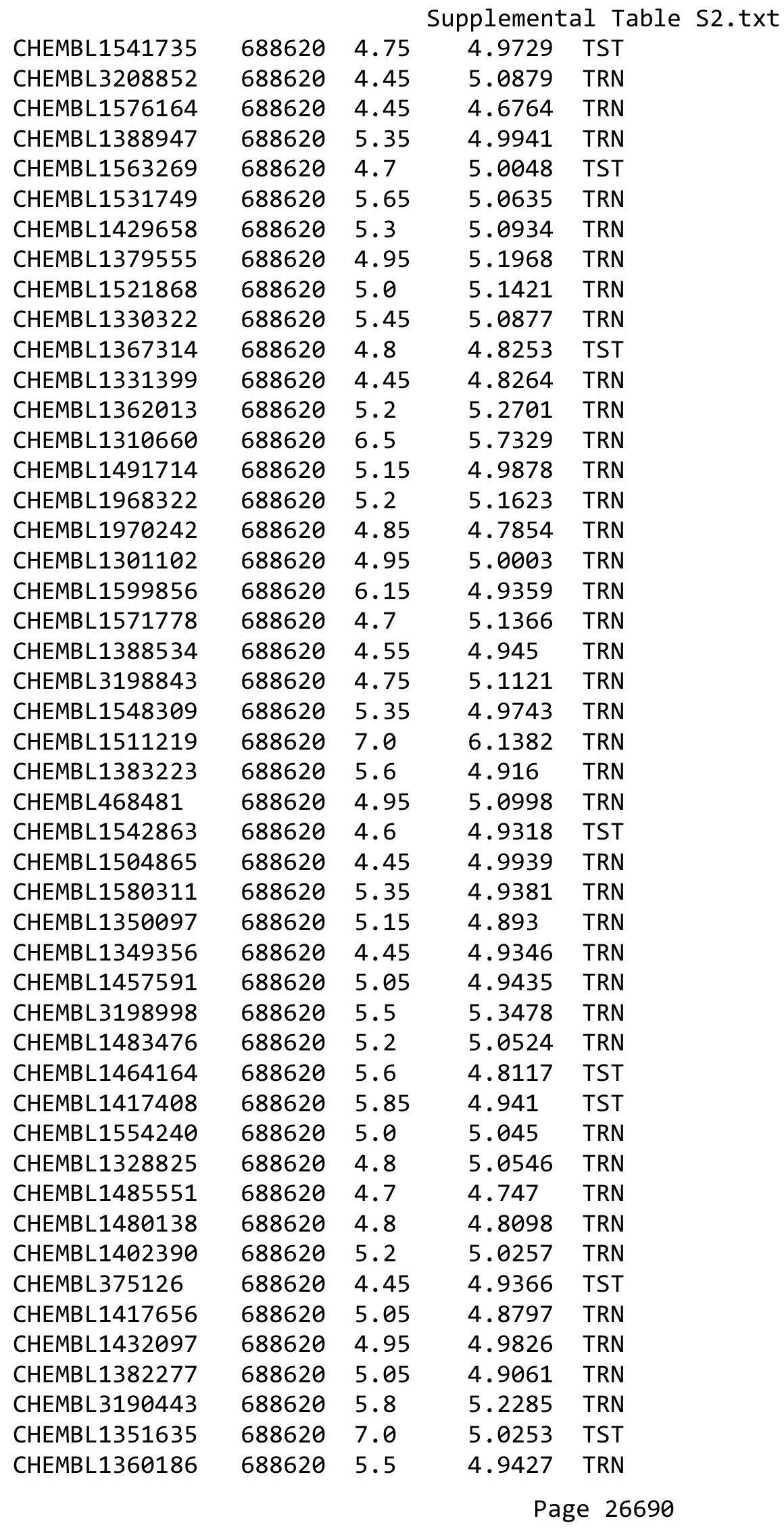




\begin{tabular}{|c|c|c|c|c|c|}
\hline \multicolumn{6}{|c|}{ Supplemental Table s2.txt } \\
\hline CHEMBL1419743 & 688620 & 5.45 & 5.2371 & TST & \\
\hline CHEMBL1371571 & 688620 & 5.3 & 5.3391 & TST & \\
\hline CHEMBL1489906 & 688620 & 5.2 & 5.0478 & TRN & \\
\hline CHEMBL1419114 & 688620 & 4.45 & 6.3478 & TRN & \\
\hline CHEMBL1606215 & 688620 & 5.15 & 5.3736 & TRN & \\
\hline CHEMBL1305179 & 688620 & 5.25 & 5.1429 & TST & \\
\hline CHEMBL1306232 & 688620 & 4.45 & 5.1417 & TRN & \\
\hline CHEMBL1453913 & 688620 & 4.95 & 5.1419 & TST & \\
\hline CHEMBL1606346 & 688620 & 4.85 & 4.9501 & TST & \\
\hline CHEMBL1427898 & 688620 & 6.95 & 5.1287 & TRN & \\
\hline CHEMBL1300497 & 688620 & 5.65 & 5.6422 & TRN & \\
\hline CHEMBL1987894 & 688620 & 5.0 & 5.0535 & TRN & \\
\hline CHEMBL1462387 & 688620 & 4.85 & 5.28700 & 3000000001 & TRN \\
\hline CHEMBL1329209 & 688620 & 4.95 & 4.9845 & TRN & \\
\hline CHEMBL3199446 & 688620 & 9.0 & 5.8236 & TRN & \\
\hline CHEMBL3208651 & 688620 & 5.55 & 5.2188 & TRN & \\
\hline CHEMBL1589186 & 688620 & 4.45 & 4.7813 & TRN & \\
\hline CHEMBL3193073 & 688620 & 4.9 & 5.0592 & TRN & \\
\hline CHEMBL1595359 & 688620 & 4.8 & 4.837 & TRN & \\
\hline CHEMBL1305302 & 688620 & 6.05 & 5.6592 & TRN & \\
\hline CHEMBL1600519 & 688620 & 5.1 & 4.9861 & TRN & \\
\hline CHEMBL1386233 & 688620 & 5.65 & 5.1672 & TRN & \\
\hline CHEMBL3190103 & 688620 & 5.8 & 5.4176 & TST & \\
\hline CHEMBL1428211 & 688620 & 6.0 & 4.8642 & TRN & \\
\hline CHEMBL1415024 & 688620 & 5.5 & 5.3756 & TRN & \\
\hline CHEMBL1451196 & 688620 & 5.25 & 5.0729 & TST & \\
\hline CHEMBL1317220 & 688620 & 6.2 & 5.1441 & TRN & \\
\hline CHEMBL3196175 & 688620 & 4.7 & 5.11 & TRN & \\
\hline CHEMBL1476381 & 688620 & 4.75 & 5.1411 & TRN & \\
\hline CHEMBL1326083 & 688620 & 5.55 & 5.9609 & TRN & \\
\hline CHEMBL1586899 & 688620 & 5.45 & 5.4696 & TRN & \\
\hline CHEMBL1413608 & 688620 & 6.0 & 5.4813 & TST & \\
\hline CHEMBL1557018 & 688620 & 5.75 & 4.7087 & TRN & \\
\hline CHEMBL1350706 & 688620 & 5.95 & 5.7372 & TRN & \\
\hline CHEMBL1359536 & 688620 & 5.2 & 4.9732 & TRN & \\
\hline CHEMBL1491037 & 688620 & 4.9 & 5.0522 & TRN & \\
\hline CHEMBL1533622 & 688620 & 5.0 & 4.9499 & TST & \\
\hline CHEMBL 2146209 & 688620 & 4.8 & 5.3956 & TST & \\
\hline CHEMBL1403489 & 688620 & 5.25 & 5.4819 & TRN & \\
\hline CHEMBL1385324 & 688620 & 5.45 & 5.1073 & TST & \\
\hline CHEMBL1375532 & 688620 & 4.45 & 4.8434 & TRN & \\
\hline CHEMBL1526433 & 688620 & 4.45 & 4.8747 & TST & \\
\hline CHEMBL1545539 & 688620 & 4.8 & 4.9714 & TST & \\
\hline CHEMBL1547690 & 688620 & 4.65 & 4.6818 & TRN & \\
\hline CHEMBL1310911 & 688620 & 6.1 & 5.5626 & TST & \\
\hline CHEMBL1483638 & 688620 & 5.45 & 5.1958 & TRN & \\
\hline CHEMBL1363485 & 688620 & 4.35 & 4.7288 & TRN & \\
\hline CHEMBL1488185 & 688620 & 4.85 & 4.8864 & TRN & \\
\hline
\end{tabular}




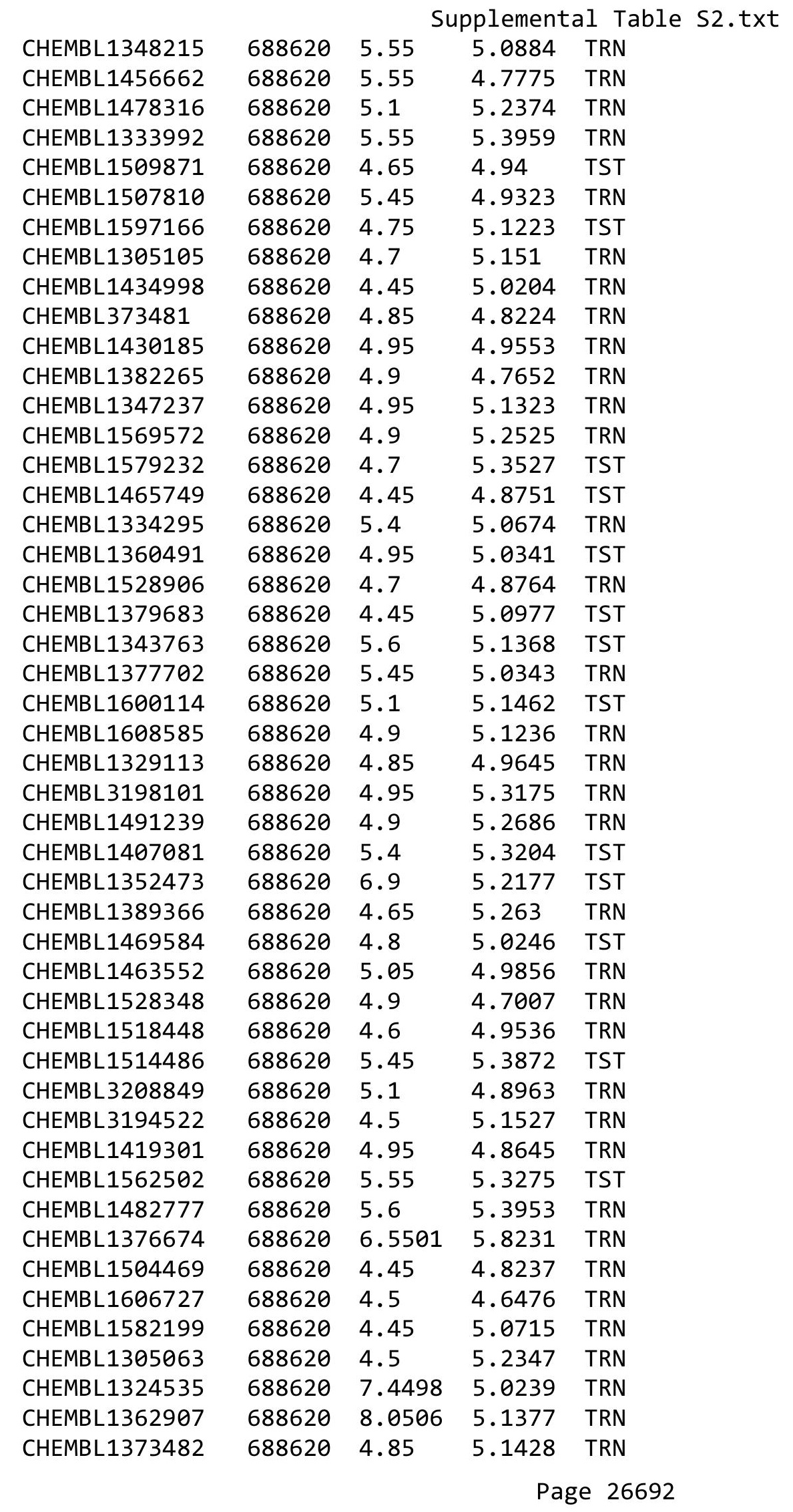




\begin{tabular}{|c|c|c|c|c|c|}
\hline \multicolumn{6}{|c|}{ Supplemental Table s2.txt } \\
\hline CHEMBL1313436 & 688620 & 5.0 & 5.0917 & TRN & \\
\hline CHEMBL1558778 & 688620 & 4.45 & 5.3498 & TST & \\
\hline CHEMBL1326101 & 688620 & 4.55 & 4.8713 & TRN & \\
\hline CHEMBL 3207838 & 688620 & 5.0 & 5.0444 & TST & \\
\hline CHEMBL3189394 & 688620 & 5.45 & 5.2113 & TRN & \\
\hline CHEMBL1485109 & 688620 & 8.301 & 4.9433 & TRN & \\
\hline CHEMBL1541657 & 688620 & 4.7 & 4.8134 & TRN & \\
\hline CHEMBL1338689 & 688620 & 4.7 & 4.813 & TRN & \\
\hline CHEMBL1541334 & 688620 & 4.85 & 5.3248 & TRN & \\
\hline CHEMBL1309635 & 688620 & 5.0 & 5.0619 & TRN & \\
\hline CHEMBL1544872 & 688620 & 5.35 & 5.1098 & TRN & \\
\hline CHEMBL1505060 & 688620 & 5.6 & 5.5204 & TRN & \\
\hline CHEMBL1433926 & 688620 & 5.45 & 5.2125 & TST & \\
\hline CHEMBL1460901 & 688620 & 4.45 & 4.985 & TRN & \\
\hline CHEMBL1361167 & 688620 & 4.45 & 4.976 & TRN & \\
\hline CHEMBL3193841 & 688620 & 4.75 & 4.9463 & TRN & \\
\hline CHEMBL1432803 & 688620 & 4.9 & 4.8763 & TRN & \\
\hline CHEMBL1455906 & 688620 & 6.35 & 5.4889 & TST & \\
\hline CHEMBL 381518 & 688620 & 4.95 & 5.3347 & TST & \\
\hline CHEMBL1603748 & 688620 & 5.9 & 5.1002 & TST & \\
\hline CHEMBL1464010 & 688620 & 4.5 & 4.9922 & TST & \\
\hline CHEMBL1542704 & 688620 & 4.95 & 5.2396 & TRN & \\
\hline CHEMBL1349809 & 688620 & 5.35 & 5.1621 & TRN & \\
\hline CHEMBL1493869 & 688620 & 5.9 & 5.53299 & 99999999995 & TRN \\
\hline CHEMBL1611828 & 688620 & 5.55 & 5.2905 & TRN & \\
\hline CHEMBL1441058 & 688620 & 5.0 & 5.3259 & TRN & \\
\hline CHEMBL1585849 & 688620 & 5.15 & 5.0081 & TRN & \\
\hline CHEMBL1386788 & 688620 & 5.3 & 5.7689 & TRN & \\
\hline CHEMBL1506728 & 688620 & 6.25 & 6.1756 & TRN & \\
\hline CHEMBL1539786 & 688620 & 5.15 & 5.1445 & TRN & \\
\hline CHEMBL1563739 & 688620 & 4.8 & 4.9688 & TRN & \\
\hline CHEMBL 3193444 & 688620 & 5.2 & 5.3228 & TRN & \\
\hline CHEMBL1483058 & 688620 & 5.9 & 5.0961 & TRN & \\
\hline CHEMBL618 & 688620 & 8.301 & 5.0623 & TST & \\
\hline CHEMBL1608506 & 688620 & 4.8 & 5.2276 & TRN & \\
\hline CHEMBL42870 & 688620 & 4.9 & 5.303 & TST & \\
\hline CHEMBL1565980 & 688620 & 5.05 & 5.0189 & TRN & \\
\hline CHEMBL1574261 & 688620 & 4.85 & 4.8569 & TRN & \\
\hline CHEMBL1527002 & 688620 & 5.15 & 5.0403 & TRN & \\
\hline CHEMBL1335660 & 688620 & 5.1 & 4.8385 & TST & \\
\hline CHEMBL1507119 & 688620 & 4.85 & 5.0794 & TST & \\
\hline CHEMBL1321795 & 688620 & 5.2 & 5.3052 & TRN & \\
\hline CHEMBL1331820 & 688620 & 5.35 & 5.4796 & TRN & \\
\hline CHEMBL1319296 & 688620 & 4.45 & 4.7492 & TRN & \\
\hline CHEMBL1354077 & 688620 & 5.2 & 4.812 & TRN & \\
\hline CHEMBL1306569 & 688620 & 5.0 & 4.9108 & TRN & \\
\hline CHEMBL1429285 & 688620 & 4.45 & 4.9531 & TST & \\
\hline CHEMBL1589096 & 688620 & 5.55 & 5.5163 & TRN & \\
\hline
\end{tabular}




\begin{tabular}{|c|c|c|c|c|c|}
\hline \multicolumn{6}{|c|}{ Supplemental Table S2.txt } \\
\hline CHEMBL1342723 & 688620 & 4.7 & 5.7308 & TRN & \\
\hline CHEMBL1345475 & 688620 & 4.95 & 4.9643 & TRN & \\
\hline CHEMBL1372251 & 688620 & 4.45 & 5.1362 & TRN & \\
\hline CHEMBL1363027 & 688620 & 6.15 & 5.4326 & TRN & \\
\hline CHEMBL1359551 & 688620 & 4.75 & 4.746 & TRN & \\
\hline CHEMBL1496058 & 688620 & 5.9 & 5.7744 & TRN & \\
\hline CHEMBL3199523 & 688620 & 4.8 & 5.0446 & TST & \\
\hline CHEMBL1488007 & 688620 & 4.65 & 5.0621 & TRN & \\
\hline CHEMBL1322233 & 688620 & 4.9 & 4.9803 & TRN & \\
\hline CHEMBL3199400 & 688620 & 5.05 & 5.0299 & TRN & \\
\hline CHEMBL1387636 & 688620 & 5.0 & 5.3463 & TRN & \\
\hline CHEMBL1969929 & 688620 & 5.9 & 5.1398 & TRN & \\
\hline CHEMBL1566877 & 688620 & 5.45 & 6.0165 & TST & \\
\hline CHEMBL1431909 & 688620 & 5.05 & 4.9915 & TRN & \\
\hline CHEMBL1542048 & 688620 & 4.8 & 5.0035 & TRN & \\
\hline CHEMBL1608362 & 688620 & 4.45 & 4.81 & TRN & \\
\hline CHEMBL1303401 & 688620 & 4.7 & 4.8943 & TRN & \\
\hline CHEMBL1359066 & 688620 & 5.0 & 4.86600 & 00000000005 & TRN \\
\hline CHEMBL1418642 & 688620 & 6.7001 & 5.1384 & TST & \\
\hline CHEMBL1574669 & 688620 & 4.75 & 5.1205 & TRN & \\
\hline CHEMBL1374491 & 688620 & 4.45 & 5.1038 & TRN & \\
\hline CHEMBL1313979 & 688620 & 5.65 & 5.6712 & TRN & \\
\hline CHEMBL1494823 & 688620 & 4.7 & 5.3002 & TRN & \\
\hline CHEMBL1470141 & 688620 & 4.85 & 5.0575 & TRN & \\
\hline CHEMBL1365627 & 688620 & 4.8 & 4.8413 & TST & \\
\hline CHEMBL1360355 & 688620 & 4.65 & 5.2964 & TRN & \\
\hline CHEMBL1495991 & 688620 & 5.65 & 5.2989 & TST & \\
\hline CHEMBL1986570 & 688620 & 4.55 & 4.9903 & TRN & \\
\hline CHEMBL1588090 & 688620 & 4.45 & 5.04 & TRN & \\
\hline CHEMBL1599502 & 688620 & 4.65 & 5.0436 & TRN & \\
\hline CHEMBL1365906 & 688620 & 4.45 & 4.8847 & TRN & \\
\hline CHEMBL1971267 & 688620 & 4.85 & 5.2037 & TRN & \\
\hline CHEMBL1525808 & 688620 & 5.55 & 5.1214 & TRN & \\
\hline CHEMBL1458541 & 688620 & 4.9 & 4.9194 & TRN & \\
\hline CHEMBL1980120 & 688620 & 4.9 & 4.9945 & TRN & \\
\hline CHEMBL1359995 & 688620 & 5.0 & 5.0848 & TRN & \\
\hline CHEMBL1301770 & 688620 & 4.45 & 5.25799 & 9999999999 & TRN \\
\hline CHEMBL1595221 & 688620 & 5.35 & 4.9896 & TRN & \\
\hline CHEMBL3197361 & 688620 & 5.5 & 5.2042 & TST & \\
\hline CHEMBL 2369272 & 688620 & 4.95 & 5.1291 & TRN & \\
\hline CHEMBL3199020 & 688620 & 5.35 & 5.54899 & 99999999995 & TRN \\
\hline CHEMBL1362336 & 688620 & 4.9 & 5.0056 & TRN & \\
\hline CHEMBL1462337 & 688620 & 6.25 & 4.9382 & TST & \\
\hline CHEMBL1425420 & 688620 & 4.45 & 5.0498 & TRN & \\
\hline CHEMBL1548940 & 688620 & 4.95 & 5.0019 & TRN & \\
\hline CHEMBL494255 & 688620 & 5.2 & 5.1582 & TRN & \\
\hline CHEMBL1596869 & 688620 & 4.8 & 4.9936 & TRN & \\
\hline CHEMBL1374527 & 688620 & 4.85 & 4.9353 & TRN & \\
\hline
\end{tabular}




\begin{tabular}{|c|c|c|c|c|}
\hline & & & pplement & al $\mathrm{Ta}$ \\
\hline CHEMBL1600373 & 688620 & 5.7 & 5.6188 & TST \\
\hline CHEMBL1996068 & 688620 & 5.95 & 5.9682 & TRN \\
\hline CHEMBL1533640 & 688620 & 5.4 & 5.318 & TRN \\
\hline CHEMBL1320236 & 688620 & 4.6 & 4.8794 & TST \\
\hline CHEMBL1523171 & 688620 & 4.9 & 4.9749 & TRN \\
\hline CHEMBL1326028 & 688620 & 4.95 & 5.1924 & TRN \\
\hline CHEMBL1314011 & 688620 & 4.95 & 4.9539 & TST \\
\hline CHEMBL1599571 & 688620 & 5.0 & 5.0173 & TRN \\
\hline CHEMBL1607675 & 688620 & 6.25 & 5.0252 & TRN \\
\hline CHEMBL1425500 & 688620 & 4.7 & 4.9955 & TRN \\
\hline CHEMBL1483910 & 688620 & 6.15 & 4.9894 & TRN \\
\hline CHEMBL1303735 & 688620 & 5.6 & 5.1495 & TST \\
\hline CHEMBL1352266 & 688620 & 5.0 & 5.063 & TRN \\
\hline CHEMBL1449875 & 688620 & 5.85 & 5.4998 & TRN \\
\hline CHEMBL1301692 & 688620 & 4.95 & 4.7886 & TST \\
\hline CHEMBL1978186 & 688620 & 5.4 & 4.9661 & TRN \\
\hline CHEMBL1531213 & 688620 & 5.8 & 5.1141 & TRN \\
\hline CHEMBL502774 & 688620 & 6.3 & 4.9766 & TST \\
\hline CHEMBL1493759 & 688620 & 4.95 & 4.88 & TRN \\
\hline CHEMBL1521199 & 688620 & 4.85 & 5.0476 & TRN \\
\hline CHEMBL1459370 & 688620 & 4.45 & 4.8057 & TST \\
\hline CHEMBL1372102 & 688620 & 4.7 & 5.1489 & TST \\
\hline CHEMBL3199222 & 688620 & 4.65 & 4.8718 & TST \\
\hline CHEMBL1530943 & 688620 & 6.25 & 6.129 & TRN \\
\hline CHEMBL1368747 & 688620 & 5.15 & 5.4134 & TRN \\
\hline CHEMBL1501584 & 688620 & 4.9 & 4.9248 & TRN \\
\hline CHEMBL 3199804 & 688620 & 5.1 & 5.4403 & TRN \\
\hline CHEMBL515763 & 688620 & 4.75 & 5.1455 & TRN \\
\hline CHEMBL3213773 & 688620 & 6.15 & 5.0247 & TST \\
\hline CHEMBL1456785 & 688620 & 6.45 & 5.1441 & TRN \\
\hline CHEMBL1350168 & 688620 & 4.7 & 5.0916 & TRN \\
\hline CHEMBL1996742 & 688620 & 5.55 & 5.3981 & TRN \\
\hline CHEMBL1545679 & 688620 & 4.75 & 5.1585 & TRN \\
\hline CHEMBL1520525 & 688620 & 5.35 & 5.2835 & TRN \\
\hline CHEMBL1403983 & 688620 & 4.45 & 5.1333 & TST \\
\hline CHEMBL1450797 & 688620 & 5.35 & 5.1684 & TRN \\
\hline CHEMBL1585124 & 688620 & 8.1024 & 5.1847 & TRN \\
\hline CHEMBL1532804 & 688620 & 5.55 & 5.178 & TRN \\
\hline CHEMBL1606823 & 688620 & 4.6 & 4.7904 & TRN \\
\hline CHEMBL1536636 & 688620 & 5.35 & 5.0686 & TRN \\
\hline CHEMBL3199854 & 688620 & 4.6 & 6.0057 & TST \\
\hline CHEMBL1587612 & 688620 & 5.0 & 5.0762 & TRN \\
\hline CHEMBL1326428 & 688620 & 7.3002 & 5.3901 & TRN \\
\hline CHEMBL1575493 & 688620 & 4.85 & 5.0295 & TRN \\
\hline CHEMBL190814 & 688620 & 4.45 & 4.7723 & TRN \\
\hline CHEMBL1531935 & 688620 & 5.6 & 5.4491 & TRN \\
\hline CHEMBL1420747 & 688620 & 4.7 & 5.2333 & TRN \\
\hline CHEMBL1418360 & 688620 & 4.9 & 5.0874 & TRN \\
\hline
\end{tabular}




\begin{tabular}{|c|c|c|c|c|c|}
\hline \multicolumn{6}{|c|}{ Supplemental Table s2.txt } \\
\hline CHEMBL1500221 & 688620 & 5.8 & 5.0726 & TRN & \\
\hline CHEMBL1398324 & 688620 & 4.95 & 4.9441 & TST & \\
\hline CHEMBL3198366 & 688620 & 4.45 & 5.0926 & TRN & \\
\hline CHEMBL1505370 & 688620 & 5.45 & 5.13 & TST & \\
\hline CHEMBL1422256 & 688620 & 5.2 & 5.0478 & TRN & \\
\hline CHEMBL1371447 & 688620 & 5.75 & 5.2386 & TRN & \\
\hline CHEMBL1597431 & 688620 & 4.65 & 4.8655 & TST & \\
\hline CHEMBL1488943 & 688620 & 4.9 & 5.2136 & TRN & \\
\hline CHEMBL1979854 & 688620 & 6.5501 & 5.8809 & TRN & \\
\hline CHEMBL3194605 & 688620 & 4.45 & 5.035 & TRN & \\
\hline CHEMBL1454501 & 688620 & 5.05 & 5.2704 & TRN & \\
\hline CHEMBL1900850 & 688620 & 6.5501 & 6.1558 & TRN & \\
\hline CHEMBL1450829 & 688620 & 4.9 & 5.2048 & TST & \\
\hline CHEMBL1488035 & 688620 & 6.05 & 5.609 & TRN & \\
\hline CHEMBL1609937 & 688620 & 4.65 & 4.95100 & 00000000005 & TST \\
\hline CHEMBL3195744 & 688620 & 4.45 & 4.8383 & TRN & \\
\hline CHEMBL3190481 & 688620 & 4.75 & 5.06 & TRN & \\
\hline CHEMBL1405862 & 688620 & 5.6 & 5.3081 & TRN & \\
\hline CHEMBL1381025 & 688620 & 5.45 & 5.1443 & TRN & \\
\hline CHEMBL3199657 & 688620 & 4.5 & 5.2095 & TST & \\
\hline CHEMBL1562079 & 688620 & 6.3 & 6.226 & TRN & \\
\hline CHEMBL1390549 & 688620 & 4.95 & 5.0991 & TRN & \\
\hline CHEMBL1303703 & 688620 & 5.35 & 5.1618 & TRN & \\
\hline CHEMBL1446154 & 688620 & 4.45 & 4.7654 & TRN & \\
\hline CHEMBL1349911 & 688620 & 5.4 & 5.0184 & TST & \\
\hline CHEMBL1503173 & 688620 & 5.4 & 4.8761 & TRN & \\
\hline CHEMBL1377399 & 688620 & 4.8 & 5.1683 & TRN & \\
\hline CHEMBL1324804 & 688620 & 5.05 & 5.1904 & TRN & \\
\hline CHEMBL1995193 & 688620 & 4.95 & 5.0559 & TRN & \\
\hline CHEMBL1367601 & 688620 & 4.95 & 5.1332 & TRN & \\
\hline CHEMBL591137 & 688620 & 6.95 & 3.9913 & TRN & \\
\hline CHEMBL1545435 & 688620 & 5.6 & 5.0882 & TRN & \\
\hline CHEMBL1505055 & 688620 & 5.1 & 5.3926 & TRN & \\
\hline CHEMBL1587727 & 688620 & 4.95 & 5.12299 & 9999999999 & TRN \\
\hline CHEMBL1974180 & 688620 & 4.95 & 5.2627 & TRN & \\
\hline CHEMBL1486223 & 688620 & 4.85 & 4.9536 & TRN & \\
\hline CHEMBL1384651 & 688620 & 4.8 & 4.9607 & TRN & \\
\hline CHEMBL460602 & 688620 & 5.55 & 4.9635 & TST & \\
\hline CHEMBL 3192224 & 688620 & 5.15 & 5.2628 & TRN & \\
\hline CHEMBL1413912 & 688620 & 5.5 & 5.0867 & TRN & \\
\hline CHEMBL1555583 & 688620 & 4.65 & 4.8007 & TST & \\
\hline CHEMBL1409423 & 688620 & 5.3 & 5.1892 & TRN & \\
\hline CHEMBL1580006 & 688620 & 6.05 & 5.8453 & TRN & \\
\hline CHEMBL1969712 & 688620 & 5.95 & 5.6186 & TRN & \\
\hline CHEMBL3199894 & 688620 & 5.0 & 5.0478 & TRN & \\
\hline CHEMBL3189979 & 688620 & 5.25 & 5.237 & TRN & \\
\hline CHEMBL1302741 & 688620 & 4.45 & 5.4081 & TRN & \\
\hline CHEMBL1376511 & 688620 & 4.5 & 5.1063 & TRN & \\
\hline
\end{tabular}




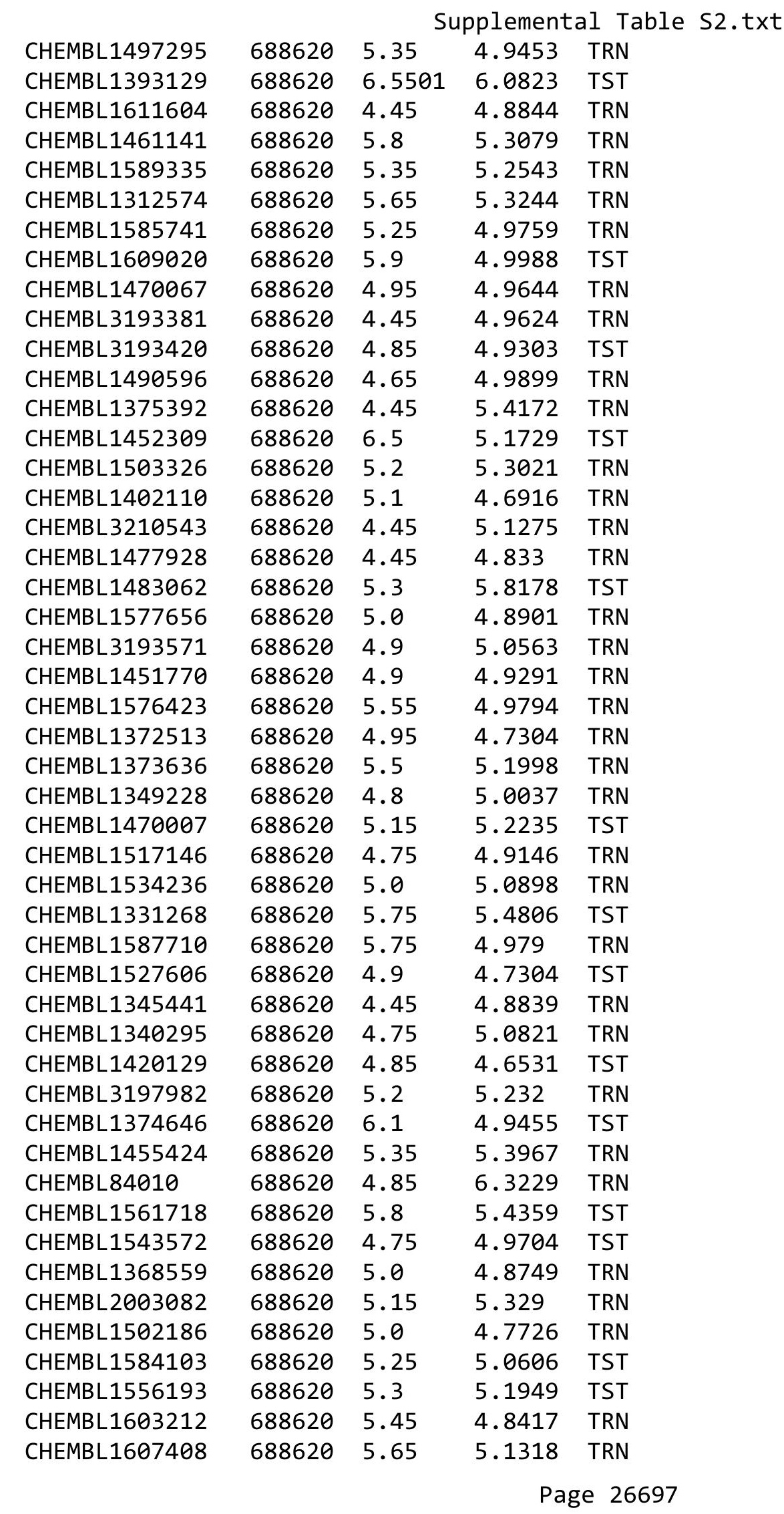




\begin{tabular}{|c|c|c|c|c|c|}
\hline \multicolumn{6}{|c|}{ Supplemental Table S2.txt } \\
\hline CHEMBL1518840 & 688620 & 4.95 & 5.1234 & TRN & \\
\hline CHEMBL1450826 & 688620 & 5.35 & 4.8383 & TRN & \\
\hline CHEMBL1381734 & 688620 & 4.95 & 5.0194 & TST & \\
\hline CHEMBL1569546 & 688620 & 4.9 & 5.3799 & TST & \\
\hline CHEMBL1308921 & 688620 & 6.95 & 5.17899 & 9999999999 & TRN \\
\hline CHEMBL1494117 & 688620 & 5.15 & 5.3613 & TRN & \\
\hline CHEMBL1406475 & 688620 & 4.6 & 5.029 & TRN & \\
\hline CHEMBL1483015 & 688620 & 4.45 & 5.178 & TST & \\
\hline CHEMBL1448425 & 688620 & 5.4 & 5.853 & TRN & \\
\hline CHEMBL1320982 & 688620 & 6.35 & 6.0438 & TRN & \\
\hline CHEMBL 1458010 & 688620 & 4.45 & 5.0473 & TRN & \\
\hline CHEMBL1598614 & 688620 & 6.4 & 5.2479 & TRN & \\
\hline CHEMBL1370259 & 688620 & 5.55 & 5.1023 & TRN & \\
\hline CHEMBL1347662 & 688620 & 4.95 & 5.2082 & TRN & \\
\hline CHEMBL1537550 & 688620 & 4.75 & 4.7129 & TRN & \\
\hline CHEMBL1433332 & 688620 & 4.9 & 4.8255 & TRN & \\
\hline CHEMBL1344591 & 688620 & 5.0 & 5.0236 & TRN & \\
\hline CHEMBL1346741 & 688620 & 4.45 & 4.9383 & TST & \\
\hline CHEMBL1540894 & 688620 & 5.55 & 5.3882 & TRN & \\
\hline CHEMBL1307515 & 688620 & 6.3 & 5.2321 & TRN & \\
\hline CHEMBL1410918 & 688620 & 4.6 & 4.9223 & TRN & \\
\hline CHEMBL1492541 & 688620 & 4.65 & 4.8985 & TRN & \\
\hline CHEMBL1594527 & 688620 & 4.45 & 4.7564 & TST & \\
\hline CHEMBL1393236 & 688620 & 4.75 & 4.9341 & TRN & \\
\hline CHEMBL1450879 & 688620 & 4.85 & 4.9621 & TST & \\
\hline CHEMBL3212207 & 688620 & 5.0 & 5.0739 & TST & \\
\hline CHEMBL3193194 & 688620 & 4.95 & 5.0963 & TRN & \\
\hline CHEMBL1570029 & 688620 & 5.25 & 5.0893 & TRN & \\
\hline CHEMBL1505969 & 688620 & 4.8 & 5.0908 & TRN & \\
\hline CHEMBL1562275 & 688620 & 5.15 & 4.896 & TRN & \\
\hline CHEMBL1993291 & 688620 & 4.9 & 4.7405 & TRN & \\
\hline CHEMBL127757 & 688620 & 4.85 & 5.2086 & TRN & \\
\hline CHEMBL1598948 & 688620 & 4.75 & 4.8864 & TRN & \\
\hline CHEMBL1587149 & 688620 & 4.95 & 5.0642 & TST & \\
\hline CHEMBL1531357 & 688620 & 4.65 & 4.6511 & TRN & \\
\hline CHEMBL1322008 & 688620 & 4.6 & 4.6405 & TST & \\
\hline CHEMBL3210836 & 688620 & 5.65 & 5.78799 & 9999999999 & TRN \\
\hline CHEMBL1567857 & 688620 & 5.7 & 4.8825 & TRN & \\
\hline CHEMBL1492229 & 688620 & 4.8 & 4.9581 & TRN & \\
\hline CHEMBL 3190880 & 688620 & 4.95 & 4.6268 & TRN & \\
\hline CHEMBL1529596 & 688620 & 5.7 & 5.3678 & TRN & \\
\hline CHEMBL1314827 & 688620 & 4.55 & 4.8745 & TRN & \\
\hline CHEMBL1546285 & 688620 & 5.4 & 5.0004 & TRN & \\
\hline CHEMBL1543731 & 688620 & 4.45 & 5.4487 & TRN & \\
\hline CHEMBL1421889 & 688620 & 4.7 & 4.979 & TRN & \\
\hline CHEMBL1568925 & 688620 & 4.45 & 4.7565 & TRN & \\
\hline CHEMBL1586171 & 688620 & 5.55 & 5.2687 & TRN & \\
\hline CHEMBL 3198478 & 688620 & 4.95 & 5.1395 & TRN & \\
\hline
\end{tabular}




\begin{tabular}{|c|c|c|c|c|}
\hline \multicolumn{5}{|c|}{ Supplemental Table s2.txt } \\
\hline CHEMBL1343078 & 688620 & 4.45 & 5.2848 & TRN \\
\hline CHEMBL1589526 & 688620 & 5.2 & 5.476 & TRN \\
\hline CHEMBL3192073 & 688620 & 4.9 & 4.9855 & TRN \\
\hline CHEMBL1299962 & 688620 & 5.0 & 4.822 & TST \\
\hline CHEMBL1393875 & 688620 & 4.45 & 5.2646 & TRN \\
\hline CHEMBL3197539 & 688620 & 5.3 & 5.2172 & TRN \\
\hline CHEMBL1517550 & 688620 & 4.75 & 5.1128 & TRN \\
\hline CHEMBL1341060 & 688620 & 5.25 & 4.8626 & TRN \\
\hline CHEMBL1508023 & 688620 & 5.2 & 5.2968 & TRN \\
\hline CHEMBL1507064 & 688620 & 4.45 & 4.9995 & TRN \\
\hline CHEMBL1508155 & 688620 & 4.6 & 5.1422 & TRN \\
\hline CHEMBL1393207 & 688620 & 6.5501 & 5.0964 & TST \\
\hline CHEMBL1371107 & 688620 & 4.45 & 4.9428 & TRN \\
\hline CHEMBL3197116 & 688620 & 4.45 & 5.0957 & TRN \\
\hline CHEMBL1375583 & 688620 & 4.9 & 5.1764 & TST \\
\hline CHEMBL1561911 & 688620 & 4.75 & 5.0207 & TRN \\
\hline CHEMBL1407129 & 688620 & 4.65 & 5.0835 & TRN \\
\hline CHEMBL1423192 & 688620 & 6.45 & 5.6282 & TRN \\
\hline CHEMBL3190873 & 688620 & 4.45 & 4.8356 & TST \\
\hline CHEMBL1505585 & 688620 & 4.45 & 4.9888 & TRN \\
\hline CHEMBL1565523 & 688620 & 5.1 & 4.9433 & TRN \\
\hline CHEMBL1361776 & 688620 & 4.95 & 5.2013 & TRN \\
\hline CHEMBL1571201 & 688620 & 4.75 & 5.0414 & TRN \\
\hline CHEMBL1501409 & 688620 & 6.05 & 5.0029 & TRN \\
\hline CHEMBL1401571 & 688620 & 5.55 & 5.1194 & TRN \\
\hline CHEMBL1433825 & 688620 & 5.0 & 4.8866 & TRN \\
\hline CHEMBL1581491 & 688620 & 4.95 & 4.7753 & TRN \\
\hline CHEMBL1509469 & 688620 & 4.45 & 5.0767 & TRN \\
\hline CHEMBL1302158 & 688620 & 5.8 & 5.6674 & TRN \\
\hline CHEMBL1493868 & 688620 & 5.9 & 5.8751 & TRN \\
\hline CHEMBL1494138 & 688620 & 4.9 & 4.9016 & TRN \\
\hline CHEMBL1531385 & 688620 & 4.45 & 4.9769 & TRN \\
\hline CHEMBL1603092 & 688620 & 6.2 & 5.8099 & TRN \\
\hline CHEMBL1500086 & 688620 & 5.3 & 5.6145 & TRN \\
\hline CHEMBL1472752 & 688620 & 5.0 & 4.9654 & TRN \\
\hline CHEMBL1526855 & 688620 & 5.0 & 5.0097 & TST \\
\hline CHEMBL1610990 & 688620 & 4.7 & 5.0135 & TRN \\
\hline CHEMBL1484962 & 688620 & 4.7 & 4.9814 & TRN \\
\hline CHEMBL1305554 & 688620 & 4.7 & 5.046 & TRN \\
\hline CHEMBL3392395 & 688620 & 7.0501 & 6.2046 & TRN \\
\hline CHEMBL1545738 & 688620 & 4.45 & 4.9864 & TRN \\
\hline CHEMBL1419909 & 688620 & 5.2 & 5.0895 & TRN \\
\hline CHEMBL1560394 & 688620 & 4.75 & 5.0363 & TRN \\
\hline CHEMBL1350805 & 688620 & 4.95 & 5.0362 & TRN \\
\hline CHEMBL3199050 & 688620 & 5.8 & 5.5933 & TRN \\
\hline CHEMBL3213075 & 688620 & 4.8 & 5.0375 & TRN \\
\hline CHEMBL1351620 & 688620 & 5.25 & 5.0594 & TRN \\
\hline CHEMBL1439573 & 688620 & 5.45 & 5.2057 & TRN \\
\hline
\end{tabular}




\begin{tabular}{|c|c|c|c|c|}
\hline \multicolumn{5}{|c|}{ Supplemental Table S2.txt } \\
\hline CHEMBL1362677 & 688620 & 5.5 & 5.211 & TRN \\
\hline CHEMBL1442421 & 688620 & 4.45 & 4.9248 & TRN \\
\hline CHEMBL3210336 & 688620 & 5.1 & 5.3058 & TRN \\
\hline CHEMBL1583266 & 688620 & 5.25 & 5.1621 & TRN \\
\hline CHEMBL1417567 & 688620 & 4.6 & 5.1253 & TRN \\
\hline CHEMBL1332723 & 688620 & 4.7 & 5.061 & TRN \\
\hline CHEMBL1449518 & 688620 & 6.9 & 5.0719 & TRN \\
\hline CHEMBL1331811 & 688620 & 4.95 & 5.0247 & TST \\
\hline CHEMBL1535581 & 688620 & 4.45 & 4.9163 & TRN \\
\hline CHEMBL1477352 & 688620 & 5.2 & 4.9249 & TRN \\
\hline CHEMBL1384858 & 688620 & 4.8 & 5.051 & TRN \\
\hline CHEMBL1389629 & 688620 & 5.25 & 5.4282 & TST \\
\hline CHEMBL1367567 & 688620 & 5.0 & 4.7191 & TRN \\
\hline CHEMBL1302890 & 688620 & 5.55 & 5.601 & TST \\
\hline CHEMBL1318976 & 688620 & 4.65 & 4.8421 & TRN \\
\hline CHEMBL1525619 & 688620 & 6.45 & 6.2661 & TRN \\
\hline CHEMBL1973188 & 688620 & 5.15 & 5.2558 & TRN \\
\hline CHEMBL3196046 & 688620 & 4.85 & 4.8846 & TRN \\
\hline CHEMBL1445360 & 688620 & 4.65 & 4.6693 & TRN \\
\hline CHEMBL1492457 & 688620 & 4.8 & 5.0923 & TST \\
\hline CHEMBL1448931 & 688620 & 5.5 & 4.765 & TRN \\
\hline CHEMBL 3198697 & 688620 & 5.1 & 4.842 & TRN \\
\hline CHEMBL2003869 & 688620 & 4.8 & 5.2185 & TRN \\
\hline CHEMBL1427270 & 688620 & 4.9 & 5.0772 & TRN \\
\hline CHEMBL1608551 & 688620 & 6.6499 & 5.7027 & TRN \\
\hline CHEMBL1605216 & 688620 & 4.7 & 5.0043 & TRN \\
\hline CHEMBL1328249 & 688620 & 4.9 & 4.8338 & TRN \\
\hline CHEMBL1464882 & 688620 & 5.0 & 5.1296 & TST \\
\hline CHEMBL1371367 & 688620 & 6.3 & 5.1058 & TRN \\
\hline CHEMBL1372817 & 688620 & 4.8 & 5.2435 & TRN \\
\hline CHEMBL1561610 & 688620 & 5.05 & 4.9194 & TRN \\
\hline CHEMBL1581879 & 688620 & 4.65 & 4.8572 & TRN \\
\hline CHEMBL1302075 & 688620 & 4.45 & 4.8812 & TRN \\
\hline CHEMBL1575937 & 688620 & 7.2503 & 5.9732 & TRN \\
\hline CHEMBL1381457 & 688620 & 5.2 & 5.1351 & TST \\
\hline CHEMBL1420632 & 688620 & 4.6 & 5.0375 & TST \\
\hline CHEMBL1607653 & 688620 & 4.45 & 4.9518 & TRN \\
\hline CHEMBL1560291 & 688620 & 5.4 & 4.9526 & TRN \\
\hline CHEMBL1563899 & 688620 & 4.45 & 4.9293 & TRN \\
\hline CHEMBL1306009 & 688620 & 4.65 & 5.2685 & TRN \\
\hline CHEMBL1502755 & 688620 & 5.2 & 4.8689 & TST \\
\hline CHEMBL1559237 & 688620 & 6.0 & 6.0736 & TRN \\
\hline CHEMBL1321172 & 688620 & 4.8 & 5.0649 & TRN \\
\hline CHEMBL1605435 & 688620 & 4.45 & 5.003 & TST \\
\hline CHEMBL1538639 & 688620 & 4.85 & 4.6912 & TST \\
\hline CHEMBL1401497 & 688620 & 4.85 & 4.9534 & TST \\
\hline CHEMBL1352056 & 688620 & 4.6 & 5.6177 & TRN \\
\hline CHEMBL1558557 & 688620 & 4.6 & 4.9319 & TRN \\
\hline
\end{tabular}




\begin{tabular}{|c|c|c|c|c|}
\hline \multicolumn{5}{|c|}{ Supplemental Table S2.txt } \\
\hline CHEMBL1531693 & 688620 & 4.95 & 4.9787 & TRN \\
\hline CHEMBL3207908 & 688620 & 6.3 & 5.1965 & TRN \\
\hline CHEMBL1561910 & 688620 & 5.7 & 5.5005 & TRN \\
\hline CHEMBL1993029 & 688620 & 4.5 & 5.0528 & TST \\
\hline CHEMBL1325873 & 688620 & 4.7 & 5.2031 & TRN \\
\hline CHEMBL3196747 & 688620 & 5.45 & 5.2137 & TRN \\
\hline CHEMBL1412884 & 688620 & 4.6 & 4.8835 & TRN \\
\hline CHEMBL1407486 & 688620 & 5.55 & 5.0938 & TRN \\
\hline CHEMBL1416062 & 688620 & 5.55 & 5.2773 & TST \\
\hline CHEMBL3192370 & 688620 & 4.95 & 5.0609 & TST \\
\hline CHEMBL1346665 & 688620 & 5.55 & 5.0511 & TST \\
\hline CHEMBL1426417 & 688620 & 4.95 & 5.0981 & TRN \\
\hline CHEMBL1340313 & 688620 & 5.0 & 5.0777 & TRN \\
\hline CHEMBL1461055 & 688620 & 5.45 & 5.2087 & TRN \\
\hline CHEMBL1571256 & 688620 & 4.8 & 5.0503 & TST \\
\hline CHEMBL1457787 & 688620 & 6.15 & 5.8508 & TRN \\
\hline CHEMBL1417021 & 688620 & 4.85 & 4.9187 & TST \\
\hline CHEMBL1972090 & 688620 & 5.1 & 5.2843 & TRN \\
\hline CHEMBL1343595 & 688620 & 4.85 & 4.81 & TST \\
\hline CHEMBL1492421 & 688620 & 5.9 & 5.3624 & TRN \\
\hline CHEMBL1603976 & 688620 & 5.35 & 5.3002 & TRN \\
\hline CHEMBL1409980 & 688620 & 5.0 & 4.9766 & TRN \\
\hline CHEMBL1604218 & 688620 & 5.0 & 5.0359 & TRN \\
\hline CHEMBL1366832 & 688620 & 4.45 & 5.3105 & TST \\
\hline CHEMBL1311783 & 688620 & 6.25 & 5.3615 & TRN \\
\hline CHEMBL1374622 & 688620 & 4.65 & 5.0766 & TRN \\
\hline CHEMBL1470997 & 688620 & 5.9 & 5.1862 & TRN \\
\hline CHEMBL3191091 & 688620 & 5.9 & 5.7537 & TRN \\
\hline CHEMBL1424387 & 688620 & 4.85 & 4.9603 & TRN \\
\hline CHEMBL1470568 & 688620 & 6.15 & 5.5133 & TRN \\
\hline CHEMBL1391490 & 688620 & 4.7 & 4.9712 & TRN \\
\hline CHEMBL1572927 & 688620 & 5.15 & 5.1769 & TRN \\
\hline CHEMBL1479921 & 688620 & 5.0 & 5.0864 & TRN \\
\hline CHEMBL1985165 & 688620 & 5.4 & 5.3151 & TRN \\
\hline CHEMBL2004241 & 688620 & 4.8 & 4.9615 & TST \\
\hline CHEMBL1538698 & 688620 & 4.95 & 5.0415 & TRN \\
\hline CHEMBL1435590 & 688620 & 4.7 & 5.2609 & TRN \\
\hline CHEMBL1361948 & 688620 & 5.35 & 5.3753 & TRN \\
\hline CHEMBL1409082 & 688620 & 4.8 & 5.0164 & TRN \\
\hline CHEMBL1299768 & 688620 & 4.85 & 4.7925 & TRN \\
\hline CHEMBL1570643 & 688620 & 4.45 & 4.7292 & TRN \\
\hline CHEMBL1362566 & 688620 & 4.75 & 4.894 & TRN \\
\hline CHEMBL1485300 & 688620 & 4.45 & 4.9802 & TRN \\
\hline CHEMBL1558038 & 688620 & 5.95 & 5.0624 & TRN \\
\hline CHEMBL1602596 & 688620 & 5.1 & 5.4154 & TRN \\
\hline CHEMBL1325039 & 688620 & 4.9 & 4.9136 & TRN \\
\hline CHEMBL1578100 & 688620 & 5.1 & 4.8029 & TRN \\
\hline CHEMBL1341936 & 688620 & 4.95 & 5.1189 & TST \\
\hline
\end{tabular}




\begin{tabular}{|c|c|c|c|c|}
\hline \multicolumn{5}{|c|}{ Supplemental Table S2.txt } \\
\hline CHEMBL1501782 & 688620 & 5.0 & 5.0335 & TRN \\
\hline CHEMBL1333370 & 688620 & 5.15 & 5.1218 & TRN \\
\hline CHEMBL1419367 & 688620 & 4.8 & 5.1781 & TST \\
\hline CHEMBL1370636 & 688620 & 5.0 & 5.1377 & TRN \\
\hline CHEMBL1345487 & 688620 & 5.0 & 5.2197 & TST \\
\hline CHEMBL1381488 & 688620 & 4.75 & 5.1134 & TRN \\
\hline CHEMBL1519034 & 688620 & 5.5 & 5.4426 & TRN \\
\hline CHEMBL1424588 & 688620 & 5.8 & 5.218 & TRN \\
\hline CHEMBL1370261 & 688620 & 4.7 & 5.2911 & TST \\
\hline CHEMBL1509605 & 688620 & 5.8 & 5.1509 & TRN \\
\hline CHEMBL1534733 & 688620 & 5.3 & 5.1836 & TRN \\
\hline CHEMBL1526447 & 688620 & 5.25 & 5.0447 & TST \\
\hline CHEMBL3198181 & 688620 & 5.25 & 5.0138 & TST \\
\hline CHEMBL1975447 & 688620 & 5.6 & 5.0837 & TRN \\
\hline CHEMBL1579555 & 688620 & 5.75 & 5.8504 & TRN \\
\hline CHEMBL1434938 & 688620 & 4.8 & 4.8066 & TST \\
\hline CHEMBL1417710 & 688620 & 4.75 & 5.3056 & TRN \\
\hline CHEMBL1532754 & 688620 & 5.8 & 5.021 & TST \\
\hline CHEMBL1590663 & 688620 & 4.65 & 4.7025 & TRN \\
\hline CHEMBL1342007 & 688620 & 5.1 & 5.0284 & TRN \\
\hline CHEMBL3197931 & 688620 & 5.45 & 5.4557 & TRN \\
\hline CHEMBL1576754 & 688620 & 4.9 & 4.9365 & TRN \\
\hline CHEMBL 3214510 & 688620 & 5.2 & 5.2041 & TRN \\
\hline CHEMBL1546106 & 688620 & 5.5 & 5.0257 & TRN \\
\hline CHEMBL1379244 & 688620 & 4.85 & 4.8974 & TRN \\
\hline CHEMBL3199674 & 688620 & 5.15 & 5.2208 & TRN \\
\hline CHEMBL1405970 & 688620 & 4.65 & 5.3404 & TRN \\
\hline CHEMBL1472145 & 688620 & 5.2 & 5.1459 & TST \\
\hline CHEMBL1381478 & 688620 & 4.75 & 5.1841 & TRN \\
\hline CHEMBL1515116 & 688620 & 5.0 & 5.0734 & TRN \\
\hline CHEMBL1472037 & 688620 & 4.95 & 4.9546 & TST \\
\hline CHEMBL1310690 & 688620 & 5.5 & 5.2125 & TRN \\
\hline CHEMBL1463829 & 688620 & 4.55 & 4.8522 & TRN \\
\hline CHEMBL1993190 & 688620 & 7.2 & 6.1568 & TRN \\
\hline CHEMBL1455113 & 688620 & 4.45 & 5.0614 & TRN \\
\hline CHEMBL1495622 & 688620 & 5.0 & 5.1642 & TRN \\
\hline CHEMBL1370595 & 688620 & 4.95 & 5.0791 & TRN \\
\hline CHEMBL1338820 & 688620 & 5.95 & 5.0547 & TRN \\
\hline CHEMBL1465381 & 688620 & 4.65 & 4.9463 & TST \\
\hline CHEMBL1983939 & 688620 & 5.5 & 5.4991 & TRN \\
\hline CHEMBL78010 & 688620 & 4.9 & 5.1963 & TRN \\
\hline CHEMBL1605531 & 688620 & 4.9 & 4.8893 & TRN \\
\hline CHEMBL3207338 & 688620 & 4.8 & 4.9971 & TRN \\
\hline CHEMBL1583538 & 688620 & 4.9 & 4.92899 & 9999999999 \\
\hline CHEMBL1607574 & 688620 & 5.15 & 4.9643 & TST \\
\hline CHEMBL3145373 & 688620 & 6.6499 & 6.1916 & TRN \\
\hline CHEMBL1550131 & 688620 & 4.9 & 4.9462 & TRN \\
\hline CHEMBL1406195 & 688620 & 5.1 & 4.7523 & TRN \\
\hline
\end{tabular}




\begin{tabular}{|c|c|c|c|c|c|}
\hline \multicolumn{6}{|c|}{ Supplemental Table S2.txt } \\
\hline CHEMBL1349459 & 688620 & 4.45 & 4.8173 & TST & \\
\hline CHEMBL3197180 & 688620 & 5.15 & 5.1972 & TRN & \\
\hline CHEMBL1490960 & 688620 & 4.45 & 5.2115 & TST & \\
\hline CHEMBL1426853 & 688620 & 5.0 & 5.1339 & TRN & \\
\hline CHEMBL1388895 & 688620 & 6.1 & 5.9361 & TRN & \\
\hline CHEMBL1301925 & 688620 & 5.2 & 4.9879 & TRN & \\
\hline CHEMBL1312643 & 688620 & 4.8 & 5.1596 & TST & \\
\hline CHEMBL1330717 & 688620 & 4.6 & 4.8692 & TRN & \\
\hline CHEMBL1498497 & 688620 & 4.75 & 5.1966 & TRN & \\
\hline CHEMBL1978643 & 688620 & 5.4 & 5.2448 & TRN & \\
\hline CHEMBL1465447 & 688620 & 4.5 & 5.0321 & TRN & \\
\hline CHEMBL486078 & 688620 & 4.9 & 4.8458 & TRN & \\
\hline CHEMBL1329008 & 688620 & 4.75 & 4.8338 & TRN & \\
\hline CHEMBL1400080 & 688620 & 5.6 & 5.6054 & TRN & \\
\hline CHEMBL1299655 & 688620 & 5.8 & 5.5423 & TRN & \\
\hline CHEMBL1440710 & 688620 & 4.95 & 5.0764 & TST & \\
\hline CHEMBL1596730 & 688620 & 4.75 & 4.8392 & TST & \\
\hline CHEMBL1586523 & 688620 & 6.05 & 5.7006 & TRN & \\
\hline CHEMBL1412905 & 688620 & 4.9 & 4.8503 & TRN & \\
\hline CHEMBL1577074 & 688620 & 5.0 & 5.2385 & TRN & \\
\hline CHEMBL1327806 & 688620 & 4.8 & 4.8781 & TRN & \\
\hline CHEMBL1373093 & 688620 & 4.5 & 5.2075 & TRN & \\
\hline CHEMBL1353771 & 688620 & 4.75 & 4.8367 & TRN & \\
\hline CHEMBL1323673 & 688620 & 5.9 & 5.8554 & TRN & \\
\hline CHEMBL1573477 & 688620 & 6.1 & 5.1182 & TRN & \\
\hline CHEMBL1472033 & 688620 & 4.95 & 4.9994 & TRN & \\
\hline CHEMBL1492319 & 688620 & 4.45 & 5.12799 & 9999999999 & TST \\
\hline CHEMBL1484770 & 688620 & 4.9 & 5.0102 & TRN & \\
\hline CHEMBL1344869 & 688620 & 5.35 & 5.085 & TRN & \\
\hline CHEMBL1374184 & 688620 & 5.15 & 5.1006 & TST & \\
\hline CHEMBL1416703 & 688620 & 5.35 & 5.3203 & TRN & \\
\hline CHEMBL1492157 & 688620 & 4.45 & 4.6037 & TRN & \\
\hline CHEMBL582070 & 688620 & 4.8 & 5.0902 & TRN & \\
\hline CHEMBL3197834 & 688620 & 4.95 & 5.1563 & TRN & \\
\hline CHEMBL1372170 & 688620 & 4.9 & 4.7833 & TRN & \\
\hline CHEMBL1604245 & 688620 & 5.55 & 5.4424 & TRN & \\
\hline CHEMBL1502224 & 688620 & 4.45 & 5.17299 & 9999999999 & TST \\
\hline CHEMBL1456156 & 688620 & 4.9 & 5.1732 & TST & \\
\hline CHEMBL1606127 & 688620 & 5.55 & 5.9442 & TRN & \\
\hline CHEMBL1306968 & 688620 & 4.65 & 4.8017 & TRN & \\
\hline CHEMBL3191291 & 688620 & 5.2 & 5.2801 & TRN & \\
\hline CHEMBL1416484 & 688620 & 5.55 & 5.1302 & TRN & \\
\hline CHEMBL1457966 & 688620 & 5.05 & 5.0375 & TST & \\
\hline CHEMBL1329061 & 688620 & 4.7 & 4.9182 & TRN & \\
\hline CHEMBL 29097 & 688620 & 4.85 & 5.5171 & TST & \\
\hline CHEMBL1388346 & 688620 & 4.7 & 4.9296 & TST & \\
\hline CHEMBL1431210 & 688620 & 6.0 & 4.9888 & TRN & \\
\hline CHEMBL1517984 & 688620 & 6.35 & 5.1455 & TRN & \\
\hline
\end{tabular}




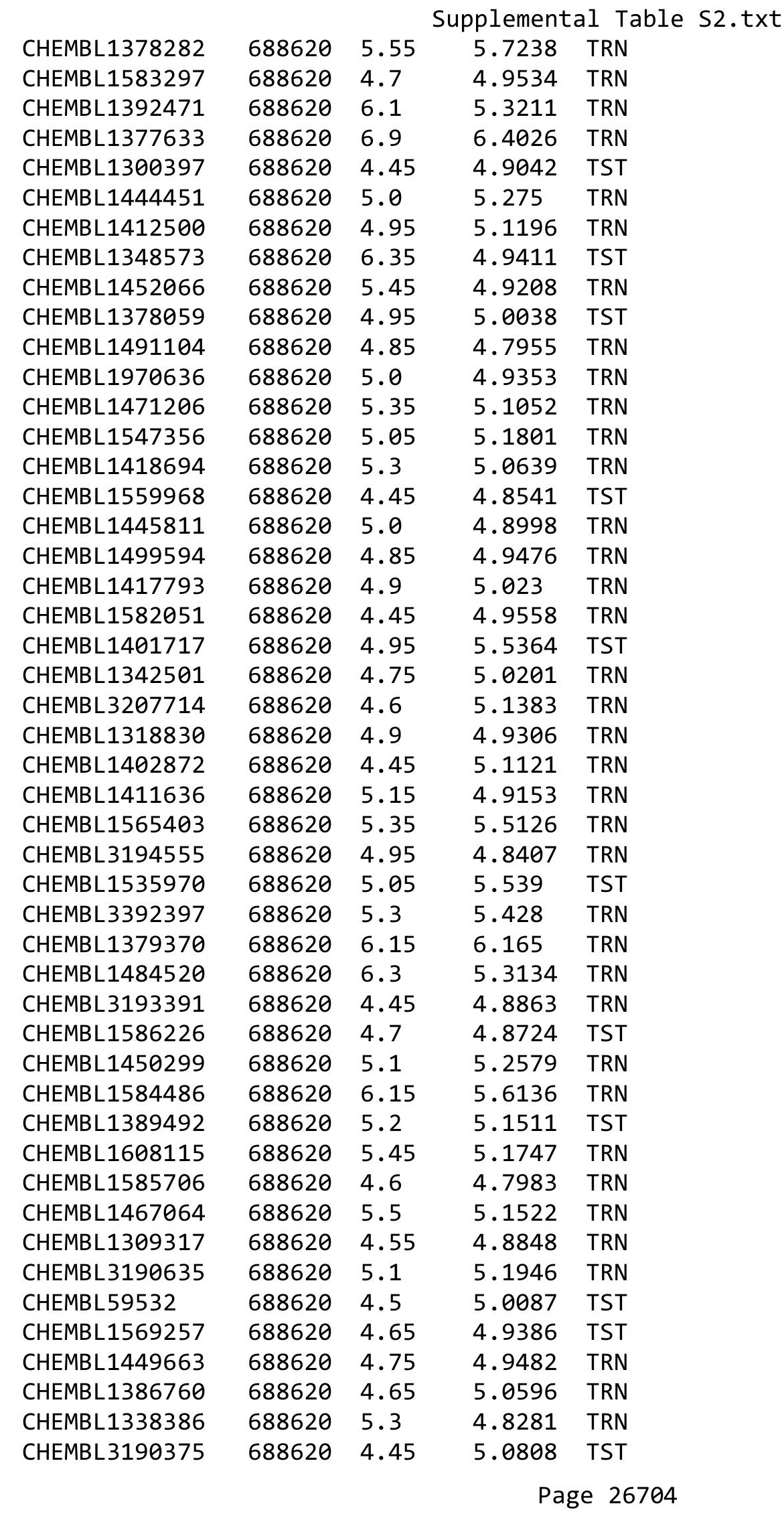




\begin{tabular}{|c|c|c|c|c|}
\hline \multicolumn{5}{|c|}{ Supplemental Table S2.txt } \\
\hline CHEMBL1310818 & 688620 & 4.9 & 4.8786 & TST \\
\hline CHEMBL1305422 & 688620 & 4.45 & 5.0902 & TST \\
\hline CHEMBL1405588 & 688620 & 5.1 & 5.4305 & TRN \\
\hline CHEMBL3392369 & 688620 & 4.5 & 5.0877 & TST \\
\hline CHEMBL 1558863 & 688620 & 4.85 & 5.3093 & TRN \\
\hline CHEMBL1475234 & 688620 & 4.75 & 4.794 & TST \\
\hline CHEMBL1443778 & 688620 & 5.15 & 5.1242 & TST \\
\hline CHEMBL1388625 & 688620 & 4.95 & 4.7502 & TRN \\
\hline CHEMBL1560273 & 688620 & 4.65 & 4.9817 & TRN \\
\hline CHEMBL1599708 & 688620 & 5.6 & 5.6652 & TRN \\
\hline CHEMBL1312775 & 688620 & 5.45 & 5.38 & TRN \\
\hline CHEMBL1309753 & 688620 & 4.7 & 4.8648 & TRN \\
\hline CHEMBL1471317 & 688620 & 6.7001 & 5.0139 & TST \\
\hline CHEMBL498677 & 688620 & 4.9 & 5.1287 & TST \\
\hline CHEMBL1425268 & 688620 & 4.85 & 5.0376 & TRN \\
\hline CHEMBL3199605 & 688620 & 4.9 & 4.9855 & TRN \\
\hline CHEMBL1456244 & 688620 & 5.0 & 4.9222 & TST \\
\hline CHEMBL1489412 & 688620 & 4.6 & 5.0611 & TST \\
\hline CHEMBL1427397 & 688620 & 4.45 & 4.8526 & TRN \\
\hline CHEMBL1460155 & 688620 & 4.95 & 5.3618 & TRN \\
\hline CHEMBL1402376 & 688620 & 5.1 & 4.8203 & TST \\
\hline CHEMBL1508959 & 688620 & 4.9 & 4.8513 & TST \\
\hline CHEMBL1384637 & 688620 & 4.9 & 4.8605 & TRN \\
\hline CHEMBL1454544 & 688620 & 4.9 & 4.6396 & TRN \\
\hline CHEMBL1361686 & 688620 & 4.45 & 4.9601 & TRN \\
\hline CHEMBL3197612 & 688620 & 4.75 & 4.9376 & TRN \\
\hline CHEMBL1547164 & 688620 & 4.45 & 4.8193 & TRN \\
\hline CHEMBL1489293 & 688620 & 4.8 & 4.9403 & TST \\
\hline CHEMBL1511421 & 688620 & 5.9 & 5.0412 & TST \\
\hline CHEMBL1587164 & 688620 & 5.35 & 5.019 & TRN \\
\hline CHEMBL 3193524 & 688620 & 5.65 & 5.306 & TST \\
\hline CHEMBL1360997 & 688620 & 4.45 & 5.2673 & TRN \\
\hline CHEMBL1467184 & 688620 & 4.75 & 5.3323 & TRN \\
\hline CHEMBL1546177 & 688620 & 4.85 & 5.2512 & TRN \\
\hline CHEMBL1504287 & 688620 & 4.55 & 4.9483 & TRN \\
\hline CHEMBL1330090 & 688620 & 4.95 & 4.6456 & TRN \\
\hline CHEMBL1516370 & 688620 & 4.8 & 5.0862 & TRN \\
\hline CHEMBL1598747 & 688620 & 4.45 & 4.8725 & TRN \\
\hline CHEMBL1989210 & 688620 & 5.9 & 5.7075 & TRN \\
\hline CHEMBL1426409 & 688620 & 4.45 & 4.9424 & TRN \\
\hline CHEMBL1349285 & 688620 & 5.0 & 5.0525 & TRN \\
\hline CHEMBL1600776 & 688620 & 5.7 & 5.0179 & TRN \\
\hline CHEMBL575073 & 688620 & 4.95 & 5.3166 & TST \\
\hline CHEMBL3197879 & 688620 & 5.0 & 5.1369 & TRN \\
\hline CHEMBL1461639 & 688620 & 4.95 & 4.8767 & TRN \\
\hline CHEMBL3210197 & 688620 & 4.95 & 5.0292 & TRN \\
\hline CHEMBL1535159 & 688620 & 5.05 & 5.3924 & TRN \\
\hline CHEMBL1457472 & 688620 & 4.85 & 5.1807 & TST \\
\hline
\end{tabular}




\begin{tabular}{|c|c|c|c|c|c|}
\hline \multicolumn{6}{|c|}{ Supplemental Table S2.txt } \\
\hline CHEMBL1327725 & 688620 & 5.15 & 5.1361 & TRN & \\
\hline CHEMBL1487807 & 688620 & 5.05 & 4.9724 & TRN & \\
\hline CHEMBL1352525 & 688620 & 4.5 & 4.9293 & TRN & \\
\hline CHEMBL1339149 & 688620 & 4.45 & 5.2179 & TST & \\
\hline CHEMBL1329125 & 688620 & 4.45 & 4.8894 & TRN & \\
\hline CHEMBL1518265 & 688620 & 5.95 & 5.7148 & TRN & \\
\hline CHEMBL1353188 & 688620 & 4.95 & 4.9804 & TST & \\
\hline CHEMBL1447239 & 688620 & 4.65 & 4.8579 & TRN & \\
\hline CHEMBL1431762 & 688620 & 4.45 & 4.6487 & TRN & \\
\hline CHEMBL1310646 & 688620 & 4.95 & 5.0991 & TRN & \\
\hline CHEMBL1550085 & 688620 & 4.8 & 4.7811 & TST & \\
\hline CHEMBL1517713 & 688620 & 5.5 & 5.1939 & TST & \\
\hline CHEMBL1382040 & 688620 & 5.0 & 5.072 & TST & \\
\hline CHEMBL1561966 & 688620 & 4.45 & 5.1576 & TST & \\
\hline CHEMBL1433152 & 688620 & 4.8 & 5.191 & TRN & \\
\hline CHEMBL1404671 & 688620 & 4.45 & 4.8986 & TRN & \\
\hline CHEMBL1988121 & 688620 & 5.85 & 5.58700 & 0000000001 & TRN \\
\hline CHEMBL1419042 & 688620 & 4.7 & 5.0973 & TRN & \\
\hline CHEMBL1988655 & 688620 & 4.95 & 5.0114 & TRN & \\
\hline CHEMBL1361719 & 688620 & 4.75 & 4.8835 & TRN & \\
\hline CHEMBL1530881 & 688620 & 4.5 & 5.0582 & TRN & \\
\hline CHEMBL1346336 & 688620 & 4.45 & 4.6027 & TRN & \\
\hline CHEMBL1423836 & 688620 & 5.0 & 5.1026 & TST & \\
\hline CHEMBL3189341 & 688620 & 5.15 & 5.0719 & TRN & \\
\hline CHEMBL1605512 & 688620 & 4.9 & 5.032 & TRN & \\
\hline CHEMBL1568899 & 688620 & 4.95 & 5.0127 & TRN & \\
\hline CHEMBL1608805 & 688620 & 5.2 & 5.0325 & TRN & \\
\hline CHEMBL1346278 & 688620 & 4.45 & 5.1737 & TRN & \\
\hline CHEMBL1372277 & 688620 & 5.1 & 5.0571 & TRN & \\
\hline CHEMBL1332761 & 688620 & 4.45 & 4.9049 & TRN & \\
\hline CHEMBL1454512 & 688620 & 5.25 & 5.3403 & TRN & \\
\hline CHEMBL1421275 & 688620 & 4.95 & 4.9991 & TRN & \\
\hline CHEMBL1332979 & 688620 & 4.8 & 5.1184 & TRN & \\
\hline CHEMBL1991779 & 688620 & 5.5 & 5.6226 & TRN & \\
\hline CHEMBL1350221 & 688620 & 4.85 & 5.0748 & TRN & \\
\hline CHEMBL1547352 & 688620 & 4.9 & 4.9541 & TRN & \\
\hline CHEMBL1505267 & 688620 & 5.3 & 5.4301 & TRN & \\
\hline CHEMBL1450020 & 688620 & 4.8 & 4.8685 & TST & \\
\hline CHEMBL 2003172 & 688620 & 5.45 & 5.0326 & TRN & \\
\hline CHEMBL3193830 & 688620 & 4.8 & 4.9238 & TRN & \\
\hline CHEMBL1498373 & 688620 & 7.0501 & 5.1194 & TRN & \\
\hline CHEMBL1714415 & 688620 & 4.75 & 4.7767 & TRN & \\
\hline CHEMBL3198941 & 688620 & 4.65 & 4.9329 & TRN & \\
\hline CHEMBL1556352 & 688620 & 4.9 & 5.0818 & TRN & \\
\hline CHEMBL1303203 & 688620 & 4.9 & 4.9387 & TST & \\
\hline CHEMBL1468908 & 688620 & 6.25 & 5.733 & TST & \\
\hline CHEMBL1305288 & 688620 & 4.8 & 5.0982 & TRN & \\
\hline CHEMBL1410498 & 688620 & 4.45 & 4.7759 & TST & \\
\hline
\end{tabular}




\begin{tabular}{|c|c|c|c|c|c|}
\hline \multirow[b]{2}{*}{ CHEMBL1361507 } & \\
\hline & 688620 & 4.9 & 4.7988 & TRN & \\
\hline CHEMBL1313955 & 688620 & 4.75 & 4.8436 & TRN & \\
\hline CHEMBL1365223 & 688620 & 4.5 & 4.8781 & TST & \\
\hline CHEMBL1360779 & 688620 & 4.45 & 5.1141 & TRN & \\
\hline CHEMBL1996867 & 688620 & 5.0 & 5.0993 & TST & \\
\hline CHEMBL1452716 & 688620 & 4.9 & 4.84399 & 9999999999 & TST \\
\hline CHEMBL1567706 & 688620 & 4.9 & 4.9337 & TRN & \\
\hline CHEMBL1392052 & 688620 & 4.65 & 5.1441 & TST & \\
\hline CHEMBL1386090 & 688620 & 5.55 & 5.3045 & TRN & \\
\hline CHEMBL1447905 & 688620 & 5.3 & 5.11600 & 00000000005 & TRN \\
\hline CHEMBL1299346 & 688620 & 5.2 & 4.8843 & TST & \\
\hline CHEMBL1345258 & 688620 & 4.95 & 4.8955 & TRN & \\
\hline CHEMBL1376861 & 688620 & 5.35 & 5.0076 & TRN & \\
\hline CHEMBL1991791 & 688620 & 4.45 & 4.8522 & TST & \\
\hline CHEMBL1481000 & 688620 & 4.45 & 4.6033 & TRN & \\
\hline CHEMBL1341809 & 688620 & 5.55 & 5.5256 & TRN & \\
\hline CHEMBL1550257 & 688620 & 5.45 & 5.25899 & 99999999995 & TST \\
\hline CHEMBL1534507 & 688620 & 4.45 & 5.0153 & TRN & \\
\hline CHEMBL1389029 & 688620 & 4.9 & 4.987 & TRN & \\
\hline CHEMBL1606935 & 688620 & 4.45 & 4.8891 & TRN & \\
\hline CHEMBL1337100 & 688620 & 4.95 & 5.0424 & TST & \\
\hline CHEMBL1563536 & 688620 & 4.85 & 5.0301 & TST & \\
\hline CHEMBL3198961 & 688620 & 5.55 & 5.5435 & TRN & \\
\hline CHEMBL1586520 & 688620 & 5.7 & 4.8942 & TST & \\
\hline CHEMBL1481810 & 688620 & 4.95 & 4.913 & TRN & \\
\hline CHEMBL1470033 & 688620 & 7.5003 & 5.1263 & TST & \\
\hline CHEMBL1877896 & 688620 & 5.55 & 5.0743 & TRN & \\
\hline CHEMBL1470338 & 688620 & 4.75 & 4.9271 & TRN & \\
\hline CHEMBL1440238 & 688620 & 7.3002 & 5.0443 & TST & \\
\hline CHEMBL1336911 & 688620 & 4.95 & 4.8068 & TRN & \\
\hline CHEMBL1538572 & 688620 & 4.5 & 5.1063 & TST & \\
\hline CHEMBL3197911 & 688620 & 5.3 & 5.2774 & TRN & \\
\hline CHEMBL1593824 & 688620 & 5.35 & 4.9265 & TRN & \\
\hline CHEMBL1374901 & 688620 & 6.95 & 4.949 & TRN & \\
\hline CHEMBL3195878 & 688620 & 6.25 & 5.6086 & TRN & \\
\hline CHEMBL1584770 & 688620 & 8.2007 & 5.06800 & 30000000005 & TRN \\
\hline CHEMBL1208858 & 688620 & 5.5 & 4.9828 & TST & \\
\hline CHEMBL1402532 & 688620 & 4.45 & 4.9685 & TST & \\
\hline CHEMBL1457361 & 688620 & 4.45 & 4.9217 & TRN & \\
\hline CHEMBL1351995 & 688620 & 4.5 & 5.1967 & TRN & \\
\hline CHEMBL1370035 & 688620 & 5.5 & 5.3056 & TRN & \\
\hline CHEMBL3209702 & 688620 & 4.45 & 5.0577 & TRN & \\
\hline CHEMBL1324192 & 688620 & 4.75 & 4.8531 & TRN & \\
\hline CHEMBL1420903 & 688620 & 4.85 & 4.9888 & TST & \\
\hline CHEMBL1309018 & 688620 & 5.65 & 5.1161 & TRN & \\
\hline CHEMBL1346791 & 688620 & 5.15 & 5.1311 & TRN & \\
\hline CHEMBL1336405 & 688620 & 5.1 & 4.7037 & TRN & \\
\hline CHEMBL1351695 & 688620 & 4.95 & 5.032 & TRN & \\
\hline
\end{tabular}




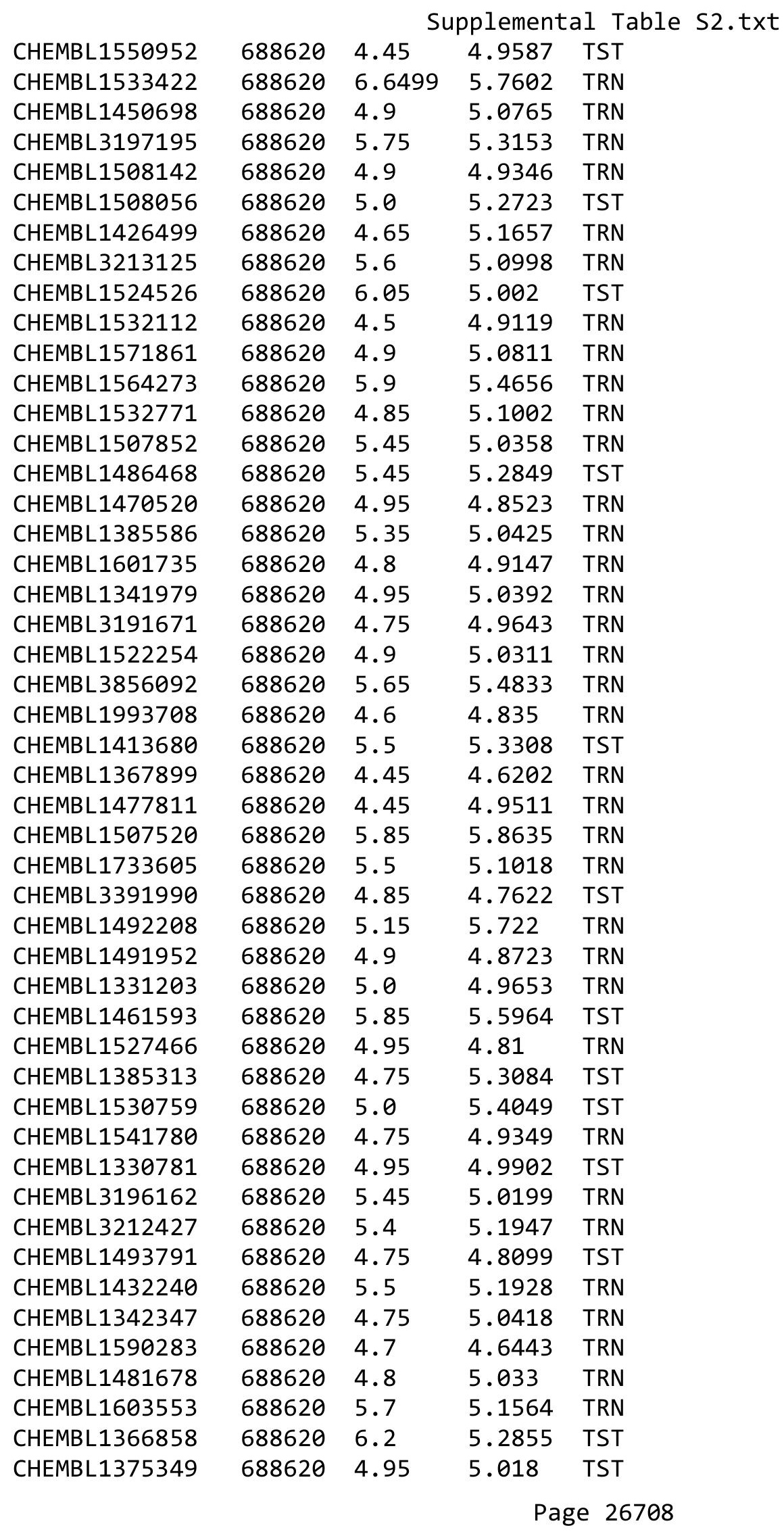




\begin{tabular}{|c|c|c|c|c|c|}
\hline & & \multicolumn{4}{|c|}{ Supplemental Table S2.txt } \\
\hline CHEMBL3191946 & 688620 & 7.5003 & 6.3276 & TRN & \\
\hline CHEMBL1379139 & 688620 & 5.3 & 5.24799 & 9999999999 & TRN \\
\hline CHEMBL3199143 & 688620 & 4.85 & 4.9453 & TRN & \\
\hline CHEMBL1442505 & 688620 & 5.0 & 5.0716 & TST & \\
\hline CHEMBL1428568 & 688620 & 4.6 & 5.15 & TRN & \\
\hline CHEMBL1427042 & 688620 & 4.9 & 4.8912 & TRN & \\
\hline CHEMBL3196666 & 688620 & 4.45 & 4.8065 & TRN & \\
\hline CHEMBL1563388 & 688620 & 4.95 & 5.0435 & TRN & \\
\hline CHEMBL3211853 & 688620 & 4.65 & 4.8899 & TRN & \\
\hline CHEMBL1367728 & 688620 & 7.3002 & 5.1774 & TRN & \\
\hline CHEMBL544348 & 688620 & 4.5 & 4.7066 & TRN & \\
\hline CHEMBL1414769 & 688620 & 5.0 & 4.942 & TRN & \\
\hline CHEMBL1500363 & 688620 & 4.85 & 4.9614 & TRN & \\
\hline CHEMBL1567373 & 688620 & 5.05 & 4.8391 & TST & \\
\hline CHEMBL1586511 & 688620 & 4.45 & 5.4107 & TRN & \\
\hline CHEMBL1381509 & 688620 & 5.3 & 5.2115 & TRN & \\
\hline CHEMBL3191509 & 688620 & 6.8499 & 5.2049 & TST & \\
\hline CHEMBL1558578 & 688620 & 4.95 & 5.0521 & TRN & \\
\hline CHEMBL1342073 & 688620 & 5.0 & 4.8946 & TST & \\
\hline CHEMBL1494153 & 688620 & 4.45 & 5.3494 & TST & \\
\hline CHEMBL1367128 & 688620 & 4.5 & 5.1915 & TST & \\
\hline CHEMBL1306193 & 688620 & 4.75 & 5.0192 & TST & \\
\hline CHEMBL1577318 & 688620 & 4.6 & 5.1367 & TST & \\
\hline CHEMBL1979756 & 688620 & 5.4 & 5.3351 & TRN & \\
\hline CHEMBL3194013 & 688620 & 5.05 & 5.2142 & TRN & \\
\hline CHEMBL1361023 & 688620 & 4.45 & 4.8729 & TST & \\
\hline CHEMBL1452235 & 688620 & 4.45 & 5.1086 & TRN & \\
\hline CHEMBL1539470 & 688620 & 5.35 & 4.9899 & TRN & \\
\hline CHEMBL3194760 & 688620 & 5.0 & 5.2464 & TRN & \\
\hline CHEMBL1335110 & 688620 & 5.05 & 5.0378 & TRN & \\
\hline CHEMBL1310842 & 688620 & 5.9 & 4.9481 & TST & \\
\hline CHEMBL1335734 & 688620 & 5.25 & 5.24299 & 9999999999 & TRN \\
\hline CHEMBL1375998 & 688620 & 4.7 & 4.7189 & TRN & \\
\hline CHEMBL1569435 & 688620 & 4.65 & 5.396 & TRN & \\
\hline CHEMBL3210930 & 688620 & 5.5 & 5.2731 & TRN & \\
\hline CHEMBL1322116 & 688620 & 4.45 & 4.8834 & TRN & \\
\hline CHEMBL1461349 & 688620 & 4.85 & 4.8258 & TST & \\
\hline CHEMBL1499433 & 688620 & 4.9 & 5.1019 & TRN & \\
\hline CHEMBL1569550 & 688620 & 4.9 & 5.0366 & TRN & \\
\hline CHEMBL1372755 & 688620 & 5.15 & 4.9228 & TRN & \\
\hline CHEMBL1500175 & 688620 & 4.45 & 4.9691 & TRN & \\
\hline CHEMBL1348675 & 688620 & 4.5 & 5.10800 & 00000000005 & TRN \\
\hline CHEMBL1321474 & 688620 & 4.45 & 5.1182 & TRN & \\
\hline CHEMBL1472418 & 688620 & 5.95 & 6.1734 & TRN & \\
\hline CHEMBL3197694 & 688620 & 4.45 & 4.8954 & TRN & \\
\hline CHEMBL3196450 & 688620 & 4.95 & 4.8462 & TRN & \\
\hline CHEMBL1534536 & 688620 & 5.0 & 4.957 & TRN & \\
\hline CHEMBL1509229 & 688620 & 4.45 & 4.647 & TRN & \\
\hline
\end{tabular}




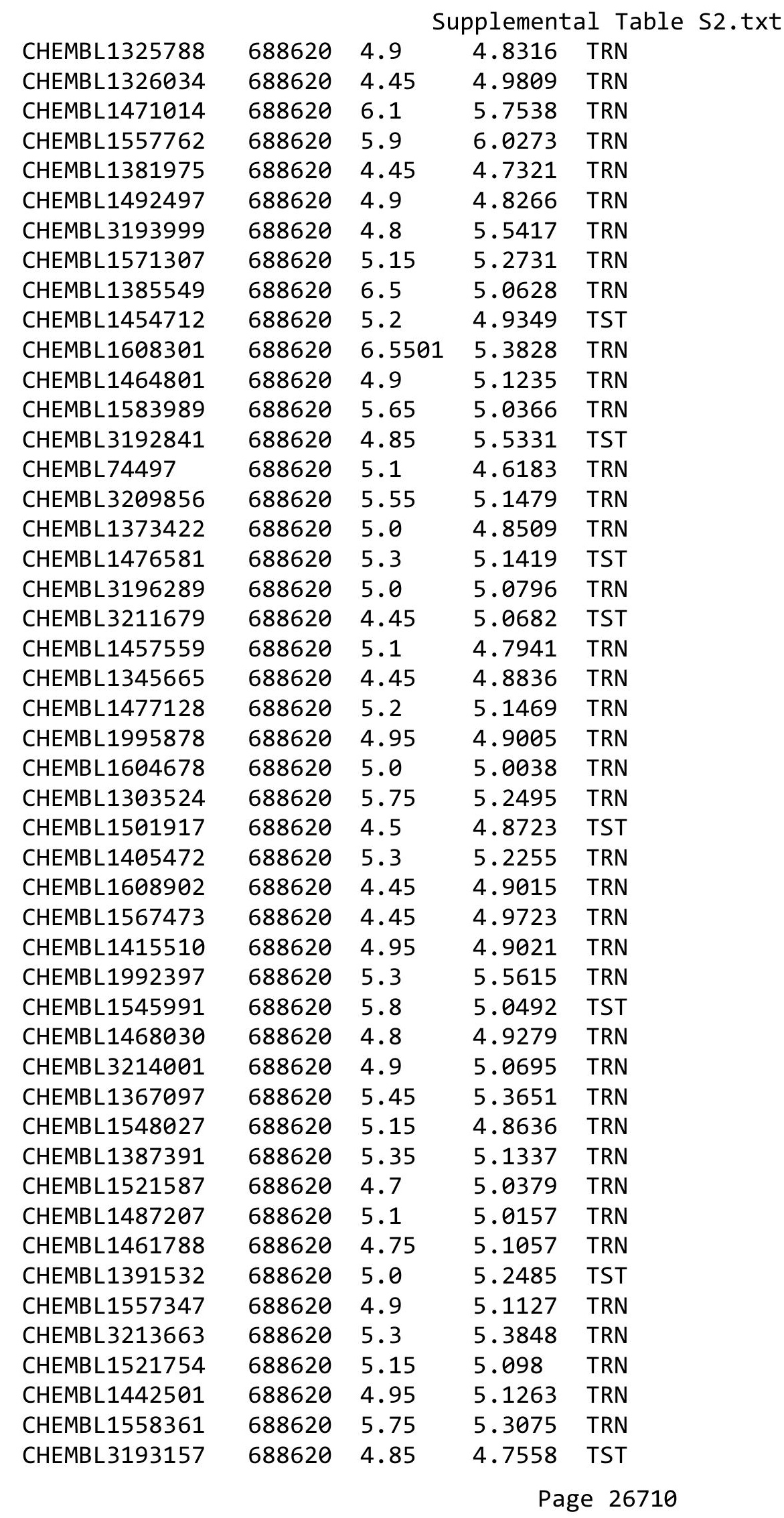




\begin{tabular}{|c|c|c|c|c|c|}
\hline \\
\hline CHEMBL1329410 & 688620 & 4.8 & 5.2014 & TRN & \\
\hline CHEMBL1388509 & 688620 & 5.15 & 4.9808 & TRN & \\
\hline CHEMBL1387432 & 688620 & 4.65 & 4.9976 & TST & \\
\hline CHEMBL1377707 & 688620 & 4.9 & 4.8309 & TST & \\
\hline CHEMBL3190163 & 688620 & 6.5501 & 5.83 & TRN & \\
\hline CHEMBL1587276 & 688620 & 6.5501 & 4.9847 & TRN & \\
\hline CHEMBL1613688 & 688620 & 8.3979 & 6.5108 & TST & \\
\hline CHEMBL1429047 & 688620 & 4.5 & 4.9635 & TRN & \\
\hline CHEMBL3208212 & 688620 & 5.25 & 5.2886 & TRN & \\
\hline CHEMBL1583311 & 688620 & 4.45 & 5.0055 & TST & \\
\hline CHEMBL1299829 & 688620 & 6.15 & 5.0662 & TRN & \\
\hline CHEMBL1585484 & 688620 & 4.85 & 5.0292 & TST & \\
\hline CHEMBL3207339 & 688620 & 4.9 & 4.8048 & TST & \\
\hline CHEMBL1271059 & 688620 & 5.25 & 4.8574 & TRN & \\
\hline CHEMBL1575252 & 688620 & 4.95 & 5.1024 & TST & \\
\hline CHEMBL1611091 & 688620 & 4.95 & 4.9899 & TRN & \\
\hline CHEMBL1300926 & 688620 & 5.2 & 4.9709 & TST & \\
\hline CHEMBL3196949 & 688620 & 4.6 & 5.5654 & TRN & \\
\hline CHEMBL1349235 & 688620 & 5.0 & 5.0025 & TST & \\
\hline CHEMBL1497773 & 688620 & 4.9 & 4.8006 & TRN & \\
\hline CHEMBL1582590 & 688620 & 5.1 & 5.0631 & TST & \\
\hline CHEMBL1453735 & 688620 & 5.15 & 4.96399 & 99999999995 & TRN \\
\hline CHEMBL1531156 & 688620 & 4.65 & 5.0418 & TRN & \\
\hline CHEMBL1580588 & 688620 & 4.9 & 4.8427 & TRN & \\
\hline CHEMBL1495730 & 688620 & 4.8 & 4.8555 & TRN & \\
\hline CHEMBL1399543 & 688620 & 5.85 & 5.3337 & TST & \\
\hline CHEMBL1451987 & 688620 & 4.75 & 5.0314 & TRN & \\
\hline CHEMBL1360714 & 688620 & 6.35 & 5.8178 & TRN & \\
\hline CHEMBL442951 & 688620 & 6.15 & 5.1746 & TST & \\
\hline CHEMBL1470061 & 688620 & 4.9 & 5.4043 & TRN & \\
\hline CHEMBL1364733 & 688620 & 4.95 & 5.9677 & TST & \\
\hline CHEMBL1323123 & 688620 & 4.8 & 5.0956 & TRN & \\
\hline CHEMBL1463446 & 688620 & 4.45 & 4.9624 & TRN & \\
\hline CHEMBL1574034 & 688620 & 4.85 & 5.3521 & TRN & \\
\hline CHEMBL3195422 & 688620 & 4.95 & 4.8997 & TRN & \\
\hline CHEMBL1326570 & 688620 & 4.45 & 4.7173 & TRN & \\
\hline CHEMBL1530097 & 688620 & 5.9 & 5.66299 & 9999999999 & TRN \\
\hline CHEMBL1315249 & 688620 & 5.55 & 4.9526 & TRN & \\
\hline CHEMBL1482358 & 688620 & 4.75 & 4.7855 & TST & \\
\hline CHEMBL1546794 & 688620 & 4.65 & 4.8623 & TRN & \\
\hline CHEMBL1568830 & 688620 & 5.75 & 5.30200 & 30000000005 & TRN \\
\hline CHEMBL1482509 & 688620 & 6.05 & 5.0097 & TST & \\
\hline CHEMBL1360482 & 688620 & 5.1 & 5.02 & TRN & \\
\hline CHEMBL1496787 & 688620 & 4.8 & 5.0613 & TST & \\
\hline CHEMBL1461668 & 688620 & 4.95 & 4.7989 & TRN & \\
\hline CHEMBL1413843 & 688620 & 4.65 & 4.9621 & TRN & \\
\hline CHEMBL1326263 & 688620 & 4.45 & 4.9334 & TRN & \\
\hline CHEMBL1403682 & 688620 & 4.45 & 4.9858 & TRN & \\
\hline
\end{tabular}




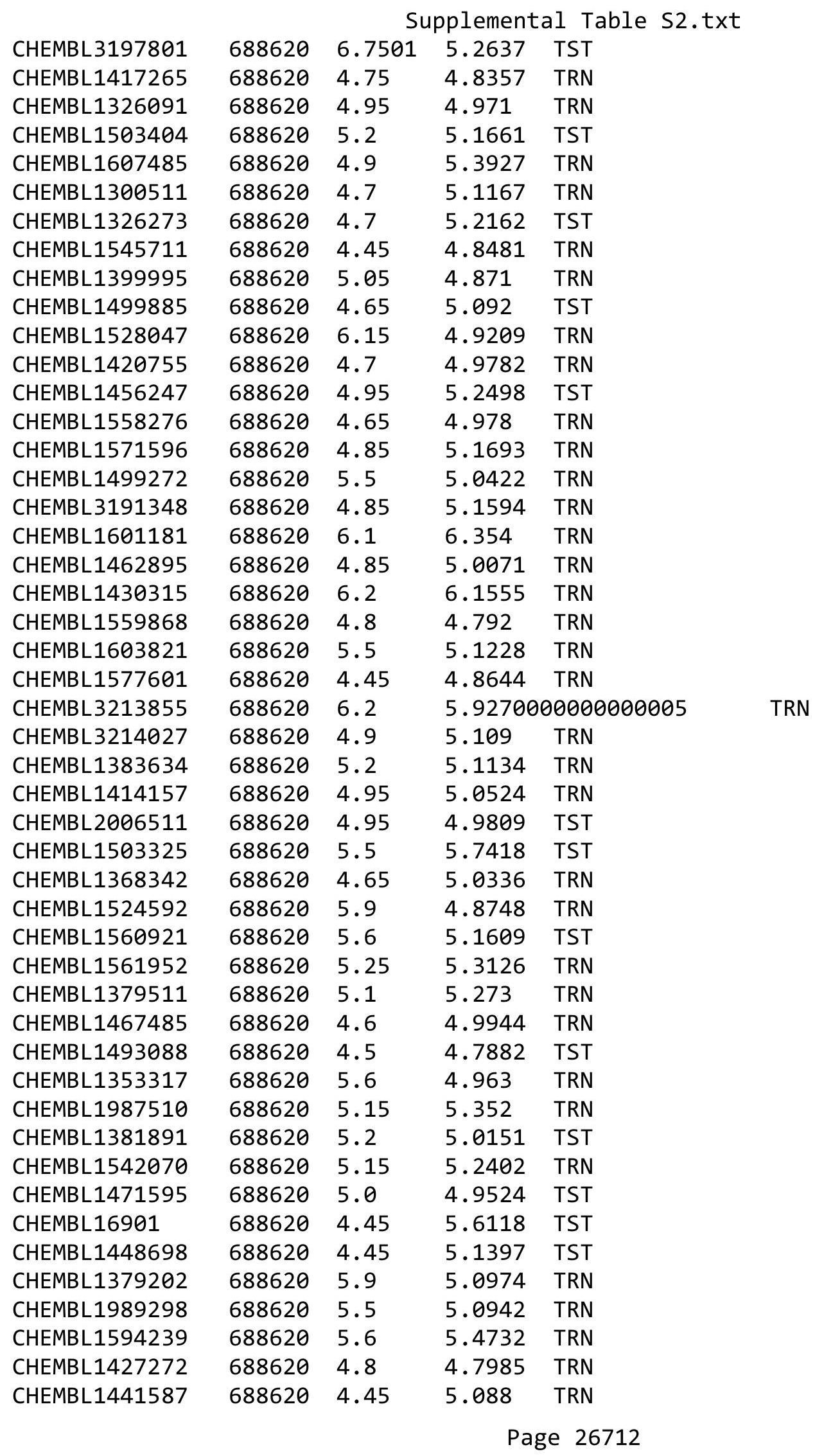




\begin{tabular}{|c|c|c|c|c|c|}
\hline & & \multicolumn{4}{|c|}{ Supplemental Table s2.txt } \\
\hline CHEMBL1486174 & 688620 & 4.95 & 5.0871 & TRN & \\
\hline CHEMBL1470605 & 688620 & 5.15 & 5.0318 & TRN & \\
\hline CHEMBL1464144 & 688620 & 5.1 & 5.8626 & TST & \\
\hline CHEMBL3190683 & 688620 & 4.45 & 5.1506 & TST & \\
\hline CHEMBL1479386 & 688620 & 4.65 & 4.9065 & TRN & \\
\hline CHEMBL3195773 & 688620 & 5.1 & 5.0613 & TST & \\
\hline CHEMBL311822 & 688620 & 5.25 & 5.0097 & TRN & \\
\hline CHEMBL1537583 & 688620 & 4.45 & 5.1344 & TST & \\
\hline CHEMBL1346827 & 688620 & 4.8 & 5.1889 & TRN & \\
\hline CHEMBL1408737 & 688620 & 5.05 & 4.9337 & TRN & \\
\hline CHEMBL3194441 & 688620 & 6.1 & 5.8028 & TRN & \\
\hline CHEMBL1369190 & 688620 & 4.7 & 4.9705 & TST & \\
\hline CHEMBL1528864 & 688620 & 4.45 & 5.2164 & TRN & \\
\hline CHEMBL1443694 & 688620 & 4.75 & 4.8976 & TST & \\
\hline CHEMBL 2007000 & 688620 & 5.5 & 4.91 & TRN & \\
\hline CHEMBL1481392 & 688620 & 4.85 & 4.8785 & TRN & \\
\hline CHEMBL1494716 & 688620 & 5.55 & 4.9828 & TST & \\
\hline CHEMBL1497488 & 688620 & 6.0 & 5.9352 & TRN & \\
\hline CHEMBL1594543 & 688620 & 5.65 & 5.3825 & TST & \\
\hline CHEMBL1373648 & 688620 & 5.4 & 5.2816 & TRN & \\
\hline CHEMBL3194059 & 688620 & 4.65 & 4.9832 & TRN & \\
\hline CHEMBL1358568 & 688620 & 4.45 & 5.185 & TRN & \\
\hline CHEMBL1974348 & 688620 & 4.45 & 5.0462 & TRN & \\
\hline CHEMBL1387561 & 688620 & 4.65 & 5.2839 & TST & \\
\hline CHEMBL1333304 & 688620 & 4.5 & 4.9589 & TRN & \\
\hline CHEMBL1583838 & 688620 & 4.75 & 5.1211 & TST & \\
\hline CHEMBL1337500 & 688620 & 5.6 & 5.4015 & TST & \\
\hline CHEMBL1368382 & 688620 & 4.45 & 5.0081 & TRN & \\
\hline CHEMBL1382096 & 688620 & 5.7 & 5.1192 & TST & \\
\hline CHEMBL1509082 & 688620 & 4.8 & 4.9397 & TRN & \\
\hline CHEMBL1585491 & 688620 & 5.9 & 5.3943 & TRN & \\
\hline CHEMBL86962 & 688620 & 4.75 & 5.395 & TRN & \\
\hline CHEMBL1518682 & 688620 & 5.05 & 5.2628 & TRN & \\
\hline CHEMBL1535048 & 688620 & 5.2 & 5.3 & TRN & \\
\hline CHEMBL1429783 & 688620 & 4.9 & 5.0031 & TRN & \\
\hline CHEMBL1502091 & 688620 & 5.7 & 5.0021 & TST & \\
\hline CHEMBL1408026 & 688620 & 4.45 & 5.0875 & TST & \\
\hline CHEMBL1498079 & 688620 & 5.2 & 5.3566 & TST & \\
\hline CHEMBL1990214 & 688620 & 5.0 & 5.1467 & TRN & \\
\hline CHEMBL1579360 & 688620 & 5.3 & 5.2716 & TST & \\
\hline CHEMBL1310816 & 688620 & 6.1 & 5.9884 & TRN & \\
\hline CHEMBL3197131 & 688620 & 4.65 & 4.7908 & TRN & \\
\hline CHEMBL1596319 & 688620 & 5.95 & 5.5237 & TRN & \\
\hline CHEMBL1561744 & 688620 & 5.25 & 5.24299 & 9999999999 & TRN \\
\hline CHEMBL3190739 & 688620 & 4.65 & 4.9538 & TST & \\
\hline CHEMBL1612531 & 688620 & 5.5 & 5.3022 & TRN & \\
\hline CHEMBL1424543 & 688620 & 4.95 & 5.0737 & TRN & \\
\hline CHEMBL1982304 & 688620 & 5.95 & 5.7596 & TRN & \\
\hline
\end{tabular}




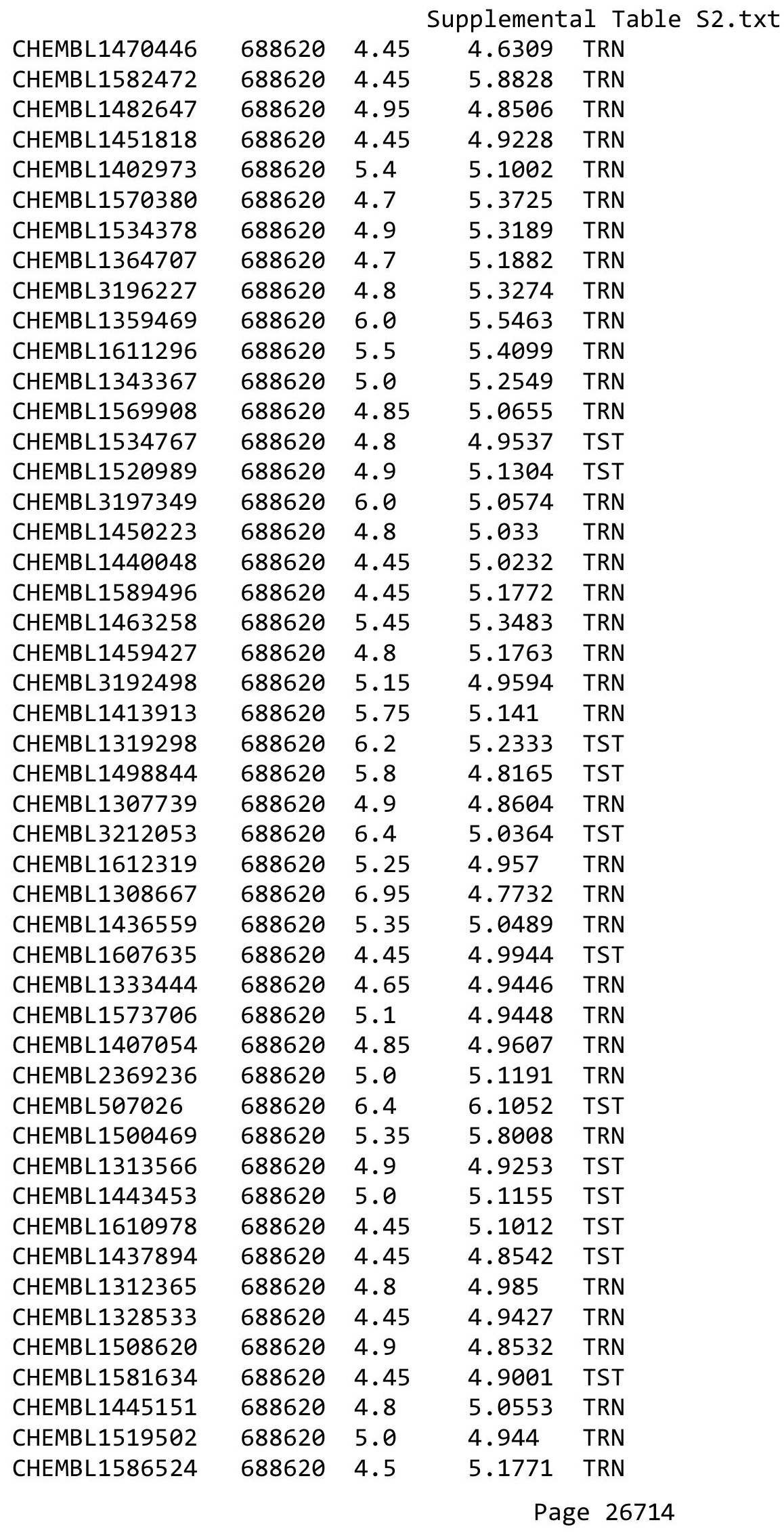




\begin{tabular}{|c|c|c|c|c|c|}
\hline \multirow[b]{2}{*}{ CHEMBL1556156 } & \multicolumn{5}{|c|}{ Supplemental Table S2.txt } \\
\hline & 688620 & 4.45 & 4.713 & TRN & \\
\hline CHEMBL1307218 & 688620 & 4.95 & 5.0476 & TRN & \\
\hline CHEMBL1425682 & 688620 & 5.15 & 5.0609 & TRN & \\
\hline CHEMBL1387096 & 688620 & 5.15 & 4.9374 & TRN & \\
\hline CHEMBL1466523 & 688620 & 5.45 & 5.1335 & TST & \\
\hline CHEMBL1383762 & 688620 & 5.55 & 5.0375 & TRN & \\
\hline CHEMBL1481301 & 688620 & 7.0501 & $5.9060 e$ & 3000000001 & TRN \\
\hline CHEMBL1459307 & 688620 & 5.1 & 5.0492 & TRN & \\
\hline CHEMBL1544695 & 688620 & 4.95 & 5.3994 & TST & \\
\hline CHEMBL1527768 & 688620 & 4.9 & 4.967 & TRN & \\
\hline CHEMBL85139 & 688620 & 4.45 & 5.1685 & TST & \\
\hline CHEMBL1411507 & 688620 & 4.5 & 5.2011 & TRN & \\
\hline CHEMBL 3193148 & 688620 & 4.45 & 5.3541 & TRN & \\
\hline CHEMBL1530525 & 688620 & 5.55 & 5.2269 & TRN & \\
\hline CHEMBL1406971 & 688620 & 4.45 & 4.8176 & TST & \\
\hline CHEMBL1498436 & 688620 & 4.45 & 5.0091 & TRN & \\
\hline CHEMBL1469803 & 688620 & 4.8 & 4.8669 & TRN & \\
\hline CHEMBL3195998 & 688620 & 5.0 & 4.979 & TRN & \\
\hline CHEMBL1387222 & 688620 & 4.45 & 5.0375 & TST & \\
\hline CHEMBL1369893 & 688620 & 5.5 & 5.5322 & TRN & \\
\hline CHEMBL1429769 & 688620 & 4.45 & 4.978 & TRN & \\
\hline CHEMBL22533 & 688620 & 4.65 & 5.1685 & TST & \\
\hline CHEMBL1369262 & 688620 & 5.3 & 5.1802 & TRN & \\
\hline CHEMBL1568334 & 688620 & 5.6 & 5.2313 & TRN & \\
\hline CHEMBL1971760 & 688620 & 7.6498 & 6.0061 & TRN & \\
\hline CHEMBL1465989 & 688620 & 4.45 & 4.8844 & TRN & \\
\hline CHEMBL1489603 & 688620 & 5.15 & $5.1770 e$ & 00000000005 & TST \\
\hline CHEMBL1310553 & 688620 & 4.45 & 5.0122 & TST & \\
\hline CHEMBL1546843 & 688620 & 5.45 & 5.4211 & TST & \\
\hline CHEMBL1410653 & 688620 & 5.3 & 4.8637 & TRN & \\
\hline CHEMBL562334 & 688620 & 4.65 & 5.2348 & TRN & \\
\hline CHEMBL1496360 & 688620 & 4.95 & 5.0116 & TRN & \\
\hline CHEMBL1241268 & 688620 & 5.25 & 4.8296 & TST & \\
\hline CHEMBL1555626 & 688620 & 4.85 & 4.9361 & TRN & \\
\hline CHEMBL1300426 & 688620 & 4.65 & 5.1016 & TRN & \\
\hline CHEMBL1571742 & 688620 & 5.2 & 5.192 & TRN & \\
\hline CHEMBL1309312 & 688620 & 5.65 & 5.4845 & TRN & \\
\hline CHEMBL3191800 & 688620 & 4.7 & 5.0281 & TRN & \\
\hline CHEMBL1450990 & 688620 & 6.05 & 5.6318 & TRN & \\
\hline CHEMBL1600566 & 688620 & 4.45 & 4.6455 & TRN & \\
\hline CHEMBL1545487 & 688620 & 4.9 & 4.9014 & TRN & \\
\hline CHEMBL1318970 & 688620 & 5.4 & 5.0234 & TRN & \\
\hline CHEMBL1546813 & 688620 & 4.9 & 5.0507 & TRN & \\
\hline CHEMBL1419072 & 688620 & 5.25 & 5.1699 & TRN & \\
\hline CHEMBL1467727 & 688620 & 5.15 & 4.9262 & TRN & \\
\hline CHEMBL1439349 & 688620 & 5.25 & 4.9853 & TST & \\
\hline CHEMBL1572433 & 688620 & 5.5 & 5.4891 & TRN & \\
\hline CHEMBL1379436 & 688620 & 6.4 & 5.1187 & TRN & \\
\hline
\end{tabular}




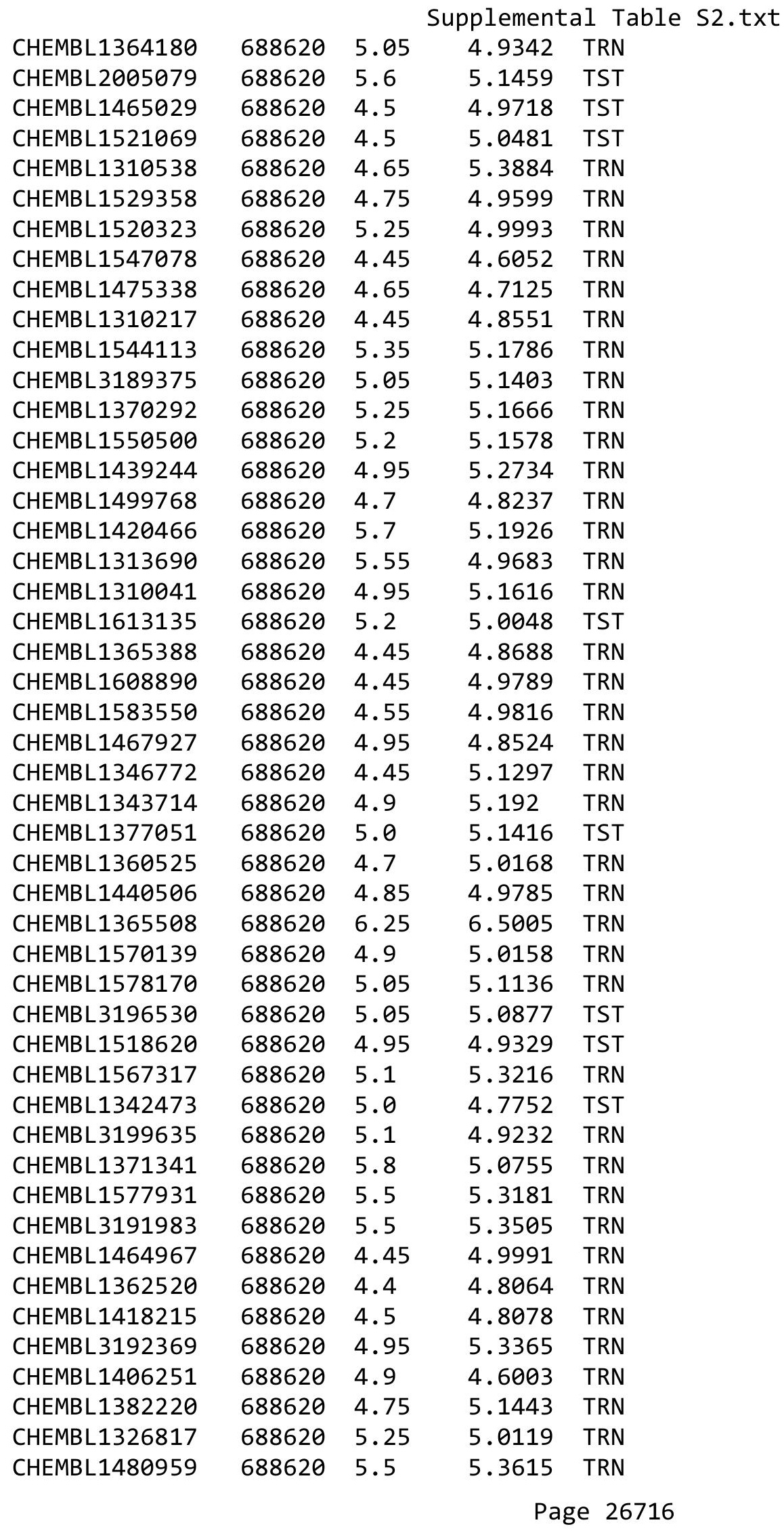




\begin{tabular}{|c|c|c|c|c|}
\hline \multicolumn{5}{|c|}{ Supplemental Table S2.txt } \\
\hline CHEMBL3191023 & 688620 & 5.3 & 5.2208 & TRN \\
\hline CHEMBL1336333 & 688620 & 4.8 & 4.971 & TRN \\
\hline CHEMBL1489362 & 688620 & 4.95 & 4.802 & TRN \\
\hline CHEMBL1588804 & 688620 & 4.75 & 4.9128 & TST \\
\hline CHEMBL1490043 & 688620 & 5.0 & 5.2973 & TRN \\
\hline CHEMBL1428580 & 688620 & 6.05 & 5.0132 & TRN \\
\hline CHEMBL1450655 & 688620 & 4.9 & 5.0612 & TST \\
\hline CHEMBL 3192441 & 688620 & 4.75 & 4.9147 & TRN \\
\hline CHEMBL1488518 & 688620 & 4.45 & 5.0299 & TST \\
\hline CHEMBL1323869 & 688620 & 4.6 & 5.4081 & TST \\
\hline CHEMBL1526681 & 688620 & 4.45 & 4.8868 & TST \\
\hline CHEMBL1439738 & 688620 & 4.45 & 4.9714 & TRN \\
\hline CHEMBL1406980 & 688620 & 4.85 & 5.3088 & TRN \\
\hline CHEMBL1331784 & 688620 & 4.45 & 5.0246 & TST \\
\hline CHEMBL1596508 & 688620 & 4.95 & 5.1566 & TRN \\
\hline CHEMBL1305022 & 688620 & 5.25 & 4.9889 & TRN \\
\hline CHEMBL1427219 & 688620 & 4.6 & 4.8701 & TRN \\
\hline CHEMBL1562439 & 688620 & 5.3 & 5.0547 & TRN \\
\hline CHEMBL1501466 & 688620 & 5.15 & 5.1733 & TRN \\
\hline CHEMBL1299628 & 688620 & 4.9 & 5.0305 & TST \\
\hline CHEMBL1303293 & 688620 & 6.5 & 5.148 & TST \\
\hline CHEMBL1585552 & 688620 & 4.45 & 4.8879 & TRN \\
\hline CHEMBL1471132 & 688620 & 5.55 & 5.1135 & TRN \\
\hline CHEMBL1573600 & 688620 & 4.45 & 5.2497 & TRN \\
\hline CHEMBL1494843 & 688620 & 5.0 & 4.9168 & TRN \\
\hline CHEMBL1302321 & 688620 & 4.9 & 4.9369 & TRN \\
\hline CHEMBL1402472 & 688620 & 5.45 & 5.099 & TST \\
\hline CHEMBL1593650 & 688620 & 5.9 & 5.1062 & TST \\
\hline CHEMBL1432535 & 688620 & 5.0 & 5.0003 & TRN \\
\hline CHEMBL1477941 & 688620 & 4.45 & 4.7834 & TRN \\
\hline CHEMBL3198408 & 688620 & 4.85 & 4.8525 & TRN \\
\hline CHEMBL1459175 & 688620 & 4.45 & 4.9508 & TST \\
\hline CHEMBL1485134 & 688620 & 4.45 & 4.9256 & TRN \\
\hline CHEMBL1353253 & 688620 & 4.75 & 4.8696 & TRN \\
\hline CHEMBL1382494 & 688620 & 4.75 & 4.9345 & TRN \\
\hline CHEMBL1464457 & 688620 & 6.0 & 5.5836 & TRN \\
\hline CHEMBL1320093 & 688620 & 6.5501 & 5.1479 & TRN \\
\hline CHEMBL1531990 & 688620 & 5.1 & 5.1711 & TST \\
\hline CHEMBL1349334 & 688620 & 4.45 & 4.8324 & TRN \\
\hline CHEMBL1508402 & 688620 & 4.45 & 4.7234 & TRN \\
\hline CHEMBL1544201 & 688620 & 4.45 & 4.7848 & TRN \\
\hline CHEMBL1477697 & 688620 & 4.95 & 4.769 & TRN \\
\hline CHEMBL1407175 & 688620 & 4.95 & 5.0278 & TST \\
\hline CHEMBL3209366 & 688620 & 4.75 & 5.1463 & TST \\
\hline CHEMBL1314742 & 688620 & 4.45 & 5.1338 & TST \\
\hline CHEMBL3192416 & 688620 & 4.95 & 4.7818 & TRN \\
\hline CHEMBL1422744 & 688620 & 4.7 & 5.0404 & TRN \\
\hline CHEMBL3192817 & 688620 & 5.45 & 5.6885 & TRN \\
\hline
\end{tabular}




\begin{tabular}{|c|c|c|c|c|}
\hline \multicolumn{5}{|c|}{ Supplemental Table S2.txt } \\
\hline CHEMBL1337242 & 688620 & 4.75 & 5.1316 & TRN \\
\hline CHEMBL1359721 & 688620 & 4.8 & 5.1854 & TRN \\
\hline CHEMBL1337933 & 688620 & 4.9 & 5.0545 & TST \\
\hline CHEMBL1579785 & 688620 & 4.45 & 4.8263 & TRN \\
\hline CHEMBL1988970 & 688620 & 4.5 & 5.0475 & TRN \\
\hline CHEMBL1548083 & 688620 & 4.45 & 4.9504 & TST \\
\hline CHEMBL1325278 & 688620 & 5.0 & 5.0293 & TRN \\
\hline CHEMBL1388744 & 688620 & 4.9 & 4.7906 & TRN \\
\hline CHEMBL1410704 & 688620 & 4.65 & 4.8253 & TRN \\
\hline CHEMBL1526725 & 688620 & 5.55 & 5.0079 & TRN \\
\hline CHEMBL1510856 & 688620 & 4.95 & 4.8711 & TRN \\
\hline CHEMBL1313672 & 688620 & 4.9 & 4.9747 & TRN \\
\hline CHEMBL1503930 & 688620 & 4.95 & 5.1603 & TRN \\
\hline CHEMBL1302447 & 688620 & 4.95 & 4.9267 & TRN \\
\hline CHEMBL3191399 & 688620 & 4.95 & 4.9168 & TRN \\
\hline CHEMBL1502931 & 688620 & 4.75 & 5.1604 & TRN \\
\hline CHEMBL1506044 & 688620 & 4.75 & 5.0278 & TRN \\
\hline CHEMBL1520374 & 688620 & 5.2 & 4.8875 & TRN \\
\hline CHEMBL1320659 & 688620 & 4.95 & 4.9231 & TST \\
\hline CHEMBL3199079 & 688620 & 4.45 & 4.987 & TRN \\
\hline CHEMBL3145369 & 688620 & 7.3002 & 7.0959 & TRN \\
\hline CHEMBL1081637 & 688620 & 4.9 & 5.3311 & TRN \\
\hline CHEMBL1504766 & 688620 & 4.65 & 5.2909 & TRN \\
\hline CHEMBL1403902 & 688620 & 4.9 & 5.0551 & TRN \\
\hline CHEMBL1440025 & 688620 & 5.0 & 5.12 & TST \\
\hline CHEMBL1598327 & 688620 & 4.7 & 5.1387 & TRN \\
\hline CHEMBL1569232 & 688620 & 4.45 & 4.9923 & TRN \\
\hline CHEMBL1529546 & 688620 & 5.4 & 5.1225 & TRN \\
\hline CHEMBL1344318 & 688620 & 4.45 & 4.7625 & TRN \\
\hline CHEMBL1510711 & 688620 & 4.95 & 5.0147 & TRN \\
\hline CHEMBL1473420 & 688620 & 4.9 & 4.9235 & TRN \\
\hline CHEMBL1567127 & 688620 & 6.1 & 4.9413 & TST \\
\hline CHEMBL1497703 & 688620 & 5.3 & 5.1869 & TRN \\
\hline CHEMBL1540717 & 688620 & 5.45 & 5.3468 & TRN \\
\hline CHEMBL1340824 & 688620 & 4.45 & 4.8218 & TRN \\
\hline CHEMBL1489283 & 688620 & 4.45 & 4.95 & TRN \\
\hline CHEMBL1370515 & 688620 & 4.65 & 4.7817 & TRN \\
\hline CHEMBL1429503 & 688620 & 5.5 & 4.9448 & TRN \\
\hline CHEMBL1576343 & 688620 & 6.1 & 5.6548 & TRN \\
\hline CHEMBL1603297 & 688620 & 4.7 & 4.9456 & TRN \\
\hline CHEMBL1977424 & 688620 & 6.2 & 5.6451 & TRN \\
\hline CHEMBL1527485 & 688620 & 5.0 & 4.9267 & TRN \\
\hline CHEMBL1549992 & 688620 & 5.25 & 5.0468 & TRN \\
\hline CHEMBL1994913 & 688620 & 4.8 & 4.6732 & TST \\
\hline CHEMBL1486955 & 688620 & 4.45 & 5.1191 & TRN \\
\hline CHEMBL1393142 & 688620 & 4.5 & 4.9207 & TST \\
\hline CHEMBL1323237 & 688620 & 4.9 & 5.282 & TST \\
\hline CHEMBL1603388 & 688620 & 4.5 & 4.7318 & TRN \\
\hline
\end{tabular}




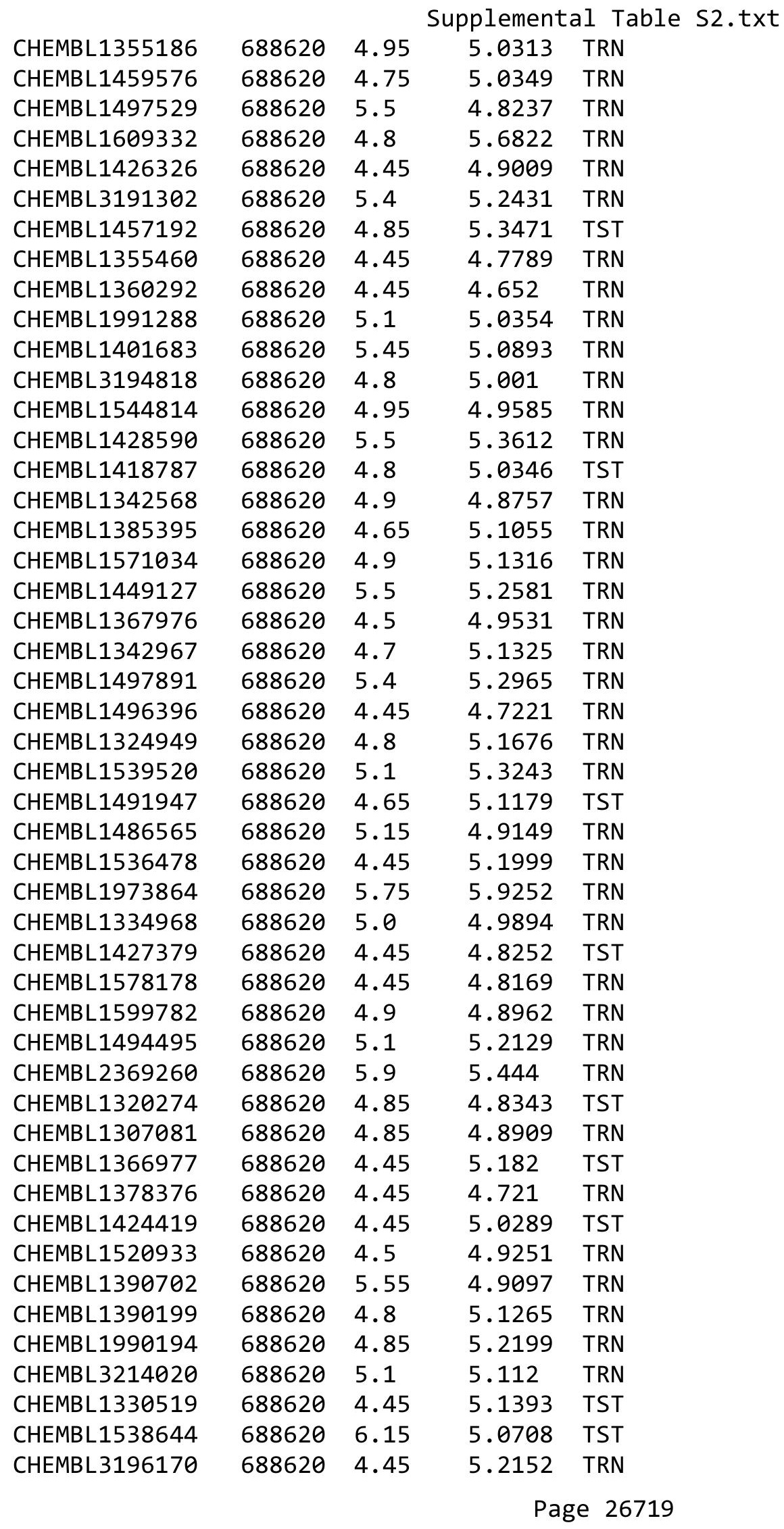




\begin{tabular}{|c|c|c|c|c|}
\hline & & & Supplement & al T \\
\hline CHEMBL1440725 & 688620 & 5.45 & 5.1019 & TRN \\
\hline CHEMBL1348786 & 688620 & 5.5 & 5.0591 & TRN \\
\hline CHEMBL1498275 & 688620 & 5.3 & 4.9371 & TRN \\
\hline CHEMBL1309887 & 688620 & 4.95 & 5.3041 & TRN \\
\hline CHEMBL1566148 & 688620 & 6.35 & 5.2104 & TRN \\
\hline CHEMBL 3213580 & 688620 & 6.0 & 5.1708 & TRN \\
\hline CHEMBL1351830 & 688620 & 4.8 & 4.9145 & TRN \\
\hline CHEMBL1515194 & 688620 & 4.7 & 4.7139 & TRN \\
\hline CHEMBL1416897 & 688620 & 4.8 & 4.9945 & TRN \\
\hline CHEMBL1417225 & 688620 & 5.55 & 5.1643 & TST \\
\hline CHEMBL1441418 & 688620 & 4.95 & 4.7088 & TRN \\
\hline CHEMBL1330272 & 688620 & 4.45 & 4.6301 & TRN \\
\hline CHEMBL1531927 & 688620 & 4.45 & 5.1171 & TRN \\
\hline CHEMBL1380877 & 688620 & 4.95 & 5.1967 & TRN \\
\hline CHEMBL1523608 & 688620 & 4.75 & 4.7991 & TST \\
\hline CHEMBL1589524 & 688620 & 4.95 & 5.2416 & TRN \\
\hline CHEMBL1573773 & 688620 & 5.35 & 5.0779 & TRN \\
\hline CHEMBL1330062 & 688620 & 5.5 & 5.1969 & TRN \\
\hline CHEMBL1546693 & 688620 & 5.5 & 6.0817 & TRN \\
\hline CHEMBL1555494 & 688620 & 4.6 & 5.0083 & TRN \\
\hline CHEMBL1490774 & 688620 & 4.45 & 5.0443 & TRN \\
\hline CHEMBL1426776 & 688620 & 5.25 & 4.9782 & TST \\
\hline CHEMBL1359319 & 688620 & 5.0 & 5.2078 & TRN \\
\hline CHEMBL1331484 & 688620 & 4.45 & 5.2723 & TST \\
\hline CHEMBL3197890 & 688620 & 6.15 & 4.8403 & TST \\
\hline CHEMBL1318261 & 688620 & 5.4 & 5.0671 & TRN \\
\hline CHEMBL1323840 & 688620 & 4.45 & 4.8717 & TRN \\
\hline CHEMBL1430821 & 688620 & 4.5 & 5.0214 & TRN \\
\hline CHEMBL1379767 & 688620 & 4.55 & 5.3378 & TST \\
\hline CHEMBL1530988 & 688620 & 4.45 & 4.5561 & TRN \\
\hline CHEMBL3199331 & 688620 & 5.25 & 5.0913 & TRN \\
\hline CHEMBL1479963 & 688620 & 4.75 & 5.3095 & TST \\
\hline CHEMBL3208917 & 688620 & 4.95 & 4.8904 & TRN \\
\hline CHEMBL1412705 & 688620 & 4.95 & 4.7542 & TST \\
\hline CHEMBL1586566 & 688620 & 4.45 & 4.7302 & TRN \\
\hline CHEMBL1324337 & 688620 & 4.8 & 5.3074 & TRN \\
\hline CHEMBL1300417 & 688620 & 4.65 & 5.0893 & TST \\
\hline CHEMBL1531955 & 688620 & 4.95 & 5.1809 & TRN \\
\hline CHEMBL1584694 & 688620 & 5.55 & 5.6736 & TRN \\
\hline CHEMBL1379888 & 688620 & 4.95 & 5.1038 & TRN \\
\hline CHEMBL3144896 & 688620 & 4.7 & 4.85 & TRN \\
\hline CHEMBL1299932 & 688620 & 4.45 & 5.1917 & TRN \\
\hline CHEMBL1299365 & 688620 & 4.45 & 4.8645 & TRN \\
\hline CHEMBL1426167 & 688620 & 4.75 & 4.8646 & TRN \\
\hline CHEMBL1488601 & 688620 & 4.45 & 5.1086 & TST \\
\hline CHEMBL1331655 & 688620 & 4.45 & 5.125 & TST \\
\hline CHEMBL1561370 & 688620 & 5.2 & 5.143 & TRN \\
\hline CHEMBL 3210449 & 688620 & 6.95 & 4.9015 & TST \\
\hline
\end{tabular}




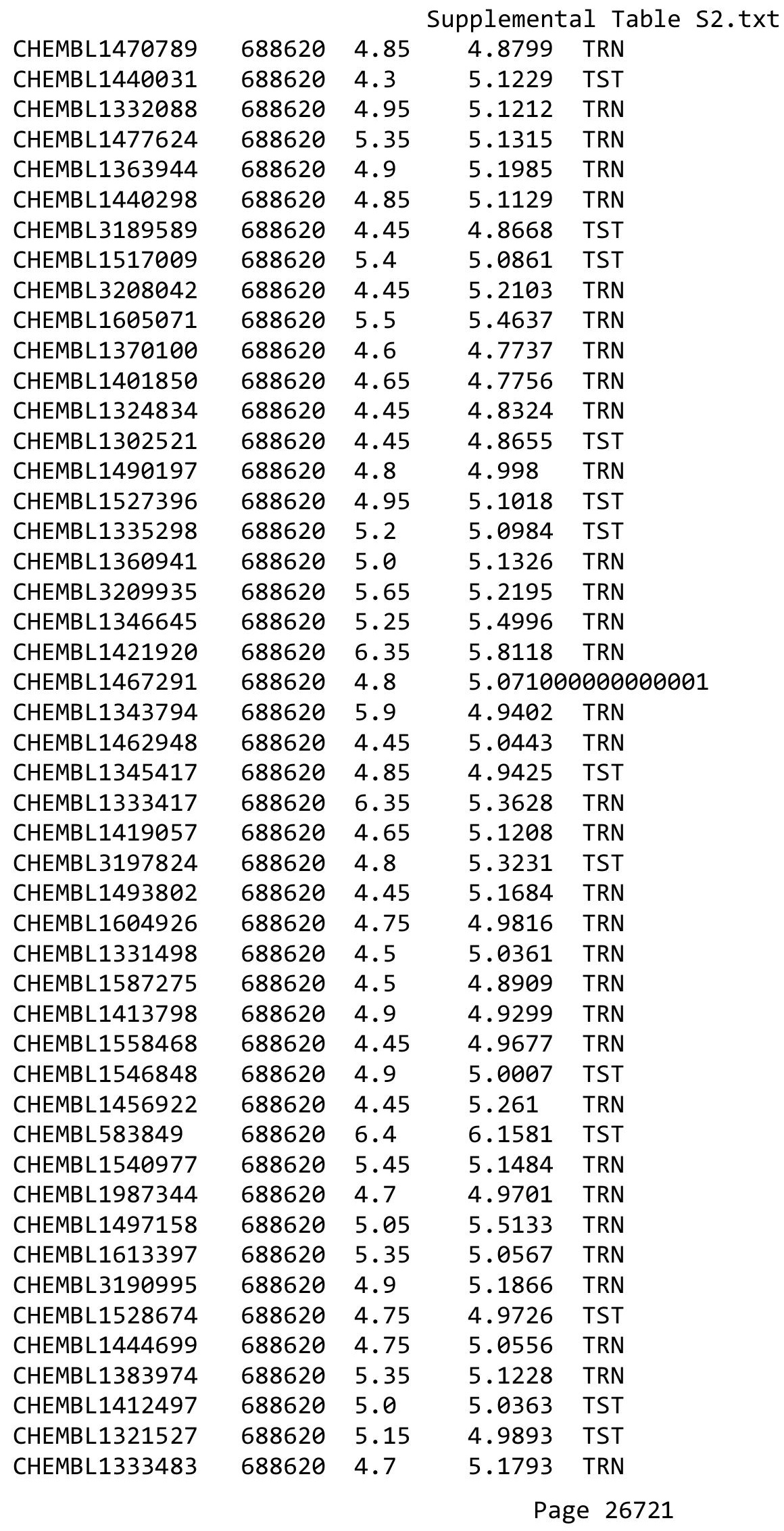

TRN 


\begin{tabular}{|c|c|c|c|c|}
\hline \multicolumn{5}{|c|}{ Supplemental Table S2.txt } \\
\hline CHEMBL1436932 & 688620 & 4.45 & 4.8277 & TRN \\
\hline CHEMBL3191970 & 688620 & 5.6 & 5.1284 & TRN \\
\hline CHEMBL1424639 & 688620 & 4.45 & 4.7434 & TRN \\
\hline CHEMBL1327542 & 688620 & 4.85 & 4.7554 & TRN \\
\hline CHEMBL 1478447 & 688620 & 6.0 & 5.1691 & TRN \\
\hline CHEMBL1465365 & 688620 & 4.8 & 5.1561 & TST \\
\hline CHEMBL1416739 & 688620 & 4.45 & 5.0711 & TRN \\
\hline CHEMBL1572247 & 688620 & 6.35 & 5.2355 & TRN \\
\hline CHEMBL1393280 & 688620 & 5.15 & 5.0097 & TRN \\
\hline CHEMBL1311879 & 688620 & 6.95 & 5.5473 & TRN \\
\hline CHEMBL1598592 & 688620 & 4.95 & 5.9967 & TST \\
\hline CHEMBL3194831 & 688620 & 5.0 & 5.0425 & TRN \\
\hline CHEMBL 2003964 & 688620 & 7.0501 & 5.8147 & TRN \\
\hline CHEMBL1338886 & 688620 & 5.25 & 5.2674 & TRN \\
\hline CHEMBL1414766 & 688620 & 5.5 & 5.229 & TRN \\
\hline CHEMBL1524927 & 688620 & 4.45 & 5.1605 & TRN \\
\hline CHEMBL1479980 & 688620 & 4.8 & 5.1039 & TRN \\
\hline CHEMBL1349593 & 688620 & 5.35 & 5.1857 & TRN \\
\hline CHEMBL 3192244 & 688620 & 4.45 & 4.9224 & TRN \\
\hline CHEMBL1595296 & 688620 & 4.9 & 4.9626 & TST \\
\hline CHEMBL1542656 & 688620 & 4.9 & 5.1953 & TRN \\
\hline CHEMBL1601231 & 688620 & 5.0 & 4.8937 & TRN \\
\hline CHEMBL1432850 & 688620 & 4.65 & 4.8437 & TRN \\
\hline CHEMBL1984315 & 688620 & 4.95 & 4.9395 & TRN \\
\hline CHEMBL1569822 & 688620 & 5.9 & 4.9392 & TRN \\
\hline CHEMBL1493037 & 688620 & 4.5 & 4.8597 & TRN \\
\hline CHEMBL1319679 & 688620 & 4.85 & 5.2273 & TRN \\
\hline CHEMBL1519965 & 688620 & 5.75 & 5.8667 & TRN \\
\hline CHEMBL1485112 & 688620 & 4.45 & 5.1663 & TRN \\
\hline CHEMBL3192766 & 688620 & 5.75 & 5.1354 & TRN \\
\hline CHEMBL1571224 & 688620 & 4.95 & 4.8539 & TST \\
\hline CHEMBL1350773 & 688620 & 4.9 & 5.1295 & TST \\
\hline CHEMBL1420064 & 688620 & 5.6 & 5.2288 & TRN \\
\hline CHEMBL1485723 & 688620 & 5.15 & 5.2384 & TST \\
\hline CHEMBL3211352 & 688620 & 5.2 & 5.1965 & TST \\
\hline CHEMBL1365205 & 688620 & 4.95 & 5.22 & TRN \\
\hline CHEMBL1562966 & 688620 & 6.6499 & 5.2728 & TRN \\
\hline CHEMBL1409657 & 688620 & 4.45 & 4.9633 & TRN \\
\hline CHEMBL1353556 & 688620 & 4.45 & 5.1422 & TST \\
\hline CHEMBL1501714 & 688620 & 4.8 & 4.8282 & TRN \\
\hline CHEMBL 2006620 & 688620 & 5.05 & 4.9082 & TRN \\
\hline CHEMBL1987895 & 688620 & 5.35 & 5.3562 & TRN \\
\hline CHEMBL1495526 & 688620 & 4.45 & 5.0309 & TST \\
\hline CHEMBL1452391 & 688620 & 4.85 & 5.0132 & TRN \\
\hline CHEMBL1213406 & 688620 & 4.9 & 5.0883 & TST \\
\hline CHEMBL1400593 & 688620 & 4.9 & 5.3874 & TST \\
\hline CHEMBL1498599 & 688620 & 5.3 & 5.0151 & TRN \\
\hline CHEMBL1519434 & 688620 & 4.45 & 4.6292 & TST \\
\hline
\end{tabular}




\begin{tabular}{|c|c|c|c|c|c|}
\hline \multicolumn{6}{|c|}{ Supplemental Table S2.txt } \\
\hline CHEMBL1552181 & 688620 & 5.55 & 4.6939 & TRN & \\
\hline CHEMBL 2006175 & 688620 & 4.45 & 5.3951 & TRN & \\
\hline CHEMBL1412534 & 688620 & 4.85 & 4.8885 & TRN & \\
\hline CHEMBL1560341 & 688620 & 4.65 & 4.8748 & TRN & \\
\hline CHEMBL1338696 & 688620 & 4.9 & 5.17200 & 0000000001 & TRN \\
\hline CHEMBL1337176 & 688620 & 4.45 & 4.9564 & TST & \\
\hline CHEMBL1607249 & 688620 & 4.6 & 5.0668 & TRN & \\
\hline CHEMBL1395241 & 688620 & 4.95 & 4.9587 & TST & \\
\hline CHEMBL1496872 & 688620 & 4.95 & 5.1053 & TRN & \\
\hline CHEMBL518430 & 688620 & 5.15 & 5.0374 & TRN & \\
\hline CHEMBL1454519 & 688620 & 5.15 & 5.0756 & TRN & \\
\hline CHEMBL3209652 & 688620 & 5.0 & 4.94300 & 00000000005 & TRN \\
\hline CHEMBL1494812 & 688620 & 5.85 & 5.0046 & TST & \\
\hline CHEMBL1314349 & 688620 & 4.95 & 4.8706 & TRN & \\
\hline CHEMBL1566464 & 688620 & 4.95 & 4.9013 & TRN & \\
\hline CHEMBL1449836 & 688620 & 4.45 & 4.6322 & TRN & \\
\hline CHEMBL1335688 & 688620 & 5.0 & 4.8595 & TRN & \\
\hline CHEMBL1428725 & 688620 & 4.7 & 4.9568 & TRN & \\
\hline CHEMBL1460167 & 688620 & 5.25 & 4.8655 & TRN & \\
\hline CHEMBL1468749 & 688620 & 4.45 & 4.9275 & TRN & \\
\hline CHEMBL1465068 & 688620 & 4.6 & 4.8867 & TRN & \\
\hline CHEMBL1401573 & 688620 & 6.8499 & 4.9023 & TRN & \\
\hline CHEMBL1359181 & 688620 & 6.0 & 5.3706 & TST & \\
\hline CHEMBL1503616 & 688620 & 4.95 & 5.0176 & TRN & \\
\hline CHEMBL1981990 & 688620 & 5.4 & 5.0698 & TRN & \\
\hline CHEMBL1581392 & 688620 & 5.15 & 5.2115 & TRN & \\
\hline CHEMBL1570531 & 688620 & 6.9 & 5.3354 & TST & \\
\hline CHEMBL1406995 & 688620 & 4.65 & 5.0729 & TRN & \\
\hline CHEMBL1543898 & 688620 & 4.85 & 5.021 & TRN & \\
\hline CHEMBL1322350 & 688620 & 4.45 & 4.6647 & TRN & \\
\hline CHEMBL1412866 & 688620 & 5.0 & 5.0873 & TRN & \\
\hline CHEMBL1402943 & 688620 & 4.75 & 4.7763 & TRN & \\
\hline CHEMBL1499328 & 688620 & 4.7 & 4.8969 & TRN & \\
\hline CHEMBL1573665 & 688620 & 4.7 & 4.9981 & TRN & \\
\hline CHEMBL1428254 & 688620 & 4.7 & 5.1295 & TRN & \\
\hline CHEMBL3198904 & 688620 & 5.2 & 5.795 & TRN & \\
\hline CHEMBL1466707 & 688620 & 4.45 & 5.0659 & TST & \\
\hline CHEMBL1481098 & 688620 & 5.45 & 5.1461 & TRN & \\
\hline CHEMBL1489787 & 688620 & 4.9 & 5.0062 & TST & \\
\hline CHEMBL1492728 & 688620 & 4.95 & 4.9642 & TST & \\
\hline CHEMBL3189714 & 688620 & 5.4 & 5.4912 & TRN & \\
\hline CHEMBL1462915 & 688620 & 5.05 & 5.2032 & TRN & \\
\hline CHEMBL1311281 & 688620 & 4.65 & 4.9164 & TRN & \\
\hline CHEMBL1380666 & 688620 & 4.65 & 4.9184 & TRN & \\
\hline CHEMBL1335863 & 688620 & 4.6 & 5.0888 & TRN & \\
\hline CHEMBL1533399 & 688620 & 4.9 & 4.6965 & TRN & \\
\hline CHEMBL1371198 & 688620 & 4.75 & 5.1492 & TRN & \\
\hline CHEMBL1480267 & 688620 & 5.0 & 5.0469 & TRN & \\
\hline
\end{tabular}




\begin{tabular}{|c|c|c|c|c|c|}
\hline \multicolumn{6}{|c|}{ Supplemental Table s2.txt } \\
\hline CHEMBL1348733 & 688620 & 6.35 & 5.8095 & TRN & \\
\hline CHEMBL1362107 & 688620 & 4.85 & 4.8196 & TST & \\
\hline CHEMBL1467499 & 688620 & 4.6 & 4.9027 & TRN & \\
\hline CHEMBL1456085 & 688620 & 4.8 & 4.8658 & TRN & \\
\hline CHEMBL1596740 & 688620 & 4.5 & 5.0277 & TRN & \\
\hline CHEMBL 3194544 & 688620 & 4.65 & 5.0695 & TRN & \\
\hline CHEMBL1607005 & 688620 & 4.95 & 4.9483 & TRN & \\
\hline CHEMBL1393807 & 688620 & 4.55 & 4.7393 & TRN & \\
\hline CHEMBL1450136 & 688620 & 5.15 & 4.9723 & TRN & \\
\hline CHEMBL1348325 & 688620 & 5.25 & 5.0267 & TRN & \\
\hline CHEMBL1313207 & 688620 & 4.9 & 5.0793 & TST & \\
\hline CHEMBL1968538 & 688620 & 4.5 & 5.4186 & TRN & \\
\hline CHEMBL3209150 & 688620 & 4.95 & 4.7237 & TRN & \\
\hline CHEMBL 2369230 & 688620 & 5.95 & 5.8446 & TRN & \\
\hline CHEMBL1994902 & 688620 & 5.5 & 5.6753 & TRN & \\
\hline CHEMBL1301332 & 688620 & 4.8 & 4.8726 & TRN & \\
\hline CHEMBL1448770 & 688620 & 4.95 & 4.8701 & TRN & \\
\hline CHEMBL1398743 & 688620 & 5.0 & 5.1078 & TST & \\
\hline CHEMBL1987709 & 688620 & 4.45 & 5.25200 & 0000000001 & TRN \\
\hline CHEMBL1495091 & 688620 & 4.95 & 5.0797 & TRN & \\
\hline CHEMBL1481433 & 688620 & 5.2 & 5.4093 & TRN & \\
\hline CHEMBL1325213 & 688620 & 6.8 & 4.9123 & TRN & \\
\hline CHEMBL1535187 & 688620 & 8.301 & 4.957 & TRN & \\
\hline CHEMBL1599256 & 688620 & 6.0 & 5.558 & TRN & \\
\hline CHEMBL1502092 & 688620 & 5.1 & 4.7751 & TRN & \\
\hline CHEMBL1607625 & 688620 & 4.45 & 4.7896 & TRN & \\
\hline CHEMBL1564540 & 688620 & 5.25 & 5.0427 & TRN & \\
\hline CHEMBL1455557 & 688620 & 4.95 & 5.1767 & TRN & \\
\hline CHEMBL1412212 & 688620 & 5.35 & 4.9576 & TRN & \\
\hline CHEMBL1556971 & 688620 & 4.85 & 4.7168 & TRN & \\
\hline CHEMBL1540436 & 688620 & 5.6 & 5.4805 & TRN & \\
\hline CHEMBL1472094 & 688620 & 4.95 & 5.0876 & TST & \\
\hline CHEMBL1603398 & 688620 & 5.35 & 5.1307 & TRN & \\
\hline CHEMBL1468468 & 688620 & 5.95 & 5.1422 & TRN & \\
\hline CHEMBL 3211237 & 688620 & 5.5 & 5.3178 & TRN & \\
\hline CHEMBL1519158 & 688620 & 4.95 & 4.7566 & TRN & \\
\hline CHEMBL1524973 & 688620 & 4.85 & 5.0105 & TRN & \\
\hline CHEMBL1343883 & 688620 & 4.65 & 4.6563 & TRN & \\
\hline CHEMBL1572001 & 688620 & 5.15 & 5.24100 & 30000000005 & TST \\
\hline CHEMBL1361443 & 688620 & 5.2 & 5.2735 & TRN & \\
\hline CHEMBL1569754 & 688620 & 4.45 & 4.9303 & TST & \\
\hline CHEMBL1607211 & 688620 & 4.45 & 4.8772 & TST & \\
\hline CHEMBL1382405 & 688620 & 5.55 & 5.3554 & TRN & \\
\hline CHEMBL1421390 & 688620 & 5.35 & 4.9195 & TRN & \\
\hline CHEMBL1543867 & 688620 & 4.7 & 5.2344 & TST & \\
\hline CHEMBL1363867 & 688620 & 6.05 & 5.6243 & TRN & \\
\hline CHEMBL1429960 & 688620 & 5.2 & 4.8609 & TRN & \\
\hline CHEMBL1304246 & 688620 & 4.45 & 4.9979 & TRN & \\
\hline
\end{tabular}




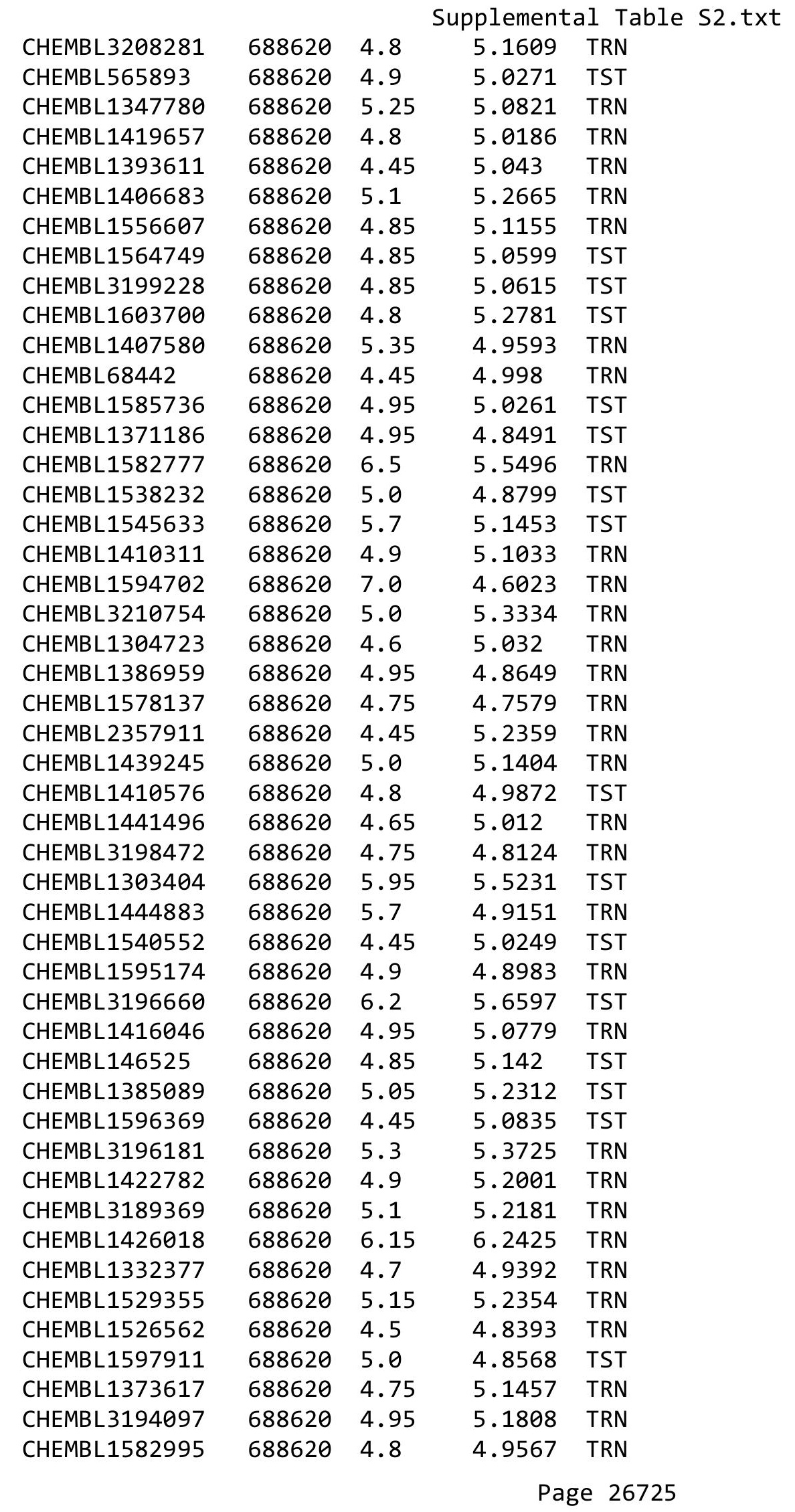




\begin{tabular}{|c|c|c|c|c|c|}
\hline & & \multicolumn{4}{|c|}{ Supplemental Table S2.txt } \\
\hline CHEMBL1568206 & 688620 & 5.5 & 5.5042 & TRN & \\
\hline CHEMBL1299906 & 688620 & 7.0501 & 5.1587 & TRN & \\
\hline CHEMBL1530953 & 688620 & 5.5 & 5.4763 & TRN & \\
\hline CHEMBL1543736 & 688620 & 4.45 & 4.7694 & TRN & \\
\hline CHEMBL1982763 & 688620 & 4.5 & 5.1374 & TRN & \\
\hline CHEMBL1343433 & 688620 & 5.75 & 5.59 & TRN & \\
\hline CHEMBL1401854 & 688620 & 4.6 & 5.2796 & TRN & \\
\hline CHEMBL3192361 & 688620 & 4.55 & 5.1987 & TRN & \\
\hline CHEMBL1345273 & 688620 & 4.7 & 5.5698 & TST & \\
\hline CHEMBL1487883 & 688620 & 6.45 & 5.23799 & 99999999995 & TRN \\
\hline CHEMBL1515385 & 688620 & 5.65 & 5.0931 & TRN & \\
\hline CHEMBL1507519 & 688620 & 4.8 & 4.997 & TRN & \\
\hline CHEMBL1407184 & 688620 & 4.85 & 5.0549 & TRN & \\
\hline CHEMBL1599327 & 688620 & 5.9 & 5.1609 & TRN & \\
\hline CHEMBL1483389 & 688620 & 5.35 & 5.5415 & TRN & \\
\hline CHEMBL1460094 & 688620 & 6.05 & 5.5431 & TRN & \\
\hline CHEMBL1999237 & 688620 & 4.9 & 4.8368 & TST & \\
\hline CHEMBL1400667 & 688620 & 4.85 & 5.1755 & TST & \\
\hline CHEMBL1570875 & 688620 & 4.45 & 4.936 & TRN & \\
\hline CHEMBL1557083 & 688620 & 4.95 & 5.0147 & TRN & \\
\hline CHEMBL1400829 & 688620 & 5.65 & 5.3696 & TST & \\
\hline CHEMBL1304887 & 688620 & 4.9 & 5.0718 & TRN & \\
\hline CHEMBL1471506 & 688620 & 4.45 & 5.3171 & TRN & \\
\hline CHEMBL1500793 & 688620 & 5.8 & 5.0578 & TRN & \\
\hline CHEMBL1405321 & 688620 & 4.45 & 5.3283 & TST & \\
\hline CHEMBL1544747 & 688620 & 4.55 & 4.9012 & TST & \\
\hline CHEMBL1469189 & 688620 & 5.0 & 4.8786 & TRN & \\
\hline CHEMBL1605705 & 688620 & 5.05 & 5.104 & TRN & \\
\hline CHEMBL2000517 & 688620 & 4.95 & 5.3297 & TRN & \\
\hline CHEMBL1427506 & 688620 & 4.95 & 5.0734 & TRN & \\
\hline CHEMBL192984 & 688620 & 5.0 & 5.1827 & TRN & \\
\hline CHEMBL1543575 & 688620 & 5.65 & 4.976 & TRN & \\
\hline CHEMBL1325260 & 688620 & 5.1 & 5.4052 & TRN & \\
\hline CHEMBL1461271 & 688620 & 4.75 & 5.2562 & TRN & \\
\hline CHEMBL1311547 & 688620 & 4.45 & 4.9192 & TRN & \\
\hline CHEMBL1367504 & 688620 & 6.7501 & 4.9815 & TRN & \\
\hline CHEMBL1466966 & 688620 & 5.9 & 4.8941 & TRN & \\
\hline CHEMBL1373767 & 688620 & 4.5 & 4.9701 & TRN & \\
\hline CHEMBL1581891 & 688620 & 4.95 & 5.0 & TST & \\
\hline CHEMBL 2004145 & 688620 & 4.9 & 5.2375 & TRN & \\
\hline CHEMBL1561858 & 688620 & 6.3 & 4.9079 & TRN & \\
\hline CHEMBL3191044 & 688620 & 4.45 & 4.789 & TST & \\
\hline CHEMBL1310454 & 688620 & 5.0 & 5.0786 & TRN & \\
\hline CHEMBL1524749 & 688620 & 5.0 & 4.9614 & TRN & \\
\hline CHEMBL1596929 & 688620 & 4.95 & 4.9808 & TRN & \\
\hline CHEMBL1975888 & 688620 & 4.85 & 4.9972 & TST & \\
\hline CHEMBL1302593 & 688620 & 4.45 & 4.8833 & TRN & \\
\hline CHEMBL1985073 & 688620 & 5.7 & 5.7152 & TRN & \\
\hline
\end{tabular}




\begin{tabular}{|c|c|c|c|c|}
\hline \multicolumn{5}{|c|}{ Supplemental Table S2.txt } \\
\hline CHEMBL1986504 & 688620 & 5.35 & 5.69 & TRN \\
\hline CHEMBL1492158 & 688620 & 5.6 & 5.0203 & TRN \\
\hline CHEMBL1381651 & 688620 & 4.8 & 4.756 & TRN \\
\hline CHEMBL1385614 & 688620 & 4.45 & 5.0619 & TST \\
\hline CHEMBL1483902 & 688620 & 4.95 & 5.1016 & TST \\
\hline CHEMBL1502303 & 688620 & 4.9 & 4.8256 & TST \\
\hline CHEMBL3194310 & 688620 & 5.45 & 5.4249 & TRN \\
\hline CHEMBL270299 & 688620 & 6.2 & 5.9196 & TST \\
\hline CHEMBL1424322 & 688620 & 5.0 & 4.8282 & TRN \\
\hline CHEMBL1410013 & 688620 & 5.2 & 5.1647 & TRN \\
\hline CHEMBL1443793 & 688620 & 5.8 & 5.2088 & TRN \\
\hline CHEMBL1387677 & 688620 & 4.75 & 4.8964 & TRN \\
\hline CHEMBL512379 & 688620 & 4.9 & 5.0653 & TRN \\
\hline CHEMBL1363016 & 688620 & 5.3 & 5.2587 & TRN \\
\hline CHEMBL1436128 & 688620 & 5.2 & 5.2309 & TRN \\
\hline CHEMBL1342911 & 688620 & 4.95 & 4.9357 & TRN \\
\hline CHEMBL1488012 & 688620 & 5.25 & 5.309 & TRN \\
\hline CHEMBL3189537 & 688620 & 4.75 & 4.8358 & TRN \\
\hline CHEMBL1453654 & 688620 & 4.45 & 4.9553 & TST \\
\hline CHEMBL1402105 & 688620 & 4.45 & 4.7713 & TRN \\
\hline CHEMBL1342665 & 688620 & 5.05 & 4.7519 & TRN \\
\hline CHEMBL1581761 & 688620 & 4.8 & 5.0647 & TRN \\
\hline CHEMBL1448357 & 688620 & 6.25 & 5.1128 & TRN \\
\hline CHEMBL1445327 & 688620 & 5.55 & 5.0943 & TRN \\
\hline CHEMBL1323300 & 688620 & 5.2 & 4.9038 & TRN \\
\hline CHEMBL1484449 & 688620 & 4.85 & 5.05 & TRN \\
\hline CHEMBL1347480 & 688620 & 4.45 & 4.9911 & TRN \\
\hline CHEMBL1425473 & 688620 & 4.9 & 5.0107 & TRN \\
\hline CHEMBL1324052 & 688620 & 5.35 & 5.2402 & TRN \\
\hline CHEMBL1554158 & 688620 & 4.95 & 5.0095 & TRN \\
\hline CHEMBL1574590 & 688620 & 4.5 & 5.245 & TRN \\
\hline CHEMBL1301567 & 688620 & 4.8 & 5.0598 & TST \\
\hline CHEMBL1609737 & 688620 & 4.65 & 5.0697 & TRN \\
\hline CHEMBL1558760 & 688620 & 5.2 & 5.1014 & TST \\
\hline CHEMBL1497978 & 688620 & 4.75 & 5.2161 & TST \\
\hline CHEMBL3208858 & 688620 & 4.65 & 4.9751 & TST \\
\hline CHEMBL1571784 & 688620 & 5.9 & 5.1079 & TRN \\
\hline CHEMBL1587586 & 688620 & 4.9 & 5.0383 & TRN \\
\hline CHEMBL1457407 & 688620 & 5.0 & 4.9474 & TRN \\
\hline CHEMBL1561956 & 688620 & 5.4 & 5.1239 & TRN \\
\hline CHEMBL1353719 & 688620 & 5.5 & 5.0212 & TST \\
\hline CHEMBL1409849 & 688620 & 4.45 & 5.0165 & TST \\
\hline CHEMBL1431496 & 688620 & 5.0 & 5.1904 & TST \\
\hline CHEMBL1308264 & 688620 & 4.55 & 4.9429 & TRN \\
\hline CHEMBL1603869 & 688620 & 5.65 & 4.8973 & TST \\
\hline CHEMBL1540679 & 688620 & 4.75 & 4.9194 & TRN \\
\hline CHEMBL1494489 & 688620 & 4.5 & 4.8617 & TRN \\
\hline CHEMBL1564529 & 688620 & 4.45 & 5.0131 & TRN \\
\hline
\end{tabular}




\begin{tabular}{|c|c|c|c|c|}
\hline \multicolumn{5}{|c|}{ Supplemental Table S2.txt } \\
\hline CHEMBL1605204 & 688620 & 4.75 & 5.047 & TRN \\
\hline CHEMBL1303794 & 688620 & 6.0 & 5.9196 & TRN \\
\hline CHEMBL1372492 & 688620 & 6.0 & 6.0399 & TRN \\
\hline CHEMBL1567635 & 688620 & 4.95 & 5.0893 & TRN \\
\hline CHEMBL3211587 & 688620 & 5.25 & 5.1607 & TRN \\
\hline CHEMBL1380023 & 688620 & 5.25 & 4.9647 & TRN \\
\hline CHEMBL1457079 & 688620 & 5.05 & 5.4571 & TRN \\
\hline CHEMBL1348061 & 688620 & 4.9 & 5.1384 & TST \\
\hline CHEMBL1456276 & 688620 & 4.8 & 5.1125 & TRN \\
\hline CHEMBL1545569 & 688620 & 4.95 & 5.0759 & TRN \\
\hline CHEMBL1602874 & 688620 & 5.2 & 5.319 & TST \\
\hline CHEMBL 3210198 & 688620 & 5.5 & 4.9783 & TRN \\
\hline CHEMBL1369124 & 688620 & 5.4 & 4.7834 & TRN \\
\hline CHEMBL 3213954 & 688620 & 4.8 & 5.2356 & TRN \\
\hline CHEMBL1579198 & 688620 & 5.55 & 5.2153 & TST \\
\hline CHEMBL1545216 & 688620 & 5.7 & 5.4154 & TRN \\
\hline CHEMBL1443360 & 688620 & 4.85 & 4.8257 & TRN \\
\hline CHEMBL1453871 & 688620 & 4.7 & 4.9357 & TRN \\
\hline CHEMBL1363461 & 688620 & 5.3 & 5.1114 & TRN \\
\hline CHEMBL1490750 & 688620 & 5.5 & 5.7239 & TRN \\
\hline CHEMBL1411684 & 688620 & 4.75 & 4.6905 & TST \\
\hline CHEMBL1407197 & 688620 & 5.55 & 5.1175 & TST \\
\hline CHEMBL3189432 & 688620 & 4.8 & 5.0883 & TST \\
\hline CHEMBL1419515 & 688620 & 5.9 & 4.9203 & TRN \\
\hline CHEMBL1360343 & 688620 & 4.45 & 4.6567 & TRN \\
\hline CHEMBL1323733 & 688620 & 5.1 & 5.0254 & TST \\
\hline CHEMBL1393117 & 688620 & 4.65 & 5.1613 & TRN \\
\hline CHEMBL1443479 & 688620 & 4.8 & 5.0353 & TST \\
\hline CHEMBL1532694 & 688620 & 4.45 & 4.8804 & TRN \\
\hline CHEMBL 3210626 & 688620 & 4.95 & 5.1962 & TST \\
\hline CHEMBL1415438 & 688620 & 5.05 & 4.9077 & TRN \\
\hline CHEMBL1608382 & 688620 & 5.2 & 5.7287 & TRN \\
\hline CHEMBL1580482 & 688620 & 5.2 & 5.1654 & TST \\
\hline CHEMBL1374039 & 688620 & 6.5501 & 5.0058 & TRN \\
\hline CHEMBL1543294 & 688620 & 5.05 & 4.9948 & TRN \\
\hline CHEMBL1393193 & 688620 & 4.45 & 4.7093 & TRN \\
\hline CHEMBL3196029 & 688620 & 5.0 & 4.8637 & TRN \\
\hline CHEMBL1468471 & 688620 & 4.95 & 4.8908 & TRN \\
\hline CHEMBL1527972 & 688620 & 4.9 & 5.2279 & TRN \\
\hline CHEMBL1541918 & 688620 & 4.45 & 5.0455 & TRN \\
\hline CHEMBL1360674 & 688620 & 5.4 & 5.4555 & TRN \\
\hline CHEMBL 1587337 & 688620 & 4.45 & 4.9678 & TRN \\
\hline CHEMBL1377849 & 688620 & 4.65 & 5.2431 & TRN \\
\hline CHEMBL1461090 & 688620 & 4.75 & 4.8214 & TRN \\
\hline CHEMBL1423461 & 688620 & 5.2 & 5.1607 & TRN \\
\hline CHEMBL1524013 & 688620 & 5.0 & 5.113 & TRN \\
\hline CHEMBL 1482448 & 688620 & 5.1 & 5.352 & TRN \\
\hline CHEMBL1459858 & 688620 & 4.95 & 4.9793 & TRN \\
\hline
\end{tabular}




\begin{tabular}{|c|c|c|c|c|}
\hline \multicolumn{5}{|c|}{ Supplemental Table S2.txt } \\
\hline CHEMBL1613711 & 688620 & 4.95 & 4.7949 & TRN \\
\hline CHEMBL1415927 & 688620 & 5.15 & 4.9262 & TST \\
\hline CHEMBL1381797 & 688620 & 4.5 & 4.9332 & TRN \\
\hline CHEMBL1449243 & 688620 & 4.95 & 5.1143 & TST \\
\hline CHEMBL1303300 & 688620 & 4.95 & 4.9556 & TST \\
\hline CHEMBL1498978 & 688620 & 5.0 & 5.0638 & TRN \\
\hline CHEMBL1340458 & 688620 & 4.45 & 5.1193 & TRN \\
\hline CHEMBL1549084 & 688620 & 5.4 & 4.7425 & TRN \\
\hline CHEMBL1516655 & 688620 & 4.6 & 4.9283 & TRN \\
\hline CHEMBL1599783 & 688620 & 4.65 & 4.8586 & TST \\
\hline CHEMBL1571051 & 688620 & 4.9 & 5.0779 & TRN \\
\hline CHEMBL1603368 & 688620 & 5.0 & 5.3376 & TRN \\
\hline CHEMBL1586612 & 688620 & 4.45 & 4.8704 & TST \\
\hline CHEMBL1550032 & 688620 & 5.35 & 5.5318 & TRN \\
\hline CHEMBL1988666 & 688620 & 6.1 & 5.8562 & TRN \\
\hline CHEMBL1409576 & 688620 & 4.5 & 4.9102 & TRN \\
\hline CHEMBL1610480 & 688620 & 4.95 & 5.1256 & TST \\
\hline CHEMBL1453809 & 688620 & 5.7 & 5.3234 & TST \\
\hline CHEMBL1340476 & 688620 & 4.95 & 4.9482 & TRN \\
\hline CHEMBL1409985 & 688620 & 4.45 & 4.8444 & TST \\
\hline CHEMBL1400111 & 688620 & 5.05 & 4.9679 & TST \\
\hline CHEMBL1611300 & 688620 & 5.2 & 5.2335 & TRN \\
\hline CHEMBL1347434 & 688620 & 4.9 & 4.88 & TST \\
\hline CHEMBL1522526 & 688620 & 7.0501 & 6.0832 & TRN \\
\hline CHEMBL1488948 & 688620 & 5.7 & 4.9048 & TRN \\
\hline CHEMBL1540810 & 688620 & 4.85 & 5.1231 & TRN \\
\hline CHEMBL1466107 & 688620 & 5.15 & 4.9269 & TRN \\
\hline CHEMBL1505552 & 688620 & 5.25 & 5.2529 & 9999999999 \\
\hline CHEMBL3195069 & 688620 & 4.65 & 4.865 & TRN \\
\hline CHEMBL1365353 & 688620 & 4.5 & 5.0114 & TRN \\
\hline CHEMBL1164374 & 688620 & 4.45 & 4.926 & TRN \\
\hline CHEMBL1967431 & 688620 & 5.4 & 5.0912 & TRN \\
\hline CHEMBL1533328 & 688620 & 4.5 & 5.0518 & TRN \\
\hline CHEMBL1510144 & 688620 & 5.8 & 5.5209 & TRN \\
\hline CHEMBL1395458 & 688620 & 4.95 & 4.9693 & TRN \\
\hline CHEMBL1399466 & 688620 & 4.75 & 5.0688 & TRN \\
\hline CHEMBL1329704 & 688620 & 5.2 & 4.9321 & TRN \\
\hline CHEMBL1329503 & 688620 & 5.05 & 5.0107 & TRN \\
\hline CHEMBL1333360 & 688620 & 5.7 & 5.5987 & TRN \\
\hline CHEMBL1585216 & 688620 & 4.8 & 5.2919 & TST \\
\hline CHEMBL1331070 & 688620 & 4.7 & 5.053 & TRN \\
\hline CHEMBL1358945 & 688620 & 5.2 & 5.5123 & TST \\
\hline CHEMBL1451977 & 688620 & 5.0 & 5.3466 & TRN \\
\hline CHEMBL1444525 & 688620 & 5.2 & 4.9195 & TRN \\
\hline CHEMBL1324755 & 688620 & 4.65 & 5.0153 & TRN \\
\hline CHEMBL1461496 & 688620 & 5.55 & 5.3781 & TRN \\
\hline CHEMBL1482221 & 688620 & 4.65 & 5.0546 & TST \\
\hline CHEMBL1603615 & 688620 & 4.85 & 5.1642 & TRN \\
\hline
\end{tabular}




\begin{tabular}{|c|c|c|c|c|c|}
\hline \multicolumn{6}{|c|}{ Supplemental Table S2.txt } \\
\hline CHEMBL1413192 & 688620 & 4.5 & 4.8631 & TST & \\
\hline CHEMBL1384442 & 688620 & 4.6 & 5.2289 & TRN & \\
\hline CHEMBL1567025 & 688620 & 4.9 & 4.9008 & TST & \\
\hline CHEMBL1343311 & 688620 & 6.15 & 5.4195 & TRN & \\
\hline CHEMBL1306994 & 688620 & 5.75 & 5.1128 & TRN & \\
\hline CHEMBL1359207 & 688620 & 4.55 & 4.8847 & TRN & \\
\hline CHEMBL1504583 & 688620 & 4.45 & 4.91 & TRN & \\
\hline CHEMBL1375731 & 688620 & 4.95 & 4.7292 & TRN & \\
\hline CHEMBL3198732 & 688620 & 6.4 & 5.9752 & TRN & \\
\hline CHEMBL1336413 & 688620 & 4.45 & $5.0310 e$ & $\partial 000000001$ & TRN \\
\hline CHEMBL1562118 & 688620 & 5.95 & 4.9142 & TRN & \\
\hline CHEMBL1300097 & 688620 & 4.45 & 4.8862 & TRN & \\
\hline CHEMBL1428763 & 688620 & 4.8 & 4.7861 & TRN & \\
\hline CHEMBL3191716 & 688620 & 4.85 & 5.1229 & TST & \\
\hline CHEMBL1390035 & 688620 & 5.4 & 5.1417 & TRN & \\
\hline CHEMBL1337026 & 688620 & 4.9 & 4.9757 & TST & \\
\hline CHEMBL1243269 & 688620 & 4.55 & 5.2212 & TST & \\
\hline CHEMBL1444508 & 688620 & 4.45 & 5.1372 & TRN & \\
\hline CHEMBL1376163 & 688620 & 4.55 & 5.1763 & TST & \\
\hline CHEMBL1381057 & 688620 & 5.9 & 5.0199 & TST & \\
\hline CHEMBL3197012 & 688620 & 4.5 & 5.4059 & TRN & \\
\hline CHEMBL1347788 & 688620 & 4.95 & 4.8825 & TRN & \\
\hline CHEMBL1489601 & 688620 & 6.05 & 5.1619 & TRN & \\
\hline CHEMBL1611121 & 688620 & 6.0 & 5.2741 & TRN & \\
\hline CHEMBL563919 & 688620 & 5.35 & 5.3198 & TRN & \\
\hline CHEMBL1429429 & 688620 & 5.2 & 5.2623 & TST & \\
\hline CHEMBL1483312 & 688620 & 4.65 & 4.6589 & TRN & \\
\hline CHEMBL1472576 & 688620 & 4.95 & 4.9486 & TRN & \\
\hline CHEMBL1419298 & 688620 & 4.8 & 5.2892 & TST & \\
\hline CHEMBL1529839 & 688620 & 5.0 & 5.0807 & TRN & \\
\hline CHEMBL1344732 & 688620 & 4.75 & 4.9346 & TRN & \\
\hline CHEMBL1390176 & 688620 & 5.9 & 5.1515 & TRN & \\
\hline CHEMBL3209421 & 688620 & 4.45 & 5.1163 & TRN & \\
\hline CHEMBL1299629 & 688620 & 5.6 & 5.4445 & TRN & \\
\hline CHEMBL1472979 & 688620 & 5.35 & 4.9531 & TRN & \\
\hline CHEMBL1498249 & 688620 & 4.8 & 4.7036 & TRN & \\
\hline CHEMBL1322901 & 688620 & 5.35 & 5.3855 & TRN & \\
\hline CHEMBL1484872 & 688620 & 4.95 & 5.0644 & TRN & \\
\hline CHEMBL1567490 & 688620 & 4.45 & 4.9914 & TRN & \\
\hline CHEMBL1540618 & 688620 & 4.45 & 5.1363 & TRN & \\
\hline CHEMBL1333050 & 688620 & 6.25 & 5.0925 & TRN & \\
\hline CHEMBL1984155 & 688620 & 5.2 & 5.2837 & TRN & \\
\hline CHEMBL1416417 & 688620 & 5.0 & 4.8871 & TST & \\
\hline CHEMBL399530 & 688620 & 4.9 & 4.7302 & TRN & \\
\hline CHEMBL1530795 & 688620 & 5.0 & 5.2017 & TRN & \\
\hline CHEMBL1598507 & 688620 & 5.65 & 5.8467 & TRN & \\
\hline CHEMBL1574454 & 688620 & 5.95 & 5.9501 & TRN & \\
\hline CHEMBL1372738 & 688620 & 4.45 & 4.7621 & TRN & \\
\hline
\end{tabular}




\begin{tabular}{|c|c|c|c|c|c|}
\hline \multirow{3}{*}{$\begin{array}{l}\text { CHEMBL1431716 } \\
\text { CHEMBL1604391 }\end{array}$} & \multirow{3}{*}{$\begin{array}{l}688620 \\
688620\end{array}$} & \multicolumn{4}{|c|}{ Supplemental Table S2.txt } \\
\hline & & 5.35 & 5.2520 & 0000000001 & TRN \\
\hline & & 4.7 & 5.1476 & TRN & \\
\hline CHEMBL1462259 & 688620 & 5.3 & 5.0215 & TRN & \\
\hline CHEMBL1536848 & 688620 & 4.5 & 5.0171 & TRN & \\
\hline CHEMBL1563623 & 688620 & 5.55 & 5.1461 & TRN & \\
\hline CHEMBL 3212957 & 688620 & 4.45 & 4.926 & TRN & \\
\hline CHEMBL1410732 & 688620 & 4.5 & 4.8687 & TRN & \\
\hline CHEMBL1401949 & 688620 & 4.9 & 4.8354 & TRN & \\
\hline CHEMBL1302460 & 688620 & 4.8 & 4.8977 & TST & \\
\hline CHEMBL3197249 & 688620 & 4.8 & 4.9081 & TRN & \\
\hline CHEMBL 3212073 & 688620 & 4.65 & 4.9325 & TRN & \\
\hline CHEMBL1377048 & 688620 & 4.9 & 5.0443 & TRN & \\
\hline CHEMBL1449398 & 688620 & 5.75 & 5.3766 & TRN & \\
\hline CHEMBL1345947 & 688620 & 4.5 & 4.7677 & TST & \\
\hline CHEMBL1439909 & 688620 & 5.7 & 5.5292 & TRN & \\
\hline CHEMBL1333465 & 688620 & 4.8 & 5.0702 & TRN & \\
\hline CHEMBL1550340 & 688620 & 5.15 & 5.5541 & TRN & \\
\hline CHEMBL1576968 & 688620 & 4.9 & 4.8912 & TST & \\
\hline CHEMBL1445950 & 688620 & 4.65 & 4.8687 & TRN & \\
\hline CHEMBL1351118 & 688620 & 5.4 & 5.1658 & TRN & \\
\hline CHEMBL1389748 & 688620 & 5.0 & 5.1126 & TRN & \\
\hline CHEMBL1317475 & 688620 & 4.45 & 5.3136 & TST & \\
\hline CHEMBL1526690 & 688620 & 5.0 & 4.8378 & TRN & \\
\hline CHEMBL1495417 & 688620 & 6.05 & 5.6577 & TRN & \\
\hline CHEMBL1323005 & 688620 & 5.4 & 5.3519 & TRN & \\
\hline CHEMBL1342708 & 688620 & 4.7 & 5.1346 & TRN & \\
\hline CHEMBL1586053 & 688620 & 5.95 & 5.3581 & TRN & \\
\hline CHEMBL1386906 & 688620 & 5.5 & 5.0643 & TST & \\
\hline CHEMBL1527656 & 688620 & 5.0 & 5.1925 & TRN & \\
\hline CHEMBL1352877 & 688620 & 4.45 & 4.853 & TRN & \\
\hline CHEMBL1474286 & 688620 & 4.9 & 5.1571 & TST & \\
\hline CHEMBL3194248 & 688620 & 5.05 & 5.1636 & TRN & \\
\hline CHEMBL380979 & 688620 & 5.8 & 5.3211 & TRN & \\
\hline CHEMBL1422340 & 688620 & 5.85 & 6.0754 & TRN & \\
\hline CHEMBL1507549 & 688620 & 6.9 & 4.9917 & TRN & \\
\hline CHEMBL1457861 & 688620 & 4.55 & 4.9888 & TRN & \\
\hline CHEMBL1407026 & 688620 & 4.4 & 5.0102 & TST & \\
\hline CHEMBL1600007 & 688620 & 5.55 & 5.3211 & TRN & \\
\hline CHEMBL1415749 & 688620 & 4.45 & 5.0132 & TST & \\
\hline CHEMBL1540070 & 688620 & 5.9 & 5.1749 & TST & \\
\hline CHEMBL3213148 & 688620 & 5.5 & 4.9498 & TRN & \\
\hline CHEMBL1570942 & 688620 & 6.45 & 5.279 & TRN & \\
\hline CHEMBL1444710 & 688620 & 5.9 & 5.0487 & TRN & \\
\hline CHEMBL1535381 & 688620 & 5.65 & 5.0193 & TRN & \\
\hline CHEMBL1485129 & 688620 & 4.45 & 5.2267 & TST & \\
\hline CHEMBL1412104 & 688620 & 4.45 & 4.7728 & TST & \\
\hline CHEMBL1537619 & 688620 & 5.1 & 4.9183 & TRN & \\
\hline CHEMBL3191612 & 688620 & 6.35 & 5.0749 & TST & \\
\hline
\end{tabular}




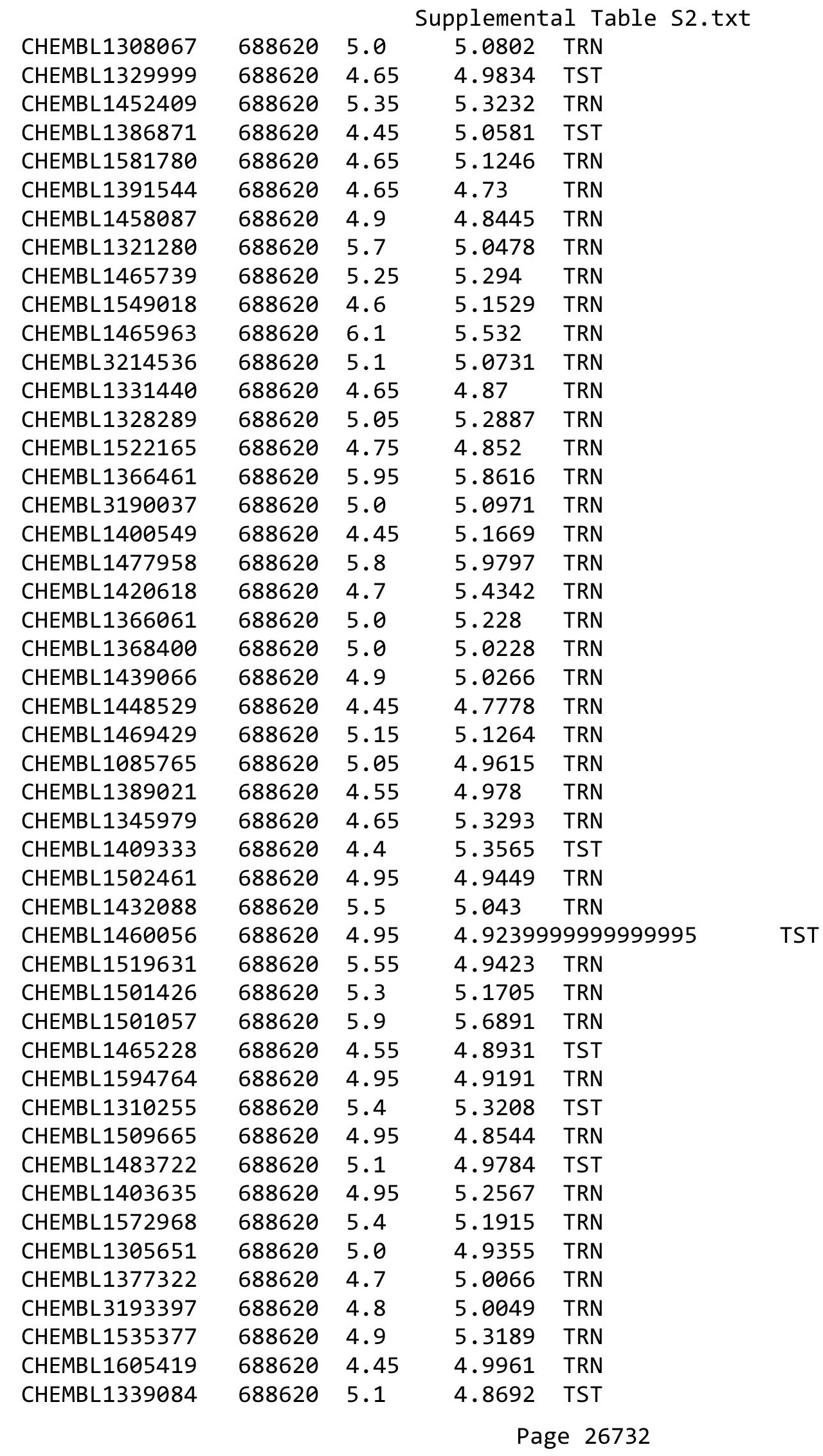




\begin{tabular}{|c|c|c|c|c|}
\hline \multicolumn{5}{|c|}{ Supplemental Table s2.txt } \\
\hline CHEMBL1459486 & 688620 & 4.8 & 5.13 & TST \\
\hline CHEMBL1384292 & 688620 & 6.2 & 5.7223 & TRN \\
\hline CHEMBL1379801 & 688620 & 4.45 & 4.9353 & TST \\
\hline CHEMBL3195555 & 688620 & 4.85 & 4.7337 & TRN \\
\hline CHEMBL1302615 & 688620 & 5.05 & 4.9599 & TRN \\
\hline CHEMBL3195760 & 688620 & 6.4 & 6.5435 & TRN \\
\hline CHEMBL1612807 & 688620 & 4.45 & 4.9411 & TRN \\
\hline CHEMBL1611189 & 688620 & 4.65 & 5.0567 & TST \\
\hline CHEMBL1538945 & 688620 & 5.45 & 5.3196 & TRN \\
\hline CHEMBL1451611 & 688620 & 4.45 & 5.0399 & TRN \\
\hline CHEMBL1600381 & 688620 & 7.0501 & 5.0679 & TST \\
\hline CHEMBL1346172 & 688620 & 4.8 & 4.9422 & TRN \\
\hline CHEMBL1445909 & 688620 & 5.9 & 5.1798 & TST \\
\hline CHEMBL1603811 & 688620 & 4.9 & 5.103 & TST \\
\hline CHEMBL1484989 & 688620 & 6.15 & 5.0613 & TRN \\
\hline CHEMBL1319210 & 688620 & 6.25 & 5.7315 & TRN \\
\hline CHEMBL1432645 & 688620 & 4.9 & 4.7888 & TRN \\
\hline CHEMBL1595546 & 688620 & 6.2 & 5.0261 & TRN \\
\hline CHEMBL1387238 & 688620 & 4.9 & 4.9373 & TRN \\
\hline CHEMBL3190960 & 688620 & 5.5 & 5.5521 & TRN \\
\hline CHEMBL1352460 & 688620 & 5.15 & 5.1293 & TRN \\
\hline CHEMBL1603294 & 688620 & 5.5 & 5.4853 & TRN \\
\hline CHEMBL 1603136 & 688620 & 5.3 & 5.1617 & TRN \\
\hline CHEMBL1589330 & 688620 & 5.15 & 5.0152 & TRN \\
\hline CHEMBL1417017 & 688620 & 4.5 & 5.3792 & TST \\
\hline CHEMBL1449876 & 688620 & 4.95 & 5.0438 & TST \\
\hline CHEMBL1306709 & 688620 & 4.6 & 4.8868 & TRN \\
\hline CHEMBL1308898 & 688620 & 5.25 & 5.1476 & TRN \\
\hline CHEMBL1348851 & 688620 & 5.0 & 4.9279 & TRN \\
\hline CHEMBL3214486 & 688620 & 4.45 & 4.989 & TRN \\
\hline CHEMBL1612750 & 688620 & 5.0 & 5.0661 & TRN \\
\hline CHEMBL1500185 & 688620 & 5.4 & 5.0038 & TRN \\
\hline CHEMBL1440636 & 688620 & 5.5 & 5.3763 & TRN \\
\hline CHEMBL1328832 & 688620 & 4.7 & 5.2598 & TRN \\
\hline CHEMBL1988708 & 688620 & 6.3 & 5.8877 & TRN \\
\hline CHEMBL1446374 & 688620 & 5.05 & 4.8328 & TRN \\
\hline CHEMBL1550025 & 688620 & 4.9 & 5.058 & TRN \\
\hline CHEMBL1526588 & 688620 & 4.7 & 4.9155 & TRN \\
\hline CHEMBL1527013 & 688620 & 4.7 & 5.0541 & TRN \\
\hline CHEMBL1393877 & 688620 & 5.2 & 5.1143 & TRN \\
\hline CHEMBL1705518 & 688620 & 4.95 & 4.8271 & TRN \\
\hline CHEMBL1520316 & 688620 & 4.8 & 4.9641 & TST \\
\hline CHEMBL1388064 & 688620 & 4.85 & 4.9279 & TRN \\
\hline CHEMBL1467283 & 688620 & 5.4 & 5.2135 & TRN \\
\hline CHEMBL1301269 & 688620 & 4.75 & 4.9541 & TRN \\
\hline CHEMBL1548433 & 688620 & 4.95 & 4.9705 & TRN \\
\hline CHEMBL1446630 & 688620 & 4.45 & 4.98600 & 0000000001 \\
\hline CHEMBL1435943 & 688620 & 4.75 & 4.6026 & TRN \\
\hline
\end{tabular}




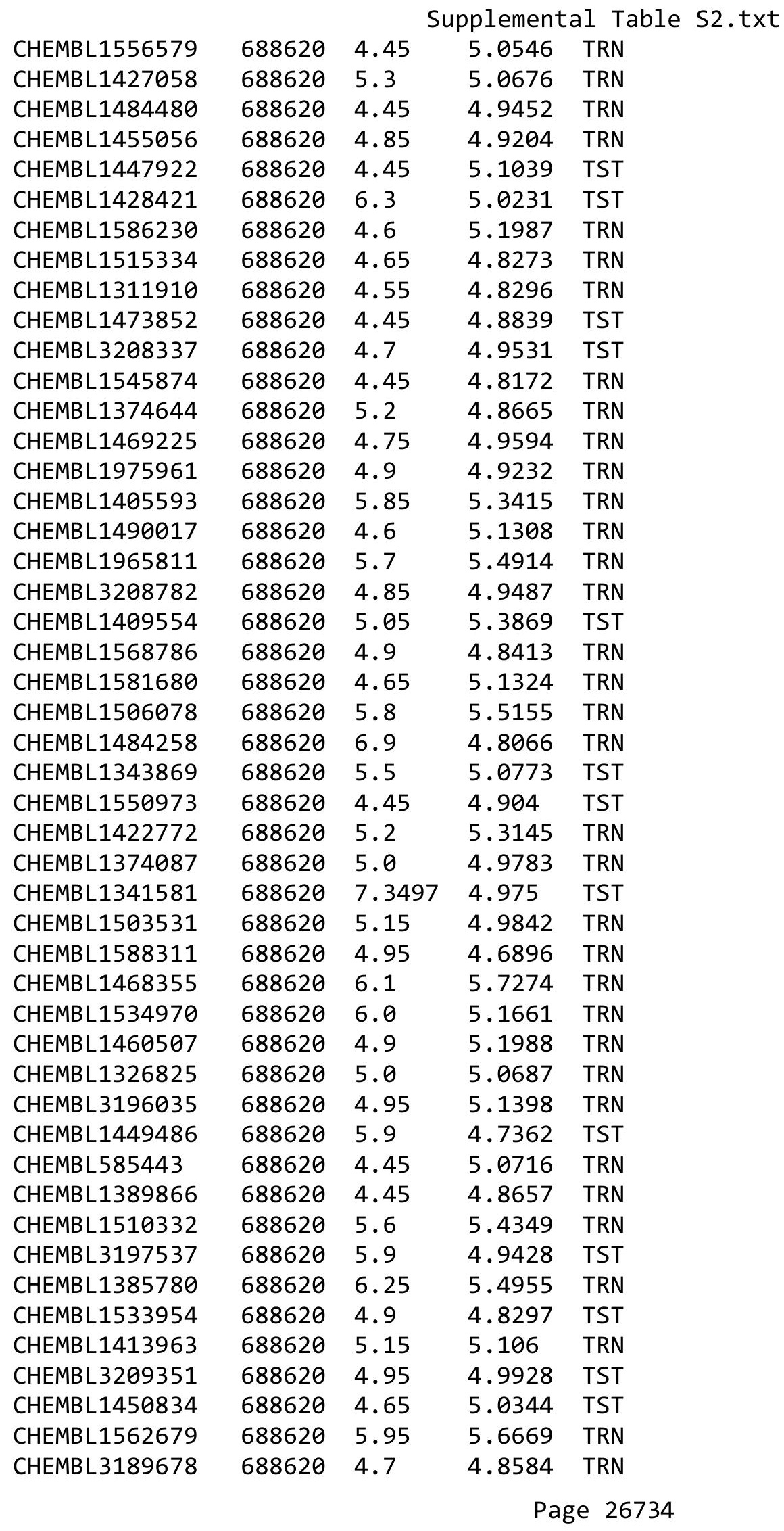




\begin{tabular}{|c|c|c|c|c|c|}
\hline \\
\hline CHEMBL1543865 & 688620 & 4.45 & 5.0638 & TRN & \\
\hline CHEMBL1607432 & 688620 & 4.85 & 4.7854 & TRN & \\
\hline CHEMBL1535025 & 688620 & 4.45 & 5.0778 & TRN & \\
\hline CHEMBL1310278 & 688620 & 5.25 & 5.5159 & TRN & \\
\hline CHEMBL1536394 & 688620 & 5.95 & 5.0221 & TRN & \\
\hline CHEMBL1348385 & 688620 & 5.5 & 5.3204 & TRN & \\
\hline CHEMBL1309436 & 688620 & 4.45 & 5.2062 & TRN & \\
\hline CHEMBL1332801 & 688620 & 4.8 & 5.0501 & TRN & \\
\hline CHEMBL126804 & 688620 & 4.45 & 5.04899 & 99999999995 & TRN \\
\hline CHEMBL578257 & 688620 & 5.2 & 5.2625 & TRN & \\
\hline CHEMBL3189536 & 688620 & 4.9 & 5.032 & TST & \\
\hline CHEMBL1346713 & 688620 & 4.8 & 4.9643 & TRN & \\
\hline CHEMBL1399602 & 688620 & 4.9 & 5.0062 & TRN & \\
\hline CHEMBL1425963 & 688620 & 4.85 & 5.0238 & TST & \\
\hline CHEMBL1352342 & 688620 & 4.45 & 4.9104 & TRN & \\
\hline CHEMBL 1440360 & 688620 & 5.55 & 5.7334 & TRN & \\
\hline CHEMBL1521764 & 688620 & 5.2 & 4.962 & TST & \\
\hline CHEMBL1328168 & 688620 & 5.45 & 5.1713 & TRN & \\
\hline CHEMBL1428003 & 688620 & 4.75 & 4.5409 & TRN & \\
\hline CHEMBL1996263 & 688620 & 5.25 & 5.2001 & TRN & \\
\hline CHEMBL1734063 & 688620 & 5.0 & 4.793 & TRN & \\
\hline CHEMBL1465350 & 688620 & 4.75 & 5.3205 & TST & \\
\hline CHEMBL1330279 & 688620 & 5.6 & 5.7639 & TRN & \\
\hline CHEMBL1370936 & 688620 & 4.9 & 5.1768 & TST & \\
\hline CHEMBL1494994 & 688620 & 6.05 & 5.0968 & TST & \\
\hline CHEMBL1564348 & 688620 & 4.45 & 4.9623 & TRN & \\
\hline CHEMBL3209454 & 688620 & 4.95 & 4.9807 & TRN & \\
\hline CHEMBL1970627 & 688620 & 5.9 & 5.2437 & TRN & \\
\hline CHEMBL1432944 & 688620 & 4.75 & 4.7978 & TRN & \\
\hline CHEMBL1457605 & 688620 & 4.95 & 4.9902 & TST & \\
\hline CHEMBL1368493 & 688620 & 4.9 & 4.9817 & TRN & \\
\hline CHEMBL1491340 & 688620 & 6.25 & 5.7509 & TST & \\
\hline CHEMBL1398224 & 688620 & 4.45 & 4.7828 & TRN & \\
\hline CHEMBL 2005317 & 688620 & 5.3 & 5.3935 & TRN & \\
\hline CHEMBL1337775 & 688620 & 4.9 & 4.9463 & TST & \\
\hline CHEMBL1487026 & 688620 & 4.85 & 5.1699 & TRN & \\
\hline CHEMBL1426312 & 688620 & 5.2 & 5.0482 & TST & \\
\hline CHEMBL1307792 & 688620 & 5.5 & 5.2078 & TST & \\
\hline CHEMBL1429788 & 688620 & 4.8 & 4.7653 & TRN & \\
\hline CHEMBL1535851 & 688620 & 4.8 & 5.0165 & TST & \\
\hline CHEMBL1425386 & 688620 & 5.2 & 4.881 & TST & \\
\hline CHEMBL1492244 & 688620 & 5.1 & 5.2569 & TRN & \\
\hline CHEMBL1325178 & 688620 & 6.6499 & 4.9879 & TRN & \\
\hline CHEMBL1969590 & 688620 & 5.85 & 5.789 & TRN & \\
\hline CHEMBL1324771 & 688620 & 4.7 & 5.1307 & TST & \\
\hline CHEMBL1519947 & 688620 & 4.8 & 5.0642 & TST & \\
\hline CHEMBL1349821 & 688620 & 4.65 & 5.1639 & TST & \\
\hline CHEMBL1303501 & 688620 & 6.05 & 5.9513 & TRN & \\
\hline
\end{tabular}




\begin{tabular}{|c|c|c|c|c|}
\hline \multicolumn{5}{|c|}{ Supplemental Table S2.txt } \\
\hline CHEMBL1557520 & 688620 & 4.95 & 5.0697 & TRN \\
\hline CHEMBL1417100 & 688620 & 5.2 & 4.8916 & TST \\
\hline CHEMBL1563541 & 688620 & 4.45 & 5.0834 & TRN \\
\hline CHEMBL1425228 & 688620 & 4.95 & 4.8554 & TRN \\
\hline CHEMBL1300246 & 688620 & 4.45 & 4.9453 & TST \\
\hline CHEMBL1504419 & 688620 & 4.7 & 5.0048 & TRN \\
\hline CHEMBL1459330 & 688620 & 4.45 & 4.7387 & TRN \\
\hline CHEMBL 3210440 & 688620 & 4.45 & 5.06 & TRN \\
\hline CHEMBL1354253 & 688620 & 4.65 & 4.8964 & TRN \\
\hline CHEMBL1595775 & 688620 & 4.75 & 5.0738 & TST \\
\hline CHEMBL3208053 & 688620 & 4.9 & 4.7907 & TRN \\
\hline CHEMBL1458483 & 688620 & 5.05 & 4.8581 & TRN \\
\hline CHEMBL1604100 & 688620 & 4.85 & 5.0907 & TRN \\
\hline CHEMBL1403165 & 688620 & 4.5 & 4.9095 & TRN \\
\hline CHEMBL1568767 & 688620 & 4.45 & 5.0648 & TRN \\
\hline CHEMBL1491848 & 688620 & 4.45 & 4.9292 & TRN \\
\hline CHEMBL1423596 & 688620 & 4.45 & 4.9364 & TRN \\
\hline CHEMBL1385457 & 688620 & 4.75 & 4.8679 & TRN \\
\hline CHEMBL1300766 & 688620 & 5.1 & 5.7059 & TRN \\
\hline CHEMBL1429832 & 688620 & 6.5501 & 5.636 & TST \\
\hline CHEMBL1302988 & 688620 & 4.45 & 4.7784 & TST \\
\hline CHEMBL1310764 & 688620 & 4.95 & 5.0411 & TRN \\
\hline CHEMBL1329722 & 688620 & 4.95 & 5.1187 & TRN \\
\hline CHEMBL1398939 & 688620 & 4.8 & 5.1313 & TST \\
\hline CHEMBL1414591 & 688620 & 7.0 & 5.1655 & TRN \\
\hline CHEMBL1612718 & 688620 & 5.8 & 5.1606 & TRN \\
\hline CHEMBL1611512 & 688620 & 5.15 & 5.0997 & TRN \\
\hline CHEMBL1334233 & 688620 & 5.7 & 5.2465 & TST \\
\hline CHEMBL1299515 & 688620 & 5.7 & 5.063 & TRN \\
\hline CHEMBL1441206 & 688620 & 4.6 & 4.9389 & TST \\
\hline CHEMBL1300612 & 688620 & 4.45 & 5.2615 & TST \\
\hline CHEMBL1486220 & 688620 & 4.6 & 5.0218 & TST \\
\hline CHEMBL1485883 & 688620 & 5.15 & 4.9735 & TRN \\
\hline CHEMBL1606323 & 688620 & 4.8 & 5.0804 & TRN \\
\hline CHEMBL1445452 & 688620 & 4.95 & 5.0861 & TST \\
\hline CHEMBL1567260 & 688620 & 4.45 & 5.1482 & TRN \\
\hline CHEMBL1383913 & 688620 & 4.95 & 5.0557 & TST \\
\hline CHEMBL1306522 & 688620 & 5.05 & 5.2462 & TRN \\
\hline CHEMBL1331568 & 688620 & 4.8 & 4.7987 & TRN \\
\hline CHEMBL1362189 & 688620 & 5.25 & 5.2032 & TRN \\
\hline CHEMBL1572576 & 688620 & 4.65 & 5.1908 & TRN \\
\hline CHEMBL1302094 & 688620 & 5.0 & 5.2948 & TRN \\
\hline CHEMBL1392545 & 688620 & 4.85 & 5.0837 & TRN \\
\hline CHEMBL1561469 & 688620 & 4.55 & 5.0693 & TRN \\
\hline CHEMBL1384606 & 688620 & 4.45 & 5.0096 & TRN \\
\hline CHEMBL1480448 & 688620 & 5.15 & 5.4021 & TRN \\
\hline CHEMBL1573382 & 688620 & 4.65 & 5.0051 & TRN \\
\hline CHEMBL1581160 & 688620 & 4.45 & 4.8243 & TRN \\
\hline
\end{tabular}




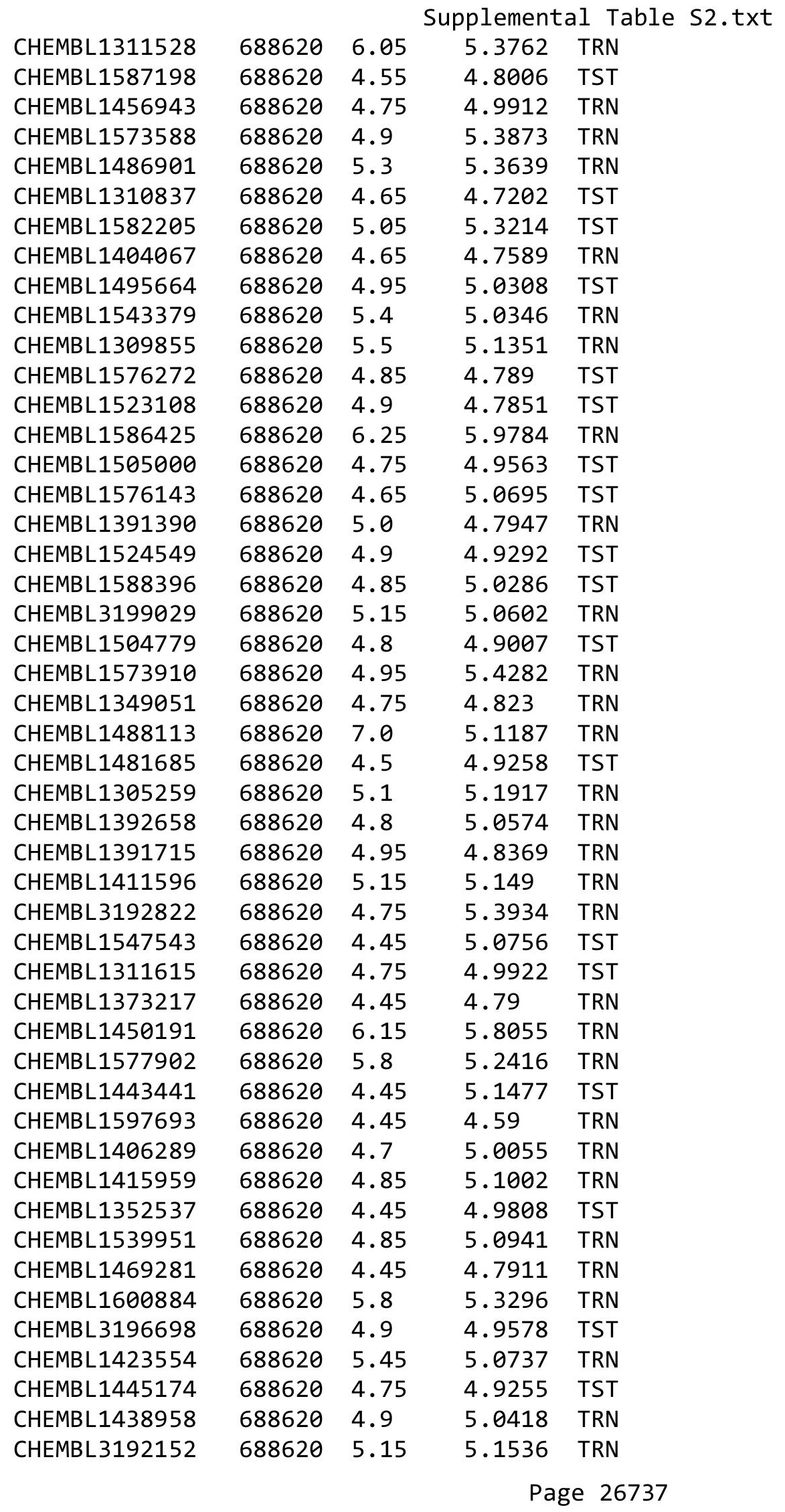




\begin{tabular}{|c|c|c|c|c|c|}
\hline \multicolumn{6}{|c|}{ lemental Table S2 } \\
\hline CHEMBL1587099 & 688620 & 4.8 & 5.1256 & TRN & \\
\hline CHEMBL1509000 & 688620 & 5.55 & 5.4082 & TST & \\
\hline CHEMBL1340513 & 688620 & 4.5 & 4.7471 & TRN & \\
\hline CHEMBL1495659 & 688620 & 4.45 & 5.08899 & 99999999995 & TRN \\
\hline CHEMBL1390791 & 688620 & 4.45 & 4.9971 & TRN & \\
\hline CHEMBL1607772 & 688620 & 4.8 & 5.0136 & TRN & \\
\hline CHEMBL1511339 & 688620 & 4.8 & 4.9535 & TRN & \\
\hline CHEMBL1432004 & 688620 & 4.7 & 5.2063 & TRN & \\
\hline CHEMBL1313918 & 688620 & 4.8 & 5.0771 & TRN & \\
\hline CHEMBL3191795 & 688620 & 4.45 & 4.8548 & TRN & \\
\hline CHEMBL3197193 & 688620 & 4.6 & 5.0498 & TRN & \\
\hline CHEMBL1419848 & 688620 & 5.65 & 5.2284 & TRN & \\
\hline CHEMBL1601986 & 688620 & 8.301 & 5.1625 & TST & \\
\hline CHEMBL1928483 & 688620 & 4.7 & 5.218 & TRN & \\
\hline CHEMBL1341080 & 688620 & 5.2 & 5.1222 & TRN & \\
\hline CHEMBL3197866 & 688620 & 4.95 & 4.6572 & TRN & \\
\hline CHEMBL1490966 & 688620 & 4.95 & 5.0314 & TRN & \\
\hline CHEMBL3210049 & 688620 & 5.1 & 4.859 & TRN & \\
\hline CHEMBL3199855 & 688620 & 5.2 & 6.1691 & TRN & \\
\hline CHEMBL1464553 & 688620 & 5.5 & 5.4023 & TRN & \\
\hline CHEMBL1429713 & 688620 & 6.3 & 5.9606 & TRN & \\
\hline CHEMBL1563223 & 688620 & 5.3 & 5.0477 & TRN & \\
\hline CHEMBL1303764 & 688620 & 4.95 & 5.0633 & TRN & \\
\hline CHEMBL1308871 & 688620 & 4.85 & 4.7802 & TST & \\
\hline CHEMBL1448972 & 688620 & 5.0 & 4.8448 & TRN & \\
\hline CHEMBL1543133 & 688620 & 5.15 & 4.6664 & TST & \\
\hline CHEMBL1434970 & 688620 & 4.45 & 5.1571 & TRN & \\
\hline CHEMBL1470624 & 688620 & 4.75 & 4.8884 & TRN & \\
\hline CHEMBL1392535 & 688620 & 4.45 & 5.1425 & TRN & \\
\hline CHEMBL1342765 & 688620 & 4.45 & 5.1793 & TRN & \\
\hline CHEMBL1540210 & 688620 & 4.85 & 4.8709 & TST & \\
\hline CHEMBL3192977 & 688620 & 5.6 & 6.1419 & TST & \\
\hline CHEMBL1310479 & 688620 & 5.55 & 4.966 & TRN & \\
\hline CHEMBL1481313 & 688620 & 4.6 & 5.1443 & TRN & \\
\hline CHEMBL1610364 & 688620 & 5.55 & 5.3637 & TRN & \\
\hline CHEMBL1330536 & 688620 & 4.85 & 5.1408 & TRN & \\
\hline CHEMBL1516827 & 688620 & 4.9 & 5.3432 & TRN & \\
\hline CHEMBL1531892 & 688620 & 4.45 & 5.1495 & TST & \\
\hline CHEMBL1464504 & 688620 & 5.6 & 5.4408 & TRN & \\
\hline CHEMBL1415957 & 688620 & 4.9 & 4.9375 & TRN & \\
\hline CHEMBL1423409 & 688620 & 5.55 & 5.2907 & TRN & \\
\hline CHEMBL1528873 & 688620 & 4.75 & 5.2038 & TRN & \\
\hline CHEMBL1372745 & 688620 & 4.85 & 5.4139 & TRN & \\
\hline CHEMBL1423635 & 688620 & 4.9 & 4.8668 & TRN & \\
\hline CHEMBL1353527 & 688620 & 4.45 & 5.0262 & TRN & \\
\hline CHEMBL3212901 & 688620 & 4.9 & 5.0777 & TRN & \\
\hline CHEMBL1535276 & 688620 & 4.75 & 4.9975 & TRN & \\
\hline CHEMBL1304526 & 688620 & 4.65 & 5.2812 & TRN & \\
\hline
\end{tabular}




\begin{tabular}{|c|c|c|c|c|c|}
\hline \multicolumn{6}{|c|}{ Supplemental Table s2.txt } \\
\hline CHEMBL1598233 & 688620 & 5.65 & 5.3827 & TRN & \\
\hline CHEMBL1607490 & 688620 & 5.25 & 4.9683 & TRN & \\
\hline CHEMBL1526617 & 688620 & 5.0 & 5.0909 & TST & \\
\hline CHEMBL1576094 & 688620 & 4.45 & 4.7718 & TST & \\
\hline CHEMBL1479800 & 688620 & 4.45 & 4.97 & TST & \\
\hline CHEMBL1486387 & 688620 & 4.65 & 4.6863 & TRN & \\
\hline CHEMBL1587335 & 688620 & 4.45 & 5.0569 & TST & \\
\hline CHEMBL1539986 & 688620 & 5.45 & 5.0249 & TST & \\
\hline CHEMBL1485297 & 688620 & 5.0 & 4.9334 & TRN & \\
\hline CHEMBL1524431 & 688620 & 5.0 & 5.3037 & TRN & \\
\hline CHEMBL1939691 & 688620 & 4.45 & 4.8562 & TRN & \\
\hline CHEMBL1501083 & 688620 & 6.5501 & 4.9395 & TRN & \\
\hline CHEMBL1603155 & 688620 & 4.45 & 5.1393 & TRN & \\
\hline CHEMBL 241858 & 688620 & 4.45 & 4.8638 & TRN & \\
\hline CHEMBL1576132 & 688620 & 4.7 & 4.8883 & TRN & \\
\hline CHEMBL1359753 & 688620 & 5.05 & 4.9227 & TRN & \\
\hline CHEMBL1483252 & 688620 & 5.9 & 5.9692 & TRN & \\
\hline CHEMBL1333009 & 688620 & 5.0 & 5.1385 & TRN & \\
\hline CHEMBL1549472 & 688620 & 4.45 & 5.2683 & TRN & \\
\hline CHEMBL1507137 & 688620 & 5.3 & 5.4303 & TRN & \\
\hline CHEMBL1545780 & 688620 & 4.45 & 4.9942 & TST & \\
\hline CHEMBL1458566 & 688620 & 4.8 & 4.9184 & TRN & \\
\hline CHEMBL1303389 & 688620 & 4.65 & 5.1303 & TRN & \\
\hline CHEMBL1379808 & 688620 & 6.4 & 4.9787 & TST & \\
\hline CHEMBL1430368 & 688620 & 4.45 & 4.832 & TST & \\
\hline CHEMBL1584711 & 688620 & 4.7 & 5.2174 & TRN & \\
\hline CHEMBL1384301 & 688620 & 5.9 & 5.7091 & TRN & \\
\hline CHEMBL1435655 & 688620 & 4.9 & 4.9717 & TRN & \\
\hline CHEMBL1586724 & 688620 & 6.3 & 5.7802 & TRN & \\
\hline CHEMBL3197208 & 688620 & 5.15 & 5.4116 & TRN & \\
\hline CHEMBL1420906 & 688620 & 4.85 & 5.1869 & TST & \\
\hline CHEMBL1404139 & 688620 & 4.45 & 4.8108 & TRN & \\
\hline CHEMBL1516556 & 688620 & 5.1 & 4.9284 & TRN & \\
\hline CHEMBL1463351 & 688620 & 5.3 & 4.9426 & TRN & \\
\hline CHEMBL1401663 & 688620 & 4.75 & 4.9941 & TST & \\
\hline CHEMBL1529652 & 688620 & 4.45 & 4.7882 & TRN & \\
\hline CHEMBL1490903 & 688620 & 5.0 & 5.1103 & TST & \\
\hline CHEMBL1566185 & 688620 & 5.6 & 4.9646 & TST & \\
\hline CHEMBL585417 & 688620 & 5.2 & 5.0275 & TRN & \\
\hline CHEMBL1337288 & 688620 & 4.8 & 4.7678 & TRN & \\
\hline CHEMBL1596511 & 688620 & 4.65 & 4.7631 & TRN & \\
\hline CHEMBL1516682 & 688620 & 4.95 & 4.9203 & TRN & \\
\hline CHEMBL1480868 & 688620 & 5.15 & 4.9783 & TRN & \\
\hline CHEMBL1509929 & 688620 & 4.9 & 5.3678 & TRN & \\
\hline CHEMBL1376835 & 688620 & 4.8 & 4.9178 & TRN & \\
\hline CHEMBL1338529 & 688620 & 5.0 & 5.1582 & TRN & \\
\hline CHEMBL3197868 & 688620 & 4.55 & 5.05399 & 9999999999 & TRN \\
\hline CHEMBL1576677 & 688620 & 4.95 & 5.1264 & TRN & \\
\hline
\end{tabular}




\begin{tabular}{|c|c|c|c|c|c|}
\hline \multicolumn{6}{|c|}{ Supplemental Table S2.txt } \\
\hline CHEMBL3209547 & 688620 & 4.6 & 5.0315 & TST & \\
\hline CHEMBL1348452 & 688620 & 4.75 & 4.8604 & TRN & \\
\hline CHEMBL1334407 & 688620 & 5.15 & 5.0118 & TRN & \\
\hline CHEMBL 267678 & 688620 & 6.8499 & 4.9427 & TST & \\
\hline CHEMBL1421164 & 688620 & 5.5 & 4.9901 & TST & \\
\hline CHEMBL1979360 & 688620 & 5.7 & 5.9906 & TRN & \\
\hline CHEMBL3189191 & 688620 & 4.95 & 4.7166 & TRN & \\
\hline CHEMBL1511507 & 688620 & 5.1 & 5.0508 & TRN & \\
\hline CHEMBL 3195226 & 688620 & 7.0501 & 6.2659 & TRN & \\
\hline CHEMBL1388419 & 688620 & 5.3 & 5.1566 & TRN & \\
\hline CHEMBL1548364 & 688620 & 4.45 & 4.9854 & TST & \\
\hline CHEMBL1603469 & 688620 & 4.45 & 5.175 & TRN & \\
\hline CHEMBL1509919 & 688620 & 4.95 & 5.0344 & TST & \\
\hline CHEMBL1506593 & 688620 & 4.95 & 5.0285 & TRN & \\
\hline CHEMBL1440197 & 688620 & 4.8 & 5.0882 & TRN & \\
\hline CHEMBL1573222 & 688620 & 4.8 & 5.2103 & TST & \\
\hline CHEMBL1546303 & 688620 & 4.55 & 4.8834 & TRN & \\
\hline CHEMBL1518118 & 688620 & 5.35 & 5.1321 & TRN & \\
\hline CHEMBL1415580 & 688620 & 5.2 & 5.1452 & TST & \\
\hline CHEMBL1580708 & 688620 & 4.85 & 4.9908 & TRN & \\
\hline CHEMBL1572346 & 688620 & 4.65 & 5.0163 & TRN & \\
\hline CHEMBL574954 & 688620 & 4.6 & 5.061 & TRN & \\
\hline CHEMBL1389707 & 688620 & 4.9 & 4.9489 & TRN & \\
\hline CHEMBL1586590 & 688620 & 6.3 & 6.2678 & TRN & \\
\hline CHEMBL1360272 & 688620 & 4.85 & 5.0208 & TST & \\
\hline CHEMBL1589316 & 688620 & 4.5 & $4.8180 e$ & 00000000005 & TRN \\
\hline CHEMBL1413134 & 688620 & 6.8499 & 6.0498 & TRN & \\
\hline CHEMBL1541182 & 688620 & 4.45 & 5.218 & TRN & \\
\hline CHEMBL1562040 & 688620 & 4.8 & 4.8283 & TRN & \\
\hline CHEMBL3194391 & 688620 & 4.8 & 5.42 & TRN & \\
\hline CHEMBL3197111 & 688620 & 4.85 & 5.2485 & TST & \\
\hline CHEMBL1534974 & 688620 & 4.9 & 5.1204 & TRN & \\
\hline CHEMBL1370412 & 688620 & 6.4 & 5.812 & TRN & \\
\hline CHEMBL1521997 & 688620 & 5.0 & 5.1978 & TRN & \\
\hline CHEMBL1423139 & 688620 & 4.45 & 5.0723 & TRN & \\
\hline CHEMBL3196335 & 688620 & 5.5 & 5.5758 & TRN & \\
\hline CHEMBL1342551 & 688620 & 4.9 & 4.9835 & TST & \\
\hline CHEMBL1378576 & 688620 & 4.9 & 4.8422 & TRN & \\
\hline CHEMBL1400247 & 688620 & 5.55 & 5.0146 & TST & \\
\hline CHEMBL1484777 & 688620 & 5.8 & 5.9706 & TRN & \\
\hline CHEMBL1993993 & 688620 & 5.95 & 5.881 & TST & \\
\hline CHEMBL1461551 & 688620 & 4.5 & 4.8989 & TST & \\
\hline CHEMBL1431545 & 688620 & 5.5 & 4.9662 & TRN & \\
\hline CHEMBL1603910 & 688620 & 4.45 & 4.88899 & 9999999999 & TRN \\
\hline CHEMBL1428750 & 688620 & 4.75 & 5.0546 & TRN & \\
\hline CHEMBL 310310 & 688620 & 6.0 & 5.4801 & TST & \\
\hline CHEMBL1460655 & 688620 & 5.45 & 5.4686 & TST & \\
\hline CHEMBL1507092 & 688620 & 5.35 & 5.1492 & TRN & \\
\hline
\end{tabular}




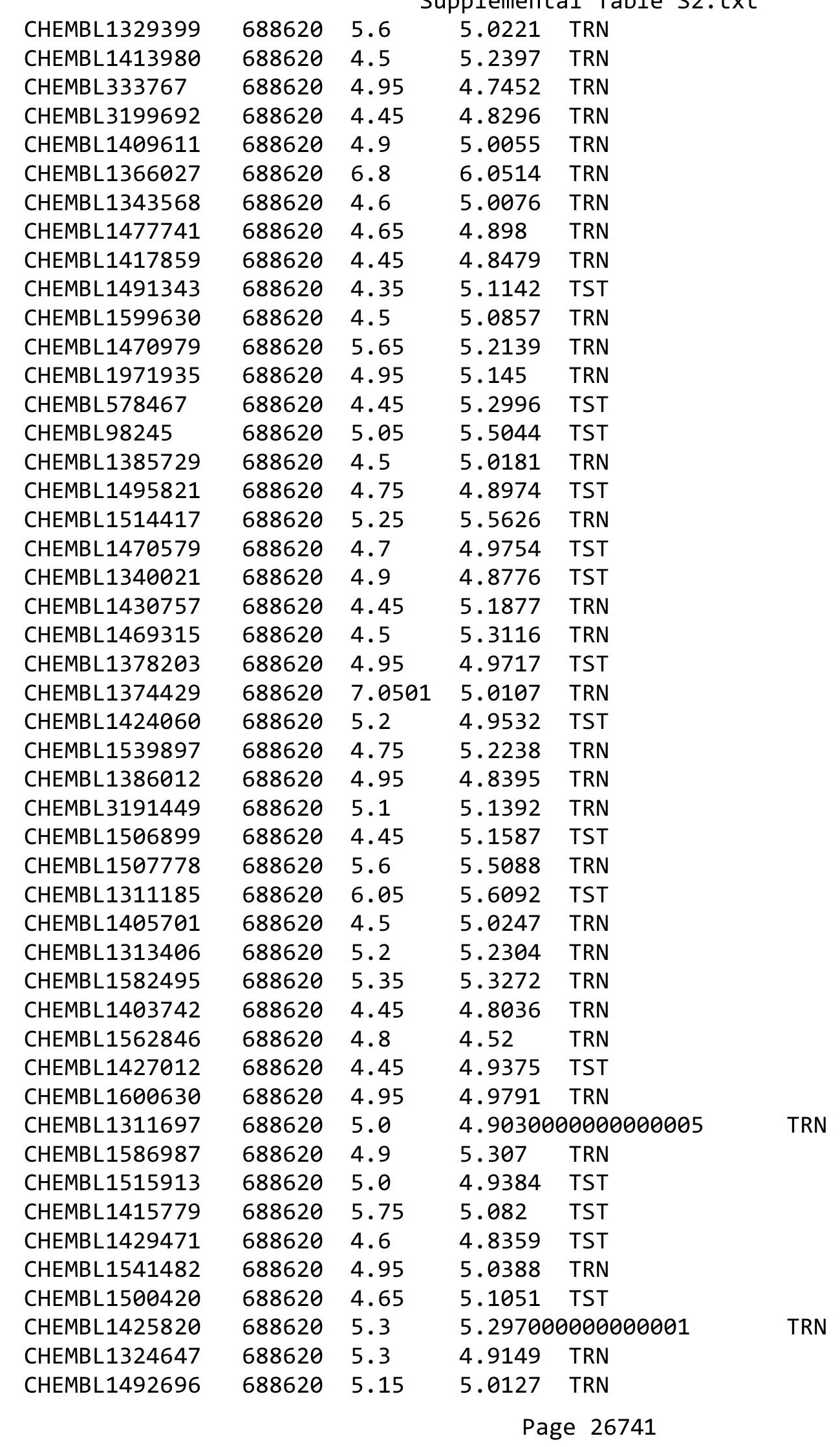




\begin{tabular}{|c|c|c|c|c|c|}
\hline \multicolumn{6}{|c|}{ splemental } \\
\hline CHEMBL2006325 & 688620 & 6.5 & 6.3175 & TRN & \\
\hline CHEMBL1586401 & 688620 & 5.45 & 5.3225 & TRN & \\
\hline CHEMBL1539572 & 688620 & 4.45 & 4.886 & TRN & \\
\hline CHEMBL1580360 & 688620 & 5.25 & 5.2738 & TRN & \\
\hline CHEMBL1310899 & 688620 & 5.5 & 5.033 & TRN & \\
\hline CHEMBL1576469 & 688620 & 4.85 & 4.9898 & TST & \\
\hline CHEMBL1501810 & 688620 & 4.9 & 4.842 & TRN & \\
\hline CHEMBL3198201 & 688620 & 5.05 & 4.9179 & TRN & \\
\hline CHEMBL1537222 & 688620 & 5.0 & 4.8629 & TST & \\
\hline CHEMBL1464773 & 688620 & 4.75 & 4.6341 & TRN & \\
\hline CHEMBL1390661 & 688620 & 4.65 & 4.7055 & TRN & \\
\hline CHEMBL1330753 & 688620 & 6.05 & 4.9119 & TRN & \\
\hline CHEMBL1479977 & 688620 & 4.7 & 4.9492 & TRN & \\
\hline CHEMBL1380437 & 688620 & 4.45 & 5.0728 & TRN & \\
\hline CHEMBL1334982 & 688620 & 5.5 & 4.993 & TRN & \\
\hline CHEMBL1554760 & 688620 & 5.0 & 4.9529 & TST & \\
\hline CHEMBL1312692 & 688620 & 4.6 & 4.9723 & TRN & \\
\hline CHEMBL1309539 & 688620 & 4.8 & 4.7152 & TRN & \\
\hline CHEMBL1368261 & 688620 & 4.85 & 5.1992 & TST & \\
\hline CHEMBL1438971 & 688620 & 4.7 & 4.9105 & TST & \\
\hline CHEMBL1525055 & 688620 & 4.95 & 4.9199 & TST & \\
\hline CHEMBL1599895 & 688620 & 5.7 & 5.1991 & TRN & \\
\hline CHEMBL1556376 & 688620 & 4.45 & 4.8423 & TRN & \\
\hline CHEMBL1404826 & 688620 & 4.5 & 5.2056 & TST & \\
\hline CHEMBL1386948 & 688620 & 6.0 & 4.9164 & TRN & \\
\hline CHEMBL 3191694 & 688620 & 4.95 & 5.0272 & TRN & \\
\hline CHEMBL1609780 & 688620 & 4.5 & 5.1943 & TRN & \\
\hline CHEMBL1348247 & 688620 & 4.65 & 5.0713 & TST & \\
\hline CHEMBL1431616 & 688620 & 4.9 & 5.1658 & TRN & \\
\hline CHEMBL1565413 & 688620 & 6.5501 & 4.9425 & TRN & \\
\hline CHEMBL1404242 & 688620 & 6.0 & 5.279 & TST & \\
\hline CHEMBL1342078 & 688620 & 4.45 & 5.1322 & TST & \\
\hline CHEMBL1318948 & 688620 & 4.8 & 5.5067 & TRN & \\
\hline CHEMBL1372889 & 688620 & 5.95 & 6.3398 & TRN & \\
\hline CHEMBL3199172 & 688620 & 5.65 & 5.82299 & 99999999995 & TRN \\
\hline CHEMBL1583148 & 688620 & 5.5 & 4.8073 & TST & \\
\hline CHEMBL1350223 & 688620 & 4.45 & 4.9053 & TRN & \\
\hline CHEMBL1346499 & 688620 & 4.45 & 4.9873 & TRN & \\
\hline CHEMBL1576166 & 688620 & 5.4 & 5.5438 & TRN & \\
\hline CHEMBL1346630 & 688620 & 5.2 & 5.0357 & TRN & \\
\hline CHEMBL1545039 & 688620 & 4.45 & 4.9379 & TST & \\
\hline CHEMBL1432406 & 688620 & 5.15 & 5.0632 & TST & \\
\hline CHEMBL1418531 & 688620 & 4.5 & 5.2539 & TRN & \\
\hline CHEMBL1489691 & 688620 & 7.5003 & 5.0728 & TST & \\
\hline CHEMBL1602290 & 688620 & 4.75 & 4.6148 & TST & \\
\hline CHEMBL1432842 & 688620 & 4.55 & 4.7814 & TRN & \\
\hline CHEMBL1538177 & 688620 & 4.65 & 4.8097 & TST & \\
\hline CHEMBL3190854 & 688620 & 4.45 & 5.0773 & TST & \\
\hline
\end{tabular}




\begin{tabular}{|c|c|c|c|c|c|}
\hline \\
\hline CHEMBL1347474 & 688620 & 4.9 & 5.2687 & TRN & \\
\hline CHEMBL1352500 & 688620 & 5.25 & 5.1042 & TRN & \\
\hline CHEMBL3211942 & 688620 & 4.95 & 5.2699 & TST & \\
\hline CHEMBL1383840 & 688620 & 4.75 & 5.3047 & TRN & \\
\hline CHEMBL3195570 & 688620 & 5.65 & 5.6148 & TRN & \\
\hline CHEMBL3194348 & 688620 & 4.45 & 5.0164 & TST & \\
\hline CHEMBL1405854 & 688620 & 5.95 & 5.4992 & TRN & \\
\hline CHEMBL1464576 & 688620 & 4.45 & 5.1666 & TRN & \\
\hline CHEMBL1309918 & 688620 & 5.5 & 4.8578 & TRN & \\
\hline CHEMBL1489825 & 688620 & 5.7 & 5.7949 & TRN & \\
\hline CHEMBL1977478 & 688620 & 5.45 & 5.3153 & TST & \\
\hline CHEMBL1379373 & 688620 & 6.6 & 5.0759 & TRN & \\
\hline CHEMBL1428712 & 688620 & 5.9 & 5.0403 & TST & \\
\hline CHEMBL1452126 & 688620 & 5.45 & 4.9368 & TST & \\
\hline CHEMBL1443328 & 688620 & 4.95 & 4.8687 & TRN & \\
\hline CHEMBL1449745 & 688620 & 4.85 & 4.8801 & TRN & \\
\hline CHEMBL1985664 & 688620 & 5.5 & 4.8476 & TRN & \\
\hline CHEMBL1487514 & 688620 & 4.95 & 5.011 & TRN & \\
\hline CHEMBL3190455 & 688620 & 5.35 & 5.4174 & TRN & \\
\hline CHEMBL1477065 & 688620 & 4.45 & 4.9555 & TRN & \\
\hline CHEMBL1365869 & 688620 & 5.2 & 5.1616 & TRN & \\
\hline CHEMBL1447751 & 688620 & 4.45 & 4.8785 & TRN & \\
\hline CHEMBL1365927 & 688620 & 4.45 & 4.9718 & TRN & \\
\hline CHEMBL1438717 & 688620 & 5.0 & 4.6988 & TRN & \\
\hline CHEMBL1446570 & 688620 & 5.4 & 4.8301 & TRN & \\
\hline CHEMBL1346619 & 688620 & 4.9 & 4.8124 & TRN & \\
\hline CHEMBL1535196 & 688620 & 4.75 & 5.0613 & TRN & \\
\hline CHEMBL 2374050 & 688620 & 6.0 & 5.6686 & TST & \\
\hline CHEMBL1503766 & 688620 & 4.9 & 4.905 & TRN & \\
\hline CHEMBL1412910 & 688620 & 5.65 & 5.1972 & TRN & \\
\hline CHEMBL3209655 & 688620 & 4.9 & 4.9681 & TST & \\
\hline CHEMBL1588518 & 688620 & 4.9 & 5.0261 & TRN & \\
\hline CHEMBL1563594 & 688620 & 5.25 & 5.1219 & TRN & \\
\hline CHEMBL1334767 & 688620 & 5.35 & 5.392 & TRN & \\
\hline CHEMBL1346210 & 688620 & 4.7 & 4.9793 & TRN & \\
\hline CHEMBL1399866 & 688620 & 4.5 & 5.0114 & TRN & \\
\hline CHEMBL1325523 & 688620 & 4.95 & 4.9815 & TRN & \\
\hline CHEMBL1332903 & 688620 & 5.1 & 4.7486 & TRN & \\
\hline CHEMBL1969987 & 688620 & 4.95 & 4.9512 & TST & \\
\hline CHEMBL1586983 & 688620 & 4.65 & 4.7007 & TRN & \\
\hline CHEMBL1536607 & 688620 & 5.25 & 5.1654 & TRN & \\
\hline CHEMBL 3189478 & 688620 & 4.45 & 5.2466 & TRN & \\
\hline CHEMBL1713992 & 688620 & 5.7 & 4.9622 & TST & \\
\hline CHEMBL3196656 & 688620 & 5.35 & 5.00899 & 99999999995 & TRN \\
\hline CHEMBL1549513 & 688620 & 4.9 & 4.8736 & TRN & \\
\hline CHEMBL1368225 & 688620 & 5.25 & 4.9956 & TRN & \\
\hline CHEMBL1606927 & 688620 & 4.9 & 4.8467 & TRN & \\
\hline CHEMBL1534610 & 688620 & 5.45 & 5.2585 & TRN & \\
\hline
\end{tabular}




\begin{tabular}{|c|c|c|c|c|c|}
\hline \multicolumn{6}{|c|}{ Supplemental Table S2.txt } \\
\hline CHEMBL1612068 & 688620 & 4.65 & 4.9564 & TRN & \\
\hline CHEMBL 3195764 & 688620 & 6.4 & 5.7451 & TRN & \\
\hline CHEMBL1582111 & 688620 & 4.95 & 5.0561 & TST & \\
\hline CHEMBL1392869 & 688620 & 4.95 & 5.1246 & TRN & \\
\hline CHEMBL600034 & 688620 & 5.6 & 5.2548 & TRN & \\
\hline CHEMBL1335358 & 688620 & 4.55 & 4.8605 & TRN & \\
\hline CHEMBL1998643 & 688620 & 5.2 & 5.1836 & TRN & \\
\hline CHEMBL602990 & 688620 & 5.6 & 5.0873 & TRN & \\
\hline CHEMBL1478512 & 688620 & 5.3 & 5.3108 & TRN & \\
\hline CHEMBL1308619 & 688620 & 5.0 & 4.8537 & TRN & \\
\hline CHEMBL1964702 & 688620 & 6.3 & 5.8095 & TRN & \\
\hline CHEMBL1490867 & 688620 & 4.95 & 4.8386 & TST & \\
\hline CHEMBL1569094 & 688620 & 4.95 & 5.141 & TRN & \\
\hline CHEMBL1372450 & 688620 & 4.45 & 5.2646 & TST & \\
\hline CHEMBL3190722 & 688620 & 4.45 & 4.8776 & TRN & \\
\hline CHEMBL1360586 & 688620 & 5.2 & 4.9066 & TST & \\
\hline CHEMBL1385725 & 688620 & 9.0969 & 5.0354 & TST & \\
\hline CHEMBL1310095 & 688620 & 5.3 & 5.0402 & TST & \\
\hline CHEMBL1340034 & 688620 & 4.5 & 4.9286 & TST & \\
\hline CHEMBL19231 & 688620 & 4.5 & 4.8241 & TST & \\
\hline CHEMBL1321343 & 688620 & 4.6 & 4.8571 & TRN & \\
\hline CHEMBL1439675 & 688620 & 5.35 & 5.102 & TRN & \\
\hline CHEMBL1459602 & 688620 & 5.0 & 5.0202 & TST & \\
\hline CHEMBL1497909 & 688620 & 4.85 & 5.0749 & TRN & \\
\hline CHEMBL1368832 & 688620 & 4.85 & 4.6949 & TST & \\
\hline CHEMBL1535991 & 688620 & 4.45 & 4.967 & TRN & \\
\hline CHEMBL1398816 & 688620 & 4.45 & 5.0292 & TRN & \\
\hline CHEMBL1447742 & 688620 & 4.7 & 4.9342 & TRN & \\
\hline CHEMBL1530089 & 688620 & 5.75 & 5.5478 & TRN & \\
\hline CHEMBL 3198747 & 688620 & 5.75 & 5.3701 & TRN & \\
\hline CHEMBL1385337 & 688620 & 4.45 & 4.9834 & TST & \\
\hline CHEMBL1362448 & 688620 & 5.3 & 5.5379 & TST & \\
\hline CHEMBL1448265 & 688620 & 4.95 & 4.7891 & TST & \\
\hline CHEMBL 3211650 & 688620 & 4.8 & 5.2387 & TRN & \\
\hline CHEMBL1429276 & 688620 & 4.45 & 4.8568 & TRN & \\
\hline CHEMBL1398724 & 688620 & 4.8 & 5.0075 & TRN & \\
\hline CHEMBL1341356 & 688620 & 5.5 & 5.5616 & TRN & \\
\hline CHEMBL1565916 & 688620 & 5.2 & 5.0101 & TRN & \\
\hline CHEMBL1485466 & 688620 & 4.8 & 5.12299 & 7999999999 & TRN \\
\hline CHEMBL3197869 & 688620 & 5.5 & 5.1915 & TRN & \\
\hline CHEMBL1300250 & 688620 & 4.9 & 6.00700 & 0000000001 & TRN \\
\hline CHEMBL1976586 & 688620 & 5.95 & 5.6047 & TRN & \\
\hline CHEMBL1572120 & 688620 & 6.25 & 5.4528 & TRN & \\
\hline CHEMBL1364016 & 688620 & 5.15 & 5.0499 & TRN & \\
\hline CHEMBL1477884 & 688620 & 4.8 & 5.2743 & TRN & \\
\hline CHEMBL1610132 & 688620 & 4.9 & 5.0049 & TST & \\
\hline CHEMBL1506865 & 688620 & 4.6 & 5.0838 & TRN & \\
\hline CHEMBL1466222 & 688620 & 6.45 & 5.7591 & TRN & \\
\hline
\end{tabular}




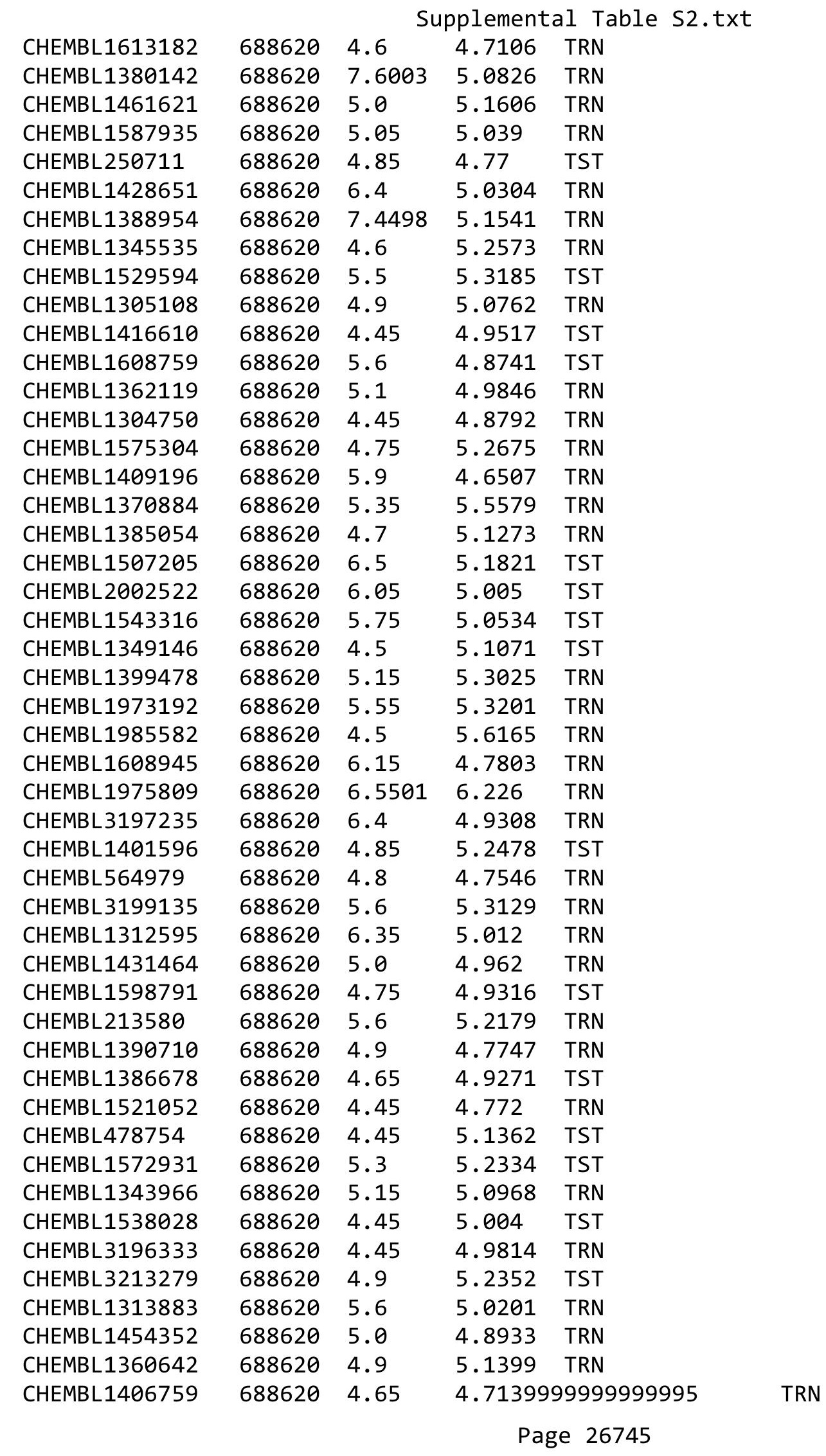




\begin{tabular}{|c|c|c|c|c|c|}
\hline \multicolumn{6}{|c|}{ Supplemental Table S2.txt } \\
\hline CHEMBL1448342 & 688620 & 4.45 & 5.0419 & TST & \\
\hline CHEMBL1541414 & 688620 & 4.95 & 5.0724 & TST & \\
\hline CHEMBL1364890 & 688620 & 4.6 & 5.0849 & TRN & \\
\hline CHEMBL 3196572 & 688620 & 5.0 & 4.9393 & TRN & \\
\hline CHEMBL1387172 & 688620 & 4.9 & 4.81800 & 00000000005 & TRN \\
\hline CHEMBL1419983 & 688620 & 4.6 & 4.8495 & TRN & \\
\hline CHEMBL1577645 & 688620 & 4.45 & 4.7526 & TRN & \\
\hline CHEMBL1552922 & 688620 & 4.95 & 5.0629 & TRN & \\
\hline CHEMBL1458515 & 688620 & 5.55 & 5.2199 & TRN & \\
\hline CHEMBL1609009 & 688620 & 4.9 & 5.171 & TRN & \\
\hline CHEMBL1414425 & 688620 & 5.35 & 5.2042 & TRN & \\
\hline CHEMBL 3214100 & 688620 & 5.5 & 5.3603 & TRN & \\
\hline CHEMBL1582324 & 688620 & 4.45 & 4.7497 & TRN & \\
\hline CHEMBL1350935 & 688620 & 4.85 & 5.194 & TRN & \\
\hline CHEMBL1309508 & 688620 & 4.9 & 5.0002 & TST & \\
\hline CHEMBL1445324 & 688620 & 5.4 & 5.1814 & TRN & \\
\hline CHEMBL1464391 & 688620 & 4.45 & 5.2733 & TST & \\
\hline CHEMBL1430574 & 688620 & 4.9 & 5.0577 & TRN & \\
\hline CHEMBL1383369 & 688620 & 4.45 & 4.7662 & TRN & \\
\hline CHEMBL1549711 & 688620 & 4.8 & 4.7915 & TRN & \\
\hline CHEMBL1609159 & 688620 & 4.85 & 4.9495 & TST & \\
\hline CHEMBL1365499 & 688620 & 4.8 & 5.1523 & TRN & \\
\hline CHEMBL1319756 & 688620 & 4.5 & 4.81800 & 00000000005 & TRN \\
\hline CHEMBL1316317 & 688620 & 4.9 & 4.7402 & TST & \\
\hline CHEMBL 3195559 & 688620 & 5.05 & 5.0647 & TRN & \\
\hline CHEMBL1387117 & 688620 & 4.45 & 4.7403 & TRN & \\
\hline CHEMBL1345610 & 688620 & 4.6 & 4.8313 & TRN & \\
\hline CHEMBL1372769 & 688620 & 4.45 & 4.9018 & TRN & \\
\hline CHEMBL3195235 & 688620 & 5.7 & 5.5125 & TRN & \\
\hline CHEMBL1321367 & 688620 & 4.95 & 5.0567 & TRN & \\
\hline CHEMBL3192277 & 688620 & 5.15 & 4.8879 & TRN & \\
\hline CHEMBL1606850 & 688620 & 4.95 & 4.8578 & TRN & \\
\hline CHEMBL1304261 & 688620 & 5.25 & 5.1145 & TRN & \\
\hline CHEMBL1314911 & 688620 & 4.65 & 4.9632 & TRN & \\
\hline CHEMBL1465353 & 688620 & 4.95 & 4.7104 & TRN & \\
\hline CHEMBL1458572 & 688620 & 5.15 & 5.0139 & TRN & \\
\hline CHEMBL3199485 & 688620 & 4.45 & 4.9302 & TRN & \\
\hline CHEMBL3193922 & 688620 & 5.1 & 5.1939 & TRN & \\
\hline CHEMBL1416441 & 688620 & 4.9 & 4.9565 & TRN & \\
\hline CHEMBL 3209829 & 688620 & 4.7 & 5.0647 & TRN & \\
\hline CHEMBL1524166 & 688620 & 5.55 & 5.2212 & TRN & \\
\hline CHEMBL1533989 & 688620 & 4.8 & 4.9925 & TRN & \\
\hline CHEMBL1421835 & 688620 & 4.9 & 4.987 & TRN & \\
\hline CHEMBL1307048 & 688620 & 4.75 & 4.9019 & TRN & \\
\hline CHEMBL 3392427 & 688620 & 5.4 & 5.5286 & TST & \\
\hline CHEMBL 3199806 & 688620 & 4.8 & 4.8728 & TRN & \\
\hline CHEMBL1311002 & 688620 & 4.7 & 4.9822 & TRN & \\
\hline CHEMBL1966512 & 688620 & 4.65 & 5.1031 & TRN & \\
\hline
\end{tabular}




\begin{tabular}{|c|c|c|c|c|}
\hline \multicolumn{5}{|c|}{ Supplemental Table s2.txt } \\
\hline CHEMBL3191308 & 688620 & 6.5501 & 5.9338 & TRN \\
\hline CHEMBL3195174 & 688620 & 5.65 & 5.0046 & TST \\
\hline CHEMBL1411739 & 688620 & 4.45 & 5.1308 & TRN \\
\hline CHEMBL1309808 & 688620 & 4.6 & 4.9296 & TRN \\
\hline CHEMBL1342213 & 688620 & 4.45 & 5.0107 & TRN \\
\hline CHEMBL1487316 & 688620 & 4.95 & 5.1881 & TRN \\
\hline CHEMBL3211678 & 688620 & 6.8499 & 5.1343 & TST \\
\hline CHEMBL1444635 & 688620 & 4.95 & 5.0243 & TRN \\
\hline CHEMBL1497106 & 688620 & 4.45 & 5.1043 & TRN \\
\hline CHEMBL1575370 & 688620 & 5.2 & 4.9576 & TRN \\
\hline CHEMBL 1321778 & 688620 & 5.2 & 4.9464 & TRN \\
\hline CHEMBL1362606 & 688620 & 4.6 & 4.8253 & TST \\
\hline CHEMBL1386689 & 688620 & 4.95 & 5.2926 & TRN \\
\hline CHEMBL1493097 & 688620 & 4.7 & 4.9602 & TRN \\
\hline CHEMBL1358820 & 688620 & 5.35 & 5.142 & TRN \\
\hline CHEMBL1576421 & 688620 & 6.4 & 5.0612 & TST \\
\hline CHEMBL1407775 & 688620 & 5.55 & 4.9634 & TST \\
\hline CHEMBL 3214488 & 688620 & 4.5 & 5.0184 & TRN \\
\hline CHEMBL1389588 & 688620 & 4.7 & 5.1824 & TRN \\
\hline CHEMBL94710 & 688620 & 4.85 & 4.9884 & TST \\
\hline CHEMBL1322937 & 688620 & 4.55 & 4.8934 & TRN \\
\hline CHEMBL3192791 & 688620 & 4.45 & 4.9976 & TRN \\
\hline CHEMBL3194138 & 688620 & 4.8 & 4.9778 & TRN \\
\hline CHEMBL1535446 & 688620 & 4.9 & 4.8189 & TRN \\
\hline CHEMBL3196826 & 688620 & 6.1 & 5.2672 & TRN \\
\hline CHEMBL 1423289 & 688620 & 4.95 & 5.1188 & TST \\
\hline CHEMBL1483191 & 688620 & 5.0 & 6.0662 & TRN \\
\hline CHEMBL1525214 & 688620 & 4.8 & 5.0579 & TST \\
\hline CHEMBL1408913 & 688620 & 5.0 & 4.9202 & TRN \\
\hline CHEMBL1993826 & 688620 & 4.45 & 4.9114 & TRN \\
\hline CHEMBL1582343 & 688620 & 5.0 & 4.9891 & TST \\
\hline CHEMBL 3145000 & 688620 & 4.45 & 4.9601 & TRN \\
\hline CHEMBL1607109 & 688620 & 4.45 & 5.0284 & TST \\
\hline CHEMBL1411156 & 688620 & 5.45 & 5.1916 & TRN \\
\hline CHEMBL3191660 & 688620 & 5.1 & 5.4014 & TRN \\
\hline CHEMBL1397325 & 688620 & 4.65 & 5.1199 & TRN \\
\hline CHEMBL1421805 & 688620 & 5.0 & 4.9608 & TRN \\
\hline CHEMBL1581709 & 688620 & 4.8 & 5.0242 & TRN \\
\hline CHEMBL1463750 & 688620 & 5.6 & 5.6525 & TRN \\
\hline CHEMBL1534743 & 688620 & 4.85 & 4.7307 & TRN \\
\hline CHEMBL1389480 & 688620 & 4.5 & 5.2918 & TRN \\
\hline CHEMBL1420176 & 688620 & 4.65 & 4.8233 & TST \\
\hline CHEMBL1503198 & 688620 & 4.45 & 5.0584 & TRN \\
\hline CHEMBL1584543 & 688620 & 4.65 & 5.1576 & TRN \\
\hline CHEMBL1402403 & 688620 & 4.55 & 5.142 & TST \\
\hline CHEMBL1372805 & 688620 & 4.7 & 4.8692 & TRN \\
\hline CHEMBL1392970 & 688620 & 4.9 & 5.0541 & TRN \\
\hline CHEMBL1469744 & 688620 & 4.8 & 5.1543 & TRN \\
\hline
\end{tabular}




\begin{tabular}{|c|c|c|c|c|}
\hline \multicolumn{5}{|c|}{ Supplemental Table S2.txt } \\
\hline CHEMBL1605045 & 688620 & 5.45 & 5.4635 & TRN \\
\hline CHEMBL1443722 & 688620 & 5.65 & 5.3247 & TST \\
\hline CHEMBL1566145 & 688620 & 5.65 & 5.5713 & TRN \\
\hline CHEMBL1312318 & 688620 & 5.6 & 5.4668 & TRN \\
\hline CHEMBL1606561 & 688620 & 4.8 & 5.2134 & TRN \\
\hline CHEMBL1371733 & 688620 & 4.7 & 4.9894 & TST \\
\hline CHEMBL1529095 & 688620 & 4.45 & 4.9431 & TRN \\
\hline CHEMBL1324168 & 688620 & 4.95 & 4.979 & TRN \\
\hline CHEMBL1495237 & 688620 & 4.9 & 4.9004 & TRN \\
\hline CHEMBL1542094 & 688620 & 4.75 & 5.1379 & TST \\
\hline CHEMBL1568108 & 688620 & 4.8 & 4.9273 & TRN \\
\hline CHEMBL 3145289 & 688620 & 4.9 & 5.0586 & TST \\
\hline CHEMBL1406024 & 688620 & 6.25 & 5.115 & TRN \\
\hline CHEMBL1582519 & 688620 & 5.9 & 4.9368 & TST \\
\hline CHEMBL1483329 & 688620 & 4.9 & 5.1866 & TRN \\
\hline CHEMBL1399952 & 688620 & 5.0 & 5.1163 & TRN \\
\hline CHEMBL1328140 & 688620 & 4.95 & 5.0708 & TRN \\
\hline CHEMBL1383312 & 688620 & 6.4 & 6.0309 & TST \\
\hline CHEMBL1415803 & 688620 & 4.45 & 4.7804 & TRN \\
\hline CHEMBL1587473 & 688620 & 5.2 & 5.0759 & TRN \\
\hline CHEMBL1494301 & 688620 & 4.95 & 4.8354 & TST \\
\hline CHEMBL 2000091 & 688620 & 4.45 & 5.0787 & TRN \\
\hline CHEMBL1502310 & 688620 & 4.9 & 5.0442 & TRN \\
\hline CHEMBL1478678 & 688620 & 4.45 & 5.033 & TRN \\
\hline CHEMBL1530915 & 688620 & 4.9 & 4.965 & TST \\
\hline CHEMBL1536811 & 688620 & 5.3 & 5.1098 & TST \\
\hline CHEMBL1447162 & 688620 & 4.9 & 4.8336 & TRN \\
\hline CHEMBL3196276 & 688620 & 6.1 & 5.3112 & TRN \\
\hline CHEMBL1596965 & 688620 & 5.85 & 5.3059 & TRN \\
\hline CHEMBL1462691 & 688620 & 4.8 & 5.2715 & TST \\
\hline CHEMBL1542172 & 688620 & 4.45 & 4.9605 & TRN \\
\hline CHEMBL1589565 & 688620 & 5.25 & 4.8564 & TRN \\
\hline CHEMBL1389594 & 688620 & 4.45 & 5.1247 & TRN \\
\hline CHEMBL1427471 & 688620 & 4.8 & 4.7923 & TRN \\
\hline CHEMBL1420893 & 688620 & 4.65 & 4.769 & TRN \\
\hline CHEMBL1371993 & 688620 & 4.85 & 4.8524 & TST \\
\hline CHEMBL 3192204 & 688620 & 5.65 & 5.1067 & TRN \\
\hline CHEMBL1380087 & 688620 & 4.8 & 5.3514 & TST \\
\hline CHEMBL1392651 & 688620 & 5.05 & 4.8886 & TST \\
\hline CHEMBL1363922 & 688620 & 4.9 & 5.2714 & TRN \\
\hline CHEMBL1517881 & 688620 & 5.4 & 5.1884 & TRN \\
\hline CHEMBL 1563520 & 688620 & 4.55 & 5.1173 & TRN \\
\hline CHEMBL1346973 & 688620 & 4.9 & 5.0341 & TST \\
\hline CHEMBL1517756 & 688620 & 4.75 & 5.1108 & TST \\
\hline CHEMBL1598785 & 688620 & 5.9 & 5.8364 & TRN \\
\hline CHEMBL1492285 & 688620 & 4.95 & 4.947 & TRN \\
\hline CHEMBL500430 & 688620 & 4.75 & 4.9977 & TRN \\
\hline CHEMBL1326489 & 688620 & 4.85 & 5.1208 & TRN \\
\hline
\end{tabular}




\begin{tabular}{|c|c|c|c|c|}
\hline \multicolumn{5}{|c|}{ Supplemental Table S2.txt } \\
\hline CHEMBL1340771 & 688620 & 4.45 & 4.7079 & TRN \\
\hline CHEMBL1303039 & 688620 & 4.45 & 5.2481 & TRN \\
\hline CHEMBL1549597 & 688620 & 4.95 & 5.0918 & TRN \\
\hline CHEMBL1488023 & 688620 & 6.4 & 5.6126 & TRN \\
\hline CHEMBL1606638 & 688620 & 4.45 & 4.7144 & TRN \\
\hline CHEMBL1426720 & 688620 & 5.0 & 5.1831 & TRN \\
\hline CHEMBL1569771 & 688620 & 5.2 & 5.4095 & TRN \\
\hline CHEMBL1367313 & 688620 & 4.95 & 5.135 & TRN \\
\hline CHEMBL1305278 & 688620 & 4.45 & 4.9714 & TRN \\
\hline CHEMBL1542815 & 688620 & 6.6499 & 5.1144 & TRN \\
\hline CHEMBL1493311 & 688620 & 4.45 & 4.8441 & TST \\
\hline CHEMBL1540026 & 688620 & 4.9 & 4.8156 & TST \\
\hline CHEMBL1309747 & 688620 & 4.7 & 5.0144 & TST \\
\hline CHEMBL1439629 & 688620 & 4.65 & 4.8485 & TRN \\
\hline CHEMBL1506193 & 688620 & 4.45 & 4.9255 & TRN \\
\hline CHEMBL1405152 & 688620 & 4.45 & 5.1161 & TST \\
\hline CHEMBL1432792 & 688620 & 4.95 & 5.0414 & TST \\
\hline CHEMBL1340339 & 688620 & 4.55 & 5.1347 & TRN \\
\hline CHEMBL1406072 & 688620 & 4.45 & 4.9675 & TRN \\
\hline CHEMBL1443240 & 688620 & 4.9 & 4.9987 & TRN \\
\hline CHEMBL1564471 & 688620 & 6.0 & 5.0311 & TRN \\
\hline CHEMBL3196810 & 688620 & 6.1 & 5.5488 & TRN \\
\hline CHEMBL1503260 & 688620 & 6.5 & 5.0945 & TRN \\
\hline CHEMBL3196283 & 688620 & 6.2 & 5.4528 & TRN \\
\hline CHEMBL1584506 & 688620 & 5.9 & 5.3709 & TRN \\
\hline CHEMBL1582976 & 688620 & 4.85 & 4.8555 & TRN \\
\hline CHEMBL1442874 & 688620 & 6.25 & 5.8423 & TRN \\
\hline CHEMBL3209293 & 688620 & 4.85 & 5.0767 & TST \\
\hline CHEMBL1586657 & 688620 & 6.95 & 5.1558 & TRN \\
\hline CHEMBL1533098 & 688620 & 5.5 & 5.1052 & TST \\
\hline CHEMBL1558816 & 688620 & 4.6 & 5.1612 & TST \\
\hline CHEMBL1451901 & 688620 & 5.65 & 5.7271 & TST \\
\hline CHEMBL1388435 & 688620 & 4.9 & 5.3176 & TRN \\
\hline CHEMBL1352429 & 688620 & 5.25 & 5.2532 & TST \\
\hline CHEMBL1361533 & 688620 & 5.6 & 5.4016 & TRN \\
\hline CHEMBL1450643 & 688620 & 5.0 & 5.0317 & TRN \\
\hline CHEMBL1558561 & 688620 & 5.6 & 5.4007 & TRN \\
\hline CHEMBL1308520 & 688620 & 5.4 & 4.9039 & TST \\
\hline CHEMBL1489880 & 688620 & 4.9 & 5.14 & TRN \\
\hline CHEMBL1492256 & 688620 & 4.8 & 5.546 & TRN \\
\hline CHEMBL1409721 & 688620 & 4.45 & 4.9024 & TRN \\
\hline CHEMBL1323258 & 688620 & 4.7 & 4.9628 & TRN \\
\hline CHEMBL1382857 & 688620 & 4.45 & 5.0282 & TRN \\
\hline CHEMBL1302807 & 688620 & 4.95 & 4.8171 & TRN \\
\hline CHEMBL1517642 & 688620 & 4.9 & 4.9438 & TRN \\
\hline CHEMBL1437745 & 688620 & 4.85 & 4.9531 & TST \\
\hline CHEMBL1527473 & 688620 & 5.5 & 5.1852 & TRN \\
\hline CHEMBL 272465 & 688620 & 5.3 & 5.0883 & TST \\
\hline
\end{tabular}




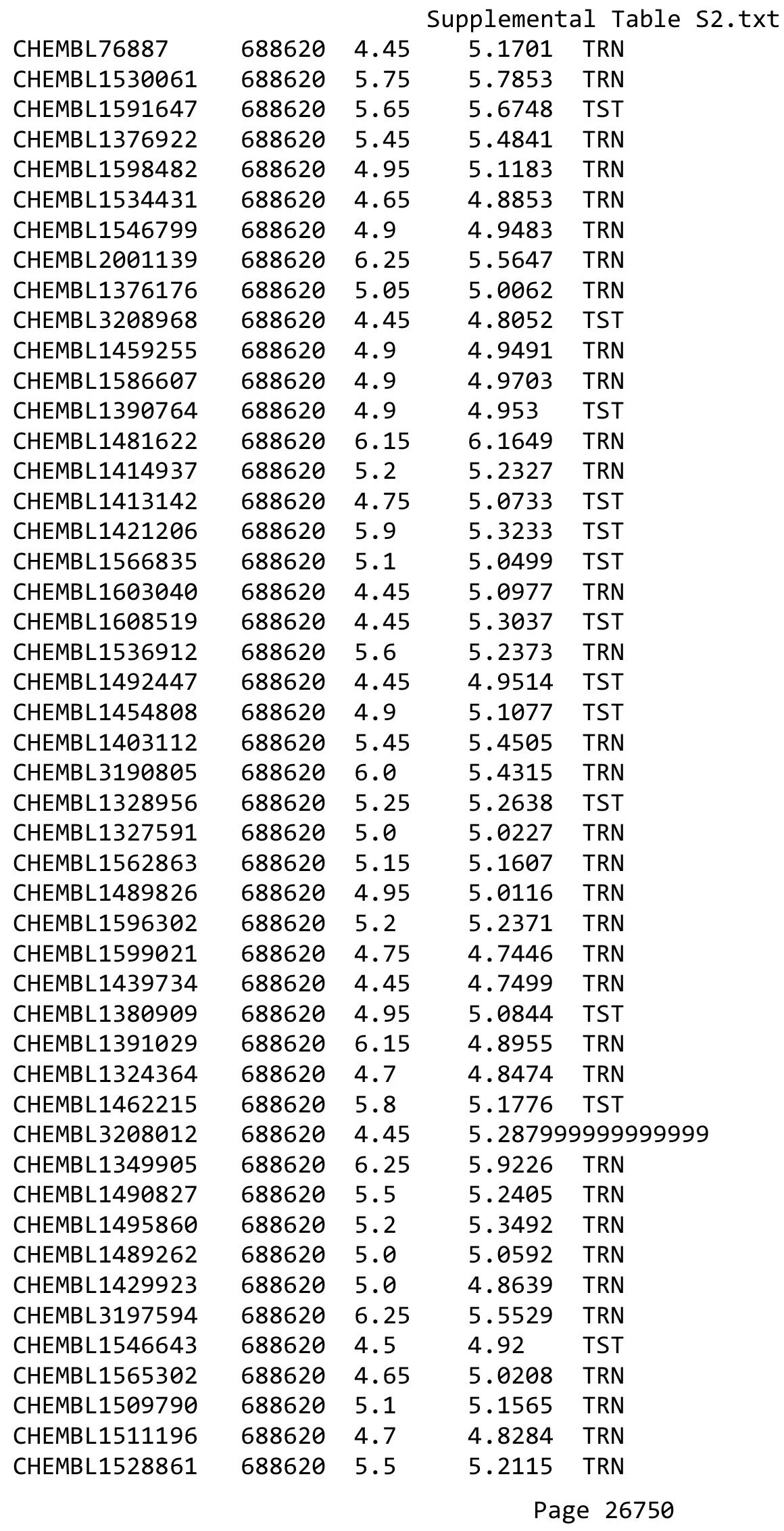




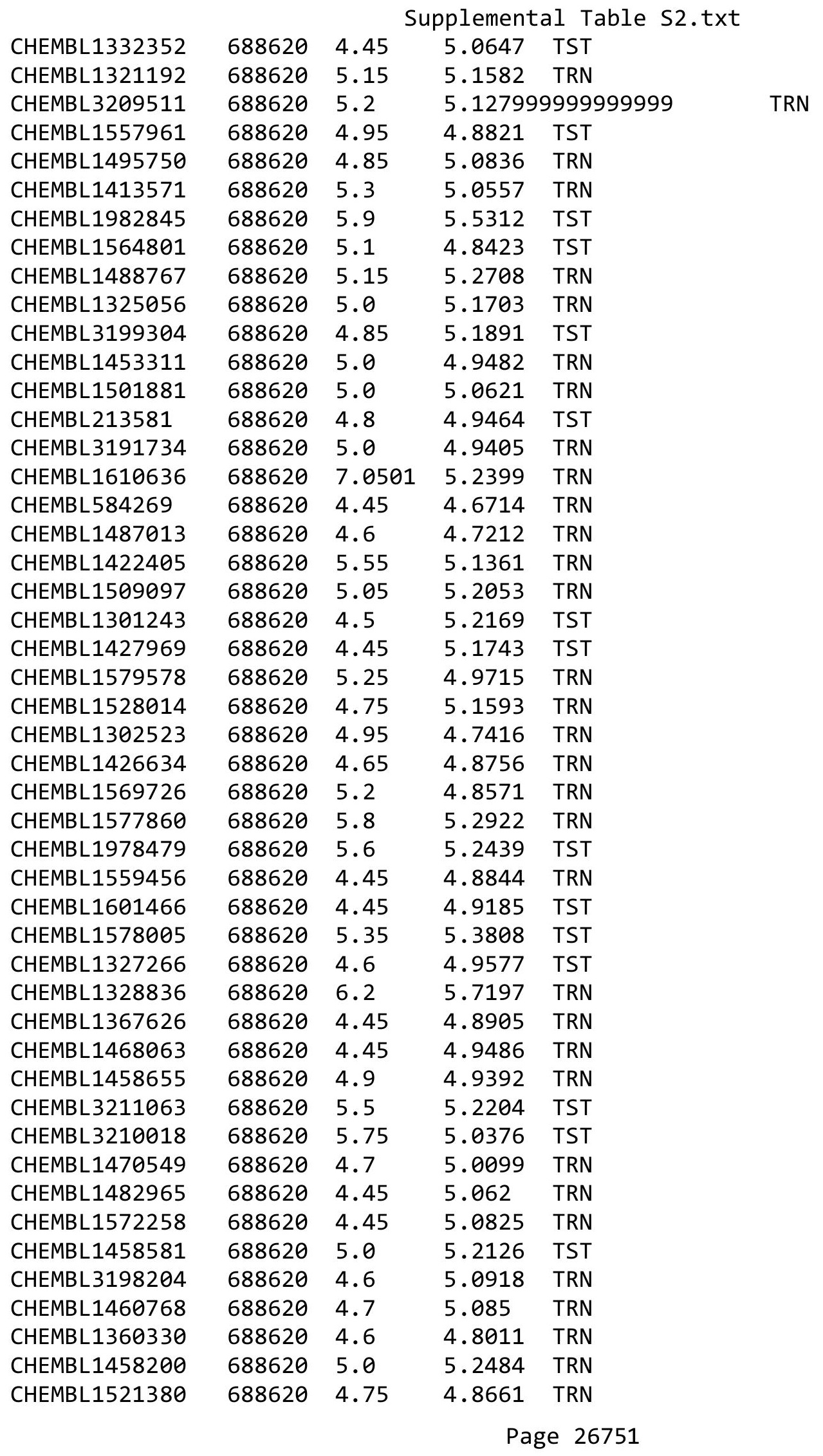




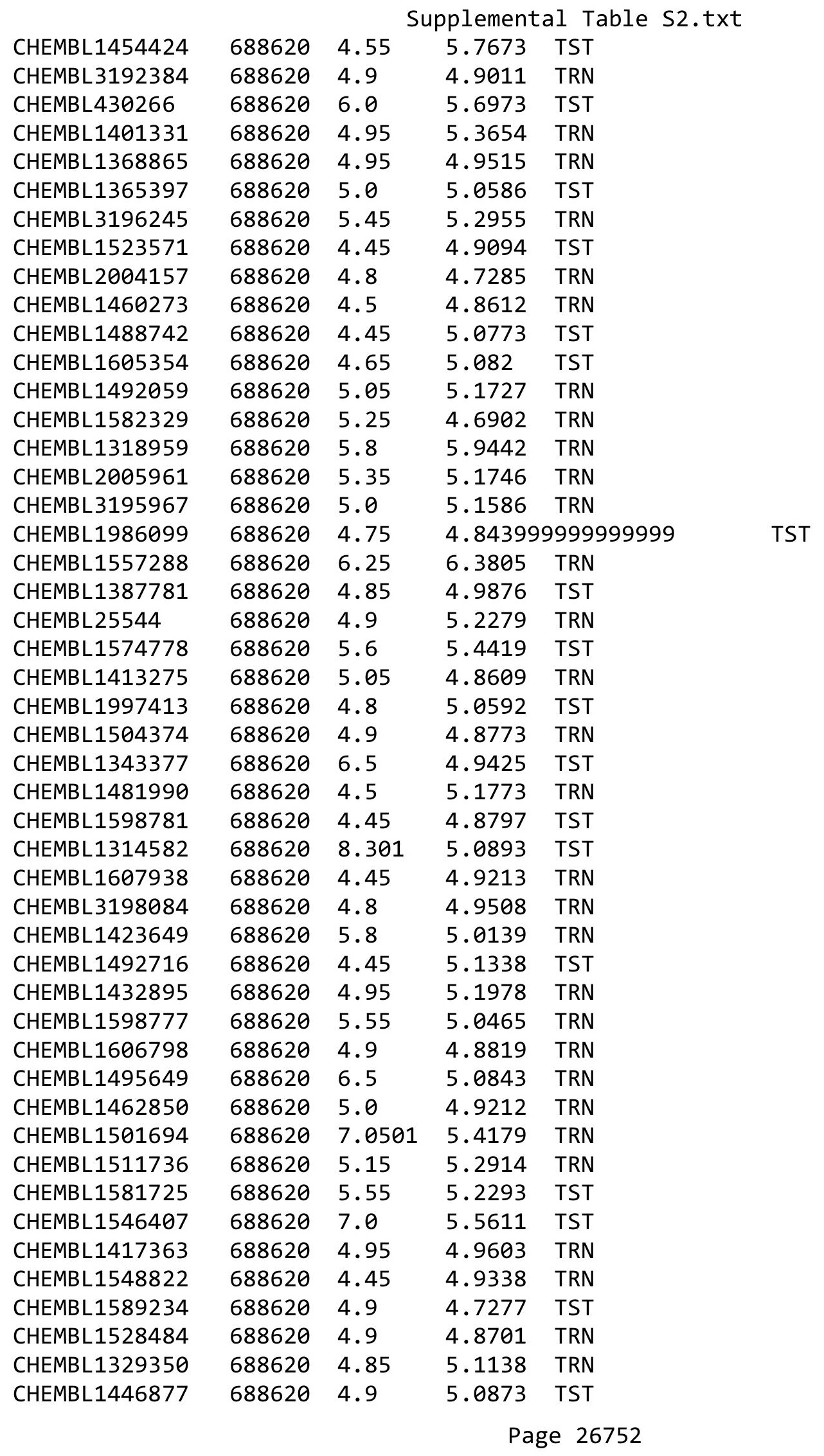




\begin{tabular}{|c|c|c|c|c|}
\hline \multicolumn{5}{|c|}{ Supplemental Table S2.txt } \\
\hline CHEMBL1567335 & 688620 & 5.1 & 5.2211 & TRN \\
\hline CHEMBL1393981 & 688620 & 5.65 & 5.0171 & TRN \\
\hline CHEMBL1481885 & 688620 & 4.8 & 5.0138 & TST \\
\hline CHEMBL1307254 & 688620 & 4.9 & 5.1728 & TRN \\
\hline CHEMBL3199203 & 688620 & 4.65 & 4.672 & TRN \\
\hline CHEMBL1445116 & 688620 & 4.45 & 5.3158 & TRN \\
\hline CHEMBL1407537 & 688620 & 5.4 & 4.9823 & TST \\
\hline CHEMBL1424290 & 688620 & 4.45 & 4.8997 & TST \\
\hline CHEMBL1461643 & 688620 & 4.45 & 4.9532 & TRN \\
\hline CHEMBL1586916 & 688620 & 5.05 & 4.9484 & TRN \\
\hline CHEMBL1577072 & 688620 & 6.45 & 5.7509 & TRN \\
\hline CHEMBL1445685 & 688620 & 5.3 & 5.092 & TST \\
\hline CHEMBL1342620 & 688620 & 5.45 & 5.0748 & TRN \\
\hline CHEMBL1501632 & 688620 & 5.1 & 5.0359 & TRN \\
\hline CHEMBL1358873 & 688620 & 5.05 & 4.8557 & TRN \\
\hline CHEMBL1305398 & 688620 & 4.95 & 5.1367 & TRN \\
\hline CHEMBL1430093 & 688620 & 4.9 & 5.0637 & TST \\
\hline CHEMBL1331374 & 688620 & 4.45 & 4.8168 & TRN \\
\hline CHEMBL1306856 & 688620 & 5.35 & 5.232 & TRN \\
\hline CHEMBL1446353 & 688620 & 4.5 & 5.1835 & TRN \\
\hline CHEMBL1379799 & 688620 & 4.45 & 5.0866 & TRN \\
\hline CHEMBL1538941 & 688620 & 4.7 & 5.0333 & TRN \\
\hline CHEMBL1547657 & 688620 & 5.2 & 5.0503 & TRN \\
\hline CHEMBL482050 & 688620 & 5.45 & 4.9453 & TST \\
\hline CHEMBL1503432 & 688620 & 4.8 & 5.023 & TRN \\
\hline CHEMBL3192613 & 688620 & 4.95 & 4.8443 & TRN \\
\hline CHEMBL1539975 & 688620 & 4.45 & 5.0782 & TRN \\
\hline CHEMBL1601355 & 688620 & 4.85 & 5.6478 & TRN \\
\hline CHEMBL1555761 & 688620 & 4.95 & 5.0458 & TRN \\
\hline CHEMBL601618 & 688620 & 4.45 & 5.1498 & TST \\
\hline CHEMBL1979243 & 688620 & 5.8 & 5.0438 & TRN \\
\hline CHEMBL1612295 & 688620 & 5.0 & 5.0408 & TRN \\
\hline CHEMBL1608390 & 688620 & 4.85 & 5.1165 & TRN \\
\hline CHEMBL1385190 & 688620 & 4.8 & 5.0089 & TST \\
\hline CHEMBL1309476 & 688620 & 5.5 & 4.9334 & TST \\
\hline CHEMBL1449393 & 688620 & 5.25 & 5.1995 & TRN \\
\hline CHEMBL1337817 & 688620 & 5.4 & 5.3087 & TRN \\
\hline CHEMBL1382329 & 688620 & 4.9 & 4.6925 & TRN \\
\hline CHEMBL1465372 & 688620 & 5.0 & 4.6841 & TRN \\
\hline CHEMBL3193123 & 688620 & 4.7 & 4.9553 & TST \\
\hline CHEMBL1353392 & 688620 & 5.3 & 5.2032 & TRN \\
\hline CHEMBL1380041 & 688620 & 5.15 & 4.9254 & TRN \\
\hline CHEMBL1594757 & 688620 & 5.9 & 4.9446 & TST \\
\hline CHEMBL1368469 & 688620 & 4.95 & 5.2181 & TRN \\
\hline CHEMBL1454602 & 688620 & 6.15 & 5.4846 & TRN \\
\hline CHEMBL3213492 & 688620 & 4.65 & 4.9887 & TRN \\
\hline CHEMBL1313983 & 688620 & 4.8 & 4.9946 & TRN \\
\hline CHEMBL1426309 & 688620 & 4.8 & 5.3445 & TRN \\
\hline
\end{tabular}




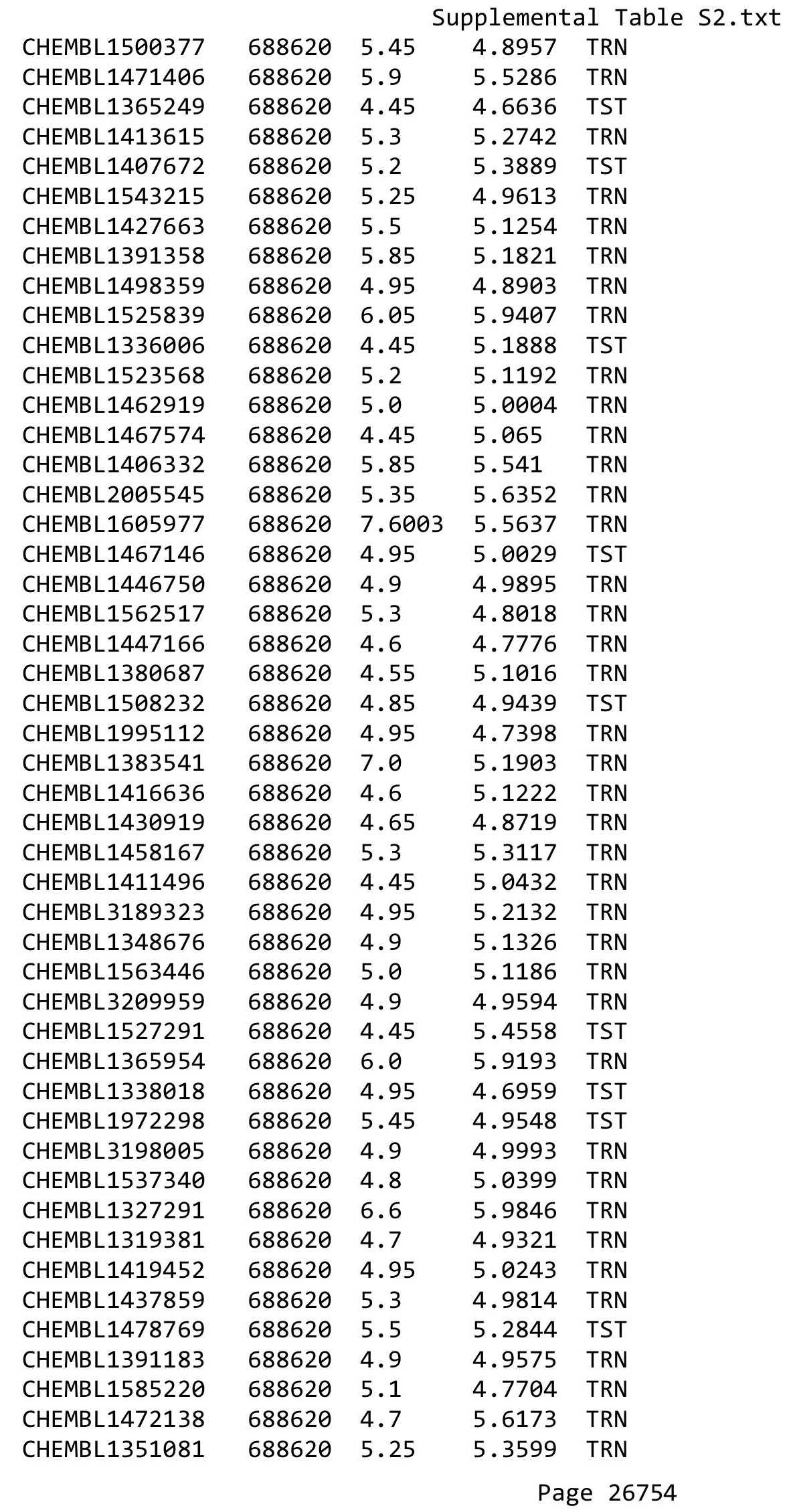




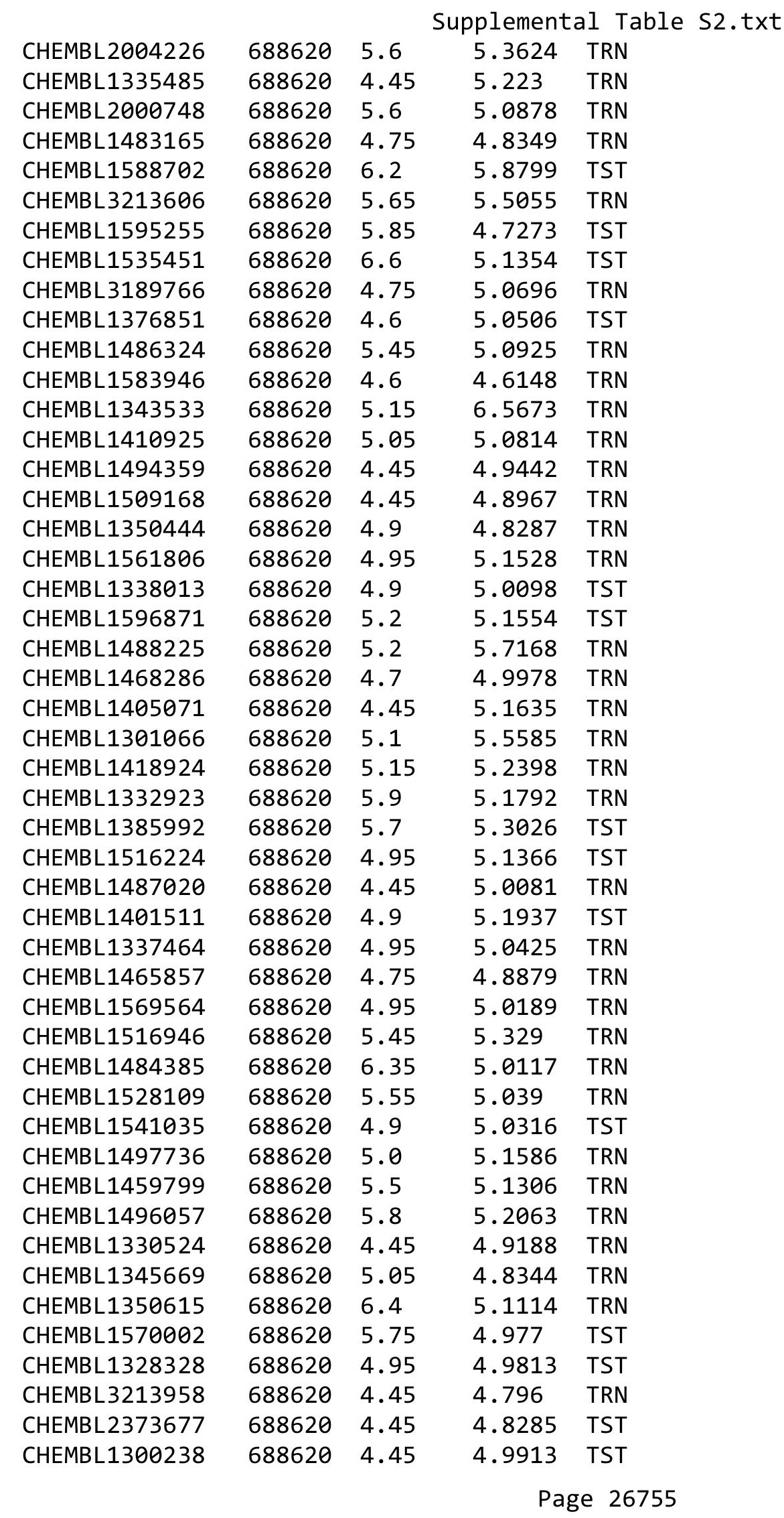




\begin{tabular}{|c|c|c|c|c|}
\hline \multicolumn{5}{|c|}{ Supplemental Table S2.txt } \\
\hline CHEMBL1345328 & 688620 & 4.5 & 5.0797 & TST \\
\hline CHEMBL34450 & 688620 & 4.85 & 4.808 & TST \\
\hline CHEMBL1486012 & 688620 & 4.8 & 5.0931 & TRN \\
\hline CHEMBL 3189178 & 688620 & 5.45 & 5.2545 & TRN \\
\hline CHEMBL1413858 & 688620 & 4.85 & 5.3123 & TRN \\
\hline CHEMBL1464635 & 688620 & 4.95 & 5.1179 & TRN \\
\hline CHEMBL1983650 & 688620 & 5.9 & 5.6434 & TRN \\
\hline CHEMBL1536647 & 688620 & 4.7 & 5.2862 & TRN \\
\hline CHEMBL1379401 & 688620 & 5.25 & 5.13 & TST \\
\hline CHEMBL1518221 & 688620 & 4.8 & 5.064 & TRN \\
\hline CHEMBL1498561 & 688620 & 4.65 & 4.8016 & TST \\
\hline CHEMBL588749 & 688620 & 4.9 & 5.235 & TRN \\
\hline CHEMBL1414355 & 688620 & 4.65 & 5.1194 & TST \\
\hline CHEMBL1582641 & 688620 & 4.75 & 4.8237 & TRN \\
\hline CHEMBL1543446 & 688620 & 4.65 & 5.0235 & TRN \\
\hline CHEMBL1542313 & 688620 & 4.6 & 4.7648 & TRN \\
\hline CHEMBL1527440 & 688620 & 4.8 & 5.0861 & TST \\
\hline CHEMBL1484809 & 688620 & 4.65 & 5.005 & TST \\
\hline CHEMBL1510959 & 688620 & 4.95 & 5.0895 & TST \\
\hline CHEMBL1450551 & 688620 & 4.5 & 5.0931 & TST \\
\hline CHEMBL1452537 & 688620 & 4.7 & 4.9384 & TRN \\
\hline CHEMBL1518824 & 688620 & 5.1 & 4.6355 & TRN \\
\hline CHEMBL1454886 & 688620 & 4.7 & 5.0186 & TRN \\
\hline CHEMBL1456286 & 688620 & 4.75 & 4.9691 & TST \\
\hline CHEMBL 3214584 & 688620 & 4.45 & 5.2529 & TRN \\
\hline CHEMBL1516974 & 688620 & 5.0 & 4.9041 & TRN \\
\hline CHEMBL1360155 & 688620 & 4.7 & 4.8737 & TST \\
\hline CHEMBL1359269 & 688620 & 4.45 & 4.9548 & TRN \\
\hline CHEMBL1467697 & 688620 & 5.05 & 5.3423 & TRN \\
\hline CHEMBL1302710 & 688620 & 5.8 & 5.0838 & TST \\
\hline CHEMBL604116 & 688620 & 5.25 & 5.2437 & TRN \\
\hline CHEMBL1585988 & 688620 & 4.5 & 4.822 & TST \\
\hline CHEMBL1377067 & 688620 & 5.4 & 5.3427 & TRN \\
\hline CHEMBL1545129 & 688620 & 6.2 & 5.0968 & TRN \\
\hline CHEMBL1381133 & 688620 & 6.8499 & 5.1324 & TRN \\
\hline CHEMBL1608010 & 688620 & 4.8 & 5.109 & TRN \\
\hline CHEMBL 3189743 & 688620 & 6.35 & 5.7132 & TRN \\
\hline CHEMBL1610372 & 688620 & 4.9 & 4.8279 & TRN \\
\hline CHEMBL1564646 & 688620 & 4.45 & 4.9374 & TRN \\
\hline CHEMBL1383650 & 688620 & 5.5 & 5.0488 & TST \\
\hline CHEMBL1506069 & 688620 & 5.85 & 5.7974 & TRN \\
\hline CHEMBL3209662 & 688620 & 5.05 & 5.0672 & TST \\
\hline CHEMBL3195783 & 688620 & 4.85 & 5.2854 & TRN \\
\hline CHEMBL1346213 & 688620 & 4.4 & 5.1118 & TST \\
\hline CHEMBL1561085 & 688620 & 4.7 & 5.8601 & TRN \\
\hline CHEMBL1545022 & 688620 & 5.45 & 5.0235 & TRN \\
\hline CHEMBL1471795 & 688620 & 4.95 & 4.7679 & TRN \\
\hline CHEMBL3199919 & 688620 & 4.8 & 4.7531 & TRN \\
\hline
\end{tabular}




\begin{tabular}{|c|c|c|c|c|c|}
\hline \multicolumn{6}{|c|}{ Supplemental Table S2.txt } \\
\hline CHEMBL1413127 & 688620 & 4.45 & 4.9972 & TST & \\
\hline CHEMBL1563360 & 688620 & 4.45 & 4.7636 & TRN & \\
\hline CHEMBL1449937 & 688620 & 4.75 & 5.0062 & TST & \\
\hline CHEMBL1510142 & 688620 & 4.95 & 4.9628 & TST & \\
\hline CHEMBL1534756 & 688620 & 5.4 & 4.6801 & TST & \\
\hline CHEMBL23731 & 688620 & 5.5 & 4.852 & TST & \\
\hline CHEMBL1438122 & 688620 & 4.95 & 5.0888 & TRN & \\
\hline CHEMBL1589031 & 688620 & 5.25 & 5.0867 & TST & \\
\hline CHEMBL1494338 & 688620 & 5.65 & 5.1763 & TRN & \\
\hline CHEMBL1488517 & 688620 & 4.45 & 5.2336 & TST & \\
\hline CHEMBL1541271 & 688620 & 6.95 & 5.1617 & TRN & \\
\hline CHEMBL1601378 & 688620 & 4.75 & 5.0764 & TRN & \\
\hline CHEMBL236268 & 688620 & 4.9 & 4.7109 & TRN & \\
\hline CHEMBL1511274 & 688620 & 4.45 & 4.6819 & TRN & \\
\hline CHEMBL3199645 & 688620 & 5.25 & 5.2761 & TRN & \\
\hline CHEMBL1460428 & 688620 & 5.45 & 5.1272 & TST & \\
\hline CHEMBL1391266 & 688620 & 4.45 & 5.25299 & 9999999999 & TRN \\
\hline CHEMBL1467298 & 688620 & 4.85 & 5.0394 & TST & \\
\hline CHEMBL3190073 & 688620 & 4.9 & 5.1723 & TRN & \\
\hline CHEMBL1606916 & 688620 & 5.15 & 5.0079 & TRN & \\
\hline CHEMBL1349182 & 688620 & 4.85 & 5.1945 & TRN & \\
\hline CHEMBL1555088 & 688620 & 4.9 & 5.1485 & TRN & \\
\hline CHEMBL1557673 & 688620 & 5.25 & 4.846 & TRN & \\
\hline CHEMBL1485294 & 688620 & 4.9 & 4.787 & TRN & \\
\hline CHEMBL1564243 & 688620 & 5.9 & 4.9855 & TRN & \\
\hline CHEMBL3195674 & 688620 & 5.35 & 5.1002 & TRN & \\
\hline CHEMBL1488050 & 688620 & 5.0 & 5.0181 & TRN & \\
\hline CHEMBL1393598 & 688620 & 5.05 & 5.1768 & TRN & \\
\hline CHEMBL1453524 & 688620 & 4.95 & 4.9257 & TRN & \\
\hline CHEMBL1401194 & 688620 & 8.0 & 5.0025 & TST & \\
\hline CHEMBL1419619 & 688620 & 4.75 & 4.8038 & TRN & \\
\hline CHEMBL1478490 & 688620 & 5.3 & 5.0053 & TST & \\
\hline CHEMBL3210728 & 688620 & 4.75 & 5.2891 & TRN & \\
\hline CHEMBL1456632 & 688620 & 5.75 & 5.7516 & TRN & \\
\hline CHEMBL1431211 & 688620 & 4.95 & 4.8227 & TST & \\
\hline CHEMBL1470131 & 688620 & 5.5 & 5.0225 & TRN & \\
\hline CHEMBL1438908 & 688620 & 5.05 & 5.1163 & TRN & \\
\hline CHEMBL1578665 & 688620 & 5.55 & 5.0049 & TST & \\
\hline CHEMBL1458446 & 688620 & 6.1 & 5.5122 & TRN & \\
\hline CHEMBL1541263 & 688620 & 4.45 & 5.1087 & TRN & \\
\hline CHEMBL1425928 & 688620 & 5.55 & 5.0965 & TRN & \\
\hline CHEMBL388025 & 688620 & 5.7 & 5.265 & TRN & \\
\hline CHEMBL1414798 & 688620 & 5.5 & 4.8269 & TRN & \\
\hline CHEMBL1407386 & 688620 & 5.0 & 5.0284 & TST & \\
\hline CHEMBL1566737 & 688620 & 5.0 & 4.9725 & TRN & \\
\hline CHEMBL1303825 & 688620 & 5.2 & 5.1356 & TRN & \\
\hline CHEMBL1353938 & 688620 & 5.85 & 4.9638 & TRN & \\
\hline CHEMBL1331816 & 688620 & 6.25 & 5.6427 & TRN & \\
\hline
\end{tabular}




\begin{tabular}{|c|c|c|c|c|}
\hline \multicolumn{5}{|c|}{ Supplemental Table S2.txt } \\
\hline CHEMBL591598 & 688620 & 4.65 & 5.1138 & TRN \\
\hline CHEMBL 3189856 & 688620 & 5.3 & 5.2017 & TRN \\
\hline CHEMBL1345537 & 688620 & 4.95 & 4.9035 & TRN \\
\hline CHEMBL1415260 & 688620 & 4.45 & 4.9122 & TRN \\
\hline CHEMBL1461748 & 688620 & 6.9 & 4.9139 & TRN \\
\hline CHEMBL1600295 & 688620 & 5.8 & 4.9941 & TST \\
\hline CHEMBL1526878 & 688620 & 4.95 & 4.7951 & TRN \\
\hline CHEMBL1393831 & 688620 & 5.4 & 5.2519 & TRN \\
\hline CHEMBL1404818 & 688620 & 4.7 & 5.053 & TRN \\
\hline CHEMBL1398931 & 688620 & 5.25 & 4.9083 & TRN \\
\hline CHEMBL1469712 & 688620 & 4.45 & 5.0008 & TRN \\
\hline CHEMBL1406859 & 688620 & 4.6 & 5.2698 & TRN \\
\hline CHEMBL3192299 & 688620 & 7.15 & 5.9761 & TRN \\
\hline CHEMBL1319374 & 688620 & 4.65 & 5.0005 & TRN \\
\hline CHEMBL1502274 & 688620 & 5.2 & 5.2913 & TRN \\
\hline CHEMBL1300645 & 688620 & 4.75 & 4.8959 & TRN \\
\hline CHEMBL1543611 & 688620 & 5.4 & 5.1205 & TST \\
\hline CHEMBL1430201 & 688620 & 5.1 & 4.9508 & TST \\
\hline CHEMBL3208520 & 688620 & 4.7 & 5.1208 & TST \\
\hline CHEMBL3348955 & 688620 & 6.1 & 5.4714 & TST \\
\hline CHEMBL1588513 & 688620 & 5.6 & 5.4921 & TST \\
\hline CHEMBL1532627 & 688620 & 4.7 & 5.0498 & TRN \\
\hline CHEMBL1352607 & 688620 & 4.45 & 5.0148 & TST \\
\hline CHEMBL1568681 & 688620 & 7.4001 & 4.97 & TST \\
\hline CHEMBL1348119 & 688620 & 5.35 & 6.0186 & TRN \\
\hline CHEMBL1609380 & 688620 & 4.75 & 5.0256 & TST \\
\hline CHEMBL1605568 & 688620 & 5.0 & 5.0281 & TRN \\
\hline CHEMBL3194048 & 688620 & 5.9 & 5.0707 & TRN \\
\hline CHEMBL1506427 & 688620 & 4.8 & 4.7803 & TRN \\
\hline CHEMBL1522449 & 688620 & 5.0 & 5.0355 & TRN \\
\hline CHEMBL1504240 & 688620 & 4.5 & 4.99 & TRN \\
\hline CHEMBL3195170 & 688620 & 4.85 & 4.7852 & TRN \\
\hline CHEMBL1538235 & 688620 & 4.8 & 5.0975 & TRN \\
\hline CHEMBL1564797 & 688620 & 4.45 & 4.8915 & TST \\
\hline CHEMBL1557192 & 688620 & 4.95 & 4.8984 & TST \\
\hline CHEMBL1576151 & 688620 & 4.95 & 4.9073 & TRN \\
\hline CHEMBL1974063 & 688620 & 5.95 & 4.8615 & TST \\
\hline CHEMBL3193361 & 688620 & 5.45 & 5.1776 & TST \\
\hline CHEMBL1971316 & 688620 & 4.95 & 5.025 & TRN \\
\hline CHEMBL1459603 & 688620 & 4.5 & 4.8486 & TRN \\
\hline CHEMBL1608182 & 688620 & 5.25 & 5.0686 & TST \\
\hline CHEMBL1393562 & 688620 & 4.65 & 4.8994 & TST \\
\hline CHEMBL1390349 & 688620 & 5.0 & 4.9471 & TRN \\
\hline CHEMBL1399844 & 688620 & 4.6 & 4.6578 & TST \\
\hline CHEMBL1455571 & 688620 & 4.45 & 5.0678 & TRN \\
\hline CHEMBL1545702 & 688620 & 6.25 & 5.6877 & TST \\
\hline CHEMBL1310546 & 688620 & 4.9 & 4.8959 & TRN \\
\hline CHEMBL 221612 & 688620 & 5.2 & 4.9604 & TRN \\
\hline
\end{tabular}




\begin{tabular}{|c|c|c|c|c|c|}
\hline \multicolumn{6}{|c|}{ Supplemental Table s2.txt } \\
\hline CHEMBL1386774 & 688620 & 5.0 & 5.0581 & TRN & \\
\hline CHEMBL192566 & 688620 & 4.45 & 4.5812 & TST & \\
\hline CHEMBL1523784 & 688620 & 4.7 & 5.0128 & TRN & \\
\hline CHEMBL1543742 & 688620 & 5.3 & 5.3046 & TRN & \\
\hline CHEMBL1301374 & 688620 & 5.55 & 5.591 & TRN & \\
\hline CHEMBL 1454030 & 688620 & 4.95 & 5.0724 & TRN & \\
\hline CHEMBL1966289 & 688620 & 4.65 & 5.1917 & TRN & \\
\hline CHEMBL1360098 & 688620 & 4.75 & 5.13299 & 9999999999 & TRN \\
\hline CHEMBL1424226 & 688620 & 4.75 & 5.1141 & TRN & \\
\hline CHEMBL1414568 & 688620 & 5.35 & 5.1815 & TRN & \\
\hline CHEMBL1319880 & 688620 & 4.7 & 4.7671 & TRN & \\
\hline CHEMBL1585064 & 688620 & 4.85 & 5.2873 & TRN & \\
\hline CHEMBL1575790 & 688620 & 4.65 & 4.7164 & TRN & \\
\hline CHEMBL 3198445 & 688620 & 4.55 & 5.2879 & TRN & \\
\hline CHEMBL1329612 & 688620 & 4.5 & 5.1563 & TRN & \\
\hline CHEMBL1544881 & 688620 & 4.8 & 4.8135 & TST & \\
\hline CHEMBL3193299 & 688620 & 4.7 & 5.0024 & TST & \\
\hline CHEMBL1604325 & 688620 & 4.75 & 5.1082 & TST & \\
\hline CHEMBL1300592 & 688620 & 4.7 & 4.814 & TRN & \\
\hline CHEMBL1333049 & 688620 & 5.1 & 5.186 & TST & \\
\hline CHEMBL1537044 & 688620 & 5.45 & 5.0475 & TRN & \\
\hline CHEMBL1452136 & 688620 & 5.1 & 5.1257 & TST & \\
\hline CHEMBL1363392 & 688620 & 4.9 & 5.1571 & TRN & \\
\hline CHEMBL1462059 & 688620 & 4.85 & 4.8676 & TRN & \\
\hline CHEMBL1609633 & 688620 & 4.95 & 4.7954 & TRN & \\
\hline CHEMBL1427175 & 688620 & 4.45 & 5.0134 & TRN & \\
\hline CHEMBL1347491 & 688620 & 5.15 & 5.2643 & TRN & \\
\hline CHEMBL 3145363 & 688620 & 6.5501 & 5.9896 & TRN & \\
\hline CHEMBL1546056 & 688620 & 5.1 & 4.8804 & TRN & \\
\hline CHEMBL1611588 & 688620 & 4.75 & 4.9737 & TRN & \\
\hline CHEMBL3198812 & 688620 & 5.1 & 5.0424 & TRN & \\
\hline CHEMBL1503107 & 688620 & 4.8 & 4.791 & TRN & \\
\hline CHEMBL1305535 & 688620 & 4.95 & 4.9701 & TRN & \\
\hline CHEMBL1552542 & 688620 & 4.45 & 4.6607 & TRN & \\
\hline CHEMBL1452688 & 688620 & 4.45 & 5.0044 & TST & \\
\hline CHEMBL1422777 & 688620 & 6.05 & 5.0963 & TRN & \\
\hline CHEMBL1528592 & 688620 & 4.85 & 4.9367 & TRN & \\
\hline CHEMBL1327001 & 688620 & 5.65 & 5.1197 & TRN & \\
\hline CHEMBL1486183 & 688620 & 5.15 & 5.1312 & TST & \\
\hline CHEMBL1520140 & 688620 & 5.0 & 4.8925 & TRN & \\
\hline CHEMBL1480548 & 688620 & 5.55 & 5.3772 & TRN & \\
\hline CHEMBL1411547 & 688620 & 5.6 & 5.1329 & TRN & \\
\hline CHEMBL1363034 & 688620 & 4.8 & 4.8973 & TRN & \\
\hline CHEMBL1417167 & 688620 & 6.0 & 5.5775 & TRN & \\
\hline CHEMBL1496065 & 688620 & 5.2 & 5.0824 & TRN & \\
\hline CHEMBL1588695 & 688620 & 5.0 & 5.2092 & TRN & \\
\hline CHEMBL1576168 & 688620 & 4.9 & 4.8481 & TRN & \\
\hline CHEMBL1395007 & 688620 & 5.5 & 5.0403 & TRN & \\
\hline
\end{tabular}




\begin{tabular}{|c|c|c|c|c|}
\hline \multicolumn{5}{|c|}{ Supplemental Table S2.txt } \\
\hline CHEMBL1577393 & 688620 & 4.45 & 4.8865 & TRN \\
\hline CHEMBL1384249 & 688620 & 5.0 & 5.1425 & TRN \\
\hline CHEMBL3209027 & 688620 & 4.45 & 5.0303 & TRN \\
\hline CHEMBL1335850 & 688620 & 4.75 & 5.0619 & TRN \\
\hline CHEMBL1539203 & 688620 & 4.45 & 5.0258 & TST \\
\hline CHEMBL3194869 & 688620 & 4.45 & 5.0783 & TRN \\
\hline CHEMBL 252419 & 688620 & 4.45 & 4.9458 & TRN \\
\hline CHEMBL1507818 & 688620 & 4.45 & 5.1044 & TRN \\
\hline CHEMBL1505192 & 688620 & 4.5 & 4.9984 & TRN \\
\hline CHEMBL3210407 & 688620 & 4.95 & 4.9022 & TRN \\
\hline CHEMBL 222556 & 688620 & 5.5 & 5.1226 & TRN \\
\hline CHEMBL1309639 & 688620 & 4.7 & 5.1183 & TST \\
\hline CHEMBL1470060 & 688620 & 4.85 & 5.155 & TRN \\
\hline CHEMBL1419254 & 688620 & 5.45 & 4.9854 & TRN \\
\hline CHEMBL1495273 & 688620 & 4.45 & 5.1215 & TRN \\
\hline CHEMBL3190335 & 688620 & 4.9 & 5.2305 & TRN \\
\hline CHEMBL1333470 & 688620 & 4.9 & 4.8444 & TRN \\
\hline CHEMBL1881714 & 688620 & 5.55 & 5.4521 & TRN \\
\hline CHEMBL1430506 & 688620 & 4.65 & 4.9535 & TRN \\
\hline CHEMBL1547326 & 688620 & 4.9 & 5.0186 & TRN \\
\hline CHEMBL1457637 & 688620 & 4.85 & 5.0119 & TRN \\
\hline CHEMBL1385690 & 688620 & 5.25 & 5.1535 & TRN \\
\hline CHEMBL1541518 & 688620 & 5.25 & 5.2292 & TRN \\
\hline CHEMBL1608596 & 688620 & 5.7 & 5.269 & TRN \\
\hline CHEMBL1560760 & 688620 & 5.4 & 5.7317 & TRN \\
\hline CHEMBL1331628 & 688620 & 4.7 & 4.8585 & TST \\
\hline CHEMBL1488131 & 688620 & 4.85 & 4.6855 & TST \\
\hline CHEMBL1350580 & 688620 & 5.15 & 5.0394 & TST \\
\hline CHEMBL1456201 & 688620 & 5.55 & 5.1798 & TST \\
\hline CHEMBL1353629 & 688620 & 4.75 & 4.8472 & TRN \\
\hline CHEMBL1493838 & 688620 & 4.65 & 4.9767 & TRN \\
\hline CHEMBL1471930 & 688620 & 4.5 & 5.1551 & TST \\
\hline CHEMBL3194024 & 688620 & 5.0 & 5.1387 & TRN \\
\hline CHEMBL1300443 & 688620 & 5.5 & 5.1706 & TRN \\
\hline CHEMBL1339303 & 688620 & 4.85 & 4.8493 & TRN \\
\hline CHEMBL1371991 & 688620 & 4.5 & 4.915 & TRN \\
\hline CHEMBL1367440 & 688620 & 4.45 & 5.0637 & TST \\
\hline CHEMBL1458468 & 688620 & 5.4 & 5.6331 & TST \\
\hline CHEMBL1328054 & 688620 & 5.65 & 4.9832 & TST \\
\hline CHEMBL1608819 & 688620 & 4.75 & 5.0507 & TST \\
\hline CHEMBL1509746 & 688620 & 4.75 & 5.0547 & TRN \\
\hline CHEMBL1485796 & 688620 & 6.3 & 5.0997 & TST \\
\hline CHEMBL1399492 & 688620 & 5.3 & 5.301 & TST \\
\hline CHEMBL1539118 & 688620 & 5.65 & 5.0493 & TST \\
\hline CHEMBL1302669 & 688620 & 5.3 & 4.7809 & TST \\
\hline CHEMBL1497780 & 688620 & 4.6 & 4.7423 & TRN \\
\hline CHEMBL1425431 & 688620 & 4.95 & 5.0682 & TST \\
\hline CHEMBL1416063 & 688620 & 5.0 & 4.9119 & TRN \\
\hline
\end{tabular}




\begin{tabular}{|c|c|c|c|c|c|}
\hline \\
\hline CHEMBL1568236 & 688620 & 4.9 & 5.1414 & TRN & \\
\hline CHEMBL1369833 & 688620 & 4.45 & 5.0911 & TRN & \\
\hline CHEMBL1464730 & 688620 & 5.25 & 4.7804 & TST & \\
\hline CHEMBL1425170 & 688620 & 5.45 & 5.1027 & TRN & \\
\hline CHEMBL3189393 & 688620 & 4.95 & 5.1595 & TST & \\
\hline CHEMBL1340478 & 688620 & 4.95 & 4.9309 & TRN & \\
\hline CHEMBL1498966 & 688620 & 4.95 & 5.1164 & TRN & \\
\hline CHEMBL1353529 & 688620 & 4.85 & 5.20100 & 00000000005 & TRN \\
\hline CHEMBL1337712 & 688620 & 4.95 & 5.2294 & TST & \\
\hline CHEMBL1509227 & 688620 & 5.5 & 4.9917 & TST & \\
\hline CHEMBL1603981 & 688620 & 4.95 & 5.1809 & TRN & \\
\hline CHEMBL1382969 & 688620 & 4.45 & 4.8619 & TRN & \\
\hline CHEMBL1353773 & 688620 & 5.15 & 4.79 & TRN & \\
\hline CHEMBL1465719 & 688620 & 4.85 & 5.0929 & TRN & \\
\hline CHEMBL1531566 & 688620 & 4.65 & 5.13700 & 00000000005 & TRN \\
\hline CHEMBL1401622 & 688620 & 5.9 & 5.3156 & TRN & \\
\hline CHEMBL1465899 & 688620 & 5.8 & 4.7497 & TRN & \\
\hline CHEMBL1353907 & 688620 & 5.65 & 5.1069 & TRN & \\
\hline CHEMBL1473266 & 688620 & 4.45 & 4.8803 & TRN & \\
\hline CHEMBL1425235 & 688620 & 5.0 & 5.2604 & TRN & \\
\hline CHEMBL1465165 & 688620 & 6.6499 & 4.9871 & TST & \\
\hline CHEMBL1585091 & 688620 & 4.65 & 5.0712 & TRN & \\
\hline CHEMBL1410863 & 688620 & 5.2 & 5.085 & TRN & \\
\hline CHEMBL202131 & 688620 & 5.1 & 4.9656 & TRN & \\
\hline CHEMBL1587914 & 688620 & 4.5 & 4.9273 & TST & \\
\hline CHEMBL1356006 & 688620 & 4.85 & 4.9502 & TRN & \\
\hline CHEMBL1394121 & 688620 & 4.45 & 4.7135 & TST & \\
\hline CHEMBL1581378 & 688620 & 5.35 & 4.939 & TST & \\
\hline CHEMBL1449590 & 688620 & 6.0 & 5.0737 & TRN & \\
\hline CHEMBL1461540 & 688620 & 4.75 & 5.4341 & TRN & \\
\hline CHEMBL1361486 & 688620 & 4.9 & 5.1136 & TRN & \\
\hline CHEMBL1300242 & 688620 & 5.2 & 5.2016 & TRN & \\
\hline CHEMBL1504928 & 688620 & 4.95 & 4.9039 & TST & \\
\hline CHEMBL3209060 & 688620 & 5.05 & 5.0985 & TST & \\
\hline CHEMBL1389163 & 688620 & 6.1 & 5.0429 & TST & \\
\hline CHEMBL1384268 & 688620 & 6.1 & 5.2382 & TST & \\
\hline CHEMBL1323459 & 688620 & 4.45 & 4.6549 & TRN & \\
\hline CHEMBL1332808 & 688620 & 5.7 & 5.01699 & 99999999995 & TRN \\
\hline CHEMBL1343460 & 688620 & 4.85 & 5.4063 & TST & \\
\hline CHEMBL1411779 & 688620 & 4.5 & 4.805 & TRN & \\
\hline CHEMBL1488386 & 688620 & 7.1002 & 5.3668 & TRN & \\
\hline CHEMBL1607725 & 688620 & 4.55 & 5.0034 & TST & \\
\hline CHEMBL1545723 & 688620 & 4.4 & 4.8769 & TRN & \\
\hline CHEMBL1511796 & 688620 & 5.6 & 5.1679 & TRN & \\
\hline CHEMBL1330079 & 688620 & 5.2 & 5.4475 & TRN & \\
\hline CHEMBL1998692 & 688620 & 4.6 & 5.0283 & TRN & \\
\hline CHEMBL1305817 & 688620 & 5.4 & 5.0099 & TRN & \\
\hline CHEMBL1349206 & 688620 & 5.15 & 4.9403 & TST & \\
\hline
\end{tabular}




\begin{tabular}{|c|c|c|c|c|}
\hline & & & & al Table \\
\hline CHEMBL1352960 & 688620 & 4.8 & 5.0884 & TRN \\
\hline CHEMBL1461225 & 688620 & 5.25 & 5.7301 & TST \\
\hline CHEMBL1576406 & 688620 & 6.5 & 4.9877 & TRN \\
\hline CHEMBL1455086 & 688620 & 4.6 & 5.0361 & TRN \\
\hline CHEMBL1447106 & 688620 & 4.9 & 4.9061 & TRN \\
\hline CHEMBL3198979 & 688620 & 4.95 & 4.8629 & TRN \\
\hline CHEMBL1411071 & 688620 & 8.301 & 5.0235 & TRN \\
\hline CHEMBL1574834 & 688620 & 4.6 & 4.7813 & TST \\
\hline CHEMBL1332753 & 688620 & 4.95 & 4.9291 & TRN \\
\hline CHEMBL1367712 & 688620 & 6.1 & 5.4286 & TRN \\
\hline CHEMBL 1574041 & 688620 & 5.65 & 4.9877 & TRN \\
\hline CHEMBL1421259 & 688620 & 4.5 & 4.8543 & TRN \\
\hline CHEMBL1470847 & 688620 & 4.9 & 4.9603 & TRN \\
\hline CHEMBL1466506 & 688620 & 4.45 & 4.8504 & TRN \\
\hline CHEMBL1412426 & 688620 & 4.75 & 4.9062 & TRN \\
\hline CHEMBL1481558 & 688620 & 5.35 & 5.4674 & TRN \\
\hline CHEMBL1388059 & 688620 & 4.45 & 5.92200 & 0000000001 \\
\hline CHEMBL1420743 & 688620 & 4.65 & 4.9358 & TST \\
\hline CHEMBL3192331 & 688620 & 5.9 & 5.5013 & TRN \\
\hline CHEMBL1307798 & 688620 & 5.15 & 4.6825 & TRN \\
\hline CHEMBL1568593 & 688620 & 6.25 & 5.1967 & TRN \\
\hline CHEMBL1344291 & 688620 & 5.4 & 5.0321 & TRN \\
\hline CHEMBL1455446 & 688620 & 6.5 & 6.1376 & TRN \\
\hline CHEMBL1320665 & 688620 & 4.95 & 4.8975 & TST \\
\hline CHEMBL1501191 & 688620 & 5.5 & 5.2375 & TRN \\
\hline CHEMBL1408953 & 688620 & 4.8 & 5.0366 & TST \\
\hline CHEMBL1493432 & 688620 & 4.45 & 4.9909 & TST \\
\hline CHEMBL1412259 & 688620 & 4.9 & 4.9978 & TRN \\
\hline CHEMBL1581409 & 688620 & 4.85 & 4.8 & TRN \\
\hline CHEMBL1320905 & 688620 & 4.45 & 4.7629 & TRN \\
\hline CHEMBL1569603 & 688620 & 4.65 & 5.0658 & TRN \\
\hline CHEMBL1343012 & 688620 & 4.95 & 5.0977 & TRN \\
\hline CHEMBL1538636 & 688620 & 4.85 & 4.9676 & TRN \\
\hline CHEMBL1502255 & 688620 & 7.1002 & 4.9841 & TST \\
\hline CHEMBL1548773 & 688620 & 4.45 & 4.9574 & TRN \\
\hline CHEMBL1556861 & 688620 & 5.15 & 5.6691 & TST \\
\hline CHEMBL601970 & 688620 & 4.8 & 4.8433 & TRN \\
\hline CHEMBL1320057 & 688620 & 4.45 & 5.0232 & TRN \\
\hline CHEMBL3189817 & 688620 & 5.0 & 5.1442 & TST \\
\hline CHEMBL1451243 & 688620 & 6.25 & 4.8937 & TRN \\
\hline CHEMBL1336195 & 688620 & 4.85 & 4.9443 & TST \\
\hline CHEMBL1326849 & 688620 & 4.95 & 5.2651 & TRN \\
\hline CHEMBL1388007 & 688620 & 4.65 & 5.1163 & TRN \\
\hline CHEMBL1577233 & 688620 & 4.95 & 5.1596 & TST \\
\hline CHEMBL1572280 & 688620 & 5.35 & 5.3341 & TRN \\
\hline CHEMBL1524509 & 688620 & 4.85 & 5.0544 & TRN \\
\hline CHEMBL1488923 & 688620 & 6.7501 & 6.1167 & TRN \\
\hline CHEMBL1525875 & 688620 & 5.0 & 5.2107 & TRN \\
\hline
\end{tabular}




\begin{tabular}{|c|c|c|c|c|}
\hline \multicolumn{5}{|c|}{ Supplemental Table S2.txt } \\
\hline CHEMBL 3197935 & 688620 & 6.3 & 5.1203 & TRN \\
\hline CHEMBL1484119 & 688620 & 5.4 & 5.0985 & TRN \\
\hline CHEMBL 3196978 & 688620 & 5.05 & 5.1085 & TRN \\
\hline CHEMBL1340431 & 688620 & 4.45 & 4.837 & TST \\
\hline CHEMBL1413397 & 688620 & 4.9 & 5.2364 & TRN \\
\hline CHEMBL1380735 & 688620 & 6.2 & 5.1822 & TST \\
\hline CHEMBL1602793 & 688620 & 4.9 & 4.9688 & TRN \\
\hline CHEMBL1338672 & 688620 & 4.45 & 4.9373 & TRN \\
\hline CHEMBL 1463840 & 688620 & 4.75 & 4.9203 & TST \\
\hline CHEMBL1415702 & 688620 & 4.45 & 4.8032 & TRN \\
\hline CHEMBL1440703 & 688620 & 4.95 & 5.0155 & TST \\
\hline CHEMBL1433254 & 688620 & 5.0 & 4.9966 & TRN \\
\hline CHEMBL1540009 & 688620 & 4.75 & 5.3997 & TRN \\
\hline CHEMBL 3207466 & 688620 & 4.9 & 5.2894 & TST \\
\hline CHEMBL1544423 & 688620 & 5.25 & 4.8984 & TRN \\
\hline CHEMBL1373040 & 688620 & 5.2 & 4.9593 & TRN \\
\hline CHEMBL1564517 & 688620 & 4.45 & 5.0767 & TST \\
\hline CHEMBL1344288 & 688620 & 4.45 & 5.0496 & TST \\
\hline CHEMBL145 & 688620 & 4.9 & 4.9365 & TST \\
\hline CHEMBL1530866 & 688620 & 4.95 & 5.0049 & TRN \\
\hline CHEMBL1545862 & 688620 & 5.0 & 5.0442 & TRN \\
\hline CHEMBL1526833 & 688620 & 4.45 & 4.9417 & TRN \\
\hline CHEMBL1377777 & 688620 & 4.7 & 5.101 & TST \\
\hline CHEMBL 3190347 & 688620 & 5.35 & 5.003 & TRN \\
\hline CHEMBL1333889 & 688620 & 4.45 & 4.8816 & TST \\
\hline CHEMBL1569554 & 688620 & 4.75 & 4.9302 & TRN \\
\hline CHEMBL1343486 & 688620 & 5.0 & 5.1996 & TST \\
\hline CHEMBL 3197648 & 688620 & 5.45 & 5.4001 & TRN \\
\hline CHEMBL1405810 & 688620 & 4.8 & 4.9213 & TST \\
\hline CHEMBL1461171 & 688620 & 4.45 & 4.7281 & TRN \\
\hline CHEMBL1334106 & 688620 & 5.0 & 4.9299 & TRN \\
\hline CHEMBL1586558 & 688620 & 4.45 & 4.9019 & TST \\
\hline CHEMBL 3213034 & 688620 & 5.3 & 5.265 & TRN \\
\hline CHEMBL1457175 & 688620 & 4.85 & 5.4547 & TST \\
\hline CHEMBL1547623 & 688620 & 4.9 & 5.4757 & TST \\
\hline CHEMBL1443069 & 688620 & 5.35 & 4.7192 & TRN \\
\hline CHEMBL1540646 & 688620 & 4.45 & 5.0327 & TRN \\
\hline CHEMBL1333463 & 688620 & 4.95 & 5.1124 & TST \\
\hline CHEMBL473107 & 688620 & 5.55 & 5.3596 & TST \\
\hline CHEMBL1414812 & 688620 & 4.9 & 5.07 & TRN \\
\hline CHEMBL1353257 & 688620 & 5.3 & 5.5599 & TRN \\
\hline CHEMBL1335644 & 688620 & 4.45 & 4.8889 & TST \\
\hline CHEMBL1586819 & 688620 & 4.75 & 4.9373 & TST \\
\hline CHEMBL1430601 & 688620 & 4.65 & 4.6091 & TST \\
\hline CHEMBL1968326 & 688620 & 5.05 & 5.2942 & TRN \\
\hline CHEMBL1333798 & 688620 & 4.9 & 5.157 & TRN \\
\hline CHEMBL1386259 & 688620 & 4.9 & 5.209 & TRN \\
\hline CHEMBL1558051 & 688620 & 4.9 & 5.4573 & TRN \\
\hline
\end{tabular}




\begin{tabular}{|c|c|c|c|c|c|}
\hline \multicolumn{6}{|c|}{ Supplemental Table S2.txt } \\
\hline CHEMBL1441072 & 688620 & 4.45 & 5.1063 & TRN & \\
\hline CHEMBL1441415 & 688620 & 4.45 & 4.9873 & TRN & \\
\hline CHEMBL1416781 & 688620 & 5.25 & 5.0274 & TRN & \\
\hline CHEMBL 2004900 & 688620 & 4.75 & 5.0439 & TRN & \\
\hline CHEMBL1393245 & 688620 & 5.5 & 5.319 & TRN & \\
\hline CHEMBL1544685 & 688620 & 5.3 & 5.0881 & TST & \\
\hline CHEMBL1513174 & 688620 & 4.5 & 4.953 & TRN & \\
\hline CHEMBL1499814 & 688620 & 4.75 & 4.9647 & TST & \\
\hline CHEMBL1313329 & 688620 & 5.3 & 5.0503 & TST & \\
\hline CHEMBL1330630 & 688620 & 4.95 & 5.09699 & 99999999995 & TST \\
\hline CHEMBL1488701 & 688620 & 6.3 & 5.0925 & TST & \\
\hline CHEMBL1383082 & 688620 & 4.9 & 5.0026 & TRN & \\
\hline CHEMBL1386958 & 688620 & 5.1 & 5.1796 & TRN & \\
\hline CHEMBL1560543 & 688620 & 4.7 & 4.9798 & TST & \\
\hline CHEMBL1320353 & 688620 & 6.0 & 5.2499 & TRN & \\
\hline CHEMBL1349026 & 688620 & 5.35 & 5.1782 & TST & \\
\hline CHEMBL1572325 & 688620 & 5.05 & 5.1332 & TST & \\
\hline CHEMBL1331856 & 688620 & 4.45 & 4.7721 & TRN & \\
\hline CHEMBL1494813 & 688620 & 4.8 & 5.0015 & TRN & \\
\hline CHEMBL1472348 & 688620 & 5.15 & 4.9426 & TRN & \\
\hline CHEMBL1571019 & 688620 & 6.45 & 6.0884 & TRN & \\
\hline CHEMBL1546305 & 688620 & 8.301 & 5.0124 & TRN & \\
\hline CHEMBL1419694 & 688620 & 6.6 & 5.2852 & TST & \\
\hline CHEMBL1327781 & 688620 & 4.9 & 5.2482 & TRN & \\
\hline CHEMBL1556474 & 688620 & 4.7 & 4.989 & TRN & \\
\hline CHEMBL1414145 & 688620 & 4.9 & 5.0623 & TST & \\
\hline CHEMBL1344385 & 688620 & 4.6 & 5.0032 & TRN & \\
\hline CHEMBL1339669 & 688620 & 4.65 & 5.1443 & TRN & \\
\hline CHEMBL1487616 & 688620 & 4.45 & 4.6354 & TRN & \\
\hline CHEMBL1600848 & 688620 & 6.3 & 5.1371 & TRN & \\
\hline CHEMBL1353964 & 688620 & 5.25 & 5.3813 & TRN & \\
\hline CHEMBL1399370 & 688620 & 5.35 & 5.1933 & TRN & \\
\hline CHEMBL1373464 & 688620 & 4.75 & 5.0109 & TRN & \\
\hline CHEMBL1518483 & 688620 & 4.7 & 5.2084 & TRN & \\
\hline CHEMBL1542862 & 688620 & 5.3 & 5.4231 & TRN & \\
\hline CHEMBL1424158 & 688620 & 4.95 & 5.12799 & 9999999999 & TRN \\
\hline CHEMBL1364597 & 688620 & 4.65 & 4.9911 & TRN & \\
\hline CHEMBL1509391 & 688620 & 4.9 & 4.8157 & TRN & \\
\hline CHEMBL1539782 & 688620 & 4.8 & 4.9746 & TRN & \\
\hline CHEMBL 3211808 & 688620 & 5.6 & 5.5124 & TRN & \\
\hline CHEMBL1402822 & 688620 & 4.8 & 4.9895 & TRN & \\
\hline CHEMBL1606715 & 688620 & 5.35 & 4.8921 & TRN & \\
\hline CHEMBL3196364 & 688620 & 6.2 & 5.8284 & TRN & \\
\hline CHEMBL1458533 & 688620 & 4.45 & 5.0946 & TST & \\
\hline CHEMBL1514790 & 688620 & 4.9 & 4.8194 & TRN & \\
\hline CHEMBL1403711 & 688620 & 5.55 & 5.1799 & TRN & \\
\hline CHEMBL1393298 & 688620 & 4.45 & 4.9308 & TRN & \\
\hline CHEMBL1429396 & 688620 & 4.75 & 5.1606 & TRN & \\
\hline
\end{tabular}




\begin{tabular}{|c|c|c|c|c|c|}
\hline & & \multicolumn{4}{|c|}{ Supplemental Table s2.txt } \\
\hline CHEMBL1456328 & 688620 & 4.65 & 5.0783 & TRN & \\
\hline CHEMBL3212396 & 688620 & 4.95 & 4.9839 & TRN & \\
\hline CHEMBL1987622 & 688620 & 5.55 & 5.6393 & TST & \\
\hline CHEMBL1388700 & 688620 & 6.3 & 6.3611 & TRN & \\
\hline CHEMBL1445486 & 688620 & 4.95 & 5.2866 & TRN & \\
\hline CHEMBL1300797 & 688620 & 4.8 & 4.9888 & TRN & \\
\hline CHEMBL1598579 & 688620 & 5.65 & 5.3114 & TRN & \\
\hline CHEMBL1457185 & 688620 & 4.45 & 5.0172 & TRN & \\
\hline CHEMBL1475791 & 688620 & 4.45 & 4.8912 & TST & \\
\hline CHEMBL1303335 & 688620 & 4.45 & 5.0235 & TST & \\
\hline CHEMBL1503868 & 688620 & 4.45 & 4.7823 & TRN & \\
\hline CHEMBL1331120 & 688620 & 4.6 & 5.1601 & TRN & \\
\hline CHEMBL1462687 & 688620 & 4.8 & 4.9888 & TRN & \\
\hline CHEMBL1587235 & 688620 & 4.85 & 5.0049 & TST & \\
\hline CHEMBL1548517 & 688620 & 4.75 & 4.7588 & TRN & \\
\hline CHEMBL1495657 & 688620 & 6.6 & 4.96899 & 9999999999 & TST \\
\hline CHEMBL1555483 & 688620 & 4.85 & 5.0848 & TRN & \\
\hline CHEMBL14120 & 688620 & 4.55 & 5.0705 & TRN & \\
\hline CHEMBL3211554 & 688620 & 5.6 & 5.3408 & TRN & \\
\hline CHEMBL1441280 & 688620 & 4.7 & 5.0043 & TRN & \\
\hline CHEMBL1421129 & 688620 & 4.75 & 4.9812 & TRN & \\
\hline CHEMBL1349171 & 688620 & 5.35 & 5.1564 & TRN & \\
\hline CHEMBL1462816 & 688620 & 5.25 & 5.0277 & TRN & \\
\hline CHEMBL1486653 & 688620 & 4.85 & 4.9616 & TRN & \\
\hline CHEMBL1572726 & 688620 & 4.95 & 4.831 & TST & \\
\hline CHEMBL578689 & 688620 & 5.2 & 4.756 & TRN & \\
\hline CHEMBL3211160 & 688620 & 4.45 & 4.9486 & TRN & \\
\hline CHEMBL1491798 & 688620 & 5.0 & 5.0003 & TRN & \\
\hline CHEMBL1456647 & 688620 & 5.15 & 4.9298 & TRN & \\
\hline CHEMBL1305030 & 688620 & 4.45 & 5.0092 & TST & \\
\hline CHEMBL1511284 & 688620 & 4.9 & 5.0813 & TRN & \\
\hline CHEMBL3189303 & 688620 & 4.45 & 5.1928 & TRN & \\
\hline CHEMBL1496064 & 688620 & 4.95 & 4.8684 & TRN & \\
\hline CHEMBL1383450 & 688620 & 4.85 & 4.8403 & TRN & \\
\hline CHEMBL1347505 & 688620 & 5.2 & 5.048 & TRN & \\
\hline CHEMBL1364081 & 688620 & 4.45 & 4.9037 & TST & \\
\hline CHEMBL1305166 & 688620 & 5.1 & 5.4827 & TST & \\
\hline CHEMBL1558218 & 688620 & 4.8 & 4.7916 & TST & \\
\hline CHEMBL1448413 & 688620 & 4.85 & 5.0502 & TRN & \\
\hline CHEMBL3189348 & 688620 & 4.85 & 4.7463 & TRN & \\
\hline CHEMBL1303737 & 688620 & 5.15 & 5.0039 & TRN & \\
\hline CHEMBL1485505 & 688620 & 5.0 & 4.9726 & TRN & \\
\hline CHEMBL1507044 & 688620 & 5.25 & 5.0396 & TST & \\
\hline CHEMBL1465903 & 688620 & 4.75 & 5.0041 & TRN & \\
\hline CHEMBL1410410 & 688620 & 5.35 & 4.9074 & TST & \\
\hline CHEMBL1601384 & 688620 & 5.05 & 5.0981 & TRN & \\
\hline CHEMBL1331231 & 688620 & 4.45 & 4.6045 & TRN & \\
\hline CHEMBL1545790 & 688620 & 4.45 & 4.9417 & TRN & \\
\hline
\end{tabular}




\begin{tabular}{|c|c|c|c|c|}
\hline \multicolumn{5}{|c|}{ Supplemental Table S2.txt } \\
\hline CHEMBL1520180 & 688620 & 5.15 & 5.4844 & TRN \\
\hline CHEMBL1448015 & 688620 & 4.95 & 5.0903 & TRN \\
\hline CHEMBL1524299 & 688620 & 5.9 & 5.0903 & TST \\
\hline CHEMBL1300047 & 688620 & 4.9 & 5.334 & TRN \\
\hline CHEMBL1560516 & 688620 & 4.85 & 5.052 & TRN \\
\hline CHEMBL1484700 & 688620 & 4.45 & 5.3425 & TRN \\
\hline CHEMBL1536424 & 688620 & 4.95 & 4.9183 & TRN \\
\hline CHEMBL1518359 & 688620 & 4.65 & 5.0971 & TRN \\
\hline CHEMBL1448128 & 688620 & 5.55 & 5.6048 & TRN \\
\hline CHEMBL1470587 & 688620 & 4.55 & 4.7476 & TRN \\
\hline CHEMBL1328857 & 688620 & 4.45 & 4.7386 & TRN \\
\hline CHEMBL1540288 & 688620 & 4.95 & 4.8575 & TRN \\
\hline CHEMBL1574121 & 688620 & 6.95 & 6.723 & TRN \\
\hline CHEMBL1509792 & 688620 & 5.55 & 4.8775 & TRN \\
\hline CHEMBL1599365 & 688620 & 4.45 & 5.1191 & TRN \\
\hline CHEMBL1530011 & 688620 & 5.05 & 5.154 & TRN \\
\hline CHEMBL1300961 & 688620 & 4.45 & 4.8206 & TRN \\
\hline CHEMBL3190824 & 688620 & 5.6 & 5.3197 & TRN \\
\hline CHEMBL1384822 & 688620 & 5.25 & 5.0052 & TST \\
\hline CHEMBL1441085 & 688620 & 4.45 & 5.1083 & TST \\
\hline CHEMBL1457786 & 688620 & 4.7 & 4.9935 & TRN \\
\hline CHEMBL1462803 & 688620 & 5.3 & 5.6381 & TRN \\
\hline CHEMBL3194669 & 688620 & 5.05 & 5.2194 & TRN \\
\hline CHEMBL 3190130 & 688620 & 4.65 & 5.1577 & TRN \\
\hline CHEMBL1404887 & 688620 & 4.85 & 5.454 & TRN \\
\hline CHEMBL1504237 & 688620 & 4.85 & 5.1311 & TRN \\
\hline CHEMBL1548979 & 688620 & 5.0 & 4.9851 & TRN \\
\hline CHEMBL1331787 & 688620 & 4.9 & 5.1581 & TRN \\
\hline CHEMBL1314093 & 688620 & 4.85 & 5.2016 & TRN \\
\hline CHEMBL1303079 & 688620 & 5.55 & 5.2402 & TST \\
\hline CHEMBL1610504 & 688620 & 5.1 & 5.2281 & TST \\
\hline CHEMBL1594832 & 688620 & 4.9 & 4.9364 & TRN \\
\hline CHEMBL191750 & 688620 & 5.75 & 5.0372 & TRN \\
\hline CHEMBL1324332 & 688620 & 4.75 & 4.8361 & TRN \\
\hline CHEMBL1521350 & 688620 & 5.0 & 4.8867 & TRN \\
\hline CHEMBL1608798 & 688620 & 5.45 & 4.9251 & TRN \\
\hline CHEMBL1969293 & 688620 & 5.1 & 4.829 & TRN \\
\hline CHEMBL1455417 & 688620 & 4.8 & 4.9978 & TRN \\
\hline CHEMBL1438120 & 688620 & 6.9 & 4.9472 & TST \\
\hline CHEMBL3198641 & 688620 & 5.35 & 5.0626 & TRN \\
\hline CHEMBL1539882 & 688620 & 4.45 & 5.1021 & TST \\
\hline CHEMBL1310791 & 688620 & 4.75 & 5.1188 & TRN \\
\hline CHEMBL1606821 & 688620 & 4.45 & 4.8066 & TRN \\
\hline CHEMBL1567553 & 688620 & 4.95 & 5.0953 & TST \\
\hline CHEMBL1572129 & 688620 & 5.0 & 4.9889 & TRN \\
\hline CHEMBL1345871 & 688620 & 5.35 & 5.1425 & TRN \\
\hline CHEMBL 1445472 & 688620 & 3.95 & 5.0153 & TST \\
\hline CHEMBL1353015 & 688620 & 4.85 & 4.9608 & TRN \\
\hline
\end{tabular}




\begin{tabular}{|c|c|c|c|c|}
\hline \multicolumn{5}{|c|}{ Supplemental Table S2.txt } \\
\hline CHEMBL1345215 & 688620 & 4.65 & 4.6998 & TST \\
\hline CHEMBL1363902 & 688620 & 4.85 & 5.0268 & TRN \\
\hline CHEMBL1414853 & 688620 & 4.65 & 4.7412 & TRN \\
\hline CHEMBL1441123 & 688620 & 4.7 & 5.1513 & TST \\
\hline CHEMBL1342560 & 688620 & 5.2 & 5.0208 & TST \\
\hline CHEMBL1578549 & 688620 & 4.45 & 5.0495 & TRN \\
\hline CHEMBL1496874 & 688620 & 4.6 & 4.9596 & TRN \\
\hline CHEMBL1521565 & 688620 & 4.95 & 4.8506 & TRN \\
\hline CHEMBL 3145306 & 688620 & 4.55 & 5.0711 & TRN \\
\hline CHEMBL1546319 & 688620 & 4.95 & 4.8255 & TST \\
\hline CHEMBL1397601 & 688620 & 5.5 & 4.9154 & TRN \\
\hline CHEMBL1380519 & 688620 & 4.75 & 5.0092 & TRN \\
\hline CHEMBL1495402 & 688620 & 4.75 & 5.1093 & TRN \\
\hline CHEMBL1537738 & 688620 & 5.0 & 4.9801 & TRN \\
\hline CHEMBL1568395 & 688620 & 4.7 & 5.1903 & TRN \\
\hline CHEMBL1382429 & 688620 & 4.45 & 5.0419 & TRN \\
\hline CHEMBL1389637 & 688620 & 4.95 & 5.1778 & TST \\
\hline CHEMBL1449858 & 688620 & 5.5 & 5.1288 & TRN \\
\hline CHEMBL1432382 & 688620 & 5.15 & 5.1504 & TST \\
\hline CHEMBL3212038 & 688620 & 4.45 & 5.0263 & TRN \\
\hline CHEMBL1510369 & 688620 & 4.95 & 5.0007 & TRN \\
\hline CHEMBL 3192724 & 688620 & 4.95 & 5.0069 & TRN \\
\hline CHEMBL1521877 & 688620 & 5.15 & 5.0857 & TRN \\
\hline CHEMBL1321314 & 688620 & 5.5 & 5.2104 & TRN \\
\hline CHEMBL1541366 & 688620 & 4.75 & 5.1797 & TST \\
\hline CHEMBL1321262 & 688620 & 5.3 & 5.1647 & TRN \\
\hline CHEMBL1542184 & 688620 & 4.65 & 5.0316 & TST \\
\hline CHEMBL3194935 & 688620 & 4.85 & 5.1528 & TRN \\
\hline CHEMBL 90124 & 688620 & 6.0 & 6.3586 & TRN \\
\hline CHEMBL1491628 & 688620 & 6.5 & 4.9849 & TRN \\
\hline CHEMBL1322657 & 688620 & 4.9 & 5.211 & TRN \\
\hline CHEMBL1494735 & 688620 & 4.9 & 4.963 & TST \\
\hline CHEMBL1605430 & 688620 & 4.9 & 5.1427 & TST \\
\hline CHEMBL1486581 & 688620 & 5.6 & 4.9984 & TRN \\
\hline CHEMBL1390009 & 688620 & 5.5 & 5.0396 & TRN \\
\hline CHEMBL1560551 & 688620 & 4.9 & 5.3217 & TRN \\
\hline CHEMBL1537782 & 688620 & 4.45 & 4.9533 & TRN \\
\hline CHEMBL1325302 & 688620 & 6.0 & 6.0086 & TRN \\
\hline CHEMBL1502101 & 688620 & 5.1 & 5.3299 & TRN \\
\hline CHEMBL1492665 & 688620 & 5.15 & 5.1963 & TRN \\
\hline CHEMBL3189632 & 688620 & 5.9 & 5.3536 & TRN \\
\hline CHEMBL1370068 & 688620 & 4.95 & 4.9365 & TRN \\
\hline CHEMBL1379640 & 688620 & 4.45 & 4.9854 & TRN \\
\hline CHEMBL 2002980 & 688620 & 5.6 & 5.1289 & TRN \\
\hline CHEMBL1323986 & 688620 & 5.3 & 5.0874 & TST \\
\hline CHEMBL1338576 & 688620 & 6.3 & 4.9101 & TST \\
\hline CHEMBL1407228 & 688620 & 4.45 & 4.8546 & TST \\
\hline CHEMBL2016645 & 688620 & 5.25 & 5.532 & TRN \\
\hline
\end{tabular}




\begin{tabular}{|c|c|c|c|c|c|}
\hline \multirow[b]{2}{*}{ CHEMBL1497644 } & \multirow[b]{2}{*}{688620} & \multicolumn{4}{|c|}{ Supplemental Table S2.txt } \\
\hline & & 4.85 & 4.8489 & TRN & \\
\hline CHEMBL1387187 & 688620 & 6.1 & 5.1925 & TST & \\
\hline CHEMBL1306564 & 688620 & 4.45 & 4.9019 & TRN & \\
\hline CHEMBL1412664 & 688620 & 4.45 & 4.8566 & TRN & \\
\hline CHEMBL3213027 & 688620 & 4.8 & 4.8192 & TRN & \\
\hline CHEMBL1447947 & 688620 & 5.2 & 4.8583 & TST & \\
\hline CHEMBL1302816 & 688620 & 4.65 & \multicolumn{2}{|c|}{4.8660000000000005} & TST \\
\hline CHEMBL1550274 & 688620 & 5.65 & 5.5135 & TRN & \\
\hline CHEMBL1601652 & 688620 & 5.55 & 5.3029 & TRN & \\
\hline CHEMBL1419251 & 688620 & 4.75 & 4.9522 & TRN & \\
\hline CHEMBL3392385 & 688620 & 5.5 & 4.8631 & TRN & \\
\hline CHEMBL1498394 & 688620 & 5.2 & 5.0831 & TRN & \\
\hline CHEMBL3195600 & 688620 & 4.45 & 5.0687 & TRN & \\
\hline CHEMBL1334587 & 688620 & 4.9 & 5.0355 & TRN & \\
\hline CHEMBL1319186 & 688620 & 4.45 & 4.8215 & TRN & \\
\hline CHEMBL1363221 & 688620 & 4.45 & 5.1214 & TRN & \\
\hline CHEMBL1329054 & 688620 & 5.7 & 4.7938 & TRN & \\
\hline CHEMBL1585742 & 688620 & 5.45 & 4.9288 & TRN & \\
\hline CHEMBL1509962 & 688620 & 5.3 & 5.2293 & TRN & \\
\hline CHEMBL1412646 & 688620 & 4.45 & 4.8942 & TRN & \\
\hline CHEMBL1300876 & 688620 & 5.25 & 4.996 & TRN & \\
\hline CHEMBL1500597 & 688620 & 6.25 & 5.1525 & TRN & \\
\hline CHEMBL1501456 & 688620 & 4.9 & 4.737 & TRN & \\
\hline CHEMBL1607362 & 688620 & 5.5 & 4.7375 & TRN & \\
\hline CHEMBL1480557 & 688620 & 6.25 & 5.0461 & TST & \\
\hline CHEMBL456776 & 688620 & 4.95 & 5.0724 & TST & \\
\hline CHEMBL1370052 & 688620 & 4.45 & 4.9217 & TRN & \\
\hline CHEMBL1330122 & 688620 & 4.95 & 5.2604 & TRN & \\
\hline CHEMBL3198723 & 688620 & 4.5 & 4.9378 & TRN & \\
\hline CHEMBL1465099 & 688620 & 4.95 & 5.0454 & TRN & \\
\hline CHEMBL1408636 & 688620 & 4.45 & 5.1284 & TRN & \\
\hline CHEMBL1602860 & 688620 & 4.6 & 4.9864 & TRN & \\
\hline CHEMBL3196043 & 688620 & 4.55 & 4.9442 & TST & \\
\hline CHEMBL1364311 & 688620 & 5.75 & 5.4542 & TRN & \\
\hline CHEMBL1422040 & 688620 & 4.85 & 4.7654 & TRN & \\
\hline CHEMBL1454262 & 688620 & 4.7 & 5.2092 & TST & \\
\hline CHEMBL1411175 & 688620 & 4.9 & 4.9376 & TRN & \\
\hline CHEMBL1393155 & 688620 & 4.95 & 4.9901 & TRN & \\
\hline CHEMBL1400242 & 688620 & 4.45 & 4.8795 & TST & \\
\hline CHEMBL542700 & 688620 & 4.45 & 4.7926 & TST & \\
\hline CHEMBL1320796 & 688620 & 4.9 & 4.7696 & TRN & \\
\hline CHEMBL1506881 & 688620 & 4.45 & 5.0256 & TRN & \\
\hline CHEMBL1488913 & 688620 & 5.0 & 4.7355 & TST & \\
\hline CHEMBL1450709 & 688620 & 4.85 & 5.1623 & TRN & \\
\hline CHEMBL1557615 & 688620 & 5.95 & 5.3426 & TRN & \\
\hline CHEMBL1538744 & 688620 & 4.9 & 4.9611 & TRN & \\
\hline CHEMBL1969353 & 688620 & 5.25 & 5.1718 & TRN & \\
\hline CHEMBL1307969 & 688620 & 4.65 & 4.96399 & 99999999995 & TRN \\
\hline & & & & 2676 & \\
\hline
\end{tabular}




\begin{tabular}{|c|c|c|c|c|}
\hline \multicolumn{5}{|c|}{ Supplemental Table S2.txt } \\
\hline CHEMBL1544054 & 688620 & 5.3 & 5.6143 & TRN \\
\hline CHEMBL1389066 & 688620 & 5.45 & 5.3014 & TRN \\
\hline CHEMBL1341933 & 688620 & 5.5 & 4.8495 & TST \\
\hline CHEMBL1517755 & 688620 & 4.45 & 4.8391 & TRN \\
\hline CHEMBL1335395 & 688620 & 6.2 & 5.0449 & TRN \\
\hline CHEMBL529361 & 688620 & 5.1 & 5.1342 & TST \\
\hline CHEMBL1352411 & 688620 & 4.85 & 4.9533 & TST \\
\hline CHEMBL1401951 & 688620 & 5.0 & 4.8781 & TST \\
\hline CHEMBL1414211 & 688620 & 4.45 & 5.1924 & TST \\
\hline CHEMBL1570775 & 688620 & 4.85 & 4.9595 & TRN \\
\hline CHEMBL1496644 & 688620 & 6.7001 & 5.7782 & TST \\
\hline CHEMBL 3214581 & 688620 & 4.9 & 4.8917 & TRN \\
\hline CHEMBL1606699 & 688620 & 5.15 & 5.0614 & TRN \\
\hline CHEMBL1478880 & 688620 & 4.45 & 5.0674 & TRN \\
\hline CHEMBL1523114 & 688620 & 5.2 & 5.146 & TRN \\
\hline CHEMBL1334235 & 688620 & 6.3 & 5.1594 & TRN \\
\hline CHEMBL1347686 & 688620 & 4.95 & 5.0916 & TRN \\
\hline CHEMBL1528634 & 688620 & 5.25 & 4.891 & TRN \\
\hline CHEMBL1491362 & 688620 & 5.1 & 4.8006 & TST \\
\hline CHEMBL1303996 & 688620 & 6.15 & 5.277 & TRN \\
\hline CHEMBL1448930 & 688620 & 4.45 & 5.0675 & TRN \\
\hline CHEMBL1303810 & 688620 & 5.2 & 5.3099 & TRN \\
\hline CHEMBL1448741 & 688620 & 4.65 & 4.8787 & TRN \\
\hline CHEMBL1470904 & 688620 & 5.15 & 5.2519 & TRN \\
\hline CHEMBL1481850 & 688620 & 4.45 & 5.1163 & TRN \\
\hline CHEMBL1574908 & 688620 & 5.35 & 5.1405 & TST \\
\hline CHEMBL1478123 & 688620 & 5.55 & 5.5847 & TRN \\
\hline CHEMBL1432432 & 688620 & 4.7 & 4.8518 & TST \\
\hline CHEMBL1373527 & 688620 & 4.5 & 4.6585 & TRN \\
\hline CHEMBL1327057 & 688620 & 5.95 & 5.1164 & TRN \\
\hline CHEMBL1327846 & 688620 & 4.95 & 5.1369 & TRN \\
\hline CHEMBL1557564 & 688620 & 4.45 & 4.681 & TRN \\
\hline CHEMBL1599663 & 688620 & 4.65 & 4.9178 & TRN \\
\hline CHEMBL1419499 & 688620 & 5.5 & 5.0963 & TRN \\
\hline CHEMBL1370018 & 688620 & 5.0 & 4.8827 & TRN \\
\hline CHEMBL1565963 & 688620 & 4.95 & 4.9185 & TRN \\
\hline CHEMBL1583490 & 688620 & 4.8 & 5.0588 & TRN \\
\hline CHEMBL530499 & 688620 & 6.4 & 6.2577 & TRN \\
\hline CHEMBL1415755 & 688620 & 4.95 & 5.7033 & TRN \\
\hline CHEMBL3195405 & 688620 & 5.45 & 5.145 & TRN \\
\hline CHEMBL1577714 & 688620 & 4.6 & 5.0171 & TRN \\
\hline CHEMBL1508414 & 688620 & 4.45 & 4.8518 & TRN \\
\hline CHEMBL1308721 & 688620 & 4.5 & 5.2309 & TRN \\
\hline CHEMBL1477794 & 688620 & 4.95 & 5.0 & TRN \\
\hline CHEMBL1994594 & 688620 & 5.25 & 5.3346 & TRN \\
\hline CHEMBL1421201 & 688620 & 6.05 & 5.0976 & TRN \\
\hline CHEMBL1578993 & 688620 & 5.0 & 5.129 & TRN \\
\hline CHEMBL1364535 & 688620 & 5.75 & 4.9303 & TST \\
\hline
\end{tabular}




\begin{tabular}{|c|c|c|c|c|c|}
\hline \multicolumn{6}{|c|}{ Supplemental Table S2.txt } \\
\hline CHEMBL1349635 & 688620 & 6.4 & 6.1097 & TRN & \\
\hline CHEMBL1577400 & 688620 & 6.35 & 5.1217 & TST & \\
\hline CHEMBL1532480 & 688620 & 5.0 & 5.1515 & TRN & \\
\hline CHEMBL1308897 & 688620 & 4.95 & 4.9856 & TRN & \\
\hline CHEMBL1348389 & 688620 & 4.45 & 4.8255 & TST & \\
\hline CHEMBL1379520 & 688620 & 6.5 & 5.1406 & TRN & \\
\hline CHEMBL1332114 & 688620 & 8.2518 & 5.0375 & TRN & \\
\hline CHEMBL1400051 & 688620 & 8.301 & 5.1371 & TST & \\
\hline CHEMBL 290914 & 688620 & 5.2 & 5.1268 & TST & \\
\hline CHEMBL1588753 & 688620 & 5.6 & 5.4304 & TRN & \\
\hline CHEMBL1348000 & 688620 & 5.9 & 5.1987 & TRN & \\
\hline CHEMBL1534208 & 688620 & 6.45 & 5.043 & TST & \\
\hline CHEMBL1462360 & 688620 & 5.55 & 5.5047 & TRN & \\
\hline CHEMBL1322127 & 688620 & 5.45 & 5.086 & TST & \\
\hline CHEMBL1445985 & 688620 & 4.5 & 4.9277 & TRN & \\
\hline CHEMBL1333007 & 688620 & 4.85 & 5.0808 & TST & \\
\hline CHEMBL 270297 & 688620 & 5.9 & 5.858 & TRN & \\
\hline CHEMBL1352679 & 688620 & 4.45 & 5.0258 & TRN & \\
\hline CHEMBL1340150 & 688620 & 5.0 & 5.0677 & TST & \\
\hline CHEMBL 2007422 & 688620 & 5.35 & 5.5199 & TRN & \\
\hline CHEMBL3193835 & 688620 & 5.25 & 5.1592 & TST & \\
\hline CHEMBL1478725 & 688620 & 4.45 & 4.9586 & TST & \\
\hline CHEMBL1370221 & 688620 & 4.8 & 5.191 & TRN & \\
\hline CHEMBL1427943 & 688620 & 6.15 & 5.3292 & TRN & \\
\hline CHEMBL1570806 & 688620 & 4.85 & 5.0354 & TRN & \\
\hline CHEMBL1526149 & 688620 & 6.2 & 5.0127 & TRN & \\
\hline CHEMBL1345643 & 688620 & 8.2518 & 5.0639 & TRN & \\
\hline CHEMBL3207694 & 688620 & 4.95 & 5.0402 & TRN & \\
\hline CHEMBL1329737 & 688620 & 5.35 & 5.0419 & TRN & \\
\hline CHEMBL1478547 & 688620 & 5.65 & 5.3503 & TRN & \\
\hline CHEMBL1422805 & 688620 & 4.85 & 5.2117 & TRN & \\
\hline CHEMBL1568357 & 688620 & 5.05 & 5.0664 & TRN & \\
\hline CHEMBL 3212600 & 688620 & 5.55 & 5.0935 & TRN & \\
\hline CHEMBL1340316 & 688620 & 5.25 & 5.4628 & TRN & \\
\hline CHEMBL1465578 & 688620 & 4.65 & 5.1185 & TRN & \\
\hline CHEMBL1558029 & 688620 & 5.0 & 5.0977 & TRN & \\
\hline CHEMBL1518074 & 688620 & 4.9 & 4.935 & TRN & \\
\hline CHEMBL1584067 & 688620 & 5.15 & 5.2386 & TRN & \\
\hline CHEMBL1544988 & 688620 & 6.5 & 5.2941 & TRN & \\
\hline CHEMBL591361 & 688620 & 5.85 & 6.00200 & 0000000001 & TRN \\
\hline CHEMBL1576815 & 688620 & 4.85 & 4.8866 & TST & \\
\hline CHEMBL1366926 & 688620 & 5.0 & 4.9391 & TST & \\
\hline CHEMBL1312665 & 688620 & 4.85 & 5.2069 & TRN & \\
\hline CHEMBL1383511 & 688620 & 6.05 & 5.6027 & TRN & \\
\hline CHEMBL1359949 & 688620 & 4.65 & 4.945 & TRN & \\
\hline CHEMBL1490191 & 688620 & 5.95 & 5.5363 & TRN & \\
\hline CHEMBL3210094 & 688620 & 5.0 & 5.8197 & TRN & \\
\hline CHEMBL1445198 & 688620 & 5.55 & 5.3043 & TRN & \\
\hline
\end{tabular}




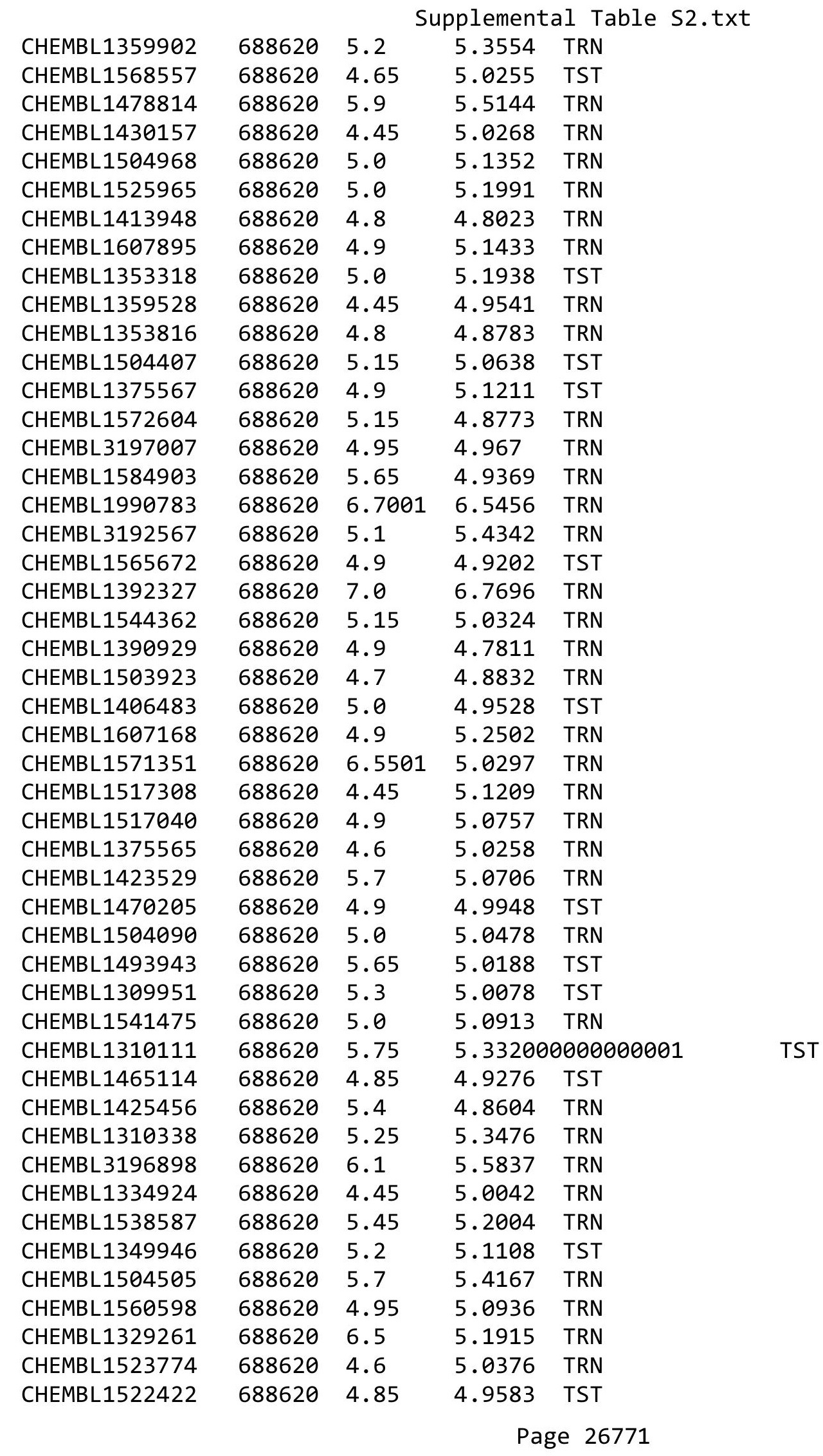




\begin{tabular}{|c|c|c|c|c|}
\hline & & & pplement & al $\mathrm{T}$ \\
\hline CHEMBL1510888 & 688620 & 5.0 & 5.2596 & TRN \\
\hline CHEMBL1319659 & 688620 & 5.4 & 5.0638 & TRN \\
\hline CHEMBL1583046 & 688620 & 4.95 & 4.9123 & TRN \\
\hline CHEMBL1313133 & 688620 & 4.5 & 5.0939 & TST \\
\hline CHEMBL1531454 & 688620 & 4.7 & 5.0602 & TRN \\
\hline CHEMBL1441395 & 688620 & 5.0 & 4.8694 & TRN \\
\hline CHEMBL3194043 & 688620 & 5.0 & 4.8022 & TRN \\
\hline CHEMBL1328153 & 688620 & 5.0 & 4.9726 & TRN \\
\hline CHEMBL1329349 & 688620 & 4.9 & 5.2527 & TRN \\
\hline CHEMBL1304194 & 688620 & 5.2 & 5.343 & TST \\
\hline CHEMBL3209776 & 688620 & 4.65 & 4.8317 & TRN \\
\hline CHEMBL1326288 & 688620 & 4.95 & 4.9415 & TRN \\
\hline CHEMBL1603763 & 688620 & 6.0 & 5.2461 & TRN \\
\hline CHEMBL1386467 & 688620 & 5.95 & 5.6715 & TST \\
\hline CHEMBL1428967 & 688620 & 4.5 & 4.8981 & TST \\
\hline CHEMBL1329705 & 688620 & 7.0501 & 4.9854 & TRN \\
\hline CHEMBL1477081 & 688620 & 5.5 & 5.2107 & TRN \\
\hline CHEMBL1324810 & 688620 & 6.15 & 5.0479 & TST \\
\hline CHEMBL1499346 & 688620 & 4.6 & 4.5544 & TRN \\
\hline CHEMBL1458897 & 688620 & 4.45 & 4.9557 & TRN \\
\hline CHEMBL1443713 & 688620 & 4.95 & 5.0661 & TRN \\
\hline CHEMBL1547001 & 688620 & 4.9 & 5.096 & TRN \\
\hline CHEMBL1454046 & 688620 & 5.8 & 5.1165 & TRN \\
\hline CHEMBL1549814 & 688620 & 4.5 & 5.0251 & TRN \\
\hline CHEMBL1342433 & 688620 & 5.6 & 5.2942 & TRN \\
\hline CHEMBL1565949 & 688620 & 4.75 & 5.1407 & TST \\
\hline CHEMBL1335148 & 688620 & 5.5 & 5.5534 & TRN \\
\hline CHEMBL2002444 & 688620 & 6.35 & 5.8331 & TRN \\
\hline CHEMBL1502062 & 688620 & 4.95 & 4.9106 & TRN \\
\hline CHEMBL1457108 & 688620 & 5.1 & 4.9633 & TRN \\
\hline CHEMBL1517699 & 688620 & 4.9 & 4.9656 & TST \\
\hline CHEMBL1493059 & 688620 & 5.05 & 4.8325 & TRN \\
\hline CHEMBL1447781 & 688620 & 4.45 & 5.398 & TRN \\
\hline CHEMBL1310492 & 688620 & 5.0 & 5.1614 & TRN \\
\hline CHEMBL1596707 & 688620 & 4.65 & 4.7831 & TST \\
\hline CHEMBL1378642 & 688620 & 5.0 & 5.0528 & TRN \\
\hline CHEMBL1524353 & 688620 & 4.5 & 4.9817 & TST \\
\hline CHEMBL1305254 & 688620 & 5.4 & 5.3886 & TST \\
\hline CHEMBL1415879 & 688620 & 5.8 & 5.1393 & TST \\
\hline CHEMBL1348690 & 688620 & 4.75 & 5.1645 & TRN \\
\hline CHEMBL1542854 & 688620 & 4.95 & 4.9537 & TRN \\
\hline CHEMBL1306012 & 688620 & 5.8 & 5.1369 & TST \\
\hline CHEMBL1610835 & 688620 & 5.5 & 5.1201 & TRN \\
\hline CHEMBL3199932 & 688620 & 5.5 & 4.9293 & TRN \\
\hline CHEMBL1977514 & 688620 & 5.5 & 5.478 & TRN \\
\hline CHEMBL1415283 & 688620 & 4.9 & 4.9569 & TRN \\
\hline CHEMBL1540175 & 688620 & 5.0 & 5.1443 & TRN \\
\hline CHEMBL1444094 & 688620 & 4.85 & 4.8413 & TRN \\
\hline
\end{tabular}




\begin{tabular}{|c|c|c|c|c|c|}
\hline & & \multicolumn{4}{|c|}{ Supplemental Table s2.txt } \\
\hline CHEMBL1299411 & 688620 & 4.45 & 4.7251 & TRN & \\
\hline CHEMBL1966948 & 688620 & 4.45 & 5.2533 & TRN & \\
\hline CHEMBL1373227 & 688620 & 4.45 & 4.9835 & TRN & \\
\hline CHEMBL1539336 & 688620 & 4.7 & 4.8618 & TRN & \\
\hline CHEMBL1339806 & 688620 & 4.75 & 5.1695 & TRN & \\
\hline CHEMBL1363703 & 688620 & 4.45 & 5.0859 & TST & \\
\hline CHEMBL1558603 & 688620 & 4.5 & 4.963 & TRN & \\
\hline CHEMBL1327568 & 688620 & 5.25 & 5.1124 & TRN & \\
\hline CHEMBL1600451 & 688620 & 4.95 & 4.928 & TRN & \\
\hline CHEMBL548540 & 688620 & 5.6 & 5.8359 & TRN & \\
\hline CHEMBL3145379 & 688620 & 6.45 & 5.99100 & 00000000005 & TRN \\
\hline CHEMBL1357717 & 688620 & 4.9 & 5.0287 & TRN & \\
\hline CHEMBL1418330 & 688620 & 5.05 & 5.05699 & 99999999995 & TST \\
\hline CHEMBL1334385 & 688620 & 4.85 & 4.9042 & TST & \\
\hline CHEMBL1971234 & 688620 & 5.15 & 5.153 & TST & \\
\hline CHEMBL1536864 & 688620 & 6.2 & 5.8094 & TRN & \\
\hline CHEMBL260624 & 688620 & 6.1 & 5.0923 & TRN & \\
\hline CHEMBL1502639 & 688620 & 5.0 & 4.9144 & TRN & \\
\hline CHEMBL1304722 & 688620 & 5.0 & 5.0462 & TRN & \\
\hline CHEMBL1322111 & 688620 & 4.8 & 4.7751 & TST & \\
\hline CHEMBL72631 & 688620 & 4.55 & 4.9928 & TST & \\
\hline CHEMBL1380726 & 688620 & 4.45 & 5.2783 & TRN & \\
\hline CHEMBL1527426 & 688620 & 4.9 & 5.0997 & TRN & \\
\hline CHEMBL1609651 & 688620 & 4.65 & 5.1635 & TST & \\
\hline CHEMBL1432507 & 688620 & 4.7 & 4.9382 & TRN & \\
\hline CHEMBL1508269 & 688620 & 4.75 & 4.998 & TRN & \\
\hline CHEMBL1470448 & 688620 & 6.0 & 6.2382 & TRN & \\
\hline CHEMBL1542276 & 688620 & 4.8 & 4.8971 & TRN & \\
\hline CHEMBL1366823 & 688620 & 4.8 & 5.1794 & TST & \\
\hline CHEMBL1557312 & 688620 & 4.95 & 5.1111 & TRN & \\
\hline CHEMBL1379443 & 688620 & 4.95 & 5.1431 & TRN & \\
\hline CHEMBL1443561 & 688620 & 4.8 & 5.3453 & TRN & \\
\hline CHEMBL1409034 & 688620 & 5.0 & 4.801 & TRN & \\
\hline CHEMBL1471701 & 688620 & 4.95 & 5.2728 & TRN & \\
\hline CHEMBL1370529 & 688620 & 4.9 & 4.7768 & TRN & \\
\hline CHEMBL1391293 & 688620 & 4.95 & 4.8985 & TRN & \\
\hline CHEMBL1472212 & 688620 & 4.95 & 5.0344 & TRN & \\
\hline CHEMBL1587771 & 688620 & 6.0 & 5.1531 & TRN & \\
\hline CHEMBL1601165 & 688620 & 4.45 & 5.1931 & TRN & \\
\hline CHEMBL1610783 & 688620 & 5.0 & 5.5053 & TRN & \\
\hline CHEMBL1483422 & 688620 & 6.0 & 5.1467 & TST & \\
\hline CHEMBL1533912 & 688620 & 5.0 & 4.9118 & TRN & \\
\hline CHEMBL1521535 & 688620 & 4.45 & 5.0465 & TRN & \\
\hline CHEMBL1571484 & 688620 & 4.8 & 4.9463 & TRN & \\
\hline CHEMBL1496432 & 688620 & 4.9 & 4.9629 & TRN & \\
\hline CHEMBL1346335 & 688620 & 5.2 & 5.0137 & TRN & \\
\hline CHEMBL3196575 & 688620 & 4.7 & 4.7932 & TST & \\
\hline CHEMBL1498850 & 688620 & 4.9 & 4.9004 & TRN & \\
\hline
\end{tabular}




\begin{tabular}{|c|c|c|c|c|c|}
\hline & & \multicolumn{4}{|c|}{ Supplemental Table S2.txt } \\
\hline CHEMBL1368820 & 688620 & 5.35 & 4.8554 & TRN & \\
\hline CHEMBL1506926 & 688620 & 5.6 & 5.2597 & TRN & \\
\hline CHEMBL1081537 & 688620 & 4.85 & 5.0433 & TRN & \\
\hline CHEMBL3192659 & 688620 & 5.3 & 5.7387 & TRN & \\
\hline CHEMBL1488927 & 688620 & 4.8 & 5.0364 & TRN & \\
\hline CHEMBL1493983 & 688620 & 4.45 & 5.1041 & TRN & \\
\hline CHEMBL603031 & 688620 & 4.6 & 4.7941 & TST & \\
\hline CHEMBL1445010 & 688620 & 5.05 & 5.4337 & TRN & \\
\hline CHEMBL1431659 & 688620 & 5.9 & 5.0712 & TRN & \\
\hline CHEMBL1435298 & 688620 & 5.15 & 4.9266 & TRN & \\
\hline CHEMBL1380201 & 688620 & 5.95 & 5.96299 & 9999999999 & TRN \\
\hline CHEMBL1498537 & 688620 & 4.95 & 4.9479 & TRN & \\
\hline CHEMBL1366886 & 688620 & 4.45 & 4.7116 & TRN & \\
\hline CHEMBL1388255 & 688620 & 5.1 & 5.2251 & TRN & \\
\hline CHEMBL1548418 & 688620 & 4.45 & 4.8905 & TRN & \\
\hline CHEMBL1471481 & 688620 & 5.35 & 4.8359 & TRN & \\
\hline CHEMBL1345299 & 688620 & 5.3 & 5.1751 & TRN & \\
\hline CHEMBL1431385 & 688620 & 6.0 & 5.135 & TRN & \\
\hline CHEMBL1444619 & 688620 & 4.95 & 5.1822 & TRN & \\
\hline CHEMBL1407864 & 688620 & 5.55 & 4.9879 & TRN & \\
\hline CHEMBL1384199 & 688620 & 4.55 & 4.8322 & TRN & \\
\hline CHEMBL1462189 & 688620 & 5.9 & 5.6025 & TRN & \\
\hline CHEMBL3192856 & 688620 & 6.0 & 5.6174 & TRN & \\
\hline CHEMBL 3213880 & 688620 & 5.55 & 5.081 & TRN & \\
\hline CHEMBL1568184 & 688620 & 4.85 & 4.8711 & TRN & \\
\hline CHEMBL1493985 & 688620 & 4.5 & 5.0624 & TRN & \\
\hline CHEMBL1529159 & 688620 & 4.9 & 5.0075 & TRN & \\
\hline CHEMBL1474804 & 688620 & 4.5 & 4.7498 & TRN & \\
\hline CHEMBL1431741 & 688620 & 4.95 & 5.0117 & TRN & \\
\hline CHEMBL1467931 & 688620 & 5.65 & 5.0824 & TST & \\
\hline CHEMBL1524008 & 688620 & 5.25 & 5.1973 & TRN & \\
\hline CHEMBL1366078 & 688620 & 4.45 & 4.8303 & TRN & \\
\hline CHEMBL1372327 & 688620 & 5.55 & 5.4609 & TRN & \\
\hline CHEMBL1366111 & 688620 & 4.9 & 5.1709 & TRN & \\
\hline CHEMBL1405368 & 688620 & 4.45 & 5.1386 & TRN & \\
\hline CHEMBL1319810 & 688620 & 5.55 & 5.4 & TRN & \\
\hline CHEMBL1542074 & 688620 & 6.0 & 5.5249 & TRN & \\
\hline CHEMBL1409143 & 688620 & 4.95 & 4.9443 & TRN & \\
\hline CHEMBL1346187 & 688620 & 5.65 & 5.4206 & TRN & \\
\hline CHEMBL1537635 & 688620 & 4.45 & 5.0998 & TRN & \\
\hline CHEMBL1573963 & 688620 & 6.0 & 5.3164 & TRN & \\
\hline CHEMBL1305911 & 688620 & 4.45 & 4.9162 & TRN & \\
\hline CHEMBL1308178 & 688620 & 4.9 & 5.2382 & TST & \\
\hline CHEMBL1508494 & 688620 & 5.2 & 5.1916 & TST & \\
\hline CHEMBL1310888 & 688620 & 4.75 & 5.008 & TRN & \\
\hline CHEMBL1424133 & 688620 & 5.2 & 4.9852 & TRN & \\
\hline CHEMBL1482757 & 688620 & 4.7 & 5.063 & TRN & \\
\hline CHEMBL1583195 & 688620 & 7.699 & 6.8163 & TRN & \\
\hline
\end{tabular}




\begin{tabular}{|c|c|c|c|c|}
\hline \multicolumn{5}{|c|}{ Supplemental Table S2.txt } \\
\hline CHEMBL3190729 & 688620 & 4.9 & 5.0392 & TRN \\
\hline CHEMBL1302225 & 688620 & 4.95 & 5.0206 & TRN \\
\hline CHEMBL1519666 & 688620 & 5.45 & 5.0584 & TRN \\
\hline CHEMBL1361326 & 688620 & 4.95 & 5.0223 & TRN \\
\hline CHEMBL1388392 & 688620 & 6.5501 & 5.1228 & TRN \\
\hline CHEMBL1311031 & 688620 & 4.85 & 4.9725 & TRN \\
\hline CHEMBL3196291 & 688620 & 5.1 & 5.0279 & TRN \\
\hline CHEMBL1438270 & 688620 & 4.9 & 5.0822 & TRN \\
\hline CHEMBL1323659 & 688620 & 4.75 & 5.0906 & TST \\
\hline CHEMBL1368507 & 688620 & 4.85 & 4.8267 & TRN \\
\hline CHEMBL1332775 & 688620 & 6.0 & 5.2283 & TRN \\
\hline CHEMBL1518205 & 688620 & 5.05 & 4.9434 & TRN \\
\hline CHEMBL1457708 & 688620 & 5.45 & 5.1988 & TRN \\
\hline CHEMBL1463416 & 688620 & 4.95 & 4.7742 & TRN \\
\hline CHEMBL1447890 & 688620 & 5.05 & 5.0609 & TRN \\
\hline CHEMBL3191329 & 688620 & 4.95 & 4.93 & TRN \\
\hline CHEMBL1348267 & 688620 & 4.7 & 4.8681 & TST \\
\hline CHEMBL1320514 & 688620 & 6.3 & 5.981 & TRN \\
\hline CHEMBL1383127 & 688620 & 4.9 & 4.8418 & TST \\
\hline CHEMBL1314279 & 688620 & 4.95 & 5.0542 & TRN \\
\hline CHEMBL1572390 & 688620 & 4.7 & 4.9959 & TST \\
\hline CHEMBL1359128 & 688620 & 5.65 & 5.5643 & TRN \\
\hline CHEMBL1390759 & 688620 & 4.9 & 5.0643 & TST \\
\hline CHEMBL1458441 & 688620 & 4.6 & 4.8719 & TST \\
\hline CHEMBL3196163 & 688620 & 4.75 & 5.3169 & TRN \\
\hline CHEMBL1613089 & 688620 & 4.9 & 5.0188 & TRN \\
\hline CHEMBL1299563 & 688620 & 5.2 & 5.3967 & TRN \\
\hline CHEMBL1992925 & 688620 & 5.0 & 4.8983 & TRN \\
\hline CHEMBL1425732 & 688620 & 5.6 & 5.6453 & TRN \\
\hline CHEMBL1529833 & 688620 & 4.8 & 4.8975 & TST \\
\hline CHEMBL1377376 & 688620 & 6.6 & 5.6474 & TST \\
\hline CHEMBL1560893 & 688620 & 5.4 & 5.0992 & TRN \\
\hline CHEMBL1389681 & 688620 & 6.95 & 5.1978 & TRN \\
\hline CHEMBL1519261 & 688620 & 4.85 & 4.7315 & TRN \\
\hline CHEMBL1548922 & 688620 & 6.1 & 5.6753 & TST \\
\hline CHEMBL1509500 & 688620 & 4.95 & 4.9328 & TRN \\
\hline CHEMBL1575947 & 688620 & 4.95 & 5.0929 & TRN \\
\hline CHEMBL1322432 & 688620 & 4.8 & 5.2092 & TRN \\
\hline CHEMBL1327129 & 688620 & 5.55 & 5.1387 & TRN \\
\hline CHEMBL1382193 & 688620 & 4.65 & 5.8201 & TRN \\
\hline CHEMBL1468680 & 688620 & 6.9 & 4.9075 & TRN \\
\hline CHEMBL1488535 & 688620 & 5.85 & 5.0605 & TRN \\
\hline CHEMBL1572456 & 688620 & 4.6 & 5.1733 & TRN \\
\hline CHEMBL1533031 & 688620 & 4.75 & 5.0782 & TRN \\
\hline CHEMBL1550236 & 688620 & 6.7501 & 5.051 & TST \\
\hline CHEMBL3210959 & 688620 & 4.95 & 4.992 & TRN \\
\hline CHEMBL1494833 & 688620 & 4.9 & 5.01 & TST \\
\hline CHEMBL1557096 & 688620 & 4.5 & 5.0965 & TRN \\
\hline
\end{tabular}




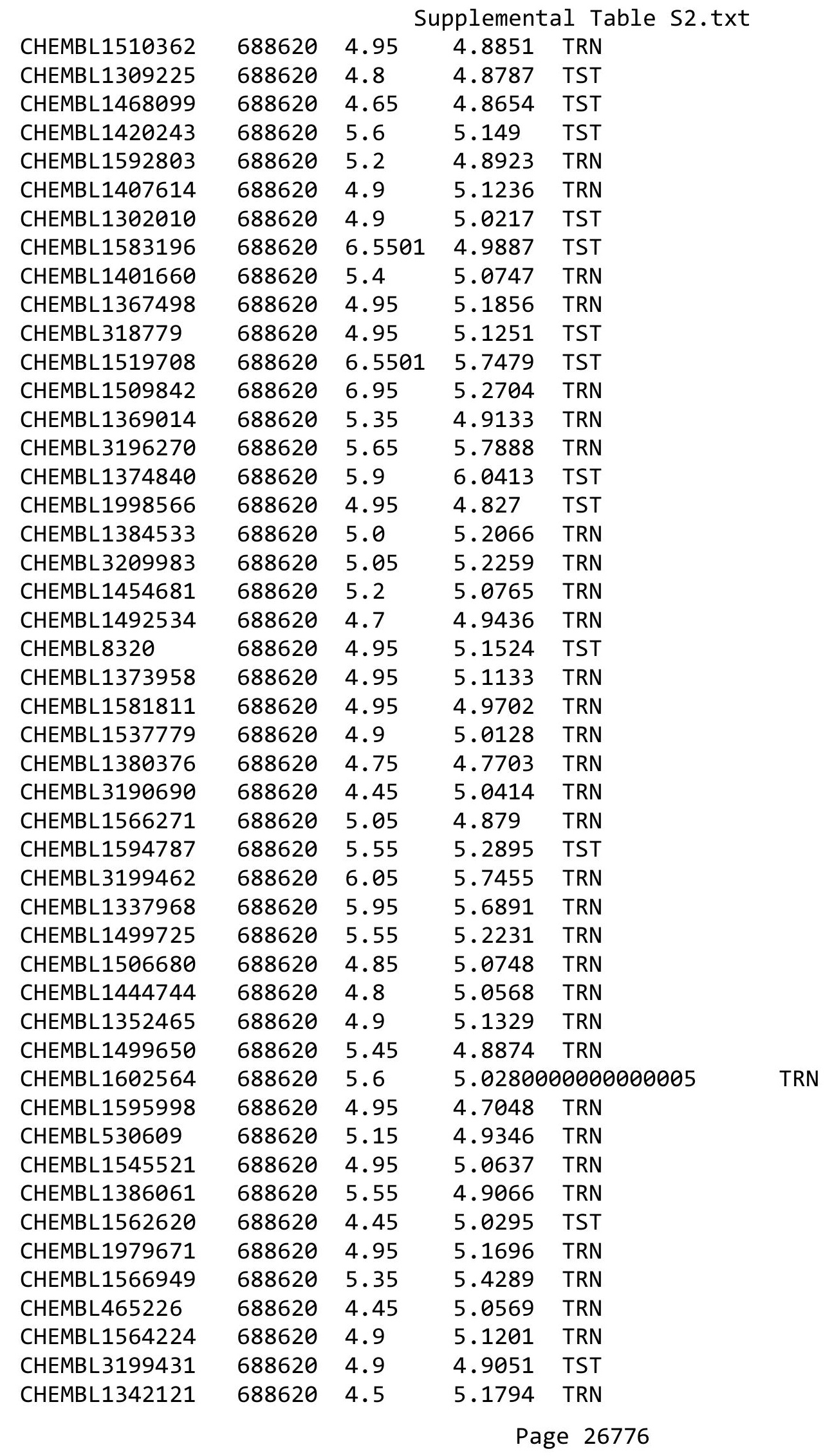




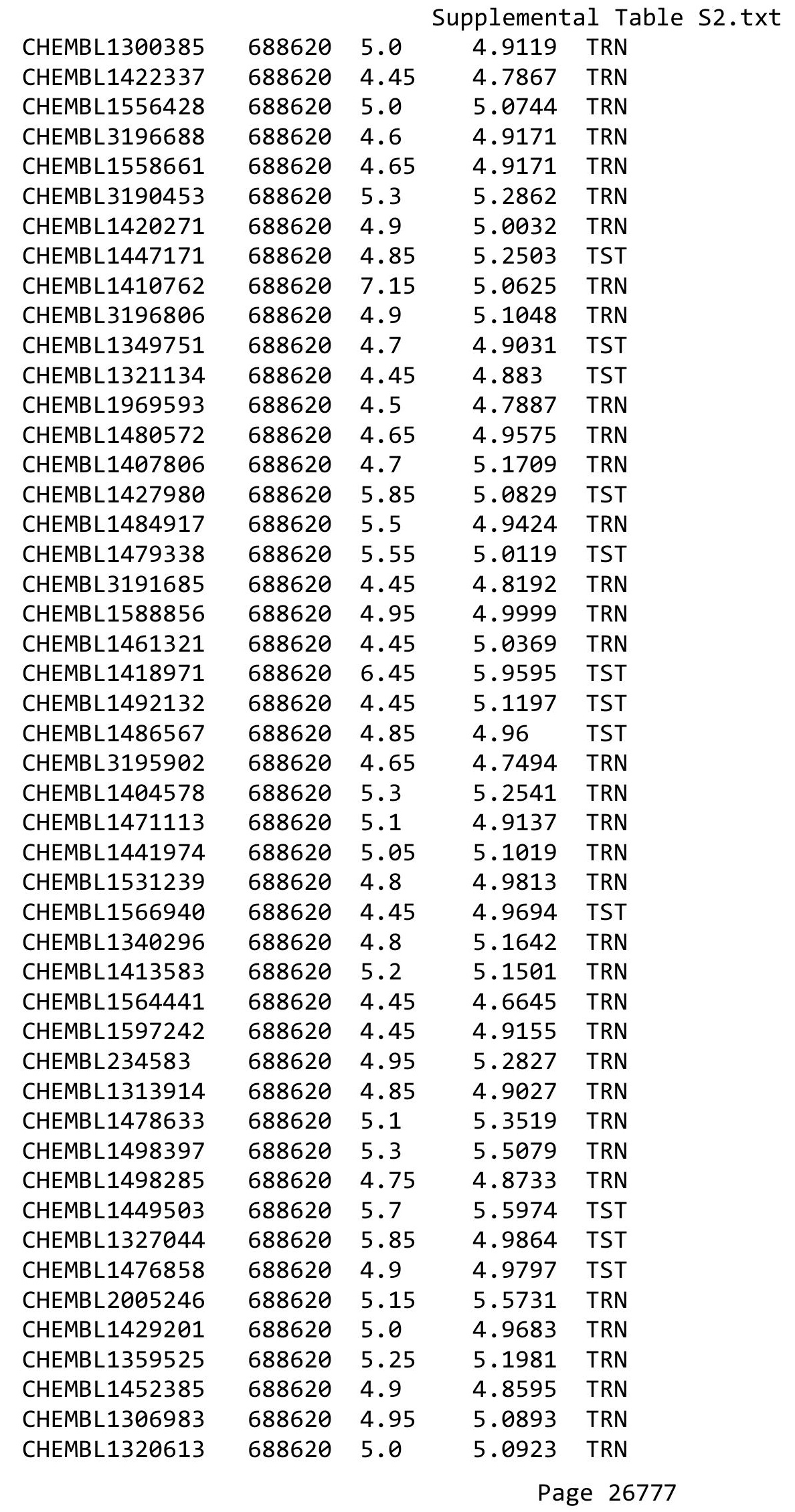




\begin{tabular}{|c|c|c|c|c|}
\hline \multicolumn{5}{|c|}{ Supplemental Table S2.txt } \\
\hline CHEMBL1518161 & 688620 & 4.6 & 5.3095 & TRN \\
\hline CHEMBL1601762 & 688620 & 4.85 & 5.0433 & TRN \\
\hline CHEMBL1595755 & 688620 & 5.0 & 4.894 & TST \\
\hline CHEMBL1303302 & 688620 & 4.45 & 4.9474 & TRN \\
\hline CHEMBL1966168 & 688620 & 4.95 & 5.1642 & TRN \\
\hline CHEMBL1532656 & 688620 & 4.75 & 5.0183 & TRN \\
\hline CHEMBL1606367 & 688620 & 6.05 & 5.5766 & TRN \\
\hline CHEMBL1604797 & 688620 & 5.5 & 5.1253 & TRN \\
\hline CHEMBL 3198962 & 688620 & 4.45 & 4.8211 & TRN \\
\hline CHEMBL1486258 & 688620 & 5.15 & 4.95 & TRN \\
\hline CHEMBL1573418 & 688620 & 6.5 & 5.026 & TRN \\
\hline CHEMBL1471912 & 688620 & 4.45 & 4.9774 & TRN \\
\hline CHEMBL1323526 & 688620 & 4.65 & 4.9809 & TST \\
\hline CHEMBL1299261 & 688620 & 4.95 & 5.0784 & TRN \\
\hline CHEMBL1359565 & 688620 & 5.15 & 5.3893 & TST \\
\hline CHEMBL1326093 & 688620 & 4.95 & 4.9251 & TRN \\
\hline CHEMBL1386755 & 688620 & 5.2 & 4.9842 & TST \\
\hline CHEMBL1564688 & 688620 & 8.301 & 4.8925 & TST \\
\hline CHEMBL 3193754 & 688620 & 4.8 & 5.1605 & TRN \\
\hline CHEMBL3193652 & 688620 & 5.9 & 5.7341 & TST \\
\hline CHEMBL1491883 & 688620 & 5.35 & 5.0594 & TRN \\
\hline CHEMBL 3197525 & 688620 & 4.45 & 5.1166 & TRN \\
\hline CHEMBL1486662 & 688620 & 4.45 & 5.029 & TRN \\
\hline CHEMBL3192019 & 688620 & 5.55 & 5.3516 & TRN \\
\hline CHEMBL1565776 & 688620 & 5.8 & 5.5376 & TRN \\
\hline CHEMBL1547862 & 688620 & 5.75 & 5.1103 & TST \\
\hline CHEMBL1444866 & 688620 & 4.65 & $5.0310 e$ & 0000000001 \\
\hline CHEMBL1346061 & 688620 & 4.75 & 4.8948 & TST \\
\hline CHEMBL1426588 & 688620 & 4.8 & 4.9879 & TRN \\
\hline CHEMBL1301835 & 688620 & 4.6 & 4.9749 & TRN \\
\hline CHEMBL1588603 & 688620 & 5.45 & 5.0021 & TRN \\
\hline CHEMBL1377025 & 688620 & 5.0 & 4.9687 & TRN \\
\hline CHEMBL1498932 & 688620 & 4.45 & 5.1437 & TRN \\
\hline CHEMBL3194907 & 688620 & 4.7 & 4.9654 & TRN \\
\hline CHEMBL1389650 & 688620 & 5.35 & 5.1569 & TRN \\
\hline CHEMBL1501634 & 688620 & 5.75 & 5.0099 & TRN \\
\hline CHEMBL3194269 & 688620 & 7.699 & 5.3053 & TRN \\
\hline CHEMBL1365828 & 688620 & 6.25 & 5.1249 & TRN \\
\hline CHEMBL1325258 & 688620 & 4.7 & 4.8163 & TRN \\
\hline CHEMBL1611370 & 688620 & 4.65 & 5.3188 & TST \\
\hline CHEMBL1554528 & 688620 & 5.25 & 5.0697 & TRN \\
\hline CHEMBL1378070 & 688620 & 5.9 & 5.4399 & TRN \\
\hline CHEMBL23327 & 688620 & 4.85 & 5.2134 & TRN \\
\hline CHEMBL1542620 & 688620 & 4.45 & 4.9828 & TRN \\
\hline CHEMBL1471211 & 688620 & 4.9 & 4.9953 & TRN \\
\hline CHEMBL1418316 & 688620 & 5.4 & 5.2228 & TRN \\
\hline CHEMBL1371598 & 688620 & 5.6 & 5.1234 & TRN \\
\hline CHEMBL1459746 & 688620 & 5.2 & 4.98 & TRN \\
\hline
\end{tabular}




\begin{tabular}{|c|c|c|c|c|c|}
\hline \\
\hline CHEMBL1558792 & 688620 & 4.6 & 5.2521 & TRN & \\
\hline CHEMBL3197977 & 688620 & 6.1 & 5.5098 & TRN & \\
\hline CHEMBL1433299 & 688620 & 4.95 & 5.1114 & TST & \\
\hline CHEMBL1497680 & 688620 & 4.95 & 5.2699 & TRN & \\
\hline CHEMBL1450756 & 688620 & 5.05 & 5.022 & TRN & \\
\hline CHEMBL1479629 & 688620 & 5.35 & 4.8624 & TRN & \\
\hline CHEMBL117966 & 688620 & 5.7 & 5.3346 & TRN & \\
\hline CHEMBL1610601 & 688620 & 6.1 & 5.1097 & TRN & \\
\hline CHEMBL3197891 & 688620 & 4.95 & 4.9785 & TRN & \\
\hline CHEMBL1403400 & 688620 & 4.45 & 5.4745 & TRN & \\
\hline CHEMBL1460126 & 688620 & 4.6 & 5.2753 & TRN & \\
\hline CHEMBL1582863 & 688620 & 4.45 & 5.145 & TRN & \\
\hline CHEMBL1306912 & 688620 & 4.95 & 5.0507 & TST & \\
\hline CHEMBL1431933 & 688620 & 4.95 & 5.184 & TRN & \\
\hline CHEMBL1452421 & 688620 & 5.25 & 5.5913 & TRN & \\
\hline CHEMBL1979747 & 688620 & 5.3 & 5.0085 & TRN & \\
\hline CHEMBL1476958 & 688620 & 4.75 & 4.955 & TST & \\
\hline CHEMBL584444 & 688620 & 4.45 & 4.6346 & TRN & \\
\hline CHEMBL1505349 & 688620 & 5.65 & 5.2227 & TRN & \\
\hline CHEMBL3193600 & 688620 & 4.5 & 5.0105 & TRN & \\
\hline CHEMBL1312130 & 688620 & 5.0 & 5.1654 & TRN & \\
\hline CHEMBL1400661 & 688620 & 4.45 & 4.9103 & TRN & \\
\hline CHEMBL3199309 & 688620 & 5.55 & 5.42700 & 00000000005 & TRN \\
\hline CHEMBL1443198 & 688620 & 6.1 & 6.1526 & TRN & \\
\hline CHEMBL1426498 & 688620 & 4.75 & 4.8207 & TST & \\
\hline CHEMBL1493958 & 688620 & 5.4 & 4.8195 & TST & \\
\hline CHEMBL1343494 & 688620 & 6.5501 & 5.1966 & TRN & \\
\hline CHEMBL1581380 & 688620 & 5.45 & 5.0193 & TRN & \\
\hline CHEMBL1576073 & 688620 & 5.3 & 5.3213 & TRN & \\
\hline CHEMBL1535915 & 688620 & 4.45 & 5.0992 & TRN & \\
\hline CHEMBL3198639 & 688620 & 4.9 & 4.9192 & TST & \\
\hline CHEMBL1541129 & 688620 & 4.95 & 5.0102 & TRN & \\
\hline CHEMBL1541549 & 688620 & 5.55 & 4.9998 & TRN & \\
\hline CHEMBL1483071 & 688620 & 4.45 & 4.8967 & TRN & \\
\hline CHEMBL3191630 & 688620 & 4.7 & 5.1919 & TRN & \\
\hline CHEMBL1432300 & 688620 & 5.25 & 4.9203 & TRN & \\
\hline CHEMBL1537124 & 688620 & 4.85 & 4.7591 & TRN & \\
\hline CHEMBL1467714 & 688620 & 4.75 & 4.9524 & TRN & \\
\hline CHEMBL1982577 & 688620 & 6.7501 & 4.7999 & TST & \\
\hline CHEMBL1498226 & 688620 & 4.5 & 5.0975 & TRN & \\
\hline CHEMBL1392623 & 688620 & 4.45 & 6.1546 & TRN & \\
\hline CHEMBL1362152 & 688620 & 4.95 & 4.9491 & TRN & \\
\hline CHEMBL1516988 & 688620 & 5.2 & 4.9517 & TST & \\
\hline CHEMBL1418019 & 688620 & 5.2 & 5.0484 & TRN & \\
\hline CHEMBL3199811 & 688620 & 4.45 & 5.1588 & TRN & \\
\hline CHEMBL1384690 & 688620 & 4.8 & 5.124 & TRN & \\
\hline CHEMBL3197552 & 688620 & 4.65 & 4.8114 & TRN & \\
\hline CHEMBL1365847 & 688620 & 4.65 & 4.9556 & TRN & \\
\hline
\end{tabular}




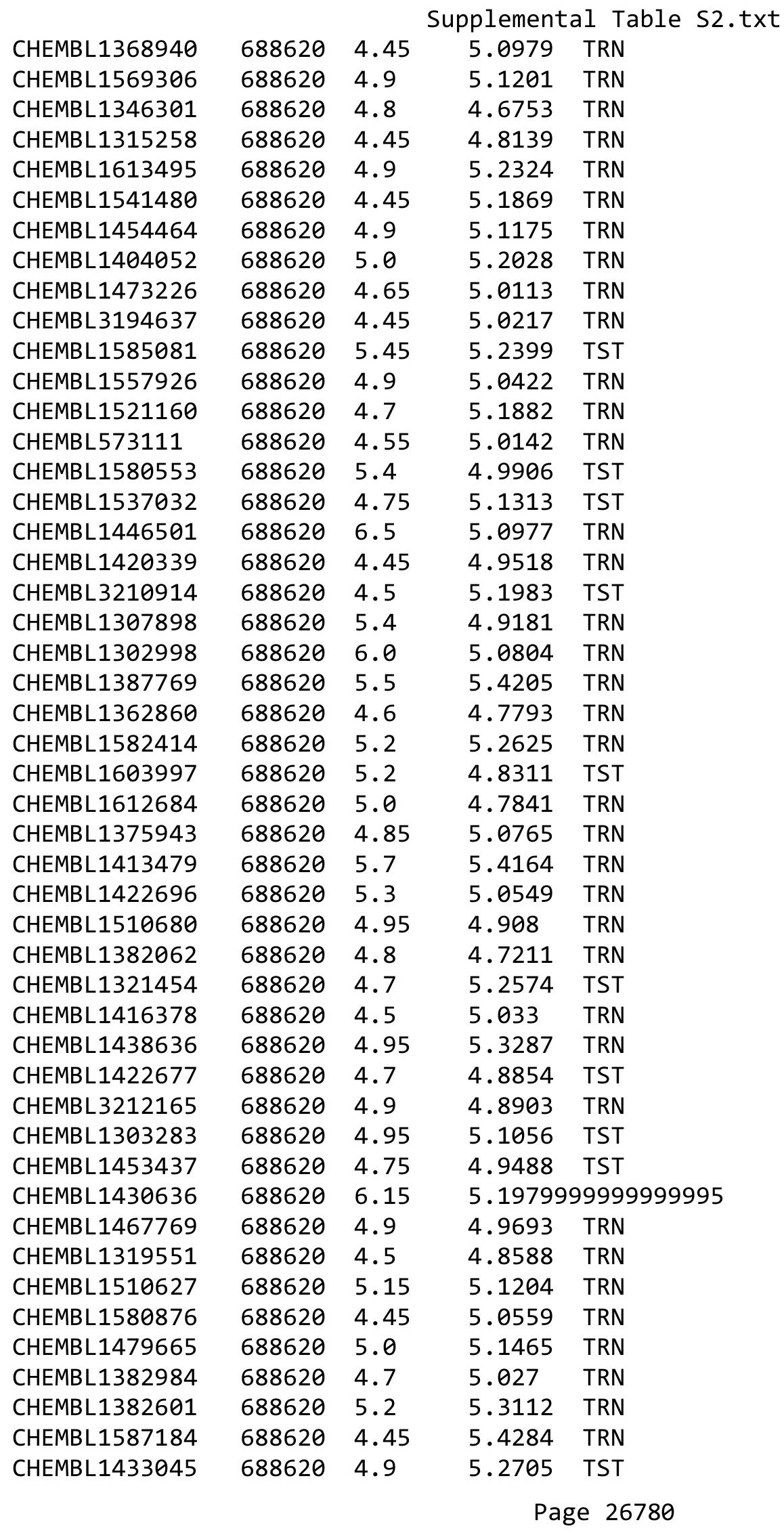




\begin{tabular}{|c|c|c|c|c|}
\hline \multicolumn{5}{|c|}{ Supplemental Table S2.txt } \\
\hline CHEMBL1447711 & 688620 & 5.5 & 5.331 & TRN \\
\hline CHEMBL1563933 & 688620 & 6.8 & 5.0108 & TRN \\
\hline CHEMBL1542157 & 688620 & 4.9 & 4.9475 & TRN \\
\hline CHEMBL1509766 & 688620 & 4.45 & 5.1609 & TRN \\
\hline CHEMBL1300890 & 688620 & 4.85 & 4.8584 & TRN \\
\hline CHEMBL3213103 & 688620 & 4.45 & 4.942 & TST \\
\hline CHEMBL1550322 & 688620 & 5.35 & 4.7222 & TRN \\
\hline CHEMBL1479578 & 688620 & 4.45 & 5.0521 & TST \\
\hline CHEMBL608699 & 688620 & 4.95 & 5.2518 & TRN \\
\hline CHEMBL1519511 & 688620 & 5.6 & 5.0141 & TRN \\
\hline CHEMBL1320180 & 688620 & 4.95 & 5.0047 & TRN \\
\hline CHEMBL3191686 & 688620 & 4.95 & 4.827 & TST \\
\hline CHEMBL1354443 & 688620 & 5.2 & 4.8408 & TRN \\
\hline CHEMBL1444110 & 688620 & 5.0 & 4.9259 & TRN \\
\hline CHEMBL1351051 & 688620 & 4.6 & 5.0196 & TST \\
\hline CHEMBL1401199 & 688620 & 4.85 & 5.1033 & TRN \\
\hline CHEMBL1417496 & 688620 & 4.45 & 4.8716 & TRN \\
\hline CHEMBL1586350 & 688620 & 4.75 & 5.1076 & TRN \\
\hline CHEMBL3207835 & 688620 & 4.5 & 5.157 & TST \\
\hline CHEMBL1471635 & 688620 & 5.15 & 5.1235 & TRN \\
\hline CHEMBL1989636 & 688620 & 4.9 & 5.0027 & TRN \\
\hline CHEMBL3192850 & 688620 & 4.9 & 5.0357 & TRN \\
\hline CHEMBL1577490 & 688620 & 8.3468 & 4.989 & TRN \\
\hline CHEMBL1425738 & 688620 & 5.75 & 5.2105 & TST \\
\hline CHEMBL1502122 & 688620 & 4.95 & 5.1527 & TRN \\
\hline CHEMBL1403893 & 688620 & 6.7001 & 4.8801 & TRN \\
\hline CHEMBL1415277 & 688620 & 5.1 & 5.1698 & TST \\
\hline CHEMBL3197105 & 688620 & 6.3 & 5.215 & TST \\
\hline CHEMBL1308768 & 688620 & 4.65 & 5.0347 & TST \\
\hline CHEMBL3196904 & 688620 & 4.75 & 5.0009 & TRN \\
\hline CHEMBL1306873 & 688620 & 4.75 & 5.033 & TRN \\
\hline CHEMBL1370862 & 688620 & 4.45 & 4.9822 & TRN \\
\hline CHEMBL388823 & 688620 & 6.45 & 5.6369 & TST \\
\hline CHEMBL1340869 & 688620 & 4.75 & 4.9021 & TRN \\
\hline CHEMBL1581536 & 688620 & 4.95 & 4.8117 & TRN \\
\hline CHEMBL3211130 & 688620 & 5.3 & 5.2263 & TRN \\
\hline CHEMBL1429692 & 688620 & 6.8499 & 5.2509 & TST \\
\hline CHEMBL1540841 & 688620 & 5.2 & 5.3898 & TRN \\
\hline CHEMBL1496077 & 688620 & 5.0 & 5.007 & TST \\
\hline CHEMBL1571227 & 688620 & 4.65 & 5.062 & TST \\
\hline CHEMBL1369003 & 688620 & 5.1 & 4.9394 & TRN \\
\hline CHEMBL1396799 & 688620 & 5.55 & 5.1319 & TST \\
\hline CHEMBL1578923 & 688620 & 4.95 & 4.9592 & TRN \\
\hline CHEMBL1427265 & 688620 & 4.75 & 5.1824 & TRN \\
\hline CHEMBL1494650 & 688620 & 5.0 & 5.1109 & TRN \\
\hline CHEMBL1411759 & 688620 & 4.75 & 4.8809 & TRN \\
\hline CHEMBL1535907 & 688620 & 5.8 & 5.016 & TRN \\
\hline CHEMBL1520716 & 688620 & 5.05 & 4.8741 & TRN \\
\hline
\end{tabular}




\begin{tabular}{|c|c|c|c|c|}
\hline \multicolumn{5}{|c|}{ Supplemental Table S2.txt } \\
\hline CHEMBL1560017 & 688620 & 4.45 & 4.7677 & TST \\
\hline CHEMBL1443798 & 688620 & 4.45 & 4.8414 & TST \\
\hline CHEMBL1587881 & 688620 & 5.6 & 5.2771 & TRN \\
\hline CHEMBL1489509 & 688620 & 4.7 & 4.9963 & TRN \\
\hline CHEMBL1348198 & 688620 & 4.45 & 4.9345 & TST \\
\hline CHEMBL1546304 & 688620 & 4.8 & 4.9608 & TRN \\
\hline CHEMBL1322702 & 688620 & 4.7 & 5.0773 & TRN \\
\hline CHEMBL1307912 & 688620 & 5.55 & 5.1177 & TRN \\
\hline CHEMBL1581674 & 688620 & 4.85 & 4.9118 & TRN \\
\hline CHEMBL1415083 & 688620 & 5.4 & 5.0316 & TST \\
\hline CHEMBL1467919 & 688620 & 5.4 & 5.1791 & TRN \\
\hline CHEMBL1511740 & 688620 & 5.1 & 5.1446 & TRN \\
\hline CHEMBL1339683 & 688620 & 4.75 & 4.9665 & TRN \\
\hline CHEMBL 3199221 & 688620 & 4.9 & 4.9339 & TST \\
\hline CHEMBL3192312 & 688620 & 5.35 & 5.1455 & TRN \\
\hline CHEMBL1487277 & 688620 & 6.2 & 5.5265 & TRN \\
\hline CHEMBL1519401 & 688620 & 5.0 & 5.0718 & TRN \\
\hline CHEMBL1528847 & 688620 & 7.3497 & 5.5058 & TRN \\
\hline CHEMBL1603530 & 688620 & 4.75 & 4.9732 & TRN \\
\hline CHEMBL1336330 & 688620 & 5.0 & 5.0402 & TRN \\
\hline CHEMBL1438127 & 688620 & 4.8 & 4.8193 & TRN \\
\hline CHEMBL1567073 & 688620 & 4.45 & 4.8903 & TRN \\
\hline CHEMBL1982202 & 688620 & 5.0 & 5.1552 & TRN \\
\hline CHEMBL259805 & 688620 & 5.45 & 5.5168 & TRN \\
\hline CHEMBL1531137 & 688620 & 5.3 & 6.1264 & TST \\
\hline CHEMBL3210873 & 688620 & 4.95 & 4.8378 & TRN \\
\hline CHEMBL3199120 & 688620 & 6.4 & 5.904 & TRN \\
\hline CHEMBL1575452 & 688620 & 4.5 & 4.9854 & TRN \\
\hline CHEMBL1600314 & 688620 & 5.25 & 5.2885 & TRN \\
\hline CHEMBL1496028 & 688620 & 4.95 & 4.8284 & TRN \\
\hline CHEMBL1432056 & 688620 & 5.45 & 4.9609 & TRN \\
\hline CHEMBL1454890 & 688620 & 4.8 & 4.925 & TST \\
\hline CHEMBL1605363 & 688620 & 4.95 & 4.7589 & TRN \\
\hline CHEMBL1565658 & 688620 & 4.7 & 5.0603 & TST \\
\hline CHEMBL2000440 & 688620 & 5.7 & 5.3194 & TRN \\
\hline CHEMBL1542121 & 688620 & 4.9 & 5.4262 & TST \\
\hline CHEMBL1995156 & 688620 & 6.7001 & 5.2404 & TRN \\
\hline CHEMBL1340715 & 688620 & 6.5 & 5.3289 & TRN \\
\hline CHEMBL1327834 & 688620 & 5.1 & 4.9791 & TRN \\
\hline CHEMBL1603888 & 688620 & 4.5 & 4.9995 & TST \\
\hline CHEMBL1533351 & 688620 & 4.9 & 4.8847 & TST \\
\hline CHEMBL 1344536 & 688620 & 4.45 & 5.027 & TST \\
\hline CHEMBL1542066 & 688620 & 4.9 & 5.3178 & TST \\
\hline CHEMBL3199236 & 688620 & 5.6 & 5.5076 & TRN \\
\hline CHEMBL1353211 & 688620 & 4.9 & 5.0552 & TRN \\
\hline CHEMBL1539153 & 688620 & 5.55 & 4.9993 & TST \\
\hline CHEMBL3191043 & 688620 & 4.6 & 5.1419 & TRN \\
\hline CHEMBL1571290 & 688620 & 6.0 & 5.4191 & TST \\
\hline
\end{tabular}




\begin{tabular}{|c|c|c|c|c|c|}
\hline \multicolumn{6}{|c|}{ oplemental Iable S2 } \\
\hline CHEMBL1334877 & 688620 & 4.8 & 4.7437 & TST & \\
\hline CHEMBL1527982 & 688620 & 5.0 & 4.8205 & TRN & \\
\hline CHEMBL1445746 & 688620 & 4.6 & 4.9704 & TRN & \\
\hline CHEMBL1365519 & 688620 & 5.6 & 5.2057 & TRN & \\
\hline CHEMBL 2094789 & 688620 & 6.45 & 5.7095 & TRN & \\
\hline CHEMBL3199851 & 688620 & 5.4 & 5.4706 & TRN & \\
\hline CHEMBL1508132 & 688620 & 4.45 & 4.904 & TRN & \\
\hline CHEMBL1423432 & 688620 & 4.6 & 4.7163 & TRN & \\
\hline CHEMBL1542330 & 688620 & 5.8 & 4.9513 & TRN & \\
\hline CHEMBL1557744 & 688620 & 4.7 & 4.8332 & TRN & \\
\hline CHEMBL1586126 & 688620 & 5.25 & 4.8638 & TST & \\
\hline CHEMBL1587218 & 688620 & 5.5 & \multicolumn{2}{|c|}{4.7589999999999995} & TST \\
\hline CHEMBL1544514 & 688620 & 5.0 & 4.8272 & TST & \\
\hline CHEMBL1489050 & 688620 & 4.95 & 5.1453 & TST & \\
\hline CHEMBL1346501 & 688620 & 4.7 & 4.9303 & TRN & \\
\hline CHEMBL1351159 & 688620 & 4.55 & 4.7164 & TST & \\
\hline CHEMBL1370480 & 688620 & 5.0 & 5.188 & TRN & \\
\hline CHEMBL1418232 & 688620 & 4.6 & 5.1188 & TRN & \\
\hline CHEMBL3194168 & 688620 & 5.0 & 4.9997 & TRN & \\
\hline CHEMBL1426802 & 688620 & 6.9 & 4.8667 & TRN & \\
\hline CHEMBL1427629 & 688620 & 5.45 & 5.3434 & TRN & \\
\hline CHEMBL1479241 & 688620 & 5.0 & 5.1058 & TRN & \\
\hline CHEMBL1500091 & 688620 & 4.65 & 4.8544 & TRN & \\
\hline CHEMBL1446604 & 688620 & 8.301 & 4.7818 & TRN & \\
\hline CHEMBL1466292 & 688620 & 6.0 & 5.5022 & TRN & \\
\hline CHEMBL483582 & 688620 & 5.3 & 5.0538 & TRN & \\
\hline CHEMBL1584471 & 688620 & 5.0 & 5.2922 & TST & \\
\hline CHEMBL1522574 & 688620 & 4.45 & 4.9634 & TRN & \\
\hline CHEMBL1469791 & 688620 & 6.3 & 5.5234 & TRN & \\
\hline CHEMBL1541252 & 688620 & 4.65 & 4.8648 & TST & \\
\hline CHEMBL1576899 & 688620 & 4.75 & 4.7745 & TRN & \\
\hline CHEMBL1422065 & 688620 & 4.8 & 5.0535 & TRN & \\
\hline CHEMBL1364533 & 688620 & 5.75 & 5.083 & TRN & \\
\hline CHEMBL1326341 & 688620 & 4.8 & 5.0394 & TRN & \\
\hline CHEMBL1340489 & 688620 & 5.3 & 5.1906 & TRN & \\
\hline CHEMBL1388017 & 688620 & 5.2 & 5.2101 & TRN & \\
\hline CHEMBL1327948 & 688620 & 4.85 & 4.9971 & TRN & \\
\hline CHEMBL1556781 & 688620 & 4.5 & 4.8899 & TST & \\
\hline CHEMBL3209565 & 688620 & 6.45 & 4.9168 & TRN & \\
\hline CHEMBL1579318 & 688620 & 4.45 & 5.0978 & TRN & \\
\hline CHEMBL1427706 & 688620 & 5.25 & 5.1654 & TST & \\
\hline CHEMBL1523053 & 688620 & 5.2 & 5.4286 & TRN & \\
\hline CHEMBL3196627 & 688620 & 4.9 & 5.3674 & TRN & \\
\hline CHEMBL1468834 & 688620 & 4.5 & 4.9511 & TST & \\
\hline CHEMBL1578580 & 688620 & 4.95 & 5.1417 & TRN & \\
\hline CHEMBL3195857 & 688620 & 6.2 & 5.7906 & TRN & \\
\hline CHEMBL3196365 & 688620 & 5.9 & 5.4779 & TRN & \\
\hline CHEMBL1567615 & 688620 & 6.0 & 5.0785 & TST & \\
\hline
\end{tabular}




\begin{tabular}{|c|c|c|c|c|}
\hline \multicolumn{5}{|c|}{ Supplemental Table S2.txt } \\
\hline CHEMBL3195396 & 688620 & 4.65 & 5.1141 & TRN \\
\hline CHEMBL1385747 & 688620 & 4.95 & 5.025 & TRN \\
\hline CHEMBL1402102 & 688620 & 7.0 & 4.9729 & TRN \\
\hline CHEMBL1517945 & 688620 & 5.2 & 4.7932 & TRN \\
\hline CHEMBL1580518 & 688620 & 4.95 & 4.9662 & TRN \\
\hline CHEMBL1449349 & 688620 & 5.25 & 5.2155 & TST \\
\hline CHEMBL 3209425 & 688620 & 4.95 & 5.0399 & TST \\
\hline CHEMBL1305736 & 688620 & 4.95 & 5.1139 & TST \\
\hline CHEMBL1556187 & 688620 & 4.95 & 5.0584 & TST \\
\hline CHEMBL1438119 & 688620 & 4.95 & 5.428 & TST \\
\hline CHEMBL 3195459 & 688620 & 5.25 & 5.2497 & TRN \\
\hline CHEMBL1078979 & 688620 & 5.3 & 5.2935 & TRN \\
\hline CHEMBL1557230 & 688620 & 4.95 & 5.1329 & TST \\
\hline CHEMBL1412489 & 688620 & 4.8 & 5.0511 & TRN \\
\hline CHEMBL1406023 & 688620 & 4.6 & 5.2684 & TST \\
\hline CHEMBL1474649 & 688620 & 5.55 & 5.1293 & TRN \\
\hline CHEMBL1544729 & 688620 & 5.2 & 4.9693 & TRN \\
\hline CHEMBL1452711 & 688620 & 5.9 & 5.6281 & TRN \\
\hline CHEMBL1533767 & 688620 & 4.95 & 5.1006 & TRN \\
\hline CHEMBL1378748 & 688620 & 4.9 & 5.0311 & TRN \\
\hline CHEMBL1557602 & 688620 & 5.05 & 5.2435 & TRN \\
\hline CHEMBL1353196 & 688620 & 4.7 & 5.0219 & TRN \\
\hline CHEMBL1399653 & 688620 & 5.3 & 5.1075 & TRN \\
\hline CHEMBL1330352 & 688620 & 7.3002 & 4.7322 & TRN \\
\hline CHEMBL1445576 & 688620 & 5.1 & 5.04 & TRN \\
\hline CHEMBL1490991 & 688620 & 5.5 & 5.2699 & TRN \\
\hline CHEMBL1353374 & 688620 & 5.45 & 4.9833 & TRN \\
\hline CHEMBL1537769 & 688620 & 5.25 & 5.0302 & TST \\
\hline CHEMBL1452555 & 688620 & 4.6 & 5.1092 & TST \\
\hline CHEMBL1545282 & 688620 & 5.05 & 4.8893 & TRN \\
\hline CHEMBL1484703 & 688620 & 4.45 & 4.9215 & TST \\
\hline CHEMBL1502485 & 688620 & 4.45 & 4.9478 & TRN \\
\hline CHEMBL1506934 & 688620 & 4.5 & 4.8808 & TRN \\
\hline CHEMBL1392145 & 688620 & 5.6 & 5.5376 & TRN \\
\hline CHEMBL1579551 & 688620 & 4.45 & 5.1033 & TRN \\
\hline CHEMBL 3208232 & 688620 & 4.95 & 4.9355 & TRN \\
\hline CHEMBL1518054 & 688620 & 4.9 & 5.2683 & TRN \\
\hline CHEMBL3189325 & 688620 & 6.25 & 5.7452 & TRN \\
\hline CHEMBL1352770 & 688620 & 5.2 & 5.315 & TST \\
\hline CHEMBL1453086 & 688620 & 5.4 & 4.8454 & TRN \\
\hline CHEMBL1541279 & 688620 & 5.05 & 5.0318 & TST \\
\hline CHEMBL 1500725 & 688620 & 5.0 & 4.8205 & TRN \\
\hline CHEMBL1458874 & 688620 & 4.7 & 5.4457 & TRN \\
\hline CHEMBL1410497 & 688620 & 5.4 & 4.8085 & TST \\
\hline CHEMBL1539093 & 688620 & 4.75 & 4.9848 & TRN \\
\hline CHEMBL1456071 & 688620 & 4.8 & 5.2722 & TRN \\
\hline CHEMBL1964943 & 688620 & 5.5 & 5.2871 & TRN \\
\hline CHEMBL1549422 & 688620 & 5.25 & 4.6885 & TRN \\
\hline
\end{tabular}




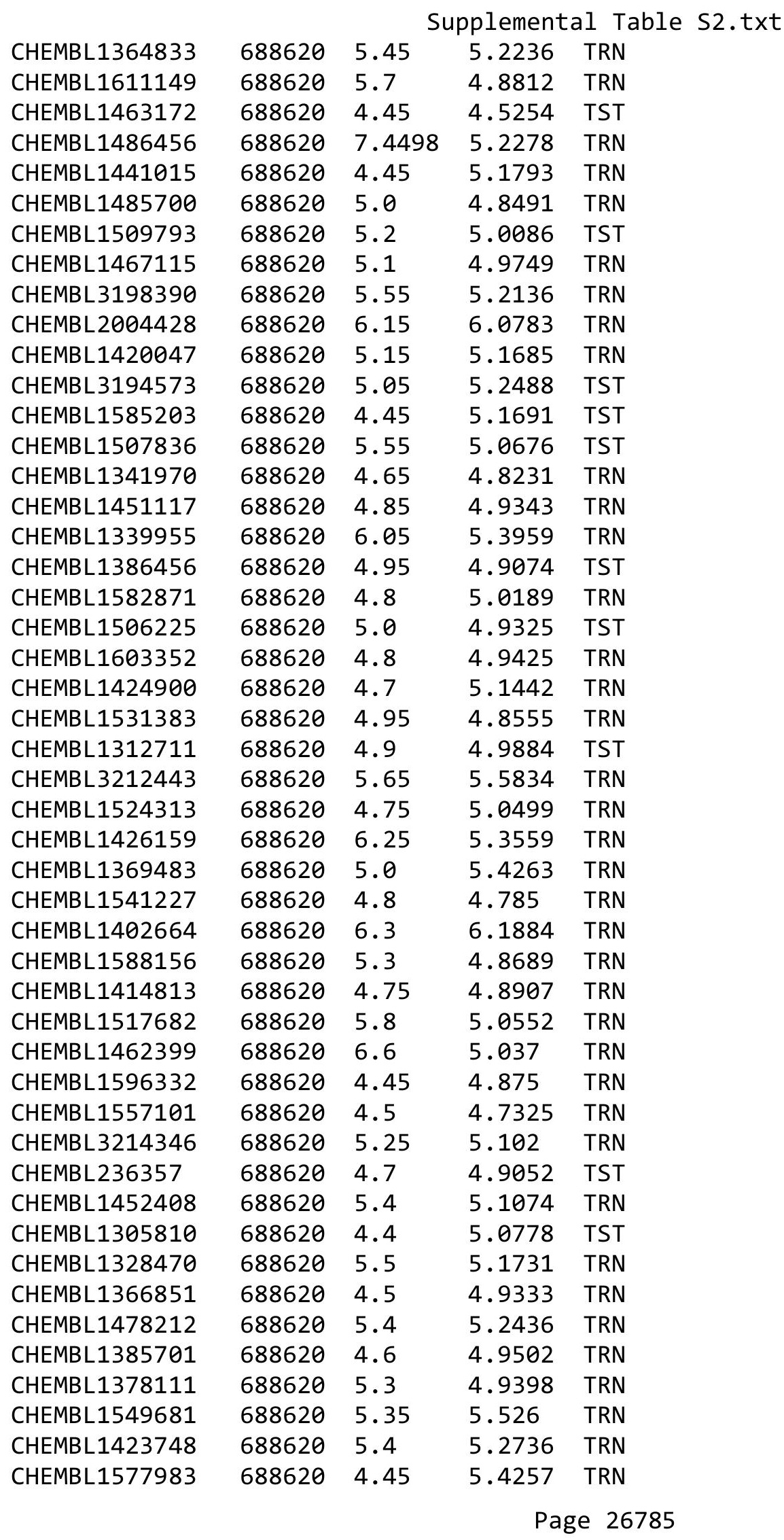




\begin{tabular}{|c|c|c|c|c|}
\hline \multicolumn{5}{|c|}{ Supplemental Table S2.txt } \\
\hline CHEMBL1405130 & 688620 & 5.25 & 5.5814 & TRN \\
\hline CHEMBL1451344 & 688620 & 4.9 & 4.8355 & TRN \\
\hline CHEMBL1498458 & 688620 & 5.2 & 5.0995 & TST \\
\hline CHEMBL1378477 & 688620 & 5.4 & 5.3246 & TST \\
\hline CHEMBL1361760 & 688620 & 4.7 & 5.1665 & TRN \\
\hline CHEMBL1353955 & 688620 & 4.45 & 5.4571 & TST \\
\hline CHEMBL 3145201 & 688620 & 4.8 & 5.3311 & TRN \\
\hline CHEMBL1966328 & 688620 & 4.7 & 5.0958 & TRN \\
\hline CHEMBL1305741 & 688620 & 5.15 & 4.7459 & TRN \\
\hline CHEMBL1608840 & 688620 & 4.95 & 4.9216 & TRN \\
\hline CHEMBL1305537 & 688620 & 4.75 & 4.9092 & TRN \\
\hline CHEMBL1325970 & 688620 & 4.45 & 4.9308 & TST \\
\hline CHEMBL3190186 & 688620 & 4.45 & 4.7164 & TRN \\
\hline CHEMBL 3194356 & 688620 & 5.3 & 5.329 & TRN \\
\hline CHEMBL1322472 & 688620 & 4.8 & 5.0118 & TRN \\
\hline CHEMBL1466004 & 688620 & 4.45 & 4.7426 & TST \\
\hline CHEMBL1545354 & 688620 & 4.9 & 5.0326 & TRN \\
\hline CHEMBL1446727 & 688620 & 4.7 & 4.9328 & TRN \\
\hline CHEMBL1456111 & 688620 & 5.0 & 5.0365 & TRN \\
\hline CHEMBL1510664 & 688620 & 5.0 & 5.2298 & TST \\
\hline CHEMBL1533871 & 688620 & 5.0 & 5.5402 & TRN \\
\hline CHEMBL1504358 & 688620 & 5.0 & 5.1845 & TRN \\
\hline CHEMBL1443123 & 688620 & 5.2 & 5.0639 & TRN \\
\hline CHEMBL1421405 & 688620 & 4.8 & 5.0581 & TST \\
\hline CHEMBL1332535 & 688620 & 4.45 & 5.0687 & TRN \\
\hline CHEMBL1577839 & 688620 & 5.75 & 5.1004 & TST \\
\hline CHEMBL1386648 & 688620 & 4.45 & 4.7491 & TST \\
\hline CHEMBL3193916 & 688620 & 5.2 & 5.0766 & TRN \\
\hline CHEMBL1344948 & 688620 & 4.85 & 5.1052 & TST \\
\hline CHEMBL1541342 & 688620 & 5.0 & 5.1062 & TST \\
\hline CHEMBL1313646 & 688620 & 5.0 & 5.0925 & TST \\
\hline CHEMBL1324951 & 688620 & 4.7 & 5.1309 & TST \\
\hline CHEMBL1428583 & 688620 & 5.25 & 4.9981 & TRN \\
\hline CHEMBL1388086 & 688620 & 5.0 & 4.9184 & TRN \\
\hline CHEMBL3212355 & 688620 & 4.8 & 4.8958 & TST \\
\hline CHEMBL1389725 & 688620 & 5.75 & 4.9333 & TRN \\
\hline CHEMBL1347933 & 688620 & 6.6 & 5.2076 & TRN \\
\hline CHEMBL1481353 & 688620 & 5.7 & 5.2486 & TST \\
\hline CHEMBL1419508 & 688620 & 4.45 & 5.1751 & TST \\
\hline CHEMBL1598075 & 688620 & 5.0 & 4.8507 & TRN \\
\hline CHEMBL1606873 & 688620 & 5.1 & 5.1011 & TRN \\
\hline CHEMBL1361173 & 688620 & 4.45 & 5.0063 & TRN \\
\hline CHEMBL1607087 & 688620 & 4.7 & 4.9402 & TST \\
\hline CHEMBL1448403 & 688620 & 5.15 & 5.4528 & TRN \\
\hline CHEMBL1422609 & 688620 & 6.0 & 5.5117 & TRN \\
\hline CHEMBL1400668 & 688620 & 4.8 & 4.9394 & TRN \\
\hline CHEMBL1594343 & 688620 & 4.65 & 4.9773 & TRN \\
\hline CHEMBL567130 & 688620 & 5.2 & 4.9537 & TRN \\
\hline
\end{tabular}




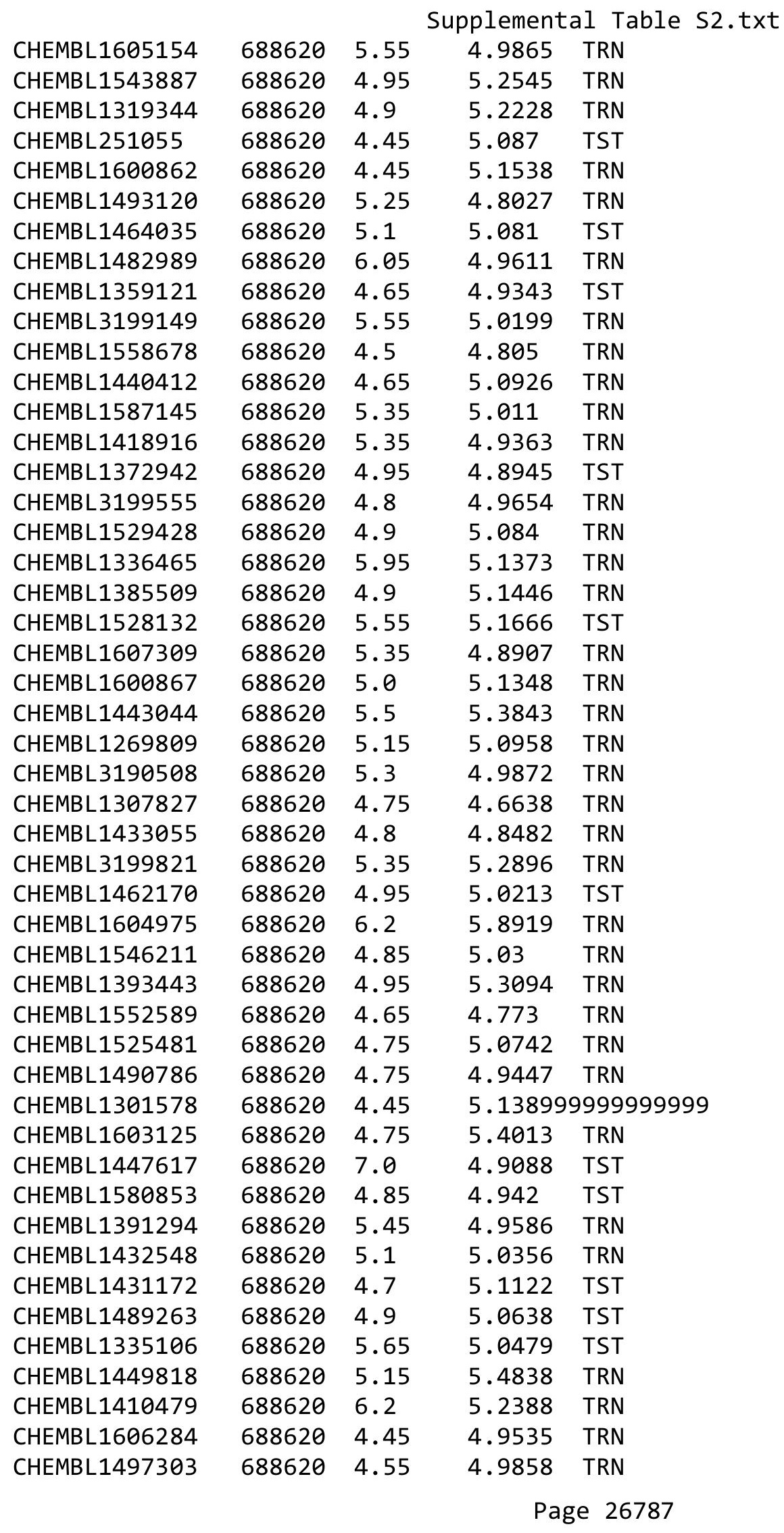




\begin{tabular}{|c|c|c|c|c|c|}
\hline \\
\hline CHEMBL1504895 & 688620 & 5.1 & 5.0745 & TRN & \\
\hline CHEMBL1589313 & 688620 & 5.85 & 4.9315 & TST & \\
\hline CHEMBL1334169 & 688620 & 5.0 & 4.652 & TRN & \\
\hline CHEMBL1433357 & 688620 & 6.4 & 5.01 & TST & \\
\hline CHEMBL1307635 & 688620 & 5.6 & 5.2276 & TRN & \\
\hline CHEMBL1457822 & 688620 & 4.95 & 5.1644 & TRN & \\
\hline CHEMBL1378826 & 688620 & 4.9 & 5.1069 & TRN & \\
\hline CHEMBL1572894 & 688620 & 6.15 & 5.0229 & TRN & \\
\hline CHEMBL1301707 & 688620 & 5.35 & 5.3634 & TRN & \\
\hline CHEMBL1352840 & 688620 & 5.6 & 5.2424 & TRN & \\
\hline CHEMBL3192913 & 688620 & 5.7 & 5.0554 & TRN & \\
\hline CHEMBL1428794 & 688620 & 4.45 & 5.0492 & TRN & \\
\hline CHEMBL1352969 & 688620 & 6.2 & 5.3487 & TRN & \\
\hline CHEMBL1506191 & 688620 & 4.95 & 5.2646 & TRN & \\
\hline CHEMBL1304619 & 688620 & 4.95 & 4.7798 & TST & \\
\hline CHEMBL1391192 & 688620 & 5.9 & 5.2416 & TRN & \\
\hline CHEMBL1516869 & 688620 & 4.85 & 4.9948 & TRN & \\
\hline CHEMBL3189593 & 688620 & 4.8 & 4.8808 & TST & \\
\hline CHEMBL1468261 & 688620 & 5.8 & 4.8891 & TRN & \\
\hline CHEMBL1376821 & 688620 & 4.8 & 4.9414 & TST & \\
\hline CHEMBL1309978 & 688620 & 4.45 & 5.2422 & TRN & \\
\hline CHEMBL1500067 & 688620 & 4.95 & 5.186 & TRN & \\
\hline CHEMBL1542858 & 688620 & 5.4 & 5.008 & TST & \\
\hline CHEMBL1346241 & 688620 & 4.6 & 4.8736 & TRN & \\
\hline CHEMBL1320242 & 688620 & 4.95 & 5.0696 & TRN & \\
\hline CHEMBL1319646 & 688620 & 4.9 & 5.1877 & TRN & \\
\hline CHEMBL1436719 & 688620 & 5.05 & 5.1258 & TRN & \\
\hline CHEMBL1549890 & 688620 & 4.75 & 5.0606 & TST & \\
\hline CHEMBL1510862 & 688620 & 4.45 & 5.1981 & TRN & \\
\hline CHEMBL1528448 & 688620 & 6.5 & 5.2879 & TRN & \\
\hline CHEMBL1611920 & 688620 & 4.5 & 5.09399 & э999999999 & TRN \\
\hline CHEMBL1612979 & 688620 & 4.85 & 5.1387 & TST & \\
\hline CHEMBL1517325 & 688620 & 4.5 & 5.2112 & TRN & \\
\hline CHEMBL1499504 & 688620 & 4.45 & 4.9663 & TRN & \\
\hline CHEMBL1363558 & 688620 & 4.8 & 5.26 & TRN & \\
\hline CHEMBL1580267 & 688620 & 4.65 & 5.2554 & TRN & \\
\hline CHEMBL3209325 & 688620 & 6.0 & 5.3384 & TRN & \\
\hline CHEMBL1401652 & 688620 & 6.45 & 5.2771 & TRN & \\
\hline CHEMBL1544282 & 688620 & 4.6 & 5.0259 & TRN & \\
\hline CHEMBL1340055 & 688620 & 5.5 & 5.0274 & TRN & \\
\hline CHEMBL1457958 & 688620 & 6.15 & 5.0155 & TST & \\
\hline CHEMBL1596376 & 688620 & 4.45 & 4.783 & TRN & \\
\hline CHEMBL1417094 & 688620 & 4.95 & 4.9839 & TRN & \\
\hline CHEMBL1491651 & 688620 & 4.45 & 4.9576 & TRN & \\
\hline CHEMBL1336060 & 688620 & 4.65 & 5.1049 & TRN & \\
\hline CHEMBL1498688 & 688620 & 4.75 & 5.1259 & TRN & \\
\hline CHEMBL1554497 & 688620 & 5.25 & 4.9138 & TST & \\
\hline CHEMBL1387297 & 688620 & 4.95 & 5.0598 & TRN & \\
\hline
\end{tabular}




\begin{tabular}{|c|c|c|c|c|}
\hline \multicolumn{5}{|c|}{ Supplemental Table } \\
\hline CHEMBL1528175 & 688620 & 6.5501 & 6.1148 & TRN \\
\hline CHEMBL1332758 & 688620 & 4.45 & 4.9273 & TST \\
\hline CHEMBL1499842 & 688620 & 4.9 & 5.1323 & TST \\
\hline CHEMBL1558922 & 688620 & 4.45 & 4.921 & TRN \\
\hline CHEMBL1348954 & 688620 & 5.1 & 5.0664 & TST \\
\hline CHEMBL1426201 & 688620 & 4.8 & 4.8895 & TRN \\
\hline CHEMBL1387529 & 688620 & 4.9 & 5.1424 & TRN \\
\hline CHEMBL3209196 & 688620 & 4.55 & 4.8762 & TST \\
\hline CHEMBL1347249 & 688620 & 4.95 & 5.0272 & TRN \\
\hline CHEMBL1385237 & 688620 & 4.7 & 5.4868 & TRN \\
\hline CHEMBL3198982 & 688620 & 4.7 & 5.0754 & TRN \\
\hline CHEMBL1346995 & 688620 & 5.3 & 5.1654 & TRN \\
\hline CHEMBL1485375 & 688620 & 5.55 & 4.9442 & TRN \\
\hline CHEMBL1515573 & 688620 & 4.45 & 5.28 & TRN \\
\hline CHEMBL1528353 & 688620 & 4.55 & 4.8543 & TRN \\
\hline CHEMBL1441881 & 688620 & 4.9 & 4.8987 & TRN \\
\hline CHEMBL1367711 & 688620 & 4.7 & 5.2605 & TRN \\
\hline CHEMBL1334115 & 688620 & 5.3 & 5.2052 & TRN \\
\hline CHEMBL1465097 & 688620 & 4.45 & 4.9734 & TRN \\
\hline CHEMBL1448590 & 688620 & 4.9 & 5.2849 & TST \\
\hline CHEMBL1582695 & 688620 & 4.45 & 5.1406 & TST \\
\hline CHEMBL1446822 & 688620 & 4.75 & 4.9454 & TST \\
\hline CHEMBL1371792 & 688620 & 5.4 & 5.4547 & TST \\
\hline CHEMBL1426039 & 688620 & 5.25 & 5.2436 & TRN \\
\hline CHEMBL 1454678 & 688620 & 5.65 & 5.0387 & TRN \\
\hline CHEMBL1464647 & 688620 & 5.55 & 5.7982 & TRN \\
\hline CHEMBL1337318 & 688620 & 4.45 & 4.9475 & TRN \\
\hline CHEMBL1356099 & 688620 & 4.9 & 4.8627 & TRN \\
\hline CHEMBL1562802 & 688620 & 4.45 & 4.8725 & TRN \\
\hline CHEMBL1525205 & 688620 & 8.1024 & 4.9945 & TRN \\
\hline CHEMBL3192023 & 688620 & 4.75 & 5.1721 & TRN \\
\hline CHEMBL3210983 & 688620 & 5.05 & 5.197 & TRN \\
\hline CHEMBL1526304 & 688620 & 4.95 & 4.7868 & TRN \\
\hline CHEMBL1440561 & 688620 & 6.05 & 5.1661 & TRN \\
\hline CHEMBL1596457 & 688620 & 4.9 & 4.9067 & TRN \\
\hline CHEMBL1300080 & 688620 & 6.7001 & 6.6475 & TRN \\
\hline CHEMBL3210326 & 688620 & 5.9 & 5.1757 & TST \\
\hline CHEMBL1568155 & 688620 & 4.85 & 5.1626 & TST \\
\hline CHEMBL1541390 & 688620 & 4.7 & 5.0275 & TRN \\
\hline CHEMBL1466414 & 688620 & 4.85 & 4.8551 & TRN \\
\hline CHEMBL1454419 & 688620 & 5.65 & 4.9858 & TRN \\
\hline CHEMBL1312582 & 688620 & 4.45 & 5.0646 & TRN \\
\hline CHEMBL1407530 & 688620 & 4.95 & 5.1128 & TRN \\
\hline CHEMBL1448045 & 688620 & 4.95 & 5.1165 & TST \\
\hline CHEMBL1550519 & 688620 & 4.95 & 5.1764 & TST \\
\hline CHEMBL1311172 & 688620 & 4.65 & 4.8815 & TST \\
\hline CHEMBL1438940 & 688620 & 5.0 & 4.9397 & TRN \\
\hline CHEMBL368700 & 688620 & 4.9 & 4.9757 & TST \\
\hline
\end{tabular}




\begin{tabular}{|c|c|c|c|c|c|}
\hline \\
\hline CHEMBL1434137 & 688620 & 4.6 & 5.0159 & TST & \\
\hline CHEMBL1325188 & 688620 & 5.55 & 5.2691 & TST & \\
\hline CHEMBL1492399 & 688620 & 5.85 & 5.6987 & TRN & \\
\hline CHEMBL1307050 & 688620 & 6.5501 & 5.3727 & TRN & \\
\hline CHEMBL1563874 & 688620 & 4.95 & 5.0897 & TRN & \\
\hline CHEMBL1482721 & 688620 & 5.55 & 4.9932 & TRN & \\
\hline CHEMBL1523496 & 688620 & 4.65 & 4.7766 & TRN & \\
\hline CHEMBL1482151 & 688620 & 4.45 & 4.7208 & TRN & \\
\hline CHEMBL1544342 & 688620 & 4.9 & 5.0933 & TRN & \\
\hline CHEMBL1438437 & 688620 & 6.95 & 4.9914 & TRN & \\
\hline CHEMBL1428936 & 688620 & 4.45 & 5.2602 & TST & \\
\hline CHEMBL416726 & 688620 & 4.45 & 5.0083 & TST & \\
\hline CHEMBL1529469 & 688620 & 4.7 & 4.9658 & TRN & \\
\hline CHEMBL1301888 & 688620 & 5.3 & 5.2488 & TRN & \\
\hline CHEMBL1549762 & 688620 & 4.9 & 5.2444 & TRN & \\
\hline CHEMBL1378128 & 688620 & 4.9 & 4.9055 & TRN & \\
\hline CHEMBL1429684 & 688620 & 4.8 & 5.1624 & TRN & \\
\hline CHEMBL1488978 & 688620 & 4.8 & 4.9273 & TRN & \\
\hline CHEMBL1375489 & 688620 & 4.45 & 4.9713 & TRN & \\
\hline CHEMBL1441991 & 688620 & 5.65 & 5.6242 & TRN & \\
\hline CHEMBL1370697 & 688620 & 4.95 & 5.0069 & TST & \\
\hline CHEMBL3192079 & 688620 & 6.15 & 6.0297 & TRN & \\
\hline CHEMBL1339208 & 688620 & 5.15 & 4.7115 & TRN & \\
\hline CHEMBL1516918 & 688620 & 5.5 & 5.17200 & 0000000001 & TRN \\
\hline CHEMBL1433211 & 688620 & 4.45 & 4.8769 & TST & \\
\hline CHEMBL1496131 & 688620 & 4.75 & 5.0622 & TST & \\
\hline CHEMBL1968316 & 688620 & 4.95 & 4.7818 & TST & \\
\hline CHEMBL1407470 & 688620 & 6.1 & 5.1009 & TRN & \\
\hline CHEMBL1588533 & 688620 & 4.8 & 4.7853 & TRN & \\
\hline CHEMBL 2374462 & 688620 & 4.5 & 4.9844 & TRN & \\
\hline CHEMBL1567825 & 688620 & 4.75 & 5.0379 & TST & \\
\hline CHEMBL1406200 & 688620 & 5.35 & 4.8677 & TRN & \\
\hline CHEMBL1470293 & 688620 & 4.85 & 5.0885 & TRN & \\
\hline CHEMBL1987145 & 688620 & 5.35 & 5.5488 & TRN & \\
\hline CHEMBL1386810 & 688620 & 6.15 & 5.1475 & TRN & \\
\hline CHEMBL1484306 & 688620 & 4.95 & 4.6212 & TRN & \\
\hline CHEMBL1375365 & 688620 & 4.75 & 4.773 & TST & \\
\hline CHEMBL1380545 & 688620 & 4.65 & 4.879 & TRN & \\
\hline CHEMBL 3191104 & 688620 & 4.9 & 4.8129 & TRN & \\
\hline CHEMBL1523319 & 688620 & 5.55 & 4.9552 & TRN & \\
\hline CHEMBL1502689 & 688620 & 4.85 & 4.9594 & TRN & \\
\hline CHEMBL1580944 & 688620 & 4.8 & 4.9779 & TRN & \\
\hline CHEMBL1586515 & 688620 & 5.5 & 5.1101 & TRN & \\
\hline CHEMBL 3214234 & 688620 & 5.55 & 5.2313 & TRN & \\
\hline CHEMBL1583579 & 688620 & 4.7 & 4.9136 & TST & \\
\hline CHEMBL1462194 & 688620 & 4.7 & 5.0044 & TRN & \\
\hline CHEMBL1351023 & 688620 & 5.05 & 4.9997 & TST & \\
\hline CHEMBL1481546 & 688620 & 5.15 & 5.1563 & TRN & \\
\hline
\end{tabular}




\begin{tabular}{|c|c|c|c|c|}
\hline \multicolumn{5}{|c|}{ Supplemental Table S2.txt } \\
\hline CHEMBL1392484 & 688620 & 7.0 & 5.3024 & TRN \\
\hline CHEMBL1453018 & 688620 & 4.7 & 5.1786 & TST \\
\hline CHEMBL1361096 & 688620 & 5.0 & 4.9604 & TRN \\
\hline CHEMBL1314482 & 688620 & 7.2503 & 4.9949 & TST \\
\hline CHEMBL1324496 & 688620 & 4.85 & 5.1354 & TRN \\
\hline CHEMBL1556020 & 688620 & 5.35 & 5.1789 & TRN \\
\hline CHEMBL3193736 & 688620 & 4.7 & 5.2404 & TRN \\
\hline CHEMBL1351158 & 688620 & 4.45 & 4.8594 & TRN \\
\hline CHEMBL 3213476 & 688620 & 6.5 & 5.0716 & TRN \\
\hline CHEMBL3189872 & 688620 & 4.95 & 5.0327 & TRN \\
\hline CHEMBL3189635 & 688620 & 4.5 & 5.2408 & TRN \\
\hline CHEMBL1447663 & 688620 & 4.7 & 4.8825 & TRN \\
\hline CHEMBL1382483 & 688620 & 4.45 & 4.7753 & TRN \\
\hline CHEMBL1481948 & 688620 & 6.05 & 4.8634 & TRN \\
\hline CHEMBL1896831 & 688620 & 5.3 & 5.1301 & TRN \\
\hline CHEMBL1490715 & 688620 & 4.95 & 5.0697 & TRN \\
\hline CHEMBL1479101 & 688620 & 6.0 & 5.0613 & TST \\
\hline CHEMBL1597970 & 688620 & 4.45 & 4.8996 & TRN \\
\hline CHEMBL1448603 & 688620 & 4.95 & 5.1073 & TRN \\
\hline CHEMBL1305038 & 688620 & 6.4 & 5.8226 & TRN \\
\hline CHEMBL1490846 & 688620 & 4.9 & 4.9372 & TST \\
\hline CHEMBL1399193 & 688620 & 5.95 & 5.3965 & TRN \\
\hline CHEMBL1583585 & 688620 & 5.2 & 5.6694 & TRN \\
\hline CHEMBL1508670 & 688620 & 4.9 & 5.0686 & TRN \\
\hline CHEMBL 3190753 & 688620 & 4.8 & 5.1409 & TRN \\
\hline CHEMBL1457697 & 688620 & 4.9 & 4.7176 & TRN \\
\hline CHEMBL1466983 & 688620 & 5.5 & 5.0546 & TST \\
\hline CHEMBL1573020 & 688620 & 6.1 & 5.1794 & TRN \\
\hline CHEMBL3195593 & 688620 & 4.45 & 4.9624 & TST \\
\hline CHEMBL1537679 & 688620 & 4.95 & 4.9849 & TRN \\
\hline CHEMBL1398606 & 688620 & 4.6 & 4.9613 & TST \\
\hline CHEMBL1462306 & 688620 & 4.9 & 4.9794 & TST \\
\hline CHEMBL3192687 & 688620 & 4.85 & 5.0679 & TRN \\
\hline CHEMBL3198591 & 688620 & 5.15 & 5.1713 & TRN \\
\hline CHEMBL1401284 & 688620 & 5.15 & 5.1712 & TRN \\
\hline CHEMBL1428950 & 688620 & 4.6 & 5.0259 & TRN \\
\hline CHEMBL1610857 & 688620 & 5.4 & 5.5212 & TRN \\
\hline CHEMBL1327789 & 688620 & 5.15 & 5.0522 & TRN \\
\hline CHEMBL1417479 & 688620 & 4.9 & 5.1451 & TRN \\
\hline CHEMBL1417842 & 688620 & 4.9 & 5.1108 & TRN \\
\hline CHEMBL1359467 & 688620 & 5.2 & 5.1245 & TRN \\
\hline CHEMBL1301323 & 688620 & 4.6 & 4.9389 & TRN \\
\hline CHEMBL3210009 & 688620 & 4.8 & 4.9689 & TRN \\
\hline CHEMBL1458824 & 688620 & 5.65 & 5.5847 & TRN \\
\hline CHEMBL 3196670 & 688620 & 4.45 & 4.9951 & TRN \\
\hline CHEMBL1541392 & 688620 & 8.2518 & 5.0022 & TST \\
\hline CHEMBL1977683 & 688620 & 5.15 & 4.9646 & TST \\
\hline CHEMBL1525357 & 688620 & 5.25 & 5.0075 & TST \\
\hline
\end{tabular}




\begin{tabular}{|c|c|c|c|c|c|}
\hline \multicolumn{6}{|c|}{ Supplemental Table s2.txt } \\
\hline CHEMBL1609706 & 688620 & 4.45 & 5.2342 & TST & \\
\hline CHEMBL1490064 & 688620 & 4.9 & 4.9219 & TRN & \\
\hline CHEMBL1432228 & 688620 & 5.5 & 5.01 & TST & \\
\hline CHEMBL1423442 & 688620 & 4.45 & 4.9624 & TST & \\
\hline CHEMBL1565442 & 688620 & 4.75 & 4.8957 & TST & \\
\hline CHEMBL1458080 & 688620 & 4.95 & 4.6367 & TRN & \\
\hline CHEMBL1392889 & 688620 & 5.2 & 5.23600 & 0000000001 & TRN \\
\hline CHEMBL1603962 & 688620 & 5.0 & 5.1158 & TRN & \\
\hline CHEMBL1483308 & 688620 & 4.65 & 4.7448 & TRN & \\
\hline CHEMBL1581193 & 688620 & 4.9 & 5.0068 & TRN & \\
\hline CHEMBL 3190842 & 688620 & 5.05 & 4.9491 & TST & \\
\hline CHEMBL 3208490 & 688620 & 5.7 & 5.6559 & TRN & \\
\hline CHEMBL3191064 & 688620 & 4.6 & 4.8967 & TRN & \\
\hline CHEMBL 3209410 & 688620 & 4.45 & 5.0226 & TST & \\
\hline CHEMBL1312714 & 688620 & 5.0 & 5.1283 & TRN & \\
\hline CHEMBL1308168 & 688620 & 5.25 & 5.1312 & TRN & \\
\hline CHEMBL1429962 & 688620 & 4.9 & 4.8597 & TRN & \\
\hline CHEMBL1448281 & 688620 & 4.7 & 4.8301 & TRN & \\
\hline CHEMBL1321574 & 688620 & 5.2 & 5.3119 & TRN & \\
\hline CHEMBL1503757 & 688620 & 5.75 & 5.1444 & TRN & \\
\hline CHEMBL465843 & 688620 & 6.0 & 5.6028 & TST & \\
\hline CHEMBL1585615 & 688620 & 4.95 & 4.8092 & TST & \\
\hline CHEMBL1588275 & 688620 & 4.85 & 4.6925 & TRN & \\
\hline CHEMBL1471104 & 688620 & 4.8 & 5.0751 & TRN & \\
\hline CHEMBL1438146 & 688620 & 4.5 & 4.9546 & TST & \\
\hline CHEMBL1574187 & 688620 & 5.35 & 4.9081 & TST & \\
\hline CHEMBL1347212 & 688620 & 5.25 & 5.4774 & TST & \\
\hline CHEMBL1588182 & 688620 & 4.95 & 5.2563 & TST & \\
\hline CHEMBL1544922 & 688620 & 4.9 & 5.1829 & TRN & \\
\hline CHEMBL3198816 & 688620 & 5.75 & 5.5724 & TRN & \\
\hline CHEMBL1509135 & 688620 & 5.0 & 5.3997 & TRN & \\
\hline CHEMBL1411170 & 688620 & 8.301 & 5.3489 & TST & \\
\hline CHEMBL1534277 & 688620 & 4.9 & 4.9014 & TST & \\
\hline CHEMBL1368484 & 688620 & 4.5 & 4.7137 & TRN & \\
\hline CHEMBL1595923 & 688620 & 5.6 & 5.12200 & 0000000001 & TRN \\
\hline CHEMBL1407566 & 688620 & 4.9 & 5.0201 & TRN & \\
\hline CHEMBL1539529 & 688620 & 5.15 & 5.5319 & TRN & \\
\hline CHEMBL1336533 & 688620 & 4.45 & 5.0148 & TRN & \\
\hline CHEMBL1517746 & 688620 & 4.75 & 5.0289 & TST & \\
\hline CHEMBL1377231 & 688620 & 4.9 & 5.1273 & TRN & \\
\hline CHEMBL1365811 & 688620 & 4.8 & 5.034 & TRN & \\
\hline CHEMBL1390578 & 688620 & 4.7 & 5.1787 & TRN & \\
\hline CHEMBL1548078 & 688620 & 4.95 & 4.9858 & TRN & \\
\hline CHEMBL1453360 & 688620 & 4.95 & 5.0878 & TST & \\
\hline CHEMBL1311101 & 688620 & 4.7 & 4.8231 & TRN & \\
\hline CHEMBL1584921 & 688620 & 5.45 & 5.2827 & TRN & \\
\hline CHEMBL1349535 & 688620 & 4.95 & 5.0928 & TRN & \\
\hline CHEMBL1549944 & 688620 & 5.25 & 5.0836 & TST & \\
\hline
\end{tabular}




\begin{tabular}{|c|c|c|c|c|c|}
\hline & & \multicolumn{4}{|c|}{ Supplemental Table s2.txt } \\
\hline CHEMBL1575038 & 688620 & 5.95 & 5.6463 & TRN & \\
\hline CHEMBL1328415 & 688620 & 4.65 & 4.8695 & TST & \\
\hline CHEMBL1360564 & 688620 & 4.95 & 5.3418 & TRN & \\
\hline CHEMBL1363656 & 688620 & 4.95 & 5.0696 & TRN & \\
\hline CHEMBL1301696 & 688620 & 5.15 & 5.0534 & TRN & \\
\hline CHEMBL1445548 & 688620 & 5.05 & 5.03600 & 00000000005 & TRN \\
\hline CHEMBL1587333 & 688620 & 5.05 & 5.015 & TRN & \\
\hline CHEMBL1470159 & 688620 & 4.85 & 5.2101 & TRN & \\
\hline CHEMBL1600296 & 688620 & 5.35 & 5.1133 & TRN & \\
\hline CHEMBL3194435 & 688620 & 4.65 & 5.0395 & TRN & \\
\hline CHEMBL583150 & 688620 & 5.85 & 5.5097 & TRN & \\
\hline CHEMBL1587031 & 688620 & 4.45 & 4.9257 & TST & \\
\hline CHEMBL1328442 & 688620 & 4.7 & 5.0146 & TRN & \\
\hline CHEMBL1527267 & 688620 & 4.45 & 5.1494 & TRN & \\
\hline CHEMBL 237444 & 688620 & 4.95 & 5.1047 & TRN & \\
\hline CHEMBL1313323 & 688620 & 5.0 & 4.8921 & TRN & \\
\hline CHEMBL1476436 & 688620 & 4.45 & 4.9204 & TST & \\
\hline CHEMBL1989592 & 688620 & 5.6 & 5.3176 & TRN & \\
\hline CHEMBL1542934 & 688620 & 4.45 & 5.0193 & TST & \\
\hline CHEMBL1530178 & 688620 & 5.5 & 5.0575 & TST & \\
\hline CHEMBL1465978 & 688620 & 4.45 & 5.1648 & TRN & \\
\hline CHEMBL1348112 & 688620 & 4.45 & 4.9483 & TRN & \\
\hline CHEMBL1449149 & 688620 & 4.85 & 5.2285 & TRN & \\
\hline CHEMBL1305372 & 688620 & 4.8 & 5.0794 & TRN & \\
\hline CHEMBL1600326 & 688620 & 4.95 & 4.9205 & TRN & \\
\hline CHEMBL1492678 & 688620 & 6.1 & 4.8931 & TST & \\
\hline CHEMBL1349472 & 688620 & 4.75 & 5.1417 & TRN & \\
\hline CHEMBL1418548 & 688620 & 5.2 & 5.0065 & TRN & \\
\hline CHEMBL1594286 & 688620 & 5.1 & 5.1108 & TRN & \\
\hline CHEMBL3193975 & 688620 & 6.45 & 6.0266 & TRN & \\
\hline CHEMBL1468543 & 688620 & 5.05 & 5.2557 & TRN & \\
\hline CHEMBL1484536 & 688620 & 5.2 & 4.9562 & TRN & \\
\hline CHEMBL1496179 & 688620 & 5.0 & 4.9907 & TRN & \\
\hline CHEMBL 2001685 & 688620 & 4.65 & 5.1003 & TST & \\
\hline CHEMBL1344767 & 688620 & 4.45 & 4.9111 & TRN & \\
\hline CHEMBL1574851 & 688620 & 4.95 & 5.121 & TRN & \\
\hline CHEMBL1537608 & 688620 & 4.45 & 4.8651 & TRN & \\
\hline CHEMBL1392469 & 688620 & 5.3 & 4.9439 & TRN & \\
\hline CHEMBL1443966 & 688620 & 5.5 & 5.1118 & TRN & \\
\hline CHEMBL1236103 & 688620 & 5.55 & 5.6453 & TST & \\
\hline CHEMBL1333504 & 688620 & 6.2 & 6.1609 & TRN & \\
\hline CHEMBL1542513 & 688620 & 4.95 & 4.9363 & TST & \\
\hline CHEMBL1507005 & 688620 & 4.95 & 5.0332 & TRN & \\
\hline CHEMBL1403958 & 688620 & 4.5 & 5.329 & TRN & \\
\hline CHEMBL1556533 & 688620 & 4.95 & 5.2493 & TST & \\
\hline CHEMBL1525735 & 688620 & 4.6 & 4.8661 & TRN & \\
\hline CHEMBL1523558 & 688620 & 4.8 & 4.8204 & TRN & \\
\hline CHEMBL1608822 & 688620 & 4.9 & 4.9028 & TRN & \\
\hline
\end{tabular}




\begin{tabular}{|c|c|c|c|c|}
\hline \multicolumn{5}{|c|}{ Supplemental Table S2.txt } \\
\hline CHEMBL1468775 & 688620 & 4.95 & 5.1495 & TRN \\
\hline CHEMBL1325162 & 688620 & 5.8 & 5.4074 & TRN \\
\hline CHEMBL1409604 & 688620 & 4.95 & 5.0949 & TRN \\
\hline CHEMBL1518049 & 688620 & 4.75 & 4.994 & TRN \\
\hline CHEMBL1352463 & 688620 & 4.45 & 5.0027 & TRN \\
\hline CHEMBL1414044 & 688620 & 5.3 & 4.9796 & TRN \\
\hline CHEMBL1549973 & 688620 & 4.8 & 5.1239 & TST \\
\hline CHEMBL1337129 & 688620 & 4.45 & 5.0597 & TRN \\
\hline CHEMBL1531073 & 688620 & 5.25 & 5.5537 & TRN \\
\hline CHEMBL1364807 & 688620 & 4.75 & 4.8229 & TRN \\
\hline CHEMBL1362054 & 688620 & 5.15 & 4.9468 & TRN \\
\hline CHEMBL1371365 & 688620 & 4.45 & 5.0295 & TRN \\
\hline CHEMBL3190759 & 688620 & 5.3 & 5.3992 & TRN \\
\hline CHEMBL1496338 & 688620 & 5.45 & 4.9675 & TRN \\
\hline CHEMBL76904 & 688620 & 6.0 & 4.8729 & TRN \\
\hline CHEMBL1452119 & 688620 & 4.45 & 4.9316 & TRN \\
\hline CHEMBL1308459 & 688620 & 4.9 & 4.9657 & TST \\
\hline CHEMBL1326903 & 688620 & 4.65 & 5.084 & TRN \\
\hline CHEMBL1584880 & 688620 & 5.05 & 5.2694 & TRN \\
\hline CHEMBL1542347 & 688620 & 4.45 & 5.0393 & TRN \\
\hline CHEMBL1567046 & 688620 & 5.95 & 6.1533 & TRN \\
\hline CHEMBL1447267 & 688620 & 5.1 & 5.1701 & TRN \\
\hline CHEMBL1427169 & 688620 & 4.75 & 4.8638 & TST \\
\hline CHEMBL1385046 & 688620 & 7.3002 & 5.0048 & TRN \\
\hline CHEMBL1489834 & 688620 & 4.45 & 4.9507 & TRN \\
\hline CHEMBL1382320 & 688620 & 5.25 & 4.9354 & TRN \\
\hline CHEMBL3196384 & 688620 & 6.5 & 5.875 & TRN \\
\hline CHEMBL1321355 & 688620 & 4.85 & 4.9625 & TRN \\
\hline CHEMBL1393625 & 688620 & 4.45 & 4.6594 & TST \\
\hline CHEMBL1438468 & 688620 & 4.95 & 4.9235 & TRN \\
\hline CHEMBL1509893 & 688620 & 7.9508 & 5.9593 & TRN \\
\hline CHEMBL1319625 & 688620 & 4.45 & 4.9798 & TRN \\
\hline CHEMBL1367012 & 688620 & 4.45 & 5.1107 & TST \\
\hline CHEMBL1516914 & 688620 & 5.05 & 4.9724 & TST \\
\hline CHEMBL1610717 & 688620 & 4.7 & 4.9164 & TRN \\
\hline CHEMBL242975 & 688620 & 7.0501 & 5.1395 & TRN \\
\hline CHEMBL1443099 & 688620 & 4.45 & 4.9933 & TRN \\
\hline CHEMBL1448987 & 688620 & 6.15 & 6.3386 & TRN \\
\hline CHEMBL1380994 & 688620 & 4.85 & 4.893 & TRN \\
\hline CHEMBL1973156 & 688620 & 4.9 & 4.9659 & TRN \\
\hline CHEMBL1301898 & 688620 & 4.65 & 5.0103 & TRN \\
\hline CHEMBL1567448 & 688620 & 4.45 & 5.5675 & TST \\
\hline CHEMBL1405220 & 688620 & 5.15 & 5.1506 & TRN \\
\hline CHEMBL1430124 & 688620 & 4.9 & 4.9149 & TRN \\
\hline CHEMBL1580521 & 688620 & 4.85 & 4.8692 & TRN \\
\hline CHEMBL1419163 & 688620 & 5.8 & 5.2653 & TRN \\
\hline CHEMBL1443470 & 688620 & 4.75 & 5.1126 & TRN \\
\hline CHEMBL1355736 & 688620 & 5.6 & 5.2448 & TST \\
\hline
\end{tabular}




\begin{tabular}{|c|c|c|c|c|c|}
\hline \multicolumn{6}{|c|}{ Supplemental Table S2.txt } \\
\hline CHEMBL1388379 & 688620 & 4.45 & 4.8228 & TRN & \\
\hline CHEMBL1498769 & 688620 & 4.45 & 5.0869 & TRN & \\
\hline CHEMBL1581195 & 688620 & 4.6 & 4.6654 & TRN & \\
\hline CHEMBL 3189485 & 688620 & 4.45 & 5.044 & TRN & \\
\hline CHEMBL1411407 & 688620 & 4.8 & 5.0832 & TRN & \\
\hline CHEMBL1595820 & 688620 & 6.5501 & 6.5494 & TRN & \\
\hline CHEMBL1349511 & 688620 & 4.85 & 5.0668 & TST & \\
\hline CHEMBL1584073 & 688620 & 4.45 & 4.9576 & TRN & \\
\hline CHEMBL1456766 & 688620 & 4.8 & 4.7624 & TRN & \\
\hline CHEMBL1599810 & 688620 & 4.45 & 5.1369 & TRN & \\
\hline CHEMBL1612142 & 688620 & 8.2518 & 5.0645 & TRN & \\
\hline CHEMBL1551485 & 688620 & 6.7001 & 5.0228 & TST & \\
\hline CHEMBL 2373648 & 688620 & 5.3 & 5.2577 & TST & \\
\hline CHEMBL1346305 & 688620 & 5.05 & 4.6987 & TRN & \\
\hline CHEMBL1992432 & 688620 & 5.05 & 5.0695 & TRN & \\
\hline CHEMBL1584758 & 688620 & 5.45 & 4.9411 & TRN & \\
\hline CHEMBL1356557 & 688620 & 5.15 & 5.1062 & TST & \\
\hline CHEMBL1401575 & 688620 & 4.75 & 4.8823 & TRN & \\
\hline CHEMBL1561181 & 688620 & 4.5 & 5.4883 & TRN & \\
\hline CHEMBL1405381 & 688620 & 5.45 & 5.0158 & TRN & \\
\hline CHEMBL1586468 & 688620 & 4.45 & 5.0247 & TRN & \\
\hline CHEMBL1524974 & 688620 & 6.6499 & 5.1861 & TST & \\
\hline CHEMBL1351835 & 688620 & 4.45 & 4.6381 & TRN & \\
\hline CHEMBL1336476 & 688620 & 4.9 & 5.09699 & 99999999995 & TRN \\
\hline CHEMBL1544997 & 688620 & 4.95 & 5.0641 & TRN & \\
\hline CHEMBL1414543 & 688620 & 5.35 & 5.0348 & TRN & \\
\hline CHEMBL1537365 & 688620 & 5.35 & 5.0372 & TST & \\
\hline CHEMBL1459315 & 688620 & 6.0 & 5.3608 & TST & \\
\hline CHEMBL1415649 & 688620 & 5.3 & 4.9709 & TRN & \\
\hline CHEMBL3196371 & 688620 & 5.35 & 5.3695 & TRN & \\
\hline CHEMBL1399129 & 688620 & 4.65 & 4.795 & TRN & \\
\hline CHEMBL1567973 & 688620 & 4.8 & 4.9933 & TRN & \\
\hline CHEMBL1458247 & 688620 & 4.8 & 4.9213 & TRN & \\
\hline CHEMBL1304077 & 688620 & 4.85 & 4.8957 & TRN & \\
\hline CHEMBL1307220 & 688620 & 4.7 & 4.7752 & TST & \\
\hline CHEMBL1389791 & 688620 & 4.75 & 5.1366 & TST & \\
\hline CHEMBL1602315 & 688620 & 4.8 & 5.0443 & TRN & \\
\hline CHEMBL1598922 & 688620 & 4.45 & 5.0925 & TRN & \\
\hline CHEMBL1319757 & 688620 & 4.95 & 5.0706 & TRN & \\
\hline CHEMBL1325641 & 688620 & 4.85 & 5.0318 & TST & \\
\hline CHEMBL1334260 & 688620 & 4.45 & 4.8445 & TRN & \\
\hline CHEMBL 3189258 & 688620 & 4.65 & 4.8281 & TST & \\
\hline CHEMBL1436543 & 688620 & 4.45 & 5.2744 & TRN & \\
\hline CHEMBL1555730 & 688620 & 5.4 & 5.2461 & TRN & \\
\hline CHEMBL1349988 & 688620 & 5.0 & 5.2015 & TRN & \\
\hline CHEMBL1543467 & 688620 & 5.0 & 4.9373 & TRN & \\
\hline CHEMBL1304757 & 688620 & 4.7 & 5.0274 & TRN & \\
\hline CHEMBL1345515 & 688620 & 4.85 & 4.9287 & TRN & \\
\hline
\end{tabular}




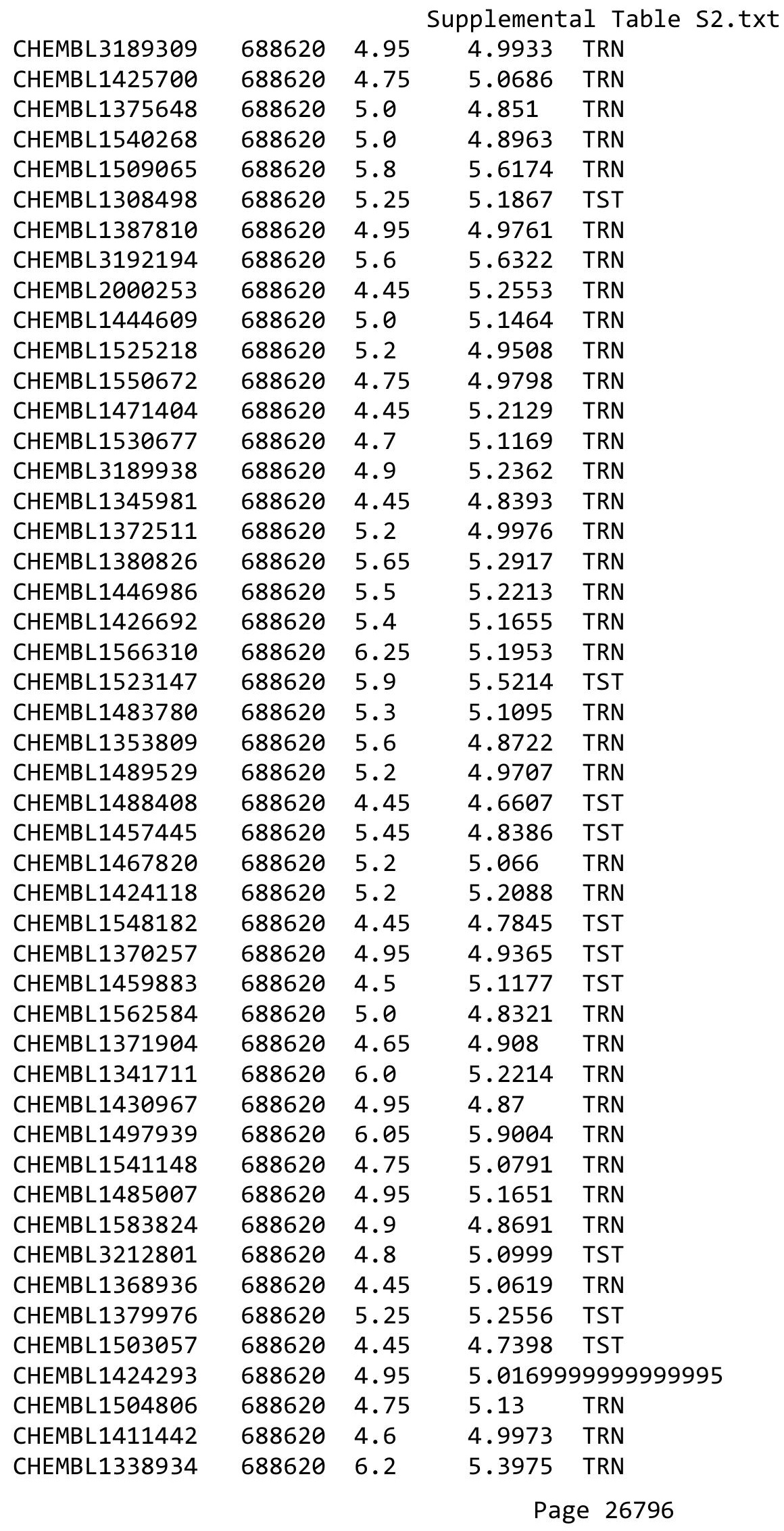

TRN 


\begin{tabular}{|c|c|c|c|c|c|}
\hline \multicolumn{6}{|c|}{ Supplemental Table S2.txt } \\
\hline CHEMBL593254 & 688620 & 4.45 & 5.1216 & TST & \\
\hline CHEMBL3144705 & 688620 & 4.65 & 5.2776 & TRN & \\
\hline CHEMBL1399980 & 688620 & 4.45 & 5.2728 & TRN & \\
\hline CHEMBL1491988 & 688620 & 4.65 & 5.3218 & TRN & \\
\hline CHEMBL1324556 & 688620 & 4.95 & 4.8273 & TRN & \\
\hline CHEMBL1445134 & 688620 & 5.7 & 5.0549 & TRN & \\
\hline CHEMBL1559636 & 688620 & 4.95 & 4.7292 & TST & \\
\hline CHEMBL1518701 & 688620 & 4.75 & 4.9301 & TST & \\
\hline CHEMBL1541761 & 688620 & 4.55 & 5.2505 & TST & \\
\hline CHEMBL1560550 & 688620 & 5.45 & 5.0764 & TRN & \\
\hline CHEMBL1494652 & 688620 & 4.5 & 5.0376 & TRN & \\
\hline CHEMBL1582554 & 688620 & 4.9 & 5.0219 & TRN & \\
\hline CHEMBL1427811 & 688620 & 4.95 & 4.9697 & TRN & \\
\hline CHEMBL1598442 & 688620 & 5.1 & 5.0411 & TRN & \\
\hline CHEMBL1560408 & 688620 & 4.65 & 4.9343 & TRN & \\
\hline CHEMBL1425350 & 688620 & 4.55 & 4.6527 & TRN & \\
\hline CHEMBL584888 & 688620 & 5.2 & 5.2817 & TRN & \\
\hline CHEMBL1987785 & 688620 & 6.35 & 5.8292 & TRN & \\
\hline CHEMBL1542419 & 688620 & 5.3 & 5.1995 & TRN & \\
\hline CHEMBL1441992 & 688620 & 5.0 & 5.0303 & TRN & \\
\hline CHEMBL1477335 & 688620 & 5.25 & 5.0942 & TRN & \\
\hline CHEMBL1566947 & 688620 & 7.0 & 5.0745 & TST & \\
\hline CHEMBL1390045 & 688620 & 4.9 & 4.9264 & TST & \\
\hline CHEMBL1544787 & 688620 & 4.45 & 5.0723 & TRN & \\
\hline CHEMBL1546582 & 688620 & 5.75 & 5.2 & TST & \\
\hline CHEMBL1401346 & 688620 & 5.65 & 5.4512 & TRN & \\
\hline CHEMBL1538950 & 688620 & 5.4 & 5.1101 & TRN & \\
\hline CHEMBL1465187 & 688620 & 5.4 & 5.1642 & TRN & \\
\hline CHEMBL1421862 & 688620 & 4.45 & 5.0741 & TST & \\
\hline CHEMBL1469825 & 688620 & 4.8 & 5.1469 & TRN & \\
\hline CHEMBL1484566 & 688620 & 4.45 & 5.0856 & TRN & \\
\hline CHEMBL1362077 & 688620 & 5.8 & 5.5331 & TRN & \\
\hline CHEMBL1599268 & 688620 & 4.45 & 5.0014 & TST & \\
\hline CHEMBL1414008 & 688620 & 5.55 & 5.5892 & TRN & \\
\hline CHEMBL1342396 & 688620 & 4.95 & 5.1121 & TRN & \\
\hline CHEMBL1572570 & 688620 & 5.6 & 5.3313 & TST & \\
\hline CHEMBL261454 & 688620 & 5.7 & 5.3255 & TST & \\
\hline CHEMBL1519486 & 688620 & 4.85 & 4.8419 & TRN & \\
\hline CHEMBL1412904 & 688620 & 4.45 & 5.71299 & 9999999999 & TRN \\
\hline CHEMBL1514750 & 688620 & 4.75 & 4.875 & TST & \\
\hline CHEMBL1595987 & 688620 & 5.5 & 5.0148 & TST & \\
\hline CHEMBL1413166 & 688620 & 4.9 & $5.0280 e$ & 00000000005 & TRN \\
\hline CHEMBL1534701 & 688620 & 5.35 & 5.1649 & TST & \\
\hline CHEMBL1342257 & 688620 & 4.85 & 4.8155 & TRN & \\
\hline CHEMBL1310460 & 688620 & 4.7 & 4.8895 & TST & \\
\hline CHEMBL1425902 & 688620 & 4.45 & 4.9121 & TST & \\
\hline CHEMBL1583768 & 688620 & 5.15 & 5.0872 & TST & \\
\hline CHEMBL1523842 & 688620 & 4.55 & 4.9225 & TRN & \\
\hline
\end{tabular}




\begin{tabular}{|c|c|c|c|c|c|}
\hline \multicolumn{6}{|c|}{ Supplemental Table S2.txt } \\
\hline CHEMBL1541689 & 688620 & 4.65 & 5.4309 & TRN & \\
\hline CHEMBL1517323 & 688620 & 4.9 & 5.2357 & TRN & \\
\hline CHEMBL1487337 & 688620 & 4.95 & 4.8646 & TRN & \\
\hline CHEMBL1403877 & 688620 & 5.55 & 5.9068 & TRN & \\
\hline CHEMBL 1450327 & 688620 & 4.65 & 5.0206 & TST & \\
\hline CHEMBL3212442 & 688620 & 5.3 & 5.0002 & TST & \\
\hline CHEMBL1561533 & 688620 & 4.45 & 5.1322 & TRN & \\
\hline CHEMBL1426615 & 688620 & 4.45 & 5.0064 & TRN & \\
\hline CHEMBL3196153 & 688620 & 4.55 & 5.3726 & TST & \\
\hline CHEMBL1546092 & 688620 & 4.9 & 4.8553 & TRN & \\
\hline CHEMBL3192864 & 688620 & 4.45 & 5.0173 & TRN & \\
\hline CHEMBL1351206 & 688620 & 5.5 & 5.0339 & TST & \\
\hline CHEMBL1492636 & 688620 & 4.5 & 4.7528 & TRN & \\
\hline CHEMBL1458524 & 688620 & 5.15 & 4.9515 & TRN & \\
\hline CHEMBL1310036 & 688620 & 4.7 & 4.7445 & TST & \\
\hline CHEMBL1381193 & 688620 & 5.15 & 5.2141 & TRN & \\
\hline CHEMBL1448329 & 688620 & 4.7 & 5.16299 & 9999999999 & TRN \\
\hline CHEMBL1998853 & 688620 & 5.45 & 5.4768 & TRN & \\
\hline CHEMBL1457136 & 688620 & 4.8 & 4.9103 & TRN & \\
\hline CHEMBL1463649 & 688620 & 4.5 & 4.9364 & TST & \\
\hline CHEMBL1580773 & 688620 & 4.6 & 4.8979 & TRN & \\
\hline CHEMBL1484291 & 688620 & 4.95 & 5.124 & TRN & \\
\hline CHEMBL536166 & 688620 & 5.2 & 5.3934 & TRN & \\
\hline CHEMBL1991610 & 688620 & 4.85 & 4.9666 & TRN & \\
\hline CHEMBL1342798 & 688620 & 4.45 & 4.9909 & TRN & \\
\hline CHEMBL1517533 & 688620 & 4.45 & 4.9217 & TRN & \\
\hline CHEMBL1509884 & 688620 & 5.1 & 5.3722 & TRN & \\
\hline CHEMBL1486055 & 688620 & 4.75 & 4.7548 & TRN & \\
\hline CHEMBL1573112 & 688620 & 4.45 & 5.1946 & TST & \\
\hline CHEMBL3144972 & 688620 & 4.45 & 5.2376 & TST & \\
\hline CHEMBL3209041 & 688620 & 4.5 & 5.0174 & TRN & \\
\hline CHEMBL1978415 & 688620 & 5.85 & 5.8488 & TRN & \\
\hline CHEMBL1424568 & 688620 & 5.35 & 5.0833 & TRN & \\
\hline CHEMBL1495891 & 688620 & 5.05 & 5.1613 & TRN & \\
\hline CHEMBL1429274 & 688620 & 4.7 & 5.0736 & TST & \\
\hline CHEMBL3145071 & 688620 & 4.8 & 5.1587 & TRN & \\
\hline CHEMBL1560903 & 688620 & 5.45 & 5.1709 & TRN & \\
\hline CHEMBL1966865 & 688620 & 5.4 & 5.2783 & TRN & \\
\hline CHEMBL1308547 & 688620 & 5.55 & 5.4072 & TRN & \\
\hline CHEMBL 3190200 & 688620 & 4.65 & 5.2808 & TST & \\
\hline CHEMBL1334157 & 688620 & 4.75 & 5.1115 & TRN & \\
\hline CHEMBL1980581 & 688620 & 5.85 & 5.5878 & TRN & \\
\hline CHEMBL1449108 & 688620 & 4.7 & 5.1496 & TRN & \\
\hline CHEMBL1405297 & 688620 & 4.9 & 4.7312 & TRN & \\
\hline CHEMBL1302818 & 688620 & 5.3 & 5.4314 & TRN & \\
\hline CHEMBL1530579 & 688620 & 4.45 & 5.7742 & TST & \\
\hline CHEMBL3198223 & 688620 & 4.9 & 5.0009 & TRN & \\
\hline CHEMBL1477217 & 688620 & 4.6 & 5.1901 & TST & \\
\hline
\end{tabular}




\begin{tabular}{|c|c|c|c|c|c|}
\hline \multicolumn{6}{|c|}{ Supplemental Table S2.txt } \\
\hline CHEMBL1480771 & 688620 & 5.75 & 5.3982 & TRN & \\
\hline CHEMBL1991626 & 688620 & 4.45 & 5.1389 & TST & \\
\hline CHEMBL3198947 & 688620 & 4.95 & 4.7167 & TST & \\
\hline CHEMBL1545771 & 688620 & 4.9 & 4.9301 & TRN & \\
\hline CHEMBL1366505 & 688620 & 4.75 & 4.9839 & TRN & \\
\hline CHEMBL1407084 & 688620 & 5.2 & 5.1563 & TST & \\
\hline CHEMBL1375814 & 688620 & 6.0 & 5.4995 & TRN & \\
\hline CHEMBL588267 & 688620 & 4.85 & 5.0018 & TST & \\
\hline CHEMBL1452279 & 688620 & 7.0 & 5.0048 & TRN & \\
\hline CHEMBL1445397 & 688620 & 4.45 & 4.9289 & TRN & \\
\hline CHEMBL1340607 & 688620 & 4.75 & 5.0998 & TRN & \\
\hline CHEMBL1368160 & 688620 & 4.45 & 4.8878 & TRN & \\
\hline CHEMBL1336910 & 688620 & 5.4 & 5.477 & TRN & \\
\hline CHEMBL1558625 & 688620 & 5.45 & 4.83899 & 99999999995 & TRN \\
\hline CHEMBL1387474 & 688620 & 4.9 & 5.1671 & TRN & \\
\hline CHEMBL1455639 & 688620 & 5.55 & 5.0839 & TRN & \\
\hline CHEMBL1582283 & 688620 & 5.45 & 6.7799 & TST & \\
\hline CHEMBL1441564 & 688620 & 5.55 & 5.0553 & TRN & \\
\hline CHEMBL1501400 & 688620 & 5.0 & 4.838 & TRN & \\
\hline CHEMBL1569124 & 688620 & 4.95 & 4.7498 & TRN & \\
\hline CHEMBL1309208 & 688620 & 6.45 & 5.9005 & TRN & \\
\hline CHEMBL1502675 & 688620 & 4.6 & 4.8921 & TRN & \\
\hline CHEMBL1530391 & 688620 & 4.65 & 5.5424 & TRN & \\
\hline CHEMBL1576566 & 688620 & 4.45 & 4.9851 & TRN & \\
\hline CHEMBL1388077 & 688620 & 5.65 & 4.9949 & TRN & \\
\hline CHEMBL1433033 & 688620 & 5.6 & 4.8886 & TRN & \\
\hline CHEMBL3213254 & 688620 & 4.9 & 4.7125 & TRN & \\
\hline CHEMBL1351820 & 688620 & 5.0 & 5.7433 & TRN & \\
\hline CHEMBL1378287 & 688620 & 4.6 & 4.8158 & TRN & \\
\hline CHEMBL1569302 & 688620 & 4.8 & 5.28799 & 9999999999 & TRN \\
\hline CHEMBL1448456 & 688620 & 4.95 & 5.0199 & TRN & \\
\hline CHEMBL3195122 & 688620 & 4.9 & 4.8304 & TRN & \\
\hline CHEMBL1508910 & 688620 & 5.1 & 5.0419 & TRN & \\
\hline CHEMBL1371724 & 688620 & 4.8 & 4.9505 & TST & \\
\hline CHEMBL1304229 & 688620 & 4.75 & 5.0013 & TST & \\
\hline CHEMBL1608481 & 688620 & 5.0 & 5.1882 & TRN & \\
\hline CHEMBL3192154 & 688620 & 4.45 & 4.6437 & TRN & \\
\hline CHEMBL1305571 & 688620 & 4.85 & 5.1006 & TRN & \\
\hline CHEMBL1303748 & 688620 & 5.7 & 5.13899 & 9999999999 & TRN \\
\hline CHEMBL3196524 & 688620 & 4.65 & 5.032 & TRN & \\
\hline CHEMBL1418091 & 688620 & 5.5 & 5.3656 & TRN & \\
\hline CHEMBL1431419 & 688620 & 4.45 & 4.7421 & TST & \\
\hline CHEMBL1497124 & 688620 & 4.65 & 4.9355 & TST & \\
\hline CHEMBL1361923 & 688620 & 4.95 & 5.013 & TRN & \\
\hline CHEMBL1508484 & 688620 & 5.0 & 5.0397 & TRN & \\
\hline CHEMBL1483140 & 688620 & 5.3 & 5.05 & TRN & \\
\hline CHEMBL1445146 & 688620 & 4.95 & 5.6583 & TRN & \\
\hline CHEMBL1449965 & 688620 & 4.9 & 5.0106 & TRN & \\
\hline
\end{tabular}




\begin{tabular}{|c|c|c|c|c|}
\hline \multicolumn{5}{|c|}{ Supplemental Table S2.txt } \\
\hline CHEMBL1558586 & 688620 & 5.75 & 4.8915 & TRN \\
\hline CHEMBL3212109 & 688620 & 4.45 & 5.1558 & TRN \\
\hline CHEMBL1573563 & 688620 & 6.3 & 5.6768 & TRN \\
\hline CHEMBL1580711 & 688620 & 4.85 & 5.0662 & TST \\
\hline CHEMBL1531815 & 688620 & 4.45 & 5.0158 & TRN \\
\hline CHEMBL3190767 & 688620 & 4.7 & 4.8554 & TRN \\
\hline CHEMBL1556901 & 688620 & 5.9 & 5.45 & TRN \\
\hline CHEMBL1481128 & 688620 & 7.2503 & 5.1571 & TRN \\
\hline CHEMBL3194335 & 688620 & 5.05 & 4.9966 & TRN \\
\hline CHEMBL1380636 & 688620 & 4.7 & 5.1034 & TRN \\
\hline CHEMBL1396181 & 688620 & 4.75 & 4.8951 & TST \\
\hline CHEMBL1468411 & 688620 & 5.4 & 5.1539 & TRN \\
\hline CHEMBL3199706 & 688620 & 4.95 & 5.3352 & TRN \\
\hline CHEMBL1452906 & 688620 & 5.15 & 5.002 & TRN \\
\hline CHEMBL1348850 & 688620 & 5.35 & 4.8383 & TRN \\
\hline CHEMBL1613654 & 688620 & 4.45 & 4.9485 & TRN \\
\hline CHEMBL1573932 & 688620 & 4.45 & 4.9802 & TRN \\
\hline CHEMBL1427492 & 688620 & 4.95 & 4.895 & TRN \\
\hline CHEMBL1406387 & 688620 & 4.45 & 5.1754 & TST \\
\hline CHEMBL1509642 & 688620 & 5.85 & 5.0006 & TST \\
\hline CHEMBL1549087 & 688620 & 5.05 & 5.0545 & TST \\
\hline CHEMBL1311566 & 688620 & 4.95 & 4.7252 & TRN \\
\hline CHEMBL1541981 & 688620 & 4.95 & 4.8597 & TST \\
\hline CHEMBL1578676 & 688620 & 7.5498 & 5.0226 & TRN \\
\hline CHEMBL1997747 & 688620 & 4.95 & 5.0734 & TRN \\
\hline CHEMBL1973454 & 688620 & 5.65 & 5.1146 & TRN \\
\hline CHEMBL1388516 & 688620 & 4.45 & 4.9137 & TST \\
\hline CHEMBL1606832 & 688620 & 4.8 & 5.0211 & TRN \\
\hline CHEMBL1491154 & 688620 & 4.55 & 4.9095 & TST \\
\hline CHEMBL1407419 & 688620 & 5.1 & 5.0088 & TRN \\
\hline CHEMBL3194040 & 688620 & 5.85 & 5.4594 & TRN \\
\hline CHEMBL1387633 & 688620 & 5.25 & 5.6052 & TST \\
\hline CHEMBL 3208674 & 688620 & 4.95 & 5.0693 & TST \\
\hline CHEMBL1510056 & 688620 & 5.6 & 5.234 & TST \\
\hline CHEMBL1540187 & 688620 & 4.85 & 5.1199 & TST \\
\hline CHEMBL1508362 & 688620 & 5.85 & 5.2284 & TRN \\
\hline CHEMBL1499461 & 688620 & 4.8 & 4.9523 & TRN \\
\hline CHEMBL1477862 & 688620 & 4.45 & 5.1919 & TRN \\
\hline CHEMBL1332860 & 688620 & 5.2 & 5.0645 & TRN \\
\hline CHEMBL3196414 & 688620 & 5.45 & 4.7937 & TRN \\
\hline CHEMBL1313700 & 688620 & 5.2 & 4.9392 & TST \\
\hline CHEMBL1303419 & 688620 & 4.75 & 5.1861 & TST \\
\hline CHEMBL1556041 & 688620 & 4.45 & 4.913 & TRN \\
\hline CHEMBL1406165 & 688620 & 5.45 & 4.9853 & TRN \\
\hline CHEMBL1450748 & 688620 & 6.4 & 5.7257 & TRN \\
\hline CHEMBL1422444 & 688620 & 4.9 & 5.105 & TRN \\
\hline CHEMBL1610654 & 688620 & 4.7 & 5.1554 & TRN \\
\hline CHEMBL1519480 & 688620 & 4.95 & 5.0443 & TRN \\
\hline
\end{tabular}




\begin{tabular}{|c|c|c|c|c|c|}
\hline \multicolumn{6}{|c|}{ Supplemental Table S2.txt } \\
\hline CHEMBL1347279 & 688620 & 4.45 & 4.9628 & TRN & \\
\hline CHEMBL1333022 & 688620 & 4.9 & 5.2971 & TRN & \\
\hline CHEMBL1610606 & 688620 & 7.0 & 4.9966 & TRN & \\
\hline CHEMBL1527677 & 688620 & 4.95 & 5.0204 & TRN & \\
\hline CHEMBL1334340 & 688620 & 4.45 & 5.086 & TRN & \\
\hline CHEMBL1584312 & 688620 & 4.45 & 4.9584 & TRN & \\
\hline CHEMBL1400397 & 688620 & 4.75 & 5.1091 & TRN & \\
\hline CHEMBL1461738 & 688620 & 5.9 & 4.8898 & TRN & \\
\hline CHEMBL1357620 & 688620 & 4.85 & 5.1495 & TRN & \\
\hline CHEMBL3199278 & 688620 & 4.5 & 4.8825 & TRN & \\
\hline CHEMBL1462693 & 688620 & 4.9 & 5.0649 & TRN & \\
\hline CHEMBL1522192 & 688620 & 5.55 & 5.0598 & TRN & \\
\hline CHEMBL1468596 & 688620 & 4.45 & 4.8262 & TRN & \\
\hline CHEMBL1326705 & 688620 & 5.15 & 5.1895 & TST & \\
\hline CHEMBL1463974 & 688620 & 5.0 & 4.9402 & TST & \\
\hline CHEMBL1300211 & 688620 & 5.95 & 5.63299 & 9999999999 & TST \\
\hline CHEMBL1507373 & 688620 & 4.95 & 4.795 & TRN & \\
\hline CHEMBL1549060 & 688620 & 5.3 & 4.9773 & TRN & \\
\hline CHEMBL1344965 & 688620 & 4.7 & 4.9838 & TRN & \\
\hline CHEMBL1458062 & 688620 & 4.7 & 4.9887 & TRN & \\
\hline CHEMBL1355522 & 688620 & 4.7 & 5.2443 & TRN & \\
\hline CHEMBL1472283 & 688620 & 4.45 & 5.1376 & TRN & \\
\hline CHEMBL1540486 & 688620 & 4.95 & 5.0086 & TRN & \\
\hline CHEMBL 312163 & 688620 & 5.65 & 4.8803 & TRN & \\
\hline CHEMBL1455956 & 688620 & 5.1 & 5.126 & TRN & \\
\hline CHEMBL1351706 & 688620 & 8.301 & 4.9496 & TST & \\
\hline CHEMBL1448069 & 688620 & 5.6 & 5.0372 & TRN & \\
\hline CHEMBL 3214253 & 688620 & 4.45 & 4.9832 & TST & \\
\hline CHEMBL1359141 & 688620 & 4.9 & 4.8147 & TST & \\
\hline CHEMBL1362486 & 688620 & 4.75 & 4.9202 & TST & \\
\hline CHEMBL1389989 & 688620 & 5.2 & 5.0491 & TRN & \\
\hline CHEMBL1335818 & 688620 & 4.95 & 5.1219 & TRN & \\
\hline CHEMBL1490718 & 688620 & 5.15 & 5.2096 & TRN & \\
\hline CHEMBL1511529 & 688620 & 8.2518 & 5.0227 & TRN & \\
\hline CHEMBL1343279 & 688620 & 6.15 & 5.1317 & TRN & \\
\hline CHEMBL1516551 & 688620 & 4.45 & 5.1104 & TST & \\
\hline CHEMBL1529435 & 688620 & 5.7 & 4.9696 & TRN & \\
\hline CHEMBL1336158 & 688620 & 4.85 & 5.11600 & 00000000005 & TST \\
\hline CHEMBL1302809 & 688620 & 5.05 & 4.9563 & TST & \\
\hline CHEMBL1428005 & 688620 & 4.7 & 5.2897 & TRN & \\
\hline CHEMBL1414869 & 688620 & 4.45 & 4.9487 & TRN & \\
\hline CHEMBL1353453 & 688620 & 4.95 & 5.0253 & TRN & \\
\hline CHEMBL487959 & 688620 & 5.35 & 5.1465 & TRN & \\
\hline CHEMBL1554997 & 688620 & 4.45 & 4.8772 & TRN & \\
\hline CHEMBL1352236 & 688620 & 5.35 & 4.9597 & TRN & \\
\hline CHEMBL1591461 & 688620 & 5.15 & 4.9379 & TST & \\
\hline CHEMBL1469710 & 688620 & 4.6 & 4.7998 & TRN & \\
\hline CHEMBL1523777 & 688620 & 5.4 & 4.7285 & TST & \\
\hline
\end{tabular}




\begin{tabular}{|c|c|c|c|c|}
\hline & & & pplement & al $\mathrm{Ta}$ \\
\hline CHEMBL3197484 & 688620 & 4.7 & 5.2083 & TST \\
\hline CHEMBL3214118 & 688620 & 4.95 & 5.1456 & TRN \\
\hline CHEMBL1344580 & 688620 & 4.45 & 4.9268 & TST \\
\hline CHEMBL1528554 & 688620 & 5.55 & 5.0901 & TRN \\
\hline CHEMBL1321647 & 688620 & 5.4 & 5.2217 & TST \\
\hline CHEMBL1375161 & 688620 & 4.65 & 4.7172 & TRN \\
\hline CHEMBL1544638 & 688620 & 4.9 & 4.9917 & TRN \\
\hline CHEMBL1546315 & 688620 & 4.95 & 5.1455 & TRN \\
\hline CHEMBL1372415 & 688620 & 4.95 & 5.0527 & TRN \\
\hline CHEMBL1373456 & 688620 & 5.45 & 5.0341 & TST \\
\hline CHEMBL1300632 & 688620 & 4.95 & 4.9498 & TRN \\
\hline CHEMBL1301571 & 688620 & 4.85 & 4.7622 & TRN \\
\hline CHEMBL1437613 & 688620 & 4.45 & 5.0188 & TRN \\
\hline CHEMBL1532556 & 688620 & 4.65 & 5.2337 & TRN \\
\hline CHEMBL1453984 & 688620 & 5.0 & 5.233 & TRN \\
\hline CHEMBL1552246 & 688620 & 5.4 & 5.0212 & TST \\
\hline CHEMBL1466079 & 688620 & 5.0 & 4.9886 & TRN \\
\hline CHEMBL1308491 & 688620 & 5.6 & 5.3299 & TRN \\
\hline CHEMBL1461714 & 688620 & 4.95 & 4.9389 & TRN \\
\hline CHEMBL1467339 & 688620 & 4.85 & 4.8545 & TRN \\
\hline CHEMBL1396142 & 688620 & 4.7 & 5.1264 & TRN \\
\hline CHEMBL1428166 & 688620 & 4.45 & 4.9346 & TST \\
\hline CHEMBL1484328 & 688620 & 4.8 & 4.7971 & TRN \\
\hline CHEMBL1447281 & 688620 & 4.65 & 5.0207 & TRN \\
\hline CHEMBL1595185 & 688620 & 4.85 & 4.8718 & TRN \\
\hline CHEMBL1404676 & 688620 & 5.15 & 4.9975 & TRN \\
\hline CHEMBL1359887 & 688620 & 5.4 & 5.4653 & TRN \\
\hline CHEMBL1537926 & 688620 & 5.4 & 4.6972 & TRN \\
\hline CHEMBL1537047 & 688620 & 4.95 & 4.8783 & TST \\
\hline CHEMBL1430499 & 688620 & 5.6 & 5.188 & TRN \\
\hline CHEMBL1460106 & 688620 & 5.0 & 5.0019 & TRN \\
\hline CHEMBL1304356 & 688620 & 5.55 & 5.3567 & TRN \\
\hline CHEMBL1430186 & 688620 & 4.45 & 5.0275 & TRN \\
\hline CHEMBL1596216 & 688620 & 5.1 & 5.3061 & TRN \\
\hline CHEMBL1536073 & 688620 & 5.0 & 5.2087 & TRN \\
\hline CHEMBL479368 & 688620 & 5.05 & 5.3369 & TRN \\
\hline CHEMBL1573714 & 688620 & 5.05 & 4.9704 & TST \\
\hline CHEMBL2000633 & 688620 & 4.65 & 5.0142 & TRN \\
\hline CHEMBL1449723 & 688620 & 4.85 & 5.1453 & TRN \\
\hline CHEMBL3208365 & 688620 & 5.0 & 5.0462 & TRN \\
\hline CHEMBL1541309 & 688620 & 4.75 & 4.9909 & TST \\
\hline CHEMBL1459424 & 688620 & 5.1 & 4.8968 & TRN \\
\hline CHEMBL1444136 & 688620 & 5.2 & 5.3532 & TST \\
\hline CHEMBL3208784 & 688620 & 5.55 & 5.1818 & TRN \\
\hline CHEMBL1330106 & 688620 & 4.8 & 5.2077 & TST \\
\hline CHEMBL1366182 & 688620 & 5.05 & 5.2109 & TRN \\
\hline CHEMBL1423056 & 688620 & 5.0 & 5.0257 & TRN \\
\hline CHEMBL1487862 & 688620 & 5.9 & 5.4493 & TRN \\
\hline
\end{tabular}




\begin{tabular}{|c|c|c|c|c|c|}
\hline \\
\hline CHEMBL1384334 & 688620 & 5.6 & 5.1669 & TRN & \\
\hline CHEMBL195789 & 688620 & 4.8 & 5.0859 & TRN & \\
\hline CHEMBL1345557 & 688620 & 4.9 & 4.9864 & TRN & \\
\hline CHEMBL1432882 & 688620 & 4.45 & 4.9391 & TST & \\
\hline CHEMBL1495560 & 688620 & 6.25 & 5.9204 & TRN & \\
\hline CHEMBL1597321 & 688620 & 5.6 & 5.0495 & TRN & \\
\hline CHEMBL1335323 & 688620 & 4.65 & 5.0273 & TRN & \\
\hline CHEMBL1329757 & 688620 & 4.7 & 4.8111 & TST & \\
\hline CHEMBL1318736 & 688620 & 5.45 & 5.6613 & TST & \\
\hline CHEMBL1470099 & 688620 & 5.3 & 5.5249 & TRN & \\
\hline CHEMBL1418146 & 688620 & 6.6 & 5.0177 & TRN & \\
\hline CHEMBL1434111 & 688620 & 4.85 & 5.0542 & TST & \\
\hline CHEMBL1456780 & 688620 & 4.7 & 4.885 & TRN & \\
\hline CHEMBL 3190058 & 688620 & 4.45 & 4.9719 & TST & \\
\hline CHEMBL1505883 & 688620 & 4.85 & 4.7184 & TST & \\
\hline CHEMBL1526757 & 688620 & 5.3 & 5.2415 & TRN & \\
\hline CHEMBL1365918 & 688620 & 4.65 & 5.1043 & TRN & \\
\hline CHEMBL1415585 & 688620 & 5.0 & 5.0662 & TST & \\
\hline CHEMBL1545480 & 688620 & 5.6 & 4.8365 & TRN & \\
\hline CHEMBL1386867 & 688620 & 4.45 & 5.0053 & TRN & \\
\hline CHEMBL1446759 & 688620 & 4.95 & 5.8049 & TRN & \\
\hline CHEMBL1577487 & 688620 & 5.2 & 5.1737 & TRN & \\
\hline CHEMBL1331158 & 688620 & 4.45 & 5.1266 & TST & \\
\hline CHEMBL1981840 & 688620 & 5.0 & 4.8484 & TST & \\
\hline CHEMBL1351707 & 688620 & 4.45 & 5.0862 & TRN & \\
\hline CHEMBL1373098 & 688620 & 6.35 & 5.0164 & TRN & \\
\hline CHEMBL1978623 & 688620 & 4.95 & 5.1403 & TRN & \\
\hline CHEMBL3192071 & 688620 & 4.8 & 5.0424 & TRN & \\
\hline CHEMBL1509590 & 688620 & 4.45 & 4.8789 & TRN & \\
\hline CHEMBL 1457525 & 688620 & 4.55 & 5.1511 & TRN & \\
\hline CHEMBL1325913 & 688620 & 4.75 & 5.2008 & TRN & \\
\hline CHEMBL 3199359 & 688620 & 4.9 & 5.0781 & TST & \\
\hline CHEMBL1573280 & 688620 & 4.55 & 4.6596 & TRN & \\
\hline CHEMBL1595936 & 688620 & 4.6 & $5.2470 €$ & 0000000001 & TST \\
\hline CHEMBL1440207 & 688620 & 5.9 & 5.3152 & TRN & \\
\hline CHEMBL1609087 & 688620 & 4.85 & 4.9558 & TST & \\
\hline CHEMBL1408928 & 688620 & 4.7 & 4.7099 & TRN & \\
\hline CHEMBL1432755 & 688620 & 4.45 & 4.9903 & TRN & \\
\hline CHEMBL1338888 & 688620 & 4.45 & 5.1205 & TST & \\
\hline CHEMBL1600946 & 688620 & 4.5 & 5.1267 & TST & \\
\hline CHEMBL1415524 & 688620 & 4.9 & 5.209 & TRN & \\
\hline CHEMBL1352974 & 688620 & 4.8 & 4.888 & TRN & \\
\hline CHEMBL1446625 & 688620 & 5.05 & 5.4033 & TST & \\
\hline CHEMBL1491196 & 688620 & 4.85 & 5.0879 & TRN & \\
\hline CHEMBL1443487 & 688620 & 5.05 & 5.2157 & TRN & \\
\hline CHEMBL1579046 & 688620 & 5.25 & 5.4531 & TRN & \\
\hline CHEMBL1609865 & 688620 & 4.5 & 5.1654 & TST & \\
\hline CHEMBL1588125 & 688620 & 4.6 & 5.0349 & TRN & \\
\hline & & & & 26803 & \\
\hline
\end{tabular}




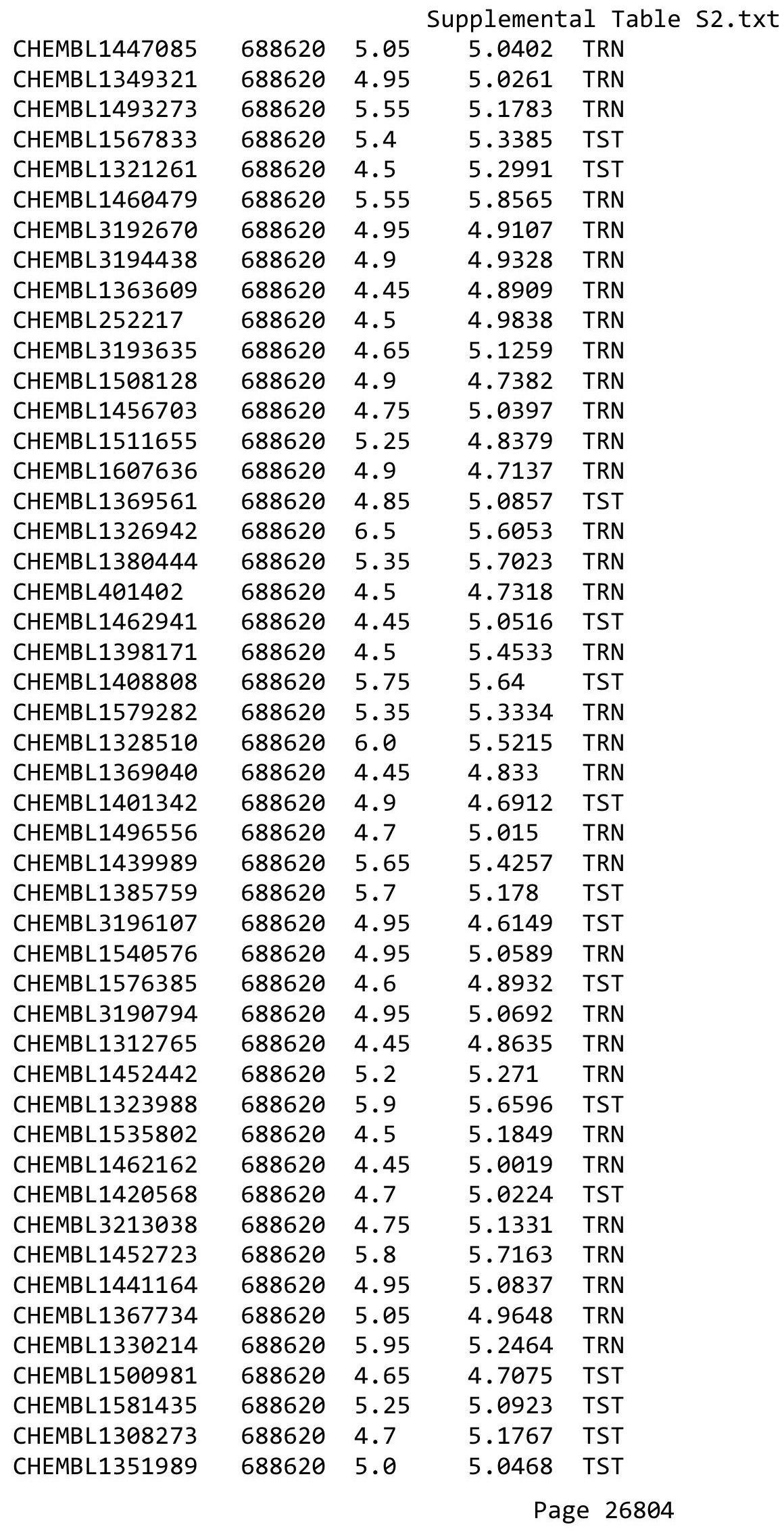




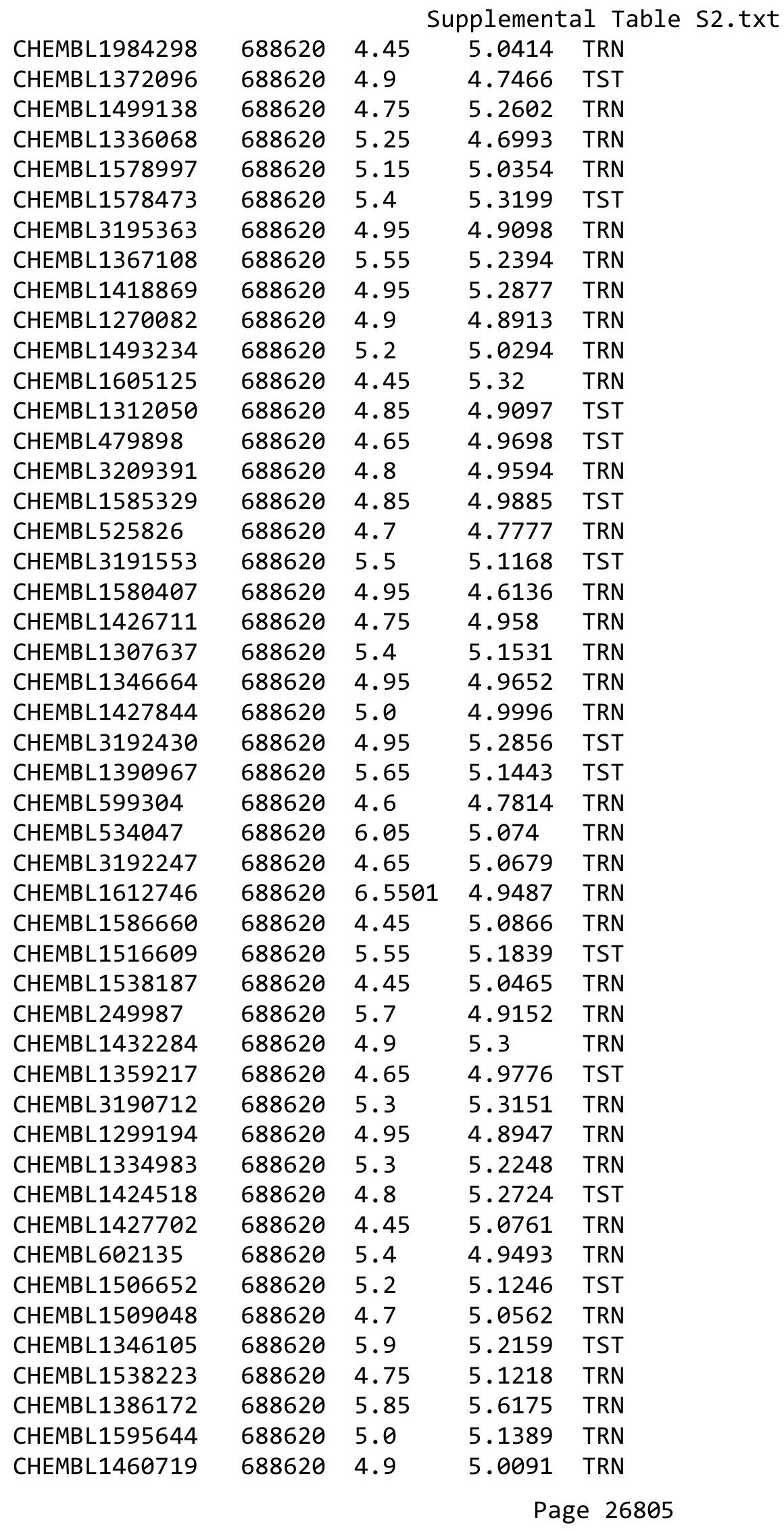




\begin{tabular}{|c|c|c|c|c|}
\hline \multirow[b]{2}{*}{ CHEMBL1339225 } & \multicolumn{4}{|c|}{ Supplemental Table S2.txt } \\
\hline & 688620 & 5.15 & 5.48 & TRN \\
\hline CHEMBL 3192214 & 688620 & 7.0 & 5.6969 & TST \\
\hline CHEMBL1483324 & 688620 & 4.9 & 5.106 & TRN \\
\hline CHEMBL 3197624 & 688620 & 4.8 & 4.9562 & TRN \\
\hline CHEMBL3191327 & 688620 & 5.0 & 5.1387 & TRN \\
\hline CHEMBL 3199824 & 688620 & 4.45 & 5.1292 & TRN \\
\hline CHEMBL1432290 & 688620 & 4.6 & 4.708 & TRN \\
\hline CHEMBL1348403 & 688620 & 4.9 & 5.0605 & TRN \\
\hline CHEMBL 3192537 & 688620 & 4.75 & 4.7478 & TRN \\
\hline CHEMBL1602358 & 688620 & 4.45 & 4.9442 & TRN \\
\hline CHEMBL1340279 & 688620 & 4.95 & 4.9046 & TST \\
\hline CHEMBL1428452 & 688620 & 5.1 & 5.3554 & TRN \\
\hline CHEMBL1392630 & 688620 & 4.45 & 4.7869 & TRN \\
\hline CHEMBL1560684 & 688620 & 4.75 & 5.1944 & TRN \\
\hline CHEMBL1599165 & 688620 & 5.65 & 5.2239 & TRN \\
\hline CHEMBL1460819 & 688620 & 4.9 & 5.0336 & TRN \\
\hline CHEMBL1491035 & 688620 & 6.3 & 5.3178 & TST \\
\hline CHEMBL3192241 & 688620 & 5.5 & 5.3675 & TST \\
\hline CHEMBL1534675 & 688620 & 5.15 & 4.9761 & TRN \\
\hline CHEMBL1985932 & 688620 & 4.45 & 5.0917 & TST \\
\hline CHEMBL1351862 & 688620 & 5.5 & 5.2634 & TST \\
\hline CHEMBL1557787 & 688620 & 5.25 & 4.9993 & TRN \\
\hline CHEMBL1598131 & 688620 & 4.75 & 5.152 & TRN \\
\hline CHEMBL1510116 & 688620 & 5.25 & 5.2207 & TRN \\
\hline CHEMBL1432322 & 688620 & 4.9 & 4.867 & TRN \\
\hline CHEMBL1559953 & 688620 & 5.15 & 5.1788 & TRN \\
\hline CHEMBL1557704 & 688620 & 4.45 & 4.9135 & TRN \\
\hline CHEMBL1470647 & 688620 & 5.15 & 5.0801 & TRN \\
\hline CHEMBL1474580 & 688620 & 4.9 & 5.1334 & TRN \\
\hline CHEMBL1354126 & 688620 & 4.95 & 4.9603 & TRN \\
\hline CHEMBL1432183 & 688620 & 4.9 & 5.0619 & TRN \\
\hline CHEMBL1421176 & 688620 & 4.8 & 4.9504 & TRN \\
\hline CHEMBL 2004690 & 688620 & 5.4 & 5.5228 & TRN \\
\hline CHEMBL1532073 & 688620 & 4.45 & 4.8494 & TRN \\
\hline CHEMBL1529084 & 688620 & 4.9 & 4.966 & TRN \\
\hline CHEMBL 2094652 & 688620 & 5.9 & 5.8855 & TRN \\
\hline CHEMBL1407946 & 688620 & 5.4 & 5.0309 & TST \\
\hline CHEMBL1372494 & 688620 & 4.55 & 4.7535 & TST \\
\hline CHEMBL1375338 & 688620 & 5.6 & 5.5553 & TRN \\
\hline CHEMBL1405721 & 688620 & 4.45 & 5.0359 & TRN \\
\hline CHEMBL1565531 & 688620 & 6.05 & 4.8911 & TST \\
\hline CHEMBL1344392 & 688620 & 4.45 & 5.0901 & TST \\
\hline CHEMBL405317 & 688620 & 5.6 & 5.9426 & TRN \\
\hline CHEMBL1568253 & 688620 & 4.8 & 4.8924 & TRN \\
\hline CHEMBL1430041 & 688620 & 4.85 & 4.9097 & TST \\
\hline CHEMBL1334027 & 688620 & 5.0 & 5.35 & TST \\
\hline CHEMBL1999595 & 688620 & 5.1 & 5.1777 & TRN \\
\hline CHEMBL3194392 & 688620 & 4.95 & 5.0354 & TRN \\
\hline
\end{tabular}




\begin{tabular}{|c|c|c|c|c|}
\hline \multicolumn{5}{|c|}{ Supplemental Table S2.txt } \\
\hline CHEMBL1441291 & 688620 & 4.85 & 5.0013 & TRN \\
\hline CHEMBL1410766 & 688620 & 4.45 & 4.8186 & TRN \\
\hline CHEMBL1547042 & 688620 & 5.4 & 4.9109 & TRN \\
\hline CHEMBL3192059 & 688620 & 5.1 & 5.0185 & TRN \\
\hline CHEMBL1606454 & 688620 & 4.75 & 5.041 & TRN \\
\hline CHEMBL1391167 & 688620 & 4.95 & 4.8806 & TRN \\
\hline CHEMBL1467198 & 688620 & 4.6 & 4.8592 & TRN \\
\hline CHEMBL1608611 & 688620 & 4.9 & 4.982 & TST \\
\hline CHEMBL1548855 & 688620 & 4.95 & 4.8668 & TST \\
\hline CHEMBL1480139 & 688620 & 6.1 & 5.0729 & TRN \\
\hline CHEMBL1595744 & 688620 & 5.5 & 4.8962 & TRN \\
\hline CHEMBL1551761 & 688620 & 4.85 & 4.9168 & TRN \\
\hline CHEMBL1342846 & 688620 & 4.9 & 5.0243 & TST \\
\hline CHEMBL1379758 & 688620 & 4.5 & 5.261 & TRN \\
\hline CHEMBL474703 & 688620 & 6.45 & 5.0688 & TRN \\
\hline CHEMBL 2000472 & 688620 & 5.0 & 5.0206 & TRN \\
\hline CHEMBL1567184 & 688620 & 5.4 & 4.9001 & TRN \\
\hline CHEMBL 83330 & 688620 & 5.25 & 5.1241 & TST \\
\hline CHEMBL1461667 & 688620 & 5.55 & 5.0792 & TRN \\
\hline CHEMBL1383470 & 688620 & 4.7 & 5.0026 & TRN \\
\hline CHEMBL1422280 & 688620 & 4.75 & $5.0310 e$ & 0000000001 \\
\hline CHEMBL1375780 & 688620 & 4.45 & 4.8524 & TST \\
\hline CHEMBL1561995 & 688620 & 4.6 & 4.9129 & TRN \\
\hline CHEMBL1422265 & 688620 & 5.0 & 5.1621 & TRN \\
\hline CHEMBL1538745 & 688620 & 4.95 & 5.3124 & TRN \\
\hline CHEMBL1352667 & 688620 & 5.5 & 5.1086 & TRN \\
\hline CHEMBL1401223 & 688620 & 4.95 & 5.0904 & TRN \\
\hline CHEMBL 3194133 & 688620 & 4.65 & 4.6838 & TRN \\
\hline CHEMBL1338533 & 688620 & 4.5 & 5.1676 & TST \\
\hline CHEMBL 1469027 & 688620 & 7.4498 & 5.115 & TRN \\
\hline CHEMBL1415724 & 688620 & 5.0 & 4.7391 & TRN \\
\hline CHEMBL1421255 & 688620 & 5.6 & 5.7301 & TRN \\
\hline CHEMBL1518077 & 688620 & 5.2 & 5.4111 & TRN \\
\hline CHEMBL1304613 & 688620 & 5.45 & 5.1651 & TRN \\
\hline CHEMBL 3190280 & 688620 & 5.9 & 5.8348 & TRN \\
\hline CHEMBL1393486 & 688620 & 5.0 & 5.3048 & TRN \\
\hline CHEMBL1375158 & 688620 & 4.7 & 4.9537 & TRN \\
\hline CHEMBL1418889 & 688620 & 4.85 & 4.9752 & TST \\
\hline CHEMBL1400918 & 688620 & 4.9 & 4.7695 & TRN \\
\hline CHEMBL1406497 & 688620 & 4.75 & 5.0206 & TRN \\
\hline CHEMBL3192285 & 688620 & 4.95 & 5.2052 & TRN \\
\hline CHEMBL1480933 & 688620 & 5.8 & 4.834 & TRN \\
\hline CHEMBL1439061 & 688620 & 5.95 & 4.9694 & TRN \\
\hline CHEMBL1507419 & 688620 & 4.45 & 5.1022 & TST \\
\hline CHEMBL1587805 & 688620 & 4.45 & 5.1541 & TST \\
\hline CHEMBL3191834 & 688620 & 6.0 & 5.4454 & TRN \\
\hline CHEMBL1302682 & 688620 & 6.4 & 5.2854 & TRN \\
\hline CHEMBL1509116 & 688620 & 4.8 & 5.1151 & TRN \\
\hline
\end{tabular}




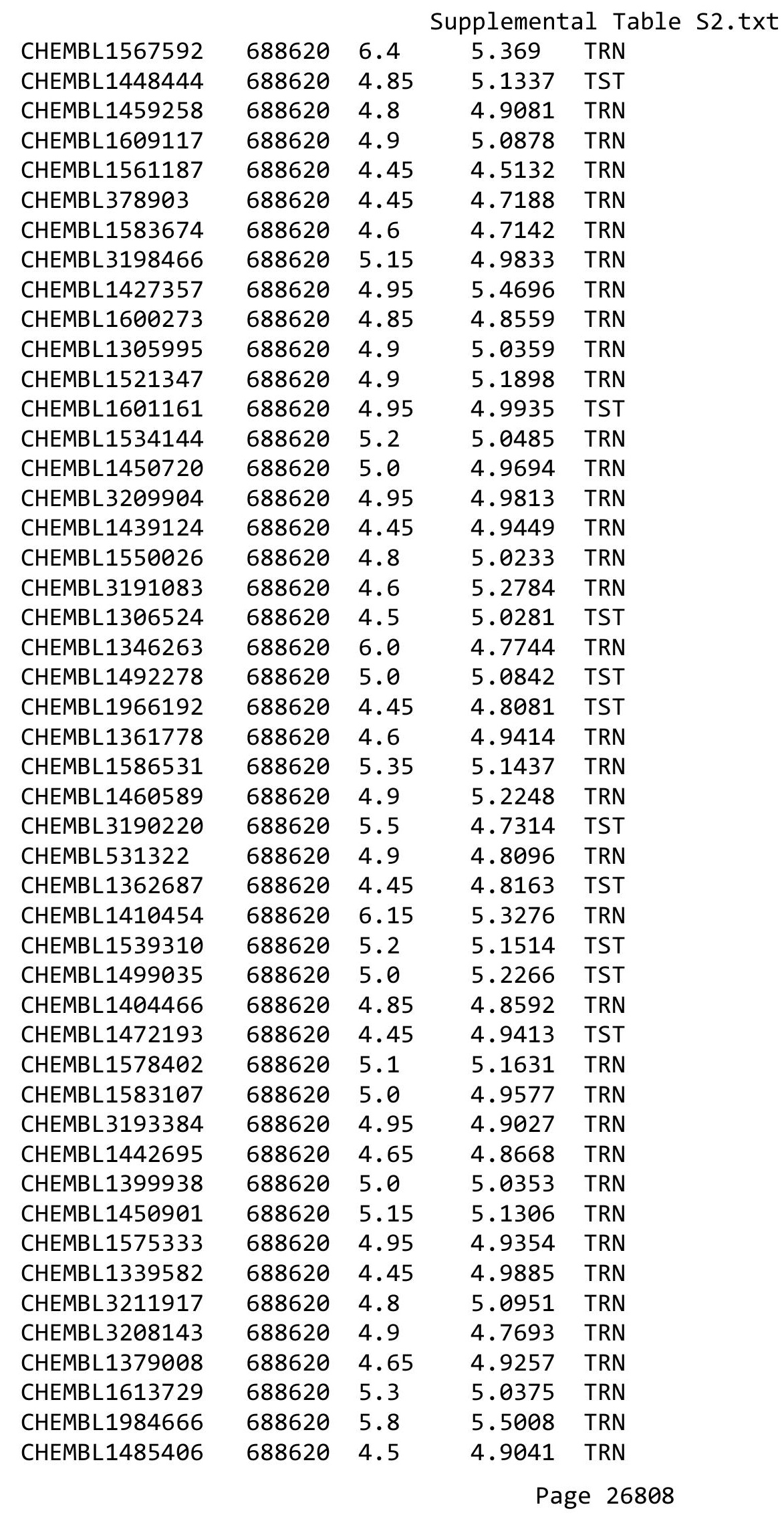




\begin{tabular}{|c|c|c|c|c|c|}
\hline \multicolumn{6}{|c|}{ Supplemental Table S2.txt } \\
\hline CHEMBL1604024 & 688620 & 5.85 & 5.6336 & TRN & \\
\hline CHEMBL1402606 & 688620 & 5.65 & 5.5394 & TRN & \\
\hline CHEMBL1425527 & 688620 & 5.6 & 5.0971 & TRN & \\
\hline CHEMBL1441723 & 688620 & 5.15 & 5.1826 & TRN & \\
\hline CHEMBL1458500 & 688620 & 4.8 & 4.9743 & TST & \\
\hline CHEMBL1366030 & 688620 & 5.4 & 5.2677 & TRN & \\
\hline CHEMBL1362952 & 688620 & 5.15 & 5.0749 & TST & \\
\hline CHEMBL1882125 & 688620 & 5.2 & 5.0801 & TRN & \\
\hline CHEMBL606532 & 688620 & 5.7 & 5.7915 & TRN & \\
\hline CHEMBL1991935 & 688620 & 4.95 & 4.8785 & TRN & \\
\hline CHEMBL93496 & 688620 & 5.6 & 4.8334 & TST & \\
\hline CHEMBL1400682 & 688620 & 4.85 & 4.8348 & TRN & \\
\hline CHEMBL1483882 & 688620 & 4.8 & 4.9438 & TST & \\
\hline CHEMBL1544460 & 688620 & 4.85 & 5.1314 & TRN & \\
\hline CHEMBL1456942 & 688620 & 5.7 & 5.4657 & TRN & \\
\hline CHEMBL3196801 & 688620 & 4.95 & 4.8695 & TRN & \\
\hline CHEMBL1582674 & 688620 & 4.95 & 5.2833 & TRN & \\
\hline CHEMBL1553218 & 688620 & 4.5 & 5.1234 & TRN & \\
\hline CHEMBL1426912 & 688620 & 6.45 & 6.4312 & TRN & \\
\hline CHEMBL1582996 & 688620 & 4.85 & 4.9589 & TRN & \\
\hline CHEMBL1599034 & 688620 & 6.0 & 5.87700 & 0000000001 & TRN \\
\hline CHEMBL1467724 & 688620 & 4.9 & 4.9903 & TRN & \\
\hline CHEMBL1368251 & 688620 & 5.3 & 5.0221 & TRN & \\
\hline CHEMBL 3212444 & 688620 & 4.5 & 4.8812 & TST & \\
\hline CHEMBL1413698 & 688620 & 4.45 & 5.1299 & TRN & \\
\hline CHEMBL1312175 & 688620 & 4.85 & 4.8496 & TRN & \\
\hline CHEMBL1569415 & 688620 & 4.45 & 4.9384 & TST & \\
\hline CHEMBL1336970 & 688620 & 5.2 & 4.99 & TRN & \\
\hline CHEMBL 3194710 & 688620 & 6.0 & 4.8642 & TRN & \\
\hline CHEMBL1498831 & 688620 & 4.75 & 4.9154 & TST & \\
\hline CHEMBL1613599 & 688620 & 4.7 & 4.8816 & TRN & \\
\hline CHEMBL3194571 & 688620 & 5.05 & 5.25899 & 99999999995 & TRN \\
\hline CHEMBL1313626 & 688620 & 4.85 & 4.9942 & TST & \\
\hline CHEMBL1581555 & 688620 & 4.5 & 5.1095 & TST & \\
\hline CHEMBL1566116 & 688620 & 5.45 & 4.8638 & TRN & \\
\hline CHEMBL1469656 & 688620 & 5.0 & 5.1334 & TRN & \\
\hline CHEMBL1570265 & 688620 & 5.5 & 5.392 & TRN & \\
\hline CHEMBL1398670 & 688620 & 4.65 & 4.915 & TRN & \\
\hline CHEMBL1527093 & 688620 & 4.85 & 5.0535 & TST & \\
\hline CHEMBL1415313 & 688620 & 4.95 & 5.0524 & TST & \\
\hline CHEMBL3145087 & 688620 & 4.65 & 4.9157 & TST & \\
\hline CHEMBL1349389 & 688620 & 5.75 & 5.2861 & TRN & \\
\hline CHEMBL1351731 & 688620 & 4.45 & 5.05399 & 9999999999 & TST \\
\hline CHEMBL1573090 & 688620 & 4.5 & 4.9012 & TRN & \\
\hline CHEMBL1407513 & 688620 & 5.3 & 5.3819 & TST & \\
\hline CHEMBL1508417 & 688620 & 5.5 & 5.2704 & TRN & \\
\hline CHEMBL1469021 & 688620 & 5.4 & 4.9467 & TRN & \\
\hline CHEMBL1329901 & 688620 & 4.8 & 5.1709 & TRN & \\
\hline
\end{tabular}




\begin{tabular}{|c|c|c|c|c|}
\hline \multicolumn{5}{|c|}{ Supplemental Table S2.txt } \\
\hline CHEMBL1401992 & 688620 & 4.9 & 5.0949 & TRN \\
\hline CHEMBL1584267 & 688620 & 4.75 & 4.9718 & TST \\
\hline CHEMBL1311932 & 688620 & 5.25 & 5.4733 & TRN \\
\hline CHEMBL1483627 & 688620 & 5.0 & 4.9198 & TRN \\
\hline CHEMBL1416497 & 688620 & 4.8 & 5.1093 & TRN \\
\hline CHEMBL1594466 & 688620 & 4.85 & 5.0212 & TRN \\
\hline CHEMBL1517836 & 688620 & 5.3 & 4.8723 & TRN \\
\hline CHEMBL1607491 & 688620 & 5.2 & 5.1354 & TST \\
\hline CHEMBL 2005664 & 688620 & 4.9 & 4.7101 & TRN \\
\hline CHEMBL1604295 & 688620 & 4.45 & 5.0945 & TST \\
\hline CHEMBL1485945 & 688620 & 5.55 & 5.2144 & TST \\
\hline CHEMBL1305523 & 688620 & 4.85 & 4.9446 & TRN \\
\hline CHEMBL1488100 & 688620 & 4.9 & 5.3025 & TST \\
\hline CHEMBL1525973 & 688620 & 4.9 & 5.153 & TRN \\
\hline CHEMBL1604928 & 688620 & 5.15 & 5.1483 & TRN \\
\hline CHEMBL1555625 & 688620 & 5.0 & 5.1887 & TRN \\
\hline CHEMBL1580401 & 688620 & 5.1 & 5.1361 & TRN \\
\hline CHEMBL3145383 & 688620 & 5.8 & 5.9537 & TRN \\
\hline CHEMBL1327926 & 688620 & 4.9 & 5.2265 & TRN \\
\hline CHEMBL1577992 & 688620 & 4.45 & 4.9467 & TRN \\
\hline CHEMBL1375260 & 688620 & 6.25 & 5.0356 & TRN \\
\hline CHEMBL1458089 & 688620 & 6.8499 & 4.9352 & TRN \\
\hline CHEMBL3189453 & 688620 & 6.4 & 5.3674 & TRN \\
\hline CHEMBL1392821 & 688620 & 6.0 & 6.0746 & TRN \\
\hline CHEMBL1528121 & 688620 & 4.9 & 4.9829 & TRN \\
\hline CHEMBL1312168 & 688620 & 5.45 & 5.188 & TST \\
\hline CHEMBL1575580 & 688620 & 5.0 & 4.8947 & TRN \\
\hline CHEMBL1455421 & 688620 & 5.3 & 5.1032 & TRN \\
\hline CHEMBL1995605 & 688620 & 4.6 & 5.0582 & TRN \\
\hline CHEMBL3199705 & 688620 & 4.8 & 5.231 & TRN \\
\hline CHEMBL1599946 & 688620 & 5.1 & 5.3118 & TST \\
\hline CHEMBL1307713 & 688620 & 4.65 & 4.9362 & TRN \\
\hline CHEMBL1420841 & 688620 & 4.45 & 4.9445 & TST \\
\hline CHEMBL1490101 & 688620 & 4.45 & 4.9509 & TRN \\
\hline CHEMBL1587351 & 688620 & 4.8 & 4.8747 & TRN \\
\hline CHEMBL 2094833 & 688620 & 6.15 & 5.7349 & TRN \\
\hline CHEMBL1463535 & 688620 & 4.55 & 5.2478 & TRN \\
\hline CHEMBL1310650 & 688620 & 4.45 & 5.0716 & TRN \\
\hline CHEMBL1581224 & 688620 & 5.25 & 5.1547 & TST \\
\hline CHEMBL1476339 & 688620 & 4.8 & 4.8014 & TST \\
\hline CHEMBL1538625 & 688620 & 5.35 & 5.4594 & TRN \\
\hline CHEMBL1323064 & 688620 & 5.35 & 4.9489 & TST \\
\hline CHEMBL1584722 & 688620 & 4.95 & 5.1948 & TRN \\
\hline CHEMBL1428073 & 688620 & 4.8 & 4.7889 & TRN \\
\hline CHEMBL1440683 & 688620 & 4.45 & 5.2804 & TRN \\
\hline CHEMBL1372085 & 688620 & 4.75 & 5.3141 & TST \\
\hline CHEMBL1337937 & 688620 & 5.15 & 5.0624 & TRN \\
\hline CHEMBL1564596 & 688620 & 4.8 & 4.7211 & TST \\
\hline
\end{tabular}




\begin{tabular}{|c|c|c|c|c|c|}
\hline & & \multicolumn{4}{|c|}{ Supplemental Table S2.txt } \\
\hline CHEMBL1463541 & 688620 & 4.8 & 4.8291 & TRN & \\
\hline CHEMBL1525819 & 688620 & 4.9 & 5.1691 & TRN & \\
\hline CHEMBL3192443 & 688620 & 4.75 & 5.13899 & 9999999999 & TRN \\
\hline CHEMBL1421149 & 688620 & 5.25 & 5.71 & TRN & \\
\hline CHEMBL1538869 & 688620 & 4.85 & 4.8923 & TST & \\
\hline CHEMBL3145330 & 688620 & 6.0 & 5.8429 & TST & \\
\hline CHEMBL1556263 & 688620 & 4.45 & 4.9502 & TRN & \\
\hline CHEMBL3195447 & 688620 & 5.25 & 5.0674 & TRN & \\
\hline CHEMBL3198080 & 688620 & 5.4 & 5.6535 & TRN & \\
\hline CHEMBL3196756 & 688620 & 4.45 & 4.8892 & TRN & \\
\hline CHEMBL1610207 & 688620 & 6.5 & 5.9076 & TST & \\
\hline CHEMBL1411449 & 688620 & 5.15 & 5.6051 & TST & \\
\hline CHEMBL1605912 & 688620 & 4.65 & 4.712 & TRN & \\
\hline CHEMBL1310610 & 688620 & 4.8 & 4.8537 & TST & \\
\hline CHEMBL 2007390 & 688620 & 4.45 & 5.0287 & TST & \\
\hline CHEMBL1477436 & 688620 & 5.45 & 4.9996 & TST & \\
\hline CHEMBL1351486 & 688620 & 5.2 & 5.0819 & TST & \\
\hline CHEMBL1354689 & 688620 & 4.85 & 4.9895 & TRN & \\
\hline CHEMBL1342546 & 688620 & 4.9 & 5.0719 & TRN & \\
\hline CHEMBL1327203 & 688620 & 5.95 & 5.0856 & TST & \\
\hline CHEMBL1581129 & 688620 & 4.45 & 5.0643 & TRN & \\
\hline CHEMBL1321722 & 688620 & 4.5 & 5.45799 & 9999999999 & TRN \\
\hline CHEMBL1371379 & 688620 & 5.5 & 4.9748 & TRN & \\
\hline CHEMBL1352253 & 688620 & 4.45 & 4.7607 & TRN & \\
\hline CHEMBL1343364 & 688620 & 4.6 & 4.7166 & TRN & \\
\hline CHEMBL1539251 & 688620 & 4.85 & 5.0524 & TRN & \\
\hline CHEMBL1998606 & 688620 & 5.9 & 5.6641 & TRN & \\
\hline CHEMBL1327583 & 688620 & 4.45 & 5.0366 & TRN & \\
\hline CHEMBL3195883 & 688620 & 4.45 & 5.29 & TST & \\
\hline CHEMBL1343506 & 688620 & 4.85 & 4.9461 & TST & \\
\hline CHEMBL1328498 & 688620 & 4.45 & 4.8756 & TST & \\
\hline CHEMBL1413061 & 688620 & 5.65 & 4.9749 & TRN & \\
\hline CHEMBL1989315 & 688620 & 5.15 & 4.9577 & TRN & \\
\hline CHEMBL1305653 & 688620 & 5.25 & 5.1011 & TST & \\
\hline CHEMBL1393476 & 688620 & 5.7 & 5.0236 & TRN & \\
\hline CHEMBL1402138 & 688620 & 4.85 & 5.0264 & TST & \\
\hline CHEMBL1558265 & 688620 & 4.9 & 5.1157 & TRN & \\
\hline CHEMBL1478397 & 688620 & 4.75 & 4.913 & TRN & \\
\hline CHEMBL1577850 & 688620 & 5.1 & 5.1498 & TRN & \\
\hline CHEMBL3196794 & 688620 & 4.9 & 5.0225 & TRN & \\
\hline CHEMBL1383316 & 688620 & 4.45 & 5.2223 & TST & \\
\hline CHEMBL1449896 & 688620 & 4.8 & 5.2655 & TRN & \\
\hline CHEMBL1325521 & 688620 & 4.95 & 4.9235 & TRN & \\
\hline CHEMBL1320971 & 688620 & 5.2 & 5.2775 & TRN & \\
\hline CHEMBL1480605 & 688620 & 4.5 & 4.8931 & TRN & \\
\hline CHEMBL1379280 & 688620 & 4.95 & 4.8947 & TRN & \\
\hline CHEMBL1392136 & 688620 & 4.45 & 4.869 & TRN & \\
\hline CHEMBL1417312 & 688620 & 5.4 & 5.0572 & TRN & \\
\hline
\end{tabular}




\begin{tabular}{|c|c|c|c|c|c|}
\hline \multicolumn{6}{|c|}{ Supplemental Table S2.txt } \\
\hline CHEMBL1971154 & 688620 & 5.95 & 5.6185 & TRN & \\
\hline CHEMBL1585733 & 688620 & 5.35 & 5.2752 & TST & \\
\hline CHEMBL1322922 & 688620 & 4.75 & 5.0206 & TRN & \\
\hline CHEMBL1466014 & 688620 & 4.65 & 4.7255 & TRN & \\
\hline CHEMBL1337826 & 688620 & 5.1 & 5.2433 & TRN & \\
\hline CHEMBL 3194095 & 688620 & 5.8 & 5.324 & TRN & \\
\hline CHEMBL1562195 & 688620 & 5.85 & 5.9106 & TRN & \\
\hline CHEMBL1346771 & 688620 & 6.0 & 5.9358 & TRN & \\
\hline CHEMBL 3195528 & 688620 & 4.5 & 4.949 & TRN & \\
\hline CHEMBL1301529 & 688620 & 4.7 & 4.7731 & TRN & \\
\hline CHEMBL1494414 & 688620 & 5.2 & 5.0201 & TRN & \\
\hline CHEMBL1493957 & 688620 & 5.0 & 5.0198 & TST & \\
\hline CHEMBL1443686 & 688620 & 4.8 & 5.0338 & TST & \\
\hline CHEMBL1423379 & 688620 & 6.3 & 4.8346 & TST & \\
\hline CHEMBL1522423 & 688620 & 6.5501 & 5.0883 & TRN & \\
\hline CHEMBL1539579 & 688620 & 4.9 & 5.1117 & TST & \\
\hline CHEMBL1411310 & 688620 & 4.65 & 4.7647 & TRN & \\
\hline CHEMBL1443539 & 688620 & 5.7 & 5.1997 & TRN & \\
\hline CHEMBL1458356 & 688620 & 4.9 & 5.1389 & TST & \\
\hline CHEMBL1324273 & 688620 & 4.8 & 5.0543 & TRN & \\
\hline CHEMBL1547372 & 688620 & 6.45 & 5.2556 & TRN & \\
\hline CHEMBL1562166 & 688620 & 4.75 & 4.9152 & TST & \\
\hline CHEMBL3198186 & 688620 & 5.55 & 5.16799 & 7999999999 & TRN \\
\hline CHEMBL1444213 & 688620 & 4.45 & 4.9297 & TRN & \\
\hline CHEMBL1517111 & 688620 & 4.45 & 5.0582 & TRN & \\
\hline CHEMBL1351290 & 688620 & 5.45 & 5.1327 & TRN & \\
\hline CHEMBL1463786 & 688620 & 5.9 & 6.2165 & TRN & \\
\hline CHEMBL1535439 & 688620 & 5.0 & 4.7628 & TRN & \\
\hline CHEMBL1307120 & 688620 & 5.6 & 5.2947 & TRN & \\
\hline CHEMBL1584356 & 688620 & 5.35 & 5.15 & TST & \\
\hline CHEMBL1376212 & 688620 & 5.0 & 4.9284 & TRN & \\
\hline CHEMBL1445640 & 688620 & 4.45 & 4.8468 & TST & \\
\hline CHEMBL1385012 & 688620 & 4.8 & 4.9478 & TST & \\
\hline CHEMBL1304308 & 688620 & 5.0 & 5.038 & TRN & \\
\hline CHEMBL1471043 & 688620 & 4.5 & 4.8235 & TST & \\
\hline CHEMBL1432624 & 688620 & 4.65 & 4.8234 & TRN & \\
\hline CHEMBL1512786 & 688620 & 4.9 & 4.7355 & TRN & \\
\hline CHEMBL3196937 & 688620 & 5.15 & 5.3266 & TRN & \\
\hline CHEMBL1401240 & 688620 & 4.45 & 5.0254 & TST & \\
\hline CHEMBL1585747 & 688620 & 4.85 & 5.3091 & TST & \\
\hline CHEMBL 3214626 & 688620 & 5.05 & 5.0285 & TRN & \\
\hline CHEMBL1332574 & 688620 & 5.0 & 5.3329 & TRN & \\
\hline CHEMBL3211131 & 688620 & 4.5 & 5.193 & TRN & \\
\hline CHEMBL1417099 & 688620 & 4.7 & 5.2865 & TST & \\
\hline CHEMBL1572766 & 688620 & 4.8 & 4.8767 & TRN & \\
\hline CHEMBL1343740 & 688620 & 5.85 & 5.0445 & TRN & \\
\hline CHEMBL1343786 & 688620 & 4.95 & 4.9083 & TRN & \\
\hline CHEMBL1612019 & 688620 & 5.6 & 5.1722 & TST & \\
\hline
\end{tabular}




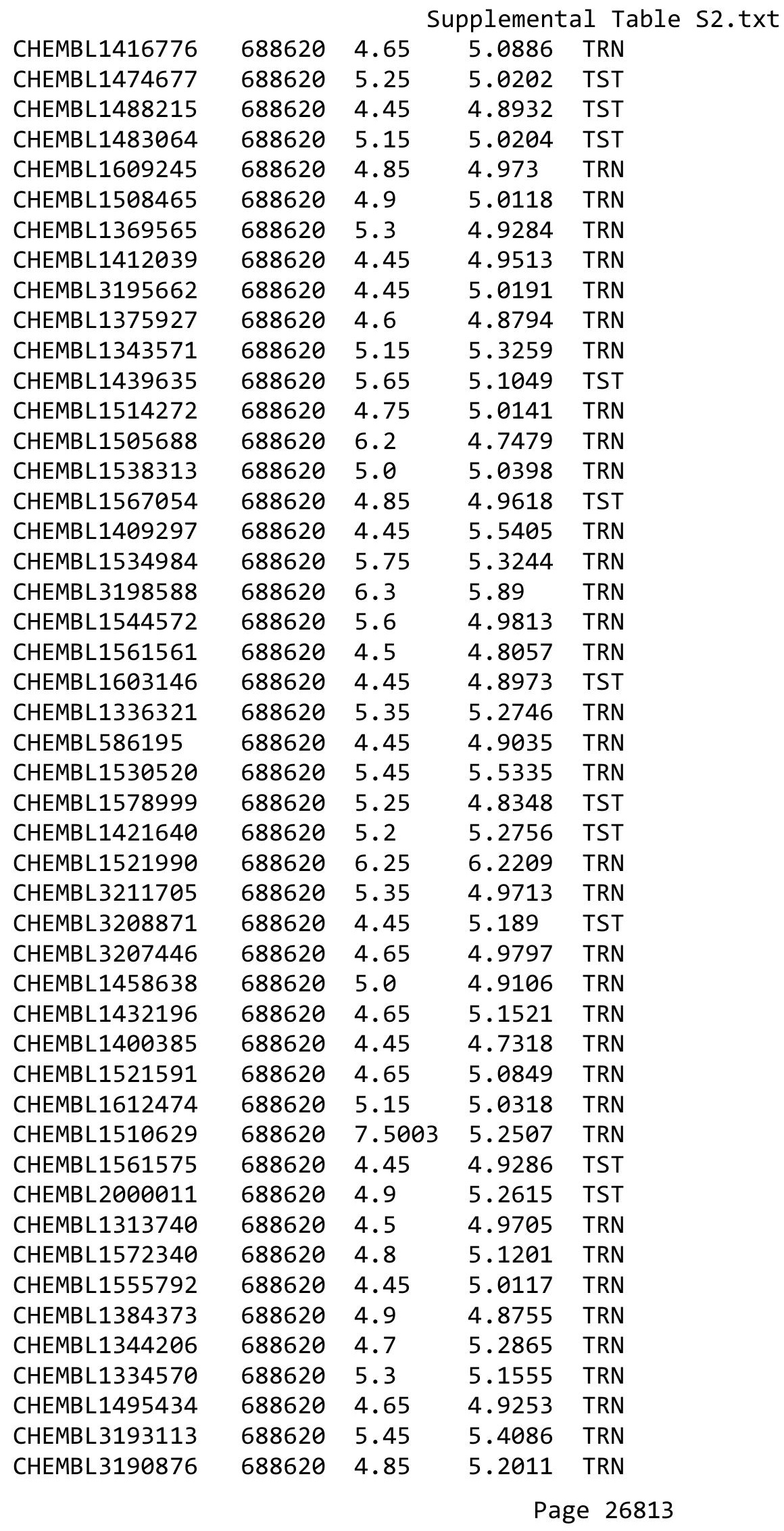




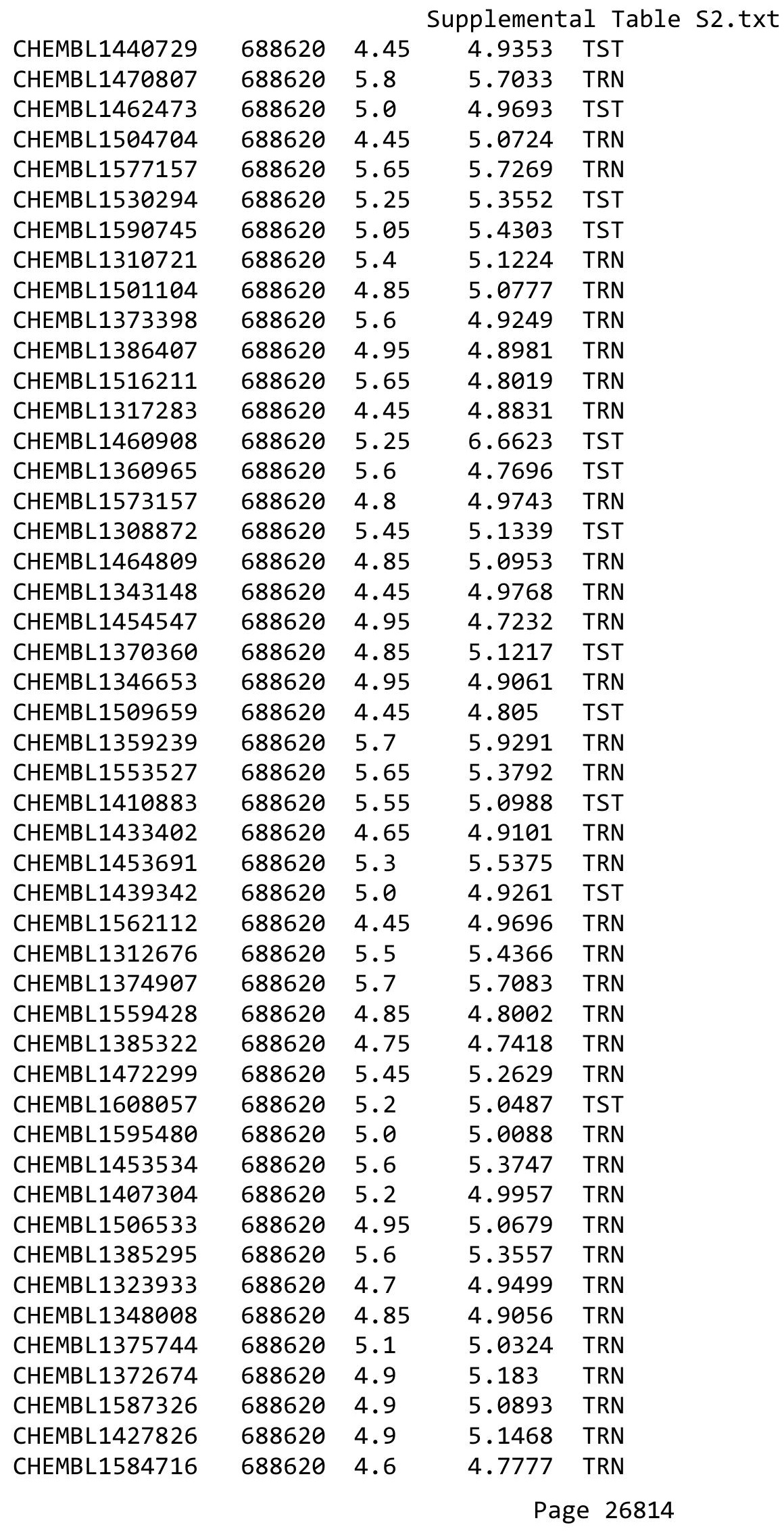




\begin{tabular}{|c|c|c|c|c|}
\hline \multicolumn{5}{|c|}{ Supplemental Table S2.txt } \\
\hline CHEMBL1478652 & 688620 & 4.45 & 4.9236 & TRN \\
\hline CHEMBL1518643 & 688620 & 6.0 & 5.0372 & TRN \\
\hline CHEMBL1372087 & 688620 & 5.55 & 5.0724 & TST \\
\hline CHEMBL1580316 & 688620 & 4.45 & 5.1022 & TRN \\
\hline CHEMBL1366384 & 688620 & 5.2 & 5.02 & TST \\
\hline CHEMBL1307537 & 688620 & 4.45 & 5.0104 & TRN \\
\hline CHEMBL1606932 & 688620 & 4.75 & 5.0219 & TST \\
\hline CHEMBL1568627 & 688620 & 6.1 & 5.7459 & TRN \\
\hline CHEMBL 3193568 & 688620 & 4.8 & 5.0265 & TST \\
\hline CHEMBL1602504 & 688620 & 4.8 & 5.0281 & TST \\
\hline CHEMBL1506207 & 688620 & 4.9 & 4.9339 & TRN \\
\hline CHEMBL1460367 & 688620 & 4.65 & 5.0305 & TST \\
\hline CHEMBL1576501 & 688620 & 4.9 & 4.9485 & TRN \\
\hline CHEMBL579322 & 688620 & 4.45 & 5.3053 & TRN \\
\hline CHEMBL1977611 & 688620 & 4.7 & 4.8803 & TST \\
\hline CHEMBL1438771 & 688620 & 4.9 & 4.8079 & TRN \\
\hline CHEMBL1549798 & 688620 & 4.5 & 4.8003 & TRN \\
\hline CHEMBL1350266 & 688620 & 4.9 & 5.0873 & TST \\
\hline CHEMBL1342378 & 688620 & 4.45 & 5.144 & TRN \\
\hline CHEMBL1537753 & 688620 & 4.75 & 4.8254 & TRN \\
\hline CHEMBL1429549 & 688620 & 4.9 & 5.2352 & TRN \\
\hline CHEMBL1561326 & 688620 & 4.45 & 4.9924 & TST \\
\hline CHEMBL1491831 & 688620 & 4.65 & 4.9481 & TST \\
\hline CHEMBL1382132 & 688620 & 4.8 & 5.1267 & TST \\
\hline CHEMBL1441242 & 688620 & 4.95 & 4.7326 & TST \\
\hline CHEMBL415506 & 688620 & 4.95 & 4.9339 & TST \\
\hline CHEMBL1361104 & 688620 & 4.45 & 5.0846 & TRN \\
\hline CHEMBL1564207 & 688620 & 5.2 & 5.082 & TRN \\
\hline CHEMBL1598552 & 688620 & 4.45 & 4.9336 & TRN \\
\hline CHEMBL1412191 & 688620 & 4.75 & 5.0251 & TST \\
\hline CHEMBL1548414 & 688620 & 4.85 & 5.074 & TST \\
\hline CHEMBL1500489 & 688620 & 4.65 & 4.7864 & TRN \\
\hline CHEMBL1563708 & 688620 & 4.45 & 4.978 & TST \\
\hline CHEMBL559612 & 688620 & 4.45 & 4.6851 & TST \\
\hline CHEMBL3190613 & 688620 & 5.8 & 4.8383 & TST \\
\hline CHEMBL1477805 & 688620 & 4.7 & 4.7816 & TRN \\
\hline CHEMBL1456705 & 688620 & 4.45 & 4.9941 & TRN \\
\hline CHEMBL1488840 & 688620 & 7.2 & 5.1057 & TST \\
\hline CHEMBL3199665 & 688620 & 4.9 & 5.3754 & TRN \\
\hline CHEMBL3193979 & 688620 & 4.8 & 5.0076 & TRN \\
\hline CHEMBL1550197 & 688620 & 4.45 & 5.1516 & TST \\
\hline CHEMBL1589418 & 688620 & 8.2518 & 5.1688 & TRN \\
\hline CHEMBL1370413 & 688620 & 4.45 & 5.1942 & TST \\
\hline CHEMBL1455893 & 688620 & 6.6 & 5.5653 & TRN \\
\hline CHEMBL1477692 & 688620 & 4.95 & 4.7745 & TRN \\
\hline CHEMBL289356 & 688620 & 4.95 & 5.1106 & TRN \\
\hline CHEMBL1365949 & 688620 & 5.25 & 4.9634 & TRN \\
\hline CHEMBL1507949 & 688620 & 5.65 & 5.518 & TRN \\
\hline
\end{tabular}




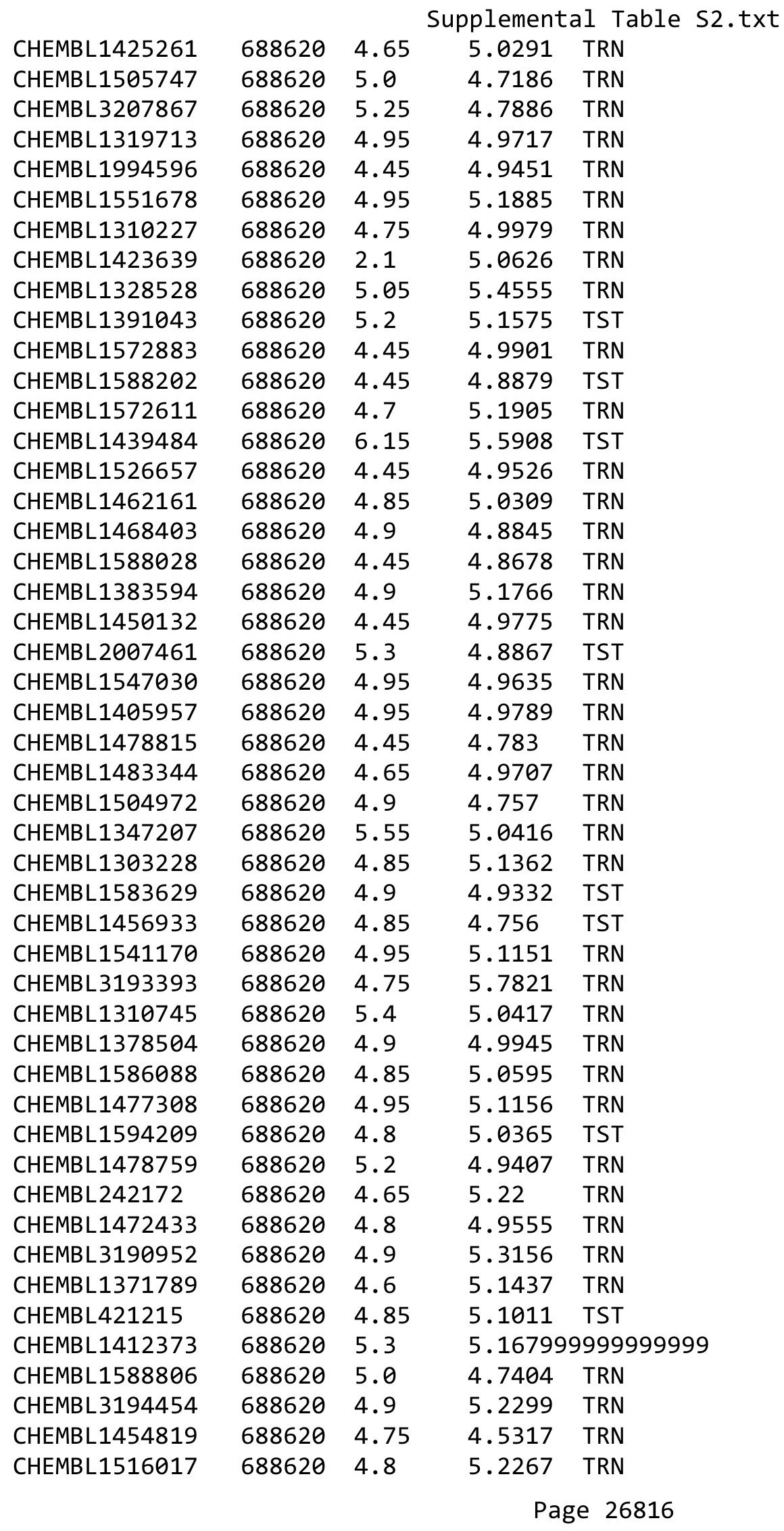

TRN 


\begin{tabular}{|c|c|c|c|c|}
\hline & & & upplement & al Table S \\
\hline CHEMBL1549975 & 688620 & 6.0 & 5.4244 & TRN \\
\hline CHEMBL 3190780 & 688620 & 5.55 & 5.7443 & TRN \\
\hline CHEMBL1492161 & 688620 & 4.85 & 5.2449 & TRN \\
\hline CHEMBL1970469 & 688620 & 5.4 & 4.7997 & TRN \\
\hline CHEMBL3209772 & 688620 & 4.8 & 4.7885 & TRN \\
\hline CHEMBL1410460 & 688620 & 5.2 & 5.4574 & TRN \\
\hline CHEMBL1557866 & 688620 & 4.45 & 4.9334 & TST \\
\hline CHEMBL1333000 & 688620 & 5.3 & 4.9971 & TRN \\
\hline CHEMBL1318995 & 688620 & 5.0 & 5.074 & TRN \\
\hline CHEMBL1380166 & 688620 & 5.55 & 4.91 & TST \\
\hline CHEMBL1375402 & 688620 & 6.1 & 5.0694 & TST \\
\hline CHEMBL1417659 & 688620 & 4.95 & 4.8205 & TST \\
\hline CHEMBL 3197712 & 688620 & 4.45 & 4.8747 & TRN \\
\hline CHEMBL1500845 & 688620 & 4.45 & 4.9393 & TRN \\
\hline CHEMBL1385173 & 688620 & 4.95 & 5.2874 & TRN \\
\hline CHEMBL1592975 & 688620 & 5.0 & 5.1813 & TST \\
\hline CHEMBL1459468 & 688620 & 6.6 & 5.9401 & TRN \\
\hline CHEMBL1433337 & 688620 & 4.9 & 5.0729 & TRN \\
\hline CHEMBL1546016 & 688620 & 5.75 & 5.2764 & TRN \\
\hline CHEMBL1523000 & 688620 & 5.5 & $5.0710 e$ & 0000000001 \\
\hline CHEMBL1303021 & 688620 & 4.45 & 4.8353 & TRN \\
\hline CHEMBL1328501 & 688620 & 5.65 & 5.3006 & TRN \\
\hline CHEMBL1421856 & 688620 & 6.25 & 5.0326 & TRN \\
\hline CHEMBL531079 & 688620 & 5.35 & 4.8851 & TRN \\
\hline CHEMBL1363417 & 688620 & 5.3 & 5.1758 & TRN \\
\hline CHEMBL1413447 & 688620 & 4.45 & 5.2091 & TST \\
\hline CHEMBL1468713 & 688620 & 5.3 & 5.2648 & TRN \\
\hline CHEMBL1480245 & 688620 & 4.95 & 5.0435 & TRN \\
\hline CHEMBL1545858 & 688620 & 4.7 & 5.1249 & TRN \\
\hline CHEMBL1503528 & 688620 & 5.05 & 5.1036 & TRN \\
\hline CHEMBL1587174 & 688620 & 5.55 & 4.9349 & TST \\
\hline CHEMBL1411730 & 688620 & 5.35 & 5.0864 & TRN \\
\hline CHEMBL1322280 & 688620 & 5.15 & 5.1749 & TRN \\
\hline CHEMBL 3211512 & 688620 & 4.85 & 5.1512 & TRN \\
\hline CHEMBL1334221 & 688620 & 4.75 & 4.7017 & TRN \\
\hline CHEMBL1310208 & 688620 & 4.9 & 4.7757 & TRN \\
\hline CHEMBL1334494 & 688620 & 5.55 & 5.0631 & TRN \\
\hline CHEMBL1424815 & 688620 & 5.2 & 4.999 & TRN \\
\hline CHEMBL1348561 & 688620 & 4.45 & 5.0475 & TST \\
\hline CHEMBL 3196962 & 688620 & 6.25 & 5.2958 & TRN \\
\hline CHEMBL1506708 & 688620 & 6.05 & 5.6128 & TST \\
\hline CHEMBL1388388 & 688620 & 6.6 & 5.28 & TRN \\
\hline CHEMBL1343370 & 688620 & 5.85 & 5.0504 & TST \\
\hline CHEMBL443462 & 688620 & 4.85 & 5.0296 & TST \\
\hline CHEMBL1580946 & 688620 & 6.0 & 5.5975 & TRN \\
\hline CHEMBL1603662 & 688620 & 5.0 & 5.1109 & TRN \\
\hline CHEMBL1344416 & 688620 & 4.75 & 4.8866 & TRN \\
\hline CHEMBL1346534 & 688620 & 4.95 & 4.9471 & TST \\
\hline
\end{tabular}




\begin{tabular}{|c|c|c|c|c|c|}
\hline \multicolumn{6}{|c|}{ Supplemental Table S2.txt } \\
\hline CHEMBL1538893 & 688620 & 4.45 & 4.9834 & TRN & \\
\hline CHEMBL1607583 & 688620 & 5.4 & 4.8065 & TST & \\
\hline CHEMBL1610051 & 688620 & 4.9 & 4.6984 & TRN & \\
\hline CHEMBL1611644 & 688620 & 5.0 & 5.0521 & TST & \\
\hline CHEMBL3193234 & 688620 & 5.4 & 5.2291 & TRN & \\
\hline CHEMBL1499550 & 688620 & 4.9 & 4.7482 & TRN & \\
\hline CHEMBL1403911 & 688620 & 4.95 & 4.7997 & TRN & \\
\hline CHEMBL1588673 & 688620 & 5.05 & 5.0534 & TRN & \\
\hline CHEMBL3192506 & 688620 & 6.2 & 5.0221 & TRN & \\
\hline CHEMBL1511768 & 688620 & 4.9 & 5.0762 & TRN & \\
\hline CHEMBL1353696 & 688620 & 4.95 & 4.7993 & TRN & \\
\hline CHEMBL1997581 & 688620 & 5.4 & 5.2333 & TRN & \\
\hline CHEMBL3194822 & 688620 & 4.9 & 5.6365 & TRN & \\
\hline CHEMBL1608049 & 688620 & 5.55 & 5.2372 & TRN & \\
\hline CHEMBL1451434 & 688620 & 5.35 & 5.1969 & TST & \\
\hline CHEMBL1452499 & 688620 & 4.9 & 4.9784 & TRN & \\
\hline CHEMBL1314913 & 688620 & 4.45 & 4.9528 & TST & \\
\hline CHEMBL1986459 & 688620 & 5.2 & 5.1429 & TRN & \\
\hline CHEMBL1412890 & 688620 & 5.35 & 5.0858 & TRN & \\
\hline CHEMBL1369101 & 688620 & 4.45 & 4.6638 & TRN & \\
\hline CHEMBL1530143 & 688620 & 4.65 & 5.0818 & TST & \\
\hline CHEMBL3208106 & 688620 & 6.15 & 5.1496 & TRN & \\
\hline CHEMBL1599082 & 688620 & 4.95 & 5.1632 & TRN & \\
\hline CHEMBL1404071 & 688620 & 5.0 & 5.12299 & 9999999999 & TRN \\
\hline CHEMBL1463131 & 688620 & 4.9 & 5.0403 & TRN & \\
\hline CHEMBL3197847 & 688620 & 5.5 & 5.5047 & TRN & \\
\hline CHEMBL1606166 & 688620 & 5.4 & 5.2513 & TRN & \\
\hline CHEMBL1904348 & 688620 & 5.9 & 5.50899 & 99999999995 & TRN \\
\hline CHEMBL1455277 & 688620 & 4.85 & 4.883 & TRN & \\
\hline CHEMBL1352661 & 688620 & 4.45 & 5.25200 & 2000000001 & TRN \\
\hline CHEMBL1404029 & 688620 & 4.55 & 4.8519 & TRN & \\
\hline CHEMBL3198840 & 688620 & 5.15 & 5.1604 & TRN & \\
\hline CHEMBL1453172 & 688620 & 5.3 & 5.4459 & TRN & \\
\hline CHEMBL1561076 & 688620 & 4.9 & 5.1978 & TST & \\
\hline CHEMBL1369165 & 688620 & 5.3 & 5.2817 & TRN & \\
\hline CHEMBL1369746 & 688620 & 4.5 & 5.0762 & TST & \\
\hline CHEMBL1560608 & 688620 & 4.85 & 4.6969 & TST & \\
\hline CHEMBL1367594 & 688620 & 5.0 & 5.0753 & TRN & \\
\hline CHEMBL1372438 & 688620 & 5.75 & 5.4811 & TRN & \\
\hline CHEMBL1406222 & 688620 & 4.6 & 5.1017 & TRN & \\
\hline CHEMBL1536344 & 688620 & 4.45 & 5.0961 & TRN & \\
\hline CHEMBL1324559 & 688620 & 4.95 & 6.5377 & TRN & \\
\hline CHEMBL1300606 & 688620 & 4.45 & 5.2521 & TRN & \\
\hline CHEMBL1501773 & 688620 & 5.0 & 4.8861 & TRN & \\
\hline CHEMBL1350319 & 688620 & 4.85 & 5.0735 & TRN & \\
\hline CHEMBL1326493 & 688620 & 4.45 & 4.9451 & TRN & \\
\hline CHEMBL1466031 & 688620 & 4.5 & 5.2126 & TRN & \\
\hline CHEMBL2374058 & 688620 & 5.0 & 4.8972 & TST & \\
\hline
\end{tabular}




\begin{tabular}{|c|c|c|c|c|c|}
\hline \\
\hline CHEMBL1466857 & 688620 & 5.2 & 5.1867 & TRN & \\
\hline CHEMBL1340602 & 688620 & 5.4 & 4.9605 & TRN & \\
\hline CHEMBL1576282 & 688620 & 5.4 & 5.2756 & TRN & \\
\hline CHEMBL1469044 & 688620 & 4.95 & 4.7832 & TRN & \\
\hline CHEMBL1311474 & 688620 & 5.35 & 5.129 & TRN & \\
\hline CHEMBL1400160 & 688620 & 4.9 & 5.3601 & TRN & \\
\hline CHEMBL546576 & 688620 & 5.45 & 5.1308 & TRN & \\
\hline CHEMBL1382011 & 688620 & 5.0 & 4.9851 & TRN & \\
\hline CHEMBL1546327 & 688620 & 5.65 & 5.8122 & TRN & \\
\hline CHEMBL1547493 & 688620 & 5.95 & 5.1278 & TRN & \\
\hline CHEMBL1482482 & 688620 & 4.45 & 4.9403 & TRN & \\
\hline CHEMBL1311510 & 688620 & 4.45 & 5.4123 & TST & \\
\hline CHEMBL1580912 & 688620 & 4.8 & 4.8617 & TRN & \\
\hline CHEMBL1544114 & 688620 & 6.5 & 6.3249 & TRN & \\
\hline CHEMBL1469874 & 688620 & 5.25 & 5.0776 & TRN & \\
\hline CHEMBL1453393 & 688620 & 4.9 & 4.7704 & TRN & \\
\hline CHEMBL1538832 & 688620 & 5.6 & 4.9262 & TST & \\
\hline CHEMBL1400404 & 688620 & 4.85 & 4.8485 & TRN & \\
\hline CHEMBL1500982 & 688620 & 4.95 & 4.9035 & TST & \\
\hline CHEMBL1573182 & 688620 & 4.8 & 4.775 & TRN & \\
\hline CHEMBL1510499 & 688620 & 4.65 & 5.1115 & TST & \\
\hline CHEMBL1547303 & 688620 & 6.95 & 5.0399 & TRN & \\
\hline CHEMBL1573166 & 688620 & 4.45 & 5.3036 & TST & \\
\hline CHEMBL1471626 & 688620 & 4.7 & 4.8493 & TRN & \\
\hline CHEMBL1314029 & 688620 & 5.0 & 5.0692 & TRN & \\
\hline CHEMBL1588844 & 688620 & 4.65 & 4.9258 & TRN & \\
\hline CHEMBL1311991 & 688620 & 5.5 & 5.042 & TRN & \\
\hline CHEMBL1352755 & 688620 & 4.65 & 5.035 & TST & \\
\hline CHEMBL1349663 & 688620 & 5.75 & 5.4207 & TRN & \\
\hline CHEMBL1599576 & 688620 & 5.25 & 5.0612 & TST & \\
\hline CHEMBL1423562 & 688620 & 5.25 & 5.0134 & TRN & \\
\hline CHEMBL1349231 & 688620 & 5.45 & 5.5 & TRN & \\
\hline CHEMBL3191543 & 688620 & 5.45 & 5.2472 & TRN & \\
\hline CHEMBL1352775 & 688620 & 5.55 & 4.919 & TRN & \\
\hline CHEMBL1302338 & 688620 & 5.2 & 5.1055 & TRN & \\
\hline CHEMBL1386240 & 688620 & 4.85 & 4.9303 & TST & \\
\hline CHEMBL3192782 & 688620 & 4.95 & 4.9293 & TST & \\
\hline CHEMBL1583254 & 688620 & 4.9 & 5.0521 & TRN & \\
\hline CHEMBL1421931 & 688620 & 4.45 & 5.0116 & TRN & \\
\hline CHEMBL1358796 & 688620 & 4.85 & 5.0139 & TRN & \\
\hline CHEMBL1380138 & 688620 & 4.45 & 4.7935 & TRN & \\
\hline CHEMBL1575906 & 688620 & 5.15 & 4.9361 & TRN & \\
\hline CHEMBL1304998 & 688620 & 5.1 & 5.2886 & TRN & \\
\hline CHEMBL1547874 & 688620 & 4.95 & 4.8499 & TRN & \\
\hline CHEMBL1331887 & 688620 & 5.15 & 5.03600 & 00000000005 & TRN \\
\hline CHEMBL1350245 & 688620 & 4.45 & 4.9247 & TRN & \\
\hline CHEMBL1556879 & 688620 & 4.45 & 4.8608 & TRN & \\
\hline CHEMBL1528089 & 688620 & 4.45 & 4.5742 & TRN & \\
\hline & & & & 26819 & \\
\hline
\end{tabular}




\begin{tabular}{|c|c|c|c|c|c|}
\hline & & \multicolumn{4}{|c|}{ Supplemental Table s2.txt } \\
\hline CHEMBL1329001 & 688620 & 4.9 & 4.814 & TRN & \\
\hline CHEMBL1552562 & 688620 & 4.45 & 4.9506 & TST & \\
\hline CHEMBL1412193 & 688620 & 4.95 & 5.1823 & TRN & \\
\hline CHEMBL3196435 & 688620 & 5.15 & 5.2349 & TRN & \\
\hline CHEMBL1375064 & 688620 & 5.9 & 5.7622 & TRN & \\
\hline CHEMBL3196210 & 688620 & 4.95 & 4.9023 & TRN & \\
\hline CHEMBL1333959 & 688620 & 5.5 & 5.024 & TST & \\
\hline CHEMBL1385639 & 688620 & 4.45 & 4.8827 & TRN & \\
\hline CHEMBL1304859 & 688620 & 5.15 & 4.904 & TST & \\
\hline CHEMBL1386625 & 688620 & 6.95 & 5.0561 & TST & \\
\hline CHEMBL1377556 & 688620 & 5.0 & 5.0993 & TRN & \\
\hline CHEMBL3191149 & 688620 & 4.45 & 4.8757 & TRN & \\
\hline CHEMBL1392102 & 688620 & 5.7 & 5.6054 & TRN & \\
\hline CHEMBL3191511 & 688620 & 4.7 & 5.1625 & TRN & \\
\hline CHEMBL3199509 & 688620 & 4.95 & 5.2212 & TRN & \\
\hline CHEMBL3145031 & 688620 & 5.45 & 5.0148 & TST & \\
\hline CHEMBL1471264 & 688620 & 5.0 & $5.1560 e$ & $\partial 000000001$ & TRN \\
\hline CHEMBL1378835 & 688620 & 5.15 & 4.7831 & TRN & \\
\hline CHEMBL1522485 & 688620 & 4.45 & 4.7552 & TRN & \\
\hline CHEMBL1599643 & 688620 & 4.8 & 4.8372 & TRN & \\
\hline CHEMBL1370024 & 688620 & 5.1 & 5.1517 & TST & \\
\hline CHEMBL1492943 & 688620 & 5.0 & 5.0563 & TRN & \\
\hline CHEMBL1472003 & 688620 & 4.45 & 4.8289 & TRN & \\
\hline CHEMBL1440181 & 688620 & 4.45 & 4.9634 & TRN & \\
\hline CHEMBL1334525 & 688620 & 6.05 & 5.2444 & TRN & \\
\hline CHEMBL3199001 & 688620 & 5.6 & 5.2775 & TRN & \\
\hline CHEMBL1425278 & 688620 & 4.45 & 5.0122 & TRN & \\
\hline CHEMBL1530078 & 688620 & 4.45 & 4.9082 & TST & \\
\hline CHEMBL1481077 & 688620 & 5.0 & 5.0798 & TST & \\
\hline CHEMBL1379322 & 688620 & 5.1 & 4.8942 & TRN & \\
\hline CHEMBL443127 & 688620 & 4.95 & 4.6011 & TST & \\
\hline CHEMBL1583581 & 688620 & 5.5 & 4.9417 & TRN & \\
\hline CHEMBL1452088 & 688620 & 6.15 & 5.1445 & TRN & \\
\hline CHEMBL1563798 & 688620 & 4.95 & 5.126 & TST & \\
\hline CHEMBL1347605 & 688620 & 4.95 & 5.0211 & TST & \\
\hline CHEMBL1566433 & 688620 & 4.9 & 5.129 & TRN & \\
\hline CHEMBL1453680 & 688620 & 4.45 & 5.1044 & TRN & \\
\hline CHEMBL1465527 & 688620 & 5.4 & 5.3215 & TST & \\
\hline CHEMBL1303929 & 688620 & 5.15 & 4.9755 & TRN & \\
\hline CHEMBL1409486 & 688620 & 4.8 & 4.857 & TRN & \\
\hline CHEMBL1580320 & 688620 & 4.45 & 5.2307 & TRN & \\
\hline CHEMBL1312599 & 688620 & 4.85 & 4.9287 & TST & \\
\hline CHEMBL1515530 & 688620 & 4.7 & 5.2018 & TST & \\
\hline CHEMBL1533024 & 688620 & 5.5 & 4.8608 & TRN & \\
\hline CHEMBL1493806 & 688620 & 4.45 & 4.8182 & TST & \\
\hline CHEMBL1984098 & 688620 & 6.3 & 5.3032 & TST & \\
\hline CHEMBL1309398 & 688620 & 5.75 & 4.9843 & TRN & \\
\hline CHEMBL1329972 & 688620 & 4.45 & 5.0856 & TRN & \\
\hline
\end{tabular}




\begin{tabular}{|c|c|c|c|c|}
\hline \multicolumn{5}{|c|}{ Supplemental Table S2.txt } \\
\hline CHEMBL1330282 & 688620 & 4.65 & 4.9482 & TRN \\
\hline CHEMBL1557869 & 688620 & 4.85 & 5.0594 & TRN \\
\hline CHEMBL3213662 & 688620 & 5.4 & 5.0714 & TRN \\
\hline CHEMBL1351194 & 688620 & 5.0 & 4.9896 & TST \\
\hline CHEMBL1588717 & 688620 & 5.3 & 5.0382 & TST \\
\hline CHEMBL1499911 & 688620 & 5.0 & 5.0419 & TRN \\
\hline CHEMBL1299890 & 688620 & 4.45 & 5.0938 & TST \\
\hline CHEMBL 3145321 & 688620 & 5.35 & 5.369 & TRN \\
\hline CHEMBL1480838 & 688620 & 4.95 & 5.1991 & TRN \\
\hline CHEMBL1359038 & 688620 & 4.95 & 5.0907 & TRN \\
\hline CHEMBL1608314 & 688620 & 5.25 & 5.015 & TRN \\
\hline CHEMBL1370838 & 688620 & 5.15 & 5.1221 & TST \\
\hline CHEMBL1521576 & 688620 & 5.35 & 5.4144 & TST \\
\hline CHEMBL1341919 & 688620 & 4.65 & 4.7391 & TST \\
\hline CHEMBL1333334 & 688620 & 4.45 & 4.9621 & TRN \\
\hline CHEMBL1412667 & 688620 & 5.2 & 5.0481 & TST \\
\hline CHEMBL1368806 & 688620 & 5.45 & 5.0362 & TRN \\
\hline CHEMBL1564901 & 688620 & 4.9 & 5.0155 & TRN \\
\hline CHEMBL1423723 & 688620 & 5.35 & 4.8377 & TRN \\
\hline CHEMBL3209831 & 688620 & 4.9 & 5.355 & TRN \\
\hline CHEMBL1349866 & 688620 & 5.2 & 5.0248 & TRN \\
\hline CHEMBL1571341 & 688620 & 5.1 & 4.9702 & TRN \\
\hline CHEMBL1455005 & 688620 & 4.65 & 5.8369 & TST \\
\hline CHEMBL1445257 & 688620 & 5.7 & 5.1345 & TRN \\
\hline CHEMBL1369302 & 688620 & 5.4 & 5.1719 & TRN \\
\hline CHEMBL1393444 & 688620 & 5.05 & 4.8376 & TRN \\
\hline CHEMBL1445714 & 688620 & 5.45 & 4.904 & TRN \\
\hline CHEMBL1419009 & 688620 & 4.45 & 5.0339 & TRN \\
\hline CHEMBL1539453 & 688620 & 8.3468 & 5.3264 & TRN \\
\hline CHEMBL3196681 & 688620 & 5.3 & 5.033 & TST \\
\hline CHEMBL1598619 & 688620 & 5.15 & 5.1295 & TRN \\
\hline CHEMBL1602407 & 688620 & 4.7 & 4.9195 & TRN \\
\hline CHEMBL1424046 & 688620 & 4.9 & 5.0446 & TRN \\
\hline CHEMBL1601590 & 688620 & 4.85 & 5.1925 & TRN \\
\hline CHEMBL1442229 & 688620 & 5.05 & 4.8155 & TRN \\
\hline CHEMBL1454991 & 688620 & 4.8 & 5.0829 & TRN \\
\hline CHEMBL1575051 & 688620 & 4.45 & 5.0091 & TRN \\
\hline CHEMBL1446624 & 688620 & 5.05 & 5.0676 & TST \\
\hline CHEMBL1346168 & 688620 & 4.95 & 4.9896 & TRN \\
\hline CHEMBL1381737 & 688620 & 5.4 & 4.9268 & TRN \\
\hline CHEMBL1498940 & 688620 & 5.3 & 5.5508 & TRN \\
\hline CHEMBL1536452 & 688620 & 5.5 & 5.32 & TRN \\
\hline CHEMBL1575517 & 688620 & 4.45 & 4.9621 & TRN \\
\hline CHEMBL1578303 & 688620 & 4.75 & 4.783 & TRN \\
\hline CHEMBL1484231 & 688620 & 6.25 & 5.6791 & TST \\
\hline CHEMBL1478819 & 688620 & 4.85 & 4.8387 & TRN \\
\hline CHEMBL1331227 & 688620 & 4.8 & 4.9788 & TST \\
\hline CHEMBL1478149 & 688620 & 4.7 & 4.8752 & TST \\
\hline
\end{tabular}




\begin{tabular}{|c|c|c|c|c|c|}
\hline \multicolumn{6}{|c|}{ Supplemental Table S2.txt } \\
\hline CHEMBL1586518 & 688620 & 4.75 & 5.1054 & TST & \\
\hline CHEMBL1493626 & 688620 & 6.15 & 5.1005 & TRN & \\
\hline CHEMBL3189319 & 688620 & 5.75 & 5.0372 & TST & \\
\hline CHEMBL 3196250 & 688620 & 5.25 & 4.9878 & TRN & \\
\hline CHEMBL1578041 & 688620 & 5.1 & 4.9634 & TST & \\
\hline CHEMBL3199736 & 688620 & 4.9 & 4.9453 & TRN & \\
\hline CHEMBL1576144 & 688620 & 4.95 & 5.0317 & TRN & \\
\hline CHEMBL1471737 & 688620 & 4.85 & 4.8354 & TST & \\
\hline CHEMBL1402428 & 688620 & 5.65 & 5.2358 & TRN & \\
\hline CHEMBL3196041 & 688620 & 4.65 & 5.0265 & TST & \\
\hline CHEMBL1510839 & 688620 & 4.45 & 5.0147 & TRN & \\
\hline CHEMBL1421905 & 688620 & 4.75 & 5.0002 & TRN & \\
\hline CHEMBL1598774 & 688620 & 4.45 & 4.832 & TRN & \\
\hline CHEMBL1425237 & 688620 & 4.85 & 4.9104 & TST & \\
\hline CHEMBL1326089 & 688620 & 5.05 & 4.8773 & TRN & \\
\hline CHEMBL1492317 & 688620 & 5.15 & 5.0288 & TRN & \\
\hline CHEMBL1430641 & 688620 & 4.45 & 5.0726 & TST & \\
\hline CHEMBL1384383 & 688620 & 4.65 & 5.0924 & TRN & \\
\hline CHEMBL1471716 & 688620 & 5.95 & 5.1972 & TRN & \\
\hline CHEMBL1449892 & 688620 & 5.95 & 4.9538 & TRN & \\
\hline CHEMBL1546725 & 688620 & 5.0 & 4.9541 & TRN & \\
\hline CHEMBL1564528 & 688620 & 4.45 & 4.9309 & TRN & \\
\hline CHEMBL1363084 & 688620 & 5.05 & 4.9666 & TRN & \\
\hline CHEMBL1423346 & 688620 & 6.3 & 5.6658 & TRN & \\
\hline CHEMBL1357005 & 688620 & 5.45 & 5.32799 & 9999999999 & TRN \\
\hline CHEMBL1359398 & 688620 & 4.75 & 4.8726 & TRN & \\
\hline CHEMBL1541804 & 688620 & 5.1 & 4.9226 & TST & \\
\hline CHEMBL1374009 & 688620 & 5.45 & 5.3226 & TRN & \\
\hline CHEMBL1583400 & 688620 & 4.85 & 4.8355 & TRN & \\
\hline CHEMBL1533832 & 688620 & 4.6 & 4.9824 & TRN & \\
\hline CHEMBL1470312 & 688620 & 5.45 & 5.4645 & TST & \\
\hline CHEMBL1589447 & 688620 & 4.95 & 5.1343 & TST & \\
\hline CHEMBL1564306 & 688620 & 5.6 & 4.947 & TST & \\
\hline CHEMBL1607279 & 688620 & 5.55 & 5.2102 & TRN & \\
\hline CHEMBL1456170 & 688620 & 4.8 & 5.0178 & TRN & \\
\hline CHEMBL1587976 & 688620 & 5.55 & 5.2861 & TST & \\
\hline CHEMBL1375655 & 688620 & 4.9 & 4.8964 & TST & \\
\hline CHEMBL1328550 & 688620 & 4.65 & 4.966 & TRN & \\
\hline CHEMBL1568990 & 688620 & 4.75 & 5.2069 & TST & \\
\hline CHEMBL1408776 & 688620 & 4.75 & 4.7746 & TRN & \\
\hline CHEMBL1523396 & 688620 & 4.95 & 4.783 & TRN & \\
\hline CHEMBL1540448 & 688620 & 4.7 & 5.1627 & TST & \\
\hline CHEMBL1526943 & 688620 & 4.45 & 5.1474 & TRN & \\
\hline CHEMBL1377154 & 688620 & 5.55 & 5.3197 & TRN & \\
\hline CHEMBL1367081 & 688620 & 5.15 & 4.9915 & TRN & \\
\hline CHEMBL1346504 & 688620 & 6.5501 & 5.1233 & TRN & \\
\hline CHEMBL1345025 & 688620 & 5.0 & 4.7429 & TRN & \\
\hline CHEMBL1333099 & 688620 & 4.45 & 4.9205 & TRN & \\
\hline
\end{tabular}




\begin{tabular}{|c|c|c|c|c|c|}
\hline \\
\hline CHEMBL1341239 & 688620 & 4.5 & 5.2334 & TRN & \\
\hline CHEMBL1339863 & 688620 & 4.9 & 4.9506 & TRN & \\
\hline CHEMBL1607330 & 688620 & 4.9 & 4.9214 & TRN & \\
\hline CHEMBL418068 & 688620 & 4.55 & 4.9262 & TST & \\
\hline CHEMBL1514307 & 688620 & 4.45 & 4.9286 & TRN & \\
\hline CHEMBL3145194 & 688620 & 5.75 & 5.1429 & TST & \\
\hline CHEMBL523663 & 688620 & 5.1 & 4.9637 & TRN & \\
\hline CHEMBL1972235 & 688620 & 4.9 & 4.6758 & TRN & \\
\hline CHEMBL1454843 & 688620 & 4.5 & 5.0086 & TRN & \\
\hline CHEMBL1577248 & 688620 & 5.2 & 5.41799 & 9999999999 & TST \\
\hline CHEMBL1433182 & 688620 & 5.1 & 5.1018 & TST & \\
\hline CHEMBL1408035 & 688620 & 5.4 & 5.0128 & TRN & \\
\hline CHEMBL1433951 & 688620 & 4.7 & 5.1682 & TRN & \\
\hline CHEMBL1510490 & 688620 & 4.95 & 4.9732 & TRN & \\
\hline CHEMBL1485346 & 688620 & 4.45 & 4.8985 & TRN & \\
\hline CHEMBL1353538 & 688620 & 5.2 & 5.0276 & TRN & \\
\hline CHEMBL1415442 & 688620 & 6.35 & 5.0248 & TRN & \\
\hline CHEMBL1538750 & 688620 & 4.45 & 5.0697 & TRN & \\
\hline CHEMBL1528931 & 688620 & 5.1 & 5.1296 & TRN & \\
\hline CHEMBL3197095 & 688620 & 4.9 & 5.0244 & TRN & \\
\hline CHEMBL1497239 & 688620 & 4.9 & 5.0861 & TRN & \\
\hline CHEMBL1384548 & 688620 & 4.95 & 4.7397 & TRN & \\
\hline CHEMBL1562420 & 688620 & 6.0 & 5.8369 & TST & \\
\hline CHEMBL1433960 & 688620 & 5.25 & 5.0771 & TRN & \\
\hline CHEMBL1450166 & 688620 & 4.9 & 4.9533 & TRN & \\
\hline CHEMBL1974091 & 688620 & 5.3 & 5.1781 & TRN & \\
\hline CHEMBL3195397 & 688620 & 5.0 & 5.1599 & TRN & \\
\hline CHEMBL1363565 & 688620 & 4.5 & 4.9624 & TRN & \\
\hline CHEMBL1440209 & 688620 & 4.45 & 4.918 & TRN & \\
\hline CHEMBL1533798 & 688620 & 5.0 & 4.9851 & TRN & \\
\hline CHEMBL1319236 & 688620 & 4.95 & 5.3175 & TRN & \\
\hline CHEMBL1524763 & 688620 & 4.9 & 5.141 & TRN & \\
\hline CHEMBL1540080 & 688620 & 5.0 & 4.73600 & 0000000001 & TRN \\
\hline CHEMBL1468632 & 688620 & 4.45 & 4.8781 & TRN & \\
\hline CHEMBL1506177 & 688620 & 4.95 & 5.5876 & TST & \\
\hline CHEMBL1586371 & 688620 & 5.0 & 4.9595 & TRN & \\
\hline CHEMBL3196668 & 688620 & 5.15 & 5.0614 & TRN & \\
\hline CHEMBL1558139 & 688620 & 4.7 & 5.2474 & TST & \\
\hline CHEMBL1506279 & 688620 & 4.95 & 5.0063 & TRN & \\
\hline CHEMBL1539525 & 688620 & 5.15 & 5.379 & TST & \\
\hline CHEMBL1486602 & 688620 & 4.75 & 6.0062 & TRN & \\
\hline CHEMBL3192479 & 688620 & 5.1 & 4.9724 & TRN & \\
\hline CHEMBL1320204 & 688620 & 5.2 & 5.0396 & TRN & \\
\hline CHEMBL1372730 & 688620 & 4.95 & 4.9044 & TRN & \\
\hline CHEMBL1403869 & 688620 & 5.35 & 5.043 & TRN & \\
\hline CHEMBL1371805 & 688620 & 4.45 & 4.8622 & TRN & \\
\hline CHEMBL1584262 & 688620 & 5.45 & 5.0835 & TRN & \\
\hline CHEMBL1466441 & 688620 & 6.25 & 5.2219 & TRN & \\
\hline
\end{tabular}




\begin{tabular}{|c|c|c|c|c|}
\hline \multirow[b]{2}{*}{ CHEMBL1547823 } & \multicolumn{4}{|c|}{ Supplemental Table S2.txt } \\
\hline & 688620 & 5.1 & 5.9671 & TRN \\
\hline CHEMBL1567111 & 688620 & 5.55 & 4.976 & TRN \\
\hline CHEMBL1479350 & 688620 & 4.55 & 5.8458 & TRN \\
\hline CHEMBL1990599 & 688620 & 6.5501 & 4.8559 & TRN \\
\hline CHEMBL1340329 & 688620 & 5.2 & 4.9158 & TRN \\
\hline CHEMBL3192786 & 688620 & 4.95 & 4.8476 & TRN \\
\hline CHEMBL1519630 & 688620 & 4.95 & 4.8779 & TRN \\
\hline CHEMBL1312225 & 688620 & 4.45 & 5.0904 & TRN \\
\hline CHEMBL1547652 & 688620 & 5.65 & 5.2432 & TRN \\
\hline CHEMBL1300078 & 688620 & 5.05 & 5.0411 & TRN \\
\hline CHEMBL1520061 & 688620 & 4.85 & 5.0296 & TRN \\
\hline CHEMBL 2001476 & 688620 & 4.65 & 5.0758 & TRN \\
\hline CHEMBL1312244 & 688620 & 4.8 & 5.0301 & TST \\
\hline CHEMBL1426243 & 688620 & 5.85 & 4.9184 & TRN \\
\hline CHEMBL1500119 & 688620 & 4.95 & 4.667 & TST \\
\hline CHEMBL1549745 & 688620 & 5.85 & 5.4501 & TRN \\
\hline CHEMBL1504247 & 688620 & 4.45 & 5.033 & TRN \\
\hline CHEMBL1336102 & 688620 & 4.75 & 4.8568 & TRN \\
\hline CHEMBL1488305 & 688620 & 4.65 & 4.7302 & TRN \\
\hline CHEMBL1576911 & 688620 & 4.65 & 4.9686 & TST \\
\hline CHEMBL1535093 & 688620 & 4.45 & 4.9898 & TST \\
\hline CHEMBL1541883 & 688620 & 5.8 & 5.9232 & TRN \\
\hline CHEMBL1606077 & 688620 & 4.65 & 4.9428 & TRN \\
\hline CHEMBL1390951 & 688620 & 4.85 & 5.0114 & TRN \\
\hline CHEMBL1309341 & 688620 & 4.45 & 4.8449 & TRN \\
\hline CHEMBL1468580 & 688620 & 4.65 & 4.9728 & TRN \\
\hline CHEMBL1372159 & 688620 & 4.85 & 5.15 & TRN \\
\hline CHEMBL1601289 & 688620 & 4.45 & 4.7954 & TRN \\
\hline CHEMBL1384990 & 688620 & 5.15 & 4.8776 & TRN \\
\hline CHEMBL1362147 & 688620 & 4.45 & 5.0732 & TRN \\
\hline CHEMBL1431827 & 688620 & 4.95 & 4.7513 & TRN \\
\hline CHEMBL1435809 & 688620 & 4.95 & 5.0286 & TRN \\
\hline CHEMBL1428415 & 688620 & 5.2 & 5.4022 & TRN \\
\hline CHEMBL1574955 & 688620 & 5.1 & 5.2462 & TRN \\
\hline CHEMBL1369413 & 688620 & 6.1 & 4.8679 & TRN \\
\hline CHEMBL1304402 & 688620 & 5.85 & 5.5333 & TRN \\
\hline CHEMBL1612337 & 688620 & 5.55 & 5.5032 & TRN \\
\hline CHEMBL3195406 & 688620 & 5.0 & 4.7196 & TRN \\
\hline CHEMBL1367356 & 688620 & 5.5 & 4.7446 & TST \\
\hline CHEMBL3190711 & 688620 & 5.7 & 5.0472 & TST \\
\hline CHEMBL1404040 & 688620 & 4.75 & 4.8396 & TRN \\
\hline CHEMBL1442499 & 688620 & 5.35 & 5.0014 & TST \\
\hline CHEMBL1313140 & 688620 & 4.8 & 4.8065 & TRN \\
\hline CHEMBL1372467 & 688620 & 4.9 & 5.1145 & TRN \\
\hline CHEMBL1363567 & 688620 & 5.3 & 5.0696 & TST \\
\hline CHEMBL1381043 & 688620 & 4.6 & 4.7918 & TRN \\
\hline CHEMBL1557491 & 688620 & 5.65 & 5.1062 & TST \\
\hline CHEMBL1322276 & 688620 & 4.95 & 4.8165 & TRN \\
\hline
\end{tabular}




\begin{tabular}{|c|c|c|c|c|c|}
\hline \multicolumn{6}{|c|}{ Supplemental Table s2.txt } \\
\hline CHEMBL1509347 & 688620 & 4.45 & 5.0332 & TST & \\
\hline CHEMBL1424867 & 688620 & 5.15 & 5.3884 & TRN & \\
\hline CHEMBL1440258 & 688620 & 5.5 & 5.1635 & TRN & \\
\hline CHEMBL1505491 & 688620 & 5.2 & 4.8196 & TST & \\
\hline CHEMBL1517348 & 688620 & 5.35 & 5.0664 & TRN & \\
\hline CHEMBL1464832 & 688620 & 5.0 & 4.6682 & TRN & \\
\hline CHEMBL3190422 & 688620 & 7.0 & 4.9929 & TRN & \\
\hline CHEMBL1503023 & 688620 & 4.65 & 4.9604 & TST & \\
\hline CHEMBL1468363 & 688620 & 4.6 & 5.1258 & TRN & \\
\hline CHEMBL1427730 & 688620 & 4.45 & 5.3345 & TRN & \\
\hline CHEMBL1351266 & 688620 & 5.65 & 4.9158 & TRN & \\
\hline CHEMBL1303767 & 688620 & 4.75 & 4.894 & TST & \\
\hline CHEMBL1460873 & 688620 & 4.95 & 4.9548 & TRN & \\
\hline CHEMBL1463044 & 688620 & 4.45 & 4.9574 & TRN & \\
\hline CHEMBL1569705 & 688620 & 4.9 & 5.0875 & TRN & \\
\hline CHEMBL3198570 & 688620 & 5.5 & 5.1923 & TRN & \\
\hline CHEMBL1427462 & 688620 & 4.5 & 4.6336 & TRN & \\
\hline CHEMBL1419905 & 688620 & 4.45 & 5.0645 & TRN & \\
\hline CHEMBL1405511 & 688620 & 6.45 & 5.1873 & TRN & \\
\hline CHEMBL1491884 & 688620 & 4.6 & 4.8518 & TRN & \\
\hline CHEMBL87791 & 688620 & 6.45 & 6.2866 & TRN & \\
\hline CHEMBL3197722 & 688620 & 5.75 & 5.0673 & TRN & \\
\hline CHEMBL1467299 & 688620 & 5.9 & 4.8819 & TST & \\
\hline CHEMBL1450091 & 688620 & 5.4 & 5.0829 & TRN & \\
\hline CHEMBL1372514 & 688620 & 4.85 & 5.1184 & TRN & \\
\hline CHEMBL1407510 & 688620 & 4.45 & 4.8127 & TRN & \\
\hline CHEMBL1341553 & 688620 & 6.25 & 5.1974 & TRN & \\
\hline CHEMBL3189797 & 688620 & 4.75 & 5.4518 & TST & \\
\hline CHEMBL1393347 & 688620 & 4.8 & 5.0818 & TRN & \\
\hline CHEMBL1364723 & 688620 & 4.6 & 5.20799 & 9999999999 & TST \\
\hline CHEMBL1336535 & 688620 & 6.95 & 7.8416 & TRN & \\
\hline CHEMBL1400348 & 688620 & 4.75 & 4.8888 & TRN & \\
\hline CHEMBL1329442 & 688620 & 4.65 & 4.9105 & TRN & \\
\hline CHEMBL1582063 & 688620 & 5.25 & 5.0996 & TRN & \\
\hline CHEMBL1343775 & 688620 & 4.95 & 5.0299 & TST & \\
\hline CHEMBL1367871 & 688620 & 5.0 & 5.1655 & TRN & \\
\hline CHEMBL1583756 & 688620 & 4.65 & 4.9038 & TRN & \\
\hline CHEMBL1460045 & 688620 & 5.35 & 5.1843 & TRN & \\
\hline CHEMBL1457442 & 688620 & 4.95 & 4.9144 & TST & \\
\hline CHEMBL1365563 & 688620 & 4.65 & 4.7374 & TST & \\
\hline CHEMBL1387081 & 688620 & 6.8499 & 5.0835 & TRN & \\
\hline CHEMBL3192248 & 688620 & 5.45 & 5.3752 & TRN & \\
\hline CHEMBL1421407 & 688620 & 5.0 & 4.8536 & TRN & \\
\hline CHEMBL1491138 & 688620 & 4.7 & 4.9714 & TRN & \\
\hline CHEMBL1407643 & 688620 & 4.95 & 5.1511 & TRN & \\
\hline CHEMBL1589879 & 688620 & 4.65 & 4.8325 & TRN & \\
\hline CHEMBL1341870 & 688620 & 4.65 & 4.9466 & TRN & \\
\hline CHEMBL1530464 & 688620 & 6.05 & 4.8936 & TRN & \\
\hline
\end{tabular}




\begin{tabular}{|c|c|c|c|c|c|}
\hline \multicolumn{6}{|c|}{ Supplemental Table S2.txt } \\
\hline CHEMBL1508604 & 688620 & 4.95 & 5.1883 & TRN & \\
\hline CHEMBL1572778 & 688620 & 4.95 & 5.2707 & TST & \\
\hline CHEMBL1555482 & 688620 & 4.6 & 4.8408 & TRN & \\
\hline CHEMBL1594349 & 688620 & 7.2503 & 5.1673 & TRN & \\
\hline CHEMBL1371124 & 688620 & 4.9 & 4.9147 & TRN & \\
\hline CHEMBL1353541 & 688620 & 5.7 & 5.32100 & 0000000001 & TRN \\
\hline CHEMBL210658 & 688620 & 6.05 & 5.8478 & TRN & \\
\hline CHEMBL1496800 & 688620 & 4.7 & 4.9955 & TRN & \\
\hline CHEMBL1334139 & 688620 & 5.2 & 5.1887 & TRN & \\
\hline CHEMBL1409400 & 688620 & 5.45 & 5.5105 & TRN & \\
\hline CHEMBL1519694 & 688620 & 6.1 & 4.9088 & TRN & \\
\hline CHEMBL1465935 & 688620 & 6.45 & 5.0418 & TRN & \\
\hline CHEMBL1343808 & 688620 & 5.2 & 4.7341 & TRN & \\
\hline CHEMBL1609674 & 688620 & 5.55 & 5.1028 & TRN & \\
\hline CHEMBL1478722 & 688620 & 5.4 & 5.1246 & TRN & \\
\hline CHEMBL179583 & 688620 & 5.2 & 4.8102 & TST & \\
\hline CHEMBL1334544 & 688620 & 5.2 & 5.2939 & TRN & \\
\hline CHEMBL1986805 & 688620 & 4.95 & 5.1323 & TRN & \\
\hline CHEMBL1369772 & 688620 & 4.45 & 4.9543 & TRN & \\
\hline CHEMBL1555652 & 688620 & 4.45 & 4.8678 & TRN & \\
\hline CHEMBL1352742 & 688620 & 5.0 & 5.1545 & TRN & \\
\hline CHEMBL1518073 & 688620 & 5.2 & 4.6665 & TST & \\
\hline CHEMBL1468254 & 688620 & 4.45 & 5.1574 & TRN & \\
\hline CHEMBL1313093 & 688620 & 4.95 & 6.1098 & TRN & \\
\hline CHEMBL1602802 & 688620 & 4.45 & 4.6691 & TRN & \\
\hline CHEMBL1430944 & 688620 & 4.95 & 5.0943 & TRN & \\
\hline CHEMBL1598251 & 688620 & 4.5 & 4.8786 & TST & \\
\hline CHEMBL1466515 & 688620 & 4.8 & 5.0203 & TRN & \\
\hline CHEMBL1331925 & 688620 & 5.1 & 5.0398 & TST & \\
\hline CHEMBL1582587 & 688620 & 4.95 & 5.0993 & TRN & \\
\hline CHEMBL1326175 & 688620 & 4.75 & 5.0731 & TRN & \\
\hline CHEMBL1365258 & 688620 & 5.65 & 5.0916 & TRN & \\
\hline CHEMBL1503584 & 688620 & 5.4 & 5.9454 & TRN & \\
\hline CHEMBL1501452 & 688620 & 4.95 & 4.8758 & TST & \\
\hline CHEMBL1321702 & 688620 & 5.15 & 5.296 & TRN & \\
\hline CHEMBL1373015 & 688620 & 4.8 & 5.0024 & TRN & \\
\hline CHEMBL1460824 & 688620 & 4.7 & 5.2289 & TRN & \\
\hline CHEMBL1604890 & 688620 & 5.1 & 4.8742 & TRN & \\
\hline CHEMBL1487048 & 688620 & 4.8 & 5.1332 & TRN & \\
\hline CHEMBL1339107 & 688620 & 5.55 & 5.1224 & TRN & \\
\hline CHEMBL1448696 & 688620 & 4.95 & 5.0786 & TRN & \\
\hline CHEMBL1334120 & 688620 & 4.45 & 5.1855 & TST & \\
\hline CHEMBL1459195 & 688620 & 6.5501 & 4.9559 & TRN & \\
\hline CHEMBL1427021 & 688620 & 4.85 & 5.0646 & TRN & \\
\hline CHEMBL1411298 & 688620 & 5.65 & 4.8791 & TRN & \\
\hline CHEMBL1544839 & 688620 & 4.95 & 4.9642 & TRN & \\
\hline CHEMBL1537939 & 688620 & 4.95 & 5.0902 & TST & \\
\hline CHEMBL1342746 & 688620 & 4.45 & 5.1632 & TRN & \\
\hline
\end{tabular}




\begin{tabular}{|c|c|c|c|c|c|}
\hline \multicolumn{6}{|c|}{ Supplemental Table S2.txt } \\
\hline CHEMBL1336019 & 688620 & 6.15 & 5.7601 & TRN & \\
\hline CHEMBL1578579 & 688620 & 4.85 & 5.1475 & TST & \\
\hline CHEMBL1490154 & 688620 & 5.1 & 5.1571 & TRN & \\
\hline CHEMBL1532544 & 688620 & 5.15 & 4.9351 & TRN & \\
\hline CHEMBL1410441 & 688620 & 4.7 & 4.9034 & TRN & \\
\hline CHEMBL1347346 & 688620 & 4.9 & 5.1276 & TST & \\
\hline CHEMBL1352697 & 688620 & 5.2 & 4.9853 & TST & \\
\hline CHEMBL1388543 & 688620 & 4.45 & 4.9662 & TRN & \\
\hline CHEMBL1381302 & 688620 & 4.45 & 5.0222 & TST & \\
\hline CHEMBL1547018 & 688620 & 5.55 & 5.2635 & TRN & \\
\hline CHEMBL1552663 & 688620 & 4.5 & 4.9513 & TST & \\
\hline CHEMBL1378790 & 688620 & 4.9 & 5.29899 & 99999999995 & TRN \\
\hline CHEMBL600734 & 688620 & 4.9 & 4.9616 & TST & \\
\hline CHEMBL1432937 & 688620 & 4.45 & 5.0118 & TRN & \\
\hline CHEMBL1375533 & 688620 & 4.95 & 5.0204 & TST & \\
\hline CHEMBL3195225 & 688620 & 6.25 & 5.8519 & TRN & \\
\hline CHEMBL1454734 & 688620 & 6.5501 & 5.8661 & TRN & \\
\hline CHEMBL1421154 & 688620 & 4.8 & 4.8769 & TRN & \\
\hline CHEMBL1440079 & 688620 & 4.85 & 5.0262 & TRN & \\
\hline CHEMBL1392611 & 688620 & 6.25 & 5.7004 & TRN & \\
\hline CHEMBL1572551 & 688620 & 4.8 & 5.1108 & TRN & \\
\hline CHEMBL1417438 & 688620 & 4.75 & 4.9455 & TRN & \\
\hline CHEMBL1533465 & 688620 & 4.8 & 4.9972 & TRN & \\
\hline CHEMBL3199337 & 688620 & 6.2 & 5.0704 & TRN & \\
\hline CHEMBL1569498 & 688620 & 5.4 & 5.113 & TST & \\
\hline CHEMBL1464025 & 688620 & 4.9 & 5.0921 & TST & \\
\hline CHEMBL1423551 & 688620 & 5.3 & 5.3364 & TRN & \\
\hline CHEMBL1496891 & 688620 & 6.5 & 5.5383 & TRN & \\
\hline CHEMBL1387309 & 688620 & 5.4 & 5.0688 & TRN & \\
\hline CHEMBL1310022 & 688620 & 4.45 & 4.6044 & TRN & \\
\hline CHEMBL1422836 & 688620 & 4.95 & 5.1081 & TRN & \\
\hline CHEMBL1979316 & 688620 & 6.9 & 5.6392 & TRN & \\
\hline CHEMBL1423609 & 688620 & 4.9 & 5.1059 & TST & \\
\hline CHEMBL1497588 & 688620 & 6.2 & 5.2855 & TRN & \\
\hline CHEMBL1420582 & 688620 & 4.45 & 4.6961 & TRN & \\
\hline CHEMBL1375589 & 688620 & 4.7 & 4.9261 & TST & \\
\hline CHEMBL1523756 & 688620 & 5.4 & 5.0544 & TRN & \\
\hline CHEMBL1311368 & 688620 & 4.45 & 4.855 & TRN & \\
\hline CHEMBL1466979 & 688620 & 4.85 & 5.0629 & TRN & \\
\hline CHEMBL1467273 & 688620 & 4.7 & 5.0031 & TRN & \\
\hline CHEMBL1549459 & 688620 & 5.85 & 5.0645 & TST & \\
\hline CHEMBL1432152 & 688620 & 4.95 & 5.0252 & TRN & \\
\hline CHEMBL1550842 & 688620 & 4.6 & 4.9323 & TST & \\
\hline CHEMBL1549604 & 688620 & 4.9 & 5.2786 & TRN & \\
\hline CHEMBL1334074 & 688620 & 5.75 & 5.3692 & TRN & \\
\hline CHEMBL1452077 & 688620 & 4.65 & 5.0177 & TST & \\
\hline CHEMBL1373745 & 688620 & 4.45 & 4.8291 & TRN & \\
\hline CHEMBL1366175 & 688620 & 5.05 & 4.8131 & TRN & \\
\hline
\end{tabular}




\begin{tabular}{|c|c|c|c|c|c|}
\hline \multicolumn{6}{|c|}{ oplemental la } \\
\hline CHEMBL1456911 & 688620 & 4.95 & 5.0074 & TRN & \\
\hline CHEMBL1548062 & 688620 & 4.95 & 4.7262 & TRN & \\
\hline CHEMBL1530087 & 688620 & 5.65 & 5.345 & TRN & \\
\hline CHEMBL1571145 & 688620 & 5.15 & 4.7834 & TRN & \\
\hline CHEMBL1524393 & 688620 & 5.0 & 5.0065 & TRN & \\
\hline CHEMBL1357910 & 688620 & 5.2 & 5.0168 & TRN & \\
\hline CHEMBL1560906 & 688620 & 4.95 & 4.9716 & TRN & \\
\hline CHEMBL1449887 & 688620 & 4.85 & 4.8395 & TRN & \\
\hline CHEMBL1379171 & 688620 & 5.6 & 5.6606 & TRN & \\
\hline CHEMBL1347551 & 688620 & 4.9 & 4.9774 & TST & \\
\hline CHEMBL1383859 & 688620 & 5.6 & 5.4949 & TRN & \\
\hline CHEMBL1568463 & 688620 & 4.45 & 4.8774 & TRN & \\
\hline CHEMBL1448341 & 688620 & 5.5 & 5.1829 & TST & \\
\hline CHEMBL1454467 & 688620 & 5.75 & 5.1733 & TRN & \\
\hline CHEMBL1493897 & 688620 & 4.7 & 5.13700 & 20000000005 & TRN \\
\hline CHEMBL1522975 & 688620 & 5.0 & 5.0133 & TRN & \\
\hline CHEMBL1371210 & 688620 & 5.95 & 4.9246 & TRN & \\
\hline CHEMBL1319635 & 688620 & 5.1 & 4.9796 & TST & \\
\hline CHEMBL1578123 & 688620 & 4.6 & 5.3828 & TRN & \\
\hline CHEMBL1379666 & 688620 & 5.0 & 5.7219 & TRN & \\
\hline CHEMBL1464474 & 688620 & 5.75 & 4.915 & TRN & \\
\hline CHEMBL1478282 & 688620 & 6.7501 & 5.7007 & TRN & \\
\hline CHEMBL1462610 & 688620 & 4.8 & 4.6892 & TRN & \\
\hline CHEMBL1526836 & 688620 & 5.0 & 5.0201 & TRN & \\
\hline CHEMBL547656 & 688620 & 7.0 & 5.0282 & TST & \\
\hline CHEMBL3193060 & 688620 & 5.0 & 5.043 & TRN & \\
\hline CHEMBL1407680 & 688620 & 4.95 & 4.9932 & TST & \\
\hline CHEMBL1335919 & 688620 & 4.95 & 4.9989 & TRN & \\
\hline CHEMBL3191151 & 688620 & 5.0 & 5.3825 & TRN & \\
\hline CHEMBL1467159 & 688620 & 5.0 & 4.9305 & TRN & \\
\hline CHEMBL3192779 & 688620 & 5.85 & 5.6399 & TRN & \\
\hline CHEMBL1446077 & 688620 & 5.0 & 4.9304 & TRN & \\
\hline CHEMBL1573176 & 688620 & 5.15 & 4.96899 & 9999999999 & TRN \\
\hline CHEMBL1490616 & 688620 & 4.95 & 5.0906 & TRN & \\
\hline CHEMBL1398613 & 688620 & 5.25 & 5.1418 & TST & \\
\hline CHEMBL1465946 & 688620 & 4.75 & 5.1712 & TRN & \\
\hline CHEMBL3193010 & 688620 & 5.2 & 5.3799 & TRN & \\
\hline CHEMBL1423712 & 688620 & 4.75 & 5.0196 & TRN & \\
\hline CHEMBL1461495 & 688620 & 4.5 & 4.9385 & TRN & \\
\hline CHEMBL1371275 & 688620 & 4.75 & 5.8823 & TRN & \\
\hline CHEMBL1424619 & 688620 & 4.95 & 5.0211 & TRN & \\
\hline CHEMBL1441977 & 688620 & 4.75 & 4.8288 & TRN & \\
\hline CHEMBL1403766 & 688620 & 4.65 & 5.0131 & TST & \\
\hline CHEMBL1350948 & 688620 & 4.95 & 4.9512 & TRN & \\
\hline CHEMBL1425983 & 688620 & 4.85 & 4.8423 & TRN & \\
\hline CHEMBL3198996 & 688620 & 5.65 & 5.3742 & TRN & \\
\hline CHEMBL1605235 & 688620 & 4.95 & 4.9001 & TST & \\
\hline CHEMBL1324909 & 688620 & 5.3 & 5.1555 & TRN & \\
\hline
\end{tabular}




\begin{tabular}{|c|c|c|c|c|c|}
\hline \multicolumn{6}{|c|}{ Supplemental Table S2.txt } \\
\hline CHEMBL1334764 & 688620 & 4.75 & 5.0057 & TRN & \\
\hline CHEMBL1341358 & 688620 & 6.15 & 5.7091 & TST & \\
\hline CHEMBL1445542 & 688620 & 4.65 & 4.90600 & 0000000001 & TRN \\
\hline CHEMBL3213556 & 688620 & 5.2 & 5.1153 & TRN & \\
\hline CHEMBL1457830 & 688620 & 5.75 & 5.9011 & TRN & \\
\hline CHEMBL1343565 & 688620 & 4.6 & 4.9715 & TRN & \\
\hline CHEMBL1505484 & 688620 & 5.45 & 5.0943 & TST & \\
\hline CHEMBL1374583 & 688620 & 4.5 & 4.802 & TRN & \\
\hline CHEMBL1578131 & 688620 & 5.45 & 5.5382 & TRN & \\
\hline CHEMBL1408274 & 688620 & 4.95 & 5.2229 & TRN & \\
\hline CHEMBL1526219 & 688620 & 4.8 & 4.7738 & TRN & \\
\hline CHEMBL1326212 & 688620 & 5.8 & 4.9471 & TRN & \\
\hline CHEMBL1575291 & 688620 & 4.45 & 4.9527 & TRN & \\
\hline CHEMBL1564143 & 688620 & 4.45 & 4.7533 & TRN & \\
\hline CHEMBL1585974 & 688620 & 4.9 & 4.8235 & TRN & \\
\hline CHEMBL490577 & 688620 & 4.8 & 4.9211 & TRN & \\
\hline CHEMBL1367828 & 688620 & 4.8 & 5.1283 & TRN & \\
\hline CHEMBL1584804 & 688620 & 4.9 & 4.9392 & TRN & \\
\hline CHEMBL1341481 & 688620 & 5.4 & 5.1743 & TST & \\
\hline CHEMBL1603852 & 688620 & 4.85 & 5.0521 & TRN & \\
\hline CHEMBL1596750 & 688620 & 5.15 & 5.1711 & TRN & \\
\hline CHEMBL1458837 & 688620 & 4.45 & 4.6238 & TRN & \\
\hline CHEMBL1474151 & 688620 & 4.45 & 4.9338 & TRN & \\
\hline CHEMBL1342321 & 688620 & 4.65 & 4.881 & TRN & \\
\hline CHEMBL1470614 & 688620 & 4.8 & 4.9111 & TRN & \\
\hline CHEMBL1530443 & 688620 & 4.9 & 4.9602 & TRN & \\
\hline CHEMBL1523368 & 688620 & 4.45 & 4.8179 & TRN & \\
\hline CHEMBL1530357 & 688620 & 5.1 & 5.2314 & TST & \\
\hline CHEMBL1495922 & 688620 & 4.45 & 5.2154 & TRN & \\
\hline CHEMBL1414628 & 688620 & 4.75 & 4.8918 & TRN & \\
\hline CHEMBL1373851 & 688620 & 5.0 & 5.1855 & TST & \\
\hline CHEMBL1545716 & 688620 & 4.65 & 4.9876 & TRN & \\
\hline CHEMBL1566613 & 688620 & 4.45 & 5.1538 & TRN & \\
\hline CHEMBL1345095 & 688620 & 4.9 & 5.4962 & TRN & \\
\hline CHEMBL1524990 & 688620 & 5.15 & 5.2002 & TST & \\
\hline CHEMBL1322160 & 688620 & 4.7 & 4.9446 & TST & \\
\hline CHEMBL1404283 & 688620 & 4.75 & 5.1212 & TRN & \\
\hline CHEMBL1999311 & 688620 & 4.8 & 5.1281 & TRN & \\
\hline CHEMBL1370486 & 688620 & 4.9 & 4.9639 & TST & \\
\hline CHEMBL1542364 & 688620 & 5.0 & 4.88 & TRN & \\
\hline CHEMBL1391709 & 688620 & 5.2 & 5.3501 & TRN & \\
\hline CHEMBL1568791 & 688620 & 4.45 & 4.9545 & TRN & \\
\hline CHEMBL1551022 & 688620 & 5.15 & 5.1851 & TRN & \\
\hline CHEMBL1329638 & 688620 & 4.85 & 5.0933 & TST & \\
\hline CHEMBL1304164 & 688620 & 5.15 & 5.1494 & TRN & \\
\hline CHEMBL1526367 & 688620 & 4.95 & 5.2054 & TRN & \\
\hline CHEMBL1883149 & 688620 & 4.95 & 5.165 & TRN & \\
\hline CHEMBL1429353 & 688620 & 5.2 & 5.2175 & TRN & \\
\hline
\end{tabular}




\begin{tabular}{|c|c|c|c|c|}
\hline \multicolumn{5}{|c|}{ Supplemental Table S2.txt } \\
\hline CHEMBL1373336 & 688620 & 5.8 & 5.1615 & TRN \\
\hline CHEMBL1364441 & 688620 & 5.8 & 5.5009 & TRN \\
\hline CHEMBL1612555 & 688620 & 4.75 & 5.2367 & TST \\
\hline CHEMBL1413758 & 688620 & 4.5 & 5.0919 & TST \\
\hline CHEMBL1371507 & 688620 & 5.6 & 5.1511 & TRN \\
\hline CHEMBL1369022 & 688620 & 4.7 & 4.9219 & TRN \\
\hline CHEMBL1454638 & 688620 & 4.7 & 5.0149 & TST \\
\hline CHEMBL1305291 & 688620 & 5.5 & 4.9743 & TRN \\
\hline CHEMBL1471278 & 688620 & 4.85 & 5.0155 & TRN \\
\hline CHEMBL1588833 & 688620 & 4.45 & 5.3281 & TRN \\
\hline CHEMBL1385798 & 688620 & 5.5 & 5.2365 & TRN \\
\hline CHEMBL1306900 & 688620 & 4.95 & 4.6651 & TRN \\
\hline CHEMBL1405577 & 688620 & 5.4 & 5.0066 & TST \\
\hline CHEMBL1596876 & 688620 & 4.45 & 4.8269 & TRN \\
\hline CHEMBL1309142 & 688620 & 5.25 & 5.0018 & TRN \\
\hline CHEMBL1337773 & 688620 & 6.4 & 4.9334 & TRN \\
\hline CHEMBL1387413 & 688620 & 4.65 & 5.3718 & TRN \\
\hline CHEMBL1568298 & 688620 & 4.8 & 4.9267 & TRN \\
\hline CHEMBL1449504 & 688620 & 5.5 & 4.9856 & TRN \\
\hline CHEMBL1399338 & 688620 & 4.95 & 4.8733 & TRN \\
\hline CHEMBL1520000 & 688620 & 4.7 & 4.9018 & TRN \\
\hline CHEMBL1306628 & 688620 & 4.7 & 5.0462 & TRN \\
\hline CHEMBL3191135 & 688620 & 4.9 & 5.1699 & TST \\
\hline CHEMBL1543104 & 688620 & 5.0 & 4.7081 & TRN \\
\hline CHEMBL1363055 & 688620 & 4.8 & 4.9939 & TRN \\
\hline CHEMBL3194821 & 688620 & 4.45 & 5.0489 & TRN \\
\hline CHEMBL1348465 & 688620 & 4.65 & 4.8455 & TRN \\
\hline CHEMBL1301725 & 688620 & 4.65 & 4.9399 & TRN \\
\hline CHEMBL1500423 & 688620 & 4.8 & 5.0199 & TST \\
\hline CHEMBL1347144 & 688620 & 4.95 & 5.113 & TRN \\
\hline CHEMBL3194227 & 688620 & 4.45 & 4.6983 & TRN \\
\hline CHEMBL 3198134 & 688620 & 5.9 & 5.4674 & TRN \\
\hline CHEMBL1307950 & 688620 & 5.25 & 5.3467 & TRN \\
\hline CHEMBL1358722 & 688620 & 6.0 & 5.8266 & TST \\
\hline CHEMBL1391542 & 688620 & 5.0 & 4.9842 & TRN \\
\hline CHEMBL3189908 & 688620 & 4.8 & 4.8062 & TRN \\
\hline CHEMBL1495682 & 688620 & 5.1 & 5.0281 & TRN \\
\hline CHEMBL3196809 & 688620 & 5.0 & 5.3099 & TST \\
\hline CHEMBL1372008 & 688620 & 5.3 & 4.9197 & TRN \\
\hline CHEMBL1375415 & 688620 & 5.15 & 4.8061 & TRN \\
\hline CHEMBL1363211 & 688620 & 4.85 & 4.9874 & TRN \\
\hline CHEMBL1588771 & 688620 & 4.8 & 5.1038 & TRN \\
\hline CHEMBL1347068 & 688620 & 5.0 & 4.8566 & TRN \\
\hline CHEMBL1547916 & 688620 & 5.65 & 5.2432 & TRN \\
\hline CHEMBL1597260 & 688620 & 4.8 & 4.9664 & TRN \\
\hline CHEMBL1410666 & 688620 & 4.7 & 4.828 & TRN \\
\hline CHEMBL1391099 & 688620 & 4.45 & 4.9731 & TRN \\
\hline CHEMBL1483596 & 688620 & 4.6 & 4.7799 & TST \\
\hline
\end{tabular}




\begin{tabular}{|c|c|c|c|c|c|}
\hline \multicolumn{6}{|c|}{ Supplemental Table S2.txt } \\
\hline CHEMBL1300171 & 688620 & 4.45 & 5.0145 & TST & \\
\hline CHEMBL1607969 & 688620 & 4.65 & 4.8594 & TRN & \\
\hline CHEMBL1414879 & 688620 & 4.55 & 6.0505 & TRN & \\
\hline CHEMBL1439373 & 688620 & 4.9 & 4.9655 & TRN & \\
\hline CHEMBL1556907 & 688620 & 4.95 & 5.1742 & TRN & \\
\hline CHEMBL3199109 & 688620 & 6.9 & 5.0254 & TRN & \\
\hline CHEMBL1367951 & 688620 & 6.35 & 5.3938 & TRN & \\
\hline CHEMBL1428443 & 688620 & 5.85 & 5.522 & TRN & \\
\hline CHEMBL1443820 & 688620 & 4.8 & 4.8578 & TRN & \\
\hline CHEMBL1584123 & 688620 & 4.45 & 5.4451 & TST & \\
\hline CHEMBL1368985 & 688620 & 4.45 & 4.5302 & TRN & \\
\hline CHEMBL1577888 & 688620 & 5.25 & 5.0019 & TRN & \\
\hline CHEMBL1312597 & 688620 & 5.0 & 4.8129 & TST & \\
\hline CHEMBL1471574 & 688620 & 4.8 & 5.0995 & TRN & \\
\hline CHEMBL1543787 & 688620 & 4.45 & 5.1203 & TST & \\
\hline CHEMBL1551065 & 688620 & 4.95 & 5.2129 & TST & \\
\hline CHEMBL1384594 & 688620 & 4.45 & 5.1843 & TRN & \\
\hline CHEMBL1519094 & 688620 & 4.45 & 5.2908 & TRN & \\
\hline CHEMBL1312328 & 688620 & 4.7 & 4.91100 & 00000000005 & TRN \\
\hline CHEMBL1463539 & 688620 & 6.6 & 5.8307 & TRN & \\
\hline CHEMBL1550182 & 688620 & 4.45 & 5.0184 & TRN & \\
\hline CHEMBL1506705 & 688620 & 4.7 & 4.9216 & TST & \\
\hline CHEMBL1395566 & 688620 & 4.95 & 5.1442 & TST & \\
\hline CHEMBL1324281 & 688620 & 4.5 & 4.8929 & TRN & \\
\hline CHEMBL1406551 & 688620 & 4.9 & 4.9719 & TST & \\
\hline CHEMBL1549208 & 688620 & 5.05 & 6.2137 & TRN & \\
\hline CHEMBL1599850 & 688620 & 5.3 & 5.0858 & TRN & \\
\hline CHEMBL1391818 & 688620 & 4.65 & 4.7899 & TRN & \\
\hline CHEMBL3190092 & 688620 & 5.45 & 5.1859 & TST & \\
\hline CHEMBL1471924 & 688620 & 4.95 & 5.0859 & TRN & \\
\hline CHEMBL1467513 & 688620 & 4.5 & 5.2328 & TRN & \\
\hline CHEMBL1444031 & 688620 & 6.5501 & 7.3863 & TRN & \\
\hline CHEMBL1547940 & 688620 & 4.5 & 4.9643 & TRN & \\
\hline CHEMBL1301393 & 688620 & 4.6 & 4.8405 & TRN & \\
\hline CHEMBL1417699 & 688620 & 5.25 & 4.9074 & TRN & \\
\hline CHEMBL1539684 & 688620 & 4.45 & 4.9533 & TST & \\
\hline CHEMBL1495859 & 688620 & 4.9 & 4.7165 & TRN & \\
\hline CHEMBL1965804 & 688620 & 4.95 & 4.8404 & TRN & \\
\hline CHEMBL1442420 & 688620 & 5.15 & 5.1415 & TRN & \\
\hline CHEMBL1313471 & 688620 & 4.9 & 4.9184 & TST & \\
\hline CHEMBL1305868 & 688620 & 5.6 & 5.0134 & TRN & \\
\hline CHEMBL1543293 & 688620 & 5.35 & 5.5657 & TRN & \\
\hline CHEMBL1322065 & 688620 & 4.45 & 4.9603 & TST & \\
\hline CHEMBL1475036 & 688620 & 4.85 & 5.0024 & TRN & \\
\hline CHEMBL3194397 & 688620 & 4.75 & 5.0812 & TST & \\
\hline CHEMBL1426520 & 688620 & 4.6 & 4.9792 & TRN & \\
\hline CHEMBL1389555 & 688620 & 5.3 & 5.3511 & TST & \\
\hline CHEMBL1348686 & 688620 & 4.7 & 4.8544 & TRN & \\
\hline
\end{tabular}




\begin{tabular}{|c|c|c|c|c|c|}
\hline \\
\hline CHEMBL1508679 & 688620 & 4.85 & 5.62700 & 0000000001 & TRN \\
\hline CHEMBL1483000 & 688620 & 5.0 & 5.0092 & TRN & \\
\hline CHEMBL1542566 & 688620 & 5.5 & 4.6464 & TRN & \\
\hline CHEMBL1511010 & 688620 & 4.75 & 4.9108 & TRN & \\
\hline CHEMBL1605239 & 688620 & 5.2 & 4.7875 & TST & \\
\hline CHEMBL1491466 & 688620 & 5.5 & 4.9691 & TRN & \\
\hline CHEMBL3210469 & 688620 & 5.2 & 5.2928 & TRN & \\
\hline CHEMBL1309378 & 688620 & 5.4 & 5.07 & TRN & \\
\hline CHEMBL1318943 & 688620 & 5.0 & 4.9165 & TST & \\
\hline CHEMBL1428037 & 688620 & 5.25 & 5.0138 & TRN & \\
\hline CHEMBL1379902 & 688620 & 5.1 & 4.9441 & TRN & \\
\hline CHEMBL1465386 & 688620 & 7.4001 & 5.2922 & TRN & \\
\hline CHEMBL1996150 & 688620 & 4.45 & 4.8857 & TRN & \\
\hline CHEMBL1369412 & 688620 & 7.0 & 5.1959 & TRN & \\
\hline CHEMBL1387948 & 688620 & 4.95 & 4.7637 & TRN & \\
\hline CHEMBL1468275 & 688620 & 5.15 & 4.8857 & TRN & \\
\hline CHEMBL1490762 & 688620 & 5.6 & 4.9455 & TRN & \\
\hline CHEMBL1353957 & 688620 & 5.0 & 4.9375 & TRN & \\
\hline CHEMBL1322764 & 688620 & 4.75 & 5.0448 & TST & \\
\hline CHEMBL1380597 & 688620 & 6.6 & 5.1609 & TST & \\
\hline CHEMBL1426794 & 688620 & 7.15 & 5.2535 & TST & \\
\hline CHEMBL1364641 & 688620 & 4.45 & 5.0404 & TST & \\
\hline CHEMBL1448295 & 688620 & 5.05 & 5.0594 & TST & \\
\hline CHEMBL1504426 & 688620 & 5.65 & 5.5145 & TRN & \\
\hline CHEMBL29898 & 688620 & 6.8 & 5.0185 & TST & \\
\hline CHEMBL1566611 & 688620 & 5.15 & 5.3485 & TRN & \\
\hline CHEMBL3199651 & 688620 & 5.8 & 5.6683 & TRN & \\
\hline CHEMBL1490213 & 688620 & 6.15 & 5.1199 & TRN & \\
\hline CHEMBL1480511 & 688620 & 5.7 & 5.0258 & TRN & \\
\hline CHEMBL1488680 & 688620 & 5.7 & 4.84 & TRN & \\
\hline CHEMBL3195876 & 688620 & 5.05 & 4.9391 & TRN & \\
\hline CHEMBL1378581 & 688620 & 4.85 & 4.8249 & TRN & \\
\hline CHEMBL1455463 & 688620 & 4.95 & 5.3509 & TRN & \\
\hline CHEMBL1505674 & 688620 & 5.55 & 5.2487 & TRN & \\
\hline CHEMBL1588896 & 688620 & 4.45 & 5.1361 & TRN & \\
\hline CHEMBL1372113 & 688620 & 5.15 & 5.2216 & TST & \\
\hline CHEMBL1444746 & 688620 & 5.2 & 4.9381 & TST & \\
\hline CHEMBL1523851 & 688620 & 5.2 & 5.1148 & TRN & \\
\hline CHEMBL1511962 & 688620 & 5.4 & 5.5204 & TRN & \\
\hline CHEMBL1379386 & 688620 & 5.25 & 5.0479 & TST & \\
\hline CHEMBL1510086 & 688620 & 5.05 & 4.9452 & TRN & \\
\hline CHEMBL1544786 & 688620 & 4.65 & 5.0591 & TRN & \\
\hline CHEMBL1422238 & 688620 & 4.7 & 4.9544 & TRN & \\
\hline CHEMBL1469653 & 688620 & 5.5 & 5.1969 & TRN & \\
\hline CHEMBL3194844 & 688620 & 6.15 & 5.1731 & TRN & \\
\hline CHEMBL1581721 & 688620 & 4.75 & 5.3937 & TRN & \\
\hline CHEMBL3194092 & 688620 & 5.0 & 5.6019 & TST & \\
\hline CHEMBL3211215 & 688620 & 4.95 & 5.1086 & TRN & \\
\hline
\end{tabular}




\begin{tabular}{|c|c|c|c|c|c|}
\hline \\
\hline CHEMBL1494784 & 688620 & 4.6 & 4.8013 & TST & \\
\hline CHEMBL1547866 & 688620 & 4.45 & 5.2855 & TST & \\
\hline CHEMBL1444266 & 688620 & 4.95 & 4.8661 & TRN & \\
\hline CHEMBL1324093 & 688620 & 4.6 & 4.8175 & TRN & \\
\hline CHEMBL1350470 & 688620 & 4.6 & 4.8806 & TRN & \\
\hline CHEMBL 2369241 & 688620 & 6.2 & 5.9597 & TRN & \\
\hline CHEMBL1557807 & 688620 & 4.9 & 5.1368 & TST & \\
\hline CHEMBL1541707 & 688620 & 4.75 & 4.7972 & TRN & \\
\hline CHEMBL1310691 & 688620 & 4.45 & 4.8986 & TRN & \\
\hline CHEMBL1576055 & 688620 & 4.9 & 4.8248 & TRN & \\
\hline CHEMBL1508684 & 688620 & 4.75 & 4.9558 & TRN & \\
\hline CHEMBL1442252 & 688620 & 5.05 & 4.8278 & TRN & \\
\hline CHEMBL1598438 & 688620 & 4.45 & 4.7038 & TRN & \\
\hline CHEMBL3190703 & 688620 & 5.15 & 4.9797 & TRN & \\
\hline CHEMBL1338713 & 688620 & 4.7 & 5.2996 & TRN & \\
\hline CHEMBL1372539 & 688620 & 4.95 & 4.7933 & TRN & \\
\hline CHEMBL1416847 & 688620 & 5.0 & 5.2468 & TRN & \\
\hline CHEMBL1389177 & 688620 & 5.8 & 5.0129 & TRN & \\
\hline CHEMBL1506505 & 688620 & 5.0 & $4.6930 €$ & 00000000005 & TST \\
\hline CHEMBL1468883 & 688620 & 4.85 & 5.121 & TRN & \\
\hline CHEMBL1991516 & 688620 & 5.75 & 5.5919 & TRN & \\
\hline CHEMBL1320289 & 688620 & 4.75 & 4.9983 & TRN & \\
\hline CHEMBL1548066 & 688620 & 6.2 & 5.1373 & TST & \\
\hline CHEMBL 2000815 & 688620 & 4.85 & 4.9492 & TRN & \\
\hline CHEMBL1579673 & 688620 & 6.1 & 5.7231 & TRN & \\
\hline CHEMBL3190357 & 688620 & 5.25 & 4.8499 & TST & \\
\hline CHEMBL1376551 & 688620 & 5.0 & 5.0175 & TST & \\
\hline CHEMBL1307326 & 688620 & 5.65 & 5.3902 & TRN & \\
\hline CHEMBL1339326 & 688620 & 4.8 & 5.1572 & TRN & \\
\hline CHEMBL3207969 & 688620 & 4.9 & 4.9505 & TST & \\
\hline CHEMBL1508000 & 688620 & 4.45 & 5.1937 & TRN & \\
\hline CHEMBL3192806 & 688620 & 4.85 & 5.2282 & TRN & \\
\hline CHEMBL1605477 & 688620 & 6.35 & 5.1065 & TST & \\
\hline CHEMBL1381092 & 688620 & 6.2 & 5.0152 & TRN & \\
\hline CHEMBL1608860 & 688620 & 5.7 & 4.9975 & TST & \\
\hline CHEMBL1306870 & 688620 & 5.2 & 5.1458 & TRN & \\
\hline CHEMBL1411867 & 688620 & 4.45 & 5.0923 & TRN & \\
\hline CHEMBL1569760 & 688620 & 6.05 & 5.1372 & TST & \\
\hline CHEMBL1424816 & 688620 & 4.7 & 4.7695 & TRN & \\
\hline CHEMBL1594515 & 688620 & 5.2 & 5.2594 & TRN & \\
\hline CHEMBL1423290 & 688620 & 5.2 & 5.0554 & TRN & \\
\hline CHEMBL1313607 & 688620 & 5.25 & 4.9672 & TST & \\
\hline CHEMBL1526724 & 688620 & 5.6 & 5.4664 & TRN & \\
\hline CHEMBL1491717 & 688620 & 4.45 & 4.6867 & TRN & \\
\hline CHEMBL1579859 & 688620 & 4.95 & 4.9633 & TRN & \\
\hline CHEMBL1436999 & 688620 & 4.5 & 5.0513 & TST & \\
\hline CHEMBL1369972 & 688620 & 5.0 & 5.0805 & TRN & \\
\hline CHEMBL1407994 & 688620 & 4.95 & 5.2087 & TRN & \\
\hline & & & & 26833 & \\
\hline
\end{tabular}




\begin{tabular}{|c|c|c|c|c|c|}
\hline \multicolumn{6}{|c|}{ plemental } \\
\hline CHEMBL1588680 & 688620 & 4.7 & 4.7587 & TRN & \\
\hline CHEMBL1458506 & 688620 & 4.85 & 4.9038 & TRN & \\
\hline CHEMBL1508278 & 688620 & 4.9 & 5.0856 & TRN & \\
\hline CHEMBL1437259 & 688620 & 4.45 & 5.1091 & TST & \\
\hline CHEMBL1698283 & 688620 & 4.45 & 5.0431 & TST & \\
\hline CHEMBL1300383 & 688620 & 4.75 & 5.003 & TST & \\
\hline CHEMBL1425267 & 688620 & 4.8 & 5.2039 & TRN & \\
\hline CHEMBL1575176 & 688620 & 4.75 & 4.7184 & TRN & \\
\hline CHEMBL1378967 & 688620 & 5.9 & 5.0088 & TRN & \\
\hline CHEMBL1568465 & 688620 & 5.35 & 5.1782 & TRN & \\
\hline CHEMBL1457336 & 688620 & 8.301 & 5.0107 & TRN & \\
\hline CHEMBL1347644 & 688620 & 4.85 & 4.8362 & TST & \\
\hline CHEMBL1428587 & 688620 & 5.6 & 4.856 & TRN & \\
\hline CHEMBL1496823 & 688620 & 5.1 & 4.9227 & TRN & \\
\hline CHEMBL1305304 & 688620 & 6.7001 & 5.1498 & TRN & \\
\hline CHEMBL1458849 & 688620 & 4.6 & 4.8471 & TRN & \\
\hline CHEMBL1377568 & 688620 & 5.0 & 4.9514 & TRN & \\
\hline CHEMBL1543948 & 688620 & 5.7 & 5.3043 & TST & \\
\hline CHEMBL1474864 & 688620 & 4.9 & 4.923 & TST & \\
\hline CHEMBL1993173 & 688620 & 7.6498 & 4.9829 & TRN & \\
\hline CHEMBL1323553 & 688620 & 5.6 & 5.5974 & TRN & \\
\hline CHEMBL1414817 & 688620 & 4.65 & 5.0154 & TST & \\
\hline CHEMBL1322732 & 688620 & 5.25 & 5.2058 & TST & \\
\hline CHEMBL1491049 & 688620 & 4.9 & 4.7992 & TRN & \\
\hline CHEMBL1501125 & 688620 & 5.1 & 5.2664 & TRN & \\
\hline CHEMBL1389181 & 688620 & 5.3 & 5.0467 & TRN & \\
\hline CHEMBL1402813 & 688620 & 5.3 & 4.9821 & TRN & \\
\hline CHEMBL1254918 & 688620 & 4.85 & 5.0433 & TRN & \\
\hline CHEMBL3209451 & 688620 & 5.95 & 5.9641 & TRN & \\
\hline CHEMBL1510973 & 688620 & 4.45 & 5.0041 & TST & \\
\hline CHEMBL1498695 & 688620 & 6.5 & 5.87799 & 9999999999 & TST \\
\hline CHEMBL1540541 & 688620 & 4.9 & 4.9407 & TRN & \\
\hline CHEMBL1613276 & 688620 & 5.2 & 5.0392 & TRN & \\
\hline CHEMBL1602831 & 688620 & 5.0 & 5.1051 & TRN & \\
\hline CHEMBL1562360 & 688620 & 5.5 & 5.2036 & TRN & \\
\hline CHEMBL1416695 & 688620 & 4.45 & 6.6153 & TRN & \\
\hline CHEMBL1520456 & 688620 & 5.0 & 5.0281 & TRN & \\
\hline CHEMBL3209170 & 688620 & 4.45 & 5.2056 & TST & \\
\hline CHEMBL1555542 & 688620 & 4.85 & 5.0025 & TRN & \\
\hline CHEMBL1367684 & 688620 & 5.0 & 5.0404 & TRN & \\
\hline CHEMBL1586513 & 688620 & 4.9 & 4.8829 & TST & \\
\hline CHEMBL1612414 & 688620 & 4.95 & 4.8951 & TST & \\
\hline CHEMBL1613385 & 688620 & 4.7 & 5.0365 & TST & \\
\hline CHEMBL 243663 & 688620 & 5.35 & 5.1033 & TST & \\
\hline CHEMBL1487609 & 688620 & 4.75 & 4.8272 & TRN & \\
\hline CHEMBL1423518 & 688620 & 4.65 & 4.9935 & TRN & \\
\hline CHEMBL1301108 & 688620 & 5.05 & 4.8336 & TRN & \\
\hline CHEMBL 3208427 & 688620 & 5.0 & 5.1209 & TRN & \\
\hline
\end{tabular}




\begin{tabular}{|c|c|c|c|c|c|}
\hline & & & & & \\
\hline CHEMBL1494674 & 688620 & 5.0 & 5.0893 & TRN & \\
\hline CHEMBL1608348 & 688620 & 5.3 & 5.261 & TRN & \\
\hline CHEMBL1498126 & 688620 & 5.65 & 4.8543 & TRN & \\
\hline CHEMBL1583096 & 688620 & 5.5 & 5.1053 & TST & \\
\hline CHEMBL1313520 & 688620 & 7.2 & 5.4824 & TRN & \\
\hline CHEMBL1165197 & 688620 & 4.95 & 4.8115 & TRN & \\
\hline CHEMBL1400840 & 688620 & 4.85 & 5.114 & TRN & \\
\hline CHEMBL1599667 & 688620 & 4.9 & 5.1021 & TRN & \\
\hline CHEMBL1532668 & 688620 & 5.7 & 5.3025 & TRN & \\
\hline CHEMBL1486325 & 688620 & 5.4 & 5.1163 & TRN & \\
\hline CHEMBL1367163 & 688620 & 4.45 & 5.3899 & TRN & \\
\hline CHEMBL1452957 & 688620 & 6.4 & 5.2184 & TST & \\
\hline CHEMBL1516483 & 688620 & 6.8 & 5.0103 & TRN & \\
\hline CHEMBL1305427 & 688620 & 6.05 & 5.1495 & TST & \\
\hline CHEMBL1312534 & 688620 & 4.45 & 4.9259 & TRN & \\
\hline CHEMBL1570760 & 688620 & 5.95 & 5.1812 & TRN & \\
\hline CHEMBL1415992 & 688620 & 4.9 & 5.0759 & TRN & \\
\hline CHEMBL1534888 & 688620 & 5.55 & 5.50899 & 99999999995 & TRN \\
\hline CHEMBL1966497 & 688620 & 5.25 & 5.55399 & 9999999999 & TRN \\
\hline CHEMBL1611776 & 688620 & 4.95 & 4.7827 & TRN & \\
\hline CHEMBL1523202 & 688620 & 4.9 & 5.0519 & TRN & \\
\hline CHEMBL1555678 & 688620 & 4.95 & 5.1091 & TRN & \\
\hline CHEMBL1503516 & 688620 & 5.25 & 5.1124 & TRN & \\
\hline CHEMBL1561346 & 688620 & 5.2 & 4.9161 & TRN & \\
\hline CHEMBL1503615 & 688620 & 4.45 & 5.1831 & TRN & \\
\hline CHEMBL1561686 & 688620 & 4.45 & 4.7935 & TRN & \\
\hline CHEMBL1407274 & 688620 & 5.25 & 5.3187 & TRN & \\
\hline CHEMBL1521970 & 688620 & 7.9508 & 4.9556 & TRN & \\
\hline CHEMBL343732 & 688620 & 4.45 & 4.6405 & TST & \\
\hline CHEMBL1360748 & 688620 & 4.95 & 4.8497 & TRN & \\
\hline CHEMBL1372994 & 688620 & 4.95 & 5.1738 & TRN & \\
\hline CHEMBL1442742 & 688620 & 4.7 & 4.8896 & TST & \\
\hline CHEMBL1568426 & 688620 & 5.0 & 5.0244 & TRN & \\
\hline CHEMBL1482536 & 688620 & 4.7 & 4.9281 & TRN & \\
\hline CHEMBL3211053 & 688620 & 4.45 & 5.2073 & TRN & \\
\hline CHEMBL1404086 & 688620 & 5.5 & 5.3203 & TRN & \\
\hline CHEMBL1408320 & 688620 & 4.45 & 4.9004 & TST & \\
\hline CHEMBL1369183 & 688620 & 4.45 & 4.9245 & TRN & \\
\hline CHEMBL1363026 & 688620 & 5.9 & 4.9321 & TRN & \\
\hline CHEMBL1561702 & 688620 & 5.05 & 5.21299 & 9999999999 & TRN \\
\hline CHEMBL1543712 & 688620 & 5.4 & 5.0196 & TRN & \\
\hline CHEMBL1507290 & 688620 & 5.1 & 5.2037 & TRN & \\
\hline CHEMBL1489999 & 688620 & 4.75 & 4.9297 & TRN & \\
\hline CHEMBL1570846 & 688620 & 5.45 & 4.9856 & TST & \\
\hline CHEMBL1333503 & 688620 & 4.7 & 5.2593 & TRN & \\
\hline CHEMBL1499985 & 688620 & 5.15 & 4.9232 & TRN & \\
\hline CHEMBL1569085 & 688620 & 4.95 & 5.0802 & TRN & \\
\hline CHEMBL1557547 & 688620 & 5.05 & 4.9363 & TRN & \\
\hline
\end{tabular}




\begin{tabular}{|c|c|c|c|c|c|}
\hline \\
\hline CHEMBL1457147 & 688620 & 4.9 & 5.067 & TST & \\
\hline CHEMBL1456502 & 688620 & 5.05 & 4.8659 & TRN & \\
\hline CHEMBL1304319 & 688620 & 5.7 & 5.4063 & TRN & \\
\hline CHEMBL3196295 & 688620 & 6.05 & 5.9992 & TRN & \\
\hline CHEMBL1582998 & 688620 & 4.45 & 4.9787 & TRN & \\
\hline CHEMBL1308056 & 688620 & 5.0 & 4.9598 & TRN & \\
\hline CHEMBL1562549 & 688620 & 5.0 & 5.1569 & TRN & \\
\hline CHEMBL2369183 & 688620 & 4.9 & 4.9026 & TRN & \\
\hline CHEMBL3208836 & 688620 & 4.9 & 5.1241 & TRN & \\
\hline CHEMBL1382630 & 688620 & 6.3 & 4.864 & TRN & \\
\hline CHEMBL1439395 & 688620 & 4.45 & 4.9293 & TRN & \\
\hline CHEMBL1417357 & 688620 & 4.5 & 5.1059 & TRN & \\
\hline CHEMBL3211364 & 688620 & 4.95 & 5.1448 & TST & \\
\hline CHEMBL1461800 & 688620 & 5.05 & 4.8272 & TRN & \\
\hline CHEMBL3191952 & 688620 & 4.45 & 5.3209 & TST & \\
\hline CHEMBL1341070 & 688620 & 4.95 & 5.0267 & TST & \\
\hline CHEMBL1541330 & 688620 & 5.2 & 4.9271 & TST & \\
\hline CHEMBL1562277 & 688620 & 4.95 & 4.9844 & TRN & \\
\hline CHEMBL1325466 & 688620 & 4.9 & 4.9709 & TRN & \\
\hline CHEMBL1368123 & 688620 & 4.9 & 5.05699 & 99999999995 & TST \\
\hline CHEMBL1588825 & 688620 & 6.5 & 5.1779 & TST & \\
\hline CHEMBL3196985 & 688620 & 4.45 & 5.0665 & TRN & \\
\hline CHEMBL1556516 & 688620 & 4.85 & 4.9513 & TST & \\
\hline CHEMBL1507759 & 688620 & 4.45 & 5.0325 & TRN & \\
\hline CHEMBL1456106 & 688620 & 5.0 & 5.0401 & TRN & \\
\hline CHEMBL1521166 & 688620 & 4.45 & 5.5479 & TRN & \\
\hline CHEMBL1466731 & 688620 & 4.6 & 4.9773 & TRN & \\
\hline CHEMBL1496375 & 688620 & 5.35 & 5.3053 & TRN & \\
\hline CHEMBL1495008 & 688620 & 5.0 & 4.8143 & TRN & \\
\hline CHEMBL1532867 & 688620 & 4.7 & 4.8361 & TRN & \\
\hline CHEMBL1359081 & 688620 & 4.45 & 5.1257 & TRN & \\
\hline CHEMBL1565401 & 688620 & 6.7001 & 5.2282 & TST & \\
\hline CHEMBL1331969 & 688620 & 4.45 & 4.9505 & TRN & \\
\hline CHEMBL1581908 & 688620 & 4.9 & 4.977 & TST & \\
\hline CHEMBL1309871 & 688620 & 4.65 & 5.0184 & TRN & \\
\hline CHEMBL1430669 & 688620 & 4.45 & 5.0006 & TRN & \\
\hline CHEMBL1468936 & 688620 & 4.9 & 4.9459 & TST & \\
\hline CHEMBL1484658 & 688620 & 4.95 & 5.0501 & TRN & \\
\hline CHEMBL1421093 & 688620 & 8.2518 & 4.9914 & TRN & \\
\hline CHEMBL1490448 & 688620 & 4.75 & 4.9626 & TST & \\
\hline CHEMBL1342038 & 688620 & 6.15 & 5.99700 & $\partial 000000001$ & TRN \\
\hline CHEMBL1403001 & 688620 & 4.85 & 4.9785 & TRN & \\
\hline CHEMBL3211316 & 688620 & 4.95 & 4.9398 & TST & \\
\hline CHEMBL1304278 & 688620 & 4.85 & 5.2231 & TST & \\
\hline CHEMBL1340838 & 688620 & 5.65 & 5.2507 & TRN & \\
\hline CHEMBL1487641 & 688620 & 5.65 & 5.6392 & TRN & \\
\hline CHEMBL 3198850 & 688620 & 4.45 & 5.0967 & TST & \\
\hline CHEMBL1508691 & 688620 & 5.35 & 5.0293 & TRN & \\
\hline
\end{tabular}




\begin{tabular}{|c|c|c|c|c|c|}
\hline \multicolumn{6}{|c|}{ Supplemental Table S2.txt } \\
\hline CHEMBL1468011 & 688620 & 6.25 & 5.8003 & TRN & \\
\hline CHEMBL1379011 & 688620 & 4.7 & 5.9616 & TRN & \\
\hline CHEMBL1576523 & 688620 & 4.65 & 5.0662 & TRN & \\
\hline CHEMBL1400744 & 688620 & 4.45 & 5.1665 & TST & \\
\hline CHEMBL1352839 & 688620 & 4.45 & 4.9984 & TRN & \\
\hline CHEMBL3192566 & 688620 & 5.15 & 4.9385 & TRN & \\
\hline CHEMBL1611827 & 688620 & 5.0 & 4.7662 & TRN & \\
\hline CHEMBL1509674 & 688620 & 4.6 & 4.9655 & TRN & \\
\hline CHEMBL1423581 & 688620 & 4.65 & 4.9775 & TRN & \\
\hline CHEMBL1327541 & 688620 & 4.8 & 4.7876 & TST & \\
\hline CHEMBL1464631 & 688620 & 5.2 & 5.2194 & TRN & \\
\hline CHEMBL1549099 & 688620 & 5.3 & 5.2705 & TRN & \\
\hline CHEMBL3195964 & 688620 & 4.95 & 4.95100 & 00000000005 & TRN \\
\hline CHEMBL1585520 & 688620 & 4.9 & 5.0865 & TRN & \\
\hline CHEMBL1375315 & 688620 & 5.7 & 4.9559 & TRN & \\
\hline CHEMBL1431108 & 688620 & 4.95 & 4.8564 & TRN & \\
\hline CHEMBL1451341 & 688620 & 5.0 & 5.0554 & TST & \\
\hline CHEMBL1533676 & 688620 & 4.85 & 4.8197 & TST & \\
\hline CHEMBL1540474 & 688620 & 4.75 & 4.8592 & TRN & \\
\hline CHEMBL3197151 & 688620 & 4.55 & 5.0487 & TRN & \\
\hline CHEMBL1307186 & 688620 & 4.7 & 4.9165 & TRN & \\
\hline CHEMBL1504282 & 688620 & 4.8 & 5.0824 & TST & \\
\hline CHEMBL1484095 & 688620 & 4.95 & 4.9535 & TRN & \\
\hline CHEMBL1975892 & 688620 & 4.8 & 4.8257 & TRN & \\
\hline CHEMBL 2006390 & 688620 & 6.0 & 5.7831 & TRN & \\
\hline CHEMBL1556786 & 688620 & 5.6 & 5.5646 & TRN & \\
\hline CHEMBL1301484 & 688620 & 4.45 & 4.766 & TRN & \\
\hline CHEMBL1164862 & 688620 & 5.25 & 5.0419 & TRN & \\
\hline CHEMBL1402912 & 688620 & 4.9 & 4.8296 & TRN & \\
\hline CHEMBL1611990 & 688620 & 4.9 & 5.1387 & TRN & \\
\hline CHEMBL1474701 & 688620 & 5.0 & 5.0113 & TST & \\
\hline CHEMBL1382101 & 688620 & 4.95 & 5.0931 & TRN & \\
\hline CHEMBL1335528 & 688620 & 4.5 & 5.0044 & TST & \\
\hline CHEMBL1607285 & 688620 & 4.85 & 5.0232 & TST & \\
\hline CHEMBL1411169 & 688620 & 4.7 & 4.8366 & TRN & \\
\hline CHEMBL1464153 & 688620 & 4.9 & 4.7818 & TRN & \\
\hline CHEMBL3193256 & 688620 & 7.15 & 5.1463 & TRN & \\
\hline CHEMBL1348831 & 688620 & 4.35 & 5.1191 & TST & \\
\hline CHEMBL 274070 & 688620 & 7.699 & 6.4237 & TRN & \\
\hline CHEMBL1412765 & 688620 & 5.6 & 5.0501 & TRN & \\
\hline CHEMBL1434915 & 688620 & 4.45 & 5.2055 & TRN & \\
\hline CHEMBL1556429 & 688620 & 5.3 & 4.9394 & TRN & \\
\hline CHEMBL1594883 & 688620 & 4.9 & 4.6872 & TRN & \\
\hline CHEMBL57196 & 688620 & 7.0501 & 4.9399 & TRN & \\
\hline CHEMBL1376043 & 688620 & 6.0 & 4.7131 & TRN & \\
\hline CHEMBL1533923 & 688620 & 6.0 & 4.6616 & TRN & \\
\hline CHEMBL1589964 & 688620 & 4.85 & 4.9019 & TRN & \\
\hline CHEMBL3193586 & 688620 & 4.9 & 5.0558 & TST & \\
\hline
\end{tabular}




\begin{tabular}{|c|c|c|c|c|c|}
\hline \\
\hline CHEMBL1318750 & 688620 & 6.3 & 5.2349 & TRN & \\
\hline CHEMBL1491516 & 688620 & 6.0 & 5.0043 & TST & \\
\hline CHEMBL1377944 & 688620 & 4.7 & 5.2682 & TRN & \\
\hline CHEMBL236554 & 688620 & 4.95 & 4.8634 & TRN & \\
\hline CHEMBL1496512 & 688620 & 5.3 & 5.0364 & TRN & \\
\hline CHEMBL1324590 & 688620 & 5.0 & 5.0133 & TRN & \\
\hline CHEMBL1350192 & 688620 & 5.5 & 4.8292 & TRN & \\
\hline CHEMBL592363 & 688620 & 4.95 & 4.5968 & TRN & \\
\hline CHEMBL1392808 & 688620 & 5.5 & 5.7064 & TRN & \\
\hline CHEMBL1972029 & 688620 & 5.75 & 5.5639 & TRN & \\
\hline CHEMBL1363413 & 688620 & 4.45 & 4.8399 & TRN & \\
\hline CHEMBL3190425 & 688620 & 5.45 & 5.4387 & TRN & \\
\hline CHEMBL1364745 & 688620 & 4.65 & 4.90600 & 0000000001 & TST \\
\hline CHEMBL1308676 & 688620 & 4.5 & 4.8233 & TRN & \\
\hline CHEMBL1526866 & 688620 & 4.75 & 5.0695 & TRN & \\
\hline CHEMBL3199937 & 688620 & 6.25 & 5.9377 & TRN & \\
\hline CHEMBL1523444 & 688620 & 4.95 & 4.8722 & TRN & \\
\hline CHEMBL1510260 & 688620 & 4.8 & 5.0651 & TST & \\
\hline CHEMBL1300093 & 688620 & 5.15 & 4.9312 & TRN & \\
\hline CHEMBL1600223 & 688620 & 5.4 & 5.3658 & TRN & \\
\hline CHEMBL1978120 & 688620 & 4.9 & 5.0407 & TRN & \\
\hline CHEMBL1584189 & 688620 & 5.1 & 5.2003 & TRN & \\
\hline CHEMBL3194542 & 688620 & 4.45 & 4.9039 & TRN & \\
\hline CHEMBL1310336 & 688620 & 4.9 & 4.9691 & TRN & \\
\hline CHEMBL1422335 & 688620 & 5.9 & 6.3093 & TRN & \\
\hline CHEMBL1584840 & 688620 & 4.45 & 4.9065 & TRN & \\
\hline CHEMBL3191897 & 688620 & 5.7 & 5.5903 & TRN & \\
\hline CHEMBL1555149 & 688620 & 4.9 & 4.8557 & TRN & \\
\hline CHEMBL1578199 & 688620 & 4.65 & 5.29299 & 9999999999 & TRN \\
\hline CHEMBL1498602 & 688620 & 4.9 & 5.0432 & TST & \\
\hline CHEMBL1325462 & 688620 & 4.45 & 5.0412 & TRN & \\
\hline CHEMBL1388307 & 688620 & 4.85 & 4.9944 & TST & \\
\hline CHEMBL1361091 & 688620 & 4.8 & 5.0296 & TRN & \\
\hline CHEMBL1318894 & 688620 & 5.25 & 5.0716 & TRN & \\
\hline CHEMBL1584818 & 688620 & 4.95 & 5.0671 & TRN & \\
\hline CHEMBL1450999 & 688620 & 4.65 & 5.0391 & TRN & \\
\hline CHEMBL1504976 & 688620 & 4.7 & 5.2269 & TRN & \\
\hline CHEMBL1580977 & 688620 & 4.75 & 4.9937 & TRN & \\
\hline CHEMBL1569045 & 688620 & 4.45 & 5.479 & TRN & \\
\hline CHEMBL1496961 & 688620 & 4.75 & 5.2919 & TRN & \\
\hline CHEMBL1305062 & 688620 & 5.35 & 5.193 & TRN & \\
\hline CHEMBL1971185 & 688620 & 5.3 & 5.1489 & TRN & \\
\hline CHEMBL1506659 & 688620 & 4.9 & 4.885 & TRN & \\
\hline CHEMBL1341477 & 688620 & 4.8 & 5.0517 & TRN & \\
\hline CHEMBL1603797 & 688620 & 5.3 & 5.0779 & TRN & \\
\hline CHEMBL1413591 & 688620 & 6.05 & 5.0682 & TRN & \\
\hline CHEMBL1413340 & 688620 & 4.95 & 5.1412 & TRN & \\
\hline CHEMBL1453693 & 688620 & 4.5 & 5.0182 & TRN & \\
\hline & & & & 268 & \\
\hline
\end{tabular}




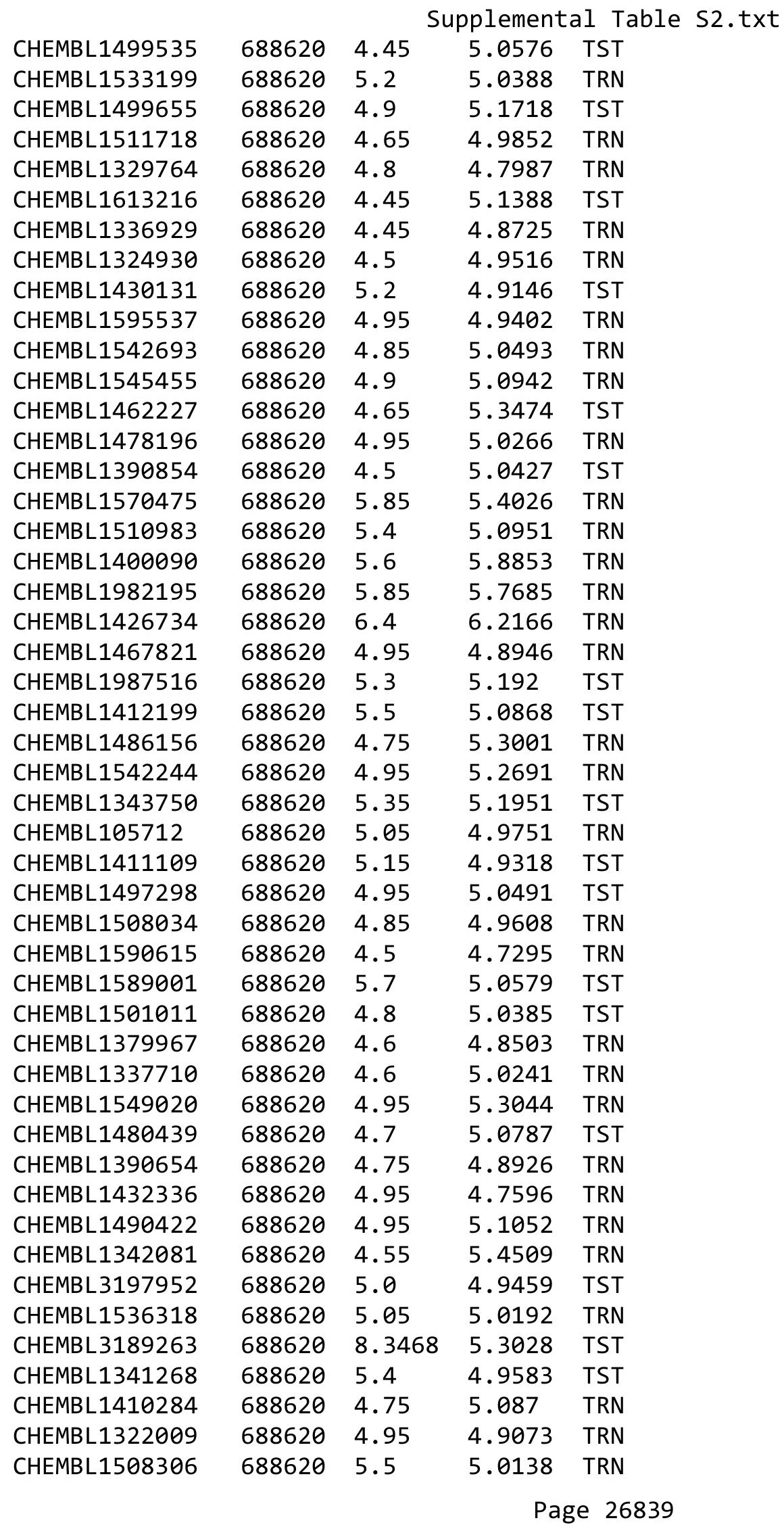




\begin{tabular}{|c|c|c|c|c|c|}
\hline \multicolumn{6}{|c|}{ Supplemental Table S2.txt } \\
\hline CHEMBL1479026 & 688620 & 4.45 & 4.7698 & TST & \\
\hline CHEMBL1478733 & 688620 & 4.85 & 4.9282 & TRN & \\
\hline CHEMBL1380165 & 688620 & 4.45 & 4.9911 & TRN & \\
\hline CHEMBL1582048 & 688620 & 5.3 & 5.0524 & TRN & \\
\hline CHEMBL1332984 & 688620 & 4.45 & 4.7757 & TRN & \\
\hline CHEMBL1419471 & 688620 & 5.05 & 4.6953 & TRN & \\
\hline CHEMBL1973773 & 688620 & 5.0 & 5.0883 & TRN & \\
\hline CHEMBL1493974 & 688620 & 6.2 & 5.1518 & TRN & \\
\hline CHEMBL 3194584 & 688620 & 4.7 & 4.9564 & TRN & \\
\hline CHEMBL1500383 & 688620 & 5.5 & 5.0262 & TRN & \\
\hline CHEMBL1553643 & 688620 & 4.95 & 4.8685 & TRN & \\
\hline CHEMBL1318989 & 688620 & 5.9 & 5.517 & TRN & \\
\hline CHEMBL1571481 & 688620 & 4.45 & 5.3315 & TRN & \\
\hline CHEMBL1376622 & 688620 & 5.0 & 4.9182 & TRN & \\
\hline CHEMBL3197372 & 688620 & 5.65 & 5.1466 & TRN & \\
\hline CHEMBL1468147 & 688620 & 5.2 & 4.9133 & TRN & \\
\hline CHEMBL1594444 & 688620 & 4.85 & 5.0799 & TRN & \\
\hline CHEMBL1586602 & 688620 & 4.65 & 4.9385 & TRN & \\
\hline CHEMBL1302836 & 688620 & 5.65 & 5.6339 & TST & \\
\hline CHEMBL1527861 & 688620 & 4.9 & 6.0816 & TRN & \\
\hline CHEMBL1518612 & 688620 & 5.2 & 5.2601 & TRN & \\
\hline CHEMBL3195594 & 688620 & 4.5 & 5.2124 & TRN & \\
\hline CHEMBL1992081 & 688620 & 5.25 & 5.4114 & TST & \\
\hline CHEMBL3198090 & 688620 & 4.7 & 4.9614 & TRN & \\
\hline CHEMBL1543947 & 688620 & 5.1 & 4.8009 & TRN & \\
\hline CHEMBL1463067 & 688620 & 5.45 & 5.3676 & TRN & \\
\hline CHEMBL1494593 & 688620 & 4.8 & 5.0963 & TRN & \\
\hline CHEMBL3197018 & 688620 & 4.5 & 4.8515 & TRN & \\
\hline CHEMBL1518326 & 688620 & 5.0 & 5.175 & TST & \\
\hline CHEMBL1470219 & 688620 & 7.0501 & 5.2036 & TRN & \\
\hline CHEMBL1345447 & 688620 & 4.45 & 5.12200 & 0000000001 & TST \\
\hline CHEMBL1409414 & 688620 & 5.15 & 5.5168 & TRN & \\
\hline CHEMBL1390861 & 688620 & 4.95 & 5.1864 & TRN & \\
\hline CHEMBL1970753 & 688620 & 4.9 & 5.0822 & TRN & \\
\hline CHEMBL1586196 & 688620 & 5.3 & 4.8809 & TST & \\
\hline CHEMBL1603779 & 688620 & 5.05 & 5.1011 & TRN & \\
\hline CHEMBL1602012 & 688620 & 4.45 & 5.2745 & TRN & \\
\hline CHEMBL1598326 & 688620 & 4.7 & 4.9402 & TRN & \\
\hline CHEMBL1609756 & 688620 & 4.9 & 4.9301 & TST & \\
\hline CHEMBL1489180 & 688620 & 4.85 & 5.0379 & TST & \\
\hline CHEMBL1498604 & 688620 & 4.45 & 4.9765 & TRN & \\
\hline CHEMBL1465103 & 688620 & 5.5 & 5.1782 & TRN & \\
\hline CHEMBL1421850 & 688620 & 4.7 & 4.8418 & TRN & \\
\hline CHEMBL1591005 & 688620 & 4.65 & 4.999 & TRN & \\
\hline CHEMBL1503386 & 688620 & 5.6 & 5.7254 & TRN & \\
\hline CHEMBL1369586 & 688620 & 4.8 & 4.9606 & TRN & \\
\hline CHEMBL1495517 & 688620 & 5.0 & 4.8061 & TRN & \\
\hline CHEMBL1378498 & 688620 & 4.75 & 5.018 & TRN & \\
\hline
\end{tabular}




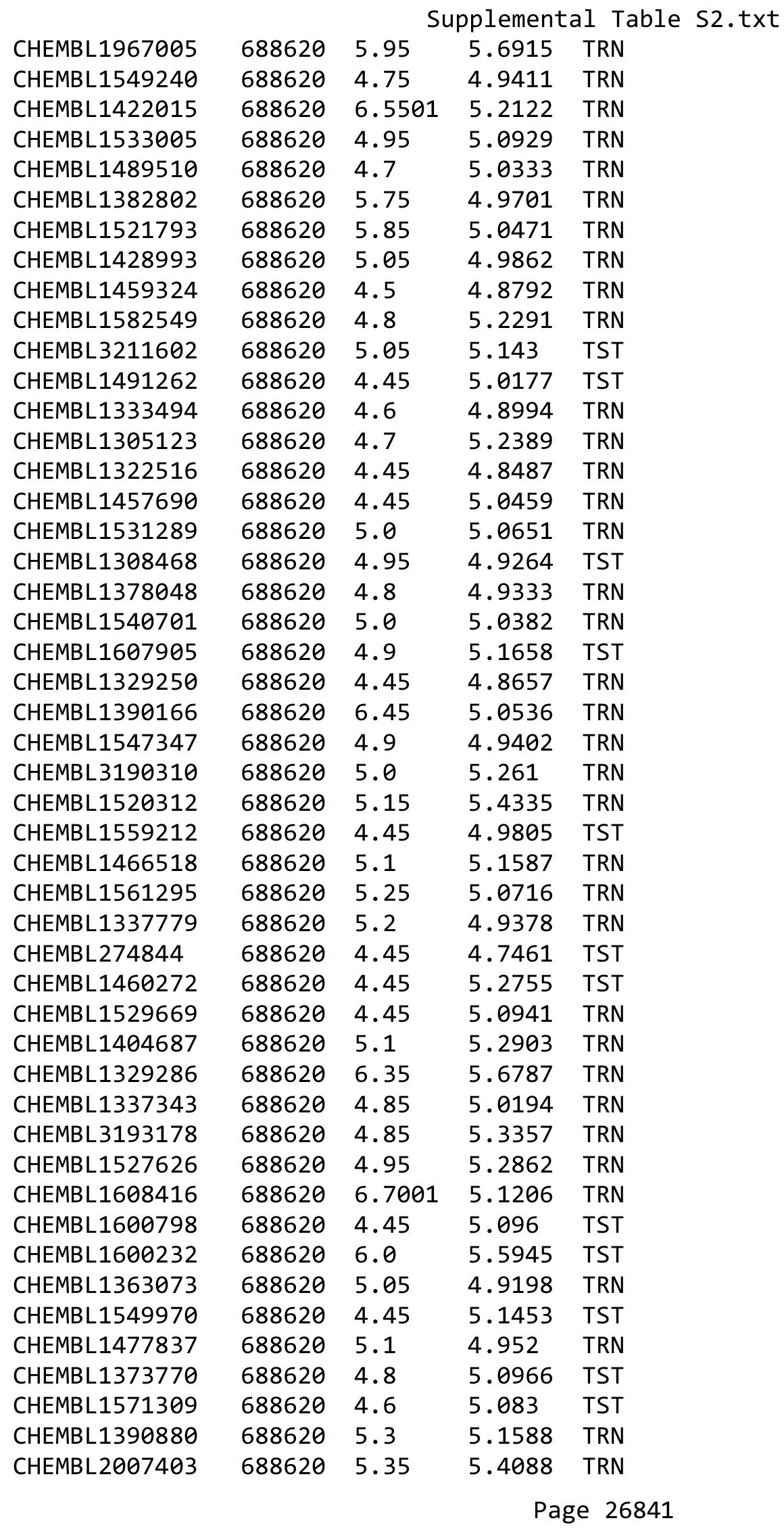




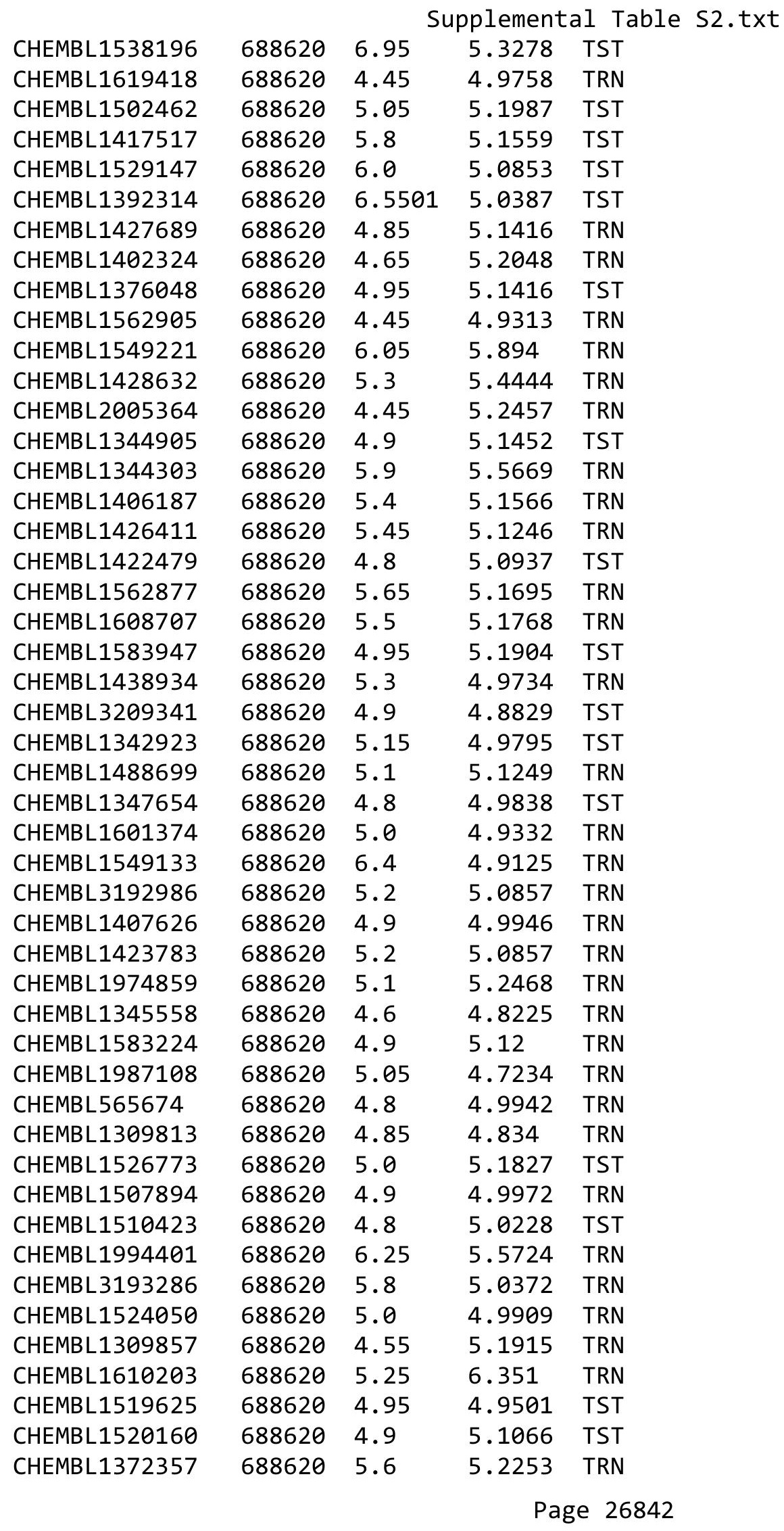




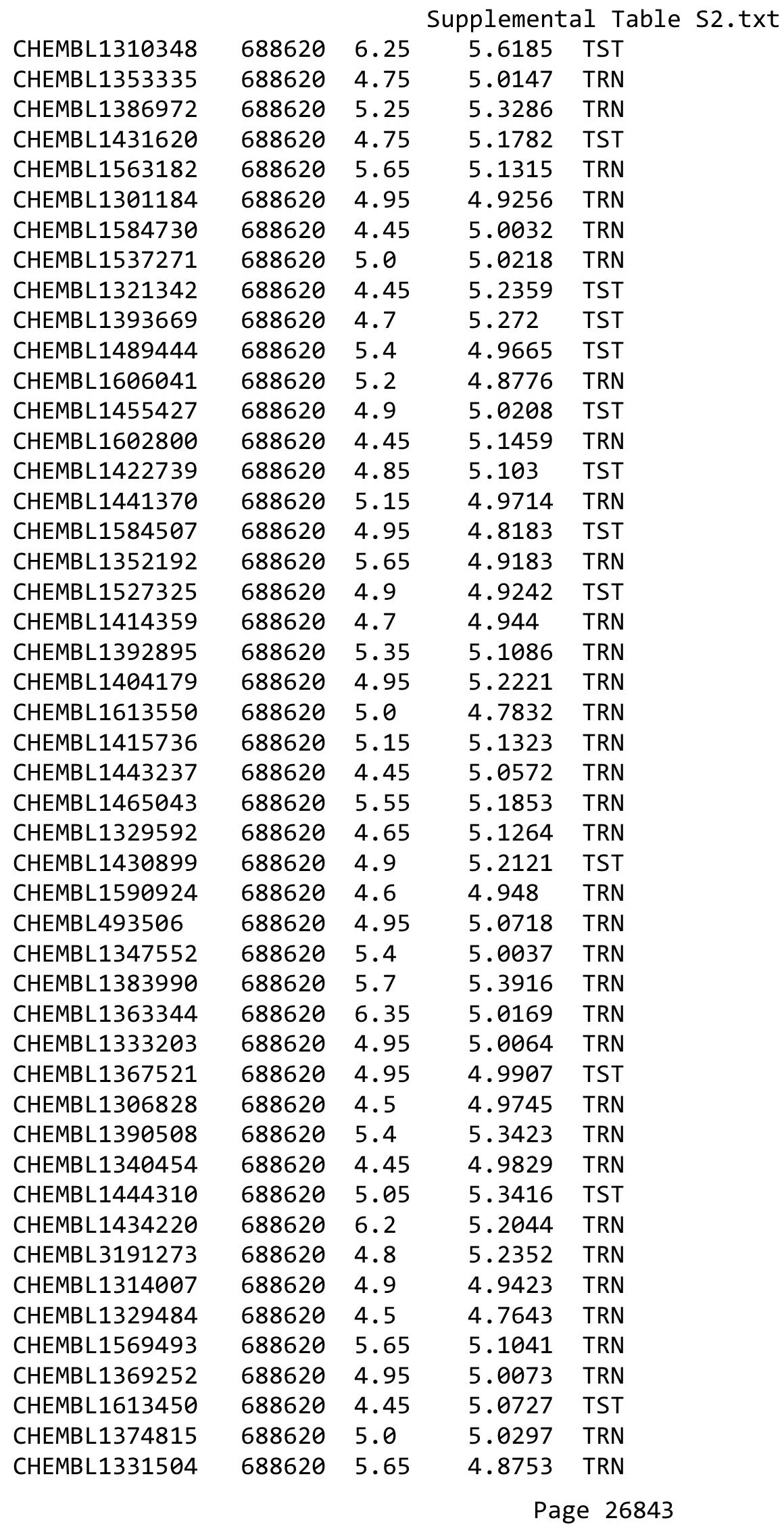




\begin{tabular}{|c|c|c|c|c|c|}
\hline \multicolumn{6}{|c|}{ Supplemental Table s2.txt } \\
\hline CHEMBL1608224 & 688620 & 4.75 & 5.0196 & TRN & \\
\hline CHEMBL1368766 & 688620 & 4.45 & 4.9872 & TRN & \\
\hline CHEMBL1361994 & 688620 & 4.45 & 4.9695 & TST & \\
\hline CHEMBL1393624 & 688620 & 4.65 & 5.0394 & TRN & \\
\hline CHEMBL1363654 & 688620 & 4.95 & 4.8783 & TST & \\
\hline CHEMBL1469638 & 688620 & 4.45 & 4.8952 & TRN & \\
\hline CHEMBL1472282 & 688620 & 5.2 & 5.0908 & TST & \\
\hline CHEMBL1499851 & 688620 & 4.95 & 5.2172 & TST & \\
\hline CHEMBL1539706 & 688620 & 4.45 & 5.2652 & TST & \\
\hline CHEMBL1507537 & 688620 & 5.7 & 4.9818 & TRN & \\
\hline CHEMBL3198058 & 688620 & 4.8 & 4.9687 & TRN & \\
\hline CHEMBL1432273 & 688620 & 4.8 & 4.9534 & TRN & \\
\hline CHEMBL1532465 & 688620 & 4.75 & 5.1249 & TST & \\
\hline CHEMBL1578699 & 688620 & 5.2 & 5.0269 & TRN & \\
\hline CHEMBL22996 & 688620 & 6.15 & 5.065 & TRN & \\
\hline CHEMBL1371114 & 688620 & 5.0 & 4.9639 & TRN & \\
\hline CHEMBL1588629 & 688620 & 4.85 & 4.9388 & TRN & \\
\hline CHEMBL1528951 & 688620 & 5.2 & 5.055 & TRN & \\
\hline CHEMBL1372929 & 688620 & 5.65 & 5.1609 & TRN & \\
\hline CHEMBL1523373 & 688620 & 4.45 & 5.0518 & TST & \\
\hline CHEMBL1494615 & 688620 & 6.0 & 5.51200 & 00000000005 & TST \\
\hline CHEMBL1305642 & 688620 & 4.45 & 4.7102 & TST & \\
\hline CHEMBL1572644 & 688620 & 5.55 & 5.0853 & TST & \\
\hline CHEMBL1333213 & 688620 & 4.45 & 5.0565 & TRN & \\
\hline CHEMBL1514227 & 688620 & 4.5 & 4.9847 & TST & \\
\hline CHEMBL1431917 & 688620 & 4.45 & 4.8654 & TST & \\
\hline CHEMBL1399830 & 688620 & 4.45 & 4.94300 & 00000000005 & TST \\
\hline CHEMBL1575970 & 688620 & 5.7 & 5.5578 & TRN & \\
\hline CHEMBL1320314 & 688620 & 4.6 & 4.8739 & TRN & \\
\hline CHEMBL1604527 & 688620 & 4.75 & 5.1868 & TRN & \\
\hline CHEMBL1411570 & 688620 & 4.6 & 5.1794 & TRN & \\
\hline CHEMBL1299527 & 688620 & 4.5 & 5.0646 & TRN & \\
\hline CHEMBL1539023 & 688620 & 4.9 & 4.9646 & TRN & \\
\hline CHEMBL1419777 & 688620 & 4.8 & 4.9465 & TRN & \\
\hline CHEMBL1448029 & 688620 & 5.35 & 5.3424 & TRN & \\
\hline CHEMBL1599616 & 688620 & 4.5 & 4.7438 & TST & \\
\hline CHEMBL1338337 & 688620 & 4.75 & 4.9647 & TRN & \\
\hline CHEMBL3211820 & 688620 & 5.05 & 5.081 & TRN & \\
\hline CHEMBL3196482 & 688620 & 5.2 & 5.1304 & TRN & \\
\hline CHEMBL1569755 & 688620 & 6.5501 & 6.4134 & TRN & \\
\hline CHEMBL1346719 & 688620 & 4.75 & 5.1092 & TST & \\
\hline CHEMBL1542614 & 688620 & 5.2 & 5.1576 & TRN & \\
\hline CHEMBL1486546 & 688620 & 4.95 & 4.8568 & TRN & \\
\hline CHEMBL3212505 & 688620 & 5.15 & 5.1552 & TRN & \\
\hline CHEMBL1579020 & 688620 & 4.95 & 4.7636 & TST & \\
\hline CHEMBL1610491 & 688620 & 4.45 & 4.7872 & TRN & \\
\hline CHEMBL1461917 & 688620 & 4.95 & 4.7685 & TRN & \\
\hline CHEMBL1325101 & 688620 & 5.0 & 4.785 & TST & \\
\hline
\end{tabular}




\begin{tabular}{|c|c|c|c|c|c|}
\hline \multicolumn{6}{|c|}{ Supplemental Table S2.txt } \\
\hline CHEMBL3210639 & 688620 & 4.85 & 5.0244 & TST & \\
\hline CHEMBL3191969 & 688620 & 5.65 & 5.6862 & TRN & \\
\hline CHEMBL1601080 & 688620 & 5.05 & 5.1615 & TRN & \\
\hline CHEMBL 3198707 & 688620 & 4.65 & 5.1246 & TRN & \\
\hline CHEMBL1574447 & 688620 & 4.75 & 5.2608 & TRN & \\
\hline CHEMBL1440038 & 688620 & 4.55 & 4.6649 & TST & \\
\hline CHEMBL1352326 & 688620 & 6.0 & 5.0246 & TRN & \\
\hline CHEMBL1327670 & 688620 & 6.5501 & 5.1792 & TRN & \\
\hline CHEMBL1351847 & 688620 & 4.8 & 5.1652 & TRN & \\
\hline CHEMBL1408846 & 688620 & 4.85 & 4.9288 & TRN & \\
\hline CHEMBL1542197 & 688620 & 5.0 & 4.98600 & 2000000001 & TRN \\
\hline CHEMBL1364100 & 688620 & 4.65 & 5.121 & TST & \\
\hline CHEMBL1324887 & 688620 & 4.55 & 4.9885 & TRN & \\
\hline CHEMBL1597443 & 688620 & 4.8 & 5.1824 & TRN & \\
\hline CHEMBL1545089 & 688620 & 7.6498 & 5.0566 & TST & \\
\hline CHEMBL1571565 & 688620 & 4.65 & 5.2112 & TST & \\
\hline CHEMBL1499770 & 688620 & 4.95 & 5.2148 & TRN & \\
\hline CHEMBL1300742 & 688620 & 4.75 & 4.8979 & TRN & \\
\hline CHEMBL1458641 & 688620 & 4.45 & 4.8742 & TRN & \\
\hline CHEMBL1456928 & 688620 & 4.45 & 4.9859 & TRN & \\
\hline CHEMBL1536745 & 688620 & 5.0 & 4.9141 & TRN & \\
\hline CHEMBL1378034 & 688620 & 4.9 & 4.7116 & TRN & \\
\hline CHEMBL1351223 & 688620 & 5.2 & 4.9604 & TRN & \\
\hline CHEMBL1588234 & 688620 & 5.4 & 5.6397 & TRN & \\
\hline CHEMBL1551103 & 688620 & 4.9 & 5.0424 & TRN & \\
\hline CHEMBL1341961 & 688620 & 4.9 & 4.6853 & TRN & \\
\hline CHEMBL1338924 & 688620 & 5.9 & 5.1094 & TRN & \\
\hline CHEMBL3209352 & 688620 & 5.75 & 5.362 & TRN & \\
\hline CHEMBL 246447 & 688620 & 5.3 & 5.0815 & TST & \\
\hline CHEMBL1394556 & 688620 & 4.45 & 5.3963 & TRN & \\
\hline CHEMBL3193055 & 688620 & 4.6 & 4.8647 & TRN & \\
\hline CHEMBL1304746 & 688620 & 4.45 & 5.1966 & TST & \\
\hline CHEMBL1335413 & 688620 & 4.5 & 5.0652 & TRN & \\
\hline CHEMBL1541120 & 688620 & 4.45 & 4.8158 & TRN & \\
\hline CHEMBL1420285 & 688620 & 4.75 & 5.1007 & TRN & \\
\hline CHEMBL1521619 & 688620 & 4.45 & 4.7793 & TRN & \\
\hline CHEMBL1611216 & 688620 & 6.15 & 4.9931 & TST & \\
\hline CHEMBL3190180 & 688620 & 4.95 & 5.0186 & TRN & \\
\hline CHEMBL3194078 & 688620 & 4.65 & 4.9943 & TST & \\
\hline CHEMBL1604227 & 688620 & 5.0 & 5.0624 & TST & \\
\hline CHEMBL1540629 & 688620 & 4.85 & 4.9917 & TRN & \\
\hline CHEMBL1494390 & 688620 & 4.45 & 4.8308 & TRN & \\
\hline CHEMBL3192946 & 688620 & 4.45 & 5.1359 & TST & \\
\hline CHEMBL1343187 & 688620 & 4.45 & 5.1369 & TST & \\
\hline CHEMBL1313341 & 688620 & 6.35 & 5.2659 & TRN & \\
\hline CHEMBL1567512 & 688620 & 4.9 & 4.8646 & TRN & \\
\hline CHEMBL1341488 & 688620 & 4.45 & 4.7432 & TRN & \\
\hline CHEMBL1369162 & 688620 & 4.9 & 4.9202 & TRN & \\
\hline
\end{tabular}




\begin{tabular}{|c|c|c|c|c|}
\hline & & & pplemen & al $\mathrm{T}$ \\
\hline CHEMBL1488549 & 688620 & 5.6 & 5.1137 & TRN \\
\hline CHEMBL1450998 & 688620 & 6.0 & 4.9621 & TRN \\
\hline CHEMBL1405980 & 688620 & 5.15 & 5.3996 & TRN \\
\hline CHEMBL1306397 & 688620 & 5.25 & 5.0007 & TST \\
\hline CHEMBL1312502 & 688620 & 5.05 & 5.0273 & TRN \\
\hline CHEMBL1363151 & 688620 & 7.0 & 4.9613 & TRN \\
\hline CHEMBL1479579 & 688620 & 5.25 & 5.657 & TRN \\
\hline CHEMBL1589463 & 688620 & 5.0 & 5.1732 & TRN \\
\hline CHEMBL1964398 & 688620 & 4.95 & 4.9992 & TRN \\
\hline CHEMBL1547628 & 688620 & 4.7 & 5.0011 & TRN \\
\hline CHEMBL1311977 & 688620 & 4.9 & 5.1987 & TRN \\
\hline CHEMBL1462777 & 688620 & 5.15 & 5.0698 & TRN \\
\hline CHEMBL1325207 & 688620 & 4.45 & 5.1888 & TRN \\
\hline CHEMBL 3198864 & 688620 & 5.8 & 5.6032 & TRN \\
\hline CHEMBL1380839 & 688620 & 6.3 & 5.6031 & TST \\
\hline CHEMBL1539320 & 688620 & 4.8 & 5.048 & TRN \\
\hline CHEMBL473735 & 688620 & 5.2 & 5.5386 & TRN \\
\hline CHEMBL1451827 & 688620 & 4.45 & 5.2669 & TST \\
\hline CHEMBL1353357 & 688620 & 4.95 & 4.9783 & TRN \\
\hline CHEMBL1329152 & 688620 & 5.85 & 5.0551 & TRN \\
\hline CHEMBL1603999 & 688620 & 4.75 & 5.0233 & TST \\
\hline CHEMBL1389792 & 688620 & 4.75 & 5.1176 & TST \\
\hline CHEMBL1430822 & 688620 & 4.8 & 5.1064 & TRN \\
\hline CHEMBL1351084 & 688620 & 5.1 & 4.9506 & TRN \\
\hline CHEMBL1348551 & 688620 & 4.95 & 5.0221 & TST \\
\hline CHEMBL1510760 & 688620 & 5.0 & 4.8041 & TRN \\
\hline CHEMBL1335452 & 688620 & 5.0 & 5.3485 & TRN \\
\hline CHEMBL1535779 & 688620 & 5.15 & 5.0052 & TRN \\
\hline CHEMBL 3190684 & 688620 & 8.2518 & 5.2616 & TRN \\
\hline CHEMBL1429902 & 688620 & 4.75 & 4.7672 & TRN \\
\hline CHEMBL1337297 & 688620 & 4.9 & 5.0492 & TRN \\
\hline CHEMBL1545628 & 688620 & 4.45 & 5.0115 & TRN \\
\hline CHEMBL1534881 & 688620 & 4.75 & 4.9557 & TRN \\
\hline CHEMBL1445165 & 688620 & 4.45 & 5.0114 & TST \\
\hline CHEMBL1331084 & 688620 & 5.55 & 5.0385 & TRN \\
\hline CHEMBL1336142 & 688620 & 5.25 & 5.0395 & TRN \\
\hline CHEMBL1573208 & 688620 & 4.45 & 4.9668 & TRN \\
\hline CHEMBL3195632 & 688620 & 4.75 & 5.0074 & TRN \\
\hline CHEMBL 3194042 & 688620 & 5.0 & 5.1251 & TRN \\
\hline CHEMBL1441523 & 688620 & 4.45 & 4.9682 & TRN \\
\hline CHEMBL1373255 & 688620 & 4.7 & 5.1357 & TRN \\
\hline CHEMBL1502402 & 688620 & 4.75 & 5.3093 & TRN \\
\hline CHEMBL1408845 & 688620 & 4.8 & 5.2848 & TRN \\
\hline CHEMBL1541614 & 688620 & 5.95 & 5.2242 & TST \\
\hline CHEMBL1320411 & 688620 & 5.9 & 4.9474 & TRN \\
\hline CHEMBL1457468 & 688620 & 4.95 & 4.8211 & TRN \\
\hline CHEMBL1612770 & 688620 & 5.25 & 5.4787 & TRN \\
\hline CHEMBL1331086 & 688620 & 4.7 & 4.9793 & TRN \\
\hline
\end{tabular}




\begin{tabular}{|c|c|c|c|c|c|}
\hline \multicolumn{6}{|c|}{ Supplemental Table S2.txt } \\
\hline CHEMBL1438780 & 688620 & 5.85 & 4.9466 & TRN & \\
\hline CHEMBL1365230 & 688620 & 4.45 & 5.1709 & TST & \\
\hline CHEMBL1977877 & 688620 & 6.4 & 5.8297 & TST & \\
\hline CHEMBL1465084 & 688620 & 4.45 & 4.8498 & TRN & \\
\hline CHEMBL 1451260 & 688620 & 4.45 & 5.2033 & TST & \\
\hline CHEMBL1402521 & 688620 & 4.8 & 5.0221 & TRN & \\
\hline CHEMBL1438407 & 688620 & 6.3 & 5.0049 & TRN & \\
\hline CHEMBL1467758 & 688620 & 4.8 & 5.1031 & TRN & \\
\hline CHEMBL1420649 & 688620 & 5.2 & 5.1066 & TRN & \\
\hline CHEMBL1337553 & 688620 & 5.2 & 5.29200 & 0000000001 & TRN \\
\hline CHEMBL3213215 & 688620 & 4.95 & 4.7455 & TRN & \\
\hline CHEMBL1412300 & 688620 & 4.5 & 5.0538 & TRN & \\
\hline CHEMBL1365369 & 688620 & 5.45 & 5.3484 & TRN & \\
\hline CHEMBL1456466 & 688620 & 4.6 & 4.9098 & TRN & \\
\hline CHEMBL1379038 & 688620 & 4.5 & 4.9296 & TRN & \\
\hline CHEMBL1598049 & 688620 & 5.0 & 4.9911 & TRN & \\
\hline CHEMBL1438466 & 688620 & 4.45 & 4.8662 & TST & \\
\hline CHEMBL1964667 & 688620 & 5.65 & 5.0311 & TST & \\
\hline CHEMBL1400122 & 688620 & 4.9 & 5.1193 & TRN & \\
\hline CHEMBL1340836 & 688620 & 4.95 & 5.0171 & TRN & \\
\hline CHEMBL3211947 & 688620 & 4.8 & 5.0749 & TST & \\
\hline CHEMBL1319994 & 688620 & 5.15 & 5.0295 & TST & \\
\hline CHEMBL3208686 & 688620 & 5.45 & 5.1964 & TRN & \\
\hline CHEMBL1611858 & 688620 & 5.55 & 5.2908 & TRN & \\
\hline CHEMBL1533381 & 688620 & 5.3 & 5.0999 & TST & \\
\hline CHEMBL3192460 & 688620 & 4.75 & 5.0184 & TST & \\
\hline CHEMBL1419795 & 688620 & 4.95 & 5.2706 & TST & \\
\hline CHEMBL1414458 & 688620 & 4.55 & 4.8879 & TST & \\
\hline CHEMBL1422034 & 688620 & 4.9 & 4.7277 & TRN & \\
\hline CHEMBL1328635 & 688620 & 4.75 & 5.2251 & TRN & \\
\hline CHEMBL1581194 & 688620 & 5.45 & 5.4808 & TST & \\
\hline CHEMBL1579680 & 688620 & 4.95 & 4.9873 & TST & \\
\hline CHEMBL1463847 & 688620 & 4.65 & 5.3232 & TRN & \\
\hline CHEMBL1361926 & 688620 & 4.65 & 5.0631 & TRN & \\
\hline CHEMBL3193878 & 688620 & 4.45 & 5.1368 & TRN & \\
\hline CHEMBL1501185 & 688620 & 5.4 & 4.9009 & TST & \\
\hline CHEMBL1373731 & 688620 & 5.0 & 5.4131 & TRN & \\
\hline CHEMBL1423419 & 688620 & 4.95 & 4.8131 & TST & \\
\hline CHEMBL1348668 & 688620 & 4.65 & 5.1671 & TRN & \\
\hline CHEMBL1449938 & 688620 & 4.45 & 5.2177 & TST & \\
\hline CHEMBL1373029 & 688620 & 5.05 & 4.98 & TRN & \\
\hline CHEMBL1602541 & 688620 & 4.65 & 5.0997 & TRN & \\
\hline CHEMBL1544368 & 688620 & 6.25 & 5.0429 & TRN & \\
\hline CHEMBL1323686 & 688620 & 4.45 & 4.7846 & TRN & \\
\hline CHEMBL1481023 & 688620 & 5.9 & 5.2728 & TRN & \\
\hline CHEMBL1482184 & 688620 & 4.95 & 4.8187 & TST & \\
\hline CHEMBL1594221 & 688620 & 5.3 & 5.2379 & TST & \\
\hline CHEMBL1360419 & 688620 & 5.2 & 5.3731 & TST & \\
\hline
\end{tabular}




\begin{tabular}{|c|c|c|c|c|c|}
\hline \multicolumn{6}{|c|}{ Supplemental Table S2.txt } \\
\hline CHEMBL3199262 & 688620 & 6.15 & 5.4419 & TST & \\
\hline CHEMBL3212531 & 688620 & 5.5 & 5.1042 & TST & \\
\hline CHEMBL1417275 & 688620 & 5.0 & 5.1293 & TRN & \\
\hline CHEMBL1301864 & 688620 & 4.45 & 5.0002 & TRN & \\
\hline CHEMBL1431506 & 688620 & 5.0 & 5.0714 & TRN & \\
\hline CHEMBL1432057 & 688620 & 5.15 & 5.4207 & TRN & \\
\hline CHEMBL1581528 & 688620 & 5.85 & 5.1793 & TRN & \\
\hline CHEMBL1308062 & 688620 & 5.3 & 5.3109 & TRN & \\
\hline CHEMBL3195005 & 688620 & 4.45 & 4.8428 & TRN & \\
\hline CHEMBL1424691 & 688620 & 4.65 & 4.7688 & TRN & \\
\hline CHEMBL1504623 & 688620 & 5.25 & 5.3055 & TRN & \\
\hline CHEMBL1384253 & 688620 & 5.45 & 5.5935 & TRN & \\
\hline CHEMBL3189433 & 688620 & 6.1 & 5.8418 & TRN & \\
\hline CHEMBL1480866 & 688620 & 4.75 & 4.9064 & TRN & \\
\hline CHEMBL1313852 & 688620 & 5.1 & 4.7313 & TRN & \\
\hline CHEMBL1322667 & 688620 & 6.0 & 5.1035 & TRN & \\
\hline CHEMBL1532065 & 688620 & 4.7 & 4.6362 & TRN & \\
\hline CHEMBL3192012 & 688620 & 5.4 & 5.3685 & TRN & \\
\hline CHEMBL1561920 & 688620 & 4.9 & 5.2011 & TST & \\
\hline CHEMBL1530758 & 688620 & 4.7 & 4.8976 & TRN & \\
\hline CHEMBL1606924 & 688620 & 4.95 & 4.8993 & TRN & \\
\hline CHEMBL1565635 & 688620 & 4.85 & 5.0703 & TRN & \\
\hline CHEMBL1409707 & 688620 & 4.45 & 4.9679 & TST & \\
\hline CHEMBL1576110 & 688620 & 5.25 & 5.2745 & TRN & \\
\hline CHEMBL1589119 & 688620 & 4.95 & 4.953 & TRN & \\
\hline CHEMBL1367222 & 688620 & 6.0 & 4.9351 & TRN & \\
\hline CHEMBL1452157 & 688620 & 5.15 & 5.3966 & TRN & \\
\hline CHEMBL1606326 & 688620 & 5.0 & 5.1684 & TRN & \\
\hline CHEMBL1476325 & 688620 & 5.15 & 4.9665 & TRN & \\
\hline CHEMBL1606098 & 688620 & 5.0 & 5.1022 & TRN & \\
\hline CHEMBL1461132 & 688620 & 4.95 & 5.0289 & TRN & \\
\hline CHEMBL1446917 & 688620 & 4.45 & 4.94300 & 00000000005 & TRN \\
\hline CHEMBL1541760 & 688620 & 4.45 & 4.9216 & TRN & \\
\hline CHEMBL1321713 & 688620 & 4.8 & 5.0101 & TRN & \\
\hline CHEMBL1598437 & 688620 & 4.75 & 4.8841 & TRN & \\
\hline CHEMBL1486751 & 688620 & 4.95 & 4.9194 & TRN & \\
\hline CHEMBL1489353 & 688620 & 6.0 & 4.9761 & TST & \\
\hline CHEMBL1314052 & 688620 & 5.2 & 5.7766 & TRN & \\
\hline CHEMBL1507315 & 688620 & 4.7 & 4.893 & TRN & \\
\hline CHEMBL1593872 & 688620 & 4.85 & 5.1716 & TRN & \\
\hline CHEMBL1366603 & 688620 & 5.0 & 5.5579 & TRN & \\
\hline CHEMBL395709 & 688620 & 4.9 & 4.8644 & TRN & \\
\hline CHEMBL1610689 & 688620 & 4.8 & 4.9027 & TRN & \\
\hline CHEMBL1469946 & 688620 & 4.45 & 5.0812 & TRN & \\
\hline CHEMBL1502883 & 688620 & 6.6 & 6.33799 & 9999999999 & TRN \\
\hline CHEMBL1319452 & 688620 & 6.0 & 5.3134 & TST & \\
\hline CHEMBL1531084 & 688620 & 7.0 & 5.073 & TRN & \\
\hline CHEMBL1303112 & 688620 & 5.2 & 4.8097 & TRN & \\
\hline
\end{tabular}




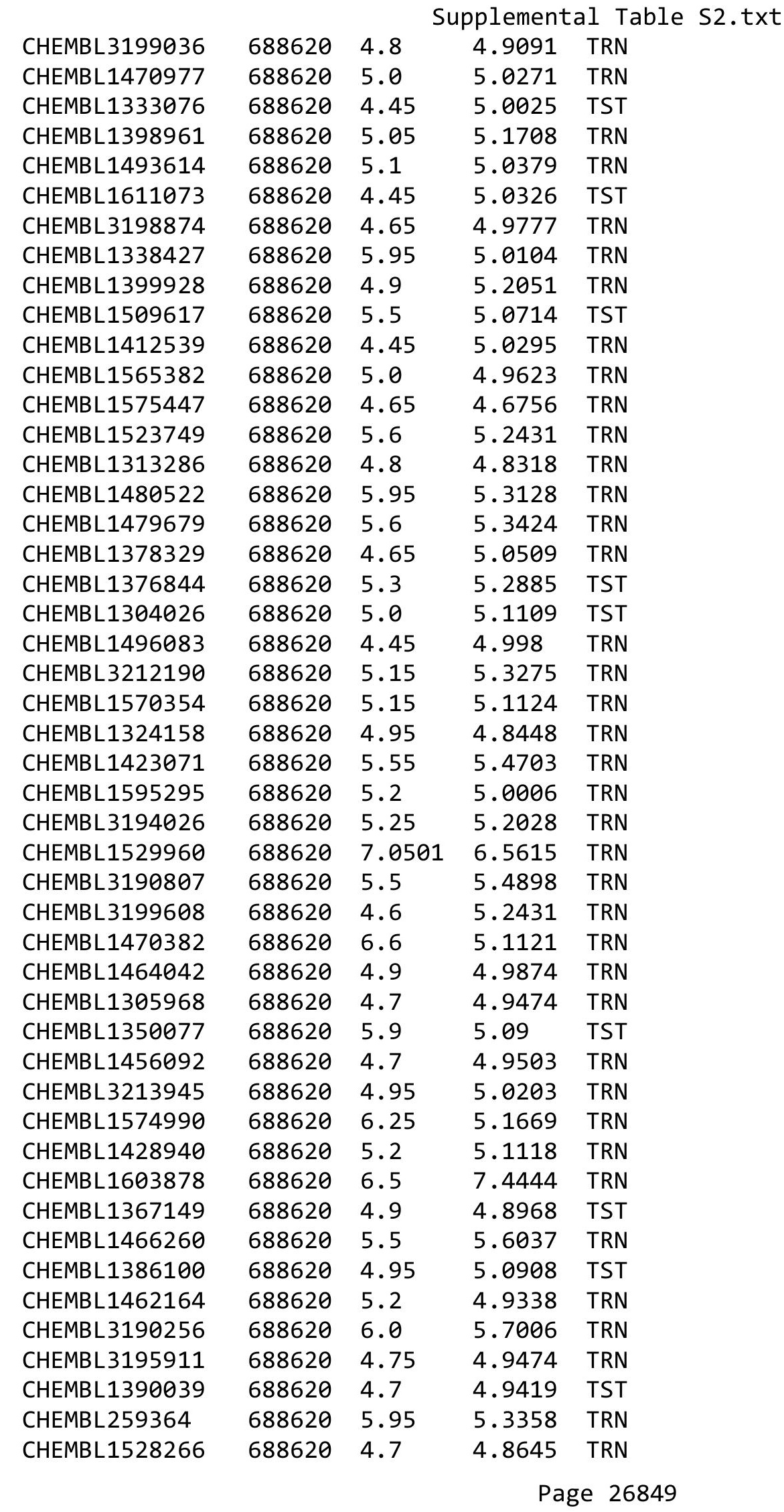




\begin{tabular}{|c|c|c|c|c|c|}
\hline & & & & & \\
\hline CHEMBL1462673 & 688620 & 4.45 & 5.1054 & TST & \\
\hline CHEMBL1546824 & 688620 & 5.65 & 5.15799 & 99999999995 & TRN \\
\hline CHEMBL1381850 & 688620 & 4.75 & 5.1857 & TRN & \\
\hline CHEMBL1348654 & 688620 & 5.0 & 4.6259 & TRN & \\
\hline CHEMBL1462936 & 688620 & 5.25 & 5.1827 & TST & \\
\hline CHEMBL1360461 & 688620 & 4.95 & 4.9635 & TRN & \\
\hline CHEMBL1583930 & 688620 & 5.25 & 5.066 & TST & \\
\hline CHEMBL3193447 & 688620 & 4.45 & 4.6674 & TRN & \\
\hline CHEMBL1986316 & 688620 & 5.5 & 5.3426 & TRN & \\
\hline CHEMBL1410414 & 688620 & 4.65 & 5.03600 & 00000000005 & TRN \\
\hline CHEMBL1584557 & 688620 & 6.5501 & 6.0651 & TRN & \\
\hline CHEMBL1543930 & 688620 & 5.6 & 4.8607 & TRN & \\
\hline CHEMBL3190001 & 688620 & 5.2 & 5.0049 & TRN & \\
\hline CHEMBL548619 & 688620 & 6.35 & 5.4911 & TRN & \\
\hline CHEMBL1391813 & 688620 & 4.75 & 5.0734 & TRN & \\
\hline CHEMBL399759 & 688620 & 4.55 & 4.9932 & TRN & \\
\hline CHEMBL1302903 & 688620 & 4.8 & 5.1838 & TST & \\
\hline CHEMBL573319 & 688620 & 6.0 & 5.6098 & TRN & \\
\hline CHEMBL1385248 & 688620 & 4.45 & 5.3493 & TST & \\
\hline CHEMBL1612695 & 688620 & 4.45 & 4.8751 & TRN & \\
\hline CHEMBL1385251 & 688620 & 5.3 & 4.6528 & TRN & \\
\hline CHEMBL1545583 & 688620 & 4.95 & 5.3213 & TST & \\
\hline CHEMBL1303494 & 688620 & 4.45 & 5.2095 & TRN & \\
\hline CHEMBL1436755 & 688620 & 4.75 & 5.0044 & TRN & \\
\hline CHEMBL1595562 & 688620 & 5.1 & 5.3191 & TRN & \\
\hline CHEMBL1485626 & 688620 & 4.45 & 4.5184 & TRN & \\
\hline CHEMBL1409270 & 688620 & 4.65 & 4.8645 & TRN & \\
\hline CHEMBL1579295 & 688620 & 4.95 & 4.7335 & TRN & \\
\hline CHEMBL1522723 & 688620 & 4.95 & 4.8084 & TRN & \\
\hline CHEMBL1393833 & 688620 & 5.0 & 4.8194 & TRN & \\
\hline CHEMBL1578485 & 688620 & 4.45 & 5.171 & TST & \\
\hline CHEMBL1597510 & 688620 & 4.45 & 4.5424 & TRN & \\
\hline CHEMBL3207418 & 688620 & 4.45 & 5.2065 & TRN & \\
\hline CHEMBL3197092 & 688620 & 5.6 & 5.3837 & TST & \\
\hline CHEMBL1332319 & 688620 & 7.4001 & 4.9273 & TST & \\
\hline CHEMBL1324532 & 688620 & 4.6 & 5.0276 & TRN & \\
\hline CHEMBL1609696 & 688620 & 4.45 & 4.6948 & TRN & \\
\hline CHEMBL 2005300 & 688620 & 5.15 & 5.3502 & TRN & \\
\hline CHEMBL1328598 & 688620 & 4.95 & 5.7165 & TRN & \\
\hline CHEMBL1413103 & 688620 & 5.15 & 4.9086 & TRN & \\
\hline CHEMBL1367750 & 688620 & 4.45 & 5.0386 & TST & \\
\hline CHEMBL1509509 & 688620 & 4.85 & 4.9477 & TRN & \\
\hline CHEMBL3191000 & 688620 & 4.65 & 5.5725 & TRN & \\
\hline CHEMBL1309733 & 688620 & 4.8 & 4.8527 & TRN & \\
\hline CHEMBL 1442598 & 688620 & 4.7 & 4.8947 & TRN & \\
\hline CHEMBL3392478 & 688620 & 5.4 & 4.9116 & TRN & \\
\hline CHEMBL1546590 & 688620 & 4.9 & 4.851 & TRN & \\
\hline CHEMBL1446323 & 688620 & 4.75 & 4.8612 & TRN & \\
\hline
\end{tabular}




\begin{tabular}{|c|c|c|c|c|}
\hline \multicolumn{5}{|c|}{ Supplemental Table S2.txt } \\
\hline CHEMBL1543659 & 688620 & 4.65 & 4.9869 & TRN \\
\hline CHEMBL1386011 & 688620 & 4.8 & 5.0193 & TRN \\
\hline CHEMBL1372421 & 688620 & 5.7 & 5.5525 & TRN \\
\hline CHEMBL1501108 & 688620 & 5.45 & 5.102 & TRN \\
\hline CHEMBL1412647 & 688620 & 6.1 & 6.1489 & TRN \\
\hline CHEMBL1331582 & 688620 & 4.95 & 5.1123 & TRN \\
\hline CHEMBL1487671 & 688620 & 4.45 & 4.949 & TRN \\
\hline CHEMBL1523524 & 688620 & 4.45 & 4.9745 & TRN \\
\hline CHEMBL1607486 & 688620 & 4.8 & 4.9076 & TRN \\
\hline CHEMBL3210268 & 688620 & 4.6 & 4.9179 & TST \\
\hline CHEMBL1336357 & 688620 & 6.6499 & 5.3111 & TRN \\
\hline CHEMBL1584397 & 688620 & 4.55 & 5.3294 & TRN \\
\hline CHEMBL1516853 & 688620 & 4.7 & 4.8927 & TRN \\
\hline CHEMBL1327969 & 688620 & 5.0 & 5.0386 & TRN \\
\hline CHEMBL3145316 & 688620 & 5.2 & 5.1796 & TST \\
\hline CHEMBL1598997 & 688620 & 4.9 & 5.0871 & TRN \\
\hline CHEMBL1302824 & 688620 & 4.9 & 4.7869 & TRN \\
\hline CHEMBL1559883 & 688620 & 4.8 & 5.6449 & TRN \\
\hline CHEMBL1516561 & 688620 & 4.45 & 4.8807 & TRN \\
\hline CHEMBL1365069 & 688620 & 5.65 & 5.1598 & TRN \\
\hline CHEMBL1373146 & 688620 & 5.05 & 5.0607 & TRN \\
\hline CHEMBL1526267 & 688620 & 4.75 & 5.0595 & TRN \\
\hline CHEMBL1332434 & 688620 & 4.45 & 4.822 & TST \\
\hline CHEMBL1385332 & 688620 & 4.8 & 5.115 & TRN \\
\hline CHEMBL1425183 & 688620 & 4.75 & 4.7621 & TRN \\
\hline CHEMBL1546176 & 688620 & 5.9 & 5.1898 & TRN \\
\hline CHEMBL1364354 & 688620 & 4.9 & 4.8547 & TRN \\
\hline CHEMBL1602753 & 688620 & 4.45 & 4.7316 & TRN \\
\hline CHEMBL1479278 & 688620 & 4.45 & 4.7791 & TRN \\
\hline CHEMBL209793 & 688620 & 4.45 & 5.1159 & TRN \\
\hline CHEMBL3189441 & 688620 & 4.95 & 5.0338 & TRN \\
\hline CHEMBL1497132 & 688620 & 5.0 & 4.9811 & TRN \\
\hline CHEMBL1576141 & 688620 & 4.5 & 4.9782 & TRN \\
\hline CHEMBL1611128 & 688620 & 5.4 & 5.2033 & TRN \\
\hline CHEMBL1534763 & 688620 & 5.5 & 4.8614 & TRN \\
\hline CHEMBL1305353 & 688620 & 4.9 & 4.9117 & TRN \\
\hline CHEMBL1478673 & 688620 & 5.05 & 4.4854 & TRN \\
\hline CHEMBL1330818 & 688620 & 5.0 & 5.19600 & 0000000001 \\
\hline CHEMBL1978355 & 688620 & 6.35 & 5.504 & TST \\
\hline CHEMBL1391031 & 688620 & 5.15 & 4.9191 & TRN \\
\hline CHEMBL1440487 & 688620 & 4.95 & 4.974 & TRN \\
\hline CHEMBL1370978 & 688620 & 5.75 & 5.0561 & TST \\
\hline CHEMBL1456910 & 688620 & 4.55 & 4.8057 & TRN \\
\hline CHEMBL1372914 & 688620 & 5.55 & 5.2495 & TRN \\
\hline CHEMBL1459380 & 688620 & 5.0 & 4.9872 & TRN \\
\hline CHEMBL1581439 & 688620 & 6.45 & 4.8525 & TRN \\
\hline CHEMBL1564773 & 688620 & 4.65 & 5.0272 & TST \\
\hline CHEMBL1430455 & 688620 & 5.05 & 5.2489 & TRN \\
\hline
\end{tabular}

TRN 


\begin{tabular}{|c|c|c|c|c|}
\hline \multicolumn{5}{|c|}{ Supplemental Table S2.txt } \\
\hline CHEMBL1414152 & 688620 & 4.45 & 4.9433 & TRN \\
\hline CHEMBL1532562 & 688620 & 4.95 & 4.9963 & TRN \\
\hline CHEMBL1342156 & 688620 & 5.25 & 4.7404 & TRN \\
\hline CHEMBL1317541 & 688620 & 4.65 & 5.0379 & TRN \\
\hline CHEMBL1481781 & 688620 & 4.95 & 5.2688 & TST \\
\hline CHEMBL1336539 & 688620 & 4.85 & 5.3188 & TRN \\
\hline CHEMBL1506317 & 688620 & 5.2 & 5.1147 & TRN \\
\hline CHEMBL1329020 & 688620 & 5.1 & 4.6396 & TST \\
\hline CHEMBL1490344 & 688620 & 4.9 & 4.9507 & TRN \\
\hline CHEMBL1536259 & 688620 & 5.1 & 4.9238 & TRN \\
\hline CHEMBL1453819 & 688620 & 5.05 & 5.119 & TRN \\
\hline CHEMBL1603256 & 688620 & 4.45 & 5.1704 & TRN \\
\hline CHEMBL 3211463 & 688620 & 4.9 & 4.7788 & TRN \\
\hline CHEMBL1527187 & 688620 & 4.9 & 4.9236 & TRN \\
\hline CHEMBL1470537 & 688620 & 4.95 & 5.3509 & TST \\
\hline CHEMBL1989467 & 688620 & 4.5 & 5.0154 & TRN \\
\hline CHEMBL1457453 & 688620 & 5.4 & 5.3981 & TRN \\
\hline CHEMBL1399717 & 688620 & 4.85 & 4.8215 & TST \\
\hline CHEMBL1431232 & 688620 & 4.95 & 4.9884 & TRN \\
\hline CHEMBL1539497 & 688620 & 4.85 & 4.8929 & TRN \\
\hline CHEMBL1575435 & 688620 & 5.5 & 4.9992 & TRN \\
\hline CHEMBL1325382 & 688620 & 4.7 & 4.8249 & TRN \\
\hline CHEMBL3190147 & 688620 & 4.45 & 4.997 & TST \\
\hline CHEMBL1370565 & 688620 & 4.6 & 5.0024 & TST \\
\hline CHEMBL1379959 & 688620 & 4.45 & 4.7517 & TRN \\
\hline CHEMBL1427536 & 688620 & 4.45 & 5.0089 & TRN \\
\hline CHEMBL1529493 & 688620 & 4.9 & 4.9078 & TRN \\
\hline CHEMBL1406889 & 688620 & 5.15 & 5.0595 & TRN \\
\hline CHEMBL1539414 & 688620 & 5.0 & 4.8987 & TRN \\
\hline CHEMBL1574150 & 688620 & 4.45 & 5.0287 & TRN \\
\hline CHEMBL1378350 & 688620 & 5.25 & 5.0438 & TRN \\
\hline CHEMBL1541064 & 688620 & 4.45 & 4.9184 & TRN \\
\hline CHEMBL1423622 & 688620 & 5.05 & 4.9913 & TRN \\
\hline CHEMBL3190740 & 688620 & 6.5 & 4.8991 & TRN \\
\hline CHEMBL1486041 & 688620 & 4.7 & 4.9373 & TST \\
\hline CHEMBL1380655 & 688620 & 5.05 & 5.2334 & TRN \\
\hline CHEMBL1996163 & 688620 & 4.75 & 4.7535 & TRN \\
\hline CHEMBL3199725 & 688620 & 6.6499 & 5.6888 & TRN \\
\hline CHEMBL1573524 & 688620 & 6.7001 & 5.3031 & TRN \\
\hline CHEMBL1992800 & 688620 & 5.2 & 5.4803 & TRN \\
\hline CHEMBL1354181 & 688620 & 4.9 & 4.7938 & TST \\
\hline CHEMBL1417893 & 688620 & 4.6 & 4.9068 & TRN \\
\hline CHEMBL1485577 & 688620 & 4.9 & 5.1253 & TRN \\
\hline CHEMBL1425715 & 688620 & 6.8499 & 5.5019 & TRN \\
\hline CHEMBL1413641 & 688620 & 4.75 & 4.9422 & TRN \\
\hline CHEMBL3198501 & 688620 & 4.45 & 5.0023 & TRN \\
\hline CHEMBL1160730 & 688620 & 4.45 & 4.9896 & TST \\
\hline CHEMBL1590855 & 688620 & 4.85 & 4.9769 & TRN \\
\hline
\end{tabular}




\begin{tabular}{|c|c|c|c|c|c|}
\hline \multicolumn{6}{|c|}{ Supplemental Table S2.txt } \\
\hline CHEMBL1550300 & 688620 & 4.55 & 4.877 & TST & \\
\hline CHEMBL1599453 & 688620 & 4.95 & 4.617 & TRN & \\
\hline CHEMBL1410412 & 688620 & 5.8 & 5.2216 & TRN & \\
\hline CHEMBL1575751 & 688620 & 4.45 & 4.735 & TST & \\
\hline CHEMBL1497012 & 688620 & 5.5 & 5.4727 & TRN & \\
\hline CHEMBL1336398 & 688620 & 4.45 & 5.0208 & TST & \\
\hline CHEMBL1396872 & 688620 & 4.8 & 5.078 & TRN & \\
\hline CHEMBL1611982 & 688620 & 5.35 & 5.1082 & TRN & \\
\hline CHEMBL1404335 & 688620 & 4.8 & 4.8638 & TST & \\
\hline CHEMBL1576660 & 688620 & 6.5501 & 5.2496 & TRN & \\
\hline CHEMBL1608400 & 688620 & 4.9 & 4.8913 & TST & \\
\hline CHEMBL1594775 & 688620 & 5.15 & 5.244 & TRN & \\
\hline CHEMBL1351231 & 688620 & 4.5 & 4.9 & TRN & \\
\hline CHEMBL1570490 & 688620 & 5.6 & 5.5664 & TRN & \\
\hline CHEMBL1576291 & 688620 & 4.45 & 4.7689 & TRN & \\
\hline CHEMBL1559713 & 688620 & 5.65 & 4.966 & TRN & \\
\hline CHEMBL1407598 & 688620 & 6.5501 & 5.9096 & TRN & \\
\hline CHEMBL1579518 & 688620 & 4.9 & 5.107 & TRN & \\
\hline CHEMBL1304951 & 688620 & 4.65 & 5.13 & TRN & \\
\hline CHEMBL1480062 & 688620 & 5.1 & 4.7496 & TST & \\
\hline CHEMBL1383731 & 688620 & 5.0 & 5.0014 & TRN & \\
\hline CHEMBL1510663 & 688620 & 4.45 & 5.0771 & TST & \\
\hline CHEMBL1392843 & 688620 & 4.95 & 4.6163 & TST & \\
\hline CHEMBL1588476 & 688620 & 4.45 & 4.8057 & TST & \\
\hline CHEMBL1325826 & 688620 & 4.7 & 4.9638 & TST & \\
\hline CHEMBL1307811 & 688620 & 4.9 & 4.9873 & TRN & \\
\hline CHEMBL478589 & 688620 & 5.2 & 5.1264 & TST & \\
\hline CHEMBL1426119 & 688620 & 4.45 & 5.1243 & TST & \\
\hline CHEMBL1382842 & 688620 & 5.2 & 4.9314 & TRN & \\
\hline CHEMBL1479077 & 688620 & 4.65 & 4.9638 & TRN & \\
\hline CHEMBL1460388 & 688620 & 4.45 & 4.9262 & TRN & \\
\hline CHEMBL1587516 & 688620 & 4.65 & 4.80399 & 9999999999 & TRN \\
\hline CHEMBL1587178 & 688620 & 5.15 & 5.1984 & TRN & \\
\hline CHEMBL3199574 & 688620 & 5.15 & 5.218 & TRN & \\
\hline CHEMBL1384512 & 688620 & 4.9 & 5.0318 & TRN & \\
\hline CHEMBL1307425 & 688620 & 4.7 & 5.0105 & TST & \\
\hline CHEMBL3198415 & 688620 & 4.95 & 5.472 & TST & \\
\hline CHEMBL1393538 & 688620 & 4.95 & 5.0938 & TRN & \\
\hline CHEMBL 3189301 & 688620 & 6.3 & 5.7232 & TRN & \\
\hline CHEMBL1465813 & 688620 & 4.5 & 4.8916 & TRN & \\
\hline CHEMBL1431451 & 688620 & 5.45 & 4.956 & TRN & \\
\hline CHEMBL1604007 & 688620 & 5.65 & 5.4251 & TRN & \\
\hline CHEMBL1501360 & 688620 & 4.65 & 4.8924 & TRN & \\
\hline CHEMBL1581769 & 688620 & 5.7 & 5.485 & TRN & \\
\hline CHEMBL1453305 & 688620 & 4.5 & 5.0373 & TRN & \\
\hline CHEMBL1433146 & 688620 & 4.9 & 4.9491 & TRN & \\
\hline CHEMBL1534193 & 688620 & 4.45 & 5.0036 & TRN & \\
\hline CHEMBL1526981 & 688620 & 5.45 & 4.8126 & TRN & \\
\hline
\end{tabular}




\begin{tabular}{|c|c|c|c|c|c|}
\hline \multicolumn{6}{|c|}{ Supplemental Table s2.txt } \\
\hline CHEMBL1429674 & 688620 & 5.45 & 5.1355 & TRN & \\
\hline CHEMBL1608986 & 688620 & 5.55 & 5.4501 & TRN & \\
\hline CHEMBL1534154 & 688620 & 6.45 & 4.9271 & TRN & \\
\hline CHEMBL1456930 & 688620 & 4.45 & 4.8597 & TRN & \\
\hline CHEMBL1448849 & 688620 & 5.15 & 4.8728 & TRN & \\
\hline CHEMBL1375115 & 688620 & 4.95 & 5.0672 & TST & \\
\hline CHEMBL1544502 & 688620 & 5.45 & 5.0938 & TST & \\
\hline CHEMBL1365685 & 688620 & 5.0 & 5.1968 & TST & \\
\hline CHEMBL 2373553 & 688620 & 4.45 & 5.1477 & TRN & \\
\hline CHEMBL1385686 & 688620 & 5.85 & 5.666 & TST & \\
\hline CHEMBL220845 & 688620 & 4.65 & 5.0867 & TRN & \\
\hline CHEMBL1307394 & 688620 & 6.0 & 5.1023 & TRN & \\
\hline CHEMBL1352270 & 688620 & 5.5 & 5.442 & TRN & \\
\hline CHEMBL3195040 & 688620 & 4.9 & 4.8017 & TRN & \\
\hline CHEMBL1442245 & 688620 & 5.5 & 5.0719 & TRN & \\
\hline CHEMBL1462028 & 688620 & 6.5 & 5.86100 & 0000000001 & TRN \\
\hline CHEMBL1389279 & 688620 & 4.9 & 4.9317 & TRN & \\
\hline CHEMBL1467043 & 688620 & 4.9 & 4.9678 & TRN & \\
\hline CHEMBL1305281 & 688620 & 4.45 & 4.9649 & TRN & \\
\hline CHEMBL1998715 & 688620 & 5.55 & 5.5324 & TRN & \\
\hline CHEMBL1419788 & 688620 & 4.9 & 5.0299 & TRN & \\
\hline CHEMBL45349 & 688620 & 4.45 & 5.0641 & TST & \\
\hline CHEMBL1559611 & 688620 & 4.7 & 4.9689 & TRN & \\
\hline CHEMBL3190693 & 688620 & 4.95 & 5.0875 & TRN & \\
\hline CHEMBL1532401 & 688620 & 4.9 & 5.13299 & 9999999999 & TST \\
\hline CHEMBL1581898 & 688620 & 5.2 & 5.0542 & TRN & \\
\hline CHEMBL1542290 & 688620 & 4.9 & 5.1348 & TRN & \\
\hline CHEMBL1424275 & 688620 & 5.05 & 5.1078 & TST & \\
\hline CHEMBL1441442 & 688620 & 5.3 & 5.1001 & TST & \\
\hline CHEMBL1546502 & 688620 & 5.0 & 5.0853 & TRN & \\
\hline CHEMBL1389789 & 688620 & 5.0 & 4.9951 & TRN & \\
\hline CHEMBL1603854 & 688620 & 5.45 & 5.215 & TST & \\
\hline CHEMBL1395710 & 688620 & 6.25 & 4.8346 & TRN & \\
\hline CHEMBL1328579 & 688620 & 4.95 & 5.20100 & 00000000005 & TST \\
\hline CHEMBL1419364 & 688620 & 5.0 & 5.0089 & TRN & \\
\hline CHEMBL1424057 & 688620 & 4.95 & 5.1372 & TRN & \\
\hline CHEMBL1510459 & 688620 & 4.5 & 4.5863 & TRN & \\
\hline CHEMBL1415839 & 688620 & 6.4 & 6.1646 & TRN & \\
\hline CHEMBL1549096 & 688620 & 5.6 & 5.7404 & TRN & \\
\hline CHEMBL1606115 & 688620 & 4.95 & 5.11 & TST & \\
\hline CHEMBL1583323 & 688620 & 5.25 & 5.1561 & TRN & \\
\hline CHEMBL1400358 & 688620 & 5.0 & 4.9842 & TST & \\
\hline CHEMBL1470195 & 688620 & 5.3 & 5.0383 & TRN & \\
\hline CHEMBL1377993 & 688620 & 4.9 & 4.8606 & TRN & \\
\hline CHEMBL3190771 & 688620 & 4.9 & 5.3285 & TRN & \\
\hline CHEMBL1587605 & 688620 & 4.65 & 4.8129 & TST & \\
\hline CHEMBL1314017 & 688620 & 4.95 & 5.032 & TRN & \\
\hline CHEMBL1433854 & 688620 & 4.85 & 5.0549 & TRN & \\
\hline
\end{tabular}




\begin{tabular}{|c|c|c|c|c|c|}
\hline \multirow[b]{2}{*}{ CHEMBL1356336 } & \multicolumn{5}{|c|}{ olemental Table S2. } \\
\hline & 688620 & 4.95 & 4.6627 & TRN & \\
\hline CHEMBL1579710 & 688620 & 5.0 & 4.9906 & TST & \\
\hline CHEMBL1352208 & 688620 & 4.8 & $4.9830 e$ & 00000000005 & TRN \\
\hline CHEMBL1585270 & 688620 & 5.15 & 5.2851 & TRN & \\
\hline CHEMBL1380763 & 688620 & 4.85 & 4.6593 & TRN & \\
\hline CHEMBL1603032 & 688620 & 5.5 & 5.2336 & TST & \\
\hline CHEMBL3209710 & 688620 & 4.9 & 4.8333 & TRN & \\
\hline CHEMBL1299517 & 688620 & 4.65 & 5.2905 & TRN & \\
\hline CHEMBL1487438 & 688620 & 5.15 & 5.17299 & 9999999999 & TST \\
\hline CHEMBL1384750 & 688620 & 5.2 & 4.9899 & TRN & \\
\hline CHEMBL1301688 & 688620 & 5.2 & 4.8685 & TST & \\
\hline CHEMBL1469898 & 688620 & 4.45 & 4.9231 & TRN & \\
\hline CHEMBL1422482 & 688620 & 5.55 & 5.5875 & TST & \\
\hline CHEMBL1320127 & 688620 & 4.85 & 5.1765 & TRN & \\
\hline CHEMBL1372781 & 688620 & 4.45 & 4.9416 & TRN & \\
\hline CHEMBL1454606 & 688620 & 5.85 & 5.0263 & TST & \\
\hline CHEMBL1598701 & 688620 & 4.75 & 5.1155 & TRN & \\
\hline CHEMBL1518244 & 688620 & 5.25 & 5.1077 & TRN & \\
\hline CHEMBL1364824 & 688620 & 5.4 & 5.1925 & TRN & \\
\hline CHEMBL1573071 & 688620 & 5.4 & 5.386 & TST & \\
\hline CHEMBL1557622 & 688620 & 5.5 & 4.7362 & TRN & \\
\hline CHEMBL1595865 & 688620 & 5.2 & 5.0976 & TST & \\
\hline CHEMBL1306023 & 688620 & 4.75 & 5.1517 & TRN & \\
\hline CHEMBL1978534 & 688620 & 4.85 & 4.9222 & TST & \\
\hline CHEMBL1572197 & 688620 & 4.8 & 4.9205 & TRN & \\
\hline CHEMBL1411665 & 688620 & 5.4 & 5.3982 & TRN & \\
\hline CHEMBL3213147 & 688620 & 4.6 & 5.2293 & TST & \\
\hline CHEMBL3198912 & 688620 & 4.65 & 5.1902 & TRN & \\
\hline CHEMBL1529236 & 688620 & 4.65 & 4.5981 & TRN & \\
\hline CHEMBL1979536 & 688620 & 4.45 & 4.755 & TRN & \\
\hline CHEMBL1510063 & 688620 & 5.15 & 4.825 & TRN & \\
\hline CHEMBL1334604 & 688620 & 4.75 & 4.9829 & TRN & \\
\hline CHEMBL1904459 & 688620 & 5.95 & 5.4327 & TRN & \\
\hline CHEMBL1309377 & 688620 & 5.45 & 5.1865 & TRN & \\
\hline CHEMBL1458024 & 688620 & 4.85 & 5.0478 & TRN & \\
\hline CHEMBL1550561 & 688620 & 4.95 & 5.0046 & TRN & \\
\hline CHEMBL1315275 & 688620 & 4.85 & 4.9516 & TRN & \\
\hline CHEMBL1299977 & 688620 & 5.1 & 5.9232 & TRN & \\
\hline CHEMBL1338471 & 688620 & 4.45 & 5.0301 & TRN & \\
\hline CHEMBL1453044 & 688620 & 4.85 & 5.029 & TST & \\
\hline CHEMBL1310171 & 688620 & 4.6 & 5.0369 & TRN & \\
\hline CHEMBL1557499 & 688620 & 5.8 & 5.0406 & TRN & \\
\hline CHEMBL1575873 & 688620 & 4.95 & 5.157 & TRN & \\
\hline CHEMBL1409547 & 688620 & 6.0 & 5.0584 & TRN & \\
\hline CHEMBL1397519 & 688620 & 5.0 & 5.1546 & TST & \\
\hline CHEMBL1579339 & 688620 & 5.2 & 5.3259 & TRN & \\
\hline CHEMBL1500973 & 688620 & 4.75 & 5.2683 & TST & \\
\hline CHEMBL1346036 & 688620 & 4.8 & 5.1248 & TST & \\
\hline & & & & 26855 & \\
\hline
\end{tabular}




\begin{tabular}{|c|c|c|c|c|c|}
\hline \multicolumn{6}{|c|}{ Supplemental Table S2.txt } \\
\hline CHEMBL1332712 & 688620 & 4.45 & 5.008 & TST & \\
\hline CHEMBL1507643 & 688620 & 4.5 & 5.0338 & TST & \\
\hline CHEMBL1578460 & 688620 & 5.15 & 5.6046 & TRN & \\
\hline CHEMBL1425572 & 688620 & 4.9 & 5.2357 & TRN & \\
\hline CHEMBL1327539 & 688620 & 4.95 & 4.843 & TST & \\
\hline CHEMBL1372953 & 688620 & 5.0 & 5.2025 & TRN & \\
\hline CHEMBL1387729 & 688620 & 4.45 & 4.9288 & TRN & \\
\hline CHEMBL1444420 & 688620 & 6.45 & 5.0933 & TRN & \\
\hline CHEMBL1547071 & 688620 & 4.75 & 4.9606 & TRN & \\
\hline CHEMBL1582214 & 688620 & 5.3 & 5.0358 & TRN & \\
\hline CHEMBL1507345 & 688620 & 4.45 & 4.7637 & TST & \\
\hline CHEMBL1448965 & 688620 & 5.3 & 5.6378 & TRN & \\
\hline CHEMBL1539056 & 688620 & 6.15 & 5.70100 & 00000000005 & TST \\
\hline CHEMBL1549820 & 688620 & 4.6 & 4.9459 & TRN & \\
\hline CHEMBL3208509 & 688620 & 4.9 & 5.0808 & TRN & \\
\hline CHEMBL1378903 & 688620 & 6.95 & 4.9617 & TST & \\
\hline CHEMBL1382865 & 688620 & 6.1 & 5.5973 & TRN & \\
\hline CHEMBL1499474 & 688620 & 5.0 & 4.9332 & TST & \\
\hline CHEMBL1525086 & 688620 & 5.1 & 4.8459 & TST & \\
\hline CHEMBL1472027 & 688620 & 5.0 & 5.0867 & TST & \\
\hline CHEMBL1456919 & 688620 & 6.8499 & 4.9926 & TRN & \\
\hline CHEMBL1549432 & 688620 & 5.55 & 5.2668 & TRN & \\
\hline CHEMBL3214597 & 688620 & 4.6 & 4.9806 & TRN & \\
\hline CHEMBL1322022 & 688620 & 4.8 & 5.0297 & TRN & \\
\hline CHEMBL1365091 & 688620 & 5.6 & 5.1063 & TRN & \\
\hline CHEMBL1376440 & 688620 & 4.95 & 4.8947 & TRN & \\
\hline CHEMBL1411205 & 688620 & 5.0 & 5.0605 & TRN & \\
\hline CHEMBL1999551 & 688620 & 5.5 & 5.2866 & TRN & \\
\hline CHEMBL1453498 & 688620 & 4.65 & 5.1743 & TST & \\
\hline CHEMBL1348147 & 688620 & 4.5 & 5.4165 & TRN & \\
\hline CHEMBL1488289 & 688620 & 4.45 & 4.9738 & TRN & \\
\hline CHEMBL1550034 & 688620 & 4.95 & 4.8348 & TRN & \\
\hline CHEMBL1537745 & 688620 & 4.5 & 4.8714 & TST & \\
\hline CHEMBL1525961 & 688620 & 5.3 & 5.3155 & TRN & \\
\hline CHEMBL1393827 & 688620 & 4.45 & 4.9907 & TST & \\
\hline CHEMBL1432341 & 688620 & 4.45 & 5.1528 & TST & \\
\hline CHEMBL1470132 & 688620 & 5.55 & 5.0588 & TRN & \\
\hline CHEMBL3193289 & 688620 & 4.85 & 5.2525 & TRN & \\
\hline CHEMBL1308343 & 688620 & 5.45 & 5.0892 & TRN & \\
\hline CHEMBL1523064 & 688620 & 4.55 & 4.9842 & TST & \\
\hline CHEMBL1387261 & 688620 & 4.55 & 4.9594 & TST & \\
\hline CHEMBL1307972 & 688620 & 5.85 & 5.4308 & TRN & \\
\hline CHEMBL3193751 & 688620 & 4.95 & 4.9153 & TRN & \\
\hline CHEMBL1459784 & 688620 & 4.95 & 4.916 & TRN & \\
\hline CHEMBL1565644 & 688620 & 5.0 & 4.9155 & TST & \\
\hline CHEMBL1574193 & 688620 & 4.5 & 5.2063 & TRN & \\
\hline CHEMBL1567571 & 688620 & 4.85 & 5.2213 & TST & \\
\hline CHEMBL1318058 & 688620 & 4.5 & 5.0425 & TST & \\
\hline
\end{tabular}




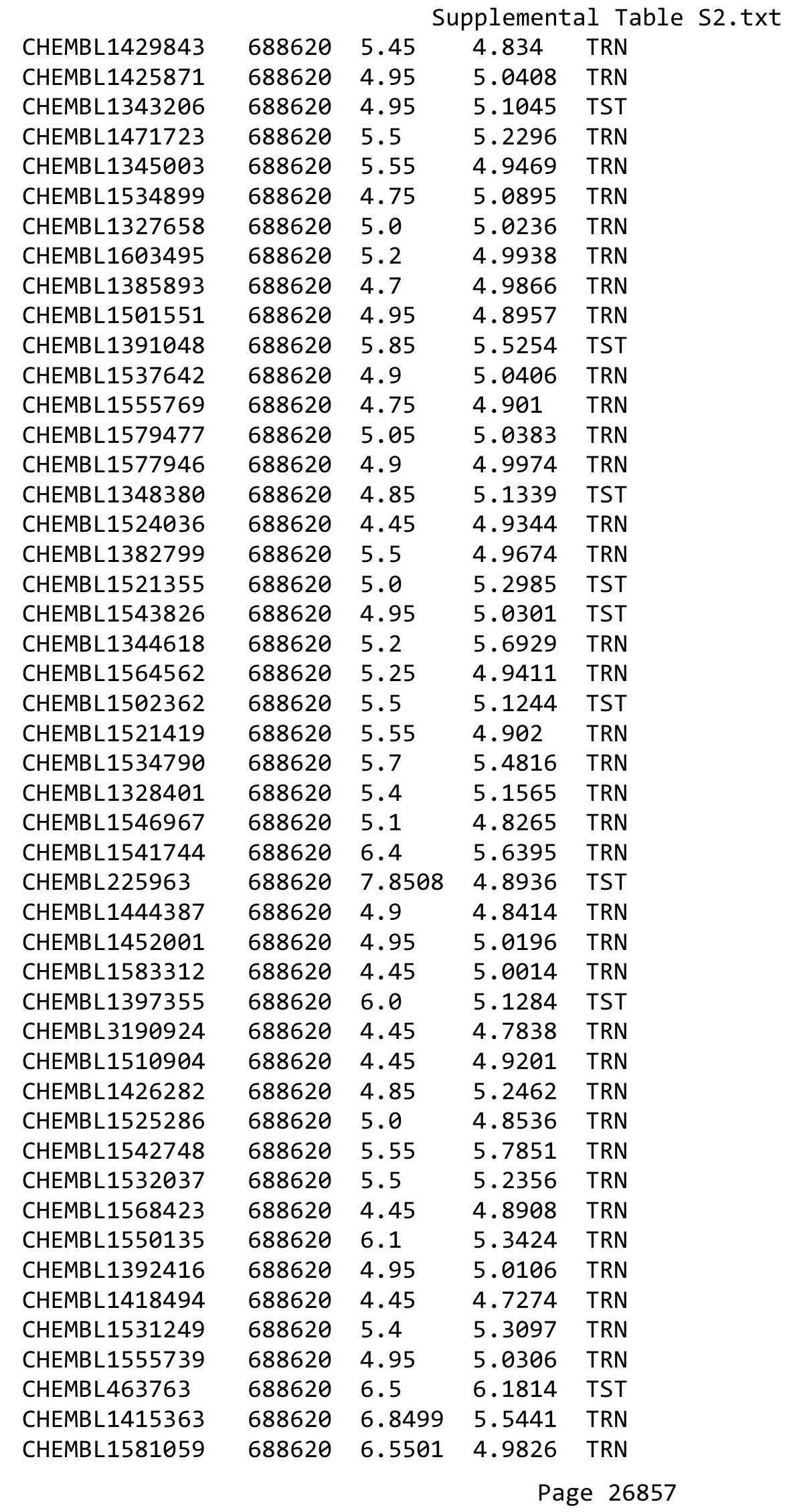




\begin{tabular}{|c|c|c|c|c|c|}
\hline \\
\hline CHEMBL3193890 & 688620 & 4.8 & 5.2247 & TRN & \\
\hline CHEMBL1519049 & 688620 & 4.45 & 5.1202 & TST & \\
\hline CHEMBL1332286 & 688620 & 4.5 & 5.1188 & TST & \\
\hline CHEMBL3208540 & 688620 & 5.4 & 5.0165 & TRN & \\
\hline CHEMBL1581301 & 688620 & 4.85 & 5.0277 & TST & \\
\hline CHEMBL1596655 & 688620 & 5.2 & 4.7341 & TST & \\
\hline CHEMBL1602768 & 688620 & 5.2 & 5.3683 & TRN & \\
\hline CHEMBL1409852 & 688620 & 4.85 & 4.96899 & 7999999999 & TRN \\
\hline CHEMBL1544090 & 688620 & 4.65 & 4.9348 & TST & \\
\hline CHEMBL1506670 & 688620 & 4.95 & 4.9771 & TRN & \\
\hline CHEMBL1478186 & 688620 & 4.95 & 5.0035 & TRN & \\
\hline CHEMBL1596403 & 688620 & 4.9 & 5.0437 & TRN & \\
\hline CHEMBL1470381 & 688620 & 4.95 & 4.9989 & TRN & \\
\hline CHEMBL1486818 & 688620 & 4.9 & 4.9798 & TRN & \\
\hline CHEMBL1537787 & 688620 & 5.5 & 5.067 & TRN & \\
\hline CHEMBL1381439 & 688620 & 4.7 & 5.2287 & TST & \\
\hline CHEMBL1487578 & 688620 & 4.9 & 4.9198 & TRN & \\
\hline CHEMBL1359087 & 688620 & 5.15 & 4.9243 & TRN & \\
\hline CHEMBL1559514 & 688620 & 4.75 & 5.3508 & TRN & \\
\hline CHEMBL1428400 & 688620 & 6.8 & 5.6046 & TRN & \\
\hline CHEMBL1487740 & 688620 & 6.6 & 4.9605 & TST & \\
\hline CHEMBL1569944 & 688620 & 5.5 & 5.1916 & TRN & \\
\hline CHEMBL516494 & 688620 & 4.95 & 4.9846 & TST & \\
\hline CHEMBL1529261 & 688620 & 8.2007 & 5.67700 & 00000000005 & TRN \\
\hline CHEMBL1453898 & 688620 & 4.9 & 4.9957 & TRN & \\
\hline CHEMBL1479744 & 688620 & 4.75 & 4.999 & TRN & \\
\hline CHEMBL1547832 & 688620 & 5.55 & 5.0474 & TRN & \\
\hline CHEMBL1361754 & 688620 & 4.65 & 4.8475 & TRN & \\
\hline CHEMBL1368330 & 688620 & 4.95 & 4.7542 & TRN & \\
\hline CHEMBL1322151 & 688620 & 4.65 & 4.7541 & TRN & \\
\hline CHEMBL1330038 & 688620 & 5.15 & 4.8938 & TRN & \\
\hline CHEMBL1595940 & 688620 & 5.95 & 5.3062 & TRN & \\
\hline CHEMBL1528686 & 688620 & 6.5 & 4.9595 & TRN & \\
\hline CHEMBL1600341 & 688620 & 4.5 & 5.1473 & TST & \\
\hline CHEMBL1311195 & 688620 & 5.5 & 4.9561 & TST & \\
\hline CHEMBL1490854 & 688620 & 5.9 & 5.2328 & TRN & \\
\hline CHEMBL1319933 & 688620 & 5.2 & 5.0007 & TRN & \\
\hline CHEMBL1478967 & 688620 & 4.85 & 4.9215 & TST & \\
\hline CHEMBL1560681 & 688620 & 5.0 & 5.0767 & TRN & \\
\hline CHEMBL1516589 & 688620 & 4.75 & 4.8786 & TRN & \\
\hline CHEMBL1335625 & 688620 & 4.85 & 5.0195 & TRN & \\
\hline CHEMBL1310057 & 688620 & 4.9 & 5.1454 & TRN & \\
\hline CHEMBL1348093 & 688620 & 5.3 & 5.2197 & TST & \\
\hline CHEMBL1306457 & 688620 & 4.45 & 4.9089 & TST & \\
\hline CHEMBL1313241 & 688620 & 4.65 & 4.8429 & TRN & \\
\hline CHEMBL1536014 & 688620 & 5.3 & 5.2188 & TRN & \\
\hline CHEMBL1535086 & 688620 & 5.4 & 5.0859 & TRN & \\
\hline CHEMBL1555120 & 688620 & 4.65 & 5.2722 & TST & \\
\hline
\end{tabular}




\begin{tabular}{|c|c|c|c|c|c|}
\hline \multicolumn{6}{|c|}{ Supplemental Table S2.txt } \\
\hline CHEMBL1365242 & 688620 & 6.0 & 5.9963 & TRN & \\
\hline CHEMBL1595329 & 688620 & 4.7 & 4.9883 & TST & \\
\hline CHEMBL1561021 & 688620 & 6.6499 & 4.9961 & TST & \\
\hline CHEMBL1550344 & 688620 & 4.8 & 4.9535 & TRN & \\
\hline CHEMBL3196754 & 688620 & 5.55 & 5.4416 & TRN & \\
\hline CHEMBL3198296 & 688620 & 5.4 & 5.0033 & TRN & \\
\hline CHEMBL1508673 & 688620 & 4.9 & 5.0192 & TRN & \\
\hline CHEMBL1376116 & 688620 & 5.2 & 5.0295 & TRN & \\
\hline CHEMBL1418789 & 688620 & 4.95 & 5.0997 & TRN & \\
\hline CHEMBL1406194 & 688620 & 4.95 & 4.9803 & TST & \\
\hline CHEMBL1503699 & 688620 & 4.9 & 4.9086 & TRN & \\
\hline CHEMBL1545639 & 688620 & 6.3 & 5.1444 & TRN & \\
\hline CHEMBL1566740 & 688620 & 4.45 & 4.9709 & TST & \\
\hline CHEMBL3211818 & 688620 & 5.6 & 5.1497 & TRN & \\
\hline CHEMBL573524 & 688620 & 5.7 & 5.1237 & TRN & \\
\hline CHEMBL1335030 & 688620 & 5.55 & 5.8745 & TRN & \\
\hline CHEMBL3199268 & 688620 & 4.75 & 4.7828 & TRN & \\
\hline CHEMBL3193544 & 688620 & 5.25 & 5.2072 & TRN & \\
\hline CHEMBL1460269 & 688620 & 4.6 & 5.0225 & TRN & \\
\hline CHEMBL3392364 & 688620 & 6.05 & 6.055 & TRN & \\
\hline CHEMBL1579831 & 688620 & 4.45 & 4.8856 & TRN & \\
\hline CHEMBL3192469 & 688620 & 4.45 & 4.9949 & TRN & \\
\hline CHEMBL1393179 & 688620 & 5.35 & 4.8572 & TRN & \\
\hline CHEMBL3209367 & 688620 & 4.5 & 4.9382 & TRN & \\
\hline CHEMBL 3210471 & 688620 & 5.0 & 5.17299 & 9999999999 & TRN \\
\hline CHEMBL1508351 & 688620 & 5.65 & 5.5369 & TRN & \\
\hline CHEMBL1569810 & 688620 & 4.45 & 5.0148 & TRN & \\
\hline CHEMBL1602402 & 688620 & 4.45 & 5.1006 & TRN & \\
\hline CHEMBL1329937 & 688620 & 5.2 & 5.0771 & TRN & \\
\hline CHEMBL1596063 & 688620 & 4.85 & 4.9496 & TRN & \\
\hline CHEMBL379179 & 688620 & 5.1 & 5.3782 & TRN & \\
\hline CHEMBL1349162 & 688620 & 4.45 & 5.1332 & TST & \\
\hline CHEMBL1377540 & 688620 & 4.9 & 5.0342 & TRN & \\
\hline CHEMBL1566503 & 688620 & 5.0 & 5.0833 & TRN & \\
\hline CHEMBL1427621 & 688620 & 6.5501 & 5.5163 & TRN & \\
\hline CHEMBL3196633 & 688620 & 5.4 & 5.5173 & TRN & \\
\hline CHEMBL1426114 & 688620 & 4.9 & 5.0954 & TRN & \\
\hline CHEMBL1384904 & 688620 & 4.6 & 5.0809 & TST & \\
\hline CHEMBL1426033 & 688620 & 6.35 & 5.2209 & TST & \\
\hline CHEMBL1471343 & 688620 & 4.85 & 4.9603 & TST & \\
\hline CHEMBL1533651 & 688620 & 4.8 & 5.2135 & TST & \\
\hline CHEMBL1427078 & 688620 & 4.7 & 5.1819 & TRN & \\
\hline CHEMBL1429718 & 688620 & 5.9 & 5.9579 & TST & \\
\hline CHEMBL1603666 & 688620 & 4.45 & 5.16700 & 0000000001 & TRN \\
\hline CHEMBL1442889 & 688620 & 5.45 & 5.0718 & TRN & \\
\hline CHEMBL1464308 & 688620 & 5.0 & 4.8187 & TRN & \\
\hline CHEMBL1518146 & 688620 & 4.95 & 4.9825 & TRN & \\
\hline CHEMBL1501284 & 688620 & 4.85 & 4.8906 & TRN & \\
\hline
\end{tabular}




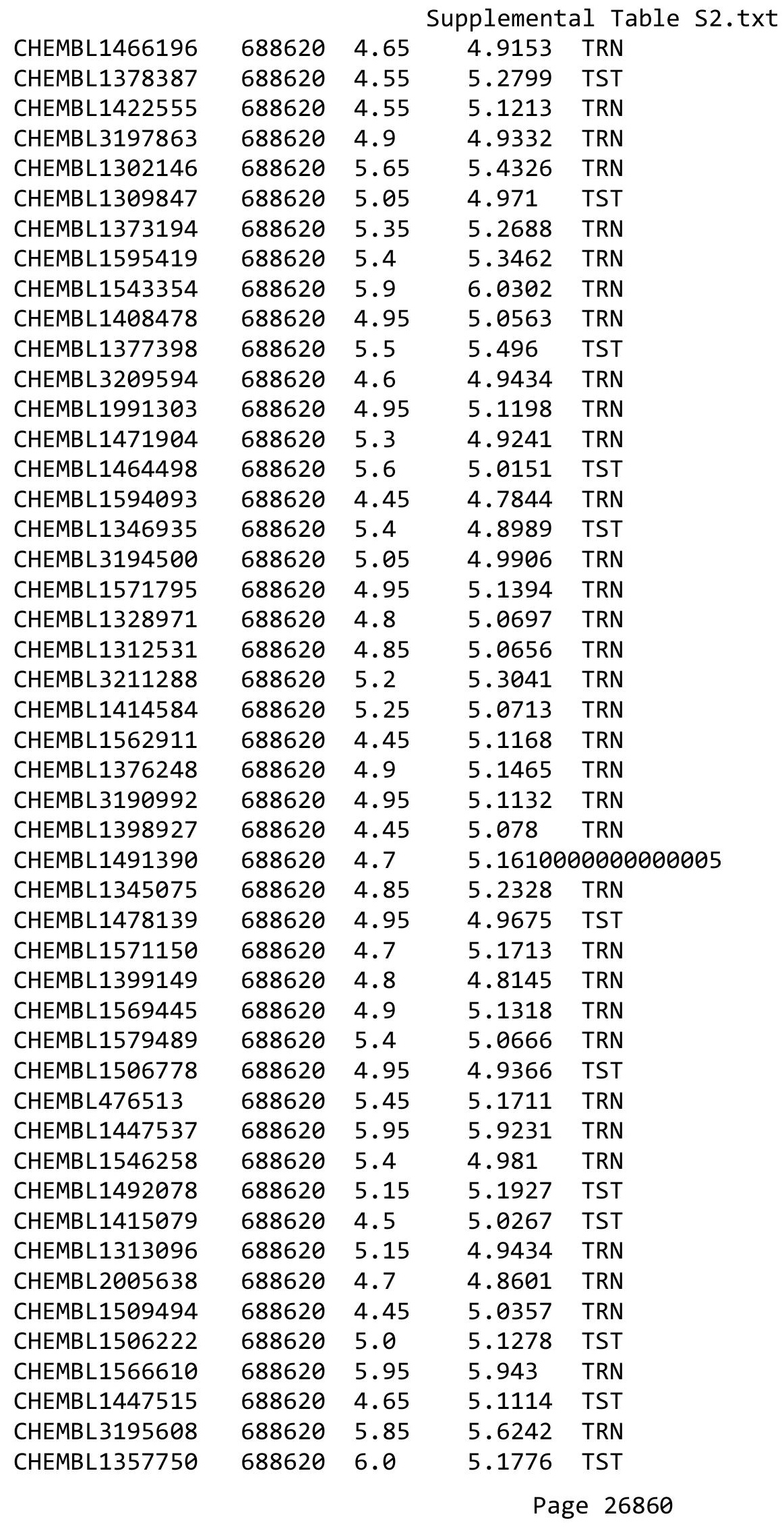




\begin{tabular}{|c|c|c|c|c|c|}
\hline & & \multicolumn{4}{|c|}{ Supplemental Table S2.txt } \\
\hline CHEMBL1376227 & 688620 & 4.45 & 4.9843 & TRN & \\
\hline CHEMBL1408101 & 688620 & 4.7 & 5.0121 & TRN & \\
\hline CHEMBL1411594 & 688620 & 4.45 & 4.9734 & TRN & \\
\hline CHEMBL1539187 & 688620 & 4.8 & 4.926 & TRN & \\
\hline CHEMBL1579069 & 688620 & 4.85 & 4.9835 & TRN & \\
\hline CHEMBL3212894 & 688620 & 6.05 & 5.9783 & TRN & \\
\hline CHEMBL1382652 & 688620 & 5.25 & 5.1502 & TST & \\
\hline CHEMBL1454792 & 688620 & 4.95 & 4.9883 & TRN & \\
\hline CHEMBL1347277 & 688620 & 4.85 & 5.074 & TRN & \\
\hline CHEMBL3196182 & 688620 & 5.65 & 4.9818 & TST & \\
\hline CHEMBL1412178 & 688620 & 4.45 & 4.9423 & TRN & \\
\hline CHEMBL1543872 & 688620 & 4.45 & 4.7695 & TRN & \\
\hline CHEMBL1469698 & 688620 & 4.95 & 4.8899 & TRN & \\
\hline CHEMBL1544250 & 688620 & 4.7 & 4.8695 & TRN & \\
\hline CHEMBL1344656 & 688620 & 4.85 & 5.2806 & TRN & \\
\hline CHEMBL1575397 & 688620 & 4.45 & 5.1813 & TRN & \\
\hline CHEMBL1317451 & 688620 & 4.6 & 4.5602 & TRN & \\
\hline CHEMBL1547643 & 688620 & 4.95 & 4.7746 & TST & \\
\hline CHEMBL1384307 & 688620 & 4.7 & 4.9435 & TRN & \\
\hline CHEMBL1502317 & 688620 & 5.4 & 5.0401 & TRN & \\
\hline CHEMBL3195616 & 688620 & 4.9 & 4.9967 & TRN & \\
\hline CHEMBL1399692 & 688620 & 5.2 & 5.3641 & TRN & \\
\hline CHEMBL1384240 & 688620 & 4.65 & 4.8127 & TST & \\
\hline CHEMBL1404519 & 688620 & 5.25 & 4.9253 & TST & \\
\hline CHEMBL3198002 & 688620 & 5.4 & 5.3341 & TRN & \\
\hline CHEMBL1332404 & 688620 & 5.4 & 5.9397 & TRN & \\
\hline CHEMBL3195319 & 688620 & 4.95 & 5.0581 & TRN & \\
\hline CHEMBL1568262 & 688620 & 4.9 & 4.9786 & TRN & \\
\hline CHEMBL1305128 & 688620 & 5.7 & 5.2156 & TST & \\
\hline CHEMBL1387885 & 688620 & 5.15 & 5.3237 & TRN & \\
\hline CHEMBL1508647 & 688620 & 5.0 & 4.9823 & TRN & \\
\hline CHEMBL1450894 & 688620 & 4.45 & 4.94300 & 00000000005 & TRN \\
\hline CHEMBL3189752 & 688620 & 4.95 & 5.1268 & TRN & \\
\hline CHEMBL3195997 & 688620 & 6.0 & 5.3626 & TRN & \\
\hline CHEMBL1406962 & 688620 & 5.6 & 5.5234 & TRN & \\
\hline CHEMBL1517916 & 688620 & 4.95 & 4.9328 & TRN & \\
\hline CHEMBL1524490 & 688620 & 5.0 & 5.2696 & TST & \\
\hline CHEMBL1577801 & 688620 & 5.0 & 4.7942 & TRN & \\
\hline CHEMBL1456846 & 688620 & 4.85 & 4.8757 & TRN & \\
\hline CHEMBL1518737 & 688620 & 4.95 & 4.9145 & TRN & \\
\hline CHEMBL1336558 & 688620 & 4.65 & 4.9282 & TRN & \\
\hline CHEMBL1370250 & 688620 & 5.35 & 5.5182 & TRN & \\
\hline CHEMBL1412289 & 688620 & 7.15 & 5.2638 & TRN & \\
\hline CHEMBL1407380 & 688620 & 6.45 & 5.6732 & TRN & \\
\hline CHEMBL1353281 & 688620 & 4.9 & 4.9298 & TRN & \\
\hline CHEMBL1542015 & 688620 & 4.45 & 5.2531 & TST & \\
\hline CHEMBL1319618 & 688620 & 5.35 & 4.89 & TRN & \\
\hline CHEMBL1372289 & 688620 & 5.0 & 5.2613 & TRN & \\
\hline
\end{tabular}




\begin{tabular}{|c|c|c|c|c|}
\hline \multicolumn{5}{|c|}{ Supplement } \\
\hline CHEMBL1457352 & 688620 & 4.55 & 4.9301 & TRN \\
\hline CHEMBL1367088 & 688620 & 4.45 & 4.7461 & TRN \\
\hline CHEMBL1582277 & 688620 & 4.5 & 5.1048 & TRN \\
\hline CHEMBL1324316 & 688620 & 4.95 & 5.0809 & TRN \\
\hline CHEMBL1463332 & 688620 & 4.75 & 5.107 & TST \\
\hline CHEMBL1478550 & 688620 & 4.9 & 5.0713 & TRN \\
\hline CHEMBL1388431 & 688620 & 4.85 & 5.0669 & TRN \\
\hline CHEMBL1319744 & 688620 & 4.45 & 4.9498 & TRN \\
\hline CHEMBL585071 & 688620 & 5.15 & 5.4715 & TRN \\
\hline CHEMBL1975660 & 688620 & 5.1 & 5.0534 & TST \\
\hline CHEMBL1555457 & 688620 & 6.8499 & 4.8802 & TRN \\
\hline CHEMBL1309348 & 688620 & 4.45 & 5.0549 & TRN \\
\hline CHEMBL1582521 & 688620 & 4.8 & 5.0743 & TST \\
\hline CHEMBL1564543 & 688620 & 5.05 & 4.8595 & TRN \\
\hline CHEMBL1462840 & 688620 & 4.85 & 5.1848 & TRN \\
\hline CHEMBL188734 & 688620 & 4.95 & 4.601 & TRN \\
\hline CHEMBL1583401 & 688620 & 7.2 & 5.0181 & TST \\
\hline CHEMBL1331849 & 688620 & 4.95 & 4.9754 & TRN \\
\hline CHEMBL1313119 & 688620 & 4.95 & 4.9435 & TRN \\
\hline CHEMBL1589501 & 688620 & 4.8 & 5.1205 & TRN \\
\hline CHEMBL1595656 & 688620 & 4.65 & 5.0267 & TST \\
\hline CHEMBL1585062 & 688620 & 5.15 & 4.7913 & TRN \\
\hline CHEMBL1585685 & 688620 & 4.95 & 4.9611 & TRN \\
\hline CHEMBL1486332 & 688620 & 4.95 & 4.7342 & TRN \\
\hline CHEMBL1545751 & 688620 & 5.4 & 4.9748 & TST \\
\hline CHEMBL1604809 & 688620 & 6.3 & 5.5197 & TRN \\
\hline CHEMBL1407552 & 688620 & 4.45 & 4.8933 & TST \\
\hline CHEMBL1561949 & 688620 & 4.9 & 5.2727 & TST \\
\hline CHEMBL1602734 & 688620 & 4.45 & 5.0544 & TST \\
\hline CHEMBL1431710 & 688620 & 6.45 & 5.2983 & TRN \\
\hline CHEMBL1461522 & 688620 & 5.15 & 4.8 & TST \\
\hline CHEMBL1463931 & 688620 & 4.5 & 4.958 & TST \\
\hline CHEMBL1412661 & 688620 & 5.2 & 5.0942 & TRN \\
\hline CHEMBL1345065 & 688620 & 4.45 & 4.8753 & TST \\
\hline CHEMBL1403969 & 688620 & 4.85 & 4.8695 & TST \\
\hline CHEMBL1448841 & 688620 & 6.6499 & 5.0791 & TRN \\
\hline CHEMBL1432814 & 688620 & 6.3 & 5.0863 & TRN \\
\hline CHEMBL3194161 & 688620 & 4.95 & 5.2598 & TST \\
\hline CHEMBL1330405 & 688620 & 5.0 & 4.9178 & TRN \\
\hline CHEMBL1971810 & 688620 & 6.0 & 4.9834 & TST \\
\hline CHEMBL1581598 & 688620 & 4.65 & 5.0974 & TRN \\
\hline CHEMBL1340682 & 688620 & 5.4 & 5.4474 & TRN \\
\hline CHEMBL1448213 & 688620 & 4.95 & 5.2147 & TRN \\
\hline CHEMBL1424316 & 688620 & 4.6 & 4.9286 & TRN \\
\hline CHEMBL1310822 & 688620 & 4.65 & 4.91 & TRN \\
\hline CHEMBL1362008 & 688620 & 5.1 & 5.1582 & TST \\
\hline CHEMBL3210347 & 688620 & 5.75 & 5.3188 & TRN \\
\hline CHEMBL1340782 & 688620 & 5.0 & 5.0705 & TRN \\
\hline
\end{tabular}




\begin{tabular}{|c|c|c|c|c|c|}
\hline \multicolumn{6}{|c|}{ Supplemental Table s2.txt } \\
\hline CHEMBL1439163 & 688620 & 5.0 & 5.2156 & TST & \\
\hline CHEMBL3199755 & 688620 & 5.0 & 5.0759 & TRN & \\
\hline CHEMBL1537653 & 688620 & 4.85 & 4.9039 & TRN & \\
\hline CHEMBL 3194306 & 688620 & 5.15 & 5.0462 & TRN & \\
\hline CHEMBL1557494 & 688620 & 5.35 & 5.0129 & TRN & \\
\hline CHEMBL1534437 & 688620 & 4.7 & 4.9283 & TRN & \\
\hline CHEMBL1490338 & 688620 & 4.9 & 5.1086 & TRN & \\
\hline CHEMBL1431584 & 688620 & 5.25 & 5.1075 & TRN & \\
\hline CHEMBL 2004745 & 688620 & 5.2 & 5.2171 & TST & \\
\hline CHEMBL1481174 & 688620 & 4.55 & 5.0495 & TST & \\
\hline CHEMBL 3211797 & 688620 & 4.45 & 5.28 & TRN & \\
\hline CHEMBL1422847 & 688620 & 4.45 & 5.0907 & TRN & \\
\hline CHEMBL1508579 & 688620 & 4.8 & 4.7866 & TRN & \\
\hline CHEMBL1471101 & 688620 & 4.9 & 5.1577 & TST & \\
\hline CHEMBL1406729 & 688620 & 5.0 & 5.0474 & TRN & \\
\hline CHEMBL1313356 & 688620 & 4.75 & 4.8947 & TRN & \\
\hline CHEMBL1993125 & 688620 & 4.9 & 4.8173 & TRN & \\
\hline CHEMBL1378687 & 688620 & 4.9 & 5.2168 & TST & \\
\hline CHEMBL1392251 & 688620 & 4.65 & 5.0471 & TST & \\
\hline CHEMBL1495313 & 688620 & 6.0 & 5.0133 & TST & \\
\hline CHEMBL1509656 & 688620 & 5.3 & 5.2459 & TRN & \\
\hline CHEMBL1573958 & 688620 & 4.75 & 4.9614 & TRN & \\
\hline CHEMBL1481137 & 688620 & 4.95 & 5.1136 & TRN & \\
\hline CHEMBL3194516 & 688620 & 5.6 & 4.9639 & TRN & \\
\hline CHEMBL1576810 & 688620 & 4.8 & 5.0781 & TST & \\
\hline CHEMBL1418214 & 688620 & 5.6 & 5.3678 & TST & \\
\hline CHEMBL1366812 & 688620 & 5.65 & 5.4572 & TRN & \\
\hline CHEMBL1388851 & 688620 & 4.9 & 5.4259 & TRN & \\
\hline CHEMBL1531651 & 688620 & 4.5 & 5.1723 & TST & \\
\hline CHEMBL 1440849 & 688620 & 4.45 & 4.9251 & TST & \\
\hline CHEMBL1534618 & 688620 & 5.15 & 4.9511 & TRN & \\
\hline CHEMBL1341145 & 688620 & 4.8 & 4.7953 & TRN & \\
\hline CHEMBL3198019 & 688620 & 5.4 & 4.9421 & TRN & \\
\hline CHEMBL1343825 & 688620 & 5.25 & 5.3479 & TRN & \\
\hline CHEMBL193872 & 688620 & 5.1 & 4.9654 & TRN & \\
\hline CHEMBL1566335 & 688620 & 5.6 & $5.4670 e$ & 00000000005 & TRN \\
\hline CHEMBL3212049 & 688620 & 4.45 & 4.8086 & TRN & \\
\hline CHEMBL1562169 & 688620 & 5.3 & 5.0816 & TRN & \\
\hline CHEMBL1991441 & 688620 & 5.65 & 5.4406 & TRN & \\
\hline CHEMBL3192433 & 688620 & 5.2 & 5.126 & TRN & \\
\hline CHEMBL1308538 & 688620 & 4.45 & 4.7907 & TRN & \\
\hline CHEMBL1468061 & 688620 & 5.2 & 4.7419 & TRN & \\
\hline CHEMBL1501718 & 688620 & 4.9 & 4.7485 & TRN & \\
\hline CHEMBL1306462 & 688620 & 5.6 & 5.0429 & TRN & \\
\hline CHEMBL1542354 & 688620 & 5.0 & 4.8973 & TRN & \\
\hline CHEMBL1309557 & 688620 & 5.9 & 5.2308 & TRN & \\
\hline CHEMBL1374926 & 688620 & 4.95 & 4.8488 & TRN & \\
\hline CHEMBL1974666 & 688620 & 5.2 & 5.481 & TRN & \\
\hline
\end{tabular}




\begin{tabular}{|c|c|c|c|c|}
\hline \multicolumn{5}{|c|}{ Supplemental Table S2.txt } \\
\hline CHEMBL3211663 & 688620 & 4.7 & 4.9755 & TRN \\
\hline CHEMBL1600061 & 688620 & 4.9 & 4.8457 & TRN \\
\hline CHEMBL1562258 & 688620 & 6.8499 & 5.2034 & TST \\
\hline CHEMBL1583665 & 688620 & 4.45 & 4.755 & TRN \\
\hline CHEMBL3211265 & 688620 & 4.45 & 4.9568 & TRN \\
\hline CHEMBL3210555 & 688620 & 5.1 & 5.0742 & TST \\
\hline CHEMBL1503205 & 688620 & 4.95 & 4.981 & TST \\
\hline CHEMBL1595589 & 688620 & 4.95 & 4.9065 & TRN \\
\hline CHEMBL1489717 & 688620 & 5.8 & 5.12 & TRN \\
\hline CHEMBL1578482 & 688620 & 5.4 & 5.4489 & TST \\
\hline CHEMBL1417732 & 688620 & 4.9 & 5.0703 & TRN \\
\hline CHEMBL1312815 & 688620 & 4.45 & 4.9797 & TRN \\
\hline CHEMBL1507291 & 688620 & 4.85 & 4.9436 & TRN \\
\hline CHEMBL3189936 & 688620 & 6.6 & 5.7537 & TRN \\
\hline CHEMBL1422733 & 688620 & 5.95 & 5.2189 & TRN \\
\hline CHEMBL1525577 & 688620 & 4.65 & 4.9676 & TRN \\
\hline CHEMBL1536831 & 688620 & 5.45 & 5.4167 & TRN \\
\hline CHEMBL3211801 & 688620 & 4.7 & 5.0507 & TRN \\
\hline CHEMBL1556323 & 688620 & 5.5 & 5.2086 & TRN \\
\hline CHEMBL1493879 & 688620 & 4.75 & 5.0481 & TRN \\
\hline CHEMBL1521125 & 688620 & 4.9 & 4.6167 & TRN \\
\hline CHEMBL1535928 & 688620 & 4.7 & 5.1516 & TRN \\
\hline CHEMBL1467858 & 688620 & 4.6 & 5.0528 & TRN \\
\hline CHEMBL1531445 & 688620 & 4.9 & 5.0793 & TRN \\
\hline CHEMBL1406753 & 688620 & 4.8 & 4.9363 & TRN \\
\hline CHEMBL1532583 & 688620 & 4.85 & 5.0078 & TRN \\
\hline CHEMBL1477601 & 688620 & 6.45 & 4.9485 & TRN \\
\hline CHEMBL1328947 & 688620 & 4.9 & 4.9685 & TST \\
\hline CHEMBL579318 & 688620 & 5.95 & 5.2922 & TRN \\
\hline CHEMBL1403666 & 688620 & 4.45 & 4.7427 & TRN \\
\hline CHEMBL1449809 & 688620 & 4.85 & 5.0716 & TST \\
\hline CHEMBL 297548 & 688620 & 4.65 & 4.8869 & TRN \\
\hline CHEMBL1977568 & 688620 & 5.5 & 4.9406 & TRN \\
\hline CHEMBL3194659 & 688620 & 5.45 & 5.1029 & TRN \\
\hline CHEMBL1533542 & 688620 & 5.0 & 5.2283 & TRN \\
\hline CHEMBL1340300 & 688620 & 4.9 & 4.7128 & TRN \\
\hline CHEMBL1409781 & 688620 & 4.6 & 4.7429 & TRN \\
\hline CHEMBL1517497 & 688620 & 5.75 & 4.9034 & TST \\
\hline CHEMBL376353 & 688620 & 5.1 & 5.1582 & TRN \\
\hline CHEMBL1456979 & 688620 & 4.95 & 5.1373 & TRN \\
\hline CHEMBL1491238 & 688620 & 4.95 & 4.9984 & TRN \\
\hline CHEMBL1423889 & 688620 & 4.6 & 4.9985 & TRN \\
\hline CHEMBL1309842 & 688620 & 4.55 & 4.8621 & TRN \\
\hline CHEMBL1530981 & 688620 & 4.85 & 5.141 & TST \\
\hline CHEMBL1301752 & 688620 & 5.05 & 5.1105 & TRN \\
\hline CHEMBL1464300 & 688620 & 4.95 & 4.7543 & TRN \\
\hline CHEMBL1365716 & 688620 & 4.9 & 5.0323 & TRN \\
\hline CHEMBL1596238 & 688620 & 4.95 & 4.9846 & TRN \\
\hline
\end{tabular}




\begin{tabular}{|c|c|c|c|c|}
\hline & & & ement & al Table S2 \\
\hline CHEMBL455399 & 688620 & 4.6 & 4.9907 & TRN \\
\hline CHEMBL1422400 & 688620 & 4.45 & 5.17399 & 99999999995 \\
\hline CHEMBL1327236 & 688620 & 4.85 & 5.0726 & TRN \\
\hline CHEMBL1492398 & 688620 & 4.75 & 5.0116 & TRN \\
\hline CHEMBL1334259 & 688620 & 4.55 & 4.9695 & TST \\
\hline CHEMBL1379136 & 688620 & 6.0 & 4.9712 & TST \\
\hline CHEMBL417727 & 688620 & 5.75 & 5.5089 & TRN \\
\hline CHEMBL1971324 & 688620 & 5.65 & 5.0764 & TRN \\
\hline CHEMBL1556001 & 688620 & 5.0 & 4.9118 & TST \\
\hline CHEMBL1408323 & 688620 & 5.75 & 5.3232 & TRN \\
\hline CHEMBL1347106 & 688620 & 4.75 & 5.0636 & TRN \\
\hline CHEMBL1495589 & 688620 & 4.45 & 4.8938 & TRN \\
\hline CHEMBL1415312 & 688620 & 5.55 & 5.4457 & TRN \\
\hline CHEMBL1986765 & 688620 & 4.8 & 4.8196 & TST \\
\hline CHEMBL1495094 & 688620 & 4.7 & 4.9 & TRN \\
\hline CHEMBL1310644 & 688620 & 5.2 & 4.9646 & TRN \\
\hline CHEMBL1402269 & 688620 & 4.8 & 5.1911 & TRN \\
\hline CHEMBL1328813 & 688620 & 6.3 & 5.1422 & TRN \\
\hline CHEMBL1429664 & 688620 & 4.65 & 5.0101 & TRN \\
\hline CHEMBL 3213684 & 688620 & 5.0 & 5.1666 & TRN \\
\hline CHEMBL1429356 & 688620 & 4.8 & 5.15 & TRN \\
\hline CHEMBL1528547 & 688620 & 4.45 & 5.0064 & TRN \\
\hline CHEMBL1432372 & 688620 & 5.85 & 5.6454 & TRN \\
\hline CHEMBL1461534 & 688620 & 4.9 & 5.2779 & TRN \\
\hline CHEMBL1318259 & 688620 & 4.85 & 5.0704 & TST \\
\hline CHEMBL3199458 & 688620 & 6.5501 & 5.0965 & TRN \\
\hline CHEMBL1388448 & 688620 & 5.6 & 5.0728 & TRN \\
\hline CHEMBL1981949 & 688620 & 5.8 & 5.1542 & TRN \\
\hline CHEMBL1467372 & 688620 & 5.0 & 5.1412 & TST \\
\hline CHEMBL1364540 & 688620 & 4.55 & 5.1126 & TRN \\
\hline CHEMBL1386703 & 688620 & 4.95 & 5.2154 & TRN \\
\hline CHEMBL29197 & 688620 & 4.9 & 5.2662 & TRN \\
\hline CHEMBL1359512 & 688620 & 4.45 & 4.9672 & TRN \\
\hline CHEMBL1467980 & 688620 & 5.0 & 4.9917 & TRN \\
\hline CHEMBL1454176 & 688620 & 4.45 & 4.918 & TRN \\
\hline CHEMBL1406702 & 688620 & 6.4 & 6.4964 & TRN \\
\hline CHEMBL1492839 & 688620 & 4.7 & 4.9215 & TRN \\
\hline CHEMBL1588870 & 688620 & 4.45 & 5.1298 & TRN \\
\hline CHEMBL1345202 & 688620 & 4.65 & 5.1335 & TRN \\
\hline CHEMBL1571002 & 688620 & 4.45 & 4.8305 & TRN \\
\hline CHEMBL1388176 & 688620 & 4.95 & 5.0845 & TRN \\
\hline CHEMBL1503734 & 688620 & 4.45 & 5.1823 & TRN \\
\hline CHEMBL1370189 & 688620 & 7.5003 & 4.9692 & TRN \\
\hline CHEMBL1406324 & 688620 & 5.9 & 4.9572 & TRN \\
\hline CHEMBL1318762 & 688620 & 6.15 & 5.3312 & TRN \\
\hline CHEMBL331627 & 688620 & 7.3497 & 5.0296 & TST \\
\hline CHEMBL1507407 & 688620 & 4.6 & 4.9949 & TRN \\
\hline CHEMBL1386834 & 688620 & 4.45 & 5.0137 & TRN \\
\hline
\end{tabular}

TRN 


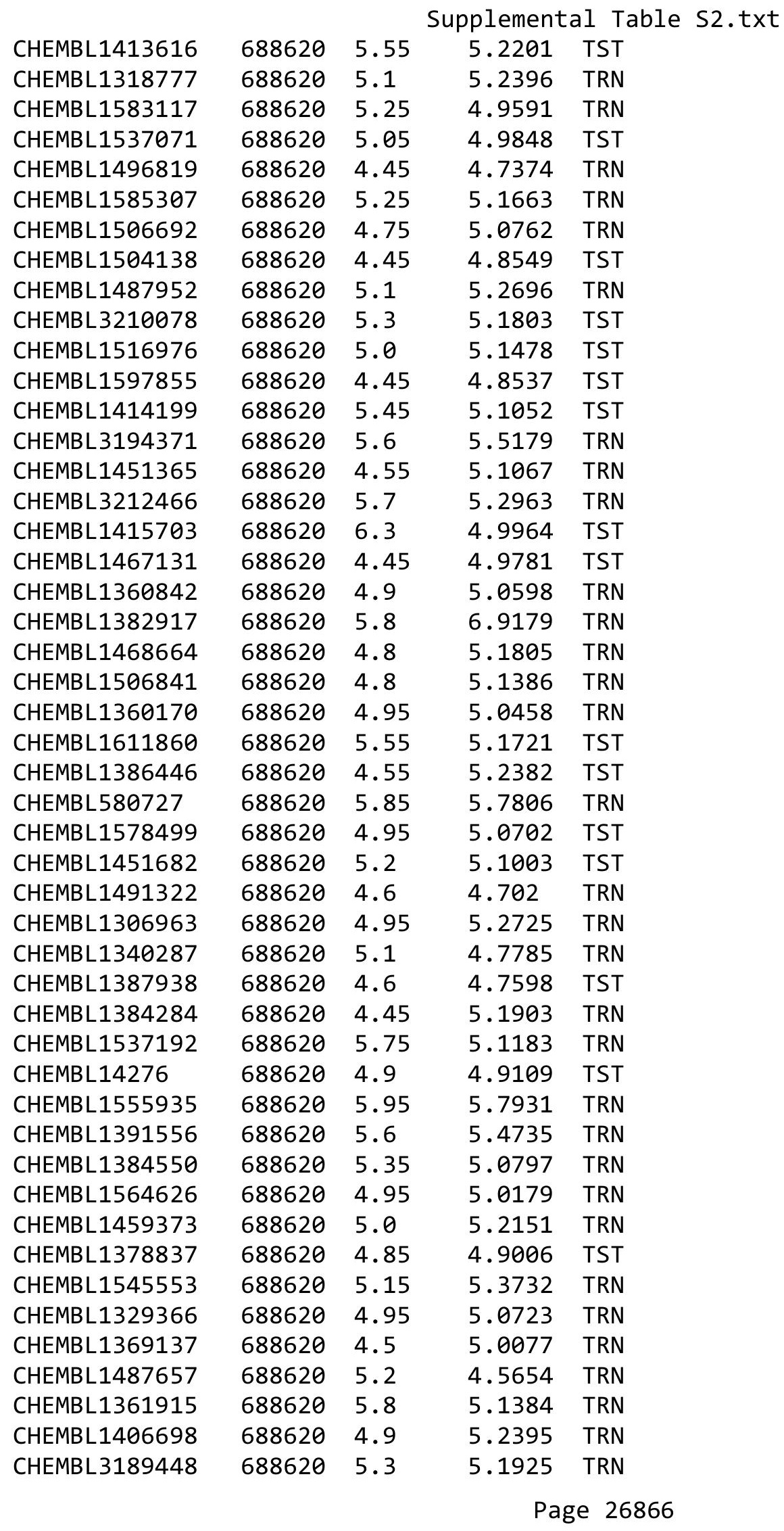




\begin{tabular}{|c|c|c|c|c|c|}
\hline \\
\hline CHEMBL1412822 & 688620 & 4.8 & 4.752 & TRN & \\
\hline CHEMBL1367204 & 688620 & 4.55 & 5.1516 & TRN & \\
\hline CHEMBL1498952 & 688620 & 4.7 & 4.9944 & TST & \\
\hline CHEMBL1511882 & 688620 & 5.15 & 5.416 & TST & \\
\hline CHEMBL1532199 & 688620 & 4.9 & 4.8908 & TST & \\
\hline CHEMBL1463979 & 688620 & 5.0 & 4.7415 & TST & \\
\hline CHEMBL1596891 & 688620 & 4.45 & 4.9078 & TRN & \\
\hline CHEMBL1322449 & 688620 & 5.45 & 4.9463 & TRN & \\
\hline CHEMBL1560912 & 688620 & 5.35 & 5.1266 & TST & \\
\hline CHEMBL1473110 & 688620 & 4.7 & 5.2025 & TRN & \\
\hline CHEMBL272005 & 688620 & 5.2 & 5.2277 & TRN & \\
\hline CHEMBL1533303 & 688620 & 4.85 & 4.8201 & TST & \\
\hline CHEMBL1406630 & 688620 & 6.15 & 5.1122 & TRN & \\
\hline CHEMBL1424006 & 688620 & 4.8 & 4.9673 & TRN & \\
\hline CHEMBL1612898 & 688620 & 5.35 & 5.0387 & TST & \\
\hline CHEMBL3189199 & 688620 & 5.5 & 5.3473 & TRN & \\
\hline CHEMBL586465 & 688620 & 5.4 & 5.0497 & TRN & \\
\hline CHEMBL1565838 & 688620 & 5.4 & 5.21299 & 9999999999 & TST \\
\hline CHEMBL1556748 & 688620 & 5.6 & 5.7483 & TST & \\
\hline CHEMBL1481697 & 688620 & 5.4 & 5.0286 & TRN & \\
\hline CHEMBL1375132 & 688620 & 4.85 & 4.7931 & TRN & \\
\hline CHEMBL1471421 & 688620 & 4.75 & 5.197 & TRN & \\
\hline CHEMBL1559524 & 688620 & 4.5 & 4.9119 & TRN & \\
\hline CHEMBL1308972 & 688620 & 5.1 & 4.909 & TRN & \\
\hline CHEMBL1579592 & 688620 & 6.3 & 6.2127 & TRN & \\
\hline CHEMBL1309052 & 688620 & 4.95 & 5.0755 & TST & \\
\hline CHEMBL268559 & 688620 & 5.6 & 5.37299 & 9999999999 & TRN \\
\hline CHEMBL1427606 & 688620 & 5.3 & 4.8816 & TST & \\
\hline CHEMBL1523452 & 688620 & 5.1 & 5.042 & TRN & \\
\hline CHEMBL1424204 & 688620 & 5.2 & 5.1395 & TRN & \\
\hline CHEMBL3196952 & 688620 & 4.9 & 4.9132 & TRN & \\
\hline CHEMBL1399203 & 688620 & 4.5 & 5.06800 & 30000000005 & TRN \\
\hline CHEMBL1466311 & 688620 & 4.8 & 4.7904 & TRN & \\
\hline CHEMBL1305586 & 688620 & 4.95 & 5.0691 & TST & \\
\hline CHEMBL1420229 & 688620 & 4.45 & 4.9176 & TRN & \\
\hline CHEMBL1612042 & 688620 & 5.95 & 5.2121 & TRN & \\
\hline CHEMBL1365689 & 688620 & 5.1 & 5.2958 & TRN & \\
\hline CHEMBL1541593 & 688620 & 4.9 & 4.8396 & TRN & \\
\hline CHEMBL1432466 & 688620 & 5.45 & 5.2043 & TRN & \\
\hline CHEMBL1307078 & 688620 & 4.85 & 5.1884 & TRN & \\
\hline CHEMBL1466712 & 688620 & 5.9 & 5.5008 & TRN & \\
\hline CHEMBL1479175 & 688620 & 6.1 & 4.9685 & TRN & \\
\hline CHEMBL1328472 & 688620 & 4.55 & 5.0404 & TRN & \\
\hline CHEMBL1306701 & 688620 & 4.9 & 5.1797 & TST & \\
\hline CHEMBL 1437560 & 688620 & 4.45 & 4.6791 & TST & \\
\hline CHEMBL1337625 & 688620 & 4.7 & 4.8136 & TRN & \\
\hline CHEMBL1579770 & 688620 & 5.15 & 4.9959 & TRN & \\
\hline CHEMBL1377175 & 688620 & 4.45 & 4.9433 & TST & \\
\hline
\end{tabular}




\begin{tabular}{|c|c|c|c|c|}
\hline \multicolumn{5}{|c|}{ Supplemental Table S2.txt } \\
\hline CHEMBL1519833 & 688620 & 4.45 & 5.2101 & TST \\
\hline CHEMBL3209842 & 688620 & 4.85 & 4.8108 & TST \\
\hline CHEMBL1364988 & 688620 & 4.9 & 5.7432 & TRN \\
\hline CHEMBL3192911 & 688620 & 4.75 & 4.9761 & TRN \\
\hline CHEMBL1372194 & 688620 & 4.95 & 5.1371 & TST \\
\hline CHEMBL1308004 & 688620 & 4.5 & 4.9871 & TRN \\
\hline CHEMBL1577174 & 688620 & 5.45 & 5.2744 & TRN \\
\hline CHEMBL1595942 & 688620 & 5.05 & 5.2925 & TRN \\
\hline CHEMBL3193628 & 688620 & 4.7 & 5.1621 & TRN \\
\hline CHEMBL1576263 & 688620 & 4.65 & 4.9692 & TRN \\
\hline CHEMBL1384942 & 688620 & 4.8 & 4.8905 & TRN \\
\hline CHEMBL1578272 & 688620 & 4.45 & 4.9038 & TRN \\
\hline CHEMBL1371273 & 688620 & 5.35 & 5.1246 & TRN \\
\hline CHEMBL 2001105 & 688620 & 4.85 & 5.065 & TRN \\
\hline CHEMBL1448984 & 688620 & 5.8 & 5.3628 & TRN \\
\hline CHEMBL1603434 & 688620 & 4.75 & 4.9295 & TRN \\
\hline CHEMBL3208105 & 688620 & 6.6499 & 4.8401 & TRN \\
\hline CHEMBL3209153 & 688620 & 4.85 & 5.1827 & TRN \\
\hline CHEMBL1456425 & 688620 & 5.0 & 5.1648 & TRN \\
\hline CHEMBL1598230 & 688620 & 5.0 & 4.9905 & TRN \\
\hline CHEMBL1387229 & 688620 & 5.3 & 5.5326 & TST \\
\hline CHEMBL1537693 & 688620 & 5.15 & 4.9947 & TRN \\
\hline CHEMBL1980103 & 688620 & 7.2 & 6.4163 & TRN \\
\hline CHEMBL1549334 & 688620 & 4.45 & 4.9314 & TRN \\
\hline CHEMBL1556470 & 688620 & 4.5 & 4.8284 & TST \\
\hline CHEMBL1508474 & 688620 & 6.25 & 6.2774 & TRN \\
\hline CHEMBL1508524 & 688620 & 4.95 & 5.0156 & TRN \\
\hline CHEMBL1422411 & 688620 & 4.7 & 5.0826 & TRN \\
\hline CHEMBL1507023 & 688620 & 4.85 & 4.7893 & TRN \\
\hline CHEMBL 7973 & 688620 & 5.7 & 5.1383 & TRN \\
\hline CHEMBL1373165 & 688620 & 5.05 & 4.9193 & TRN \\
\hline CHEMBL1595630 & 688620 & 5.65 & 4.8921 & TST \\
\hline CHEMBL1370797 & 688620 & 5.55 & 5.3075 & TRN \\
\hline CHEMBL1332364 & 688620 & 4.65 & 4.99 & TRN \\
\hline CHEMBL1422652 & 688620 & 5.0 & 4.9913 & TRN \\
\hline CHEMBL1485312 & 688620 & 5.9 & 5.6613 & TRN \\
\hline CHEMBL1474890 & 688620 & 4.5 & 4.9747 & TRN \\
\hline CHEMBL3197927 & 688620 & 4.45 & 4.9033 & TST \\
\hline CHEMBL1499282 & 688620 & 4.9 & 4.9594 & TRN \\
\hline CHEMBL1387626 & 688620 & 4.95 & 4.9371 & TRN \\
\hline CHEMBL3192181 & 688620 & 5.45 & 5.6765 & TRN \\
\hline CHEMBL1471584 & 688620 & 4.5 & 5.2097 & TST \\
\hline CHEMBL3191805 & 688620 & 5.1 & 5.1362 & TRN \\
\hline CHEMBL498373 & 688620 & 4.45 & 4.8849 & TRN \\
\hline CHEMBL1439260 & 688620 & 4.45 & 5.2774 & TRN \\
\hline CHEMBL1517483 & 688620 & 4.45 & 4.872 & TRN \\
\hline CHEMBL1353307 & 688620 & 4.65 & 5.0454 & TRN \\
\hline CHEMBL1569585 & 688620 & 6.0 & 5.7898 & TST \\
\hline
\end{tabular}




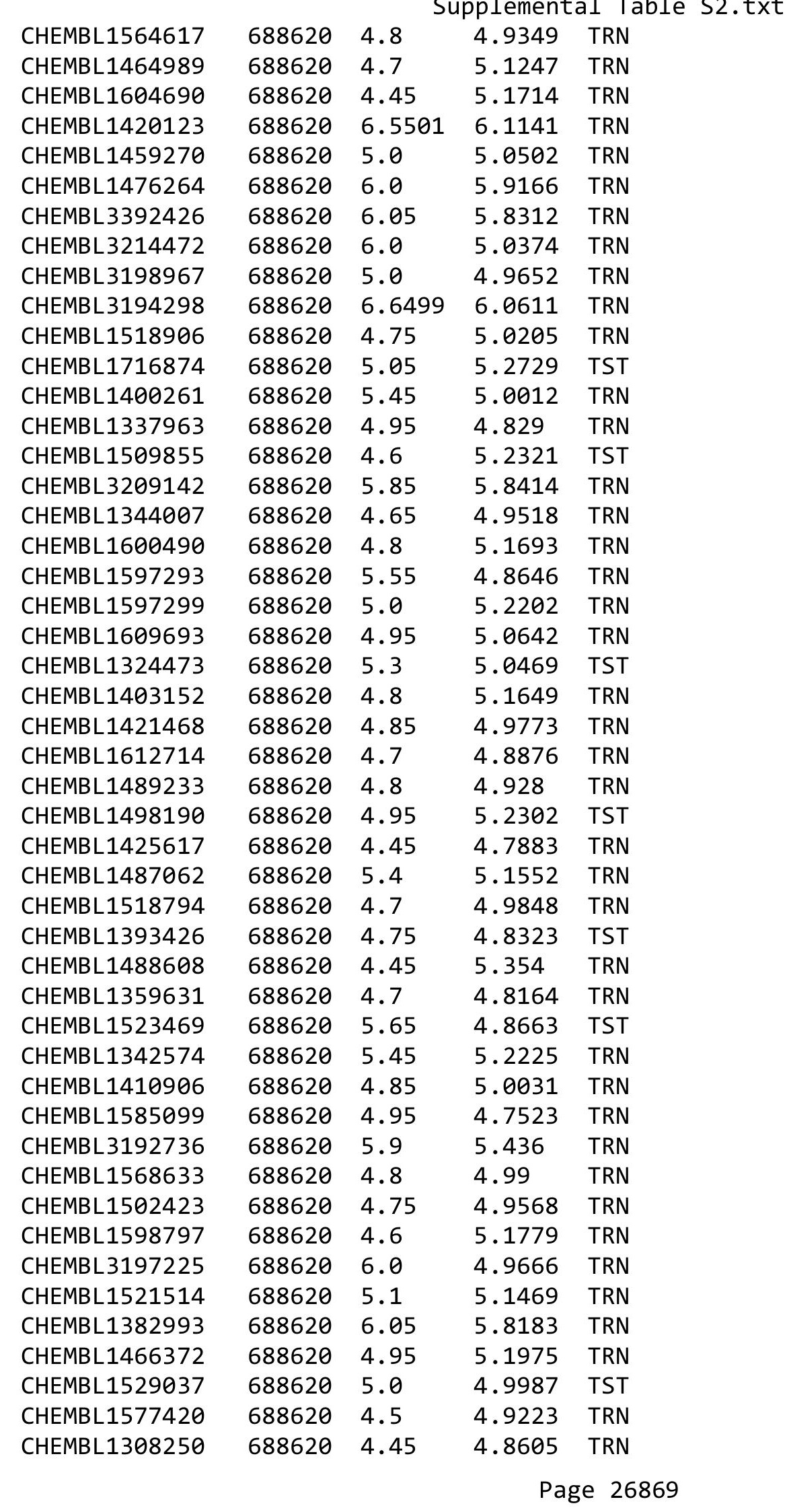




\begin{tabular}{|c|c|c|c|c|c|}
\hline \multicolumn{6}{|c|}{ Supplemental Table S2.txt } \\
\hline CHEMBL1378484 & 688620 & 6.15 & 5.0105 & TRN & \\
\hline CHEMBL1309051 & 688620 & 4.65 & 4.9656 & TRN & \\
\hline CHEMBL1610719 & 688620 & 4.65 & 5.0188 & TRN & \\
\hline CHEMBL3199162 & 688620 & 5.15 & 5.1207 & TRN & \\
\hline CHEMBL1429083 & 688620 & 5.25 & 4.966 & TRN & \\
\hline CHEMBL1326548 & 688620 & 4.85 & 5.1439 & TRN & \\
\hline CHEMBL1458511 & 688620 & 5.15 & 5.0101 & TST & \\
\hline CHEMBL1564959 & 688620 & 4.75 & 5.0406 & TRN & \\
\hline CHEMBL1489434 & 688620 & 5.4 & 5.1485 & TRN & \\
\hline CHEMBL1487166 & 688620 & 4.5 & 4.7761 & TST & \\
\hline CHEMBL1387401 & 688620 & 4.85 & 5.1314 & TRN & \\
\hline CHEMBL1363156 & 688620 & 5.15 & 4.7875 & TRN & \\
\hline CHEMBL1457608 & 688620 & 4.45 & 4.973 & TST & \\
\hline CHEMBL1992308 & 688620 & 5.55 & 5.0998 & TST & \\
\hline CHEMBL1480163 & 688620 & 5.5 & 5.0774 & TST & \\
\hline CHEMBL 3191641 & 688620 & 6.2 & 5.4686 & TST & \\
\hline CHEMBL1364002 & 688620 & 5.35 & 5.3809 & TRN & \\
\hline CHEMBL3199428 & 688620 & 5.3 & 5.3592 & TRN & \\
\hline CHEMBL1337772 & 688620 & 4.6 & 5.0453 & TST & \\
\hline CHEMBL1570941 & 688620 & 4.45 & 5.0966 & TRN & \\
\hline CHEMBL1576249 & 688620 & 5.15 & 5.1768 & TRN & \\
\hline CHEMBL1371825 & 688620 & 6.35 & 5.17399 & 99999999995 & TRN \\
\hline CHEMBL1571839 & 688620 & 5.2 & 5.3269 & TRN & \\
\hline CHEMBL1505212 & 688620 & 5.2 & 5.4173 & TRN & \\
\hline CHEMBL1379881 & 688620 & 5.8 & 5.5419 & TST & \\
\hline CHEMBL1607865 & 688620 & 4.45 & 5.2136 & TRN & \\
\hline CHEMBL1575653 & 688620 & 5.2 & 5.0902 & TRN & \\
\hline CHEMBL1358038 & 688620 & 5.1 & 4.6296 & TRN & \\
\hline CHEMBL1325146 & 688620 & 4.95 & 5.1229 & TRN & \\
\hline CHEMBL1566919 & 688620 & 4.9 & 5.092 & TRN & \\
\hline CHEMBL1464820 & 688620 & 5.9 & 5.0544 & TRN & \\
\hline CHEMBL1482980 & 688620 & 5.2 & 5.3615 & TRN & \\
\hline CHEMBL1528633 & 688620 & 4.9 & 4.9837 & TRN & \\
\hline CHEMBL1348995 & 688620 & 4.85 & 5.0367 & TRN & \\
\hline CHEMBL1491108 & 688620 & 4.95 & 5.0753 & TRN & \\
\hline CHEMBL1510565 & 688620 & 4.65 & 4.9493 & TRN & \\
\hline CHEMBL1410358 & 688620 & 5.0 & 4.9604 & TST & \\
\hline CHEMBL1336446 & 688620 & 4.9 & 4.8933 & TRN & \\
\hline CHEMBL1387673 & 688620 & 5.0 & 4.9534 & TRN & \\
\hline CHEMBL1356301 & 688620 & 4.85 & 4.9969 & TST & \\
\hline CHEMBL1583435 & 688620 & 8.2518 & 4.727 & TRN & \\
\hline CHEMBL1390442 & 688620 & 4.9 & 5.0552 & TST & \\
\hline CHEMBL1443552 & 688620 & 4.75 & 5.5272 & TRN & \\
\hline CHEMBL1564978 & 688620 & 4.85 & 5.2561 & TRN & \\
\hline CHEMBL1372952 & 688620 & 4.45 & 4.8439 & TRN & \\
\hline CHEMBL3196718 & 688620 & 5.1 & 5.0622 & TRN & \\
\hline CHEMBL1509703 & 688620 & 4.55 & 4.9556 & TRN & \\
\hline CHEMBL1998436 & 688620 & 4.45 & 5.0408 & TRN & \\
\hline
\end{tabular}




\begin{tabular}{|c|c|c|c|c|}
\hline & & & pplemen & al $\mathrm{T}$ \\
\hline CHEMBL1366225 & 688620 & 4.7 & 4.9832 & TRN \\
\hline CHEMBL1542259 & 688620 & 4.8 & 5.1762 & TRN \\
\hline CHEMBL1613408 & 688620 & 5.7 & 5.3245 & TRN \\
\hline CHEMBL1446519 & 688620 & 4.85 & 4.8638 & TST \\
\hline CHEMBL1603991 & 688620 & 4.8 & 4.813 & TRN \\
\hline CHEMBL1302991 & 688620 & 4.45 & 5.0684 & TRN \\
\hline CHEMBL1967654 & 688620 & 4.85 & 5.0167 & TRN \\
\hline CHEMBL1398664 & 688620 & 5.7 & 6.1589 & TRN \\
\hline CHEMBL1471016 & 688620 & 6.4 & 5.2032 & TRN \\
\hline CHEMBL1613147 & 688620 & 5.3 & 5.3185 & TRN \\
\hline CHEMBL588919 & 688620 & 4.7 & 5.1707 & TRN \\
\hline CHEMBL1588531 & 688620 & 4.8 & 5.0158 & TRN \\
\hline CHEMBL1367325 & 688620 & 5.1 & 5.3749 & TRN \\
\hline CHEMBL1306229 & 688620 & 6.2 & 5.7291 & TRN \\
\hline CHEMBL1576873 & 688620 & 4.45 & 5.2189 & TST \\
\hline CHEMBL3199629 & 688620 & 4.45 & 4.8284 & TRN \\
\hline CHEMBL1430549 & 688620 & 4.65 & 5.1739 & TST \\
\hline CHEMBL1382784 & 688620 & 6.2 & 5.3262 & TRN \\
\hline CHEMBL1589168 & 688620 & 4.55 & 5.1067 & TRN \\
\hline CHEMBL1411860 & 688620 & 4.85 & 5.0203 & TRN \\
\hline CHEMBL242080 & 688620 & 6.0 & 5.5973 & TST \\
\hline CHEMBL1468028 & 688620 & 6.5 & 5.1656 & TRN \\
\hline CHEMBL1345481 & 688620 & 4.45 & 5.2349 & TRN \\
\hline CHEMBL1489189 & 688620 & 5.15 & 5.0145 & TST \\
\hline CHEMBL1417195 & 688620 & 6.0 & 5.8975 & TRN \\
\hline CHEMBL3196761 & 688620 & 4.95 & 4.867 & TRN \\
\hline CHEMBL1326237 & 688620 & 5.2 & 4.8911 & TRN \\
\hline CHEMBL1468761 & 688620 & 4.95 & 4.8998 & TRN \\
\hline CHEMBL1597300 & 688620 & 7.7496 & 4.9054 & TST \\
\hline CHEMBL 3214090 & 688620 & 6.2 & 5.9823 & TRN \\
\hline CHEMBL1361562 & 688620 & 4.8 & 5.0696 & TRN \\
\hline CHEMBL1425357 & 688620 & 4.95 & 4.8989 & TRN \\
\hline CHEMBL1456899 & 688620 & 4.45 & 4.8946 & TRN \\
\hline CHEMBL 3199323 & 688620 & 6.0 & 5.1024 & TST \\
\hline CHEMBL1302127 & 688620 & 5.5 & 4.9187 & TST \\
\hline CHEMBL1466111 & 688620 & 4.45 & 4.8842 & TST \\
\hline CHEMBL 3192491 & 688620 & 4.85 & 4.9039 & TRN \\
\hline CHEMBL1970431 & 688620 & 4.9 & 4.9717 & TRN \\
\hline CHEMBL1568167 & 688620 & 4.75 & 5.1418 & TRN \\
\hline CHEMBL1341748 & 688620 & 6.05 & 5.4701 & TST \\
\hline CHEMBL1507652 & 688620 & 4.65 & 4.9088 & TRN \\
\hline CHEMBL1391459 & 688620 & 5.1 & 4.8269 & TRN \\
\hline CHEMBL1497353 & 688620 & 4.45 & 4.8859 & TRN \\
\hline CHEMBL1425519 & 688620 & 4.9 & 4.452 & TRN \\
\hline CHEMBL1535636 & 688620 & 4.45 & 4.6821 & TRN \\
\hline CHEMBL1528818 & 688620 & 4.9 & 4.8223 & TRN \\
\hline CHEMBL1398137 & 688620 & 5.0 & 4.7207 & TRN \\
\hline CHEMBL1299281 & 688620 & 4.5 & 4.8997 & TRN \\
\hline
\end{tabular}




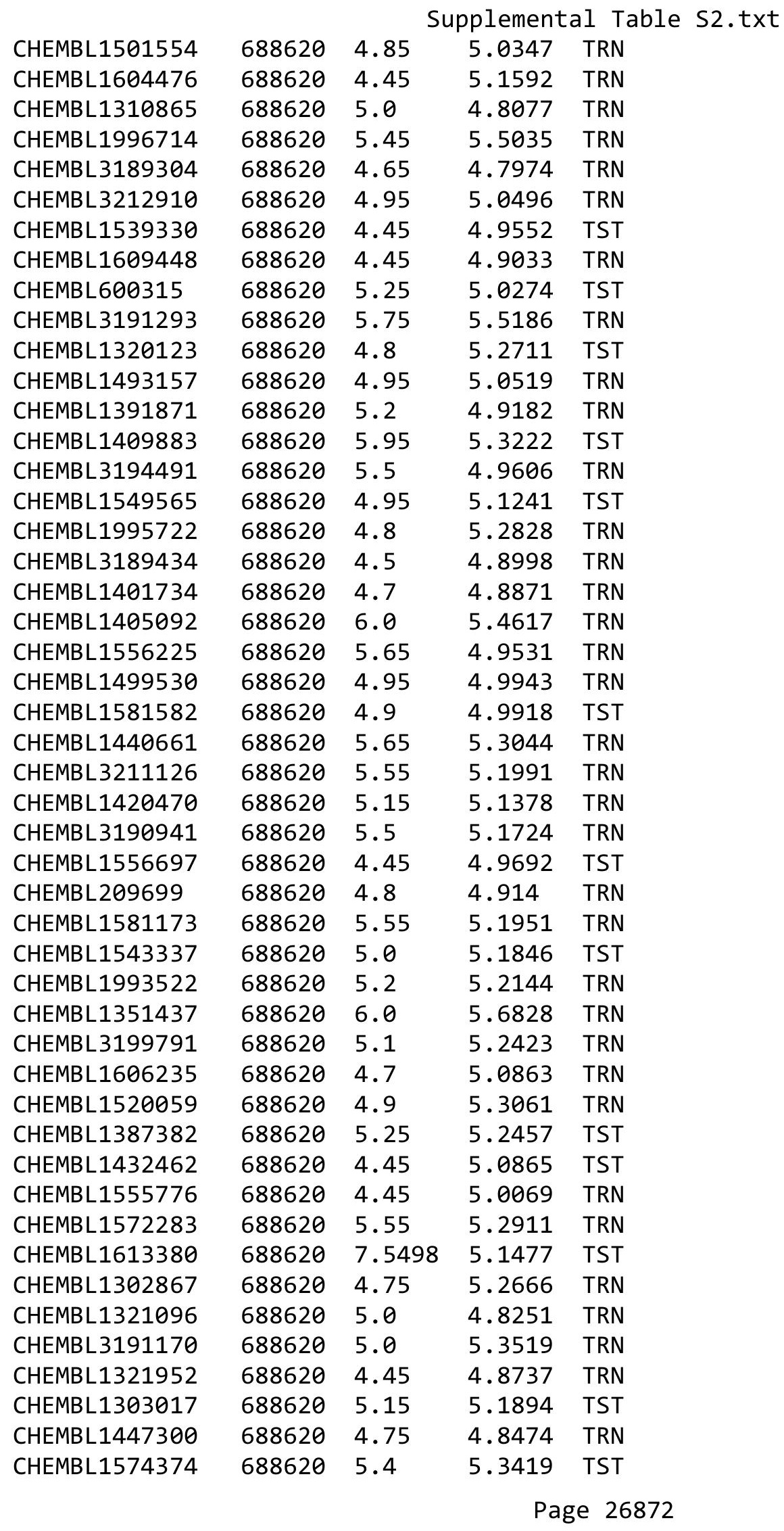




\begin{tabular}{|c|c|c|c|c|c|}
\hline \multicolumn{6}{|c|}{ suppremerticas to } \\
\hline CHEMBL1541714 & 688620 & 4.45 & 5.0789 & TRN & \\
\hline CHEMBL1547464 & 688620 & 5.0 & 4.9787 & TRN & \\
\hline CHEMBL1565212 & 688620 & 4.5 & 4.9256 & TST & \\
\hline CHEMBL1483514 & 688620 & 4.45 & 5.1496 & TST & \\
\hline CHEMBL1383320 & 688620 & 5.0 & 4.8751 & TRN & \\
\hline CHEMBL1525524 & 688620 & 4.85 & 4.937 & TRN & \\
\hline CHEMBL1540821 & 688620 & 5.25 & 4.9789 & TST & \\
\hline CHEMBL1550640 & 688620 & 5.4 & 5.3135 & TRN & \\
\hline CHEMBL1368236 & 688620 & 6.5 & 4.8496 & TRN & \\
\hline CHEMBL1595404 & 688620 & 4.8 & 4.9591 & TRN & \\
\hline CHEMBL1379353 & 688620 & 5.15 & 5.1453 & TRN & \\
\hline CHEMBL1386610 & 688620 & 4.95 & 4.9804 & TRN & \\
\hline CHEMBL1573407 & 688620 & 5.0 & 4.8609 & TRN & \\
\hline CHEMBL1540818 & 688620 & 4.9 & 5.1206 & TRN & \\
\hline CHEMBL1595747 & 688620 & 4.75 & 5.1319 & TST & \\
\hline CHEMBL1605449 & 688620 & 4.95 & 5.0723 & TST & \\
\hline CHEMBL3197827 & 688620 & 6.0 & 6.0175 & TRN & \\
\hline CHEMBL1417080 & 688620 & 5.0 & 4.9851 & TRN & \\
\hline CHEMBL1535848 & 688620 & 4.9 & 5.026 & TRN & \\
\hline CHEMBL1419423 & 688620 & 4.45 & 5.048 & TRN & \\
\hline CHEMBL1343856 & 688620 & 4.75 & 4.7041 & TRN & \\
\hline CHEMBL3193575 & 688620 & 4.65 & 4.8708 & TRN & \\
\hline CHEMBL1422849 & 688620 & 5.95 & 5.8567 & TRN & \\
\hline CHEMBL1576981 & 688620 & 4.45 & 5.103 & TRN & \\
\hline CHEMBL1429332 & 688620 & 4.45 & 4.9622 & TST & \\
\hline CHEMBL1300584 & 688620 & 4.85 & 4.8654 & TST & \\
\hline CHEMBL1561367 & 688620 & 4.9 & 4.9666 & TRN & \\
\hline CHEMBL1425242 & 688620 & 5.05 & 4.9519 & TRN & \\
\hline CHEMBL1583606 & 688620 & 4.65 & 4.9309 & TRN & \\
\hline CHEMBL1494475 & 688620 & 4.45 & 4.9071 & TRN & \\
\hline CHEMBL1458060 & 688620 & 4.95 & 5.08899 & 99999999995 & TRN \\
\hline CHEMBL1608455 & 688620 & 4.45 & 4.8359 & TRN & \\
\hline CHEMBL3213173 & 688620 & 4.6 & 4.8703 & TRN & \\
\hline CHEMBL1572500 & 688620 & 5.45 & 5.5614 & TRN & \\
\hline CHEMBL1489375 & 688620 & 4.95 & 4.9026 & TRN & \\
\hline CHEMBL1331131 & 688620 & 4.45 & 5.0033 & TRN & \\
\hline CHEMBL1445514 & 688620 & 4.95 & 5.165 & TRN & \\
\hline CHEMBL1352223 & 688620 & 4.45 & 4.9245 & TST & \\
\hline CHEMBL1325384 & 688620 & 5.35 & 4.9646 & TRN & \\
\hline CHEMBL1493671 & 688620 & 4.9 & 5.0697 & TST & \\
\hline CHEMBL1367759 & 688620 & 5.9 & 5.4984 & TST & \\
\hline CHEMBL1344136 & 688620 & 5.55 & 5.8288 & TRN & \\
\hline CHEMBL3197628 & 688620 & 5.4 & 5.0997 & TRN & \\
\hline CHEMBL1309982 & 688620 & 5.0 & $5.1560 e$ & $\partial 000000001$ & TRN \\
\hline CHEMBL1581590 & 688620 & 4.9 & 5.3049 & TRN & \\
\hline CHEMBL1476083 & 688620 & 4.8 & 4.9407 & TRN & \\
\hline CHEMBL1313396 & 688620 & 4.45 & 5.0575 & TST & \\
\hline CHEMBL1336857 & 688620 & 5.75 & 5.4716 & TRN & \\
\hline
\end{tabular}




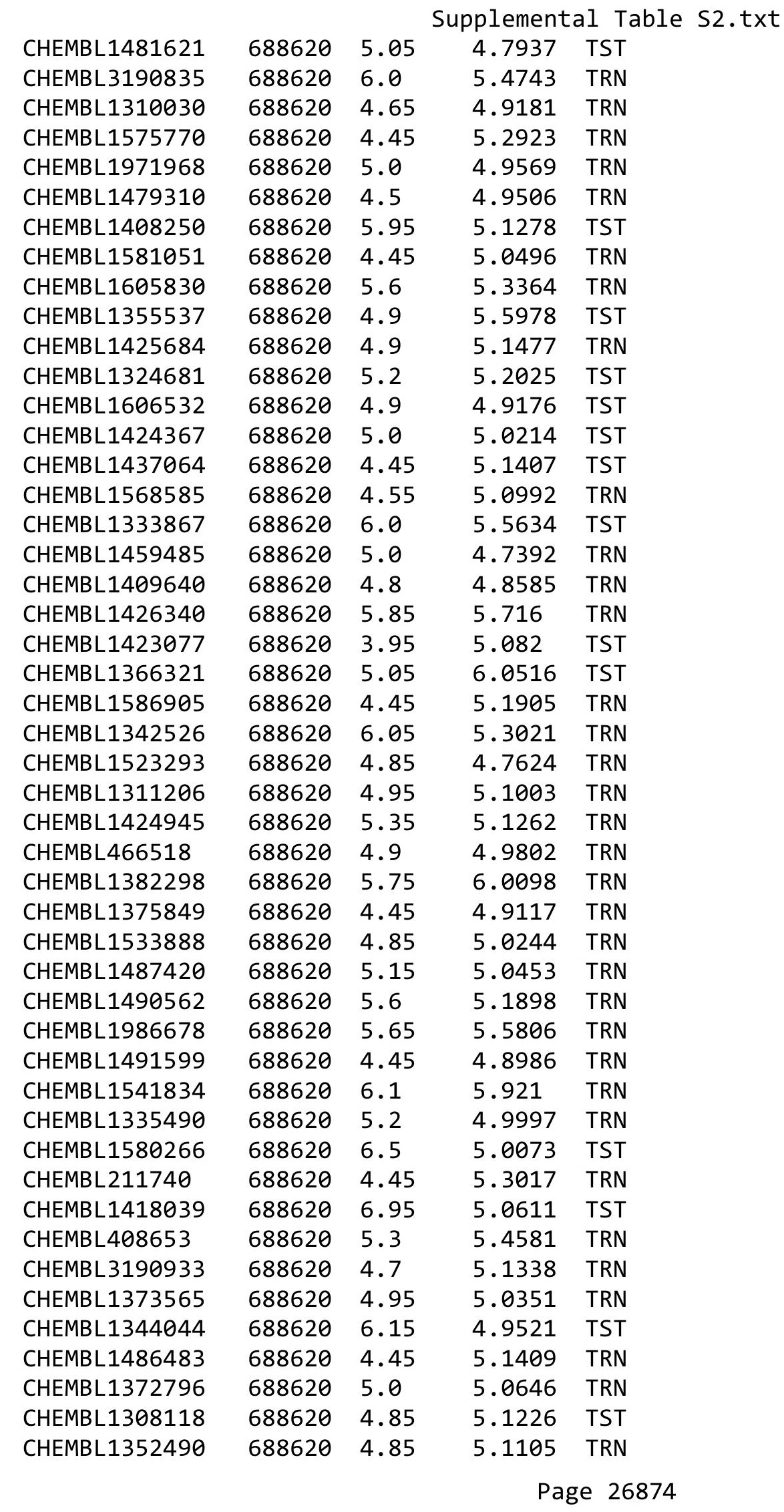




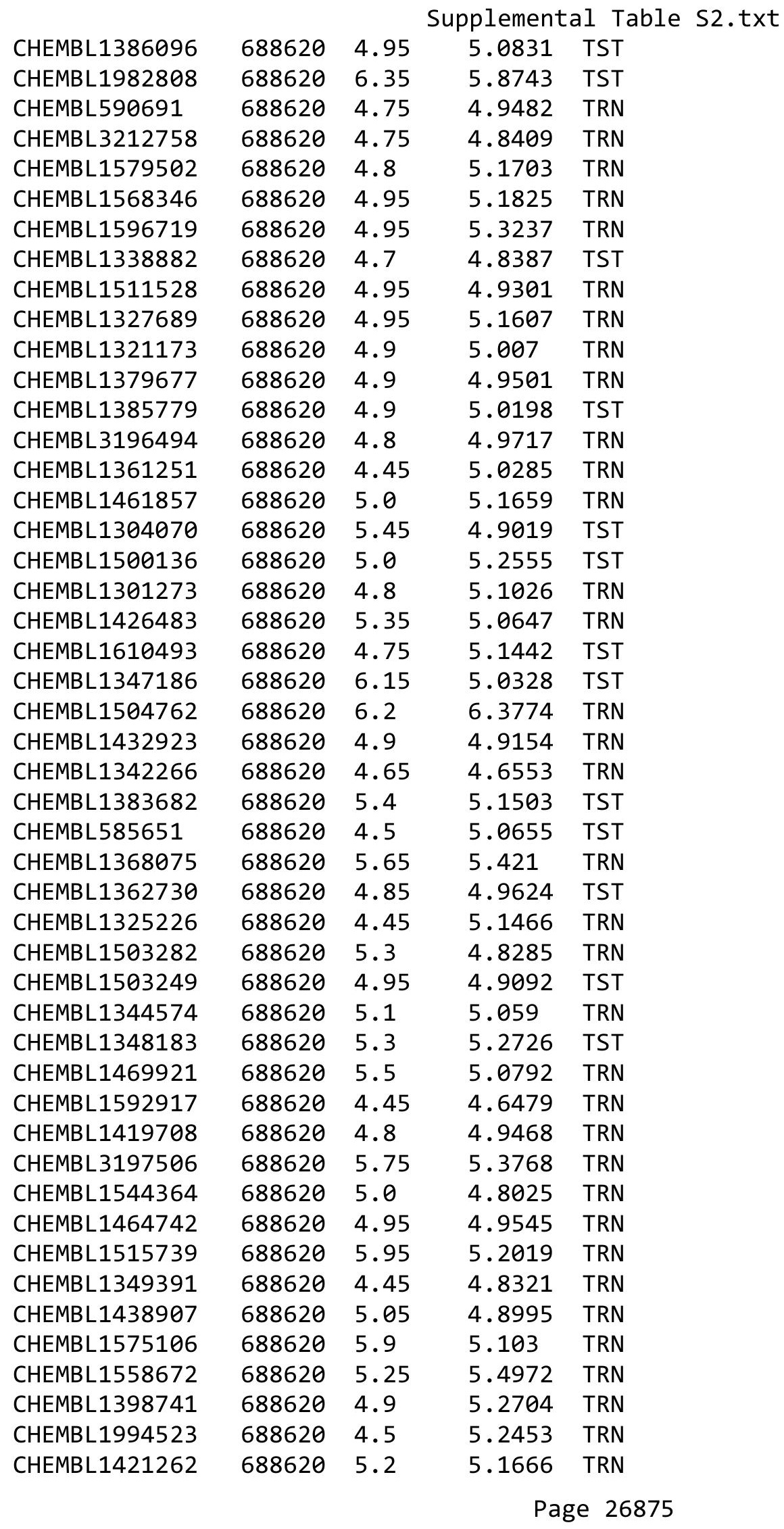




\begin{tabular}{|c|c|c|c|c|c|}
\hline & & & & & \\
\hline CHEMBL3194608 & 688620 & 5.2 & 5.0723 & TST & \\
\hline CHEMBL1412674 & 688620 & 4.7 & 4.9858 & TST & \\
\hline CHEMBL3197681 & 688620 & 5.15 & 5.1788 & TRN & \\
\hline CHEMBL1470010 & 688620 & 6.3 & 4.9855 & TST & \\
\hline CHEMBL1564212 & 688620 & 5.05 & 5.2298 & TRN & \\
\hline CHEMBL1455311 & 688620 & 4.95 & 4.9204 & TRN & \\
\hline CHEMBL3195611 & 688620 & 5.9 & 5.666 & TRN & \\
\hline CHEMBL1549205 & 688620 & 5.6 & 5.2792 & TRN & \\
\hline CHEMBL609438 & 688620 & 4.9 & 5.05699 & 99999999995 & TRN \\
\hline CHEMBL1471882 & 688620 & 4.95 & 5.0266 & TST & \\
\hline CHEMBL1461944 & 688620 & 4.45 & 4.8655 & TRN & \\
\hline CHEMBL1450414 & 688620 & 5.6 & 5.0269 & TST & \\
\hline CHEMBL3189252 & 688620 & 4.8 & 4.8622 & TRN & \\
\hline CHEMBL1522550 & 688620 & 4.75 & 4.8217 & TST & \\
\hline CHEMBL1535428 & 688620 & 5.0 & 5.1232 & TRN & \\
\hline CHEMBL1304857 & 688620 & 4.85 & 5.1731 & TRN & \\
\hline CHEMBL1588412 & 688620 & 4.95 & 5.041 & TRN & \\
\hline CHEMBL1482207 & 688620 & 6.0 & 5.5551 & TRN & \\
\hline CHEMBL 3198245 & 688620 & 4.45 & 5.2647 & TST & \\
\hline CHEMBL1368165 & 688620 & 4.5 & 5.3305 & TST & \\
\hline CHEMBL1448905 & 688620 & 5.2 & 4.8741 & TRN & \\
\hline CHEMBL1546440 & 688620 & 6.5 & 6.2859 & TRN & \\
\hline CHEMBL1599889 & 688620 & 5.7 & 5.3415 & TRN & \\
\hline CHEMBL1600551 & 688620 & 4.85 & 4.9424 & TRN & \\
\hline CHEMBL1574021 & 688620 & 4.45 & 5.1473 & TST & \\
\hline CHEMBL1324616 & 688620 & 4.5 & 5.0143 & TST & \\
\hline CHEMBL1440254 & 688620 & 5.2 & 4.9905 & TRN & \\
\hline CHEMBL3199506 & 688620 & 4.75 & 5.0792 & TRN & \\
\hline CHEMBL1330923 & 688620 & 5.1 & 5.0797 & TRN & \\
\hline CHEMBL1611067 & 688620 & 4.9 & 5.0941 & TRN & \\
\hline CHEMBL1518220 & 688620 & 5.0 & $4.9860 e$ & 0000000001 & TST \\
\hline CHEMBL1308312 & 688620 & 4.9 & 4.9673 & TST & \\
\hline CHEMBL1491444 & 688620 & 4.45 & 5.0128 & TRN & \\
\hline CHEMBL1441168 & 688620 & 5.0 & 4.9681 & TST & \\
\hline CHEMBL1438047 & 688620 & 4.85 & 5.0776 & TRN & \\
\hline CHEMBL1547882 & 688620 & 4.9 & 4.9911 & TRN & \\
\hline CHEMBL 21260 & 688620 & 5.95 & 5.1851 & TRN & \\
\hline CHEMBL1372535 & 688620 & 5.05 & 5.2145 & TST & \\
\hline CHEMBL1607374 & 688620 & 4.45 & 5.1056 & TRN & \\
\hline CHEMBL 276473 & 688620 & 4.95 & 4.7311 & TRN & \\
\hline CHEMBL1575294 & 688620 & 5.35 & 5.3303 & TRN & \\
\hline CHEMBL1371339 & 688620 & 5.4 & 5.2651 & TRN & \\
\hline CHEMBL1506742 & 688620 & 5.85 & 5.23 & TST & \\
\hline CHEMBL1417971 & 688620 & 4.85 & 4.8526 & TRN & \\
\hline CHEMBL1965976 & 688620 & 4.8 & 5.3399 & TRN & \\
\hline CHEMBL1548178 & 688620 & 4.45 & 4.9842 & TRN & \\
\hline CHEMBL597251 & 688620 & 4.7 & 4.7175 & TST & \\
\hline CHEMBL1428704 & 688620 & 4.75 & 4.9789 & TRN & \\
\hline & & & & 26876 & \\
\hline
\end{tabular}




\begin{tabular}{|c|c|c|c|c|}
\hline \multicolumn{5}{|c|}{ Supplemental Table S2.txt } \\
\hline CHEMBL1564140 & 688620 & 5.25 & 5.3027 & TRN \\
\hline CHEMBL1530707 & 688620 & 4.5 & 5.0833 & TST \\
\hline CHEMBL1542809 & 688620 & 5.4 & 5.3477 & TRN \\
\hline CHEMBL1445784 & 688620 & 4.85 & 4.838 & TRN \\
\hline CHEMBL1467353 & 688620 & 6.25 & 5.0932 & TRN \\
\hline CHEMBL1332989 & 688620 & 5.05 & 5.1202 & TRN \\
\hline CHEMBL1543250 & 688620 & 5.85 & 5.2927 & TRN \\
\hline CHEMBL1347198 & 688620 & 5.05 & 5.0643 & TRN \\
\hline CHEMBL1526040 & 688620 & 6.5 & 5.1321 & TRN \\
\hline CHEMBL3190494 & 688620 & 5.7 & 5.4044 & TRN \\
\hline CHEMBL1570329 & 688620 & 5.1 & 5.0686 & TRN \\
\hline CHEMBL1485266 & 688620 & 4.5 & 5.0592 & TST \\
\hline CHEMBL1389505 & 688620 & 5.3 & 5.7415 & TRN \\
\hline CHEMBL 3195650 & 688620 & 5.5 & 5.4954 & TRN \\
\hline CHEMBL1533940 & 688620 & 7.15 & 5.0528 & TRN \\
\hline CHEMBL1310220 & 688620 & 4.45 & 5.0922 & TRN \\
\hline CHEMBL1596412 & 688620 & 4.8 & 5.0111 & TST \\
\hline CHEMBL1559452 & 688620 & 4.8 & 4.725 & TST \\
\hline CHEMBL1416331 & 688620 & 4.7 & 5.1126 & TRN \\
\hline CHEMBL1498111 & 688620 & 4.9 & 5.0109 & TRN \\
\hline CHEMBL1502141 & 688620 & 5.3 & 5.4058 & TRN \\
\hline CHEMBL1305740 & 688620 & 4.45 & 5.4811 & TST \\
\hline CHEMBL3196180 & 688620 & 5.25 & 5.1175 & TST \\
\hline CHEMBL1990870 & 688620 & 4.9 & 4.9862 & TRN \\
\hline CHEMBL1464076 & 688620 & 6.1 & 5.0523 & TRN \\
\hline CHEMBL1441435 & 688620 & 5.95 & 5.0635 & TRN \\
\hline CHEMBL1465205 & 688620 & 4.9 & 5.1667 & TRN \\
\hline CHEMBL1523422 & 688620 & 5.95 & 5.0633 & TRN \\
\hline CHEMBL1302272 & 688620 & 4.95 & 4.9418 & TST \\
\hline CHEMBL1373560 & 688620 & 4.95 & 4.9803 & TRN \\
\hline CHEMBL3191560 & 688620 & 4.5 & 5.0095 & TST \\
\hline CHEMBL1409606 & 688620 & 5.0 & 4.8377 & TST \\
\hline CHEMBL 3189745 & 688620 & 5.05 & 4.954 & TRN \\
\hline CHEMBL1613518 & 688620 & 4.9 & 4.7702 & TRN \\
\hline CHEMBL1580779 & 688620 & 4.9 & 4.9661 & TRN \\
\hline CHEMBL1605196 & 688620 & 5.65 & 5.1006 & TRN \\
\hline CHEMBL1566191 & 688620 & 5.35 & 5.1141 & TRN \\
\hline CHEMBL1389937 & 688620 & 4.8 & 4.9948 & TRN \\
\hline CHEMBL1331643 & 688620 & 4.65 & 5.2641 & TST \\
\hline CHEMBL1584174 & 688620 & 4.45 & 5.0803 & TRN \\
\hline CHEMBL3210775 & 688620 & 4.45 & 5.1941 & TRN \\
\hline CHEMBL 1454786 & 688620 & 4.9 & 4.9892 & TRN \\
\hline CHEMBL1502201 & 688620 & 5.5 & 5.4517 & TRN \\
\hline CHEMBL1570963 & 688620 & 4.45 & 4.7875 & TRN \\
\hline CHEMBL1324944 & 688620 & 5.45 & 5.8691 & TRN \\
\hline CHEMBL1402325 & 688620 & 4.85 & 4.8957 & TRN \\
\hline CHEMBL3194060 & 688620 & 6.35 & 5.9326 & TRN \\
\hline CHEMBL1536091 & 688620 & 7.0 & 6.7022 & TRN \\
\hline
\end{tabular}




\begin{tabular}{|c|c|c|c|c|c|}
\hline \multicolumn{6}{|c|}{ Supplemental Table S2.txt } \\
\hline CHEMBL1444895 & 688620 & 5.05 & 5.1174 & TST & \\
\hline CHEMBL1440084 & 688620 & 4.65 & 4.7553 & TRN & \\
\hline CHEMBL1303075 & 688620 & 4.75 & 4.9908 & TRN & \\
\hline CHEMBL1599891 & 688620 & 5.0 & 5.0603 & TRN & \\
\hline CHEMBL1339400 & 688620 & 4.55 & 5.0341 & TRN & \\
\hline CHEMBL1370572 & 688620 & 6.8499 & 5.0554 & TRN & \\
\hline CHEMBL1421597 & 688620 & 4.8 & 4.8131 & TRN & \\
\hline CHEMBL1968694 & 688620 & 4.95 & 5.2344 & TRN & \\
\hline CHEMBL1575537 & 688620 & 4.75 & 5.0149 & TRN & \\
\hline CHEMBL1386612 & 688620 & 4.45 & 4.9689 & TRN & \\
\hline CHEMBL 2004475 & 688620 & 5.25 & 4.8355 & TST & \\
\hline CHEMBL1584130 & 688620 & 6.0 & 5.54700 & 0000000001 & TRN \\
\hline CHEMBL1347002 & 688620 & 5.2 & 4.855 & TST & \\
\hline CHEMBL1546958 & 688620 & 5.0 & 5.28799 & 9999999999 & TRN \\
\hline CHEMBL1585837 & 688620 & 6.2 & 4.9439 & TRN & \\
\hline CHEMBL3198711 & 688620 & 4.9 & 5.0391 & TST & \\
\hline CHEMBL1481335 & 688620 & 6.1 & 5.3376 & TRN & \\
\hline CHEMBL1604031 & 688620 & 4.45 & 4.8805 & TRN & \\
\hline CHEMBL1542251 & 688620 & 5.55 & 4.9955 & TRN & \\
\hline CHEMBL1339266 & 688620 & 4.9 & 4.8049 & TRN & \\
\hline CHEMBL1381286 & 688620 & 4.7 & 5.3171 & TRN & \\
\hline CHEMBL1491215 & 688620 & 4.95 & 4.9403 & TRN & \\
\hline CHEMBL1523713 & 688620 & 4.7 & 5.0025 & TST & \\
\hline CHEMBL1399702 & 688620 & 5.15 & 5.4388 & TRN & \\
\hline CHEMBL1438129 & 688620 & 5.0 & 5.0289 & TRN & \\
\hline CHEMBL3197391 & 688620 & 6.5 & 6.0013 & TRN & \\
\hline CHEMBL1476108 & 688620 & 4.75 & 5.0707 & TST & \\
\hline CHEMBL1392075 & 688620 & 6.0 & 5.0403 & TRN & \\
\hline CHEMBL1565536 & 688620 & 6.1 & 5.5051 & TST & \\
\hline CHEMBL1567773 & 688620 & 5.05 & 5.1387 & TRN & \\
\hline CHEMBL1381936 & 688620 & 5.5 & 5.49799 & 9999999999 & TRN \\
\hline CHEMBL1308783 & 688620 & 5.0 & 4.8724 & TST & \\
\hline CHEMBL1488833 & 688620 & 4.45 & 4.8431 & TST & \\
\hline CHEMBL1311478 & 688620 & 4.6 & 4.8739 & TRN & \\
\hline CHEMBL1420829 & 688620 & 4.9 & 5.0561 & TRN & \\
\hline CHEMBL1480424 & 688620 & 5.15 & 5.3017 & TRN & \\
\hline CHEMBL1460352 & 688620 & 5.4 & 5.6413 & TST & \\
\hline CHEMBL1506256 & 688620 & 5.7 & 5.4666 & TST & \\
\hline CHEMBL590184 & 688620 & 5.4 & 5.6802 & TRN & \\
\hline CHEMBL1569256 & 688620 & 4.85 & 4.9966 & TRN & \\
\hline CHEMBL1498063 & 688620 & 4.45 & 4.9657 & TST & \\
\hline CHEMBL1319020 & 688620 & 4.9 & 5.519 & TRN & \\
\hline CHEMBL1565626 & 688620 & 5.45 & 5.0245 & TRN & \\
\hline CHEMBL3207678 & 688620 & 5.65 & 5.3221 & TRN & \\
\hline CHEMBL1530189 & 688620 & 4.95 & 4.977 & TST & \\
\hline CHEMBL591404 & 688620 & 4.45 & 4.8518 & TRN & \\
\hline CHEMBL1449042 & 688620 & 5.45 & 5.4767 & TRN & \\
\hline CHEMBL3199942 & 688620 & 4.85 & 5.1319 & TRN & \\
\hline
\end{tabular}





\begin{tabular}{|c|c|c|c|c|}
\hline \multicolumn{5}{|c|}{ Supplemental Table S2.txt } \\
\hline CHEMBL1582945 & 688620 & 5.7 & 5.263 & TRN \\
\hline CHEMBL3191188 & 688620 & 5.6 & 5.309 & TRN \\
\hline CHEMBL1496127 & 688620 & 4.9 & 4.7857 & TRN \\
\hline CHEMBL3212131 & 688620 & 5.35 & 4.9582 & TRN \\
\hline CHEMBL1586119 & 688620 & 4.85 & 4.8998 & TRN \\
\hline CHEMBL3197411 & 688620 & 5.85 & 5.9042 & TST \\
\hline CHEMBL 3194200 & 688620 & 4.95 & 4.8824 & TRN \\
\hline CHEMBL1336848 & 688620 & 4.9 & 5.1924 & TST \\
\hline CHEMBL1988376 & 688620 & 4.7 & 5.0425 & TRN \\
\hline CHEMBL1319427 & 688620 & 4.9 & 5.1777 & TRN \\
\hline CHEMBL1353567 & 688620 & 4.85 & 5.1099 & TST \\
\hline CHEMBL1586979 & 688620 & 4.65 & 4.7777 & TST \\
\hline CHEMBL1467383 & 688620 & 4.75 & 4.8391 & TRN \\
\hline CHEMBL3197215 & 688620 & 5.65 & 5.3439 & TRN \\
\hline CHEMBL1308122 & 688620 & 4.5 & 4.7576 & TST \\
\hline CHEMBL1550389 & 688620 & 4.7 & 5.1732 & TRN \\
\hline CHEMBL1425446 & 688620 & 5.45 & 5.5398 & TST \\
\hline CHEMBL3197912 & 688620 & 6.5 & 6.3546 & TRN \\
\hline CHEMBL1468104 & 688620 & 4.45 & 4.9059 & TST \\
\hline CHEMBL1320062 & 688620 & 4.95 & 5.0588 & TRN \\
\hline CHEMBL1309188 & 688620 & 5.85 & 5.3424 & TRN \\
\hline CHEMBL1431399 & 688620 & 4.6 & 4.9619 & TST \\
\hline CHEMBL339561 & 688620 & 5.0 & 5.1219 & TRN \\
\hline CHEMBL1494997 & 688620 & 5.0 & 5.075 & TST \\
\hline CHEMBL1310072 & 688620 & 5.45 & 5.4583 & TRN \\
\hline CHEMBL1329756 & 688620 & 5.0 & 4.853 & TRN \\
\hline CHEMBL1346408 & 688620 & 6.0 & 5.7218 & TRN \\
\hline CHEMBL1341929 & 688620 & 4.95 & 5.1016 & TRN \\
\hline CHEMBL1401841 & 688620 & 4.5 & 4.9879 & TST \\
\hline CHEMBL1420996 & 688620 & 5.3 & 5.1926 & TRN \\
\hline CHEMBL1571835 & 688620 & 5.25 & 5.0683 & TST \\
\hline CHEMBL3193692 & 688620 & 4.7 & 4.7177 & TRN \\
\hline CHEMBL1466151 & 688620 & 4.9 & 5.1794 & TRN \\
\hline CHEMBL1351321 & 688620 & 4.6 & 5.04 & TRN \\
\hline CHEMBL1613199 & 688620 & 4.8 & 5.14 & TRN \\
\hline CHEMBL1497661 & 688620 & 4.45 & 4.9324 & TRN \\
\hline CHEMBL 1538878 & 688620 & 4.5 & 5.166 & TST \\
\hline CHEMBL1474443 & 688620 & 4.75 & 4.9786 & TST \\
\hline CHEMBL3192578 & 688620 & 5.95 & 5.2867 & TST \\
\hline CHEMBL1584679 & 688620 & 4.45 & 4.773 & TRN \\
\hline CHEMBL1408586 & 688620 & 4.45 & 4.8402 & TRN \\
\hline CHEMBL1528149 & 688620 & 5.25 & 4.9364 & TST \\
\hline CHEMBL1452252 & 688620 & 4.9 & 5.1216 & TST \\
\hline CHEMBL1544302 & 688620 & 4.5 & 5.0185 & TRN \\
\hline CHEMBL1442509 & 688620 & 5.65 & 5.016 & TST \\
\hline CHEMBL1361128 & 688620 & 4.8 & 5.1495 & TRN \\
\hline CHEMBL1404792 & 688620 & 6.0 & 6.0443 & TRN \\
\hline CHEMBL1333831 & 688620 & 5.7 & 5.0914 & TRN \\
\hline
\end{tabular}




\begin{tabular}{|c|c|c|c|c|}
\hline \multicolumn{5}{|c|}{ Supplemental Table S2.txt } \\
\hline CHEMBL3195086 & 688620 & 4.65 & 5.1855 & TRN \\
\hline CHEMBL1550124 & 688620 & 4.95 & 5.3332 & TRN \\
\hline CHEMBL1375192 & 688620 & 5.65 & 5.2331 & TRN \\
\hline CHEMBL1605726 & 688620 & 5.25 & 5.021 & TRN \\
\hline CHEMBL1325563 & 688620 & 4.95 & 5.1147 & TST \\
\hline CHEMBL1556975 & 688620 & 5.4 & 5.1684 & TST \\
\hline CHEMBL1380100 & 688620 & 6.4 & 5.0523 & TRN \\
\hline CHEMBL3190095 & 688620 & 5.15 & 4.8531 & TST \\
\hline CHEMBL1574508 & 688620 & 4.8 & 5.0082 & TST \\
\hline CHEMBL1549441 & 688620 & 4.45 & 5.1401 & TRN \\
\hline CHEMBL1417833 & 688620 & 4.45 & 4.9466 & TRN \\
\hline CHEMBL1530685 & 688620 & 5.35 & 5.0434 & TRN \\
\hline CHEMBL1572031 & 688620 & 5.35 & 5.3192 & TRN \\
\hline CHEMBL1301741 & 688620 & 4.9 & 5.0014 & TRN \\
\hline CHEMBL1430179 & 688620 & 4.7 & 4.9208 & TRN \\
\hline CHEMBL1402055 & 688620 & 4.85 & 4.8782 & TST \\
\hline CHEMBL1447076 & 688620 & 4.45 & 4.5983 & TST \\
\hline CHEMBL3190709 & 688620 & 4.9 & 5.23 & TST \\
\hline CHEMBL1384831 & 688620 & 4.9 & 5.0693 & TST \\
\hline CHEMBL1311025 & 688620 & 4.9 & 4.947 & TRN \\
\hline CHEMBL1452115 & 688620 & 4.75 & 4.7387 & TRN \\
\hline CHEMBL574491 & 688620 & 5.25 & 5.1688 & TRN \\
\hline CHEMBL1529455 & 688620 & 4.45 & 4.7832 & TRN \\
\hline CHEMBL1361983 & 688620 & 6.25 & 5.1493 & TRN \\
\hline CHEMBL1605809 & 688620 & 5.75 & 5.3929 & TRN \\
\hline CHEMBL1299599 & 688620 & 4.75 & 4.9721 & TRN \\
\hline CHEMBL3212052 & 688620 & 4.45 & 4.9088 & TST \\
\hline CHEMBL1302078 & 688620 & 5.5 & 4.9266 & TST \\
\hline CHEMBL1541900 & 688620 & 5.0 & 4.9643 & TRN \\
\hline CHEMBL1540984 & 688620 & 5.05 & 4.9448 & TRN \\
\hline CHEMBL1544093 & 688620 & 5.4 & 5.3681 & TRN \\
\hline CHEMBL3197857 & 688620 & 4.85 & 5.0235 & TRN \\
\hline CHEMBL1465226 & 688620 & 5.5 & 5.331 & TRN \\
\hline CHEMBL1359788 & 688620 & 5.35 & 5.5123 & TRN \\
\hline CHEMBL505863 & 688620 & 5.2 & 5.2304 & TST \\
\hline CHEMBL1392789 & 688620 & 4.65 & 4.8478 & TRN \\
\hline CHEMBL1464547 & 688620 & 5.4 & 5.274 & TST \\
\hline CHEMBL1336596 & 688620 & 4.45 & 4.8974 & TRN \\
\hline CHEMBL1433246 & 688620 & 4.75 & 4.9227 & TRN \\
\hline CHEMBL1574120 & 688620 & 4.95 & 5.0905 & TRN \\
\hline CHEMBL1332448 & 688620 & 5.3 & 5.234 & TRN \\
\hline CHEMBL1321240 & 688620 & 5.35 & 5.2386 & TRN \\
\hline CHEMBL1335689 & 688620 & 4.7 & 4.9534 & TST \\
\hline CHEMBL3197431 & 688620 & 5.05 & 5.3778 & TRN \\
\hline CHEMBL1520156 & 688620 & 4.9 & 4.944 & TST \\
\hline CHEMBL1530781 & 688620 & 4.9 & 5.0082 & TRN \\
\hline CHEMBL1967952 & 688620 & 4.95 & 4.9073 & TST \\
\hline CHEMBL1462111 & 688620 & 5.5 & 5.1402 & TRN \\
\hline
\end{tabular}




\begin{tabular}{|c|c|c|c|c|}
\hline & & & pplemen & al $\mathrm{T}$ \\
\hline CHEMBL1452764 & 688620 & 5.2 & 5.2158 & TST \\
\hline CHEMBL1602993 & 688620 & 4.8 & 4.6891 & TRN \\
\hline CHEMBL1569305 & 688620 & 4.7 & 5.5312 & TRN \\
\hline CHEMBL1414748 & 688620 & 4.45 & 5.0125 & TST \\
\hline CHEMBL1529837 & 688620 & 4.85 & 4.8302 & TRN \\
\hline CHEMBL 3212346 & 688620 & 4.9 & 4.9111 & TRN \\
\hline CHEMBL1560399 & 688620 & 4.95 & 4.7334 & TRN \\
\hline CHEMBL1530687 & 688620 & 5.0 & 5.3799 & TRN \\
\hline CHEMBL1375488 & 688620 & 4.9 & 5.1977 & TRN \\
\hline CHEMBL1568871 & 688620 & 5.15 & 5.1408 & TRN \\
\hline CHEMBL1310449 & 688620 & 5.3 & 5.6165 & TRN \\
\hline CHEMBL1343837 & 688620 & 4.9 & 5.1207 & TRN \\
\hline CHEMBL1371873 & 688620 & 4.45 & 4.6514 & TST \\
\hline CHEMBL1377303 & 688620 & 5.1 & 5.0724 & TRN \\
\hline CHEMBL1312186 & 688620 & 6.95 & 6.228 & TRN \\
\hline CHEMBL1577923 & 688620 & 4.95 & 5.0795 & TRN \\
\hline CHEMBL1578728 & 688620 & 4.55 & 4.8152 & TST \\
\hline CHEMBL1573948 & 688620 & 4.45 & 4.9864 & TST \\
\hline CHEMBL1497195 & 688620 & 4.9 & 5.1784 & TRN \\
\hline CHEMBL1534941 & 688620 & 4.75 & 4.9891 & TRN \\
\hline CHEMBL1993544 & 688620 & 5.25 & 5.1624 & TRN \\
\hline CHEMBL1428486 & 688620 & 5.2 & 5.1238 & TRN \\
\hline CHEMBL1558131 & 688620 & 5.2 & 4.9685 & TST \\
\hline CHEMBL407294 & 688620 & 4.8 & 5.2754 & TRN \\
\hline CHEMBL1325273 & 688620 & 4.9 & 5.1831 & TST \\
\hline CHEMBL1547860 & 688620 & 5.45 & 5.5149 & TRN \\
\hline CHEMBL1341008 & 688620 & 5.35 & 5.2318 & TST \\
\hline CHEMBL1609172 & 688620 & 4.85 & 5.1789 & TST \\
\hline CHEMBL1564522 & 688620 & 4.95 & 5.0865 & TST \\
\hline CHEMBL1340076 & 688620 & 4.75 & 5.013 & TRN \\
\hline CHEMBL1492262 & 688620 & 4.65 & 4.8459 & TST \\
\hline CHEMBL1606325 & 688620 & 4.65 & 5.0657 & TRN \\
\hline CHEMBL1425364 & 688620 & 5.15 & 5.0071 & TRN \\
\hline CHEMBL1979558 & 688620 & 6.1 & 4.8616 & TRN \\
\hline CHEMBL1346474 & 688620 & 4.7 & 4.9835 & TST \\
\hline CHEMBL1604098 & 688620 & 4.7 & 4.9251 & TRN \\
\hline CHEMBL1312160 & 688620 & 5.2 & 4.8651 & TRN \\
\hline CHEMBL1609718 & 688620 & 6.15 & 5.7988 & TRN \\
\hline CHEMBL1585055 & 688620 & 7.0 & 5.2326 & TRN \\
\hline CHEMBL1365914 & 688620 & 5.4 & 5.0941 & TRN \\
\hline CHEMBL1364790 & 688620 & 4.95 & 5.0565 & TST \\
\hline CHEMBL1539046 & 688620 & 5.35 & 5.5686 & TRN \\
\hline CHEMBL1452055 & 688620 & 4.45 & 5.1156 & TRN \\
\hline CHEMBL1458322 & 688620 & 4.45 & 5.0777 & TRN \\
\hline CHEMBL1487415 & 688620 & 5.3 & 5.1024 & TRN \\
\hline CHEMBL1607172 & 688620 & 5.0 & 5.2043 & TRN \\
\hline CHEMBL1442562 & 688620 & 4.8 & 5.0329 & TRN \\
\hline CHEMBL1377648 & 688620 & 5.0 & 5.0138 & TRN \\
\hline
\end{tabular}




\begin{tabular}{|c|c|c|c|c|c|}
\hline & & \multicolumn{4}{|c|}{ Supplemental Table s2.txt } \\
\hline CHEMBL3199211 & 688620 & 6.15 & 5.2761 & TRN & \\
\hline CHEMBL1547363 & 688620 & 5.25 & 4.9459 & TRN & \\
\hline CHEMBL1492120 & 688620 & 5.7 & 5.0403 & TRN & \\
\hline CHEMBL1304810 & 688620 & 5.6 & 5.1534 & TRN & \\
\hline CHEMBL1418885 & 688620 & 4.55 & 4.8374 & TRN & \\
\hline CHEMBL1532221 & 688620 & 5.55 & 5.0926 & TRN & \\
\hline CHEMBL1414639 & 688620 & 4.5 & 4.9606 & TRN & \\
\hline CHEMBL1413969 & 688620 & 6.0 & 5.3676 & TRN & \\
\hline CHEMBL1411899 & 688620 & 6.1 & 5.073 & TST & \\
\hline CHEMBL1505174 & 688620 & 4.95 & 5.2181 & TST & \\
\hline CHEMBL1600832 & 688620 & 4.6 & 4.8231 & TRN & \\
\hline CHEMBL1408781 & 688620 & 4.85 & 4.9406 & TRN & \\
\hline CHEMBL1308234 & 688620 & 4.65 & 4.9154 & TRN & \\
\hline CHEMBL 3190784 & 688620 & 4.95 & 4.9889 & TRN & \\
\hline CHEMBL1525147 & 688620 & 4.95 & 4.9563 & TRN & \\
\hline CHEMBL1451087 & 688620 & 4.5 & 4.79899 & 99999999995 & TST \\
\hline CHEMBL1547435 & 688620 & 4.9 & 4.7454 & TRN & \\
\hline CHEMBL1525545 & 688620 & 6.0 & 5.5542 & TRN & \\
\hline CHEMBL1353968 & 688620 & 4.5 & 4.8842 & TRN & \\
\hline CHEMBL1335718 & 688620 & 4.45 & 4.7731 & TRN & \\
\hline CHEMBL1496108 & 688620 & 5.95 & 5.0109 & TRN & \\
\hline CHEMBL1360677 & 688620 & 4.95 & 5.2756 & TRN & \\
\hline CHEMBL1304128 & 688620 & 5.0 & 5.1682 & TRN & \\
\hline CHEMBL1510606 & 688620 & 5.0 & 5.1864 & TRN & \\
\hline CHEMBL1351799 & 688620 & 4.95 & 4.933 & TRN & \\
\hline CHEMBL1540161 & 688620 & 4.5 & 4.9492 & TRN & \\
\hline CHEMBL1418545 & 688620 & 6.15 & 5.0727 & TST & \\
\hline CHEMBL3196102 & 688620 & 5.1 & 5.1696 & TRN & \\
\hline CHEMBL1506239 & 688620 & 4.85 & 4.8705 & TRN & \\
\hline CHEMBL1531783 & 688620 & 5.0 & 4.9377 & TRN & \\
\hline CHEMBL1593813 & 688620 & 4.65 & 4.7949 & TRN & \\
\hline CHEMBL1306570 & 688620 & 6.1 & 5.3571 & TRN & \\
\hline CHEMBL3194405 & 688620 & 4.45 & 4.7004 & TRN & \\
\hline CHEMBL1573966 & 688620 & 4.85 & 5.1975 & TRN & \\
\hline CHEMBL3198413 & 688620 & 5.95 & 5.7293 & TRN & \\
\hline CHEMBL1382334 & 688620 & 6.4 & 5.1423 & TST & \\
\hline CHEMBL1493509 & 688620 & 4.9 & 5.1411 & TRN & \\
\hline CHEMBL1439902 & 688620 & 4.45 & 5.0304 & TST & \\
\hline CHEMBL1383092 & 688620 & 4.45 & 5.0015 & TST & \\
\hline CHEMBL1445786 & 688620 & 4.75 & 4.831 & TRN & \\
\hline CHEMBL3195871 & 688620 & 4.45 & 4.9521 & TRN & \\
\hline CHEMBL1507387 & 688620 & 4.9 & 4.915 & TRN & \\
\hline CHEMBL1450679 & 688620 & 4.9 & 4.7984 & TRN & \\
\hline CHEMBL1543776 & 688620 & 6.45 & 6.0205 & TRN & \\
\hline CHEMBL1575098 & 688620 & 4.9 & 4.8821 & TRN & \\
\hline CHEMBL1340334 & 688620 & 4.65 & 5.0118 & TRN & \\
\hline CHEMBL1339740 & 688620 & 4.45 & 4.8719 & TRN & \\
\hline CHEMBL1381857 & 688620 & 4.45 & 5.0165 & TRN & \\
\hline
\end{tabular}




\begin{tabular}{|c|c|c|c|c|c|}
\hline \multicolumn{6}{|c|}{ Supplemental Table S2.txt } \\
\hline CHEMBL1526565 & 688620 & 4.5 & 5.0039 & TRN & \\
\hline CHEMBL1449100 & 688620 & 4.45 & 4.8273 & TRN & \\
\hline CHEMBL1973921 & 688620 & 6.7001 & 5.9219 & TRN & \\
\hline CHEMBL1538883 & 688620 & 4.45 & 4.8696 & TST & \\
\hline CHEMBL1518154 & 688620 & 6.7001 & 6.2272 & TRN & \\
\hline CHEMBL3145102 & 688620 & 6.8 & 5.235 & TST & \\
\hline CHEMBL3191680 & 688620 & 4.95 & 4.9983 & TRN & \\
\hline CHEMBL1452465 & 688620 & 4.9 & 5.0962 & TRN & \\
\hline CHEMBL1481578 & 688620 & 4.9 & 4.899 & TRN & \\
\hline CHEMBL1334376 & 688620 & 5.25 & 5.0558 & TRN & \\
\hline CHEMBL1432532 & 688620 & 4.5 & 5.1578 & TST & \\
\hline CHEMBL1506597 & 688620 & 7.3497 & 5.2807 & TRN & \\
\hline CHEMBL1579548 & 688620 & 4.8 & 4.6825 & TRN & \\
\hline CHEMBL1390028 & 688620 & 5.75 & 5.1168 & TRN & \\
\hline CHEMBL1367292 & 688620 & 4.45 & 4.9525 & TRN & \\
\hline CHEMBL1998716 & 688620 & 4.7 & 4.8799 & TRN & \\
\hline CHEMBL1388666 & 688620 & 7.0501 & 5.7945 & TST & \\
\hline CHEMBL3191503 & 688620 & 5.75 & 5.6304 & TRN & \\
\hline CHEMBL1459725 & 688620 & 4.85 & 4.8989 & TRN & \\
\hline CHEMBL1330345 & 688620 & 4.9 & 4.9921 & TST & \\
\hline CHEMBL343002 & 688620 & 5.65 & 5.1566 & TST & \\
\hline CHEMBL1424321 & 688620 & 5.05 & 4.7776 & TRN & \\
\hline CHEMBL1556269 & 688620 & 4.75 & 5.0486 & TRN & \\
\hline CHEMBL3392039 & 688620 & 5.1 & 5.0793 & TRN & \\
\hline CHEMBL1502351 & 688620 & 5.8 & 5.2355 & TRN & \\
\hline CHEMBL1523184 & 688620 & 4.45 & 4.9795 & TRN & \\
\hline CHEMBL3207353 & 688620 & 5.45 & 5.1154 & TRN & \\
\hline CHEMBL1299925 & 688620 & 4.85 & 4.8382 & TST & \\
\hline CHEMBL1534363 & 688620 & 5.15 & 5.1392 & TRN & \\
\hline CHEMBL1594322 & 688620 & 5.7 & 5.414 & TRN & \\
\hline CHEMBL1347942 & 688620 & 4.9 & 5.5136 & TST & \\
\hline CHEMBL1560492 & 688620 & 5.3 & 5.2131 & TST & \\
\hline CHEMBL1607184 & 688620 & 4.5 & 4.88399 & 99999999995 & TRN \\
\hline CHEMBL1308296 & 688620 & 4.9 & 5.0435 & TST & \\
\hline CHEMBL1370194 & 688620 & 4.7 & 5.2865 & TRN & \\
\hline CHEMBL1408438 & 688620 & 5.3 & 5.1803 & TRN & \\
\hline CHEMBL1486097 & 688620 & 5.6 & 4.823 & TRN & \\
\hline CHEMBL1319867 & 688620 & 5.45 & 5.2707 & TRN & \\
\hline CHEMBL1437520 & 688620 & 4.85 & 5.0201 & TRN & \\
\hline CHEMBL1595409 & 688620 & 4.65 & 5.0884 & TRN & \\
\hline CHEMBL1321829 & 688620 & 5.5 & 5.0144 & TST & \\
\hline CHEMBL1303674 & 688620 & 5.6 & 5.1075 & TRN & \\
\hline CHEMBL1531881 & 688620 & 4.6 & 5.2299 & TST & \\
\hline CHEMBL1470162 & 688620 & 4.85 & 4.6531 & TRN & \\
\hline CHEMBL1581323 & 688620 & 4.55 & 5.1719 & TST & \\
\hline CHEMBL3198701 & 688620 & 5.8 & 5.3009 & TRN & \\
\hline CHEMBL1343633 & 688620 & 5.5 & 5.1325 & TRN & \\
\hline CHEMBL3192020 & 688620 & 4.45 & 5.29899 & & TRN \\
\hline & & & & 2688 & \\
\hline
\end{tabular}




\begin{tabular}{|c|c|c|c|c|}
\hline \multicolumn{5}{|c|}{ Supplemental Table S2.txt } \\
\hline CHEMBL1326060 & 688620 & 6.2 & 6.3538 & TRN \\
\hline CHEMBL1577991 & 688620 & 4.75 & 4.6603 & TRN \\
\hline CHEMBL1548393 & 688620 & 5.2 & 5.0166 & TST \\
\hline CHEMBL1544712 & 688620 & 5.0 & 4.868 & TRN \\
\hline CHEMBL1428932 & 688620 & 4.7 & 5.2681 & TRN \\
\hline CHEMBL 3213348 & 688620 & 5.65 & 5.0828 & TRN \\
\hline CHEMBL1564611 & 688620 & 5.2 & 4.976 & TRN \\
\hline CHEMBL1520586 & 688620 & 5.3 & 5.3166 & TRN \\
\hline CHEMBL1605356 & 688620 & 4.45 & 4.7914 & TRN \\
\hline CHEMBL1525294 & 688620 & 5.1 & 5.0155 & TRN \\
\hline CHEMBL1350396 & 688620 & 4.9 & 4.7549 & TRN \\
\hline CHEMBL1311042 & 688620 & 4.75 & 4.9739 & TST \\
\hline CHEMBL1414696 & 688620 & 6.1 & 5.2562 & TST \\
\hline CHEMBL1529396 & 688620 & 4.65 & 4.8797 & TRN \\
\hline CHEMBL1415233 & 688620 & 4.65 & 4.8038 & TRN \\
\hline CHEMBL1362387 & 688620 & 4.75 & 5.0418 & TST \\
\hline CHEMBL1487152 & 688620 & 4.9 & 5.8 & TRN \\
\hline CHEMBL1341741 & 688620 & 4.45 & 5.0881 & TST \\
\hline CHEMBL 3195025 & 688620 & 4.95 & 4.8633 & TST \\
\hline CHEMBL1459671 & 688620 & 5.05 & 5.2315 & TST \\
\hline CHEMBL3193494 & 688620 & 5.0 & 5.3549 & TST \\
\hline CHEMBL1370490 & 688620 & 5.3 & 5.4972 & TRN \\
\hline CHEMBL1417344 & 688620 & 4.7 & 4.9953 & TRN \\
\hline CHEMBL1528380 & 688620 & 4.65 & 4.8848 & TST \\
\hline CHEMBL1978354 & 688620 & 4.95 & 5.5497 & TRN \\
\hline CHEMBL1466809 & 688620 & 4.65 & 4.9081 & TST \\
\hline CHEMBL1350727 & 688620 & 4.45 & 4.8143 & TRN \\
\hline CHEMBL1377210 & 688620 & 4.7 & 4.7789 & TRN \\
\hline CHEMBL1407735 & 688620 & 6.7501 & 5.6363 & TRN \\
\hline CHEMBL1506068 & 688620 & 4.8 & 5.3302 & TST \\
\hline CHEMBL1376770 & 688620 & 4.9 & 4.894 & TST \\
\hline CHEMBL1549877 & 688620 & 5.15 & 5.0809 & TRN \\
\hline CHEMBL1536566 & 688620 & 5.45 & 5.103 & TRN \\
\hline CHEMBL1524932 & 688620 & 5.4 & 5.2618 & TRN \\
\hline CHEMBL1365699 & 688620 & 4.95 & 5.058 & TRN \\
\hline CHEMBL1528357 & 688620 & 4.45 & 4.8773 & TRN \\
\hline CHEMBL1515246 & 688620 & 4.45 & 5.083 & TRN \\
\hline CHEMBL1376601 & 688620 & 4.55 & 5.4402 & TRN \\
\hline CHEMBL1346575 & 688620 & 5.6 & 5.2091 & TST \\
\hline CHEMBL1346663 & 688620 & 4.45 & 4.9435 & TST \\
\hline CHEMBL1990527 & 688620 & 4.9 & 4.9649 & TRN \\
\hline CHEMBL1422806 & 688620 & 5.1 & 4.6722 & TRN \\
\hline CHEMBL1605066 & 688620 & 4.95 & 5.0387 & TRN \\
\hline CHEMBL1330036 & 688620 & 5.05 & 4.9386 & TRN \\
\hline CHEMBL1501113 & 688620 & 4.9 & 4.7078 & TRN \\
\hline CHEMBL1533893 & 688620 & 4.45 & 5.0561 & TRN \\
\hline CHEMBL1584417 & 688620 & 4.45 & 4.7419 & TST \\
\hline CHEMBL3196049 & 688620 & 4.45 & 4.7922 & TRN \\
\hline
\end{tabular}




\begin{tabular}{|c|c|c|c|c|c|}
\hline \\
\hline CHEMBL1608476 & 688620 & 5.5 & 5.3879 & TRN & \\
\hline CHEMBL3214419 & 688620 & 7.2 & 5.1813 & TRN & \\
\hline CHEMBL1313258 & 688620 & 4.45 & 4.7762 & TRN & \\
\hline CHEMBL1504368 & 688620 & 5.2 & 5.0944 & TST & \\
\hline CHEMBL1380384 & 688620 & 4.8 & 5.069 & TST & \\
\hline CHEMBL1479039 & 688620 & 4.7 & $5.0760 e$ & 00000000005 & TRN \\
\hline CHEMBL1469171 & 688620 & 4.45 & 4.7494 & TRN & \\
\hline CHEMBL1392378 & 688620 & 4.85 & 5.0451 & TST & \\
\hline CHEMBL1451540 & 688620 & 4.45 & 4.97 & TRN & \\
\hline CHEMBL1505572 & 688620 & 4.65 & 4.7736 & TST & \\
\hline CHEMBL1575958 & 688620 & 4.95 & 4.9052 & TRN & \\
\hline CHEMBL3199921 & 688620 & 4.85 & 5.1353 & TST & \\
\hline CHEMBL1356949 & 688620 & 4.75 & 4.7656 & TRN & \\
\hline CHEMBL1976677 & 688620 & 5.55 & 5.5715 & TRN & \\
\hline CHEMBL1603456 & 688620 & 4.75 & 5.0015 & TRN & \\
\hline CHEMBL1201091 & 688620 & 4.45 & 5.151 & TRN & \\
\hline CHEMBL1494490 & 688620 & 4.45 & 5.1799 & TST & \\
\hline CHEMBL1350715 & 688620 & 5.45 & 5.1243 & TST & \\
\hline CHEMBL1360922 & 688620 & 4.9 & 5.2023 & TRN & \\
\hline CHEMBL1479499 & 688620 & 4.65 & 5.0298 & TRN & \\
\hline CHEMBL1429055 & 688620 & 4.45 & 5.0781 & TST & \\
\hline CHEMBL1556417 & 688620 & 4.45 & 4.9919 & TST & \\
\hline CHEMBL1451813 & 688620 & 4.95 & 4.8517 & TRN & \\
\hline CHEMBL1589682 & 688620 & 4.9 & 4.9016 & TRN & \\
\hline CHEMBL1421244 & 688620 & 5.3 & 5.5547 & TRN & \\
\hline CHEMBL1383037 & 688620 & 4.9 & 4.8014 & TST & \\
\hline CHEMBL1545429 & 688620 & 6.0 & 5.7534 & TRN & \\
\hline CHEMBL1547201 & 688620 & 4.85 & 5.1041 & TRN & \\
\hline CHEMBL1418000 & 688620 & 5.55 & 4.9435 & TST & \\
\hline CHEMBL1335464 & 688620 & 5.65 & 5.0928 & TRN & \\
\hline CHEMBL1332624 & 688620 & 4.8 & 4.8737 & TRN & \\
\hline CHEMBL1465049 & 688620 & 4.6 & 4.7357 & TRN & \\
\hline CHEMBL1468181 & 688620 & 6.8 & 5.352 & TRN & \\
\hline CHEMBL1441404 & 688620 & 5.2 & 5.1674 & TST & \\
\hline CHEMBL1388021 & 688620 & 4.8 & 5.1913 & TST & \\
\hline CHEMBL1579385 & 688620 & 4.45 & 4.9539 & TRN & \\
\hline CHEMBL1542533 & 688620 & 5.0 & 5.1559 & TST & \\
\hline CHEMBL 3198441 & 688620 & 4.75 & 4.9029 & TRN & \\
\hline CHEMBL1595076 & 688620 & 5.35 & 5.166 & TRN & \\
\hline CHEMBL1406632 & 688620 & 4.45 & 5.0108 & TRN & \\
\hline CHEMBL1322923 & 688620 & 4.45 & 4.9421 & TRN & \\
\hline CHEMBL1325063 & 688620 & 6.0 & 4.7611 & TST & \\
\hline CHEMBL1477588 & 688620 & 5.0 & 5.2718 & TST & \\
\hline CHEMBL1583885 & 688620 & 5.1 & 5.2167 & TRN & \\
\hline CHEMBL1401098 & 688620 & 4.45 & 5.047 & TST & \\
\hline CHEMBL1351323 & 688620 & 4.55 & 5.0788 & TRN & \\
\hline CHEMBL1550666 & 688620 & 4.45 & 4.8818 & TRN & \\
\hline CHEMBL1588162 & 688620 & 5.35 & 5.021 & TRN & \\
\hline
\end{tabular}




\begin{tabular}{|c|c|c|c|c|c|}
\hline \multirow{2}{*}{\multicolumn{2}{|c|}{ CHEMBL1553637 }} & \\
\hline & & 4.6 & 5.1729 & TRN & \\
\hline CHEMBL1439704 & 688620 & 5.0 & 4.9169 & TRN & \\
\hline CHEMBL1520808 & 688620 & 4.45 & 4.8336 & TRN & \\
\hline CHEMBL1470511 & 688620 & 4.95 & 4.9407 & TRN & \\
\hline CHEMBL3207963 & 688620 & 4.95 & 4.8705 & TRN & \\
\hline CHEMBL1444950 & 688620 & 4.75 & 5.0646 & TST & \\
\hline CHEMBL1395454 & 688620 & 4.6 & 4.84399 & 9999999999 & TRN \\
\hline CHEMBL1509975 & 688620 & 4.8 & 4.9661 & TRN & \\
\hline CHEMBL1377825 & 688620 & 5.7 & 5.5142 & TRN & \\
\hline CHEMBL1411813 & 688620 & 4.85 & 4.99100 & 00000000005 & TRN \\
\hline CHEMBL1977173 & 688620 & 4.45 & 4.8339 & TRN & \\
\hline CHEMBL1466407 & 688620 & 4.85 & 5.2822 & TRN & \\
\hline CHEMBL1595703 & 688620 & 5.0 & 5.1421 & TRN & \\
\hline CHEMBL1503966 & 688620 & 4.85 & 4.9244 & TRN & \\
\hline CHEMBL 253408 & 688620 & 4.7 & 4.8045 & TRN & \\
\hline CHEMBL1506570 & 688620 & 5.2 & 5.0966 & TRN & \\
\hline CHEMBL1307894 & 688620 & 5.75 & 5.3166 & TRN & \\
\hline CHEMBL1578429 & 688620 & 4.95 & 4.8846 & TRN & \\
\hline CHEMBL1383597 & 688620 & 5.55 & 5.3722 & TRN & \\
\hline CHEMBL1310405 & 688620 & 4.55 & 5.0991 & TST & \\
\hline CHEMBL1589796 & 688620 & 5.25 & 5.2926 & TRN & \\
\hline CHEMBL1385288 & 688620 & 5.05 & 4.9581 & TST & \\
\hline CHEMBL3211272 & 688620 & 4.95 & 5.0648 & TRN & \\
\hline CHEMBL1325194 & 688620 & 4.75 & 5.2721 & TST & \\
\hline CHEMBL1997668 & 688620 & 5.9 & 5.0965 & TRN & \\
\hline CHEMBL1539322 & 688620 & 4.45 & 5.102 & TRN & \\
\hline CHEMBL1479010 & 688620 & 5.0 & 5.0812 & TST & \\
\hline CHEMBL1483194 & 688620 & 4.8 & 4.9098 & TRN & \\
\hline CHEMBL1313001 & 688620 & 4.85 & 5.16200 & $\partial 000000001$ & TRN \\
\hline CHEMBL1464376 & 688620 & 4.45 & 4.8431 & TRN & \\
\hline CHEMBL1509508 & 688620 & 5.5 & 5.9963 & TRN & \\
\hline CHEMBL1411721 & 688620 & 5.25 & 5.3666 & TRN & \\
\hline CHEMBL1416115 & 688620 & 4.9 & 5.2654 & TRN & \\
\hline CHEMBL1398687 & 688620 & 5.5 & 5.5953 & TRN & \\
\hline CHEMBL1344836 & 688620 & 5.0 & 4.7622 & TST & \\
\hline CHEMBL1411712 & 688620 & 6.15 & 5.6359 & TRN & \\
\hline CHEMBL1361558 & 688620 & 4.8 & 4.9661 & TRN & \\
\hline CHEMBL1573523 & 688620 & 5.55 & 4.9261 & TRN & \\
\hline CHEMBL1573608 & 688620 & 4.95 & 5.1213 & TRN & \\
\hline CHEMBL1518859 & 688620 & 4.45 & 4.9848 & TRN & \\
\hline CHEMBL1324467 & 688620 & 4.95 & 4.8115 & TST & \\
\hline CHEMBL1313942 & 688620 & 4.55 & 5.0189 & TRN & \\
\hline CHEMBL1433015 & 688620 & 6.0 & 5.6211 & TRN & \\
\hline CHEMBL1585557 & 688620 & 5.5 & 5.254 & TRN & \\
\hline CHEMBL1471489 & 688620 & 4.65 & 5.0464 & TRN & \\
\hline CHEMBL1469000 & 688620 & 4.45 & 4.9113 & TRN & \\
\hline CHEMBL3198769 & 688620 & 4.9 & 5.1477 & TRN & \\
\hline CHEMBL1459533 & 688620 & 4.75 & 5.125 & TRN & \\
\hline & & & & 26887 & \\
\hline
\end{tabular}




\begin{tabular}{|c|c|c|c|c|c|}
\hline \\
\hline CHEMBL1424787 & 688620 & 4.7 & 5.0952 & TRN & \\
\hline CHEMBL1505760 & 688620 & 6.15 & 6.0998 & TRN & \\
\hline CHEMBL1484898 & 688620 & 5.55 & 5.1815 & TRN & \\
\hline CHEMBL1342230 & 688620 & 4.95 & 4.8359 & TRN & \\
\hline CHEMBL1390810 & 688620 & 4.95 & 5.0741 & TRN & \\
\hline CHEMBL3210890 & 688620 & 4.45 & 4.9594 & TRN & \\
\hline CHEMBL1981379 & 688620 & 4.45 & 5.0972 & TST & \\
\hline CHEMBL1502840 & 688620 & 6.1 & 5.7895 & TRN & \\
\hline CHEMBL1583552 & 688620 & 5.05 & 4.8145 & TRN & \\
\hline CHEMBL3190715 & 688620 & 5.25 & 5.0175 & TRN & \\
\hline CHEMBL1538975 & 688620 & 4.8 & 4.8342 & TRN & \\
\hline CHEMBL1413441 & 688620 & 4.9 & 5.05399 & 9999999999 & TRN \\
\hline CHEMBL1489200 & 688620 & 5.75 & 5.41200 & 0000000001 & TRN \\
\hline CHEMBL1505383 & 688620 & 4.95 & 5.0582 & TRN & \\
\hline CHEMBL1598706 & 688620 & 4.65 & 4.8978 & TRN & \\
\hline CHEMBL1447656 & 688620 & 4.9 & 4.9407 & TRN & \\
\hline CHEMBL1477771 & 688620 & 6.2 & 5.141 & TRN & \\
\hline CHEMBL1306079 & 688620 & 4.45 & 5.0038 & TRN & \\
\hline CHEMBL1472147 & 688620 & 5.2 & 4.8781 & TRN & \\
\hline CHEMBL1609134 & 688620 & 4.9 & 5.2932 & TRN & \\
\hline CHEMBL1452415 & 688620 & 5.2 & 5.4605 & TST & \\
\hline CHEMBL1553149 & 688620 & 4.8 & 5.2449 & TRN & \\
\hline CHEMBL1499302 & 688620 & 4.95 & 4.8436 & TRN & \\
\hline CHEMBL1608372 & 688620 & 5.0 & 5.0219 & TRN & \\
\hline CHEMBL581880 & 688620 & 4.4 & 4.8241 & TRN & \\
\hline CHEMBL1467116 & 688620 & 5.1 & 4.6336 & TRN & \\
\hline CHEMBL1585877 & 688620 & 4.9 & 4.9194 & TRN & \\
\hline CHEMBL3195709 & 688620 & 5.55 & 5.2559 & TST & \\
\hline CHEMBL1575989 & 688620 & 4.45 & 4.9116 & TRN & \\
\hline CHEMBL1581889 & 688620 & 4.45 & 5.0125 & TST & \\
\hline CHEMBL1423586 & 688620 & 4.45 & 4.8158 & TST & \\
\hline CHEMBL1580731 & 688620 & 4.9 & 5.1713 & TRN & \\
\hline CHEMBL1341534 & 688620 & 4.9 & 4.9204 & TRN & \\
\hline CHEMBL1391672 & 688620 & 5.3 & 5.0923 & TRN & \\
\hline CHEMBL1432932 & 688620 & 4.85 & 5.047 & TRN & \\
\hline CHEMBL1977087 & 688620 & 5.2 & 5.1616 & TRN & \\
\hline CHEMBL1342162 & 688620 & 4.9 & 4.9677 & TRN & \\
\hline CHEMBL1454937 & 688620 & 5.1 & 5.0817 & TRN & \\
\hline CHEMBL3189814 & 688620 & 4.8 & 4.7142 & TST & \\
\hline CHEMBL1366331 & 688620 & 5.2 & 5.0337 & TRN & \\
\hline CHEMBL1372608 & 688620 & 7.3497 & 5.00899 & 99999999995 & TRN \\
\hline CHEMBL1487411 & 688620 & 4.9 & 5.1397 & TST & \\
\hline CHEMBL1330374 & 688620 & 4.45 & 5.0474 & TRN & \\
\hline CHEMBL1486699 & 688620 & 4.8 & 5.0962 & TST & \\
\hline CHEMBL1548533 & 688620 & 4.85 & 4.852 & TRN & \\
\hline CHEMBL1361040 & 688620 & 4.7 & 4.9096 & TRN & \\
\hline CHEMBL1406227 & 688620 & 5.0 & 4.9586 & TRN & \\
\hline CHEMBL1414723 & 688620 & 5.8 & 5.1345 & TST & \\
\hline
\end{tabular}




\begin{tabular}{|c|c|c|c|c|}
\hline \multicolumn{5}{|c|}{ Supplemental Table S2.txt } \\
\hline CHEMBL1341298 & 688620 & 5.45 & 4.8105 & TST \\
\hline CHEMBL1426657 & 688620 & 4.85 & 5.0324 & TRN \\
\hline CHEMBL1581730 & 688620 & 5.8 & 5.3193 & TRN \\
\hline CHEMBL1498985 & 688620 & 4.9 & 5.2236 & TRN \\
\hline CHEMBL 1413348 & 688620 & 5.4 & 5.0552 & TST \\
\hline CHEMBL1541516 & 688620 & 6.0 & 5.0972 & TST \\
\hline CHEMBL1454923 & 688620 & 4.95 & 5.0563 & TST \\
\hline CHEMBL1564713 & 688620 & 6.05 & 5.5324 & TRN \\
\hline CHEMBL1467239 & 688620 & 4.45 & 5.0604 & TRN \\
\hline CHEMBL1463834 & 688620 & 5.1 & 4.9922 & TRN \\
\hline CHEMBL1404507 & 688620 & 4.5 & 4.7102 & TRN \\
\hline CHEMBL1525769 & 688620 & 5.15 & 5.0629 & TRN \\
\hline CHEMBL1532349 & 688620 & 4.45 & 4.9127 & TRN \\
\hline CHEMBL1506517 & 688620 & 4.5 & 4.8212 & TRN \\
\hline CHEMBL1353131 & 688620 & 5.0 & 4.8421 & TST \\
\hline CHEMBL1530806 & 688620 & 6.0 & 5.1601 & TRN \\
\hline CHEMBL1485655 & 688620 & 4.9 & 5.0971 & TRN \\
\hline CHEMBL1523704 & 688620 & 4.7 & 5.056 & TRN \\
\hline CHEMBL1352059 & 688620 & 4.95 & 4.8945 & TRN \\
\hline CHEMBL1547223 & 688620 & 4.45 & 5.1649 & TRN \\
\hline CHEMBL1992382 & 688620 & 6.0 & 5.4859 & TRN \\
\hline CHEMBL1601449 & 688620 & 4.7 & 5.1215 & TRN \\
\hline CHEMBL1576431 & 688620 & 4.7 & 4.9516 & TRN \\
\hline CHEMBL1484963 & 688620 & 6.0 & 5.0423 & TRN \\
\hline CHEMBL1577782 & 688620 & 5.5 & 5.415 & TRN \\
\hline CHEMBL1305922 & 688620 & 6.3 & 5.0928 & TRN \\
\hline CHEMBL1344290 & 688620 & 4.95 & 5.1617 & TRN \\
\hline CHEMBL1404906 & 688620 & 5.0 & 5.3269 & TRN \\
\hline CHEMBL1480930 & 688620 & 5.5 & 5.0822 & TRN \\
\hline CHEMBL3192258 & 688620 & 4.45 & 5.0393 & TST \\
\hline CHEMBL1528596 & 688620 & 4.85 & 5.0097 & TRN \\
\hline CHEMBL1492461 & 688620 & 5.25 & 5.5463 & TRN \\
\hline CHEMBL1475487 & 688620 & 5.2 & 4.9072 & TST \\
\hline CHEMBL1542061 & 688620 & 4.8 & 4.8846 & TRN \\
\hline CHEMBL1532303 & 688620 & 4.45 & 4.7205 & TST \\
\hline CHEMBL1423129 & 688620 & 5.15 & 5.5264 & TRN \\
\hline CHEMBL1528664 & 688620 & 5.0 & 5.0274 & TST \\
\hline CHEMBL1524139 & 688620 & 4.45 & 4.9063 & TST \\
\hline CHEMBL1469303 & 688620 & 4.45 & 5.1935 & TRN \\
\hline CHEMBL1321246 & 688620 & 4.7 & 4.7882 & TRN \\
\hline CHEMBL1518837 & 688620 & 5.2 & 4.979 & TRN \\
\hline CHEMBL1600771 & 688620 & 4.75 & 4.9405 & TRN \\
\hline CHEMBL1483640 & 688620 & 4.55 & 5.6084 & TRN \\
\hline CHEMBL1575479 & 688620 & 4.5 & 4.6923 & TRN \\
\hline CHEMBL3214610 & 688620 & 5.0 & 4.925 & TRN \\
\hline CHEMBL1467603 & 688620 & 4.95 & 5.0578 & TRN \\
\hline CHEMBL 1447500 & 688620 & 4.75 & 4.8994 & TRN \\
\hline CHEMBL1566451 & 688620 & 5.6 & 5.1152 & TRN \\
\hline
\end{tabular}




\begin{tabular}{|c|c|c|c|c|c|}
\hline \\
\hline CHEMBL1429388 & 688620 & 5.5 & 5.0781 & TRN & \\
\hline CHEMBL1335664 & 688620 & 4.95 & 5.1028 & TRN & \\
\hline CHEMBL1383096 & 688620 & 6.5 & 4.9667 & TRN & \\
\hline CHEMBL1388083 & 688620 & 4.8 & 5.0629 & TST & \\
\hline CHEMBL1556692 & 688620 & 6.8 & 5.4917 & TST & \\
\hline CHEMBL1378988 & 688620 & 4.75 & 5.2528 & TST & \\
\hline CHEMBL1519443 & 688620 & 4.45 & 4.9795 & TRN & \\
\hline CHEMBL1353875 & 688620 & 4.45 & 5.2349 & TRN & \\
\hline CHEMBL1601853 & 688620 & 4.85 & 5.1245 & TST & \\
\hline CHEMBL1435053 & 688620 & 5.1 & 5.1245 & TST & \\
\hline CHEMBL1522436 & 688620 & 5.25 & 5.0784 & TRN & \\
\hline CHEMBL1537920 & 688620 & 4.45 & 4.7874 & TRN & \\
\hline CHEMBL1379619 & 688620 & 5.3 & 5.5104 & TRN & \\
\hline CHEMBL602807 & 688620 & 5.0 & 4.7655 & TRN & \\
\hline CHEMBL1359796 & 688620 & 4.85 & 4.9978 & TRN & \\
\hline CHEMBL1412727 & 688620 & 4.45 & 4.9311 & TRN & \\
\hline CHEMBL1467732 & 688620 & 5.45 & 5.041 & TRN & \\
\hline CHEMBL1558995 & 688620 & 5.8 & 5.2319 & TRN & \\
\hline CHEMBL1328569 & 688620 & 4.95 & 5.2403 & TRN & \\
\hline CHEMBL1310024 & 688620 & 4.85 & 5.042 & TRN & \\
\hline CHEMBL1493000 & 688620 & 4.65 & 4.8791 & TRN & \\
\hline CHEMBL1465317 & 688620 & 4.8 & 5.1898 & TRN & \\
\hline CHEMBL1466525 & 688620 & 5.4 & 5.3589 & TRN & \\
\hline CHEMBL1493850 & 688620 & 5.0 & 4.9957 & TRN & \\
\hline CHEMBL 2005947 & 688620 & 5.6 & 5.1799 & TST & \\
\hline CHEMBL1405741 & 688620 & 4.65 & 5.0147 & TST & \\
\hline CHEMBL1471874 & 688620 & 4.65 & 5.0382 & TRN & \\
\hline CHEMBL1353869 & 688620 & 4.95 & 5.0253 & TST & \\
\hline CHEMBL1566434 & 688620 & 5.3 & 5.17200 & 0000000001 & TST \\
\hline CHEMBL1400339 & 688620 & 5.75 & 4.9528 & TRN & \\
\hline CHEMBL1410344 & 688620 & 5.35 & 4.9418 & TRN & \\
\hline CHEMBL1519580 & 688620 & 4.55 & 4.9549 & TRN & \\
\hline CHEMBL1465520 & 688620 & 5.1 & 5.0398 & TRN & \\
\hline CHEMBL1479630 & 688620 & 5.05 & 5.24100 & 00000000005 & TRN \\
\hline CHEMBL1547973 & 688620 & 4.7 & 4.92399 & 99999999995 & TRN \\
\hline CHEMBL1446054 & 688620 & 4.95 & 5.1069 & TST & \\
\hline CHEMBL1449868 & 688620 & 5.2 & 5.1044 & TRN & \\
\hline CHEMBL1545516 & 688620 & 4.95 & 4.8121 & TST & \\
\hline CHEMBL1482402 & 688620 & 4.85 & 4.9153 & TST & \\
\hline CHEMBL1477969 & 688620 & 5.5 & 4.8921 & TRN & \\
\hline CHEMBL1405976 & 688620 & 4.85 & 5.119 & TRN & \\
\hline CHEMBL1321591 & 688620 & 5.3 & 5.0737 & TRN & \\
\hline CHEMBL1302984 & 688620 & 4.9 & 4.8038 & TRN & \\
\hline CHEMBL1476184 & 688620 & 4.7 & 4.9561 & TRN & \\
\hline CHEMBL1556728 & 688620 & 5.25 & 5.1673 & TST & \\
\hline CHEMBL1468242 & 688620 & 4.85 & 4.997 & TRN & \\
\hline CHEMBL1522629 & 688620 & 4.9 & 5.0258 & TRN & \\
\hline CHEMBL1490537 & 688620 & 4.65 & 5.0009 & TRN & \\
\hline
\end{tabular}




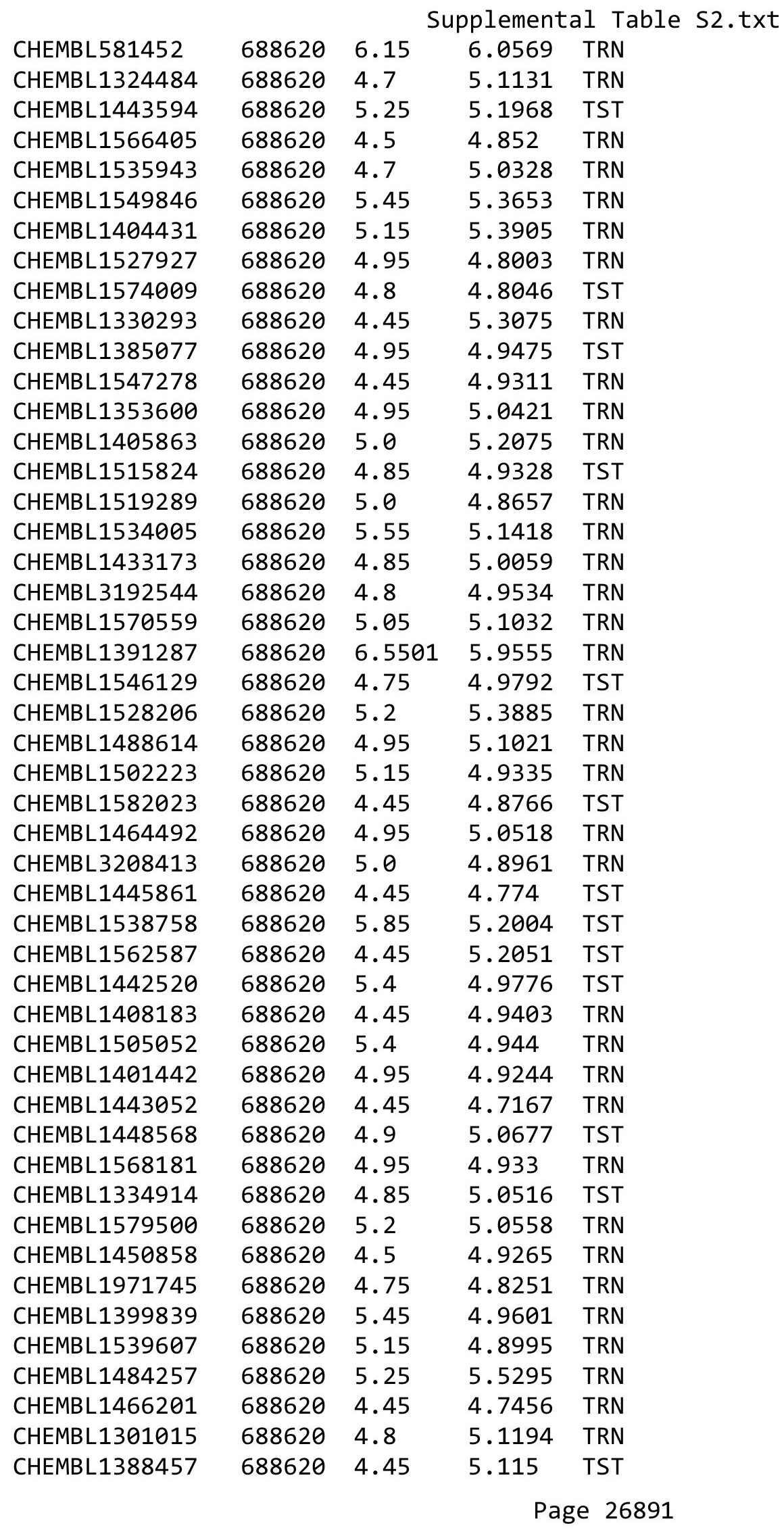




\begin{tabular}{|c|c|c|c|c|c|}
\hline \multicolumn{6}{|c|}{ Supplemental Table S2.txt } \\
\hline CHEMBL1493749 & 688620 & 4.45 & 4.9988 & TST & \\
\hline CHEMBL1332037 & 688620 & 4.55 & 5.0151 & TRN & \\
\hline CHEMBL1341805 & 688620 & 4.45 & 4.8001 & TRN & \\
\hline CHEMBL1489182 & 688620 & 4.95 & 4.8412 & TRN & \\
\hline CHEMBL1502942 & 688620 & 4.65 & 4.8952 & TRN & \\
\hline CHEMBL1609162 & 688620 & 5.6 & 5.2254 & TRN & \\
\hline CHEMBL1406893 & 688620 & 4.75 & 5.1216 & TRN & \\
\hline CHEMBL1535050 & 688620 & 5.65 & 5.3473 & TRN & \\
\hline CHEMBL1608130 & 688620 & 4.9 & 5.0391 & TRN & \\
\hline CHEMBL1597716 & 688620 & 4.45 & 5.0758 & TRN & \\
\hline CHEMBL1299463 & 688620 & 4.8 & 4.8054 & TST & \\
\hline CHEMBL1497484 & 688620 & 4.75 & 5.09699 & 99999999995 & TRN \\
\hline CHEMBL3197396 & 688620 & 5.2 & 5.3367 & TRN & \\
\hline CHEMBL1346950 & 688620 & 4.45 & 4.9892 & TST & \\
\hline CHEMBL1968355 & 688620 & 4.7 & 4.8938 & TRN & \\
\hline CHEMBL1401800 & 688620 & 5.4 & 4.9209 & TRN & \\
\hline CHEMBL1419324 & 688620 & 4.65 & 5.1662 & TRN & \\
\hline CHEMBL1548116 & 688620 & 4.6 & 4.9738 & TRN & \\
\hline CHEMBL1987587 & 688620 & 5.4 & 4.9261 & TRN & \\
\hline CHEMBL1347328 & 688620 & 4.95 & 5.0237 & TRN & \\
\hline CHEMBL1445757 & 688620 & 5.0 & 4.9155 & TST & \\
\hline CHEMBL1529827 & 688620 & 4.65 & 4.9462 & TRN & \\
\hline CHEMBL1440555 & 688620 & 4.7 & 5.0377 & TRN & \\
\hline CHEMBL1343911 & 688620 & 6.0 & 5.8323 & TRN & \\
\hline CHEMBL1306237 & 688620 & 5.7 & 5.0954 & TRN & \\
\hline CHEMBL1325779 & 688620 & 4.45 & 4.8896 & TRN & \\
\hline CHEMBL1406751 & 688620 & 4.9 & 4.8766 & TST & \\
\hline CHEMBL1456386 & 688620 & 4.8 & 5.1867 & TST & \\
\hline CHEMBL1367319 & 688620 & 4.45 & 5.2056 & TST & \\
\hline CHEMBL1484586 & 688620 & 4.65 & 4.752 & TRN & \\
\hline CHEMBL1498623 & 688620 & 5.9 & 6.0561 & TRN & \\
\hline CHEMBL3193962 & 688620 & 5.3 & 5.5823 & TRN & \\
\hline CHEMBL1413003 & 688620 & 4.85 & 4.9477 & TRN & \\
\hline CHEMBL3191579 & 688620 & 5.0 & 4.9291 & TRN & \\
\hline CHEMBL1595774 & 688620 & 5.3 & 5.0877 & TST & \\
\hline CHEMBL1368875 & 688620 & 4.95 & 4.9328 & TRN & \\
\hline CHEMBL1578678 & 688620 & 4.9 & 5.0821 & TRN & \\
\hline CHEMBL3191975 & 688620 & 6.3 & 5.5495 & TRN & \\
\hline CHEMBL1607988 & 688620 & 4.6 & 5.0054 & TRN & \\
\hline CHEMBL1503651 & 688620 & 4.45 & 5.3538 & TRN & \\
\hline CHEMBL1491888 & 688620 & 5.4 & 4.9808 & TST & \\
\hline CHEMBL1347895 & 688620 & 4.85 & 4.748 & TRN & \\
\hline CHEMBL1455739 & 688620 & 4.7 & 5.0821 & TRN & \\
\hline CHEMBL1414606 & 688620 & 4.5 & 5.1487 & TST & \\
\hline CHEMBL3198050 & 688620 & 6.05 & 5.2372 & TRN & \\
\hline CHEMBL1565387 & 688620 & 4.45 & 4.9419 & TRN & \\
\hline CHEMBL1300723 & 688620 & 5.0 & 5.2052 & TRN & \\
\hline CHEMBL1485014 & 688620 & 4.45 & 5.2945 & TST & \\
\hline
\end{tabular}




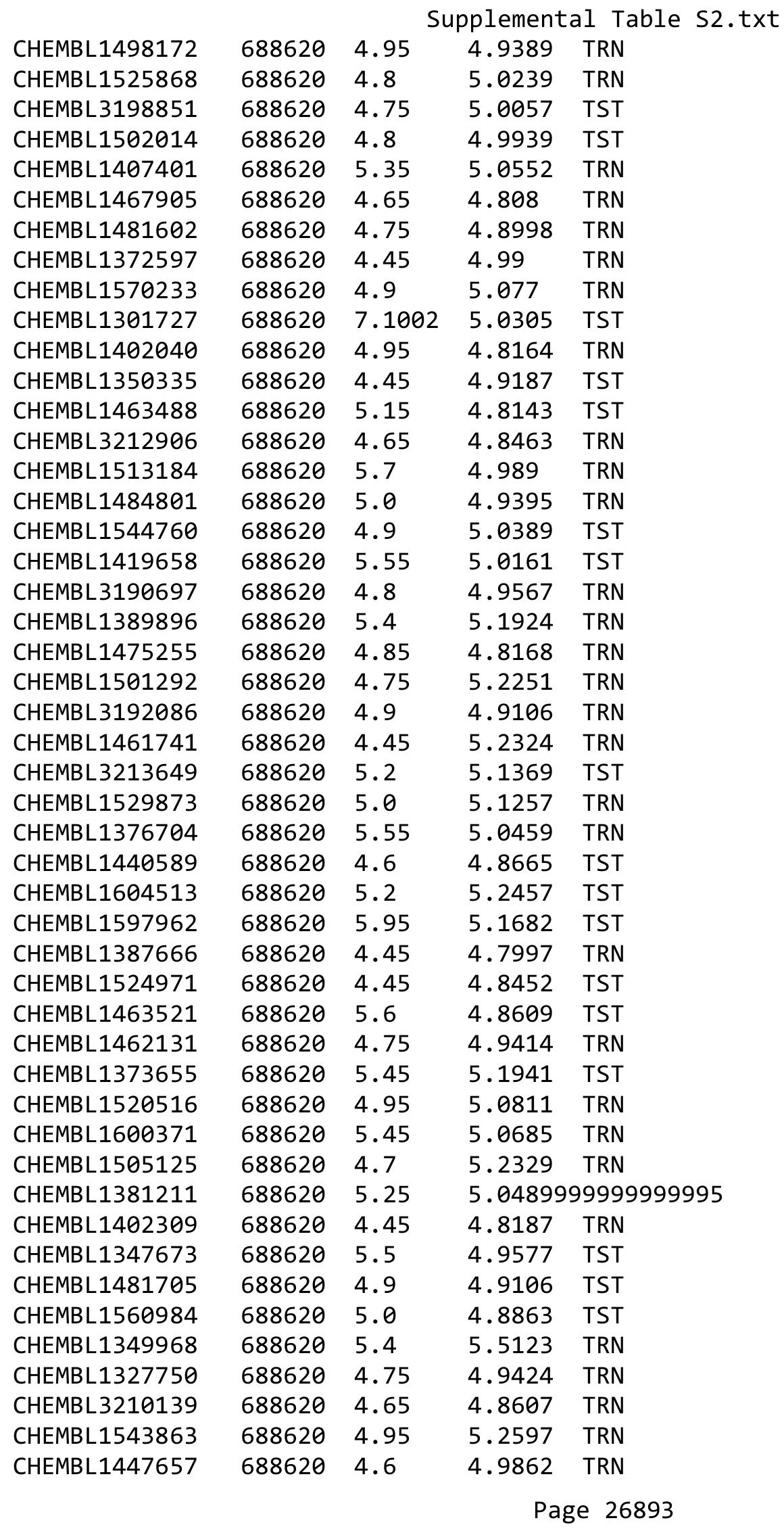




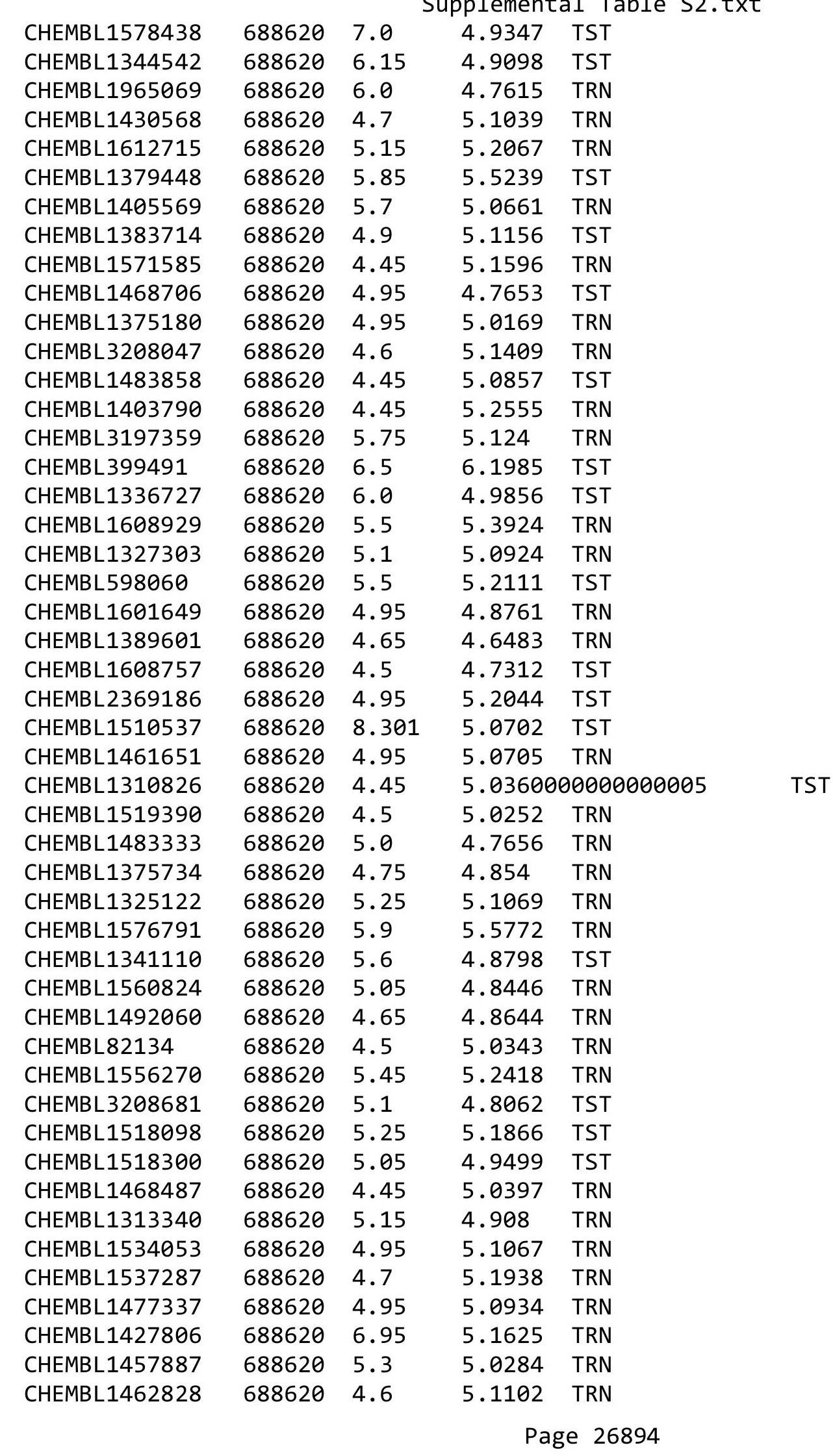




\begin{tabular}{|c|c|c|c|c|c|}
\hline \\
\hline CHEMBL3210743 & 688620 & 4.7 & 5.0786 & TRN & \\
\hline CHEMBL1500507 & 688620 & 4.45 & 6.9154 & TRN & \\
\hline CHEMBL1440769 & 688620 & 6.1 & 5.0864 & TST & \\
\hline CHEMBL1403402 & 688620 & 4.6 & 5.3068 & TRN & \\
\hline CHEMBL1523236 & 688620 & 6.15 & 5.995 & TRN & \\
\hline CHEMBL610463 & 688620 & 4.85 & 4.88399 & 99999999995 & TRN \\
\hline CHEMBL1340541 & 688620 & 4.8 & 5.44799 & 99999999995 & TRN \\
\hline CHEMBL1360862 & 688620 & 4.8 & 4.8912 & TRN & \\
\hline CHEMBL1578452 & 688620 & 5.0 & 5.065 & TRN & \\
\hline CHEMBL3189613 & 688620 & 5.25 & 5.2391 & TRN & \\
\hline CHEMBL1459642 & 688620 & 4.8 & 5.0214 & TST & \\
\hline CHEMBL1609841 & 688620 & 4.7 & 4.8005 & TRN & \\
\hline CHEMBL1322489 & 688620 & 4.8 & 5.1553 & TST & \\
\hline CHEMBL1496441 & 688620 & 4.9 & 5.9343 & TRN & \\
\hline CHEMBL1469727 & 688620 & 5.35 & 5.0671 & TRN & \\
\hline CHEMBL1417206 & 688620 & 4.75 & 4.963 & TST & \\
\hline CHEMBL1414301 & 688620 & 5.2 & 5.2544 & TRN & \\
\hline CHEMBL1326403 & 688620 & 4.7 & 4.6576 & TRN & \\
\hline CHEMBL1557477 & 688620 & 4.7 & 5.3882 & TRN & \\
\hline CHEMBL1563897 & 688620 & 4.95 & 4.9411 & TRN & \\
\hline CHEMBL1478797 & 688620 & 4.9 & 4.8691 & TRN & \\
\hline CHEMBL1372112 & 688620 & 4.8 & 4.7718 & TRN & \\
\hline CHEMBL1310020 & 688620 & 4.8 & 4.8892 & TST & \\
\hline CHEMBL1508258 & 688620 & 4.45 & 5.0277 & TST & \\
\hline CHEMBL1534519 & 688620 & 6.25 & 5.8147 & TST & \\
\hline CHEMBL1506252 & 688620 & 4.95 & 5.1936 & TRN & \\
\hline CHEMBL1305507 & 688620 & 4.9 & 5.0089 & TRN & \\
\hline CHEMBL1535167 & 688620 & 5.6 & 5.0167 & TRN & \\
\hline CHEMBL1347987 & 688620 & 4.45 & 5.0431 & TST & \\
\hline CHEMBL1588696 & 688620 & 4.95 & 4.8629 & TRN & \\
\hline CHEMBL1364678 & 688620 & 6.0 & 4.8445 & TRN & \\
\hline CHEMBL1611364 & 688620 & 5.2 & 5.3996 & TRN & \\
\hline CHEMBL1404835 & 688620 & 4.85 & 5.1334 & TRN & \\
\hline CHEMBL1332353 & 688620 & 5.0 & 4.8408 & TRN & \\
\hline CHEMBL3190169 & 688620 & 5.5 & 5.3113 & TRN & \\
\hline CHEMBL1507572 & 688620 & 4.45 & 4.8923 & TRN & \\
\hline CHEMBL1539401 & 688620 & 4.45 & 4.8846 & TRN & \\
\hline CHEMBL3193367 & 688620 & 4.45 & 5.3182 & TST & \\
\hline CHEMBL169 & 688620 & 6.0 & 5.0848 & TRN & \\
\hline CHEMBL3191999 & 688620 & 5.15 & 5.1056 & TRN & \\
\hline CHEMBL1578835 & 688620 & 4.95 & 5.064 & TRN & \\
\hline CHEMBL1478175 & 688620 & 4.7 & 4.8307 & TRN & \\
\hline CHEMBL1468333 & 688620 & 4.9 & 5.1138 & TRN & \\
\hline CHEMBL393749 & 688620 & 7.3002 & 5.7339 & TRN & \\
\hline CHEMBL1411649 & 688620 & 4.9 & 5.051 & TRN & \\
\hline CHEMBL1337035 & 688620 & 4.75 & 5.7531 & TST & \\
\hline CHEMBL1527035 & 688620 & 4.95 & 5.0727 & TRN & \\
\hline CHEMBL1491692 & 688620 & 5.15 & 5.1735 & TST & \\
\hline
\end{tabular}




\begin{tabular}{|c|c|c|c|c|}
\hline \multicolumn{5}{|c|}{ Supplemental Table S2.txt } \\
\hline CHEMBL1562591 & 688620 & 4.6 & 5.1766 & TST \\
\hline CHEMBL1478620 & 688620 & 5.35 & 5.1391 & TST \\
\hline CHEMBL1486465 & 688620 & 6.0 & 5.735 & TRN \\
\hline CHEMBL167423 & 688620 & 4.65 & 4.9815 & TRN \\
\hline CHEMBL1224757 & 688620 & 5.9 & 5.3494 & TRN \\
\hline CHEMBL1343599 & 688620 & 5.85 & 5.4577 & TRN \\
\hline CHEMBL1411621 & 688620 & 5.3 & 4.9271 & TRN \\
\hline CHEMBL 3207397 & 688620 & 5.05 & 5.084 & TRN \\
\hline CHEMBL1483431 & 688620 & 5.25 & 5.0896 & TST \\
\hline CHEMBL1544756 & 688620 & 4.65 & 4.7717 & TST \\
\hline CHEMBL1438254 & 688620 & 5.15 & 5.0575 & TST \\
\hline CHEMBL1427468 & 688620 & 4.7 & 4.8272 & TRN \\
\hline CHEMBL3213183 & 688620 & 4.95 & 5.0666 & TRN \\
\hline CHEMBL1460076 & 688620 & 4.75 & 4.9559 & TST \\
\hline CHEMBL1393469 & 688620 & 4.8 & 5.0477 & TRN \\
\hline CHEMBL1465476 & 688620 & 4.75 & 5.004 & TRN \\
\hline CHEMBL1315429 & 688620 & 6.45 & 6.0732 & TRN \\
\hline CHEMBL1311742 & 688620 & 4.7 & 4.8124 & TST \\
\hline CHEMBL56731 & 688620 & 4.75 & 4.8082 & TRN \\
\hline CHEMBL3210749 & 688620 & 5.55 & 5.5816 & TRN \\
\hline CHEMBL1385375 & 688620 & 4.45 & 4.8723 & TST \\
\hline CHEMBL1455518 & 688620 & 4.45 & 4.9585 & TRN \\
\hline CHEMBL1299511 & 688620 & 4.95 & 4.9558 & TST \\
\hline CHEMBL 3192547 & 688620 & 5.4 & 5.2616 & TRN \\
\hline CHEMBL1538726 & 688620 & 5.3 & 5.3384 & TRN \\
\hline CHEMBL1473676 & 688620 & 6.0 & 5.591 & TRN \\
\hline CHEMBL1353886 & 688620 & 4.95 & 4.7916 & TST \\
\hline CHEMBL1380670 & 688620 & 5.1 & 5.1783 & TRN \\
\hline CHEMBL 3214515 & 688620 & 6.0 & 5.6586 & TRN \\
\hline CHEMBL1324324 & 688620 & 5.15 & 5.5943 & TRN \\
\hline CHEMBL1324469 & 688620 & 5.05 & 4.6953 & TRN \\
\hline CHEMBL1574721 & 688620 & 8.301 & 5.0433 & TST \\
\hline CHEMBL 3212000 & 688620 & 4.8 & 5.0354 & TST \\
\hline CHEMBL1426273 & 688620 & 4.95 & 5.0056 & TRN \\
\hline CHEMBL1492238 & 688620 & 4.45 & 5.0244 & TST \\
\hline CHEMBL1441798 & 688620 & 4.45 & 4.8886 & TST \\
\hline CHEMBL1419888 & 688620 & 5.85 & 5.2871 & TST \\
\hline CHEMBL1509321 & 688620 & 7.0 & 5.3468 & TRN \\
\hline CHEMBL1303376 & 688620 & 5.0 & 5.0991 & TST \\
\hline CHEMBL 3196834 & 688620 & 4.7 & 4.8235 & TRN \\
\hline CHEMBL1510594 & 688620 & 4.65 & 5.048 & TRN \\
\hline CHEMBL1374393 & 688620 & 4.65 & 4.8111 & TST \\
\hline CHEMBL1332960 & 688620 & 6.9 & 4.9457 & TRN \\
\hline CHEMBL1549464 & 688620 & 4.45 & 4.987 & TRN \\
\hline CHEMBL1507729 & 688620 & 4.5 & 5.0295 & TRN \\
\hline CHEMBL1352251 & 688620 & 5.8 & 5.4633 & TRN \\
\hline CHEMBL1431930 & 688620 & 6.3 & 5.1322 & TST \\
\hline CHEMBL86104 & 688620 & 5.25 & 5.2648 & TRN \\
\hline
\end{tabular}




\begin{tabular}{|c|c|c|c|c|c|}
\hline \multicolumn{6}{|c|}{ Supplemental Table S2.txt } \\
\hline CHEMBL1400861 & 688620 & 4.95 & 4.985 & TRN & \\
\hline CHEMBL1450689 & 688620 & 5.2 & 5.0584 & TRN & \\
\hline CHEMBL1392210 & 688620 & 5.2 & 5.301 & TRN & \\
\hline CHEMBL1502900 & 688620 & 5.15 & 4.8855 & TRN & \\
\hline CHEMBL1495594 & 688620 & 5.5 & 5.1894 & TST & \\
\hline CHEMBL1392427 & 688620 & 6.15 & 5.8732 & TRN & \\
\hline CHEMBL1392447 & 688620 & 4.45 & 5.0142 & TRN & \\
\hline CHEMBL1499330 & 688620 & 4.85 & 5.0945 & TST & \\
\hline CHEMBL1465144 & 688620 & 4.95 & 4.7712 & TRN & \\
\hline CHEMBL1450391 & 688620 & 5.1 & 5.2594 & TST & \\
\hline CHEMBL1602665 & 688620 & 4.95 & 5.0848 & TRN & \\
\hline CHEMBL1536668 & 688620 & 4.65 & 5.1437 & TRN & \\
\hline CHEMBL 3189647 & 688620 & 5.2 & 4.6631 & TRN & \\
\hline CHEMBL1408580 & 688620 & 4.9 & 5.0418 & TRN & \\
\hline CHEMBL1537286 & 688620 & 5.45 & 5.1941 & TST & \\
\hline CHEMBL1369354 & 688620 & 4.85 & 5.0718 & TRN & \\
\hline CHEMBL1602923 & 688620 & 4.65 & 5.2888 & TRN & \\
\hline CHEMBL1486739 & 688620 & 5.6 & 5.421 & TRN & \\
\hline CHEMBL1548667 & 688620 & 4.7 & 4.9192 & TST & \\
\hline CHEMBL1369555 & 688620 & 5.4 & 5.2312 & TRN & \\
\hline CHEMBL1438789 & 688620 & 4.7 & 4.9115 & TST & \\
\hline CHEMBL1490741 & 688620 & 4.85 & 5.0087 & TRN & \\
\hline CHEMBL1473049 & 688620 & 4.9 & 5.1604 & TRN & \\
\hline CHEMBL1331155 & 688620 & 4.85 & 5.1649 & TRN & \\
\hline CHEMBL577455 & 688620 & 6.0 & 5.3669 & TST & \\
\hline CHEMBL1582332 & 688620 & 5.05 & 5.26399 & 9999999999 & TRN \\
\hline CHEMBL1360119 & 688620 & 4.7 & 5.136 & TRN & \\
\hline CHEMBL1467916 & 688620 & 8.3468 & 5.1702 & TRN & \\
\hline CHEMBL1337416 & 688620 & 5.2 & 5.3319 & TRN & \\
\hline CHEMBL1449626 & 688620 & 5.1 & 5.3215 & TRN & \\
\hline CHEMBL 3208370 & 688620 & 4.5 & 5.1303 & TST & \\
\hline CHEMBL1596764 & 688620 & 4.95 & 5.0198 & TST & \\
\hline CHEMBL1369781 & 688620 & 4.85 & 4.9741 & TRN & \\
\hline CHEMBL1388896 & 688620 & 5.5 & 5.0947 & TST & \\
\hline CHEMBL1504299 & 688620 & 4.45 & 4.6467 & TRN & \\
\hline CHEMBL1440699 & 688620 & 4.8 & 5.1587 & TRN & \\
\hline CHEMBL 3190048 & 688620 & 5.05 & 5.2559 & TRN & \\
\hline CHEMBL1451539 & 688620 & 5.6 & 5.3712 & TST & \\
\hline CHEMBL1509441 & 688620 & 4.45 & 4.8694 & TRN & \\
\hline CHEMBL1423734 & 688620 & 4.45 & 5.0346 & TRN & \\
\hline CHEMBL1305450 & 688620 & 4.45 & 5.0582 & TST & \\
\hline CHEMBL1412182 & 688620 & 5.0 & 5.0217 & TRN & \\
\hline CHEMBL1466187 & 688620 & 4.65 & 4.9854 & TRN & \\
\hline CHEMBL1548914 & 688620 & 5.25 & 5.1437 & TRN & \\
\hline CHEMBL3210577 & 688620 & 5.5 & 5.0372 & TRN & \\
\hline CHEMBL1319070 & 688620 & 4.65 & 5.056 & TRN & \\
\hline CHEMBL 2005825 & 688620 & 4.9 & 5.0858 & TRN & \\
\hline CHEMBL1335873 & 688620 & 4.7 & 4.9991 & TRN & \\
\hline
\end{tabular}




\begin{tabular}{|c|c|c|c|c|c|}
\hline \multicolumn{6}{|c|}{ Supplemental Table S2.txt } \\
\hline CHEMBL1998852 & 688620 & 4.55 & 5.2016 & TRN & \\
\hline CHEMBL1343397 & 688620 & 6.15 & 6.2715 & TRN & \\
\hline CHEMBL1301797 & 688620 & 4.65 & 4.9634 & TRN & \\
\hline CHEMBL1498045 & 688620 & 4.65 & 5.1862 & TRN & \\
\hline CHEMBL1992394 & 688620 & 4.85 & 4.9806 & TRN & \\
\hline CHEMBL3195843 & 688620 & 4.45 & 5.1485 & TRN & \\
\hline CHEMBL1556838 & 688620 & 5.5 & 5.1281 & TST & \\
\hline CHEMBL1391461 & 688620 & 6.95 & 5.13700 & 00000000005 & TRN \\
\hline CHEMBL1348912 & 688620 & 4.5 & 5.3937 & TST & \\
\hline CHEMBL540848 & 688620 & 4.45 & 4.7216 & TST & \\
\hline CHEMBL1366888 & 688620 & 4.95 & 4.9113 & TRN & \\
\hline CHEMBL1974937 & 688620 & 5.2 & 4.9844 & TRN & \\
\hline CHEMBL1576018 & 688620 & 4.45 & 4.9674 & TRN & \\
\hline CHEMBL1520766 & 688620 & 4.7 & 5.0629 & TST & \\
\hline CHEMBL1302643 & 688620 & 4.95 & 4.789 & TST & \\
\hline CHEMBL1467763 & 688620 & 4.75 & 4.8969 & TRN & \\
\hline CHEMBL3212145 & 688620 & 6.5501 & 5.34200 & 00000000005 & TST \\
\hline CHEMBL1308461 & 688620 & 4.9 & 4.8901 & TST & \\
\hline CHEMBL1587837 & 688620 & 4.55 & 4.8959 & TST & \\
\hline CHEMBL1524388 & 688620 & 4.65 & 4.7608 & TRN & \\
\hline CHEMBL1482840 & 688620 & 4.45 & 4.6804 & TRN & \\
\hline CHEMBL1345552 & 688620 & 5.8 & 5.1665 & TST & \\
\hline CHEMBL1477355 & 688620 & 5.55 & 5.2641 & TRN & \\
\hline CHEMBL1348507 & 688620 & 6.8 & 5.2479 & TRN & \\
\hline CHEMBL3197170 & 688620 & 6.45 & 5.8051 & TRN & \\
\hline CHEMBL3193599 & 688620 & 5.35 & 4.9403 & TRN & \\
\hline CHEMBL1540413 & 688620 & 5.0 & 5.1688 & TRN & \\
\hline CHEMBL1967474 & 688620 & 6.0 & 5.6894 & TRN & \\
\hline CHEMBL3196503 & 688620 & 4.65 & 5.0644 & TRN & \\
\hline CHEMBL1604282 & 688620 & 4.8 & 4.9736 & TRN & \\
\hline CHEMBL1568641 & 688620 & 4.45 & 4.949 & TST & \\
\hline CHEMBL1579163 & 688620 & 5.0 & 5.1554 & TRN & \\
\hline CHEMBL1304081 & 688620 & 4.9 & 5.0235 & TST & \\
\hline CHEMBL1310575 & 688620 & 5.2 & 5.1329 & TST & \\
\hline CHEMBL1587939 & 688620 & 4.5 & 5.0555 & TST & \\
\hline CHEMBL1534571 & 688620 & 4.85 & 5.1163 & TST & \\
\hline CHEMBL 1390086 & 688620 & 4.7 & 5.0241 & TRN & \\
\hline CHEMBL1333616 & 688620 & 4.45 & 5.0147 & TRN & \\
\hline CHEMBL1412887 & 688620 & 4.45 & 4.8116 & TST & \\
\hline CHEMBL1463479 & 688620 & 4.7 & 5.0915 & TRN & \\
\hline CHEMBL1372746 & 688620 & 5.85 & 5.7981 & TRN & \\
\hline CHEMBL1333314 & 688620 & 4.5 & 4.9047 & TRN & \\
\hline CHEMBL1486726 & 688620 & 5.15 & 5.2309 & TRN & \\
\hline CHEMBL1538131 & 688620 & 5.0 & 5.1339 & TST & \\
\hline CHEMBL1542889 & 688620 & 5.0 & 5.2476 & TRN & \\
\hline CHEMBL1525271 & 688620 & 5.55 & 5.3027 & TRN & \\
\hline CHEMBL 1472492 & 688620 & 5.3 & 5.083 & TRN & \\
\hline CHEMBL1351688 & 688620 & 4.5 & 4.7838 & TRN & \\
\hline
\end{tabular}




\begin{tabular}{|c|c|c|c|c|c|}
\hline \multicolumn{6}{|c|}{ Supplemental Table S2.txt } \\
\hline CHEMBL3189643 & 688620 & 6.2 & 5.7969 & TRN & \\
\hline CHEMBL1567898 & 688620 & 4.85 & 5.0288 & TST & \\
\hline CHEMBL1468921 & 688620 & 5.1 & 5.0398 & TST & \\
\hline CHEMBL1499672 & 688620 & 5.0 & 5.1975 & TRN & \\
\hline CHEMBL3207448 & 688620 & 4.9 & 4.7776 & TRN & \\
\hline CHEMBL1598511 & 688620 & 4.75 & 5.0307 & TST & \\
\hline CHEMBL1350946 & 688620 & 5.0 & 5.1546 & TRN & \\
\hline CHEMBL1324954 & 688620 & 4.9 & 4.7363 & TRN & \\
\hline CHEMBL1382456 & 688620 & 4.9 & 5.0847 & TRN & \\
\hline CHEMBL1324553 & 688620 & 4.45 & 4.9364 & TST & \\
\hline CHEMBL1489799 & 688620 & 4.45 & 5.2278 & TRN & \\
\hline CHEMBL1360240 & 688620 & 5.2 & 5.0545 & TST & \\
\hline CHEMBL1367461 & 688620 & 5.25 & 6.9412 & TRN & \\
\hline CHEMBL1451817 & 688620 & 5.35 & 5.2501 & TRN & \\
\hline CHEMBL1365963 & 688620 & 4.45 & 5.2502 & TRN & \\
\hline CHEMBL1458297 & 688620 & 5.55 & 5.1732 & TRN & \\
\hline CHEMBL3192383 & 688620 & 5.15 & 5.3064 & TRN & \\
\hline CHEMBL1459993 & 688620 & 4.75 & 5.254 & TST & \\
\hline CHEMBL1608149 & 688620 & 4.8 & 4.8165 & TRN & \\
\hline CHEMBL1525097 & 688620 & 5.05 & 5.5334 & TST & \\
\hline CHEMBL3199872 & 688620 & 4.55 & 5.1903 & TRN & \\
\hline CHEMBL1466406 & 688620 & 5.5 & 5.4968 & TRN & \\
\hline CHEMBL1170485 & 688620 & 6.6499 & 4.94300 & 00000000005 & TST \\
\hline CHEMBL1422311 & 688620 & 4.8 & 4.8596 & TRN & \\
\hline CHEMBL1406577 & 688620 & 4.95 & 4.86600 & 00000000005 & TRN \\
\hline CHEMBL1446055 & 688620 & 4.75 & 4.9054 & TRN & \\
\hline CHEMBL1464723 & 688620 & 4.8 & 5.019 & TST & \\
\hline CHEMBL1421063 & 688620 & 4.8 & 5.2147 & TRN & \\
\hline CHEMBL1508347 & 688620 & 4.95 & 5.1915 & TRN & \\
\hline CHEMBL3196925 & 688620 & 5.0 & 4.9619 & TST & \\
\hline CHEMBL1349879 & 688620 & 5.75 & 5.4287 & TRN & \\
\hline CHEMBL1472955 & 688620 & 4.7 & 4.8728 & TRN & \\
\hline CHEMBL 3211227 & 688620 & 4.9 & 5.2027 & TRN & \\
\hline CHEMBL1561991 & 688620 & 4.6 & 5.0157 & TRN & \\
\hline CHEMBL1488359 & 688620 & 4.45 & 5.2467 & TST & \\
\hline CHEMBL1369529 & 688620 & 4.45 & 5.1918 & TST & \\
\hline CHEMBL1433240 & 688620 & 4.6 & 4.8639 & TST & \\
\hline CHEMBL1446987 & 688620 & 6.45 & 5.0389 & TRN & \\
\hline CHEMBL1388490 & 688620 & 5.55 & 5.1487 & TRN & \\
\hline CHEMBL3189238 & 688620 & 5.05 & 4.8401 & TRN & \\
\hline CHEMBL1499812 & 688620 & 4.5 & 4.683 & TRN & \\
\hline CHEMBL1301125 & 688620 & 5.25 & 5.5423 & TRN & \\
\hline CHEMBL1335611 & 688620 & 5.2 & 4.9535 & TRN & \\
\hline CHEMBL1312897 & 688620 & 5.9 & 4.8993 & TRN & \\
\hline CHEMBL1588453 & 688620 & 5.0 & 5.17899 & 9999999999 & TRN \\
\hline CHEMBL3190064 & 688620 & 4.95 & 5.0717 & TRN & \\
\hline CHEMBL1409923 & 688620 & 4.7 & 4.8426 & TRN & \\
\hline CHEMBL3191217 & 688620 & 6.15 & 5.4563 & TRN & \\
\hline
\end{tabular}




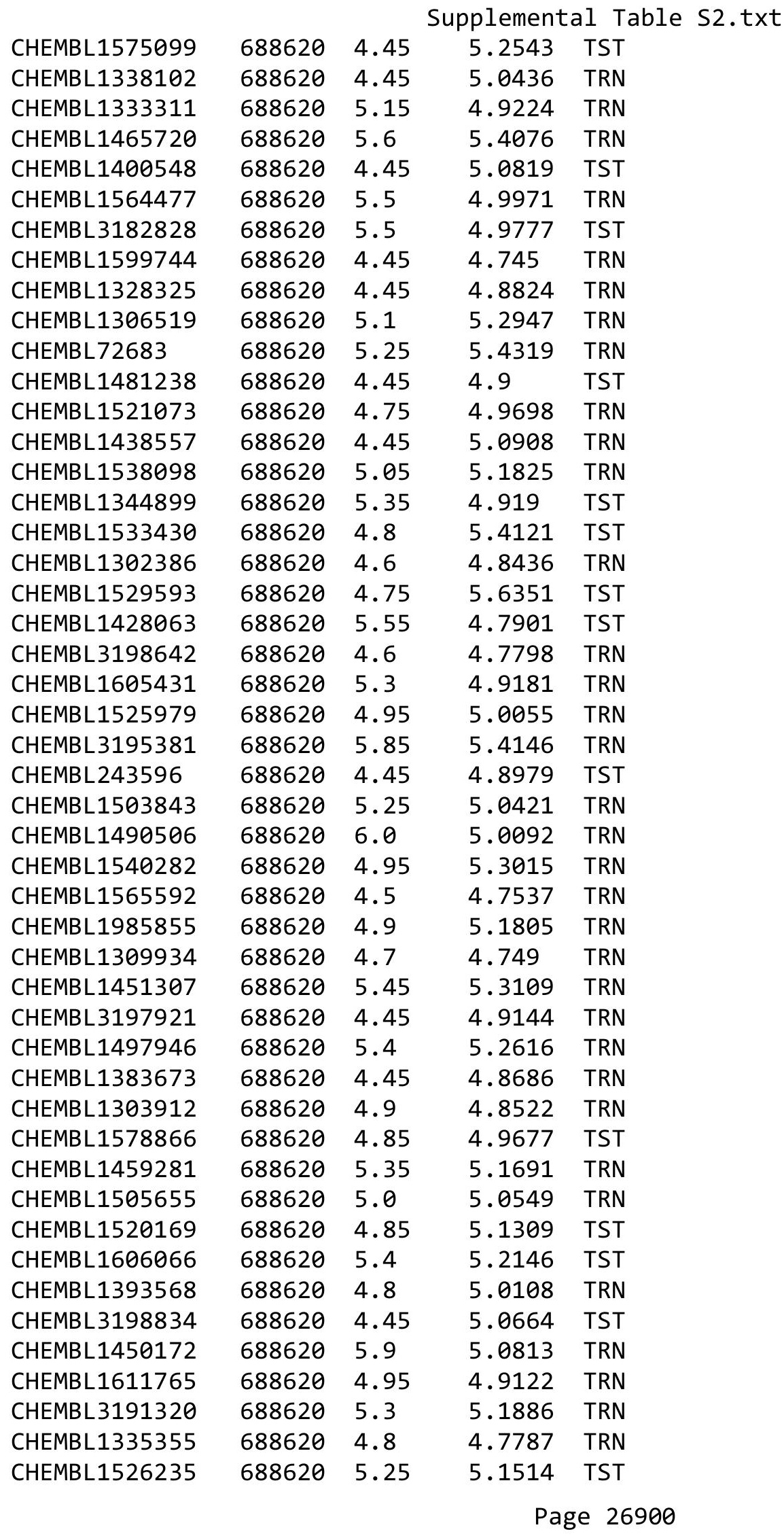




\begin{tabular}{|c|c|c|c|c|}
\hline \multicolumn{5}{|c|}{ Supplemental Table S2.txt } \\
\hline CHEMBL3189701 & 688620 & 4.85 & 4.9458 & TST \\
\hline CHEMBL1448391 & 688620 & 4.95 & 5.0428 & TRN \\
\hline CHEMBL1577183 & 688620 & 5.2 & 5.4653 & TRN \\
\hline CHEMBL1332318 & 688620 & 4.95 & 4.99 & TRN \\
\hline CHEMBL1573288 & 688620 & 4.45 & 5.1412 & TRN \\
\hline CHEMBL2003605 & 688620 & 5.15 & 5.0358 & TRN \\
\hline CHEMBL1460503 & 688620 & 4.85 & 4.94 & TRN \\
\hline CHEMBL1527433 & 688620 & 5.4 & 5.4047 & TRN \\
\hline CHEMBL1576713 & 688620 & 5.55 & 5.5014 & TRN \\
\hline CHEMBL1561767 & 688620 & 5.3 & 5.5547 & TRN \\
\hline CHEMBL1457223 & 688620 & 4.7 & 5.1518 & TST \\
\hline CHEMBL1422803 & 688620 & 4.95 & 4.9873 & TST \\
\hline CHEMBL1402803 & 688620 & 4.8 & 4.8447 & TRN \\
\hline CHEMBL 3199044 & 688620 & 5.5 & 5.4523 & TRN \\
\hline CHEMBL1311267 & 688620 & 4.9 & 4.8828 & TRN \\
\hline CHEMBL1601125 & 688620 & 6.4 & 5.3861 & TST \\
\hline CHEMBL3199300 & 688620 & 5.2 & 5.3588 & TRN \\
\hline CHEMBL1549140 & 688620 & 5.5 & 5.1145 & TRN \\
\hline CHEMBL2001996 & 688620 & 4.8 & 4.8784 & TRN \\
\hline CHEMBL1313548 & 688620 & 5.4 & 6.2553 & TRN \\
\hline CHEMBL1482343 & 688620 & 4.45 & 4.8119 & TRN \\
\hline CHEMBL1610465 & 688620 & 4.65 & 5.0879 & TRN \\
\hline CHEMBL1361921 & 688620 & 4.95 & 5.0446 & TST \\
\hline CHEMBL1490050 & 688620 & 4.45 & 4.7586 & TRN \\
\hline CHEMBL1382252 & 688620 & 4.85 & 4.9381 & TRN \\
\hline CHEMBL1530145 & 688620 & 5.55 & 5.6007 & TRN \\
\hline CHEMBL1990748 & 688620 & 5.4 & 5.0864 & TRN \\
\hline CHEMBL1339547 & 688620 & 6.25 & 4.9799 & TRN \\
\hline CHEMBL1309232 & 688620 & 5.35 & 5.4571 & TRN \\
\hline CHEMBL1311941 & 688620 & 4.95 & 4.8538 & TRN \\
\hline CHEMBL333889 & 688620 & 8.2518 & 5.3273 & TRN \\
\hline CHEMBL1480119 & 688620 & 4.95 & 5.0916 & TRN \\
\hline CHEMBL1484885 & 688620 & 4.65 & 4.8363 & TRN \\
\hline CHEMBL1409019 & 688620 & 4.95 & 5.0648 & TRN \\
\hline CHEMBL1382567 & 688620 & 5.4 & 5.1634 & TST \\
\hline CHEMBL1600415 & 688620 & 5.55 & 5.3586 & TRN \\
\hline CHEMBL1529472 & 688620 & 4.85 & 5.2017 & TST \\
\hline CHEMBL1974253 & 688620 & 4.65 & 5.1351 & TRN \\
\hline CHEMBL1602128 & 688620 & 4.95 & 4.9299 & TRN \\
\hline CHEMBL1535587 & 688620 & 4.45 & 4.6859 & TST \\
\hline CHEMBL1321883 & 688620 & 6.15 & 5.4775 & TRN \\
\hline CHEMBL3193989 & 688620 & 5.5 & 5.0882 & TRN \\
\hline CHEMBL1573794 & 688620 & 4.5 & 4.9965 & TST \\
\hline CHEMBL1379892 & 688620 & 6.25 & 5.5706 & TRN \\
\hline CHEMBL1578962 & 688620 & 5.1 & 5.0751 & TRN \\
\hline CHEMBL1350326 & 688620 & 5.0 & 5.0418 & TRN \\
\hline CHEMBL1526686 & 688620 & 5.15 & 4.8343 & TRN \\
\hline CHEMBL1978701 & 688620 & 5.6 & 5.6205 & TRN \\
\hline
\end{tabular}




\begin{tabular}{|c|c|c|c|c|}
\hline \multicolumn{5}{|c|}{ Supplemental Table S2.txt } \\
\hline CHEMBL3199697 & 688620 & 5.35 & 5.1461 & TRN \\
\hline CHEMBL1299796 & 688620 & 4.9 & 5.1142 & TRN \\
\hline CHEMBL1380614 & 688620 & 4.95 & 5.1638 & TRN \\
\hline CHEMBL1304575 & 688620 & 6.45 & 6.1736 & TRN \\
\hline CHEMBL1542471 & 688620 & 5.25 & 4.8673 & TRN \\
\hline CHEMBL1547133 & 688620 & 4.65 & 4.8147 & TRN \\
\hline CHEMBL1309458 & 688620 & 4.65 & 4.6664 & TST \\
\hline CHEMBL1511125 & 688620 & 4.45 & 4.9601 & TRN \\
\hline CHEMBL1609759 & 688620 & 5.5 & 5.0043 & TST \\
\hline CHEMBL1522383 & 688620 & 4.45 & 4.8256 & TRN \\
\hline CHEMBL 3198674 & 688620 & 5.55 & 5.1393 & TRN \\
\hline CHEMBL1546442 & 688620 & 5.1 & 5.1914 & TRN \\
\hline CHEMBL3199856 & 688620 & 4.95 & 5.1648 & TRN \\
\hline CHEMBL1382020 & 688620 & 4.45 & 4.9456 & TRN \\
\hline CHEMBL1544256 & 688620 & 5.35 & 5.0598 & TRN \\
\hline CHEMBL3191203 & 688620 & 4.45 & 4.9649 & TRN \\
\hline CHEMBL1555271 & 688620 & 5.55 & 5.7457 & TRN \\
\hline CHEMBL1366176 & 688620 & 5.35 & 5.5421 & TRN \\
\hline CHEMBL1353005 & 688620 & 4.45 & 5.0218 & TST \\
\hline CHEMBL1550188 & 688620 & 4.45 & 4.7984 & TRN \\
\hline CHEMBL1533254 & 688620 & 4.45 & 4.9796 & TRN \\
\hline CHEMBL3199085 & 688620 & 5.0 & 5.2029 & TRN \\
\hline CHEMBL1611689 & 688620 & 4.75 & 4.7778 & TRN \\
\hline CHEMBL1603224 & 688620 & 4.45 & 4.9738 & TRN \\
\hline CHEMBL1984295 & 688620 & 5.5 & 5.5148 & TRN \\
\hline CHEMBL1345687 & 688620 & 5.05 & 5.3997 & TRN \\
\hline CHEMBL1547621 & 688620 & 4.45 & 4.7839 & TRN \\
\hline CHEMBL1465135 & 688620 & 4.9 & 5.026 & TST \\
\hline CHEMBL1524554 & 688620 & 4.45 & 4.6278 & TRN \\
\hline CHEMBL1597015 & 688620 & 4.8 & 5.0163 & TRN \\
\hline CHEMBL1391640 & 688620 & 5.65 & 5.0509 & TST \\
\hline CHEMBL3194816 & 688620 & 5.55 & 5.3366 & TRN \\
\hline CHEMBL1475990 & 688620 & 4.9 & 5.033 & TRN \\
\hline CHEMBL1509306 & 688620 & 4.9 & 4.7028 & TRN \\
\hline CHEMBL1411101 & 688620 & 6.1 & 5.2242 & TST \\
\hline CHEMBL1392599 & 688620 & 4.9 & 5.0532 & TRN \\
\hline CHEMBL1598864 & 688620 & 5.6 & 5.0597 & TRN \\
\hline CHEMBL1558850 & 688620 & 5.05 & 5.2055 & TRN \\
\hline CHEMBL1560582 & 688620 & 5.0 & 4.9533 & TRN \\
\hline CHEMBL1549004 & 688620 & 5.0 & 4.8629 & TRN \\
\hline CHEMBL1445222 & 688620 & 4.45 & 5.0862 & TRN \\
\hline CHEMBL1368717 & 688620 & 4.45 & 5.0785 & TST \\
\hline CHEMBL1433860 & 688620 & 5.45 & 5.3382 & TRN \\
\hline CHEMBL1449320 & 688620 & 5.2 & 5.4478 & TRN \\
\hline CHEMBL1471858 & 688620 & 4.95 & 5.0731 & TST \\
\hline CHEMBL1576138 & 688620 & 5.0 & 4.9342 & TRN \\
\hline CHEMBL1368756 & 688620 & 4.95 & 4.8 & TRN \\
\hline CHEMBL1451796 & 688620 & 4.45 & 4.6661 & TRN \\
\hline
\end{tabular}




\begin{tabular}{|c|c|c|c|c|c|}
\hline \multicolumn{6}{|c|}{ Supplemental Table S2.txt } \\
\hline CHEMBL1351121 & 688620 & 5.15 & 5.3337 & TRN & \\
\hline CHEMBL1468783 & 688620 & 5.0 & 5.2952 & TRN & \\
\hline CHEMBL1404337 & 688620 & 5.7 & 5.6253 & TRN & \\
\hline CHEMBL1403612 & 688620 & 4.85 & 4.9615 & TRN & \\
\hline CHEMBL1311666 & 688620 & 6.1 & 5.7318 & TRN & \\
\hline CHEMBL1522066 & 688620 & 5.35 & 4.883 & TRN & \\
\hline CHEMBL1390285 & 688620 & 4.95 & 5.0254 & TST & \\
\hline CHEMBL90181 & 688620 & 5.85 & 5.3649 & TST & \\
\hline CHEMBL1382411 & 688620 & 4.55 & 4.7461 & TRN & \\
\hline CHEMBL1501295 & 688620 & 4.45 & 4.8986 & TRN & \\
\hline CHEMBL1498173 & 688620 & 4.45 & 5.16700 & 0000000001 & TRN \\
\hline CHEMBL1346640 & 688620 & 4.8 & 4.7556 & TRN & \\
\hline CHEMBL1348029 & 688620 & 4.95 & 5.0664 & TRN & \\
\hline CHEMBL1403143 & 688620 & 4.45 & 4.873 & TRN & \\
\hline CHEMBL1576619 & 688620 & 5.55 & 5.0761 & TRN & \\
\hline CHEMBL1311815 & 688620 & 4.85 & 4.9019 & TRN & \\
\hline CHEMBL1613571 & 688620 & 4.65 & 4.7883 & TRN & \\
\hline CHEMBL1379425 & 688620 & 5.25 & 5.0495 & TST & \\
\hline CHEMBL1507147 & 688620 & 4.5 & 5.0683 & TRN & \\
\hline CHEMBL1393187 & 688620 & 6.5501 & 5.1326 & TRN & \\
\hline CHEMBL1345246 & 688620 & 5.05 & 5.3009 & TRN & \\
\hline CHEMBL3190216 & 688620 & 4.75 & 4.8999 & TRN & \\
\hline CHEMBL1434022 & 688620 & 4.45 & 4.6858 & TRN & \\
\hline CHEMBL1464721 & 688620 & 4.95 & 4.8242 & TRN & \\
\hline CHEMBL1544887 & 688620 & 5.05 & 4.7139 & TRN & \\
\hline CHEMBL3199325 & 688620 & 6.15 & 5.92899 & 9999999999 & TRN \\
\hline CHEMBL1392584 & 688620 & 4.75 & 5.0293 & TST & \\
\hline CHEMBL1382260 & 688620 & 5.05 & 5.0064 & TST & \\
\hline CHEMBL1540415 & 688620 & 5.1 & 5.0619 & TRN & \\
\hline CHEMBL1406361 & 688620 & 5.9 & 4.9736 & TRN & \\
\hline CHEMBL1406416 & 688620 & 5.25 & 5.1947 & TRN & \\
\hline CHEMBL1422138 & 688620 & 4.9 & 5.0608 & TRN & \\
\hline CHEMBL1504070 & 688620 & 5.0 & 5.2536 & TRN & \\
\hline CHEMBL1504264 & 688620 & 5.4 & 5.1205 & TRN & \\
\hline CHEMBL1578523 & 688620 & 5.0 & 5.0473 & TRN & \\
\hline CHEMBL1613474 & 688620 & 4.45 & 4.9502 & TRN & \\
\hline CHEMBL1547095 & 688620 & 5.95 & 5.6026 & TRN & \\
\hline CHEMBL494326 & 688620 & 4.65 & 5.023 & TRN & \\
\hline CHEMBL1380221 & 688620 & 4.45 & 4.9159 & TRN & \\
\hline CHEMBL1523746 & 688620 & 4.9 & 4.8587 & TRN & \\
\hline CHEMBL1461992 & 688620 & 5.0 & 4.8853 & TRN & \\
\hline CHEMBL1325019 & 688620 & 4.85 & 5.1358 & TST & \\
\hline CHEMBL1504079 & 688620 & 4.85 & 4.9912 & TST & \\
\hline CHEMBL1327156 & 688620 & 4.95 & 5.0822 & TRN & \\
\hline CHEMBL1511276 & 688620 & 6.0 & 5.544 & TRN & \\
\hline CHEMBL1256974 & 688620 & 4.45 & 4.9224 & TRN & \\
\hline CHEMBL1367701 & 688620 & 4.45 & 5.4078 & TRN & \\
\hline CHEMBL1481132 & 688620 & 4.9 & 4.6923 & TRN & \\
\hline
\end{tabular}




\begin{tabular}{|c|c|c|c|c|}
\hline \multicolumn{5}{|c|}{ Supplemental Table S2.txt } \\
\hline CHEMBL 3212424 & 688620 & 5.0 & 5.1315 & TST \\
\hline CHEMBL3145018 & 688620 & 4.45 & 4.9427 & TRN \\
\hline CHEMBL1590066 & 688620 & 4.85 & 5.1249 & TST \\
\hline CHEMBL1548924 & 688620 & 5.05 & 4.9978 & TRN \\
\hline CHEMBL1379983 & 688620 & 5.2 & 4.843 & TRN \\
\hline CHEMBL1540399 & 688620 & 4.95 & 5.1584 & TRN \\
\hline CHEMBL1329916 & 688620 & 6.6499 & 5.1272 & TRN \\
\hline CHEMBL1577207 & 688620 & 4.95 & 5.1115 & TST \\
\hline CHEMBL1538783 & 688620 & 4.95 & 5.0579 & TRN \\
\hline CHEMBL1351315 & 688620 & 4.8 & 4.8706 & TST \\
\hline CHEMBL2369172 & 688620 & 4.7 & 4.7072 & TRN \\
\hline CHEMBL1511261 & 688620 & 5.0 & 5.0794 & TRN \\
\hline CHEMBL1568798 & 688620 & 5.15 & 5.103 & TST \\
\hline CHEMBL1976940 & 688620 & 4.45 & 5.0947 & TST \\
\hline CHEMBL1447036 & 688620 & 5.35 & 5.0645 & TST \\
\hline CHEMBL1561809 & 688620 & 4.65 & 4.8078 & TRN \\
\hline CHEMBL3195513 & 688620 & 5.0 & 5.0257 & TRN \\
\hline CHEMBL578675 & 688620 & 4.85 & 5.2233 & TRN \\
\hline CHEMBL1391165 & 688620 & 4.9 & 4.8729 & TST \\
\hline CHEMBL1524262 & 688620 & 5.15 & 4.7128 & TRN \\
\hline CHEMBL1446984 & 688620 & 4.95 & 5.033 & TRN \\
\hline CHEMBL1446083 & 688620 & 4.45 & 4.928 & TRN \\
\hline CHEMBL1588656 & 688620 & 5.45 & 5.5238 & TRN \\
\hline CHEMBL1595175 & 688620 & 4.95 & 4.8744 & TRN \\
\hline CHEMBL1558090 & 688620 & 5.45 & 5.1985 & TRN \\
\hline CHEMBL1347465 & 688620 & 6.8 & 4.9394 & TST \\
\hline CHEMBL1522233 & 688620 & 4.95 & 5.1293 & TST \\
\hline CHEMBL1406997 & 688620 & 5.65 & 5.3289 & TRN \\
\hline CHEMBL1543590 & 688620 & 6.5501 & 4.9858 & TRN \\
\hline CHEMBL256042 & 688620 & 6.0 & 5.9632 & TRN \\
\hline CHEMBL1965579 & 688620 & 5.25 & 5.1783 & TRN \\
\hline CHEMBL1573265 & 688620 & 8.301 & 5.0888 & TST \\
\hline CHEMBL1588141 & 688620 & 4.8 & 5.0604 & TRN \\
\hline CHEMBL1464133 & 688620 & 6.8499 & 5.2955 & TST \\
\hline CHEMBL1405091 & 688620 & 5.05 & 5.0647 & TRN \\
\hline CHEMBL1969046 & 688620 & 4.65 & 5.0081 & TRN \\
\hline CHEMBL3195475 & 688620 & 5.65 & 5.5208 & TRN \\
\hline CHEMBL1342061 & 688620 & 4.95 & 5.0729 & TRN \\
\hline CHEMBL1328641 & 688620 & 4.45 & 5.2462 & TST \\
\hline CHEMBL1576769 & 688620 & 4.45 & 5.0386 & TRN \\
\hline CHEMBL1550800 & 688620 & 4.95 & 5.3053 & TST \\
\hline CHEMBL1543095 & 688620 & 5.0 & 4.9722 & TST \\
\hline CHEMBL1349641 & 688620 & 4.55 & 4.9295 & TST \\
\hline CHEMBL1570375 & 688620 & 5.0 & 5.0775 & TRN \\
\hline CHEMBL1489962 & 688620 & 5.15 & 5.0453 & TRN \\
\hline CHEMBL1464138 & 688620 & 4.7 & 4.8523 & TST \\
\hline CHEMBL1381997 & 688620 & 5.05 & 5.2452 & TRN \\
\hline CHEMBL1409822 & 688620 & 5.8 & 5.7961 & TRN \\
\hline
\end{tabular}




\begin{tabular}{|c|c|c|c|c|c|}
\hline & & \multicolumn{4}{|c|}{ Supplemental Table S2.txt } \\
\hline CHEMBL1351908 & 688620 & 7.4498 & 5.6283 & TRN & \\
\hline CHEMBL1602567 & 688620 & 5.5 & 5.2571 & TRN & \\
\hline CHEMBL1541017 & 688620 & 6.15 & 5.3748 & TST & \\
\hline CHEMBL586602 & 688620 & 5.4 & 5.3934 & TRN & \\
\hline CHEMBL1578747 & 688620 & 5.0 & 4.7839 & TRN & \\
\hline CHEMBL1384037 & 688620 & 4.9 & 5.0673 & TST & \\
\hline CHEMBL1581016 & 688620 & 4.95 & 5.3809 & TRN & \\
\hline CHEMBL3208372 & 688620 & 4.65 & 5.2479 & TRN & \\
\hline CHEMBL1583914 & 688620 & 4.5 & 5.2993 & TRN & \\
\hline CHEMBL1386983 & 688620 & 5.4 & 5.2507 & TRN & \\
\hline CHEMBL1333583 & 688620 & 5.0 & 4.7651 & TST & \\
\hline CHEMBL1565183 & 688620 & 6.45 & 4.9841 & TST & \\
\hline CHEMBL1505803 & 688620 & 6.05 & 5.0981 & TRN & \\
\hline CHEMBL1385735 & 688620 & 4.6 & 4.9302 & TST & \\
\hline CHEMBL1483281 & 688620 & 5.15 & 4.9622 & TRN & \\
\hline CHEMBL1538678 & 688620 & 4.45 & 5.1122 & TST & \\
\hline CHEMBL1387189 & 688620 & 4.95 & 4.875 & TRN & \\
\hline CHEMBL1580603 & 688620 & 5.3 & 4.9537 & TRN & \\
\hline CHEMBL1599688 & 688620 & 7.0501 & 4.9366 & TRN & \\
\hline CHEMBL 3198400 & 688620 & 5.3 & 5.655 & TRN & \\
\hline CHEMBL1532452 & 688620 & 4.75 & 4.8565 & TRN & \\
\hline CHEMBL1351916 & 688620 & 4.95 & 5.0885 & TST & \\
\hline CHEMBL1467989 & 688620 & 5.4 & 4.9133 & TRN & \\
\hline CHEMBL1503392 & 688620 & 4.45 & 4.9954 & TRN & \\
\hline CHEMBL1384624 & 688620 & 5.25 & 4.88399 & 99999999995 & TST \\
\hline CHEMBL1584206 & 688620 & 4.9 & 5.1043 & TRN & \\
\hline CHEMBL1499109 & 688620 & 4.95 & 4.8345 & TRN & \\
\hline CHEMBL1306439 & 688620 & 6.7001 & 5.0951 & TRN & \\
\hline CHEMBL1471415 & 688620 & 5.0 & 5.3675 & TST & \\
\hline CHEMBL1449111 & 688620 & 5.25 & 5.2723 & TRN & \\
\hline CHEMBL 3197341 & 688620 & 5.2 & 4.8645 & TRN & \\
\hline CHEMBL1603211 & 688620 & 4.8 & 4.88 & TST & \\
\hline CHEMBL1532729 & 688620 & 4.7 & 5.0493 & TRN & \\
\hline CHEMBL1388349 & 688620 & 4.8 & 5.0007 & TRN & \\
\hline CHEMBL1325461 & 688620 & 4.75 & 4.8966 & TST & \\
\hline CHEMBL3210250 & 688620 & 6.35 & 6.0806 & TRN & \\
\hline CHEMBL1349725 & 688620 & 4.85 & 4.993 & TRN & \\
\hline CHEMBL1595892 & 688620 & 5.0 & 5.0262 & TRN & \\
\hline CHEMBL1370657 & 688620 & 5.6 & 5.0748 & TST & \\
\hline CHEMBL1460974 & 688620 & 5.1 & 5.0298 & TRN & \\
\hline CHEMBL1319778 & 688620 & 4.45 & 4.9044 & TRN & \\
\hline CHEMBL1490845 & 688620 & 4.8 & 4.9809 & TRN & \\
\hline CHEMBL1526756 & 688620 & 4.9 & 5.1309 & TRN & \\
\hline CHEMBL1322625 & 688620 & 4.85 & 5.0726 & TRN & \\
\hline CHEMBL1507486 & 688620 & 5.15 & 5.1435 & TRN & \\
\hline CHEMBL1518596 & 688620 & 4.9 & 5.1776 & TRN & \\
\hline CHEMBL1430382 & 688620 & 4.95 & 5.0652 & TRN & \\
\hline CHEMBL1325958 & 688620 & 4.6 & 4.8543 & TRN & \\
\hline
\end{tabular}




\begin{tabular}{|c|c|c|c|c|c|}
\hline & & & & & \\
\hline CHEMBL1470598 & 688620 & 5.3 & 5.1219 & TRN & \\
\hline CHEMBL1381215 & 688620 & 4.9 & 5.0079 & TRN & \\
\hline CHEMBL1483819 & 688620 & 5.6 & 5.3205 & TST & \\
\hline CHEMBL1588742 & 688620 & 4.85 & 4.95 & TST & \\
\hline CHEMBL1381136 & 688620 & 5.65 & 5.2863 & TRN & \\
\hline CHEMBL1354773 & 688620 & 4.75 & 4.9575 & TST & \\
\hline CHEMBL1377042 & 688620 & 5.25 & 5.1532 & TST & \\
\hline CHEMBL1406910 & 688620 & 5.0 & 4.8902 & TRN & \\
\hline CHEMBL1327148 & 688620 & 5.25 & 4.9722 & TRN & \\
\hline CHEMBL1523468 & 688620 & 5.0 & 6.3076 & TRN & \\
\hline CHEMBL567529 & 688620 & 5.75 & 5.49299 & 9999999999 & TRN \\
\hline CHEMBL1343664 & 688620 & 5.75 & 5.6023 & TRN & \\
\hline CHEMBL1345376 & 688620 & 5.45 & 5.0992 & TRN & \\
\hline CHEMBL1508874 & 688620 & 5.05 & 4.9143 & TRN & \\
\hline CHEMBL1485684 & 688620 & 5.25 & 5.0855 & TRN & \\
\hline CHEMBL1525300 & 688620 & 4.5 & 5.6037 & TRN & \\
\hline CHEMBL1308750 & 688620 & 5.1 & 5.5011 & TRN & \\
\hline CHEMBL1465414 & 688620 & 4.45 & 4.9369 & TRN & \\
\hline CHEMBL1321600 & 688620 & 4.9 & 4.89199 & 99999999995 & TST \\
\hline CHEMBL20562 & 688620 & 4.5 & 4.8806 & TST & \\
\hline CHEMBL1367872 & 688620 & 4.85 & 4.7661 & TRN & \\
\hline CHEMBL1483619 & 688620 & 4.95 & 4.8891 & TST & \\
\hline CHEMBL1462586 & 688620 & 5.2 & 5.0496 & TRN & \\
\hline CHEMBL1562605 & 688620 & 4.7 & 4.7831 & TRN & \\
\hline CHEMBL1384559 & 688620 & 4.45 & 4.8825 & TRN & \\
\hline CHEMBL1494793 & 688620 & 5.05 & 5.00899 & 99999999995 & TRN \\
\hline CHEMBL1359318 & 688620 & 4.5 & 4.7955 & TST & \\
\hline CHEMBL1864040 & 688620 & 5.3 & 5.4004 & TRN & \\
\hline CHEMBL 3212627 & 688620 & 5.0 & 4.9983 & TRN & \\
\hline CHEMBL1449165 & 688620 & 5.25 & 4.9755 & TRN & \\
\hline CHEMBL1526105 & 688620 & 4.7 & 4.9305 & TRN & \\
\hline CHEMBL1312122 & 688620 & 4.45 & 4.7615 & TST & \\
\hline CHEMBL75349 & 688620 & 5.0 & 5.0911 & TRN & \\
\hline CHEMBL1430427 & 688620 & 4.8 & 4.8809 & TRN & \\
\hline CHEMBL1302524 & 688620 & 4.55 & 4.7455 & TST & \\
\hline CHEMBL305695 & 688620 & 6.0 & 4.8808 & TRN & \\
\hline CHEMBL1425868 & 688620 & 6.15 & 5.398 & TST & \\
\hline CHEMBL1568946 & 688620 & 6.0 & 5.4063 & TRN & \\
\hline CHEMBL1341098 & 688620 & 5.2 & 4.8418 & TRN & \\
\hline CHEMBL1452139 & 688620 & 4.75 & 4.9709 & TRN & \\
\hline CHEMBL1356038 & 688620 & 4.85 & 4.7019 & TRN & \\
\hline CHEMBL1346130 & 688620 & 4.45 & 4.8463 & TRN & \\
\hline CHEMBL1981570 & 688620 & 6.95 & 6.0522 & TRN & \\
\hline CHEMBL1326055 & 688620 & 4.7 & 4.9526 & TRN & \\
\hline CHEMBL1304368 & 688620 & 5.0 & 5.3261 & TRN & \\
\hline CHEMBL1484486 & 688620 & 5.0 & 4.8701 & TRN & \\
\hline CHEMBL1300313 & 688620 & 5.3 & 5.5631 & TST & \\
\hline CHEMBL1369598 & 688620 & 5.9 & 5.0753 & TRN & \\
\hline & & & & 26906 & \\
\hline
\end{tabular}




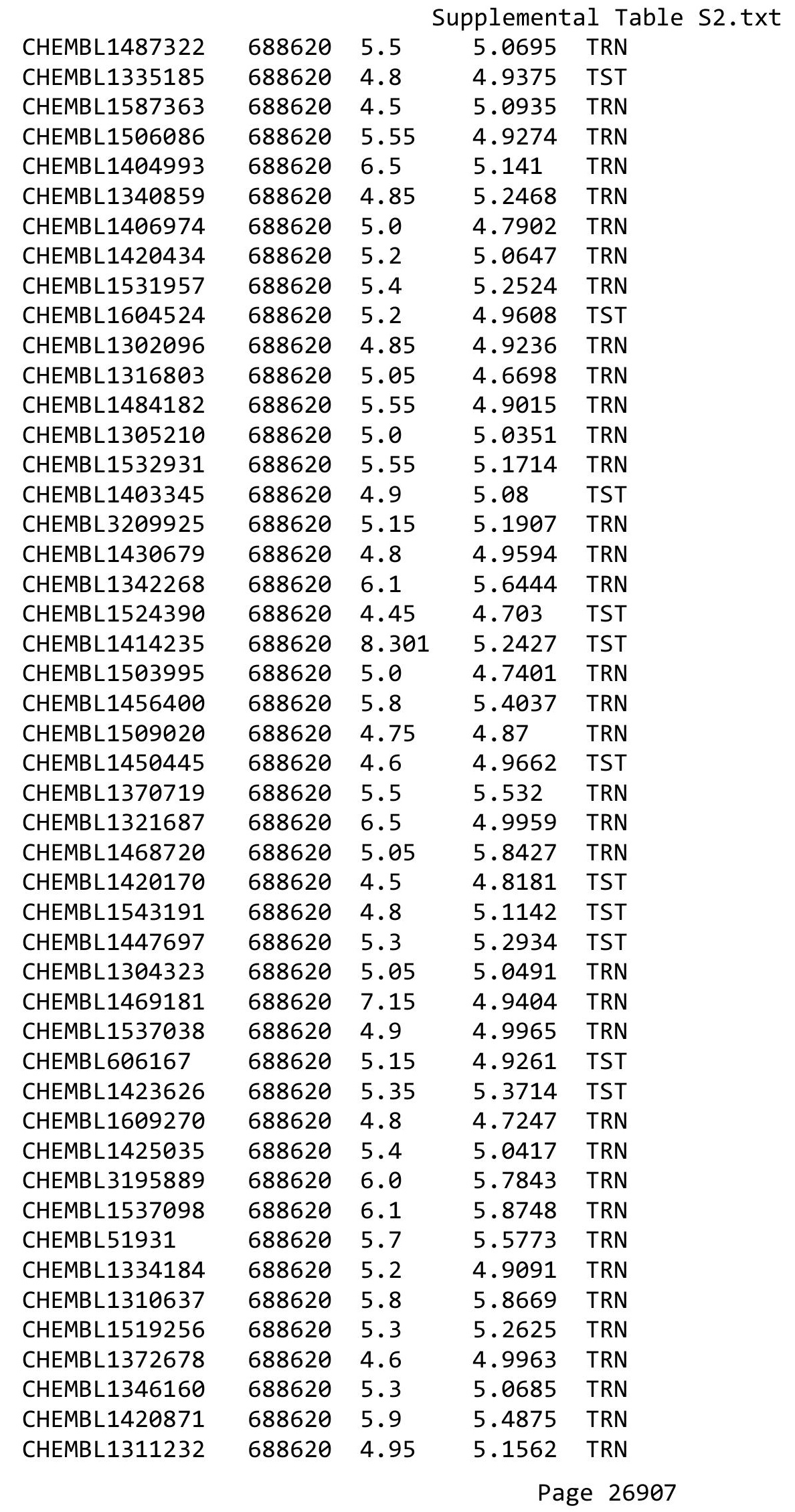




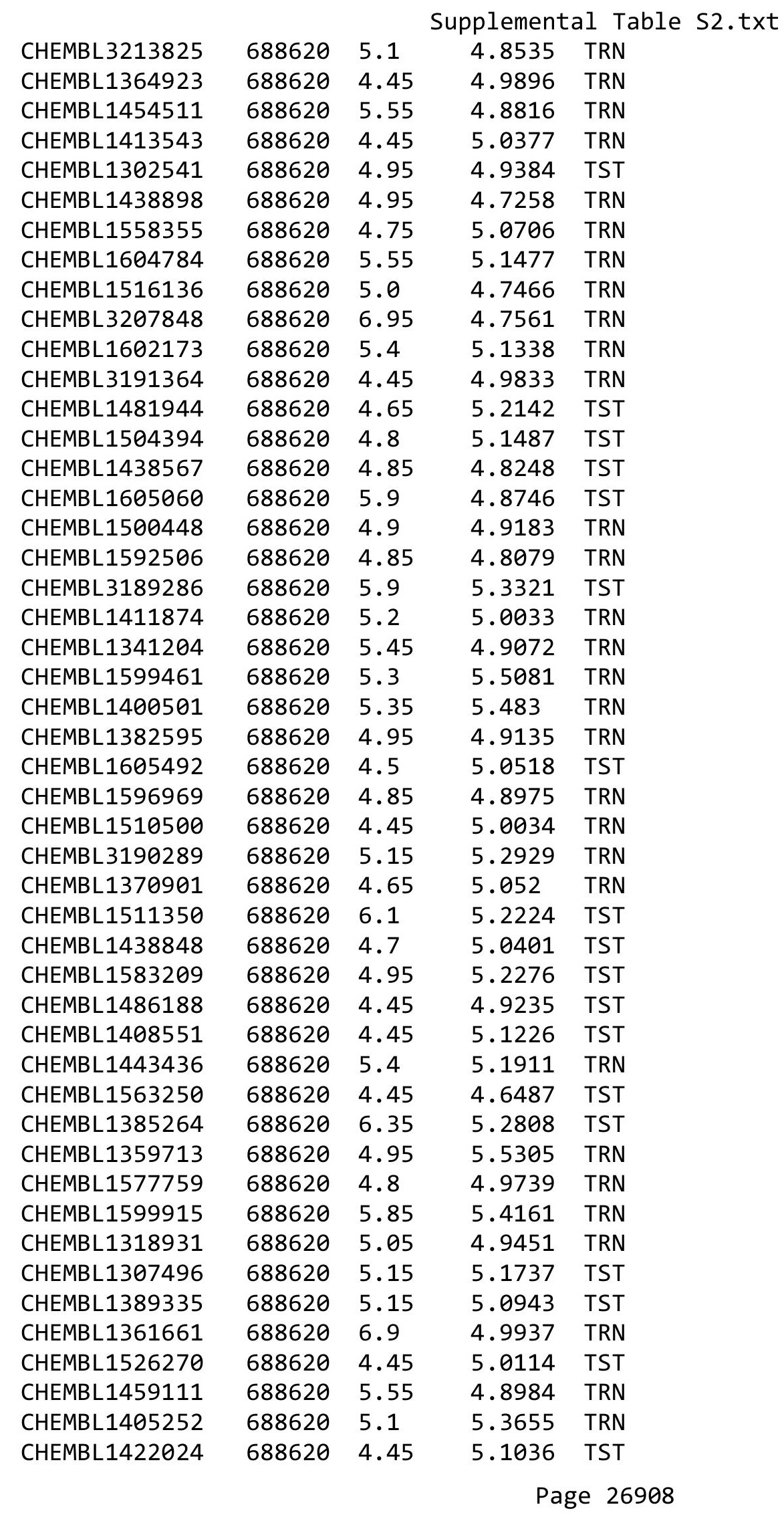




\begin{tabular}{|c|c|c|c|c|}
\hline \multicolumn{5}{|c|}{ Supplemental Table S2.txt } \\
\hline CHEMBL3195036 & 688620 & 5.45 & 5.3817 & TRN \\
\hline CHEMBL1318878 & 688620 & 4.85 & 5.1184 & TRN \\
\hline CHEMBL1596357 & 688620 & 4.7 & 4.9616 & TRN \\
\hline CHEMBL1345081 & 688620 & 4.9 & 5.2754 & TRN \\
\hline CHEMBL1523699 & 688620 & 4.55 & 4.7727 & TRN \\
\hline CHEMBL1405364 & 688620 & 5.55 & 4.9501 & TRN \\
\hline CHEMBL1374193 & 688620 & 4.7 & 5.2342 & TRN \\
\hline CHEMBL1359216 & 688620 & 6.7501 & 5.0477 & TST \\
\hline CHEMBL1301158 & 688620 & 5.15 & 5.2733 & TST \\
\hline CHEMBL3190669 & 688620 & 6.8 & 5.905 & TRN \\
\hline CHEMBL1595363 & 688620 & 4.85 & 5.0381 & TST \\
\hline CHEMBL1609363 & 688620 & 7.15 & 6.2429 & TRN \\
\hline CHEMBL1329962 & 688620 & 5.1 & 4.6998 & TST \\
\hline CHEMBL1581066 & 688620 & 5.7 & 5.4678 & TRN \\
\hline CHEMBL2001337 & 688620 & 4.95 & 4.8133 & TRN \\
\hline CHEMBL1359668 & 688620 & 5.45 & 5.1616 & TRN \\
\hline CHEMBL1570322 & 688620 & 4.9 & 5.1143 & TRN \\
\hline CHEMBL1385661 & 688620 & 4.45 & 4.9993 & TRN \\
\hline CHEMBL1307269 & 688620 & 5.0 & 5.0551 & TRN \\
\hline CHEMBL1487596 & 688620 & 5.0 & 5.2121 & TRN \\
\hline CHEMBL1362395 & 688620 & 4.9 & 5.0577 & TRN \\
\hline CHEMBL1549322 & 688620 & 4.85 & 5.0029 & TRN \\
\hline CHEMBL1300348 & 688620 & 5.0 & 5.1778 & TRN \\
\hline CHEMBL1345584 & 688620 & 5.1 & 4.9866 & TRN \\
\hline CHEMBL3192387 & 688620 & 5.0 & 5.0607 & TRN \\
\hline CHEMBL1601730 & 688620 & 5.6 & 4.9422 & TRN \\
\hline CHEMBL1548211 & 688620 & 4.65 & 4.98 & TRN \\
\hline CHEMBL1546778 & 688620 & 4.45 & 4.798 & TRN \\
\hline CHEMBL1490048 & 688620 & 5.55 & 5.2635 & TRN \\
\hline CHEMBL1306539 & 688620 & 4.45 & 5.0842 & TST \\
\hline CHEMBL571436 & 688620 & 5.15 & 5.1181 & TRN \\
\hline CHEMBL2369166 & 688620 & 4.7 & 4.9469 & TST \\
\hline CHEMBL1416366 & 688620 & 5.85 & 5.4113 & TRN \\
\hline CHEMBL 2000619 & 688620 & 4.9 & 5.2901 & TST \\
\hline CHEMBL1374871 & 688620 & 4.5 & 4.9666 & TST \\
\hline CHEMBL1478146 & 688620 & 4.75 & 4.9384 & TRN \\
\hline CHEMBL1464930 & 688620 & 4.45 & 4.5407 & TRN \\
\hline CHEMBL1372169 & 688620 & 4.75 & 4.9716 & TRN \\
\hline CHEMBL453974 & 688620 & 6.0 & 5.7521 & TST \\
\hline CHEMBL1543187 & 688620 & 4.7 & 4.9052 & TRN \\
\hline CHEMBL1478665 & 688620 & 5.25 & 5.0056 & TRN \\
\hline CHEMBL1466319 & 688620 & 4.9 & 4.8912 & TRN \\
\hline CHEMBL1530724 & 688620 & 5.4 & 5.5811 & TRN \\
\hline CHEMBL1349374 & 688620 & 5.0 & 5.3234 & TRN \\
\hline CHEMBL1391718 & 688620 & 4.95 & 5.0881 & TRN \\
\hline CHEMBL1503190 & 688620 & 5.3 & 5.1798 & TST \\
\hline CHEMBL1438700 & 688620 & 4.9 & 5.1517 & TRN \\
\hline CHEMBL1986073 & 688620 & 4.85 & 4.7584 & TST \\
\hline
\end{tabular}




\begin{tabular}{|c|c|c|c|c|c|}
\hline \multirow{3}{*}{$\begin{array}{l}\text { CHEMBL1301747 } \\
\text { CHEMBL1311148 }\end{array}$} & \multirow{3}{*}{$\begin{array}{l}688620 \\
688620\end{array}$} & \multicolumn{4}{|c|}{ Supplemental Table S2.txt } \\
\hline & & 6.1 & \multicolumn{2}{|c|}{5.332999999999999} & TRN \\
\hline & & 5.0 & 5.0349 & TRN & \\
\hline CHEMBL1477708 & 688620 & 4.75 & 4.9146 & TRN & \\
\hline CHEMBL1482670 & 688620 & 4.85 & 5.206 & TRN & \\
\hline CHEMBL1520352 & 688620 & 4.85 & 4.9449 & TRN & \\
\hline CHEMBL3196391 & 688620 & 5.6 & 5.3237 & TRN & \\
\hline CHEMBL1349845 & 688620 & 5.0 & 5.0499 & TRN & \\
\hline CHEMBL1582082 & 688620 & 5.9 & 5.0275 & TRN & \\
\hline CHEMBL1563149 & 688620 & 5.15 & 5.3109 & TRN & \\
\hline CHEMBL1312231 & 688620 & 5.95 & 6.0319 & TRN & \\
\hline CHEMBL1407156 & 688620 & 4.45 & 5.0456 & TRN & \\
\hline CHEMBL1424856 & 688620 & 5.0 & 5.0592 & TRN & \\
\hline CHEMBL1336373 & 688620 & 5.15 & 5.1445 & TRN & \\
\hline CHEMBL1448373 & 688620 & 4.85 & 5.0307 & TRN & \\
\hline CHEMBL1460682 & 688620 & 4.9 & 5.3695 & TRN & \\
\hline CHEMBL1301417 & 688620 & 6.2 & 5.083 & TRN & \\
\hline CHEMBL1363310 & 688620 & 4.9 & 5.1051 & TST & \\
\hline CHEMBL1302036 & 688620 & 4.65 & 5.4694 & TRN & \\
\hline CHEMBL317172 & 688620 & 6.5501 & 5.0524 & TST & \\
\hline CHEMBL1324102 & 688620 & 5.2 & 5.1204 & TST & \\
\hline CHEMBL1456986 & 688620 & 4.65 & 4.982 & TRN & \\
\hline CHEMBL1532411 & 688620 & 6.5501 & 5.1003 & TST & \\
\hline CHEMBL1563407 & 688620 & 6.15 & 5.0864 & TRN & \\
\hline CHEMBL1353636 & 688620 & 5.4 & 4.8984 & TRN & \\
\hline CHEMBL3212196 & 688620 & 4.8 & 4.8109 & TRN & \\
\hline CHEMBL1605090 & 688620 & 8.2518 & 5.3082 & TST & \\
\hline CHEMBL1305910 & 688620 & 4.45 & 4.8625 & TRN & \\
\hline CHEMBL1412386 & 688620 & 4.75 & 4.7079 & TRN & \\
\hline CHEMBL1556158 & 688620 & 5.0 & 4.9253 & TRN & \\
\hline CHEMBL 3145067 & 688620 & 4.95 & 5.1802 & TST & \\
\hline CHEMBL1527549 & 688620 & 4.9 & 4.7493 & TST & \\
\hline CHEMBL1351539 & 688620 & 6.1 & 5.4257 & TST & \\
\hline CHEMBL1561353 & 688620 & 4.45 & 4.9457 & TRN & \\
\hline CHEMBL3214238 & 688620 & 4.65 & 5.0575 & TRN & \\
\hline CHEMBL1452986 & 688620 & 4.6 & 4.7002 & TST & \\
\hline CHEMBL1348765 & 688620 & 5.3 & 5.3634 & TST & \\
\hline CHEMBL1439271 & 688620 & 4.45 & 5.0218 & TRN & \\
\hline CHEMBL1409264 & 688620 & 4.8 & 5.0469 & TST & \\
\hline CHEMBL1336948 & 688620 & 5.0 & 4.8682 & TST & \\
\hline CHEMBL1511674 & 688620 & 5.45 & 5.2179 & TST & \\
\hline CHEMBL1408752 & 688620 & 5.5 & 5.4389 & TRN & \\
\hline CHEMBL1338958 & 688620 & 5.25 & 4.8903 & TRN & \\
\hline CHEMBL1445772 & 688620 & 4.85 & 4.8541 & TST & \\
\hline CHEMBL1313724 & 688620 & 4.8 & 5.1057 & TRN & \\
\hline CHEMBL1393026 & 688620 & 4.45 & 5.1295 & TST & \\
\hline CHEMBL1422356 & 688620 & 5.3 & 5.0052 & TRN & \\
\hline CHEMBL1423547 & 688620 & 4.9 & 5.0101 & TRN & \\
\hline CHEMBL1339956 & 688620 & 4.45 & 4.6287 & TRN & \\
\hline
\end{tabular}




\begin{tabular}{|c|c|c|c|c|}
\hline \multirow[b]{2}{*}{ CHEMBL1346826 } & \multicolumn{4}{|c|}{ Supplemental Ta } \\
\hline & 688620 & 4.8 & 5.0117 & TST \\
\hline CHEMBL1496792 & 688620 & 4.45 & 4.9747 & TRN \\
\hline CHEMBL1443036 & 688620 & 4.95 & 4.8827 & TRN \\
\hline CHEMBL1456168 & 688620 & 4.9 & 4.9015 & TRN \\
\hline CHEMBL1982896 & 688620 & 4.95 & 5.0943 & TRN \\
\hline CHEMBL1501857 & 688620 & 6.05 & 6.8104 & TST \\
\hline CHEMBL3190162 & 688620 & 4.55 & 4.8918 & TRN \\
\hline CHEMBL1441918 & 688620 & 5.0 & 5.2492 & TST \\
\hline CHEMBL1456096 & 688620 & 5.55 & 5.3002 & TRN \\
\hline CHEMBL1414859 & 688620 & 4.85 & 4.9434 & TRN \\
\hline CHEMBL1331975 & 688620 & 4.8 & 5.1879 & TRN \\
\hline CHEMBL1470630 & 688620 & 4.45 & 5.1819 & TST \\
\hline CHEMBL1458175 & 688620 & 5.85 & 5.2714 & TRN \\
\hline CHEMBL1596327 & 688620 & 4.9 & 5.0388 & TST \\
\hline CHEMBL1412008 & 688620 & 4.65 & 4.9081 & TRN \\
\hline CHEMBL1409364 & 688620 & 5.4 & 4.926 & TRN \\
\hline CHEMBL1502686 & 688620 & 4.75 & 4.8614 & TRN \\
\hline CHEMBL1578392 & 688620 & 5.6 & 5.3042 & TRN \\
\hline CHEMBL1521374 & 688620 & 4.45 & 4.8611 & TRN \\
\hline CHEMBL1386877 & 688620 & 4.65 & 4.9633 & TRN \\
\hline CHEMBL1523113 & 688620 & 4.5 & 5.0846 & TRN \\
\hline CHEMBL3196577 & 688620 & 4.75 & 5.0088 & TST \\
\hline CHEMBL1547552 & 688620 & 4.95 & 4.8236 & TST \\
\hline CHEMBL1467284 & 688620 & 4.6 & 4.8298 & TRN \\
\hline CHEMBL1596385 & 688620 & 5.55 & 4.9666 & TRN \\
\hline CHEMBL1330087 & 688620 & 6.0 & 4.9888 & TRN \\
\hline CHEMBL1574282 & 688620 & 5.2 & 5.0024 & TRN \\
\hline CHEMBL1323186 & 688620 & 4.45 & 4.7656 & TRN \\
\hline CHEMBL1347203 & 688620 & 5.55 & 5.2504 & TRN \\
\hline CHEMBL1393695 & 688620 & 4.95 & 4.8308 & TRN \\
\hline CHEMBL1347499 & 688620 & 4.65 & 4.7782 & TST \\
\hline CHEMBL1521744 & 688620 & 4.7 & 4.9937 & TRN \\
\hline CHEMBL1570793 & 688620 & 4.45 & 4.9401 & TRN \\
\hline CHEMBL1399134 & 688620 & 5.0 & 5.1447 & TST \\
\hline CHEMBL1520804 & 688620 & 5.2 & 5.0291 & TRN \\
\hline CHEMBL1534781 & 688620 & 5.1 & 5.3293 & TRN \\
\hline CHEMBL1338764 & 688620 & 4.45 & 4.7936 & TRN \\
\hline CHEMBL411307 & 688620 & 4.95 & 5.2302 & TRN \\
\hline CHEMBL1597739 & 688620 & 5.05 & 5.2858 & TRN \\
\hline CHEMBL1485532 & 688620 & 5.25 & 5.0692 & TST \\
\hline CHEMBL3214327 & 688620 & 4.65 & 4.9295 & TRN \\
\hline CHEMBL1523697 & 688620 & 5.0 & 5.033 & TRN \\
\hline CHEMBL1587373 & 688620 & 4.45 & 4.7659 & TST \\
\hline CHEMBL1994683 & 688620 & 5.6 & 5.6086 & TRN \\
\hline CHEMBL1487345 & 688620 & 4.7 & 4.9345 & TRN \\
\hline CHEMBL1306943 & 688620 & 4.8 & 5.2727 & TST \\
\hline CHEMBL1508325 & 688620 & 5.25 & 5.459 & TRN \\
\hline CHEMBL1546216 & 688620 & 5.75 & 4.9956 & TRN \\
\hline
\end{tabular}




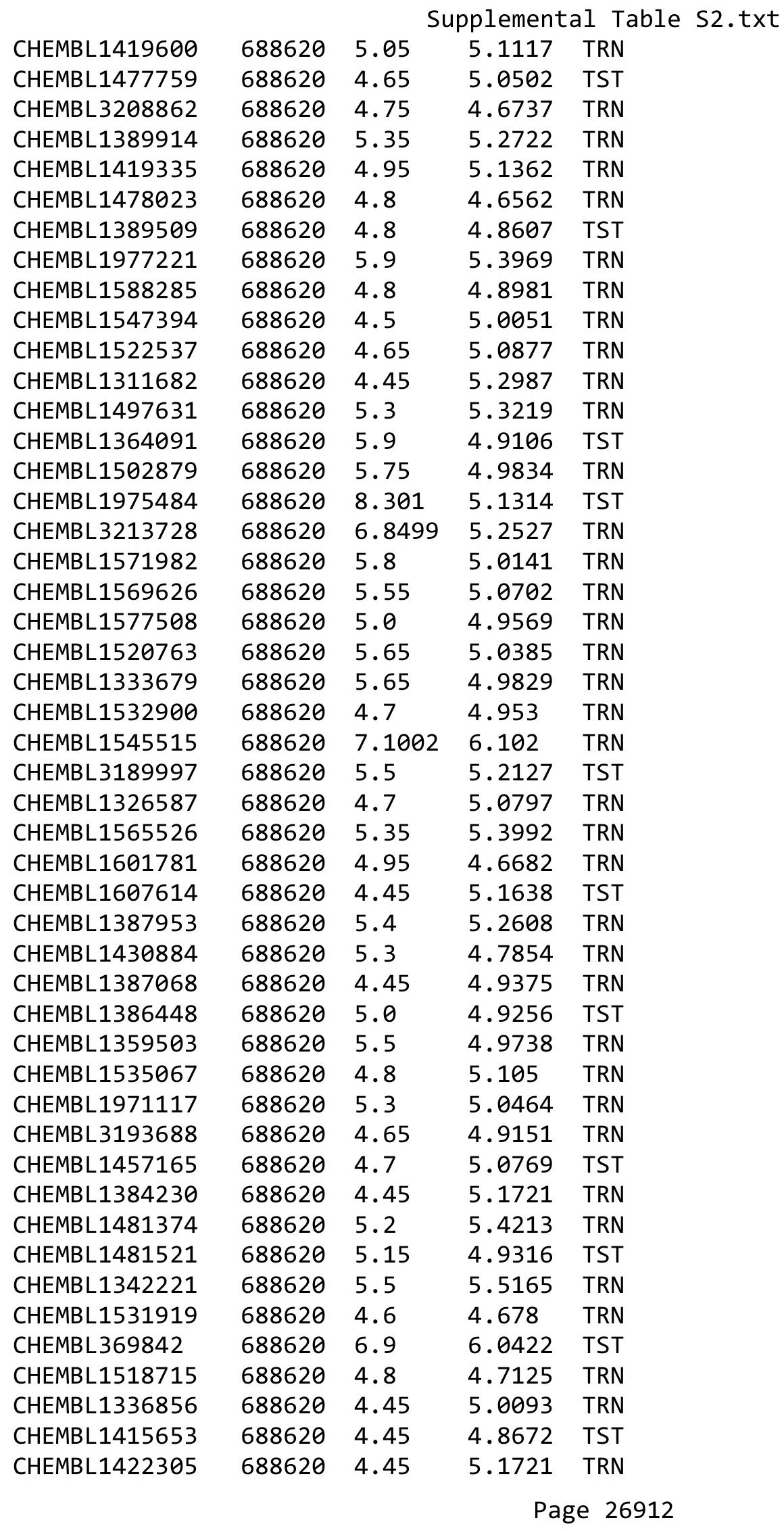




\begin{tabular}{|c|c|c|c|c|c|}
\hline \multicolumn{6}{|c|}{ Supplemental Table S2.txt } \\
\hline CHEMBL1368998 & 688620 & 4.65 & 5.1555 & TST & \\
\hline CHEMBL3190250 & 688620 & 4.65 & 4.9553 & TRN & \\
\hline CHEMBL1387416 & 688620 & 5.45 & 5.1802 & TRN & \\
\hline CHEMBL585426 & 688620 & 4.45 & 5.0987 & TRN & \\
\hline CHEMBL1522601 & 688620 & 5.0 & 5.037 & TST & \\
\hline CHEMBL3208000 & 688620 & 5.0 & 4.9571 & TRN & \\
\hline CHEMBL1405158 & 688620 & 4.9 & 5.2304 & TST & \\
\hline CHEMBL1330029 & 688620 & 4.9 & 5.26399 & э999999999 & TRN \\
\hline CHEMBL1332468 & 688620 & 4.95 & 4.9716 & TRN & \\
\hline CHEMBL1522226 & 688620 & 4.6 & 5.1794 & TRN & \\
\hline CHEMBL1349757 & 688620 & 5.65 & 5.0832 & TRN & \\
\hline CHEMBL1382105 & 688620 & 4.95 & 5.4507 & TRN & \\
\hline CHEMBL1344543 & 688620 & 4.45 & 5.1735 & TRN & \\
\hline CHEMBL1385092 & 688620 & 6.5 & 5.2255 & TRN & \\
\hline CHEMBL1539400 & 688620 & 5.8 & 5.3724 & TRN & \\
\hline CHEMBL1417776 & 688620 & 5.55 & 5.4901 & TRN & \\
\hline CHEMBL1407128 & 688620 & 4.9 & 4.9967 & TST & \\
\hline CHEMBL1465088 & 688620 & 5.95 & 5.1869 & TRN & \\
\hline CHEMBL1402332 & 688620 & 5.25 & 5.5024 & TRN & \\
\hline CHEMBL1305752 & 688620 & 5.35 & 4.8835 & TRN & \\
\hline CHEMBL 225903 & 688620 & 5.7 & 5.5935 & TRN & \\
\hline CHEMBL1509355 & 688620 & 4.6 & 4.9841 & TRN & \\
\hline CHEMBL1972506 & 688620 & 5.55 & 5.1663 & TRN & \\
\hline CHEMBL1349839 & 688620 & 5.15 & 4.9842 & TRN & \\
\hline CHEMBL1500447 & 688620 & 4.9 & 4.9428 & TRN & \\
\hline CHEMBL1379178 & 688620 & 5.6 & 5.472 & TST & \\
\hline CHEMBL1389953 & 688620 & 4.9 & 5.0575 & TRN & \\
\hline CHEMBL1447517 & 688620 & 6.5501 & 5.2723 & TRN & \\
\hline CHEMBL1467322 & 688620 & 5.05 & 4.9265 & TRN & \\
\hline CHEMBL1347370 & 688620 & 4.45 & 5.3105 & TRN & \\
\hline CHEMBL1300388 & 688620 & 5.2 & 5.0095 & TRN & \\
\hline CHEMBL 2252289 & 688620 & 4.65 & 5.3174 & TST & \\
\hline CHEMBL1477140 & 688620 & 4.9 & 4.8647 & TRN & \\
\hline CHEMBL1958251 & 688620 & 5.5 & 5.2726 & TRN & \\
\hline CHEMBL1598696 & 688620 & 5.25 & 5.5326 & TRN & \\
\hline CHEMBL1552150 & 688620 & 5.6 & 5.1277 & TRN & \\
\hline CHEMBL1375437 & 688620 & 4.8 & 5.1677 & TRN & \\
\hline CHEMBL1546592 & 688620 & 5.15 & 5.0739 & TRN & \\
\hline CHEMBL1347623 & 688620 & 4.8 & 5.1804 & TRN & \\
\hline CHEMBL1366720 & 688620 & 4.9 & 5.8688 & TRN & \\
\hline CHEMBL1448248 & 688620 & 4.95 & 4.7657 & TST & \\
\hline CHEMBL1375373 & 688620 & 6.8499 & 6.1691 & TRN & \\
\hline CHEMBL1418962 & 688620 & 4.65 & 5.2108 & TST & \\
\hline CHEMBL1494293 & 688620 & 5.75 & 5.4926 & TRN & \\
\hline CHEMBL1460435 & 688620 & 5.4 & 5.1849 & TST & \\
\hline CHEMBL1606735 & 688620 & 6.7001 & 5.6417 & TRN & \\
\hline CHEMBL1485510 & 688620 & 4.6 & 4.8656 & TST & \\
\hline CHEMBL1304465 & 688620 & 4.5 & 4.9252 & TST & \\
\hline
\end{tabular}




\begin{tabular}{|c|c|c|c|c|c|}
\hline \multicolumn{6}{|c|}{ Supplemental Table S2.txt } \\
\hline CHEMBL1575547 & 688620 & 5.05 & 5.4345 & TRN & \\
\hline CHEMBL3195622 & 688620 & 4.45 & 5.0824 & TRN & \\
\hline CHEMBL1535665 & 688620 & 5.65 & 5.3909 & TST & \\
\hline CHEMBL1507745 & 688620 & 5.55 & 4.8327 & TRN & \\
\hline CHEMBL3209179 & 688620 & 5.8 & 5.1729 & TST & \\
\hline CHEMBL1494431 & 688620 & 6.2 & 5.0095 & TRN & \\
\hline CHEMBL1412078 & 688620 & 4.4 & 5.2716 & TST & \\
\hline CHEMBL1965654 & 688620 & 6.6499 & 5.9845 & TRN & \\
\hline CHEMBL1459187 & 688620 & 4.75 & 4.9763 & TRN & \\
\hline CHEMBL1342909 & 688620 & 4.95 & 5.0986 & TRN & \\
\hline CHEMBL1372204 & 688620 & 6.8499 & 5.1764 & TRN & \\
\hline CHEMBL1332033 & 688620 & 4.45 & 4.8728 & TST & \\
\hline CHEMBL1545244 & 688620 & 5.15 & 5.3856 & TRN & \\
\hline CHEMBL1367717 & 688620 & 5.0 & 5.1405 & TRN & \\
\hline CHEMBL1479804 & 688620 & 6.5501 & 5.1277 & TRN & \\
\hline CHEMBL1308713 & 688620 & 4.45 & 5.09399 & 9999999999 & TRN \\
\hline CHEMBL1305448 & 688620 & 4.45 & 4.8693 & TST & \\
\hline CHEMBL1586809 & 688620 & 4.5 & 5.5188 & TRN & \\
\hline CHEMBL1983418 & 688620 & 5.9 & 6.03 & TRN & \\
\hline CHEMBL1300452 & 688620 & 5.1 & 5.067 & TRN & \\
\hline CHEMBL1338895 & 688620 & 4.65 & 4.7371 & TRN & \\
\hline CHEMBL1303590 & 688620 & 5.55 & 5.2961 & TRN & \\
\hline CHEMBL1510979 & 688620 & 4.65 & 4.6778 & TST & \\
\hline CHEMBL1377287 & 688620 & 4.65 & 5.0599 & TRN & \\
\hline CHEMBL1556387 & 688620 & 4.65 & 5.0616 & TRN & \\
\hline CHEMBL1486076 & 688620 & 4.75 & 4.9783 & TRN & \\
\hline CHEMBL1342952 & 688620 & 4.65 & 5.1498 & TRN & \\
\hline CHEMBL1583512 & 688620 & 5.1 & 5.16200 & 0000000001 & TRN \\
\hline CHEMBL1569063 & 688620 & 5.15 & 5.0529 & TRN & \\
\hline CHEMBL1502410 & 688620 & 5.25 & 5.0658 & TRN & \\
\hline CHEMBL1432360 & 688620 & 4.45 & 4.9112 & TST & \\
\hline CHEMBL1441315 & 688620 & 4.75 & 5.2098 & TRN & \\
\hline CHEMBL1533891 & 688620 & 4.85 & 4.6781 & TRN & \\
\hline CHEMBL1525865 & 688620 & 4.55 & 5.07 & TST & \\
\hline CHEMBL1452881 & 688620 & 4.95 & 4.7847 & TST & \\
\hline CHEMBL1337417 & 688620 & 4.7 & 5.0048 & TRN & \\
\hline CHEMBL1303385 & 688620 & 4.7 & 4.8084 & TRN & \\
\hline CHEMBL1313194 & 688620 & 4.45 & 4.9874 & TRN & \\
\hline CHEMBL1342130 & 688620 & 4.45 & 4.8675 & TST & \\
\hline CHEMBL1412298 & 688620 & 4.9 & 4.7131 & TST & \\
\hline CHEMBL1331681 & 688620 & 5.2 & 4.9249 & TRN & \\
\hline CHEMBL1454201 & 688620 & 4.75 & 4.9374 & TRN & \\
\hline CHEMBL1471871 & 688620 & 4.6 & 4.8205 & TRN & \\
\hline CHEMBL1348818 & 688620 & 4.7 & 5.226 & TST & \\
\hline CHEMBL1341318 & 688620 & 4.95 & 5.0062 & TRN & \\
\hline CHEMBL1480398 & 688620 & 4.45 & 4.7644 & TST & \\
\hline CHEMBL1548454 & 688620 & 4.95 & 4.9969 & TRN & \\
\hline CHEMBL1572827 & 688620 & 5.8 & 5.2113 & TST & \\
\hline
\end{tabular}




\begin{tabular}{|c|c|c|c|c|}
\hline & & & Supplement & al Table S \\
\hline CHEMBL1345173 & 688620 & 4.45 & 4.9265 & TST \\
\hline CHEMBL1368049 & 688620 & 5.1 & 4.9757 & TRN \\
\hline CHEMBL1519475 & 688620 & 4.95 & 5.1174 & TRN \\
\hline CHEMBL1338076 & 688620 & 4.65 & 4.8908 & TRN \\
\hline CHEMBL1498865 & 688620 & 4.65 & 5.0173 & TST \\
\hline CHEMBL1427324 & 688620 & 5.0 & 5.0132 & TRN \\
\hline CHEMBL1536639 & 688620 & 5.6 & 4.9259 & TRN \\
\hline CHEMBL1542525 & 688620 & 4.9 & 5.3077 & TST \\
\hline CHEMBL1539727 & 688620 & 5.2 & 5.1172 & TST \\
\hline CHEMBL1484314 & 688620 & 4.6 & 5.1594 & TST \\
\hline CHEMBL1489572 & 688620 & 6.35 & 6.0001 & TRN \\
\hline CHEMBL1613588 & 688620 & 4.75 & 5.2407 & TRN \\
\hline CHEMBL1606872 & 688620 & 5.3 & 5.2387 & TRN \\
\hline CHEMBL1588869 & 688620 & 4.95 & 4.6687 & TRN \\
\hline CHEMBL1493112 & 688620 & 4.95 & 4.992 & TRN \\
\hline CHEMBL1610967 & 688620 & 4.65 & 5.0851 & TRN \\
\hline CHEMBL3213665 & 688620 & 5.55 & 5.4645 & TRN \\
\hline CHEMBL1421726 & 688620 & 4.5 & 4.9281 & TRN \\
\hline CHEMBL1547813 & 688620 & 4.9 & 5.0271 & TRN \\
\hline CHEMBL1418940 & 688620 & 5.3 & 5.3894 & TRN \\
\hline CHEMBL1418279 & 688620 & 4.5 & 4.998 & TRN \\
\hline CHEMBL1589132 & 688620 & 4.45 & 5.0262 & TST \\
\hline CHEMBL1511752 & 688620 & 5.9 & 4.981 & TRN \\
\hline CHEMBL1369080 & 688620 & 4.7 & 4.9519 & TRN \\
\hline CHEMBL1405373 & 688620 & 4.95 & 5.3226 & TRN \\
\hline CHEMBL1315259 & 688620 & 4.9 & 5.2115 & TRN \\
\hline CHEMBL1594895 & 688620 & 5.05 & 5.1097 & TRN \\
\hline CHEMBL1471389 & 688620 & 4.95 & 4.9216 & TRN \\
\hline CHEMBL1482655 & 688620 & 4.45 & 4.9958 & TRN \\
\hline CHEMBL1426490 & 688620 & 4.45 & 4.9158 & TRN \\
\hline CHEMBL1352779 & 688620 & 4.8 & 4.8116 & TRN \\
\hline CHEMBL1376239 & 688620 & 5.4 & 5.1664 & TRN \\
\hline CHEMBL1404979 & 688620 & 5.5 & 4.9837 & TST \\
\hline CHEMBL1371353 & 688620 & 4.9 & 4.6914 & TRN \\
\hline CHEMBL1406909 & 688620 & 4.8 & 4.8366 & TRN \\
\hline CHEMBL1539518 & 688620 & 5.3 & 5.2118 & TRN \\
\hline CHEMBL1583622 & 688620 & 5.6 & 5.1169 & TRN \\
\hline CHEMBL1603103 & 688620 & 5.55 & 5.3649 & TRN \\
\hline CHEMBL1341259 & 688620 & 4.65 & 5.087 & TRN \\
\hline CHEMBL1302199 & 688620 & 4.9 & 5.7131 & TRN \\
\hline CHEMBL1574199 & 688620 & 5.2 & 5.0307 & TRN \\
\hline CHEMBL1348619 & 688620 & 5.15 & 5.034 & TRN \\
\hline CHEMBL3194866 & 688620 & 5.0 & 5.5492 & TRN \\
\hline CHEMBL1369171 & 688620 & 4.9 & 4.9323 & TST \\
\hline CHEMBL1501939 & 688620 & 4.7 & 5.0407 & TRN \\
\hline CHEMBL 3196581 & 688620 & 5.25 & 5.2549 & TRN \\
\hline CHEMBL1535354 & 688620 & 4.45 & 5.0349 & TST \\
\hline \multirow[t]{2}{*}{ CHEMBL1472243 } & 688620 & 4.9 & 4.88899 & 9999999999 \\
\hline & & & \multicolumn{2}{|c|}{ Page 26915} \\
\hline
\end{tabular}




\begin{tabular}{|c|c|c|c|c|c|}
\hline \multicolumn{6}{|c|}{ Supplemental Table S2.txt } \\
\hline CHEMBL1370673 & 688620 & 4.6 & 5.1207 & TRN & \\
\hline CHEMBL1560679 & 688620 & 4.9 & 5.3089 & TST & \\
\hline CHEMBL3197528 & 688620 & 4.9 & 4.9375 & TRN & \\
\hline CHEMBL1495525 & 688620 & 4.7 & 4.9362 & TST & \\
\hline CHEMBL 2006357 & 688620 & 4.95 & 5.0017 & TRN & \\
\hline CHEMBL1384827 & 688620 & 5.7 & 5.4251 & TRN & \\
\hline CHEMBL1336798 & 688620 & 5.65 & 5.0218 & TST & \\
\hline CHEMBL1353522 & 688620 & 5.3 & 5.193 & TST & \\
\hline CHEMBL1383915 & 688620 & 6.9 & 5.5958 & TRN & \\
\hline CHEMBL1456692 & 688620 & 4.95 & 4.8579 & TRN & \\
\hline CHEMBL1337250 & 688620 & 4.95 & 4.9259 & TRN & \\
\hline CHEMBL3191925 & 688620 & 6.4 & 5.5134 & TRN & \\
\hline CHEMBL1457959 & 688620 & 4.85 & 4.9755 & TRN & \\
\hline CHEMBL3191354 & 688620 & 4.9 & 4.9054 & TRN & \\
\hline CHEMBL1337384 & 688620 & 4.8 & 4.8822 & TRN & \\
\hline CHEMBL1422543 & 688620 & 4.95 & 5.1038 & TRN & \\
\hline CHEMBL1451175 & 688620 & 6.5 & 6.1795 & TRN & \\
\hline CHEMBL3198504 & 688620 & 4.45 & 4.9815 & TST & \\
\hline CHEMBL1585757 & 688620 & 4.95 & 5.0482 & TST & \\
\hline CHEMBL3195551 & 688620 & 5.25 & 5.4062 & TRN & \\
\hline CHEMBL1499752 & 688620 & 5.05 & 4.9029 & TRN & \\
\hline CHEMBL1336692 & 688620 & 4.85 & 4.923 & TRN & \\
\hline CHEMBL3214455 & 688620 & 5.05 & 5.7866 & TRN & \\
\hline CHEMBL1400924 & 688620 & 4.45 & 4.7031 & TRN & \\
\hline CHEMBL1483396 & 688620 & 4.9 & 4.9364 & TRN & \\
\hline CHEMBL3197719 & 688620 & 4.9 & 4.82600 & 00000000005 & TRN \\
\hline CHEMBL1368341 & 688620 & 4.6 & 4.9452 & TST & \\
\hline CHEMBL1494352 & 688620 & 4.95 & 5.1242 & TRN & \\
\hline CHEMBL3189911 & 688620 & 4.7 & 4.7569 & TRN & \\
\hline CHEMBL1438375 & 688620 & 5.2 & 5.0633 & TRN & \\
\hline CHEMBL1413243 & 688620 & 6.6499 & 6.676 & TST & \\
\hline CHEMBL1970032 & 688620 & 4.9 & 5.0089 & TRN & \\
\hline CHEMBL1342907 & 688620 & 5.15 & 5.0042 & TRN & \\
\hline CHEMBL1470599 & 688620 & 6.1 & 5.0579 & TRN & \\
\hline CHEMBL1497379 & 688620 & 5.5 & 5.0057 & TRN & \\
\hline CHEMBL1319828 & 688620 & 4.9 & 5.0799 & TRN & \\
\hline CHEMBL1403148 & 688620 & 4.8 & 4.8096 & TRN & \\
\hline CHEMBL1486871 & 688620 & 4.75 & 5.1014 & TRN & \\
\hline CHEMBL1308712 & 688620 & 4.65 & 4.8779 & TRN & \\
\hline CHEMBL3192175 & 688620 & 4.65 & 5.1324 & TRN & \\
\hline CHEMBL1490692 & 688620 & 4.95 & 5.3683 & TST & \\
\hline CHEMBL3199812 & 688620 & 4.45 & 4.7781 & TRN & \\
\hline CHEMBL 2003872 & 688620 & 5.4 & 5.6918 & TRN & \\
\hline CHEMBL1501408 & 688620 & 7.1002 & 4.919 & TST & \\
\hline CHEMBL1332999 & 688620 & 4.7 & 4.9702 & TRN & \\
\hline CHEMBL1968824 & 688620 & 4.45 & 4.9442 & TRN & \\
\hline CHEMBL1519948 & 688620 & 5.9 & 5.21 & TRN & \\
\hline CHEMBL1471601 & 688620 & 5.0 & 5.5124 & TST & \\
\hline
\end{tabular}




\begin{tabular}{|c|c|c|c|c|}
\hline \multicolumn{5}{|c|}{ Supplemental Table S2.txt } \\
\hline CHEMBL1471841 & 688620 & 4.75 & 4.9931 & TRN \\
\hline CHEMBL1413700 & 688620 & 6.0 & 5.0686 & TRN \\
\hline CHEMBL1378041 & 688620 & 5.75 & 5.2363 & TRN \\
\hline CHEMBL1321582 & 688620 & 5.4 & 5.0663 & TST \\
\hline CHEMBL1429488 & 688620 & 5.15 & 5.1822 & TST \\
\hline CHEMBL1546793 & 688620 & 4.65 & 4.695 & TRN \\
\hline CHEMBL1532949 & 688620 & 4.65 & 4.9708 & TRN \\
\hline CHEMBL1413220 & 688620 & 4.8 & 5.3081 & TRN \\
\hline CHEMBL1497504 & 688620 & 4.45 & 4.8223 & TST \\
\hline CHEMBL1340648 & 688620 & 4.45 & 4.7579 & TRN \\
\hline CHEMBL 3195123 & 688620 & 5.6 & 5.29200 & 0000000001 \\
\hline CHEMBL1535157 & 688620 & 4.5 & 4.8565 & TRN \\
\hline CHEMBL1322330 & 688620 & 5.25 & 5.2411 & TRN \\
\hline CHEMBL3209420 & 688620 & 4.95 & 4.8351 & TST \\
\hline CHEMBL1482949 & 688620 & 4.85 & 5.0956 & TRN \\
\hline CHEMBL1524454 & 688620 & 4.9 & 4.9484 & TRN \\
\hline CHEMBL527620 & 688620 & 4.65 & 4.8601 & TRN \\
\hline CHEMBL1470617 & 688620 & 5.15 & 5.2207 & TRN \\
\hline CHEMBL1340060 & 688620 & 5.85 & 5.7121 & TRN \\
\hline CHEMBL1507963 & 688620 & 6.6 & 5.0496 & TRN \\
\hline CHEMBL1577103 & 688620 & 4.45 & 4.6607 & TRN \\
\hline CHEMBL1505288 & 688620 & 4.75 & 4.9534 & TRN \\
\hline CHEMBL1495669 & 688620 & 4.75 & 4.8632 & TRN \\
\hline CHEMBL1310632 & 688620 & 5.85 & 5.9386 & TRN \\
\hline CHEMBL1542210 & 688620 & 4.85 & 5.2098 & TST \\
\hline CHEMBL1503629 & 688620 & 5.0 & 5.1023 & TRN \\
\hline CHEMBL1549231 & 688620 & 5.7 & 5.1184 & TRN \\
\hline CHEMBL1607404 & 688620 & 5.7 & 5.5502 & TRN \\
\hline CHEMBL1484968 & 688620 & 4.8 & 5.0914 & TRN \\
\hline CHEMBL1427464 & 688620 & 5.05 & 4.9306 & TRN \\
\hline CHEMBL1548873 & 688620 & 4.7 & 4.7129 & TRN \\
\hline CHEMBL1419932 & 688620 & 5.25 & 4.8752 & TST \\
\hline CHEMBL1980614 & 688620 & 4.45 & 5.1171 & TRN \\
\hline CHEMBL1602217 & 688620 & 5.1 & 4.8887 & TRN \\
\hline CHEMBL1390973 & 688620 & 4.45 & 4.7155 & TRN \\
\hline CHEMBL 253203 & 688620 & 4.5 & 4.9393 & TRN \\
\hline CHEMBL1526419 & 688620 & 5.75 & 5.4114 & TRN \\
\hline CHEMBL1353509 & 688620 & 4.8 & 4.855 & TRN \\
\hline CHEMBL3193310 & 688620 & 5.55 & 5.2909 & TRN \\
\hline CHEMBL1339003 & 688620 & 4.95 & 5.3093 & TRN \\
\hline CHEMBL1451599 & 688620 & 5.15 & 5.0251 & TRN \\
\hline CHEMBL1304617 & 688620 & 4.65 & 5.0618 & TST \\
\hline CHEMBL1392428 & 688620 & 6.5 & 5.0019 & TRN \\
\hline CHEMBL1487918 & 688620 & 4.95 & 5.1144 & TST \\
\hline CHEMBL1535017 & 688620 & 4.45 & 5.093 & TRN \\
\hline CHEMBL1559091 & 688620 & 4.5 & 4.9553 & TST \\
\hline CHEMBL1352789 & 688620 & 5.25 & 5.2442 & TRN \\
\hline CHEMBL 3190324 & 688620 & 4.5 & 5.0927 & TRN \\
\hline
\end{tabular}




\begin{tabular}{|c|c|c|c|c|}
\hline \multicolumn{5}{|c|}{ Supplemental Table S2.txt } \\
\hline CHEMBL1403917 & 688620 & 6.4 & 6.1148 & TRN \\
\hline CHEMBL3196918 & 688620 & 4.9 & 4.9348 & TST \\
\hline CHEMBL3208755 & 688620 & 4.8 & 4.8104 & TRN \\
\hline CHEMBL1373855 & 688620 & 4.5 & 5.1691 & TRN \\
\hline CHEMBL1444899 & 688620 & 4.45 & 5.0879 & TRN \\
\hline CHEMBL1578242 & 688620 & 4.95 & 5.4347 & TRN \\
\hline CHEMBL1478221 & 688620 & 4.45 & 5.0027 & TST \\
\hline CHEMBL3211776 & 688620 & 4.45 & 4.9095 & TRN \\
\hline CHEMBL1568735 & 688620 & 4.95 & 4.8282 & TRN \\
\hline CHEMBL1555573 & 688620 & 6.9 & 4.8883 & TRN \\
\hline CHEMBL1405135 & 688620 & 4.45 & 5.0383 & TST \\
\hline CHEMBL1424418 & 688620 & 5.45 & 5.2542 & TST \\
\hline CHEMBL1369290 & 688620 & 4.45 & 5.0141 & TST \\
\hline CHEMBL1450463 & 688620 & 4.5 & 4.9895 & TRN \\
\hline CHEMBL3209181 & 688620 & 5.45 & 5.3256 & TST \\
\hline CHEMBL1365471 & 688620 & 5.95 & 5.2038 & TRN \\
\hline CHEMBL1540133 & 688620 & 5.1 & 5.0161 & TST \\
\hline CHEMBL1383249 & 688620 & 4.45 & 4.8956 & TST \\
\hline CHEMBL1527584 & 688620 & 6.0 & 5.2955 & TRN \\
\hline CHEMBL603945 & 688620 & 4.7 & 4.8528 & TRN \\
\hline CHEMBL1500130 & 688620 & 4.95 & 5.0956 & TRN \\
\hline CHEMBL1582683 & 688620 & 5.85 & 5.2417 & TRN \\
\hline CHEMBL1519411 & 688620 & 4.6 & 4.8611 & TST \\
\hline CHEMBL1368190 & 688620 & 4.8 & 5.0889 & TST \\
\hline CHEMBL1303361 & 688620 & 4.9 & 4.5854 & TRN \\
\hline CHEMBL1522464 & 688620 & 5.55 & 5.0096 & TRN \\
\hline CHEMBL1429303 & 688620 & 4.65 & 5.3587 & TRN \\
\hline CHEMBL1421811 & 688620 & 6.15 & 5.3683 & TRN \\
\hline CHEMBL1544904 & 688620 & 4.75 & 4.9137 & TRN \\
\hline CHEMBL1305701 & 688620 & 5.2 & 5.3059 & TRN \\
\hline CHEMBL1370235 & 688620 & 5.35 & 5.091 & TRN \\
\hline CHEMBL1340167 & 688620 & 5.45 & 4.9895 & TRN \\
\hline CHEMBL1387436 & 688620 & 5.75 & 5.3243 & TRN \\
\hline CHEMBL1575402 & 688620 & 6.45 & 5.7589 & TRN \\
\hline CHEMBL1478412 & 688620 & 5.65 & 5.2835 & TRN \\
\hline CHEMBL1308127 & 688620 & 5.0 & 4.9451 & TRN \\
\hline CHEMBL1969912 & 688620 & 6.2 & 5.5951 & TST \\
\hline CHEMBL1498849 & 688620 & 4.9 & 5.0239 & TST \\
\hline CHEMBL1564643 & 688620 & 4.95 & 5.0264 & TRN \\
\hline CHEMBL1330226 & 688620 & 5.1 & 5.0546 & TST \\
\hline CHEMBL1547879 & 688620 & 5.2 & 4.9363 & TST \\
\hline CHEMBL1602085 & 688620 & 5.2 & 5.3171 & TRN \\
\hline CHEMBL1466507 & 688620 & 5.05 & 5.1946 & TST \\
\hline CHEMBL1425916 & 688620 & 4.8 & 5.0223 & TST \\
\hline CHEMBL1421591 & 688620 & 4.75 & 4.8768 & TST \\
\hline CHEMBL1421361 & 688620 & 4.45 & 5.1282 & TRN \\
\hline CHEMBL1304397 & 688620 & 5.2 & 5.0316 & TRN \\
\hline CHEMBL1585355 & 688620 & 4.55 & 4.8196 & TST \\
\hline
\end{tabular}




\begin{tabular}{|c|c|c|c|c|c|}
\hline \multicolumn{6}{|c|}{ Supplemental Table S2.txt } \\
\hline CHEMBL1307206 & 688620 & 5.1 & 4.6915 & TRN & \\
\hline CHEMBL1453970 & 688620 & 4.6 & 4.9774 & TST & \\
\hline CHEMBL1550086 & 688620 & 5.2 & 5.3241 & TRN & \\
\hline CHEMBL1400288 & 688620 & 4.8 & 5.0051 & TRN & \\
\hline CHEMBL1383168 & 688620 & 5.0 & 5.0909 & TRN & \\
\hline CHEMBL1439234 & 688620 & 4.45 & 5.1101 & TRN & \\
\hline CHEMBL1332236 & 688620 & 4.8 & 5.0869 & TST & \\
\hline CHEMBL1565866 & 688620 & 5.05 & 5.0928 & TRN & \\
\hline CHEMBL 3208894 & 688620 & 5.05 & 5.1492 & TRN & \\
\hline CHEMBL1516990 & 688620 & 4.45 & 4.7725 & TRN & \\
\hline CHEMBL1307361 & 688620 & 4.7 & 4.723 & TST & \\
\hline CHEMBL1555674 & 688620 & 4.85 & 5.234 & TRN & \\
\hline CHEMBL1599777 & 688620 & 4.45 & 4.9427 & TRN & \\
\hline CHEMBL3193907 & 688620 & 7.3497 & 6.5744 & TRN & \\
\hline CHEMBL1987579 & 688620 & 6.4 & 5.8701 & TRN & \\
\hline CHEMBL1487987 & 688620 & 4.45 & 4.90600 & 0000000001 & TRN \\
\hline CHEMBL1601570 & 688620 & 5.45 & 5.1302 & TRN & \\
\hline CHEMBL585221 & 688620 & 4.7 & 4.7875 & TST & \\
\hline CHEMBL1577606 & 688620 & 4.85 & 5.3879 & TRN & \\
\hline CHEMBL1365452 & 688620 & 4.45 & 5.0041 & TST & \\
\hline CHEMBL1504973 & 688620 & 5.5 & 5.4003 & TRN & \\
\hline CHEMBL1609858 & 688620 & 4.5 & 4.8799 & TRN & \\
\hline CHEMBL1305973 & 688620 & 6.0 & 5.6308 & TRN & \\
\hline CHEMBL1523018 & 688620 & 5.85 & 5.0633 & TST & \\
\hline CHEMBL1522262 & 688620 & 6.8499 & 5.8521 & TST & \\
\hline CHEMBL1464848 & 688620 & 4.45 & 5.104 & TST & \\
\hline CHEMBL3191773 & 688620 & 5.45 & 5.472 & TST & \\
\hline CHEMBL1996376 & 688620 & 4.45 & 5.2156 & TRN & \\
\hline CHEMBL1488229 & 688620 & 6.45 & 5.8637 & TRN & \\
\hline CHEMBL1559025 & 688620 & 5.4 & 5.0168 & TRN & \\
\hline CHEMBL1433252 & 688620 & 4.45 & 5.1713 & TRN & \\
\hline CHEMBL1354330 & 688620 & 4.55 & 4.8347 & TRN & \\
\hline CHEMBL1569162 & 688620 & 7.4498 & 5.218 & TRN & \\
\hline CHEMBL3193566 & 688620 & 4.7 & 5.1013 & TST & \\
\hline CHEMBL1301298 & 688620 & 4.65 & 5.23 & TRN & \\
\hline CHEMBL1517195 & 688620 & 5.7 & 4.9355 & TRN & \\
\hline CHEMBL1403955 & 688620 & 5.95 & 5.8021 & TRN & \\
\hline CHEMBL3211136 & 688620 & 5.15 & 5.026 & TRN & \\
\hline CHEMBL1601800 & 688620 & 5.6 & 5.0879 & TRN & \\
\hline CHEMBL1552019 & 688620 & 4.85 & 4.8988 & TST & \\
\hline CHEMBL1556955 & 688620 & 4.9 & 4.8332 & TRN & \\
\hline CHEMBL1596594 & 688620 & 4.55 & 5.0444 & TRN & \\
\hline CHEMBL1339546 & 688620 & 5.05 & 4.984 & TRN & \\
\hline CHEMBL1332156 & 688620 & 4.8 & 4.8476 & TRN & \\
\hline CHEMBL1587395 & 688620 & 5.25 & 5.0357 & TRN & \\
\hline CHEMBL145897 & 688620 & 6.05 & 5.6284 & TRN & \\
\hline CHEMBL1404731 & 688620 & 4.7 & 5.1204 & TRN & \\
\hline CHEMBL1458139 & 688620 & 5.45 & 4.9932 & TRN & \\
\hline
\end{tabular}




\begin{tabular}{|c|c|c|c|c|c|}
\hline \multirow[b]{2}{*}{ CHEMBL1412825 } & \multirow{2}{*}{688620} & \multicolumn{4}{|c|}{ Supplemental Table S2.t } \\
\hline & & 4.95 & 5.0213 & TST & \\
\hline CHEMBL1589029 & 688620 & 5.75 & 5.9321 & TRN & \\
\hline CHEMBL1584754 & 688620 & 5.1 & 4.8875 & TST & \\
\hline CHEMBL1542108 & 688620 & 4.9 & 5.0358 & TRN & \\
\hline CHEMBL1529506 & 688620 & 4.85 & 5.0356 & TRN & \\
\hline CHEMBL1462278 & 688620 & 4.45 & 5.0102 & TRN & \\
\hline CHEMBL1587281 & 688620 & 5.5 & 5.0207 & TRN & \\
\hline CHEMBL1457988 & 688620 & 4.65 & 4.9697 & TRN & \\
\hline CHEMBL1321371 & 688620 & 5.0 & 5.2083 & TRN & \\
\hline CHEMBL1388189 & 688620 & 4.65 & 5.1635 & TRN & \\
\hline CHEMBL1563677 & 688620 & 5.55 & 5.183 & TRN & \\
\hline CHEMBL1541186 & 688620 & 4.95 & 4.9499 & TST & \\
\hline CHEMBL1538596 & 688620 & 4.45 & 5.0708 & TST & \\
\hline CHEMBL1387470 & 688620 & 5.5 & 5.1913 & TRN & \\
\hline CHEMBL1508669 & 688620 & 4.9 & 4.9635 & TRN & \\
\hline CHEMBL1566153 & 688620 & 5.35 & 5.6536 & TRN & \\
\hline CHEMBL3196447 & 688620 & 4.9 & 4.7895 & TRN & \\
\hline CHEMBL1468790 & 688620 & 4.45 & 5.0563 & TST & \\
\hline CHEMBL1388967 & 688620 & 4.45 & 4.9697 & TRN & \\
\hline CHEMBL1491228 & 688620 & 5.55 & 5.2162 & TRN & \\
\hline CHEMBL1388496 & 688620 & 6.8499 & 5.2189 & TST & \\
\hline CHEMBL3208835 & 688620 & 5.65 & 5.1487 & TRN & \\
\hline CHEMBL1431765 & 688620 & 5.2 & 4.9777 & TRN & \\
\hline CHEMBL1556431 & 688620 & 4.45 & 4.5527 & TRN & \\
\hline CHEMBL1427378 & 688620 & 5.9 & 5.1727 & TST & \\
\hline CHEMBL1500823 & 688620 & 4.9 & 4.9561 & TRN & \\
\hline CHEMBL1561889 & 688620 & 4.65 & 4.9829 & TST & \\
\hline CHEMBL1448774 & 688620 & 4.75 & 5.0654 & TRN & \\
\hline CHEMBL1306638 & 688620 & 6.3 & 5.1997 & TRN & \\
\hline CHEMBL1340217 & 688620 & 5.1 & 5.1054 & TRN & \\
\hline CHEMBL1594282 & 688620 & 5.3 & 5.4479 & TRN & \\
\hline CHEMBL1532997 & 688620 & 5.65 & 5.44799 & 99999999995 & TST \\
\hline CHEMBL1423600 & 688620 & 5.85 & 5.1963 & TRN & \\
\hline CHEMBL 2005139 & 688620 & 4.95 & 5.09399 & 9999999999 & TST \\
\hline CHEMBL1384938 & 688620 & 5.8 & 4.9685 & TST & \\
\hline CHEMBL579224 & 688620 & 6.9 & 5.1978 & TST & \\
\hline CHEMBL1556527 & 688620 & 5.45 & 5.4416 & TRN & \\
\hline CHEMBL1439531 & 688620 & 5.15 & 5.4557 & TRN & \\
\hline CHEMBL1475995 & 688620 & 4.75 & 5.0509 & TRN & \\
\hline CHEMBL1322984 & 688620 & 4.75 & 4.9692 & TRN & \\
\hline CHEMBL3193542 & 688620 & 5.15 & 5.5164 & TRN & \\
\hline CHEMBL1518419 & 688620 & 4.9 & 5.0713 & TST & \\
\hline CHEMBL1975032 & 688620 & 4.45 & 5.0046 & TST & \\
\hline CHEMBL1564460 & 688620 & 4.8 & 4.9842 & TRN & \\
\hline CHEMBL3197761 & 688620 & 5.6 & 5.7599 & TRN & \\
\hline CHEMBL1544739 & 688620 & 4.45 & 4.9355 & TST & \\
\hline CHEMBL3198937 & 688620 & 4.95 & 4.9894 & TRN & \\
\hline CHEMBL1416655 & 688620 & 4.9 & 5.0843 & TRN & \\
\hline & & & $\mathrm{Pa}$ & 26920 & \\
\hline
\end{tabular}




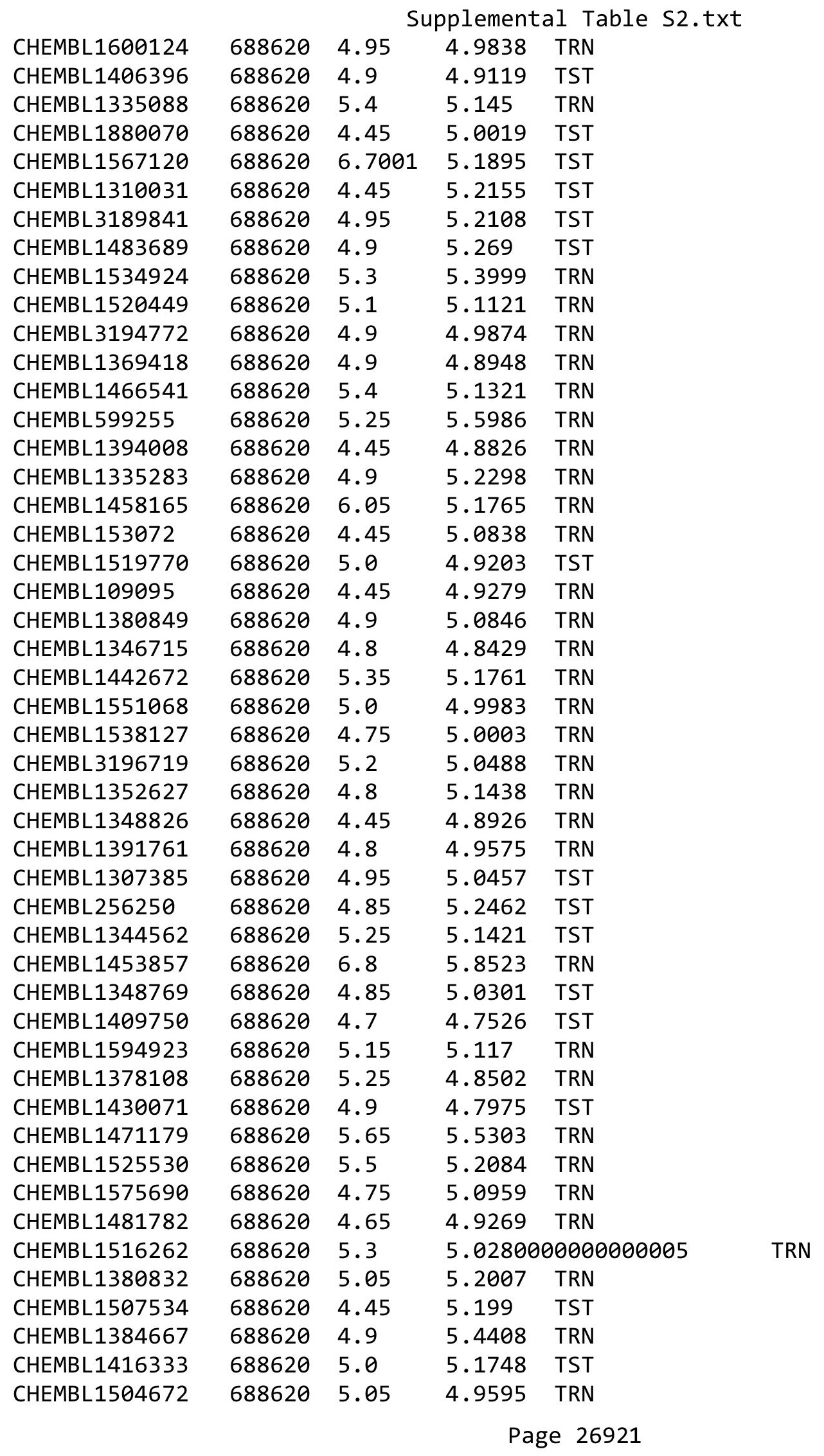




\begin{tabular}{|c|c|c|c|c|}
\hline \multicolumn{5}{|c|}{ Supplemental Table S2.txt } \\
\hline CHEMBL1386602 & 688620 & 7.0 & 5.0843 & TRN \\
\hline CHEMBL1585627 & 688620 & 4.95 & 4.8583 & TST \\
\hline CHEMBL1452547 & 688620 & 4.95 & 4.8577 & TRN \\
\hline CHEMBL1491402 & 688620 & 5.6 & 5.2824 & TRN \\
\hline CHEMBL1359554 & 688620 & 5.25 & 4.988 & TST \\
\hline CHEMBL2005284 & 688620 & 4.95 & 5.1481 & TRN \\
\hline CHEMBL1568922 & 688620 & 4.45 & 4.9172 & TRN \\
\hline CHEMBL1469481 & 688620 & 4.5 & 5.0326 & TST \\
\hline CHEMBL1422426 & 688620 & 4.85 & 4.6802 & TRN \\
\hline CHEMBL1535339 & 688620 & 5.7 & 5.3863 & TRN \\
\hline CHEMBL1505972 & 688620 & 4.45 & 5.0395 & TRN \\
\hline CHEMBL1521974 & 688620 & 6.25 & 5.2832 & TRN \\
\hline CHEMBL1338755 & 688620 & 5.3 & 5.1887 & TST \\
\hline CHEMBL1594997 & 688620 & 4.9 & 5.2565 & TST \\
\hline CHEMBL1595172 & 688620 & 4.75 & 4.9874 & TRN \\
\hline CHEMBL1384837 & 688620 & 4.95 & 5.1568 & TRN \\
\hline CHEMBL1557582 & 688620 & 7.0 & 5.4 & TRN \\
\hline CHEMBL1605892 & 688620 & 4.9 & 5.0882 & TRN \\
\hline CHEMBL1437965 & 688620 & 4.65 & 5.2057 & TRN \\
\hline CHEMBL1490351 & 688620 & 5.9 & 5.193 & TRN \\
\hline CHEMBL1390537 & 688620 & 8.301 & 5.1856 & TST \\
\hline CHEMBL1372465 & 688620 & 5.2 & 5.1924 & TRN \\
\hline CHEMBL1341806 & 688620 & 5.0 & 4.9996 & TRN \\
\hline CHEMBL1454425 & 688620 & 4.85 & 4.9366 & TRN \\
\hline CHEMBL1334613 & 688620 & 4.95 & 5.2597 & TRN \\
\hline CHEMBL1523688 & 688620 & 5.2 & 5.2036 & TRN \\
\hline CHEMBL1368670 & 688620 & 5.4 & 4.6683 & TRN \\
\hline CHEMBL1409254 & 688620 & 4.45 & 4.8037 & TRN \\
\hline CHEMBL1571897 & 688620 & 7.0501 & 4.843 & TRN \\
\hline CHEMBL1402615 & 688620 & 4.8 & 4.9064 & TRN \\
\hline CHEMBL9352 & 688620 & 6.0 & 5.1056 & TRN \\
\hline CHEMBL 3189464 & 688620 & 5.05 & 5.0348 & TRN \\
\hline CHEMBL1506112 & 688620 & 4.85 & 5.0269 & TST \\
\hline CHEMBL1388752 & 688620 & 5.0 & 5.1946 & TRN \\
\hline CHEMBL1511663 & 688620 & 4.9 & 4.6437 & TST \\
\hline CHEMBL1980204 & 688620 & 5.2 & 4.8296 & TRN \\
\hline CHEMBL1966023 & 688620 & 6.05 & 5.3567 & TRN \\
\hline CHEMBL1382296 & 688620 & 5.55 & 5.3745 & TRN \\
\hline CHEMBL1481543 & 688620 & 5.3 & 5.3727 & TRN \\
\hline CHEMBL1305222 & 688620 & 6.0 & 5.0808 & TST \\
\hline CHEMBL1344082 & 688620 & 4.7 & 5.131 & TRN \\
\hline CHEMBL1370701 & 688620 & 6.2 & 5.6495 & TRN \\
\hline CHEMBL1563851 & 688620 & 4.75 & 5.0185 & TRN \\
\hline CHEMBL1586927 & 688620 & 5.15 & 5.0932 & TRN \\
\hline CHEMBL1577178 & 688620 & 5.3 & 5.1866 & TRN \\
\hline CHEMBL1544407 & 688620 & 4.45 & 5.045 & TRN \\
\hline CHEMBL1483688 & 688620 & 5.0 & 4.9617 & TRN \\
\hline CHEMBL1309497 & 688620 & 6.35 & 5.0422 & TRN \\
\hline
\end{tabular}




\begin{tabular}{|c|c|c|c|c|c|}
\hline \multicolumn{6}{|c|}{ Supplemental Table s2.txt } \\
\hline CHEMBL1305918 & 688620 & 5.5 & 5.3878 & TRN & \\
\hline CHEMBL1511114 & 688620 & 4.95 & 5.0497 & TRN & \\
\hline CHEMBL1533768 & 688620 & 5.4 & 5.311 & TRN & \\
\hline CHEMBL1501913 & 688620 & 4.65 & 5.1641 & TRN & \\
\hline CHEMBL1384607 & 688620 & 5.25 & 5.09699 & 99999999995 & TRN \\
\hline CHEMBL1540845 & 688620 & 4.65 & 5.0364 & TRN & \\
\hline CHEMBL1538188 & 688620 & 4.85 & 4.8956 & TST & \\
\hline CHEMBL1342690 & 688620 & 4.8 & 4.9389 & TRN & \\
\hline CHEMBL1582112 & 688620 & 4.9 & 4.7361 & TRN & \\
\hline CHEMBL1340169 & 688620 & 4.6 & 4.9601 & TRN & \\
\hline CHEMBL1548757 & 688620 & 4.85 & 4.997 & TST & \\
\hline CHEMBL1375027 & 688620 & 5.75 & 6.1117 & TRN & \\
\hline CHEMBL3195968 & 688620 & 5.0 & 5.1667 & TRN & \\
\hline CHEMBL 3198277 & 688620 & 4.95 & 4.7432 & TRN & \\
\hline CHEMBL1407288 & 688620 & 4.75 & 4.8658 & TRN & \\
\hline CHEMBL1478629 & 688620 & 5.0 & 5.1089 & TRN & \\
\hline CHEMBL1565942 & 688620 & 5.5 & 5.0128 & TRN & \\
\hline CHEMBL251815 & 688620 & 4.85 & 4.9197 & TRN & \\
\hline CHEMBL1332390 & 688620 & 4.45 & 4.8592 & TST & \\
\hline CHEMBL1377857 & 688620 & 4.95 & 5.0269 & TRN & \\
\hline CHEMBL1375584 & 688620 & 5.6 & 4.8994 & TRN & \\
\hline CHEMBL1384770 & 688620 & 4.5 & 4.8039 & TRN & \\
\hline CHEMBL1425450 & 688620 & 4.55 & 5.0469 & TRN & \\
\hline CHEMBL1505209 & 688620 & 4.95 & 5.0025 & TRN & \\
\hline CHEMBL1458396 & 688620 & 4.65 & 4.9952 & TRN & \\
\hline CHEMBL1459240 & 688620 & 5.15 & 5.0411 & TST & \\
\hline CHEMBL1328395 & 688620 & 5.0 & 5.319 & TRN & \\
\hline CHEMBL233894 & 688620 & 5.05 & 5.0069 & TRN & \\
\hline CHEMBL3196422 & 688620 & 7.0 & 5.2113 & TST & \\
\hline CHEMBL1474479 & 688620 & 6.25 & 5.5738 & TRN & \\
\hline CHEMBL602575 & 688620 & 6.6 & 5.7121 & TST & \\
\hline CHEMBL 3210154 & 688620 & 5.9 & 5.7584 & TRN & \\
\hline CHEMBL1550892 & 688620 & 4.75 & 4.9931 & TRN & \\
\hline CHEMBL1470019 & 688620 & 5.3 & 5.1733 & TRN & \\
\hline CHEMBL1385773 & 688620 & 4.95 & 5.1382 & TST & \\
\hline CHEMBL1486922 & 688620 & 4.8 & 5.3807 & TRN & \\
\hline CHEMBL1368578 & 688620 & 4.9 & 5.037 & TRN & \\
\hline CHEMBL1890591 & 688620 & 4.75 & 5.093 & TRN & \\
\hline CHEMBL1371394 & 688620 & 4.85 & 5.0092 & TST & \\
\hline CHEMBL1324739 & 688620 & 4.95 & 5.1413 & TRN & \\
\hline CHEMBL1508384 & 688620 & 4.95 & 5.3815 & TST & \\
\hline CHEMBL1998940 & 688620 & 5.5 & 5.0598 & TRN & \\
\hline CHEMBL1325155 & 688620 & 4.45 & 5.0571 & TST & \\
\hline CHEMBL1463543 & 688620 & 5.1 & 4.9742 & TRN & \\
\hline CHEMBL1327777 & 688620 & 4.45 & 5.0822 & TST & \\
\hline CHEMBL1309163 & 688620 & 5.05 & 4.9981 & TRN & \\
\hline CHEMBL1333339 & 688620 & 4.95 & 5.2672 & TRN & \\
\hline CHEMBL1402415 & 688620 & 4.75 & 4.9342 & TRN & \\
\hline
\end{tabular}




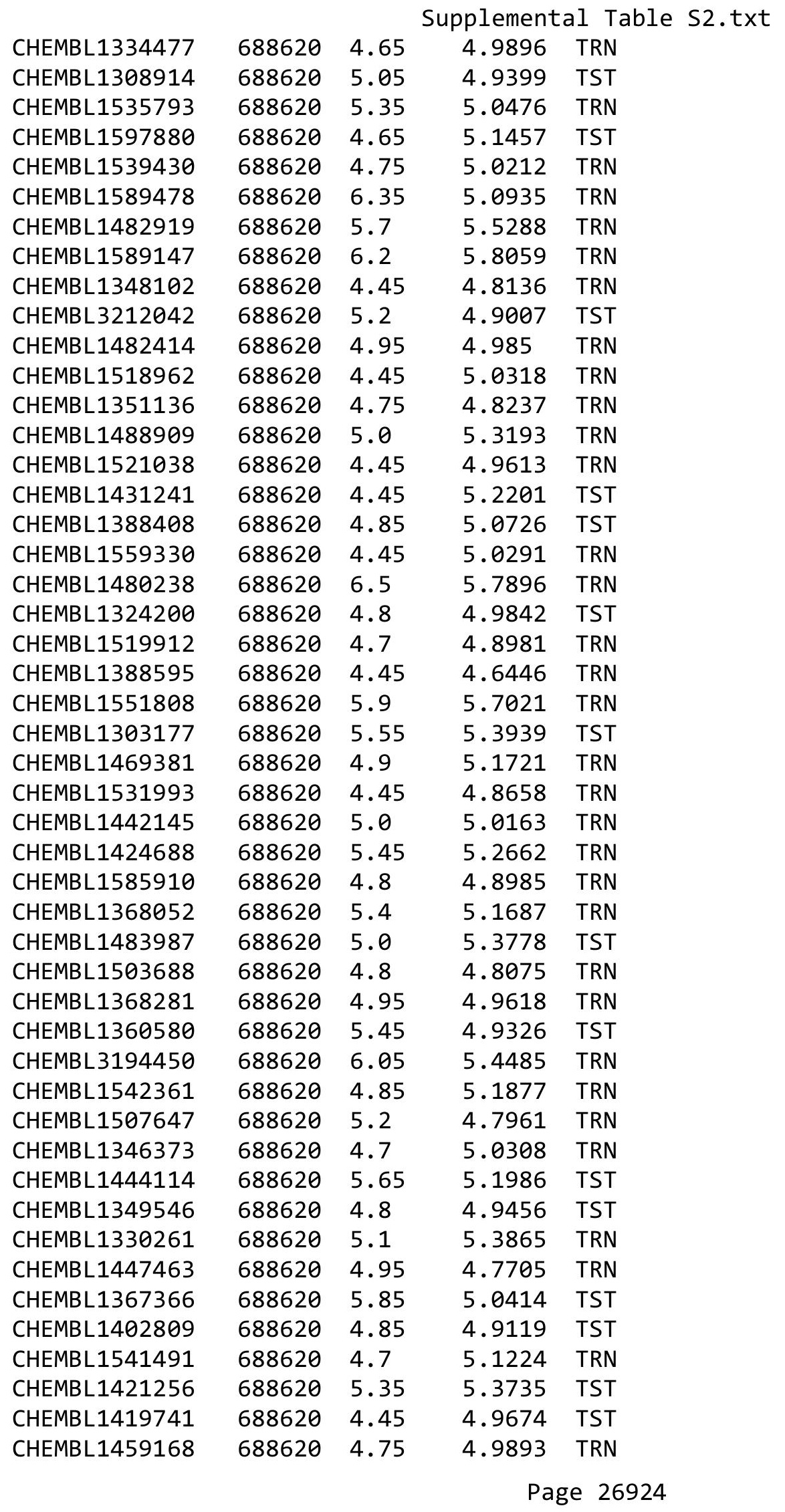




\begin{tabular}{|c|c|c|c|c|}
\hline \multicolumn{5}{|c|}{ Supplemental Table S2.txt } \\
\hline CHEMBL1422992 & 688620 & 4.9 & 4.9294 & TRN \\
\hline CHEMBL1378561 & 688620 & 5.2 & 4.9585 & TRN \\
\hline CHEMBL3214155 & 688620 & 4.85 & 4.6405 & TRN \\
\hline CHEMBL1323165 & 688620 & 4.6 & 5.0588 & TRN \\
\hline CHEMBL253204 & 688620 & 4.45 & 4.9308 & TRN \\
\hline CHEMBL1375965 & 688620 & 4.85 & 4.7451 & TRN \\
\hline CHEMBL1443383 & 688620 & 5.55 & 5.2973 & TRN \\
\hline CHEMBL1489287 & 688620 & 4.45 & 5.2318 & TRN \\
\hline CHEMBL1426693 & 688620 & 5.15 & 5.0251 & TRN \\
\hline CHEMBL1421408 & 688620 & 4.5 & 5.0067 & TRN \\
\hline CHEMBL 3192050 & 688620 & 5.0 & 5.0319 & TRN \\
\hline CHEMBL1567308 & 688620 & 6.25 & 5.7454 & TRN \\
\hline CHEMBL1441851 & 688620 & 5.5 & 5.1056 & TST \\
\hline CHEMBL1382316 & 688620 & 4.75 & 5.0526 & TST \\
\hline CHEMBL1370623 & 688620 & 6.5 & 5.5229 & TRN \\
\hline CHEMBL1556970 & 688620 & 6.5 & 5.0965 & TRN \\
\hline CHEMBL1368794 & 688620 & 6.3 & 6.1569 & TRN \\
\hline CHEMBL1545295 & 688620 & 6.9 & 5.2739 & TRN \\
\hline CHEMBL1549886 & 688620 & 4.8 & 5.1927 & TRN \\
\hline CHEMBL1377852 & 688620 & 4.45 & 4.7649 & TRN \\
\hline CHEMBL1444124 & 688620 & 5.3 & 5.2912 & TST \\
\hline CHEMBL1423009 & 688620 & 4.95 & 4.872 & TRN \\
\hline CHEMBL1551270 & 688620 & 4.6 & 4.9121 & TRN \\
\hline CHEMBL3192815 & 688620 & 5.0 & 4.8196 & TRN \\
\hline CHEMBL3209500 & 688620 & 4.7 & 5.041 & TRN \\
\hline CHEMBL1504097 & 688620 & 5.9 & 5.5872 & TRN \\
\hline CHEMBL1568385 & 688620 & 4.5 & 5.0973 & TST \\
\hline CHEMBL1499127 & 688620 & 5.55 & 5.1455 & TRN \\
\hline CHEMBL1992283 & 688620 & 4.45 & 4.8647 & TST \\
\hline CHEMBL1465093 & 688620 & 5.5 & 5.0628 & TRN \\
\hline CHEMBL1532061 & 688620 & 4.95 & 5.1531 & TRN \\
\hline CHEMBL1455325 & 688620 & 4.6 & 4.9786 & TRN \\
\hline CHEMBL90846 & 688620 & 5.0 & 5.0019 & TRN \\
\hline CHEMBL1602549 & 688620 & 4.9 & 5.0541 & TST \\
\hline CHEMBL1329513 & 688620 & 4.95 & 4.8545 & TST \\
\hline CHEMBL1545960 & 688620 & 4.95 & 5.1653 & TRN \\
\hline CHEMBL1415153 & 688620 & 4.75 & 4.7923 & TRN \\
\hline CHEMBL1373061 & 688620 & 5.95 & 5.19 & TRN \\
\hline CHEMBL504977 & 688620 & 7.7496 & 6.096 & TRN \\
\hline CHEMBL1469709 & 688620 & 4.65 & 4.8899 & TRN \\
\hline CHEMBL1482457 & 688620 & 4.45 & 4.845 & TRN \\
\hline CHEMBL1529254 & 688620 & 5.05 & 5.1286 & TRN \\
\hline CHEMBL1546458 & 688620 & 5.0 & 4.8766 & TRN \\
\hline CHEMBL1509939 & 688620 & 4.9 & 5.0869 & TST \\
\hline CHEMBL1504019 & 688620 & 4.75 & 4.8433 & TRN \\
\hline CHEMBL3191683 & 688620 & 6.2 & 4.9868 & TRN \\
\hline CHEMBL1584454 & 688620 & 4.45 & 4.9075 & TRN \\
\hline CHEMBL1457121 & 688620 & 4.95 & 5.3565 & TST \\
\hline
\end{tabular}




\begin{tabular}{|c|c|c|c|c|}
\hline & & & pplement & al $\mathrm{Ta}$ \\
\hline CHEMBL1451449 & 688620 & 5.2 & 5.1208 & TRN \\
\hline CHEMBL1360390 & 688620 & 4.45 & 4.9256 & TRN \\
\hline CHEMBL1568189 & 688620 & 5.45 & 4.8516 & TRN \\
\hline CHEMBL1366838 & 688620 & 4.9 & 5.0835 & TST \\
\hline CHEMBL1537867 & 688620 & 4.45 & 4.9325 & TRN \\
\hline CHEMBL1491996 & 688620 & 4.85 & 4.9888 & TST \\
\hline CHEMBL1572527 & 688620 & 5.8 & 5.1707 & TST \\
\hline CHEMBL1463898 & 688620 & 4.6 & 4.9432 & TRN \\
\hline CHEMBL1547785 & 688620 & 6.0 & 4.8992 & TRN \\
\hline CHEMBL1486197 & 688620 & 4.65 & 5.0899 & TRN \\
\hline CHEMBL 1400778 & 688620 & 4.45 & 4.9168 & TST \\
\hline CHEMBL1510375 & 688620 & 4.6 & 5.1663 & TRN \\
\hline CHEMBL1443622 & 688620 & 5.05 & 4.9298 & TRN \\
\hline CHEMBL1328750 & 688620 & 5.05 & 4.9845 & TRN \\
\hline CHEMBL3199303 & 688620 & 4.65 & 4.7295 & TRN \\
\hline CHEMBL1369090 & 688620 & 5.5 & 4.9328 & TRN \\
\hline CHEMBL565862 & 688620 & 4.65 & 5.129 & TRN \\
\hline CHEMBL1535113 & 688620 & 4.65 & 4.8971 & TRN \\
\hline CHEMBL1304058 & 688620 & 5.15 & 5.0601 & TST \\
\hline CHEMBL1400061 & 688620 & 4.75 & 5.1782 & TST \\
\hline CHEMBL1366268 & 688620 & 4.45 & 4.7818 & TST \\
\hline CHEMBL 2000420 & 688620 & 6.45 & 6.3217 & TRN \\
\hline CHEMBL1482325 & 688620 & 4.5 & 5.0194 & TRN \\
\hline CHEMBL1556189 & 688620 & 5.05 & 5.1023 & TRN \\
\hline CHEMBL1363130 & 688620 & 4.45 & 5.0545 & TRN \\
\hline CHEMBL1390333 & 688620 & 5.6 & 4.8624 & TRN \\
\hline CHEMBL1528414 & 688620 & 4.95 & 5.1753 & TRN \\
\hline CHEMBL1505663 & 688620 & 4.45 & 4.7369 & TRN \\
\hline CHEMBL1311730 & 688620 & 4.95 & 5.3039 & TRN \\
\hline CHEMBL1606719 & 688620 & 5.85 & 5.1045 & TRN \\
\hline CHEMBL1602694 & 688620 & 6.95 & 5.2017 & TRN \\
\hline CHEMBL1305599 & 688620 & 4.75 & 5.0309 & TRN \\
\hline CHEMBL1299288 & 688620 & 5.5 & 5.4694 & TST \\
\hline CHEMBL1345096 & 688620 & 4.45 & 4.9709 & TRN \\
\hline CHEMBL 3198224 & 688620 & 5.05 & 5.2071 & TRN \\
\hline CHEMBL1498114 & 688620 & 4.95 & 4.7848 & TRN \\
\hline CHEMBL1608089 & 688620 & 4.85 & 4.88 & TRN \\
\hline CHEMBL1425768 & 688620 & 4.6 & 5.0241 & TRN \\
\hline CHEMBL1505070 & 688620 & 4.45 & 5.1168 & TRN \\
\hline CHEMBL1344838 & 688620 & 4.45 & 4.9354 & TRN \\
\hline CHEMBL1422730 & 688620 & 4.45 & 5.0252 & TRN \\
\hline CHEMBL1463769 & 688620 & 4.9 & 4.9506 & TRN \\
\hline CHEMBL1379820 & 688620 & 4.85 & 5.2077 & TRN \\
\hline CHEMBL1569188 & 688620 & 5.75 & 5.2099 & TRN \\
\hline CHEMBL3196994 & 688620 & 4.95 & 4.7834 & TRN \\
\hline CHEMBL1325381 & 688620 & 5.05 & 5.3261 & TRN \\
\hline CHEMBL1302703 & 688620 & 4.45 & 5.0849 & TRN \\
\hline CHEMBL1546467 & 688620 & 4.65 & 5.0615 & TRN \\
\hline
\end{tabular}




\begin{tabular}{|c|c|c|c|c|}
\hline \multicolumn{5}{|c|}{ Supplemental Table S2.txt } \\
\hline CHEMBL1485053 & 688620 & 6.4 & 6.3591 & TRN \\
\hline CHEMBL1538929 & 688620 & 4.95 & 5.2088 & TRN \\
\hline CHEMBL1449364 & 688620 & 8.301 & 4.931 & TST \\
\hline CHEMBL1501276 & 688620 & 6.05 & 5.20200 & 0000000001 \\
\hline CHEMBL1503314 & 688620 & 5.2 & 4.9233 & TRN \\
\hline CHEMBL1379513 & 688620 & 4.55 & 4.9818 & TRN \\
\hline CHEMBL1510926 & 688620 & 5.05 & 4.863 & TRN \\
\hline CHEMBL1597102 & 688620 & 4.95 & 5.3223 & TST \\
\hline CHEMBL1442653 & 688620 & 4.75 & 4.9212 & TRN \\
\hline CHEMBL1088657 & 688620 & 4.65 & 5.1668 & TRN \\
\hline CHEMBL1461640 & 688620 & 6.45 & 5.0413 & TST \\
\hline CHEMBL1540921 & 688620 & 4.85 & 4.9882 & TRN \\
\hline CHEMBL1574055 & 688620 & 6.0 & 5.0785 & TRN \\
\hline CHEMBL1329376 & 688620 & 4.45 & 5.025 & TRN \\
\hline CHEMBL1457791 & 688620 & 4.95 & 4.8311 & TRN \\
\hline CHEMBL1388310 & 688620 & 5.1 & 5.1308 & TST \\
\hline CHEMBL1561504 & 688620 & 4.95 & 5.0004 & TRN \\
\hline CHEMBL1354019 & 688620 & 4.45 & 4.7148 & TRN \\
\hline CHEMBL3191039 & 688620 & 4.9 & 5.2727 & TRN \\
\hline CHEMBL1551025 & 688620 & 4.75 & 4.9322 & TST \\
\hline CHEMBL1324991 & 688620 & 4.95 & 5.3278 & TST \\
\hline CHEMBL 1455396 & 688620 & 4.65 & 5.0528 & TST \\
\hline CHEMBL3194636 & 688620 & 4.65 & 4.7297 & TRN \\
\hline CHEMBL1403350 & 688620 & 5.2 & 5.2475 & TRN \\
\hline CHEMBL1991751 & 688620 & 4.75 & 4.9859 & TRN \\
\hline CHEMBL1383622 & 688620 & 4.95 & 4.8169 & TST \\
\hline CHEMBL3194303 & 688620 & 6.4 & 5.5399 & TRN \\
\hline CHEMBL3196737 & 688620 & 5.95 & 5.6578 & TRN \\
\hline CHEMBL 3214216 & 688620 & 6.6 & 5.2308 & TRN \\
\hline CHEMBL1505437 & 688620 & 4.95 & 5.4282 & TST \\
\hline CHEMBL1992858 & 688620 & 4.85 & 5.0837 & TRN \\
\hline CHEMBL3196646 & 688620 & 4.65 & 5.1761 & TST \\
\hline CHEMBL1506134 & 688620 & 4.75 & 4.9973 & TRN \\
\hline CHEMBL1375069 & 688620 & 4.5 & 5.1845 & TRN \\
\hline CHEMBL1376656 & 688620 & 4.45 & 5.0338 & TRN \\
\hline CHEMBL1350581 & 688620 & 4.45 & 4.7594 & TRN \\
\hline CHEMBL 1457644 & 688620 & 5.9 & 5.9054 & TRN \\
\hline CHEMBL1595029 & 688620 & 4.75 & 5.1241 & TRN \\
\hline CHEMBL3197242 & 688620 & 5.4 & 4.9996 & TRN \\
\hline CHEMBL1460324 & 688620 & 4.9 & 4.8779 & TRN \\
\hline CHEMBL1462732 & 688620 & 4.45 & 4.8958 & TRN \\
\hline CHEMBL1360735 & 688620 & 4.45 & 5.0235 & TRN \\
\hline CHEMBL1541803 & 688620 & 6.8499 & 5.0355 & TRN \\
\hline CHEMBL1347607 & 688620 & 5.1 & 5.5564 & TRN \\
\hline CHEMBL1363849 & 688620 & 5.0 & 5.0811 & TST \\
\hline CHEMBL1486226 & 688620 & 5.35 & 5.2842 & TRN \\
\hline CHEMBL1355503 & 688620 & 5.8 & 4.9031 & TST \\
\hline CHEMBL1446279 & 688620 & 4.45 & 4.9555 & TST \\
\hline
\end{tabular}




\begin{tabular}{|c|c|c|c|c|}
\hline \multicolumn{5}{|c|}{ Supplemental Table S2.txt } \\
\hline CHEMBL1420492 & 688620 & 5.8 & 5.1714 & TRN \\
\hline CHEMBL1407504 & 688620 & 4.7 & 5.0714 & TRN \\
\hline CHEMBL3196772 & 688620 & 6.05 & 6.0455 & TRN \\
\hline CHEMBL1366683 & 688620 & 4.9 & 4.9049 & TRN \\
\hline CHEMBL1567765 & 688620 & 4.95 & 5.0427 & TRN \\
\hline CHEMBL1321137 & 688620 & 5.35 & 5.3311 & TRN \\
\hline CHEMBL1548232 & 688620 & 5.25 & 4.8301 & TRN \\
\hline CHEMBL1382570 & 688620 & 5.5 & 4.8962 & TRN \\
\hline CHEMBL1509488 & 688620 & 4.45 & 5.1211 & TRN \\
\hline CHEMBL1425679 & 688620 & 4.45 & 4.7786 & TRN \\
\hline CHEMBL1487901 & 688620 & 5.35 & 5.4312 & TRN \\
\hline CHEMBL1574524 & 688620 & 5.0 & 4.9196 & TRN \\
\hline CHEMBL1521090 & 688620 & 5.0 & 5.0703 & TRN \\
\hline CHEMBL1421750 & 688620 & 4.9 & 4.9823 & TRN \\
\hline CHEMBL1989852 & 688620 & 4.65 & 4.9503 & TRN \\
\hline CHEMBL1359057 & 688620 & 4.7 & 5.1033 & TST \\
\hline CHEMBL1360881 & 688620 & 4.45 & 4.7806 & TRN \\
\hline CHEMBL1377258 & 688620 & 4.8 & 5.0906 & TRN \\
\hline CHEMBL1392608 & 688620 & 4.95 & 4.7506 & TRN \\
\hline CHEMBL1597446 & 688620 & 5.65 & 5.5384 & TRN \\
\hline CHEMBL1566928 & 688620 & 4.45 & 5.4255 & TST \\
\hline CHEMBL1534083 & 688620 & 4.9 & 4.996 & TST \\
\hline CHEMBL1498894 & 688620 & 4.9 & 5.1179 & TRN \\
\hline CHEMBL1369417 & 688620 & 5.5 & 5.3769 & TRN \\
\hline CHEMBL3191432 & 688620 & 5.35 & 5.1647 & TRN \\
\hline CHEMBL1429502 & 688620 & 5.0 & 5.2584 & TRN \\
\hline CHEMBL1341168 & 688620 & 4.65 & 5.2037 & TST \\
\hline CHEMBL1416018 & 688620 & 4.65 & 4.9229 & TST \\
\hline CHEMBL1420340 & 688620 & 4.75 & 4.7127 & TRN \\
\hline CHEMBL1550081 & 688620 & 5.25 & 5.1018 & TST \\
\hline CHEMBL1385480 & 688620 & 5.15 & 5.3949 & TRN \\
\hline CHEMBL1305863 & 688620 & 4.9 & 5.1072 & TRN \\
\hline CHEMBL1498292 & 688620 & 4.95 & 5.1175 & TRN \\
\hline CHEMBL1450855 & 688620 & 4.6 & 4.7718 & TRN \\
\hline CHEMBL1602756 & 688620 & 4.45 & 4.8483 & TRN \\
\hline CHEMBL1485892 & 688620 & 6.5501 & 5.4467 & TRN \\
\hline CHEMBL3196624 & 688620 & 6.05 & 5.8808 & TST \\
\hline CHEMBL1524515 & 688620 & 5.7 & 5.1869 & TRN \\
\hline CHEMBL 2006740 & 688620 & 5.7 & 5.5486 & TRN \\
\hline CHEMBL1558555 & 688620 & 5.2 & 4.8945 & TRN \\
\hline CHEMBL1573368 & 688620 & 5.15 & 5.4482 & TRN \\
\hline CHEMBL1500327 & 688620 & 5.25 & 5.0346 & TRN \\
\hline CHEMBL1372203 & 688620 & 5.6 & 5.9997 & TRN \\
\hline CHEMBL1452315 & 688620 & 4.9 & 4.7623 & TST \\
\hline CHEMBL1449478 & 688620 & 5.6 & 5.2004 & TRN \\
\hline CHEMBL1495066 & 688620 & 5.1 & 4.8325 & TST \\
\hline CHEMBL1410578 & 688620 & 4.8 & 5.1429 & TRN \\
\hline CHEMBL3190174 & 688620 & 4.9 & 4.9163 & TRN \\
\hline
\end{tabular}




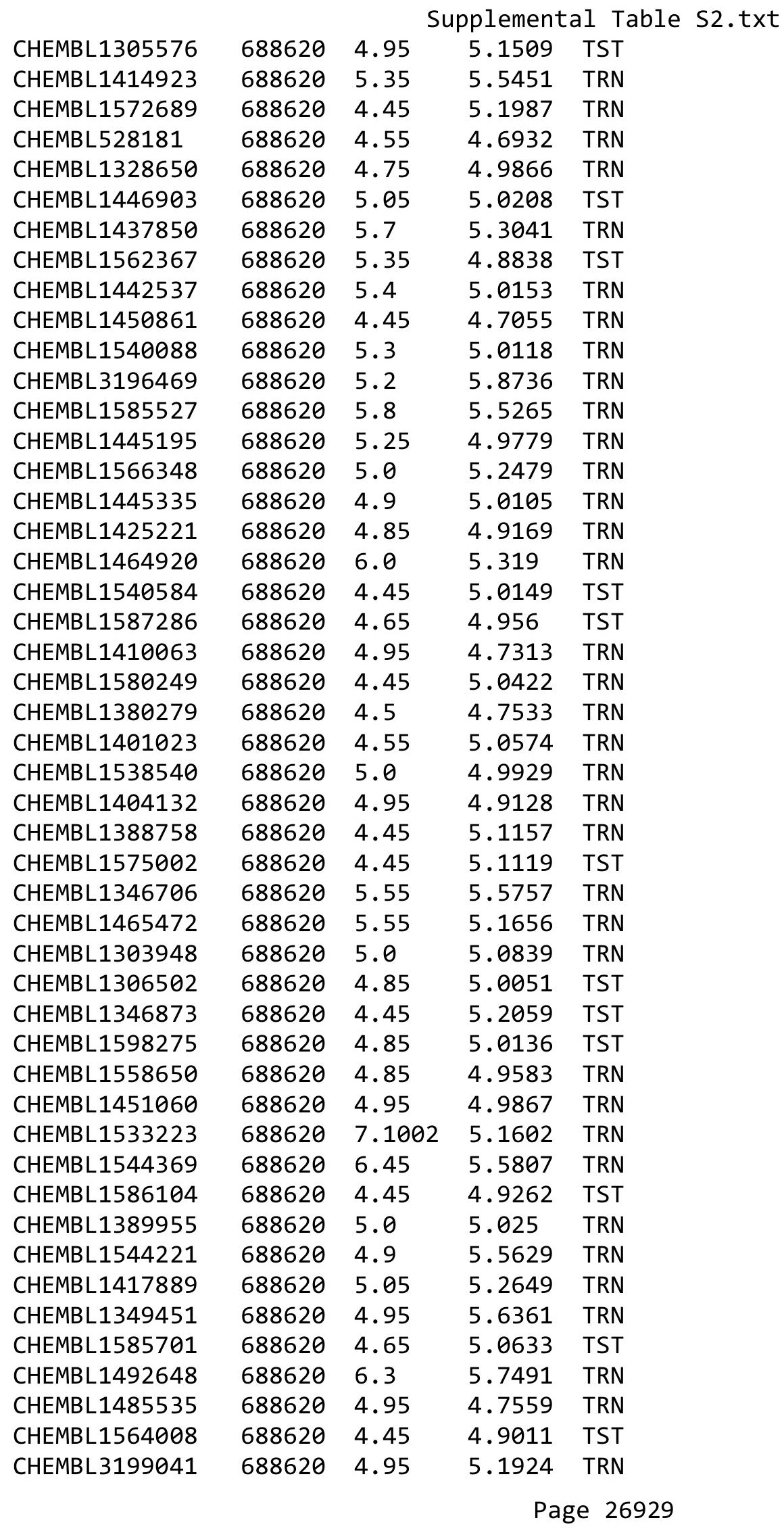




\begin{tabular}{|c|c|c|c|c|c|}
\hline \multicolumn{6}{|c|}{ Supplemental Table s2.txt } \\
\hline CHEMBL1341913 & 688620 & 6.0 & 4.9988 & TRN & \\
\hline CHEMBL1508635 & 688620 & 4.95 & 4.869 & TRN & \\
\hline CHEMBL1601908 & 688620 & 5.05 & 4.9016 & TRN & \\
\hline CHEMBL1450943 & 688620 & 4.95 & 5.954 & TRN & \\
\hline CHEMBL1368463 & 688620 & 4.95 & 5.1321 & TRN & \\
\hline CHEMBL1323633 & 688620 & 6.45 & 5.1247 & TRN & \\
\hline CHEMBL1546535 & 688620 & 4.95 & 5.2929 & TRN & \\
\hline CHEMBL3199502 & 688620 & 7.4498 & 5.0071 & TRN & \\
\hline CHEMBL1407293 & 688620 & 6.6499 & 4.9973 & TST & \\
\hline CHEMBL1588309 & 688620 & 4.8 & 5.0045 & TRN & \\
\hline CHEMBL1497036 & 688620 & 4.45 & 5.0101 & TRN & \\
\hline CHEMBL1463211 & 688620 & 6.5 & 6.1188 & TRN & \\
\hline CHEMBL1566586 & 688620 & 4.7 & 5.0092 & TST & \\
\hline CHEMBL1549145 & 688620 & 4.5 & 4.9764 & TRN & \\
\hline CHEMBL1596660 & 688620 & 4.75 & 4.9102 & TRN & \\
\hline CHEMBL1971875 & 688620 & 5.9 & 5.5018 & TRN & \\
\hline CHEMBL1379416 & 688620 & 5.35 & 5.4625 & TRN & \\
\hline CHEMBL1498263 & 688620 & 5.35 & 5.0346 & TRN & \\
\hline CHEMBL1561874 & 688620 & 5.05 & 4.8818 & TRN & \\
\hline CHEMBL1604853 & 688620 & 4.7 & 5.0712 & TRN & \\
\hline CHEMBL1391810 & 688620 & 5.95 & 5.4041 & TRN & \\
\hline CHEMBL1444299 & 688620 & 7.5003 & 4.9349 & TRN & \\
\hline CHEMBL1311810 & 688620 & 4.45 & 5.3802 & TRN & \\
\hline CHEMBL1451769 & 688620 & 5.05 & 5.2451 & TRN & \\
\hline CHEMBL1549103 & 688620 & 5.3 & 5.256 & TRN & \\
\hline CHEMBL1502961 & 688620 & 4.85 & 4.97199 & 99999999995 & TRN \\
\hline CHEMBL1532619 & 688620 & 4.75 & 5.0781 & TST & \\
\hline CHEMBL1329471 & 688620 & 5.5 & 5.2191 & TRN & \\
\hline CHEMBL1992883 & 688620 & 6.3 & 5.1442 & TRN & \\
\hline CHEMBL1313487 & 688620 & 4.65 & 4.8306 & TST & \\
\hline CHEMBL1432327 & 688620 & 5.3 & 5.2182 & TST & \\
\hline CHEMBL1411921 & 688620 & 6.9 & 4.7624 & TRN & \\
\hline CHEMBL1349526 & 688620 & 6.2 & 5.03 & TST & \\
\hline CHEMBL1381206 & 688620 & 5.45 & 4.8597 & TST & \\
\hline CHEMBL1556779 & 688620 & 4.9 & 4.78100 & 0000000001 & TRN \\
\hline CHEMBL1588456 & 688620 & 4.5 & 5.0942 & TRN & \\
\hline CHEMBL1438080 & 688620 & 4.85 & 5.21 & TRN & \\
\hline CHEMBL3198540 & 688620 & 6.15 & 6.1636 & TRN & \\
\hline CHEMBL1451137 & 688620 & 4.45 & 5.1186 & TRN & \\
\hline CHEMBL1339505 & 688620 & 6.0 & 6.2027 & TRN & \\
\hline CHEMBL1446067 & 688620 & 5.3 & 5.3486 & TRN & \\
\hline CHEMBL1413737 & 688620 & 5.7 & 5.4334 & TRN & \\
\hline CHEMBL1998531 & 688620 & 4.95 & 4.8762 & TRN & \\
\hline CHEMBL1318839 & 688620 & 4.85 & 4.9907 & TST & \\
\hline CHEMBL1466359 & 688620 & 4.45 & 4.9339 & TRN & \\
\hline CHEMBL1449424 & 688620 & 5.0 & 5.0157 & TRN & \\
\hline CHEMBL1610919 & 688620 & 4.9 & 4.9483 & TRN & \\
\hline CHEMBL1471060 & 688620 & 4.75 & 5.0213 & TST & \\
\hline
\end{tabular}




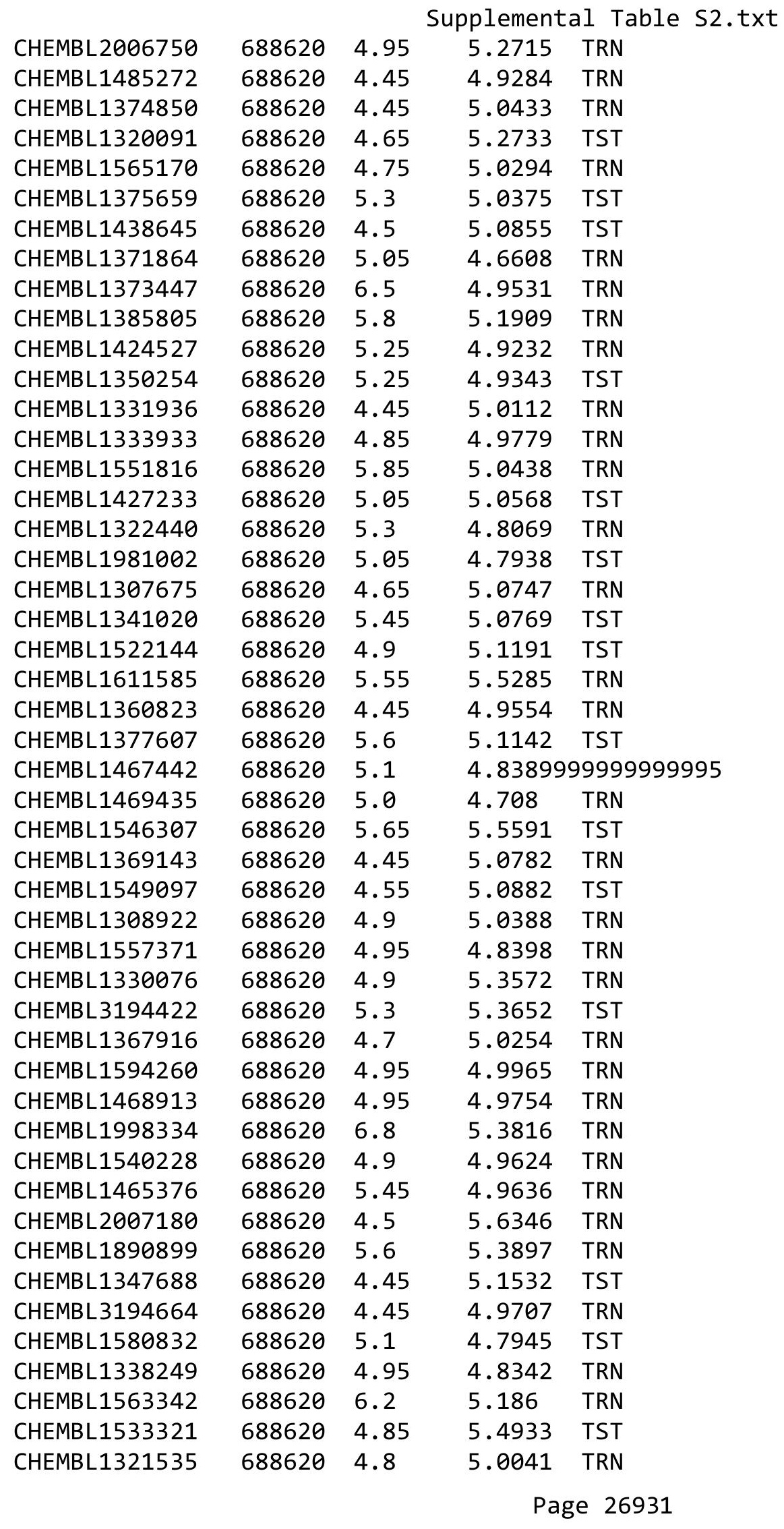




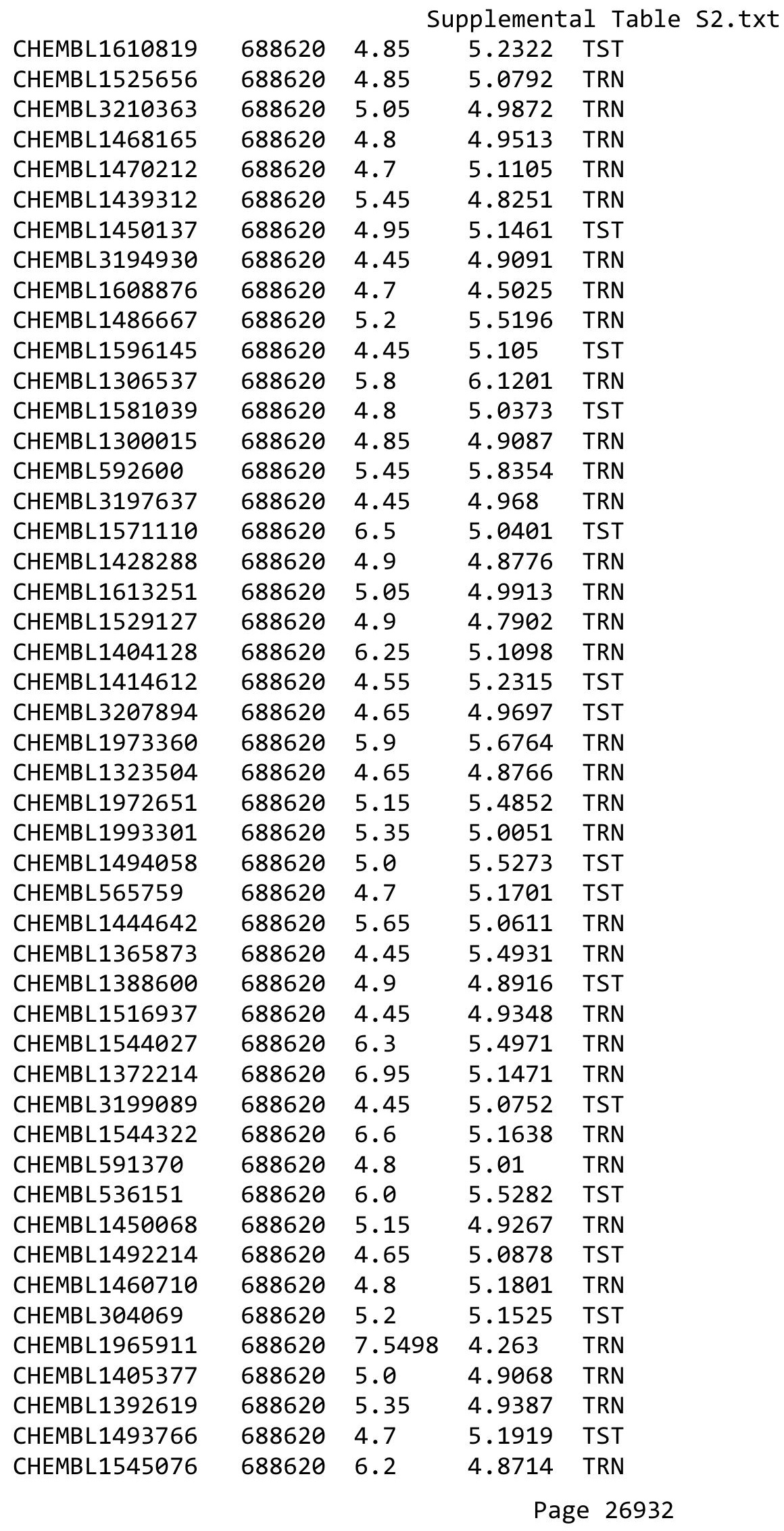




\begin{tabular}{|c|c|c|c|c|}
\hline \multicolumn{5}{|c|}{ Supplemental Table S2.txt } \\
\hline CHEMBL1362514 & 688620 & 5.4 & 5.2295 & TRN \\
\hline CHEMBL1559596 & 688620 & 4.65 & 4.8968 & TRN \\
\hline CHEMBL3198887 & 688620 & 4.6 & 4.9803 & TST \\
\hline CHEMBL1601802 & 688620 & 6.0 & 4.8683 & TRN \\
\hline CHEMBL1367465 & 688620 & 4.45 & 4.9736 & TRN \\
\hline CHEMBL1322304 & 688620 & 4.85 & 5.0228 & TRN \\
\hline CHEMBL1563147 & 688620 & 6.0 & 5.0798 & TST \\
\hline CHEMBL1563858 & 688620 & 4.95 & 4.8098 & TRN \\
\hline CHEMBL1539271 & 688620 & 5.55 & 5.3553 & TRN \\
\hline CHEMBL1341882 & 688620 & 5.0 & 5.1276 & TST \\
\hline CHEMBL1502390 & 688620 & 4.45 & 4.9435 & TST \\
\hline CHEMBL1466122 & 688620 & 4.95 & 5.1544 & TRN \\
\hline CHEMBL 2007612 & 688620 & 6.15 & 5.7035 & TRN \\
\hline CHEMBL1319104 & 688620 & 4.95 & 5.0743 & TST \\
\hline CHEMBL1346507 & 688620 & 4.5 & 4.7714 & TRN \\
\hline CHEMBL1505489 & 688620 & 4.75 & 5.0788 & TRN \\
\hline CHEMBL1465119 & 688620 & 6.15 & 5.9197 & TRN \\
\hline CHEMBL1383012 & 688620 & 6.25 & 6.2993 & TRN \\
\hline CHEMBL1318915 & 688620 & 5.5 & 5.3053 & TRN \\
\hline CHEMBL1521121 & 688620 & 4.75 & 5.1741 & TST \\
\hline CHEMBL1454350 & 688620 & 6.8 & 5.059 & TRN \\
\hline CHEMBL1465410 & 688620 & 4.85 & 5.2093 & TRN \\
\hline CHEMBL1605208 & 688620 & 6.0 & 5.98 & TRN \\
\hline CHEMBL1564566 & 688620 & 6.2 & 5.2327 & TST \\
\hline CHEMBL1528025 & 688620 & 6.1 & 6.1021 & TRN \\
\hline CHEMBL1529507 & 688620 & 4.65 & 5.2088 & TRN \\
\hline CHEMBL1458234 & 688620 & 4.8 & 4.9971 & TST \\
\hline CHEMBL1371315 & 688620 & 4.85 & 5.1321 & TST \\
\hline CHEMBL1361863 & 688620 & 4.45 & 4.8832 & TRN \\
\hline CHEMBL1307117 & 688620 & 4.95 & 5.0432 & TST \\
\hline CHEMBL1501451 & 688620 & 5.1 & 5.0488 & TRN \\
\hline CHEMBL1548527 & 688620 & 4.8 & 5.1708 & TRN \\
\hline CHEMBL1508837 & 688620 & 5.2 & 5.2788 & TRN \\
\hline CHEMBL486541 & 688620 & 5.05 & 4.7036 & TRN \\
\hline CHEMBL3209314 & 688620 & 4.45 & 5.1235 & TRN \\
\hline CHEMBL1556882 & 688620 & 4.45 & 5.2121 & TRN \\
\hline CHEMBL1527899 & 688620 & 4.9 & 5.9957 & TST \\
\hline CHEMBL1501680 & 688620 & 4.9 & $4.9430 e$ & 20000000005 \\
\hline CHEMBL1422230 & 688620 & 5.05 & 5.0411 & TRN \\
\hline CHEMBL1375452 & 688620 & 4.8 & 4.9429 & TST \\
\hline CHEMBL1495658 & 688620 & 4.65 & 4.9597 & TRN \\
\hline CHEMBL1361534 & 688620 & 5.1 & 5.404 & TRN \\
\hline CHEMBL1978373 & 688620 & 5.55 & 5.3861 & TRN \\
\hline CHEMBL1365116 & 688620 & 4.45 & 5.0288 & TRN \\
\hline CHEMBL1392538 & 688620 & 5.05 & 4.9672 & TST \\
\hline CHEMBL3209732 & 688620 & 4.95 & 4.9499 & TST \\
\hline CHEMBL1335175 & 688620 & 5.4 & 4.918 & TRN \\
\hline CHEMBL1567139 & 688620 & 4.7 & 4.8305 & TRN \\
\hline
\end{tabular}




\begin{tabular}{|c|c|c|c|c|c|}
\hline \multicolumn{6}{|c|}{ Supplemental Table S2.txt } \\
\hline CHEMBL1453863 & 688620 & 4.95 & 4.7252 & TRN & \\
\hline CHEMBL1360255 & 688620 & 4.65 & 5.1761 & TRN & \\
\hline CHEMBL1478041 & 688620 & 6.45 & 6.3199 & TRN & \\
\hline CHEMBL 3214404 & 688620 & 4.45 & 5.1486 & TRN & \\
\hline CHEMBL1541000 & 688620 & 4.8 & 5.1718 & TRN & \\
\hline CHEMBL1476872 & 688620 & 4.95 & 5.0632 & TRN & \\
\hline CHEMBL1393962 & 688620 & 4.45 & 5.0386 & TRN & \\
\hline CHEMBL1420135 & 688620 & 4.45 & 5.0197 & TRN & \\
\hline CHEMBL1526086 & 688620 & 5.6 & 5.0951 & TST & \\
\hline CHEMBL1422202 & 688620 & 4.45 & 5.2148 & TRN & \\
\hline CHEMBL1313592 & 688620 & 5.05 & 4.9946 & TRN & \\
\hline CHEMBL1494419 & 688620 & 4.9 & 4.8362 & TRN & \\
\hline CHEMBL1587261 & 688620 & 6.3 & 5.7517 & TRN & \\
\hline CHEMBL1461387 & 688620 & 4.95 & 5.1098 & TST & \\
\hline CHEMBL 260342 & 688620 & 4.5 & 5.1978 & TRN & \\
\hline CHEMBL579380 & 688620 & 4.75 & 4.8883 & TST & \\
\hline CHEMBL1596726 & 688620 & 4.45 & 5.1595 & TRN & \\
\hline CHEMBL3194210 & 688620 & 5.25 & 5.0791 & TRN & \\
\hline CHEMBL1352046 & 688620 & 5.05 & 4.9477 & TST & \\
\hline CHEMBL1581187 & 688620 & 6.7501 & 4.9388 & TRN & \\
\hline CHEMBL1517072 & 688620 & 5.05 & 5.2554 & TRN & \\
\hline CHEMBL1544816 & 688620 & 4.95 & 4.9029 & TRN & \\
\hline CHEMBL3191590 & 688620 & 5.25 & 5.1212 & TRN & \\
\hline CHEMBL1387383 & 688620 & 6.0 & 4.9994 & TRN & \\
\hline CHEMBL3198748 & 688620 & 4.45 & 5.7655 & TRN & \\
\hline CHEMBL1316828 & 688620 & 4.95 & 4.9401 & TST & \\
\hline CHEMBL1557597 & 688620 & 5.0 & 5.2172 & TST & \\
\hline CHEMBL1330004 & 688620 & 4.45 & 5.0016 & TRN & \\
\hline CHEMBL1388267 & 688620 & 4.85 & 5.1218 & TRN & \\
\hline CHEMBL1544885 & 688620 & 4.45 & 4.8171 & TRN & \\
\hline CHEMBL1461819 & 688620 & 5.85 & 5.3872 & TRN & \\
\hline CHEMBL3191159 & 688620 & 4.45 & 5.0149 & TRN & \\
\hline CHEMBL1555980 & 688620 & 4.95 & 5.0718 & TRN & \\
\hline CHEMBL3197725 & 688620 & 4.4 & 4.999 & TST & \\
\hline CHEMBL3198953 & 688620 & 5.35 & 5.0692 & TST & \\
\hline CHEMBL1387191 & 688620 & 4.7 & 5.0542 & TST & \\
\hline CHEMBL3194029 & 688620 & 5.15 & 5.3212 & TRN & \\
\hline CHEMBL3195128 & 688620 & 6.0 & 5.30399 & 9999999999 & TRN \\
\hline CHEMBL3198511 & 688620 & 6.45 & 6.3663 & TST & \\
\hline CHEMBL1978997 & 688620 & 6.5501 & 5.8049 & TRN & \\
\hline CHEMBL1397808 & 688620 & 4.9 & 5.1612 & TRN & \\
\hline CHEMBL1458326 & 688620 & 5.15 & 4.7807 & TRN & \\
\hline CHEMBL1337604 & 688620 & 4.85 & 5.0967 & TRN & \\
\hline CHEMBL1330623 & 688620 & 4.45 & 5.03600 & 00000000005 & TRN \\
\hline CHEMBL1342874 & 688620 & 5.0 & 4.8451 & TRN & \\
\hline CHEMBL1548492 & 688620 & 5.6 & 5.8739 & TRN & \\
\hline CHEMBL1361693 & 688620 & 5.05 & 5.0977 & TST & \\
\hline CHEMBL1343467 & 688620 & 4.95 & 5.1067 & TST & \\
\hline
\end{tabular}




\begin{tabular}{|c|c|c|c|c|c|}
\hline \multicolumn{6}{|c|}{ Supplemental Table S2.txt } \\
\hline CHEMBL1352955 & 688620 & 4.5 & 5.1601 & TRN & \\
\hline CHEMBL1510013 & 688620 & 5.0 & 4.9223 & TRN & \\
\hline CHEMBL1546343 & 688620 & 4.95 & 4.7907 & TST & \\
\hline CHEMBL1301837 & 688620 & 6.45 & 4.9433 & TRN & \\
\hline CHEMBL1595565 & 688620 & 4.45 & 5.0026 & TRN & \\
\hline CHEMBL1336996 & 688620 & 5.2 & 5.0908 & TRN & \\
\hline CHEMBL1539940 & 688620 & 4.9 & 4.8621 & TST & \\
\hline CHEMBL1387220 & 688620 & 5.2 & 4.8678 & TRN & \\
\hline CHEMBL1415882 & 688620 & 4.95 & 4.9292 & TRN & \\
\hline CHEMBL1566983 & 688620 & 5.75 & 5.0415 & TST & \\
\hline CHEMBL 3213240 & 688620 & 4.65 & 4.9203 & TRN & \\
\hline CHEMBL1578351 & 688620 & 5.0 & 4.9255 & TRN & \\
\hline CHEMBL1367699 & 688620 & 6.3 & 6.3037 & TRN & \\
\hline CHEMBL1382491 & 688620 & 4.5 & 4.9866 & TST & \\
\hline CHEMBL1388691 & 688620 & 4.6 & 4.8357 & TRN & \\
\hline CHEMBL1359889 & 688620 & 5.05 & 5.2129 & TRN & \\
\hline CHEMBL1367915 & 688620 & 5.4 & 5.1459 & TRN & \\
\hline CHEMBL 3192418 & 688620 & 5.25 & 4.80699 & 99999999995 & TRN \\
\hline CHEMBL1537419 & 688620 & 5.1 & 4.9765 & TRN & \\
\hline CHEMBL1510542 & 688620 & 5.1 & 5.315 & TRN & \\
\hline CHEMBL1402349 & 688620 & 4.95 & 5.0942 & TRN & \\
\hline CHEMBL1600447 & 688620 & 4.8 & 4.9935 & TST & \\
\hline CHEMBL1423091 & 688620 & 5.15 & 4.8079 & TST & \\
\hline CHEMBL1515255 & 688620 & 4.8 & 5.0674 & TRN & \\
\hline CHEMBL1376820 & 688620 & 5.0 & 4.7143 & TRN & \\
\hline CHEMBL1506227 & 688620 & 4.75 & 5.1026 & TRN & \\
\hline CHEMBL1437741 & 688620 & 4.7 & 4.7466 & TRN & \\
\hline CHEMBL1996441 & 688620 & 5.95 & 5.4422 & TRN & \\
\hline CHEMBL1429655 & 688620 & 5.5 & 5.6598 & TST & \\
\hline CHEMBL1611580 & 688620 & 5.45 & 5.2598 & TRN & \\
\hline CHEMBL3195526 & 688620 & 4.7 & 5.0449 & TRN & \\
\hline CHEMBL1499354 & 688620 & 4.6 & 5.1787 & TST & \\
\hline CHEMBL312487 & 688620 & 5.5 & 5.4079 & TRN & \\
\hline CHEMBL3198425 & 688620 & 6.2 & 5.9686 & TRN & \\
\hline CHEMBL 3195258 & 688620 & 5.35 & 5.3213 & TRN & \\
\hline CHEMBL1581374 & 688620 & 5.0 & 5.0328 & TRN & \\
\hline CHEMBL3198323 & 688620 & 5.55 & 5.2724 & TST & \\
\hline CHEMBL1338327 & 688620 & 5.2 & 4.918 & TRN & \\
\hline CHEMBL1419820 & 688620 & 5.65 & 4.82 & TRN & \\
\hline CHEMBL599890 & 688620 & 4.45 & 4.7159 & TRN & \\
\hline CHEMBL1546139 & 688620 & 4.45 & 4.896 & TST & \\
\hline CHEMBL411666 & 688620 & 4.75 & 4.7751 & TRN & \\
\hline CHEMBL1382479 & 688620 & 4.45 & 5.1449 & TRN & \\
\hline CHEMBL1564723 & 688620 & 5.15 & 5.0473 & TRN & \\
\hline CHEMBL1334348 & 688620 & 4.7 & 5.0307 & TRN & \\
\hline CHEMBL1479141 & 688620 & 4.95 & 4.9414 & TRN & \\
\hline CHEMBL1428258 & 688620 & 6.05 & 5.5639 & TRN & \\
\hline CHEMBL1470321 & 688620 & 4.95 & 5.0627 & TRN & \\
\hline
\end{tabular}




\begin{tabular}{|c|c|c|c|c|c|}
\hline \multicolumn{6}{|c|}{ plementa } \\
\hline CHEMBL1301287 & 688620 & 4.9 & 5.2922 & TST & \\
\hline CHEMBL1430605 & 688620 & 5.5 & 5.0235 & TRN & \\
\hline CHEMBL1438496 & 688620 & 4.55 & 4.965 & TRN & \\
\hline CHEMBL1448894 & 688620 & 5.4 & 4.8404 & TRN & \\
\hline CHEMBL1573154 & 688620 & 4.45 & 5.1294 & TST & \\
\hline CHEMBL3189809 & 688620 & 5.4 & 5.4346 & TRN & \\
\hline CHEMBL1523566 & 688620 & 5.85 & 5.7821 & TRN & \\
\hline CHEMBL1461634 & 688620 & 4.95 & 5.13200 & 0000000001 & TRN \\
\hline CHEMBL1546964 & 688620 & 4.9 & 4.6185 & TRN & \\
\hline CHEMBL1504174 & 688620 & 5.65 & 5.5709 & TRN & \\
\hline CHEMBL1378851 & 688620 & 5.0 & 4.9308 & TRN & \\
\hline CHEMBL1463886 & 688620 & 5.15 & 5.0255 & TRN & \\
\hline CHEMBL3194117 & 688620 & 4.45 & 5.3334 & TRN & \\
\hline CHEMBL3190599 & 688620 & 5.0 & 4.8706 & TRN & \\
\hline CHEMBL1509667 & 688620 & 4.95 & 4.8733 & TRN & \\
\hline CHEMBL1604051 & 688620 & 5.0 & 4.8149 & TST & \\
\hline CHEMBL1603301 & 688620 & 4.45 & 4.9201 & TST & \\
\hline CHEMBL1483462 & 688620 & 5.4 & 5.0513 & TRN & \\
\hline CHEMBL1461721 & 688620 & 4.75 & 5.2196 & TRN & \\
\hline CHEMBL1400237 & 688620 & 5.85 & 6.0674 & TRN & \\
\hline CHEMBL1548647 & 688620 & 5.2 & 5.1973 & TRN & \\
\hline CHEMBL1401164 & 688620 & 4.45 & 4.8709 & TST & \\
\hline CHEMBL1383163 & 688620 & 4.85 & 5.2935 & TST & \\
\hline CHEMBL3194536 & 688620 & 4.75 & 5.2096 & TRN & \\
\hline CHEMBL1578937 & 688620 & 5.45 & 4.8514 & TRN & \\
\hline CHEMBL1489932 & 688620 & 4.75 & 5.0232 & TRN & \\
\hline CHEMBL1532373 & 688620 & 4.45 & 4.695 & TRN & \\
\hline CHEMBL1425594 & 688620 & 4.45 & 5.0573 & TRN & \\
\hline CHEMBL1464246 & 688620 & 5.1 & 5.1196 & TST & \\
\hline CHEMBL1526751 & 688620 & 5.35 & 5.1044 & TRN & \\
\hline CHEMBL1370770 & 688620 & 4.45 & 4.9077 & TRN & \\
\hline CHEMBL1360178 & 688620 & 5.15 & 4.9668 & TRN & \\
\hline CHEMBL1401605 & 688620 & 4.45 & 4.9278 & TRN & \\
\hline CHEMBL1466396 & 688620 & 4.8 & 4.9337 & TRN & \\
\hline CHEMBL1441485 & 688620 & 4.9 & 4.8429 & TRN & \\
\hline CHEMBL1505788 & 688620 & 5.25 & 5.3205 & TRN & \\
\hline CHEMBL1541656 & 688620 & 4.6 & 4.9919 & TRN & \\
\hline CHEMBL1341600 & 688620 & 5.15 & 5.084 & TRN & \\
\hline CHEMBL1465131 & 688620 & 4.45 & 5.0793 & TST & \\
\hline CHEMBL1369323 & 688620 & 5.0 & 5.0405 & TRN & \\
\hline CHEMBL1420757 & 688620 & 4.9 & 5.48799 & 99999999995 & TST \\
\hline CHEMBL1483112 & 688620 & 5.8 & 4.9411 & TRN & \\
\hline CHEMBL1374660 & 688620 & 5.4 & 4.9792 & TRN & \\
\hline CHEMBL1568104 & 688620 & 4.45 & 5.0888 & TST & \\
\hline CHEMBL1496696 & 688620 & 4.9 & 5.0418 & TST & \\
\hline CHEMBL261681 & 688620 & 6.15 & 6.2757 & TRN & \\
\hline CHEMBL1519457 & 688620 & 5.5 & 4.8046 & TRN & \\
\hline CHEMBL1487748 & 688620 & 4.5 & 4.7967 & TRN & \\
\hline
\end{tabular}




\begin{tabular}{|c|c|c|c|c|c|}
\hline \multicolumn{6}{|c|}{ Supplemental Table S2.txt } \\
\hline CHEMBL1548273 & 688620 & 4.95 & 5.065 & TRN & \\
\hline CHEMBL1556727 & 688620 & 4.65 & 4.9881 & TRN & \\
\hline CHEMBL1567255 & 688620 & 6.6 & 4.9828 & TRN & \\
\hline CHEMBL3195014 & 688620 & 4.65 & 4.8848 & TST & \\
\hline CHEMBL1448495 & 688620 & 5.45 & 5.3134 & TRN & \\
\hline CHEMBL1443051 & 688620 & 4.45 & 4.9208 & TST & \\
\hline CHEMBL1432459 & 688620 & 4.95 & 5.1063 & TRN & \\
\hline CHEMBL1606200 & 688620 & 4.5 & 4.8359 & TRN & \\
\hline CHEMBL1392780 & 688620 & 4.65 & 4.9433 & TST & \\
\hline CHEMBL460518 & 688620 & 4.85 & 5.4143 & TRN & \\
\hline CHEMBL1303872 & 688620 & 4.95 & 4.8842 & TRN & \\
\hline CHEMBL1559923 & 688620 & 5.45 & 5.41700 & 0000000001 & TRN \\
\hline CHEMBL1339121 & 688620 & 5.45 & 5.4105 & TRN & \\
\hline CHEMBL1454982 & 688620 & 6.3 & 6.2645 & TRN & \\
\hline CHEMBL1422443 & 688620 & 5.2 & 4.915 & TRN & \\
\hline CHEMBL1481857 & 688620 & 4.45 & 5.0451 & TRN & \\
\hline CHEMBL1470371 & 688620 & 4.95 & 5.1413 & TST & \\
\hline CHEMBL1580861 & 688620 & 5.1 & 5.0849 & TST & \\
\hline CHEMBL1425544 & 688620 & 4.7 & 5.0097 & TRN & \\
\hline CHEMBL1300159 & 688620 & 5.05 & 5.0107 & TRN & \\
\hline CHEMBL1491957 & 688620 & 5.0 & 5.0278 & TRN & \\
\hline CHEMBL1385158 & 688620 & 5.0 & 5.2246 & TRN & \\
\hline CHEMBL3191890 & 688620 & 4.85 & 5.2923 & TRN & \\
\hline CHEMBL1594951 & 688620 & 6.0 & 5.0766 & TRN & \\
\hline CHEMBL1440123 & 688620 & 4.95 & 4.9077 & TRN & \\
\hline CHEMBL1510484 & 688620 & 4.8 & 4.748 & TRN & \\
\hline CHEMBL3193759 & 688620 & 4.7 & 4.7971 & TRN & \\
\hline CHEMBL1528165 & 688620 & 4.45 & 5.0176 & TRN & \\
\hline CHEMBL3197531 & 688620 & 5.5 & 5.5673 & TRN & \\
\hline CHEMBL1984554 & 688620 & 5.05 & 5.1961 & TRN & \\
\hline CHEMBL1514401 & 688620 & 5.2 & 5.3245 & TRN & \\
\hline CHEMBL1384412 & 688620 & 4.55 & 4.9851 & TST & \\
\hline CHEMBL1434378 & 688620 & 4.6 & 4.9387 & TST & \\
\hline CHEMBL1562637 & 688620 & 5.05 & 4.8964 & TST & \\
\hline CHEMBL1306125 & 688620 & 4.8 & 4.9514 & TRN & \\
\hline CHEMBL1502446 & 688620 & 4.45 & 4.8397 & TRN & \\
\hline CHEMBL1458704 & 688620 & 4.9 & 4.831 & TRN & \\
\hline CHEMBL1609903 & 688620 & 4.65 & 5.2548 & TST & \\
\hline CHEMBL1313090 & 688620 & 6.5 & 5.1109 & TRN & \\
\hline CHEMBL1336839 & 688620 & 4.45 & 4.9598 & TRN & \\
\hline CHEMBL3198398 & 688620 & 5.05 & 4.7456 & TRN & \\
\hline CHEMBL1434230 & 688620 & 4.6 & 4.9501 & TRN & \\
\hline CHEMBL1323433 & 688620 & 5.05 & 4.9731 & TRN & \\
\hline CHEMBL1364324 & 688620 & 4.8 & 5.21200 & 0000000001 & TST \\
\hline CHEMBL1310662 & 688620 & 4.45 & 4.7473 & TRN & \\
\hline CHEMBL1524491 & 688620 & 4.95 & 5.0075 & TRN & \\
\hline CHEMBL1400220 & 688620 & 4.7 & 5.0643 & TRN & \\
\hline CHEMBL1375292 & 688620 & 4.95 & 4.8297 & TRN & \\
\hline
\end{tabular}




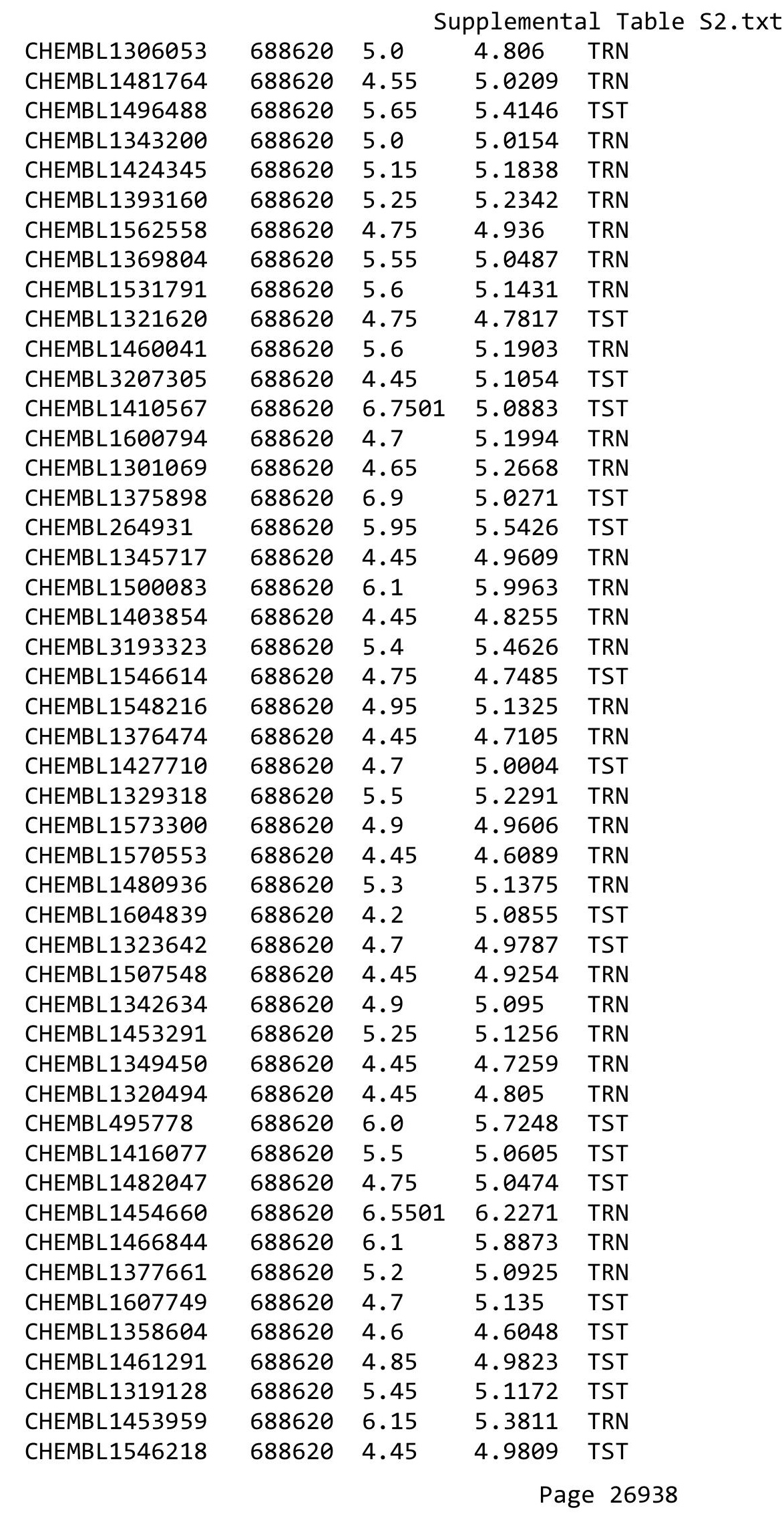




\begin{tabular}{|c|c|c|c|c|c|}
\hline CHEMBL1587606 & 688620 & 4.5 & \multicolumn{2}{|c|}{4.7780000000000005} & TST \\
\hline CHEMBL1368319 & 688620 & 4.75 & 5.0508 & TRN & \\
\hline CHEMBL1414624 & 688620 & 4.9 & 5.2152 & TRN & \\
\hline CHEMBL1351873 & 688620 & 4.45 & 4.9364 & TST & \\
\hline CHEMBL1388715 & 688620 & 5.2 & 4.9595 & TST & \\
\hline CHEMBL1311076 & 688620 & 4.7 & 5.0661 & TRN & \\
\hline CHEMBL1576446 & 688620 & 5.15 & 5.2152 & TRN & \\
\hline CHEMBL1559947 & 688620 & 4.95 & 4.9171 & TRN & \\
\hline CHEMBL1444517 & 688620 & 4.4 & 5.1168 & TRN & \\
\hline CHEMBL1569543 & 688620 & 5.7 & 5.9734 & TRN & \\
\hline CHEMBL1445382 & 688620 & 5.65 & 4.9552 & TRN & \\
\hline CHEMBL3198073 & 688620 & 6.15 & 5.9138 & TRN & \\
\hline CHEMBL1462622 & 688620 & 4.45 & 4.9725 & TRN & \\
\hline CHEMBL1594440 & 688620 & 5.55 & 5.5245 & TRN & \\
\hline CHEMBL1331212 & 688620 & 4.9 & 4.9172 & TRN & \\
\hline CHEMBL1393325 & 688620 & 4.45 & 4.9218 & TRN & \\
\hline CHEMBL1311548 & 688620 & 4.8 & 5.0623 & TRN & \\
\hline CHEMBL1385800 & 688620 & 4.85 & 5.0275 & TST & \\
\hline CHEMBL1484472 & 688620 & 4.45 & 4.9663 & TST & \\
\hline CHEMBL1387550 & 688620 & 5.45 & 4.8977 & TRN & \\
\hline CHEMBL1457803 & 688620 & 4.85 & 5.4008 & TRN & \\
\hline CHEMBL1358788 & 688620 & 4.8 & 5.117 & TRN & \\
\hline CHEMBL1326694 & 688620 & 5.4 & 5.0864 & TRN & \\
\hline CHEMBL1483287 & 688620 & 6.25 & 5.9791 & TRN & \\
\hline CHEMBL1387313 & 688620 & 5.05 & 4.7117 & TRN & \\
\hline CHEMBL1488550 & 688620 & 5.3 & 5.1437 & TST & \\
\hline CHEMBL1485496 & 688620 & 5.15 & 4.9999 & TST & \\
\hline CHEMBL1456422 & 688620 & 5.55 & 5.0783 & TRN & \\
\hline CHEMBL1567223 & 688620 & 5.6 & 5.3717 & TRN & \\
\hline CHEMBL1499789 & 688620 & 6.5 & 5.6586 & TRN & \\
\hline CHEMBL1433181 & 688620 & 5.0 & 5.4503 & TRN & \\
\hline CHEMBL180917 & 688620 & 5.35 & 4.9954 & TST & \\
\hline CHEMBL1311207 & 688620 & 4.7 & 5.8848 & TST & \\
\hline CHEMBL1540429 & 688620 & 4.45 & 4.5939 & TRN & \\
\hline CHEMBL1441276 & 688620 & 4.85 & 4.9918 & TRN & \\
\hline CHEMBL1563490 & 688620 & 5.35 & 5.0891 & TRN & \\
\hline CHEMBL1608330 & 688620 & 5.3 & 5.3867 & TST & \\
\hline CHEMBL1524331 & 688620 & 5.4 & 5.8981 & TRN & \\
\hline CHEMBL1527754 & 688620 & 4.5 & 4.9765 & TST & \\
\hline CHEMBL1308831 & 688620 & 4.65 & 5.0004 & TST & \\
\hline CHEMBL1543105 & 688620 & 4.9 & 5.1129 & TRN & \\
\hline CHEMBL1544797 & 688620 & 4.8 & 4.8486 & TRN & \\
\hline CHEMBL1353141 & 688620 & 5.1 & 4.8979 & TRN & \\
\hline CHEMBL1503290 & 688620 & 5.45 & 5.0964 & TRN & \\
\hline CHEMBL1427996 & 688620 & 6.1 & 5.8118 & TRN & \\
\hline CHEMBL1491762 & 688620 & 4.85 & 4.9611 & TRN & \\
\hline CHEMBL1410264 & 688620 & 4.45 & 5.1477 & TST & \\
\hline CHEMBL1540702 & 688620 & 5.5 & 5.1881 & TRN & \\
\hline & & & & 6939 & \\
\hline
\end{tabular}




\begin{tabular}{|c|c|c|c|c|}
\hline \multicolumn{5}{|c|}{ Supplemental Table S2.txt } \\
\hline CHEMBL1345675 & 688620 & 5.45 & 5.4855 & TRN \\
\hline CHEMBL1438507 & 688620 & 4.7 & 4.8755 & TRN \\
\hline CHEMBL1521629 & 688620 & 4.9 & 5.1872 & TST \\
\hline CHEMBL1380089 & 688620 & 6.4 & 5.0612 & TST \\
\hline CHEMBL1453021 & 688620 & 6.0 & 5.0503 & TST \\
\hline CHEMBL1328966 & 688620 & 6.5 & 6.2562 & TRN \\
\hline CHEMBL483633 & 688620 & 5.45 & 5.1316 & TRN \\
\hline CHEMBL3192161 & 688620 & 6.6499 & 5.643 & TRN \\
\hline CHEMBL1391001 & 688620 & 4.45 & 5.0686 & TRN \\
\hline CHEMBL3194196 & 688620 & 4.95 & 5.1121 & TRN \\
\hline CHEMBL1463212 & 688620 & 5.25 & 4.8121 & TRN \\
\hline CHEMBL1611258 & 688620 & 6.95 & 4.9757 & TST \\
\hline CHEMBL1568399 & 688620 & 5.2 & 4.9545 & TST \\
\hline CHEMBL 3210546 & 688620 & 4.9 & 4.9376 & TRN \\
\hline CHEMBL1310988 & 688620 & 5.15 & 5.2461 & TRN \\
\hline CHEMBL1441984 & 688620 & 5.3 & 5.5568 & TRN \\
\hline CHEMBL1495409 & 688620 & 5.4 & 5.3075 & TST \\
\hline CHEMBL1330098 & 688620 & 5.5 & 5.1609 & TRN \\
\hline CHEMBL1560290 & 688620 & 4.7 & 4.8318 & TRN \\
\hline CHEMBL1523839 & 688620 & 4.65 & 4.9963 & TRN \\
\hline CHEMBL1324043 & 688620 & 5.25 & 5.4808 & TRN \\
\hline CHEMBL1384679 & 688620 & 4.8 & 5.2226 & TRN \\
\hline CHEMBL1563576 & 688620 & 4.9 & 4.8829 & TRN \\
\hline CHEMBL 3210997 & 688620 & 5.75 & 5.2147 & TRN \\
\hline CHEMBL1386364 & 688620 & 4.8 & 5.3311 & TRN \\
\hline CHEMBL1412702 & 688620 & 5.15 & 5.1115 & TRN \\
\hline CHEMBL1562478 & 688620 & 5.0 & 4.6575 & TRN \\
\hline CHEMBL1385413 & 688620 & 6.0 & 5.6377 & TRN \\
\hline CHEMBL1418866 & 688620 & 4.45 & 5.124 & TST \\
\hline CHEMBL1317930 & 688620 & 4.8 & 4.9913 & TRN \\
\hline CHEMBL1602240 & 688620 & 5.55 & 5.6462 & TRN \\
\hline CHEMBL1453664 & 688620 & 5.0 & 4.9224 & TRN \\
\hline CHEMBL1545660 & 688620 & 5.35 & 5.4409 & TRN \\
\hline CHEMBL1376933 & 688620 & 5.75 & 5.2954 & TRN \\
\hline CHEMBL1528869 & 688620 & 5.35 & 5.2024 & TRN \\
\hline CHEMBL1460319 & 688620 & 5.0 & 5.0919 & TRN \\
\hline CHEMBL1589360 & 688620 & 5.1 & 5.1737 & TRN \\
\hline CHEMBL1377770 & 688620 & 4.45 & 4.9985 & TST \\
\hline CHEMBL1347843 & 688620 & 4.9 & 5.2668 & TRN \\
\hline CHEMBL1384487 & 688620 & 5.35 & 5.7757 & TRN \\
\hline CHEMBL1589808 & 688620 & 5.25 & 4.8301 & TRN \\
\hline CHEMBL1392625 & 688620 & 4.9 & 4.8424 & TRN \\
\hline CHEMBL1303785 & 688620 & 5.4 & 5.3215 & TRN \\
\hline CHEMBL1464260 & 688620 & 5.35 & 4.9405 & TRN \\
\hline CHEMBL3189889 & 688620 & 5.45 & 5.2556 & TRN \\
\hline CHEMBL1603974 & 688620 & 4.55 & 4.791 & TRN \\
\hline CHEMBL1369167 & 688620 & 4.9 & 5.1089 & TRN \\
\hline CHEMBL1467363 & 688620 & 7.699 & 5.1182 & TRN \\
\hline
\end{tabular}




\begin{tabular}{|c|c|c|c|c|c|}
\hline \\
\hline CHEMBL1450524 & 688620 & 4.5 & 5.038 & TRN & \\
\hline CHEMBL1482957 & 688620 & 4.9 & 4.8891 & TRN & \\
\hline CHEMBL1412137 & 688620 & 5.0 & 5.3615 & TRN & \\
\hline CHEMBL1585304 & 688620 & 4.95 & 4.7591 & TRN & \\
\hline CHEMBL1379286 & 688620 & 5.55 & 5.2272 & TST & \\
\hline CHEMBL171279 & 688620 & 4.85 & 4.7653 & TRN & \\
\hline CHEMBL1364014 & 688620 & 4.45 & 5.2145 & TST & \\
\hline CHEMBL1409633 & 688620 & 5.15 & 5.2064 & TRN & \\
\hline CHEMBL1566720 & 688620 & 4.45 & 4.8595 & TRN & \\
\hline CHEMBL1401826 & 688620 & 5.75 & 4.9444 & TRN & \\
\hline CHEMBL1965821 & 688620 & 4.95 & 4.9785 & TRN & \\
\hline CHEMBL1547004 & 688620 & 5.45 & 4.934 & TST & \\
\hline CHEMBL1427981 & 688620 & 5.95 & 5.0067 & TRN & \\
\hline CHEMBL3211259 & 688620 & 6.95 & 5.09 & TST & \\
\hline CHEMBL1311324 & 688620 & 4.45 & 4.819 & TRN & \\
\hline CHEMBL1409135 & 688620 & 5.2 & 5.13700 & j0000000005 & TST \\
\hline CHEMBL1305191 & 688620 & 4.95 & 5.1889 & TST & \\
\hline CHEMBL84685 & 688620 & 4.9 & 5.1615 & TRN & \\
\hline CHEMBL1377899 & 688620 & 5.5 & 5.0252 & TRN & \\
\hline CHEMBL1562710 & 688620 & 6.2 & 5.0043 & TRN & \\
\hline CHEMBL1522113 & 688620 & 4.5 & 5.1178 & TST & \\
\hline CHEMBL3190912 & 688620 & 4.95 & 5.0253 & TRN & \\
\hline CHEMBL1331821 & 688620 & 5.2 & 5.0924 & TST & \\
\hline CHEMBL3195074 & 688620 & 4.95 & 4.9261 & TRN & \\
\hline CHEMBL3196525 & 688620 & 4.45 & 5.0672 & TRN & \\
\hline CHEMBL492418 & 688620 & 5.9 & 4.8856 & TST & \\
\hline CHEMBL3195007 & 688620 & 5.4 & 5.1773 & TST & \\
\hline CHEMBL1368706 & 688620 & 4.9 & 4.8439 & TRN & \\
\hline CHEMBL1464276 & 688620 & 4.6 & 4.9489 & TRN & \\
\hline CHEMBL1563787 & 688620 & 5.65 & 5.2243 & TRN & \\
\hline CHEMBL3193300 & 688620 & 5.4 & 5.45700 & $\partial 000000001$ & TRN \\
\hline CHEMBL1379862 & 688620 & 4.9 & 4.9744 & TRN & \\
\hline CHEMBL1539279 & 688620 & 5.1 & 4.8045 & TRN & \\
\hline CHEMBL1325676 & 688620 & 4.75 & 4.8874 & TST & \\
\hline CHEMBL1353905 & 688620 & 5.0 & 4.8204 & TRN & \\
\hline CHEMBL1427922 & 688620 & 4.7 & 5.1859 & TRN & \\
\hline CHEMBL3196470 & 688620 & 4.8 & 5.0894 & TRN & \\
\hline CHEMBL1420895 & 688620 & 4.95 & 5.0469 & TST & \\
\hline CHEMBL1525596 & 688620 & 4.95 & 5.1205 & TRN & \\
\hline CHEMBL1361989 & 688620 & 5.05 & 4.9643 & TRN & \\
\hline CHEMBL3190600 & 688620 & 4.45 & 4.7194 & TRN & \\
\hline CHEMBL1438082 & 688620 & 4.75 & 5.0675 & TST & \\
\hline CHEMBL1423972 & 688620 & 4.45 & 4.9845 & TRN & \\
\hline CHEMBL1464110 & 688620 & 4.95 & 4.9673 & TST & \\
\hline CHEMBL1311386 & 688620 & 4.65 & 5.1013 & TRN & \\
\hline CHEMBL1382110 & 688620 & 4.6 & 5.1717 & TST & \\
\hline CHEMBL1612849 & 688620 & 5.6 & 5.2765 & TRN & \\
\hline CHEMBL3197504 & 688620 & 5.6 & 4.8943 & TRN & \\
\hline
\end{tabular}




\begin{tabular}{|c|c|c|c|c|}
\hline \multicolumn{5}{|c|}{ Supplemental Table S2.txt } \\
\hline CHEMBL1431856 & 688620 & 4.9 & 4.8485 & TRN \\
\hline CHEMBL1495798 & 688620 & 4.8 & 4.8108 & TRN \\
\hline CHEMBL1472066 & 688620 & 5.1 & 5.1477 & TRN \\
\hline CHEMBL1301790 & 688620 & 5.0 & 4.8167 & TRN \\
\hline CHEMBL1332887 & 688620 & 5.05 & 4.8856 & TRN \\
\hline CHEMBL1498136 & 688620 & 5.05 & 4.8513 & TST \\
\hline CHEMBL1309573 & 688620 & 6.15 & 5.83 & TRN \\
\hline CHEMBL1336642 & 688620 & 5.35 & 4.9433 & TRN \\
\hline CHEMBL1322001 & 688620 & 5.0 & 4.9384 & TRN \\
\hline CHEMBL1304472 & 688620 & 4.45 & 4.9848 & TRN \\
\hline CHEMBL1320108 & 688620 & 5.4 & 5.2112 & TRN \\
\hline CHEMBL1341945 & 688620 & 5.45 & 4.9181 & TST \\
\hline CHEMBL1331485 & 688620 & 6.45 & 6.2704 & TRN \\
\hline CHEMBL1385116 & 688620 & 4.85 & 5.0383 & TRN \\
\hline CHEMBL 2002972 & 688620 & 4.65 & 5.2758 & TST \\
\hline CHEMBL1445077 & 688620 & 4.5 & 5.0706 & TST \\
\hline CHEMBL1447011 & 688620 & 4.5 & 5.0247 & TRN \\
\hline CHEMBL491953 & 688620 & 4.5 & 4.8255 & TRN \\
\hline CHEMBL1507939 & 688620 & 5.85 & 5.5694 & TRN \\
\hline CHEMBL1446460 & 688620 & 4.5 & 5.2373 & TST \\
\hline CHEMBL3198823 & 688620 & 5.1 & 5.1726 & TRN \\
\hline CHEMBL1491705 & 688620 & 5.65 & 5.5585 & TST \\
\hline CHEMBL1387923 & 688620 & 4.95 & 5.0808 & TRN \\
\hline CHEMBL1587436 & 688620 & 5.75 & 5.1118 & TRN \\
\hline CHEMBL1439408 & 688620 & 5.3 & 4.8149 & TST \\
\hline CHEMBL1463772 & 688620 & 4.95 & 4.9846 & TRN \\
\hline CHEMBL1410974 & 688620 & 4.95 & 5.0965 & TST \\
\hline CHEMBL1478944 & 688620 & 5.55 & 5.0118 & TRN \\
\hline CHEMBL1565817 & 688620 & 7.0501 & 6.2822 & TST \\
\hline CHEMBL1610081 & 688620 & 4.85 & 4.9815 & TRN \\
\hline CHEMBL1496629 & 688620 & 5.1 & 4.9716 & TRN \\
\hline CHEMBL1404362 & 688620 & 4.45 & 5.3914 & TRN \\
\hline CHEMBL1465060 & 688620 & 4.65 & 5.1045 & TST \\
\hline CHEMBL 2002274 & 688620 & 4.45 & 5.0342 & TRN \\
\hline CHEMBL1506118 & 688620 & 4.7 & 5.1687 & TRN \\
\hline CHEMBL1344739 & 688620 & 4.95 & 5.0145 & TST \\
\hline CHEMBL3196457 & 688620 & 4.75 & 5.098 & TRN \\
\hline CHEMBL1463608 & 688620 & 4.9 & 5.0242 & TRN \\
\hline CHEMBL1587397 & 688620 & 4.95 & 4.9948 & TRN \\
\hline CHEMBL1522193 & 688620 & 4.8 & 5.026 & TRN \\
\hline CHEMBL1386615 & 688620 & 5.0 & 4.9358 & TRN \\
\hline CHEMBL1370810 & 688620 & 4.7 & 5.1305 & TRN \\
\hline CHEMBL1492268 & 688620 & 5.0 & 4.9725 & TRN \\
\hline CHEMBL1324062 & 688620 & 4.95 & 4.9076 & TRN \\
\hline CHEMBL1503033 & 688620 & 5.9 & 5.0699 & TST \\
\hline CHEMBL1368838 & 688620 & 4.45 & 5.081 & TRN \\
\hline CHEMBL1419187 & 688620 & 6.7501 & 4.8157 & TRN \\
\hline CHEMBL1575647 & 688620 & 5.6 & 5.2504 & TRN \\
\hline
\end{tabular}




\begin{tabular}{|c|c|c|c|c|c|}
\hline \multicolumn{6}{|c|}{ Supplemental Table S2.txt } \\
\hline CHEMBL1381178 & 688620 & 4.95 & 5.0353 & TST & \\
\hline CHEMBL1411500 & 688620 & 4.9 & 5.2733 & TRN & \\
\hline CHEMBL1384673 & 688620 & 5.15 & 5.2699 & TRN & \\
\hline CHEMBL1500112 & 688620 & 5.15 & 5.3354 & TRN & \\
\hline CHEMBL1471741 & 688620 & 5.5 & 5.3703 & TRN & \\
\hline CHEMBL1409958 & 688620 & 5.25 & 5.2587 & TRN & \\
\hline CHEMBL1478291 & 688620 & 4.45 & 4.9759 & TRN & \\
\hline CHEMBL1609237 & 688620 & 6.5501 & 5.1577 & TRN & \\
\hline CHEMBL1304269 & 688620 & 4.95 & 5.0747 & TRN & \\
\hline CHEMBL1409738 & 688620 & 5.8 & 5.0864 & TRN & \\
\hline CHEMBL1373992 & 688620 & 5.0 & 4.9747 & TST & \\
\hline CHEMBL1319800 & 688620 & 5.2 & 5.0742 & TST & \\
\hline CHEMBL1457897 & 688620 & 5.2 & 5.0988 & TRN & \\
\hline CHEMBL1564227 & 688620 & 4.8 & 5.0201 & TRN & \\
\hline CHEMBL1303592 & 688620 & 5.45 & 5.1345 & TRN & \\
\hline CHEMBL1375105 & 688620 & 4.5 & 5.1145 & TRN & \\
\hline CHEMBL1579933 & 688620 & 4.95 & 4.9539 & TST & \\
\hline CHEMBL1417059 & 688620 & 5.5 & 5.4619 & TRN & \\
\hline CHEMBL1493976 & 688620 & 4.95 & 4.9011 & TRN & \\
\hline CHEMBL1498475 & 688620 & 4.8 & 5.131 & TRN & \\
\hline CHEMBL1484356 & 688620 & 6.0 & 5.1415 & TST & \\
\hline CHEMBL1595831 & 688620 & 5.6 & 4.8821 & TST & \\
\hline CHEMBL3193084 & 688620 & 5.1 & 5.1648 & TRN & \\
\hline CHEMBL1321895 & 688620 & 4.9 & 5.2077 & TRN & \\
\hline CHEMBL1546713 & 688620 & 6.4 & 5.4133 & TRN & \\
\hline CHEMBL1379712 & 688620 & 5.5 & 5.155 & TRN & \\
\hline CHEMBL1360377 & 688620 & 5.5 & 4.9596 & TST & \\
\hline CHEMBL1446676 & 688620 & 5.3 & 5.5204 & TRN & \\
\hline CHEMBL1345845 & 688620 & 6.6 & 5.16100 & 00000000005 & TRN \\
\hline CHEMBL1463111 & 688620 & 4.6 & 5.16 & TRN & \\
\hline CHEMBL1337716 & 688620 & 5.5 & 5.2721 & TRN & \\
\hline CHEMBL1606682 & 688620 & 5.0 & 5.0137 & TST & \\
\hline CHEMBL1458726 & 688620 & 5.45 & 5.2486 & TRN & \\
\hline CHEMBL1489149 & 688620 & 5.75 & 5.374 & TST & \\
\hline CHEMBL1483774 & 688620 & 4.45 & 4.713 & TRN & \\
\hline CHEMBL1343458 & 688620 & 5.0 & 5.2158 & TST & \\
\hline CHEMBL1529565 & 688620 & 4.85 & 5.2718 & TRN & \\
\hline CHEMBL1309278 & 688620 & 5.4 & 5.2529 & TRN & \\
\hline CHEMBL1529676 & 688620 & 4.45 & 4.8998 & TST & \\
\hline CHEMBL1586728 & 688620 & 4.95 & 5.1623 & TST & \\
\hline CHEMBL1569753 & 688620 & 5.6 & 5.4942 & TRN & \\
\hline CHEMBL1610497 & 688620 & 5.5 & 5.3154 & TRN & \\
\hline CHEMBL1390984 & 688620 & 5.9 & 5.5193 & TRN & \\
\hline CHEMBL1454299 & 688620 & 4.5 & 4.9928 & TRN & \\
\hline CHEMBL1559723 & 688620 & 5.2 & 5.0143 & TST & \\
\hline CHEMBL1338045 & 688620 & 5.25 & 5.2108 & TRN & \\
\hline CHEMBL1509438 & 688620 & 5.45 & 5.2142 & TRN & \\
\hline CHEMBL1561102 & 688620 & 4.65 & 4.8196 & TST & \\
\hline
\end{tabular}




\begin{tabular}{|c|c|c|c|c|}
\hline & & & pplement & al $\mathrm{Ta}$ \\
\hline CHEMBL1607568 & 688620 & 5.3 & 5.4226 & TRN \\
\hline CHEMBL1412651 & 688620 & 4.75 & 5.1254 & TRN \\
\hline CHEMBL3197334 & 688620 & 5.4 & 5.0068 & TST \\
\hline CHEMBL1506487 & 688620 & 5.3 & 5.2561 & TRN \\
\hline CHEMBL1335731 & 688620 & 4.95 & 4.8483 & TRN \\
\hline CHEMBL1307633 & 688620 & 5.2 & 4.9247 & TRN \\
\hline CHEMBL1464673 & 688620 & 4.7 & 4.9849 & TRN \\
\hline CHEMBL1381827 & 688620 & 5.25 & 5.0021 & TST \\
\hline CHEMBL1388140 & 688620 & 5.15 & 5.1226 & TST \\
\hline CHEMBL3196122 & 688620 & 5.7 & 5.109 & TRN \\
\hline CHEMBL1497156 & 688620 & 4.75 & 5.0295 & TRN \\
\hline CHEMBL1417863 & 688620 & 5.0 & 4.9434 & TRN \\
\hline CHEMBL1450251 & 688620 & 6.15 & 5.1317 & TST \\
\hline CHEMBL175858 & 688620 & 5.45 & 5.7741 & TST \\
\hline CHEMBL1411255 & 688620 & 4.65 & 5.192 & TST \\
\hline CHEMBL1530004 & 688620 & 4.9 & 5.0617 & TRN \\
\hline CHEMBL1601310 & 688620 & 4.8 & 5.0567 & TRN \\
\hline CHEMBL1412996 & 688620 & 5.9 & 5.0956 & TRN \\
\hline CHEMBL1353578 & 688620 & 4.65 & 5.0456 & TRN \\
\hline CHEMBL1506951 & 688620 & 4.45 & 4.9839 & TRN \\
\hline CHEMBL1462397 & 688620 & 6.45 & 5.109 & TRN \\
\hline CHEMBL1379204 & 688620 & 4.9 & 5.0395 & TRN \\
\hline CHEMBL1496193 & 688620 & 4.45 & 5.045 & TRN \\
\hline CHEMBL1348015 & 688620 & 4.5 & 5.0048 & TST \\
\hline CHEMBL1326459 & 688620 & 4.55 & 4.8795 & TRN \\
\hline CHEMBL1366475 & 688620 & 4.45 & 5.0356 & TRN \\
\hline CHEMBL3192112 & 688620 & 5.05 & 4.9072 & TRN \\
\hline CHEMBL1438894 & 688620 & 4.95 & 4.9095 & TRN \\
\hline CHEMBL1371370 & 688620 & 5.55 & 5.2549 & TRN \\
\hline CHEMBL1413910 & 688620 & 4.45 & 4.9959 & TST \\
\hline CHEMBL3214530 & 688620 & 6.35 & 4.8976 & TST \\
\hline CHEMBL1419482 & 688620 & 5.15 & 5.1956 & TST \\
\hline CHEMBL1509148 & 688620 & 4.45 & 5.2581 & TRN \\
\hline CHEMBL1320354 & 688620 & 4.5 & 4.7206 & TRN \\
\hline CHEMBL1529691 & 688620 & 4.45 & 5.0406 & TST \\
\hline CHEMBL1455197 & 688620 & 4.9 & 4.9396 & TRN \\
\hline CHEMBL1480457 & 688620 & 5.85 & 5.0258 & TRN \\
\hline CHEMBL 2369301 & 688620 & 6.1 & 5.8317 & TRN \\
\hline CHEMBL 3192833 & 688620 & 5.0 & 5.4853 & TRN \\
\hline CHEMBL1434304 & 688620 & 4.8 & 4.9575 & TRN \\
\hline CHEMBL1421868 & 688620 & 4.85 & 4.9218 & TRN \\
\hline CHEMBL3212135 & 688620 & 5.45 & 5.8628 & TRN \\
\hline CHEMBL1569857 & 688620 & 4.9 & 4.9431 & TRN \\
\hline CHEMBL1307715 & 688620 & 4.9 & 4.8695 & TRN \\
\hline CHEMBL 3191420 & 688620 & 4.7 & 5.0904 & TRN \\
\hline CHEMBL1497446 & 688620 & 4.9 & 5.1757 & TRN \\
\hline CHEMBL1336753 & 688620 & 4.45 & 5.3781 & TRN \\
\hline CHEMBL1319225 & 688620 & 4.95 & 5.0951 & TST \\
\hline
\end{tabular}




\begin{tabular}{|c|c|c|c|c|c|}
\hline \multicolumn{6}{|c|}{ Supplemental Table S2.txt } \\
\hline CHEMBL3194241 & 688620 & 4.65 & 4.905 & TRN & \\
\hline CHEMBL1427974 & 688620 & 5.6 & 5.0363 & TST & \\
\hline CHEMBL1302042 & 688620 & 4.8 & 4.867 & TST & \\
\hline CHEMBL1567331 & 688620 & 5.05 & 5.3302 & TST & \\
\hline CHEMBL1336589 & 688620 & 4.65 & 4.9535 & TRN & \\
\hline CHEMBL1530629 & 688620 & 5.15 & 4.9932 & TRN & \\
\hline CHEMBL1422453 & 688620 & 5.7 & 5.1207 & TST & \\
\hline CHEMBL1370113 & 688620 & 4.65 & 5.21399 & 99999999995 & TRN \\
\hline CHEMBL3194704 & 688620 & 5.7 & 5.4034 & TRN & \\
\hline CHEMBL1547782 & 688620 & 5.6 & 5.5304 & TST & \\
\hline CHEMBL1331875 & 688620 & 5.7 & 5.2611 & TRN & \\
\hline CHEMBL1333733 & 688620 & 5.0 & 4.9453 & TRN & \\
\hline CHEMBL1466793 & 688620 & 4.65 & 5.0814 & TRN & \\
\hline CHEMBL1339496 & 688620 & 4.85 & 5.0908 & TRN & \\
\hline CHEMBL1532909 & 688620 & 5.7 & 5.3415 & TST & \\
\hline CHEMBL3198569 & 688620 & 5.1 & 4.8899 & TRN & \\
\hline CHEMBL1388101 & 688620 & 4.95 & 5.1653 & TRN & \\
\hline CHEMBL1541138 & 688620 & 4.95 & 4.8313 & TRN & \\
\hline CHEMBL1496854 & 688620 & 6.0 & 5.4527 & TST & \\
\hline CHEMBL1460075 & 688620 & 4.9 & 4.8458 & TST & \\
\hline CHEMBL1603708 & 688620 & 6.6 & 5.3101 & TST & \\
\hline CHEMBL151937 & 688620 & 5.65 & 5.0757 & TST & \\
\hline CHEMBL1431276 & 688620 & 4.7 & 5.25200 & 0000000001 & TRN \\
\hline CHEMBL1469178 & 688620 & 4.95 & 4.8565 & TRN & \\
\hline CHEMBL 3144856 & 688620 & 4.9 & 4.8713 & TRN & \\
\hline CHEMBL1418598 & 688620 & 4.6 & 4.7417 & TRN & \\
\hline CHEMBL1531076 & 688620 & 4.95 & 4.9965 & TRN & \\
\hline CHEMBL1501283 & 688620 & 4.45 & 4.9313 & TRN & \\
\hline CHEMBL1550295 & 688620 & 4.8 & 4.9124 & TST & \\
\hline CHEMBL1401355 & 688620 & 5.25 & 4.9099 & TST & \\
\hline CHEMBL1611105 & 688620 & 4.75 & 4.8398 & TRN & \\
\hline CHEMBL1496130 & 688620 & 4.85 & 4.9511 & TRN & \\
\hline CHEMBL1482190 & 688620 & 5.0 & 5.1682 & TRN & \\
\hline CHEMBL1582780 & 688620 & 4.45 & 5.0724 & TRN & \\
\hline CHEMBL1426446 & 688620 & 5.7 & 5.0839 & TRN & \\
\hline CHEMBL1452090 & 688620 & 5.6 & 5.6483 & TRN & \\
\hline CHEMBL1367682 & 688620 & 5.0 & 4.9956 & TRN & \\
\hline CHEMBL1522581 & 688620 & 4.6 & 4.8548 & TRN & \\
\hline CHEMBL1365344 & 688620 & 4.95 & 5.092 & TRN & \\
\hline CHEMBL1331499 & 688620 & 5.45 & 4.9215 & TRN & \\
\hline CHEMBL1504390 & 688620 & 5.45 & 5.1549 & TRN & \\
\hline CHEMBL528414 & 688620 & 4.7 & 4.9703 & TRN & \\
\hline CHEMBL1483765 & 688620 & 5.85 & 5.3856 & TRN & \\
\hline CHEMBL1557150 & 688620 & 4.95 & 4.976 & TRN & \\
\hline CHEMBL1577655 & 688620 & 4.65 & 4.9763 & TRN & \\
\hline CHEMBL1539676 & 688620 & 4.8 & 5.1239 & TST & \\
\hline CHEMBL1373201 & 688620 & 4.95 & 4.9783 & TST & \\
\hline CHEMBL1459626 & 688620 & 4.9 & 4.7307 & TRN & \\
\hline
\end{tabular}




\begin{tabular}{|c|c|c|c|c|c|}
\hline \multicolumn{6}{|c|}{ Supplemental Table S2.txt } \\
\hline CHEMBL1363249 & 688620 & 5.55 & 5.4105 & TRN & \\
\hline CHEMBL1536122 & 688620 & 4.85 & 4.9988 & TRN & \\
\hline CHEMBL1557860 & 688620 & 5.55 & 5.0103 & TRN & \\
\hline CHEMBL1455507 & 688620 & 5.45 & 4.7154 & TRN & \\
\hline CHEMBL1497653 & 688620 & 5.2 & 5.0026 & TRN & \\
\hline CHEMBL1421625 & 688620 & 5.35 & 5.3185 & TRN & \\
\hline CHEMBL66654 & 688620 & 4.85 & 5.0747 & TST & \\
\hline CHEMBL1333254 & 688620 & 4.8 & 5.1916 & TRN & \\
\hline CHEMBL1565059 & 688620 & 4.65 & 4.9921 & TRN & \\
\hline CHEMBL1365325 & 688620 & 5.0 & 4.9397 & TRN & \\
\hline CHEMBL1379502 & 688620 & 4.9 & 4.9735 & TRN & \\
\hline CHEMBL1541948 & 688620 & 4.85 & 5.1326 & TRN & \\
\hline CHEMBL1330415 & 688620 & 4.9 & 4.9378 & TRN & \\
\hline CHEMBL1372920 & 688620 & 5.9 & 5.0397 & TST & \\
\hline CHEMBL1998741 & 688620 & 6.15 & 5.4679 & TRN & \\
\hline CHEMBL1539924 & 688620 & 5.0 & 4.9378 & TST & \\
\hline CHEMBL1412390 & 688620 & 4.8 & 4.7867 & TRN & \\
\hline CHEMBL1575262 & 688620 & 4.45 & 4.9902 & TST & \\
\hline CHEMBL1416509 & 688620 & 4.6 & 5.1187 & TRN & \\
\hline CHEMBL3195436 & 688620 & 5.4 & 5.2326 & TRN & \\
\hline CHEMBL1364685 & 688620 & 4.7 & 5.0953 & TRN & \\
\hline CHEMBL1561717 & 688620 & 4.3 & 4.8627 & TRN & \\
\hline CHEMBL 275311 & 688620 & 5.15 & 5.13399 & 99999999995 & TST \\
\hline CHEMBL1366836 & 688620 & 4.9 & 4.9136 & TST & \\
\hline CHEMBL1468207 & 688620 & 4.65 & 4.8502 & TST & \\
\hline CHEMBL1611328 & 688620 & 4.85 & 4.8876 & TRN & \\
\hline CHEMBL 3191315 & 688620 & 4.7 & 5.05699 & 99999999995 & TRN \\
\hline CHEMBL1323111 & 688620 & 4.45 & 5.0582 & TRN & \\
\hline CHEMBL1606012 & 688620 & 5.2 & 5.1205 & TST & \\
\hline CHEMBL1484172 & 688620 & 4.9 & 4.9458 & TRN & \\
\hline CHEMBL 2006568 & 688620 & 4.95 & 5.1808 & TRN & \\
\hline CHEMBL1449336 & 688620 & 4.85 & 4.9622 & TST & \\
\hline CHEMBL1418774 & 688620 & 4.85 & 5.1429 & TST & \\
\hline CHEMBL1421419 & 688620 & 4.95 & 4.8908 & TRN & \\
\hline CHEMBL1422135 & 688620 & 4.45 & 4.8652 & TRN & \\
\hline CHEMBL1460296 & 688620 & 4.9 & 5.0654 & TRN & \\
\hline CHEMBL1430437 & 688620 & 4.45 & 5.0104 & TRN & \\
\hline CHEMBL1409801 & 688620 & 6.05 & 5.1175 & TRN & \\
\hline CHEMBL1585118 & 688620 & 5.0 & 5.0421 & TRN & \\
\hline CHEMBL197649 & 688620 & 4.9 & 4.9454 & TRN & \\
\hline CHEMBL1565886 & 688620 & 6.2 & 5.0234 & TST & \\
\hline CHEMBL1511687 & 688620 & 4.95 & 5.0271 & TRN & \\
\hline CHEMBL1451375 & 688620 & 6.25 & 4.9905 & TRN & \\
\hline CHEMBL1534587 & 688620 & 5.05 & 4.9135 & TST & \\
\hline CHEMBL1431920 & 688620 & 6.95 & 5.1361 & TRN & \\
\hline CHEMBL1439650 & 688620 & 4.95 & 4.9936 & TRN & \\
\hline CHEMBL1430799 & 688620 & 4.75 & 5.1726 & TRN & \\
\hline CHEMBL1359908 & 688620 & 4.7 & 5.3882 & TRN & \\
\hline
\end{tabular}




\begin{tabular}{|c|c|c|c|c|}
\hline \multicolumn{5}{|c|}{ Supplemental Table S2.txt } \\
\hline CHEMBL1490887 & 688620 & 5.65 & 4.9688 & TRN \\
\hline CHEMBL1358236 & 688620 & 4.45 & 4.8568 & TST \\
\hline CHEMBL1613690 & 688620 & 5.0 & 4.8232 & TRN \\
\hline CHEMBL 3197400 & 688620 & 5.0 & 5.0473 & TRN \\
\hline CHEMBL1309324 & 688620 & 7.3002 & 5.2087 & TRN \\
\hline CHEMBL1422079 & 688620 & 4.45 & 5.0494 & TRN \\
\hline CHEMBL1490122 & 688620 & 5.75 & 5.4023 & TST \\
\hline CHEMBL1413255 & 688620 & 5.45 & 4.7986 & TST \\
\hline CHEMBL1562839 & 688620 & 4.5 & 4.8254 & TST \\
\hline CHEMBL1532444 & 688620 & 5.3 & 4.8308 & TRN \\
\hline CHEMBL1463869 & 688620 & 6.7001 & 5.7776 & TRN \\
\hline CHEMBL1997928 & 688620 & 4.45 & 4.8569 & TRN \\
\hline CHEMBL1528400 & 688620 & 4.8 & 5.0268 & TRN \\
\hline CHEMBL1507793 & 688620 & 5.0 & 5.0298 & TRN \\
\hline CHEMBL3197094 & 688620 & 4.45 & 4.8304 & TRN \\
\hline CHEMBL3194091 & 688620 & 4.45 & 4.6498 & TST \\
\hline CHEMBL1398789 & 688620 & 5.65 & 5.0497 & TST \\
\hline CHEMBL1582363 & 688620 & 5.25 & 5.2655 & TRN \\
\hline CHEMBL1365899 & 688620 & 4.95 & 4.9289 & TST \\
\hline CHEMBL1569425 & 688620 & 4.7 & 5.0828 & TRN \\
\hline CHEMBL1332849 & 688620 & 5.0 & 5.2594 & TRN \\
\hline CHEMBL1527692 & 688620 & 6.9 & 5.0579 & TST \\
\hline CHEMBL1385035 & 688620 & 6.3 & 4.9493 & TST \\
\hline CHEMBL1482886 & 688620 & 5.5 & 5.6081 & TRN \\
\hline CHEMBL1344397 & 688620 & 5.05 & 5.02 & TRN \\
\hline CHEMBL1489660 & 688620 & 5.6 & 5.2517 & TRN \\
\hline CHEMBL1497568 & 688620 & 4.95 & 4.9858 & TRN \\
\hline CHEMBL1351247 & 688620 & 4.95 & 5.0708 & TST \\
\hline CHEMBL1400761 & 688620 & 5.05 & 4.9552 & TRN \\
\hline CHEMBL1305312 & 688620 & 4.9 & 4.7876 & TST \\
\hline CHEMBL1316409 & 688620 & 4.95 & 5.0825 & TRN \\
\hline CHEMBL1565419 & 688620 & 5.55 & 5.3552 & TST \\
\hline CHEMBL1501318 & 688620 & 4.65 & 5.0526 & TST \\
\hline CHEMBL1442981 & 688620 & 4.5 & 5.2441 & TRN \\
\hline CHEMBL3198681 & 688620 & 5.3 & 5.4695 & TST \\
\hline CHEMBL1351069 & 688620 & 4.45 & 4.9941 & TRN \\
\hline CHEMBL1533353 & 688620 & 5.1 & 5.0628 & TST \\
\hline CHEMBL1489479 & 688620 & 4.9 & 5.284 & TRN \\
\hline CHEMBL1332025 & 688620 & 7.4001 & 3.9754 & TST \\
\hline CHEMBL1495842 & 688620 & 8.3468 & 5.1158 & TRN \\
\hline CHEMBL1511757 & 688620 & 5.8 & 4.9266 & TRN \\
\hline CHEMBL1337778 & 688620 & 5.15 & 5.1897 & TRN \\
\hline CHEMBL1385873 & 688620 & 7.3497 & 5.1804 & TST \\
\hline CHEMBL1539367 & 688620 & 4.45 & 5.1514 & TRN \\
\hline CHEMBL1377814 & 688620 & 5.0 & 4.9744 & TRN \\
\hline CHEMBL1323966 & 688620 & 4.85 & 4.9476 & TST \\
\hline CHEMBL1406534 & 688620 & 4.5 & 5.0027 & TRN \\
\hline CHEMBL1329311 & 688620 & 4.5 & 4.824 & TRN \\
\hline
\end{tabular}




\begin{tabular}{|c|c|c|c|c|}
\hline \multicolumn{5}{|c|}{ Supplemental Table s2.txt } \\
\hline CHEMBL1968290 & 688620 & 4.95 & 4.7875 & TST \\
\hline CHEMBL1462087 & 688620 & 5.3 & 4.9214 & TRN \\
\hline CHEMBL1544266 & 688620 & 4.8 & 5.0223 & TRN \\
\hline CHEMBL1299790 & 688620 & 4.95 & 4.8905 & TST \\
\hline CHEMBL1425943 & 688620 & 5.9 & 4.7281 & TRN \\
\hline CHEMBL1458074 & 688620 & 4.45 & 5.2468 & TRN \\
\hline CHEMBL1575600 & 688620 & 6.3 & 5.8787 & TRN \\
\hline CHEMBL1446949 & 688620 & 4.45 & 4.887 & TST \\
\hline CHEMBL1448041 & 688620 & 4.8 & 5.0662 & TST \\
\hline CHEMBL1307177 & 688620 & 4.6 & 5.0234 & TRN \\
\hline CHEMBL1581919 & 688620 & 5.6 & 5.3555 & TRN \\
\hline CHEMBL1531684 & 688620 & 5.15 & 5.0895 & TRN \\
\hline CHEMBL1580372 & 688620 & 5.35 & 5.5491 & TRN \\
\hline CHEMBL1301896 & 688620 & 4.7 & 4.9175 & TRN \\
\hline CHEMBL1343617 & 688620 & 4.75 & 5.0942 & TST \\
\hline CHEMBL1458822 & 688620 & 5.25 & 5.0293 & TST \\
\hline CHEMBL1482466 & 688620 & 4.45 & 4.7227 & TRN \\
\hline CHEMBL1310444 & 688620 & 5.15 & 5.0834 & TRN \\
\hline CHEMBL1420268 & 688620 & 4.95 & 4.7735 & TST \\
\hline CHEMBL1583647 & 688620 & 4.95 & 5.2235 & TRN \\
\hline CHEMBL1431035 & 688620 & 5.15 & 5.1192 & TRN \\
\hline CHEMBL1989294 & 688620 & 5.45 & 5.4141 & TRN \\
\hline CHEMBL1384511 & 688620 & 4.45 & 5.0026 & TST \\
\hline CHEMBL1519755 & 688620 & 5.1 & 5.1816 & TRN \\
\hline CHEMBL1972648 & 688620 & 4.6 & 5.0947 & TRN \\
\hline CHEMBL1484622 & 688620 & 5.55 & 5.4513 & TRN \\
\hline CHEMBL3213421 & 688620 & 4.8 & 4.9984 & TRN \\
\hline CHEMBL1470679 & 688620 & 4.45 & 4.9958 & TRN \\
\hline CHEMBL1547295 & 688620 & 5.5 & 5.0747 & TRN \\
\hline CHEMBL1411865 & 688620 & 4.9 & 5.0454 & TRN \\
\hline CHEMBL1455146 & 688620 & 6.7501 & 5.4633 & TRN \\
\hline CHEMBL1387604 & 688620 & 4.85 & 5.0805 & TST \\
\hline CHEMBL1581798 & 688620 & 4.8 & 4.7641 & TRN \\
\hline CHEMBL1549516 & 688620 & 4.9 & 4.865 & TRN \\
\hline CHEMBL1344391 & 688620 & 5.2 & 5.019 & TST \\
\hline CHEMBL1505975 & 688620 & 5.0 & 4.8806 & TRN \\
\hline CHEMBL1607203 & 688620 & 4.45 & 4.9662 & TRN \\
\hline CHEMBL1392810 & 688620 & 4.75 & 4.8474 & TRN \\
\hline CHEMBL1546758 & 688620 & 5.0 & 4.8807 & TRN \\
\hline CHEMBL31156 & 688620 & 4.9 & 4.88899 & 9999999999 \\
\hline CHEMBL1385176 & 688620 & 7.2503 & 5.051 & TST \\
\hline CHEMBL1401839 & 688620 & 5.5 & 5.038 & TRN \\
\hline CHEMBL3199022 & 688620 & 6.15 & 6.0498 & TRN \\
\hline CHEMBL3212305 & 688620 & 5.55 & 5.5772 & TRN \\
\hline CHEMBL 3197021 & 688620 & 6.3 & 5.8274 & TRN \\
\hline CHEMBL1430255 & 688620 & 5.35 & 5.6218 & TST \\
\hline CHEMBL1534443 & 688620 & 5.35 & 5.2245 & TRN \\
\hline CHEMBL1531675 & 688620 & 5.0 & 4.9969 & TRN \\
\hline
\end{tabular}




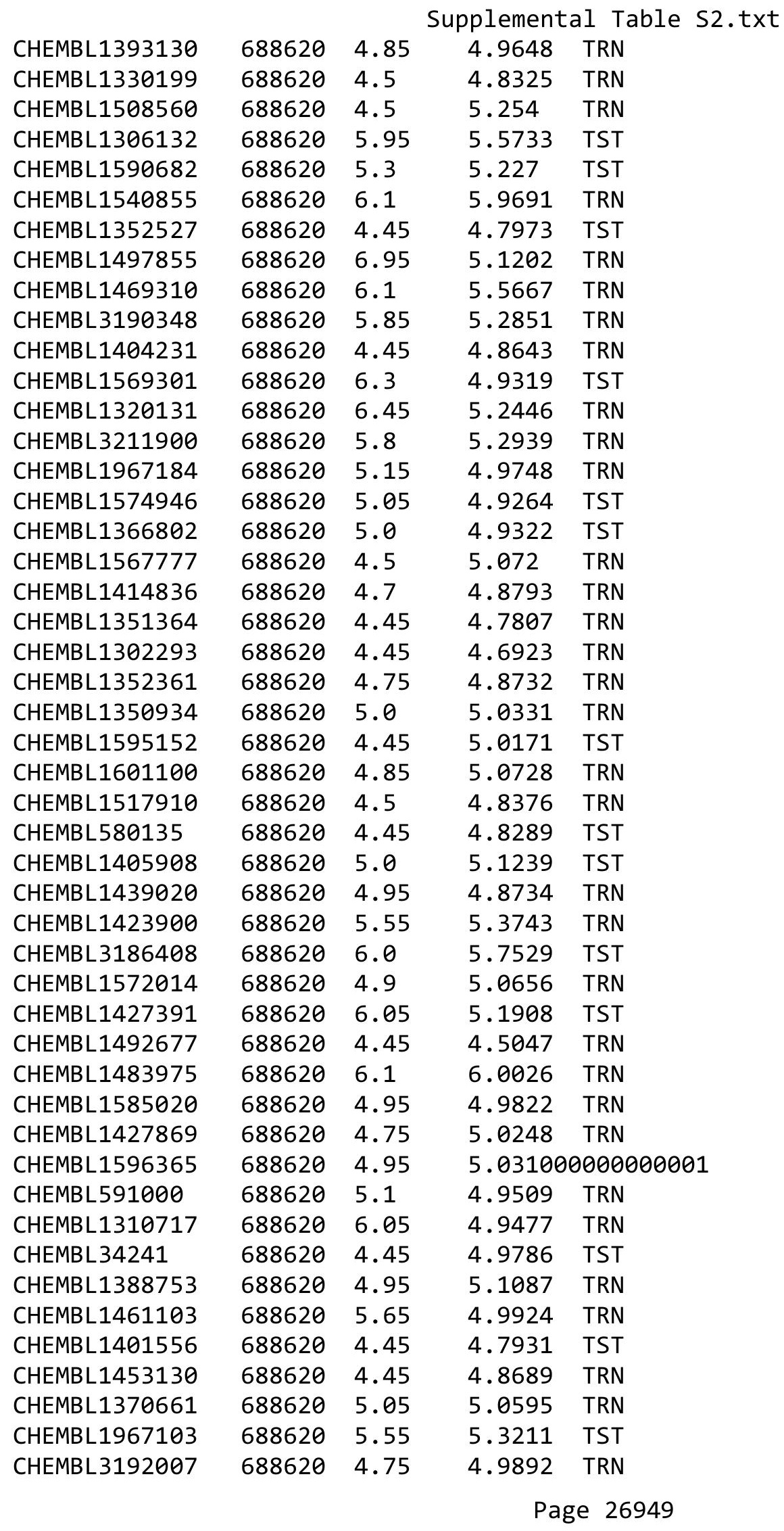

TRN 


\begin{tabular}{|c|c|c|c|c|c|}
\hline \multicolumn{6}{|c|}{ Supplemental Table S2.txt } \\
\hline CHEMBL3194707 & 688620 & 4.85 & 4.8624 & TRN & \\
\hline CHEMBL3193064 & 688620 & 4.9 & 4.9514 & TST & \\
\hline CHEMBL254275 & 688620 & 4.45 & 4.823 & TRN & \\
\hline CHEMBL 3192606 & 688620 & 4.9 & 5.1128 & TRN & \\
\hline CHEMBL1470840 & 688620 & 5.5 & 5.2714 & TRN & \\
\hline CHEMBL1323868 & 688620 & 4.95 & 4.8703 & TRN & \\
\hline CHEMBL3196706 & 688620 & 4.45 & 4.7599 & TRN & \\
\hline CHEMBL1367094 & 688620 & 4.65 & 4.9507 & TRN & \\
\hline CHEMBL1530313 & 688620 & 5.15 & 5.1305 & TRN & \\
\hline CHEMBL1546188 & 688620 & 4.5 & 5.0012 & TRN & \\
\hline CHEMBL1981357 & 688620 & 4.5 & 5.2747 & TST & \\
\hline CHEMBL341904 & 688620 & 6.3 & 6.1085 & TST & \\
\hline CHEMBL1389266 & 688620 & 4.85 & 5.0406 & TRN & \\
\hline CHEMBL1378984 & 688620 & 4.45 & 5.1095 & TRN & \\
\hline CHEMBL1435154 & 688620 & 4.95 & 4.9958 & TRN & \\
\hline CHEMBL1471295 & 688620 & 4.45 & 4.817 & TRN & \\
\hline CHEMBL1338492 & 688620 & 5.05 & 4.8244 & TRN & \\
\hline CHEMBL1453082 & 688620 & 5.55 & 5.0886 & TRN & \\
\hline CHEMBL1366566 & 688620 & 6.5501 & 5.1269 & TST & \\
\hline CHEMBL1976526 & 688620 & 4.85 & 4.9579 & TRN & \\
\hline CHEMBL1384167 & 688620 & 5.95 & 5.4689 & TRN & \\
\hline CHEMBL1454770 & 688620 & 4.65 & 4.8604 & TST & \\
\hline CHEMBL1508534 & 688620 & 4.9 & 4.9147 & TRN & \\
\hline CHEMBL1462016 & 688620 & 4.95 & 4.93199 & 99999999995 & TRN \\
\hline CHEMBL1551610 & 688620 & 5.5 & 5.4897 & TST & \\
\hline CHEMBL1541697 & 688620 & 4.45 & 4.6794 & TST & \\
\hline CHEMBL1310710 & 688620 & 4.85 & 4.8012 & TRN & \\
\hline CHEMBL1405320 & 688620 & 7.15 & 6.1638 & TRN & \\
\hline CHEMBL1566235 & 688620 & 4.45 & 5.0629 & TST & \\
\hline CHEMBL1583716 & 688620 & 4.85 & 4.9041 & TRN & \\
\hline CHEMBL1304589 & 688620 & 4.75 & 4.7767 & TRN & \\
\hline CHEMBL500272 & 688620 & 4.65 & 4.9997 & TST & \\
\hline CHEMBL1541904 & 688620 & 5.55 & 5.4835 & TRN & \\
\hline CHEMBL1431718 & 688620 & 4.8 & 5.1495 & TRN & \\
\hline CHEMBL1342728 & 688620 & 5.65 & 5.2431 & TRN & \\
\hline CHEMBL1370183 & 688620 & 5.05 & 4.8458 & TRN & \\
\hline CHEMBL1575590 & 688620 & 4.75 & 4.7114 & TRN & \\
\hline CHEMBL1484332 & 688620 & 5.05 & 5.1756 & TST & \\
\hline CHEMBL1301104 & 688620 & 5.15 & 5.3357 & TRN & \\
\hline CHEMBL1432104 & 688620 & 4.9 & 5.1872 & TRN & \\
\hline CHEMBL1551336 & 688620 & 5.15 & 4.9571 & TRN & \\
\hline CHEMBL3196432 & 688620 & 6.05 & 5.0897 & TRN & \\
\hline CHEMBL1449657 & 688620 & 4.95 & 5.0153 & TRN & \\
\hline CHEMBL1452706 & 688620 & 5.3 & 5.1016 & TRN & \\
\hline CHEMBL1604166 & 688620 & 5.55 & 5.1851 & TRN & \\
\hline CHEMBL1384782 & 688620 & 5.0 & 5.3441 & TRN & \\
\hline CHEMBL1979195 & 688620 & 5.35 & 5.5244 & TRN & \\
\hline CHEMBL1484462 & 688620 & 4.95 & 5.2089 & TST & \\
\hline
\end{tabular}




\begin{tabular}{|c|c|c|c|c|}
\hline \multicolumn{5}{|c|}{ Supplemental Table S2.txt } \\
\hline CHEMBL1582663 & 688620 & 4.5 & 5.0757 & TRN \\
\hline CHEMBL1486647 & 688620 & 4.85 & 4.9493 & TRN \\
\hline CHEMBL3199549 & 688620 & 4.95 & 5.0897 & TRN \\
\hline CHEMBL1596906 & 688620 & 4.7 & 4.8676 & TRN \\
\hline CHEMBL3193229 & 688620 & 4.95 & 5.2185 & TRN \\
\hline CHEMBL3212079 & 688620 & 6.05 & 5.2592 & TRN \\
\hline CHEMBL1480793 & 688620 & 5.75 & 5.3646 & TRN \\
\hline CHEMBL1369525 & 688620 & 4.75 & 4.9523 & TRN \\
\hline CHEMBL1313342 & 688620 & 5.1 & 5.0781 & TRN \\
\hline CHEMBL1611613 & 688620 & 4.5 & 4.9232 & TST \\
\hline CHEMBL1339718 & 688620 & 4.65 & 5.095 & TST \\
\hline CHEMBL1338166 & 688620 & 5.45 & 5.1265 & TRN \\
\hline CHEMBL1413019 & 688620 & 4.8 & 5.1942 & TRN \\
\hline CHEMBL1448690 & 688620 & 5.5 & 5.1951 & TRN \\
\hline CHEMBL1347572 & 688620 & 4.45 & 4.8979 & TST \\
\hline CHEMBL1418671 & 688620 & 5.15 & 5.0237 & TRN \\
\hline CHEMBL1532830 & 688620 & 5.2 & 5.075 & TRN \\
\hline CHEMBL1529932 & 688620 & 5.05 & 5.3664 & TRN \\
\hline CHEMBL3210386 & 688620 & 5.2 & 5.3927 & TRN \\
\hline CHEMBL1596460 & 688620 & 4.9 & 4.9728 & TRN \\
\hline CHEMBL1487063 & 688620 & 5.2 & 4.9651 & TRN \\
\hline CHEMBL1431910 & 688620 & 4.9 & 4.9766 & TST \\
\hline CHEMBL1528581 & 688620 & 4.95 & 5.2058 & TRN \\
\hline CHEMBL1464885 & 688620 & 5.0 & 4.9049 & TST \\
\hline CHEMBL3213086 & 688620 & 5.15 & 5.2178 & TRN \\
\hline CHEMBL3191957 & 688620 & 5.6 & 5.4326 & TRN \\
\hline CHEMBL1521026 & 688620 & 4.75 & 5.0153 & TST \\
\hline CHEMBL1300446 & 688620 & 6.1 & 6.3107 & TRN \\
\hline CHEMBL1389442 & 688620 & 4.45 & 5.1088 & TST \\
\hline CHEMBL1455331 & 688620 & 5.0 & 4.9293 & TRN \\
\hline CHEMBL1563189 & 688620 & 4.9 & 4.9907 & TRN \\
\hline CHEMBL1349243 & 688620 & 5.5 & 5.3314 & TST \\
\hline CHEMBL1462498 & 688620 & 5.55 & 5.0295 & TRN \\
\hline CHEMBL1320038 & 688620 & 4.8 & 5.0392 & TRN \\
\hline CHEMBL1541713 & 688620 & 5.5 & 5.4775 & TRN \\
\hline CHEMBL1306695 & 688620 & 5.4 & 5.1025 & TRN \\
\hline CHEMBL1561653 & 688620 & 5.0 & 5.0425 & TRN \\
\hline CHEMBL1478503 & 688620 & 4.65 & 4.9648 & TRN \\
\hline CHEMBL1482027 & 688620 & 4.45 & 5.2942 & TRN \\
\hline CHEMBL1403966 & 688620 & 4.95 & 5.0454 & TST \\
\hline CHEMBL1573039 & 688620 & 5.0 & 5.2167 & TRN \\
\hline CHEMBL1487117 & 688620 & 5.4 & 5.4291 & TRN \\
\hline CHEMBL1378907 & 688620 & 4.45 & 4.7503 & TST \\
\hline CHEMBL1407235 & 688620 & 4.45 & 4.8464 & TRN \\
\hline CHEMBL179288 & 688620 & 5.0 & 4.8759 & TST \\
\hline CHEMBL1408790 & 688620 & 4.6 & 4.8623 & TRN \\
\hline CHEMBL1524542 & 688620 & 6.0 & 4.9333 & TRN \\
\hline CHEMBL1583242 & 688620 & 4.9 & 4.8333 & TRN \\
\hline
\end{tabular}




\begin{tabular}{|c|c|c|c|c|}
\hline \multicolumn{5}{|c|}{ Supplemental Table S2.txt } \\
\hline CHEMBL1536068 & 688620 & 4.65 & 5.0825 & TRN \\
\hline CHEMBL1320946 & 688620 & 4.7 & 5.1287 & TRN \\
\hline CHEMBL1313593 & 688620 & 4.9 & 5.1911 & TRN \\
\hline CHEMBL1425769 & 688620 & 4.7 & 5.2762 & TST \\
\hline CHEMBL1301207 & 688620 & 6.2 & 5.1093 & TST \\
\hline CHEMBL1440320 & 688620 & 6.35 & 5.0949 & TST \\
\hline CHEMBL1356838 & 688620 & 4.9 & 5.1229 & TRN \\
\hline CHEMBL1968974 & 688620 & 5.1 & 5.0419 & TRN \\
\hline CHEMBL1605552 & 688620 & 6.45 & 5.9137 & TRN \\
\hline CHEMBL1497753 & 688620 & 4.7 & 5.0098 & TRN \\
\hline CHEMBL1522109 & 688620 & 5.0 & 5.1956 & TRN \\
\hline CHEMBL1384501 & 688620 & 5.1 & 5.1438 & TRN \\
\hline CHEMBL1568442 & 688620 & 4.95 & 5.0096 & TST \\
\hline CHEMBL1383321 & 688620 & 5.0 & 5.2642 & TRN \\
\hline CHEMBL1461833 & 688620 & 5.25 & 4.7953 & TRN \\
\hline CHEMBL1577162 & 688620 & 5.25 & 5.1114 & TRN \\
\hline CHEMBL1457508 & 688620 & 5.05 & 4.8755 & TRN \\
\hline CHEMBL1519949 & 688620 & 4.9 & 5.2002 & TST \\
\hline CHEMBL1604027 & 688620 & 4.45 & 4.7617 & TRN \\
\hline CHEMBL1448753 & 688620 & 4.6 & 4.9356 & TRN \\
\hline CHEMBL3145296 & 688620 & 6.5501 & 6.2813 & TST \\
\hline CHEMBL1585826 & 688620 & 5.2 & 4.5887 & TST \\
\hline CHEMBL1344866 & 688620 & 5.4 & 5.0554 & TST \\
\hline CHEMBL1477507 & 688620 & 4.8 & 4.8441 & TRN \\
\hline CHEMBL1352110 & 688620 & 4.45 & 5.0264 & TRN \\
\hline CHEMBL1458786 & 688620 & 4.85 & 4.8813 & TST \\
\hline CHEMBL3207695 & 688620 & 4.9 & 4.7468 & TRN \\
\hline CHEMBL1367619 & 688620 & 5.55 & 5.1503 & TST \\
\hline CHEMBL1408579 & 688620 & 4.9 & 5.3639 & TRN \\
\hline CHEMBL1493490 & 688620 & 5.45 & 5.2927 & TST \\
\hline CHEMBL1363057 & 688620 & 4.95 & 4.9694 & TST \\
\hline CHEMBL1430565 & 688620 & 4.9 & 5.0698 & TRN \\
\hline CHEMBL1368389 & 688620 & 4.7 & 5.0594 & TST \\
\hline CHEMBL1462116 & 688620 & 5.6 & 5.7765 & TRN \\
\hline CHEMBL1355712 & 688620 & 4.95 & 4.8829 & TRN \\
\hline CHEMBL1588987 & 688620 & 5.2 & 5.3674 & TST \\
\hline CHEMBL1413988 & 688620 & 4.8 & 5.0637 & TRN \\
\hline CHEMBL1588928 & 688620 & 4.7 & 4.9537 & TRN \\
\hline CHEMBL1451835 & 688620 & 4.75 & 4.8778 & TST \\
\hline CHEMBL1577440 & 688620 & 4.85 & 4.8414 & TST \\
\hline CHEMBL3198525 & 688620 & 5.6 & 4.9954 & TRN \\
\hline CHEMBL1329693 & 688620 & 4.45 & 4.9799 & TRN \\
\hline CHEMBL1390513 & 688620 & 4.45 & 5.0334 & TRN \\
\hline CHEMBL1546122 & 688620 & 4.55 & 5.3002 & TRN \\
\hline CHEMBL1456739 & 688620 & 5.0 & 4.9188 & TRN \\
\hline CHEMBL1518994 & 688620 & 6.2 & 5.6315 & TRN \\
\hline CHEMBL1524904 & 688620 & 4.85 & 4.9189 & TRN \\
\hline CHEMBL1427146 & 688620 & 5.3 & 5.7865 & TRN \\
\hline
\end{tabular}




\begin{tabular}{|c|c|c|c|c|c|}
\hline \multirow{2}{*}{ CHEMBL1964512 } & \multicolumn{5}{|c|}{ plement } \\
\hline & 688620 & 5.0 & 5.0821 & TRN & \\
\hline CHEMBL1346078 & 688620 & 4.7 & 5.04899 & 99999999995 & TRN \\
\hline CHEMBL1416800 & 688620 & 4.45 & 4.8779 & TRN & \\
\hline CHEMBL1590811 & 688620 & 4.95 & 5.0325 & TRN & \\
\hline CHEMBL3189206 & 688620 & 5.0 & 5.0646 & TRN & \\
\hline CHEMBL1441295 & 688620 & 5.15 & 4.9983 & TRN & \\
\hline CHEMBL1460523 & 688620 & 4.95 & 4.9078 & TST & \\
\hline CHEMBL1539406 & 688620 & 4.45 & 4.9147 & TRN & \\
\hline CHEMBL1603286 & 688620 & 4.45 & 5.0528 & TST & \\
\hline CHEMBL1367425 & 688620 & 4.8 & 5.034 & TRN & \\
\hline CHEMBL 2007357 & 688620 & 4.65 & 5.5024 & TRN & \\
\hline CHEMBL3212879 & 688620 & 5.25 & 5.1711 & TRN & \\
\hline CHEMBL1461601 & 688620 & 4.5 & 5.0174 & TRN & \\
\hline CHEMBL1606978 & 688620 & 5.5 & 4.9005 & TRN & \\
\hline CHEMBL1308385 & 688620 & 6.05 & 5.4546 & TST & \\
\hline CHEMBL3190770 & 688620 & 7.0 & 5.0104 & TRN & \\
\hline CHEMBL1336886 & 688620 & 4.95 & 5.0172 & TRN & \\
\hline CHEMBL1421559 & 688620 & 5.25 & 5.2176 & TRN & \\
\hline CHEMBL3209204 & 688620 & 4.7 & 4.9245 & TRN & \\
\hline CHEMBL1466628 & 688620 & 6.5501 & 6.1599 & TRN & \\
\hline CHEMBL1456381 & 688620 & 4.75 & 4.8155 & TRN & \\
\hline CHEMBL1342522 & 688620 & 5.1 & 4.8737 & TRN & \\
\hline CHEMBL1549142 & 688620 & 4.45 & 4.9845 & TST & \\
\hline CHEMBL1571570 & 688620 & 5.4 & 5.0775 & TST & \\
\hline CHEMBL1968859 & 688620 & 6.15 & 6.2891 & TRN & \\
\hline CHEMBL1350329 & 688620 & 4.8 & 4.6443 & TRN & \\
\hline CHEMBL1595510 & 688620 & 4.6 & 4.7069 & TRN & \\
\hline CHEMBL1368336 & 688620 & 4.95 & 5.1066 & TST & \\
\hline CHEMBL1307273 & 688620 & 4.6 & 4.8764 & TST & \\
\hline CHEMBL261870 & 688620 & 5.05 & 5.2965 & TRN & \\
\hline CHEMBL1343329 & 688620 & 4.95 & 4.7545 & TST & \\
\hline CHEMBL1360458 & 688620 & 4.9 & 5.1158 & TRN & \\
\hline CHEMBL1485855 & 688620 & 4.8 & 5.13399 & 99999999995 & TRN \\
\hline CHEMBL1470721 & 688620 & 5.5 & 5.1322 & TST & \\
\hline CHEMBL1410981 & 688620 & 6.1 & 5.0495 & TRN & \\
\hline CHEMBL1594427 & 688620 & 6.1 & 4.9599 & TRN & \\
\hline CHEMBL1461679 & 688620 & 4.95 & 5.0137 & TST & \\
\hline CHEMBL1578964 & 688620 & 4.9 & 5.0479 & TRN & \\
\hline CHEMBL1443860 & 688620 & 4.85 & 4.9203 & TRN & \\
\hline CHEMBL1302670 & 688620 & 5.2 & 5.4823 & TRN & \\
\hline CHEMBL 600070 & 688620 & 4.95 & 5.4304 & TRN & \\
\hline CHEMBL1354927 & 688620 & 4.65 & 4.96899 & 9999999999 & TRN \\
\hline CHEMBL1538489 & 688620 & 4.9 & 5.1838 & TRN & \\
\hline CHEMBL1579331 & 688620 & 5.25 & 5.2632 & TST & \\
\hline CHEMBL1533826 & 688620 & 4.45 & 5.0065 & TST & \\
\hline CHEMBL1440902 & 688620 & 4.45 & 4.7822 & TRN & \\
\hline CHEMBL1328433 & 688620 & 4.95 & 5.0286 & TRN & \\
\hline CHEMBL1607115 & 688620 & 5.85 & 5.5305 & TRN & \\
\hline
\end{tabular}




\begin{tabular}{|c|c|c|c|c|}
\hline \multicolumn{5}{|c|}{ Supplemental Table S2.txt } \\
\hline CHEMBL1369471 & 688620 & 4.9 & 4.9746 & TRN \\
\hline CHEMBL1507611 & 688620 & 4.9 & 5.2071 & TST \\
\hline CHEMBL1487639 & 688620 & 6.0 & 5.6947 & TRN \\
\hline CHEMBL1441337 & 688620 & 4.45 & 4.8364 & TRN \\
\hline CHEMBL376426 & 688620 & 4.45 & 4.8525 & TRN \\
\hline CHEMBL1450314 & 688620 & 4.9 & 5.0674 & TST \\
\hline CHEMBL1304197 & 688620 & 4.45 & 5.2182 & TRN \\
\hline CHEMBL1544983 & 688620 & 4.9 & 5.078 & TRN \\
\hline CHEMBL1328544 & 688620 & 4.45 & 5.4263 & TRN \\
\hline CHEMBL1579097 & 688620 & 4.65 & 5.0647 & TRN \\
\hline CHEMBL1337301 & 688620 & 5.25 & 5.2575 & TRN \\
\hline CHEMBL1517806 & 688620 & 5.0 & 4.92 & TRN \\
\hline CHEMBL1601688 & 688620 & 5.5 & 5.0355 & TRN \\
\hline CHEMBL1454214 & 688620 & 4.45 & 4.6405 & TRN \\
\hline CHEMBL1533658 & 688620 & 4.95 & 4.9526 & TRN \\
\hline CHEMBL1578176 & 688620 & 4.45 & 4.9794 & TRN \\
\hline CHEMBL2004916 & 688620 & 6.3 & 4.8614 & TST \\
\hline CHEMBL1326050 & 688620 & 5.0 & 5.1484 & TRN \\
\hline CHEMBL1504323 & 688620 & 5.15 & 5.0976 & TRN \\
\hline CHEMBL3210092 & 688620 & 4.9 & 4.8795 & TRN \\
\hline CHEMBL1492514 & 688620 & 4.9 & 5.0658 & TRN \\
\hline CHEMBL1570542 & 688620 & 4.85 & 5.1992 & TRN \\
\hline CHEMBL1469735 & 688620 & 4.95 & 4.9752 & TRN \\
\hline CHEMBL1358743 & 688620 & 6.0 & 5.629 & TST \\
\hline CHEMBL1359861 & 688620 & 5.05 & 5.2498 & TST \\
\hline CHEMBL1497594 & 688620 & 4.45 & 4.7843 & TRN \\
\hline CHEMBL1603908 & 688620 & 5.15 & 5.1962 & TRN \\
\hline CHEMBL1428752 & 688620 & 4.45 & 4.8624 & TRN \\
\hline CHEMBL1491910 & 688620 & 4.8 & 5.438 & TRN \\
\hline CHEMBL1596232 & 688620 & 4.9 & 4.8839 & TRN \\
\hline CHEMBL1487043 & 688620 & 4.8 & 5.066 & TST \\
\hline CHEMBL3197910 & 688620 & 5.0 & 4.8079 & TRN \\
\hline CHEMBL1538064 & 688620 & 5.5 & 5.1194 & TST \\
\hline CHEMBL1562332 & 688620 & 4.45 & 4.9661 & TST \\
\hline CHEMBL1540864 & 688620 & 4.45 & 5.1982 & TRN \\
\hline CHEMBL1565609 & 688620 & 4.5 & 5.1121 & TRN \\
\hline CHEMBL1461471 & 688620 & 5.15 & 5.2173 & TRN \\
\hline CHEMBL3198992 & 688620 & 5.15 & 4.8386 & TST \\
\hline CHEMBL1387295 & 688620 & 4.45 & 5.1921 & TRN \\
\hline CHEMBL1531020 & 688620 & 4.75 & 5.1275 & TST \\
\hline CHEMBL1505423 & 688620 & 4.45 & 4.8691 & TRN \\
\hline CHEMBL1308784 & 688620 & 4.95 & 5.2201 & TST \\
\hline CHEMBL123 & 688620 & 5.0 & 5.5965 & TST \\
\hline CHEMBL1451512 & 688620 & 4.9 & 5.2618 & TRN \\
\hline CHEMBL1527248 & 688620 & 4.65 & 5.1485 & TRN \\
\hline CHEMBL1312941 & 688620 & 5.2 & 4.9382 & TRN \\
\hline CHEMBL3197728 & 688620 & 4.75 & 5.3105 & TRN \\
\hline CHEMBL1333359 & 688620 & 5.5 & 4.9928 & TRN \\
\hline
\end{tabular}




\begin{tabular}{|c|c|c|c|c|}
\hline & & & pplemen & al $\mathrm{T}$ \\
\hline CHEMBL1458626 & 688620 & 4.5 & 4.8226 & TRN \\
\hline CHEMBL1518456 & 688620 & 6.5 & 4.8788 & TRN \\
\hline CHEMBL3213458 & 688620 & 4.95 & 5.1681 & TRN \\
\hline CHEMBL1965975 & 688620 & 5.0 & 5.1266 & TRN \\
\hline CHEMBL3197353 & 688620 & 4.95 & 5.0195 & TRN \\
\hline CHEMBL1418632 & 688620 & 5.75 & 5.2274 & TRN \\
\hline CHEMBL1567906 & 688620 & 4.95 & 5.3457 & TST \\
\hline CHEMBL1432186 & 688620 & 4.85 & 5.159 & TST \\
\hline CHEMBL1359417 & 688620 & 5.2 & 5.4812 & TRN \\
\hline CHEMBL3144884 & 688620 & 4.95 & 4.7633 & TST \\
\hline CHEMBL1341009 & 688620 & 4.45 & 4.9141 & TST \\
\hline CHEMBL1457571 & 688620 & 4.75 & 5.237 & TRN \\
\hline CHEMBL1300795 & 688620 & 4.65 & 4.987 & TST \\
\hline CHEMBL1389248 & 688620 & 4.6 & 5.1404 & TST \\
\hline CHEMBL1327546 & 688620 & 4.9 & 5.1045 & TST \\
\hline CHEMBL1449821 & 688620 & 5.05 & 5.3064 & TST \\
\hline CHEMBL1303184 & 688620 & 4.75 & 4.9609 & TST \\
\hline CHEMBL1542685 & 688620 & 4.9 & 5.0559 & TST \\
\hline CHEMBL1457356 & 688620 & 4.9 & 5.0553 & TST \\
\hline CHEMBL1584953 & 688620 & 4.45 & 5.2643 & TRN \\
\hline CHEMBL1386664 & 688620 & 5.2 & 5.3685 & TRN \\
\hline CHEMBL1305095 & 688620 & 4.7 & 4.8282 & TRN \\
\hline CHEMBL1331419 & 688620 & 4.45 & 5.0021 & TRN \\
\hline CHEMBL1535227 & 688620 & 4.75 & 4.9864 & TST \\
\hline CHEMBL1372314 & 688620 & 4.95 & 4.8436 & TRN \\
\hline CHEMBL1607585 & 688620 & 4.8 & 4.842 & TRN \\
\hline CHEMBL1405578 & 688620 & 4.7 & 5.0505 & TRN \\
\hline CHEMBL3197474 & 688620 & 5.15 & 5.1412 & TRN \\
\hline CHEMBL1377688 & 688620 & 4.8 & 5.2621 & TST \\
\hline CHEMBL3208293 & 688620 & 4.7 & 5.2863 & TRN \\
\hline CHEMBL1504902 & 688620 & 5.2 & 5.0556 & TST \\
\hline CHEMBL1488328 & 688620 & 5.55 & 5.039 & TRN \\
\hline CHEMBL1391399 & 688620 & 4.95 & 5.1501 & TRN \\
\hline CHEMBL1478575 & 688620 & 4.85 & 4.9064 & TRN \\
\hline CHEMBL1341567 & 688620 & 6.0 & 4.9929 & TST \\
\hline CHEMBL1455027 & 688620 & 5.15 & 5.1973 & TRN \\
\hline CHEMBL1327935 & 688620 & 5.5 & 5.1598 & TRN \\
\hline CHEMBL1588338 & 688620 & 4.9 & 5.1502 & TRN \\
\hline CHEMBL1353884 & 688620 & 4.9 & 4.9456 & TRN \\
\hline CHEMBL1386895 & 688620 & 4.95 & 5.0274 & TRN \\
\hline CHEMBL1979338 & 688620 & 5.35 & 5.3788 & TRN \\
\hline CHEMBL1345999 & 688620 & 4.65 & 4.7467 & TRN \\
\hline CHEMBL1299591 & 688620 & 4.9 & 5.1003 & TRN \\
\hline CHEMBL3196673 & 688620 & 5.75 & 4.933 & TRN \\
\hline CHEMBL1564492 & 688620 & 4.45 & 4.9144 & TRN \\
\hline CHEMBL1336953 & 688620 & 5.0 & 5.0009 & TRN \\
\hline CHEMBL1304996 & 688620 & 5.35 & 5.1966 & TRN \\
\hline CHEMBL1613268 & 688620 & 4.45 & 5.0749 & TRN \\
\hline
\end{tabular}




\begin{tabular}{|c|c|c|c|c|c|}
\hline \multicolumn{6}{|c|}{ Supplemental Table S2.txt } \\
\hline CHEMBL1490342 & 688620 & 4.95 & 5.0534 & TST & \\
\hline CHEMBL1562064 & 688620 & 4.8 & 5.0387 & TST & \\
\hline CHEMBL1495321 & 688620 & 5.05 & 4.8443 & TRN & \\
\hline CHEMBL1997543 & 688620 & 5.95 & 5.5932 & TST & \\
\hline CHEMBL3209330 & 688620 & 4.45 & 5.0838 & TRN & \\
\hline CHEMBL1362304 & 688620 & 5.15 & 4.9259 & TRN & \\
\hline CHEMBL1569387 & 688620 & 5.25 & 4.9635 & TRN & \\
\hline CHEMBL1431452 & 688620 & 4.45 & 4.9111 & TST & \\
\hline CHEMBL1376514 & 688620 & 4.8 & 4.9466 & TST & \\
\hline CHEMBL3194611 & 688620 & 5.4 & 5.3012 & TRN & \\
\hline CHEMBL1413742 & 688620 & 4.9 & 4.8689 & TST & \\
\hline CHEMBL1346908 & 688620 & 4.8 & 4.871 & TRN & \\
\hline CHEMBL1307765 & 688620 & 6.3 & 5.1248 & TRN & \\
\hline CHEMBL 297304 & 688620 & 6.4 & 5.42399 & 99999999995 & TST \\
\hline CHEMBL1504833 & 688620 & 4.45 & 4.4911 & TRN & \\
\hline CHEMBL1389431 & 688620 & 4.8 & 5.2244 & TRN & \\
\hline CHEMBL1315948 & 688620 & 4.95 & 4.668 & TRN & \\
\hline CHEMBL1535938 & 688620 & 5.15 & 5.096 & TST & \\
\hline CHEMBL1456929 & 688620 & 4.45 & 4.9587 & TRN & \\
\hline CHEMBL1409917 & 688620 & 4.45 & 4.7834 & TRN & \\
\hline CHEMBL1610003 & 688620 & 4.9 & 4.8946 & TRN & \\
\hline CHEMBL3189469 & 688620 & 5.15 & 5.2136 & TST & \\
\hline CHEMBL1573043 & 688620 & 6.1 & 5.3221 & TRN & \\
\hline CHEMBL1361282 & 688620 & 4.85 & 4.8879 & TRN & \\
\hline CHEMBL1494925 & 688620 & 4.75 & 4.7831 & TRN & \\
\hline CHEMBL1517120 & 688620 & 5.9 & 5.2279 & TST & \\
\hline CHEMBL1351750 & 688620 & 4.85 & 4.9598 & TRN & \\
\hline CHEMBL1392442 & 688620 & 5.65 & 5.1045 & TRN & \\
\hline CHEMBL1396886 & 688620 & 4.7 & 5.084 & TRN & \\
\hline CHEMBL1563210 & 688620 & 4.45 & 5.1545 & TRN & \\
\hline CHEMBL1426349 & 688620 & 4.9 & 4.9897 & TRN & \\
\hline CHEMBL1305534 & 688620 & 6.8499 & 5.0827 & TRN & \\
\hline CHEMBL1311288 & 688620 & 4.45 & 4.859 & TRN & \\
\hline CHEMBL1345811 & 688620 & 5.3 & 5.0544 & TRN & \\
\hline CHEMBL1489459 & 688620 & 5.3 & 5.4292 & TRN & \\
\hline CHEMBL1488480 & 688620 & 6.4 & 4.8892 & TRN & \\
\hline CHEMBL1529276 & 688620 & 5.05 & 4.8012 & TRN & \\
\hline CHEMBL1593722 & 688620 & 4.95 & 5.1536 & TST & \\
\hline CHEMBL1358925 & 688620 & 5.15 & 5.1812 & TRN & \\
\hline CHEMBL1597705 & 688620 & 4.8 & 5.235 & TST & \\
\hline CHEMBL1336234 & 688620 & 5.5 & 5.1843 & TST & \\
\hline CHEMBL1549158 & 688620 & 5.6 & 4.8521 & TST & \\
\hline CHEMBL1591140 & 688620 & 5.0 & 4.9914 & TRN & \\
\hline CHEMBL1487384 & 688620 & 4.7 & 4.9116 & TRN & \\
\hline CHEMBL1442369 & 688620 & 4.45 & 4.8991 & TRN & \\
\hline CHEMBL1277546 & 688620 & 5.85 & 5.7492 & TST & \\
\hline CHEMBL1304454 & 688620 & 4.9 & 4.6788 & TRN & \\
\hline CHEMBL3195891 & 688620 & 5.0 & 5.0609 & TRN & \\
\hline
\end{tabular}




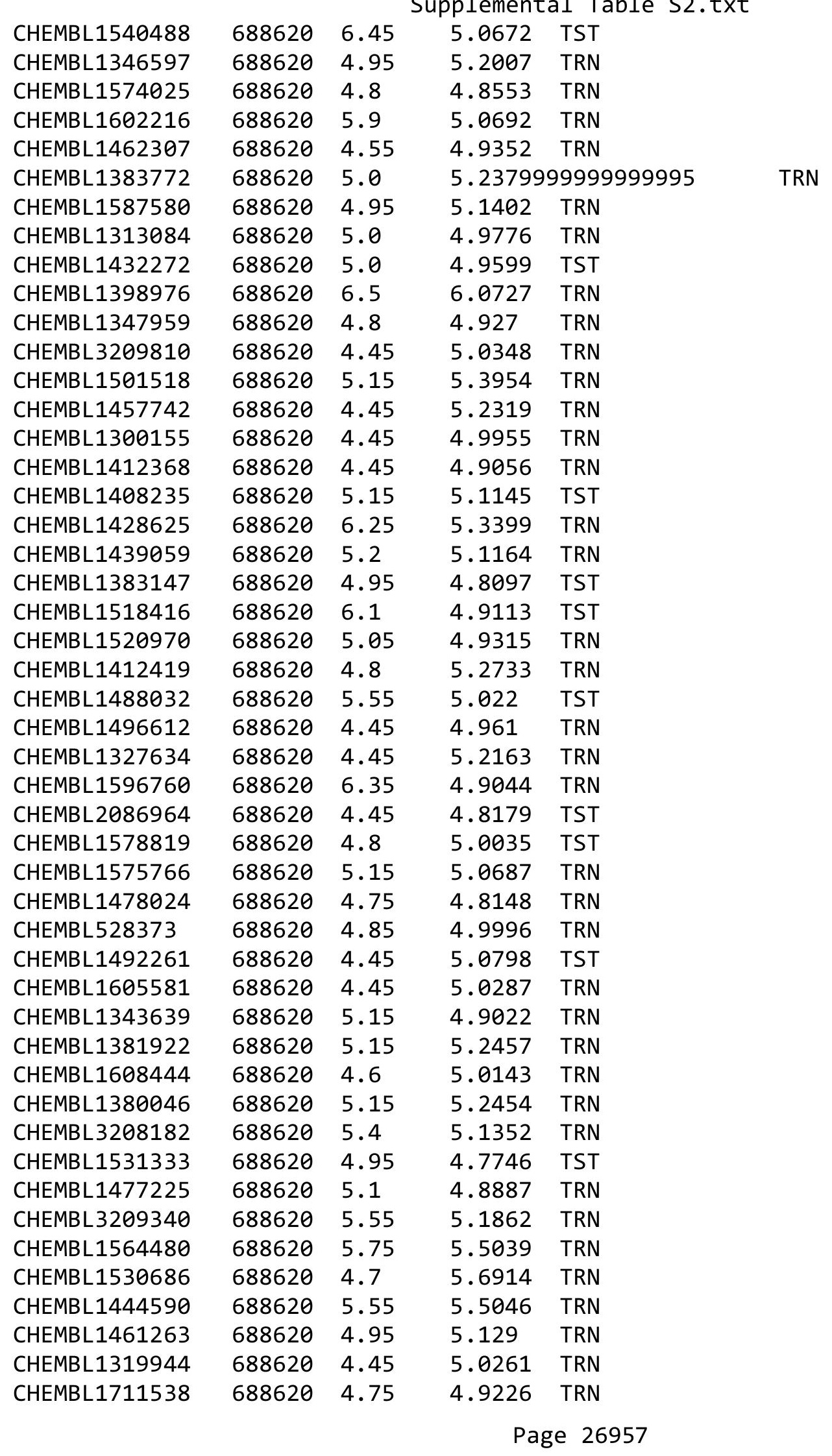




\begin{tabular}{|c|c|c|c|c|c|}
\hline & & \multicolumn{4}{|c|}{ Supplemental Table S2.txt } \\
\hline CHEMBL1538806 & 688620 & 4.45 & 4.7989 & TRN & \\
\hline CHEMBL1462507 & 688620 & 4.5 & 5.1437 & TRN & \\
\hline CHEMBL1456595 & 688620 & 4.6 & 4.7339 & TRN & \\
\hline CHEMBL1577590 & 688620 & 4.45 & 5.061 & TRN & \\
\hline CHEMBL1451096 & 688620 & 5.2 & 5.2288 & TRN & \\
\hline CHEMBL1336664 & 688620 & 4.95 & 4.9979 & TST & \\
\hline CHEMBL1540062 & 688620 & 4.8 & 4.9076 & TRN & \\
\hline CHEMBL1504303 & 688620 & 4.75 & 5.0279 & TRN & \\
\hline CHEMBL1333630 & 688620 & 4.45 & 5.0384 & TRN & \\
\hline CHEMBL1471517 & 688620 & 5.45 & 5.0939 & TST & \\
\hline CHEMBL1405503 & 688620 & 5.5 & 5.0774 & TRN & \\
\hline CHEMBL1362901 & 688620 & 5.2 & 5.2109 & TST & \\
\hline CHEMBL1471226 & 688620 & 4.95 & 4.9772 & TRN & \\
\hline CHEMBL1367275 & 688620 & 5.6 & 4.8222 & TRN & \\
\hline CHEMBL1326394 & 688620 & 4.85 & 5.3354 & TRN & \\
\hline CHEMBL1457924 & 688620 & 4.9 & 4.9255 & TRN & \\
\hline CHEMBL1304170 & 688620 & 4.5 & 4.87 & TST & \\
\hline CHEMBL1462048 & 688620 & 4.8 & 4.9396 & TST & \\
\hline CHEMBL1418194 & 688620 & 4.5 & 4.9908 & TRN & \\
\hline CHEMBL1533551 & 688620 & 5.1 & 4.883 & TST & \\
\hline CHEMBL1542736 & 688620 & 4.65 & 4.96399 & 99999999995 & TRN \\
\hline CHEMBL1319488 & 688620 & 5.9 & 5.5944 & TRN & \\
\hline CHEMBL1389836 & 688620 & 6.0 & 5.6694 & TRN & \\
\hline CHEMBL1323491 & 688620 & 5.05 & 5.3468 & TST & \\
\hline CHEMBL1574205 & 688620 & 4.85 & 4.8669 & TRN & \\
\hline CHEMBL1388138 & 688620 & 4.65 & 4.7708 & TRN & \\
\hline CHEMBL1484879 & 688620 & 5.0 & 4.7848 & TRN & \\
\hline CHEMBL1419442 & 688620 & 4.95 & 5.0643 & TRN & \\
\hline CHEMBL1302934 & 688620 & 4.95 & 5.1152 & TRN & \\
\hline CHEMBL1459641 & 688620 & 5.5 & 5.3041 & TRN & \\
\hline CHEMBL3194721 & 688620 & 5.45 & 5.1932 & TRN & \\
\hline CHEMBL521653 & 688620 & 5.7 & 4.8141 & TRN & \\
\hline CHEMBL1475166 & 688620 & 4.95 & 5.1227 & TST & \\
\hline CHEMBL1457616 & 688620 & 5.05 & 4.8407 & TRN & \\
\hline CHEMBL1575549 & 688620 & 4.75 & 5.1944 & TST & \\
\hline CHEMBL1523465 & 688620 & 4.55 & 5.1854 & TRN & \\
\hline CHEMBL1569989 & 688620 & 6.1 & 6.8946 & TRN & \\
\hline CHEMBL1481733 & 688620 & 4.9 & 5.2217 & TST & \\
\hline CHEMBL1599168 & 688620 & 6.15 & 5.5472 & TRN & \\
\hline CHEMBL1359648 & 688620 & 5.6 & 5.4307 & TRN & \\
\hline CHEMBL532412 & 688620 & 4.45 & 4.9708 & TRN & \\
\hline CHEMBL1363275 & 688620 & 4.95 & 4.647 & TRN & \\
\hline CHEMBL1533683 & 688620 & 4.7 & 4.9488 & TRN & \\
\hline CHEMBL1708510 & 688620 & 5.9 & 5.2671 & TST & \\
\hline CHEMBL1390557 & 688620 & 5.0 & 4.9845 & TRN & \\
\hline CHEMBL1460038 & 688620 & 5.55 & 5.1879 & TRN & \\
\hline CHEMBL1540779 & 688620 & 4.45 & 5.1272 & TRN & \\
\hline CHEMBL 3195185 & 688620 & 6.35 & 5.5985 & TRN & \\
\hline
\end{tabular}




\begin{tabular}{|c|c|c|c|c|}
\hline \multicolumn{5}{|c|}{ Supplemental Table S2.txt } \\
\hline CHEMBL1510343 & 688620 & 5.15 & 5.1026 & TST \\
\hline CHEMBL1365945 & 688620 & 5.1 & 4.9798 & TRN \\
\hline CHEMBL1448671 & 688620 & 4.45 & 5.0002 & TRN \\
\hline CHEMBL1393205 & 688620 & 4.45 & 4.7621 & TRN \\
\hline CHEMBL560579 & 688620 & 4.6 & 5.0191 & TST \\
\hline CHEMBL1449562 & 688620 & 5.9 & 5.131 & TRN \\
\hline CHEMBL1320005 & 688620 & 4.45 & 5.0948 & TRN \\
\hline CHEMBL1463227 & 688620 & 4.75 & 4.9866 & TST \\
\hline CHEMBL1558250 & 688620 & 5.5 & 5.2021 & TRN \\
\hline CHEMBL1532113 & 688620 & 4.45 & 5.0686 & TRN \\
\hline CHEMBL 2003567 & 688620 & 6.2 & 5.8814 & TRN \\
\hline CHEMBL1457262 & 688620 & 4.45 & 4.8707 & TST \\
\hline CHEMBL1347577 & 688620 & 4.45 & 4.9814 & TST \\
\hline CHEMBL1986343 & 688620 & 6.05 & 5.8127 & TRN \\
\hline CHEMBL3191258 & 688620 & 4.45 & 5.1625 & TST \\
\hline CHEMBL1502112 & 688620 & 4.85 & 4.9184 & TRN \\
\hline CHEMBL1555886 & 688620 & 5.1 & 4.8824 & TRN \\
\hline CHEMBL1307112 & 688620 & 4.9 & 5.1042 & TST \\
\hline CHEMBL1339764 & 688620 & 4.9 & 5.2439 & TST \\
\hline CHEMBL1538246 & 688620 & 4.9 & 5.2228 & TRN \\
\hline CHEMBL1454995 & 688620 & 5.45 & 5.1065 & TRN \\
\hline CHEMBL1436042 & 688620 & 5.0 & 4.8944 & TRN \\
\hline CHEMBL398206 & 688620 & 4.95 & 5.3181 & TRN \\
\hline CHEMBL1596903 & 688620 & 4.5 & 5.0817 & TST \\
\hline CHEMBL1970272 & 688620 & 5.55 & 5.2377 & TST \\
\hline CHEMBL1488793 & 688620 & 5.45 & 5.1247 & TRN \\
\hline CHEMBL1527629 & 688620 & 4.75 & 5.0262 & TRN \\
\hline CHEMBL1391068 & 688620 & 4.45 & 4.9457 & TRN \\
\hline CHEMBL1492420 & 688620 & 5.45 & 5.2036 & TRN \\
\hline CHEMBL1530979 & 688620 & 4.9 & 5.1326 & TST \\
\hline CHEMBL1457794 & 688620 & 5.75 & 4.7189 & TST \\
\hline CHEMBL1358774 & 688620 & 5.5 & 5.2244 & TRN \\
\hline CHEMBL1602147 & 688620 & 4.55 & 4.9343 & TRN \\
\hline CHEMBL1523157 & 688620 & 5.15 & 5.1481 & TRN \\
\hline CHEMBL1583849 & 688620 & 4.8 & 5.1978 & TRN \\
\hline CHEMBL1421441 & 688620 & 4.8 & 4.7994 & TRN \\
\hline CHEMBL1469111 & 688620 & 6.2 & 6.3345 & TRN \\
\hline CHEMBL1490661 & 688620 & 5.05 & 5.0353 & TST \\
\hline CHEMBL1607369 & 688620 & 4.8 & 4.9498 & TST \\
\hline CHEMBL1495013 & 688620 & 5.0 & 4.9392 & TRN \\
\hline CHEMBL1581928 & 688620 & 4.75 & 4.9456 & TST \\
\hline CHEMBL1378829 & 688620 & 4.45 & 4.9935 & TRN \\
\hline CHEMBL3192495 & 688620 & 6.1 & 5.1756 & TRN \\
\hline CHEMBL262347 & 688620 & 6.45 & 5.2792 & TRN \\
\hline CHEMBL1559045 & 688620 & 6.5 & 5.0016 & TST \\
\hline CHEMBL1595277 & 688620 & 5.0 & 4.8697 & TRN \\
\hline CHEMBL1306401 & 688620 & 6.15 & 4.957 & TRN \\
\hline CHEMBL1494551 & 688620 & 4.45 & 5.1111 & TRN \\
\hline
\end{tabular}




\begin{tabular}{|c|c|c|c|c|}
\hline \\
\hline CHEMBL1601046 & 688620 & 4.9 & 4.9421 & TRN \\
\hline CHEMBL1583505 & 688620 & 5.7 & 5.1768 & TRN \\
\hline CHEMBL1366124 & 688620 & 4.55 & 4.9067 & TRN \\
\hline CHEMBL1344192 & 688620 & 4.95 & 4.9835 & TRN \\
\hline CHEMBL1613522 & 688620 & 4.95 & 5.0138 & TRN \\
\hline CHEMBL1490055 & 688620 & 5.4 & 4.9654 & TRN \\
\hline CHEMBL1546134 & 688620 & 5.35 & 5.1766 & TRN \\
\hline CHEMBL3191208 & 688620 & 5.3 & 4.7194 & TRN \\
\hline CHEMBL1449558 & 688620 & 5.25 & 4.9185 & TRN \\
\hline CHEMBL1517143 & 688620 & 4.95 & 5.3405 & TRN \\
\hline CHEMBL1380365 & 688620 & 4.85 & 4.831 & TRN \\
\hline CHEMBL1341197 & 688620 & 4.75 & 5.0482 & TRN \\
\hline CHEMBL1360044 & 688620 & 4.95 & 6.1591 & TRN \\
\hline CHEMBL1559671 & 688620 & 5.15 & 5.1457 & TST \\
\hline CHEMBL1452585 & 688620 & 5.4 & 5.1308 & TST \\
\hline CHEMBL1518080 & 688620 & 5.0 & 4.8535 & TST \\
\hline CHEMBL1315868 & 688620 & 4.45 & 5.0009 & TST \\
\hline CHEMBL1375216 & 688620 & 4.95 & 5.0335 & TRN \\
\hline CHEMBL1466699 & 688620 & 4.45 & 5.0997 & TRN \\
\hline CHEMBL1315338 & 688620 & 4.9 & 4.8359 & TRN \\
\hline CHEMBL1459544 & 688620 & 4.45 & 4.9353 & TST \\
\hline CHEMBL1498500 & 688620 & 4.45 & 4.8837 & TRN \\
\hline CHEMBL3195461 & 688620 & 4.65 & 4.9661 & TST \\
\hline CHEMBL1418554 & 688620 & 5.7 & 5.0302 & TRN \\
\hline CHEMBL3209149 & 688620 & 5.2 & 4.8855 & TRN \\
\hline CHEMBL1498431 & 688620 & 4.8 & 5.0044 & TRN \\
\hline CHEMBL1300275 & 688620 & 4.8 & 5.058 & TRN \\
\hline CHEMBL1464645 & 688620 & 5.8 & 5.478 & TRN \\
\hline CHEMBL1427525 & 688620 & 4.75 & 4.9778 & TRN \\
\hline CHEMBL1566993 & 688620 & 4.95 & 4.7434 & TRN \\
\hline CHEMBL1336284 & 688620 & 4.85 & 5.2808 & TST \\
\hline CHEMBL1349615 & 688620 & 4.7 & 4.9203 & TRN \\
\hline CHEMBL1598281 & 688620 & 4.85 & 5.1484 & TST \\
\hline CHEMBL1538075 & 688620 & 4.45 & 5.1412 & TRN \\
\hline CHEMBL1493447 & 688620 & 5.45 & 5.2648 & TRN \\
\hline CHEMBL1556644 & 688620 & 4.45 & 4.9796 & TRN \\
\hline CHEMBL1303886 & 688620 & 4.75 & 5.0645 & TRN \\
\hline CHEMBL1460624 & 688620 & 4.65 & 4.9245 & TST \\
\hline CHEMBL1529622 & 688620 & 5.0 & 4.8943 & TST \\
\hline CHEMBL1508074 & 688620 & 4.9 & 5.0964 & TRN \\
\hline CHEMBL1523659 & 688620 & 5.55 & 4.9404 & TRN \\
\hline CHEMBL1533104 & 688620 & 4.45 & 5.1128 & TRN \\
\hline CHEMBL1550095 & 688620 & 5.2 & $5.1620 e$ & 0000000001 \\
\hline CHEMBL1575772 & 688620 & 4.6 & 4.9597 & TRN \\
\hline CHEMBL1510572 & 688620 & 5.3 & 5.0318 & TRN \\
\hline CHEMBL1435812 & 688620 & 4.9 & 4.908 & TRN \\
\hline CHEMBL1992286 & 688620 & 4.45 & 4.8435 & TRN \\
\hline CHEMBL1381607 & 688620 & 4.45 & 4.9981 & TRN \\
\hline
\end{tabular}

TRN 


\begin{tabular}{|c|c|c|c|c|c|}
\hline \multirow[b]{2}{*}{ CHEMBL1446722 } & \multicolumn{5}{|c|}{ Supplemental Table S2.txt } \\
\hline & 688620 & 5.95 & 5.2931 & TRN & \\
\hline CHEMBL1328741 & 688620 & 5.85 & 5.17399 & 99999999995 & TRN \\
\hline CHEMBL1595228 & 688620 & 4.9 & 4.9371 & TRN & \\
\hline CHEMBL3191242 & 688620 & 4.95 & 5.2483 & TRN & \\
\hline CHEMBL1379749 & 688620 & 5.15 & 5.0779 & TRN & \\
\hline CHEMBL1308789 & 688620 & 4.45 & 4.8339 & TRN & \\
\hline CHEMBL1494725 & 688620 & 4.65 & 4.904 & TST & \\
\hline CHEMBL452328 & 688620 & 4.95 & 4.8007 & TRN & \\
\hline CHEMBL1320386 & 688620 & 6.25 & 5.5212 & TRN & \\
\hline CHEMBL1499152 & 688620 & 5.95 & 5.2768 & TRN & \\
\hline CHEMBL3193408 & 688620 & 4.9 & 5.1417 & TRN & \\
\hline CHEMBL1350400 & 688620 & 4.45 & 4.8487 & TRN & \\
\hline CHEMBL1571228 & 688620 & 4.6 & 4.9773 & TRN & \\
\hline CHEMBL1469846 & 688620 & 5.6 & 5.3159 & TRN & \\
\hline CHEMBL1482746 & 688620 & 4.95 & 5.0954 & TST & \\
\hline CHEMBL1567101 & 688620 & 4.45 & 5.0439 & TRN & \\
\hline CHEMBL1335489 & 688620 & 4.9 & 5.1497 & TRN & \\
\hline CHEMBL3190921 & 688620 & 4.45 & 4.8181 & TRN & \\
\hline CHEMBL3213016 & 688620 & 5.15 & 5.3466 & TRN & \\
\hline CHEMBL1369149 & 688620 & 4.6 & 4.9235 & TRN & \\
\hline CHEMBL1421073 & 688620 & 4.8 & 5.0736 & TRN & \\
\hline CHEMBL1421086 & 688620 & 5.0 & 5.1265 & TRN & \\
\hline CHEMBL1403318 & 688620 & 5.75 & 5.0723 & TRN & \\
\hline CHEMBL1530260 & 688620 & 4.7 & 4.7165 & TRN & \\
\hline CHEMBL1601036 & 688620 & 4.9 & 5.1898 & TRN & \\
\hline CHEMBL1427614 & 688620 & 4.75 & 4.928 & TRN & \\
\hline CHEMBL1597128 & 688620 & 4.45 & 4.729 & TRN & \\
\hline CHEMBL1435296 & 688620 & 4.95 & 5.0669 & TRN & \\
\hline CHEMBL1332361 & 688620 & 4.8 & 4.9979 & TRN & \\
\hline CHEMBL1501676 & 688620 & 5.45 & 5.5957 & TRN & \\
\hline CHEMBL1345814 & 688620 & 6.25 & 5.0122 & TRN & \\
\hline CHEMBL1966224 & 688620 & 4.7 & 4.7531 & TST & \\
\hline CHEMBL1527084 & 688620 & 4.65 & 4.8278 & TST & \\
\hline CHEMBL1531260 & 688620 & 4.45 & 4.9934 & TRN & \\
\hline CHEMBL1499533 & 688620 & 5.2 & 5.28299 & 99999999995 & TST \\
\hline CHEMBL1555562 & 688620 & 8.4949 & 5.2012 & TRN & \\
\hline CHEMBL1605150 & 688620 & 4.6 & 5.0786 & TST & \\
\hline CHEMBL1340965 & 688620 & 4.45 & 4.7916 & TRN & \\
\hline CHEMBL 3191444 & 688620 & 5.8 & 5.3479 & TRN & \\
\hline CHEMBL1426440 & 688620 & 4.8 & 5.3016 & TRN & \\
\hline CHEMBL1567268 & 688620 & 6.1 & 4.9642 & TRN & \\
\hline CHEMBL1506962 & 688620 & 4.65 & 4.808 & TRN & \\
\hline CHEMBL1521888 & 688620 & 5.0 & 5.0229 & TRN & \\
\hline CHEMBL1483076 & 688620 & 4.95 & 5.1012 & TRN & \\
\hline CHEMBL1504179 & 688620 & 4.6 & 4.9572 & TST & \\
\hline CHEMBL1971151 & 688620 & 4.6 & 4.7612 & TRN & \\
\hline CHEMBL3199154 & 688620 & 4.95 & 5.1224 & TRN & \\
\hline CHEMBL1336396 & 688620 & 4.65 & 4.8286 & TST & \\
\hline
\end{tabular}




\begin{tabular}{|c|c|c|c|c|c|}
\hline \\
\hline CHEMBL1459701 & 688620 & 5.3 & 5.1684 & TRN & \\
\hline CHEMBL1508450 & 688620 & 4.95 & 4.8016 & TRN & \\
\hline CHEMBL1558787 & 688620 & 4.45 & 5.0252 & TRN & \\
\hline CHEMBL1531732 & 688620 & 6.4 & 5.0269 & TRN & \\
\hline CHEMBL1350252 & 688620 & 4.45 & 5.2888 & TRN & \\
\hline CHEMBL1393659 & 688620 & 4.5 & 5.1263 & TRN & \\
\hline CHEMBL1496075 & 688620 & 5.0 & 5.0287 & TST & \\
\hline CHEMBL1477707 & 688620 & 4.45 & 4.8561 & TST & \\
\hline CHEMBL1373063 & 688620 & 5.0 & 5.1457 & TST & \\
\hline CHEMBL3193389 & 688620 & 6.35 & 5.715 & TRN & \\
\hline CHEMBL1347511 & 688620 & 5.15 & 5.0171 & TRN & \\
\hline CHEMBL 281980 & 688620 & 4.45 & 5.6267 & TRN & \\
\hline CHEMBL1605865 & 688620 & 5.05 & 4.9676 & TRN & \\
\hline CHEMBL3191922 & 688620 & 5.3 & 5.157 & TRN & \\
\hline CHEMBL3198332 & 688620 & 5.8 & 5.4013 & TRN & \\
\hline CHEMBL1418843 & 688620 & 4.45 & 5.0786 & TRN & \\
\hline CHEMBL1585669 & 688620 & 4.45 & 5.0072 & TRN & \\
\hline CHEMBL1524889 & 688620 & 6.0 & 5.3579 & TRN & \\
\hline CHEMBL1415617 & 688620 & 5.15 & 4.92399 & 99999999995 & TRN \\
\hline CHEMBL1997059 & 688620 & 6.1 & 5.1864 & TST & \\
\hline CHEMBL1446190 & 688620 & 4.45 & 5.1001 & TST & \\
\hline CHEMBL1470650 & 688620 & 5.8 & 5.1392 & TRN & \\
\hline CHEMBL1486569 & 688620 & 5.3 & 5.2893 & TST & \\
\hline CHEMBL1364157 & 688620 & 4.9 & 5.0654 & TRN & \\
\hline CHEMBL1524403 & 688620 & 4.45 & 4.6222 & TRN & \\
\hline CHEMBL1484227 & 688620 & 4.9 & 5.0009 & TST & \\
\hline CHEMBL1347099 & 688620 & 5.15 & 5.121 & TRN & \\
\hline CHEMBL1546631 & 688620 & 5.65 & 5.0304 & TRN & \\
\hline CHEMBL1340853 & 688620 & 5.0 & 4.9947 & TRN & \\
\hline CHEMBL1345564 & 688620 & 4.95 & 5.1652 & TRN & \\
\hline CHEMBL1559258 & 688620 & 6.45 & 6.13200 & 0000000001 & TRN \\
\hline CHEMBL1561880 & 688620 & 5.1 & 4.9023 & TRN & \\
\hline CHEMBL1451228 & 688620 & 4.65 & 5.4173 & TRN & \\
\hline CHEMBL1487730 & 688620 & 5.35 & 5.1927 & TRN & \\
\hline CHEMBL1501625 & 688620 & 4.35 & 5.075 & TRN & \\
\hline CHEMBL483190 & 688620 & 4.45 & 4.7989 & TRN & \\
\hline CHEMBL1306426 & 688620 & 5.05 & 4.9068 & TRN & \\
\hline CHEMBL1579451 & 688620 & 6.05 & 5.8035 & TRN & \\
\hline CHEMBL1606858 & 688620 & 5.05 & 4.9036 & TRN & \\
\hline CHEMBL1542109 & 688620 & 4.65 & 4.9131 & TRN & \\
\hline CHEMBL1565407 & 688620 & 4.95 & 4.9215 & TRN & \\
\hline CHEMBL1524664 & 688620 & 4.95 & 5.0126 & TRN & \\
\hline CHEMBL1300363 & 688620 & 4.65 & 5.0858 & TRN & \\
\hline CHEMBL3199102 & 688620 & 4.95 & 4.8852 & TRN & \\
\hline CHEMBL1313352 & 688620 & 5.05 & 4.89199 & 99999999995 & TRN \\
\hline CHEMBL1331573 & 688620 & 5.2 & 5.285 & TST & \\
\hline CHEMBL1445489 & 688620 & 4.95 & 4.8334 & TRN & \\
\hline CHEMBL1443875 & 688620 & 5.65 & 5.4252 & TRN & \\
\hline
\end{tabular}




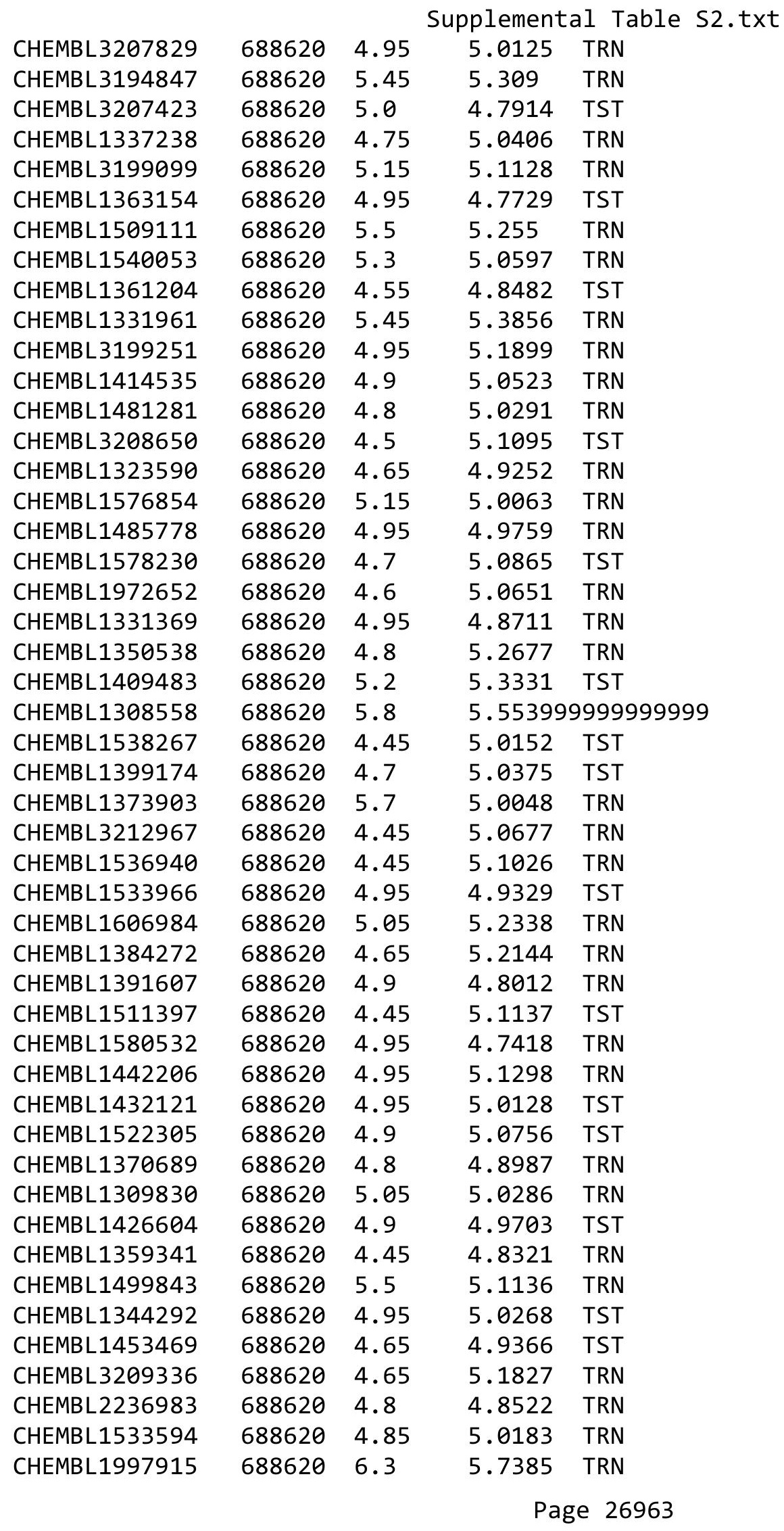




\begin{tabular}{|c|c|c|c|c|c|}
\hline \multicolumn{6}{|c|}{ Supplemental Table S2.txt } \\
\hline CHEMBL1412731 & 688620 & 4.95 & 5.0548 & TRN & \\
\hline CHEMBL3196976 & 688620 & 5.6 & 5.5474 & TRN & \\
\hline CHEMBL1341722 & 688620 & 4.85 & 5.2317 & TRN & \\
\hline CHEMBL1387154 & 688620 & 4.45 & 5.2122 & TRN & \\
\hline CHEMBL1342903 & 688620 & 5.1 & 5.0277 & TRN & \\
\hline CHEMBL1505492 & 688620 & 5.2 & 4.9437 & TRN & \\
\hline CHEMBL1584584 & 688620 & 4.85 & 4.566 & TRN & \\
\hline CHEMBL1346226 & 688620 & 5.75 & 4.7928 & TRN & \\
\hline CHEMBL1506551 & 688620 & 4.9 & 4.9996 & TRN & \\
\hline CHEMBL1579346 & 688620 & 5.05 & 5.1154 & TRN & \\
\hline CHEMBL1300563 & 688620 & 5.2 & 5.1836 & TRN & \\
\hline CHEMBL1566030 & 688620 & 4.75 & 4.944 & TRN & \\
\hline CHEMBL1567314 & 688620 & 4.95 & 5.0046 & TRN & \\
\hline CHEMBL1539273 & 688620 & 4.95 & 4.8777 & TRN & \\
\hline CHEMBL1338369 & 688620 & 4.45 & 5.1155 & TRN & \\
\hline CHEMBL1582890 & 688620 & 5.55 & 5.0336 & TRN & \\
\hline CHEMBL1598219 & 688620 & 8.301 & 5.1692 & TRN & \\
\hline CHEMBL1549800 & 688620 & 4.95 & 5.0771 & TRN & \\
\hline CHEMBL1501209 & 688620 & 5.25 & 4.8977 & TST & \\
\hline CHEMBL1339071 & 688620 & 4.65 & 4.7911 & TRN & \\
\hline CHEMBL1334246 & 688620 & 4.75 & 5.1748 & TRN & \\
\hline CHEMBL1452597 & 688620 & 4.95 & 5.2051 & TRN & \\
\hline CHEMBL1364278 & 688620 & 5.5 & $4.8580 e$ & 00000000005 & TRN \\
\hline CHEMBL1382827 & 688620 & 4.95 & 5.4705 & TRN & \\
\hline CHEMBL3195514 & 688620 & 4.9 & 5.1788 & TST & \\
\hline CHEMBL1308307 & 688620 & 5.0 & 5.1858 & TST & \\
\hline CHEMBL1451787 & 688620 & 4.9 & 5.1109 & TRN & \\
\hline CHEMBL472437 & 688620 & 5.55 & 5.3992 & TST & \\
\hline CHEMBL3192928 & 688620 & 5.2 & 5.7179 & TRN & \\
\hline CHEMBL1994803 & 688620 & 4.75 & 4.9872 & TRN & \\
\hline CHEMBL1488183 & 688620 & 5.5 & 5.1928 & TRN & \\
\hline CHEMBL1603638 & 688620 & 4.85 & 5.0953 & TRN & \\
\hline CHEMBL1455522 & 688620 & 4.95 & 5.0922 & TRN & \\
\hline CHEMBL1348903 & 688620 & 6.1 & 5.1966 & TRN & \\
\hline CHEMBL1335091 & 688620 & 5.2 & 5.0151 & TRN & \\
\hline CHEMBL1422310 & 688620 & 4.5 & 5.0887 & TST & \\
\hline CHEMBL1980737 & 688620 & 5.0 & 5.2097 & TRN & \\
\hline CHEMBL1447125 & 688620 & 4.45 & 5.1325 & TRN & \\
\hline CHEMBL1533770 & 688620 & 5.55 & 5.5221 & TRN & \\
\hline CHEMBL1577900 & 688620 & 4.9 & 5.2821 & TST & \\
\hline CHEMBL1375644 & 688620 & 5.2 & 4.925 & TRN & \\
\hline CHEMBL1604117 & 688620 & 4.45 & 4.8213 & TRN & \\
\hline CHEMBL1438962 & 688620 & 4.8 & 5.0937 & TST & \\
\hline CHEMBL1374003 & 688620 & 4.45 & 5.1253 & TST & \\
\hline CHEMBL3199297 & 688620 & 4.95 & 5.0813 & TRN & \\
\hline CHEMBL1426350 & 688620 & 4.85 & 5.0748 & TRN & \\
\hline CHEMBL1534202 & 688620 & 4.45 & $5.1610 e$ & 20000000005 & TST \\
\hline CHEMBL1324812 & 688620 & 5.5 & 5.171 & TRN & \\
\hline
\end{tabular}




\begin{tabular}{|c|c|c|c|c|c|}
\hline \\
\hline CHEMBL3198170 & 688620 & 4.95 & 4.8861 & TST & \\
\hline CHEMBL1556824 & 688620 & 4.45 & 5.1014 & TST & \\
\hline CHEMBL1367269 & 688620 & 5.3 & 5.4509 & TRN & \\
\hline CHEMBL1439370 & 688620 & 4.45 & 4.8784 & TRN & \\
\hline CHEMBL1377632 & 688620 & 5.85 & 5.2878 & TST & \\
\hline CHEMBL1563240 & 688620 & 5.45 & 5.1017 & TRN & \\
\hline CHEMBL1421596 & 688620 & 5.0 & 5.095 & TRN & \\
\hline CHEMBL1411457 & 688620 & 4.85 & 4.8883 & TRN & \\
\hline CHEMBL1448249 & 688620 & 5.4 & 5.1459 & TRN & \\
\hline CHEMBL1451922 & 688620 & 4.65 & 5.1997 & TST & \\
\hline CHEMBL1544253 & 688620 & 5.1 & 5.0643 & TRN & \\
\hline CHEMBL1526648 & 688620 & 5.1 & 4.8631 & TRN & \\
\hline CHEMBL1498207 & 688620 & 4.95 & 4.8597 & TRN & \\
\hline CHEMBL1344157 & 688620 & 4.6 & 4.71 & TST & \\
\hline CHEMBL1347692 & 688620 & 5.0 & 5.05699 & 99999999995 & TST \\
\hline CHEMBL1437982 & 688620 & 8.301 & 4.9605 & TRN & \\
\hline CHEMBL1335237 & 688620 & 4.65 & 5.0283 & TST & \\
\hline CHEMBL1363564 & 688620 & 4.45 & 5.1203 & TRN & \\
\hline CHEMBL1583765 & 688620 & 4.6 & 4.8642 & TRN & \\
\hline CHEMBL1587973 & 688620 & 4.8 & 4.8676 & TST & \\
\hline CHEMBL1586738 & 688620 & 4.95 & 5.2067 & TRN & \\
\hline CHEMBL1336193 & 688620 & 4.5 & 5.2541 & TRN & \\
\hline CHEMBL1305592 & 688620 & 5.1 & 5.0894 & TRN & \\
\hline CHEMBL1600187 & 688620 & 5.5 & 5.2126 & TRN & \\
\hline CHEMBL1375563 & 688620 & 4.95 & 4.8438 & TRN & \\
\hline CHEMBL1516369 & 688620 & 5.25 & 5.9986 & TRN & \\
\hline CHEMBL1419433 & 688620 & 4.8 & 5.0379 & TRN & \\
\hline CHEMBL1577659 & 688620 & 4.45 & 4.9227 & TST & \\
\hline CHEMBL1343309 & 688620 & 5.05 & 5.1524 & TRN & \\
\hline CHEMBL1470373 & 688620 & 4.6 & 4.4934 & TST & \\
\hline CHEMBL1302696 & 688620 & 4.95 & 4.9002 & TRN & \\
\hline CHEMBL1544108 & 688620 & 4.45 & 4.9617 & TRN & \\
\hline CHEMBL1519463 & 688620 & 4.45 & 4.9151 & TST & \\
\hline CHEMBL1496167 & 688620 & 4.45 & 5.3029 & TST & \\
\hline CHEMBL1322066 & 688620 & 4.45 & 4.9699 & TST & \\
\hline CHEMBL1483585 & 688620 & 5.7 & 5.0522 & TRN & \\
\hline CHEMBL1542911 & 688620 & 4.45 & 4.7047 & TST & \\
\hline CHEMBL1495602 & 688620 & 4.9 & 4.6814 & TST & \\
\hline CHEMBL3196613 & 688620 & 5.05 & 5.0883 & TRN & \\
\hline CHEMBL1995330 & 688620 & 5.8 & 4.7674 & TRN & \\
\hline CHEMBL1422504 & 688620 & 5.0 & 5.1605 & TRN & \\
\hline CHEMBL1401074 & 688620 & 6.2 & 6.0927 & TRN & \\
\hline CHEMBL1305091 & 688620 & 4.85 & 5.1444 & TRN & \\
\hline CHEMBL1417731 & 688620 & 4.75 & 5.0951 & TST & \\
\hline CHEMBL1556427 & 688620 & 5.4 & 4.975 & TRN & \\
\hline CHEMBL1350344 & 688620 & 4.7 & 4.9212 & TST & \\
\hline CHEMBL1309311 & 688620 & 4.9 & 5.038 & TRN & \\
\hline CHEMBL1350960 & 688620 & 4.95 & 5.2166 & TRN & \\
\hline
\end{tabular}




\begin{tabular}{|c|c|c|c|c|c|}
\hline & & \multicolumn{4}{|c|}{ Supplemental Table s2.txt } \\
\hline CHEMBL3194367 & 688620 & 5.85 & 5.0128 & TRN & \\
\hline CHEMBL1588926 & 688620 & 5.05 & 5.5126 & TRN & \\
\hline CHEMBL1340612 & 688620 & 5.7 & 5.2098 & TRN & \\
\hline CHEMBL1359568 & 688620 & 4.45 & 5.0803 & TST & \\
\hline CHEMBL1519574 & 688620 & 4.95 & 4.9857 & TRN & \\
\hline CHEMBL1443638 & 688620 & 4.55 & 5.3256 & TST & \\
\hline CHEMBL1569669 & 688620 & 4.85 & 4.9513 & TST & \\
\hline CHEMBL1339346 & 688620 & 5.3 & 5.0336 & TRN & \\
\hline CHEMBL1599802 & 688620 & 4.85 & 5.2361 & TST & \\
\hline CHEMBL3196400 & 688620 & 4.9 & 4.8927 & TRN & \\
\hline CHEMBL1584090 & 688620 & 4.95 & 5.5308 & TRN & \\
\hline CHEMBL1393123 & 688620 & 4.8 & 5.0671 & TST & \\
\hline CHEMBL3211941 & 688620 & 5.5 & 5.3079 & TRN & \\
\hline CHEMBL1578370 & 688620 & 5.25 & 4.9978 & TRN & \\
\hline CHEMBL1471587 & 688620 & 5.95 & 5.3525 & TRN & \\
\hline CHEMBL1322491 & 688620 & 4.65 & 4.9968 & TRN & \\
\hline CHEMBL1330390 & 688620 & 4.7 & 4.9542 & TRN & \\
\hline CHEMBL3191006 & 688620 & 4.7 & 4.8809 & TRN & \\
\hline CHEMBL1604158 & 688620 & 4.9 & 4.9623 & TST & \\
\hline CHEMBL1379303 & 688620 & 5.15 & 5.1193 & TRN & \\
\hline CHEMBL1538118 & 688620 & 4.7 & 4.8121 & TRN & \\
\hline CHEMBL1392256 & 688620 & 4.8 & 4.8559 & TRN & \\
\hline CHEMBL1596914 & 688620 & 5.2 & 5.1442 & TRN & \\
\hline CHEMBL1469227 & 688620 & 5.2 & 5.2823 & TRN & \\
\hline CHEMBL1395990 & 688620 & 4.95 & 4.9655 & TRN & \\
\hline CHEMBL1543273 & 688620 & 4.45 & 5.0545 & TST & \\
\hline CHEMBL1587756 & 688620 & 5.1 & 5.1217 & TRN & \\
\hline CHEMBL1506983 & 688620 & 4.95 & 4.9473 & TRN & \\
\hline CHEMBL1432171 & 688620 & 4.9 & 5.0449 & TST & \\
\hline CHEMBL1425034 & 688620 & 5.3 & 5.5535 & TRN & \\
\hline CHEMBL1323871 & 688620 & 4.95 & 5.2676 & TRN & \\
\hline CHEMBL1333477 & 688620 & 4.45 & 4.9484 & TRN & \\
\hline CHEMBL3191324 & 688620 & 6.2 & 5.8523 & TRN & \\
\hline CHEMBL1430139 & 688620 & 5.25 & 4.6888 & TRN & \\
\hline CHEMBL2373651 & 688620 & 5.55 & 5.29200 & 0000000001 & TST \\
\hline CHEMBL1489130 & 688620 & 5.05 & 4.9364 & TRN & \\
\hline CHEMBL1373340 & 688620 & 5.15 & 4.9846 & TRN & \\
\hline CHEMBL1303979 & 688620 & 5.3 & 4.7889 & TRN & \\
\hline CHEMBL1603730 & 688620 & 4.85 & 4.9518 & TST & \\
\hline CHEMBL1579494 & 688620 & 5.15 & 5.2691 & TRN & \\
\hline CHEMBL1521935 & 688620 & 6.1 & 5.7702 & TRN & \\
\hline CHEMBL1405370 & 688620 & 4.9 & 5.2387 & TST & \\
\hline CHEMBL1467382 & 688620 & 6.35 & 5.38 & TRN & \\
\hline CHEMBL1576010 & 688620 & 4.95 & 5.12299 & 9999999999 & TRN \\
\hline CHEMBL1378126 & 688620 & 4.9 & 4.8949 & TRN & \\
\hline CHEMBL1559387 & 688620 & 4.75 & 4.8729 & TRN & \\
\hline CHEMBL1351825 & 688620 & 5.8 & 5.1104 & TST & \\
\hline CHEMBL1506367 & 688620 & 4.95 & 5.09399 & 9999999999 & TRN \\
\hline & & & & 2696 & \\
\hline
\end{tabular}




\begin{tabular}{|c|c|c|c|c|c|}
\hline \multicolumn{6}{|c|}{ Supplemental Table s2.txt } \\
\hline CHEMBL1414384 & 688620 & 5.25 & 4.8568 & TRN & \\
\hline CHEMBL1528791 & 688620 & 4.85 & 5.1299 & TRN & \\
\hline CHEMBL1531577 & 688620 & 4.95 & 5.0639 & TST & \\
\hline CHEMBL1472107 & 688620 & 5.6 & 4.8975 & TRN & \\
\hline CHEMBL1600496 & 688620 & 4.45 & 5.0077 & TST & \\
\hline CHEMBL1530152 & 688620 & 5.0 & 5.2522 & TRN & \\
\hline CHEMBL1594215 & 688620 & 4.9 & 4.9865 & TST & \\
\hline CHEMBL1611913 & 688620 & 5.5 & 4.9604 & TRN & \\
\hline CHEMBL1555845 & 688620 & 4.9 & 5.142 & TRN & \\
\hline CHEMBL1886301 & 688620 & 5.0 & 4.9884 & TRN & \\
\hline CHEMBL1500187 & 688620 & 4.65 & 4.8933 & TRN & \\
\hline CHEMBL1381941 & 688620 & 5.6 & 5.4155 & TRN & \\
\hline CHEMBL1313166 & 688620 & 4.9 & 5.0923 & TRN & \\
\hline CHEMBL 286721 & 688620 & 5.05 & 5.1738 & TRN & \\
\hline CHEMBL1565847 & 688620 & 4.75 & 4.9297 & TST & \\
\hline CHEMBL1378605 & 688620 & 4.95 & 4.9888 & TST & \\
\hline CHEMBL1351986 & 688620 & 5.5 & 5.1351 & TRN & \\
\hline CHEMBL1596793 & 688620 & 5.2 & 5.4381 & TRN & \\
\hline CHEMBL1472345 & 688620 & 4.9 & 4.6057 & TRN & \\
\hline CHEMBL3211298 & 688620 & 4.95 & 5.0871 & TRN & \\
\hline CHEMBL1529751 & 688620 & 4.95 & 5.1828 & TRN & \\
\hline CHEMBL1527588 & 688620 & 5.55 & 5.4363 & TST & \\
\hline CHEMBL1577716 & 688620 & 7.4001 & 4.9762 & TST & \\
\hline CHEMBL1417936 & 688620 & 4.95 & 4.8393 & TRN & \\
\hline CHEMBL1613632 & 688620 & 5.0 & 4.994 & TRN & \\
\hline CHEMBL3195324 & 688620 & 5.45 & 5.4129 & TRN & \\
\hline CHEMBL1576053 & 688620 & 4.9 & 4.9243 & TST & \\
\hline CHEMBL1394738 & 688620 & 4.6 & 5.0585 & TRN & \\
\hline CHEMBL1566079 & 688620 & 4.95 & 5.0061 & TRN & \\
\hline CHEMBL1529299 & 688620 & 4.95 & 4.8099 & TST & \\
\hline CHEMBL1410633 & 688620 & 4.9 & 5.0054 & TRN & \\
\hline CHEMBL1517776 & 688620 & 5.2 & 4.9762 & TST & \\
\hline CHEMBL1318728 & 688620 & 5.45 & 4.915 & TRN & \\
\hline CHEMBL1324719 & 688620 & 4.45 & 5.121 & TST & \\
\hline CHEMBL391533 & 688620 & 5.0 & 4.881 & TRN & \\
\hline CHEMBL1439466 & 688620 & 4.95 & 5.0351 & TRN & \\
\hline CHEMBL1483038 & 688620 & 5.7 & 5.9989 & TRN & \\
\hline CHEMBL1989354 & 688620 & 5.15 & 5.29899 & 99999999995 & TRN \\
\hline CHEMBL1310318 & 688620 & 5.5 & 5.4406 & TST & \\
\hline CHEMBL1348191 & 688620 & 4.55 & 5.1035 & TRN & \\
\hline CHEMBL1496901 & 688620 & 4.45 & 4.9287 & TST & \\
\hline CHEMBL1536470 & 688620 & 5.0 & 4.897 & TRN & \\
\hline CHEMBL1330853 & 688620 & 4.8 & 5.13700 & 00000000005 & TRN \\
\hline CHEMBL1341769 & 688620 & 7.0501 & 5.227 & TRN & \\
\hline CHEMBL1464689 & 688620 & 4.45 & 4.9607 & TRN & \\
\hline CHEMBL1365535 & 688620 & 6.5 & 5.7423 & TRN & \\
\hline CHEMBL1303905 & 688620 & 5.2 & 5.0358 & TRN & \\
\hline CHEMBL1522566 & 688620 & 5.35 & 5.3838 & TRN & \\
\hline
\end{tabular}




\begin{tabular}{|c|c|c|c|c|}
\hline \multicolumn{5}{|c|}{ Supplemental Table S2.txt } \\
\hline CHEMBL1420103 & 688620 & 5.25 & 5.1925 & TRN \\
\hline CHEMBL 3199817 & 688620 & 5.0 & 4.933 & TRN \\
\hline CHEMBL1340525 & 688620 & 5.0 & 4.8094 & TRN \\
\hline CHEMBL 393244 & 688620 & 4.95 & 5.276 & TRN \\
\hline CHEMBL1426245 & 688620 & 4.95 & 4.7114 & TRN \\
\hline CHEMBL1429129 & 688620 & 4.8 & 5.0879 & TST \\
\hline CHEMBL 3209648 & 688620 & 4.65 & 5.0076 & TRN \\
\hline CHEMBL 3194667 & 688620 & 6.6499 & 6.3011 & TRN \\
\hline CHEMBL1965444 & 688620 & 5.85 & 5.4982 & TRN \\
\hline CHEMBL3195545 & 688620 & 5.95 & 4.9713 & TRN \\
\hline CHEMBL 3198417 & 688620 & 6.05 & 5.9042 & TRN \\
\hline CHEMBL1404142 & 688620 & 6.15 & 4.9712 & TRN \\
\hline CHEMBL1315391 & 688620 & 4.45 & 4.9655 & TRN \\
\hline CHEMBL1503359 & 688620 & 5.4 & 5.1781 & TST \\
\hline CHEMBL1447245 & 688620 & 5.65 & 5.6172 & TRN \\
\hline CHEMBL1384108 & 688620 & 6.15 & 5.0041 & TST \\
\hline CHEMBL1487885 & 688620 & 4.9 & 5.1033 & TRN \\
\hline CHEMBL1566501 & 688620 & 4.65 & 4.9194 & TRN \\
\hline CHEMBL1506531 & 688620 & 4.7 & 4.9208 & TRN \\
\hline CHEMBL1555400 & 688620 & 4.9 & 5.0583 & TRN \\
\hline CHEMBL1344685 & 688620 & 4.9 & 5.0747 & TRN \\
\hline CHEMBL 3191261 & 688620 & 4.75 & 5.1796 & TST \\
\hline CHEMBL1330702 & 688620 & 5.0 & 4.9004 & TRN \\
\hline CHEMBL1443343 & 688620 & 5.95 & 5.1639 & TST \\
\hline CHEMBL1305664 & 688620 & 5.6 & 5.0186 & TRN \\
\hline CHEMBL1309176 & 688620 & 4.45 & 5.0742 & TST \\
\hline CHEMBL1452021 & 688620 & 4.9 & 4.9907 & TRN \\
\hline CHEMBL1531578 & 688620 & 5.1 & 4.9797 & TRN \\
\hline CHEMBL1353292 & 688620 & 5.4 & 4.9206 & TRN \\
\hline CHEMBL1361847 & 688620 & 4.95 & 4.7138 & TRN \\
\hline CHEMBL1454183 & 688620 & 5.5 & 5.5081 & TST \\
\hline CHEMBL1461209 & 688620 & 4.5 & 5.4466 & TRN \\
\hline CHEMBL1569783 & 688620 & 4.95 & 4.8896 & TRN \\
\hline CHEMBL1375531 & 688620 & 4.9 & 5.0833 & TRN \\
\hline CHEMBL1299766 & 688620 & 5.6 & 5.0014 & TRN \\
\hline CHEMBL1302927 & 688620 & 7.0 & 4.9019 & TST \\
\hline CHEMBL1374416 & 688620 & 4.45 & 4.8167 & TST \\
\hline CHEMBL1487959 & 688620 & 5.25 & 5.1097 & TST \\
\hline CHEMBL1343001 & 688620 & 4.65 & 4.9953 & TRN \\
\hline CHEMBL1425659 & 688620 & 5.45 & 5.1435 & TRN \\
\hline CHEMBL 3198846 & 688620 & 4.9 & 5.0177 & TRN \\
\hline CHEMBL1967859 & 688620 & 6.6 & 5.6386 & TRN \\
\hline CHEMBL1416262 & 688620 & 5.9 & 5.7403 & TRN \\
\hline CHEMBL1331892 & 688620 & 5.5 & 5.3339 & TRN \\
\hline CHEMBL1311052 & 688620 & 4.55 & 4.9816 & TRN \\
\hline CHEMBL1470712 & 688620 & 4.9 & 5.1527 & TRN \\
\hline CHEMBL577635 & 688620 & 6.0 & 5.5955 & TST \\
\hline CHEMBL1422763 & 688620 & 4.6 & 4.7719 & TST \\
\hline
\end{tabular}




\begin{tabular}{|c|c|c|c|c|c|}
\hline \multicolumn{6}{|c|}{ Supplemental Table S2.txt } \\
\hline CHEMBL1546310 & 688620 & 4.45 & 4.941 & TST & \\
\hline CHEMBL1600480 & 688620 & 6.15 & 6.0075 & TRN & \\
\hline CHEMBL1319179 & 688620 & 8.2518 & 5.1375 & TST & \\
\hline CHEMBL1582801 & 688620 & 4.55 & 5.2322 & TRN & \\
\hline CHEMBL3145320 & 688620 & 6.3 & 5.9469 & TST & \\
\hline CHEMBL1380895 & 688620 & 4.45 & 5.012 & TRN & \\
\hline CHEMBL1546700 & 688620 & 4.65 & 5.1186 & TRN & \\
\hline CHEMBL1365140 & 688620 & 4.8 & 4.7113 & TRN & \\
\hline CHEMBL1342068 & 688620 & 4.75 & 5.16100 & 00000000005 & TRN \\
\hline CHEMBL1314153 & 688620 & 6.35 & 4.9339 & TRN & \\
\hline CHEMBL1427568 & 688620 & 5.05 & 4.9809 & TRN & \\
\hline CHEMBL1539505 & 688620 & 4.45 & 5.0909 & TRN & \\
\hline CHEMBL1560952 & 688620 & 5.2 & 5.2369 & TST & \\
\hline CHEMBL1980959 & 688620 & 5.2 & 5.1135 & TRN & \\
\hline CHEMBL1334567 & 688620 & 5.0 & 5.1065 & TRN & \\
\hline CHEMBL1348092 & 688620 & 4.45 & 5.0653 & TRN & \\
\hline CHEMBL1573038 & 688620 & 4.9 & 5.0478 & TRN & \\
\hline CHEMBL1409981 & 688620 & 4.9 & 5.0001 & TRN & \\
\hline CHEMBL1427004 & 688620 & 5.25 & 5.3734 & TRN & \\
\hline CHEMBL1389184 & 688620 & 4.8 & 4.9236 & TRN & \\
\hline CHEMBL1407952 & 688620 & 5.4 & 5.8446 & TRN & \\
\hline CHEMBL1348714 & 688620 & 4.85 & 4.977 & TST & \\
\hline CHEMBL1451125 & 688620 & 7.0501 & 6.2598 & TRN & \\
\hline CHEMBL1416041 & 688620 & 4.45 & 4.8205 & TRN & \\
\hline CHEMBL1507454 & 688620 & 5.2 & 4.9449 & TRN & \\
\hline CHEMBL1369116 & 688620 & 5.0 & 5.0052 & TRN & \\
\hline CHEMBL1504804 & 688620 & 6.5501 & 5.0491 & TRN & \\
\hline CHEMBL1341192 & 688620 & 5.1 & 5.1667 & TRN & \\
\hline CHEMBL1534650 & 688620 & 5.0 & 4.9517 & TST & \\
\hline CHEMBL1449666 & 688620 & 4.45 & 5.0039 & TST & \\
\hline CHEMBL1312346 & 688620 & 4.9 & 5.1791 & TST & \\
\hline CHEMBL1523195 & 688620 & 4.45 & 5.1026 & TST & \\
\hline CHEMBL1519697 & 688620 & 5.85 & 5.4592 & TST & \\
\hline CHEMBL1600057 & 688620 & 5.0 & 5.0444 & TST & \\
\hline CHEMBL1607384 & 688620 & 5.15 & 4.7892 & TRN & \\
\hline CHEMBL1337075 & 688620 & 4.95 & 4.9287 & TRN & \\
\hline CHEMBL1405166 & 688620 & 5.15 & 4.8061 & TRN & \\
\hline CHEMBL1491491 & 688620 & 5.25 & 5.6504 & TRN & \\
\hline CHEMBL1351894 & 688620 & 4.6 & 5.0156 & TST & \\
\hline CHEMBL1411646 & 688620 & 4.45 & 4.8012 & TRN & \\
\hline CHEMBL3194326 & 688620 & 4.95 & 4.9458 & TRN & \\
\hline CHEMBL1528509 & 688620 & 4.8 & 4.7695 & TRN & \\
\hline CHEMBL1542320 & 688620 & 5.55 & 4.9976 & TRN & \\
\hline CHEMBL 1453140 & 688620 & 4.45 & 4.7467 & TST & \\
\hline CHEMBL3197515 & 688620 & 4.65 & 5.1173 & TST & \\
\hline CHEMBL1557932 & 688620 & 5.0 & 5.0416 & TRN & \\
\hline CHEMBL1462316 & 688620 & 5.0 & 5.0596 & TRN & \\
\hline CHEMBL1993287 & 688620 & 4.45 & 5.1428 & TRN & \\
\hline
\end{tabular}




\begin{tabular}{|c|c|c|c|c|}
\hline \multicolumn{5}{|c|}{ Supplemental Table S2.txt } \\
\hline CHEMBL1423692 & 688620 & 5.25 & 4.9194 & TST \\
\hline CHEMBL1463103 & 688620 & 4.8 & 5.1951 & TRN \\
\hline CHEMBL1347311 & 688620 & 4.45 & 4.7669 & TRN \\
\hline CHEMBL1349909 & 688620 & 4.45 & 5.0112 & TST \\
\hline CHEMBL1581280 & 688620 & 6.3 & 4.8339 & TRN \\
\hline CHEMBL1446084 & 688620 & 4.95 & 5.106 & TRN \\
\hline CHEMBL1330148 & 688620 & 5.0 & 5.0998 & TRN \\
\hline CHEMBL1607142 & 688620 & 4.95 & 5.1491 & TRN \\
\hline CHEMBL1456416 & 688620 & 4.95 & 5.0419 & TRN \\
\hline CHEMBL1361929 & 688620 & 4.9 & 4.9999 & TRN \\
\hline CHEMBL1448400 & 688620 & 4.9 & 5.1283 & TRN \\
\hline CHEMBL1427972 & 688620 & 5.45 & 5.5059 & TRN \\
\hline CHEMBL1450453 & 688620 & 4.95 & 5.1736 & TRN \\
\hline CHEMBL1520792 & 688620 & 5.15 & 5.0538 & TRN \\
\hline CHEMBL1498178 & 688620 & 4.85 & 5.0048 & TRN \\
\hline CHEMBL1488014 & 688620 & 4.7 & 5.2276 & TRN \\
\hline CHEMBL1579416 & 688620 & 5.05 & 5.2314 & TRN \\
\hline CHEMBL3193405 & 688620 & 4.45 & 5.2717 & TRN \\
\hline CHEMBL1347562 & 688620 & 5.5 & 4.8995 & TRN \\
\hline CHEMBL1568575 & 688620 & 4.7 & 4.9673 & TRN \\
\hline CHEMBL1415099 & 688620 & 4.8 & 5.0134 & TRN \\
\hline CHEMBL1503305 & 688620 & 5.1 & 5.0213 & TRN \\
\hline CHEMBL1341895 & 688620 & 4.75 & 4.9302 & TRN \\
\hline CHEMBL1420472 & 688620 & 4.45 & 5.1089 & TRN \\
\hline CHEMBL1497501 & 688620 & 4.45 & 5.0282 & TST \\
\hline CHEMBL1506607 & 688620 & 6.0 & 5.1907 & TRN \\
\hline CHEMBL1511190 & 688620 & 5.0 & 5.3307 & TRN \\
\hline CHEMBL1339742 & 688620 & 6.25 & 4.94 & TRN \\
\hline CHEMBL1368361 & 688620 & 4.9 & 4.7221 & TST \\
\hline CHEMBL1456774 & 688620 & 4.8 & 4.8777 & TST \\
\hline CHEMBL1567175 & 688620 & 6.5 & 5.0376 & TRN \\
\hline CHEMBL1541391 & 688620 & 5.6 & 5.5393 & TRN \\
\hline CHEMBL1550545 & 688620 & 4.45 & 4.9816 & TST \\
\hline CHEMBL1586349 & 688620 & 7.2503 & 5.0963 & TRN \\
\hline CHEMBL1584418 & 688620 & 4.45 & 5.0356 & TRN \\
\hline CHEMBL1366760 & 688620 & 5.1 & 5.2115 & TRN \\
\hline CHEMBL1579073 & 688620 & 4.6 & 5.15 & TRN \\
\hline CHEMBL1558545 & 688620 & 5.0 & 5.0719 & TRN \\
\hline CHEMBL1334943 & 688620 & 4.45 & 5.1538 & TRN \\
\hline CHEMBL1581166 & 688620 & 6.95 & 5.1739 & TST \\
\hline CHEMBL1501891 & 688620 & 5.4 & 4.9079 & TST \\
\hline CHEMBL1978193 & 688620 & 5.1 & 5.2626 & TRN \\
\hline CHEMBL242711 & 688620 & 4.8 & 5.0885 & TST \\
\hline CHEMBL1326006 & 688620 & 5.2 & 4.829 & TST \\
\hline CHEMBL1535766 & 688620 & 4.9 & 4.9443 & TRN \\
\hline CHEMBL1306922 & 688620 & 4.8 & 5.2191 & TRN \\
\hline CHEMBL3211875 & 688620 & 6.8 & 5.1049 & TST \\
\hline CHEMBL1472593 & 688620 & 5.5 & 4.9951 & TRN \\
\hline
\end{tabular}




\begin{tabular}{|c|c|c|c|c|c|}
\hline \multirow[b]{2}{*}{ CHEMBL1464317 } & \multirow[b]{2}{*}{688620} & \multicolumn{4}{|c|}{ Supplemental Table S2.txt } \\
\hline & & 5.05 & 5.0841 & TRN & \\
\hline CHEMBL1613582 & 688620 & 4.45 & 4.9018 & TST & \\
\hline CHEMBL1381884 & 688620 & 4.7 & 5.0973 & TRN & \\
\hline CHEMBL1438826 & 688620 & 6.4 & 5.02800 & 00000000005 & TST \\
\hline CHEMBL1441191 & 688620 & 4.8 & 5.0916 & TRN & \\
\hline CHEMBL1352198 & 688620 & 4.75 & 4.8736 & TRN & \\
\hline CHEMBL1333297 & 688620 & 4.45 & 5.1309 & TRN & \\
\hline CHEMBL590927 & 688620 & 5.75 & 5.8161 & TRN & \\
\hline CHEMBL1540416 & 688620 & 4.45 & 4.7034 & TST & \\
\hline CHEMBL1360457 & 688620 & 4.45 & 4.8261 & TST & \\
\hline CHEMBL1601331 & 688620 & 4.7 & 4.7238 & TRN & \\
\hline CHEMBL1389051 & 688620 & 4.65 & 5.1189 & TST & \\
\hline CHEMBL3196116 & 688620 & 5.25 & 5.3053 & TRN & \\
\hline CHEMBL1418027 & 688620 & 5.7 & 4.8863 & TRN & \\
\hline CHEMBL1385655 & 688620 & 4.95 & 5.15 & TRN & \\
\hline CHEMBL1330724 & 688620 & 5.45 & 5.2715 & TST & \\
\hline CHEMBL3145172 & 688620 & 5.05 & 5.3048 & TRN & \\
\hline CHEMBL1360296 & 688620 & 5.2 & 5.3348 & TRN & \\
\hline CHEMBL1303172 & 688620 & 4.65 & 4.9189 & TRN & \\
\hline CHEMBL1347192 & 688620 & 5.0 & 5.0579 & TST & \\
\hline CHEMBL1491643 & 688620 & 4.45 & 4.9282 & TRN & \\
\hline CHEMBL1568248 & 688620 & 4.8 & 4.8256 & TRN & \\
\hline CHEMBL1387754 & 688620 & 4.5 & 5.2151 & TST & \\
\hline CHEMBL2003195 & 688620 & 5.5 & 5.5244 & TST & \\
\hline CHEMBL1441350 & 688620 & 5.15 & 5.1954 & TRN & \\
\hline CHEMBL1503941 & 688620 & 5.0 & 5.1456 & TRN & \\
\hline CHEMBL1603416 & 688620 & 4.75 & 4.8072 & TST & \\
\hline CHEMBL3198435 & 688620 & 4.85 & 5.029 & TRN & \\
\hline CHEMBL 3190584 & 688620 & 4.7 & 5.0285 & TST & \\
\hline CHEMBL1360028 & 688620 & 5.55 & 5.0773 & TST & \\
\hline CHEMBL1969470 & 688620 & 5.95 & 5.7981 & TRN & \\
\hline CHEMBL1346128 & 688620 & 5.15 & 5.4526 & TRN & \\
\hline CHEMBL1345287 & 688620 & 4.95 & 4.9845 & TRN & \\
\hline CHEMBL1338073 & 688620 & 4.95 & 5.2479 & TST & \\
\hline CHEMBL143399 & 688620 & 8.1487 & 5.0824 & TST & \\
\hline CHEMBL1438594 & 688620 & 4.45 & 5.1947 & TRN & \\
\hline CHEMBL1516821 & 688620 & 6.15 & 6.1722 & TRN & \\
\hline CHEMBL1463939 & 688620 & 4.85 & 5.1493 & TRN & \\
\hline CHEMBL1996724 & 688620 & 5.15 & 5.5249 & TRN & \\
\hline CHEMBL1449219 & 688620 & 5.0 & 4.8141 & TRN & \\
\hline CHEMBL1574991 & 688620 & 4.7 & 5.0858 & TST & \\
\hline CHEMBL 1442502 & 688620 & 5.1 & 5.0471 & TRN & \\
\hline CHEMBL1536625 & 688620 & 4.85 & 4.754 & TRN & \\
\hline CHEMBL1502242 & 688620 & 4.45 & 4.8822 & TST & \\
\hline CHEMBL1418016 & 688620 & 5.3 & 5.0835 & TRN & \\
\hline CHEMBL1356068 & 688620 & 5.0 & 5.2501 & TST & \\
\hline CHEMBL1523058 & 688620 & 4.8 & 5.1057 & TST & \\
\hline CHEMBL1319083 & 688620 & 4.45 & 4.7072 & TST & \\
\hline
\end{tabular}




\begin{tabular}{|c|c|c|c|c|c|}
\hline & & \multicolumn{4}{|c|}{ Supplemental Table s2.txt } \\
\hline CHEMBL1307539 & 688620 & 4.75 & 4.9476 & TRN & \\
\hline CHEMBL3198016 & 688620 & 4.8 & 4.7197 & TST & \\
\hline CHEMBL1363437 & 688620 & 4.45 & 5.0464 & TRN & \\
\hline CHEMBL1367512 & 688620 & 4.45 & 4.8756 & TST & \\
\hline CHEMBL1339135 & 688620 & 5.1 & 5.0909 & TRN & \\
\hline CHEMBL1426225 & 688620 & 4.95 & 5.1355 & TST & \\
\hline CHEMBL1305705 & 688620 & 6.0 & 4.96 & TRN & \\
\hline CHEMBL1345289 & 688620 & 4.85 & 4.851 & TRN & \\
\hline CHEMBL1464512 & 688620 & 4.85 & 5.0614 & TRN & \\
\hline CHEMBL1349804 & 688620 & 4.5 & 5.0568 & TRN & \\
\hline CHEMBL1468829 & 688620 & 4.8 & 4.9396 & TRN & \\
\hline CHEMBL1312276 & 688620 & 5.8 & 5.1149 & TRN & \\
\hline CHEMBL1527250 & 688620 & 4.9 & 5.0076 & TRN & \\
\hline CHEMBL1556848 & 688620 & 5.7 & 5.055 & TRN & \\
\hline CHEMBL1492058 & 688620 & 4.85 & 5.1591 & TRN & \\
\hline CHEMBL1427684 & 688620 & 5.0 & 4.9573 & TST & \\
\hline CHEMBL1301858 & 688620 & 5.9 & 5.8327 & TRN & \\
\hline CHEMBL1299459 & 688620 & 5.35 & 5.1065 & TRN & \\
\hline CHEMBL1393597 & 688620 & 5.0 & 5.1257 & TRN & \\
\hline CHEMBL1392560 & 688620 & 5.15 & 5.2742 & TRN & \\
\hline CHEMBL1565519 & 688620 & 4.55 & 4.9681 & TRN & \\
\hline CHEMBL1536084 & 688620 & 5.7 & 5.4499 & TRN & \\
\hline CHEMBL1351493 & 688620 & 4.9 & 4.8927 & TRN & \\
\hline CHEMBL1485029 & 688620 & 4.95 & 5.0043 & TST & \\
\hline CHEMBL1340265 & 688620 & 4.55 & 4.6604 & TRN & \\
\hline CHEMBL1330568 & 688620 & 4.5 & 5.0873 & TST & \\
\hline CHEMBL1323959 & 688620 & 4.85 & 5.1 & TST & \\
\hline CHEMBL1328852 & 688620 & 6.3 & 5.0402 & TRN & \\
\hline CHEMBL1336836 & 688620 & 4.5 & 4.8435 & TST & \\
\hline CHEMBL495069 & 688620 & 4.85 & 5.0694 & TRN & \\
\hline CHEMBL1467410 & 688620 & 5.7 & 5.6487 & TRN & \\
\hline CHEMBL3209412 & 688620 & 6.95 & 5.316 & TRN & \\
\hline CHEMBL1575708 & 688620 & 5.1 & 5.3892 & TRN & \\
\hline CHEMBL1451353 & 688620 & 5.45 & 5.54799 & 9999999999 & TRN \\
\hline CHEMBL1405994 & 688620 & 8.2518 & 5.1457 & TST & \\
\hline CHEMBL1380777 & 688620 & 4.9 & 4.9656 & TRN & \\
\hline CHEMBL1380772 & 688620 & 4.45 & 5.1869 & TRN & \\
\hline CHEMBL3191127 & 688620 & 5.35 & 5.3713 & TRN & \\
\hline CHEMBL548615 & 688620 & 5.9 & 5.9087 & TRN & \\
\hline CHEMBL1998502 & 688620 & 5.95 & 5.1945 & TRN & \\
\hline CHEMBL1539502 & 688620 & 5.7 & 5.5445 & TRN & \\
\hline CHEMBL1348037 & 688620 & 5.8 & 5.2949 & TRN & \\
\hline CHEMBL458767 & 688620 & 4.9 & 5.0043 & TST & \\
\hline CHEMBL3208588 & 688620 & 4.75 & 5.1144 & TRN & \\
\hline CHEMBL1609763 & 688620 & 5.25 & 4.8091 & TRN & \\
\hline CHEMBL1580742 & 688620 & 4.45 & 4.9337 & TRN & \\
\hline CHEMBL1516871 & 688620 & 6.05 & 5.5076 & TRN & \\
\hline CHEMBL1495729 & 688620 & 4.55 & 4.9414 & TRN & \\
\hline
\end{tabular}




\begin{tabular}{|c|c|c|c|c|c|}
\hline \multicolumn{6}{|c|}{ Supplemental Table S2.txt } \\
\hline CHEMBL1431341 & 688620 & 4.5 & 5.0928 & TRN & \\
\hline CHEMBL1584810 & 688620 & 6.5 & 5.8069 & TRN & \\
\hline CHEMBL1441467 & 688620 & 6.8499 & 5.144 & TRN & \\
\hline CHEMBL1331682 & 688620 & 6.3 & 5.11100 & 2000000001 & TRN \\
\hline CHEMBL3193414 & 688620 & 6.3 & 5.8973 & TRN & \\
\hline CHEMBL1451690 & 688620 & 5.85 & 5.8211 & TRN & \\
\hline CHEMBL1511563 & 688620 & 4.85 & 4.8929 & TRN & \\
\hline CHEMBL 3213942 & 688620 & 4.9 & 4.9211 & TST & \\
\hline CHEMBL1566561 & 688620 & 5.1 & 5.0176 & TST & \\
\hline CHEMBL3195999 & 688620 & 4.9 & 4.9948 & TRN & \\
\hline CHEMBL1532460 & 688620 & 4.75 & 5.0605 & TRN & \\
\hline CHEMBL1372808 & 688620 & 5.75 & 5.8217 & TRN & \\
\hline CHEMBL1471422 & 688620 & 4.85 & 5.1503 & TST & \\
\hline CHEMBL 3190090 & 688620 & 5.55 & 5.2541 & TRN & \\
\hline CHEMBL1462058 & 688620 & 6.0 & 5.0887 & TRN & \\
\hline CHEMBL1312487 & 688620 & 4.95 & 5.1483 & TRN & \\
\hline CHEMBL1455414 & 688620 & 5.65 & 5.0534 & TRN & \\
\hline CHEMBL1602552 & 688620 & 5.7 & 5.1294 & TST & \\
\hline CHEMBL1506512 & 688620 & 4.75 & 5.0277 & TRN & \\
\hline CHEMBL1449057 & 688620 & 4.5 & 4.9802 & TRN & \\
\hline CHEMBL3213129 & 688620 & 5.5 & 5.1642 & TRN & \\
\hline CHEMBL1491623 & 688620 & 4.65 & 5.0071 & TRN & \\
\hline CHEMBL153036 & 688620 & 5.45 & 5.0351 & TST & \\
\hline CHEMBL1472004 & 688620 & 5.1 & 4.8697 & TRN & \\
\hline CHEMBL1414848 & 688620 & 5.2 & 5.26399 & 9999999999 & TRN \\
\hline CHEMBL1613220 & 688620 & 6.0 & 5.5457 & TST & \\
\hline CHEMBL3199081 & 688620 & 5.2 & 5.0313 & TRN & \\
\hline CHEMBL1507495 & 688620 & 4.45 & 5.0768 & TRN & \\
\hline CHEMBL1480372 & 688620 & 4.45 & 4.9401 & TRN & \\
\hline CHEMBL1488441 & 688620 & 4.6 & 5.2434 & TRN & \\
\hline CHEMBL1539856 & 688620 & 4.85 & 4.8476 & TRN & \\
\hline CHEMBL1426331 & 688620 & 6.1 & 5.2142 & TST & \\
\hline CHEMBL1427522 & 688620 & 5.25 & 4.9693 & TRN & \\
\hline CHEMBL1541975 & 688620 & 4.7 & 4.7656 & TST & \\
\hline CHEMBL1464354 & 688620 & 4.95 & 5.0111 & TST & \\
\hline CHEMBL1486623 & 688620 & 4.7 & 4.8781 & TRN & \\
\hline CHEMBL1458812 & 688620 & 4.95 & 4.6389 & TST & \\
\hline CHEMBL1446863 & 688620 & 5.0 & 4.939 & TST & \\
\hline CHEMBL1320798 & 688620 & 5.1 & 4.941 & TST & \\
\hline CHEMBL1484694 & 688620 & 4.8 & 5.1678 & TRN & \\
\hline CHEMBL1369476 & 688620 & 4.45 & 5.2102 & TRN & \\
\hline CHEMBL1537947 & 688620 & 5.4 & 5.3808 & TRN & \\
\hline CHEMBL1370927 & 688620 & 4.95 & 4.9255 & TRN & \\
\hline CHEMBL1325007 & 688620 & 5.75 & 5.1007 & TRN & \\
\hline CHEMBL1480698 & 688620 & 5.05 & 5.0405 & TRN & \\
\hline CHEMBL1426361 & 688620 & 6.5 & 5.0545 & TRN & \\
\hline CHEMBL603156 & 688620 & 6.0 & 5.6563 & TST & \\
\hline CHEMBL1358840 & 688620 & 5.05 & 5.1732 & TRN & \\
\hline
\end{tabular}




\begin{tabular}{|c|c|c|c|c|}
\hline \multicolumn{5}{|c|}{ Supplemental Table S2.txt } \\
\hline CHEMBL1439462 & 688620 & 4.9 & 4.9227 & TST \\
\hline CHEMBL1378153 & 688620 & 4.8 & 4.8003 & TRN \\
\hline CHEMBL1599150 & 688620 & 5.8 & 5.3189 & TRN \\
\hline CHEMBL1419443 & 688620 & 4.45 & 4.8806 & TRN \\
\hline CHEMBL3192046 & 688620 & 5.6 & 5.0003 & TRN \\
\hline CHEMBL1346099 & 688620 & 4.9 & 4.7325 & TRN \\
\hline CHEMBL1423414 & 688620 & 4.9 & 5.2048 & TST \\
\hline CHEMBL1605162 & 688620 & 4.85 & 5.0584 & TRN \\
\hline CHEMBL1369927 & 688620 & 5.3 & 5.2144 & TRN \\
\hline CHEMBL1452820 & 688620 & 6.95 & 5.0394 & TST \\
\hline CHEMBL1579409 & 688620 & 4.95 & 5.0023 & TRN \\
\hline CHEMBL1559811 & 688620 & 6.0 & 5.3862 & TRN \\
\hline CHEMBL2373662 & 688620 & 4.85 & 4.7853 & TST \\
\hline CHEMBL1367850 & 688620 & 4.9 & 4.8035 & TRN \\
\hline CHEMBL1431769 & 688620 & 5.6 & 5.688 & TRN \\
\hline CHEMBL1491836 & 688620 & 4.8 & 4.8485 & TST \\
\hline CHEMBL1388405 & 688620 & 4.45 & 4.7663 & TST \\
\hline CHEMBL1544146 & 688620 & 4.75 & 5.0002 & TRN \\
\hline CHEMBL1576804 & 688620 & 4.65 & 4.8908 & TST \\
\hline CHEMBL1379352 & 688620 & 4.9 & 5.5124 & TRN \\
\hline CHEMBL1407173 & 688620 & 5.2 & 4.8934 & TST \\
\hline CHEMBL1463529 & 688620 & 5.15 & 5.3765 & TRN \\
\hline CHEMBL1347924 & 688620 & 6.05 & 5.4906 & TRN \\
\hline CHEMBL1566354 & 688620 & 4.95 & 4.638 & TRN \\
\hline CHEMBL 3199620 & 688620 & 5.1 & 4.9527 & TRN \\
\hline CHEMBL1601621 & 688620 & 4.45 & 4.9698 & TRN \\
\hline CHEMBL1360481 & 688620 & 5.2 & 5.2153 & TST \\
\hline CHEMBL1529701 & 688620 & 4.9 & 5.13 & TRN \\
\hline CHEMBL1467648 & 688620 & 4.9 & 4.7651 & TST \\
\hline CHEMBL1469317 & 688620 & 6.1 & 5.3898 & TRN \\
\hline CHEMBL1585185 & 688620 & 4.9 & 4.5763 & TRN \\
\hline CHEMBL1430979 & 688620 & 4.6 & 4.8228 & TST \\
\hline CHEMBL1501275 & 688620 & 5.2 & 5.0894 & TRN \\
\hline CHEMBL1418339 & 688620 & 6.25 & 4.9431 & TRN \\
\hline CHEMBL1611070 & 688620 & 4.45 & 4.8899 & TST \\
\hline CHEMBL1422767 & 688620 & 6.0 & 4.702 & TRN \\
\hline CHEMBL585059 & 688620 & 4.9 & 5.0798 & TRN \\
\hline CHEMBL1322780 & 688620 & 4.9 & 4.9519 & TST \\
\hline CHEMBL 3211624 & 688620 & 6.1 & 5.9605 & TRN \\
\hline CHEMBL1456824 & 688620 & 5.25 & 4.8326 & TRN \\
\hline CHEMBL1344333 & 688620 & 4.85 & 5.1478 & TST \\
\hline CHEMBL1341981 & 688620 & 5.15 & 5.2781 & TRN \\
\hline CHEMBL1484814 & 688620 & 4.45 & 4.8933 & TST \\
\hline CHEMBL1441361 & 688620 & 5.2 & 4.92 & TRN \\
\hline CHEMBL1308364 & 688620 & 4.7 & 5.0502 & TRN \\
\hline CHEMBL1447755 & 688620 & 4.75 & 5.1246 & TRN \\
\hline CHEMBL 3190067 & 688620 & 5.3 & 5.0936 & TRN \\
\hline CHEMBL1410610 & 688620 & 4.7 & 5.6447 & TRN \\
\hline
\end{tabular}




\begin{tabular}{|c|c|c|c|c|}
\hline \multicolumn{5}{|c|}{ Supplemental Table S2.txt } \\
\hline CHEMBL1979830 & 688620 & 5.5 & 5.5324 & TRN \\
\hline CHEMBL1597758 & 688620 & 4.45 & 4.9528 & TRN \\
\hline CHEMBL1607648 & 688620 & 4.95 & 5.2029 & TRN \\
\hline CHEMBL1381059 & 688620 & 5.05 & 4.9952 & TRN \\
\hline CHEMBL1537140 & 688620 & 4.85 & 5.0195 & TRN \\
\hline CHEMBL1528128 & 688620 & 4.6 & 5.0045 & TRN \\
\hline CHEMBL1411186 & 688620 & 3.85 & 4.944 & TRN \\
\hline CHEMBL1479292 & 688620 & 4.45 & 4.7911 & TRN \\
\hline CHEMBL1375191 & 688620 & 5.45 & 4.9733 & TST \\
\hline CHEMBL1388123 & 688620 & 4.75 & 5.1925 & TRN \\
\hline CHEMBL1412927 & 688620 & 6.45 & 5.3917 & TRN \\
\hline CHEMBL1525787 & 688620 & 5.9 & 4.945 & TRN \\
\hline CHEMBL1499559 & 688620 & 4.45 & 4.8613 & TRN \\
\hline CHEMBL1385515 & 688620 & 4.85 & 4.9255 & TRN \\
\hline CHEMBL1334413 & 688620 & 4.9 & 4.9089 & TRN \\
\hline CHEMBL1421380 & 688620 & 4.9 & 5.0883 & TST \\
\hline CHEMBL3190251 & 688620 & 5.1 & 5.081 & TRN \\
\hline CHEMBL1330285 & 688620 & 5.15 & 4.9366 & TRN \\
\hline CHEMBL3192051 & 688620 & 5.05 & 5.3233 & TRN \\
\hline CHEMBL1588367 & 688620 & 4.7 & 4.9783 & TST \\
\hline CHEMBL1465374 & 688620 & 4.8 & 5.16700 & 0000000001 \\
\hline CHEMBL1348262 & 688620 & 4.95 & 5.1988 & TST \\
\hline CHEMBL1303287 & 688620 & 5.15 & 5.1953 & TRN \\
\hline CHEMBL1995645 & 688620 & 5.15 & 5.4608 & TRN \\
\hline CHEMBL1542180 & 688620 & 5.0 & 4.673 & TRN \\
\hline CHEMBL122360 & 688620 & 4.65 & 4.8263 & TST \\
\hline CHEMBL1326911 & 688620 & 4.65 & 4.7268 & TRN \\
\hline CHEMBL3193437 & 688620 & 6.05 & 6.0219 & TRN \\
\hline CHEMBL1458920 & 688620 & 4.95 & 5.0217 & TRN \\
\hline CHEMBL3211115 & 688620 & 5.6 & 5.688 & TRN \\
\hline CHEMBL1391990 & 688620 & 4.8 & 5.0776 & TRN \\
\hline CHEMBL1496919 & 688620 & 4.45 & 5.2203 & TRN \\
\hline CHEMBL3191562 & 688620 & 4.95 & 5.0943 & TST \\
\hline CHEMBL1308025 & 688620 & 5.0 & 4.9845 & TRN \\
\hline CHEMBL1468127 & 688620 & 4.95 & 5.04 & TRN \\
\hline CHEMBL 2000814 & 688620 & 4.65 & 5.1153 & TST \\
\hline CHEMBL3191770 & 688620 & 4.9 & 5.2517 & TRN \\
\hline CHEMBL1163763 & 688620 & 5.0 & 5.2016 & TST \\
\hline CHEMBL451260 & 688620 & 6.0 & 5.5357 & TRN \\
\hline CHEMBL1482964 & 688620 & 4.9 & 4.9907 & TRN \\
\hline CHEMBL3196251 & 688620 & 4.45 & 5.2282 & TRN \\
\hline CHEMBL1399956 & 688620 & 5.2 & 4.8343 & TRN \\
\hline CHEMBL1497717 & 688620 & 5.0 & 4.812 & TRN \\
\hline CHEMBL1388817 & 688620 & 5.95 & 5.1812 & TRN \\
\hline CHEMBL1363614 & 688620 & 4.75 & 4.8337 & TST \\
\hline CHEMBL1424106 & 688620 & 4.45 & 4.9486 & TRN \\
\hline CHEMBL1562030 & 688620 & 6.7001 & 4.9997 & TRN \\
\hline CHEMBL1510769 & 688620 & 5.95 & 5.6023 & TRN \\
\hline
\end{tabular}




\begin{tabular}{|c|c|c|c|c|c|}
\hline \multicolumn{6}{|c|}{ Supplemental Table s2.txt } \\
\hline CHEMBL1563773 & 688620 & 4.7 & 4.9226 & TRN & \\
\hline CHEMBL1449021 & 688620 & 5.15 & 5.3127 & TRN & \\
\hline CHEMBL1374832 & 688620 & 4.65 & 4.925 & TRN & \\
\hline CHEMBL3191943 & 688620 & 4.45 & 4.7593 & TST & \\
\hline CHEMBL1584642 & 688620 & 4.45 & 5.0128 & TRN & \\
\hline CHEMBL1547901 & 688620 & 4.45 & 4.9715 & TST & \\
\hline CHEMBL1548992 & 688620 & 5.95 & 5.34200 & 00000000005 & TRN \\
\hline CHEMBL1320383 & 688620 & 5.0 & 4.8834 & TRN & \\
\hline CHEMBL1331646 & 688620 & 5.0 & 5.0865 & TST & \\
\hline CHEMBL1468737 & 688620 & 4.85 & 4.8332 & TST & \\
\hline CHEMBL1307251 & 688620 & 5.0 & 4.9323 & TRN & \\
\hline CHEMBL1606251 & 688620 & 5.45 & 5.0977 & TRN & \\
\hline CHEMBL1306480 & 688620 & 5.85 & 5.2568 & TRN & \\
\hline CHEMBL1333638 & 688620 & 6.5 & 5.301 & TST & \\
\hline CHEMBL1529330 & 688620 & 4.95 & 4.8933 & TRN & \\
\hline CHEMBL1523867 & 688620 & 4.75 & 5.2471 & TRN & \\
\hline CHEMBL1570353 & 688620 & 4.45 & 5.0489 & TRN & \\
\hline CHEMBL1452515 & 688620 & 6.1 & 5.8457 & TRN & \\
\hline CHEMBL1430219 & 688620 & 4.9 & 5.0773 & TRN & \\
\hline CHEMBL1331555 & 688620 & 4.65 & 5.0377 & TRN & \\
\hline CHEMBL1502621 & 688620 & 6.6 & 4.9141 & TRN & \\
\hline CHEMBL1482951 & 688620 & 5.2 & 5.2411 & TRN & \\
\hline CHEMBL1534128 & 688620 & 4.95 & 5.2228 & TRN & \\
\hline CHEMBL1509878 & 688620 & 6.7501 & 7.6479 & TRN & \\
\hline CHEMBL1385126 & 688620 & 5.5 & 5.9009 & TRN & \\
\hline CHEMBL1462570 & 688620 & 4.75 & 4.8831 & TST & \\
\hline CHEMBL1487163 & 688620 & 5.45 & 4.9222 & TRN & \\
\hline CHEMBL3193790 & 688620 & 4.95 & 5.2748 & TST & \\
\hline CHEMBL1442141 & 688620 & 4.45 & 4.6842 & TRN & \\
\hline CHEMBL1400582 & 688620 & 4.9 & 5.0638 & TRN & \\
\hline CHEMBL3212542 & 688620 & 5.05 & 5.1276 & TRN & \\
\hline CHEMBL1341160 & 688620 & 5.1 & 5.4712 & TRN & \\
\hline CHEMBL1484001 & 688620 & 5.1 & 5.0696 & TRN & \\
\hline CHEMBL3190939 & 688620 & 4.75 & 5.4018 & TST & \\
\hline CHEMBL3191225 & 688620 & 4.95 & 4.78 & TST & \\
\hline CHEMBL1325753 & 688620 & 4.9 & 4.8538 & TST & \\
\hline CHEMBL490592 & 688620 & 5.45 & 5.3255 & TRN & \\
\hline CHEMBL1416045 & 688620 & 5.45 & 5.1864 & TST & \\
\hline CHEMBL403419 & 688620 & 6.1 & 5.4854 & TRN & \\
\hline CHEMBL1483608 & 688620 & 4.8 & 5.1433 & TST & \\
\hline CHEMBL533529 & 688620 & 4.85 & 5.00899 & 99999999995 & TRN \\
\hline CHEMBL1579076 & 688620 & 4.45 & 4.8326 & TRN & \\
\hline CHEMBL1409982 & 688620 & 4.75 & 4.9753 & TRN & \\
\hline CHEMBL1367285 & 688620 & 5.4 & 5.3264 & TRN & \\
\hline CHEMBL1439518 & 688620 & 5.05 & 5.0497 & TRN & \\
\hline CHEMBL1450416 & 688620 & 5.5 & 5.191 & TST & \\
\hline CHEMBL1581671 & 688620 & 4.65 & 5.0051 & TRN & \\
\hline CHEMBL3212211 & 688620 & 5.5 & 5.1704 & TST & \\
\hline
\end{tabular}




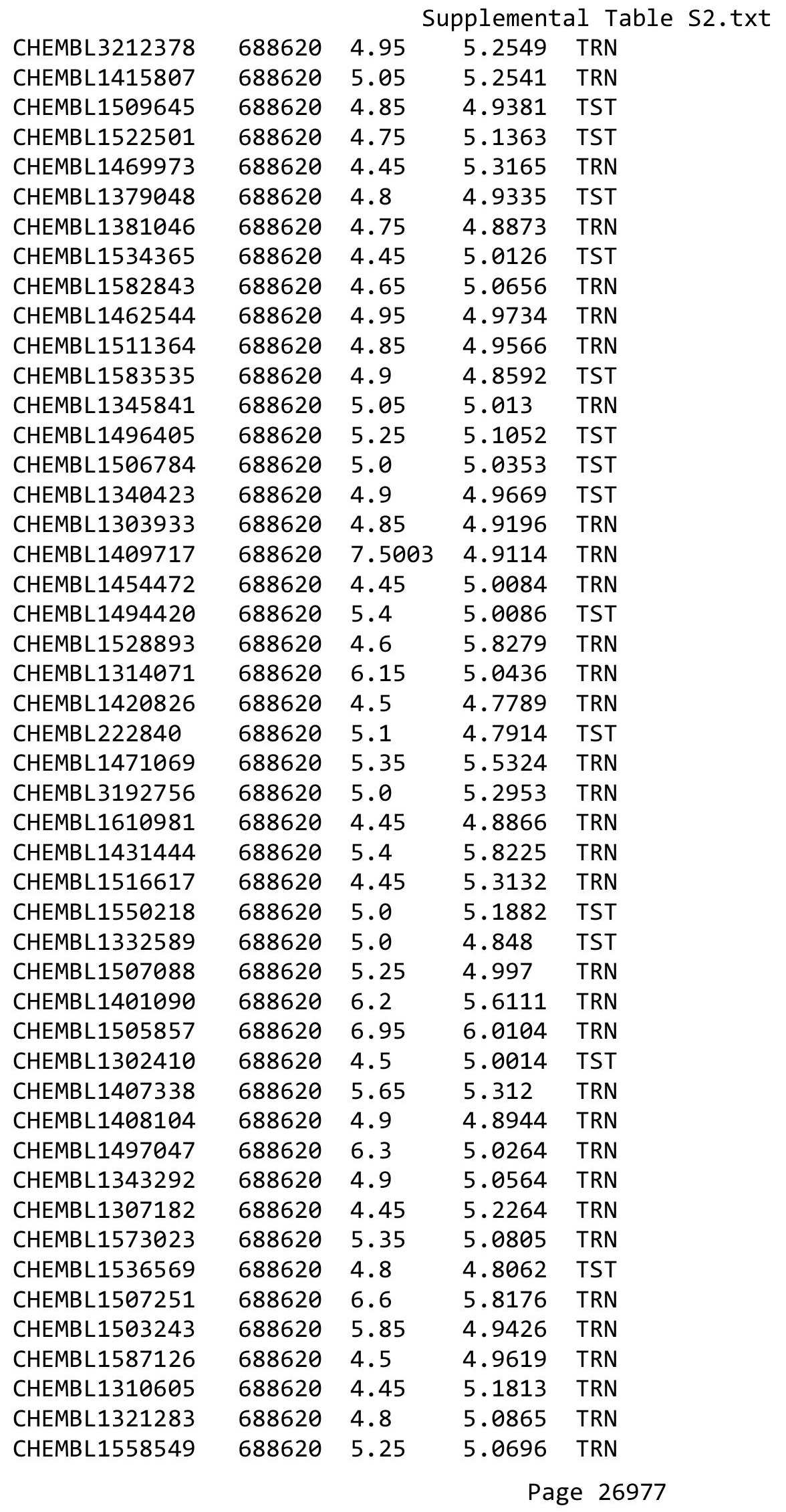




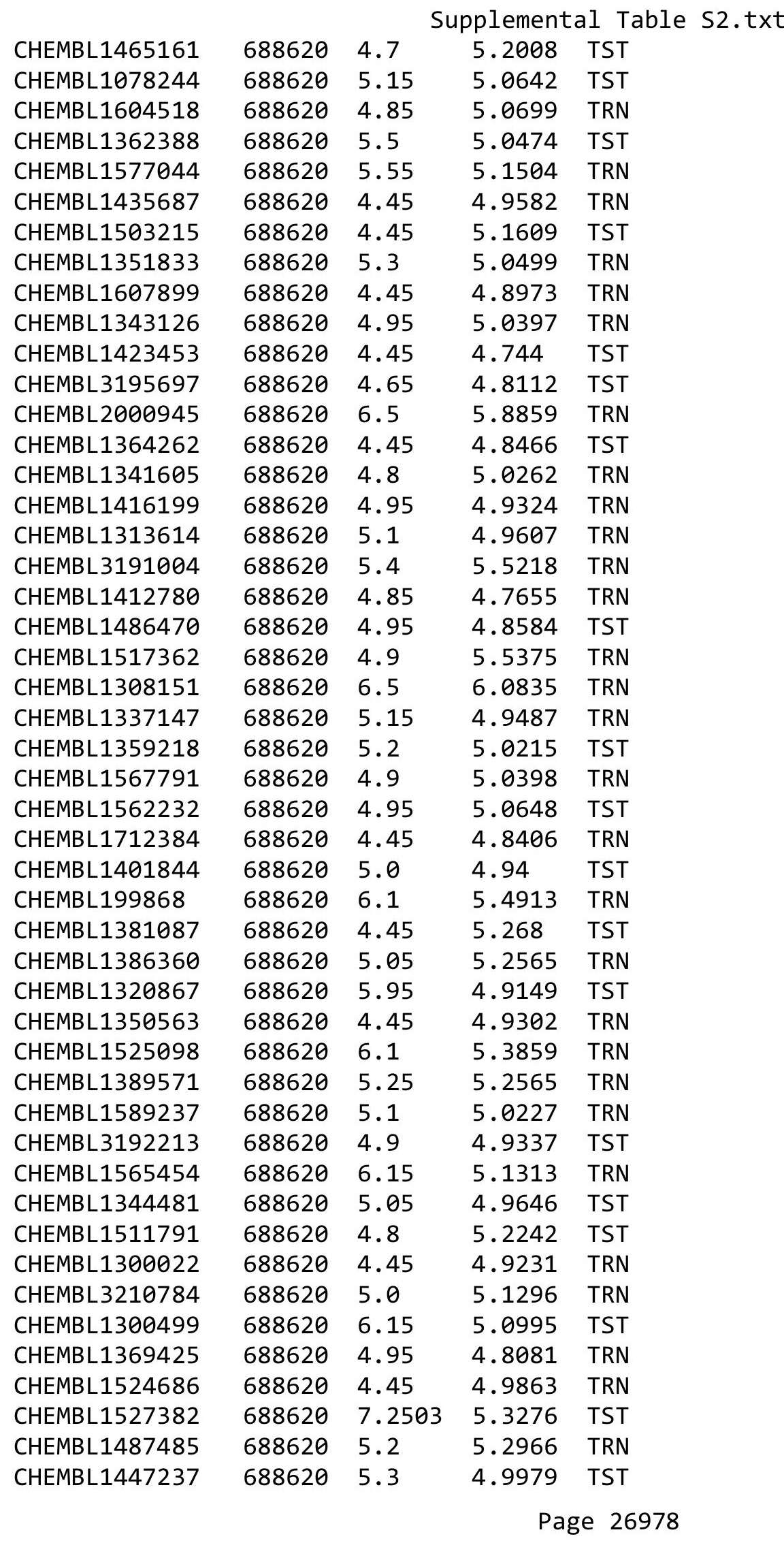




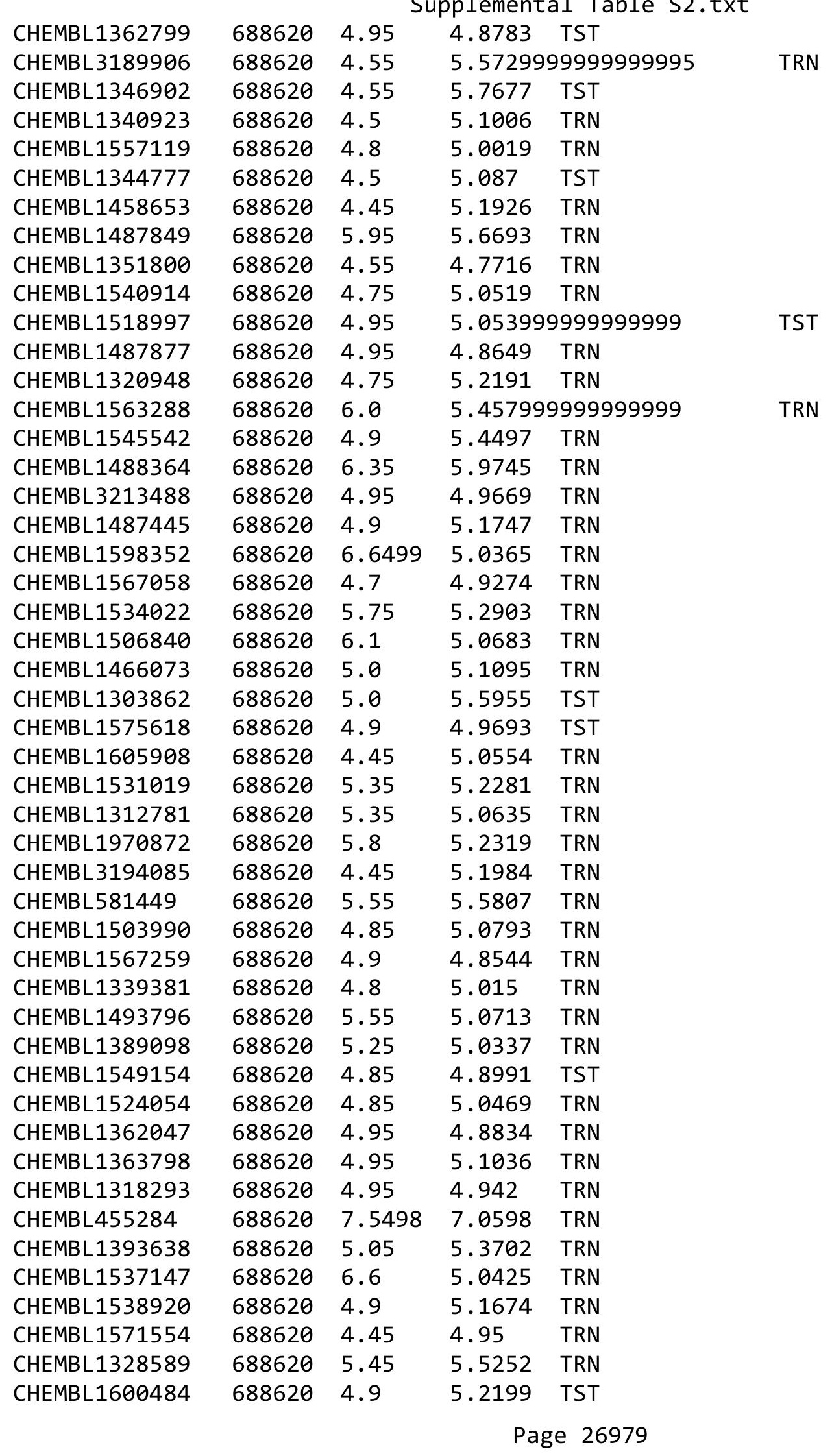




\begin{tabular}{|c|c|c|c|c|c|}
\hline \multicolumn{6}{|c|}{ Supplemental Table S2.txt } \\
\hline CHEMBL1383036 & 688620 & 5.4 & 5.539 & TRN & \\
\hline CHEMBL1508053 & 688620 & 5.15 & 5.1098 & TRN & \\
\hline CHEMBL1375957 & 688620 & 4.95 & 4.9038 & TRN & \\
\hline CHEMBL1335052 & 688620 & 6.05 & 5.5569 & TST & \\
\hline CHEMBL1351468 & 688620 & 5.15 & \multicolumn{2}{|c|}{5.361000000000001} & TRN \\
\hline CHEMBL1490594 & 688620 & 5.25 & 5.1216 & TRN & \\
\hline CHEMBL1525563 & 688620 & 8.2518 & 5.1226 & TST & \\
\hline CHEMBL1389851 & 688620 & 5.85 & 5.1835 & TST & \\
\hline CHEMBL1865547 & 688620 & 4.8 & 4.9397 & TST & \\
\hline CHEMBL1365184 & 688620 & 5.25 & 5.2198 & TST & \\
\hline CHEMBL1994599 & 688620 & 4.9 & 5.3772 & TRN & \\
\hline CHEMBL1505715 & 688620 & 4.5 & 5.0905 & TST & \\
\hline CHEMBL1569988 & 688620 & 5.95 & 5.2828 & TRN & \\
\hline CHEMBL1561395 & 688620 & 5.45 & 5.2986 & TRN & \\
\hline CHEMBL1404378 & 688620 & 5.35 & 5.1801 & TST & \\
\hline CHEMBL1606948 & 688620 & 4.45 & 4.7567 & TRN & \\
\hline CHEMBL1571482 & 688620 & 4.55 & 5.0355 & TRN & \\
\hline CHEMBL1541829 & 688620 & 4.45 & 4.8398 & TST & \\
\hline CHEMBL3195083 & 688620 & 7.0 & 5.8902 & TST & \\
\hline CHEMBL1448711 & 688620 & 4.45 & 4.8578 & TRN & \\
\hline CHEMBL1600701 & 688620 & 4.45 & 4.7669 & TRN & \\
\hline CHEMBL1588483 & 688620 & 4.65 & 4.8241 & TRN & \\
\hline CHEMBL1441629 & 688620 & 5.15 & 4.83 & TRN & \\
\hline CHEMBL1342051 & 688620 & 4.45 & 5.1386 & TST & \\
\hline CHEMBL1966921 & 688620 & 6.8 & 5.8147 & TRN & \\
\hline CHEMBL1326120 & 688620 & 6.5 & 5.152 & TST & \\
\hline CHEMBL1415134 & 688620 & 5.45 & 5.0091 & TST & \\
\hline CHEMBL1990959 & 688620 & 6.15 & 5.7409 & TRN & \\
\hline CHEMBL3197913 & 688620 & 4.95 & \multicolumn{2}{|c|}{4.9030000000000005} & TRN \\
\hline CHEMBL1372815 & 688620 & 4.95 & 5.0556 & TRN & \\
\hline CHEMBL1406782 & 688620 & 4.95 & 5.2926 & TRN & \\
\hline CHEMBL3193196 & 688620 & 7.4001 & 5.1223 & TST & \\
\hline CHEMBL1586093 & 688620 & 4.95 & 4.9852 & TRN & \\
\hline CHEMBL1603521 & 688620 & 4.9 & 5.2347 & TRN & \\
\hline CHEMBL1300605 & 688620 & 4.95 & 4.8887 & TRN & \\
\hline CHEMBL1563863 & 688620 & 4.45 & 4.6088 & TRN & \\
\hline CHEMBL1510185 & 688620 & 5.1 & 5.2245 & TST & \\
\hline CHEMBL1351991 & 688620 & 5.55 & \multicolumn{2}{|c|}{5.5360000000000005} & TRN \\
\hline CHEMBL1467047 & 688620 & 5.35 & 5.6564 & TRN & \\
\hline CHEMBL1420026 & 688620 & 5.4 & 4.9222 & TRN & \\
\hline CHEMBL1311636 & 688620 & 5.15 & 4.8756 & TRN & \\
\hline CHEMBL3195989 & 688620 & 5.05 & 5.1936 & TRN & \\
\hline CHEMBL3191184 & 688620 & 4.95 & 5.0404 & TST & \\
\hline CHEMBL1405915 & 688620 & 4.5 & 5.1073 & TRN & \\
\hline CHEMBL1403184 & 688620 & 4.45 & 5.1326 & TST & \\
\hline CHEMBL1498545 & 688620 & 4.75 & 4.976 & TRN & \\
\hline CHEMBL1604705 & 688620 & 5.05 & 5.0352 & TRN & \\
\hline \multirow[t]{2}{*}{ CHEMBL1486577 } & 688620 & 5.45 & \multicolumn{2}{|c|}{5.4110000000000005} & TRN \\
\hline & & & & 2698 & \\
\hline
\end{tabular}




\begin{tabular}{|c|c|c|c|c|c|}
\hline \multicolumn{6}{|c|}{ plemental } \\
\hline CHEMBL1399608 & 688620 & 5.5 & 5.3476 & TRN & \\
\hline CHEMBL3190559 & 688620 & 5.0 & 4.9042 & TRN & \\
\hline CHEMBL1496202 & 688620 & 5.55 & 5.4991 & TRN & \\
\hline CHEMBL1520935 & 688620 & 5.9 & 5.2927 & TRN & \\
\hline CHEMBL1402069 & 688620 & 5.8 & 4.8777 & TRN & \\
\hline CHEMBL1539510 & 688620 & 4.9 & 5.019 & TST & \\
\hline CHEMBL1597245 & 688620 & 5.4 & 5.2924 & TRN & \\
\hline CHEMBL1502935 & 688620 & 6.45 & 5.0776 & TRN & \\
\hline CHEMBL1532472 & 688620 & 5.7 & 5.4406 & TRN & \\
\hline CHEMBL1529252 & 688620 & 5.35 & 4.9637 & TRN & \\
\hline CHEMBL1559928 & 688620 & 5.05 & 4.96399 & 99999999995 & TRN \\
\hline CHEMBL1380781 & 688620 & 6.9 & 5.0976 & TRN & \\
\hline CHEMBL1390745 & 688620 & 4.9 & 5.1099 & TRN & \\
\hline CHEMBL1430450 & 688620 & 4.45 & 4.6187 & TRN & \\
\hline CHEMBL1332653 & 688620 & 4.7 & 5.0461 & TRN & \\
\hline CHEMBL1408236 & 688620 & 6.45 & 5.5106 & TRN & \\
\hline CHEMBL1507656 & 688620 & 4.45 & 5.1102 & TRN & \\
\hline CHEMBL3190135 & 688620 & 4.7 & 4.9864 & TRN & \\
\hline CHEMBL1506956 & 688620 & 5.2 & 5.3991 & TST & \\
\hline CHEMBL1336598 & 688620 & 4.9 & 4.9424 & TST & \\
\hline CHEMBL1483370 & 688620 & 6.1 & 5.102 & TST & \\
\hline CHEMBL1342790 & 688620 & 5.1 & 5.1813 & TRN & \\
\hline CHEMBL1423348 & 688620 & 4.7 & 5.0503 & TRN & \\
\hline CHEMBL1497797 & 688620 & 4.5 & 5.2146 & TST & \\
\hline CHEMBL3190328 & 688620 & 4.65 & 4.91100 & 00000000005 & TST \\
\hline CHEMBL1597585 & 688620 & 4.9 & 4.9768 & TRN & \\
\hline CHEMBL3198172 & 688620 & 5.4 & 5.01699 & 99999999995 & TST \\
\hline CHEMBL1393493 & 688620 & 4.45 & 4.9999 & TRN & \\
\hline CHEMBL1505658 & 688620 & 7.7496 & 5.1276 & TST & \\
\hline CHEMBL1536926 & 688620 & 4.9 & 5.0838 & TST & \\
\hline CHEMBL1447072 & 688620 & 4.7 & 5.022 & TRN & \\
\hline CHEMBL3198300 & 688620 & 5.3 & 5.3203 & TST & \\
\hline CHEMBL1578824 & 688620 & 4.45 & 4.8829 & TST & \\
\hline CHEMBL1330657 & 688620 & 4.8 & 5.0803 & TRN & \\
\hline CHEMBL1459821 & 688620 & 5.15 & 5.126 & TRN & \\
\hline CHEMBL1469851 & 688620 & 6.8499 & 5.11100 & 3000000001 & TST \\
\hline CHEMBL3192106 & 688620 & 5.0 & 5.065 & TST & \\
\hline CHEMBL1324011 & 688620 & 6.95 & 5.8721 & TRN & \\
\hline CHEMBL1608582 & 688620 & 5.75 & 5.3623 & TRN & \\
\hline CHEMBL1325171 & 688620 & 4.45 & 5.0387 & TST & \\
\hline CHEMBL3192706 & 688620 & 5.25 & 5.4275 & TRN & \\
\hline CHEMBL1488284 & 688620 & 4.45 & 5.0996 & TRN & \\
\hline CHEMBL1404209 & 688620 & 4.65 & 4.9645 & TRN & \\
\hline CHEMBL1428629 & 688620 & 5.25 & 5.1536 & TRN & \\
\hline CHEMBL1306271 & 688620 & 4.5 & 4.9638 & TRN & \\
\hline CHEMBL1385145 & 688620 & 5.05 & 4.9975 & TRN & \\
\hline CHEMBL1546215 & 688620 & 4.55 & 4.9732 & TST & \\
\hline CHEMBL1503115 & 688620 & 4.95 & 4.8409 & TRN & \\
\hline
\end{tabular}




\begin{tabular}{|c|c|c|c|c|}
\hline \multicolumn{5}{|c|}{ Supplemental Table s2.txt } \\
\hline CHEMBL3209362 & 688620 & 4.5 & 5.0176 & TRN \\
\hline CHEMBL1344295 & 688620 & 4.65 & 4.7853 & TRN \\
\hline CHEMBL1379912 & 688620 & 4.8 & 4.819 & TRN \\
\hline CHEMBL1422379 & 688620 & 5.25 & 5.1713 & TRN \\
\hline CHEMBL3192398 & 688620 & 5.25 & 5.2571 & TRN \\
\hline CHEMBL1567196 & 688620 & 5.95 & 5.0768 & TRN \\
\hline CHEMBL3190183 & 688620 & 5.95 & 5.035 & TRN \\
\hline CHEMBL1390072 & 688620 & 4.45 & 4.9217 & TRN \\
\hline CHEMBL1462366 & 688620 & 4.9 & 5.0189 & TRN \\
\hline CHEMBL1976540 & 688620 & 4.75 & 5.147 & TRN \\
\hline CHEMBL1303719 & 688620 & 4.8 & 5.0142 & TRN \\
\hline CHEMBL1538160 & 688620 & 5.5 & 4.8724 & TRN \\
\hline CHEMBL1532531 & 688620 & 4.85 & 4.9563 & TRN \\
\hline CHEMBL1581345 & 688620 & 4.65 & 4.9645 & TST \\
\hline CHEMBL1510883 & 688620 & 7.0501 & 4.9763 & TRN \\
\hline CHEMBL1545360 & 688620 & 4.45 & 4.8425 & TRN \\
\hline CHEMBL3193651 & 688620 & 4.95 & 4.9688 & TRN \\
\hline CHEMBL1417477 & 688620 & 4.45 & 4.7789 & TRN \\
\hline CHEMBL1477875 & 688620 & 4.95 & 4.8477 & TST \\
\hline CHEMBL1598405 & 688620 & 5.3 & 5.2475 & TRN \\
\hline CHEMBL1995550 & 688620 & 4.75 & 4.9047 & TST \\
\hline CHEMBL1302817 & 688620 & 6.3 & 5.0736 & TST \\
\hline CHEMBL1411744 & 688620 & 5.45 & 4.9854 & TRN \\
\hline CHEMBL3199178 & 688620 & 5.35 & 5.5505 & TST \\
\hline CHEMBL1405735 & 688620 & 4.8 & 5.046 & TRN \\
\hline CHEMBL1441619 & 688620 & 5.5 & 5.2496 & TRN \\
\hline CHEMBL1400203 & 688620 & 4.85 & 4.8569 & TST \\
\hline CHEMBL1405504 & 688620 & 4.6 & 5.1243 & TRN \\
\hline CHEMBL1504510 & 688620 & 4.9 & 5.1674 & TRN \\
\hline CHEMBL1420733 & 688620 & 4.45 & 5.2446 & TRN \\
\hline CHEMBL1469842 & 688620 & 4.95 & 4.9533 & TRN \\
\hline CHEMBL1602717 & 688620 & 5.95 & 5.4411 & TRN \\
\hline CHEMBL3207902 & 688620 & 5.65 & 5.09 & TRN \\
\hline CHEMBL1483768 & 688620 & 4.45 & 4.8797 & TRN \\
\hline CHEMBL1466324 & 688620 & 4.75 & 4.8891 & TST \\
\hline CHEMBL1339933 & 688620 & 4.45 & 5.0262 & TST \\
\hline CHEMBL1305287 & 688620 & 5.4 & 5.2695 & TRN \\
\hline CHEMBL1587983 & 688620 & 4.75 & 4.90300 & 00000000005 \\
\hline CHEMBL1567253 & 688620 & 4.65 & 5.2443 & TST \\
\hline CHEMBL3198370 & 688620 & 6.2 & 5.3524 & TST \\
\hline CHEMBL1404892 & 688620 & 4.45 & 5.1416 & TRN \\
\hline CHEMBL1485648 & 688620 & 4.95 & 5.1514 & TST \\
\hline CHEMBL1518652 & 688620 & 6.45 & 5.6353 & TRN \\
\hline CHEMBL1579125 & 688620 & 4.95 & 4.9497 & TRN \\
\hline CHEMBL1358145 & 688620 & 4.95 & 5.1294 & TST \\
\hline CHEMBL1360325 & 688620 & 5.0 & 5.0998 & TRN \\
\hline CHEMBL1415426 & 688620 & 7.2503 & 5.0484 & TRN \\
\hline CHEMBL1450485 & 688620 & 4.9 & 4.7088 & TRN \\
\hline
\end{tabular}




\begin{tabular}{|c|c|c|c|c|}
\hline & & & pplement & al $\mathrm{Ta}$ \\
\hline CHEMBL1376028 & 688620 & 4.9 & 5.0419 & TRN \\
\hline CHEMBL1492422 & 688620 & 5.5 & 4.9322 & TRN \\
\hline CHEMBL1313225 & 688620 & 4.95 & 4.7766 & TRN \\
\hline CHEMBL1300351 & 688620 & 4.95 & 5.0307 & TST \\
\hline CHEMBL1375242 & 688620 & 4.9 & 5.0284 & TRN \\
\hline CHEMBL1559455 & 688620 & 4.45 & 4.9837 & TRN \\
\hline CHEMBL1510582 & 688620 & 4.45 & 4.8715 & TRN \\
\hline CHEMBL1303510 & 688620 & 5.05 & 5.0391 & TST \\
\hline CHEMBL1582510 & 688620 & 6.2 & 5.3997 & TST \\
\hline CHEMBL1306839 & 688620 & 4.9 & 4.6877 & TRN \\
\hline CHEMBL1307208 & 688620 & 5.0 & 5.0376 & TRN \\
\hline CHEMBL1978031 & 688620 & 5.2 & 5.3175 & TRN \\
\hline CHEMBL1310399 & 688620 & 5.55 & 5.3089 & TRN \\
\hline CHEMBL1604060 & 688620 & 4.45 & 5.0825 & TRN \\
\hline CHEMBL1489820 & 688620 & 4.5 & 4.8689 & TRN \\
\hline CHEMBL1534726 & 688620 & 5.05 & 4.8093 & TRN \\
\hline CHEMBL1426136 & 688620 & 5.9 & 4.9988 & TRN \\
\hline CHEMBL 3189497 & 688620 & 4.45 & 4.8016 & TRN \\
\hline CHEMBL1334226 & 688620 & 4.8 & 5.081 & TRN \\
\hline CHEMBL1388258 & 688620 & 4.45 & 5.0323 & TRN \\
\hline CHEMBL1368329 & 688620 & 4.5 & 5.0486 & TRN \\
\hline CHEMBL1443830 & 688620 & 5.1 & 4.8755 & TRN \\
\hline CHEMBL1543936 & 688620 & 4.45 & 5.1884 & TRN \\
\hline CHEMBL1402368 & 688620 & 4.85 & 4.8867 & TRN \\
\hline CHEMBL1538582 & 688620 & 5.0 & 4.9085 & TRN \\
\hline CHEMBL1430453 & 688620 & 4.85 & 5.5734 & TRN \\
\hline CHEMBL1361413 & 688620 & 5.75 & 5.1402 & TRN \\
\hline CHEMBL1566409 & 688620 & 4.9 & 5.1052 & TRN \\
\hline CHEMBL1305386 & 688620 & 7.5498 & 5.1476 & TRN \\
\hline CHEMBL1563966 & 688620 & 4.9 & 5.1684 & TST \\
\hline CHEMBL1331634 & 688620 & 6.0 & 4.8132 & TRN \\
\hline CHEMBL1416769 & 688620 & 4.7 & 4.6708 & TRN \\
\hline CHEMBL1607317 & 688620 & 4.9 & 5.1357 & TRN \\
\hline CHEMBL 3192814 & 688620 & 4.65 & 4.7687 & TRN \\
\hline CHEMBL1419186 & 688620 & 5.25 & 4.8449 & TRN \\
\hline CHEMBL1529539 & 688620 & 4.7 & 5.3415 & TRN \\
\hline CHEMBL1379262 & 688620 & 4.8 & 4.7744 & TRN \\
\hline CHEMBL1396741 & 688620 & 4.45 & 5.3735 & TRN \\
\hline CHEMBL1531245 & 688620 & 4.8 & 5.2637 & TST \\
\hline CHEMBL1383873 & 688620 & 4.8 & 4.8153 & TST \\
\hline CHEMBL1471524 & 688620 & 4.9 & 5.0543 & TRN \\
\hline CHEMBL1421229 & 688620 & 4.95 & 5.1014 & TRN \\
\hline CHEMBL1339164 & 688620 & 4.95 & 4.8454 & TRN \\
\hline CHEMBL1466219 & 688620 & 4.8 & 5.185 & TRN \\
\hline CHEMBL1607858 & 688620 & 4.9 & 4.9611 & TRN \\
\hline CHEMBL1546699 & 688620 & 4.9 & 4.8973 & TST \\
\hline CHEMBL1566382 & 688620 & 5.0 & 4.9251 & TRN \\
\hline CHEMBL1300622 & 688620 & 4.8 & 4.8741 & TST \\
\hline
\end{tabular}




\begin{tabular}{|c|c|c|c|c|}
\hline & & & upplement & al \\
\hline CHEMBL1569548 & 688620 & 4.65 & 4.9127 & TRN \\
\hline CHEMBL576244 & 688620 & 4.9 & 5.0294 & TRN \\
\hline CHEMBL1602606 & 688620 & 5.65 & 4.879 & TRN \\
\hline CHEMBL1984115 & 688620 & 4.95 & 5.4574 & TRN \\
\hline CHEMBL1445071 & 688620 & 4.85 & 4.8654 & TST \\
\hline CHEMBL1339429 & 688620 & 5.4 & 4.8498 & TRN \\
\hline CHEMBL1532651 & 688620 & 4.45 & 5.0262 & TRN \\
\hline CHEMBL1442786 & 688620 & 4.75 & 4.7627 & TRN \\
\hline CHEMBL1432156 & 688620 & 5.25 & 5.2226 & TST \\
\hline CHEMBL1386367 & 688620 & 4.8 & 4.9325 & TRN \\
\hline CHEMBL1333993 & 688620 & 4.45 & 5.2914 & TRN \\
\hline CHEMBL1403871 & 688620 & 5.4 & 5.355 & TRN \\
\hline CHEMBL1378919 & 688620 & 4.7 & 5.1146 & TRN \\
\hline CHEMBL1336346 & 688620 & 4.45 & 4.7826 & TST \\
\hline CHEMBL1984804 & 688620 & 5.05 & 4.9895 & TST \\
\hline CHEMBL1544356 & 688620 & 4.5 & 4.9318 & TRN \\
\hline CHEMBL 3197554 & 688620 & 4.85 & 4.9735 & TRN \\
\hline CHEMBL1406799 & 688620 & 5.8 & 5.5141 & TST \\
\hline CHEMBL1557270 & 688620 & 5.85 & 5.2441 & TST \\
\hline CHEMBL3191933 & 688620 & 4.95 & 5.1782 & TRN \\
\hline CHEMBL1593847 & 688620 & 4.45 & 5.1407 & TST \\
\hline CHEMBL1390734 & 688620 & 5.05 & 4.9401 & TRN \\
\hline CHEMBL1612507 & 688620 & 4.45 & 4.8104 & TRN \\
\hline CHEMBL3193415 & 688620 & 5.05 & 5.1395 & TRN \\
\hline CHEMBL1489672 & 688620 & 4.65 & 5.027 & TRN \\
\hline CHEMBL3209438 & 688620 & 5.55 & 5.1392 & TRN \\
\hline CHEMBL1540099 & 688620 & 4.8 & 4.9784 & TRN \\
\hline CHEMBL1370696 & 688620 & 5.2 & 5.0879 & TRN \\
\hline CHEMBL1511227 & 688620 & 4.95 & 4.9545 & TRN \\
\hline CHEMBL1353601 & 688620 & 5.65 & 5.2393 & TST \\
\hline CHEMBL1506578 & 688620 & 5.45 & 5.1342 & TRN \\
\hline CHEMBL1591190 & 688620 & 5.45 & 5.1122 & TRN \\
\hline CHEMBL1388233 & 688620 & 4.45 & 5.2748 & TRN \\
\hline CHEMBL1313866 & 688620 & 6.05 & 5.1427 & TST \\
\hline CHEMBL3189322 & 688620 & 6.1 & 5.4882 & TRN \\
\hline CHEMBL1460711 & 688620 & 4.7 & 4.9411 & TST \\
\hline CHEMBL1549638 & 688620 & 5.15 & 4.8461 & TRN \\
\hline CHEMBL3193093 & 688620 & 5.95 & 5.694 & TRN \\
\hline CHEMBL1528225 & 688620 & 4.45 & 4.9608 & TRN \\
\hline CHEMBL243677 & 688620 & 4.85 & 5.0962 & TRN \\
\hline CHEMBL1997491 & 688620 & 5.5 & 5.6247 & TRN \\
\hline CHEMBL3199360 & 688620 & 4.65 & 4.9795 & TST \\
\hline CHEMBL1992801 & 688620 & 5.0 & 5.006 & TRN \\
\hline CHEMBL1366573 & 688620 & 4.85 & 4.8575 & TRN \\
\hline CHEMBL1469042 & 688620 & 4.45 & 5.0659 & TST \\
\hline CHEMBL1346869 & 688620 & 4.95 & 4.9584 & TRN \\
\hline CHEMBL 2000338 & 688620 & 5.0 & 5.1103 & TRN \\
\hline CHEMBL339304 & 688620 & 5.1 & 5.3795 & TRN \\
\hline
\end{tabular}




\begin{tabular}{|c|c|c|c|c|c|}
\hline \\
\hline CHEMBL1387530 & 688620 & 5.7 & 4.7307 & TRN & \\
\hline CHEMBL1610801 & 688620 & 4.95 & 5.0501 & TST & \\
\hline CHEMBL1463117 & 688620 & 4.65 & 5.0286 & TRN & \\
\hline CHEMBL3194593 & 688620 & 5.6 & 5.2055 & TRN & \\
\hline CHEMBL1578586 & 688620 & 6.0 & 5.1085 & TRN & \\
\hline CHEMBL503552 & 688620 & 4.45 & 5.1398 & TRN & \\
\hline CHEMBL1440469 & 688620 & 5.05 & 4.9523 & TRN & \\
\hline CHEMBL1429375 & 688620 & 4.9 & 4.8995 & TRN & \\
\hline CHEMBL1311574 & 688620 & 5.9 & 5.2682 & TRN & \\
\hline CHEMBL1505307 & 688620 & 4.45 & 4.9855 & TRN & \\
\hline CHEMBL1332450 & 688620 & 6.25 & 6.1285 & TRN & \\
\hline CHEMBL1584579 & 688620 & 6.05 & 5.5918 & TRN & \\
\hline CHEMBL1425938 & 688620 & 5.1 & 5.1859 & TRN & \\
\hline CHEMBL1392799 & 688620 & 5.1 & 4.928 & TRN & \\
\hline CHEMBL1613719 & 688620 & 4.9 & 4.9427 & TST & \\
\hline CHEMBL1493620 & 688620 & 4.5 & 4.8941 & TRN & \\
\hline CHEMBL3212238 & 688620 & 5.1 & 5.1049 & TRN & \\
\hline CHEMBL1546739 & 688620 & 6.45 & 5.7424 & TST & \\
\hline CHEMBL 3194524 & 688620 & 4.95 & 4.8213 & TRN & \\
\hline CHEMBL1574573 & 688620 & 4.95 & 4.6324 & TRN & \\
\hline CHEMBL3198532 & 688620 & 4.45 & 4.6643 & TRN & \\
\hline CHEMBL1336422 & 688620 & 5.05 & 4.8617 & TRN & \\
\hline CHEMBL1487830 & 688620 & 4.45 & 4.8793 & TRN & \\
\hline CHEMBL1321003 & 688620 & 5.05 & 5.0208 & TRN & \\
\hline CHEMBL1601128 & 688620 & 4.9 & 5.142 & TRN & \\
\hline CHEMBL1326973 & 688620 & 4.75 & 4.9911 & TRN & \\
\hline CHEMBL1390641 & 688620 & 4.9 & 5.186 & TRN & \\
\hline CHEMBL1500265 & 688620 & 5.4 & 5.4997 & TRN & \\
\hline CHEMBL 3211264 & 688620 & 5.15 & 5.3968 & TRN & \\
\hline CHEMBL1583330 & 688620 & 4.85 & 5.0562 & TRN & \\
\hline CHEMBL1557263 & 688620 & 4.55 & 4.9112 & TST & \\
\hline CHEMBL1302271 & 688620 & 4.45 & 5.0084 & TST & \\
\hline CHEMBL1538010 & 688620 & 4.85 & 4.9352 & TRN & \\
\hline CHEMBL1511234 & 688620 & 5.45 & 4.8594 & TRN & \\
\hline CHEMBL1426500 & 688620 & 4.85 & 5.1746 & TST & \\
\hline CHEMBL1453039 & 688620 & 4.95 & 5.4268 & TRN & \\
\hline CHEMBL1343290 & 688620 & 4.9 & 4.9795 & TST & \\
\hline CHEMBL1423660 & 688620 & 6.05 & 5.7632 & TRN & \\
\hline CHEMBL1462065 & 688620 & 6.9 & 4.7929 & TRN & \\
\hline CHEMBL1492297 & 688620 & 4.45 & 5.0196 & TST & \\
\hline CHEMBL1424734 & 688620 & 5.3 & 5.3475 & TRN & \\
\hline CHEMBL1425161 & 688620 & 5.3 & 5.1677 & TST & \\
\hline CHEMBL1453521 & 688620 & 5.35 & 5.1247 & TRN & \\
\hline CHEMBL1462258 & 688620 & 4.9 & 4.6883 & TRN & \\
\hline CHEMBL1336858 & 688620 & 4.45 & 5.1985 & TRN & \\
\hline CHEMBL1359814 & 688620 & 4.45 & 4.8243 & TST & \\
\hline CHEMBL1432989 & 688620 & 4.45 & 5.0545 & TRN & \\
\hline CHEMBL1409990 & 688620 & 5.1 & 5.25799 & 9999999999 & TRN \\
\hline & & & & 26985 & \\
\hline
\end{tabular}




\begin{tabular}{|c|c|c|c|c|c|}
\hline & & \multicolumn{4}{|c|}{ Supplemental Table S2.txt } \\
\hline CHEMBL1393761 & 688620 & 4.95 & 4.7558 & TRN & \\
\hline CHEMBL1323968 & 688620 & 4.95 & 5.3927 & TST & \\
\hline CHEMBL1385487 & 688620 & 4.45 & 4.9064 & TST & \\
\hline CHEMBL1598022 & 688620 & 5.15 & 4.9437 & TRN & \\
\hline CHEMBL1481988 & 688620 & 4.75 & 5.1333 & TRN & \\
\hline CHEMBL1582853 & 688620 & 6.1 & 5.096 & TRN & \\
\hline CHEMBL1972491 & 688620 & 4.85 & 5.2491 & TRN & \\
\hline CHEMBL1299470 & 688620 & 4.45 & 5.1965 & TRN & \\
\hline CHEMBL1500049 & 688620 & 4.45 & 5.1318 & TRN & \\
\hline CHEMBL1451815 & 688620 & 4.9 & 5.0291 & TRN & \\
\hline CHEMBL1566952 & 688620 & 4.85 & 4.9575 & TRN & \\
\hline CHEMBL1468287 & 688620 & 5.8 & 5.0468 & TST & \\
\hline CHEMBL1486315 & 688620 & 5.0 & 4.9521 & TST & \\
\hline CHEMBL1432518 & 688620 & 5.7 & 5.0885 & TRN & \\
\hline CHEMBL3210166 & 688620 & 4.95 & 5.2108 & TRN & \\
\hline CHEMBL1594464 & 688620 & 4.9 & 4.9634 & TRN & \\
\hline CHEMBL 2007352 & 688620 & 5.35 & 5.6366 & TRN & \\
\hline CHEMBL1526934 & 688620 & 5.0 & 5.1612 & TRN & \\
\hline CHEMBL1561214 & 688620 & 4.8 & 4.9528 & TST & \\
\hline CHEMBL1337236 & 688620 & 5.2 & 4.936 & TRN & \\
\hline CHEMBL1979106 & 688620 & 4.9 & 4.9213 & TRN & \\
\hline CHEMBL1426681 & 688620 & 5.15 & 5.6691 & TST & \\
\hline CHEMBL1458664 & 688620 & 5.5 & 4.89199 & 99999999995 & TRN \\
\hline CHEMBL1498341 & 688620 & 4.85 & 5.0827 & TRN & \\
\hline CHEMBL3191627 & 688620 & 4.95 & 4.9878 & TRN & \\
\hline CHEMBL1327962 & 688620 & 4.9 & 4.9704 & TST & \\
\hline CHEMBL403271 & 688620 & 5.2 & 5.1686 & TRN & \\
\hline CHEMBL1489461 & 688620 & 4.65 & 5.1453 & TRN & \\
\hline CHEMBL1560010 & 688620 & 5.2 & 4.9385 & TRN & \\
\hline CHEMBL1440472 & 688620 & 4.45 & 5.0674 & TST & \\
\hline CHEMBL1566083 & 688620 & 4.8 & 4.8168 & TRN & \\
\hline CHEMBL1541098 & 688620 & 4.95 & 4.7331 & TRN & \\
\hline CHEMBL1458601 & 688620 & 5.15 & 5.1829 & TST & \\
\hline CHEMBL1601295 & 688620 & 5.65 & 5.224 & TRN & \\
\hline CHEMBL1313483 & 688620 & 4.8 & 5.0798 & TRN & \\
\hline CHEMBL1351844 & 688620 & 5.95 & 5.1463 & TRN & \\
\hline CHEMBL1403817 & 688620 & 4.65 & 4.7847 & TRN & \\
\hline CHEMBL1461584 & 688620 & 4.9 & 4.88399 & 99999999995 & TST \\
\hline CHEMBL1401029 & 688620 & 5.0 & 4.9565 & TRN & \\
\hline CHEMBL1466204 & 688620 & 5.85 & 5.6738 & TRN & \\
\hline CHEMBL 3198453 & 688620 & 4.8 & 5.2007 & TRN & \\
\hline CHEMBL1485860 & 688620 & 6.05 & 5.5249 & TRN & \\
\hline CHEMBL1507100 & 688620 & 4.9 & 4.7831 & TRN & \\
\hline CHEMBL1545922 & 688620 & 4.7 & 4.78 & TRN & \\
\hline CHEMBL1352175 & 688620 & 4.45 & 4.8664 & TRN & \\
\hline CHEMBL1564403 & 688620 & 5.55 & 5.4564 & TRN & \\
\hline CHEMBL1611956 & 688620 & 4.85 & 4.9293 & TRN & \\
\hline CHEMBL3198539 & 688620 & 4.45 & 5.0092 & TRN & \\
\hline
\end{tabular}




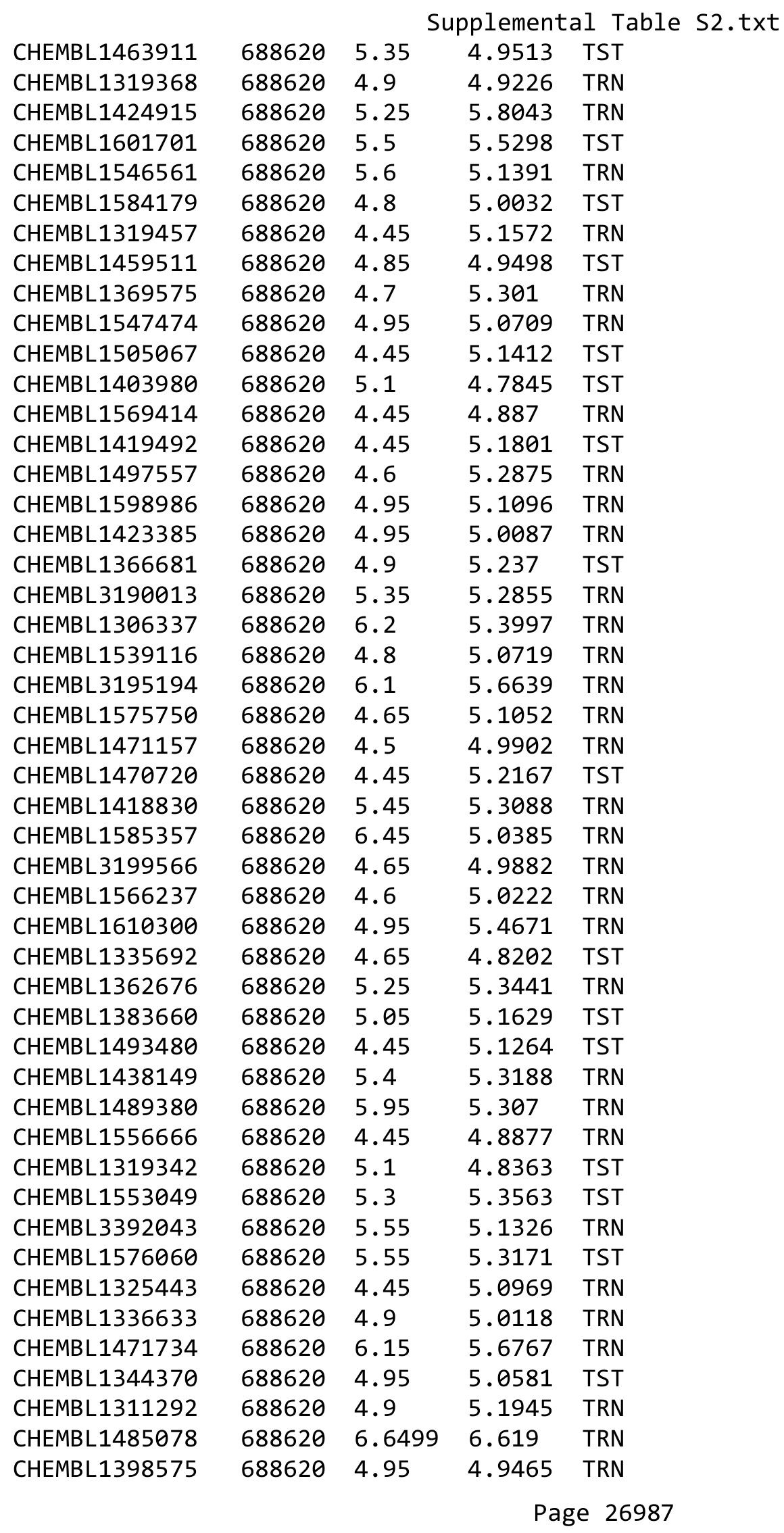




\begin{tabular}{|c|c|c|c|c|c|}
\hline \multicolumn{6}{|c|}{ Supplemental Table s2.txt } \\
\hline CHEMBL 3208543 & 688620 & 4.7 & 5.1546 & TRN & \\
\hline CHEMBL1430019 & 688620 & 5.0 & 5.0493 & TRN & \\
\hline CHEMBL3210375 & 688620 & 4.65 & 4.8188 & TRN & \\
\hline CHEMBL1504011 & 688620 & 5.0 & 4.8778 & TRN & \\
\hline CHEMBL1406457 & 688620 & 5.7 & 5.2976 & TST & \\
\hline CHEMBL1498815 & 688620 & 4.85 & 4.9922 & TST & \\
\hline CHEMBL3195456 & 688620 & 4.95 & 5.0657 & TRN & \\
\hline CHEMBL1423593 & 688620 & 6.0 & 5.4563 & TRN & \\
\hline CHEMBL1448804 & 688620 & 5.45 & 5.0765 & TST & \\
\hline CHEMBL1406828 & 688620 & 4.9 & 4.8628 & TRN & \\
\hline CHEMBL1417705 & 688620 & 4.9 & 4.92899 & 9999999999 & TST \\
\hline CHEMBL1373164 & 688620 & 4.75 & 6.0533 & TRN & \\
\hline CHEMBL1490040 & 688620 & 4.45 & 5.2213 & TRN & \\
\hline CHEMBL1606342 & 688620 & 5.15 & 5.0256 & TRN & \\
\hline CHEMBL1549282 & 688620 & 5.5 & 5.0166 & TST & \\
\hline CHEMBL1527874 & 688620 & 4.95 & 5.0734 & TRN & \\
\hline CHEMBL1353667 & 688620 & 5.7 & 5.1229 & TRN & \\
\hline CHEMBL1483966 & 688620 & 4.8 & 5.1389 & TRN & \\
\hline CHEMBL3190692 & 688620 & 5.0 & 4.9666 & TRN & \\
\hline CHEMBL1361559 & 688620 & 4.75 & 5.225 & TRN & \\
\hline CHEMBL1445850 & 688620 & 6.7001 & 6.1856 & TRN & \\
\hline CHEMBL1342510 & 688620 & 5.35 & 5.2522 & TRN & \\
\hline CHEMBL1339714 & 688620 & 4.5 & 5.1691 & TRN & \\
\hline CHEMBL3207417 & 688620 & 4.75 & 5.1106 & TRN & \\
\hline CHEMBL1390299 & 688620 & 4.95 & 5.1173 & TRN & \\
\hline CHEMBL1465242 & 688620 & 4.45 & 5.3445 & TRN & \\
\hline CHEMBL1412160 & 688620 & 4.55 & 4.8478 & TRN & \\
\hline CHEMBL1363533 & 688620 & 4.9 & 5.1318 & TRN & \\
\hline CHEMBL1429841 & 688620 & 5.7 & 5.3609 & TRN & \\
\hline CHEMBL1347859 & 688620 & 5.15 & 5.0726 & TRN & \\
\hline CHEMBL1452821 & 688620 & 4.45 & 5.1645 & TST & \\
\hline CHEMBL1531574 & 688620 & 4.85 & 4.8094 & TRN & \\
\hline CHEMBL1606712 & 688620 & 5.0 & 4.9646 & TST & \\
\hline CHEMBL1330948 & 688620 & 4.95 & 4.8736 & TST & \\
\hline CHEMBL1392681 & 688620 & 4.45 & 4.6729 & TST & \\
\hline CHEMBL1330586 & 688620 & 4.95 & 5.3818 & TRN & \\
\hline CHEMBL1549577 & 688620 & 5.15 & 5.2987 & TRN & \\
\hline CHEMBL1470923 & 688620 & 5.6 & 5.67700 & 00000000005 & TST \\
\hline CHEMBL1381586 & 688620 & 5.0 & 5.0346 & TRN & \\
\hline CHEMBL1609054 & 688620 & 5.35 & 4.7937 & TST & \\
\hline CHEMBL1368802 & 688620 & 5.0 & 5.046 & TRN & \\
\hline CHEMBL1542512 & 688620 & 5.15 & 5.1221 & TRN & \\
\hline CHEMBL1426774 & 688620 & 4.5 & 5.1182 & TRN & \\
\hline CHEMBL1492145 & 688620 & 5.4 & 4.6859 & TRN & \\
\hline CHEMBL1405223 & 688620 & 5.3 & 4.935 & TRN & \\
\hline CHEMBL1561498 & 688620 & 4.45 & 5.3483 & TST & \\
\hline CHEMBL1426346 & 688620 & 4.5 & 4.9773 & TRN & \\
\hline CHEMBL1584960 & 688620 & 5.2 & 5.0095 & TRN & \\
\hline
\end{tabular}




\begin{tabular}{|c|c|c|c|c|c|}
\hline \multicolumn{6}{|c|}{ Supplemental Table S2.txt } \\
\hline CHEMBL1333308 & 688620 & 4.45 & 4.9329 & TST & \\
\hline CHEMBL1554680 & 688620 & 4.9 & 4.91 & TRN & \\
\hline CHEMBL1312885 & 688620 & 4.45 & 4.9337 & TRN & \\
\hline CHEMBL1307028 & 688620 & 4.45 & 5.3627 & TRN & \\
\hline CHEMBL1563561 & 688620 & 4.45 & 5.0207 & TRN & \\
\hline CHEMBL3192967 & 688620 & 4.9 & 5.0452 & TRN & \\
\hline CHEMBL1322589 & 688620 & 4.75 & 4.8775 & TRN & \\
\hline CHEMBL1577285 & 688620 & 5.25 & 4.9364 & TRN & \\
\hline CHEMBL1326811 & 688620 & 4.6 & 5.0621 & TRN & \\
\hline CHEMBL1509216 & 688620 & 4.95 & 5.6382 & TST & \\
\hline CHEMBL1369966 & 688620 & 4.95 & 4.999 & TRN & \\
\hline CHEMBL1384920 & 688620 & 4.55 & 4.9272 & TRN & \\
\hline CHEMBL1299297 & 688620 & 4.9 & 5.135 & TRN & \\
\hline CHEMBL1569910 & 688620 & 5.25 & 5.1311 & TRN & \\
\hline CHEMBL1466896 & 688620 & 4.75 & 5.0651 & TRN & \\
\hline CHEMBL1386460 & 688620 & 6.4 & 5.1118 & TRN & \\
\hline CHEMBL3392383 & 688620 & 4.45 & 4.8845 & TRN & \\
\hline CHEMBL3211206 & 688620 & 4.45 & 5.32100 & 0000000001 & TRN \\
\hline CHEMBL1503890 & 688620 & 5.5 & 4.845 & TST & \\
\hline CHEMBL1313608 & 688620 & 4.45 & 5.0531 & TRN & \\
\hline CHEMBL1444546 & 688620 & 4.45 & 4.9662 & TRN & \\
\hline CHEMBL1465654 & 688620 & 5.6 & 4.9886 & TRN & \\
\hline CHEMBL1309286 & 688620 & 5.5 & 5.1966 & TRN & \\
\hline CHEMBL1588827 & 688620 & 4.95 & 4.8549 & TRN & \\
\hline CHEMBL1606486 & 688620 & 6.05 & 5.5928 & TRN & \\
\hline CHEMBL1546228 & 688620 & 5.2 & 5.3871 & TST & \\
\hline CHEMBL1521021 & 688620 & 4.65 & 4.7005 & TST & \\
\hline CHEMBL1540130 & 688620 & 5.5 & 5.3462 & TRN & \\
\hline CHEMBL1542298 & 688620 & 5.25 & 5.0413 & TRN & \\
\hline CHEMBL1340177 & 688620 & 5.55 & 5.0258 & TRN & \\
\hline CHEMBL1353310 & 688620 & 4.5 & 5.0775 & TRN & \\
\hline CHEMBL1379971 & 688620 & 5.4 & 5.4694 & TRN & \\
\hline CHEMBL1566765 & 688620 & 5.2 & 4.9768 & TRN & \\
\hline CHEMBL3199737 & 688620 & 6.5501 & 5.3356 & TST & \\
\hline CHEMBL1595516 & 688620 & 4.9 & 4.9497 & TRN & \\
\hline CHEMBL3212695 & 688620 & 5.2 & 5.0095 & TST & \\
\hline CHEMBL 1377035 & 688620 & 4.8 & 4.7704 & TRN & \\
\hline CHEMBL1307918 & 688620 & 4.95 & 4.9671 & TRN & \\
\hline CHEMBL1604200 & 688620 & 5.0 & 5.3102 & TRN & \\
\hline CHEMBL1329046 & 688620 & 5.2 & 5.3634 & TRN & \\
\hline CHEMBL1483258 & 688620 & 4.8 & 5.0739 & TST & \\
\hline CHEMBL1540902 & 688620 & 5.35 & 5.2214 & TRN & \\
\hline CHEMBL1432080 & 688620 & 5.4 & 5.2844 & TRN & \\
\hline CHEMBL3192311 & 688620 & 4.45 & 4.9449 & TRN & \\
\hline CHEMBL3207730 & 688620 & 4.95 & 5.2401 & TST & \\
\hline CHEMBL1589750 & 688620 & 4.9 & 4.9442 & TRN & \\
\hline CHEMBL1490059 & 688620 & 8.301 & 5.0908 & TRN & \\
\hline CHEMBL1366656 & 688620 & 4.95 & 4.8558 & TRN & \\
\hline
\end{tabular}




\begin{tabular}{|c|c|c|c|c|c|}
\hline \\
\hline CHEMBL1511417 & 688620 & 4.5 & 5.1606 & TRN & \\
\hline CHEMBL1426152 & 688620 & 4.45 & 4.8293 & TST & \\
\hline CHEMBL1338968 & 688620 & 4.9 & 5.0981 & TRN & \\
\hline CHEMBL1328895 & 688620 & 5.0 & 4.8017 & TRN & \\
\hline CHEMBL1453501 & 688620 & 4.45 & 5.0774 & TST & \\
\hline CHEMBL1513792 & 688620 & 4.95 & 5.0444 & TRN & \\
\hline CHEMBL1548809 & 688620 & 4.75 & 4.8093 & TRN & \\
\hline CHEMBL1440083 & 688620 & 4.65 & 4.9545 & TRN & \\
\hline CHEMBL1544126 & 688620 & 5.25 & 5.1838 & TRN & \\
\hline CHEMBL3198038 & 688620 & 5.2 & 5.3638 & TRN & \\
\hline CHEMBL1493439 & 688620 & 4.85 & 4.8091 & TRN & \\
\hline CHEMBL1443771 & 688620 & 4.95 & 4.8672 & TRN & \\
\hline CHEMBL1448474 & 688620 & 5.0 & 5.193 & TRN & \\
\hline CHEMBL1405916 & 688620 & 5.6 & 5.4407 & TRN & \\
\hline CHEMBL1402627 & 688620 & 5.45 & 5.25299 & 9999999999 & TRN \\
\hline CHEMBL1610469 & 688620 & 5.1 & 4.7135 & TRN & \\
\hline CHEMBL1610650 & 688620 & 4.9 & 4.9935 & TRN & \\
\hline CHEMBL1448958 & 688620 & 5.45 & 5.4449 & TRN & \\
\hline CHEMBL1521601 & 688620 & 6.15 & 5.0089 & TRN & \\
\hline CHEMBL3195671 & 688620 & 5.25 & 5.10800 & 00000000005 & TST \\
\hline CHEMBL1443859 & 688620 & 5.3 & 4.8925 & TST & \\
\hline CHEMBL1500308 & 688620 & 4.85 & 5.0726 & TRN & \\
\hline CHEMBL1319476 & 688620 & 4.6 & 4.8887 & TRN & \\
\hline CHEMBL1556682 & 688620 & 5.2 & 4.9073 & TST & \\
\hline CHEMBL1422234 & 688620 & 4.8 & 5.0844 & TRN & \\
\hline CHEMBL1390325 & 688620 & 5.15 & 4.9156 & TRN & \\
\hline CHEMBL1530581 & 688620 & 6.0 & 5.6469 & TRN & \\
\hline CHEMBL1328875 & 688620 & 5.2 & 4.874 & TRN & \\
\hline CHEMBL1367321 & 688620 & 5.6 & 5.1245 & TST & \\
\hline CHEMBL1604058 & 688620 & 5.15 & 5.1198 & TRN & \\
\hline CHEMBL1339210 & 688620 & 4.8 & 4.7776 & TST & \\
\hline CHEMBL1609757 & 688620 & 6.5 & 5.1139 & TRN & \\
\hline CHEMBL1383381 & 688620 & 5.3 & 5.0672 & TRN & \\
\hline CHEMBL3198289 & 688620 & 4.45 & 5.187 & TST & \\
\hline CHEMBL1448312 & 688620 & 4.9 & 4.7842 & TRN & \\
\hline CHEMBL1300520 & 688620 & 4.65 & 5.083 & TST & \\
\hline CHEMBL1330874 & 688620 & 5.55 & 5.2139 & TRN & \\
\hline CHEMBL1533591 & 688620 & 4.45 & 5.011 & TRN & \\
\hline CHEMBL1393903 & 688620 & 4.75 & 5.1111 & TRN & \\
\hline CHEMBL1504575 & 688620 & 4.85 & 5.5749 & TRN & \\
\hline CHEMBL3189547 & 688620 & 5.6 & 5.4209 & TRN & \\
\hline CHEMBL1511268 & 688620 & 4.7 & 5.1024 & TST & \\
\hline CHEMBL1609658 & 688620 & 4.95 & 5.12299 & 9999999999 & TRN \\
\hline CHEMBL1409131 & 688620 & 5.8 & 5.0664 & TRN & \\
\hline CHEMBL1991055 & 688620 & 5.95 & 5.5344 & TRN & \\
\hline CHEMBL1557999 & 688620 & 5.1 & 5.2375 & TRN & \\
\hline CHEMBL1994179 & 688620 & 5.2 & 5.4297 & TRN & \\
\hline CHEMBL3193818 & 688620 & 4.8 & 4.9143 & TRN & \\
\hline
\end{tabular}




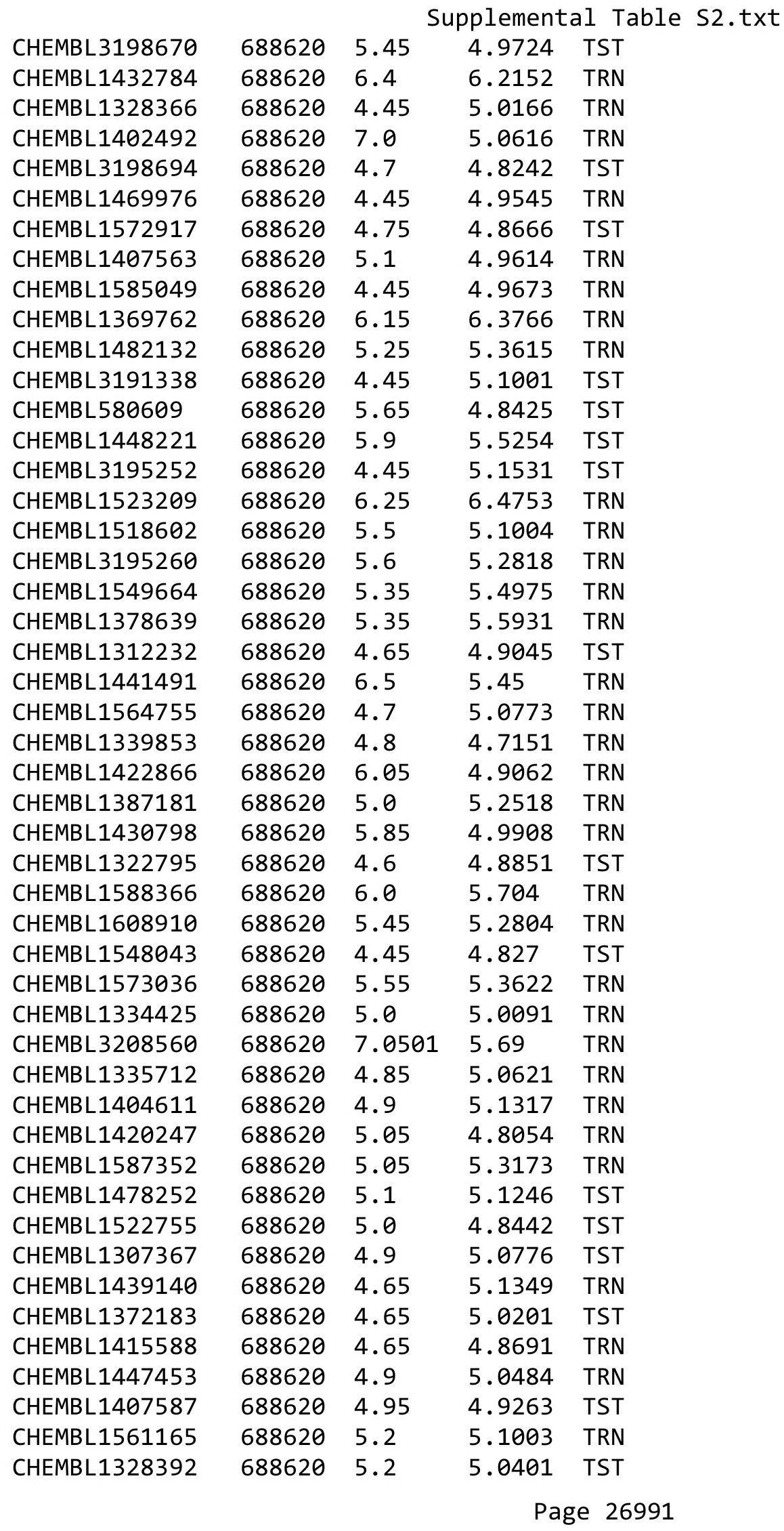




\begin{tabular}{|c|c|c|c|c|}
\hline \multicolumn{5}{|c|}{ Supplemental Table S2.txt } \\
\hline CHEMBL1391071 & 688620 & 4.95 & 5.0124 & TRN \\
\hline CHEMBL1402262 & 688620 & 4.9 & 5.392 & TRN \\
\hline CHEMBL1309301 & 688620 & 4.65 & 4.9223 & TRN \\
\hline CHEMBL579082 & 688620 & 4.85 & 4.9941 & TST \\
\hline CHEMBL501617 & 688620 & 6.4 & 5.2662 & TST \\
\hline CHEMBL1523998 & 688620 & 5.0 & 4.9745 & TRN \\
\hline CHEMBL1549407 & 688620 & 4.9 & 4.9523 & TRN \\
\hline CHEMBL1385987 & 688620 & 5.25 & 4.9981 & TRN \\
\hline CHEMBL1986986 & 688620 & 5.65 & 5.7445 & TRN \\
\hline CHEMBL1442319 & 688620 & 4.45 & 4.9567 & TRN \\
\hline CHEMBL1325295 & 688620 & 4.85 & 4.859 & TRN \\
\hline CHEMBL 285480 & 688620 & 5.15 & 4.8469 & TRN \\
\hline CHEMBL1585848 & 688620 & 5.05 & 5.0956 & TRN \\
\hline CHEMBL1550741 & 688620 & 4.45 & 4.8605 & TRN \\
\hline CHEMBL3195664 & 688620 & 4.85 & 5.026 & TRN \\
\hline CHEMBL1337410 & 688620 & 5.55 & 5.4942 & TST \\
\hline CHEMBL1460529 & 688620 & 5.25 & 5.2503 & TRN \\
\hline CHEMBL1559306 & 688620 & 5.45 & 5.7333 & TRN \\
\hline CHEMBL1369531 & 688620 & 4.95 & 5.0432 & TRN \\
\hline CHEMBL1491475 & 688620 & 4.9 & 4.7733 & TRN \\
\hline CHEMBL1540355 & 688620 & 5.45 & 5.1562 & TRN \\
\hline CHEMBL3193169 & 688620 & 4.7 & 4.7622 & TRN \\
\hline CHEMBL1523379 & 688620 & 4.7 & 5.1022 & TRN \\
\hline CHEMBL1562926 & 688620 & 7.7496 & 6.1739 & TRN \\
\hline CHEMBL1599375 & 688620 & 5.45 & 5.4308 & TRN \\
\hline CHEMBL1536156 & 688620 & 5.05 & 4.7919 & TRN \\
\hline CHEMBL1575502 & 688620 & 5.25 & 6.9373 & TRN \\
\hline CHEMBL1528977 & 688620 & 5.2 & 4.9449 & TRN \\
\hline CHEMBL1386643 & 688620 & 4.9 & 4.9749 & TRN \\
\hline CHEMBL3210126 & 688620 & 5.8 & 5.6243 & TST \\
\hline CHEMBL1486019 & 688620 & 5.7 & 5.2239 & TRN \\
\hline CHEMBL1599258 & 688620 & 5.8 & 4.9419 & TRN \\
\hline CHEMBL1345820 & 688620 & 5.7 & 5.5679 & TRN \\
\hline CHEMBL1483472 & 688620 & 6.2 & 5.5158 & TRN \\
\hline CHEMBL1344957 & 688620 & 5.45 & 5.164 & TST \\
\hline CHEMBL1484239 & 688620 & 5.1 & 5.1599 & TRN \\
\hline CHEMBL3199912 & 688620 & 4.95 & 5.0265 & TRN \\
\hline CHEMBL3195470 & 688620 & 4.9 & 5.0819 & TRN \\
\hline CHEMBL1578810 & 688620 & 6.5 & 4.9335 & TRN \\
\hline CHEMBL1368387 & 688620 & 4.45 & 4.9589 & TRN \\
\hline CHEMBL1460114 & 688620 & 5.25 & 5.0706 & TRN \\
\hline CHEMBL1990825 & 688620 & 4.9 & 5.0801 & TST \\
\hline CHEMBL1415380 & 688620 & 4.95 & 5.0027 & TST \\
\hline CHEMBL1543269 & 688620 & 4.45 & 4.7526 & TRN \\
\hline CHEMBL1525157 & 688620 & 5.2 & 5.0414 & TRN \\
\hline CHEMBL1588103 & 688620 & 4.95 & 5.2046 & TRN \\
\hline CHEMBL1361943 & 688620 & 4.95 & 4.9943 & TRN \\
\hline CHEMBL1430105 & 688620 & 4.8 & 4.831 & TST \\
\hline
\end{tabular}




\begin{tabular}{|c|c|c|c|c|c|}
\hline \multicolumn{6}{|c|}{ Supplemental Table S2.txt } \\
\hline CHEMBL1470441 & 688620 & 4.7 & 4.7511 & TRN & \\
\hline CHEMBL1587090 & 688620 & 5.6 & 5.3483 & TST & \\
\hline CHEMBL1351983 & 688620 & 5.5 & 4.8741 & TRN & \\
\hline CHEMBL1370130 & 688620 & 4.85 & 4.8318 & TRN & \\
\hline CHEMBL1462603 & 688620 & 5.15 & 4.9102 & TRN & \\
\hline CHEMBL1410988 & 688620 & 5.05 & 5.1124 & TRN & \\
\hline CHEMBL1347665 & 688620 & 5.25 & 4.9332 & TST & \\
\hline CHEMBL1372071 & 688620 & 7.1002 & 5.4955 & TST & \\
\hline CHEMBL1341736 & 688620 & 5.75 & 5.4206 & TRN & \\
\hline CHEMBL1429406 & 688620 & 5.1 & 4.8167 & TRN & \\
\hline CHEMBL1471735 & 688620 & 4.45 & 4.9437 & TRN & \\
\hline CHEMBL1387124 & 688620 & 4.9 & 5.1614 & TST & \\
\hline CHEMBL1578534 & 688620 & 4.65 & 4.8818 & TRN & \\
\hline CHEMBL3194909 & 688620 & 5.25 & 5.066 & TRN & \\
\hline CHEMBL1500026 & 688620 & 5.5 & 5.5884 & TRN & \\
\hline CHEMBL1523955 & 688620 & 5.15 & 5.471 & TRN & \\
\hline CHEMBL1450130 & 688620 & 4.9 & 5.0424 & TRN & \\
\hline CHEMBL2004919 & 688620 & 5.0 & 5.1518 & TRN & \\
\hline CHEMBL1368402 & 688620 & 4.95 & 4.9976 & TRN & \\
\hline CHEMBL1519441 & 688620 & 4.7 & 4.9506 & TRN & \\
\hline CHEMBL1421428 & 688620 & 5.05 & 5.0244 & TRN & \\
\hline CHEMBL3211420 & 688620 & 4.45 & 4.92899 & 9999999999 & TRN \\
\hline CHEMBL1427774 & 688620 & 4.45 & 5.1155 & TRN & \\
\hline CHEMBL1479799 & 688620 & 5.25 & 5.0044 & TST & \\
\hline CHEMBL1391482 & 688620 & 4.65 & 4.7989 & TST & \\
\hline CHEMBL1453822 & 688620 & 4.7 & 5.0566 & TRN & \\
\hline CHEMBL1422913 & 688620 & 5.0 & 4.9762 & TRN & \\
\hline CHEMBL1578067 & 688620 & 5.45 & 4.942 & TRN & \\
\hline CHEMBL1447913 & 688620 & 4.85 & 4.9932 & TRN & \\
\hline CHEMBL1352766 & 688620 & 4.45 & 5.0342 & TRN & \\
\hline CHEMBL1379646 & 688620 & 5.8 & 5.0856 & TRN & \\
\hline CHEMBL1499003 & 688620 & 4.95 & 5.1717 & TRN & \\
\hline CHEMBL1339243 & 688620 & 4.5 & 4.936 & TRN & \\
\hline CHEMBL1349609 & 688620 & 4.45 & 4.8497 & TRN & \\
\hline CHEMBL1426380 & 688620 & 5.35 & 5.5332 & TRN & \\
\hline CHEMBL1369585 & 688620 & 4.65 & 4.8977 & TRN & \\
\hline CHEMBL3196257 & 688620 & 6.05 & 5.96 & TRN & \\
\hline CHEMBL1299725 & 688620 & 4.65 & 5.3453 & TRN & \\
\hline CHEMBL1306259 & 688620 & 4.85 & 5.0058 & TRN & \\
\hline CHEMBL1595355 & 688620 & 6.5 & 4.9182 & TRN & \\
\hline CHEMBL3189477 & 688620 & 5.15 & 5.1987 & TRN & \\
\hline CHEMBL1549689 & 688620 & 4.85 & 5.0337 & TST & \\
\hline CHEMBL1502528 & 688620 & 4.6 & 4.9496 & TST & \\
\hline CHEMBL1457139 & 688620 & 5.7 & 5.5834 & TRN & \\
\hline CHEMBL1537241 & 688620 & 5.7 & 5.2635 & TST & \\
\hline CHEMBL1604747 & 688620 & 4.75 & 5.0513 & TRN & \\
\hline CHEMBL 202752 & 688620 & 5.6 & 5.1025 & TRN & \\
\hline CHEMBL1300251 & 688620 & 4.95 & 4.9552 & TST & \\
\hline
\end{tabular}




\begin{tabular}{|c|c|c|c|c|}
\hline \multicolumn{5}{|c|}{ Supplemental Table S2.txt } \\
\hline CHEMBL1459390 & 688620 & 5.05 & 5.0046 & TRN \\
\hline CHEMBL1516839 & 688620 & 4.9 & 4.9918 & TRN \\
\hline CHEMBL1310416 & 688620 & 4.5 & 4.8108 & TST \\
\hline CHEMBL1539485 & 688620 & 5.75 & 5.2352 & TRN \\
\hline CHEMBL1393635 & 688620 & 4.95 & 5.4008 & TRN \\
\hline CHEMBL1588498 & 688620 & 5.25 & 5.266 & TRN \\
\hline CHEMBL1438970 & 688620 & 5.85 & 5.3381 & TRN \\
\hline CHEMBL1364835 & 688620 & 5.7 & 4.9235 & TRN \\
\hline CHEMBL1341650 & 688620 & 4.45 & 4.9781 & TRN \\
\hline CHEMBL1465829 & 688620 & 4.95 & 4.8797 & TST \\
\hline CHEMBL1603696 & 688620 & 5.15 & 4.905 & TRN \\
\hline CHEMBL1586620 & 688620 & 4.95 & 5.1065 & TRN \\
\hline CHEMBL1606457 & 688620 & 5.2 & 5.0142 & TRN \\
\hline CHEMBL1527612 & 688620 & 5.0 & 4.9305 & TRN \\
\hline CHEMBL3191966 & 688620 & 5.65 & 5.0522 & TRN \\
\hline CHEMBL1551645 & 688620 & 5.95 & 5.1598 & TRN \\
\hline CHEMBL1497555 & 688620 & 6.05 & 4.9479 & TRN \\
\hline CHEMBL1995040 & 688620 & 5.6 & 5.178 & TST \\
\hline CHEMBL1564490 & 688620 & 4.7 & 4.8384 & TRN \\
\hline CHEMBL1973571 & 688620 & 5.0 & 5.1581 & TRN \\
\hline CHEMBL1331185 & 688620 & 5.25 & 5.1942 & TRN \\
\hline CHEMBL1337377 & 688620 & 4.9 & 5.0772 & TRN \\
\hline CHEMBL1470049 & 688620 & 5.0 & 5.0753 & TRN \\
\hline CHEMBL1336526 & 688620 & 4.65 & 5.3547 & TRN \\
\hline CHEMBL1389219 & 688620 & 4.45 & 5.0748 & TRN \\
\hline CHEMBL1339313 & 688620 & 5.05 & 5.2044 & TST \\
\hline CHEMBL1562216 & 688620 & 4.9 & 4.6395 & TRN \\
\hline CHEMBL1459689 & 688620 & 4.6 & 4.8121 & TRN \\
\hline CHEMBL1372573 & 688620 & 5.05 & 5.0441 & TRN \\
\hline CHEMBL1565037 & 688620 & 5.1 & 5.2336 & TRN \\
\hline CHEMBL1333865 & 688620 & 5.1 & 5.051 & TRN \\
\hline CHEMBL1371803 & 688620 & 4.95 & 4.9642 & TRN \\
\hline CHEMBL1580346 & 688620 & 4.9 & 5.3313 & TST \\
\hline CHEMBL1581022 & 688620 & 5.8 & 4.9052 & TRN \\
\hline CHEMBL1460499 & 688620 & 4.9 & 5.2832 & TRN \\
\hline CHEMBL1343069 & 688620 & 4.85 & 5.1072 & TRN \\
\hline CHEMBL1429941 & 688620 & 4.75 & 4.8003 & TRN \\
\hline CHEMBL1584992 & 688620 & 4.75 & 4.9938 & TST \\
\hline CHEMBL3192745 & 688620 & 4.45 & 5.007 & TRN \\
\hline CHEMBL1603691 & 688620 & 4.85 & 4.9432 & TST \\
\hline CHEMBL1532745 & 688620 & 5.25 & 5.0659 & TRN \\
\hline CHEMBL1571574 & 688620 & 4.95 & 5.0033 & TST \\
\hline CHEMBL1536089 & 688620 & 5.7 & 4.9678 & TRN \\
\hline CHEMBL1344444 & 688620 & 4.45 & 5.101 & TRN \\
\hline CHEMBL1524740 & 688620 & 4.45 & 4.9589 & TRN \\
\hline CHEMBL1547847 & 688620 & 4.8 & 5.0108 & TRN \\
\hline CHEMBL1974506 & 688620 & 5.85 & 5.604 & TRN \\
\hline CHEMBL1471369 & 688620 & 4.45 & 5.1106 & TRN \\
\hline
\end{tabular}




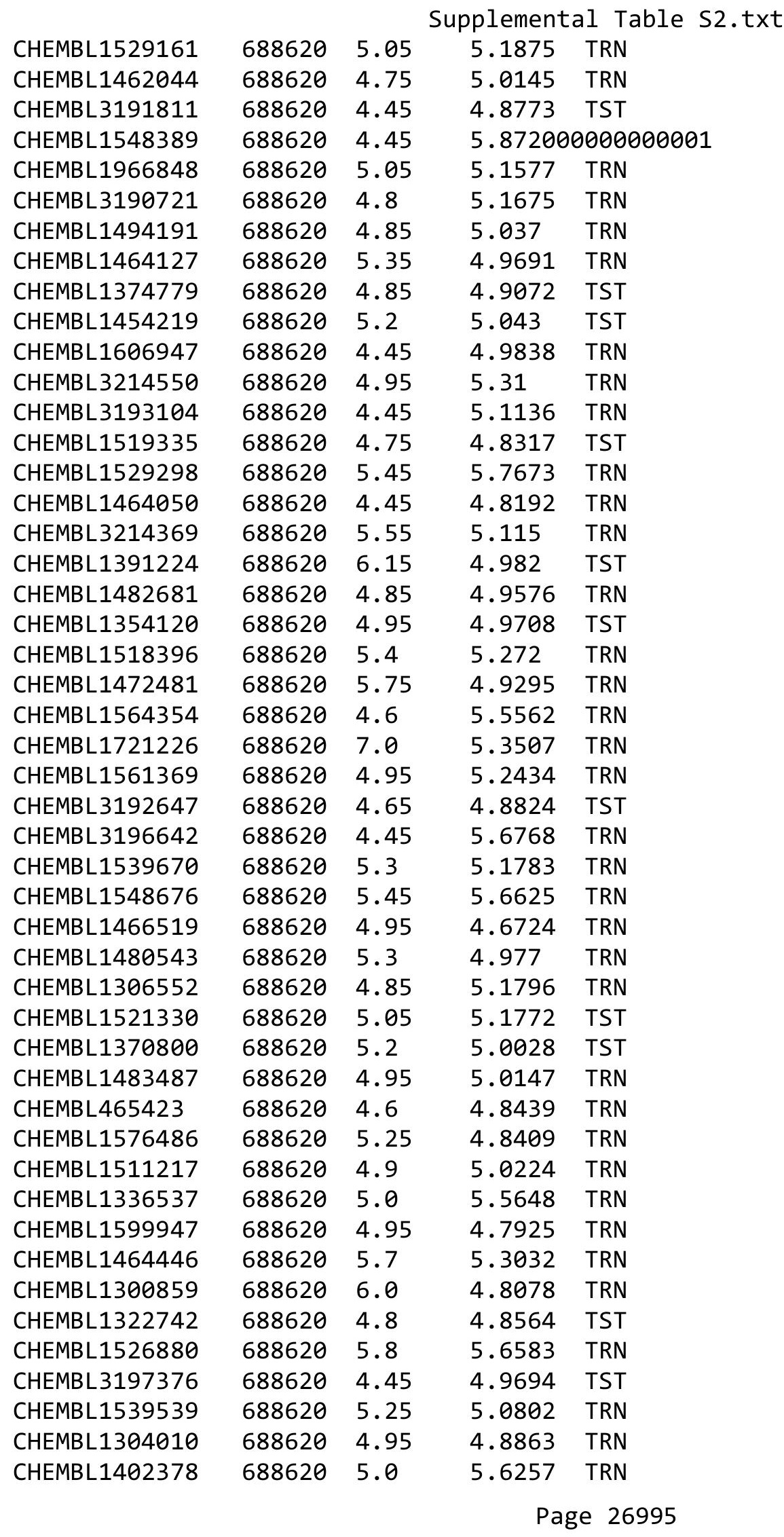

TRN 


\begin{tabular}{|c|c|c|c|c|}
\hline \multicolumn{5}{|c|}{ Supplemental Table S2.txt } \\
\hline CHEMBL1412564 & 688620 & 4.6 & 5.0959 & TRN \\
\hline CHEMBL1569037 & 688620 & 4.95 & 5.2113 & TRN \\
\hline CHEMBL1317657 & 688620 & 6.3 & 5.9024 & TRN \\
\hline CHEMBL15768 & 688620 & 6.6 & 5.2549 & TST \\
\hline CHEMBL1507666 & 688620 & 5.05 & 4.7677 & TRN \\
\hline CHEMBL1412089 & 688620 & 4.8 & 5.0154 & TRN \\
\hline CHEMBL1984052 & 688620 & 5.25 & 5.1079 & TRN \\
\hline CHEMBL1344260 & 688620 & 4.9 & 4.9914 & TST \\
\hline CHEMBL1542165 & 688620 & 4.9 & 5.1141 & TRN \\
\hline CHEMBL1384186 & 688620 & 6.05 & 6.2799 & TRN \\
\hline CHEMBL1488267 & 688620 & 5.9 & 5.1857 & TRN \\
\hline CHEMBL3208296 & 688620 & 5.0 & 4.879 & TRN \\
\hline CHEMBL1472530 & 688620 & 5.6 & 5.2685 & TRN \\
\hline CHEMBL1412161 & 688620 & 4.45 & 4.9201 & TRN \\
\hline CHEMBL1417165 & 688620 & 5.55 & 5.5014 & TRN \\
\hline CHEMBL3192752 & 688620 & 4.45 & 5.2101 & TRN \\
\hline CHEMBL1527817 & 688620 & 4.5 & 4.9755 & TST \\
\hline CHEMBL1360394 & 688620 & 4.85 & 5.1716 & TRN \\
\hline CHEMBL1584538 & 688620 & 4.65 & 5.0536 & TRN \\
\hline CHEMBL1613052 & 688620 & 4.45 & 5.0381 & TST \\
\hline CHEMBL1384725 & 688620 & 4.95 & 4.8194 & TRN \\
\hline CHEMBL1316893 & 688620 & 4.75 & 4.9898 & TRN \\
\hline CHEMBL1503867 & 688620 & 5.2 & 4.774 & TST \\
\hline CHEMBL1341400 & 688620 & 4.9 & 5.1053 & TRN \\
\hline CHEMBL1402713 & 688620 & 5.35 & 5.1992 & TRN \\
\hline CHEMBL1609956 & 688620 & 4.95 & 5.1436 & TST \\
\hline CHEMBL1522140 & 688620 & 5.0 & 5.303 & TRN \\
\hline CHEMBL1332955 & 688620 & 4.65 & 5.1643 & TRN \\
\hline CHEMBL1581795 & 688620 & 4.45 & 4.668 & TST \\
\hline CHEMBL1425600 & 688620 & 4.45 & 4.5927 & TRN \\
\hline CHEMBL1467765 & 688620 & 4.75 & 4.9419 & TRN \\
\hline CHEMBL1464683 & 688620 & 5.95 & 5.0546 & TST \\
\hline CHEMBL1339487 & 688620 & 5.95 & 5.5676 & TST \\
\hline CHEMBL1359353 & 688620 & 5.2 & 5.0755 & TRN \\
\hline CHEMBL3193163 & 688620 & 4.8 & 5.0931 & TST \\
\hline CHEMBL1469806 & 688620 & 5.2 & 5.2218 & TST \\
\hline CHEMBL1381855 & 688620 & 6.2 & 5.2007 & TRN \\
\hline CHEMBL1528614 & 688620 & 5.45 & 5.2041 & TRN \\
\hline CHEMBL3192643 & 688620 & 5.25 & 4.9131 & TST \\
\hline CHEMBL1536901 & 688620 & 4.9 & 5.0025 & TRN \\
\hline CHEMBL1598418 & 688620 & 5.3 & 5.1063 & TRN \\
\hline CHEMBL1429409 & 688620 & 4.95 & 4.9346 & TRN \\
\hline CHEMBL 244328 & 688620 & 4.45 & 4.996 & TRN \\
\hline CHEMBL1540879 & 688620 & 5.2 & 5.0766 & TRN \\
\hline CHEMBL1988339 & 688620 & 4.6 & 5.4827 & TRN \\
\hline CHEMBL1303028 & 688620 & 4.45 & 4.8784 & TRN \\
\hline CHEMBL1462497 & 688620 & 5.0 & 4.8668 & TST \\
\hline CHEMBL1584534 & 688620 & 5.85 & 5.8031 & TRN \\
\hline
\end{tabular}




\begin{tabular}{|c|c|c|c|c|c|}
\hline \\
\hline CHEMBL1380035 & 688620 & 4.8 & 5.0049 & TRN & \\
\hline CHEMBL1516724 & 688620 & 6.5 & 5.0885 & TRN & \\
\hline CHEMBL1449718 & 688620 & 5.85 & 5.07100 & 0000000001 & TRN \\
\hline CHEMBL1321328 & 688620 & 4.45 & 5.2332 & TRN & \\
\hline CHEMBL1537086 & 688620 & 5.75 & 5.76399 & 9999999999 & TRN \\
\hline CHEMBL357389 & 688620 & 4.45 & 4.9971 & TST & \\
\hline CHEMBL1508839 & 688620 & 4.95 & 5.0397 & TST & \\
\hline CHEMBL1421125 & 688620 & 4.95 & 5.1646 & TRN & \\
\hline CHEMBL1527900 & 688620 & 4.95 & 4.8992 & TRN & \\
\hline CHEMBL1429998 & 688620 & 5.95 & 5.5851 & TRN & \\
\hline CHEMBL1408463 & 688620 & 4.55 & 4.8166 & TRN & \\
\hline CHEMBL1976917 & 688620 & 4.5 & 4.9181 & TRN & \\
\hline CHEMBL1470004 & 688620 & 4.95 & 5.0051 & TST & \\
\hline CHEMBL1372520 & 688620 & 5.25 & 4.9056 & TRN & \\
\hline CHEMBL1432283 & 688620 & 4.55 & 4.9485 & TRN & \\
\hline CHEMBL1480406 & 688620 & 6.2 & 4.958 & TRN & \\
\hline CHEMBL1489201 & 688620 & 4.7 & 5.2828 & TRN & \\
\hline CHEMBL3197858 & 688620 & 6.0 & 5.8789 & TRN & \\
\hline CHEMBL1494942 & 688620 & 4.45 & 5.0744 & TRN & \\
\hline CHEMBL1442821 & 688620 & 4.45 & 5.1417 & TRN & \\
\hline CHEMBL1600833 & 688620 & 4.95 & 5.0401 & TRN & \\
\hline CHEMBL1613160 & 688620 & 5.8 & 5.1741 & TRN & \\
\hline CHEMBL1509545 & 688620 & 4.45 & 4.7591 & TST & \\
\hline CHEMBL1429906 & 688620 & 6.6 & 5.2201 & TST & \\
\hline CHEMBL 3145287 & 688620 & 5.55 & 5.5581 & TRN & \\
\hline CHEMBL1575396 & 688620 & 4.9 & 5.0835 & TST & \\
\hline CHEMBL1613398 & 688620 & 4.8 & 4.8703 & TST & \\
\hline CHEMBL1329027 & 688620 & 5.0 & 5.237 & TST & \\
\hline CHEMBL1379636 & 688620 & 4.65 & 5.0771 & TST & \\
\hline CHEMBL1582870 & 688620 & 5.05 & 5.02800 & 00000000005 & TST \\
\hline CHEMBL3194874 & 688620 & 5.65 & 5.095 & TRN & \\
\hline CHEMBL1535946 & 688620 & 5.1 & 5.5491 & TRN & \\
\hline CHEMBL1598116 & 688620 & 4.5 & 5.4582 & TRN & \\
\hline CHEMBL1350724 & 688620 & 4.45 & 4.8538 & TRN & \\
\hline CHEMBL3190563 & 688620 & 4.45 & 5.0932 & TST & \\
\hline CHEMBL1484296 & 688620 & 4.85 & 4.9884 & TST & \\
\hline CHEMBL1338961 & 688620 & 5.75 & 5.4303 & TRN & \\
\hline CHEMBL1507372 & 688620 & 5.1 & 4.8628 & TRN & \\
\hline CHEMBL1869875 & 688620 & 7.4498 & 6.0338 & TRN & \\
\hline CHEMBL1427905 & 688620 & 6.25 & 5.1043 & TRN & \\
\hline CHEMBL1451419 & 688620 & 5.45 & 5.2323 & TRN & \\
\hline CHEMBL1410115 & 688620 & 4.45 & 4.7251 & TRN & \\
\hline CHEMBL1600617 & 688620 & 4.95 & 4.9864 & TST & \\
\hline CHEMBL1320544 & 688620 & 4.95 & 5.178 & TRN & \\
\hline CHEMBL1789979 & 688620 & 4.95 & 4.9363 & TST & \\
\hline CHEMBL1420782 & 688620 & 4.9 & 5.1313 & TRN & \\
\hline CHEMBL1390121 & 688620 & 6.25 & 5.506 & TST & \\
\hline CHEMBL1549630 & 688620 & 5.0 & 4.9707 & TRN & \\
\hline
\end{tabular}




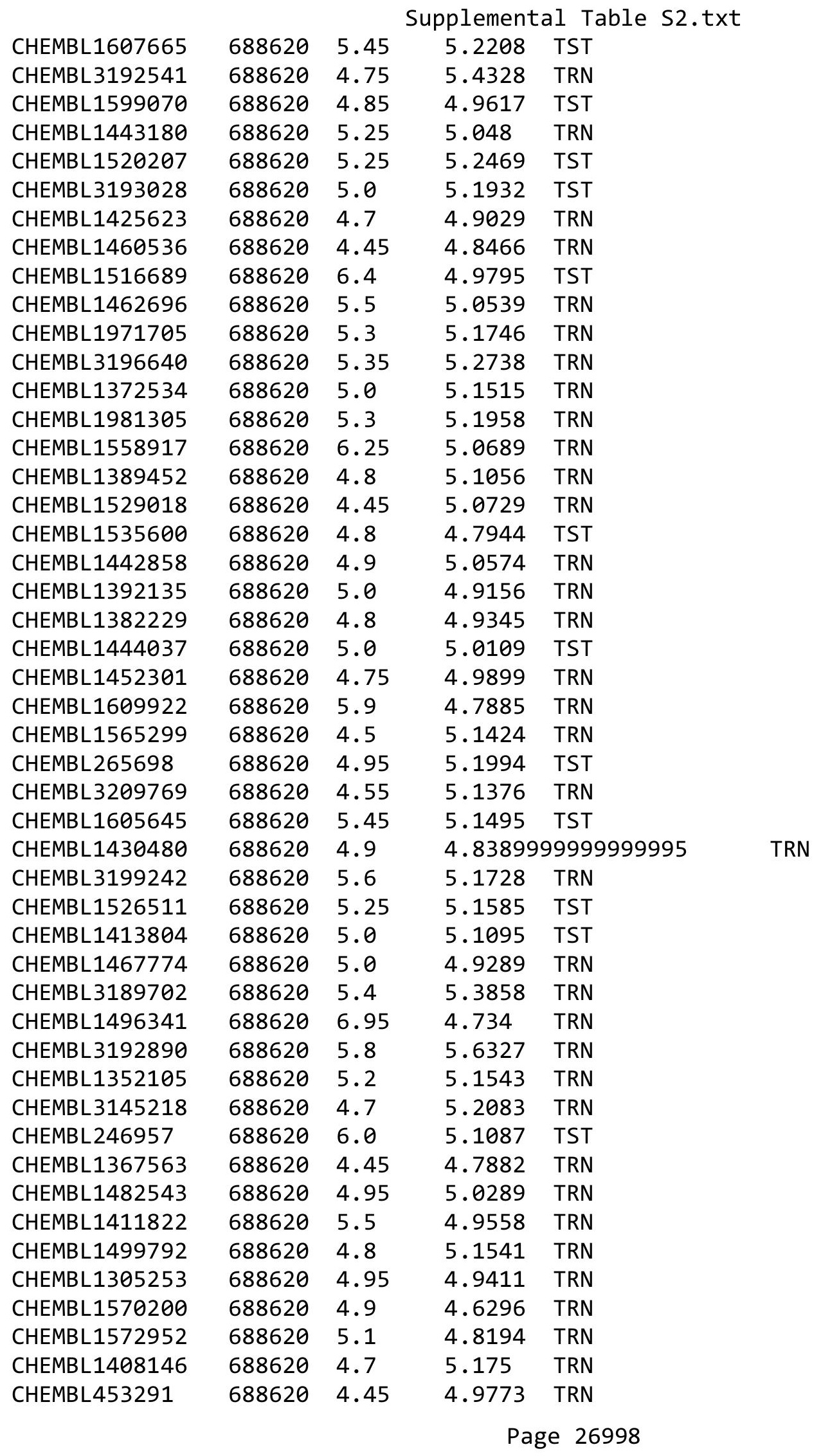




\begin{tabular}{|c|c|c|c|c|}
\hline \multicolumn{5}{|c|}{ Supplemental Table S2.txt } \\
\hline CHEMBL1402473 & 688620 & 4.45 & 4.9299 & TST \\
\hline CHEMBL1613191 & 688620 & 5.0 & 5.1682 & TST \\
\hline CHEMBL1353643 & 688620 & 4.8 & 4.6147 & TRN \\
\hline CHEMBL1595202 & 688620 & 5.15 & 4.9082 & TRN \\
\hline CHEMBL1565328 & 688620 & 5.5 & 5.4224 & TRN \\
\hline CHEMBL1445001 & 688620 & 4.75 & 5.1991 & TRN \\
\hline CHEMBL1313246 & 688620 & 4.45 & 5.0986 & TST \\
\hline CHEMBL1412215 & 688620 & 5.25 & 5.1186 & TRN \\
\hline CHEMBL 3198875 & 688620 & 5.2 & 4.9346 & TRN \\
\hline CHEMBL1535808 & 688620 & 4.65 & 5.0602 & TRN \\
\hline CHEMBL1461578 & 688620 & 4.9 & 4.9542 & TRN \\
\hline CHEMBL1445851 & 688620 & 4.45 & 4.8545 & TRN \\
\hline CHEMBL1375600 & 688620 & 4.45 & 4.7656 & TRN \\
\hline CHEMBL1373910 & 688620 & 5.8 & 5.136 & TRN \\
\hline CHEMBL1446697 & 688620 & 5.0 & 4.8322 & TRN \\
\hline CHEMBL1525631 & 688620 & 4.45 & 5.6006 & TRN \\
\hline CHEMBL1459105 & 688620 & 4.5 & 4.9594 & TRN \\
\hline CHEMBL1431979 & 688620 & 8.2518 & 4.7453 & TST \\
\hline CHEMBL1494438 & 688620 & 5.5 & 5.2298 & TRN \\
\hline CHEMBL3196535 & 688620 & 5.35 & 5.1086 & TRN \\
\hline CHEMBL1490140 & 688620 & 4.45 & 4.9626 & TRN \\
\hline CHEMBL1364924 & 688620 & 5.25 & 5.0882 & TRN \\
\hline CHEMBL1573413 & 688620 & 4.8 & 5.0084 & TRN \\
\hline CHEMBL1463409 & 688620 & 4.45 & 5.1318 & TRN \\
\hline CHEMBL118009 & 688620 & 4.85 & 5.0773 & TRN \\
\hline CHEMBL1313660 & 688620 & 5.0 & 5.3925 & TRN \\
\hline CHEMBL3192873 & 688620 & 6.0 & 5.5259 & TRN \\
\hline CHEMBL1585941 & 688620 & 5.1 & 5.581 & TRN \\
\hline CHEMBL1449802 & 688620 & 5.4 & 4.8996 & TRN \\
\hline CHEMBL1534281 & 688620 & 5.0 & 4.9795 & TRN \\
\hline CHEMBL1498924 & 688620 & 4.7 & 4.7576 & TST \\
\hline CHEMBL3197410 & 688620 & 5.15 & 5.0824 & TRN \\
\hline CHEMBL1299956 & 688620 & 4.8 & 5.0092 & TST \\
\hline CHEMBL1409258 & 688620 & 4.85 & 5.1554 & TRN \\
\hline CHEMBL303516 & 688620 & 6.1 & 5.0264 & TST \\
\hline CHEMBL1495727 & 688620 & 5.15 & 4.9676 & TRN \\
\hline CHEMBL1340422 & 688620 & 5.4 & 4.8064 & TRN \\
\hline CHEMBL1414166 & 688620 & 5.35 & 5.1281 & TST \\
\hline CHEMBL1331935 & 688620 & 4.5 & 4.9911 & TRN \\
\hline CHEMBL1331095 & 688620 & 4.85 & 4.925 & TST \\
\hline CHEMBL1483674 & 688620 & 6.5 & 5.0476 & TRN \\
\hline CHEMBL1526744 & 688620 & 4.7 & 5.1342 & TST \\
\hline CHEMBL1985575 & 688620 & 4.9 & 5.8596 & TRN \\
\hline CHEMBL1306518 & 688620 & 4.45 & 5.2977 & TRN \\
\hline CHEMBL1974613 & 688620 & 4.7 & 5.1177 & TRN \\
\hline CHEMBL1557843 & 688620 & 4.45 & 5.0388 & TST \\
\hline CHEMBL1420406 & 688620 & 4.7 & 5.5223 & TRN \\
\hline CHEMBL1361080 & 688620 & 4.5 & 5.0755 & TRN \\
\hline
\end{tabular}




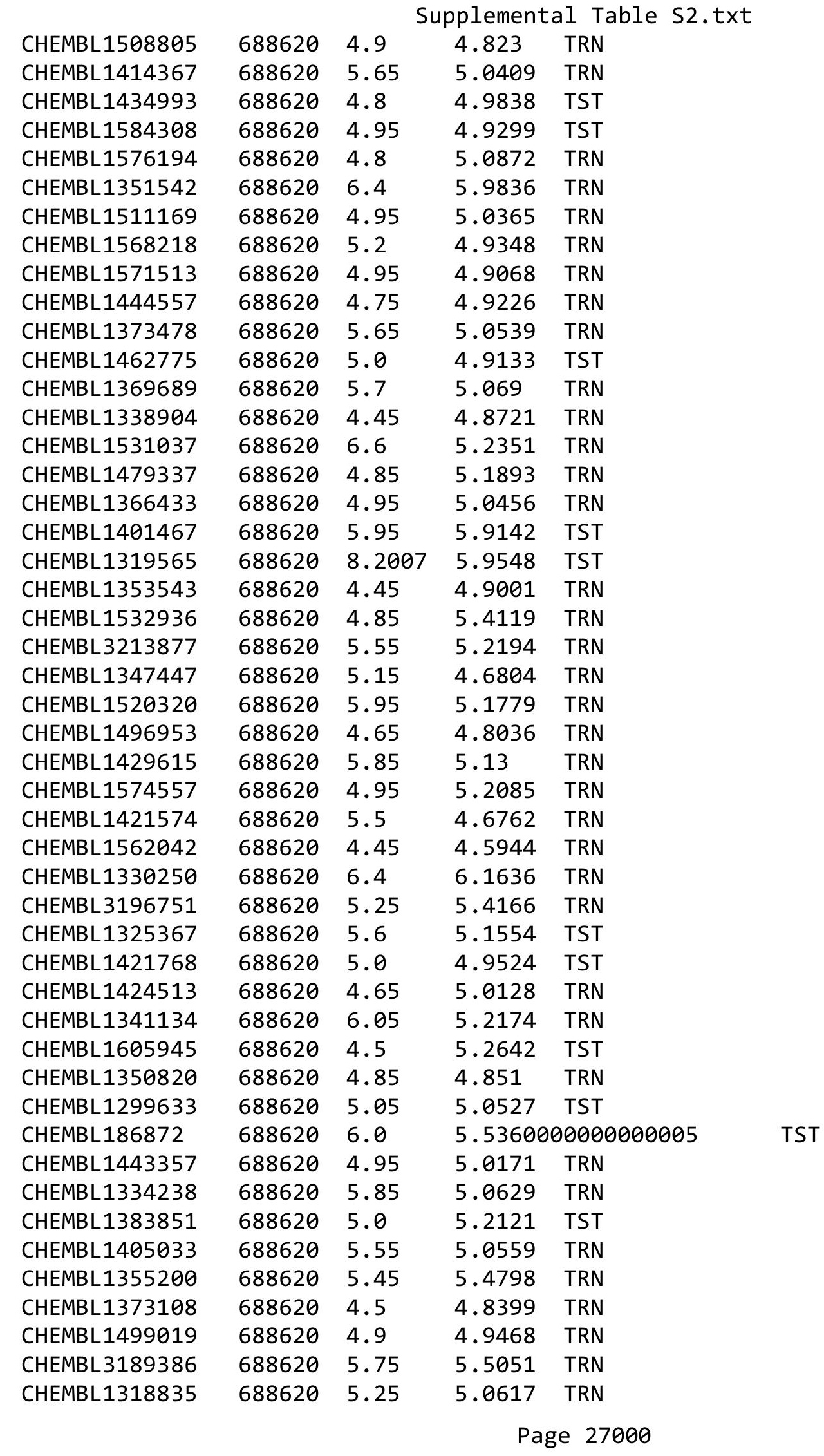




\begin{tabular}{|c|c|c|c|c|}
\hline \multicolumn{5}{|c|}{ Supplemental Tabl } \\
\hline CHEMBL1386928 & 688620 & 4.95 & 5.013 & TRN \\
\hline CHEMBL1322445 & 688620 & 4.85 & 4.8902 & TRN \\
\hline CHEMBL1344835 & 688620 & 4.65 & 4.937 & TRN \\
\hline CHEMBL1324644 & 688620 & 4.5 & 4.8771 & TRN \\
\hline CHEMBL1445534 & 688620 & 6.1 & 4.9073 & TRN \\
\hline CHEMBL1328504 & 688620 & 5.65 & 5.3398 & TRN \\
\hline CHEMBL1382702 & 688620 & 4.45 & 4.7499 & TST \\
\hline CHEMBL1497160 & 688620 & 5.35 & 4.9539 & TRN \\
\hline CHEMBL1542082 & 688620 & 5.0 & 5.1866 & TRN \\
\hline CHEMBL1561904 & 688620 & 6.05 & 5.8208 & TRN \\
\hline CHEMBL1608143 & 688620 & 5.25 & 4.9002 & TST \\
\hline CHEMBL3194837 & 688620 & 5.35 & 5.2016 & TRN \\
\hline CHEMBL1366367 & 688620 & 4.95 & 4.7259 & TRN \\
\hline CHEMBL1566045 & 688620 & 6.3 & 5.3351 & TST \\
\hline CHEMBL1481947 & 688620 & 4.95 & 5.1489 & TST \\
\hline CHEMBL1462205 & 688620 & 4.45 & 4.6522 & TST \\
\hline CHEMBL1334168 & 688620 & 4.8 & 4.9273 & TRN \\
\hline CHEMBL3196069 & 688620 & 4.45 & 4.9 & TRN \\
\hline CHEMBL1341492 & 688620 & 6.1 & 5.0099 & TRN \\
\hline CHEMBL1414267 & 688620 & 4.45 & 5.0539 & TRN \\
\hline CHEMBL1384017 & 688620 & 5.6 & 4.9996 & TRN \\
\hline CHEMBL1425330 & 688620 & 5.05 & 5.3198 & TRN \\
\hline CHEMBL1419483 & 688620 & 4.7 & 5.1504 & TST \\
\hline CHEMBL1406664 & 688620 & 4.45 & 5.0438 & TST \\
\hline CHEMBL1572112 & 688620 & 4.55 & 4.936 & TRN \\
\hline CHEMBL1384771 & 688620 & 5.3 & 5.4551 & TST \\
\hline CHEMBL1600429 & 688620 & 4.45 & 4.9132 & TRN \\
\hline CHEMBL1441178 & 688620 & 4.65 & 4.7855 & TST \\
\hline CHEMBL1527567 & 688620 & 4.45 & 5.0296 & TRN \\
\hline CHEMBL1601981 & 688620 & 4.8 & 5.1067 & TRN \\
\hline CHEMBL1480736 & 688620 & 4.65 & 5.1302 & TRN \\
\hline CHEMBL1524213 & 688620 & 6.05 & 5.1538 & TRN \\
\hline CHEMBL1415043 & 688620 & 5.55 & 5.3329 & TRN \\
\hline CHEMBL1540254 & 688620 & 4.8 & 4.9842 & TST \\
\hline CHEMBL1338992 & 688620 & 4.95 & 5.083 & TST \\
\hline CHEMBL1556364 & 688620 & 4.95 & 4.9313 & TRN \\
\hline CHEMBL1391552 & 688620 & 5.05 & 5.0131 & TRN \\
\hline CHEMBL1328983 & 688620 & 8.301 & 4.9715 & TST \\
\hline CHEMBL1520355 & 688620 & 4.75 & 5.1388 & TRN \\
\hline CHEMBL1430956 & 688620 & 4.45 & 4.879 & TRN \\
\hline CHEMBL1413059 & 688620 & 4.45 & 4.8393 & TRN \\
\hline CHEMBL1491854 & 688620 & 4.45 & 4.9467 & TRN \\
\hline CHEMBL3194235 & 688620 & 6.0 & 5.6331 & TRN \\
\hline CHEMBL 1444103 & 688620 & 5.55 & 5.4444 & TST \\
\hline CHEMBL1412046 & 688620 & 4.8 & 5.1054 & TRN \\
\hline CHEMBL1494937 & 688620 & 5.0 & 5.2402 & TRN \\
\hline CHEMBL1987820 & 688620 & 6.45 & 5.6171 & TRN \\
\hline CHEMBL3190609 & 688620 & 4.65 & 4.8663 & TRN \\
\hline
\end{tabular}




\begin{tabular}{|c|c|c|c|c|}
\hline \multicolumn{5}{|c|}{ Supplemental Table S2.txt } \\
\hline CHEMBL1613479 & 688620 & 6.0 & 5.1019 & TRN \\
\hline CHEMBL1373314 & 688620 & 5.25 & 5.2157 & TST \\
\hline CHEMBL1602058 & 688620 & 5.15 & 4.7458 & TRN \\
\hline CHEMBL1466517 & 688620 & 4.9 & 5.072 & TRN \\
\hline CHEMBL1585059 & 688620 & 4.9 & 4.9964 & TRN \\
\hline CHEMBL1512116 & 688620 & 4.95 & 4.8777 & TRN \\
\hline CHEMBL 3189578 & 688620 & 5.2 & 5.1649 & TRN \\
\hline CHEMBL444376 & 688620 & 5.5 & 5.2151 & TRN \\
\hline CHEMBL1452297 & 688620 & 5.5 & 5.4336 & TRN \\
\hline CHEMBL1420939 & 688620 & 5.65 & 5.4806 & TST \\
\hline CHEMBL3199122 & 688620 & 4.85 & 5.1715 & TRN \\
\hline CHEMBL1402546 & 688620 & 5.25 & 5.0043 & TST \\
\hline CHEMBL1328166 & 688620 & 5.9 & 5.6265 & TRN \\
\hline CHEMBL1589405 & 688620 & 4.95 & 4.8628 & TRN \\
\hline CHEMBL3198047 & 688620 & 4.9 & 5.0245 & TRN \\
\hline CHEMBL1369742 & 688620 & 5.5 & 5.5918 & TRN \\
\hline CHEMBL595700 & 688620 & 5.55 & 4.8365 & TRN \\
\hline CHEMBL1410646 & 688620 & 5.6 & 5.0281 & TRN \\
\hline CHEMBL1493993 & 688620 & 4.85 & 5.2301 & TRN \\
\hline CHEMBL1426248 & 688620 & 4.9 & 4.9525 & TST \\
\hline CHEMBL1611972 & 688620 & 4.45 & 4.8681 & TRN \\
\hline CHEMBL1526370 & 688620 & 6.9 & 5.7201 & TST \\
\hline CHEMBL1415812 & 688620 & 5.15 & 5.117 & TRN \\
\hline CHEMBL1460673 & 688620 & 4.45 & 5.0096 & TRN \\
\hline CHEMBL1451935 & 688620 & 4.75 & 4.6317 & TST \\
\hline CHEMBL1393694 & 688620 & 4.8 & 4.8889 & TRN \\
\hline CHEMBL1539277 & 688620 & 4.85 & 5.0826 & TRN \\
\hline CHEMBL1409613 & 688620 & 5.05 & 4.8154 & TRN \\
\hline CHEMBL3190849 & 688620 & 5.15 & 5.3565 & TRN \\
\hline CHEMBL1351406 & 688620 & 5.1 & 4.8175 & TRN \\
\hline CHEMBL1442243 & 688620 & 5.45 & 5.2644 & TRN \\
\hline CHEMBL1600203 & 688620 & 4.95 & 5.2542 & TRN \\
\hline CHEMBL1567690 & 688620 & 5.1 & 5.1006 & TRN \\
\hline CHEMBL1338068 & 688620 & 5.15 & 5.0759 & TST \\
\hline CHEMBL1337145 & 688620 & 4.45 & 4.9265 & TST \\
\hline CHEMBL475198 & 688620 & 4.95 & 4.9396 & TRN \\
\hline CHEMBL1599574 & 688620 & 4.95 & 5.0301 & TRN \\
\hline CHEMBL1503124 & 688620 & 7.3497 & 5.6938 & TRN \\
\hline CHEMBL1375975 & 688620 & 4.65 & 4.8567 & TRN \\
\hline CHEMBL3189610 & 688620 & 4.6 & 5.8279 & TRN \\
\hline CHEMBL3192255 & 688620 & 5.35 & 5.1827 & TST \\
\hline CHEMBL1432745 & 688620 & 5.65 & 5.2125 & TRN \\
\hline CHEMBL1608811 & 688620 & 4.45 & 5.102 & TRN \\
\hline CHEMBL1424179 & 688620 & 4.45 & 4.9328 & TRN \\
\hline CHEMBL369513 & 688620 & 4.45 & 5.2618 & TRN \\
\hline CHEMBL1371890 & 688620 & 5.4 & 5.2923 & TRN \\
\hline CHEMBL1459681 & 688620 & 5.65 & 5.2556 & TRN \\
\hline CHEMBL1331148 & 688620 & 4.45 & 4.8952 & TRN \\
\hline
\end{tabular}




\begin{tabular}{|c|c|c|c|c|c|}
\hline \\
\hline CHEMBL1533944 & 688620 & 5.9 & 4.9233 & TST & \\
\hline CHEMBL1403641 & 688620 & 5.5 & 5.1413 & TST & \\
\hline CHEMBL 3189236 & 688620 & 4.65 & 4.7873 & TRN & \\
\hline CHEMBL1520297 & 688620 & 5.9 & 5.0162 & TST & \\
\hline CHEMBL1346912 & 688620 & 4.9 & 4.9164 & TRN & \\
\hline CHEMBL1407627 & 688620 & 4.45 & 4.8482 & TRN & \\
\hline CHEMBL1336520 & 688620 & 5.05 & 5.2296 & TRN & \\
\hline CHEMBL1467304 & 688620 & 5.2 & 5.1324 & TST & \\
\hline CHEMBL1301756 & 688620 & 4.8 & 4.9822 & TRN & \\
\hline CHEMBL1516034 & 688620 & 5.3 & 5.1073 & TRN & \\
\hline CHEMBL 3209844 & 688620 & 5.0 & 5.0674 & TST & \\
\hline CHEMBL1462914 & 688620 & 4.95 & 5.1787 & TRN & \\
\hline CHEMBL1537648 & 688620 & 5.35 & 5.0891 & TRN & \\
\hline CHEMBL1527580 & 688620 & 5.75 & 5.8093 & TRN & \\
\hline CHEMBL1568475 & 688620 & 4.7 & 4.88899 & 9999999999 & TRN \\
\hline CHEMBL1607980 & 688620 & 4.95 & 5.012 & TRN & \\
\hline CHEMBL1388482 & 688620 & 4.5 & 5.4164 & TST & \\
\hline CHEMBL1569220 & 688620 & 4.95 & 5.1742 & TRN & \\
\hline CHEMBL1378033 & 688620 & 4.8 & 4.8005 & TRN & \\
\hline CHEMBL 3196800 & 688620 & 6.45 & 5.8785 & TRN & \\
\hline CHEMBL1577673 & 688620 & 5.15 & 5.2174 & TRN & \\
\hline CHEMBL1335753 & 688620 & 4.45 & 4.9469 & TRN & \\
\hline CHEMBL1406094 & 688620 & 5.55 & 4.8488 & TRN & \\
\hline CHEMBL1401900 & 688620 & 4.9 & 4.7343 & TRN & \\
\hline CHEMBL1333249 & 688620 & 6.0 & 5.1056 & TRN & \\
\hline CHEMBL1464449 & 688620 & 4.45 & 5.1261 & TRN & \\
\hline CHEMBL1609769 & 688620 & 4.95 & 5.0977 & TRN & \\
\hline CHEMBL1967857 & 688620 & 5.05 & 5.3259 & TRN & \\
\hline CHEMBL1308409 & 688620 & 5.2 & 5.2611 & TRN & \\
\hline CHEMBL 1402312 & 688620 & 4.6 & 5.1989 & TRN & \\
\hline CHEMBL1305432 & 688620 & 5.25 & 5.1138 & TST & \\
\hline CHEMBL1334230 & 688620 & 4.65 & 4.8718 & TRN & \\
\hline CHEMBL 3196515 & 688620 & 4.45 & 4.7895 & TST & \\
\hline CHEMBL 3191730 & 688620 & 5.45 & 6.0361 & TRN & \\
\hline CHEMBL 1423725 & 688620 & 4.95 & 4.9908 & TRN & \\
\hline CHEMBL1405700 & 688620 & 4.8 & 5.1762 & TRN & \\
\hline CHEMBL3198957 & 688620 & 5.0 & 5.1497 & TRN & \\
\hline CHEMBL1585913 & 688620 & 5.1 & 4.833 & TRN & \\
\hline CHEMBL1301242 & 688620 & 5.3 & 5.034 & TRN & \\
\hline CHEMBL1543238 & 688620 & 5.95 & 5.5918 & TRN & \\
\hline CHEMBL1364012 & 688620 & 4.95 & 5.1648 & TST & \\
\hline CHEMBL1451833 & 688620 & 5.15 & 5.1321 & TST & \\
\hline CHEMBL1559858 & 688620 & 6.1 & 5.77 & TRN & \\
\hline CHEMBL3209991 & 688620 & 5.0 & 4.9065 & TRN & \\
\hline CHEMBL1542732 & 688620 & 5.25 & 5.0995 & TRN & \\
\hline CHEMBL1314009 & 688620 & 4.95 & 4.9656 & TST & \\
\hline CHEMBL1572097 & 688620 & 4.85 & 5.307 & TRN & \\
\hline CHEMBL1432137 & 688620 & 4.45 & 4.9702 & TRN & \\
\hline
\end{tabular}




\begin{tabular}{|c|c|c|c|c|c|}
\hline \multicolumn{6}{|c|}{ Supplemental Table S2.txt } \\
\hline CHEMBL1375751 & 688620 & 6.9 & 4.9843 & TST & \\
\hline CHEMBL1310833 & 688620 & 5.2 & 5.1657 & TST & \\
\hline CHEMBL1443113 & 688620 & 4.45 & 5.9872 & TST & \\
\hline CHEMBL1439482 & 688620 & 4.8 & 5.2164 & TST & \\
\hline CHEMBL1350943 & 688620 & 4.65 & 5.2627 & TRN & \\
\hline CHEMBL1579916 & 688620 & 4.5 & 4.8339 & TRN & \\
\hline CHEMBL1556391 & 688620 & 5.25 & 5.3278 & TRN & \\
\hline CHEMBL1323655 & 688620 & 4.5 & 4.8529 & TRN & \\
\hline CHEMBL586946 & 688620 & 4.8 & 4.931 & TST & \\
\hline CHEMBL1301678 & 688620 & 4.65 & 5.0535 & TRN & \\
\hline CHEMBL1442973 & 688620 & 5.3 & 4.8534 & TST & \\
\hline CHEMBL1455957 & 688620 & 4.9 & 4.6424 & TST & \\
\hline CHEMBL1312733 & 688620 & 5.85 & 5.143 & TST & \\
\hline CHEMBL1362990 & 688620 & 4.45 & 5.0297 & TRN & \\
\hline CHEMBL1606120 & 688620 & 4.95 & 4.8698 & TRN & \\
\hline CHEMBL1478213 & 688620 & 4.95 & 4.7455 & TST & \\
\hline CHEMBL1993666 & 688620 & 6.2 & 5.3885 & TRN & \\
\hline CHEMBL1471750 & 688620 & 4.6 & 4.7103 & TRN & \\
\hline CHEMBL1539870 & 688620 & 4.7 & 5.1105 & TST & \\
\hline CHEMBL3212619 & 688620 & 6.25 & 5.3348 & TRN & \\
\hline CHEMBL1348909 & 688620 & 4.6 & 4.9553 & TRN & \\
\hline CHEMBL1410491 & 688620 & 6.0 & 5.7031 & TRN & \\
\hline CHEMBL 3212735 & 688620 & 5.5 & 5.0809 & TRN & \\
\hline CHEMBL1547948 & 688620 & 4.45 & 4.9528 & TST & \\
\hline CHEMBL1972844 & 688620 & 5.15 & 5.5715 & TRN & \\
\hline CHEMBL1431252 & 688620 & 5.0 & 5.3332 & TST & \\
\hline CHEMBL1526188 & 688620 & 5.05 & 5.0667 & TRN & \\
\hline CHEMBL1466078 & 688620 & 4.45 & 4.749 & TRN & \\
\hline CHEMBL1503110 & 688620 & 4.95 & 4.9714 & TRN & \\
\hline CHEMBL3196961 & 688620 & 6.35 & 6.0201 & TRN & \\
\hline CHEMBL1369112 & 688620 & 5.2 & 4.9715 & TST & \\
\hline CHEMBL1310614 & 688620 & 5.75 & 5.2199 & TRN & \\
\hline CHEMBL1371580 & 688620 & 5.1 & 4.9537 & TST & \\
\hline CHEMBL1535868 & 688620 & 5.25 & 5.1947 & TST & \\
\hline CHEMBL7724 & 688620 & 4.45 & 5.0092 & TRN & \\
\hline CHEMBL1377324 & 688620 & 6.5 & 4.9376 & TRN & \\
\hline CHEMBL1446646 & 688620 & 7.15 & 5.0598 & TRN & \\
\hline CHEMBL1468964 & 688620 & 4.8 & 5.1126 & TST & \\
\hline CHEMBL3213461 & 688620 & 4.45 & 5.1809 & TST & \\
\hline CHEMBL1332416 & 688620 & 4.45 & 5.01699 & 99999999995 & \\
\hline CHEMBL3210025 & 688620 & 5.8 & 5.3448 & TRN & \\
\hline CHEMBL1499786 & 688620 & 5.75 & 5.0579 & TST & \\
\hline CHEMBL1383995 & 688620 & 4.7 & 5.0746 & TST & \\
\hline CHEMBL1375506 & 688620 & 5.05 & 4.9423 & TRN & \\
\hline CHEMBL1611458 & 688620 & 4.75 & 4.9044 & TST & \\
\hline CHEMBL1576653 & 688620 & 5.15 & 4.7747 & TRN & \\
\hline CHEMBL1585019 & 688620 & 6.5501 & 5.3261 & TRN & \\
\hline CHEMBL3190885 & 688620 & 5.9 & 5.1872 & TST & \\
\hline
\end{tabular}




\begin{tabular}{|c|c|c|c|c|c|}
\hline \\
\hline CHEMBL1444347 & 688620 & 4.45 & 4.8561 & TRN & \\
\hline CHEMBL1321948 & 688620 & 5.25 & 5.1157 & TST & \\
\hline CHEMBL1506966 & 688620 & 4.8 & 4.928 & TST & \\
\hline CHEMBL1487907 & 688620 & 5.1 & 5.1487 & TRN & \\
\hline CHEMBL1545970 & 688620 & 4.95 & 5.1661 & TST & \\
\hline CHEMBL1433013 & 688620 & 4.75 & 4.9237 & TRN & \\
\hline CHEMBL1571809 & 688620 & 5.25 & 4.9234 & TRN & \\
\hline CHEMBL1384263 & 688620 & 5.5 & 4.8764 & TRN & \\
\hline CHEMBL1611583 & 688620 & 4.45 & 4.9252 & TRN & \\
\hline CHEMBL1386851 & 688620 & 4.45 & 5.1805 & TRN & \\
\hline CHEMBL 3209860 & 688620 & 5.35 & 5.1292 & TRN & \\
\hline CHEMBL1407924 & 688620 & 4.75 & 4.8309 & TST & \\
\hline CHEMBL1339443 & 688620 & 4.45 & 4.9784 & TRN & \\
\hline CHEMBL1367740 & 688620 & 6.9 & 5.0299 & TRN & \\
\hline CHEMBL1562575 & 688620 & 6.5501 & 6.1009 & TRN & \\
\hline CHEMBL1325365 & 688620 & 4.45 & 5.0636 & TRN & \\
\hline CHEMBL1404701 & 688620 & 4.7 & 5.0012 & TRN & \\
\hline CHEMBL1372344 & 688620 & 4.45 & 5.1614 & TRN & \\
\hline CHEMBL1340706 & 688620 & 5.45 & 4.9818 & TST & \\
\hline CHEMBL1350736 & 688620 & 4.85 & 4.8725 & TRN & \\
\hline CHEMBL1328581 & 688620 & 4.7 & 5.2364 & TST & \\
\hline CHEMBL1554099 & 688620 & 4.45 & 5.2213 & TST & \\
\hline CHEMBL1438488 & 688620 & 4.8 & 4.8293 & TRN & \\
\hline CHEMBL1453721 & 688620 & 5.35 & 4.9096 & TST & \\
\hline CHEMBL1307757 & 688620 & 4.95 & 5.1051 & TST & \\
\hline CHEMBL1456762 & 688620 & 5.5 & 5.6086 & TRN & \\
\hline CHEMBL1391677 & 688620 & 4.8 & 4.9678 & TST & \\
\hline CHEMBL116919 & 688620 & 5.55 & 5.2411 & TRN & \\
\hline CHEMBL1543124 & 688620 & 4.45 & 5.0616 & TST & \\
\hline CHEMBL1309217 & 688620 & 5.3 & 5.2043 & TRN & \\
\hline CHEMBL1522080 & 688620 & 4.45 & $5.2520 e$ & 0000000001 & TST \\
\hline CHEMBL3211852 & 688620 & 4.8 & 5.1282 & TST & \\
\hline CHEMBL1546313 & 688620 & 4.9 & 5.0369 & TRN & \\
\hline CHEMBL1556149 & 688620 & 5.4 & 5.0473 & TRN & \\
\hline CHEMBL1406263 & 688620 & 5.55 & 5.0774 & TRN & \\
\hline CHEMBL1557754 & 688620 & 4.95 & 4.8901 & TRN & \\
\hline CHEMBL 3214215 & 688620 & 4.75 & 4.9747 & TST & \\
\hline CHEMBL1502432 & 688620 & 4.95 & 5.0287 & TST & \\
\hline CHEMBL1489723 & 688620 & 4.75 & 4.8713 & TRN & \\
\hline CHEMBL 3196302 & 688620 & 4.65 & 5.2473 & TST & \\
\hline CHEMBL 3192320 & 688620 & 5.8 & 5.468 & TRN & \\
\hline CHEMBL1466948 & 688620 & 5.6 & $5.5120 e$ & 00000000005 & TRN \\
\hline CHEMBL1363198 & 688620 & 4.8 & 4.994 & TRN & \\
\hline CHEMBL1609425 & 688620 & 6.5 & 5.1783 & TST & \\
\hline CHEMBL1364390 & 688620 & 4.45 & 4.895 & TRN & \\
\hline CHEMBL1600741 & 688620 & 4.45 & 4.9145 & TST & \\
\hline CHEMBL1451376 & 688620 & 4.45 & 4.7451 & TRN & \\
\hline CHEMBL1409441 & 688620 & 4.7 & 5.2426 & TRN & \\
\hline
\end{tabular}




\begin{tabular}{|c|c|c|c|c|}
\hline \multicolumn{5}{|c|}{ Supplemental Table S2.txt } \\
\hline CHEMBL1340133 & 688620 & 5.3 & 5.0337 & TRN \\
\hline CHEMBL1309457 & 688620 & 6.95 & 5.0431 & TST \\
\hline CHEMBL1438926 & 688620 & 6.05 & 5.0362 & TRN \\
\hline CHEMBL1307726 & 688620 & 4.45 & 4.7475 & TRN \\
\hline CHEMBL3193153 & 688620 & 5.0 & 4.9469 & TRN \\
\hline CHEMBL3190293 & 688620 & 6.1 & 5.5435 & TST \\
\hline CHEMBL 1608578 & 688620 & 4.65 & 4.8686 & TST \\
\hline CHEMBL1462107 & 688620 & 4.75 & 5.09399 & 9999999999 \\
\hline CHEMBL1339825 & 688620 & 4.95 & 5.181 & TRN \\
\hline CHEMBL1540814 & 688620 & 5.0 & 4.871 & TRN \\
\hline CHEMBL1498828 & 688620 & 5.45 & 5.5374 & TRN \\
\hline CHEMBL1380863 & 688620 & 5.0 & 4.9744 & TRN \\
\hline CHEMBL1609367 & 688620 & 5.0 & 5.0001 & TRN \\
\hline CHEMBL549208 & 688620 & 4.45 & 5.0679 & TRN \\
\hline CHEMBL1613576 & 688620 & 4.6 & 5.0104 & TST \\
\hline CHEMBL1371939 & 688620 & 5.5 & 5.6262 & TRN \\
\hline CHEMBL1471353 & 688620 & 4.45 & 4.8642 & TRN \\
\hline CHEMBL1332409 & 688620 & 5.15 & 4.8719 & TST \\
\hline CHEMBL1465313 & 688620 & 6.0 & 5.1072 & TST \\
\hline CHEMBL1363706 & 688620 & 4.45 & 5.1204 & TRN \\
\hline CHEMBL1563120 & 688620 & 5.0 & 4.9856 & TRN \\
\hline CHEMBL1378845 & 688620 & 4.45 & 5.0688 & TST \\
\hline CHEMBL1305411 & 688620 & 4.6 & 5.1842 & TRN \\
\hline CHEMBL1307240 & 688620 & 4.7 & 4.9423 & TST \\
\hline CHEMBL1427870 & 688620 & 4.45 & 5.152 & TST \\
\hline CHEMBL1400757 & 688620 & 4.85 & 5.1344 & TRN \\
\hline CHEMBL1404424 & 688620 & 4.8 & 5.0645 & TST \\
\hline CHEMBL1407514 & 688620 & 5.7 & 4.7939 & TST \\
\hline CHEMBL1458367 & 688620 & 5.0 & 5.1083 & TST \\
\hline CHEMBL1329938 & 688620 & 4.95 & 5.274 & TST \\
\hline CHEMBL3198499 & 688620 & 5.8 & 5.3555 & TRN \\
\hline CHEMBL1348352 & 688620 & 5.45 & 5.1259 & TRN \\
\hline CHEMBL1461034 & 688620 & 4.9 & 4.6951 & TRN \\
\hline CHEMBL1311570 & 688620 & 4.85 & 4.6486 & TRN \\
\hline CHEMBL 2003688 & 688620 & 6.0 & 5.7764 & TRN \\
\hline CHEMBL1453358 & 688620 & 5.1 & 4.913 & TRN \\
\hline CHEMBL1558536 & 688620 & 4.45 & 4.8924 & TRN \\
\hline CHEMBL1566924 & 688620 & 5.55 & 4.9986 & TRN \\
\hline CHEMBL1518085 & 688620 & 6.6 & 5.4155 & TRN \\
\hline CHEMBL1462022 & 688620 & 4.75 & 4.9509 & TRN \\
\hline CHEMBL1576790 & 688620 & 5.0 & 5.0488 & TRN \\
\hline CHEMBL1537017 & 688620 & 4.7 & 4.7381 & TRN \\
\hline CHEMBL1485791 & 688620 & 5.3 & 5.0078 & TRN \\
\hline CHEMBL1598532 & 688620 & 4.55 & 5.2396 & TRN \\
\hline CHEMBL1489992 & 688620 & 5.5 & 5.1911 & TST \\
\hline CHEMBL1600106 & 688620 & 4.45 & 4.9123 & TRN \\
\hline CHEMBL1596486 & 688620 & 5.0 & 5.1332 & TRN \\
\hline CHEMBL1978608 & 688620 & 4.9 & 5.1222 & TRN \\
\hline
\end{tabular}




\begin{tabular}{|c|c|c|c|c|c|}
\hline \multicolumn{6}{|c|}{ Supplemental Table S2.txt } \\
\hline CHEMBL1432941 & 688620 & 4.7 & 5.0216 & TRN & \\
\hline CHEMBL1519705 & 688620 & 4.45 & 5.1438 & TRN & \\
\hline CHEMBL1527258 & 688620 & 5.2 & 5.3134 & TRN & \\
\hline CHEMBL1534433 & 688620 & 4.45 & 5.1407 & TST & \\
\hline CHEMBL1448114 & 688620 & 5.2 & 5.0623 & TRN & \\
\hline CHEMBL1422477 & 688620 & 5.0 & 5.0391 & TRN & \\
\hline CHEMBL1328795 & 688620 & 4.7 & 5.0987 & TRN & \\
\hline CHEMBL1387950 & 688620 & 6.5 & 5.9283 & TRN & \\
\hline CHEMBL1458995 & 688620 & 5.15 & 5.1775 & TRN & \\
\hline CHEMBL1499215 & 688620 & 4.85 & 4.8891 & TRN & \\
\hline CHEMBL1567152 & 688620 & 4.7 & 5.2126 & TRN & \\
\hline CHEMBL1422163 & 688620 & 6.5501 & 5.0315 & TRN & \\
\hline CHEMBL3191715 & 688620 & 7.1002 & 5.8534 & TRN & \\
\hline CHEMBL1482412 & 688620 & 5.45 & 5.5364 & TRN & \\
\hline CHEMBL3196836 & 688620 & 5.05 & 4.9168 & TRN & \\
\hline CHEMBL1528813 & 688620 & 4.85 & 5.2419 & TRN & \\
\hline CHEMBL1566437 & 688620 & 5.4 & 5.1383 & TRN & \\
\hline CHEMBL1421023 & 688620 & 4.65 & 4.7463 & TRN & \\
\hline CHEMBL1489045 & 688620 & 4.7 & 4.9414 & TRN & \\
\hline CHEMBL 2002573 & 688620 & 5.4 & 5.6564 & TRN & \\
\hline CHEMBL1346613 & 688620 & 4.75 & 4.7758 & TRN & \\
\hline CHEMBL1469916 & 688620 & 5.5 & 5.4797 & TRN & \\
\hline CHEMBL1464103 & 688620 & 5.05 & 4.9887 & TST & \\
\hline CHEMBL1312788 & 688620 & 5.3 & 5.4482 & TRN & \\
\hline CHEMBL1335174 & 688620 & 5.0 & 5.1675 & TRN & \\
\hline CHEMBL1485656 & 688620 & 4.65 & 4.9756 & TST & \\
\hline CHEMBL1312418 & 688620 & 5.05 & 5.0242 & TRN & \\
\hline CHEMBL1549699 & 688620 & 4.45 & 4.945 & TST & \\
\hline CHEMBL3193805 & 688620 & 6.6499 & 5.772 & TRN & \\
\hline CHEMBL1419031 & 688620 & 5.3 & 5.3645 & TRN & \\
\hline CHEMBL1439553 & 688620 & 8.301 & 5.0966 & TST & \\
\hline CHEMBL1383119 & 688620 & 4.75 & 5.0474 & TRN & \\
\hline CHEMBL1557445 & 688620 & 4.9 & 5.0765 & TRN & \\
\hline CHEMBL1480718 & 688620 & 4.55 & 4.9376 & TRN & \\
\hline CHEMBL1558022 & 688620 & 4.8 & $4.9460 e$ & 0000000001 & TRN \\
\hline CHEMBL1480024 & 688620 & 4.65 & 4.6637 & TST & \\
\hline CHEMBL1536075 & 688620 & 4.8 & 5.48 & TRN & \\
\hline CHEMBL1371046 & 688620 & 4.85 & 5.1333 & TRN & \\
\hline CHEMBL1418601 & 688620 & 4.85 & 4.6759 & TRN & \\
\hline CHEMBL 2007425 & 688620 & 4.95 & 4.6979 & TST & \\
\hline CHEMBL1431286 & 688620 & 4.95 & 4.9859 & TRN & \\
\hline CHEMBL1594856 & 688620 & 5.4 & 4.9112 & TRN & \\
\hline CHEMBL1327400 & 688620 & 4.5 & 5.0475 & TST & \\
\hline CHEMBL1583580 & 688620 & 4.45 & 5.0588 & TRN & \\
\hline CHEMBL1313764 & 688620 & 4.95 & 4.9234 & TRN & \\
\hline CHEMBL1426767 & 688620 & 4.45 & 4.8928 & TRN & \\
\hline CHEMBL1510981 & 688620 & 4.7 & 4.876 & TST & \\
\hline CHEMBL1304623 & 688620 & 4.95 & 5.0893 & TRN & \\
\hline
\end{tabular}




\begin{tabular}{|c|c|c|c|c|c|}
\hline \multicolumn{6}{|c|}{ Supplemental Table s2.txt } \\
\hline CHEMBL1451350 & 688620 & 4.55 & 5.2192 & TST & \\
\hline CHEMBL1586972 & 688620 & 4.95 & 5.0283 & TRN & \\
\hline CHEMBL1497336 & 688620 & 4.45 & 5.0948 & TST & \\
\hline CHEMBL1379610 & 688620 & 5.35 & 5.2402 & TRN & \\
\hline CHEMBL1507645 & 688620 & 5.2 & 5.2886 & TRN & \\
\hline CHEMBL1499884 & 688620 & 4.45 & 5.1269 & TST & \\
\hline CHEMBL1488934 & 688620 & 5.3 & 5.0 & TRN & \\
\hline CHEMBL1471540 & 688620 & 5.0 & 5.148 & TRN & \\
\hline CHEMBL1332165 & 688620 & 4.95 & 5.1158 & TRN & \\
\hline CHEMBL1555952 & 688620 & 4.45 & 5.0475 & TRN & \\
\hline CHEMBL1365007 & 688620 & 4.45 & 5.1774 & TRN & \\
\hline CHEMBL1344133 & 688620 & 4.8 & 4.9585 & TST & \\
\hline CHEMBL1370667 & 688620 & 5.2 & 4.957 & TRN & \\
\hline CHEMBL1429804 & 688620 & 4.6 & 4.9327 & TRN & \\
\hline CHEMBL1505724 & 688620 & 6.8 & 5.0143 & TST & \\
\hline CHEMBL1587624 & 688620 & 4.8 & 4.94 & TST & \\
\hline CHEMBL3194022 & 688620 & 4.9 & 4.9858 & TRN & \\
\hline CHEMBL1399115 & 688620 & 4.95 & 4.887 & TRN & \\
\hline CHEMBL1429975 & 688620 & 4.8 & 5.0404 & TRN & \\
\hline CHEMBL1577049 & 688620 & 5.3 & 5.2622 & TRN & \\
\hline CHEMBL1545761 & 688620 & 4.8 & 4.7777 & TRN & \\
\hline CHEMBL1565245 & 688620 & 4.45 & 4.8375 & TRN & \\
\hline CHEMBL1375651 & 688620 & 5.95 & 5.7168 & TRN & \\
\hline CHEMBL1445768 & 688620 & 5.8 & 5.5071 & TRN & \\
\hline CHEMBL1446181 & 688620 & 4.7 & 4.944 & TST & \\
\hline CHEMBL1516567 & 688620 & 4.65 & 5.0503 & TST & \\
\hline CHEMBL1332770 & 688620 & 5.7 & 4.9906 & TST & \\
\hline CHEMBL1384521 & 688620 & 5.1 & 5.08899 & 99999999995 & TRN \\
\hline CHEMBL1555585 & 688620 & 4.45 & 5.08899 & 99999999995 & TRN \\
\hline CHEMBL1308958 & 688620 & 5.0 & 5.1537 & TRN & \\
\hline CHEMBL407817 & 688620 & 5.75 & 5.5926 & TRN & \\
\hline CHEMBL1387355 & 688620 & 4.65 & 5.0504 & TRN & \\
\hline CHEMBL1406564 & 688620 & 5.5 & 5.0283 & TST & \\
\hline CHEMBL1405147 & 688620 & 5.2 & 5.1961 & TST & \\
\hline CHEMBL1532233 & 688620 & 4.45 & 5.2094 & TST & \\
\hline CHEMBL1399182 & 688620 & 4.85 & 5.0676 & TRN & \\
\hline CHEMBL3199292 & 688620 & 4.95 & 4.8927 & TST & \\
\hline CHEMBL 2001474 & 688620 & 4.95 & 5.1416 & TRN & \\
\hline CHEMBL1372862 & 688620 & 4.85 & 4.948 & TRN & \\
\hline CHEMBL1430337 & 688620 & 4.85 & 4.8077 & TRN & \\
\hline CHEMBL1612097 & 688620 & 4.95 & 5.0949 & TST & \\
\hline CHEMBL1480192 & 688620 & 4.5 & 5.006 & TRN & \\
\hline CHEMBL1306748 & 688620 & 4.8 & 5.1414 & TRN & \\
\hline CHEMBL1550035 & 688620 & 5.65 & 5.1932 & TST & \\
\hline CHEMBL1533315 & 688620 & 4.9 & 4.837 & TRN & \\
\hline CHEMBL1498754 & 688620 & 5.3 & 5.1565 & TRN & \\
\hline CHEMBL1421912 & 688620 & 5.3 & 4.8668 & TRN & \\
\hline CHEMBL1543989 & 688620 & 4.45 & 5.0877 & TST & \\
\hline
\end{tabular}




\begin{tabular}{|c|c|c|c|c|c|}
\hline \multicolumn{6}{|c|}{ Supplemental Table S2.txt } \\
\hline CHEMBL1310356 & 688620 & 4.75 & 5.1122 & TRN & \\
\hline CHEMBL1451664 & 688620 & 4.65 & 4.875 & TRN & \\
\hline CHEMBL1304367 & 688620 & 5.45 & 5.0689 & TRN & \\
\hline CHEMBL1492732 & 688620 & 6.0 & 5.3059 & TRN & \\
\hline CHEMBL1408281 & 688620 & 5.1 & 4.9133 & TRN & \\
\hline CHEMBL1604115 & 688620 & 5.25 & 5.0364 & TRN & \\
\hline CHEMBL1567402 & 688620 & 4.45 & 4.8549 & TST & \\
\hline CHEMBL1338428 & 688620 & 4.45 & 4.9796 & TRN & \\
\hline CHEMBL1402985 & 688620 & 4.45 & 5.2098 & TRN & \\
\hline CHEMBL1392031 & 688620 & 6.3 & 6.0829 & TRN & \\
\hline CHEMBL1503604 & 688620 & 4.45 & 4.9236 & TST & \\
\hline CHEMBL 3210263 & 688620 & 4.65 & 4.8515 & TRN & \\
\hline CHEMBL1375025 & 688620 & 4.45 & 5.0805 & TST & \\
\hline CHEMBL1556229 & 688620 & 4.95 & 4.998 & TST & \\
\hline CHEMBL1564355 & 688620 & 4.8 & 5.0497 & TRN & \\
\hline CHEMBL1558210 & 688620 & 5.6 & 5.2664 & TRN & \\
\hline CHEMBL1443980 & 688620 & 5.4 & 5.5459 & TRN & \\
\hline CHEMBL1371589 & 688620 & 4.65 & 4.9339 & TRN & \\
\hline CHEMBL1538161 & 688620 & 4.7 & 4.9498 & TRN & \\
\hline CHEMBL1422078 & 688620 & 6.2 & 6.0718 & TRN & \\
\hline CHEMBL1478531 & 688620 & 4.9 & 5.4386 & TRN & \\
\hline CHEMBL1426069 & 688620 & 4.7 & 4.9601 & TRN & \\
\hline CHEMBL1359189 & 688620 & 4.45 & 5.1546 & TRN & \\
\hline CHEMBL 3189401 & 688620 & 4.45 & 4.8616 & TRN & \\
\hline CHEMBL1446002 & 688620 & 4.45 & 5.1298 & TST & \\
\hline CHEMBL1341305 & 688620 & 4.9 & 4.7747 & TRN & \\
\hline CHEMBL1541659 & 688620 & 4.7 & 5.1468 & TRN & \\
\hline CHEMBL1312723 & 688620 & 4.45 & 4.8406 & TRN & \\
\hline CHEMBL1461649 & 688620 & 4.7 & 4.8192 & TRN & \\
\hline CHEMBL1559654 & 688620 & 4.9 & 4.977 & TST & \\
\hline CHEMBL1404945 & 688620 & 4.95 & 5.1326 & TRN & \\
\hline CHEMBL1386027 & 688620 & 4.9 & 4.9312 & TRN & \\
\hline CHEMBL1392982 & 688620 & 4.95 & 4.64199 & 99999999995 & TRN \\
\hline CHEMBL1604118 & 688620 & 4.45 & 4.8881 & TRN & \\
\hline CHEMBL1441139 & 688620 & 4.85 & 4.9931 & TRN & \\
\hline CHEMBL1504564 & 688620 & 4.9 & 4.9593 & TST & \\
\hline CHEMBL1339023 & 688620 & 5.6 & 5.0205 & TRN & \\
\hline CHEMBL3210413 & 688620 & 4.95 & 5.1329 & TST & \\
\hline CHEMBL1406371 & 688620 & 5.15 & 4.9156 & TRN & \\
\hline CHEMBL1507679 & 688620 & 5.15 & 5.0999 & TRN & \\
\hline CHEMBL1581420 & 688620 & 4.45 & 4.8631 & TST & \\
\hline CHEMBL3193808 & 688620 & 5.0 & 4.9831 & TST & \\
\hline CHEMBL1341424 & 688620 & 4.45 & 4.7277 & TRN & \\
\hline CHEMBL1510598 & 688620 & 5.7 & 5.7461 & TST & \\
\hline CHEMBL1419681 & 688620 & 6.8 & 4.933 & TST & \\
\hline CHEMBL3191323 & 688620 & 5.15 & 5.1269 & TRN & \\
\hline CHEMBL 1582347 & 688620 & 5.8 & 4.9909 & TRN & \\
\hline CHEMBL3191623 & 688620 & 5.65 & 5.1836 & TRN & \\
\hline
\end{tabular}




\begin{tabular}{|c|c|c|c|c|c|}
\hline & & \multicolumn{4}{|c|}{ Supplemental Table s2.txt } \\
\hline CHEMBL1526171 & 688620 & 5.55 & 5.1063 & TRN & \\
\hline CHEMBL1459479 & 688620 & 4.6 & 5.1236 & TST & \\
\hline CHEMBL3194455 & 688620 & 4.7 & 5.1557 & TRN & \\
\hline CHEMBL1411070 & 688620 & 4.7 & 5.0508 & TST & \\
\hline CHEMBL1871495 & 688620 & 5.65 & 5.3605 & TRN & \\
\hline CHEMBL1507579 & 688620 & 5.2 & 5.234 & TST & \\
\hline CHEMBL1415241 & 688620 & 4.45 & 5.1273 & TRN & \\
\hline CHEMBL1361262 & 688620 & 5.25 & 4.9738 & TRN & \\
\hline CHEMBL1387072 & 688620 & 4.45 & 5.1122 & TST & \\
\hline CHEMBL3145192 & 688620 & 4.95 & 4.9229 & TRN & \\
\hline CHEMBL1486842 & 688620 & 4.95 & 4.815 & TRN & \\
\hline CHEMBL1444076 & 688620 & 4.75 & 4.959 & TST & \\
\hline CHEMBL1361424 & 688620 & 6.4 & 5.1025 & TST & \\
\hline CHEMBL1328716 & 688620 & 5.2 & 5.3803 & TRN & \\
\hline CHEMBL1965453 & 688620 & 4.7 & 5.0432 & TRN & \\
\hline CHEMBL3197688 & 688620 & 4.5 & 5.3116 & TRN & \\
\hline CHEMBL3196020 & 688620 & 6.5 & 6.28299 & 99999999995 & TRN \\
\hline CHEMBL1603221 & 688620 & 4.5 & 4.833 & TRN & \\
\hline CHEMBL1501752 & 688620 & 5.55 & 5.2061 & TRN & \\
\hline CHEMBL1458378 & 688620 & 5.1 & 4.9704 & TRN & \\
\hline CHEMBL1612736 & 688620 & 6.5 & 5.106 & TRN & \\
\hline CHEMBL1600260 & 688620 & 5.3 & 5.3699 & TRN & \\
\hline CHEMBL1377490 & 688620 & 7.0 & 5.0724 & TST & \\
\hline CHEMBL1500475 & 688620 & 4.45 & 5.2412 & TRN & \\
\hline CHEMBL1509824 & 688620 & 5.45 & 5.3953 & TRN & \\
\hline CHEMBL1443553 & 688620 & 5.05 & 5.2249 & TRN & \\
\hline CHEMBL1607594 & 688620 & 5.2 & 4.9057 & TRN & \\
\hline CHEMBL3192017 & 688620 & 4.45 & 4.7657 & TRN & \\
\hline CHEMBL1600767 & 688620 & 5.25 & 5.0365 & TST & \\
\hline CHEMBL1609102 & 688620 & 4.9 & 4.9071 & TRN & \\
\hline CHEMBL1328817 & 688620 & 4.8 & 4.8507 & TRN & \\
\hline CHEMBL1432409 & 688620 & 4.65 & 5.1254 & TST & \\
\hline CHEMBL 3210048 & 688620 & 4.9 & 5.1229 & TRN & \\
\hline CHEMBL1420967 & 688620 & 4.45 & 5.1346 & TRN & \\
\hline CHEMBL1561335 & 688620 & 5.2 & 5.0343 & TRN & \\
\hline CHEMBL1571425 & 688620 & 4.45 & 4.9289 & TRN & \\
\hline CHEMBL1502403 & 688620 & 5.0 & 5.2616 & TRN & \\
\hline CHEMBL1518057 & 688620 & 5.3 & 5.0807 & TRN & \\
\hline CHEMBL1457126 & 688620 & 5.25 & 5.0054 & TST & \\
\hline CHEMBL1579281 & 688620 & 4.95 & 5.1118 & TRN & \\
\hline CHEMBL1347437 & 688620 & 5.7 & 5.206 & TRN & \\
\hline CHEMBL1310132 & 688620 & 4.9 & 5.4317 & TRN & \\
\hline CHEMBL1344902 & 688620 & 5.0 & 4.8882 & TRN & \\
\hline CHEMBL1320454 & 688620 & 4.45 & 5.0995 & TRN & \\
\hline CHEMBL1383896 & 688620 & 4.45 & 5.1991 & TST & \\
\hline CHEMBL3211925 & 688620 & 4.45 & 4.9248 & TRN & \\
\hline CHEMBL1503041 & 688620 & 5.3 & 5.1918 & TRN & \\
\hline CHEMBL1386167 & 688620 & 5.45 & 5.0026 & TRN & \\
\hline
\end{tabular}




\begin{tabular}{|c|c|c|c|c|}
\hline \multicolumn{5}{|c|}{ Supplemental Table S2.txt } \\
\hline CHEMBL591876 & 688620 & 5.35 & 5.7431 & TRN \\
\hline CHEMBL1413672 & 688620 & 4.65 & 4.9648 & TRN \\
\hline CHEMBL3197259 & 688620 & 5.2 & 5.2873 & TST \\
\hline CHEMBL1562397 & 688620 & 4.6 & 4.8076 & TRN \\
\hline CHEMBL1389966 & 688620 & 5.9 & 5.1906 & TRN \\
\hline CHEMBL1383641 & 688620 & 5.85 & 5.1514 & TST \\
\hline CHEMBL1496839 & 688620 & 6.95 & 4.9835 & TST \\
\hline CHEMBL1360854 & 688620 & 4.6 & 5.0548 & TRN \\
\hline CHEMBL1390926 & 688620 & 4.7 & 5.1029 & TST \\
\hline CHEMBL1558000 & 688620 & 5.5 & 4.9315 & TRN \\
\hline CHEMBL1537770 & 688620 & 5.1 & 5.1114 & TRN \\
\hline CHEMBL1546383 & 688620 & 5.1 & 4.9163 & TRN \\
\hline CHEMBL1304982 & 688620 & 5.55 & 5.1669 & TRN \\
\hline CHEMBL1333696 & 688620 & 5.0 & 4.9681 & TRN \\
\hline CHEMBL1468645 & 688620 & 4.95 & 5.1024 & TRN \\
\hline CHEMBL1484644 & 688620 & 4.85 & 5.0548 & TRN \\
\hline CHEMBL 29726 & 688620 & 4.5 & 5.3477 & TST \\
\hline CHEMBL1491117 & 688620 & 4.95 & 4.8553 & TST \\
\hline CHEMBL1999667 & 688620 & 6.2 & 5.3543 & TRN \\
\hline CHEMBL1580852 & 688620 & 5.85 & 5.0631 & TRN \\
\hline CHEMBL1609121 & 688620 & 6.1 & 5.4768 & TST \\
\hline CHEMBL1988042 & 688620 & 5.5 & 5.4582 & TRN \\
\hline CHEMBL1544703 & 688620 & 4.9 & 4.8382 & TRN \\
\hline CHEMBL3199125 & 688620 & 5.6 & 5.0563 & TRN \\
\hline CHEMBL1539083 & 688620 & 6.15 & 5.5656 & TRN \\
\hline CHEMBL1399033 & 688620 & 4.85 & 5.0555 & TST \\
\hline CHEMBL1306578 & 688620 & 5.8 & 4.8784 & TRN \\
\hline CHEMBL1585538 & 688620 & 5.05 & 5.3361 & TRN \\
\hline CHEMBL1999137 & 688620 & 4.6 & 4.7652 & TRN \\
\hline CHEMBL3198795 & 688620 & 4.45 & 5.1103 & TRN \\
\hline CHEMBL1413419 & 688620 & 6.45 & 5.1272 & TRN \\
\hline CHEMBL1330963 & 688620 & 4.8 & 4.7292 & TRN \\
\hline CHEMBL1311508 & 688620 & 5.0 & 4.9834 & TRN \\
\hline CHEMBL1374444 & 688620 & 4.9 & 5.0548 & TRN \\
\hline CHEMBL1548769 & 688620 & 4.8 & 4.9085 & TRN \\
\hline CHEMBL1530038 & 688620 & 4.95 & 4.8697 & TRN \\
\hline CHEMBL1377318 & 688620 & 4.95 & 5.2076 & TST \\
\hline CHEMBL1406434 & 688620 & 5.95 & 5.5385 & TST \\
\hline CHEMBL1492484 & 688620 & 4.9 & 5.1032 & TRN \\
\hline CHEMBL1343047 & 688620 & 4.45 & 5.1055 & TRN \\
\hline CHEMBL1347992 & 688620 & 4.45 & 4.9204 & TST \\
\hline CHEMBL1416282 & 688620 & 5.15 & 5.1474 & TRN \\
\hline CHEMBL1343357 & 688620 & 5.25 & 5.2939 & TRN \\
\hline CHEMBL3196273 & 688620 & 4.75 & 5.5656 & TRN \\
\hline CHEMBL1377754 & 688620 & 5.25 & 5.0746 & TRN \\
\hline CHEMBL3213033 & 688620 & 4.45 & 5.103 & TRN \\
\hline CHEMBL1544641 & 688620 & 5.6 & 6.1166 & TRN \\
\hline CHEMBL1407317 & 688620 & 5.6 & 5.2548 & TRN \\
\hline
\end{tabular}




\begin{tabular}{|c|c|c|c|c|c|}
\hline \\
\hline CHEMBL1382978 & 688620 & 4.8 & 5.1271 & TRN & \\
\hline CHEMBL1556473 & 688620 & 4.8 & 4.7774 & TRN & \\
\hline CHEMBL1526469 & 688620 & 5.85 & 5.0825 & TRN & \\
\hline CHEMBL1351497 & 688620 & 4.45 & 5.0943 & TRN & \\
\hline CHEMBL1421679 & 688620 & 5.1 & 5.0607 & TRN & \\
\hline CHEMBL1406667 & 688620 & 5.3 & 5.15 & TRN & \\
\hline CHEMBL1299698 & 688620 & 4.75 & 4.9765 & TRN & \\
\hline CHEMBL1394018 & 688620 & 4.9 & 5.0474 & TRN & \\
\hline CHEMBL1361975 & 688620 & 4.85 & 4.9406 & TST & \\
\hline CHEMBL1359343 & 688620 & 5.55 & 5.8021 & TRN & \\
\hline CHEMBL1493448 & 688620 & 5.65 & 5.4404 & TRN & \\
\hline CHEMBL1423032 & 688620 & 4.45 & 4.9184 & TRN & \\
\hline CHEMBL1344277 & 688620 & 5.65 & 5.1007 & TRN & \\
\hline CHEMBL1325583 & 688620 & 4.65 & 4.9047 & TRN & \\
\hline CHEMBL1563552 & 688620 & 4.8 & 4.9947 & TRN & \\
\hline CHEMBL1303295 & 688620 & 6.3 & $5.2120 e$ & 0000000001 & TRN \\
\hline CHEMBL1964405 & 688620 & 4.5 & 5.1862 & TRN & \\
\hline CHEMBL1301396 & 688620 & 4.45 & 4.8126 & TRN & \\
\hline CHEMBL1305275 & 688620 & 4.65 & 5.0406 & TST & \\
\hline CHEMBL1450692 & 688620 & 4.75 & 4.8532 & TRN & \\
\hline CHEMBL1572080 & 688620 & 5.55 & 5.018 & TRN & \\
\hline CHEMBL 273386 & 688620 & 6.0 & 5.4624 & TRN & \\
\hline CHEMBL1432764 & 688620 & 4.85 & 4.8605 & TST & \\
\hline CHEMBL1306061 & 688620 & 4.95 & 5.0593 & TRN & \\
\hline CHEMBL1578300 & 688620 & 7.0 & 5.9936 & TRN & \\
\hline CHEMBL1422941 & 688620 & 5.45 & 5.1043 & TRN & \\
\hline CHEMBL1600885 & 688620 & 4.65 & 4.9121 & TRN & \\
\hline CHEMBL1506771 & 688620 & 4.9 & 5.0012 & TRN & \\
\hline CHEMBL1971604 & 688620 & 4.95 & 5.2977 & TRN & \\
\hline CHEMBL1969597 & 688620 & 4.9 & 5.2555 & TST & \\
\hline CHEMBL261693 & 688620 & 5.95 & 5.477 & TRN & \\
\hline CHEMBL1502997 & 688620 & 5.7 & 5.4551 & TRN & \\
\hline CHEMBL1424465 & 688620 & 4.6 & 4.9812 & TRN & \\
\hline CHEMBL1489241 & 688620 & 4.45 & 5.005 & TRN & \\
\hline CHEMBL1497466 & 688620 & 4.45 & 5.0247 & TRN & \\
\hline CHEMBL1594639 & 688620 & 4.9 & 5.0705 & TRN & \\
\hline CHEMBL1418079 & 688620 & 5.0 & 5.1978 & TST & \\
\hline CHEMBL1612422 & 688620 & 5.45 & 5.1226 & TRN & \\
\hline CHEMBL1382530 & 688620 & 4.6 & 4.6387 & TRN & \\
\hline CHEMBL1304673 & 688620 & 4.45 & 4.9213 & TST & \\
\hline CHEMBL1310134 & 688620 & 6.05 & 5.0719 & TRN & \\
\hline CHEMBL1341433 & 688620 & 4.9 & 4.9233 & TRN & \\
\hline CHEMBL1340619 & 688620 & 4.45 & 5.0511 & TRN & \\
\hline CHEMBL1544674 & 688620 & 4.45 & 4.9799 & TRN & \\
\hline CHEMBL1379979 & 688620 & 4.45 & 5.0704 & TRN & \\
\hline CHEMBL1329557 & 688620 & 4.45 & 4.8493 & TST & \\
\hline CHEMBL1543386 & 688620 & 5.55 & 5.4838 & TRN & \\
\hline CHEMBL1604217 & 688620 & 5.55 & 5.7072 & TRN & \\
\hline
\end{tabular}




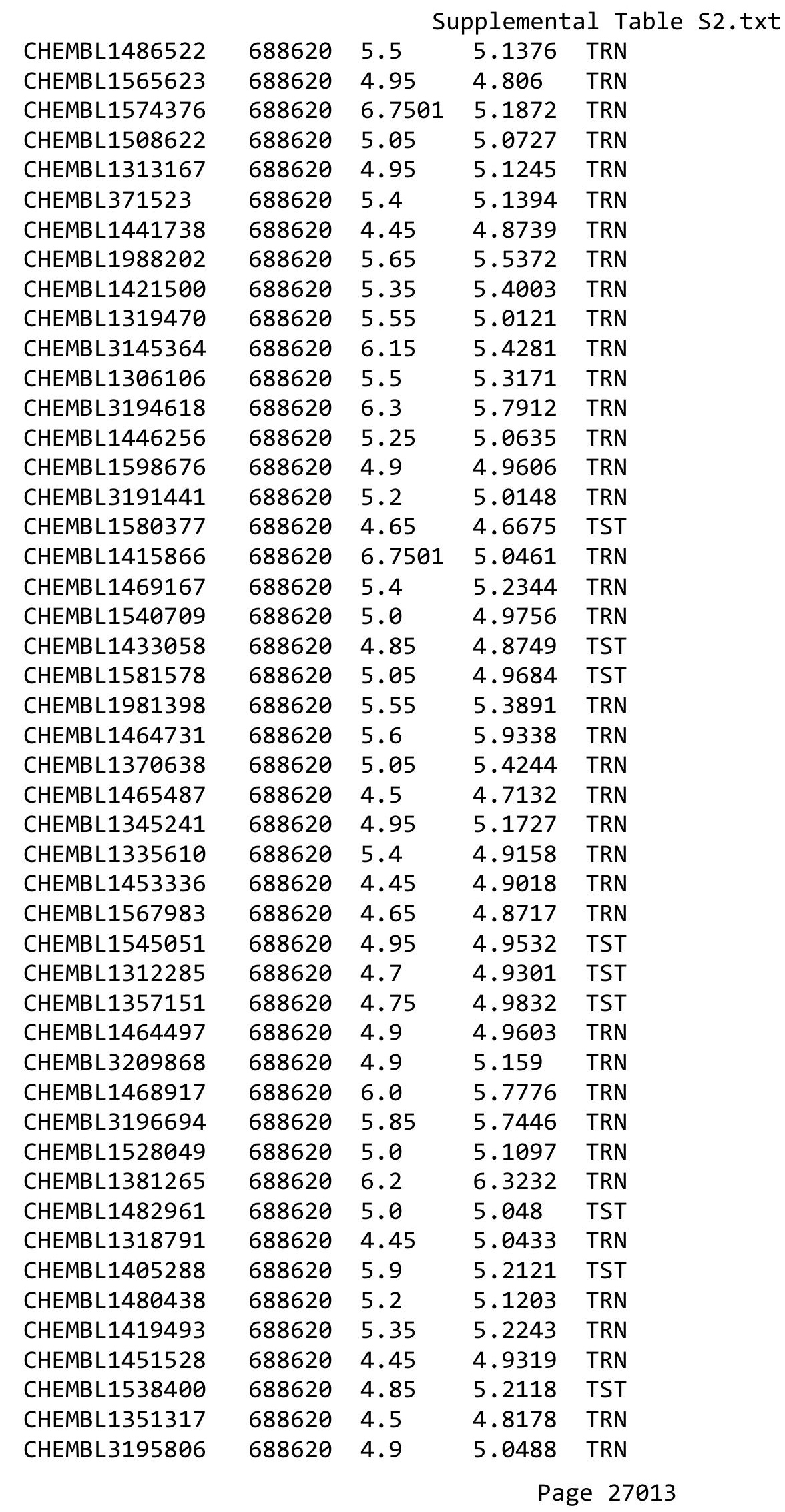




\begin{tabular}{|c|c|c|c|c|c|}
\hline \multicolumn{6}{|c|}{ Supplemental Table S2.txt } \\
\hline CHEMBL1371463 & 688620 & 4.85 & 5.0541 & TRN & \\
\hline CHEMBL1518452 & 688620 & 4.9 & 5.2013 & TRN & \\
\hline CHEMBL1568020 & 688620 & 4.7 & 4.9169 & TST & \\
\hline CHEMBL 2001408 & 688620 & 5.1 & 4.6942 & TRN & \\
\hline CHEMBL1465468 & 688620 & 4.95 & 5.1313 & TRN & \\
\hline CHEMBL1449747 & 688620 & 5.55 & 5.3643 & TRN & \\
\hline CHEMBL3196124 & 688620 & 5.6 & 5.3245 & TRN & \\
\hline CHEMBL1327607 & 688620 & 4.9 & 5.0637 & TRN & \\
\hline CHEMBL1313581 & 688620 & 6.95 & 6.2746 & TRN & \\
\hline CHEMBL1351403 & 688620 & 5.2 & 5.1717 & TST & \\
\hline CHEMBL1455000 & 688620 & 4.45 & 4.9379 & TST & \\
\hline CHEMBL1376772 & 688620 & 5.85 & 5.0429 & TST & \\
\hline CHEMBL1348813 & 688620 & 4.65 & 4.8349 & TST & \\
\hline CHEMBL1481616 & 688620 & 5.4 & 6.0264 & TRN & \\
\hline CHEMBL1445885 & 688620 & 5.05 & 5.20700 & 0000000001 & TRN \\
\hline CHEMBL3193345 & 688620 & 4.9 & 5.0045 & TRN & \\
\hline CHEMBL3198537 & 688620 & 4.95 & 5.0442 & TRN & \\
\hline CHEMBL1609818 & 688620 & 4.7 & 4.6943 & TRN & \\
\hline CHEMBL1301723 & 688620 & 5.3 & 5.6704 & TRN & \\
\hline CHEMBL1566500 & 688620 & 5.95 & 5.0667 & TRN & \\
\hline CHEMBL1583405 & 688620 & 4.45 & 5.1894 & TRN & \\
\hline CHEMBL1451149 & 688620 & 4.55 & 5.1024 & TRN & \\
\hline CHEMBL1609140 & 688620 & 5.0 & 5.1194 & TRN & \\
\hline CHEMBL1547385 & 688620 & 5.0 & 5.1326 & TRN & \\
\hline CHEMBL1416408 & 688620 & 5.15 & 4.9546 & TRN & \\
\hline CHEMBL1612250 & 688620 & 4.45 & 4.9358 & TRN & \\
\hline CHEMBL1589123 & 688620 & 5.15 & 4.9636 & TRN & \\
\hline CHEMBL1582831 & 688620 & 5.85 & 5.6298 & TRN & \\
\hline CHEMBL1487466 & 688620 & 5.05 & 5.2264 & TRN & \\
\hline CHEMBL 2086626 & 688620 & 4.9 & 4.9008 & TRN & \\
\hline CHEMBL1411436 & 688620 & 4.7 & 5.1262 & TRN & \\
\hline CHEMBL3191908 & 688620 & 4.85 & 5.4358 & TRN & \\
\hline CHEMBL1609827 & 688620 & 5.55 & 5.4772 & TRN & \\
\hline CHEMBL1386756 & 688620 & 4.7 & 5.0497 & TRN & \\
\hline CHEMBL1465688 & 688620 & 4.65 & 5.0602 & TRN & \\
\hline CHEMBL3351063 & 688620 & 5.05 & 5.0819 & TRN & \\
\hline CHEMBL1493883 & 688620 & 5.1 & 5.1154 & TST & \\
\hline CHEMBL1455842 & 688620 & 5.0 & 5.0528 & TST & \\
\hline CHEMBL1365994 & 688620 & 4.95 & 5.0233 & TRN & \\
\hline CHEMBL1570612 & 688620 & 5.6 & 5.0236 & TST & \\
\hline CHEMBL1304139 & 688620 & 4.45 & 5.0415 & TRN & \\
\hline CHEMBL1606843 & 688620 & 5.25 & 5.0728 & TRN & \\
\hline CHEMBL1526970 & 688620 & 4.65 & 5.0642 & TRN & \\
\hline CHEMBL1378796 & 688620 & 4.45 & 5.2262 & TST & \\
\hline CHEMBL1468558 & 688620 & 4.8 & 4.9953 & TRN & \\
\hline CHEMBL1399884 & 688620 & 5.0 & 4.9618 & TRN & \\
\hline CHEMBL1405943 & 688620 & 4.45 & 4.9745 & TST & \\
\hline CHEMBL1500935 & 688620 & 5.45 & 4.9356 & TRN & \\
\hline
\end{tabular}




\begin{tabular}{|c|c|c|c|c|c|}
\hline \multicolumn{6}{|c|}{ Supplemental Table S2.txt } \\
\hline CHEMBL1348545 & 688620 & 4.45 & 4.8633 & TRN & \\
\hline CHEMBL1597158 & 688620 & 4.7 & 4.7413 & TRN & \\
\hline CHEMBL1497055 & 688620 & 4.9 & 4.9823 & TRN & \\
\hline CHEMBL1426199 & 688620 & 6.4 & 5.3316 & TRN & \\
\hline CHEMBL1980322 & 688620 & 5.8 & 5.8811 & TRN & \\
\hline CHEMBL399761 & 688620 & 4.7 & 5.0976 & TRN & \\
\hline CHEMBL1501777 & 688620 & 4.95 & 5.1538 & TST & \\
\hline CHEMBL1469733 & 688620 & 6.3 & 5.8939 & TRN & \\
\hline CHEMBL1531987 & 688620 & 4.85 & 5.0553 & TST & \\
\hline CHEMBL3195460 & 688620 & 5.85 & 5.4882 & TRN & \\
\hline CHEMBL1343038 & 688620 & 4.75 & 4.8237 & TRN & \\
\hline CHEMBL1582564 & 688620 & 4.9 & 4.9369 & TST & \\
\hline CHEMBL1466288 & 688620 & 4.8 & 5.1378 & TST & \\
\hline CHEMBL1575442 & 688620 & 4.45 & 4.7606 & TST & \\
\hline CHEMBL3189180 & 688620 & 4.45 & 4.7956 & TST & \\
\hline CHEMBL3190821 & 688620 & 4.45 & 5.0724 & TRN & \\
\hline CHEMBL3192879 & 688620 & 5.9 & 5.4513 & TRN & \\
\hline CHEMBL1383315 & 688620 & 4.5 & 5.1135 & TRN & \\
\hline CHEMBL1408557 & 688620 & 4.65 & 4.9865 & TST & \\
\hline CHEMBL1313663 & 688620 & 4.5 & 4.6881 & TRN & \\
\hline CHEMBL1351885 & 688620 & 4.5 & 5.0023 & TST & \\
\hline CHEMBL1411288 & 688620 & 4.85 & 4.9628 & TST & \\
\hline CHEMBL1596003 & 688620 & 4.45 & 4.7422 & TRN & \\
\hline CHEMBL1610520 & 688620 & 5.0 & 5.1604 & TST & \\
\hline CHEMBL1311713 & 688620 & 4.85 & 5.0691 & TST & \\
\hline CHEMBL1451405 & 688620 & 4.9 & 5.1197 & TRN & \\
\hline CHEMBL1450098 & 688620 & 4.75 & 5.3632 & TRN & \\
\hline CHEMBL1305011 & 688620 & 6.3 & 5.3933 & TRN & \\
\hline CHEMBL3198534 & 688620 & 4.85 & 5.2454 & TRN & \\
\hline CHEMBL3145094 & 688620 & 5.05 & 5.231 & TRN & \\
\hline CHEMBL1536226 & 688620 & 5.45 & 5.0603 & TRN & \\
\hline CHEMBL577589 & 688620 & 5.25 & 5.05399 & & TST \\
\hline CHEMBL1509896 & 688620 & 4.5 & 5.1761 & TRN & \\
\hline CHEMBL1391698 & 688620 & 5.0 & 5.2534 & TRN & \\
\hline CHEMBL1586981 & 688620 & 5.0 & 5.0391 & TRN & \\
\hline CHEMBL1447469 & 688620 & 5.3 & 5.1033 & TRN & \\
\hline CHEMBL1460429 & 688620 & 4.45 & 4.86600 & 00000000005 & TRN \\
\hline CHEMBL1409915 & 688620 & 4.5 & 5.055 & TST & \\
\hline CHEMBL1581302 & 688620 & 4.6 & 5.3701 & TST & \\
\hline CHEMBL1565467 & 688620 & 4.95 & 4.8861 & TRN & \\
\hline CHEMBL1610644 & 688620 & 4.45 & 5.489 & TRN & \\
\hline CHEMBL1324768 & 688620 & 5.0 & 5.1213 & TRN & \\
\hline CHEMBL1322685 & 688620 & 4.75 & 5.0231 & TST & \\
\hline CHEMBL1982539 & 688620 & 5.45 & 5.7295 & TRN & \\
\hline CHEMBL1540579 & 688620 & 6.35 & 5.9888 & TRN & \\
\hline CHEMBL1513092 & 688620 & 4.85 & 5.0747 & TST & \\
\hline CHEMBL1408827 & 688620 & 4.45 & 5.3803 & TRN & \\
\hline CHEMBL3207664 & 688620 & 4.95 & 5.069 & TST & \\
\hline
\end{tabular}




\begin{tabular}{|c|c|c|c|c|c|}
\hline \\
\hline CHEMBL1398933 & 688620 & 4.5 & 5.0987 & TRN & \\
\hline CHEMBL1362188 & 688620 & 5.2 & 4.8163 & TRN & \\
\hline CHEMBL3192307 & 688620 & 6.3 & 5.5606 & TRN & \\
\hline CHEMBL1581538 & 688620 & 5.1 & 5.0606 & TRN & \\
\hline CHEMBL1337164 & 688620 & 6.0 & 5.0127 & TRN & \\
\hline CHEMBL1319974 & 688620 & 4.85 & 4.8845 & TRN & \\
\hline CHEMBL1560581 & 688620 & 4.95 & 5.3991 & TRN & \\
\hline CHEMBL48310 & 688620 & 6.0 & 5.4728 & TST & \\
\hline CHEMBL1333457 & 688620 & 4.9 & 4.9859 & TST & \\
\hline CHEMBL1384254 & 688620 & 4.5 & 5.0299 & TST & \\
\hline CHEMBL1306224 & 688620 & 4.95 & 4.7736 & TRN & \\
\hline CHEMBL1373316 & 688620 & 5.0 & 5.2115 & TST & \\
\hline CHEMBL1323432 & 688620 & 5.4 & 5.1751 & TRN & \\
\hline CHEMBL1373752 & 688620 & 4.9 & 5.1278 & TST & \\
\hline CHEMBL3199844 & 688620 & 5.3 & 4.8092 & TRN & \\
\hline CHEMBL1526935 & 688620 & 4.75 & 5.1978 & TST & \\
\hline CHEMBL 3198116 & 688620 & 4.9 & 4.8594 & TRN & \\
\hline CHEMBL1536976 & 688620 & 5.4 & 5.0636 & TRN & \\
\hline CHEMBL1458064 & 688620 & 4.7 & 5.0146 & TRN & \\
\hline CHEMBL1608947 & 688620 & 5.4 & 5.1991 & TST & \\
\hline CHEMBL1342915 & 688620 & 4.45 & 4.8896 & TST & \\
\hline CHEMBL1612961 & 688620 & 5.55 & 5.0671 & TRN & \\
\hline CHEMBL1372891 & 688620 & 4.45 & $4.7810 e$ & 0000000001 & TRN \\
\hline CHEMBL1608561 & 688620 & 4.9 & 4.9488 & TST & \\
\hline CHEMBL1301033 & 688620 & 4.95 & 5.0889 & TRN & \\
\hline CHEMBL1467873 & 688620 & 5.6 & 5.1 & TST & \\
\hline CHEMBL1596583 & 688620 & 5.2 & 5.0198 & TST & \\
\hline CHEMBL1333077 & 688620 & 4.9 & 5.1293 & TST & \\
\hline CHEMBL1511450 & 688620 & 4.45 & 5.0118 & TRN & \\
\hline CHEMBL1993855 & 688620 & 5.1 & 4.9442 & TRN & \\
\hline CHEMBL3190986 & 688620 & 5.85 & 5.7687 & TRN & \\
\hline CHEMBL1378934 & 688620 & 5.7 & 4.9026 & TRN & \\
\hline CHEMBL1459552 & 688620 & 5.55 & 5.0081 & TST & \\
\hline CHEMBL1492459 & 688620 & 5.6 & 5.3102 & TST & \\
\hline CHEMBL1242180 & 688620 & 5.15 & 5.6414 & TRN & \\
\hline CHEMBL1556197 & 688620 & 5.2 & 5.2611 & TRN & \\
\hline CHEMBL1381894 & 688620 & 4.45 & 4.768 & TRN & \\
\hline CHEMBL1524865 & 688620 & 4.8 & 4.8537 & TRN & \\
\hline CHEMBL3189553 & 688620 & 6.8499 & 5.2463 & TRN & \\
\hline CHEMBL1312180 & 688620 & 5.35 & 4.9629 & TRN & \\
\hline CHEMBL1343819 & 688620 & 4.5 & 5.0797 & TRN & \\
\hline CHEMBL3189645 & 688620 & 4.95 & 5.0304 & TRN & \\
\hline CHEMBL1543856 & 688620 & 4.8 & 4.7715 & TRN & \\
\hline CHEMBL1328393 & 688620 & 4.8 & 5.0649 & TRN & \\
\hline CHEMBL1453757 & 688620 & 5.05 & 5.2525 & TRN & \\
\hline CHEMBL1509155 & 688620 & 4.85 & 5.2518 & TRN & \\
\hline CHEMBL1533012 & 688620 & 5.1 & 4.965 & TRN & \\
\hline CHEMBL1518391 & 688620 & 4.9 & 5.0706 & TRN & \\
\hline & & & & 7016 & \\
\hline
\end{tabular}




\begin{tabular}{|c|c|c|c|c|}
\hline \multicolumn{5}{|c|}{ Supplemental Table S2.txt } \\
\hline CHEMBL1477849 & 688620 & 4.75 & 4.7834 & TRN \\
\hline CHEMBL1546360 & 688620 & 5.0 & 5.1743 & TST \\
\hline CHEMBL1497659 & 688620 & 4.95 & 4.9264 & TRN \\
\hline CHEMBL1479176 & 688620 & 5.1 & 5.0856 & TST \\
\hline CHEMBL1389449 & 688620 & 4.7 & 4.9154 & TRN \\
\hline CHEMBL1429887 & 688620 & 4.75 & 5.1342 & TRN \\
\hline CHEMBL1533536 & 688620 & 5.45 & 4.9893 & TRN \\
\hline CHEMBL1377741 & 688620 & 4.95 & 5.1866 & TRN \\
\hline CHEMBL1492713 & 688620 & 5.45 & 4.9268 & TRN \\
\hline CHEMBL1601772 & 688620 & 5.05 & 4.919 & TST \\
\hline CHEMBL1426880 & 688620 & 6.2 & 5.9067 & TRN \\
\hline CHEMBL1611989 & 688620 & 7.0 & 5.0075 & TRN \\
\hline CHEMBL3196463 & 688620 & 4.9 & 4.797 & TRN \\
\hline CHEMBL3193139 & 688620 & 6.0 & 5.6655 & TRN \\
\hline CHEMBL1349080 & 688620 & 5.35 & 5.251 & TRN \\
\hline CHEMBL1481478 & 688620 & 5.4 & 4.9164 & TRN \\
\hline CHEMBL1534947 & 688620 & 4.7 & 4.874 & TRN \\
\hline CHEMBL1486398 & 688620 & 4.65 & 4.9281 & TRN \\
\hline CHEMBL1488654 & 688620 & 4.85 & 4.9173 & TRN \\
\hline CHEMBL1340410 & 688620 & 5.6 & 5.2751 & TRN \\
\hline CHEMBL1543455 & 688620 & 4.45 & 5.1116 & TST \\
\hline CHEMBL1602772 & 688620 & 4.8 & 5.1339 & TRN \\
\hline CHEMBL1343058 & 688620 & 4.7 & 4.7539 & TRN \\
\hline CHEMBL1573592 & 688620 & 6.6499 & 5.083 & TRN \\
\hline CHEMBL1341552 & 688620 & 5.15 & 4.913 & TRN \\
\hline CHEMBL1503878 & 688620 & 4.45 & 4.916 & TST \\
\hline CHEMBL1354149 & 688620 & 4.65 & 5.1562 & TRN \\
\hline CHEMBL1581444 & 688620 & 4.85 & 5.0392 & TST \\
\hline CHEMBL1350043 & 688620 & 6.35 & 5.1673 & TST \\
\hline CHEMBL 3213653 & 688620 & 5.2 & 5.0172 & TRN \\
\hline CHEMBL1417492 & 688620 & 4.75 & 4.8328 & TRN \\
\hline CHEMBL1419938 & 688620 & 5.0 & 5.2789 & TRN \\
\hline CHEMBL1484529 & 688620 & 4.45 & 5.2143 & TRN \\
\hline CHEMBL1375712 & 688620 & 5.4 & 5.0647 & TST \\
\hline CHEMBL1582184 & 688620 & 4.9 & 5.0359 & TST \\
\hline CHEMBL1576759 & 688620 & 4.45 & 4.8805 & TRN \\
\hline CHEMBL1456373 & 688620 & 4.7 & 4.7226 & TRN \\
\hline CHEMBL1496707 & 688620 & 6.5 & 5.0755 & TST \\
\hline CHEMBL1322367 & 688620 & 5.0 & 5.0264 & TST \\
\hline CHEMBL1511048 & 688620 & 5.05 & 5.1568 & TST \\
\hline CHEMBL1496305 & 688620 & 4.5 & 4.9361 & TST \\
\hline CHEMBL1306373 & 688620 & 4.85 & 4.9918 & TRN \\
\hline CHEMBL1432577 & 688620 & 6.25 & 6.2676 & TRN \\
\hline CHEMBL1486308 & 688620 & 5.1 & 4.8784 & TRN \\
\hline CHEMBL1486177 & 688620 & 4.9 & 5.0494 & TST \\
\hline CHEMBL1422200 & 688620 & 4.85 & 4.996 & TST \\
\hline CHEMBL1561553 & 688620 & 7.6003 & 5.0958 & TST \\
\hline CHEMBL1424420 & 688620 & 5.15 & 5.0268 & TRN \\
\hline
\end{tabular}




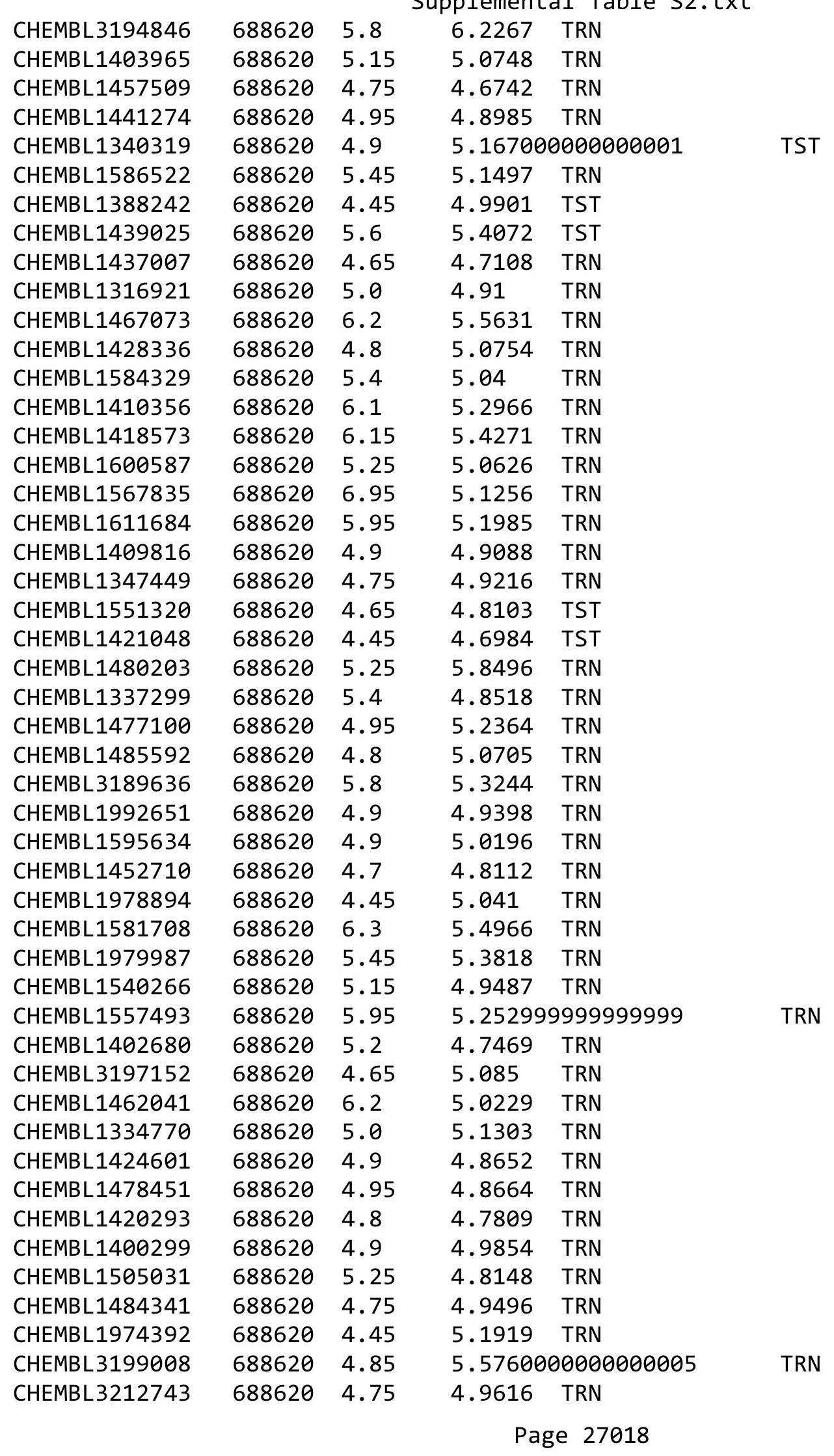




\begin{tabular}{|c|c|c|c|c|}
\hline \multicolumn{5}{|c|}{ Supplemental Table S2.txt } \\
\hline CHEMBL1608635 & 688620 & 5.4 & 5.4988 & TRN \\
\hline CHEMBL1518557 & 688620 & 4.45 & 4.8952 & TST \\
\hline CHEMBL1469565 & 688620 & 5.1 & 5.1794 & TST \\
\hline CHEMBL1401184 & 688620 & 4.45 & 5.0625 & TST \\
\hline CHEMBL1583966 & 688620 & 4.7 & 5.1162 & TST \\
\hline CHEMBL1354829 & 688620 & 4.5 & 4.7585 & TRN \\
\hline CHEMBL1523762 & 688620 & 4.45 & 5.0711 & TRN \\
\hline CHEMBL1613634 & 688620 & 4.95 & 4.8603 & TST \\
\hline CHEMBL1486131 & 688620 & 4.6 & 4.8198 & TRN \\
\hline CHEMBL3199765 & 688620 & 5.5 & 5.3116 & TRN \\
\hline CHEMBL1484081 & 688620 & 5.0 & 4.999 & TRN \\
\hline CHEMBL3198636 & 688620 & 4.95 & 5.072 & TRN \\
\hline CHEMBL3207297 & 688620 & 5.45 & 4.8675 & TRN \\
\hline CHEMBL1372052 & 688620 & 5.75 & 5.3734 & TRN \\
\hline CHEMBL1393098 & 688620 & 5.25 & 5.4651 & TRN \\
\hline CHEMBL1366034 & 688620 & 4.55 & 5.007 & TRN \\
\hline CHEMBL 3198274 & 688620 & 6.5501 & 6.0002 & TRN \\
\hline CHEMBL1487938 & 688620 & 4.9 & 4.8971 & TST \\
\hline CHEMBL1420087 & 688620 & 4.75 & 5.3741 & TRN \\
\hline CHEMBL1511346 & 688620 & 8.3468 & 5.1403 & TST \\
\hline CHEMBL1997052 & 688620 & 4.9 & 5.1938 & TRN \\
\hline CHEMBL1390582 & 688620 & 5.2 & 4.8692 & TRN \\
\hline CHEMBL1352941 & 688620 & 5.15 & 5.1983 & TRN \\
\hline CHEMBL1343246 & 688620 & 4.45 & 5.2752 & TRN \\
\hline CHEMBL3194914 & 688620 & 4.65 & 5.1291 & TST \\
\hline CHEMBL1387180 & 688620 & 5.2 & 5.1775 & TRN \\
\hline CHEMBL1496176 & 688620 & 4.9 & 5.0198 & TRN \\
\hline CHEMBL1451762 & 688620 & 5.3 & 4.9708 & TRN \\
\hline CHEMBL1332269 & 688620 & 4.9 & 4.9973 & TST \\
\hline CHEMBL1365640 & 688620 & 6.35 & 4.9251 & TRN \\
\hline CHEMBL1538711 & 688620 & 7.3002 & 5.3386 & TST \\
\hline CHEMBL1516746 & 688620 & 5.6 & 5.2824 & TRN \\
\hline CHEMBL3196305 & 688620 & 6.2 & 5.5262 & TRN \\
\hline CHEMBL1466881 & 688620 & 4.95 & 5.1353 & TRN \\
\hline CHEMBL1359723 & 688620 & 5.1 & 5.2279 & TST \\
\hline CHEMBL1384796 & 688620 & 5.65 & 5.4431 & TRN \\
\hline CHEMBL1499709 & 688620 & 5.2 & 5.1829 & TRN \\
\hline CHEMBL1376806 & 688620 & 5.05 & 4.9446 & TRN \\
\hline CHEMBL1484936 & 688620 & 4.45 & 5.059 & TRN \\
\hline CHEMBL1510087 & 688620 & 4.6 & 4.6648 & TRN \\
\hline CHEMBL 210730 & 688620 & 5.2 & 5.4163 & TRN \\
\hline CHEMBL3191870 & 688620 & 5.05 & 5.2021 & TRN \\
\hline CHEMBL1544013 & 688620 & 4.85 & 5.2193 & TST \\
\hline CHEMBL1350674 & 688620 & 4.45 & 4.9551 & TRN \\
\hline CHEMBL1417932 & 688620 & 5.1 & 5.2233 & TRN \\
\hline CHEMBL1375247 & 688620 & 5.65 & 5.5186 & TRN \\
\hline CHEMBL1548187 & 688620 & 4.8 & 4.9906 & TRN \\
\hline CHEMBL1447219 & 688620 & 6.25 & 5.9642 & TRN \\
\hline
\end{tabular}




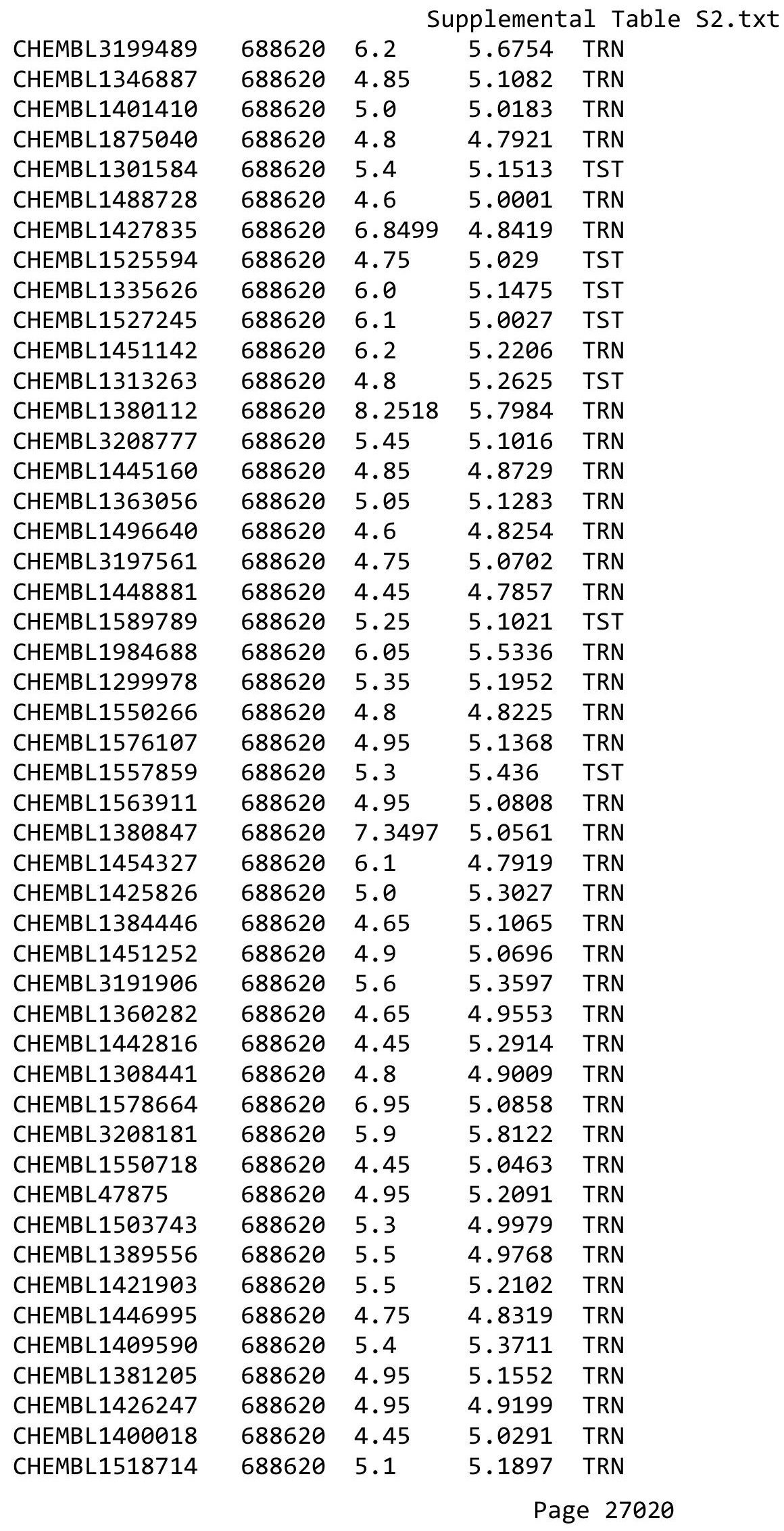




\begin{tabular}{|c|c|c|c|c|c|}
\hline \multicolumn{6}{|c|}{ Supplemental Table S2.txt } \\
\hline CHEMBL1561293 & 688620 & 4.6 & 4.7256 & TRN & \\
\hline CHEMBL600908 & 688620 & 4.75 & 4.8442 & TRN & \\
\hline CHEMBL1570947 & 688620 & 4.9 & 4.9468 & TRN & \\
\hline CHEMBL1492131 & 688620 & 5.25 & 4.8473 & TRN & \\
\hline CHEMBL1336406 & 688620 & 5.3 & 5.1399 & TRN & \\
\hline CHEMBL3197070 & 688620 & 6.6 & 6.1854 & TRN & \\
\hline CHEMBL1520053 & 688620 & 4.45 & 4.8676 & TRN & \\
\hline CHEMBL19954 & 688620 & 5.5 & 5.289 & TST & \\
\hline CHEMBL1492064 & 688620 & 4.7 & 4.953 & TRN & \\
\hline CHEMBL1362588 & 688620 & 4.85 & 5.1709 & TRN & \\
\hline CHEMBL1535475 & 688620 & 5.0 & 4.698 & TRN & \\
\hline CHEMBL1453273 & 688620 & 5.4 & 5.0149 & TRN & \\
\hline CHEMBL1541660 & 688620 & 5.25 & 4.9319 & TRN & \\
\hline CHEMBL 1387356 & 688620 & 4.45 & 4.8577 & TRN & \\
\hline CHEMBL1432362 & 688620 & 5.7 & 5.4729 & TRN & \\
\hline CHEMBL607309 & 688620 & 4.5 & 4.7632 & TST & \\
\hline CHEMBL1459032 & 688620 & 8.2518 & 4.901 & TST & \\
\hline CHEMBL1407586 & 688620 & 4.9 & 5.1323 & TRN & \\
\hline CHEMBL1542558 & 688620 & 4.45 & 4.9296 & TRN & \\
\hline CHEMBL1413893 & 688620 & 5.25 & 5.5326 & TRN & \\
\hline CHEMBL1486411 & 688620 & 4.6 & 4.9598 & TRN & \\
\hline CHEMBL1499314 & 688620 & 5.5 & 5.4413 & TRN & \\
\hline CHEMBL1566699 & 688620 & 5.45 & 5.1874 & TRN & \\
\hline CHEMBL1499359 & 688620 & 5.55 & 5.53799 & & TRN \\
\hline CHEMBL1499554 & 688620 & 5.5 & 4.9412 & TRN & \\
\hline CHEMBL3209333 & 688620 & 5.65 & 5.1264 & TRN & \\
\hline CHEMBL234180 & 688620 & 4.8 & 4.7636 & TRN & \\
\hline CHEMBL1391546 & 688620 & 4.6 & 5.0683 & TST & \\
\hline CHEMBL1445484 & 688620 & 4.7 & 4.9551 & TST & \\
\hline CHEMBL3196600 & 688620 & 6.05 & 5.3669 & TRN & \\
\hline CHEMBL1426980 & 688620 & 4.8 & 4.9489 & TRN & \\
\hline CHEMBL1509266 & 688620 & 4.5 & 4.89 & TRN & \\
\hline CHEMBL1305890 & 688620 & 5.1 & 4.9709 & TRN & \\
\hline CHEMBL1366140 & 688620 & 4.95 & 4.7286 & TRN & \\
\hline CHEMBL1326349 & 688620 & 6.05 & 5.3829 & TST & \\
\hline CHEMBL1992631 & 688620 & 5.2 & 5.0267 & TRN & \\
\hline CHEMBL1489853 & 688620 & 4.45 & 4.9646 & TRN & \\
\hline CHEMBL1419481 & 688620 & 5.35 & 5.0201 & TRN & \\
\hline CHEMBL 1455810 & 688620 & 6.05 & 5.1803 & TST & \\
\hline CHEMBL1464179 & 688620 & 5.4 & 5.3127 & TRN & \\
\hline CHEMBL1599579 & 688620 & 5.0 & 5.0824 & TST & \\
\hline CHEMBL1533706 & 688620 & 4.9 & 5.0285 & TST & \\
\hline CHEMBL1506241 & 688620 & 4.9 & 4.8606 & TRN & \\
\hline CHEMBL1549636 & 688620 & 4.45 & 4.8711 & TRN & \\
\hline CHEMBL1564590 & 688620 & 4.9 & 5.1551 & TRN & \\
\hline CHEMBL1368924 & 688620 & 4.95 & 4.9831 & TRN & \\
\hline CHEMBL1505665 & 688620 & 5.0 & 4.8225 & TRN & \\
\hline CHEMBL1424567 & 688620 & 4.65 & 4.8788 & TRN & \\
\hline
\end{tabular}




\begin{tabular}{|c|c|c|c|c|}
\hline \multicolumn{5}{|c|}{ Supplemental Table } \\
\hline CHEMBL1578607 & 688620 & 5.85 & 6.2619 & TRN \\
\hline CHEMBL1496630 & 688620 & 5.4 & 5.3642 & TST \\
\hline CHEMBL1303546 & 688620 & 4.8 & 5.0837 & TRN \\
\hline CHEMBL1405975 & 688620 & 5.0 & 5.1519 & TRN \\
\hline CHEMBL141477 & 688620 & 5.2 & 5.1399 & TST \\
\hline CHEMBL1364763 & 688620 & 4.95 & 5.2219 & TRN \\
\hline CHEMBL1607304 & 688620 & 5.0 & 5.1308 & TRN \\
\hline CHEMBL3193856 & 688620 & 6.5 & 5.8607 & TRN \\
\hline CHEMBL1459120 & 688620 & 5.2 & 5.1729 & TRN \\
\hline CHEMBL1527294 & 688620 & 4.45 & 4.7776 & TRN \\
\hline CHEMBL1439998 & 688620 & 4.8 & 5.0312 & TRN \\
\hline CHEMBL1078717 & 688620 & 4.7 & 5.1665 & TRN \\
\hline CHEMBL1577079 & 688620 & 4.9 & 4.9675 & TRN \\
\hline CHEMBL1599048 & 688620 & 4.5 & 5.0462 & TST \\
\hline CHEMBL1528743 & 688620 & 4.6 & 5.2013 & TRN \\
\hline CHEMBL1359694 & 688620 & 4.45 & 5.0823 & TRN \\
\hline CHEMBL1597638 & 688620 & 5.0 & 4.7019 & TRN \\
\hline CHEMBL1477915 & 688620 & 4.45 & 4.8152 & TST \\
\hline CHEMBL1526167 & 688620 & 5.1 & 5.1235 & TRN \\
\hline CHEMBL1448540 & 688620 & 5.1 & 4.9118 & TRN \\
\hline CHEMBL1319034 & 688620 & 4.45 & 4.9816 & TRN \\
\hline CHEMBL1533317 & 688620 & 4.95 & 4.8919 & TRN \\
\hline CHEMBL243216 & 688620 & 4.45 & 4.8213 & TRN \\
\hline CHEMBL1458212 & 688620 & 4.45 & 5.0341 & TRN \\
\hline CHEMBL1421508 & 688620 & 4.45 & 5.0836 & TST \\
\hline CHEMBL1410469 & 688620 & 4.65 & 4.9617 & TRN \\
\hline CHEMBL1390575 & 688620 & 5.4 & 5.6049 & TRN \\
\hline CHEMBL1535305 & 688620 & 4.45 & 5.1298 & TST \\
\hline CHEMBL1322899 & 688620 & 5.3 & 5.1072 & TRN \\
\hline CHEMBL602158 & 688620 & 5.0 & 5.0758 & TRN \\
\hline CHEMBL1461841 & 688620 & 4.7 & 5.0388 & TRN \\
\hline CHEMBL1419242 & 688620 & 5.65 & 5.0445 & TRN \\
\hline CHEMBL1407234 & 688620 & 4.85 & 4.699 & TST \\
\hline CHEMBL1509816 & 688620 & 5.5 & 4.9972 & TST \\
\hline CHEMBL1340284 & 688620 & 4.85 & 5.0097 & TST \\
\hline CHEMBL1442019 & 688620 & 5.0 & 4.9798 & TRN \\
\hline CHEMBL1498517 & 688620 & 5.5 & 5.4439 & TST \\
\hline CHEMBL1383428 & 688620 & 4.8 & 4.8843 & TRN \\
\hline CHEMBL1577776 & 688620 & 4.45 & 4.8519 & TRN \\
\hline CHEMBL1570958 & 688620 & 5.35 & 5.2029 & TRN \\
\hline CHEMBL3208216 & 688620 & 5.55 & 5.4609 & TRN \\
\hline CHEMBL1430930 & 688620 & 4.95 & 5.0796 & TRN \\
\hline CHEMBL1561523 & 688620 & 4.85 & 5.0956 & TRN \\
\hline CHEMBL1449971 & 688620 & 5.2 & 4.865 & TRN \\
\hline CHEMBL1431303 & 688620 & 7.2 & 4.9367 & TRN \\
\hline CHEMBL1510137 & 688620 & 5.25 & 4.8491 & TRN \\
\hline CHEMBL1461896 & 688620 & 4.65 & 5.0205 & TRN \\
\hline CHEMBL1340308 & 688620 & 6.1 & 5.2216 & TRN \\
\hline
\end{tabular}




\begin{tabular}{|c|c|c|c|c|}
\hline \multicolumn{5}{|c|}{ Supplemental Table } \\
\hline CHEMBL1502157 & 688620 & 4.95 & 5.0148 & TRN \\
\hline CHEMBL1567814 & 688620 & 4.7 & 4.8273 & TRN \\
\hline CHEMBL1521238 & 688620 & 4.8 & 5.1344 & TRN \\
\hline CHEMBL 3209382 & 688620 & 8.3468 & 5.3046 & TRN \\
\hline CHEMBL1308909 & 688620 & 5.9 & 5.0499 & TRN \\
\hline CHEMBL1376685 & 688620 & 4.85 & 4.9326 & TRN \\
\hline CHEMBL1373529 & 688620 & 4.65 & 4.746 & TRN \\
\hline CHEMBL3213319 & 688620 & 4.75 & 4.8312 & TST \\
\hline CHEMBL1373631 & 688620 & 4.45 & 5.0142 & TRN \\
\hline CHEMBL1442475 & 688620 & 5.1 & 4.9726 & TRN \\
\hline CHEMBL62136 & 688620 & 5.7 & 5.055 & TST \\
\hline CHEMBL1484215 & 688620 & 4.75 & 4.9615 & TRN \\
\hline CHEMBL1438855 & 688620 & 5.05 & 5.0484 & TST \\
\hline CHEMBL1485315 & 688620 & 6.4 & 5.8615 & TRN \\
\hline CHEMBL1401923 & 688620 & 5.2 & 5.511 & TRN \\
\hline CHEMBL1573847 & 688620 & 5.15 & 4.8719 & TRN \\
\hline CHEMBL 2001029 & 688620 & 5.15 & 5.084 & TRN \\
\hline CHEMBL3195142 & 688620 & 5.3 & 5.307 & TRN \\
\hline CHEMBL1300013 & 688620 & 5.0 & 5.0854 & TRN \\
\hline CHEMBL1504607 & 688620 & 5.0 & 4.6837 & TRN \\
\hline CHEMBL1494079 & 688620 & 4.8 & 4.6433 & TST \\
\hline CHEMBL1307059 & 688620 & 4.75 & 4.6894 & TRN \\
\hline CHEMBL1537211 & 688620 & 5.05 & 5.1401 & TST \\
\hline CHEMBL1607687 & 688620 & 5.15 & 4.9639 & TRN \\
\hline CHEMBL1512801 & 688620 & 4.9 & 5.0507 & TST \\
\hline CHEMBL3210286 & 688620 & 4.8 & 4.8198 & TRN \\
\hline CHEMBL1465303 & 688620 & 4.95 & 4.9464 & TRN \\
\hline CHEMBL1443205 & 688620 & 5.95 & 5.814 & TRN \\
\hline CHEMBL1371050 & 688620 & 8.3468 & 5.0182 & TST \\
\hline CHEMBL1367055 & 688620 & 4.9 & 5.0097 & TST \\
\hline CHEMBL1524438 & 688620 & 4.85 & 5.1655 & TRN \\
\hline CHEMBL1582494 & 688620 & 4.55 & 4.9724 & TRN \\
\hline CHEMBL448515 & 688620 & 5.55 & 5.4002 & TST \\
\hline CHEMBL1561887 & 688620 & 5.9 & 4.9099 & TST \\
\hline CHEMBL3195172 & 688620 & 4.45 & 4.8067 & TRN \\
\hline CHEMBL1497217 & 688620 & 5.6 & 5.3673 & TRN \\
\hline CHEMBL1560502 & 688620 & 4.85 & 4.9944 & TRN \\
\hline CHEMBL1585075 & 688620 & 5.45 & 5.1002 & TRN \\
\hline CHEMBL1598561 & 688620 & 4.9 & 4.7777 & TST \\
\hline CHEMBL1466834 & 688620 & 4.8 & 4.9796 & TRN \\
\hline CHEMBL3209231 & 688620 & 5.6 & 4.9738 & TST \\
\hline CHEMBL1466106 & 688620 & 4.95 & 5.2228 & TRN \\
\hline CHEMBL1465140 & 688620 & 4.65 & 4.9877 & TRN \\
\hline CHEMBL1462298 & 688620 & 5.75 & 4.8938 & TRN \\
\hline CHEMBL3191655 & 688620 & 4.85 & 4.806 & TRN \\
\hline CHEMBL1491969 & 688620 & 4.45 & 5.2038 & TST \\
\hline CHEMBL1443814 & 688620 & 6.05 & 5.3808 & TRN \\
\hline CHEMBL3213501 & 688620 & 6.25 & 6.0019 & TRN \\
\hline
\end{tabular}




\begin{tabular}{|c|c|c|c|c|c|}
\hline \multicolumn{6}{|c|}{ Supplemental Table S2.txt } \\
\hline CHEMBL1504125 & 688620 & 6.4 & 6.0386 & TRN & \\
\hline CHEMBL1487692 & 688620 & 5.9 & 5.5404 & TST & \\
\hline CHEMBL1457119 & 688620 & 4.75 & 5.1052 & TRN & \\
\hline CHEMBL1305716 & 688620 & 4.7 & 4.8779 & TST & \\
\hline CHEMBL1414898 & 688620 & 4.45 & 5.0689 & TRN & \\
\hline CHEMBL1605677 & 688620 & 4.65 & 5.0634 & TST & \\
\hline CHEMBL 260560 & 688620 & 4.8 & 5.3674 & TRN & \\
\hline CHEMBL1526121 & 688620 & 4.45 & 5.1224 & TST & \\
\hline CHEMBL1429867 & 688620 & 5.85 & 5.2029 & TRN & \\
\hline CHEMBL1607495 & 688620 & 5.0 & 4.9781 & TRN & \\
\hline CHEMBL3193218 & 688620 & 5.0 & 5.2677 & TRN & \\
\hline CHEMBL 3189746 & 688620 & 5.65 & 5.3837 & TRN & \\
\hline CHEMBL1444221 & 688620 & 4.6 & 4.7456 & TRN & \\
\hline CHEMBL1563531 & 688620 & 4.65 & 4.7665 & TRN & \\
\hline CHEMBL1500256 & 688620 & 5.5 & 5.0156 & TRN & \\
\hline CHEMBL1507560 & 688620 & 5.45 & 5.2999 & TRN & \\
\hline CHEMBL3189893 & 688620 & 4.75 & 4.9629 & TRN & \\
\hline CHEMBL1465797 & 688620 & 4.9 & 4.6416 & TRN & \\
\hline CHEMBL1549673 & 688620 & 4.9 & 5.2603 & TRN & \\
\hline CHEMBL1542076 & 688620 & 5.15 & 4.9 & TRN & \\
\hline CHEMBL1326322 & 688620 & 5.0 & 5.1695 & TRN & \\
\hline CHEMBL1501975 & 688620 & 5.0 & 5.0125 & TRN & \\
\hline CHEMBL1540525 & 688620 & 5.0 & 5.0612 & TRN & \\
\hline CHEMBL1328229 & 688620 & 5.75 & 5.5963 & TRN & \\
\hline CHEMBL1432287 & 688620 & 5.0 & 5.4401 & TRN & \\
\hline CHEMBL1576336 & 688620 & 5.05 & 4.9859 & TRN & \\
\hline CHEMBL1450133 & 688620 & 5.2 & 5.0939 & TRN & \\
\hline CHEMBL3196056 & 688620 & 4.9 & 5.117 & TRN & \\
\hline CHEMBL1382723 & 688620 & 5.4 & 5.2015 & TRN & \\
\hline CHEMBL1388951 & 688620 & 4.5 & 4.9022 & TRN & \\
\hline CHEMBL1520491 & 688620 & 6.25 & 5.1369 & TRN & \\
\hline CHEMBL1340417 & 688620 & 5.3 & 5.2655 & TST & \\
\hline CHEMBL1524396 & 688620 & 5.65 & 4.7677 & TRN & \\
\hline CHEMBL1308259 & 688620 & 4.45 & 4.9173 & TST & \\
\hline CHEMBL1442427 & 688620 & 5.5 & 5.5296 & TRN & \\
\hline CHEMBL3212140 & 688620 & 4.95 & 5.2723 & TST & \\
\hline CHEMBL1371150 & 688620 & 4.75 & 5.0889 & TRN & \\
\hline CHEMBL1604431 & 688620 & 5.5 & 5.0567 & TRN & \\
\hline CHEMBL 3210460 & 688620 & 4.75 & 4.9736 & TRN & \\
\hline CHEMBL88961 & 688620 & 4.45 & 4.89199 & 99999999995 & TST \\
\hline CHEMBL1339569 & 688620 & 5.1 & 5.1539 & TRN & \\
\hline CHEMBL1493354 & 688620 & 6.2 & 4.9028 & TRN & \\
\hline CHEMBL3196804 & 688620 & 4.9 & 5.0427 & TRN & \\
\hline CHEMBL1371734 & 688620 & 4.85 & $5.1080 e$ & 00000000005 & TRN \\
\hline CHEMBL1995879 & 688620 & 5.65 & 5.5833 & TRN & \\
\hline CHEMBL1300019 & 688620 & 4.5 & 4.8934 & TRN & \\
\hline CHEMBL1325021 & 688620 & 4.95 & 4.9733 & TRN & \\
\hline CHEMBL1303967 & 688620 & 6.5501 & 5.0515 & TRN & \\
\hline
\end{tabular}




\begin{tabular}{|c|c|c|c|c|c|}
\hline & & \multicolumn{4}{|c|}{ Supplemental Table S2.txt } \\
\hline CHEMBL1607307 & 688620 & 5.25 & 5.188 & TRN & \\
\hline CHEMBL1538109 & 688620 & 6.8 & 5.1391 & TRN & \\
\hline CHEMBL1463148 & 688620 & 5.7 & 5.1101 & TRN & \\
\hline CHEMBL1518867 & 688620 & 5.25 & 4.9755 & TST & \\
\hline CHEMBL1574911 & 688620 & 4.65 & 5.216 & TRN & \\
\hline CHEMBL1420537 & 688620 & 4.7 & 4.8741 & TST & \\
\hline CHEMBL1542604 & 688620 & 5.4 & 4.9215 & TRN & \\
\hline CHEMBL1573400 & 688620 & 5.45 & 5.1059 & TRN & \\
\hline CHEMBL1592020 & 688620 & 4.9 & 4.9226 & TRN & \\
\hline CHEMBL1577799 & 688620 & 5.7 & 5.1208 & TRN & \\
\hline CHEMBL1371027 & 688620 & 4.8 & 5.0163 & TRN & \\
\hline CHEMBL1992154 & 688620 & 4.45 & 4.75899 & 99999999995 & TRN \\
\hline CHEMBL3189225 & 688620 & 4.9 & 4.9891 & TRN & \\
\hline CHEMBL1452412 & 688620 & 5.6 & 5.3347 & TRN & \\
\hline CHEMBL337173 & 688620 & 6.0 & 5.6941 & TRN & \\
\hline CHEMBL1342912 & 688620 & 4.45 & 4.7517 & TRN & \\
\hline CHEMBL1360306 & 688620 & 5.25 & 5.12 & TST & \\
\hline CHEMBL1390853 & 688620 & 4.55 & 5.073 & TST & \\
\hline CHEMBL1459456 & 688620 & 6.4 & 5.0856 & TRN & \\
\hline CHEMBL1388327 & 688620 & 5.3 & 5.4146 & TRN & \\
\hline CHEMBL1424235 & 688620 & 5.05 & 4.994 & TST & \\
\hline CHEMBL1466990 & 688620 & 5.45 & 5.1531 & TRN & \\
\hline CHEMBL3197889 & 688620 & 4.45 & 5.084 & TRN & \\
\hline CHEMBL3196696 & 688620 & 4.7 & 5.2431 & TRN & \\
\hline CHEMBL1600035 & 688620 & 5.3 & 5.2803 & TRN & \\
\hline CHEMBL3196614 & 688620 & 4.95 & 5.1113 & TRN & \\
\hline CHEMBL1471160 & 688620 & 4.45 & 4.7543 & TST & \\
\hline CHEMBL3196591 & 688620 & 4.95 & 5.1864 & TRN & \\
\hline CHEMBL1530420 & 688620 & 5.45 & 5.3596 & TRN & \\
\hline CHEMBL1310016 & 688620 & 4.45 & 4.8233 & TST & \\
\hline CHEMBL1531885 & 688620 & 5.05 & 4.8937 & TRN & \\
\hline CHEMBL1588871 & 688620 & 4.85 & 5.0565 & TRN & \\
\hline CHEMBL1548270 & 688620 & 5.0 & 4.9305 & TRN & \\
\hline CHEMBL3194186 & 688620 & 6.25 & 5.643 & TST & \\
\hline CHEMBL1345266 & 688620 & 4.5 & 4.8956 & TRN & \\
\hline CHEMBL1528331 & 688620 & 5.65 & 4.9047 & TST & \\
\hline CHEMBL583578 & 688620 & 6.0 & 5.1181 & TRN & \\
\hline CHEMBL1449648 & 688620 & 5.95 & 5.2206 & TRN & \\
\hline CHEMBL1594846 & 688620 & 4.85 & 4.76399 & 9999999999 & TRN \\
\hline CHEMBL1483692 & 688620 & 4.9 & 5.1215 & TST & \\
\hline CHEMBL1309165 & 688620 & 4.7 & 4.8434 & TRN & \\
\hline CHEMBL1587821 & 688620 & 6.8 & 5.0028 & TRN & \\
\hline CHEMBL1320297 & 688620 & 4.95 & 4.7818 & TST & \\
\hline CHEMBL1441962 & 688620 & 5.0 & 4.9437 & TST & \\
\hline CHEMBL1562787 & 688620 & 4.85 & 4.9656 & TRN & \\
\hline CHEMBL1346981 & 688620 & 4.45 & 4.7085 & TST & \\
\hline CHEMBL1508110 & 688620 & 5.8 & 4.9271 & TRN & \\
\hline CHEMBL3196139 & 688620 & 7.0 & 6.3736 & TRN & \\
\hline
\end{tabular}




\begin{tabular}{|c|c|c|c|c|c|}
\hline \multicolumn{6}{|c|}{ Supplemental Table S2.txt } \\
\hline CHEMBL1321434 & 688620 & 4.95 & 5.008 & TRN & \\
\hline CHEMBL 2003149 & 688620 & 4.75 & 5.3719 & TRN & \\
\hline CHEMBL1486333 & 688620 & 6.8499 & 5.1726 & TRN & \\
\hline CHEMBL1447505 & 688620 & 4.95 & 4.7295 & TRN & \\
\hline CHEMBL1487430 & 688620 & 5.5 & 5.0796 & TRN & \\
\hline CHEMBL1462274 & 688620 & 5.5 & 5.1201 & TRN & \\
\hline CHEMBL1419183 & 688620 & 5.45 & 5.1272 & TST & \\
\hline CHEMBL1439325 & 688620 & 7.8996 & 5.1496 & TST & \\
\hline CHEMBL3214152 & 688620 & 4.9 & 5.1305 & TRN & \\
\hline CHEMBL1427976 & 688620 & 4.45 & 4.9952 & TST & \\
\hline CHEMBL1964690 & 688620 & 5.6 & 4.9573 & TST & \\
\hline CHEMBL1424538 & 688620 & 4.85 & 5.037 & TRN & \\
\hline CHEMBL1526050 & 688620 & 4.75 & 4.9988 & TRN & \\
\hline CHEMBL1977226 & 688620 & 4.95 & 5.4556 & TRN & \\
\hline CHEMBL1305693 & 688620 & 4.95 & 4.8722 & TRN & \\
\hline CHEMBL1360754 & 688620 & 5.0 & 4.9701 & TRN & \\
\hline CHEMBL1341669 & 688620 & 5.4 & 4.859 & TRN & \\
\hline CHEMBL1558892 & 688620 & 5.15 & 4.94 & TRN & \\
\hline CHEMBL1544544 & 688620 & 6.25 & 6.2927 & TRN & \\
\hline CHEMBL3208636 & 688620 & 4.45 & 5.2501 & TRN & \\
\hline CHEMBL1432165 & 688620 & 4.65 & 5.0613 & TST & \\
\hline CHEMBL1549029 & 688620 & 4.7 & 5.1596 & TRN & \\
\hline CHEMBL1601663 & 688620 & 5.4 & 5.5208 & TRN & \\
\hline CHEMBL1390855 & 688620 & 4.95 & 4.9598 & TST & \\
\hline CHEMBL1508482 & 688620 & 4.8 & 4.9539 & TRN & \\
\hline CHEMBL1606206 & 688620 & 4.85 & 4.7792 & TRN & \\
\hline CHEMBL1373481 & 688620 & 4.9 & 5.1172 & TRN & \\
\hline CHEMBL1320718 & 688620 & 4.45 & 5.0925 & TRN & \\
\hline CHEMBL1565719 & 688620 & 5.25 & 4.9279 & TST & \\
\hline CHEMBL1364581 & 688620 & 4.75 & 5.0078 & TST & \\
\hline CHEMBL1420631 & 688620 & 4.85 & 5.0637 & TRN & \\
\hline CHEMBL590422 & 688620 & 4.65 & 4.6937 & TRN & \\
\hline CHEMBL3198969 & 688620 & 5.05 & 5.0278 & TST & \\
\hline CHEMBL1558963 & 688620 & 5.25 & 5.101 & TRN & \\
\hline CHEMBL1562777 & 688620 & 6.0 & 5.1606 & TRN & \\
\hline CHEMBL1304942 & 688620 & 4.75 & 4.9315 & TRN & \\
\hline CHEMBL1366035 & 688620 & 5.6 & 5.2866 & TRN & \\
\hline CHEMBL1980677 & 688620 & 4.45 & 4.92399 & 99999999995 & TRN \\
\hline CHEMBL1577218 & 688620 & 4.95 & 5.0952 & TRN & \\
\hline CHEMBL1564127 & 688620 & 5.0 & 4.7529 & TRN & \\
\hline CHEMBL1609146 & 688620 & 5.5 & 5.0751 & TRN & \\
\hline CHEMBL3192163 & 688620 & 5.3 & $5.1110 e$ & 0000000001 & TRN \\
\hline CHEMBL1498246 & 688620 & 5.0 & 5.0051 & TRN & \\
\hline CHEMBL1359675 & 688620 & 4.45 & 4.7896 & TRN & \\
\hline CHEMBL1451459 & 688620 & 4.45 & 4.8009 & TRN & \\
\hline CHEMBL1993643 & 688620 & 4.45 & 5.37299 & 9999999999 & TRN \\
\hline CHEMBL1579390 & 688620 & 4.45 & 5.2213 & TRN & \\
\hline CHEMBL1459353 & 688620 & 5.7 & 5.3673 & TRN & \\
\hline
\end{tabular}




\begin{tabular}{|c|c|c|c|c|}
\hline & & & ipplemen & al $\mathrm{T}$ \\
\hline CHEMBL1472553 & 688620 & 4.45 & 4.8274 & TRN \\
\hline CHEMBL1581596 & 688620 & 4.45 & 5.0691 & TRN \\
\hline CHEMBL1337409 & 688620 & 6.0 & 5.481 & TRN \\
\hline CHEMBL1379789 & 688620 & 4.45 & 4.9739 & TRN \\
\hline CHEMBL1610659 & 688620 & 4.9 & 5.1865 & TST \\
\hline CHEMBL1489194 & 688620 & 4.75 & 4.9442 & TRN \\
\hline CHEMBL1352758 & 688620 & 6.05 & 5.1256 & TRN \\
\hline CHEMBL1471715 & 688620 & 5.65 & 5.3774 & TRN \\
\hline CHEMBL1330478 & 688620 & 5.4 & 5.2155 & TRN \\
\hline CHEMBL1510148 & 688620 & 5.1 & 5.0263 & TRN \\
\hline CHEMBL1549677 & 688620 & 4.55 & 5.2236 & TRN \\
\hline CHEMBL1566730 & 688620 & 4.95 & 5.3913 & TRN \\
\hline CHEMBL1313901 & 688620 & 5.6 & 5.4386 & TRN \\
\hline CHEMBL3190866 & 688620 & 6.0 & 5.595 & TRN \\
\hline CHEMBL1561171 & 688620 & 5.0 & 5.3989 & TST \\
\hline CHEMBL1407958 & 688620 & 4.8 & 5.0684 & TST \\
\hline CHEMBL1588339 & 688620 & 4.95 & 4.7496 & TRN \\
\hline CHEMBL1594316 & 688620 & 5.2 & 5.2321 & TRN \\
\hline CHEMBL1301364 & 688620 & 4.45 & 4.8628 & TST \\
\hline CHEMBL3213843 & 688620 & 4.95 & 5.0402 & TRN \\
\hline CHEMBL1369217 & 688620 & 4.5 & 5.0561 & TRN \\
\hline CHEMBL1610053 & 688620 & 4.65 & 4.8082 & TST \\
\hline CHEMBL1442385 & 688620 & 5.4 & 5.3442 & TRN \\
\hline CHEMBL1410021 & 688620 & 4.45 & 5.2541 & TST \\
\hline CHEMBL1487453 & 688620 & 4.85 & 5.0705 & TRN \\
\hline CHEMBL1369655 & 688620 & 5.25 & 5.5065 & TRN \\
\hline CHEMBL1305084 & 688620 & 4.95 & 5.0302 & TST \\
\hline CHEMBL3190917 & 688620 & 6.0 & 5.665 & TRN \\
\hline CHEMBL1414165 & 688620 & 4.9 & 5.0189 & TRN \\
\hline CHEMBL1547025 & 688620 & 4.6 & 4.7291 & TRN \\
\hline CHEMBL1333325 & 688620 & 5.25 & 5.1456 & TRN \\
\hline CHEMBL3197667 & 688620 & 4.45 & 4.7959 & TRN \\
\hline CHEMBL1583319 & 688620 & 5.0 & 5.077 & TRN \\
\hline CHEMBL3211722 & 688620 & 5.0 & 5.0574 & TRN \\
\hline CHEMBL1408661 & 688620 & 4.45 & 5.2645 & TRN \\
\hline CHEMBL530788 & 688620 & 4.45 & 5.0243 & TRN \\
\hline CHEMBL1583285 & 688620 & 5.25 & 5.0512 & TRN \\
\hline CHEMBL1465440 & 688620 & 5.6 & 5.3082 & TRN \\
\hline CHEMBL1510742 & 688620 & 4.45 & 4.9357 & TRN \\
\hline CHEMBL1412359 & 688620 & 5.1 & 4.6222 & TRN \\
\hline CHEMBL1503585 & 688620 & 5.2 & 5.2123 & TST \\
\hline CHEMBL1399284 & 688620 & 5.15 & 5.0333 & TRN \\
\hline CHEMBL1329650 & 688620 & 4.95 & 5.1298 & TRN \\
\hline CHEMBL1490080 & 688620 & 4.85 & 4.8821 & TRN \\
\hline CHEMBL1412457 & 688620 & 4.9 & 4.954 & TRN \\
\hline CHEMBL398765 & 688620 & 6.3 & 5.4235 & TRN \\
\hline CHEMBL1556055 & 688620 & 5.15 & 5.0142 & TRN \\
\hline CHEMBL1345505 & 688620 & 5.5 & 5.5535 & TRN \\
\hline
\end{tabular}




\begin{tabular}{|c|c|c|c|c|c|}
\hline \\
\hline CHEMBL1386146 & 688620 & 4.9 & 5.1237 & TST & \\
\hline CHEMBL1556606 & 688620 & 4.45 & 4.9839 & TRN & \\
\hline CHEMBL1400508 & 688620 & 4.95 & 5.3128 & TRN & \\
\hline CHEMBL1975298 & 688620 & 5.2 & 4.9958 & TRN & \\
\hline CHEMBL1530086 & 688620 & 6.25 & 5.4987 & TRN & \\
\hline CHEMBL1302681 & 688620 & 4.45 & 4.9357 & TRN & \\
\hline CHEMBL1555873 & 688620 & 4.95 & 5.4343 & TRN & \\
\hline CHEMBL1518578 & 688620 & 4.85 & 5.2308 & TRN & \\
\hline CHEMBL1310098 & 688620 & 4.75 & 4.9087 & TST & \\
\hline CHEMBL1544793 & 688620 & 4.85 & 4.7285 & TST & \\
\hline CHEMBL1592914 & 688620 & 4.8 & 4.9386 & TST & \\
\hline CHEMBL1518703 & 688620 & 5.15 & 5.0695 & TRN & \\
\hline CHEMBL1511685 & 688620 & 4.5 & 5.0274 & TRN & \\
\hline CHEMBL3191158 & 688620 & 6.3 & 5.6613 & TRN & \\
\hline CHEMBL1325431 & 688620 & 4.7 & 5.106 & TRN & \\
\hline CHEMBL1586652 & 688620 & 4.45 & 5.1724 & TST & \\
\hline CHEMBL3194588 & 688620 & 4.75 & 4.8761 & TRN & \\
\hline CHEMBL1544260 & 688620 & 4.95 & 4.7862 & TST & \\
\hline CHEMBL1424965 & 688620 & 4.45 & 5.0403 & TRN & \\
\hline CHEMBL1525325 & 688620 & 4.9 & 5.2403 & TRN & \\
\hline CHEMBL1374266 & 688620 & 5.15 & 5.0556 & TRN & \\
\hline CHEMBL1319098 & 688620 & 5.5 & 5.1771 & TRN & \\
\hline CHEMBL1393068 & 688620 & 4.85 & 5.2367 & TRN & \\
\hline CHEMBL1413679 & 688620 & 4.95 & 4.8806 & TRN & \\
\hline CHEMBL1424091 & 688620 & 4.5 & 4.8211 & TRN & \\
\hline CHEMBL1492323 & 688620 & 6.0 & 5.7776 & TRN & \\
\hline CHEMBL1458368 & 688620 & 4.6 & 4.9222 & TRN & \\
\hline CHEMBL1468137 & 688620 & 6.0 & 5.1635 & TST & \\
\hline CHEMBL1453880 & 688620 & 4.9 & 4.706 & TRN & \\
\hline CHEMBL3191007 & 688620 & 4.6 & 4.7239 & TRN & \\
\hline CHEMBL1500868 & 688620 & 4.95 & 5.2561 & TRN & \\
\hline CHEMBL1567701 & 688620 & 4.7 & 4.868 & TST & \\
\hline CHEMBL1558893 & 688620 & 6.0 & 4.9076 & TST & \\
\hline CHEMBL1464342 & 688620 & 5.05 & 5.0222 & TRN & \\
\hline CHEMBL1309521 & 688620 & 4.65 & 5.0569 & TRN & \\
\hline CHEMBL1440785 & 688620 & 4.45 & 4.98300 & 30000000005 & TRN \\
\hline CHEMBL1487010 & 688620 & 4.9 & 5.2107 & TST & \\
\hline CHEMBL1344950 & 688620 & 4.5 & 4.9079 & TRN & \\
\hline CHEMBL1332630 & 688620 & 4.95 & 4.9403 & TRN & \\
\hline CHEMBL1523189 & 688620 & 5.2 & 5.1354 & TRN & \\
\hline CHEMBL1358016 & 688620 & 5.2 & 5.0809 & TRN & \\
\hline CHEMBL161957 & 688620 & 4.65 & 5.1566 & TRN & \\
\hline CHEMBL1326776 & 688620 & 5.45 & 5.1596 & TRN & \\
\hline CHEMBL3198519 & 688620 & 5.0 & 5.0697 & TRN & \\
\hline CHEMBL1387605 & 688620 & 6.5 & 5.9455 & TRN & \\
\hline CHEMBL1520399 & 688620 & 4.5 & 5.0071 & TRN & \\
\hline CHEMBL1581425 & 688620 & 4.7 & 4.8608 & TST & \\
\hline CHEMBL1415500 & 688620 & 4.9 & 4.8601 & TRN & \\
\hline
\end{tabular}




\begin{tabular}{|c|c|c|c|c|}
\hline \multicolumn{5}{|c|}{ Supplemental Table S2.txt } \\
\hline CHEMBL1533653 & 688620 & 4.95 & 4.8127 & TRN \\
\hline CHEMBL1538637 & 688620 & 5.3 & 5.1589 & TRN \\
\hline CHEMBL3192212 & 688620 & 4.45 & 5.0114 & TRN \\
\hline CHEMBL1504651 & 688620 & 4.45 & 4.9885 & TRN \\
\hline CHEMBL1543315 & 688620 & 4.8 & 4.8303 & TRN \\
\hline CHEMBL1353110 & 688620 & 4.8 & 4.9938 & TRN \\
\hline CHEMBL1343453 & 688620 & 4.95 & 4.8781 & TST \\
\hline CHEMBL1589180 & 688620 & 4.9 & 5.1447 & TRN \\
\hline CHEMBL 2004205 & 688620 & 5.2 & 5.3801 & TST \\
\hline CHEMBL1417563 & 688620 & 5.45 & 5.1103 & TRN \\
\hline CHEMBL1369528 & 688620 & 4.85 & 4.9878 & TRN \\
\hline CHEMBL1603053 & 688620 & 5.0 & 5.1782 & TRN \\
\hline CHEMBL1323564 & 688620 & 4.85 & 5.1971 & TST \\
\hline CHEMBL1395197 & 688620 & 4.65 & 5.3259 & TRN \\
\hline CHEMBL1438590 & 688620 & 5.15 & 4.7767 & TRN \\
\hline CHEMBL1536622 & 688620 & 5.3 & 5.0483 & TRN \\
\hline CHEMBL1375177 & 688620 & 4.65 & 5.2504 & TRN \\
\hline CHEMBL1365692 & 688620 & 6.4 & 5.0039 & TRN \\
\hline CHEMBL1334492 & 688620 & 4.8 & 5.1368 & TST \\
\hline CHEMBL1565984 & 688620 & 4.65 & 5.0271 & TRN \\
\hline CHEMBL1347341 & 688620 & 5.55 & 5.2926 & TRN \\
\hline CHEMBL1565854 & 688620 & 5.0 & 5.0918 & TST \\
\hline CHEMBL1516517 & 688620 & 4.8 & 4.9199 & TST \\
\hline CHEMBL1594305 & 688620 & 4.9 & 5.2325 & TRN \\
\hline CHEMBL1340385 & 688620 & 6.0 & 5.2465 & TRN \\
\hline CHEMBL1973886 & 688620 & 4.7 & 4.9439 & TST \\
\hline CHEMBL1341169 & 688620 & 4.85 & 5.3051 & TRN \\
\hline CHEMBL1507840 & 688620 & 4.45 & 4.7405 & TRN \\
\hline CHEMBL1422557 & 688620 & 4.95 & 5.0573 & TRN \\
\hline CHEMBL3196736 & 688620 & 4.95 & 5.4131 & TST \\
\hline CHEMBL1328916 & 688620 & 4.75 & 5.1619 & TRN \\
\hline CHEMBL1413122 & 688620 & 5.5 & 5.1598 & TRN \\
\hline CHEMBL1481757 & 688620 & 4.95 & 5.1123 & TRN \\
\hline CHEMBL1394791 & 688620 & 7.2503 & 4.9796 & TRN \\
\hline CHEMBL1495847 & 688620 & 7.0 & 6.7655 & TRN \\
\hline CHEMBL1379058 & 688620 & 5.3 & 4.9765 & TRN \\
\hline CHEMBL1413755 & 688620 & 5.0 & 5.104 & TRN \\
\hline CHEMBL3194125 & 688620 & 4.8 & 5.1002 & TRN \\
\hline CHEMBL1427457 & 688620 & 4.9 & 5.0276 & TRN \\
\hline CHEMBL1372009 & 688620 & 4.45 & 5.0057 & TRN \\
\hline CHEMBL1423840 & 688620 & 5.4 & 4.9833 & TRN \\
\hline CHEMBL1507615 & 688620 & 4.7 & 5.0823 & TST \\
\hline CHEMBL1319689 & 688620 & 5.0 & 5.0618 & TRN \\
\hline CHEMBL1505964 & 688620 & 4.95 & 4.7796 & TRN \\
\hline CHEMBL1985629 & 688620 & 5.95 & 5.7755 & TRN \\
\hline CHEMBL1543857 & 688620 & 6.95 & 4.8484 & TRN \\
\hline CHEMBL1402549 & 688620 & 5.5 & 5.3006 & TRN \\
\hline CHEMBL1580704 & 688620 & 5.0 & 5.0758 & TRN \\
\hline
\end{tabular}




\begin{tabular}{|c|c|c|c|c|c|}
\hline & & \multicolumn{4}{|c|}{ Supplemental Table S2.txt } \\
\hline CHEMBL1528568 & 688620 & 4.75 & 5.0261 & TRN & \\
\hline CHEMBL3197006 & 688620 & 4.45 & 5.2361 & TRN & \\
\hline CHEMBL1394581 & 688620 & 4.65 & 4.9525 & TST & \\
\hline CHEMBL1508004 & 688620 & 5.9 & 4.9744 & TRN & \\
\hline CHEMBL1988660 & 688620 & 5.0 & 5.1471 & TRN & \\
\hline CHEMBL1421774 & 688620 & 6.15 & 4.8276 & TRN & \\
\hline CHEMBL1418505 & 688620 & 5.25 & 5.5044 & TRN & \\
\hline CHEMBL1469521 & 688620 & 4.95 & 5.0456 & TST & \\
\hline CHEMBL1557619 & 688620 & 5.65 & 5.2949 & TRN & \\
\hline CHEMBL1447164 & 688620 & 6.0 & 6.1592 & TRN & \\
\hline CHEMBL1343219 & 688620 & 4.95 & 4.7893 & TRN & \\
\hline CHEMBL1467026 & 688620 & 5.5 & 5.2556 & TRN & \\
\hline CHEMBL1507172 & 688620 & 4.9 & 4.9343 & TRN & \\
\hline CHEMBL1990210 & 688620 & 5.0 & 5.0654 & TRN & \\
\hline CHEMBL1361820 & 688620 & 4.45 & 5.0091 & TST & \\
\hline CHEMBL1568273 & 688620 & 4.8 & 5.0333 & TST & \\
\hline CHEMBL1580632 & 688620 & 8.0 & 5.2953 & TRN & \\
\hline CHEMBL1484558 & 688620 & 4.6 & 4.9162 & TST & \\
\hline CHEMBL1324251 & 688620 & 4.9 & 5.1901 & TST & \\
\hline CHEMBL1492020 & 688620 & 4.75 & 5.6836 & TST & \\
\hline CHEMBL1321622 & 688620 & 5.05 & 5.0794 & TRN & \\
\hline CHEMBL1345060 & 688620 & 4.45 & 4.9211 & TRN & \\
\hline CHEMBL1350541 & 688620 & 4.45 & 4.9347 & TST & \\
\hline CHEMBL3210595 & 688620 & 4.45 & 5.3066 & TST & \\
\hline CHEMBL1496483 & 688620 & 4.95 & 5.1232 & TRN & \\
\hline CHEMBL1342054 & 688620 & 4.45 & 4.8271 & TRN & \\
\hline CHEMBL1335190 & 688620 & 4.95 & 4.8685 & TST & \\
\hline CHEMBL1305388 & 688620 & 5.05 & 5.1116 & TRN & \\
\hline CHEMBL1300988 & 688620 & 5.05 & 5.1836 & TST & \\
\hline CHEMBL1732228 & 688620 & 4.75 & 4.7663 & TRN & \\
\hline CHEMBL3192110 & 688620 & 4.45 & 5.1562 & TRN & \\
\hline CHEMBL3199035 & 688620 & 5.45 & 5.3561 & TRN & \\
\hline CHEMBL3195715 & 688620 & 4.95 & 4.9291 & TRN & \\
\hline CHEMBL1417036 & 688620 & 4.45 & 5.3346 & TRN & \\
\hline CHEMBL1612230 & 688620 & 4.9 & 4.9008 & TRN & \\
\hline CHEMBL516954 & 688620 & 5.0 & 4.9492 & TRN & \\
\hline CHEMBL1527176 & 688620 & 5.05 & 5.1329 & TRN & \\
\hline CHEMBL1391839 & 688620 & 4.45 & 5.7969 & TRN & \\
\hline CHEMBL1510446 & 688620 & 4.45 & 5.78799 & 9999999999 & TST \\
\hline CHEMBL1612093 & 688620 & 5.2 & 5.1615 & TRN & \\
\hline CHEMBL1485866 & 688620 & 4.45 & 5.0655 & TST & \\
\hline CHEMBL1586256 & 688620 & 5.0 & 4.9946 & TRN & \\
\hline CHEMBL1360197 & 688620 & 5.05 & 5.0829 & TST & \\
\hline CHEMBL1459271 & 688620 & 5.0 & 5.0248 & TRN & \\
\hline CHEMBL1461246 & 688620 & 4.9 & 4.8806 & TRN & \\
\hline CHEMBL1574999 & 688620 & 5.65 & 5.20200 & 0000000001 & TRN \\
\hline CHEMBL1383025 & 688620 & 6.05 & 5.5501 & TST & \\
\hline CHEMBL1569675 & 688620 & 4.8 & 4.8798 & TST & \\
\hline
\end{tabular}




\begin{tabular}{|c|c|c|c|c|c|}
\hline \multicolumn{6}{|c|}{ Supplemental Table S2.txt } \\
\hline CHEMBL1451132 & 688620 & 4.95 & 4.9215 & TST & \\
\hline CHEMBL3198388 & 688620 & 4.6 & 4.8165 & TRN & \\
\hline CHEMBL3193718 & 688620 & 5.45 & 4.9938 & TRN & \\
\hline CHEMBL1521960 & 688620 & 5.55 & 5.5633 & TST & \\
\hline CHEMBL1587073 & 688620 & 4.65 & 5.0289 & TST & \\
\hline CHEMBL1311221 & 688620 & 5.3 & 5.6216 & TRN & \\
\hline CHEMBL3190777 & 688620 & 5.2 & 5.2817 & TRN & \\
\hline CHEMBL1375844 & 688620 & 5.5 & 4.9987 & TRN & \\
\hline CHEMBL1492539 & 688620 & 4.75 & 4.8525 & TRN & \\
\hline CHEMBL1605412 & 688620 & 4.8 & 4.85 & TRN & \\
\hline CHEMBL1458129 & 688620 & 4.9 & 4.9525 & TRN & \\
\hline CHEMBL1348007 & 688620 & 5.35 & 4.7707 & TRN & \\
\hline CHEMBL3210191 & 688620 & 5.05 & 4.9445 & TRN & \\
\hline CHEMBL1583939 & 688620 & 5.05 & 5.0025 & TRN & \\
\hline CHEMBL1308284 & 688620 & 4.45 & 4.9135 & TRN & \\
\hline CHEMBL1505131 & 688620 & 5.05 & 5.0291 & TST & \\
\hline CHEMBL1511680 & 688620 & 5.15 & 5.0557 & TST & \\
\hline CHEMBL1345980 & 688620 & 4.45 & 5.25200 & 0000000001 & TRN \\
\hline CHEMBL1373120 & 688620 & 5.6 & 5.7232 & TRN & \\
\hline CHEMBL1511860 & 688620 & 4.45 & 4.882 & TRN & \\
\hline CHEMBL1596998 & 688620 & 5.3 & 4.8841 & TRN & \\
\hline CHEMBL1471935 & 688620 & 4.75 & 5.1133 & TRN & \\
\hline CHEMBL1569494 & 688620 & 4.75 & 4.9841 & TRN & \\
\hline CHEMBL1498 & 688620 & 4.45 & 5.1228 & TST & \\
\hline CHEMBL1418937 & 688620 & 5.3 & 4.92399 & 99999999995 & TRN \\
\hline CHEMBL1595879 & 688620 & 4.45 & 5.1792 & TRN & \\
\hline CHEMBL1525841 & 688620 & 4.9 & 5.0011 & TST & \\
\hline CHEMBL1583847 & 688620 & 4.95 & 5.1438 & TST & \\
\hline CHEMBL1463137 & 688620 & 5.0 & 5.1785 & TRN & \\
\hline CHEMBL1312730 & 688620 & 5.45 & 4.9782 & TST & \\
\hline CHEMBL1447619 & 688620 & 4.95 & 5.4253 & TST & \\
\hline CHEMBL1423966 & 688620 & 6.5 & 5.0169 & TRN & \\
\hline CHEMBL1322453 & 688620 & 4.9 & 5.1782 & TRN & \\
\hline CHEMBL1401959 & 688620 & 5.45 & 5.67200 & $\partial 000000001$ & TRN \\
\hline CHEMBL1458634 & 688620 & 4.65 & 5.005 & TST & \\
\hline CHEMBL1353843 & 688620 & 5.65 & 5.3773 & TST & \\
\hline CHEMBL1324224 & 688620 & 5.0 & 4.9746 & TRN & \\
\hline CHEMBL1421406 & 688620 & 4.55 & 5.1263 & TST & \\
\hline CHEMBL1531906 & 688620 & 5.4 & 5.2093 & TRN & \\
\hline CHEMBL1500816 & 688620 & 4.9 & 4.7778 & TRN & \\
\hline CHEMBL1332559 & 688620 & 6.95 & 5.0438 & TRN & \\
\hline CHEMBL1406681 & 688620 & 4.8 & 4.8048 & TRN & \\
\hline CHEMBL1372554 & 688620 & 4.45 & 5.2251 & TST & \\
\hline CHEMBL1581570 & 688620 & 5.1 & 5.1165 & TRN & \\
\hline CHEMBL1431204 & 688620 & 5.0 & 5.0508 & TRN & \\
\hline CHEMBL1432490 & 688620 & 5.0 & 5.2934 & TRN & \\
\hline CHEMBL1351355 & 688620 & 4.6 & 4.9671 & TRN & \\
\hline CHEMBL1545968 & 688620 & 5.85 & 4.9296 & TST & \\
\hline
\end{tabular}




\begin{tabular}{|c|c|c|c|c|}
\hline \multicolumn{5}{|c|}{ Supplemental Table S2.txt } \\
\hline CHEMBL1608096 & 688620 & 4.9 & 5.2744 & TRN \\
\hline CHEMBL1603419 & 688620 & 5.5 & 4.9063 & TST \\
\hline CHEMBL1391885 & 688620 & 4.45 & 4.9963 & TST \\
\hline CHEMBL1348414 & 688620 & 4.75 & 5.0745 & TRN \\
\hline CHEMBL 3196263 & 688620 & 5.8 & 5.4596 & TRN \\
\hline CHEMBL1370098 & 688620 & 4.45 & 5.0406 & TST \\
\hline CHEMBL1517374 & 688620 & 4.45 & 4.8156 & TST \\
\hline CHEMBL582005 & 688620 & 4.45 & 4.811 & TST \\
\hline CHEMBL1341965 & 688620 & 4.95 & 5.0476 & TRN \\
\hline CHEMBL1336100 & 688620 & 4.9 & 4.8482 & TRN \\
\hline CHEMBL1518454 & 688620 & 4.85 & 4.8335 & TRN \\
\hline CHEMBL1342950 & 688620 & 5.85 & 5.6918 & TRN \\
\hline CHEMBL1349286 & 688620 & 4.45 & 4.8871 & TRN \\
\hline CHEMBL1361373 & 688620 & 5.65 & 4.9705 & TRN \\
\hline CHEMBL1311775 & 688620 & 5.95 & 6.4092 & TRN \\
\hline CHEMBL1420295 & 688620 & 4.5 & 4.9352 & TST \\
\hline CHEMBL1503987 & 688620 & 4.75 & 5.0907 & TST \\
\hline CHEMBL1532811 & 688620 & 4.95 & 5.2238 & TRN \\
\hline CHEMBL1350336 & 688620 & 5.25 & 5.1265 & TRN \\
\hline CHEMBL3210964 & 688620 & 6.25 & 5.0937 & TST \\
\hline CHEMBL1583166 & 688620 & 4.95 & 4.9961 & TST \\
\hline CHEMBL1517130 & 688620 & 4.65 & 5.0085 & TST \\
\hline CHEMBL1333929 & 688620 & 4.45 & 5.7128 & TRN \\
\hline CHEMBL1534979 & 688620 & 5.65 & 5.2879 & TRN \\
\hline CHEMBL1373950 & 688620 & 4.95 & 4.9129 & TST \\
\hline CHEMBL1568007 & 688620 & 4.8 & 5.2992 & TRN \\
\hline CHEMBL1310847 & 688620 & 4.95 & 4.9964 & TRN \\
\hline CHEMBL1492910 & 688620 & 6.5501 & 5.07 & TRN \\
\hline CHEMBL1377612 & 688620 & 5.0 & 4.8615 & TRN \\
\hline CHEMBL1472971 & 688620 & 4.45 & 5.109 & TRN \\
\hline CHEMBL1359961 & 688620 & 5.9 & 5.2731 & TRN \\
\hline CHEMBL1462776 & 688620 & 6.1 & 5.6825 & TRN \\
\hline CHEMBL1414611 & 688620 & 5.2 & 5.0811 & TRN \\
\hline CHEMBL 3209840 & 688620 & 4.5 & 4.8786 & TST \\
\hline CHEMBL1342337 & 688620 & 4.95 & 4.9063 & TST \\
\hline CHEMBL1561002 & 688620 & 5.05 & 5.2844 & TST \\
\hline CHEMBL1520507 & 688620 & 5.9 & 5.1473 & TRN \\
\hline CHEMBL1470805 & 688620 & 6.8499 & 4.9631 & TRN \\
\hline CHEMBL 3211687 & 688620 & 5.8 & 5.3958 & TRN \\
\hline CHEMBL1303307 & 688620 & 4.9 & 5.0811 & TRN \\
\hline CHEMBL1425873 & 688620 & 4.7 & 4.9386 & TRN \\
\hline CHEMBL1503657 & 688620 & 4.9 & 5.0435 & TRN \\
\hline CHEMBL530038 & 688620 & 6.4 & 5.9377 & TRN \\
\hline CHEMBL1494766 & 688620 & 4.6 & 5.2028 & TRN \\
\hline CHEMBL1424477 & 688620 & 5.25 & 4.9012 & TST \\
\hline CHEMBL523200 & 688620 & 4.95 & 4.8754 & TRN \\
\hline CHEMBL1584846 & 688620 & 4.85 & 5.3229 & TRN \\
\hline CHEMBL1547514 & 688620 & 4.7 & 5.3571 & TRN \\
\hline
\end{tabular}




\begin{tabular}{|c|c|c|c|c|c|}
\hline \multicolumn{6}{|c|}{ Supplemental Table S2.txt } \\
\hline CHEMBL1455053 & 688620 & 5.25 & 5.6156 & TRN & \\
\hline CHEMBL1540493 & 688620 & 5.45 & 5.5293 & TRN & \\
\hline CHEMBL1302889 & 688620 & 7.4001 & 5.1263 & TST & \\
\hline CHEMBL1499053 & 688620 & 5.85 & 5.2721 & TRN & \\
\hline CHEMBL1447392 & 688620 & 5.3 & 4.9304 & TRN & \\
\hline CHEMBL294009 & 688620 & 5.4 & 5.1974 & TRN & \\
\hline CHEMBL3196437 & 688620 & 4.6 & 5.2713 & TRN & \\
\hline CHEMBL1429753 & 688620 & 5.2 & 5.0998 & TRN & \\
\hline CHEMBL1597933 & 688620 & 5.2 & 5.8171 & TST & \\
\hline CHEMBL1407475 & 688620 & 5.2 & 5.3924 & TRN & \\
\hline CHEMBL1489259 & 688620 & 4.95 & 4.8053 & TRN & \\
\hline CHEMBL1324462 & 688620 & 4.9 & 4.92 & TST & \\
\hline CHEMBL1544036 & 688620 & 4.65 & 4.8613 & TST & \\
\hline CHEMBL1366042 & 688620 & 5.5 & 4.9654 & TRN & \\
\hline CHEMBL1409963 & 688620 & 5.1 & 5.1068 & TRN & \\
\hline CHEMBL1612971 & 688620 & 4.95 & 4.9538 & TRN & \\
\hline CHEMBL1557816 & 688620 & 4.5 & 4.7895 & TST & \\
\hline CHEMBL1484360 & 688620 & 4.85 & 5.1391 & TRN & \\
\hline CHEMBL1585673 & 688620 & 4.6 & 4.9359 & TST & \\
\hline CHEMBL1365796 & 688620 & 4.95 & 4.88 & TRN & \\
\hline CHEMBL1589090 & 688620 & 4.9 & 5.1788 & TST & \\
\hline CHEMBL1596715 & 688620 & 4.55 & 4.9031 & TRN & \\
\hline CHEMBL1299270 & 688620 & 5.55 & 5.4616 & TRN & \\
\hline CHEMBL1493560 & 688620 & 4.45 & 4.8931 & TST & \\
\hline CHEMBL1453357 & 688620 & 4.45 & 4.8658 & TRN & \\
\hline CHEMBL1459698 & 688620 & 5.0 & 5.1766 & TST & \\
\hline CHEMBL1534029 & 688620 & 5.0 & 4.9561 & TRN & \\
\hline CHEMBL1407553 & 688620 & 6.1 & 5.117 & TRN & \\
\hline CHEMBL1330516 & 688620 & 5.0 & 5.6773 & TRN & \\
\hline CHEMBL1427574 & 688620 & 4.75 & 5.0154 & TRN & \\
\hline CHEMBL1568850 & 688620 & 4.65 & 5.0832 & TRN & \\
\hline CHEMBL1447350 & 688620 & 5.1 & 5.3847 & TRN & \\
\hline CHEMBL1338258 & 688620 & 5.0 & 5.2262 & TRN & \\
\hline CHEMBL1530180 & 688620 & 5.4 & 4.9717 & TRN & \\
\hline CHEMBL1412013 & 688620 & 4.8 & 5.58899 & 99999999995 & TRN \\
\hline CHEMBL1336637 & 688620 & 6.05 & 5.0385 & TRN & \\
\hline CHEMBL1505298 & 688620 & 4.95 & 5.1649 & TRN & \\
\hline CHEMBL3191559 & 688620 & 4.45 & 4.8764 & TRN & \\
\hline CHEMBL1541436 & 688620 & 4.75 & 5.1496 & TST & \\
\hline CHEMBL1539498 & 688620 & 5.05 & 4.9987 & TST & \\
\hline CHEMBL1304508 & 688620 & 5.0 & 4.9027 & TRN & \\
\hline CHEMBL1540389 & 688620 & 5.85 & 5.012 & TST & \\
\hline CHEMBL1508500 & 688620 & 5.15 & 5.095 & TRN & \\
\hline CHEMBL1964793 & 688620 & 5.1 & 5.222 & TRN & \\
\hline CHEMBL1583053 & 688620 & 4.75 & 5.105 & TRN & \\
\hline CHEMBL298461 & 688620 & 8.4949 & 4.9797 & TST & \\
\hline CHEMBL3191336 & 688620 & 4.95 & 5.0479 & TRN & \\
\hline CHEMBL1403123 & 688620 & 4.45 & 5.1387 & TRN & \\
\hline
\end{tabular}




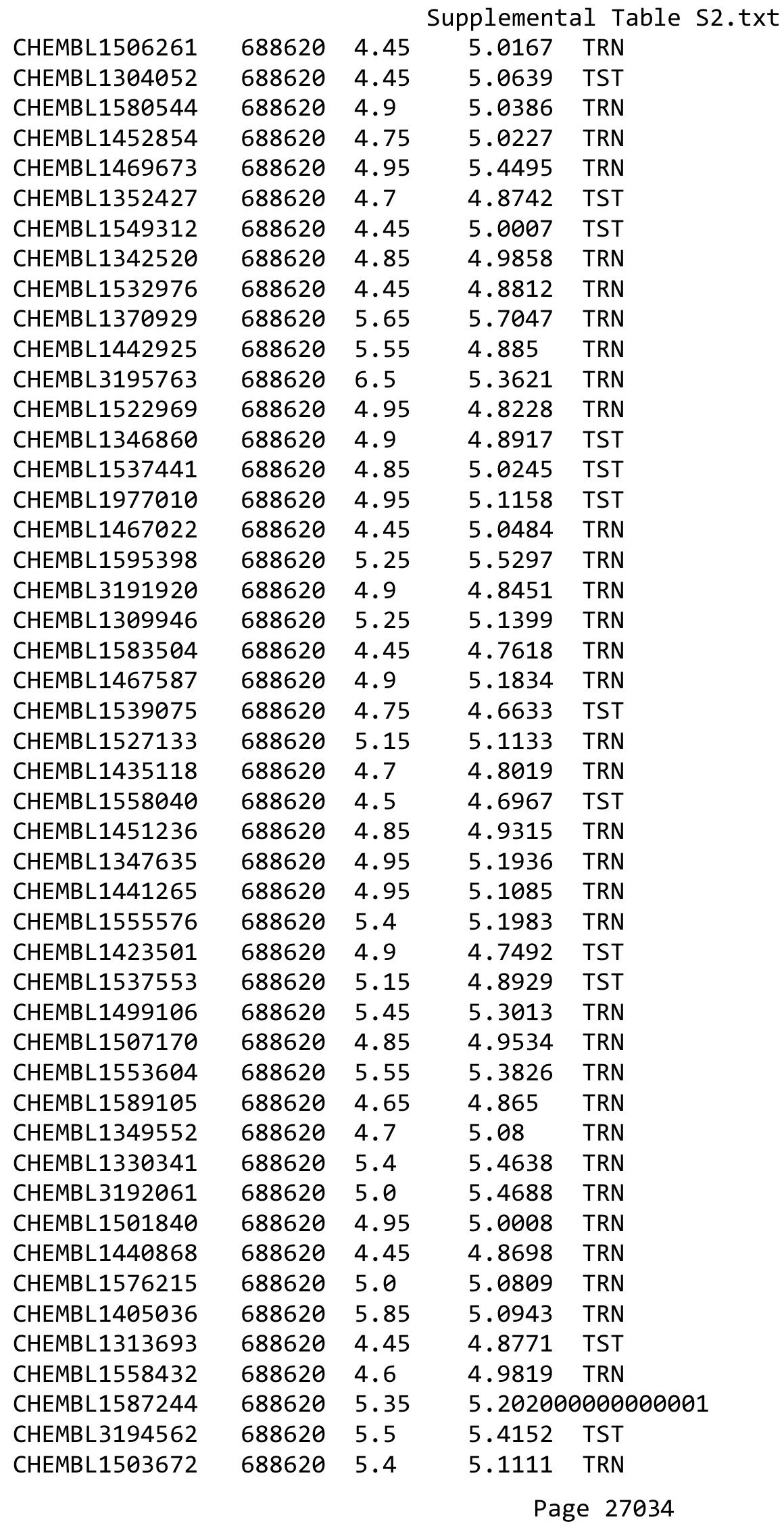

TRN 


\begin{tabular}{|c|c|c|c|c|c|}
\hline \multicolumn{6}{|c|}{ Supplemental Table S2.txt } \\
\hline CHEMBL1299464 & 688620 & 4.9 & 4.8604 & TRN & \\
\hline CHEMBL1529378 & 688620 & 4.75 & 5.5351 & TRN & \\
\hline CHEMBL1515369 & 688620 & 5.15 & 4.8352 & TRN & \\
\hline CHEMBL1550862 & 688620 & 4.9 & 4.8928 & TRN & \\
\hline CHEMBL1459338 & 688620 & 5.25 & 5.1222 & TRN & \\
\hline CHEMBL1463008 & 688620 & 4.65 & 5.0123 & TRN & \\
\hline CHEMBL1459005 & 688620 & 4.45 & 4.8061 & TRN & \\
\hline CHEMBL1432076 & 688620 & 4.8 & 4.918 & TST & \\
\hline CHEMBL1441707 & 688620 & 5.1 & 4.7009 & TST & \\
\hline CHEMBL1417305 & 688620 & 4.45 & 4.6605 & TST & \\
\hline CHEMBL1319495 & 688620 & 4.8 & 5.1513 & TRN & \\
\hline CHEMBL1334717 & 688620 & 5.4 & 5.1324 & TRN & \\
\hline CHEMBL1302583 & 688620 & 5.2 & 5.1624 & TRN & \\
\hline CHEMBL1428758 & 688620 & 4.45 & 5.4272 & TRN & \\
\hline CHEMBL1485045 & 688620 & 6.9 & 6.4594 & TRN & \\
\hline CHEMBL1577920 & 688620 & 5.25 & 4.9911 & TRN & \\
\hline CHEMBL1428449 & 688620 & 4.45 & 5.0842 & TRN & \\
\hline CHEMBL1351874 & 688620 & 4.45 & 5.1825 & TST & \\
\hline CHEMBL1352654 & 688620 & 4.85 & 5.1657 & TRN & \\
\hline CHEMBL3208787 & 688620 & 5.2 & 4.9642 & TRN & \\
\hline CHEMBL1420116 & 688620 & 4.9 & 4.8397 & TST & \\
\hline CHEMBL1344254 & 688620 & 5.9 & 5.0838 & TRN & \\
\hline CHEMBL1509696 & 688620 & 4.45 & 4.9217 & TST & \\
\hline CHEMBL1584661 & 688620 & 4.5 & 4.90606 & 0000000001 & TRN \\
\hline CHEMBL1602891 & 688620 & 5.9 & 5.2020 & 0000000001 & TST \\
\hline CHEMBL1511385 & 688620 & 6.05 & 5.4431 & TRN & \\
\hline CHEMBL1355762 & 688620 & 4.45 & 5.2065 & TST & \\
\hline CHEMBL1587596 & 688620 & 5.35 & 5.598 & TRN & \\
\hline CHEMBL1349814 & 688620 & 6.4 & 5.1176 & TRN & \\
\hline CHEMBL1598226 & 688620 & 5.15 & 5.3218 & TRN & \\
\hline CHEMBL1467611 & 688620 & 5.1 & 5.0949 & TRN & \\
\hline CHEMBL1338263 & 688620 & 6.0 & 5.9425 & TRN & \\
\hline CHEMBL3195164 & 688620 & 6.95 & 5.1954 & TST & \\
\hline CHEMBL1585095 & 688620 & 5.2 & 5.2239 & TRN & \\
\hline CHEMBL1430790 & 688620 & 4.7 & 5.0775 & TST & \\
\hline CHEMBL1602964 & 688620 & 4.9 & 4.9938 & TST & \\
\hline CHEMBL1326324 & 688620 & 5.05 & 4.8453 & TRN & \\
\hline CHEMBL3209038 & 688620 & 5.0 & 4.9423 & TRN & \\
\hline CHEMBL1541557 & 688620 & 4.85 & 5.0467 & TRN & \\
\hline CHEMBL1331563 & 688620 & 4.85 & 4.7299 & TRN & \\
\hline CHEMBL1466737 & 688620 & 4.8 & 5.0665 & TRN & \\
\hline CHEMBL1419903 & 688620 & 4.7 & 4.9993 & TST & \\
\hline CHEMBL1418287 & 688620 & 6.1 & 5.4439 & TRN & \\
\hline CHEMBL1426553 & 688620 & 4.95 & 4.934 & TRN & \\
\hline CHEMBL1506571 & 688620 & 4.45 & 5.0534 & TRN & \\
\hline CHEMBL1304087 & 688620 & 7.2503 & 4.9532 & TRN & \\
\hline CHEMBL3207547 & 688620 & 5.2 & 5.0212 & TRN & \\
\hline CHEMBL1567875 & 688620 & 4.45 & 4.9309 & TRN & \\
\hline
\end{tabular}




\begin{tabular}{|c|c|c|c|c|c|}
\hline \multicolumn{6}{|c|}{ Supplemental Table s2.txt } \\
\hline CHEMBL1530699 & 688620 & 5.05 & 4.897 & TRN & \\
\hline CHEMBL3196366 & 688620 & 5.6 & 5.8457 & TRN & \\
\hline CHEMBL1324073 & 688620 & 5.45 & 4.7678 & TRN & \\
\hline CHEMBL1346471 & 688620 & 4.45 & 5.0489 & TRN & \\
\hline CHEMBL1412428 & 688620 & 4.6 & 4.9616 & TRN & \\
\hline CHEMBL1537363 & 688620 & 5.1 & 5.1205 & TRN & \\
\hline CHEMBL1373439 & 688620 & 4.45 & 4.9854 & TRN & \\
\hline CHEMBL1499797 & 688620 & 4.6 & 5.0889 & TST & \\
\hline CHEMBL1310971 & 688620 & 5.25 & 5.0444 & TRN & \\
\hline CHEMBL1482459 & 688620 & 5.25 & 5.0413 & TRN & \\
\hline CHEMBL576208 & 688620 & 5.1 & 4.9119 & TRN & \\
\hline CHEMBL1410058 & 688620 & 5.55 & 5.1193 & TRN & \\
\hline CHEMBL1376686 & 688620 & 4.85 & 4.8356 & TRN & \\
\hline CHEMBL1347466 & 688620 & 5.0 & 5.1126 & TRN & \\
\hline CHEMBL1469998 & 688620 & 8.301 & 5.1436 & TRN & \\
\hline CHEMBL1400409 & 688620 & 5.15 & 5.12799 & 9999999999 & TRN \\
\hline CHEMBL1428036 & 688620 & 5.25 & 4.9749 & TRN & \\
\hline CHEMBL3192707 & 688620 & 4.45 & 4.9829 & TRN & \\
\hline CHEMBL1391742 & 688620 & 5.4 & 5.3243 & TRN & \\
\hline CHEMBL1374298 & 688620 & 5.15 & 4.7492 & TST & \\
\hline CHEMBL1442682 & 688620 & 4.45 & 4.9492 & TST & \\
\hline CHEMBL1478172 & 688620 & 5.85 & 5.136 & TRN & \\
\hline CHEMBL1421263 & 688620 & 6.7001 & 6.059 & TRN & \\
\hline CHEMBL1449500 & 688620 & 6.1 & 5.2091 & TRN & \\
\hline CHEMBL1362715 & 688620 & 4.8 & 4.9035 & TRN & \\
\hline CHEMBL1328519 & 688620 & 4.7 & 4.7169 & TRN & \\
\hline CHEMBL1339349 & 688620 & 4.45 & 5.1522 & TST & \\
\hline CHEMBL1491158 & 688620 & 5.0 & 4.9098 & TRN & \\
\hline CHEMBL1494447 & 688620 & 4.45 & 5.1033 & TST & \\
\hline CHEMBL1601529 & 688620 & 4.7 & 4.8351 & TST & \\
\hline CHEMBL1327226 & 688620 & 4.9 & 4.8743 & TST & \\
\hline CHEMBL1540929 & 688620 & 5.3 & 5.1561 & TRN & \\
\hline CHEMBL1390249 & 688620 & 4.8 & 4.98 & TRN & \\
\hline CHEMBL1325877 & 688620 & 4.45 & 4.6628 & TRN & \\
\hline CHEMBL1508440 & 688620 & 5.65 & 5.4614 & TRN & \\
\hline CHEMBL1457743 & 688620 & 4.75 & 5.1294 & TRN & \\
\hline CHEMBL1543404 & 688620 & 5.0 & 5.0824 & TST & \\
\hline CHEMBL1424786 & 688620 & 4.8 & 5.0205 & TRN & \\
\hline CHEMBL1363823 & 688620 & 5.65 & 5.42299 & 9999999999 & TRN \\
\hline CHEMBL1508565 & 688620 & 4.9 & 5.2073 & TRN & \\
\hline CHEMBL1337628 & 688620 & 4.5 & 4.9746 & TRN & \\
\hline CHEMBL1491099 & 688620 & 4.45 & 4.9826 & TST & \\
\hline CHEMBL1568669 & 688620 & 4.85 & 5.0984 & TRN & \\
\hline CHEMBL1358939 & 688620 & 5.55 & 5.17700 & 00000000005 & TRN \\
\hline CHEMBL1344660 & 688620 & 5.45 & 4.7999 & TRN & \\
\hline CHEMBL1331732 & 688620 & 4.9 & 4.7915 & TRN & \\
\hline CHEMBL3207529 & 688620 & 4.45 & 5.0562 & TRN & \\
\hline CHEMBL1486472 & 688620 & 6.95 & 5.0966 & TST & \\
\hline
\end{tabular}




\begin{tabular}{|c|c|c|c|c|}
\hline \multicolumn{5}{|c|}{ Supplemental Table S2.txt } \\
\hline CHEMBL1539216 & 688620 & 4.8 & 4.834 & TRN \\
\hline CHEMBL1367073 & 688620 & 5.0 & 4.9199 & TRN \\
\hline CHEMBL1550823 & 688620 & 5.2 & 5.1881 & TRN \\
\hline CHEMBL1450776 & 688620 & 5.55 & 5.1732 & TRN \\
\hline CHEMBL1568526 & 688620 & 4.45 & 4.8935 & TST \\
\hline CHEMBL1453565 & 688620 & 6.4 & 5.496 & TRN \\
\hline CHEMBL1349293 & 688620 & 4.95 & 5.0961 & TRN \\
\hline CHEMBL1465727 & 688620 & 5.65 & 5.0813 & TRN \\
\hline CHEMBL1558312 & 688620 & 4.95 & 4.8716 & TRN \\
\hline CHEMBL1502852 & 688620 & 5.45 & 5.4526 & TRN \\
\hline CHEMBL1390682 & 688620 & 4.45 & 4.9354 & TST \\
\hline CHEMBL1470242 & 688620 & 5.1 & 5.2814 & TRN \\
\hline CHEMBL1457828 & 688620 & 4.45 & 4.8995 & TST \\
\hline CHEMBL3194900 & 688620 & 5.5 & 5.2461 & TRN \\
\hline CHEMBL1504763 & 688620 & 4.9 & 5.0979 & TRN \\
\hline CHEMBL1556886 & 688620 & 5.05 & 4.9267 & TRN \\
\hline CHEMBL1603278 & 688620 & 4.95 & 5.1409 & TRN \\
\hline CHEMBL528694 & 688620 & 7.6498 & 4.9791 & TRN \\
\hline CHEMBL1547931 & 688620 & 4.6 & 5.0403 & TRN \\
\hline CHEMBL1425521 & 688620 & 4.5 & 5.07 & TRN \\
\hline CHEMBL1487656 & 688620 & 5.65 & 4.9028 & TST \\
\hline CHEMBL1403068 & 688620 & 4.9 & 5.0946 & TRN \\
\hline CHEMBL1442833 & 688620 & 4.45 & 4.9938 & TST \\
\hline CHEMBL1461108 & 688620 & 4.95 & 5.0226 & TST \\
\hline CHEMBL1444324 & 688620 & 5.0 & 4.982 & TRN \\
\hline CHEMBL1557721 & 688620 & 4.7 & 5.2554 & TRN \\
\hline CHEMBL1415960 & 688620 & 5.6 & 5.3968 & TRN \\
\hline CHEMBL3213953 & 688620 & 4.45 & 5.2706 & TRN \\
\hline CHEMBL1311280 & 688620 & 4.95 & 5.1359 & TRN \\
\hline CHEMBL1546564 & 688620 & 4.85 & 5.0338 & TRN \\
\hline CHEMBL1302015 & 688620 & 4.45 & 4.9253 & TST \\
\hline CHEMBL1530694 & 688620 & 4.75 & 5.2642 & TRN \\
\hline CHEMBL1324182 & 688620 & 4.75 & 4.7563 & TST \\
\hline CHEMBL1501310 & 688620 & 4.95 & 4.9848 & TRN \\
\hline CHEMBL1991710 & 688620 & 4.9 & 4.8833 & TRN \\
\hline CHEMBL1407854 & 688620 & 5.1 & 5.0385 & TST \\
\hline CHEMBL1586959 & 688620 & 4.95 & 5.0287 & TRN \\
\hline CHEMBL1598685 & 688620 & 6.1 & 5.7564 & TRN \\
\hline CHEMBL1364147 & 688620 & 6.5 & 5.2453 & TRN \\
\hline CHEMBL1336258 & 688620 & 5.15 & 4.9915 & TRN \\
\hline CHEMBL1419331 & 688620 & 6.45 & 5.1008 & TRN \\
\hline CHEMBL1399053 & 688620 & 5.45 & 5.1848 & TST \\
\hline CHEMBL3210582 & 688620 & 4.45 & 4.6888 & TRN \\
\hline CHEMBL1492339 & 688620 & 5.15 & 5.0368 & TST \\
\hline CHEMBL1413211 & 688620 & 4.5 & 4.942 & TRN \\
\hline CHEMBL 2005572 & 688620 & 4.45 & 5.4736 & TRN \\
\hline CHEMBL1470214 & 688620 & 4.65 & 5.0601 & TST \\
\hline CHEMBL3196281 & 688620 & 4.8 & 5.1504 & TRN \\
\hline
\end{tabular}




\begin{tabular}{|c|c|c|c|c|c|}
\hline \multicolumn{6}{|c|}{ Supplemental Table S2.txt } \\
\hline CHEMBL1610903 & 688620 & 4.85 & 5.2085 & TRN & \\
\hline CHEMBL1401739 & 688620 & 4.45 & 5.0586 & TST & \\
\hline CHEMBL1605038 & 688620 & 5.15 & 5.2808 & TRN & \\
\hline CHEMBL1345023 & 688620 & 4.8 & 4.9209 & TST & \\
\hline CHEMBL1450726 & 688620 & 4.9 & 5.1437 & TST & \\
\hline CHEMBL1526799 & 688620 & 5.75 & 5.3232 & TRN & \\
\hline CHEMBL1458038 & 688620 & 4.6 & 5.002 & TRN & \\
\hline CHEMBL1514186 & 688620 & 4.45 & 4.9728 & TST & \\
\hline CHEMBL 3197438 & 688620 & 5.0 & 5.2516 & TRN & \\
\hline CHEMBL1585333 & 688620 & 4.45 & 4.6484 & TRN & \\
\hline CHEMBL 3212005 & 688620 & 5.0 & 4.9439 & TRN & \\
\hline CHEMBL1406091 & 688620 & 4.75 & 4.9186 & TRN & \\
\hline CHEMBL1568896 & 688620 & 5.5 & 5.0115 & TST & \\
\hline CHEMBL1502352 & 688620 & 4.45 & 5.1698 & TRN & \\
\hline CHEMBL1482289 & 688620 & 4.45 & 5.0146 & TRN & \\
\hline CHEMBL1533063 & 688620 & 6.5 & 5.3945 & TRN & \\
\hline CHEMBL1608738 & 688620 & 7.4498 & 5.0712 & TRN & \\
\hline CHEMBL1366398 & 688620 & 4.45 & 5.0002 & TRN & \\
\hline CHEMBL1606205 & 688620 & 5.35 & 5.0152 & TRN & \\
\hline CHEMBL1507423 & 688620 & 4.5 & 4.9551 & TRN & \\
\hline CHEMBL1381322 & 688620 & 5.0 & 5.211 & TRN & \\
\hline CHEMBL3207556 & 688620 & 4.45 & 5.0884 & TRN & \\
\hline CHEMBL1513736 & 688620 & 4.9 & 5.1834 & TST & \\
\hline CHEMBL1563369 & 688620 & 5.3 & 5.3276 & TRN & \\
\hline CHEMBL1343366 & 688620 & 4.45 & 5.28100 & 0000000001 & TRN \\
\hline CHEMBL1302519 & 688620 & 5.65 & 5.3022 & TST & \\
\hline CHEMBL1363765 & 688620 & 4.45 & 4.9319 & TST & \\
\hline CHEMBL1500889 & 688620 & 4.95 & 5.0491 & TRN & \\
\hline CHEMBL1467411 & 688620 & 4.95 & 5.6939 & TRN & \\
\hline CHEMBL1979455 & 688620 & 6.0 & 5.7139 & TRN & \\
\hline CHEMBL3199332 & 688620 & 4.45 & 4.957 & TRN & \\
\hline CHEMBL1465837 & 688620 & 4.85 & 5.0987 & TRN & \\
\hline CHEMBL1523019 & 688620 & 5.3 & 5.5718 & TRN & \\
\hline CHEMBL1535660 & 688620 & 4.8 & 4.9147 & TRN & \\
\hline CHEMBL1595623 & 688620 & 4.45 & 5.1442 & TST & \\
\hline CHEMBL1397181 & 688620 & 4.65 & 5.09399 & 9999999999 & TRN \\
\hline CHEMBL1465878 & 688620 & 4.95 & 4.8636 & TRN & \\
\hline CHEMBL1587766 & 688620 & 4.45 & 5.1615 & TST & \\
\hline CHEMBL1559204 & 688620 & 4.85 & 4.9858 & TRN & \\
\hline CHEMBL1586263 & 688620 & 4.85 & 4.9151 & TRN & \\
\hline CHEMBL3213220 & 688620 & 5.55 & 5.6105 & TRN & \\
\hline CHEMBL1347351 & 688620 & 5.9 & 5.5439 & TRN & \\
\hline CHEMBL1322995 & 688620 & 4.8 & 4.9564 & TRN & \\
\hline CHEMBL1607497 & 688620 & 4.65 & 4.8476 & TRN & \\
\hline CHEMBL1579888 & 688620 & 5.5 & 5.2534 & TRN & \\
\hline CHEMBL1432457 & 688620 & 4.65 & 5.0414 & TRN & \\
\hline CHEMBL1312735 & 688620 & 4.6 & 4.9171 & TRN & \\
\hline CHEMBL1159655 & 688620 & 4.95 & 4.9293 & TST & \\
\hline
\end{tabular}




\begin{tabular}{|c|c|c|c|c|c|}
\hline \multicolumn{6}{|c|}{ Supplemental Table S2.txt } \\
\hline CHEMBL1362714 & 688620 & 5.05 & 4.8167 & TST & \\
\hline CHEMBL1373822 & 688620 & 8.3468 & 4.9615 & TRN & \\
\hline CHEMBL1334675 & 688620 & 4.85 & 4.9515 & TST & \\
\hline CHEMBL1459600 & 688620 & 4.8 & 4.78100 & 0000000001 & TRN \\
\hline CHEMBL1555930 & 688620 & 4.8 & 5.1263 & TRN & \\
\hline CHEMBL1397888 & 688620 & 4.5 & 5.0312 & TRN & \\
\hline CHEMBL1466756 & 688620 & 4.6 & 5.0436 & TST & \\
\hline CHEMBL1491241 & 688620 & 4.65 & 4.9407 & TRN & \\
\hline CHEMBL1402672 & 688620 & 4.6 & 4.7208 & TRN & \\
\hline CHEMBL1582219 & 688620 & 4.9 & 5.2288 & TRN & \\
\hline CHEMBL1415911 & 688620 & 4.75 & 4.8431 & TRN & \\
\hline CHEMBL1501311 & 688620 & 4.8 & 4.8738 & TRN & \\
\hline CHEMBL1577070 & 688620 & 7.699 & 5.1334 & TRN & \\
\hline CHEMBL1305742 & 688620 & 7.0501 & 5.1169 & TRN & \\
\hline CHEMBL1969761 & 688620 & 5.6 & 5.4861 & TRN & \\
\hline CHEMBL1323536 & 688620 & 4.45 & 4.7564 & TST & \\
\hline CHEMBL1334984 & 688620 & 5.45 & 5.5629 & TRN & \\
\hline CHEMBL3192658 & 688620 & 4.8 & 4.9442 & TRN & \\
\hline CHEMBL1462848 & 688620 & 5.5 & 5.5512 & TRN & \\
\hline CHEMBL3198796 & 688620 & 5.35 & 5.5431 & TRN & \\
\hline CHEMBL1299986 & 688620 & 4.45 & 4.9924 & TRN & \\
\hline CHEMBL1422889 & 688620 & 5.3 & 5.3469 & TRN & \\
\hline CHEMBL1580391 & 688620 & 6.05 & 5.3048 & TRN & \\
\hline CHEMBL1351201 & 688620 & 4.95 & 5.0033 & TRN & \\
\hline CHEMBL3197342 & 688620 & 5.15 & 4.8824 & TST & \\
\hline CHEMBL1478881 & 688620 & 4.5 & 4.9887 & TST & \\
\hline CHEMBL1387431 & 688620 & 5.15 & 4.9689 & TRN & \\
\hline CHEMBL1312191 & 688620 & 5.7 & 5.5788 & TRN & \\
\hline CHEMBL1545465 & 688620 & 4.45 & 5.0277 & TRN & \\
\hline CHEMBL1448744 & 688620 & 4.45 & 5.0119 & TRN & \\
\hline CHEMBL1498622 & 688620 & 4.8 & 5.04 & TRN & \\
\hline CHEMBL1361747 & 688620 & 4.7 & 4.8955 & TRN & \\
\hline CHEMBL1453454 & 688620 & 4.8 & 5.1622 & TRN & \\
\hline CHEMBL1613405 & 688620 & 5.55 & 5.0881 & TRN & \\
\hline CHEMBL1309334 & 688620 & 4.95 & 5.1106 & TST & \\
\hline CHEMBL1561687 & 688620 & 4.45 & 5.1225 & TST & \\
\hline CHEMBL1604264 & 688620 & 5.1 & 5.0826 & TRN & \\
\hline CHEMBL1307450 & 688620 & 5.6 & 4.8239 & TRN & \\
\hline CHEMBL1581682 & 688620 & 4.9 & 4.8651 & TRN & \\
\hline CHEMBL467590 & 688620 & 4.9 & 5.1135 & TRN & \\
\hline CHEMBL1462313 & 688620 & 6.6 & 6.2164 & TRN & \\
\hline CHEMBL1342135 & 688620 & 4.9 & 4.8469 & TRN & \\
\hline CHEMBL1485251 & 688620 & 4.45 & 5.0887 & TRN & \\
\hline CHEMBL1370045 & 688620 & 4.8 & 5.2257 & TRN & \\
\hline CHEMBL1490780 & 688620 & 4.95 & 4.9822 & TRN & \\
\hline CHEMBL1372549 & 688620 & 4.75 & 5.0025 & TRN & \\
\hline CHEMBL1345739 & 688620 & 4.9 & 4.9195 & TRN & \\
\hline CHEMBL1386418 & 688620 & 4.65 & 4.7517 & TRN & \\
\hline
\end{tabular}




\begin{tabular}{|c|c|c|c|c|}
\hline \multicolumn{5}{|c|}{ Supplemental Table S2.txt } \\
\hline CHEMBL1389904 & 688620 & 5.85 & 5.0703 & TRN \\
\hline CHEMBL1406509 & 688620 & 4.95 & 5.0696 & TRN \\
\hline CHEMBL1319939 & 688620 & 4.45 & 4.9564 & TST \\
\hline CHEMBL15594 & 688620 & 6.0 & 4.9141 & TRN \\
\hline CHEMBL1466095 & 688620 & 5.2 & 5.1352 & TRN \\
\hline CHEMBL1445491 & 688620 & 4.7 & 4.8989 & TRN \\
\hline CHEMBL1456302 & 688620 & 5.55 & 5.002 & TST \\
\hline CHEMBL1613062 & 688620 & 4.75 & 5.0411 & TRN \\
\hline CHEMBL3192734 & 688620 & 4.95 & 4.7432 & TRN \\
\hline CHEMBL1493886 & 688620 & 5.0 & 5.0137 & TRN \\
\hline CHEMBL1497635 & 688620 & 7.2503 & 4.9444 & TST \\
\hline CHEMBL1559529 & 688620 & 5.0 & 5.1107 & TRN \\
\hline CHEMBL1497390 & 688620 & 4.45 & 5.0535 & TRN \\
\hline CHEMBL1401565 & 688620 & 6.05 & 5.7859 & TRN \\
\hline CHEMBL1331855 & 688620 & 5.65 & 4.9623 & TST \\
\hline CHEMBL1353314 & 688620 & 4.8 & 5.1101 & TRN \\
\hline CHEMBL1368196 & 688620 & 4.9 & 5.1397 & TST \\
\hline CHEMBL586830 & 688620 & 4.45 & 5.2739 & TRN \\
\hline CHEMBL1580860 & 688620 & 5.9 & 6.1232 & TRN \\
\hline CHEMBL1510579 & 688620 & 5.55 & 5.1712 & TRN \\
\hline CHEMBL1485905 & 688620 & 6.1 & 5.1674 & TST \\
\hline CHEMBL1366698 & 688620 & 4.95 & 5.0653 & TRN \\
\hline CHEMBL1612574 & 688620 & 5.3 & 4.9725 & TRN \\
\hline CHEMBL1373122 & 688620 & 5.55 & 5.0101 & TST \\
\hline CHEMBL1388191 & 688620 & 5.7 & 5.8501 & TRN \\
\hline CHEMBL1350984 & 688620 & 4.45 & 4.9615 & TST \\
\hline CHEMBL3194327 & 688620 & 6.1 & 5.7466 & TRN \\
\hline CHEMBL1429650 & 688620 & 4.95 & 5.0803 & TRN \\
\hline CHEMBL1500977 & 688620 & 5.4 & 4.9124 & TRN \\
\hline CHEMBL1311822 & 688620 & 4.7 & 5.101 & TRN \\
\hline CHEMBL1548759 & 688620 & 4.8 & 5.0719 & TST \\
\hline CHEMBL1449292 & 688620 & 4.9 & 5.0286 & TRN \\
\hline CHEMBL1544553 & 688620 & 6.2 & 5.6788 & TST \\
\hline CHEMBL3190473 & 688620 & 4.95 & 4.9079 & TST \\
\hline CHEMBL1455419 & 688620 & 5.5 & 5.0051 & TST \\
\hline CHEMBL612129 & 688620 & 5.9 & 5.6265 & TST \\
\hline CHEMBL 1316155 & 688620 & 5.0 & 5.0609 & TRN \\
\hline CHEMBL1559282 & 688620 & 4.7 & 5.1929 & TRN \\
\hline CHEMBL1497075 & 688620 & 4.45 & 4.9737 & TRN \\
\hline CHEMBL1573887 & 688620 & 4.45 & 4.9128 & TRN \\
\hline CHEMBL1345321 & 688620 & 5.3 & 5.2178 & TRN \\
\hline CHEMBL1564362 & 688620 & 4.6 & 4.7927 & TRN \\
\hline CHEMBL1377183 & 688620 & 4.45 & 5.0628 & TRN \\
\hline CHEMBL1300431 & 688620 & 4.5 & 5.0 & TRN \\
\hline CHEMBL577662 & 688620 & 5.3 & 5.1776 & TRN \\
\hline CHEMBL1485887 & 688620 & 4.65 & 5.0982 & TRN \\
\hline CHEMBL1505974 & 688620 & 5.1 & 5.1353 & TRN \\
\hline CHEMBL1588393 & 688620 & 4.9 & 5.3218 & TRN \\
\hline
\end{tabular}




\begin{tabular}{|c|c|c|c|c|}
\hline \multicolumn{5}{|c|}{ Supplemental Table S2.txt } \\
\hline CHEMBL1579806 & 688620 & 4.65 & 4.9397 & TRN \\
\hline CHEMBL1586077 & 688620 & 4.9 & 4.8234 & TRN \\
\hline CHEMBL1460286 & 688620 & 5.2 & 5.0486 & TRN \\
\hline CHEMBL1487461 & 688620 & 4.95 & 5.5801 & TRN \\
\hline CHEMBL1387961 & 688620 & 5.6 & 5.0672 & TRN \\
\hline CHEMBL1502398 & 688620 & 5.35 & 5.2165 & TST \\
\hline CHEMBL1309516 & 688620 & 6.0 & 5.2384 & TRN \\
\hline CHEMBL1584171 & 688620 & 4.95 & 4.9198 & TST \\
\hline CHEMBL405857 & 688620 & 4.75 & 4.6173 & TRN \\
\hline CHEMBL1528425 & 688620 & 6.5501 & 4.8312 & TST \\
\hline CHEMBL1521187 & 688620 & 5.75 & 5.6021 & TRN \\
\hline CHEMBL1421237 & 688620 & 5.25 & 5.165 & TRN \\
\hline CHEMBL1562026 & 688620 & 4.45 & 4.9962 & TST \\
\hline CHEMBL1579717 & 688620 & 4.45 & 4.82 & TRN \\
\hline CHEMBL1461422 & 688620 & 4.8 & 5.0619 & TRN \\
\hline CHEMBL3191886 & 688620 & 4.6 & 4.8726 & TST \\
\hline CHEMBL1455512 & 688620 & 4.75 & 5.0447 & TRN \\
\hline CHEMBL1589351 & 688620 & 4.9 & 5.0864 & TST \\
\hline CHEMBL1333757 & 688620 & 4.9 & 4.871 & TRN \\
\hline CHEMBL1377188 & 688620 & 5.55 & 5.3522 & TST \\
\hline CHEMBL1460248 & 688620 & 5.9 & 5.2078 & TRN \\
\hline CHEMBL1558306 & 688620 & 5.85 & 5.81 & TRN \\
\hline CHEMBL3193840 & 688620 & 4.7 & 4.9301 & TRN \\
\hline CHEMBL1579572 & 688620 & 4.8 & 5.021 & TRN \\
\hline CHEMBL1410865 & 688620 & 6.45 & 5.0772 & TRN \\
\hline CHEMBL1305809 & 688620 & 4.45 & 5.0467 & TRN \\
\hline CHEMBL1499467 & 688620 & 5.0 & 5.0949 & TRN \\
\hline CHEMBL122355 & 688620 & 4.45 & 4.7545 & TST \\
\hline CHEMBL1609015 & 688620 & 8.3468 & 5.2688 & TST \\
\hline CHEMBL1322655 & 688620 & 4.65 & 4.9551 & TRN \\
\hline CHEMBL1596628 & 688620 & 6.35 & 6.1388 & TRN \\
\hline CHEMBL1569501 & 688620 & 5.55 & 4.8157 & TRN \\
\hline CHEMBL1565315 & 688620 & 5.35 & 4.8851 & TRN \\
\hline CHEMBL1501755 & 688620 & 5.05 & 4.8646 & TRN \\
\hline CHEMBL1422461 & 688620 & 5.95 & 5.2813 & TRN \\
\hline CHEMBL1498407 & 688620 & 4.45 & 4.9581 & TRN \\
\hline CHEMBL1588263 & 688620 & 5.0 & 5.1064 & TST \\
\hline CHEMBL1578951 & 688620 & 6.2 & 4.735 & TRN \\
\hline CHEMBL3199656 & 688620 & 5.15 & 4.9485 & TRN \\
\hline CHEMBL1353389 & 688620 & 5.05 & 5.1574 & TRN \\
\hline CHEMBL1346392 & 688620 & 5.0 & 4.9776 & TST \\
\hline CHEMBL1500011 & 688620 & 4.9 & 4.9808 & TST \\
\hline CHEMBL1529741 & 688620 & 5.8 & 5.0883 & TRN \\
\hline CHEMBL3211981 & 688620 & 5.05 & 5.0051 & TRN \\
\hline CHEMBL1502601 & 688620 & 5.15 & 4.5793 & TRN \\
\hline CHEMBL1343298 & 688620 & 4.45 & 4.9323 & TRN \\
\hline CHEMBL1494973 & 688620 & 4.45 & 5.1574 & TRN \\
\hline CHEMBL1348808 & 688620 & 5.4 & 5.1862 & TRN \\
\hline
\end{tabular}




\begin{tabular}{|c|c|c|c|c|c|}
\hline \multicolumn{6}{|c|}{ Supplemental Table S2.txt } \\
\hline CHEMBL1438667 & 688620 & 4.45 & 5.0842 & TRN & \\
\hline CHEMBL1979574 & 688620 & 4.45 & 5.2577 & TST & \\
\hline CHEMBL1565496 & 688620 & 4.5 & 4.7031 & TST & \\
\hline CHEMBL1416476 & 688620 & 4.45 & 4.9159 & TRN & \\
\hline CHEMBL1516500 & 688620 & 5.65 & 5.3529 & TRN & \\
\hline CHEMBL1492967 & 688620 & 5.15 & 4.9563 & TST & \\
\hline CHEMBL1978424 & 688620 & 5.4 & 5.5886 & TRN & \\
\hline CHEMBL1500317 & 688620 & 5.25 & 5.2832 & TRN & \\
\hline CHEMBL1542265 & 688620 & 4.65 & 4.9248 & TST & \\
\hline CHEMBL3193481 & 688620 & 6.25 & 6.0046 & TRN & \\
\hline CHEMBL1561902 & 688620 & 4.8 & 5.0564 & TRN & \\
\hline CHEMBL1323804 & 688620 & 5.6 & 5.1834 & TRN & \\
\hline CHEMBL1403883 & 688620 & 5.0 & 5.0553 & TRN & \\
\hline CHEMBL1423140 & 688620 & 4.45 & 5.0007 & TRN & \\
\hline CHEMBL1427530 & 688620 & 4.75 & 4.9494 & TRN & \\
\hline CHEMBL1547495 & 688620 & 4.45 & 5.0343 & TRN & \\
\hline CHEMBL1333624 & 688620 & 5.0 & 5.1283 & TRN & \\
\hline CHEMBL1477565 & 688620 & 5.25 & 5.2866 & TRN & \\
\hline CHEMBL1410618 & 688620 & 6.4 & 6.0768 & TRN & \\
\hline CHEMBL1312249 & 688620 & 4.95 & 4.9889 & TRN & \\
\hline CHEMBL1500239 & 688620 & 4.5 & 4.9009 & TRN & \\
\hline CHEMBL1406342 & 688620 & 5.6 & 5.2836 & TRN & \\
\hline CHEMBL3196659 & 688620 & 4.55 & 5.2726 & TST & \\
\hline CHEMBL1415651 & 688620 & 4.95 & 5.2284 & TST & \\
\hline CHEMBL3211726 & 688620 & 6.05 & 5.4305 & TRN & \\
\hline CHEMBL1413861 & 688620 & 5.5 & 5.16700 & 0000000001 & TRN \\
\hline CHEMBL1583075 & 688620 & 5.05 & 5.1534 & TST & \\
\hline CHEMBL244645 & 688620 & 4.95 & 4.9664 & TRN & \\
\hline CHEMBL1983839 & 688620 & 5.75 & 5.7408 & TRN & \\
\hline CHEMBL1400960 & 688620 & 4.95 & 5.0902 & TRN & \\
\hline CHEMBL1558527 & 688620 & 5.1 & 5.0495 & TST & \\
\hline CHEMBL1378769 & 688620 & 5.55 & 4.9759 & TST & \\
\hline CHEMBL1349518 & 688620 & 7.5498 & 5.0493 & TST & \\
\hline CHEMBL224214 & 688620 & 5.95 & 5.556 & TRN & \\
\hline CHEMBL1351519 & 688620 & 5.4 & 5.1088 & TST & \\
\hline CHEMBL1498473 & 688620 & 4.6 & 5.0071 & TST & \\
\hline CHEMBL1340647 & 688620 & 4.85 & 4.9302 & TRN & \\
\hline CHEMBL1373433 & 688620 & 4.9 & 5.0904 & TRN & \\
\hline CHEMBL1503809 & 688620 & 5.45 & 5.1098 & TRN & \\
\hline CHEMBL1486612 & 688620 & 4.75 & 5.2356 & TST & \\
\hline CHEMBL1301399 & 688620 & 4.95 & 5.2854 & TRN & \\
\hline CHEMBL1480738 & 688620 & 4.95 & 4.7876 & TRN & \\
\hline CHEMBL1606026 & 688620 & 4.8 & 5.0666 & TRN & \\
\hline CHEMBL1533225 & 688620 & 4.9 & 5.1912 & TRN & \\
\hline CHEMBL1442820 & 688620 & 4.7 & 5.1698 & TRN & \\
\hline CHEMBL3211986 & 688620 & 5.0 & 5.185 & TST & \\
\hline CHEMBL1309724 & 688620 & 5.4 & 4.9988 & TST & \\
\hline CHEMBL1499436 & 688620 & 5.45 & 5.0148 & TST & \\
\hline
\end{tabular}




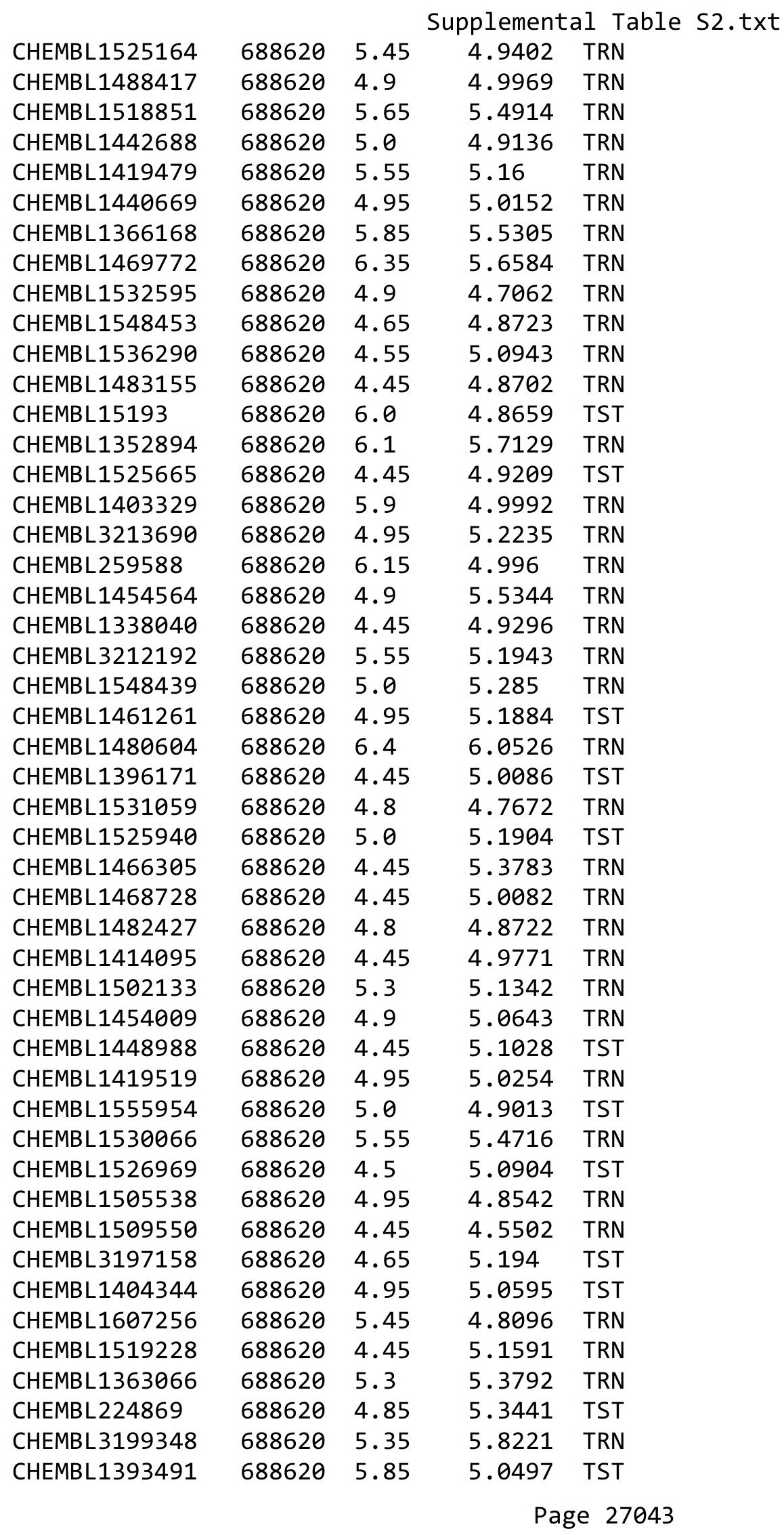




\begin{tabular}{|c|c|c|c|c|}
\hline \multicolumn{5}{|c|}{ Supplemental Table S2.txt } \\
\hline CHEMBL1567899 & 688620 & 5.6 & 5.3204 & TRN \\
\hline CHEMBL1965172 & 688620 & 4.55 & 4.7338 & TRN \\
\hline CHEMBL1423908 & 688620 & 4.9 & 5.0338 & TRN \\
\hline CHEMBL1415497 & 688620 & 4.45 & 4.8835 & TRN \\
\hline CHEMBL1344002 & 688620 & 4.8 & 4.9621 & TST \\
\hline CHEMBL1477881 & 688620 & 4.9 & 5.267 & TRN \\
\hline CHEMBL1479382 & 688620 & 4.85 & 4.939 & TRN \\
\hline CHEMBL1432136 & 688620 & 4.45 & 4.9874 & TST \\
\hline CHEMBL3195031 & 688620 & 4.9 & 5.1654 & TRN \\
\hline CHEMBL1385928 & 688620 & 4.65 & 5.1268 & TRN \\
\hline CHEMBL 3196026 & 688620 & 6.4 & 5.9783 & TRN \\
\hline CHEMBL1505994 & 688620 & 5.0 & 5.0316 & TRN \\
\hline CHEMBL1431754 & 688620 & 6.8499 & 5.2151 & TRN \\
\hline CHEMBL1471990 & 688620 & 5.15 & 5.1065 & TRN \\
\hline CHEMBL1348627 & 688620 & 4.95 & 5.1098 & TST \\
\hline CHEMBL1417751 & 688620 & 4.45 & 5.1112 & TST \\
\hline CHEMBL1550209 & 688620 & 5.5 & 5.3662 & TRN \\
\hline CHEMBL1606977 & 688620 & 4.9 & 4.8952 & TRN \\
\hline CHEMBL1578093 & 688620 & 4.9 & 5.3234 & TRN \\
\hline CHEMBL1353980 & 688620 & 5.35 & 5.2376 & TST \\
\hline CHEMBL1482160 & 688620 & 5.8 & 5.1647 & TRN \\
\hline CHEMBL1361931 & 688620 & 4.6 & 4.9787 & TRN \\
\hline CHEMBL1495397 & 688620 & 4.45 & 4.9274 & TRN \\
\hline CHEMBL1580966 & 688620 & 4.45 & 4.9639 & TRN \\
\hline CHEMBL1416132 & 688620 & 4.95 & 4.9232 & TRN \\
\hline CHEMBL1389453 & 688620 & 4.9 & 4.7901 & TRN \\
\hline CHEMBL1987441 & 688620 & 5.85 & 5.5353 & TRN \\
\hline CHEMBL3210903 & 688620 & 4.45 & 4.7084 & TRN \\
\hline CHEMBL1302275 & 688620 & 4.45 & 5.1153 & TRN \\
\hline CHEMBL1500504 & 688620 & 4.85 & 5.0924 & TST \\
\hline CHEMBL1467945 & 688620 & 5.05 & 4.9396 & TRN \\
\hline CHEMBL1549345 & 688620 & 4.5 & 4.9401 & TRN \\
\hline CHEMBL1309960 & 688620 & 5.45 & 5.0558 & TST \\
\hline CHEMBL1421877 & 688620 & 4.45 & 5.0227 & TRN \\
\hline CHEMBL3197969 & 688620 & 5.2 & 5.191 & TRN \\
\hline CHEMBL1571462 & 688620 & 5.0 & 4.8399 & TRN \\
\hline CHEMBL 1607870 & 688620 & 4.8 & 4.7434 & TRN \\
\hline CHEMBL1348066 & 688620 & 8.3468 & 5.3256 & TRN \\
\hline CHEMBL1532713 & 688620 & 4.45 & 4.6557 & TRN \\
\hline CHEMBL1581227 & 688620 & 6.0 & 5.0017 & TRN \\
\hline CHEMBL572806 & 688620 & 4.95 & 4.8652 & TST \\
\hline CHEMBL1457149 & 688620 & 4.55 & 5.0127 & TRN \\
\hline CHEMBL1312017 & 688620 & 4.45 & 4.9494 & TRN \\
\hline CHEMBL1545357 & 688620 & 4.5 & 4.8398 & TRN \\
\hline CHEMBL1565370 & 688620 & 4.45 & 4.9561 & TST \\
\hline CHEMBL1320643 & 688620 & 5.0 & 5.1035 & TRN \\
\hline CHEMBL1525989 & 688620 & 4.45 & 5.1729 & TST \\
\hline CHEMBL3193044 & 688620 & 5.65 & 5.5048 & TRN \\
\hline
\end{tabular}




\begin{tabular}{|c|c|c|c|c|}
\hline \multicolumn{5}{|c|}{ Supplemental Table S2.txt } \\
\hline CHEMBL1481592 & 688620 & 6.95 & 5.0069 & TRN \\
\hline CHEMBL582444 & 688620 & 6.0 & 4.7832 & TST \\
\hline CHEMBL1412795 & 688620 & 5.05 & 5.3313 & TRN \\
\hline CHEMBL1345120 & 688620 & 5.0 & 4.9259 & TRN \\
\hline CHEMBL3191610 & 688620 & 5.35 & 5.2499 & TRN \\
\hline CHEMBL1505057 & 688620 & 5.85 & 5.401 & TRN \\
\hline CHEMBL1320736 & 688620 & 5.55 & 4.8965 & TRN \\
\hline CHEMBL1409120 & 688620 & 4.9 & 5.1264 & TRN \\
\hline CHEMBL1335588 & 688620 & 5.05 & 4.8691 & TRN \\
\hline CHEMBL1521111 & 688620 & 4.45 & 5.1001 & TRN \\
\hline CHEMBL1342364 & 688620 & 4.95 & 4.9931 & TRN \\
\hline CHEMBL1329824 & 688620 & 5.15 & 5.006 & TRN \\
\hline CHEMBL1303722 & 688620 & 4.9 & 4.8364 & TRN \\
\hline CHEMBL1347926 & 688620 & 5.6 & 4.8174 & TRN \\
\hline CHEMBL1443690 & 688620 & 4.45 & 5.02 & TST \\
\hline CHEMBL1438540 & 688620 & 4.6 & 4.9261 & TRN \\
\hline CHEMBL1407927 & 688620 & 4.45 & 4.9056 & TRN \\
\hline CHEMBL1595232 & 688620 & 8.2518 & 5.2129 & TST \\
\hline CHEMBL1472570 & 688620 & 3.9 & 5.7654 & TRN \\
\hline CHEMBL1410183 & 688620 & 5.0 & 4.9834 & TRN \\
\hline CHEMBL1348296 & 688620 & 4.45 & 4.7933 & TRN \\
\hline CHEMBL3210654 & 688620 & 4.6 & 4.968 & TRN \\
\hline CHEMBL1383646 & 688620 & 6.0 & 5.245 & TRN \\
\hline CHEMBL1502644 & 688620 & 4.75 & 5.1747 & TST \\
\hline CHEMBL1392636 & 688620 & 4.85 & 4.8866 & TST \\
\hline CHEMBL1575814 & 688620 & 4.45 & 4.9351 & TST \\
\hline CHEMBL1407258 & 688620 & 5.55 & 5.4827 & TRN \\
\hline CHEMBL1456696 & 688620 & 6.0 & 5.7715 & TRN \\
\hline CHEMBL1441226 & 688620 & 5.0 & 4.96 & TRN \\
\hline CHEMBL1574128 & 688620 & 4.25 & 6.1778 & TST \\
\hline CHEMBL1384697 & 688620 & 5.05 & 4.8424 & TRN \\
\hline CHEMBL 255068 & 688620 & 5.15 & 5.0201 & TRN \\
\hline CHEMBL229907 & 688620 & 6.0 & 5.5073 & TRN \\
\hline CHEMBL1569833 & 688620 & 4.45 & 5.1263 & TRN \\
\hline CHEMBL1306606 & 688620 & 4.7 & 5.2016 & TRN \\
\hline CHEMBL1330125 & 688620 & 4.95 & 4.9783 & TRN \\
\hline CHEMBL 1457174 & 688620 & 4.45 & 4.8585 & TRN \\
\hline CHEMBL1478375 & 688620 & 4.95 & 4.8441 & TST \\
\hline CHEMBL1477182 & 688620 & 6.0 & 5.2117 & TRN \\
\hline CHEMBL1609218 & 688620 & 4.75 & 4.9758 & TRN \\
\hline CHEMBL1403819 & 688620 & 4.7 & 5.1431 & TST \\
\hline CHEMBL1405722 & 688620 & 5.35 & 5.7748 & TRN \\
\hline CHEMBL3197327 & 688620 & 5.05 & 4.8942 & TRN \\
\hline CHEMBL1423597 & 688620 & 5.0 & 5.2214 & TST \\
\hline CHEMBL1550115 & 688620 & 5.05 & 5.2089 & TRN \\
\hline CHEMBL1507817 & 688620 & 5.75 & 4.8764 & TRN \\
\hline CHEMBL1501387 & 688620 & 4.45 & 4.9938 & TRN \\
\hline CHEMBL1488893 & 688620 & 5.6 & 5.7044 & TRN \\
\hline
\end{tabular}




\begin{tabular}{|c|c|c|c|c|c|}
\hline \multirow[b]{2}{*}{ CHEMBL141689 } & \\
\hline & 688620 & 4.9 & 5.0533 & TST & \\
\hline CHEMBL1338298 & 688620 & 6.05 & 4.9989 & TST & \\
\hline CHEMBL1381024 & 688620 & 4.95 & 5.0192 & TST & \\
\hline CHEMBL 252418 & 688620 & 4.65 & 5.0012 & TRN & \\
\hline CHEMBL1543030 & 688620 & 4.8 & 5.3111 & TRN & \\
\hline CHEMBL1509630 & 688620 & 4.55 & 4.95100 & 20000000005 & TRN \\
\hline CHEMBL1423327 & 688620 & 4.95 & 5.1845 & TST & \\
\hline CHEMBL3198706 & 688620 & 5.0 & 5.0193 & TST & \\
\hline CHEMBL1300539 & 688620 & 4.85 & 4.9575 & TRN & \\
\hline CHEMBL1325458 & 688620 & 4.9 & 4.855 & TRN & \\
\hline CHEMBL1561126 & 688620 & 6.0 & 5.9545 & TRN & \\
\hline CHEMBL1522480 & 688620 & 4.75 & 4.9765 & TRN & \\
\hline CHEMBL3208205 & 688620 & 4.75 & 5.0281 & TRN & \\
\hline CHEMBL1382361 & 688620 & 4.6 & 5.1207 & TRN & \\
\hline CHEMBL3194790 & 688620 & 6.6499 & 5.8041 & TRN & \\
\hline CHEMBL3193763 & 688620 & 6.5 & 5.16 & TST & \\
\hline CHEMBL1481584 & 688620 & 5.6 & 5.0807 & TRN & \\
\hline CHEMBL136008 & 688620 & 5.0 & 5.1096 & TRN & \\
\hline CHEMBL1419293 & 688620 & 5.8 & 5.2383 & TRN & \\
\hline CHEMBL1399858 & 688620 & 4.45 & 4.9529 & TST & \\
\hline CHEMBL1470016 & 688620 & 6.35 & 6.0532 & TRN & \\
\hline CHEMBL1319049 & 688620 & 4.45 & 4.9532 & TRN & \\
\hline CHEMBL1321811 & 688620 & 8.301 & 5.0248 & TRN & \\
\hline CHEMBL1460843 & 688620 & 4.95 & 4.9803 & TRN & \\
\hline CHEMBL1967019 & 688620 & 5.35 & 5.6474 & TRN & \\
\hline CHEMBL1386936 & 688620 & 5.9 & 5.3174 & TRN & \\
\hline CHEMBL1581789 & 688620 & 4.65 & 5.0379 & TRN & \\
\hline CHEMBL1487761 & 688620 & 4.45 & 4.9265 & TRN & \\
\hline CHEMBL1385603 & 688620 & 5.6 & 5.1618 & TRN & \\
\hline CHEMBL1593754 & 688620 & 6.0 & 5.0247 & TST & \\
\hline CHEMBL1582381 & 688620 & 4.95 & 4.9723 & TRN & \\
\hline CHEMBL1378361 & 688620 & 4.45 & 5.1242 & TRN & \\
\hline CHEMBL1518151 & 688620 & 5.3 & 4.9739 & TRN & \\
\hline CHEMBL1520068 & 688620 & 5.9 & 5.751 & TRN & \\
\hline CHEMBL1494296 & 688620 & 5.2 & 5.1248 & TRN & \\
\hline CHEMBL1366474 & 688620 & 5.55 & 5.1137 & TRN & \\
\hline CHEMBL1479043 & 688620 & 5.8 & 5.0962 & TST & \\
\hline CHEMBL1578132 & 688620 & 4.75 & 5.1306 & TRN & \\
\hline CHEMBL1374587 & 688620 & 4.95 & 5.0758 & TRN & \\
\hline CHEMBL3193556 & 688620 & 5.2 & 5.1277 & TRN & \\
\hline CHEMBL1345547 & 688620 & 5.45 & 4.7231 & TST & \\
\hline CHEMBL1278181 & 688620 & 4.9 & 5.0726 & TRN & \\
\hline CHEMBL262861 & 688620 & 5.45 & 5.5504 & TRN & \\
\hline CHEMBL1393139 & 688620 & 5.7 & 5.2392 & TRN & \\
\hline CHEMBL3189803 & 688620 & 4.7 & 4.5399 & TRN & \\
\hline CHEMBL1393007 & 688620 & 4.45 & 5.0523 & TRN & \\
\hline CHEMBL1326054 & 688620 & 4.9 & 4.8838 & TRN & \\
\hline CHEMBL1416824 & 688620 & 5.35 & 5.0884 & TRN & \\
\hline & & & & 27046 & \\
\hline
\end{tabular}




\begin{tabular}{|c|c|c|c|c|c|}
\hline \multicolumn{6}{|c|}{ Supplemental Table S2.txt } \\
\hline CHEMBL1520407 & 688620 & 5.05 & 4.9607 & TST & \\
\hline CHEMBL1500545 & 688620 & 4.95 & 5.1961 & TRN & \\
\hline CHEMBL1590493 & 688620 & 4.85 & 5.1341 & TRN & \\
\hline CHEMBL1477512 & 688620 & 4.75 & 4.8408 & TRN & \\
\hline CHEMBL1582072 & 688620 & 6.2 & 5.1081 & TST & \\
\hline CHEMBL1372132 & 688620 & 4.45 & 4.9812 & TST & \\
\hline CHEMBL1473834 & 688620 & 5.45 & 5.1893 & TRN & \\
\hline CHEMBL1319773 & 688620 & 5.55 & 4.857 & TRN & \\
\hline CHEMBL1402411 & 688620 & 4.75 & 5.0882 & TRN & \\
\hline CHEMBL1998863 & 688620 & 5.75 & 5.6893 & TRN & \\
\hline CHEMBL1555618 & 688620 & 4.45 & 4.8982 & TRN & \\
\hline CHEMBL1486520 & 688620 & 5.9 & 4.8237 & TST & \\
\hline CHEMBL1440507 & 688620 & 6.05 & 4.9468 & TST & \\
\hline CHEMBL1575374 & 688620 & 4.95 & 5.394 & TRN & \\
\hline CHEMBL1417251 & 688620 & 4.85 & 5.0379 & TST & \\
\hline CHEMBL259784 & 688620 & 7.4001 & 6.0432 & TRN & \\
\hline CHEMBL3189995 & 688620 & 4.45 & 5.0403 & TST & \\
\hline CHEMBL1304433 & 688620 & 5.35 & 5.1115 & TRN & \\
\hline CHEMBL1471895 & 688620 & 4.45 & 5.1183 & TST & \\
\hline CHEMBL75967 & 688620 & 6.0 & 5.6339 & TRN & \\
\hline CHEMBL1550430 & 688620 & 7.0501 & 6.3004 & TRN & \\
\hline CHEMBL1409594 & 688620 & 4.9 & 4.8009 & TRN & \\
\hline CHEMBL 258767 & 688620 & 6.0 & 5.5573 & TRN & \\
\hline CHEMBL1352117 & 688620 & 4.45 & 4.6867 & TRN & \\
\hline CHEMBL3192894 & 688620 & 6.95 & 5.8716 & TRN & \\
\hline CHEMBL3197079 & 688620 & 6.3 & 5.1628 & TRN & \\
\hline CHEMBL1496506 & 688620 & 4.85 & 4.96899 & & TRN \\
\hline CHEMBL1320808 & 688620 & 4.95 & 4.803 & TRN & \\
\hline CHEMBL1470120 & 688620 & 5.9 & 5.1937 & TST & \\
\hline CHEMBL1318679 & 688620 & 4.75 & 5.183 & TRN & \\
\hline CHEMBL1560121 & 688620 & 4.45 & 4.8619 & TRN & \\
\hline CHEMBL1382807 & 688620 & 4.85 & 4.7968 & TRN & \\
\hline CHEMBL1334489 & 688620 & 4.9 & 4.91100 & 00000000005 & TRN \\
\hline CHEMBL1518148 & 688620 & 5.3 & 5.0192 & TRN & \\
\hline CHEMBL1378096 & 688620 & 4.55 & 4.9174 & TRN & \\
\hline CHEMBL1457349 & 688620 & 5.05 & 4.9914 & TRN & \\
\hline CHEMBL1485503 & 688620 & 4.95 & 4.9129 & TST & \\
\hline CHEMBL1587905 & 688620 & 4.8 & 4.8622 & TRN & \\
\hline CHEMBL1338677 & 688620 & 5.8 & 5.9642 & TRN & \\
\hline CHEMBL1464502 & 688620 & 4.8 & 4.8318 & TRN & \\
\hline CHEMBL1998281 & 688620 & 5.2 & 5.6365 & TRN & \\
\hline CHEMBL1531659 & 688620 & 5.45 & 4.9903 & TRN & \\
\hline CHEMBL1420149 & 688620 & 4.9 & 4.7115 & TRN & \\
\hline CHEMBL1536460 & 688620 & 5.35 & 5.4732 & TRN & \\
\hline CHEMBL572203 & 688620 & 5.05 & 4.9063 & TRN & \\
\hline CHEMBL1973532 & 688620 & 6.0 & 5.9967 & TRN & \\
\hline CHEMBL1491004 & 688620 & 5.3 & 5.2703 & TRN & \\
\hline CHEMBL1508174 & 688620 & 4.45 & 5.1251 & TST & \\
\hline
\end{tabular}




\begin{tabular}{|c|c|c|c|c|}
\hline & & & upplement & $\mathrm{T}$ \\
\hline CHEMBL1480110 & 688620 & 4.65 & 5.075 & TRN \\
\hline CHEMBL1405650 & 688620 & 4.95 & 5.1532 & TRN \\
\hline CHEMBL1428502 & 688620 & 4.75 & 4.9877 & TRN \\
\hline CHEMBL1442026 & 688620 & 4.9 & 4.9182 & TRN \\
\hline CHEMBL1450329 & 688620 & 5.1 & 4.9239 & TRN \\
\hline CHEMBL1534479 & 688620 & 5.0 & 5.2118 & TRN \\
\hline CHEMBL1351253 & 688620 & 5.8 & 5.3092 & TRN \\
\hline CHEMBL1607116 & 688620 & 4.95 & 4.8309 & TRN \\
\hline CHEMBL1316156 & 688620 & 4.85 & 4.957 & TRN \\
\hline CHEMBL3213332 & 688620 & 5.2 & 5.0512 & TRN \\
\hline CHEMBL1537141 & 688620 & 4.6 & 5.1388 & TST \\
\hline CHEMBL1490209 & 688620 & 6.2 & 5.6963 & TRN \\
\hline CHEMBL1541092 & 688620 & 4.8 & 5.1793 & TRN \\
\hline CHEMBL 3191481 & 688620 & 5.7 & 5.4615 & TRN \\
\hline CHEMBL1600990 & 688620 & 4.85 & 4.7373 & TRN \\
\hline CHEMBL1484185 & 688620 & 5.2 & 5.2424 & TRN \\
\hline CHEMBL1431154 & 688620 & 4.55 & 4.933 & TST \\
\hline CHEMBL1525331 & 688620 & 6.9 & 5.2216 & TRN \\
\hline CHEMBL1533488 & 688620 & 5.65 & 5.4338 & TST \\
\hline CHEMBL1572028 & 688620 & 7.2 & 5.1545 & TRN \\
\hline CHEMBL1970274 & 688620 & 4.95 & 4.8921 & TRN \\
\hline CHEMBL1332063 & 688620 & 4.45 & 4.9614 & TRN \\
\hline CHEMBL1606630 & 688620 & 5.05 & 4.8423 & TRN \\
\hline CHEMBL1488317 & 688620 & 4.45 & 5.0098 & TRN \\
\hline CHEMBL1510386 & 688620 & 4.85 & 4.841 & TRN \\
\hline CHEMBL1375888 & 688620 & 4.45 & 4.8006 & TRN \\
\hline CHEMBL1257078 & 688620 & 4.9 & 5.0643 & TST \\
\hline CHEMBL1307566 & 688620 & 5.25 & 5.1414 & TST \\
\hline CHEMBL3189722 & 688620 & 5.0 & 4.9532 & TRN \\
\hline CHEMBL1507473 & 688620 & 5.05 & 4.7153 & TRN \\
\hline CHEMBL1384806 & 688620 & 4.45 & 4.9595 & TST \\
\hline CHEMBL1510156 & 688620 & 4.9 & 4.8327 & TST \\
\hline CHEMBL1343061 & 688620 & 4.45 & 4.9861 & TRN \\
\hline CHEMBL1516360 & 688620 & 5.65 & 5.1735 & TST \\
\hline CHEMBL3191692 & 688620 & 5.3 & 5.2196 & TRN \\
\hline CHEMBL1372368 & 688620 & 5.6 & 5.5961 & TST \\
\hline CHEMBL1498612 & 688620 & 5.35 & 5.2646 & TRN \\
\hline CHEMBL1503539 & 688620 & 5.8 & 5.0293 & TST \\
\hline CHEMBL1452392 & 688620 & 5.4 & 5.2936 & TRN \\
\hline CHEMBL1313865 & 688620 & 4.85 & 5.1224 & TST \\
\hline CHEMBL1567594 & 688620 & 4.9 & 4.9617 & TRN \\
\hline CHEMBL1488955 & 688620 & 5.4 & 4.9408 & TST \\
\hline CHEMBL3144890 & 688620 & 4.95 & 4.8772 & TST \\
\hline CHEMBL1321494 & 688620 & 5.4 & 4.8339 & TRN \\
\hline CHEMBL1510339 & 688620 & 5.2 & 5.3851 & TRN \\
\hline CHEMBL3194971 & 688620 & 4.9 & 4.9427 & TRN \\
\hline CHEMBL1609181 & 688620 & 4.95 & 5.1389 & TRN \\
\hline CHEMBL1484386 & 688620 & 5.0 & 5.0112 & TRN \\
\hline
\end{tabular}




\begin{tabular}{|c|c|c|c|c|}
\hline \multicolumn{5}{|c|}{ Supplemental Table } \\
\hline CHEMBL1382203 & 688620 & 4.85 & 4.8883 & TRN \\
\hline CHEMBL1557613 & 688620 & 4.9 & 4.9363 & TRN \\
\hline CHEMBL1339706 & 688620 & 4.45 & 4.9483 & TRN \\
\hline CHEMBL1588058 & 688620 & 5.25 & 5.3082 & TST \\
\hline CHEMBL1486467 & 688620 & 5.25 & 5.3182 & TRN \\
\hline CHEMBL1335241 & 688620 & 4.45 & 5.0184 & TRN \\
\hline CHEMBL1497845 & 688620 & 4.85 & 4.8381 & TRN \\
\hline CHEMBL1496476 & 688620 & 4.9 & 4.9286 & TRN \\
\hline CHEMBL1391575 & 688620 & 4.5 & 5.0538 & TST \\
\hline CHEMBL1478616 & 688620 & 5.1 & 5.2127 & TRN \\
\hline CHEMBL1305469 & 688620 & 5.3 & 4.9842 & TRN \\
\hline CHEMBL1496231 & 688620 & 4.8 & 5.2681 & TST \\
\hline CHEMBL1324105 & 688620 & 4.45 & 5.2445 & TST \\
\hline CHEMBL1993058 & 688620 & 5.25 & 4.9861 & TRN \\
\hline CHEMBL1552210 & 688620 & 4.9 & 4.7679 & TRN \\
\hline CHEMBL1304540 & 688620 & 5.65 & 5.2825 & TRN \\
\hline CHEMBL1466827 & 688620 & 5.0 & 4.8361 & TRN \\
\hline CHEMBL1363488 & 688620 & 5.65 & 4.9075 & TRN \\
\hline CHEMBL1378244 & 688620 & 4.45 & 5.1409 & TRN \\
\hline CHEMBL1469035 & 688620 & 5.35 & 5.468 & TST \\
\hline CHEMBL1450648 & 688620 & 4.85 & 5.215 & TST \\
\hline CHEMBL1463513 & 688620 & 4.45 & 4.9894 & TRN \\
\hline CHEMBL1477419 & 688620 & 4.9 & 4.9896 & TRN \\
\hline CHEMBL1546161 & 688620 & 4.9 & 4.8596 & TRN \\
\hline CHEMBL1341281 & 688620 & 4.95 & 4.9704 & TST \\
\hline CHEMBL1441465 & 688620 & 5.4 & 5.0967 & TRN \\
\hline CHEMBL1599113 & 688620 & 5.2 & 4.5765 & TST \\
\hline CHEMBL1605733 & 688620 & 5.5 & 5.37 & TRN \\
\hline CHEMBL1487283 & 688620 & 4.65 & 4.877 & TRN \\
\hline CHEMBL1549816 & 688620 & 5.0 & 4.9519 & TST \\
\hline CHEMBL1584761 & 688620 & 5.05 & 5.1465 & TRN \\
\hline CHEMBL1353204 & 688620 & 4.45 & 4.9682 & TRN \\
\hline CHEMBL1333162 & 688620 & 5.15 & 5.1667 & TRN \\
\hline CHEMBL1481531 & 688620 & 4.45 & 4.8204 & TST \\
\hline CHEMBL1400786 & 688620 & 4.6 & 5.2245 & TRN \\
\hline CHEMBL1344230 & 688620 & 4.5 & 4.9897 & TRN \\
\hline CHEMBL1508861 & 688620 & 4.45 & 5.171 & TRN \\
\hline CHEMBL1367649 & 688620 & 5.1 & 4.9145 & TRN \\
\hline CHEMBL1569514 & 688620 & 4.85 & 4.9167 & TRN \\
\hline CHEMBL1338495 & 688620 & 4.8 & 4.816 & TRN \\
\hline CHEMBL1163965 & 688620 & 4.55 & 4.94 & TRN \\
\hline CHEMBL1579314 & 688620 & 4.75 & 5.2049 & TRN \\
\hline CHEMBL1393900 & 688620 & 4.7 & 4.8946 & TRN \\
\hline CHEMBL1433838 & 688620 & 5.5 & 5.2533 & TST \\
\hline CHEMBL1452559 & 688620 & 5.4 & 5.0956 & TRN \\
\hline CHEMBL1421807 & 688620 & 6.2 & 5.1534 & TRN \\
\hline CHEMBL1587581 & 688620 & 5.2 & 5.2063 & TRN \\
\hline CHEMBL1382866 & 688620 & 5.0 & 4.8966 & TRN \\
\hline
\end{tabular}




\begin{tabular}{|c|c|c|c|c|c|}
\hline \multicolumn{6}{|c|}{ Supplemental Table S2.txt } \\
\hline CHEMBL1455704 & 688620 & 4.9 & 4.756 & TST & \\
\hline CHEMBL1507302 & 688620 & 4.45 & 5.0153 & TRN & \\
\hline CHEMBL1454889 & 688620 & 4.85 & 5.0967 & TST & \\
\hline CHEMBL1456123 & 688620 & 5.05 & 4.9382 & TRN & \\
\hline CHEMBL1433193 & 688620 & 4.95 & 4.9915 & TRN & \\
\hline CHEMBL1364618 & 688620 & 4.9 & 4.8804 & TRN & \\
\hline CHEMBL1450156 & 688620 & 6.0 & 5.5027 & TRN & \\
\hline CHEMBL1463284 & 688620 & 4.75 & 4.7 & TRN & \\
\hline CHEMBL1564352 & 688620 & 6.7001 & 5.2125 & TRN & \\
\hline CHEMBL2369316 & 688620 & 4.6 & 4.9484 & TST & \\
\hline CHEMBL2003806 & 688620 & 5.4 & 5.4182 & TRN & \\
\hline CHEMBL1525037 & 688620 & 4.95 & 4.9399 & TRN & \\
\hline CHEMBL1426189 & 688620 & 5.25 & 5.2705 & TST & \\
\hline CHEMBL1412109 & 688620 & 5.0 & 5.05399 & 9999999999 & TRN \\
\hline CHEMBL1445188 & 688620 & 4.95 & 5.1662 & TST & \\
\hline CHEMBL1573851 & 688620 & 4.95 & 5.0969 & TRN & \\
\hline CHEMBL1502703 & 688620 & 4.9 & 5.0373 & TRN & \\
\hline CHEMBL1391770 & 688620 & 5.1 & 5.0341 & TRN & \\
\hline CHEMBL1379864 & 688620 & 4.45 & 4.9913 & TRN & \\
\hline CHEMBL1343602 & 688620 & 4.85 & 5.3081 & TRN & \\
\hline CHEMBL1384764 & 688620 & 4.95 & 4.9042 & TRN & \\
\hline CHEMBL1589608 & 688620 & 4.8 & 5.1011 & TRN & \\
\hline CHEMBL1966367 & 688620 & 4.45 & 4.8165 & TRN & \\
\hline CHEMBL1469639 & 688620 & 5.1 & 5.058 & TRN & \\
\hline CHEMBL1488595 & 688620 & 5.75 & 5.1707 & TST & \\
\hline CHEMBL1532183 & 688620 & 5.1 & 4.9312 & TRN & \\
\hline CHEMBL1584524 & 688620 & 4.8 & 5.0665 & TRN & \\
\hline CHEMBL1351689 & 688620 & 4.45 & 5.052 & TRN & \\
\hline CHEMBL1333144 & 688620 & 4.45 & 5.1822 & TRN & \\
\hline CHEMBL1378190 & 688620 & 4.5 & 4.7742 & TRN & \\
\hline CHEMBL1476297 & 688620 & 6.0 & 5.0378 & TRN & \\
\hline CHEMBL1582011 & 688620 & 4.45 & 4.7616 & TRN & \\
\hline CHEMBL1369922 & 688620 & 4.95 & 5.2097 & TRN & \\
\hline CHEMBL1610999 & 688620 & 6.05 & 5.3618 & TST & \\
\hline CHEMBL1545197 & 688620 & 4.45 & 5.1257 & TST & \\
\hline CHEMBL1466224 & 688620 & 4.45 & 5.0114 & TST & \\
\hline CHEMBL1380803 & 688620 & 4.45 & 4.8919 & TST & \\
\hline CHEMBL1506815 & 688620 & 4.85 & 5.41700 & 3000000001 & TRN \\
\hline CHEMBL3192865 & 688620 & 5.75 & 5.3098 & TRN & \\
\hline CHEMBL1571402 & 688620 & 4.45 & 5.5652 & TRN & \\
\hline CHEMBL1310019 & 688620 & 5.3 & 4.9669 & TRN & \\
\hline CHEMBL1564958 & 688620 & 5.65 & 5.7658 & TRN & \\
\hline CHEMBL1994221 & 688620 & 5.9 & 5.4859 & TRN & \\
\hline CHEMBL1540809 & 688620 & 5.3 & 5.1938 & TST & \\
\hline CHEMBL3208018 & 688620 & 5.0 & 5.0051 & TRN & \\
\hline CHEMBL1399949 & 688620 & 5.3 & 4.9753 & TRN & \\
\hline CHEMBL1432182 & 688620 & 4.65 & 5.1009 & TRN & \\
\hline CHEMBL1534345 & 688620 & 5.95 & 5.395 & TRN & \\
\hline
\end{tabular}




\begin{tabular}{|c|c|c|c|c|c|}
\hline \multicolumn{6}{|c|}{ Supplemental Table S2.txt } \\
\hline CHEMBL1541339 & 688620 & 5.25 & 5.5212 & TST & \\
\hline CHEMBL 2359467 & 688620 & 4.45 & 5.3339 & TRN & \\
\hline CHEMBL1603745 & 688620 & 4.9 & 5.0131 & TST & \\
\hline CHEMBL3196943 & 688620 & 4.95 & 5.4235 & TRN & \\
\hline CHEMBL1399805 & 688620 & 4.45 & 5.0304 & TST & \\
\hline CHEMBL1984272 & 688620 & 5.7 & 5.0623 & TRN & \\
\hline CHEMBL1589323 & 688620 & 4.65 & 4.8437 & TRN & \\
\hline CHEMBL1374727 & 688620 & 4.95 & 5.0922 & TRN & \\
\hline CHEMBL1371663 & 688620 & 5.25 & 4.9158 & TRN & \\
\hline CHEMBL3190816 & 688620 & 4.85 & 5.7837 & TRN & \\
\hline CHEMBL1426671 & 688620 & 5.0 & 5.0512 & TRN & \\
\hline CHEMBL1540405 & 688620 & 5.85 & 5.8294 & TST & \\
\hline CHEMBL1379713 & 688620 & 6.95 & 6.6459 & TRN & \\
\hline CHEMBL1546634 & 688620 & 5.45 & 4.8016 & TRN & \\
\hline CHEMBL1453084 & 688620 & 4.65 & 5.1098 & TST & \\
\hline CHEMBL1460871 & 688620 & 5.15 & 5.0506 & TRN & \\
\hline CHEMBL1556807 & 688620 & 4.8 & 5.0568 & TST & \\
\hline CHEMBL3197881 & 688620 & 4.45 & 4.9977 & TRN & \\
\hline CHEMBL1427225 & 688620 & 5.9 & 4.8647 & TRN & \\
\hline CHEMBL1350115 & 688620 & 4.9 & 4.8913 & TRN & \\
\hline CHEMBL1433073 & 688620 & 4.5 & 5.0646 & TST & \\
\hline CHEMBL3197876 & 688620 & 6.35 & 5.6023 & TRN & \\
\hline CHEMBL1361242 & 688620 & 4.65 & 5.1748 & TRN & \\
\hline CHEMBL3191193 & 688620 & 5.4 & 5.3176 & TRN & \\
\hline CHEMBL1596898 & 688620 & 4.95 & 4.6992 & TRN & \\
\hline CHEMBL1564687 & 688620 & 5.55 & 5.2741 & TRN & \\
\hline CHEMBL1994837 & 688620 & 5.15 & 5.0972 & TRN & \\
\hline CHEMBL1373211 & 688620 & 5.5 & 5.23799 & 99999999995 & TRN \\
\hline CHEMBL1451778 & 688620 & 5.1 & 5.0614 & TST & \\
\hline CHEMBL1585659 & 688620 & 4.8 & 5.0597 & TRN & \\
\hline CHEMBL1556240 & 688620 & 5.0 & 5.2018 & TRN & \\
\hline CHEMBL1479340 & 688620 & 4.7 & 4.8795 & TST & \\
\hline CHEMBL1420837 & 688620 & 4.95 & 5.0295 & TRN & \\
\hline CHEMBL1413590 & 688620 & 4.7 & 5.09399 & 9999999999 & TRN \\
\hline CHEMBL1522013 & 688620 & 4.45 & 5.1391 & TRN & \\
\hline CHEMBL1304605 & 688620 & 4.45 & 5.0499 & TRN & \\
\hline CHEMBL1355816 & 688620 & 6.9 & 5.0441 & TRN & \\
\hline CHEMBL1418750 & 688620 & 5.2 & 5.4315 & TRN & \\
\hline CHEMBL1308605 & 688620 & 4.7 & 5.0912 & TST & \\
\hline CHEMBL1611170 & 688620 & 4.5 & 4.7562 & TRN & \\
\hline CHEMBL1549744 & 688620 & 4.8 & 4.89 & TRN & \\
\hline CHEMBL1995152 & 688620 & 4.8 & 4.813 & TRN & \\
\hline CHEMBL1492922 & 688620 & 6.15 & 5.7503 & TST & \\
\hline CHEMBL1521932 & 688620 & 4.8 & 5.2946 & TRN & \\
\hline CHEMBL1607187 & 688620 & 4.45 & 5.4758 & TRN & \\
\hline CHEMBL1519274 & 688620 & 4.7 & 5.3031 & TRN & \\
\hline CHEMBL1446538 & 688620 & 4.95 & 5.1292 & TST & \\
\hline CHEMBL1485326 & 688620 & 4.85 & 4.9716 & TRN & \\
\hline
\end{tabular}




\begin{tabular}{|c|c|c|c|c|c|}
\hline & & \multicolumn{4}{|c|}{ Supplemental Table s2.txt } \\
\hline CHEMBL1404528 & 688620 & 5.35 & 5.1367 & TRN & \\
\hline CHEMBL42288 & 688620 & 5.85 & 5.5407 & TRN & \\
\hline CHEMBL1303261 & 688620 & 5.5 & 5.1838 & TRN & \\
\hline CHEMBL1524022 & 688620 & 5.25 & 4.9939 & TRN & \\
\hline CHEMBL1589432 & 688620 & 5.0 & 4.8317 & TRN & \\
\hline CHEMBL1567001 & 688620 & 4.95 & 5.1236 & TST & \\
\hline CHEMBL1506268 & 688620 & 4.55 & 4.868 & TRN & \\
\hline CHEMBL1579650 & 688620 & 5.8 & 5.4134 & TRN & \\
\hline CHEMBL1588627 & 688620 & 5.25 & 4.9314 & TRN & \\
\hline CHEMBL2369165 & 688620 & 4.9 & 5.1753 & TST & \\
\hline CHEMBL1503222 & 688620 & 4.5 & 5.3646 & TRN & \\
\hline CHEMBL1311469 & 688620 & 4.95 & 4.9656 & TRN & \\
\hline CHEMBL1455485 & 688620 & 6.9 & 5.8268 & TST & \\
\hline CHEMBL1463415 & 688620 & 6.9 & 5.335 & TRN & \\
\hline CHEMBL1439726 & 688620 & 5.05 & 5.0052 & TRN & \\
\hline CHEMBL3199327 & 688620 & 5.95 & 5.0747 & TRN & \\
\hline CHEMBL1431958 & 688620 & 4.5 & 4.9706 & TRN & \\
\hline CHEMBL1308931 & 688620 & 5.15 & 5.13200 & $\partial 000000001$ & TRN \\
\hline CHEMBL1455161 & 688620 & 4.8 & 5.0187 & TST & \\
\hline CHEMBL1528189 & 688620 & 4.7 & 4.8553 & TRN & \\
\hline CHEMBL1416387 & 688620 & 4.45 & 5.4903 & TRN & \\
\hline CHEMBL1561833 & 688620 & 6.05 & 4.9408 & TRN & \\
\hline CHEMBL1339765 & 688620 & 4.8 & 5.0151 & TRN & \\
\hline CHEMBL1383877 & 688620 & 4.85 & 5.1254 & TRN & \\
\hline CHEMBL1424113 & 688620 & 4.9 & 4.9754 & TRN & \\
\hline CHEMBL1603129 & 688620 & 5.25 & 5.0613 & TRN & \\
\hline CHEMBL1344647 & 688620 & 5.5 & 5.1183 & TRN & \\
\hline CHEMBL1400691 & 688620 & 4.85 & 4.9971 & TRN & \\
\hline CHEMBL1525956 & 688620 & 4.45 & 4.7658 & TRN & \\
\hline CHEMBL1571348 & 688620 & 5.0 & 5.0181 & TRN & \\
\hline CHEMBL1313763 & 688620 & 4.9 & 5.1291 & TRN & \\
\hline CHEMBL1369078 & 688620 & 5.9 & 5.1616 & TRN & \\
\hline CHEMBL 3212380 & 688620 & 4.45 & 5.0601 & TRN & \\
\hline CHEMBL1410964 & 688620 & 5.6 & 5.2683 & TRN & \\
\hline CHEMBL1581271 & 688620 & 5.2 & 5.0359 & TRN & \\
\hline CHEMBL1496920 & 688620 & 4.75 & 4.8799 & TRN & \\
\hline CHEMBL3208729 & 688620 & 4.95 & 4.9371 & TST & \\
\hline CHEMBL1348089 & 688620 & 5.5 & 5.3173 & TRN & \\
\hline CHEMBL1477630 & 688620 & 4.95 & 5.0649 & TST & \\
\hline CHEMBL1534860 & 688620 & 4.7 & 4.9926 & TRN & \\
\hline CHEMBL3192649 & 688620 & 4.8 & 4.8435 & TRN & \\
\hline CHEMBL1430650 & 688620 & 4.95 & 5.245 & TRN & \\
\hline CHEMBL1385607 & 688620 & 4.45 & 4.9701 & TRN & \\
\hline CHEMBL1448448 & 688620 & 4.85 & 5.10800 & 00000000005 & TST \\
\hline CHEMBL1561933 & 688620 & 5.0 & 5.0611 & TRN & \\
\hline CHEMBL1410586 & 688620 & 4.8 & 5.0539 & TST & \\
\hline CHEMBL1421317 & 688620 & 4.65 & 4.9388 & TRN & \\
\hline CHEMBL1323904 & 688620 & 4.45 & 4.9942 & TST & \\
\hline
\end{tabular}




\begin{tabular}{|c|c|c|c|c|c|}
\hline & & & & & \\
\hline CHEMBL1442750 & 688620 & 4.45 & 4.979 & TST & \\
\hline CHEMBL513436 & 688620 & 5.4 & 5.5714 & TRN & \\
\hline CHEMBL1300033 & 688620 & 5.1 & 5.3918 & TRN & \\
\hline CHEMBL1423269 & 688620 & 4.95 & 4.9633 & TRN & \\
\hline CHEMBL1544147 & 688620 & 5.25 & 5.0612 & TST & \\
\hline CHEMBL1549882 & 688620 & 4.65 & 4.8103 & TST & \\
\hline CHEMBL1508218 & 688620 & 4.85 & 5.0046 & TRN & \\
\hline CHEMBL1300253 & 688620 & 4.95 & 5.02800 & 00000000005 & TRN \\
\hline CHEMBL3191949 & 688620 & 5.35 & 5.0669 & TRN & \\
\hline CHEMBL1349631 & 688620 & 7.2503 & 4.5455 & TRN & \\
\hline CHEMBL1363479 & 688620 & 5.5 & 4.9484 & TRN & \\
\hline CHEMBL1453388 & 688620 & 5.0 & 5.1397 & TRN & \\
\hline CHEMBL1523979 & 688620 & 4.7 & 4.75899 & 99999999995 & TRN \\
\hline CHEMBL1445361 & 688620 & 4.95 & 4.9577 & TST & \\
\hline CHEMBL1319807 & 688620 & 4.75 & 4.7466 & TRN & \\
\hline CHEMBL1453604 & 688620 & 6.5 & 4.9346 & TRN & \\
\hline CHEMBL1453544 & 688620 & 5.9 & 5.2266 & TRN & \\
\hline CHEMBL1469417 & 688620 & 5.4 & 5.0418 & TST & \\
\hline CHEMBL1502611 & 688620 & 4.45 & 4.8756 & TST & \\
\hline CHEMBL1564158 & 688620 & 4.7 & 5.0988 & TRN & \\
\hline CHEMBL1365239 & 688620 & 5.0 & 5.0546 & TRN & \\
\hline CHEMBL1491079 & 688620 & 4.9 & 4.8076 & TRN & \\
\hline CHEMBL3210297 & 688620 & 4.95 & 5.061 & TRN & \\
\hline CHEMBL1337347 & 688620 & 6.45 & 5.1816 & TRN & \\
\hline CHEMBL1549510 & 688620 & 4.45 & 4.9757 & TRN & \\
\hline CHEMBL3211535 & 688620 & 5.45 & 5.1571 & TRN & \\
\hline CHEMBL1410101 & 688620 & 5.45 & 5.2258 & TRN & \\
\hline CHEMBL1366672 & 688620 & 4.45 & 4.8793 & TST & \\
\hline CHEMBL1492308 & 688620 & 5.55 & 5.3828 & TRN & \\
\hline CHEMBL3193285 & 688620 & 5.1 & 5.1033 & TRN & \\
\hline CHEMBL1613707 & 688620 & 5.2 & 4.9351 & TRN & \\
\hline CHEMBL1389530 & 688620 & 4.45 & 4.9 & TRN & \\
\hline CHEMBL1486416 & 688620 & 4.45 & 5.1472 & TRN & \\
\hline CHEMBL1611408 & 688620 & 5.4 & 5.1891 & TRN & \\
\hline CHEMBL1301582 & 688620 & 6.1 & 5.0848 & TST & \\
\hline CHEMBL1428524 & 688620 & 4.45 & 5.0801 & TRN & \\
\hline CHEMBL1363178 & 688620 & 5.15 & 5.4812 & TRN & \\
\hline CHEMBL1408872 & 688620 & 4.8 & 4.7335 & TRN & \\
\hline CHEMBL1459261 & 688620 & 4.5 & 4.9016 & TRN & \\
\hline CHEMBL1455200 & 688620 & 4.45 & 5.0687 & TRN & \\
\hline CHEMBL1533963 & 688620 & 4.45 & 4.9815 & TST & \\
\hline CHEMBL1468307 & 688620 & 6.6499 & 5.227 & TRN & \\
\hline CHEMBL1541030 & 688620 & 4.8 & 4.851 & TRN & \\
\hline CHEMBL3191413 & 688620 & 5.1 & 4.8511 & TST & \\
\hline CHEMBL1323770 & 688620 & 5.45 & 5.1746 & TRN & \\
\hline CHEMBL1489087 & 688620 & 4.85 & 5.0425 & TRN & \\
\hline CHEMBL1393533 & 688620 & 5.8 & 5.0451 & TST & \\
\hline CHEMBL1481381 & 688620 & 4.65 & 4.8358 & TST & \\
\hline
\end{tabular}




\begin{tabular}{|c|c|c|c|c|c|}
\hline \\
\hline CHEMBL1986725 & 688620 & 5.9 & 5.7056 & TRN & \\
\hline CHEMBL1403614 & 688620 & 4.9 & 4.886 & TRN & \\
\hline CHEMBL592124 & 688620 & 4.9 & 5.1075 & TRN & \\
\hline CHEMBL1447282 & 688620 & 4.55 & 5.0515 & TST & \\
\hline CHEMBL1556698 & 688620 & 5.65 & 5.2619 & TST & \\
\hline CHEMBL1424207 & 688620 & 6.4 & 5.2629 & TRN & \\
\hline CHEMBL1479111 & 688620 & 4.8 & 4.9026 & TRN & \\
\hline CHEMBL1431829 & 688620 & 4.4 & 5.0949 & TST & \\
\hline CHEMBL1420875 & 688620 & 4.65 & 5.0547 & TRN & \\
\hline CHEMBL1509557 & 688620 & 5.55 & 5.1035 & TRN & \\
\hline CHEMBL1560672 & 688620 & 5.0 & 4.9603 & TRN & \\
\hline CHEMBL1376799 & 688620 & 4.8 & 4.6087 & TRN & \\
\hline CHEMBL1512251 & 688620 & 5.05 & 5.0642 & TRN & \\
\hline CHEMBL1582919 & 688620 & 5.3 & 5.1523 & TRN & \\
\hline CHEMBL1499620 & 688620 & 4.75 & 4.9566 & TRN & \\
\hline CHEMBL3211754 & 688620 & 5.35 & 4.9007 & TRN & \\
\hline CHEMBL1573692 & 688620 & 4.45 & 4.7157 & TRN & \\
\hline CHEMBL3210625 & 688620 & 5.05 & 4.9074 & TRN & \\
\hline CHEMBL1478640 & 688620 & 4.95 & 5.1163 & TST & \\
\hline CHEMBL1445185 & 688620 & 4.65 & 5.0916 & TST & \\
\hline CHEMBL1363203 & 688620 & 5.0 & 5.0017 & TRN & \\
\hline CHEMBL1430263 & 688620 & 4.7 & 4.9836 & TRN & \\
\hline CHEMBL1573657 & 688620 & 4.9 & 5.2915 & TRN & \\
\hline CHEMBL1579696 & 688620 & 7.0 & 4.9509 & TRN & \\
\hline CHEMBL3198165 & 688620 & 5.25 & 5.1691 & TST & \\
\hline CHEMBL1299564 & 688620 & 4.55 & 4.9972 & TRN & \\
\hline CHEMBL3196068 & 688620 & 4.7 & 5.1837 & TRN & \\
\hline CHEMBL1477668 & 688620 & 4.45 & 5.1389 & TRN & \\
\hline CHEMBL1305385 & 688620 & 4.6 & 5.1932 & TRN & \\
\hline CHEMBL1481357 & 688620 & 4.45 & 4.9958 & TST & \\
\hline CHEMBL1411641 & 688620 & 5.4 & $4.9510 e$ & 20000000005 & TRN \\
\hline CHEMBL3197979 & 688620 & 5.2 & 5.2802 & TRN & \\
\hline CHEMBL3194527 & 688620 & 5.55 & 4.8297 & TST & \\
\hline CHEMBL1490160 & 688620 & 4.95 & 4.9529 & TRN & \\
\hline CHEMBL1426137 & 688620 & 5.7 & 5.0487 & TST & \\
\hline CHEMBL1416153 & 688620 & 5.6 & 5.3556 & TRN & \\
\hline CHEMBL1416645 & 688620 & 4.65 & 4.8176 & TST & \\
\hline CHEMBL1469689 & 688620 & 5.55 & 5.5451 & TRN & \\
\hline CHEMBL1499987 & 688620 & 4.5 & 4.8589 & TRN & \\
\hline CHEMBL1585234 & 688620 & 4.85 & 4.8736 & TRN & \\
\hline CHEMBL3194815 & 688620 & 4.75 & 5.0241 & TRN & \\
\hline CHEMBL1579602 & 688620 & 4.8 & 5.0544 & TST & \\
\hline CHEMBL1576051 & 688620 & 4.5 & 4.9653 & TRN & \\
\hline CHEMBL1493905 & 688620 & 4.5 & 5.0811 & TRN & \\
\hline CHEMBL1445531 & 688620 & 4.95 & 4.8326 & TRN & \\
\hline CHEMBL1980198 & 688620 & 4.45 & 5.1102 & TRN & \\
\hline CHEMBL1379837 & 688620 & 4.85 & 4.9928 & TRN & \\
\hline CHEMBL1501989 & 688620 & 4.75 & 5.0094 & TRN & \\
\hline
\end{tabular}




\begin{tabular}{|c|c|c|c|c|}
\hline \multicolumn{5}{|c|}{ Supplemental Table S2.txt } \\
\hline CHEMBL3144821 & 688620 & 4.95 & 5.0986 & TRN \\
\hline CHEMBL1390698 & 688620 & 6.25 & 5.4814 & TRN \\
\hline CHEMBL1304819 & 688620 & 5.1 & 5.0535 & TRN \\
\hline CHEMBL1374467 & 688620 & 4.95 & 4.9809 & TRN \\
\hline CHEMBL1431647 & 688620 & 4.95 & 5.2982 & TRN \\
\hline CHEMBL1608332 & 688620 & 4.95 & 5.0264 & TST \\
\hline CHEMBL3198261 & 688620 & 4.95 & 4.9396 & TRN \\
\hline CHEMBL1415785 & 688620 & 4.45 & 4.7431 & TRN \\
\hline CHEMBL1964899 & 688620 & 5.45 & 5.3044 & TST \\
\hline CHEMBL1587878 & 688620 & 5.25 & 5.4129 & TRN \\
\hline CHEMBL1322896 & 688620 & 5.3 & 5.2132 & TRN \\
\hline CHEMBL1973500 & 688620 & 5.3 & 5.064 & TST \\
\hline CHEMBL1350543 & 688620 & 5.2 & 5.1437 & TRN \\
\hline CHEMBL1396446 & 688620 & 4.65 & 5.5387 & TST \\
\hline CHEMBL1369533 & 688620 & 5.7 & 5.1011 & TRN \\
\hline CHEMBL1485032 & 688620 & 4.45 & 5.17 & TRN \\
\hline CHEMBL1343097 & 688620 & 5.2 & 4.8912 & TRN \\
\hline CHEMBL1447058 & 688620 & 4.85 & 4.5739 & TRN \\
\hline CHEMBL1361515 & 688620 & 4.8 & 4.7011 & TRN \\
\hline CHEMBL1453479 & 688620 & 5.35 & 4.7818 & TRN \\
\hline CHEMBL1587318 & 688620 & 4.45 & 4.9281 & TST \\
\hline CHEMBL3192252 & 688620 & 4.95 & 5.1907 & TRN \\
\hline CHEMBL1322695 & 688620 & 5.95 & 5.4538 & TRN \\
\hline CHEMBL1357226 & 688620 & 5.0 & 5.0192 & TST \\
\hline CHEMBL1344201 & 688620 & 4.95 & 5.1164 & TRN \\
\hline CHEMBL1494955 & 688620 & 4.45 & 5.4435 & TST \\
\hline CHEMBL3199397 & 688620 & 4.85 & 4.8774 & TRN \\
\hline CHEMBL1529617 & 688620 & 4.45 & 4.9851 & TRN \\
\hline CHEMBL1445186 & 688620 & 4.45 & 4.9936 & TST \\
\hline CHEMBL 3214543 & 688620 & 4.45 & 5.1388 & TRN \\
\hline CHEMBL1484249 & 688620 & 5.2 & 5.2409 & TRN \\
\hline CHEMBL1487300 & 688620 & 4.45 & 5.0344 & TST \\
\hline CHEMBL1508180 & 688620 & 4.45 & 5.0539 & TRN \\
\hline CHEMBL1367846 & 688620 & 5.0 & 5.2643 & TST \\
\hline CHEMBL1541530 & 688620 & 5.35 & 5.012 & TRN \\
\hline CHEMBL3210179 & 688620 & 4.75 & 5.1572 & TST \\
\hline CHEMBL 1392228 & 688620 & 6.0 & 5.5893 & TRN \\
\hline CHEMBL1354850 & 688620 & 4.45 & 4.7239 & TRN \\
\hline CHEMBL1342792 & 688620 & 5.2 & 5.0413 & TRN \\
\hline CHEMBL1566509 & 688620 & 6.1 & 5.2442 & TST \\
\hline CHEMBL1556047 & 688620 & 5.1 & 5.22 & TRN \\
\hline CHEMBL1368212 & 688620 & 6.35 & 5.7766 & TRN \\
\hline CHEMBL1581042 & 688620 & 6.25 & 5.3214 & TRN \\
\hline CHEMBL1581942 & 688620 & 4.95 & 4.8969 & TRN \\
\hline CHEMBL1538113 & 688620 & 8.2007 & 5.1437 & TST \\
\hline CHEMBL1497430 & 688620 & 5.75 & 5.2038 & TST \\
\hline CHEMBL1305111 & 688620 & 5.1 & 4.5972 & TRN \\
\hline CHEMBL1320785 & 688620 & 4.8 & 5.0719 & TRN \\
\hline
\end{tabular}




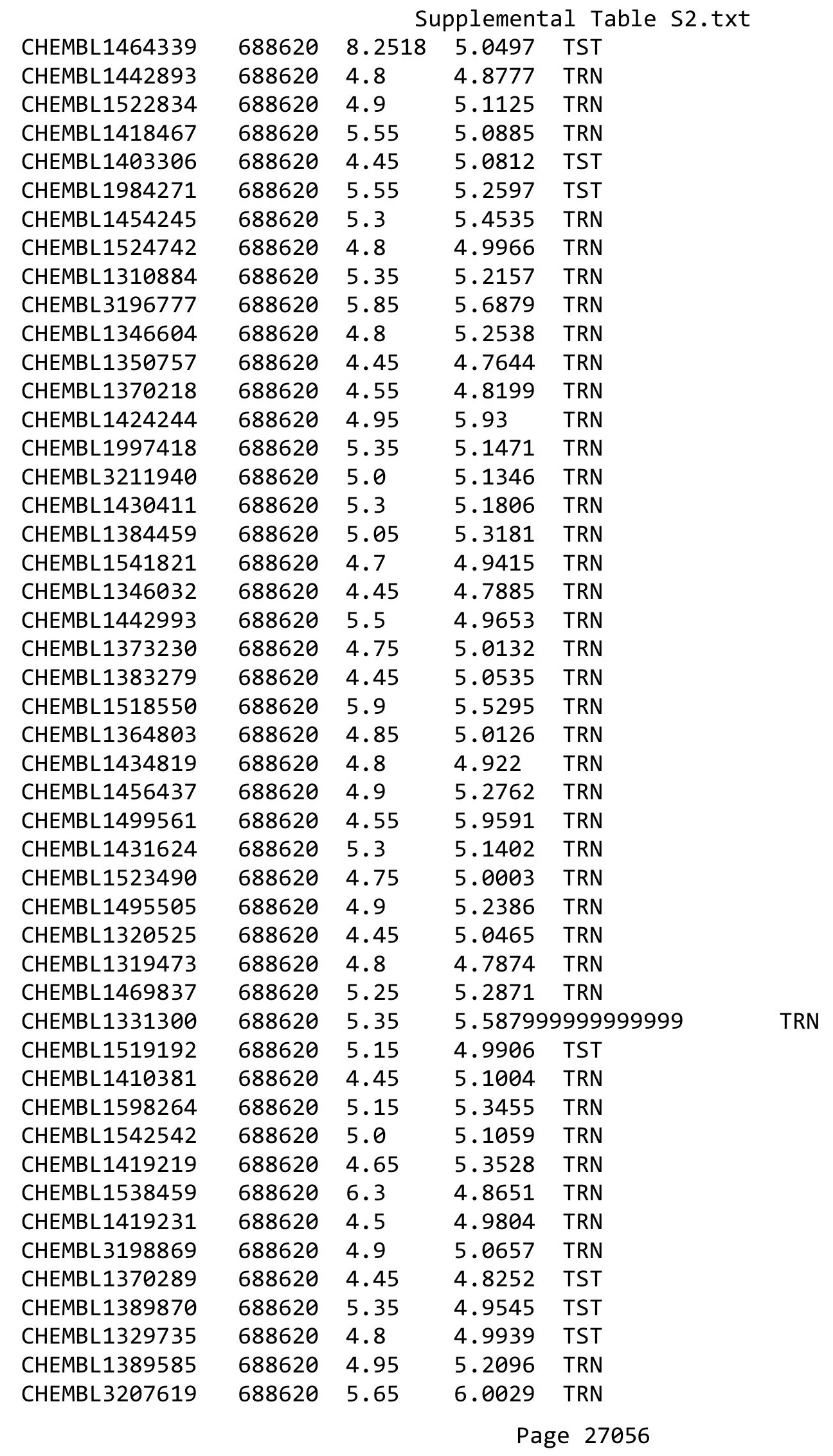




\begin{tabular}{|c|c|c|c|c|c|}
\hline \multicolumn{6}{|c|}{ Supplemental Table S2.txt } \\
\hline CHEMBL1450526 & 688620 & 6.2 & 6.0359 & TRN & \\
\hline CHEMBL1342050 & 688620 & 5.25 & 5.0898 & TST & \\
\hline CHEMBL1305434 & 688620 & 5.0 & 5.0949 & TRN & \\
\hline CHEMBL1558462 & 688620 & 5.45 & 5.6048 & TRN & \\
\hline CHEMBL1549210 & 688620 & 5.0 & 4.8979 & TST & \\
\hline CHEMBL1368116 & 688620 & 4.9 & 4.8951 & TRN & \\
\hline CHEMBL1611433 & 688620 & 5.1 & 5.1507 & TRN & \\
\hline CHEMBL1540611 & 688620 & 5.8 & 5.2733 & TRN & \\
\hline CHEMBL1556373 & 688620 & 5.9 & 5.3171 & TRN & \\
\hline CHEMBL1347618 & 688620 & 4.45 & 4.6807 & TST & \\
\hline CHEMBL3192927 & 688620 & 4.55 & 5.0168 & TRN & \\
\hline CHEMBL1327338 & 688620 & 8.2518 & 6.3119 & TRN & \\
\hline CHEMBL1399221 & 688620 & 6.0 & 5.8462 & TRN & \\
\hline CHEMBL1604614 & 688620 & 5.0 & 4.7799 & TRN & \\
\hline CHEMBL518292 & 688620 & 5.85 & 5.4525 & TST & \\
\hline CHEMBL1351044 & 688620 & 5.8 & 5.1556 & TST & \\
\hline CHEMBL1378117 & 688620 & 5.05 & 5.1579 & TST & \\
\hline CHEMBL1320590 & 688620 & 5.2 & 5.1687 & TST & \\
\hline CHEMBL3194477 & 688620 & 5.75 & 5.9424 & TRN & \\
\hline CHEMBL1607555 & 688620 & 4.8 & 5.0894 & TRN & \\
\hline CHEMBL1467212 & 688620 & 5.05 & 4.9762 & TST & \\
\hline CHEMBL1365476 & 688620 & 4.85 & 5.0561 & TRN & \\
\hline CHEMBL1392106 & 688620 & 5.65 & 5.5335 & TST & \\
\hline CHEMBL3193526 & 688620 & 5.4 & 4.967 & TST & \\
\hline CHEMBL1544985 & 688620 & 5.6 & 5.49299 & 9999999999 & TRN \\
\hline CHEMBL1479472 & 688620 & 5.0 & 4.8597 & TRN & \\
\hline CHEMBL1602486 & 688620 & 5.25 & 5.0654 & TST & \\
\hline CHEMBL1586765 & 688620 & 4.9 & 5.0089 & TRN & \\
\hline CHEMBL1577793 & 688620 & 5.4 & 4.7679 & TRN & \\
\hline CHEMBL1527101 & 688620 & 4.7 & 5.1808 & TST & \\
\hline CHEMBL1425099 & 688620 & 5.2 & 5.0152 & TRN & \\
\hline CHEMBL1577056 & 688620 & 6.5501 & 6.0293 & TRN & \\
\hline CHEMBL1566938 & 688620 & 4.85 & 4.8987 & TST & \\
\hline CHEMBL1399214 & 688620 & 4.95 & 5.193 & TST & \\
\hline CHEMBL1982107 & 688620 & 5.25 & 5.0468 & TRN & \\
\hline CHEMBL1537169 & 688620 & 4.8 & 5.1778 & TRN & \\
\hline CHEMBL24909 & 688620 & 5.15 & 5.1179 & TRN & \\
\hline CHEMBL1341409 & 688620 & 5.2 & 5.0602 & TST & \\
\hline CHEMBL1588029 & 688620 & 4.45 & 4.9458 & TST & \\
\hline CHEMBL1492670 & 688620 & 4.95 & 5.0851 & TRN & \\
\hline CHEMBL1541564 & 688620 & 5.25 & 5.1505 & TRN & \\
\hline CHEMBL1360190 & 688620 & 4.85 & 5.0277 & TRN & \\
\hline CHEMBL1370146 & 688620 & 6.45 & 5.0593 & TRN & \\
\hline CHEMBL1412271 & 688620 & 4.9 & 5.0446 & TST & \\
\hline CHEMBL1591487 & 688620 & 6.15 & 5.0459 & TRN & \\
\hline CHEMBL582081 & 688620 & 4.7 & 5.0644 & TRN & \\
\hline CHEMBL1415184 & 688620 & 5.9 & 5.5949 & TRN & \\
\hline CHEMBL3190738 & 688620 & 4.45 & 4.9728 & TRN & \\
\hline
\end{tabular}




\begin{tabular}{|c|c|c|c|c|c|}
\hline \multicolumn{6}{|c|}{ Supplemental Table S2.txt } \\
\hline CHEMBL1371245 & 688620 & 4.8 & 4.8398 & TRN & \\
\hline CHEMBL1393813 & 688620 & 6.15 & 5.4544 & TRN & \\
\hline CHEMBL1302757 & 688620 & 5.0 & 5.1678 & TRN & \\
\hline CHEMBL1989897 & 688620 & 5.5 & 5.5158 & TRN & \\
\hline CHEMBL1403632 & 688620 & 5.15 & 4.9198 & TRN & \\
\hline CHEMBL1564136 & 688620 & 6.25 & 5.9751 & TST & \\
\hline CHEMBL1603580 & 688620 & 5.2 & 5.0486 & TRN & \\
\hline CHEMBL1569740 & 688620 & 5.7 & 5.21399 & 99999999995 & TRN \\
\hline CHEMBL1474542 & 688620 & 4.85 & 4.9819 & TRN & \\
\hline CHEMBL1448153 & 688620 & 5.15 & 5.1335 & TRN & \\
\hline CHEMBL1468515 & 688620 & 4.9 & 5.2855 & TST & \\
\hline CHEMBL1575940 & 688620 & 4.55 & 4.7167 & TRN & \\
\hline CHEMBL1558070 & 688620 & 7.0 & 5.974 & TRN & \\
\hline CHEMBL1388207 & 688620 & 4.7 & 5.0942 & TRN & \\
\hline CHEMBL1534188 & 688620 & 4.9 & 4.9942 & TRN & \\
\hline CHEMBL1441848 & 688620 & 4.85 & 5.0002 & TRN & \\
\hline CHEMBL1531848 & 688620 & 5.25 & 4.8313 & TRN & \\
\hline CHEMBL1352783 & 688620 & 5.0 & 5.1784 & TRN & \\
\hline CHEMBL1576129 & 688620 & 4.8 & 5.0546 & TRN & \\
\hline CHEMBL1604769 & 688620 & 5.15 & 4.9983 & TST & \\
\hline CHEMBL1588052 & 688620 & 4.95 & 5.2054 & TRN & \\
\hline CHEMBL1436498 & 688620 & 5.0 & 4.9139 & TRN & \\
\hline CHEMBL1370153 & 688620 & 7.0 & 5.1252 & TRN & \\
\hline CHEMBL1579305 & 688620 & 4.65 & 5.0115 & TRN & \\
\hline CHEMBL1306433 & 688620 & 4.95 & 4.7248 & TRN & \\
\hline CHEMBL3193344 & 688620 & 6.5 & 6.0072 & TRN & \\
\hline CHEMBL1479242 & 688620 & 4.8 & 5.1651 & TRN & \\
\hline CHEMBL1491243 & 688620 & 4.9 & 4.9948 & TRN & \\
\hline CHEMBL1345444 & 688620 & 4.9 & 5.0705 & TRN & \\
\hline CHEMBL1550377 & 688620 & 4.9 & 5.0274 & TRN & \\
\hline CHEMBL1431389 & 688620 & 5.5 & 5.1117 & TRN & \\
\hline CHEMBL1445627 & 688620 & 5.0 & 4.9432 & TRN & \\
\hline CHEMBL3194623 & 688620 & 6.0 & 5.7915 & TRN & \\
\hline CHEMBL1492000 & 688620 & 4.55 & 5.4374 & TST & \\
\hline CHEMBL1544663 & 688620 & 5.25 & 5.2511 & TST & \\
\hline CHEMBL1383128 & 688620 & 6.5501 & 4.9983 & TST & \\
\hline CHEMBL1556721 & 688620 & 5.7 & 5.4914 & TRN & \\
\hline CHEMBL1387706 & 688620 & 7.6003 & 4.7433 & TRN & \\
\hline CHEMBL1510652 & 688620 & 4.8 & 4.6712 & TRN & \\
\hline CHEMBL1583507 & 688620 & 5.35 & 4.9262 & TST & \\
\hline CHEMBL1424363 & 688620 & 4.95 & 5.0843 & TST & \\
\hline CHEMBL1503112 & 688620 & 5.55 & 5.3122 & TRN & \\
\hline CHEMBL1368127 & 688620 & 4.7 & 5.5655 & TRN & \\
\hline CHEMBL1426738 & 688620 & 4.95 & 4.9813 & TST & \\
\hline CHEMBL1497967 & 688620 & 4.7 & 5.0279 & TST & \\
\hline CHEMBL1522065 & 688620 & 4.8 & 5.2035 & TRN & \\
\hline CHEMBL1312703 & 688620 & 5.05 & 5.1123 & TST & \\
\hline CHEMBL1584598 & 688620 & 5.1 & 5.4687 & TRN & \\
\hline
\end{tabular}




\begin{tabular}{|c|c|c|c|c|c|}
\hline \\
\hline CHEMBL2006039 & 688620 & 4.9 & 5.0301 & TRN & \\
\hline CHEMBL1346589 & 688620 & 5.5 & 5.0147 & TST & \\
\hline CHEMBL1382798 & 688620 & 5.5 & 5.3164 & TRN & \\
\hline CHEMBL1441642 & 688620 & 5.2 & 5.1867 & TRN & \\
\hline CHEMBL1305273 & 688620 & 7.0501 & 5.1585 & TST & \\
\hline CHEMBL1587919 & 688620 & 4.75 & 5.0723 & TRN & \\
\hline CHEMBL1501480 & 688620 & 5.0 & 5.1028 & TRN & \\
\hline CHEMBL1498087 & 688620 & 5.5 & 5.2689 & TRN & \\
\hline CHEMBL1349408 & 688620 & 4.45 & 5.26200 & 00000000005 & TST \\
\hline CHEMBL1411009 & 688620 & 4.45 & 5.1185 & TRN & \\
\hline CHEMBL1400223 & 688620 & 4.9 & 5.0719 & TRN & \\
\hline CHEMBL1557691 & 688620 & 4.45 & 4.9046 & TRN & \\
\hline CHEMBL1520321 & 688620 & 4.5 & 5.0604 & TRN & \\
\hline CHEMBL1401904 & 688620 & 4.8 & 5.4536 & TRN & \\
\hline CHEMBL1457567 & 688620 & 5.0 & 5.58 & TRN & \\
\hline CHEMBL1463800 & 688620 & 4.65 & 5.0158 & TRN & \\
\hline CHEMBL1413424 & 688620 & 5.55 & 5.3983 & TRN & \\
\hline CHEMBL1253382 & 688620 & 5.0 & 5.1571 & TRN & \\
\hline CHEMBL1586932 & 688620 & 6.2 & 5.3327 & TRN & \\
\hline CHEMBL1420422 & 688620 & 4.85 & 5.3458 & TST & \\
\hline CHEMBL1306892 & 688620 & 4.45 & 4.6183 & TRN & \\
\hline CHEMBL1448767 & 688620 & 4.85 & 5.0172 & TST & \\
\hline CHEMBL1595909 & 688620 & 5.0 & 4.8199 & TRN & \\
\hline CHEMBL1392656 & 688620 & 4.9 & 4.9117 & TRN & \\
\hline CHEMBL1576752 & 688620 & 5.7 & 5.0736 & TRN & \\
\hline CHEMBL1485231 & 688620 & 5.0 & 4.8272 & TRN & \\
\hline CHEMBL1303992 & 688620 & 4.8 & 4.6562 & TST & \\
\hline CHEMBL1328388 & 688620 & 5.0 & 5.0574 & TRN & \\
\hline CHEMBL1304876 & 688620 & 5.0 & 5.0267 & TRN & \\
\hline CHEMBL3195057 & 688620 & 4.55 & 5.2106 & TRN & \\
\hline CHEMBL1457783 & 688620 & 6.6 & 5.1625 & TST & \\
\hline CHEMBL1455527 & 688620 & 4.65 & 5.36600 & 00000000005 & TST \\
\hline CHEMBL1301926 & 688620 & 4.95 & 4.9614 & TST & \\
\hline CHEMBL1403523 & 688620 & 4.75 & 4.745 & TRN & \\
\hline CHEMBL579390 & 688620 & 5.95 & 5.1805 & TST & \\
\hline CHEMBL3213748 & 688620 & 5.5 & 4.6309 & TRN & \\
\hline CHEMBL1308674 & 688620 & 4.5 & 5.0468 & TST & \\
\hline CHEMBL1348614 & 688620 & 4.95 & 4.9341 & TRN & \\
\hline CHEMBL3198492 & 688620 & 5.5 & 5.2832 & TST & \\
\hline CHEMBL 1350255 & 688620 & 5.2 & 5.06800 & 00000000005 & TRN \\
\hline CHEMBL1532676 & 688620 & 5.5 & 5.0066 & TRN & \\
\hline CHEMBL1520199 & 688620 & 4.95 & 5.0177 & TRN & \\
\hline CHEMBL1308991 & 688620 & 4.45 & 4.8613 & TRN & \\
\hline CHEMBL3192160 & 688620 & 6.0 & 5.5705 & TRN & \\
\hline CHEMBL1469347 & 688620 & 4.9 & 5.3488 & TRN & \\
\hline CHEMBL3196505 & 688620 & 4.7 & 4.9499 & TRN & \\
\hline CHEMBL1382658 & 688620 & 5.35 & 5.3343 & TRN & \\
\hline CHEMBL1489516 & 688620 & 5.0 & 5.517 & TRN & \\
\hline
\end{tabular}




\begin{tabular}{|c|c|c|c|c|c|}
\hline & & \multicolumn{4}{|c|}{ Supplemental Table S2.txt } \\
\hline CHEMBL433680 & 688620 & 7.5003 & 7.5415 & TST & \\
\hline CHEMBL3190295 & 688620 & 4.6 & 5.1513 & TRN & \\
\hline CHEMBL1327011 & 688620 & 4.95 & 4.7485 & TRN & \\
\hline CHEMBL1429178 & 688620 & 4.9 & 4.9368 & TRN & \\
\hline CHEMBL1599603 & 688620 & 4.6 & 4.8863 & TRN & \\
\hline CHEMBL3198613 & 688620 & 4.95 & 4.8802 & TRN & \\
\hline CHEMBL1504982 & 688620 & 5.75 & 5.3546 & TRN & \\
\hline CHEMBL1510128 & 688620 & 5.75 & 4.9502 & TRN & \\
\hline CHEMBL1505047 & 688620 & 4.8 & 4.9872 & TST & \\
\hline CHEMBL1347927 & 688620 & 4.45 & 4.7697 & TRN & \\
\hline CHEMBL1498669 & 688620 & 6.8499 & 5.2619 & TRN & \\
\hline CHEMBL1478690 & 688620 & 5.4 & 5.42299 & 9999999999 & TRN \\
\hline CHEMBL3191677 & 688620 & 5.65 & 5.2661 & TRN & \\
\hline CHEMBL3190964 & 688620 & 4.45 & 5.1612 & TRN & \\
\hline CHEMBL1329788 & 688620 & 5.4 & 4.8065 & TRN & \\
\hline CHEMBL1368778 & 688620 & 4.9 & 5.3565 & TST & \\
\hline CHEMBL1597544 & 688620 & 4.45 & 5.5814 & TRN & \\
\hline CHEMBL1363550 & 688620 & 4.7 & 4.9751 & TRN & \\
\hline CHEMBL1392477 & 688620 & 4.95 & 4.8436 & TRN & \\
\hline CHEMBL491547 & 688620 & 5.05 & 4.8971 & TRN & \\
\hline CHEMBL1537884 & 688620 & 5.5 & 5.5191 & TRN & \\
\hline CHEMBL1522803 & 688620 & 4.95 & 5.1383 & TST & \\
\hline CHEMBL1438596 & 688620 & 4.65 & 4.928 & TST & \\
\hline CHEMBL1582691 & 688620 & 5.05 & 4.8266 & TRN & \\
\hline CHEMBL1475080 & 688620 & 5.2 & 5.1839 & TST & \\
\hline CHEMBL1610044 & 688620 & 4.95 & 4.9944 & TST & \\
\hline CHEMBL1303555 & 688620 & 4.45 & 5.0765 & TRN & \\
\hline CHEMBL3199803 & 688620 & 4.95 & 5.0481 & TRN & \\
\hline CHEMBL1510814 & 688620 & 5.0 & 5.0005 & TRN & \\
\hline CHEMBL3195803 & 688620 & 6.0 & 5.9049 & TRN & \\
\hline CHEMBL1449225 & 688620 & 4.45 & 4.8978 & TRN & \\
\hline CHEMBL1488027 & 688620 & 4.95 & 4.9113 & TRN & \\
\hline CHEMBL3193985 & 688620 & 4.95 & 4.9727 & TRN & \\
\hline CHEMBL 1484500 & 688620 & 4.65 & 5.2033 & TST & \\
\hline CHEMBL1324386 & 688620 & 5.15 & 4.9453 & TRN & \\
\hline CHEMBL1420629 & 688620 & 5.8 & 5.7626 & TRN & \\
\hline CHEMBL1393323 & 688620 & 4.95 & 5.1989 & TRN & \\
\hline CHEMBL1599208 & 688620 & 4.65 & 4.7035 & TRN & \\
\hline CHEMBL3199224 & 688620 & 4.8 & 5.0675 & TRN & \\
\hline CHEMBL1393814 & 688620 & 5.65 & 5.4107 & TST & \\
\hline CHEMBL1421891 & 688620 & 5.1 & 5.1157 & TST & \\
\hline CHEMBL1558144 & 688620 & 4.85 & 4.8682 & TRN & \\
\hline CHEMBL1367631 & 688620 & 5.0 & 5.0446 & TRN & \\
\hline CHEMBL1508694 & 688620 & 4.8 & 5.2008 & TRN & \\
\hline CHEMBL3192858 & 688620 & 6.1 & 5.8032 & TRN & \\
\hline CHEMBL1577778 & 688620 & 5.35 & 5.3371 & TRN & \\
\hline CHEMBL1333542 & 688620 & 5.6 & 5.0897 & TRN & \\
\hline CHEMBL1334491 & 688620 & 5.45 & 4.9081 & TRN & \\
\hline
\end{tabular}




\begin{tabular}{|c|c|c|c|c|}
\hline \multicolumn{5}{|c|}{ Supplemental Table S2.txt } \\
\hline CHEMBL1347104 & 688620 & 5.0 & 4.6997 & TRN \\
\hline CHEMBL1589626 & 688620 & 5.25 & 5.2085 & TRN \\
\hline CHEMBL1500549 & 688620 & 5.4 & 4.9861 & TRN \\
\hline CHEMBL1428267 & 688620 & 7.0501 & 4.9635 & TRN \\
\hline CHEMBL587449 & 688620 & 4.8 & 5.2843 & TST \\
\hline CHEMBL443510 & 688620 & 5.8 & 5.263 & TST \\
\hline CHEMBL1486574 & 688620 & 4.7 & 4.7717 & TST \\
\hline CHEMBL1381882 & 688620 & 5.0 & 5.2139 & TRN \\
\hline CHEMBL1430014 & 688620 & 5.0 & 5.1167 & TST \\
\hline CHEMBL1479901 & 688620 & 6.0 & 5.0537 & TRN \\
\hline CHEMBL1575654 & 688620 & 4.45 & 5.15 & TRN \\
\hline CHEMBL1511477 & 688620 & 5.25 & 5.3065 & TST \\
\hline CHEMBL1445303 & 688620 & 4.95 & 4.9081 & TRN \\
\hline CHEMBL1402399 & 688620 & 6.3 & 4.9889 & TRN \\
\hline CHEMBL 2003178 & 688620 & 4.95 & 5.1374 & TRN \\
\hline CHEMBL1300237 & 688620 & 5.2 & 5.2674 & TRN \\
\hline CHEMBL1571371 & 688620 & 5.0 & 4.898 & TRN \\
\hline CHEMBL1341854 & 688620 & 4.95 & 4.8935 & TRN \\
\hline CHEMBL1612988 & 688620 & 4.45 & 4.8293 & TRN \\
\hline CHEMBL3210349 & 688620 & 4.65 & 5.1884 & TRN \\
\hline CHEMBL1470828 & 688620 & 7.5003 & 5.0589 & TRN \\
\hline CHEMBL3190115 & 688620 & 5.45 & 5.4431 & TRN \\
\hline CHEMBL3193924 & 688620 & 5.4 & 4.9687 & TRN \\
\hline CHEMBL3199283 & 688620 & 5.1 & 4.9068 & TRN \\
\hline CHEMBL1328426 & 688620 & 5.25 & 5.7202 & TRN \\
\hline CHEMBL1463396 & 688620 & 4.45 & 5.0325 & TRN \\
\hline CHEMBL1464307 & 688620 & 5.55 & 4.9347 & TST \\
\hline CHEMBL3189529 & 688620 & 6.45 & 5.7246 & TRN \\
\hline CHEMBL1326836 & 688620 & 4.7 & 5.3549 & TRN \\
\hline CHEMBL1302139 & 688620 & 5.45 & 5.3292 & TRN \\
\hline CHEMBL1497571 & 688620 & 4.95 & 5.1287 & TRN \\
\hline CHEMBL1309514 & 688620 & 4.8 & 5.245 & TST \\
\hline CHEMBL1332488 & 688620 & 6.0 & 4.9879 & TRN \\
\hline CHEMBL1377335 & 688620 & 4.65 & 5.1629 & TRN \\
\hline CHEMBL1509720 & 688620 & 4.9 & 5.074 & TST \\
\hline CHEMBL 237442 & 688620 & 5.2 & 4.9574 & TRN \\
\hline CHEMBL1393334 & 688620 & 4.8 & 5.0827 & TST \\
\hline CHEMBL1546681 & 688620 & 4.45 & 4.9256 & TST \\
\hline CHEMBL1578744 & 688620 & 4.45 & 5.0926 & TRN \\
\hline CHEMBL1384695 & 688620 & 4.9 & 4.9662 & TST \\
\hline CHEMBL1387015 & 688620 & 5.0 & 4.9633 & TRN \\
\hline CHEMBL1594844 & 688620 & 4.95 & 5.1399 & TST \\
\hline CHEMBL3190198 & 688620 & 6.45 & 5.7539 & TRN \\
\hline CHEMBL1528914 & 688620 & 4.55 & 5.1599 & TRN \\
\hline CHEMBL1413068 & 688620 & 4.6 & 5.0467 & TRN \\
\hline CHEMBL1385689 & 688620 & 4.8 & 5.0473 & TRN \\
\hline CHEMBL1324890 & 688620 & 5.1 & 5.0147 & TST \\
\hline CHEMBL3212246 & 688620 & 6.0 & 5.4219 & TRN \\
\hline
\end{tabular}




\begin{tabular}{|c|c|c|c|c|c|}
\hline & & \multicolumn{4}{|c|}{ Supplemental Table S2.txt } \\
\hline CHEMBL1442546 & 688620 & 5.35 & 4.6769 & TST & \\
\hline CHEMBL1330520 & 688620 & 5.3 & 4.8924 & TRN & \\
\hline CHEMBL1600052 & 688620 & 6.95 & 5.1152 & TST & \\
\hline CHEMBL3199347 & 688620 & 4.8 & 5.0518 & TST & \\
\hline CHEMBL3192902 & 688620 & 4.7 & 5.0293 & TRN & \\
\hline CHEMBL577764 & 688620 & 5.0 & 4.9879 & TST & \\
\hline CHEMBL1304089 & 688620 & 5.15 & 5.2712 & TST & \\
\hline CHEMBL2003741 & 688620 & 6.3 & 5.4236 & TRN & \\
\hline CHEMBL1508563 & 688620 & 5.85 & 5.4479 & TST & \\
\hline CHEMBL1388866 & 688620 & 4.8 & 5.2118 & TRN & \\
\hline CHEMBL1440192 & 688620 & 4.65 & 5.0563 & TRN & \\
\hline CHEMBL1460733 & 688620 & 5.05 & 4.993 & TRN & \\
\hline CHEMBL1526490 & 688620 & 4.5 & 4.7608 & TRN & \\
\hline CHEMBL1531556 & 688620 & 4.45 & 4.8707 & TST & \\
\hline CHEMBL1520573 & 688620 & 4.8 & 4.9115 & TRN & \\
\hline CHEMBL1531846 & 688620 & 5.85 & 5.50299 & 9999999999 & TST \\
\hline CHEMBL3197842 & 688620 & 6.25 & 5.5437 & TST & \\
\hline CHEMBL1504920 & 688620 & 5.4 & 5.05699 & 99999999995 & TRN \\
\hline CHEMBL1567985 & 688620 & 4.95 & 5.2683 & TRN & \\
\hline CHEMBL1501562 & 688620 & 4.45 & 5.06800 & 00000000005 & TST \\
\hline CHEMBL1469100 & 688620 & 5.45 & 5.2615 & TRN & \\
\hline CHEMBL1580758 & 688620 & 4.9 & 5.0766 & TST & \\
\hline CHEMBL1578252 & 688620 & 4.7 & 5.2973 & TRN & \\
\hline CHEMBL1469728 & 688620 & 4.45 & 5.1288 & TRN & \\
\hline CHEMBL1438205 & 688620 & 4.95 & 4.9911 & TRN & \\
\hline CHEMBL1576122 & 688620 & 4.5 & 4.9474 & TRN & \\
\hline CHEMBL3214563 & 688620 & 5.5 & 4.9996 & TST & \\
\hline CHEMBL1343143 & 688620 & 4.45 & 4.6775 & TRN & \\
\hline CHEMBL3193207 & 688620 & 4.9 & 4.9316 & TRN & \\
\hline CHEMBL1313024 & 688620 & 5.5 & 5.1234 & TST & \\
\hline CHEMBL1994007 & 688620 & 4.7 & 4.8439 & TST & \\
\hline CHEMBL1532628 & 688620 & 5.45 & 5.0982 & TRN & \\
\hline CHEMBL1587932 & 688620 & 5.6 & 4.9592 & TRN & \\
\hline CHEMBL1333265 & 688620 & 5.0 & 4.9251 & TRN & \\
\hline CHEMBL1542804 & 688620 & 5.1 & 5.0662 & TRN & \\
\hline CHEMBL1530491 & 688620 & 5.15 & 5.3843 & TRN & \\
\hline CHEMBL1587405 & 688620 & 4.8 & 5.0541 & TST & \\
\hline CHEMBL1451241 & 688620 & 4.95 & 4.874 & TST & \\
\hline CHEMBL3189239 & 688620 & 4.65 & 5.2938 & TRN & \\
\hline CHEMBL1513972 & 688620 & 4.45 & 4.7958 & TST & \\
\hline CHEMBL1336874 & 688620 & 4.9 & 5.1185 & TRN & \\
\hline CHEMBL34398 & 688620 & 4.45 & 4.9947 & TRN & \\
\hline CHEMBL1306640 & 688620 & 6.3 & 5.0791 & TRN & \\
\hline CHEMBL3196807 & 688620 & 4.75 & 5.0356 & TRN & \\
\hline CHEMBL1320653 & 688620 & 4.65 & 5.0653 & TRN & \\
\hline CHEMBL1407554 & 688620 & 5.0 & 4.7257 & TRN & \\
\hline CHEMBL1550145 & 688620 & 4.55 & 4.9722 & TRN & \\
\hline CHEMBL1609292 & 688620 & 5.05 & 5.0385 & TRN & \\
\hline
\end{tabular}




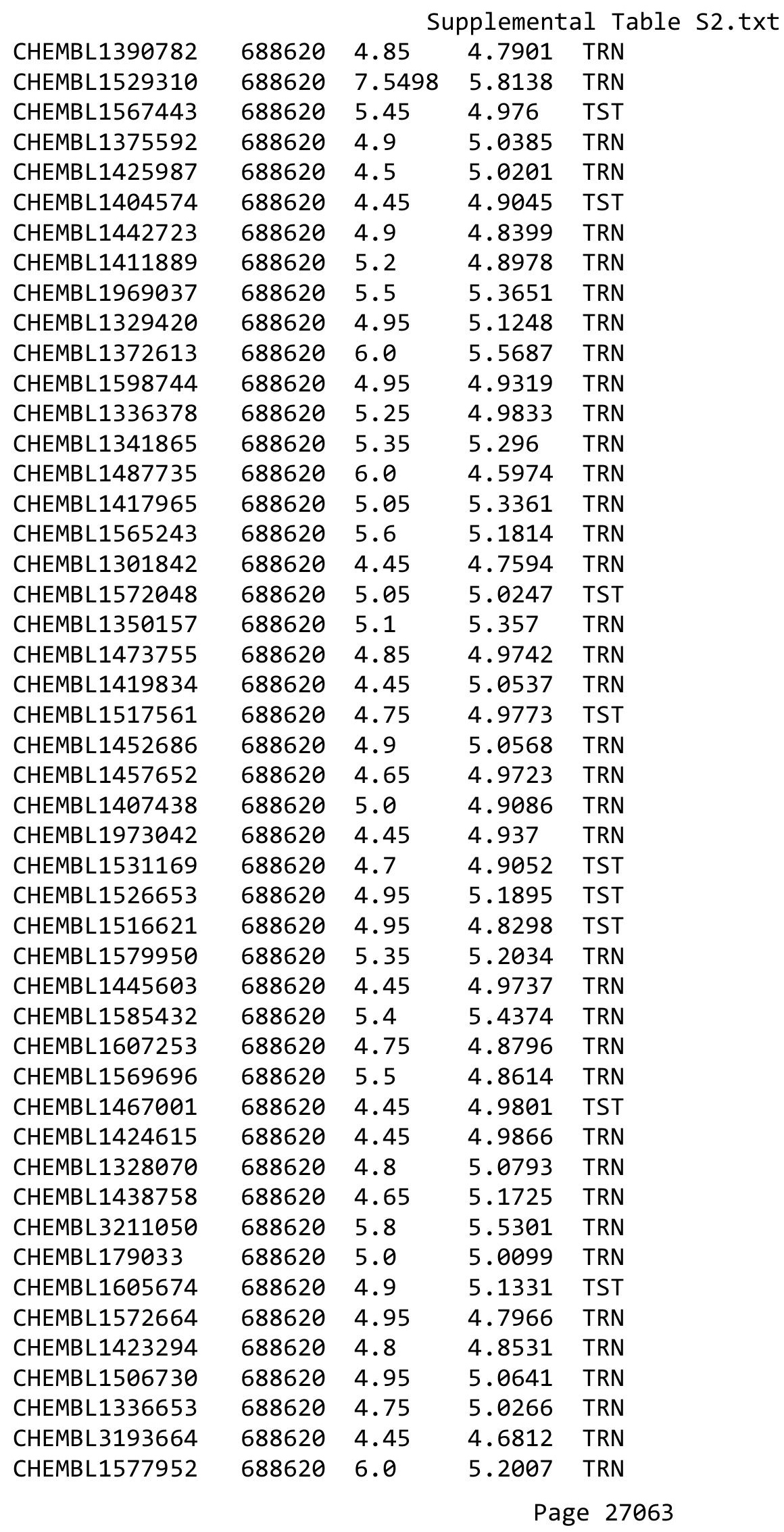




\begin{tabular}{|c|c|c|c|c|c|}
\hline & & \multicolumn{4}{|c|}{ Supplemental Table S2.txt } \\
\hline CHEMBL1569357 & 688620 & 5.2 & 5.2435 & TRN & \\
\hline CHEMBL1538197 & 688620 & 6.95 & 5.2688 & TRN & \\
\hline CHEMBL1383116 & 688620 & 4.6 & 5.00899 & 99999999995 & TRN \\
\hline CHEMBL1524288 & 688620 & 4.7 & 4.8353 & TRN & \\
\hline CHEMBL1541960 & 688620 & 4.95 & 5.0601 & TRN & \\
\hline CHEMBL1404718 & 688620 & 4.95 & 4.82 & TRN & \\
\hline CHEMBL1473632 & 688620 & 4.85 & 4.672 & TRN & \\
\hline CHEMBL1371065 & 688620 & 4.8 & 4.9053 & TRN & \\
\hline CHEMBL1305798 & 688620 & 4.75 & 5.2628 & TRN & \\
\hline CHEMBL1538073 & 688620 & 4.45 & 5.0528 & TRN & \\
\hline CHEMBL1313259 & 688620 & 5.35 & 4.9199 & TRN & \\
\hline CHEMBL3198067 & 688620 & 4.75 & 5.126 & TRN & \\
\hline CHEMBL1376905 & 688620 & 4.6 & 4.9841 & TRN & \\
\hline CHEMBL1300538 & 688620 & 4.75 & 5.1377 & TST & \\
\hline CHEMBL1380579 & 688620 & 5.6 & 5.1973 & TST & \\
\hline CHEMBL1415309 & 688620 & 4.95 & 5.0002 & TRN & \\
\hline CHEMBL1423526 & 688620 & 4.45 & 4.9397 & TST & \\
\hline CHEMBL1451437 & 688620 & 4.45 & 5.1746 & TRN & \\
\hline CHEMBL1313175 & 688620 & 4.65 & 4.9679 & TRN & \\
\hline CHEMBL1410862 & 688620 & 4.9 & 5.1308 & TST & \\
\hline CHEMBL1378953 & 688620 & 5.0 & 5.0481 & TST & \\
\hline CHEMBL1518107 & 688620 & 5.45 & 4.8239 & TRN & \\
\hline CHEMBL 3198270 & 688620 & 5.0 & 5.0182 & TRN & \\
\hline CHEMBL1338836 & 688620 & 4.85 & 4.9714 & TRN & \\
\hline CHEMBL1325275 & 688620 & 4.6 & 5.041 & TST & \\
\hline CHEMBL1569841 & 688620 & 5.0 & 4.9949 & TST & \\
\hline CHEMBL1343804 & 688620 & 4.45 & 4.7279 & TRN & \\
\hline CHEMBL1547825 & 688620 & 6.15 & 5.32 & TRN & \\
\hline CHEMBL1595491 & 688620 & 4.9 & 5.4026 & TRN & \\
\hline CHEMBL1598517 & 688620 & 4.45 & 4.8248 & TRN & \\
\hline CHEMBL1529434 & 688620 & 4.85 & 4.9261 & TRN & \\
\hline CHEMBL1508170 & 688620 & 4.9 & 5.0021 & TRN & \\
\hline CHEMBL1353681 & 688620 & 5.15 & 4.9152 & TST & \\
\hline CHEMBL1587041 & 688620 & 6.9 & 5.0278 & TRN & \\
\hline CHEMBL1385188 & 688620 & 4.8 & 5.0007 & TST & \\
\hline CHEMBL1452153 & 688620 & 6.0 & 5.4776 & TRN & \\
\hline CHEMBL1579453 & 688620 & 6.1 & 5.1576 & TST & \\
\hline CHEMBL1606648 & 688620 & 4.45 & 5.0251 & TRN & \\
\hline CHEMBL1561026 & 688620 & 4.95 & 5.1286 & TRN & \\
\hline CHEMBL1429197 & 688620 & 4.95 & 4.8106 & TRN & \\
\hline CHEMBL3193296 & 688620 & 4.8 & 5.2043 & TRN & \\
\hline CHEMBL1531805 & 688620 & 4.95 & 4.8627 & TST & \\
\hline CHEMBL1407250 & 688620 & 4.6 & 4.9999 & TST & \\
\hline CHEMBL1480195 & 688620 & 4.95 & 5.0739 & TRN & \\
\hline CHEMBL1423219 & 688620 & 5.0 & 5.2754 & TRN & \\
\hline CHEMBL3189891 & 688620 & 5.1 & 5.087 & TRN & \\
\hline CHEMBL1605843 & 688620 & 5.25 & 5.2188 & TRN & \\
\hline CHEMBL1501302 & 688620 & 4.7 & 4.9116 & TRN & \\
\hline
\end{tabular}




\begin{tabular}{|c|c|c|c|c|}
\hline \multicolumn{5}{|c|}{ Supplemental Table S2.txt } \\
\hline CHEMBL1580073 & 688620 & 5.25 & 4.9843 & TST \\
\hline CHEMBL1547570 & 688620 & 4.95 & 5.2107 & TRN \\
\hline CHEMBL1611083 & 688620 & 5.05 & 5.0984 & TRN \\
\hline CHEMBL1351877 & 688620 & 4.9 & 4.8903 & TRN \\
\hline CHEMBL1412237 & 688620 & 4.9 & 4.644 & TRN \\
\hline CHEMBL1522746 & 688620 & 5.7 & 5.518 & TRN \\
\hline CHEMBL1469493 & 688620 & 5.75 & 5.5286 & TRN \\
\hline CHEMBL1525784 & 688620 & 4.9 & 4.8542 & TRN \\
\hline CHEMBL1401459 & 688620 & 4.95 & 4.961 & TRN \\
\hline CHEMBL1322204 & 688620 & 4.7 & 4.9737 & TRN \\
\hline CHEMBL1588566 & 688620 & 5.15 & 5.4637 & TRN \\
\hline CHEMBL1532650 & 688620 & 5.0 & 4.8313 & TRN \\
\hline CHEMBL1405286 & 688620 & 4.8 & 4.6526 & TST \\
\hline CHEMBL1362793 & 688620 & 4.45 & 5.1082 & TRN \\
\hline CHEMBL1968327 & 688620 & 4.6 & 4.9169 & TRN \\
\hline CHEMBL1388875 & 688620 & 4.5 & 5.0794 & TRN \\
\hline CHEMBL1397395 & 688620 & 6.0 & 5.7581 & TRN \\
\hline CHEMBL1994635 & 688620 & 4.85 & 5.2223 & TRN \\
\hline CHEMBL1410134 & 688620 & 5.6 & 5.1683 & TST \\
\hline CHEMBL1576297 & 688620 & 5.0 & 4.9554 & TRN \\
\hline CHEMBL1503017 & 688620 & 5.4 & 4.7239 & TST \\
\hline CHEMBL3193035 & 688620 & 5.05 & 5.074 & TRN \\
\hline CHEMBL1622981 & 688620 & 4.45 & 4.9158 & TST \\
\hline CHEMBL1503106 & 688620 & 4.8 & 5.0256 & TRN \\
\hline CHEMBL3197345 & 688620 & 5.35 & 4.9439 & TRN \\
\hline CHEMBL1497232 & 688620 & 4.6 & 5.0037 & TRN \\
\hline CHEMBL1586760 & 688620 & 4.65 & 5.0273 & TRN \\
\hline CHEMBL 3196840 & 688620 & 5.0 & 4.7666 & TRN \\
\hline CHEMBL1417964 & 688620 & 4.45 & 5.1141 & TST \\
\hline CHEMBL1431474 & 688620 & 4.45 & 4.8759 & TRN \\
\hline CHEMBL1352884 & 688620 & 5.05 & 4.9958 & TST \\
\hline CHEMBL1360207 & 688620 & 5.65 & 5.3688 & TRN \\
\hline CHEMBL1580923 & 688620 & 4.9 & 4.9989 & TRN \\
\hline CHEMBL1428872 & 688620 & 5.65 & 5.0329 & TRN \\
\hline CHEMBL1420139 & 688620 & 5.35 & 5.1697 & TRN \\
\hline CHEMBL1467649 & 688620 & 6.25 & 5.2121 & TRN \\
\hline CHEMBL1541007 & 688620 & 4.9 & 4.8272 & TST \\
\hline CHEMBL1446331 & 688620 & 4.45 & 4.8593 & TRN \\
\hline CHEMBL1511854 & 688620 & 4.95 & 5.1305 & TRN \\
\hline CHEMBL3198616 & 688620 & 4.75 & 5.0529 & TRN \\
\hline CHEMBL1311801 & 688620 & 5.85 & 6.1001 & TRN \\
\hline CHEMBL1384454 & 688620 & 4.55 & 5.06 & TST \\
\hline CHEMBL1426404 & 688620 & 4.95 & 5.0491 & TST \\
\hline CHEMBL1312666 & 688620 & 4.9 & 5.0594 & TRN \\
\hline CHEMBL1584683 & 688620 & 4.95 & 4.8994 & TST \\
\hline CHEMBL548017 & 688620 & 4.45 & 4.9965 & TRN \\
\hline CHEMBL1966151 & 688620 & 5.85 & 5.5565 & TRN \\
\hline CHEMBL1415826 & 688620 & 4.95 & 5.0969 & TRN \\
\hline
\end{tabular}




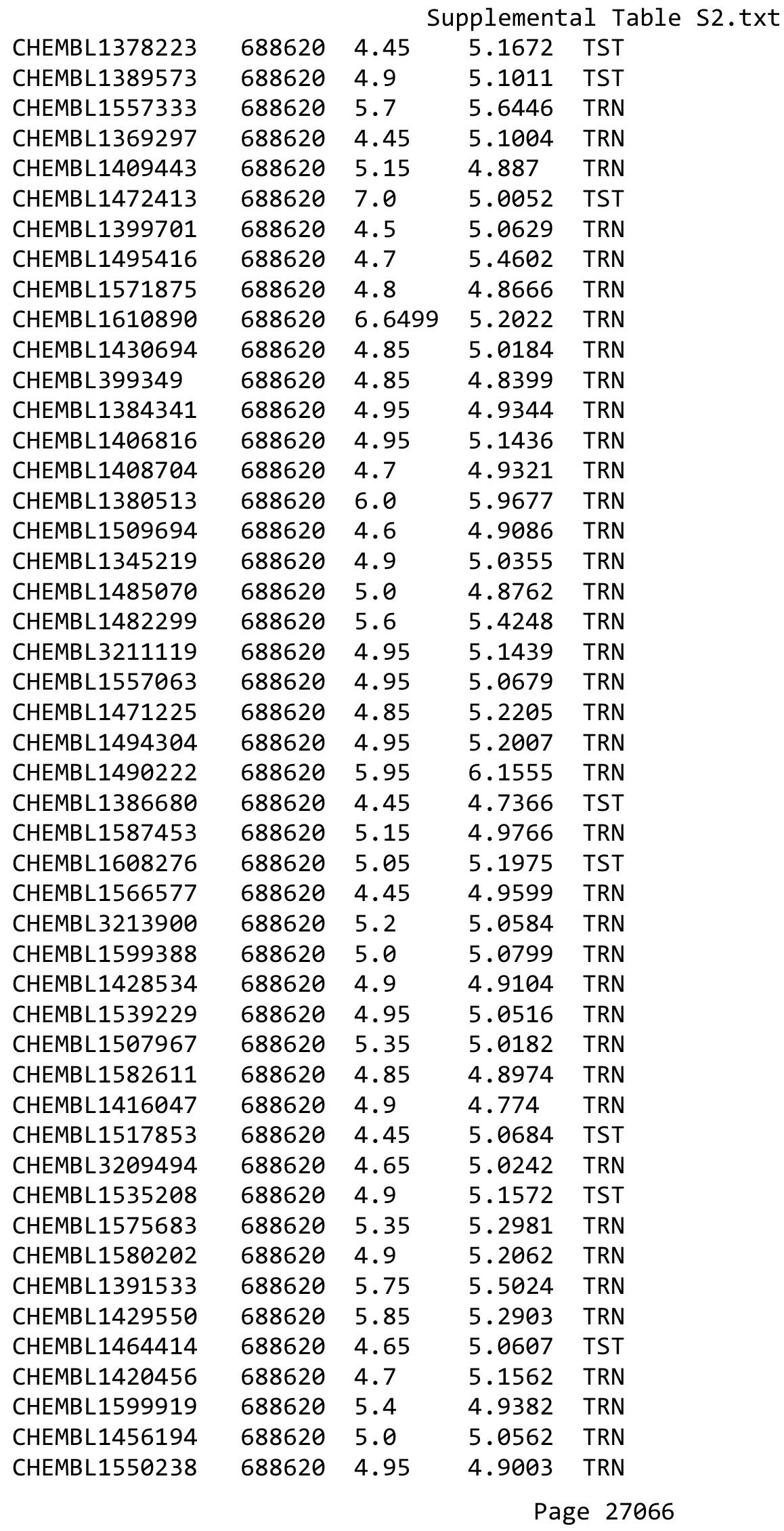




\begin{tabular}{|c|c|c|c|c|c|}
\hline \\
\hline CHEMBL1547758 & 688620 & 4.9 & 5.2373 & TST & \\
\hline CHEMBL1492937 & 688620 & 4.95 & 4.8203 & TRN & \\
\hline CHEMBL1561727 & 688620 & 4.45 & 5.096 & TRN & \\
\hline CHEMBL3191726 & 688620 & 5.5 & 5.0934 & TRN & \\
\hline CHEMBL1609758 & 688620 & 5.45 & 4.9613 & TST & \\
\hline CHEMBL1423731 & 688620 & 4.7 & 5.0659 & TST & \\
\hline CHEMBL3190274 & 688620 & 5.15 & 4.9798 & TRN & \\
\hline CHEMBL1466182 & 688620 & 5.1 & 5.0687 & TRN & \\
\hline CHEMBL3214205 & 688620 & 5.05 & 4.9222 & TRN & \\
\hline CHEMBL1373979 & 688620 & 4.9 & 5.065 & TRN & \\
\hline CHEMBL1483623 & 688620 & 4.65 & 5.1394 & TRN & \\
\hline CHEMBL 3192542 & 688620 & 5.0 & 5.1737 & TRN & \\
\hline CHEMBL1469054 & 688620 & 4.8 & 5.1522 & TRN & \\
\hline CHEMBL1383786 & 688620 & 4.95 & 5.0372 & TRN & \\
\hline CHEMBL 2004739 & 688620 & 4.55 & 5.1525 & TST & \\
\hline CHEMBL383041 & 688620 & 4.7 & 4.8923 & TST & \\
\hline CHEMBL1318987 & 688620 & 4.7 & 5.0453 & TST & \\
\hline CHEMBL1421445 & 688620 & 5.2 & 5.3171 & TRN & \\
\hline CHEMBL1576686 & 688620 & 6.05 & 5.046 & TRN & \\
\hline CHEMBL1555879 & 688620 & 6.2 & 4.9141 & TRN & \\
\hline CHEMBL1307228 & 688620 & 4.45 & 5.0088 & TRN & \\
\hline CHEMBL1519758 & 688620 & 4.45 & 5.3245 & TRN & \\
\hline CHEMBL1495174 & 688620 & 5.85 & 5.185 & TRN & \\
\hline CHEMBL3209804 & 688620 & 5.4 & 5.1156 & TRN & \\
\hline CHEMBL1412617 & 688620 & 4.9 & 5.0968 & TRN & \\
\hline CHEMBL1302183 & 688620 & 4.45 & 5.02800 & 00000000005 & TRN \\
\hline CHEMBL1470158 & 688620 & 5.45 & 5.364 & TRN & \\
\hline CHEMBL1580187 & 688620 & 4.45 & 5.2904 & TST & \\
\hline CHEMBL3211937 & 688620 & 5.0 & 5.0494 & TRN & \\
\hline CHEMBL1459303 & 688620 & 4.45 & 4.9468 & TST & \\
\hline CHEMBL1495884 & 688620 & 5.1 & 5.1643 & TST & \\
\hline CHEMBL1520824 & 688620 & 4.7 & 5.1741 & TRN & \\
\hline CHEMBL1336716 & 688620 & 4.45 & 5.2348 & TRN & \\
\hline CHEMBL1524357 & 688620 & 5.35 & 5.1598 & TRN & \\
\hline CHEMBL1464087 & 688620 & 4.75 & 4.8446 & TRN & \\
\hline CHEMBL1539898 & 688620 & 4.8 & 5.0156 & TST & \\
\hline CHEMBL1511269 & 688620 & 4.65 & 5.0056 & TRN & \\
\hline CHEMBL1517034 & 688620 & 4.95 & 5.0808 & TRN & \\
\hline CHEMBL1464105 & 688620 & 4.8 & 5.0111 & TRN & \\
\hline CHEMBL1478525 & 688620 & 4.95 & 4.8237 & TRN & \\
\hline CHEMBL1447872 & 688620 & 4.55 & 4.5757 & TRN & \\
\hline CHEMBL1338297 & 688620 & 4.45 & 4.9593 & TRN & \\
\hline CHEMBL1438626 & 688620 & 5.0 & 4.9737 & TRN & \\
\hline CHEMBL1352016 & 688620 & 4.95 & 4.768 & TST & \\
\hline CHEMBL1318480 & 688620 & 4.75 & 4.9955 & TRN & \\
\hline CHEMBL3213935 & 688620 & 4.45 & 4.918 & TRN & \\
\hline CHEMBL1561232 & 688620 & 4.8 & 5.0388 & TRN & \\
\hline CHEMBL1360061 & 688620 & 5.2 & 4.9197 & TST & \\
\hline
\end{tabular}




\begin{tabular}{|c|c|c|c|c|c|}
\hline \multicolumn{6}{|c|}{ Supplemental Table s2.txt } \\
\hline CHEMBL1479654 & 688620 & 4.7 & 5.0313 & TST & \\
\hline CHEMBL1552997 & 688620 & 4.45 & 4.8524 & TST & \\
\hline CHEMBL1428237 & 688620 & 4.85 & 4.8498 & TRN & \\
\hline CHEMBL516699 & 688620 & 6.6 & 4.9805 & TST & \\
\hline CHEMBL1519140 & 688620 & 6.35 & 4.8833 & TRN & \\
\hline CHEMBL1300893 & 688620 & 4.95 & 5.1079 & TST & \\
\hline CHEMBL1311985 & 688620 & 4.8 & 4.9446 & TRN & \\
\hline CHEMBL1378921 & 688620 & 4.95 & 4.8708 & TRN & \\
\hline CHEMBL3199013 & 688620 & 6.35 & 5.9509 & TRN & \\
\hline CHEMBL1605244 & 688620 & 4.9 & 4.8225 & TRN & \\
\hline CHEMBL1485676 & 688620 & 4.8 & 4.949 & TST & \\
\hline CHEMBL1317358 & 688620 & 4.45 & 4.9306 & TRN & \\
\hline CHEMBL3192701 & 688620 & 5.2 & 5.136 & TRN & \\
\hline CHEMBL1367263 & 688620 & 4.45 & 5.0445 & TST & \\
\hline CHEMBL1443262 & 688620 & 6.15 & 5.9355 & TRN & \\
\hline CHEMBL1517964 & 688620 & 4.7 & 4.8842 & TST & \\
\hline CHEMBL1459658 & 688620 & 8.8861 & 4.1881 & TRN & \\
\hline CHEMBL1414188 & 688620 & 5.2 & 4.6436 & TRN & \\
\hline CHEMBL1463699 & 688620 & 4.45 & 4.7633 & TST & \\
\hline CHEMBL1578324 & 688620 & 4.8 & 4.651 & TRN & \\
\hline CHEMBL1344694 & 688620 & 4.8 & 5.25899 & 99999999995 & TST \\
\hline CHEMBL1570812 & 688620 & 4.9 & 4.9162 & TRN & \\
\hline CHEMBL1213045 & 688620 & 5.45 & 5.0777 & TRN & \\
\hline CHEMBL1430723 & 688620 & 6.8 & 5.3086 & TRN & \\
\hline CHEMBL1572347 & 688620 & 4.95 & 5.0297 & TRN & \\
\hline CHEMBL3214133 & 688620 & 5.45 & 5.1811 & TST & \\
\hline CHEMBL1338395 & 688620 & 4.8 & 4.8511 & TRN & \\
\hline CHEMBL3199372 & 688620 & 5.1 & 5.1035 & TRN & \\
\hline CHEMBL1598989 & 688620 & 4.9 & 5.1374 & TRN & \\
\hline CHEMBL1496284 & 688620 & 4.45 & 5.0916 & TST & \\
\hline CHEMBL1303809 & 688620 & 5.1 & 5.1 & TST & \\
\hline CHEMBL1330039 & 688620 & 5.3 & 5.0539 & TRN & \\
\hline CHEMBL1370683 & 688620 & 6.0 & 5.0888 & TRN & \\
\hline CHEMBL1482387 & 688620 & 6.5 & 6.4651 & TRN & \\
\hline CHEMBL1500404 & 688620 & 4.45 & 5.1969 & TRN & \\
\hline CHEMBL1506996 & 688620 & 4.75 & 5.0207 & TRN & \\
\hline CHEMBL1346621 & 688620 & 5.5 & 4.8069 & TRN & \\
\hline CHEMBL1545664 & 688620 & 6.1 & 5.8519 & TRN & \\
\hline CHEMBL3191902 & 688620 & 5.9 & 4.9311 & TST & \\
\hline CHEMBL1393096 & 688620 & 4.85 & 5.0109 & TRN & \\
\hline CHEMBL1339373 & 688620 & 4.65 & 4.8879 & TST & \\
\hline CHEMBL1543054 & 688620 & 5.0 & 4.923 & TRN & \\
\hline CHEMBL1489471 & 688620 & 4.85 & 5.3932 & TRN & \\
\hline CHEMBL1477471 & 688620 & 4.95 & 5.1342 & TRN & \\
\hline CHEMBL32147 & 688620 & 4.45 & 4.8298 & TRN & \\
\hline CHEMBL1358777 & 688620 & 4.45 & 5.4316 & TST & \\
\hline CHEMBL1414465 & 688620 & 4.55 & 4.9093 & TRN & \\
\hline CHEMBL1528947 & 688620 & 4.7 & 5.0542 & TRN & \\
\hline
\end{tabular}




\begin{tabular}{|c|c|c|c|c|c|}
\hline \multicolumn{6}{|c|}{ Supplemental Table S2.txt } \\
\hline CHEMBL1406161 & 688620 & 4.7 & 4.9449 & TRN & \\
\hline CHEMBL1423282 & 688620 & 5.5 & 5.0015 & TRN & \\
\hline CHEMBL1595632 & 688620 & 6.15 & 5.7294 & TRN & \\
\hline CHEMBL1441833 & 688620 & 5.55 & 5.0636 & TRN & \\
\hline CHEMBL1440761 & 688620 & 4.45 & 4.8691 & TST & \\
\hline CHEMBL1493456 & 688620 & 4.7 & 4.9355 & TST & \\
\hline CHEMBL1508248 & 688620 & 5.6 & 5.0048 & TST & \\
\hline CHEMBL1417800 & 688620 & 6.3 & 5.0345 & TRN & \\
\hline CHEMBL1381567 & 688620 & 4.7 & 4.8363 & TRN & \\
\hline CHEMBL1597561 & 688620 & 4.85 & 5.4177 & TRN & \\
\hline CHEMBL1529903 & 688620 & 4.6 & 5.1647 & TRN & \\
\hline CHEMBL1588265 & 688620 & 6.1 & 5.1925 & TRN & \\
\hline CHEMBL1540246 & 688620 & 4.8 & 5.0022 & TRN & \\
\hline CHEMBL1453187 & 688620 & 5.25 & 5.0929 & TST & \\
\hline CHEMBL3199427 & 688620 & 4.75 & 5.3835 & TRN & \\
\hline CHEMBL1360232 & 688620 & 4.75 & 4.9053 & TRN & \\
\hline CHEMBL1544862 & 688620 & 4.45 & 5.0786 & TRN & \\
\hline CHEMBL1364933 & 688620 & 4.95 & 4.91100 & 00000000005 & TRN \\
\hline CHEMBL1529494 & 688620 & 4.85 & 5.0234 & TRN & \\
\hline CHEMBL1546288 & 688620 & 4.95 & 5.2022 & TST & \\
\hline CHEMBL3196616 & 688620 & 4.9 & 5.0456 & TRN & \\
\hline CHEMBL1350497 & 688620 & 5.3 & 4.9764 & TRN & \\
\hline CHEMBL1379684 & 688620 & 5.9 & 5.688 & TRN & \\
\hline CHEMBL1327971 & 688620 & 5.05 & 5.0194 & TRN & \\
\hline CHEMBL1478473 & 688620 & 5.0 & 5.1348 & TRN & \\
\hline CHEMBL3196308 & 688620 & 4.9 & 4.8716 & TRN & \\
\hline CHEMBL1507111 & 688620 & 4.8 & 5.0933 & TRN & \\
\hline CHEMBL1589267 & 688620 & 6.05 & 5.8482 & TRN & \\
\hline CHEMBL3212016 & 688620 & 5.0 & 5.1945 & TRN & \\
\hline CHEMBL1504867 & 688620 & 5.65 & 4.829 & TRN & \\
\hline CHEMBL3199234 & 688620 & 6.4 & 5.7129 & TRN & \\
\hline CHEMBL1449742 & 688620 & 5.3 & 5.2837 & TRN & \\
\hline CHEMBL3198074 & 688620 & 5.0 & 4.6534 & TRN & \\
\hline CHEMBL1320151 & 688620 & 4.6 & 4.98300 & 20000000005 & TST \\
\hline CHEMBL1564220 & 688620 & 4.45 & 4.9456 & TRN & \\
\hline CHEMBL1423038 & 688620 & 4.9 & 4.8053 & TRN & \\
\hline CHEMBL3212312 & 688620 & 5.05 & 5.2059 & TRN & \\
\hline CHEMBL1581527 & 688620 & 4.8 & 5.1524 & TST & \\
\hline CHEMBL1334670 & 688620 & 4.95 & 4.8962 & TST & \\
\hline CHEMBL 2000259 & 688620 & 4.45 & 4.8702 & TST & \\
\hline CHEMBL1302585 & 688620 & 5.55 & 4.9457 & TRN & \\
\hline CHEMBL1972638 & 688620 & 5.2 & 5.2328 & TST & \\
\hline CHEMBL1524045 & 688620 & 4.45 & 5.0176 & TRN & \\
\hline CHEMBL1429984 & 688620 & 4.9 & 4.9268 & TRN & \\
\hline CHEMBL1492909 & 688620 & 4.5 & 4.954 & TRN & \\
\hline CHEMBL1539409 & 688620 & 5.85 & 5.7425 & TRN & \\
\hline CHEMBL3197896 & 688620 & 4.6 & 5.0892 & TRN & \\
\hline CHEMBL1546660 & 688620 & 5.7 & 5.2424 & TRN & \\
\hline
\end{tabular}




\begin{tabular}{|c|c|c|c|c|c|}
\hline \multicolumn{6}{|c|}{ Supplemental Table S2.txt } \\
\hline CHEMBL1332635 & 688620 & 6.45 & 4.9673 & TST & \\
\hline CHEMBL1374305 & 688620 & 4.75 & 4.9095 & TRN & \\
\hline CHEMBL1524657 & 688620 & 4.45 & 4.97 & TST & \\
\hline CHEMBL1301885 & 688620 & 5.6 & 4.9544 & TRN & \\
\hline CHEMBL1386630 & 688620 & 6.35 & 5.5698 & TRN & \\
\hline CHEMBL1419556 & 688620 & 4.95 & 4.9799 & TST & \\
\hline CHEMBL1312161 & 688620 & 4.5 & 4.8572 & TRN & \\
\hline CHEMBL1502358 & 688620 & 5.4 & 4.9991 & TST & \\
\hline CHEMBL1306004 & 688620 & 4.8 & 5.0065 & TST & \\
\hline CHEMBL1607268 & 688620 & 5.85 & 5.0481 & TRN & \\
\hline CHEMBL1501940 & 688620 & 4.8 & 5.1316 & TRN & \\
\hline CHEMBL1606795 & 688620 & 4.7 & 5.0675 & TST & \\
\hline CHEMBL1582553 & 688620 & 5.75 & 4.992 & TRN & \\
\hline CHEMBL1331181 & 688620 & 5.05 & 5.2842 & TRN & \\
\hline CHEMBL1530433 & 688620 & 4.45 & 4.9398 & TST & \\
\hline CHEMBL3208692 & 688620 & 5.5 & 5.1953 & TRN & \\
\hline CHEMBL1587205 & 688620 & 5.0 & 4.8117 & TRN & \\
\hline CHEMBL3208442 & 688620 & 5.35 & 4.9603 & TST & \\
\hline CHEMBL1300212 & 688620 & 4.75 & 5.0247 & TRN & \\
\hline CHEMBL1491255 & 688620 & 4.95 & 5.0138 & TST & \\
\hline CHEMBL1439470 & 688620 & 6.9 & 4.95100 & 00000000005 & TRN \\
\hline CHEMBL1377385 & 688620 & 5.0 & 5.1554 & TRN & \\
\hline CHEMBL66620 & 688620 & 5.55 & 5.4603 & TRN & \\
\hline CHEMBL1412556 & 688620 & 4.8 & 4.8454 & TST & \\
\hline CHEMBL1304630 & 688620 & 4.8 & 5.007 & TST & \\
\hline CHEMBL1399547 & 688620 & 5.55 & 5.0276 & TRN & \\
\hline CHEMBL1385055 & 688620 & 4.9 & 5.0658 & TST & \\
\hline CHEMBL1544987 & 688620 & 5.55 & 5.1418 & TRN & \\
\hline CHEMBL1423489 & 688620 & 4.75 & 5.1001 & TRN & \\
\hline CHEMBL1517825 & 688620 & 4.95 & 4.9303 & TRN & \\
\hline CHEMBL 3194277 & 688620 & 4.45 & 4.9072 & TRN & \\
\hline CHEMBL1346786 & 688620 & 7.1002 & 5.0665 & TRN & \\
\hline CHEMBL1448945 & 688620 & 4.45 & 4.9683 & TRN & \\
\hline CHEMBL 1438741 & 688620 & 6.15 & 5.0212 & TRN & \\
\hline CHEMBL378104 & 688620 & 5.05 & 5.0079 & TRN & \\
\hline CHEMBL1480817 & 688620 & 4.85 & 5.0722 & TRN & \\
\hline CHEMBL1612483 & 688620 & 5.35 & 5.2427 & TRN & \\
\hline CHEMBL1541903 & 688620 & 5.1 & 4.9867 & TRN & \\
\hline CHEMBL1387867 & 688620 & 5.15 & 4.9557 & TRN & \\
\hline CHEMBL1478094 & 688620 & 4.45 & 4.9993 & TST & \\
\hline CHEMBL1322419 & 688620 & 4.75 & 4.7784 & TRN & \\
\hline CHEMBL1973626 & 688620 & 7.0501 & 5.5186 & TRN & \\
\hline CHEMBL1303670 & 688620 & 5.0 & 4.8663 & TRN & \\
\hline CHEMBL1548087 & 688620 & 4.65 & 5.0393 & TST & \\
\hline CHEMBL1333149 & 688620 & 4.8 & 5.1195 & TRN & \\
\hline CHEMBL1474684 & 688620 & 4.45 & 4.9867 & TST & \\
\hline CHEMBL3199766 & 688620 & 4.45 & 5.3206 & TRN & \\
\hline CHEMBL3195411 & 688620 & 5.55 & 5.1756 & TRN & \\
\hline
\end{tabular}




\begin{tabular}{|c|c|c|c|c|c|}
\hline \\
\hline CHEMBL3191296 & 688620 & 5.3 & 4.9297 & TRN & \\
\hline CHEMBL1388566 & 688620 & 5.2 & 5.2393 & TRN & \\
\hline CHEMBL1309113 & 688620 & 5.05 & 5.3321 & TRN & \\
\hline CHEMBL1610219 & 688620 & 5.95 & 5.5637 & TST & \\
\hline CHEMBL1454793 & 688620 & 4.45 & 4.8299 & TRN & \\
\hline CHEMBL3190041 & 688620 & 5.05 & 4.6688 & TST & \\
\hline CHEMBL1377915 & 688620 & 5.7 & 5.4482 & TRN & \\
\hline CHEMBL410355 & 688620 & 5.4 & 5.0506 & TST & \\
\hline CHEMBL1585372 & 688620 & 6.3 & 5.0716 & TST & \\
\hline CHEMBL1525518 & 688620 & 5.95 & 5.2638 & TRN & \\
\hline CHEMBL1407661 & 688620 & 4.95 & 4.9808 & TST & \\
\hline CHEMBL1565483 & 688620 & 4.65 & 4.9471 & TRN & \\
\hline CHEMBL1604622 & 688620 & 4.9 & 4.874 & TRN & \\
\hline CHEMBL1447889 & 688620 & 4.85 & 4.8747 & TRN & \\
\hline CHEMBL1392635 & 688620 & 5.1 & 5.0248 & TRN & \\
\hline CHEMBL1499545 & 688620 & 5.35 & 5.4197 & TRN & \\
\hline CHEMBL1611106 & 688620 & 5.0 & 4.9111 & TRN & \\
\hline CHEMBL3194634 & 688620 & 5.45 & 5.1303 & TRN & \\
\hline CHEMBL1453826 & 688620 & 4.45 & 5.0266 & TST & \\
\hline CHEMBL3210172 & 688620 & 4.75 & 5.1727 & TRN & \\
\hline CHEMBL1386839 & 688620 & 5.5 & 4.953 & TRN & \\
\hline CHEMBL528451 & 688620 & 5.05 & 4.7991 & TRN & \\
\hline CHEMBL1976861 & 688620 & 6.3 & 5.474 & TRN & \\
\hline CHEMBL1392359 & 688620 & 4.5 & 4.8658 & TST & \\
\hline CHEMBL1482173 & 688620 & 5.1 & 5.0022 & TRN & \\
\hline CHEMBL1420729 & 688620 & 4.55 & 5.0522 & TRN & \\
\hline CHEMBL1987082 & 688620 & 5.0 & 5.0278 & TRN & \\
\hline CHEMBL1595494 & 688620 & 8.2518 & 5.6047 & TST & \\
\hline CHEMBL1472154 & 688620 & 4.95 & 4.7827 & TRN & \\
\hline CHEMBL1366313 & 688620 & 4.45 & 4.8707 & TRN & \\
\hline CHEMBL 3145370 & 688620 & 6.5 & 5.8984 & TRN & \\
\hline CHEMBL3213936 & 688620 & 4.9 & 5.5139 & TRN & \\
\hline CHEMBL1360831 & 688620 & 4.45 & 4.8675 & TRN & \\
\hline CHEMBL3210678 & 688620 & 5.0 & 5.0276 & TRN & \\
\hline CHEMBL1970368 & 688620 & 5.35 & 5.4378 & TRN & \\
\hline CHEMBL1577613 & 688620 & 6.1 & 5.3295 & TRN & \\
\hline CHEMBL259139 & 688620 & 4.85 & 4.9253 & TST & \\
\hline CHEMBL1534021 & 688620 & 5.15 & 5.2023 & TRN & \\
\hline CHEMBL1306160 & 688620 & 4.65 & 4.9825 & TRN & \\
\hline CHEMBL3198562 & 688620 & 5.9 & 4.9778 & TRN & \\
\hline CHEMBL1401601 & 688620 & 4.7 & 4.98306 & 00000000005 & TST \\
\hline CHEMBL1374293 & 688620 & 5.2 & 5.1623 & TRN & \\
\hline CHEMBL1424580 & 688620 & 8.0506 & 4.9178 & TRN & \\
\hline CHEMBL1607801 & 688620 & 7.6003 & 6.0013 & TRN & \\
\hline CHEMBL1170612 & 688620 & 5.05 & 5.038 & TRN & \\
\hline CHEMBL1575494 & 688620 & 4.45 & 4.9556 & TRN & \\
\hline CHEMBL1461881 & 688620 & 4.85 & 5.2148 & TRN & \\
\hline CHEMBL1578287 & 688620 & 5.45 & 5.1293 & TRN & \\
\hline & & & & 27071 & \\
\hline
\end{tabular}




\begin{tabular}{|c|c|c|c|c|}
\hline \multicolumn{5}{|c|}{ Supplemental Table s2.txt } \\
\hline CHEMBL1402004 & 688620 & 5.15 & 5.1398 & TRN \\
\hline CHEMBL1587764 & 688620 & 5.5 & 5.3413 & TST \\
\hline CHEMBL1600782 & 688620 & 5.35 & 5.1707 & TRN \\
\hline CHEMBL451191 & 688620 & 5.35 & 4.9935 & TRN \\
\hline CHEMBL1329663 & 688620 & 5.55 & 4.9274 & TRN \\
\hline CHEMBL1451470 & 688620 & 5.05 & 5.0865 & TRN \\
\hline CHEMBL1420610 & 688620 & 5.65 & 5.1783 & TRN \\
\hline CHEMBL1458286 & 688620 & 4.45 & 4.7662 & TRN \\
\hline CHEMBL1388118 & 688620 & 5.4 & 4.7674 & TRN \\
\hline CHEMBL1419956 & 688620 & 4.45 & 4.9626 & TRN \\
\hline CHEMBL1976507 & 688620 & 7.0 & 6.0297 & TRN \\
\hline CHEMBL3190811 & 688620 & 5.6 & 5.2165 & TRN \\
\hline CHEMBL1508551 & 688620 & 4.95 & 4.9464 & TST \\
\hline CHEMBL1570497 & 688620 & 4.8 & 4.8871 & TST \\
\hline CHEMBL3192895 & 688620 & 5.2 & 5.0506 & TRN \\
\hline CHEMBL1432115 & 688620 & 6.25 & 5.5648 & TRN \\
\hline CHEMBL1424884 & 688620 & 6.1 & 5.09 & TST \\
\hline CHEMBL1610499 & 688620 & 4.85 & 4.769 & TRN \\
\hline CHEMBL3191122 & 688620 & 5.2 & 5.2478 & TRN \\
\hline CHEMBL3199025 & 688620 & 4.75 & 5.0612 & TRN \\
\hline CHEMBL3193836 & 688620 & 5.1 & 4.9805 & TRN \\
\hline CHEMBL3197076 & 688620 & 6.05 & 5.6493 & TST \\
\hline CHEMBL1450107 & 688620 & 5.4 & 5.2727 & TST \\
\hline CHEMBL393136 & 688620 & 4.45 & 4.8693 & TRN \\
\hline CHEMBL 3210277 & 688620 & 4.95 & 5.0379 & TRN \\
\hline CHEMBL1304625 & 688620 & 4.6 & 4.9788 & TST \\
\hline CHEMBL1310367 & 688620 & 4.95 & 4.7525 & TRN \\
\hline CHEMBL1443946 & 688620 & 5.1 & 5.1693 & TRN \\
\hline CHEMBL1423271 & 688620 & 4.9 & 4.9232 & TRN \\
\hline CHEMBL1574944 & 688620 & 4.45 & 4.8749 & TST \\
\hline CHEMBL1501375 & 688620 & 5.9 & 5.4874 & TRN \\
\hline CHEMBL1430815 & 688620 & 6.9 & 5.0183 & TRN \\
\hline CHEMBL1368700 & 688620 & 5.45 & 5.0157 & TST \\
\hline CHEMBL1458742 & 688620 & 4.45 & 5.0673 & TRN \\
\hline CHEMBL1531320 & 688620 & 5.0 & 5.3311 & TST \\
\hline CHEMBL3193885 & 688620 & 5.55 & 5.2398 & TRN \\
\hline CHEMBL1437977 & 688620 & 4.45 & 4.9473 & TST \\
\hline CHEMBL1530103 & 688620 & 4.9 & 5.0621 & TST \\
\hline CHEMBL1595905 & 688620 & 5.0 & 5.1594 & TRN \\
\hline CHEMBL1424585 & 688620 & 4.85 & 5.5211 & TRN \\
\hline CHEMBL1353157 & 688620 & 5.1 & 5.374 & TRN \\
\hline CHEMBL1514719 & 688620 & 6.15 & 4.9702 & TST \\
\hline CHEMBL1326422 & 688620 & 4.85 & 4.9323 & TST \\
\hline CHEMBL1310168 & 688620 & 4.55 & 5.0022 & TRN \\
\hline CHEMBL1611360 & 688620 & 5.5 & 5.0731 & TST \\
\hline CHEMBL1374851 & 688620 & 4.85 & 5.2879 & TRN \\
\hline CHEMBL1967436 & 688620 & 5.6 & 4.8825 & TRN \\
\hline CHEMBL3193682 & 688620 & 4.65 & 5.0282 & TRN \\
\hline
\end{tabular}




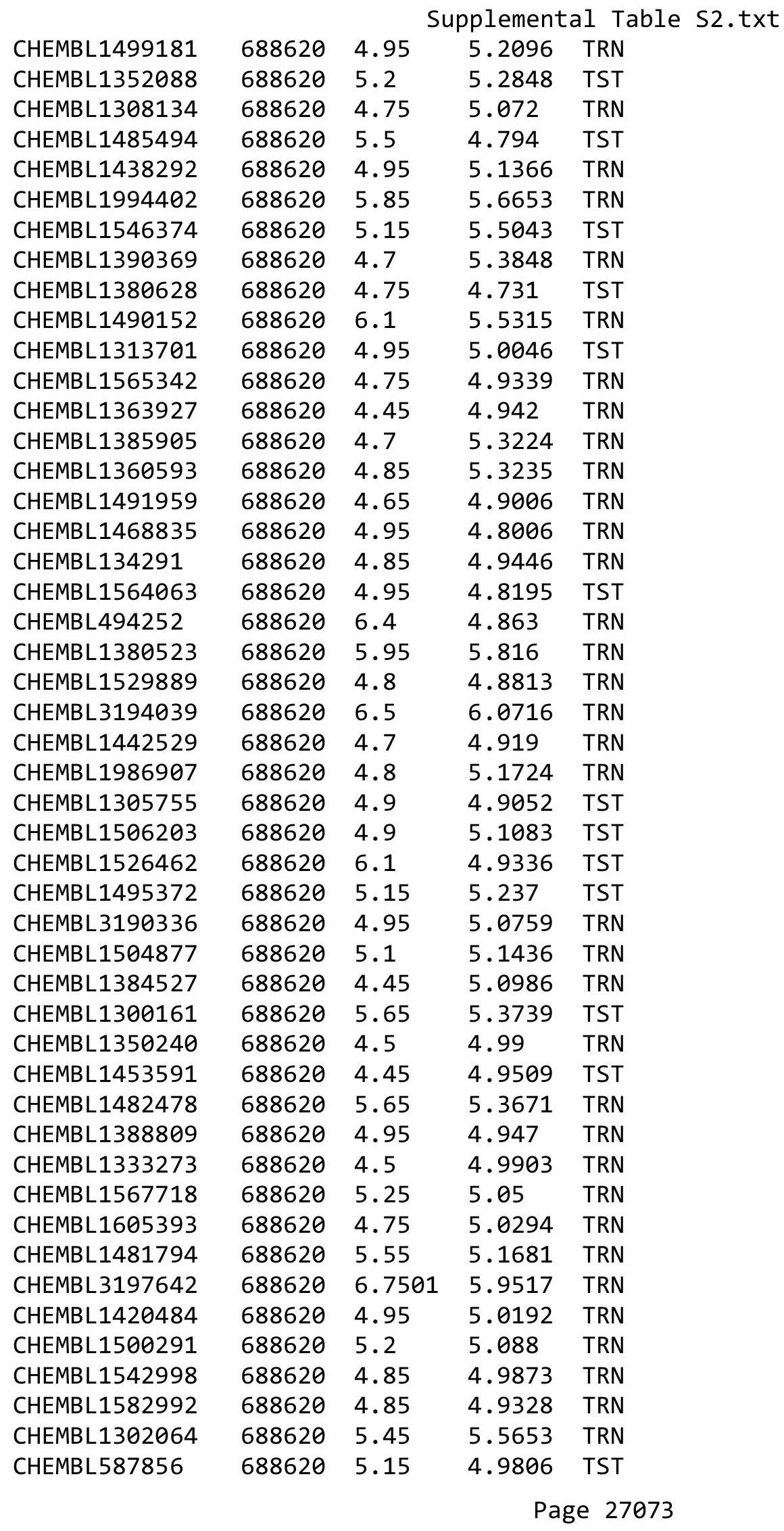




\begin{tabular}{|c|c|c|c|c|}
\hline \multicolumn{5}{|c|}{ Supplemental Table S2.txt } \\
\hline CHEMBL1411932 & 688620 & 4.95 & 4.9355 & TRN \\
\hline CHEMBL1351166 & 688620 & 4.85 & 5.0551 & TRN \\
\hline CHEMBL1530234 & 688620 & 4.5 & 5.0698 & TRN \\
\hline CHEMBL1606911 & 688620 & 4.45 & 5.0595 & TST \\
\hline CHEMBL1523087 & 688620 & 4.45 & 4.9484 & TRN \\
\hline CHEMBL1326724 & 688620 & 5.4 & 5.0522 & TRN \\
\hline CHEMBL1570603 & 688620 & 5.0 & 5.0645 & TRN \\
\hline CHEMBL1330435 & 688620 & 4.75 & 4.9531 & TST \\
\hline CHEMBL1541378 & 688620 & 5.5 & 4.9625 & TRN \\
\hline CHEMBL1604342 & 688620 & 5.4 & 5.2111 & TST \\
\hline CHEMBL 1457870 & 688620 & 5.2 & 5.0359 & TRN \\
\hline CHEMBL1470495 & 688620 & 5.1 & 5.1424 & TRN \\
\hline CHEMBL236267 & 688620 & 5.35 & 5.4864 & TRN \\
\hline CHEMBL1547470 & 688620 & 6.1 & 5.8022 & TRN \\
\hline CHEMBL1311416 & 688620 & 4.9 & 4.7382 & TRN \\
\hline CHEMBL1432130 & 688620 & 4.8 & 5.1857 & TST \\
\hline CHEMBL 3190071 & 688620 & 4.8 & 4.9306 & TRN \\
\hline CHEMBL1343057 & 688620 & 4.6 & 4.9832 & TST \\
\hline CHEMBL1303272 & 688620 & 5.5 & 5.0614 & TST \\
\hline CHEMBL1370428 & 688620 & 4.75 & 4.9479 & TRN \\
\hline CHEMBL1408871 & 688620 & 5.0 & 5.0379 & TRN \\
\hline CHEMBL103769 & 688620 & 4.9 & 5.1953 & TST \\
\hline CHEMBL1596397 & 688620 & 5.0 & 4.9845 & TRN \\
\hline CHEMBL1503059 & 688620 & 4.45 & 5.0801 & TRN \\
\hline CHEMBL1348237 & 688620 & 4.65 & 4.8192 & TRN \\
\hline CHEMBL1545909 & 688620 & 5.65 & 5.0062 & TST \\
\hline CHEMBL1426402 & 688620 & 5.25 & 4.9856 & TRN \\
\hline CHEMBL 3189808 & 688620 & 6.05 & 5.6842 & TRN \\
\hline CHEMBL 3199751 & 688620 & 4.6 & 4.992 & TRN \\
\hline CHEMBL1382312 & 688620 & 5.35 & 5.069 & TRN \\
\hline CHEMBL1600892 & 688620 & 5.15 & 4.9199 & TST \\
\hline CHEMBL1457688 & 688620 & 6.5 & 5.5354 & TRN \\
\hline CHEMBL3189471 & 688620 & 5.0 & 5.1541 & TRN \\
\hline CHEMBL1435865 & 688620 & 4.8 & 4.9939 & TST \\
\hline CHEMBL1454279 & 688620 & 4.45 & 4.8796 & TRN \\
\hline CHEMBL 3208514 & 688620 & 6.5 & 5.2466 & TRN \\
\hline CHEMBL1404559 & 688620 & 4.45 & 4.6371 & TRN \\
\hline CHEMBL1411206 & 688620 & 4.75 & 4.9608 & TRN \\
\hline CHEMBL1569732 & 688620 & 4.45 & 4.8494 & TRN \\
\hline CHEMBL1299783 & 688620 & 4.5 & 4.897 & TRN \\
\hline CHEMBL1584440 & 688620 & 4.9 & 5.1201 & TRN \\
\hline CHEMBL 1467940 & 688620 & 5.2 & 5.0427 & TRN \\
\hline CHEMBL1363318 & 688620 & 4.95 & 4.933 & TST \\
\hline CHEMBL1308112 & 688620 & 4.9 & 4.8904 & TRN \\
\hline CHEMBL140425 & 688620 & 6.15 & 5.5925 & TRN \\
\hline CHEMBL1404450 & 688620 & 4.95 & 5.0071 & TST \\
\hline CHEMBL1541649 & 688620 & 5.4 & 5.4069 & TRN \\
\hline CHEMBL1525615 & 688620 & 4.5 & 4.8376 & TRN \\
\hline
\end{tabular}




\begin{tabular}{|c|c|c|c|c|c|}
\hline \multicolumn{6}{|c|}{ Supplemental Table S2.txt } \\
\hline CHEMBL1351907 & 688620 & 5.85 & 5.1335 & TRN & \\
\hline CHEMBL1423935 & 688620 & 5.35 & 4.9957 & TRN & \\
\hline CHEMBL1575211 & 688620 & 4.9 & 5.148 & TRN & \\
\hline CHEMBL1430800 & 688620 & 5.3 & 5.511 & TRN & \\
\hline CHEMBL1425986 & 688620 & 4.8 & 4.8774 & TRN & \\
\hline CHEMBL1397653 & 688620 & 4.85 & 5.0889 & TRN & \\
\hline CHEMBL1508591 & 688620 & 4.75 & 5.0112 & TST & \\
\hline CHEMBL1421264 & 688620 & 4.45 & 4.9679 & TRN & \\
\hline CHEMBL1420318 & 688620 & 5.6 & 4.9243 & TRN & \\
\hline CHEMBL1383049 & 688620 & 4.95 & 5.2848 & TRN & \\
\hline CHEMBL1312712 & 688620 & 5.05 & 5.4038 & TRN & \\
\hline CHEMBL1609077 & 688620 & 4.95 & 4.769 & TRN & \\
\hline CHEMBL580421 & 688620 & 6.0 & 5.6756 & TST & \\
\hline CHEMBL1565084 & 688620 & 4.5 & 4.8945 & TRN & \\
\hline CHEMBL1540862 & 688620 & 5.0 & 5.1745 & TRN & \\
\hline CHEMBL1521626 & 688620 & 5.2 & 4.8816 & TST & \\
\hline CHEMBL1404909 & 688620 & 4.65 & 5.0887 & TRN & \\
\hline CHEMBL1386922 & 688620 & 4.45 & 5.04899 & 99999999995 & TST \\
\hline CHEMBL3196304 & 688620 & 6.35 & 5.4816 & TRN & \\
\hline CHEMBL1416097 & 688620 & 5.0 & 4.9671 & TRN & \\
\hline CHEMBL1587571 & 688620 & 5.0 & 5.1118 & TRN & \\
\hline CHEMBL1383582 & 688620 & 5.6 & 5.1354 & TRN & \\
\hline CHEMBL1424288 & 688620 & 5.9 & 5.0029 & TRN & \\
\hline CHEMBL1608195 & 688620 & 4.95 & 5.1366 & TRN & \\
\hline CHEMBL1451338 & 688620 & 4.9 & 5.1511 & TRN & \\
\hline CHEMBL1538100 & 688620 & 5.55 & 5.3574 & TRN & \\
\hline CHEMBL1388352 & 688620 & 7.0501 & 4.8814 & TRN & \\
\hline CHEMBL1481337 & 688620 & 4.8 & 4.9265 & TRN & \\
\hline CHEMBL1362259 & 688620 & 4.45 & 4.9966 & TRN & \\
\hline CHEMBL1562964 & 688620 & 4.85 & 5.16700 & 2000000001 & TRN \\
\hline CHEMBL1533037 & 688620 & 4.85 & 5.2471 & TRN & \\
\hline CHEMBL1579258 & 688620 & 6.1 & 5.4357 & TRN & \\
\hline CHEMBL3192753 & 688620 & 4.95 & 5.0102 & TRN & \\
\hline CHEMBL1464642 & 688620 & 4.8 & 4.8901 & TRN & \\
\hline CHEMBL1328240 & 688620 & 4.95 & 5.2087 & TRN & \\
\hline CHEMBL1534840 & 688620 & 4.9 & 5.1264 & TRN & \\
\hline CHEMBL1461477 & 688620 & 4.7 & 5.33200 & 0000000001 & TRN \\
\hline CHEMBL1505014 & 688620 & 4.9 & 5.2392 & TST & \\
\hline CHEMBL1504701 & 688620 & 5.2 & 5.5957 & TRN & \\
\hline CHEMBL3195238 & 688620 & 6.7501 & 5.7899 & TRN & \\
\hline CHEMBL1985759 & 688620 & 5.25 & 5.5757 & TRN & \\
\hline CHEMBL1584752 & 688620 & 4.85 & 4.8874 & TRN & \\
\hline CHEMBL1497874 & 688620 & 4.75 & 4.8821 & TST & \\
\hline CHEMBL3193078 & 688620 & 4.85 & 5.0403 & TRN & \\
\hline CHEMBL1520368 & 688620 & 4.45 & 4.993 & TST & \\
\hline CHEMBL1526689 & 688620 & 5.45 & 4.9732 & TRN & \\
\hline CHEMBL1378939 & 688620 & 4.85 & 5.0142 & TST & \\
\hline CHEMBL1335585 & 688620 & 4.85 & 5.0448 & TRN & \\
\hline
\end{tabular}




\begin{tabular}{|c|c|c|c|c|c|}
\hline \multicolumn{6}{|c|}{ Supplemental Table S2.txt } \\
\hline CHEMBL574011 & 688620 & 4.8 & 5.1303 & TRN & \\
\hline CHEMBL1444191 & 688620 & 4.45 & 4.8028 & TST & \\
\hline CHEMBL1455237 & 688620 & 4.75 & 4.9669 & TST & \\
\hline CHEMBL1533442 & 688620 & 4.75 & 4.9992 & TRN & \\
\hline CHEMBL3195027 & 688620 & 4.95 & 4.8926 & TST & \\
\hline CHEMBL1341712 & 688620 & 5.25 & 5.2016 & TRN & \\
\hline CHEMBL1313320 & 688620 & 5.65 & 5.11100 & 0000000001 & TRN \\
\hline CHEMBL1385406 & 688620 & 4.8 & 5.2651 & TRN & \\
\hline CHEMBL1359517 & 688620 & 5.4 & 4.9785 & TRN & \\
\hline CHEMBL1522542 & 688620 & 4.45 & 4.7654 & TRN & \\
\hline CHEMBL1598531 & 688620 & 5.65 & 4.8751 & TST & \\
\hline CHEMBL1579301 & 688620 & 4.85 & 4.9197 & TRN & \\
\hline CHEMBL1988857 & 688620 & 4.65 & 5.3581 & TRN & \\
\hline CHEMBL1571984 & 688620 & 5.35 & 5.1569 & TRN & \\
\hline CHEMBL1376586 & 688620 & 5.3 & 5.2758 & TRN & \\
\hline CHEMBL1411285 & 688620 & 6.3 & 5.8941 & TRN & \\
\hline CHEMBL1566459 & 688620 & 7.0 & 5.2739 & TRN & \\
\hline CHEMBL1337528 & 688620 & 6.9 & 5.2686 & TRN & \\
\hline CHEMBL1345527 & 688620 & 4.65 & 5.0471 & TRN & \\
\hline CHEMBL3189405 & 688620 & 5.65 & 5.5911 & TRN & \\
\hline CHEMBL1583867 & 688620 & 4.45 & 4.9865 & TST & \\
\hline CHEMBL1451248 & 688620 & 4.7 & 5.0894 & TST & \\
\hline CHEMBL1605027 & 688620 & 5.1 & 5.0002 & TRN & \\
\hline CHEMBL1416715 & 688620 & 4.95 & 4.9846 & TRN & \\
\hline CHEMBL1602560 & 688620 & 5.0 & 5.1472 & TRN & \\
\hline CHEMBL1505396 & 688620 & 5.05 & 4.9133 & TRN & \\
\hline CHEMBL1524940 & 688620 & 4.45 & 5.3739 & TRN & \\
\hline CHEMBL3194410 & 688620 & 5.0 & 4.9756 & TRN & \\
\hline CHEMBL1468023 & 688620 & 5.2 & 5.0 & TRN & \\
\hline CHEMBL1509104 & 688620 & 5.4 & 5.0134 & TRN & \\
\hline CHEMBL1333481 & 688620 & 4.9 & 4.8933 & TRN & \\
\hline CHEMBL1562314 & 688620 & 6.45 & 5.0154 & TRN & \\
\hline CHEMBL1527027 & 688620 & 4.5 & 4.8346 & TRN & \\
\hline CHEMBL1375251 & 688620 & 5.25 & 5.1418 & TRN & \\
\hline CHEMBL1973669 & 688620 & 6.0 & 6.1497 & TRN & \\
\hline CHEMBL1313464 & 688620 & 4.8 & 4.931 & TST & \\
\hline CHEMBL3190641 & 688620 & 4.45 & 4.8469 & TRN & \\
\hline CHEMBL1571010 & 688620 & 4.9 & 4.9964 & TRN & \\
\hline CHEMBL1348979 & 688620 & 5.1 & 4.9639 & TRN & \\
\hline CHEMBL1557015 & 688620 & 5.8 & 4.9931 & TRN & \\
\hline CHEMBL1406569 & 688620 & 4.45 & 5.1612 & TST & \\
\hline CHEMBL1361099 & 688620 & 4.95 & 4.5672 & TRN & \\
\hline CHEMBL3195648 & 688620 & 5.1 & 5.0399 & TRN & \\
\hline CHEMBL1503129 & 688620 & 4.85 & 4.9266 & TRN & \\
\hline CHEMBL1324001 & 688620 & 4.45 & 4.8736 & TST & \\
\hline CHEMBL1488586 & 688620 & 5.15 & 5.3691 & TRN & \\
\hline CHEMBL1545981 & 688620 & 4.85 & 4.94 & TST & \\
\hline CHEMBL1303946 & 688620 & 4.9 & 4.9637 & TST & \\
\hline
\end{tabular}




\begin{tabular}{|c|c|c|c|c|}
\hline \multicolumn{5}{|c|}{ Supplemental Table S2.txt } \\
\hline CHEMBL 3210480 & 688620 & 5.45 & 5.1817 & TRN \\
\hline CHEMBL1508051 & 688620 & 4.95 & 5.1268 & TST \\
\hline CHEMBL1416327 & 688620 & 4.9 & 5.164 & TST \\
\hline CHEMBL1562960 & 688620 & 5.5 & 5.4236 & TRN \\
\hline CHEMBL1567806 & 688620 & 5.0 & 5.1351 & TRN \\
\hline CHEMBL1449817 & 688620 & 4.95 & 5.0036 & TRN \\
\hline CHEMBL1413713 & 688620 & 8.301 & 5.0865 & TRN \\
\hline CHEMBL1478314 & 688620 & 5.25 & 4.9605 & TRN \\
\hline CHEMBL1968085 & 688620 & 5.85 & 5.6507 & TRN \\
\hline CHEMBL1407910 & 688620 & 4.45 & 4.827 & TRN \\
\hline CHEMBL1564165 & 688620 & 5.1 & 4.8315 & TRN \\
\hline CHEMBL1380037 & 688620 & 4.45 & 5.0677 & TRN \\
\hline CHEMBL1565111 & 688620 & 5.35 & 5.1852 & TRN \\
\hline CHEMBL1344224 & 688620 & 4.85 & 5.2195 & TRN \\
\hline CHEMBL1487852 & 688620 & 5.95 & 4.9602 & TST \\
\hline CHEMBL1301657 & 688620 & 5.0 & 5.1081 & TRN \\
\hline CHEMBL1410423 & 688620 & 4.8 & 4.9051 & TRN \\
\hline CHEMBL1343817 & 688620 & 5.3 & 5.2072 & TRN \\
\hline CHEMBL1461558 & 688620 & 4.95 & 4.8835 & TRN \\
\hline CHEMBL1391259 & 688620 & 5.7 & 5.0256 & TRN \\
\hline CHEMBL1566383 & 688620 & 4.95 & 4.9639 & TRN \\
\hline CHEMBL1541113 & 688620 & 4.9 & 5.1333 & TRN \\
\hline CHEMBL1519493 & 688620 & 5.45 & 5.5207 & TRN \\
\hline CHEMBL1347202 & 688620 & 4.65 & 4.4908 & TRN \\
\hline CHEMBL 3195583 & 688620 & 5.75 & 5.3051 & TRN \\
\hline CHEMBL1337988 & 688620 & 6.05 & 5.0119 & TRN \\
\hline CHEMBL1320080 & 688620 & 4.95 & 5.0883 & TST \\
\hline CHEMBL1397914 & 688620 & 4.9 & 4.9727 & TRN \\
\hline CHEMBL1414108 & 688620 & 4.8 & 4.846 & TRN \\
\hline CHEMBL1518248 & 688620 & 4.85 & 5.2344 & TST \\
\hline CHEMBL1440269 & 688620 & 4.5 & 5.1304 & TST \\
\hline CHEMBL1570594 & 688620 & 4.9 & 4.9974 & TRN \\
\hline CHEMBL3190809 & 688620 & 6.1 & 5.4929 & TRN \\
\hline CHEMBL1313411 & 688620 & 5.35 & 5.3529 & TRN \\
\hline CHEMBL1340370 & 688620 & 5.1 & 5.3037 & TRN \\
\hline CHEMBL1587745 & 688620 & 5.05 & 5.0003 & TST \\
\hline CHEMBL1429073 & 688620 & 4.5 & 5.2681 & TST \\
\hline CHEMBL1450631 & 688620 & 4.85 & 4.9156 & TRN \\
\hline CHEMBL1559888 & 688620 & 4.85 & 5.3278 & TST \\
\hline CHEMBL1540010 & 688620 & 4.45 & 5.0036 & TRN \\
\hline CHEMBL1344489 & 688620 & 5.6 & 5.2261 & TRN \\
\hline CHEMBL1340587 & 688620 & 4.95 & 4.9833 & TRN \\
\hline CHEMBL1346468 & 688620 & 5.6 & 5.5878 & TST \\
\hline CHEMBL1444277 & 688620 & 4.95 & 5.3073 & TRN \\
\hline CHEMBL1579833 & 688620 & 4.45 & 4.7245 & TST \\
\hline CHEMBL1544215 & 688620 & 4.75 & 4.7681 & TST \\
\hline CHEMBL1431314 & 688620 & 5.45 & 5.6797 & TRN \\
\hline CHEMBL599098 & 688620 & 4.95 & 4.9819 & TRN \\
\hline
\end{tabular}




\begin{tabular}{|c|c|c|c|c|c|}
\hline & & \multicolumn{4}{|c|}{ Supplemental Table s2.txt } \\
\hline CHEMBL1560146 & 688620 & 4.95 & 4.9467 & TST & \\
\hline CHEMBL1463349 & 688620 & 6.0 & 5.7745 & TRN & \\
\hline CHEMBL1524451 & 688620 & 4.65 & 5.2289 & TST & \\
\hline CHEMBL1381242 & 688620 & 6.25 & 6.1517 & TRN & \\
\hline CHEMBL1494526 & 688620 & 4.45 & 4.9534 & TRN & \\
\hline CHEMBL533082 & 688620 & 4.95 & 5.0156 & TRN & \\
\hline CHEMBL1410105 & 688620 & 6.95 & 4.8891 & TRN & \\
\hline CHEMBL 3195779 & 688620 & 5.95 & 6.3111 & TRN & \\
\hline CHEMBL1544156 & 688620 & 4.9 & 4.9745 & TRN & \\
\hline CHEMBL1505989 & 688620 & 5.6 & 5.0638 & TRN & \\
\hline CHEMBL1488472 & 688620 & 4.45 & 4.7714 & TRN & \\
\hline CHEMBL3191512 & 688620 & 4.45 & 5.1435 & TRN & \\
\hline CHEMBL1521964 & 688620 & 6.3 & 5.0913 & TST & \\
\hline CHEMBL1307549 & 688620 & 5.55 & 4.9244 & TRN & \\
\hline CHEMBL1426772 & 688620 & 5.95 & 4.8381 & TRN & \\
\hline CHEMBL1600901 & 688620 & 6.3 & 5.2176 & TRN & \\
\hline CHEMBL1349308 & 688620 & 4.55 & 4.9741 & TST & \\
\hline CHEMBL3190016 & 688620 & 5.4 & 5.3116 & TRN & \\
\hline CHEMBL1531720 & 688620 & 4.75 & 5.093 & TRN & \\
\hline CHEMBL1610389 & 688620 & 5.0 & 5.0281 & TST & \\
\hline CHEMBL1346913 & 688620 & 4.85 & 5.0831 & TRN & \\
\hline CHEMBL1349365 & 688620 & 4.45 & 4.8921 & TRN & \\
\hline CHEMBL1504312 & 688620 & 5.9 & 4.8443 & TRN & \\
\hline CHEMBL1417619 & 688620 & 4.6 & 5.062 & TRN & \\
\hline CHEMBL1533680 & 688620 & 4.45 & 4.9482 & TST & \\
\hline CHEMBL1370687 & 688620 & 4.45 & 4.9102 & TST & \\
\hline CHEMBL1309764 & 688620 & 5.0 & 5.3188 & TST & \\
\hline CHEMBL1463207 & 688620 & 4.5 & 5.5474 & TRN & \\
\hline CHEMBL1405423 & 688620 & 5.35 & 4.9064 & TRN & \\
\hline CHEMBL1561758 & 688620 & 6.2 & 4.9487 & TRN & \\
\hline CHEMBL132222 & 688620 & 4.5 & 5.0275 & TST & \\
\hline CHEMBL1550475 & 688620 & 5.3 & 5.1791 & TRN & \\
\hline CHEMBL1419484 & 688620 & 5.15 & 5.0906 & TRN & \\
\hline CHEMBL1595841 & 688620 & 4.45 & 4.8468 & TRN & \\
\hline CHEMBL1480264 & 688620 & 4.45 & 4.94 & TRN & \\
\hline CHEMBL 3213976 & 688620 & 4.65 & 5.0321 & TRN & \\
\hline CHEMBL1598851 & 688620 & 5.2 & 5.0953 & TST & \\
\hline CHEMBL3210384 & 688620 & 5.95 & 5.67399 & 99999999995 & TRN \\
\hline CHEMBL1364134 & 688620 & 4.65 & 5.0878 & TRN & \\
\hline CHEMBL1422794 & 688620 & 5.7 & 5.2504 & TRN & \\
\hline CHEMBL1545088 & 688620 & 5.15 & 5.0767 & TRN & \\
\hline CHEMBL1471998 & 688620 & 4.45 & 4.6643 & TRN & \\
\hline CHEMBL1612344 & 688620 & 4.9 & 5.0265 & TRN & \\
\hline CHEMBL1415683 & 688620 & 4.65 & 4.9904 & TRN & \\
\hline CHEMBL1595675 & 688620 & 4.85 & 4.9682 & TRN & \\
\hline CHEMBL1479772 & 688620 & 5.5 & 5.431 & TRN & \\
\hline CHEMBL1381958 & 688620 & 4.75 & 4.9006 & TRN & \\
\hline CHEMBL1405153 & 688620 & 4.95 & 4.9746 & TRN & \\
\hline
\end{tabular}




\begin{tabular}{|c|c|c|c|c|c|}
\hline \multicolumn{6}{|c|}{ Supplemental Table S2.txt } \\
\hline CHEMBL1439893 & 688620 & 5.3 & 5.1852 & TRN & \\
\hline CHEMBL3191794 & 688620 & 4.95 & 5.0703 & TRN & \\
\hline CHEMBL2311878 & 688620 & 5.95 & 5.6827 & TRN & \\
\hline CHEMBL1453581 & 688620 & 5.1 & 5.2105 & TRN & \\
\hline CHEMBL1341538 & 688620 & 4.55 & 4.8817 & TST & \\
\hline CHEMBL3210652 & 688620 & 4.9 & 4.9129 & TST & \\
\hline CHEMBL1384654 & 688620 & 4.45 & 5.1816 & TRN & \\
\hline CHEMBL1368627 & 688620 & 5.2 & 5.1079 & TST & \\
\hline CHEMBL1342809 & 688620 & 4.45 & 5.2735 & TST & \\
\hline CHEMBL1576867 & 688620 & 5.5 & 5.0771 & TRN & \\
\hline CHEMBL1442788 & 688620 & 5.8 & 5.3886 & TST & \\
\hline CHEMBL1523123 & 688620 & 5.0 & 5.0894 & TRN & \\
\hline CHEMBL1379161 & 688620 & 5.55 & 5.5082 & TRN & \\
\hline CHEMBL1307663 & 688620 & 5.35 & 5.0734 & TRN & \\
\hline CHEMBL1364519 & 688620 & 4.7 & 4.9492 & TRN & \\
\hline CHEMBL1471944 & 688620 & 4.85 & 5.0299 & TST & \\
\hline CHEMBL1304455 & 688620 & 4.45 & 4.9503 & TRN & \\
\hline CHEMBL1550318 & 688620 & 4.95 & 4.9602 & TST & \\
\hline CHEMBL1563821 & 688620 & 4.45 & 6.1988 & TST & \\
\hline CHEMBL1505807 & 688620 & 5.0 & 5.2723 & TST & \\
\hline CHEMBL1438914 & 688620 & 4.9 & 5.2659 & TST & \\
\hline CHEMBL1976433 & 688620 & 5.45 & 5.5945 & TRN & \\
\hline CHEMBL1558494 & 688620 & 5.65 & 5.1581 & TRN & \\
\hline CHEMBL 3194280 & 688620 & 4.45 & 4.9009 & TRN & \\
\hline CHEMBL1466498 & 688620 & 4.95 & 5.0759 & TST & \\
\hline CHEMBL1385217 & 688620 & 6.1 & 5.7266 & TST & \\
\hline CHEMBL1353662 & 688620 & 4.45 & 4.90300 & 00000000005 & TRN \\
\hline CHEMBL1612111 & 688620 & 4.45 & 4.7215 & TST & \\
\hline CHEMBL1435295 & 688620 & 4.85 & 4.8896 & TRN & \\
\hline CHEMBL1529791 & 688620 & 4.45 & 5.0043 & TST & \\
\hline CHEMBL1306875 & 688620 & 5.35 & 5.0253 & TRN & \\
\hline CHEMBL1301141 & 688620 & 5.15 & 4.9818 & TRN & \\
\hline CHEMBL1613024 & 688620 & 5.4 & 5.3555 & TRN & \\
\hline CHEMBL 2004344 & 688620 & 5.15 & 5.2315 & TRN & \\
\hline CHEMBL1510371 & 688620 & 4.45 & 4.8629 & TRN & \\
\hline CHEMBL1526189 & 688620 & 4.95 & 4.8599 & TRN & \\
\hline CHEMBL1312023 & 688620 & 4.95 & 4.9843 & TRN & \\
\hline CHEMBL3198377 & 688620 & 5.05 & 4.8718 & TRN & \\
\hline CHEMBL1579121 & 688620 & 4.7 & 5.016 & TST & \\
\hline CHEMBL1610842 & 688620 & 5.55 & 5.0678 & TRN & \\
\hline CHEMBL1337505 & 688620 & 4.75 & 5.0447 & TST & \\
\hline CHEMBL1555840 & 688620 & 4.6 & 5.3334 & TRN & \\
\hline CHEMBL3195161 & 688620 & 7.0501 & 5.8285 & TRN & \\
\hline CHEMBL1571395 & 688620 & 4.45 & 4.9085 & TST & \\
\hline CHEMBL1370293 & 688620 & 4.45 & 5.2637 & TRN & \\
\hline CHEMBL1364862 & 688620 & 5.15 & 5.2942 & TRN & \\
\hline CHEMBL3195751 & 688620 & 5.1 & 5.2657 & TRN & \\
\hline CHEMBL1599252 & 688620 & 4.9 & 5.1207 & TRN & \\
\hline
\end{tabular}




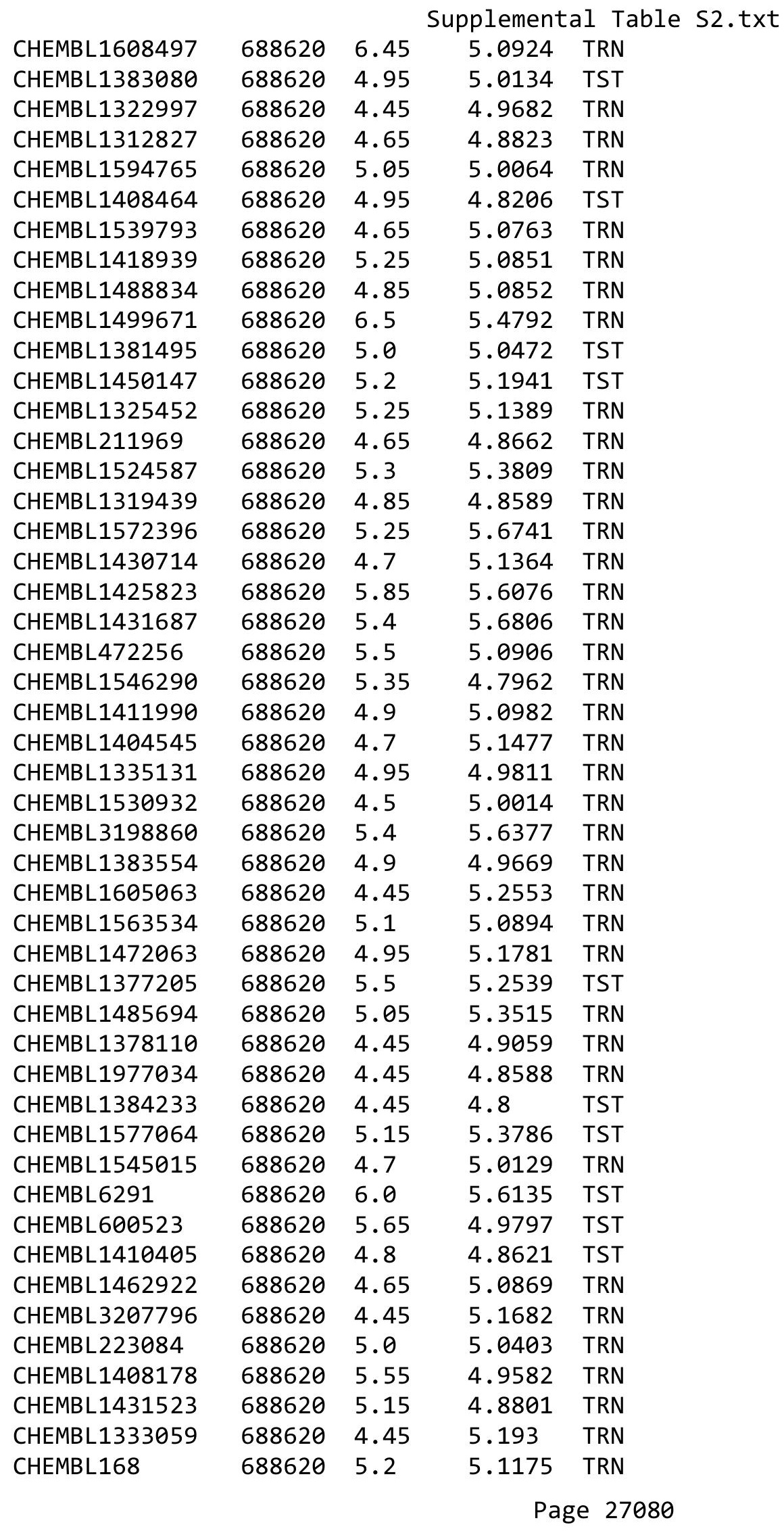




\begin{tabular}{|c|c|c|c|c|}
\hline \multicolumn{5}{|c|}{ Supplemental Table S2.txt } \\
\hline CHEMBL1349033 & 688620 & 5.0 & 4.9483 & TRN \\
\hline CHEMBL1506557 & 688620 & 4.45 & 4.9624 & TST \\
\hline CHEMBL1343131 & 688620 & 4.95 & 4.7653 & TRN \\
\hline CHEMBL1610337 & 688620 & 4.45 & 4.8027 & TRN \\
\hline CHEMBL3192192 & 688620 & 4.95 & 4.9873 & TRN \\
\hline CHEMBL1468811 & 688620 & 5.15 & 5.1837 & TRN \\
\hline CHEMBL1595553 & 688620 & 4.65 & 4.8413 & TST \\
\hline CHEMBL1418414 & 688620 & 4.9 & 4.9488 & TST \\
\hline CHEMBL1537393 & 688620 & 4.9 & 5.1216 & TST \\
\hline CHEMBL3196654 & 688620 & 5.7 & 5.4141 & TRN \\
\hline CHEMBL1421678 & 688620 & 4.9 & 4.7008 & TRN \\
\hline CHEMBL1583419 & 688620 & 4.6 & 4.8321 & TST \\
\hline CHEMBL1303281 & 688620 & 5.65 & 5.4789 & TRN \\
\hline CHEMBL 3194342 & 688620 & 4.45 & 5.0677 & TST \\
\hline CHEMBL1506645 & 688620 & 5.0 & 4.9934 & TST \\
\hline CHEMBL1484164 & 688620 & 6.6 & 5.0001 & TRN \\
\hline CHEMBL1405335 & 688620 & 5.5 & 5.1708 & TRN \\
\hline CHEMBL1352098 & 688620 & 4.85 & 4.6321 & TRN \\
\hline CHEMBL1417282 & 688620 & 5.2 & 5.0902 & TRN \\
\hline CHEMBL1489985 & 688620 & 4.95 & 4.8606 & TRN \\
\hline CHEMBL3192667 & 688620 & 4.45 & 4.8261 & TRN \\
\hline CHEMBL1600546 & 688620 & 4.65 & 5.1732 & TST \\
\hline CHEMBL1494458 & 688620 & 5.05 & 4.7579 & TST \\
\hline CHEMBL1548815 & 688620 & 4.7 & 4.7042 & TRN \\
\hline CHEMBL1419690 & 688620 & 4.9 & 4.9797 & TRN \\
\hline CHEMBL1577380 & 688620 & 4.9 & 5.0649 & TST \\
\hline CHEMBL1573402 & 688620 & 4.45 & 5.0994 & TRN \\
\hline CHEMBL1527882 & 688620 & 4.7 & 5.1142 & TRN \\
\hline CHEMBL 2004322 & 688620 & 5.4 & 4.8052 & TRN \\
\hline CHEMBL1606835 & 688620 & 4.9 & 4.9788 & TST \\
\hline CHEMBL1447124 & 688620 & 4.45 & 5.1824 & TST \\
\hline CHEMBL1430590 & 688620 & 5.0 & 4.8322 & TRN \\
\hline CHEMBL1347467 & 688620 & 4.75 & 5.0682 & TRN \\
\hline CHEMBL1421098 & 688620 & 4.75 & 5.0277 & TST \\
\hline CHEMBL 3197530 & 688620 & 5.5 & 5.4861 & TRN \\
\hline CHEMBL1428810 & 688620 & 5.15 & 5.1378 & TST \\
\hline CHEMBL1382036 & 688620 & 4.45 & 4.8692 & TRN \\
\hline CHEMBL1347733 & 688620 & 5.0 & 5.2844 & TRN \\
\hline CHEMBL1455883 & 688620 & 4.75 & 4.7341 & TRN \\
\hline CHEMBL1405952 & 688620 & 6.5501 & 5.6301 & TRN \\
\hline CHEMBL1444235 & 688620 & 4.9 & 4.9853 & TRN \\
\hline CHEMBL1601324 & 688620 & 6.95 & 5.034 & TRN \\
\hline CHEMBL3210920 & 688620 & 4.55 & 5.1967 & TRN \\
\hline CHEMBL1309858 & 688620 & 4.45 & 5.0126 & TST \\
\hline CHEMBL1481828 & 688620 & 4.95 & 4.7298 & TRN \\
\hline CHEMBL1412490 & 688620 & 5.3 & 5.0821 & TRN \\
\hline CHEMBL1504829 & 688620 & 4.7 & 4.8191 & TRN \\
\hline CHEMBL1367993 & 688620 & 4.9 & 5.0041 & TST \\
\hline
\end{tabular}




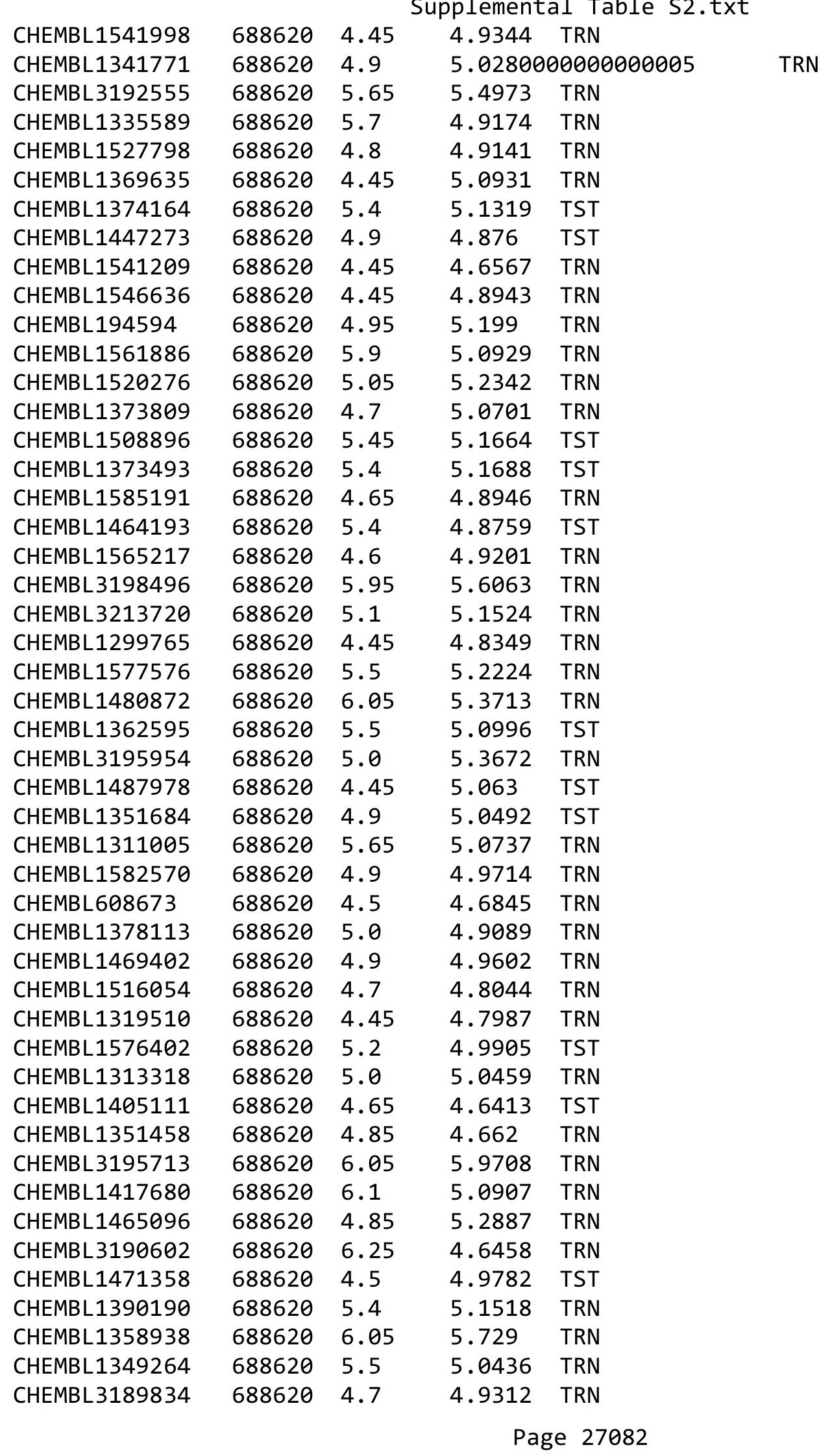




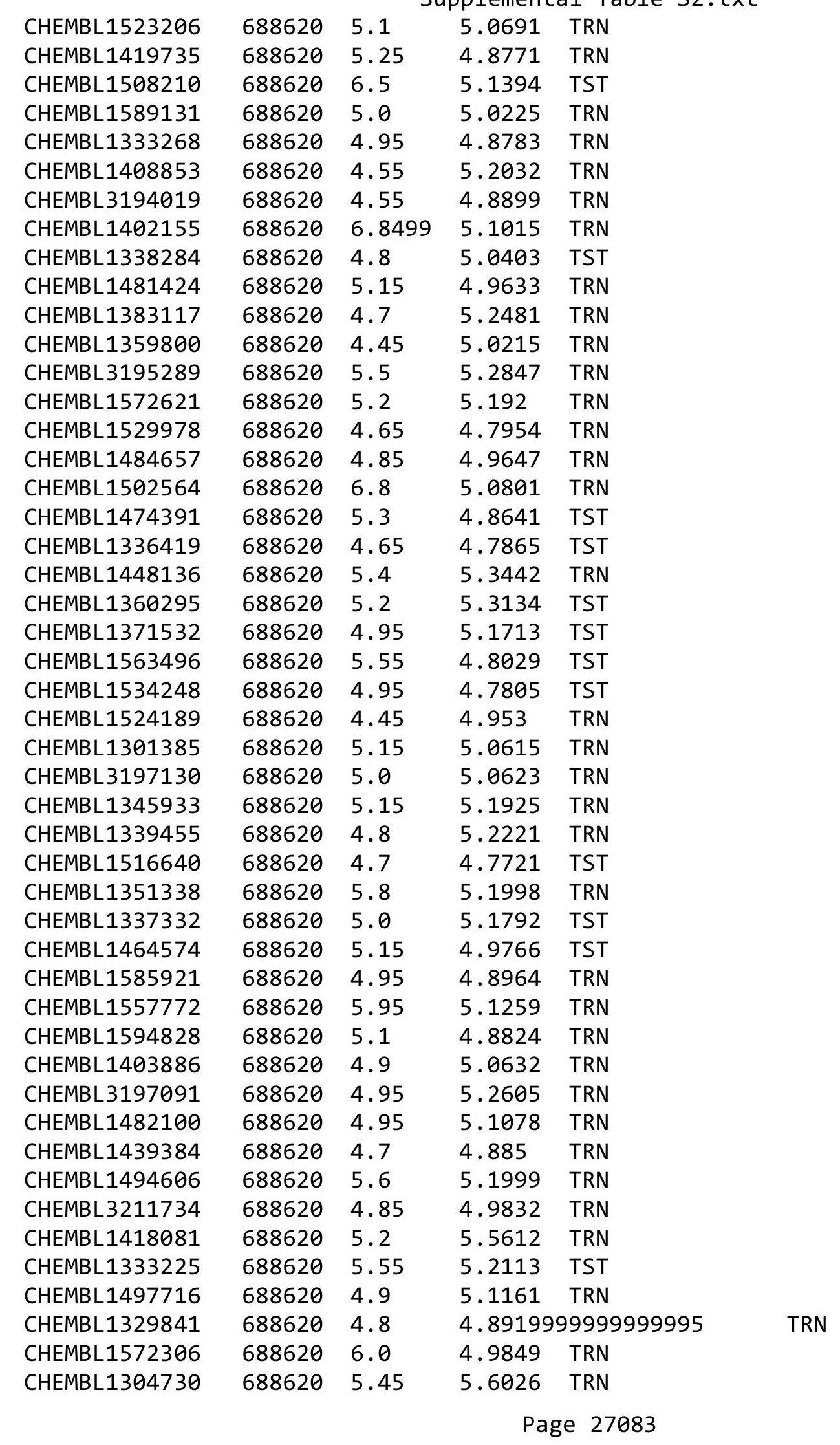




\begin{tabular}{|c|c|c|c|c|c|}
\hline & & \multicolumn{4}{|c|}{ Supplemental Table S2.txt } \\
\hline CHEMBL1563058 & 688620 & 5.2 & 5.2013 & TRN & \\
\hline CHEMBL1328215 & 688620 & 5.45 & 5.5049 & TRN & \\
\hline CHEMBL1610972 & 688620 & 5.5 & 5.115 & TRN & \\
\hline CHEMBL1351491 & 688620 & 5.05 & 5.2019 & TST & \\
\hline CHEMBL1581396 & 688620 & 4.45 & 4.7312 & TRN & \\
\hline CHEMBL1577149 & 688620 & 5.8 & 4.8183 & TRN & \\
\hline CHEMBL1372635 & 688620 & 4.9 & 5.6769 & TRN & \\
\hline CHEMBL1983220 & 688620 & 5.4 & 4.9714 & TST & \\
\hline CHEMBL1416058 & 688620 & 4.9 & 5.0499 & TRN & \\
\hline CHEMBL1500454 & 688620 & 4.9 & 5.2024 & TRN & \\
\hline CHEMBL1447566 & 688620 & 4.45 & 4.9757 & TRN & \\
\hline CHEMBL1301857 & 688620 & 5.1 & 4.8363 & TRN & \\
\hline CHEMBL 2007601 & 688620 & 4.95 & 5.6881 & TST & \\
\hline CHEMBL1367484 & 688620 & 4.65 & 5.2879 & TRN & \\
\hline CHEMBL3210966 & 688620 & 5.4 & 5.3087 & TRN & \\
\hline CHEMBL1558849 & 688620 & 5.7 & 4.9585 & TRN & \\
\hline CHEMBL1332881 & 688620 & 4.8 & $5.2020 e$ & 0000000001 & TRN \\
\hline CHEMBL1480889 & 688620 & 4.95 & 5.1168 & TRN & \\
\hline CHEMBL1349446 & 688620 & 4.95 & 5.1574 & TRN & \\
\hline CHEMBL1360013 & 688620 & 4.45 & 4.9881 & TRN & \\
\hline CHEMBL3196408 & 688620 & 5.15 & 5.6493 & TRN & \\
\hline CHEMBL3214553 & 688620 & 5.15 & 4.9156 & TRN & \\
\hline CHEMBL1501121 & 688620 & 6.6 & 5.1572 & TST & \\
\hline CHEMBL1308911 & 688620 & 4.9 & 4.8852 & TRN & \\
\hline CHEMBL1570443 & 688620 & 4.85 & 5.0815 & TST & \\
\hline CHEMBL3190487 & 688620 & 6.25 & 5.2853 & TST & \\
\hline CHEMBL1373956 & 688620 & 4.95 & 4.8567 & TRN & \\
\hline CHEMBL1489971 & 688620 & 4.8 & 5.1598 & TRN & \\
\hline CHEMBL3195636 & 688620 & 4.65 & 4.9357 & TRN & \\
\hline CHEMBL1449822 & 688620 & 4.9 & 5.0499 & TRN & \\
\hline CHEMBL1403190 & 688620 & 4.85 & 5.048 & TRN & \\
\hline CHEMBL1417480 & 688620 & 4.9 & 4.8132 & TRN & \\
\hline CHEMBL1509094 & 688620 & 4.6 & 4.7808 & TRN & \\
\hline CHEMBL1592493 & 688620 & 5.65 & 5.414 & TST & \\
\hline CHEMBL1451802 & 688620 & 4.5 & 4.9469 & TRN & \\
\hline CHEMBL1521853 & 688620 & 4.9 & 5.2357 & TST & \\
\hline CHEMBL1339250 & 688620 & 4.95 & 5.0152 & TRN & \\
\hline CHEMBL1531329 & 688620 & 4.85 & 4.9352 & TRN & \\
\hline CHEMBL1502943 & 688620 & 5.1 & 5.2878 & TST & \\
\hline CHEMBL1376213 & 688620 & 5.3 & 5.1329 & TRN & \\
\hline CHEMBL1465247 & 688620 & 4.8 & 4.9789 & TRN & \\
\hline CHEMBL1331872 & 688620 & 4.65 & 4.8523 & TST & \\
\hline CHEMBL1366075 & 688620 & 4.6 & 4.8851 & TST & \\
\hline CHEMBL1503788 & 688620 & 5.9 & 4.95 & TRN & \\
\hline CHEMBL1611785 & 688620 & 4.5 & 4.9136 & TRN & \\
\hline CHEMBL1383041 & 688620 & 4.45 & 4.9146 & TRN & \\
\hline CHEMBL1376476 & 688620 & 5.35 & 4.9889 & TRN & \\
\hline CHEMBL1333915 & 688620 & 4.95 & 4.9869 & TRN & \\
\hline
\end{tabular}




\begin{tabular}{|c|c|c|c|c|c|}
\hline \multicolumn{6}{|c|}{ Supplemental Table S2.txt } \\
\hline CHEMBL3196040 & 688620 & 4.45 & 4.7505 & TRN & \\
\hline CHEMBL1364899 & 688620 & 6.0 & 5.776 & TRN & \\
\hline CHEMBL1485335 & 688620 & 4.85 & 4.8753 & TST & \\
\hline CHEMBL 3198375 & 688620 & 5.45 & 4.9924 & TRN & \\
\hline CHEMBL53898 & 688620 & 4.65 & 5.442 & TRN & \\
\hline CHEMBL1608875 & 688620 & 4.95 & 5.0625 & TST & \\
\hline CHEMBL1473073 & 688620 & 4.8 & 5.0422 & TRN & \\
\hline CHEMBL1328497 & 688620 & 6.25 & 5.7353 & TRN & \\
\hline CHEMBL1537765 & 688620 & 4.95 & 4.9919 & TRN & \\
\hline CHEMBL1387194 & 688620 & 4.45 & 4.7846 & TST & \\
\hline CHEMBL3191572 & 688620 & 5.2 & 5.4625 & TRN & \\
\hline CHEMBL1735892 & 688620 & 5.35 & 4.9905 & TRN & \\
\hline CHEMBL3190949 & 688620 & 6.15 & 5.7139 & TRN & \\
\hline CHEMBL1333594 & 688620 & 4.5 & 4.9121 & TRN & \\
\hline CHEMBL3191201 & 688620 & 5.75 & 5.67399 & 99999999995 & TRN \\
\hline CHEMBL1545376 & 688620 & 5.95 & 4.9963 & TST & \\
\hline CHEMBL1353597 & 688620 & 5.0 & 4.9532 & TRN & \\
\hline CHEMBL3198394 & 688620 & 6.1 & 5.7633 & TRN & \\
\hline CHEMBL73451 & 688620 & 4.95 & 4.698 & TST & \\
\hline CHEMBL1538303 & 688620 & 4.95 & 4.9389 & TRN & \\
\hline CHEMBL1546675 & 688620 & 4.45 & 4.921 & TST & \\
\hline CHEMBL1458159 & 688620 & 4.45 & 4.9064 & TRN & \\
\hline CHEMBL3210117 & 688620 & 4.95 & 4.98300 & 00000000005 & TRN \\
\hline CHEMBL1451727 & 688620 & 5.9 & 5.4439 & TRN & \\
\hline CHEMBL1501682 & 688620 & 5.7 & 5.4406 & TRN & \\
\hline CHEMBL1554942 & 688620 & 4.85 & 5.0507 & TRN & \\
\hline CHEMBL303958 & 688620 & 6.0 & 4.9057 & TST & \\
\hline CHEMBL1540682 & 688620 & 6.25 & 5.6205 & TRN & \\
\hline CHEMBL1542043 & 688620 & 5.95 & 5.0187 & TRN & \\
\hline CHEMBL1566537 & 688620 & 4.85 & 5.0075 & TST & \\
\hline CHEMBL1486729 & 688620 & 5.4 & 5.2638 & TST & \\
\hline CHEMBL1334643 & 688620 & 4.5 & 5.3135 & TRN & \\
\hline CHEMBL1584894 & 688620 & 4.45 & 4.9668 & TRN & \\
\hline CHEMBL1359819 & 688620 & 4.65 & 5.1226 & TRN & \\
\hline CHEMBL1535089 & 688620 & 5.35 & 5.0433 & TST & \\
\hline CHEMBL1368516 & 688620 & 4.9 & 5.0084 & TRN & \\
\hline CHEMBL1483267 & 688620 & 4.75 & 4.9499 & TST & \\
\hline CHEMBL1606685 & 688620 & 6.2 & 5.6225 & TST & \\
\hline CHEMBL1493701 & 688620 & 4.5 & 4.8767 & TST & \\
\hline CHEMBL 3193482 & 688620 & 4.8 & 5.1062 & TRN & \\
\hline CHEMBL1458069 & 688620 & 5.15 & 5.1221 & TRN & \\
\hline CHEMBL1417770 & 688620 & 5.05 & 4.7412 & TRN & \\
\hline CHEMBL3211803 & 688620 & 4.95 & 4.8789 & TST & \\
\hline CHEMBL1557555 & 688620 & 4.45 & 4.9094 & TRN & \\
\hline CHEMBL1310713 & 688620 & 5.15 & 5.1038 & TRN & \\
\hline CHEMBL1487681 & 688620 & 5.35 & 5.3386 & TST & \\
\hline CHEMBL1550972 & 688620 & 4.85 & 4.8901 & TRN & \\
\hline CHEMBL3195432 & 688620 & 4.95 & 5.7712 & TRN & \\
\hline
\end{tabular}




\begin{tabular}{|c|c|c|c|c|}
\hline \multicolumn{5}{|c|}{ Supplemental Table } \\
\hline CHEMBL 2004756 & 688620 & 5.45 & 5.0285 & TRN \\
\hline CHEMBL1477318 & 688620 & 6.5 & 4.9866 & TRN \\
\hline CHEMBL1305734 & 688620 & 4.65 & 5.2466 & TRN \\
\hline CHEMBL1608526 & 688620 & 4.95 & 4.8088 & TRN \\
\hline CHEMBL 1497726 & 688620 & 4.45 & 4.9963 & TRN \\
\hline CHEMBL1336309 & 688620 & 4.45 & 4.9209 & TRN \\
\hline CHEMBL 3198374 & 688620 & 6.2 & 5.2586 & TRN \\
\hline CHEMBL1329446 & 688620 & 6.4 & 5.6178 & TST \\
\hline CHEMBL1430559 & 688620 & 4.65 & 5.0991 & TST \\
\hline CHEMBL1368233 & 688620 & 4.9 & 4.8512 & TRN \\
\hline CHEMBL442925 & 688620 & 6.15 & 5.3645 & TRN \\
\hline CHEMBL1326236 & 688620 & 4.7 & 4.876 & TST \\
\hline CHEMBL1403847 & 688620 & 5.3 & 5.1912 & TRN \\
\hline CHEMBL1595234 & 688620 & 4.85 & 4.8915 & TRN \\
\hline CHEMBL1569018 & 688620 & 5.85 & 4.8392 & TST \\
\hline CHEMBL1579525 & 688620 & 5.2 & 5.0506 & TRN \\
\hline CHEMBL1366284 & 688620 & 4.9 & 5.073 & TST \\
\hline CHEMBL1583545 & 688620 & 4.7 & 4.898 & TRN \\
\hline CHEMBL3196378 & 688620 & 4.65 & 5.1376 & TRN \\
\hline CHEMBL1353950 & 688620 & 4.75 & 4.8311 & TRN \\
\hline CHEMBL1600893 & 688620 & 5.0 & 5.0864 & TRN \\
\hline CHEMBL1582694 & 688620 & 6.15 & 4.9138 & TRN \\
\hline CHEMBL1390253 & 688620 & 5.0 & 5.0985 & TST \\
\hline CHEMBL1482898 & 688620 & 4.45 & 5.0496 & TRN \\
\hline CHEMBL3190476 & 688620 & 5.3 & 5.1823 & TRN \\
\hline CHEMBL1335738 & 688620 & 5.0 & 5.1372 & TRN \\
\hline CHEMBL1418441 & 688620 & 4.45 & 5.0175 & TRN \\
\hline CHEMBL1446883 & 688620 & 4.9 & 5.1273 & TRN \\
\hline CHEMBL1439344 & 688620 & 5.65 & 5.3868 & TRN \\
\hline CHEMBL1384567 & 688620 & 4.7 & 4.9819 & TST \\
\hline CHEMBL1531272 & 688620 & 5.2 & 5.1474 & TRN \\
\hline CHEMBL1393358 & 688620 & 5.3 & 5.7 & TRN \\
\hline CHEMBL3197662 & 688620 & 4.85 & 4.8659 & TRN \\
\hline CHEMBL1489637 & 688620 & 4.9 & 5.1323 & TRN \\
\hline CHEMBL1376395 & 688620 & 4.5 & 4.7984 & TRN \\
\hline CHEMBL1415467 & 688620 & 6.35 & 5.9785 & TRN \\
\hline CHEMBL1539327 & 688620 & 4.5 & 4.9588 & TRN \\
\hline CHEMBL1510632 & 688620 & 5.45 & 4.9644 & TRN \\
\hline CHEMBL1505418 & 688620 & 5.4 & 5.0266 & TST \\
\hline CHEMBL1496535 & 688620 & 4.45 & 4.8868 & TST \\
\hline CHEMBL3195232 & 688620 & 4.45 & 5.0476 & TRN \\
\hline CHEMBL1303241 & 688620 & 5.2 & 4.9381 & TRN \\
\hline CHEMBL1422262 & 688620 & 4.45 & 4.8504 & TRN \\
\hline CHEMBL1416364 & 688620 & 6.2 & 4.9797 & TRN \\
\hline CHEMBL3190022 & 688620 & 5.05 & 5.2099 & TRN \\
\hline CHEMBL1405314 & 688620 & 4.7 & 4.8906 & TRN \\
\hline CHEMBL1356248 & 688620 & 4.8 & 5.0296 & TST \\
\hline CHEMBL1481069 & 688620 & 6.3 & 5.6892 & TRN \\
\hline
\end{tabular}




\begin{tabular}{|c|c|c|c|c|}
\hline \multirow[b]{2}{*}{ CHEMBL1573496 } & \multicolumn{4}{|c|}{ Supplemental Table S2.txt } \\
\hline & 688620 & 5.6 & 5.0308 & TST \\
\hline CHEMBL1522414 & 688620 & 5.55 & 4.9927 & TRN \\
\hline CHEMBL3209173 & 688620 & 4.45 & 4.8858 & TST \\
\hline CHEMBL1447796 & 688620 & 4.95 & 5.0603 & TST \\
\hline CHEMBL1446226 & 688620 & 4.45 & 5.0205 & TRN \\
\hline CHEMBL1608261 & 688620 & 5.0 & 5.1713 & TST \\
\hline CHEMBL1555951 & 688620 & 4.65 & 4.9631 & TST \\
\hline CHEMBL1600459 & 688620 & 5.4 & 5.3159 & TRN \\
\hline CHEMBL479219 & 688620 & 4.65 & 5.1976 & TRN \\
\hline CHEMBL1522279 & 688620 & 5.0 & 4.7474 & TRN \\
\hline CHEMBL1428384 & 688620 & 5.05 & 4.9417 & TRN \\
\hline CHEMBL118175 & 688620 & 4.65 & 5.3197 & TRN \\
\hline CHEMBL1406051 & 688620 & 7.3002 & 6.3282 & TRN \\
\hline CHEMBL1452586 & 688620 & 4.7 & 5.3648 & TRN \\
\hline CHEMBL589715 & 688620 & 5.5 & 4.8562 & TRN \\
\hline CHEMBL1503948 & 688620 & 4.9 & 4.7855 & TRN \\
\hline CHEMBL1488030 & 688620 & 6.35 & 5.2514 & TRN \\
\hline CHEMBL1510532 & 688620 & 4.85 & 5.0916 & TRN \\
\hline CHEMBL1458107 & 688620 & 5.4 & 5.0453 & TRN \\
\hline CHEMBL1373307 & 688620 & 5.55 & 5.1892 & TRN \\
\hline CHEMBL1601350 & 688620 & 5.85 & 5.0619 & TRN \\
\hline CHEMBL1306992 & 688620 & 4.5 & 5.511 & TRN \\
\hline CHEMBL1542097 & 688620 & 5.6 & 5.151 & TRN \\
\hline CHEMBL1365234 & 688620 & 4.45 & 4.9371 & TST \\
\hline CHEMBL1575132 & 688620 & 4.95 & 4.9695 & TRN \\
\hline CHEMBL1605579 & 688620 & 5.25 & 5.1834 & TRN \\
\hline CHEMBL1370432 & 688620 & 4.85 & 5.084 & TRN \\
\hline CHEMBL1449123 & 688620 & 6.4 & 5.0351 & TRN \\
\hline CHEMBL1412159 & 688620 & 5.6 & 5.4611 & TRN \\
\hline CHEMBL1607209 & 688620 & 4.9 & 4.9892 & TRN \\
\hline CHEMBL3192976 & 688620 & 5.15 & 5.0284 & TRN \\
\hline CHEMBL1540965 & 688620 & 5.95 & 5.1307 & TRN \\
\hline CHEMBL1349903 & 688620 & 5.6 & 5.0043 & TST \\
\hline CHEMBL1375100 & 688620 & 5.0 & 4.982 & TST \\
\hline CHEMBL3191867 & 688620 & 4.8 & 5.2034 & TRN \\
\hline CHEMBL1391480 & 688620 & 4.65 & 4.9475 & TRN \\
\hline CHEMBL1477826 & 688620 & 4.45 & 4.6927 & TRN \\
\hline CHEMBL1330177 & 688620 & 5.9 & 5.6389 & TRN \\
\hline CHEMBL1367598 & 688620 & 4.8 & 5.1598 & TST \\
\hline CHEMBL1609515 & 688620 & 5.25 & 5.037 & TRN \\
\hline CHEMBL1349759 & 688620 & 4.95 & 5.2145 & TRN \\
\hline CHEMBL1434547 & 688620 & 5.8 & 4.8037 & TST \\
\hline CHEMBL1384063 & 688620 & 4.6 & 4.9821 & TRN \\
\hline CHEMBL1466768 & 688620 & 4.95 & 5.15 & TRN \\
\hline CHEMBL1323989 & 688620 & 4.45 & 5.1325 & TRN \\
\hline CHEMBL1491784 & 688620 & 5.85 & 5.5076 & TRN \\
\hline CHEMBL1547276 & 688620 & 5.75 & 5.0762 & TRN \\
\hline CHEMBL1308366 & 688620 & 4.85 & 4.8164 & TRN \\
\hline
\end{tabular}




\begin{tabular}{|c|c|c|c|c|c|}
\hline & & \multicolumn{4}{|c|}{ Supplemental Table S2.txt } \\
\hline CHEMBL3208432 & 688620 & 5.15 & 5.0938 & TRN & \\
\hline CHEMBL1456875 & 688620 & 4.9 & 5.0559 & TRN & \\
\hline CHEMBL3199134 & 688620 & 5.9 & 4.9803 & TRN & \\
\hline CHEMBL1570705 & 688620 & 6.35 & 5.909 & TRN & \\
\hline CHEMBL 3197088 & 688620 & 4.45 & 5.0718 & TRN & \\
\hline CHEMBL1984190 & 688620 & 6.3 & 5.5039 & TRN & \\
\hline CHEMBL1545210 & 688620 & 6.9 & 5.105 & TST & \\
\hline CHEMBL1349719 & 688620 & 5.45 & 5.3745 & TRN & \\
\hline CHEMBL1468919 & 688620 & 4.75 & 5.0115 & TRN & \\
\hline CHEMBL1477517 & 688620 & 5.0 & 4.9825 & TST & \\
\hline CHEMBL1431995 & 688620 & 5.1 & 5.2823 & TRN & \\
\hline CHEMBL1500626 & 688620 & 4.45 & 5.0761 & TST & \\
\hline CHEMBL526191 & 688620 & 6.9 & 5.0504 & TRN & \\
\hline CHEMBL1547349 & 688620 & 5.5 & 5.142 & TRN & \\
\hline CHEMBL1401466 & 688620 & 6.35 & 5.0029 & TRN & \\
\hline CHEMBL1506071 & 688620 & 5.3 & 5.0924 & TRN & \\
\hline CHEMBL3211069 & 688620 & 5.2 & 5.109 & TRN & \\
\hline CHEMBL1597410 & 688620 & 4.8 & 4.9354 & TRN & \\
\hline CHEMBL 2004417 & 688620 & 5.45 & 5.4646 & TRN & \\
\hline CHEMBL1588560 & 688620 & 5.6 & 5.0676 & TST & \\
\hline CHEMBL1404229 & 688620 & 5.3 & 5.2088 & TRN & \\
\hline CHEMBL1546670 & 688620 & 5.2 & 5.1666 & TRN & \\
\hline CHEMBL585502 & 688620 & 5.1 & 5.5878 & TST & \\
\hline CHEMBL1494123 & 688620 & 4.9 & 5.0879 & TRN & \\
\hline CHEMBL1344689 & 688620 & 5.25 & 5.1527 & TRN & \\
\hline CHEMBL1509725 & 688620 & 5.25 & 5.1507 & TST & \\
\hline CHEMBL1324937 & 688620 & 4.95 & 5.0369 & TRN & \\
\hline CHEMBL1471824 & 688620 & 4.75 & 4.8202 & TRN & \\
\hline CHEMBL1558208 & 688620 & 4.95 & 5.0172 & TRN & \\
\hline CHEMBL1418357 & 688620 & 5.2 & 5.1755 & TST & \\
\hline CHEMBL1578342 & 688620 & 4.95 & 4.9869 & TST & \\
\hline CHEMBL1369159 & 688620 & 5.25 & 5.1183 & TRN & \\
\hline CHEMBL1366082 & 688620 & 4.7 & 4.774 & TRN & \\
\hline CHEMBL1386683 & 688620 & 4.8 & 4.7575 & TRN & \\
\hline CHEMBL1372111 & 688620 & 4.55 & 5.0247 & TRN & \\
\hline CHEMBL3207783 & 688620 & 5.05 & 5.0569 & TRN & \\
\hline CHEMBL1478999 & 688620 & 5.45 & 5.0388 & TRN & \\
\hline CHEMBL1538347 & 688620 & 4.75 & 4.9214 & TRN & \\
\hline CHEMBL1381644 & 688620 & 4.95 & 4.9441 & TST & \\
\hline CHEMBL1452810 & 688620 & 5.0 & 4.8503 & TRN & \\
\hline CHEMBL1490916 & 688620 & 4.95 & 5.1488 & TRN & \\
\hline CHEMBL 3212243 & 688620 & 4.45 & 5.1083 & TRN & \\
\hline CHEMBL1323732 & 688620 & 5.15 & 4.9885 & TRN & \\
\hline CHEMBL1549939 & 688620 & 5.25 & 4.9986 & TRN & \\
\hline CHEMBL1461201 & 688620 & 5.0 & 4.886 & TST & \\
\hline CHEMBL1423809 & 688620 & 5.35 & 5.0233 & TRN & \\
\hline CHEMBL1530558 & 688620 & 5.0 & 5.07100 & 0000000001 & TRN \\
\hline CHEMBL3196860 & 688620 & 5.0 & 4.808 & TRN & \\
\hline
\end{tabular}




\begin{tabular}{|c|c|c|c|c|}
\hline \multicolumn{5}{|c|}{ Supplemental Table S2.txt } \\
\hline CHEMBL1610820 & 688620 & 4.6 & 4.8904 & TST \\
\hline CHEMBL1522456 & 688620 & 4.95 & 4.9823 & TRN \\
\hline CHEMBL1404629 & 688620 & 4.8 & 4.9394 & TST \\
\hline CHEMBL1579358 & 688620 & 4.95 & 5.0782 & TST \\
\hline CHEMBL3191442 & 688620 & 5.15 & 5.2004 & TRN \\
\hline CHEMBL1305566 & 688620 & 5.3 & 5.3024 & TRN \\
\hline CHEMBL1302429 & 688620 & 4.45 & 4.8872 & TRN \\
\hline CHEMBL269163 & 688620 & 5.0 & 5.5591 & TRN \\
\hline CHEMBL3198251 & 688620 & 4.9 & 5.1359 & TST \\
\hline CHEMBL3198736 & 688620 & 5.65 & 5.6975 & TST \\
\hline CHEMBL1562673 & 688620 & 4.85 & 4.8987 & TRN \\
\hline CHEMBL1537101 & 688620 & 4.55 & 4.9301 & TST \\
\hline CHEMBL1393126 & 688620 & 4.8 & 5.3788 & TRN \\
\hline CHEMBL1535908 & 688620 & 4.95 & 4.7354 & TRN \\
\hline CHEMBL1470768 & 688620 & 5.85 & 5.9575 & TRN \\
\hline CHEMBL1486571 & 688620 & 4.45 & 5.1376 & TST \\
\hline CHEMBL1376219 & 688620 & 5.2 & 5.1131 & TRN \\
\hline CHEMBL1489152 & 688620 & 6.95 & 5.2504 & TST \\
\hline CHEMBL1385806 & 688620 & 5.1 & 4.8445 & TST \\
\hline CHEMBL1509574 & 688620 & 5.05 & 5.0172 & TRN \\
\hline CHEMBL1476236 & 688620 & 6.15 & 5.1607 & TST \\
\hline CHEMBL1604813 & 688620 & 4.45 & 4.997 & TRN \\
\hline CHEMBL3189694 & 688620 & 4.65 & 4.8213 & TRN \\
\hline CHEMBL3212323 & 688620 & 5.0 & 4.6417 & TRN \\
\hline CHEMBL1458926 & 688620 & 4.7 & 4.7483 & TRN \\
\hline CHEMBL1384349 & 688620 & 4.45 & 4.7206 & TRN \\
\hline CHEMBL1311227 & 688620 & 4.45 & 4.9198 & TRN \\
\hline CHEMBL1402767 & 688620 & 5.3 & 5.2452 & TRN \\
\hline CHEMBL3199324 & 688620 & 5.35 & 5.4543 & TRN \\
\hline CHEMBL1323049 & 688620 & 5.1 & 5.3072 & TRN \\
\hline CHEMBL1530166 & 688620 & 4.5 & 4.9971 & TRN \\
\hline CHEMBL1539888 & 688620 & 5.0 & 4.9756 & TST \\
\hline CHEMBL1339566 & 688620 & 5.05 & 5.0113 & TRN \\
\hline CHEMBL1395036 & 688620 & 4.8 & 5.1047 & TST \\
\hline CHEMBL3195808 & 688620 & 6.1 & 5.766 & TRN \\
\hline CHEMBL1588895 & 688620 & 4.8 & 5.0464 & TST \\
\hline CHEMBL3196231 & 688620 & 4.45 & 5.159 & TRN \\
\hline CHEMBL1589475 & 688620 & 4.45 & 4.9876 & TRN \\
\hline CHEMBL1539159 & 688620 & 4.65 & 5.1405 & TST \\
\hline CHEMBL1968361 & 688620 & 4.75 & 4.886 & TRN \\
\hline CHEMBL1400587 & 688620 & 4.45 & 5.1163 & TST \\
\hline CHEMBL1570257 & 688620 & 4.95 & 4.9978 & TRN \\
\hline CHEMBL1309899 & 688620 & 5.4 & 5.6033 & TRN \\
\hline CHEMBL1589299 & 688620 & 5.2 & 5.0658 & TST \\
\hline CHEMBL1332298 & 688620 & 4.65 & 5.1105 & TRN \\
\hline CHEMBL1371633 & 688620 & 4.95 & 5.1462 & TRN \\
\hline CHEMBL1543038 & 688620 & 5.35 & 5.0568 & TRN \\
\hline CHEMBL1401329 & 688620 & 6.25 & 5.1219 & TRN \\
\hline
\end{tabular}




\begin{tabular}{|c|c|c|c|c|c|}
\hline \multicolumn{6}{|c|}{ Supplemental Table S2.txt } \\
\hline CHEMBL1562712 & 688620 & 5.15 & 5.3255 & TRN & \\
\hline CHEMBL3192108 & 688620 & 7.699 & 5.5092 & TRN & \\
\hline CHEMBL1568820 & 688620 & 5.0 & 5.3132 & TRN & \\
\hline CHEMBL492468 & 688620 & 5.0 & 4.9773 & TST & \\
\hline CHEMBL1373480 & 688620 & 5.35 & 5.4934 & TRN & \\
\hline CHEMBL1350824 & 688620 & 4.65 & 4.7914 & TRN & \\
\hline CHEMBL1439210 & 688620 & 5.2 & 5.2103 & TRN & \\
\hline CHEMBL1348606 & 688620 & 4.85 & 5.12799 & 7999999999 & TRN \\
\hline CHEMBL1613363 & 688620 & 6.95 & 5.053 & TRN & \\
\hline CHEMBL1377167 & 688620 & 6.5 & 5.1731 & TRN & \\
\hline CHEMBL3213770 & 688620 & 4.65 & 5.3401 & TST & \\
\hline CHEMBL1328929 & 688620 & 4.45 & 5.0864 & TST & \\
\hline CHEMBL1331726 & 688620 & 5.95 & 5.2053 & TRN & \\
\hline CHEMBL 1588780 & 688620 & 6.5 & 5.8305 & TST & \\
\hline CHEMBL1451023 & 688620 & 4.45 & 4.8042 & TRN & \\
\hline CHEMBL1452081 & 688620 & 4.45 & 5.24700 & 0000000001 & TST \\
\hline CHEMBL1431943 & 688620 & 5.1 & 5.0404 & TRN & \\
\hline CHEMBL1471832 & 688620 & 5.2 & 5.0025 & TRN & \\
\hline CHEMBL1425197 & 688620 & 5.1 & 4.966 & TRN & \\
\hline CHEMBL1486784 & 688620 & 4.95 & 4.9675 & TST & \\
\hline CHEMBL1405160 & 688620 & 5.0 & 5.1396 & TRN & \\
\hline CHEMBL1472439 & 688620 & 4.95 & 4.8339 & TRN & \\
\hline CHEMBL1537694 & 688620 & 4.6 & 5.0586 & TRN & \\
\hline CHEMBL1543363 & 688620 & 5.0 & 4.9151 & TRN & \\
\hline CHEMBL1538040 & 688620 & 5.45 & 5.1063 & TRN & \\
\hline CHEMBL 2369296 & 688620 & 6.15 & 5.8461 & TRN & \\
\hline CHEMBL1421232 & 688620 & 6.5 & 5.1396 & TRN & \\
\hline CHEMBL1610733 & 688620 & 4.75 & 4.7735 & TRN & \\
\hline CHEMBL1402954 & 688620 & 7.0 & 5.0065 & TST & \\
\hline CHEMBL1534503 & 688620 & 4.95 & 5.0028 & TRN & \\
\hline CHEMBL1468693 & 688620 & 4.45 & 5.109 & TRN & \\
\hline CHEMBL1600826 & 688620 & 7.3497 & 5.1893 & TRN & \\
\hline CHEMBL1577977 & 688620 & 5.0 & 5.1632 & TRN & \\
\hline CHEMBL3190512 & 688620 & 4.95 & 5.0614 & TRN & \\
\hline CHEMBL1377868 & 688620 & 5.15 & 4.8178 & TRN & \\
\hline CHEMBL1316382 & 688620 & 4.45 & 5.084 & TRN & \\
\hline CHEMBL1480996 & 688620 & 5.95 & 5.1116 & TST & \\
\hline CHEMBL1374845 & 688620 & 4.95 & 5.0384 & TST & \\
\hline CHEMBL3196358 & 688620 & 4.9 & 4.9192 & TRN & \\
\hline CHEMBL1371706 & 688620 & 5.05 & 5.3031 & TRN & \\
\hline CHEMBL1346375 & 688620 & 4.45 & 5.0636 & TST & \\
\hline CHEMBL1370704 & 688620 & 4.75 & 5.0682 & TRN & \\
\hline CHEMBL1347431 & 688620 & 4.5 & 5.0001 & TRN & \\
\hline CHEMBL1427339 & 688620 & 5.2 & 5.1005 & TRN & \\
\hline CHEMBL 2001071 & 688620 & 5.4 & 5.5056 & TRN & \\
\hline CHEMBL3197790 & 688620 & 5.6 & 5.3067 & TRN & \\
\hline CHEMBL1524024 & 688620 & 5.25 & 5.2939 & TRN & \\
\hline CHEMBL1363693 & 688620 & 4.95 & 5.0686 & TRN & \\
\hline
\end{tabular}




\begin{tabular}{|c|c|c|c|c|c|}
\hline \multicolumn{6}{|c|}{ Supplemental Table S2.txt } \\
\hline CHEMBL1605708 & 688620 & 4.65 & 4.9575 & TRN & \\
\hline CHEMBL1332431 & 688620 & 4.8 & 5.0114 & TRN & \\
\hline CHEMBL1427655 & 688620 & 4.95 & 5.2742 & TST & \\
\hline CHEMBL1322203 & 688620 & 4.45 & 4.8624 & TST & \\
\hline CHEMBL1432415 & 688620 & 4.45 & 5.2724 & TRN & \\
\hline CHEMBL1418530 & 688620 & 5.15 & 5.0574 & TRN & \\
\hline CHEMBL1380174 & 688620 & 5.15 & 5.0883 & TST & \\
\hline CHEMBL1415308 & 688620 & 5.55 & 4.7915 & TRN & \\
\hline CHEMBL1319562 & 688620 & 6.5501 & 4.9729 & TRN & \\
\hline CHEMBL1582713 & 688620 & 6.05 & 5.5744 & TRN & \\
\hline CHEMBL262627 & 688620 & 4.75 & 5.159 & TRN & \\
\hline CHEMBL1325640 & 688620 & 4.95 & 4.7913 & TRN & \\
\hline CHEMBL1482428 & 688620 & 4.7 & 4.6939 & TRN & \\
\hline CHEMBL1532258 & 688620 & 4.85 & 5.2364 & TRN & \\
\hline CHEMBL1310565 & 688620 & 4.65 & 5.0625 & TRN & \\
\hline CHEMBL1563770 & 688620 & 4.9 & 5.0095 & TST & \\
\hline CHEMBL1505141 & 688620 & 4.9 & 4.9683 & TRN & \\
\hline CHEMBL3211291 & 688620 & 4.95 & 4.9057 & TRN & \\
\hline CHEMBL1408154 & 688620 & 5.4 & 4.9079 & TRN & \\
\hline CHEMBL1564827 & 688620 & 4.95 & 5.13899 & 9999999999 & TRN \\
\hline CHEMBL1586443 & 688620 & 4.7 & 4.9934 & TST & \\
\hline CHEMBL1499047 & 688620 & 4.45 & 4.9981 & TRN & \\
\hline CHEMBL1372398 & 688620 & 4.45 & 4.69600 & 0000000001 & TRN \\
\hline CHEMBL1519902 & 688620 & 6.5501 & 6.2867 & TRN & \\
\hline CHEMBL1348960 & 688620 & 4.45 & 5.1671 & TRN & \\
\hline CHEMBL1414482 & 688620 & 4.7 & 5.0009 & TRN & \\
\hline CHEMBL1379300 & 688620 & 4.9 & 4.893 & TRN & \\
\hline CHEMBL1542028 & 688620 & 5.6 & 5.2726 & TRN & \\
\hline CHEMBL1535598 & 688620 & 5.5 & 5.0234 & TRN & \\
\hline CHEMBL1488906 & 688620 & 5.75 & 5.0423 & TRN & \\
\hline CHEMBL1463728 & 688620 & 4.6 & 4.8636 & TRN & \\
\hline CHEMBL1392796 & 688620 & 4.95 & 4.9008 & TRN & \\
\hline CHEMBL1507497 & 688620 & 4.8 & 4.9532 & TRN & \\
\hline CHEMBL1359202 & 688620 & 4.9 & 4.9281 & TRN & \\
\hline CHEMBL1582045 & 688620 & 5.0 & 5.1517 & TST & \\
\hline CHEMBL1393664 & 688620 & 4.75 & 4.726 & TST & \\
\hline CHEMBL1555432 & 688620 & 4.7 & 5.0845 & TRN & \\
\hline CHEMBL1322308 & 688620 & 5.35 & 5.1561 & TRN & \\
\hline CHEMBL1979727 & 688620 & 6.1 & 5.9416 & TRN & \\
\hline CHEMBL1232474 & 688620 & 5.2 & 5.0847 & TST & \\
\hline CHEMBL1343386 & 688620 & 5.25 & 5.0808 & TST & \\
\hline CHEMBL1565713 & 688620 & 4.95 & 4.9923 & TST & \\
\hline CHEMBL1361855 & 688620 & 4.95 & 5.0166 & TST & \\
\hline CHEMBL1327091 & 688620 & 4.45 & 4.8504 & TST & \\
\hline CHEMBL1343689 & 688620 & 6.05 & 5.5529 & TRN & \\
\hline CHEMBL3195358 & 688620 & 4.95 & 4.7003 & TST & \\
\hline CHEMBL 1425570 & 688620 & 4.45 & 5.061 & TST & \\
\hline CHEMBL1409737 & 688620 & 4.8 & 5.2676 & TRN & \\
\hline
\end{tabular}




\begin{tabular}{|c|c|c|c|c|c|}
\hline \\
\hline CHEMBL1577814 & 688620 & 5.2 & 5.1176 & TRN & \\
\hline CHEMBL3192120 & 688620 & 5.5 & 5.3201 & TRN & \\
\hline CHEMBL1402980 & 688620 & 4.8 & 5.0172 & TRN & \\
\hline CHEMBL1330342 & 688620 & 5.1 & 5.2145 & TRN & \\
\hline CHEMBL3191445 & 688620 & 6.1 & 5.1888 & TST & \\
\hline CHEMBL1421546 & 688620 & 5.0 & 5.1596 & TRN & \\
\hline CHEMBL1458408 & 688620 & 4.7 & 5.1216 & TRN & \\
\hline CHEMBL3209462 & 688620 & 4.45 & 5.2119 & TRN & \\
\hline CHEMBL1342945 & 688620 & 4.9 & 4.8297 & TRN & \\
\hline CHEMBL1371536 & 688620 & 4.9 & 4.8444 & TST & \\
\hline CHEMBL1498639 & 688620 & 5.65 & 5.3561 & TRN & \\
\hline CHEMBL3195903 & 688620 & 4.9 & 5.1141 & TRN & \\
\hline CHEMBL1528536 & 688620 & 4.45 & 4.9181 & TST & \\
\hline CHEMBL1303927 & 688620 & 4.7 & 4.784 & TRN & \\
\hline CHEMBL1402670 & 688620 & 6.7001 & 6.348 & TRN & \\
\hline CHEMBL1521736 & 688620 & 5.05 & 5.17899 & 9999999999 & TRN \\
\hline CHEMBL1336146 & 688620 & 4.8 & 5.0655 & TRN & \\
\hline CHEMBL1587460 & 688620 & 5.45 & 4.8371 & TST & \\
\hline CHEMBL1388963 & 688620 & 4.9 & 5.0233 & TRN & \\
\hline CHEMBL1530555 & 688620 & 5.95 & 5.0313 & TST & \\
\hline CHEMBL1381375 & 688620 & 4.45 & 4.9771 & TRN & \\
\hline CHEMBL1405856 & 688620 & 4.6 & 5.0406 & TRN & \\
\hline CHEMBL1568220 & 688620 & 5.9 & 5.1562 & TRN & \\
\hline CHEMBL1493982 & 688620 & 4.75 & 4.9548 & TRN & \\
\hline CHEMBL1306696 & 688620 & 5.5 & 5.0922 & TST & \\
\hline CHEMBL1604486 & 688620 & 5.25 & 5.2576 & TRN & \\
\hline CHEMBL1345574 & 688620 & 4.45 & 4.9461 & TST & \\
\hline CHEMBL1374788 & 688620 & 4.85 & 5.0909 & TST & \\
\hline CHEMBL1421001 & 688620 & 4.45 & 5.0841 & TRN & \\
\hline CHEMBL1392348 & 688620 & 5.05 & 5.106 & TST & \\
\hline CHEMBL 301507 & 688620 & 5.05 & 5.0598 & TRN & \\
\hline CHEMBL1456813 & 688620 & 5.05 & 5.1348 & TRN & \\
\hline CHEMBL1453261 & 688620 & 4.95 & 5.1341 & TRN & \\
\hline CHEMBL3198531 & 688620 & 5.5 & 5.0668 & TRN & \\
\hline CHEMBL3197508 & 688620 & 4.45 & 4.7078 & TRN & \\
\hline CHEMBL3189857 & 688620 & 4.95 & 5.2906 & TRN & \\
\hline CHEMBL1608847 & 688620 & 4.45 & 5.02800 & 00000000005 & TST \\
\hline CHEMBL1411787 & 688620 & 5.5 & 5.2277 & TRN & \\
\hline CHEMBL1575785 & 688620 & 5.0 & 4.8956 & TRN & \\
\hline CHEMBL1535458 & 688620 & 5.0 & 5.1533 & TRN & \\
\hline CHEMBL1502859 & 688620 & 4.9 & 4.9595 & TRN & \\
\hline CHEMBL1560435 & 688620 & 5.4 & 5.1669 & TRN & \\
\hline CHEMBL1322391 & 688620 & 4.7 & 5.0499 & TRN & \\
\hline CHEMBL1372989 & 688620 & 6.15 & 5.12299 & 9999999999 & TST \\
\hline CHEMBL1467942 & 688620 & 5.15 & 5.0256 & TRN & \\
\hline CHEMBL1312683 & 688620 & 4.45 & 5.0505 & TRN & \\
\hline CHEMBL1548977 & 688620 & 4.95 & 4.7546 & TRN & \\
\hline CHEMBL1308138 & 688620 & 4.85 & 5.1091 & TST & \\
\hline
\end{tabular}




\begin{tabular}{|c|c|c|c|c|}
\hline \multirow[b]{2}{*}{ CHEMBL1565747 } & \multicolumn{4}{|c|}{ Supplemental Table s2.txt } \\
\hline & 688620 & 4.45 & 5.0095 & TRN \\
\hline CHEMBL1318940 & 688620 & 5.05 & 5.1429 & TRN \\
\hline CHEMBL1444045 & 688620 & 4.95 & 4.8962 & TRN \\
\hline CHEMBL3193915 & 688620 & 4.8 & 4.8274 & TRN \\
\hline CHEMBL1339723 & 688620 & 4.45 & 5.0489 & TRN \\
\hline CHEMBL1388639 & 688620 & 5.3 & 5.5175 & TRN \\
\hline CHEMBL122701 & 688620 & 4.5 & 5.0482 & TRN \\
\hline CHEMBL1392922 & 688620 & 4.7 & 4.9786 & TRN \\
\hline CHEMBL1609061 & 688620 & 5.25 & 4.9127 & TST \\
\hline CHEMBL3194045 & 688620 & 5.6 & 5.1586 & TRN \\
\hline CHEMBL1390212 & 688620 & 5.5 & 5.5687 & TST \\
\hline CHEMBL482116 & 688620 & 6.15 & 5.6817 & TRN \\
\hline CHEMBL1403556 & 688620 & 4.7 & 4.9515 & TRN \\
\hline CHEMBL1603152 & 688620 & 4.9 & 4.9363 & TRN \\
\hline CHEMBL1489067 & 688620 & 4.45 & 4.984 & TRN \\
\hline CHEMBL1406208 & 688620 & 5.0 & 5.6353 & TST \\
\hline CHEMBL1350461 & 688620 & 4.55 & 5.1169 & TST \\
\hline CHEMBL3195951 & 688620 & 5.2 & 5.2402 & TRN \\
\hline CHEMBL1336823 & 688620 & 5.65 & 5.2863 & TST \\
\hline CHEMBL1464740 & 688620 & 4.45 & 4.8944 & TRN \\
\hline CHEMBL1987461 & 688620 & 5.85 & 5.1935 & TRN \\
\hline CHEMBL1538796 & 688620 & 4.9 & 5.0118 & TRN \\
\hline CHEMBL1507689 & 688620 & 4.45 & 5.3596 & TST \\
\hline CHEMBL1563714 & 688620 & 5.45 & 5.2155 & TRN \\
\hline CHEMBL1608268 & 688620 & 4.45 & 4.8161 & TRN \\
\hline CHEMBL1235568 & 688620 & 5.2 & 5.4396 & TRN \\
\hline CHEMBL1479408 & 688620 & 4.45 & 4.8009 & TRN \\
\hline CHEMBL 3208465 & 688620 & 5.4 & 5.0434 & TRN \\
\hline CHEMBL1536513 & 688620 & 5.15 & 5.0402 & TST \\
\hline CHEMBL1491697 & 688620 & 4.45 & 4.9893 & TRN \\
\hline CHEMBL1475708 & 688620 & 4.5 & 4.9866 & TRN \\
\hline CHEMBL 3195657 & 688620 & 7.3497 & 6.2521 & TRN \\
\hline CHEMBL1570491 & 688620 & 4.95 & 4.888 & TRN \\
\hline CHEMBL1479974 & 688620 & 5.1 & 5.8904 & TRN \\
\hline CHEMBL1974032 & 688620 & 4.7 & 5.0878 & TST \\
\hline CHEMBL1308154 & 688620 & 4.45 & 4.5364 & TRN \\
\hline CHEMBL1596840 & 688620 & 4.95 & 5.0059 & TRN \\
\hline CHEMBL1386564 & 688620 & 4.5 & 4.8471 & TST \\
\hline CHEMBL 3189918 & 688620 & 5.55 & 5.2649 & TRN \\
\hline CHEMBL1427780 & 688620 & 5.15 & 5.1285 & TST \\
\hline CHEMBL1353709 & 688620 & 4.8 & 4.6656 & TST \\
\hline CHEMBL1527276 & 688620 & 4.95 & 4.956 & TRN \\
\hline CHEMBL1531787 & 688620 & 4.95 & 4.8706 & TST \\
\hline CHEMBL1425529 & 688620 & 6.8 & 5.1838 & TRN \\
\hline CHEMBL1342141 & 688620 & 5.3 & 5.2784 & TRN \\
\hline CHEMBL1417391 & 688620 & 5.2 & 5.2795 & TRN \\
\hline CHEMBL1573700 & 688620 & 4.7 & 5.2153 & TST \\
\hline CHEMBL1488150 & 688620 & 4.45 & 4.7174 & TRN \\
\hline
\end{tabular}




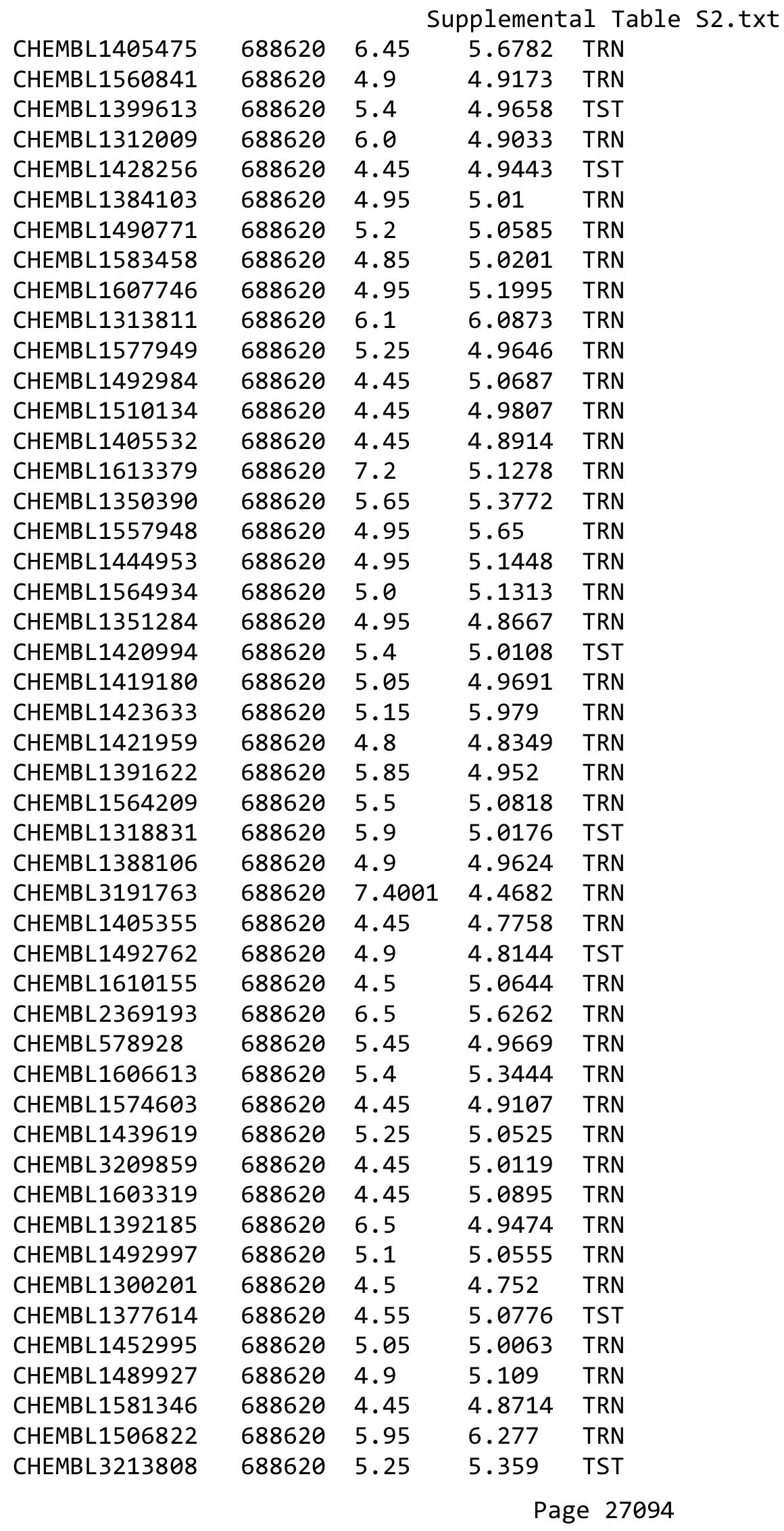




\begin{tabular}{|c|c|c|c|c|}
\hline \multicolumn{5}{|c|}{ Supplemental Table S2.txt } \\
\hline CHEMBL1341343 & 688620 & 4.45 & 5.0208 & TRN \\
\hline CHEMBL428064 & 688620 & 5.9 & 5.4909 & TRN \\
\hline CHEMBL1327493 & 688620 & 5.2 & 5.1404 & TRN \\
\hline CHEMBL1371877 & 688620 & 5.1 & 5.0254 & TRN \\
\hline CHEMBL1446532 & 688620 & 6.5501 & 5.2142 & TRN \\
\hline CHEMBL1438171 & 688620 & 6.25 & 5.1271 & TRN \\
\hline CHEMBL1580935 & 688620 & 5.05 & 5.1908 & TRN \\
\hline CHEMBL1339117 & 688620 & 5.3 & 4.9473 & TRN \\
\hline CHEMBL1322645 & 688620 & 6.0 & 4.9179 & TRN \\
\hline CHEMBL1370471 & 688620 & 4.45 & 4.9304 & TRN \\
\hline CHEMBL3193777 & 688620 & 4.45 & 5.2333 & TST \\
\hline CHEMBL1328261 & 688620 & 5.5 & 5.7995 & TRN \\
\hline CHEMBL1467993 & 688620 & 4.95 & 4.9185 & TST \\
\hline CHEMBL3195308 & 688620 & 4.65 & 5.0462 & TRN \\
\hline CHEMBL1565108 & 688620 & 4.7 & 4.8525 & TRN \\
\hline CHEMBL1456772 & 688620 & 4.95 & 5.2435 & TRN \\
\hline CHEMBL3190774 & 688620 & 5.5 & 5.2644 & TRN \\
\hline CHEMBL1589366 & 688620 & 6.05 & 5.2968 & TST \\
\hline CHEMBL1304848 & 688620 & 5.1 & 5.2298 & TRN \\
\hline CHEMBL1539953 & 688620 & 4.45 & 5.2056 & TRN \\
\hline CHEMBL3208421 & 688620 & 5.6 & 5.0519 & TST \\
\hline CHEMBL1490252 & 688620 & 5.0 & 5.205 & TRN \\
\hline CHEMBL1489273 & 688620 & 5.05 & 4.9924 & TST \\
\hline CHEMBL62044 & 688620 & 5.0 & 4.9896 & TRN \\
\hline CHEMBL1350803 & 688620 & 4.45 & 4.9773 & TRN \\
\hline CHEMBL588965 & 688620 & 4.8 & 4.8162 & TST \\
\hline CHEMBL1419763 & 688620 & 4.45 & 5.0633 & TRN \\
\hline CHEMBL1522434 & 688620 & 6.35 & 5.0212 & TST \\
\hline CHEMBL 3192417 & 688620 & 4.95 & 4.9862 & TRN \\
\hline CHEMBL447876 & 688620 & 5.45 & 5.1867 & TST \\
\hline CHEMBL1454120 & 688620 & 4.85 & 4.8255 & TRN \\
\hline CHEMBL1441609 & 688620 & 5.15 & 5.2622 & TRN \\
\hline CHEMBL1475682 & 688620 & 4.5 & 4.8068 & TRN \\
\hline CHEMBL1372563 & 688620 & 4.45 & 4.7543 & TRN \\
\hline CHEMBL3197926 & 688620 & 4.95 & 4.9521 & TRN \\
\hline CHEMBL483847 & 688620 & 5.25 & 4.9706 & TST \\
\hline CHEMBL1448812 & 688620 & 4.5 & 4.9334 & TRN \\
\hline CHEMBL1477475 & 688620 & 6.8499 & 4.9808 & TRN \\
\hline CHEMBL1482736 & 688620 & 4.95 & 4.8613 & TRN \\
\hline CHEMBL1365054 & 688620 & 4.85 & 5.0003 & TRN \\
\hline CHEMBL1549163 & 688620 & 5.15 & 5.082 & TRN \\
\hline CHEMBL3197362 & 688620 & 4.95 & 5.3062 & TRN \\
\hline CHEMBL1502940 & 688620 & 4.9 & 4.9278 & TRN \\
\hline CHEMBL1583577 & 688620 & 4.95 & 4.9641 & TRN \\
\hline CHEMBL1380209 & 688620 & 4.45 & 4.9521 & TRN \\
\hline CHEMBL1538391 & 688620 & 5.0 & 5.0767 & TRN \\
\hline CHEMBL1517025 & 688620 & 6.9 & 5.1733 & TRN \\
\hline CHEMBL1391353 & 688620 & 5.55 & 4.8143 & TRN \\
\hline
\end{tabular}




\begin{tabular}{|c|c|c|c|c|c|}
\hline \multicolumn{6}{|c|}{ Supplemental Table S2.txt } \\
\hline CHEMBL1328833 & 688620 & 6.15 & 5.026 & TRN & \\
\hline CHEMBL1466261 & 688620 & 4.9 & 4.7405 & TRN & \\
\hline CHEMBL1388470 & 688620 & 4.9 & 5.026 & TST & \\
\hline CHEMBL1338685 & 688620 & 4.9 & 4.8262 & TRN & \\
\hline CHEMBL1369666 & 688620 & 4.95 & 4.7797 & TST & \\
\hline CHEMBL1322517 & 688620 & 6.7001 & 4.80399 & 9999999999 & TST \\
\hline CHEMBL3209430 & 688620 & 4.7 & 4.9323 & TRN & \\
\hline CHEMBL1395038 & 688620 & 5.0 & 5.1848 & TST & \\
\hline CHEMBL374632 & 688620 & 5.55 & 5.6062 & TRN & \\
\hline CHEMBL1336261 & 688620 & 4.8 & 4.7638 & TRN & \\
\hline CHEMBL2369258 & 688620 & 5.7 & 5.6444 & TRN & \\
\hline CHEMBL1509384 & 688620 & 4.95 & 4.9194 & TRN & \\
\hline CHEMBL1370548 & 688620 & 4.75 & 4.8676 & TRN & \\
\hline CHEMBL1580285 & 688620 & 5.3 & 4.8387 & TRN & \\
\hline CHEMBL3208447 & 688620 & 6.45 & 5.8398 & TRN & \\
\hline CHEMBL1582973 & 688620 & 4.75 & 4.9572 & TRN & \\
\hline CHEMBL1335438 & 688620 & 5.4 & 4.90300 & 00000000005 & TRN \\
\hline CHEMBL1533132 & 688620 & 5.25 & 5.0424 & TRN & \\
\hline CHEMBL1386857 & 688620 & 4.45 & 4.8803 & TST & \\
\hline CHEMBL1363410 & 688620 & 4.8 & 4.9567 & TRN & \\
\hline CHEMBL1459149 & 688620 & 4.45 & 4.9551 & TST & \\
\hline CHEMBL1367382 & 688620 & 4.8 & 4.8826 & TRN & \\
\hline CHEMBL1404522 & 688620 & 5.1 & 5.2762 & TRN & \\
\hline CHEMBL3191894 & 688620 & 4.75 & 4.81800 & 00000000005 & TRN \\
\hline CHEMBL1445097 & 688620 & 4.85 & 4.9891 & TRN & \\
\hline CHEMBL1974456 & 688620 & 4.65 & 4.8674 & TRN & \\
\hline CHEMBL1328534 & 688620 & 4.9 & 5.0978 & TST & \\
\hline CHEMBL1506660 & 688620 & 6.3 & 4.8141 & TST & \\
\hline CHEMBL1404222 & 688620 & 4.8 & 4.9291 & TRN & \\
\hline CHEMBL1338736 & 688620 & 5.4 & 5.3703 & TRN & \\
\hline CHEMBL1575461 & 688620 & 4.55 & 5.0483 & TRN & \\
\hline CHEMBL3191365 & 688620 & 4.95 & 4.7721 & TST & \\
\hline CHEMBL1444516 & 688620 & 4.45 & 4.651 & TRN & \\
\hline CHEMBL1527683 & 688620 & 5.9 & 5.0522 & TST & \\
\hline CHEMBL1570871 & 688620 & 4.5 & 4.7234 & TST & \\
\hline CHEMBL1331539 & 688620 & 5.9 & 5.0062 & TRN & \\
\hline CHEMBL1498152 & 688620 & 5.45 & 5.6119 & TRN & \\
\hline CHEMBL1425000 & 688620 & 4.9 & 4.953 & TST & \\
\hline CHEMBL1303087 & 688620 & 4.4 & 5.0568 & TST & \\
\hline CHEMBL3193092 & 688620 & 6.3 & 5.1135 & TRN & \\
\hline CHEMBL1445436 & 688620 & 5.5 & 5.2933 & TRN & \\
\hline CHEMBL1346079 & 688620 & 4.8 & 4.9825 & TRN & \\
\hline CHEMBL1584334 & 688620 & 5.2 & 5.1642 & TRN & \\
\hline CHEMBL1981856 & 688620 & 6.2 & 5.625 & TRN & \\
\hline CHEMBL1374745 & 688620 & 4.85 & 4.94 & TRN & \\
\hline CHEMBL1589359 & 688620 & 4.75 & 5.0007 & TRN & \\
\hline CHEMBL1368203 & 688620 & 4.45 & 5.0285 & TST & \\
\hline CHEMBL1428887 & 688620 & 4.45 & 5.0944 & TRN & \\
\hline
\end{tabular}




\begin{tabular}{|c|c|c|c|c|c|}
\hline \multicolumn{6}{|c|}{ Supplemental Table S2.txt } \\
\hline CHEMBL1605300 & 688620 & 5.45 & 5.0865 & TRN & \\
\hline CHEMBL1571245 & 688620 & 4.8 & 4.8116 & TRN & \\
\hline CHEMBL1330054 & 688620 & 4.5 & 4.9476 & TRN & \\
\hline CHEMBL3198185 & 688620 & 5.95 & 5.9134 & TRN & \\
\hline CHEMBL1572507 & 688620 & 6.15 & 5.3224 & TRN & \\
\hline CHEMBL1419137 & 688620 & 5.15 & 4.8932 & TRN & \\
\hline CHEMBL1348884 & 688620 & 4.95 & 5.3182 & TRN & \\
\hline CHEMBL1491788 & 688620 & 4.9 & 4.9659 & TRN & \\
\hline CHEMBL1520954 & 688620 & 6.1 & 5.0774 & TST & \\
\hline CHEMBL 1456015 & 688620 & 4.95 & 4.9522 & TRN & \\
\hline CHEMBL1500885 & 688620 & 6.3 & 5.2873 & TRN & \\
\hline CHEMBL1566768 & 688620 & 5.9 & 4.91100 & 00000000005 & TRN \\
\hline CHEMBL1580114 & 688620 & 5.25 & 4.9018 & TRN & \\
\hline CHEMBL1586376 & 688620 & 5.45 & 5.1064 & TRN & \\
\hline CHEMBL1448773 & 688620 & 6.25 & 5.4732 & TRN & \\
\hline CHEMBL1503819 & 688620 & 5.5 & 4.9776 & TRN & \\
\hline CHEMBL578109 & 688620 & 4.65 & 4.8879 & TST & \\
\hline CHEMBL1334804 & 688620 & 4.45 & 4.8396 & TST & \\
\hline CHEMBL1321374 & 688620 & 4.45 & 5.0592 & TRN & \\
\hline CHEMBL1348704 & 688620 & 4.95 & 4.8661 & TRN & \\
\hline CHEMBL1571448 & 688620 & 4.8 & 5.0607 & TST & \\
\hline CHEMBL1599989 & 688620 & 5.3 & 4.9576 & TRN & \\
\hline CHEMBL1971458 & 688620 & 4.5 & 5.3368 & TRN & \\
\hline CHEMBL167260 & 688620 & 5.45 & 5.0778 & TST & \\
\hline CHEMBL1385433 & 688620 & 4.45 & 4.8109 & TST & \\
\hline CHEMBL1348410 & 688620 & 6.0 & 5.7417 & TRN & \\
\hline CHEMBL1458131 & 688620 & 5.25 & 5.5122 & TRN & \\
\hline CHEMBL1302053 & 688620 & 6.05 & 5.6243 & TRN & \\
\hline CHEMBL1402459 & 688620 & 5.0 & 5.0471 & TRN & \\
\hline CHEMBL1418929 & 688620 & 4.45 & 4.8974 & TRN & \\
\hline CHEMBL3195761 & 688620 & 5.65 & 5.5826 & TST & \\
\hline CHEMBL3195991 & 688620 & 4.85 & 5.0338 & TRN & \\
\hline CHEMBL3191012 & 688620 & 5.0 & 4.9999 & TRN & \\
\hline CHEMBL1408414 & 688620 & 5.3 & 5.2431 & TRN & \\
\hline CHEMBL1443934 & 688620 & 5.35 & 5.1417 & TST & \\
\hline CHEMBL1549036 & 688620 & 5.25 & 4.9751 & TRN & \\
\hline CHEMBL1604479 & 688620 & 7.3002 & 5.1589 & TRN & \\
\hline CHEMBL1519202 & 688620 & 5.2 & 5.3906 & TRN & \\
\hline CHEMBL1328109 & 688620 & 5.7 & 4.9611 & TST & \\
\hline CHEMBL1584469 & 688620 & 4.45 & 4.9833 & TRN & \\
\hline CHEMBL1500815 & 688620 & 4.65 & 5.1571 & TRN & \\
\hline CHEMBL1464949 & 688620 & 4.65 & 5.0458 & TST & \\
\hline CHEMBL602987 & 688620 & 4.85 & 4.7322 & TST & \\
\hline CHEMBL138921 & 688620 & 4.95 & 4.8622 & TRN & \\
\hline CHEMBL1491816 & 688620 & 6.1 & 5.5859 & TRN & \\
\hline CHEMBL1391949 & 688620 & 4.45 & 4.9026 & TST & \\
\hline CHEMBL 1440674 & 688620 & 5.75 & 5.1574 & TRN & \\
\hline CHEMBL1468270 & 688620 & 4.9 & 4.8696 & TRN & \\
\hline
\end{tabular}




\begin{tabular}{|c|c|c|c|c|}
\hline \multicolumn{5}{|c|}{ Supplemental Table S2.txt } \\
\hline CHEMBL1453108 & 688620 & 6.0 & 5.778 & TRN \\
\hline CHEMBL1584796 & 688620 & 5.25 & 4.8467 & TST \\
\hline CHEMBL1454096 & 688620 & 5.4 & 5.0189 & TRN \\
\hline CHEMBL1468863 & 688620 & 4.5 & 5.4122 & TRN \\
\hline CHEMBL1389502 & 688620 & 4.45 & 5.2419 & TRN \\
\hline CHEMBL1424843 & 688620 & 5.55 & 4.7666 & TRN \\
\hline CHEMBL3191034 & 688620 & 5.45 & 5.4122 & TST \\
\hline CHEMBL 3213774 & 688620 & 4.45 & 4.9608 & TRN \\
\hline CHEMBL1339834 & 688620 & 4.65 & 5.1272 & TST \\
\hline CHEMBL1420194 & 688620 & 6.05 & 5.1449 & TRN \\
\hline CHEMBL3189307 & 688620 & 5.95 & 5.8098 & TRN \\
\hline CHEMBL1535149 & 688620 & 5.65 & 5.2999 & TRN \\
\hline CHEMBL1470438 & 688620 & 5.0 & 5.2753 & TST \\
\hline CHEMBL1349736 & 688620 & 5.7 & 5.2698 & TRN \\
\hline CHEMBL1352943 & 688620 & 4.45 & 4.8058 & TRN \\
\hline CHEMBL533293 & 688620 & 5.15 & 5.2462 & TST \\
\hline CHEMBL1416187 & 688620 & 4.45 & 5.0172 & TRN \\
\hline CHEMBL1398595 & 688620 & 4.5 & 4.9 & TRN \\
\hline CHEMBL1563827 & 688620 & 4.6 & 4.8905 & TRN \\
\hline CHEMBL1366370 & 688620 & 4.7 & 4.9372 & TRN \\
\hline CHEMBL1575576 & 688620 & 5.15 & 5.0248 & TRN \\
\hline CHEMBL1302878 & 688620 & 4.95 & 4.8602 & TRN \\
\hline CHEMBL1472513 & 688620 & 5.35 & 5.0902 & TRN \\
\hline CHEMBL1495292 & 688620 & 4.45 & 5.0146 & TRN \\
\hline CHEMBL1486484 & 688620 & 6.05 & 5.6198 & TRN \\
\hline CHEMBL1454217 & 688620 & 4.65 & 4.8594 & TST \\
\hline CHEMBL1362828 & 688620 & 6.15 & 5.2976 & TST \\
\hline CHEMBL1423217 & 688620 & 4.45 & 4.8636 & TRN \\
\hline CHEMBL1578606 & 688620 & 4.8 & 5.0642 & TRN \\
\hline CHEMBL1461851 & 688620 & 4.95 & 4.9898 & TRN \\
\hline CHEMBL1525542 & 688620 & 5.05 & 4.8214 & TST \\
\hline CHEMBL1333227 & 688620 & 4.45 & 5.2725 & TRN \\
\hline CHEMBL1345769 & 688620 & 4.65 & 5.1742 & TST \\
\hline CHEMBL1394646 & 688620 & 5.35 & 4.9724 & TST \\
\hline CHEMBL1328024 & 688620 & 5.45 & 5.8615 & TRN \\
\hline CHEMBL602646 & 688620 & 5.6 & 5.3503 & TST \\
\hline CHEMBL1481675 & 688620 & 4.8 & 5.7347 & TRN \\
\hline CHEMBL1300984 & 688620 & 4.95 & 4.6241 & TRN \\
\hline CHEMBL1465506 & 688620 & 4.95 & 4.925 & TRN \\
\hline CHEMBL1428997 & 688620 & 5.2 & 4.9775 & TST \\
\hline CHEMBL1392353 & 688620 & 4.8 & 5.1026 & TRN \\
\hline CHEMBL 1464510 & 688620 & 4.75 & 5.2264 & TRN \\
\hline CHEMBL1524814 & 688620 & 4.45 & 4.9152 & TST \\
\hline CHEMBL1544183 & 688620 & 6.25 & 4.9456 & TRN \\
\hline CHEMBL1342784 & 688620 & 4.75 & 4.8882 & TRN \\
\hline CHEMBL1310570 & 688620 & 4.65 & 4.9928 & TRN \\
\hline CHEMBL1984924 & 688620 & 5.2 & 4.963 & TST \\
\hline CHEMBL1566275 & 688620 & 5.05 & 5.1203 & TRN \\
\hline
\end{tabular}




\begin{tabular}{|c|c|c|c|c|}
\hline & & & pplement & $T_{2}$ \\
\hline CHEMBL3193501 & 688620 & 4.8 & 5.0191 & TRN \\
\hline CHEMBL1996271 & 688620 & 4.7 & 5.0322 & TRN \\
\hline CHEMBL1353653 & 688620 & 4.45 & 4.875 & TRN \\
\hline CHEMBL1606360 & 688620 & 4.9 & 5.3284 & TRN \\
\hline CHEMBL 1406070 & 688620 & 4.95 & 4.8662 & TRN \\
\hline CHEMBL1366506 & 688620 & 4.9 & 4.9226 & TRN \\
\hline CHEMBL1540233 & 688620 & 6.2 & 5.1474 & TST \\
\hline CHEMBL1577210 & 688620 & 5.75 & 5.0402 & TRN \\
\hline CHEMBL1520279 & 688620 & 4.65 & 4.9366 & TRN \\
\hline CHEMBL1569544 & 688620 & 4.6 & 5.1242 & TRN \\
\hline CHEMBL1550722 & 688620 & 4.85 & 4.8614 & TRN \\
\hline CHEMBL562193 & 688620 & 4.45 & 4.8291 & TRN \\
\hline CHEMBL3210824 & 688620 & 4.95 & 4.8698 & TRN \\
\hline CHEMBL1488337 & 688620 & 5.3 & 5.7321 & TST \\
\hline CHEMBL1604664 & 688620 & 4.45 & 5.1182 & TRN \\
\hline CHEMBL1531206 & 688620 & 5.65 & 5.0805 & TRN \\
\hline CHEMBL1308668 & 688620 & 4.95 & 4.9755 & TRN \\
\hline CHEMBL1400975 & 688620 & 4.95 & 5.0361 & TST \\
\hline CHEMBL 3208285 & 688620 & 4.45 & 5.1445 & TRN \\
\hline CHEMBL1375601 & 688620 & 4.8 & 4.8797 & TRN \\
\hline CHEMBL1387000 & 688620 & 4.9 & 5.0851 & TRN \\
\hline CHEMBL1351161 & 688620 & 5.2 & 4.963 & TRN \\
\hline CHEMBL1411839 & 688620 & 4.9 & 4.9159 & TST \\
\hline CHEMBL1468364 & 688620 & 4.95 & 5.0638 & TRN \\
\hline CHEMBL1531513 & 688620 & 5.2 & 4.7656 & TRN \\
\hline CHEMBL1375847 & 688620 & 4.9 & 5.1686 & TRN \\
\hline CHEMBL1462125 & 688620 & 4.65 & 4.8042 & TRN \\
\hline CHEMBL1343455 & 688620 & 4.75 & 5.0144 & TRN \\
\hline CHEMBL1608668 & 688620 & 5.1 & 5.0253 & TRN \\
\hline CHEMBL1486102 & 688620 & 4.75 & 5.0292 & TST \\
\hline CHEMBL1539580 & 688620 & 5.7 & 5.1813 & TST \\
\hline CHEMBL1326118 & 688620 & 5.0 & 4.7905 & TRN \\
\hline CHEMBL1420432 & 688620 & 4.55 & 5.301 & TRN \\
\hline CHEMBL1501509 & 688620 & 4.45 & 5.0615 & TRN \\
\hline CHEMBL1493396 & 688620 & 4.8 & 4.7381 & TST \\
\hline CHEMBL1416184 & 688620 & 5.55 & 5.1765 & TRN \\
\hline CHEMBL3194245 & 688620 & 4.95 & 5.0863 & TRN \\
\hline CHEMBL1503961 & 688620 & 4.7 & 4.8972 & TST \\
\hline CHEMBL1425046 & 688620 & 5.95 & 5.1294 & TRN \\
\hline CHEMBL455984 & 688620 & 5.0 & 4.7973 & TRN \\
\hline CHEMBL1607173 & 688620 & 4.45 & 4.8654 & TRN \\
\hline CHEMBL1587287 & 688620 & 5.6 & 4.878 & TRN \\
\hline CHEMBL1579807 & 688620 & 5.1 & 5.1472 & TST \\
\hline CHEMBL1564600 & 688620 & 7.0 & 5.2699 & TST \\
\hline CHEMBL3196765 & 688620 & 4.45 & 4.8449 & TRN \\
\hline CHEMBL3212209 & 688620 & 5.75 & 4.9432 & TRN \\
\hline CHEMBL1300542 & 688620 & 4.45 & 5.1284 & TST \\
\hline CHEMBL1609063 & 688620 & 4.8 & 5.3612 & TST \\
\hline
\end{tabular}




\begin{tabular}{|c|c|c|c|c|}
\hline \multicolumn{5}{|c|}{ Supplemental Table } \\
\hline CHEMBL1376130 & 688620 & 5.15 & 4.9814 & TRN \\
\hline CHEMBL3196861 & 688620 & 5.5 & 5.2027 & TRN \\
\hline CHEMBL1351772 & 688620 & 5.45 & 5.107 & TRN \\
\hline CHEMBL1300717 & 688620 & 5.1 & 4.9101 & TRN \\
\hline CHEMBL1613378 & 688620 & 4.75 & 5.0839 & TST \\
\hline CHEMBL1511013 & 688620 & 4.95 & 5.1444 & TRN \\
\hline CHEMBL1491308 & 688620 & 4.65 & 4.9739 & TRN \\
\hline CHEMBL1524495 & 688620 & 4.8 & 5.0998 & TRN \\
\hline CHEMBL1569174 & 688620 & 5.25 & 5.2501 & TRN \\
\hline CHEMBL1535189 & 688620 & 5.1 & 5.092 & TST \\
\hline CHEMBL3207376 & 688620 & 5.45 & 5.109 & TST \\
\hline CHEMBL3197136 & 688620 & 5.15 & 4.9599 & TRN \\
\hline CHEMBL1569208 & 688620 & 6.0 & 5.7987 & TRN \\
\hline CHEMBL1336550 & 688620 & 6.0 & 5.2524 & TRN \\
\hline CHEMBL605584 & 688620 & 4.8 & 5.1098 & TRN \\
\hline CHEMBL3196568 & 688620 & 5.4 & 5.1515 & TRN \\
\hline CHEMBL1469773 & 688620 & 4.45 & 4.8791 & TRN \\
\hline CHEMBL1522575 & 688620 & 4.75 & 5.0486 & TST \\
\hline CHEMBL1545470 & 688620 & 5.35 & 5.0786 & TRN \\
\hline CHEMBL1496464 & 688620 & 5.0 & 4.9063 & TST \\
\hline CHEMBL1339050 & 688620 & 4.45 & 4.8973 & TRN \\
\hline CHEMBL427692 & 688620 & 4.9 & 4.8627 & TRN \\
\hline CHEMBL1304864 & 688620 & 4.9 & 4.9422 & TST \\
\hline CHEMBL1427709 & 688620 & 5.35 & 4.9656 & TRN \\
\hline CHEMBL1480798 & 688620 & 4.9 & 5.2925 & TRN \\
\hline CHEMBL3208046 & 688620 & 4.85 & 5.0179 & TRN \\
\hline CHEMBL1519797 & 688620 & 6.5 & 5.0789 & TST \\
\hline CHEMBL1486521 & 688620 & 5.55 & 5.3788 & TRN \\
\hline CHEMBL1331106 & 688620 & 5.35 & 5.251 & TRN \\
\hline CHEMBL1344070 & 688620 & 5.0 & 5.1555 & TST \\
\hline CHEMBL1306076 & 688620 & 4.6 & 4.7091 & TST \\
\hline CHEMBL1610883 & 688620 & 4.45 & 5.0691 & TRN \\
\hline CHEMBL1378220 & 688620 & 4.95 & 4.5931 & TRN \\
\hline CHEMBL1464798 & 688620 & 5.2 & 5.3183 & TRN \\
\hline CHEMBL1418980 & 688620 & 4.75 & 4.8353 & TRN \\
\hline CHEMBL 3210447 & 688620 & 6.0 & 5.0924 & TST \\
\hline CHEMBL 3207787 & 688620 & 4.75 & 5.0278 & TST \\
\hline CHEMBL1303587 & 688620 & 4.5 & 4.7915 & TRN \\
\hline CHEMBL1420952 & 688620 & 4.65 & 4.9454 & TRN \\
\hline CHEMBL1597556 & 688620 & 4.85 & 4.9242 & TRN \\
\hline CHEMBL1465250 & 688620 & 4.45 & 5.1302 & TRN \\
\hline CHEMBL1531172 & 688620 & 5.05 & 5.0068 & TRN \\
\hline CHEMBL1340835 & 688620 & 4.8 & 5.0639 & TRN \\
\hline CHEMBL1504289 & 688620 & 4.5 & 5.282 & TRN \\
\hline CHEMBL1393079 & 688620 & 4.85 & 5.0593 & TRN \\
\hline CHEMBL1464020 & 688620 & 4.45 & 4.8582 & TRN \\
\hline CHEMBL1541032 & 688620 & 4.7 & 5.2681 & TST \\
\hline CHEMBL1362635 & 688620 & 4.95 & 4.8628 & TRN \\
\hline
\end{tabular}




\begin{tabular}{|c|c|c|c|c|}
\hline & & & pplement & $T_{2}$ \\
\hline CHEMBL1570543 & 688620 & 5.5 & 4.9623 & TRN \\
\hline CHEMBL68613 & 688620 & 4.85 & 5.1943 & TRN \\
\hline CHEMBL1511222 & 688620 & 4.9 & 4.9767 & TRN \\
\hline CHEMBL1438861 & 688620 & 4.9 & 5.0669 & TRN \\
\hline CHEMBL1596890 & 688620 & 6.35 & 5.1906 & TRN \\
\hline CHEMBL1601690 & 688620 & 5.15 & 5.2479 & TRN \\
\hline CHEMBL1464413 & 688620 & 5.0 & 4.822 & TRN \\
\hline CHEMBL1465918 & 688620 & 4.9 & 4.8968 & TRN \\
\hline CHEMBL1441104 & 688620 & 4.45 & 4.9822 & TRN \\
\hline CHEMBL3199083 & 688620 & 5.5 & 5.2395 & TRN \\
\hline CHEMBL1447393 & 688620 & 5.65 & 5.2112 & TRN \\
\hline CHEMBL1593168 & 688620 & 4.75 & 4.9625 & TST \\
\hline CHEMBL1392791 & 688620 & 6.1 & 4.8558 & TRN \\
\hline CHEMBL1418700 & 688620 & 6.6 & 5.1555 & TST \\
\hline CHEMBL1498979 & 688620 & 5.05 & 4.9824 & TRN \\
\hline CHEMBL1459781 & 688620 & 4.9 & 4.838 & TRN \\
\hline CHEMBL1487159 & 688620 & 4.45 & 4.9553 & TST \\
\hline CHEMBL1309890 & 688620 & 5.55 & 5.6284 & TRN \\
\hline CHEMBL1493743 & 688620 & 4.8 & 5.0686 & TRN \\
\hline CHEMBL1598083 & 688620 & 4.85 & 5.3829 & TRN \\
\hline CHEMBL1511911 & 688620 & 4.5 & 5.1187 & TRN \\
\hline CHEMBL3194403 & 688620 & 4.45 & 5.0206 & TRN \\
\hline CHEMBL1508624 & 688620 & 4.75 & 4.6446 & TRN \\
\hline CHEMBL1424468 & 688620 & 4.95 & 5.0494 & TRN \\
\hline CHEMBL551604 & 688620 & 5.65 & 5.1138 & TST \\
\hline CHEMBL1582978 & 688620 & 4.45 & 5.0458 & TRN \\
\hline CHEMBL1455938 & 688620 & 5.65 & 5.4069 & TRN \\
\hline CHEMBL1503007 & 688620 & 4.85 & 4.8209 & TST \\
\hline CHEMBL1469362 & 688620 & 4.95 & 4.83 & TRN \\
\hline CHEMBL1480661 & 688620 & 4.75 & 4.9855 & TRN \\
\hline CHEMBL1459454 & 688620 & 4.9 & 5.0249 & TRN \\
\hline CHEMBL1466855 & 688620 & 5.3 & 5.2167 & TRN \\
\hline CHEMBL1503774 & 688620 & 4.45 & 4.9897 & TRN \\
\hline CHEMBL1471070 & 688620 & 4.95 & 5.1677 & TST \\
\hline CHEMBL1409101 & 688620 & 4.9 & 4.9889 & TRN \\
\hline CHEMBL1362116 & 688620 & 4.7 & 4.8811 & TRN \\
\hline CHEMBL1359690 & 688620 & 6.1 & 5.0129 & TRN \\
\hline CHEMBL1517667 & 688620 & 4.9 & 5.1083 & TST \\
\hline CHEMBL1333094 & 688620 & 4.45 & 4.9608 & TRN \\
\hline CHEMBL1609832 & 688620 & 5.0 & 4.8768 & TST \\
\hline CHEMBL1571584 & 688620 & 4.9 & 5.0343 & TRN \\
\hline CHEMBL1969343 & 688620 & 4.95 & 5.05 & TRN \\
\hline CHEMBL1461329 & 688620 & 5.6 & 4.9941 & TRN \\
\hline CHEMBL1468152 & 688620 & 4.95 & 4.9238 & TST \\
\hline CHEMBL1393222 & 688620 & 4.45 & 5.1183 & TRN \\
\hline CHEMBL1508195 & 688620 & 4.95 & 5.0523 & TRN \\
\hline CHEMBL1595423 & 688620 & 4.9 & 4.9334 & TRN \\
\hline CHEMBL3392034 & 688620 & 4.75 & 4.8314 & TRN \\
\hline
\end{tabular}




\begin{tabular}{|c|c|c|c|c|c|}
\hline & & & & & \\
\hline CHEMBL1483008 & 688620 & 5.6 & 4.8381 & TRN & \\
\hline CHEMBL1329554 & 688620 & 5.6 & 5.6335 & TRN & \\
\hline CHEMBL1414485 & 688620 & 6.95 & 5.0686 & TRN & \\
\hline CHEMBL1452220 & 688620 & 4.85 & 4.9434 & TST & \\
\hline CHEMBL1350851 & 688620 & 4.75 & 4.67 & TST & \\
\hline CHEMBL1422981 & 688620 & 4.6 & 5.0595 & TRN & \\
\hline CHEMBL1569370 & 688620 & 4.85 & 4.8949 & TRN & \\
\hline CHEMBL1419282 & 688620 & 4.9 & 4.8701 & TRN & \\
\hline CHEMBL1566006 & 688620 & 5.0 & 4.84399 & 9999999999 & TRN \\
\hline CHEMBL1462576 & 688620 & 4.45 & 4.7784 & TRN & \\
\hline CHEMBL1431484 & 688620 & 4.95 & 4.97199 & 99999999995 & TRN \\
\hline CHEMBL1439006 & 688620 & 7.1002 & 5.4475 & TRN & \\
\hline CHEMBL1560423 & 688620 & 4.75 & 4.8059 & TRN & \\
\hline CHEMBL3196275 & 688620 & 4.8 & 5.2154 & TST & \\
\hline CHEMBL1509230 & 688620 & 5.65 & 5.3623 & TRN & \\
\hline CHEMBL 2002332 & 688620 & 5.4 & 5.1525 & TRN & \\
\hline CHEMBL1537935 & 688620 & 4.9 & 5.1656 & TRN & \\
\hline CHEMBL1469351 & 688620 & 5.05 & 5.0712 & TRN & \\
\hline CHEMBL1534592 & 688620 & 5.4 & 4.9881 & TRN & \\
\hline CHEMBL1582520 & 688620 & 6.3 & 4.9752 & TST & \\
\hline CHEMBL1406247 & 688620 & 5.0 & 5.0751 & TRN & \\
\hline CHEMBL1309876 & 688620 & 5.2 & 5.3099 & TST & \\
\hline CHEMBL1508393 & 688620 & 4.65 & 4.9654 & TRN & \\
\hline CHEMBL1370698 & 688620 & 4.9 & 4.8747 & TST & \\
\hline CHEMBL 3189147 & 688620 & 5.65 & 5.3368 & TRN & \\
\hline CHEMBL528165 & 688620 & 4.45 & 4.8756 & TST & \\
\hline CHEMBL 1478572 & 688620 & 5.45 & 4.7997 & TRN & \\
\hline CHEMBL1555983 & 688620 & 4.8 & 4.7523 & TRN & \\
\hline CHEMBL1343334 & 688620 & 5.15 & 5.0522 & TRN & \\
\hline CHEMBL1566729 & 688620 & 4.8 & 4.7898 & TRN & \\
\hline CHEMBL1364782 & 688620 & 4.65 & 5.199 & TRN & \\
\hline CHEMBL1418623 & 688620 & 6.25 & 5.5972 & TRN & \\
\hline CHEMBL3194596 & 688620 & 5.75 & 5.4086 & TRN & \\
\hline CHEMBL1613038 & 688620 & 5.0 & 4.8758 & TRN & \\
\hline CHEMBL1568012 & 688620 & 5.95 & 4.8316 & TST & \\
\hline CHEMBL1581441 & 688620 & 5.45 & 5.1588 & TRN & \\
\hline CHEMBL 1361600 & 688620 & 4.45 & 4.7638 & TRN & \\
\hline CHEMBL1440909 & 688620 & 4.9 & 4.8829 & TRN & \\
\hline CHEMBL1602192 & 688620 & 4.95 & 5.1807 & TRN & \\
\hline CHEMBL1326159 & 688620 & 5.6 & 5.0535 & TRN & \\
\hline CHEMBL1427092 & 688620 & 5.15 & 4.8065 & TRN & \\
\hline CHEMBL1324245 & 688620 & 4.75 & 4.8878 & TRN & \\
\hline CHEMBL1608392 & 688620 & 4.45 & 4.7697 & TRN & \\
\hline CHEMBL 3194845 & 688620 & 4.7 & 5.1211 & TRN & \\
\hline CHEMBL1310737 & 688620 & 4.75 & 4.8888 & TRN & \\
\hline CHEMBL1459245 & 688620 & 4.9 & 5.0752 & TRN & \\
\hline CHEMBL1382928 & 688620 & 4.45 & 4.7231 & TRN & \\
\hline CHEMBL1306692 & 688620 & 4.45 & 5.0939 & TRN & \\
\hline & & & & 27102 & \\
\hline
\end{tabular}




\begin{tabular}{|c|c|c|c|c|}
\hline \multicolumn{5}{|c|}{ Supplemental Table S2.txt } \\
\hline CHEMBL1382956 & 688620 & 4.95 & 4.8899 & TST \\
\hline CHEMBL1988501 & 688620 & 4.8 & 4.9906 & TRN \\
\hline CHEMBL3193156 & 688620 & 4.75 & 4.812 & TST \\
\hline CHEMBL1550076 & 688620 & 4.45 & 4.9286 & TRN \\
\hline CHEMBL1605789 & 688620 & 4.8 & 5.1465 & TST \\
\hline CHEMBL1431017 & 688620 & 4.45 & 5.0847 & TRN \\
\hline CHEMBL1345409 & 688620 & 4.45 & 5.104 & TRN \\
\hline CHEMBL 3145131 & 688620 & 4.8 & 5.1288 & TRN \\
\hline CHEMBL1388430 & 688620 & 4.8 & 5.0941 & TRN \\
\hline CHEMBL1300041 & 688620 & 5.2 & 5.1192 & TRN \\
\hline CHEMBL1571432 & 688620 & 4.95 & 5.2375 & TST \\
\hline CHEMBL1487046 & 688620 & 4.95 & 5.1365 & TST \\
\hline CHEMBL1572800 & 688620 & 4.95 & 5.0858 & TRN \\
\hline CHEMBL1533547 & 688620 & 5.2 & 5.0611 & TRN \\
\hline CHEMBL1548302 & 688620 & 4.65 & 5.1509 & TST \\
\hline CHEMBL1492396 & 688620 & 4.85 & 4.7387 & TRN \\
\hline CHEMBL1496555 & 688620 & 4.9 & 5.1286 & TRN \\
\hline CHEMBL1446480 & 688620 & 4.45 & 4.8958 & TRN \\
\hline CHEMBL1564345 & 688620 & 4.85 & 5.1479 & TRN \\
\hline CHEMBL1426669 & 688620 & 5.15 & 5.0427 & TRN \\
\hline CHEMBL1380397 & 688620 & 5.9 & 4.9739 & TRN \\
\hline CHEMBL1599897 & 688620 & 4.95 & 5.1299 & TRN \\
\hline CHEMBL1412987 & 688620 & 4.85 & 5.8004 & TRN \\
\hline CHEMBL1439269 & 688620 & 4.8 & 4.8399 & TST \\
\hline CHEMBL1598455 & 688620 & 4.5 & 4.981 & TRN \\
\hline CHEMBL1567551 & 688620 & 5.45 & 5.0947 & TRN \\
\hline CHEMBL596674 & 688620 & 5.55 & 5.2513 & TST \\
\hline CHEMBL3207817 & 688620 & 5.25 & 5.4729 & TRN \\
\hline CHEMBL1526578 & 688620 & 5.4 & 5.0256 & TST \\
\hline CHEMBL1337131 & 688620 & 4.7 & 5.1452 & TRN \\
\hline CHEMBL1482246 & 688620 & 5.5 & 5.1175 & TRN \\
\hline CHEMBL1585233 & 688620 & 4.95 & 4.7526 & TRN \\
\hline CHEMBL1325637 & 688620 & 5.0 & 5.0752 & TRN \\
\hline CHEMBL1448427 & 688620 & 4.9 & 5.0009 & TST \\
\hline CHEMBL1371752 & 688620 & 4.45 & 5.0607 & TST \\
\hline CHEMBL1464439 & 688620 & 5.75 & 4.9466 & TRN \\
\hline CHEMBL1393064 & 688620 & 4.95 & 5.1285 & TRN \\
\hline CHEMBL3199913 & 688620 & 5.05 & 4.8934 & TRN \\
\hline CHEMBL1565236 & 688620 & 5.2 & 5.3193 & TRN \\
\hline CHEMBL1404762 & 688620 & 4.8 & 4.9506 & TRN \\
\hline CHEMBL1093246 & 688620 & 5.35 & 5.0117 & TST \\
\hline CHEMBL1468470 & 688620 & 4.9 & 5.1331 & TRN \\
\hline CHEMBL1463004 & 688620 & 6.95 & 5.1918 & TST \\
\hline CHEMBL1570503 & 688620 & 4.75 & 5.0018 & TRN \\
\hline CHEMBL1524384 & 688620 & 5.1 & 5.1093 & TRN \\
\hline CHEMBL1339422 & 688620 & 6.95 & 5.1434 & TRN \\
\hline CHEMBL1525830 & 688620 & 5.4 & 4.8449 & TRN \\
\hline CHEMBL1484158 & 688620 & 4.85 & 5.1766 & TRN \\
\hline
\end{tabular}




\begin{tabular}{|c|c|c|c|c|c|}
\hline \multicolumn{6}{|c|}{ Supplemental Table S2.txt } \\
\hline CHEMBL1613616 & 688620 & 4.45 & 4.8175 & TST & \\
\hline CHEMBL1450808 & 688620 & 5.2 & 4.9812 & TST & \\
\hline CHEMBL1417850 & 688620 & 4.7 & 5.1292 & TRN & \\
\hline CHEMBL1519550 & 688620 & 5.65 & 5.2057 & TRN & \\
\hline CHEMBL 3194446 & 688620 & 5.55 & 5.3344 & TRN & \\
\hline CHEMBL1505756 & 688620 & 5.7 & 5.1936 & TRN & \\
\hline CHEMBL1999548 & 688620 & 5.5 & 5.7437 & TRN & \\
\hline CHEMBL1424779 & 688620 & 4.5 & 4.8198 & TST & \\
\hline CHEMBL 3214221 & 688620 & 5.05 & 5.0319 & TRN & \\
\hline CHEMBL1479387 & 688620 & 4.45 & 4.9856 & TST & \\
\hline CHEMBL1377684 & 688620 & 4.7 & 4.9543 & TST & \\
\hline CHEMBL1374308 & 688620 & 4.95 & 5.1957 & TRN & \\
\hline CHEMBL1483809 & 688620 & 4.8 & 5.0542 & TRN & \\
\hline CHEMBL1337003 & 688620 & 6.0 & 4.9118 & TRN & \\
\hline CHEMBL1304193 & 688620 & 4.95 & 5.0825 & TST & \\
\hline CHEMBL1994034 & 688620 & 5.6 & 5.2427 & TRN & \\
\hline CHEMBL 3193038 & 688620 & 4.9 & 5.0184 & TRN & \\
\hline CHEMBL3192448 & 688620 & 4.9 & 5.0997 & TRN & \\
\hline CHEMBL1467949 & 688620 & 4.95 & 5.0547 & TRN & \\
\hline CHEMBL1549071 & 688620 & 6.5501 & 4.9226 & TRN & \\
\hline CHEMBL1446091 & 688620 & 5.5 & 5.065 & TRN & \\
\hline CHEMBL1477316 & 688620 & 4.65 & 4.7733 & TRN & \\
\hline CHEMBL1361809 & 688620 & 5.1 & 4.9272 & TRN & \\
\hline CHEMBL1403250 & 688620 & 5.05 & 5.17899 & 9999999999 & TRN \\
\hline CHEMBL 3198356 & 688620 & 4.45 & 4.7968 & TRN & \\
\hline CHEMBL 3210072 & 688620 & 5.95 & 5.8276 & TST & \\
\hline CHEMBL1544170 & 688620 & 4.45 & 4.9362 & TRN & \\
\hline CHEMBL1539318 & 688620 & 4.8 & 4.9516 & TRN & \\
\hline CHEMBL1465924 & 688620 & 5.55 & 5.0757 & TRN & \\
\hline CHEMBL1463930 & 688620 & 4.8 & 4.8567 & TST & \\
\hline CHEMBL1521905 & 688620 & 5.55 & 4.8322 & TRN & \\
\hline CHEMBL1464812 & 688620 & 4.85 & 5.0991 & TRN & \\
\hline CHEMBL1489567 & 688620 & 4.85 & 5.0996 & TRN & \\
\hline CHEMBL1367143 & 688620 & 4.85 & 5.101 & TRN & \\
\hline CHEMBL1610391 & 688620 & 5.45 & 4.8923 & TRN & \\
\hline CHEMBL1502873 & 688620 & 5.6 & 5.1548 & TRN & \\
\hline CHEMBL1549591 & 688620 & 4.85 & 5.1939 & TRN & \\
\hline CHEMBL1465148 & 688620 & 5.2 & 5.0005 & TST & \\
\hline CHEMBL1454920 & 688620 & 4.65 & 4.9409 & TRN & \\
\hline CHEMBL1997174 & 688620 & 7.0 & 5.1667 & TRN & \\
\hline CHEMBL1324080 & 688620 & 4.45 & 5.2356 & TRN & \\
\hline CHEMBL1571722 & 688620 & 5.2 & 4.8192 & TRN & \\
\hline CHEMBL1501388 & 688620 & 4.45 & 5.256 & TRN & \\
\hline CHEMBL1519603 & 688620 & 5.2 & 5.2853 & TST & \\
\hline CHEMBL1508309 & 688620 & 4.6 & 5.0103 & TRN & \\
\hline CHEMBL1586713 & 688620 & 6.4 & 4.8627 & TRN & \\
\hline CHEMBL1607266 & 688620 & 4.65 & 5.0617 & TRN & \\
\hline CHEMBL1601265 & 688620 & 4.5 & 4.9931 & TRN & \\
\hline
\end{tabular}




\begin{tabular}{|c|c|c|c|c|}
\hline \multicolumn{5}{|c|}{ Supplemental Table S2.txt } \\
\hline CHEMBL1391337 & 688620 & 5.0 & 5.001 & TST \\
\hline CHEMBL1481581 & 688620 & 5.95 & 5.0907 & TRN \\
\hline CHEMBL1527739 & 688620 & 4.45 & 4.5967 & TRN \\
\hline CHEMBL1547021 & 688620 & 5.25 & 5.3377 & TRN \\
\hline CHEMBL1594890 & 688620 & 5.0 & 4.8129 & TST \\
\hline CHEMBL1347270 & 688620 & 5.05 & 5.0109 & TRN \\
\hline CHEMBL1378557 & 688620 & 5.7 & 5.5538 & TRN \\
\hline CHEMBL2004291 & 688620 & 4.45 & 4.8183 & TRN \\
\hline CHEMBL1403195 & 688620 & 5.15 & 5.0655 & TRN \\
\hline CHEMBL65374 & 688620 & 5.3 & 5.273 & TRN \\
\hline CHEMBL1527106 & 688620 & 4.45 & 4.9247 & TRN \\
\hline CHEMBL1430410 & 688620 & 5.1 & 4.9831 & TRN \\
\hline CHEMBL1594208 & 688620 & 4.95 & 4.9429 & TST \\
\hline CHEMBL1400481 & 688620 & 5.4 & 5.1171 & TST \\
\hline CHEMBL1458291 & 688620 & 4.95 & 4.9065 & TRN \\
\hline CHEMBL1527367 & 688620 & 4.45 & 4.9179 & TRN \\
\hline CHEMBL3190745 & 688620 & 5.85 & 5.4893 & TRN \\
\hline CHEMBL1419641 & 688620 & 5.05 & 4.8692 & TRN \\
\hline CHEMBL3195952 & 688620 & 5.5 & 5.0746 & TRN \\
\hline CHEMBL1409766 & 688620 & 4.75 & 5.1433 & TRN \\
\hline CHEMBL1519450 & 688620 & 5.65 & 5.5985 & TRN \\
\hline CHEMBL2003651 & 688620 & 4.45 & 4.8569 & TRN \\
\hline CHEMBL3198306 & 688620 & 5.55 & 5.2737 & TST \\
\hline CHEMBL1555369 & 688620 & 4.45 & 4.8362 & TST \\
\hline CHEMBL1333561 & 688620 & 5.0 & 5.0839 & TRN \\
\hline CHEMBL1495893 & 688620 & 4.45 & 5.0596 & TST \\
\hline CHEMBL1441614 & 688620 & 4.45 & 4.9276 & TRN \\
\hline CHEMBL1352211 & 688620 & 4.75 & 4.7943 & TRN \\
\hline CHEMBL1338004 & 688620 & 5.15 & 4.8845 & TRN \\
\hline CHEMBL1476383 & 688620 & 4.9 & 5.1442 & TRN \\
\hline CHEMBL1321826 & 688620 & 4.8 & 4.8927 & TST \\
\hline CHEMBL3213957 & 688620 & 5.05 & 5.1853 & TST \\
\hline CHEMBL1375188 & 688620 & 4.8 & 4.9504 & TST \\
\hline CHEMBL1532080 & 688620 & 4.95 & 5.1589 & TRN \\
\hline CHEMBL1608599 & 688620 & 5.3 & 4.9946 & TRN \\
\hline CHEMBL1341853 & 688620 & 5.85 & 5.2294 & TST \\
\hline CHEMBL1351261 & 688620 & 4.9 & 4.9565 & TRN \\
\hline CHEMBL1546779 & 688620 & 4.9 & 5.0463 & TRN \\
\hline CHEMBL1368410 & 688620 & 4.95 & 5.2979 & TRN \\
\hline CHEMBL3189828 & 688620 & 4.65 & 4.9946 & TST \\
\hline CHEMBL1405968 & 688620 & 5.15 & 5.3137 & TST \\
\hline CHEMBL1453960 & 688620 & 4.45 & 5.0747 & TRN \\
\hline CHEMBL 2005967 & 688620 & 4.6 & 5.0921 & TRN \\
\hline CHEMBL1519781 & 688620 & 4.65 & 5.0109 & TST \\
\hline CHEMBL1499613 & 688620 & 5.8 & 5.042 & TRN \\
\hline CHEMBL1383706 & 688620 & 6.5501 & 5.0369 & TST \\
\hline CHEMBL1611468 & 688620 & 5.15 & 5.3218 & TRN \\
\hline CHEMBL1422880 & 688620 & 4.45 & 4.9398 & TRN \\
\hline
\end{tabular}




\begin{tabular}{|c|c|c|c|c|}
\hline \multicolumn{5}{|c|}{ Supplemental Table S2.txt } \\
\hline CHEMBL1603330 & 688620 & 6.2 & 5.5385 & TRN \\
\hline CHEMBL1383406 & 688620 & 4.9 & 4.9053 & TRN \\
\hline CHEMBL1431664 & 688620 & 4.95 & 5.2468 & TRN \\
\hline CHEMBL1581517 & 688620 & 4.75 & 4.9847 & TRN \\
\hline CHEMBL1543120 & 688620 & 5.9 & 5.0546 & TRN \\
\hline CHEMBL1458706 & 688620 & 6.1 & 5.0843 & TRN \\
\hline CHEMBL1393424 & 688620 & 4.85 & 4.6848 & TRN \\
\hline CHEMBL1325945 & 688620 & 5.85 & 5.5542 & TRN \\
\hline CHEMBL1368180 & 688620 & 5.0 & 4.8266 & TRN \\
\hline CHEMBL1499260 & 688620 & 4.9 & 4.8308 & TRN \\
\hline CHEMBL1545482 & 688620 & 6.6499 & 4.9289 & TRN \\
\hline CHEMBL 3190726 & 688620 & 5.85 & 4.8839 & TRN \\
\hline CHEMBL1609163 & 688620 & 5.3 & 4.9808 & TRN \\
\hline CHEMBL1388154 & 688620 & 5.5 & 5.0064 & TRN \\
\hline CHEMBL1401589 & 688620 & 5.0 & 5.8866 & TRN \\
\hline CHEMBL1490593 & 688620 & 4.7 & 5.043 & TST \\
\hline CHEMBL1450484 & 688620 & 5.7 & 5.1298 & TRN \\
\hline CHEMBL1386401 & 688620 & 6.8499 & 4.9322 & TRN \\
\hline CHEMBL1336887 & 688620 & 5.1 & 5.1981 & TRN \\
\hline CHEMBL3193938 & 688620 & 4.95 & 4.8134 & TRN \\
\hline CHEMBL1404996 & 688620 & 6.15 & 5.0364 & TST \\
\hline CHEMBL1383824 & 688620 & 5.05 & 5.0436 & TRN \\
\hline CHEMBL1470751 & 688620 & 4.5 & 5.1918 & TST \\
\hline CHEMBL1971629 & 688620 & 5.05 & 4.871 & TRN \\
\hline CHEMBL 3191048 & 688620 & 6.5501 & 5.4165 & TRN \\
\hline CHEMBL1466455 & 688620 & 4.45 & 4.7362 & TRN \\
\hline CHEMBL1499686 & 688620 & 4.75 & 4.8301 & TRN \\
\hline CHEMBL1509409 & 688620 & 4.9 & 5.1193 & TRN \\
\hline CHEMBL1541409 & 688620 & 4.65 & 4.9845 & TRN \\
\hline CHEMBL1528620 & 688620 & 5.5 & 4.9372 & TRN \\
\hline CHEMBL1537106 & 688620 & 5.1 & 4.8692 & TST \\
\hline CHEMBL1310922 & 688620 & 5.0 & 4.947 & TRN \\
\hline CHEMBL1491120 & 688620 & 5.55 & 5.4112 & TRN \\
\hline CHEMBL1968217 & 688620 & 5.0 & 4.9878 & TRN \\
\hline CHEMBL1966679 & 688620 & 5.9 & 5.5949 & TRN \\
\hline CHEMBL1383048 & 688620 & 4.6 & 4.8333 & TRN \\
\hline CHEMBL1575190 & 688620 & 4.85 & 5.2294 & TST \\
\hline CHEMBL1312504 & 688620 & 5.4 & 5.2948 & TRN \\
\hline CHEMBL1364752 & 688620 & 4.45 & 5.2613 & TST \\
\hline CHEMBL1523860 & 688620 & 4.45 & 4.9874 & TRN \\
\hline CHEMBL 2374266 & 688620 & 4.6 & 4.8592 & TRN \\
\hline CHEMBL1392872 & 688620 & 4.9 & 4.9509 & TST \\
\hline CHEMBL1506614 & 688620 & 4.75 & 4.9096 & TST \\
\hline CHEMBL2296993 & 688620 & 5.15 & 5.1978 & TRN \\
\hline CHEMBL1375474 & 688620 & 4.85 & 5.1557 & TRN \\
\hline CHEMBL1530741 & 688620 & 4.9 & 4.7995 & TST \\
\hline CHEMBL1348795 & 688620 & 4.45 & 4.7805 & TRN \\
\hline CHEMBL1338577 & 688620 & 4.95 & 4.9186 & TRN \\
\hline
\end{tabular}




\begin{tabular}{|c|c|c|c|c|c|}
\hline & & & & & \\
\hline CHEMBL1585797 & 688620 & 4.9 & 5.0292 & TRN & \\
\hline CHEMBL1371556 & 688620 & 4.45 & 4.962 & TST & \\
\hline CHEMBL1966316 & 688620 & 5.3 & 4.905 & TRN & \\
\hline CHEMBL1522758 & 688620 & 4.9 & 4.9623 & TST & \\
\hline CHEMBL1584914 & 688620 & 5.25 & 5.0403 & TST & \\
\hline CHEMBL1400410 & 688620 & 4.8 & 4.9668 & TRN & \\
\hline CHEMBL1415425 & 688620 & 5.3 & 5.2393 & TRN & \\
\hline CHEMBL1469751 & 688620 & 4.45 & 5.0024 & TRN & \\
\hline CHEMBL1569507 & 688620 & 4.65 & 4.9052 & TRN & \\
\hline CHEMBL1360105 & 688620 & 4.6 & 4.9856 & TRN & \\
\hline CHEMBL1534170 & 688620 & 4.45 & 5.24799 & 9999999999 & TST \\
\hline CHEMBL1525807 & 688620 & 4.95 & 5.0144 & TRN & \\
\hline CHEMBL1604542 & 688620 & 5.0 & 4.829 & TRN & \\
\hline CHEMBL3196492 & 688620 & 4.85 & 5.2066 & TST & \\
\hline CHEMBL1353455 & 688620 & 6.5501 & 5.2619 & TST & \\
\hline CHEMBL1374476 & 688620 & 4.95 & 5.0197 & TRN & \\
\hline CHEMBL1390460 & 688620 & 4.65 & 5.3282 & TRN & \\
\hline CHEMBL1566419 & 688620 & 4.95 & 5.0577 & TST & \\
\hline CHEMBL1503452 & 688620 & 4.45 & 4.7298 & TRN & \\
\hline CHEMBL1481444 & 688620 & 5.55 & 5.1642 & TRN & \\
\hline CHEMBL1342292 & 688620 & 4.5 & 5.0709 & TST & \\
\hline CHEMBL1989110 & 688620 & 4.85 & 4.9707 & TRN & \\
\hline CHEMBL1535530 & 688620 & 4.8 & 5.1423 & TRN & \\
\hline CHEMBL1375481 & 688620 & 4.7 & 4.8339 & TRN & \\
\hline CHEMBL1417806 & 688620 & 5.25 & 5.0948 & TRN & \\
\hline CHEMBL1381019 & 688620 & 4.9 & 4.8161 & TRN & \\
\hline CHEMBL1521708 & 688620 & 4.9 & 5.4175 & TRN & \\
\hline CHEMBL1339361 & 688620 & 4.8 & 4.872 & TST & \\
\hline CHEMBL1565677 & 688620 & 4.75 & 4.9922 & TST & \\
\hline CHEMBL3197953 & 688620 & 5.15 & 4.9044 & TRN & \\
\hline CHEMBL1406617 & 688620 & 4.85 & 4.78100 & 0000000001 & TST \\
\hline CHEMBL1464104 & 688620 & 5.05 & 5.17200 & 0000000001 & TRN \\
\hline CHEMBL1332636 & 688620 & 4.6 & 4.9339 & TRN & \\
\hline CHEMBL1324883 & 688620 & 6.3 & 5.3325 & TRN & \\
\hline CHEMBL1536010 & 688620 & 4.45 & 5.0398 & TRN & \\
\hline CHEMBL3189775 & 688620 & 5.15 & 5.1991 & TRN & \\
\hline CHEMBL1407442 & 688620 & 4.85 & 5.0255 & TRN & \\
\hline CHEMBL1554220 & 688620 & 4.95 & 4.9569 & TRN & \\
\hline CHEMBL1550860 & 688620 & 5.05 & 5.0624 & TRN & \\
\hline CHEMBL1399605 & 688620 & 4.9 & 4.931 & TRN & \\
\hline CHEMBL1385817 & 688620 & 4.45 & 4.9881 & TRN & \\
\hline CHEMBL1535117 & 688620 & 4.95 & 5.0662 & TST & \\
\hline CHEMBL1476449 & 688620 & 5.0 & 4.9627 & TRN & \\
\hline CHEMBL1468437 & 688620 & 4.95 & 4.8428 & TRN & \\
\hline CHEMBL1522419 & 688620 & 4.8 & 5.5816 & TST & \\
\hline CHEMBL1454166 & 688620 & 5.0 & 4.8895 & TRN & \\
\hline CHEMBL1343700 & 688620 & 5.05 & 5.223 & TRN & \\
\hline CHEMBL1351848 & 688620 & 4.95 & 4.876 & TRN & \\
\hline & & & & 27107 & \\
\hline
\end{tabular}




\begin{tabular}{|c|c|c|c|c|c|}
\hline \multicolumn{6}{|c|}{ Supplemental Table S2.txt } \\
\hline CHEMBL1523781 & 688620 & 5.55 & 4.8292 & TRN & \\
\hline CHEMBL1365387 & 688620 & 4.85 & 4.8939 & TRN & \\
\hline CHEMBL1580310 & 688620 & 4.9 & 5.0385 & TST & \\
\hline CHEMBL1531997 & 688620 & 4.95 & 4.8689 & TRN & \\
\hline CHEMBL1459237 & 688620 & 4.7 & 5.0107 & TST & \\
\hline CHEMBL3192882 & 688620 & 4.65 & 4.9221 & TRN & \\
\hline CHEMBL1389262 & 688620 & 4.45 & 4.82600 & 00000000005 & TRN \\
\hline CHEMBL1990598 & 688620 & 5.55 & 5.5014 & TST & \\
\hline CHEMBL1389155 & 688620 & 4.75 & 4.9558 & TRN & \\
\hline CHEMBL1338972 & 688620 & 4.95 & 5.2362 & TRN & \\
\hline CHEMBL1313441 & 688620 & 5.5 & 4.9958 & TRN & \\
\hline CHEMBL1501097 & 688620 & 4.45 & 5.0637 & TRN & \\
\hline CHEMBL1551012 & 688620 & 4.95 & 5.2659 & TRN & \\
\hline CHEMBL1386452 & 688620 & 4.95 & 5.0895 & TRN & \\
\hline CHEMBL1977473 & 688620 & 5.55 & 5.6252 & TRN & \\
\hline CHEMBL1472095 & 688620 & 6.4 & 5.0054 & TRN & \\
\hline CHEMBL3192678 & 688620 & 4.95 & 5.1708 & TRN & \\
\hline CHEMBL1372333 & 688620 & 5.2 & 5.1453 & TRN & \\
\hline CHEMBL1536437 & 688620 & 4.95 & 5.1109 & TRN & \\
\hline CHEMBL1573309 & 688620 & 6.7501 & 5.1963 & TST & \\
\hline CHEMBL1481574 & 688620 & 4.9 & 5.1204 & TRN & \\
\hline CHEMBL1423276 & 688620 & 4.75 & 5.0126 & TRN & \\
\hline CHEMBL1601288 & 688620 & 5.0 & 5.1226 & TRN & \\
\hline CHEMBL 263116 & 688620 & 4.9 & 5.1813 & TRN & \\
\hline CHEMBL1466348 & 688620 & 5.0 & 5.3276 & TRN & \\
\hline CHEMBL1409890 & 688620 & 4.85 & 5.0574 & TRN & \\
\hline CHEMBL1471700 & 688620 & 4.6 & 5.0324 & TST & \\
\hline CHEMBL1396211 & 688620 & 4.8 & 5.0121 & TRN & \\
\hline CHEMBL1601211 & 688620 & 4.45 & 5.0334 & TRN & \\
\hline CHEMBL1359768 & 688620 & 4.45 & 5.1632 & TRN & \\
\hline CHEMBL578515 & 688620 & 4.55 & 4.7221 & TRN & \\
\hline CHEMBL1461258 & 688620 & 4.9 & 5.0688 & TST & \\
\hline CHEMBL1333047 & 688620 & 4.8 & 5.09699 & 99999999995 & TRN \\
\hline CHEMBL1529872 & 688620 & 7.1002 & 5.0766 & TRN & \\
\hline CHEMBL1503292 & 688620 & 5.05 & 4.8571 & TRN & \\
\hline CHEMBL1584098 & 688620 & 4.8 & 4.9023 & TST & \\
\hline CHEMBL1340776 & 688620 & 5.9 & 5.5342 & TRN & \\
\hline CHEMBL1496347 & 688620 & 5.0 & 5.1782 & TRN & \\
\hline CHEMBL1307904 & 688620 & 4.75 & 4.7997 & TRN & \\
\hline CHEMBL3210517 & 688620 & 5.4 & 5.3497 & TST & \\
\hline CHEMBL1421518 & 688620 & 5.25 & 4.8816 & TRN & \\
\hline CHEMBL3196576 & 688620 & 5.0 & 4.8348 & TRN & \\
\hline CHEMBL1489421 & 688620 & 4.8 & 5.0578 & TRN & \\
\hline CHEMBL1497963 & 688620 & 5.35 & 5.1597 & TRN & \\
\hline CHEMBL1362669 & 688620 & 5.0 & 5.1555 & TRN & \\
\hline CHEMBL1322435 & 688620 & 4.45 & 4.9533 & TST & \\
\hline CHEMBL1486016 & 688620 & 4.9 & 5.073 & TRN & \\
\hline CHEMBL1603704 & 688620 & 5.95 & 5.763 & TRN & \\
\hline
\end{tabular}




\begin{tabular}{|c|c|c|c|c|}
\hline \multicolumn{5}{|c|}{ Supplemental Table S2.txt } \\
\hline CHEMBL1579003 & 688620 & 5.2 & 4.9314 & TRN \\
\hline CHEMBL1405737 & 688620 & 5.2 & 5.14 & TRN \\
\hline CHEMBL1404775 & 688620 & 4.65 & 5.0267 & TRN \\
\hline CHEMBL1361417 & 688620 & 4.95 & 5.1388 & TST \\
\hline CHEMBL1428831 & 688620 & 4.95 & 5.0174 & TRN \\
\hline CHEMBL1389788 & 688620 & 4.95 & 4.9243 & TRN \\
\hline CHEMBL1556661 & 688620 & 4.85 & 5.228 & TST \\
\hline CHEMBL1458709 & 688620 & 4.45 & 5.0896 & TST \\
\hline CHEMBL1330915 & 688620 & 4.85 & 4.9955 & TRN \\
\hline CHEMBL1441217 & 688620 & 4.45 & 5.0329 & TRN \\
\hline CHEMBL1360928 & 688620 & 5.65 & 5.3874 & TRN \\
\hline CHEMBL1309912 & 688620 & 5.2 & 4.9516 & TRN \\
\hline CHEMBL1606262 & 688620 & 4.7 & 4.822 & TRN \\
\hline CHEMBL1568021 & 688620 & 5.05 & 5.0 & TRN \\
\hline CHEMBL1366596 & 688620 & 4.45 & 5.195 & TST \\
\hline CHEMBL1456001 & 688620 & 6.0 & 4.8216 & TRN \\
\hline CHEMBL1504055 & 688620 & 4.45 & 4.9382 & TRN \\
\hline CHEMBL3193897 & 688620 & 4.6 & 4.6159 & TRN \\
\hline CHEMBL1380643 & 688620 & 5.35 & 5.0273 & TRN \\
\hline CHEMBL1493746 & 688620 & 4.5 & 5.0065 & TST \\
\hline CHEMBL1323629 & 688620 & 5.6 & 5.2405 & TRN \\
\hline CHEMBL450223 & 688620 & 5.3 & 4.9984 & TST \\
\hline CHEMBL1539493 & 688620 & 7.15 & 4.9542 & TST \\
\hline CHEMBL1311532 & 688620 & 4.8 & 4.8829 & TRN \\
\hline CHEMBL1311319 & 688620 & 5.45 & 5.1498 & TRN \\
\hline CHEMBL1438200 & 688620 & 4.45 & 5.2143 & TRN \\
\hline CHEMBL198630 & 688620 & 6.15 & 5.9097 & TRN \\
\hline CHEMBL1451926 & 688620 & 4.9 & 5.0859 & TRN \\
\hline CHEMBL1343554 & 688620 & 7.15 & 5.7637 & TST \\
\hline CHEMBL1382461 & 688620 & 6.25 & 5.3092 & TST \\
\hline CHEMBL1555880 & 688620 & 4.95 & 4.8938 & TRN \\
\hline CHEMBL1400571 & 688620 & 5.65 & 5.1525 & TST \\
\hline CHEMBL1386178 & 688620 & 5.3 & 5.3117 & TRN \\
\hline CHEMBL1502004 & 688620 & 5.5 & 4.9126 & TRN \\
\hline CHEMBL1323696 & 688620 & 5.2 & 5.2185 & TRN \\
\hline CHEMBL1438683 & 688620 & 4.9 & 4.8827 & TST \\
\hline CHEMBL1572281 & 688620 & 5.15 & 4.9493 & TRN \\
\hline CHEMBL1305180 & 688620 & 4.95 & 4.9989 & TST \\
\hline CHEMBL1425049 & 688620 & 5.1 & 4.9163 & TRN \\
\hline CHEMBL1505316 & 688620 & 4.9 & 5.1996 & TST \\
\hline CHEMBL1482760 & 688620 & 4.8 & 5.3271 & TRN \\
\hline CHEMBL1383386 & 688620 & 4.85 & 4.5967 & TRN \\
\hline CHEMBL1418261 & 688620 & 4.6 & 4.9534 & TRN \\
\hline CHEMBL1545743 & 688620 & 4.5 & 5.0325 & TRN \\
\hline CHEMBL1311819 & 688620 & 4.9 & 5.1215 & TRN \\
\hline CHEMBL 2007529 & 688620 & 5.0 & 5.0355 & TRN \\
\hline CHEMBL1328400 & 688620 & 4.45 & 4.9706 & TST \\
\hline CHEMBL1562371 & 688620 & 5.15 & 5.1243 & TRN \\
\hline
\end{tabular}




\begin{tabular}{|c|c|c|c|c|c|}
\hline \multicolumn{6}{|c|}{ Supplemental Table S2.txt } \\
\hline CHEMBL1392326 & 688620 & 4.45 & 4.9978 & TST & \\
\hline CHEMBL1462925 & 688620 & 4.95 & 5.1427 & TST & \\
\hline CHEMBL1539861 & 688620 & 5.1 & 5.23799 & 99999999995 & TRN \\
\hline CHEMBL1377544 & 688620 & 4.7 & 4.9726 & TST & \\
\hline CHEMBL1608194 & 688620 & 5.0 & 5.0834 & TRN & \\
\hline CHEMBL1466025 & 688620 & 4.9 & 4.8966 & TRN & \\
\hline CHEMBL1535318 & 688620 & 6.7001 & 5.75899 & 99999999995 & TST \\
\hline CHEMBL1501661 & 688620 & 5.0 & 5.015 & TST & \\
\hline CHEMBL1363060 & 688620 & 4.65 & 4.9672 & TRN & \\
\hline CHEMBL1406716 & 688620 & 4.45 & 5.0782 & TST & \\
\hline CHEMBL1420908 & 688620 & 6.15 & 5.4816 & TRN & \\
\hline CHEMBL1420001 & 688620 & 4.8 & 4.9469 & TRN & \\
\hline CHEMBL3210973 & 688620 & 4.7 & 4.9312 & TST & \\
\hline CHEMBL1311476 & 688620 & 4.45 & 5.1798 & TRN & \\
\hline CHEMBL1393633 & 688620 & 5.85 & 5.6189 & TRN & \\
\hline CHEMBL1542501 & 688620 & 5.25 & 5.1463 & TRN & \\
\hline CHEMBL3194234 & 688620 & 5.25 & 5.0771 & TST & \\
\hline CHEMBL1423439 & 688620 & 4.8 & 5.0448 & TRN & \\
\hline CHEMBL3208399 & 688620 & 4.45 & 4.9721 & TST & \\
\hline CHEMBL1411077 & 688620 & 4.8 & 4.9023 & TRN & \\
\hline CHEMBL1343726 & 688620 & 5.15 & 4.7017 & TRN & \\
\hline CHEMBL1584061 & 688620 & 5.2 & 5.0458 & TST & \\
\hline CHEMBL3193530 & 688620 & 7.699 & 6.7691 & TRN & \\
\hline CHEMBL592068 & 688620 & 4.9 & 4.8283 & TRN & \\
\hline CHEMBL1301418 & 688620 & 4.95 & 5.2607 & TRN & \\
\hline CHEMBL1340977 & 688620 & 4.85 & 5.0013 & TRN & \\
\hline CHEMBL31840 & 688620 & 5.55 & 5.2066 & TRN & \\
\hline CHEMBL1339357 & 688620 & 5.05 & 4.9341 & TST & \\
\hline CHEMBL1338671 & 688620 & 5.05 & 5.5958 & TRN & \\
\hline CHEMBL1501472 & 688620 & 4.45 & 5.1204 & TST & \\
\hline CHEMBL1517624 & 688620 & 5.75 & 5.4133 & TRN & \\
\hline CHEMBL 236033 & 688620 & 4.55 & 4.7951 & TST & \\
\hline CHEMBL1575919 & 688620 & 5.25 & 5.0758 & TST & \\
\hline CHEMBL1520048 & 688620 & 4.9 & 4.83 & TRN & \\
\hline CHEMBL1499122 & 688620 & 4.9 & 5.2579 & TRN & \\
\hline CHEMBL 306783 & 688620 & 5.25 & 5.3278 & TRN & \\
\hline CHEMBL1557320 & 688620 & 5.55 & 4.9494 & TST & \\
\hline CHEMBL1428173 & 688620 & 4.7 & 4.9981 & TRN & \\
\hline CHEMBL1324170 & 688620 & 4.75 & 5.0827 & TST & \\
\hline CHEMBL1349010 & 688620 & 4.45 & 4.7461 & TST & \\
\hline CHEMBL1975652 & 688620 & 5.1 & 5.2472 & TRN & \\
\hline CHEMBL1398590 & 688620 & 5.8 & 4.9314 & TRN & \\
\hline CHEMBL80658 & 688620 & 5.2 & 4.9923 & TRN & \\
\hline CHEMBL3190203 & 688620 & 6.15 & 5.5978 & TRN & \\
\hline CHEMBL3191737 & 688620 & 5.25 & 5.1028 & TST & \\
\hline CHEMBL1600074 & 688620 & 4.5 & 5.1384 & TRN & \\
\hline CHEMBL1331068 & 688620 & 4.8 & 5.09 & TRN & \\
\hline CHEMBL1538361 & 688620 & 5.1 & 5.0156 & TRN & \\
\hline
\end{tabular}




\begin{tabular}{|c|c|c|c|c|c|}
\hline \multirow[b]{2}{*}{ CHEMBL1368229 } & \multirow[b]{2}{*}{688620} & \\
\hline & & 5.1 & 4.9917 & TRN & \\
\hline CHEMBL1459406 & 688620 & 5.25 & 5.6335 & TRN & \\
\hline CHEMBL1344663 & 688620 & 4.65 & 4.944 & TST & \\
\hline CHEMBL1382398 & 688620 & 4.95 & 4.9577 & TRN & \\
\hline CHEMBL3191143 & 688620 & 5.35 & 5.0933 & TST & \\
\hline CHEMBL1343922 & 688620 & 4.95 & 5.0397 & TRN & \\
\hline CHEMBL1317810 & 688620 & 5.7 & 5.2489 & TRN & \\
\hline CHEMBL1308322 & 688620 & 4.45 & 4.9047 & TST & \\
\hline CHEMBL1375202 & 688620 & 4.85 & 4.9447 & TRN & \\
\hline CHEMBL1453193 & 688620 & 4.65 & 5.0846 & TRN & \\
\hline CHEMBL1538183 & 688620 & 4.95 & 4.8338 & TST & \\
\hline CHEMBL1349819 & 688620 & 6.15 & 5.1368 & TRN & \\
\hline CHEMBL3194346 & 688620 & 4.95 & 4.8234 & TRN & \\
\hline CHEMBL1386143 & 688620 & 4.45 & 5.1543 & TST & \\
\hline CHEMBL3213330 & 688620 & 6.3 & 5.7036 & TRN & \\
\hline CHEMBL3208669 & 688620 & 5.25 & 5.1186 & TRN & \\
\hline CHEMBL1378661 & 688620 & 4.7 & 4.9558 & TRN & \\
\hline CHEMBL1300234 & 688620 & 4.9 & 5.2414 & TRN & \\
\hline CHEMBL1390775 & 688620 & 4.95 & 4.9571 & TRN & \\
\hline CHEMBL1311538 & 688620 & 5.55 & 5.3755 & TRN & \\
\hline CHEMBL1595993 & 688620 & 5.35 & 5.1262 & TRN & \\
\hline CHEMBL1378873 & 688620 & 4.95 & 4.8249 & TRN & \\
\hline CHEMBL1467685 & 688620 & 6.1 & 5.6464 & TRN & \\
\hline CHEMBL3191322 & 688620 & 4.65 & 5.67700 & 30000000005 & TRN \\
\hline CHEMBL1602317 & 688620 & 4.65 & 4.6832 & TRN & \\
\hline CHEMBL1329322 & 688620 & 5.2 & 5.21299 & 9999999999 & TRN \\
\hline CHEMBL1363165 & 688620 & 5.65 & 5.164 & TRN & \\
\hline CHEMBL1996589 & 688620 & 5.75 & 5.7223 & TRN & \\
\hline CHEMBL1487686 & 688620 & 5.8 & 4.7831 & TRN & \\
\hline CHEMBL1352540 & 688620 & 5.0 & 5.1562 & TRN & \\
\hline CHEMBL1449619 & 688620 & 4.8 & 5.078 & TRN & \\
\hline CHEMBL1492084 & 688620 & 4.65 & 4.8975 & TRN & \\
\hline CHEMBL1458346 & 688620 & 5.0 & 5.2072 & TRN & \\
\hline CHEMBL1431941 & 688620 & 4.95 & 4.88899 & 9999999999 & TRN \\
\hline CHEMBL501557 & 688620 & 4.95 & 4.8554 & TRN & \\
\hline CHEMBL1306932 & 688620 & 5.2 & 5.1924 & TRN & \\
\hline CHEMBL1526895 & 688620 & 4.45 & 4.9222 & TRN & \\
\hline CHEMBL1382470 & 688620 & 5.95 & 5.0938 & TRN & \\
\hline CHEMBL3196648 & 688620 & 5.3 & 5.2412 & TRN & \\
\hline CHEMBL1507488 & 688620 & 4.9 & 5.0002 & TRN & \\
\hline CHEMBL1300496 & 688620 & 4.9 & 4.842 & TRN & \\
\hline CHEMBL1556185 & 688620 & 4.65 & 5.0116 & TST & \\
\hline CHEMBL3199275 & 688620 & 4.45 & 5.0663 & TRN & \\
\hline CHEMBL1378944 & 688620 & 5.6 & 5.5658 & TRN & \\
\hline CHEMBL1600313 & 688620 & 4.7 & 4.98 & TST & \\
\hline CHEMBL1455819 & 688620 & 5.9 & 5.0391 & TRN & \\
\hline CHEMBL1326923 & 688620 & 4.95 & 4.8756 & TRN & \\
\hline CHEMBL1488667 & 688620 & 5.0 & 5.8109 & TRN & \\
\hline & & & & 27111 & \\
\hline
\end{tabular}




\begin{tabular}{|c|c|c|c|c|c|}
\hline \multirow[b]{2}{*}{ CHEMBL1548862 } & \multirow[b]{2}{*}{688620} & \\
\hline & & 5.9 & 5.4411 & TRN & \\
\hline CHEMBL1965814 & 688620 & 5.0 & 4.8966 & TRN & \\
\hline CHEMBL1560769 & 688620 & 5.0 & 4.9787 & TRN & \\
\hline CHEMBL1497287 & 688620 & 6.0 & 4.8547 & TRN & \\
\hline CHEMBL3190606 & 688620 & 4.45 & 4.9513 & TRN & \\
\hline CHEMBL1444859 & 688620 & 5.6 & 5.5324 & TRN & \\
\hline CHEMBL1391054 & 688620 & 4.75 & 5.0125 & TRN & \\
\hline CHEMBL1604350 & 688620 & 4.45 & 4.9202 & TRN & \\
\hline CHEMBL1526339 & 688620 & 4.8 & 5.2303 & TST & \\
\hline CHEMBL1426818 & 688620 & 4.45 & 4.7571 & TST & \\
\hline CHEMBL1312836 & 688620 & 4.45 & 4.8145 & TRN & \\
\hline CHEMBL1325549 & 688620 & 5.0 & 4.9262 & TRN & \\
\hline CHEMBL1343752 & 688620 & 4.95 & 4.9164 & TRN & \\
\hline CHEMBL1485813 & 688620 & 4.9 & 5.3326 & TRN & \\
\hline CHEMBL3192355 & 688620 & 5.7 & 5.8529 & TST & \\
\hline CHEMBL1566475 & 688620 & 4.95 & 4.8232 & TRN & \\
\hline CHEMBL1464137 & 688620 & 5.45 & 5.4246 & TRN & \\
\hline CHEMBL1371603 & 688620 & 4.45 & 5.0182 & TST & \\
\hline CHEMBL1560772 & 688620 & 4.65 & 4.8229 & TRN & \\
\hline CHEMBL1423193 & 688620 & 4.45 & 4.9516 & TRN & \\
\hline CHEMBL1452765 & 688620 & 4.7 & 5.1959 & TST & \\
\hline CHEMBL336718 & 688620 & 4.65 & 5.2401 & TRN & \\
\hline CHEMBL1370682 & 688620 & 5.5 & 5.3089 & TST & \\
\hline CHEMBL3198327 & 688620 & 5.4 & 5.2878 & TRN & \\
\hline CHEMBL1585038 & 688620 & 4.45 & 4.9042 & TRN & \\
\hline CHEMBL1306794 & 688620 & 4.7 & 4.9393 & TST & \\
\hline CHEMBL3189467 & 688620 & 4.85 & 4.9123 & TRN & \\
\hline CHEMBL1566507 & 688620 & 5.55 & $5.3660 e$ & 20000000005 & TRN \\
\hline CHEMBL1462890 & 688620 & 4.65 & 5.2333 & TST & \\
\hline CHEMBL1546492 & 688620 & 4.5 & 4.8946 & TRN & \\
\hline CHEMBL1992977 & 688620 & 5.35 & 5.2488 & TRN & \\
\hline CHEMBL3192772 & 688620 & 5.05 & 5.1318 & TRN & \\
\hline CHEMBL1577647 & 688620 & 4.45 & 5.3671 & TRN & \\
\hline CHEMBL172997 & 688620 & 4.8 & 5.0296 & TRN & \\
\hline CHEMBL1556254 & 688620 & 5.2 & 5.5228 & TRN & \\
\hline CHEMBL1591712 & 688620 & 4.9 & 4.8805 & TRN & \\
\hline CHEMBL1400855 & 688620 & 4.95 & 4.9955 & TRN & \\
\hline CHEMBL1501582 & 688620 & 5.05 & 5.069 & TST & \\
\hline CHEMBL1542262 & 688620 & 4.8 & 5.1935 & TST & \\
\hline CHEMBL3198970 & 688620 & 4.45 & 4.9265 & TRN & \\
\hline CHEMBL3190812 & 688620 & 5.1 & 5.6795 & TRN & \\
\hline CHEMBL3192146 & 688620 & 4.45 & 4.99 & TST & \\
\hline CHEMBL1303889 & 688620 & 4.95 & 4.7997 & TRN & \\
\hline CHEMBL1352054 & 688620 & 4.8 & 5.2159 & TRN & \\
\hline CHEMBL3209701 & 688620 & 6.5501 & 5.0087 & TST & \\
\hline CHEMBL1364720 & 688620 & 4.95 & 5.1284 & TST & \\
\hline CHEMBL1391454 & 688620 & 4.45 & 4.8198 & TRN & \\
\hline CHEMBL1532422 & 688620 & 8.301 & 5.1071 & TRN & \\
\hline & & & & 27112 & \\
\hline
\end{tabular}




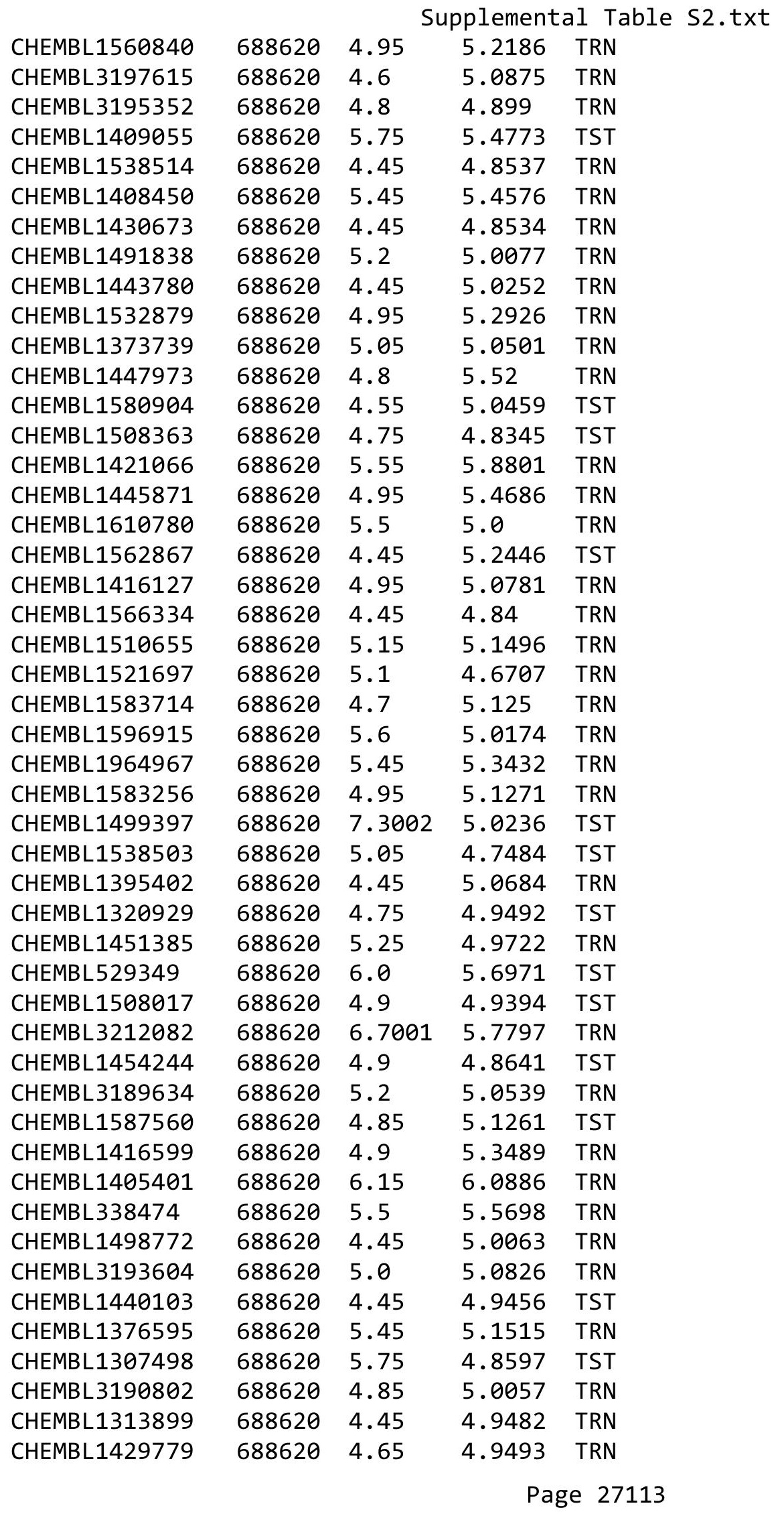




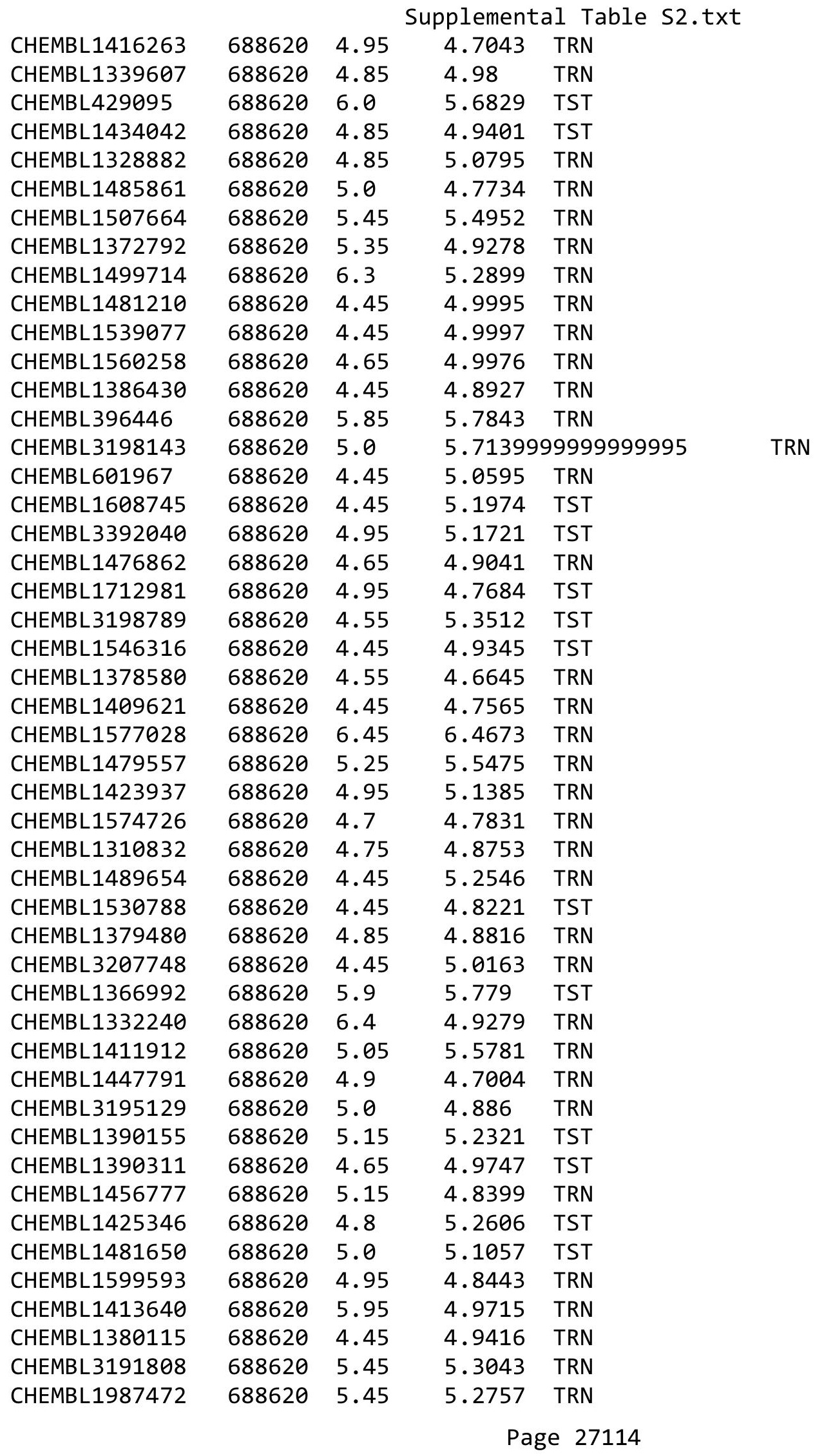




\begin{tabular}{|c|c|c|c|c|c|}
\hline \multicolumn{6}{|c|}{ Supplemental Table s2.txt } \\
\hline CHEMBL1976754 & 688620 & 5.9 & 5.5725 & TRN & \\
\hline CHEMBL1346883 & 688620 & 4.95 & 4.746 & TRN & \\
\hline CHEMBL1996757 & 688620 & 5.95 & 5.7523 & TRN & \\
\hline CHEMBL1380851 & 688620 & 4.8 & 5.1565 & TST & \\
\hline CHEMBL1421772 & 688620 & 5.05 & 5.0041 & TST & \\
\hline CHEMBL1477792 & 688620 & 4.65 & 4.9582 & TRN & \\
\hline CHEMBL1429682 & 688620 & 6.25 & 6.0089 & TRN & \\
\hline CHEMBL1549077 & 688620 & 4.8 & 5.0106 & TRN & \\
\hline CHEMBL1469228 & 688620 & 4.75 & 4.9708 & TST & \\
\hline CHEMBL1600539 & 688620 & 5.15 & 5.355 & TRN & \\
\hline CHEMBL1558878 & 688620 & 5.55 & 5.146 & TRN & \\
\hline CHEMBL1431945 & 688620 & 4.65 & 4.9102 & TRN & \\
\hline CHEMBL1409586 & 688620 & 4.45 & 4.8416 & TRN & \\
\hline CHEMBL1308687 & 688620 & 5.0 & 4.9286 & TRN & \\
\hline CHEMBL1569349 & 688620 & 4.9 & 4.9514 & TST & \\
\hline CHEMBL1446836 & 688620 & 8.301 & 5.1754 & TRN & \\
\hline CHEMBL1387307 & 688620 & 4.55 & 4.7511 & TST & \\
\hline CHEMBL1350317 & 688620 & 4.95 & 4.9636 & TST & \\
\hline CHEMBL1411456 & 688620 & 4.65 & 5.3614 & TRN & \\
\hline CHEMBL1985345 & 688620 & 5.55 & 5.1088 & TRN & \\
\hline CHEMBL1586651 & 688620 & 4.45 & 4.9816 & TRN & \\
\hline CHEMBL1409041 & 688620 & 5.6 & 5.3054 & TRN & \\
\hline CHEMBL1419035 & 688620 & 5.55 & 5.083 & TST & \\
\hline CHEMBL1559256 & 688620 & 5.6 & 5.1059 & TRN & \\
\hline CHEMBL1455211 & 688620 & 6.0 & 5.6491 & TST & \\
\hline CHEMBL1393447 & 688620 & 5.0 & 5.1438 & TRN & \\
\hline CHEMBL1575448 & 688620 & 4.9 & 4.945 & TRN & \\
\hline CHEMBL1402869 & 688620 & 4.7 & 4.9435 & TRN & \\
\hline CHEMBL1454956 & 688620 & 4.5 & 4.9127 & TRN & \\
\hline CHEMBL1565386 & 688620 & 4.45 & 5.3916 & TST & \\
\hline CHEMBL1400031 & 688620 & 5.15 & 5.32799 & & TRN \\
\hline CHEMBL1343481 & 688620 & 5.3 & 4.7496 & TRN & \\
\hline CHEMBL1368553 & 688620 & 4.45 & 4.7026 & TST & \\
\hline CHEMBL3145372 & 688620 & 6.5501 & 6.0553 & TRN & \\
\hline CHEMBL1522440 & 688620 & 4.45 & 5.0179 & TST & \\
\hline CHEMBL1431812 & 688620 & 4.95 & 5.0828 & TST & \\
\hline CHEMBL3196832 & 688620 & 5.15 & 5.1476 & TRN & \\
\hline CHEMBL1483562 & 688620 & 4.95 & 5.052 & TRN & \\
\hline CHEMBL1333554 & 688620 & 5.95 & 5.8598 & TRN & \\
\hline CHEMBL1466472 & 688620 & 5.0 & 5.085 & TRN & \\
\hline CHEMBL1506852 & 688620 & 4.8 & 4.9931 & TRN & \\
\hline CHEMBL1419967 & 688620 & 4.95 & 4.82 & TRN & \\
\hline CHEMBL1317820 & 688620 & 4.65 & 4.8556 & TST & \\
\hline CHEMBL1573805 & 688620 & 5.05 & 4.8723 & TRN & \\
\hline CHEMBL1477793 & 688620 & 5.45 & 4.7789 & TRN & \\
\hline CHEMBL1361738 & 688620 & 5.2 & 5.1661 & TST & \\
\hline CHEMBL1564093 & 688620 & 4.6 & 5.0278 & TRN & \\
\hline CHEMBL1453368 & 688620 & 4.9 & 5.1827 & TST & \\
\hline
\end{tabular}




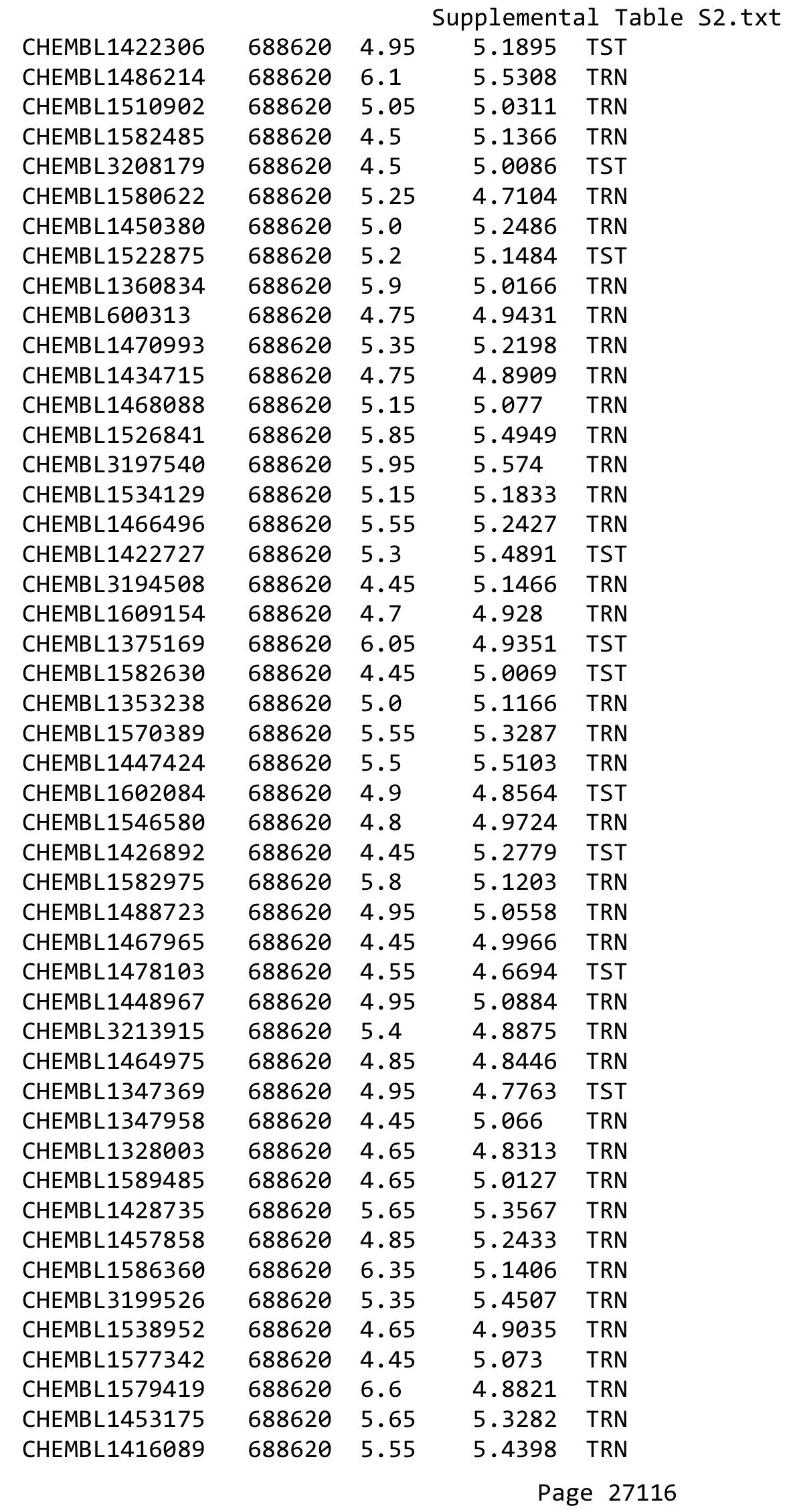




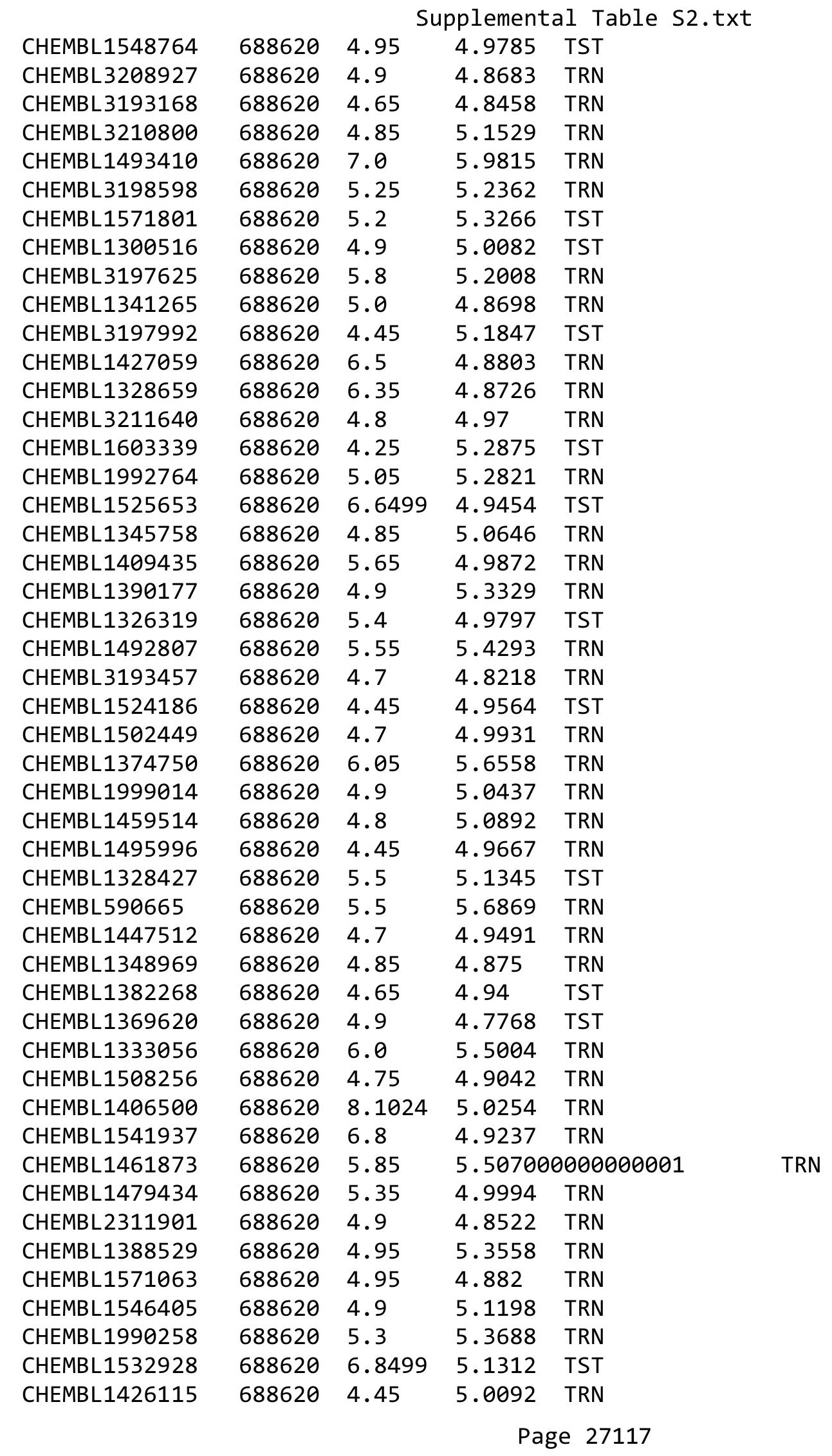




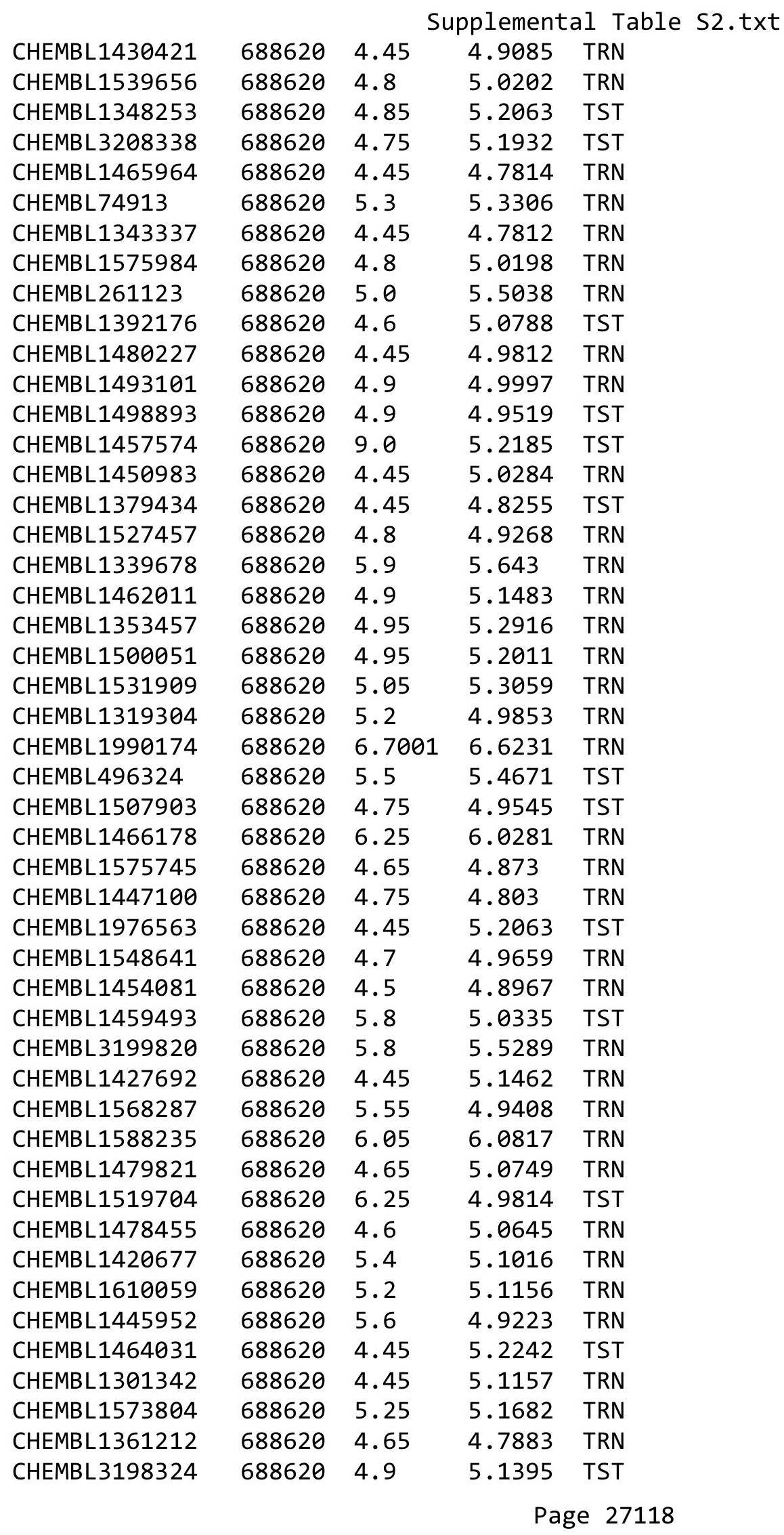




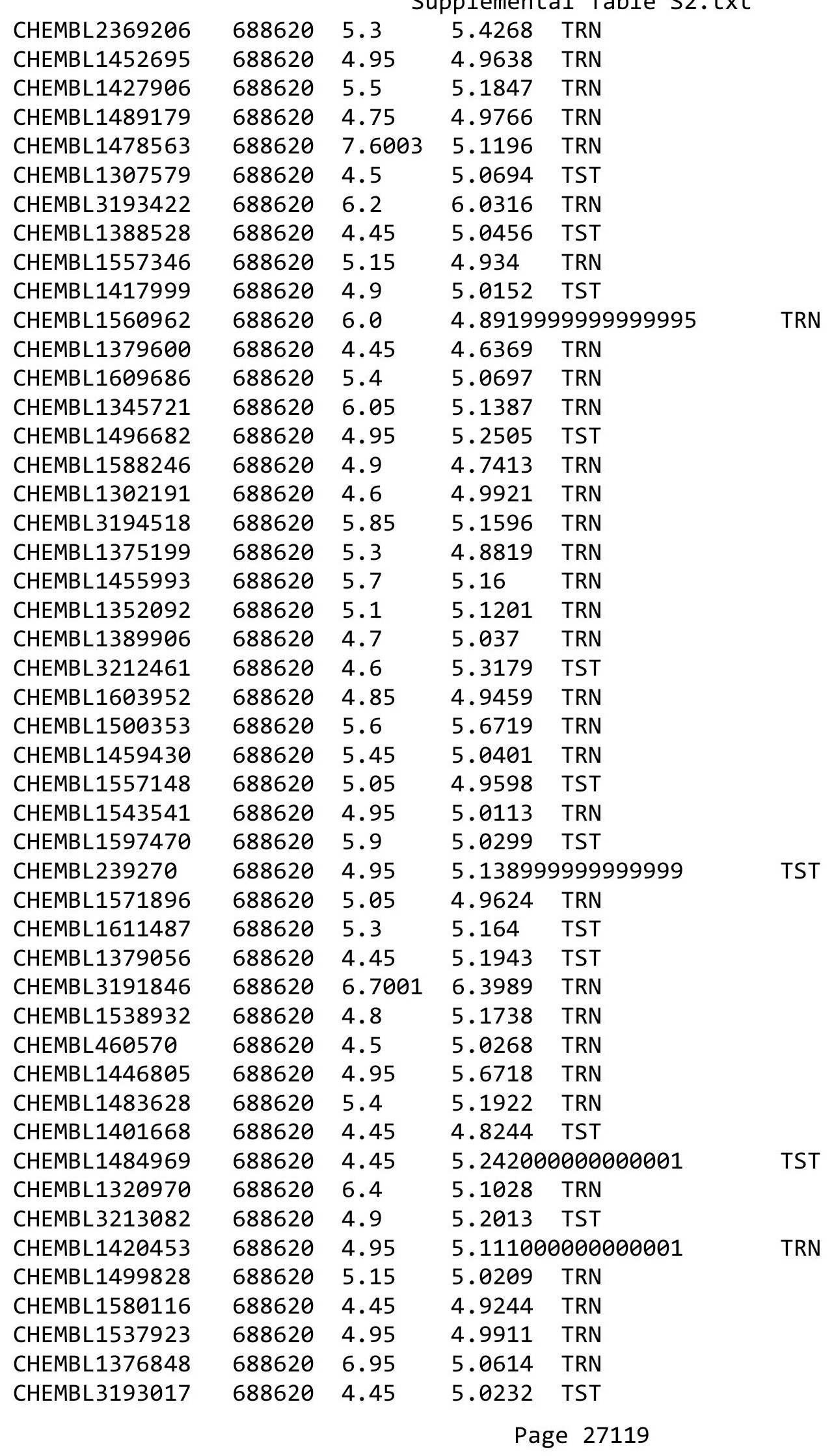




\begin{tabular}{|c|c|c|c|c|c|}
\hline \multicolumn{6}{|c|}{ oplemental Table s } \\
\hline CHEMBL1595508 & 688620 & 4.75 & 5.0103 & TRN & \\
\hline CHEMBL1304868 & 688620 & 5.4 & 5.215 & TRN & \\
\hline CHEMBL3192679 & 688620 & 4.9 & 4.8911 & TST & \\
\hline CHEMBL1548488 & 688620 & 4.95 & 4.8383 & TST & \\
\hline CHEMBL1444431 & 688620 & 4.65 & 5.085 & TRN & \\
\hline CHEMBL1558469 & 688620 & 5.45 & 5.3908 & TRN & \\
\hline CHEMBL1367264 & 688620 & 5.9 & 5.0995 & TST & \\
\hline CHEMBL1545794 & 688620 & 5.15 & 4.7877 & TRN & \\
\hline CHEMBL1414053 & 688620 & 4.5 & 5.3302 & TRN & \\
\hline CHEMBL1455892 & 688620 & 5.9 & 5.0597 & TST & \\
\hline CHEMBL1423463 & 688620 & 4.45 & 4.9103 & TRN & \\
\hline CHEMBL1541652 & 688620 & 5.9 & 5.0801 & TRN & \\
\hline CHEMBL1500543 & 688620 & 4.85 & 5.7617 & TRN & \\
\hline CHEMBL1484736 & 688620 & 5.45 & 5.1633 & TST & \\
\hline CHEMBL1545947 & 688620 & 5.45 & 5.0552 & TST & \\
\hline CHEMBL1338834 & 688620 & 4.95 & 5.079 & TST & \\
\hline CHEMBL1449490 & 688620 & 4.95 & 5.0886 & TST & \\
\hline CHEMBL1500629 & 688620 & 4.95 & 5.25200 & 0000000001 & TRN \\
\hline CHEMBL1428623 & 688620 & 5.6 & 5.2244 & TRN & \\
\hline CHEMBL1307080 & 688620 & 5.35 & 5.1835 & TST & \\
\hline CHEMBL1344560 & 688620 & 4.45 & 4.7621 & TST & \\
\hline CHEMBL1563283 & 688620 & 5.6 & 5.226 & TRN & \\
\hline CHEMBL 272221 & 688620 & 4.55 & 5.0136 & TST & \\
\hline CHEMBL1427773 & 688620 & 4.95 & 4.6992 & TRN & \\
\hline CHEMBL1365142 & 688620 & 4.95 & 5.0556 & TRN & \\
\hline CHEMBL1458697 & 688620 & 5.35 & 5.0174 & TST & \\
\hline CHEMBL1503414 & 688620 & 5.7 & 5.7432 & TRN & \\
\hline CHEMBL1575862 & 688620 & 4.85 & 5.0956 & TRN & \\
\hline CHEMBL1423715 & 688620 & 5.9 & 4.7167 & TST & \\
\hline CHEMBL 224282 & 688620 & 4.65 & 5.277 & TST & \\
\hline CHEMBL584619 & 688620 & 4.45 & 5.0661 & TRN & \\
\hline CHEMBL1498707 & 688620 & 4.95 & 4.9369 & TRN & \\
\hline CHEMBL540851 & 688620 & 4.45 & 5.399 & TST & \\
\hline CHEMBL1499338 & 688620 & 4.65 & 4.8915 & TST & \\
\hline CHEMBL1406878 & 688620 & 5.15 & 5.3913 & TRN & \\
\hline CHEMBL1484097 & 688620 & 5.05 & 4.9039 & TRN & \\
\hline CHEMBL1333858 & 688620 & 5.45 & 5.2749 & TRN & \\
\hline CHEMBL1340361 & 688620 & 4.65 & 4.8472 & TST & \\
\hline CHEMBL1380337 & 688620 & 4.45 & 4.8502 & TRN & \\
\hline CHEMBL1601985 & 688620 & 4.75 & 5.1386 & TRN & \\
\hline CHEMBL1599508 & 688620 & 5.7 & 5.8349 & TRN & \\
\hline CHEMBL1478219 & 688620 & 4.45 & 5.2611 & TRN & \\
\hline CHEMBL1571626 & 688620 & 4.75 & 4.8668 & TRN & \\
\hline CHEMBL1602556 & 688620 & 4.45 & 4.7728 & TRN & \\
\hline CHEMBL1516729 & 688620 & 5.0 & 4.9676 & TRN & \\
\hline CHEMBL1321987 & 688620 & 4.75 & 4.9276 & TRN & \\
\hline CHEMBL1324319 & 688620 & 5.0 & 5.1761 & TRN & \\
\hline CHEMBL3199273 & 688620 & 5.5 & 4.8405 & TRN & \\
\hline
\end{tabular}




\begin{tabular}{|c|c|c|c|c|}
\hline \multicolumn{5}{|c|}{ Supplemental Table S2.txt } \\
\hline CHEMBL1450079 & 688620 & 5.45 & 5.4174 & TRN \\
\hline CHEMBL 3192364 & 688620 & 4.9 & 5.0391 & TRN \\
\hline CHEMBL1482425 & 688620 & 5.0 & 5.0624 & TST \\
\hline CHEMBL1532646 & 688620 & 7.7496 & 5.0436 & TST \\
\hline CHEMBL1612965 & 688620 & 4.95 & 5.2348 & TRN \\
\hline CHEMBL1508455 & 688620 & 4.45 & 4.697 & TRN \\
\hline CHEMBL1444987 & 688620 & 4.95 & 5.1675 & TRN \\
\hline CHEMBL1463377 & 688620 & 5.55 & 5.3371 & TRN \\
\hline CHEMBL1349680 & 688620 & 4.65 & 5.1121 & TRN \\
\hline CHEMBL1495234 & 688620 & 5.5 & 5.5146 & TRN \\
\hline CHEMBL1604864 & 688620 & 4.75 & 5.1225 & TRN \\
\hline CHEMBL3211849 & 688620 & 4.85 & 5.0631 & TRN \\
\hline CHEMBL1496884 & 688620 & 5.15 & 4.8062 & TRN \\
\hline CHEMBL1870697 & 688620 & 4.45 & 4.8704 & TST \\
\hline CHEMBL1366876 & 688620 & 4.45 & 5.0106 & TRN \\
\hline CHEMBL1367765 & 688620 & 5.5 & 5.1422 & TRN \\
\hline CHEMBL1457324 & 688620 & 5.2 & 4.6929 & TST \\
\hline CHEMBL1401711 & 688620 & 4.45 & 5.0177 & TRN \\
\hline CHEMBL1437670 & 688620 & 4.9 & 4.9323 & TRN \\
\hline CHEMBL1300669 & 688620 & 4.45 & 4.9237 & TRN \\
\hline CHEMBL1461574 & 688620 & 4.9 & 5.0991 & TST \\
\hline CHEMBL1366207 & 688620 & 4.65 & 4.8722 & TST \\
\hline CHEMBL1409011 & 688620 & 4.65 & 4.8498 & TRN \\
\hline CHEMBL1419981 & 688620 & 5.0 & 5.1214 & TST \\
\hline CHEMBL1343611 & 688620 & 5.05 & 5.2288 & TST \\
\hline CHEMBL1526628 & 688620 & 4.8 & 5.0695 & TRN \\
\hline CHEMBL1970739 & 688620 & 5.0 & 5.1742 & TRN \\
\hline CHEMBL1446576 & 688620 & 4.45 & 5.1731 & TRN \\
\hline CHEMBL1449548 & 688620 & 5.4 & 4.9575 & TRN \\
\hline CHEMBL1464407 & 688620 & 4.9 & 4.9882 & TRN \\
\hline CHEMBL1305452 & 688620 & 5.45 & 4.8911 & TRN \\
\hline CHEMBL1371841 & 688620 & 4.65 & 5.0635 & TST \\
\hline CHEMBL1376868 & 688620 & 6.3 & 5.4281 & TRN \\
\hline CHEMBL1378331 & 688620 & 4.45 & 4.9402 & TST \\
\hline CHEMBL1477807 & 688620 & 4.75 & 5.0817 & TRN \\
\hline CHEMBL1330307 & 688620 & 5.95 & 5.681 & TRN \\
\hline CHEMBL1509247 & 688620 & 4.45 & 5.1244 & TST \\
\hline CHEMBL1339206 & 688620 & 5.9 & 5.4849 & TST \\
\hline CHEMBL 3212062 & 688620 & 5.4 & 5.0741 & TST \\
\hline CHEMBL1347888 & 688620 & 5.15 & 5.1947 & TRN \\
\hline CHEMBL1562411 & 688620 & 4.5 & 4.9362 & TRN \\
\hline CHEMBL1418656 & 688620 & 5.1 & 5.1185 & TRN \\
\hline CHEMBL2007313 & 688620 & 4.9 & 5.2457 & TST \\
\hline CHEMBL 3195981 & 688620 & 5.0 & 5.2618 & TRN \\
\hline CHEMBL3211767 & 688620 & 4.45 & 5.2119 & TRN \\
\hline CHEMBL1580144 & 688620 & 5.7 & 6.2847 & TRN \\
\hline CHEMBL1501592 & 688620 & 5.15 & 4.9468 & TRN \\
\hline CHEMBL1586665 & 688620 & 4.45 & 5.0209 & TST \\
\hline
\end{tabular}




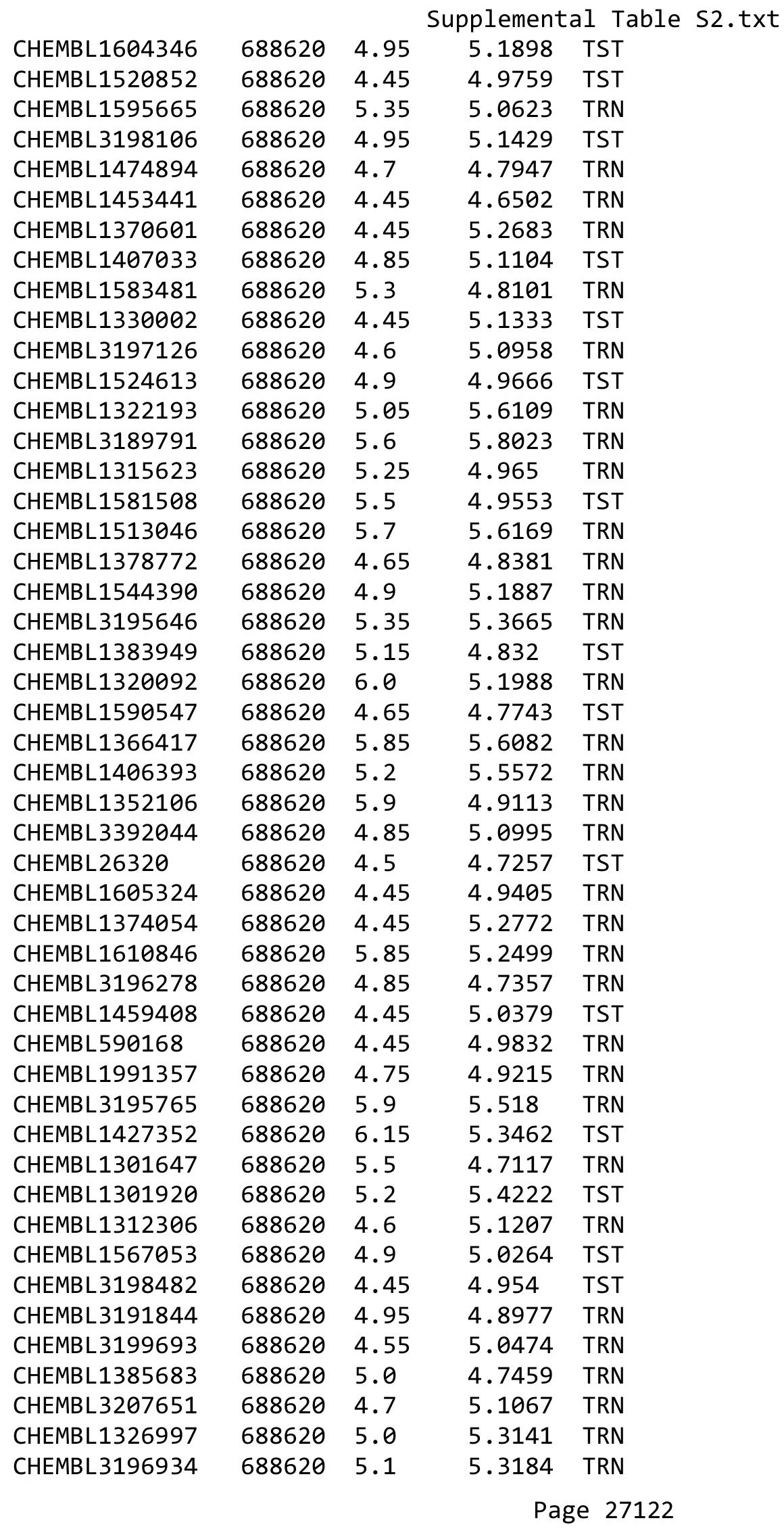




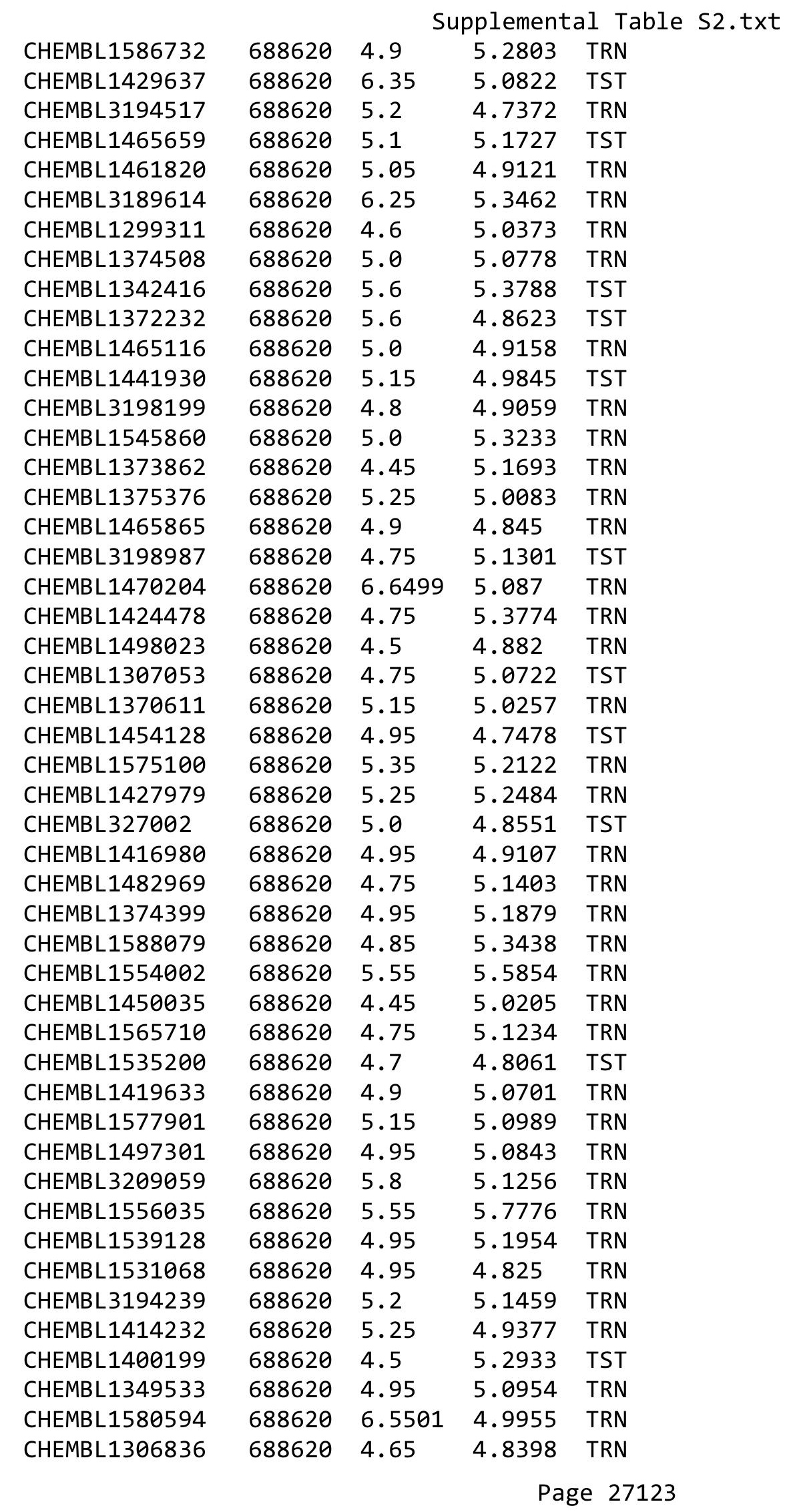




\begin{tabular}{|c|c|c|c|c|c|}
\hline \\
\hline CHEMBL1580862 & 688620 & 4.7 & 4.8695 & TRN & \\
\hline CHEMBL1400086 & 688620 & 5.15 & 5.1309 & TRN & \\
\hline CHEMBL1423060 & 688620 & 5.0 & 5.1833 & TRN & \\
\hline CHEMBL1502964 & 688620 & 5.0 & 4.9572 & TRN & \\
\hline CHEMBL1541157 & 688620 & 4.45 & 5.04899 & 99999999995 & TRN \\
\hline CHEMBL1418463 & 688620 & 4.8 & 5.1 & TST & \\
\hline CHEMBL1496142 & 688620 & 5.45 & 5.2182 & TRN & \\
\hline CHEMBL3196390 & 688620 & 5.25 & 5.124 & TRN & \\
\hline CHEMBL1477847 & 688620 & 5.2 & 4.9422 & TRN & \\
\hline CHEMBL1306448 & 688620 & 4.8 & 4.7756 & TRN & \\
\hline CHEMBL3210290 & 688620 & 5.85 & 5.45700 & $\partial 000000001$ & TRN \\
\hline CHEMBL1411884 & 688620 & 7.4001 & 6.1915 & TST & \\
\hline CHEMBL1405800 & 688620 & 4.7 & 4.9863 & TST & \\
\hline CHEMBL3210714 & 688620 & 4.65 & 5.0181 & TRN & \\
\hline CHEMBL1374761 & 688620 & 4.45 & 4.9445 & TRN & \\
\hline CHEMBL1497807 & 688620 & 5.8 & 5.6482 & TRN & \\
\hline CHEMBL1300358 & 688620 & 4.9 & 5.0045 & TST & \\
\hline CHEMBL1510111 & 688620 & 5.9 & 5.2602 & TRN & \\
\hline CHEMBL1466570 & 688620 & 5.4 & 4.9532 & TST & \\
\hline CHEMBL1612467 & 688620 & 5.05 & 4.9303 & TRN & \\
\hline CHEMBL1605247 & 688620 & 5.05 & 4.9155 & TRN & \\
\hline CHEMBL1383683 & 688620 & 4.5 & 4.9832 & TRN & \\
\hline CHEMBL1537902 & 688620 & 4.8 & 4.8411 & TRN & \\
\hline CHEMBL1362785 & 688620 & 4.65 & 5.0382 & TST & \\
\hline CHEMBL1368797 & 688620 & 5.1 & 5.2492 & TRN & \\
\hline CHEMBL1974563 & 688620 & 6.7001 & 5.718 & TRN & \\
\hline CHEMBL1361585 & 688620 & 5.35 & 5.1371 & TRN & \\
\hline CHEMBL1374226 & 688620 & 4.95 & 5.0573 & TRN & \\
\hline CHEMBL1382154 & 688620 & 5.0 & 5.0455 & TRN & \\
\hline CHEMBL3191829 & 688620 & 4.45 & 5.0982 & TRN & \\
\hline CHEMBL1310599 & 688620 & 5.1 & 4.9505 & TRN & \\
\hline CHEMBL1391617 & 688620 & 5.85 & 4.6622 & TST & \\
\hline CHEMBL1331380 & 688620 & 5.4 & 5.273 & TRN & \\
\hline CHEMBL1481412 & 688620 & 4.45 & 4.6294 & TRN & \\
\hline CHEMBL1526509 & 688620 & 4.9 & 4.8638 & TRN & \\
\hline CHEMBL1482275 & 688620 & 4.85 & 4.9074 & TST & \\
\hline CHEMBL1610496 & 688620 & 4.95 & 4.9181 & TRN & \\
\hline CHEMBL1581270 & 688620 & 5.85 & 5.4579 & TRN & \\
\hline CHEMBL1901606 & 688620 & 4.7 & 4.7148 & TRN & \\
\hline CHEMBL1485473 & 688620 & 4.75 & 4.8721 & TRN & \\
\hline CHEMBL3193960 & 688620 & 4.8 & 4.7746 & TRN & \\
\hline CHEMBL1479092 & 688620 & 4.85 & 5.0071 & TRN & \\
\hline CHEMBL388342 & 688620 & 4.55 & 5.2923 & TRN & \\
\hline CHEMBL1586046 & 688620 & 4.85 & 4.9704 & TRN & \\
\hline CHEMBL1379503 & 688620 & 4.45 & 4.9383 & TRN & \\
\hline CHEMBL1399697 & 688620 & 4.9 & 4.8889 & TRN & \\
\hline CHEMBL3211166 & 688620 & 5.5 & 5.149 & TRN & \\
\hline CHEMBL1544028 & 688620 & 4.45 & 5.0811 & TRN & \\
\hline
\end{tabular}




\begin{tabular}{|c|c|c|c|c|c|}
\hline \multirow[b]{2}{*}{ CHEMBL1457024 } & \\
\hline & 688620 & 5.1 & 5.0397 & TST & \\
\hline CHEMBL1577681 & 688620 & 4.45 & 4.8437 & TRN & \\
\hline CHEMBL3194910 & 688620 & 4.5 & 5.3023 & TRN & \\
\hline CHEMBL1305861 & 688620 & 6.35 & 4.7136 & TST & \\
\hline CHEMBL1488445 & 688620 & 6.8499 & 4.8944 & TRN & \\
\hline CHEMBL1461296 & 688620 & 5.9 & 5.1274 & TST & \\
\hline CHEMBL1597723 & 688620 & 4.9 & 4.8583 & TRN & \\
\hline CHEMBL1439300 & 688620 & 4.45 & 4.843 & TST & \\
\hline CHEMBL1400349 & 688620 & 4.95 & 5.3041 & TRN & \\
\hline CHEMBL3198827 & 688620 & 5.0 & 4.9845 & TRN & \\
\hline CHEMBL1381537 & 688620 & 4.45 & 4.9529 & TRN & \\
\hline CHEMBL1402278 & 688620 & 4.85 & 5.0311 & TRN & \\
\hline CHEMBL1461180 & 688620 & 5.15 & 5.0766 & TRN & \\
\hline CHEMBL1451272 & 688620 & 5.5 & 5.0476 & TRN & \\
\hline CHEMBL1985495 & 688620 & 4.65 & 4.9739 & TRN & \\
\hline CHEMBL1510254 & 688620 & 7.6003 & 6.9162 & TRN & \\
\hline CHEMBL1478754 & 688620 & 4.8 & 5.0109 & TRN & \\
\hline CHEMBL3212614 & 688620 & 4.45 & 4.8481 & TRN & \\
\hline CHEMBL1556952 & 688620 & 4.75 & 4.7671 & TST & \\
\hline CHEMBL1313095 & 688620 & 4.55 & 4.9552 & TRN & \\
\hline CHEMBL1510635 & 688620 & 4.75 & 4.9366 & TRN & \\
\hline CHEMBL1487635 & 688620 & 6.0 & 5.9459 & TRN & \\
\hline CHEMBL1562915 & 688620 & 6.3 & 5.4375 & TRN & \\
\hline CHEMBL271958 & 688620 & 4.9 & 4.9683 & TST & \\
\hline CHEMBL1602849 & 688620 & 4.8 & 4.73600 & $\partial 000000001$ & TRN \\
\hline CHEMBL1305505 & 688620 & 4.9 & 5.0681 & TRN & \\
\hline CHEMBL1385784 & 688620 & 4.45 & 4.8906 & TRN & \\
\hline CHEMBL421088 & 688620 & 5.05 & 5.1875 & TRN & \\
\hline CHEMBL1343608 & 688620 & 4.75 & 4.753 & TRN & \\
\hline CHEMBL1368174 & 688620 & 5.35 & 5.2255 & TST & \\
\hline CHEMBL1546916 & 688620 & 4.95 & 4.9243 & TST & \\
\hline CHEMBL1478271 & 688620 & 5.2 & 5.4172 & TRN & \\
\hline CHEMBL1429449 & 688620 & 4.9 & 4.9566 & TRN & \\
\hline CHEMBL1383534 & 688620 & 5.45 & 5.3361 & TRN & \\
\hline CHEMBL1369629 & 688620 & 4.45 & 4.8675 & TRN & \\
\hline CHEMBL1418610 & 688620 & 4.45 & 4.9797 & TST & \\
\hline CHEMBL1422221 & 688620 & 4.75 & 5.1547 & TST & \\
\hline CHEMBL1516739 & 688620 & 8.2518 & 4.9084 & TRN & \\
\hline CHEMBL1534496 & 688620 & 5.95 & 5.2628 & TRN & \\
\hline CHEMBL1524449 & 688620 & 5.15 & 4.814 & TRN & \\
\hline CHEMBL1481186 & 688620 & 5.35 & 4.737 & TRN & \\
\hline CHEMBL 2007091 & 688620 & 4.8 & 5.0409 & TRN & \\
\hline CHEMBL1530900 & 688620 & 4.85 & 4.9262 & TRN & \\
\hline CHEMBL1489726 & 688620 & 4.8 & 5.124 & TST & \\
\hline CHEMBL1459396 & 688620 & 4.95 & 4.9729 & TRN & \\
\hline CHEMBL1345352 & 688620 & 5.55 & 5.3849 & TRN & \\
\hline CHEMBL1533634 & 688620 & 6.95 & 5.2512 & TRN & \\
\hline CHEMBL1432751 & 688620 & 4.7 & 5.4602 & TRN & \\
\hline & & & & 7125 & \\
\hline
\end{tabular}




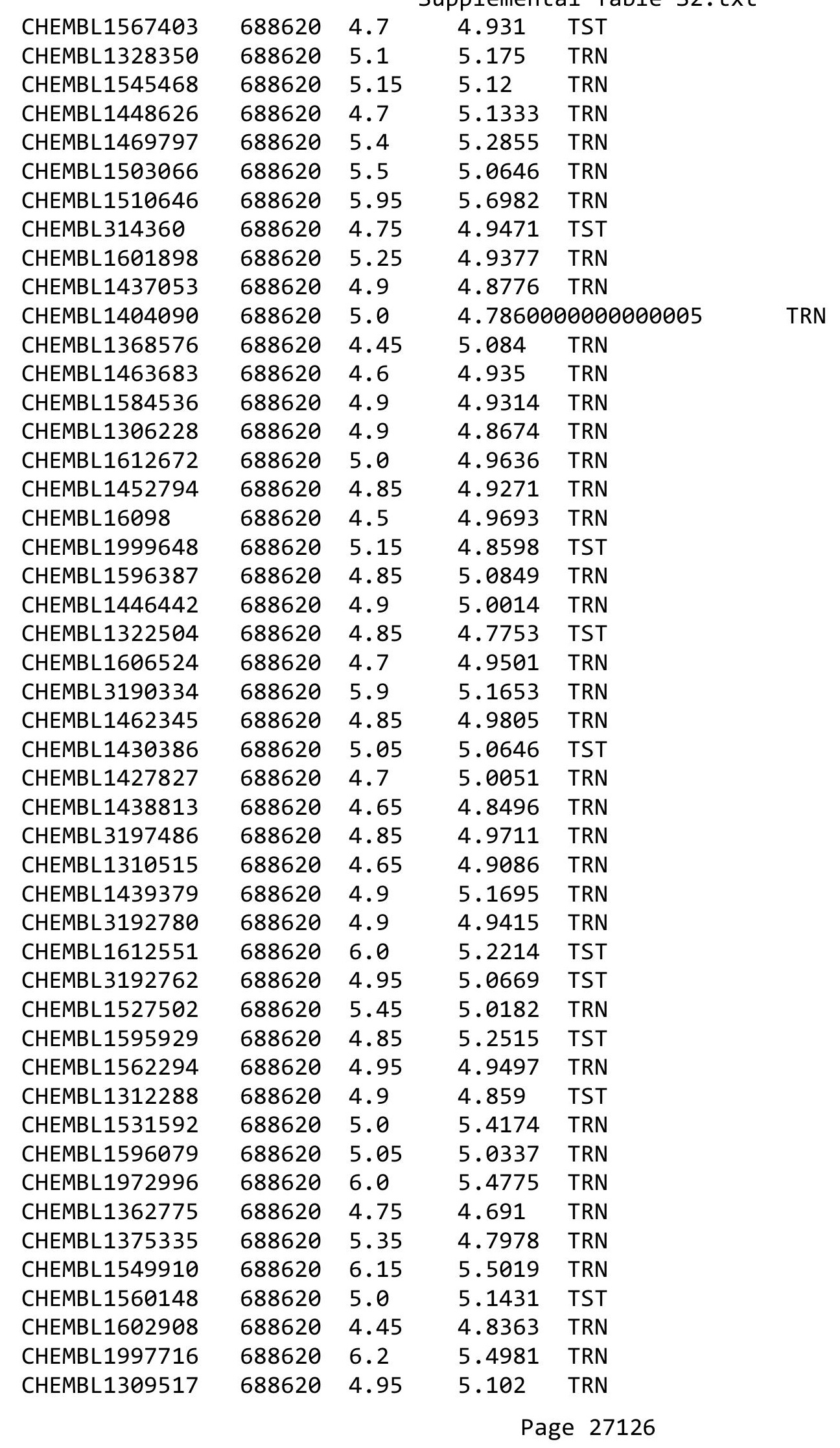




\begin{tabular}{|c|c|c|c|c|}
\hline \multicolumn{5}{|c|}{ Supplemental Table S2.txt } \\
\hline CHEMBL3192511 & 688620 & 4.95 & 5.1112 & TRN \\
\hline CHEMBL1522306 & 688620 & 4.45 & 5.1285 & TRN \\
\hline CHEMBL1579860 & 688620 & 4.95 & 5.0099 & TRN \\
\hline CHEMBL1534533 & 688620 & 5.15 & 5.0211 & TST \\
\hline CHEMBL1321900 & 688620 & 5.0 & 5.0669 & TST \\
\hline CHEMBL580955 & 688620 & 5.65 & 5.8838 & TRN \\
\hline CHEMBL1425787 & 688620 & 5.25 & 4.8305 & TRN \\
\hline CHEMBL1446248 & 688620 & 6.25 & 5.7684 & TRN \\
\hline CHEMBL1451996 & 688620 & 4.95 & 4.8478 & TRN \\
\hline CHEMBL1402502 & 688620 & 4.45 & 4.857 & TRN \\
\hline CHEMBL1449103 & 688620 & 4.5 & 5.2184 & TRN \\
\hline CHEMBL489 & 688620 & 4.45 & 4.8494 & TST \\
\hline CHEMBL1432253 & 688620 & 5.0 & 4.9413 & TST \\
\hline CHEMBL 2003602 & 688620 & 5.45 & 5.3365 & TRN \\
\hline CHEMBL121336 & 688620 & 4.45 & 4.8932 & TRN \\
\hline CHEMBL1519910 & 688620 & 5.3 & 5.3569 & TRN \\
\hline CHEMBL1303373 & 688620 & 4.85 & 4.8538 & TRN \\
\hline CHEMBL1325494 & 688620 & 5.2 & 5.2988 & TRN \\
\hline CHEMBL1360723 & 688620 & 4.9 & 4.9835 & TST \\
\hline CHEMBL3145170 & 688620 & 5.0 & 5.3109 & TRN \\
\hline CHEMBL1400047 & 688620 & 5.2 & 5.1495 & TST \\
\hline CHEMBL1452676 & 688620 & 5.05 & 4.8027 & TRN \\
\hline CHEMBL1558102 & 688620 & 4.95 & 4.8627 & TRN \\
\hline CHEMBL1466060 & 688620 & 5.45 & 5.1867 & TRN \\
\hline CHEMBL1572006 & 688620 & 5.0 & 4.8525 & TST \\
\hline CHEMBL1339915 & 688620 & 4.85 & 4.9216 & TRN \\
\hline CHEMBL1448538 & 688620 & 5.2 & 4.9482 & TST \\
\hline CHEMBL1344000 & 688620 & 5.9 & 5.2905 & TRN \\
\hline CHEMBL1310728 & 688620 & 5.1 & 5.2335 & TRN \\
\hline CHEMBL1299748 & 688620 & 5.3 & 5.5086 & TRN \\
\hline CHEMBL1704074 & 688620 & 6.35 & 5.9019 & TRN \\
\hline CHEMBL1461188 & 688620 & 4.75 & 4.8185 & TST \\
\hline CHEMBL1381035 & 688620 & 6.25 & 5.0698 & TST \\
\hline CHEMBL1536910 & 688620 & 5.35 & 5.2072 & TRN \\
\hline CHEMBL1406019 & 688620 & 6.0 & 4.9967 & TRN \\
\hline CHEMBL1311804 & 688620 & 5.25 & 5.0954 & TST \\
\hline CHEMBL1477097 & 688620 & 4.8 & 4.7976 & TRN \\
\hline CHEMBL1312151 & 688620 & 4.95 & 5.1485 & TRN \\
\hline CHEMBL1604919 & 688620 & 4.5 & 5.1221 & TRN \\
\hline CHEMBL1471217 & 688620 & 4.5 & 4.7596 & TRN \\
\hline CHEMBL1358680 & 688620 & 6.05 & 5.2527 & TRN \\
\hline CHEMBL1501953 & 688620 & 4.95 & 4.7049 & TST \\
\hline CHEMBL1406239 & 688620 & 4.45 & 4.6828 & TRN \\
\hline CHEMBL1419104 & 688620 & 4.5 & 5.1273 & TRN \\
\hline CHEMBL1472578 & 688620 & 4.95 & 4.7088 & TST \\
\hline CHEMBL1430711 & 688620 & 4.9 & 5.1115 & TRN \\
\hline CHEMBL1498242 & 688620 & 7.0501 & 5.0005 & TST \\
\hline CHEMBL3191069 & 688620 & 5.2 & 5.0514 & TRN \\
\hline
\end{tabular}




\begin{tabular}{|c|c|c|c|c|c|}
\hline \multicolumn{6}{|c|}{ Supplemental Table S2.txt } \\
\hline CHEMBL191334 & 688620 & 4.95 & 5.0914 & TST & \\
\hline CHEMBL1519607 & 688620 & 6.0 & 4.8934 & TRN & \\
\hline CHEMBL1328462 & 688620 & 5.0 & 5.1722 & TRN & \\
\hline CHEMBL1500176 & 688620 & 4.45 & 5.0564 & TRN & \\
\hline CHEMBL1499489 & 688620 & 4.7 & 4.8731 & TRN & \\
\hline CHEMBL1611354 & 688620 & 5.95 & 5.4302 & TRN & \\
\hline CHEMBL1470744 & 688620 & 4.45 & 4.8061 & TRN & \\
\hline CHEMBL1588500 & 688620 & 4.95 & 4.9993 & TRN & \\
\hline CHEMBL1540176 & 688620 & 5.1 & 5.1522 & TRN & \\
\hline CHEMBL1426804 & 688620 & 4.45 & 5.0069 & TRN & \\
\hline CHEMBL1424818 & 688620 & 5.6 & 5.0761 & TRN & \\
\hline CHEMBL1578704 & 688620 & 4.95 & 5.0701 & TRN & \\
\hline CHEMBL1548436 & 688620 & 4.65 & 5.1858 & TRN & \\
\hline CHEMBL1604089 & 688620 & 4.95 & 5.0857 & TRN & \\
\hline CHEMBL1426173 & 688620 & 4.75 & 4.7147 & TRN & \\
\hline CHEMBL1498192 & 688620 & 5.05 & 5.0367 & TRN & \\
\hline CHEMBL1557538 & 688620 & 4.85 & 4.6871 & TRN & \\
\hline CHEMBL1354089 & 688620 & 4.65 & 4.9645 & TRN & \\
\hline CHEMBL1343489 & 688620 & 4.7 & 4.77800 & 00000000005 & TRN \\
\hline CHEMBL1608762 & 688620 & 4.9 & 5.151 & TRN & \\
\hline CHEMBL1352067 & 688620 & 5.0 & 4.9223 & TRN & \\
\hline CHEMBL1579814 & 688620 & 4.45 & 5.0691 & TST & \\
\hline CHEMBL1403539 & 688620 & 5.15 & 4.9716 & TRN & \\
\hline CHEMBL1489552 & 688620 & 6.95 & 4.9186 & TRN & \\
\hline CHEMBL1469715 & 688620 & 4.85 & 4.9745 & TRN & \\
\hline CHEMBL1575685 & 688620 & 7.4001 & 5.0556 & TST & \\
\hline CHEMBL1504736 & 688620 & 4.75 & 4.8057 & TST & \\
\hline CHEMBL1499059 & 688620 & 4.9 & 5.1086 & TRN & \\
\hline CHEMBL1302686 & 688620 & 4.9 & 5.0163 & TRN & \\
\hline CHEMBL1345332 & 688620 & 5.0 & 4.7688 & TST & \\
\hline CHEMBL3190678 & 688620 & 5.3 & 5.3205 & TRN & \\
\hline CHEMBL1994856 & 688620 & 6.0 & 5.4074 & TRN & \\
\hline CHEMBL1992793 & 688620 & 5.95 & 6.0262 & TRN & \\
\hline CHEMBL1532362 & 688620 & 4.45 & 5.1812 & TRN & \\
\hline CHEMBL1578495 & 688620 & 6.5501 & 5.3478 & TST & \\
\hline CHEMBL1504206 & 688620 & 4.95 & 5.0736 & TRN & \\
\hline CHEMBL1597394 & 688620 & 4.95 & 4.93 & TST & \\
\hline CHEMBL1428009 & 688620 & 4.6 & 4.7505 & TST & \\
\hline CHEMBL1485329 & 688620 & 4.95 & 4.9105 & TRN & \\
\hline CHEMBL 3210640 & 688620 & 5.45 & 4.8552 & TRN & \\
\hline CHEMBL1507483 & 688620 & 5.0 & 4.8525 & TRN & \\
\hline CHEMBL1500316 & 688620 & 5.35 & 5.2085 & TST & \\
\hline CHEMBL1388751 & 688620 & 5.0 & 4.9991 & TRN & \\
\hline CHEMBL1384675 & 688620 & 5.85 & 5.2022 & TRN & \\
\hline CHEMBL1511490 & 688620 & 4.45 & 5.1657 & TRN & \\
\hline CHEMBL1311515 & 688620 & 4.45 & 4.8958 & TRN & \\
\hline CHEMBL 70902 & 688620 & 4.8 & 4.9625 & TST & \\
\hline CHEMBL1421558 & 688620 & 4.85 & 4.9883 & TRN & \\
\hline
\end{tabular}




\begin{tabular}{|c|c|c|c|c|}
\hline \multicolumn{5}{|c|}{ Supplemental Table S2.txt } \\
\hline CHEMBL1500819 & 688620 & 5.4 & 5.3101 & TST \\
\hline CHEMBL1348617 & 688620 & 6.2 & 6.2033 & TRN \\
\hline CHEMBL1971441 & 688620 & 4.9 & 5.0525 & TRN \\
\hline CHEMBL1429535 & 688620 & 5.0 & 4.9634 & TST \\
\hline CHEMBL 1445728 & 688620 & 5.45 & 4.9606 & TRN \\
\hline CHEMBL1612106 & 688620 & 5.3 & 5.3001 & TRN \\
\hline CHEMBL1398992 & 688620 & 4.45 & 5.0934 & TRN \\
\hline CHEMBL1311914 & 688620 & 5.5 & 4.979 & TRN \\
\hline CHEMBL1335117 & 688620 & 5.4 & 4.9746 & TRN \\
\hline CHEMBL1350585 & 688620 & 5.65 & 5.6349 & TRN \\
\hline CHEMBL1612874 & 688620 & 4.65 & 4.9633 & TRN \\
\hline CHEMBL1424888 & 688620 & 4.9 & 4.8433 & TRN \\
\hline CHEMBL1548942 & 688620 & 4.45 & 4.901 & TRN \\
\hline CHEMBL1528209 & 688620 & 5.0 & 4.9331 & TRN \\
\hline CHEMBL1576795 & 688620 & 6.0 & 4.7973 & TRN \\
\hline CHEMBL1602206 & 688620 & 4.65 & 4.9357 & TST \\
\hline CHEMBL1505133 & 688620 & 4.7 & 4.9081 & TRN \\
\hline CHEMBL1506665 & 688620 & 4.45 & 4.9048 & TRN \\
\hline CHEMBL3189161 & 688620 & 6.6499 & 6.3459 & TRN \\
\hline CHEMBL1578769 & 688620 & 5.55 & 5.1695 & TRN \\
\hline CHEMBL1528052 & 688620 & 5.0 & 4.9571 & TRN \\
\hline CHEMBL1424885 & 688620 & 4.9 & 5.1167 & TRN \\
\hline CHEMBL1611335 & 688620 & 4.9 & 4.9982 & TRN \\
\hline CHEMBL1415660 & 688620 & 4.45 & 4.8456 & TST \\
\hline CHEMBL1317931 & 688620 & 6.0 & 5.2183 & TST \\
\hline CHEMBL1462963 & 688620 & 4.45 & 5.1025 & TRN \\
\hline CHEMBL1404709 & 688620 & 5.15 & 5.4189 & TRN \\
\hline CHEMBL3199825 & 688620 & 4.65 & 5.348 & TST \\
\hline CHEMBL1450473 & 688620 & 5.3 & 4.9997 & TRN \\
\hline CHEMBL1465379 & 688620 & 5.6 & 5.5771 & TRN \\
\hline CHEMBL1561843 & 688620 & 4.5 & 4.9322 & TST \\
\hline CHEMBL1448063 & 688620 & 4.9 & 5.2125 & TRN \\
\hline CHEMBL603129 & 688620 & 4.9 & 4.9558 & TST \\
\hline CHEMBL1477408 & 688620 & 4.45 & 5.0005 & TRN \\
\hline CHEMBL1429574 & 688620 & 4.95 & 5.2042 & TST \\
\hline CHEMBL1583137 & 688620 & 5.2 & 5.1684 & TRN \\
\hline CHEMBL1471719 & 688620 & 6.3 & 5.1319 & TST \\
\hline CHEMBL1605661 & 688620 & 6.1 & 4.8291 & TRN \\
\hline CHEMBL1559622 & 688620 & 4.95 & 5.1161 & TRN \\
\hline CHEMBL1404493 & 688620 & 6.0 & 5.9319 & TRN \\
\hline CHEMBL1328373 & 688620 & 5.25 & 4.9088 & TRN \\
\hline CHEMBL1566997 & 688620 & 4.85 & 5.0157 & TRN \\
\hline CHEMBL1441236 & 688620 & 4.45 & 4.8543 & TRN \\
\hline CHEMBL3193534 & 688620 & 5.95 & 5.6447 & TRN \\
\hline CHEMBL1564577 & 688620 & 4.75 & 5.0046 & TRN \\
\hline CHEMBL1609988 & 688620 & 5.25 & 4.8549 & TRN \\
\hline CHEMBL1603776 & 688620 & 6.2 & 5.3947 & TST \\
\hline CHEMBL1578053 & 688620 & 6.15 & 5.2653 & TRN \\
\hline
\end{tabular}




\begin{tabular}{|c|c|c|c|c|c|}
\hline \\
\hline CHEMBL1458848 & 688620 & 4.7 & 5.89 & TRN & \\
\hline CHEMBL1570857 & 688620 & 4.55 & 4.9606 & TST & \\
\hline CHEMBL1304291 & 688620 & 6.4 & 5.2697 & TRN & \\
\hline CHEMBL1414009 & 688620 & 4.75 & 5.0004 & TST & \\
\hline CHEMBL1586051 & 688620 & 4.95 & 5.1648 & TRN & \\
\hline CHEMBL1459215 & 688620 & 4.9 & 4.8806 & TRN & \\
\hline CHEMBL1471252 & 688620 & 4.45 & 4.7424 & TRN & \\
\hline CHEMBL1540181 & 688620 & 4.85 & 4.7214 & TRN & \\
\hline CHEMBL1431605 & 688620 & 4.85 & 4.8571 & TRN & \\
\hline CHEMBL1493323 & 688620 & 5.05 & 5.2718 & TRN & \\
\hline CHEMBL1496935 & 688620 & 4.5 & 5.0521 & TRN & \\
\hline CHEMBL3209207 & 688620 & 4.95 & $5.1670 e$ & 0000000001 & TRN \\
\hline CHEMBL1374511 & 688620 & 4.8 & 4.9915 & TRN & \\
\hline CHEMBL1347185 & 688620 & 4.65 & 4.8961 & TRN & \\
\hline CHEMBL1573291 & 688620 & 5.0 & 4.9466 & TRN & \\
\hline CHEMBL1459767 & 688620 & 5.15 & 5.2417 & TST & \\
\hline CHEMBL1493326 & 688620 & 4.45 & 5.1613 & TST & \\
\hline CHEMBL3194390 & 688620 & 4.75 & 5.1717 & TRN & \\
\hline CHEMBL1342286 & 688620 & 4.8 & 4.9674 & TST & \\
\hline CHEMBL3199362 & 688620 & 6.05 & 5.777 & TST & \\
\hline CHEMBL1357180 & 688620 & 5.05 & 5.0879 & TST & \\
\hline CHEMBL1415217 & 688620 & 4.95 & 4.9874 & TRN & \\
\hline CHEMBL1598657 & 688620 & 5.2 & 5.0209 & TRN & \\
\hline CHEMBL1410093 & 688620 & 5.65 & 5.646 & TRN & \\
\hline CHEMBL3210267 & 688620 & 5.55 & 5.7568 & TRN & \\
\hline CHEMBL3207653 & 688620 & 5.2 & 5.1287 & TRN & \\
\hline CHEMBL2005761 & 688620 & 4.9 & 4.9854 & TRN & \\
\hline CHEMBL1521818 & 688620 & 3.95 & 5.1328 & TRN & \\
\hline CHEMBL1495424 & 688620 & 4.95 & 5.0802 & TRN & \\
\hline CHEMBL607553 & 688620 & 4.7 & 5.1788 & TRN & \\
\hline CHEMBL1469857 & 688620 & 5.0 & 5.0893 & TRN & \\
\hline CHEMBL1328036 & 688620 & 4.75 & 5.0368 & TRN & \\
\hline CHEMBL1367808 & 688620 & 5.65 & 5.0564 & TRN & \\
\hline CHEMBL1449126 & 688620 & 5.7 & 4.9101 & TRN & \\
\hline CHEMBL1553023 & 688620 & 7.6003 & 6.4058 & TST & \\
\hline CHEMBL1340366 & 688620 & 5.15 & 5.2068 & TRN & \\
\hline CHEMBL1482583 & 688620 & 4.45 & 4.8945 & TST & \\
\hline CHEMBL1311028 & 688620 & 4.65 & 4.8276 & TRN & \\
\hline CHEMBL1483939 & 688620 & 4.6 & 5.0934 & TRN & \\
\hline CHEMBL1405295 & 688620 & 6.95 & 5.1317 & TST & \\
\hline CHEMBL1407753 & 688620 & 4.9 & 5.1174 & TRN & \\
\hline CHEMBL3190535 & 688620 & 4.45 & 5.0693 & TRN & \\
\hline CHEMBL1562797 & 688620 & 5.15 & 5.0486 & TRN & \\
\hline CHEMBL1397089 & 688620 & 6.6 & 5.7054 & TRN & \\
\hline CHEMBL1590291 & 688620 & 4.65 & 5.1135 & TRN & \\
\hline CHEMBL3194677 & 688620 & 5.05 & 4.9718 & TRN & \\
\hline CHEMBL3211107 & 688620 & 4.8 & 5.0983 & TRN & \\
\hline CHEMBL1430452 & 688620 & 5.7 & 5.3453 & TRN & \\
\hline
\end{tabular}




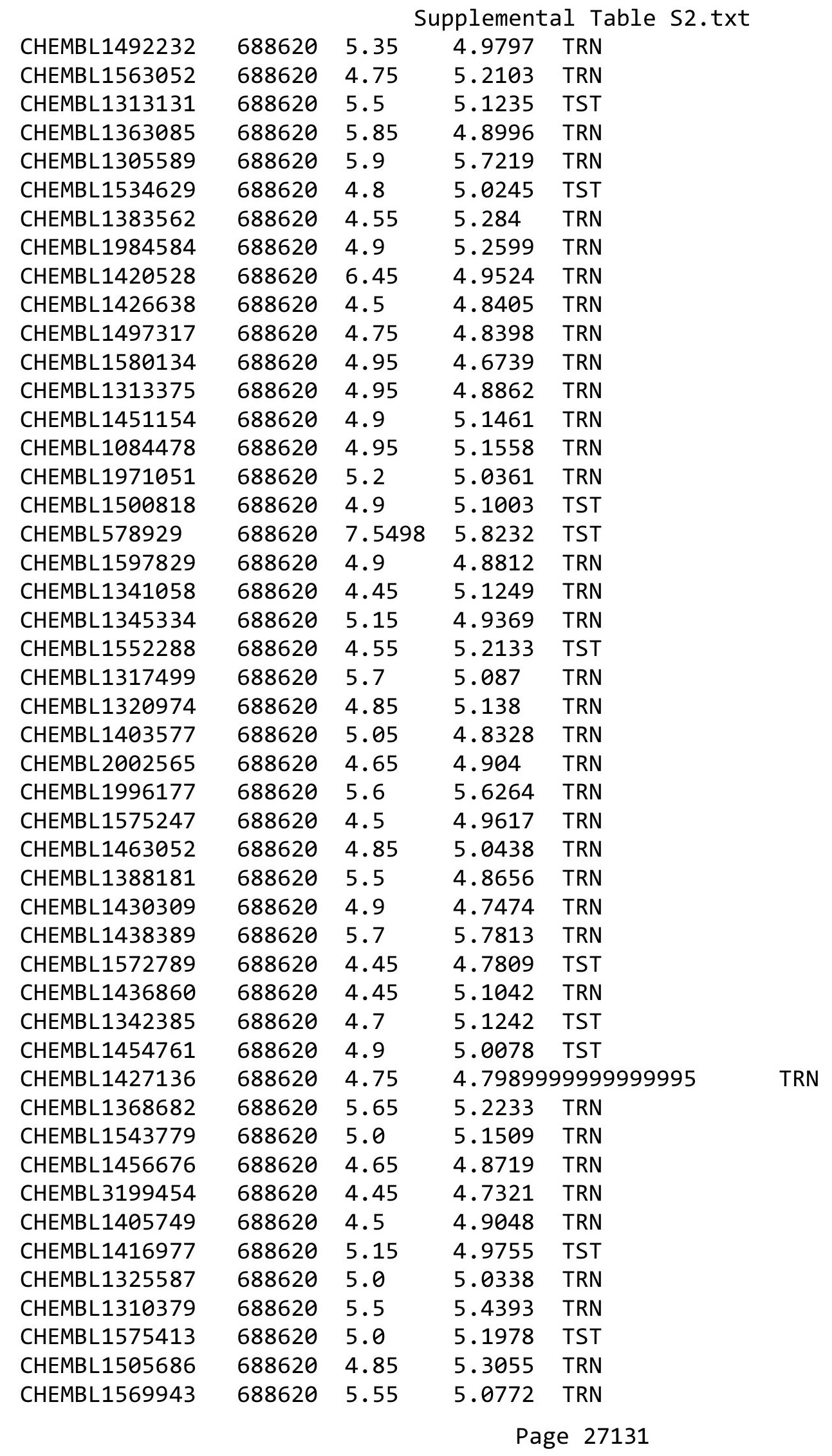




\begin{tabular}{|c|c|c|c|c|}
\hline \multicolumn{5}{|c|}{ Supplemental Tabl } \\
\hline CHEMBL1352586 & 688620 & 5.55 & 5.1841 & TST \\
\hline CHEMBL1560306 & 688620 & 5.3 & 5.1733 & TRN \\
\hline CHEMBL3196851 & 688620 & 4.95 & 5.2965 & TRN \\
\hline CHEMBL1595760 & 688620 & 5.15 & 4.9978 & TRN \\
\hline CHEMBL1479657 & 688620 & 6.0 & 5.2722 & TST \\
\hline CHEMBL1588978 & 688620 & 4.9 & 5.2715 & TST \\
\hline CHEMBL1483274 & 688620 & 6.25 & 4.9542 & TST \\
\hline CHEMBL1488994 & 688620 & 5.15 & 5.3067 & TST \\
\hline CHEMBL1539620 & 688620 & 4.45 & 4.6462 & TRN \\
\hline CHEMBL1565007 & 688620 & 4.95 & 4.8965 & TRN \\
\hline CHEMBL1319820 & 688620 & 4.45 & 5.1477 & TRN \\
\hline CHEMBL1501215 & 688620 & 4.75 & 4.7612 & TST \\
\hline CHEMBL1379963 & 688620 & 4.95 & 4.9882 & TRN \\
\hline CHEMBL1431112 & 688620 & 4.65 & 4.9339 & TRN \\
\hline CHEMBL1300120 & 688620 & 4.95 & 4.8921 & TRN \\
\hline CHEMBL1308615 & 688620 & 6.5 & 5.9953 & TRN \\
\hline CHEMBL1382476 & 688620 & 4.45 & 4.8138 & TST \\
\hline CHEMBL3196187 & 688620 & 4.45 & 4.8612 & TRN \\
\hline CHEMBL1311391 & 688620 & 5.15 & 5.2725 & TRN \\
\hline CHEMBL1442635 & 688620 & 5.5 & 4.9454 & TRN \\
\hline CHEMBL1538775 & 688620 & 5.15 & 5.2074 & TRN \\
\hline CHEMBL1999513 & 688620 & 4.7 & 5.1369 & TRN \\
\hline CHEMBL1502917 & 688620 & 4.65 & 5.0589 & TST \\
\hline CHEMBL3213759 & 688620 & 5.65 & 4.8761 & TST \\
\hline CHEMBL1477916 & 688620 & 5.2 & 5.0795 & TRN \\
\hline CHEMBL1335744 & 688620 & 5.2 & 5.0435 & TRN \\
\hline CHEMBL1386860 & 688620 & 5.5 & 5.083 & TRN \\
\hline CHEMBL1563177 & 688620 & 4.45 & 4.9576 & TRN \\
\hline CHEMBL1446441 & 688620 & 4.95 & 4.9599 & TST \\
\hline CHEMBL1491056 & 688620 & 5.15 & 5.0194 & TRN \\
\hline CHEMBL1582524 & 688620 & 4.45 & 5.2041 & TST \\
\hline CHEMBL1524500 & 688620 & 5.6 & 5.5527 & TRN \\
\hline CHEMBL1507784 & 688620 & 4.9 & 5.0578 & TRN \\
\hline CHEMBL1486617 & 688620 & 4.95 & 4.988 & TST \\
\hline CHEMBL1482285 & 688620 & 4.9 & 5.0207 & TST \\
\hline CHEMBL72135 & 688620 & 5.2 & 5.0229 & TST \\
\hline CHEMBL1545406 & 688620 & 4.75 & 5.0199 & TRN \\
\hline CHEMBL3193197 & 688620 & 4.9 & 4.9658 & TST \\
\hline CHEMBL1444402 & 688620 & 4.45 & 4.9574 & TRN \\
\hline CHEMBL1321664 & 688620 & 4.75 & 4.9 & TRN \\
\hline CHEMBL1404447 & 688620 & 4.45 & 4.9178 & TRN \\
\hline CHEMBL1973166 & 688620 & 5.15 & 4.9205 & TRN \\
\hline CHEMBL1518020 & 688620 & 5.0 & 5.4656 & TST \\
\hline CHEMBL1336200 & 688620 & 4.7 & 4.8563 & TRN \\
\hline CHEMBL1589324 & 688620 & 5.0 & 4.879 & TRN \\
\hline CHEMBL581886 & 688620 & 6.5 & 6.9899 & TRN \\
\hline CHEMBL1347767 & 688620 & 5.5 & 5.3398 & TRN \\
\hline CHEMBL1565563 & 688620 & 5.0 & 4.813 & TRN \\
\hline
\end{tabular}




\begin{tabular}{|c|c|c|c|c|}
\hline \multicolumn{5}{|c|}{ Supplemental Table S2.txt } \\
\hline CHEMBL3196550 & 688620 & 4.95 & 5.0721 & TRN \\
\hline CHEMBL1560957 & 688620 & 4.55 & 4.8263 & TRN \\
\hline CHEMBL1311314 & 688620 & 4.75 & 5.0495 & TRN \\
\hline CHEMBL1306879 & 688620 & 4.45 & 5.0116 & TRN \\
\hline CHEMBL1462804 & 688620 & 4.45 & 4.9564 & TRN \\
\hline CHEMBL3192148 & 688620 & 4.55 & 4.8871 & TRN \\
\hline CHEMBL1306073 & 688620 & 5.0 & 4.9294 & TRN \\
\hline CHEMBL1493385 & 688620 & 6.05 & 5.0673 & TRN \\
\hline CHEMBL1423211 & 688620 & 4.8 & 5.1887 & TST \\
\hline CHEMBL1439396 & 688620 & 5.9 & 5.4625 & TRN \\
\hline CHEMBL1582859 & 688620 & 4.45 & 4.7756 & TRN \\
\hline CHEMBL1377705 & 688620 & 5.5 & 4.7203 & TRN \\
\hline CHEMBL1559385 & 688620 & 4.9 & 5.2056 & TRN \\
\hline CHEMBL1399314 & 688620 & 5.25 & 5.187 & TRN \\
\hline CHEMBL1455060 & 688620 & 6.2 & 5.425 & TST \\
\hline CHEMBL3197096 & 688620 & 5.7 & 5.2626 & TRN \\
\hline CHEMBL1303139 & 688620 & 4.85 & 5.1256 & TST \\
\hline CHEMBL1472201 & 688620 & 4.45 & 5.1767 & TRN \\
\hline CHEMBL1410809 & 688620 & 5.0 & 4.7833 & TRN \\
\hline CHEMBL1537900 & 688620 & 8.3468 & 5.2224 & TST \\
\hline CHEMBL1526240 & 688620 & 5.55 & 5.4761 & TRN \\
\hline CHEMBL1550062 & 688620 & 5.6 & 4.9865 & TRN \\
\hline CHEMBL1987816 & 688620 & 4.85 & 5.197 & TRN \\
\hline CHEMBL1499607 & 688620 & 4.6 & 5.3468 & TRN \\
\hline CHEMBL1548582 & 688620 & 4.45 & 5.0442 & TST \\
\hline CHEMBL1342795 & 688620 & 4.45 & 4.9423 & TRN \\
\hline CHEMBL1467785 & 688620 & 4.75 & 4.8543 & TRN \\
\hline CHEMBL3199546 & 688620 & 4.45 & 5.0932 & TRN \\
\hline CHEMBL1562310 & 688620 & 5.15 & 5.1442 & TRN \\
\hline CHEMBL1329080 & 688620 & 5.75 & 5.2036 & TRN \\
\hline CHEMBL1983587 & 688620 & 5.0 & 5.1686 & TRN \\
\hline CHEMBL1329925 & 688620 & 4.75 & 5.0171 & TST \\
\hline CHEMBL1380792 & 688620 & 5.9 & 5.1148 & TST \\
\hline CHEMBL1538419 & 688620 & 4.95 & 4.8577 & TST \\
\hline CHEMBL1478355 & 688620 & 4.75 & 4.9063 & TRN \\
\hline CHEMBL1443971 & 688620 & 4.6 & 5.0151 & TRN \\
\hline CHEMBL1497899 & 688620 & 4.95 & 5.0091 & TRN \\
\hline CHEMBL1503152 & 688620 & 4.55 & 4.6605 & TRN \\
\hline CHEMBL 3213428 & 688620 & 5.4 & 5.2041 & TRN \\
\hline CHEMBL1468629 & 688620 & 5.15 & 5.1496 & TRN \\
\hline CHEMBL45152 & 688620 & 5.45 & 5.6663 & TRN \\
\hline CHEMBL1352683 & 688620 & 4.85 & 5.1284 & TRN \\
\hline CHEMBL1965612 & 688620 & 6.1 & 6.1085 & TRN \\
\hline CHEMBL1335944 & 688620 & 4.95 & 5.0618 & TRN \\
\hline CHEMBL1418282 & 688620 & 4.95 & 4.9927 & TST \\
\hline CHEMBL1452840 & 688620 & 5.5 & 5.6472 & TST \\
\hline CHEMBL1519507 & 688620 & 4.45 & 5.154 & TRN \\
\hline CHEMBL1585373 & 688620 & 4.65 & 4.849 & TRN \\
\hline
\end{tabular}




\begin{tabular}{|c|c|c|c|c|}
\hline \multicolumn{5}{|c|}{ Supplemental Table S2.txt } \\
\hline CHEMBL1570390 & 688620 & 5.55 & 4.8425 & TRN \\
\hline CHEMBL1361824 & 688620 & 4.95 & 4.8225 & TRN \\
\hline CHEMBL1421102 & 688620 & 5.15 & 5.0354 & TST \\
\hline CHEMBL1332620 & 688620 & 4.45 & 4.8472 & TRN \\
\hline CHEMBL1376397 & 688620 & 4.7 & 4.8208 & TRN \\
\hline CHEMBL1451641 & 688620 & 5.5 & 5.065 & TRN \\
\hline CHEMBL578487 & 688620 & 4.8 & 5.2593 & TRN \\
\hline CHEMBL1367414 & 688620 & 4.45 & 4.8495 & TRN \\
\hline CHEMBL1559403 & 688620 & 5.2 & 5.0889 & TRN \\
\hline CHEMBL1332022 & 688620 & 4.45 & 5.1259 & TRN \\
\hline CHEMBL1322374 & 688620 & 4.75 & 5.0475 & TRN \\
\hline CHEMBL 3194343 & 688620 & 4.45 & 5.1004 & TST \\
\hline CHEMBL1491174 & 688620 & 5.55 & 5.3899 & TRN \\
\hline CHEMBL1612976 & 688620 & 4.8 & 4.6536 & TRN \\
\hline CHEMBL1300337 & 688620 & 4.85 & 4.9243 & TRN \\
\hline CHEMBL388979 & 688620 & 4.75 & 4.8459 & TST \\
\hline CHEMBL1349745 & 688620 & 4.75 & 4.8065 & TRN \\
\hline CHEMBL1486352 & 688620 & 5.3 & 5.2683 & TRN \\
\hline CHEMBL3191958 & 688620 & 6.6 & 6.4366 & TRN \\
\hline CHEMBL 2002169 & 688620 & 4.8 & 4.896 & TRN \\
\hline CHEMBL1606968 & 688620 & 5.0 & 5.1288 & TRN \\
\hline CHEMBL1385633 & 688620 & 5.45 & 5.3397 & TRN \\
\hline CHEMBL1539040 & 688620 & 5.2 & 5.1123 & TRN \\
\hline CHEMBL1412114 & 688620 & 4.45 & 4.81 & TST \\
\hline CHEMBL1559094 & 688620 & 5.45 & 5.0183 & TST \\
\hline CHEMBL1452607 & 688620 & 5.05 & 4.9547 & TRN \\
\hline CHEMBL1304900 & 688620 & 4.95 & 5.0788 & TRN \\
\hline CHEMBL1521490 & 688620 & 4.9 & 4.8911 & TRN \\
\hline CHEMBL1418831 & 688620 & 6.35 & 6.0578 & TST \\
\hline CHEMBL1494005 & 688620 & 5.1 & 4.9846 & TRN \\
\hline CHEMBL1568747 & 688620 & 6.05 & 5.164 & TRN \\
\hline CHEMBL1489650 & 688620 & 5.45 & 5.3807 & TRN \\
\hline CHEMBL3199889 & 688620 & 4.5 & 4.9629 & TRN \\
\hline CHEMBL1333235 & 688620 & 4.6 & 4.8389 & TRN \\
\hline CHEMBL1479468 & 688620 & 4.9 & 4.9453 & TRN \\
\hline CHEMBL3210669 & 688620 & 5.0 & 5.1008 & TRN \\
\hline CHEMBL1398761 & 688620 & 4.65 & 5.0387 & TRN \\
\hline CHEMBL1467761 & 688620 & 4.45 & 4.8439 & TST \\
\hline CHEMBL3196242 & 688620 & 4.75 & 5.1705 & TST \\
\hline CHEMBL3209588 & 688620 & 4.45 & 4.7839 & TRN \\
\hline CHEMBL1313821 & 688620 & 4.45 & 4.6098 & TRN \\
\hline CHEMBL1342062 & 688620 & 4.55 & 4.6944 & TRN \\
\hline CHEMBL1387915 & 688620 & 4.95 & 4.9981 & TRN \\
\hline CHEMBL1369229 & 688620 & 4.5 & 4.9745 & TRN \\
\hline CHEMBL1319574 & 688620 & 4.65 & 4.9367 & TST \\
\hline CHEMBL1372798 & 688620 & 4.75 & 5.0567 & TST \\
\hline CHEMBL1385886 & 688620 & 4.75 & 4.8462 & TRN \\
\hline CHEMBL1546766 & 688620 & 5.15 & 5.1067 & TRN \\
\hline
\end{tabular}




\begin{tabular}{|c|c|c|c|c|c|}
\hline \multicolumn{6}{|c|}{ Supplemental Table S2.txt } \\
\hline CHEMBL1445254 & 688620 & 4.7 & 5.1493 & TRN & \\
\hline CHEMBL1429443 & 688620 & 5.0 & 5.1595 & TST & \\
\hline CHEMBL3196693 & 688620 & 5.15 & 5.0486 & TRN & \\
\hline CHEMBL1990036 & 688620 & 5.6 & 5.7468 & TRN & \\
\hline CHEMBL1557486 & 688620 & 7.0 & 5.2854 & TST & \\
\hline CHEMBL1443408 & 688620 & 4.45 & 4.8962 & TRN & \\
\hline CHEMBL1381054 & 688620 & 5.3 & 5.7367 & TRN & \\
\hline CHEMBL1562296 & 688620 & 4.95 & 5.0882 & TRN & \\
\hline CHEMBL1498284 & 688620 & 6.0 & 5.7219 & TRN & \\
\hline CHEMBL1447144 & 688620 & 4.65 & 5.1506 & TRN & \\
\hline CHEMBL1345110 & 688620 & 4.45 & 5.0953 & TRN & \\
\hline CHEMBL1305103 & 688620 & 5.0 & 4.9927 & TST & \\
\hline CHEMBL1456547 & 688620 & 5.5 & 5.0596 & TRN & \\
\hline CHEMBL1427738 & 688620 & 5.3 & 5.0598 & TST & \\
\hline CHEMBL1559067 & 688620 & 4.55 & 4.92899 & 9999999999 & TRN \\
\hline CHEMBL3214345 & 688620 & 6.1 & 5.348 & TRN & \\
\hline CHEMBL1496439 & 688620 & 4.45 & 5.2272 & TRN & \\
\hline CHEMBL1371679 & 688620 & 5.25 & 5.1782 & TRN & \\
\hline CHEMBL1987106 & 688620 & 4.6 & 4.9623 & TST & \\
\hline CHEMBL1386345 & 688620 & 5.0 & 4.7739 & TRN & \\
\hline CHEMBL1362788 & 688620 & 4.95 & 5.0136 & TRN & \\
\hline CHEMBL1551765 & 688620 & 4.45 & 5.0636 & TST & \\
\hline CHEMBL1466165 & 688620 & 4.9 & 5.0384 & TST & \\
\hline CHEMBL1583770 & 688620 & 4.45 & 5.1538 & TST & \\
\hline CHEMBL1544722 & 688620 & 6.2 & 5.0586 & TST & \\
\hline CHEMBL1405047 & 688620 & 4.6 & $5.1770 e$ & 00000000005 & TRN \\
\hline CHEMBL1584309 & 688620 & 4.8 & 5.0205 & TST & \\
\hline CHEMBL1497387 & 688620 & 5.55 & 5.1975 & TRN & \\
\hline CHEMBL1342700 & 688620 & 4.45 & 4.7454 & TRN & \\
\hline CHEMBL3191976 & 688620 & 4.65 & 5.2475 & TRN & \\
\hline CHEMBL1605015 & 688620 & 5.7 & 5.4632 & TRN & \\
\hline CHEMBL1421112 & 688620 & 5.4 & 5.2247 & TRN & \\
\hline CHEMBL1312208 & 688620 & 5.15 & 5.2828 & TST & \\
\hline CHEMBL1522915 & 688620 & 4.95 & 5.0572 & TST & \\
\hline CHEMBL1379160 & 688620 & 4.95 & 5.0545 & TRN & \\
\hline CHEMBL1601579 & 688620 & 6.8 & 5.0116 & TRN & \\
\hline CHEMBL1539098 & 688620 & 4.9 & 5.098 & TST & \\
\hline CHEMBL1558269 & 688620 & 5.25 & 5.0591 & TRN & \\
\hline CHEMBL1544252 & 688620 & 4.7 & 5.322 & TRN & \\
\hline CHEMBL1348356 & 688620 & 6.15 & 5.7044 & TRN & \\
\hline CHEMBL1550441 & 688620 & 5.8 & 5.2452 & TRN & \\
\hline CHEMBL1587181 & 688620 & 4.9 & 4.8453 & TRN & \\
\hline CHEMBL1390925 & 688620 & 6.1 & 4.739 & TST & \\
\hline CHEMBL1550279 & 688620 & 4.45 & 4.9438 & TST & \\
\hline CHEMBL 247378 & 688620 & 4.75 & 5.105 & TST & \\
\hline CHEMBL3213960 & 688620 & 5.4 & 5.4381 & TRN & \\
\hline CHEMBL1524380 & 688620 & 4.9 & 4.9774 & TST & \\
\hline CHEMBL1549538 & 688620 & 5.25 & 5.041 & TRN & \\
\hline
\end{tabular}




\begin{tabular}{|c|c|c|c|c|c|}
\hline \multicolumn{6}{|c|}{ Supplemental Table S2.txt } \\
\hline CHEMBL1330896 & 688620 & 5.1 & 5.2641 & TRN & \\
\hline CHEMBL3211055 & 688620 & 4.95 & 4.9782 & TRN & \\
\hline CHEMBL1412144 & 688620 & 4.45 & 4.7768 & TRN & \\
\hline CHEMBL1463249 & 688620 & 4.95 & 4.8931 & TST & \\
\hline CHEMBL1507070 & 688620 & 4.9 & 5.2506 & TST & \\
\hline CHEMBL88272 & 688620 & 4.9 & 4.7951 & TST & \\
\hline CHEMBL1578467 & 688620 & 4.95 & 5.1378 & TST & \\
\hline CHEMBL1342349 & 688620 & 5.4 & 5.0799 & TRN & \\
\hline CHEMBL1340487 & 688620 & 4.7 & 4.5903 & TRN & \\
\hline CHEMBL1300477 & 688620 & 4.75 & 5.0386 & TRN & \\
\hline CHEMBL1503176 & 688620 & 6.15 & 6.3436 & TRN & \\
\hline CHEMBL1970924 & 688620 & 5.0 & 5.0732 & TRN & \\
\hline CHEMBL1460676 & 688620 & 5.0 & 4.9471 & TRN & \\
\hline CHEMBL1554934 & 688620 & 4.6 & 5.0957 & TRN & \\
\hline CHEMBL1467505 & 688620 & 6.0 & 5.9713 & TRN & \\
\hline CHEMBL1302170 & 688620 & 4.75 & 4.8715 & TRN & \\
\hline CHEMBL1334866 & 688620 & 4.95 & 4.812 & TRN & \\
\hline CHEMBL1316075 & 688620 & 4.8 & 4.9829 & TRN & \\
\hline CHEMBL1497465 & 688620 & 4.9 & $5.1720 e$ & 3000000001 & TRN \\
\hline CHEMBL1466752 & 688620 & 4.95 & 4.9798 & TRN & \\
\hline CHEMBL3211666 & 688620 & 4.45 & 4.9138 & TRN & \\
\hline CHEMBL1399553 & 688620 & 4.9 & 5.1006 & TST & \\
\hline CHEMBL1597322 & 688620 & 5.45 & 5.3222 & TRN & \\
\hline CHEMBL1498085 & 688620 & 5.0 & 4.9938 & TRN & \\
\hline CHEMBL1409358 & 688620 & 4.9 & 4.7971 & TRN & \\
\hline CHEMBL1308918 & 688620 & 5.1 & 4.8649 & TRN & \\
\hline CHEMBL1438013 & 688620 & 4.45 & 4.9215 & TRN & \\
\hline CHEMBL1222145 & 688620 & 4.45 & 5.0638 & TRN & \\
\hline CHEMBL1405107 & 688620 & 5.0 & 4.9744 & TRN & \\
\hline CHEMBL1544832 & 688620 & 5.55 & 5.0829 & TRN & \\
\hline CHEMBL1421941 & 688620 & 5.35 & 5.4762 & TRN & \\
\hline CHEMBL1305862 & 688620 & 4.95 & 5.0618 & TRN & \\
\hline CHEMBL1403122 & 688620 & 5.0 & 4.6691 & TRN & \\
\hline CHEMBL1522849 & 688620 & 4.9 & 5.0837 & TRN & \\
\hline CHEMBL1459140 & 688620 & 6.0 & 5.6882 & TRN & \\
\hline CHEMBL1527152 & 688620 & 4.95 & 5.0124 & TRN & \\
\hline CHEMBL1422612 & 688620 & 5.0 & 5.0414 & TRN & \\
\hline CHEMBL1484701 & 688620 & 5.4 & 5.1479 & TST & \\
\hline CHEMBL1582400 & 688620 & 6.3 & 5.6354 & TRN & \\
\hline CHEMBL1418605 & 688620 & 4.55 & 4.7005 & TRN & \\
\hline CHEMBL1543606 & 688620 & 5.0 & 5.0254 & TRN & \\
\hline CHEMBL 281622 & 688620 & 4.8 & 4.9434 & TRN & \\
\hline CHEMBL530361 & 688620 & 6.05 & 5.1513 & TRN & \\
\hline CHEMBL3195603 & 688620 & 4.95 & 5.0676 & TRN & \\
\hline CHEMBL3195812 & 688620 & 5.35 & 5.2016 & TRN & \\
\hline CHEMBL1521849 & 688620 & 4.45 & 5.3108 & TRN & \\
\hline CHEMBL3197272 & 688620 & 6.05 & 5.7382 & TRN & \\
\hline CHEMBL1303193 & 688620 & 5.05 & 5.1881 & TRN & \\
\hline
\end{tabular}




\begin{tabular}{|c|c|c|c|c|c|}
\hline \multirow[b]{2}{*}{ CHEMBL1488018 } & \multirow[b]{2}{*}{688620} & \multicolumn{4}{|c|}{ Supplemental Table s2.txt } \\
\hline & & 4.45 & 4.9221 & TRN & \\
\hline CHEMBL1309594 & 688620 & 5.7 & 5.2642 & TST & \\
\hline CHEMBL598263 & 688620 & 6.0 & 5.9309 & TST & \\
\hline CHEMBL1546540 & 688620 & 4.45 & 4.9643 & TRN & \\
\hline CHEMBL1411724 & 688620 & 4.8 & 4.8557 & TRN & \\
\hline CHEMBL1566662 & 688620 & 5.0 & 4.9507 & TRN & \\
\hline CHEMBL1418069 & 688620 & 4.45 & 5.0965 & TST & \\
\hline CHEMBL1481552 & 688620 & 4.45 & 4.8947 & TST & \\
\hline CHEMBL45068 & 688620 & 4.5 & 5.0762 & TST & \\
\hline CHEMBL1344315 & 688620 & 6.1 & 4.8575 & TRN & \\
\hline CHEMBL 3198734 & 688620 & 5.9 & 5.1586 & TRN & \\
\hline CHEMBL1380317 & 688620 & 4.95 & 4.8729 & TRN & \\
\hline CHEMBL1300449 & 688620 & 4.85 & 5.0999 & TRN & \\
\hline CHEMBL1342119 & 688620 & 5.0 & 5.3398 & TRN & \\
\hline CHEMBL1536301 & 688620 & 4.45 & 5.1926 & TST & \\
\hline CHEMBL3193700 & 688620 & 4.95 & 4.8993 & TRN & \\
\hline CHEMBL1446691 & 688620 & 4.9 & 4.7911 & TRN & \\
\hline CHEMBL1578113 & 688620 & 5.15 & 5.3201 & TRN & \\
\hline CHEMBL1977247 & 688620 & 5.75 & 4.8826 & TRN & \\
\hline CHEMBL1550965 & 688620 & 5.4 & 5.08 & TRN & \\
\hline CHEMBL1427370 & 688620 & 5.55 & 5.49200 & 0000000001 & TRN \\
\hline CHEMBL3190504 & 688620 & 4.6 & 4.7284 & TRN & \\
\hline CHEMBL1581764 & 688620 & 4.9 & 5.0705 & TRN & \\
\hline CHEMBL1481441 & 688620 & 6.5 & 5.1223 & TRN & \\
\hline CHEMBL1422048 & 688620 & 5.25 & 5.4562 & TST & \\
\hline CHEMBL1353760 & 688620 & 4.45 & 5.4973 & TRN & \\
\hline CHEMBL1387563 & 688620 & 4.45 & 4.8369 & TRN & \\
\hline CHEMBL3199871 & 688620 & 4.6 & 5.0969 & TRN & \\
\hline CHEMBL495068 & 688620 & 4.9 & 4.7606 & TRN & \\
\hline CHEMBL1426112 & 688620 & 5.0 & 5.0106 & TST & \\
\hline CHEMBL1532886 & 688620 & 4.5 & 5.0574 & TST & \\
\hline CHEMBL1586220 & 688620 & 4.45 & 5.0961 & TRN & \\
\hline CHEMBL1583719 & 688620 & 4.95 & 5.0489 & TRN & \\
\hline CHEMBL1302380 & 688620 & 5.5 & 5.1047 & TRN & \\
\hline CHEMBL1349986 & 688620 & 4.75 & 5.1038 & TST & \\
\hline CHEMBL226876 & 688620 & 4.9 & 4.7554 & TRN & \\
\hline CHEMBL3198836 & 688620 & 4.7 & 4.9721 & TST & \\
\hline CHEMBL1440603 & 688620 & 4.5 & 5.0103 & TRN & \\
\hline CHEMBL1420685 & 688620 & 4.9 & 5.3065 & TST & \\
\hline CHEMBL1540935 & 688620 & 5.25 & 5.3802 & TRN & \\
\hline CHEMBL1504176 & 688620 & 5.15 & 4.9354 & TST & \\
\hline CHEMBL1424382 & 688620 & 6.25 & 5.606 & TRN & \\
\hline CHEMBL1349480 & 688620 & 5.05 & 5.20799 & 9999999999 & TRN \\
\hline CHEMBL1375089 & 688620 & 8.4949 & 5.0016 & TST & \\
\hline CHEMBL1338594 & 688620 & 4.7 & 4.7931 & TRN & \\
\hline CHEMBL1417258 & 688620 & 4.45 & 4.9113 & TRN & \\
\hline CHEMBL1574431 & 688620 & 5.0 & 5.1846 & TRN & \\
\hline CHEMBL1420619 & 688620 & 4.95 & 5.16700 & 0000000001 & TST \\
\hline & & & & 27137 & \\
\hline
\end{tabular}




\begin{tabular}{|c|c|c|c|c|}
\hline \multicolumn{5}{|c|}{ Supplemental Table S2.txt } \\
\hline CHEMBL1348780 & 688620 & 4.75 & 4.8585 & TRN \\
\hline CHEMBL1569751 & 688620 & 5.15 & 5.1054 & TRN \\
\hline CHEMBL1574887 & 688620 & 5.75 & 5.2539 & TRN \\
\hline CHEMBL1495002 & 688620 & 5.0 & 5.0241 & TRN \\
\hline CHEMBL1549731 & 688620 & 4.95 & 5.1924 & TRN \\
\hline CHEMBL1332730 & 688620 & 5.6 & 5.4263 & TRN \\
\hline CHEMBL1486952 & 688620 & 4.85 & 4.9779 & TRN \\
\hline CHEMBL1399803 & 688620 & 5.6 & 5.3132 & TRN \\
\hline CHEMBL1604558 & 688620 & 4.85 & 5.2999 & TRN \\
\hline CHEMBL1311922 & 688620 & 4.95 & 5.1696 & TRN \\
\hline CHEMBL1389226 & 688620 & 4.95 & 5.3457 & TST \\
\hline CHEMBL1381098 & 688620 & 5.2 & 5.1574 & TST \\
\hline CHEMBL1539841 & 688620 & 5.45 & 5.027 & TRN \\
\hline CHEMBL1549967 & 688620 & 5.65 & 5.3693 & TRN \\
\hline CHEMBL1577139 & 688620 & 5.8 & 5.3084 & TRN \\
\hline CHEMBL1997922 & 688620 & 4.85 & 5.1379 & TRN \\
\hline CHEMBL1533088 & 688620 & 4.6 & 5.0674 & TST \\
\hline CHEMBL1520790 & 688620 & 4.95 & 5.0095 & TRN \\
\hline CHEMBL 3213842 & 688620 & 4.95 & 4.8299 & TRN \\
\hline CHEMBL1467195 & 688620 & 4.9 & 4.9261 & TRN \\
\hline CHEMBL1380740 & 688620 & 4.6 & 4.7704 & TST \\
\hline CHEMBL1544141 & 688620 & 6.3 & 5.604 & TRN \\
\hline CHEMBL1580130 & 688620 & 4.7 & 5.037 & TRN \\
\hline CHEMBL1540116 & 688620 & 6.15 & 5.8793 & TRN \\
\hline CHEMBL 3193771 & 688620 & 4.45 & 4.8132 & TRN \\
\hline CHEMBL1583801 & 688620 & 5.5 & 5.0755 & TRN \\
\hline CHEMBL1307360 & 688620 & 4.65 & 4.9425 & TRN \\
\hline CHEMBL1381367 & 688620 & 4.95 & 5.6503 & TRN \\
\hline CHEMBL1430855 & 688620 & 4.95 & 4.9912 & TRN \\
\hline CHEMBL1392802 & 688620 & 5.0 & 5.1416 & TRN \\
\hline CHEMBL1488473 & 688620 & 5.5 & 5.0058 & TRN \\
\hline CHEMBL1574260 & 688620 & 5.55 & 5.0566 & TST \\
\hline CHEMBL1580040 & 688620 & 5.3 & 5.2703 & TRN \\
\hline CHEMBL1308455 & 688620 & 4.9 & 5.0097 & TRN \\
\hline CHEMBL1318556 & 688620 & 4.95 & 5.0766 & TRN \\
\hline CHEMBL1506138 & 688620 & 6.35 & 5.072 & TST \\
\hline CHEMBL1443335 & 688620 & 5.05 & 5.1144 & TRN \\
\hline CHEMBL1345699 & 688620 & 5.5 & 5.3711 & TRN \\
\hline CHEMBL1530181 & 688620 & 4.45 & 5.1032 & TRN \\
\hline CHEMBL1344339 & 688620 & 4.5 & 5.0771 & TST \\
\hline CHEMBL1492729 & 688620 & 6.0 & 5.5128 & TRN \\
\hline CHEMBL1418563 & 688620 & 7.0 & 5.0273 & TST \\
\hline CHEMBL1469601 & 688620 & 6.5 & 5.0015 & TRN \\
\hline CHEMBL1575353 & 688620 & 6.0 & 4.8794 & TRN \\
\hline CHEMBL1401534 & 688620 & 4.45 & 4.8656 & TRN \\
\hline CHEMBL1446063 & 688620 & 5.5 & 5.0105 & TRN \\
\hline CHEMBL 1447576 & 688620 & 4.85 & 5.0054 & TRN \\
\hline CHEMBL1372283 & 688620 & 4.45 & 4.6514 & TST \\
\hline
\end{tabular}




\begin{tabular}{|c|c|c|c|c|}
\hline & & & pplement & al $\mathrm{Ta}$ \\
\hline CHEMBL1479447 & 688620 & 4.95 & 5.0206 & TRN \\
\hline CHEMBL1549428 & 688620 & 4.95 & 4.8409 & TRN \\
\hline CHEMBL1586596 & 688620 & 4.4 & 4.9429 & TST \\
\hline CHEMBL1609376 & 688620 & 4.8 & 5.1293 & TRN \\
\hline CHEMBL1313490 & 688620 & 5.45 & 5.0657 & TST \\
\hline CHEMBL1480978 & 688620 & 4.45 & 5.1988 & TRN \\
\hline CHEMBL1444051 & 688620 & 4.95 & 5.2218 & TST \\
\hline CHEMBL1594293 & 688620 & 4.9 & 5.0394 & TST \\
\hline CHEMBL1345890 & 688620 & 5.25 & 5.0852 & TRN \\
\hline CHEMBL1358974 & 688620 & 5.25 & 5.0039 & TST \\
\hline CHEMBL3199893 & 688620 & 5.9 & 5.6047 & TRN \\
\hline CHEMBL1500992 & 688620 & 6.3 & 5.1307 & TRN \\
\hline CHEMBL1342753 & 688620 & 4.85 & 4.9933 & TRN \\
\hline CHEMBL1505900 & 688620 & 4.6 & 4.9116 & TRN \\
\hline CHEMBL1612324 & 688620 & 6.2 & 4.8818 & TRN \\
\hline CHEMBL1465065 & 688620 & 6.4 & 4.9544 & TRN \\
\hline CHEMBL1300955 & 688620 & 4.5 & 4.9155 & TRN \\
\hline CHEMBL3189249 & 688620 & 4.75 & 5.0913 & TRN \\
\hline CHEMBL1400762 & 688620 & 4.45 & 4.9961 & TRN \\
\hline CHEMBL 3194287 & 688620 & 5.2 & 4.9762 & TST \\
\hline CHEMBL1543388 & 688620 & 5.1 & 5.0704 & TST \\
\hline CHEMBL1446941 & 688620 & 6.6 & 5.2126 & TRN \\
\hline CHEMBL 3210402 & 688620 & 4.85 & 5.2164 & TRN \\
\hline CHEMBL1332933 & 688620 & 5.5 & 5.3962 & TRN \\
\hline CHEMBL 3199540 & 688620 & 5.25 & 5.0566 & TRN \\
\hline CHEMBL1532571 & 688620 & 5.85 & 5.1423 & TST \\
\hline CHEMBL1424022 & 688620 & 4.8 & 4.9831 & TRN \\
\hline CHEMBL1484011 & 688620 & 5.4 & 4.8373 & TRN \\
\hline CHEMBL346516 & 688620 & 4.95 & 5.1424 & TST \\
\hline CHEMBL1602975 & 688620 & 4.6 & 4.9723 & TST \\
\hline CHEMBL1467412 & 688620 & 4.75 & 4.9855 & TST \\
\hline CHEMBL1589672 & 688620 & 4.45 & 5.2774 & TST \\
\hline CHEMBL 2136569 & 688620 & 5.15 & 5.18 & TRN \\
\hline CHEMBL 3210953 & 688620 & 4.95 & 4.952 & TRN \\
\hline CHEMBL1309228 & 688620 & 4.8 & 5.0477 & TRN \\
\hline CHEMBL1484972 & 688620 & 5.4 & 5.1262 & TRN \\
\hline CHEMBL1530557 & 688620 & 4.45 & 4.7503 & TRN \\
\hline CHEMBL1331161 & 688620 & 6.6 & 4.9865 & TST \\
\hline CHEMBL1609168 & 688620 & 5.85 & 5.271 & TRN \\
\hline CHEMBL1533439 & 688620 & 4.45 & 5.1344 & TST \\
\hline CHEMBL1304430 & 688620 & 4.6 & 4.9569 & TRN \\
\hline CHEMBL3189821 & 688620 & 6.1 & 5.0105 & TST \\
\hline CHEMBL1376787 & 688620 & 4.7 & 4.937 & TRN \\
\hline CHEMBL1528954 & 688620 & 4.75 & 5.2656 & TST \\
\hline CHEMBL1422505 & 688620 & 4.6 & 4.7651 & TRN \\
\hline CHEMBL3192797 & 688620 & 4.45 & 5.0037 & TRN \\
\hline CHEMBL1313374 & 688620 & 4.45 & 4.8693 & TRN \\
\hline CHEMBL1483598 & 688620 & 4.65 & 5.0546 & TRN \\
\hline
\end{tabular}




\begin{tabular}{|c|c|c|c|c|}
\hline \multicolumn{5}{|c|}{ Supplemental Table S2.txt } \\
\hline CHEMBL1558488 & 688620 & 4.45 & 5.3332 & TRN \\
\hline CHEMBL1597669 & 688620 & 5.5 & 5.5856 & TRN \\
\hline CHEMBL3196968 & 688620 & 4.8 & 5.2583 & TRN \\
\hline CHEMBL 3207601 & 688620 & 4.8 & 4.8355 & TRN \\
\hline CHEMBL1518954 & 688620 & 4.85 & 5.1326 & TRN \\
\hline CHEMBL3192666 & 688620 & 6.2 & 5.2272 & TRN \\
\hline CHEMBL1443766 & 688620 & 6.7501 & 5.8263 & TRN \\
\hline CHEMBL1598730 & 688620 & 5.0 & 5.0153 & TST \\
\hline CHEMBL1500188 & 688620 & 4.7 & 5.2227 & TST \\
\hline CHEMBL1469536 & 688620 & 5.0 & 4.7471 & TRN \\
\hline CHEMBL 3213091 & 688620 & 5.0 & 5.0527 & TRN \\
\hline CHEMBL1577791 & 688620 & 5.55 & 5.0749 & TST \\
\hline CHEMBL1608250 & 688620 & 5.05 & 5.0709 & TRN \\
\hline CHEMBL1494450 & 688620 & 5.35 & 5.3682 & TRN \\
\hline CHEMBL1546012 & 688620 & 6.5501 & 5.9955 & TRN \\
\hline CHEMBL1387589 & 688620 & 4.75 & 5.2134 & TST \\
\hline CHEMBL1596211 & 688620 & 4.45 & 4.9369 & TRN \\
\hline CHEMBL3392447 & 688620 & 4.65 & 5.0256 & TRN \\
\hline CHEMBL1324999 & 688620 & 5.45 & 5.1291 & TRN \\
\hline CHEMBL1402496 & 688620 & 6.35 & 5.3149 & TST \\
\hline CHEMBL 3145030 & 688620 & 5.25 & 5.5313 & TRN \\
\hline CHEMBL3198175 & 688620 & 4.95 & 4.8414 & TST \\
\hline CHEMBL1500993 & 688620 & 5.4 & 4.8498 & TST \\
\hline CHEMBL3199926 & 688620 & 5.45 & 5.3429 & TRN \\
\hline CHEMBL1462375 & 688620 & 4.9 & 4.955 & TRN \\
\hline CHEMBL1344296 & 688620 & 5.6 & 5.4033 & TRN \\
\hline CHEMBL1399944 & 688620 & 4.5 & 4.9516 & TST \\
\hline CHEMBL1585632 & 688620 & 4.45 & 5.2382 & TRN \\
\hline CHEMBL1564068 & 688620 & 4.45 & 5.0449 & TRN \\
\hline CHEMBL1511612 & 688620 & 5.2 & 5.2523 & TRN \\
\hline CHEMBL1546970 & 688620 & 6.4 & 6.1047 & TRN \\
\hline CHEMBL3213012 & 688620 & 5.05 & 4.9669 & TRN \\
\hline CHEMBL3196939 & 688620 & 5.15 & 5.4139 & TRN \\
\hline CHEMBL 3191542 & 688620 & 5.25 & 5.3178 & TRN \\
\hline CHEMBL1460451 & 688620 & 4.5 & 4.98 & TRN \\
\hline CHEMBL1307453 & 688620 & 5.65 & 5.4362 & TRN \\
\hline CHEMBL1461508 & 688620 & 4.45 & 4.6117 & TRN \\
\hline CHEMBL1427752 & 688620 & 4.65 & 4.8865 & TRN \\
\hline CHEMBL1525483 & 688620 & 5.45 & 5.0905 & TRN \\
\hline CHEMBL1594604 & 688620 & 4.65 & 4.8394 & TST \\
\hline CHEMBL1391240 & 688620 & 4.9 & 5.0657 & TST \\
\hline CHEMBL1504346 & 688620 & 4.8 & 4.8485 & TRN \\
\hline CHEMBL1339039 & 688620 & 5.0 & 5.0716 & TRN \\
\hline CHEMBL1598047 & 688620 & 5.0 & 5.3652 & TRN \\
\hline CHEMBL1486354 & 688620 & 5.3 & 5.4894 & TRN \\
\hline CHEMBL3198131 & 688620 & 4.45 & 5.0808 & TRN \\
\hline CHEMBL1376134 & 688620 & 5.05 & 5.4149 & TRN \\
\hline CHEMBL1311554 & 688620 & 5.5 & 5.2379 & TRN \\
\hline
\end{tabular}




\begin{tabular}{|c|c|c|c|c|c|}
\hline \\
\hline CHEMBL1462940 & 688620 & 5.2 & 5.0293 & TST & \\
\hline CHEMBL1364603 & 688620 & 6.2 & 5.1337 & TRN & \\
\hline CHEMBL1557639 & 688620 & 5.0 & 4.9498 & TRN & \\
\hline CHEMBL1320907 & 688620 & 4.8 & 4.9816 & TRN & \\
\hline CHEMBL1382979 & 688620 & 4.9 & 5.09 & TRN & \\
\hline CHEMBL1462237 & 688620 & 4.7 & 5.1616 & TRN & \\
\hline CHEMBL1607824 & 688620 & 5.05 & 5.0434 & TST & \\
\hline CHEMBL1529278 & 688620 & 4.8 & 4.965 & TRN & \\
\hline CHEMBL1498133 & 688620 & 5.25 & 5.2579 & TST & \\
\hline CHEMBL1561096 & 688620 & 5.35 & 5.4122 & TRN & \\
\hline CHEMBL1388440 & 688620 & 4.95 & 5.0647 & TRN & \\
\hline CHEMBL 2001714 & 688620 & 5.25 & 5.078 & TRN & \\
\hline CHEMBL3199461 & 688620 & 4.55 & 5.3945 & TRN & \\
\hline CHEMBL3190596 & 688620 & 5.7 & 5.216 & TRN & \\
\hline CHEMBL1326664 & 688620 & 5.25 & 4.864 & TRN & \\
\hline CHEMBL1572988 & 688620 & 4.45 & 4.9759 & TRN & \\
\hline CHEMBL1457402 & 688620 & 4.85 & 5.1666 & TRN & \\
\hline CHEMBL1451169 & 688620 & 6.1 & 5.9691 & TRN & \\
\hline CHEMBL3199649 & 688620 & 4.95 & 5.004 & TST & \\
\hline CHEMBL1604090 & 688620 & 4.45 & 4.9258 & TST & \\
\hline CHEMBL1520228 & 688620 & 5.6 & 5.2769 & TRN & \\
\hline CHEMBL1526662 & 688620 & 4.95 & 4.8863 & TRN & \\
\hline CHEMBL1511453 & 688620 & 4.45 & 4.9639 & TRN & \\
\hline CHEMBL1526961 & 688620 & 6.05 & 4.9515 & TST & \\
\hline CHEMBL1537963 & 688620 & 5.55 & 5.0321 & TST & \\
\hline CHEMBL1385005 & 688620 & 4.85 & 5.1186 & TRN & \\
\hline CHEMBL524664 & 688620 & 6.0 & 5.5374 & TST & \\
\hline CHEMBL1346356 & 688620 & 4.6 & 4.9934 & TRN & \\
\hline CHEMBL1519655 & 688620 & 4.45 & 5.1428 & TST & \\
\hline CHEMBL3191198 & 688620 & 5.05 & 5.0681 & TRN & \\
\hline CHEMBL 3213023 & 688620 & 4.65 & 4.9726 & TRN & \\
\hline CHEMBL1465346 & 688620 & 5.55 & 5.5073 & TRN & \\
\hline CHEMBL1385815 & 688620 & 4.8 & 5.0283 & TRN & \\
\hline CHEMBL1539335 & 688620 & 4.8 & 4.8453 & TRN & \\
\hline CHEMBL1453420 & 688620 & 4.8 & 4.80699 & 99999999995 & TST \\
\hline CHEMBL1459144 & 688620 & 4.8 & 5.0138 & TRN & \\
\hline CHEMBL568556 & 688620 & 5.75 & 4.993 & TRN & \\
\hline CHEMBL1416434 & 688620 & 4.7 & 5.0655 & TRN & \\
\hline CHEMBL1609354 & 688620 & 4.65 & 4.8905 & TRN & \\
\hline CHEMBL1336649 & 688620 & 5.0 & 4.916 & TRN & \\
\hline CHEMBL1411203 & 688620 & 4.85 & 5.1303 & TRN & \\
\hline CHEMBL1708832 & 688620 & 5.0 & 4.9302 & TRN & \\
\hline CHEMBL1494142 & 688620 & 5.0 & 5.0122 & TST & \\
\hline CHEMBL1322720 & 688620 & 4.45 & 5.2507 & TST & \\
\hline CHEMBL1521604 & 688620 & 4.95 & 5.1522 & TRN & \\
\hline CHEMBL1329388 & 688620 & 4.45 & 5.6157 & TRN & \\
\hline CHEMBL1303750 & 688620 & 4.9 & 5.03600 & 20000000005 & TRN \\
\hline CHEMBL1549911 & 688620 & 4.45 & 4.9447 & TRN & \\
\hline & & & & 27141 & \\
\hline
\end{tabular}




\begin{tabular}{|c|c|c|c|c|c|}
\hline \multicolumn{6}{|c|}{ Supplemental Table S2.txt } \\
\hline CHEMBL1421414 & 688620 & 4.85 & 4.9573 & TST & \\
\hline CHEMBL1416965 & 688620 & 4.4 & 5.0576 & TST & \\
\hline CHEMBL1515132 & 688620 & 5.25 & 4.9783 & TST & \\
\hline CHEMBL155563 & 688620 & 4.9 & 5.0507 & TRN & \\
\hline CHEMBL1432116 & 688620 & 5.35 & 5.3689 & TRN & \\
\hline CHEMBL1380554 & 688620 & 5.05 & 4.9159 & TRN & \\
\hline CHEMBL1562738 & 688620 & 4.9 & 4.9307 & TRN & \\
\hline CHEMBL1323046 & 688620 & 4.5 & 4.8334 & TRN & \\
\hline CHEMBL1414318 & 688620 & 4.45 & 4.9764 & TRN & \\
\hline CHEMBL1330835 & 688620 & 4.45 & 4.8899 & TRN & \\
\hline CHEMBL1544002 & 688620 & 4.5 & 5.0067 & TRN & \\
\hline CHEMBL1496275 & 688620 & 5.15 & 5.4262 & TRN & \\
\hline CHEMBL3194456 & 688620 & 4.45 & 5.0159 & TST & \\
\hline CHEMBL3194197 & 688620 & 6.2 & 5.3357 & TRN & \\
\hline CHEMBL1301168 & 688620 & 5.3 & 4.6574 & TRN & \\
\hline CHEMBL1406382 & 688620 & 5.0 & 5.0543 & TRN & \\
\hline CHEMBL1540581 & 688620 & 4.9 & 4.868 & TRN & \\
\hline CHEMBL154580 & 688620 & 6.2 & 5.7026 & TST & \\
\hline CHEMBL1557608 & 688620 & 5.05 & 4.8718 & TRN & \\
\hline CHEMBL1419867 & 688620 & 4.45 & 5.0194 & TST & \\
\hline CHEMBL1366534 & 688620 & 4.45 & 5.3223 & TRN & \\
\hline CHEMBL1349894 & 688620 & 5.0 & 5.1173 & TRN & \\
\hline CHEMBL1483146 & 688620 & 5.4 & $5.2810 e$ & 2000000001 & TRN \\
\hline CHEMBL1410147 & 688620 & 5.05 & 5.1414 & TST & \\
\hline CHEMBL1436968 & 688620 & 5.75 & 4.9239 & TRN & \\
\hline CHEMBL1486346 & 688620 & 4.65 & 5.0432 & TRN & \\
\hline CHEMBL1532794 & 688620 & 4.65 & 4.9342 & TST & \\
\hline CHEMBL1523098 & 688620 & 4.45 & 5.2042 & TRN & \\
\hline CHEMBL1408935 & 688620 & 5.45 & 4.8819 & TRN & \\
\hline CHEMBL1543907 & 688620 & 5.15 & 5.2242 & TRN & \\
\hline CHEMBL1565083 & 688620 & 5.9 & 4.8588 & TRN & \\
\hline CHEMBL1392298 & 688620 & 4.9 & 4.7756 & TRN & \\
\hline CHEMBL1310782 & 688620 & 5.2 & 4.8721 & TRN & \\
\hline CHEMBL1369594 & 688620 & 5.5 & 5.1065 & TRN & \\
\hline CHEMBL1602850 & 688620 & 5.55 & 5.4032 & TRN & \\
\hline CHEMBL1532195 & 688620 & 4.45 & 5.0459 & TRN & \\
\hline CHEMBL3194991 & 688620 & 5.25 & 5.4113 & TRN & \\
\hline CHEMBL1545411 & 688620 & 4.45 & 5.0652 & TRN & \\
\hline CHEMBL1606065 & 688620 & 5.0 & 4.9431 & TST & \\
\hline CHEMBL1498006 & 688620 & 4.8 & 4.9885 & TRN & \\
\hline CHEMBL1504995 & 688620 & 4.5 & 5.2151 & TRN & \\
\hline CHEMBL1606733 & 688620 & 5.8 & 5.6527 & TRN & \\
\hline CHEMBL1371519 & 688620 & 4.45 & 4.9414 & TST & \\
\hline CHEMBL1305722 & 688620 & 4.7 & 4.9173 & TRN & \\
\hline CHEMBL1333065 & 688620 & 4.9 & 4.7609 & TRN & \\
\hline CHEMBL1402433 & 688620 & 5.2 & 5.0848 & TRN & \\
\hline CHEMBL1521319 & 688620 & 4.95 & 4.8716 & TRN & \\
\hline CHEMBL1604436 & 688620 & 5.05 & $4.9510 e$ & 00000000005 & TRN \\
\hline & & & & 27142 & \\
\hline
\end{tabular}




\begin{tabular}{|c|c|c|c|c|}
\hline \multicolumn{5}{|c|}{ Supplemental Table S2.txt } \\
\hline CHEMBL1994623 & 688620 & 4.9 & 5.6579 & TRN \\
\hline CHEMBL1302762 & 688620 & 5.8 & 5.2926 & TRN \\
\hline CHEMBL1501925 & 688620 & 6.05 & 4.8816 & TRN \\
\hline CHEMBL1457097 & 688620 & 4.9 & 5.0467 & TRN \\
\hline CHEMBL1367683 & 688620 & 4.85 & 4.9133 & TST \\
\hline CHEMBL1384304 & 688620 & 5.65 & 5.331 & TRN \\
\hline CHEMBL1333737 & 688620 & 4.8 & 5.1128 & TST \\
\hline CHEMBL1458319 & 688620 & 4.8 & 5.2665 & TRN \\
\hline CHEMBL1453282 & 688620 & 4.8 & 5.051 & TRN \\
\hline CHEMBL1386152 & 688620 & 4.5 & 5.0241 & TRN \\
\hline CHEMBL1441819 & 688620 & 4.45 & 4.8464 & TST \\
\hline CHEMBL1525565 & 688620 & 5.4 & 4.8412 & TST \\
\hline CHEMBL1332346 & 688620 & 4.45 & 4.8521 & TRN \\
\hline CHEMBL1419188 & 688620 & 5.4 & 5.2294 & TRN \\
\hline CHEMBL1545208 & 688620 & 8.2518 & 5.0531 & TST \\
\hline CHEMBL3198060 & 688620 & 4.45 & 5.0412 & TRN \\
\hline CHEMBL1424664 & 688620 & 4.75 & 4.8784 & TRN \\
\hline CHEMBL1572850 & 688620 & 5.0 & 5.2869 & TRN \\
\hline CHEMBL1445152 & 688620 & 4.95 & 5.0674 & TRN \\
\hline CHEMBL1344166 & 688620 & 5.15 & 4.9944 & TRN \\
\hline CHEMBL1342960 & 688620 & 4.9 & 5.0353 & TRN \\
\hline CHEMBL1364769 & 688620 & 4.45 & 4.849 & TRN \\
\hline CHEMBL3189422 & 688620 & 5.0 & 5.454 & TRN \\
\hline CHEMBL1383259 & 688620 & 4.85 & 4.9712 & TRN \\
\hline CHEMBL1506950 & 688620 & 5.45 & 5.1372 & TST \\
\hline CHEMBL1466210 & 688620 & 4.5 & 4.8821 & TRN \\
\hline CHEMBL533388 & 688620 & 5.0 & 4.8333 & TRN \\
\hline CHEMBL1530213 & 688620 & 4.85 & 4.8661 & TRN \\
\hline CHEMBL1557359 & 688620 & 4.9 & 5.0056 & TRN \\
\hline CHEMBL1517022 & 688620 & 5.2 & 5.2662 & TST \\
\hline CHEMBL1531775 & 688620 & 4.95 & 5.0763 & TRN \\
\hline CHEMBL1413470 & 688620 & 4.45 & 5.4052 & TST \\
\hline CHEMBL1366319 & 688620 & 5.3 & 5.2138 & TRN \\
\hline CHEMBL1551939 & 688620 & 4.6 & 5.1506 & TST \\
\hline CHEMBL1343713 & 688620 & 5.35 & 4.9374 & TST \\
\hline CHEMBL1453460 & 688620 & 5.45 & 5.2981 & TRN \\
\hline CHEMBL1462999 & 688620 & 5.35 & 5.4598 & TRN \\
\hline CHEMBL1582446 & 688620 & 4.6 & 5.0411 & TRN \\
\hline CHEMBL1565344 & 688620 & 5.6 & 5.3608 & TRN \\
\hline CHEMBL1582069 & 688620 & 4.8 & 5.0326 & TRN \\
\hline CHEMBL1304384 & 688620 & 4.95 & 4.7666 & TRN \\
\hline CHEMBL1370700 & 688620 & 5.25 & 5.4051 & TRN \\
\hline CHEMBL1611136 & 688620 & 4.8 & 5.0027 & TST \\
\hline CHEMBL1610179 & 688620 & 5.1 & 4.9222 & TRN \\
\hline CHEMBL1376243 & 688620 & 4.85 & 5.0146 & TRN \\
\hline CHEMBL1495102 & 688620 & 5.05 & 4.965 & TST \\
\hline CHEMBL1530474 & 688620 & 5.25 & 5.2241 & TRN \\
\hline CHEMBL3196965 & 688620 & 4.5 & 4.7704 & TRN \\
\hline
\end{tabular}




\begin{tabular}{|c|c|c|c|c|}
\hline \multicolumn{5}{|c|}{ Supplemental Table S2.txt } \\
\hline CHEMBL 3210453 & 688620 & 4.6 & 4.8574 & TRN \\
\hline CHEMBL 2261072 & 688620 & 4.95 & 4.9417 & TRN \\
\hline CHEMBL1366420 & 688620 & 4.45 & 5.5922 & TRN \\
\hline CHEMBL1467200 & 688620 & 5.6 & 4.8256 & TRN \\
\hline CHEMBL1302723 & 688620 & 4.85 & 4.9526 & TRN \\
\hline CHEMBL1527239 & 688620 & 4.8 & 5.3027 & TRN \\
\hline CHEMBL1305014 & 688620 & 4.75 & 4.9062 & TRN \\
\hline CHEMBL1381582 & 688620 & 5.25 & 5.2014 & TRN \\
\hline CHEMBL1557418 & 688620 & 5.0 & 4.7442 & TRN \\
\hline CHEMBL1456254 & 688620 & 4.5 & 4.9674 & TRN \\
\hline CHEMBL1370066 & 688620 & 6.5501 & 5.9083 & TRN \\
\hline CHEMBL1460565 & 688620 & 4.85 & 5.2739 & TRN \\
\hline CHEMBL1555519 & 688620 & 4.9 & 4.9727 & TRN \\
\hline CHEMBL1982290 & 688620 & 4.45 & 5.0221 & TRN \\
\hline CHEMBL1328912 & 688620 & 4.75 & 5.1387 & TRN \\
\hline CHEMBL1545114 & 688620 & 4.45 & 5.0718 & TST \\
\hline CHEMBL1378579 & 688620 & 4.9 & 5.1074 & TRN \\
\hline CHEMBL1486503 & 688620 & 4.95 & 5.0586 & TRN \\
\hline CHEMBL1303280 & 688620 & 5.95 & 5.561 & TRN \\
\hline CHEMBL1469763 & 688620 & 5.15 & 5.2578 & TST \\
\hline CHEMBL1364007 & 688620 & 4.8 & 5.0002 & TRN \\
\hline CHEMBL1341892 & 688620 & 4.6 & 4.883 & TST \\
\hline CHEMBL1559701 & 688620 & 4.85 & 4.8351 & TRN \\
\hline CHEMBL1445658 & 688620 & 4.6 & 4.6757 & TST \\
\hline CHEMBL1339270 & 688620 & 6.95 & 6.6776 & TRN \\
\hline CHEMBL1401274 & 688620 & 6.6 & 6.0238 & TRN \\
\hline CHEMBL1565242 & 688620 & 6.8499 & 5.0399 & TRN \\
\hline CHEMBL1516531 & 688620 & 4.9 & 4.9428 & TRN \\
\hline CHEMBL1540761 & 688620 & 5.15 & 5.6763 & TRN \\
\hline CHEMBL1984338 & 688620 & 4.95 & 5.0948 & TRN \\
\hline CHEMBL1364646 & 688620 & 5.0 & 5.3223 & TST \\
\hline CHEMBL1420437 & 688620 & 4.8 & 5.1285 & TRN \\
\hline CHEMBL1486046 & 688620 & 4.65 & 4.8982 & TRN \\
\hline CHEMBL579919 & 688620 & 4.55 & 4.8578 & TRN \\
\hline CHEMBL1982915 & 688620 & 5.5 & 5.1313 & TRN \\
\hline CHEMBL1535631 & 688620 & 5.9 & 5.9306 & TRN \\
\hline CHEMBL 1451118 & 688620 & 4.45 & 5.0374 & TST \\
\hline CHEMBL1300555 & 688620 & 4.9 & 4.8673 & TRN \\
\hline CHEMBL1480042 & 688620 & 5.2 & 5.0644 & TRN \\
\hline CHEMBL1386865 & 688620 & 4.95 & 4.9358 & TRN \\
\hline CHEMBL1505879 & 688620 & 5.35 & 5.8085 & TRN \\
\hline CHEMBL1488652 & 688620 & 5.0 & 5.1335 & TRN \\
\hline CHEMBL1597967 & 688620 & 4.6 & 4.5773 & TRN \\
\hline CHEMBL1426814 & 688620 & 4.85 & 4.9132 & TRN \\
\hline CHEMBL3211236 & 688620 & 5.05 & 5.2162 & TRN \\
\hline CHEMBL1431798 & 688620 & 5.15 & 4.9794 & TST \\
\hline CHEMBL1977678 & 688620 & 5.1 & 5.2429 & TRN \\
\hline CHEMBL3190786 & 688620 & 5.95 & 6.0533 & TRN \\
\hline
\end{tabular}




\begin{tabular}{|c|c|c|c|c|c|}
\hline \multirow[b]{2}{*}{ CHEMBL1441677 } & \\
\hline & 688620 & 4.7 & 4.8884 & TRN & \\
\hline CHEMBL1536262 & 688620 & 4.9 & 4.9441 & TRN & \\
\hline CHEMBL1458016 & 688620 & 4.9 & 4.947 & TRN & \\
\hline CHEMBL1525057 & 688620 & 5.2 & 5.2269 & TRN & \\
\hline CHEMBL1431214 & 688620 & 4.65 & 5.4268 & TRN & \\
\hline CHEMBL1497937 & 688620 & 5.0 & 5.1041 & TRN & \\
\hline CHEMBL1499761 & 688620 & 5.45 & 5.4703 & TRN & \\
\hline CHEMBL2374044 & 688620 & 4.8 & 4.685 & TST & \\
\hline CHEMBL1486981 & 688620 & 5.5 & 5.3507 & TRN & \\
\hline CHEMBL1510599 & 688620 & 5.7 & 5.2933 & TST & \\
\hline CHEMBL1374866 & 688620 & 4.6 & 5.1288 & TRN & \\
\hline CHEMBL1420811 & 688620 & 4.95 & 5.2765 & TRN & \\
\hline CHEMBL1371298 & 688620 & 6.2 & 5.6616 & TRN & \\
\hline CHEMBL1453410 & 688620 & 4.75 & 4.9617 & TRN & \\
\hline CHEMBL1451524 & 688620 & 5.0 & 4.93199 & 99999999995 & TRN \\
\hline CHEMBL1446036 & 688620 & 4.75 & 4.7575 & TRN & \\
\hline CHEMBL1425718 & 688620 & 4.75 & 4.8128 & TRN & \\
\hline CHEMBL1411943 & 688620 & 4.65 & 4.78100 & 0000000001 & TRN \\
\hline CHEMBL1323622 & 688620 & 4.85 & 4.9854 & TRN & \\
\hline CHEMBL1382609 & 688620 & 5.2 & 5.2575 & TRN & \\
\hline CHEMBL1339053 & 688620 & 4.95 & 5.1325 & TRN & \\
\hline CHEMBL1438587 & 688620 & 5.1 & 5.2408 & TST & \\
\hline CHEMBL1421605 & 688620 & 4.85 & 4.8606 & TST & \\
\hline CHEMBL1421444 & 688620 & 4.45 & 5.146 & TRN & \\
\hline CHEMBL3191855 & 688620 & 5.0 & 5.2482 & TRN & \\
\hline CHEMBL1483347 & 688620 & 4.45 & 4.9152 & TRN & \\
\hline CHEMBL1544763 & 688620 & 4.6 & 5.1784 & TST & \\
\hline CHEMBL1300177 & 688620 & 4.95 & 5.0096 & TRN & \\
\hline CHEMBL3208339 & 688620 & 4.75 & 4.8701 & TRN & \\
\hline CHEMBL1561382 & 688620 & 4.45 & 4.9389 & TRN & \\
\hline CHEMBL1421199 & 688620 & 4.95 & 5.1347 & TRN & \\
\hline CHEMBL1371509 & 688620 & 4.75 & 5.0967 & TRN & \\
\hline CHEMBL1507042 & 688620 & 6.5501 & 5.0585 & TRN & \\
\hline CHEMBL1400379 & 688620 & 5.95 & 5.37299 & 9999999999 & TRN \\
\hline CHEMBL1374860 & 688620 & 4.75 & 5.1183 & TRN & \\
\hline CHEMBL1524929 & 688620 & 6.2 & 5.6814 & TRN & \\
\hline CHEMBL1463070 & 688620 & 4.8 & 4.8727 & TRN & \\
\hline CHEMBL1319015 & 688620 & 4.85 & 4.8926 & TRN & \\
\hline CHEMBL1449621 & 688620 & 4.7 & 5.0631 & TRN & \\
\hline CHEMBL1577560 & 688620 & 5.35 & 4.9157 & TRN & \\
\hline CHEMBL1367686 & 688620 & 4.9 & 5.2499 & TRN & \\
\hline CHEMBL1393312 & 688620 & 4.7 & 5.0091 & TRN & \\
\hline CHEMBL1400613 & 688620 & 5.3 & 5.1599 & TST & \\
\hline CHEMBL1502835 & 688620 & 5.15 & 4.9433 & TRN & \\
\hline CHEMBL1530303 & 688620 & 6.45 & 5.0381 & TRN & \\
\hline CHEMBL1309799 & 688620 & 4.6 & 4.8708 & TRN & \\
\hline CHEMBL1339472 & 688620 & 4.6 & 5.0087 & TRN & \\
\hline CHEMBL1410684 & 688620 & 6.6499 & 6.3014 & TRN & \\
\hline
\end{tabular}




\begin{tabular}{|c|c|c|c|c|c|}
\hline & & \multicolumn{4}{|c|}{ Supplemental Table S2.txt } \\
\hline CHEMBL1322961 & 688620 & 4.85 & 4.8312 & TRN & \\
\hline CHEMBL1518774 & 688620 & 5.9 & 5.3223 & TRN & \\
\hline CHEMBL1425894 & 688620 & 4.7 & 4.8768 & TRN & \\
\hline CHEMBL 3192468 & 688620 & 4.85 & 5.1385 & TRN & \\
\hline CHEMBL1347194 & 688620 & 4.75 & 5.2031 & TST & \\
\hline CHEMBL1322180 & 688620 & 4.9 & 4.684 & TST & \\
\hline CHEMBL1379926 & 688620 & 4.95 & 4.8727 & TRN & \\
\hline CHEMBL1446011 & 688620 & 4.55 & 4.6166 & TRN & \\
\hline CHEMBL1312862 & 688620 & 5.0 & 4.8174 & TRN & \\
\hline CHEMBL1481346 & 688620 & 4.45 & 5.0627 & TRN & \\
\hline CHEMBL1512460 & 688620 & 5.5 & 5.0915 & TRN & \\
\hline CHEMBL1548711 & 688620 & 5.05 & 5.1323 & TRN & \\
\hline CHEMBL1365438 & 688620 & 4.8 & 5.1539 & TST & \\
\hline CHEMBL1505536 & 688620 & 4.5 & 5.357 & TRN & \\
\hline CHEMBL3192357 & 688620 & 5.8 & 5.5193 & TRN & \\
\hline CHEMBL1393361 & 688620 & 4.45 & 5.0034 & TRN & \\
\hline CHEMBL1482199 & 688620 & 5.55 & 5.6192 & TRN & \\
\hline CHEMBL1542379 & 688620 & 4.85 & 4.9928 & TRN & \\
\hline CHEMBL1606030 & 688620 & 4.95 & 5.2922 & TRN & \\
\hline CHEMBL3190861 & 688620 & 4.45 & 5.05399 & 9999999999 & TRN \\
\hline CHEMBL1404619 & 688620 & 7.15 & 5.2504 & TST & \\
\hline CHEMBL1348154 & 688620 & 4.65 & 5.0765 & TST & \\
\hline CHEMBL541505 & 688620 & 4.5 & 5.1321 & TST & \\
\hline CHEMBL1548970 & 688620 & 5.2 & 5.0169 & TRN & \\
\hline CHEMBL1470925 & 688620 & 7.2 & 6.0858 & TRN & \\
\hline CHEMBL1587339 & 688620 & 5.25 & 4.9992 & TST & \\
\hline CHEMBL1981464 & 688620 & 5.0 & 4.8862 & TRN & \\
\hline CHEMBL1391733 & 688620 & 4.9 & 4.9575 & TST & \\
\hline CHEMBL1323098 & 688620 & 4.45 & 4.8378 & TST & \\
\hline CHEMBL1334887 & 688620 & 4.85 & 4.8342 & TST & \\
\hline CHEMBL1376269 & 688620 & 4.95 & 4.8383 & TRN & \\
\hline CHEMBL1458403 & 688620 & 4.9 & 4.7235 & TRN & \\
\hline CHEMBL1362225 & 688620 & 4.9 & 4.9527 & TRN & \\
\hline CHEMBL1540854 & 688620 & 4.45 & 5.1423 & TRN & \\
\hline CHEMBL1573661 & 688620 & 4.45 & 4.8796 & TRN & \\
\hline CHEMBL1323414 & 688620 & 4.95 & 5.0742 & TST & \\
\hline CHEMBL1420989 & 688620 & 5.0 & 5.1265 & TRN & \\
\hline CHEMBL1529225 & 688620 & 4.65 & 4.8515 & TRN & \\
\hline CHEMBL1548794 & 688620 & 6.8 & 4.9418 & TRN & \\
\hline CHEMBL1520718 & 688620 & 4.45 & 4.80699 & 99999999995 & TRN \\
\hline CHEMBL584442 & 688620 & 5.1 & 5.0396 & TRN & \\
\hline CHEMBL1467378 & 688620 & 5.15 & 5.1824 & TRN & \\
\hline CHEMBL1384909 & 688620 & 5.5 & 5.5101 & TRN & \\
\hline CHEMBL1300553 & 688620 & 5.15 & 5.069 & TST & \\
\hline CHEMBL1371149 & 688620 & 5.9 & 4.9546 & TST & \\
\hline CHEMBL1560846 & 688620 & 4.95 & 5.0604 & TRN & \\
\hline CHEMBL1499956 & 688620 & 5.15 & 5.1773 & TRN & \\
\hline CHEMBL3195006 & 688620 & 4.45 & 4.9935 & TRN & \\
\hline
\end{tabular}




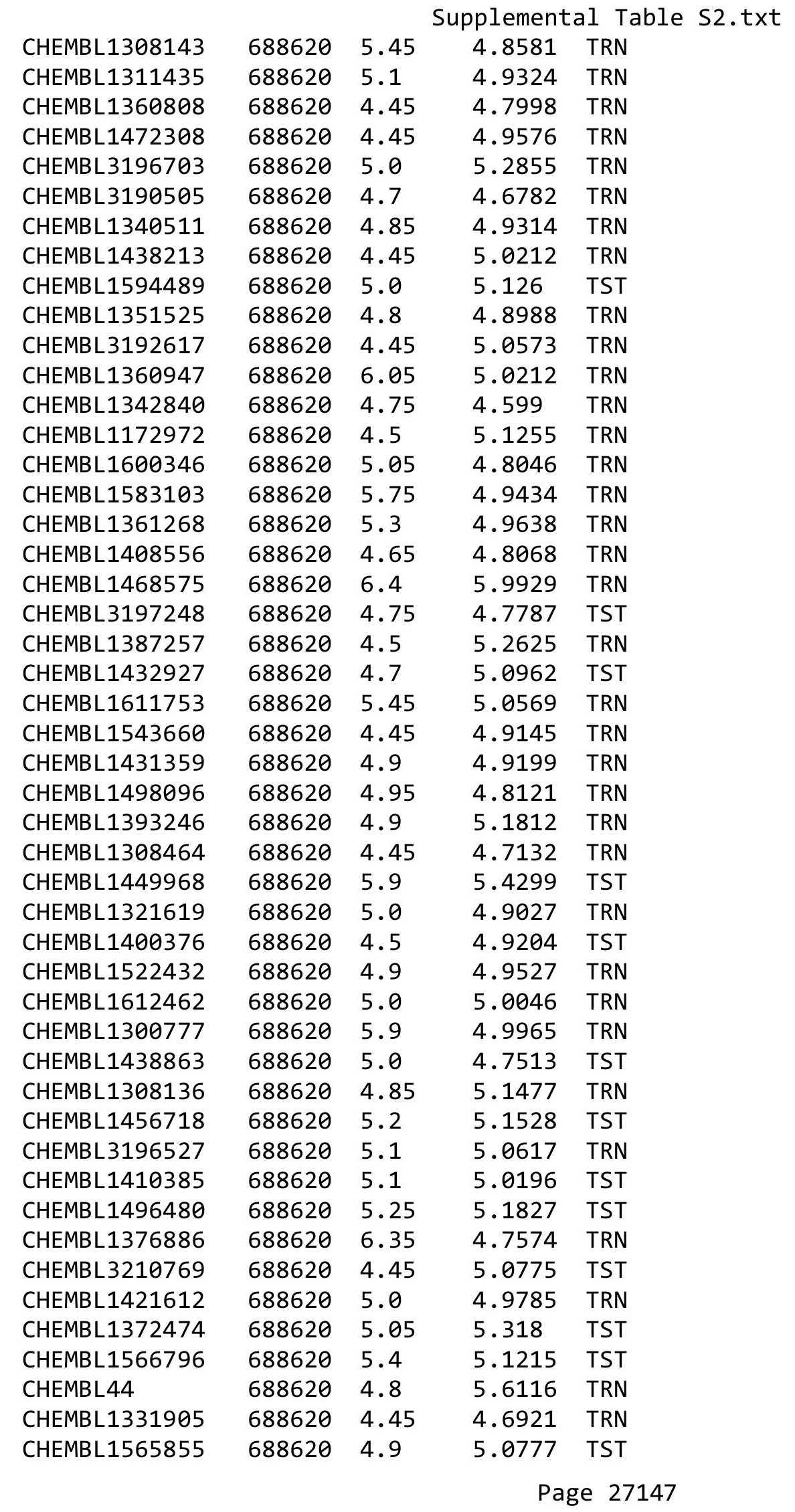




\begin{tabular}{|c|c|c|c|c|c|}
\hline \multicolumn{6}{|c|}{ Supplemental Table S2.txt } \\
\hline CHEMBL 3194473 & 688620 & 6.35 & 5.8031 & TRN & \\
\hline CHEMBL1371682 & 688620 & 5.1 & 5.2279 & TRN & \\
\hline CHEMBL1595416 & 688620 & 6.1 & 5.1376 & TRN & \\
\hline CHEMBL 3194407 & 688620 & 5.0 & 5.0388 & TRN & \\
\hline CHEMBL1582379 & 688620 & 4.8 & 4.9708 & TST & \\
\hline CHEMBL1483120 & 688620 & 4.95 & 4.9673 & TRN & \\
\hline CHEMBL 3190332 & 688620 & 5.55 & 5.0605 & TST & \\
\hline CHEMBL1348050 & 688620 & 4.8 & 5.2181 & TRN & \\
\hline CHEMBL1381722 & 688620 & 5.0 & 4.9104 & TRN & \\
\hline CHEMBL1546959 & 688620 & 5.2 & 5.0686 & TRN & \\
\hline CHEMBL1408861 & 688620 & 8.301 & 5.4606 & TRN & \\
\hline CHEMBL1319554 & 688620 & 5.35 & 5.2029 & TRN & \\
\hline CHEMBL1334164 & 688620 & 4.45 & 4.7874 & TST & \\
\hline CHEMBL1388890 & 688620 & 4.45 & 5.0962 & TRN & \\
\hline CHEMBL1343516 & 688620 & 5.0 & 4.6186 & TST & \\
\hline CHEMBL3195985 & 688620 & 5.0 & 4.9672 & TRN & \\
\hline CHEMBL 2002875 & 688620 & 5.0 & 4.7375 & TRN & \\
\hline CHEMBL1343098 & 688620 & 5.1 & 5.1843 & TRN & \\
\hline CHEMBL1332001 & 688620 & 5.45 & 4.7678 & TST & \\
\hline CHEMBL1424131 & 688620 & 4.75 & 5.2347 & TRN & \\
\hline CHEMBL1341999 & 688620 & 4.45 & 4.7245 & TRN & \\
\hline CHEMBL1577536 & 688620 & 5.55 & 5.2751 & TST & \\
\hline CHEMBL 3193513 & 688620 & 4.8 & 4.9119 & TRN & \\
\hline CHEMBL1315346 & 688620 & 4.95 & 4.9216 & TST & \\
\hline CHEMBL1466391 & 688620 & 5.6 & 5.1205 & TRN & \\
\hline CHEMBL1589092 & 688620 & 4.8 & 5.2884 & TST & \\
\hline CHEMBL1338183 & 688620 & 5.7 & 5.0458 & TRN & \\
\hline CHEMBL1326828 & 688620 & 4.6 & 5.726 & TRN & \\
\hline CHEMBL1301572 & 688620 & 4.75 & 5.0009 & TST & \\
\hline CHEMBL1486877 & 688620 & 4.5 & 5.3064 & TRN & \\
\hline CHEMBL1506080 & 688620 & 4.55 & 4.9927 & TST & \\
\hline CHEMBL1443974 & 688620 & 4.55 & 4.9805 & TST & \\
\hline CHEMBL1539309 & 688620 & 4.9 & 5.2022 & TRN & \\
\hline CHEMBL1506119 & 688620 & 5.1 & 4.9238 & TST & \\
\hline CHEMBL1349669 & 688620 & 6.25 & 5.073 & TST & \\
\hline CHEMBL1605947 & 688620 & 4.5 & 5.07100 & 0000000001 & TST \\
\hline CHEMBL1449623 & 688620 & 4.45 & 5.0709 & TST & \\
\hline CHEMBL1334568 & 688620 & 5.15 & 5.3076 & TRN & \\
\hline CHEMBL1441441 & 688620 & 4.7 & 4.8638 & TRN & \\
\hline CHEMBL1561348 & 688620 & 5.4 & 5.0185 & TRN & \\
\hline CHEMBL1380213 & 688620 & 4.95 & 4.9888 & TRN & \\
\hline CHEMBL1501135 & 688620 & 4.45 & 4.9362 & TST & \\
\hline CHEMBL1527757 & 688620 & 5.05 & 5.519 & TRN & \\
\hline CHEMBL1539807 & 688620 & 5.6 & 4.7706 & TRN & \\
\hline CHEMBL1503166 & 688620 & 4.95 & 4.9759 & TRN & \\
\hline CHEMBL1439925 & 688620 & 4.45 & 4.7981 & TRN & \\
\hline CHEMBL1480049 & 688620 & 5.1 & 5.0588 & TRN & \\
\hline CHEMBL1323596 & 688620 & 6.4 & 5.1644 & TRN & \\
\hline
\end{tabular}




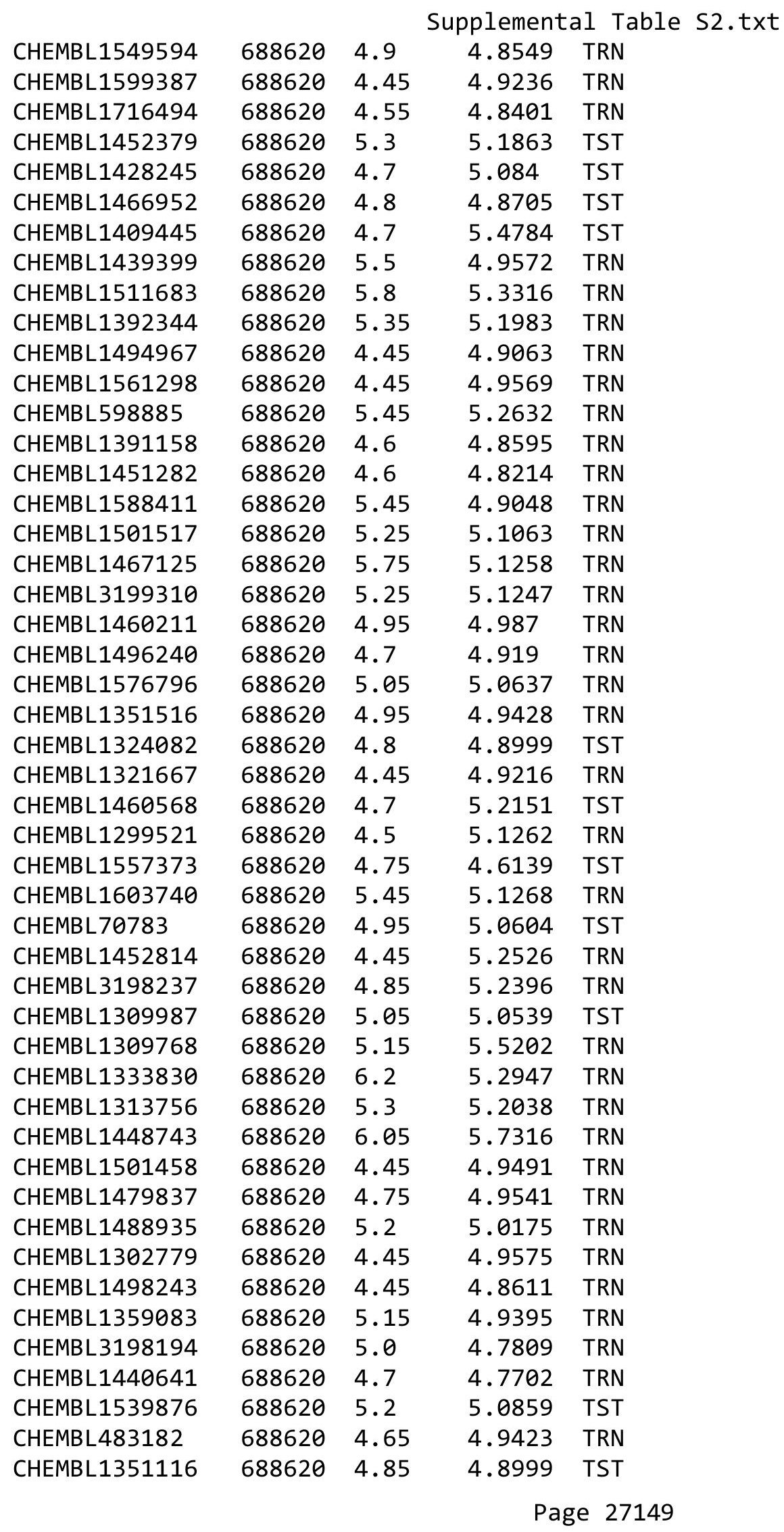




\begin{tabular}{|c|c|c|c|c|c|}
\hline \\
\hline CHEMBL1557689 & 688620 & 4.9 & 4.9967 & TST & \\
\hline CHEMBL1979937 & 688620 & 4.45 & 4.9465 & TRN & \\
\hline CHEMBL1430882 & 688620 & 4.9 & 4.7838 & TST & \\
\hline CHEMBL1410035 & 688620 & 4.95 & 5.1429 & TRN & \\
\hline CHEMBL1466232 & 688620 & 5.0 & 5.1041 & TST & \\
\hline CHEMBL1549250 & 688620 & 4.75 & 4.9547 & TRN & \\
\hline CHEMBL1524779 & 688620 & 5.1 & 5.1021 & TRN & \\
\hline CHEMBL1348139 & 688620 & 5.05 & 4.9613 & TRN & \\
\hline CHEMBL1594647 & 688620 & 4.55 & 4.9169 & TRN & \\
\hline CHEMBL1426946 & 688620 & 5.05 & 5.3689 & TST & \\
\hline CHEMBL3198338 & 688620 & 5.15 & 5.0332 & TRN & \\
\hline CHEMBL1431981 & 688620 & 4.75 & 5.1954 & TRN & \\
\hline CHEMBL1306816 & 688620 & 4.45 & 4.792 & TST & \\
\hline CHEMBL1486451 & 688620 & 5.0 & 5.0749 & TRN & \\
\hline CHEMBL1526600 & 688620 & 4.45 & 5.1152 & TST & \\
\hline CHEMBL1477259 & 688620 & 5.35 & 5.2674 & TRN & \\
\hline CHEMBL304291 & 688620 & 6.0 & 5.1096 & TRN & \\
\hline CHEMBL1383295 & 688620 & 5.45 & 4.9894 & TST & \\
\hline CHEMBL 2095128 & 688620 & 5.85 & 5.6867 & TRN & \\
\hline CHEMBL1580645 & 688620 & 4.45 & 4.9804 & TRN & \\
\hline CHEMBL1432787 & 688620 & 5.1 & 4.9219 & TRN & \\
\hline CHEMBL1586758 & 688620 & 5.0 & 4.9715 & TRN & \\
\hline CHEMBL1467180 & 688620 & 4.6 & 5.0443 & TRN & \\
\hline CHEMBL1505263 & 688620 & 4.95 & 4.9817 & TRN & \\
\hline CHEMBL1519309 & 688620 & 4.9 & 4.8467 & TRN & \\
\hline CHEMBL1468554 & 688620 & 4.95 & 5.0829 & TST & \\
\hline CHEMBL1563331 & 688620 & 5.3 & 4.9536 & TRN & \\
\hline CHEMBL488028 & 688620 & 5.7 & 5.0421 & TRN & \\
\hline CHEMBL1374826 & 688620 & 4.8 & 4.9957 & TRN & \\
\hline CHEMBL1438451 & 688620 & 5.3 & 5.2742 & TRN & \\
\hline CHEMBL1466545 & 688620 & 5.0 & 4.7569 & TST & \\
\hline CHEMBL1369582 & 688620 & 4.8 & 5.0384 & TRN & \\
\hline CHEMBL1432867 & 688620 & 5.35 & 5.1368 & TRN & \\
\hline CHEMBL3209779 & 688620 & 5.15 & 4.8734 & TRN & \\
\hline CHEMBL1530548 & 688620 & 5.15 & 5.20200 & 0000000001 & TRN \\
\hline CHEMBL1369295 & 688620 & 5.05 & 5.3837 & TST & \\
\hline CHEMBL1430516 & 688620 & 4.95 & 4.9576 & TRN & \\
\hline CHEMBL3392393 & 688620 & 4.6 & 4.9003 & TRN & \\
\hline CHEMBL1487765 & 688620 & 5.25 & 5.0886 & TST & \\
\hline CHEMBL1417489 & 688620 & 4.9 & 5.1309 & TRN & \\
\hline CHEMBL1566617 & 688620 & 5.0 & 4.7506 & TST & \\
\hline CHEMBL1563006 & 688620 & 4.45 & 5.2281 & TST & \\
\hline CHEMBL1533249 & 688620 & 4.9 & 4.936 & TRN & \\
\hline CHEMBL1566080 & 688620 & 4.65 & 5.2156 & TRN & \\
\hline CHEMBL1609072 & 688620 & 4.95 & 4.9522 & TRN & \\
\hline CHEMBL261641 & 688620 & 4.45 & 4.8141 & TST & \\
\hline CHEMBL1308224 & 688620 & 4.7 & 4.65 & TRN & \\
\hline CHEMBL1502324 & 688620 & 4.8 & 5.268 & TRN & \\
\hline
\end{tabular}




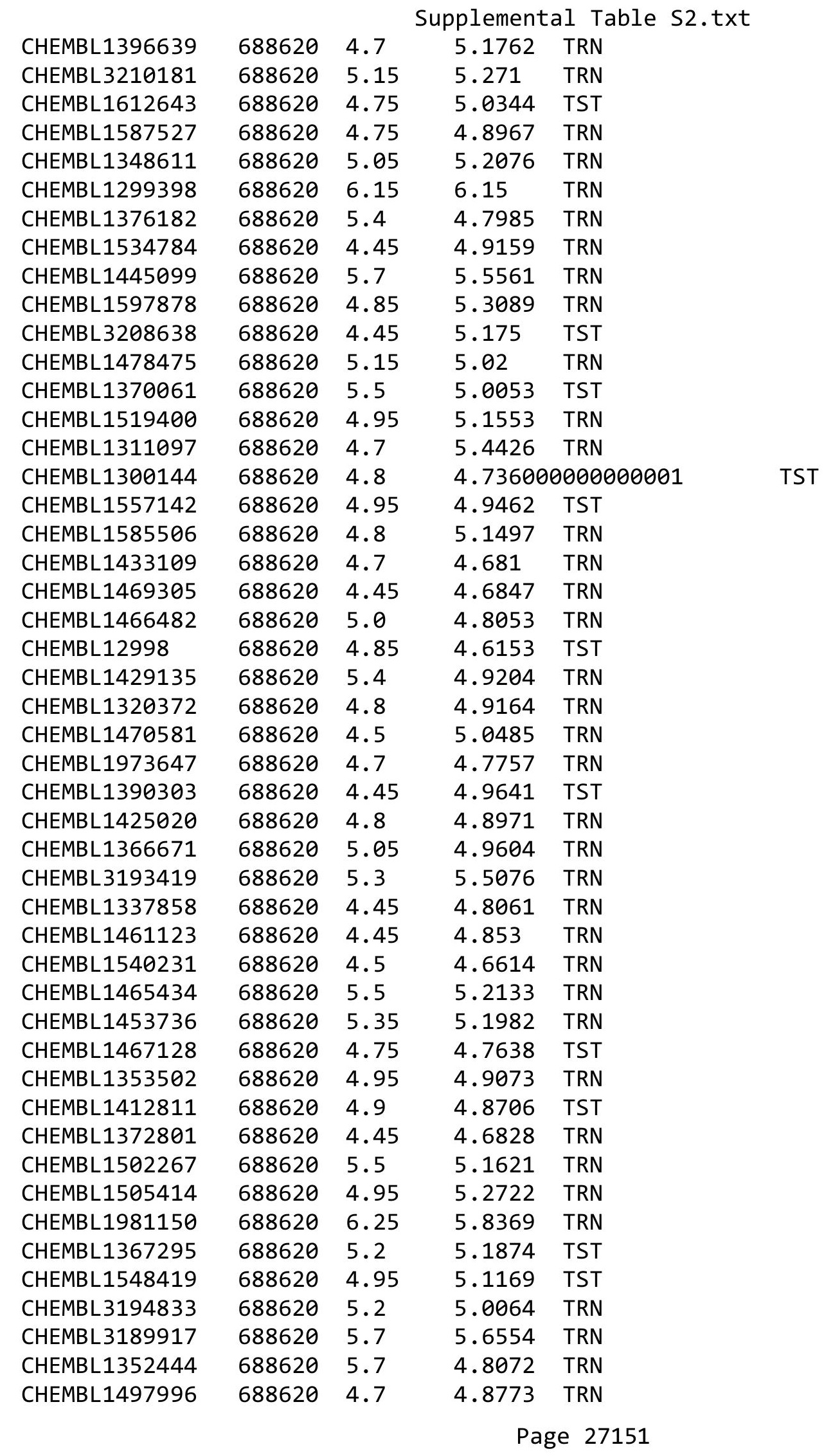




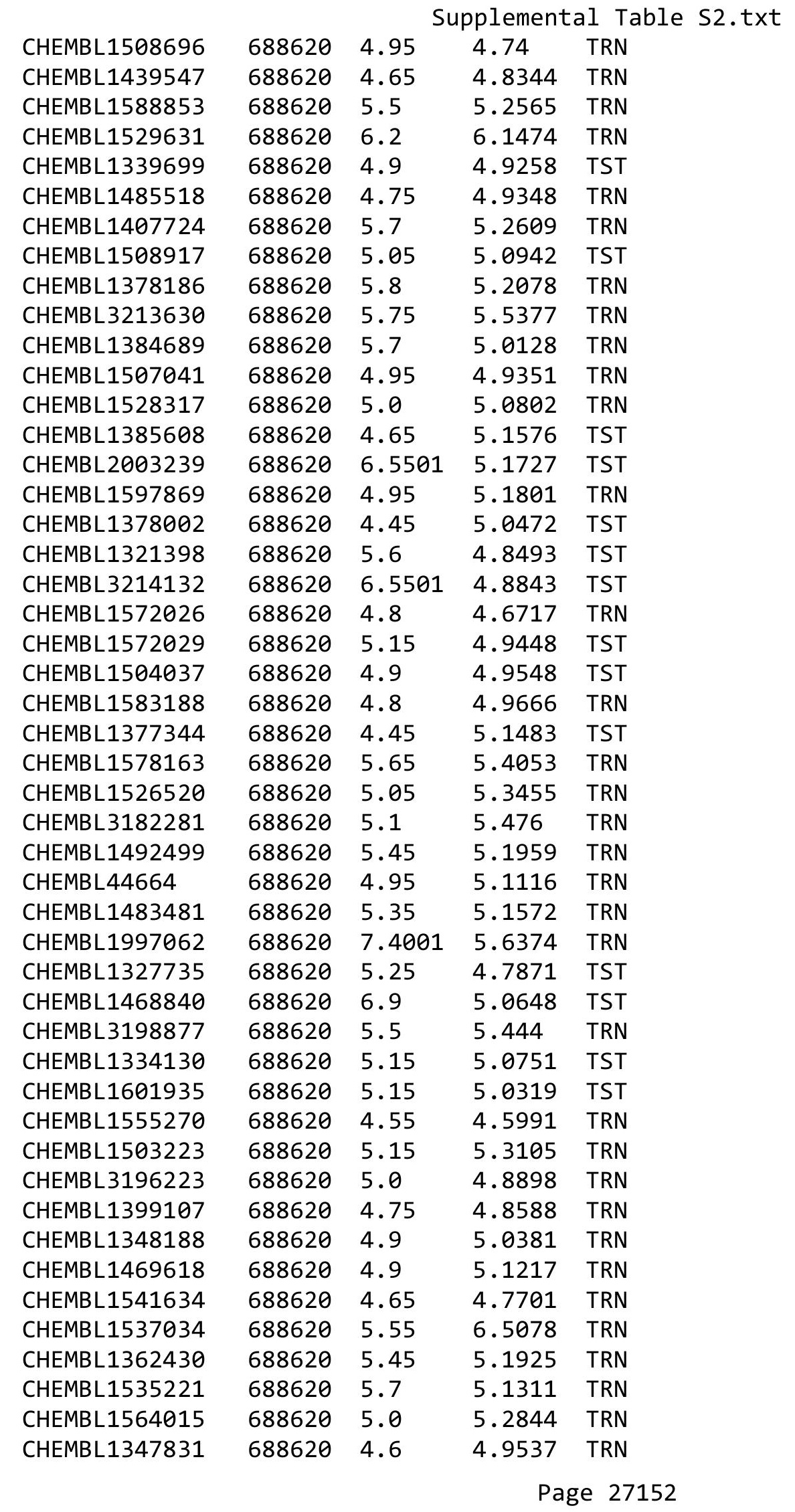




\begin{tabular}{|c|c|c|c|c|c|}
\hline \multicolumn{6}{|c|}{ Supplemental Table S2.txt } \\
\hline CHEMBL1369916 & 688620 & 5.15 & 5.0284 & TRN & \\
\hline CHEMBL1401837 & 688620 & 5.85 & 5.1125 & TRN & \\
\hline CHEMBL1539281 & 688620 & 5.1 & 5.1121 & TRN & \\
\hline CHEMBL1407782 & 688620 & 4.5 & 4.9474 & TRN & \\
\hline CHEMBL1304831 & 688620 & 5.05 & 5.0589 & TRN & \\
\hline CHEMBL1328784 & 688620 & 4.85 & 4.8668 & TST & \\
\hline CHEMBL1544435 & 688620 & 4.45 & 4.876 & TST & \\
\hline CHEMBL3189993 & 688620 & 5.5 & 4.75899 & 99999999995 & TRN \\
\hline CHEMBL1390825 & 688620 & 4.7 & 4.8809 & TST & \\
\hline CHEMBL1503131 & 688620 & 4.7 & 4.9427 & TST & \\
\hline CHEMBL1329433 & 688620 & 4.9 & 5.0387 & TRN & \\
\hline CHEMBL1462765 & 688620 & 5.45 & 5.3384 & TRN & \\
\hline CHEMBL1524484 & 688620 & 6.05 & 6.2841 & TST & \\
\hline CHEMBL1387941 & 688620 & 4.9 & 5.1686 & TRN & \\
\hline CHEMBL 1385272 & 688620 & 4.85 & 5.1457 & TRN & \\
\hline CHEMBL1440054 & 688620 & 5.0 & 4.9612 & TRN & \\
\hline CHEMBL1583031 & 688620 & 4.45 & 4.9308 & TST & \\
\hline CHEMBL1366500 & 688620 & 5.85 & 5.4586 & TRN & \\
\hline CHEMBL1496044 & 688620 & 5.1 & 5.0375 & TST & \\
\hline CHEMBL1560563 & 688620 & 4.65 & 4.9438 & TRN & \\
\hline CHEMBL1431459 & 688620 & 5.0 & 4.67 & TRN & \\
\hline CHEMBL 3208087 & 688620 & 5.45 & 5.0682 & TRN & \\
\hline CHEMBL1422173 & 688620 & 4.7 & 4.8637 & TRN & \\
\hline CHEMBL1483686 & 688620 & 4.9 & 5.5124 & TRN & \\
\hline CHEMBL2005998 & 688620 & 6.4 & 5.553 & TST & \\
\hline CHEMBL3190657 & 688620 & 5.65 & 5.3613 & TRN & \\
\hline CHEMBL1344361 & 688620 & 4.9 & 5.0512 & TRN & \\
\hline CHEMBL1307209 & 688620 & 5.1 & 4.9522 & TRN & \\
\hline CHEMBL1318726 & 688620 & 4.65 & 4.9405 & TRN & \\
\hline CHEMBL1352589 & 688620 & 4.75 & 5.2006 & TST & \\
\hline CHEMBL1345466 & 688620 & 5.45 & 5.1176 & TRN & \\
\hline CHEMBL1576070 & 688620 & 4.95 & 4.7768 & TRN & \\
\hline CHEMBL3199517 & 688620 & 4.7 & 5.1245 & TST & \\
\hline CHEMBL1485889 & 688620 & 4.75 & 5.0298 & TRN & \\
\hline CHEMBL1610991 & 688620 & 5.55 & 5.3177 & TST & \\
\hline CHEMBL1965687 & 688620 & 4.75 & 5.2226 & TRN & \\
\hline CHEMBL1325950 & 688620 & 4.45 & 4.8924 & TST & \\
\hline CHEMBL3208220 & 688620 & 4.95 & 4.9909 & TST & \\
\hline CHEMBL1397125 & 688620 & 6.0 & 5.6777 & TRN & \\
\hline CHEMBL1318913 & 688620 & 5.0 & 5.0783 & TRN & \\
\hline CHEMBL1597240 & 688620 & 5.0 & 5.3294 & TRN & \\
\hline CHEMBL1577844 & 688620 & 4.95 & 5.44 & TRN & \\
\hline CHEMBL1423539 & 688620 & 5.2 & 5.151 & TRN & \\
\hline CHEMBL3144928 & 688620 & 5.0 & 5.2852 & TST & \\
\hline CHEMBL1550584 & 688620 & 4.6 & 5.4384 & TRN & \\
\hline CHEMBL1493478 & 688620 & 5.5 & 4.9418 & TST & \\
\hline CHEMBL1364686 & 688620 & 4.9 & 4.9908 & TRN & \\
\hline CHEMBL1396107 & 688620 & 5.2 & 5.2112 & TRN & \\
\hline
\end{tabular}




\begin{tabular}{|c|c|c|c|c|c|}
\hline & & \multicolumn{4}{|c|}{ Supplemental Table S2.txt } \\
\hline CHEMBL1399072 & 688620 & 5.05 & 4.713 & TRN & \\
\hline CHEMBL3198362 & 688620 & 5.0 & 5.3942 & TRN & \\
\hline CHEMBL1582391 & 688620 & 5.25 & 5.1244 & TST & \\
\hline CHEMBL1329228 & 688620 & 5.1 & 5.1649 & TRN & \\
\hline CHEMBL602408 & 688620 & 4.45 & 5.13399 & 99999999995 & TST \\
\hline CHEMBL1991736 & 688620 & 4.45 & 4.9764 & TRN & \\
\hline CHEMBL1565912 & 688620 & 4.7 & 5.0277 & TRN & \\
\hline CHEMBL1547667 & 688620 & 4.5 & 5.0001 & TRN & \\
\hline CHEMBL1320915 & 688620 & 4.45 & 5.0143 & TRN & \\
\hline CHEMBL1426781 & 688620 & 4.85 & 4.9745 & TRN & \\
\hline CHEMBL3190747 & 688620 & 5.25 & 5.0094 & TST & \\
\hline CHEMBL1344388 & 688620 & 5.35 & 5.0823 & TRN & \\
\hline CHEMBL1379329 & 688620 & 5.15 & 5.4756 & TRN & \\
\hline CHEMBL1578500 & 688620 & 6.35 & 5.0839 & TST & \\
\hline CHEMBL1493910 & 688620 & 4.45 & 4.7761 & TRN & \\
\hline CHEMBL586061 & 688620 & 5.25 & 5.3912 & TRN & \\
\hline CHEMBL1375465 & 688620 & 4.8 & 4.6313 & TST & \\
\hline CHEMBL 3211860 & 688620 & 4.75 & 5.0137 & TRN & \\
\hline CHEMBL1385164 & 688620 & 5.4 & 5.0439 & TRN & \\
\hline CHEMBL3190006 & 688620 & 5.25 & 5.0362 & TRN & \\
\hline CHEMBL1306590 & 688620 & 4.95 & 5.3155 & TST & \\
\hline CHEMBL 3214330 & 688620 & 5.35 & 5.50700 & 0000000001 & TRN \\
\hline CHEMBL1983929 & 688620 & 5.7 & 4.9646 & TRN & \\
\hline CHEMBL1494074 & 688620 & 5.05 & 5.0233 & TRN & \\
\hline CHEMBL1336644 & 688620 & 4.95 & 4.8074 & TRN & \\
\hline CHEMBL1334289 & 688620 & 6.0 & 4.8661 & TRN & \\
\hline CHEMBL1308492 & 688620 & 4.45 & 4.9343 & TST & \\
\hline CHEMBL1386122 & 688620 & 4.75 & 5.1547 & TST & \\
\hline CHEMBL 3208237 & 688620 & 6.1 & 5.7503 & TRN & \\
\hline CHEMBL1464309 & 688620 & 5.3 & 4.9969 & TRN & \\
\hline CHEMBL1566037 & 688620 & 4.9 & 4.9553 & TRN & \\
\hline CHEMBL1968789 & 688620 & 5.5 & 5.2356 & TRN & \\
\hline CHEMBL1463322 & 688620 & 5.45 & 5.2705 & TST & \\
\hline CHEMBL1583911 & 688620 & 6.45 & 5.0249 & TRN & \\
\hline CHEMBL1301847 & 688620 & 4.45 & 5.0186 & TRN & \\
\hline CHEMBL1987343 & 688620 & 5.7 & 5.2927 & TRN & \\
\hline CHEMBL1612298 & 688620 & 4.55 & 4.9079 & TST & \\
\hline CHEMBL162783 & 688620 & 5.4 & 5.2429 & TST & \\
\hline CHEMBL1467093 & 688620 & 5.05 & 4.7667 & TST & \\
\hline CHEMBL1529781 & 688620 & 4.95 & 5.435 & TRN & \\
\hline CHEMBL1170377 & 688620 & 5.0 & 5.0831 & TST & \\
\hline CHEMBL1537499 & 688620 & 5.95 & 5.5221 & TRN & \\
\hline CHEMBL1584689 & 688620 & 5.45 & 5.4694 & TRN & \\
\hline CHEMBL3194857 & 688620 & 4.45 & 5.0614 & TST & \\
\hline CHEMBL1417471 & 688620 & 4.8 & 4.9038 & TRN & \\
\hline CHEMBL1984648 & 688620 & 4.95 & 4.7529 & TRN & \\
\hline CHEMBL1425875 & 688620 & 5.6 & 5.745 & TRN & \\
\hline CHEMBL1301259 & 688620 & 5.35 & 5.152 & TRN & \\
\hline
\end{tabular}




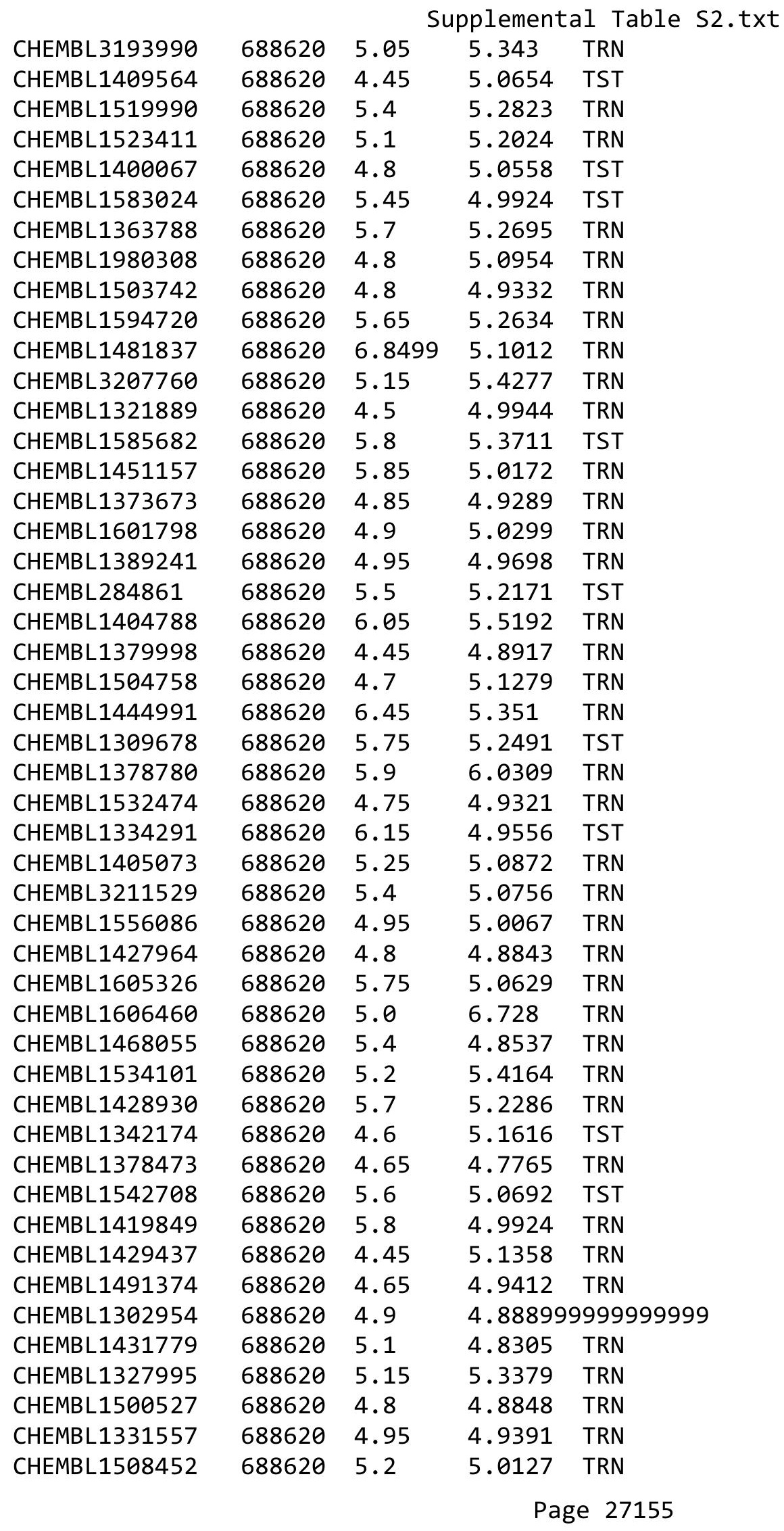

TRN 


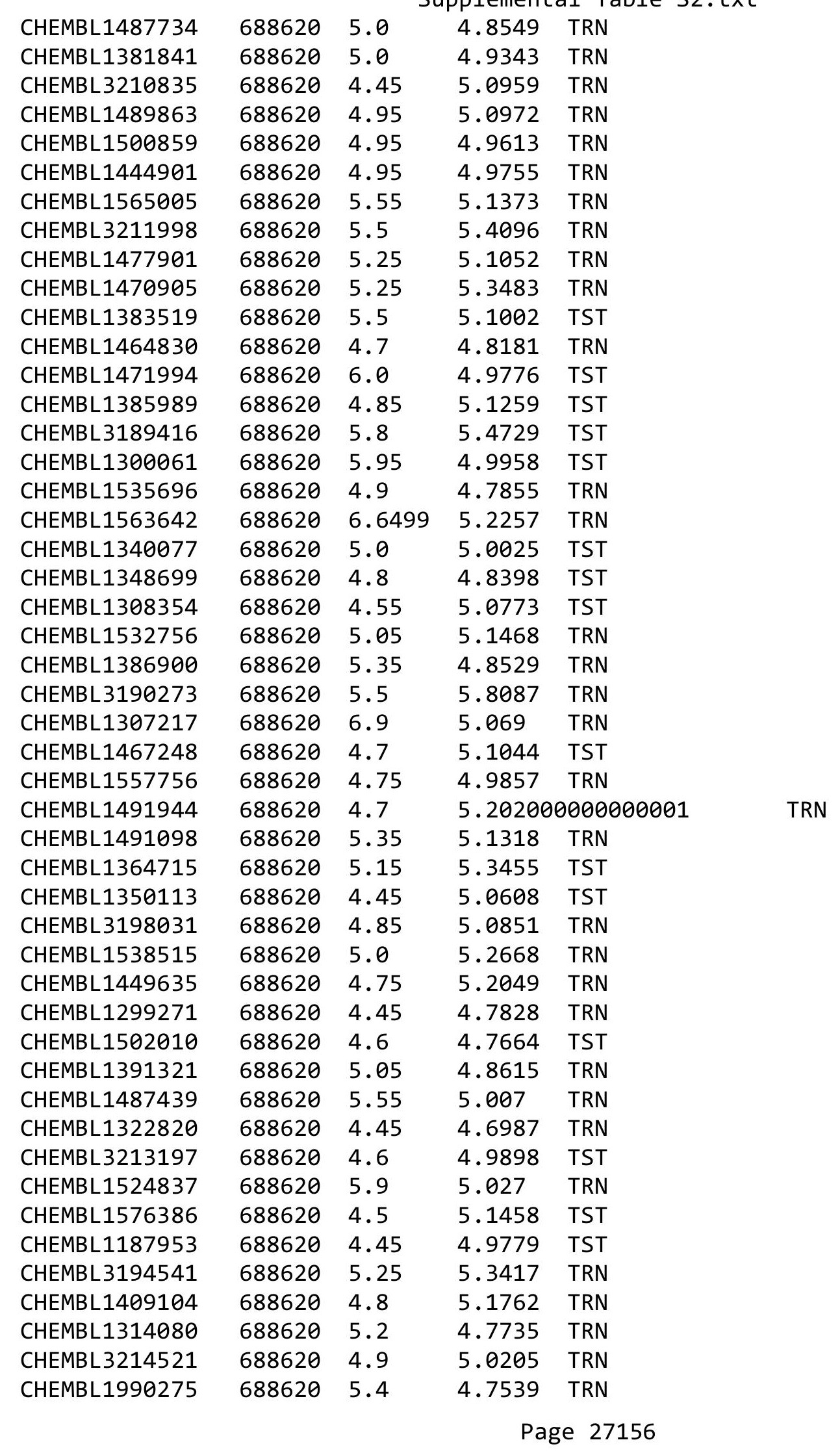




\begin{tabular}{|c|c|c|c|c|c|}
\hline \multirow{2}{*}{ CHEMBL1462944 } & \multirow[b]{2}{*}{688620} & \\
\hline & & 5.3 & 5.524 & TRN & \\
\hline CHEMBL3196087 & 688620 & 5.1 & 5.5711 & TRN & \\
\hline CHEMBL1613478 & 688620 & 5.0 & 4.8682 & TRN & \\
\hline CHEMBL1303997 & 688620 & 5.85 & 5.4802 & TRN & \\
\hline CHEMBL1517284 & 688620 & 5.8 & 5.5384 & TRN & \\
\hline CHEMBL3209504 & 688620 & 4.9 & 5.3817 & TRN & \\
\hline CHEMBL1342384 & 688620 & 5.3 & 4.949 & TRN & \\
\hline CHEMBL1484411 & 688620 & 5.15 & 5.126 & TST & \\
\hline CHEMBL1315991 & 688620 & 4.75 & 4.9647 & TRN & \\
\hline CHEMBL1598582 & 688620 & 4.95 & 5.2496 & TRN & \\
\hline CHEMBL1335386 & 688620 & 4.9 & 5.1822 & TST & \\
\hline CHEMBL1589500 & 688620 & 4.9 & 4.9188 & TRN & \\
\hline CHEMBL1547123 & 688620 & 5.7 & 5.0995 & TRN & \\
\hline CHEMBL1409482 & 688620 & 4.45 & \multicolumn{2}{|c|}{5.031000000000001} & TST \\
\hline CHEMBL1381228 & 688620 & 4.65 & 4.907 & TRN & \\
\hline CHEMBL1402936 & 688620 & 5.5 & 5.1683 & TRN & \\
\hline CHEMBL1558656 & 688620 & 4.95 & 5.275 & TRN & \\
\hline CHEMBL1580449 & 688620 & 4.45 & 5.0406 & TRN & \\
\hline CHEMBL3211923 & 688620 & 5.15 & 5.1432 & TRN & \\
\hline CHEMBL1372408 & 688620 & 4.95 & 5.0365 & TRN & \\
\hline CHEMBL1419432 & 688620 & 4.7 & 5.0469 & TRN & \\
\hline CHEMBL1437807 & 688620 & 4.8 & 5.0028 & TST & \\
\hline CHEMBL1498827 & 688620 & 4.7 & 5.0131 & TRN & \\
\hline CHEMBL1567847 & 688620 & 5.5 & 4.8025 & TRN & \\
\hline CHEMBL1543361 & 688620 & 4.95 & 5.1645 & TRN & \\
\hline CHEMBL1545036 & 688620 & 4.45 & 4.7697 & TRN & \\
\hline CHEMBL1382868 & 688620 & 5.4 & 4.8388 & TRN & \\
\hline CHEMBL1490031 & 688620 & 4.6 & 5.5086 & TRN & \\
\hline CHEMBL1469283 & 688620 & 4.95 & 5.0308 & TST & \\
\hline CHEMBL1501508 & 688620 & 5.3 & 5.1144 & TRN & \\
\hline CHEMBL1406618 & 688620 & 4.85 & 5.1383 & TST & \\
\hline CHEMBL1425131 & 688620 & 4.85 & 5.0212 & TRN & \\
\hline CHEMBL1324197 & 688620 & 5.35 & 5.0697 & TRN & \\
\hline CHEMBL1588873 & 688620 & 6.15 & 6.0036 & TRN & \\
\hline CHEMBL3213820 & 688620 & 5.1 & 4.8494 & TRN & \\
\hline CHEMBL1451427 & 688620 & 6.5 & 5.0529 & TST & \\
\hline CHEMBL1391973 & 688620 & 6.0 & 6.102 & TRN & \\
\hline CHEMBL1532240 & 688620 & 4.9 & 5.0718 & TRN & \\
\hline CHEMBL1497617 & 688620 & 4.45 & 5.1715 & TRN & \\
\hline CHEMBL1583777 & 688620 & 4.45 & 4.9847 & TST & \\
\hline CHEMBL3198870 & 688620 & 4.95 & 5.6906 & TRN & \\
\hline CHEMBL1407861 & 688620 & 4.9 & 5.1104 & TRN & \\
\hline CHEMBL3194476 & 688620 & 4.95 & 5.0579 & TRN & \\
\hline CHEMBL1300339 & 688620 & 4.7 & 4.6919 & TRN & \\
\hline CHEMBL1531186 & 688620 & 5.0 & 4.85 & TRN & \\
\hline CHEMBL1585618 & 688620 & 4.65 & 5.1175 & TST & \\
\hline CHEMBL1312613 & 688620 & 6.5501 & 5.7273 & TRN & \\
\hline \multirow[t]{2}{*}{ CHEMBL1361057 } & 688620 & 5.0 & 5.01 & TRN & \\
\hline & & \multicolumn{4}{|c|}{ Page 27157} \\
\hline
\end{tabular}




\begin{tabular}{|c|c|c|c|c|}
\hline \multicolumn{5}{|c|}{ Supplemental Table S2.txt } \\
\hline CHEMBL1373461 & 688620 & 4.45 & 4.9772 & TRN \\
\hline CHEMBL1339697 & 688620 & 4.85 & 5.1567 & TST \\
\hline CHEMBL1467816 & 688620 & 4.8 & 4.9155 & TRN \\
\hline CHEMBL1360080 & 688620 & 4.45 & 4.8601 & TRN \\
\hline CHEMBL1586902 & 688620 & 4.75 & 4.8029 & TRN \\
\hline CHEMBL1561574 & 688620 & 4.95 & 4.849 & TRN \\
\hline CHEMBL1476311 & 688620 & 5.4 & 5.1325 & TRN \\
\hline CHEMBL1402629 & 688620 & 4.5 & 4.982 & TRN \\
\hline CHEMBL1551649 & 688620 & 5.05 & 4.6663 & TRN \\
\hline CHEMBL1329312 & 688620 & 4.85 & 5.0962 & TST \\
\hline CHEMBL1424926 & 688620 & 5.0 & 4.803 & TRN \\
\hline CHEMBL1463909 & 688620 & 4.85 & 5.0216 & TRN \\
\hline CHEMBL1422001 & 688620 & 4.9 & 5.085 & TRN \\
\hline CHEMBL1302080 & 688620 & 4.8 & 4.8952 & TRN \\
\hline CHEMBL1379997 & 688620 & 5.05 & 4.9516 & TRN \\
\hline CHEMBL1496513 & 688620 & 5.4 & 4.8682 & TRN \\
\hline CHEMBL1463115 & 688620 & 4.95 & 4.9925 & TRN \\
\hline CHEMBL1401740 & 688620 & 5.15 & 4.7672 & TST \\
\hline CHEMBL1489936 & 688620 & 5.4 & 4.9153 & TRN \\
\hline CHEMBL1561951 & 688620 & 4.45 & 5.1073 & TST \\
\hline CHEMBL1419822 & 688620 & 5.4 & 5.2674 & TRN \\
\hline CHEMBL 225270 & 688620 & 5.2 & 5.0247 & TRN \\
\hline CHEMBL1508786 & 688620 & 4.7 & 5.0461 & TRN \\
\hline CHEMBL1997130 & 688620 & 5.0 & 5.1774 & TRN \\
\hline CHEMBL1328943 & 688620 & 5.05 & 5.2233 & TRN \\
\hline CHEMBL1384601 & 688620 & 4.65 & 5.164 & TST \\
\hline CHEMBL1550508 & 688620 & 4.75 & 5.3203 & TRN \\
\hline CHEMBL1985429 & 688620 & 5.2 & 5.1935 & TRN \\
\hline CHEMBL1540174 & 688620 & 5.65 & 4.8739 & TRN \\
\hline CHEMBL1484818 & 688620 & 6.5 & 5.0358 & TRN \\
\hline CHEMBL1488250 & 688620 & 4.85 & 5.2539 & TRN \\
\hline CHEMBL1459859 & 688620 & 5.55 & 5.1501 & TST \\
\hline CHEMBL1559441 & 688620 & 4.95 & 5.118 & TRN \\
\hline CHEMBL1310739 & 688620 & 5.15 & 5.0505 & TRN \\
\hline CHEMBL1517625 & 688620 & 4.5 & 4.5922 & TRN \\
\hline CHEMBL1595769 & 688620 & 4.95 & 4.8949 & TRN \\
\hline CHEMBL1335084 & 688620 & 5.0 & 4.916 & TRN \\
\hline CHEMBL1366850 & 688620 & 4.45 & 4.708 & TRN \\
\hline CHEMBL1325790 & 688620 & 4.45 & 4.9579 & TRN \\
\hline CHEMBL1516649 & 688620 & 4.45 & 4.7973 & TST \\
\hline CHEMBL1501198 & 688620 & 4.7 & 4.8919 & TRN \\
\hline CHEMBL1502867 & 688620 & 4.95 & 4.8269 & TRN \\
\hline CHEMBL1550751 & 688620 & 4.45 & 5.1113 & TST \\
\hline CHEMBL1572244 & 688620 & 5.4 & 5.0658 & TRN \\
\hline CHEMBL1313273 & 688620 & 5.35 & 5.2056 & TRN \\
\hline CHEMBL1964615 & 688620 & 4.9 & 4.7424 & TST \\
\hline CHEMBL1562019 & 688620 & 4.95 & 4.92 & TRN \\
\hline CHEMBL1422068 & 688620 & 5.0 & 5.1148 & TRN \\
\hline
\end{tabular}




\begin{tabular}{|c|c|c|c|c|c|}
\hline \\
\hline CHEMBL1500761 & 688620 & 4.9 & 5.0378 & TRN & \\
\hline CHEMBL1501824 & 688620 & 5.1 & 4.9587 & TRN & \\
\hline CHEMBL1303309 & 688620 & 4.45 & 5.2182 & TRN & \\
\hline CHEMBL1402750 & 688620 & 4.9 & 5.1346 & TST & \\
\hline CHEMBL1585924 & 688620 & 5.05 & 5.02800 & 00000000005 & TRN \\
\hline CHEMBL1384700 & 688620 & 5.15 & 4.9481 & TRN & \\
\hline CHEMBL1567764 & 688620 & 5.05 & 5.1268 & TST & \\
\hline CHEMBL3191979 & 688620 & 4.8 & 4.9819 & TRN & \\
\hline CHEMBL1423970 & 688620 & 5.05 & 5.1186 & TRN & \\
\hline CHEMBL1342662 & 688620 & 4.65 & 4.8995 & TRN & \\
\hline CHEMBL1488916 & 688620 & 5.7 & 5.2123 & TRN & \\
\hline CHEMBL3207628 & 688620 & 6.1 & 4.8943 & TST & \\
\hline CHEMBL3213002 & 688620 & 4.45 & 5.1727 & TRN & \\
\hline CHEMBL1533534 & 688620 & 5.65 & 5.2966 & TRN & \\
\hline CHEMBL3194598 & 688620 & 5.65 & 5.0298 & TST & \\
\hline CHEMBL3191435 & 688620 & 4.9 & 4.9729 & TRN & \\
\hline CHEMBL1440652 & 688620 & 5.05 & 5.0616 & TRN & \\
\hline CHEMBL1459532 & 688620 & 4.45 & 4.9991 & TRN & \\
\hline CHEMBL1343287 & 688620 & 4.65 & 5.0709 & TRN & \\
\hline CHEMBL1577857 & 688620 & 6.5501 & 5.6089 & TRN & \\
\hline CHEMBL1388790 & 688620 & 4.45 & 4.7797 & TRN & \\
\hline CHEMBL1594475 & 688620 & 5.55 & 5.6285 & TRN & \\
\hline CHEMBL1502471 & 688620 & 6.25 & 4.9663 & TRN & \\
\hline CHEMBL1362306 & 688620 & 5.25 & 5.0969 & TST & \\
\hline CHEMBL3190052 & 688620 & 4.85 & 4.9208 & TRN & \\
\hline CHEMBL1452484 & 688620 & 4.45 & 4.7775 & TRN & \\
\hline CHEMBL3191071 & 688620 & 4.85 & 5.1433 & TST & \\
\hline CHEMBL1361145 & 688620 & 5.2 & 5.1186 & TRN & \\
\hline CHEMBL1344841 & 688620 & 5.15 & 4.9902 & TRN & \\
\hline CHEMBL1460708 & 688620 & 5.6 & 5.1236 & TRN & \\
\hline CHEMBL304621 & 688620 & 4.85 & 5.1911 & TRN & \\
\hline CHEMBL1321788 & 688620 & 5.35 & 4.9994 & TRN & \\
\hline CHEMBL1503138 & 688620 & 4.75 & 4.907 & TRN & \\
\hline CHEMBL1429179 & 688620 & 5.05 & 4.9838 & TRN & \\
\hline CHEMBL1489226 & 688620 & 4.8 & 4.9397 & TRN & \\
\hline CHEMBL1393212 & 688620 & 5.05 & 4.8771 & TRN & \\
\hline CHEMBL1325289 & 688620 & 4.65 & 4.756 & TRN & \\
\hline CHEMBL1423331 & 688620 & 5.6 & 5.3467 & TRN & \\
\hline CHEMBL1588902 & 688620 & 4.95 & 4.9581 & TST & \\
\hline CHEMBL1511142 & 688620 & 5.8 & 5.2528 & TRN & \\
\hline CHEMBL1334754 & 688620 & 4.8 & 5.0362 & TST & \\
\hline CHEMBL1368409 & 688620 & 5.8 & 5.3678 & TRN & \\
\hline CHEMBL1564157 & 688620 & 5.35 & 5.1293 & TST & \\
\hline CHEMBL1541773 & 688620 & 5.85 & 5.2343 & TST & \\
\hline CHEMBL1598229 & 688620 & 4.8 & 5.032 & TRN & \\
\hline CHEMBL3199617 & 688620 & 4.9 & 5.0087 & TRN & \\
\hline CHEMBL 1457672 & 688620 & 4.45 & 5.0314 & TRN & \\
\hline CHEMBL1557009 & 688620 & 4.45 & 4.984 & TRN & \\
\hline
\end{tabular}




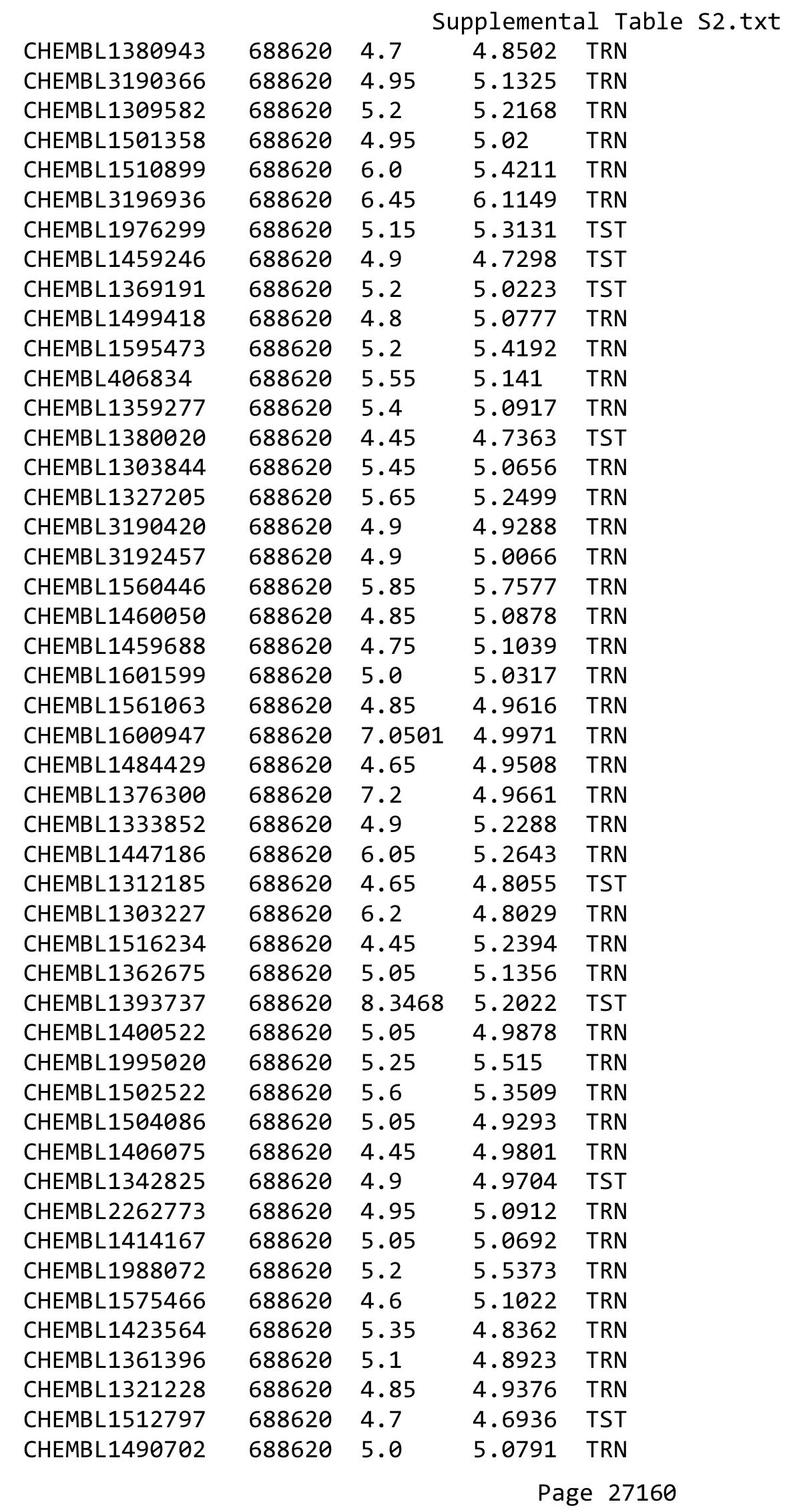




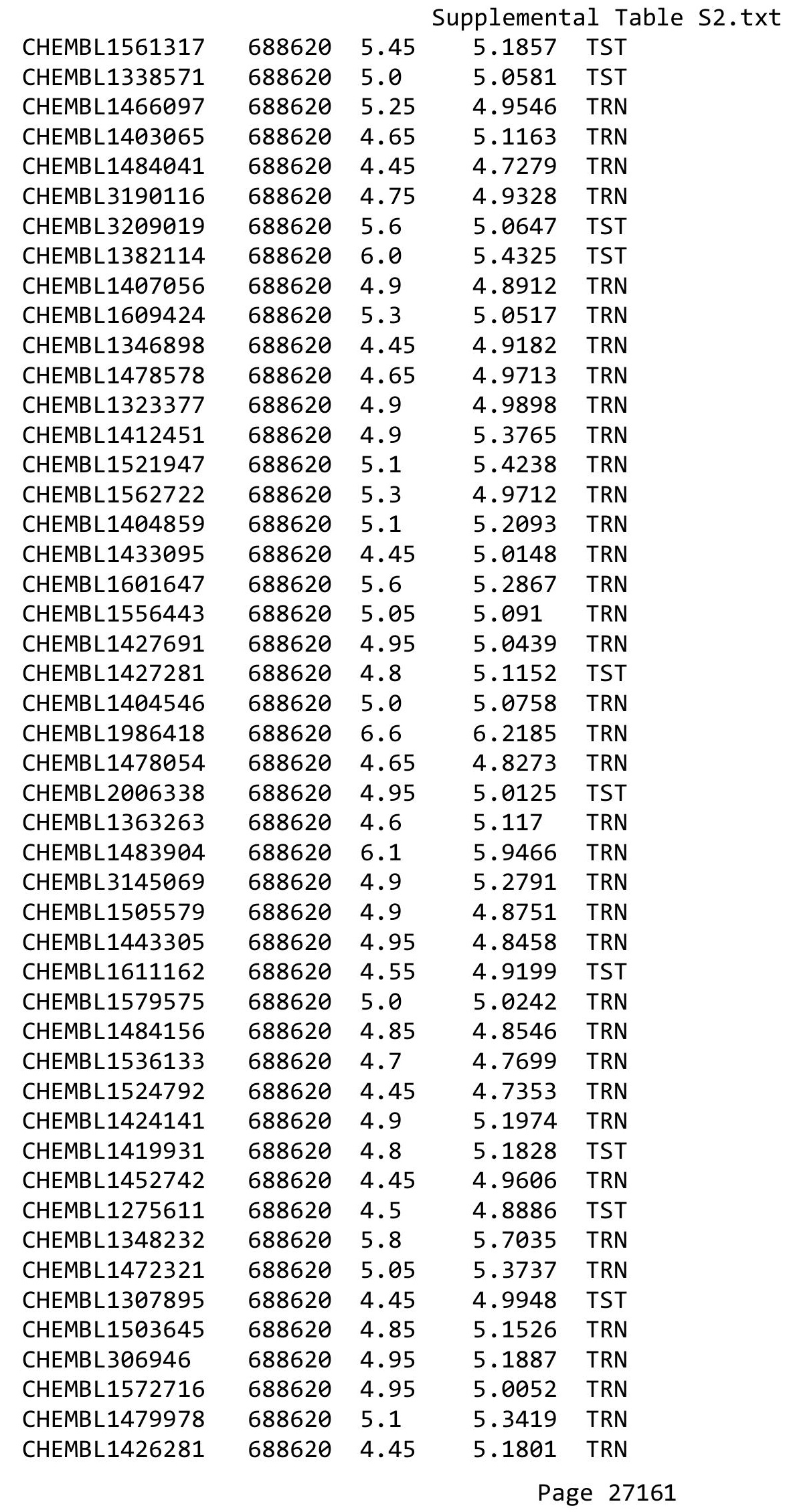




\begin{tabular}{|c|c|c|c|c|}
\hline \multicolumn{5}{|c|}{ Supplemental Table S2.txt } \\
\hline CHEMBL 3193844 & 688620 & 6.4 & 5.9109 & TST \\
\hline CHEMBL1466755 & 688620 & 5.6 & 5.0259 & TRN \\
\hline CHEMBL1411463 & 688620 & 4.95 & 5.1097 & TRN \\
\hline CHEMBL1366719 & 688620 & 5.25 & 5.4649 & TRN \\
\hline CHEMBL1382941 & 688620 & 4.9 & 4.7929 & TRN \\
\hline CHEMBL1316178 & 688620 & 6.0 & 5.2042 & TRN \\
\hline CHEMBL1422695 & 688620 & 4.95 & 5.1289 & TRN \\
\hline CHEMBL1303226 & 688620 & 5.0 & 4.9135 & TRN \\
\hline CHEMBL1335096 & 688620 & 4.85 & 5.1718 & TRN \\
\hline CHEMBL1582512 & 688620 & 5.35 & 4.8176 & TRN \\
\hline CHEMBL1389553 & 688620 & 4.45 & 4.9108 & TRN \\
\hline CHEMBL1338082 & 688620 & 4.85 & 5.231 & TRN \\
\hline CHEMBL1312182 & 688620 & 5.0 & 4.8909 & TRN \\
\hline CHEMBL1531120 & 688620 & 5.0 & 5.129 & TST \\
\hline CHEMBL1517166 & 688620 & 5.2 & 5.0674 & TRN \\
\hline CHEMBL1317232 & 688620 & 4.85 & 5.0158 & TRN \\
\hline CHEMBL1499871 & 688620 & 5.05 & 4.9658 & TRN \\
\hline CHEMBL1452050 & 688620 & 6.5501 & 5.1902 & TRN \\
\hline CHEMBL1412624 & 688620 & 5.35 & 5.1567 & TRN \\
\hline CHEMBL567531 & 688620 & 4.8 & 4.8723 & TRN \\
\hline CHEMBL3191914 & 688620 & 4.9 & 5.1311 & TRN \\
\hline CHEMBL1429781 & 688620 & 4.45 & 5.1401 & TRN \\
\hline CHEMBL1349495 & 688620 & 4.45 & 4.9027 & TRN \\
\hline CHEMBL1308048 & 688620 & 5.1 & 5.072 & TRN \\
\hline CHEMBL1557747 & 688620 & 5.45 & 4.9754 & TRN \\
\hline CHEMBL1407183 & 688620 & 4.75 & 4.7154 & TRN \\
\hline CHEMBL1535755 & 688620 & 4.95 & 4.9679 & TST \\
\hline CHEMBL1604484 & 688620 & 4.9 & 4.9549 & TRN \\
\hline CHEMBL 252721 & 688620 & 4.95 & 5.0487 & TRN \\
\hline CHEMBL1423307 & 688620 & 4.9 & 5.0955 & TRN \\
\hline CHEMBL1305869 & 688620 & 5.3 & 5.2411 & TRN \\
\hline CHEMBL1582642 & 688620 & 4.65 & 5.0369 & TRN \\
\hline CHEMBL 3197640 & 688620 & 6.25 & 5.4217 & TST \\
\hline CHEMBL1416239 & 688620 & 5.0 & 4.9976 & TST \\
\hline CHEMBL1423757 & 688620 & 5.15 & 5.2357 & TRN \\
\hline CHEMBL1563513 & 688620 & 5.3 & 5.5315 & TRN \\
\hline CHEMBL1506886 & 688620 & 4.75 & 4.9904 & TRN \\
\hline CHEMBL1373901 & 688620 & 5.3 & 5.3621 & TRN \\
\hline CHEMBL1446815 & 688620 & 5.9 & 4.8201 & TRN \\
\hline CHEMBL3208846 & 688620 & 4.9 & 5.0115 & TRN \\
\hline CHEMBL1319821 & 688620 & 6.15 & 5.0215 & TRN \\
\hline CHEMBL1519239 & 688620 & 6.15 & 5.6985 & TRN \\
\hline CHEMBL1325605 & 688620 & 4.75 & 4.9831 & TRN \\
\hline CHEMBL1467582 & 688620 & 4.45 & 5.0537 & TRN \\
\hline CHEMBL1439595 & 688620 & 4.95 & 5.1276 & TST \\
\hline CHEMBL1533338 & 688620 & 4.95 & 5.0635 & TST \\
\hline CHEMBL1349893 & 688620 & 5.25 & 5.0324 & TST \\
\hline CHEMBL1442058 & 688620 & 4.9 & 5.2754 & TRN \\
\hline
\end{tabular}




\begin{tabular}{|c|c|c|c|c|c|}
\hline \multicolumn{6}{|c|}{ Supplemental Table S2.txt } \\
\hline CHEMBL175266 & 688620 & 4.85 & 5.1941 & TRN & \\
\hline CHEMBL1429470 & 688620 & 4.45 & 5.0586 & TRN & \\
\hline CHEMBL3193654 & 688620 & 5.05 & 4.9955 & TRN & \\
\hline CHEMBL1545634 & 688620 & 6.0 & 5.5444 & TRN & \\
\hline CHEMBL1458158 & 688620 & 4.95 & 5.2404 & TRN & \\
\hline CHEMBL1974818 & 688620 & 4.65 & 4.9558 & TRN & \\
\hline CHEMBL 2005446 & 688620 & 5.5 & 5.5244 & TRN & \\
\hline CHEMBL1499688 & 688620 & 4.9 & 5.25799 & 9999999999 & TRN \\
\hline CHEMBL1481525 & 688620 & 4.45 & 4.9238 & TRN & \\
\hline CHEMBL1454143 & 688620 & 5.25 & 5.0897 & TST & \\
\hline CHEMBL1581261 & 688620 & 4.9 & 5.0698 & TRN & \\
\hline CHEMBL505209 & 688620 & 5.95 & 5.7139 & TRN & \\
\hline CHEMBL1579869 & 688620 & 4.45 & 5.0408 & TRN & \\
\hline CHEMBL1410647 & 688620 & 5.35 & 5.13700 & 00000000005 & TRN \\
\hline CHEMBL1728821 & 688620 & 4.65 & 5.0885 & TRN & \\
\hline CHEMBL1489113 & 688620 & 5.95 & 5.6355 & TRN & \\
\hline CHEMBL1500986 & 688620 & 4.8 & 5.1767 & TRN & \\
\hline CHEMBL1470083 & 688620 & 4.8 & 5.3282 & TST & \\
\hline CHEMBL1489358 & 688620 & 4.65 & 5.0537 & TRN & \\
\hline CHEMBL1565520 & 688620 & 4.45 & 4.8304 & TRN & \\
\hline CHEMBL1482310 & 688620 & 5.8 & 4.9315 & TRN & \\
\hline CHEMBL1359410 & 688620 & 4.9 & 5.1269 & TRN & \\
\hline CHEMBL1602296 & 688620 & 4.95 & 4.9358 & TRN & \\
\hline CHEMBL1574620 & 688620 & 5.15 & 5.0765 & TST & \\
\hline CHEMBL3191387 & 688620 & 4.5 & 5.0069 & TRN & \\
\hline CHEMBL1402025 & 688620 & 5.0 & 4.8223 & TRN & \\
\hline CHEMBL1459502 & 688620 & 5.15 & 5.2695 & TRN & \\
\hline CHEMBL1531098 & 688620 & 5.0 & 4.9344 & TRN & \\
\hline CHEMBL1392116 & 688620 & 6.3 & 5.0319 & TST & \\
\hline CHEMBL1327500 & 688620 & 4.75 & 5.0316 & TRN & \\
\hline CHEMBL1371219 & 688620 & 4.85 & 5.0492 & TRN & \\
\hline CHEMBL1975756 & 688620 & 5.5 & 5.17200 & 0000000001 & TST \\
\hline CHEMBL1605161 & 688620 & 5.7 & 4.8902 & TRN & \\
\hline CHEMBL1541343 & 688620 & 7.5498 & 6.8524 & TRN & \\
\hline CHEMBL1339058 & 688620 & 5.55 & 5.4324 & TRN & \\
\hline CHEMBL3189684 & 688620 & 4.95 & 4.9323 & TRN & \\
\hline CHEMBL1469133 & 688620 & 4.65 & 5.0505 & TRN & \\
\hline CHEMBL1510749 & 688620 & 4.6 & 5.0699 & TST & \\
\hline CHEMBL3191815 & 688620 & 5.25 & 4.8949 & TST & \\
\hline CHEMBL1465938 & 688620 & 4.9 & 4.88 & TST & \\
\hline CHEMBL1977978 & 688620 & 5.9 & 5.3767 & TRN & \\
\hline CHEMBL1382389 & 688620 & 4.45 & 5.169 & TRN & \\
\hline CHEMBL1443080 & 688620 & 5.2 & 5.0645 & TRN & \\
\hline CHEMBL1610014 & 688620 & 4.9 & 5.015 & TRN & \\
\hline CHEMBL1518052 & 688620 & 4.8 & 4.9172 & TRN & \\
\hline CHEMBL1346316 & 688620 & 5.0 & 4.9311 & TRN & \\
\hline CHEMBL1378577 & 688620 & 4.75 & 4.875 & TRN & \\
\hline CHEMBL1419933 & 688620 & 6.0 & 5.0131 & TRN & \\
\hline
\end{tabular}




\begin{tabular}{|c|c|c|c|c|}
\hline \multicolumn{5}{|c|}{ Supplemental Table S2.txt } \\
\hline CHEMBL1326379 & 688620 & 4.45 & 4.9049 & TRN \\
\hline CHEMBL1967938 & 688620 & 4.8 & 4.8405 & TRN \\
\hline CHEMBL1454988 & 688620 & 5.1 & 5.3194 & TRN \\
\hline CHEMBL1489456 & 688620 & 5.05 & 4.9112 & TRN \\
\hline CHEMBL1497193 & 688620 & 5.1 & 5.0095 & TRN \\
\hline CHEMBL1333926 & 688620 & 4.9 & 5.2039 & TRN \\
\hline CHEMBL1428862 & 688620 & 4.45 & 4.8021 & TRN \\
\hline CHEMBL1578511 & 688620 & 4.95 & 5.0362 & TST \\
\hline CHEMBL1321120 & 688620 & 5.5 & 4.9202 & TRN \\
\hline CHEMBL1578802 & 688620 & 6.6 & 4.9922 & TST \\
\hline CHEMBL1424907 & 688620 & 5.1 & 5.2299 & TRN \\
\hline CHEMBL484744 & 688620 & 5.45 & 5.1403 & TRN \\
\hline CHEMBL1475515 & 688620 & 4.8 & 5.1042 & TRN \\
\hline CHEMBL1524678 & 688620 & 4.6 & 4.8988 & TST \\
\hline CHEMBL1469259 & 688620 & 4.45 & 5.2694 & TST \\
\hline CHEMBL1503937 & 688620 & 5.55 & 5.0521 & TRN \\
\hline CHEMBL1340089 & 688620 & 5.2 & 5.5029 & TRN \\
\hline CHEMBL1401437 & 688620 & 6.15 & 5.0186 & TST \\
\hline CHEMBL1489246 & 688620 & 7.3497 & 4.9333 & TRN \\
\hline CHEMBL1330488 & 688620 & 6.35 & 4.9899 & TST \\
\hline CHEMBL1483080 & 688620 & 4.9 & 5.0603 & TST \\
\hline CHEMBL1424380 & 688620 & 6.15 & 6.3734 & TRN \\
\hline CHEMBL1428165 & 688620 & 5.0 & 4.8818 & TRN \\
\hline CHEMBL1431671 & 688620 & 5.0 & 5.1807 & TRN \\
\hline CHEMBL1543680 & 688620 & 4.45 & 5.004 & TRN \\
\hline CHEMBL1325147 & 688620 & 4.9 & 5.1699 & TST \\
\hline CHEMBL1504609 & 688620 & 5.05 & 4.8668 & TRN \\
\hline CHEMBL1418754 & 688620 & 4.45 & 4.8613 & TRN \\
\hline CHEMBL1524529 & 688620 & 4.5 & 4.9459 & TRN \\
\hline CHEMBL1311109 & 688620 & 5.8 & 5.0445 & TRN \\
\hline CHEMBL1491069 & 688620 & 4.95 & 4.9326 & TRN \\
\hline CHEMBL1557713 & 688620 & 4.7 & 4.8982 & TRN \\
\hline CHEMBL1983125 & 688620 & 6.2 & 5.6295 & TRN \\
\hline CHEMBL1608703 & 688620 & 4.9 & 4.994 & TRN \\
\hline CHEMBL1370642 & 688620 & 6.3 & 5.0244 & TRN \\
\hline CHEMBL1546836 & 688620 & 6.7001 & 5.032 & TRN \\
\hline CHEMBL 246655 & 688620 & 4.6 & 5.032 & TRN \\
\hline CHEMBL1410870 & 688620 & 5.2 & 5.1329 & TST \\
\hline CHEMBL1503467 & 688620 & 6.15 & 5.1872 & TST \\
\hline CHEMBL1387872 & 688620 & 4.65 & 5.1152 & TRN \\
\hline CHEMBL1466429 & 688620 & 5.05 & 4.9511 & TRN \\
\hline CHEMBL1511447 & 688620 & 4.95 & 5.0564 & TRN \\
\hline CHEMBL1493826 & 688620 & 4.85 & 5.0596 & TRN \\
\hline CHEMBL182150 & 688620 & 4.45 & 4.8406 & TST \\
\hline CHEMBL1976059 & 688620 & 5.85 & 5.4434 & TRN \\
\hline CHEMBL1467749 & 688620 & 4.8 & 4.7766 & TST \\
\hline CHEMBL1426744 & 688620 & 4.85 & 4.6697 & TST \\
\hline CHEMBL1428851 & 688620 & 4.8 & 5.2176 & TRN \\
\hline
\end{tabular}




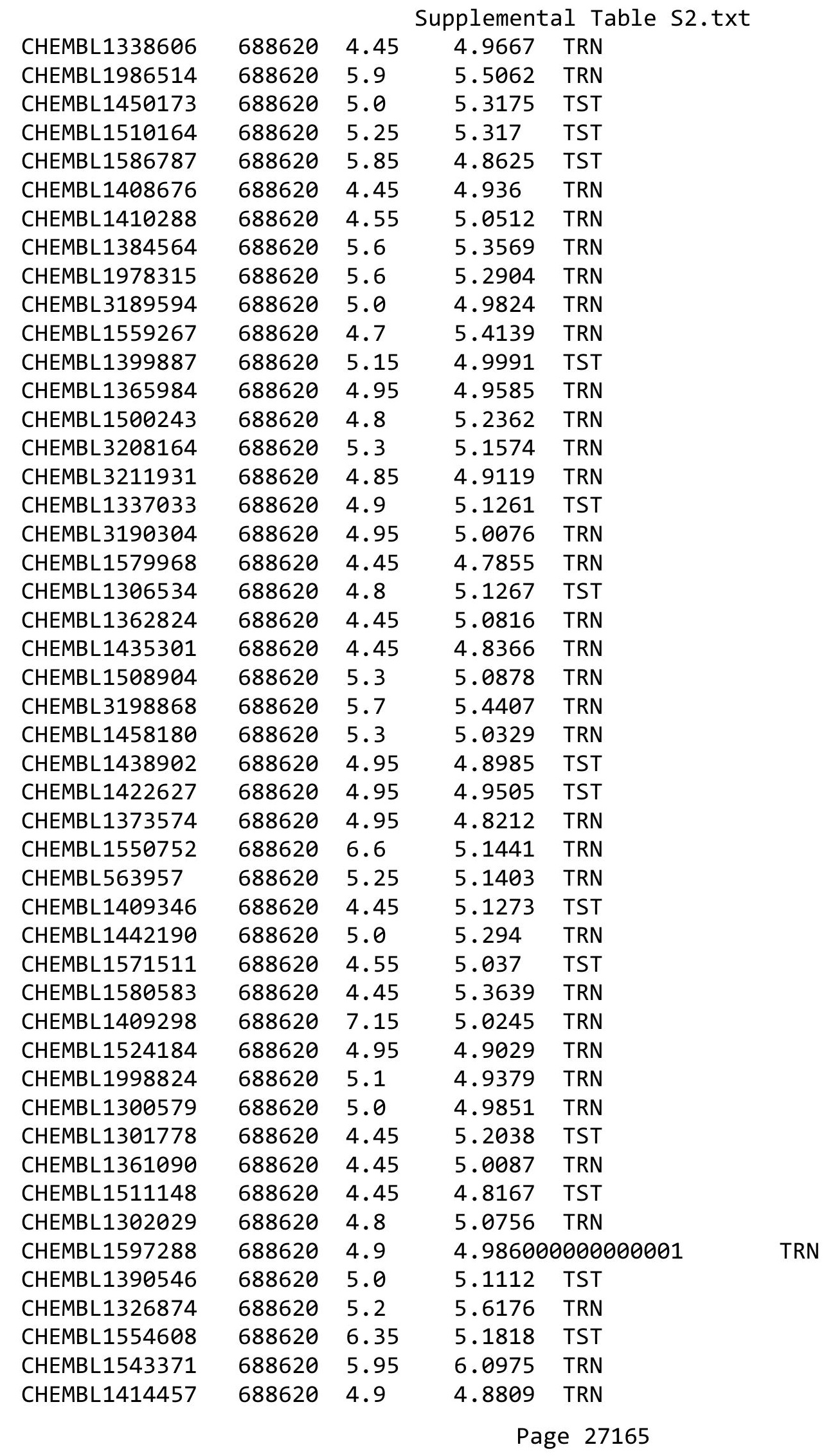




\begin{tabular}{|c|c|c|c|c|}
\hline \multicolumn{5}{|c|}{ pplemental $\mathrm{T}$} \\
\hline CHEMBL1505755 & 688620 & 4.8 & 4.9211 & TST \\
\hline CHEMBL1441850 & 688620 & 6.0 & 5.8528 & TRN \\
\hline CHEMBL1327928 & 688620 & 4.45 & 4.9441 & TST \\
\hline CHEMBL1455230 & 688620 & 5.35 & 5.3212 & TRN \\
\hline CHEMBL1351891 & 688620 & 4.8 & 5.0954 & TRN \\
\hline CHEMBL1429485 & 688620 & 4.45 & 4.9851 & TRN \\
\hline CHEMBL1426283 & 688620 & 4.8 & 4.9021 & TST \\
\hline CHEMBL3193661 & 688620 & 4.45 & 4.8426 & TRN \\
\hline CHEMBL1489297 & 688620 & 5.05 & 4.8893 & TRN \\
\hline CHEMBL1446133 & 688620 & 4.45 & 5.2616 & TRN \\
\hline CHEMBL1440860 & 688620 & 5.0 & 5.3539 & TST \\
\hline CHEMBL1347497 & 688620 & 4.45 & 4.6938 & TST \\
\hline CHEMBL1457623 & 688620 & 5.0 & 5.1279 & TRN \\
\hline CHEMBL1998893 & 688620 & 4.45 & 4.9815 & TRN \\
\hline CHEMBL1347093 & 688620 & 6.2 & 5.8034 & TST \\
\hline CHEMBL1579248 & 688620 & 5.25 & 4.8929 & TRN \\
\hline CHEMBL1438872 & 688620 & 4.55 & 4.9331 & TST \\
\hline CHEMBL1505687 & 688620 & 4.75 & 4.9959 & TRN \\
\hline CHEMBL1408847 & 688620 & 5.35 & 4.8614 & TST \\
\hline CHEMBL1376479 & 688620 & 5.0 & 4.9034 & TST \\
\hline CHEMBL1353515 & 688620 & 4.95 & 4.8962 & TST \\
\hline CHEMBL1550366 & 688620 & 4.95 & 5.0052 & TST \\
\hline CHEMBL1482355 & 688620 & 4.45 & 4.9263 & TRN \\
\hline CHEMBL1372053 & 688620 & 5.0 & 5.1429 & TST \\
\hline CHEMBL1348320 & 688620 & 7.2 & 5.0408 & TST \\
\hline CHEMBL1489190 & 688620 & 4.95 & 5.2145 & TRN \\
\hline CHEMBL1438069 & 688620 & 4.5 & 4.8478 & TST \\
\hline CHEMBL1587054 & 688620 & 4.95 & 4.7025 & TRN \\
\hline CHEMBL1411555 & 688620 & 4.45 & 5.0021 & TRN \\
\hline CHEMBL1309528 & 688620 & 4.85 & 4.9853 & TST \\
\hline CHEMBL1600073 & 688620 & 4.9 & 5.1039 & TRN \\
\hline CHEMBL1470275 & 688620 & 5.0 & 5.0078 & TST \\
\hline CHEMBL1399698 & 688620 & 5.25 & 5.5819 & TRN \\
\hline CHEMBL1426059 & 688620 & 4.8 & 5.2088 & TRN \\
\hline CHEMBL1597059 & 688620 & 5.7 & 4.9998 & TRN \\
\hline CHEMBL1563042 & 688620 & 4.95 & 5.0434 & TST \\
\hline CHEMBL1347842 & 688620 & 5.45 & 5.3222 & TRN \\
\hline CHEMBL1549628 & 688620 & 4.9 & 5.0726 & TRN \\
\hline CHEMBL1313303 & 688620 & 4.8 & 5.0032 & TRN \\
\hline CHEMBL1415457 & 688620 & 4.8 & 5.0855 & TRN \\
\hline CHEMBL1348309 & 688620 & 4.45 & 5.0667 & TST \\
\hline CHEMBL1387016 & 688620 & 5.65 & 5.3222 & TST \\
\hline CHEMBL1469625 & 688620 & 4.7 & 4.9007 & TRN \\
\hline CHEMBL1507620 & 688620 & 4.5 & 5.0085 & TRN \\
\hline CHEMBL1605720 & 688620 & 5.3 & 5.1372 & TRN \\
\hline CHEMBL1385665 & 688620 & 4.45 & 5.1645 & TRN \\
\hline CHEMBL1387775 & 688620 & 5.7 & 5.1188 & TRN \\
\hline CHEMBL1382822 & 688620 & 5.0 & 4.8932 & TRN \\
\hline
\end{tabular}




\begin{tabular}{|c|c|c|c|c|c|}
\hline \multicolumn{6}{|c|}{ Supplemental Table S2.txt } \\
\hline CHEMBL1601299 & 688620 & 6.15 & 5.1401 & TRN & \\
\hline CHEMBL1484220 & 688620 & 5.0 & 5.1806 & TST & \\
\hline CHEMBL3195010 & 688620 & 5.5 & 5.1365 & TRN & \\
\hline CHEMBL1478190 & 688620 & 4.45 & 4.8056 & TRN & \\
\hline CHEMBL1592298 & 688620 & 4.85 & 5.0111 & TRN & \\
\hline CHEMBL1486757 & 688620 & 4.9 & 4.885 & TST & \\
\hline CHEMBL1500598 & 688620 & 4.45 & 5.0792 & TRN & \\
\hline CHEMBL1383333 & 688620 & 5.7 & 5.7219 & TRN & \\
\hline CHEMBL1305196 & 688620 & 5.65 & 5.2404 & TRN & \\
\hline CHEMBL1346159 & 688620 & 4.75 & 5.0747 & TRN & \\
\hline CHEMBL1313816 & 688620 & 6.35 & 5.0766 & TRN & \\
\hline CHEMBL1348110 & 688620 & 4.9 & 4.944 & TRN & \\
\hline CHEMBL1352902 & 688620 & 5.15 & 5.09699 & 99999999995 & TRN \\
\hline CHEMBL1471350 & 688620 & 5.0 & 5.0702 & TST & \\
\hline CHEMBL1443210 & 688620 & 4.7 & 4.7444 & TST & \\
\hline CHEMBL1573902 & 688620 & 5.15 & 5.1163 & TST & \\
\hline CHEMBL1594835 & 688620 & 5.7 & 5.3437 & TRN & \\
\hline CHEMBL1309162 & 688620 & 5.5 & 5.3669 & TRN & \\
\hline CHEMBL1529895 & 688620 & 5.85 & 5.2167 & TST & \\
\hline CHEMBL1567586 & 688620 & 4.85 & 5.107 & TRN & \\
\hline CHEMBL1348379 & 688620 & 5.3 & 5.0309 & TRN & \\
\hline CHEMBL1320908 & 688620 & 4.85 & 4.9847 & TRN & \\
\hline CHEMBL1450537 & 688620 & 5.05 & 5.2096 & TST & \\
\hline CHEMBL1585105 & 688620 & 4.65 & 5.2047 & TRN & \\
\hline CHEMBL1444846 & 688620 & 4.65 & 5.0545 & TRN & \\
\hline CHEMBL1344512 & 688620 & 4.5 & 5.1536 & TRN & \\
\hline CHEMBL1580925 & 688620 & 4.45 & 5.0827 & TST & \\
\hline CHEMBL1489966 & 688620 & 4.7 & 5.3236 & TST & \\
\hline CHEMBL1430415 & 688620 & 7.3497 & 5.0368 & TRN & \\
\hline CHEMBL258881 & 688620 & 4.95 & 5.1566 & TRN & \\
\hline CHEMBL1501618 & 688620 & 4.8 & 4.8277 & TRN & \\
\hline CHEMBL 2374081 & 688620 & 6.45 & 5.2418 & TST & \\
\hline CHEMBL1492352 & 688620 & 4.95 & 4.9627 & TST & \\
\hline CHEMBL1303245 & 688620 & 4.95 & 4.9467 & TRN & \\
\hline CHEMBL1568140 & 688620 & 4.45 & 5.0587 & TST & \\
\hline CHEMBL1972133 & 688620 & 4.8 & 5.0014 & TRN & \\
\hline CHEMBL1409514 & 688620 & 4.95 & 4.893 & TST & \\
\hline CHEMBL1602774 & 688620 & 4.9 & 5.1171 & TST & \\
\hline CHEMBL1550490 & 688620 & 4.8 & 4.7516 & TRN & \\
\hline CHEMBL1386571 & 688620 & 5.0 & 4.9035 & TRN & \\
\hline CHEMBL1519014 & 688620 & 5.75 & 5.0808 & TST & \\
\hline CHEMBL1371766 & 688620 & 6.0 & 5.4828 & TRN & \\
\hline CHEMBL1576382 & 688620 & 4.5 & 4.8978 & TRN & \\
\hline CHEMBL1339385 & 688620 & 4.65 & 4.8253 & TRN & \\
\hline CHEMBL1301581 & 688620 & 5.25 & 5.1196 & TRN & \\
\hline CHEMBL1485525 & 688620 & 4.55 & 4.8986 & TRN & \\
\hline CHEMBL1494038 & 688620 & 4.65 & 4.8756 & TST & \\
\hline CHEMBL1439851 & 688620 & 5.3 & 5.5034 & TRN & \\
\hline
\end{tabular}




\begin{tabular}{|c|c|c|c|c|c|}
\hline \multicolumn{6}{|c|}{ Supplemental Table S2.txt } \\
\hline CHEMBL1459586 & 688620 & 6.25 & 5.1825 & TRN & \\
\hline CHEMBL1330356 & 688620 & 4.45 & 5.0361 & TRN & \\
\hline CHEMBL1310857 & 688620 & 4.6 & 4.71399 & 99999999995 & TRN \\
\hline CHEMBL1337919 & 688620 & 4.9 & 4.8933 & TRN & \\
\hline CHEMBL1462972 & 688620 & 5.2 & 4.9697 & TRN & \\
\hline CHEMBL1578428 & 688620 & 4.95 & 5.1576 & TRN & \\
\hline CHEMBL1982623 & 688620 & 5.4 & 5.3073 & TRN & \\
\hline CHEMBL1510242 & 688620 & 5.6 & 4.7947 & TRN & \\
\hline CHEMBL1438348 & 688620 & 4.95 & 5.1038 & TST & \\
\hline CHEMBL1597816 & 688620 & 6.2 & 5.227 & TRN & \\
\hline CHEMBL3191689 & 688620 & 4.45 & 4.8491 & TRN & \\
\hline CHEMBL1330459 & 688620 & 4.85 & 5.6254 & TST & \\
\hline CHEMBL1542925 & 688620 & 4.95 & 5.1177 & TRN & \\
\hline CHEMBL1379350 & 688620 & 5.5 & 5.4357 & TRN & \\
\hline CHEMBL1507250 & 688620 & 7.699 & 6.3543 & TRN & \\
\hline CHEMBL 2001739 & 688620 & 6.8499 & 6.0908 & TRN & \\
\hline CHEMBL1528833 & 688620 & 5.0 & 4.8084 & TRN & \\
\hline CHEMBL1548509 & 688620 & 4.8 & 5.0086 & TST & \\
\hline CHEMBL1574656 & 688620 & 5.2 & 4.8717 & TST & \\
\hline CHEMBL1520137 & 688620 & 6.0 & 5.341 & TRN & \\
\hline CHEMBL1595373 & 688620 & 4.85 & 5.3571 & TRN & \\
\hline CHEMBL1314042 & 688620 & 5.25 & 5.1758 & TRN & \\
\hline CHEMBL1572469 & 688620 & 5.0 & 4.8515 & TRN & \\
\hline CHEMBL3207777 & 688620 & 4.55 & 5.17 & TRN & \\
\hline CHEMBL1431113 & 688620 & 5.25 & 4.8996 & TRN & \\
\hline CHEMBL1374746 & 688620 & 4.8 & 5.19600 & 0000000001 & TST \\
\hline CHEMBL1576339 & 688620 & 5.25 & 4.9757 & TST & \\
\hline CHEMBL1326699 & 688620 & 4.9 & 4.8841 & TRN & \\
\hline CHEMBL1533260 & 688620 & 4.75 & 5.2723 & TRN & \\
\hline CHEMBL1502635 & 688620 & 4.8 & 5.8675 & TRN & \\
\hline CHEMBL1459441 & 688620 & 4.45 & 4.9867 & TST & \\
\hline CHEMBL1407501 & 688620 & 4.45 & 4.6482 & TRN & \\
\hline CHEMBL1313294 & 688620 & 4.75 & 5.1367 & TRN & \\
\hline CHEMBL1525544 & 688620 & 4.95 & 5.0944 & TST & \\
\hline CHEMBL3189520 & 688620 & 6.25 & 5.0446 & TRN & \\
\hline CHEMBL3194662 & 688620 & 5.0 & 5.3712 & TRN & \\
\hline CHEMBL1374834 & 688620 & 4.8 & 5.1589 & TRN & \\
\hline CHEMBL1325097 & 688620 & 5.4 & 4.9269 & TRN & \\
\hline CHEMBL1967772 & 688620 & 4.45 & 4.9976 & TRN & \\
\hline CHEMBL1406158 & 688620 & 4.8 & 4.9594 & TRN & \\
\hline CHEMBL1571281 & 688620 & 4.55 & 4.8863 & TRN & \\
\hline CHEMBL1549937 & 688620 & 4.45 & 4.9178 & TRN & \\
\hline CHEMBL1439392 & 688620 & 5.0 & 5.0151 & TST & \\
\hline CHEMBL1465915 & 688620 & 4.6 & 5.1074 & TRN & \\
\hline CHEMBL1451542 & 688620 & 5.9 & 5.0842 & TST & \\
\hline CHEMBL3193111 & 688620 & 5.25 & 5.4216 & TRN & \\
\hline CHEMBL1493493 & 688620 & 4.95 & 5.0784 & TST & \\
\hline CHEMBL2369239 & 688620 & 4.45 & 4.5623 & TRN & \\
\hline
\end{tabular}




\begin{tabular}{|c|c|c|c|c|c|}
\hline \multirow{3}{*}{$\begin{array}{l}\text { CHEMBL1443736 } \\
\text { CHEMBL1519962 }\end{array}$} & \multirow{3}{*}{$\begin{array}{l}688620 \\
688620\end{array}$} & \multicolumn{4}{|c|}{ Supplemental Table S2.txt } \\
\hline & & 4.9 & \multicolumn{2}{|c|}{5.013999999999999} & TRN \\
\hline & & 5.25 & 4.926 & TRN & \\
\hline CHEMBL1562934 & 688620 & 5.6 & 5.521 & TRN & \\
\hline CHEMBL1369745 & 688620 & 5.7 & 4.8035 & TST & \\
\hline CHEMBL1371842 & 688620 & 4.45 & 4.9664 & TRN & \\
\hline CHEMBL1504017 & 688620 & 5.55 & 4.8318 & TRN & \\
\hline CHEMBL3199258 & 688620 & 4.75 & 5.308 & TRN & \\
\hline CHEMBL1477524 & 688620 & 4.95 & 5.3022 & TST & \\
\hline CHEMBL3209007 & 688620 & 5.5 & 5.0342 & TST & \\
\hline CHEMBL3194082 & 688620 & 4.75 & 5.5835 & TRN & \\
\hline CHEMBL1564919 & 688620 & 5.35 & 5.3634 & TRN & \\
\hline CHEMBL1463996 & 688620 & 4.45 & 5.0465 & TRN & \\
\hline CHEMBL3208652 & 688620 & 4.45 & 5.1172 & TRN & \\
\hline CHEMBL 2006848 & 688620 & 5.45 & 5.5728 & TRN & \\
\hline CHEMBL1610720 & 688620 & 5.2 & 4.9624 & TRN & \\
\hline CHEMBL1321717 & 688620 & 5.7 & 4.8916 & TST & \\
\hline CHEMBL1393976 & 688620 & 4.65 & 5.1695 & TRN & \\
\hline CHEMBL3192945 & 688620 & 4.45 & 5.1535 & TST & \\
\hline CHEMBL1526130 & 688620 & 5.15 & 5.0153 & TRN & \\
\hline CHEMBL1324254 & 688620 & 4.8 & 5.0055 & TST & \\
\hline CHEMBL1520326 & 688620 & 4.65 & 4.8124 & TST & \\
\hline CHEMBL1551000 & 688620 & 4.7 & 5.1294 & TST & \\
\hline CHEMBL1360784 & 688620 & 4.75 & 5.0408 & TRN & \\
\hline CHEMBL1470674 & 688620 & 4.95 & 4.9261 & TST & \\
\hline CHEMBL1491574 & 688620 & 4.75 & 4.9981 & TRN & \\
\hline CHEMBL1453644 & 688620 & 5.45 & 5.0404 & TRN & \\
\hline CHEMBL1462774 & 688620 & 4.9 & 4.8897 & TRN & \\
\hline CHEMBL1372287 & 688620 & 4.85 & 5.2645 & TRN & \\
\hline CHEMBL1582453 & 688620 & 4.9 & 5.1267 & TRN & \\
\hline CHEMBL1381472 & 688620 & 5.35 & 5.4254 & TRN & \\
\hline CHEMBL1602896 & 688620 & 4.45 & 4.9206 & TRN & \\
\hline CHEMBL1445329 & 688620 & 4.95 & 5.0873 & TST & \\
\hline CHEMBL1541550 & 688620 & 4.95 & 5.1089 & TRN & \\
\hline CHEMBL1558042 & 688620 & 4.45 & 4.832 & TRN & \\
\hline CHEMBL1989586 & 688620 & 5.65 & 5.6408 & TRN & \\
\hline CHEMBL1341379 & 688620 & 4.9 & 5.0839 & TST & \\
\hline CHEMBL1450097 & 688620 & 4.45 & 4.9317 & TRN & \\
\hline CHEMBL1364703 & 688620 & 5.05 & 5.1661 & TRN & \\
\hline CHEMBL1538156 & 688620 & 4.65 & 5.0801 & TST & \\
\hline CHEMBL1604152 & 688620 & 5.65 & 4.9217 & TST & \\
\hline CHEMBL1455586 & 688620 & 4.75 & 5.1549 & TRN & \\
\hline CHEMBL1382232 & 688620 & 5.2 & 5.0609 & TRN & \\
\hline CHEMBL1539237 & 688620 & 5.7 & 4.7974 & TRN & \\
\hline CHEMBL1968080 & 688620 & 6.25 & 5.7346 & TRN & \\
\hline CHEMBL1434064 & 688620 & 4.9 & 5.0494 & TRN & \\
\hline CHEMBL1404780 & 688620 & 5.1 & 5.8702 & TST & \\
\hline CHEMBL1487868 & 688620 & 4.95 & 4.8877 & TRN & \\
\hline CHEMBL1601144 & 688620 & 4.95 & 4.8571 & TST & \\
\hline
\end{tabular}




\begin{tabular}{|c|c|c|c|c|c|}
\hline \multicolumn{6}{|c|}{ Supplemental Table S2.txt } \\
\hline CHEMBL1522473 & 688620 & 4.75 & 4.9693 & TRN & \\
\hline CHEMBL1585323 & 688620 & 4.95 & 4.8145 & TST & \\
\hline CHEMBL1477998 & 688620 & 4.8 & 5.0222 & TRN & \\
\hline CHEMBL1313043 & 688620 & 5.0 & 5.1775 & TRN & \\
\hline CHEMBL1370991 & 688620 & 6.4 & 6.5824 & TRN & \\
\hline CHEMBL1529346 & 688620 & 5.2 & 5.2682 & TRN & \\
\hline CHEMBL3189686 & 688620 & 4.9 & 5.5095 & TRN & \\
\hline CHEMBL1558328 & 688620 & 4.8 & 4.7887 & TRN & \\
\hline CHEMBL1605128 & 688620 & 4.6 & 5.0771 & TRN & \\
\hline CHEMBL1471454 & 688620 & 4.9 & 5.0312 & TRN & \\
\hline CHEMBL1413246 & 688620 & 4.45 & 5.0577 & TST & \\
\hline CHEMBL1523417 & 688620 & 5.0 & 4.8405 & TRN & \\
\hline CHEMBL1331842 & 688620 & 5.45 & 5.0941 & TRN & \\
\hline CHEMBL1345453 & 688620 & 4.7 & 5.0045 & TRN & \\
\hline CHEMBL1540023 & 688620 & 4.5 & 5.2998 & TRN & \\
\hline CHEMBL1367272 & 688620 & 6.25 & 5.0685 & TST & \\
\hline CHEMBL1541251 & 688620 & 5.55 & 4.8477 & TRN & \\
\hline CHEMBL1502095 & 688620 & 4.95 & 4.8578 & TRN & \\
\hline CHEMBL1403837 & 688620 & 4.45 & 4.9524 & TRN & \\
\hline CHEMBL546493 & 688620 & 4.45 & 5.2711 & TRN & \\
\hline CHEMBL1446479 & 688620 & 4.85 & 4.99100 & 00000000005 & TRN \\
\hline CHEMBL3189543 & 688620 & 4.9 & 4.9339 & TRN & \\
\hline CHEMBL1339237 & 688620 & 5.35 & 5.1848 & TRN & \\
\hline CHEMBL 3214357 & 688620 & 5.25 & 5.2994 & TRN & \\
\hline CHEMBL1547898 & 688620 & 4.8 & 5.0549 & TRN & \\
\hline CHEMBL1321222 & 688620 & 4.7 & 4.8938 & TRN & \\
\hline CHEMBL1970527 & 688620 & 5.0 & 4.9743 & TRN & \\
\hline CHEMBL1390492 & 688620 & 5.45 & 5.2768 & TRN & \\
\hline CHEMBL1980306 & 688620 & 4.9 & 5.0539 & TRN & \\
\hline CHEMBL1493071 & 688620 & 4.45 & 4.7862 & TRN & \\
\hline CHEMBL164791 & 688620 & 4.95 & 5.0127 & TST & \\
\hline CHEMBL1342371 & 688620 & 4.45 & 4.9759 & TST & \\
\hline CHEMBL1337160 & 688620 & 5.15 & 5.2901 & TRN & \\
\hline CHEMBL1313954 & 688620 & 4.9 & 4.9675 & TST & \\
\hline CHEMBL1584316 & 688620 & 4.5 & 4.9771 & TRN & \\
\hline CHEMBL1347556 & 688620 & 4.95 & 4.9904 & TRN & \\
\hline CHEMBL1459183 & 688620 & 5.15 & 4.9627 & TST & \\
\hline CHEMBL1357674 & 688620 & 5.0 & 4.9467 & TST & \\
\hline CHEMBL3193531 & 688620 & 4.45 & 5.0349 & TRN & \\
\hline CHEMBL1419618 & 688620 & 5.4 & 5.0607 & TRN & \\
\hline CHEMBL1354424 & 688620 & 5.15 & 4.8384 & TRN & \\
\hline CHEMBL3193359 & 688620 & 5.2 & 5.348 & TRN & \\
\hline CHEMBL1450838 & 688620 & 6.1 & 4.7477 & TST & \\
\hline CHEMBL1965280 & 688620 & 5.05 & 4.9813 & TRN & \\
\hline CHEMBL1427736 & 688620 & 5.7 & 5.2845 & TRN & \\
\hline CHEMBL1095276 & 688620 & 5.25 & 5.8204 & TRN & \\
\hline CHEMBL3196186 & 688620 & 6.2 & 5.9807 & TRN & \\
\hline CHEMBL1573719 & 688620 & 4.45 & 5.1653 & TST & \\
\hline
\end{tabular}




\begin{tabular}{|c|c|c|c|c|c|}
\hline \multirow{2}{*}{ CHEMBL1613025 } & \multicolumn{5}{|c|}{ plementa } \\
\hline & 688620 & 4.95 & 4.9977 & TST & \\
\hline CHEMBL1346212 & 688620 & 4.85 & 4.9093 & TST & \\
\hline CHEMBL1416156 & 688620 & 5.35 & 5.16 & TRN & \\
\hline CHEMBL1311796 & 688620 & 4.85 & 5.4118 & TRN & \\
\hline CHEMBL1501060 & 688620 & 5.4 & 5.0164 & TRN & \\
\hline CHEMBL1424586 & 688620 & 5.35 & 5.0619 & TRN & \\
\hline CHEMBL3208808 & 688620 & 5.1 & 4.9773 & TST & \\
\hline CHEMBL1393038 & 688620 & 4.7 & 4.7269 & TST & \\
\hline CHEMBL1352867 & 688620 & 6.5501 & 5.7812 & TRN & \\
\hline CHEMBL1547853 & 688620 & 4.95 & 5.1797 & TST & \\
\hline CHEMBL8747 & 688620 & 4.45 & 4.9396 & TST & \\
\hline CHEMBL1465707 & 688620 & 4.45 & 4.8348 & TRN & \\
\hline CHEMBL1985863 & 688620 & 5.55 & 5.051 & TRN & \\
\hline CHEMBL1997376 & 688620 & 6.35 & 5.0674 & TRN & \\
\hline CHEMBL1607561 & 688620 & 5.45 & 5.3473 & TRN & \\
\hline CHEMBL3210150 & 688620 & 4.8 & 5.1218 & TST & \\
\hline CHEMBL1445380 & 688620 & 4.9 & 4.9128 & TRN & \\
\hline CHEMBL1381815 & 688620 & 4.5 & 4.9303 & TRN & \\
\hline CHEMBL3193925 & 688620 & 5.05 & 5.1618 & TRN & \\
\hline CHEMBL1443425 & 688620 & 4.45 & 4.8323 & TRN & \\
\hline CHEMBL1329192 & 688620 & 5.25 & 5.1824 & TRN & \\
\hline CHEMBL1408465 & 688620 & 5.45 & 5.2281 & TRN & \\
\hline CHEMBL1459091 & 688620 & 4.45 & 4.9878 & TRN & \\
\hline CHEMBL1474402 & 688620 & 4.5 & 5.0811 & TRN & \\
\hline CHEMBL1380478 & 688620 & 6.1 & 5.1623 & TST & \\
\hline CHEMBL1300277 & 688620 & 4.7 & 4.97199 & 99999999995 & TRN \\
\hline CHEMBL1346266 & 688620 & 4.9 & 5.1958 & TRN & \\
\hline CHEMBL1398645 & 688620 & 5.35 & 5.4407 & TST & \\
\hline CHEMBL1572157 & 688620 & 4.6 & 5.0442 & TRN & \\
\hline CHEMBL1392901 & 688620 & 4.9 & 4.93199 & 99999999995 & TRN \\
\hline CHEMBL1304441 & 688620 & 4.8 & 5.0442 & TRN & \\
\hline CHEMBL1447720 & 688620 & 4.7 & 5.1022 & TRN & \\
\hline CHEMBL1426087 & 688620 & 4.45 & 5.0857 & TST & \\
\hline CHEMBL1603540 & 688620 & 4.45 & 4.9997 & TST & \\
\hline CHEMBL3210849 & 688620 & 4.5 & 4.9604 & TRN & \\
\hline CHEMBL1564137 & 688620 & 4.9 & 5.0447 & TRN & \\
\hline CHEMBL1431576 & 688620 & 4.65 & 4.8893 & TRN & \\
\hline CHEMBL1998074 & 688620 & 4.8 & 4.9343 & TRN & \\
\hline CHEMBL1586404 & 688620 & 4.65 & 4.7863 & TRN & \\
\hline CHEMBL1567008 & 688620 & 4.45 & 4.8875 & TRN & \\
\hline CHEMBL1369094 & 688620 & 4.45 & 5.1109 & TRN & \\
\hline CHEMBL1467492 & 688620 & 4.65 & 4.8275 & TRN & \\
\hline CHEMBL1558941 & 688620 & 4.45 & 4.5364 & TRN & \\
\hline CHEMBL 3194737 & 688620 & 4.45 & 5.0926 & TRN & \\
\hline CHEMBL601351 & 688620 & 4.7 & 4.9369 & TST & \\
\hline CHEMBL1451550 & 688620 & 5.65 & 4.9255 & TST & \\
\hline CHEMBL1374464 & 688620 & 5.4 & 5.06800 & 20000000005 & TRN \\
\hline CHEMBL1350435 & 688620 & 5.35 & 5.0552 & TRN & \\
\hline & & & & 27171 & \\
\hline
\end{tabular}




\begin{tabular}{|c|c|c|c|c|c|}
\hline \multirow{2}{*}{ CHEMBL 1605010} & \multirow{2}{*}{688620} & \\
\hline & & 5.0 & 5.0129 & \multicolumn{2}{|l|}{ TRN } \\
\hline CHEMBL1548890 & 688620 & 4.9 & 4.7691 & \multicolumn{2}{|l|}{ TRN } \\
\hline CHEMBL1431441 & 688620 & 4.6 & 4.6611 & \multicolumn{2}{|l|}{ TRN } \\
\hline CHEMBL3210312 & 688620 & 4.5 & 4.9835 & \multicolumn{2}{|l|}{ TRN } \\
\hline CHEMBL1442725 & 688620 & 5.05 & 4.988 & \multicolumn{2}{|l|}{ TRN } \\
\hline CHEMBL1330105 & 688620 & 4.45 & 5.0794 & \multicolumn{2}{|l|}{ TRN } \\
\hline CHEMBL1301294 & 688620 & 4.45 & 5.0561 & \multicolumn{2}{|l|}{ TRN } \\
\hline CHEMBL3198646 & 688620 & 4.45 & 4.8256 & \multicolumn{2}{|l|}{ TRN } \\
\hline CHEMBL1568039 & 688620 & 4.45 & 4.9699 & \multicolumn{2}{|l|}{ TRN } \\
\hline CHEMBL1347315 & 688620 & 5.15 & 5.1383 & \multicolumn{2}{|l|}{ TST } \\
\hline CHEMBL1424393 & 688620 & 4.45 & 4.9426 & \multicolumn{2}{|l|}{ TRN } \\
\hline CHEMBL1305463 & 688620 & 6.35 & 5.0566 & \multicolumn{2}{|l|}{ TRN } \\
\hline CHEMBL1545668 & 688620 & 5.4 & 4.9999 & \multicolumn{2}{|l|}{ TRN } \\
\hline CHEMBL1363884 & 688620 & 5.55 & 5.1127 & \multicolumn{2}{|l|}{ TRN } \\
\hline CHEMBL1589707 & 688620 & 4.45 & 4.8991 & \multicolumn{2}{|l|}{ TRN } \\
\hline CHEMBL 1464670 & 688620 & 5.05 & 4.7642 & \multicolumn{2}{|l|}{ TRN } \\
\hline CHEMBL1606729 & 688620 & 4.45 & 5.2305 & \multicolumn{2}{|l|}{ TST } \\
\hline CHEMBL1370356 & 688620 & 5.05 & 4.9936 & TRN & \\
\hline CHEMBL1405870 & 688620 & 4.45 & 4.9536 & TRN & \\
\hline CHEMBL1344702 & 688620 & 4.45 & 4.8949 & TRN & \\
\hline CHEMBL1585801 & 688620 & 5.05 & 5.0807 & TRN & \\
\hline CHEMBL1404896 & 688620 & 5.5 & 5.199 & TRN & \\
\hline CHEMBL1342047 & 688620 & 4.8 & 4.699 & TRN & \\
\hline CHEMBL1466500 & 688620 & 4.45 & 4.805 & TRN & \\
\hline CHEMBL1596097 & 688620 & 4.9 & 4.8806 & TRN & \\
\hline CHEMBL1545810 & 688620 & 6.45 & 5.7836 & TRN & \\
\hline CHEMBL1580448 & 688620 & 5.05 & 4.9547 & TRN & \\
\hline CHEMBL1510693 & 688620 & 5.2 & 4.9962 & TRN & \\
\hline CHEMBL1481909 & 688620 & 4.95 & 5.0771 & TRN & \\
\hline CHEMBL1445101 & 688620 & 5.4 & 5.4403 & TST & \\
\hline CHEMBL1569981 & 688620 & 5.2 & 4.8336 & TST & \\
\hline CHEMBL1527934 & 688620 & 4.75 & 4.97199 & 99999999995 & TRN \\
\hline CHEMBL1576057 & 688620 & 4.85 & 4.9905 & TRN & \\
\hline CHEMBL1563444 & 688620 & 4.85 & 4.9024 & TRN & \\
\hline CHEMBL1478329 & 688620 & 4.95 & 5.0587 & TST & \\
\hline CHEMBL1402863 & 688620 & 4.8 & 5.0892 & TRN & \\
\hline CHEMBL1565562 & 688620 & 5.1 & 5.2105 & TRN & \\
\hline CHEMBL1584080 & 688620 & 4.45 & 4.6672 & TRN & \\
\hline CHEMBL3198173 & 688620 & 4.75 & 5.2297 & TRN & \\
\hline CHEMBL1340756 & 688620 & 5.25 & 5.0452 & TST & \\
\hline CHEMBL1478359 & 688620 & 5.0 & 5.0187 & TRN & \\
\hline CHEMBL1393596 & 688620 & 4.9 & 5.0287 & TST & \\
\hline CHEMBL1390470 & 688620 & 5.0 & 5.1404 & TST & \\
\hline CHEMBL1511771 & 688620 & 4.9 & 5.0928 & TRN & \\
\hline CHEMBL1431353 & 688620 & 4.45 & 4.9189 & TRN & \\
\hline CHEMBL1417120 & 688620 & 4.65 & 5.1339 & TRN & \\
\hline CHEMBL3194115 & 688620 & 4.9 & 5.42299 & 9999999999 & TRN \\
\hline CHEMBL1477499 & 688620 & 5.25 & 5.1823 & TRN & \\
\hline & & & & 27172 & \\
\hline
\end{tabular}




\begin{tabular}{|c|c|c|c|c|}
\hline \multicolumn{5}{|c|}{ Supplemental Table S2.txt } \\
\hline CHEMBL1545595 & 688620 & 6.3 & 5.2985 & TRN \\
\hline CHEMBL1558326 & 688620 & 4.8 & 5.0207 & TRN \\
\hline CHEMBL1382562 & 688620 & 4.65 & 4.8642 & TST \\
\hline CHEMBL1428850 & 688620 & 5.2 & 5.2384 & TST \\
\hline CHEMBL1402807 & 688620 & 6.5 & 4.9332 & TRN \\
\hline CHEMBL1458980 & 688620 & 4.9 & 4.8947 & TRN \\
\hline CHEMBL1504324 & 688620 & 5.4 & 5.003 & TRN \\
\hline CHEMBL1368932 & 688620 & 5.7 & 5.4064 & TRN \\
\hline CHEMBL1562221 & 688620 & 4.95 & 5.2055 & TRN \\
\hline CHEMBL1409075 & 688620 & 5.9 & 5.4192 & TST \\
\hline CHEMBL1576826 & 688620 & 4.9 & 4.9311 & TST \\
\hline CHEMBL3192235 & 688620 & 5.45 & 5.3377 & TRN \\
\hline CHEMBL1427553 & 688620 & 6.4 & 5.9796 & TRN \\
\hline CHEMBL1469288 & 688620 & 5.2 & 5.4451 & TRN \\
\hline CHEMBL129795 & 688620 & 6.0 & 5.6227 & TRN \\
\hline CHEMBL1486586 & 688620 & 7.0 & 5.3027 & TRN \\
\hline CHEMBL1565628 & 688620 & 4.65 & 5.1939 & TRN \\
\hline CHEMBL1313238 & 688620 & 6.1 & 5.4154 & TRN \\
\hline CHEMBL1412192 & 688620 & 5.0 & 4.9995 & TST \\
\hline CHEMBL1365469 & 688620 & 5.35 & 4.8837 & TRN \\
\hline CHEMBL3193693 & 688620 & 5.0 & 5.0649 & TRN \\
\hline CHEMBL1408069 & 688620 & 4.8 & 4.9268 & TST \\
\hline CHEMBL1509207 & 688620 & 5.5 & 5.3377 & TRN \\
\hline CHEMBL1565668 & 688620 & 5.4 & 5.4146 & TRN \\
\hline CHEMBL1393628 & 688620 & 4.95 & 5.0244 & TRN \\
\hline CHEMBL1342932 & 688620 & 5.05 & 4.9347 & TST \\
\hline CHEMBL1485516 & 688620 & 5.45 & 5.1061 & TRN \\
\hline CHEMBL1331684 & 688620 & 5.6 & 5.0018 & TRN \\
\hline CHEMBL1484616 & 688620 & 4.95 & 5.0525 & TRN \\
\hline CHEMBL1418518 & 688620 & 4.9 & 5.1737 & TRN \\
\hline CHEMBL1555267 & 688620 & 5.15 & 5.0406 & TRN \\
\hline CHEMBL1407622 & 688620 & 4.75 & 5.2725 & TRN \\
\hline CHEMBL3189193 & 688620 & 5.9 & 5.9992 & TRN \\
\hline CHEMBL1460315 & 688620 & 5.45 & 4.7024 & TRN \\
\hline CHEMBL1321818 & 688620 & 6.1 & 5.0789 & TST \\
\hline CHEMBL1338384 & 688620 & 4.45 & 4.9389 & TRN \\
\hline CHEMBL1415534 & 688620 & 4.75 & 5.0021 & TRN \\
\hline CHEMBL1308557 & 688620 & 5.0 & 5.0639 & TST \\
\hline CHEMBL1527814 & 688620 & 5.25 & 5.1012 & TRN \\
\hline CHEMBL1506653 & 688620 & 5.3 & 5.1146 & TRN \\
\hline CHEMBL1576750 & 688620 & 4.6 & 5.0665 & TRN \\
\hline CHEMBL1496501 & 688620 & 7.0 & 5.0482 & TRN \\
\hline CHEMBL1530785 & 688620 & 4.7 & 5.1606 & TST \\
\hline CHEMBL1303733 & 688620 & 4.55 & 4.7755 & TRN \\
\hline CHEMBL1539487 & 688620 & 5.2 & 5.1088 & TRN \\
\hline CHEMBL1987938 & 688620 & 6.45 & 6.4289 & TRN \\
\hline CHEMBL1599462 & 688620 & 4.85 & 4.992 & TRN \\
\hline CHEMBL1588605 & 688620 & 5.5 & 5.5331 & TRN \\
\hline
\end{tabular}




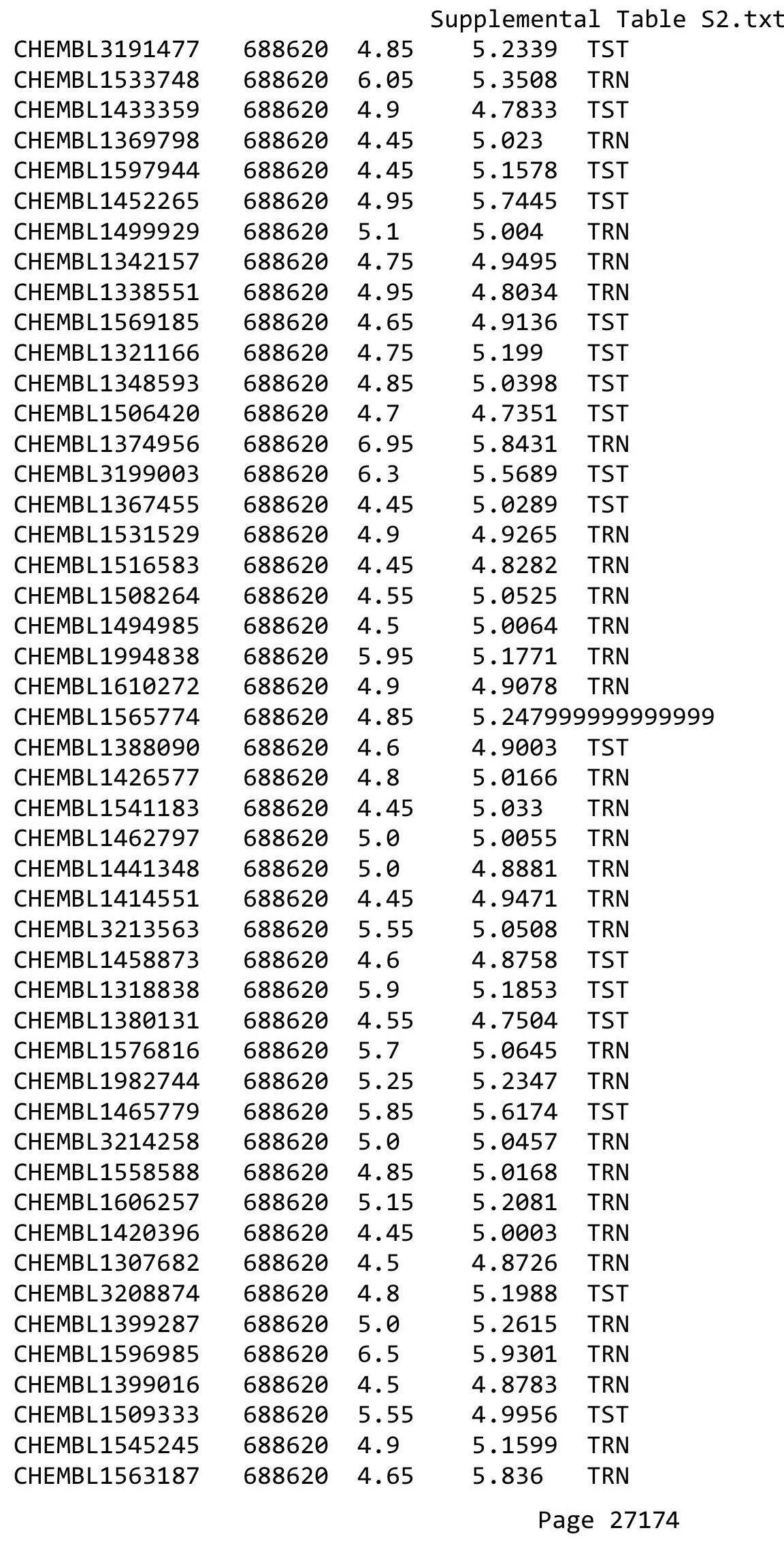




\begin{tabular}{|c|c|c|c|c|c|}
\hline \multicolumn{6}{|c|}{ Supplemental Table S2.txt } \\
\hline CHEMBL1575275 & 688620 & 5.5 & 5.8729 & TRN & \\
\hline CHEMBL1546077 & 688620 & 4.45 & 5.19 & TRN & \\
\hline CHEMBL1403005 & 688620 & 5.45 & 5.4209 & TRN & \\
\hline CHEMBL3199578 & 688620 & 5.6 & 5.1426 & TRN & \\
\hline CHEMBL1430931 & 688620 & 4.85 & 4.9898 & TRN & \\
\hline CHEMBL3210528 & 688620 & 4.45 & 4.8347 & TRN & \\
\hline CHEMBL1385926 & 688620 & 4.45 & 5.0022 & TRN & \\
\hline CHEMBL1461249 & 688620 & 4.75 & 5.1702 & TRN & \\
\hline CHEMBL1520663 & 688620 & 5.0 & 5.3167 & TRN & \\
\hline CHEMBL1403420 & 688620 & 4.8 & 4.6869 & TRN & \\
\hline CHEMBL3190218 & 688620 & 4.6 & 4.6135 & TRN & \\
\hline CHEMBL1529212 & 688620 & 4.45 & 4.8967 & TRN & \\
\hline CHEMBL1522171 & 688620 & 5.9 & 5.6549 & TRN & \\
\hline CHEMBL1523662 & 688620 & 4.9 & 4.8522 & TRN & \\
\hline CHEMBL1527336 & 688620 & 5.5 & 5.23799 & 99999999995 & TRN \\
\hline CHEMBL1448138 & 688620 & 6.0 & 5.1565 & TRN & \\
\hline CHEMBL1525425 & 688620 & 5.25 & 4.9886 & TRN & \\
\hline CHEMBL1453351 & 688620 & 5.0 & 4.9212 & TRN & \\
\hline CHEMBL1412468 & 688620 & 5.4 & 4.9706 & TRN & \\
\hline CHEMBL1383991 & 688620 & 5.6 & 5.4812 & TRN & \\
\hline CHEMBL1578546 & 688620 & 4.45 & 4.8102 & TRN & \\
\hline CHEMBL1482307 & 688620 & 4.9 & 4.9323 & TRN & \\
\hline CHEMBL1484022 & 688620 & 4.75 & 5.1968 & TRN & \\
\hline CHEMBL1335869 & 688620 & 5.25 & 5.1331 & TRN & \\
\hline CHEMBL1346479 & 688620 & 4.7 & 4.8533 & TRN & \\
\hline CHEMBL1524994 & 688620 & 5.2 & 5.1863 & TRN & \\
\hline CHEMBL1495966 & 688620 & 4.95 & 4.8016 & TRN & \\
\hline CHEMBL1324805 & 688620 & 5.55 & 5.28799 & 9999999999 & TRN \\
\hline CHEMBL1999959 & 688620 & 4.9 & 5.1284 & TST & \\
\hline CHEMBL1362285 & 688620 & 4.85 & 4.9798 & TRN & \\
\hline CHEMBL1457401 & 688620 & 4.75 & 5.1915 & TRN & \\
\hline CHEMBL1538895 & 688620 & 5.0 & 5.2707 & TRN & \\
\hline CHEMBL1300980 & 688620 & 4.8 & 4.8107 & TST & \\
\hline CHEMBL1489294 & 688620 & 5.1 & 5.0797 & TRN & \\
\hline CHEMBL1443824 & 688620 & 4.9 & 4.8005 & TRN & \\
\hline CHEMBL1497938 & 688620 & 4.95 & 5.0618 & TRN & \\
\hline CHEMBL1459755 & 688620 & 4.45 & 4.7926 & TRN & \\
\hline CHEMBL1400752 & 688620 & 4.75 & 4.8936 & TST & \\
\hline CHEMBL1498340 & 688620 & 5.0 & 4.8894 & TRN & \\
\hline CHEMBL1391414 & 688620 & 4.85 & 5.1565 & TST & \\
\hline CHEMBL 202721 & 688620 & 4.6 & 5.1598 & TST & \\
\hline CHEMBL1357872 & 688620 & 5.8 & 4.8126 & TRN & \\
\hline CHEMBL116548 & 688620 & 4.45 & 5.0245 & TST & \\
\hline CHEMBL1269154 & 688620 & 4.95 & 5.0684 & TRN & \\
\hline CHEMBL1431072 & 688620 & 5.0 & 5.1458 & TRN & \\
\hline CHEMBL1399871 & 688620 & 4.95 & 5.0543 & TST & \\
\hline CHEMBL1310006 & 688620 & 5.0 & 5.0385 & TRN & \\
\hline CHEMBL1529267 & 688620 & 5.75 & 5.2975 & TRN & \\
\hline
\end{tabular}




\begin{tabular}{|c|c|c|c|c|}
\hline \multicolumn{5}{|c|}{ Supplemental Table S2.txt } \\
\hline CHEMBL 22062 & 688620 & 4.65 & 5.0453 & TRN \\
\hline CHEMBL1390659 & 688620 & 4.9 & 4.9521 & TRN \\
\hline CHEMBL15192 & 688620 & 5.6 & 5.2819 & TST \\
\hline CHEMBL1567602 & 688620 & 4.45 & 5.1111 & TRN \\
\hline CHEMBL1303449 & 688620 & 4.8 & 4.9492 & TRN \\
\hline CHEMBL 3190217 & 688620 & 4.7 & 5.6057 & TRN \\
\hline CHEMBL1603366 & 688620 & 4.9 & 4.9469 & TRN \\
\hline CHEMBL1327733 & 688620 & 5.0 & 4.9318 & TST \\
\hline CHEMBL1389272 & 688620 & 4.6 & 5.147 & TRN \\
\hline CHEMBL1348874 & 688620 & 5.2 & 5.5099 & TRN \\
\hline CHEMBL 3145366 & 688620 & 6.4 & 6.1275 & TRN \\
\hline CHEMBL1491927 & 688620 & 4.95 & 5.3623 & TRN \\
\hline CHEMBL1577093 & 688620 & 6.0 & 5.5531 & TST \\
\hline CHEMBL1351738 & 688620 & 4.9 & 5.1808 & TRN \\
\hline CHEMBL3189493 & 688620 & 5.35 & 5.5025 & TRN \\
\hline CHEMBL1380961 & 688620 & 5.1 & 5.3026 & TST \\
\hline CHEMBL1458147 & 688620 & 5.0 & 5.2014 & TRN \\
\hline CHEMBL1338232 & 688620 & 4.9 & 4.9029 & TRN \\
\hline CHEMBL1610788 & 688620 & 6.7501 & 4.9227 & TST \\
\hline CHEMBL1300485 & 688620 & 5.05 & 5.0196 & TST \\
\hline CHEMBL3193631 & 688620 & 5.05 & 5.3283 & TRN \\
\hline CHEMBL1440612 & 688620 & 6.1 & 4.7879 & TRN \\
\hline CHEMBL1577004 & 688620 & 4.7 & 4.8221 & TST \\
\hline CHEMBL1549790 & 688620 & 4.9 & 5.0787 & TRN \\
\hline CHEMBL1307464 & 688620 & 4.45 & 4.9349 & TRN \\
\hline CHEMBL1481773 & 688620 & 4.8 & 5.0791 & TRN \\
\hline CHEMBL1365262 & 688620 & 5.6 & 4.6913 & TRN \\
\hline CHEMBL1548540 & 688620 & 4.75 & 4.9716 & TRN \\
\hline CHEMBL1309589 & 688620 & 4.9 & 5.1421 & TRN \\
\hline CHEMBL1572498 & 688620 & 4.9 & 4.8774 & TRN \\
\hline CHEMBL1482357 & 688620 & 4.35 & 6.093 & TRN \\
\hline CHEMBL1521259 & 688620 & 4.45 & 4.7206 & TRN \\
\hline CHEMBL1522697 & 688620 & 4.75 & 5.0226 & TST \\
\hline CHEMBL1488910 & 688620 & 4.75 & 5.0042 & TRN \\
\hline CHEMBL1455196 & 688620 & 4.9 & 5.0776 & TRN \\
\hline CHEMBL 3210234 & 688620 & 4.9 & 5.5477 & TST \\
\hline CHEMBL1431189 & 688620 & 5.3 & 5.1299 & TRN \\
\hline CHEMBL1559109 & 688620 & 5.45 & 5.3771 & TST \\
\hline CHEMBL1459796 & 688620 & 5.2 & 4.9092 & TRN \\
\hline CHEMBL1348761 & 688620 & 4.65 & 4.9809 & TRN \\
\hline CHEMBL1494619 & 688620 & 4.95 & 4.975 & TST \\
\hline CHEMBL1359787 & 688620 & 4.5 & 5.1945 & TRN \\
\hline CHEMBL1539127 & 688620 & 5.55 & 4.9432 & TRN \\
\hline CHEMBL1977376 & 688620 & 5.35 & 5.1878 & TRN \\
\hline CHEMBL1361273 & 688620 & 5.95 & 5.6779 & TST \\
\hline CHEMBL1433108 & 688620 & 5.5 & 4.796 & TRN \\
\hline CHEMBL 1505240 & 688620 & 5.35 & 4.9414 & TRN \\
\hline CHEMBL1506434 & 688620 & 4.5 & 4.9529 & TRN \\
\hline
\end{tabular}




\begin{tabular}{|c|c|c|c|c|c|}
\hline \multicolumn{6}{|c|}{ Supplemental Table s2.txt } \\
\hline CHEMBL1389194 & 688620 & 5.65 & 5.4413 & TRN & \\
\hline CHEMBL1305267 & 688620 & 5.1 & 5.0608 & TRN & \\
\hline CHEMBL1586719 & 688620 & 4.85 & 5.0154 & TRN & \\
\hline CHEMBL1589039 & 688620 & 4.45 & 5.0338 & TRN & \\
\hline CHEMBL1541699 & 688620 & 5.6 & 4.9973 & TRN & \\
\hline CHEMBL511499 & 688620 & 5.5 & 5.1052 & TST & \\
\hline CHEMBL1549095 & 688620 & 4.9 & 5.2248 & TRN & \\
\hline CHEMBL1377497 & 688620 & 4.9 & 5.0393 & TST & \\
\hline CHEMBL1503244 & 688620 & 4.8 & 5.0258 & TST & \\
\hline CHEMBL1343171 & 688620 & 4.85 & 4.9963 & TST & \\
\hline CHEMBL 3195371 & 688620 & 6.25 & 5.5122 & TRN & \\
\hline CHEMBL 3196732 & 688620 & 4.8 & 4.9945 & TST & \\
\hline CHEMBL1522087 & 688620 & 5.1 & 5.7711 & TRN & \\
\hline CHEMBL528791 & 688620 & 4.8 & 4.7664 & TRN & \\
\hline CHEMBL1386672 & 688620 & 6.5501 & 5.043 & TST & \\
\hline CHEMBL1469864 & 688620 & 4.7 & 4.8643 & TST & \\
\hline CHEMBL1582197 & 688620 & 5.2 & 5.2865 & TRN & \\
\hline CHEMBL1548151 & 688620 & 5.1 & 5.021 & TRN & \\
\hline CHEMBL1350032 & 688620 & 5.4 & 5.218 & TRN & \\
\hline CHEMBL1888628 & 688620 & 5.15 & 4.7925 & TRN & \\
\hline CHEMBL1491324 & 688620 & 5.75 & 5.3275 & TRN & \\
\hline CHEMBL1424443 & 688620 & 4.55 & 4.8669 & TST & \\
\hline CHEMBL1505779 & 688620 & 4.45 & 5.11600 & 00000000005 & TRN \\
\hline CHEMBL1345942 & 688620 & 4.45 & 4.9298 & TST & \\
\hline CHEMBL2001936 & 688620 & 4.95 & 4.9421 & TRN & \\
\hline CHEMBL1352750 & 688620 & 4.45 & 4.9558 & TRN & \\
\hline CHEMBL1322727 & 688620 & 5.55 & 5.0849 & TRN & \\
\hline CHEMBL1426642 & 688620 & 5.0 & 5.0283 & TRN & \\
\hline CHEMBL1605816 & 688620 & 4.95 & 4.9455 & TST & \\
\hline CHEMBL1299230 & 688620 & 5.95 & 5.0967 & TRN & \\
\hline CHEMBL 3198407 & 688620 & 5.2 & 5.6138 & TRN & \\
\hline CHEMBL1548784 & 688620 & 5.2 & 4.8357 & TRN & \\
\hline CHEMBL1510057 & 688620 & 4.9 & 5.2689 & TRN & \\
\hline CHEMBL1568138 & 688620 & 5.1 & 5.0697 & TRN & \\
\hline CHEMBL1338951 & 688620 & 4.65 & 5.0401 & TRN & \\
\hline CHEMBL1304273 & 688620 & 4.85 & 5.0684 & TST & \\
\hline CHEMBL1405669 & 688620 & 4.95 & 4.8935 & TRN & \\
\hline CHEMBL1372396 & 688620 & 4.7 & 5.0717 & TRN & \\
\hline CHEMBL1327056 & 688620 & 4.85 & 5.08899 & 99999999995 & TRN \\
\hline CHEMBL1585976 & 688620 & 4.45 & 5.1874 & TST & \\
\hline CHEMBL 3190480 & 688620 & 4.45 & 4.8509 & TST & \\
\hline CHEMBL1572752 & 688620 & 5.4 & 5.1819 & TRN & \\
\hline CHEMBL1452398 & 688620 & 4.9 & 4.9063 & TRN & \\
\hline CHEMBL1441871 & 688620 & 5.2 & 5.079 & TRN & \\
\hline CHEMBL1299902 & 688620 & 6.95 & 4.9229 & TRN & \\
\hline CHEMBL1313598 & 688620 & 5.6 & 5.1873 & TRN & \\
\hline CHEMBL1598284 & 688620 & 5.95 & 5.379 & TRN & \\
\hline CHEMBL1504089 & 688620 & 6.3 & 5.3052 & TRN & \\
\hline
\end{tabular}




\begin{tabular}{|c|c|c|c|c|}
\hline \multicolumn{5}{|c|}{ Supplemental Table S2.txt } \\
\hline CHEMBL1606155 & 688620 & 4.45 & 5.1187 & TRN \\
\hline CHEMBL1572134 & 688620 & 4.5 & 4.6619 & TRN \\
\hline CHEMBL1352555 & 688620 & 6.6 & 4.7873 & TRN \\
\hline CHEMBL1580430 & 688620 & 5.0 & 4.7493 & TRN \\
\hline CHEMBL1567456 & 688620 & 4.45 & 4.9433 & TRN \\
\hline CHEMBL1597850 & 688620 & 5.7 & 5.0152 & TRN \\
\hline CHEMBL1500481 & 688620 & 4.85 & 5.1366 & TRN \\
\hline CHEMBL1303333 & 688620 & 5.15 & 5.1316 & TRN \\
\hline CHEMBL1338698 & 688620 & 5.7 & 5.07 & TRN \\
\hline CHEMBL1346114 & 688620 & 4.95 & 5.2628 & TST \\
\hline CHEMBL1408401 & 688620 & 4.95 & 4.9725 & TRN \\
\hline CHEMBL1307621 & 688620 & 5.3 & 4.9319 & TRN \\
\hline CHEMBL1603961 & 688620 & 4.45 & 5.1313 & TRN \\
\hline CHEMBL1445225 & 688620 & 7.4001 & 5.0878 & TST \\
\hline CHEMBL1610403 & 688620 & 4.85 & 4.914 & TRN \\
\hline CHEMBL1526303 & 688620 & 4.5 & 4.8832 & TRN \\
\hline CHEMBL1425215 & 688620 & 5.6 & 5.2052 & TRN \\
\hline CHEMBL1336442 & 688620 & 4.6 & 4.7747 & TRN \\
\hline CHEMBL1525257 & 688620 & 5.0 & 4.8769 & TRN \\
\hline CHEMBL1423171 & 688620 & 4.75 & 4.9659 & TRN \\
\hline CHEMBL1405708 & 688620 & 4.9 & 4.7847 & TRN \\
\hline CHEMBL1520541 & 688620 & 4.5 & 5.2131 & TRN \\
\hline CHEMBL1565468 & 688620 & 4.45 & 4.9193 & TRN \\
\hline CHEMBL1485136 & 688620 & 4.65 & 5.0372 & TST \\
\hline CHEMBL3190541 & 688620 & 4.95 & 5.1442 & TRN \\
\hline CHEMBL1318817 & 688620 & 4.45 & 4.8627 & TRN \\
\hline CHEMBL1432925 & 688620 & 4.95 & 5.2058 & TST \\
\hline CHEMBL3191252 & 688620 & 4.95 & 5.0567 & TRN \\
\hline CHEMBL1451874 & 688620 & 4.95 & 5.1162 & TRN \\
\hline CHEMBL1525197 & 688620 & 4.9 & 5.1478 & TRN \\
\hline CHEMBL1536689 & 688620 & 5.75 & 5.3743 & TRN \\
\hline CHEMBL1596993 & 688620 & 4.65 & 5.0251 & TRN \\
\hline CHEMBL1488626 & 688620 & 5.75 & 5.0938 & TRN \\
\hline CHEMBL1483852 & 688620 & 4.75 & 5.0344 & TRN \\
\hline CHEMBL1352290 & 688620 & 5.4 & 5.2721 & TRN \\
\hline CHEMBL1457264 & 688620 & 4.75 & 5.0868 & TRN \\
\hline CHEMBL1562819 & 688620 & 4.55 & 4.7719 & TRN \\
\hline CHEMBL1488705 & 688620 & 5.15 & 5.2759 & TRN \\
\hline CHEMBL1328282 & 688620 & 4.45 & 5.0889 & TRN \\
\hline CHEMBL1414625 & 688620 & 4.8 & 4.9671 & TRN \\
\hline CHEMBL1458442 & 688620 & 4.75 & 5.1365 & TST \\
\hline CHEMBL1480989 & 688620 & 4.9 & 5.0485 & TRN \\
\hline CHEMBL1343570 & 688620 & 4.65 & 5.1809 & TST \\
\hline CHEMBL1430377 & 688620 & 4.7 & 5.1194 & TRN \\
\hline CHEMBL1325121 & 688620 & 5.0 & 5.0154 & TRN \\
\hline CHEMBL1323552 & 688620 & 4.45 & 5.046 & TST \\
\hline CHEMBL1492825 & 688620 & 6.2 & 5.3051 & TRN \\
\hline CHEMBL486706 & 688620 & 4.45 & 5.0854 & TST \\
\hline
\end{tabular}




\begin{tabular}{|c|c|c|c|c|c|}
\hline \multicolumn{6}{|c|}{ Supplemental Table S2.txt } \\
\hline CHEMBL1374691 & 688620 & 6.0 & 5.2495 & TRN & \\
\hline CHEMBL3207986 & 688620 & 4.45 & 4.8457 & TRN & \\
\hline CHEMBL3198991 & 688620 & 4.45 & 4.8698 & TRN & \\
\hline CHEMBL1451330 & 688620 & 4.95 & 5.1975 & TST & \\
\hline CHEMBL1341625 & 688620 & 4.9 & 5.0827 & TRN & \\
\hline CHEMBL3189742 & 688620 & 5.95 & 5.0281 & TRN & \\
\hline CHEMBL1973139 & 688620 & 6.5501 & 5.0981 & TRN & \\
\hline CHEMBL1529973 & 688620 & 5.7 & 5.1337 & TRN & \\
\hline CHEMBL1980829 & 688620 & 5.25 & 5.0042 & TST & \\
\hline CHEMBL3197462 & 688620 & 4.95 & 5.4596 & TRN & \\
\hline CHEMBL1581149 & 688620 & 4.95 & 4.9739 & TRN & \\
\hline CHEMBL1464234 & 688620 & 5.25 & 5.0303 & TST & \\
\hline CHEMBL1520841 & 688620 & 5.1 & 5.2557 & TRN & \\
\hline CHEMBL1390719 & 688620 & 4.9 & 5.2332 & TRN & \\
\hline CHEMBL1462869 & 688620 & 6.1 & 5.0737 & TST & \\
\hline CHEMBL1425613 & 688620 & 5.0 & 4.8189 & TRN & \\
\hline CHEMBL1398775 & 688620 & 5.1 & 4.9243 & TST & \\
\hline CHEMBL169520 & 688620 & 5.0 & 5.0792 & TRN & \\
\hline CHEMBL1304596 & 688620 & 6.15 & 5.4737 & TRN & \\
\hline CHEMBL1418098 & 688620 & 5.05 & 4.9351 & TRN & \\
\hline CHEMBL1523136 & 688620 & 5.2 & 5.0261 & TRN & \\
\hline CHEMBL1302977 & 688620 & 5.6 & 4.9128 & TRN & \\
\hline CHEMBL1610049 & 688620 & 5.35 & 5.22 & TRN & \\
\hline CHEMBL1521276 & 688620 & 4.75 & 5.265 & TRN & \\
\hline CHEMBL1524482 & 688620 & 4.45 & 5.3255 & TRN & \\
\hline CHEMBL1363219 & 688620 & 5.8 & 5.1865 & TRN & \\
\hline CHEMBL3199597 & 688620 & 5.15 & 5.2856 & TRN & \\
\hline CHEMBL1506734 & 688620 & 8.1487 & 5.2456 & TRN & \\
\hline CHEMBL1573461 & 688620 & 4.95 & 5.0029 & TST & \\
\hline CHEMBL3211375 & 688620 & 5.15 & 5.0718 & TRN & \\
\hline CHEMBL1382443 & 688620 & 4.8 & 4.9667 & TST & \\
\hline CHEMBL1455549 & 688620 & 4.45 & 4.9117 & TST & \\
\hline CHEMBL1335431 & 688620 & 5.0 & 5.2487 & TRN & \\
\hline CHEMBL1334526 & 688620 & 5.45 & 5.1957 & TST & \\
\hline CHEMBL1971965 & 688620 & 4.45 & 4.7432 & TRN & \\
\hline CHEMBL1315455 & 688620 & 4.65 & 4.9512 & TRN & \\
\hline CHEMBL1579593 & 688620 & 4.5 & 4.9286 & TRN & \\
\hline CHEMBL1964928 & 688620 & 6.15 & 5.3896 & TRN & \\
\hline CHEMBL1538958 & 688620 & 4.45 & 5.0035 & TRN & \\
\hline CHEMBL1501330 & 688620 & 4.85 & 5.1268 & TST & \\
\hline CHEMBL1428197 & 688620 & 4.45 & 5.0046 & TRN & \\
\hline CHEMBL1539789 & 688620 & 5.15 & 5.311 & TRN & \\
\hline CHEMBL1337254 & 688620 & 4.45 & 5.0806 & TRN & \\
\hline CHEMBL1387249 & 688620 & 4.6 & 4.957 & TRN & \\
\hline CHEMBL1413806 & 688620 & 4.45 & 5.17700 & 00000000005 & TRN \\
\hline CHEMBL1424777 & 688620 & 5.65 & 4.9542 & TRN & \\
\hline CHEMBL1349138 & 688620 & 4.85 & 4.8406 & TRN & \\
\hline CHEMBL1323312 & 688620 & 4.85 & 5.2971 & TRN & \\
\hline
\end{tabular}




\begin{tabular}{|c|c|c|c|c|c|}
\hline & & \multicolumn{4}{|c|}{ Supplemental Table S2.txt } \\
\hline CHEMBL1389856 & 688620 & 5.05 & 4.7934 & TRN & \\
\hline CHEMBL1545925 & 688620 & 4.8 & 5.0987 & TRN & \\
\hline CHEMBL1346208 & 688620 & 4.45 & 4.8384 & TRN & \\
\hline CHEMBL1312641 & 688620 & 5.0 & 5.2208 & TRN & \\
\hline CHEMBL1338372 & 688620 & 4.95 & 5.0079 & TRN & \\
\hline CHEMBL1545441 & 688620 & 4.9 & 4.9104 & TRN & \\
\hline CHEMBL1533143 & 688620 & 4.65 & \multicolumn{2}{|c|}{5.0680000000000005} & TRN \\
\hline CHEMBL 3192245 & 688620 & 4.65 & 4.9013 & TST & \\
\hline CHEMBL1610492 & 688620 & 4.85 & 4.996 & TRN & \\
\hline CHEMBL1480787 & 688620 & 5.0 & 4.7766 & TRN & \\
\hline CHEMBL1347495 & 688620 & 4.65 & 5.1324 & TRN & \\
\hline CHEMBL1505136 & 688620 & 5.15 & 4.9571 & TRN & \\
\hline CHEMBL1580736 & 688620 & 4.95 & 5.1041 & TST & \\
\hline CHEMBL1312642 & 688620 & 4.85 & 4.9795 & TRN & \\
\hline CHEMBL1443633 & 688620 & 5.5 & 4.9418 & TST & \\
\hline CHEMBL1391448 & 688620 & 5.0 & 5.0094 & TRN & \\
\hline CHEMBL1426549 & 688620 & 6.0 & 5.0709 & TRN & \\
\hline CHEMBL1512909 & 688620 & 5.5 & 5.2438 & TST & \\
\hline CHEMBL1375930 & 688620 & 4.85 & 4.8691 & TRN & \\
\hline CHEMBL1469790 & 688620 & 5.2 & 4.9766 & TRN & \\
\hline CHEMBL1488377 & 688620 & 5.3 & 5.4084 & TRN & \\
\hline CHEMBL1516647 & 688620 & 6.0 & 5.2724 & TRN & \\
\hline CHEMBL1436041 & 688620 & 5.1 & 4.774 & TRN & \\
\hline CHEMBL1324270 & 688620 & 4.75 & 4.8545 & TRN & \\
\hline CHEMBL1586355 & 688620 & 4.7 & 5.0729 & TRN & \\
\hline CHEMBL1319269 & 688620 & 4.8 & 4.9793 & TST & \\
\hline CHEMBL1333464 & 688620 & 4.7 & 5.0432 & TST & \\
\hline CHEMBL1585984 & 688620 & 4.65 & 5.0559 & TST & \\
\hline CHEMBL1382006 & 688620 & 4.95 & 4.8883 & TST & \\
\hline CHEMBL1540577 & 688620 & 4.85 & 5.0474 & TRN & \\
\hline CHEMBL1521681 & 688620 & 5.15 & 5.2355 & TST & \\
\hline CHEMBL1595282 & 688620 & 4.65 & 5.3047 & TRN & \\
\hline CHEMBL1468211 & 688620 & 4.95 & 5.0583 & TST & \\
\hline CHEMBL1438160 & 688620 & 4.95 & \multicolumn{2}{|c|}{5.2829999999999995} & TRN \\
\hline CHEMBL1419929 & 688620 & 4.45 & 5.0568 & TRN & \\
\hline CHEMBL1500704 & 688620 & 6.5 & 5.776 & TRN & \\
\hline CHEMBL1458071 & 688620 & 4.75 & 5.2965 & TRN & \\
\hline CHEMBL1450849 & 688620 & 5.35 & 5.1605 & TRN & \\
\hline CHEMBL1532214 & 688620 & 5.4 & 4.8804 & TRN & \\
\hline CHEMBL1603857 & 688620 & 6.1 & 5.2122 & TRN & \\
\hline CHEMBL1491357 & 688620 & 4.9 & 5.1316 & TRN & \\
\hline CHEMBL1566618 & 688620 & 5.0 & 4.9248 & TRN & \\
\hline CHEMBL1965889 & 688620 & 4.45 & 4.9949 & TRN & \\
\hline CHEMBL1595098 & 688620 & 5.8 & 5.6882 & TRN & \\
\hline CHEMBL1361904 & 688620 & 4.45 & 4.9897 & TST & \\
\hline CHEMBL1605746 & 688620 & 4.9 & 4.9655 & TRN & \\
\hline CHEMBL1469602 & 688620 & 5.0 & 5.1268 & TRN & \\
\hline CHEMBL1537781 & 688620 & 5.0 & 5.1009 & TRN & \\
\hline
\end{tabular}




\begin{tabular}{|c|c|c|c|c|c|}
\hline & & & & & \\
\hline CHEMBL1607340 & 688620 & 5.3 & 5.187 & TST & \\
\hline CHEMBL1305787 & 688620 & 5.65 & 5.1955 & TST & \\
\hline CHEMBL1362932 & 688620 & 4.45 & 4.9477 & TRN & \\
\hline CHEMBL1585478 & 688620 & 4.9 & 4.9631 & TRN & \\
\hline CHEMBL1319294 & 688620 & 4.95 & 4.9748 & TRN & \\
\hline CHEMBL1521482 & 688620 & 5.6 & 5.6409 & TRN & \\
\hline CHEMBL1504541 & 688620 & 4.95 & 4.9082 & TRN & \\
\hline CHEMBL1508650 & 688620 & 4.45 & 4.9275 & TRN & \\
\hline CHEMBL1499523 & 688620 & 4.7 & 5.1047 & TRN & \\
\hline CHEMBL1363509 & 688620 & 4.95 & 5.0004 & TRN & \\
\hline CHEMBL1392215 & 688620 & 4.75 & 4.995 & TST & \\
\hline CHEMBL1548071 & 688620 & 5.3 & 5.24 & TRN & \\
\hline CHEMBL1544495 & 688620 & 4.95 & 5.0244 & TRN & \\
\hline CHEMBL3196323 & 688620 & 4.45 & 5.231 & TRN & \\
\hline CHEMBL1965873 & 688620 & 4.45 & 4.7401 & TST & \\
\hline CHEMBL1994935 & 688620 & 4.85 & 5.0145 & TRN & \\
\hline CHEMBL1534710 & 688620 & 4.45 & 4.689 & TRN & \\
\hline CHEMBL1431002 & 688620 & 4.45 & 4.742 & TRN & \\
\hline CHEMBL1429228 & 688620 & 5.1 & 5.039 & TRN & \\
\hline CHEMBL1418958 & 688620 & 5.2 & 5.2122 & TRN & \\
\hline CHEMBL1531772 & 688620 & 5.05 & 5.0414 & TRN & \\
\hline CHEMBL1549098 & 688620 & 7.0501 & 5.2815 & TST & \\
\hline CHEMBL1489334 & 688620 & 5.8 & 5.0786 & TST & \\
\hline CHEMBL1332260 & 688620 & 4.95 & 4.9548 & TRN & \\
\hline CHEMBL1403874 & 688620 & 4.45 & 4.8329 & TRN & \\
\hline CHEMBL1324077 & 688620 & 6.05 & 5.3306 & TRN & \\
\hline CHEMBL3195104 & 688620 & 4.65 & 4.8222 & TRN & \\
\hline CHEMBL1545996 & 688620 & 4.95 & 4.9817 & TRN & \\
\hline CHEMBL1596094 & 688620 & 4.8 & 4.9634 & TST & \\
\hline CHEMBL1408037 & 688620 & 4.8 & 4.9182 & TRN & \\
\hline CHEMBL1578557 & 688620 & 5.45 & 4.89199 & 99999999995 & TRN \\
\hline CHEMBL1337759 & 688620 & 4.6 & 4.9714 & TRN & \\
\hline CHEMBL1428995 & 688620 & 5.45 & 4.7238 & TRN & \\
\hline CHEMBL1567345 & 688620 & 5.0 & 4.8122 & TRN & \\
\hline CHEMBL1524324 & 688620 & 5.5 & 4.8484 & TRN & \\
\hline CHEMBL1501983 & 688620 & 5.9 & 5.9611 & TRN & \\
\hline CHEMBL1450163 & 688620 & 5.55 & 5.3906 & TRN & \\
\hline CHEMBL1580662 & 688620 & 5.7 & 5.2318 & TRN & \\
\hline CHEMBL1498579 & 688620 & 4.45 & 4.8801 & TRN & \\
\hline CHEMBL1407688 & 688620 & 4.9 & 5.0158 & TRN & \\
\hline CHEMBL1573529 & 688620 & 6.0 & 5.5195 & TST & \\
\hline CHEMBL1568160 & 688620 & 4.45 & 4.973 & TRN & \\
\hline CHEMBL1511307 & 688620 & 6.1 & 5.1439 & TRN & \\
\hline CHEMBL1444294 & 688620 & 4.4 & 4.8831 & TRN & \\
\hline CHEMBL1548987 & 688620 & 4.8 & 5.0465 & TST & \\
\hline CHEMBL1366515 & 688620 & 5.0 & 4.9414 & TRN & \\
\hline CHEMBL1454252 & 688620 & 4.9 & 4.8769 & TRN & \\
\hline CHEMBL1335453 & 688620 & 4.85 & 4.9086 & TRN & \\
\hline & & & & 718 & \\
\hline
\end{tabular}




\begin{tabular}{|c|c|c|c|c|}
\hline \multicolumn{5}{|c|}{ Supplemental Table S2.txt } \\
\hline CHEMBL3199595 & 688620 & 4.9 & 5.2711 & TRN \\
\hline CHEMBL1443575 & 688620 & 6.0 & 4.9165 & TRN \\
\hline CHEMBL1609116 & 688620 & 5.5 & 4.8995 & TRN \\
\hline CHEMBL1360015 & 688620 & 5.2 & 5.064 & TRN \\
\hline CHEMBL1388908 & 688620 & 5.25 & 5.0927 & TRN \\
\hline CHEMBL1521848 & 688620 & 4.6 & 5.0295 & TRN \\
\hline CHEMBL1487834 & 688620 & 5.35 & 4.8382 & TRN \\
\hline CHEMBL1359806 & 688620 & 5.2 & 4.9321 & TRN \\
\hline CHEMBL1420942 & 688620 & 4.7 & 4.9984 & TRN \\
\hline CHEMBL1304103 & 688620 & 5.15 & 5.1488 & TRN \\
\hline CHEMBL1385464 & 688620 & 4.6 & 5.0767 & TRN \\
\hline CHEMBL1610677 & 688620 & 4.85 & 5.008 & TRN \\
\hline CHEMBL1421542 & 688620 & 4.65 & 5.1542 & TRN \\
\hline CHEMBL1334972 & 688620 & 4.9 & 4.9658 & TRN \\
\hline CHEMBL1417661 & 688620 & 5.6 & 4.9541 & TST \\
\hline CHEMBL1387621 & 688620 & 4.45 & 5.0331 & TST \\
\hline CHEMBL1502975 & 688620 & 4.95 & 5.0213 & TRN \\
\hline CHEMBL53268 & 688620 & 5.55 & 4.9824 & TST \\
\hline CHEMBL1533565 & 688620 & 5.0 & 5.1108 & TRN \\
\hline CHEMBL1502906 & 688620 & 4.8 & 4.8151 & TST \\
\hline CHEMBL1521485 & 688620 & 5.3 & 5.5619 & TRN \\
\hline CHEMBL3199411 & 688620 & 6.6 & 5.816 & TRN \\
\hline CHEMBL1376181 & 688620 & 6.45 & 5.0794 & TST \\
\hline CHEMBL1538287 & 688620 & 5.75 & 5.2039 & TRN \\
\hline CHEMBL1429205 & 688620 & 5.35 & 5.2496 & TRN \\
\hline CHEMBL1395128 & 688620 & 5.0 & 5.0247 & TST \\
\hline CHEMBL1343333 & 688620 & 6.95 & 5.0606 & TST \\
\hline CHEMBL1498886 & 688620 & 5.15 & 5.0821 & TST \\
\hline CHEMBL3199440 & 688620 & 5.05 & 5.0741 & TRN \\
\hline CHEMBL3191825 & 688620 & 5.75 & 4.7957 & TRN \\
\hline CHEMBL1333626 & 688620 & 5.1 & 5.0196 & TRN \\
\hline CHEMBL1487125 & 688620 & 4.6 & 5.1889 & TRN \\
\hline CHEMBL1453239 & 688620 & 5.2 & 4.7899 & TST \\
\hline CHEMBL1584939 & 688620 & 6.3 & 5.1064 & TRN \\
\hline CHEMBL1610254 & 688620 & 6.2 & 5.0258 & TRN \\
\hline CHEMBL1327302 & 688620 & 4.75 & 5.0099 & TRN \\
\hline CHEMBL1532925 & 688620 & 5.55 & 4.7814 & TRN \\
\hline CHEMBL1486913 & 688620 & 4.95 & 4.7825 & TST \\
\hline CHEMBL1447788 & 688620 & 5.25 & 5.0715 & TRN \\
\hline CHEMBL1468115 & 688620 & 4.9 & 5.1144 & TST \\
\hline CHEMBL1347975 & 688620 & 4.65 & 4.5972 & TST \\
\hline CHEMBL1610727 & 688620 & 5.0 & 5.2095 & TST \\
\hline CHEMBL1600142 & 688620 & 4.45 & 5.2676 & TRN \\
\hline CHEMBL1467972 & 688620 & 4.8 & 5.0985 & TST \\
\hline CHEMBL1588662 & 688620 & 5.3 & 5.0018 & TST \\
\hline CHEMBL1522586 & 688620 & 4.45 & 4.9579 & TRN \\
\hline CHEMBL1595375 & 688620 & 5.8 & 5.0021 & TRN \\
\hline CHEMBL1334310 & 688620 & 4.75 & 4.905 & TRN \\
\hline
\end{tabular}




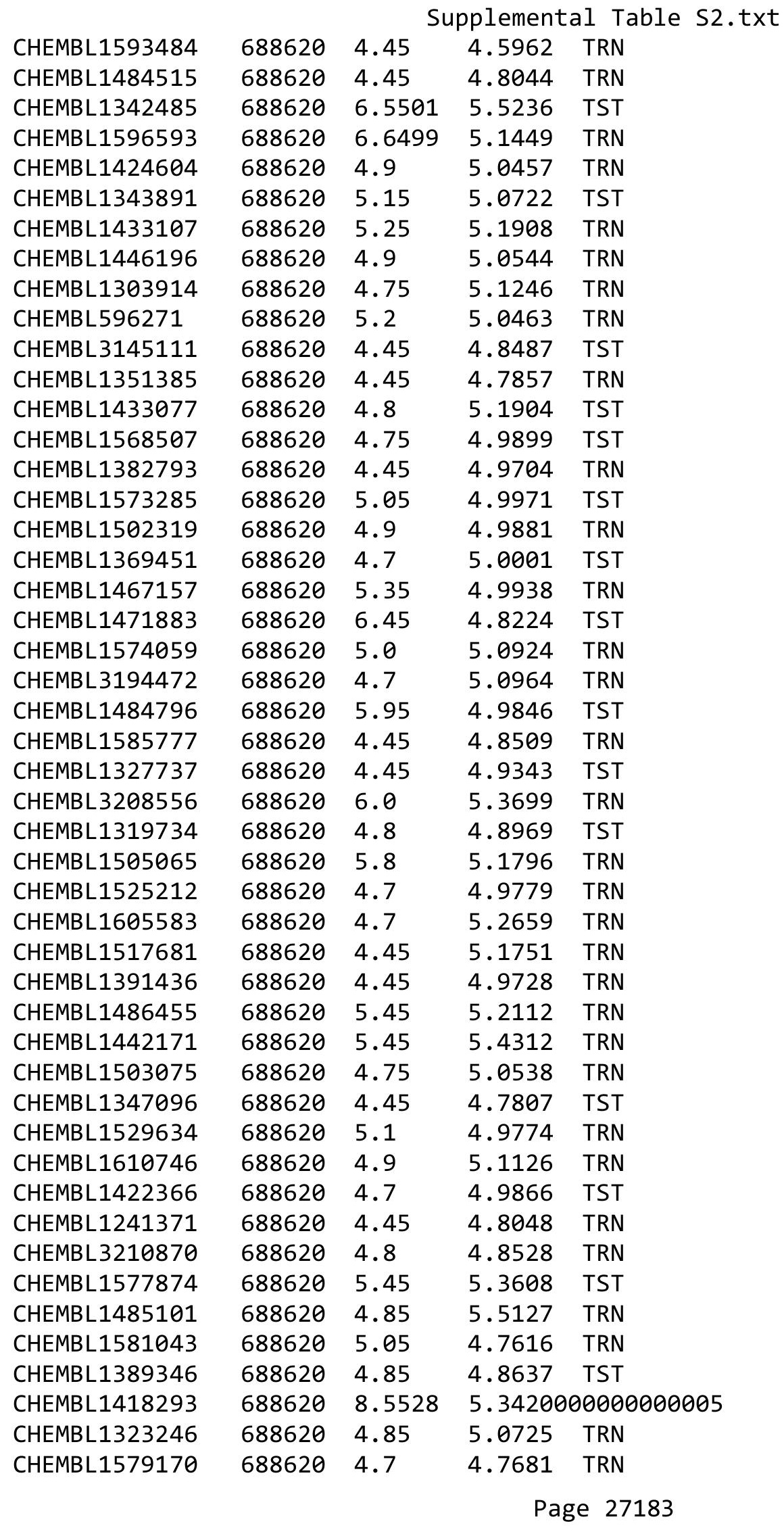

TRN 


\begin{tabular}{|c|c|c|c|c|c|}
\hline \multicolumn{6}{|c|}{ Supplemental Table S2.txt } \\
\hline CHEMBL1574799 & 688620 & 7.0 & 5.6678 & TRN & \\
\hline CHEMBL3194678 & 688620 & 4.65 & 5.3219 & TRN & \\
\hline CHEMBL3212642 & 688620 & 4.9 & 5.3985 & TRN & \\
\hline CHEMBL1579082 & 688620 & 4.95 & 4.9668 & TRN & \\
\hline CHEMBL1587998 & 688620 & 4.6 & 5.1452 & TRN & \\
\hline CHEMBL1409148 & 688620 & 4.5 & 5.1455 & TRN & \\
\hline CHEMBL3213311 & 688620 & 4.65 & 5.0366 & TRN & \\
\hline CHEMBL1374352 & 688620 & 5.55 & 5.1563 & TRN & \\
\hline CHEMBL1328184 & 688620 & 5.05 & 4.962 & TRN & \\
\hline CHEMBL1407309 & 688620 & 4.6 & 4.8172 & TRN & \\
\hline CHEMBL1462935 & 688620 & 5.0 & 4.89199 & 99999999995 & TRN \\
\hline CHEMBL1595790 & 688620 & 7.3002 & 5.7771 & TST & \\
\hline CHEMBL1501381 & 688620 & 4.85 & 4.9438 & TRN & \\
\hline CHEMBL1327013 & 688620 & 5.45 & 5.1074 & TRN & \\
\hline CHEMBL1486161 & 688620 & 5.2 & 5.2606 & TRN & \\
\hline CHEMBL1392190 & 688620 & 5.7 & 5.3506 & TRN & \\
\hline CHEMBL1481819 & 688620 & 4.45 & 4.8641 & TRN & \\
\hline CHEMBL1401669 & 688620 & 5.4 & 5.4213 & TRN & \\
\hline CHEMBL1443235 & 688620 & 4.7 & 5.0084 & TST & \\
\hline CHEMBL1611047 & 688620 & 4.9 & 5.0532 & TRN & \\
\hline CHEMBL1520332 & 688620 & 5.4 & 5.1406 & TRN & \\
\hline CHEMBL1994272 & 688620 & 4.65 & 5.5659 & TRN & \\
\hline CHEMBL1428298 & 688620 & 4.45 & 4.7991 & TRN & \\
\hline CHEMBL1363810 & 688620 & 4.75 & 4.7854 & TRN & \\
\hline CHEMBL1594237 & 688620 & 5.5 & 4.7834 & TRN & \\
\hline CHEMBL1470463 & 688620 & 5.1 & 5.3411 & TRN & \\
\hline CHEMBL1326629 & 688620 & 5.25 & 5.0546 & TRN & \\
\hline CHEMBL1436649 & 688620 & 4.5 & 5.0598 & TRN & \\
\hline CHEMBL1544268 & 688620 & 4.5 & 5.1391 & TRN & \\
\hline CHEMBL3191599 & 688620 & 5.35 & 5.0365 & TRN & \\
\hline CHEMBL1429745 & 688620 & 4.9 & 4.9847 & TRN & \\
\hline CHEMBL 3199880 & 688620 & 4.95 & 5.1176 & TST & \\
\hline CHEMBL1525997 & 688620 & 5.1 & 5.0413 & TST & \\
\hline CHEMBL1582771 & 688620 & 5.0 & 6.4996 & TST & \\
\hline CHEMBL1399232 & 688620 & 4.95 & 4.7196 & TRN & \\
\hline CHEMBL1384194 & 688620 & 4.7 & 4.6406 & TRN & \\
\hline CHEMBL1565154 & 688620 & 4.9 & 4.7993 & TRN & \\
\hline CHEMBL1534634 & 688620 & 5.65 & 5.0587 & TST & \\
\hline CHEMBL1374475 & 688620 & 5.1 & 4.8958 & TRN & \\
\hline CHEMBL1380121 & 688620 & 4.45 & 4.6011 & TRN & \\
\hline CHEMBL1417241 & 688620 & 6.4 & 5.307 & TST & \\
\hline CHEMBL1545478 & 688620 & 5.15 & 5.2916 & TST & \\
\hline CHEMBL1320914 & 688620 & 5.95 & 5.1166 & TST & \\
\hline CHEMBL1982484 & 688620 & 4.7 & 5.1924 & TRN & \\
\hline CHEMBL1423530 & 688620 & 4.95 & 4.9673 & TRN & \\
\hline CHEMBL1382535 & 688620 & 4.5 & 5.1765 & TRN & \\
\hline CHEMBL1576760 & 688620 & 5.0 & 5.1157 & TRN & \\
\hline CHEMBL1613652 & 688620 & 4.85 & 4.8747 & TST & \\
\hline
\end{tabular}




\begin{tabular}{|c|c|c|c|c|c|}
\hline \multicolumn{6}{|c|}{ premertice } \\
\hline CHEMBL1541901 & 688620 & 5.8 & 4.9333 & TRN & \\
\hline CHEMBL1406036 & 688620 & 5.15 & 5.0484 & TRN & \\
\hline CHEMBL1547695 & 688620 & 5.75 & 5.0931 & TRN & \\
\hline CHEMBL3213309 & 688620 & 4.45 & 4.9868 & TRN & \\
\hline CHEMBL1450636 & 688620 & 5.75 & 5.5839 & TRN & \\
\hline CHEMBL1478269 & 688620 & 4.5 & 5.0809 & TRN & \\
\hline CHEMBL1436644 & 688620 & 4.8 & 4.838 & TST & \\
\hline CHEMBL1419165 & 688620 & 5.95 & 6.1227 & TRN & \\
\hline CHEMBL1501393 & 688620 & 4.95 & 5.0503 & TST & \\
\hline CHEMBL1304303 & 688620 & 4.9 & 4.9685 & TRN & \\
\hline CHEMBL1420443 & 688620 & 4.95 & 5.0616 & TST & \\
\hline CHEMBL1606022 & 688620 & 5.85 & 4.8494 & TRN & \\
\hline CHEMBL1303383 & 688620 & 5.35 & 4.8494 & TRN & \\
\hline CHEMBL1313662 & 688620 & 4.65 & 4.9694 & TRN & \\
\hline CHEMBL1522753 & 688620 & 5.0 & 5.0877 & TRN & \\
\hline CHEMBL1603555 & 688620 & 5.0 & 5.0727 & TRN & \\
\hline CHEMBL1359508 & 688620 & 4.75 & 4.8652 & TRN & \\
\hline CHEMBL1438890 & 688620 & 4.7 & 4.7409 & TRN & \\
\hline CHEMBL1491554 & 688620 & 5.15 & 5.0649 & TRN & \\
\hline CHEMBL1508627 & 688620 & 5.25 & $4.9860 e$ & 2000000001 & TST \\
\hline CHEMBL1360093 & 688620 & 4.55 & 5.3947 & TRN & \\
\hline CHEMBL3191651 & 688620 & 4.9 & 5.1641 & TRN & \\
\hline CHEMBL1416660 & 688620 & 5.15 & 5.3007 & TST & \\
\hline CHEMBL3213907 & 688620 & 5.25 & 4.956 & TRN & \\
\hline CHEMBL2369281 & 688620 & 5.25 & 5.3045 & TST & \\
\hline CHEMBL1527855 & 688620 & 4.45 & 4.9397 & TRN & \\
\hline CHEMBL1571007 & 688620 & 5.2 & 5.19799 & 99999999995 & TST \\
\hline CHEMBL1489028 & 688620 & 5.0 & 4.8663 & TRN & \\
\hline CHEMBL1583666 & 688620 & 4.9 & 4.8827 & TRN & \\
\hline CHEMBL1502987 & 688620 & 5.25 & 5.2387 & TRN & \\
\hline CHEMBL1414311 & 688620 & 4.8 & 5.222 & TRN & \\
\hline CHEMBL1444886 & 688620 & 4.75 & 4.9327 & TST & \\
\hline CHEMBL1354434 & 688620 & 4.65 & 4.7878 & TRN & \\
\hline CHEMBL3189262 & 688620 & 4.65 & 4.9883 & TRN & \\
\hline CHEMBL1499736 & 688620 & 4.75 & 4.7099 & TRN & \\
\hline CHEMBL1538097 & 688620 & 5.55 & 5.0348 & TRN & \\
\hline CHEMBL1967586 & 688620 & 5.45 & 5.033 & TST & \\
\hline CHEMBL1458858 & 688620 & 4.7 & 4.7086 & TRN & \\
\hline CHEMBL1490850 & 688620 & 5.25 & 5.17 & TRN & \\
\hline CHEMBL1327547 & 688620 & 5.5 & 5.3189 & TST & \\
\hline CHEMBL1419880 & 688620 & 5.65 & 5.3084 & TRN & \\
\hline CHEMBL1319930 & 688620 & 4.9 & 5.0453 & TST & \\
\hline CHEMBL1507115 & 688620 & 4.45 & 5.1585 & TRN & \\
\hline CHEMBL1462203 & 688620 & 5.9 & 5.1909 & TRN & \\
\hline CHEMBL1588659 & 688620 & 4.95 & 5.0243 & TRN & \\
\hline CHEMBL1349034 & 688620 & 5.95 & 5.0204 & TST & \\
\hline CHEMBL1607997 & 688620 & 4.95 & 4.9256 & TRN & \\
\hline CHEMBL1320702 & 688620 & 6.45 & 5.2663 & TRN & \\
\hline
\end{tabular}




\begin{tabular}{|c|c|c|c|c|c|}
\hline \multicolumn{6}{|c|}{ Supplemental Table S2.txt } \\
\hline CHEMBL1378295 & 688620 & 4.75 & 4.9899 & TRN & \\
\hline CHEMBL1400896 & 688620 & 5.45 & 5.3874 & TST & \\
\hline CHEMBL1374685 & 688620 & 4.8 & 4.8712 & TRN & \\
\hline CHEMBL1440967 & 688620 & 5.05 & 4.7592 & TST & \\
\hline CHEMBL1323757 & 688620 & 4.9 & \multicolumn{2}{|c|}{5.0360000000000005} & TST \\
\hline CHEMBL1597550 & 688620 & 4.9 & 4.9506 & TRN & \\
\hline CHEMBL1586153 & 688620 & 4.45 & 5.0697 & TST & \\
\hline CHEMBL1580753 & 688620 & 4.8 & 5.0035 & TST & \\
\hline CHEMBL1399583 & 688620 & 4.75 & 5.2392 & TST & \\
\hline CHEMBL1345374 & 688620 & 6.0 & 5.4004 & TRN & \\
\hline CHEMBL1498880 & 688620 & 4.95 & \multicolumn{2}{|c|}{4.968999999999999} & TST \\
\hline CHEMBL3198617 & 688620 & 4.75 & 5.0724 & TRN & \\
\hline CHEMBL1534399 & 688620 & 5.1 & 4.9956 & TRN & \\
\hline CHEMBL1351309 & 688620 & 4.7 & 5.0973 & TRN & \\
\hline CHEMBL1595964 & 688620 & 6.05 & 5.0455 & TST & \\
\hline CHEMBL1324701 & 688620 & 4.8 & 5.0936 & TRN & \\
\hline CHEMBL3194350 & 688620 & 5.2 & 4.8397 & TRN & \\
\hline CHEMBL1441408 & 688620 & 4.9 & 4.8791 & TST & \\
\hline CHEMBL1609095 & 688620 & 4.95 & 5.1065 & TRN & \\
\hline CHEMBL1589352 & 688620 & 4.95 & 4.9222 & TRN & \\
\hline CHEMBL1555208 & 688620 & 4.65 & 4.7733 & TRN & \\
\hline CHEMBL3195171 & 688620 & 5.3 & 5.4411 & TRN & \\
\hline CHEMBL1333089 & 688620 & 6.95 & 5.0072 & TRN & \\
\hline CHEMBL1596639 & 688620 & 4.9 & 4.9658 & TRN & \\
\hline CHEMBL1578341 & 688620 & 4.9 & 5.1081 & TRN & \\
\hline CHEMBL 2006909 & 688620 & 4.85 & 4.9189 & TRN & \\
\hline CHEMBL3198886 & 688620 & 7.0 & 6.0837 & TRN & \\
\hline CHEMBL1384820 & 688620 & 4.45 & 4.9761 & TRN & \\
\hline CHEMBL1387373 & 688620 & 4.75 & 4.9645 & TST & \\
\hline CHEMBL3198312 & 688620 & 4.95 & 5.0262 & TRN & \\
\hline CHEMBL1589637 & 688620 & 4.85 & 5.2114 & TRN & \\
\hline CHEMBL1511520 & 688620 & 4.9 & 4.8512 & TRN & \\
\hline CHEMBL1431915 & 688620 & 4.6 & 4.9316 & TST & \\
\hline CHEMBL1330276 & 688620 & 6.5501 & 5.2512 & TRN & \\
\hline CHEMBL1611549 & 688620 & 4.75 & 4.7844 & TRN & \\
\hline CHEMBL1497532 & 688620 & 6.15 & 5.2683 & TRN & \\
\hline CHEMBL1597086 & 688620 & 4.45 & 5.1103 & TST & \\
\hline CHEMBL1342920 & 688620 & 4.8 & 4.9727 & TRN & \\
\hline CHEMBL1400505 & 688620 & 5.05 & 5.4246 & TRN & \\
\hline CHEMBL1539538 & 688620 & 5.05 & 4.9732 & TRN & \\
\hline CHEMBL1605131 & 688620 & 5.05 & 5.1881 & TRN & \\
\hline CHEMBL1484582 & 688620 & 5.25 & 5.351 & TRN & \\
\hline CHEMBL1541894 & 688620 & 4.45 & 4.8887 & TRN & \\
\hline CHEMBL1560632 & 688620 & 5.6 & 5.0088 & TST & \\
\hline CHEMBL1485445 & 688620 & 4.45 & 4.6394 & TRN & \\
\hline CHEMBL1346363 & 688620 & 6.35 & 5.0469 & TRN & \\
\hline CHEMBL1405914 & 688620 & 5.4 & 5.38299 & 9999999999 & TRN \\
\hline CHEMBL1529988 & 688620 & 4.45 & 5.3006 & TRN & \\
\hline
\end{tabular}




\begin{tabular}{|c|c|c|c|c|}
\hline \multicolumn{5}{|c|}{ Supplemental Table S2.txt } \\
\hline CHEMBL1470135 & 688620 & 5.55 & 5.4098 & TRN \\
\hline CHEMBL1377749 & 688620 & 4.85 & 5.0064 & TRN \\
\hline CHEMBL1400514 & 688620 & 5.05 & 4.9624 & TRN \\
\hline CHEMBL1335500 & 688620 & 4.75 & 5.1584 & TRN \\
\hline CHEMBL1562415 & 688620 & 4.9 & 5.1615 & TRN \\
\hline CHEMBL1382131 & 688620 & 4.95 & 5.16299 & 9999999999 \\
\hline CHEMBL1339846 & 688620 & 5.7 & 4.8653 & TST \\
\hline CHEMBL1300627 & 688620 & 4.7 & 5.0833 & TST \\
\hline CHEMBL1555726 & 688620 & 5.3 & 5.4947 & TRN \\
\hline CHEMBL585591 & 688620 & 4.9 & 5.7899 & TST \\
\hline CHEMBL1997098 & 688620 & 5.9 & 5.357 & TRN \\
\hline CHEMBL1451931 & 688620 & 4.8 & 4.7553 & TRN \\
\hline CHEMBL1330318 & 688620 & 6.1 & 5.4784 & TRN \\
\hline CHEMBL580819 & 688620 & 4.45 & 4.6412 & TRN \\
\hline CHEMBL3194829 & 688620 & 4.65 & 4.841 & TRN \\
\hline CHEMBL1394681 & 688620 & 6.25 & 6.0335 & TRN \\
\hline CHEMBL3193150 & 688620 & 4.95 & 5.1149 & TST \\
\hline CHEMBL1485187 & 688620 & 4.9 & 4.9019 & TRN \\
\hline CHEMBL1352573 & 688620 & 5.25 & 4.8658 & TST \\
\hline CHEMBL1429241 & 688620 & 4.45 & 5.1021 & TST \\
\hline CHEMBL1323964 & 688620 & 6.1 & 5.0643 & TST \\
\hline CHEMBL1599481 & 688620 & 4.6 & 4.7499 & TRN \\
\hline CHEMBL1508228 & 688620 & 4.55 & 5.1106 & TRN \\
\hline CHEMBL1572316 & 688620 & 4.95 & 4.9548 & TST \\
\hline CHEMBL1457529 & 688620 & 5.15 & 4.8483 & TRN \\
\hline CHEMBL1549849 & 688620 & 5.85 & 5.3831 & TRN \\
\hline CHEMBL1517935 & 688620 & 4.5 & 4.8108 & TRN \\
\hline CHEMBL1359643 & 688620 & 5.7 & 5.0571 & TRN \\
\hline CHEMBL1466010 & 688620 & 5.0 & 5.0268 & TST \\
\hline CHEMBL1526371 & 688620 & 4.45 & 5.2471 & TRN \\
\hline CHEMBL1370387 & 688620 & 5.5 & 4.8654 & TRN \\
\hline CHEMBL1452644 & 688620 & 4.45 & 4.9306 & TRN \\
\hline CHEMBL1559823 & 688620 & 6.8499 & 5.1093 & TST \\
\hline CHEMBL1499237 & 688620 & 4.8 & 5.0753 & TRN \\
\hline CHEMBL1542057 & 688620 & 4.45 & 4.9133 & TRN \\
\hline CHEMBL1440188 & 688620 & 5.0 & 5.1757 & TRN \\
\hline CHEMBL1568806 & 688620 & 5.25 & 5.0251 & TRN \\
\hline CHEMBL1368135 & 688620 & 4.7 & 5.0278 & TRN \\
\hline CHEMBL1411031 & 688620 & 8.2007 & 4.9782 & TRN \\
\hline CHEMBL1464345 & 688620 & 5.4 & 5.3462 & TRN \\
\hline CHEMBL1380758 & 688620 & 4.45 & 4.9379 & TRN \\
\hline CHEMBL1602618 & 688620 & 4.9 & 4.9784 & TRN \\
\hline CHEMBL1585868 & 688620 & 4.45 & 5.0681 & TRN \\
\hline CHEMBL1372414 & 688620 & 5.3 & 5.6986 & TRN \\
\hline CHEMBL1473086 & 688620 & 4.45 & 5.0039 & TRN \\
\hline CHEMBL1477481 & 688620 & 4.45 & 5.0747 & TRN \\
\hline CHEMBL1593479 & 688620 & 4.65 & 4.9328 & TRN \\
\hline CHEMBL1587775 & 688620 & 5.1 & 5.0566 & TRN \\
\hline
\end{tabular}




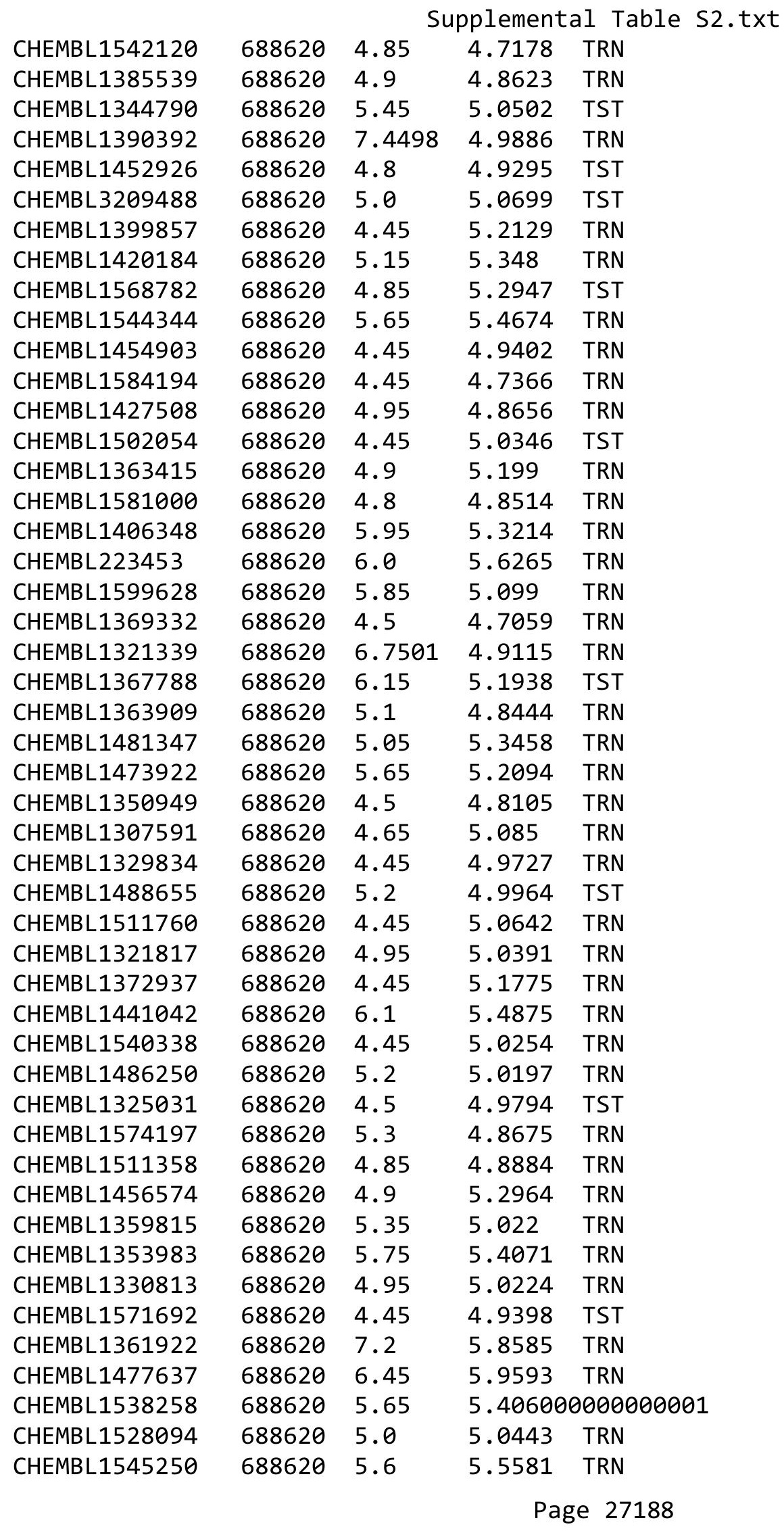

TRN 


\begin{tabular}{|c|c|c|c|c|}
\hline \multicolumn{5}{|c|}{ Supplemental Table S2.txt } \\
\hline CHEMBL1419631 & 688620 & 4.95 & 4.7722 & TRN \\
\hline CHEMBL1329795 & 688620 & 5.9 & 5.065 & TRN \\
\hline CHEMBL1555574 & 688620 & 5.4 & 4.8995 & TRN \\
\hline CHEMBL1508134 & 688620 & 4.9 & 5.0781 & TRN \\
\hline CHEMBL1490327 & 688620 & 5.85 & 5.0739 & TRN \\
\hline CHEMBL199405 & 688620 & 5.2 & 5.6 & TRN \\
\hline CHEMBL1424064 & 688620 & 4.8 & 4.9886 & TRN \\
\hline CHEMBL1503871 & 688620 & 5.7 & 4.8169 & TST \\
\hline CHEMBL1419383 & 688620 & 4.9 & 5.1644 & TRN \\
\hline CHEMBL1521926 & 688620 & 4.45 & 4.6918 & TRN \\
\hline CHEMBL 3144830 & 688620 & 5.6 & 5.2088 & TST \\
\hline CHEMBL1464433 & 688620 & 4.45 & 5.2938 & TRN \\
\hline CHEMBL1534959 & 688620 & 6.0 & 5.1152 & TRN \\
\hline CHEMBL1570848 & 688620 & 6.5 & 5.1571 & TRN \\
\hline CHEMBL1510023 & 688620 & 5.45 & 5.1517 & TST \\
\hline CHEMBL1584592 & 688620 & 5.0 & 5.1066 & TST \\
\hline CHEMBL1568027 & 688620 & 5.45 & 5.3695 & TST \\
\hline CHEMBL1575743 & 688620 & 4.95 & 4.9103 & TRN \\
\hline CHEMBL1391171 & 688620 & 5.5 & 5.0497 & TST \\
\hline CHEMBL1300184 & 688620 & 4.75 & 5.0798 & TST \\
\hline CHEMBL3199470 & 688620 & 6.05 & 5.864 & TRN \\
\hline CHEMBL1349876 & 688620 & 4.45 & 4.9046 & TST \\
\hline CHEMBL1467359 & 688620 & 5.5 & 5.0611 & TRN \\
\hline CHEMBL1415768 & 688620 & 4.5 & 5.1043 & TST \\
\hline CHEMBL1598735 & 688620 & 6.5 & 4.7856 & TRN \\
\hline CHEMBL1301363 & 688620 & 5.4 & 5.0452 & TST \\
\hline CHEMBL1324188 & 688620 & 6.4 & 5.5818 & TST \\
\hline CHEMBL1461025 & 688620 & 5.65 & 5.3035 & TRN \\
\hline CHEMBL1339492 & 688620 & 5.5 & 5.4915 & TRN \\
\hline CHEMBL1354142 & 688620 & 5.55 & 5.1296 & TST \\
\hline CHEMBL1332805 & 688620 & 4.7 & 4.7795 & TRN \\
\hline CHEMBL1341017 & 688620 & 4.95 & 5.0227 & TRN \\
\hline CHEMBL1557660 & 688620 & 4.45 & 5.0482 & TST \\
\hline CHEMBL1469774 & 688620 & 6.6499 & 5.164 & TRN \\
\hline CHEMBL1326180 & 688620 & 4.8 & 4.8758 & TRN \\
\hline CHEMBL1368337 & 688620 & 4.9 & 5.1945 & TST \\
\hline CHEMBL1458203 & 688620 & 4.6 & 4.6896 & TRN \\
\hline CHEMBL1544409 & 688620 & 5.85 & 5.2395 & TRN \\
\hline CHEMBL1450400 & 688620 & 4.7 & 4.8678 & TRN \\
\hline CHEMBL1591258 & 688620 & 6.0 & 5.6435 & TST \\
\hline CHEMBL1375118 & 688620 & 4.45 & 4.9143 & TRN \\
\hline CHEMBL1500064 & 688620 & 4.8 & 5.093 & TST \\
\hline CHEMBL1991215 & 688620 & 4.45 & 4.9297 & TRN \\
\hline CHEMBL1404888 & 688620 & 4.95 & 5.1655 & TRN \\
\hline CHEMBL1386790 & 688620 & 4.45 & 4.9725 & TST \\
\hline CHEMBL3208221 & 688620 & 4.85 & 4.9294 & TST \\
\hline CHEMBL 3213777 & 688620 & 5.55 & 5.2478 & TST \\
\hline CHEMBL1503154 & 688620 & 5.35 & 5.0571 & TRN \\
\hline
\end{tabular}




\begin{tabular}{|c|c|c|c|c|}
\hline \multicolumn{5}{|c|}{ Supplemental Table S2.txt } \\
\hline CHEMBL1560329 & 688620 & 7.1002 & 4.9545 & TST \\
\hline CHEMBL1450597 & 688620 & 5.45 & 5.3413 & TRN \\
\hline CHEMBL1482203 & 688620 & 4.55 & 4.8905 & TRN \\
\hline CHEMBL1533434 & 688620 & 5.35 & 5.0355 & TST \\
\hline CHEMBL3191631 & 688620 & 4.95 & 5.0809 & TRN \\
\hline CHEMBL1541324 & 688620 & 5.15 & 4.883 & TRN \\
\hline CHEMBL1570527 & 688620 & 4.7 & 5.0538 & TRN \\
\hline CHEMBL1400965 & 688620 & 5.15 & 5.3319 & TRN \\
\hline CHEMBL1374602 & 688620 & 4.8 & 5.3699 & TRN \\
\hline CHEMBL1433275 & 688620 & 5.2 & 5.2566 & TRN \\
\hline CHEMBL1413284 & 688620 & 4.85 & 4.9792 & TST \\
\hline CHEMBL3189336 & 688620 & 4.45 & 4.8121 & TRN \\
\hline CHEMBL1536631 & 688620 & 5.3 & 5.0062 & TRN \\
\hline CHEMBL1419464 & 688620 & 4.9 & 4.9491 & TRN \\
\hline CHEMBL1431259 & 688620 & 4.8 & 4.9981 & TRN \\
\hline CHEMBL1365212 & 688620 & 4.95 & 5.1974 & TRN \\
\hline CHEMBL1432880 & 688620 & 5.4 & 5.1047 & TST \\
\hline CHEMBL1373722 & 688620 & 5.85 & 5.0253 & TRN \\
\hline CHEMBL3194892 & 688620 & 5.2 & 5.0919 & TRN \\
\hline CHEMBL1605857 & 688620 & 5.85 & 5.6212 & TRN \\
\hline CHEMBL1548366 & 688620 & 5.35 & 5.2285 & TST \\
\hline CHEMBL1446971 & 688620 & 5.95 & 5.4334 & TST \\
\hline CHEMBL1577950 & 688620 & 5.45 & 5.1401 & TRN \\
\hline CHEMBL1478460 & 688620 & 6.2 & 6.0773 & TRN \\
\hline CHEMBL1482210 & 688620 & 4.75 & 5.0008 & TRN \\
\hline CHEMBL1351040 & 688620 & 6.95 & 5.2093 & TRN \\
\hline CHEMBL1408053 & 688620 & 4.95 & 4.7256 & TRN \\
\hline CHEMBL3195868 & 688620 & 5.0 & 4.9802 & TRN \\
\hline CHEMBL1327575 & 688620 & 4.45 & 4.9547 & TST \\
\hline CHEMBL1444970 & 688620 & 5.5 & 5.1114 & TST \\
\hline CHEMBL1403169 & 688620 & 5.1 & 5.2968 & TRN \\
\hline CHEMBL1413541 & 688620 & 5.35 & 4.9203 & TRN \\
\hline CHEMBL188423 & 688620 & 4.55 & 4.9164 & TRN \\
\hline CHEMBL3193982 & 688620 & 4.45 & 4.9562 & TRN \\
\hline CHEMBL1419941 & 688620 & 5.8 & 5.5914 & TRN \\
\hline CHEMBL1371226 & 688620 & 4.95 & 5.1174 & TRN \\
\hline CHEMBL1312424 & 688620 & 5.55 & 5.2833 & TST \\
\hline CHEMBL1579393 & 688620 & 4.8 & 4.8844 & TST \\
\hline CHEMBL1455953 & 688620 & 4.95 & 5.0052 & TRN \\
\hline CHEMBL1378339 & 688620 & 4.95 & 5.2695 & TST \\
\hline CHEMBL1302928 & 688620 & 4.8 & 5.2061 & TRN \\
\hline CHEMBL1538854 & 688620 & 5.0 & 5.6982 & TRN \\
\hline CHEMBL1444370 & 688620 & 5.9 & 5.0574 & TRN \\
\hline CHEMBL1990248 & 688620 & 4.65 & 5.2541 & TST \\
\hline CHEMBL1511423 & 688620 & 5.6 & 5.6072 & TRN \\
\hline CHEMBL1412689 & 688620 & 4.65 & 5.2284 & TRN \\
\hline CHEMBL1385192 & 688620 & 4.8 & 5.0726 & TRN \\
\hline CHEMBL1572542 & 688620 & 5.7 & 5.1302 & TST \\
\hline
\end{tabular}




\begin{tabular}{|c|c|c|c|c|c|}
\hline \multicolumn{6}{|c|}{ Supplemental Table S2.txt } \\
\hline CHEMBL1419831 & 688620 & 6.8 & 5.0233 & TRN & \\
\hline CHEMBL1447940 & 688620 & 4.45 & 4.8275 & TRN & \\
\hline CHEMBL3199569 & 688620 & 6.1 & 5.0121 & TST & \\
\hline CHEMBL1528163 & 688620 & 5.2 & 5.4578 & TRN & \\
\hline CHEMBL3208776 & 688620 & 5.0 & 5.2134 & TRN & \\
\hline CHEMBL1608799 & 688620 & 4.85 & 5.1522 & TRN & \\
\hline CHEMBL1566077 & 688620 & 5.55 & 5.561 & TRN & \\
\hline CHEMBL1420932 & 688620 & 4.8 & 4.7257 & TRN & \\
\hline CHEMBL 9843 & 688620 & 4.6 & 4.9551 & TRN & \\
\hline CHEMBL1483948 & 688620 & 4.75 & 4.785 & TRN & \\
\hline CHEMBL1486357 & 688620 & 6.0 & 5.1509 & TST & \\
\hline CHEMBL1489390 & 688620 & 4.9 & 4.885 & TRN & \\
\hline CHEMBL1469047 & 688620 & 5.45 & 5.1888 & TRN & \\
\hline CHEMBL3199794 & 688620 & 7.6498 & 5.4472 & TRN & \\
\hline CHEMBL1421266 & 688620 & 5.1 & 5.0508 & TST & \\
\hline CHEMBL1426524 & 688620 & 4.85 & 4.9356 & TRN & \\
\hline CHEMBL1431170 & 688620 & 4.9 & 5.065 & TRN & \\
\hline CHEMBL1363996 & 688620 & 4.85 & 4.888 & TRN & \\
\hline CHEMBL1382738 & 688620 & 4.7 & 4.9154 & TRN & \\
\hline CHEMBL1415338 & 688620 & 4.45 & 5.0971 & TRN & \\
\hline CHEMBL1429494 & 688620 & 4.75 & 5.0376 & TRN & \\
\hline CHEMBL1448201 & 688620 & 4.45 & 4.9383 & TRN & \\
\hline CHEMBL1320262 & 688620 & 4.9 & 4.8045 & TRN & \\
\hline CHEMBL1524828 & 688620 & 5.95 & 5.4977 & TRN & \\
\hline CHEMBL1611529 & 688620 & 4.65 & 4.9886 & TRN & \\
\hline CHEMBL1572370 & 688620 & 4.45 & 5.1795 & TRN & \\
\hline CHEMBL1582088 & 688620 & 4.45 & 4.93199 & 99999999995 & TRN \\
\hline CHEMBL1360609 & 688620 & 4.9 & 5.0191 & TRN & \\
\hline CHEMBL1560693 & 688620 & 5.5 & 5.5828 & TRN & \\
\hline CHEMBL1320082 & 688620 & 4.9 & 4.8454 & TRN & \\
\hline CHEMBL3207810 & 688620 & 4.85 & 5.0562 & TRN & \\
\hline CHEMBL1985499 & 688620 & 5.35 & 5.3429 & TRN & \\
\hline CHEMBL 2028186 & 688620 & 5.0 & 5.0621 & TST & \\
\hline CHEMBL1508029 & 688620 & 4.75 & 4.993 & TRN & \\
\hline CHEMBL1540051 & 688620 & 4.95 & 5.36100 & 0000000001 & TRN \\
\hline CHEMBL1399415 & 688620 & 4.85 & 4.8575 & TST & \\
\hline CHEMBL 222334 & 688620 & 6.0 & 5.6186 & TST & \\
\hline CHEMBL1598132 & 688620 & 4.95 & 5.0954 & TRN & \\
\hline CHEMBL1610987 & 688620 & 4.45 & 5.0538 & TST & \\
\hline CHEMBL3208515 & 688620 & 5.05 & 5.154 & TRN & \\
\hline CHEMBL1462123 & 688620 & 5.05 & 5.039 & TRN & \\
\hline CHEMBL1450447 & 688620 & 4.45 & 4.6358 & TRN & \\
\hline CHEMBL1586211 & 688620 & 5.5 & 5.4847 & TRN & \\
\hline CHEMBL1575854 & 688620 & 7.0501 & 5.2238 & TST & \\
\hline CHEMBL1431007 & 688620 & 4.9 & 5.0969 & TRN & \\
\hline CHEMBL1364548 & 688620 & 4.8 & 5.1602 & TRN & \\
\hline CHEMBL1599632 & 688620 & 5.05 & 5.2611 & TST & \\
\hline CHEMBL1363123 & 688620 & 4.75 & 4.7483 & TRN & \\
\hline
\end{tabular}




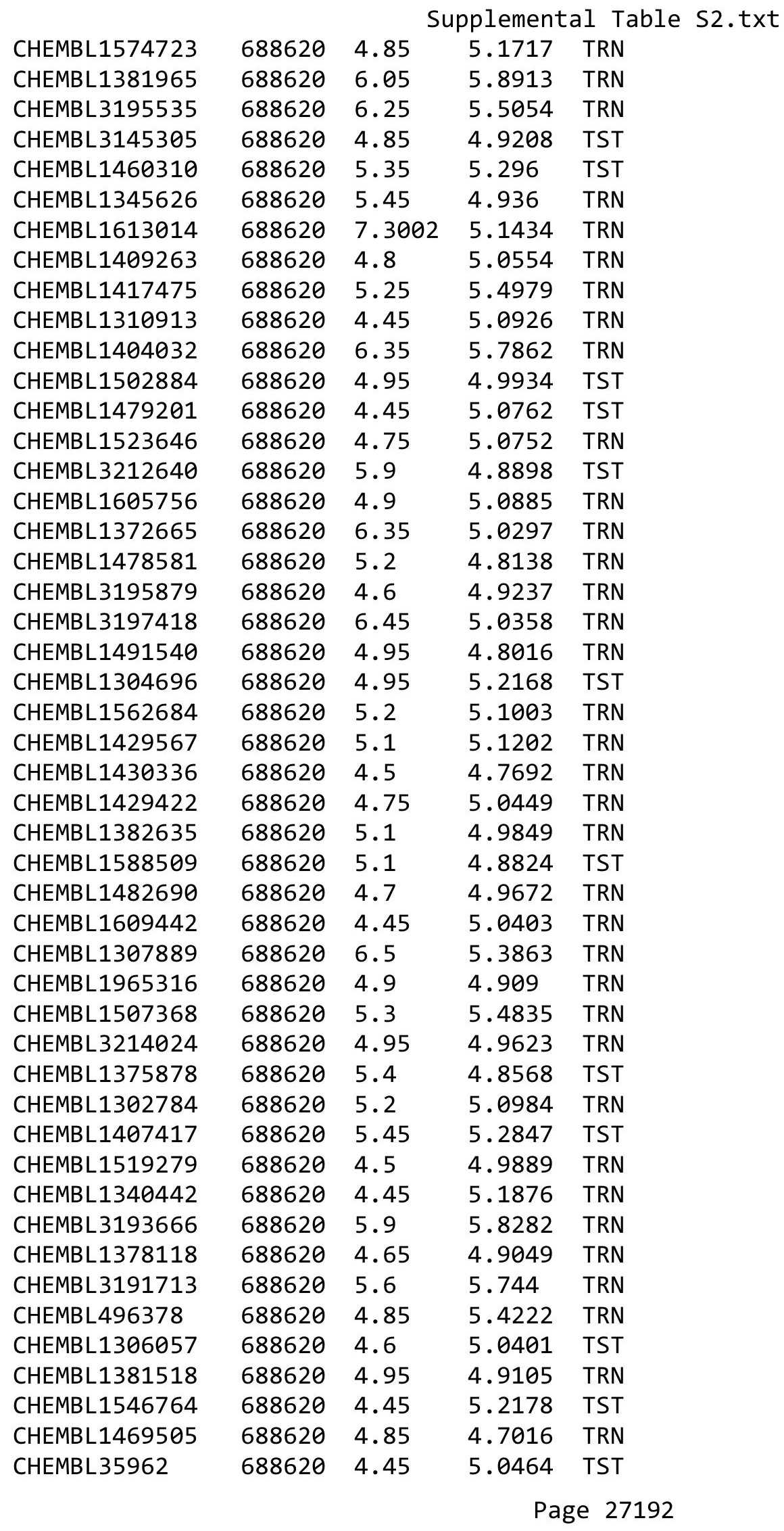




\begin{tabular}{|c|c|c|c|c|c|}
\hline \\
\hline CHEMBL1390650 & 688620 & 4.9 & 5.3023 & TRN & \\
\hline CHEMBL1408942 & 688620 & 4.6 & 4.909 & TST & \\
\hline CHEMBL1601460 & 688620 & 5.8 & 5.1374 & TRN & \\
\hline CHEMBL1601646 & 688620 & 6.1 & 4.8533 & TST & \\
\hline CHEMBL1092115 & 688620 & 4.7 & 4.8729 & TST & \\
\hline CHEMBL1415356 & 688620 & 6.3 & 5.0341 & TRN & \\
\hline CHEMBL1354208 & 688620 & 4.45 & 5.1014 & TRN & \\
\hline CHEMBL1535213 & 688620 & 6.4 & 4.8818 & TST & \\
\hline CHEMBL1583682 & 688620 & 5.55 & 5.4875 & TST & \\
\hline CHEMBL1518594 & 688620 & 4.75 & 4.93199 & 99999999995 & TRN \\
\hline CHEMBL1466302 & 688620 & 4.45 & 5.0362 & TST & \\
\hline CHEMBL1403575 & 688620 & 4.8 & 4.9658 & TRN & \\
\hline CHEMBL1586466 & 688620 & 4.7 & 5.1293 & TRN & \\
\hline CHEMBL1353431 & 688620 & 4.7 & 4.9472 & TRN & \\
\hline CHEMBL446313 & 688620 & 4.95 & 4.7588 & TRN & \\
\hline CHEMBL1324072 & 688620 & 4.65 & 4.8958 & TST & \\
\hline CHEMBL1538182 & 688620 & 4.9 & 5.1514 & TRN & \\
\hline CHEMBL3193616 & 688620 & 5.0 & 4.9808 & TRN & \\
\hline CHEMBL1578804 & 688620 & 4.45 & 5.0408 & TRN & \\
\hline CHEMBL1312198 & 688620 & 4.5 & 4.6993 & TRN & \\
\hline CHEMBL1582169 & 688620 & 4.8 & 4.9022 & TRN & \\
\hline CHEMBL1467136 & 688620 & 4.9 & 4.9984 & TRN & \\
\hline CHEMBL1870032 & 688620 & 4.6 & 5.1297 & TST & \\
\hline CHEMBL1368599 & 688620 & 5.25 & 5.4276 & TRN & \\
\hline CHEMBL1403108 & 688620 & 5.0 & 4.9579 & TRN & \\
\hline CHEMBL1506154 & 688620 & 4.45 & 5.0224 & TRN & \\
\hline CHEMBL1429856 & 688620 & 4.85 & 4.9725 & TRN & \\
\hline CHEMBL1387044 & 688620 & 5.7 & 5.2852 & TRN & \\
\hline CHEMBL1300278 & 688620 & 4.45 & 5.2082 & TST & \\
\hline CHEMBL1467520 & 688620 & 4.75 & 4.9897 & TRN & \\
\hline CHEMBL1542879 & 688620 & 4.5 & 4.7678 & TST & \\
\hline CHEMBL1478889 & 688620 & 4.95 & 5.022 & TST & \\
\hline CHEMBL1558954 & 688620 & 4.45 & 4.8827 & TRN & \\
\hline CHEMBL1568310 & 688620 & 6.25 & 6.2116 & TRN & \\
\hline CHEMBL1350339 & 688620 & 4.45 & 5.1936 & TRN & \\
\hline CHEMBL1498656 & 688620 & 5.55 & 4.9961 & TRN & \\
\hline CHEMBL1457910 & 688620 & 5.3 & 4.8341 & TRN & \\
\hline CHEMBL1331809 & 688620 & 4.9 & 4.8444 & TST & \\
\hline CHEMBL 365161 & 688620 & 5.0 & 5.3209 & TST & \\
\hline CHEMBL1311755 & 688620 & 4.75 & 4.7595 & TRN & \\
\hline CHEMBL1339453 & 688620 & 4.55 & 5.004 & TRN & \\
\hline CHEMBL1607650 & 688620 & 4.75 & 5.0705 & TST & \\
\hline CHEMBL1416520 & 688620 & 5.15 & 5.046 & TST & \\
\hline CHEMBL1468982 & 688620 & 4.8 & 4.9593 & TRN & \\
\hline CHEMBL3192268 & 688620 & 5.65 & 5.7249 & TST & \\
\hline CHEMBL1328025 & 688620 & 4.95 & 5.2869 & TRN & \\
\hline CHEMBL1375149 & 688620 & 4.45 & 4.8479 & TRN & \\
\hline CHEMBL1343079 & 688620 & 4.9 & 4.9628 & TST & \\
\hline
\end{tabular}




\begin{tabular}{|c|c|c|c|c|}
\hline \multicolumn{5}{|c|}{ Supplemental Table s2.txt } \\
\hline CHEMBL1335013 & 688620 & 4.6 & 4.8819 & TRN \\
\hline CHEMBL1301828 & 688620 & 5.8 & 5.0244 & TST \\
\hline CHEMBL1604606 & 688620 & 4.95 & 5.0395 & TST \\
\hline CHEMBL1526856 & 688620 & 5.0 & 4.9014 & TRN \\
\hline CHEMBL1568484 & 688620 & 8.3468 & 5.1491 & TRN \\
\hline CHEMBL1542798 & 688620 & 7.1002 & 5.15 & TRN \\
\hline CHEMBL1600462 & 688620 & 4.95 & 4.9963 & TRN \\
\hline CHEMBL1335480 & 688620 & 4.95 & 5.0915 & TRN \\
\hline CHEMBL1451791 & 688620 & 5.0 & 5.2832 & TRN \\
\hline CHEMBL1480223 & 688620 & 4.65 & 5.2296 & TRN \\
\hline CHEMBL1353618 & 688620 & 5.85 & 5.2176 & TRN \\
\hline CHEMBL1554917 & 688620 & 4.75 & 4.9618 & TRN \\
\hline CHEMBL1530459 & 688620 & 4.8 & 4.9394 & TST \\
\hline CHEMBL3196034 & 688620 & 4.9 & 5.2467 & TRN \\
\hline CHEMBL3197780 & 688620 & 4.45 & 4.8418 & TRN \\
\hline CHEMBL1396078 & 688620 & 5.6 & 5.0437 & TRN \\
\hline CHEMBL1423452 & 688620 & 4.95 & 5.063 & TST \\
\hline CHEMBL1598883 & 688620 & 5.7 & 5.6042 & TRN \\
\hline CHEMBL1548788 & 688620 & 4.45 & 5.087 & TST \\
\hline CHEMBL1575959 & 688620 & 6.35 & 5.0269 & TRN \\
\hline CHEMBL3208482 & 688620 & 4.45 & 5.0313 & TRN \\
\hline CHEMBL1425652 & 688620 & 5.95 & 5.3518 & TRN \\
\hline CHEMBL1386111 & 688620 & 4.95 & 5.0528 & TRN \\
\hline CHEMBL1605713 & 688620 & 4.9 & 4.9441 & TST \\
\hline CHEMBL1502458 & 688620 & 4.95 & 5.1207 & TRN \\
\hline CHEMBL1469464 & 688620 & 4.65 & 4.802 & TRN \\
\hline CHEMBL1889837 & 688620 & 5.55 & 5.0938 & TRN \\
\hline CHEMBL1463050 & 688620 & 6.6499 & 5.4956 & TRN \\
\hline CHEMBL1532635 & 688620 & 4.95 & 5.0915 & TST \\
\hline CHEMBL 2369211 & 688620 & 4.7 & 5.4454 & TRN \\
\hline CHEMBL1447269 & 688620 & 4.95 & 5.0491 & TST \\
\hline CHEMBL1521564 & 688620 & 4.9 & 5.0337 & TRN \\
\hline CHEMBL515998 & 688620 & 4.45 & 4.6914 & TST \\
\hline CHEMBL1303631 & 688620 & 5.35 & 4.9137 & TRN \\
\hline CHEMBL1547551 & 688620 & 5.4 & 5.2559 & TRN \\
\hline CHEMBL1518538 & 688620 & 4.85 & 5.0396 & TST \\
\hline CHEMBL1300816 & 688620 & 4.8 & 5.13299 & 9999999999 \\
\hline CHEMBL1524148 & 688620 & 6.05 & 4.9668 & TST \\
\hline CHEMBL1578583 & 688620 & 4.95 & 5.2698 & TRN \\
\hline CHEMBL1320281 & 688620 & 5.0 & 5.1173 & TST \\
\hline CHEMBL1328521 & 688620 & 5.45 & 4.9968 & TRN \\
\hline CHEMBL3196551 & 688620 & 5.85 & 5.1396 & TST \\
\hline CHEMBL1418481 & 688620 & 4.6 & 4.9029 & TST \\
\hline CHEMBL1439775 & 688620 & 5.65 & 4.9289 & TRN \\
\hline CHEMBL 3145304 & 688620 & 6.1 & 5.7965 & TRN \\
\hline CHEMBL 3212254 & 688620 & 5.75 & 5.2393 & TRN \\
\hline CHEMBL1313346 & 688620 & 4.5 & 5.0344 & TST \\
\hline CHEMBL1334431 & 688620 & 5.8 & 5.1623 & TST \\
\hline
\end{tabular}




\begin{tabular}{|c|c|c|c|c|c|}
\hline \multicolumn{6}{|c|}{ Supplemental Table S2.txt } \\
\hline CHEMBL1425804 & 688620 & 5.4 & 5.019 & TRN & \\
\hline CHEMBL1550961 & 688620 & 4.45 & 4.855 & TST & \\
\hline CHEMBL1401778 & 688620 & 4.7 & 5.0599 & TRN & \\
\hline CHEMBL1550689 & 688620 & 4.45 & 5.0068 & TST & \\
\hline CHEMBL1610956 & 688620 & 4.9 & 4.9459 & TST & \\
\hline CHEMBL1546760 & 688620 & 5.6 & 5.75799 & 9999999999 & TRN \\
\hline CHEMBL 3212782 & 688620 & 4.45 & 4.8769 & TST & \\
\hline CHEMBL1594869 & 688620 & 5.2 & 5.1058 & TRN & \\
\hline CHEMBL1584742 & 688620 & 4.45 & 4.9068 & TRN & \\
\hline CHEMBL1409561 & 688620 & 5.65 & 5.3119 & TRN & \\
\hline CHEMBL3196269 & 688620 & 5.0 & 5.0113 & TRN & \\
\hline CHEMBL1522369 & 688620 & 4.45 & 4.9049 & TRN & \\
\hline CHEMBL3189356 & 688620 & 4.9 & 5.0143 & TRN & \\
\hline CHEMBL1305004 & 688620 & 5.45 & 5.5324 & TRN & \\
\hline CHEMBL1579059 & 688620 & 5.1 & 5.0472 & TRN & \\
\hline CHEMBL1538015 & 688620 & 4.45 & 4.7047 & TRN & \\
\hline CHEMBL1299778 & 688620 & 4.65 & 5.2462 & TST & \\
\hline CHEMBL1393751 & 688620 & 6.0 & 5.1718 & TST & \\
\hline CHEMBL1502903 & 688620 & 4.45 & 4.9909 & TST & \\
\hline CHEMBL1459472 & 688620 & 5.0 & 5.1083 & TRN & \\
\hline CHEMBL3192702 & 688620 & 4.45 & 5.2573 & TRN & \\
\hline CHEMBL1416026 & 688620 & 5.15 & 4.8301 & TRN & \\
\hline CHEMBL1486621 & 688620 & 4.95 & 4.9123 & TRN & \\
\hline CHEMBL1413364 & 688620 & 4.9 & 4.9752 & TST & \\
\hline CHEMBL1584875 & 688620 & 5.0 & 5.3693 & TRN & \\
\hline CHEMBL449690 & 688620 & 6.0 & 5.7466 & TRN & \\
\hline CHEMBL1443354 & 688620 & 8.301 & 4.8478 & TST & \\
\hline CHEMBL3192897 & 688620 & 4.9 & 5.0405 & TST & \\
\hline CHEMBL1383496 & 688620 & 4.5 & 4.6733 & TRN & \\
\hline CHEMBL1601870 & 688620 & 5.05 & 5.1179 & TRN & \\
\hline CHEMBL1510709 & 688620 & 5.9 & 4.8184 & TRN & \\
\hline CHEMBL1444354 & 688620 & 4.95 & 4.9918 & TST & \\
\hline CHEMBL1509078 & 688620 & 4.95 & 4.7848 & TRN & \\
\hline CHEMBL1571590 & 688620 & 4.95 & 5.0867 & TRN & \\
\hline CHEMBL1456722 & 688620 & 5.35 & 5.4392 & TST & \\
\hline CHEMBL1580839 & 688620 & 5.35 & 5.3024 & TRN & \\
\hline CHEMBL1612094 & 688620 & 4.9 & 5.0608 & TRN & \\
\hline CHEMBL1591894 & 688620 & 4.45 & 4.939 & TRN & \\
\hline CHEMBL1415163 & 688620 & 5.05 & 5.0993 & TRN & \\
\hline CHEMBL1534682 & 688620 & 4.85 & 5.0509 & TRN & \\
\hline CHEMBL574583 & 688620 & 5.0 & 4.8082 & TST & \\
\hline CHEMBL1573500 & 688620 & 4.5 & 5.0411 & TRN & \\
\hline CHEMBL1464195 & 688620 & 4.95 & 4.8522 & TRN & \\
\hline CHEMBL1605635 & 688620 & 5.9 & 5.2234 & TRN & \\
\hline CHEMBL1584023 & 688620 & 4.6 & 4.9775 & TST & \\
\hline CHEMBL3191174 & 688620 & 4.45 & 4.88899 & 9999999999 & TRN \\
\hline CHEMBL1528669 & 688620 & 4.7 & 5.0934 & TRN & \\
\hline CHEMBL1483957 & 688620 & 4.65 & 5.2326 & TRN & \\
\hline
\end{tabular}




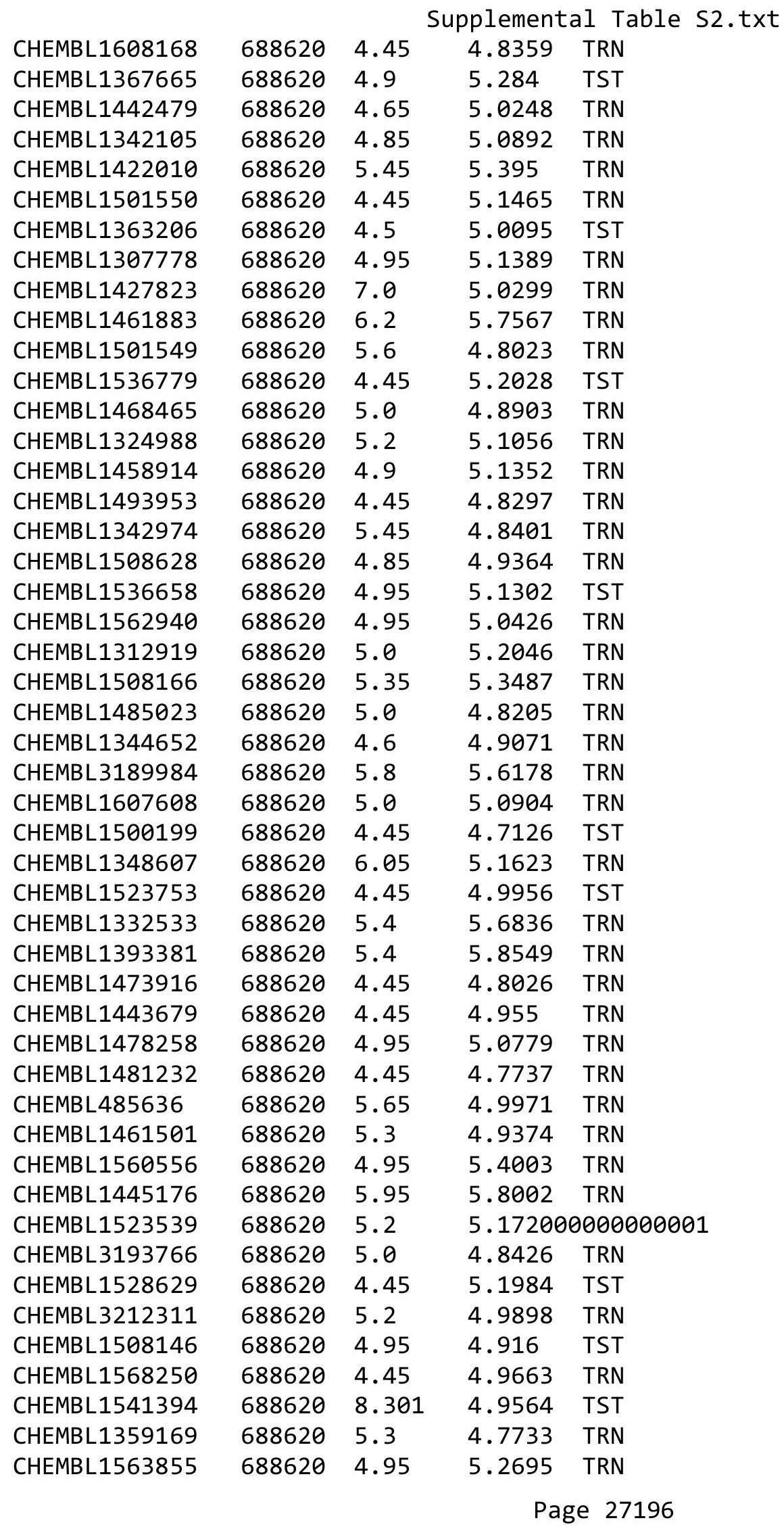




\begin{tabular}{|c|c|c|c|c|c|}
\hline & & & & & \\
\hline CHEMBL1576870 & 688620 & 5.5 & 5.3407 & TRN & \\
\hline CHEMBL1331920 & 688620 & 5.1 & 5.1503 & TRN & \\
\hline CHEMBL1367818 & 688620 & 5.5 & 5.0867 & TRN & \\
\hline CHEMBL1364962 & 688620 & 5.0 & 5.0591 & TST & \\
\hline CHEMBL1536765 & 688620 & 4.45 & 5.03600 & 00000000005 & TRN \\
\hline CHEMBL1402371 & 688620 & 4.45 & 5.0983 & TRN & \\
\hline CHEMBL3191803 & 688620 & 4.75 & 4.8076 & TRN & \\
\hline CHEMBL1408856 & 688620 & 4.7 & 5.0183 & TRN & \\
\hline CHEMBL1487269 & 688620 & 5.15 & 4.9316 & TRN & \\
\hline CHEMBL1603775 & 688620 & 5.2 & 4.9781 & TRN & \\
\hline CHEMBL1354012 & 688620 & 4.45 & 4.8421 & TRN & \\
\hline CHEMBL1609373 & 688620 & 5.35 & 5.0028 & TRN & \\
\hline CHEMBL1310254 & 688620 & 5.15 & 5.0446 & TRN & \\
\hline CHEMBL1384658 & 688620 & 6.5 & 5.1744 & TRN & \\
\hline CHEMBL1349934 & 688620 & 5.2 & 4.9811 & TRN & \\
\hline CHEMBL1578670 & 688620 & 4.45 & 5.8037 & TRN & \\
\hline CHEMBL1331108 & 688620 & 5.3 & 5.0971 & TST & \\
\hline CHEMBL1586005 & 688620 & 5.55 & 5.0309 & TRN & \\
\hline CHEMBL1370326 & 688620 & 4.85 & 4.9101 & TST & \\
\hline CHEMBL3197290 & 688620 & 5.15 & 5.2908 & TRN & \\
\hline CHEMBL1325645 & 688620 & 5.0 & 4.8671 & TRN & \\
\hline CHEMBL1338621 & 688620 & 5.0 & 5.1917 & TRN & \\
\hline CHEMBL1545985 & 688620 & 4.45 & 4.9064 & TRN & \\
\hline CHEMBL1444873 & 688620 & 4.65 & 4.9009 & TRN & \\
\hline CHEMBL1421779 & 688620 & 5.25 & 4.8951 & TST & \\
\hline CHEMBL1366428 & 688620 & 4.45 & 5.0021 & TRN & \\
\hline CHEMBL1346851 & 688620 & 5.05 & 5.1794 & TST & \\
\hline CHEMBL1347877 & 688620 & 8.301 & 5.0564 & TRN & \\
\hline CHEMBL1498043 & 688620 & 5.6 & 4.5519 & TRN & \\
\hline CHEMBL1360066 & 688620 & 4.6 & 4.6749 & TRN & \\
\hline CHEMBL1432817 & 688620 & 5.5 & 5.0323 & TST & \\
\hline CHEMBL1539504 & 688620 & 4.9 & 5.3593 & TST & \\
\hline CHEMBL3194156 & 688620 & 4.45 & 4.9053 & TRN & \\
\hline CHEMBL1365988 & 688620 & 5.25 & 5.5712 & TRN & \\
\hline CHEMBL1404393 & 688620 & 4.95 & 5.0199 & TST & \\
\hline CHEMBL1335722 & 688620 & 5.0 & 5.1876 & TRN & \\
\hline CHEMBL1331601 & 688620 & 4.45 & 4.9124 & TRN & \\
\hline CHEMBL1334720 & 688620 & 4.45 & 4.9416 & TRN & \\
\hline CHEMBL1534203 & 688620 & 4.95 & 4.6746 & TRN & \\
\hline CHEMBL1488177 & 688620 & 4.45 & 5.1541 & TRN & \\
\hline CHEMBL1535021 & 688620 & 5.4 & 5.3033 & TST & \\
\hline CHEMBL1561780 & 688620 & 4.6 & 4.9246 & TRN & \\
\hline CHEMBL1580028 & 688620 & 4.8 & 4.8646 & TST & \\
\hline CHEMBL1371352 & 688620 & 4.8 & 4.8602 & TRN & \\
\hline CHEMBL1379339 & 688620 & 4.85 & 5.1166 & TRN & \\
\hline CHEMBL1346723 & 688620 & 5.2 & 5.3779 & TST & \\
\hline CHEMBL1530503 & 688620 & 4.5 & 4.8921 & TRN & \\
\hline CHEMBL1373486 & 688620 & 4.45 & 4.6846 & TST & \\
\hline & & & & 27197 & \\
\hline
\end{tabular}




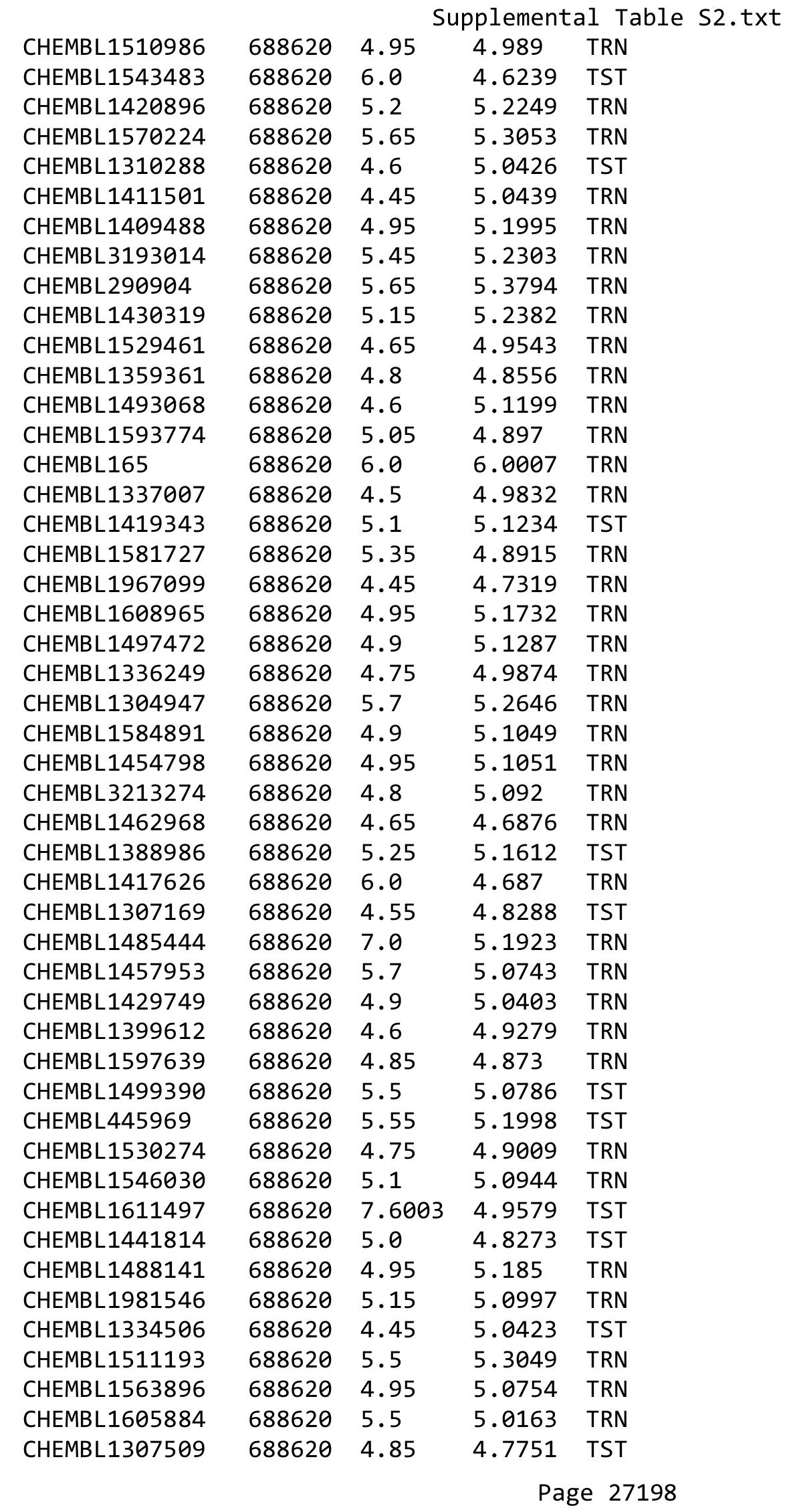




\begin{tabular}{|c|c|c|c|c|c|}
\hline \multicolumn{6}{|c|}{ Supplemental Table S2.txt } \\
\hline CHEMBL1386558 & 688620 & 5.25 & 5.4483 & TRN & \\
\hline CHEMBL1478443 & 688620 & 4.55 & 5.0357 & TST & \\
\hline CHEMBL1584365 & 688620 & 4.95 & 5.1688 & TRN & \\
\hline CHEMBL1376759 & 688620 & 5.4 & 4.8297 & TRN & \\
\hline CHEMBL1468806 & 688620 & 4.45 & 5.0394 & TST & \\
\hline CHEMBL1516375 & 688620 & 4.8 & 5.1132 & TST & \\
\hline CHEMBL1562157 & 688620 & 6.7001 & 5.83799 & 9999999999 & TRN \\
\hline CHEMBL1420679 & 688620 & 4.7 & 5.0547 & TRN & \\
\hline CHEMBL1994362 & 688620 & 4.85 & 4.9436 & TRN & \\
\hline CHEMBL1356882 & 688620 & 4.9 & 5.4761 & TRN & \\
\hline CHEMBL1312675 & 688620 & 4.8 & 4.8504 & TST & \\
\hline CHEMBL1540530 & 688620 & 4.7 & 5.121 & TRN & \\
\hline CHEMBL1561089 & 688620 & 5.5 & 5.3989 & TST & \\
\hline CHEMBL1439472 & 688620 & 8.301 & 5.1869 & TRN & \\
\hline CHEMBL1509722 & 688620 & 4.65 & 5.1561 & TST & \\
\hline CHEMBL1321338 & 688620 & 4.45 & 5.0874 & TST & \\
\hline CHEMBL1559564 & 688620 & 4.7 & 4.9686 & TRN & \\
\hline CHEMBL1394302 & 688620 & 5.05 & 4.7658 & TRN & \\
\hline CHEMBL1607405 & 688620 & 4.75 & 5.1738 & TST & \\
\hline CHEMBL1366006 & 688620 & 5.0 & 5.1668 & TRN & \\
\hline CHEMBL1559027 & 688620 & 5.1 & 5.2287 & TRN & \\
\hline CHEMBL1326216 & 688620 & 5.55 & 5.78799 & & TRN \\
\hline CHEMBL1487334 & 688620 & 5.75 & 5.1366 & TRN & \\
\hline CHEMBL1546868 & 688620 & 5.55 & 4.9719 & TRN & \\
\hline CHEMBL3211467 & 688620 & 4.45 & 4.9503 & TRN & \\
\hline CHEMBL1337974 & 688620 & 5.9 & 4.9563 & TRN & \\
\hline CHEMBL1377656 & 688620 & 5.1 & 4.8634 & TRN & \\
\hline CHEMBL1606017 & 688620 & 4.45 & 4.7964 & TST & \\
\hline CHEMBL1431377 & 688620 & 5.0 & 5.2935 & TST & \\
\hline CHEMBL1489692 & 688620 & 4.45 & 5.0604 & TRN & \\
\hline CHEMBL1498107 & 688620 & 8.3468 & 5.0323 & TRN & \\
\hline CHEMBL1322823 & 688620 & 5.0 & 4.9469 & TST & \\
\hline CHEMBL1421218 & 688620 & 4.65 & 4.8948 & TRN & \\
\hline CHEMBL1558496 & 688620 & 4.85 & 4.8655 & TST & \\
\hline CHEMBL1484460 & 688620 & 5.55 & 4.863 & TST & \\
\hline CHEMBL1347048 & 688620 & 5.3 & 4.90600 & 0000000001 & TRN \\
\hline CHEMBL3198406 & 688620 & 5.1 & 5.3738 & TRN & \\
\hline CHEMBL3190311 & 688620 & 4.8 & 4.9491 & TRN & \\
\hline CHEMBL1392043 & 688620 & 4.8 & 5.1836 & TST & \\
\hline CHEMBL1964843 & 688620 & 4.9 & 4.9639 & TRN & \\
\hline CHEMBL1477856 & 688620 & 4.7 & 5.0041 & TRN & \\
\hline CHEMBL3195992 & 688620 & 4.8 & 5.1255 & TRN & \\
\hline CHEMBL1378258 & 688620 & 4.45 & 4.791 & TRN & \\
\hline CHEMBL3199092 & 688620 & 4.45 & 4.7756 & TRN & \\
\hline CHEMBL1440414 & 688620 & 4.7 & 4.9087 & TRN & \\
\hline CHEMBL1349296 & 688620 & 4.85 & 4.9494 & TRN & \\
\hline CHEMBL1339158 & 688620 & 4.95 & 5.1232 & TRN & \\
\hline CHEMBL1588022 & 688620 & 5.35 & 5.1484 & TST & \\
\hline
\end{tabular}




\begin{tabular}{|c|c|c|c|c|c|}
\hline \multicolumn{6}{|c|}{ Supplemental Table S2.txt } \\
\hline CHEMBL1299409 & 688620 & 4.95 & 5.0461 & TRN & \\
\hline CHEMBL1543561 & 688620 & 4.45 & 4.8123 & TRN & \\
\hline CHEMBL1567172 & 688620 & 4.9 & 5.4568 & TRN & \\
\hline CHEMBL1323163 & 688620 & 4.45 & 4.8612 & TRN & \\
\hline CHEMBL1467814 & 688620 & 4.95 & 5.4308 & TRN & \\
\hline CHEMBL1444853 & 688620 & 4.9 & 4.8629 & TRN & \\
\hline CHEMBL1451911 & 688620 & 5.6 & 5.0875 & TST & \\
\hline CHEMBL1444080 & 688620 & 4.8 & 5.0865 & TRN & \\
\hline CHEMBL1448409 & 688620 & 4.7 & 4.8786 & TST & \\
\hline CHEMBL1532534 & 688620 & 4.55 & 4.8827 & TRN & \\
\hline CHEMBL1335995 & 688620 & 5.0 & 4.8144 & TRN & \\
\hline CHEMBL1429943 & 688620 & 5.5 & 5.0107 & TRN & \\
\hline CHEMBL1544790 & 688620 & 5.15 & 5.3027 & TST & \\
\hline CHEMBL1471433 & 688620 & 5.1 & 5.0775 & TRN & \\
\hline CHEMBL1988782 & 688620 & 6.2 & 5.9281 & TRN & \\
\hline CHEMBL3191892 & 688620 & 5.05 & 5.07600 & 00000000005 & TRN \\
\hline CHEMBL1545987 & 688620 & 4.9 & 4.7432 & TST & \\
\hline CHEMBL1612420 & 688620 & 4.9 & 5.1177 & TRN & \\
\hline CHEMBL1511616 & 688620 & 5.5 & 5.0333 & TST & \\
\hline CHEMBL 2004144 & 688620 & 5.0 & 4.9169 & TRN & \\
\hline CHEMBL1325767 & 688620 & 5.8 & 4.9883 & TRN & \\
\hline CHEMBL1373465 & 688620 & 4.8 & 5.15 & TST & \\
\hline CHEMBL1484838 & 688620 & 4.5 & 5.1011 & TRN & \\
\hline CHEMBL1577179 & 688620 & 5.8 & 4.9514 & TRN & \\
\hline CHEMBL1603490 & 688620 & 4.8 & 4.6664 & TRN & \\
\hline CHEMBL1604958 & 688620 & 5.5 & 5.3885 & TRN & \\
\hline CHEMBL3192665 & 688620 & 5.2 & 4.956 & TST & \\
\hline CHEMBL1495198 & 688620 & 4.95 & 5.1926 & TRN & \\
\hline CHEMBL1583021 & 688620 & 6.7501 & 5.1646 & TRN & \\
\hline CHEMBL1593129 & 688620 & 4.6 & 4.9144 & TRN & \\
\hline CHEMBL1609794 & 688620 & 5.5 & 4.7559 & TST & \\
\hline CHEMBL1559491 & 688620 & 4.45 & 4.9779 & TRN & \\
\hline CHEMBL1409509 & 688620 & 5.4 & 5.3142 & TRN & \\
\hline CHEMBL1466963 & 688620 & 4.9 & 5.1893 & TRN & \\
\hline CHEMBL1558842 & 688620 & 4.9 & 4.8939 & TRN & \\
\hline CHEMBL1339997 & 688620 & 5.5 & 5.3303 & TRN & \\
\hline CHEMBL1584950 & 688620 & 5.5 & 4.8951 & TST & \\
\hline CHEMBL1309210 & 688620 & 4.85 & 4.6977 & TRN & \\
\hline CHEMBL1516495 & 688620 & 5.2 & 4.7599 & TRN & \\
\hline CHEMBL1581228 & 688620 & 4.45 & 5.0159 & TRN & \\
\hline CHEMBL13097 & 688620 & 4.8 & 5.1404 & TRN & \\
\hline CHEMBL1473529 & 688620 & 4.45 & 4.7902 & TRN & \\
\hline CHEMBL1334638 & 688620 & 6.25 & 5.0493 & TRN & \\
\hline CHEMBL3191571 & 688620 & 5.0 & 5.8847 & TRN & \\
\hline CHEMBL1322004 & 688620 & 4.45 & 4.9849 & TRN & \\
\hline CHEMBL1344268 & 688620 & 4.9 & 4.8991 & TRN & \\
\hline CHEMBL1429106 & 688620 & 4.95 & 5.3361 & TRN & \\
\hline CHEMBL1595434 & 688620 & 4.95 & 5.2239 & TRN & \\
\hline
\end{tabular}




\begin{tabular}{|c|c|c|c|c|}
\hline \multicolumn{5}{|c|}{ Supplemental Table S2.txt } \\
\hline CHEMBL1415790 & 688620 & 4.6 & 4.9124 & TRN \\
\hline CHEMBL1313652 & 688620 & 5.45 & 4.8119 & TRN \\
\hline CHEMBL3211522 & 688620 & 4.5 & 4.8393 & TST \\
\hline CHEMBL1403042 & 688620 & 4.75 & 5.0047 & TRN \\
\hline CHEMBL1390574 & 688620 & 5.55 & 4.9912 & TRN \\
\hline CHEMBL3392448 & 688620 & 5.95 & 5.9976 & TRN \\
\hline CHEMBL1526099 & 688620 & 4.7 & 4.7881 & TRN \\
\hline CHEMBL1519675 & 688620 & 7.4001 & 5.0565 & TRN \\
\hline CHEMBL1540739 & 688620 & 8.2007 & 5.1222 & TRN \\
\hline CHEMBL1575421 & 688620 & 4.7 & 4.8632 & TRN \\
\hline CHEMBL1599778 & 688620 & 4.95 & 5.4437 & TRN \\
\hline CHEMBL1594717 & 688620 & 4.75 & 5.0193 & TRN \\
\hline CHEMBL3191989 & 688620 & 4.7 & 4.993 & TRN \\
\hline CHEMBL 3209520 & 688620 & 5.2 & 4.7788 & TRN \\
\hline CHEMBL1472794 & 688620 & 5.0 & 4.9524 & TST \\
\hline CHEMBL1445894 & 688620 & 5.05 & 5.2596 & TRN \\
\hline CHEMBL1337484 & 688620 & 5.55 & 4.7824 & TRN \\
\hline CHEMBL1574918 & 688620 & 6.7501 & 5.0922 & TRN \\
\hline CHEMBL1458166 & 688620 & 5.55 & 4.9957 & TRN \\
\hline CHEMBL1597234 & 688620 & 4.45 & 4.8071 & TRN \\
\hline CHEMBL1698037 & 688620 & 4.9 & 5.1919 & TRN \\
\hline CHEMBL1471849 & 688620 & 6.5501 & 6.0781 & TRN \\
\hline CHEMBL1556453 & 688620 & 4.95 & 4.9412 & TRN \\
\hline CHEMBL1534623 & 688620 & 7.4498 & 4.8474 & TST \\
\hline CHEMBL1596777 & 688620 & 5.0 & 4.8037 & TRN \\
\hline CHEMBL1502199 & 688620 & 5.45 & 4.909 & TRN \\
\hline CHEMBL2369311 & 688620 & 7.4498 & 5.5259 & TST \\
\hline CHEMBL3192975 & 688620 & 4.8 & 5.1444 & TRN \\
\hline CHEMBL1450010 & 688620 & 4.9 & 5.0143 & TRN \\
\hline CHEMBL1601122 & 688620 & 4.95 & 5.1498 & TRN \\
\hline CHEMBL1364960 & 688620 & 4.45 & 4.7406 & TST \\
\hline CHEMBL1608279 & 688620 & 5.6 & 5.3791 & TRN \\
\hline CHEMBL1393399 & 688620 & 5.0 & 4.8842 & TRN \\
\hline CHEMBL1498135 & 688620 & 5.65 & 4.9586 & TRN \\
\hline CHEMBL1378722 & 688620 & 4.8 & 5.0417 & TRN \\
\hline CHEMBL1392322 & 688620 & 5.2 & 5.0808 & TST \\
\hline CHEMBL1518977 & 688620 & 4.85 & 5.1472 & TRN \\
\hline CHEMBL3190465 & 688620 & 4.75 & 5.0002 & TRN \\
\hline CHEMBL1964614 & 688620 & 6.1 & 5.9609 & TRN \\
\hline CHEMBL1554693 & 688620 & 5.6 & 4.9331 & TRN \\
\hline CHEMBL 2374062 & 688620 & 4.8 & 5.2006 & TST \\
\hline CHEMBL1313243 & 688620 & 4.9 & 5.0483 & TST \\
\hline CHEMBL1460378 & 688620 & 4.65 & 4.8704 & TRN \\
\hline CHEMBL1346780 & 688620 & 4.75 & 5.0204 & TST \\
\hline CHEMBL1499048 & 688620 & 4.9 & 5.1089 & TST \\
\hline CHEMBL1374211 & 688620 & 4.9 & 4.7725 & TST \\
\hline CHEMBL419564 & 688620 & 5.6 & 4.9029 & TRN \\
\hline CHEMBL1308075 & 688620 & 4.7 & 4.8216 & TRN \\
\hline
\end{tabular}




\begin{tabular}{|c|c|c|c|c|}
\hline & & & oplement & al $\mathrm{T}$ \\
\hline CHEMBL1328903 & 688620 & 4.45 & 4.947 & TRN \\
\hline CHEMBL1365426 & 688620 & 4.45 & 5.0355 & TRN \\
\hline CHEMBL1520245 & 688620 & 4.45 & 4.6927 & TRN \\
\hline CHEMBL 2001455 & 688620 & 5.5 & 5.5368 & TRN \\
\hline CHEMBL1588820 & 688620 & 5.85 & 5.2 & TRN \\
\hline CHEMBL1589303 & 688620 & 4.95 & 5.1786 & TRN \\
\hline CHEMBL1366555 & 688620 & 5.45 & 5.4753 & TRN \\
\hline CHEMBL1373084 & 688620 & 4.95 & 4.7408 & TRN \\
\hline CHEMBL211481 & 688620 & 4.85 & 5.0929 & TRN \\
\hline CHEMBL407491 & 688620 & 6.5501 & 6.3244 & TRN \\
\hline CHEMBL126077 & 688620 & 5.0 & 5.0812 & TST \\
\hline CHEMBL1501078 & 688620 & 4.8 & 4.8651 & TRN \\
\hline CHEMBL1422689 & 688620 & 4.95 & 4.77 & TRN \\
\hline CHEMBL1532737 & 688620 & 4.8 & 4.9871 & TRN \\
\hline CHEMBL1582855 & 688620 & 4.95 & 5.1781 & TRN \\
\hline CHEMBL1561669 & 688620 & 4.45 & 4.88 & TRN \\
\hline CHEMBL1510639 & 688620 & 4.9 & 4.9766 & TRN \\
\hline CHEMBL77098 & 688620 & 5.2 & 5.0006 & TRN \\
\hline CHEMBL1343060 & 688620 & 7.1002 & 5.1427 & TST \\
\hline CHEMBL1420825 & 688620 & 6.7001 & 5.0036 & TST \\
\hline CHEMBL1549030 & 688620 & 4.45 & 4.8149 & TST \\
\hline CHEMBL1497102 & 688620 & 5.3 & 4.9523 & TST \\
\hline CHEMBL1352387 & 688620 & 4.85 & 5.0084 & TST \\
\hline CHEMBL1548570 & 688620 & 4.9 & 4.9072 & TRN \\
\hline CHEMBL1991487 & 688620 & 6.0 & 5.8618 & TRN \\
\hline CHEMBL1589322 & 688620 & 5.25 & 4.9521 & TRN \\
\hline CHEMBL1608386 & 688620 & 4.65 & 4.8244 & TRN \\
\hline CHEMBL1500101 & 688620 & 6.15 & 5.8815 & TRN \\
\hline CHEMBL1363917 & 688620 & 4.9 & 4.9874 & TRN \\
\hline CHEMBL1427423 & 688620 & 6.4 & 5.5984 & TRN \\
\hline CHEMBL1584778 & 688620 & 4.7 & 4.7224 & TRN \\
\hline CHEMBL1376762 & 688620 & 4.75 & 4.7578 & TST \\
\hline CHEMBL3190810 & 688620 & 6.2 & 5.0766 & TRN \\
\hline CHEMBL1467671 & 688620 & 4.75 & 5.1203 & TST \\
\hline CHEMBL 2004185 & 688620 & 6.15 & 5.7646 & TRN \\
\hline CHEMBL1543216 & 688620 & 5.5 & 5.3768 & TRN \\
\hline CHEMBL1452369 & 688620 & 4.45 & 4.9885 & TST \\
\hline CHEMBL1330510 & 688620 & 5.7 & 5.7398 & TRN \\
\hline CHEMBL1438498 & 688620 & 4.45 & 5.4079 & TRN \\
\hline CHEMBL1587255 & 688620 & 4.7 & 6.1595 & TRN \\
\hline CHEMBL1496051 & 688620 & 5.05 & 4.8595 & TRN \\
\hline CHEMBL3193161 & 688620 & 5.05 & 5.2614 & TRN \\
\hline CHEMBL1301650 & 688620 & 5.5 & 5.5924 & TRN \\
\hline CHEMBL1304364 & 688620 & 5.05 & 4.9092 & TRN \\
\hline CHEMBL1379648 & 688620 & 5.0 & 4.9324 & TST \\
\hline CHEMBL1488591 & 688620 & 5.35 & 5.3304 & TRN \\
\hline CHEMBL1556488 & 688620 & 4.75 & 5.4017 & TST \\
\hline CHEMBL1327134 & 688620 & 6.05 & 5.1871 & TRN \\
\hline
\end{tabular}




\begin{tabular}{|c|c|c|c|c|c|}
\hline \\
\hline CHEMBL573419 & 688620 & 4.9 & 5.0457 & TST & \\
\hline CHEMBL1334882 & 688620 & 4.95 & 4.9021 & TRN & \\
\hline CHEMBL1324517 & 688620 & 4.45 & 5.0303 & TST & \\
\hline CHEMBL1600333 & 688620 & 4.9 & 5.2017 & TST & \\
\hline CHEMBL1384102 & 688620 & 5.55 & 5.093 & TRN & \\
\hline CHEMBL1488557 & 688620 & 4.75 & 4.994 & TRN & \\
\hline CHEMBL1486204 & 688620 & 4.95 & 5.0266 & TRN & \\
\hline CHEMBL1531500 & 688620 & 5.7 & 5.3155 & TRN & \\
\hline CHEMBL1307707 & 688620 & 5.95 & 5.231 & TRN & \\
\hline CHEMBL3189875 & 688620 & 4.85 & 5.1842 & TRN & \\
\hline CHEMBL1471198 & 688620 & 5.3 & 4.8752 & TRN & \\
\hline CHEMBL 252403 & 688620 & 5.2 & 5.5493 & TRN & \\
\hline CHEMBL1452429 & 688620 & 4.75 & 5.0842 & TST & \\
\hline CHEMBL1501703 & 688620 & 4.45 & 4.9902 & TST & \\
\hline CHEMBL1299702 & 688620 & 4.9 & 5.0947 & TRN & \\
\hline CHEMBL1427227 & 688620 & 4.65 & 5.1018 & TRN & \\
\hline CHEMBL1414426 & 688620 & 4.5 & 4.8695 & TRN & \\
\hline CHEMBL1401555 & 688620 & 5.15 & 5.13299 & 9999999999 & TRN \\
\hline CHEMBL1605199 & 688620 & 5.35 & 5.0537 & TRN & \\
\hline CHEMBL1380305 & 688620 & 4.65 & 4.9436 & TRN & \\
\hline CHEMBL1346260 & 688620 & 4.95 & 5.1061 & TRN & \\
\hline CHEMBL1373942 & 688620 & 4.5 & 5.1095 & TRN & \\
\hline CHEMBL1457898 & 688620 & 5.2 & 5.13899 & 9999999999 & TRN \\
\hline CHEMBL1329458 & 688620 & 4.75 & 5.1249 & TST & \\
\hline CHEMBL1320566 & 688620 & 4.75 & 4.8772 & TRN & \\
\hline CHEMBL1311645 & 688620 & 4.85 & 5.0237 & TRN & \\
\hline CHEMBL1539998 & 688620 & 6.35 & 5.28600 & 30000000005 & TRN \\
\hline CHEMBL1449009 & 688620 & 5.1 & 4.7706 & TRN & \\
\hline CHEMBL1381730 & 688620 & 4.8 & 4.8695 & TRN & \\
\hline CHEMBL1322182 & 688620 & 4.95 & 4.8933 & TRN & \\
\hline CHEMBL1493877 & 688620 & 4.75 & 5.0779 & TRN & \\
\hline CHEMBL1388500 & 688620 & 4.45 & 5.0336 & TRN & \\
\hline CHEMBL1506406 & 688620 & 5.2 & 4.9996 & TRN & \\
\hline CHEMBL1422559 & 688620 & 4.45 & 5.1067 & TST & \\
\hline CHEMBL1311220 & 688620 & 4.8 & 4.9361 & TRN & \\
\hline CHEMBL3198266 & 688620 & 5.8 & 5.6376 & TRN & \\
\hline CHEMBL1503412 & 688620 & 4.75 & 5.2031 & TST & \\
\hline CHEMBL1586123 & 688620 & 4.9 & 4.8929 & TRN & \\
\hline CHEMBL1567092 & 688620 & 4.45 & 4.9877 & TRN & \\
\hline CHEMBL1309230 & 688620 & 4.9 & 4.941 & TRN & \\
\hline CHEMBL3191780 & 688620 & 5.65 & 5.4385 & TRN & \\
\hline CHEMBL1561456 & 688620 & 4.45 & 5.3295 & TRN & \\
\hline CHEMBL1559649 & 688620 & 4.7 & 4.8616 & TRN & \\
\hline CHEMBL1549195 & 688620 & 4.65 & 5.1051 & TRN & \\
\hline CHEMBL1429789 & 688620 & 5.85 & 5.5202 & TRN & \\
\hline CHEMBL1322290 & 688620 & 5.1 & 4.9784 & TST & \\
\hline CHEMBL1505548 & 688620 & 5.0 & 4.9107 & TST & \\
\hline CHEMBL1502613 & 688620 & 5.0 & 4.9937 & TST & \\
\hline
\end{tabular}




\begin{tabular}{|c|c|c|c|c|}
\hline \multicolumn{5}{|c|}{ Supplemental Table S2.txt } \\
\hline CHEMBL1533027 & 688620 & 5.65 & 5.3504 & TRN \\
\hline CHEMBL 2369277 & 688620 & 4.5 & 4.966 & TRN \\
\hline CHEMBL1325615 & 688620 & 5.05 & 4.9678 & TRN \\
\hline CHEMBL1330931 & 688620 & 4.75 & 4.9955 & TRN \\
\hline CHEMBL1429737 & 688620 & 4.65 & 5.0231 & TRN \\
\hline CHEMBL1577929 & 688620 & 5.6 & 5.1058 & TRN \\
\hline CHEMBL1595549 & 688620 & 5.5 & 5.0367 & TST \\
\hline CHEMBL1467317 & 688620 & 4.45 & 5.0335 & TRN \\
\hline CHEMBL1600847 & 688620 & 4.7 & 4.8744 & TRN \\
\hline CHEMBL1528930 & 688620 & 5.85 & 5.2411 & TRN \\
\hline CHEMBL1588046 & 688620 & 6.95 & 6.1854 & TRN \\
\hline CHEMBL1612398 & 688620 & 5.5 & 4.7921 & TST \\
\hline CHEMBL1585912 & 688620 & 5.25 & 6.2269 & TRN \\
\hline CHEMBL1522020 & 688620 & 4.9 & 5.1868 & TST \\
\hline CHEMBL1334312 & 688620 & 4.65 & 5.0842 & TST \\
\hline CHEMBL1457935 & 688620 & 4.95 & 5.2409 & TRN \\
\hline CHEMBL357992 & 688620 & 4.95 & 4.9105 & TST \\
\hline CHEMBL3192303 & 688620 & 6.0 & 5.569 & TRN \\
\hline CHEMBL1368647 & 688620 & 4.6 & 5.3615 & TRN \\
\hline CHEMBL1557910 & 688620 & 7.5498 & 5.051 & TRN \\
\hline CHEMBL1331520 & 688620 & 5.5 & 5.4056 & TST \\
\hline CHEMBL3189400 & 688620 & 5.0 & 5.1974 & TRN \\
\hline CHEMBL1488461 & 688620 & 6.2 & 4.9863 & TRN \\
\hline CHEMBL1569591 & 688620 & 4.8 & 4.8679 & TRN \\
\hline CHEMBL1323854 & 688620 & 5.5 & 5.1342 & TRN \\
\hline CHEMBL3197945 & 688620 & 4.45 & 4.9746 & TRN \\
\hline CHEMBL1402909 & 688620 & 5.25 & 5.0654 & TST \\
\hline CHEMBL1441180 & 688620 & 4.45 & 4.7887 & TST \\
\hline CHEMBL1443077 & 688620 & 5.05 & 4.8463 & TRN \\
\hline CHEMBL1569525 & 688620 & 4.85 & 4.9992 & TST \\
\hline CHEMBL1582448 & 688620 & 5.6 & 5.3406 & TRN \\
\hline CHEMBL 30454 & 688620 & 4.45 & 4.9818 & TRN \\
\hline CHEMBL1584961 & 688620 & 5.65 & 5.2872 & TST \\
\hline CHEMBL1534255 & 688620 & 5.4 & 5.146 & TRN \\
\hline CHEMBL1451657 & 688620 & 6.6 & 5.1521 & TST \\
\hline CHEMBL1540901 & 688620 & 5.85 & 4.9858 & TRN \\
\hline CHEMBL3190124 & 688620 & 4.9 & 5.1138 & TST \\
\hline CHEMBL1385199 & 688620 & 5.0 & 5.1216 & TRN \\
\hline CHEMBL1575783 & 688620 & 4.95 & 5.0705 & TST \\
\hline CHEMBL1084644 & 688620 & 5.05 & 4.6563 & TST \\
\hline CHEMBL1390834 & 688620 & 4.45 & 5.052 & TRN \\
\hline CHEMBL1378337 & 688620 & 4.9 & 4.8949 & TRN \\
\hline CHEMBL1300137 & 688620 & 5.0 & 5.3083 & TRN \\
\hline CHEMBL3191699 & 688620 & 4.45 & 5.0637 & TRN \\
\hline CHEMBL1362995 & 688620 & 4.45 & 5.0224 & TRN \\
\hline CHEMBL3198965 & 688620 & 4.6 & 5.3076 & TRN \\
\hline CHEMBL1347970 & 688620 & 4.45 & 5.1381 & TST \\
\hline CHEMBL1481801 & 688620 & 5.05 & 5.1628 & TRN \\
\hline
\end{tabular}




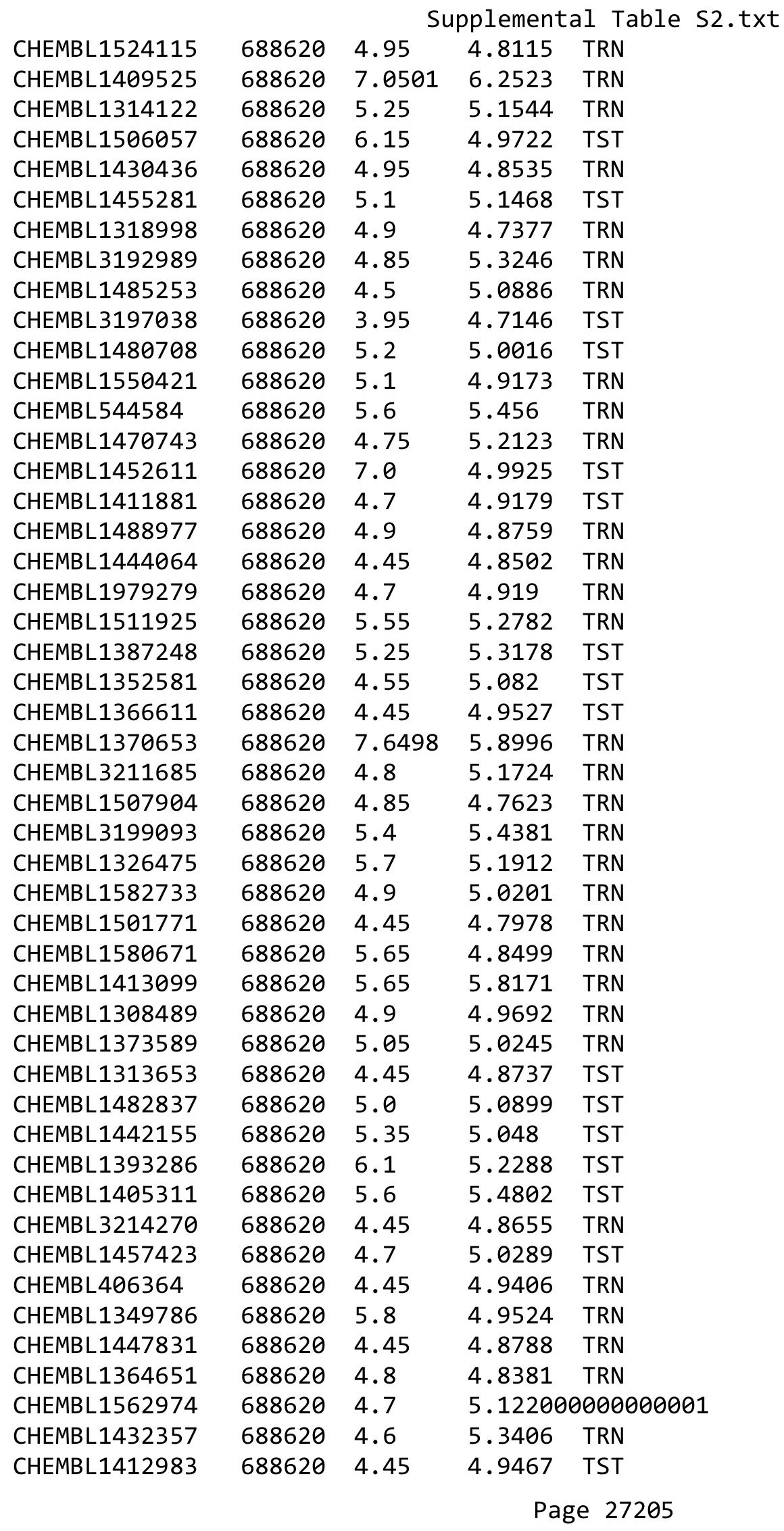

TRN 


\begin{tabular}{|c|c|c|c|c|c|}
\hline \multicolumn{6}{|c|}{ Supplemental Table s2.txt } \\
\hline CHEMBL1363753 & 688620 & 4.45 & 4.8415 & TRN & \\
\hline CHEMBL3196061 & 688620 & 5.95 & 5.6154 & TRN & \\
\hline CHEMBL1472181 & 688620 & 4.7 & 5.0007 & TST & \\
\hline CHEMBL1389621 & 688620 & 4.5 & 4.7808 & TRN & \\
\hline CHEMBL1380161 & 688620 & 4.55 & 5.1669 & TRN & \\
\hline CHEMBL1332106 & 688620 & 5.65 & 5.0149 & TRN & \\
\hline CHEMBL1594618 & 688620 & 5.3 & 4.7785 & TST & \\
\hline CHEMBL 3210193 & 688620 & 5.7 & 5.0577 & TRN & \\
\hline CHEMBL1548075 & 688620 & 7.4001 & 5.239 & TRN & \\
\hline CHEMBL3195189 & 688620 & 5.2 & 5.5151 & TRN & \\
\hline CHEMBL1436169 & 688620 & 4.45 & 4.7166 & TRN & \\
\hline CHEMBL1506668 & 688620 & 5.4 & 5.1565 & TRN & \\
\hline CHEMBL1309791 & 688620 & 4.8 & 4.8624 & TRN & \\
\hline CHEMBL1582387 & 688620 & 5.15 & 4.9334 & TST & \\
\hline CHEMBL1468582 & 688620 & 5.6 & 5.1588 & TST & \\
\hline CHEMBL1345877 & 688620 & 5.3 & 4.9327 & TRN & \\
\hline CHEMBL1428089 & 688620 & 5.3 & 4.8728 & TRN & \\
\hline CHEMBL1441970 & 688620 & 4.75 & 4.8488 & TRN & \\
\hline CHEMBL1529766 & 688620 & 5.0 & 4.7218 & TST & \\
\hline CHEMBL1412194 & 688620 & 4.9 & 4.8575 & TST & \\
\hline CHEMBL1994709 & 688620 & 5.7 & 5.5597 & TRN & \\
\hline CHEMBL1519864 & 688620 & 5.05 & 5.1871 & TRN & \\
\hline CHEMBL1557911 & 688620 & 5.3 & 4.6137 & TRN & \\
\hline CHEMBL48802 & 688620 & 5.5 & 5.1231 & TST & \\
\hline CHEMBL1349652 & 688620 & 4.75 & 4.99 & TST & \\
\hline CHEMBL1610753 & 688620 & 4.85 & 5.0007 & TST & \\
\hline CHEMBL1375285 & 688620 & 4.45 & 4.9956 & TRN & \\
\hline CHEMBL1338493 & 688620 & 4.95 & 5.0579 & TRN & \\
\hline CHEMBL1499202 & 688620 & 5.5 & 5.3839 & TRN & \\
\hline CHEMBL1570916 & 688620 & 4.85 & 5.0877 & TRN & \\
\hline CHEMBL1507517 & 688620 & 5.5 & 5.0896 & TRN & \\
\hline CHEMBL1560487 & 688620 & 4.9 & 5.20299 & 9999999999 & TRN \\
\hline CHEMBL3192054 & 688620 & 4.75 & 4.7794 & TRN & \\
\hline CHEMBL1484487 & 688620 & 4.95 & 5.3013 & TST & \\
\hline CHEMBL1413868 & 688620 & 4.65 & 4.9378 & TRN & \\
\hline CHEMBL1485521 & 688620 & 4.8 & 4.8054 & TRN & \\
\hline CHEMBL1325374 & 688620 & 4.9 & 5.0124 & TRN & \\
\hline CHEMBL1540263 & 688620 & 8.2518 & 4.9331 & TST & \\
\hline CHEMBL1967814 & 688620 & 4.9 & 5.2421 & TRN & \\
\hline CHEMBL1563191 & 688620 & 4.45 & 4.8461 & TST & \\
\hline CHEMBL1534233 & 688620 & 4.85 & 5.1737 & TRN & \\
\hline CHEMBL1326372 & 688620 & 4.65 & 4.9366 & TRN & \\
\hline CHEMBL3196080 & 688620 & 5.7 & 5.3331 & TRN & \\
\hline CHEMBL1523201 & 688620 & 4.45 & 5.0968 & TRN & \\
\hline CHEMBL1596041 & 688620 & 6.3 & 6.0251 & TRN & \\
\hline CHEMBL1493820 & 688620 & 7.8013 & 5.0657 & TRN & \\
\hline CHEMBL3191475 & 688620 & 4.9 & 5.1277 & TRN & \\
\hline CHEMBL1588836 & 688620 & 4.85 & 5.11600 & 00000000005 & TRN \\
\hline & & & & 27206 & \\
\hline
\end{tabular}




\begin{tabular}{|c|c|c|c|c|}
\hline \multicolumn{5}{|c|}{ Supplemental Table S2.txt } \\
\hline CHEMBL3198207 & 688620 & 4.95 & 5.415 & TRN \\
\hline CHEMBL1611484 & 688620 & 5.55 & 5.2291 & TRN \\
\hline CHEMBL1269379 & 688620 & 4.45 & 4.7681 & TST \\
\hline CHEMBL1572924 & 688620 & 4.9 & 4.8891 & TRN \\
\hline CHEMBL 1477317 & 688620 & 4.9 & 5.2692 & TRN \\
\hline CHEMBL1561222 & 688620 & 5.5 & 5.3329 & TRN \\
\hline CHEMBL1428217 & 688620 & 5.85 & 5.0046 & TRN \\
\hline CHEMBL1575828 & 688620 & 4.45 & 4.7047 & TST \\
\hline CHEMBL1524790 & 688620 & 4.5 & 4.7501 & TRN \\
\hline CHEMBL1553168 & 688620 & 5.0 & 5.0901 & TRN \\
\hline CHEMBL1337908 & 688620 & 4.45 & 5.1985 & TRN \\
\hline CHEMBL1611653 & 688620 & 5.15 & 5.334 & TRN \\
\hline CHEMBL1573001 & 688620 & 4.85 & 4.9976 & TRN \\
\hline CHEMBL1442010 & 688620 & 5.65 & 4.854 & TRN \\
\hline CHEMBL1976317 & 688620 & 5.5 & 5.2498 & TRN \\
\hline CHEMBL1343785 & 688620 & 4.45 & 4.9885 & TST \\
\hline CHEMBL1338761 & 688620 & 4.65 & 4.9254 & TRN \\
\hline CHEMBL1326590 & 688620 & 4.8 & 4.9694 & TST \\
\hline CHEMBL1585902 & 688620 & 4.8 & 5.2235 & TRN \\
\hline CHEMBL1543179 & 688620 & 5.0 & 5.0282 & TRN \\
\hline CHEMBL1351344 & 688620 & 5.15 & 5.2914 & TST \\
\hline CHEMBL1581754 & 688620 & 4.85 & 5.0766 & TRN \\
\hline CHEMBL1570079 & 688620 & 5.35 & 4.9971 & TRN \\
\hline CHEMBL1350905 & 688620 & 4.9 & 5.0497 & TRN \\
\hline CHEMBL3189659 & 688620 & 4.6 & 4.9258 & TRN \\
\hline CHEMBL1429861 & 688620 & 6.6 & 5.7613 & TRN \\
\hline CHEMBL1393626 & 688620 & 4.8 & 5.1596 & TRN \\
\hline CHEMBL3190929 & 688620 & 4.85 & 5.1689 & TRN \\
\hline CHEMBL1369837 & 688620 & 4.45 & 4.7611 & TRN \\
\hline CHEMBL1459166 & 688620 & 4.6 & 4.9097 & TRN \\
\hline CHEMBL1525363 & 688620 & 6.5501 & 5.0361 & TRN \\
\hline CHEMBL1585390 & 688620 & 6.0 & 5.3677 & TRN \\
\hline CHEMBL1423548 & 688620 & 4.8 & 4.9187 & TRN \\
\hline CHEMBL1532956 & 688620 & 4.75 & 4.8041 & TST \\
\hline CHEMBL1510534 & 688620 & 7.4498 & 4.9077 & TST \\
\hline CHEMBL1300881 & 688620 & 4.95 & 5.1775 & TRN \\
\hline CHEMBL1334527 & 688620 & 4.45 & 4.984 & TST \\
\hline CHEMBL1350678 & 688620 & 4.45 & 4.9931 & TRN \\
\hline CHEMBL1450294 & 688620 & 6.1 & 5.8102 & TRN \\
\hline CHEMBL1343103 & 688620 & 5.55 & 5.1835 & TST \\
\hline CHEMBL1494072 & 688620 & 4.85 & 4.9918 & TRN \\
\hline CHEMBL1468802 & 688620 & 4.8 & 4.9926 & TRN \\
\hline CHEMBL1391811 & 688620 & 4.95 & 5.1349 & TST \\
\hline CHEMBL1408650 & 688620 & 4.6 & 5.0799 & TST \\
\hline CHEMBL1332003 & 688620 & 6.15 & 5.8656 & TRN \\
\hline CHEMBL1423250 & 688620 & 4.75 & 5.1613 & TRN \\
\hline CHEMBL1516441 & 688620 & 5.2 & 5.0722 & TST \\
\hline CHEMBL1444558 & 688620 & 4.9 & 5.1614 & TST \\
\hline
\end{tabular}




\begin{tabular}{|c|c|c|c|c|}
\hline \multicolumn{5}{|c|}{ Supplemental Table } \\
\hline CHEMBL1467666 & 688620 & 6.6 & 5.0346 & TRN \\
\hline CHEMBL1331125 & 688620 & 4.75 & 4.8128 & TRN \\
\hline CHEMBL1494181 & 688620 & 7.0501 & 5.1148 & TST \\
\hline CHEMBL1502020 & 688620 & 5.7 & 5.5942 & TRN \\
\hline CHEMBL1351634 & 688620 & 4.85 & 4.966 & TRN \\
\hline CHEMBL1302732 & 688620 & 5.35 & 4.9098 & TRN \\
\hline CHEMBL1509295 & 688620 & 4.9 & 4.9397 & TST \\
\hline CHEMBL1611077 & 688620 & 5.0 & 4.9696 & TRN \\
\hline CHEMBL1346580 & 688620 & 4.7 & 5.0754 & TRN \\
\hline CHEMBL1560607 & 688620 & 5.0 & 5.1608 & TST \\
\hline CHEMBL1321927 & 688620 & 4.75 & 4.7987 & TRN \\
\hline CHEMBL 3199840 & 688620 & 4.95 & 5.152 & TRN \\
\hline CHEMBL1524861 & 688620 & 4.9 & 4.9302 & TRN \\
\hline CHEMBL557419 & 688620 & 5.05 & 4.8489 & TRN \\
\hline CHEMBL1539878 & 688620 & 5.1 & 5.1113 & TST \\
\hline CHEMBL1327359 & 688620 & 4.95 & 5.0048 & TRN \\
\hline CHEMBL1480403 & 688620 & 4.9 & 5.2325 & TRN \\
\hline CHEMBL1353763 & 688620 & 5.05 & 5.1717 & TRN \\
\hline CHEMBL1467672 & 688620 & 7.6498 & 5.4858 & TST \\
\hline CHEMBL1575991 & 688620 & 5.0 & 4.8578 & TRN \\
\hline CHEMBL1505880 & 688620 & 4.9 & 4.7718 & TRN \\
\hline CHEMBL1612825 & 688620 & 5.3 & 4.891 & TST \\
\hline CHEMBL1331226 & 688620 & 4.85 & 5.0476 & TRN \\
\hline CHEMBL1447529 & 688620 & 5.85 & 5.2528 & TRN \\
\hline CHEMBL1558673 & 688620 & 4.8 & 4.9247 & TST \\
\hline CHEMBL1334636 & 688620 & 4.45 & 4.8767 & TRN \\
\hline CHEMBL1522579 & 688620 & 6.15 & 4.8613 & TRN \\
\hline CHEMBL1482869 & 688620 & 5.55 & 5.6075 & TRN \\
\hline CHEMBL1465778 & 688620 & 4.45 & 4.895 & TST \\
\hline CHEMBL118109 & 688620 & 5.25 & 4.9456 & TST \\
\hline CHEMBL1329721 & 688620 & 4.8 & 4.9004 & TRN \\
\hline CHEMBL1503259 & 688620 & 4.45 & 4.9423 & TST \\
\hline CHEMBL1442777 & 688620 & 4.9 & 4.9029 & TRN \\
\hline CHEMBL1427072 & 688620 & 5.6 & 5.5271 & TRN \\
\hline CHEMBL1565673 & 688620 & 5.25 & 5.0231 & TRN \\
\hline CHEMBL1392192 & 688620 & 4.85 & 5.0715 & TRN \\
\hline CHEMBL1605507 & 688620 & 4.45 & 4.8473 & TRN \\
\hline CHEMBL 2001857 & 688620 & 5.35 & 5.4557 & TRN \\
\hline CHEMBL392680 & 688620 & 6.3 & 5.5644 & TRN \\
\hline CHEMBL1340116 & 688620 & 4.6 & 5.1165 & TRN \\
\hline CHEMBL1973722 & 688620 & 4.8 & 5.0674 & TRN \\
\hline CHEMBL1382061 & 688620 & 5.25 & 5.1368 & TST \\
\hline CHEMBL1300311 & 688620 & 4.8 & 4.8191 & TRN \\
\hline CHEMBL1382740 & 688620 & 5.15 & 4.7464 & TRN \\
\hline CHEMBL1578012 & 688620 & 4.95 & 5.0596 & TRN \\
\hline CHEMBL1483128 & 688620 & 5.1 & 5.2259 & TST \\
\hline CHEMBL3194586 & 688620 & 4.9 & 5.1381 & TRN \\
\hline CHEMBL1559375 & 688620 & 5.15 & 4.9833 & TRN \\
\hline
\end{tabular}




\begin{tabular}{|c|c|c|c|c|}
\hline & & & pplemen & al $\mathrm{T}$ \\
\hline CHEMBL1446150 & 688620 & 4.9 & 4.7788 & TRN \\
\hline CHEMBL1529687 & 688620 & 6.3 & 5.7067 & TRN \\
\hline CHEMBL1566594 & 688620 & 5.05 & 5.5574 & TRN \\
\hline CHEMBL1328595 & 688620 & 4.95 & 5.2437 & TRN \\
\hline CHEMBL3191185 & 688620 & 5.2 & 5.5985 & TRN \\
\hline CHEMBL1416300 & 688620 & 4.45 & 4.923 & TST \\
\hline CHEMBL1602934 & 688620 & 5.45 & 5.0896 & TRN \\
\hline CHEMBL1487134 & 688620 & 5.6 & 5.4428 & TRN \\
\hline CHEMBL1588268 & 688620 & 4.45 & 5.2612 & TRN \\
\hline CHEMBL1576863 & 688620 & 5.2 & 5.2146 & TRN \\
\hline CHEMBL601119 & 688620 & 5.7 & 5.9706 & TRN \\
\hline CHEMBL1310245 & 688620 & 5.25 & 5.0982 & TRN \\
\hline CHEMBL1610489 & 688620 & 6.35 & 5.4618 & TST \\
\hline CHEMBL1459720 & 688620 & 4.7 & 5.1591 & TST \\
\hline CHEMBL1466554 & 688620 & 5.2 & 4.8378 & TRN \\
\hline CHEMBL3190057 & 688620 & 4.95 & 5.0574 & TST \\
\hline CHEMBL 3214046 & 688620 & 5.6 & 5.2083 & TST \\
\hline CHEMBL1301644 & 688620 & 4.45 & 5.2004 & TRN \\
\hline CHEMBL1390524 & 688620 & 4.9 & 5.0056 & TST \\
\hline CHEMBL1559877 & 688620 & 4.9 & 4.9772 & TST \\
\hline CHEMBL1321601 & 688620 & 5.55 & 5.0783 & TRN \\
\hline CHEMBL1500272 & 688620 & 5.4 & 5.0226 & TRN \\
\hline CHEMBL1500048 & 688620 & 4.85 & 4.8196 & TRN \\
\hline CHEMBL1613227 & 688620 & 5.3 & 4.749 & TST \\
\hline CHEMBL1500500 & 688620 & 4.6 & 4.9026 & TRN \\
\hline CHEMBL1493129 & 688620 & 6.5 & 5.0848 & TST \\
\hline CHEMBL3195531 & 688620 & 5.3 & 5.3138 & TRN \\
\hline CHEMBL1536309 & 688620 & 5.4 & 5.0455 & TRN \\
\hline CHEMBL1446390 & 688620 & 5.15 & 5.0482 & TRN \\
\hline CHEMBL1372429 & 688620 & 4.65 & 5.0144 & TRN \\
\hline CHEMBL1484316 & 688620 & 4.45 & 4.8611 & TST \\
\hline CHEMBL1429164 & 688620 & 5.45 & 4.8283 & TRN \\
\hline CHEMBL1537587 & 688620 & 5.9 & 5.2071 & TRN \\
\hline CHEMBL1524877 & 688620 & 6.0 & 5.0057 & TRN \\
\hline CHEMBL1607659 & 688620 & 6.3 & 4.9761 & TST \\
\hline CHEMBL1518893 & 688620 & 5.55 & 5.2255 & TRN \\
\hline CHEMBL1583881 & 688620 & 5.85 & 5.306 & TST \\
\hline CHEMBL1532005 & 688620 & 4.95 & 4.8024 & TRN \\
\hline CHEMBL1547436 & 688620 & 4.95 & 5.0679 & TRN \\
\hline CHEMBL1347883 & 688620 & 5.45 & 4.8443 & TST \\
\hline CHEMBL1562633 & 688620 & 4.6 & 4.7406 & TRN \\
\hline CHEMBL1370980 & 688620 & 5.0 & 5.2396 & TST \\
\hline CHEMBL1312553 & 688620 & 4.95 & 4.9784 & TST \\
\hline CHEMBL 3195841 & 688620 & 5.45 & 5.3153 & TRN \\
\hline CHEMBL 1405328 & 688620 & 4.9 & 4.9247 & TRN \\
\hline CHEMBL1338935 & 688620 & 4.6 & 4.7414 & TST \\
\hline CHEMBL1443405 & 688620 & 4.45 & 4.9932 & TRN \\
\hline CHEMBL1452333 & 688620 & 8.301 & 4.9422 & TRN \\
\hline
\end{tabular}




\begin{tabular}{|c|c|c|c|c|}
\hline \multicolumn{5}{|c|}{ Supplemental Table S2.txt } \\
\hline CHEMBL1441304 & 688620 & 5.75 & 5.3969 & TRN \\
\hline CHEMBL1423224 & 688620 & 5.1 & 5.1475 & TRN \\
\hline CHEMBL1540128 & 688620 & 4.9 & 4.8953 & TRN \\
\hline CHEMBL1476271 & 688620 & 4.9 & 5.2899 & TST \\
\hline CHEMBL1982028 & 688620 & 4.95 & 4.9745 & TRN \\
\hline CHEMBL1556349 & 688620 & 5.2 & 5.0793 & TRN \\
\hline CHEMBL1594628 & 688620 & 4.8 & 4.9778 & TRN \\
\hline CHEMBL 3194087 & 688620 & 4.95 & 5.6242 & TRN \\
\hline CHEMBL3196086 & 688620 & 4.7 & 4.9623 & TST \\
\hline CHEMBL1580589 & 688620 & 5.5 & 5.0167 & TST \\
\hline CHEMBL1482500 & 688620 & 5.55 & 6.072 & TRN \\
\hline CHEMBL1371729 & 688620 & 4.6 & 5.0056 & TRN \\
\hline CHEMBL1586838 & 688620 & 4.9 & 4.9855 & TST \\
\hline CHEMBL1310341 & 688620 & 5.3 & 5.5038 & TRN \\
\hline CHEMBL1399773 & 688620 & 4.95 & 5.084 & TRN \\
\hline CHEMBL1467235 & 688620 & 5.05 & 4.8521 & TRN \\
\hline CHEMBL1461964 & 688620 & 4.45 & 4.7982 & TST \\
\hline CHEMBL1385069 & 688620 & 4.65 & 5.0201 & TRN \\
\hline CHEMBL1424169 & 688620 & 5.4 & 5.0807 & TRN \\
\hline CHEMBL1537740 & 688620 & 5.4 & 5.1008 & TRN \\
\hline CHEMBL1363773 & 688620 & 5.5 & 5.3851 & TRN \\
\hline CHEMBL1517696 & 688620 & 4.5 & 4.8457 & TRN \\
\hline CHEMBL1374543 & 688620 & 4.9 & 4.7462 & TST \\
\hline CHEMBL1511632 & 688620 & 5.3 & 5.1778 & TRN \\
\hline CHEMBL1427910 & 688620 & 5.55 & 4.9491 & TRN \\
\hline CHEMBL1303699 & 688620 & 4.5 & 5.1471 & TRN \\
\hline CHEMBL3195546 & 688620 & 4.45 & 4.9948 & TRN \\
\hline CHEMBL1539742 & 688620 & 5.15 & 5.1499 & TRN \\
\hline CHEMBL1340122 & 688620 & 4.9 & 5.1264 & TST \\
\hline CHEMBL1511924 & 688620 & 5.45 & 5.0251 & TRN \\
\hline CHEMBL1506419 & 688620 & 4.65 & 5.0486 & TRN \\
\hline CHEMBL1322619 & 688620 & 6.5501 & 5.0462 & TRN \\
\hline CHEMBL1373938 & 688620 & 4.9 & 4.9144 & TST \\
\hline CHEMBL1476099 & 688620 & 5.3 & 5.9148 & TRN \\
\hline CHEMBL1518284 & 688620 & 5.0 & 4.7961 & TST \\
\hline CHEMBL1509380 & 688620 & 5.45 & 4.7448 & TRN \\
\hline CHEMBL1561759 & 688620 & 4.75 & 5.1158 & TRN \\
\hline CHEMBL1353664 & 688620 & 4.45 & 4.6714 & TST \\
\hline CHEMBL1585493 & 688620 & 5.0 & 5.1973 & TRN \\
\hline CHEMBL581251 & 688620 & 5.3 & 5.5347 & TST \\
\hline CHEMBL1515776 & 688620 & 4.45 & 4.9705 & TRN \\
\hline CHEMBL3198561 & 688620 & 4.6 & 4.6593 & TRN \\
\hline CHEMBL3193410 & 688620 & 4.45 & 4.8799 & TST \\
\hline CHEMBL1338777 & 688620 & 4.75 & 5.0989 & TRN \\
\hline CHEMBL1323208 & 688620 & 6.25 & 5.529 & TRN \\
\hline CHEMBL1523089 & 688620 & 6.8499 & 5.0098 & TRN \\
\hline CHEMBL1419766 & 688620 & 5.1 & 5.3829 & TRN \\
\hline CHEMBL1387714 & 688620 & 4.9 & 4.7998 & TST \\
\hline
\end{tabular}




\begin{tabular}{|c|c|c|c|c|}
\hline \multicolumn{5}{|c|}{ pplemental $\mathrm{T}$} \\
\hline CHEMBL3193307 & 688620 & 4.8 & 4.9577 & TST \\
\hline CHEMBL3209711 & 688620 & 4.45 & 5.0823 & TRN \\
\hline CHEMBL1469645 & 688620 & 4.9 & 4.8754 & TRN \\
\hline CHEMBL195008 & 688620 & 6.0 & 5.2792 & TST \\
\hline CHEMBL1480151 & 688620 & 4.5 & 4.9582 & TST \\
\hline CHEMBL1503915 & 688620 & 4.8 & 5.0102 & TRN \\
\hline CHEMBL1453566 & 688620 & 4.45 & 5.0304 & TRN \\
\hline CHEMBL1359367 & 688620 & 4.9 & 5.1201 & TRN \\
\hline CHEMBL1374624 & 688620 & 4.85 & 5.1474 & TRN \\
\hline CHEMBL1500286 & 688620 & 4.65 & 5.0566 & TST \\
\hline CHEMBL1559292 & 688620 & 4.7 & 4.8803 & TRN \\
\hline CHEMBL1377634 & 688620 & 4.85 & 4.8387 & TRN \\
\hline CHEMBL1322462 & 688620 & 5.0 & 4.8589 & TRN \\
\hline CHEMBL1410119 & 688620 & 4.75 & 5.0057 & TRN \\
\hline CHEMBL3197789 & 688620 & 5.6 & 5.1517 & TRN \\
\hline CHEMBL1528130 & 688620 & 4.8 & 5.1754 & TRN \\
\hline CHEMBL1400768 & 688620 & 5.1 & 4.8608 & TRN \\
\hline CHEMBL1599063 & 688620 & 5.45 & 5.048 & TRN \\
\hline CHEMBL1426292 & 688620 & 5.45 & 5.5141 & TRN \\
\hline CHEMBL1325688 & 688620 & 5.2 & 4.8714 & TRN \\
\hline CHEMBL3195762 & 688620 & 4.95 & 5.1997 & TRN \\
\hline CHEMBL1968540 & 688620 & 5.9 & 5.3298 & TRN \\
\hline CHEMBL3213351 & 688620 & 5.2 & 4.8547 & TRN \\
\hline CHEMBL1587779 & 688620 & 4.9 & 4.9954 & TST \\
\hline CHEMBL1321584 & 688620 & 4.45 & 4.9632 & TST \\
\hline CHEMBL1307222 & 688620 & 4.65 & 5.0882 & TRN \\
\hline CHEMBL1367886 & 688620 & 6.3 & 5.0113 & TST \\
\hline CHEMBL1558648 & 688620 & 4.95 & 4.9518 & TRN \\
\hline CHEMBL1582123 & 688620 & 4.8 & 4.7556 & TRN \\
\hline CHEMBL1360665 & 688620 & 4.95 & 4.9436 & TRN \\
\hline CHEMBL1334792 & 688620 & 5.2 & 5.1116 & TRN \\
\hline CHEMBL1448685 & 688620 & 7.2 & 5.0875 & TST \\
\hline CHEMBL1381837 & 688620 & 5.5 & 5.3943 & TRN \\
\hline CHEMBL1313789 & 688620 & 5.3 & 4.98 & TRN \\
\hline CHEMBL1309071 & 688620 & 5.1 & 4.7869 & TST \\
\hline CHEMBL1391891 & 688620 & 5.9 & 4.9544 & TRN \\
\hline CHEMBL1410982 & 688620 & 4.45 & 4.9445 & TRN \\
\hline CHEMBL1455035 & 688620 & 4.95 & 5.0933 & TST \\
\hline CHEMBL1311088 & 688620 & 4.9 & 4.7482 & TRN \\
\hline CHEMBL1485360 & 688620 & 5.55 & 5.1767 & TST \\
\hline CHEMBL1574298 & 688620 & 4.95 & 5.3976 & TRN \\
\hline CHEMBL1427917 & 688620 & 4.9 & 5.0008 & TST \\
\hline CHEMBL1380995 & 688620 & 4.45 & 4.9295 & TRN \\
\hline CHEMBL3199226 & 688620 & 4.75 & 4.7749 & TRN \\
\hline CHEMBL1447503 & 688620 & 4.8 & 4.8096 & TST \\
\hline CHEMBL1568660 & 688620 & 6.5 & 4.9106 & TST \\
\hline CHEMBL1461449 & 688620 & 5.0 & 5.1013 & TRN \\
\hline CHEMBL1440440 & 688620 & 5.25 & 4.8485 & TST \\
\hline
\end{tabular}




\begin{tabular}{|c|c|c|c|c|}
\hline \multicolumn{5}{|c|}{ Supplemental Table S2.txt } \\
\hline CHEMBL1418667 & 688620 & 4.9 & 4.9862 & TRN \\
\hline CHEMBL3208154 & 688620 & 4.45 & 4.853 & TRN \\
\hline CHEMBL1395687 & 688620 & 5.65 & 5.1527 & TRN \\
\hline CHEMBL1405781 & 688620 & 4.85 & 5.07100 & 0000000001 \\
\hline CHEMBL1531828 & 688620 & 4.45 & 4.5618 & TRN \\
\hline CHEMBL1462209 & 688620 & 5.15 & 5.3082 & TRN \\
\hline CHEMBL1543203 & 688620 & 5.9 & 4.8683 & TRN \\
\hline CHEMBL1602132 & 688620 & 4.9 & 4.7666 & TST \\
\hline CHEMBL1459931 & 688620 & 4.45 & 4.9745 & TST \\
\hline CHEMBL1371264 & 688620 & 4.65 & 4.8355 & TRN \\
\hline CHEMBL1420060 & 688620 & 4.75 & 4.7502 & TRN \\
\hline CHEMBL1974450 & 688620 & 4.7 & 4.9799 & TRN \\
\hline CHEMBL1412082 & 688620 & 5.1 & 4.8872 & TRN \\
\hline CHEMBL1431656 & 688620 & 4.45 & 5.1084 & TRN \\
\hline CHEMBL454580 & 688620 & 4.7 & 4.6713 & TRN \\
\hline CHEMBL1526284 & 688620 & 5.15 & 5.2536 & TST \\
\hline CHEMBL1458245 & 688620 & 5.0 & 4.8453 & TRN \\
\hline CHEMBL1421080 & 688620 & 4.45 & 4.7168 & TRN \\
\hline CHEMBL1450498 & 688620 & 6.45 & 5.0017 & TRN \\
\hline CHEMBL1516741 & 688620 & 4.85 & 5.1095 & TRN \\
\hline CHEMBL1974640 & 688620 & 4.95 & 5.1388 & TRN \\
\hline CHEMBL1532728 & 688620 & 5.05 & 4.9939 & TRN \\
\hline CHEMBL 2001381 & 688620 & 5.6 & 5.731 & TRN \\
\hline CHEMBL1426666 & 688620 & 4.8 & 4.9142 & TST \\
\hline CHEMBL1351332 & 688620 & 5.55 & 5.0734 & TRN \\
\hline CHEMBL1466730 & 688620 & 4.65 & 5.1224 & TST \\
\hline CHEMBL1362961 & 688620 & 4.45 & 4.6956 & TRN \\
\hline CHEMBL1572228 & 688620 & 4.45 & 5.2112 & TRN \\
\hline CHEMBL1608081 & 688620 & 4.95 & 5.2626 & TRN \\
\hline CHEMBL1373821 & 688620 & 5.7 & 4.9442 & TRN \\
\hline CHEMBL1558045 & 688620 & 4.7 & 5.0457 & TRN \\
\hline CHEMBL1425574 & 688620 & 5.6 & 5.2276 & TST \\
\hline CHEMBL3209229 & 688620 & 4.45 & 5.0742 & TST \\
\hline CHEMBL1520182 & 688620 & 5.05 & 5.1215 & TRN \\
\hline CHEMBL1411468 & 688620 & 6.6 & 5.121 & TRN \\
\hline CHEMBL1305443 & 688620 & 5.5 & 5.3746 & TRN \\
\hline CHEMBL1390809 & 688620 & 4.45 & 5.0602 & TST \\
\hline CHEMBL1303994 & 688620 & 4.7 & 5.0207 & TST \\
\hline CHEMBL1462980 & 688620 & 5.0 & 4.9453 & TRN \\
\hline CHEMBL1332111 & 688620 & 5.5 & 5.9125 & TRN \\
\hline CHEMBL3198227 & 688620 & 5.6 & 5.5033 & TRN \\
\hline CHEMBL1442958 & 688620 & 4.7 & 4.9875 & TST \\
\hline CHEMBL1586616 & 688620 & 4.95 & 4.7722 & TST \\
\hline CHEMBL1430911 & 688620 & 5.55 & 4.9805 & TST \\
\hline CHEMBL1321180 & 688620 & 4.95 & 4.9537 & TST \\
\hline CHEMBL1504295 & 688620 & 5.0 & 4.8218 & TRN \\
\hline CHEMBL1413876 & 688620 & 7.0501 & 5.3318 & TST \\
\hline CHEMBL1477597 & 688620 & 5.95 & 5.2964 & TST \\
\hline
\end{tabular}




\begin{tabular}{|c|c|c|c|c|}
\hline \multicolumn{5}{|c|}{ Supplemental Table S2.txt } \\
\hline CHEMBL3191207 & 688620 & 4.65 & 4.7241 & TRN \\
\hline CHEMBL1459197 & 688620 & 4.5 & 4.8041 & TRN \\
\hline CHEMBL1315463 & 688620 & 4.7 & 4.4849 & TRN \\
\hline CHEMBL1428504 & 688620 & 4.5 & 5.0448 & TST \\
\hline CHEMBL1425369 & 688620 & 4.8 & 4.9824 & TRN \\
\hline CHEMBL1438108 & 688620 & 4.7 & 4.9712 & TST \\
\hline CHEMBL1367151 & 688620 & 5.5 & 5.0399 & TRN \\
\hline CHEMBL1543878 & 688620 & 4.95 & 4.5476 & TRN \\
\hline CHEMBL1347055 & 688620 & 4.7 & 5.0544 & TRN \\
\hline CHEMBL1608911 & 688620 & 4.85 & 5.5169 & TRN \\
\hline CHEMBL1613336 & 688620 & 4.45 & 5.0375 & TST \\
\hline CHEMBL1535525 & 688620 & 6.0 & 5.6282 & TRN \\
\hline CHEMBL1333906 & 688620 & 4.45 & 5.1153 & TST \\
\hline CHEMBL1508519 & 688620 & 5.0 & 5.1276 & TRN \\
\hline CHEMBL1353666 & 688620 & 4.45 & 4.6959 & TRN \\
\hline CHEMBL1564229 & 688620 & 4.95 & 4.9515 & TST \\
\hline CHEMBL1497986 & 688620 & 4.45 & 5.2036 & TRN \\
\hline CHEMBL1546143 & 688620 & 5.0 & 4.9069 & TRN \\
\hline CHEMBL1468643 & 688620 & 4.9 & 4.8904 & TRN \\
\hline CHEMBL1458467 & 688620 & 5.05 & 5.1101 & TRN \\
\hline CHEMBL1481205 & 688620 & 4.95 & 4.8115 & TST \\
\hline CHEMBL1565763 & 688620 & 7.15 & 5.1458 & TRN \\
\hline CHEMBL1438214 & 688620 & 4.75 & 5.0912 & TRN \\
\hline CHEMBL3192826 & 688620 & 5.05 & 5.091 & TRN \\
\hline CHEMBL1542538 & 688620 & 4.55 & 4.9023 & TRN \\
\hline CHEMBL1339854 & 688620 & 4.95 & 4.9707 & TRN \\
\hline CHEMBL1348406 & 688620 & 5.5 & 4.8636 & TRN \\
\hline CHEMBL1580802 & 688620 & 4.45 & 4.9502 & TRN \\
\hline CHEMBL1598572 & 688620 & 4.95 & 4.8175 & TRN \\
\hline CHEMBL1322170 & 688620 & 5.25 & 5.0818 & TST \\
\hline CHEMBL1572474 & 688620 & 5.7 & 5.6067 & TRN \\
\hline CHEMBL1558012 & 688620 & 4.45 & 5.2956 & TRN \\
\hline CHEMBL3189709 & 688620 & 5.15 & 4.982 & TRN \\
\hline CHEMBL3199662 & 688620 & 5.35 & 5.4391 & TRN \\
\hline CHEMBL1584717 & 688620 & 5.0 & 5.2426 & TRN \\
\hline CHEMBL3190284 & 688620 & 6.05 & 5.7829 & TST \\
\hline CHEMBL 1349666 & 688620 & 4.45 & 4.9799 & TRN \\
\hline CHEMBL1300895 & 688620 & 5.4 & 5.3588 & TRN \\
\hline CHEMBL1578097 & 688620 & 4.7 & 5.0402 & TST \\
\hline CHEMBL1599151 & 688620 & 4.45 & 4.9912 & TST \\
\hline CHEMBL3193096 & 688620 & 4.45 & 5.1258 & TST \\
\hline CHEMBL 1305704 & 688620 & 4.5 & 4.5771 & TST \\
\hline CHEMBL444293 & 688620 & 5.05 & 5.1586 & TRN \\
\hline CHEMBL1518749 & 688620 & 4.45 & 5.0311 & TRN \\
\hline CHEMBL1539477 & 688620 & 4.65 & 5.0099 & TRN \\
\hline CHEMBL3190093 & 688620 & 5.0 & 5.0611 & TST \\
\hline CHEMBL1516845 & 688620 & 4.45 & 4.9889 & TRN \\
\hline CHEMBL1438684 & 688620 & 4.9 & 5.1818 & TRN \\
\hline
\end{tabular}




\begin{tabular}{|c|c|c|c|c|c|}
\hline \multicolumn{6}{|c|}{ Supplemental Table S2.txt } \\
\hline CHEMBL1302706 & 688620 & 5.25 & 5.0404 & TST & \\
\hline CHEMBL1604932 & 688620 & 5.0 & 5.4757 & TRN & \\
\hline CHEMBL1595678 & 688620 & 5.05 & 5.0491 & TRN & \\
\hline CHEMBL1451326 & 688620 & 6.6499 & 5.1196 & TRN & \\
\hline CHEMBL1561205 & 688620 & 4.45 & 5.0003 & TRN & \\
\hline CHEMBL1487392 & 688620 & 4.65 & 4.9032 & TRN & \\
\hline CHEMBL1556773 & 688620 & 4.65 & 4.842 & TST & \\
\hline CHEMBL1440827 & 688620 & 5.55 & 5.4671 & TRN & \\
\hline CHEMBL1991388 & 688620 & 5.15 & 5.2135 & TRN & \\
\hline CHEMBL1392099 & 688620 & 4.6 & 4.7559 & TRN & \\
\hline CHEMBL1376495 & 688620 & 5.15 & 4.7943 & TRN & \\
\hline CHEMBL1492045 & 688620 & 4.85 & 5.1116 & TRN & \\
\hline CHEMBL1407265 & 688620 & 5.7 & 5.2966 & TRN & \\
\hline CHEMBL1366094 & 688620 & 5.0 & 5.2697 & TST & \\
\hline CHEMBL3214219 & 688620 & 5.6 & 5.1426 & TST & \\
\hline CHEMBL1313599 & 688620 & 4.45 & 5.086 & TRN & \\
\hline CHEMBL1523375 & 688620 & 5.15 & 4.9361 & TRN & \\
\hline CHEMBL1382834 & 688620 & 4.45 & 4.6672 & TST & \\
\hline CHEMBL1534546 & 688620 & 6.3 & 5.3833 & TRN & \\
\hline CHEMBL1589564 & 688620 & 6.15 & 5.1225 & TRN & \\
\hline CHEMBL1417919 & 688620 & 5.5 & 4.9014 & TRN & \\
\hline CHEMBL1350408 & 688620 & 5.15 & 5.0361 & TRN & \\
\hline CHEMBL1526933 & 688620 & 5.85 & 5.0073 & TST & \\
\hline CHEMBL1546560 & 688620 & 4.7 & 4.9524 & TRN & \\
\hline CHEMBL1497559 & 688620 & 7.1002 & 5.1527 & TRN & \\
\hline CHEMBL1320771 & 688620 & 5.45 & 4.8964 & TRN & \\
\hline CHEMBL1605599 & 688620 & 4.75 & 4.9455 & TRN & \\
\hline CHEMBL1327662 & 688620 & 4.9 & 5.0003 & TRN & \\
\hline CHEMBL1579959 & 688620 & 4.8 & 4.7362 & TRN & \\
\hline CHEMBL1465980 & 688620 & 8.301 & 5.388 & TRN & \\
\hline CHEMBL1422254 & 688620 & 5.5 & 5.1609 & TRN & \\
\hline CHEMBL1431720 & 688620 & 4.6 & 4.9982 & TST & \\
\hline CHEMBL1566161 & 688620 & 4.95 & 4.9354 & TRN & \\
\hline CHEMBL1610751 & 688620 & 5.4 & 4.9562 & TRN & \\
\hline CHEMBL 3189574 & 688620 & 6.4 & 5.7464 & TRN & \\
\hline CHEMBL1417844 & 688620 & 5.0 & 4.9835 & TST & \\
\hline CHEMBL1465891 & 688620 & 4.9 & 5.0099 & TRN & \\
\hline CHEMBL1383327 & 688620 & 5.05 & 4.9089 & TRN & \\
\hline CHEMBL 3196566 & 688620 & 5.45 & 5.6918 & TST & \\
\hline CHEMBL1608528 & 688620 & 4.5 & 5.0299 & TRN & \\
\hline CHEMBL1348428 & 688620 & 6.2 & 5.08899 & 99999999995 & TRN \\
\hline CHEMBL1374091 & 688620 & 4.85 & 5.435 & TRN & \\
\hline CHEMBL1506725 & 688620 & 4.95 & 4.8715 & TRN & \\
\hline CHEMBL1556669 & 688620 & 4.8 & 4.8756 & TRN & \\
\hline CHEMBL3191703 & 688620 & 4.75 & 5.0355 & TRN & \\
\hline CHEMBL1452358 & 688620 & 4.9 & 4.8116 & TRN & \\
\hline CHEMBL2006168 & 688620 & 6.45 & 5.7122 & TST & \\
\hline CHEMBL1545268 & 688620 & 4.7 & 4.9992 & TRN & \\
\hline
\end{tabular}




\begin{tabular}{|c|c|c|c|c|c|}
\hline \multirow{2}{*}{ CHEMBL1556415 } & \\
\hline & 688620 & 6.3 & 5.3492 & TRN & \\
\hline CHEMBL3189531 & 688620 & 4.8 & 4.9196 & TST & \\
\hline CHEMBL1385060 & 688620 & 6.8 & 4.9055 & TRN & \\
\hline CHEMBL1420521 & 688620 & 4.45 & 5.2089 & TRN & \\
\hline CHEMBL1535181 & 688620 & 5.0 & 4.9905 & TRN & \\
\hline CHEMBL3199734 & 688620 & 4.45 & 5.1996 & TRN & \\
\hline CHEMBL1583056 & 688620 & 4.85 & 4.9951 & TRN & \\
\hline CHEMBL3191517 & 688620 & 5.45 & 5.16299 & 9999999999 & TRN \\
\hline CHEMBL1409819 & 688620 & 4.7 & 4.9949 & TST & \\
\hline CHEMBL1572895 & 688620 & 5.3 & 4.8752 & TRN & \\
\hline CHEMBL1587162 & 688620 & 5.7 & 5.1384 & TRN & \\
\hline CHEMBL1487423 & 688620 & 5.2 & 5.1412 & TRN & \\
\hline CHEMBL1335714 & 688620 & 5.4 & 4.8685 & TRN & \\
\hline CHEMBL3213432 & 688620 & 5.65 & 5.8186 & TRN & \\
\hline CHEMBL1459949 & 688620 & 5.0 & 4.7081 & TST & \\
\hline CHEMBL1380722 & 688620 & 4.85 & 5.478 & TRN & \\
\hline CHEMBL192509 & 688620 & 6.0 & $5.7410 €$ & 00000000005 & TRN \\
\hline CHEMBL380370 & 688620 & 6.7001 & 5.08899 & 99999999995 & TRN \\
\hline CHEMBL1586022 & 688620 & 7.5003 & 5.6709 & TRN & \\
\hline CHEMBL585685 & 688620 & 4.8 & 4.7888 & TRN & \\
\hline CHEMBL1301620 & 688620 & 4.45 & 5.0091 & TRN & \\
\hline CHEMBL1383971 & 688620 & 4.95 & 4.8575 & TRN & \\
\hline CHEMBL1967395 & 688620 & 4.9 & 5.0804 & TRN & \\
\hline CHEMBL1545233 & 688620 & 5.2 & 5.2539 & TRN & \\
\hline CHEMBL1496932 & 688620 & 4.8 & 5.0875 & TRN & \\
\hline CHEMBL3197336 & 688620 & 6.1 & 5.5794 & TRN & \\
\hline CHEMBL1502104 & 688620 & 5.35 & 5.2793 & TST & \\
\hline CHEMBL1348091 & 688620 & 4.9 & 4.94 & TRN & \\
\hline CHEMBL1369553 & 688620 & 5.0 & 5.209 & TRN & \\
\hline CHEMBL462430 & 688620 & 4.9 & 4.8589 & TRN & \\
\hline CHEMBL1447974 & 688620 & 7.4498 & 5.2355 & TRN & \\
\hline CHEMBL1568297 & 688620 & 4.85 & 4.9987 & TST & \\
\hline CHEMBL1336541 & 688620 & 6.1 & 5.4023 & TST & \\
\hline CHEMBL1299443 & 688620 & 5.2 & 5.0916 & TST & \\
\hline CHEMBL1430676 & 688620 & 4.9 & 5.2968 & TST & \\
\hline CHEMBL1344968 & 688620 & 5.1 & 4.942 & TRN & \\
\hline CHEMBL1533785 & 688620 & 5.2 & 4.9728 & TST & \\
\hline CHEMBL1387048 & 688620 & 4.5 & 5.1306 & TST & \\
\hline CHEMBL1487508 & 688620 & 4.95 & 5.1613 & TRN & \\
\hline CHEMBL1580277 & 688620 & 5.2 & 4.8864 & TRN & \\
\hline CHEMBL3211802 & 688620 & 4.45 & 4.8097 & TRN & \\
\hline CHEMBL1607028 & 688620 & 4.95 & 5.24706 & $\partial 000000001$ & TRN \\
\hline CHEMBL323554 & 688620 & 5.4 & 5.1233 & TRN & \\
\hline CHEMBL1439091 & 688620 & 5.4 & 5.0334 & TRN & \\
\hline CHEMBL1319925 & 688620 & 4.45 & 5.1878 & TRN & \\
\hline CHEMBL1462207 & 688620 & 4.85 & 4.9206 & TRN & \\
\hline CHEMBL1257234 & 688620 & 5.55 & 4.9541 & TRN & \\
\hline CHEMBL3196548 & 688620 & 5.5 & 5.7905 & TRN & \\
\hline & & & & 72 & \\
\hline
\end{tabular}




\begin{tabular}{|c|c|c|c|c|c|}
\hline \multicolumn{6}{|c|}{ Supplemental Table s2.txt } \\
\hline CHEMBL1574026 & 688620 & 5.4 & 5.1152 & TRN & \\
\hline CHEMBL1574173 & 688620 & 4.75 & 4.6443 & TST & \\
\hline CHEMBL1698464 & 688620 & 4.85 & 5.0883 & TST & \\
\hline CHEMBL1501152 & 688620 & 4.45 & 4.8819 & TRN & \\
\hline CHEMBL3212902 & 688620 & 4.85 & 4.7837 & TRN & \\
\hline CHEMBL 285241 & 688620 & 4.65 & 4.846 & TRN & \\
\hline CHEMBL1583097 & 688620 & 4.9 & 4.7371 & TRN & \\
\hline CHEMBL1546709 & 688620 & 5.05 & 5.3399 & TRN & \\
\hline CHEMBL1342379 & 688620 & 4.7 & 4.8601 & TRN & \\
\hline CHEMBL567323 & 688620 & 4.45 & 5.0327 & TST & \\
\hline CHEMBL1380241 & 688620 & 4.7 & 5.4605 & TST & \\
\hline CHEMBL 294018 & 688620 & 5.95 & 5.7246 & TST & \\
\hline CHEMBL1413689 & 688620 & 4.55 & 4.9153 & TRN & \\
\hline CHEMBL 3212793 & 688620 & 4.45 & 5.3078 & TST & \\
\hline CHEMBL1562033 & 688620 & 5.55 & 5.6377 & TRN & \\
\hline CHEMBL1458548 & 688620 & 5.95 & 5.5266 & TRN & \\
\hline CHEMBL1546781 & 688620 & 4.9 & 5.1918 & TRN & \\
\hline CHEMBL1373799 & 688620 & 5.25 & 5.0527 & TRN & \\
\hline CHEMBL1382860 & 688620 & 4.9 & 4.9208 & TRN & \\
\hline CHEMBL1564215 & 688620 & 5.2 & 5.0193 & TST & \\
\hline CHEMBL1971072 & 688620 & 4.9 & 4.9623 & TRN & \\
\hline CHEMBL3209300 & 688620 & 4.8 & 5.14 & TRN & \\
\hline CHEMBL1600695 & 688620 & 5.0 & 5.1333 & TST & \\
\hline CHEMBL1561095 & 688620 & 4.8 & 5.0205 & TRN & \\
\hline CHEMBL1547827 & 688620 & 4.8 & 5.1382 & TRN & \\
\hline CHEMBL1369782 & 688620 & 4.45 & 5.13 & TRN & \\
\hline CHEMBL1964591 & 688620 & 4.7 & 4.9308 & TRN & \\
\hline CHEMBL1369859 & 688620 & 4.8 & 4.9303 & TRN & \\
\hline CHEMBL1549505 & 688620 & 6.2 & 6.21899 & 9999999999 & TRN \\
\hline CHEMBL1416496 & 688620 & 4.7 & 5.1222 & TRN & \\
\hline CHEMBL1549479 & 688620 & 4.9 & 5.2312 & TRN & \\
\hline CHEMBL1481109 & 688620 & 4.95 & 4.8806 & TRN & \\
\hline CHEMBL1368178 & 688620 & 6.4 & 4.9934 & TRN & \\
\hline CHEMBL1558812 & 688620 & 6.35 & 5.0434 & TRN & \\
\hline CHEMBL1336204 & 688620 & 4.6 & 5.0643 & TRN & \\
\hline CHEMBL1359019 & 688620 & 5.8 & 5.6631 & TRN & \\
\hline CHEMBL1565510 & 688620 & 4.9 & 4.9181 & TST & \\
\hline CHEMBL3192953 & 688620 & 4.9 & 5.114 & TRN & \\
\hline CHEMBL1566600 & 688620 & 4.65 & 4.9288 & TRN & \\
\hline CHEMBL1530821 & 688620 & 4.75 & 4.9973 & TST & \\
\hline CHEMBL1378785 & 688620 & 5.3 & 6.2622 & TRN & \\
\hline CHEMBL3199580 & 688620 & 5.85 & 5.4986 & TST & \\
\hline CHEMBL1385230 & 688620 & 4.45 & 5.0357 & TRN & \\
\hline CHEMBL1549384 & 688620 & 4.8 & 4.9686 & TRN & \\
\hline CHEMBL1400996 & 688620 & 6.1 & 6.0681 & TRN & \\
\hline CHEMBL1402880 & 688620 & 5.0 & 5.0782 & TRN & \\
\hline CHEMBL1391911 & 688620 & 4.45 & 4.8469 & TRN & \\
\hline CHEMBL1602809 & 688620 & 4.7 & 4.9957 & TRN & \\
\hline
\end{tabular}




\begin{tabular}{|c|c|c|c|c|c|}
\hline \multicolumn{6}{|c|}{ Supplemental Table S2.txt } \\
\hline CHEMBL3197870 & 688620 & 4.45 & 4.8498 & TRN & \\
\hline CHEMBL1410417 & 688620 & 4.75 & 4.7627 & TRN & \\
\hline CHEMBL1589530 & 688620 & 4.45 & 4.9714 & TRN & \\
\hline CHEMBL1332454 & 688620 & 5.2 & 5.4618 & TRN & \\
\hline CHEMBL1432633 & 688620 & 4.45 & 5.2282 & TST & \\
\hline CHEMBL1507856 & 688620 & 4.45 & 4.925 & TRN & \\
\hline CHEMBL1303434 & 688620 & 4.95 & 5.3687 & TRN & \\
\hline CHEMBL1458123 & 688620 & 4.45 & 4.9889 & TRN & \\
\hline CHEMBL1518421 & 688620 & 4.95 & 4.8244 & TRN & \\
\hline CHEMBL1372677 & 688620 & 5.0 & 5.0129 & TRN & \\
\hline CHEMBL587849 & 688620 & 4.45 & 5.0269 & TST & \\
\hline CHEMBL1578267 & 688620 & 6.15 & 5.8092 & TRN & \\
\hline CHEMBL1384895 & 688620 & 6.6 & 4.6862 & TST & \\
\hline CHEMBL1421604 & 688620 & 4.8 & 4.6891 & TST & \\
\hline CHEMBL1470769 & 688620 & 4.65 & 5.1951 & TRN & \\
\hline CHEMBL1400950 & 688620 & 4.95 & 5.1259 & TRN & \\
\hline CHEMBL1487943 & 688620 & 4.65 & 4.9682 & TRN & \\
\hline CHEMBL1349025 & 688620 & 5.0 & 4.95100 & 00000000005 & TRN \\
\hline CHEMBL1990425 & 688620 & 5.35 & 5.2289 & TRN & \\
\hline CHEMBL1506673 & 688620 & 4.45 & 4.9526 & TST & \\
\hline CHEMBL3211782 & 688620 & 4.9 & 4.8765 & TRN & \\
\hline CHEMBL3197816 & 688620 & 5.7 & 5.586 & TRN & \\
\hline CHEMBL1546359 & 688620 & 5.0 & 5.3737 & TST & \\
\hline CHEMBL1506543 & 688620 & 5.85 & 5.5441 & TST & \\
\hline CHEMBL1535607 & 688620 & 4.45 & 5.2094 & TST & \\
\hline CHEMBL1323411 & 688620 & 4.55 & 5.0227 & TST & \\
\hline CHEMBL1557861 & 688620 & 5.0 & 4.8925 & TRN & \\
\hline CHEMBL1352328 & 688620 & 5.7 & 5.2456 & TST & \\
\hline CHEMBL1461902 & 688620 & 5.0 & 5.0961 & TRN & \\
\hline CHEMBL1582849 & 688620 & 5.55 & 5.2633 & TRN & \\
\hline CHEMBL1605776 & 688620 & 5.3 & 5.4983 & TRN & \\
\hline CHEMBL1352069 & 688620 & 4.85 & 5.3457 & TRN & \\
\hline CHEMBL1584582 & 688620 & 5.35 & 5.0694 & TRN & \\
\hline CHEMBL1404987 & 688620 & 4.9 & 5.0394 & TRN & \\
\hline CHEMBL3207465 & 688620 & 5.15 & 4.8955 & TRN & \\
\hline CHEMBL1479964 & 688620 & 4.95 & 5.0979 & TRN & \\
\hline CHEMBL1381161 & 688620 & 5.35 & 4.9947 & TRN & \\
\hline CHEMBL1510650 & 688620 & 5.3 & 5.1344 & TRN & \\
\hline CHEMBL 2000529 & 688620 & 5.35 & 4.948 & TRN & \\
\hline CHEMBL1606662 & 688620 & 4.75 & 4.9522 & TRN & \\
\hline CHEMBL1364119 & 688620 & 5.5 & 5.059 & TRN & \\
\hline CHEMBL1612052 & 688620 & 4.45 & 4.8466 & TRN & \\
\hline CHEMBL1301431 & 688620 & 4.85 & 4.9066 & TRN & \\
\hline CHEMBL1392299 & 688620 & 4.9 & 5.3232 & TST & \\
\hline CHEMBL1374260 & 688620 & 4.95 & 5.1008 & TRN & \\
\hline CHEMBL3190719 & 688620 & 5.75 & 5.5218 & TRN & \\
\hline CHEMBL1446027 & 688620 & 4.65 & 4.7357 & TRN & \\
\hline CHEMBL1995692 & 688620 & 5.35 & 4.9575 & TRN & \\
\hline
\end{tabular}




\begin{tabular}{|c|c|c|c|c|c|}
\hline \multicolumn{6}{|c|}{ Supplemental Table S2.txt } \\
\hline CHEMBL3191453 & 688620 & 5.35 & 5.2914 & TRN & \\
\hline CHEMBL1597435 & 688620 & 6.5501 & 6.1805 & TRN & \\
\hline CHEMBL1524007 & 688620 & 4.6 & 4.8271 & TRN & \\
\hline CHEMBL1390757 & 688620 & 4.8 & 4.9372 & TRN & \\
\hline CHEMBL1345523 & 688620 & 4.95 & 4.8433 & TRN & \\
\hline CHEMBL1532052 & 688620 & 4.75 & 5.0609 & TRN & \\
\hline CHEMBL1399600 & 688620 & 6.8 & 5.1913 & TRN & \\
\hline CHEMBL1987483 & 688620 & 4.45 & 4.7823 & TRN & \\
\hline CHEMBL1341698 & 688620 & 6.35 & 4.9491 & TST & \\
\hline CHEMBL10284 & 688620 & 5.8 & 5.0417 & TST & \\
\hline CHEMBL1319487 & 688620 & 4.95 & 5.148 & TRN & \\
\hline CHEMBL1309234 & 688620 & 6.15 & 5.5472 & TRN & \\
\hline CHEMBL1426896 & 688620 & 4.45 & 5.0275 & TRN & \\
\hline CHEMBL1376429 & 688620 & 6.25 & 5.15600 & 0000000001 & TST \\
\hline CHEMBL1302093 & 688620 & 5.45 & 4.8566 & TRN & \\
\hline CHEMBL1338462 & 688620 & 5.1 & 4.7954 & TST & \\
\hline CHEMBL1469326 & 688620 & 5.0 & 5.0379 & TST & \\
\hline CHEMBL1980982 & 688620 & 4.65 & 4.7739 & TRN & \\
\hline CHEMBL1575594 & 688620 & 5.55 & 5.3832 & TRN & \\
\hline CHEMBL1327275 & 688620 & 6.1 & 5.1681 & TRN & \\
\hline CHEMBL1445655 & 688620 & 5.6 & 5.1829 & TRN & \\
\hline CHEMBL1529735 & 688620 & 4.85 & 5.0747 & TRN & \\
\hline CHEMBL1546328 & 688620 & 4.85 & 5.0358 & TRN & \\
\hline CHEMBL1306326 & 688620 & 4.95 & 4.8675 & TRN & \\
\hline CHEMBL3193838 & 688620 & 4.65 & 4.8287 & TRN & \\
\hline CHEMBL1545731 & 688620 & 6.6499 & 5.1162 & TRN & \\
\hline CHEMBL1588146 & 688620 & 4.85 & 4.9819 & TRN & \\
\hline CHEMBL1509569 & 688620 & 5.65 & 5.5155 & TRN & \\
\hline CHEMBL3210607 & 688620 & 4.95 & 4.9367 & TRN & \\
\hline CHEMBL1321837 & 688620 & 4.45 & 4.9962 & TRN & \\
\hline CHEMBL3198906 & 688620 & 4.95 & 5.0761 & TRN & \\
\hline CHEMBL1568337 & 688620 & 6.5501 & 5.17 & TRN & \\
\hline CHEMBL3145130 & 688620 & 5.0 & 5.0589 & TST & \\
\hline CHEMBL1370414 & 688620 & 5.7 & 4.9256 & TRN & \\
\hline CHEMBL1581464 & 688620 & 5.6 & 5.1493 & TST & \\
\hline CHEMBL3190423 & 688620 & 4.65 & 4.8585 & TST & \\
\hline CHEMBL1611022 & 688620 & 4.45 & 4.9763 & TST & \\
\hline CHEMBL1405435 & 688620 & 5.05 & 5.2154 & TRN & \\
\hline CHEMBL1584324 & 688620 & 5.65 & 4.9748 & TRN & \\
\hline CHEMBL1458795 & 688620 & 6.15 & 4.8099 & TRN & \\
\hline CHEMBL1567039 & 688620 & 4.45 & 4.9041 & TRN & \\
\hline CHEMBL1453146 & 688620 & 5.3 & 5.0024 & TRN & \\
\hline CHEMBL1966886 & 688620 & 5.0 & 5.0305 & TRN & \\
\hline CHEMBL1443336 & 688620 & 4.75 & 4.8631 & TRN & \\
\hline CHEMBL1539808 & 688620 & 4.45 & 4.6729 & TRN & \\
\hline CHEMBL1407040 & 688620 & 4.65 & 5.1769 & TRN & \\
\hline CHEMBL1344675 & 688620 & 4.45 & 4.6958 & TRN & \\
\hline CHEMBL1455502 & 688620 & 4.9 & 4.8164 & TRN & \\
\hline
\end{tabular}




\begin{tabular}{|c|c|c|c|c|c|}
\hline \multicolumn{6}{|c|}{ premen } \\
\hline CHEMBL1584250 & 688620 & 6.0 & 5.8134 & TRN & \\
\hline CHEMBL1467522 & 688620 & 5.7 & \multicolumn{2}{|c|}{4.9910000000000005} & TRN \\
\hline CHEMBL3197371 & 688620 & 4.9 & 5.1983 & TST & \\
\hline CHEMBL1428094 & 688620 & 4.9 & 4.9104 & TST & \\
\hline CHEMBL1527447 & 688620 & 5.15 & 4.8785 & TRN & \\
\hline CHEMBL1489778 & 688620 & 5.35 & 5.3668 & TRN & \\
\hline CHEMBL1445513 & 688620 & 4.45 & 5.0985 & TRN & \\
\hline CHEMBL1432799 & 688620 & 4.65 & 4.9016 & TRN & \\
\hline CHEMBL2369309 & 688620 & 5.1 & 4.9799 & TRN & \\
\hline CHEMBL3196351 & 688620 & 5.25 & \multicolumn{2}{|c|}{5.297000000000001} & TRN \\
\hline CHEMBL1333209 & 688620 & 5.55 & 5.3068 & TRN & \\
\hline CHEMBL1448100 & 688620 & 4.65 & 5.3463 & TRN & \\
\hline CHEMBL1370022 & 688620 & 5.65 & 5.3166 & TRN & \\
\hline CHEMBL1384554 & 688620 & 4.9 & 5.0255 & TST & \\
\hline CHEMBL3189562 & 688620 & 5.65 & 5.1932 & TRN & \\
\hline CHEMBL1613512 & 688620 & 5.9 & 6.0227 & TRN & \\
\hline CHEMBL1481951 & 688620 & 5.6 & 5.0834 & TRN & \\
\hline CHEMBL1386830 & 688620 & 5.0 & 5.2069 & TRN & \\
\hline CHEMBL1529776 & 688620 & 4.85 & 4.9967 & TRN & \\
\hline CHEMBL1579586 & 688620 & 6.1 & 5.0125 & TST & \\
\hline CHEMBL1362364 & 688620 & 4.85 & 5.0289 & TRN & \\
\hline CHEMBL1438478 & 688620 & 5.4 & 5.0498 & TST & \\
\hline CHEMBL3212716 & 688620 & 4.65 & 4.955 & TRN & \\
\hline CHEMBL1451017 & 688620 & 5.0 & 4.6991 & TRN & \\
\hline CHEMBL1426572 & 688620 & 5.85 & 5.251 & TRN & \\
\hline CHEMBL1554921 & 688620 & 4.9 & 4.9956 & TST & \\
\hline CHEMBL1541610 & 688620 & 6.3 & 5.0925 & TRN & \\
\hline CHEMBL1445078 & 688620 & 4.75 & 4.6956 & TRN & \\
\hline CHEMBL1520641 & 688620 & 4.45 & 5.0083 & TST & \\
\hline CHEMBL401504 & 688620 & 6.25 & 5.8671 & TRN & \\
\hline CHEMBL1439586 & 688620 & 4.45 & 5.0441 & TST & \\
\hline CHEMBL3190507 & 688620 & 5.65 & 5.8449 & TRN & \\
\hline CHEMBL1497277 & 688620 & 5.3 & 5.2378 & TRN & \\
\hline CHEMBL1491934 & 688620 & 5.5 & 5.4738 & TST & \\
\hline CHEMBL1506259 & 688620 & 5.1 & 4.9603 & TRN & \\
\hline CHEMBL1433006 & 688620 & 4.45 & 4.8519 & TST & \\
\hline CHEMBL1597306 & 688620 & 5.0 & 4.895 & TRN & \\
\hline CHEMBL1510543 & 688620 & 4.45 & 4.7187 & TST & \\
\hline CHEMBL1485384 & 688620 & 4.75 & 4.8511 & TRN & \\
\hline CHEMBL1519530 & 688620 & 4.7 & 5.1659 & TRN & \\
\hline CHEMBL602776 & 688620 & 4.65 & 4.7952 & TRN & \\
\hline CHEMBL3190025 & 688620 & 5.15 & 5.0925 & TRN & \\
\hline CHEMBL1609399 & 688620 & 4.65 & 4.8501 & TRN & \\
\hline CHEMBL1393595 & 688620 & 4.85 & 5.2953 & TST & \\
\hline CHEMBL1481417 & 688620 & 5.35 & 4.9492 & TST & \\
\hline CHEMBL1502673 & 688620 & 5.1 & 5.0866 & TRN & \\
\hline CHEMBL1529277 & 688620 & 4.45 & 4.8578 & TRN & \\
\hline CHEMBL1362068 & 688620 & 4.95 & 5.0155 & TRN & \\
\hline
\end{tabular}




\begin{tabular}{|c|c|c|c|c|c|}
\hline \multicolumn{6}{|c|}{ Supplemental Table S2.txt } \\
\hline CHEMBL1367078 & 688620 & 4.75 & 5.0848 & TRN & \\
\hline CHEMBL1496673 & 688620 & 4.9 & 4.933 & TST & \\
\hline CHEMBL1417505 & 688620 & 5.15 & 5.0116 & TRN & \\
\hline CHEMBL1494021 & 688620 & 5.1 & 5.0052 & TRN & \\
\hline CHEMBL1545442 & 688620 & 5.2 & 5.1662 & TST & \\
\hline CHEMBL1359909 & 688620 & 4.65 & 4.9547 & TRN & \\
\hline CHEMBL1465815 & 688620 & 5.55 & 4.9389 & TRN & \\
\hline CHEMBL1431142 & 688620 & 8.3468 & 5.0643 & TRN & \\
\hline CHEMBL1588733 & 688620 & 4.75 & 4.9236 & TST & \\
\hline CHEMBL1985987 & 688620 & 4.45 & 5.0255 & TRN & \\
\hline CHEMBL1518196 & 688620 & 4.45 & 5.0037 & TST & \\
\hline CHEMBL1502720 & 688620 & 4.6 & 5.0446 & TRN & \\
\hline CHEMBL1444771 & 688620 & 5.0 & 5.2613 & TRN & \\
\hline CHEMBL607140 & 688620 & 5.25 & 5.8489 & TRN & \\
\hline CHEMBL1351565 & 688620 & 5.45 & 4.9638 & TST & \\
\hline CHEMBL1372401 & 688620 & 5.25 & 4.8937 & TRN & \\
\hline CHEMBL1472318 & 688620 & 4.85 & 4.8326 & TRN & \\
\hline CHEMBL1415937 & 688620 & 5.0 & 4.7628 & TRN & \\
\hline CHEMBL1469822 & 688620 & 4.9 & 5.1176 & TRN & \\
\hline CHEMBL1607066 & 688620 & 4.45 & 5.0491 & TRN & \\
\hline CHEMBL1470294 & 688620 & 6.2 & 4.9082 & TRN & \\
\hline CHEMBL1558744 & 688620 & 6.1 & 5.3743 & TRN & \\
\hline CHEMBL1600749 & 688620 & 4.85 & 4.9849 & TRN & \\
\hline CHEMBL2002392 & 688620 & 4.8 & 4.8567 & TRN & \\
\hline CHEMBL1340112 & 688620 & 4.45 & 5.3916 & TRN & \\
\hline CHEMBL3193572 & 688620 & 6.35 & 5.4423 & TRN & \\
\hline CHEMBL1308348 & 688620 & 4.9 & 4.7549 & TRN & \\
\hline CHEMBL1329830 & 688620 & 5.75 & 4.913 & TST & \\
\hline CHEMBL1566964 & 688620 & 5.15 & 4.58899 & 99999999995 & TST \\
\hline CHEMBL1421600 & 688620 & 4.8 & 5.0891 & TRN & \\
\hline CHEMBL3212943 & 688620 & 5.35 & 5.3324 & TRN & \\
\hline CHEMBL3209195 & 688620 & 4.45 & 5.2405 & TRN & \\
\hline CHEMBL1487044 & 688620 & 4.65 & 5.1418 & TST & \\
\hline CHEMBL1338857 & 688620 & 4.9 & 4.9446 & TRN & \\
\hline CHEMBL93334 & 688620 & 5.85 & 5.6174 & TRN & \\
\hline CHEMBL3190533 & 688620 & 4.75 & 4.9731 & TRN & \\
\hline CHEMBL1483713 & 688620 & 4.6 & 4.953 & TRN & \\
\hline CHEMBL1558337 & 688620 & 4.45 & 4.6798 & TRN & \\
\hline CHEMBL1613685 & 688620 & 4.45 & 4.9576 & TRN & \\
\hline CHEMBL3199019 & 688620 & 4.85 & 5.1964 & TRN & \\
\hline CHEMBL1360615 & 688620 & 4.85 & 4.7975 & TRN & \\
\hline CHEMBL1584066 & 688620 & 5.9 & 5.0595 & TST & \\
\hline CHEMBL1427595 & 688620 & 5.55 & 4.9919 & TRN & \\
\hline CHEMBL1400485 & 688620 & 7.0501 & 5.1102 & TRN & \\
\hline CHEMBL1421261 & 688620 & 4.45 & 4.8819 & TRN & \\
\hline CHEMBL1300370 & 688620 & 4.95 & 5.0435 & TST & \\
\hline CHEMBL1523920 & 688620 & 6.3 & 5.1519 & TRN & \\
\hline CHEMBL3209877 & 688620 & 6.4 & 5.7672 & TRN & \\
\hline
\end{tabular}




\begin{tabular}{|c|c|c|c|c|}
\hline & & & upplement & al $\mathrm{Ta}$ \\
\hline CHEMBL1524147 & 688620 & 4.45 & 4.8257 & TRN \\
\hline CHEMBL1381741 & 688620 & 4.45 & 4.9398 & TRN \\
\hline CHEMBL1477867 & 688620 & 5.0 & 4.8679 & TRN \\
\hline CHEMBL1525599 & 688620 & 6.0 & 5.1485 & TRN \\
\hline CHEMBL1347829 & 688620 & 4.45 & 4.9762 & TRN \\
\hline CHEMBL1341720 & 688620 & 4.45 & 4.7151 & TRN \\
\hline CHEMBL1589010 & 688620 & 5.15 & 4.7427 & TST \\
\hline CHEMBL1607737 & 688620 & 5.45 & 5.3276 & TRN \\
\hline CHEMBL1516638 & 688620 & 4.95 & 4.8968 & TST \\
\hline CHEMBL1403898 & 688620 & 4.45 & 5.0078 & TST \\
\hline CHEMBL1471915 & 688620 & 4.75 & 4.8434 & TRN \\
\hline CHEMBL1386322 & 688620 & 4.85 & 5.1656 & TRN \\
\hline CHEMBL1401489 & 688620 & 5.7 & 5.6486 & TST \\
\hline CHEMBL1459059 & 688620 & 4.5 & 4.7524 & TRN \\
\hline CHEMBL1347818 & 688620 & 4.5 & 4.6633 & TRN \\
\hline CHEMBL 243185 & 688620 & 4.8 & 5.1633 & TRN \\
\hline CHEMBL1461224 & 688620 & 4.45 & 5.2607 & TRN \\
\hline CHEMBL1377522 & 688620 & 4.95 & 4.7915 & TRN \\
\hline CHEMBL1367823 & 688620 & 4.65 & 4.9973 & TRN \\
\hline CHEMBL1460641 & 688620 & 4.9 & 5.199 & TRN \\
\hline CHEMBL1412954 & 688620 & 5.0 & 5.0003 & TRN \\
\hline CHEMBL1599093 & 688620 & 4.45 & 5.2846 & TST \\
\hline CHEMBL1305184 & 688620 & 4.8 & 5.0022 & TRN \\
\hline CHEMBL1569613 & 688620 & 4.85 & 5.1694 & TRN \\
\hline CHEMBL1459757 & 688620 & 4.45 & 4.5976 & TRN \\
\hline CHEMBL1556459 & 688620 & 4.85 & 5.0675 & TRN \\
\hline CHEMBL3211295 & 688620 & 4.6 & 5.1963 & TRN \\
\hline CHEMBL1988780 & 688620 & 5.5 & 5.1684 & TRN \\
\hline CHEMBL3199677 & 688620 & 4.55 & 5.1375 & TST \\
\hline CHEMBL1309484 & 688620 & 5.3 & 5.1581 & TST \\
\hline CHEMBL1504569 & 688620 & 5.5 & 5.9025 & TRN \\
\hline CHEMBL1415265 & 688620 & 4.8 & 5.0621 & TRN \\
\hline CHEMBL1537331 & 688620 & 4.45 & 5.1108 & TST \\
\hline CHEMBL1609025 & 688620 & 4.45 & 5.0232 & TRN \\
\hline CHEMBL1423674 & 688620 & 4.45 & 4.8223 & TST \\
\hline CHEMBL1559789 & 688620 & 4.9 & 5.1832 & TRN \\
\hline CHEMBL1403995 & 688620 & 4.75 & 4.8325 & TRN \\
\hline CHEMBL3212189 & 688620 & 5.35 & 5.3954 & TST \\
\hline CHEMBL1471722 & 688620 & 4.75 & 5.0294 & TRN \\
\hline CHEMBL1771411 & 688620 & 4.75 & 5.0259 & TRN \\
\hline CHEMBL91844 & 688620 & 5.25 & 4.9282 & TRN \\
\hline CHEMBL1363713 & 688620 & 5.85 & 5.3444 & TRN \\
\hline CHEMBL1460699 & 688620 & 4.45 & 4.9757 & TST \\
\hline CHEMBL1369652 & 688620 & 4.7 & 4.9182 & TRN \\
\hline CHEMBL1549957 & 688620 & 4.85 & 4.9167 & TRN \\
\hline CHEMBL1379254 & 688620 & 5.35 & 5.129 & TRN \\
\hline CHEMBL1307458 & 688620 & 4.95 & 5.0233 & TRN \\
\hline CHEMBL1547975 & 688620 & 4.85 & 5.2544 & TRN \\
\hline
\end{tabular}




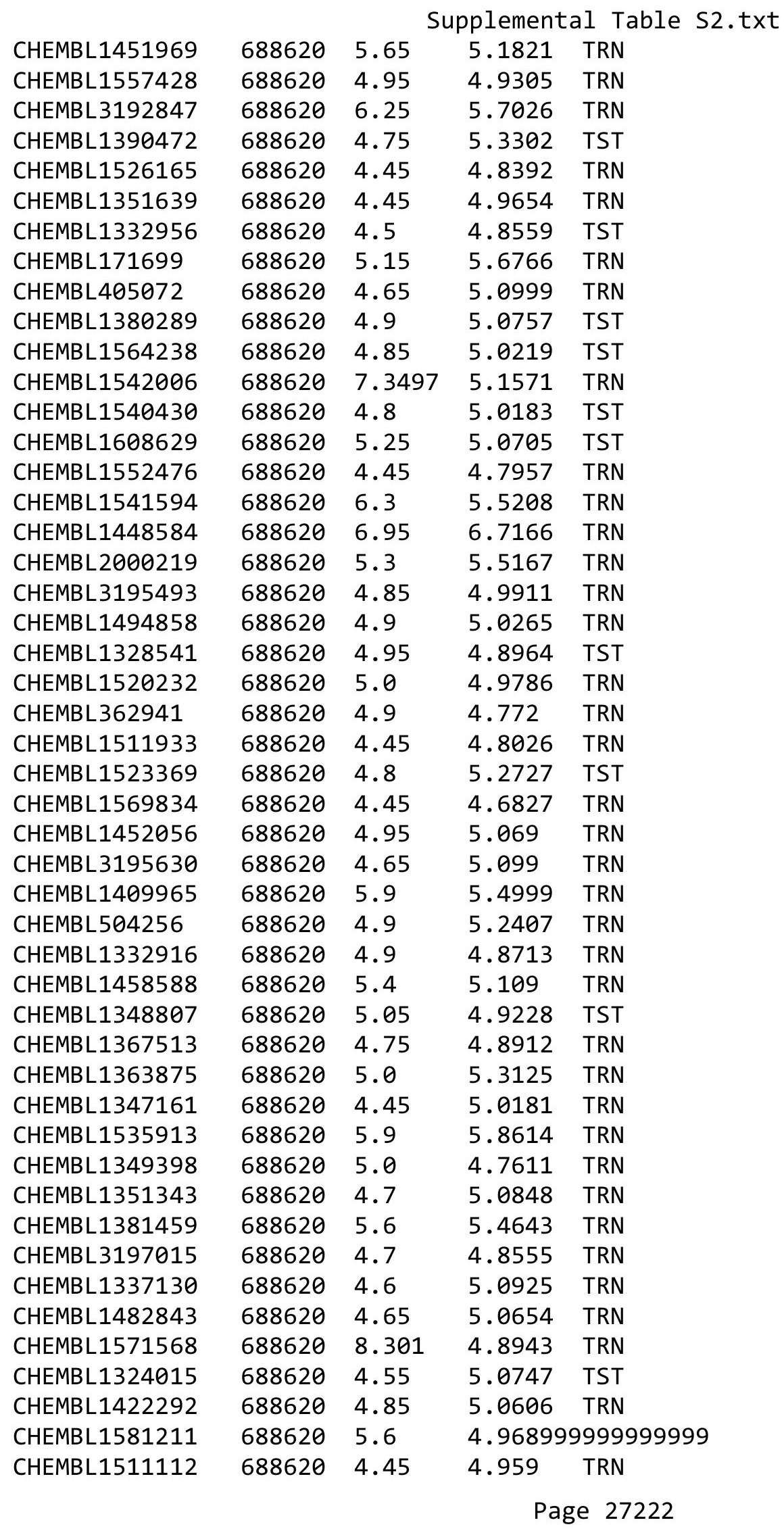




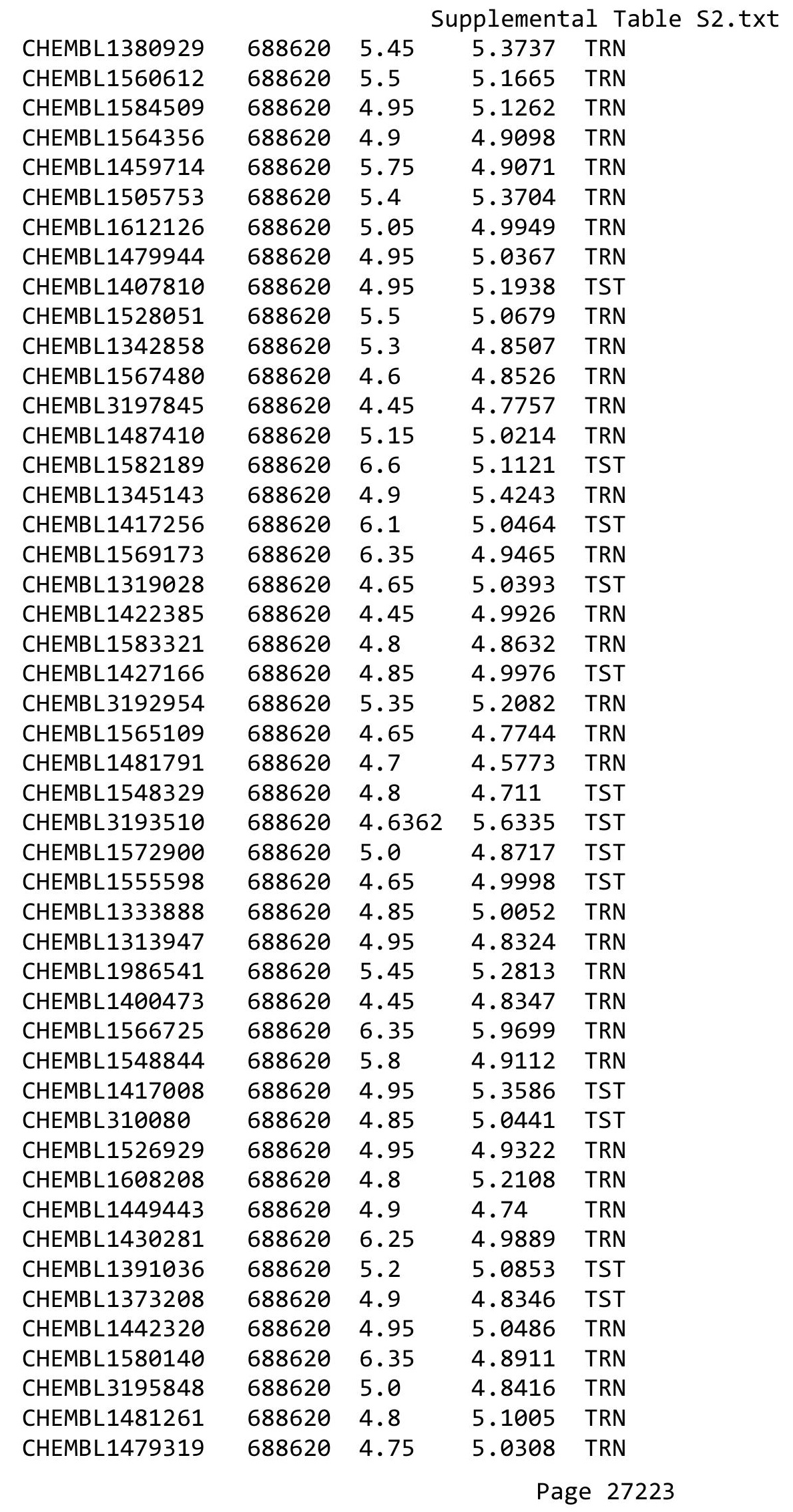




\begin{tabular}{|c|c|c|c|c|c|}
\hline \\
\hline CHEMBL1586067 & 688620 & 4.9 & 4.9693 & TRN & \\
\hline CHEMBL3199382 & 688620 & 5.0 & 4.9094 & TRN & \\
\hline CHEMBL1928491 & 688620 & 4.45 & 5.052 & TRN & \\
\hline CHEMBL1981538 & 688620 & 5.55 & 5.1455 & TRN & \\
\hline CHEMBL1405061 & 688620 & 4.45 & 5.1622 & TRN & \\
\hline CHEMBL1379965 & 688620 & 5.45 & 5.2098 & TRN & \\
\hline CHEMBL1322943 & 688620 & 5.2 & 5.3597 & TRN & \\
\hline CHEMBL1319159 & 688620 & 4.65 & 4.8935 & TRN & \\
\hline CHEMBL1362026 & 688620 & 5.25 & 4.9027 & TRN & \\
\hline CHEMBL1308222 & 688620 & 4.95 & 4.8055 & TRN & \\
\hline CHEMBL1404879 & 688620 & 4.45 & 4.715 & TRN & \\
\hline CHEMBL1539889 & 688620 & 5.55 & 5.3779 & TRN & \\
\hline CHEMBL1529192 & 688620 & 5.3 & 5.0789 & TRN & \\
\hline CHEMBL1568018 & 688620 & 4.6 & 4.9169 & TRN & \\
\hline CHEMBL1382402 & 688620 & 4.9 & 5.0693 & TRN & \\
\hline CHEMBL1501236 & 688620 & 5.8 & 5.6583 & TRN & \\
\hline CHEMBL1498115 & 688620 & 4.45 & 5.0988 & TRN & \\
\hline CHEMBL3199305 & 688620 & 5.55 & 5.2371 & TRN & \\
\hline CHEMBL1418359 & 688620 & 4.8 & 5.0958 & TST & \\
\hline CHEMBL1471197 & 688620 & 5.05 & 5.4039 & TRN & \\
\hline CHEMBL1474526 & 688620 & 4.65 & 4.9832 & TRN & \\
\hline CHEMBL 3213140 & 688620 & 6.25 & 5.9449 & TRN & \\
\hline CHEMBL1490334 & 688620 & 4.9 & 5.0732 & TRN & \\
\hline CHEMBL1458238 & 688620 & 4.45 & 5.0673 & TRN & \\
\hline CHEMBL 302004 & 688620 & 4.7 & 5.3444 & TRN & \\
\hline CHEMBL1384832 & 688620 & 5.0 & 6.1551 & TRN & \\
\hline CHEMBL1599029 & 688620 & 4.9 & 4.9452 & TRN & \\
\hline CHEMBL3213413 & 688620 & 5.9 & 5.5807 & TRN & \\
\hline CHEMBL1536767 & 688620 & 4.95 & 4.8179 & TRN & \\
\hline CHEMBL313737 & 688620 & 4.95 & 5.0668 & TST & \\
\hline CHEMBL1517747 & 688620 & 4.9 & 5.1043 & TST & \\
\hline CHEMBL1588066 & 688620 & 4.7 & 5.2062 & TRN & \\
\hline CHEMBL1466711 & 688620 & 5.55 & 5.0376 & TRN & \\
\hline CHEMBL1408128 & 688620 & 4.7 & 5.2021 & TST & \\
\hline CHEMBL1502750 & 688620 & 4.95 & 5.0641 & TRN & \\
\hline CHEMBL1457381 & 688620 & 4.7 & $5.1960 e$ & 0000000001 & TRN \\
\hline CHEMBL1400434 & 688620 & 4.45 & 5.0716 & TRN & \\
\hline CHEMBL1406317 & 688620 & 5.2 & 5.0517 & TST & \\
\hline CHEMBL1486001 & 688620 & 4.7 & 5.0958 & TRN & \\
\hline CHEMBL3196626 & 688620 & 5.45 & 5.4836 & TRN & \\
\hline CHEMBL1368708 & 688620 & 5.1 & 5.2656 & TRN & \\
\hline CHEMBL1520801 & 688620 & 5.15 & 5.1749 & TRN & \\
\hline CHEMBL1377682 & 688620 & 4.9 & 5.2594 & TRN & \\
\hline CHEMBL1541683 & 688620 & 5.4 & 5.0032 & TRN & \\
\hline CHEMBL1498566 & 688620 & 6.15 & 5.1266 & TRN & \\
\hline CHEMBL1420039 & 688620 & 5.35 & 5.7487 & TRN & \\
\hline CHEMBL1537964 & 688620 & 5.35 & 5.0456 & TRN & \\
\hline CHEMBL1309785 & 688620 & 5.25 & 5.2493 & TRN & \\
\hline
\end{tabular}




\begin{tabular}{|c|c|c|c|c|c|}
\hline \multicolumn{6}{|c|}{ plemental } \\
\hline CHEMBL1353163 & 688620 & 4.5 & 4.8682 & TRN & \\
\hline CHEMBL1485126 & 688620 & 5.15 & 5.2844 & TRN & \\
\hline CHEMBL1470357 & 688620 & 4.45 & 5.0907 & TST & \\
\hline CHEMBL1361461 & 688620 & 5.25 & 5.1319 & TRN & \\
\hline CHEMBL1301126 & 688620 & 4.45 & 4.919 & TST & \\
\hline CHEMBL3191015 & 688620 & 4.45 & 5.2883 & TRN & \\
\hline CHEMBL1606972 & 688620 & 4.9 & 5.0563 & TRN & \\
\hline CHEMBL1381175 & 688620 & 5.5 & 5.3188 & TRN & \\
\hline CHEMBL1567455 & 688620 & 4.95 & 5.23 & TST & \\
\hline CHEMBL1317680 & 688620 & 4.95 & 4.7807 & TRN & \\
\hline CHEMBL1431696 & 688620 & 4.9 & 5.0096 & TRN & \\
\hline CHEMBL1352554 & 688620 & 6.95 & 6.0918 & TRN & \\
\hline CHEMBL1972436 & 688620 & 7.3497 & 5.4399 & TRN & \\
\hline CHEMBL1321294 & 688620 & 5.0 & 5.296 & TST & \\
\hline CHEMBL1339660 & 688620 & 4.45 & 5.2412 & TRN & \\
\hline CHEMBL1477833 & 688620 & 4.8 & 5.0352 & TRN & \\
\hline CHEMBL1420533 & 688620 & 4.5 & 4.8226 & TRN & \\
\hline CHEMBL1461623 & 688620 & 4.65 & 5.0336 & TRN & \\
\hline CHEMBL1491933 & 688620 & 5.55 & 5.2685 & TST & \\
\hline CHEMBL1497742 & 688620 & 6.05 & 5.1559 & TRN & \\
\hline CHEMBL1519750 & 688620 & 5.35 & 4.9729 & TST & \\
\hline CHEMBL1408814 & 688620 & 4.75 & 4.8312 & TST & \\
\hline CHEMBL1367270 & 688620 & 4.75 & 5.0978 & TRN & \\
\hline CHEMBL1311374 & 688620 & 5.65 & 5.099 & TST & \\
\hline CHEMBL1308791 & 688620 & 5.15 & 5.0008 & TRN & \\
\hline CHEMBL1331753 & 688620 & 6.9 & 5.6535 & TRN & \\
\hline CHEMBL1333621 & 688620 & 4.9 & 5.2664 & TRN & \\
\hline CHEMBL1564613 & 688620 & 5.1 & 4.9634 & TRN & \\
\hline CHEMBL1326239 & 688620 & 5.25 & 5.0209 & TRN & \\
\hline CHEMBL1409320 & 688620 & 6.0 & 5.0977 & TRN & \\
\hline CHEMBL1340914 & 688620 & 5.35 & 4.9759 & TRN & \\
\hline CHEMBL1451752 & 688620 & 4.55 & 4.976 & TRN & \\
\hline CHEMBL1482364 & 688620 & 5.2 & 5.0496 & TRN & \\
\hline CHEMBL1560669 & 688620 & 4.45 & 5.0987 & TST & \\
\hline CHEMBL1613064 & 688620 & 4.65 & 4.9984 & TST & \\
\hline CHEMBL1303938 & 688620 & 6.95 & 5.1813 & TRN & \\
\hline CHEMBL1530526 & 688620 & 6.9 & 4.83899 & 99999999995 & TRN \\
\hline CHEMBL1439445 & 688620 & 5.25 & 5.3815 & TRN & \\
\hline CHEMBL1513114 & 688620 & 4.75 & 5.0995 & TRN & \\
\hline CHEMBL1596274 & 688620 & 4.45 & 4.99100 & j0000000005 & TST \\
\hline CHEMBL1528183 & 688620 & 5.9 & 5.2625 & TST & \\
\hline CHEMBL3210362 & 688620 & 4.95 & 4.9291 & TRN & \\
\hline CHEMBL75267 & 688620 & 5.0 & 4.8396 & TRN & \\
\hline CHEMBL1462266 & 688620 & 4.8 & 5.0277 & TRN & \\
\hline CHEMBL1567738 & 688620 & 6.5501 & 5.8288 & TRN & \\
\hline CHEMBL1477236 & 688620 & 5.1 & 5.0357 & TST & \\
\hline CHEMBL1335050 & 688620 & 4.9 & 4.8269 & TRN & \\
\hline CHEMBL1370730 & 688620 & 4.95 & 4.8689 & TRN & \\
\hline
\end{tabular}




\begin{tabular}{|c|c|c|c|c|}
\hline \multicolumn{5}{|c|}{ Supplemental Table S2.txt } \\
\hline CHEMBL1492445 & 688620 & 6.2 & 5.0057 & TRN \\
\hline CHEMBL1479749 & 688620 & 4.8 & 4.9845 & TST \\
\hline CHEMBL1602581 & 688620 & 4.45 & 4.8399 & TST \\
\hline CHEMBL3190911 & 688620 & 4.9 & 5.0547 & TRN \\
\hline CHEMBL1345327 & 688620 & 4.9 & 5.3804 & TRN \\
\hline CHEMBL1600849 & 688620 & 6.7001 & 5.8175 & TRN \\
\hline CHEMBL1436575 & 688620 & 5.15 & 5.0036 & TRN \\
\hline CHEMBL1333643 & 688620 & 4.75 & 5.0812 & TRN \\
\hline CHEMBL1482488 & 688620 & 5.4 & 5.381 & TRN \\
\hline CHEMBL1414682 & 688620 & 4.45 & 4.8991 & TST \\
\hline CHEMBL1500708 & 688620 & 4.65 & 4.992 & TRN \\
\hline CHEMBL1560482 & 688620 & 6.95 & 5.0494 & TRN \\
\hline CHEMBL1367048 & 688620 & 6.6 & 5.0747 & TRN \\
\hline CHEMBL1499074 & 688620 & 5.2 & 5.5904 & TRN \\
\hline CHEMBL1482621 & 688620 & 5.1 & 5.1061 & TRN \\
\hline CHEMBL1471090 & 688620 & 4.75 & 5.0786 & TRN \\
\hline CHEMBL1560074 & 688620 & 5.25 & 4.8707 & TST \\
\hline CHEMBL1494713 & 688620 & 4.95 & 4.8314 & TRN \\
\hline CHEMBL1497748 & 688620 & 4.85 & 4.8997 & TST \\
\hline CHEMBL3197106 & 688620 & 4.95 & 4.878 & TST \\
\hline CHEMBL1557180 & 688620 & 5.1 & 4.9415 & TRN \\
\hline CHEMBL1333461 & 688620 & 6.0 & 6.1239 & TRN \\
\hline CHEMBL1430068 & 688620 & 5.05 & 4.8186 & TRN \\
\hline CHEMBL1305480 & 688620 & 5.85 & 4.8595 & TST \\
\hline CHEMBL1556792 & 688620 & 5.0 & 4.6727 & TRN \\
\hline CHEMBL1336601 & 688620 & 4.75 & 5.0889 & TST \\
\hline CHEMBL1349263 & 688620 & 4.9 & 5.1135 & TRN \\
\hline CHEMBL1451245 & 688620 & 4.75 & 5.1666 & TRN \\
\hline CHEMBL1464866 & 688620 & 4.65 & 5.0745 & TST \\
\hline CHEMBL1344422 & 688620 & 4.65 & 5.0115 & TRN \\
\hline CHEMBL1535261 & 688620 & 4.75 & 4.8247 & TRN \\
\hline CHEMBL1384382 & 688620 & 5.25 & 4.9887 & TST \\
\hline CHEMBL1457776 & 688620 & 5.45 & 5.0978 & TRN \\
\hline CHEMBL 3197310 & 688620 & 6.2 & 5.9751 & TRN \\
\hline CHEMBL 3195800 & 688620 & 5.15 & 5.0203 & TRN \\
\hline CHEMBL1588142 & 688620 & 4.95 & 4.967 & TST \\
\hline CHEMBL1378068 & 688620 & 4.85 & 5.126 & TRN \\
\hline CHEMBL3191230 & 688620 & 4.45 & 5.0694 & TRN \\
\hline CHEMBL1471323 & 688620 & 4.95 & 5.0182 & TST \\
\hline CHEMBL1502724 & 688620 & 5.3 & 5.2772 & TRN \\
\hline CHEMBL1490686 & 688620 & 4.45 & 4.9699 & TST \\
\hline CHEMBL3190958 & 688620 & 5.2 & 5.4023 & TRN \\
\hline CHEMBL1523923 & 688620 & 4.45 & 5.1335 & TRN \\
\hline CHEMBL1375283 & 688620 & 5.55 & 4.92 & TST \\
\hline CHEMBL1388378 & 688620 & 5.35 & 5.4867 & TRN \\
\hline CHEMBL1346708 & 688620 & 4.8 & 4.7475 & TRN \\
\hline CHEMBL1327627 & 688620 & 4.95 & 4.8256 & TRN \\
\hline CHEMBL1496609 & 688620 & 4.45 & 5.1449 & TST \\
\hline
\end{tabular}




\begin{tabular}{|c|c|c|c|c|c|}
\hline & & \multicolumn{4}{|c|}{ Supplemental Table s2.txt } \\
\hline CHEMBL1341881 & 688620 & 5.95 & 4.9628 & TRN & \\
\hline CHEMBL1322844 & 688620 & 4.75 & 5.1316 & TRN & \\
\hline CHEMBL1458825 & 688620 & 5.45 & 5.1154 & TRN & \\
\hline CHEMBL1347001 & 688620 & 5.95 & 5.0248 & TST & \\
\hline CHEMBL1472210 & 688620 & 4.75 & 4.8783 & TST & \\
\hline CHEMBL1464403 & 688620 & 5.9 & 4.8633 & TST & \\
\hline CHEMBL3199841 & 688620 & 6.05 & 5.3923 & TST & \\
\hline CHEMBL3190645 & 688620 & 4.45 & 5.0416 & TST & \\
\hline CHEMBL1448119 & 688620 & 6.25 & 5.2764 & TRN & \\
\hline CHEMBL3196439 & 688620 & 4.9 & 5.2213 & TST & \\
\hline CHEMBL1540123 & 688620 & 5.2 & 5.159 & TRN & \\
\hline CHEMBL1587004 & 688620 & 4.45 & 4.9931 & TRN & \\
\hline CHEMBL1521023 & 688620 & 5.8 & 5.1912 & TRN & \\
\hline CHEMBL1588495 & 688620 & 5.15 & 5.0775 & TRN & \\
\hline CHEMBL1368227 & 688620 & 4.7 & 5.0108 & TRN & \\
\hline CHEMBL1351720 & 688620 & 5.25 & 5.2276 & TRN & \\
\hline CHEMBL3196268 & 688620 & 4.8 & 5.2551 & TRN & \\
\hline CHEMBL1501516 & 688620 & 4.9 & \multicolumn{2}{|c|}{4.9719999999999995} & TRN \\
\hline CHEMBL1468740 & 688620 & 4.8 & 5.0538 & TRN & \\
\hline CHEMBL1387069 & 688620 & 4.95 & 4.9216 & TRN & \\
\hline CHEMBL1402174 & 688620 & 5.2 & 5.1644 & TRN & \\
\hline CHEMBL1309087 & 688620 & 4.8 & 5.2695 & TST & \\
\hline CHEMBL1440613 & 688620 & 5.6 & 5.1342 & TST & \\
\hline CHEMBL1398680 & 688620 & 4.95 & 4.9871 & TRN & \\
\hline CHEMBL1565595 & 688620 & 4.85 & 4.857 & TRN & \\
\hline CHEMBL1346421 & 688620 & 4.45 & 4.8229 & TST & \\
\hline CHEMBL3196796 & 688620 & 5.15 & 5.2936 & TRN & \\
\hline CHEMBL1505084 & 688620 & 4.9 & 5.0727 & TRN & \\
\hline CHEMBL1398520 & 688620 & 5.45 & 5.2436 & TRN & \\
\hline CHEMBL1390699 & 688620 & 4.45 & 5.1763 & TRN & \\
\hline CHEMBL1594602 & 688620 & 4.95 & 5.0833 & TST & \\
\hline CHEMBL1319149 & 688620 & 4.9 & 5.0401 & TRN & \\
\hline CHEMBL1559870 & 688620 & 4.9 & 4.9042 & TRN & \\
\hline CHEMBL1562669 & 688620 & 4.45 & 5.0151 & TRN & \\
\hline CHEMBL1430235 & 688620 & 6.15 & 5.7443 & TRN & \\
\hline CHEMBL1609774 & 688620 & 4.9 & 5.1543 & TST & \\
\hline CHEMBL1612257 & 688620 & 4.95 & 5.1489 & TST & \\
\hline CHEMBL1302567 & 688620 & 4.45 & 5.0634 & TRN & \\
\hline CHEMBL1472203 & 688620 & 4.9 & 4.787 & TRN & \\
\hline CHEMBL1429300 & 688620 & 4.45 & 5.7652 & TRN & \\
\hline CHEMBL1566838 & 688620 & 4.95 & 5.3557 & TRN & \\
\hline CHEMBL1400370 & 688620 & 6.45 & 5.3432 & TRN & \\
\hline CHEMBL1324328 & 688620 & 5.0 & 4.9469 & TRN & \\
\hline CHEMBL3208528 & 688620 & 5.45 & 4.9361 & TST & \\
\hline CHEMBL1566028 & 688620 & 4.45 & 4.7644 & TST & \\
\hline CHEMBL1307020 & 688620 & 4.8 & 5.023 & TST & \\
\hline CHEMBL1363457 & 688620 & 7.0 & 5.0558 & TRN & \\
\hline \multirow[t]{2}{*}{ CHEMBL1466229 } & 688620 & 5.05 & 5.12799 & 9999999999 & TST \\
\hline & & \multicolumn{4}{|c|}{ Page 27227} \\
\hline
\end{tabular}




\begin{tabular}{|c|c|c|c|c|}
\hline \multicolumn{5}{|c|}{ Supplemental Table S2.txt } \\
\hline CHEMBL1380844 & 688620 & 4.85 & 4.9713 & TRN \\
\hline CHEMBL1371455 & 688620 & 4.45 & 4.9094 & TRN \\
\hline CHEMBL1408075 & 688620 & 5.15 & 4.9443 & TST \\
\hline CHEMBL1307416 & 688620 & 5.0 & 5.0002 & TST \\
\hline CHEMBL1540891 & 688620 & 4.5 & 5.184 & TST \\
\hline CHEMBL1438706 & 688620 & 7.2503 & 5.2545 & TRN \\
\hline CHEMBL1560125 & 688620 & 4.7 & 5.0985 & TST \\
\hline CHEMBL1976499 & 688620 & 4.8 & 4.8243 & TRN \\
\hline CHEMBL1301271 & 688620 & 4.45 & 5.2273 & TRN \\
\hline CHEMBL1408346 & 688620 & 5.05 & 5.2148 & TRN \\
\hline CHEMBL1496373 & 688620 & 4.6 & 5.0434 & TRN \\
\hline CHEMBL1432436 & 688620 & 5.55 & 4.7809 & TST \\
\hline CHEMBL1544833 & 688620 & 5.4 & 5.1444 & TRN \\
\hline CHEMBL1471391 & 688620 & 4.5 & 5.1218 & TST \\
\hline CHEMBL1500959 & 688620 & 5.15 & 5.0673 & TRN \\
\hline CHEMBL1310274 & 688620 & 4.7 & 4.8927 & TRN \\
\hline CHEMBL1517934 & 688620 & 4.8 & 4.97 & TRN \\
\hline CHEMBL1405281 & 688620 & 4.55 & 4.763 & TRN \\
\hline CHEMBL1353695 & 688620 & 5.1 & 5.1749 & TST \\
\hline CHEMBL1392861 & 688620 & 4.45 & 5.0846 & TST \\
\hline CHEMBL1438365 & 688620 & 6.9 & 4.9848 & TRN \\
\hline CHEMBL 3197082 & 688620 & 5.2 & 4.9266 & TRN \\
\hline CHEMBL1525712 & 688620 & 4.45 & 5.2443 & TRN \\
\hline CHEMBL1485586 & 688620 & 4.9 & 5.0696 & TRN \\
\hline CHEMBL1559424 & 688620 & 4.9 & 4.9835 & TRN \\
\hline CHEMBL1346672 & 688620 & 5.5 & 4.8653 & TRN \\
\hline CHEMBL3190029 & 688620 & 5.25 & 5.0834 & TRN \\
\hline CHEMBL3193889 & 688620 & 5.55 & 5.0273 & TST \\
\hline CHEMBL1572912 & 688620 & 4.95 & 4.9905 & TRN \\
\hline CHEMBL1579890 & 688620 & 4.9 & 4.8892 & TST \\
\hline CHEMBL1582043 & 688620 & 4.55 & 5.1253 & TRN \\
\hline CHEMBL1540305 & 688620 & 4.9 & 5.0832 & TRN \\
\hline CHEMBL1565737 & 688620 & 4.45 & 4.8851 & TRN \\
\hline CHEMBL1990093 & 688620 & 6.25 & 5.6839 & TRN \\
\hline CHEMBL1453337 & 688620 & 4.95 & 5.0967 & TRN \\
\hline CHEMBL1309439 & 688620 & 4.85 & 5.0685 & TRN \\
\hline CHEMBL1982674 & 688620 & 4.8 & 5.0893 & TRN \\
\hline CHEMBL1399832 & 688620 & 5.0 & 4.9874 & TRN \\
\hline CHEMBL1460688 & 688620 & 4.75 & 5.4161 & TST \\
\hline CHEMBL1479325 & 688620 & 4.7 & 5.1109 & TRN \\
\hline CHEMBL1460328 & 688620 & 5.2 & 5.0193 & TST \\
\hline CHEMBL1503586 & 688620 & 4.55 & 5.0707 & TRN \\
\hline CHEMBL1308734 & 688620 & 4.75 & 4.9625 & TRN \\
\hline CHEMBL1341869 & 688620 & 4.95 & 5.0027 & TRN \\
\hline CHEMBL1576589 & 688620 & 5.4 & 5.2822 & TRN \\
\hline CHEMBL1375895 & 688620 & 5.1 & 5.2216 & TRN \\
\hline CHEMBL 1542660 & 688620 & 5.75 & 5.1356 & TRN \\
\hline CHEMBL1388768 & 688620 & 4.9 & 5.1128 & TST \\
\hline
\end{tabular}




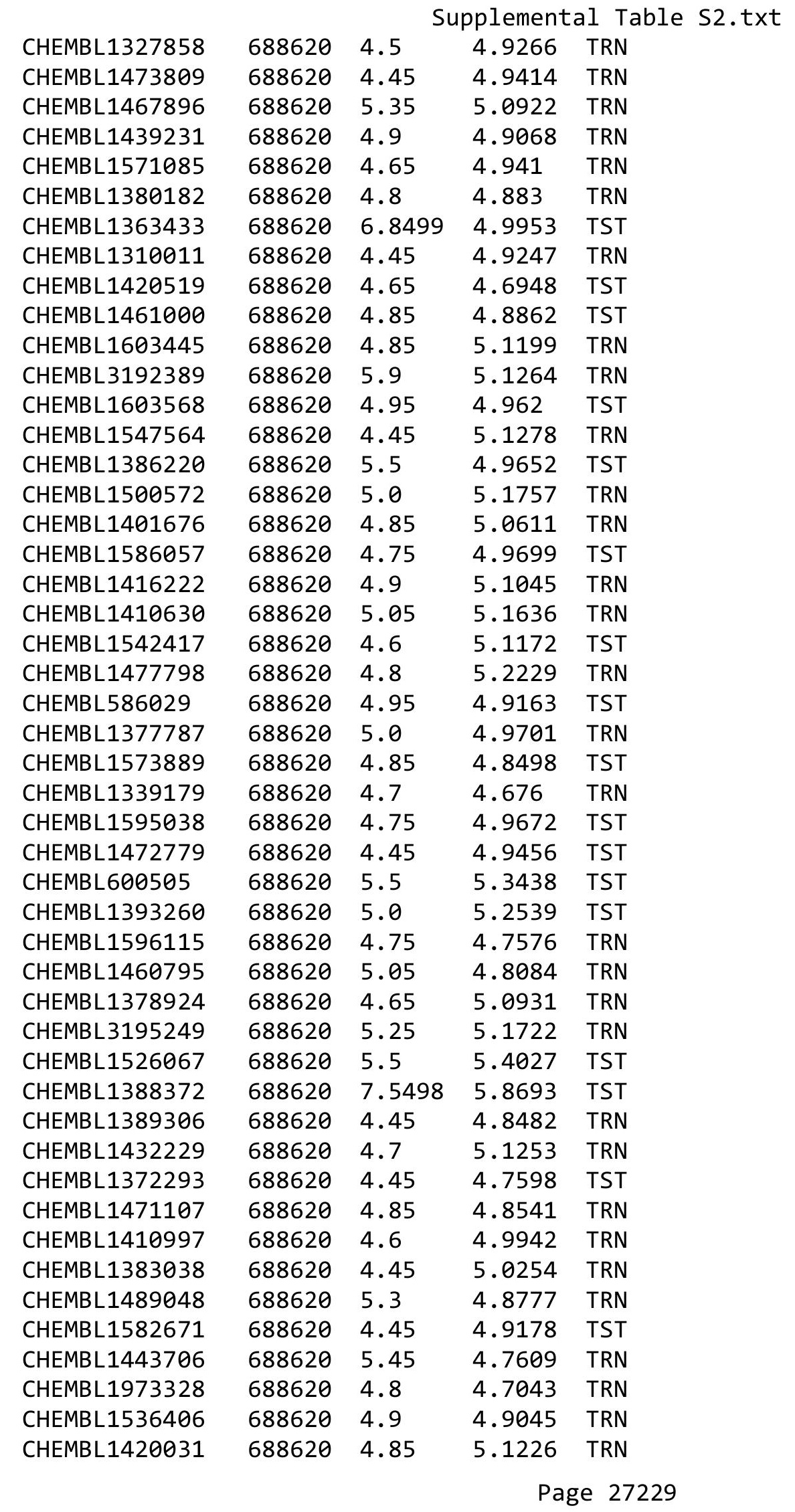




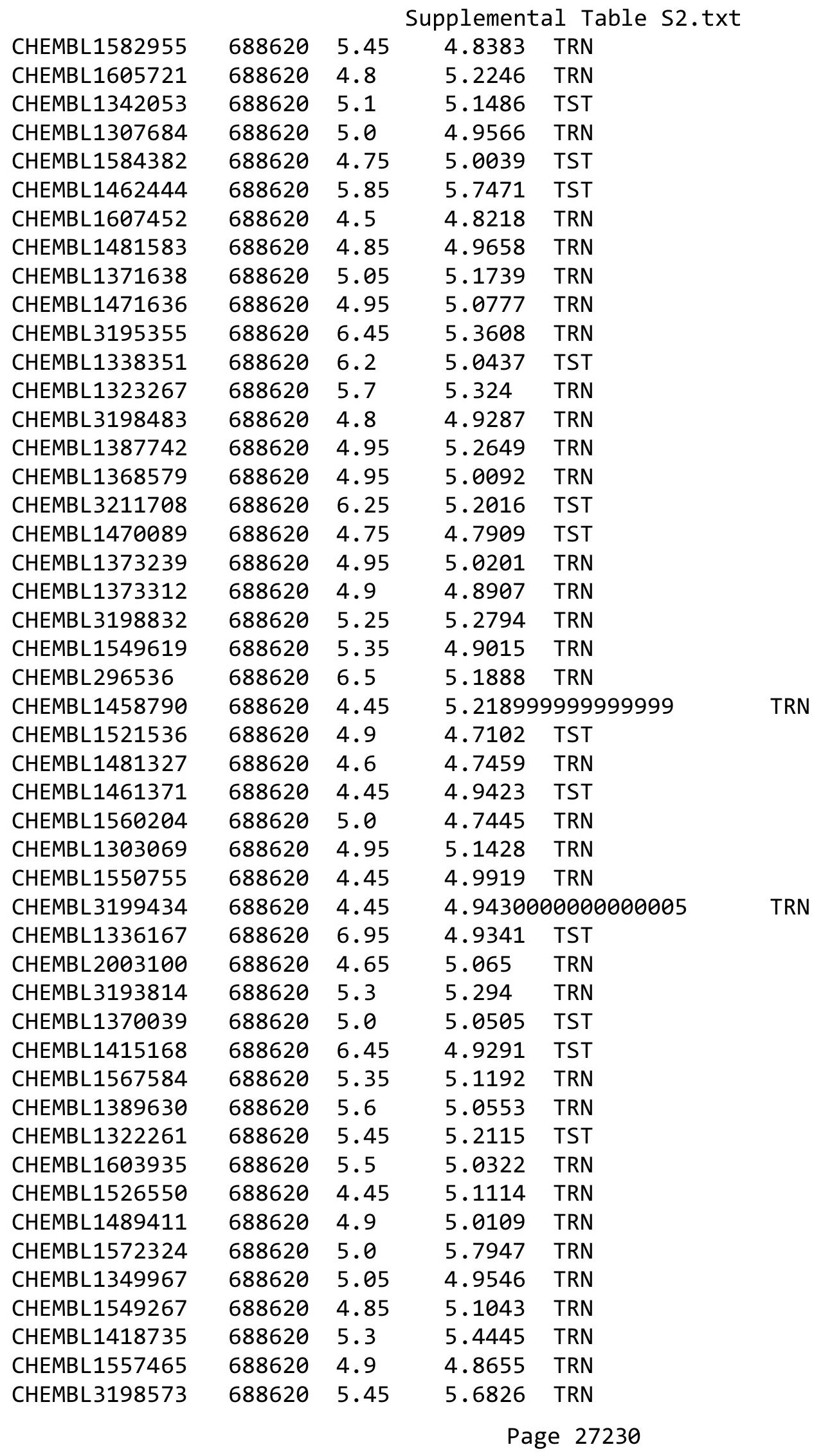




\begin{tabular}{|c|c|c|c|c|c|}
\hline \multicolumn{6}{|c|}{ Supplemental Table S2.txt } \\
\hline CHEMBL1528464 & 688620 & 4.9 & 5.3402 & TRN & \\
\hline CHEMBL1412669 & 688620 & 5.35 & 5.1484 & TRN & \\
\hline CHEMBL1506021 & 688620 & 6.15 & 5.4527 & TST & \\
\hline CHEMBL452002 & 688620 & 4.9 & 4.8984 & TRN & \\
\hline CHEMBL487187 & 688620 & 4.45 & 5.2319 & TRN & \\
\hline CHEMBL1451742 & 688620 & 5.4 & 5.7032 & TRN & \\
\hline CHEMBL1533584 & 688620 & 4.95 & 4.9172 & TRN & \\
\hline CHEMBL1521758 & 688620 & 4.95 & 4.8075 & TRN & \\
\hline CHEMBL1309065 & 688620 & 4.75 & 5.0831 & TST & \\
\hline CHEMBL1567428 & 688620 & 4.45 & 5.0451 & TRN & \\
\hline CHEMBL1968356 & 688620 & 5.5 & 5.397 & TRN & \\
\hline CHEMBL1979295 & 688620 & 5.0 & 5.1939 & TRN & \\
\hline CHEMBL1483847 & 688620 & 6.05 & 5.1168 & TRN & \\
\hline CHEMBL264702 & 688620 & 5.7 & 5.3195 & TST & \\
\hline CHEMBL 2369315 & 688620 & 5.55 & 5.0654 & TST & \\
\hline CHEMBL1461775 & 688620 & 4.7 & 4.9845 & TRN & \\
\hline CHEMBL1568851 & 688620 & 4.8 & 5.0295 & TRN & \\
\hline CHEMBL589313 & 688620 & 4.7 & 4.8621 & TST & \\
\hline CHEMBL1393113 & 688620 & 5.3 & 4.9316 & TRN & \\
\hline CHEMBL1403333 & 688620 & 5.15 & 4.9378 & TRN & \\
\hline CHEMBL3199916 & 688620 & 5.3 & 5.2268 & TRN & \\
\hline CHEMBL1470431 & 688620 & 5.45 & 5.2191 & TRN & \\
\hline CHEMBL 3213376 & 688620 & 4.85 & 5.0108 & TRN & \\
\hline CHEMBL3198256 & 688620 & 4.85 & 4.9588 & TRN & \\
\hline CHEMBL1348537 & 688620 & 5.05 & 4.726 & TST & \\
\hline CHEMBL1503493 & 688620 & 5.1 & 4.9768 & TRN & \\
\hline CHEMBL1406665 & 688620 & 5.05 & 5.2798 & TRN & \\
\hline CHEMBL1346781 & 688620 & 4.65 & 4.8569 & TRN & \\
\hline CHEMBL1538518 & 688620 & 5.2 & 4.85800 & 00000000005 & TRN \\
\hline CHEMBL1343679 & 688620 & 4.95 & 4.9688 & TST & \\
\hline CHEMBL1450229 & 688620 & 5.5 & 5.2704 & TST & \\
\hline CHEMBL1352986 & 688620 & 4.95 & 5.4605 & TRN & \\
\hline CHEMBL1416038 & 688620 & 4.9 & 4.9011 & TST & \\
\hline CHEMBL1569594 & 688620 & 4.45 & 4.8817 & TRN & \\
\hline CHEMBL1492611 & 688620 & 5.1 & 4.9485 & TRN & \\
\hline CHEMBL1602160 & 688620 & 6.0 & 5.6927 & TST & \\
\hline CHEMBL1430150 & 688620 & 4.7 & 5.0691 & TRN & \\
\hline CHEMBL1344484 & 688620 & 4.45 & 4.8971 & TRN & \\
\hline CHEMBL1527429 & 688620 & 4.45 & 4.9302 & TRN & \\
\hline CHEMBL3199294 & 688620 & 4.8 & 5.2549 & TRN & \\
\hline CHEMBL1366342 & 688620 & 4.85 & 4.9032 & TRN & \\
\hline CHEMBL1541650 & 688620 & 4.75 & 4.9404 & TRN & \\
\hline CHEMBL3190028 & 688620 & 5.9 & 5.5448 & TRN & \\
\hline CHEMBL1375245 & 688620 & 6.35 & 5.9089 & TRN & \\
\hline CHEMBL3211104 & 688620 & 5.65 & 6.028 & TRN & \\
\hline CHEMBL1547039 & 688620 & 5.8 & 4.9952 & TRN & \\
\hline CHEMBL1487402 & 688620 & 4.45 & 4.8126 & TRN & \\
\hline CHEMBL515670 & 688620 & 4.85 & 4.9172 & TRN & \\
\hline
\end{tabular}




\begin{tabular}{|c|c|c|c|c|}
\hline \multicolumn{5}{|c|}{ Supplemental Table S2.txt } \\
\hline CHEMBL1364575 & 688620 & 4.5 & 4.9249 & TST \\
\hline CHEMBL3193016 & 688620 & 5.1 & 4.9078 & TRN \\
\hline CHEMBL1340460 & 688620 & 5.3 & 4.9221 & TST \\
\hline CHEMBL1582426 & 688620 & 5.0 & 4.975 & TRN \\
\hline CHEMBL1500604 & 688620 & 6.1 & 4.8839 & TST \\
\hline CHEMBL1560761 & 688620 & 5.0 & 4.8842 & TST \\
\hline CHEMBL1455107 & 688620 & 4.65 & 4.8919 & TRN \\
\hline CHEMBL1330081 & 688620 & 4.9 & 4.9786 & TRN \\
\hline CHEMBL 3213323 & 688620 & 5.95 & 5.0957 & TRN \\
\hline CHEMBL1318979 & 688620 & 8.3468 & 5.1071 & TRN \\
\hline CHEMBL1440706 & 688620 & 5.85 & 4.7589 & TRN \\
\hline CHEMBL3189156 & 688620 & 5.65 & 5.6421 & TRN \\
\hline CHEMBL353759 & 688620 & 5.75 & 5.1129 & TST \\
\hline CHEMBL1608592 & 688620 & 4.9 & 4.9719 & TRN \\
\hline CHEMBL1429775 & 688620 & 5.5 & 5.2972 & TRN \\
\hline CHEMBL3198587 & 688620 & 4.8 & 5.0737 & TRN \\
\hline CHEMBL1350452 & 688620 & 4.8 & 4.975 & TRN \\
\hline CHEMBL 3208781 & 688620 & 4.7 & 5.1862 & TST \\
\hline CHEMBL1379697 & 688620 & 4.65 & 4.6879 & TRN \\
\hline CHEMBL1428240 & 688620 & 5.45 & 4.9866 & TRN \\
\hline CHEMBL1443787 & 688620 & 4.7 & 4.8547 & TRN \\
\hline CHEMBL1606530 & 688620 & 5.05 & 4.8758 & TRN \\
\hline CHEMBL1364395 & 688620 & 5.15 & 4.9734 & TRN \\
\hline CHEMBL1340174 & 688620 & 4.85 & 5.0256 & TRN \\
\hline CHEMBL1389615 & 688620 & 4.5 & 5.1324 & TST \\
\hline CHEMBL1503639 & 688620 & 4.95 & 5.0869 & TRN \\
\hline CHEMBL3190219 & 688620 & 4.85 & 4.9229 & TRN \\
\hline CHEMBL1550139 & 688620 & 4.9 & 5.1076 & TST \\
\hline CHEMBL1374108 & 688620 & 4.45 & 5.6415 & TRN \\
\hline CHEMBL1382100 & 688620 & 4.9 & 5.1741 & TRN \\
\hline CHEMBL1544649 & 688620 & 4.95 & 5.0465 & TST \\
\hline CHEMBL1531572 & 688620 & 4.8 & 4.7516 & TRN \\
\hline CHEMBL1455738 & 688620 & 4.75 & 4.9906 & TST \\
\hline CHEMBL1329413 & 688620 & 4.9 & 4.9314 & TRN \\
\hline CHEMBL3195836 & 688620 & 4.55 & 5.015 & TRN \\
\hline CHEMBL1302400 & 688620 & 4.45 & 4.6947 & TRN \\
\hline CHEMBL1505147 & 688620 & 5.5 & 5.0756 & TRN \\
\hline CHEMBL1303958 & 688620 & 4.85 & 5.0275 & TRN \\
\hline CHEMBL1374910 & 688620 & 5.0 & 4.9539 & TST \\
\hline CHEMBL1452124 & 688620 & 4.45 & 5.1472 & TRN \\
\hline CHEMBL1303129 & 688620 & 6.6 & 5.0985 & TST \\
\hline CHEMBL1493792 & 688620 & 5.25 & 5.2108 & TST \\
\hline CHEMBL3193753 & 688620 & 4.7 & 4.9138 & TRN \\
\hline CHEMBL1343141 & 688620 & 4.95 & 4.7458 & TRN \\
\hline CHEMBL1442727 & 688620 & 5.1 & 4.9902 & TRN \\
\hline CHEMBL1462791 & 688620 & 5.25 & 5.0616 & TRN \\
\hline CHEMBL1540683 & 688620 & 4.45 & 5.0636 & TST \\
\hline CHEMBL1601572 & 688620 & 4.75 & 5.0002 & TRN \\
\hline
\end{tabular}




\begin{tabular}{|c|c|c|c|c|c|}
\hline \multicolumn{6}{|c|}{ Supplemental Table S2.txt } \\
\hline CHEMBL1610687 & 688620 & 4.75 & 5.0196 & TRN & \\
\hline CHEMBL1460746 & 688620 & 5.6 & 5.5328 & TRN & \\
\hline CHEMBL2002008 & 688620 & 5.75 & 5.6584 & TRN & \\
\hline CHEMBL1344711 & 688620 & 4.95 & 4.7695 & TRN & \\
\hline CHEMBL3392455 & 688620 & 5.4 & 5.4382 & TRN & \\
\hline CHEMBL1579808 & 688620 & 4.45 & 5.0908 & TST & \\
\hline CHEMBL1411749 & 688620 & 4.45 & 5.2221 & TST & \\
\hline CHEMBL1401244 & 688620 & 4.7 & 4.8634 & TST & \\
\hline CHEMBL1509966 & 688620 & 4.7 & 5.024 & TRN & \\
\hline CHEMBL1328712 & 688620 & 4.45 & 4.9926 & TST & \\
\hline CHEMBL1303887 & 688620 & 5.45 & 5.0835 & TST & \\
\hline CHEMBL1470872 & 688620 & 4.65 & 5.1102 & TST & \\
\hline CHEMBL1520457 & 688620 & 5.45 & 4.9182 & TRN & \\
\hline CHEMBL1363669 & 688620 & 5.15 & 4.9683 & TRN & \\
\hline CHEMBL1350056 & 688620 & 5.25 & 4.8837 & TST & \\
\hline CHEMBL1424181 & 688620 & 4.6 & 4.8622 & TRN & \\
\hline CHEMBL1576289 & 688620 & 4.65 & 5.1257 & TRN & \\
\hline CHEMBL229887 & 688620 & 4.6 & 5.1531 & TRN & \\
\hline CHEMBL1411634 & 688620 & 4.45 & 5.2245 & TRN & \\
\hline CHEMBL3197211 & 688620 & 5.3 & 5.0517 & TRN & \\
\hline CHEMBL1411847 & 688620 & 5.1 & 5.164 & TRN & \\
\hline CHEMBL408563 & 688620 & 5.15 & 5.2033 & TRN & \\
\hline CHEMBL3193211 & 688620 & 5.0 & 5.4746 & TRN & \\
\hline CHEMBL1604214 & 688620 & 6.05 & 5.3239 & TRN & \\
\hline CHEMBL1382257 & 688620 & 5.0 & 5.0171 & TRN & \\
\hline CHEMBL1422747 & 688620 & 6.5501 & 5.2169 & TRN & \\
\hline CHEMBL1338442 & 688620 & 4.45 & 4.9677 & TRN & \\
\hline CHEMBL1345414 & 688620 & 4.85 & 4.9324 & TST & \\
\hline CHEMBL1377774 & 688620 & 5.45 & 5.0465 & TRN & \\
\hline CHEMBL1391380 & 688620 & 6.1 & 5.8929 & TST & \\
\hline CHEMBL1417649 & 688620 & 4.95 & 5.0973 & TRN & \\
\hline CHEMBL 2002482 & 688620 & 4.75 & 5.1707 & TRN & \\
\hline CHEMBL3210895 & 688620 & 5.2 & 4.8838 & TST & \\
\hline CHEMBL1455605 & 688620 & 5.0 & 5.0478 & TRN & \\
\hline CHEMBL1305465 & 688620 & 5.65 & 5.301 & TRN & \\
\hline CHEMBL1410588 & 688620 & 5.8 & 5.5289 & TST & \\
\hline CHEMBL1544402 & 688620 & 4.65 & 4.77 & TST & \\
\hline CHEMBL1341066 & 688620 & 4.9 & 5.1032 & TST & \\
\hline CHEMBL1347324 & 688620 & 5.55 & 5.3561 & TRN & \\
\hline CHEMBL1535974 & 688620 & 6.15 & 4.8842 & TRN & \\
\hline CHEMBL1363228 & 688620 & 5.2 & $5.2410 e$ & 00000000005 & TST \\
\hline CHEMBL1304107 & 688620 & 4.5 & 5.063 & TST & \\
\hline CHEMBL1410350 & 688620 & 5.8 & 5.4235 & TST & \\
\hline CHEMBL1348639 & 688620 & 4.6 & 4.8469 & TRN & \\
\hline CHEMBL1256674 & 688620 & 4.5 & 5.1561 & TST & \\
\hline CHEMBL1470578 & 688620 & 5.0 & 4.8669 & TRN & \\
\hline CHEMBL1584444 & 688620 & 4.65 & 4.8461 & TRN & \\
\hline CHEMBL1492697 & 688620 & 5.7 & 5.3759 & TRN & \\
\hline
\end{tabular}




\begin{tabular}{|c|c|c|c|c|}
\hline & & & ipplement & al Table S \\
\hline CHEMBL1467388 & 688620 & 4.9 & 5.1271 & TST \\
\hline CHEMBL1338413 & 688620 & 4.85 & 5.0548 & TRN \\
\hline CHEMBL3198291 & 688620 & 7.0 & 4.9369 & TST \\
\hline CHEMBL1603117 & 688620 & 4.95 & 5.11100 & 0000000001 \\
\hline CHEMBL1425196 & 688620 & 4.45 & 5.0792 & TST \\
\hline CHEMBL1528133 & 688620 & 4.95 & 5.0719 & TRN \\
\hline CHEMBL1574756 & 688620 & 5.35 & 5.2447 & TRN \\
\hline CHEMBL1566565 & 688620 & 4.45 & 5.0383 & TST \\
\hline CHEMBL1429569 & 688620 & 5.1 & 5.1967 & TRN \\
\hline CHEMBL1346449 & 688620 & 4.95 & 4.9149 & TRN \\
\hline CHEMBL1468610 & 688620 & 4.9 & 5.0719 & TRN \\
\hline CHEMBL 3194439 & 688620 & 5.45 & 5.416 & TRN \\
\hline CHEMBL1301191 & 688620 & 4.45 & 4.8608 & TRN \\
\hline CHEMBL1442224 & 688620 & 4.45 & 4.9539 & TST \\
\hline CHEMBL1577849 & 688620 & 4.45 & 4.8594 & TST \\
\hline CHEMBL1396374 & 688620 & 4.45 & 4.7181 & TRN \\
\hline CHEMBL1983569 & 688620 & 4.9 & 4.8444 & TST \\
\hline CHEMBL1997717 & 688620 & 6.3 & 5.8686 & TRN \\
\hline CHEMBL1469938 & 688620 & 5.35 & 5.3778 & TRN \\
\hline CHEMBL1376187 & 688620 & 5.9 & 5.0076 & TST \\
\hline CHEMBL1457780 & 688620 & 6.45 & 5.9439 & TRN \\
\hline CHEMBL1510454 & 688620 & 4.55 & 4.9598 & TST \\
\hline CHEMBL1599870 & 688620 & 5.65 & 5.5809 & TRN \\
\hline CHEMBL1481220 & 688620 & 5.45 & 5.3499 & TRN \\
\hline CHEMBL1442120 & 688620 & 4.9 & 4.9231 & TST \\
\hline CHEMBL1312928 & 688620 & 6.0 & 6.1417 & TRN \\
\hline CHEMBL1523175 & 688620 & 4.65 & 5.2771 & TRN \\
\hline CHEMBL1567795 & 688620 & 6.35 & 5.0435 & TRN \\
\hline CHEMBL1423098 & 688620 & 5.6 & 5.0927 & TRN \\
\hline CHEMBL1581929 & 688620 & 5.05 & 5.1842 & TST \\
\hline CHEMBL1470284 & 688620 & 4.95 & 5.1042 & TRN \\
\hline CHEMBL1579444 & 688620 & 4.95 & 4.8386 & TRN \\
\hline CHEMBL104732 & 688620 & 4.45 & 4.9044 & TRN \\
\hline CHEMBL1578304 & 688620 & 5.45 & 4.9105 & TRN \\
\hline CHEMBL1338587 & 688620 & 4.75 & 4.8772 & TRN \\
\hline CHEMBL1406045 & 688620 & 4.65 & 5.0389 & TRN \\
\hline CHEMBL 3212518 & 688620 & 5.0 & 4.9745 & TRN \\
\hline CHEMBL1524226 & 688620 & 5.55 & 5.1016 & TST \\
\hline CHEMBL3195443 & 688620 & 5.35 & 4.926 & TRN \\
\hline CHEMBL1611924 & 688620 & 6.4 & 5.3772 & TST \\
\hline CHEMBL3194162 & 688620 & 4.95 & 5.2529 & TRN \\
\hline CHEMBL1448193 & 688620 & 5.05 & 5.1158 & TRN \\
\hline CHEMBL1418469 & 688620 & 5.55 & 5.4708 & TRN \\
\hline CHEMBL1536638 & 688620 & 4.9 & 5.0513 & TST \\
\hline CHEMBL1321420 & 688620 & 5.15 & 5.1457 & TRN \\
\hline CHEMBL1493421 & 688620 & 4.9 & 5.2402 & TRN \\
\hline CHEMBL2369200 & 688620 & 5.45 & 5.568 & TRN \\
\hline CHEMBL1586235 & 688620 & 5.0 & 5.1307 & TRN \\
\hline
\end{tabular}




\begin{tabular}{|c|c|c|c|c|c|}
\hline \multicolumn{6}{|c|}{ Supplemental Table S2.txt } \\
\hline CHEMBL1389269 & 688620 & 5.5 & 5.2115 & TRN & \\
\hline CHEMBL3195304 & 688620 & 4.95 & 5.1999 & TST & \\
\hline CHEMBL1332456 & 688620 & 4.45 & 5.0103 & TST & \\
\hline CHEMBL1562446 & 688620 & 5.05 & 5.1937 & TRN & \\
\hline CHEMBL1578181 & 688620 & 5.5 & 5.2272 & TRN & \\
\hline CHEMBL1400015 & 688620 & 4.8 & 5.2976 & TRN & \\
\hline CHEMBL1498247 & 688620 & 4.95 & 4.9329 & TRN & \\
\hline CHEMBL1582049 & 688620 & 4.9 & 5.0164 & TST & \\
\hline CHEMBL1375577 & 688620 & 4.95 & 4.763 & TRN & \\
\hline CHEMBL1471622 & 688620 & 4.9 & 4.9673 & TRN & \\
\hline CHEMBL1603192 & 688620 & 5.05 & 4.8411 & TRN & \\
\hline CHEMBL1606797 & 688620 & 4.8 & 4.9016 & TRN & \\
\hline CHEMBL1586182 & 688620 & 5.65 & 5.0965 & TRN & \\
\hline CHEMBL 1451346 & 688620 & 4.45 & 4.8489 & TST & \\
\hline CHEMBL3197754 & 688620 & 4.45 & 4.8453 & TRN & \\
\hline CHEMBL1407420 & 688620 & 4.95 & 5.1286 & TRN & \\
\hline CHEMBL162598 & 688620 & 5.3 & 5.593 & TST & \\
\hline CHEMBL3199761 & 688620 & 5.0 & 5.229 & TRN & \\
\hline CHEMBL 1340855 & 688620 & 5.5 & 5.2676 & TRN & \\
\hline CHEMBL1563823 & 688620 & 4.75 & 4.9927 & TST & \\
\hline CHEMBL1591543 & 688620 & 4.9 & 4.9406 & TRN & \\
\hline CHEMBL1361821 & 688620 & 4.8 & 5.2428 & TRN & \\
\hline CHEMBL1466678 & 688620 & 4.45 & 4.9822 & TRN & \\
\hline CHEMBL1371100 & 688620 & 4.7 & 4.9494 & TRN & \\
\hline CHEMBL1580837 & 688620 & 4.45 & 5.1315 & TST & \\
\hline CHEMBL1449204 & 688620 & 5.55 & 5.33299 & 9999999999 & TRN \\
\hline CHEMBL1463119 & 688620 & 4.8 & 5.0708 & TRN & \\
\hline CHEMBL1455409 & 688620 & 6.1 & 5.8702 & TRN & \\
\hline CHEMBL1521044 & 688620 & 4.9 & 5.2415 & TRN & \\
\hline CHEMBL1498220 & 688620 & 6.1 & 4.886 & TRN & \\
\hline CHEMBL1401744 & 688620 & 5.8 & 5.5496 & TRN & \\
\hline CHEMBL1453900 & 688620 & 6.5501 & 5.8685 & TRN & \\
\hline CHEMBL1322723 & 688620 & 4.9 & 5.0256 & TRN & \\
\hline CHEMBL1494139 & 688620 & 4.45 & 4.8482 & TST & \\
\hline CHEMBL1370062 & 688620 & 4.45 & 4.8723 & TRN & \\
\hline CHEMBL1359409 & 688620 & 4.75 & 5.2082 & TST & \\
\hline CHEMBL1423724 & 688620 & 4.45 & 4.94600 & 0000000001 & TRN \\
\hline CHEMBL1407955 & 688620 & 5.9 & 5.437 & TST & \\
\hline CHEMBL1369872 & 688620 & 5.9 & 4.879 & TRN & \\
\hline CHEMBL1491925 & 688620 & 4.45 & 5.2975 & TRN & \\
\hline CHEMBL1501279 & 688620 & 4.9 & 5.0106 & TRN & \\
\hline CHEMBL1494034 & 688620 & 5.3 & 4.9521 & TRN & \\
\hline CHEMBL1507526 & 688620 & 4.45 & 5.1967 & TRN & \\
\hline CHEMBL1403390 & 688620 & 4.8 & 4.7708 & TRN & \\
\hline CHEMBL1549101 & 688620 & 5.1 & 5.4927 & TRN & \\
\hline CHEMBL1441056 & 688620 & 4.95 & 4.8521 & TRN & \\
\hline CHEMBL3194375 & 688620 & 4.8 & 5.0244 & TRN & \\
\hline CHEMBL1307131 & 688620 & 4.8 & 5.1519 & TRN & \\
\hline
\end{tabular}




\begin{tabular}{|c|c|c|c|c|}
\hline & & & pplemen & al $\mathrm{T}$ \\
\hline CHEMBL1334188 & 688620 & 5.5 & 5.2772 & TRN \\
\hline CHEMBL1410136 & 688620 & 5.5 & 4.9126 & TRN \\
\hline CHEMBL1368038 & 688620 & 4.7 & 4.8916 & TRN \\
\hline CHEMBL1364974 & 688620 & 5.15 & 5.3723 & TRN \\
\hline CHEMBL1337874 & 688620 & 5.0 & 4.9652 & TRN \\
\hline CHEMBL1476974 & 688620 & 4.5 & 4.9184 & TRN \\
\hline CHEMBL1585647 & 688620 & 4.7 & 5.2518 & TRN \\
\hline CHEMBL1516177 & 688620 & 4.95 & 5.4408 & TRN \\
\hline CHEMBL1419255 & 688620 & 6.0 & 5.7667 & TRN \\
\hline CHEMBL3192635 & 688620 & 4.95 & 5.0326 & TRN \\
\hline CHEMBL1302649 & 688620 & 4.7 & 5.1281 & TRN \\
\hline CHEMBL1538790 & 688620 & 4.85 & 4.8608 & TRN \\
\hline CHEMBL1498783 & 688620 & 4.85 & 5.0461 & TST \\
\hline CHEMBL1507069 & 688620 & 5.0 & 4.9794 & TRN \\
\hline CHEMBL1313428 & 688620 & 5.15 & 5.1984 & TRN \\
\hline CHEMBL3145054 & 688620 & 5.0 & 5.0223 & TST \\
\hline CHEMBL1416108 & 688620 & 5.2 & 5.0852 & TST \\
\hline CHEMBL1397323 & 688620 & 4.8 & 5.0682 & TRN \\
\hline CHEMBL1472304 & 688620 & 5.35 & 5.1334 & TRN \\
\hline CHEMBL1312646 & 688620 & 4.5 & 4.9679 & TRN \\
\hline CHEMBL1994048 & 688620 & 4.8 & 4.8192 & TRN \\
\hline CHEMBL1414789 & 688620 & 5.1 & 5.0674 & TRN \\
\hline CHEMBL1575272 & 688620 & 6.2 & 5.4347 & TST \\
\hline CHEMBL1441993 & 688620 & 4.6 & 5.1684 & TRN \\
\hline CHEMBL1595766 & 688620 & 4.95 & 4.98 & TRN \\
\hline CHEMBL1312233 & 688620 & 4.9 & 4.9872 & TST \\
\hline CHEMBL1508467 & 688620 & 4.45 & 4.9009 & TRN \\
\hline CHEMBL1413673 & 688620 & 4.6 & 4.6998 & TRN \\
\hline CHEMBL1609148 & 688620 & 4.65 & 4.9067 & TST \\
\hline CHEMBL1518985 & 688620 & 4.65 & 5.3111 & TRN \\
\hline CHEMBL1522322 & 688620 & 5.5 & 4.9102 & TRN \\
\hline CHEMBL1580970 & 688620 & 4.7 & 5.9938 & TRN \\
\hline CHEMBL1319615 & 688620 & 4.95 & 5.1048 & TST \\
\hline CHEMBL1469087 & 688620 & 4.95 & 5.0641 & TST \\
\hline CHEMBL1301101 & 688620 & 5.4 & 5.0165 & TST \\
\hline CHEMBL1603039 & 688620 & 5.15 & 4.8196 & TRN \\
\hline CHEMBL1464694 & 688620 & 4.7 & 5.3005 & TRN \\
\hline CHEMBL1547079 & 688620 & 5.55 & 5.2337 & TRN \\
\hline CHEMBL3192010 & 688620 & 5.75 & 5.7582 & TRN \\
\hline CHEMBL1419958 & 688620 & 5.65 & 4.9309 & TRN \\
\hline CHEMBL1320587 & 688620 & 4.45 & 4.8352 & TST \\
\hline CHEMBL1524624 & 688620 & 4.65 & 5.1582 & TST \\
\hline CHEMBL1341842 & 688620 & 6.35 & 6.2152 & TRN \\
\hline CHEMBL1510392 & 688620 & 4.45 & 4.8939 & TRN \\
\hline CHEMBL3199117 & 688620 & 5.1 & 5.1146 & TRN \\
\hline CHEMBL1390801 & 688620 & 4.9 & 4.8574 & TRN \\
\hline CHEMBL1409789 & 688620 & 6.1 & 5.499 & TRN \\
\hline CHEMBL1969492 & 688620 & 4.95 & 4.805 & TST \\
\hline
\end{tabular}




\begin{tabular}{|c|c|c|c|c|}
\hline \multicolumn{5}{|c|}{ Supplemental Table s2.txt } \\
\hline CHEMBL1308313 & 688620 & 5.4 & 5.3084 & TRN \\
\hline CHEMBL1345800 & 688620 & 6.5 & 5.2009 & TRN \\
\hline CHEMBL1430288 & 688620 & 5.4 & 5.1977 & TST \\
\hline CHEMBL 3193632 & 688620 & 4.6 & 5.0212 & TRN \\
\hline CHEMBL1604084 & 688620 & 5.3 & 5.0148 & TRN \\
\hline CHEMBL1495194 & 688620 & 6.1 & 5.1757 & TRN \\
\hline CHEMBL1377980 & 688620 & 5.15 & 5.0569 & TRN \\
\hline CHEMBL1332718 & 688620 & 5.0 & 4.9808 & TRN \\
\hline CHEMBL1406565 & 688620 & 4.95 & 4.9468 & TST \\
\hline CHEMBL1367429 & 688620 & 4.5 & 4.8417 & TRN \\
\hline CHEMBL609110 & 688620 & 4.95 & 5.0722 & TRN \\
\hline CHEMBL1606523 & 688620 & 4.45 & 5.5601 & TRN \\
\hline CHEMBL1588805 & 688620 & 4.75 & 4.9626 & TRN \\
\hline CHEMBL 3189587 & 688620 & 4.95 & 5.1671 & TRN \\
\hline CHEMBL1497417 & 688620 & 4.65 & 4.9225 & TST \\
\hline CHEMBL1345853 & 688620 & 4.9 & 4.9799 & TRN \\
\hline CHEMBL3191767 & 688620 & 4.95 & 4.8523 & TRN \\
\hline CHEMBL418353 & 688620 & 4.45 & 4.9288 & TRN \\
\hline CHEMBL1323747 & 688620 & 5.95 & 5.3768 & TRN \\
\hline CHEMBL1578890 & 688620 & 4.95 & 4.6349 & TRN \\
\hline CHEMBL1538785 & 688620 & 5.45 & 4.9257 & TST \\
\hline CHEMBL1382906 & 688620 & 6.2 & 4.9819 & TST \\
\hline CHEMBL1480814 & 688620 & 4.9 & 5.2052 & TRN \\
\hline CHEMBL1489785 & 688620 & 5.35 & 5.3313 & TRN \\
\hline CHEMBL1309448 & 688620 & 4.45 & 4.9951 & TRN \\
\hline CHEMBL3198209 & 688620 & 5.65 & 5.3371 & TRN \\
\hline CHEMBL1426506 & 688620 & 5.1 & 4.896 & TRN \\
\hline CHEMBL1304199 & 688620 & 7.3497 & 5.2511 & TRN \\
\hline CHEMBL3193649 & 688620 & 4.8 & 5.2036 & TRN \\
\hline CHEMBL1543405 & 688620 & 6.9 & 5.0148 & TST \\
\hline CHEMBL1509862 & 688620 & 4.95 & 5.0808 & TRN \\
\hline CHEMBL1571796 & 688620 & 4.95 & 5.0397 & TRN \\
\hline CHEMBL1481523 & 688620 & 4.95 & 5.0113 & TRN \\
\hline CHEMBL1504595 & 688620 & 5.25 & 4.6824 & TST \\
\hline CHEMBL1432848 & 688620 & 4.45 & 5.0274 & TST \\
\hline CHEMBL1416348 & 688620 & 7.0501 & 5.5912 & TRN \\
\hline CHEMBL1550278 & 688620 & 6.3 & 5.4289 & TRN \\
\hline CHEMBL1546860 & 688620 & 4.9 & 5.1024 & TRN \\
\hline CHEMBL1415305 & 688620 & 4.5 & $4.8610 e$ & 0000000001 \\
\hline CHEMBL1337614 & 688620 & 6.15 & 5.5783 & TRN \\
\hline CHEMBL1420759 & 688620 & 4.45 & 4.9401 & TRN \\
\hline CHEMBL1339623 & 688620 & 5.0 & 4.8877 & TRN \\
\hline CHEMBL1547674 & 688620 & 5.2 & 5.0909 & TST \\
\hline CHEMBL3197573 & 688620 & 4.9 & 4.9553 & TRN \\
\hline CHEMBL3195592 & 688620 & 5.75 & 5.5265 & TRN \\
\hline CHEMBL1372606 & 688620 & 5.35 & 5.2437 & TRN \\
\hline CHEMBL1330947 & 688620 & 6.5501 & 5.0163 & TRN \\
\hline CHEMBL3189569 & 688620 & 5.6 & 5.2073 & TRN \\
\hline
\end{tabular}




\begin{tabular}{|c|c|c|c|c|c|}
\hline \multicolumn{6}{|c|}{ Supplemental Table S2.txt } \\
\hline CHEMBL3196367 & 688620 & 5.2 & 5.4246 & TRN & \\
\hline CHEMBL1402159 & 688620 & 5.15 & 5.04 & TRN & \\
\hline CHEMBL1336276 & 688620 & 5.25 & 4.9862 & TRN & \\
\hline CHEMBL1441256 & 688620 & 4.5 & 5.0774 & TRN & \\
\hline CHEMBL1458689 & 688620 & 5.15 & 5.3594 & TRN & \\
\hline CHEMBL1446541 & 688620 & 5.4 & 5.0408 & TRN & \\
\hline CHEMBL1466340 & 688620 & 4.6 & 5.0177 & TST & \\
\hline CHEMBL1364999 & 688620 & 5.1 & 5.3114 & TST & \\
\hline CHEMBL1368368 & 688620 & 4.8 & 4.9353 & TRN & \\
\hline CHEMBL1555077 & 688620 & 4.95 & 4.8083 & TRN & \\
\hline CHEMBL1341380 & 688620 & 4.95 & 5.185 & TRN & \\
\hline CHEMBL1496702 & 688620 & 4.85 & 5.0268 & TRN & \\
\hline CHEMBL1563592 & 688620 & 5.5 & 4.7542 & TRN & \\
\hline CHEMBL3192732 & 688620 & 4.6 & 5.1259 & TST & \\
\hline CHEMBL1388234 & 688620 & 4.45 & 4.6485 & TRN & \\
\hline CHEMBL1440375 & 688620 & 4.9 & 5.1978 & TST & \\
\hline CHEMBL1383476 & 688620 & 4.9 & 5.0183 & TRN & \\
\hline CHEMBL1363932 & 688620 & 5.55 & 5.3303 & TRN & \\
\hline CHEMBL1374413 & 688620 & 4.45 & 4.8676 & TST & \\
\hline CHEMBL1508383 & 688620 & 4.95 & 5.0858 & TRN & \\
\hline CHEMBL1990081 & 688620 & 4.45 & 5.073 & TRN & \\
\hline CHEMBL1306063 & 688620 & 5.0 & 5.2777 & TRN & \\
\hline CHEMBL1335252 & 688620 & 4.8 & 4.9139 & TST & \\
\hline CHEMBL1505859 & 688620 & 4.45 & 5.0644 & TRN & \\
\hline CHEMBL1414633 & 688620 & 4.9 & 4.97199 & 99999999995 & TRN \\
\hline CHEMBL1405693 & 688620 & 4.5 & 5.1205 & TRN & \\
\hline CHEMBL1340362 & 688620 & 5.5 & 5.3631 & TRN & \\
\hline CHEMBL1346289 & 688620 & 4.45 & 5.1622 & TST & \\
\hline CHEMBL1351433 & 688620 & 5.0 & 5.8345 & TRN & \\
\hline CHEMBL1439956 & 688620 & 5.3 & 5.0673 & TRN & \\
\hline CHEMBL3197078 & 688620 & 4.75 & 4.8119 & TRN & \\
\hline CHEMBL1990091 & 688620 & 4.8 & 5.6136 & TRN & \\
\hline CHEMBL1571491 & 688620 & 4.95 & 4.9784 & TRN & \\
\hline CHEMBL1433052 & 688620 & 5.1 & 4.9449 & TST & \\
\hline CHEMBL1361743 & 688620 & 5.0 & 5.1568 & TRN & \\
\hline CHEMBL1577884 & 688620 & 4.45 & 4.9817 & TST & \\
\hline CHEMBL1505917 & 688620 & 4.95 & 5.1444 & TST & \\
\hline CHEMBL1394464 & 688620 & 4.8 & 5.0748 & TST & \\
\hline CHEMBL1376635 & 688620 & 4.8 & 4.73600 & 0000000001 & TRN \\
\hline CHEMBL1500169 & 688620 & 4.55 & 4.8472 & TRN & \\
\hline CHEMBL1574539 & 688620 & 6.9 & 5.1252 & TRN & \\
\hline CHEMBL1587529 & 688620 & 4.75 & 5.1307 & TRN & \\
\hline CHEMBL1565251 & 688620 & 4.45 & 4.7818 & TRN & \\
\hline CHEMBL1604323 & 688620 & 4.9 & 5.1762 & TST & \\
\hline CHEMBL1435439 & 688620 & 4.45 & 4.8773 & TRN & \\
\hline CHEMBL1977589 & 688620 & 4.8 & 5.2335 & TRN & \\
\hline CHEMBL3195399 & 688620 & 4.95 & 4.8522 & TRN & \\
\hline CHEMBL1386509 & 688620 & 5.0 & 4.9423 & TST & \\
\hline
\end{tabular}




\begin{tabular}{|c|c|c|c|c|c|}
\hline \multirow[b]{2}{*}{ CHEMBL1365202 } & \multirow[b]{2}{*}{688620} & \\
\hline & & 4.5 & 4.8933 & TRN & \\
\hline CHEMBL1417093 & 688620 & 5.05 & 5.1295 & TST & \\
\hline CHEMBL1376200 & 688620 & 6.0 & 4.9556 & TRN & \\
\hline CHEMBL1337422 & 688620 & 4.7 & 4.7151 & TRN & \\
\hline CHEMBL1603623 & 688620 & 5.1 & 4.9543 & TRN & \\
\hline CHEMBL3211779 & 688620 & 4.45 & \multicolumn{2}{|c|}{5.127999999999999} & TRN \\
\hline CHEMBL1369319 & 688620 & 5.25 & 5.1877 & TST & \\
\hline CHEMBL1419676 & 688620 & 5.25 & 5.101 & TST & \\
\hline CHEMBL1497453 & 688620 & 4.55 & 4.9337 & TRN & \\
\hline CHEMBL1348642 & 688620 & 5.2 & 5.0621 & TST & \\
\hline CHEMBL1469531 & 688620 & 5.25 & 5.1304 & TRN & \\
\hline CHEMBL1384262 & 688620 & 4.95 & 5.0463 & TST & \\
\hline CHEMBL3199119 & 688620 & 4.95 & 5.2791 & TRN & \\
\hline CHEMBL1375039 & 688620 & 4.45 & 4.8565 & TRN & \\
\hline CHEMBL1531193 & 688620 & 4.95 & 5.112 & TST & \\
\hline CHEMBL1506498 & 688620 & 4.6 & 5.1562 & TRN & \\
\hline CHEMBL1544056 & 688620 & 5.7 & 5.2986 & TRN & \\
\hline CHEMBL1345985 & 688620 & 4.9 & 4.8429 & TST & \\
\hline CHEMBL1516503 & 688620 & 4.5 & 4.8799 & TRN & \\
\hline CHEMBL1338422 & 688620 & 5.45 & 4.7778 & TRN & \\
\hline CHEMBL1402207 & 688620 & 6.3 & 5.8129 & TRN & \\
\hline CHEMBL1592227 & 688620 & 4.7 & 4.7325 & TRN & \\
\hline CHEMBL1305654 & 688620 & 4.55 & 4.8648 & TRN & \\
\hline CHEMBL1574485 & 688620 & 4.65 & 4.9561 & TST & \\
\hline CHEMBL1525138 & 688620 & 4.75 & 5.0699 & TRN & \\
\hline CHEMBL1477547 & 688620 & 4.85 & 4.6471 & TST & \\
\hline CHEMBL1370547 & 688620 & 5.9 & 5.3476 & TRN & \\
\hline CHEMBL1306536 & 688620 & 4.9 & 4.9161 & TST & \\
\hline CHEMBL1539189 & 688620 & 5.0 & 4.855 & TRN & \\
\hline CHEMBL1578809 & 688620 & 4.9 & 4.9099 & TST & \\
\hline CHEMBL1353424 & 688620 & 5.1 & 5.2323 & TRN & \\
\hline CHEMBL1511637 & 688620 & 5.0 & 5.1557 & TRN & \\
\hline CHEMBL1492901 & 688620 & 6.9 & 5.2479 & TRN & \\
\hline CHEMBL1563168 & 688620 & 4.45 & 4.708 & TRN & \\
\hline CHEMBL1507988 & 688620 & 4.45 & 5.2753 & TST & \\
\hline CHEMBL1390591 & 688620 & 4.9 & 4.8683 & TRN & \\
\hline CHEMBL1380641 & 688620 & 4.8 & 5.3249 & TST & \\
\hline CHEMBL1300892 & 688620 & 6.3 & 5.2505 & TRN & \\
\hline CHEMBL1540446 & 688620 & 4.6 & 4.7739 & TRN & \\
\hline CHEMBL1468634 & 688620 & 5.15 & 4.9876 & TRN & \\
\hline CHEMBL1392663 & 688620 & 4.6 & 4.8066 & TRN & \\
\hline CHEMBL1364155 & 688620 & 5.2 & 5.05399 & 9999999999 & TRN \\
\hline CHEMBL3212938 & 688620 & 4.75 & 4.9743 & TRN & \\
\hline CHEMBL1586951 & 688620 & 4.45 & 4.917 & TRN & \\
\hline CHEMBL1521557 & 688620 & 4.85 & 4.9211 & TRN & \\
\hline CHEMBL1393102 & 688620 & 4.95 & 4.7488 & TST & \\
\hline CHEMBL1390421 & 688620 & 5.0 & 5.36 & TRN & \\
\hline CHEMBL3210575 & 688620 & 4.6 & 5.1508 & TST & \\
\hline & & & & 27239 & \\
\hline
\end{tabular}




\begin{tabular}{|c|c|c|c|c|c|}
\hline \multicolumn{6}{|c|}{ Supplemental Table S2.txt } \\
\hline CHEMBL1307910 & 688620 & 5.15 & 5.4382 & TRN & \\
\hline CHEMBL1986619 & 688620 & 4.75 & 5.096 & TST & \\
\hline CHEMBL1430241 & 688620 & 4.45 & 4.9653 & TST & \\
\hline CHEMBL1541696 & 688620 & 4.45 & 5.0933 & TRN & \\
\hline CHEMBL1506449 & 688620 & 4.9 & 4.8933 & TRN & \\
\hline CHEMBL1452989 & 688620 & 7.4498 & 5.0143 & TST & \\
\hline CHEMBL1392529 & 688620 & 5.3 & 5.153 & TST & \\
\hline CHEMBL1534944 & 688620 & 4.95 & 4.5029 & TRN & \\
\hline CHEMBL1444133 & 688620 & 5.1 & 5.1572 & TRN & \\
\hline CHEMBL1426435 & 688620 & 5.55 & 5.4372 & TRN & \\
\hline CHEMBL1580295 & 688620 & 4.9 & 5.1968 & TRN & \\
\hline CHEMBL1383764 & 688620 & 5.95 & 5.0118 & TRN & \\
\hline CHEMBL1339725 & 688620 & 4.5 & 5.1235 & TRN & \\
\hline CHEMBL1471790 & 688620 & 5.65 & 5.4883 & TRN & \\
\hline CHEMBL1516725 & 688620 & 4.9 & $5.1320 e$ & 0000000001 & TRN \\
\hline CHEMBL1499801 & 688620 & 4.45 & 4.9056 & TRN & \\
\hline CHEMBL1370435 & 688620 & 4.95 & 5.0795 & TRN & \\
\hline CHEMBL1587663 & 688620 & 4.95 & 4.9117 & TRN & \\
\hline CHEMBL1339327 & 688620 & 4.85 & 4.9007 & TRN & \\
\hline CHEMBL3191515 & 688620 & 5.2 & 5.52 & TST & \\
\hline CHEMBL1570956 & 688620 & 5.95 & 5.3814 & TRN & \\
\hline CHEMBL1577184 & 688620 & 4.45 & 4.9443 & TRN & \\
\hline CHEMBL 1605056 & 688620 & 4.65 & 4.8866 & TST & \\
\hline CHEMBL1420849 & 688620 & 5.05 & 5.0575 & TST & \\
\hline CHEMBL1412879 & 688620 & 4.7 & 5.1165 & TRN & \\
\hline CHEMBL1302320 & 688620 & 5.15 & 5.3909 & TRN & \\
\hline CHEMBL1563660 & 688620 & 4.95 & 4.9125 & TST & \\
\hline CHEMBL1532179 & 688620 & 4.45 & 4.9552 & TRN & \\
\hline CHEMBL1446329 & 688620 & 5.8 & 5.688 & TRN & \\
\hline CHEMBL1331042 & 688620 & 5.3 & 5.4367 & TRN & \\
\hline CHEMBL1346303 & 688620 & 4.45 & 4.8209 & TRN & \\
\hline CHEMBL1387515 & 688620 & 5.1 & 5.0659 & TST & \\
\hline CHEMBL1453596 & 688620 & 5.4 & 5.1711 & TRN & \\
\hline CHEMBL1535680 & 688620 & 5.15 & 5.296 & TRN & \\
\hline CHEMBL1418562 & 688620 & 4.55 & 5.9007 & TST & \\
\hline CHEMBL1401539 & 688620 & 4.9 & 5.2187 & TRN & \\
\hline CHEMBL3191276 & 688620 & 5.15 & 5.1782 & TRN & \\
\hline CHEMBL3197846 & 688620 & 5.5 & 5.1372 & TST & \\
\hline CHEMBL1511444 & 688620 & 4.45 & 5.03 & TST & \\
\hline CHEMBL1309765 & 688620 & 4.65 & 4.9074 & TRN & \\
\hline CHEMBL1479002 & 688620 & 5.0 & 5.2041 & TRN & \\
\hline CHEMBL1594821 & 688620 & 6.2 & 5.426 & TRN & \\
\hline CHEMBL1340096 & 688620 & 5.4 & 5.3225 & TRN & \\
\hline CHEMBL1496348 & 688620 & 4.45 & 4.8711 & TRN & \\
\hline CHEMBL1544699 & 688620 & 4.45 & 4.9764 & TRN & \\
\hline CHEMBL3198485 & 688620 & 6.2 & 5.7425 & TRN & \\
\hline CHEMBL 1465117 & 688620 & 5.4 & 5.1451 & TST & \\
\hline CHEMBL1497974 & 688620 & 4.9 & 4.9376 & TRN & \\
\hline
\end{tabular}




\begin{tabular}{|c|c|c|c|c|c|}
\hline \\
\hline CHEMBL1364777 & 688620 & 5.0 & 5.1766 & TRN & \\
\hline CHEMBL1448851 & 688620 & 5.0 & 5.1816 & TRN & \\
\hline CHEMBL1391798 & 688620 & 5.05 & 4.9633 & TRN & \\
\hline CHEMBL1332578 & 688620 & 4.95 & 4.9491 & TRN & \\
\hline CHEMBL1564311 & 688620 & 4.8 & 5.1832 & TRN & \\
\hline CHEMBL1607021 & 688620 & 4.45 & 5.1018 & TRN & \\
\hline CHEMBL1426371 & 688620 & 4.9 & 5.0361 & TRN & \\
\hline CHEMBL1373090 & 688620 & 5.3 & 5.3779 & TRN & \\
\hline CHEMBL1423257 & 688620 & 5.35 & 5.4408 & TRN & \\
\hline CHEMBL2002995 & 688620 & 5.3 & 5.1669 & TRN & \\
\hline CHEMBL1547509 & 688620 & 5.55 & $5.3370 €$ & 2000000001 & TST \\
\hline CHEMBL3197848 & 688620 & 4.9 & 4.8937 & TRN & \\
\hline CHEMBL1577943 & 688620 & 4.45 & 5.0895 & TRN & \\
\hline CHEMBL1335518 & 688620 & 5.3 & 5.0217 & TRN & \\
\hline CHEMBL199387 & 688620 & 4.8 & 5.474 & TRN & \\
\hline CHEMBL1559981 & 688620 & 4.95 & 4.8099 & TST & \\
\hline CHEMBL1462156 & 688620 & 4.95 & 4.956 & TRN & \\
\hline CHEMBL1448182 & 688620 & 4.95 & 4.7962 & TRN & \\
\hline CHEMBL1571005 & 688620 & 5.0 & 5.1662 & TRN & \\
\hline CHEMBL1521913 & 688620 & 5.15 & 5.2316 & TRN & \\
\hline CHEMBL1313155 & 688620 & 4.7 & 4.812 & TST & \\
\hline CHEMBL1392592 & 688620 & 4.75 & 4.914 & TRN & \\
\hline CHEMBL1402979 & 688620 & 6.0 & 5.0665 & TST & \\
\hline CHEMBL1425212 & 688620 & 6.45 & $5.1370 e$ & 00000000005 & TRN \\
\hline CHEMBL1494643 & 688620 & 4.45 & 5.0321 & TST & \\
\hline CHEMBL1375761 & 688620 & 4.9 & 4.939 & TST & \\
\hline CHEMBL1373197 & 688620 & 5.1 & 4.925 & TRN & \\
\hline CHEMBL1308887 & 688620 & 5.45 & 5.1952 & TRN & \\
\hline CHEMBL1490410 & 688620 & 4.9 & 4.853 & TRN & \\
\hline CHEMBL1451881 & 688620 & 6.5 & 5.0672 & TST & \\
\hline CHEMBL1329628 & 688620 & 4.9 & 4.9498 & TRN & \\
\hline CHEMBL1426934 & 688620 & 5.3 & 5.1589 & TST & \\
\hline CHEMBL1420545 & 688620 & 4.7 & 5.0092 & TST & \\
\hline CHEMBL1472773 & 688620 & 4.65 & 5.1625 & TST & \\
\hline CHEMBL1517172 & 688620 & 4.85 & 4.9732 & TRN & \\
\hline CHEMBL3208594 & 688620 & 4.55 & 5.1245 & TRN & \\
\hline CHEMBL1485605 & 688620 & 4.55 & 5.043 & TRN & \\
\hline CHEMBL389162 & 688620 & 4.45 & 4.7654 & TRN & \\
\hline CHEMBL1561190 & 688620 & 5.25 & 5.0436 & TRN & \\
\hline CHEMBL1508576 & 688620 & 5.3 & 5.1746 & TRN & \\
\hline CHEMBL1339892 & 688620 & 4.7 & 5.176 & TRN & \\
\hline CHEMBL1402675 & 688620 & 4.95 & 5.1087 & TST & \\
\hline CHEMBL1571422 & 688620 & 4.9 & 4.8826 & TRN & \\
\hline CHEMBL1418435 & 688620 & 5.25 & 5.1823 & TST & \\
\hline CHEMBL3209365 & 688620 & 5.0 & 4.9609 & TRN & \\
\hline CHEMBL1603122 & 688620 & 5.45 & 5.1001 & TRN & \\
\hline CHEMBL1420831 & 688620 & 4.95 & 5.1586 & TRN & \\
\hline CHEMBL1368881 & 688620 & 4.45 & 5.0862 & TRN & \\
\hline & & & & 272 & \\
\hline
\end{tabular}




\begin{tabular}{|c|c|c|c|c|c|}
\hline \\
\hline CHEMBL1305077 & 688620 & 5.3 & 5.3393 & TST & \\
\hline CHEMBL1987891 & 688620 & 4.95 & 4.9555 & TRN & \\
\hline CHEMBL1589056 & 688620 & 4.9 & 4.919 & TRN & \\
\hline CHEMBL1377446 & 688620 & 4.7 & 4.753 & TRN & \\
\hline CHEMBL3194001 & 688620 & 4.9 & 5.1026 & TRN & \\
\hline CHEMBL1372316 & 688620 & 4.9 & 5.0913 & TRN & \\
\hline CHEMBL1501968 & 688620 & 4.7 & 4.735 & TST & \\
\hline CHEMBL1536598 & 688620 & 5.05 & 5.1498 & TRN & \\
\hline CHEMBL1543198 & 688620 & 4.95 & 5.1069 & TST & \\
\hline CHEMBL1559186 & 688620 & 4.45 & 4.9748 & TRN & \\
\hline CHEMBL1459748 & 688620 & 5.0 & 4.9961 & TRN & \\
\hline CHEMBL1307735 & 688620 & 5.65 & 5.3072 & TRN & \\
\hline CHEMBL1509228 & 688620 & 4.9 & 5.0859 & TST & \\
\hline CHEMBL1429000 & 688620 & 4.7 & 4.9354 & TST & \\
\hline CHEMBL1565394 & 688620 & 6.0 & 5.3765 & TRN & \\
\hline CHEMBL1536728 & 688620 & 5.3 & 5.1574 & TRN & \\
\hline CHEMBL1561831 & 688620 & 5.2 & 4.8004 & TRN & \\
\hline CHEMBL3191792 & 688620 & 4.65 & 4.7079 & TRN & \\
\hline CHEMBL 3145245 & 688620 & 6.3 & 5.8149 & TRN & \\
\hline CHEMBL1471282 & 688620 & 5.1 & 4.9008 & TRN & \\
\hline CHEMBL3207452 & 688620 & 4.75 & 5.0798 & TST & \\
\hline CHEMBL1541842 & 688620 & 5.7 & 4.9846 & TRN & \\
\hline CHEMBL1422640 & 688620 & 4.45 & 4.7326 & TRN & \\
\hline CHEMBL1312173 & 688620 & 4.65 & 5.1203 & TRN & \\
\hline CHEMBL1607457 & 688620 & 5.45 & 5.3786 & TRN & \\
\hline CHEMBL1468973 & 688620 & 5.0 & 5.1061 & TST & \\
\hline CHEMBL1519066 & 688620 & 4.75 & 4.9343 & TRN & \\
\hline CHEMBL1352182 & 688620 & 4.95 & 5.186 & TRN & \\
\hline CHEMBL1969851 & 688620 & 5.55 & 4.9916 & TRN & \\
\hline CHEMBL1488675 & 688620 & 4.95 & 4.8613 & TST & \\
\hline CHEMBL579075 & 688620 & 4.45 & 4.9843 & TRN & \\
\hline CHEMBL164968 & 688620 & 5.85 & 5.53799 & 9999999999 & TRN \\
\hline CHEMBL1373412 & 688620 & 4.85 & 5.1097 & TRN & \\
\hline CHEMBL1429768 & 688620 & 4.95 & 5.1007 & TST & \\
\hline CHEMBL1424036 & 688620 & 4.45 & 4.9033 & TRN & \\
\hline CHEMBL1300049 & 688620 & 4.45 & 5.0974 & TRN & \\
\hline CHEMBL1445819 & 688620 & 4.45 & 5.0281 & TRN & \\
\hline CHEMBL1396203 & 688620 & 5.1 & 5.0595 & TRN & \\
\hline CHEMBL1594473 & 688620 & 4.8 & 5.1491 & TST & \\
\hline CHEMBL1362201 & 688620 & 4.45 & 5.1713 & TST & \\
\hline CHEMBL1349606 & 688620 & 4.45 & 5.1073 & TRN & \\
\hline CHEMBL1585151 & 688620 & 4.9 & 5.0751 & TRN & \\
\hline CHEMBL3392440 & 688620 & 4.65 & 4.7667 & TST & \\
\hline CHEMBL1523942 & 688620 & 5.05 & 4.9343 & TST & \\
\hline CHEMBL 3193627 & 688620 & 5.9 & 5.7473 & TRN & \\
\hline CHEMBL1384415 & 688620 & 4.7 & 4.9719 & TRN & \\
\hline CHEMBL 3191788 & 688620 & 4.8 & 4.8223 & TRN & \\
\hline CHEMBL3191566 & 688620 & 6.0 & 5.6119 & TRN & \\
\hline
\end{tabular}




\begin{tabular}{|c|c|c|c|c|c|}
\hline \multicolumn{6}{|c|}{ Supplemental Table S2.txt } \\
\hline CHEMBL1350242 & 688620 & 4.45 & 4.9652 & TRN & \\
\hline CHEMBL1348615 & 688620 & 4.9 & 5.4691 & TRN & \\
\hline CHEMBL1531898 & 688620 & 4.85 & 5.3347 & TRN & \\
\hline CHEMBL1563109 & 688620 & 7.3497 & 5.1288 & TRN & \\
\hline CHEMBL1410739 & 688620 & 5.0 & 4.7168 & TRN & \\
\hline CHEMBL1519804 & 688620 & 4.65 & 4.9612 & TRN & \\
\hline CHEMBL1545319 & 688620 & 5.55 & 5.1429 & TRN & \\
\hline CHEMBL1389011 & 688620 & 4.75 & 4.985 & TRN & \\
\hline CHEMBL1557206 & 688620 & 4.65 & 5.0239 & TRN & \\
\hline CHEMBL1326868 & 688620 & 4.75 & 5.1657 & TST & \\
\hline CHEMBL1443601 & 688620 & 5.95 & 5.251 & TRN & \\
\hline CHEMBL1321756 & 688620 & 5.4 & 5.1192 & TRN & \\
\hline CHEMBL1579805 & 688620 & 4.45 & 5.0227 & TRN & \\
\hline CHEMBL1597701 & 688620 & 4.85 & 5.0652 & TST & \\
\hline CHEMBL1328771 & 688620 & 4.95 & 4.7403 & TRN & \\
\hline CHEMBL1589559 & 688620 & 5.15 & 5.1499 & TST & \\
\hline CHEMBL1607043 & 688620 & 4.95 & 5.0383 & TRN & \\
\hline CHEMBL1497537 & 688620 & 5.5 & 5.1495 & TRN & \\
\hline CHEMBL1408412 & 688620 & 4.95 & 4.8211 & TRN & \\
\hline CHEMBL1451630 & 688620 & 4.9 & 4.8812 & TRN & \\
\hline CHEMBL1401928 & 688620 & 6.0 & 5.6771 & TRN & \\
\hline CHEMBL1380561 & 688620 & 4.95 & 5.0966 & TST & \\
\hline CHEMBL1432736 & 688620 & 4.45 & 5.1034 & TRN & \\
\hline CHEMBL3209346 & 688620 & 5.65 & 5.2168 & TRN & \\
\hline CHEMBL1506312 & 688620 & 4.95 & 4.9192 & TRN & \\
\hline CHEMBL1371111 & 688620 & 4.7 & 4.842 & TRN & \\
\hline CHEMBL1600986 & 688620 & 4.9 & 4.7199 & TST & \\
\hline CHEMBL1457056 & 688620 & 4.95 & 4.9161 & TST & \\
\hline CHEMBL1403707 & 688620 & 4.65 & 5.1112 & TST & \\
\hline CHEMBL1403248 & 688620 & 4.55 & 4.8647 & TRN & \\
\hline CHEMBL1552505 & 688620 & 4.6 & 5.0003 & TRN & \\
\hline CHEMBL1307181 & 688620 & 6.25 & 5.7918 & TST & \\
\hline CHEMBL1554027 & 688620 & 6.0 & 4.95100 & 00000000005 & TRN \\
\hline CHEMBL1387100 & 688620 & 4.95 & 4.7581 & TRN & \\
\hline CHEMBL1477384 & 688620 & 5.0 & 5.1902 & TST & \\
\hline CHEMBL1525219 & 688620 & 4.8 & 4.9775 & TRN & \\
\hline CHEMBL1529086 & 688620 & 5.6 & 4.9162 & TRN & \\
\hline CHEMBL1510038 & 688620 & 4.85 & 4.8793 & TRN & \\
\hline CHEMBL1463674 & 688620 & 4.95 & 5.0235 & TRN & \\
\hline CHEMBL1541441 & 688620 & 5.3 & 5.4613 & TRN & \\
\hline CHEMBL1607313 & 688620 & 5.2 & 5.1166 & TRN & \\
\hline CHEMBL1540112 & 688620 & 5.7 & 5.4925 & TRN & \\
\hline CHEMBL3194238 & 688620 & 4.5 & 4.8937 & TRN & \\
\hline CHEMBL1562444 & 688620 & 4.8 & 4.9954 & TRN & \\
\hline CHEMBL1501728 & 688620 & 4.9 & 4.8057 & TRN & \\
\hline CHEMBL1468009 & 688620 & 4.45 & 4.93199 & 99999999995 & TRN \\
\hline CHEMBL3197647 & 688620 & 5.35 & 5.284 & TRN & \\
\hline CHEMBL1545099 & 688620 & 4.45 & 5.1432 & TRN & \\
\hline
\end{tabular}




\begin{tabular}{|c|c|c|c|c|c|}
\hline \multicolumn{6}{|c|}{ Supplemental Table s2.txt } \\
\hline CHEMBL1353759 & 688620 & 7.0 & 5.415 & TRN & \\
\hline CHEMBL1482365 & 688620 & 4.45 & 4.8556 & TRN & \\
\hline CHEMBL1404645 & 688620 & 5.7 & 5.0338 & TRN & \\
\hline CHEMBL1377193 & 688620 & 5.4 & 5.3932 & TRN & \\
\hline CHEMBL1435292 & 688620 & 5.1 & 4.9096 & TST & \\
\hline CHEMBL1460555 & 688620 & 4.7 & 5.0807 & TST & \\
\hline CHEMBL1489104 & 688620 & 4.45 & 4.8797 & TRN & \\
\hline CHEMBL1316471 & 688620 & 6.5 & 5.1991 & TRN & \\
\hline CHEMBL1440995 & 688620 & 6.15 & 4.7638 & TRN & \\
\hline CHEMBL1320542 & 688620 & 6.4 & 6.1678 & TRN & \\
\hline CHEMBL1499897 & 688620 & 4.9 & 5.0145 & TRN & \\
\hline CHEMBL1539955 & 688620 & 4.65 & 5.0281 & TST & \\
\hline CHEMBL1560377 & 688620 & 4.7 & 5.0841 & TST & \\
\hline CHEMBL1568776 & 688620 & 5.3 & 5.2014 & TRN & \\
\hline CHEMBL1393379 & 688620 & 4.9 & 4.7195 & TRN & \\
\hline CHEMBL3192726 & 688620 & 5.3 & 4.7884 & TRN & \\
\hline CHEMBL1352146 & 688620 & 4.85 & 5.0599 & TRN & \\
\hline CHEMBL1458814 & 688620 & 5.7 & 4.93 & TRN & \\
\hline CHEMBL1555697 & 688620 & 5.0 & 5.0358 & TST & \\
\hline CHEMBL1340481 & 688620 & 4.45 & 4.9253 & TST & \\
\hline CHEMBL1370340 & 688620 & 4.45 & 4.75 & TST & \\
\hline CHEMBL1457096 & 688620 & 4.95 & 5.401 & TRN & \\
\hline CHEMBL1387868 & 688620 & 5.5 & 5.1509 & TST & \\
\hline CHEMBL1337784 & 688620 & 5.4 & 5.5544 & TRN & \\
\hline CHEMBL1541078 & 688620 & 4.95 & 4.9356 & TRN & \\
\hline CHEMBL1991888 & 688620 & 5.35 & $5.1670 e$ & 0000000001 & TRN \\
\hline CHEMBL1412306 & 688620 & 5.65 & 5.5326 & TRN & \\
\hline CHEMBL1580655 & 688620 & 4.6 & 4.8511 & TRN & \\
\hline CHEMBL3194010 & 688620 & 5.3 & 5.7535 & TRN & \\
\hline CHEMBL1445785 & 688620 & 5.65 & 4.8975 & TRN & \\
\hline CHEMBL1575742 & 688620 & 5.4 & 4.8062 & TST & \\
\hline CHEMBL3194643 & 688620 & 5.7 & 5.4501 & TRN & \\
\hline CHEMBL1598690 & 688620 & 4.9 & 4.9378 & TRN & \\
\hline CHEMBL1544860 & 688620 & 5.2 & 4.9698 & TST & \\
\hline CHEMBL1502718 & 688620 & 4.45 & 4.7287 & TRN & \\
\hline CHEMBL1578022 & 688620 & 4.85 & 4.7516 & TRN & \\
\hline CHEMBL1529081 & 688620 & 5.2 & 5.0333 & TRN & \\
\hline CHEMBL1469594 & 688620 & 4.7 & 5.1548 & TRN & \\
\hline CHEMBL1327191 & 688620 & 4.8 & 5.0804 & TST & \\
\hline CHEMBL1454286 & 688620 & 4.5 & 5.1322 & TST & \\
\hline CHEMBL3194103 & 688620 & 5.0 & 5.0519 & TRN & \\
\hline CHEMBL16223 & 688620 & 4.45 & 4.9081 & TRN & \\
\hline CHEMBL1375966 & 688620 & 5.05 & 4.9804 & TRN & \\
\hline CHEMBL1542962 & 688620 & 4.95 & 4.9249 & TST & \\
\hline CHEMBL1454233 & 688620 & 5.0 & 4.9395 & TST & \\
\hline CHEMBL1550483 & 688620 & 4.75 & 4.9369 & TST & \\
\hline CHEMBL1600573 & 688620 & 4.9 & 4.8584 & TRN & \\
\hline CHEMBL1468130 & 688620 & 5.65 & 5.7968 & TST & \\
\hline
\end{tabular}




\begin{tabular}{|c|c|c|c|c|c|}
\hline & & \multicolumn{4}{|c|}{ Supplemental Table S2.txt } \\
\hline CHEMBL1500692 & 688620 & 4.45 & 4.7886 & TRN & \\
\hline CHEMBL1578920 & 688620 & 4.5 & 4.8343 & TRN & \\
\hline CHEMBL1303181 & 688620 & 5.05 & 4.9557 & TST & \\
\hline CHEMBL1412200 & 688620 & 4.45 & 5.2361 & TRN & \\
\hline CHEMBL1384569 & 688620 & 4.95 & 5.2522 & TST & \\
\hline CHEMBL1611831 & 688620 & 4.45 & 4.8956 & TST & \\
\hline CHEMBL1568658 & 688620 & 5.0 & 4.8628 & TST & \\
\hline CHEMBL1494148 & 688620 & 4.95 & 5.0838 & TRN & \\
\hline CHEMBL1577378 & 688620 & 4.45 & 4.9624 & TST & \\
\hline CHEMBL1534509 & 688620 & 5.5 & 5.0963 & TRN & \\
\hline CHEMBL1540806 & 688620 & 4.9 & 4.9683 & TRN & \\
\hline CHEMBL1474514 & 688620 & 5.05 & 5.0046 & TRN & \\
\hline CHEMBL1722566 & 688620 & 5.2 & 5.1772 & TST & \\
\hline CHEMBL1524635 & 688620 & 6.25 & 4.9873 & TRN & \\
\hline CHEMBL1583584 & 688620 & 6.15 & 5.2863 & TRN & \\
\hline CHEMBL1449943 & 688620 & 4.5 & 4.9897 & TRN & \\
\hline CHEMBL1400406 & 688620 & 5.25 & 5.9147 & TRN & \\
\hline CHEMBL1500926 & 688620 & 4.85 & 5.3497 & TST & \\
\hline CHEMBL1366347 & 688620 & 5.4 & 5.0854 & TRN & \\
\hline CHEMBL1365801 & 688620 & 4.8 & 5.0443 & TRN & \\
\hline CHEMBL1999630 & 688620 & 4.95 & 5.1694 & TRN & \\
\hline CHEMBL1603187 & 688620 & 5.5 & 4.806 & TRN & \\
\hline CHEMBL1457570 & 688620 & 5.0 & 5.13399 & 99999999995 & TRN \\
\hline CHEMBL1349942 & 688620 & 5.0 & 5.1939 & TRN & \\
\hline CHEMBL1389969 & 688620 & 5.25 & 5.2193 & TRN & \\
\hline CHEMBL3191568 & 688620 & 4.8 & 5.3049 & TRN & \\
\hline CHEMBL1545587 & 688620 & 5.2 & 5.106 & TRN & \\
\hline CHEMBL1492906 & 688620 & 5.05 & 5.1623 & TST & \\
\hline CHEMBL1422647 & 688620 & 5.2 & 5.9466 & TRN & \\
\hline CHEMBL1479024 & 688620 & 4.7 & 5.0793 & TRN & \\
\hline CHEMBL1457601 & 688620 & 4.9 & 4.936 & TRN & \\
\hline CHEMBL1367596 & 688620 & 6.0 & 5.6793 & TST & \\
\hline CHEMBL1387408 & 688620 & 5.0 & 4.8909 & TRN & \\
\hline CHEMBL3198328 & 688620 & 6.15 & 5.0785 & TST & \\
\hline CHEMBL3209203 & 688620 & 4.5 & 4.9177 & TRN & \\
\hline CHEMBL1597038 & 688620 & 4.5 & 4.8125 & TST & \\
\hline CHEMBL3197238 & 688620 & 6.1 & 5.8761 & TRN & \\
\hline CHEMBL1509655 & 688620 & 7.5003 & 5.1867 & TST & \\
\hline CHEMBL1542064 & 688620 & 5.0 & 5.1854 & TST & \\
\hline CHEMBL1563885 & 688620 & 4.8 & 4.9735 & TRN & \\
\hline CHEMBL1578360 & 688620 & 5.95 & 5.6004 & TRN & \\
\hline CHEMBL1422510 & 688620 & 5.0 & 4.9163 & TRN & \\
\hline CHEMBL1362220 & 688620 & 4.45 & 5.2223 & TRN & \\
\hline CHEMBL1499710 & 688620 & 4.65 & 4.6652 & TST & \\
\hline CHEMBL1342471 & 688620 & 4.9 & 5.118 & TRN & \\
\hline CHEMBL1525141 & 688620 & 4.45 & 4.9922 & TRN & \\
\hline CHEMBL1540981 & 688620 & 4.75 & 5.142 & TRN & \\
\hline CHEMBL3199392 & 688620 & 4.7 & 4.8374 & TRN & \\
\hline
\end{tabular}




\begin{tabular}{|c|c|c|c|c|}
\hline & & & Supplement & \\
\hline CHEMBL1383505 & 688620 & 4.45 & 4.9818 & TRN \\
\hline CHEMBL1602782 & 688620 & 5.0 & 4.7827 & TRN \\
\hline CHEMBL1325460 & 688620 & 4.65 & 4.637 & TRN \\
\hline CHEMBL1334239 & 688620 & 4.45 & 4.9763 & TRN \\
\hline CHEMBL1402000 & 688620 & 4.6 & 5.2284 & TRN \\
\hline CHEMBL1363949 & 688620 & 4.75 & 5.0205 & TRN \\
\hline CHEMBL1362609 & 688620 & 4.6 & 4.9739 & TRN \\
\hline CHEMBL1494214 & 688620 & 5.45 & 5.4146 & TRN \\
\hline CHEMBL1459126 & 688620 & 4.95 & 4.9011 & TRN \\
\hline CHEMBL1595616 & 688620 & 5.55 & 5.012 & TRN \\
\hline CHEMBL1541932 & 688620 & 4.95 & 5.218 & TRN \\
\hline CHEMBL1578653 & 688620 & 4.9 & 5.1769 & TRN \\
\hline CHEMBL1453005 & 688620 & 4.9 & 5.2649 & TRN \\
\hline CHEMBL1568147 & 688620 & 5.15 & 5.2094 & TRN \\
\hline CHEMBL1465080 & 688620 & 5.15 & 4.9599 & TRN \\
\hline CHEMBL3197291 & 688620 & 4.45 & 4.7317 & TRN \\
\hline CHEMBL1329119 & 688620 & 4.5 & 5.0603 & TRN \\
\hline CHEMBL1606164 & 688620 & 5.5 & 5.1237 & TRN \\
\hline CHEMBL1556350 & 688620 & 5.85 & 5.7273 & TRN \\
\hline CHEMBL1402010 & 688620 & 5.6 & 5.4613 & TRN \\
\hline CHEMBL1509308 & 688620 & 4.7 & 4.9066 & TRN \\
\hline CHEMBL1452734 & 688620 & 5.0 & 5.0623 & TRN \\
\hline CHEMBL1502192 & 688620 & 5.6 & 5.3519 & TRN \\
\hline CHEMBL1610679 & 688620 & 5.85 & 5.5667 & TST \\
\hline CHEMBL3191632 & 688620 & 5.05 & 4.8852 & TRN \\
\hline CHEMBL3199684 & 688620 & 4.95 & 4.9968 & TRN \\
\hline CHEMBL1324333 & 688620 & 4.45 & 5.1976 & TRN \\
\hline CHEMBL1361269 & 688620 & 4.55 & 4.9843 & TST \\
\hline CHEMBL1381702 & 688620 & 4.45 & 4.9033 & TRN \\
\hline CHEMBL1338095 & 688620 & 5.0 & 4.9893 & TRN \\
\hline CHEMBL1462852 & 688620 & 4.85 & 4.8947 & TRN \\
\hline CHEMBL1989179 & 688620 & 4.95 & 4.9378 & TRN \\
\hline CHEMBL1305710 & 688620 & 4.85 & 5.0264 & TRN \\
\hline CHEMBL1299274 & 688620 & 5.25 & 4.9412 & TST \\
\hline CHEMBL1383004 & 688620 & 4.9 & 5.0404 & TST \\
\hline CHEMBL1516373 & 688620 & 5.85 & 4.9151 & TRN \\
\hline CHEMBL1537717 & 688620 & 4.85 & 5.305 & TST \\
\hline CHEMBL1547706 & 688620 & 4.85 & 5.4482 & TRN \\
\hline CHEMBL1991009 & 688620 & 5.3 & 5.0398 & TRN \\
\hline CHEMBL1400240 & 688620 & 5.2 & 5.1295 & TRN \\
\hline CHEMBL1511671 & 688620 & 4.8 & 4.8447 & TRN \\
\hline CHEMBL 1449020 & 688620 & 5.0 & 4.9824 & TRN \\
\hline CHEMBL1308677 & 688620 & 5.5 & 4.8044 & TRN \\
\hline CHEMBL3209141 & 688620 & 4.95 & 5.0226 & TST \\
\hline CHEMBL1421990 & 688620 & 5.25 & 4.8695 & TRN \\
\hline CHEMBL1545990 & 688620 & 5.55 & 4.6924 & TST \\
\hline CHEMBL1505253 & 688620 & 4.85 & 5.0503 & TRN \\
\hline CHEMBL1469839 & 688620 & 4.45 & 5.0523 & TST \\
\hline
\end{tabular}




\begin{tabular}{|c|c|c|c|c|c|}
\hline \multicolumn{6}{|c|}{ Supplemental Table S2.txt } \\
\hline CHEMBL 3193144 & 688620 & 4.75 & 5.4711 & TST & \\
\hline CHEMBL1526277 & 688620 & 4.95 & 4.9136 & TRN & \\
\hline CHEMBL1539755 & 688620 & 4.9 & 4.9586 & TST & \\
\hline CHEMBL1486883 & 688620 & 4.45 & 4.9268 & TST & \\
\hline CHEMBL1521675 & 688620 & 4.45 & 5.0588 & TRN & \\
\hline CHEMBL3189392 & 688620 & 4.75 & 4.8467 & TRN & \\
\hline CHEMBL1313107 & 688620 & 5.35 & 5.1631 & TRN & \\
\hline CHEMBL1308033 & 688620 & 5.45 & 4.9952 & TRN & \\
\hline CHEMBL1428118 & 688620 & 4.6 & 4.8393 & TRN & \\
\hline CHEMBL1477773 & 688620 & 4.65 & 4.933 & TRN & \\
\hline CHEMBL1501158 & 688620 & 5.3 & 5.025 & TRN & \\
\hline CHEMBL1536446 & 688620 & 4.95 & 4.9263 & TRN & \\
\hline CHEMBL1420938 & 688620 & 4.45 & 5.18 & TRN & \\
\hline CHEMBL3195853 & 688620 & 5.1 & 5.0937 & TRN & \\
\hline CHEMBL1489576 & 688620 & 4.65 & 4.9687 & TST & \\
\hline CHEMBL1449652 & 688620 & 4.45 & 4.9672 & TRN & \\
\hline CHEMBL1431625 & 688620 & 4.65 & 4.9432 & TST & \\
\hline CHEMBL1529603 & 688620 & 4.45 & 4.9345 & TST & \\
\hline CHEMBL1319597 & 688620 & 5.45 & 4.8824 & TRN & \\
\hline CHEMBL1371326 & 688620 & 4.95 & 5.0047 & TST & \\
\hline CHEMBL1386817 & 688620 & 4.65 & 5.0691 & TRN & \\
\hline CHEMBL1339654 & 688620 & 5.7 & 4.92 & TRN & \\
\hline CHEMBL3195302 & 688620 & 5.0 & 5.2388 & TRN & \\
\hline CHEMBL1498083 & 688620 & 5.15 & 5.2664 & TST & \\
\hline CHEMBL1432059 & 688620 & 5.7 & 5.6146 & TRN & \\
\hline CHEMBL1546443 & 688620 & 4.65 & 5.0906 & TRN & \\
\hline CHEMBL1541199 & 688620 & 4.45 & 4.7846 & TRN & \\
\hline CHEMBL1500614 & 688620 & 4.45 & 4.8602 & TRN & \\
\hline CHEMBL1448672 & 688620 & 4.45 & 5.0397 & TST & \\
\hline CHEMBL1340168 & 688620 & 4.45 & 5.0875 & TST & \\
\hline CHEMBL3190996 & 688620 & 4.45 & 5.0372 & TRN & \\
\hline CHEMBL1584036 & 688620 & 5.4 & 4.8993 & TRN & \\
\hline CHEMBL1306850 & 688620 & 4.75 & 5.3259 & TRN & \\
\hline CHEMBL1413321 & 688620 & 5.0 & 5.0343 & TRN & \\
\hline CHEMBL1488874 & 688620 & 4.45 & 4.962 & TRN & \\
\hline CHEMBL1487433 & 688620 & 5.2 & 4.9073 & TST & \\
\hline CHEMBL1536007 & 688620 & 6.25 & 5.0959 & TRN & \\
\hline CHEMBL1524845 & 688620 & 5.0 & 5.1711 & TRN & \\
\hline CHEMBL1556801 & 688620 & 5.4 & 4.8224 & TRN & \\
\hline CHEMBL268809 & 688620 & 5.5 & 5.2049 & TRN & \\
\hline CHEMBL1445141 & 688620 & 4.45 & 5.4572 & TST & \\
\hline CHEMBL1577760 & 688620 & 5.35 & $4.9830 e$ & 00000000005 & TST \\
\hline CHEMBL1576310 & 688620 & 4.95 & 5.9923 & TST & \\
\hline CHEMBL1492876 & 688620 & 4.9 & 5.0739 & TST & \\
\hline CHEMBL3196755 & 688620 & 5.75 & 5.0587 & TST & \\
\hline CHEMBL1611543 & 688620 & 5.6 & 4.9177 & TRN & \\
\hline CHEMBL1437138 & 688620 & 6.0 & $5.6170 e$ & 0000000001 & TRN \\
\hline CHEMBL1573000 & 688620 & 6.15 & $5.6270 e$ & 0000000001 & TRN \\
\hline & & & & 27247 & \\
\hline
\end{tabular}




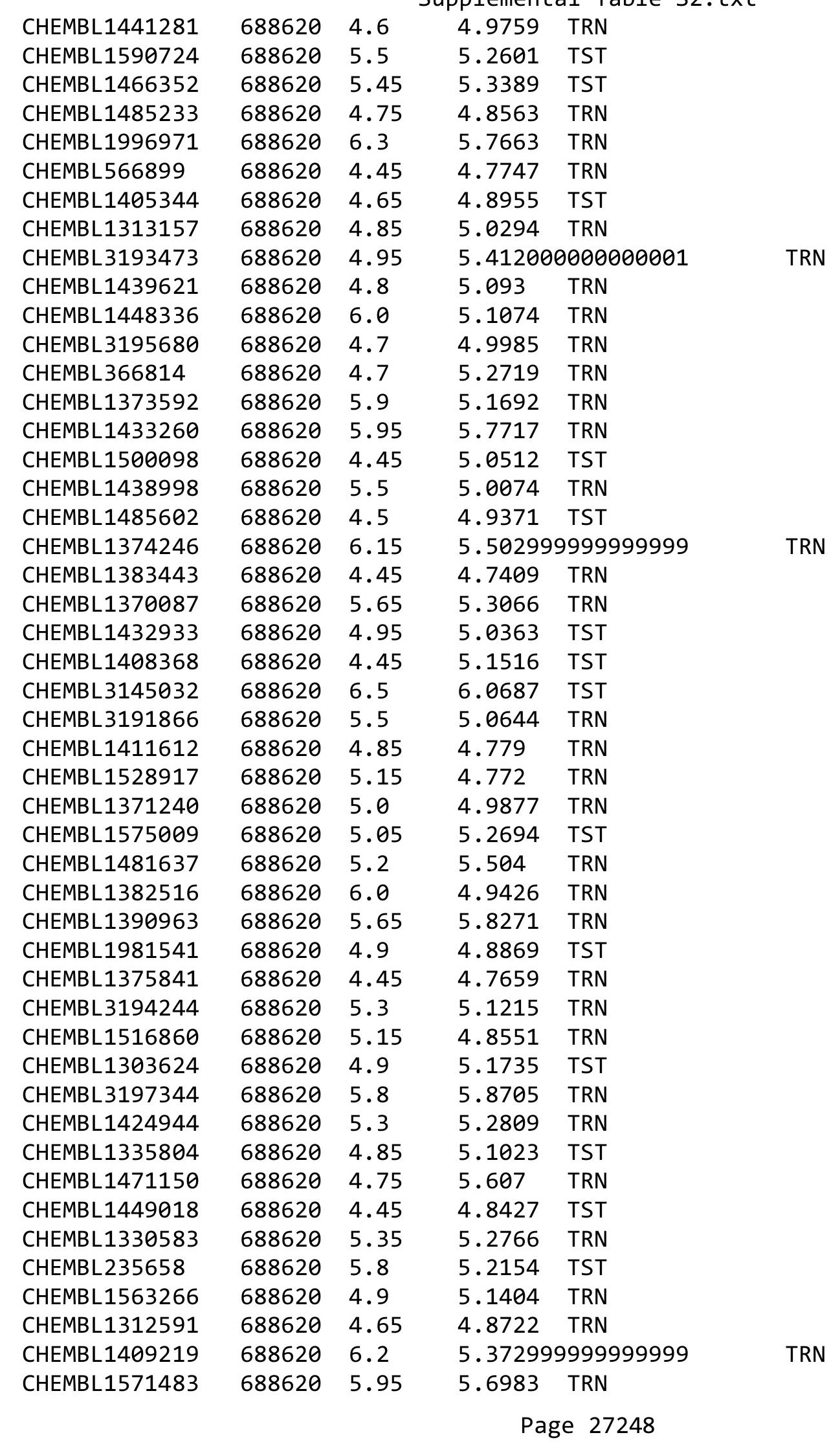




\begin{tabular}{|c|c|c|c|c|c|}
\hline CHEMBL1306323 & 688620 & 5.7 & 5.4971 & TRN & \\
\hline CHEMBL1348582 & 688620 & 5.2 & 5.3404 & TRN & \\
\hline CHEMBL1349496 & 688620 & 4.55 & 4.8827 & TRN & \\
\hline CHEMBL1359255 & 688620 & 5.3 & 5.1612 & TRN & \\
\hline CHEMBL1567087 & 688620 & 5.25 & 4.8055 & TST & \\
\hline CHEMBL1564312 & 688620 & 4.85 & 5.0045 & TST & \\
\hline CHEMBL1329971 & 688620 & 7.0 & 4.97199 & 99999999995 & TRN \\
\hline CHEMBL1416856 & 688620 & 4.45 & 5.1255 & TST & \\
\hline CHEMBL 2004141 & 688620 & 7.0 & 5.8304 & TRN & \\
\hline CHEMBL1535436 & 688620 & 4.95 & 5.0379 & TRN & \\
\hline CHEMBL408850 & 688620 & 4.85 & 5.3461 & TRN & \\
\hline CHEMBL1587636 & 688620 & 5.0 & 5.12299 & 9999999999 & TRN \\
\hline CHEMBL1315654 & 688620 & 4.65 & 5.1109 & TST & \\
\hline CHEMBL3197323 & 688620 & 5.5 & 5.5653 & TRN & \\
\hline CHEMBL1327987 & 688620 & 4.45 & 4.9166 & TRN & \\
\hline CHEMBL3191343 & 688620 & 4.95 & 4.8522 & TRN & \\
\hline CHEMBL1549336 & 688620 & 4.85 & 5.0774 & TST & \\
\hline CHEMBL1398151 & 688620 & 5.1 & 4.9785 & TRN & \\
\hline CHEMBL1470098 & 688620 & 5.5 & 5.2351 & TRN & \\
\hline CHEMBL1567824 & 688620 & 5.0 & 5.0045 & TRN & \\
\hline CHEMBL1498938 & 688620 & 4.45 & 4.9705 & TRN & \\
\hline CHEMBL1964628 & 688620 & 4.7 & 5.0732 & TRN & \\
\hline CHEMBL 244649 & 688620 & 5.05 & 4.9979 & TST & \\
\hline CHEMBL1439924 & 688620 & 4.5 & 4.9106 & TRN & \\
\hline CHEMBL1349727 & 688620 & 4.95 & 4.9871 & TRN & \\
\hline CHEMBL1472083 & 688620 & 5.6 & 4.7516 & TRN & \\
\hline CHEMBL1596347 & 688620 & 4.95 & 5.0912 & TST & \\
\hline CHEMBL1545203 & 688620 & 5.15 & 5.3436 & TRN & \\
\hline CHEMBL1333847 & 688620 & 6.0 & 5.5083 & TST & \\
\hline CHEMBL1486363 & 688620 & 4.9 & 4.9022 & TRN & \\
\hline CHEMBL1586685 & 688620 & 4.7 & 4.8515 & TST & \\
\hline CHEMBL3208453 & 688620 & 7.5498 & 4.9506 & TST & \\
\hline CHEMBL 3145280 & 688620 & 6.25 & 5.8846 & TRN & \\
\hline CHEMBL485070 & 688620 & 4.45 & 4.8861 & TST & \\
\hline CHEMBL1318640 & 688620 & 4.9 & 4.8854 & TRN & \\
\hline CHEMBL3191406 & 688620 & 4.45 & 5.0825 & TRN & \\
\hline CHEMBL1362768 & 688620 & 5.6 & 5.0828 & TST & \\
\hline CHEMBL1343213 & 688620 & 4.65 & 5.2431 & TRN & \\
\hline CHEMBL1455052 & 688620 & 4.45 & 5.0082 & TRN & \\
\hline CHEMBL1466811 & 688620 & 5.2 & 5.0271 & TRN & \\
\hline CHEMBL3213659 & 688620 & 4.95 & 5.2946 & TRN & \\
\hline CHEMBL1592647 & 688620 & 5.15 & 4.8293 & TRN & \\
\hline CHEMBL1577873 & 688620 & 5.4 & 5.2992 & TRN & \\
\hline CHEMBL1448081 & 688620 & 4.95 & 5.011 & TRN & \\
\hline CHEMBL1399191 & 688620 & 4.45 & 5.0434 & TST & \\
\hline CHEMBL1549333 & 688620 & 4.45 & 5.0618 & TRN & \\
\hline CHEMBL1438159 & 688620 & 4.75 & 5.1492 & TRN & \\
\hline \multirow[t]{2}{*}{ CHEMBL3209257 } & 688620 & 4.95 & 5.1045 & TRN & \\
\hline & & \multicolumn{4}{|c|}{ Page 27249} \\
\hline
\end{tabular}




\begin{tabular}{|c|c|c|c|c|}
\hline \multicolumn{5}{|c|}{ Supplemental Tabl } \\
\hline CHEMBL3192239 & 688620 & 6.15 & 5.6928 & TRN \\
\hline CHEMBL1410682 & 688620 & 6.1 & 4.9819 & TRN \\
\hline CHEMBL1313535 & 688620 & 5.95 & 5.0163 & TRN \\
\hline CHEMBL1339885 & 688620 & 4.85 & 5.0074 & TST \\
\hline CHEMBL3190118 & 688620 & 5.55 & 5.3883 & TRN \\
\hline CHEMBL1519691 & 688620 & 4.4 & 5.3018 & TRN \\
\hline CHEMBL1380940 & 688620 & 5.0 & 5.1127 & TST \\
\hline CHEMBL3189810 & 688620 & 6.25 & 5.8044 & TRN \\
\hline CHEMBL1503509 & 688620 & 5.0 & 5.083 & TRN \\
\hline CHEMBL1598382 & 688620 & 4.45 & 4.9865 & TRN \\
\hline CHEMBL1376419 & 688620 & 4.45 & 4.9739 & TST \\
\hline CHEMBL1309091 & 688620 & 5.15 & 5.2865 & TRN \\
\hline CHEMBL1467762 & 688620 & 5.2 & 5.3034 & TST \\
\hline CHEMBL1421096 & 688620 & 4.75 & 4.8793 & TRN \\
\hline CHEMBL1998425 & 688620 & 4.9 & 5.1681 & TRN \\
\hline CHEMBL1385848 & 688620 & 4.9 & 4.863 & TRN \\
\hline CHEMBL1541014 & 688620 & 4.85 & 5.0132 & TRN \\
\hline CHEMBL1359195 & 688620 & 4.85 & 4.8968 & TST \\
\hline CHEMBL1396887 & 688620 & 4.7 & 4.9985 & TRN \\
\hline CHEMBL 3213078 & 688620 & 5.3 & 5.3165 & TST \\
\hline CHEMBL1307769 & 688620 & 4.7 & 5.1241 & TRN \\
\hline CHEMBL1409187 & 688620 & 4.95 & 5.1934 & TRN \\
\hline CHEMBL1552156 & 688620 & 6.4 & 5.0519 & TRN \\
\hline CHEMBL3193388 & 688620 & 4.95 & 4.7626 & TRN \\
\hline CHEMBL1496473 & 688620 & 4.8 & 5.0161 & TST \\
\hline CHEMBL1451089 & 688620 & 4.95 & 4.8743 & TRN \\
\hline CHEMBL151 & 688620 & 6.0 & 5.8261 & TRN \\
\hline CHEMBL1538093 & 688620 & 4.75 & 5.0545 & TRN \\
\hline CHEMBL1508141 & 688620 & 5.25 & 5.2538 & TRN \\
\hline CHEMBL1331718 & 688620 & 4.85 & 5.1848 & TST \\
\hline CHEMBL1312656 & 688620 & 6.3 & 5.4365 & TRN \\
\hline CHEMBL1518788 & 688620 & 4.45 & 5.0061 & TRN \\
\hline CHEMBL1366024 & 688620 & 5.4 & 5.1841 & TRN \\
\hline CHEMBL1440008 & 688620 & 4.5 & 4.8973 & TRN \\
\hline CHEMBL1449023 & 688620 & 5.55 & 5.7123 & TRN \\
\hline CHEMBL1408163 & 688620 & 4.95 & 5.0583 & TRN \\
\hline CHEMBL1353383 & 688620 & 5.1 & 4.9477 & TRN \\
\hline CHEMBL 1466580 & 688620 & 5.2 & 4.9732 & TST \\
\hline CHEMBL1465279 & 688620 & 4.8 & 5.126 & TRN \\
\hline CHEMBL1350708 & 688620 & 4.6 & 5.0374 & TST \\
\hline CHEMBL1413072 & 688620 & 5.4 & 5.4485 & TRN \\
\hline CHEMBL1432637 & 688620 & 4.75 & 5.1549 & TST \\
\hline CHEMBL1348005 & 688620 & 5.2 & 5.0379 & TRN \\
\hline CHEMBL1580917 & 688620 & 4.55 & 4.9577 & TRN \\
\hline CHEMBL 3208744 & 688620 & 4.75 & 5.2092 & TST \\
\hline CHEMBL1449016 & 688620 & 4.45 & 5.1342 & TRN \\
\hline CHEMBL1533563 & 688620 & 4.9 & 4.8227 & TRN \\
\hline CHEMBL1302678 & 688620 & 7.3002 & 5.0336 & TRN \\
\hline
\end{tabular}

Page 27250 


\begin{tabular}{|c|c|c|c|c|c|}
\hline \multicolumn{6}{|c|}{ Supplemental Table S2.txt } \\
\hline CHEMBL1516897 & 688620 & 5.05 & 4.9588 & TRN & \\
\hline CHEMBL3207993 & 688620 & 4.7 & 4.8323 & TST & \\
\hline CHEMBL1486457 & 688620 & 5.1 & 4.8645 & TRN & \\
\hline CHEMBL1451724 & 688620 & 4.85 & 5.0079 & TRN & \\
\hline CHEMBL1498328 & 688620 & 4.65 & 4.8337 & TRN & \\
\hline CHEMBL1319938 & 688620 & 5.7 & 5.2161 & TRN & \\
\hline CHEMBL1992689 & 688620 & 5.9 & 5.4947 & TST & \\
\hline CHEMBL259507 & 688620 & 4.7 & 4.8824 & TST & \\
\hline CHEMBL1332842 & 688620 & 5.05 & 5.1863 & TST & \\
\hline CHEMBL1471465 & 688620 & 4.5 & 4.9739 & TRN & \\
\hline CHEMBL3196192 & 688620 & 4.45 & 5.1732 & TRN & \\
\hline CHEMBL1327489 & 688620 & 5.1 & 4.9287 & TRN & \\
\hline CHEMBL1386892 & 688620 & 5.45 & 5.4809 & TST & \\
\hline CHEMBL1603343 & 688620 & 4.7 & 4.8529 & TRN & \\
\hline CHEMBL1420680 & 688620 & 5.0 & 5.0524 & TST & \\
\hline CHEMBL532160 & 688620 & 5.4 & 5.4304 & TRN & \\
\hline CHEMBL1498508 & 688620 & 4.5 & 5.2311 & TRN & \\
\hline CHEMBL1388194 & 688620 & 5.2 & 5.34399 & 9999999999 & TRN \\
\hline CHEMBL1486619 & 688620 & 4.85 & 4.5625 & TRN & \\
\hline CHEMBL1435327 & 688620 & 4.45 & 4.6563 & TRN & \\
\hline CHEMBL1613092 & 688620 & 6.45 & 6.0237 & TRN & \\
\hline CHEMBL1421378 & 688620 & 5.2 & 5.0932 & TRN & \\
\hline CHEMBL1497951 & 688620 & 4.65 & 5.0476 & TRN & \\
\hline CHEMBL1585003 & 688620 & 4.45 & 4.8363 & TST & \\
\hline CHEMBL1466460 & 688620 & 5.15 & 5.2212 & TRN & \\
\hline CHEMBL1308246 & 688620 & 5.2 & 5.1293 & TRN & \\
\hline CHEMBL1500358 & 688620 & 4.65 & 5.4201 & TST & \\
\hline CHEMBL1538099 & 688620 & 4.45 & 4.7971 & TST & \\
\hline CHEMBL1306639 & 688620 & 5.0 & 4.8804 & TRN & \\
\hline CHEMBL1308179 & 688620 & 4.95 & 4.9261 & TST & \\
\hline CHEMBL1360428 & 688620 & 5.15 & 4.9296 & TRN & \\
\hline CHEMBL1611225 & 688620 & 4.65 & 4.9279 & TST & \\
\hline CHEMBL1582410 & 688620 & 4.6 & 5.0111 & TST & \\
\hline CHEMBL3191907 & 688620 & 4.45 & 5.2307 & TRN & \\
\hline CHEMBL1461502 & 688620 & 5.45 & 5.278 & TRN & \\
\hline CHEMBL1403115 & 688620 & 5.2 & 4.9885 & TRN & \\
\hline CHEMBL3197360 & 688620 & 4.85 & 5.1092 & TRN & \\
\hline CHEMBL1511881 & 688620 & 4.65 & 5.1379 & TRN & \\
\hline CHEMBL1595071 & 688620 & 6.15 & 5.6598 & TRN & \\
\hline CHEMBL1405558 & 688620 & 5.25 & 5.1675 & TRN & \\
\hline CHEMBL1533657 & 688620 & 4.9 & 4.9765 & TRN & \\
\hline CHEMBL1451327 & 688620 & 4.9 & 5.1834 & TST & \\
\hline CHEMBL259615 & 688620 & 5.3 & 5.1504 & TRN & \\
\hline CHEMBL1997508 & 688620 & 5.0 & 5.0854 & TRN & \\
\hline CHEMBL1389061 & 688620 & 5.85 & 5.5848 & TRN & \\
\hline CHEMBL1312783 & 688620 & 5.2 & 5.2276 & TST & \\
\hline CHEMBL1965236 & 688620 & 4.65 & 4.8368 & TRN & \\
\hline CHEMBL1332303 & 688620 & 4.65 & 5.0302 & TRN & \\
\hline
\end{tabular}




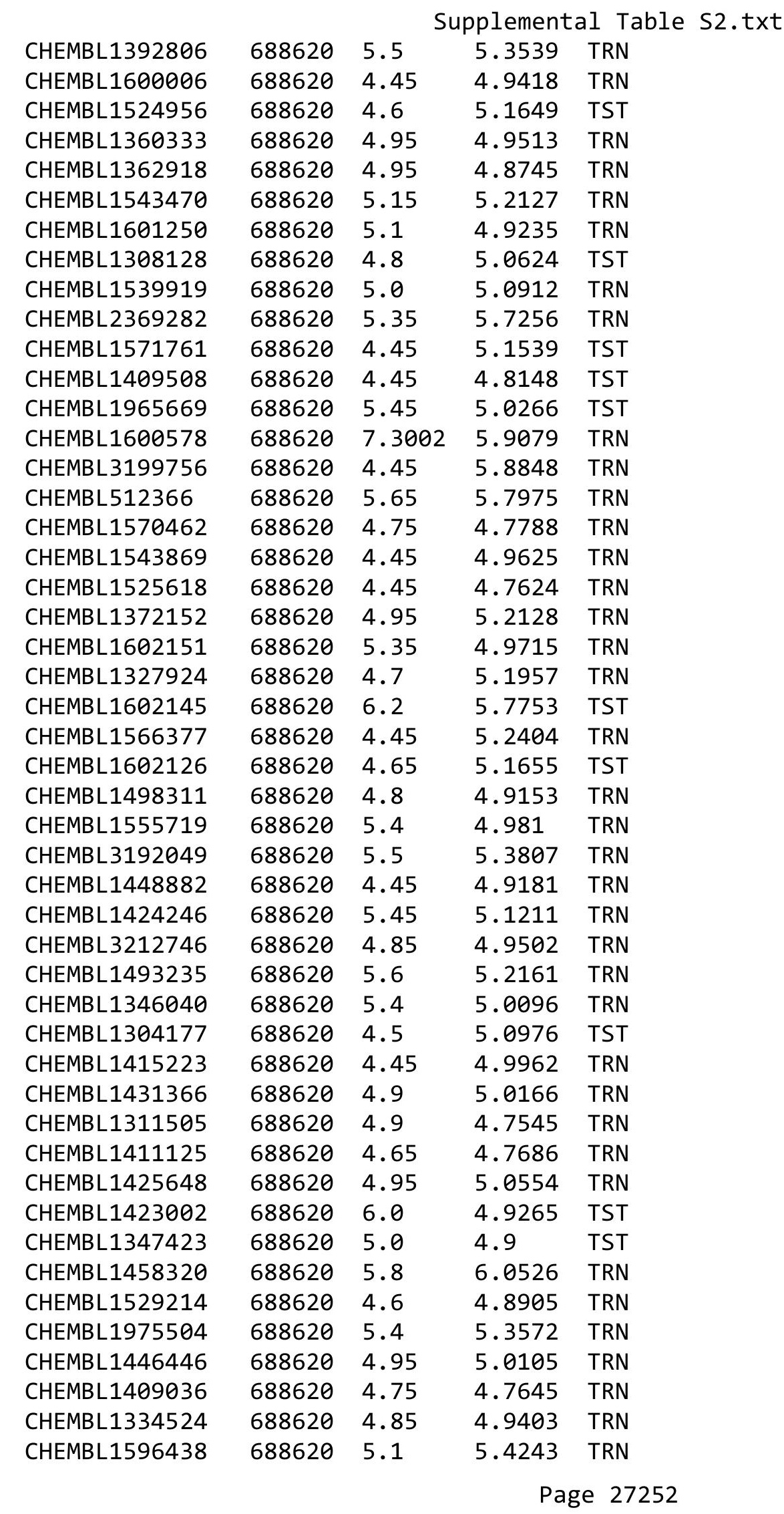




\begin{tabular}{|c|c|c|c|c|c|}
\hline \multicolumn{6}{|c|}{ Supplemental Table S2.txt } \\
\hline CHEMBL1526840 & 688620 & 4.45 & 4.8703 & TRN & \\
\hline CHEMBL1574177 & 688620 & 4.45 & 5.0428 & TST & \\
\hline CHEMBL1559503 & 688620 & 4.6 & 4.8364 & TRN & \\
\hline CHEMBL1544189 & 688620 & 5.7 & 5.0016 & TRN & \\
\hline CHEMBL1353497 & 688620 & 5.95 & 5.6395 & TRN & \\
\hline CHEMBL1979954 & 688620 & 6.2 & 5.8865 & TST & \\
\hline CHEMBL1562057 & 688620 & 5.05 & 5.029 & TRN & \\
\hline CHEMBL1571917 & 688620 & 5.75 & 5.0271 & TST & \\
\hline CHEMBL1977480 & 688620 & 5.45 & 5.3059 & TRN & \\
\hline CHEMBL1544629 & 688620 & 5.45 & 5.2061 & TRN & \\
\hline CHEMBL1563779 & 688620 & 4.95 & 5.0483 & TRN & \\
\hline CHEMBL1431082 & 688620 & 4.45 & 4.9604 & TRN & \\
\hline CHEMBL1474515 & 688620 & 5.05 & 4.8264 & TRN & \\
\hline CHEMBL1303211 & 688620 & 5.25 & 5.1045 & TRN & \\
\hline CHEMBL1536785 & 688620 & 4.85 & 5.0204 & TRN & \\
\hline CHEMBL1575716 & 688620 & 5.5 & 5.3658 & TRN & \\
\hline CHEMBL 3190209 & 688620 & 6.45 & 6.2108 & TRN & \\
\hline CHEMBL1522918 & 688620 & 4.55 & 5.2098 & TRN & \\
\hline CHEMBL1486191 & 688620 & 5.8 & 5.6673 & TST & \\
\hline CHEMBL1578845 & 688620 & 4.7 & 5.0216 & TRN & \\
\hline CHEMBL1313509 & 688620 & 4.85 & 4.7109 & TRN & \\
\hline CHEMBL 3197641 & 688620 & 4.65 & 5.2113 & TRN & \\
\hline CHEMBL1358883 & 688620 & 4.45 & 5.40799 & 99999999995 & TRN \\
\hline CHEMBL1378545 & 688620 & 5.05 & 4.9009 & TRN & \\
\hline CHEMBL1457288 & 688620 & 4.7 & 5.0514 & TRN & \\
\hline CHEMBL1372804 & 688620 & 4.45 & 4.9532 & TRN & \\
\hline CHEMBL1364569 & 688620 & 5.4 & 4.9386 & TRN & \\
\hline CHEMBL1493305 & 688620 & 6.5501 & 4.985 & TST & \\
\hline CHEMBL1547232 & 688620 & 5.7 & 4.9307 & TRN & \\
\hline CHEMBL1307435 & 688620 & 4.9 & 4.8415 & TRN & \\
\hline CHEMBL1585213 & 688620 & 4.8 & 5.3101 & TRN & \\
\hline CHEMBL3196880 & 688620 & 5.45 & 5.3317 & TRN & \\
\hline CHEMBL1576298 & 688620 & 4.75 & 4.9418 & TRN & \\
\hline CHEMBL1508902 & 688620 & 4.8 & 4.8793 & TRN & \\
\hline CHEMBL1484410 & 688620 & 5.2 & 5.1588 & TST & \\
\hline CHEMBL1548704 & 688620 & 5.3 & 4.8959 & TST & \\
\hline CHEMBL1391126 & 688620 & 4.65 & 4.7514 & TRN & \\
\hline CHEMBL1420550 & 688620 & 4.9 & 4.9387 & TRN & \\
\hline CHEMBL1493174 & 688620 & 4.45 & 4.9174 & TRN & \\
\hline CHEMBL1381261 & 688620 & 4.65 & 4.9354 & TRN & \\
\hline CHEMBL1556967 & 688620 & 4.9 & 5.2181 & TST & \\
\hline CHEMBL1307692 & 688620 & 4.45 & 5.0746 & TRN & \\
\hline CHEMBL1415598 & 688620 & 5.4 & 5.2658 & TRN & \\
\hline CHEMBL1370713 & 688620 & 4.95 & 5.1994 & TST & \\
\hline CHEMBL1370461 & 688620 & 5.5 & 5.1601 & TRN & \\
\hline CHEMBL1344169 & 688620 & 4.85 & 4.9701 & TST & \\
\hline CHEMBL1469915 & 688620 & 4.45 & 5.0598 & TST & \\
\hline CHEMBL1580091 & 688620 & 5.05 & 5.1239 & TRN & \\
\hline
\end{tabular}




\begin{tabular}{|c|c|c|c|c|c|}
\hline \multicolumn{6}{|c|}{ Supplemental Table S2.txt } \\
\hline CHEMBL1588210 & 688620 & 5.45 & 4.9777 & TRN & \\
\hline CHEMBL1597655 & 688620 & 6.0 & 5.4994 & TRN & \\
\hline CHEMBL1454922 & 688620 & 8.3468 & 5.1242 & TRN & \\
\hline CHEMBL1462564 & 688620 & 5.0 & 5.1912 & TRN & \\
\hline CHEMBL1596735 & 688620 & 5.35 & 5.25899 & 99999999995 & TRN \\
\hline CHEMBL 3194585 & 688620 & 5.0 & 5.0342 & TRN & \\
\hline CHEMBL1968842 & 688620 & 5.25 & 5.4895 & TRN & \\
\hline CHEMBL1342408 & 688620 & 4.55 & 4.9001 & TRN & \\
\hline CHEMBL1418904 & 688620 & 4.6 & 5.074 & TRN & \\
\hline CHEMBL3196558 & 688620 & 4.45 & 5.1004 & TRN & \\
\hline CHEMBL1565664 & 688620 & 5.2 & 5.1393 & TRN & \\
\hline CHEMBL1609593 & 688620 & 4.7 & 4.7555 & TRN & \\
\hline CHEMBL1446264 & 688620 & 5.0 & 4.7674 & TRN & \\
\hline CHEMBL1544679 & 688620 & 4.9 & 5.0693 & TRN & \\
\hline CHEMBL1607507 & 688620 & 6.15 & 4.7429 & TRN & \\
\hline CHEMBL1540649 & 688620 & 4.5 & 5.1606 & TST & \\
\hline CHEMBL1425985 & 688620 & 4.6 & 4.9289 & TRN & \\
\hline CHEMBL1544633 & 688620 & 5.8 & 6.0269 & TRN & \\
\hline CHEMBL1424150 & 688620 & 5.25 & 5.1851 & TRN & \\
\hline CHEMBL1532982 & 688620 & 4.6 & 4.7881 & TRN & \\
\hline CHEMBL1464765 & 688620 & 4.8 & 5.119 & TRN & \\
\hline CHEMBL1359946 & 688620 & 5.0 & 4.9331 & TRN & \\
\hline CHEMBL1544106 & 688620 & 5.0 & 4.9146 & TST & \\
\hline CHEMBL1583602 & 688620 & 5.95 & 5.0202 & TRN & \\
\hline CHEMBL1320721 & 688620 & 5.15 & 5.2098 & TRN & \\
\hline CHEMBL1556209 & 688620 & 4.45 & 4.9798 & TRN & \\
\hline CHEMBL1510600 & 688620 & 4.9 & 4.8432 & TST & \\
\hline CHEMBL1489956 & 688620 & 5.1 & 4.9879 & TST & \\
\hline CHEMBL1424769 & 688620 & 6.4 & 5.3845 & TST & \\
\hline CHEMBL1432823 & 688620 & 5.2 & 4.9995 & TRN & \\
\hline CHEMBL1549022 & 688620 & 5.25 & 5.25299 & 9999999999 & TRN \\
\hline CHEMBL1299489 & 688620 & 5.7 & 5.1665 & TRN & \\
\hline CHEMBL1600601 & 688620 & 5.35 & 5.3246 & TRN & \\
\hline CHEMBL 3196770 & 688620 & 5.9 & 5.5683 & TRN & \\
\hline CHEMBL1422567 & 688620 & 5.5 & 4.8092 & TRN & \\
\hline CHEMBL1424725 & 688620 & 4.65 & 4.8519 & TRN & \\
\hline CHEMBL1586452 & 688620 & 4.85 & 4.9743 & TRN & \\
\hline CHEMBL3199710 & 688620 & 5.25 & 5.0962 & TRN & \\
\hline CHEMBL1594685 & 688620 & 4.95 & 5.032 & TRN & \\
\hline CHEMBL1312301 & 688620 & 4.45 & 4.768 & TRN & \\
\hline CHEMBL1534901 & 688620 & 4.95 & 5.059 & TRN & \\
\hline CHEMBL1611778 & 688620 & 5.4 & 5.3037 & TRN & \\
\hline CHEMBL1568078 & 688620 & 5.55 & 5.6018 & TRN & \\
\hline CHEMBL1546431 & 688620 & 4.45 & 4.8049 & TST & \\
\hline CHEMBL3199884 & 688620 & 4.75 & 4.6845 & TRN & \\
\hline CHEMBL1508157 & 688620 & 5.75 & 4.9374 & TRN & \\
\hline CHEMBL1360012 & 688620 & 5.05 & 5.2509 & TST & \\
\hline CHEMBL1329507 & 688620 & 5.15 & 5.3208 & TST & \\
\hline
\end{tabular}




\begin{tabular}{|c|c|c|c|c|c|}
\hline \multicolumn{6}{|c|}{ Supplemental Table S2.txt } \\
\hline CHEMBL1555417 & 688620 & 4.9 & 5.1032 & TRN & \\
\hline CHEMBL1584649 & 688620 & 4.45 & 5.0376 & TRN & \\
\hline CHEMBL1376872 & 688620 & 5.0 & 5.1393 & TRN & \\
\hline CHEMBL1526650 & 688620 & 4.95 & 4.9356 & TRN & \\
\hline CHEMBL1501117 & 688620 & 5.4 & 5.1467 & TRN & \\
\hline CHEMBL1416543 & 688620 & 5.8 & 4.745 & TST & \\
\hline CHEMBL1413033 & 688620 & 5.7 & 5.7089 & TRN & \\
\hline CHEMBL1469017 & 688620 & 4.65 & 4.9872 & TST & \\
\hline CHEMBL1457758 & 688620 & 4.6 & 5.0067 & TRN & \\
\hline CHEMBL1439347 & 688620 & 4.45 & 5.4978 & TRN & \\
\hline CHEMBL1336132 & 688620 & 4.45 & 5.155 & TST & \\
\hline CHEMBL1336739 & 688620 & 4.45 & 5.0945 & TST & \\
\hline CHEMBL398233 & 688620 & 4.65 & 4.9264 & TST & \\
\hline CHEMBL1412330 & 688620 & 5.45 & 5.1471 & TRN & \\
\hline CHEMBL1312988 & 688620 & 4.85 & 4.8106 & TRN & \\
\hline CHEMBL3195197 & 688620 & 5.5 & 5.1588 & TRN & \\
\hline CHEMBL3190615 & 688620 & 4.45 & 5.1695 & TRN & \\
\hline CHEMBL1353216 & 688620 & 4.45 & 5.0017 & TRN & \\
\hline CHEMBL1385320 & 688620 & 6.0 & 5.3713 & TRN & \\
\hline CHEMBL1984884 & 688620 & 5.05 & 5.1192 & TRN & \\
\hline CHEMBL1339861 & 688620 & 4.9 & 5.0867 & TRN & \\
\hline CHEMBL1566583 & 688620 & 5.8 & 5.1953 & TRN & \\
\hline CHEMBL 2006634 & 688620 & 4.8 & 5.1033 & TRN & \\
\hline CHEMBL1613684 & 688620 & 5.05 & 5.0115 & TST & \\
\hline CHEMBL3208752 & 688620 & 5.25 & 5.2597 & TRN & \\
\hline CHEMBL1256816 & 688620 & 5.15 & 4.8748 & TST & \\
\hline CHEMBL1299954 & 688620 & 5.05 & 5.0784 & TRN & \\
\hline CHEMBL3194503 & 688620 & 4.9 & 4.90300 & 00000000005 & TRN \\
\hline CHEMBL1318079 & 688620 & 5.05 & 5.2412 & TRN & \\
\hline CHEMBL1534873 & 688620 & 4.7 & 4.7512 & TST & \\
\hline CHEMBL1350882 & 688620 & 5.25 & 5.0192 & TRN & \\
\hline CHEMBL1346013 & 688620 & 4.75 & 5.1713 & TST & \\
\hline CHEMBL1319860 & 688620 & 5.0 & 5.0992 & TRN & \\
\hline CHEMBL1302073 & 688620 & 6.25 & 5.0566 & TRN & \\
\hline CHEMBL1467194 & 688620 & 4.9 & 5.06 & TST & \\
\hline CHEMBL1489709 & 688620 & 5.55 & 5.3941 & TRN & \\
\hline CHEMBL1330726 & 688620 & 4.45 & 4.8678 & TRN & \\
\hline CHEMBL1305109 & 688620 & 4.85 & 5.144 & TST & \\
\hline CHEMBL1337659 & 688620 & 5.35 & 4.9404 & TRN & \\
\hline CHEMBL1300326 & 688620 & 4.65 & 4.862 & TRN & \\
\hline CHEMBL1606626 & 688620 & 5.05 & 4.8472 & TRN & \\
\hline CHEMBL1347256 & 688620 & 4.9 & 4.9183 & TRN & \\
\hline CHEMBL3198469 & 688620 & 5.55 & 5.4699 & TST & \\
\hline CHEMBL1429046 & 688620 & 4.75 & 4.8223 & TST & \\
\hline CHEMBL1483711 & 688620 & 5.05 & 5.0253 & TRN & \\
\hline CHEMBL3194718 & 688620 & 4.45 & 4.8234 & TRN & \\
\hline CHEMBL1499623 & 688620 & 5.0 & 5.2051 & TST & \\
\hline CHEMBL1566050 & 688620 & 4.9 & 5.0506 & TRN & \\
\hline
\end{tabular}




\begin{tabular}{|c|c|c|c|c|}
\hline \multicolumn{5}{|c|}{ Supplemental Table S2.txt } \\
\hline CHEMBL1577336 & 688620 & 4.95 & 4.7112 & TST \\
\hline CHEMBL3199200 & 688620 & 4.95 & 5.0112 & TRN \\
\hline CHEMBL1537609 & 688620 & 4.85 & 5.0081 & TRN \\
\hline CHEMBL1447748 & 688620 & 4.5 & 4.6604 & TRN \\
\hline CHEMBL1588024 & 688620 & 4.95 & 5.1113 & TRN \\
\hline CHEMBL1509927 & 688620 & 4.8 & 5.1509 & TRN \\
\hline CHEMBL1604790 & 688620 & 4.95 & 5.8327 & TST \\
\hline CHEMBL1327502 & 688620 & 5.85 & 5.1132 & TRN \\
\hline CHEMBL1468166 & 688620 & 4.95 & 5.1989 & TRN \\
\hline CHEMBL1458102 & 688620 & 5.5 & 4.9928 & TRN \\
\hline CHEMBL1337111 & 688620 & 4.7 & 5.0465 & TRN \\
\hline CHEMBL1479436 & 688620 & 5.05 & 4.95 & TRN \\
\hline CHEMBL1428921 & 688620 & 4.85 & 4.8848 & TRN \\
\hline CHEMBL1427763 & 688620 & 4.75 & 4.8942 & TST \\
\hline CHEMBL3192883 & 688620 & 4.95 & 4.9969 & TRN \\
\hline CHEMBL1972217 & 688620 & 5.65 & 5.6673 & TRN \\
\hline CHEMBL1305119 & 688620 & 4.8 & 5.1281 & TST \\
\hline CHEMBL1408425 & 688620 & 4.6 & 5.0004 & TRN \\
\hline CHEMBL1320578 & 688620 & 4.85 & 5.1642 & TRN \\
\hline CHEMBL1430795 & 688620 & 4.6 & 4.9733 & TST \\
\hline CHEMBL1417237 & 688620 & 5.55 & 5.4026 & TRN \\
\hline CHEMBL1443438 & 688620 & 4.95 & 5.027 & TST \\
\hline CHEMBL1442344 & 688620 & 5.45 & 5.3274 & TRN \\
\hline CHEMBL1343832 & 688620 & 4.45 & 4.8304 & TRN \\
\hline CHEMBL1448901 & 688620 & 5.5 & 4.7044 & TRN \\
\hline CHEMBL1610150 & 688620 & 5.25 & 4.9624 & TRN \\
\hline CHEMBL1365006 & 688620 & 4.75 & 4.7137 & TRN \\
\hline CHEMBL1387439 & 688620 & 4.75 & 5.1341 & TST \\
\hline CHEMBL1581348 & 688620 & 5.5 & 5.2123 & TRN \\
\hline CHEMBL3193589 & 688620 & 4.45 & 4.8003 & TRN \\
\hline CHEMBL1361549 & 688620 & 4.5 & 4.789 & TST \\
\hline CHEMBL1545727 & 688620 & 4.95 & 4.7059 & TRN \\
\hline CHEMBL396994 & 688620 & 4.9 & 5.0003 & TST \\
\hline CHEMBL3195066 & 688620 & 4.65 & 5.1249 & TRN \\
\hline CHEMBL1367142 & 688620 & 4.95 & 4.9812 & TRN \\
\hline CHEMBL1581521 & 688620 & 4.95 & 5.0164 & TRN \\
\hline CHEMBL1429551 & 688620 & 5.25 & 4.9834 & TRN \\
\hline CHEMBL1409689 & 688620 & 5.1 & 5.0009 & TST \\
\hline CHEMBL1418716 & 688620 & 5.95 & 4.8641 & TRN \\
\hline CHEMBL1444693 & 688620 & 5.2 & 5.2739 & TRN \\
\hline CHEMBL1465990 & 688620 & 5.05 & 4.9316 & TRN \\
\hline CHEMBL1442056 & 688620 & 5.4 & 4.7179 & TST \\
\hline CHEMBL253239 & 688620 & 4.65 & 4.9492 & TRN \\
\hline CHEMBL1332277 & 688620 & 5.05 & 5.4268 & TRN \\
\hline CHEMBL1359027 & 688620 & 4.8 & 4.9993 & TRN \\
\hline CHEMBL3198714 & 688620 & 4.45 & 4.7439 & TRN \\
\hline CHEMBL3199593 & 688620 & 5.15 & 4.9447 & TRN \\
\hline CHEMBL1415075 & 688620 & 5.0 & 4.9773 & TRN \\
\hline
\end{tabular}




\begin{tabular}{|c|c|c|c|c|}
\hline \multicolumn{5}{|c|}{ Supplemental Table S2.txt } \\
\hline CHEMBL3208127 & 688620 & 4.45 & 4.7681 & TRN \\
\hline CHEMBL1377529 & 688620 & 4.45 & 5.5672 & TRN \\
\hline CHEMBL3211276 & 688620 & 4.9 & 5.6812 & TRN \\
\hline CHEMBL3208141 & 688620 & 5.25 & 5.1745 & TRN \\
\hline CHEMBL1569797 & 688620 & 4.45 & 5.1085 & TRN \\
\hline CHEMBL1598640 & 688620 & 4.95 & 4.8602 & TRN \\
\hline CHEMBL1965373 & 688620 & 6.2 & 5.6246 & TRN \\
\hline CHEMBL1308731 & 688620 & 4.9 & 4.7548 & TRN \\
\hline CHEMBL1386738 & 688620 & 4.95 & 4.9096 & TRN \\
\hline CHEMBL1305217 & 688620 & 6.1 & 5.3571 & TRN \\
\hline CHEMBL1340414 & 688620 & 4.45 & 5.1409 & TRN \\
\hline CHEMBL1463856 & 688620 & 5.95 & 5.9261 & TRN \\
\hline CHEMBL1307262 & 688620 & 4.45 & 4.9824 & TRN \\
\hline CHEMBL1323995 & 688620 & 5.35 & 5.2164 & TST \\
\hline CHEMBL1583944 & 688620 & 4.45 & 4.9574 & TRN \\
\hline CHEMBL1330432 & 688620 & 4.7 & 4.9482 & TRN \\
\hline CHEMBL1985061 & 688620 & 5.55 & 4.8839 & TRN \\
\hline CHEMBL1389096 & 688620 & 5.45 & 4.8993 & TRN \\
\hline CHEMBL1978855 & 688620 & 4.95 & 4.9378 & TRN \\
\hline CHEMBL1527054 & 688620 & 4.8 & 5.2932 & TRN \\
\hline CHEMBL1499088 & 688620 & 4.95 & 5.2399 & TST \\
\hline CHEMBL1084643 & 688620 & 5.55 & 4.7032 & TRN \\
\hline CHEMBL1427687 & 688620 & 5.25 & 5.2319 & TRN \\
\hline CHEMBL1497139 & 688620 & 5.45 & 5.7138 & TRN \\
\hline CHEMBL1510359 & 688620 & 4.8 & 4.8536 & TST \\
\hline CHEMBL1515025 & 688620 & 5.55 & 4.9482 & TRN \\
\hline CHEMBL1320524 & 688620 & 5.2 & 5.3694 & TRN \\
\hline CHEMBL1365218 & 688620 & 4.75 & 5.0747 & TST \\
\hline CHEMBL1493633 & 688620 & 4.45 & 4.9058 & TRN \\
\hline CHEMBL1343040 & 688620 & 4.9 & 5.1688 & TST \\
\hline CHEMBL1534632 & 688620 & 4.95 & 5.1121 & TRN \\
\hline CHEMBL1344797 & 688620 & 4.95 & 5.0233 & TRN \\
\hline CHEMBL1496223 & 688620 & 5.65 & 4.8855 & TRN \\
\hline CHEMBL1406164 & 688620 & 4.6 & 5.148 & TRN \\
\hline CHEMBL1497480 & 688620 & 5.45 & 5.0786 & TRN \\
\hline CHEMBL1542336 & 688620 & 4.9 & 4.9201 & TRN \\
\hline CHEMBL1354003 & 688620 & 5.5 & 5.1791 & TST \\
\hline CHEMBL1546524 & 688620 & 5.4 & 5.3179 & TRN \\
\hline CHEMBL1549780 & 688620 & 4.45 & 4.8827 & TRN \\
\hline CHEMBL1511160 & 688620 & 5.0 & 4.9402 & TRN \\
\hline CHEMBL458094 & 688620 & 5.4 & 5.1313 & TRN \\
\hline CHEMBL1301471 & 688620 & 6.4 & 6.0843 & TRN \\
\hline CHEMBL1364243 & 688620 & 4.45 & 4.9276 & TRN \\
\hline CHEMBL1485368 & 688620 & 4.85 & 4.8125 & TRN \\
\hline CHEMBL 1477843 & 688620 & 4.95 & $5.0360 e$ & 00000000005 \\
\hline CHEMBL1999862 & 688620 & 4.95 & 4.9064 & TRN \\
\hline CHEMBL1564368 & 688620 & 4.9 & 5.1242 & TRN \\
\hline CHEMBL1481547 & 688620 & 4.45 & 5.1732 & TST \\
\hline
\end{tabular}




\begin{tabular}{|c|c|c|c|c|}
\hline \multicolumn{5}{|c|}{ Supplemental Table } \\
\hline CHEMBL1381374 & 688620 & 4.75 & 4.9184 & TRN \\
\hline CHEMBL1539398 & 688620 & 5.05 & 5.2468 & TRN \\
\hline CHEMBL1417108 & 688620 & 4.95 & 5.1459 & TRN \\
\hline CHEMBL1424045 & 688620 & 4.95 & 5.2541 & TRN \\
\hline CHEMBL1485135 & 688620 & 4.95 & 5.0012 & TRN \\
\hline CHEMBL3192789 & 688620 & 5.35 & 5.3002 & TRN \\
\hline CHEMBL1596553 & 688620 & 5.9 & 6.0187 & TRN \\
\hline CHEMBL1438056 & 688620 & 5.6 & 5.0322 & TRN \\
\hline CHEMBL1406465 & 688620 & 4.45 & 4.883 & TRN \\
\hline CHEMBL1333662 & 688620 & 5.45 & 4.8106 & TST \\
\hline CHEMBL486569 & 688620 & 4.9 & 5.4933 & TRN \\
\hline CHEMBL1976692 & 688620 & 4.95 & 4.7314 & TRN \\
\hline CHEMBL1563479 & 688620 & 4.7 & 5.0602 & TRN \\
\hline CHEMBL1493423 & 688620 & 4.45 & 5.0748 & TRN \\
\hline CHEMBL1382056 & 688620 & 4.95 & 5.0069 & TRN \\
\hline CHEMBL1449441 & 688620 & 8.2518 & 5.2593 & TRN \\
\hline CHEMBL1329870 & 688620 & 6.95 & 5.1167 & TST \\
\hline CHEMBL1429823 & 688620 & 4.45 & 4.9918 & TST \\
\hline CHEMBL1327034 & 688620 & 4.8 & 4.9486 & TRN \\
\hline CHEMBL1593867 & 688620 & 5.05 & 5.4183 & TST \\
\hline CHEMBL1486388 & 688620 & 5.45 & 5.0159 & TST \\
\hline CHEMBL1535188 & 688620 & 4.7 & 5.0494 & TRN \\
\hline CHEMBL1603385 & 688620 & 4.95 & 5.186 & TRN \\
\hline CHEMBL1378665 & 688620 & 5.2 & 4.8351 & TRN \\
\hline CHEMBL1994673 & 688620 & 4.95 & 5.0492 & TRN \\
\hline CHEMBL1511320 & 688620 & 4.45 & 5.0047 & TRN \\
\hline CHEMBL1374795 & 688620 & 4.45 & 5.0946 & TRN \\
\hline CHEMBL1590126 & 688620 & 4.55 & 4.9448 & TST \\
\hline CHEMBL1373825 & 688620 & 5.0 & 5.0382 & TST \\
\hline CHEMBL1339376 & 688620 & 6.05 & 5.0837 & TRN \\
\hline CHEMBL1570327 & 688620 & 5.0 & 5.0159 & TRN \\
\hline CHEMBL1311891 & 688620 & 7.0 & 4.8976 & TRN \\
\hline CHEMBL1344929 & 688620 & 4.7 & 4.9515 & TRN \\
\hline CHEMBL1525559 & 688620 & 4.45 & 4.9834 & TST \\
\hline CHEMBL3212046 & 688620 & 4.85 & 5.0536 & TRN \\
\hline CHEMBL3193275 & 688620 & 4.45 & 4.7259 & TRN \\
\hline CHEMBL1562044 & 688620 & 6.1 & 5.7655 & TRN \\
\hline CHEMBL1607836 & 688620 & 4.6 & 4.8919 & TRN \\
\hline CHEMBL1359636 & 688620 & 5.0 & 4.9446 & TRN \\
\hline CHEMBL1424391 & 688620 & 6.95 & 4.902 & TRN \\
\hline CHEMBL1351702 & 688620 & 4.65 & 5.0034 & TRN \\
\hline CHEMBL1440303 & 688620 & 5.9 & 5.3739 & TST \\
\hline CHEMBL1548637 & 688620 & 4.85 & 4.707 & TRN \\
\hline CHEMBL1396432 & 688620 & 4.95 & 4.9334 & TRN \\
\hline CHEMBL1486903 & 688620 & 4.5 & 4.9518 & TRN \\
\hline CHEMBL1606855 & 688620 & 4.7 & 5.0619 & TST \\
\hline CHEMBL1461695 & 688620 & 5.45 & 5.1504 & TRN \\
\hline CHEMBL3210615 & 688620 & 4.6 & 5.4415 & TRN \\
\hline
\end{tabular}




\begin{tabular}{|c|c|c|c|c|c|}
\hline \multicolumn{6}{|c|}{ Supplemental Table S2.txt } \\
\hline CHEMBL1605123 & 688620 & 4.45 & 5.0571 & TST & \\
\hline CHEMBL1977063 & 688620 & 4.8 & 5.0624 & TRN & \\
\hline CHEMBL1578578 & 688620 & 4.85 & 5.1153 & TRN & \\
\hline CHEMBL1530194 & 688620 & 5.0 & 4.8071 & TRN & \\
\hline CHEMBL 3210636 & 688620 & 5.15 & 4.8204 & TRN & \\
\hline CHEMBL 3189842 & 688620 & 5.0 & 4.7971 & TRN & \\
\hline CHEMBL1470716 & 688620 & 5.15 & 4.8093 & TRN & \\
\hline CHEMBL1569111 & 688620 & 5.15 & 5.0352 & TRN & \\
\hline CHEMBL1307609 & 688620 & 4.6 & 4.9177 & TST & \\
\hline CHEMBL1386017 & 688620 & 5.05 & 5.3695 & TST & \\
\hline CHEMBL1419472 & 688620 & 4.45 & 5.1582 & TST & \\
\hline CHEMBL1359820 & 688620 & 5.7 & 5.2769 & TRN & \\
\hline CHEMBL1449325 & 688620 & 4.45 & 5.3272 & TRN & \\
\hline CHEMBL1461548 & 688620 & 4.65 & 5.0409 & TST & \\
\hline CHEMBL1414139 & 688620 & 4.95 & 5.0661 & TRN & \\
\hline CHEMBL1366395 & 688620 & 4.9 & 4.9446 & TRN & \\
\hline CHEMBL 3195660 & 688620 & 5.5 & 4.7215 & TST & \\
\hline CHEMBL1464373 & 688620 & 4.65 & 5.1218 & TST & \\
\hline CHEMBL1309456 & 688620 & 5.9 & 5.5275 & TRN & \\
\hline CHEMBL1532159 & 688620 & 4.8 & 5.0275 & TRN & \\
\hline CHEMBL1510950 & 688620 & 4.8 & 4.9637 & TRN & \\
\hline CHEMBL1534646 & 688620 & 5.55 & 5.1406 & TRN & \\
\hline CHEMBL1462958 & 688620 & 5.3 & 5.348 & TRN & \\
\hline CHEMBL1524898 & 688620 & 4.95 & 5.035 & TRN & \\
\hline CHEMBL 3189452 & 688620 & 5.1 & 4.98600 & 0000000001 & TRN \\
\hline CHEMBL1611013 & 688620 & 4.95 & 4.619 & TST & \\
\hline CHEMBL 1450140 & 688620 & 4.45 & 5.0064 & TRN & \\
\hline CHEMBL1542618 & 688620 & 5.25 & 5.0911 & TRN & \\
\hline CHEMBL1463714 & 688620 & 4.7 & 4.6647 & TRN & \\
\hline CHEMBL1540021 & 688620 & 4.75 & 5.1421 & TST & \\
\hline CHEMBL 3196643 & 688620 & 5.7 & 4.8321 & TRN & \\
\hline CHEMBL1389421 & 688620 & 5.35 & 5.0169 & TRN & \\
\hline CHEMBL1344533 & 688620 & 8.2518 & 5.1449 & TRN & \\
\hline CHEMBL1412710 & 688620 & 4.9 & 5.0406 & TST & \\
\hline CHEMBL1480397 & 688620 & 4.95 & 5.0459 & TRN & \\
\hline CHEMBL1529460 & 688620 & 5.0 & 5.1886 & TST & \\
\hline CHEMBL1578847 & 688620 & 5.0 & 4.9514 & TRN & \\
\hline CHEMBL1450521 & 688620 & 4.8 & 4.7177 & TRN & \\
\hline CHEMBL1431261 & 688620 & 7.2 & 5.1532 & TST & \\
\hline CHEMBL1480730 & 688620 & 4.9 & 5.3573 & TST & \\
\hline CHEMBL1424898 & 688620 & 4.8 & 4.921 & TRN & \\
\hline CHEMBL1612237 & 688620 & 4.95 & 5.0322 & TRN & \\
\hline CHEMBL1338487 & 688620 & 4.95 & 4.9034 & TRN & \\
\hline CHEMBL1487629 & 688620 & 4.75 & 5.0505 & TRN & \\
\hline CHEMBL1522785 & 688620 & 4.55 & 5.0523 & TRN & \\
\hline CHEMBL1339777 & 688620 & 4.45 & 4.5445 & TRN & \\
\hline CHEMBL1347512 & 688620 & 6.5 & 5.5638 & TRN & \\
\hline CHEMBL1366497 & 688620 & 6.8499 & 5.1767 & TST & \\
\hline
\end{tabular}




\begin{tabular}{|c|c|c|c|c|}
\hline & & & upplement & al $\mathrm{T}$ \\
\hline CHEMBL3196380 & 688620 & 4.65 & 5.1405 & TST \\
\hline CHEMBL1429982 & 688620 & 5.25 & 5.2879 & TRN \\
\hline CHEMBL1392036 & 688620 & 4.9 & 4.9169 & TRN \\
\hline CHEMBL1602215 & 688620 & 6.35 & 5.2026 & TST \\
\hline CHEMBL1519547 & 688620 & 4.9 & 4.8692 & TRN \\
\hline CHEMBL1376590 & 688620 & 5.15 & 5.1803 & TRN \\
\hline CHEMBL1455250 & 688620 & 4.65 & 5.1496 & TRN \\
\hline CHEMBL1538296 & 688620 & 6.5 & 5.1563 & TRN \\
\hline CHEMBL1393615 & 688620 & 5.8 & 5.4875 & TRN \\
\hline CHEMBL1528067 & 688620 & 4.95 & 5.1073 & TRN \\
\hline CHEMBL1409160 & 688620 & 5.0 & 4.9107 & TRN \\
\hline CHEMBL1388709 & 688620 & 4.45 & 5.7339 & TRN \\
\hline CHEMBL1563119 & 688620 & 4.7 & 5.1238 & TST \\
\hline CHEMBL1555061 & 688620 & 4.85 & 4.7185 & TRN \\
\hline CHEMBL1408535 & 688620 & 4.95 & 4.7279 & TRN \\
\hline CHEMBL1353565 & 688620 & 5.05 & 5.1024 & TRN \\
\hline CHEMBL1302234 & 688620 & 5.0 & 5.1598 & TRN \\
\hline CHEMBL1382989 & 688620 & 5.6 & 5.1177 & TRN \\
\hline CHEMBL1305082 & 688620 & 4.65 & 4.8847 & TRN \\
\hline CHEMBL1501605 & 688620 & 4.45 & 5.0374 & TRN \\
\hline CHEMBL1525074 & 688620 & 5.8 & 5.5295 & TRN \\
\hline CHEMBL1361652 & 688620 & 4.45 & 5.1026 & TRN \\
\hline CHEMBL1370473 & 688620 & 4.65 & 5.0755 & TRN \\
\hline CHEMBL1600987 & 688620 & 4.85 & 5.178 & TRN \\
\hline CHEMBL1484063 & 688620 & 4.45 & 5.0606 & TRN \\
\hline CHEMBL1385727 & 688620 & 5.35 & 5.6587 & TRN \\
\hline CHEMBL1324005 & 688620 & 6.45 & 5.8473 & TRN \\
\hline CHEMBL 3198248 & 688620 & 4.45 & 5.0036 & TRN \\
\hline CHEMBL1545734 & 688620 & 4.8 & 4.8316 & TRN \\
\hline CHEMBL1539241 & 688620 & 4.8 & 5.3848 & TRN \\
\hline CHEMBL1333618 & 688620 & 5.55 & 4.9292 & TRN \\
\hline CHEMBL1575610 & 688620 & 4.75 & 5.6944 & TST \\
\hline CHEMBL3194998 & 688620 & 5.0 & 4.936 & TST \\
\hline CHEMBL1986690 & 688620 & 5.0 & 4.996 & TST \\
\hline CHEMBL1490760 & 688620 & 4.8 & 4.9241 & TRN \\
\hline CHEMBL1494012 & 688620 & 5.15 & 4.9476 & TRN \\
\hline CHEMBL3193634 & 688620 & 4.45 & 4.9618 & TST \\
\hline CHEMBL1308037 & 688620 & 5.05 & 4.9303 & TRN \\
\hline CHEMBL1583180 & 688620 & 4.7 & 4.7314 & TRN \\
\hline CHEMBL1477816 & 688620 & 5.45 & 5.4967 & TRN \\
\hline CHEMBL1597956 & 688620 & 4.55 & 5.0776 & TRN \\
\hline CHEMBL1583543 & 688620 & 5.05 & 4.9551 & TRN \\
\hline CHEMBL1424392 & 688620 & 5.0 & 4.9606 & TRN \\
\hline CHEMBL1481155 & 688620 & 5.0 & 5.1531 & TST \\
\hline CHEMBL1304162 & 688620 & 4.9 & 4.8316 & TRN \\
\hline CHEMBL1432806 & 688620 & 5.6 & 5.1537 & TRN \\
\hline CHEMBL1369393 & 688620 & 4.65 & 5.0365 & TRN \\
\hline CHEMBL1300173 & 688620 & 5.4 & 5.1417 & TST \\
\hline
\end{tabular}




\begin{tabular}{|c|c|c|c|c|c|}
\hline \multicolumn{6}{|c|}{ Supplemental Table S2.txt } \\
\hline CHEMBL1481465 & 688620 & 5.05 & 4.9323 & TST & \\
\hline CHEMBL1456749 & 688620 & 8.5528 & 5.0215 & TRN & \\
\hline CHEMBL1363626 & 688620 & 4.9 & 4.9752 & TRN & \\
\hline CHEMBL 3198980 & 688620 & 4.9 & 5.0655 & TRN & \\
\hline CHEMBL1531728 & 688620 & 4.65 & 4.9255 & TRN & \\
\hline CHEMBL1568292 & 688620 & 5.35 & 5.23799 & 99999999995 & TRN \\
\hline CHEMBL1503002 & 688620 & 6.35 & 5.9844 & TRN & \\
\hline CHEMBL1306977 & 688620 & 5.7 & 5.0785 & TRN & \\
\hline CHEMBL1368857 & 688620 & 4.45 & 5.0615 & TRN & \\
\hline CHEMBL1560105 & 688620 & 4.75 & 4.9422 & TRN & \\
\hline CHEMBL1458749 & 688620 & 4.45 & 4.8466 & TST & \\
\hline CHEMBL1338269 & 688620 & 4.85 & 5.0255 & TRN & \\
\hline CHEMBL3208214 & 688620 & 4.55 & 4.921 & TRN & \\
\hline CHEMBL1424473 & 688620 & 5.1 & 4.9862 & TRN & \\
\hline CHEMBL1392740 & 688620 & 4.8 & 5.0572 & TRN & \\
\hline CHEMBL1530299 & 688620 & 4.9 & 5.1682 & TRN & \\
\hline CHEMBL1559097 & 688620 & 4.45 & 4.8871 & TRN & \\
\hline CHEMBL1585571 & 688620 & 4.55 & 5.2916 & TRN & \\
\hline CHEMBL1565265 & 688620 & 4.45 & 4.9583 & TST & \\
\hline CHEMBL1499105 & 688620 & 4.85 & 5.2333 & TST & \\
\hline CHEMBL1610357 & 688620 & 4.8 & 5.00899 & 99999999995 & TRN \\
\hline CHEMBL1543271 & 688620 & 4.9 & 4.9887 & TRN & \\
\hline CHEMBL1304004 & 688620 & 6.95 & 5.2136 & TRN & \\
\hline CHEMBL1518267 & 688620 & 6.8 & 5.254 & TRN & \\
\hline CHEMBL1371804 & 688620 & 5.2 & 5.16 & TRN & \\
\hline CHEMBL1529092 & 688620 & 4.9 & 5.3149 & TRN & \\
\hline CHEMBL1304541 & 688620 & 4.85 & 5.1787 & TRN & \\
\hline CHEMBL3211135 & 688620 & 5.8 & 5.6809 & TRN & \\
\hline CHEMBL1330169 & 688620 & 4.85 & 4.9816 & TRN & \\
\hline CHEMBL1325786 & 688620 & 5.05 & 5.0755 & TRN & \\
\hline CHEMBL1370746 & 688620 & 4.75 & 4.8971 & TRN & \\
\hline CHEMBL69612 & 688620 & 5.25 & 5.2405 & TST & \\
\hline CHEMBL1506476 & 688620 & 5.95 & 4.9432 & TRN & \\
\hline CHEMBL1393548 & 688620 & 4.45 & 5.2368 & TST & \\
\hline CHEMBL1585805 & 688620 & 4.85 & 4.9357 & TST & \\
\hline CHEMBL1573487 & 688620 & 5.35 & 4.9657 & TRN & \\
\hline CHEMBL3144906 & 688620 & 4.7 & 4.8509 & TRN & \\
\hline CHEMBL1499544 & 688620 & 4.95 & 4.7433 & TST & \\
\hline CHEMBL1573393 & 688620 & 4.45 & 5.0158 & TRN & \\
\hline CHEMBL1459410 & 688620 & 6.0 & 5.8533 & TRN & \\
\hline CHEMBL1348483 & 688620 & 4.8 & 5.0625 & TRN & \\
\hline CHEMBL1544965 & 688620 & 5.0 & 4.8216 & TRN & \\
\hline CHEMBL1354529 & 688620 & 6.0 & 4.8565 & TST & \\
\hline CHEMBL1471373 & 688620 & 4.85 & 5.0984 & TRN & \\
\hline CHEMBL1971767 & 688620 & 4.85 & 5.2594 & TRN & \\
\hline CHEMBL1547041 & 688620 & 5.55 & 5.2029 & TRN & \\
\hline CHEMBL1576555 & 688620 & 4.85 & 5.0514 & TRN & \\
\hline CHEMBL1340980 & 688620 & 6.5501 & 5.0471 & TRN & \\
\hline
\end{tabular}




\begin{tabular}{|c|c|c|c|c|}
\hline & & & pplement & al $\mathrm{T}$ \\
\hline CHEMBL1372157 & 688620 & 5.2 & 5.441 & TRN \\
\hline CHEMBL1543510 & 688620 & 5.1 & 4.6491 & TRN \\
\hline CHEMBL1340259 & 688620 & 5.1 & 5.1798 & TRN \\
\hline CHEMBL1496647 & 688620 & 5.5 & 4.905 & TRN \\
\hline CHEMBL1345952 & 688620 & 5.5 & 5.0148 & TST \\
\hline CHEMBL3197338 & 688620 & 5.1 & 5.1087 & TRN \\
\hline CHEMBL1326139 & 688620 & 4.9 & 5.2011 & TRN \\
\hline CHEMBL1387799 & 688620 & 4.95 & 5.2309 & TST \\
\hline CHEMBL1307319 & 688620 & 4.45 & 5.3372 & TST \\
\hline CHEMBL1599815 & 688620 & 6.15 & 5.9783 & TRN \\
\hline CHEMBL1973226 & 688620 & 4.8 & 5.2344 & TRN \\
\hline CHEMBL1392346 & 688620 & 4.85 & 4.8091 & TST \\
\hline CHEMBL1329398 & 688620 & 5.95 & 4.9262 & TRN \\
\hline CHEMBL1597697 & 688620 & 4.45 & 5.0968 & TRN \\
\hline CHEMBL400912 & 688620 & 5.2 & 5.4687 & TRN \\
\hline CHEMBL1460661 & 688620 & 5.0 & 5.0971 & TRN \\
\hline CHEMBL1554866 & 688620 & 4.45 & 4.8882 & TST \\
\hline CHEMBL1328662 & 688620 & 4.65 & 4.7606 & TRN \\
\hline CHEMBL1582929 & 688620 & 7.0 & 5.0248 & TRN \\
\hline CHEMBL1526042 & 688620 & 7.0501 & 5.0243 & TRN \\
\hline CHEMBL1447159 & 688620 & 4.9 & 5.2062 & TRN \\
\hline CHEMBL1580077 & 688620 & 4.6 & 5.086 & TST \\
\hline CHEMBL1459216 & 688620 & 4.45 & 5.14 & TRN \\
\hline CHEMBL192627 & 688620 & 6.0 & 4.9955 & TST \\
\hline CHEMBL1351769 & 688620 & 5.45 & 5.1382 & TRN \\
\hline CHEMBL1606565 & 688620 & 4.8 & 4.9187 & TRN \\
\hline CHEMBL1536975 & 688620 & 5.85 & 5.2767 & TRN \\
\hline CHEMBL 2005944 & 688620 & 6.6 & 5.7877 & TRN \\
\hline CHEMBL1507018 & 688620 & 5.55 & 4.9197 & TRN \\
\hline CHEMBL1580790 & 688620 & 4.75 & 5.0502 & TST \\
\hline CHEMBL1463564 & 688620 & 5.0 & 4.7419 & TRN \\
\hline CHEMBL1479018 & 688620 & 4.7 & 5.374 & TRN \\
\hline CHEMBL 3198213 & 688620 & 6.9 & 5.5875 & TST \\
\hline CHEMBL1329680 & 688620 & 4.45 & 5.0439 & TRN \\
\hline CHEMBL 3198517 & 688620 & 4.9 & 4.8336 & TRN \\
\hline CHEMBL1538628 & 688620 & 4.65 & 5.1177 & TRN \\
\hline CHEMBL 3196820 & 688620 & 4.8 & 4.9383 & TRN \\
\hline CHEMBL1577253 & 688620 & 7.3002 & 4.9859 & TRN \\
\hline CHEMBL1337234 & 688620 & 4.6 & 4.968 & TRN \\
\hline CHEMBL1323410 & 688620 & 5.75 & 5.0683 & TST \\
\hline CHEMBL1598534 & 688620 & 4.95 & 4.8989 & TRN \\
\hline CHEMBL1470136 & 688620 & 5.0 & 5.3735 & TRN \\
\hline CHEMBL1511090 & 688620 & 4.8 & 4.9693 & TRN \\
\hline CHEMBL1465339 & 688620 & 4.45 & 4.7887 & TRN \\
\hline CHEMBL 1445025 & 688620 & 5.9 & 4.9116 & TRN \\
\hline CHEMBL1576722 & 688620 & 4.8 & 5.027 & TRN \\
\hline CHEMBL1581626 & 688620 & 5.9 & 5.2014 & TRN \\
\hline CHEMBL1597412 & 688620 & 5.2 & 5.0629 & TST \\
\hline
\end{tabular}




\begin{tabular}{|c|c|c|c|c|c|}
\hline \multicolumn{6}{|c|}{ Supplemental Table s2.txt } \\
\hline CHEMBL1501735 & 688620 & 4.95 & 5.0651 & TRN & \\
\hline CHEMBL1566754 & 688620 & 4.95 & 4.9669 & TRN & \\
\hline CHEMBL1597471 & 688620 & 5.05 & 5.1097 & TST & \\
\hline CHEMBL1494313 & 688620 & 4.65 & 4.8261 & TRN & \\
\hline CHEMBL1370453 & 688620 & 5.55 & 4.8254 & TST & \\
\hline CHEMBL3197237 & 688620 & 5.4 & 5.2943 & TST & \\
\hline CHEMBL1486418 & 688620 & 5.35 & 5.1811 & TST & \\
\hline CHEMBL3199080 & 688620 & 4.65 & 4.962 & TRN & \\
\hline CHEMBL1467932 & 688620 & 4.8 & 4.9599 & TRN & \\
\hline CHEMBL1585162 & 688620 & 4.95 & 5.1712 & TRN & \\
\hline CHEMBL1995314 & 688620 & 4.6 & 5.1809 & TRN & \\
\hline CHEMBL3190913 & 688620 & 4.9 & 4.9759 & TRN & \\
\hline CHEMBL1351356 & 688620 & 5.0 & 4.8355 & TRN & \\
\hline CHEMBL1373664 & 688620 & 5.05 & 5.1996 & TRN & \\
\hline CHEMBL1336931 & 688620 & 5.6 & 5.0326 & TRN & \\
\hline CHEMBL1462833 & 688620 & 5.1 & 5.0971 & TRN & \\
\hline CHEMBL1510974 & 688620 & 5.6 & 5.3852 & TRN & \\
\hline CHEMBL1376412 & 688620 & 6.45 & 5.0091 & TRN & \\
\hline CHEMBL1301928 & 688620 & 4.95 & 5.2599 & TRN & \\
\hline CHEMBL1593013 & 688620 & 5.4 & 4.8496 & TST & \\
\hline CHEMBL1414932 & 688620 & 4.95 & 5.0132 & TRN & \\
\hline CHEMBL1535895 & 688620 & 5.0 & 4.7242 & TRN & \\
\hline CHEMBL1579737 & 688620 & 4.75 & 4.8013 & TRN & \\
\hline CHEMBL1365267 & 688620 & 4.45 & 4.8518 & TRN & \\
\hline CHEMBL1459299 & 688620 & 4.8 & 5.1461 & TRN & \\
\hline CHEMBL1978764 & 688620 & 6.6499 & 5.8316 & TRN & \\
\hline CHEMBL1339856 & 688620 & 4.75 & 5.1752 & TRN & \\
\hline CHEMBL3190623 & 688620 & 5.0 & 5.01699 & 99999999995 & TRN \\
\hline CHEMBL3199393 & 688620 & 4.95 & 5.0233 & TRN & \\
\hline CHEMBL1340588 & 688620 & 4.85 & 4.9155 & TRN & \\
\hline CHEMBL1532654 & 688620 & 4.65 & 5.16 & TST & \\
\hline CHEMBL1456330 & 688620 & 4.9 & 5.0183 & TST & \\
\hline CHEMBL1390807 & 688620 & 4.95 & 5.0823 & TST & \\
\hline CHEMBL591126 & 688620 & 5.4 & 5.9938 & TRN & \\
\hline CHEMBL3191089 & 688620 & 4.45 & 5.1467 & TRN & \\
\hline CHEMBL1222382 & 688620 & 5.05 & 5.5562 & TRN & \\
\hline CHEMBL1349888 & 688620 & 5.0 & 5.0219 & TRN & \\
\hline CHEMBL1390676 & 688620 & 4.65 & 4.9858 & TRN & \\
\hline CHEMBL1573242 & 688620 & 4.45 & 4.95 & TST & \\
\hline CHEMBL1313278 & 688620 & 5.45 & 5.105 & TRN & \\
\hline CHEMBL1443902 & 688620 & 6.0 & 6.0638 & TRN & \\
\hline CHEMBL1328797 & 688620 & 5.55 & 5.0061 & TST & \\
\hline CHEMBL1529890 & 688620 & 5.0 & 4.8344 & TRN & \\
\hline CHEMBL 2003808 & 688620 & 5.5 & 5.5263 & TRN & \\
\hline CHEMBL1418857 & 688620 & 4.65 & 5.0635 & TST & \\
\hline CHEMBL1421878 & 688620 & 7.0 & 5.38899 & 9999999999 & TST \\
\hline CHEMBL 2006519 & 688620 & 5.6 & 5.5375 & TRN & \\
\hline CHEMBL1369033 & 688620 & 5.75 & 5.0248 & TST & \\
\hline
\end{tabular}




\begin{tabular}{|c|c|c|c|c|c|}
\hline \multicolumn{6}{|c|}{ Supplemental Table S2.txt } \\
\hline CHEMBL 2001316 & 688620 & 5.65 & 5.6708 & TRN & \\
\hline CHEMBL1356775 & 688620 & 4.55 & 4.8937 & TRN & \\
\hline CHEMBL1377629 & 688620 & 5.6 & 4.6964 & TRN & \\
\hline CHEMBL1527911 & 688620 & 5.45 & 4.78 & TRN & \\
\hline CHEMBL1580784 & 688620 & 4.45 & 4.8203 & TRN & \\
\hline CHEMBL1609513 & 688620 & 4.9 & 4.9933 & TRN & \\
\hline CHEMBL1447496 & 688620 & 5.0 & 4.5321 & TRN & \\
\hline CHEMBL1357865 & 688620 & 4.85 & 4.8716 & TRN & \\
\hline CHEMBL3191353 & 688620 & 4.7 & 5.0044 & TRN & \\
\hline CHEMBL 1365356 & 688620 & 5.3 & 4.9317 & TRN & \\
\hline CHEMBL1413521 & 688620 & 4.75 & 4.8983 & TST & \\
\hline CHEMBL1562359 & 688620 & 5.0 & 4.9378 & TST & \\
\hline CHEMBL1330876 & 688620 & 4.45 & 5.2093 & TRN & \\
\hline CHEMBL1577688 & 688620 & 5.85 & 4.9351 & TRN & \\
\hline CHEMBL1535599 & 688620 & 5.4 & 5.0574 & TRN & \\
\hline CHEMBL1521193 & 688620 & 4.95 & 4.8849 & TRN & \\
\hline CHEMBL1444688 & 688620 & 5.65 & 5.1287 & TST & \\
\hline CHEMBL1349009 & 688620 & 4.45 & 5.0829 & TRN & \\
\hline CHEMBL1314982 & 688620 & 4.5 & 5.0731 & TST & \\
\hline CHEMBL1466250 & 688620 & 5.5 & 5.1708 & TRN & \\
\hline CHEMBL1541993 & 688620 & 4.85 & 4.8119 & TRN & \\
\hline CHEMBL1302047 & 688620 & 4.95 & 4.7679 & TRN & \\
\hline CHEMBL1575309 & 688620 & 5.4 & 5.1349 & TRN & \\
\hline CHEMBL1518540 & 688620 & 4.85 & 4.9825 & TRN & \\
\hline CHEMBL1371119 & 688620 & 5.0 & 4.9736 & TRN & \\
\hline CHEMBL1506984 & 688620 & 4.7 & 4.9287 & TRN & \\
\hline CHEMBL1516385 & 688620 & 5.4 & 5.0123 & TRN & \\
\hline CHEMBL1428575 & 688620 & 6.05 & 5.541 & TRN & \\
\hline CHEMBL1594333 & 688620 & 6.7001 & 5.3486 & TST & \\
\hline CHEMBL3191831 & 688620 & 5.0 & 5.1625 & TRN & \\
\hline CHEMBL1480176 & 688620 & 4.85 & 5.16706 & 0000000001 & TRN \\
\hline CHEMBL1362672 & 688620 & 4.65 & 4.9966 & TRN & \\
\hline CHEMBL1495080 & 688620 & 4.9 & 4.7233 & TRN & \\
\hline CHEMBL1503294 & 688620 & 5.25 & 5.0878 & TRN & \\
\hline CHEMBL 1496623 & 688620 & 4.45 & 4.8975 & TRN & \\
\hline CHEMBL1365436 & 688620 & 5.3 & 5.0914 & TRN & \\
\hline CHEMBL1409579 & 688620 & 5.4 & 5.3285 & TRN & \\
\hline CHEMBL1340517 & 688620 & 5.15 & 5.0042 & TRN & \\
\hline CHEMBL1501374 & 688620 & 4.8 & 5.1599 & TST & \\
\hline CHEMBL 1470473 & 688620 & 4.8 & 4.9088 & TST & \\
\hline CHEMBL1408191 & 688620 & 5.65 & 5.1495 & TRN & \\
\hline CHEMBL1307996 & 688620 & 5.15 & 5.136 & TRN & \\
\hline CHEMBL1562041 & 688620 & 4.8 & 4.8969 & TRN & \\
\hline CHEMBL1347561 & 688620 & 4.9 & 4.7522 & TST & \\
\hline CHEMBL 1334510 & 688620 & 5.65 & 5.1353 & TRN & \\
\hline CHEMBL3193801 & 688620 & 5.65 & 5.6029 & TRN & \\
\hline CHEMBL3190532 & 688620 & 4.9 & 4.9944 & TRN & \\
\hline CHEMBL 1374812 & 688620 & 6.7001 & 4.9094 & TRN & \\
\hline
\end{tabular}

Page 27264 


\begin{tabular}{|c|c|c|c|c|c|}
\hline \multicolumn{6}{|c|}{ Supplemental Table S2.txt } \\
\hline CHEMBL1365725 & 688620 & 5.2 & 5.2699 & TST & \\
\hline CHEMBL1501390 & 688620 & 4.85 & 4.8654 & TRN & \\
\hline CHEMBL1485443 & 688620 & 4.75 & 5.0091 & TRN & \\
\hline CHEMBL1495747 & 688620 & 4.75 & 4.9718 & TRN & \\
\hline CHEMBL1968986 & 688620 & 4.95 & 4.8789 & TRN & \\
\hline CHEMBL1405761 & 688620 & 4.9 & 4.9589 & TRN & \\
\hline CHEMBL1382898 & 688620 & 5.4 & 5.2686 & TRN & \\
\hline CHEMBL3196165 & 688620 & 4.45 & 4.9888 & TRN & \\
\hline CHEMBL1498010 & 688620 & 5.05 & 5.1058 & TRN & \\
\hline CHEMBL1347368 & 688620 & 5.75 & 5.3805 & TRN & \\
\hline CHEMBL3196745 & 688620 & 6.15 & 5.1113 & TRN & \\
\hline CHEMBL1320435 & 688620 & 4.5 & 4.8539 & TRN & \\
\hline CHEMBL1489721 & 688620 & 4.45 & 4.7052 & TRN & \\
\hline CHEMBL1547465 & 688620 & 4.45 & 5.0703 & TRN & \\
\hline CHEMBL1482669 & 688620 & 5.65 & 4.8577 & TRN & \\
\hline CHEMBL1507614 & 688620 & 5.95 & 5.0025 & TRN & \\
\hline CHEMBL1584755 & 688620 & 4.65 & 4.8597 & TST & \\
\hline CHEMBL1444677 & 688620 & 4.85 & 5.143 & TRN & \\
\hline CHEMBL1379674 & 688620 & 5.6 & 5.4818 & TRN & \\
\hline CHEMBL1400278 & 688620 & 4.95 & 4.7336 & TRN & \\
\hline CHEMBL1591209 & 688620 & 4.45 & 4.8234 & TRN & \\
\hline CHEMBL1368468 & 688620 & 4.5 & 5.1081 & TRN & \\
\hline CHEMBL1495125 & 688620 & 4.8 & 4.9236 & TRN & \\
\hline CHEMBL1331740 & 688620 & 5.05 & 5.074 & TRN & \\
\hline CHEMBL1322826 & 688620 & 6.15 & 5.1168 & TRN & \\
\hline CHEMBL1403629 & 688620 & 4.85 & 5.0694 & TST & \\
\hline CHEMBL1328527 & 688620 & 5.4 & 5.3453 & TRN & \\
\hline CHEMBL1344961 & 688620 & 4.85 & 4.9681 & TRN & \\
\hline CHEMBL1306250 & 688620 & 4.8 & 4.9836 & TST & \\
\hline CHEMBL1456500 & 688620 & 5.75 & 5.1127 & TST & \\
\hline CHEMBL1352461 & 688620 & 4.6 & 5.0814 & TRN & \\
\hline CHEMBL1308346 & 688620 & 4.55 & 4.8374 & TRN & \\
\hline CHEMBL1457135 & 688620 & 4.95 & 5.1227 & TRN & \\
\hline CHEMBL1563192 & 688620 & 5.0 & 5.2495 & TRN & \\
\hline CHEMBL1598769 & 688620 & 5.35 & 5.4142 & TRN & \\
\hline CHEMBL3210819 & 688620 & 4.75 & 5.0636 & TRN & \\
\hline CHEMBL1505475 & 688620 & 4.8 & 4.9174 & TRN & \\
\hline CHEMBL1572461 & 688620 & 6.0 & 5.4615 & TST & \\
\hline CHEMBL1526904 & 688620 & 5.05 & 5.2165 & TRN & \\
\hline CHEMBL221300 & 688620 & 4.85 & 5.1036 & TRN & \\
\hline CHEMBL1594287 & 688620 & 5.05 & 5.0405 & TRN & \\
\hline CHEMBL1332531 & 688620 & 4.5 & 5.28299 & 99999999995 & TST \\
\hline CHEMBL1545506 & 688620 & 4.75 & 5.077 & TST & \\
\hline CHEMBL1559601 & 688620 & 6.7501 & 4.9431 & TST & \\
\hline CHEMBL1582482 & 688620 & 5.25 & 5.1047 & TST & \\
\hline CHEMBL1487705 & 688620 & 4.8 & 4.8791 & TRN & \\
\hline CHEMBL1342351 & 688620 & 4.8 & 4.909 & TST & \\
\hline CHEMBL1567225 & 688620 & 4.65 & 4.955 & TST & \\
\hline
\end{tabular}




\begin{tabular}{|c|c|c|c|c|c|}
\hline \multicolumn{6}{|c|}{ Supplemental Table S2.txt } \\
\hline CHEMBL3211167 & 688620 & 4.75 & 5.3735 & TRN & \\
\hline CHEMBL1398990 & 688620 & 4.95 & 4.9083 & TRN & \\
\hline CHEMBL1485562 & 688620 & 4.45 & 4.7889 & TRN & \\
\hline CHEMBL1542192 & 688620 & 5.55 & 5.3139 & TRN & \\
\hline CHEMBL1438031 & 688620 & 5.45 & 5.0947 & TRN & \\
\hline CHEMBL1302085 & 688620 & 4.65 & 4.9395 & TST & \\
\hline CHEMBL1374045 & 688620 & 4.75 & 5.0903 & TRN & \\
\hline CHEMBL1325723 & 688620 & 4.95 & 4.885 & TST & \\
\hline CHEMBL1547420 & 688620 & 4.8 & 5.0904 & TRN & \\
\hline CHEMBL1320072 & 688620 & 5.4 & 5.2758 & TRN & \\
\hline CHEMBL1393450 & 688620 & 4.9 & 4.8205 & TRN & \\
\hline CHEMBL 1457573 & 688620 & 5.0 & 5.0701 & TRN & \\
\hline CHEMBL1557389 & 688620 & 4.9 & 5.1 & TRN & \\
\hline CHEMBL1565636 & 688620 & 5.3 & 5.183 & TRN & \\
\hline CHEMBL1410225 & 688620 & 4.45 & 4.9563 & TRN & \\
\hline CHEMBL1381584 & 688620 & 5.7 & 5.3563 & TRN & \\
\hline CHEMBL1484005 & 688620 & 5.45 & 5.0916 & TRN & \\
\hline CHEMBL1324798 & 688620 & 4.6 & 5.0542 & TRN & \\
\hline CHEMBL1609197 & 688620 & 4.6 & 5.0247 & TRN & \\
\hline CHEMBL1456019 & 688620 & 4.75 & 4.8759 & TRN & \\
\hline CHEMBL1542218 & 688620 & 5.0 & 5.0137 & TRN & \\
\hline CHEMBL1382064 & 688620 & 6.0 & 5.1892 & TRN & \\
\hline CHEMBL1322473 & 688620 & 4.9 & 4.961 & TRN & \\
\hline CHEMBL1613525 & 688620 & 4.45 & 5.0493 & TRN & \\
\hline CHEMBL36296 & 688620 & 4.45 & 4.9862 & TST & \\
\hline CHEMBL1569210 & 688620 & 5.35 & 5.4412 & TRN & \\
\hline CHEMBL1507460 & 688620 & 4.55 & 4.9692 & TRN & \\
\hline CHEMBL1441800 & 688620 & 5.2 & 5.1991 & TST & \\
\hline CHEMBL1558840 & 688620 & 5.45 & 5.1402 & TST & \\
\hline CHEMBL1501576 & 688620 & 4.8 & 5.0856 & TRN & \\
\hline CHEMBL1558474 & 688620 & 5.8 & 5.1268 & TRN & \\
\hline CHEMBL1343180 & 688620 & 4.8 & 5.1914 & TST & \\
\hline CHEMBL1497574 & 688620 & 4.8 & 5.2921 & TRN & \\
\hline CHEMBL3194319 & 688620 & 4.85 & 4.78606 & 00000000005 & TST \\
\hline CHEMBL1565498 & 688620 & 4.45 & 5.0253 & TST & \\
\hline CHEMBL1337612 & 688620 & 5.0 & 4.832 & TRN & \\
\hline CHEMBL1501376 & 688620 & 4.45 & 4.6007 & TRN & \\
\hline CHEMBL1468451 & 688620 & 4.9 & 4.9291 & TRN & \\
\hline CHEMBL1408520 & 688620 & 6.0 & 4.8735 & TST & \\
\hline CHEMBL1410999 & 688620 & 5.1 & 4.9545 & TRN & \\
\hline CHEMBL1533153 & 688620 & 8.0506 & 5.3149 & TRN & \\
\hline CHEMBL1383569 & 688620 & 5.9 & 5.414 & TRN & \\
\hline CHEMBL1425381 & 688620 & 4.45 & 4.8385 & TRN & \\
\hline CHEMBL1464169 & 688620 & 5.55 & 4.6508 & TRN & \\
\hline CHEMBL3196342 & 688620 & 4.95 & 4.9961 & TST & \\
\hline CHEMBL1464206 & 688620 & 4.45 & 4.6964 & TRN & \\
\hline CHEMBL1346225 & 688620 & 4.7 & 4.7627 & TRN & \\
\hline CHEMBL3212557 & 688620 & 4.5 & 5.1933 & TST & \\
\hline
\end{tabular}




\begin{tabular}{|c|c|c|c|c|c|}
\hline \multicolumn{6}{|c|}{ Supplemental Table S2.txt } \\
\hline CHEMBL582675 & 688620 & 5.0 & 4.7907 & TRN & \\
\hline CHEMBL3199033 & 688620 & 5.65 & 5.3411 & TRN & \\
\hline CHEMBL1412085 & 688620 & 5.05 & 5.119 & TRN & \\
\hline CHEMBL252017 & 688620 & 4.45 & 4.9712 & TRN & \\
\hline CHEMBL1449613 & 688620 & 4.65 & 4.9254 & TRN & \\
\hline CHEMBL1581700 & 688620 & 4.95 & 5.147 & TST & \\
\hline CHEMBL3199112 & 688620 & 5.0 & 4.8793 & TRN & \\
\hline CHEMBL1393801 & 688620 & 4.5 & 5.0711 & TST & \\
\hline CHEMBL1420494 & 688620 & 5.45 & 5.2764 & TRN & \\
\hline CHEMBL1312754 & 688620 & 4.45 & 5.0627 & TRN & \\
\hline CHEMBL1504524 & 688620 & 5.75 & 4.9625 & TRN & \\
\hline CHEMBL1492289 & 688620 & 4.6 & 4.9757 & TRN & \\
\hline CHEMBL1375891 & 688620 & 4.45 & 4.9485 & TRN & \\
\hline CHEMBL1378489 & 688620 & 5.3 & 5.2251 & TST & \\
\hline CHEMBL1504316 & 688620 & 4.65 & 4.8177 & TRN & \\
\hline CHEMBL1235966 & 688620 & 5.95 & 5.2611 & TRN & \\
\hline CHEMBL571700 & 688620 & 5.2 & 5.5929 & TST & \\
\hline CHEMBL1322602 & 688620 & 4.7 & 5.0618 & TRN & \\
\hline CHEMBL1414093 & 688620 & 4.45 & 4.9466 & TST & \\
\hline CHEMBL1360633 & 688620 & 5.95 & 5.42399 & 99999999995 & TRN \\
\hline CHEMBL1451573 & 688620 & 5.6 & 5.0013 & TRN & \\
\hline CHEMBL1557232 & 688620 & 5.05 & 5.0796 & TRN & \\
\hline CHEMBL1342097 & 688620 & 5.05 & 5.209 & TRN & \\
\hline CHEMBL1374526 & 688620 & 4.6 & 4.7109 & TRN & \\
\hline CHEMBL3194145 & 688620 & 4.9 & 4.8389 & TRN & \\
\hline CHEMBL1543627 & 688620 & 4.45 & 5.0392 & TRN & \\
\hline CHEMBL1536316 & 688620 & 5.75 & 5.0413 & TRN & \\
\hline CHEMBL1419798 & 688620 & 5.55 & 5.4236 & TRN & \\
\hline CHEMBL1333181 & 688620 & 4.7 & 5.032 & TRN & \\
\hline CHEMBL1582550 & 688620 & 5.0 & 5.1898 & TRN & \\
\hline CHEMBL1393257 & 688620 & 4.85 & 4.8657 & TST & \\
\hline CHEMBL1418861 & 688620 & 5.0 & 4.9396 & TRN & \\
\hline CHEMBL1573389 & 688620 & 4.45 & 5.0518 & TRN & \\
\hline CHEMBL1386804 & 688620 & 6.5 & 6.5948 & TRN & \\
\hline CHEMBL603967 & 688620 & 4.45 & 4.9389 & TRN & \\
\hline CHEMBL1451433 & 688620 & 4.6 & 5.086 & TRN & \\
\hline CHEMBL1416848 & 688620 & 5.75 & 5.2998 & TRN & \\
\hline CHEMBL1411494 & 688620 & 5.15 & 5.2024 & TRN & \\
\hline CHEMBL1405509 & 688620 & 4.6 & 5.0063 & TST & \\
\hline CHEMBL1342613 & 688620 & 4.8 & 4.84399 & & TRN \\
\hline CHEMBL1444616 & 688620 & 4.9 & 5.2123 & TRN & \\
\hline CHEMBL1506075 & 688620 & 4.45 & 5.0533 & TRN & \\
\hline CHEMBL1489504 & 688620 & 5.0 & 5.0503 & TRN & \\
\hline CHEMBL1983533 & 688620 & 4.95 & 5.0443 & TRN & \\
\hline CHEMBL1385489 & 688620 & 4.95 & 5.0513 & TST & \\
\hline CHEMBL1561387 & 688620 & 4.95 & 4.931 & TRN & \\
\hline CHEMBL1355323 & 688620 & 6.0 & 5.1705 & TST & \\
\hline CHEMBL1538389 & 688620 & 4.45 & 4.9865 & TRN & \\
\hline
\end{tabular}




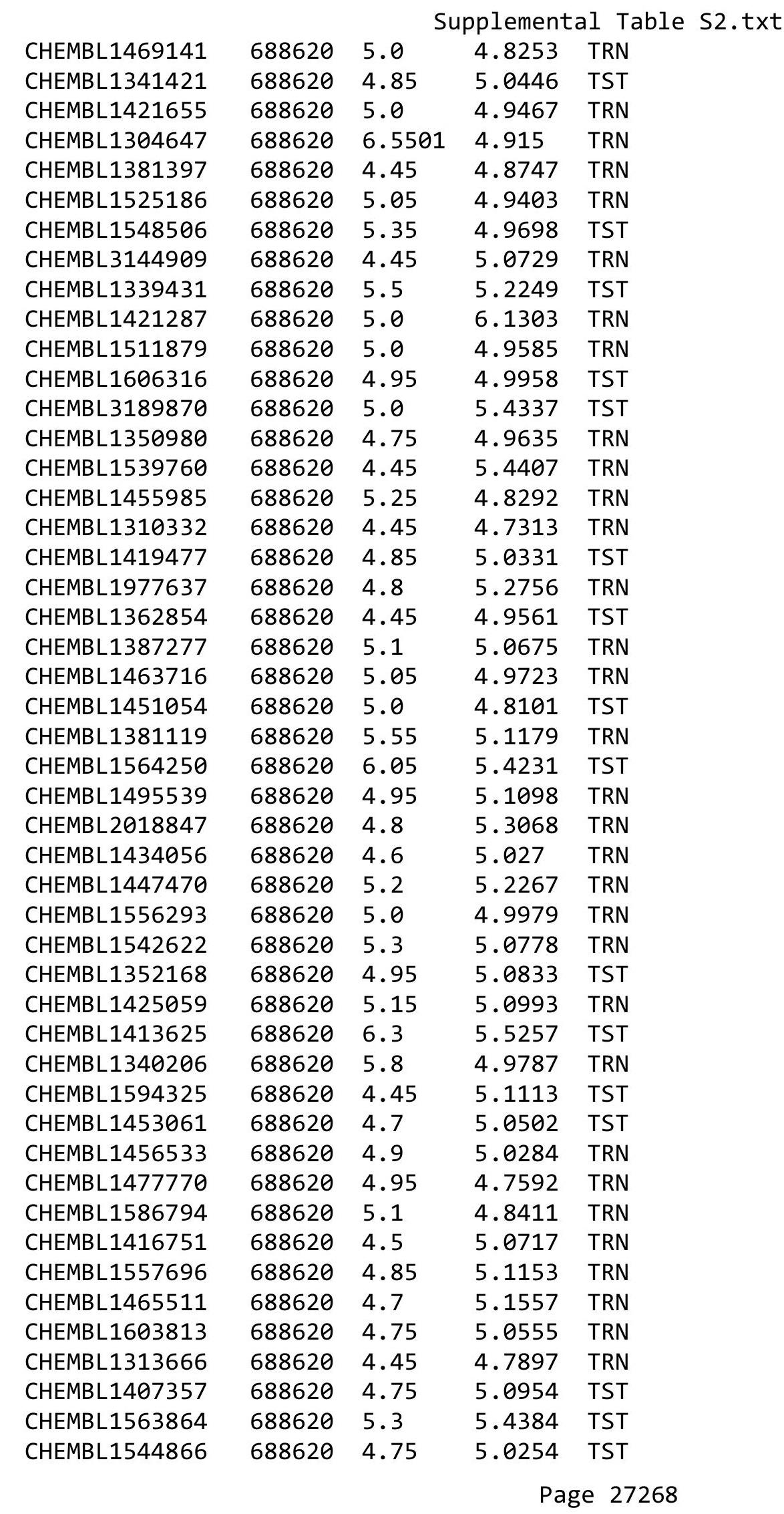




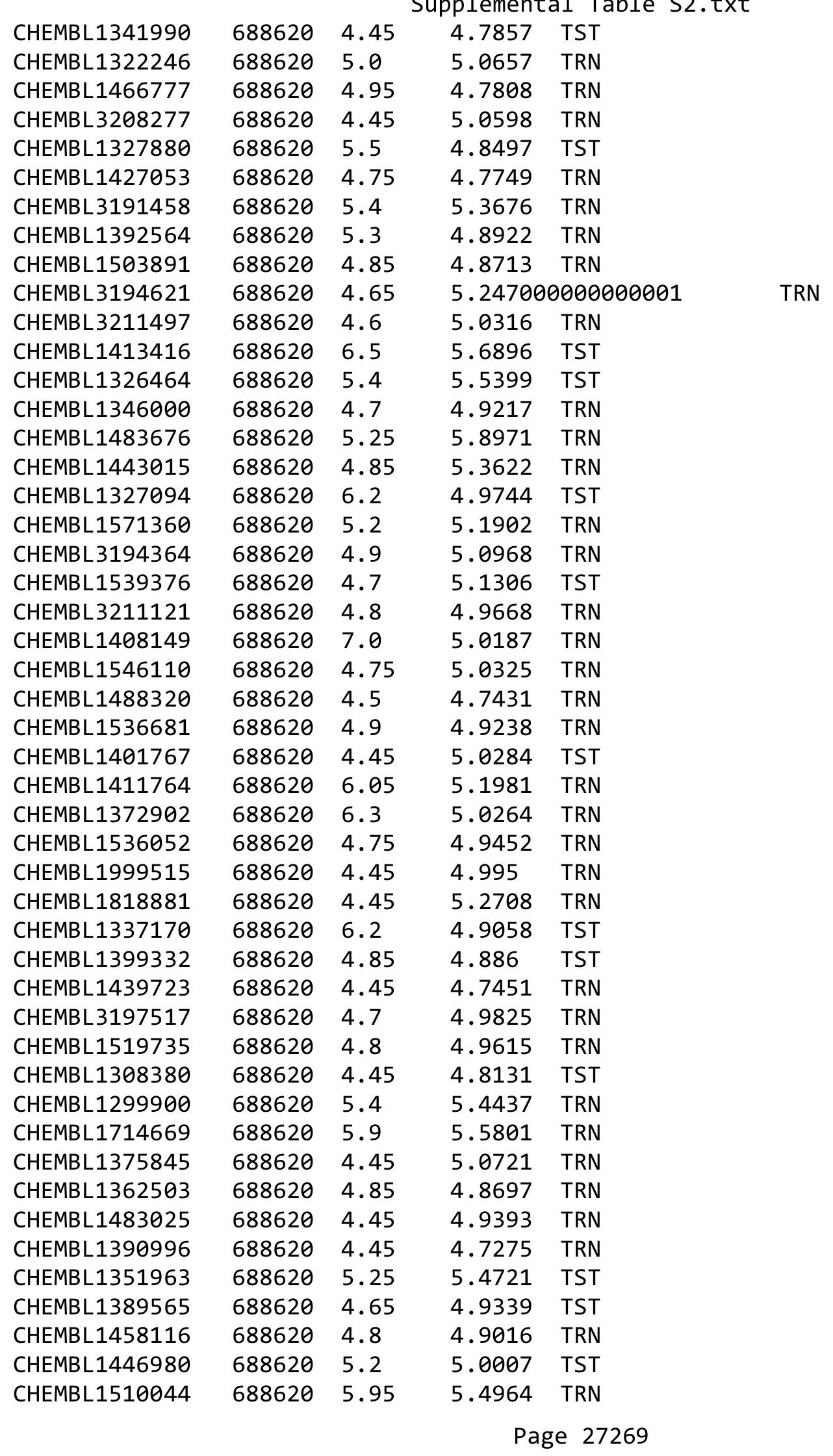




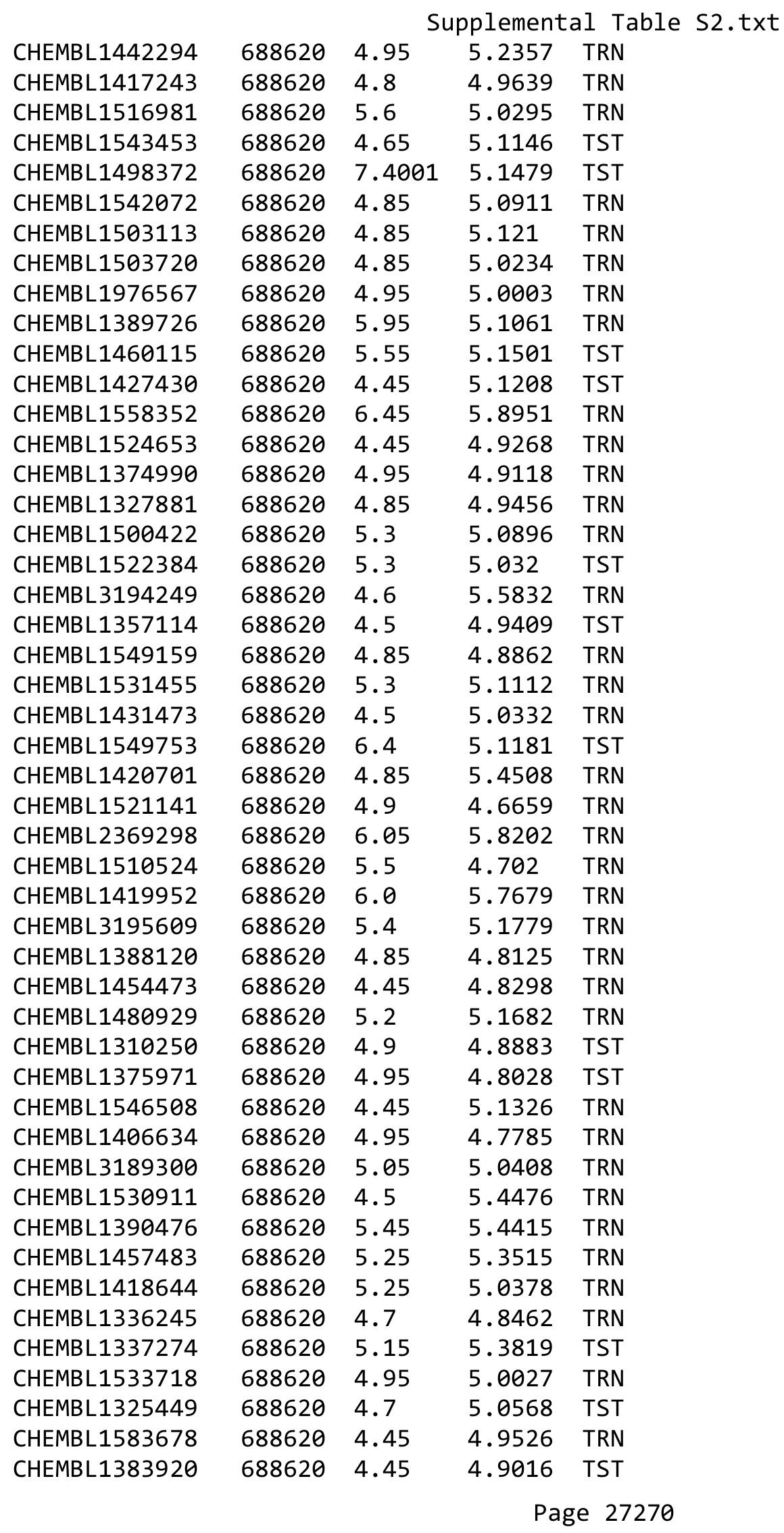




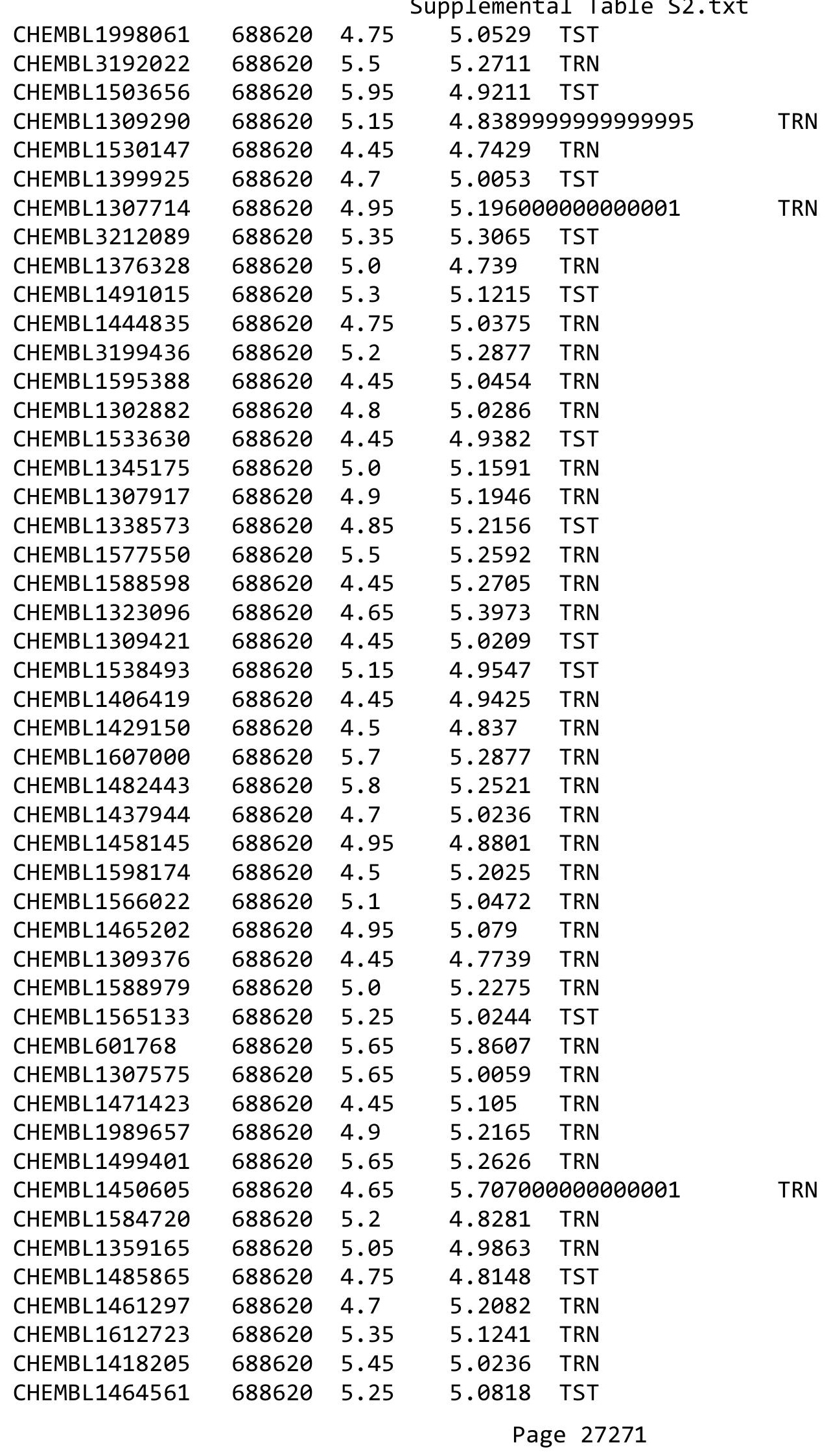




\begin{tabular}{|c|c|c|c|c|c|}
\hline \multicolumn{6}{|c|}{ Supplemental Table S2.txt } \\
\hline CHEMBL1418444 & 688620 & 4.75 & 5.0143 & TRN & \\
\hline CHEMBL1512260 & 688620 & 4.45 & 4.9269 & TRN & \\
\hline CHEMBL1522741 & 688620 & 4.45 & 4.8622 & TRN & \\
\hline CHEMBL1342754 & 688620 & 4.95 & 4.9273 & TRN & \\
\hline CHEMBL1609247 & 688620 & 5.45 & 5.0309 & TST & \\
\hline CHEMBL1500882 & 688620 & 4.8 & 5.1711 & TST & \\
\hline CHEMBL1388940 & 688620 & 4.9 & 4.7069 & TRN & \\
\hline CHEMBL1534854 & 688620 & 5.15 & 4.9348 & TRN & \\
\hline CHEMBL1580300 & 688620 & 4.45 & 5.5484 & TRN & \\
\hline CHEMBL1455876 & 688620 & 4.9 & 5.0772 & TRN & \\
\hline CHEMBL1565214 & 688620 & 4.5 & 4.9636 & TST & \\
\hline CHEMBL1511432 & 688620 & 4.45 & 4.7691 & TRN & \\
\hline CHEMBL1306207 & 688620 & 4.45 & 4.8748 & TRN & \\
\hline CHEMBL1364973 & 688620 & 6.6499 & 5.1452 & TRN & \\
\hline CHEMBL1301413 & 688620 & 5.0 & 4.9971 & TRN & \\
\hline CHEMBL1417532 & 688620 & 5.2 & 4.9841 & TRN & \\
\hline CHEMBL3208533 & 688620 & 4.45 & 4.7753 & TST & \\
\hline CHEMBL1366447 & 688620 & 4.95 & 4.8573 & TST & \\
\hline CHEMBL1405067 & 688620 & 4.9 & 4.837 & TRN & \\
\hline CHEMBL1480892 & 688620 & 4.8 & 5.079 & TRN & \\
\hline CHEMBL1377622 & 688620 & 5.0 & 5.2513 & TST & \\
\hline CHEMBL1467507 & 688620 & 6.4 & 5.1921 & TRN & \\
\hline CHEMBL1480539 & 688620 & 4.75 & 5.4188 & TRN & \\
\hline CHEMBL1475058 & 688620 & 5.25 & 5.1545 & TRN & \\
\hline CHEMBL589238 & 688620 & 5.95 & 5.4898 & TST & \\
\hline CHEMBL1326036 & 688620 & 4.45 & 4.8896 & TRN & \\
\hline CHEMBL3198190 & 688620 & 5.15 & 5.0425 & TRN & \\
\hline CHEMBL1381542 & 688620 & 4.5 & 5.0474 & TRN & \\
\hline CHEMBL1441827 & 688620 & 4.65 & 4.7659 & TRN & \\
\hline CHEMBL1534986 & 688620 & 5.1 & 5.2102 & TRN & \\
\hline CHEMBL1469660 & 688620 & 5.5 & 5.3051 & TRN & \\
\hline CHEMBL1401156 & 688620 & 5.05 & 5.0343 & TRN & \\
\hline CHEMBL1271047 & 688620 & 4.75 & 4.8737 & TST & \\
\hline CHEMBL1424806 & 688620 & 4.65 & 4.8035 & TRN & \\
\hline CHEMBL1483047 & 688620 & 4.45 & 4.82600 & 00000000005 & TRN \\
\hline CHEMBL1493646 & 688620 & 5.1 & 5.0956 & TST & \\
\hline CHEMBL1476799 & 688620 & 4.9 & 4.9364 & TRN & \\
\hline CHEMBL1361889 & 688620 & 4.85 & 4.7567 & TST & \\
\hline CHEMBL1581244 & 688620 & 4.55 & 4.9342 & TST & \\
\hline CHEMBL1446839 & 688620 & 6.5501 & 5.1416 & TRN & \\
\hline CHEMBL1442105 & 688620 & 5.55 & 5.2942 & TRN & \\
\hline CHEMBL1495205 & 688620 & 4.8 & 4.7895 & TRN & \\
\hline CHEMBL1529190 & 688620 & 5.7 & 5.9811 & TRN & \\
\hline CHEMBL1448533 & 688620 & 5.0 & 4.8231 & TRN & \\
\hline CHEMBL1976308 & 688620 & 6.15 & 5.3821 & TRN & \\
\hline CHEMBL3207385 & 688620 & 4.85 & 4.8981 & TRN & \\
\hline CHEMBL1519280 & 688620 & 5.05 & 5.0189 & TRN & \\
\hline CHEMBL1511505 & 688620 & 5.0 & 5.1071 & TRN & \\
\hline
\end{tabular}




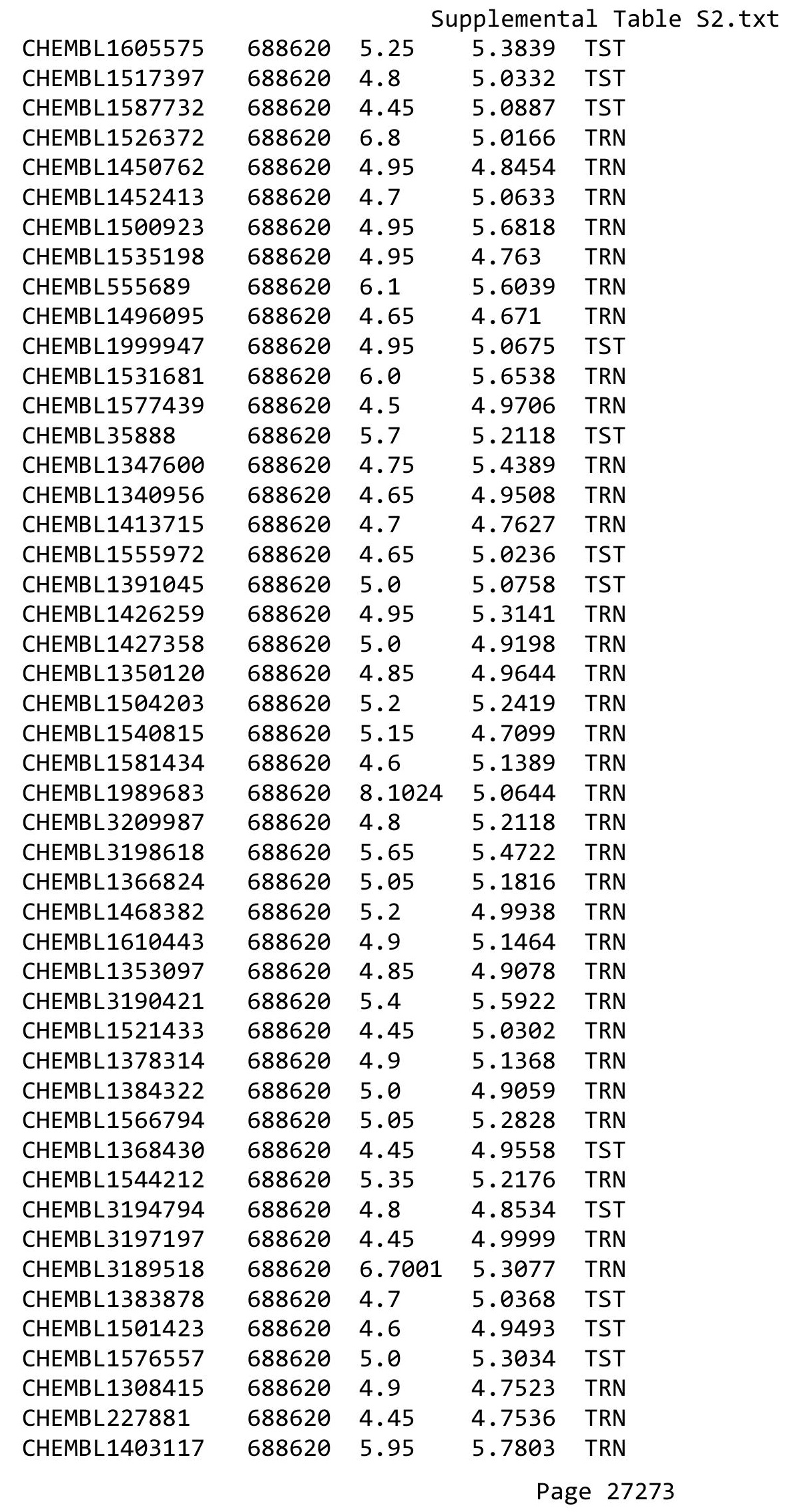




\begin{tabular}{|c|c|c|c|c|c|}
\hline \multicolumn{6}{|c|}{ Supplemental Table S2.txt } \\
\hline CHEMBL1359271 & 688620 & 5.2 & 4.8754 & TRN & \\
\hline CHEMBL3212048 & 688620 & 4.45 & 4.7469 & TRN & \\
\hline CHEMBL1413277 & 688620 & 5.0 & 5.4192 & TRN & \\
\hline CHEMBL1582001 & 688620 & 4.45 & 4.9295 & TRN & \\
\hline CHEMBL1445960 & 688620 & 5.2 & 4.8751 & TST & \\
\hline CHEMBL1323086 & 688620 & 4.95 & 5.1392 & TST & \\
\hline CHEMBL1499033 & 688620 & 5.25 & 4.9963 & TST & \\
\hline CHEMBL 3199240 & 688620 & 5.45 & 5.1775 & TRN & \\
\hline CHEMBL1402086 & 688620 & 5.3 & 4.9439 & TRN & \\
\hline CHEMBL1495910 & 688620 & 5.4 & 5.166 & TST & \\
\hline CHEMBL1501300 & 688620 & 4.6 & 4.8042 & TRN & \\
\hline CHEMBL1455110 & 688620 & 7.0501 & 4.9177 & TST & \\
\hline CHEMBL1968273 & 688620 & 4.55 & 5.2552 & TRN & \\
\hline CHEMBL1317088 & 688620 & 4.45 & 4.8998 & TRN & \\
\hline CHEMBL1506358 & 688620 & 5.35 & 5.16299 & 9999999999 & TRN \\
\hline CHEMBL1308241 & 688620 & 4.45 & 4.8408 & TRN & \\
\hline CHEMBL1585131 & 688620 & 4.6 & 5.0739 & TST & \\
\hline CHEMBL1478382 & 688620 & 4.9 & 4.8682 & TRN & \\
\hline CHEMBL1574119 & 688620 & 4.5 & 5.1964 & TRN & \\
\hline CHEMBL1596856 & 688620 & 4.95 & 4.9871 & TRN & \\
\hline CHEMBL1497019 & 688620 & 5.8 & 5.5396 & TRN & \\
\hline CHEMBL1381159 & 688620 & 4.8 & 4.7377 & TRN & \\
\hline CHEMBL1467629 & 688620 & 6.5 & 4.8411 & TST & \\
\hline CHEMBL1442281 & 688620 & 5.5 & 4.9495 & TST & \\
\hline CHEMBL1326360 & 688620 & 4.65 & 4.8814 & TRN & \\
\hline CHEMBL1604213 & 688620 & 4.45 & 5.027 & TRN & \\
\hline CHEMBL1599428 & 688620 & 5.25 & 5.0329 & TRN & \\
\hline CHEMBL1606829 & 688620 & 4.6 & 5.0163 & TRN & \\
\hline CHEMBL1531790 & 688620 & 4.45 & 5.2961 & TST & \\
\hline CHEMBL1575572 & 688620 & 4.75 & 4.8926 & TRN & \\
\hline CHEMBL1518757 & 688620 & 6.05 & 4.9016 & TRN & \\
\hline CHEMBL1559667 & 688620 & 5.25 & 5.114 & TRN & \\
\hline CHEMBL1366979 & 688620 & 4.45 & 5.12 & TRN & \\
\hline CHEMBL1533819 & 688620 & 5.5 & 4.8062 & TRN & \\
\hline CHEMBL1399019 & 688620 & 4.45 & 4.8989 & TST & \\
\hline CHEMBL1477786 & 688620 & 5.05 & 5.1199 & TRN & \\
\hline CHEMBL1532761 & 688620 & 4.7 & 5.0979 & TRN & \\
\hline CHEMBL1441026 & 688620 & 4.9 & 5.2366 & TRN & \\
\hline CHEMBL1413258 & 688620 & 4.95 & 5.1959 & TST & \\
\hline CHEMBL1363001 & 688620 & 5.0 & 5.2264 & TRN & \\
\hline CHEMBL1587102 & 688620 & 5.05 & 4.9846 & TRN & \\
\hline CHEMBL1432251 & 688620 & 5.3 & 5.4621 & TRN & \\
\hline CHEMBL1549026 & 688620 & 5.05 & 5.188 & TRN & \\
\hline CHEMBL1302439 & 688620 & 5.8 & 5.9406 & TRN & \\
\hline CHEMBL1586012 & 688620 & 4.7 & 4.8006 & TST & \\
\hline CHEMBL1516675 & 688620 & 4.8 & 5.1999 & TST & \\
\hline CHEMBL1599069 & 688620 & 4.95 & 4.9632 & TRN & \\
\hline CHEMBL1495182 & 688620 & 5.2 & 5.0699 & TRN & \\
\hline
\end{tabular}




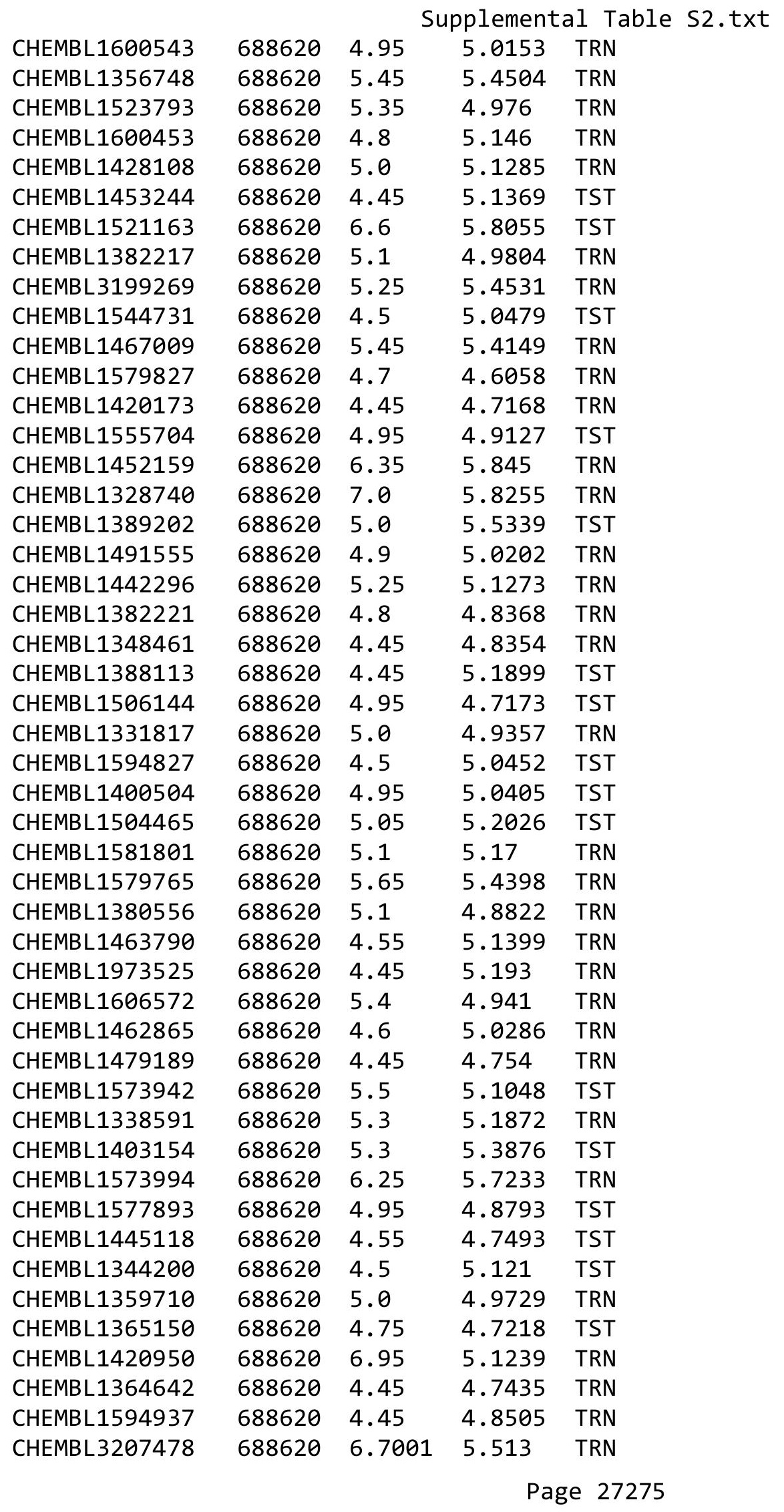




\begin{tabular}{|c|c|c|c|c|}
\hline & & & pplement & al $\mathrm{Ta}$ \\
\hline CHEMBL1550488 & 688620 & 4.7 & 4.9966 & TST \\
\hline CHEMBL1349551 & 688620 & 4.95 & 5.0616 & TRN \\
\hline CHEMBL3195058 & 688620 & 4.55 & 4.7535 & TRN \\
\hline CHEMBL3191635 & 688620 & 5.05 & 4.9305 & TST \\
\hline CHEMBL1548295 & 688620 & 4.75 & 4.6492 & TRN \\
\hline CHEMBL1333728 & 688620 & 4.8 & 4.7318 & TRN \\
\hline CHEMBL1401043 & 688620 & 4.95 & 4.9929 & TST \\
\hline CHEMBL1461020 & 688620 & 5.2 & 5.0197 & TST \\
\hline CHEMBL3192115 & 688620 & 5.7 & 5.6137 & TRN \\
\hline CHEMBL1376992 & 688620 & 4.9 & 4.9706 & TST \\
\hline CHEMBL3208834 & 688620 & 4.9 & 4.7923 & TRN \\
\hline CHEMBL1511495 & 688620 & 5.0 & 4.7982 & TRN \\
\hline CHEMBL1458458 & 688620 & 4.65 & 4.8871 & TST \\
\hline CHEMBL1300543 & 688620 & 4.75 & 5.1414 & TRN \\
\hline CHEMBL1505450 & 688620 & 5.55 & 4.9663 & TRN \\
\hline CHEMBL3214055 & 688620 & 4.55 & 4.9963 & TST \\
\hline CHEMBL1300738 & 688620 & 5.2 & 5.2868 & TST \\
\hline CHEMBL1451110 & 688620 & 5.2 & 5.2269 & TRN \\
\hline CHEMBL1477694 & 688620 & 4.7 & 4.9979 & TRN \\
\hline CHEMBL1342709 & 688620 & 4.9 & 5.0563 & TRN \\
\hline CHEMBL1995904 & 688620 & 4.75 & 5.0967 & TRN \\
\hline CHEMBL1607902 & 688620 & 4.8 & 4.9779 & TRN \\
\hline CHEMBL1400206 & 688620 & 4.45 & 5.0305 & TRN \\
\hline CHEMBL3192256 & 688620 & 4.7 & 5.8141 & TRN \\
\hline CHEMBL1471435 & 688620 & 5.15 & 4.9106 & TRN \\
\hline CHEMBL1532241 & 688620 & 7.6498 & 4.9324 & TRN \\
\hline CHEMBL1548259 & 688620 & 5.55 & 4.9088 & TRN \\
\hline CHEMBL1602242 & 688620 & 4.45 & 4.9477 & TRN \\
\hline CHEMBL1311099 & 688620 & 5.1 & 4.9302 & TST \\
\hline CHEMBL1479830 & 688620 & 4.9 & 5.0089 & TST \\
\hline CHEMBL1304206 & 688620 & 5.15 & 4.8646 & TRN \\
\hline CHEMBL1456841 & 688620 & 5.05 & 5.0262 & TRN \\
\hline CHEMBL1494260 & 688620 & 7.0501 & 5.3015 & TRN \\
\hline CHEMBL1328939 & 688620 & 4.6 & 4.6222 & TRN \\
\hline CHEMBL1421182 & 688620 & 4.95 & 4.7503 & TRN \\
\hline CHEMBL1609372 & 688620 & 4.85 & 4.9778 & TRN \\
\hline CHEMBL1464522 & 688620 & 5.3 & 4.762 & TRN \\
\hline CHEMBL588804 & 688620 & 6.1 & 5.8202 & TRN \\
\hline CHEMBL1350156 & 688620 & 4.4 & 5.0971 & TST \\
\hline CHEMBL1502209 & 688620 & 4.45 & 5.2237 & TRN \\
\hline CHEMBL1423482 & 688620 & 5.3 & 5.2834 & TRN \\
\hline CHEMBL1529922 & 688620 & 4.6 & 4.9093 & TRN \\
\hline CHEMBL1302821 & 688620 & 4.95 & 5.3028 & TRN \\
\hline CHEMBL1353845 & 688620 & 5.75 & 5.5508 & TRN \\
\hline CHEMBL1333939 & 688620 & 7.4498 & 5.006 & TST \\
\hline CHEMBL1583170 & 688620 & 4.45 & 5.0683 & TRN \\
\hline CHEMBL1609746 & 688620 & 4.45 & 4.9789 & TRN \\
\hline CHEMBL1422478 & 688620 & 5.0 & 5.1262 & TST \\
\hline
\end{tabular}




\begin{tabular}{|c|c|c|c|c|c|}
\hline & & & & & \\
\hline CHEMBL1342524 & 688620 & 4.9 & 5.0829 & TST & \\
\hline CHEMBL1546853 & 688620 & 4.45 & 4.7628 & TRN & \\
\hline CHEMBL1387811 & 688620 & 4.85 & 4.9606 & TRN & \\
\hline CHEMBL1535058 & 688620 & 4.6 & 5.0544 & TST & \\
\hline CHEMBL1394387 & 688620 & 4.85 & 5.0234 & TRN & \\
\hline CHEMBL1420471 & 688620 & 4.9 & 5.1337 & TRN & \\
\hline CHEMBL 2000592 & 688620 & 4.45 & 5.2567 & TST & \\
\hline CHEMBL1597923 & 688620 & 5.2 & 4.91100 & 00000000005 & TRN \\
\hline CHEMBL1589588 & 688620 & 4.5 & 5.041 & TST & \\
\hline CHEMBL 2004918 & 688620 & 4.45 & 5.2143 & TST & \\
\hline CHEMBL3210869 & 688620 & 5.2 & 5.0278 & TST & \\
\hline CHEMBL1430531 & 688620 & 5.35 & 5.3042 & TRN & \\
\hline CHEMBL1369478 & 688620 & 4.9 & 5.1623 & TST & \\
\hline CHEMBL1306215 & 688620 & 5.0 & 4.9778 & TST & \\
\hline CHEMBL1521167 & 688620 & 6.0 & 5.34399 & 9999999999 & TRN \\
\hline CHEMBL1531514 & 688620 & 5.5 & 4.9907 & TRN & \\
\hline CHEMBL1604106 & 688620 & 5.35 & 5.2004 & TST & \\
\hline CHEMBL1562493 & 688620 & 6.0 & 5.5605 & TRN & \\
\hline CHEMBL 227423 & 688620 & 4.7 & 4.7574 & TRN & \\
\hline CHEMBL1526081 & 688620 & 6.1 & 5.9902 & TRN & \\
\hline CHEMBL1521669 & 688620 & 5.15 & 5.3415 & TRN & \\
\hline CHEMBL1352186 & 688620 & 4.45 & 4.912 & TST & \\
\hline CHEMBL1506173 & 688620 & 4.7 & 4.9256 & TRN & \\
\hline CHEMBL1490937 & 688620 & 4.75 & 4.9137 & TRN & \\
\hline CHEMBL1426584 & 688620 & 4.65 & 4.835 & TRN & \\
\hline CHEMBL1996749 & 688620 & 5.75 & 5.4626 & TRN & \\
\hline CHEMBL1466057 & 688620 & 8.0506 & 4.9093 & TST & \\
\hline CHEMBL1413175 & 688620 & 4.9 & 4.9713 & TRN & \\
\hline CHEMBL1606716 & 688620 & 6.0 & 6.0369 & TRN & \\
\hline CHEMBL1498509 & 688620 & 5.5 & 5.5333 & TRN & \\
\hline CHEMBL1431383 & 688620 & 4.65 & 5.1309 & TRN & \\
\hline CHEMBL1509103 & 688620 & 4.45 & 5.0432 & TST & \\
\hline CHEMBL1332598 & 688620 & 5.9 & 5.4098 & TST & \\
\hline CHEMBL 3194549 & 688620 & 5.0 & 4.9232 & TRN & \\
\hline CHEMBL3193201 & 688620 & 5.85 & 5.315 & TRN & \\
\hline CHEMBL3195776 & 688620 & 5.1 & 5.2615 & TRN & \\
\hline CHEMBL1560784 & 688620 & 4.45 & 4.7054 & TRN & \\
\hline CHEMBL1324425 & 688620 & 5.05 & 5.0534 & TST & \\
\hline CHEMBL1376883 & 688620 & 5.6 & 5.4571 & TRN & \\
\hline CHEMBL1506906 & 688620 & 6.9 & 4.9245 & TRN & \\
\hline CHEMBL1398592 & 688620 & 4.45 & 4.6759 & TRN & \\
\hline CHEMBL1391223 & 688620 & 6.05 & 5.0565 & TST & \\
\hline CHEMBL1567800 & 688620 & 4.95 & 4.8025 & TST & \\
\hline CHEMBL1310290 & 688620 & 4.95 & 5.1566 & TST & \\
\hline CHEMBL1364556 & 688620 & 4.8 & 4.9332 & TRN & \\
\hline CHEMBL1393582 & 688620 & 4.9 & 4.84 & TRN & \\
\hline CHEMBL1485538 & 688620 & 4.8 & 5.0073 & TRN & \\
\hline CHEMBL1416253 & 688620 & 4.95 & 5.1329 & TRN & \\
\hline
\end{tabular}




\begin{tabular}{|c|c|c|c|c|}
\hline & & & upplemen & al $\mathrm{T}$ \\
\hline CHEMBL3192205 & 688620 & 4.9 & 5.2219 & TST \\
\hline CHEMBL1327682 & 688620 & 5.0 & 5.0149 & TRN \\
\hline CHEMBL3192055 & 688620 & 4.85 & 5.0305 & TRN \\
\hline CHEMBL1588623 & 688620 & 5.5 & 5.2108 & TST \\
\hline CHEMBL1450669 & 688620 & 5.9 & 5.4766 & TRN \\
\hline CHEMBL1411226 & 688620 & 4.65 & 5.1919 & TRN \\
\hline CHEMBL1544830 & 688620 & 4.45 & 4.8151 & TRN \\
\hline CHEMBL1429330 & 688620 & 4.5 & 5.2088 & TRN \\
\hline CHEMBL1588749 & 688620 & 5.4 & 5.0242 & TST \\
\hline CHEMBL1530137 & 688620 & 5.95 & 4.9509 & TRN \\
\hline CHEMBL1375289 & 688620 & 5.55 & 4.9085 & TRN \\
\hline CHEMBL1558957 & 688620 & 5.25 & 5.0155 & TRN \\
\hline CHEMBL1427380 & 688620 & 5.15 & 5.1279 & TST \\
\hline CHEMBL1431052 & 688620 & 4.45 & 4.9439 & TRN \\
\hline CHEMBL1510316 & 688620 & 5.05 & 5.099 & TST \\
\hline CHEMBL1370456 & 688620 & 6.15 & 5.2436 & TST \\
\hline CHEMBL1347555 & 688620 & 5.05 & 5.0083 & TRN \\
\hline CHEMBL3198358 & 688620 & 4.7 & 5.1216 & TRN \\
\hline CHEMBL1493616 & 688620 & 4.65 & 5.0206 & TRN \\
\hline CHEMBL1394135 & 688620 & 4.85 & 4.8419 & TRN \\
\hline CHEMBL1590261 & 688620 & 4.45 & 4.8205 & TRN \\
\hline CHEMBL1362631 & 688620 & 4.45 & 4.8764 & TST \\
\hline CHEMBL1428282 & 688620 & 5.9 & 5.0142 & TRN \\
\hline CHEMBL1517912 & 688620 & 5.05 & 4.8379 & TRN \\
\hline CHEMBL1489644 & 688620 & 4.8 & 4.9994 & TRN \\
\hline CHEMBL1379723 & 688620 & 5.05 & 5.0683 & TRN \\
\hline CHEMBL1352368 & 688620 & 5.9 & 5.8603 & TRN \\
\hline CHEMBL1492194 & 688620 & 4.7 & 4.8547 & TRN \\
\hline CHEMBL1440746 & 688620 & 4.85 & 5.0048 & TRN \\
\hline CHEMBL1496625 & 688620 & 5.0 & 4.8701 & TRN \\
\hline CHEMBL3191179 & 688620 & 4.5 & 5.0284 & TRN \\
\hline CHEMBL1481123 & 688620 & 4.45 & 4.9907 & TST \\
\hline CHEMBL1362352 & 688620 & 5.2 & 4.8685 & TRN \\
\hline CHEMBL1359872 & 688620 & 4.8 & 5.0143 & TRN \\
\hline CHEMBL3189169 & 688620 & 5.3 & 5.4195 & TRN \\
\hline CHEMBL1484987 & 688620 & 5.2 & 4.8672 & TRN \\
\hline CHEMBL3196113 & 688620 & 4.45 & 4.8212 & TRN \\
\hline CHEMBL1400056 & 688620 & 4.45 & 4.8306 & TRN \\
\hline CHEMBL3191125 & 688620 & 5.2 & 4.7334 & TRN \\
\hline CHEMBL1454187 & 688620 & 4.95 & 4.8952 & TST \\
\hline CHEMBL1323909 & 688620 & 5.6 & 5.7238 & TRN \\
\hline CHEMBL1586177 & 688620 & 4.75 & 5.0152 & TRN \\
\hline CHEMBL3190125 & 688620 & 5.75 & 5.9612 & TRN \\
\hline CHEMBL1497282 & 688620 & 5.25 & 5.7901 & TRN \\
\hline CHEMBL1271916 & 688620 & 4.6 & 4.891 & TRN \\
\hline CHEMBL1451521 & 688620 & 4.8 & 5.3221 & TRN \\
\hline CHEMBL1501437 & 688620 & 4.7 & 4.6906 & TRN \\
\hline CHEMBL1458249 & 688620 & 5.65 & 4.9571 & TST \\
\hline
\end{tabular}




\begin{tabular}{|c|c|c|c|c|}
\hline \multicolumn{5}{|c|}{ Supplemental Table S2.txt } \\
\hline CHEMBL1371080 & 688620 & 4.45 & 5.3711 & TRN \\
\hline CHEMBL1471641 & 688620 & 4.5 & 4.8328 & TRN \\
\hline CHEMBL 3193702 & 688620 & 5.7 & 5.3781 & TST \\
\hline CHEMBL1469532 & 688620 & 4.45 & 4.9481 & TRN \\
\hline CHEMBL1461091 & 688620 & 4.7 & 5.0738 & TST \\
\hline CHEMBL1333647 & 688620 & 5.25 & 5.8177 & TST \\
\hline CHEMBL1539266 & 688620 & 4.85 & 5.0684 & TST \\
\hline CHEMBL1447540 & 688620 & 5.5 & 5.2068 & TST \\
\hline CHEMBL1392838 & 688620 & 4.45 & 5.6605 & TRN \\
\hline CHEMBL1415810 & 688620 & 5.4 & 5.3015 & TRN \\
\hline CHEMBL1310328 & 688620 & 4.5 & 4.8701 & TRN \\
\hline CHEMBL1490598 & 688620 & 7.15 & 4.9321 & TST \\
\hline CHEMBL1426921 & 688620 & 4.85 & 5.1602 & TRN \\
\hline CHEMBL1568504 & 688620 & 5.15 & 4.9672 & TRN \\
\hline CHEMBL1517787 & 688620 & 4.45 & 5.0163 & TRN \\
\hline CHEMBL1395485 & 688620 & 4.45 & 4.6802 & TRN \\
\hline CHEMBL 3194208 & 688620 & 5.0 & 5.2812 & TRN \\
\hline CHEMBL1444912 & 688620 & 4.6 & 4.8607 & TRN \\
\hline CHEMBL1537672 & 688620 & 5.9 & 5.0787 & TST \\
\hline CHEMBL1609070 & 688620 & 5.0 & 4.7267 & TRN \\
\hline CHEMBL1365552 & 688620 & 4.85 & 5.0334 & TRN \\
\hline CHEMBL1964338 & 688620 & 4.7 & 5.2228 & TST \\
\hline CHEMBL1612323 & 688620 & 4.85 & 5.0775 & TRN \\
\hline CHEMBL 3209383 & 688620 & 5.75 & 5.5341 & TRN \\
\hline CHEMBL1589210 & 688620 & 4.8 & 4.7994 & TRN \\
\hline CHEMBL1557454 & 688620 & 5.05 & 5.1193 & TRN \\
\hline CHEMBL1380996 & 688620 & 4.75 & 4.8983 & TRN \\
\hline CHEMBL1472342 & 688620 & 4.95 & 5.0138 & TRN \\
\hline CHEMBL1603441 & 688620 & 4.55 & 5.1506 & TRN \\
\hline CHEMBL1366114 & 688620 & 5.6 & 5.6029 & TRN \\
\hline CHEMBL1428935 & 688620 & 5.3 & 5.697 & TRN \\
\hline CHEMBL589062 & 688620 & 4.6 & 4.8691 & TRN \\
\hline CHEMBL1459627 & 688620 & 5.0 & 5.0666 & TST \\
\hline CHEMBL1305366 & 688620 & 7.0501 & 5.1031 & TRN \\
\hline CHEMBL1386801 & 688620 & 7.0501 & 5.0985 & TRN \\
\hline CHEMBL1335392 & 688620 & 4.5 & 4.9902 & TRN \\
\hline CHEMBL1600209 & 688620 & 4.9 & 4.9356 & TST \\
\hline CHEMBL1527610 & 688620 & 4.8 & 4.9008 & TST \\
\hline CHEMBL1482540 & 688620 & 5.9 & 6.0695 & TRN \\
\hline CHEMBL1537977 & 688620 & 5.2 & 5.1896 & TRN \\
\hline CHEMBL1970836 & 688620 & 6.8499 & 6.1734 & TRN \\
\hline CHEMBL1324334 & 688620 & 4.8 & 4.7443 & TRN \\
\hline CHEMBL1303880 & 688620 & 4.45 & 4.6884 & TRN \\
\hline CHEMBL1360402 & 688620 & 4.9 & 5.0714 & TST \\
\hline CHEMBL1450621 & 688620 & 4.9 & 4.8312 & TRN \\
\hline CHEMBL1520176 & 688620 & 4.45 & 5.1404 & TST \\
\hline CHEMBL3196067 & 688620 & 5.05 & 5.1356 & TRN \\
\hline CHEMBL1573534 & 688620 & 5.25 & 5.2138 & TRN \\
\hline
\end{tabular}




\begin{tabular}{|c|c|c|c|c|}
\hline \multicolumn{5}{|c|}{ Supplemental Table S2.txt } \\
\hline CHEMBL3195767 & 688620 & 4.8 & 5.279 & TRN \\
\hline CHEMBL1539136 & 688620 & 4.75 & 4.8985 & TRN \\
\hline CHEMBL592111 & 688620 & 4.75 & 4.7985 & TRN \\
\hline CHEMBL3210738 & 688620 & 4.45 & 5.0333 & TST \\
\hline CHEMBL1471158 & 688620 & 4.65 & 5.029 & TRN \\
\hline CHEMBL1451422 & 688620 & 5.3 & 5.6243 & TRN \\
\hline CHEMBL1307045 & 688620 & 4.45 & 5.0839 & TST \\
\hline CHEMBL1534669 & 688620 & 4.55 & 4.8305 & TST \\
\hline CHEMBL1517503 & 688620 & 8.301 & 5.0281 & TRN \\
\hline CHEMBL1457272 & 688620 & 5.15 & 4.9644 & TRN \\
\hline CHEMBL1441160 & 688620 & 4.45 & 4.8081 & TRN \\
\hline CHEMBL1969760 & 688620 & 4.55 & 4.8308 & TRN \\
\hline CHEMBL427449 & 688620 & 5.15 & 4.7065 & TRN \\
\hline CHEMBL1544671 & 688620 & 4.45 & 5.0301 & TST \\
\hline CHEMBL 3212607 & 688620 & 4.45 & 5.1896 & TST \\
\hline CHEMBL1434420 & 688620 & 4.45 & 4.9406 & TRN \\
\hline CHEMBL 366884 & 688620 & 4.95 & 4.774 & TRN \\
\hline CHEMBL1473548 & 688620 & 4.9 & 5.519 & TRN \\
\hline CHEMBL1380507 & 688620 & 4.6 & 5.1491 & TRN \\
\hline CHEMBL1398147 & 688620 & 4.9 & 4.7534 & TST \\
\hline CHEMBL3189476 & 688620 & 4.9 & 5.0997 & TST \\
\hline CHEMBL1335755 & 688620 & 5.0 & 4.8857 & TRN \\
\hline CHEMBL1357197 & 688620 & 4.9 & 4.9288 & TRN \\
\hline CHEMBL1460249 & 688620 & 4.45 & 4.8971 & TST \\
\hline CHEMBL1413485 & 688620 & 5.2 & 5.2043 & TRN \\
\hline CHEMBL1347902 & 688620 & 4.65 & 4.9581 & TRN \\
\hline CHEMBL1352154 & 688620 & 4.95 & 5.25 & TRN \\
\hline CHEMBL1467061 & 688620 & 5.4 & 5.4058 & TRN \\
\hline CHEMBL1505823 & 688620 & 4.9 & 5.3101 & TRN \\
\hline CHEMBL1536945 & 688620 & 4.8 & 5.3386 & TRN \\
\hline CHEMBL1464957 & 688620 & 5.15 & 5.1791 & TRN \\
\hline CHEMBL1978564 & 688620 & 4.75 & 4.7994 & TRN \\
\hline CHEMBL1549415 & 688620 & 4.95 & 5.0546 & TRN \\
\hline CHEMBL1365113 & 688620 & 5.05 & 5.0352 & TRN \\
\hline CHEMBL1379538 & 688620 & 5.3 & 4.9866 & TRN \\
\hline CHEMBL3190291 & 688620 & 5.1 & 4.9779 & TRN \\
\hline CHEMBL1539809 & 688620 & 4.95 & 4.8922 & TRN \\
\hline CHEMBL1539644 & 688620 & 4.45 & 5.3227 & TST \\
\hline CHEMBL1571275 & 688620 & 5.35 & 5.1359 & TRN \\
\hline CHEMBL1386445 & 688620 & 4.8 & 4.8946 & TRN \\
\hline CHEMBL3191742 & 688620 & 5.95 & 5.0451 & TRN \\
\hline CHEMBL1469922 & 688620 & 4.8 & 6.3073 & TRN \\
\hline CHEMBL1501014 & 688620 & 4.9 & 5.2462 & TST \\
\hline CHEMBL1363569 & 688620 & 6.1 & 5.329 & TRN \\
\hline CHEMBL1486941 & 688620 & 5.3 & 4.9704 & TRN \\
\hline CHEMBL 3194870 & 688620 & 5.75 & 5.1208 & TRN \\
\hline CHEMBL1606450 & 688620 & 4.75 & 4.8589 & TST \\
\hline CHEMBL1346932 & 688620 & 4.45 & 4.8583 & TST \\
\hline
\end{tabular}




\begin{tabular}{|c|c|c|c|c|c|}
\hline & & \multicolumn{4}{|c|}{ Supplemental Table S2.txt } \\
\hline CHEMBL1570624 & 688620 & 6.5501 & 5.5048 & TST & \\
\hline CHEMBL1402514 & 688620 & 4.85 & 5.05699 & 99999999995 & TRN \\
\hline CHEMBL1611440 & 688620 & 6.05 & 5.2452 & TST & \\
\hline CHEMBL1575781 & 688620 & 5.45 & 5.0651 & TRN & \\
\hline CHEMBL1340813 & 688620 & 4.6 & 4.9199 & TRN & \\
\hline CHEMBL1499914 & 688620 & 4.8 & 5.3833 & TRN & \\
\hline CHEMBL1478224 & 688620 & 4.45 & 5.0416 & TST & \\
\hline CHEMBL1445412 & 688620 & 4.95 & 5.1694 & TST & \\
\hline CHEMBL1305429 & 688620 & 4.45 & 5.1322 & TRN & \\
\hline CHEMBL487958 & 688620 & 5.45 & 5.1225 & TRN & \\
\hline CHEMBL1328934 & 688620 & 5.65 & 4.9877 & TST & \\
\hline CHEMBL1557695 & 688620 & 6.1 & 4.9543 & TST & \\
\hline CHEMBL1461250 & 688620 & 5.35 & 4.9996 & TRN & \\
\hline CHEMBL1487272 & 688620 & 4.45 & 4.7276 & TST & \\
\hline CHEMBL1588708 & 688620 & 5.95 & 5.7251 & TRN & \\
\hline CHEMBL1527779 & 688620 & 4.75 & 4.8995 & TRN & \\
\hline CHEMBL1544877 & 688620 & 5.35 & 5.191 & TRN & \\
\hline CHEMBL276618 & 688620 & 4.9 & 4.8765 & TRN & \\
\hline CHEMBL1526958 & 688620 & 4.7 & 4.9071 & TST & \\
\hline CHEMBL1445372 & 688620 & 4.95 & 5.2469 & TRN & \\
\hline CHEMBL1538495 & 688620 & 4.45 & 4.9134 & TRN & \\
\hline CHEMBL1416084 & 688620 & 4.85 & 4.9581 & TST & \\
\hline CHEMBL1549549 & 688620 & 4.75 & 4.8423 & TRN & \\
\hline CHEMBL1607984 & 688620 & 4.6 & 5.1825 & TST & \\
\hline CHEMBL1412177 & 688620 & 5.7 & 5.3593 & TRN & \\
\hline CHEMBL1325331 & 688620 & 4.85 & 5.1046 & TST & \\
\hline CHEMBL1565769 & 688620 & 4.45 & 5.0054 & TST & \\
\hline CHEMBL1389308 & 688620 & 5.0 & 4.8013 & TRN & \\
\hline CHEMBL1451386 & 688620 & 7.0 & 5.1083 & TST & \\
\hline CHEMBL1508937 & 688620 & 4.7 & 5.2414 & TRN & \\
\hline CHEMBL1386656 & 688620 & 4.45 & 4.9113 & TRN & \\
\hline CHEMBL1466357 & 688620 & 4.45 & 4.9208 & TRN & \\
\hline CHEMBL1602859 & 688620 & 5.8 & 5.3803 & TRN & \\
\hline CHEMBL1591374 & 688620 & 4.45 & 4.6432 & TRN & \\
\hline CHEMBL1345747 & 688620 & 5.45 & 5.0414 & TRN & \\
\hline CHEMBL1345771 & 688620 & 4.65 & 5.2199 & TST & \\
\hline CHEMBL1610388 & 688620 & 5.15 & 5.1148 & TRN & \\
\hline CHEMBL1451139 & 688620 & 5.0 & 4.9636 & TST & \\
\hline CHEMBL1570403 & 688620 & 4.85 & 5.1696 & TRN & \\
\hline CHEMBL1390905 & 688620 & 4.95 & 4.9789 & TRN & \\
\hline CHEMBL1602086 & 688620 & 5.95 & 5.9559 & TRN & \\
\hline CHEMBL3189700 & 688620 & 5.6 & 5.599 & TRN & \\
\hline CHEMBL1489111 & 688620 & 4.7 & 4.7566 & TRN & \\
\hline CHEMBL1545575 & 688620 & 5.45 & 5.2139 & TRN & \\
\hline CHEMBL1440648 & 688620 & 4.45 & 5.0096 & TST & \\
\hline CHEMBL1503960 & 688620 & 4.95 & 5.0199 & TRN & \\
\hline CHEMBL3190877 & 688620 & 4.45 & 4.6924 & TRN & \\
\hline CHEMBL1550164 & 688620 & 4.85 & 5.0874 & TRN & \\
\hline
\end{tabular}




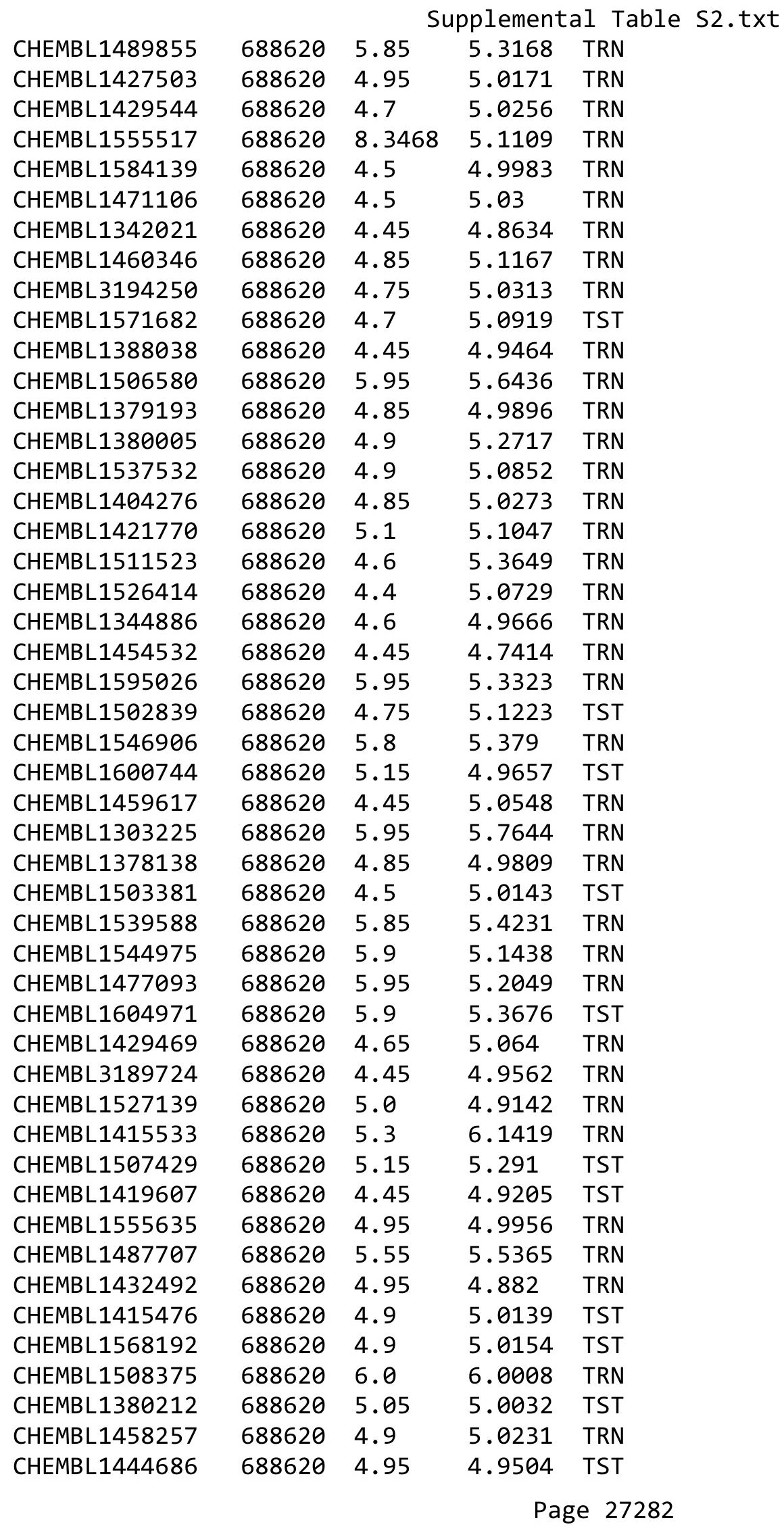




\begin{tabular}{|c|c|c|c|c|c|}
\hline & & \multicolumn{4}{|c|}{ Supplemental Table S2.txt } \\
\hline CHEMBL1550728 & 688620 & 7.7496 & 5.2294 & TRN & \\
\hline CHEMBL1455676 & 688620 & 4.85 & 5.1633 & TST & \\
\hline CHEMBL1370383 & 688620 & 5.05 & 4.9707 & TRN & \\
\hline CHEMBL1550664 & 688620 & 5.1 & 5.1707 & TRN & \\
\hline CHEMBL1467418 & 688620 & 5.15 & 5.1736 & TRN & \\
\hline CHEMBL3190389 & 688620 & 5.6 & 4.8735 & TRN & \\
\hline CHEMBL1504712 & 688620 & 5.0 & 4.7599 & TRN & \\
\hline CHEMBL1599309 & 688620 & 4.8 & 5.0583 & TRN & \\
\hline CHEMBL1507823 & 688620 & 5.4 & 5.36799 & 9999999999 & TRN \\
\hline CHEMBL1379649 & 688620 & 4.95 & 5.1902 & TRN & \\
\hline CHEMBL1462826 & 688620 & 4.85 & 5.3718 & TST & \\
\hline CHEMBL1464249 & 688620 & 4.65 & 4.6718 & TRN & \\
\hline CHEMBL1423661 & 688620 & 4.9 & 5.1002 & TST & \\
\hline CHEMBL1434683 & 688620 & 4.95 & 5.0342 & TRN & \\
\hline CHEMBL1428906 & 688620 & 5.2 & 5.1406 & TRN & \\
\hline CHEMBL602218 & 688620 & 5.0 & 5.2944 & TRN & \\
\hline CHEMBL3190826 & 688620 & 4.8 & 5.0862 & TRN & \\
\hline CHEMBL1411056 & 688620 & 4.5 & 4.8822 & TRN & \\
\hline CHEMBL1347743 & 688620 & 4.95 & 5.06800 & 00000000005 & TST \\
\hline CHEMBL1390128 & 688620 & 6.15 & 5.2554 & TRN & \\
\hline CHEMBL3189819 & 688620 & 5.0 & 4.8853 & TRN & \\
\hline CHEMBL1397534 & 688620 & 5.9 & 5.0602 & TST & \\
\hline CHEMBL1324063 & 688620 & 4.9 & 5.0279 & TRN & \\
\hline CHEMBL1580066 & 688620 & 5.75 & 4.9111 & TRN & \\
\hline CHEMBL1478462 & 688620 & 5.5 & 4.9428 & TRN & \\
\hline CHEMBL1491867 & 688620 & 5.0 & 4.9846 & TST & \\
\hline CHEMBL1311367 & 688620 & 4.55 & 4.9234 & TST & \\
\hline CHEMBL1463156 & 688620 & 4.7 & 4.8342 & TRN & \\
\hline CHEMBL1392045 & 688620 & 5.4 & 4.9929 & TRN & \\
\hline CHEMBL1582602 & 688620 & 5.25 & 5.1092 & TST & \\
\hline CHEMBL1511336 & 688620 & 6.45 & 5.1746 & TRN & \\
\hline CHEMBL1440011 & 688620 & 4.5 & 5.0082 & TRN & \\
\hline CHEMBL1365313 & 688620 & 4.95 & 5.1471 & TRN & \\
\hline CHEMBL3199776 & 688620 & 5.0 & 5.1623 & TRN & \\
\hline CHEMBL1417558 & 688620 & 4.95 & 5.2553 & TRN & \\
\hline CHEMBL1372428 & 688620 & 5.0 & 5.8348 & TRN & \\
\hline CHEMBL1345994 & 688620 & 4.95 & 5.0969 & TRN & \\
\hline CHEMBL1558571 & 688620 & 4.9 & 4.8105 & TST & \\
\hline CHEMBL1425704 & 688620 & 6.05 & 5.4032 & TRN & \\
\hline CHEMBL1322834 & 688620 & 5.75 & 5.0878 & TRN & \\
\hline CHEMBL1585499 & 688620 & 4.45 & 4.8551 & TRN & \\
\hline CHEMBL1502497 & 688620 & 4.95 & 4.8623 & TST & \\
\hline CHEMBL1379687 & 688620 & 5.0 & 5.4146 & TRN & \\
\hline CHEMBL3199577 & 688620 & 5.6 & 5.6505 & TRN & \\
\hline CHEMBL1365705 & 688620 & 7.0 & 6.1285 & TRN & \\
\hline CHEMBL1599906 & 688620 & 4.45 & 5.0059 & TST & \\
\hline CHEMBL1316236 & 688620 & 4.45 & 4.8419 & TRN & \\
\hline CHEMBL1465145 & 688620 & 5.0 & 5.0912 & TST & \\
\hline
\end{tabular}




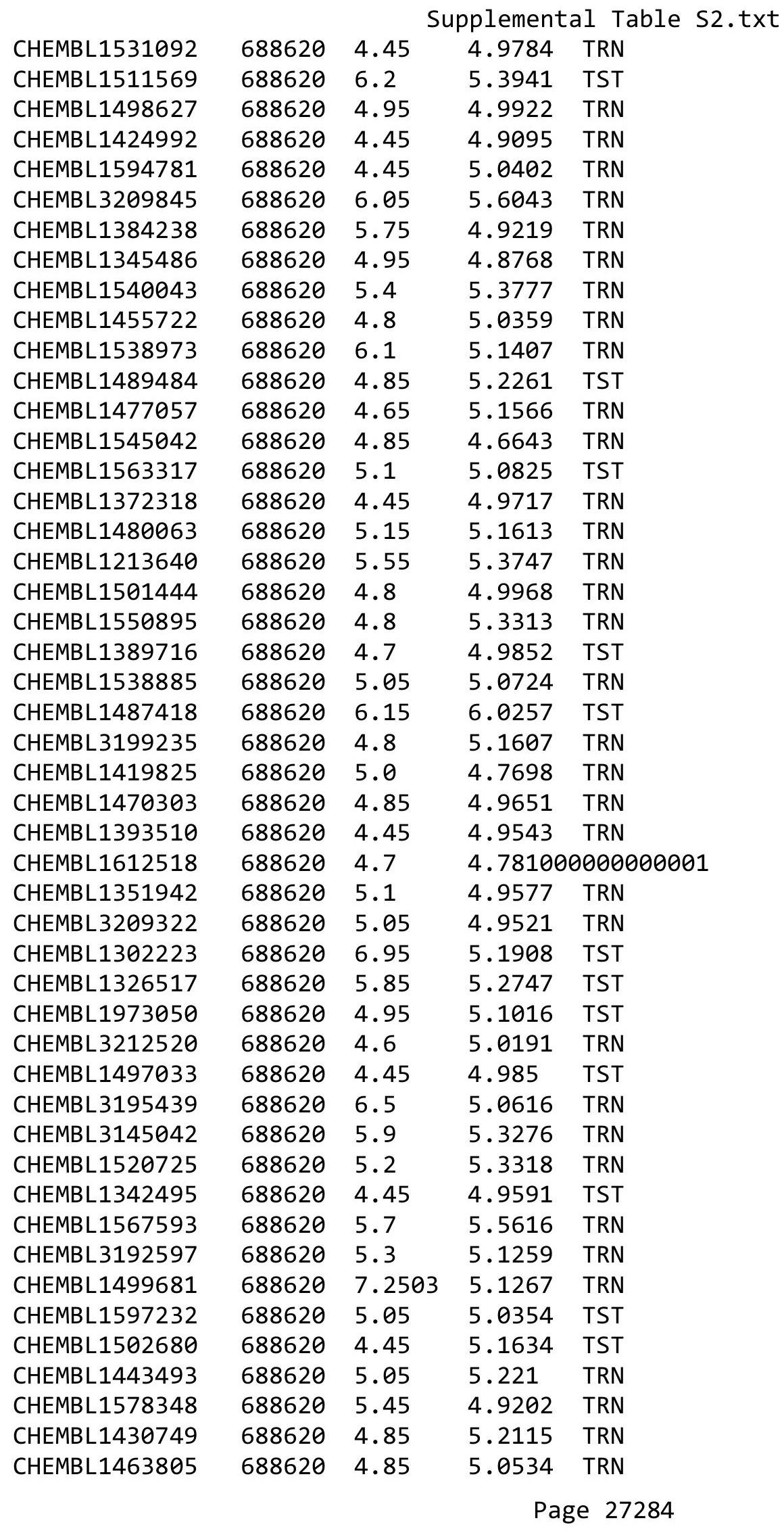




\begin{tabular}{|c|c|c|c|c|c|}
\hline & & \multicolumn{4}{|c|}{ Supplemental Table S2.txt } \\
\hline CHEMBL1303570 & 688620 & 5.05 & 5.1104 & TRN & \\
\hline CHEMBL1560360 & 688620 & 4.85 & 5.0639 & TRN & \\
\hline CHEMBL1535055 & 688620 & 4.75 & 4.8782 & TST & \\
\hline CHEMBL1338313 & 688620 & 4.45 & 5.0782 & TRN & \\
\hline CHEMBL1391267 & 688620 & 4.9 & 5.2123 & TRN & \\
\hline CHEMBL1337406 & 688620 & 5.3 & 5.1513 & TRN & \\
\hline CHEMBL3210962 & 688620 & 5.5 & 5.1774 & TRN & \\
\hline CHEMBL1300347 & 688620 & 5.0 & 5.3137 & TRN & \\
\hline CHEMBL3199822 & 688620 & 5.55 & 5.3505 & TRN & \\
\hline CHEMBL1462541 & 688620 & 5.3 & 5.4068 & TRN & \\
\hline CHEMBL3193112 & 688620 & 4.8 & 5.1681 & TRN & \\
\hline CHEMBL1599292 & 688620 & 4.85 & 4.918 & TRN & \\
\hline CHEMBL1525334 & 688620 & 5.35 & 5.2452 & TRN & \\
\hline CHEMBL1607226 & 688620 & 4.9 & 5.0148 & TRN & \\
\hline CHEMBL1539256 & 688620 & 5.5 & 4.8983 & TRN & \\
\hline CHEMBL1492328 & 688620 & 4.85 & 5.1917 & TST & \\
\hline CHEMBL1491641 & 688620 & 5.05 & 5.1507 & TST & \\
\hline CHEMBL1409216 & 688620 & 5.6 & 4.8736 & TRN & \\
\hline CHEMBL1370871 & 688620 & 4.75 & 5.1889 & TRN & \\
\hline CHEMBL3198948 & 688620 & 4.6 & 4.6997 & TST & \\
\hline CHEMBL1241671 & 688620 & 4.9 & 5.0443 & TST & \\
\hline CHEMBL1421347 & 688620 & 5.95 & 5.1016 & TST & \\
\hline CHEMBL3190558 & 688620 & 4.45 & 4.8852 & TST & \\
\hline CHEMBL1599226 & 688620 & 5.7 & 5.0465 & TRN & \\
\hline CHEMBL1301808 & 688620 & 5.4 & 4.9298 & TRN & \\
\hline CHEMBL1461546 & 688620 & 4.45 & 4.9321 & TST & \\
\hline CHEMBL1554199 & 688620 & 4.95 & 4.819 & TRN & \\
\hline CHEMBL1480681 & 688620 & 4.85 & 5.1567 & TRN & \\
\hline CHEMBL1507613 & 688620 & 5.3 & 4.84399 & 9999999999 & TRN \\
\hline CHEMBL1530754 & 688620 & 4.85 & 5.0202 & TRN & \\
\hline CHEMBL3193303 & 688620 & 5.5 & 5.3133 & TRN & \\
\hline CHEMBL1591107 & 688620 & 5.4 & 4.941 & TRN & \\
\hline CHEMBL1601856 & 688620 & 4.45 & 5.0669 & TRN & \\
\hline CHEMBL1312906 & 688620 & 4.65 & 5.4043 & TST & \\
\hline CHEMBL1321243 & 688620 & 4.85 & 4.9986 & TRN & \\
\hline CHEMBL1302488 & 688620 & 5.35 & 4.8501 & TRN & \\
\hline CHEMBL1602778 & 688620 & 5.2 & 5.0856 & TRN & \\
\hline CHEMBL1448713 & 688620 & 5.35 & 5.0971 & TRN & \\
\hline CHEMBL1364018 & 688620 & 4.65 & 4.8833 & TRN & \\
\hline CHEMBL1564743 & 688620 & 4.65 & 5.1849 & TST & \\
\hline CHEMBL1299763 & 688620 & 5.8 & 5.5133 & TRN & \\
\hline CHEMBL1424066 & 688620 & 4.85 & 5.3135 & TRN & \\
\hline CHEMBL1305580 & 688620 & 4.65 & 5.0381 & TST & \\
\hline CHEMBL1299704 & 688620 & 4.5 & 4.9959 & TST & \\
\hline CHEMBL1425262 & 688620 & 4.95 & 5.0832 & TST & \\
\hline CHEMBL1345398 & 688620 & 4.9 & 4.7937 & TRN & \\
\hline CHEMBL1509214 & 688620 & 5.5 & 5.4748 & TRN & \\
\hline CHEMBL3190570 & 688620 & 5.5 & 5.4463 & TRN & \\
\hline
\end{tabular}




\begin{tabular}{|c|c|c|c|c|c|}
\hline \multicolumn{6}{|c|}{ Supplemental Table S2.txt } \\
\hline CHEMBL1985479 & 688620 & 5.25 & 5.096 & TRN & \\
\hline CHEMBL3191549 & 688620 & 5.85 & 5.4642 & TRN & \\
\hline CHEMBL363419 & 688620 & 4.65 & 4.9933 & TST & \\
\hline CHEMBL1483225 & 688620 & 4.45 & 4.9936 & TST & \\
\hline CHEMBL1332746 & 688620 & 4.9 & 4.7927 & TST & \\
\hline CHEMBL1460577 & 688620 & 4.45 & 4.9091 & TRN & \\
\hline CHEMBL1543444 & 688620 & 4.45 & 5.026 & TRN & \\
\hline CHEMBL1575589 & 688620 & 4.45 & 5.0739 & TRN & \\
\hline CHEMBL1574727 & 688620 & 4.75 & 4.8782 & TRN & \\
\hline CHEMBL1444315 & 688620 & 4.45 & 4.7477 & TST & \\
\hline CHEMBL1447804 & 688620 & 4.95 & 5.0408 & TRN & \\
\hline CHEMBL1424424 & 688620 & 4.8 & 4.7086 & TST & \\
\hline CHEMBL1364404 & 688620 & 5.6 & 5.5117 & TST & \\
\hline CHEMBL1447523 & 688620 & 7.6498 & 5.0632 & TRN & \\
\hline CHEMBL1462933 & 688620 & 4.5 & 5.0467 & TST & \\
\hline CHEMBL1329358 & 688620 & 5.35 & 5.3791 & TRN & \\
\hline CHEMBL1587728 & 688620 & 4.8 & 5.13299 & & TST \\
\hline CHEMBL 2000847 & 688620 & 4.55 & 5.1298 & TRN & \\
\hline CHEMBL1308361 & 688620 & 6.05 & 5.7471 & TRN & \\
\hline CHEMBL1452208 & 688620 & 5.7 & 5.2278 & TRN & \\
\hline CHEMBL1565199 & 688620 & 4.65 & 5.043 & TST & \\
\hline CHEMBL1456271 & 688620 & 4.95 & 4.9992 & TRN & \\
\hline CHEMBL1466041 & 688620 & 4.9 & 5.0646 & TRN & \\
\hline CHEMBL3198503 & 688620 & 5.75 & 5.5625 & TRN & \\
\hline CHEMBL1448904 & 688620 & 4.5 & 4.8896 & TST & \\
\hline CHEMBL1456683 & 688620 & 4.8 & 4.9368 & TRN & \\
\hline CHEMBL1332308 & 688620 & 4.95 & 4.9341 & TST & \\
\hline CHEMBL1388620 & 688620 & 4.85 & 5.2559 & TRN & \\
\hline CHEMBL1549860 & 688620 & 4.95 & 5.0342 & TRN & \\
\hline CHEMBL1420252 & 688620 & 5.45 & 5.0367 & TRN & \\
\hline CHEMBL1442118 & 688620 & 4.9 & 5.1476 & TRN & \\
\hline CHEMBL 2297588 & 688620 & 5.25 & 5.2592 & TST & \\
\hline CHEMBL1471024 & 688620 & 4.45 & 5.0111 & TRN & \\
\hline CHEMBL3197782 & 688620 & 4.8 & 5.0946 & TRN & \\
\hline CHEMBL1347392 & 688620 & 4.9 & 4.9673 & TRN & \\
\hline CHEMBL1345140 & 688620 & 4.5 & 5.369 & TST & \\
\hline CHEMBL1511887 & 688620 & 4.95 & 4.9699 & TRN & \\
\hline CHEMBL1498625 & 688620 & 5.05 & 5.1861 & TRN & \\
\hline CHEMBL1530657 & 688620 & 4.7 & 4.9396 & TST & \\
\hline CHEMBL1492280 & 688620 & 5.25 & 5.0125 & TST & \\
\hline CHEMBL1305561 & 688620 & 5.15 & 4.8527 & TRN & \\
\hline CHEMBL1560815 & 688620 & 4.95 & 5.0051 & TRN & \\
\hline CHEMBL1313588 & 688620 & 5.9 & 5.5158 & TRN & \\
\hline CHEMBL1533489 & 688620 & 6.05 & 5.7367 & TRN & \\
\hline CHEMBL1528860 & 688620 & 4.7 & 4.9011 & TRN & \\
\hline CHEMBL1534641 & 688620 & 4.85 & 5.0198 & TST & \\
\hline CHEMBL1418189 & 688620 & 4.45 & 5.0635 & TRN & \\
\hline CHEMBL1611198 & 688620 & 5.2 & 5.3019 & TRN & \\
\hline
\end{tabular}




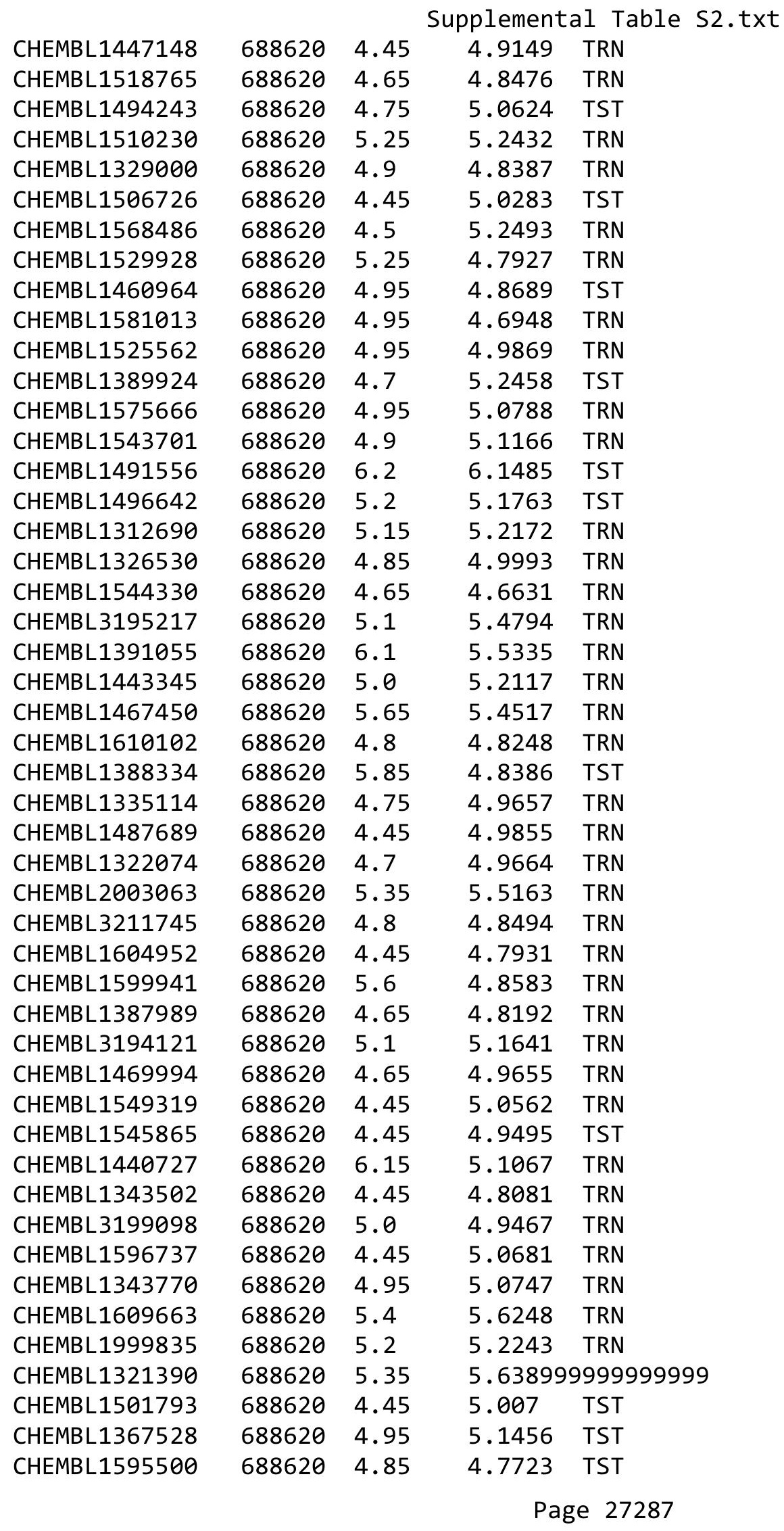

TRN 


\begin{tabular}{|c|c|c|c|c|}
\hline \multicolumn{5}{|c|}{ Supplemental Table S2.txt } \\
\hline CHEMBL3196467 & 688620 & 4.75 & 4.7601 & TRN \\
\hline CHEMBL169233 & 688620 & 6.0 & 5.1464 & TST \\
\hline CHEMBL1983234 & 688620 & 6.0 & 5.6355 & TRN \\
\hline CHEMBL1339585 & 688620 & 4.9 & 5.3574 & TST \\
\hline CHEMBL1309032 & 688620 & 5.1 & 5.1298 & TRN \\
\hline CHEMBL1497445 & 688620 & 5.35 & 4.9602 & TRN \\
\hline CHEMBL1544009 & 688620 & 5.55 & 5.1666 & TRN \\
\hline CHEMBL1429597 & 688620 & 4.45 & 5.4164 & TRN \\
\hline CHEMBL1520173 & 688620 & 4.9 & 5.0462 & TST \\
\hline CHEMBL1501005 & 688620 & 5.25 & 5.0981 & TRN \\
\hline CHEMBL1570688 & 688620 & 4.75 & 4.7633 & TRN \\
\hline CHEMBL1439755 & 688620 & 5.95 & 5.5473 & TRN \\
\hline CHEMBL1443625 & 688620 & 4.85 & 5.0716 & TRN \\
\hline CHEMBL1599128 & 688620 & 5.7 & 5.8693 & TRN \\
\hline CHEMBL1465644 & 688620 & 6.15 & 5.5111 & TST \\
\hline CHEMBL1463761 & 688620 & 4.45 & 4.7822 & TST \\
\hline CHEMBL1578550 & 688620 & 4.45 & 5.0647 & TST \\
\hline CHEMBL1523419 & 688620 & 5.15 & 5.0269 & TRN \\
\hline CHEMBL1328707 & 688620 & 5.7 & 5.6124 & TRN \\
\hline CHEMBL1307433 & 688620 & 4.75 & 4.9227 & TRN \\
\hline CHEMBL1333147 & 688620 & 5.45 & 5.0849 & TST \\
\hline CHEMBL3190625 & 688620 & 4.6 & 5.3241 & TST \\
\hline CHEMBL1587862 & 688620 & 5.45 & 5.459 & TRN \\
\hline CHEMBL1528749 & 688620 & 4.45 & 5.2724 & TRN \\
\hline CHEMBL1980584 & 688620 & 5.5 & 5.1191 & TST \\
\hline CHEMBL1544718 & 688620 & 4.75 & 4.9034 & TRN \\
\hline CHEMBL1517752 & 688620 & 6.1 & 5.6919 & TRN \\
\hline CHEMBL1387367 & 688620 & 4.95 & 5.1623 & TRN \\
\hline CHEMBL1452783 & 688620 & 4.45 & 5.1435 & TRN \\
\hline CHEMBL1409517 & 688620 & 5.1 & 4.7978 & TRN \\
\hline CHEMBL1415349 & 688620 & 4.45 & 5.0427 & TRN \\
\hline CHEMBL1486158 & 688620 & 4.9 & 5.431 & TRN \\
\hline CHEMBL1327498 & 688620 & 4.8 & 5.1204 & TRN \\
\hline CHEMBL1477253 & 688620 & 6.8499 & 5.154 & TRN \\
\hline CHEMBL1598311 & 688620 & 5.9 & 5.0734 & TST \\
\hline CHEMBL1544186 & 688620 & 4.8 & 4.7121 & TRN \\
\hline CHEMBL1325023 & 688620 & 4.85 & 4.9516 & TRN \\
\hline CHEMBL1322183 & 688620 & 4.95 & 4.988 & TRN \\
\hline CHEMBL1381340 & 688620 & 4.7 & 4.7639 & TRN \\
\hline CHEMBL1609315 & 688620 & 5.8 & 4.9835 & TRN \\
\hline CHEMBL1425401 & 688620 & 4.5 & 4.8123 & TST \\
\hline CHEMBL1385142 & 688620 & 5.1 & 4.8264 & TRN \\
\hline CHEMBL1574132 & 688620 & 6.5501 & 6.7759 & TRN \\
\hline CHEMBL1586715 & 688620 & 5.15 & 5.5005 & TRN \\
\hline CHEMBL1398983 & 688620 & 4.7 & 4.8036 & TST \\
\hline CHEMBL1965956 & 688620 & 4.9 & 5.1439 & TRN \\
\hline CHEMBL1422136 & 688620 & 5.3 & 5.1273 & TRN \\
\hline CHEMBL3207865 & 688620 & 6.15 & 5.0856 & TRN \\
\hline
\end{tabular}




\begin{tabular}{|c|c|c|c|c|}
\hline \multicolumn{5}{|c|}{ Supplemental Table S2.txt } \\
\hline CHEMBL1340684 & 688620 & 4.7 & 5.0587 & TST \\
\hline CHEMBL1462300 & 688620 & 6.15 & 5.1105 & TRN \\
\hline CHEMBL1573185 & 688620 & 4.45 & 5.0761 & TST \\
\hline CHEMBL1309535 & 688620 & 4.95 & 5.2538 & TRN \\
\hline CHEMBL1488213 & 688620 & 4.45 & 4.8269 & TRN \\
\hline CHEMBL1543657 & 688620 & 4.9 & 5.0429 & TRN \\
\hline CHEMBL1490608 & 688620 & 4.45 & 4.9423 & TRN \\
\hline CHEMBL 3191872 & 688620 & 5.85 & 5.3215 & TRN \\
\hline CHEMBL1486985 & 688620 & 6.0 & 5.1402 & TST \\
\hline CHEMBL1557319 & 688620 & 5.0 & 5.1877 & TRN \\
\hline CHEMBL1331928 & 688620 & 5.55 & 5.2151 & TRN \\
\hline CHEMBL1350896 & 688620 & 4.9 & 5.1103 & TST \\
\hline CHEMBL1361492 & 688620 & 6.2 & 5.2683 & TRN \\
\hline CHEMBL1496456 & 688620 & 6.45 & 4.9001 & TRN \\
\hline CHEMBL1404217 & 688620 & 5.45 & 5.1776 & TRN \\
\hline CHEMBL1543527 & 688620 & 5.15 & 4.8937 & TRN \\
\hline CHEMBL1462835 & 688620 & 4.95 & 4.9181 & TRN \\
\hline CHEMBL1438722 & 688620 & 6.95 & 4.936 & TRN \\
\hline CHEMBL1526731 & 688620 & 4.6 & 4.9186 & TRN \\
\hline CHEMBL1368114 & 688620 & 4.8 & 4.7892 & TRN \\
\hline CHEMBL1613411 & 688620 & 5.8 & 5.0525 & TRN \\
\hline CHEMBL1425851 & 688620 & 5.2 & 5.1487 & TRN \\
\hline CHEMBL1302959 & 688620 & 5.95 & 4.9656 & TRN \\
\hline CHEMBL 3197490 & 688620 & 4.95 & 5.1806 & TRN \\
\hline CHEMBL1328408 & 688620 & 4.9 & 5.0942 & TRN \\
\hline CHEMBL1558303 & 688620 & 4.45 & 4.9773 & TST \\
\hline CHEMBL528068 & 688620 & 5.15 & 5.0048 & TRN \\
\hline CHEMBL 3208474 & 688620 & 5.65 & 5.4982 & TRN \\
\hline CHEMBL 1482782 & 688620 & 4.8 & 5.0023 & TRN \\
\hline CHEMBL1370513 & 688620 & 6.3 & 5.8193 & TRN \\
\hline CHEMBL1582423 & 688620 & 5.15 & 5.0211 & TRN \\
\hline CHEMBL1393988 & 688620 & 4.45 & 5.289 & TRN \\
\hline CHEMBL3193656 & 688620 & 5.05 & 5.0673 & TRN \\
\hline CHEMBL1413363 & 688620 & 5.05 & 4.7181 & TRN \\
\hline CHEMBL1562603 & 688620 & 6.25 & 5.0063 & TRN \\
\hline CHEMBL1504637 & 688620 & 4.5 & 4.6904 & TRN \\
\hline CHEMBL1442300 & 688620 & 4.9 & 4.9111 & TST \\
\hline CHEMBL1469995 & 688620 & 4.95 & 5.1351 & TST \\
\hline CHEMBL1489415 & 688620 & 4.95 & 5.1987 & TRN \\
\hline CHEMBL1404130 & 688620 & 4.9 & 4.8786 & TRN \\
\hline CHEMBL1335866 & 688620 & 5.0 & 4.9593 & TRN \\
\hline CHEMBL1566864 & 688620 & 5.3 & 5.0246 & TRN \\
\hline CHEMBL1496658 & 688620 & 4.9 & 4.8878 & TRN \\
\hline CHEMBL1269811 & 688620 & 5.9 & 5.6 & TRN \\
\hline CHEMBL1406956 & 688620 & 5.6 & 5.1119 & TST \\
\hline CHEMBL1338544 & 688620 & 5.1 & 5.2685 & TST \\
\hline CHEMBL1497704 & 688620 & 5.0 & 4.9751 & TST \\
\hline CHEMBL1470838 & 688620 & 4.65 & 4.8103 & TST \\
\hline
\end{tabular}




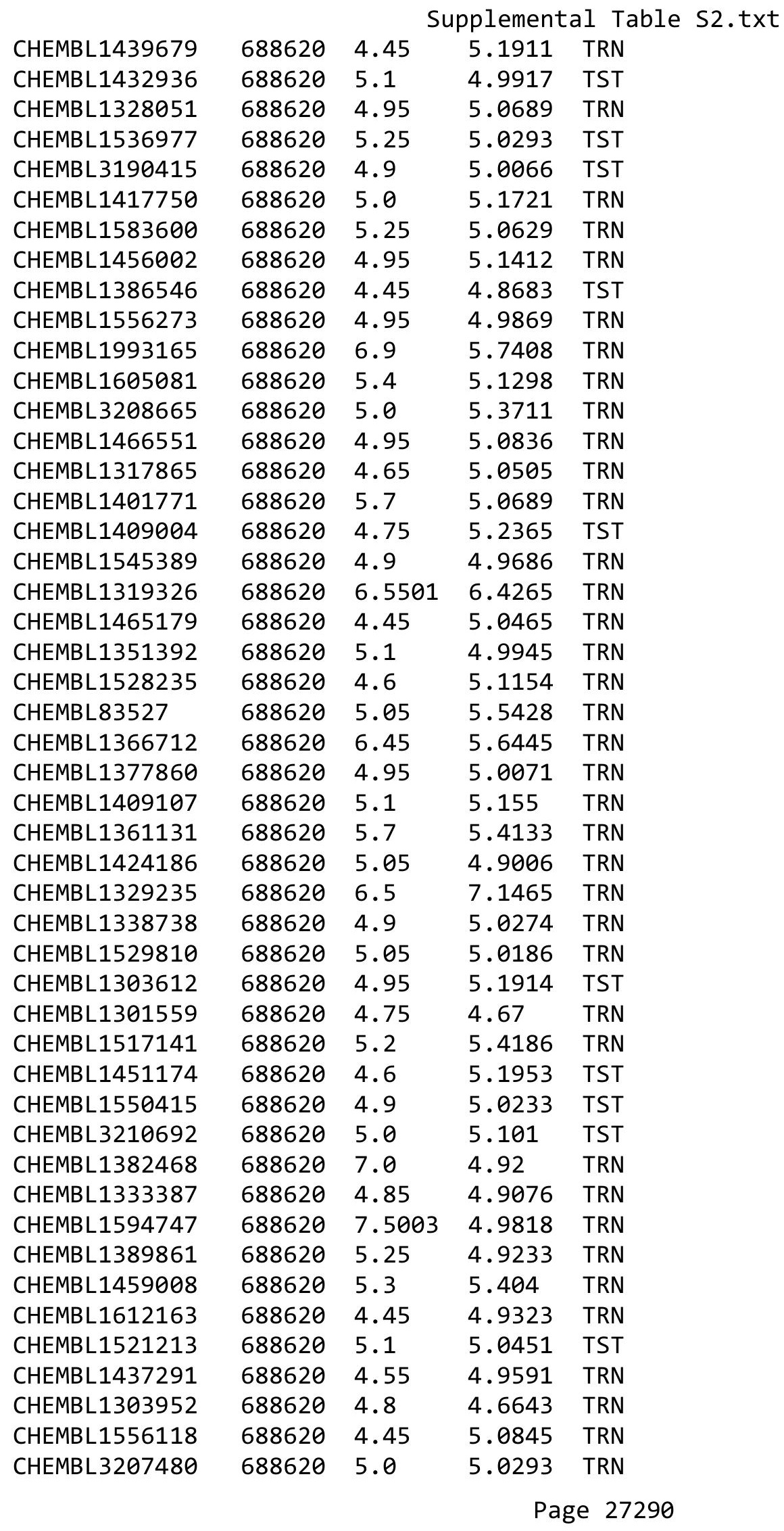




\begin{tabular}{|c|c|c|c|c|c|}
\hline \multicolumn{6}{|c|}{ Supplemental Table S2.txt } \\
\hline CHEMBL1338251 & 688620 & 4.9 & 4.931 & TRN & \\
\hline CHEMBL1532938 & 688620 & 5.0 & 5.1454 & TRN & \\
\hline CHEMBL1465463 & 688620 & 4.95 & 5.1251 & TRN & \\
\hline CHEMBL1377079 & 688620 & 4.45 & 5.2132 & TST & \\
\hline CHEMBL1346566 & 688620 & 4.75 & 5.0065 & TRN & \\
\hline CHEMBL1349330 & 688620 & 4.75 & 5.1919 & TRN & \\
\hline CHEMBL1471783 & 688620 & 5.0 & 4.9839 & TRN & \\
\hline CHEMBL1568055 & 688620 & 4.65 & 4.7814 & TRN & \\
\hline CHEMBL1399077 & 688620 & 4.8 & 5.2501 & TST & \\
\hline CHEMBL1406119 & 688620 & 4.85 & 4.7523 & TRN & \\
\hline CHEMBL1321185 & 688620 & 5.3 & 5.0782 & TRN & \\
\hline CHEMBL1990932 & 688620 & 4.8 & 5.1064 & TRN & \\
\hline CHEMBL 3199680 & 688620 & 4.75 & 5.0182 & TRN & \\
\hline CHEMBL1313306 & 688620 & 4.55 & 5.0466 & TRN & \\
\hline CHEMBL1409713 & 688620 & 4.55 & 5.0358 & TST & \\
\hline CHEMBL1340046 & 688620 & 4.5 & 4.8646 & TRN & \\
\hline CHEMBL1447427 & 688620 & 7.0501 & 5.0091 & TRN & \\
\hline CHEMBL3211289 & 688620 & 4.95 & 5.49299 & 9999999999 & TRN \\
\hline CHEMBL1568223 & 688620 & 5.15 & 5.1377 & TRN & \\
\hline CHEMBL1470497 & 688620 & 5.25 & 5.3275 & TRN & \\
\hline CHEMBL3189364 & 688620 & 6.2 & 5.4982 & TRN & \\
\hline CHEMBL1348163 & 688620 & 4.45 & 4.8695 & TRN & \\
\hline CHEMBL1370419 & 688620 & 5.7 & 5.5602 & TRN & \\
\hline CHEMBL3208621 & 688620 & 5.2 & 5.21299 & 9999999999 & TRN \\
\hline CHEMBL1331721 & 688620 & 4.45 & 4.9534 & TST & \\
\hline CHEMBL1584502 & 688620 & 5.15 & 4.9258 & TST & \\
\hline CHEMBL1569790 & 688620 & 6.1 & 5.1176 & TRN & \\
\hline CHEMBL1422410 & 688620 & 4.5 & 5.1233 & TRN & \\
\hline CHEMBL1569764 & 688620 & 5.2 & 4.985 & TRN & \\
\hline CHEMBL1993788 & 688620 & 5.9 & 5.6726 & TRN & \\
\hline CHEMBL3193978 & 688620 & 5.7 & 5.432 & TRN & \\
\hline CHEMBL1580915 & 688620 & 4.75 & 5.0532 & TRN & \\
\hline CHEMBL1478511 & 688620 & 4.5 & 4.8077 & TST & \\
\hline CHEMBL1486323 & 688620 & 5.6 & 5.3497 & TRN & \\
\hline CHEMBL1588357 & 688620 & 4.45 & 4.9079 & TRN & \\
\hline CHEMBL1348803 & 688620 & 5.5 & 4.9923 & TRN & \\
\hline CHEMBL1369017 & 688620 & 4.5 & 5.0168 & TRN & \\
\hline CHEMBL199925 & 688620 & 4.7 & 4.9036 & TRN & \\
\hline CHEMBL3192627 & 688620 & 4.95 & 5.0417 & TRN & \\
\hline CHEMBL1601718 & 688620 & 5.7 & 5.2002 & TRN & \\
\hline CHEMBL1308899 & 688620 & 4.5 & 4.9708 & TST & \\
\hline CHEMBL1415639 & 688620 & 4.45 & 4.9208 & TST & \\
\hline CHEMBL1601549 & 688620 & 4.65 & 5.1717 & TRN & \\
\hline CHEMBL1564501 & 688620 & 5.9 & 5.37200 & 2000000001 & TST \\
\hline CHEMBL1489339 & 688620 & 5.0 & 5.0276 & TRN & \\
\hline CHEMBL1309401 & 688620 & 4.45 & 4.8388 & TST & \\
\hline CHEMBL1609848 & 688620 & 4.95 & 5.0089 & TRN & \\
\hline CHEMBL1445973 & 688620 & 5.45 & 5.3335 & TRN & \\
\hline
\end{tabular}




\begin{tabular}{|c|c|c|c|c|c|}
\hline \multicolumn{6}{|c|}{ Supplemental Table S2.txt } \\
\hline CHEMBL1405717 & 688620 & 5.4 & 4.9697 & TRN & \\
\hline CHEMBL1489409 & 688620 & 4.45 & 5.355 & TST & \\
\hline CHEMBL1362564 & 688620 & 5.3 & 5.2546 & TRN & \\
\hline CHEMBL1558065 & 688620 & 5.95 & 6.2588 & TRN & \\
\hline CHEMBL1381317 & 688620 & 4.45 & 4.8104 & TRN & \\
\hline CHEMBL3195234 & 688620 & 4.85 & 5.2005 & TRN & \\
\hline CHEMBL1594217 & 688620 & 4.6 & 5.0615 & TST & \\
\hline CHEMBL1424369 & 688620 & 4.7 & 5.0285 & TRN & \\
\hline CHEMBL1540724 & 688620 & 5.15 & 5.1578 & TRN & \\
\hline CHEMBL3195720 & 688620 & 5.25 & 5.2574 & TRN & \\
\hline CHEMBL1411317 & 688620 & 5.9 & 5.7363 & TRN & \\
\hline CHEMBL1349912 & 688620 & 4.55 & 4.9154 & TST & \\
\hline CHEMBL1479344 & 688620 & 5.1 & 5.0771 & TRN & \\
\hline CHEMBL1970958 & 688620 & 6.4 & 5.9961 & TRN & \\
\hline CHEMBL1969543 & 688620 & 5.1 & 4.9166 & TRN & \\
\hline CHEMBL1462038 & 688620 & 4.9 & 4.9062 & TRN & \\
\hline CHEMBL1462276 & 688620 & 5.0 & 4.9653 & TRN & \\
\hline CHEMBL1307841 & 688620 & 5.7 & 5.3091 & TRN & \\
\hline CHEMBL2369209 & 688620 & 5.95 & 5.4018 & TRN & \\
\hline CHEMBL1448731 & 688620 & 5.5 & $4.9060 e$ & 0000000001 & TRN \\
\hline CHEMBL1547705 & 688620 & 4.9 & 4.8629 & TRN & \\
\hline CHEMBL3189855 & 688620 & 5.85 & 5.1879 & TRN & \\
\hline CHEMBL1507893 & 688620 & 5.1 & 4.8772 & TRN & \\
\hline CHEMBL259103 & 688620 & 5.45 & 5.1748 & TRN & \\
\hline CHEMBL1346906 & 688620 & 4.85 & 4.8304 & TRN & \\
\hline CHEMBL1458083 & 688620 & 4.8 & 5.21899 & 9999999999 & TRN \\
\hline CHEMBL3190830 & 688620 & 4.45 & 4.9346 & TST & \\
\hline CHEMBL1493367 & 688620 & 4.45 & 5.1988 & TRN & \\
\hline CHEMBL1362653 & 688620 & 4.75 & 4.9925 & TRN & \\
\hline CHEMBL1605237 & 688620 & 4.45 & 4.9072 & TST & \\
\hline CHEMBL1579873 & 688620 & 5.25 & 5.3897 & TST & \\
\hline CHEMBL3193732 & 688620 & 5.0 & 5.0779 & TRN & \\
\hline CHEMBL1502098 & 688620 & 4.85 & 4.6855 & TRN & \\
\hline CHEMBL1374655 & 688620 & 4.45 & 5.2898 & TRN & \\
\hline CHEMBL1363295 & 688620 & 5.45 & 4.9744 & TRN & \\
\hline CHEMBL1351299 & 688620 & 4.9 & 5.3166 & TST & \\
\hline CHEMBL1344582 & 688620 & 5.8 & 5.5775 & TRN & \\
\hline CHEMBL1428308 & 688620 & 5.15 & 4.9215 & TRN & \\
\hline CHEMBL1310930 & 688620 & 4.7 & 4.6512 & TRN & \\
\hline CHEMBL1386816 & 688620 & 5.0 & 4.7629 & TST & \\
\hline CHEMBL1336728 & 688620 & 4.45 & 4.9967 & TRN & \\
\hline CHEMBL1367206 & 688620 & 4.9 & 5.2421 & TRN & \\
\hline CHEMBL1465495 & 688620 & 5.35 & 5.0183 & TRN & \\
\hline CHEMBL1583990 & 688620 & 5.2 & 4.9454 & TST & \\
\hline CHEMBL1364872 & 688620 & 4.9 & 5.0881 & TRN & \\
\hline CHEMBL1453210 & 688620 & 4.8 & 4.9637 & TRN & \\
\hline CHEMBL1534143 & 688620 & 4.9 & 5.9887 & TST & \\
\hline CHEMBL1597320 & 688620 & 4.45 & 5.1601 & TRN & \\
\hline
\end{tabular}




\begin{tabular}{|c|c|c|c|c|c|}
\hline \multicolumn{6}{|c|}{ Supplemental Table S2.txt } \\
\hline CHEMBL1985103 & 688620 & 6.15 & 5.2141 & TRN & \\
\hline CHEMBL1530292 & 688620 & 5.15 & 4.8673 & TRN & \\
\hline CHEMBL1425240 & 688620 & 4.8 & 4.9301 & TRN & \\
\hline CHEMBL1514247 & 688620 & 5.75 & 5.1284 & TST & \\
\hline CHEMBL1399331 & 688620 & 4.9 & 4.8059 & TST & \\
\hline CHEMBL1539633 & 688620 & 4.8 & 4.9281 & TRN & \\
\hline CHEMBL1604990 & 688620 & 4.9 & 4.819 & TRN & \\
\hline CHEMBL1367347 & 688620 & 5.6 & 4.8116 & TRN & \\
\hline CHEMBL1533428 & 688620 & 5.15 & 5.0495 & TST & \\
\hline CHEMBL1598237 & 688620 & 4.45 & 4.8178 & TRN & \\
\hline CHEMBL1497656 & 688620 & 5.15 & 4.8292 & TRN & \\
\hline CHEMBL1413042 & 688620 & 4.45 & 5.0969 & TRN & \\
\hline CHEMBL1381056 & 688620 & 4.65 & 4.9325 & TRN & \\
\hline CHEMBL1482637 & 688620 & 5.25 & 4.9017 & TST & \\
\hline CHEMBL1553873 & 688620 & 4.45 & 5.1306 & TST & \\
\hline CHEMBL1353581 & 688620 & 4.85 & 4.6758 & TRN & \\
\hline CHEMBL1405688 & 688620 & 5.65 & 5.005 & TRN & \\
\hline CHEMBL 3190091 & 688620 & 5.3 & 5.8404 & TRN & \\
\hline CHEMBL1530630 & 688620 & 5.5 & 5.1311 & TRN & \\
\hline CHEMBL1400921 & 688620 & 4.45 & 4.8141 & TRN & \\
\hline CHEMBL1342983 & 688620 & 4.5 & 4.7915 & TRN & \\
\hline CHEMBL1403722 & 688620 & 5.1 & 5.2414 & TRN & \\
\hline CHEMBL1572967 & 688620 & 4.45 & 5.314 & TRN & \\
\hline CHEMBL602366 & 688620 & 4.5 & 4.7487 & TRN & \\
\hline CHEMBL1351651 & 688620 & 4.55 & 5.3904 & TST & \\
\hline CHEMBL1461391 & 688620 & 4.85 & 5.2723 & TRN & \\
\hline CHEMBL1303426 & 688620 & 5.4 & 5.32100 & 0000000001 & TRN \\
\hline CHEMBL1594906 & 688620 & 4.45 & 4.97 & TRN & \\
\hline CHEMBL3197453 & 688620 & 5.0 & 5.0025 & TRN & \\
\hline CHEMBL 3212718 & 688620 & 5.15 & 5.5257 & TST & \\
\hline CHEMBL1465621 & 688620 & 4.45 & 4.9772 & TRN & \\
\hline CHEMBL1522027 & 688620 & 4.45 & 4.7999 & TRN & \\
\hline CHEMBL1570464 & 688620 & 5.55 & 6.0871 & TST & \\
\hline CHEMBL1582193 & 688620 & 5.3 & 5.045 & TRN & \\
\hline CHEMBL1333510 & 688620 & 4.45 & 5.1421 & TRN & \\
\hline CHEMBL1474143 & 688620 & 4.95 & 5.2023 & TST & \\
\hline CHEMBL1392355 & 688620 & 4.9 & 5.0811 & TST & \\
\hline CHEMBL1478570 & 688620 & 5.8 & 5.1225 & TRN & \\
\hline CHEMBL1520777 & 688620 & 4.45 & 4.7172 & TST & \\
\hline CHEMBL1425250 & 688620 & 4.45 & 4.8627 & TST & \\
\hline CHEMBL1585127 & 688620 & 6.0 & 5.9437 & TRN & \\
\hline CHEMBL1359315 & 688620 & 5.55 & 5.4601 & TRN & \\
\hline CHEMBL3194702 & 688620 & 4.45 & 5.093 & TRN & \\
\hline CHEMBL1574078 & 688620 & 5.25 & 4.9248 & TRN & \\
\hline CHEMBL1510253 & 688620 & 4.8 & 4.8212 & TST & \\
\hline CHEMBL1312300 & 688620 & 5.0 & 5.1094 & TRN & \\
\hline CHEMBL1388552 & 688620 & 5.2 & 4.9522 & TRN & \\
\hline CHEMBL1539537 & 688620 & 5.0 & 4.7414 & TRN & \\
\hline
\end{tabular}




\begin{tabular}{|c|c|c|c|c|c|}
\hline \multicolumn{6}{|c|}{ Supplemental Table S2.txt } \\
\hline CHEMBL1482556 & 688620 & 6.35 & 5.3287 & TRN & \\
\hline CHEMBL1422039 & 688620 & 5.55 & 5.2629 & TRN & \\
\hline CHEMBL1485775 & 688620 & 5.1 & 4.9779 & TRN & \\
\hline CHEMBL1354232 & 688620 & 4.8 & 4.8513 & TRN & \\
\hline CHEMBL1602077 & 688620 & 4.8 & 4.8996 & TST & \\
\hline CHEMBL1477354 & 688620 & 6.3 & 5.2065 & TRN & \\
\hline CHEMBL1469865 & 688620 & 8.301 & 5.2747 & TRN & \\
\hline CHEMBL1329175 & 688620 & 5.45 & 4.9095 & TRN & \\
\hline CHEMBL1604254 & 688620 & 6.2 & 5.0 & TST & \\
\hline CHEMBL1321076 & 688620 & 5.55 & 5.3809 & TRN & \\
\hline CHEMBL1565365 & 688620 & 4.95 & 5.0868 & TRN & \\
\hline CHEMBL3195101 & 688620 & 6.0 & 5.7386 & TRN & \\
\hline CHEMBL1437208 & 688620 & 4.9 & 4.8004 & TRN & \\
\hline CHEMBL1459125 & 688620 & 4.5 & 4.713 & TRN & \\
\hline CHEMBL3194012 & 688620 & 4.85 & 5.0934 & TST & \\
\hline CHEMBL1326218 & 688620 & 4.45 & 4.9536 & TST & \\
\hline CHEMBL1334616 & 688620 & 5.5 & 5.2435 & TRN & \\
\hline CHEMBL1578437 & 688620 & 6.05 & 5.1211 & TRN & \\
\hline CHEMBL3193341 & 688620 & 4.85 & 4.9985 & TRN & \\
\hline CHEMBL1449719 & 688620 & 5.05 & 4.9449 & TST & \\
\hline CHEMBL1433443 & 688620 & 5.0 & 4.84399 & 9999999999 & TST \\
\hline CHEMBL1566965 & 688620 & 4.9 & 5.0104 & TRN & \\
\hline CHEMBL1487452 & 688620 & 4.45 & 4.8893 & TRN & \\
\hline CHEMBL1573364 & 688620 & 5.7 & 5.0039 & TRN & \\
\hline CHEMBL1480405 & 688620 & 5.0 & 5.0346 & TRN & \\
\hline CHEMBL1399498 & 688620 & 4.45 & 4.5637 & TRN & \\
\hline CHEMBL1605299 & 688620 & 4.45 & 4.9586 & TST & \\
\hline CHEMBL1363373 & 688620 & 4.8 & 4.975 & TRN & \\
\hline CHEMBL1579700 & 688620 & 4.85 & 5.0793 & TRN & \\
\hline CHEMBL1403438 & 688620 & 5.5 & 5.4607 & TST & \\
\hline CHEMBL3195417 & 688620 & 4.5 & 5.1809 & TST & \\
\hline CHEMBL1605001 & 688620 & 4.45 & 4.9982 & TRN & \\
\hline CHEMBL1567005 & 688620 & 5.5 & 5.2847 & TRN & \\
\hline CHEMBL1497961 & 688620 & 5.0 & 5.0163 & TST & \\
\hline CHEMBL1600981 & 688620 & 5.15 & 5.078 & TST & \\
\hline CHEMBL1605432 & 688620 & 4.7 & 4.94300 & 00000000005 & TRN \\
\hline CHEMBL 1348774 & 688620 & 5.15 & 5.4942 & TRN & \\
\hline CHEMBL1504691 & 688620 & 4.45 & 4.9679 & TST & \\
\hline CHEMBL1590124 & 688620 & 4.95 & 4.787 & TST & \\
\hline CHEMBL1522953 & 688620 & 5.25 & 5.2378 & TRN & \\
\hline CHEMBL1423973 & 688620 & 4.45 & 5.0401 & TRN & \\
\hline CHEMBL1580910 & 688620 & 4.65 & 4.8007 & TST & \\
\hline CHEMBL3195941 & 688620 & 4.55 & 5.5191 & TRN & \\
\hline CHEMBL1319984 & 688620 & 5.2 & 5.341 & TRN & \\
\hline CHEMBL1386201 & 688620 & 4.45 & 5.0878 & TRN & \\
\hline CHEMBL1472327 & 688620 & 4.65 & 4.8146 & TRN & \\
\hline CHEMBL1386419 & 688620 & 5.6 & 5.4833 & TRN & \\
\hline CHEMBL1368496 & 688620 & 4.85 & 4.9422 & TRN & \\
\hline
\end{tabular}




\begin{tabular}{|c|c|c|c|c|c|}
\hline \multicolumn{6}{|c|}{ Supplemental Table S2.txt } \\
\hline CHEMBL1483326 & 688620 & 6.1 & 5.2638 & TRN & \\
\hline CHEMBL1348679 & 688620 & 4.9 & 4.8452 & TRN & \\
\hline CHEMBL1601293 & 688620 & 5.05 & 5.1918 & TRN & \\
\hline CHEMBL1604985 & 688620 & 5.25 & 5.1214 & TRN & \\
\hline CHEMBL1448077 & 688620 & 4.85 & 4.8859 & TST & \\
\hline CHEMBL1391093 & 688620 & 5.4 & 5.2763 & TRN & \\
\hline CHEMBL1455629 & 688620 & 4.45 & 4.8066 & TRN & \\
\hline CHEMBL1457404 & 688620 & 6.45 & 4.8113 & TRN & \\
\hline CHEMBL1311739 & 688620 & 5.1 & 5.0325 & TRN & \\
\hline CHEMBL1506318 & 688620 & 4.95 & 4.8055 & TRN & \\
\hline CHEMBL3199204 & 688620 & 6.35 & 5.522 & TRN & \\
\hline CHEMBL1304763 & 688620 & 4.65 & 4.803 & TRN & \\
\hline CHEMBL1498972 & 688620 & 6.5 & 5.2124 & TRN & \\
\hline CHEMBL1432151 & 688620 & 4.7 & 5.0667 & TRN & \\
\hline CHEMBL1376467 & 688620 & 5.0 & 5.1434 & TRN & \\
\hline CHEMBL1418145 & 688620 & 4.85 & 5.7857 & TST & \\
\hline CHEMBL1572024 & 688620 & 5.2 & 5.0114 & TRN & \\
\hline CHEMBL1326801 & 688620 & 4.8 & 5.0042 & TRN & \\
\hline CHEMBL1537005 & 688620 & 4.45 & 5.0666 & TRN & \\
\hline CHEMBL1438543 & 688620 & 4.7 & 4.9488 & TRN & \\
\hline CHEMBL1568911 & 688620 & 4.95 & 4.8458 & TRN & \\
\hline CHEMBL1535980 & 688620 & 4.45 & 4.8026 & TRN & \\
\hline CHEMBL1481931 & 688620 & 4.45 & 4.9705 & TRN & \\
\hline CHEMBL1540976 & 688620 & 6.2 & 6.0254 & TRN & \\
\hline CHEMBL156040 & 688620 & 6.15 & 5.2452 & TRN & \\
\hline CHEMBL1554976 & 688620 & 4.95 & 4.7655 & TRN & \\
\hline CHEMBL1424737 & 688620 & 4.8 & 4.8999 & TRN & \\
\hline CHEMBL1518905 & 688620 & 5.85 & 5.396 & TST & \\
\hline CHEMBL1335146 & 688620 & 4.9 & 5.2593 & TRN & \\
\hline CHEMBL1346508 & 688620 & 4.65 & 5.0952 & TRN & \\
\hline CHEMBL1460105 & 688620 & 4.75 & 5.0292 & TRN & \\
\hline CHEMBL 3193624 & 688620 & 5.6 & 5.0729 & TRN & \\
\hline CHEMBL1413859 & 688620 & 5.5 & 5.6095 & TRN & \\
\hline CHEMBL1430210 & 688620 & 4.45 & 4.9572 & TST & \\
\hline CHEMBL1561393 & 688620 & 5.05 & 5.4336 & TRN & \\
\hline CHEMBL1562727 & 688620 & 5.65 & 5.2321 & TST & \\
\hline CHEMBL1561688 & 688620 & 4.95 & $5.0310 e$ & 0000000001 & TRN \\
\hline CHEMBL1530352 & 688620 & 4.95 & 5.0367 & TST & \\
\hline CHEMBL1528570 & 688620 & 5.05 & 5.0755 & TRN & \\
\hline CHEMBL1556105 & 688620 & 4.9 & 5.1706 & TRN & \\
\hline CHEMBL1504131 & 688620 & 5.2 & 5.0976 & TST & \\
\hline CHEMBL1450607 & 688620 & 5.65 & 5.3668 & TST & \\
\hline CHEMBL1522606 & 688620 & 4.8 & 5.1042 & TRN & \\
\hline CHEMBL1312007 & 688620 & 5.0 & 5.1044 & TST & \\
\hline CHEMBL1327200 & 688620 & 5.0 & 5.2311 & TRN & \\
\hline CHEMBL1568022 & 688620 & 5.25 & 5.479 & TRN & \\
\hline CHEMBL1490716 & 688620 & 6.1 & 5.126 & TST & \\
\hline CHEMBL1532999 & 688620 & 4.45 & 4.7626 & TRN & \\
\hline
\end{tabular}




\begin{tabular}{|c|c|c|c|c|}
\hline \multicolumn{5}{|c|}{ Supplemental Table S2.txt } \\
\hline CHEMBL1407731 & 688620 & 4.9 & 5.1072 & TRN \\
\hline CHEMBL1334550 & 688620 & 5.25 & 5.5412 & TRN \\
\hline CHEMBL1491427 & 688620 & 5.25 & 4.9123 & TRN \\
\hline CHEMBL1543943 & 688620 & 4.95 & 5.206 & TRN \\
\hline CHEMBL1409900 & 688620 & 6.0 & 6.1612 & TRN \\
\hline CHEMBL1306030 & 688620 & 4.9 & 4.9737 & TST \\
\hline CHEMBL3198763 & 688620 & 5.6 & 5.4775 & TRN \\
\hline CHEMBL1416276 & 688620 & 4.7 & 4.788 & TRN \\
\hline CHEMBL1371662 & 688620 & 4.5 & 4.9555 & TST \\
\hline CHEMBL1443649 & 688620 & 4.45 & 5.0121 & TRN \\
\hline CHEMBL1337683 & 688620 & 4.9 & 4.7122 & TST \\
\hline CHEMBL1975473 & 688620 & 5.5 & 5.2962 & TRN \\
\hline CHEMBL3197279 & 688620 & 4.9 & 4.9784 & TRN \\
\hline CHEMBL1445565 & 688620 & 4.95 & 5.0913 & TST \\
\hline CHEMBL1607817 & 688620 & 4.45 & 4.9435 & TRN \\
\hline CHEMBL1526051 & 688620 & 4.45 & 4.8064 & TRN \\
\hline CHEMBL1442809 & 688620 & 5.0 & 5.3438 & TRN \\
\hline CHEMBL1578425 & 688620 & 4.95 & 4.8301 & TRN \\
\hline CHEMBL1605969 & 688620 & 5.15 & 5.3464 & TRN \\
\hline CHEMBL1328924 & 688620 & 6.5 & 5.1796 & TST \\
\hline CHEMBL1417631 & 688620 & 4.95 & 4.7223 & TRN \\
\hline CHEMBL1585057 & 688620 & 5.65 & 5.0829 & TRN \\
\hline CHEMBL1416171 & 688620 & 4.75 & 5.0871 & TST \\
\hline CHEMBL1410238 & 688620 & 5.3 & 5.2444 & TST \\
\hline CHEMBL1300131 & 688620 & 5.0 & 5.0733 & TRN \\
\hline CHEMBL1394472 & 688620 & 4.6 & 5.1635 & TST \\
\hline CHEMBL1532941 & 688620 & 5.75 & 5.5327 & TRN \\
\hline CHEMBL1349590 & 688620 & 5.15 & 5.1212 & TRN \\
\hline CHEMBL1494325 & 688620 & 5.0 & 5.1583 & TRN \\
\hline CHEMBL1386149 & 688620 & 5.35 & 5.2533 & TST \\
\hline CHEMBL1491541 & 688620 & 4.95 & 5.0786 & TRN \\
\hline CHEMBL1442800 & 688620 & 4.65 & 5.039 & TRN \\
\hline CHEMBL1575823 & 688620 & 4.9 & 5.0092 & TRN \\
\hline CHEMBL3197314 & 688620 & 5.4 & 5.5065 & TRN \\
\hline CHEMBL1528245 & 688620 & 5.6 & 5.0337 & TRN \\
\hline CHEMBL1456730 & 688620 & 4.45 & 5.0529 & TST \\
\hline CHEMBL1491932 & 688620 & 5.55 & 5.3864 & TRN \\
\hline CHEMBL1497423 & 688620 & 4.85 & 5.1049 & TRN \\
\hline CHEMBL1302261 & 688620 & 5.0 & 5.0527 & TRN \\
\hline CHEMBL1464530 & 688620 & 6.6 & 4.9683 & TST \\
\hline CHEMBL1525669 & 688620 & 4.65 & 4.9001 & TRN \\
\hline CHEMBL1457022 & 688620 & 5.2 & 5.1816 & TRN \\
\hline CHEMBL1412830 & 688620 & 5.15 & 5.2782 & TRN \\
\hline CHEMBL1393220 & 688620 & 7.5498 & 5.2218 & TRN \\
\hline CHEMBL1451295 & 688620 & 6.5 & 4.9781 & TRN \\
\hline CHEMBL1390570 & 688620 & 6.25 & 5.3804 & TST \\
\hline CHEMBL1371380 & 688620 & 4.65 & 4.9194 & TRN \\
\hline CHEMBL1371974 & 688620 & 4.9 & 5.3324 & TRN \\
\hline
\end{tabular}




\begin{tabular}{|c|c|c|c|c|}
\hline \multicolumn{5}{|c|}{ Supplemental Table S2.txt } \\
\hline CHEMBL1299811 & 688620 & 5.35 & 5.1466 & TST \\
\hline CHEMBL1327356 & 688620 & 4.9 & 4.6398 & TRN \\
\hline CHEMBL3191594 & 688620 & 5.4 & 5.5877 & TRN \\
\hline CHEMBL1403266 & 688620 & 4.6 & 4.9567 & TRN \\
\hline CHEMBL1359855 & 688620 & 4.45 & 4.7941 & TRN \\
\hline CHEMBL1371654 & 688620 & 5.05 & 4.8604 & TRN \\
\hline CHEMBL1536786 & 688620 & 4.95 & 5.0828 & TRN \\
\hline CHEMBL1459982 & 688620 & 4.95 & 5.0452 & TRN \\
\hline CHEMBL1362999 & 688620 & 4.45 & 4.7782 & TST \\
\hline CHEMBL1525602 & 688620 & 4.45 & 4.7827 & TRN \\
\hline CHEMBL1404915 & 688620 & 4.45 & 4.88899 & 9999999999 \\
\hline CHEMBL1459106 & 688620 & 4.95 & 5.0152 & TRN \\
\hline CHEMBL1390243 & 688620 & 4.95 & 4.8538 & TRN \\
\hline CHEMBL1481343 & 688620 & 5.65 & 5.4516 & TRN \\
\hline CHEMBL3198061 & 688620 & 4.45 & 4.6445 & TST \\
\hline CHEMBL1346148 & 688620 & 4.45 & 4.8063 & TRN \\
\hline CHEMBL1608709 & 688620 & 6.05 & 4.9667 & TRN \\
\hline CHEMBL1326458 & 688620 & 4.45 & 5.0619 & TRN \\
\hline CHEMBL1577249 & 688620 & 6.05 & 5.0967 & TRN \\
\hline CHEMBL3197355 & 688620 & 4.45 & 4.8291 & TRN \\
\hline CHEMBL1447341 & 688620 & 4.7 & 5.1605 & TRN \\
\hline CHEMBL1480275 & 688620 & 4.95 & 4.967 & TST \\
\hline CHEMBL1548976 & 688620 & 4.45 & 5.0511 & TST \\
\hline CHEMBL1431498 & 688620 & 4.45 & 4.8427 & TRN \\
\hline CHEMBL1332026 & 688620 & 5.1 & 4.7811 & TRN \\
\hline CHEMBL1313038 & 688620 & 6.2 & 5.5999 & TRN \\
\hline CHEMBL1432494 & 688620 & 5.1 & 4.8428 & TST \\
\hline CHEMBL1498381 & 688620 & 5.9 & 4.9337 & TRN \\
\hline CHEMBL1346955 & 688620 & 4.8 & 5.0408 & TRN \\
\hline CHEMBL2369169 & 688620 & 5.05 & 5.0043 & TRN \\
\hline CHEMBL1539631 & 688620 & 5.3 & 4.9121 & TRN \\
\hline CHEMBL1992261 & 688620 & 5.5 & 5.2693 & TRN \\
\hline CHEMBL1410644 & 688620 & 5.1 & 5.41 & TRN \\
\hline CHEMBL1369897 & 688620 & 5.2 & 5.0779 & TRN \\
\hline CHEMBL1370241 & 688620 & 5.45 & 4.9351 & TRN \\
\hline CHEMBL1426433 & 688620 & 4.65 & 5.0082 & TRN \\
\hline CHEMBL1479522 & 688620 & 5.1 & 5.0162 & TRN \\
\hline CHEMBL1565580 & 688620 & 4.7 & 5.0142 & TRN \\
\hline CHEMBL1502227 & 688620 & 4.55 & 4.724 & TST \\
\hline CHEMBL1540244 & 688620 & 5.4 & 4.9933 & TST \\
\hline CHEMBL1597010 & 688620 & 4.65 & 5.0047 & TRN \\
\hline CHEMBL1385193 & 688620 & 7.5498 & 5.0465 & TST \\
\hline CHEMBL1362105 & 688620 & 4.45 & 5.0082 & TRN \\
\hline CHEMBL1599642 & 688620 & 6.1 & 5.0134 & TST \\
\hline CHEMBL1425102 & 688620 & 5.1 & 4.9016 & TRN \\
\hline CHEMBL1476966 & 688620 & 4.8 & 5.2163 & TRN \\
\hline CHEMBL1564620 & 688620 & 4.85 & 5.0978 & TST \\
\hline CHEMBL1306402 & 688620 & 4.95 & 4.9356 & TST \\
\hline
\end{tabular}




\begin{tabular}{|c|c|c|c|c|c|}
\hline \\
\hline CHEMBL1582542 & 688620 & 4.9 & 5.1261 & TRN & \\
\hline CHEMBL1492188 & 688620 & 5.25 & 4.7624 & TRN & \\
\hline CHEMBL1542902 & 688620 & 4.8 & 4.6834 & TRN & \\
\hline CHEMBL1419625 & 688620 & 4.95 & 4.7108 & TRN & \\
\hline CHEMBL1540663 & 688620 & 5.0 & 4.891 & TRN & \\
\hline CHEMBL1511236 & 688620 & 4.85 & 4.9905 & TRN & \\
\hline CHEMBL1583970 & 688620 & 4.9 & 5.2336 & TRN & \\
\hline CHEMBL1306325 & 688620 & 4.8 & 5.0973 & TRN & \\
\hline CHEMBL1364394 & 688620 & 4.45 & 4.9257 & TST & \\
\hline CHEMBL1546029 & 688620 & 5.0 & 5.0895 & TST & \\
\hline CHEMBL1536340 & 688620 & 4.9 & 5.2774 & TRN & \\
\hline CHEMBL1565040 & 688620 & 4.6 & 4.8017 & TST & \\
\hline CHEMBL1470073 & 688620 & 4.5 & 4.82 & TRN & \\
\hline CHEMBL1482277 & 688620 & 4.65 & 5.146 & TRN & \\
\hline CHEMBL1325227 & 688620 & 4.45 & 4.9618 & TST & \\
\hline CHEMBL1302492 & 688620 & 4.45 & 4.9842 & TRN & \\
\hline CHEMBL1597484 & 688620 & 4.45 & 4.7871 & TST & \\
\hline CHEMBL1989750 & 688620 & 4.95 & 5.6474 & TRN & \\
\hline CHEMBL1605841 & 688620 & 5.25 & 5.0381 & TST & \\
\hline CHEMBL1581141 & 688620 & 4.6 & 5.1921 & TRN & \\
\hline CHEMBL1585633 & 688620 & 4.45 & 4.8696 & TST & \\
\hline CHEMBL1417583 & 688620 & 4.45 & 4.7948 & TST & \\
\hline CHEMBL1387499 & 688620 & 4.45 & 4.6584 & TRN & \\
\hline CHEMBL3197405 & 688620 & 4.7 & 4.9546 & TRN & \\
\hline CHEMBL1595442 & 688620 & 5.25 & 5.2645 & TST & \\
\hline CHEMBL1306128 & 688620 & 5.5 & 4.8636 & TST & \\
\hline CHEMBL1346718 & 688620 & 4.9 & 4.9873 & TRN & \\
\hline CHEMBL1498464 & 688620 & 5.1 & 5.0341 & TST & \\
\hline CHEMBL1449792 & 688620 & 5.4 & 5.0652 & TRN & \\
\hline CHEMBL1583204 & 688620 & 5.35 & 5.4399 & TRN & \\
\hline CHEMBL3197120 & 688620 & 5.55 & 5.3634 & TRN & \\
\hline CHEMBL1532525 & 688620 & 4.5 & 5.0087 & TRN & \\
\hline CHEMBL 3213184 & 688620 & 4.85 & 4.7636 & TRN & \\
\hline CHEMBL1363543 & 688620 & 5.5 & 5.4051 & TST & \\
\hline CHEMBL1499017 & 688620 & 4.45 & 4.6264 & TRN & \\
\hline CHEMBL1476247 & 688620 & 5.25 & 4.9788 & TRN & \\
\hline CHEMBL1561486 & 688620 & 4.45 & 4.9566 & TRN & \\
\hline CHEMBL1370190 & 688620 & 5.2 & 4.9061 & TRN & \\
\hline CHEMBL1387298 & 688620 & 4.8 & 4.7167 & TRN & \\
\hline CHEMBL1557307 & 688620 & 4.8 & 5.09699 & 99999999995 & TRN \\
\hline CHEMBL1313321 & 688620 & 4.45 & 4.7213 & TST & \\
\hline CHEMBL1364247 & 688620 & 4.9 & 5.1479 & TRN & \\
\hline CHEMBL1392478 & 688620 & 5.35 & 4.9169 & TST & \\
\hline CHEMBL1970265 & 688620 & 4.45 & 4.9917 & TRN & \\
\hline CHEMBL1500217 & 688620 & 4.95 & 4.9979 & TST & \\
\hline CHEMBL1596589 & 688620 & 4.7 & 4.8226 & TRN & \\
\hline CHEMBL3198966 & 688620 & 4.45 & 4.9596 & TRN & \\
\hline CHEMBL1523836 & 688620 & 4.45 & 4.8819 & TST & \\
\hline
\end{tabular}




\begin{tabular}{|c|c|c|c|c|c|}
\hline \multicolumn{6}{|c|}{ Supplemental Table S2.txt } \\
\hline CHEMBL1413048 & 688620 & 4.6 & 4.9859 & TRN & \\
\hline CHEMBL1404897 & 688620 & 4.85 & 5.1635 & TST & \\
\hline CHEMBL1608041 & 688620 & 4.45 & 5.0256 & TST & \\
\hline CHEMBL1453386 & 688620 & 6.1 & 5.91299 & 9999999999 & TRN \\
\hline CHEMBL1464415 & 688620 & 6.5501 & 5.8276 & TRN & \\
\hline CHEMBL1400205 & 688620 & 5.35 & 5.0236 & TST & \\
\hline CHEMBL1414030 & 688620 & 4.65 & 5.0836 & TST & \\
\hline CHEMBL1528739 & 688620 & 5.4 & 4.7816 & TRN & \\
\hline CHEMBL1562741 & 688620 & 4.45 & 5.0826 & TRN & \\
\hline CHEMBL1379987 & 688620 & 4.65 & 4.6796 & TRN & \\
\hline CHEMBL1478782 & 688620 & 4.9 & 4.6648 & TRN & \\
\hline CHEMBL1406607 & 688620 & 5.6 & 6.0761 & TST & \\
\hline CHEMBL1363820 & 688620 & 4.85 & 4.9362 & TRN & \\
\hline CHEMBL1373283 & 688620 & 4.6 & 4.8794 & TRN & \\
\hline CHEMBL1556085 & 688620 & 4.45 & 5.0212 & TRN & \\
\hline CHEMBL1384419 & 688620 & 4.8 & 4.9255 & TRN & \\
\hline CHEMBL1421858 & 688620 & 5.3 & 5.1722 & TRN & \\
\hline CHEMBL1457594 & 688620 & 4.45 & 4.9415 & TRN & \\
\hline CHEMBL1502544 & 688620 & 5.1 & 5.2137 & TRN & \\
\hline CHEMBL1376410 & 688620 & 5.5 & 5.4136 & TRN & \\
\hline CHEMBL1545318 & 688620 & 4.95 & 5.0925 & TRN & \\
\hline CHEMBL1323744 & 688620 & 5.5 & 5.5184 & TRN & \\
\hline CHEMBL1390474 & 688620 & 4.45 & 4.838 & TST & \\
\hline CHEMBL1393490 & 688620 & 4.7 & 4.9599 & TRN & \\
\hline CHEMBL1491624 & 688620 & 4.9 & 4.8557 & TRN & \\
\hline CHEMBL1552655 & 688620 & 4.95 & 4.8651 & TRN & \\
\hline CHEMBL 1405850 & 688620 & 6.6499 & 4.9315 & TST & \\
\hline CHEMBL1311961 & 688620 & 4.45 & 4.8532 & TST & \\
\hline CHEMBL1500274 & 688620 & 5.5 & 4.9578 & TRN & \\
\hline CHEMBL1500258 & 688620 & 5.15 & 5.206 & TRN & \\
\hline CHEMBL1365741 & 688620 & 5.0 & 5.7238 & TRN & \\
\hline CHEMBL1423866 & 688620 & 4.95 & 4.898 & TST & \\
\hline CHEMBL1509074 & 688620 & 4.8 & 4.8953 & TST & \\
\hline CHEMBL1564463 & 688620 & 4.65 & 4.9036 & TST & \\
\hline CHEMBL3208373 & 688620 & 6.0 & 5.5321 & TRN & \\
\hline CHEMBL1463360 & 688620 & 5.3 & 5.1095 & TRN & \\
\hline CHEMBL1536916 & 688620 & 4.8 & 5.0494 & TST & \\
\hline CHEMBL1319033 & 688620 & 4.45 & 5.0157 & TRN & \\
\hline CHEMBL1490632 & 688620 & 5.55 & 5.4142 & TRN & \\
\hline CHEMBL1573324 & 688620 & 4.8 & 5.0653 & TRN & \\
\hline CHEMBL3213146 & 688620 & 5.05 & 4.8506 & TRN & \\
\hline CHEMBL1373187 & 688620 & 4.9 & 4.7238 & TRN & \\
\hline CHEMBL1558810 & 688620 & 4.45 & 5.0742 & TRN & \\
\hline CHEMBL1429490 & 688620 & 4.5 & 4.9783 & TRN & \\
\hline CHEMBL1460517 & 688620 & 5.65 & 5.1291 & TRN & \\
\hline CHEMBL1587742 & 688620 & 4.95 & 4.8853 & TRN & \\
\hline CHEMBL1425148 & 688620 & 5.35 & 4.939 & TST & \\
\hline CHEMBL1319779 & 688620 & 4.5 & 4.8317 & TRN & \\
\hline
\end{tabular}




\begin{tabular}{|c|c|c|c|c|}
\hline \multicolumn{5}{|c|}{ Supplemental Table S2.txt } \\
\hline CHEMBL 3190145 & 688620 & 4.7 & 4.9889 & TRN \\
\hline CHEMBL3213761 & 688620 & 4.95 & 4.8846 & TRN \\
\hline CHEMBL 2000175 & 688620 & 4.95 & 4.8454 & TST \\
\hline CHEMBL 3213079 & 688620 & 4.95 & 5.2588 & TRN \\
\hline CHEMBL1509260 & 688620 & 4.95 & 4.9567 & TRN \\
\hline CHEMBL3196429 & 688620 & 4.65 & 4.9885 & TRN \\
\hline CHEMBL1492919 & 688620 & 4.5 & 4.8478 & TRN \\
\hline CHEMBL1413507 & 688620 & 4.95 & 4.8807 & TST \\
\hline CHEMBL1495442 & 688620 & 4.85 & 4.8212 & TRN \\
\hline CHEMBL1369584 & 688620 & 4.45 & 5.1424 & TRN \\
\hline CHEMBL1359557 & 688620 & 5.05 & 5.0773 & TRN \\
\hline CHEMBL3213668 & 688620 & 6.0 & 4.907 & TST \\
\hline CHEMBL1373504 & 688620 & 4.5 & 5.0517 & TRN \\
\hline CHEMBL1384276 & 688620 & 4.5 & 5.0723 & TRN \\
\hline CHEMBL1412992 & 688620 & 4.45 & 5.1012 & TST \\
\hline CHEMBL3190433 & 688620 & 6.3 & 5.8174 & TRN \\
\hline CHEMBL1549779 & 688620 & 5.25 & 5.0256 & TST \\
\hline CHEMBL1490764 & 688620 & 4.7 & 4.8995 & TRN \\
\hline CHEMBL1610706 & 688620 & 5.5 & 4.9334 & TRN \\
\hline CHEMBL1523716 & 688620 & 4.95 & 5.1396 & TRN \\
\hline CHEMBL1548593 & 688620 & 5.45 & 5.1011 & TST \\
\hline CHEMBL1359734 & 688620 & 5.6 & 5.3294 & TRN \\
\hline CHEMBL1299502 & 688620 & 5.05 & 5.0642 & TST \\
\hline CHEMBL1327456 & 688620 & 5.05 & 5.0131 & TRN \\
\hline CHEMBL1301856 & 688620 & 5.4 & 5.034 & TST \\
\hline CHEMBL1421108 & 688620 & 5.95 & 4.9693 & TRN \\
\hline CHEMBL1339219 & 688620 & 4.7 & 5.0655 & TRN \\
\hline CHEMBL1465665 & 688620 & 4.85 & 5.1703 & TST \\
\hline CHEMBL1464424 & 688620 & 5.6 & 5.5638 & TRN \\
\hline CHEMBL1470245 & 688620 & 4.95 & 5.1325 & TRN \\
\hline CHEMBL1421904 & 688620 & 5.7 & 5.1618 & TST \\
\hline CHEMBL1426610 & 688620 & 4.9 & 4.9738 & TRN \\
\hline CHEMBL589711 & 688620 & 4.8 & 4.9138 & TRN \\
\hline CHEMBL1508616 & 688620 & 7.0501 & 6.1521 & TRN \\
\hline CHEMBL1492634 & 688620 & 5.1 & 5.5249 & TRN \\
\hline CHEMBL3192039 & 688620 & 4.45 & 4.9966 & TRN \\
\hline CHEMBL1986081 & 688620 & 5.5 & 5.0974 & TST \\
\hline CHEMBL1471188 & 688620 & 5.25 & 5.0056 & TRN \\
\hline CHEMBL1479226 & 688620 & 5.1 & 4.939 & TRN \\
\hline CHEMBL1542759 & 688620 & 4.8 & 5.2122 & TRN \\
\hline CHEMBL1455084 & 688620 & 6.15 & 5.1524 & TRN \\
\hline CHEMBL1324460 & 688620 & 4.95 & 5.1659 & TST \\
\hline CHEMBL1504441 & 688620 & 5.2 & 5.1927 & TST \\
\hline CHEMBL1533067 & 688620 & 4.85 & 4.8908 & TST \\
\hline CHEMBL1501726 & 688620 & 4.45 & 4.5406 & TRN \\
\hline CHEMBL1364282 & 688620 & 5.9 & 5.6449 & TRN \\
\hline CHEMBL1452634 & 688620 & 5.5 & 5.5342 & TRN \\
\hline CHEMBL3196784 & 688620 & 6.3 & 5.3872 & TST \\
\hline
\end{tabular}




\begin{tabular}{|c|c|c|c|c|c|}
\hline \multicolumn{6}{|c|}{ Supplemental Table S2.txt } \\
\hline CHEMBL1339298 & 688620 & 4.75 & 5.0331 & TST & \\
\hline CHEMBL1452106 & 688620 & 6.45 & 5.0672 & TST & \\
\hline CHEMBL1421687 & 688620 & 5.1 & 4.7607 & TRN & \\
\hline CHEMBL3189804 & 688620 & 4.95 & 4.7905 & TRN & \\
\hline CHEMBL1503698 & 688620 & 4.75 & 4.747 & TRN & \\
\hline CHEMBL1459101 & 688620 & 5.5 & 4.8025 & TRN & \\
\hline CHEMBL1978150 & 688620 & 4.45 & 4.82600 & 00000000005 & TRN \\
\hline CHEMBL1407002 & 688620 & 4.45 & 4.8659 & TST & \\
\hline CHEMBL1598790 & 688620 & 5.05 & 5.1909 & TRN & \\
\hline CHEMBL1486111 & 688620 & 5.75 & 5.2077 & TRN & \\
\hline CHEMBL1587028 & 688620 & 4.95 & 4.8855 & TST & \\
\hline CHEMBL1414322 & 688620 & 6.15 & 5.1682 & TST & \\
\hline CHEMBL1572959 & 688620 & 5.45 & 5.2533 & TST & \\
\hline CHEMBL1410761 & 688620 & 5.15 & 4.9071 & TST & \\
\hline CHEMBL1430300 & 688620 & 4.45 & 4.9709 & TST & \\
\hline CHEMBL3197604 & 688620 & 5.45 & 5.2931 & TRN & \\
\hline CHEMBL1444478 & 688620 & 6.0 & 5.192 & TRN & \\
\hline CHEMBL3199917 & 688620 & 5.8 & 5.4485 & TRN & \\
\hline CHEMBL1336777 & 688620 & 4.8 & 5.0426 & TST & \\
\hline CHEMBL1510875 & 688620 & 5.4 & 5.1701 & TRN & \\
\hline CHEMBL1499827 & 688620 & 6.2 & 5.2201 & TRN & \\
\hline CHEMBL1595761 & 688620 & 5.15 & 5.1269 & TRN & \\
\hline CHEMBL1532819 & 688620 & 5.1 & 5.0245 & TRN & \\
\hline CHEMBL1336039 & 688620 & 5.45 & 5.688 & TRN & \\
\hline CHEMBL1545271 & 688620 & 4.65 & 4.9266 & TRN & \\
\hline CHEMBL1452750 & 688620 & 4.45 & 4.6604 & TRN & \\
\hline CHEMBL407232 & 688620 & 4.8 & 5.2924 & TST & \\
\hline CHEMBL1433019 & 688620 & 4.45 & 4.904 & TRN & \\
\hline CHEMBL3210013 & 688620 & 6.1 & 5.0335 & TRN & \\
\hline CHEMBL1541257 & 688620 & 4.45 & 4.9683 & TRN & \\
\hline CHEMBL1300243 & 688620 & 4.65 & 5.0968 & TRN & \\
\hline CHEMBL1521269 & 688620 & 5.6 & 4.9367 & TRN & \\
\hline CHEMBL1401211 & 688620 & 5.2 & 4.896 & TRN & \\
\hline CHEMBL1524503 & 688620 & 4.85 & 4.84699 & 99999999995 & TRN \\
\hline CHEMBL1343614 & 688620 & 5.25 & 5.2734 & TRN & \\
\hline CHEMBL1485902 & 688620 & 5.15 & 5.3167 & TRN & \\
\hline CHEMBL1490844 & 688620 & 5.3 & 5.2654 & TST & \\
\hline CHEMBL1322948 & 688620 & 4.45 & 4.8531 & TRN & \\
\hline CHEMBL1426149 & 688620 & 4.6 & 4.9022 & TRN & \\
\hline CHEMBL55285 & 688620 & 5.25 & 4.9737 & TST & \\
\hline CHEMBL1343424 & 688620 & 4.8 & 4.8723 & TRN & \\
\hline CHEMBL3194437 & 688620 & 5.25 & 5.2169 & TRN & \\
\hline CHEMBL1345843 & 688620 & 5.05 & 4.7531 & TRN & \\
\hline CHEMBL1322748 & 688620 & 4.9 & 4.9738 & TST & \\
\hline CHEMBL1342659 & 688620 & 4.6 & 5.0426 & TST & \\
\hline CHEMBL1453222 & 688620 & 5.0 & 4.7987 & TRN & \\
\hline CHEMBL1507331 & 688620 & 5.25 & 5.1628 & TRN & \\
\hline CHEMBL1524915 & 688620 & 5.5 & 5.0474 & TRN & \\
\hline
\end{tabular}




\begin{tabular}{|c|c|c|c|c|c|}
\hline \multicolumn{6}{|c|}{ Supplemental Table s2.txt } \\
\hline CHEMBL1325378 & 688620 & 5.25 & 5.1586 & TRN & \\
\hline CHEMBL1583035 & 688620 & 5.0 & 5.3259 & TRN & \\
\hline CHEMBL1469980 & 688620 & 6.45 & 6.0851 & TRN & \\
\hline CHEMBL1392873 & 688620 & 4.9 & 5.4918 & TST & \\
\hline CHEMBL1362612 & 688620 & 4.9 & 4.9958 & TRN & \\
\hline CHEMBL1421974 & 688620 & 5.1 & 5.0278 & TST & \\
\hline CHEMBL1571070 & 688620 & 6.15 & 4.8799 & TST & \\
\hline CHEMBL1526321 & 688620 & 5.25 & 5.4644 & TRN & \\
\hline CHEMBL 3192208 & 688620 & 4.75 & 5.0897 & TRN & \\
\hline CHEMBL1588245 & 688620 & 4.65 & 4.9962 & TRN & \\
\hline CHEMBL1581001 & 688620 & 4.9 & 5.13 & TRN & \\
\hline CHEMBL1320020 & 688620 & 4.85 & 4.9223 & TST & \\
\hline CHEMBL1326292 & 688620 & 5.2 & 5.1223 & TRN & \\
\hline CHEMBL1331100 & 688620 & 4.95 & 5.2749 & TRN & \\
\hline CHEMBL1549614 & 688620 & 4.45 & 5.0245 & TRN & \\
\hline CHEMBL1584315 & 688620 & 5.0 & 5.0796 & TST & \\
\hline CHEMBL71999 & 688620 & 4.95 & 4.9552 & TRN & \\
\hline CHEMBL1456272 & 688620 & 4.65 & 5.1755 & TRN & \\
\hline CHEMBL1466443 & 688620 & 4.95 & 4.9246 & TRN & \\
\hline CHEMBL1390514 & 688620 & 4.85 & 5.0082 & TRN & \\
\hline CHEMBL1457724 & 688620 & 8.301 & 5.07100 & 0000000001 & TST \\
\hline CHEMBL1477485 & 688620 & 4.45 & 4.9694 & TST & \\
\hline CHEMBL1318363 & 688620 & 4.45 & 5.0692 & TRN & \\
\hline CHEMBL1494636 & 688620 & 4.95 & 5.1529 & TRN & \\
\hline CHEMBL1530031 & 688620 & 5.3 & 4.882 & TST & \\
\hline CHEMBL1431053 & 688620 & 4.85 & 5.6146 & TST & \\
\hline CHEMBL 259073 & 688620 & 6.0 & 4.8457 & TRN & \\
\hline CHEMBL1441728 & 688620 & 4.65 & 5.2504 & TST & \\
\hline CHEMBL1524043 & 688620 & 5.05 & 5.0124 & TST & \\
\hline CHEMBL1390419 & 688620 & 4.95 & 5.1105 & TRN & \\
\hline CHEMBL1482241 & 688620 & 5.3 & 4.9129 & TRN & \\
\hline CHEMBL1542955 & 688620 & 5.25 & 5.1125 & TRN & \\
\hline CHEMBL1541216 & 688620 & 4.95 & 5.0445 & TRN & \\
\hline CHEMBL1487887 & 688620 & 4.45 & 4.8798 & TRN & \\
\hline CHEMBL1485699 & 688620 & 5.4 & 5.0448 & TST & \\
\hline CHEMBL 3207534 & 688620 & 4.9 & 5.311 & TRN & \\
\hline CHEMBL405358 & 688620 & 6.0 & 5.4979 & TST & \\
\hline CHEMBL1609391 & 688620 & 5.45 & 4.9374 & TST & \\
\hline CHEMBL1457093 & 688620 & 5.2 & 4.8299 & TRN & \\
\hline CHEMBL1360311 & 688620 & 4.9 & 4.8604 & TST & \\
\hline CHEMBL1500472 & 688620 & 5.15 & 5.2601 & TRN & \\
\hline CHEMBL1527846 & 688620 & 4.9 & 4.9 & TRN & \\
\hline CHEMBL1489018 & 688620 & 6.5 & 5.5616 & TRN & \\
\hline CHEMBL1569120 & 688620 & 4.95 & 5.0906 & TRN & \\
\hline CHEMBL1371289 & 688620 & 5.0 & 5.37200 & 0000000001 & TRN \\
\hline CHEMBL1418884 & 688620 & 4.65 & 4.6357 & TST & \\
\hline CHEMBL3197129 & 688620 & 5.5 & 4.8005 & TST & \\
\hline CHEMBL3210812 & 688620 & 4.75 & 4.9323 & TRN & \\
\hline
\end{tabular}




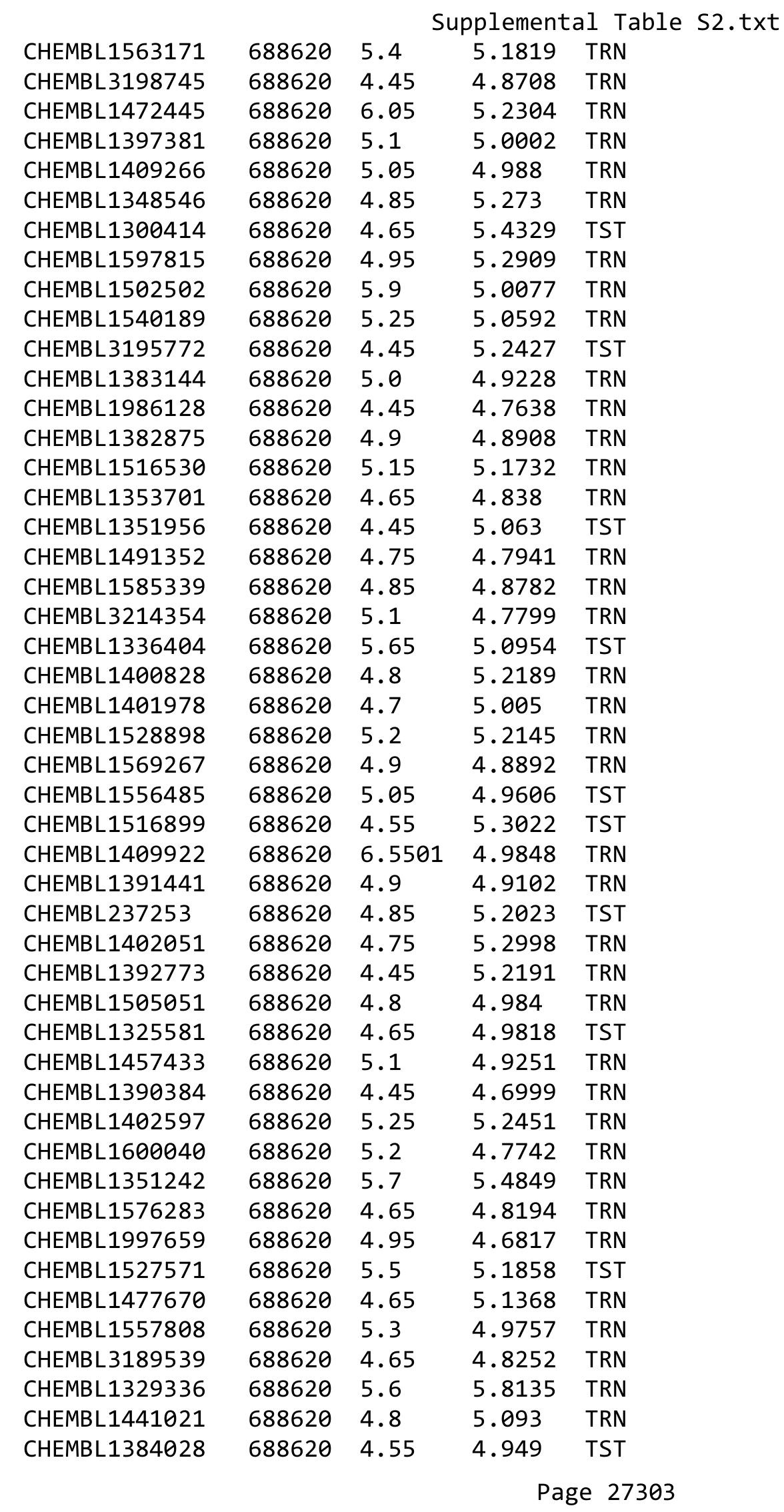




\begin{tabular}{|c|c|c|c|c|c|}
\hline \multicolumn{6}{|c|}{ Supplemental Table S2.txt } \\
\hline CHEMBL1576454 & 688620 & 5.45 & 5.046 & TRN & \\
\hline CHEMBL1584128 & 688620 & 5.2 & 5.5127 & TRN & \\
\hline CHEMBL 3190484 & 688620 & 5.55 & 5.54 & TRN & \\
\hline CHEMBL1383057 & 688620 & 6.0 & 5.8406 & TRN & \\
\hline CHEMBL1445962 & 688620 & 4.45 & 4.6587 & TRN & \\
\hline CHEMBL1497706 & 688620 & 4.8 & 5.1065 & TST & \\
\hline CHEMBL1966298 & 688620 & 6.1 & 5.33299 & 9999999999 & TRN \\
\hline CHEMBL1497589 & 688620 & 5.65 & 4.9324 & TRN & \\
\hline CHEMBL1367591 & 688620 & 5.25 & 5.021 & TRN & \\
\hline CHEMBL1311560 & 688620 & 4.9 & 4.8277 & TRN & \\
\hline CHEMBL1464628 & 688620 & 5.35 & 5.2082 & TST & \\
\hline CHEMBL1349864 & 688620 & 6.15 & 6.0503 & TRN & \\
\hline CHEMBL1479114 & 688620 & 4.7 & 4.877 & TST & \\
\hline CHEMBL1539479 & 688620 & 5.85 & 5.5163 & TRN & \\
\hline CHEMBL1518878 & 688620 & 5.0 & 4.9956 & TRN & \\
\hline CHEMBL1309597 & 688620 & 4.8 & 5.047 & TRN & \\
\hline CHEMBL1529447 & 688620 & 4.45 & 4.8942 & TRN & \\
\hline CHEMBL1381717 & 688620 & 5.3 & 4.9246 & TRN & \\
\hline CHEMBL1426158 & 688620 & 4.8 & 5.0375 & TST & \\
\hline CHEMBL1348176 & 688620 & 5.2 & 5.0675 & TRN & \\
\hline CHEMBL1495733 & 688620 & 5.2 & 5.1657 & TST & \\
\hline CHEMBL1337183 & 688620 & 4.45 & 4.8767 & TRN & \\
\hline CHEMBL1973429 & 688620 & 5.55 & 5.3351 & TST & \\
\hline CHEMBL1386912 & 688620 & 6.1 & 5.0899 & TST & \\
\hline CHEMBL1338617 & 688620 & 4.95 & 4.982 & TRN & \\
\hline CHEMBL1604591 & 688620 & 5.25 & 5.1039 & TRN & \\
\hline CHEMBL1438627 & 688620 & 5.6 & 5.042 & TRN & \\
\hline CHEMBL1302828 & 688620 & 4.45 & 5.0068 & TST & \\
\hline CHEMBL1374058 & 688620 & 5.55 & 4.9583 & TRN & \\
\hline CHEMBL1327972 & 688620 & 4.95 & 5.0305 & TRN & \\
\hline CHEMBL1560494 & 688620 & 4.45 & 5.0846 & TRN & \\
\hline CHEMBL1469920 & 688620 & 5.15 & 5.2976 & TST & \\
\hline CHEMBL1299256 & 688620 & 4.7 & 5.0375 & TRN & \\
\hline CHEMBL1338083 & 688620 & 4.9 & 4.944 & TST & \\
\hline CHEMBL1393012 & 688620 & 6.25 & 4.9798 & TST & \\
\hline CHEMBL1579595 & 688620 & 4.85 & 4.9682 & TST & \\
\hline CHEMBL1595727 & 688620 & 6.0 & 5.2073 & TRN & \\
\hline CHEMBL1543949 & 688620 & 4.9 & 5.0461 & TRN & \\
\hline CHEMBL3211692 & 688620 & 4.9 & 4.959 & TST & \\
\hline CHEMBL1528668 & 688620 & 4.95 & 5.4263 & TRN & \\
\hline CHEMBL1584705 & 688620 & 4.45 & 4.9583 & TRN & \\
\hline CHEMBL3199744 & 688620 & 5.55 & 5.1562 & TRN & \\
\hline CHEMBL3193802 & 688620 & 4.9 & 5.2722 & TRN & \\
\hline CHEMBL 3198448 & 688620 & 4.45 & 4.9817 & TST & \\
\hline CHEMBL1900654 & 688620 & 5.5 & 5.1552 & TRN & \\
\hline CHEMBL1490016 & 688620 & 5.65 & 5.5209 & TST & \\
\hline CHEMBL1466791 & 688620 & 5.0 & 4.8696 & TRN & \\
\hline CHEMBL1447565 & 688620 & 5.55 & 4.7558 & TRN & \\
\hline
\end{tabular}




\begin{tabular}{|c|c|c|c|c|c|}
\hline & & \multicolumn{4}{|c|}{ Supplemental Table S2.txt } \\
\hline CHEMBL1363071 & 688620 & 6.0 & 5.2026 & TST & \\
\hline CHEMBL1386225 & 688620 & 4.95 & 5.0957 & TRN & \\
\hline CHEMBL1604016 & 688620 & 7.0 & 5.2389 & TRN & \\
\hline CHEMBL1582302 & 688620 & 5.15 & 4.8262 & TST & \\
\hline CHEMBL1324867 & 688620 & 4.85 & 5.0249 & TST & \\
\hline CHEMBL1497509 & 688620 & 5.1 & 5.0308 & TST & \\
\hline CHEMBL1375628 & 688620 & 4.9 & 5.1866 & TRN & \\
\hline CHEMBL1328367 & 688620 & 4.95 & 4.8566 & TRN & \\
\hline CHEMBL1550577 & 688620 & 4.45 & 5.1038 & TRN & \\
\hline CHEMBL1580973 & 688620 & 5.5 & 5.1774 & TRN & \\
\hline CHEMBL1492221 & 688620 & 5.5 & 5.0823 & TRN & \\
\hline CHEMBL1532436 & 688620 & 4.45 & 4.9242 & TRN & \\
\hline CHEMBL1964306 & 688620 & 5.5 & 4.89 & TST & \\
\hline CHEMBL1493894 & 688620 & 4.65 & 4.8127 & TRN & \\
\hline CHEMBL1391121 & 688620 & 4.7 & 5.1604 & TST & \\
\hline CHEMBL1529170 & 688620 & 5.4 & 5.1242 & TRN & \\
\hline CHEMBL1415958 & 688620 & 4.85 & 5.1631 & TRN & \\
\hline CHEMBL1361987 & 688620 & 4.75 & 4.8847 & TRN & \\
\hline CHEMBL1572700 & 688620 & 4.55 & 5.2787 & TST & \\
\hline CHEMBL1332824 & 688620 & 6.4 & 5.0126 & TRN & \\
\hline CHEMBL1481224 & 688620 & 4.95 & 5.0378 & TRN & \\
\hline CHEMBL1451126 & 688620 & 4.45 & 4.9057 & TRN & \\
\hline CHEMBL1424887 & 688620 & 4.45 & 5.2486 & TRN & \\
\hline CHEMBL1328637 & 688620 & 5.15 & 5.2756 & TRN & \\
\hline CHEMBL1576513 & 688620 & 6.45 & 4.8874 & TRN & \\
\hline CHEMBL1967770 & 688620 & 4.75 & 4.8774 & TRN & \\
\hline CHEMBL1302206 & 688620 & 4.75 & 5.0224 & TRN & \\
\hline CHEMBL1484908 & 688620 & 4.7 & 4.8263 & TRN & \\
\hline CHEMBL1507682 & 688620 & 4.9 & 4.7485 & TST & \\
\hline CHEMBL1576718 & 688620 & 4.85 & 5.015 & TRN & \\
\hline CHEMBL1527565 & 688620 & 5.15 & 5.1065 & TST & \\
\hline CHEMBL1546624 & 688620 & 5.0 & 4.8224 & TRN & \\
\hline CHEMBL1530670 & 688620 & 4.65 & 5.0521 & TST & \\
\hline CHEMBL1508961 & 688620 & 5.2 & 4.9755 & TST & \\
\hline CHEMBL1456699 & 688620 & 5.2 & 4.9038 & TRN & \\
\hline CHEMBL1490704 & 688620 & 6.4 & 5.4141 & TRN & \\
\hline CHEMBL3192947 & 688620 & 5.35 & 5.2871 & TRN & \\
\hline CHEMBL1409776 & 688620 & 5.85 & 5.5182 & TRN & \\
\hline CHEMBL1486109 & 688620 & 6.25 & 6.239 & TRN & \\
\hline CHEMBL1485358 & 688620 & 5.0 & 4.9843 & TST & \\
\hline CHEMBL1570072 & 688620 & 4.75 & 4.9887 & TST & \\
\hline CHEMBL1548383 & 688620 & 5.7 & 5.53799 & 9999999999 & TRN \\
\hline CHEMBL1478413 & 688620 & 4.95 & 4.7478 & TRN & \\
\hline CHEMBL1475408 & 688620 & 4.95 & 5.0494 & TST & \\
\hline CHEMBL1502307 & 688620 & 4.85 & 4.8874 & TRN & \\
\hline CHEMBL1501884 & 688620 & 5.45 & 5.03600 & 00000000005 & TRN \\
\hline CHEMBL1334405 & 688620 & 4.45 & 4.8407 & TRN & \\
\hline CHEMBL3194609 & 688620 & 4.45 & 4.7078 & TRN & \\
\hline
\end{tabular}




\begin{tabular}{|c|c|c|c|c|}
\hline \multicolumn{5}{|c|}{ Supplemental Table s2.txt } \\
\hline CHEMBL1329659 & 688620 & 4.6 & 4.6659 & TRN \\
\hline CHEMBL1574414 & 688620 & 4.45 & 5.1149 & TRN \\
\hline CHEMBL1534782 & 688620 & 4.55 & 4.7936 & TRN \\
\hline CHEMBL1440200 & 688620 & 5.2 & 5.1163 & TRN \\
\hline CHEMBL 3193259 & 688620 & 6.5501 & 5.9661 & TRN \\
\hline CHEMBL1612438 & 688620 & 4.5 & 5.1645 & TST \\
\hline CHEMBL1507186 & 688620 & 5.45 & 4.9307 & TST \\
\hline CHEMBL1479678 & 688620 & 5.45 & 5.4937 & TRN \\
\hline CHEMBL1440939 & 688620 & 5.05 & 4.8954 & TRN \\
\hline CHEMBL1308642 & 688620 & 4.9 & 5.1478 & TRN \\
\hline CHEMBL1520417 & 688620 & 5.0 & 4.8929 & TRN \\
\hline CHEMBL1308989 & 688620 & 4.95 & 5.0079 & TRN \\
\hline CHEMBL1448047 & 688620 & 4.7 & 4.8883 & TRN \\
\hline CHEMBL1613351 & 688620 & 4.85 & 5.1029 & TRN \\
\hline CHEMBL1348332 & 688620 & 5.15 & 5.3406 & TST \\
\hline CHEMBL3192549 & 688620 & 5.1 & 5.1534 & TRN \\
\hline CHEMBL1489074 & 688620 & 4.9 & 4.9987 & TRN \\
\hline CHEMBL1509317 & 688620 & 5.0 & 5.0479 & TST \\
\hline CHEMBL1556827 & 688620 & 6.95 & 5.1102 & TRN \\
\hline CHEMBL1375669 & 688620 & 4.45 & 4.8685 & TRN \\
\hline CHEMBL1345865 & 688620 & 4.7 & 5.0017 & TRN \\
\hline CHEMBL1362754 & 688620 & 4.8 & 4.9023 & TRN \\
\hline CHEMBL 3212885 & 688620 & 4.75 & 5.06 & TRN \\
\hline CHEMBL1456036 & 688620 & 6.05 & 5.0882 & TRN \\
\hline CHEMBL1339788 & 688620 & 4.95 & 4.9207 & TST \\
\hline CHEMBL 1587552 & 688620 & 4.45 & 5.008 & TRN \\
\hline CHEMBL 3198000 & 688620 & 5.0 & 5.1047 & TRN \\
\hline CHEMBL1342109 & 688620 & 4.95 & 5.1644 & TRN \\
\hline CHEMBL3209339 & 688620 & 5.7 & 5.1363 & TST \\
\hline CHEMBL1611772 & 688620 & 5.45 & 5.2193 & TRN \\
\hline CHEMBL1303867 & 688620 & 4.45 & 5.3294 & TRN \\
\hline CHEMBL1386941 & 688620 & 4.85 & 4.9117 & TRN \\
\hline CHEMBL1411403 & 688620 & 5.0 & 5.2813 & TRN \\
\hline CHEMBL1991431 & 688620 & 7.1002 & 6.3409 & TRN \\
\hline CHEMBL1373827 & 688620 & 4.45 & 5.0216 & TRN \\
\hline CHEMBL1465704 & 688620 & 4.45 & 4.9579 & TRN \\
\hline CHEMBL1329360 & 688620 & 4.8 & 5.1703 & TRN \\
\hline CHEMBL1415770 & 688620 & 4.95 & 4.9893 & TST \\
\hline CHEMBL1584637 & 688620 & 6.15 & 6.2512 & TRN \\
\hline CHEMBL1422962 & 688620 & 5.45 & 5.353 & TRN \\
\hline CHEMBL1521164 & 688620 & 5.1 & 5.1436 & TRN \\
\hline CHEMBL1487742 & 688620 & 5.45 & 4.9879 & TRN \\
\hline CHEMBL1471341 & 688620 & 5.3 & 5.5245 & TRN \\
\hline CHEMBL1573287 & 688620 & 5.5 & 5.551 & TRN \\
\hline CHEMBL 3194247 & 688620 & 4.95 & 5.8932 & TRN \\
\hline CHEMBL1326046 & 688620 & 4.95 & 4.9226 & TRN \\
\hline CHEMBL1580379 & 688620 & 4.65 & 5.1892 & TRN \\
\hline CHEMBL3192067 & 688620 & 4.95 & $5.1770 e$ & 00000000005 \\
\hline & & & & 27306 \\
\hline
\end{tabular}




\begin{tabular}{|c|c|c|c|c|c|}
\hline & & \multicolumn{4}{|c|}{ Supplemental Table S2.txt } \\
\hline CHEMBL1411869 & 688620 & 5.0 & 4.8837 & TRN & \\
\hline CHEMBL1429837 & 688620 & 4.45 & 5.0635 & TRN & \\
\hline CHEMBL1421039 & 688620 & 4.6 & 4.7384 & TST & \\
\hline CHEMBL1547379 & 688620 & 5.0 & 4.9775 & TRN & \\
\hline CHEMBL1321915 & 688620 & 4.45 & 4.9531 & TRN & \\
\hline CHEMBL1599509 & 688620 & 4.95 & 5.0392 & TRN & \\
\hline CHEMBL1359366 & 688620 & 4.6 & 4.9269 & TRN & \\
\hline CHEMBL1384540 & 688620 & 6.95 & 5.1004 & TRN & \\
\hline CHEMBL1457015 & 688620 & 4.65 & 4.8769 & TRN & \\
\hline CHEMBL1387843 & 688620 & 4.9 & 5.1623 & TST & \\
\hline CHEMBL1506626 & 688620 & 5.1 & 4.9015 & TRN & \\
\hline CHEMBL1501203 & 688620 & 5.95 & 5.0986 & TRN & \\
\hline CHEMBL1380644 & 688620 & 5.2 & 4.9487 & TST & \\
\hline CHEMBL1301312 & 688620 & 5.0 & 4.8534 & TRN & \\
\hline CHEMBL1330788 & 688620 & 4.9 & 5.0392 & TRN & \\
\hline CHEMBL1498967 & 688620 & 4.9 & $5.0360 e$ & 00000000005 & TRN \\
\hline CHEMBL1411623 & 688620 & 4.45 & 4.828 & TRN & \\
\hline CHEMBL1591486 & 688620 & 4.45 & $5.2410 e$ & 00000000005 & TST \\
\hline CHEMBL1446341 & 688620 & 4.85 & 5.0057 & TRN & \\
\hline CHEMBL1368777 & 688620 & 4.7 & 5.0045 & TRN & \\
\hline CHEMBL1344460 & 688620 & 4.9 & 5.05 & TRN & \\
\hline CHEMBL1421780 & 688620 & 5.05 & 5.0528 & TRN & \\
\hline CHEMBL1557966 & 688620 & 5.9 & 5.3204 & TST & \\
\hline CHEMBL1527581 & 688620 & 5.45 & 5.1215 & TRN & \\
\hline CHEMBL1545549 & 688620 & 4.85 & 4.7198 & TRN & \\
\hline CHEMBL1574982 & 688620 & 5.6 & 5.0723 & TRN & \\
\hline CHEMBL1506823 & 688620 & 4.6 & 5.249 & TRN & \\
\hline CHEMBL1568228 & 688620 & 4.8 & 4.9995 & TRN & \\
\hline CHEMBL1300502 & 688620 & 5.2 & 4.7814 & TRN & \\
\hline CHEMBL1340462 & 688620 & 4.9 & 5.1078 & TRN & \\
\hline CHEMBL3198683 & 688620 & 5.45 & 5.3901 & TRN & \\
\hline CHEMBL1309183 & 688620 & 4.5 & 4.8559 & TRN & \\
\hline CHEMBL1400130 & 688620 & 4.45 & 4.9257 & TST & \\
\hline CHEMBL3193020 & 688620 & 4.5 & 5.0945 & TST & \\
\hline CHEMBL1595193 & 688620 & 5.55 & 5.2042 & TST & \\
\hline CHEMBL1573138 & 688620 & 5.95 & 5.0606 & TRN & \\
\hline CHEMBL1989917 & 688620 & 5.45 & 5.1686 & TRN & \\
\hline CHEMBL1308140 & 688620 & 4.9 & 5.0497 & TRN & \\
\hline CHEMBL1555767 & 688620 & 4.95 & 5.1684 & TRN & \\
\hline CHEMBL1456379 & 688620 & 4.95 & 5.1421 & TRN & \\
\hline CHEMBL1557212 & 688620 & 5.55 & 5.5488 & TRN & \\
\hline CHEMBL1441886 & 688620 & 5.05 & 5.2716 & TRN & \\
\hline CHEMBL1342094 & 688620 & 5.05 & 5.1967 & TRN & \\
\hline CHEMBL1587948 & 688620 & 4.9 & 4.9605 & TST & \\
\hline CHEMBL1460194 & 688620 & 4.45 & $5.1270 e$ & 2000000001 & TRN \\
\hline CHEMBL1409578 & 688620 & 4.9 & 5.0932 & TRN & \\
\hline CHEMBL1353558 & 688620 & 4.45 & 4.8927 & TRN & \\
\hline CHEMBL1490362 & 688620 & 4.55 & 4.9582 & TRN & \\
\hline
\end{tabular}




\begin{tabular}{|c|c|c|c|c|}
\hline \multirow[b]{2}{*}{ CHEMBL1304225 } & \multicolumn{4}{|c|}{ Supplemental Table S2.txt } \\
\hline & 688620 & 4.75 & 4.9188 & TST \\
\hline CHEMBL1575995 & 688620 & 4.5 & 5.0157 & TRN \\
\hline CHEMBL1533265 & 688620 & 5.55 & 4.8878 & TRN \\
\hline CHEMBL1586701 & 688620 & 5.35 & 4.9594 & TRN \\
\hline CHEMBL1333987 & 688620 & 5.45 & 5.7268 & TRN \\
\hline CHEMBL1383158 & 688620 & 4.65 & 5.0578 & TST \\
\hline CHEMBL1454586 & 688620 & 5.25 & 5.0546 & TRN \\
\hline CHEMBL1501373 & 688620 & 4.85 & 4.9684 & TRN \\
\hline CHEMBL1594613 & 688620 & 5.85 & 4.9564 & TRN \\
\hline CHEMBL1561020 & 688620 & 4.75 & 5.3548 & TRN \\
\hline CHEMBL1529891 & 688620 & 4.45 & 5.0366 & TRN \\
\hline CHEMBL1456197 & 688620 & 5.75 & 5.3035 & TST \\
\hline CHEMBL1402714 & 688620 & 6.8 & 5.073 & TST \\
\hline CHEMBL3191871 & 688620 & 7.0 & 6.0548 & TRN \\
\hline CHEMBL1431813 & 688620 & 4.85 & 4.8316 & TRN \\
\hline CHEMBL1491790 & 688620 & 6.15 & 4.9785 & TRN \\
\hline CHEMBL1611954 & 688620 & 4.75 & 5.0966 & TRN \\
\hline CHEMBL1359358 & 688620 & 4.75 & 5.7673 & TRN \\
\hline CHEMBL3208715 & 688620 & 4.9 & 5.0051 & TRN \\
\hline CHEMBL1417917 & 688620 & 4.75 & 4.9538 & TRN \\
\hline CHEMBL1430520 & 688620 & 5.5 & 4.8595 & TRN \\
\hline CHEMBL259389 & 688620 & 5.9 & 4.7685 & TST \\
\hline CHEMBL1582580 & 688620 & 5.25 & 5.426 & TRN \\
\hline CHEMBL1558701 & 688620 & 4.45 & 4.7284 & TRN \\
\hline CHEMBL1524335 & 688620 & 5.0 & 5.0849 & TST \\
\hline CHEMBL1449992 & 688620 & 5.15 & 4.8562 & TRN \\
\hline CHEMBL1568655 & 688620 & 4.9 & 5.0138 & TRN \\
\hline CHEMBL1308319 & 688620 & 6.05 & 5.9779 & TST \\
\hline CHEMBL1200471 & 688620 & 7.1002 & 6.0825 & TST \\
\hline CHEMBL1326515 & 688620 & 4.8 & 5.2691 & TRN \\
\hline CHEMBL1532516 & 688620 & 4.45 & 5.2783 & TST \\
\hline CHEMBL1326246 & 688620 & 5.35 & 5.2621 & TST \\
\hline CHEMBL428496 & 688620 & 6.0 & 5.895 & TST \\
\hline CHEMBL1544693 & 688620 & 4.8 & 5.1106 & TST \\
\hline CHEMBL1524478 & 688620 & 5.6 & 5.0921 & TST \\
\hline CHEMBL1494586 & 688620 & 4.65 & 4.909 & TST \\
\hline CHEMBL1611246 & 688620 & 4.85 & 5.058 & TST \\
\hline CHEMBL1604761 & 688620 & 5.0 & 5.065 & TRN \\
\hline CHEMBL1306343 & 688620 & 4.45 & 5.4448 & TRN \\
\hline CHEMBL1612493 & 688620 & 5.8 & 5.8646 & TRN \\
\hline CHEMBL1350152 & 688620 & 5.25 & 5.1434 & TRN \\
\hline CHEMBL1527298 & 688620 & 4.45 & 5.0814 & TST \\
\hline CHEMBL1432358 & 688620 & 4.9 & 5.2292 & TRN \\
\hline CHEMBL1491273 & 688620 & 5.0 & 5.0228 & TRN \\
\hline CHEMBL1417610 & 688620 & 5.45 & 5.1592 & TRN \\
\hline CHEMBL1589431 & 688620 & 4.6 & 4.8733 & TRN \\
\hline CHEMBL1406661 & 688620 & 4.9 & 5.0047 & TRN \\
\hline CHEMBL1368012 & 688620 & 4.45 & 5.0431 & TRN \\
\hline
\end{tabular}




\begin{tabular}{|c|c|c|c|c|}
\hline & & & pplement & $\mathrm{T}$ \\
\hline CHEMBL1473874 & 688620 & 5.1 & 5.225 & TST \\
\hline CHEMBL1344933 & 688620 & 4.95 & 4.9521 & TRN \\
\hline CHEMBL1432239 & 688620 & 5.3 & 5.2439 & TRN \\
\hline CHEMBL1455879 & 688620 & 4.65 & 4.8521 & TRN \\
\hline CHEMBL1568284 & 688620 & 4.45 & 5.2315 & TRN \\
\hline CHEMBL1310319 & 688620 & 4.7 & 5.362 & TST \\
\hline CHEMBL1393867 & 688620 & 6.2 & 5.3059 & TRN \\
\hline CHEMBL1450105 & 688620 & 4.9 & 4.9761 & TRN \\
\hline CHEMBL3197932 & 688620 & 4.95 & 5.0748 & TST \\
\hline CHEMBL3189565 & 688620 & 5.8 & 5.3063 & TRN \\
\hline CHEMBL3197668 & 688620 & 4.7 & 5.17 & TRN \\
\hline CHEMBL1600752 & 688620 & 5.0 & 5.1133 & TST \\
\hline CHEMBL1597733 & 688620 & 4.5 & 5.0032 & TRN \\
\hline CHEMBL1401122 & 688620 & 6.15 & 5.8173 & TRN \\
\hline CHEMBL1455475 & 688620 & 4.8 & 4.9689 & TRN \\
\hline CHEMBL1523322 & 688620 & 4.75 & 5.1177 & TST \\
\hline CHEMBL1398705 & 688620 & 5.05 & 4.999 & TST \\
\hline CHEMBL3191243 & 688620 & 6.4 & 5.6349 & TRN \\
\hline CHEMBL1606581 & 688620 & 4.95 & 4.8667 & TRN \\
\hline CHEMBL3192563 & 688620 & 5.1 & 4.9952 & TST \\
\hline CHEMBL1417341 & 688620 & 6.05 & 5.0265 & TST \\
\hline CHEMBL1483494 & 688620 & 4.75 & 5.0375 & TRN \\
\hline CHEMBL1300968 & 688620 & 5.55 & 5.1592 & TRN \\
\hline CHEMBL1487374 & 688620 & 4.45 & 5.0645 & TRN \\
\hline CHEMBL1312344 & 688620 & 4.9 & 5.2113 & TST \\
\hline CHEMBL1444875 & 688620 & 5.3 & 5.3727 & TRN \\
\hline CHEMBL1479708 & 688620 & 6.0 & 5.7049 & TRN \\
\hline CHEMBL1419015 & 688620 & 4.75 & 4.9023 & TRN \\
\hline CHEMBL1340033 & 688620 & 4.85 & 5.0945 & TRN \\
\hline CHEMBL1503822 & 688620 & 4.5 & 4.9561 & TST \\
\hline CHEMBL1373318 & 688620 & 4.45 & 4.8564 & TST \\
\hline CHEMBL1390307 & 688620 & 4.5 & 5.1508 & TRN \\
\hline CHEMBL1567832 & 688620 & 4.65 & 5.6379 & TRN \\
\hline CHEMBL1347209 & 688620 & 5.0 & 5.0408 & TRN \\
\hline CHEMBL1511564 & 688620 & 6.35 & 5.9037 & TRN \\
\hline CHEMBL1462794 & 688620 & 5.0 & 4.9999 & TST \\
\hline CHEMBL1394483 & 688620 & 6.4 & 5.1137 & TRN \\
\hline CHEMBL1390665 & 688620 & 4.75 & 5.0169 & TRN \\
\hline CHEMBL1402183 & 688620 & 6.05 & 5.0625 & TRN \\
\hline CHEMBL1965758 & 688620 & 5.25 & 4.9096 & TRN \\
\hline CHEMBL3189288 & 688620 & 4.45 & 5.0004 & TRN \\
\hline CHEMBL1573856 & 688620 & 5.15 & 5.1164 & TRN \\
\hline CHEMBL1311383 & 688620 & 4.55 & 4.9282 & TRN \\
\hline CHEMBL1342493 & 688620 & 8.301 & 5.0984 & TRN \\
\hline CHEMBL1567166 & 688620 & 5.55 & 5.2269 & TRN \\
\hline CHEMBL1342122 & 688620 & 5.05 & 4.7635 & TRN \\
\hline CHEMBL 1446440 & 688620 & 4.8 & 5.1396 & TRN \\
\hline CHEMBL1478551 & 688620 & 4.95 & 5.1829 & TRN \\
\hline
\end{tabular}




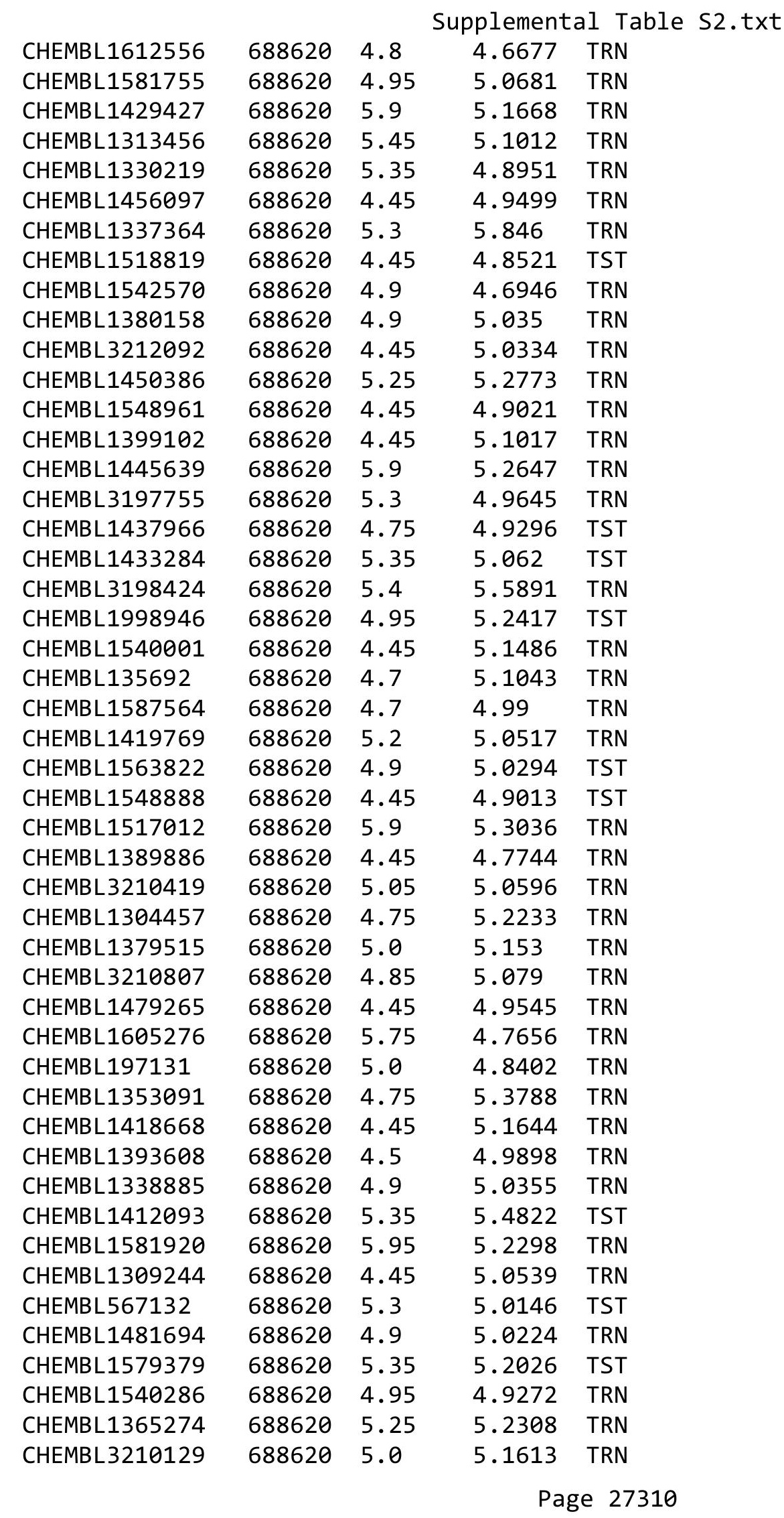




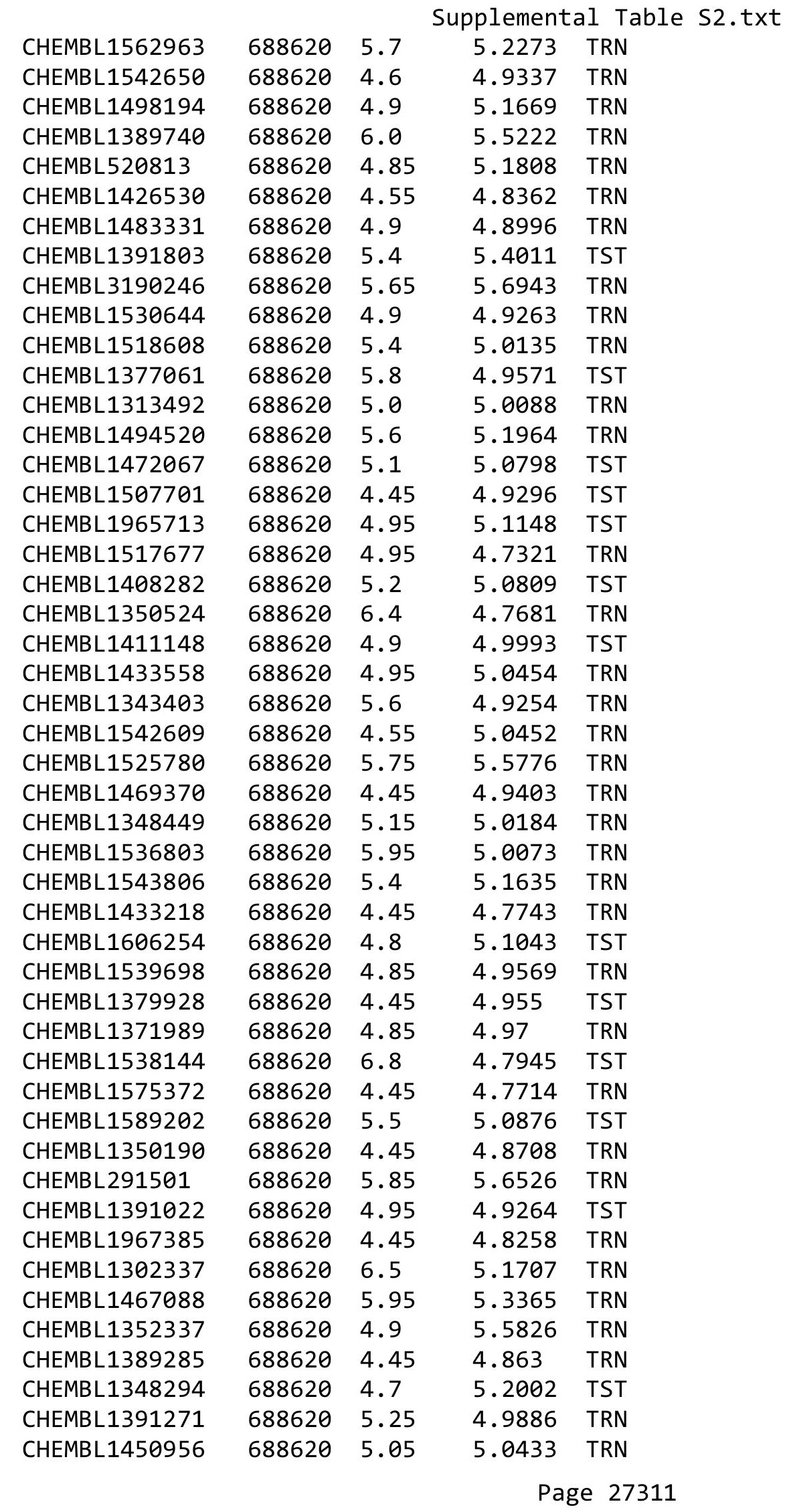




\begin{tabular}{|c|c|c|c|c|}
\hline & & & pplement & at \\
\hline CHEMBL1565971 & 688620 & 4.5 & 4.9242 & TRN \\
\hline CHEMBL1447602 & 688620 & 4.9 & 4.9783 & TRN \\
\hline CHEMBL1467429 & 688620 & 4.9 & 4.9179 & TST \\
\hline CHEMBL1332759 & 688620 & 4.85 & 4.978 & TRN \\
\hline CHEMBL1387665 & 688620 & 4.9 & 4.9046 & TRN \\
\hline CHEMBL1549650 & 688620 & 4.95 & 4.9814 & TST \\
\hline CHEMBL1313074 & 688620 & 4.9 & 5.0286 & TST \\
\hline CHEMBL1345573 & 688620 & 4.8 & 5.6109 & TRN \\
\hline CHEMBL1400159 & 688620 & 5.6 & 5.2426 & TRN \\
\hline CHEMBL3191270 & 688620 & 4.8 & 5.0827 & TRN \\
\hline CHEMBL1416081 & 688620 & 4.9 & 4.9907 & TST \\
\hline CHEMBL1351164 & 688620 & 4.45 & 5.0475 & TRN \\
\hline CHEMBL1548577 & 688620 & 4.9 & 4.8561 & TRN \\
\hline CHEMBL1352423 & 688620 & 4.85 & 5.0018 & TRN \\
\hline CHEMBL1565369 & 688620 & 6.5 & 6.2029 & TRN \\
\hline CHEMBL1420839 & 688620 & 4.45 & 4.9866 & TRN \\
\hline CHEMBL1500255 & 688620 & 4.45 & 4.9973 & TST \\
\hline CHEMBL1423773 & 688620 & 4.8 & 5.0348 & TRN \\
\hline CHEMBL1461168 & 688620 & 5.0 & 5.0359 & TRN \\
\hline CHEMBL1537714 & 688620 & 4.8 & 4.9957 & TST \\
\hline CHEMBL1569768 & 688620 & 4.45 & 5.0913 & TST \\
\hline CHEMBL1420157 & 688620 & 5.4 & 5.1546 & TST \\
\hline CHEMBL1450772 & 688620 & 5.0 & 4.9308 & TRN \\
\hline CHEMBL1570129 & 688620 & 4.45 & 5.2078 & TRN \\
\hline CHEMBL1337351 & 688620 & 4.7 & 5.0442 & TRN \\
\hline CHEMBL1537825 & 688620 & 6.2 & 5.4884 & TRN \\
\hline CHEMBL1968628 & 688620 & 5.85 & 5.7436 & TRN \\
\hline CHEMBL1604871 & 688620 & 5.8 & 4.9517 & TRN \\
\hline CHEMBL1534857 & 688620 & 4.65 & 5.7442 & TRN \\
\hline CHEMBL1568277 & 688620 & 5.85 & 5.5763 & TRN \\
\hline CHEMBL1604834 & 688620 & 4.95 & 5.176 & TRN \\
\hline CHEMBL1326851 & 688620 & 4.65 & 4.9642 & TST \\
\hline CHEMBL1372267 & 688620 & 4.95 & 5.0363 & TRN \\
\hline CHEMBL1482084 & 688620 & 4.95 & 5.0426 & TST \\
\hline CHEMBL1304776 & 688620 & 4.85 & 5.0049 & TST \\
\hline CHEMBL1358189 & 688620 & 4.8 & 4.8619 & TRN \\
\hline CHEMBL3198822 & 688620 & 4.45 & 5.0013 & TRN \\
\hline CHEMBL1485369 & 688620 & 4.95 & 4.8916 & TRN \\
\hline CHEMBL1339364 & 688620 & 5.4 & 4.9016 & TRN \\
\hline CHEMBL1505623 & 688620 & 5.7 & 5.2266 & TRN \\
\hline CHEMBL1984721 & 688620 & 5.6 & 5.3897 & TRN \\
\hline CHEMBL1344425 & 688620 & 5.95 & 5.1208 & TRN \\
\hline CHEMBL1412303 & 688620 & 5.35 & 5.1859 & TRN \\
\hline CHEMBL1468473 & 688620 & 4.75 & 4.8938 & TRN \\
\hline CHEMBL1538749 & 688620 & 5.2 & 5.3507 & TRN \\
\hline CHEMBL1428857 & 688620 & 5.6 & 5.5455 & TRN \\
\hline CHEMBL1403859 & 688620 & 5.4 & 5.289 & TRN \\
\hline CHEMBL1438323 & 688620 & 5.85 & 4.6436 & TRN \\
\hline
\end{tabular}




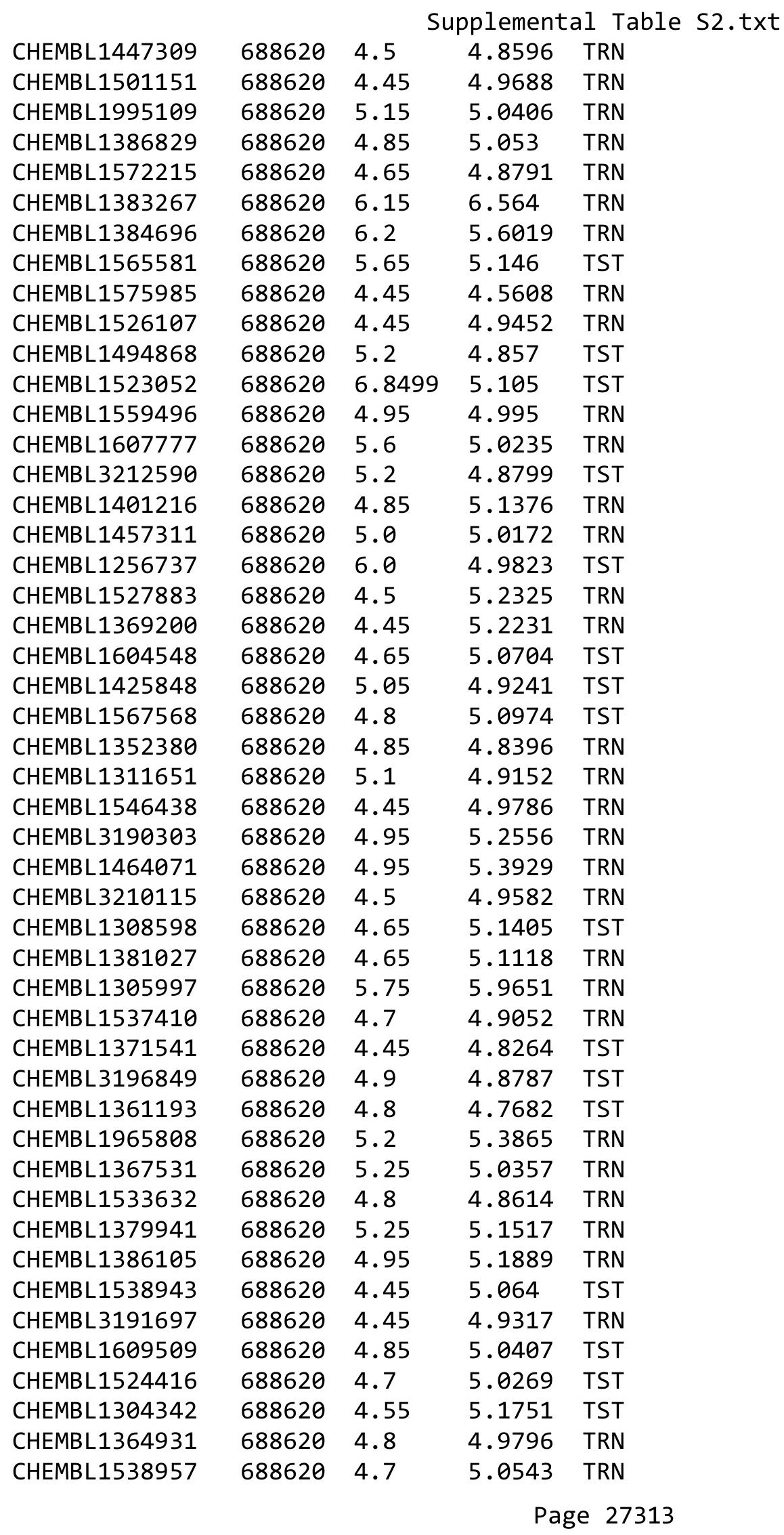




\begin{tabular}{|c|c|c|c|c|c|}
\hline \multicolumn{6}{|c|}{ Supplemental Table S2.txt } \\
\hline CHEMBL1407012 & 688620 & 4.85 & 5.0048 & TST & \\
\hline CHEMBL1499213 & 688620 & 4.7 & 4.785 & TRN & \\
\hline CHEMBL1505791 & 688620 & 8.3468 & 5.2193 & TST & \\
\hline CHEMBL1569100 & 688620 & 8.2518 & 5.1465 & TRN & \\
\hline CHEMBL1571931 & 688620 & 4.5 & 5.2843 & TRN & \\
\hline CHEMBL1519308 & 688620 & 7.0 & 5.2322 & TST & \\
\hline CHEMBL1999700 & 688620 & 5.7 & 5.1197 & TST & \\
\hline CHEMBL1432894 & 688620 & 4.7 & 4.8485 & TRN & \\
\hline CHEMBL1471818 & 688620 & 5.1 & 5.2744 & TST & \\
\hline CHEMBL1567614 & 688620 & 4.8 & 4.85800 & 00000000005 & TRN \\
\hline CHEMBL1547309 & 688620 & 4.8 & 4.8427 & TRN & \\
\hline CHEMBL1576631 & 688620 & 5.35 & 5.0888 & TRN & \\
\hline CHEMBL1527522 & 688620 & 4.45 & 5.0159 & TRN & \\
\hline CHEMBL1303788 & 688620 & 4.7 & 4.9044 & TST & \\
\hline CHEMBL1487474 & 688620 & 5.05 & 5.1202 & TRN & \\
\hline CHEMBL1422851 & 688620 & 5.2 & 5.2521 & TRN & \\
\hline CHEMBL1320672 & 688620 & 4.45 & 5.118 & TRN & \\
\hline CHEMBL1566343 & 688620 & 4.6 & 5.118 & TST & \\
\hline CHEMBL1449750 & 688620 & 4.8 & 5.065 & TRN & \\
\hline CHEMBL1300577 & 688620 & 4.85 & 5.0133 & TRN & \\
\hline CHEMBL1486200 & 688620 & 5.45 & 4.9733 & TRN & \\
\hline CHEMBL1495832 & 688620 & 5.75 & 4.8809 & TRN & \\
\hline CHEMBL1483153 & 688620 & 5.55 & 5.271 & TRN & \\
\hline CHEMBL1532161 & 688620 & 4.85 & 4.9049 & TRN & \\
\hline CHEMBL3195652 & 688620 & 5.3 & 5.435 & TRN & \\
\hline CHEMBL1471292 & 688620 & 4.85 & 4.9873 & TRN & \\
\hline CHEMBL1375130 & 688620 & 4.75 & 5.053 & TRN & \\
\hline CHEMBL1342518 & 688620 & 6.15 & 5.4831 & TST & \\
\hline CHEMBL1550613 & 688620 & 4.9 & 5.0548 & TRN & \\
\hline CHEMBL1377420 & 688620 & 5.15 & 5.1669 & TRN & \\
\hline CHEMBL1498430 & 688620 & 4.95 & 5.1184 & TRN & \\
\hline CHEMBL1540317 & 688620 & 5.15 & 4.8985 & TRN & \\
\hline CHEMBL3192284 & 688620 & 5.65 & 5.5658 & TRN & \\
\hline CHEMBL1463825 & 688620 & 6.1 & 5.5763 & TRN & \\
\hline CHEMBL1336808 & 688620 & 5.0 & 5.0346 & TRN & \\
\hline CHEMBL1539328 & 688620 & 4.85 & 4.9856 & TRN & \\
\hline CHEMBL 3145049 & 688620 & 4.85 & 4.67899 & 9999999999 & TRN \\
\hline CHEMBL1322023 & 688620 & 5.85 & 4.9581 & TST & \\
\hline CHEMBL1587117 & 688620 & 5.8 & 5.3726 & TRN & \\
\hline CHEMBL1992582 & 688620 & 5.2 & 5.3315 & TRN & \\
\hline CHEMBL1517581 & 688620 & 4.6 & 4.97 & TST & \\
\hline CHEMBL1353715 & 688620 & 6.1 & 5.2833 & TRN & \\
\hline CHEMBL3194469 & 688620 & 6.2 & 5.9629 & TRN & \\
\hline CHEMBL1412519 & 688620 & 5.25 & 4.9962 & TST & \\
\hline CHEMBL1338833 & 688620 & 5.15 & 5.0257 & TST & \\
\hline CHEMBL1511603 & 688620 & 5.0 & 4.8277 & TST & \\
\hline CHEMBL1425328 & 688620 & 5.0 & 5.0176 & TRN & \\
\hline CHEMBL1391066 & 688620 & 4.9 & 4.8663 & TRN & \\
\hline
\end{tabular}




\begin{tabular}{|c|c|c|c|c|c|}
\hline \multicolumn{6}{|c|}{ Supplemental Table S2.txt } \\
\hline CHEMBL1342727 & 688620 & 4.75 & 5.1399 & TST & \\
\hline CHEMBL1476089 & 688620 & 4.6 & 4.9051 & TST & \\
\hline CHEMBL1575267 & 688620 & 4.45 & 5.0238 & TST & \\
\hline CHEMBL1575886 & 688620 & 4.9 & 5.035 & TST & \\
\hline CHEMBL1323872 & 688620 & 5.95 & 5.6873 & TRN & \\
\hline CHEMBL1576369 & 688620 & 5.0 & 5.2082 & TST & \\
\hline CHEMBL1542107 & 688620 & 5.0 & 5.1626 & TST & \\
\hline CHEMBL1442263 & 688620 & 4.75 & 5.0112 & TST & \\
\hline CHEMBL3199586 & 688620 & 5.05 & 5.0367 & TRN & \\
\hline CHEMBL317757 & 688620 & 4.55 & 5.0924 & TST & \\
\hline CHEMBL1427743 & 688620 & 6.8499 & 5.44 & TRN & \\
\hline CHEMBL1556239 & 688620 & 5.25 & 4.8962 & TST & \\
\hline CHEMBL1299253 & 688620 & 4.7 & 4.7657 & TRN & \\
\hline CHEMBL1569923 & 688620 & 6.15 & 5.1703 & TRN & \\
\hline CHEMBL1426006 & 688620 & 4.45 & 4.9921 & TST & \\
\hline CHEMBL1337752 & 688620 & 5.7 & 5.3638 & TRN & \\
\hline CHEMBL1503520 & 688620 & 4.45 & 4.8946 & TRN & \\
\hline CHEMBL1365057 & 688620 & 4.85 & 5.0041 & TRN & \\
\hline CHEMBL1399109 & 688620 & 4.95 & 4.8987 & TST & \\
\hline CHEMBL1520753 & 688620 & 5.45 & 5.4964 & TST & \\
\hline CHEMBL1573483 & 688620 & 4.85 & 4.7982 & TRN & \\
\hline CHEMBL1499854 & 688620 & 6.8499 & 5.0679 & TST & \\
\hline CHEMBL1415051 & 688620 & 6.8499 & 5.1324 & TRN & \\
\hline CHEMBL3196123 & 688620 & 6.5 & 5.8094 & TRN & \\
\hline CHEMBL1502550 & 688620 & 4.75 & 4.8301 & TRN & \\
\hline CHEMBL3145329 & 688620 & 5.2 & 5.6777 & TST & \\
\hline CHEMBL1407508 & 688620 & 5.5 & 5.1404 & TRN & \\
\hline CHEMBL1383253 & 688620 & 5.55 & 5.3207 & TRN & \\
\hline CHEMBL1461214 & 688620 & 5.35 & 5.0244 & TST & \\
\hline CHEMBL1330666 & 688620 & 4.8 & 4.7685 & TRN & \\
\hline CHEMBL1438232 & 688620 & 4.55 & 4.7508 & TRN & \\
\hline CHEMBL1402331 & 688620 & 5.45 & 5.2889 & TRN & \\
\hline CHEMBL3190459 & 688620 & 5.65 & 5.7737 & TRN & \\
\hline CHEMBL1432618 & 688620 & 5.25 & 4.8364 & TRN & \\
\hline CHEMBL1342826 & 688620 & 5.3 & 5.0878 & TRN & \\
\hline CHEMBL1478651 & 688620 & 4.45 & 4.6951 & TRN & \\
\hline CHEMBL3198729 & 688620 & 5.2 & 5.1854 & TRN & \\
\hline CHEMBL1406811 & 688620 & 4.45 & 4.6356 & TRN & \\
\hline CHEMBL1560799 & 688620 & 4.95 & 5.2392 & TRN & \\
\hline CHEMBL1602111 & 688620 & 4.9 & 5.5835 & TRN & \\
\hline CHEMBL1594201 & 688620 & 4.45 & 4.9383 & TRN & \\
\hline CHEMBL1385933 & 688620 & 5.3 & 5.435 & TRN & \\
\hline CHEMBL1302130 & 688620 & 6.3 & 5.5347 & TRN & \\
\hline CHEMBL1566664 & 688620 & 4.45 & $4.8210 e$ & 2000000001 & TRN \\
\hline CHEMBL1307632 & 688620 & 5.85 & 5.025 & TRN & \\
\hline CHEMBL1483903 & 688620 & 4.9 & 4.8636 & TRN & \\
\hline CHEMBL1339203 & 688620 & 4.45 & 5.0851 & TRN & \\
\hline CHEMBL1365696 & 688620 & 5.5 & 5.1609 & TRN & \\
\hline
\end{tabular}




\begin{tabular}{|c|c|c|c|c|c|}
\hline \multirow[b]{2}{*}{ CHEMBL1588748 } & \multicolumn{5}{|c|}{ lemental Table S2 } \\
\hline & 688620 & 4.95 & 5.0551 & TRN & \\
\hline CHEMBL1358468 & 688620 & 4.45 & 4.7764 & TST & \\
\hline CHEMBL1534136 & 688620 & 5.9 & 5.0135 & TRN & \\
\hline CHEMBL1418758 & 688620 & 5.45 & \multicolumn{2}{|c|}{5.127999999999999} & \multirow[t]{2}{*}{ TRN } \\
\hline CHEMBL1578622 & 688620 & 5.35 & 4.8349 & TRN & \\
\hline CHEMBL158507 & 688620 & 5.45 & 5.2798 & TST & \\
\hline CHEMBL1368967 & 688620 & 4.9 & 5.1843 & TRN & \\
\hline CHEMBL3198035 & 688620 & 5.3 & 5.3945 & TRN & \\
\hline CHEMBL1301443 & 688620 & 5.15 & 4.9947 & TST & \\
\hline CHEMBL1568043 & 688620 & 4.45 & 4.7952 & TRN & \\
\hline CHEMBL1357551 & 688620 & 7.3497 & 5.0093 & TRN & \\
\hline CHEMBL1337122 & 688620 & 5.1 & 4.9907 & TST & \\
\hline CHEMBL1445578 & 688620 & 4.45 & 5.0107 & TRN & \\
\hline CHEMBL1328069 & 688620 & 4.9 & 4.9935 & TRN & \\
\hline CHEMBL1466526 & 688620 & 4.95 & 4.6828 & TST & \\
\hline CHEMBL1479952 & 688620 & 4.45 & 4.9572 & TRN & \\
\hline CHEMBL546170 & 688620 & 7.3497 & 4.6098 & TRN & \\
\hline CHEMBL1389975 & 688620 & 4.95 & 5.0183 & TRN & \\
\hline CHEMBL3194599 & 688620 & 5.35 & 5.0061 & TST & \\
\hline CHEMBL1572303 & 688620 & 4.95 & 5.1768 & TRN & \\
\hline CHEMBL1464567 & 688620 & 5.05 & 4.9483 & TST & \\
\hline CHEMBL1476521 & 688620 & 5.05 & 4.8959 & TRN & \\
\hline CHEMBL1497867 & 688620 & 4.95 & 5.0602 & TRN & \\
\hline CHEMBL1318099 & 688620 & 4.45 & 5.2704 & TRN & \\
\hline CHEMBL 3192674 & 688620 & 4.95 & 4.9599 & TRN & \\
\hline CHEMBL1574783 & 688620 & 4.75 & 4.9571 & TST & \\
\hline CHEMBL1417098 & 688620 & 4.8 & 4.6846 & TRN & \\
\hline CHEMBL3195150 & 688620 & 4.95 & 5.1221 & TRN & \\
\hline CHEMBL1401242 & 688620 & 5.75 & 5.3821 & TRN & \\
\hline CHEMBL1405350 & 688620 & 4.95 & 4.8703 & TRN & \\
\hline CHEMBL1444829 & 688620 & 4.95 & 5.0213 & TRN & \\
\hline CHEMBL1607098 & 688620 & 5.35 & 5.0582 & TRN & \\
\hline CHEMBL3209126 & 688620 & 5.0 & 4.9142 & TRN & \\
\hline CHEMBL1510188 & 688620 & 4.45 & 5.1218 & TRN & \\
\hline CHEMBL1491342 & 688620 & 4.9 & 4.9094 & TRN & \\
\hline CHEMBL1386701 & 688620 & 5.45 & 5.0766 & TRN & \\
\hline CHEMBL 3214525 & 688620 & 4.85 & 4.935 & TRN & \\
\hline CHEMBL1382959 & 688620 & 4.95 & 5.0243 & TRN & \\
\hline CHEMBL 3197050 & 688620 & 4.95 & 5.28600 & 00000000005 & TRN \\
\hline CHEMBL1440799 & 688620 & 4.8 & 4.9518 & TRN & \\
\hline CHEMBL1322941 & 688620 & 5.55 & 5.2171 & TRN & \\
\hline CHEMBL1526499 & 688620 & 5.1 & 5.2152 & TRN & \\
\hline CHEMBL3196327 & 688620 & 5.4 & 5.2984 & TST & \\
\hline CHEMBL1529404 & 688620 & 5.1 & 5.4451 & TRN & \\
\hline CHEMBL1334517 & 688620 & 5.45 & 5.3565 & TRN & \\
\hline CHEMBL1539624 & 688620 & 6.5 & 6.3131 & TST & \\
\hline CHEMBL1446525 & 688620 & 5.6 & 5.20100 & 00000000005 & TST \\
\hline CHEMBL1330503 & 688620 & 4.45 & 5.0219 & TRN & \\
\hline & & & & 27316 & \\
\hline
\end{tabular}




\begin{tabular}{|c|c|c|c|c|c|}
\hline \multicolumn{6}{|c|}{ Supplemental Table S2.txt } \\
\hline CHEMBL1457711 & 688620 & 5.35 & 5.1198 & TRN & \\
\hline CHEMBL1583664 & 688620 & 5.35 & 5.1481 & TRN & \\
\hline CHEMBL1461987 & 688620 & 4.55 & 4.6783 & TRN & \\
\hline CHEMBL1457058 & 688620 & 5.65 & 5.0408 & TST & \\
\hline CHEMBL1470481 & 688620 & 4.8 & 4.9363 & TST & \\
\hline CHEMBL1508433 & 688620 & 6.0 & 5.7648 & TRN & \\
\hline CHEMBL1537312 & 688620 & 4.65 & 5.1905 & TRN & \\
\hline CHEMBL1508357 & 688620 & 5.0 & 5.0 & TST & \\
\hline CHEMBL1546721 & 688620 & 4.45 & 4.9513 & TRN & \\
\hline CHEMBL3197887 & 688620 & 5.0 & 5.4648 & TRN & \\
\hline CHEMBL 2095095 & 688620 & 5.35 & 5.3561 & TRN & \\
\hline CHEMBL1340728 & 688620 & 4.8 & 4.8358 & TRN & \\
\hline CHEMBL1537052 & 688620 & 5.2 & 5.045 & TRN & \\
\hline CHEMBL1466599 & 688620 & 5.25 & 5.1744 & TRN & \\
\hline CHEMBL1357982 & 688620 & 4.95 & 4.9061 & TRN & \\
\hline CHEMBL1460048 & 688620 & 4.9 & 5.0712 & TRN & \\
\hline CHEMBL600541 & 688620 & 6.5 & 5.0375 & TST & \\
\hline CHEMBL1486824 & 688620 & 4.85 & 5.062 & TRN & \\
\hline CHEMBL 3208391 & 688620 & 4.45 & 4.8223 & TRN & \\
\hline CHEMBL1523237 & 688620 & 4.5 & 5.0274 & TRN & \\
\hline CHEMBL1401321 & 688620 & 5.5 & 5.064 & TST & \\
\hline CHEMBL1574541 & 688620 & 5.4 & 5.2757 & TRN & \\
\hline CHEMBL1540332 & 688620 & 4.75 & 5.1206 & TRN & \\
\hline CHEMBL1457907 & 688620 & 5.4 & 4.862 & TST & \\
\hline CHEMBL1441174 & 688620 & 5.0 & 5.1689 & TRN & \\
\hline CHEMBL3197154 & 688620 & 4.85 & 4.8993 & TRN & \\
\hline CHEMBL1500958 & 688620 & 4.45 & 4.8757 & TST & \\
\hline CHEMBL1492739 & 688620 & 5.0 & 5.0618 & TRN & \\
\hline CHEMBL 3192274 & 688620 & 5.55 & 5.1738 & TRN & \\
\hline CHEMBL1347129 & 688620 & 5.4 & 5.0801 & TST & \\
\hline CHEMBL1544639 & 688620 & 4.75 & 5.1404 & TST & \\
\hline CHEMBL 3199490 & 688620 & 4.45 & 5.0859 & TRN & \\
\hline CHEMBL3192996 & 688620 & 5.45 & 5.5363 & TRN & \\
\hline CHEMBL1421954 & 688620 & 4.95 & 4.7374 & TRN & \\
\hline CHEMBL1562114 & 688620 & 5.0 & 4.8852 & TRN & \\
\hline CHEMBL1496779 & 688620 & 4.9 & 5.0137 & TRN & \\
\hline CHEMBL1428706 & 688620 & 4.5 & 5.0318 & TST & \\
\hline CHEMBL1595426 & 688620 & 5.15 & 5.0472 & TRN & \\
\hline CHEMBL1385051 & 688620 & 6.35 & 4.97199 & 99999999995 & TRN \\
\hline CHEMBL1339029 & 688620 & 4.65 & 5.0774 & TST & \\
\hline CHEMBL1438134 & 688620 & 4.85 & 5.0315 & TRN & \\
\hline CHEMBL1445277 & 688620 & 4.6 & 4.8283 & TRN & \\
\hline CHEMBL1438906 & 688620 & 5.9 & 5.0648 & TRN & \\
\hline CHEMBL1585383 & 688620 & 4.7 & 5.0088 & TST & \\
\hline CHEMBL1496896 & 688620 & 5.1 & 4.729 & TRN & \\
\hline CHEMBL1497259 & 688620 & 4.45 & 4.8676 & TRN & \\
\hline CHEMBL1577286 & 688620 & 6.5501 & 5.2373 & TST & \\
\hline CHEMBL1343952 & 688620 & 4.6 & 4.6488 & TRN & \\
\hline
\end{tabular}




\begin{tabular}{|c|c|c|c|c|c|}
\hline & & \multicolumn{4}{|c|}{ Supplemental Table s2.txt } \\
\hline CHEMBL1978051 & 688620 & 5.15 & 5.5495 & TRN & \\
\hline CHEMBL1403895 & 688620 & 5.4 & 5.2465 & TRN & \\
\hline CHEMBL1576176 & 688620 & 4.45 & 5.0322 & TST & \\
\hline CHEMBL1560954 & 688620 & 5.15 & 5.1714 & TRN & \\
\hline CHEMBL1299227 & 688620 & 4.95 & 4.9279 & TST & \\
\hline CHEMBL1526638 & 688620 & 4.85 & 4.9898 & TRN & \\
\hline CHEMBL1319643 & 688620 & 4.9 & 5.1445 & TST & \\
\hline CHEMBL1348653 & 688620 & 4.85 & 4.9187 & TRN & \\
\hline CHEMBL1584558 & 688620 & 4.95 & 4.6119 & TRN & \\
\hline CHEMBL1511708 & 688620 & 5.55 & 5.0732 & TST & \\
\hline CHEMBL1539227 & 688620 & 4.45 & 5.0504 & TST & \\
\hline CHEMBL1520855 & 688620 & 5.2 & 5.1431 & TRN & \\
\hline CHEMBL1414210 & 688620 & 4.95 & 5.0971 & TRN & \\
\hline CHEMBL1588310 & 688620 & 5.25 & 5.044 & TST & \\
\hline CHEMBL1339483 & 688620 & 5.6 & 5.4217 & TRN & \\
\hline CHEMBL1588582 & 688620 & 4.95 & 4.8703 & TRN & \\
\hline CHEMBL1458942 & 688620 & 4.95 & 5.1626 & TRN & \\
\hline CHEMBL1564712 & 688620 & 5.55 & 5.2484 & TRN & \\
\hline CHEMBL1546014 & 688620 & 4.6 & 4.6085 & TST & \\
\hline CHEMBL1492101 & 688620 & 4.9 & 5.23600 & 0000000001 & TRN \\
\hline CHEMBL1531180 & 688620 & 4.75 & 4.8239 & TRN & \\
\hline CHEMBL1583325 & 688620 & 5.4 & 5.1521 & TST & \\
\hline CHEMBL1502019 & 688620 & 5.6 & 5.3085 & TRN & \\
\hline CHEMBL1504357 & 688620 & 5.05 & 5.2386 & TRN & \\
\hline CHEMBL1345343 & 688620 & 4.9 & 5.1658 & TRN & \\
\hline CHEMBL3196334 & 688620 & 6.95 & 5.7412 & TRN & \\
\hline CHEMBL1570835 & 688620 & 4.85 & 4.9959 & TRN & \\
\hline CHEMBL1462716 & 688620 & 4.55 & 4.9509 & TRN & \\
\hline CHEMBL1587722 & 688620 & 4.5 & 4.956 & TRN & \\
\hline CHEMBL1319818 & 688620 & 5.65 & 5.052 & TRN & \\
\hline CHEMBL1439681 & 688620 & 4.95 & 4.7267 & TST & \\
\hline CHEMBL1484646 & 688620 & 6.9 & 4.7382 & TRN & \\
\hline CHEMBL1420485 & 688620 & 5.35 & 5.315 & TRN & \\
\hline CHEMBL1534080 & 688620 & 5.65 & 5.0065 & TRN & \\
\hline CHEMBL1354150 & 688620 & 4.45 & 4.8777 & TRN & \\
\hline CHEMBL1382939 & 688620 & 4.95 & 5.0365 & TST & \\
\hline CHEMBL1598695 & 688620 & 5.6 & 4.9274 & TRN & \\
\hline CHEMBL1566276 & 688620 & 4.85 & 5.0271 & TRN & \\
\hline CHEMBL1573801 & 688620 & 4.9 & 5.0169 & TRN & \\
\hline CHEMBL1467636 & 688620 & 4.8 & 4.9564 & TRN & \\
\hline CHEMBL1424094 & 688620 & 4.65 & 5.0919 & TRN & \\
\hline CHEMBL1583637 & 688620 & 5.25 & 4.9592 & TST & \\
\hline CHEMBL1331456 & 688620 & 4.45 & 4.8073 & TRN & \\
\hline CHEMBL1535724 & 688620 & 5.3 & 5.1435 & TRN & \\
\hline CHEMBL1509467 & 688620 & 5.0 & 5.1216 & TRN & \\
\hline CHEMBL1372592 & 688620 & 4.45 & 4.6633 & TRN & \\
\hline CHEMBL1603943 & 688620 & 5.7 & 5.2199 & TRN & \\
\hline CHEMBL1535689 & 688620 & 5.2 & 5.0845 & TRN & \\
\hline
\end{tabular}




\begin{tabular}{|c|c|c|c|c|}
\hline \multicolumn{5}{|c|}{ Supplemental Table S2.txt } \\
\hline CHEMBL1538330 & 688620 & 4.45 & 4.8626 & TRN \\
\hline CHEMBL1485353 & 688620 & 5.0 & 5.0366 & TRN \\
\hline CHEMBL1526508 & 688620 & 4.85 & 5.13899 & 9999999999 \\
\hline CHEMBL3213414 & 688620 & 4.8 & 5.2141 & TST \\
\hline CHEMBL1537300 & 688620 & 4.45 & 4.7744 & TRN \\
\hline CHEMBL1570276 & 688620 & 6.2 & 5.0297 & TST \\
\hline CHEMBL1393303 & 688620 & 4.65 & 5.285 & TRN \\
\hline CHEMBL1307190 & 688620 & 4.9 & 5.0706 & TRN \\
\hline CHEMBL1388656 & 688620 & 5.05 & 4.9089 & TRN \\
\hline CHEMBL 3214191 & 688620 & 5.2 & 5.5066 & TRN \\
\hline CHEMBL1336519 & 688620 & 4.8 & 5.1477 & TST \\
\hline CHEMBL1500875 & 688620 & 6.8499 & 5.1191 & TRN \\
\hline CHEMBL3193230 & 688620 & 4.45 & 5.1563 & TRN \\
\hline CHEMBL3198056 & 688620 & 4.6 & 5.0157 & TST \\
\hline CHEMBL 3212002 & 688620 & 4.8 & 4.9686 & TST \\
\hline CHEMBL1326467 & 688620 & 5.35 & 5.1329 & TST \\
\hline CHEMBL1333723 & 688620 & 5.3 & 4.8072 & TRN \\
\hline CHEMBL1336917 & 688620 & 4.45 & 5.025 & TRN \\
\hline CHEMBL1353559 & 688620 & 4.9 & 4.8283 & TRN \\
\hline CHEMBL1537372 & 688620 & 5.45 & 5.7375 & TRN \\
\hline CHEMBL1536646 & 688620 & 4.75 & 4.8512 & TRN \\
\hline CHEMBL1461622 & 688620 & 4.85 & 4.8797 & TRN \\
\hline CHEMBL1571049 & 688620 & 4.45 & 4.9807 & TRN \\
\hline CHEMBL1585906 & 688620 & 6.0 & 5.7767 & TRN \\
\hline CHEMBL 3192783 & 688620 & 5.25 & 5.1008 & TRN \\
\hline CHEMBL1537905 & 688620 & 7.15 & 4.8026 & TRN \\
\hline CHEMBL3198578 & 688620 & 5.85 & 5.3865 & TST \\
\hline CHEMBL1377054 & 688620 & 5.3 & 5.1459 & TRN \\
\hline CHEMBL1525726 & 688620 & 4.55 & 4.8862 & TRN \\
\hline CHEMBL1606386 & 688620 & 4.9 & 4.7729 & TRN \\
\hline CHEMBL3194523 & 688620 & 6.05 & 5.7087 & TRN \\
\hline CHEMBL1435744 & 688620 & 5.0 & 5.0697 & TST \\
\hline CHEMBL1308194 & 688620 & 5.1 & 4.8662 & TRN \\
\hline CHEMBL1543503 & 688620 & 4.45 & 5.02 & TRN \\
\hline CHEMBL1419762 & 688620 & 5.65 & 5.3598 & TRN \\
\hline CHEMBL1569683 & 688620 & 6.2 & 5.3976 & TRN \\
\hline CHEMBL1346096 & 688620 & 7.0501 & 5.6361 & TST \\
\hline CHEMBL1421397 & 688620 & 4.45 & 4.9232 & TRN \\
\hline CHEMBL3193912 & 688620 & 4.45 & 4.8807 & TRN \\
\hline CHEMBL1531305 & 688620 & 5.65 & 5.2325 & TST \\
\hline CHEMBL1470104 & 688620 & 5.25 & 5.3246 & TRN \\
\hline CHEMBL1969610 & 688620 & 5.0 & 5.2676 & TRN \\
\hline CHEMBL1403099 & 688620 & 5.2 & 5.524 & TRN \\
\hline CHEMBL1528008 & 688620 & 5.65 & 5.104 & TRN \\
\hline CHEMBL1444707 & 688620 & 5.0 & 5.1831 & TST \\
\hline CHEMBL1412040 & 688620 & 4.85 & 4.9744 & TRN \\
\hline CHEMBL1505389 & 688620 & 5.6 & 5.1317 & TRN \\
\hline CHEMBL1360971 & 688620 & 4.8 & 5.0768 & TST \\
\hline
\end{tabular}

TRN 


\begin{tabular}{|c|c|c|c|c|c|}
\hline \multicolumn{6}{|c|}{ Supplemental Table S2.txt } \\
\hline CHEMBL1379659 & 688620 & 4.5 & 4.9066 & TRN & \\
\hline CHEMBL 2001582 & 688620 & 4.45 & 4.9352 & TRN & \\
\hline CHEMBL1490339 & 688620 & 6.3 & 5.9266 & TRN & \\
\hline CHEMBL1517002 & 688620 & 4.9 & 5.1453 & TRN & \\
\hline CHEMBL1491507 & 688620 & 4.45 & 5.2433 & TRN & \\
\hline CHEMBL1449894 & 688620 & 4.45 & 4.9885 & TRN & \\
\hline CHEMBL1571446 & 688620 & 4.9 & 4.6998 & TST & \\
\hline CHEMBL1505247 & 688620 & 5.15 & 5.129 & TRN & \\
\hline CHEMBL1424311 & 688620 & 5.2 & 5.5587 & TRN & \\
\hline CHEMBL1493936 & 688620 & 6.8499 & 5.6302 & TRN & \\
\hline CHEMBL1351809 & 688620 & 4.7 & 5.0286 & TRN & \\
\hline CHEMBL1332174 & 688620 & 5.45 & 5.3296 & TRN & \\
\hline CHEMBL1479279 & 688620 & 4.9 & 5.0782 & TRN & \\
\hline CHEMBL1447571 & 688620 & 5.35 & 5.1975 & TRN & \\
\hline CHEMBL1364010 & 688620 & 5.55 & 6.0442 & TRN & \\
\hline CHEMBL1390216 & 688620 & 5.75 & 5.1481 & TST & \\
\hline CHEMBL1492955 & 688620 & 4.9 & 5.4923 & TRN & \\
\hline CHEMBL1459596 & 688620 & 4.9 & 4.9284 & TRN & \\
\hline CHEMBL1520809 & 688620 & 4.85 & 4.9922 & TST & \\
\hline CHEMBL1422363 & 688620 & 4.45 & $4.9860 e$ & 0000000001 & TRN \\
\hline CHEMBL1558024 & 688620 & 5.15 & 5.1246 & TRN & \\
\hline CHEMBL1537221 & 688620 & 4.45 & 5.3065 & TRN & \\
\hline CHEMBL1595593 & 688620 & 5.25 & 4.9803 & TST & \\
\hline CHEMBL1383557 & 688620 & 5.0 & 4.9651 & TRN & \\
\hline CHEMBL1422386 & 688620 & 6.45 & 6.0478 & TRN & \\
\hline CHEMBL1531286 & 688620 & 5.35 & 4.9112 & TRN & \\
\hline CHEMBL1519367 & 688620 & 5.4 & 5.1041 & TRN & \\
\hline CHEMBL1490563 & 688620 & 5.15 & 5.0492 & TRN & \\
\hline CHEMBL1563716 & 688620 & 4.8 & 5.102 & TRN & \\
\hline CHEMBL1587243 & 688620 & 4.85 & 4.8916 & TRN & \\
\hline CHEMBL1432724 & 688620 & 4.5 & 4.9873 & TST & \\
\hline CHEMBL1497363 & 688620 & 5.65 & 5.5959 & TRN & \\
\hline CHEMBL1313236 & 688620 & 4.95 & 4.9272 & TRN & \\
\hline CHEMBL1372129 & 688620 & 4.9 & 4.8382 & TRN & \\
\hline CHEMBL1563117 & 688620 & 4.6 & 4.7629 & TST & \\
\hline CHEMBL1501077 & 688620 & 4.5 & 5.0775 & TRN & \\
\hline CHEMBL1495085 & 688620 & 4.75 & 6.0508 & TST & \\
\hline CHEMBL1576225 & 688620 & 5.5 & 5.0302 & TST & \\
\hline CHEMBL1336959 & 688620 & 5.3 & 5.7305 & TRN & \\
\hline CHEMBL3192045 & 688620 & 5.15 & 5.3602 & TRN & \\
\hline CHEMBL1321513 & 688620 & 4.9 & 4.8679 & TRN & \\
\hline CHEMBL1604894 & 688620 & 6.6499 & 5.2553 & TST & \\
\hline CHEMBL1353768 & 688620 & 5.0 & 5.1919 & TST & \\
\hline CHEMBL1969064 & 688620 & 5.2 & 4.8449 & TRN & \\
\hline CHEMBL1423138 & 688620 & 4.6 & 4.9132 & TRN & \\
\hline CHEMBL1457777 & 688620 & 4.65 & 5.0664 & TST & \\
\hline CHEMBL1560352 & 688620 & 5.0 & 5.222 & TST & \\
\hline CHEMBL1542439 & 688620 & 4.95 & 4.9751 & TST & \\
\hline
\end{tabular}




\begin{tabular}{|c|c|c|c|c|c|}
\hline \multicolumn{6}{|c|}{ Supplemental Table S2.txt } \\
\hline CHEMBL1390247 & 688620 & 4.45 & 4.9542 & TRN & \\
\hline CHEMBL1376012 & 688620 & 5.2 & 5.0136 & TRN & \\
\hline CHEMBL1511100 & 688620 & 5.6 & 4.9 & TRN & \\
\hline CHEMBL1469866 & 688620 & 6.05 & 4.9097 & TST & \\
\hline CHEMBL1370019 & 688620 & 4.45 & 4.687 & TRN & \\
\hline CHEMBL1477560 & 688620 & 5.2 & 4.8793 & TST & \\
\hline CHEMBL1382949 & 688620 & 5.0 & 4.6963 & TST & \\
\hline CHEMBL1420096 & 688620 & 4.8 & 5.1083 & TST & \\
\hline CHEMBL1549175 & 688620 & 5.35 & 5.206 & TRN & \\
\hline CHEMBL1413626 & 688620 & 5.2 & 5.3217 & TRN & \\
\hline CHEMBL1432616 & 688620 & 4.7 & 5.3675 & TRN & \\
\hline CHEMBL 3198772 & 688620 & 5.05 & 5.7525 & TRN & \\
\hline CHEMBL3199628 & 688620 & 5.4 & 5.3672 & TRN & \\
\hline CHEMBL1339993 & 688620 & 5.25 & 5.0439 & TRN & \\
\hline CHEMBL1543818 & 688620 & 5.2 & 5.2821 & TRN & \\
\hline CHEMBL1310836 & 688620 & 4.95 & 5.17399 & 99999999995 & TRN \\
\hline CHEMBL1381331 & 688620 & 5.0 & 5.1066 & TRN & \\
\hline CHEMBL1528880 & 688620 & 4.45 & 4.9668 & TRN & \\
\hline CHEMBL1497745 & 688620 & 4.95 & 4.8426 & TST & \\
\hline CHEMBL1489221 & 688620 & 6.3 & 5.2282 & TRN & \\
\hline CHEMBL1348026 & 688620 & 5.4 & 4.8861 & TRN & \\
\hline CHEMBL1329408 & 688620 & 4.65 & 5.0198 & TRN & \\
\hline CHEMBL1602759 & 688620 & 5.75 & 5.5612 & TRN & \\
\hline CHEMBL1306573 & 688620 & 5.3 & 5.3716 & TST & \\
\hline CHEMBL1446101 & 688620 & 5.1 & 5.2446 & TRN & \\
\hline CHEMBL1546905 & 688620 & 5.5 & 5.1353 & TRN & \\
\hline CHEMBL1322247 & 688620 & 4.85 & 5.2697 & TRN & \\
\hline CHEMBL1565081 & 688620 & 4.45 & 5.9223 & TRN & \\
\hline CHEMBL1387897 & 688620 & 4.9 & 5.0487 & TRN & \\
\hline CHEMBL1611153 & 688620 & 4.7 & 5.0212 & TRN & \\
\hline CHEMBL1457597 & 688620 & 4.5 & 5.0916 & TRN & \\
\hline CHEMBL1495376 & 688620 & 4.7 & 4.9746 & TRN & \\
\hline CHEMBL1382590 & 688620 & 4.65 & 4.8424 & TRN & \\
\hline CHEMBL3212242 & 688620 & 5.45 & 5.1918 & TST & \\
\hline CHEMBL1533730 & 688620 & 4.45 & 4.9663 & TST & \\
\hline CHEMBL1507177 & 688620 & 4.65 & 5.0766 & TRN & \\
\hline CHEMBL364032 & 688620 & 4.5 & 5.0137 & TST & \\
\hline CHEMBL1351271 & 688620 & 5.6 & 5.3912 & TRN & \\
\hline CHEMBL1575018 & 688620 & 4.95 & 5.0103 & TRN & \\
\hline CHEMBL1386803 & 688620 & 4.75 & 5.0466 & TRN & \\
\hline CHEMBL1490293 & 688620 & 6.5 & 6.4156 & TRN & \\
\hline CHEMBL1346370 & 688620 & 5.0 & 4.8703 & TRN & \\
\hline CHEMBL1505569 & 688620 & 6.3 & 5.1944 & TST & \\
\hline CHEMBL1353341 & 688620 & 4.9 & 5.3949 & TRN & \\
\hline CHEMBL1578432 & 688620 & 4.95 & 5.107 & TRN & \\
\hline CHEMBL1408910 & 688620 & 5.45 & 5.1187 & TRN & \\
\hline CHEMBL3197039 & 688620 & 5.05 & 5.1499 & TRN & \\
\hline CHEMBL1501043 & 688620 & 4.95 & 4.9797 & TRN & \\
\hline
\end{tabular}




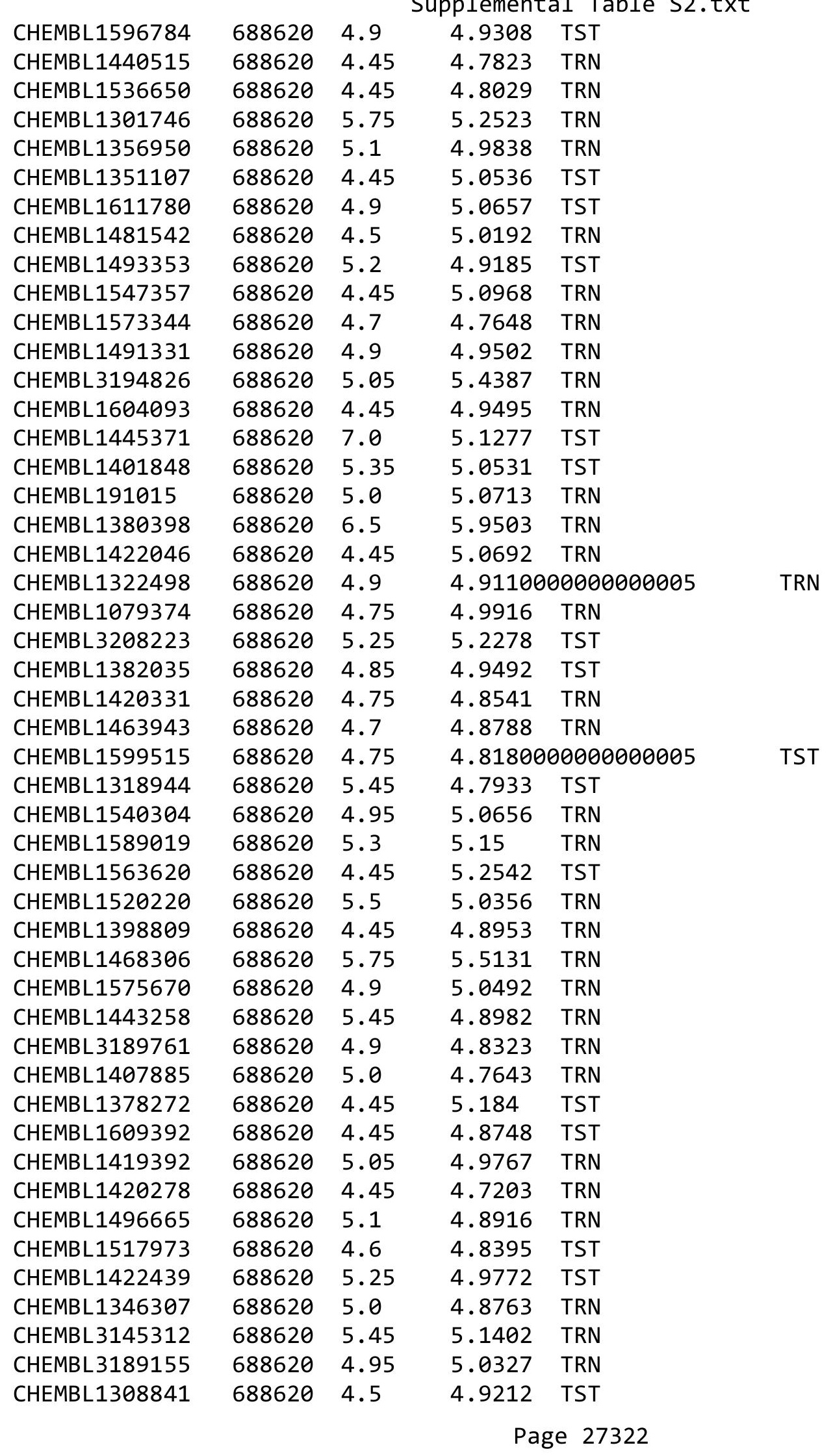




\begin{tabular}{|c|c|c|c|c|c|}
\hline \multirow[b]{2}{*}{ CHEMBL1567309 } & \multicolumn{5}{|c|}{ plemental Table S } \\
\hline & 688620 & 4.45 & 4.7581 & TRN & \\
\hline CHEMBL1353711 & 688620 & 5.0 & 4.9793 & TRN & \\
\hline CHEMBL1353506 & 688620 & 5.0 & 4.9097 & TRN & \\
\hline CHEMBL1572930 & 688620 & 4.8 & 4.9806 & TST & \\
\hline CHEMBL1364704 & 688620 & 4.45 & 5.0996 & TRN & \\
\hline CHEMBL1444455 & 688620 & 5.6 & 5.2951 & TRN & \\
\hline CHEMBL1410071 & 688620 & 5.45 & 5.0653 & TST & \\
\hline CHEMBL1509236 & 688620 & 4.6 & 4.8566 & TRN & \\
\hline CHEMBL1504599 & 688620 & 4.5 & 4.9426 & TST & \\
\hline CHEMBL2369288 & 688620 & 4.85 & 5.1165 & TRN & \\
\hline CHEMBL1502264 & 688620 & 4.45 & 5.0021 & TST & \\
\hline CHEMBL1604876 & 688620 & 4.95 & 5.0523 & TST & \\
\hline CHEMBL1380637 & 688620 & 4.6 & 4.7156 & TRN & \\
\hline CHEMBL469362 & 688620 & 5.2 & 5.2448 & TRN & \\
\hline CHEMBL1602385 & 688620 & 4.65 & 4.9573 & TST & \\
\hline CHEMBL1569121 & 688620 & 6.05 & 5.5072 & TRN & \\
\hline CHEMBL1564634 & 688620 & 4.7 & 4.9617 & TST & \\
\hline CHEMBL1360614 & 688620 & 5.05 & 4.9582 & TRN & \\
\hline CHEMBL1383778 & 688620 & 4.5 & 5.103 & TRN & \\
\hline CHEMBL1606512 & 688620 & 4.65 & 5.0492 & TRN & \\
\hline CHEMBL1301139 & 688620 & 5.05 & 5.2725 & TST & \\
\hline CHEMBL1580185 & 688620 & 4.9 & 5.0849 & TRN & \\
\hline CHEMBL1380869 & 688620 & 5.5 & 5.4717 & TRN & \\
\hline CHEMBL1328021 & 688620 & 6.5501 & 5.73 & TRN & \\
\hline CHEMBL1334611 & 688620 & 4.55 & 4.8818 & TRN & \\
\hline CHEMBL1968732 & 688620 & 5.45 & 5.325 & TRN & \\
\hline CHEMBL1611922 & 688620 & 4.95 & 4.8576 & TRN & \\
\hline CHEMBL 3190384 & 688620 & 4.65 & 5.2632 & TST & \\
\hline CHEMBL1545752 & 688620 & 4.7 & 5.0948 & TRN & \\
\hline CHEMBL1517027 & 688620 & 4.65 & 4.9261 & TRN & \\
\hline CHEMBL1572923 & 688620 & 4.8 & 5.0019 & TRN & \\
\hline CHEMBL1550852 & 688620 & 4.45 & 5.1081 & TRN & \\
\hline CHEMBL1459897 & 688620 & 4.95 & 5.0784 & TRN & \\
\hline CHEMBL3193967 & 688620 & 5.0 & 4.9594 & TRN & \\
\hline CHEMBL1313706 & 688620 & 5.25 & 5.4455 & TRN & \\
\hline CHEMBL1498224 & 688620 & 4.85 & 4.96899 & 9999999999 & TRN \\
\hline CHEMBL1568289 & 688620 & 5.25 & 5.3745 & TRN & \\
\hline CHEMBL 1445570 & 688620 & 4.75 & 4.92899 & 9999999999 & TRN \\
\hline CHEMBL1311181 & 688620 & 4.95 & 5.0739 & TRN & \\
\hline CHEMBL1433141 & 688620 & 4.9 & 4.9243 & TRN & \\
\hline CHEMBL1506689 & 688620 & 4.9 & 4.9513 & TRN & \\
\hline CHEMBL1409429 & 688620 & 4.45 & 5.2652 & TRN & \\
\hline CHEMBL1426475 & 688620 & 5.9 & 5.5681 & TST & \\
\hline CHEMBL1599249 & 688620 & 4.9 & 4.6344 & TRN & \\
\hline CHEMBL1458522 & 688620 & 5.5 & 5.1768 & TRN & \\
\hline CHEMBL1528714 & 688620 & 5.4 & 5.0173 & TST & \\
\hline CHEMBL1449322 & 688620 & 4.45 & 4.8637 & TST & \\
\hline CHEMBL1393657 & 688620 & 4.45 & 5.0468 & TST & \\
\hline & & & & 27323 & \\
\hline
\end{tabular}




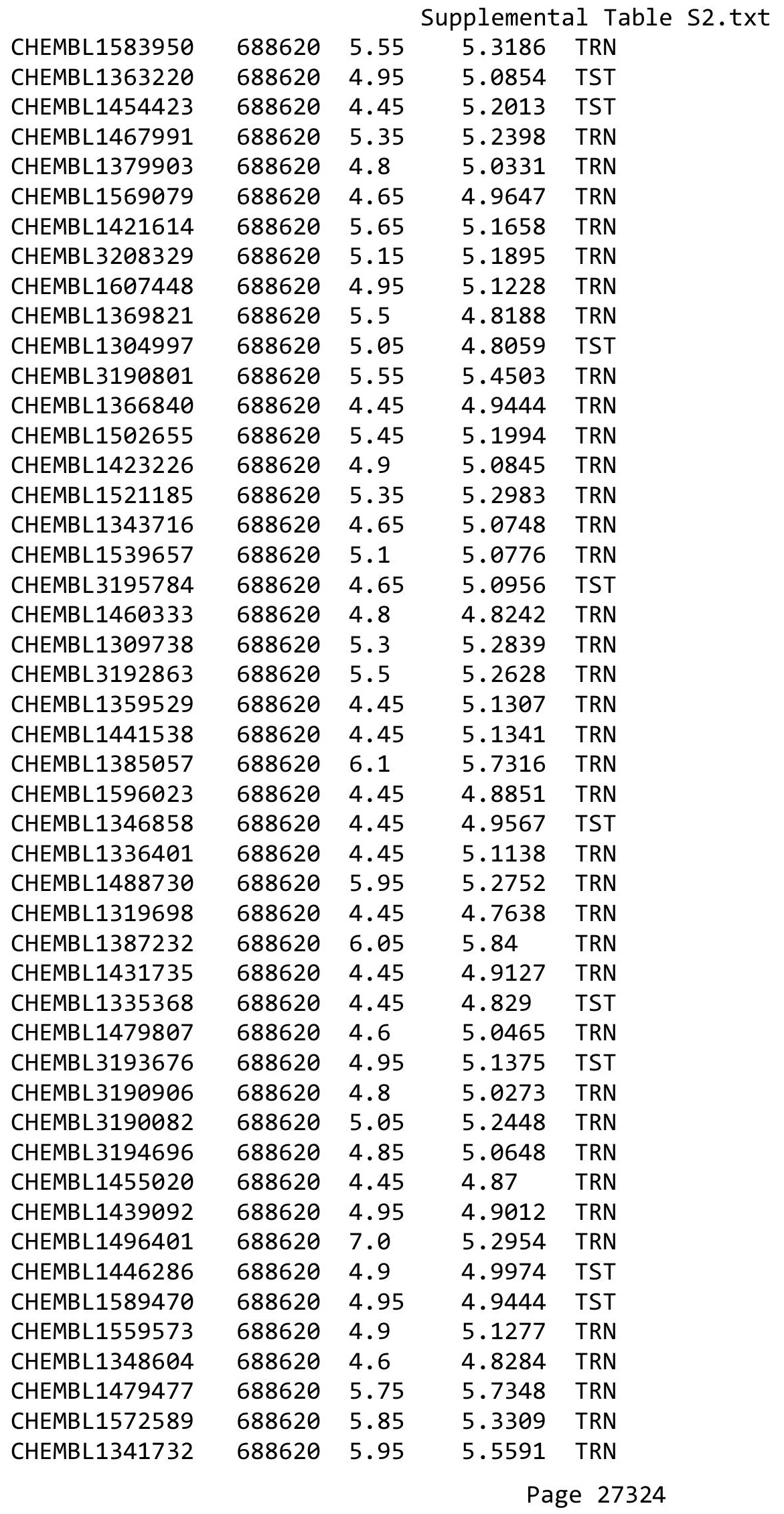




\begin{tabular}{|c|c|c|c|c|c|}
\hline CHEMBL1381149 & 688620 & 4.7 & \multicolumn{2}{|c|}{4.6610000000000005} & TST \\
\hline CHEMBL1328906 & 688620 & 4.45 & 4.8932 & TRN & \\
\hline CHEMBL1348077 & 688620 & 4.85 & 4.8786 & TRN & \\
\hline CHEMBL1594492 & 688620 & 4.85 & 5.1079 & TST & \\
\hline CHEMBL1323985 & 688620 & 5.0 & 5.3017 & TRN & \\
\hline CHEMBL1496980 & 688620 & 4.65 & 4.9813 & TRN & \\
\hline CHEMBL1420784 & 688620 & 5.55 & 4.9824 & TRN & \\
\hline CHEMBL1371482 & 688620 & 4.45 & 4.8783 & TRN & \\
\hline CHEMBL1445829 & 688620 & 4.8 & 4.899 & TST & \\
\hline CHEMBL1508930 & 688620 & 5.35 & 4.8294 & TST & \\
\hline CHEMBL1548705 & 688620 & 4.9 & 4.8911 & TRN & \\
\hline CHEMBL1418654 & 688620 & 4.5 & 5.3625 & TRN & \\
\hline CHEMBL1369289 & 688620 & 4.8 & 5.0243 & TRN & \\
\hline CHEMBL1571069 & 688620 & 4.9 & 4.7851 & TRN & \\
\hline CHEMBL1329630 & 688620 & 4.45 & 4.876 & TRN & \\
\hline CHEMBL1539903 & 688620 & 4.65 & 5.2741 & TRN & \\
\hline CHEMBL388978 & 688620 & 8.0506 & 5.5973 & TST & \\
\hline CHEMBL3194233 & 688620 & 5.25 & 5.325 & TRN & \\
\hline CHEMBL1360368 & 688620 & 6.25 & 5.4482 & TRN & \\
\hline CHEMBL1447893 & 688620 & 5.1 & 4.7739 & TRN & \\
\hline CHEMBL1449505 & 688620 & 5.65 & 5.4064 & TST & \\
\hline CHEMBL1353811 & 688620 & 4.45 & 5.0049 & TRN & \\
\hline CHEMBL1447031 & 688620 & 4.45 & 5.0558 & TRN & \\
\hline CHEMBL1416853 & 688620 & 5.35 & 6.0196 & TRN & \\
\hline CHEMBL1509382 & 688620 & 5.6 & 5.7327 & TRN & \\
\hline CHEMBL1522138 & 688620 & 6.25 & 5.0785 & TRN & \\
\hline CHEMBL1422601 & 688620 & 5.0 & 4.9912 & TST & \\
\hline CHEMBL1564188 & 688620 & 4.95 & 5.0417 & TST & \\
\hline CHEMBL1424355 & 688620 & 5.4 & 4.8949 & TRN & \\
\hline CHEMBL1578756 & 688620 & 5.0 & 5.2689 & TRN & \\
\hline CHEMBL1448185 & 688620 & 4.85 & 5.1336 & TRN & \\
\hline CHEMBL1577966 & 688620 & 4.45 & 5.131 & TST & \\
\hline CHEMBL1558086 & 688620 & 5.05 & 4.9945 & TRN & \\
\hline CHEMBL1503238 & 688620 & 4.95 & 5.1701 & TRN & \\
\hline CHEMBL1336407 & 688620 & 5.5 & 5.1073 & TST & \\
\hline CHEMBL1502617 & 688620 & 4.8 & 4.883 & TRN & \\
\hline CHEMBL1419873 & 688620 & 5.15 & 5.0492 & TRN & \\
\hline CHEMBL1367502 & 688620 & 4.75 & 4.8769 & TRN & \\
\hline CHEMBL1427891 & 688620 & 4.65 & 5.0734 & TRN & \\
\hline CHEMBL1997463 & 688620 & 5.25 & 5.2266 & TRN & \\
\hline CHEMBL1418771 & 688620 & 4.95 & 4.8951 & TRN & \\
\hline CHEMBL1343330 & 688620 & 5.05 & 4.864 & TRN & \\
\hline CHEMBL1543177 & 688620 & 5.05 & 5.0306 & TRN & \\
\hline CHEMBL1583722 & 688620 & 5.2 & 5.1924 & TRN & \\
\hline CHEMBL1528628 & 688620 & 4.5 & 5.2029 & TRN & \\
\hline CHEMBL1319601 & 688620 & 5.2 & 5.1936 & TST & \\
\hline CHEMBL1490583 & 688620 & 5.6 & 4.9886 & TST & \\
\hline CHEMBL1562132 & 688620 & 4.45 & 4.8402 & TRN & \\
\hline
\end{tabular}




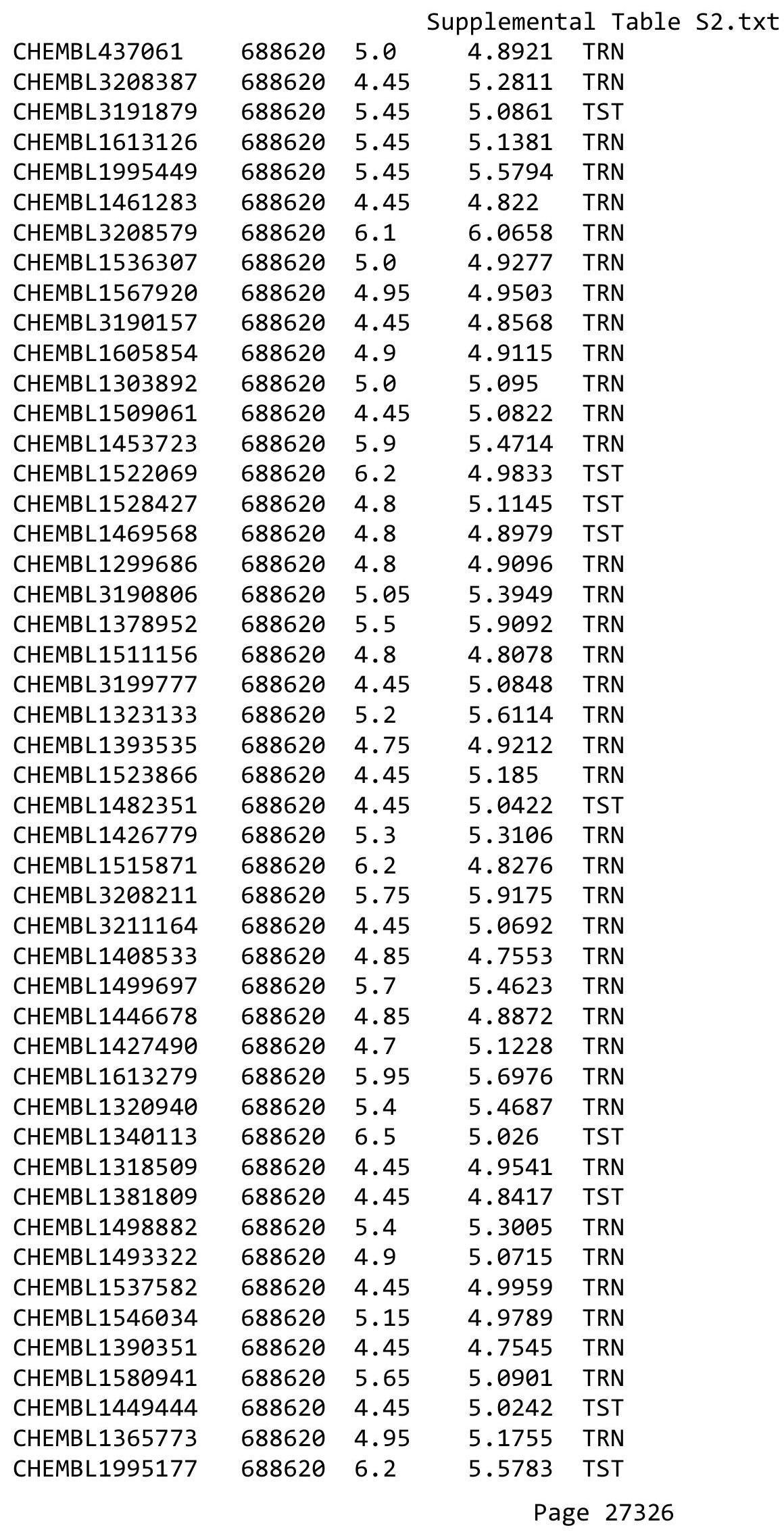




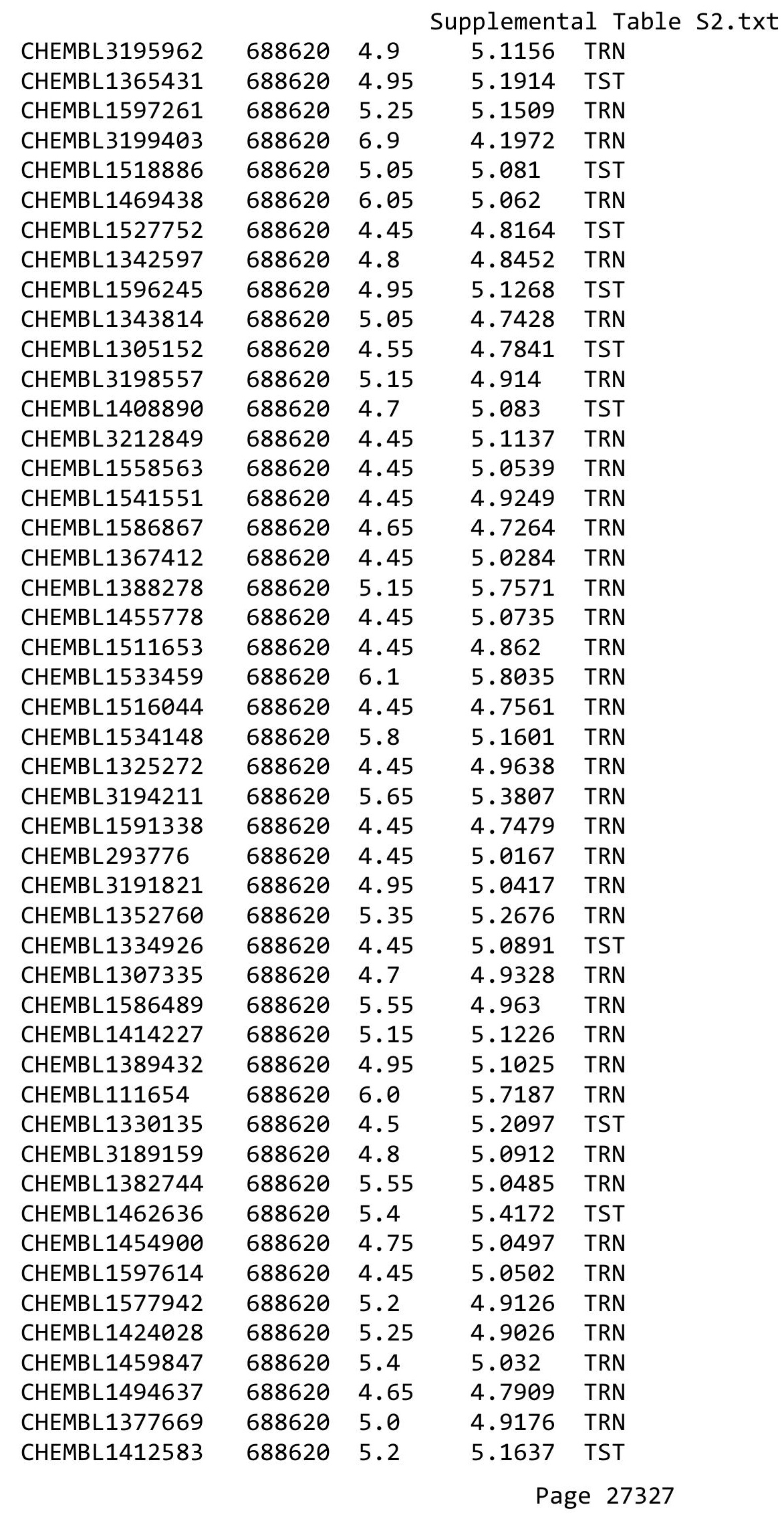




\begin{tabular}{|c|c|c|c|c|}
\hline \multicolumn{5}{|c|}{ Supplemental Table S2.txt } \\
\hline CHEMBL1382803 & 688620 & 6.8 & 4.8648 & TST \\
\hline CHEMBL1572785 & 688620 & 4.45 & 4.8968 & TST \\
\hline CHEMBL601933 & 688620 & 5.0 & 5.4911 & TRN \\
\hline CHEMBL1300834 & 688620 & 5.45 & 4.9751 & TRN \\
\hline CHEMBL1544847 & 688620 & 5.3 & 5.3707 & TRN \\
\hline CHEMBL1412461 & 688620 & 4.85 & 4.976 & TRN \\
\hline CHEMBL1311691 & 688620 & 4.5 & 4.9224 & TRN \\
\hline CHEMBL3199473 & 688620 & 5.55 & 5.3784 & TST \\
\hline CHEMBL 3190401 & 688620 & 6.5501 & 5.2096 & TRN \\
\hline CHEMBL1483647 & 688620 & 4.95 & 5.0884 & TST \\
\hline CHEMBL1463432 & 688620 & 4.6 & 4.9566 & TRN \\
\hline CHEMBL3195216 & 688620 & 4.6 & 5.1412 & TRN \\
\hline CHEMBL3196157 & 688620 & 5.25 & 4.9327 & TRN \\
\hline CHEMBL1509461 & 688620 & 4.65 & 5.0469 & TRN \\
\hline CHEMBL1326157 & 688620 & 6.0 & 5.3514 & TRN \\
\hline CHEMBL1361829 & 688620 & 4.45 & 4.8661 & TST \\
\hline CHEMBL 3191910 & 688620 & 5.05 & 4.8309 & TRN \\
\hline CHEMBL1577981 & 688620 & 4.95 & 5.0595 & TRN \\
\hline CHEMBL1994211 & 688620 & 5.45 & 5.3828 & TRN \\
\hline CHEMBL1487221 & 688620 & 4.65 & 4.7532 & TRN \\
\hline CHEMBL1587456 & 688620 & 4.5 & 5.0564 & TRN \\
\hline CHEMBL1395964 & 688620 & 4.8 & 5.0752 & TRN \\
\hline CHEMBL1509473 & 688620 & 5.0 & 5.4522 & TRN \\
\hline CHEMBL1367322 & 688620 & 4.9 & 5.2496 & TRN \\
\hline CHEMBL1603141 & 688620 & 5.8 & 5.2812 & TRN \\
\hline CHEMBL1508027 & 688620 & 4.5 & 4.9821 & TRN \\
\hline CHEMBL1542674 & 688620 & 4.45 & 4.934 & TRN \\
\hline CHEMBL3196440 & 688620 & 4.65 & 5.0169 & TRN \\
\hline CHEMBL1311826 & 688620 & 6.1 & 6.0965 & TRN \\
\hline CHEMBL3189706 & 688620 & 4.7 & 4.9494 & TRN \\
\hline CHEMBL1432681 & 688620 & 7.15 & 5.2301 & TRN \\
\hline CHEMBL1386819 & 688620 & 4.65 & 5.0257 & TRN \\
\hline CHEMBL1571904 & 688620 & 4.85 & 5.1762 & TRN \\
\hline CHEMBL1309816 & 688620 & 4.65 & 5.1125 & TST \\
\hline CHEMBL1574571 & 688620 & 6.1 & 5.3482 & TRN \\
\hline CHEMBL1508699 & 688620 & 4.45 & 5.1461 & TRN \\
\hline CHEMBL1407761 & 688620 & 5.0 & 5.0819 & TRN \\
\hline CHEMBL1308718 & 688620 & 4.85 & 4.9437 & TRN \\
\hline CHEMBL1426562 & 688620 & 5.45 & 5.20700 & 0000000001 \\
\hline CHEMBL1492564 & 688620 & 4.5 & 4.8308 & TST \\
\hline CHEMBL1472346 & 688620 & 4.85 & 5.0458 & TST \\
\hline CHEMBL1520225 & 688620 & 5.65 & 5.4148 & TRN \\
\hline CHEMBL1602632 & 688620 & 5.55 & 5.1372 & TST \\
\hline CHEMBL1597827 & 688620 & 5.95 & 4.9369 & TRN \\
\hline CHEMBL1465909 & 688620 & 4.95 & 4.9433 & TRN \\
\hline CHEMBL1450527 & 688620 & 4.95 & 5.4728 & TRN \\
\hline CHEMBL1393926 & 688620 & 4.45 & 4.8816 & TST \\
\hline CHEMBL1582067 & 688620 & 5.0 & 4.9738 & TRN \\
\hline
\end{tabular}




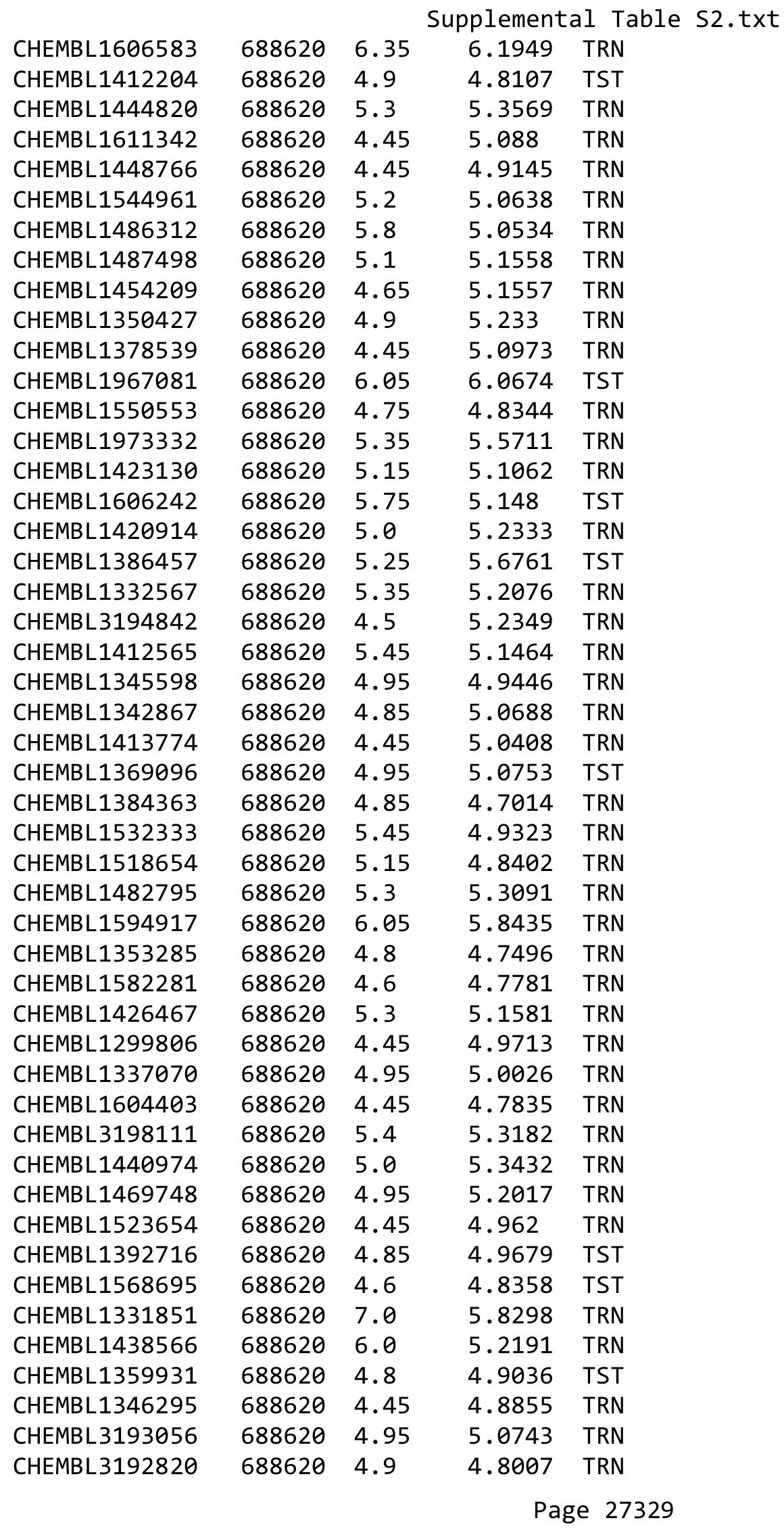




\begin{tabular}{|c|c|c|c|c|c|}
\hline & & \multicolumn{4}{|c|}{ Supplemental Table S2.txt } \\
\hline CHEMBL1550591 & 688620 & 5.45 & 5.2612 & TST & \\
\hline CHEMBL3199249 & 688620 & 5.05 & 5.0199 & TST & \\
\hline CHEMBL1417657 & 688620 & 5.05 & 5.0404 & TRN & \\
\hline CHEMBL1440304 & 688620 & 4.9 & 5.0393 & TRN & \\
\hline CHEMBL1546072 & 688620 & 5.15 & 5.1495 & TST & \\
\hline CHEMBL1608333 & 688620 & 5.15 & 5.2351 & TRN & \\
\hline CHEMBL1612088 & 688620 & 4.45 & 4.981 & TRN & \\
\hline CHEMBL1344803 & 688620 & 6.1 & 5.1678 & TRN & \\
\hline CHEMBL1311531 & 688620 & 4.8 & 4.9084 & TRN & \\
\hline CHEMBL1546052 & 688620 & 5.2 & 4.7523 & TST & \\
\hline CHEMBL1499960 & 688620 & 5.1 & 4.8296 & TRN & \\
\hline CHEMBL3189712 & 688620 & 5.1 & 5.29899 & 99999999995 & TST \\
\hline CHEMBL3190431 & 688620 & 5.15 & 5.1454 & TST & \\
\hline CHEMBL1582376 & 688620 & 4.85 & 4.8524 & TST & \\
\hline CHEMBL1409039 & 688620 & 4.8 & 4.9119 & TRN & \\
\hline CHEMBL1567685 & 688620 & 5.25 & 4.7726 & TRN & \\
\hline CHEMBL1533968 & 688620 & 4.8 & 4.9045 & TST & \\
\hline CHEMBL3145169 & 688620 & 4.75 & 5.2609 & TRN & \\
\hline CHEMBL1550727 & 688620 & 4.9 & 5.0387 & TRN & \\
\hline CHEMBL1439732 & 688620 & 6.3 & 5.1969 & TRN & \\
\hline CHEMBL1403923 & 688620 & 4.9 & 5.0022 & TRN & \\
\hline CHEMBL1484049 & 688620 & 4.45 & 4.9647 & TRN & \\
\hline CHEMBL1545205 & 688620 & 4.6 & 4.8628 & TST & \\
\hline CHEMBL1371783 & 688620 & 5.55 & 5.1738 & TRN & \\
\hline CHEMBL1410437 & 688620 & 5.1 & 4.8844 & TRN & \\
\hline CHEMBL1427734 & 688620 & 4.75 & 5.2799 & TRN & \\
\hline CHEMBL1605942 & 688620 & 4.8 & 5.1077 & TRN & \\
\hline CHEMBL1557666 & 688620 & 4.8 & 5.0313 & TRN & \\
\hline CHEMBL1556634 & 688620 & 4.8 & 4.6454 & TRN & \\
\hline CHEMBL1517036 & 688620 & 5.4 & 5.1104 & TRN & \\
\hline CHEMBL1387522 & 688620 & 4.7 & 5.04 & TRN & \\
\hline CHEMBL1306770 & 688620 & 4.6 & 5.3157 & TST & \\
\hline CHEMBL1353260 & 688620 & 4.75 & 4.7552 & TRN & \\
\hline CHEMBL1411431 & 688620 & 4.65 & 4.8964 & TRN & \\
\hline CHEMBL1565008 & 688620 & 5.1 & 5.2201 & TRN & \\
\hline CHEMBL1400888 & 688620 & 5.55 & 5.2615 & TST & \\
\hline CHEMBL1506503 & 688620 & 6.45 & 5.6727 & TRN & \\
\hline CHEMBL1367279 & 688620 & 5.0 & 4.8993 & TRN & \\
\hline CHEMBL3193711 & 688620 & 5.5 & 5.3269 & TRN & \\
\hline CHEMBL1596210 & 688620 & 4.9 & 5.1531 & TST & \\
\hline CHEMBL1375160 & 688620 & 5.75 & 5.5624 & TRN & \\
\hline CHEMBL1419270 & 688620 & 4.45 & 5.1221 & TRN & \\
\hline CHEMBL1419927 & 688620 & 4.45 & 5.1787 & TRN & \\
\hline CHEMBL1321322 & 688620 & 4.85 & 5.2756 & TST & \\
\hline CHEMBL1535988 & 688620 & 5.0 & 5.1158 & TRN & \\
\hline CHEMBL1417046 & 688620 & 4.45 & 4.8433 & TRN & \\
\hline CHEMBL1461506 & 688620 & 5.1 & 5.1836 & TRN & \\
\hline CHEMBL1399930 & 688620 & 5.6 & 5.6288 & TRN & \\
\hline
\end{tabular}




\begin{tabular}{|c|c|c|c|c|}
\hline \multicolumn{5}{|c|}{ Supplemental Table S2.txt } \\
\hline CHEMBL 3198857 & 688620 & 5.3 & 5.3271 & TRN \\
\hline CHEMBL1431340 & 688620 & 5.9 & 5.4143 & TRN \\
\hline CHEMBL1407075 & 688620 & 4.95 & 4.9405 & TRN \\
\hline CHEMBL1487332 & 688620 & 5.5 & 5.2102 & TRN \\
\hline CHEMBL1497918 & 688620 & 4.55 & 4.8391 & TST \\
\hline CHEMBL1586767 & 688620 & 4.65 & 4.9689 & TST \\
\hline CHEMBL1395408 & 688620 & 5.85 & 5.1961 & TRN \\
\hline CHEMBL1451832 & 688620 & 4.45 & 4.9224 & TRN \\
\hline CHEMBL1581359 & 688620 & 5.0 & 4.9539 & TRN \\
\hline CHEMBL1601731 & 688620 & 4.95 & 5.3129 & TRN \\
\hline CHEMBL1374895 & 688620 & 4.95 & 5.0653 & TRN \\
\hline CHEMBL1460376 & 688620 & 5.0 & 5.0701 & TRN \\
\hline CHEMBL1442031 & 688620 & 4.5 & 4.992 & TRN \\
\hline CHEMBL1350793 & 688620 & 4.95 & 4.7145 & TST \\
\hline CHEMBL1599631 & 688620 & 6.25 & 5.0671 & TST \\
\hline CHEMBL1998967 & 688620 & 5.7 & 5.4897 & TRN \\
\hline CHEMBL1360252 & 688620 & 5.85 & 5.4476 & TRN \\
\hline CHEMBL1609047 & 688620 & 5.5 & 5.1099 & TST \\
\hline CHEMBL1387415 & 688620 & 4.85 & 5.0139 & TRN \\
\hline CHEMBL1315968 & 688620 & 5.45 & 5.0783 & TRN \\
\hline CHEMBL3190036 & 688620 & 4.45 & 5.1191 & TST \\
\hline CHEMBL1510344 & 688620 & 5.0 & 4.9217 & TRN \\
\hline CHEMBL1547682 & 688620 & 4.45 & 4.9736 & TRN \\
\hline CHEMBL1381082 & 688620 & 4.55 & 4.8375 & TRN \\
\hline CHEMBL1546668 & 688620 & 5.0 & 4.8421 & TRN \\
\hline CHEMBL505057 & 688620 & 4.6 & 4.8989 & TRN \\
\hline CHEMBL1303720 & 688620 & 4.9 & 4.971 & TRN \\
\hline CHEMBL1354658 & 688620 & 5.0 & 4.774 & TST \\
\hline CHEMBL1430271 & 688620 & 4.45 & 4.8679 & TRN \\
\hline CHEMBL1503287 & 688620 & 5.5 & 5.3415 & TRN \\
\hline CHEMBL1427661 & 688620 & 5.5 & 5.8392 & TRN \\
\hline CHEMBL1495361 & 688620 & 5.65 & 5.0596 & TRN \\
\hline CHEMBL1483746 & 688620 & 6.45 & 5.5989 & TST \\
\hline CHEMBL1511583 & 688620 & 6.7001 & 5.6733 & TST \\
\hline CHEMBL1563483 & 688620 & 6.15 & 5.7976 & TST \\
\hline CHEMBL3191019 & 688620 & 4.65 & 4.6802 & TRN \\
\hline CHEMBL3195213 & 688620 & 4.95 & 5.0829 & TRN \\
\hline CHEMBL1499463 & 688620 & 4.45 & 5.047 & TRN \\
\hline CHEMBL1326110 & 688620 & 5.35 & 5.2579 & TRN \\
\hline CHEMBL 1448440 & 688620 & 5.0 & 4.9245 & TST \\
\hline CHEMBL1399756 & 688620 & 4.8 & 4.8616 & TRN \\
\hline CHEMBL1300839 & 688620 & 4.9 & 4.9955 & TRN \\
\hline CHEMBL1451846 & 688620 & 4.95 & 4.9571 & TST \\
\hline CHEMBL1404560 & 688620 & 5.25 & 4.7366 & TRN \\
\hline CHEMBL1380360 & 688620 & 5.15 & 4.9673 & TRN \\
\hline CHEMBL1608727 & 688620 & 5.9 & 5.1753 & TST \\
\hline CHEMBL1447430 & 688620 & 4.45 & 4.8499 & TST \\
\hline CHEMBL1596267 & 688620 & 5.15 & 5.1481 & TRN \\
\hline
\end{tabular}




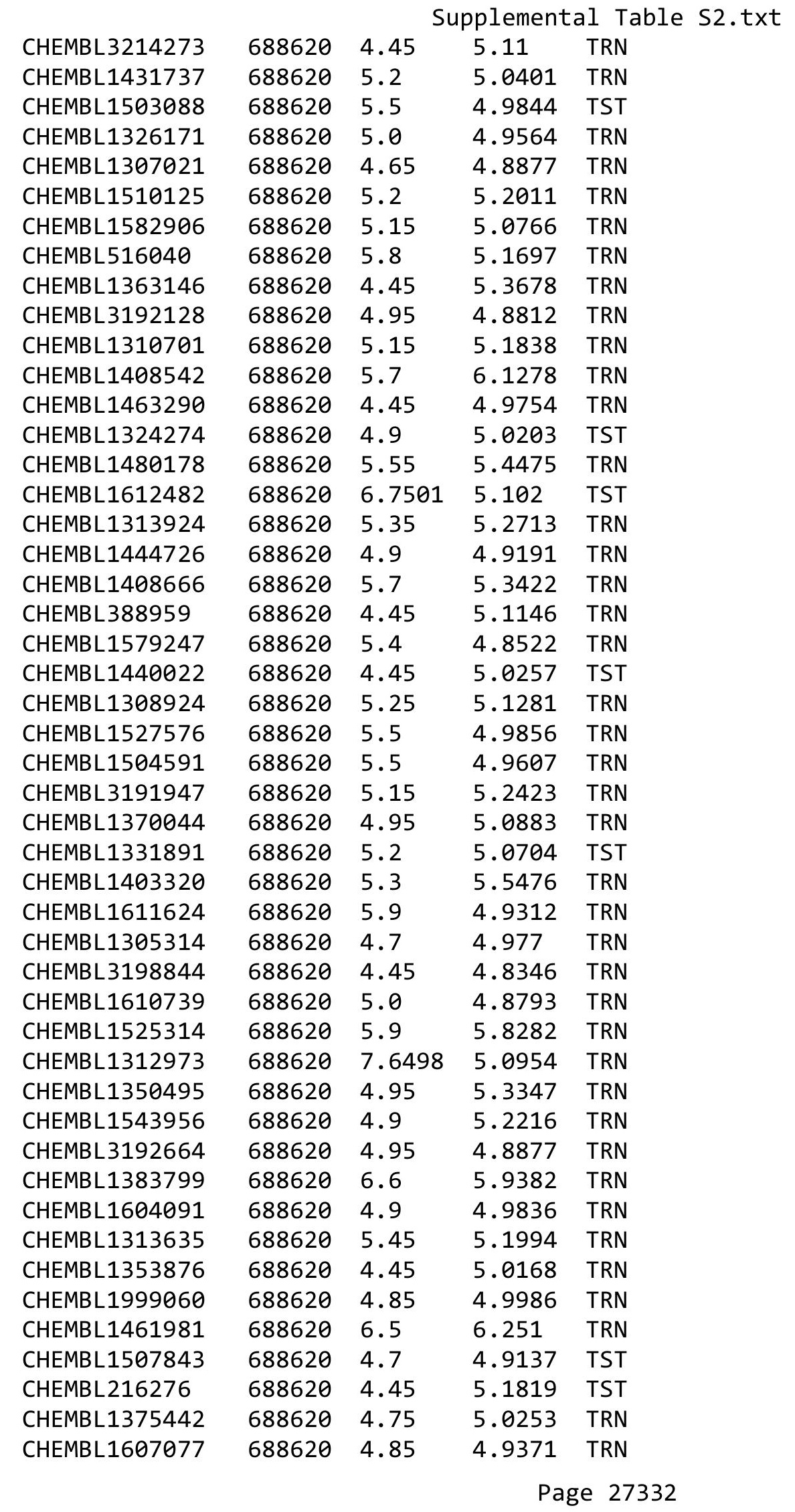




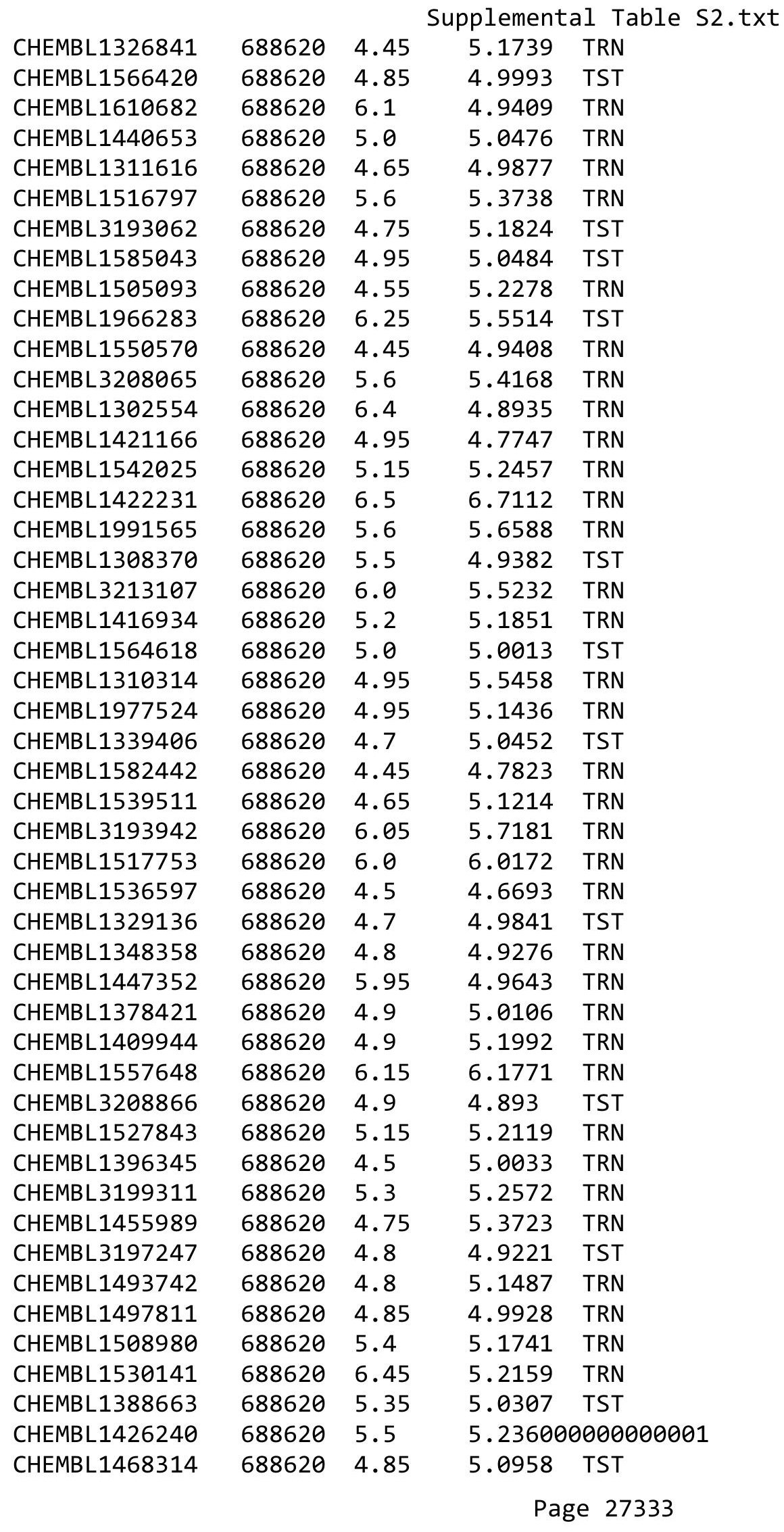

TRN 


\begin{tabular}{|c|c|c|c|c|}
\hline \multicolumn{5}{|c|}{ Supplemental Table S2.txt } \\
\hline CHEMBL1500060 & 688620 & 4.9 & 5.3688 & TRN \\
\hline CHEMBL1510443 & 688620 & 4.85 & 5.0415 & TRN \\
\hline CHEMBL1361699 & 688620 & 4.75 & 4.8469 & TRN \\
\hline CHEMBL1534880 & 688620 & 4.75 & 5.0252 & TRN \\
\hline CHEMBL528734 & 688620 & 5.0 & 4.9575 & TST \\
\hline CHEMBL1976810 & 688620 & 5.25 & 5.3204 & TRN \\
\hline CHEMBL602718 & 688620 & 5.3 & 5.5705 & TRN \\
\hline CHEMBL1555905 & 688620 & 5.5 & 4.9941 & TST \\
\hline CHEMBL1324214 & 688620 & 4.7 & 4.9975 & TRN \\
\hline CHEMBL1392231 & 688620 & 4.75 & 5.0268 & TRN \\
\hline CHEMBL1371322 & 688620 & 5.0 & 5.1832 & TRN \\
\hline CHEMBL1471684 & 688620 & 4.9 & 5.3185 & TST \\
\hline CHEMBL1401390 & 688620 & 5.0 & 5.1042 & TRN \\
\hline CHEMBL1569375 & 688620 & 4.45 & 5.1935 & TRN \\
\hline CHEMBL1563758 & 688620 & 4.9 & 4.9302 & TRN \\
\hline CHEMBL1555354 & 688620 & 6.2 & 5.4249 & TST \\
\hline CHEMBL1555721 & 688620 & 4.9 & 5.0243 & TST \\
\hline CHEMBL3190468 & 688620 & 5.7 & 5.5755 & TRN \\
\hline CHEMBL1389409 & 688620 & 5.5 & 5.4115 & TRN \\
\hline CHEMBL1450903 & 688620 & 4.85 & 5.0829 & TRN \\
\hline CHEMBL1449797 & 688620 & 4.75 & 4.9282 & TRN \\
\hline CHEMBL1338167 & 688620 & 5.6 & 5.7389 & TRN \\
\hline CHEMBL1364740 & 688620 & 4.95 & 5.1317 & TRN \\
\hline CHEMBL1327117 & 688620 & 4.85 & 5.1069 & TRN \\
\hline CHEMBL1525757 & 688620 & 5.15 & 5.2092 & TRN \\
\hline CHEMBL1377728 & 688620 & 5.5 & 4.9754 & TRN \\
\hline CHEMBL1601213 & 688620 & 4.9 & 5.0525 & TRN \\
\hline CHEMBL1544559 & 688620 & 5.0 & 4.7534 & TRN \\
\hline CHEMBL1381872 & 688620 & 5.55 & 5.3614 & TST \\
\hline CHEMBL1510447 & 688620 & 5.6 & 5.1472 & TRN \\
\hline CHEMBL1302249 & 688620 & 5.5 & 5.3044 & TRN \\
\hline CHEMBL1475199 & 688620 & 5.95 & 4.9848 & TRN \\
\hline CHEMBL1415885 & 688620 & 5.0 & 4.9818 & TRN \\
\hline CHEMBL1401895 & 688620 & 4.9 & 4.7505 & TRN \\
\hline CHEMBL1349917 & 688620 & 5.4 & 5.3006 & TRN \\
\hline CHEMBL1555580 & 688620 & 4.7 & 5.0372 & TST \\
\hline CHEMBL1467018 & 688620 & 5.5 & 5.0975 & TRN \\
\hline CHEMBL1479895 & 688620 & 5.3 & 4.9108 & TRN \\
\hline CHEMBL1590886 & 688620 & 4.9 & 4.8273 & TRN \\
\hline CHEMBL1601668 & 688620 & 5.95 & 5.6142 & TRN \\
\hline CHEMBL3199401 & 688620 & 5.55 & 5.2942 & TRN \\
\hline CHEMBL1456336 & 688620 & 4.65 & 5.121 & TRN \\
\hline CHEMBL3213887 & 688620 & 4.45 & 4.8016 & TRN \\
\hline CHEMBL1527871 & 688620 & 4.45 & 4.9165 & TST \\
\hline CHEMBL1313499 & 688620 & 5.45 & 5.5049 & TST \\
\hline CHEMBL1452827 & 688620 & 5.15 & 4.8477 & TRN \\
\hline CHEMBL1460463 & 688620 & 4.45 & 4.9159 & TRN \\
\hline CHEMBL1334665 & 688620 & 5.9 & 4.869 & TRN \\
\hline
\end{tabular}




\begin{tabular}{|c|c|c|c|c|c|}
\hline \multirow{3}{*}{$\begin{array}{l}\text { CHEMBL1323935 } \\
\text { CHEMBL1431184 }\end{array}$} & \multirow{3}{*}{$\begin{array}{l}688620 \\
688620\end{array}$} & \multicolumn{4}{|c|}{ Supplemental Table S2.txt } \\
\hline & & 5.1 & \multicolumn{2}{|c|}{5.172999999999999} & TRN \\
\hline & & 4.45 & 5.0039 & TST & \\
\hline CHEMBL1404301 & 688620 & 5.25 & 4.9906 & TRN & \\
\hline CHEMBL1414269 & 688620 & 4.45 & 5.0291 & TRN & \\
\hline CHEMBL1417778 & 688620 & 4.65 & 4.88399 & 99999999995 & TRN \\
\hline CHEMBL1515666 & 688620 & 4.9 & 5.1491 & TRN & \\
\hline CHEMBL1411223 & 688620 & 4.95 & 5.1147 & TRN & \\
\hline CHEMBL1540200 & 688620 & 4.45 & 5.4278 & TRN & \\
\hline CHEMBL1385454 & 688620 & 4.65 & 4.9803 & TRN & \\
\hline CHEMBL1549722 & 688620 & 4.8 & 4.9148 & TRN & \\
\hline CHEMBL1349409 & 688620 & 4.45 & 4.9801 & TRN & \\
\hline CHEMBL3191239 & 688620 & 5.0 & 5.3129 & TRN & \\
\hline CHEMBL1478909 & 688620 & 4.7 & 4.9634 & TRN & \\
\hline CHEMBL1507685 & 688620 & 4.85 & 4.797 & TRN & \\
\hline CHEMBL1320741 & 688620 & 5.7 & 5.5494 & TRN & \\
\hline CHEMBL1612138 & 688620 & 5.55 & 5.3294 & TST & \\
\hline CHEMBL1429154 & 688620 & 5.9 & 5.7642 & TST & \\
\hline CHEMBL1307550 & 688620 & 4.75 & 5.0901 & TRN & \\
\hline CHEMBL1444406 & 688620 & 4.9 & 5.1017 & TRN & \\
\hline CHEMBL1455638 & 688620 & 4.8 & 5.0034 & TRN & \\
\hline CHEMBL1549656 & 688620 & 4.75 & 5.0423 & TRN & \\
\hline CHEMBL1469807 & 688620 & 5.35 & 5.3532 & TRN & \\
\hline CHEMBL1406528 & 688620 & 4.95 & 5.4893 & TRN & \\
\hline CHEMBL3190552 & 688620 & 5.2 & 5.047 & TRN & \\
\hline CHEMBL1537079 & 688620 & 5.05 & 4.9883 & TRN & \\
\hline CHEMBL1489961 & 688620 & 4.9 & 4.9099 & TRN & \\
\hline CHEMBL1372767 & 688620 & 4.9 & 5.3607 & TRN & \\
\hline CHEMBL1391972 & 688620 & 5.2 & 5.1832 & TRN & \\
\hline CHEMBL 74852 & 688620 & 4.9 & 4.9878 & TRN & \\
\hline CHEMBL1463916 & 688620 & 7.0 & 5.2912 & TRN & \\
\hline CHEMBL1437854 & 688620 & 4.9 & 4.9763 & TST & \\
\hline CHEMBL1448801 & 688620 & 4.45 & 4.9083 & TRN & \\
\hline CHEMBL1429218 & 688620 & 5.0 & 5.3344 & TRN & \\
\hline CHEMBL1577140 & 688620 & 5.15 & 5.1187 & TRN & \\
\hline CHEMBL3199107 & 688620 & 4.75 & 5.4766 & TRN & \\
\hline CHEMBL1585907 & 688620 & 5.0 & 5.1757 & TRN & \\
\hline CHEMBL1455631 & 688620 & 4.45 & 4.8207 & TRN & \\
\hline CHEMBL1418397 & 688620 & 5.0 & 5.0373 & TRN & \\
\hline CHEMBL1311725 & 688620 & 4.45 & 5.0497 & TST & \\
\hline CHEMBL3191942 & 688620 & 6.0 & 5.8494 & TRN & \\
\hline CHEMBL1450153 & 688620 & 4.85 & 4.8668 & TRN & \\
\hline CHEMBL1582468 & 688620 & 5.75 & 5.0643 & TST & \\
\hline CHEMBL1350877 & 688620 & 5.2 & 5.1222 & TRN & \\
\hline CHEMBL1578219 & 688620 & 5.95 & 5.0948 & TRN & \\
\hline CHEMBL1363762 & 688620 & 4.85 & 4.9852 & TRN & \\
\hline CHEMBL1359012 & 688620 & 4.9 & 5.2271 & TST & \\
\hline CHEMBL1576047 & 688620 & 4.75 & 4.9691 & TRN & \\
\hline CHEMBL1420347 & 688620 & 5.95 & 5.4034 & TRN & \\
\hline
\end{tabular}




\begin{tabular}{|c|c|c|c|c|c|}
\hline \multicolumn{6}{|c|}{ Supplemental Table s2.txt } \\
\hline CHEMBL1589539 & 688620 & 4.45 & 5.1394 & TRN & \\
\hline CHEMBL3198068 & 688620 & 6.05 & 5.1718 & TST & \\
\hline CHEMBL3210233 & 688620 & 5.75 & 5.4537 & TRN & \\
\hline CHEMBL 3144900 & 688620 & 4.55 & 5.0671 & TRN & \\
\hline CHEMBL1590770 & 688620 & 5.05 & 5.06 & TST & \\
\hline CHEMBL1608197 & 688620 & 5.4 & 4.9359 & TRN & \\
\hline CHEMBL1373563 & 688620 & 6.0 & 5.8006 & TRN & \\
\hline CHEMBL1573929 & 688620 & 5.15 & 5.13899 & 9999999999 & TRN \\
\hline CHEMBL3195746 & 688620 & 5.35 & 5.3558 & TRN & \\
\hline CHEMBL1525407 & 688620 & 8.3468 & 4.9772 & TST & \\
\hline CHEMBL1368189 & 688620 & 5.15 & 5.2735 & TRN & \\
\hline CHEMBL3207526 & 688620 & 5.75 & 5.0824 & TRN & \\
\hline CHEMBL1404397 & 688620 & 5.95 & 5.0308 & TRN & \\
\hline CHEMBL1383895 & 688620 & 4.95 & 4.9794 & TRN & \\
\hline CHEMBL1503164 & 688620 & 4.75 & 5.0195 & TRN & \\
\hline CHEMBL1533228 & 688620 & 5.85 & 5.0306 & TRN & \\
\hline CHEMBL1345720 & 688620 & 6.6499 & 5.1804 & TRN & \\
\hline CHEMBL1457965 & 688620 & 5.25 & 5.1607 & TRN & \\
\hline CHEMBL1608713 & 688620 & 4.65 & 5.0212 & TRN & \\
\hline CHEMBL1462457 & 688620 & 4.85 & 5.1481 & TRN & \\
\hline CHEMBL572994 & 688620 & 5.65 & 5.3257 & TST & \\
\hline CHEMBL1299247 & 688620 & 5.6 & 5.2063 & TRN & \\
\hline CHEMBL1526721 & 688620 & 4.75 & 4.9359 & TST & \\
\hline CHEMBL3194167 & 688620 & 6.05 & 6.0331 & TRN & \\
\hline CHEMBL1547257 & 688620 & 5.25 & 4.8662 & TST & \\
\hline CHEMBL3195597 & 688620 & 4.85 & 5.1299 & TRN & \\
\hline CHEMBL1305671 & 688620 & 4.85 & 5.0897 & TRN & \\
\hline CHEMBL1411208 & 688620 & 5.55 & 5.1112 & TRN & \\
\hline CHEMBL1594758 & 688620 & 5.1 & 4.9214 & TRN & \\
\hline CHEMBL3189260 & 688620 & 4.9 & 5.114 & TRN & \\
\hline CHEMBL1584975 & 688620 & 4.8 & 5.0182 & TRN & \\
\hline CHEMBL1440473 & 688620 & 4.65 & 5.1427 & TRN & \\
\hline CHEMBL1486570 & 688620 & 4.75 & 4.9616 & TST & \\
\hline CHEMBL1532140 & 688620 & 4.45 & 5.5348 & TST & \\
\hline CHEMBL1549313 & 688620 & 4.45 & 5.0075 & TRN & \\
\hline CHEMBL1542328 & 688620 & 5.25 & 5.5001 & TRN & \\
\hline CHEMBL1342697 & 688620 & 4.45 & 4.9081 & TST & \\
\hline CHEMBL1607466 & 688620 & 5.05 & 4.8176 & TRN & \\
\hline CHEMBL1583644 & 688620 & 4.95 & 4.9448 & TRN & \\
\hline CHEMBL1551024 & 688620 & 4.45 & 5.016 & TRN & \\
\hline CHEMBL1462373 & 688620 & 4.95 & 5.228 & TRN & \\
\hline CHEMBL1379195 & 688620 & 4.8 & 5.1402 & TST & \\
\hline CHEMBL1300956 & 688620 & 4.9 & 4.9419 & TRN & \\
\hline CHEMBL3193340 & 688620 & 7.0 & 5.38700 & 00000000005 & TST \\
\hline CHEMBL1369549 & 688620 & 4.45 & 5.1561 & TRN & \\
\hline CHEMBL1319967 & 688620 & 4.5 & 5.0259 & TRN & \\
\hline CHEMBL1413504 & 688620 & 4.7 & 4.8725 & TRN & \\
\hline CHEMBL1504413 & 688620 & 4.65 & 4.9307 & TRN & \\
\hline
\end{tabular}




\begin{tabular}{|c|c|c|c|c|}
\hline \multicolumn{5}{|c|}{ Supplemental Table S2.txt } \\
\hline CHEMBL 3212655 & 688620 & 5.2 & 5.155 & TRN \\
\hline CHEMBL1450850 & 688620 & 4.45 & 4.978 & TRN \\
\hline CHEMBL1531776 & 688620 & 4.45 & 4.9692 & TRN \\
\hline CHEMBL1340628 & 688620 & 4.7 & 5.0659 & TRN \\
\hline CHEMBL 1477285 & 688620 & 4.8 & 5.0766 & TST \\
\hline CHEMBL1586742 & 688620 & 4.95 & 5.1332 & TRN \\
\hline CHEMBL1489546 & 688620 & 4.5 & 4.9378 & TRN \\
\hline CHEMBL 3198402 & 688620 & 5.15 & 5.0599 & TRN \\
\hline CHEMBL1594676 & 688620 & 4.8 & 4.9434 & TRN \\
\hline CHEMBL1490489 & 688620 & 5.0 & 5.1241 & TRN \\
\hline CHEMBL1462406 & 688620 & 5.3 & 5.2117 & TRN \\
\hline CHEMBL1369560 & 688620 & 4.7 & 5.0989 & TRN \\
\hline CHEMBL1468847 & 688620 & 5.75 & 5.0645 & TRN \\
\hline CHEMBL1368871 & 688620 & 4.95 & 5.0102 & TRN \\
\hline CHEMBL1409899 & 688620 & 4.95 & 4.9696 & TST \\
\hline CHEMBL1577127 & 688620 & 4.45 & 5.4246 & TST \\
\hline CHEMBL1501567 & 688620 & 5.15 & 5.3568 & TST \\
\hline CHEMBL1470278 & 688620 & 4.45 & 4.7936 & TRN \\
\hline CHEMBL1558793 & 688620 & 5.0 & 5.1379 & TRN \\
\hline CHEMBL1520538 & 688620 & 5.45 & 4.9807 & TRN \\
\hline CHEMBL1587767 & 688620 & 6.1 & 5.879 & TRN \\
\hline CHEMBL1418106 & 688620 & 4.65 & 5.0194 & TST \\
\hline CHEMBL1411222 & 688620 & 7.0 & 5.7649 & TST \\
\hline CHEMBL1569012 & 688620 & 4.9 & 5.4388 & TRN \\
\hline CHEMBL1592127 & 688620 & 5.0 & 4.8338 & TST \\
\hline CHEMBL1483403 & 688620 & 5.5 & 5.1138 & TRN \\
\hline CHEMBL1460747 & 688620 & 4.95 & 5.0339 & TST \\
\hline CHEMBL1999437 & 688620 & 5.65 & 5.2765 & TRN \\
\hline CHEMBL1569226 & 688620 & 5.05 & 4.912 & TST \\
\hline CHEMBL1368792 & 688620 & 4.9 & 5.0955 & TRN \\
\hline CHEMBL1567830 & 688620 & 5.25 & 5.6267 & TRN \\
\hline CHEMBL1321190 & 688620 & 5.5 & 5.1734 & TST \\
\hline CHEMBL1350047 & 688620 & 4.9 & 4.9056 & TRN \\
\hline CHEMBL1476114 & 688620 & 5.75 & 5.1172 & TRN \\
\hline CHEMBL1546566 & 688620 & 4.95 & 4.9359 & TRN \\
\hline CHEMBL1992088 & 688620 & 4.9 & 4.9863 & TRN \\
\hline CHEMBL1412970 & 688620 & 5.4 & 5.1814 & TRN \\
\hline CHEMBL221190 & 688620 & 5.0 & 5.1626 & TST \\
\hline CHEMBL1463885 & 688620 & 5.15 & 4.9547 & TRN \\
\hline CHEMBL1525540 & 688620 & 5.85 & 4.773 & TST \\
\hline CHEMBL1429986 & 688620 & 7.6003 & 5.2782 & TST \\
\hline CHEMBL1587121 & 688620 & 4.95 & 4.9202 & TRN \\
\hline CHEMBL1301753 & 688620 & 6.1 & 5.0932 & TRN \\
\hline CHEMBL1367966 & 688620 & 5.4 & 5.2076 & TRN \\
\hline CHEMBL1509472 & 688620 & 4.8 & 5.0153 & TRN \\
\hline CHEMBL1414204 & 688620 & 5.7 & 5.2367 & TRN \\
\hline CHEMBL3189324 & 688620 & 5.0 & 5.4649 & TRN \\
\hline CHEMBL1558868 & 688620 & 5.4 & 5.2854 & TST \\
\hline
\end{tabular}




\begin{tabular}{|c|c|c|c|c|c|}
\hline \multicolumn{6}{|c|}{ Supplemental Table S2.txt } \\
\hline CHEMBL1431531 & 688620 & 5.2 & 4.9886 & TRN & \\
\hline CHEMBL1412281 & 688620 & 5.1 & 5.0247 & TRN & \\
\hline CHEMBL1399439 & 688620 & 5.0 & 5.1794 & TRN & \\
\hline CHEMBL 3199594 & 688620 & 5.6 & 4.9179 & TRN & \\
\hline CHEMBL3198465 & 688620 & 6.6499 & 5.2555 & TRN & \\
\hline CHEMBL1980967 & 688620 & 5.15 & 5.1524 & TRN & \\
\hline CHEMBL1305840 & 688620 & 5.2 & 5.2085 & TRN & \\
\hline CHEMBL1443122 & 688620 & 5.15 & 5.0917 & TRN & \\
\hline CHEMBL1535679 & 688620 & 5.95 & 4.9457 & TST & \\
\hline CHEMBL1371797 & 688620 & 7.15 & 5.1607 & TRN & \\
\hline CHEMBL1547180 & 688620 & 4.8 & 5.0592 & TRN & \\
\hline CHEMBL1606309 & 688620 & 5.0 & 4.9759 & TRN & \\
\hline CHEMBL405914 & 688620 & 5.4 & 5.4787 & TRN & \\
\hline CHEMBL 3192253 & 688620 & 6.2 & 5.1586 & TST & \\
\hline CHEMBL1416559 & 688620 & 4.45 & 5.1225 & TRN & \\
\hline CHEMBL1520311 & 688620 & 6.6 & 5.2199 & TRN & \\
\hline CHEMBL1507043 & 688620 & 5.85 & 5.6049 & TRN & \\
\hline CHEMBL1299438 & 688620 & 4.45 & 5.0805 & TST & \\
\hline CHEMBL1460348 & 688620 & 6.0 & 4.9644 & TRN & \\
\hline CHEMBL1367985 & 688620 & 6.1 & 5.9895 & TRN & \\
\hline CHEMBL1428642 & 688620 & 5.3 & 4.9615 & TRN & \\
\hline CHEMBL1445168 & 688620 & 5.55 & 5.6377 & TRN & \\
\hline CHEMBL3192415 & 688620 & 5.3 & 5.4453 & TRN & \\
\hline CHEMBL1613445 & 688620 & 4.45 & 4.7265 & TRN & \\
\hline CHEMBL1310645 & 688620 & 4.65 & 4.9472 & TRN & \\
\hline CHEMBL1338723 & 688620 & 4.9 & 4.7419 & TRN & \\
\hline CHEMBL1422092 & 688620 & 4.45 & 4.8235 & TST & \\
\hline CHEMBL1428827 & 688620 & 5.6 & 5.6017 & TRN & \\
\hline CHEMBL1463602 & 688620 & 4.45 & 4.7888 & TST & \\
\hline CHEMBL1387964 & 688620 & 4.6 & 5.1256 & TRN & \\
\hline CHEMBL1480494 & 688620 & 4.7 & 5.0075 & TRN & \\
\hline CHEMBL1379756 & 688620 & 4.9 & 4.9975 & TRN & \\
\hline CHEMBL1597777 & 688620 & 5.65 & 5.4337 & TRN & \\
\hline CHEMBL1374806 & 688620 & 4.9 & 5.0417 & TRN & \\
\hline CHEMBL1477399 & 688620 & 4.8 & 5.0797 & TST & \\
\hline CHEMBL1310467 & 688620 & 4.6 & 4.7297 & TST & \\
\hline CHEMBL1993613 & 688620 & 4.9 & 4.9329 & TRN & \\
\hline CHEMBL1416329 & 688620 & 4.9 & 4.6579 & TST & \\
\hline CHEMBL1502919 & 688620 & 4.45 & 4.7879 & TRN & \\
\hline CHEMBL1580581 & 688620 & 4.65 & 4.75 & TRN & \\
\hline CHEMBL1530816 & 688620 & 5.6 & 5.21399 & 99999999995 & \\
\hline CHEMBL1299720 & 688620 & 6.4 & 5.7651 & TRN & \\
\hline CHEMBL1510647 & 688620 & 5.1 & 4.9423 & TRN & \\
\hline CHEMBL1427320 & 688620 & 4.7 & 5.0467 & TST & \\
\hline CHEMBL1418647 & 688620 & 6.7501 & 5.0149 & TRN & \\
\hline CHEMBL1980657 & 688620 & 6.6499 & 5.7447 & TRN & \\
\hline CHEMBL1544664 & 688620 & 5.2 & 4.8217 & TRN & \\
\hline CHEMBL1380684 & 688620 & 6.0 & 5.8397 & TRN & \\
\hline
\end{tabular}




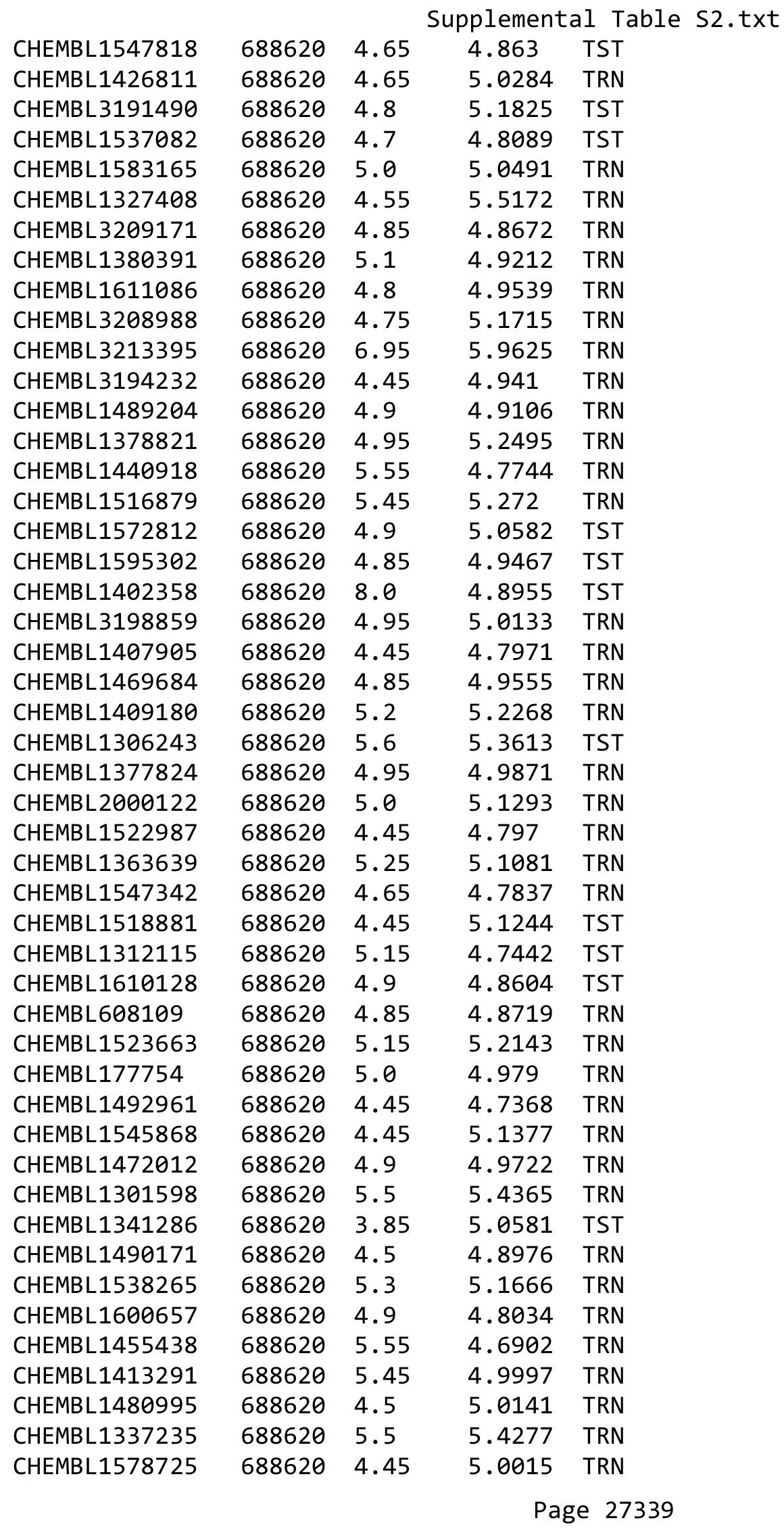




\begin{tabular}{|c|c|c|c|c|c|}
\hline & & & & & \\
\hline CHEMBL1970918 & 688620 & 5.6 & 5.5932 & TRN & \\
\hline CHEMBL1405461 & 688620 & 4.7 & 4.8806 & TRN & \\
\hline CHEMBL1429346 & 688620 & 5.0 & 4.9876 & TRN & \\
\hline CHEMBL1425849 & 688620 & 5.0 & 5.025 & TST & \\
\hline CHEMBL1338560 & 688620 & 4.7 & 5.0316 & TRN & \\
\hline CHEMBL1451691 & 688620 & 5.6 & 5.3913 & TRN & \\
\hline CHEMBL1481094 & 688620 & 4.5 & 4.7885 & TRN & \\
\hline CHEMBL1413931 & 688620 & 5.05 & 5.4237 & TRN & \\
\hline CHEMBL3190356 & 688620 & 6.05 & 5.766 & TRN & \\
\hline CHEMBL3213455 & 688620 & 5.3 & 5.0383 & TRN & \\
\hline CHEMBL1463363 & 688620 & 5.45 & 5.3669 & TST & \\
\hline CHEMBL1509105 & 688620 & 5.2 & 5.1859 & TRN & \\
\hline CHEMBL1368608 & 688620 & 4.7 & 5.0684 & TRN & \\
\hline CHEMBL1432711 & 688620 & 4.95 & 4.8797 & TRN & \\
\hline CHEMBL1437997 & 688620 & 4.9 & 5.3053 & TST & \\
\hline CHEMBL1301368 & 688620 & 4.75 & 5.1579 & TRN & \\
\hline CHEMBL1531463 & 688620 & 5.55 & 5.4642 & TST & \\
\hline CHEMBL1418046 & 688620 & 5.15 & 5.2793 & TST & \\
\hline CHEMBL1573451 & 688620 & 4.45 & 4.8284 & TRN & \\
\hline CHEMBL1383516 & 688620 & 4.7 & 4.6956 & TST & \\
\hline CHEMBL1427096 & 688620 & 5.15 & $5.2470 e$ & 0000000001 & TRN \\
\hline CHEMBL1440664 & 688620 & 4.8 & 5.0638 & TRN & \\
\hline CHEMBL1595610 & 688620 & 4.45 & 5.3258 & TRN & \\
\hline CHEMBL1471326 & 688620 & 4.95 & 5.3438 & TRN & \\
\hline CHEMBL1469965 & 688620 & 4.85 & 5.0603 & TRN & \\
\hline CHEMBL3197576 & 688620 & 5.15 & 5.2506 & TRN & \\
\hline CHEMBL1569652 & 688620 & 4.9 & 5.165 & TRN & \\
\hline CHEMBL1321957 & 688620 & 4.45 & 4.9257 & TRN & \\
\hline CHEMBL1547204 & 688620 & 5.6 & 5.3029 & TRN & \\
\hline CHEMBL1438115 & 688620 & 4.7 & 5.082 & TST & \\
\hline CHEMBL1496329 & 688620 & 4.75 & 4.6771 & TRN & \\
\hline CHEMBL1584783 & 688620 & 5.8 & 5.0973 & TRN & \\
\hline CHEMBL1561040 & 688620 & 5.75 & 5.5438 & TST & \\
\hline CHEMBL1582741 & 688620 & 4.8 & 5.2324 & TRN & \\
\hline CHEMBL599503 & 688620 & 4.65 & 4.5136 & TRN & \\
\hline CHEMBL1569452 & 688620 & 4.85 & 5.4214 & TRN & \\
\hline CHEMBL3144976 & 688620 & 5.7 & 5.6671 & TRN & \\
\hline CHEMBL1449236 & 688620 & 4.85 & 5.0398 & TST & \\
\hline CHEMBL1401525 & 688620 & 4.9 & 4.9142 & TST & \\
\hline CHEMBL1376055 & 688620 & 4.45 & 4.9353 & TRN & \\
\hline CHEMBL1400978 & 688620 & 4.95 & 5.0854 & TST & \\
\hline CHEMBL1471276 & 688620 & 4.7 & 4.9348 & TST & \\
\hline CHEMBL1334465 & 688620 & 5.0 & 5.233 & TST & \\
\hline CHEMBL1424714 & 688620 & 4.45 & 5.0443 & TST & \\
\hline CHEMBL1404786 & 688620 & 4.85 & 5.1743 & TRN & \\
\hline CHEMBL1495741 & 688620 & 6.45 & 5.0326 & TST & \\
\hline CHEMBL1489990 & 688620 & 5.35 & 5.1889 & TST & \\
\hline CHEMBL1523477 & 688620 & 5.9 & 5.53799 & 9999999999 & TST \\
\hline & & & & 27340 & \\
\hline
\end{tabular}




\begin{tabular}{|c|c|c|c|c|}
\hline \multicolumn{5}{|c|}{ Supplemental Table S2.txt } \\
\hline CHEMBL1529528 & 688620 & 4.45 & 4.9605 & TRN \\
\hline CHEMBL 3189729 & 688620 & 5.0 & 5.4104 & TRN \\
\hline CHEMBL1410917 & 688620 & 4.7 & 5.0188 & TST \\
\hline CHEMBL1500163 & 688620 & 4.9 & 5.0283 & TRN \\
\hline CHEMBL1471095 & 688620 & 5.05 & 5.0169 & TRN \\
\hline CHEMBL1579683 & 688620 & 4.45 & 4.9541 & TST \\
\hline CHEMBL1371941 & 688620 & 5.05 & 5.0697 & TRN \\
\hline CHEMBL1459508 & 688620 & 5.0 & 4.9488 & TRN \\
\hline CHEMBL1350024 & 688620 & 4.65 & 4.9244 & TRN \\
\hline CHEMBL1497426 & 688620 & 5.25 & 4.7733 & TRN \\
\hline CHEMBL1331444 & 688620 & 5.0 & 5.2679 & TRN \\
\hline CHEMBL 3207617 & 688620 & 5.8 & 5.4368 & TRN \\
\hline CHEMBL1427160 & 688620 & 5.05 & 4.9011 & TRN \\
\hline CHEMBL1507431 & 688620 & 4.45 & 5.1878 & TRN \\
\hline CHEMBL3193486 & 688620 & 6.3 & 6.1058 & TRN \\
\hline CHEMBL1495055 & 688620 & 4.45 & 5.3408 & TRN \\
\hline CHEMBL1440920 & 688620 & 5.05 & 4.8546 & TRN \\
\hline CHEMBL1456623 & 688620 & 6.0 & 5.4241 & TRN \\
\hline CHEMBL1412157 & 688620 & 5.9 & 5.6741 & TRN \\
\hline CHEMBL1459877 & 688620 & 4.5 & 5.2804 & TST \\
\hline CHEMBL1392559 & 688620 & 5.0 & 4.9848 & TRN \\
\hline CHEMBL1467704 & 688620 & 5.75 & 5.2854 & TRN \\
\hline CHEMBL1992109 & 688620 & 5.65 & 5.5926 & TRN \\
\hline CHEMBL1361584 & 688620 & 4.5 & 4.7852 & TST \\
\hline CHEMBL1385562 & 688620 & 4.95 & 4.9644 & TRN \\
\hline CHEMBL3198663 & 688620 & 4.85 & 4.9873 & TRN \\
\hline CHEMBL 3208443 & 688620 & 6.05 & 5.9083 & TRN \\
\hline CHEMBL1510951 & 688620 & 5.55 & 5.3003 & TRN \\
\hline CHEMBL1341377 & 688620 & 4.45 & 5.1348 & TRN \\
\hline CHEMBL 3199163 & 688620 & 4.95 & 5.2631 & TRN \\
\hline CHEMBL1527117 & 688620 & 5.55 & 4.9855 & TRN \\
\hline CHEMBL1449996 & 688620 & 4.9 & 4.9934 & TRN \\
\hline CHEMBL1598652 & 688620 & 5.15 & 5.0804 & TRN \\
\hline CHEMBL1449731 & 688620 & 4.45 & 4.8599 & TST \\
\hline CHEMBL1369196 & 688620 & 5.05 & 5.256 & TRN \\
\hline CHEMBL1602477 & 688620 & 4.95 & 4.9752 & TRN \\
\hline CHEMBL 1538740 & 688620 & 4.95 & 4.914 & TST \\
\hline CHEMBL1480410 & 688620 & 4.45 & 4.8921 & TRN \\
\hline CHEMBL1448431 & 688620 & 5.95 & 5.9185 & TRN \\
\hline CHEMBL1332362 & 688620 & 4.8 & 5.084 & TRN \\
\hline CHEMBL36654 & 688620 & 5.15 & 5.2039 & TRN \\
\hline CHEMBL1360607 & 688620 & 4.45 & 5.1131 & TST \\
\hline CHEMBL1541300 & 688620 & 5.2 & 4.7392 & TRN \\
\hline CHEMBL1452602 & 688620 & 4.75 & 4.918 & TST \\
\hline CHEMBL1400729 & 688620 & 4.9 & 5.4315 & TRN \\
\hline CHEMBL1321838 & 688620 & 5.5 & 5.0838 & TST \\
\hline CHEMBL 1587323 & 688620 & 5.25 & 5.1298 & TRN \\
\hline CHEMBL3209681 & 688620 & 4.9 & 4.8744 & TRN \\
\hline
\end{tabular}




\begin{tabular}{|c|c|c|c|c|}
\hline & & & pplement & al $\mathrm{Ta}$ \\
\hline CHEMBL3197254 & 688620 & 5.2 & 5.2492 & TST \\
\hline CHEMBL1523983 & 688620 & 5.05 & 5.0908 & TST \\
\hline CHEMBL1365670 & 688620 & 5.05 & 5.4157 & TRN \\
\hline CHEMBL1444333 & 688620 & 5.15 & 5.3256 & TRN \\
\hline CHEMBL 3190653 & 688620 & 4.4 & 5.9096 & TRN \\
\hline CHEMBL1439624 & 688620 & 5.4 & 4.8806 & TRN \\
\hline CHEMBL270635 & 688620 & 4.6 & 5.8646 & TRN \\
\hline CHEMBL1504481 & 688620 & 4.8 & 5.0938 & TST \\
\hline CHEMBL1460485 & 688620 & 5.55 & 5.346 & TRN \\
\hline CHEMBL1583455 & 688620 & 5.75 & 5.1561 & TST \\
\hline CHEMBL1983581 & 688620 & 4.95 & 4.7438 & TRN \\
\hline CHEMBL1425636 & 688620 & 5.3 & 5.25 & TRN \\
\hline CHEMBL1453884 & 688620 & 5.45 & 4.9495 & TRN \\
\hline CHEMBL3193235 & 688620 & 5.65 & 5.5462 & TRN \\
\hline CHEMBL1383199 & 688620 & 4.7 & 4.6827 & TST \\
\hline CHEMBL1384845 & 688620 & 4.45 & 4.9264 & TST \\
\hline CHEMBL1604650 & 688620 & 5.15 & 5.1455 & TRN \\
\hline CHEMBL590947 & 688620 & 4.95 & 4.931 & TRN \\
\hline CHEMBL1591983 & 688620 & 4.95 & 5.1306 & TRN \\
\hline CHEMBL3196689 & 688620 & 4.6 & 4.9255 & TRN \\
\hline CHEMBL3192024 & 688620 & 4.45 & 4.9191 & TRN \\
\hline CHEMBL1466574 & 688620 & 4.7 & 4.9082 & TST \\
\hline CHEMBL1328473 & 688620 & 5.5 & 5.2183 & TRN \\
\hline CHEMBL1543777 & 688620 & 4.95 & 5.0968 & TST \\
\hline CHEMBL1530684 & 688620 & 4.6 & 4.9317 & TRN \\
\hline CHEMBL1967640 & 688620 & 6.6 & 5.0933 & TRN \\
\hline CHEMBL1464555 & 688620 & 5.1 & 5.2805 & TRN \\
\hline CHEMBL1572397 & 688620 & 4.8 & 5.0043 & TRN \\
\hline CHEMBL1326104 & 688620 & 4.65 & 4.8791 & TRN \\
\hline CHEMBL1344449 & 688620 & 5.25 & 5.1211 & TRN \\
\hline CHEMBL1603760 & 688620 & 4.85 & 4.7866 & TRN \\
\hline CHEMBL1450557 & 688620 & 4.45 & 5.1094 & TST \\
\hline CHEMBL1378852 & 688620 & 5.2 & 5.2896 & TRN \\
\hline CHEMBL1550422 & 688620 & 5.4 & 4.8808 & TST \\
\hline CHEMBL1333666 & 688620 & 4.65 & 5.0181 & TST \\
\hline CHEMBL1487546 & 688620 & 4.45 & 4.8077 & TRN \\
\hline CHEMBL1601405 & 688620 & 6.15 & 5.0626 & TRN \\
\hline CHEMBL1398836 & 688620 & 5.0 & 6.1553 & TRN \\
\hline CHEMBL1368741 & 688620 & 4.45 & 5.1046 & TRN \\
\hline CHEMBL1387704 & 688620 & 5.2 & 5.2142 & TRN \\
\hline CHEMBL1483908 & 688620 & 4.5 & 5.3585 & TRN \\
\hline CHEMBL1347628 & 688620 & 5.95 & 5.9465 & TRN \\
\hline CHEMBL1461200 & 688620 & 4.45 & 5.0313 & TST \\
\hline CHEMBL1523881 & 688620 & 4.9 & 5.0877 & TRN \\
\hline CHEMBL1549899 & 688620 & 6.0 & 4.8485 & TRN \\
\hline CHEMBL1561882 & 688620 & 4.7 & 5.1059 & TRN \\
\hline CHEMBL1558069 & 688620 & 5.2 & 5.0737 & TRN \\
\hline CHEMBL1365067 & 688620 & 4.9 & 4.9153 & TRN \\
\hline
\end{tabular}




\begin{tabular}{|c|c|c|c|c|c|}
\hline \multicolumn{6}{|c|}{ Supplemental Table S2.txt } \\
\hline CHEMBL1465639 & 688620 & 4.95 & 4.9097 & TST & \\
\hline CHEMBL1541173 & 688620 & 4.45 & 4.9003 & TRN & \\
\hline CHEMBL1352235 & 688620 & 4.45 & 4.9131 & TST & \\
\hline CHEMBL1504945 & 688620 & 5.2 & 5.3339 & TRN & \\
\hline CHEMBL1306934 & 688620 & 5.2 & 5.2304 & TST & \\
\hline CHEMBL1363430 & 688620 & 6.4 & 5.05699 & 99999999995 & TRN \\
\hline CHEMBL1403308 & 688620 & 4.45 & 4.73 & TRN & \\
\hline CHEMBL3198548 & 688620 & 4.45 & 5.0406 & TST & \\
\hline CHEMBL1498870 & 688620 & 4.45 & 4.8711 & TRN & \\
\hline CHEMBL1484886 & 688620 & 5.9 & 5.2895 & TRN & \\
\hline CHEMBL171620 & 688620 & 4.5 & 4.8865 & TST & \\
\hline CHEMBL1368784 & 688620 & 5.35 & 4.793 & TST & \\
\hline CHEMBL1524254 & 688620 & 4.85 & 5.2594 & TRN & \\
\hline CHEMBL1603510 & 688620 & 4.75 & 4.9707 & TST & \\
\hline CHEMBL3192710 & 688620 & 5.2 & 4.9072 & TRN & \\
\hline CHEMBL1576113 & 688620 & 5.75 & 5.1972 & TST & \\
\hline CHEMBL1376365 & 688620 & 4.45 & 4.8896 & TST & \\
\hline CHEMBL1373949 & 688620 & 5.45 & 5.4183 & TRN & \\
\hline CHEMBL3198502 & 688620 & 4.95 & 5.0157 & TRN & \\
\hline CHEMBL1346258 & 688620 & 3.3 & 5.5389 & TRN & \\
\hline CHEMBL1346217 & 688620 & 4.95 & 5.2292 & TRN & \\
\hline CHEMBL1304582 & 688620 & 4.5 & 4.9742 & TRN & \\
\hline CHEMBL 2004182 & 688620 & 4.45 & 5.2112 & TRN & \\
\hline CHEMBL 2369289 & 688620 & 4.95 & 5.0388 & TRN & \\
\hline CHEMBL1375678 & 688620 & 4.55 & 5.0612 & TRN & \\
\hline CHEMBL1325354 & 688620 & 4.95 & 4.9923 & TRN & \\
\hline CHEMBL1456167 & 688620 & 4.5 & 5.1221 & TRN & \\
\hline CHEMBL1565371 & 688620 & 5.15 & 5.2618 & TST & \\
\hline CHEMBL1575217 & 688620 & 4.75 & 5.0248 & TST & \\
\hline CHEMBL1302491 & 688620 & 6.05 & 4.8876 & TRN & \\
\hline CHEMBL1431953 & 688620 & 4.95 & 4.9545 & TST & \\
\hline CHEMBL1366092 & 688620 & 4.75 & 4.8704 & TRN & \\
\hline CHEMBL1964407 & 688620 & 4.95 & 4.8607 & TST & \\
\hline CHEMBL1463157 & 688620 & 8.0 & 5.1395 & TRN & \\
\hline CHEMBL1974319 & 688620 & 4.6 & 5.0176 & TST & \\
\hline CHEMBL1529322 & 688620 & 4.9 & 5.1004 & TRN & \\
\hline CHEMBL3213480 & 688620 & 4.7 & 4.8325 & TRN & \\
\hline CHEMBL1582006 & 688620 & 4.95 & 5.1358 & TRN & \\
\hline CHEMBL1299791 & 688620 & 4.75 & 5.4895 & TST & \\
\hline CHEMBL1458776 & 688620 & 4.85 & 4.7869 & TRN & \\
\hline CHEMBL1372330 & 688620 & 6.0 & 4.8602 & TRN & \\
\hline CHEMBL1490579 & 688620 & 6.05 & 5.2208 & TRN & \\
\hline CHEMBL3194978 & 688620 & 5.0 & 4.7855 & TRN & \\
\hline CHEMBL1427132 & 688620 & 4.95 & 4.9001 & TRN & \\
\hline CHEMBL1438089 & 688620 & 6.3 & 5.159 & TRN & \\
\hline CHEMBL1381562 & 688620 & 6.6499 & 5.0084 & TRN & \\
\hline CHEMBL1532718 & 688620 & 4.95 & 4.9162 & TRN & \\
\hline CHEMBL1503208 & 688620 & 5.2 & 5.3066 & TRN & \\
\hline
\end{tabular}




\begin{tabular}{|c|c|c|c|c|c|}
\hline \multicolumn{6}{|c|}{ Supplemental Table S2.txt } \\
\hline CHEMBL1425314 & 688620 & 5.45 & 5.1033 & TST & \\
\hline CHEMBL1573079 & 688620 & 4.45 & 5.0654 & TRN & \\
\hline CHEMBL1386256 & 688620 & 4.45 & 4.792 & TRN & \\
\hline CHEMBL 3199868 & 688620 & 6.1 & 5.5824 & TRN & \\
\hline CHEMBL1599533 & 688620 & 4.65 & 5.0407 & TRN & \\
\hline CHEMBL3194733 & 688620 & 4.45 & 4.8352 & TRN & \\
\hline CHEMBL1367580 & 688620 & 5.05 & 4.9325 & TST & \\
\hline CHEMBL3190612 & 688620 & 5.2 & 5.29899 & 99999999995 & TRN \\
\hline CHEMBL1498663 & 688620 & 4.9 & 5.1037 & TRN & \\
\hline CHEMBL1384396 & 688620 & 4.7 & 5.275 & TRN & \\
\hline CHEMBL1304799 & 688620 & 5.0 & 4.7465 & TST & \\
\hline CHEMBL1479316 & 688620 & 6.0 & 5.8507 & TRN & \\
\hline CHEMBL1469430 & 688620 & 4.45 & 5.2152 & TST & \\
\hline CHEMBL1338344 & 688620 & 4.45 & 5.0238 & TST & \\
\hline CHEMBL1393265 & 688620 & 6.2 & 5.0952 & TST & \\
\hline CHEMBL1530791 & 688620 & 6.5501 & 5.0545 & TST & \\
\hline CHEMBL1453678 & 688620 & 4.65 & 4.8519 & TRN & \\
\hline CHEMBL1312243 & 688620 & 4.8 & 4.8358 & TRN & \\
\hline CHEMBL1343285 & 688620 & 5.8 & 5.041 & TRN & \\
\hline CHEMBL1352296 & 688620 & 6.25 & 5.1293 & TST & \\
\hline CHEMBL1426651 & 688620 & 4.45 & 5.0226 & TRN & \\
\hline CHEMBL3189182 & 688620 & 5.0 & 5.0724 & TRN & \\
\hline CHEMBL1384045 & 688620 & 5.45 & 4.863 & TRN & \\
\hline CHEMBL1607628 & 688620 & 5.4 & 5.035 & TRN & \\
\hline CHEMBL1329724 & 688620 & 5.2 & 5.05699 & 99999999995 & TST \\
\hline CHEMBL1392009 & 688620 & 5.75 & 5.5447 & TRN & \\
\hline CHEMBL1573482 & 688620 & 4.75 & 4.9925 & TRN & \\
\hline CHEMBL 2004880 & 688620 & 4.65 & 5.0353 & TST & \\
\hline CHEMBL1528267 & 688620 & 5.25 & 5.1041 & TST & \\
\hline CHEMBL1446788 & 688620 & 5.35 & 5.4426 & TRN & \\
\hline CHEMBL1428259 & 688620 & 5.25 & 4.7904 & TRN & \\
\hline CHEMBL1380402 & 688620 & 4.9 & 4.9739 & TRN & \\
\hline CHEMBL1547617 & 688620 & 4.7 & 4.9678 & TRN & \\
\hline CHEMBL3198307 & 688620 & 5.0 & 4.8531 & TRN & \\
\hline CHEMBL1456530 & 688620 & 4.95 & 4.6898 & TST & \\
\hline CHEMBL1517564 & 688620 & 5.35 & 5.6795 & TRN & \\
\hline CHEMBL1472175 & 688620 & 4.7 & 4.957 & TRN & \\
\hline CHEMBL602363 & 688620 & 5.65 & 5.4203 & TST & \\
\hline CHEMBL1376609 & 688620 & 4.95 & 4.8628 & TST & \\
\hline CHEMBL1497095 & 688620 & 6.3 & 5.069 & TRN & \\
\hline CHEMBL1462997 & 688620 & 4.8 & 4.94300 & 00000000005 & TST \\
\hline CHEMBL1502894 & 688620 & 4.65 & 4.9731 & TST & \\
\hline CHEMBL1416350 & 688620 & 4.9 & 4.6509 & TRN & \\
\hline CHEMBL1386045 & 688620 & 4.75 & 5.0429 & TRN & \\
\hline CHEMBL1488204 & 688620 & 5.0 & 5.3094 & TRN & \\
\hline CHEMBL1382207 & 688620 & 6.0 & 4.8861 & TRN & \\
\hline CHEMBL1506739 & 688620 & 4.85 & 4.9441 & TRN & \\
\hline CHEMBL3198316 & 688620 & 4.45 & 4.9692 & TRN & \\
\hline
\end{tabular}




\begin{tabular}{|c|c|c|c|c|}
\hline \multicolumn{5}{|c|}{ Supplemental Table S2.txt } \\
\hline CHEMBL3208353 & 688620 & 4.45 & 5.0165 & TST \\
\hline CHEMBL1340678 & 688620 & 6.0 & 5.6327 & TRN \\
\hline CHEMBL 2000025 & 688620 & 5.75 & 5.6194 & TRN \\
\hline CHEMBL1428096 & 688620 & 4.45 & 4.8225 & TRN \\
\hline CHEMBL3192328 & 688620 & 6.35 & 5.6852 & TRN \\
\hline CHEMBL1541201 & 688620 & 4.75 & 5.0041 & TST \\
\hline CHEMBL1349559 & 688620 & 5.0 & 5.11 & TRN \\
\hline CHEMBL213896 & 688620 & 5.35 & 4.8998 & TRN \\
\hline CHEMBL1606328 & 688620 & 6.0 & 5.2152 & TRN \\
\hline CHEMBL3192186 & 688620 & 4.95 & 5.096 & TRN \\
\hline CHEMBL1346828 & 688620 & 4.45 & 5.1258 & TRN \\
\hline CHEMBL1401170 & 688620 & 5.2 & 5.2896 & TRN \\
\hline CHEMBL1522764 & 688620 & 4.9 & 5.0015 & TST \\
\hline CHEMBL3190012 & 688620 & 6.0 & 5.6712 & TRN \\
\hline CHEMBL1487563 & 688620 & 4.45 & 4.7464 & TRN \\
\hline CHEMBL1359193 & 688620 & 4.75 & 5.2066 & TRN \\
\hline CHEMBL1579151 & 688620 & 4.75 & 5.0607 & TRN \\
\hline CHEMBL 3210057 & 688620 & 5.3 & 4.9896 & TRN \\
\hline CHEMBL1584136 & 688620 & 4.95 & 5.0847 & TST \\
\hline CHEMBL3189719 & 688620 & 5.0 & 4.9015 & TRN \\
\hline CHEMBL1544109 & 688620 & 4.95 & 4.8666 & TRN \\
\hline CHEMBL1990772 & 688620 & 5.5 & 5.3603 & TRN \\
\hline CHEMBL1423270 & 688620 & 5.0 & 5.1143 & TRN \\
\hline CHEMBL1571121 & 688620 & 4.85 & 4.716 & TST \\
\hline CHEMBL1385853 & 688620 & 5.0 & 5.0369 & TRN \\
\hline CHEMBL1348131 & 688620 & 4.6 & 5.2508 & TRN \\
\hline CHEMBL1465787 & 688620 & 5.05 & 5.0915 & TRN \\
\hline CHEMBL1491461 & 688620 & 5.05 & 5.0196 & TST \\
\hline CHEMBL1418440 & 688620 & 4.75 & 4.9582 & TRN \\
\hline CHEMBL1530139 & 688620 & 4.8 & 4.834 & TRN \\
\hline CHEMBL1986151 & 688620 & 5.75 & 5.5852 & TRN \\
\hline CHEMBL1359639 & 688620 & 5.25 & 5.0546 & TRN \\
\hline CHEMBL1489054 & 688620 & 4.45 & 5.1183 & TRN \\
\hline CHEMBL3191180 & 688620 & 4.7 & 5.0781 & TRN \\
\hline CHEMBL1993778 & 688620 & 5.2 & 5.4958 & TST \\
\hline CHEMBL1332931 & 688620 & 4.95 & 4.9626 & TRN \\
\hline CHEMBL1978063 & 688620 & 5.05 & 5.3645 & TRN \\
\hline CHEMBL1405264 & 688620 & 5.85 & 5.1358 & TRN \\
\hline CHEMBL1604017 & 688620 & 4.75 & 5.0792 & TST \\
\hline CHEMBL1546912 & 688620 & 4.95 & 4.9756 & TRN \\
\hline CHEMBL1423317 & 688620 & 6.15 & 6.1617 & TRN \\
\hline CHEMBL1374918 & 688620 & 4.8 & 5.1875 & TRN \\
\hline CHEMBL1577720 & 688620 & 4.9 & 5.0951 & TST \\
\hline CHEMBL1335216 & 688620 & 5.0 & 4.8023 & TST \\
\hline CHEMBL1570213 & 688620 & 4.8 & 5.1132 & TRN \\
\hline CHEMBL1353427 & 688620 & 6.15 & 5.5064 & TST \\
\hline CHEMBL3194563 & 688620 & 6.5501 & 6.1653 & TRN \\
\hline CHEMBL1391094 & 688620 & 5.15 & 5.2384 & TRN \\
\hline
\end{tabular}




\begin{tabular}{|c|c|c|c|c|c|}
\hline \\
\hline CHEMBL1600937 & 688620 & 4.8 & 4.8053 & TRN & \\
\hline CHEMBL1541779 & 688620 & 5.0 & 5.0964 & TRN & \\
\hline CHEMBL1412730 & 688620 & 5.7 & 4.9889 & TRN & \\
\hline CHEMBL1604930 & 688620 & 4.85 & 4.8129 & TRN & \\
\hline CHEMBL1499205 & 688620 & 5.35 & 5.0954 & TRN & \\
\hline CHEMBL1335492 & 688620 & 6.4 & 5.2677 & TST & \\
\hline CHEMBL1471643 & 688620 & 4.45 & 5.1514 & TST & \\
\hline CHEMBL1372475 & 688620 & 6.2 & 5.1749 & TST & \\
\hline CHEMBL1530379 & 688620 & 5.1 & 5.2939 & TRN & \\
\hline CHEMBL3195437 & 688620 & 6.25 & 5.9472 & TRN & \\
\hline CHEMBL1402442 & 688620 & 4.9 & 5.1214 & TRN & \\
\hline CHEMBL1325593 & 688620 & 5.45 & 5.2118 & TRN & \\
\hline CHEMBL1384432 & 688620 & 5.0 & 5.2106 & TST & \\
\hline CHEMBL1579509 & 688620 & 5.5 & 4.8237 & TST & \\
\hline CHEMBL1582930 & 688620 & 5.35 & 4.9433 & TST & \\
\hline CHEMBL1482153 & 688620 & 5.85 & 5.2527 & TST & \\
\hline CHEMBL1366809 & 688620 & 4.9 & 4.9961 & TRN & \\
\hline CHEMBL1602907 & 688620 & 5.15 & 4.9581 & TRN & \\
\hline CHEMBL1400580 & 688620 & 5.05 & 5.1064 & TRN & \\
\hline CHEMBL1606232 & 688620 & 5.55 & 5.4524 & TRN & \\
\hline CHEMBL1565379 & 688620 & 4.5 & 4.8202 & TRN & \\
\hline CHEMBL1339082 & 688620 & 4.45 & 4.9542 & TRN & \\
\hline CHEMBL1565267 & 688620 & 5.35 & 4.9939 & TST & \\
\hline CHEMBL1382833 & 688620 & 5.0 & 4.9579 & TRN & \\
\hline CHEMBL1441816 & 688620 & 4.65 & 5.1391 & TST & \\
\hline CHEMBL1589513 & 688620 & 4.45 & 5.1142 & TST & \\
\hline CHEMBL1443399 & 688620 & 5.3 & 5.1536 & TST & \\
\hline CHEMBL1380541 & 688620 & 4.45 & 4.84399 & 9999999999 & TRN \\
\hline CHEMBL1582450 & 688620 & 4.65 & 4.9944 & TRN & \\
\hline CHEMBL1589665 & 688620 & 5.35 & 5.2079 & TRN & \\
\hline CHEMBL1511140 & 688620 & 6.05 & 4.8869 & TST & \\
\hline CHEMBL1337989 & 688620 & 5.3 & 4.8493 & TST & \\
\hline CHEMBL1965045 & 688620 & 5.25 & 5.2613 & TRN & \\
\hline CHEMBL3199724 & 688620 & 5.55 & 5.4528 & TRN & \\
\hline CHEMBL1383664 & 688620 & 5.35 & 5.0682 & TST & \\
\hline CHEMBL1456511 & 688620 & 4.7 & 4.9341 & TRN & \\
\hline CHEMBL1343515 & 688620 & 5.3 & 4.9209 & TST & \\
\hline CHEMBL1389750 & 688620 & 4.95 & 5.0585 & TST & \\
\hline CHEMBL1412697 & 688620 & 5.1 & 5.1063 & TRN & \\
\hline CHEMBL1443687 & 688620 & 4.65 & 4.8188 & TRN & \\
\hline CHEMBL1384058 & 688620 & 4.45 & 4.9778 & TRN & \\
\hline CHEMBL1603565 & 688620 & 5.0 & 5.091 & TRN & \\
\hline CHEMBL1536919 & 688620 & 4.75 & 4.9951 & TRN & \\
\hline CHEMBL1382951 & 688620 & 5.5 & 5.1288 & TRN & \\
\hline CHEMBL1529740 & 688620 & 4.85 & 4.8793 & TRN & \\
\hline CHEMBL1438265 & 688620 & 4.65 & 5.0768 & TRN & \\
\hline CHEMBL1586492 & 688620 & 5.5 & 5.4299 & TRN & \\
\hline CHEMBL1548089 & 688620 & 5.0 & 4.7932 & TRN & \\
\hline & & & & 27346 & \\
\hline
\end{tabular}




\begin{tabular}{|c|c|c|c|c|}
\hline \multicolumn{5}{|c|}{ Supplemental Table S2.txt } \\
\hline CHEMBL1438308 & 688620 & 4.45 & 4.995 & TST \\
\hline CHEMBL1966751 & 688620 & 4.9 & 4.8873 & TST \\
\hline CHEMBL1450606 & 688620 & 6.1 & 5.107 & TRN \\
\hline CHEMBL1490777 & 688620 & 5.1 & 4.9725 & TST \\
\hline CHEMBL1597798 & 688620 & 4.8 & 4.9855 & TST \\
\hline CHEMBL1311191 & 688620 & 5.1 & 4.9781 & TRN \\
\hline CHEMBL3199945 & 688620 & 6.0 & 5.1856 & TRN \\
\hline CHEMBL1424743 & 688620 & 6.5501 & 5.1918 & TST \\
\hline CHEMBL1991234 & 688620 & 5.85 & 5.0795 & TRN \\
\hline CHEMBL256835 & 688620 & 4.65 & 5.15600 & 0000000001 \\
\hline CHEMBL1968781 & 688620 & 4.9 & 4.8076 & TRN \\
\hline CHEMBL429023 & 688620 & 6.0 & 5.9004 & TRN \\
\hline CHEMBL1589921 & 688620 & 5.8 & 5.3912 & TST \\
\hline CHEMBL1470694 & 688620 & 4.45 & 5.0573 & TRN \\
\hline CHEMBL3194973 & 688620 & 5.0 & 5.1426 & TRN \\
\hline CHEMBL3196385 & 688620 & 4.5 & 4.9662 & TRN \\
\hline CHEMBL1449119 & 688620 & 5.6 & 5.2434 & TRN \\
\hline CHEMBL1380817 & 688620 & 4.9 & 5.0311 & TRN \\
\hline CHEMBL1301722 & 688620 & 6.0 & 5.7773 & TST \\
\hline CHEMBL1325794 & 688620 & 4.5 & 5.318 & TST \\
\hline CHEMBL1519454 & 688620 & 6.7501 & 5.7326 & TST \\
\hline CHEMBL1449618 & 688620 & 6.45 & 5.0522 & TRN \\
\hline CHEMBL1551854 & 688620 & 4.95 & 5.2971 & TRN \\
\hline CHEMBL3199338 & 688620 & 5.45 & 5.1938 & TST \\
\hline CHEMBL1464538 & 688620 & 5.4 & 4.9291 & TRN \\
\hline CHEMBL1318114 & 688620 & 4.8 & 4.7892 & TRN \\
\hline CHEMBL1546946 & 688620 & 5.1 & 5.3808 & TRN \\
\hline CHEMBL1572219 & 688620 & 5.2 & 4.7775 & TRN \\
\hline CHEMBL1410394 & 688620 & 4.95 & 5.2447 & TRN \\
\hline CHEMBL1377169 & 688620 & 6.7001 & 5.0262 & TST \\
\hline CHEMBL1531899 & 688620 & 4.85 & 4.9966 & TRN \\
\hline CHEMBL1365179 & 688620 & 5.5 & 5.2032 & TRN \\
\hline CHEMBL1544448 & 688620 & 5.5 & 5.016 & TRN \\
\hline CHEMBL1360235 & 688620 & 5.0 & 5.1354 & TRN \\
\hline CHEMBL3197958 & 688620 & 5.4 & 5.2825 & TRN \\
\hline CHEMBL1517441 & 688620 & 5.2 & 5.1553 & TRN \\
\hline CHEMBL1347018 & 688620 & 4.95 & 5.091 & TRN \\
\hline CHEMBL1498273 & 688620 & 5.85 & 6.2365 & TRN \\
\hline CHEMBL1371568 & 688620 & 4.8 & 4.7508 & TRN \\
\hline CHEMBL1409229 & 688620 & 5.45 & 5.2034 & TRN \\
\hline CHEMBL3208036 & 688620 & 5.0 & 5.0981 & TRN \\
\hline CHEMBL1301911 & 688620 & 4.45 & 4.9914 & TRN \\
\hline CHEMBL1393709 & 688620 & 8.2007 & 5.185 & TRN \\
\hline CHEMBL1384893 & 688620 & 4.45 & 4.979 & TRN \\
\hline CHEMBL1529724 & 688620 & 5.05 & 5.1287 & TRN \\
\hline CHEMBL1483345 & 688620 & 4.55 & 5.1382 & TST \\
\hline CHEMBL1469012 & 688620 & 5.05 & 5.12 & TRN \\
\hline CHEMBL1588104 & 688620 & 4.45 & 4.97 & TST \\
\hline
\end{tabular}




\begin{tabular}{|c|c|c|c|c|c|}
\hline \multirow{2}{*}{ CHEMBL1335254 } & \multirow{2}{*}{688620} & \multirow{2}{*}{4.5} & \\
\hline & & & 4.9158 & \multicolumn{2}{|l|}{ TRN } \\
\hline CHEMBL1543734 & 688620 & 5.5 & 5.6835 & \multicolumn{2}{|l|}{ TRN } \\
\hline CHEMBL3198419 & 688620 & 6.0 & 5.7905 & \multicolumn{2}{|l|}{ TRN } \\
\hline CHEMBL1444351 & 688620 & 4.9 & 4.9907 & \multicolumn{2}{|l|}{ TST } \\
\hline CHEMBL1332139 & 688620 & 5.4 & 5.3927 & \multicolumn{2}{|l|}{ TRN } \\
\hline CHEMBL1419159 & 688620 & 4.45 & 4.8308 & \multicolumn{2}{|l|}{ TST } \\
\hline CHEMBL1530571 & 688620 & 6.2 & 5.6782 & \multicolumn{2}{|l|}{ TRN } \\
\hline CHEMBL1406594 & 688620 & 4.95 & 5.0612 & \multicolumn{2}{|l|}{ TRN } \\
\hline CHEMBL1303332 & 688620 & 4.9 & 4.945 & \multicolumn{2}{|l|}{ TRN } \\
\hline CHEMBL3211039 & 688620 & 5.05 & 5.2385 & \multicolumn{2}{|l|}{ TST } \\
\hline CHEMBL1424062 & 688620 & 5.05 & 5.146 & \multicolumn{2}{|l|}{ TRN } \\
\hline CHEMBL1491586 & 688620 & 4.45 & 4.9738 & \multicolumn{2}{|l|}{ TST } \\
\hline CHEMBL1388489 & 688620 & 4.7 & 5.1772 & \multicolumn{2}{|l|}{ TRN } \\
\hline CHEMBL1372464 & 688620 & 5.45 & 5.1727 & \multicolumn{2}{|l|}{ TRN } \\
\hline CHEMBL1456625 & 688620 & 4.9 & 5.0075 & \multicolumn{2}{|l|}{ TRN } \\
\hline CHEMBL1461688 & 688620 & 4.45 & 5.0701 & \multicolumn{2}{|l|}{ TST } \\
\hline CHEMBL 2003794 & 688620 & 4.95 & 5.6146 & \multicolumn{2}{|l|}{ TRN } \\
\hline CHEMBL1548000 & 688620 & 4.9 & 5.0809 & TRN & \\
\hline CHEMBL1393685 & 688620 & 4.9 & 4.8993 & TRN & \\
\hline CHEMBL1355307 & 688620 & 5.0 & 4.8661 & TRN & \\
\hline CHEMBL1358782 & 688620 & 4.45 & 4.7283 & TRN & \\
\hline CHEMBL1304060 & 688620 & 4.5 & 4.8582 & TST & \\
\hline CHEMBL1438346 & 688620 & 5.05 & 5.2174 & TRN & \\
\hline CHEMBL1521936 & 688620 & 5.3 & 5.1141 & TRN & \\
\hline CHEMBL3199186 & 688620 & 5.65 & 5.4981 & TRN & \\
\hline CHEMBL1362253 & 688620 & 4.85 & 4.6789 & TRN & \\
\hline CHEMBL1477487 & 688620 & 4.45 & 4.9052 & TST & \\
\hline CHEMBL1558525 & 688620 & 6.4 & 5.056 & TRN & \\
\hline CHEMBL1458453 & 688620 & 5.15 & 5.1087 & TRN & \\
\hline CHEMBL1309561 & 688620 & 4.45 & 4.8685 & TRN & \\
\hline CHEMBL1524081 & 688620 & 4.45 & 5.0477 & TRN & \\
\hline CHEMBL334707 & 688620 & 5.55 & 5.4623 & TRN & \\
\hline CHEMBL1470314 & 688620 & 4.85 & 4.9415 & TST & \\
\hline CHEMBL1340639 & 688620 & 5.3 & 5.5287 & TST & \\
\hline CHEMBL3191556 & 688620 & 5.6 & 5.4547 & TST & \\
\hline CHEMBL1382905 & 688620 & 4.95 & 4.9558 & TRN & \\
\hline CHEMBL1967821 & 688620 & 5.55 & 5.3469 & TRN & \\
\hline CHEMBL1384060 & 688620 & 4.95 & 5.1573 & TST & \\
\hline CHEMBL1977301 & 688620 & 5.4 & 5.5219 & TRN & \\
\hline CHEMBL1409800 & 688620 & 4.45 & 4.841 & TRN & \\
\hline CHEMBL1452645 & 688620 & 5.0 & 4.9702 & TST & \\
\hline CHEMBL1519613 & 688620 & 4.45 & 4.8182 & TRN & \\
\hline CHEMBL1537709 & 688620 & 4.7 & 4.8767 & TRN & \\
\hline CHEMBL1412916 & 688620 & 5.65 & 4.9781 & TRN & \\
\hline CHEMBL1401424 & 688620 & 4.65 & 6.1377 & TRN & \\
\hline CHEMBL1341674 & 688620 & 4.95 & 5.2727 & TST & \\
\hline CHEMBL1499556 & 688620 & 4.85 & 5.03600 & 00000000005 & TRN \\
\hline CHEMBL1496706 & 688620 & 4.9 & 4.9951 & TRN & \\
\hline & & & & 27348 & \\
\hline
\end{tabular}




\begin{tabular}{|c|c|c|c|c|c|}
\hline & & \multicolumn{4}{|c|}{ Supplemental Table S2.txt } \\
\hline CHEMBL3198012 & 688620 & 5.15 & 5.1278 & TRN & \\
\hline CHEMBL260148 & 688620 & 5.35 & 5.2582 & TRN & \\
\hline CHEMBL1302838 & 688620 & 4.45 & 5.0745 & TST & \\
\hline CHEMBL3196315 & 688620 & 6.25 & 5.3934 & TRN & \\
\hline CHEMBL1319307 & 688620 & 4.45 & 5.0311 & TRN & \\
\hline CHEMBL1602799 & 688620 & 4.8 & 4.8132 & TRN & \\
\hline CHEMBL1487973 & 688620 & 4.55 & 4.952 & TRN & \\
\hline CHEMBL1384528 & 688620 & 4.95 & 5.2792 & TRN & \\
\hline CHEMBL1450665 & 688620 & 6.05 & 5.48799 & 99999999995 & TRN \\
\hline CHEMBL3193305 & 688620 & 5.9 & 5.76 & TRN & \\
\hline CHEMBL1343720 & 688620 & 4.95 & 5.0193 & TRN & \\
\hline CHEMBL1460705 & 688620 & 6.1 & 5.6285 & TRN & \\
\hline CHEMBL1398247 & 688620 & 4.8 & 4.9343 & TRN & \\
\hline CHEMBL1543962 & 688620 & 5.9 & 5.7715 & TRN & \\
\hline CHEMBL1372472 & 688620 & 4.7 & 5.1069 & TST & \\
\hline CHEMBL1390171 & 688620 & 5.2 & 5.0236 & TRN & \\
\hline CHEMBL1549283 & 688620 & 4.55 & 5.0598 & TRN & \\
\hline CHEMBL1340811 & 688620 & 5.7 & 5.0884 & TRN & \\
\hline CHEMBL1440720 & 688620 & 5.1 & 4.8738 & TRN & \\
\hline CHEMBL1585485 & 688620 & 5.2 & 4.9885 & TRN & \\
\hline CHEMBL1528382 & 688620 & 4.5 & 5.0016 & TST & \\
\hline CHEMBL1461497 & 688620 & 4.9 & 4.9854 & TST & \\
\hline CHEMBL1480547 & 688620 & 4.95 & 5.2049 & TRN & \\
\hline CHEMBL1548033 & 688620 & 4.8 & 4.7125 & TRN & \\
\hline CHEMBL1337331 & 688620 & 5.15 & 5.2631 & TRN & \\
\hline CHEMBL 29542 & 688620 & 4.95 & 5.1129 & TRN & \\
\hline CHEMBL1311399 & 688620 & 4.85 & 5.0594 & TRN & \\
\hline CHEMBL1496605 & 688620 & 4.85 & 4.8276 & TRN & \\
\hline CHEMBL1431228 & 688620 & 5.0 & 4.9818 & TRN & \\
\hline CHEMBL1494284 & 688620 & 5.65 & 5.974 & TRN & \\
\hline CHEMBL1412447 & 688620 & 4.8 & 4.8065 & TRN & \\
\hline CHEMBL1388469 & 688620 & 4.7 & 4.7038 & TRN & \\
\hline CHEMBL1563626 & 688620 & 5.2 & 5.0854 & TST & \\
\hline CHEMBL1567823 & 688620 & 4.6 & 4.7312 & TRN & \\
\hline CHEMBL1483889 & 688620 & 4.65 & 5.2852 & TST & \\
\hline CHEMBL1587177 & 688620 & 4.8 & 4.7952 & TRN & \\
\hline CHEMBL1418496 & 688620 & 4.5 & 4.9913 & TRN & \\
\hline CHEMBL1390941 & 688620 & 4.65 & 5.0717 & TRN & \\
\hline CHEMBL1536462 & 688620 & 4.9 & 5.002 & TRN & \\
\hline CHEMBL1359031 & 688620 & 4.7 & 4.7606 & TST & \\
\hline CHEMBL1384524 & 688620 & 6.5 & 6.6252 & TRN & \\
\hline CHEMBL1368060 & 688620 & 4.9 & 5.0444 & TRN & \\
\hline CHEMBL1582298 & 688620 & 4.7 & 5.0997 & TRN & \\
\hline CHEMBL1350167 & 688620 & 4.75 & 4.7307 & TRN & \\
\hline CHEMBL1462302 & 688620 & 4.65 & 5.17700 & 00000000005 & TRN \\
\hline CHEMBL1341816 & 688620 & 4.85 & 5.2525 & TRN & \\
\hline CHEMBL1410920 & 688620 & 4.95 & 5.0549 & TST & \\
\hline CHEMBL1331319 & 688620 & 4.95 & 4.9822 & TST & \\
\hline
\end{tabular}




\begin{tabular}{|c|c|c|c|c|c|}
\hline \multicolumn{6}{|c|}{ Supplemental Table S2.txt } \\
\hline CHEMBL1423458 & 688620 & 4.95 & 5.1748 & TRN & \\
\hline CHEMBL1428238 & 688620 & 4.75 & 5.1093 & TRN & \\
\hline CHEMBL1417763 & 688620 & 4.95 & 4.8891 & TRN & \\
\hline CHEMBL1486585 & 688620 & 5.95 & 5.6446 & TRN & \\
\hline CHEMBL 3193094 & 688620 & 5.55 & 5.6327 & TRN & \\
\hline CHEMBL1349475 & 688620 & 4.45 & 4.8012 & TST & \\
\hline CHEMBL1443478 & 688620 & 5.15 & 5.2177 & TRN & \\
\hline CHEMBL 2003445 & 688620 & 5.25 & 5.2525 & TRN & \\
\hline CHEMBL1494909 & 688620 & 4.75 & 4.9534 & TST & \\
\hline CHEMBL1330651 & 688620 & 6.45 & 5.1053 & TRN & \\
\hline CHEMBL1536907 & 688620 & 4.45 & 4.9219 & TST & \\
\hline CHEMBL1490792 & 688620 & 5.85 & 5.276 & TST & \\
\hline CHEMBL1546886 & 688620 & 4.75 & 4.7329 & TRN & \\
\hline CHEMBL1459374 & 688620 & 4.8 & 4.82 & TST & \\
\hline CHEMBL 3145362 & 688620 & 6.95 & 6.3072 & TRN & \\
\hline CHEMBL1338852 & 688620 & 6.0 & 5.0825 & TST & \\
\hline CHEMBL1426861 & 688620 & 5.6 & 5.45 & TRN & \\
\hline CHEMBL1568257 & 688620 & 5.0 & 4.953 & TST & \\
\hline CHEMBL1416413 & 688620 & 4.95 & 5.2172 & TRN & \\
\hline CHEMBL1438373 & 688620 & 4.7 & 5.1946 & TST & \\
\hline CHEMBL1364690 & 688620 & 4.75 & 5.1442 & TST & \\
\hline CHEMBL1609957 & 688620 & 4.6 & 5.3572 & TRN & \\
\hline CHEMBL1560356 & 688620 & 5.2 & 5.0341 & TRN & \\
\hline CHEMBL1399398 & 688620 & 4.55 & 5.2233 & TRN & \\
\hline CHEMBL1550547 & 688620 & 4.45 & 4.8009 & TRN & \\
\hline CHEMBL1370840 & 688620 & 5.35 & 5.0355 & TRN & \\
\hline CHEMBL3193102 & 688620 & 4.9 & 5.0888 & TRN & \\
\hline CHEMBL1582744 & 688620 & 4.85 & 5.2623 & TRN & \\
\hline CHEMBL3189563 & 688620 & 6.2 & 5.6129 & TRN & \\
\hline CHEMBL1371260 & 688620 & 4.7 & 4.9772 & TST & \\
\hline CHEMBL1563487 & 688620 & 4.65 & 5.2567 & TST & \\
\hline CHEMBL1437813 & 688620 & 4.95 & 5.0877 & TRN & \\
\hline CHEMBL1303704 & 688620 & 4.65 & 5.21899 & & TRN \\
\hline CHEMBL1417608 & 688620 & 5.15 & 5.2278 & TRN & \\
\hline CHEMBL1366463 & 688620 & 4.45 & 4.6638 & TRN & \\
\hline CHEMBL1499858 & 688620 & 4.9 & 4.9652 & TRN & \\
\hline CHEMBL1340698 & 688620 & 6.1 & 6.1961 & TRN & \\
\hline CHEMBL1357130 & 688620 & 4.85 & 5.2159 & TST & \\
\hline CHEMBL1372288 & 688620 & 5.0 & 4.9726 & TRN & \\
\hline CHEMBL1604783 & 688620 & 5.3 & 5.1038 & TRN & \\
\hline CHEMBL1329129 & 688620 & 4.9 & 5.5141 & TRN & \\
\hline CHEMBL1307406 & 688620 & 4.85 & 5.1605 & TRN & \\
\hline CHEMBL256366 & 688620 & 6.7501 & 4.9839 & TST & \\
\hline CHEMBL1489117 & 688620 & 4.45 & 5.0659 & TST & \\
\hline CHEMBL1351380 & 688620 & 4.7 & 5.1574 & TRN & \\
\hline CHEMBL1303754 & 688620 & 4.85 & 4.9421 & TRN & \\
\hline CHEMBL3193671 & 688620 & 5.85 & 5.7867 & TRN & \\
\hline CHEMBL1495939 & 688620 & 4.45 & 4.8381 & TST & \\
\hline
\end{tabular}




\begin{tabular}{|c|c|c|c|c|c|}
\hline \multicolumn{6}{|c|}{ Supplemental Table S2.txt } \\
\hline CHEMBL1440503 & 688620 & 5.0 & 4.957 & TST & \\
\hline CHEMBL1502834 & 688620 & 4.45 & 4.8914 & TRN & \\
\hline CHEMBL1585681 & 688620 & 5.45 & 5.09399 & 9999999999 & TRN \\
\hline CHEMBL1414127 & 688620 & 5.15 & 5.1119 & TST & \\
\hline CHEMBL1478806 & 688620 & 5.5 & 5.3823 & TRN & \\
\hline CHEMBL1383285 & 688620 & 6.05 & 5.2042 & TRN & \\
\hline CHEMBL3192216 & 688620 & 6.05 & 5.0187 & TRN & \\
\hline CHEMBL1511121 & 688620 & 4.5 & 5.0642 & TRN & \\
\hline CHEMBL1458579 & 688620 & 4.7 & 4.9837 & TRN & \\
\hline CHEMBL1438552 & 688620 & 4.9 & 4.9122 & TRN & \\
\hline CHEMBL1488422 & 688620 & 4.8 & 4.8927 & TST & \\
\hline CHEMBL1352435 & 688620 & 4.65 & 4.7005 & TRN & \\
\hline CHEMBL1709028 & 688620 & 6.05 & 5.8044 & TRN & \\
\hline CHEMBL1380868 & 688620 & 6.4 & 5.0546 & TRN & \\
\hline CHEMBL1442855 & 688620 & 5.2 & 5.0511 & TRN & \\
\hline CHEMBL1612914 & 688620 & 4.75 & 4.9841 & TRN & \\
\hline CHEMBL1389101 & 688620 & 5.25 & 4.9445 & TST & \\
\hline CHEMBL1364801 & 688620 & 6.5501 & 5.6334 & TST & \\
\hline CHEMBL1570797 & 688620 & 4.6 & 4.6067 & TRN & \\
\hline CHEMBL1326742 & 688620 & 4.9 & 5.1948 & TRN & \\
\hline CHEMBL551004 & 688620 & 4.7 & 5.2079 & TRN & \\
\hline CHEMBL1461453 & 688620 & 4.8 & 5.2539 & TST & \\
\hline CHEMBL1084441 & 688620 & 4.9 & 4.9463 & TRN & \\
\hline CHEMBL374569 & 688620 & 4.85 & 5.4166 & TST & \\
\hline CHEMBL1389239 & 688620 & 4.75 & 5.1139 & TRN & \\
\hline CHEMBL1391270 & 688620 & 4.9 & 4.8572 & TST & \\
\hline CHEMBL1968569 & 688620 & 5.15 & 5.15799 & 99999999995 & TRN \\
\hline CHEMBL1588475 & 688620 & 4.65 & 5.2152 & TST & \\
\hline CHEMBL1611344 & 688620 & 5.2 & 5.0519 & TRN & \\
\hline CHEMBL1506510 & 688620 & 4.95 & 4.9132 & TRN & \\
\hline CHEMBL1388079 & 688620 & 6.1 & 5.36 & TRN & \\
\hline CHEMBL1416440 & 688620 & 4.75 & 4.9406 & TST & \\
\hline CHEMBL1462422 & 688620 & 4.45 & 5.059 & TRN & \\
\hline CHEMBL1363679 & 688620 & 4.45 & 5.2196 & TRN & \\
\hline CHEMBL1536278 & 688620 & 6.0 & 5.006 & TST & \\
\hline CHEMBL1471564 & 688620 & 5.5 & 5.2332 & TRN & \\
\hline CHEMBL1379238 & 688620 & 4.75 & 5.0913 & TRN & \\
\hline CHEMBL1419256 & 688620 & 4.7 & 5.0381 & TST & \\
\hline CHEMBL1389320 & 688620 & 4.85 & 5.0508 & TRN & \\
\hline CHEMBL1415737 & 688620 & 4.45 & 4.8952 & TRN & \\
\hline CHEMBL1578739 & 688620 & 4.7 & 4.9832 & TRN & \\
\hline CHEMBL1361742 & 688620 & 5.5 & 5.5219 & TRN & \\
\hline CHEMBL1392878 & 688620 & 5.15 & 5.2894 & TST & \\
\hline CHEMBL1558160 & 688620 & 5.3 & 5.2042 & TRN & \\
\hline CHEMBL1309123 & 688620 & 5.05 & 5.2883 & TRN & \\
\hline CHEMBL3194515 & 688620 & 4.8 & 5.0617 & TRN & \\
\hline CHEMBL1543910 & 688620 & 4.5 & 5.007 & TST & \\
\hline CHEMBL1477603 & 688620 & 4.45 & 4.784 & TRN & \\
\hline
\end{tabular}




\begin{tabular}{|c|c|c|c|c|c|}
\hline \multicolumn{6}{|c|}{ plemental Table S } \\
\hline CHEMBL1450087 & 688620 & 4.95 & 5.0638 & TST & \\
\hline CHEMBL1493895 & 688620 & 5.2 & 5.42700 & 00000000005 & TRN \\
\hline CHEMBL1603614 & 688620 & 4.85 & 5.2003 & TST & \\
\hline CHEMBL1367384 & 688620 & 4.85 & 5.0275 & TRN & \\
\hline CHEMBL1351135 & 688620 & 4.8 & 5.1111 & TST & \\
\hline CHEMBL1585181 & 688620 & 5.3 & 5.1951 & TRN & \\
\hline CHEMBL1483201 & 688620 & 5.95 & 5.2637 & TST & \\
\hline CHEMBL1443784 & 688620 & 6.5501 & 6.5316 & TRN & \\
\hline CHEMBL1505604 & 688620 & 6.6499 & 5.8228 & TRN & \\
\hline CHEMBL1330919 & 688620 & 4.8 & 4.9977 & TRN & \\
\hline CHEMBL1399987 & 688620 & 5.1 & 5.0866 & TRN & \\
\hline CHEMBL1322264 & 688620 & 4.45 & 4.9088 & TRN & \\
\hline CHEMBL1302531 & 688620 & 5.45 & 5.1747 & TRN & \\
\hline CHEMBL3193429 & 688620 & 5.65 & 5.3716 & TRN & \\
\hline CHEMBL1362662 & 688620 & 4.8 & 5.0918 & TRN & \\
\hline CHEMBL1576403 & 688620 & 4.95 & 5.1814 & TRN & \\
\hline CHEMBL1599179 & 688620 & 4.45 & 5.0123 & TRN & \\
\hline CHEMBL1429064 & 688620 & 5.2 & 5.0225 & TRN & \\
\hline CHEMBL1411651 & 688620 & 5.0 & 5.0212 & TST & \\
\hline CHEMBL1420455 & 688620 & 6.1 & 4.9491 & TRN & \\
\hline CHEMBL1455599 & 688620 & 4.9 & 4.8815 & TRN & \\
\hline CHEMBL1530173 & 688620 & 4.45 & 5.0803 & TRN & \\
\hline CHEMBL3190307 & 688620 & 4.45 & 5.0911 & TRN & \\
\hline CHEMBL1420218 & 688620 & 5.9 & 4.7863 & TRN & \\
\hline CHEMBL3192545 & 688620 & 4.95 & 5.09699 & & TRN \\
\hline CHEMBL1432340 & 688620 & 4.45 & 4.9375 & TRN & \\
\hline CHEMBL1433032 & 688620 & 4.45 & 4.9907 & TST & \\
\hline CHEMBL1535810 & 688620 & 5.0 & 4.9525 & TRN & \\
\hline CHEMBL3192308 & 688620 & 4.75 & 5.1481 & TRN & \\
\hline CHEMBL1519257 & 688620 & 4.95 & 4.7097 & TRN & \\
\hline CHEMBL290426 & 688620 & 6.6 & 4.9381 & TRN & \\
\hline CHEMBL1389379 & 688620 & 4.95 & 4.9138 & TRN & \\
\hline CHEMBL3198513 & 688620 & 5.5 & 5.6963 & TRN & \\
\hline CHEMBL3189839 & 688620 & 4.45 & 4.8148 & TRN & \\
\hline CHEMBL1611695 & 688620 & 4.45 & 4.6505 & TRN & \\
\hline CHEMBL1489738 & 688620 & 5.5 & 4.9491 & TRN & \\
\hline CHEMBL1462467 & 688620 & 5.75 & 5.2674 & TRN & \\
\hline CHEMBL1450935 & 688620 & 6.45 & 5.0574 & TRN & \\
\hline CHEMBL3195635 & 688620 & 5.0 & 4.867 & TRN & \\
\hline CHEMBL1434337 & 688620 & 5.4 & 5.146 & TRN & \\
\hline CHEMBL1448732 & 688620 & 5.15 & 5.2941 & TST & \\
\hline CHEMBL1407778 & 688620 & 4.7 & 5.2932 & TRN & \\
\hline CHEMBL469664 & 688620 & 5.05 & 5.0485 & TRN & \\
\hline CHEMBL1504253 & 688620 & 5.85 & 5.8222 & TRN & \\
\hline CHEMBL1519544 & 688620 & 5.6 & 5.3937 & TRN & \\
\hline CHEMBL1504659 & 688620 & 4.75 & 4.8221 & TRN & \\
\hline CHEMBL1331549 & 688620 & 5.0 & 5.0389 & TRN & \\
\hline CHEMBL1539600 & 688620 & 4.8 & 5.1358 & TRN & \\
\hline
\end{tabular}




\begin{tabular}{|c|c|c|c|c|}
\hline \multicolumn{5}{|c|}{ Supplemental Table S2.txt } \\
\hline CHEMBL1489071 & 688620 & 6.3 & 5.8557 & TST \\
\hline CHEMBL3199344 & 688620 & 5.5 & 5.187 & TRN \\
\hline CHEMBL1529866 & 688620 & 4.95 & 4.6838 & TRN \\
\hline CHEMBL1607638 & 688620 & 4.45 & 5.0405 & TRN \\
\hline CHEMBL1454658 & 688620 & 6.0 & 4.9575 & TRN \\
\hline CHEMBL1411089 & 688620 & 4.85 & 5.2014 & TRN \\
\hline CHEMBL1304667 & 688620 & 5.35 & 4.8786 & TRN \\
\hline CHEMBL1478401 & 688620 & 4.5 & 4.8747 & TRN \\
\hline CHEMBL1430825 & 688620 & 4.5 & 4.9316 & TRN \\
\hline CHEMBL3197086 & 688620 & 4.75 & 4.9638 & TRN \\
\hline CHEMBL1364279 & 688620 & 4.8 & 5.0712 & TRN \\
\hline CHEMBL 3212507 & 688620 & 4.8 & 4.8061 & TRN \\
\hline CHEMBL3211944 & 688620 & 5.05 & 6.1954 & TRN \\
\hline CHEMBL3198805 & 688620 & 5.6 & 5.2541 & TRN \\
\hline CHEMBL1536384 & 688620 & 6.1 & 5.1846 & TRN \\
\hline CHEMBL1610937 & 688620 & 5.75 & 5.2078 & TRN \\
\hline CHEMBL1337805 & 688620 & 4.45 & 5.0651 & TRN \\
\hline CHEMBL600572 & 688620 & 5.5 & 5.3039 & TRN \\
\hline CHEMBL1432762 & 688620 & 5.25 & 4.8451 & TRN \\
\hline CHEMBL1581741 & 688620 & 4.95 & 5.1093 & TST \\
\hline CHEMBL1455227 & 688620 & 5.3 & 5.3718 & TRN \\
\hline CHEMBL1545207 & 688620 & 4.45 & 5.4769 & TRN \\
\hline CHEMBL1527183 & 688620 & 5.05 & 4.9128 & TRN \\
\hline CHEMBL1561240 & 688620 & 4.45 & 4.6362 & TRN \\
\hline CHEMBL1382452 & 688620 & 4.85 & 6.6675 & TRN \\
\hline CHEMBL1425511 & 688620 & 5.55 & 5.1086 & TST \\
\hline CHEMBL1309534 & 688620 & 6.8499 & 5.1239 & TST \\
\hline CHEMBL1326488 & 688620 & 4.45 & 4.973 & TRN \\
\hline CHEMBL1555696 & 688620 & 6.1 & 4.8331 & TRN \\
\hline CHEMBL3197214 & 688620 & 5.75 & 5.6539 & TST \\
\hline CHEMBL3195575 & 688620 & 4.75 & 4.8384 & TRN \\
\hline CHEMBL1496319 & 688620 & 4.45 & 5.0041 & TRN \\
\hline CHEMBL1392856 & 688620 & 5.5 & 5.0113 & TRN \\
\hline CHEMBL1528795 & 688620 & 4.7 & 4.7828 & TRN \\
\hline CHEMBL1391717 & 688620 & 5.45 & 4.9729 & TST \\
\hline CHEMBL1363825 & 688620 & 4.45 & 5.25 & TRN \\
\hline CHEMBL1441257 & 688620 & 4.65 & 4.9773 & TRN \\
\hline CHEMBL1482852 & 688620 & 4.45 & 4.789 & TRN \\
\hline CHEMBL1607086 & 688620 & 6.05 & 5.3483 & TRN \\
\hline CHEMBL1412167 & 688620 & 5.4 & 5.1818 & TRN \\
\hline CHEMBL1487658 & 688620 & 6.1 & 5.8781 & TRN \\
\hline CHEMBL183 & 688620 & 4.45 & 5.3069 & TST \\
\hline CHEMBL3197478 & 688620 & 5.75 & 5.6842 & TRN \\
\hline CHEMBL1414064 & 688620 & 5.3 & 5.1321 & TRN \\
\hline CHEMBL1613264 & 688620 & 5.2 & 4.8345 & TST \\
\hline CHEMBL1493829 & 688620 & 6.45 & 4.789 & TRN \\
\hline CHEMBL1566418 & 688620 & 4.6 & 5.2668 & TRN \\
\hline CHEMBL3194470 & 688620 & 5.0 & 5.2162 & TRN \\
\hline
\end{tabular}




\begin{tabular}{|c|c|c|c|c|c|}
\hline \\
\hline CHEMBL1495849 & 688620 & 5.7 & 5.7028 & TRN & \\
\hline CHEMBL1383577 & 688620 & 4.55 & 5.1373 & TRN & \\
\hline CHEMBL3194759 & 688620 & 4.9 & 5.1015 & TRN & \\
\hline CHEMBL1542881 & 688620 & 4.45 & 4.9991 & TRN & \\
\hline CHEMBL1453731 & 688620 & 5.7 & 5.6564 & TRN & \\
\hline CHEMBL1451747 & 688620 & 5.55 & 5.3285 & TRN & \\
\hline CHEMBL1305313 & 688620 & 6.45 & 5.0267 & TRN & \\
\hline CHEMBL1492432 & 688620 & 4.45 & 5.0813 & TRN & \\
\hline CHEMBL1328530 & 688620 & 4.75 & 5.12299 & 9999999999 & TST \\
\hline CHEMBL1390657 & 688620 & 4.7 & 4.9073 & TRN & \\
\hline CHEMBL1506651 & 688620 & 4.9 & 4.9437 & TRN & \\
\hline CHEMBL1608065 & 688620 & 4.65 & 4.9399 & TRN & \\
\hline CHEMBL1566953 & 688620 & 5.05 & 5.0638 & TRN & \\
\hline CHEMBL1451278 & 688620 & 5.45 & 4.8794 & TRN & \\
\hline CHEMBL3189942 & 688620 & 5.5 & 5.2552 & TST & \\
\hline CHEMBL1528666 & 688620 & 6.9 & 5.3754 & TST & \\
\hline CHEMBL1464333 & 688620 & 6.6499 & 4.9817 & TRN & \\
\hline CHEMBL1399966 & 688620 & 4.9 & 5.0102 & TRN & \\
\hline CHEMBL1412110 & 688620 & 5.15 & 5.0375 & TRN & \\
\hline CHEMBL1383353 & 688620 & 4.45 & 4.8059 & TRN & \\
\hline CHEMBL 2007318 & 688620 & 4.7 & 5.086 & TRN & \\
\hline CHEMBL1421667 & 688620 & 5.0 & 5.4782 & TRN & \\
\hline CHEMBL3189973 & 688620 & 5.05 & 5.2868 & TRN & \\
\hline CHEMBL1492872 & 688620 & 4.8 & 5.0636 & TRN & \\
\hline CHEMBL1491513 & 688620 & 4.5 & 5.0932 & TRN & \\
\hline CHEMBL1388707 & 688620 & 5.0 & 5.1882 & TRN & \\
\hline CHEMBL3198286 & 688620 & 5.35 & 5.3501 & TRN & \\
\hline CHEMBL1564254 & 688620 & 4.45 & 4.8499 & TST & \\
\hline CHEMBL1306513 & 688620 & 4.45 & 5.0526 & TRN & \\
\hline CHEMBL1486297 & 688620 & 6.1 & 5.1047 & TRN & \\
\hline CHEMBL3198847 & 688620 & 4.95 & 4.8477 & TRN & \\
\hline CHEMBL3190892 & 688620 & 4.9 & 4.96399 & 99999999995 & TRN \\
\hline CHEMBL1339247 & 688620 & 4.65 & 5.1289 & TST & \\
\hline CHEMBL1519490 & 688620 & 4.65 & 5.1254 & TST & \\
\hline CHEMBL1466789 & 688620 & 4.9 & 4.7711 & TRN & \\
\hline CHEMBL1444510 & 688620 & 5.3 & 5.011 & TST & \\
\hline CHEMBL1349108 & 688620 & 5.6 & 5.4257 & TRN & \\
\hline CHEMBL1549112 & 688620 & 4.95 & 5.271 & TST & \\
\hline CHEMBL473314 & 688620 & 6.15 & 6.0169 & TRN & \\
\hline CHEMBL1351775 & 688620 & 4.9 & 5.5051 & TRN & \\
\hline CHEMBL1344650 & 688620 & 4.9 & 5.0982 & TRN & \\
\hline CHEMBL1459538 & 688620 & 5.35 & 5.0402 & TRN & \\
\hline CHEMBL1516662 & 688620 & 4.95 & 4.8927 & TRN & \\
\hline CHEMBL3213979 & 688620 & 4.45 & 4.8756 & TST & \\
\hline CHEMBL1505977 & 688620 & 5.1 & 4.9948 & TST & \\
\hline CHEMBL1550791 & 688620 & 4.7 & 5.0167 & TRN & \\
\hline CHEMBL3211390 & 688620 & 4.45 & 5.0291 & TRN & \\
\hline CHEMBL1340433 & 688620 & 6.25 & 4.9443 & TST & \\
\hline
\end{tabular}




\begin{tabular}{|c|c|c|c|c|c|}
\hline \multicolumn{6}{|c|}{ Supplemental Table S2.txt } \\
\hline CHEMBL1313949 & 688620 & 4.45 & 4.7784 & TRN & \\
\hline CHEMBL1398780 & 688620 & 4.6 & 4.8371 & TRN & \\
\hline CHEMBL1440994 & 688620 & 5.35 & 5.0435 & TST & \\
\hline CHEMBL1342139 & 688620 & 4.95 & 5.1518 & TST & \\
\hline CHEMBL1455997 & 688620 & 4.6 & 5.2106 & TST & \\
\hline CHEMBL1395977 & 688620 & 5.1 & 5.0944 & TST & \\
\hline CHEMBL1299975 & 688620 & 4.75 & 5.1908 & TRN & \\
\hline CHEMBL1420969 & 688620 & 5.1 & 4.8807 & TRN & \\
\hline CHEMBL1381328 & 688620 & 5.95 & 5.6168 & TRN & \\
\hline CHEMBL1369263 & 688620 & 4.6 & 5.0016 & TRN & \\
\hline CHEMBL1510327 & 688620 & 5.35 & 5.1832 & TRN & \\
\hline CHEMBL1495959 & 688620 & 4.5 & 4.958 & TRN & \\
\hline CHEMBL1500450 & 688620 & 6.5501 & 4.6991 & TRN & \\
\hline CHEMBL 3193274 & 688620 & 5.6 & 5.1242 & TRN & \\
\hline CHEMBL1542492 & 688620 & 5.3 & 5.3523 & TRN & \\
\hline CHEMBL1362246 & 688620 & 5.2 & 4.8012 & TST & \\
\hline CHEMBL1548792 & 688620 & 5.25 & 5.186 & TRN & \\
\hline CHEMBL1565905 & 688620 & 5.6 & 5.2877 & TRN & \\
\hline CHEMBL1509392 & 688620 & 4.95 & 5.2558 & TRN & \\
\hline CHEMBL1422619 & 688620 & 4.65 & 5.0401 & TRN & \\
\hline CHEMBL1497479 & 688620 & 5.5 & 5.3059 & TST & \\
\hline CHEMBL 3198650 & 688620 & 5.0 & 4.9023 & TRN & \\
\hline CHEMBL1456383 & 688620 & 4.95 & 4.9866 & TRN & \\
\hline CHEMBL1371570 & 688620 & 4.45 & 4.98300 & 00000000005 & TRN \\
\hline CHEMBL1392137 & 688620 & 5.5 & 4.8787 & TRN & \\
\hline CHEMBL1439978 & 688620 & 4.65 & 4.9864 & TRN & \\
\hline CHEMBL1415103 & 688620 & 4.45 & 5.1622 & TRN & \\
\hline CHEMBL1335085 & 688620 & 4.45 & 5.0637 & TRN & \\
\hline CHEMBL1350809 & 688620 & 4.85 & 5.0525 & TRN & \\
\hline CHEMBL1364655 & 688620 & 4.5 & 4.9354 & TRN & \\
\hline CHEMBL1301359 & 688620 & 4.9 & 4.981 & TRN & \\
\hline CHEMBL1531896 & 688620 & 4.7 & 5.0612 & TST & \\
\hline CHEMBL1550247 & 688620 & 4.45 & 5.1112 & TRN & \\
\hline CHEMBL1501111 & 688620 & 4.95 & 5.0243 & TRN & \\
\hline CHEMBL1370856 & 688620 & 4.55 & 5.2235 & TST & \\
\hline CHEMBL1377743 & 688620 & 5.0 & 5.0489 & TST & \\
\hline CHEMBL1362818 & 688620 & 5.2 & 5.1059 & TRN & \\
\hline CHEMBL1367791 & 688620 & 5.4 & 5.593 & TST & \\
\hline CHEMBL1362524 & 688620 & 4.45 & 4.7876 & TRN & \\
\hline CHEMBL1588352 & 688620 & 4.95 & 5.1967 & TRN & \\
\hline CHEMBL1467760 & 688620 & 4.9 & 5.2332 & TST & \\
\hline CHEMBL1572436 & 688620 & 4.85 & 5.1576 & TRN & \\
\hline CHEMBL1573366 & 688620 & 5.6 & 5.4662 & TRN & \\
\hline CHEMBL1353885 & 688620 & 6.05 & 5.7848 & TRN & \\
\hline CHEMBL1523456 & 688620 & 5.0 & 4.914 & TRN & \\
\hline CHEMBL1531146 & 688620 & 4.9 & 5.336 & TRN & \\
\hline CHEMBL447620 & 688620 & 5.4 & 5.3822 & TRN & \\
\hline CHEMBL3392389 & 688620 & 4.95 & 6.4233 & TST & \\
\hline
\end{tabular}




\begin{tabular}{|c|c|c|c|c|}
\hline \multicolumn{5}{|c|}{ Supplemental Table S2.txt } \\
\hline CHEMBL1587416 & 688620 & 4.65 & 4.9324 & TRN \\
\hline CHEMBL1427537 & 688620 & 4.75 & 4.9574 & TRN \\
\hline CHEMBL1600919 & 688620 & 5.5 & 5.3796 & TRN \\
\hline CHEMBL1314088 & 688620 & 6.7001 & 5.2536 & TRN \\
\hline CHEMBL3197731 & 688620 & 6.2 & 6.0239 & TRN \\
\hline CHEMBL1387022 & 688620 & 4.8 & 5.228 & TRN \\
\hline CHEMBL1377903 & 688620 & 5.15 & 5.2333 & TST \\
\hline CHEMBL1316462 & 688620 & 4.9 & 5.2373 & TRN \\
\hline CHEMBL1520494 & 688620 & 4.9 & 4.8119 & TRN \\
\hline CHEMBL3925157 & 688620 & 5.8 & 4.7233 & TRN \\
\hline CHEMBL1458484 & 688620 & 5.0 & 5.1093 & TRN \\
\hline CHEMBL1569650 & 688620 & 4.45 & 4.8889 & TRN \\
\hline CHEMBL1576706 & 688620 & 4.45 & 4.9351 & TRN \\
\hline CHEMBL1375740 & 688620 & 6.15 & 5.66 & TRN \\
\hline CHEMBL1372760 & 688620 & 5.45 & 5.2134 & TRN \\
\hline CHEMBL1331847 & 688620 & 4.45 & 5.0862 & TRN \\
\hline CHEMBL3192393 & 688620 & 4.45 & 4.8151 & TRN \\
\hline CHEMBL1572167 & 688620 & 5.05 & 4.8091 & TRN \\
\hline CHEMBL1378333 & 688620 & 5.6 & 5.1228 & TRN \\
\hline CHEMBL1389120 & 688620 & 4.45 & 4.9002 & TRN \\
\hline CHEMBL1370217 & 688620 & 4.45 & 4.9664 & TST \\
\hline CHEMBL1520842 & 688620 & 5.2 & 4.7837 & TRN \\
\hline CHEMBL1568611 & 688620 & 4.65 & 4.8629 & TRN \\
\hline CHEMBL1548011 & 688620 & 4.45 & 4.8947 & TRN \\
\hline CHEMBL1308756 & 688620 & 4.75 & 4.9115 & TRN \\
\hline CHEMBL1533711 & 688620 & 5.1 & 5.2646 & TRN \\
\hline CHEMBL1367500 & 688620 & 4.9 & 4.7146 & TRN \\
\hline CHEMBL1432657 & 688620 & 4.85 & 5.3846 & TRN \\
\hline CHEMBL1492005 & 688620 & 5.9 & 5.1163 & TRN \\
\hline CHEMBL1995707 & 688620 & 5.55 & 5.0712 & TRN \\
\hline CHEMBL598204 & 688620 & 4.95 & 4.9027 & TRN \\
\hline CHEMBL1477154 & 688620 & 4.8 & 5.2767 & TRN \\
\hline CHEMBL1390583 & 688620 & 4.45 & 5.2578 & TRN \\
\hline CHEMBL3209414 & 688620 & 4.9 & 5.2092 & TRN \\
\hline CHEMBL1369845 & 688620 & 5.0 & 5.0206 & TRN \\
\hline CHEMBL1370102 & 688620 & 4.95 & 5.1033 & TRN \\
\hline CHEMBL1454433 & 688620 & 4.75 & 5.0018 & TST \\
\hline CHEMBL1572329 & 688620 & 4.75 & 5.316 & TRN \\
\hline CHEMBL1613725 & 688620 & 4.45 & 5.0625 & TRN \\
\hline CHEMBL1529946 & 688620 & 4.85 & 5.2325 & TST \\
\hline CHEMBL3199626 & 688620 & 5.05 & 5.1275 & TRN \\
\hline CHEMBL1301096 & 688620 & 4.85 & 4.9438 & TRN \\
\hline CHEMBL1499277 & 688620 & 4.45 & 5.1938 & TRN \\
\hline CHEMBL1338114 & 688620 & 5.4 & 4.7257 & TST \\
\hline CHEMBL1317016 & 688620 & 5.95 & 5.0541 & TST \\
\hline CHEMBL1488178 & 688620 & 4.85 & 5.0515 & TRN \\
\hline CHEMBL1339024 & 688620 & 6.1 & 4.9733 & TRN \\
\hline CHEMBL571087 & 688620 & 4.65 & 4.6673 & TRN \\
\hline
\end{tabular}




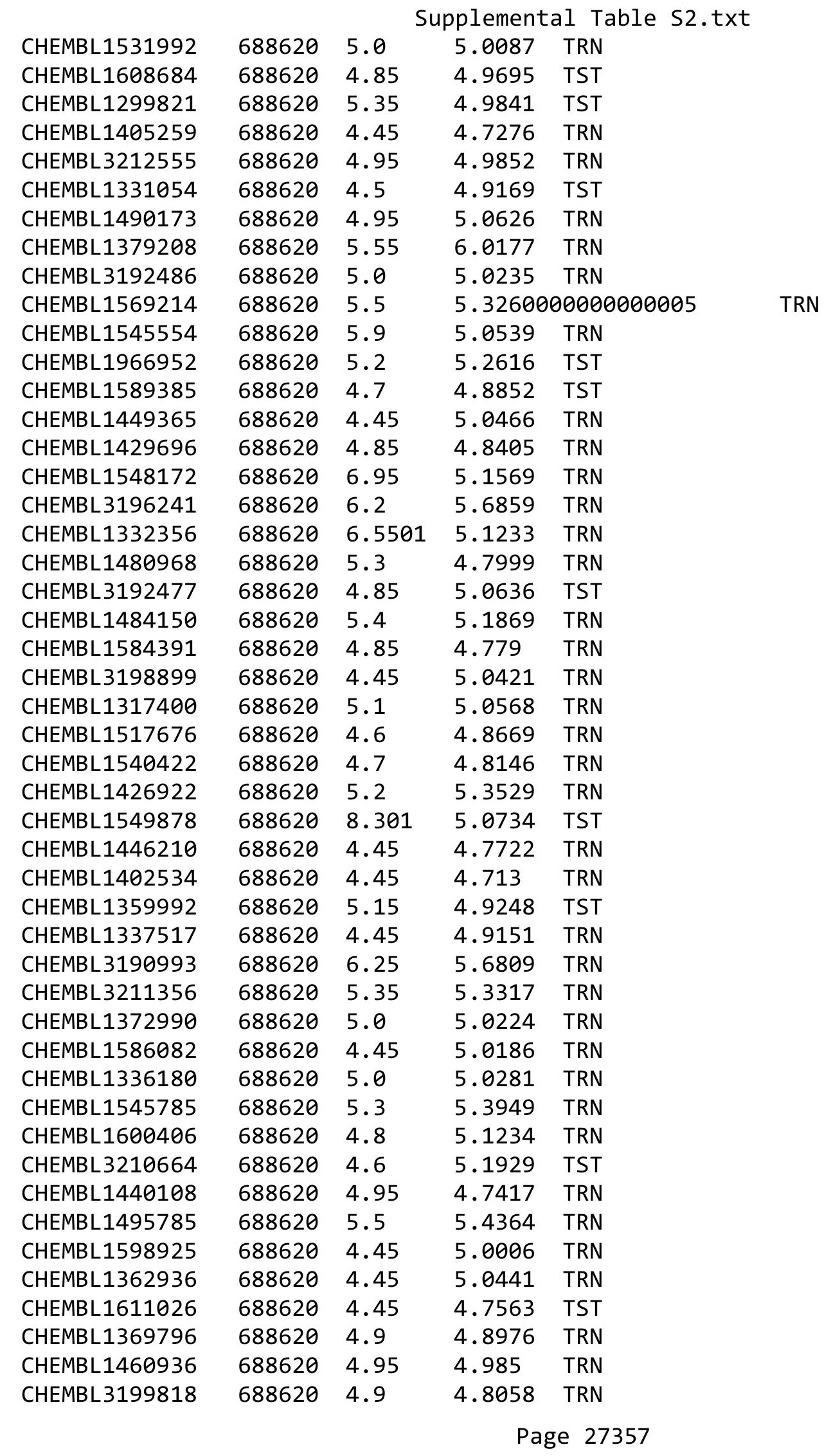




\begin{tabular}{|c|c|c|c|c|}
\hline & & & pplement & al $\mathrm{T}$ \\
\hline CHEMBL1306267 & 688620 & 6.3 & 7.1551 & TRN \\
\hline CHEMBL1429586 & 688620 & 4.7 & 5.0938 & TST \\
\hline CHEMBL1302510 & 688620 & 5.05 & 4.9576 & TST \\
\hline CHEMBL3192047 & 688620 & 5.15 & 5.1884 & TRN \\
\hline CHEMBL1545105 & 688620 & 6.4 & 6.2779 & TRN \\
\hline CHEMBL1567006 & 688620 & 4.9 & 5.0381 & TRN \\
\hline CHEMBL1348980 & 688620 & 5.6 & 5.4763 & TST \\
\hline CHEMBL1517153 & 688620 & 4.8 & 5.0596 & TRN \\
\hline CHEMBL3211380 & 688620 & 5.85 & 5.5293 & TRN \\
\hline CHEMBL1499283 & 688620 & 4.95 & 5.0231 & TRN \\
\hline CHEMBL1455899 & 688620 & 4.65 & 5.0406 & TRN \\
\hline CHEMBL3198229 & 688620 & 5.1 & 5.3902 & TRN \\
\hline CHEMBL1333386 & 688620 & 5.85 & 6.0719 & TRN \\
\hline CHEMBL1440317 & 688620 & 5.55 & 5.3998 & TRN \\
\hline CHEMBL1323470 & 688620 & 5.55 & 5.4511 & TRN \\
\hline CHEMBL1483040 & 688620 & 4.65 & 5.244 & TST \\
\hline CHEMBL1505108 & 688620 & 5.0 & 4.9959 & TST \\
\hline CHEMBL1586706 & 688620 & 4.45 & 4.8266 & TRN \\
\hline CHEMBL1332745 & 688620 & 4.45 & 4.8854 & TRN \\
\hline CHEMBL1583212 & 688620 & 4.95 & 5.3603 & TST \\
\hline CHEMBL1586662 & 688620 & 4.6 & 5.1548 & TRN \\
\hline CHEMBL 227432 & 688620 & 4.95 & 4.75 & TRN \\
\hline CHEMBL1459487 & 688620 & 7.1002 & 5.2608 & TRN \\
\hline CHEMBL1424768 & 688620 & 6.45 & 4.8643 & TRN \\
\hline CHEMBL1582333 & 688620 & 5.45 & 5.0746 & TRN \\
\hline CHEMBL1562103 & 688620 & 5.0 & 5.1422 & TRN \\
\hline CHEMBL1529349 & 688620 & 5.0 & 5.0201 & TRN \\
\hline CHEMBL1612784 & 688620 & 4.8 & 5.1495 & TST \\
\hline CHEMBL1508201 & 688620 & 5.25 & 5.2475 & TRN \\
\hline CHEMBL1529307 & 688620 & 4.8 & 4.9317 & TRN \\
\hline CHEMBL1529417 & 688620 & 5.65 & 4.9269 & TRN \\
\hline CHEMBL1576158 & 688620 & 4.5 & 5.0588 & TRN \\
\hline CHEMBL3209052 & 688620 & 5.15 & 4.9794 & TRN \\
\hline CHEMBL1484454 & 688620 & 5.3 & 5.2748 & TRN \\
\hline CHEMBL3195430 & 688620 & 6.25 & 5.822 & TST \\
\hline CHEMBL1585758 & 688620 & 6.2 & 5.6476 & TRN \\
\hline CHEMBL1532232 & 688620 & 4.9 & 4.8422 & TST \\
\hline CHEMBL1496413 & 688620 & 4.95 & 5.6272 & TRN \\
\hline CHEMBL1470903 & 688620 & 5.3 & 5.0653 & TST \\
\hline CHEMBL1412213 & 688620 & 4.45 & 5.1443 & TRN \\
\hline CHEMBL3190292 & 688620 & 4.65 & 5.1031 & TRN \\
\hline CHEMBL1598612 & 688620 & 4.95 & 5.2276 & TRN \\
\hline CHEMBL1368535 & 688620 & 6.2 & 5.5894 & TST \\
\hline CHEMBL1501529 & 688620 & 5.2 & 5.0972 & TRN \\
\hline CHEMBL3194483 & 688620 & 5.15 & 5.1174 & TRN \\
\hline CHEMBL1310873 & 688620 & 4.45 & 5.1698 & TST \\
\hline CHEMBL1378458 & 688620 & 8.2007 & 5.1824 & TST \\
\hline CHEMBL1432815 & 688620 & 4.9 & 4.9125 & TRN \\
\hline
\end{tabular}




\begin{tabular}{|c|c|c|c|c|}
\hline \multicolumn{5}{|c|}{ Supplemental Table S2.txt } \\
\hline CHEMBL1430233 & 688620 & 6.6 & 5.0395 & TRN \\
\hline CHEMBL1610009 & 688620 & 5.0 & 5.1442 & TRN \\
\hline CHEMBL1300745 & 688620 & 5.5 & 5.6506 & TRN \\
\hline CHEMBL1607247 & 688620 & 6.15 & 4.7922 & TST \\
\hline CHEMBL1570945 & 688620 & 4.45 & 4.7972 & TRN \\
\hline CHEMBL3208946 & 688620 & 4.45 & 4.7893 & TST \\
\hline CHEMBL1079664 & 688620 & 5.1 & 5.2244 & TRN \\
\hline CHEMBL1498265 & 688620 & 5.0 & 4.8507 & TRN \\
\hline CHEMBL1350008 & 688620 & 4.45 & 4.8844 & TST \\
\hline CHEMBL3195466 & 688620 & 5.55 & 5.3784 & TRN \\
\hline CHEMBL1313788 & 688620 & 4.45 & 5.2453 & TRN \\
\hline CHEMBL1559559 & 688620 & 4.7 & 4.9283 & TRN \\
\hline CHEMBL1445229 & 688620 & 5.55 & 4.9324 & TRN \\
\hline CHEMBL1425603 & 688620 & 5.0 & 4.8807 & TRN \\
\hline CHEMBL1602479 & 688620 & 5.35 & 5.2359 & TRN \\
\hline CHEMBL1363844 & 688620 & 4.65 & 4.9312 & TST \\
\hline CHEMBL1421181 & 688620 & 4.45 & 5.0726 & TRN \\
\hline CHEMBL1344456 & 688620 & 4.7 & 4.9313 & TRN \\
\hline CHEMBL1334330 & 688620 & 5.45 & 4.9728 & TRN \\
\hline CHEMBL1550489 & 688620 & 4.7 & 4.9732 & TST \\
\hline CHEMBL1539943 & 688620 & 4.9 & 5.0556 & TRN \\
\hline CHEMBL1581440 & 688620 & 4.85 & 5.0562 & TRN \\
\hline CHEMBL1540065 & 688620 & 4.95 & 5.0356 & TRN \\
\hline CHEMBL1429885 & 688620 & 4.9 & 5.0264 & TRN \\
\hline CHEMBL3189910 & 688620 & 4.75 & 5.0176 & TRN \\
\hline CHEMBL1436988 & 688620 & 4.8 & 4.8927 & TRN \\
\hline CHEMBL3213257 & 688620 & 4.45 & 4.9831 & TRN \\
\hline CHEMBL3193021 & 688620 & 4.9 & 4.9162 & TRN \\
\hline CHEMBL1606259 & 688620 & 4.8 & 4.7945 & TRN \\
\hline CHEMBL1581911 & 688620 & 4.45 & 4.8859 & TRN \\
\hline CHEMBL1526624 & 688620 & 4.85 & 4.8241 & TRN \\
\hline CHEMBL1460130 & 688620 & 4.45 & 4.9424 & TST \\
\hline CHEMBL1443442 & 688620 & 4.9 & 5.0785 & TRN \\
\hline CHEMBL1496632 & 688620 & 4.75 & 5.0422 & TRN \\
\hline CHEMBL1459394 & 688620 & 4.85 & 5.4127 & TRN \\
\hline CHEMBL1337375 & 688620 & 4.85 & 5.1202 & TRN \\
\hline CHEMBL1543035 & 688620 & 4.9 & 5.0472 & TST \\
\hline CHEMBL1340292 & 688620 & 4.65 & 5.182 & TRN \\
\hline CHEMBL1482113 & 688620 & 5.25 & 5.1121 & TRN \\
\hline CHEMBL1320464 & 688620 & 4.9 & 4.7794 & TRN \\
\hline CHEMBL1471596 & 688620 & 5.15 & 4.977 & TST \\
\hline CHEMBL1302109 & 688620 & 4.75 & 4.9308 & TRN \\
\hline CHEMBL1338630 & 688620 & 4.5 & 4.685 & TRN \\
\hline CHEMBL1520414 & 688620 & 4.7 & 4.8364 & TRN \\
\hline CHEMBL1520652 & 688620 & 4.45 & 4.9261 & TRN \\
\hline CHEMBL 253644 & 688620 & 4.7 & 4.8589 & TRN \\
\hline CHEMBL1445375 & 688620 & 4.95 & 5.1266 & TRN \\
\hline CHEMBL1348724 & 688620 & 4.9 & 4.9153 & TST \\
\hline
\end{tabular}




\begin{tabular}{|c|c|c|c|c|c|}
\hline \multicolumn{6}{|c|}{ Supplemental Table S2.txt } \\
\hline CHEMBL1612481 & 688620 & 4.45 & 5.2893 & TRN & \\
\hline CHEMBL1463094 & 688620 & 5.45 & 5.22 & TRN & \\
\hline CHEMBL1397548 & 688620 & 4.65 & 4.9739 & TRN & \\
\hline CHEMBL313339 & 688620 & 5.1 & 5.3152 & TRN & \\
\hline CHEMBL1487389 & 688620 & 4.95 & 4.9273 & TRN & \\
\hline CHEMBL1428760 & 688620 & 4.7 & 5.1396 & TRN & \\
\hline CHEMBL3189753 & 688620 & 4.8 & 4.732 & TRN & \\
\hline CHEMBL1431684 & 688620 & 4.85 & 4.8493 & TRN & \\
\hline CHEMBL1408116 & 688620 & 5.65 & 5.2105 & TST & \\
\hline CHEMBL1369641 & 688620 & 6.4 & 5.8508 & TRN & \\
\hline CHEMBL1595951 & 688620 & 4.95 & 4.999 & TST & \\
\hline CHEMBL1498961 & 688620 & 4.8 & 4.8902 & TRN & \\
\hline CHEMBL1597316 & 688620 & 4.95 & 4.9333 & TST & \\
\hline CHEMBL1532899 & 688620 & 4.95 & 5.0815 & TST & \\
\hline CHEMBL260799 & 688620 & 4.45 & 4.8394 & TRN & \\
\hline CHEMBL1579839 & 688620 & 6.15 & 6.108 & TRN & \\
\hline CHEMBL1574029 & 688620 & 4.45 & 5.0258 & TST & \\
\hline CHEMBL1400336 & 688620 & 6.9 & 5.0343 & TST & \\
\hline CHEMBL1536981 & 688620 & 5.0 & 4.7135 & TRN & \\
\hline CHEMBL1596590 & 688620 & 5.6 & 5.4871 & TRN & \\
\hline CHEMBL1362888 & 688620 & 6.4 & 4.8828 & TST & \\
\hline CHEMBL1582905 & 688620 & 5.0 & 5.2153 & TRN & \\
\hline CHEMBL1388670 & 688620 & 5.2 & 5.0636 & TRN & \\
\hline CHEMBL1305256 & 688620 & 5.15 & 5.2312 & TRN & \\
\hline CHEMBL1376423 & 688620 & 4.85 & 5.0811 & TST & \\
\hline CHEMBL3211634 & 688620 & 5.25 & 5.0351 & TRN & \\
\hline CHEMBL1427185 & 688620 & 5.3 & 5.24799 & 9999999999 & TRN \\
\hline CHEMBL1404207 & 688620 & 4.95 & 4.9945 & TST & \\
\hline CHEMBL1383149 & 688620 & 4.95 & 5.0741 & TRN & \\
\hline CHEMBL3199277 & 688620 & 4.95 & 5.218 & TRN & \\
\hline CHEMBL1468657 & 688620 & 4.95 & 4.8167 & TRN & \\
\hline CHEMBL1543691 & 688620 & 4.85 & 5.1998 & TRN & \\
\hline CHEMBL1556266 & 688620 & 4.95 & 5.374 & TRN & \\
\hline CHEMBL1596677 & 688620 & 5.9 & 4.9874 & TRN & \\
\hline CHEMBL1450751 & 688620 & 7.1002 & 5.2609 & TRN & \\
\hline CHEMBL1383141 & 688620 & 4.9 & 5.1566 & TRN & \\
\hline CHEMBL1407037 & 688620 & 5.0 & 5.0294 & TRN & \\
\hline CHEMBL1454196 & 688620 & 4.6 & 4.9159 & TST & \\
\hline CHEMBL1545697 & 688620 & 6.95 & 5.8637 & TRN & \\
\hline CHEMBL1410364 & 688620 & 5.8 & 5.2497 & TST & \\
\hline CHEMBL1472189 & 688620 & 5.7 & 5.0064 & TRN & \\
\hline CHEMBL1364635 & 688620 & 4.85 & 4.9559 & TRN & \\
\hline CHEMBL1503905 & 688620 & 4.45 & 4.9084 & TRN & \\
\hline CHEMBL1462341 & 688620 & 4.45 & 4.7194 & TRN & \\
\hline CHEMBL 2007297 & 688620 & 6.25 & 5.6329 & TRN & \\
\hline CHEMBL 2001211 & 688620 & 8.301 & 5.4345 & TRN & \\
\hline CHEMBL1498342 & 688620 & 5.45 & 5.0713 & TRN & \\
\hline CHEMBL1563883 & 688620 & 4.9 & 5.2425 & TST & \\
\hline
\end{tabular}




\begin{tabular}{|c|c|c|c|c|c|}
\hline \multicolumn{6}{|c|}{ oplemental labıe s. } \\
\hline CHEMBL1574585 & 688620 & 4.95 & 4.9065 & TST & \\
\hline CHEMBL1432343 & 688620 & 4.95 & 5.1472 & TRN & \\
\hline CHEMBL1303360 & 688620 & 5.6 & 5.0933 & TST & \\
\hline CHEMBL 3189257 & 688620 & 4.65 & 4.8828 & TRN & \\
\hline CHEMBL1603050 & 688620 & 4.55 & 4.7288 & TST & \\
\hline CHEMBL3199832 & 688620 & 5.5 & 5.1915 & TST & \\
\hline CHEMBL1522998 & 688620 & 4.95 & 4.8998 & TST & \\
\hline CHEMBL1433120 & 688620 & 4.5 & 4.9513 & TST & \\
\hline CHEMBL1489969 & 688620 & 5.4 & 5.0772 & TRN & \\
\hline CHEMBL1352375 & 688620 & 4.45 & 4.723 & TST & \\
\hline CHEMBL1599636 & 688620 & 5.0 & 5.05 & TRN & \\
\hline CHEMBL3190038 & 688620 & 4.65 & 5.3028 & TRN & \\
\hline CHEMBL3199180 & 688620 & 6.1 & 5.9604 & TRN & \\
\hline CHEMBL1422470 & 688620 & 4.9 & 4.6979 & TST & \\
\hline CHEMBL1599555 & 688620 & 4.75 & 5.5812 & TRN & \\
\hline CHEMBL1473000 & 688620 & 4.85 & 5.0673 & TRN & \\
\hline CHEMBL1546858 & 688620 & 4.7 & 5.1424 & TRN & \\
\hline CHEMBL1521893 & 688620 & 4.5 & 4.8736 & TRN & \\
\hline CHEMBL1312296 & 688620 & 5.2 & 5.0058 & TRN & \\
\hline CHEMBL1435261 & 688620 & 6.2 & 5.1548 & TRN & \\
\hline CHEMBL1545415 & 688620 & 4.95 & 4.8482 & TRN & \\
\hline CHEMBL1386434 & 688620 & 4.9 & 5.0449 & TRN & \\
\hline CHEMBL1526629 & 688620 & 5.5 & 5.1313 & TRN & \\
\hline CHEMBL1326450 & 688620 & 5.3 & 5.0722 & TST & \\
\hline CHEMBL3199630 & 688620 & 5.3 & 5.5428 & TST & \\
\hline CHEMBL1481651 & 688620 & 4.95 & 5.2735 & TST & \\
\hline CHEMBL1469462 & 688620 & 4.6 & 4.7724 & TRN & \\
\hline CHEMBL1305396 & 688620 & 4.45 & 4.913 & TRN & \\
\hline CHEMBL 3199077 & 688620 & 4.65 & 4.8427 & TRN & \\
\hline CHEMBL3192118 & 688620 & 4.85 & 5.0437 & TRN & \\
\hline CHEMBL1362724 & 688620 & 4.75 & 4.9311 & TRN & \\
\hline CHEMBL3195471 & 688620 & 7.1002 & 5.65799 & 99999999995 & TRN \\
\hline CHEMBL1432296 & 688620 & 5.0 & 4.9685 & TST & \\
\hline CHEMBL1430772 & 688620 & 4.75 & 4.7476 & TRN & \\
\hline CHEMBL1469561 & 688620 & 5.15 & 5.0566 & TRN & \\
\hline CHEMBL1381606 & 688620 & 5.45 & 5.0358 & TRN & \\
\hline CHEMBL1606709 & 688620 & 5.75 & 5.7429 & TST & \\
\hline CHEMBL1518549 & 688620 & 5.35 & 5.0807 & TRN & \\
\hline CHEMBL1358459 & 688620 & 4.85 & 5.0129 & TST & \\
\hline CHEMBL1367364 & 688620 & 5.15 & 5.399 & TRN & \\
\hline CHEMBL 3194867 & 688620 & 4.45 & 4.8726 & TRN & \\
\hline CHEMBL1369853 & 688620 & 5.5 & 4.8171 & TRN & \\
\hline CHEMBL1453006 & 688620 & 5.95 & 5.073 & TRN & \\
\hline CHEMBL1569932 & 688620 & 4.9 & 4.9102 & TST & \\
\hline CHEMBL3190426 & 688620 & 4.65 & 5.0662 & TST & \\
\hline CHEMBL1365210 & 688620 & 4.45 & 4.7871 & TST & \\
\hline CHEMBL1339192 & 688620 & 5.6 & 5.065 & TRN & \\
\hline CHEMBL 3212575 & 688620 & 5.25 & 5.0784 & TST & \\
\hline
\end{tabular}




\begin{tabular}{|c|c|c|c|c|}
\hline \multicolumn{5}{|c|}{ Supplemental Table s2.txt } \\
\hline CHEMBL1488495 & 688620 & 4.85 & 5.0929 & TRN \\
\hline CHEMBL1580677 & 688620 & 4.9 & 4.7501 & TRN \\
\hline CHEMBL1377535 & 688620 & 4.8 & 5.1163 & TST \\
\hline CHEMBL1449746 & 688620 & 4.6 & 5.0731 & TRN \\
\hline CHEMBL1451105 & 688620 & 7.0 & 5.3271 & TRN \\
\hline CHEMBL1382198 & 688620 & 4.75 & 4.6417 & TRN \\
\hline CHEMBL1344328 & 688620 & 5.9 & 5.0073 & TRN \\
\hline CHEMBL1377700 & 688620 & 4.65 & 4.9932 & TRN \\
\hline CHEMBL1509577 & 688620 & 5.15 & 5.047 & TRN \\
\hline CHEMBL1583171 & 688620 & 5.1 & 4.7124 & TRN \\
\hline CHEMBL 2007173 & 688620 & 5.15 & 4.7867 & TRN \\
\hline CHEMBL1385306 & 688620 & 4.8 & 5.1629 & TST \\
\hline CHEMBL1580371 & 688620 & 7.4001 & 5.2614 & TRN \\
\hline CHEMBL1408482 & 688620 & 4.75 & 5.2485 & TST \\
\hline CHEMBL1343994 & 688620 & 5.0 & 5.1304 & TST \\
\hline CHEMBL1564226 & 688620 & 4.7 & 4.9068 & TST \\
\hline CHEMBL 3145112 & 688620 & 5.0 & 4.898 & TRN \\
\hline CHEMBL1386785 & 688620 & 4.9 & 5.1759 & TRN \\
\hline CHEMBL1566570 & 688620 & 5.8 & 5.0256 & TRN \\
\hline CHEMBL1373808 & 688620 & 5.65 & 5.2843 & TRN \\
\hline CHEMBL 3144960 & 688620 & 5.7 & 5.4851 & TRN \\
\hline CHEMBL300389 & 688620 & 5.75 & 5.6992 & TST \\
\hline CHEMBL1306181 & 688620 & 4.45 & 4.7903 & TRN \\
\hline CHEMBL1525121 & 688620 & 5.0 & 5.0604 & TST \\
\hline CHEMBL1521475 & 688620 & 4.9 & 4.9657 & TRN \\
\hline CHEMBL1351661 & 688620 & 5.15 & 4.8198 & TRN \\
\hline CHEMBL1330011 & 688620 & 6.45 & 6.0108 & TRN \\
\hline CHEMBL1386624 & 688620 & 5.0 & 4.9477 & TST \\
\hline CHEMBL1353928 & 688620 & 5.0 & 4.9816 & TRN \\
\hline CHEMBL1383793 & 688620 & 4.65 & 5.4554 & TRN \\
\hline CHEMBL1478520 & 688620 & 4.95 & 5.0036 & TRN \\
\hline CHEMBL1329798 & 688620 & 5.75 & 5.5351 & TST \\
\hline CHEMBL1468076 & 688620 & 5.2 & 5.0812 & TST \\
\hline CHEMBL1462938 & 688620 & 4.45 & 4.9292 & TST \\
\hline CHEMBL1402539 & 688620 & 4.75 & 5.0027 & TST \\
\hline CHEMBL3193642 & 688620 & 5.3 & 5.5589 & TRN \\
\hline CHEMBL1503246 & 688620 & 5.35 & 5.0862 & TRN \\
\hline CHEMBL1529450 & 688620 & 5.3 & 5.0247 & TRN \\
\hline CHEMBL1966872 & 688620 & 4.55 & 4.9651 & TRN \\
\hline CHEMBL601751 & 688620 & 5.15 & 5.3706 & TRN \\
\hline CHEMBL1380186 & 688620 & 4.5 & 5.2537 & TRN \\
\hline CHEMBL1414933 & 688620 & 5.4 & 5.0636 & TRN \\
\hline CHEMBL1456521 & 688620 & 4.85 & 5.0294 & TRN \\
\hline CHEMBL 3189272 & 688620 & 5.7 & 5.519 & TST \\
\hline CHEMBL1549669 & 688620 & 5.15 & 5.1472 & TRN \\
\hline CHEMBL1610509 & 688620 & 4.45 & 5.3962 & TST \\
\hline CHEMBL1422362 & 688620 & 5.15 & 4.9225 & TRN \\
\hline CHEMBL1507568 & 688620 & 5.05 & 4.8752 & TRN \\
\hline
\end{tabular}




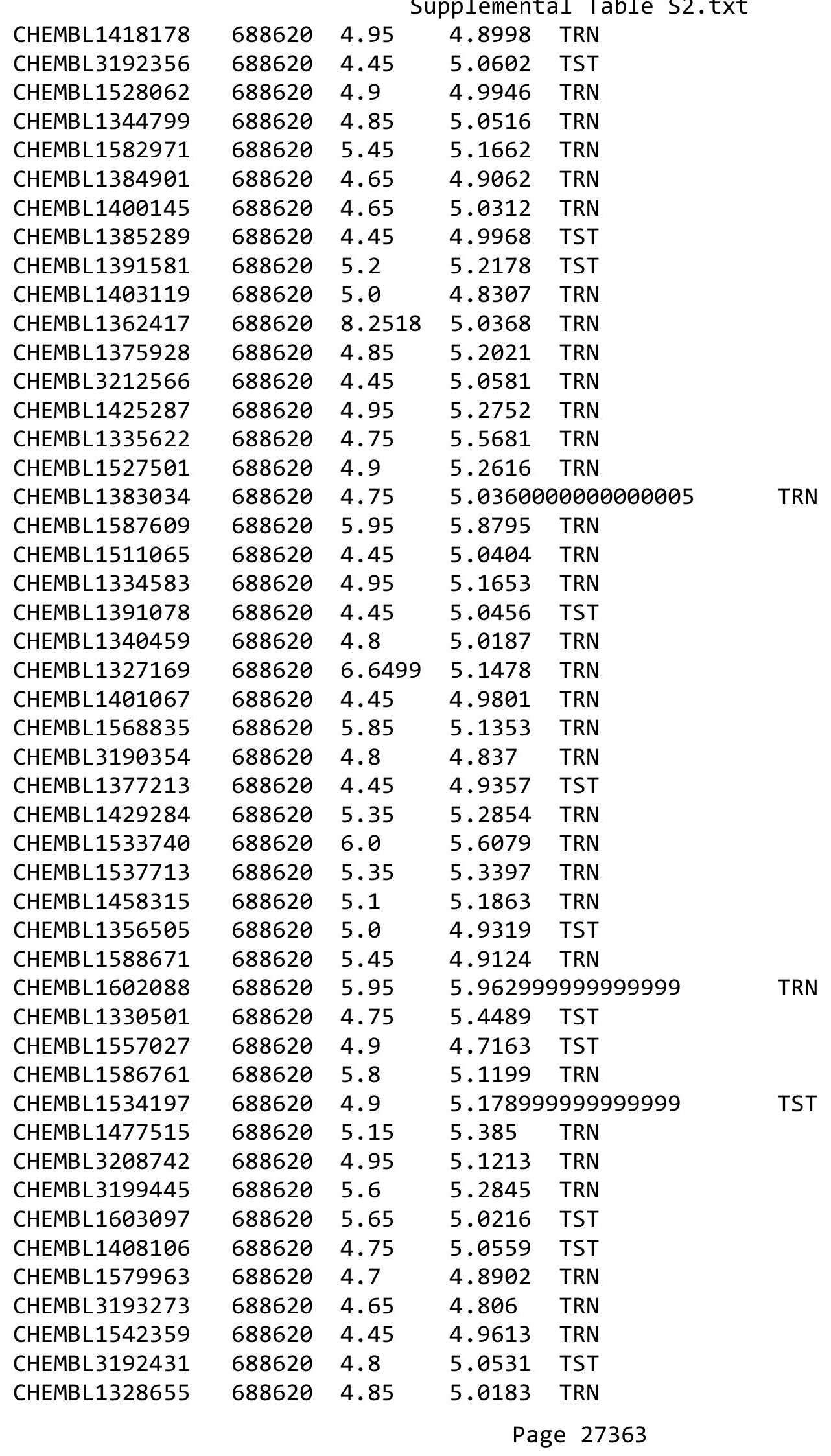




\begin{tabular}{|c|c|c|c|c|c|}
\hline \multicolumn{6}{|c|}{ Supplemental Table S2.txt } \\
\hline CHEMBL1605964 & 688620 & 4.9 & 5.1896 & TST & \\
\hline CHEMBL1369779 & 688620 & 4.45 & 4.921 & TRN & \\
\hline CHEMBL3198368 & 688620 & 5.75 & 5.7252 & TRN & \\
\hline CHEMBL3198964 & 688620 & 4.9 & 5.3435 & TST & \\
\hline CHEMBL1331503 & 688620 & 5.65 & 5.3165 & TRN & \\
\hline CHEMBL1564870 & 688620 & 5.4 & 4.8127 & TST & \\
\hline CHEMBL1601031 & 688620 & 4.7 & 5.0036 & TST & \\
\hline CHEMBL1432782 & 688620 & 5.4 & 5.0281 & TRN & \\
\hline CHEMBL1351628 & 688620 & 4.45 & 4.9685 & TRN & \\
\hline CHEMBL1579037 & 688620 & 5.9 & 5.3576 & TST & \\
\hline CHEMBL1450373 & 688620 & 4.45 & 4.8834 & TST & \\
\hline CHEMBL1310616 & 688620 & 5.05 & 4.9124 & TST & \\
\hline CHEMBL1367315 & 688620 & 4.95 & 5.2335 & TRN & \\
\hline CHEMBL1344085 & 688620 & 8.3468 & 5.0788 & TRN & \\
\hline CHEMBL1453212 & 688620 & 4.85 & 4.9513 & TST & \\
\hline CHEMBL1400179 & 688620 & 5.55 & 5.3007 & TRN & \\
\hline CHEMBL1352347 & 688620 & 4.65 & 4.7371 & TST & \\
\hline CHEMBL1388975 & 688620 & 4.45 & 4.9302 & TRN & \\
\hline CHEMBL1363342 & 688620 & 4.45 & 4.8579 & TRN & \\
\hline CHEMBL1398640 & 688620 & 5.15 & 5.0579 & TRN & \\
\hline CHEMBL1455962 & 688620 & 4.9 & 4.8922 & TRN & \\
\hline CHEMBL1490871 & 688620 & 5.65 & 5.2792 & TRN & \\
\hline CHEMBL1535997 & 688620 & 4.8 & 4.9681 & TRN & \\
\hline CHEMBL3207579 & 688620 & 5.25 & 4.9936 & TRN & \\
\hline CHEMBL1470900 & 688620 & 4.45 & 4.9677 & TRN & \\
\hline CHEMBL1307786 & 688620 & 5.35 & 5.0505 & TRN & \\
\hline CHEMBL3198171 & 688620 & 4.65 & 5.0149 & TRN & \\
\hline CHEMBL1480614 & 688620 & 5.1 & 4.9197 & TRN & \\
\hline CHEMBL1373402 & 688620 & 4.5 & 5.0842 & TRN & \\
\hline CHEMBL3211179 & 688620 & 4.65 & 5.21899 & 9999999999 & TRN \\
\hline CHEMBL1607524 & 688620 & 6.3 & 5.0716 & TRN & \\
\hline CHEMBL3196262 & 688620 & 6.7501 & 5.2358 & TRN & \\
\hline CHEMBL3211832 & 688620 & 5.55 & 4.9982 & TRN & \\
\hline CHEMBL1494737 & 688620 & 4.6 & 4.8917 & TST & \\
\hline CHEMBL1413104 & 688620 & 5.5 & 5.271 & TRN & \\
\hline CHEMBL1568518 & 688620 & 4.9 & 5.2057 & TRN & \\
\hline CHEMBL1414939 & 688620 & 4.45 & 5.0834 & TRN & \\
\hline CHEMBL1483479 & 688620 & 5.25 & 5.2058 & TRN & \\
\hline CHEMBL1407147 & 688620 & 4.45 & 5.1146 & TRN & \\
\hline CHEMBL3191235 & 688620 & 5.55 & 5.3831 & TRN & \\
\hline CHEMBL1496234 & 688620 & 5.2 & 5.1337 & TRN & \\
\hline CHEMBL1505902 & 688620 & 4.9 & 5.2389 & TST & \\
\hline CHEMBL1320576 & 688620 & 4.6 & 5.109 & TRN & \\
\hline CHEMBL114950 & 688620 & 4.45 & 4.9858 & TST & \\
\hline CHEMBL1445247 & 688620 & 7.6498 & 5.6783 & TRN & \\
\hline CHEMBL1409173 & 688620 & 4.8 & 5.0091 & TRN & \\
\hline CHEMBL1412533 & 688620 & 4.95 & 5.0826 & TST & \\
\hline CHEMBL3209677 & 688620 & 5.55 & 5.0229 & TRN & \\
\hline
\end{tabular}




\begin{tabular}{|c|c|c|c|c|}
\hline \multirow[b]{2}{*}{ CHEMBL1466795 } & \multicolumn{4}{|c|}{ Supplemental Table S2. } \\
\hline & 688620 & 4.7 & 4.9935 & TST \\
\hline CHEMBL1596813 & 688620 & 4.65 & 5.0218 & TST \\
\hline CHEMBL1606956 & 688620 & 4.8 & 5.0515 & TRN \\
\hline CHEMBL1425438 & 688620 & 4.65 & 5.0065 & TRN \\
\hline CHEMBL1999906 & 688620 & 4.45 & 4.7993 & TRN \\
\hline CHEMBL1323765 & 688620 & 4.5 & 5.0492 & TRN \\
\hline CHEMBL1496377 & 688620 & 4.85 & \multicolumn{2}{|c|}{4.9830000000000005} \\
\hline CHEMBL1372076 & 688620 & 4.45 & 4.9116 & TRN \\
\hline CHEMBL1491825 & 688620 & 4.75 & 5.3431 & TST \\
\hline CHEMBL1350677 & 688620 & 6.2 & 4.8616 & TST \\
\hline CHEMBL1576649 & 688620 & 5.95 & 5.7934 & TRN \\
\hline CHEMBL1303799 & 688620 & 4.7 & 4.9275 & TRN \\
\hline CHEMBL1599767 & 688620 & 4.9 & 5.2114 & TRN \\
\hline CHEMBL1557067 & 688620 & 6.95 & 4.9046 & TST \\
\hline CHEMBL1427112 & 688620 & 5.2 & 5.1849 & TRN \\
\hline CHEMBL1389702 & 688620 & 5.1 & 5.2958 & TRN \\
\hline CHEMBL1543609 & 688620 & 4.95 & 4.7941 & TRN \\
\hline CHEMBL1569186 & 688620 & 4.7 & 4.9248 & TRN \\
\hline CHEMBL1493818 & 688620 & 5.05 & 5.0062 & TRN \\
\hline CHEMBL1409635 & 688620 & 4.45 & 5.0537 & TST \\
\hline CHEMBL1343925 & 688620 & 5.25 & 4.8465 & TRN \\
\hline CHEMBL1313916 & 688620 & 5.0 & 4.937 & TRN \\
\hline CHEMBL3198488 & 688620 & 4.85 & 5.2175 & TRN \\
\hline CHEMBL1545527 & 688620 & 4.95 & 5.0996 & TRN \\
\hline CHEMBL 3194887 & 688620 & 6.0 & 5.4476 & TRN \\
\hline CHEMBL1532400 & 688620 & 6.5 & 5.0764 & TRN \\
\hline CHEMBL1599549 & 688620 & 4.8 & 4.8835 & TRN \\
\hline CHEMBL1549310 & 688620 & 5.9 & 5.5405 & TRN \\
\hline CHEMBL1496313 & 688620 & 4.95 & 4.9818 & TST \\
\hline CHEMBL602383 & 688620 & 4.45 & 4.851 & TRN \\
\hline CHEMBL1555809 & 688620 & 5.35 & 5.2186 & TST \\
\hline CHEMBL1581813 & 688620 & 5.6 & 5.3645 & TRN \\
\hline CHEMBL1582509 & 688620 & 5.05 & 4.9341 & TRN \\
\hline CHEMBL1569616 & 688620 & 4.75 & 4.794 & TRN \\
\hline CHEMBL3213430 & 688620 & 5.85 & 5.0399 & TRN \\
\hline CHEMBL1468774 & 688620 & 4.9 & 5.6035 & TRN \\
\hline CHEMBL1487401 & 688620 & 6.6 & 6.1819 & TRN \\
\hline CHEMBL 3199034 & 688620 & 4.8 & 5.4118 & TRN \\
\hline CHEMBL1597859 & 688620 & 4.75 & 4.8367 & TST \\
\hline CHEMBL1493429 & 688620 & 5.55 & 5.4817 & TRN \\
\hline CHEMBL1349063 & 688620 & 5.45 & 5.8196 & TRN \\
\hline CHEMBL1445425 & 688620 & 5.35 & 5.4451 & TRN \\
\hline CHEMBL1372853 & 688620 & 5.0 & 4.792 & TRN \\
\hline CHEMBL 1477844 & 688620 & 5.0 & 4.681 & TRN \\
\hline CHEMBL1385418 & 688620 & 4.8 & 5.0378 & TRN \\
\hline CHEMBL1489024 & 688620 & 5.3 & 5.4729 & TRN \\
\hline CHEMBL1505555 & 688620 & 4.7 & 4.9421 & TRN \\
\hline CHEMBL 3190272 & 688620 & 5.2 & 5.4142 & TRN \\
\hline & & & & 27365 \\
\hline
\end{tabular}




\begin{tabular}{|c|c|c|c|c|c|}
\hline \\
\hline CHEMBL1424789 & 688620 & 4.8 & 5.1006 & TST & \\
\hline CHEMBL1300716 & 688620 & 5.55 & 5.744 & TRN & \\
\hline CHEMBL1420254 & 688620 & 5.15 & 5.2036 & TRN & \\
\hline CHEMBL1483203 & 688620 & 4.45 & 5.0813 & TRN & \\
\hline CHEMBL1531394 & 688620 & 4.7 & 4.8902 & TRN & \\
\hline CHEMBL1540005 & 688620 & 4.6 & 4.9221 & TST & \\
\hline CHEMBL3194329 & 688620 & 4.7 & 5.0194 & TST & \\
\hline CHEMBL1607502 & 688620 & 4.75 & 5.1962 & TRN & \\
\hline CHEMBL1610197 & 688620 & 5.4 & 4.9621 & TRN & \\
\hline CHEMBL1487935 & 688620 & 5.3 & 4.8147 & TRN & \\
\hline CHEMBL1369340 & 688620 & 4.85 & 4.862 & TRN & \\
\hline CHEMBL451532 & 688620 & 6.15 & 4.8959 & TST & \\
\hline CHEMBL1574879 & 688620 & 6.0 & 5.7011 & TRN & \\
\hline CHEMBL3193270 & 688620 & 5.1 & 4.7961 & TRN & \\
\hline CHEMBL3190622 & 688620 & 5.5 & 5.1841 & TRN & \\
\hline CHEMBL3211833 & 688620 & 4.55 & 4.9284 & TRN & \\
\hline CHEMBL1333529 & 688620 & 4.95 & 4.71399 & & TRN \\
\hline CHEMBL3209533 & 688620 & 4.95 & 4.8425 & TRN & \\
\hline CHEMBL1506782 & 688620 & 4.65 & 4.8922 & TRN & \\
\hline CHEMBL1391313 & 688620 & 5.1 & 5.2221 & TRN & \\
\hline CHEMBL1319270 & 688620 & 5.0 & 5.1337 & TRN & \\
\hline CHEMBL1504429 & 688620 & 5.45 & 5.2086 & TRN & \\
\hline CHEMBL1506026 & 688620 & 4.9 & 5.065 & TRN & \\
\hline CHEMBL1526940 & 688620 & 4.65 & 5.2072 & TST & \\
\hline CHEMBL1360505 & 688620 & 5.5 & 4.7808 & TRN & \\
\hline CHEMBL1428097 & 688620 & 5.25 & 4.9734 & TRN & \\
\hline CHEMBL1569866 & 688620 & 6.05 & 5.0865 & TRN & \\
\hline CHEMBL1510040 & 688620 & 4.9 & 4.8699 & TRN & \\
\hline CHEMBL1327603 & 688620 & 5.1 & 5.1125 & TRN & \\
\hline CHEMBL1607959 & 688620 & 5.25 & 4.9619 & TRN & \\
\hline CHEMBL594957 & 688620 & 6.9 & 5.0565 & TST & \\
\hline CHEMBL1509343 & 688620 & 4.6 & 4.8692 & TRN & \\
\hline CHEMBL1197556 & 688620 & 5.05 & 5.4877 & TRN & \\
\hline CHEMBL1504946 & 688620 & 4.8 & 5.1008 & TST & \\
\hline CHEMBL1426269 & 688620 & 4.9 & 5.439 & TRN & \\
\hline CHEMBL1379214 & 688620 & 5.0 & 4.8392 & TRN & \\
\hline CHEMBL1530792 & 688620 & 4.9 & 4.7633 & TST & \\
\hline CHEMBL1447884 & 688620 & 5.35 & 5.3124 & TST & \\
\hline CHEMBL1468511 & 688620 & 4.7 & 5.2784 & TRN & \\
\hline CHEMBL1525869 & 688620 & 4.95 & 5.1516 & TRN & \\
\hline CHEMBL 2269362 & 688620 & 4.8 & 5.3308 & TST & \\
\hline CHEMBL1465399 & 688620 & 5.0 & 5.0488 & TST & \\
\hline CHEMBL1493371 & 688620 & 4.9 & 5.1546 & TRN & \\
\hline CHEMBL1414346 & 688620 & 5.1 & 5.3563 & TST & \\
\hline CHEMBL1472638 & 688620 & 5.0 & 4.8036 & TRN & \\
\hline CHEMBL1548217 & 688620 & 5.6 & 5.1198 & TRN & \\
\hline CHEMBL1402384 & 688620 & 4.95 & 5.0015 & TST & \\
\hline CHEMBL1511041 & 688620 & 4.5 & 5.0421 & TRN & \\
\hline
\end{tabular}




\begin{tabular}{|c|c|c|c|c|}
\hline \multicolumn{5}{|c|}{ pplemen } \\
\hline CHEMBL1470330 & 688620 & 4.5 & 4.9415 & TST \\
\hline CHEMBL1350340 & 688620 & 4.65 & 4.7392 & TRN \\
\hline CHEMBL3196441 & 688620 & 6.2 & 5.9574 & TRN \\
\hline CHEMBL1440422 & 688620 & 4.45 & 5.3774 & TRN \\
\hline CHEMBL1599714 & 688620 & 5.0 & 4.816 & TRN \\
\hline CHEMBL1442164 & 688620 & 4.85 & 4.9459 & TRN \\
\hline CHEMBL1457455 & 688620 & 4.7 & 4.8864 & TRN \\
\hline CHEMBL1518734 & 688620 & 4.7 & 5.0161 & TRN \\
\hline CHEMBL1388358 & 688620 & 4.95 & 4.9077 & TRN \\
\hline CHEMBL1986591 & 688620 & 4.95 & 5.3047 & TRN \\
\hline CHEMBL1351302 & 688620 & 4.75 & 4.9311 & TST \\
\hline CHEMBL1556416 & 688620 & 4.95 & 4.9325 & TST \\
\hline CHEMBL1491850 & 688620 & 4.95 & 5.0439 & TRN \\
\hline CHEMBL3212364 & 688620 & 5.0 & 5.3317 & TRN \\
\hline CHEMBL1538308 & 688620 & 4.45 & 5.0088 & TRN \\
\hline CHEMBL1389624 & 688620 & 4.95 & 5.1566 & TRN \\
\hline CHEMBL3189256 & 688620 & 4.9 & 5.0133 & TRN \\
\hline CHEMBL1390607 & 688620 & 4.45 & 5.0757 & TRN \\
\hline CHEMBL1327322 & 688620 & 4.6 & 5.0625 & TRN \\
\hline CHEMBL1349774 & 688620 & 4.75 & 4.9558 & TRN \\
\hline CHEMBL108766 & 688620 & 4.5 & 5.0719 & TRN \\
\hline CHEMBL1549268 & 688620 & 4.95 & 5.1514 & TRN \\
\hline CHEMBL3210221 & 688620 & 5.55 & 5.0593 & TST \\
\hline CHEMBL1605229 & 688620 & 5.55 & 5.4289 & TRN \\
\hline CHEMBL1460027 & 688620 & 4.85 & 5.2183 & TRN \\
\hline CHEMBL1521260 & 688620 & 5.4 & 5.2148 & TRN \\
\hline CHEMBL1414010 & 688620 & 4.9 & 5.3088 & TRN \\
\hline CHEMBL3192855 & 688620 & 5.1 & 5.4439 & TRN \\
\hline CHEMBL3209698 & 688620 & 5.65 & 5.0455 & TST \\
\hline CHEMBL1547007 & 688620 & 4.45 & 4.8949 & TRN \\
\hline CHEMBL1612924 & 688620 & 4.95 & 4.8994 & TRN \\
\hline CHEMBL1346194 & 688620 & 4.45 & 4.8108 & TST \\
\hline CHEMBL1352313 & 688620 & 4.95 & 5.2007 & TRN \\
\hline CHEMBL1399982 & 688620 & 4.8 & 5.1576 & TRN \\
\hline CHEMBL1483988 & 688620 & 4.45 & 5.0981 & TRN \\
\hline CHEMBL1337986 & 688620 & 4.7 & 5.2571 & TRN \\
\hline CHEMBL1333216 & 688620 & 5.0 & 5.1797 & TRN \\
\hline CHEMBL1382283 & 688620 & 5.2 & 4.9718 & TST \\
\hline CHEMBL1375302 & 688620 & 4.95 & 4.7884 & TST \\
\hline CHEMBL1389643 & 688620 & 5.7 & 5.3844 & TST \\
\hline CHEMBL1567159 & 688620 & 4.95 & 4.8839 & TST \\
\hline CHEMBL1540177 & 688620 & 5.55 & 4.8626 & TRN \\
\hline CHEMBL1376699 & 688620 & 4.9 & 5.025 & TST \\
\hline CHEMBL1539429 & 688620 & 4.95 & 4.8366 & TRN \\
\hline CHEMBL3194992 & 688620 & 5.85 & 5.3039 & TRN \\
\hline CHEMBL1390836 & 688620 & 5.0 & 5.1297 & TRN \\
\hline CHEMBL412010 & 688620 & 6.1 & 4.8912 & TRN \\
\hline CHEMBL1379634 & 688620 & 5.55 & 4.9784 & TRN \\
\hline
\end{tabular}




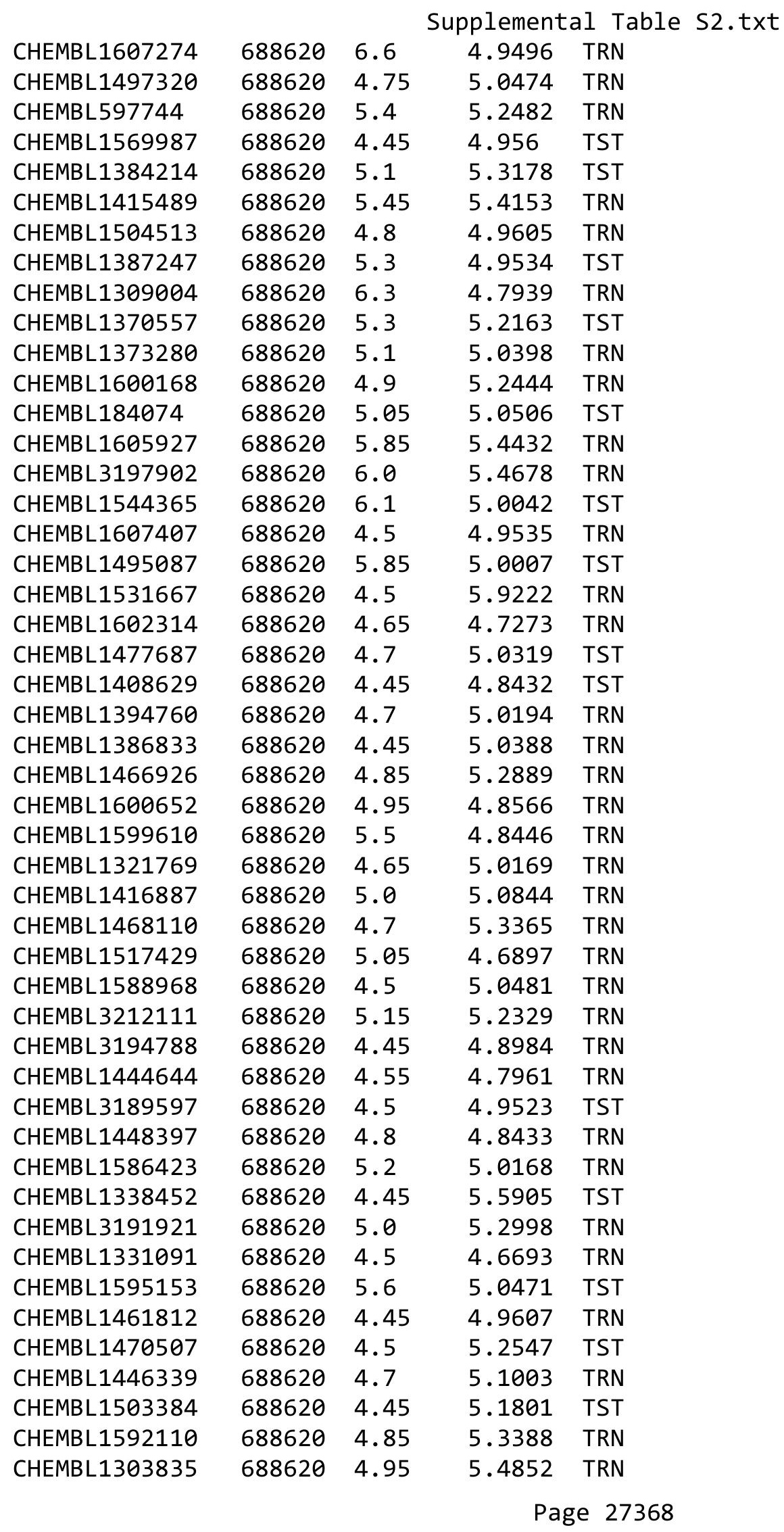




\begin{tabular}{|c|c|c|c|c|c|}
\hline \multicolumn{6}{|c|}{ Supplemental Table S2.txt } \\
\hline CHEMBL3195445 & 688620 & 5.45 & 5.5175 & TST & \\
\hline CHEMBL1464872 & 688620 & 5.85 & 5.0709 & TRN & \\
\hline CHEMBL1350579 & 688620 & 5.05 & 5.1567 & TST & \\
\hline CHEMBL1438391 & 688620 & 7.4498 & 5.19600 & 0000000001 & TRN \\
\hline CHEMBL1998521 & 688620 & 6.4 & 5.9938 & TRN & \\
\hline CHEMBL1413268 & 688620 & 5.55 & 5.4028 & TRN & \\
\hline CHEMBL1550452 & 688620 & 4.95 & 5.16799 & 9999999999 & TRN \\
\hline CHEMBL1533708 & 688620 & 4.9 & 5.1284 & TRN & \\
\hline CHEMBL1430534 & 688620 & 4.65 & 5.3122 & TST & \\
\hline CHEMBL1456240 & 688620 & 4.45 & 5.0164 & TRN & \\
\hline CHEMBL1602744 & 688620 & 5.2 & 4.9077 & TRN & \\
\hline CHEMBL3189251 & 688620 & 4.8 & 5.2291 & TRN & \\
\hline CHEMBL1988416 & 688620 & 5.3 & 4.8836 & TST & \\
\hline CHEMBL1996203 & 688620 & 4.45 & 5.0837 & TST & \\
\hline CHEMBL1536221 & 688620 & 4.9 & 4.9155 & TRN & \\
\hline CHEMBL1400463 & 688620 & 4.9 & 4.99100 & 00000000005 & TRN \\
\hline CHEMBL1561790 & 688620 & 4.65 & 4.9194 & TST & \\
\hline CHEMBL1313711 & 688620 & 6.6 & 5.1297 & TRN & \\
\hline CHEMBL1558503 & 688620 & 4.95 & 4.857 & TRN & \\
\hline CHEMBL1549118 & 688620 & 4.8 & 4.8955 & TRN & \\
\hline CHEMBL1428163 & 688620 & 4.45 & 4.9294 & TRN & \\
\hline CHEMBL1580664 & 688620 & 4.8 & 5.0761 & TST & \\
\hline CHEMBL1608985 & 688620 & 5.15 & 5.1619 & TRN & \\
\hline CHEMBL1383631 & 688620 & 5.9 & 5.5915 & TRN & \\
\hline CHEMBL1588956 & 688620 & 4.65 & 4.6251 & TRN & \\
\hline CHEMBL518575 & 688620 & 5.7 & 5.0908 & TRN & \\
\hline CHEMBL1520939 & 688620 & 4.6 & 5.2274 & TRN & \\
\hline CHEMBL1558581 & 688620 & 5.9 & 4.9708 & TRN & \\
\hline CHEMBL1488192 & 688620 & 5.1 & 5.2877 & TST & \\
\hline CHEMBL1430989 & 688620 & 4.8 & 4.7265 & TRN & \\
\hline CHEMBL1463391 & 688620 & 4.9 & 4.9912 & TST & \\
\hline CHEMBL1311282 & 688620 & 5.0 & 5.0745 & TRN & \\
\hline CHEMBL1445125 & 688620 & 5.1 & 5.3724 & TRN & \\
\hline CHEMBL1300457 & 688620 & 5.2 & 5.0638 & TRN & \\
\hline CHEMBL1331206 & 688620 & 4.85 & 4.6978 & TRN & \\
\hline CHEMBL1322075 & 688620 & 4.8 & 5.2376 & TRN & \\
\hline CHEMBL1472218 & 688620 & 5.9 & 5.3264 & TRN & \\
\hline CHEMBL1511179 & 688620 & 5.9 & 5.6246 & TST & \\
\hline CHEMBL1606593 & 688620 & 4.45 & 4.8247 & TRN & \\
\hline CHEMBL260451 & 688620 & 6.6499 & 5.2593 & TRN & \\
\hline CHEMBL1386913 & 688620 & 6.0 & 5.8148 & TRN & \\
\hline CHEMBL1419374 & 688620 & 4.75 & 5.0677 & TST & \\
\hline CHEMBL1551453 & 688620 & 4.45 & 4.9484 & TRN & \\
\hline CHEMBL1480271 & 688620 & 5.65 & 5.5947 & TRN & \\
\hline CHEMBL1312843 & 688620 & 5.0 & 5.5699 & TRN & \\
\hline CHEMBL1380177 & 688620 & 4.8 & 4.6793 & TRN & \\
\hline CHEMBL1449849 & 688620 & 4.9 & 5.1957 & TRN & \\
\hline CHEMBL1544714 & 688620 & 5.05 & 4.9562 & TST & \\
\hline
\end{tabular}




\begin{tabular}{|c|c|c|c|c|c|}
\hline \multicolumn{6}{|c|}{ plemental labıe S2. } \\
\hline CHEMBL1508723 & 688620 & 4.95 & 4.9155 & TRN & \\
\hline CHEMBL1388874 & 688620 & 5.4 & 4.8126 & TRN & \\
\hline CHEMBL1310969 & 688620 & 4.7 & 4.8471 & TRN & \\
\hline CHEMBL1544946 & 688620 & 4.65 & 5.0845 & TRN & \\
\hline CHEMBL1508593 & 688620 & 4.45 & 4.8525 & TRN & \\
\hline CHEMBL1557171 & 688620 & 5.0 & 4.8848 & TST & \\
\hline CHEMBL3193855 & 688620 & 5.4 & 4.956 & TRN & \\
\hline CHEMBL1332720 & 688620 & 4.8 & 5.0504 & TST & \\
\hline CHEMBL1547404 & 688620 & 4.95 & 5.0482 & TRN & \\
\hline CHEMBL1469579 & 688620 & 5.55 & 5.2669 & TRN & \\
\hline CHEMBL1506254 & 688620 & 5.4 & 5.1601 & TST & \\
\hline CHEMBL1299584 & 688620 & 5.05 & 4.9837 & TST & \\
\hline CHEMBL1442043 & 688620 & 5.05 & 4.9021 & TRN & \\
\hline CHEMBL1371385 & 688620 & 6.6 & 6.0618 & TRN & \\
\hline CHEMBL1548790 & 688620 & 4.95 & 5.0469 & TRN & \\
\hline CHEMBL1541195 & 688620 & 4.75 & 4.9426 & TST & \\
\hline CHEMBL3197805 & 688620 & 5.05 & 5.3929 & TRN & \\
\hline CHEMBL1344969 & 688620 & 4.45 & 5.1938 & TRN & \\
\hline CHEMBL1511172 & 688620 & 4.45 & 5.0632 & TRN & \\
\hline CHEMBL1311362 & 688620 & 4.9 & 5.0561 & TRN & \\
\hline CHEMBL1498536 & 688620 & 4.8 & 4.9887 & TST & \\
\hline CHEMBL1334530 & 688620 & 4.95 & 4.765 & TRN & \\
\hline CHEMBL1319388 & 688620 & 4.9 & 4.8244 & TRN & \\
\hline CHEMBL1542554 & 688620 & 6.4 & 5.70799 & 9999999999 & TRN \\
\hline CHEMBL1530878 & 688620 & 4.45 & 4.8042 & TRN & \\
\hline CHEMBL3192531 & 688620 & 5.25 & 5.1097 & TRN & \\
\hline CHEMBL1477349 & 688620 & 4.95 & 5.0379 & TRN & \\
\hline CHEMBL1431549 & 688620 & 4.65 & 5.1571 & TRN & \\
\hline CHEMBL1430891 & 688620 & 5.5 & 5.1381 & TST & \\
\hline CHEMBL1378761 & 688620 & 4.85 & 5.117 & TST & \\
\hline CHEMBL1981242 & 688620 & 4.95 & 5.2681 & TRN & \\
\hline CHEMBL1566084 & 688620 & 6.15 & 5.7806 & TRN & \\
\hline CHEMBL1487575 & 688620 & 6.05 & 4.9833 & TRN & \\
\hline CHEMBL3199447 & 688620 & 5.6 & 5.0459 & TRN & \\
\hline CHEMBL3197831 & 688620 & 5.55 & 5.608 & TRN & \\
\hline CHEMBL584520 & 688620 & 5.55 & 5.2896 & TST & \\
\hline CHEMBL1561565 & 688620 & 4.95 & 5.091 & TRN & \\
\hline CHEMBL1399554 & 688620 & 4.95 & 5.0241 & TRN & \\
\hline CHEMBL1446705 & 688620 & 5.35 & 5.4933 & TRN & \\
\hline CHEMBL1483414 & 688620 & 5.3 & 5.2842 & TRN & \\
\hline CHEMBL3191663 & 688620 & 4.7 & 5.1422 & TST & \\
\hline CHEMBL1483803 & 688620 & 4.9 & 5.0357 & TST & \\
\hline CHEMBL1376716 & 688620 & 5.05 & 5.0994 & TST & \\
\hline CHEMBL1470225 & 688620 & 5.0 & 4.9481 & TRN & \\
\hline CHEMBL1379793 & 688620 & 5.6 & 4.8509 & TRN & \\
\hline CHEMBL1594896 & 688620 & 5.1 & 4.76699 & 99999999995 & TRN \\
\hline CHEMBL1479249 & 688620 & 5.6 & 5.38 & TST & \\
\hline CHEMBL1366854 & 688620 & 4.75 & 4.9031 & TRN & \\
\hline
\end{tabular}




\begin{tabular}{|c|c|c|c|c|c|}
\hline \multicolumn{6}{|c|}{ oplemental lable s } \\
\hline CHEMBL1464993 & 688620 & 5.3 & 5.1907 & TRN & \\
\hline CHEMBL1463860 & 688620 & 5.85 & $4.9460 e$ & 0000000001 & TRN \\
\hline CHEMBL1379347 & 688620 & 5.25 & 4.8161 & TST & \\
\hline CHEMBL1456308 & 688620 & 4.45 & 4.9302 & TRN & \\
\hline CHEMBL1387943 & 688620 & 5.25 & 4.9539 & TST & \\
\hline CHEMBL1432391 & 688620 & 4.65 & 4.9687 & TRN & \\
\hline CHEMBL1421675 & 688620 & 4.9 & 4.8269 & TRN & \\
\hline CHEMBL1492304 & 688620 & 5.3 & 5.0068 & TRN & \\
\hline CHEMBL1524752 & 688620 & 4.7 & 5.1382 & TRN & \\
\hline CHEMBL1361737 & 688620 & 4.9 & 5.0304 & TRN & \\
\hline CHEMBL1382306 & 688620 & 5.25 & 4.9547 & TRN & \\
\hline CHEMBL3189582 & 688620 & 6.35 & 5.7395 & TRN & \\
\hline CHEMBL1333306 & 688620 & 5.25 & 5.1849 & TRN & \\
\hline CHEMBL1585169 & 688620 & 4.45 & 5.1172 & TRN & \\
\hline CHEMBL3191810 & 688620 & 5.5 & 5.0591 & TRN & \\
\hline CHEMBL1401926 & 688620 & 5.95 & 5.3006 & TRN & \\
\hline CHEMBL1307178 & 688620 & 4.95 & 4.8808 & TRN & \\
\hline CHEMBL1401594 & 688620 & 4.85 & 5.3943 & TST & \\
\hline CHEMBL1349539 & 688620 & 4.55 & 4.8595 & TST & \\
\hline CHEMBL1589551 & 688620 & 4.45 & 5.0562 & TRN & \\
\hline CHEMBL1543646 & 688620 & 5.0 & 5.2019 & TST & \\
\hline CHEMBL1453247 & 688620 & 4.7 & 5.1115 & TRN & \\
\hline CHEMBL1349908 & 688620 & 6.0 & 5.6001 & TRN & \\
\hline CHEMBL1596996 & 688620 & 4.9 & 4.8211 & TRN & \\
\hline CHEMBL1573230 & 688620 & 4.6 & 4.8426 & TST & \\
\hline CHEMBL3213175 & 688620 & 4.45 & 5.2304 & TST & \\
\hline CHEMBL1464976 & 688620 & 5.0 & 5.1685 & TRN & \\
\hline CHEMBL1455469 & 688620 & 5.15 & 5.0306 & TRN & \\
\hline CHEMBL3190201 & 688620 & 4.5 & 5.0322 & TRN & \\
\hline CHEMBL1490899 & 688620 & 4.95 & 4.7722 & TRN & \\
\hline CHEMBL1392151 & 688620 & 4.65 & 4.8759 & TST & \\
\hline CHEMBL448620 & 688620 & 4.45 & 4.7761 & TST & \\
\hline CHEMBL1430684 & 688620 & 5.1 & 4.8549 & TRN & \\
\hline CHEMBL1373549 & 688620 & 5.35 & 5.0023 & TST & \\
\hline CHEMBL1519060 & 688620 & 4.9 & 4.7306 & TST & \\
\hline CHEMBL1478402 & 688620 & 4.45 & 5.1139 & TRN & \\
\hline CHEMBL1405021 & 688620 & 4.85 & 4.9569 & TRN & \\
\hline CHEMBL1467860 & 688620 & 4.45 & 4.8158 & TRN & \\
\hline CHEMBL 2141886 & 688620 & 4.95 & 5.021 & TST & \\
\hline CHEMBL1494929 & 688620 & 4.75 & 4.8028 & TRN & \\
\hline CHEMBL1444588 & 688620 & 4.7 & 5.2163 & TRN & \\
\hline CHEMBL1428292 & 688620 & 4.5 & 4.746 & TRN & \\
\hline CHEMBL3191084 & 688620 & 4.45 & 4.7364 & TRN & \\
\hline CHEMBL1569945 & 688620 & 7.5003 & 5.3739 & TRN & \\
\hline CHEMBL1338044 & 688620 & 4.45 & 5.1325 & TST & \\
\hline CHEMBL499363 & 688620 & 5.35 & 5.1084 & TST & \\
\hline CHEMBL1308101 & 688620 & 4.65 & 4.8125 & TST & \\
\hline CHEMBL1445731 & 688620 & 4.65 & 5.0126 & TST & \\
\hline
\end{tabular}




\begin{tabular}{|c|c|c|c|c|}
\hline & & & oplement & al $\mathrm{T}$ \\
\hline CHEMBL1384362 & 688620 & 4.45 & 5.1762 & TRN \\
\hline CHEMBL1479928 & 688620 & 4.85 & 4.899 & TRN \\
\hline CHEMBL1384857 & 688620 & 5.05 & 4.9587 & TST \\
\hline CHEMBL1434334 & 688620 & 5.0 & 5.3216 & TRN \\
\hline CHEMBL1560348 & 688620 & 4.85 & 4.9465 & TRN \\
\hline CHEMBL492886 & 688620 & 4.85 & 5.2117 & TST \\
\hline CHEMBL422237 & 688620 & 4.95 & 4.9645 & TRN \\
\hline CHEMBL1518934 & 688620 & 4.45 & 5.0068 & TRN \\
\hline CHEMBL3145141 & 688620 & 4.6 & 4.8778 & TRN \\
\hline CHEMBL1578731 & 688620 & 4.5 & 4.9689 & TRN \\
\hline CHEMBL1343895 & 688620 & 5.25 & 5.2721 & TRN \\
\hline CHEMBL1547537 & 688620 & 5.0 & 5.0968 & TST \\
\hline CHEMBL1438142 & 688620 & 5.3 & 5.255 & TRN \\
\hline CHEMBL1401197 & 688620 & 4.65 & 5.1662 & TRN \\
\hline CHEMBL1471751 & 688620 & 4.85 & 4.9696 & TRN \\
\hline CHEMBL567332 & 688620 & 5.7 & 5.2555 & TRN \\
\hline CHEMBL1462667 & 688620 & 6.25 & 5.2283 & TST \\
\hline CHEMBL1508491 & 688620 & 4.85 & 4.7795 & TRN \\
\hline CHEMBL3194947 & 688620 & 6.0 & 5.1746 & TRN \\
\hline CHEMBL1386067 & 688620 & 5.25 & 5.442 & TRN \\
\hline CHEMBL1568500 & 688620 & 8.3468 & 4.8953 & TRN \\
\hline CHEMBL1361420 & 688620 & 4.95 & 5.2462 & TRN \\
\hline CHEMBL1328221 & 688620 & 5.0 & 5.0301 & TRN \\
\hline CHEMBL1581278 & 688620 & 4.8 & 5.2391 & TRN \\
\hline CHEMBL1334711 & 688620 & 5.9 & 5.4165 & TRN \\
\hline CHEMBL1372291 & 688620 & 5.0 & 5.1325 & TRN \\
\hline CHEMBL1527992 & 688620 & 5.0 & 5.2196 & TRN \\
\hline CHEMBL1485047 & 688620 & 4.6 & 5.1 & TRN \\
\hline CHEMBL3193622 & 688620 & 5.6 & 4.8833 & TST \\
\hline CHEMBL1361856 & 688620 & 4.45 & 5.1283 & TST \\
\hline CHEMBL1477071 & 688620 & 6.2 & 5.124 & TST \\
\hline CHEMBL1585531 & 688620 & 4.5 & 5.0469 & TRN \\
\hline CHEMBL1466654 & 688620 & 5.05 & 5.1953 & TRN \\
\hline CHEMBL1503906 & 688620 & 5.0 & 5.0718 & TST \\
\hline CHEMBL1576104 & 688620 & 5.0 & 4.9013 & TRN \\
\hline CHEMBL1424807 & 688620 & 6.4 & 4.9989 & TST \\
\hline CHEMBL1502247 & 688620 & 4.5 & 5.2584 & TST \\
\hline CHEMBL392978 & 688620 & 4.95 & 5.0149 & TRN \\
\hline CHEMBL1511795 & 688620 & 5.0 & 4.7785 & TRN \\
\hline CHEMBL1409389 & 688620 & 6.25 & 5.6986 & TRN \\
\hline CHEMBL1584508 & 688620 & 4.75 & 4.9247 & TST \\
\hline CHEMBL1391591 & 688620 & 4.45 & 4.9669 & TST \\
\hline CHEMBL1468085 & 688620 & 4.45 & 5.1588 & TRN \\
\hline CHEMBL3199345 & 688620 & 4.45 & 4.9781 & TRN \\
\hline CHEMBL1571647 & 688620 & 4.9 & 5.3535 & TRN \\
\hline CHEMBL1461241 & 688620 & 4.9 & 4.8977 & TRN \\
\hline CHEMBL1502991 & 688620 & 5.25 & 5.1002 & TST \\
\hline CHEMBL1525515 & 688620 & 5.3 & 4.9732 & TRN \\
\hline
\end{tabular}




\begin{tabular}{|c|c|c|c|c|}
\hline \multicolumn{5}{|c|}{ Supplemental Table S2.txt } \\
\hline CHEMBL1432655 & 688620 & 5.9 & 5.4715 & TRN \\
\hline CHEMBL1985797 & 688620 & 5.15 & 5.4638 & TRN \\
\hline CHEMBL1256772 & 688620 & 4.9 & 5.19 & TST \\
\hline CHEMBL1431593 & 688620 & 4.7 & 4.9434 & TRN \\
\hline CHEMBL3197704 & 688620 & 5.0 & 5.0749 & TRN \\
\hline CHEMBL1456572 & 688620 & 4.6 & 5.2749 & TRN \\
\hline CHEMBL1974810 & 688620 & 5.25 & 5.3179 & TRN \\
\hline CHEMBL3197099 & 688620 & 7.3002 & 6.2255 & TRN \\
\hline CHEMBL1447057 & 688620 & 5.9 & 4.9841 & TRN \\
\hline CHEMBL1416002 & 688620 & 5.1 & 4.9189 & TRN \\
\hline CHEMBL1490933 & 688620 & 4.75 & 4.9538 & TRN \\
\hline CHEMBL1565992 & 688620 & 5.8 & 5.0107 & TRN \\
\hline CHEMBL1330611 & 688620 & 4.65 & 4.9363 & TRN \\
\hline CHEMBL1570378 & 688620 & 4.45 & 5.0362 & TRN \\
\hline CHEMBL1523034 & 688620 & 4.8 & 5.0292 & TRN \\
\hline CHEMBL3197098 & 688620 & 5.25 & 5.4932 & TRN \\
\hline CHEMBL1326373 & 688620 & 4.55 & 4.9503 & TST \\
\hline CHEMBL1575153 & 688620 & 4.45 & 5.2187 & TRN \\
\hline CHEMBL1526293 & 688620 & 4.7 & 5.2619 & TST \\
\hline CHEMBL3191592 & 688620 & 5.05 & 5.0563 & TRN \\
\hline CHEMBL3196054 & 688620 & 5.15 & 5.2743 & TRN \\
\hline CHEMBL1601953 & 688620 & 4.75 & 5.1255 & TRN \\
\hline CHEMBL1518547 & 688620 & 4.95 & 5.1309 & TRN \\
\hline CHEMBL1329746 & 688620 & 5.2 & 5.0659 & TST \\
\hline CHEMBL1499034 & 688620 & 4.9 & 4.8659 & TRN \\
\hline CHEMBL1500303 & 688620 & 4.8 & 5.2588 & TRN \\
\hline CHEMBL1352044 & 688620 & 5.95 & 4.9123 & TST \\
\hline CHEMBL1595776 & 688620 & 4.85 & 4.8943 & TRN \\
\hline CHEMBL1371031 & 688620 & 4.45 & 5.0202 & TST \\
\hline CHEMBL1529458 & 688620 & 6.15 & 5.0965 & TST \\
\hline CHEMBL 3212423 & 688620 & 4.85 & 5.1679 & TRN \\
\hline CHEMBL1549476 & 688620 & 4.65 & 4.7665 & TRN \\
\hline CHEMBL1309755 & 688620 & 7.1002 & 5.1508 & TRN \\
\hline CHEMBL3192162 & 688620 & 5.15 & 5.0614 & TRN \\
\hline CHEMBL1443873 & 688620 & 6.5 & 5.6364 & TRN \\
\hline CHEMBL1342775 & 688620 & 5.0 & 4.7976 & TRN \\
\hline CHEMBL1390868 & 688620 & 5.0 & 5.07 & TST \\
\hline CHEMBL1605454 & 688620 & 5.0 & 5.0575 & TRN \\
\hline CHEMBL1508879 & 688620 & 4.95 & 4.9502 & TRN \\
\hline CHEMBL2369302 & 688620 & 6.2 & 5.556 & TST \\
\hline CHEMBL1450424 & 688620 & 4.65 & 5.0567 & TRN \\
\hline CHEMBL3199448 & 688620 & 5.35 & 5.3191 & TRN \\
\hline CHEMBL1545594 & 688620 & 5.0 & 4.8252 & TST \\
\hline CHEMBL1471731 & 688620 & 5.0 & 5.2692 & TRN \\
\hline CHEMBL1344911 & 688620 & 6.3 & 4.9755 & TRN \\
\hline CHEMBL3192493 & 688620 & 4.45 & 4.6992 & TST \\
\hline CHEMBL1497443 & 688620 & 5.7 & 4.8505 & TRN \\
\hline CHEMBL1549574 & 688620 & 5.0 & 5.0147 & TST \\
\hline
\end{tabular}




\begin{tabular}{|c|c|c|c|c|}
\hline & & & oplement & al $\mathrm{T}$ \\
\hline CHEMBL1606353 & 688620 & 4.95 & 5.0654 & TRN \\
\hline CHEMBL1482292 & 688620 & 5.2 & 5.2548 & TST \\
\hline CHEMBL1988896 & 688620 & 4.3 & 4.918 & TRN \\
\hline CHEMBL1326434 & 688620 & 6.45 & 4.8983 & TST \\
\hline CHEMBL1495254 & 688620 & 6.5 & 6.1998 & TRN \\
\hline CHEMBL1379806 & 688620 & 4.45 & 4.9498 & TRN \\
\hline CHEMBL1342486 & 688620 & 4.95 & 4.9482 & TST \\
\hline CHEMBL1307362 & 688620 & 5.3 & 5.1256 & TRN \\
\hline CHEMBL1603124 & 688620 & 4.9 & 4.9991 & TRN \\
\hline CHEMBL1585980 & 688620 & 5.4 & 5.1624 & TRN \\
\hline CHEMBL3196501 & 688620 & 4.95 & 5.1244 & TRN \\
\hline CHEMBL1601116 & 688620 & 4.9 & 4.9956 & TRN \\
\hline CHEMBL1334716 & 688620 & 4.75 & 5.0815 & TRN \\
\hline CHEMBL1607286 & 688620 & 4.6 & 4.8997 & TST \\
\hline CHEMBL1989847 & 688620 & 4.95 & 5.1741 & TST \\
\hline CHEMBL1995862 & 688620 & 4.75 & 4.8248 & TRN \\
\hline CHEMBL1521158 & 688620 & 5.55 & 5.1351 & TRN \\
\hline CHEMBL1507792 & 688620 & 5.0 & 5.0654 & TRN \\
\hline CHEMBL3196529 & 688620 & 5.35 & 4.8497 & TRN \\
\hline CHEMBL1510905 & 688620 & 7.0501 & 6.0438 & TRN \\
\hline CHEMBL1337675 & 688620 & 4.95 & 4.8502 & TRN \\
\hline CHEMBL1988133 & 688620 & 5.05 & 5.1897 & TRN \\
\hline CHEMBL1612932 & 688620 & 7.0 & 5.0791 & TST \\
\hline CHEMBL1595582 & 688620 & 5.65 & 5.4045 & TRN \\
\hline CHEMBL3192081 & 688620 & 5.1 & 4.9348 & TST \\
\hline CHEMBL1401756 & 688620 & 5.75 & 4.8826 & TRN \\
\hline CHEMBL1363915 & 688620 & 4.5 & 4.6959 & TRN \\
\hline CHEMBL1378436 & 688620 & 4.75 & 4.742 & TRN \\
\hline CHEMBL1303974 & 688620 & 4.6 & 4.7874 & TRN \\
\hline CHEMBL1362910 & 688620 & 4.95 & 5.0431 & TST \\
\hline CHEMBL1444606 & 688620 & 5.3 & 4.8859 & TRN \\
\hline CHEMBL1511618 & 688620 & 6.45 & 4.9408 & TRN \\
\hline CHEMBL1610676 & 688620 & 5.0 & 4.7557 & TRN \\
\hline CHEMBL1527910 & 688620 & 4.7 & 5.1506 & TRN \\
\hline CHEMBL1504370 & 688620 & 5.6 & 5.2062 & TRN \\
\hline CHEMBL3190793 & 688620 & 5.5 & 5.1168 & TRN \\
\hline CHEMBL1535454 & 688620 & 4.8 & 4.8753 & TST \\
\hline CHEMBL1386462 & 688620 & 5.55 & 5.1181 & TRN \\
\hline CHEMBL1558267 & 688620 & 5.2 & 5.0715 & TRN \\
\hline CHEMBL1428785 & 688620 & 4.85 & 4.9175 & TST \\
\hline CHEMBL1478921 & 688620 & 5.1 & 5.0665 & TRN \\
\hline CHEMBL3195605 & 688620 & 4.45 & 5.0021 & TRN \\
\hline CHEMBL1499214 & 688620 & 6.8 & 4.9366 & TST \\
\hline CHEMBL1406715 & 688620 & 4.95 & 5.1896 & TRN \\
\hline CHEMBL1498227 & 688620 & 4.75 & 4.9081 & TRN \\
\hline CHEMBL3214582 & 688620 & 4.65 & 5.2225 & TRN \\
\hline CHEMBL1370977 & 688620 & 4.95 & 5.1381 & TRN \\
\hline CHEMBL1479542 & 688620 & 5.45 & 5.1903 & TRN \\
\hline
\end{tabular}




\begin{tabular}{|c|c|c|c|c|c|}
\hline \multicolumn{6}{|c|}{ Supplemental Table s2.txt } \\
\hline CHEMBL1606431 & 688620 & 5.5 & 5.1274 & TST & \\
\hline CHEMBL1978733 & 688620 & 4.95 & 5.2112 & TRN & \\
\hline CHEMBL1463684 & 688620 & 4.75 & 4.8617 & TRN & \\
\hline CHEMBL1401481 & 688620 & 4.45 & 4.8633 & TRN & \\
\hline CHEMBL1516632 & 688620 & 5.55 & 5.228 & TRN & \\
\hline CHEMBL1309105 & 688620 & 5.0 & 5.1066 & TRN & \\
\hline CHEMBL1560947 & 688620 & 4.45 & 5.0674 & TRN & \\
\hline CHEMBL1528650 & 688620 & 4.5 & 4.8862 & TRN & \\
\hline CHEMBL1361649 & 688620 & 4.75 & 4.9545 & TRN & \\
\hline CHEMBL2359911 & 688620 & 5.5 & 5.3165 & TRN & \\
\hline CHEMBL1521214 & 688620 & 4.45 & 4.9178 & TRN & \\
\hline CHEMBL1590378 & 688620 & 4.85 & 5.2053 & TST & \\
\hline CHEMBL1361020 & 688620 & 4.85 & 4.9998 & TST & \\
\hline CHEMBL1345490 & 688620 & 4.5 & $5.3610 e$ & 0000000001 & TST \\
\hline CHEMBL1407379 & 688620 & 4.95 & 5.1325 & TST & \\
\hline CHEMBL1477851 & 688620 & 4.45 & 4.9225 & TRN & \\
\hline CHEMBL1573924 & 688620 & 6.15 & 4.8663 & TRN & \\
\hline CHEMBL 3210600 & 688620 & 4.95 & 4.8371 & TRN & \\
\hline CHEMBL1511024 & 688620 & 4.9 & 5.2001 & TRN & \\
\hline CHEMBL1587934 & 688620 & 5.0 & 5.0052 & TST & \\
\hline CHEMBL1564414 & 688620 & 4.65 & 4.9016 & TRN & \\
\hline CHEMBL1425847 & 688620 & 4.8 & 4.9456 & TST & \\
\hline CHEMBL1349032 & 688620 & 4.45 & 4.8171 & TRN & \\
\hline CHEMBL1446539 & 688620 & 5.3 & 5.1578 & TRN & \\
\hline CHEMBL1369423 & 688620 & 4.45 & 5.0918 & TST & \\
\hline CHEMBL1482529 & 688620 & 4.95 & 5.0798 & TRN & \\
\hline CHEMBL1324585 & 688620 & 5.55 & 5.0481 & TST & \\
\hline CHEMBL1581938 & 688620 & 4.9 & 5.1249 & TST & \\
\hline CHEMBL1522508 & 688620 & 5.7 & 4.9818 & TRN & \\
\hline CHEMBL1401567 & 688620 & 4.95 & 5.0533 & TRN & \\
\hline CHEMBL1517410 & 688620 & 4.45 & 5.0645 & TST & \\
\hline CHEMBL1484161 & 688620 & 5.05 & 4.9738 & TST & \\
\hline CHEMBL1569586 & 688620 & 4.95 & 4.95 & TST & \\
\hline CHEMBL1418906 & 688620 & 5.25 & 4.8411 & TST & \\
\hline CHEMBL1563219 & 688620 & 5.3 & 5.1556 & TRN & \\
\hline CHEMBL3145378 & 688620 & 6.5 & 5.4491 & TRN & \\
\hline CHEMBL1328353 & 688620 & 6.05 & 4.8914 & TST & \\
\hline CHEMBL1347730 & 688620 & 6.35 & 6.0409 & TRN & \\
\hline CHEMBL1303452 & 688620 & 4.95 & 5.0014 & TRN & \\
\hline CHEMBL3197171 & 688620 & 5.55 & 5.519 & TRN & \\
\hline CHEMBL1549399 & 688620 & 6.2 & 6.1049 & TRN & \\
\hline CHEMBL1543813 & 688620 & 5.35 & 5.2347 & TRN & \\
\hline CHEMBL1505308 & 688620 & 4.95 & 5.1657 & TRN & \\
\hline CHEMBL1370845 & 688620 & 4.9 & 5.3341 & TST & \\
\hline CHEMBL1550109 & 688620 & 4.45 & 5.1303 & TRN & \\
\hline CHEMBL3196876 & 688620 & 4.95 & 5.0955 & TRN & \\
\hline CHEMBL1581655 & 688620 & 5.0 & 4.7078 & TRN & \\
\hline CHEMBL1321350 & 688620 & 5.65 & 4.8503 & TRN & \\
\hline
\end{tabular}




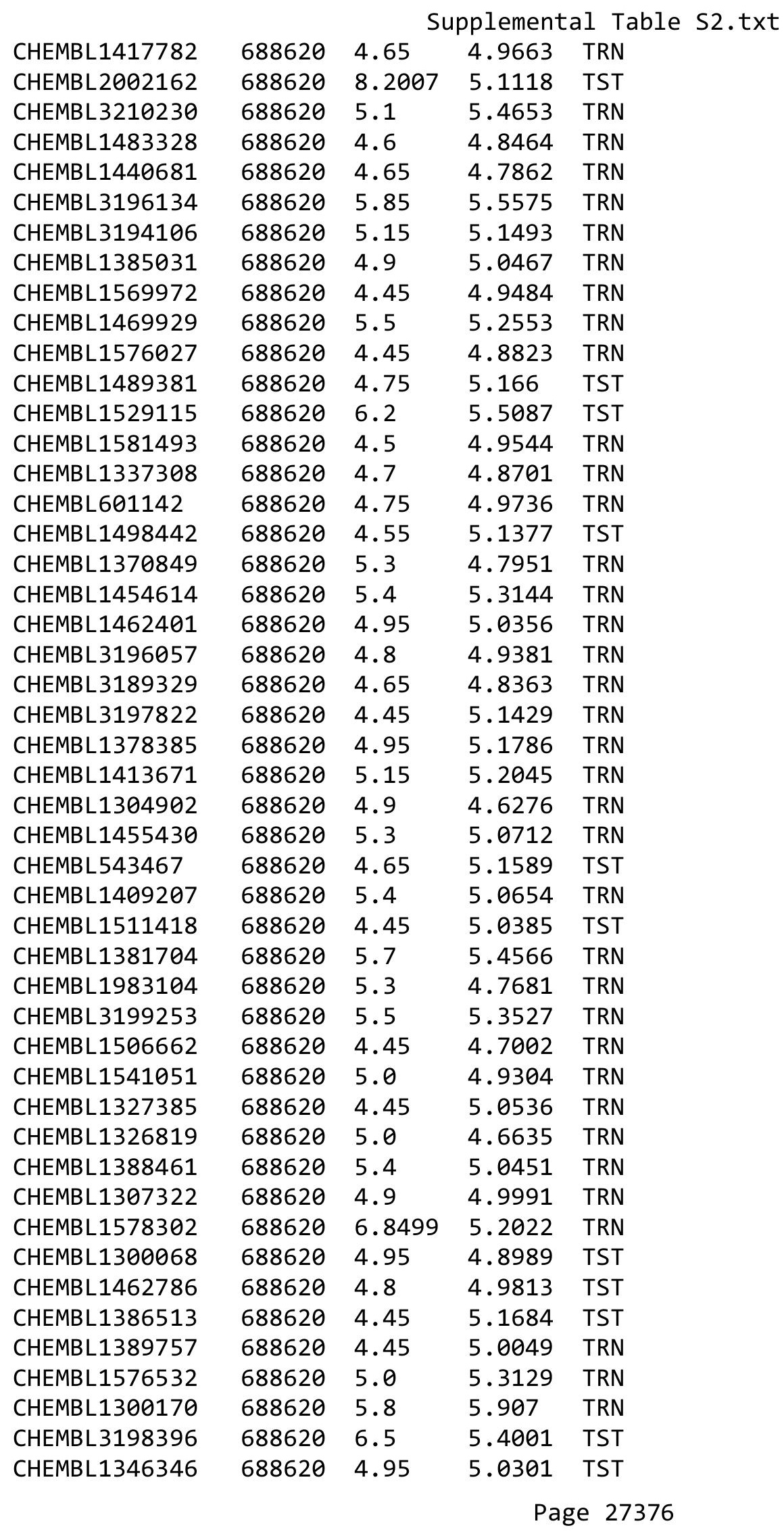




\begin{tabular}{|c|c|c|c|c|c|}
\hline \multicolumn{6}{|c|}{ Supplemental Table S2.txt } \\
\hline CHEMBL1586542 & 688620 & 5.0 & 5.0724 & TRN & \\
\hline CHEMBL1542927 & 688620 & 6.5 & 5.2211 & TRN & \\
\hline CHEMBL1506387 & 688620 & 5.55 & 5.3758 & TRN & \\
\hline CHEMBL1555607 & 688620 & 7.5003 & 5.0982 & TRN & \\
\hline CHEMBL1431231 & 688620 & 5.0 & 5.4233 & TRN & \\
\hline CHEMBL1301003 & 688620 & 4.7 & 4.8806 & TRN & \\
\hline CHEMBL602828 & 688620 & 5.7 & 4.9601 & TST & \\
\hline CHEMBL1534716 & 688620 & 5.7 & 5.8272 & TRN & \\
\hline CHEMBL1582052 & 688620 & 4.45 & 4.8265 & TRN & \\
\hline CHEMBL1365783 & 688620 & 4.9 & 4.8719 & TRN & \\
\hline CHEMBL1543670 & 688620 & 4.95 & 5.0618 & TRN & \\
\hline CHEMBL1332696 & 688620 & 4.95 & 5.0421 & TRN & \\
\hline CHEMBL1500632 & 688620 & 4.55 & 5.1838 & TRN & \\
\hline CHEMBL1563048 & 688620 & 5.55 & 5.0543 & TRN & \\
\hline CHEMBL1325646 & 688620 & 4.8 & 5.1826 & TRN & \\
\hline CHEMBL1426877 & 688620 & 5.2 & 5.459 & TRN & \\
\hline CHEMBL1329655 & 688620 & 5.0 & 5.0993 & TRN & \\
\hline CHEMBL1331694 & 688620 & 6.15 & 5.7738 & TRN & \\
\hline CHEMBL1421704 & 688620 & 4.8 & 5.1637 & TST & \\
\hline CHEMBL1601624 & 688620 & 4.65 & 4.7842 & TRN & \\
\hline CHEMBL1352919 & 688620 & 4.55 & 4.84699 & 99999999995 & TST \\
\hline CHEMBL582737 & 688620 & 4.45 & 4.7685 & TRN & \\
\hline CHEMBL1604438 & 688620 & 5.0 & 5.2583 & TRN & \\
\hline CHEMBL1308929 & 688620 & 4.9 & 5.0276 & TRN & \\
\hline CHEMBL261692 & 688620 & 4.75 & 4.981 & TRN & \\
\hline CHEMBL1430125 & 688620 & 4.9 & 4.7993 & TRN & \\
\hline CHEMBL1563366 & 688620 & 4.85 & 5.0514 & TRN & \\
\hline CHEMBL1609371 & 688620 & 4.8 & 4.9086 & TRN & \\
\hline CHEMBL1581782 & 688620 & 4.8 & 5.0844 & TRN & \\
\hline CHEMBL1342830 & 688620 & 4.95 & 4.7692 & TRN & \\
\hline CHEMBL1410546 & 688620 & 6.1 & 5.2058 & TST & \\
\hline CHEMBL1603418 & 688620 & 4.75 & 5.0491 & TRN & \\
\hline CHEMBL1495621 & 688620 & 4.9 & 4.7559 & TRN & \\
\hline CHEMBL1332688 & 688620 & 5.2 & 5.2683 & TRN & \\
\hline CHEMBL1993929 & 688620 & 5.9 & 5.7211 & TRN & \\
\hline CHEMBL1303690 & 688620 & 5.0 & 4.9156 & TRN & \\
\hline CHEMBL1548173 & 688620 & 6.0 & 5.5804 & TRN & \\
\hline CHEMBL1603193 & 688620 & 5.6 & 5.0427 & TRN & \\
\hline CHEMBL3211092 & 688620 & 5.7 & 5.0554 & TRN & \\
\hline CHEMBL1481437 & 688620 & 5.15 & 5.118 & TRN & \\
\hline CHEMBL1338156 & 688620 & 4.45 & 5.3693 & TST & \\
\hline CHEMBL1386372 & 688620 & 4.95 & 4.6649 & TRN & \\
\hline CHEMBL1502228 & 688620 & 5.15 & 5.0272 & TST & \\
\hline CHEMBL1533448 & 688620 & 4.85 & 5.0072 & TRN & \\
\hline CHEMBL1380801 & 688620 & 4.9 & 5.0693 & TRN & \\
\hline CHEMBL1547170 & 688620 & 4.6 & 4.8237 & TRN & \\
\hline CHEMBL1304002 & 688620 & 4.95 & 5.0409 & TRN & \\
\hline CHEMBL1520249 & 688620 & 4.45 & 4.9725 & TRN & \\
\hline
\end{tabular}




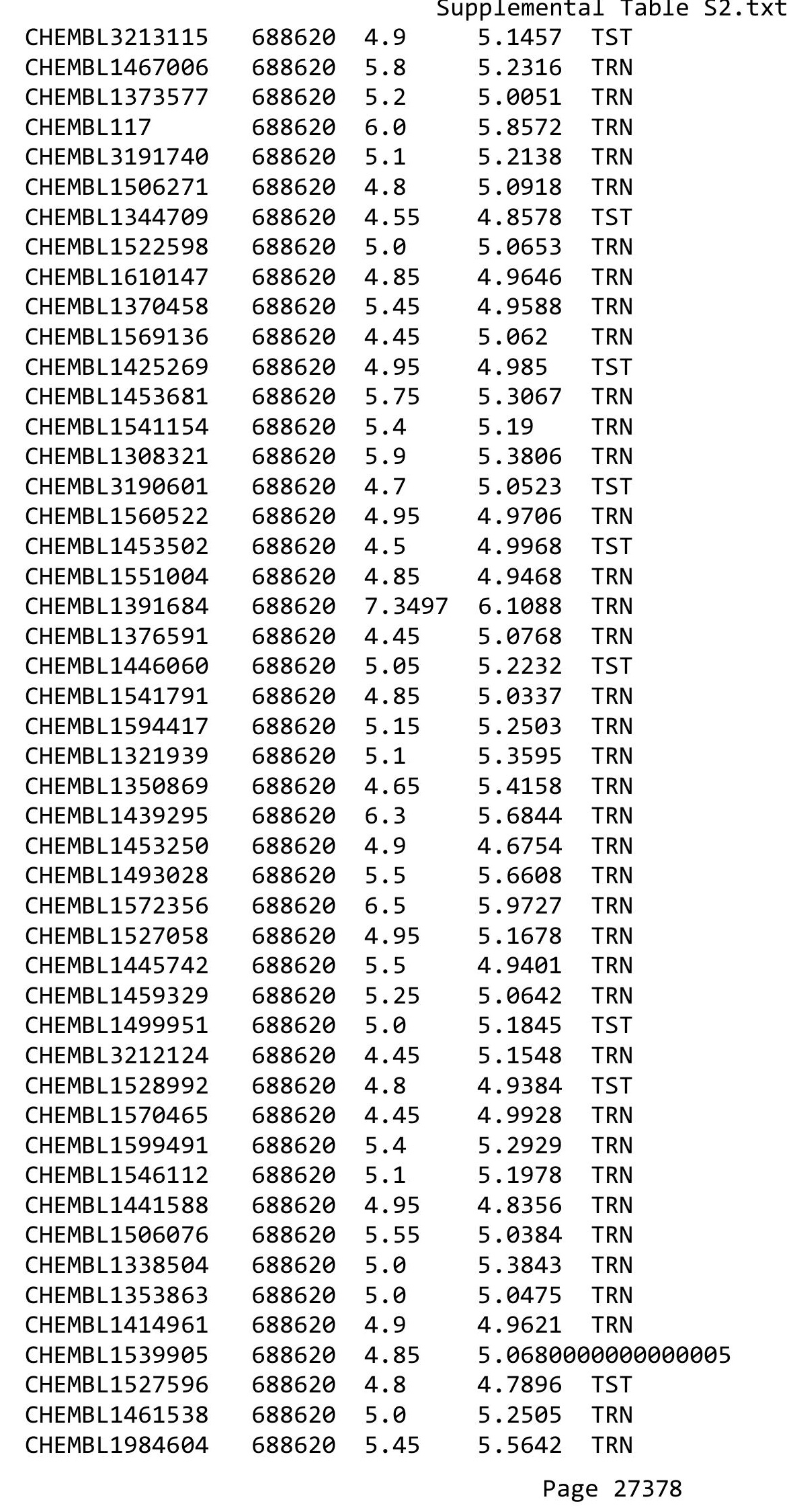




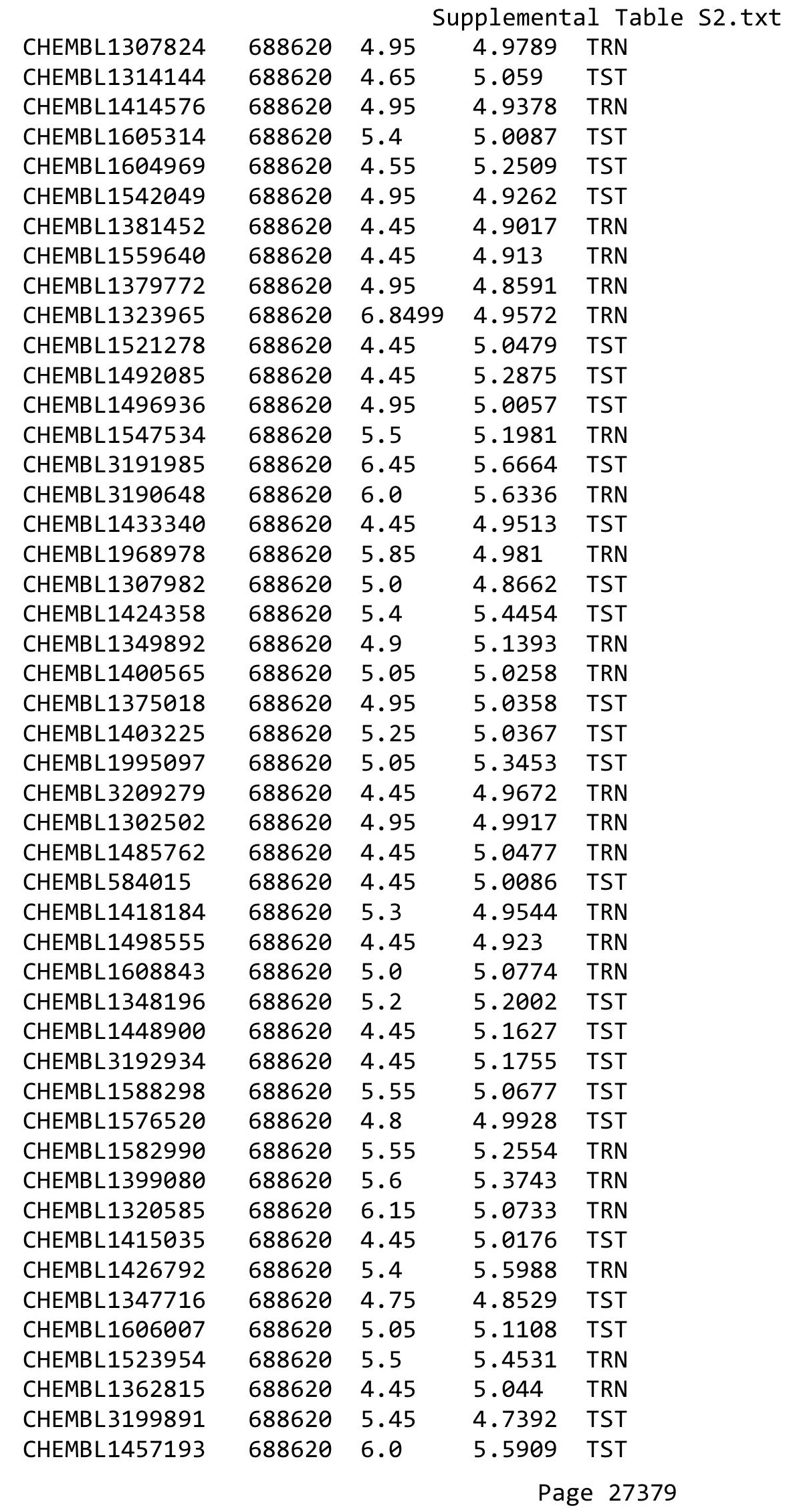




\begin{tabular}{|c|c|c|c|c|}
\hline & & & upplement & al $\mathrm{T}$ \\
\hline CHEMBL 1350078 & 688620 & 4.45 & 5.2288 & TRN \\
\hline CHEMBL1411447 & 688620 & 5.55 & 5.3992 & TRN \\
\hline CHEMBL1383357 & 688620 & 4.9 & 5.1835 & TRN \\
\hline CHEMBL1504168 & 688620 & 4.45 & 5.0747 & TRN \\
\hline CHEMBL1507477 & 688620 & 4.8 & 5.1085 & TRN \\
\hline CHEMBL1490229 & 688620 & 4.45 & 4.8272 & TRN \\
\hline CHEMBL1500910 & 688620 & 4.85 & 4.9293 & TRN \\
\hline CHEMBL1470043 & 688620 & 4.9 & 5.0906 & TRN \\
\hline CHEMBL1603890 & 688620 & 4.6 & 4.8539 & TST \\
\hline CHEMBL1597450 & 688620 & 5.1 & 5.0661 & TRN \\
\hline CHEMBL1567960 & 688620 & 4.95 & 4.7691 & TRN \\
\hline CHEMBL1572571 & 688620 & 5.2 & 4.974 & TST \\
\hline CHEMBL1517542 & 688620 & 4.85 & 5.0801 & TRN \\
\hline CHEMBL1971532 & 688620 & 5.25 & 4.7642 & TRN \\
\hline CHEMBL1429266 & 688620 & 4.9 & 4.9937 & TRN \\
\hline CHEMBL1492357 & 688620 & 4.9 & 4.9721 & TRN \\
\hline CHEMBL1466591 & 688620 & 4.45 & 4.9847 & TST \\
\hline CHEMBL1325264 & 688620 & 5.0 & 4.8613 & TST \\
\hline CHEMBL1541302 & 688620 & 4.5 & 5.2456 & TST \\
\hline CHEMBL1384368 & 688620 & 6.35 & 6.5294 & TRN \\
\hline CHEMBL1341023 & 688620 & 4.45 & 4.8703 & TST \\
\hline CHEMBL3212753 & 688620 & 4.8 & 5.4051 & TST \\
\hline CHEMBL1307124 & 688620 & 5.2 & 5.1846 & TRN \\
\hline CHEMBL1320633 & 688620 & 4.45 & 4.978 & TRN \\
\hline CHEMBL1528493 & 688620 & 5.35 & 5.3539 & TRN \\
\hline CHEMBL1555808 & 688620 & 4.95 & 5.0021 & TRN \\
\hline CHEMBL1410146 & 688620 & 5.9 & 4.9942 & TRN \\
\hline CHEMBL1483520 & 688620 & 4.9 & 5.0208 & TRN \\
\hline CHEMBL1549933 & 688620 & 5.0 & 4.7237 & TST \\
\hline CHEMBL1511540 & 688620 & 4.5 & 5.0648 & TRN \\
\hline CHEMBL3195109 & 688620 & 6.15 & 5.5925 & TRN \\
\hline CHEMBL1596470 & 688620 & 4.9 & 4.7697 & TRN \\
\hline CHEMBL78223 & 688620 & 4.8 & 5.0836 & TRN \\
\hline CHEMBL1375248 & 688620 & 5.35 & 4.9452 & TRN \\
\hline CHEMBL1340634 & 688620 & 4.9 & 5.2194 & TST \\
\hline CHEMBL1585581 & 688620 & 5.3 & 5.0729 & TRN \\
\hline CHEMBL1456070 & 688620 & 4.9 & 5.2139 & TRN \\
\hline CHEMBL1427087 & 688620 & 4.6 & 4.9974 & TRN \\
\hline CHEMBL1501105 & 688620 & 5.6 & 5.0612 & TST \\
\hline CHEMBL1611985 & 688620 & 4.8 & 4.937 & TRN \\
\hline CHEMBL 3207583 & 688620 & 4.65 & 5.1094 & TRN \\
\hline CHEMBL1549705 & 688620 & 4.95 & 5.0346 & TRN \\
\hline CHEMBL1510852 & 688620 & 6.15 & 6.1928 & TRN \\
\hline CHEMBL3144970 & 688620 & 4.85 & 4.7272 & TRN \\
\hline CHEMBL1312902 & 688620 & 5.05 & 4.9042 & TRN \\
\hline CHEMBL1340646 & 688620 & 4.45 & 5.011 & TST \\
\hline CHEMBL3194972 & 688620 & 4.45 & 5.0863 & TRN \\
\hline CHEMBL1543677 & 688620 & 5.25 & 5.1296 & TRN \\
\hline
\end{tabular}




\begin{tabular}{|c|c|c|c|c|}
\hline \multicolumn{5}{|c|}{ Supplemental Table S2.txt } \\
\hline CHEMBL1568848 & 688620 & 6.1 & 4.7335 & TRN \\
\hline CHEMBL1584697 & 688620 & 5.4 & 5.1833 & TRN \\
\hline CHEMBL1570896 & 688620 & 4.95 & 4.9773 & TST \\
\hline CHEMBL1600801 & 688620 & 4.45 & 5.4268 & TRN \\
\hline CHEMBL1587156 & 688620 & 5.45 & 5.4724 & TRN \\
\hline CHEMBL3196641 & 688620 & 5.25 & 5.1371 & TRN \\
\hline CHEMBL1471395 & 688620 & 4.95 & 5.0791 & TST \\
\hline CHEMBL1378383 & 688620 & 5.4 & 5.0638 & TRN \\
\hline CHEMBL16685 & 688620 & 6.0 & 4.9212 & TRN \\
\hline CHEMBL1509368 & 688620 & 4.7 & 5.0357 & TST \\
\hline CHEMBL1526463 & 688620 & 5.3 & 5.221 & TRN \\
\hline CHEMBL1525307 & 688620 & 4.45 & 4.8866 & TRN \\
\hline CHEMBL1438690 & 688620 & 4.75 & 4.6916 & TRN \\
\hline CHEMBL1486205 & 688620 & 4.8 & 4.9781 & TRN \\
\hline CHEMBL1313360 & 688620 & 4.95 & 5.0343 & TRN \\
\hline CHEMBL1370162 & 688620 & 5.25 & 4.8897 & TST \\
\hline CHEMBL1383568 & 688620 & 4.85 & 5.0198 & TST \\
\hline CHEMBL1511331 & 688620 & 5.1 & 5.2455 & TRN \\
\hline CHEMBL1534474 & 688620 & 4.9 & 5.1879 & TRN \\
\hline CHEMBL1362510 & 688620 & 5.2 & 5.2542 & TRN \\
\hline CHEMBL1517045 & 688620 & 4.9 & 5.3994 & TRN \\
\hline CHEMBL1491666 & 688620 & 5.3 & 5.3052 & TRN \\
\hline CHEMBL1363746 & 688620 & 5.4 & 5.0207 & TRN \\
\hline CHEMBL1984114 & 688620 & 4.75 & 4.8271 & TRN \\
\hline CHEMBL1505666 & 688620 & 5.2 & 5.073 & TRN \\
\hline CHEMBL1976197 & 688620 & 5.35 & 5.1773 & TRN \\
\hline CHEMBL 1353426 & 688620 & 5.55 & 5.7879 & TRN \\
\hline CHEMBL1607089 & 688620 & 4.95 & 5.0273 & TRN \\
\hline CHEMBL1423123 & 688620 & 4.65 & 4.8345 & TRN \\
\hline CHEMBL1436865 & 688620 & 4.45 & 4.5951 & TRN \\
\hline CHEMBL1509327 & 688620 & 5.15 & 4.9868 & TRN \\
\hline CHEMBL1579072 & 688620 & 5.4 & 5.0278 & TST \\
\hline CHEMBL1460755 & 688620 & 5.8 & 5.2169 & TST \\
\hline CHEMBL590285 & 688620 & 4.75 & 5.2689 & TRN \\
\hline CHEMBL1354657 & 688620 & 4.45 & 4.9722 & TRN \\
\hline CHEMBL1491522 & 688620 & 5.55 & 5.0949 & TST \\
\hline CHEMBL1611394 & 688620 & 5.35 & 5.0299 & TRN \\
\hline CHEMBL1396099 & 688620 & 4.65 & 5.1143 & TST \\
\hline CHEMBL1384489 & 688620 & 4.75 & 4.7698 & TRN \\
\hline CHEMBL1302477 & 688620 & 4.95 & 5.0802 & TRN \\
\hline CHEMBL1356160 & 688620 & 5.1 & 5.019 & TRN \\
\hline CHEMBL1301482 & 688620 & 4.45 & 4.9729 & TRN \\
\hline CHEMBL1329279 & 688620 & 4.5 & 4.6781 & TRN \\
\hline CHEMBL1576539 & 688620 & 6.3 & 5.1212 & TRN \\
\hline CHEMBL1339380 & 688620 & 4.45 & 5.1065 & TRN \\
\hline CHEMBL3210486 & 688620 & 4.9 & 5.0802 & TRN \\
\hline CHEMBL1370953 & 688620 & 4.45 & 4.9294 & TST \\
\hline CHEMBL1461478 & 688620 & 4.45 & 5.0843 & TRN \\
\hline
\end{tabular}




\begin{tabular}{|c|c|c|c|c|c|}
\hline & & \multicolumn{4}{|c|}{ Supplemental Table S2.txt } \\
\hline CHEMBL1477974 & 688620 & 7.4001 & 5.041 & TST & \\
\hline CHEMBL1578985 & 688620 & 4.85 & 5.1427 & TRN & \\
\hline CHEMBL1496741 & 688620 & 4.8 & 5.2796 & TRN & \\
\hline CHEMBL1306015 & 688620 & 5.3 & 4.7316 & TST & \\
\hline CHEMBL1489492 & 688620 & 4.45 & 5.3366 & TRN & \\
\hline CHEMBL1373933 & 688620 & 4.95 & 4.7182 & TRN & \\
\hline CHEMBL1307849 & 688620 & 5.0 & 5.0726 & TRN & \\
\hline CHEMBL1375274 & 688620 & 5.3 & 5.13899 & 9999999999 & TRN \\
\hline CHEMBL1467736 & 688620 & 5.2 & 5.1615 & TST & \\
\hline CHEMBL3211017 & 688620 & 6.35 & 4.9555 & TRN & \\
\hline CHEMBL1548261 & 688620 & 4.9 & 4.8344 & TST & \\
\hline CHEMBL579837 & 688620 & 4.45 & 4.7674 & TRN & \\
\hline CHEMBL1380767 & 688620 & 5.15 & 4.9401 & TRN & \\
\hline CHEMBL1327986 & 688620 & 5.25 & 4.8501 & TRN & \\
\hline CHEMBL3193425 & 688620 & 5.85 & 5.7166 & TRN & \\
\hline CHEMBL1427716 & 688620 & 5.5 & 5.2842 & TRN & \\
\hline CHEMBL1477094 & 688620 & 4.45 & 4.9165 & TRN & \\
\hline CHEMBL1303183 & 688620 & 4.9 & 4.9073 & TRN & \\
\hline CHEMBL1378480 & 688620 & 5.9 & 5.4041 & TRN & \\
\hline CHEMBL248779 & 688620 & 5.0 & 5.0467 & TRN & \\
\hline CHEMBL1602064 & 688620 & 7.1002 & 5.0922 & TST & \\
\hline CHEMBL1408701 & 688620 & 6.25 & 5.0996 & TST & \\
\hline CHEMBL1604272 & 688620 & 5.25 & 4.9318 & TRN & \\
\hline CHEMBL1544587 & 688620 & 4.8 & 5.1559 & TRN & \\
\hline CHEMBL1457002 & 688620 & 4.45 & 5.0131 & TRN & \\
\hline CHEMBL1391837 & 688620 & 5.45 & 5.078 & TRN & \\
\hline CHEMBL1982991 & 688620 & 6.25 & 5.6954 & TRN & \\
\hline CHEMBL1534356 & 688620 & 4.5 & 4.9357 & TRN & \\
\hline CHEMBL1350622 & 688620 & 5.9 & 5.4157 & TRN & \\
\hline CHEMBL1522804 & 688620 & 8.2007 & 5.0578 & TRN & \\
\hline CHEMBL1423407 & 688620 & 4.8 & 4.8054 & TRN & \\
\hline CHEMBL1516826 & 688620 & 5.2 & 4.9043 & TRN & \\
\hline CHEMBL1334903 & 688620 & 4.45 & 4.8615 & TST & \\
\hline CHEMBL1601318 & 688620 & 6.45 & 5.2581 & TRN & \\
\hline CHEMBL3190321 & 688620 & 5.45 & 5.274 & TRN & \\
\hline CHEMBL1528926 & 688620 & 5.6 & 4.8946 & TRN & \\
\hline CHEMBL1568716 & 688620 & 5.35 & 5.6744 & TRN & \\
\hline CHEMBL1463988 & 688620 & 6.35 & 5.5799 & TRN & \\
\hline CHEMBL1422269 & 688620 & 4.9 & 5.0356 & TRN & \\
\hline CHEMBL1497524 & 688620 & 5.05 & 5.2123 & TST & \\
\hline CHEMBL1383668 & 688620 & 4.95 & 5.0648 & TST & \\
\hline CHEMBL1451905 & 688620 & 4.95 & 4.9066 & TST & \\
\hline CHEMBL1380252 & 688620 & 7.0 & 5.1768 & TRN & \\
\hline CHEMBL1354242 & 688620 & 4.7 & 4.9627 & TST & \\
\hline CHEMBL1308481 & 688620 & 4.8 & 4.9788 & TST & \\
\hline CHEMBL1418181 & 688620 & 4.7 & 4.9419 & TST & \\
\hline CHEMBL1586070 & 688620 & 5.0 & 5.0625 & TRN & \\
\hline CHEMBL75412 & 688620 & 4.45 & 4.7887 & TRN & \\
\hline
\end{tabular}




\begin{tabular}{|c|c|c|c|c|}
\hline \multicolumn{5}{|c|}{ Supplemental Table S2.txt } \\
\hline CHEMBL1442670 & 688620 & 4.45 & 4.9324 & TRN \\
\hline CHEMBL1440890 & 688620 & 4.55 & 4.9582 & TRN \\
\hline CHEMBL1508400 & 688620 & 4.9 & 4.9908 & TST \\
\hline CHEMBL1368439 & 688620 & 6.1 & 5.0728 & TST \\
\hline CHEMBL 3199441 & 688620 & 5.45 & 5.2397 & TRN \\
\hline CHEMBL1483028 & 688620 & 5.6 & 5.2919 & TST \\
\hline CHEMBL1540058 & 688620 & 4.65 & 5.2955 & TRN \\
\hline CHEMBL1365192 & 688620 & 6.35 & 5.0241 & TST \\
\hline CHEMBL1360883 & 688620 & 4.65 & 5.5182 & TRN \\
\hline CHEMBL3190379 & 688620 & 6.2 & 5.3476 & TRN \\
\hline CHEMBL1525809 & 688620 & 4.9 & 5.0811 & TRN \\
\hline CHEMBL 3189154 & 688620 & 4.95 & 4.9913 & TRN \\
\hline CHEMBL1322689 & 688620 & 5.35 & 5.2266 & TRN \\
\hline CHEMBL1521225 & 688620 & 4.95 & 5.0271 & TRN \\
\hline CHEMBL1564871 & 688620 & 5.1 & 5.0263 & TRN \\
\hline CHEMBL3213363 & 688620 & 5.0 & 5.0575 & TRN \\
\hline CHEMBL1597276 & 688620 & 4.9 & 5.2574 & TRN \\
\hline CHEMBL 3209870 & 688620 & 4.65 & 4.8639 & TRN \\
\hline CHEMBL1400472 & 688620 & 4.7 & 4.9626 & TRN \\
\hline CHEMBL1595336 & 688620 & 4.75 & 4.8022 & TRN \\
\hline CHEMBL1789993 & 688620 & 5.45 & 5.0103 & TRN \\
\hline CHEMBL1453218 & 688620 & 5.7 & 5.2302 & TRN \\
\hline CHEMBL1559178 & 688620 & 6.6499 & 5.1182 & TRN \\
\hline CHEMBL 3190748 & 688620 & 4.75 & 5.2948 & TRN \\
\hline CHEMBL1465006 & 688620 & 4.9 & 4.9201 & TST \\
\hline CHEMBL1464040 & 688620 & 6.3 & 4.9176 & TRN \\
\hline CHEMBL3194330 & 688620 & 4.75 & 5.0329 & TST \\
\hline CHEMBL 261055 & 688620 & 5.15 & 5.3401 & TRN \\
\hline CHEMBL1371502 & 688620 & 5.45 & 5.0563 & TRN \\
\hline CHEMBL1453582 & 688620 & 4.8 & 4.9469 & TST \\
\hline CHEMBL1579716 & 688620 & 4.95 & 4.8693 & TRN \\
\hline CHEMBL1389268 & 688620 & 5.5 & 5.647 & TRN \\
\hline CHEMBL3212436 & 688620 & 4.75 & 5.0122 & TST \\
\hline CHEMBL1341978 & 688620 & 4.9 & 4.8746 & TST \\
\hline CHEMBL1505420 & 688620 & 4.9 & 4.8094 & TRN \\
\hline CHEMBL1346550 & 688620 & 4.55 & 4.7164 & TST \\
\hline CHEMBL1306400 & 688620 & 4.45 & 5.0084 & TST \\
\hline CHEMBL1332829 & 688620 & 4.65 & 5.0014 & TRN \\
\hline CHEMBL1319928 & 688620 & 4.45 & 4.9954 & TRN \\
\hline CHEMBL1353430 & 688620 & 8.301 & 5.1981 & TST \\
\hline CHEMBL1497547 & 688620 & 4.8 & 5.2122 & TST \\
\hline CHEMBL1610173 & 688620 & 5.25 & 5.3971 & TRN \\
\hline CHEMBL1480666 & 688620 & 6.8499 & 5.2434 & TRN \\
\hline CHEMBL1390667 & 688620 & 4.45 & 5.0524 & TRN \\
\hline CHEMBL1517493 & 688620 & 4.95 & 4.7696 & TST \\
\hline CHEMBL 257286 & 688620 & 6.0 & 5.9118 & TRN \\
\hline CHEMBL1329421 & 688620 & 4.5 & 5.1326 & TRN \\
\hline CHEMBL1421223 & 688620 & 5.25 & 4.8794 & TRN \\
\hline
\end{tabular}




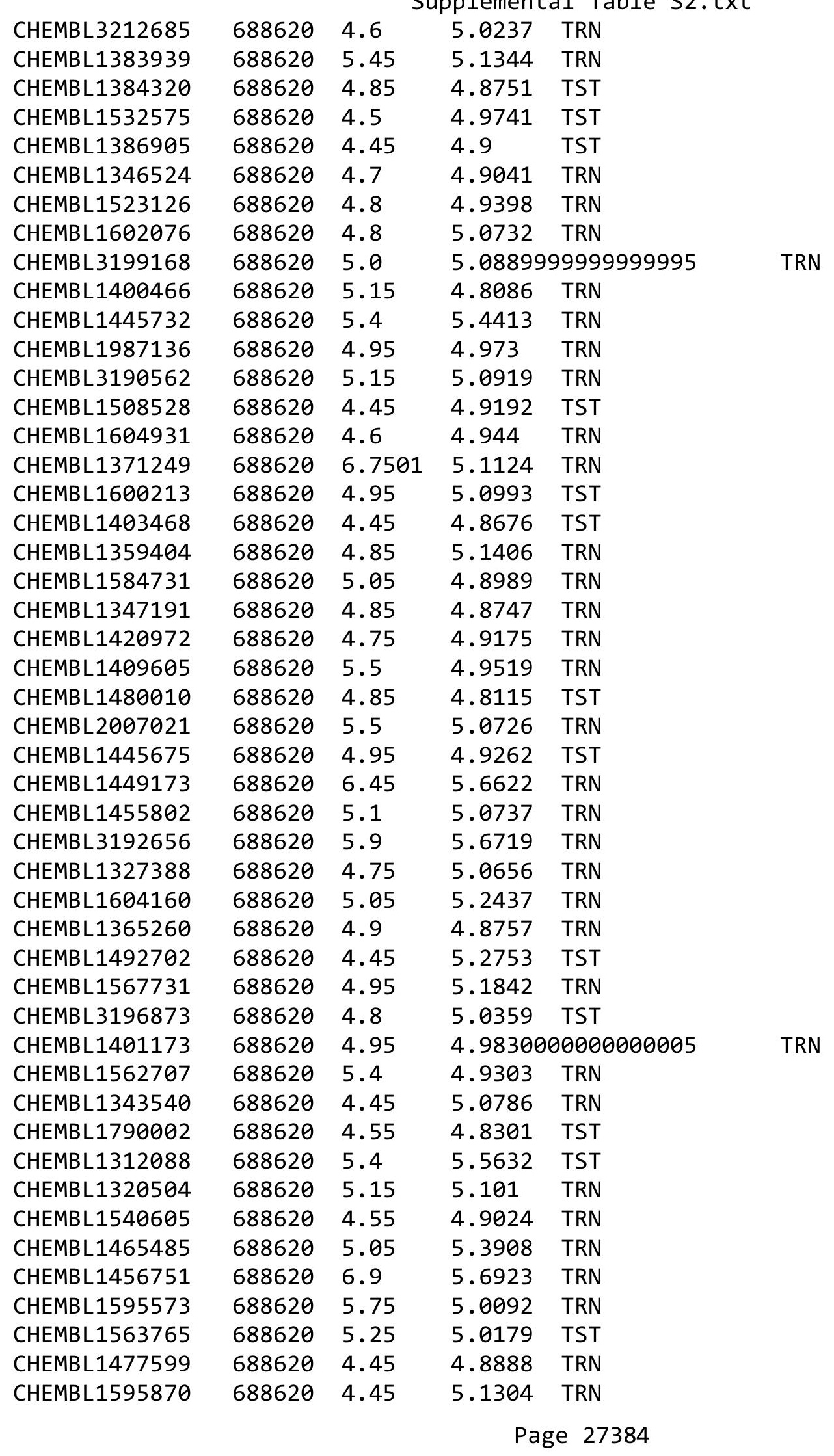




\begin{tabular}{|c|c|c|c|c|c|}
\hline & & \multicolumn{4}{|c|}{ Supplemental Table s2.txt } \\
\hline CHEMBL1502731 & 688620 & 5.05 & 5.1357 & TRN & \\
\hline CHEMBL1478242 & 688620 & 5.6 & 5.0124 & TST & \\
\hline CHEMBL1402668 & 688620 & 4.65 & 5.0101 & TRN & \\
\hline CHEMBL1526273 & 688620 & 5.45 & 4.9416 & TRN & \\
\hline CHEMBL 3213210 & 688620 & 4.9 & 4.9728 & TRN & \\
\hline CHEMBL1602810 & 688620 & 5.15 & 4.8559 & TRN & \\
\hline CHEMBL1572185 & 688620 & 4.6 & 5.1978 & TST & \\
\hline CHEMBL1588489 & 688620 & 5.2 & 5.1916 & TST & \\
\hline CHEMBL1410548 & 688620 & 4.95 & 5.0205 & TRN & \\
\hline CHEMBL1605120 & 688620 & 5.85 & 5.1039 & TRN & \\
\hline CHEMBL1362914 & 688620 & 4.7 & 4.8441 & TRN & \\
\hline CHEMBL1468873 & 688620 & 4.55 & 4.9303 & TRN & \\
\hline CHEMBL1475077 & 688620 & 4.45 & 4.7137 & TRN & \\
\hline CHEMBL1597250 & 688620 & 5.25 & 5.5308 & TRN & \\
\hline CHEMBL1407543 & 688620 & 6.1 & 5.5368 & TRN & \\
\hline CHEMBL1572139 & 688620 & 6.95 & 5.7002 & TRN & \\
\hline CHEMBL1302305 & 688620 & 6.1 & 5.278 & TST & \\
\hline CHEMBL1608171 & 688620 & 4.45 & 4.8575 & TRN & \\
\hline CHEMBL1502230 & 688620 & 4.7 & 4.8416 & TST & \\
\hline CHEMBL3209643 & 688620 & 4.95 & 4.9356 & TRN & \\
\hline CHEMBL1345298 & 688620 & 4.45 & 5.0431 & TST & \\
\hline CHEMBL1545306 & 688620 & 4.9 & 4.9319 & TRN & \\
\hline CHEMBL1471064 & 688620 & 4.45 & 5.1099 & TST & \\
\hline CHEMBL1360591 & 688620 & 4.8 & 4.6568 & TRN & \\
\hline CHEMBL1606697 & 688620 & 6.2 & 5.3039 & TRN & \\
\hline CHEMBL1491028 & 688620 & 5.7 & 5.1293 & TRN & \\
\hline CHEMBL1583924 & 688620 & 5.95 & 4.717 & TRN & \\
\hline CHEMBL1422180 & 688620 & 5.3 & 4.8295 & TST & \\
\hline CHEMBL1347079 & 688620 & 5.05 & 5.2248 & TRN & \\
\hline CHEMBL1338014 & 688620 & 5.0 & 5.0388 & TRN & \\
\hline CHEMBL1421533 & 688620 & 4.65 & 4.9204 & TST & \\
\hline CHEMBL1519347 & 688620 & 5.55 & 4.8844 & TRN & \\
\hline CHEMBL1532268 & 688620 & 4.45 & 4.8409 & TRN & \\
\hline CHEMBL1557557 & 688620 & 4.95 & 5.2337 & TRN & \\
\hline CHEMBL1562110 & 688620 & 4.45 & 5.3623 & TRN & \\
\hline CHEMBL1525576 & 688620 & 5.3 & 5.1742 & TRN & \\
\hline CHEMBL1362844 & 688620 & 5.15 & 5.2019 & TRN & \\
\hline CHEMBL1489407 & 688620 & 5.6 & 5.6235 & TRN & \\
\hline CHEMBL1539560 & 688620 & 5.65 & 5.3545 & TRN & \\
\hline CHEMBL3198597 & 688620 & 5.0 & 4.9023 & TST & \\
\hline CHEMBL1536572 & 688620 & 5.9 & 5.6031 & TRN & \\
\hline CHEMBL1385812 & 688620 & 4.9 & 5.0229 & TST & \\
\hline CHEMBL1500767 & 688620 & 4.45 & 4.7561 & TRN & \\
\hline CHEMBL1550444 & 688620 & 5.25 & 4.92899 & 9999999999 & TRN \\
\hline CHEMBL1498443 & 688620 & 5.25 & 4.9946 & TST & \\
\hline CHEMBL1424589 & 688620 & 4.8 & 4.9744 & TRN & \\
\hline CHEMBL1427962 & 688620 & 4.65 & 4.982 & TRN & \\
\hline CHEMBL3210852 & 688620 & 5.2 & 5.1886 & TST & \\
\hline
\end{tabular}




\begin{tabular}{|c|c|c|c|c|}
\hline \multicolumn{5}{|c|}{ Supplemental Table S2.txt } \\
\hline CHEMBL1342868 & 688620 & 4.8 & 4.9314 & TRN \\
\hline CHEMBL1581949 & 688620 & 5.25 & 5.3477 & TRN \\
\hline CHEMBL1457406 & 688620 & 4.45 & 5.0728 & TRN \\
\hline CHEMBL1539107 & 688620 & 4.8 & 5.2341 & TST \\
\hline CHEMBL1319652 & 688620 & 4.45 & 4.8248 & TRN \\
\hline CHEMBL1371049 & 688620 & 5.0 & 5.3727 & TRN \\
\hline CHEMBL1417064 & 688620 & 8.2518 & 5.38 & TRN \\
\hline CHEMBL1384205 & 688620 & 4.95 & 4.8094 & TST \\
\hline CHEMBL1558479 & 688620 & 5.2 & 5.0483 & TRN \\
\hline CHEMBL1337367 & 688620 & 4.95 & 5.5242 & TRN \\
\hline CHEMBL1393553 & 688620 & 5.3 & 5.1193 & TRN \\
\hline CHEMBL579859 & 688620 & 4.95 & 4.8032 & TRN \\
\hline CHEMBL1611336 & 688620 & 4.9 & 4.9149 & TST \\
\hline CHEMBL1527735 & 688620 & 4.75 & 5.2903 & TST \\
\hline CHEMBL1609060 & 688620 & 4.55 & 4.9216 & TRN \\
\hline CHEMBL1369623 & 688620 & 5.0 & 5.0324 & TRN \\
\hline CHEMBL1388764 & 688620 & 5.0 & 5.2284 & TRN \\
\hline CHEMBL1575625 & 688620 & 4.45 & 5.0214 & TRN \\
\hline CHEMBL1335843 & 688620 & 6.0 & 5.3672 & TRN \\
\hline CHEMBL1404615 & 688620 & 5.15 & 4.9849 & TRN \\
\hline CHEMBL1327333 & 688620 & 4.45 & 4.9769 & TRN \\
\hline CHEMBL1500642 & 688620 & 5.1 & 5.1204 & TRN \\
\hline CHEMBL1401302 & 688620 & 5.0 & 4.9292 & TST \\
\hline CHEMBL1307272 & 688620 & 5.1 & 5.1564 & TST \\
\hline CHEMBL578915 & 688620 & 4.95 & 4.8226 & TRN \\
\hline CHEMBL1366670 & 688620 & 5.1 & 5.2063 & TRN \\
\hline CHEMBL1540191 & 688620 & 4.8 & 5.3285 & TRN \\
\hline CHEMBL1428343 & 688620 & 4.45 & 4.9972 & TST \\
\hline CHEMBL1549738 & 688620 & 4.65 & 5.005 & TST \\
\hline CHEMBL1565919 & 688620 & 4.95 & 5.0088 & TRN \\
\hline CHEMBL1533593 & 688620 & 4.5 & 5.0231 & TRN \\
\hline CHEMBL1584150 & 688620 & 5.15 & 5.1253 & TST \\
\hline CHEMBL1422471 & 688620 & 4.85 & 4.8933 & TRN \\
\hline CHEMBL1380600 & 688620 & 5.0 & 5.2427 & TRN \\
\hline CHEMBL1431991 & 688620 & 4.45 & 5.1596 & TRN \\
\hline CHEMBL1333989 & 688620 & 5.2 & 5.0459 & TRN \\
\hline CHEMBL1458067 & 688620 & 5.2 & 5.1129 & TRN \\
\hline CHEMBL1371912 & 688620 & 4.45 & 4.9223 & TST \\
\hline CHEMBL1481505 & 688620 & 5.05 & 5.152 & TST \\
\hline CHEMBL1450497 & 688620 & 8.301 & 6.7541 & TRN \\
\hline CHEMBL1421117 & 688620 & 4.85 & 5.2768 & TRN \\
\hline CHEMBL1408630 & 688620 & 5.0 & 5.17299 & 9999999999 \\
\hline CHEMBL1448282 & 688620 & 5.65 & 5.7799 & TRN \\
\hline CHEMBL1497327 & 688620 & 4.45 & 5.1909 & TRN \\
\hline CHEMBL1593559 & 688620 & 5.3 & 4.8067 & TRN \\
\hline CHEMBL1371520 & 688620 & 4.8 & 4.9562 & TRN \\
\hline CHEMBL1477425 & 688620 & 4.8 & 4.8456 & TRN \\
\hline CHEMBL1412968 & 688620 & 5.75 & 4.9329 & TST \\
\hline
\end{tabular}

TRN 


\begin{tabular}{|c|c|c|c|c|c|}
\hline \multicolumn{6}{|c|}{ Supplemental Table S2.txt } \\
\hline CHEMBL1344723 & 688620 & 4.95 & 5.0915 & TRN & \\
\hline CHEMBL1413825 & 688620 & 5.3 & 5.4188 & TRN & \\
\hline CHEMBL1343670 & 688620 & 4.95 & 4.8945 & TRN & \\
\hline CHEMBL1619026 & 688620 & 4.95 & 4.7774 & TST & \\
\hline CHEMBL1485307 & 688620 & 4.85 & 5.0266 & TRN & \\
\hline CHEMBL1385236 & 688620 & 4.45 & 5.0664 & TRN & \\
\hline CHEMBL1454747 & 688620 & 5.2 & 5.2007 & TRN & \\
\hline CHEMBL1305446 & 688620 & 5.4 & 5.2676 & TST & \\
\hline CHEMBL1484278 & 688620 & 5.4 & 4.827 & TST & \\
\hline CHEMBL1576405 & 688620 & 5.85 & 5.7333 & TRN & \\
\hline CHEMBL310798 & 688620 & 4.65 & 4.8066 & TRN & \\
\hline CHEMBL1342653 & 688620 & 4.65 & 5.1971 & TRN & \\
\hline CHEMBL1530412 & 688620 & 4.95 & 5.2604 & TRN & \\
\hline CHEMBL1420354 & 688620 & 4.7 & 4.7722 & TRN & \\
\hline CHEMBL1453868 & 688620 & 5.0 & 4.8286 & TRN & \\
\hline CHEMBL 3189243 & 688620 & 4.9 & 4.9645 & TST & \\
\hline CHEMBL1609235 & 688620 & 4.45 & 5.0155 & TRN & \\
\hline CHEMBL1594242 & 688620 & 4.65 & 5.1021 & TST & \\
\hline CHEMBL1441782 & 688620 & 5.8 & 5.8345 & TRN & \\
\hline CHEMBL1457998 & 688620 & 5.05 & 5.0787 & TRN & \\
\hline CHEMBL1605016 & 688620 & 4.9 & 5.0193 & TRN & \\
\hline CHEMBL1450897 & 688620 & 4.45 & 5.1203 & TST & \\
\hline CHEMBL1610923 & 688620 & 4.9 & 4.7805 & TRN & \\
\hline CHEMBL1391518 & 688620 & 5.2 & 5.0328 & TRN & \\
\hline CHEMBL 2069121 & 688620 & 5.65 & 5.13700 & 00000000005 & TRN \\
\hline CHEMBL1534306 & 688620 & 4.45 & 4.7461 & TST & \\
\hline CHEMBL1537418 & 688620 & 5.25 & 5.3114 & TRN & \\
\hline CHEMBL3198345 & 688620 & 4.95 & 5.0662 & TRN & \\
\hline CHEMBL1343656 & 688620 & 5.0 & 4.8325 & TRN & \\
\hline CHEMBL1465927 & 688620 & 4.45 & 5.1851 & TST & \\
\hline CHEMBL1537962 & 688620 & 5.15 & 5.1823 & TST & \\
\hline CHEMBL324389 & 688620 & 4.8 & 5.1473 & TRN & \\
\hline CHEMBL1491627 & 688620 & 4.75 & 4.99 & TRN & \\
\hline CHEMBL1441634 & 688620 & 4.95 & 4.7613 & TRN & \\
\hline CHEMBL1442410 & 688620 & 5.15 & 5.0865 & TST & \\
\hline CHEMBL1364384 & 688620 & 4.45 & 4.9582 & TRN & \\
\hline CHEMBL1333961 & 688620 & 4.45 & 5.0862 & TST & \\
\hline CHEMBL1450241 & 688620 & 4.9 & 4.9048 & TST & \\
\hline CHEMBL1453896 & 688620 & 4.7 & 5.1353 & TRN & \\
\hline CHEMBL1504415 & 688620 & 4.85 & 5.0087 & TST & \\
\hline CHEMBL1501873 & 688620 & 6.8 & 5.0378 & TST & \\
\hline CHEMBL1567944 & 688620 & 6.0 & 6.1855 & TRN & \\
\hline CHEMBL3214173 & 688620 & 4.45 & 4.82 & TRN & \\
\hline CHEMBL1611041 & 688620 & 4.65 & 4.6595 & TST & \\
\hline CHEMBL1338475 & 688620 & 5.6 & 5.8179 & TRN & \\
\hline CHEMBL1997112 & 688620 & 4.7 & 4.918 & TST & \\
\hline CHEMBL1482245 & 688620 & 4.9 & 4.9316 & TRN & \\
\hline CHEMBL1509029 & 688620 & 4.5 & 4.9936 & TRN & \\
\hline
\end{tabular}




\begin{tabular}{|c|c|c|c|c|}
\hline \multicolumn{5}{|c|}{ Supplemental Table S2.txt } \\
\hline CHEMBL1535222 & 688620 & 4.5 & 4.9171 & TRN \\
\hline CHEMBL1382820 & 688620 & 5.35 & 5.4282 & TST \\
\hline CHEMBL3194497 & 688620 & 5.55 & 5.3084 & TRN \\
\hline CHEMBL1362011 & 688620 & 5.4 & 5.1742 & TRN \\
\hline CHEMBL1375093 & 688620 & 4.8 & 4.9311 & TRN \\
\hline CHEMBL1511593 & 688620 & 4.6 & 5.2247 & TRN \\
\hline CHEMBL1484180 & 688620 & 4.45 & 5.0319 & TST \\
\hline CHEMBL1399351 & 688620 & 5.05 & 4.9618 & TRN \\
\hline CHEMBL1547805 & 688620 & 5.0 & 4.9591 & TRN \\
\hline CHEMBL1448060 & 688620 & 4.85 & 5.1859 & TRN \\
\hline CHEMBL1486591 & 688620 & 5.0 & 4.9562 & TRN \\
\hline CHEMBL1504775 & 688620 & 5.7 & 5.3752 & TRN \\
\hline CHEMBL534084 & 688620 & 4.45 & 4.8878 & TRN \\
\hline CHEMBL1999149 & 688620 & 4.95 & 4.9116 & TST \\
\hline CHEMBL1311398 & 688620 & 5.0 & 5.0255 & TRN \\
\hline CHEMBL1412492 & 688620 & 4.9 & 5.1718 & TRN \\
\hline CHEMBL1386721 & 688620 & 4.45 & 4.8187 & TST \\
\hline CHEMBL1343313 & 688620 & 4.5 & 5.0707 & TRN \\
\hline CHEMBL3212330 & 688620 & 5.8 & 5.3043 & TST \\
\hline CHEMBL1390617 & 688620 & 4.9 & 5.1435 & TRN \\
\hline CHEMBL1500921 & 688620 & 5.1 & 4.9921 & TRN \\
\hline CHEMBL3191080 & 688620 & 5.65 & 5.1064 & TST \\
\hline CHEMBL1561421 & 688620 & 5.45 & 4.9149 & TST \\
\hline CHEMBL1425756 & 688620 & 4.6 & 4.9675 & TRN \\
\hline CHEMBL1382587 & 688620 & 5.1 & 4.9514 & TRN \\
\hline CHEMBL24510 & 688620 & 6.0 & 5.7317 & TRN \\
\hline CHEMBL1568436 & 688620 & 4.65 & 5.1642 & TRN \\
\hline CHEMBL1502386 & 688620 & 5.05 & 4.8709 & TRN \\
\hline CHEMBL3197849 & 688620 & 4.95 & 4.9705 & TRN \\
\hline CHEMBL1585300 & 688620 & 4.75 & 5.0399 & TRN \\
\hline CHEMBL3193439 & 688620 & 4.45 & 4.7566 & TST \\
\hline CHEMBL3209373 & 688620 & 4.9 & 4.9406 & TST \\
\hline CHEMBL1401868 & 688620 & 4.7 & 4.971 & TRN \\
\hline CHEMBL1544511 & 688620 & 4.75 & 5.0297 & TRN \\
\hline CHEMBL1556856 & 688620 & 4.9 & 5.2459 & TRN \\
\hline CHEMBL1568203 & 688620 & 4.45 & 5.0386 & TRN \\
\hline CHEMBL3198022 & 688620 & 5.2 & 5.1176 & TRN \\
\hline CHEMBL1375782 & 688620 & 5.85 & 5.2176 & TST \\
\hline CHEMBL1446477 & 688620 & 4.45 & 4.8887 & TRN \\
\hline CHEMBL1385544 & 688620 & 4.75 & 5.0571 & TRN \\
\hline CHEMBL1399835 & 688620 & 5.15 & 5.0964 & TRN \\
\hline CHEMBL1443499 & 688620 & 5.45 & 5.4755 & TRN \\
\hline CHEMBL1412862 & 688620 & 4.45 & 5.1393 & TST \\
\hline CHEMBL1444371 & 688620 & 5.65 & 5.2717 & TRN \\
\hline CHEMBL1534174 & 688620 & 6.05 & 5.1856 & TRN \\
\hline CHEMBL1559139 & 688620 & 4.9 & 5.0406 & TRN \\
\hline CHEMBL1388025 & 688620 & 4.45 & 4.9703 & TRN \\
\hline CHEMBL1583463 & 688620 & 4.45 & 5.0927 & TST \\
\hline
\end{tabular}




\begin{tabular}{|c|c|c|c|c|}
\hline \multicolumn{5}{|c|}{ Supplemental Table S2.txt } \\
\hline CHEMBL1605577 & 688620 & 5.0 & 5.0357 & TRN \\
\hline CHEMBL1407181 & 688620 & 5.2 & 5.2405 & TST \\
\hline CHEMBL1612699 & 688620 & 5.2 & 5.0731 & TRN \\
\hline CHEMBL1531630 & 688620 & 6.8 & 5.0837 & TRN \\
\hline CHEMBL1393506 & 688620 & 5.45 & 4.8965 & TST \\
\hline CHEMBL1440100 & 688620 & 4.95 & 5.0088 & TST \\
\hline CHEMBL1456729 & 688620 & 5.1 & 5.0789 & TST \\
\hline CHEMBL1432227 & 688620 & 5.25 & 5.2765 & TRN \\
\hline CHEMBL1568577 & 688620 & 5.2 & 5.0203 & TRN \\
\hline CHEMBL1371319 & 688620 & 5.7 & 4.8531 & TRN \\
\hline CHEMBL1967744 & 688620 & 6.15 & 5.4962 & TRN \\
\hline CHEMBL1445481 & 688620 & 5.0 & 4.7936 & TRN \\
\hline CHEMBL3210913 & 688620 & 4.75 & 4.9971 & TRN \\
\hline CHEMBL1312320 & 688620 & 4.95 & 4.8877 & TRN \\
\hline CHEMBL3196619 & 688620 & 6.25 & 5.8332 & TRN \\
\hline CHEMBL1394086 & 688620 & 6.7501 & 5.1351 & TST \\
\hline CHEMBL1583011 & 688620 & 4.55 & 4.7915 & TRN \\
\hline CHEMBL1584547 & 688620 & 4.45 & 5.1133 & TRN \\
\hline CHEMBL1301129 & 688620 & 4.45 & 4.5829 & TRN \\
\hline CHEMBL1427338 & 688620 & 4.45 & 4.8699 & TRN \\
\hline CHEMBL3144931 & 688620 & 6.95 & 5.9448 & TRN \\
\hline CHEMBL1545456 & 688620 & 5.0 & 5.0237 & TST \\
\hline CHEMBL1371623 & 688620 & 4.7 & 4.9335 & TRN \\
\hline CHEMBL1445710 & 688620 & 5.2 & 5.0955 & TRN \\
\hline CHEMBL3197452 & 688620 & 5.85 & 5.5818 & TRN \\
\hline CHEMBL1540241 & 688620 & 5.0 & 4.9681 & TRN \\
\hline CHEMBL1588190 & 688620 & 4.45 & 4.8726 & TRN \\
\hline CHEMBL3207377 & 688620 & 4.8 & 5.0565 & TST \\
\hline CHEMBL1414720 & 688620 & 4.7 & 5.1478 & TRN \\
\hline CHEMBL1405555 & 688620 & 4.7 & 5.0593 & TRN \\
\hline CHEMBL1486372 & 688620 & 4.9 & 5.1281 & TST \\
\hline CHEMBL 3212868 & 688620 & 5.6 & 5.3184 & TRN \\
\hline CHEMBL3196460 & 688620 & 4.95 & 5.0065 & TRN \\
\hline CHEMBL1567224 & 688620 & 4.95 & 5.115 & TRN \\
\hline CHEMBL1499747 & 688620 & 5.45 & 5.2766 & TRN \\
\hline CHEMBL1320016 & 688620 & 4.45 & 4.8928 & TRN \\
\hline CHEMBL1509671 & 688620 & 5.3 & 5.2235 & TST \\
\hline CHEMBL524222 & 688620 & 4.8 & 5.0504 & TRN \\
\hline CHEMBL1439954 & 688620 & 4.95 & 5.7377 & TRN \\
\hline CHEMBL1429849 & 688620 & 4.85 & 5.0418 & TST \\
\hline CHEMBL1329081 & 688620 & 5.0 & 5.3207 & TST \\
\hline CHEMBL1582685 & 688620 & 4.7 & 5.0796 & TRN \\
\hline CHEMBL1453369 & 688620 & 5.35 & 5.0112 & TRN \\
\hline CHEMBL3199682 & 688620 & 5.35 & 5.0764 & TRN \\
\hline CHEMBL1330911 & 688620 & 4.75 & 4.9238 & TRN \\
\hline CHEMBL1430456 & 688620 & 4.95 & 4.6174 & TRN \\
\hline CHEMBL1594432 & 688620 & 4.6 & 4.7375 & TRN \\
\hline CHEMBL1419563 & 688620 & 4.65 & 4.8443 & TRN \\
\hline
\end{tabular}




\begin{tabular}{|c|c|c|c|c|}
\hline \multicolumn{5}{|c|}{ Supplemental Table S2.txt } \\
\hline CHEMBL1382433 & 688620 & 4.9 & 5.1527 & TST \\
\hline CHEMBL1612772 & 688620 & 5.2 & 5.0935 & TRN \\
\hline CHEMBL1407241 & 688620 & 5.65 & 5.36 & TRN \\
\hline CHEMBL1549854 & 688620 & 5.0 & 5.0592 & TRN \\
\hline CHEMBL1390565 & 688620 & 6.5501 & 5.8159 & TRN \\
\hline CHEMBL1483542 & 688620 & 4.9 & 5.0866 & TRN \\
\hline CHEMBL3208696 & 688620 & 5.35 & 4.9648 & TRN \\
\hline CHEMBL1378644 & 688620 & 5.15 & 5.2157 & TST \\
\hline CHEMBL1406793 & 688620 & 4.75 & 4.8419 & TRN \\
\hline CHEMBL1599084 & 688620 & 5.45 & 5.1636 & TRN \\
\hline CHEMBL2436539 & 688620 & 4.45 & 5.1873 & TRN \\
\hline CHEMBL1429321 & 688620 & 5.15 & 4.9843 & TRN \\
\hline CHEMBL1444518 & 688620 & 6.2 & 5.9248 & TRN \\
\hline CHEMBL1407968 & 688620 & 4.5 & 4.9622 & TRN \\
\hline CHEMBL1321730 & 688620 & 6.1 & 5.0524 & TST \\
\hline CHEMBL1423761 & 688620 & 4.65 & 4.7888 & TST \\
\hline CHEMBL1541776 & 688620 & 4.45 & 5.2693 & TST \\
\hline CHEMBL1510337 & 688620 & 4.45 & 4.8758 & TRN \\
\hline CHEMBL 3210417 & 688620 & 4.45 & 5.0475 & TST \\
\hline CHEMBL1385676 & 688620 & 6.0 & 5.9299 & TRN \\
\hline CHEMBL1461485 & 688620 & 5.0 & 4.7738 & TRN \\
\hline CHEMBL1465115 & 688620 & 4.8 & 5.1632 & TRN \\
\hline CHEMBL1558717 & 688620 & 5.4 & 5.0843 & TRN \\
\hline CHEMBL1507555 & 688620 & 4.45 & 5.0657 & TST \\
\hline CHEMBL1410002 & 688620 & 4.45 & 5.1485 & TST \\
\hline CHEMBL3197409 & 688620 & 4.45 & 5.2625 & TST \\
\hline CHEMBL1577345 & 688620 & 4.8 & 4.7916 & TST \\
\hline CHEMBL1567488 & 688620 & 4.5 & 4.8584 & TRN \\
\hline CHEMBL1439433 & 688620 & 4.95 & 5.1222 & TST \\
\hline CHEMBL1439346 & 688620 & 4.45 & 5.0855 & TRN \\
\hline CHEMBL1601859 & 688620 & 5.05 & 4.9738 & TRN \\
\hline CHEMBL1474674 & 688620 & 5.8 & 5.2935 & TST \\
\hline CHEMBL1460897 & 688620 & 4.5 & 4.7522 & TST \\
\hline CHEMBL1588835 & 688620 & 7.15 & 5.0184 & TRN \\
\hline CHEMBL1505116 & 688620 & 6.05 & 4.7515 & TRN \\
\hline CHEMBL1327674 & 688620 & 5.9 & 4.9034 & TRN \\
\hline CHEMBL1460651 & 688620 & 4.95 & 4.9727 & TRN \\
\hline CHEMBL1488633 & 688620 & 5.55 & 5.1603 & TRN \\
\hline CHEMBL1361999 & 688620 & 5.75 & 5.0648 & TRN \\
\hline CHEMBL1467955 & 688620 & 4.5 & 4.9592 & TRN \\
\hline CHEMBL1368039 & 688620 & 5.0 & 5.0967 & TRN \\
\hline CHEMBL3193934 & 688620 & 4.95 & 5.0628 & TRN \\
\hline CHEMBL1528784 & 688620 & 4.65 & 4.9187 & TRN \\
\hline CHEMBL1575967 & 688620 & 5.05 & 5.2612 & TST \\
\hline CHEMBL1613166 & 688620 & 4.7 & 5.1865 & TRN \\
\hline CHEMBL1993555 & 688620 & 4.45 & 4.8419 & TRN \\
\hline CHEMBL1499155 & 688620 & 4.45 & 4.8632 & TRN \\
\hline CHEMBL1495240 & 688620 & 4.85 & 4.8722 & TRN \\
\hline
\end{tabular}




\begin{tabular}{|c|c|c|c|c|}
\hline \multicolumn{5}{|c|}{ Supplemental Table S2.txt } \\
\hline CHEMBL1511486 & 688620 & 5.1 & 5.0353 & TRN \\
\hline CHEMBL1548192 & 688620 & 5.1 & 4.9643 & TRN \\
\hline CHEMBL1335352 & 688620 & 4.45 & 4.86600 & 20000000005 \\
\hline CHEMBL1599741 & 688620 & 5.8 & 4.9219 & TRN \\
\hline CHEMBL1302367 & 688620 & 4.9 & 5.0565 & TRN \\
\hline CHEMBL1584466 & 688620 & 6.05 & 5.1197 & TRN \\
\hline CHEMBL1585869 & 688620 & 4.95 & 4.8622 & TRN \\
\hline CHEMBL3193819 & 688620 & 6.05 & 5.2103 & TST \\
\hline CHEMBL1429262 & 688620 & 4.8 & 4.8837 & TST \\
\hline CHEMBL1362803 & 688620 & 4.65 & 5.0145 & TRN \\
\hline CHEMBL3190632 & 688620 & 5.0 & 5.2632 & TRN \\
\hline CHEMBL1570205 & 688620 & 4.9 & 5.131 & TRN \\
\hline CHEMBL1380251 & 688620 & 8.5528 & 8.0741 & TRN \\
\hline CHEMBL1517919 & 688620 & 5.25 & 4.6116 & TRN \\
\hline CHEMBL1302740 & 688620 & 4.95 & 4.9674 & TST \\
\hline CHEMBL1598843 & 688620 & 4.45 & 4.879 & TRN \\
\hline CHEMBL1586094 & 688620 & 5.35 & 5.0429 & TRN \\
\hline CHEMBL1497141 & 688620 & 5.55 & 5.6481 & TRN \\
\hline CHEMBL1538799 & 688620 & 5.1 & 5.0566 & TRN \\
\hline CHEMBL1497685 & 688620 & 4.8 & 4.7856 & TRN \\
\hline CHEMBL1383863 & 688620 & 5.0 & 4.874 & TRN \\
\hline CHEMBL1463268 & 688620 & 5.4 & 5.5102 & TRN \\
\hline CHEMBL1390139 & 688620 & 4.6 & 4.6678 & TST \\
\hline CHEMBL 3209543 & 688620 & 5.25 & 5.1369 & TRN \\
\hline CHEMBL1454811 & 688620 & 4.85 & 4.919 & TST \\
\hline CHEMBL1430406 & 688620 & 4.8 & 5.0405 & TRN \\
\hline CHEMBL1995769 & 688620 & 4.5 & 5.0015 & TRN \\
\hline CHEMBL1587810 & 688620 & 5.15 & 5.3712 & TST \\
\hline CHEMBL1530856 & 688620 & 4.95 & 5.0367 & TRN \\
\hline CHEMBL1378818 & 688620 & 4.85 & 4.8783 & TRN \\
\hline CHEMBL1520559 & 688620 & 6.0 & 5.5226 & TRN \\
\hline CHEMBL1362516 & 688620 & 5.0 & 4.9442 & TRN \\
\hline CHEMBL1599829 & 688620 & 4.45 & 4.8415 & TRN \\
\hline CHEMBL1382364 & 688620 & 4.6 & 4.9693 & TRN \\
\hline CHEMBL3213463 & 688620 & 5.55 & 5.1601 & TRN \\
\hline CHEMBL1389370 & 688620 & 4.45 & 4.9857 & TRN \\
\hline CHEMBL1482891 & 688620 & 4.45 & 5.0593 & TST \\
\hline CHEMBL1303620 & 688620 & 5.25 & 5.5293 & TRN \\
\hline CHEMBL3213545 & 688620 & 4.8 & 4.9708 & TRN \\
\hline CHEMBL449928 & 688620 & 4.65 & 4.9192 & TRN \\
\hline CHEMBL1610002 & 688620 & 5.4 & 5.0402 & TST \\
\hline CHEMBL1363089 & 688620 & 5.15 & 5.3979 & TRN \\
\hline CHEMBL3209490 & 688620 & 4.95 & 5.0829 & TRN \\
\hline CHEMBL1401456 & 688620 & 4.45 & 4.9759 & TRN \\
\hline CHEMBL1322575 & 688620 & 5.0 & 4.961 & TST \\
\hline CHEMBL 2003939 & 688620 & 5.75 & 5.6675 & TST \\
\hline CHEMBL1517212 & 688620 & 5.0 & 5.1944 & TST \\
\hline CHEMBL1403014 & 688620 & 5.1 & 5.3403 & TST \\
\hline
\end{tabular}

TRN 


\begin{tabular}{|c|c|c|c|c|c|}
\hline \multicolumn{6}{|c|}{ Supplemental Table S2.txt } \\
\hline CHEMBL1382695 & 688620 & 5.1 & 5.0465 & TRN & \\
\hline CHEMBL1573634 & 688620 & 6.1 & 5.1608 & TRN & \\
\hline CHEMBL1467681 & 688620 & 5.5 & 5.0654 & TRN & \\
\hline CHEMBL1507780 & 688620 & 5.55 & 5.0763 & TRN & \\
\hline CHEMBL1339398 & 688620 & 4.45 & 4.8895 & TST & \\
\hline CHEMBL1606863 & 688620 & 7.0501 & 5.0782 & TST & \\
\hline CHEMBL3212503 & 688620 & 4.55 & 4.7672 & TRN & \\
\hline CHEMBL1557071 & 688620 & 5.2 & 5.079 & TST & \\
\hline CHEMBL1607348 & 688620 & 6.95 & 5.2262 & TST & \\
\hline CHEMBL1343875 & 688620 & 4.55 & 4.746 & TRN & \\
\hline CHEMBL1387831 & 688620 & 4.45 & 5.0349 & TRN & \\
\hline CHEMBL1583731 & 688620 & 4.8 & 4.988 & TRN & \\
\hline CHEMBL1581998 & 688620 & 6.1 & 5.0629 & TRN & \\
\hline CHEMBL1581242 & 688620 & 4.75 & 4.8592 & TRN & \\
\hline CHEMBL1497159 & 688620 & 6.5 & 5.2099 & TRN & \\
\hline CHEMBL1440193 & 688620 & 5.35 & 5.1327 & TRN & \\
\hline CHEMBL3195826 & 688620 & 4.85 & 4.8825 & TRN & \\
\hline CHEMBL1534478 & 688620 & 5.7 & 5.49799 & 9999999999 & TRN \\
\hline CHEMBL1601133 & 688620 & 5.55 & 5.6142 & TRN & \\
\hline CHEMBL1581673 & 688620 & 5.05 & 5.2527 & TRN & \\
\hline CHEMBL116569 & 688620 & 4.8 & 4.9937 & TRN & \\
\hline CHEMBL1347477 & 688620 & 5.55 & 5.5209 & TRN & \\
\hline CHEMBL1488059 & 688620 & 4.95 & 4.9473 & TRN & \\
\hline CHEMBL1520318 & 688620 & 6.9 & 4.6714 & TRN & \\
\hline CHEMBL1442478 & 688620 & 4.45 & 4.9934 & TRN & \\
\hline CHEMBL1607790 & 688620 & 5.05 & 5.0041 & TRN & \\
\hline CHEMBL1353087 & 688620 & 6.0 & 5.0095 & TRN & \\
\hline CHEMBL1578593 & 688620 & 5.5 & 4.8852 & TRN & \\
\hline CHEMBL1503976 & 688620 & 5.4 & 5.0927 & TRN & \\
\hline CHEMBL3210576 & 688620 & 5.45 & 4.9355 & TRN & \\
\hline CHEMBL1568488 & 688620 & 4.85 & 5.245 & TST & \\
\hline CHEMBL1507355 & 688620 & 5.0 & 5.0882 & TRN & \\
\hline CHEMBL 228078 & 688620 & 6.0 & 5.8218 & TRN & \\
\hline CHEMBL1441488 & 688620 & 4.45 & 5.0669 & TST & \\
\hline CHEMBL1466922 & 688620 & 4.45 & 5.0891 & TRN & \\
\hline CHEMBL3192639 & 688620 & 4.9 & 5.0285 & TRN & \\
\hline CHEMBL1323821 & 688620 & 5.55 & 5.3247 & TST & \\
\hline CHEMBL1198608 & 688620 & 4.65 & 5.5221 & TRN & \\
\hline CHEMBL1516579 & 688620 & 4.75 & 5.0343 & TST & \\
\hline CHEMBL1450071 & 688620 & 5.3 & 5.073 & TRN & \\
\hline CHEMBL1496237 & 688620 & 5.45 & 5.5188 & TRN & \\
\hline CHEMBL1977563 & 688620 & 4.45 & 4.95 & TRN & \\
\hline CHEMBL1608865 & 688620 & 4.9 & 4.7782 & TRN & \\
\hline CHEMBL1507030 & 688620 & 4.45 & 5.0691 & TST & \\
\hline CHEMBL1463003 & 688620 & 5.2 & 5.0196 & TRN & \\
\hline CHEMBL1327836 & 688620 & 4.65 & 4.8733 & TST & \\
\hline CHEMBL1483531 & 688620 & 5.35 & 5.2045 & TRN & \\
\hline CHEMBL1439063 & 688620 & 4.85 & 5.0084 & TRN & \\
\hline
\end{tabular}




\begin{tabular}{|c|c|c|c|c|}
\hline \multicolumn{5}{|c|}{ Supplemental Table S2.txt } \\
\hline CHEMBL1383925 & 688620 & 5.05 & 5.1048 & TRN \\
\hline CHEMBL1541119 & 688620 & 4.9 & 5.1964 & TRN \\
\hline CHEMBL1545693 & 688620 & 5.05 & 5.1205 & TRN \\
\hline CHEMBL1352043 & 688620 & 4.65 & 4.7175 & TRN \\
\hline CHEMBL1352626 & 688620 & 4.7 & 4.9852 & TRN \\
\hline CHEMBL1366610 & 688620 & 4.9 & 5.0318 & TST \\
\hline CHEMBL1366128 & 688620 & 5.55 & 5.3756 & TRN \\
\hline CHEMBL1517690 & 688620 & 4.9 & 5.0557 & TST \\
\hline CHEMBL1477280 & 688620 & 5.0 & 5.5404 & TST \\
\hline CHEMBL1531753 & 688620 & 4.85 & 4.9907 & TRN \\
\hline CHEMBL1465159 & 688620 & 4.9 & 4.9476 & TRN \\
\hline CHEMBL1572734 & 688620 & 4.95 & 4.9911 & TRN \\
\hline CHEMBL1453371 & 688620 & 4.9 & 5.0267 & TRN \\
\hline CHEMBL1575961 & 688620 & 4.85 & 5.2543 & TRN \\
\hline CHEMBL1399950 & 688620 & 5.45 & 5.0459 & TST \\
\hline CHEMBL3211905 & 688620 & 4.5 & 4.8257 & TRN \\
\hline CHEMBL1412746 & 688620 & 5.15 & 5.1328 & TRN \\
\hline CHEMBL 3195192 & 688620 & 6.2 & 5.1767 & TRN \\
\hline CHEMBL445184 & 688620 & 5.55 & 5.3704 & TRN \\
\hline CHEMBL1389993 & 688620 & 7.0 & 5.4348 & TRN \\
\hline CHEMBL1454465 & 688620 & 7.3002 & 6.2871 & TRN \\
\hline CHEMBL1587422 & 688620 & 5.0 & 5.1236 & TRN \\
\hline CHEMBL1598890 & 688620 & 4.95 & 5.01699 & 99999999995 \\
\hline CHEMBL1478848 & 688620 & 5.6 & 5.1622 & TRN \\
\hline CHEMBL1401610 & 688620 & 5.05 & 4.9871 & TRN \\
\hline CHEMBL1305572 & 688620 & 5.3 & 4.9939 & TRN \\
\hline CHEMBL1369997 & 688620 & 5.0 & 5.1896 & TST \\
\hline CHEMBL1498022 & 688620 & 4.95 & 4.8171 & TRN \\
\hline CHEMBL1354009 & 688620 & 4.8 & 4.9072 & TRN \\
\hline CHEMBL1518428 & 688620 & 6.25 & 5.8028 & TRN \\
\hline CHEMBL1465390 & 688620 & 5.15 & 5.0769 & TST \\
\hline CHEMBL1383313 & 688620 & 6.1 & 6.4358 & TST \\
\hline CHEMBL1381456 & 688620 & 4.7 & 4.8545 & TRN \\
\hline CHEMBL1460935 & 688620 & 5.45 & 5.1193 & TRN \\
\hline CHEMBL1547058 & 688620 & 5.05 & 5.0327 & TRN \\
\hline CHEMBL1303614 & 688620 & 4.95 & 4.9157 & TRN \\
\hline CHEMBL1609327 & 688620 & 5.2 & 5.1213 & TST \\
\hline CHEMBL125044 & 688620 & 5.6 & 5.4894 & TRN \\
\hline CHEMBL1334594 & 688620 & 5.95 & 5.5698 & TRN \\
\hline CHEMBL1511620 & 688620 & 4.45 & 4.9941 & TRN \\
\hline CHEMBL1333706 & 688620 & 4.45 & 5.1569 & TST \\
\hline CHEMBL1456792 & 688620 & 4.95 & 4.9751 & TRN \\
\hline CHEMBL1448466 & 688620 & 4.9 & 5.1036 & TRN \\
\hline CHEMBL1566980 & 688620 & 4.45 & 5.0651 & TRN \\
\hline CHEMBL235891 & 688620 & 5.4 & 5.5329 & TRN \\
\hline CHEMBL1537547 & 688620 & 5.6 & 4.9481 & TRN \\
\hline CHEMBL1423377 & 688620 & 5.1 & 5.4012 & TRN \\
\hline CHEMBL1432404 & 688620 & 4.75 & 4.748 & TRN \\
\hline
\end{tabular}




\begin{tabular}{|c|c|c|c|c|}
\hline & & & oplement & al Table S \\
\hline CHEMBL1515360 & 688620 & 4.8 & 4.84 & TRN \\
\hline CHEMBL1577231 & 688620 & 5.0 & 5.4556 & TRN \\
\hline CHEMBL1520896 & 688620 & 6.8 & 6.2996 & TRN \\
\hline CHEMBL1965860 & 688620 & 5.75 & 5.5954 & TRN \\
\hline CHEMBL1564685 & 688620 & 4.85 & 5.0094 & TRN \\
\hline CHEMBL 2204883 & 688620 & 5.95 & 5.535 & TRN \\
\hline CHEMBL1566365 & 688620 & 5.4 & 5.1837 & TRN \\
\hline CHEMBL1381503 & 688620 & 4.8 & 5.1716 & TRN \\
\hline CHEMBL1371639 & 688620 & 4.9 & 5.1115 & TRN \\
\hline CHEMBL3189179 & 688620 & 5.85 & 6.0366 & TST \\
\hline CHEMBL1371705 & 688620 & 4.7 & 4.86100 & 0000000001 \\
\hline CHEMBL1299475 & 688620 & 4.95 & 5.4206 & TRN \\
\hline CHEMBL1303246 & 688620 & 4.45 & 4.9526 & TST \\
\hline CHEMBL1412222 & 688620 & 4.45 & 5.1294 & TRN \\
\hline CHEMBL1331406 & 688620 & 4.95 & 5.0482 & TRN \\
\hline CHEMBL1484117 & 688620 & 4.65 & 5.2518 & TST \\
\hline CHEMBL1371690 & 688620 & 4.95 & 5.0041 & TRN \\
\hline CHEMBL 3209472 & 688620 & 4.45 & 4.9505 & TRN \\
\hline CHEMBL1404099 & 688620 & 6.95 & 5.0457 & TST \\
\hline CHEMBL1970135 & 688620 & 5.7 & 6.1587 & TRN \\
\hline CHEMBL1364949 & 688620 & 5.4 & 5.4597 & TRN \\
\hline CHEMBL1582916 & 688620 & 5.0 & 4.8996 & TST \\
\hline CHEMBL1443811 & 688620 & 4.85 & 4.9888 & TRN \\
\hline CHEMBL1597490 & 688620 & 6.3 & 4.9313 & TRN \\
\hline CHEMBL 3194694 & 688620 & 4.95 & 5.164 & TST \\
\hline CHEMBL3210548 & 688620 & 8.3468 & 5.0447 & TRN \\
\hline CHEMBL1420246 & 688620 & 4.9 & 4.9852 & TRN \\
\hline CHEMBL1427726 & 688620 & 5.35 & 4.7896 & TRN \\
\hline CHEMBL1550963 & 688620 & 4.7 & 5.0148 & TRN \\
\hline CHEMBL1422365 & 688620 & 5.05 & 5.2637 & TST \\
\hline CHEMBL1327417 & 688620 & 5.25 & 5.2394 & TRN \\
\hline CHEMBL1453545 & 688620 & 4.5 & 4.7615 & TRN \\
\hline CHEMBL1429794 & 688620 & 4.45 & 4.9908 & TRN \\
\hline CHEMBL1979988 & 688620 & 5.35 & 5.2879 & TRN \\
\hline CHEMBL1327009 & 688620 & 4.95 & 5.0604 & TST \\
\hline CHEMBL1379999 & 688620 & 4.65 & 5.0808 & TRN \\
\hline CHEMBL3196319 & 688620 & 4.6 & 5.1109 & TRN \\
\hline CHEMBL1431608 & 688620 & 5.5 & 5.4995 & TRN \\
\hline CHEMBL1339171 & 688620 & 6.6499 & 5.1266 & TRN \\
\hline CHEMBL1309598 & 688620 & 5.4 & 5.3251 & TRN \\
\hline CHEMBL1561133 & 688620 & 4.75 & 4.7379 & TRN \\
\hline CHEMBL1527435 & 688620 & 4.6 & 5.0685 & TRN \\
\hline CHEMBL3209766 & 688620 & 6.7501 & 5.4384 & TRN \\
\hline CHEMBL1554550 & 688620 & 5.45 & 5.3996 & TRN \\
\hline CHEMBL 1437884 & 688620 & 7.0501 & 5.1186 & TRN \\
\hline CHEMBL1500275 & 688620 & 5.25 & 5.2312 & TRN \\
\hline CHEMBL1986187 & 688620 & 4.45 & 5.1123 & TRN \\
\hline CHEMBL1560186 & 688620 & 5.0 & 5.2492 & TRN \\
\hline
\end{tabular}




\begin{tabular}{|c|c|c|c|c|c|}
\hline \\
\hline CHEMBL1610374 & 688620 & 4.8 & 5.1235 & TRN & \\
\hline CHEMBL1310664 & 688620 & 5.75 & 4.7616 & TST & \\
\hline CHEMBL1340532 & 688620 & 6.9 & 5.1663 & TRN & \\
\hline CHEMBL1585596 & 688620 & 4.45 & 4.8532 & TRN & \\
\hline CHEMBL1362046 & 688620 & 4.8 & 5.12200 & 0000000001 & TRN \\
\hline CHEMBL1598141 & 688620 & 5.0 & 4.8506 & TRN & \\
\hline CHEMBL1588110 & 688620 & 5.9 & 5.29899 & 99999999995 & TRN \\
\hline CHEMBL1988457 & 688620 & 4.95 & 5.0134 & TRN & \\
\hline CHEMBL1489291 & 688620 & 5.5 & 5.0251 & TRN & \\
\hline CHEMBL1445017 & 688620 & 6.8 & 4.8672 & TST & \\
\hline CHEMBL1605859 & 688620 & 5.15 & 5.0284 & TRN & \\
\hline CHEMBL1484682 & 688620 & 5.0 & 5.1026 & TRN & \\
\hline CHEMBL1420286 & 688620 & 4.95 & 4.7446 & TRN & \\
\hline CHEMBL1369236 & 688620 & 4.95 & 4.6694 & TST & \\
\hline CHEMBL1522033 & 688620 & 5.35 & 4.8086 & TRN & \\
\hline CHEMBL1382099 & 688620 & 5.1 & 5.2496 & TST & \\
\hline CHEMBL1365214 & 688620 & 5.2 & 5.0966 & TRN & \\
\hline CHEMBL1579720 & 688620 & 5.1 & 4.7976 & TRN & \\
\hline CHEMBL1324088 & 688620 & 4.5 & 4.9564 & TRN & \\
\hline CHEMBL1495319 & 688620 & 4.95 & 5.0091 & TRN & \\
\hline CHEMBL1308764 & 688620 & 4.45 & 4.8416 & TRN & \\
\hline CHEMBL1308993 & 688620 & 4.45 & 4.8566 & TRN & \\
\hline CHEMBL1608311 & 688620 & 4.65 & 5.1 & TRN & \\
\hline CHEMBL1968064 & 688620 & 5.3 & 5.1859 & TRN & \\
\hline CHEMBL1428819 & 688620 & 4.9 & 5.0843 & TST & \\
\hline CHEMBL1417398 & 688620 & 4.65 & 4.9102 & TRN & \\
\hline CHEMBL1312636 & 688620 & 5.0 & 4.8405 & TST & \\
\hline CHEMBL1579104 & 688620 & 5.25 & 5.4849 & TRN & \\
\hline CHEMBL3856090 & 688620 & 6.2 & 5.6314 & TST & \\
\hline CHEMBL1320438 & 688620 & 4.95 & 4.995 & TRN & \\
\hline CHEMBL1468373 & 688620 & 4.95 & 5.1675 & TRN & \\
\hline CHEMBL1543295 & 688620 & 4.7 & 4.7822 & TST & \\
\hline CHEMBL1607060 & 688620 & 4.9 & 4.9313 & TRN & \\
\hline CHEMBL1403442 & 688620 & 5.3 & 5.1048 & TRN & \\
\hline CHEMBL1372025 & 688620 & 6.8 & 5.4094 & TST & \\
\hline CHEMBL1304704 & 688620 & 5.55 & 5.2363 & TRN & \\
\hline CHEMBL1378788 & 688620 & 5.45 & 5.0903 & TRN & \\
\hline CHEMBL1377316 & 688620 & 5.5 & 5.5267 & TRN & \\
\hline CHEMBL1488197 & 688620 & 6.0 & 5.3933 & TRN & \\
\hline CHEMBL3198167 & 688620 & 5.95 & 6.1391 & TRN & \\
\hline CHEMBL1302363 & 688620 & 4.45 & 4.92399 & 99999999995 & TRN \\
\hline CHEMBL1556520 & 688620 & 4.7 & 4.9789 & TRN & \\
\hline CHEMBL1483999 & 688620 & 4.85 & 5.0269 & TST & \\
\hline CHEMBL1372585 & 688620 & 5.05 & 5.0709 & TRN & \\
\hline CHEMBL1556944 & 688620 & 5.25 & 5.4357 & TRN & \\
\hline CHEMBL1506255 & 688620 & 4.95 & 4.8798 & TRN & \\
\hline CHEMBL1602864 & 688620 & 4.8 & 4.9511 & TRN & \\
\hline CHEMBL3191067 & 688620 & 4.95 & 5.1272 & TRN & \\
\hline
\end{tabular}




\begin{tabular}{|c|c|c|c|c|c|}
\hline \\
\hline CHEMBL1478976 & 688620 & 4.6 & 5.1419 & TRN & \\
\hline CHEMBL1612072 & 688620 & 4.9 & 5.1018 & TRN & \\
\hline CHEMBL1452615 & 688620 & 4.7 & 5.1654 & TRN & \\
\hline CHEMBL1352655 & 688620 & 4.45 & 4.8344 & TST & \\
\hline CHEMBL1306201 & 688620 & 5.25 & 4.927 & TRN & \\
\hline CHEMBL1499630 & 688620 & 5.3 & 5.1128 & TRN & \\
\hline CHEMBL1377992 & 688620 & 5.15 & 5.3111 & TST & \\
\hline CHEMBL1439489 & 688620 & 5.25 & 5.0265 & TST & \\
\hline CHEMBL1549986 & 688620 & 4.85 & 5.0732 & TST & \\
\hline CHEMBL1333995 & 688620 & 5.25 & 5.4005 & TRN & \\
\hline CHEMBL1967031 & 688620 & 5.15 & 5.442 & TRN & \\
\hline CHEMBL1503134 & 688620 & 4.9 & 5.0737 & TST & \\
\hline CHEMBL1303491 & 688620 & 4.95 & 4.9547 & TRN & \\
\hline CHEMBL3190110 & 688620 & 5.25 & 5.05 & TRN & \\
\hline CHEMBL1338990 & 688620 & 4.5 & 4.9728 & TST & \\
\hline CHEMBL1432352 & 688620 & 5.4 & 5.0869 & TRN & \\
\hline CHEMBL1461617 & 688620 & 4.5 & 4.9216 & TRN & \\
\hline CHEMBL1557963 & 688620 & 4.45 & 4.9987 & TRN & \\
\hline CHEMBL1417947 & 688620 & 4.7 & 5.0195 & TRN & \\
\hline CHEMBL1311634 & 688620 & 4.45 & 5.2394 & TRN & \\
\hline CHEMBL1323741 & 688620 & 6.0 & 5.7511 & TRN & \\
\hline CHEMBL1592829 & 688620 & 4.45 & 4.8172 & TRN & \\
\hline CHEMBL1345436 & 688620 & 4.45 & 4.9889 & TRN & \\
\hline CHEMBL1517645 & 688620 & 4.55 & 5.1398 & TST & \\
\hline CHEMBL1990796 & 688620 & 4.8 & 4.9058 & TRN & \\
\hline CHEMBL1447577 & 688620 & 5.7 & 5.20206 & $\partial 000000001$ & TRN \\
\hline CHEMBL1333416 & 688620 & 4.9 & $4.9830 e$ & 00000000005 & TRN \\
\hline CHEMBL1325757 & 688620 & 5.55 & 5.0478 & TRN & \\
\hline CHEMBL1321104 & 688620 & 4.75 & 5.4124 & TST & \\
\hline CHEMBL1378782 & 688620 & 4.55 & 5.1014 & TRN & \\
\hline CHEMBL1557136 & 688620 & 6.6 & 5.1505 & TRN & \\
\hline CHEMBL1611953 & 688620 & 5.7 & 5.0221 & TRN & \\
\hline CHEMBL1461308 & 688620 & 5.15 & 5.2907 & TRN & \\
\hline CHEMBL1376969 & 688620 & 5.0 & 5.029 & TRN & \\
\hline CHEMBL3191845 & 688620 & 4.5 & 5.00899 & 99999999995 & TST \\
\hline CHEMBL3191118 & 688620 & 4.85 & 5.1007 & TRN & \\
\hline CHEMBL1385169 & 688620 & 4.75 & 5.315 & TRN & \\
\hline CHEMBL3189184 & 688620 & 4.45 & 4.9434 & TRN & \\
\hline CHEMBL1479427 & 688620 & 4.95 & 4.8396 & TRN & \\
\hline CHEMBL3193804 & 688620 & 5.0 & 5.1635 & TRN & \\
\hline CHEMBL1344174 & 688620 & 4.9 & 5.2327 & TRN & \\
\hline CHEMBL1523890 & 688620 & 4.7 & 4.9948 & TRN & \\
\hline CHEMBL1461236 & 688620 & 4.45 & 4.6978 & TST & \\
\hline CHEMBL3197110 & 688620 & 4.95 & 5.2825 & TST & \\
\hline CHEMBL1332358 & 688620 & 4.45 & 5.0073 & TRN & \\
\hline CHEMBL1433135 & 688620 & 5.05 & 5.2348 & TRN & \\
\hline CHEMBL1329154 & 688620 & 4.45 & 5.1092 & TST & \\
\hline CHEMBL1338809 & 688620 & 5.15 & 5.1211 & TRN & \\
\hline & & & & 2739 & \\
\hline
\end{tabular}




\begin{tabular}{|c|c|c|c|c|}
\hline & & & upplemen & al $\mathrm{T}$ \\
\hline CHEMBL1444808 & 688620 & 4.95 & 4.947 & TRN \\
\hline CHEMBL1422161 & 688620 & 4.65 & 4.915 & TRN \\
\hline CHEMBL1339020 & 688620 & 4.75 & 5.3692 & TRN \\
\hline CHEMBL1541174 & 688620 & 4.75 & 4.9704 & TRN \\
\hline CHEMBL601146 & 688620 & 5.1 & 5.5596 & TRN \\
\hline CHEMBL1609026 & 688620 & 4.45 & 4.9684 & TRN \\
\hline CHEMBL1409802 & 688620 & 5.85 & 5.3279 & TST \\
\hline CHEMBL1419925 & 688620 & 4.7 & 4.8274 & TRN \\
\hline CHEMBL1603958 & 688620 & 4.45 & 4.8612 & TST \\
\hline CHEMBL1389060 & 688620 & 4.75 & 5.3128 & TRN \\
\hline CHEMBL1399917 & 688620 & 6.9 & 5.3309 & TRN \\
\hline CHEMBL1487818 & 688620 & 5.3 & 4.939 & TRN \\
\hline CHEMBL1547026 & 688620 & 5.1 & 5.1744 & TRN \\
\hline CHEMBL3208433 & 688620 & 4.8 & 5.1441 & TRN \\
\hline CHEMBL1407945 & 688620 & 5.05 & 5.0451 & TRN \\
\hline CHEMBL1601973 & 688620 & 5.45 & 5.3736 & TRN \\
\hline CHEMBL1312054 & 688620 & 5.9 & 5.6215 & TRN \\
\hline CHEMBL 2138014 & 688620 & 5.4 & 5.1318 & TRN \\
\hline CHEMBL1525719 & 688620 & 5.1 & 4.9955 & TRN \\
\hline CHEMBL1424504 & 688620 & 4.9 & 5.1433 & TRN \\
\hline CHEMBL1475424 & 688620 & 5.45 & 5.0617 & TRN \\
\hline CHEMBL1554936 & 688620 & 5.45 & 5.1766 & TRN \\
\hline CHEMBL1477358 & 688620 & 4.65 & 5.1238 & TRN \\
\hline CHEMBL1212984 & 688620 & 6.05 & 5.1491 & TRN \\
\hline CHEMBL1367089 & 688620 & 4.5 & 4.9303 & TRN \\
\hline CHEMBL1535448 & 688620 & 4.95 & 5.0927 & TRN \\
\hline CHEMBL1466493 & 688620 & 4.95 & 4.9463 & TRN \\
\hline CHEMBL1311901 & 688620 & 5.2 & 5.073 & TST \\
\hline CHEMBL1508735 & 688620 & 5.65 & 5.2864 & TRN \\
\hline CHEMBL 1453750 & 688620 & 4.85 & 5.1094 & TST \\
\hline CHEMBL1597370 & 688620 & 4.9 & 4.9398 & TRN \\
\hline CHEMBL1426353 & 688620 & 4.85 & 5.0906 & TRN \\
\hline CHEMBL3208919 & 688620 & 5.25 & 5.4438 & TRN \\
\hline CHEMBL1428207 & 688620 & 4.8 & 4.7241 & TRN \\
\hline CHEMBL1545971 & 688620 & 4.9 & 4.8506 & TRN \\
\hline CHEMBL1309707 & 688620 & 5.4 & 5.1226 & TRN \\
\hline CHEMBL1581337 & 688620 & 4.65 & 4.6834 & TRN \\
\hline CHEMBL1353570 & 688620 & 4.85 & 4.9301 & TST \\
\hline CHEMBL1413901 & 688620 & 5.25 & 5.5281 & TRN \\
\hline CHEMBL1997108 & 688620 & 5.1 & 5.0412 & TRN \\
\hline CHEMBL1302005 & 688620 & 5.5 & 5.2076 & TRN \\
\hline CHEMBL1601612 & 688620 & 4.45 & 4.8496 & TRN \\
\hline CHEMBL1451772 & 688620 & 4.8 & 4.902 & TRN \\
\hline CHEMBL1367562 & 688620 & 5.35 & 5.2112 & TST \\
\hline CHEMBL1582294 & 688620 & 5.75 & 5.4743 & TRN \\
\hline CHEMBL1599587 & 688620 & 4.85 & 4.9517 & TST \\
\hline CHEMBL1305860 & 688620 & 4.55 & 4.6906 & TRN \\
\hline CHEMBL1602737 & 688620 & 5.0 & 4.942 & TRN \\
\hline
\end{tabular}




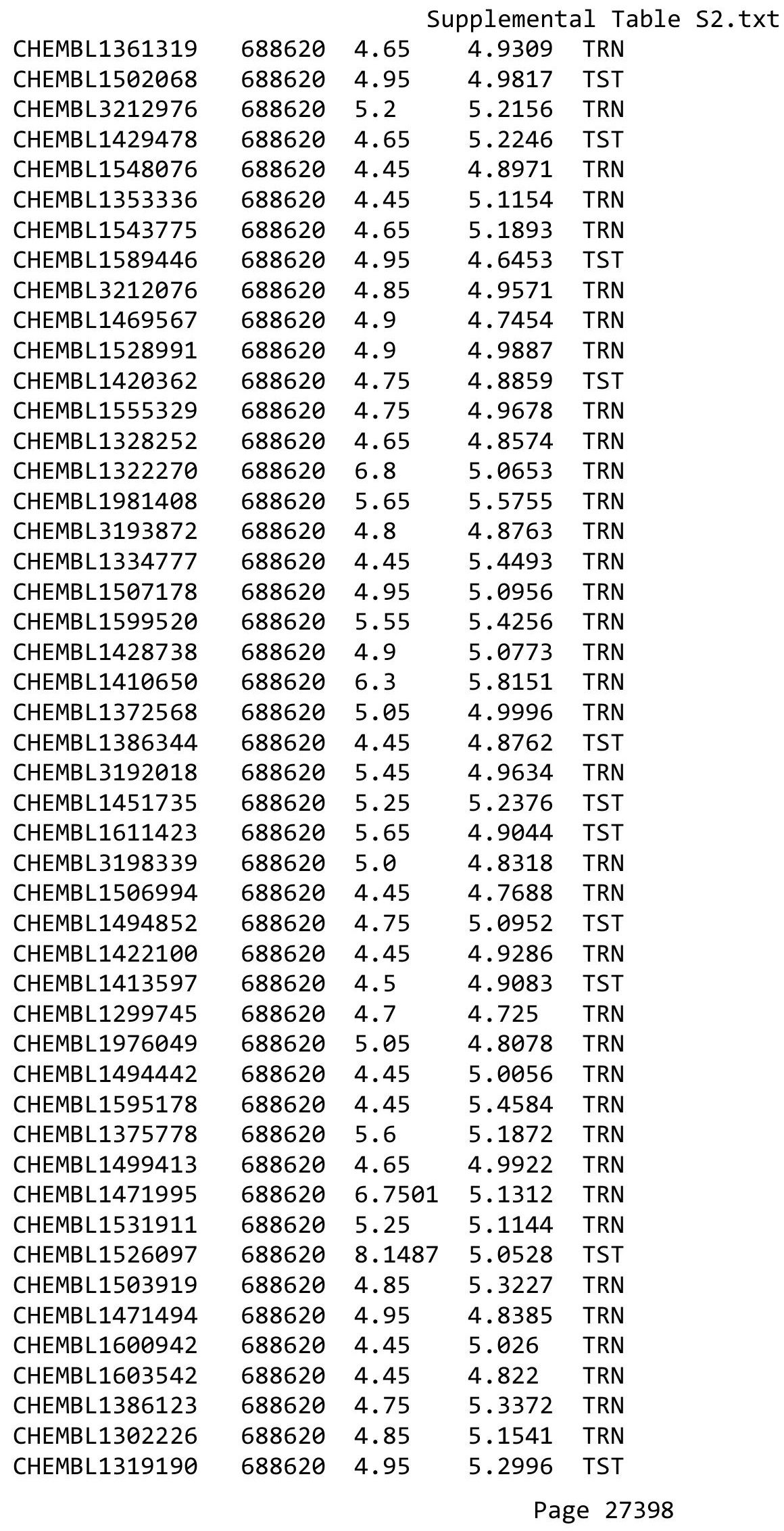




\begin{tabular}{|c|c|c|c|c|c|}
\hline \multicolumn{6}{|c|}{ Supplemental Table S2.txt } \\
\hline CHEMBL1539444 & 688620 & 4.8 & 4.9591 & TRN & \\
\hline CHEMBL1543163 & 688620 & 4.45 & 5.0322 & TST & \\
\hline CHEMBL1409532 & 688620 & 4.75 & 4.7627 & TRN & \\
\hline CHEMBL1531253 & 688620 & 5.55 & 5.3267 & TST & \\
\hline CHEMBL1426732 & 688620 & 6.6 & 5.2608 & TRN & \\
\hline CHEMBL1556652 & 688620 & 5.75 & 5.1099 & TRN & \\
\hline CHEMBL568092 & 688620 & 5.1 & 5.4911 & TRN & \\
\hline CHEMBL1461408 & 688620 & 4.45 & 4.9672 & TST & \\
\hline CHEMBL1584405 & 688620 & 4.85 & 5.1118 & TST & \\
\hline CHEMBL1579771 & 688620 & 4.7 & 4.9827 & TRN & \\
\hline CHEMBL1299566 & 688620 & 4.95 & 4.907 & TRN & \\
\hline CHEMBL187845 & 688620 & 5.1 & 5.1413 & TRN & \\
\hline CHEMBL1304620 & 688620 & 4.75 & 4.8669 & TRN & \\
\hline CHEMBL1594941 & 688620 & 5.35 & 5.1734 & TST & \\
\hline CHEMBL1377078 & 688620 & 4.6 & 4.8105 & TRN & \\
\hline CHEMBL1529418 & 688620 & 5.4 & 5.0416 & TST & \\
\hline CHEMBL1586980 & 688620 & 4.55 & 5.0943 & TST & \\
\hline CHEMBL3198687 & 688620 & 4.45 & 4.88899 & 7999999999 & TRN \\
\hline CHEMBL1429041 & 688620 & 4.75 & 4.9879 & TRN & \\
\hline CHEMBL3198352 & 688620 & 4.65 & 4.8914 & TRN & \\
\hline CHEMBL1587176 & 688620 & 6.2 & 5.1193 & TST & \\
\hline CHEMBL1420074 & 688620 & 5.0 & 5.0117 & TST & \\
\hline CHEMBL1301445 & 688620 & 5.15 & 4.8505 & TST & \\
\hline CHEMBL602526 & 688620 & 4.8 & 5.151 & TRN & \\
\hline CHEMBL1589329 & 688620 & 4.45 & 4.8214 & TRN & \\
\hline CHEMBL310396 & 688620 & 4.65 & 5.0625 & TST & \\
\hline CHEMBL1432626 & 688620 & 6.15 & 5.1586 & TRN & \\
\hline CHEMBL1492826 & 688620 & 4.75 & 5.1134 & TRN & \\
\hline CHEMBL1311982 & 688620 & 4.45 & 5.0601 & TRN & \\
\hline CHEMBL1310410 & 688620 & 5.05 & 4.8257 & TRN & \\
\hline CHEMBL1425286 & 688620 & 4.5 & 4.67 & TRN & \\
\hline CHEMBL1559945 & 688620 & 5.7 & 5.5242 & TRN & \\
\hline CHEMBL1541647 & 688620 & 4.95 & 4.9914 & TRN & \\
\hline CHEMBL1558936 & 688620 & 4.95 & 5.1369 & TRN & \\
\hline CHEMBL1322815 & 688620 & 4.95 & 5.105 & TRN & \\
\hline CHEMBL1450760 & 688620 & 5.15 & 4.9103 & TRN & \\
\hline CHEMBL1347726 & 688620 & 5.65 & 6.1946 & TRN & \\
\hline CHEMBL1323619 & 688620 & 4.45 & 5.0733 & TST & \\
\hline CHEMBL1625031 & 688620 & 5.05 & 4.9386 & TRN & \\
\hline CHEMBL1351967 & 688620 & 4.85 & 4.7913 & TRN & \\
\hline CHEMBL1388042 & 688620 & 5.3 & 5.6117 & TRN & \\
\hline CHEMBL1548825 & 688620 & 5.6 & 4.7124 & TST & \\
\hline CHEMBL1411991 & 688620 & 4.9 & 5.0675 & TRN & \\
\hline CHEMBL1331296 & 688620 & 4.9 & 5.021 & TRN & \\
\hline CHEMBL1329846 & 688620 & 4.95 & 4.7607 & TRN & \\
\hline CHEMBL1995800 & 688620 & 5.35 & 5.3501 & TRN & \\
\hline CHEMBL1421333 & 688620 & 4.7 & 5.1723 & TRN & \\
\hline CHEMBL3194615 & 688620 & 5.55 & 5.189 & TRN & \\
\hline
\end{tabular}




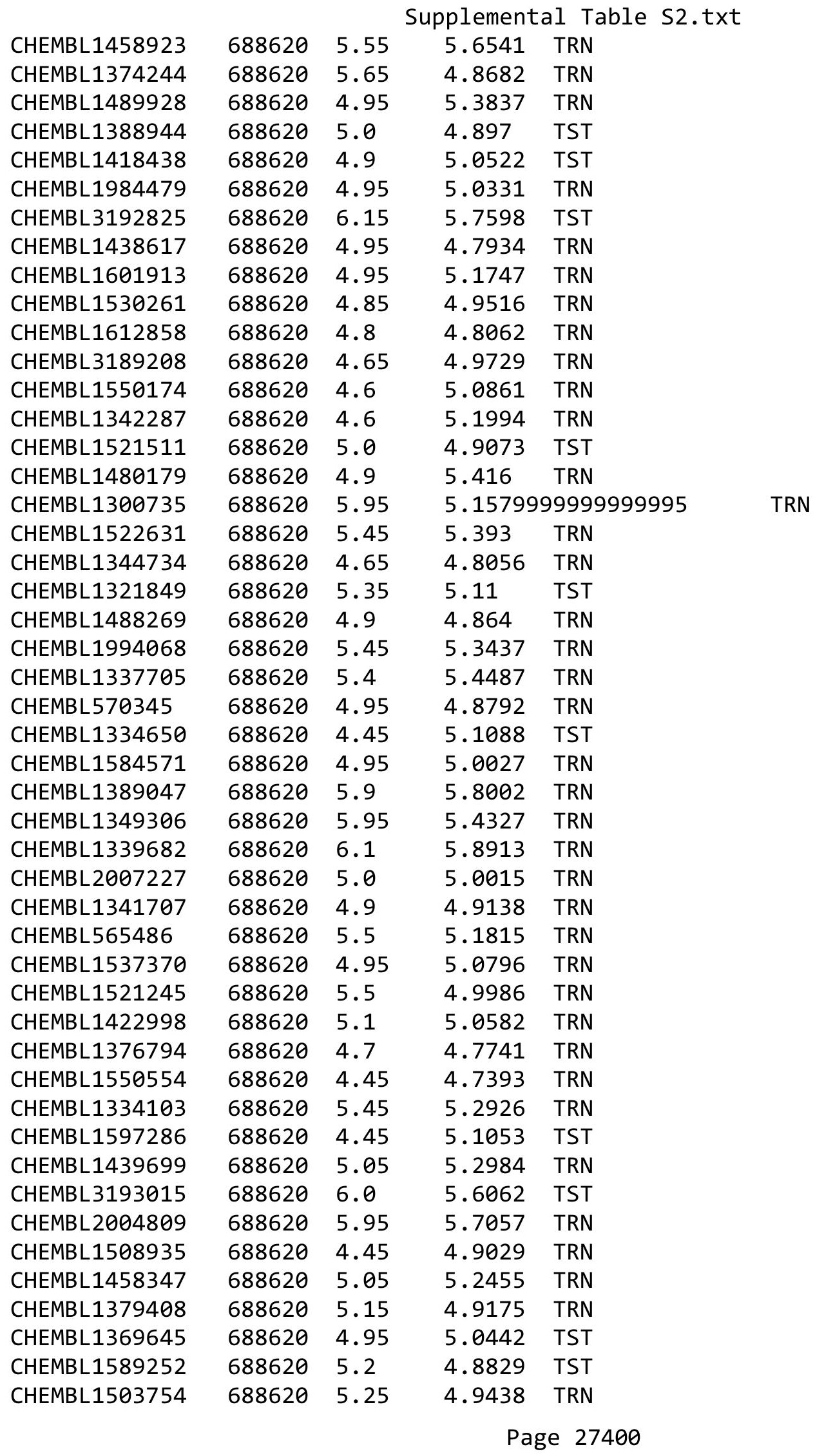




\begin{tabular}{|c|c|c|c|c|c|}
\hline \multicolumn{6}{|c|}{ Supplemental Table S2.txt } \\
\hline CHEMBL1472598 & 688620 & 5.35 & 5.1628 & TRN & \\
\hline CHEMBL1980226 & 688620 & 6.1 & 5.5672 & TRN & \\
\hline CHEMBL1373914 & 688620 & 5.15 & 6.2105 & TST & \\
\hline CHEMBL1461579 & 688620 & 5.1 & 4.9979 & TRN & \\
\hline CHEMBL1490736 & 688620 & 5.35 & 5.012 & TRN & \\
\hline CHEMBL1340210 & 688620 & 6.95 & 5.1942 & TRN & \\
\hline CHEMBL1599458 & 688620 & 6.35 & 6.0127 & TRN & \\
\hline CHEMBL1443900 & 688620 & 5.25 & 5.4193 & TST & \\
\hline CHEMBL 3212063 & 688620 & 5.05 & 5.2147 & TST & \\
\hline CHEMBL1596241 & 688620 & 5.3 & 4.8848 & TRN & \\
\hline CHEMBL1585349 & 688620 & 5.9 & 5.8118 & TRN & \\
\hline CHEMBL1368072 & 688620 & 6.5501 & 4.9932 & TRN & \\
\hline CHEMBL1373521 & 688620 & 4.45 & 5.0598 & TRN & \\
\hline CHEMBL63426 & 688620 & 4.8 & \multicolumn{2}{|c|}{ 4.7669999999999995 } & TST \\
\hline CHEMBL1439324 & 688620 & 4.9 & 5.0051 & TRN & \\
\hline CHEMBL1424212 & 688620 & 4.45 & 5.1259 & TRN & \\
\hline CHEMBL3199522 & 688620 & 4.65 & 4.9697 & TRN & \\
\hline CHEMBL1445416 & 688620 & 5.35 & 5.4498 & TRN & \\
\hline CHEMBL1398644 & 688620 & 5.05 & 5.1419 & TRN & \\
\hline CHEMBL1380039 & 688620 & 5.25 & 5.2456 & TRN & \\
\hline CHEMBL1345282 & 688620 & 4.45 & 4.7126 & TRN & \\
\hline CHEMBL1321025 & 688620 & 5.6 & \multicolumn{2}{|c|}{5.678999999999999} & TRN \\
\hline CHEMBL1447040 & 688620 & 4.95 & 5.0254 & TRN & \\
\hline CHEMBL1428549 & 688620 & 7.4001 & 5.0916 & TRN & \\
\hline CHEMBL1321994 & 688620 & 4.8 & 4.9441 & TRN & \\
\hline CHEMBL1350518 & 688620 & 5.3 & 4.8465 & TRN & \\
\hline CHEMBL1457257 & 688620 & 4.65 & 4.8816 & TST & \\
\hline CHEMBL1532847 & 688620 & 4.45 & 5.0056 & TRN & \\
\hline CHEMBL1318954 & 688620 & 4.8 & 4.8035 & TST & \\
\hline CHEMBL1417172 & 688620 & 5.0 & 5.0951 & TRN & \\
\hline CHEMBL1415899 & 688620 & 4.8 & 4.9697 & TRN & \\
\hline CHEMBL1611222 & 688620 & 4.85 & 5.1279 & TRN & \\
\hline CHEMBL1332843 & 688620 & 4.45 & 4.9426 & TRN & \\
\hline CHEMBL1486610 & 688620 & 6.15 & 4.9725 & TST & \\
\hline CHEMBL3199869 & 688620 & 4.85 & 4.8461 & TRN & \\
\hline CHEMBL1416252 & 688620 & 4.85 & 5.0351 & TST & \\
\hline CHEMBL1449083 & 688620 & 5.2 & 5.0417 & TRN & \\
\hline CHEMBL601140 & 688620 & 4.65 & 4.9692 & TST & \\
\hline CHEMBL 3212342 & 688620 & 5.65 & 5.183 & TRN & \\
\hline CHEMBL1389528 & 688620 & 4.9 & 4.9528 & TRN & \\
\hline CHEMBL1568474 & 688620 & 4.65 & 4.8695 & TST & \\
\hline CHEMBL1434126 & 688620 & 5.25 & 5.1904 & TRN & \\
\hline CHEMBL3211842 & 688620 & 4.65 & 4.9259 & TST & \\
\hline CHEMBL1526333 & 688620 & 6.95 & 5.165 & TRN & \\
\hline CHEMBL1383365 & 688620 & 4.45 & 5.0596 & TRN & \\
\hline CHEMBL1456341 & 688620 & 4.95 & 4.994 & TRN & \\
\hline CHEMBL1456809 & 688620 & 5.9 & 5.0499 & TRN & \\
\hline CHEMBL238188 & 688620 & 4.45 & 5.4153 & TST & \\
\hline
\end{tabular}




\begin{tabular}{|c|c|c|c|c|c|}
\hline \multicolumn{6}{|c|}{ Supplemental Table S2.txt } \\
\hline CHEMBL1347624 & 688620 & 5.95 & 5.1777 & TRN & \\
\hline CHEMBL3208406 & 688620 & 4.9 & 4.9259 & TRN & \\
\hline CHEMBL1966905 & 688620 & 4.8 & 4.8624 & TRN & \\
\hline CHEMBL1428711 & 688620 & 4.8 & 4.9644 & TRN & \\
\hline CHEMBL3194218 & 688620 & 4.7 & 4.8118 & TRN & \\
\hline CHEMBL1511811 & 688620 & 4.5 & 5.0481 & TRN & \\
\hline CHEMBL1426443 & 688620 & 4.9 & 4.9133 & TRN & \\
\hline CHEMBL1532182 & 688620 & 7.0501 & 5.3893 & TST & \\
\hline CHEMBL1424480 & 688620 & 4.8 & 4.8572 & TRN & \\
\hline CHEMBL1301278 & 688620 & 4.8 & 4.8463 & TST & \\
\hline CHEMBL1498993 & 688620 & 4.45 & 4.9403 & TRN & \\
\hline CHEMBL1453576 & 688620 & 5.35 & 5.1428 & TRN & \\
\hline CHEMBL1467277 & 688620 & 7.0501 & 5.2079 & TRN & \\
\hline CHEMBL1349704 & 688620 & 4.8 & 5.0157 & TRN & \\
\hline CHEMBL3207991 & 688620 & 5.5 & 5.2018 & TRN & \\
\hline CHEMBL1407756 & 688620 & 4.65 & 5.19799 & 99999999995 & TRN \\
\hline CHEMBL1503770 & 688620 & 5.0 & 5.0137 & TST & \\
\hline CHEMBL1576130 & 688620 & 5.05 & 5.146 & TST & \\
\hline CHEMBL1407093 & 688620 & 6.1 & 4.8569 & TST & \\
\hline CHEMBL1403294 & 688620 & 4.5 & 5.1924 & TRN & \\
\hline CHEMBL1964415 & 688620 & 4.45 & 4.9429 & TST & \\
\hline CHEMBL1458153 & 688620 & 5.0 & 4.6852 & TRN & \\
\hline CHEMBL1575805 & 688620 & 4.95 & 5.0138 & TRN & \\
\hline CHEMBL1604138 & 688620 & 4.9 & 4.8408 & TRN & \\
\hline CHEMBL1392199 & 688620 & 4.65 & 5.2299 & TRN & \\
\hline CHEMBL1429563 & 688620 & 5.65 & 5.1965 & TRN & \\
\hline CHEMBL1416298 & 688620 & 4.85 & 4.8663 & TST & \\
\hline CHEMBL1403269 & 688620 & 5.05 & 4.9971 & TRN & \\
\hline CHEMBL1550291 & 688620 & 4.9 & 4.8095 & TST & \\
\hline CHEMBL1378017 & 688620 & 5.0 & 5.1854 & TRN & \\
\hline CHEMBL1521147 & 688620 & 5.0 & 4.9498 & TRN & \\
\hline CHEMBL1558216 & 688620 & 4.95 & 5.1553 & TRN & \\
\hline CHEMBL3191488 & 688620 & 4.5 & 5.3516 & TRN & \\
\hline CHEMBL1491876 & 688620 & 5.25 & 5.0012 & TST & \\
\hline CHEMBL3208479 & 688620 & 5.15 & 4.9046 & TRN & \\
\hline CHEMBL1556279 & 688620 & 4.55 & 5.0623 & TST & \\
\hline CHEMBL1310193 & 688620 & 7.0 & 6.0337 & TRN & \\
\hline CHEMBL1507073 & 688620 & 4.85 & 5.0232 & TRN & \\
\hline CHEMBL1330009 & 688620 & 4.7 & 5.0232 & TST & \\
\hline CHEMBL3199583 & 688620 & 4.45 & 4.9795 & TRN & \\
\hline CHEMBL1306184 & 688620 & 6.5501 & 5.9332 & TRN & \\
\hline CHEMBL3197464 & 688620 & 4.8 & 4.8992 & TRN & \\
\hline CHEMBL1547410 & 688620 & 5.25 & 5.1547 & TRN & \\
\hline CHEMBL3194345 & 688620 & 4.55 & 4.987 & TRN & \\
\hline CHEMBL3195094 & 688620 & 4.8 & 5.106 & TST & \\
\hline CHEMBL1484883 & 688620 & 4.95 & 4.7231 & TRN & \\
\hline CHEMBL1455464 & 688620 & 5.3 & 5.336 & TRN & \\
\hline CHEMBL3210850 & 688620 & 5.8 & 5.3598 & TRN & \\
\hline
\end{tabular}




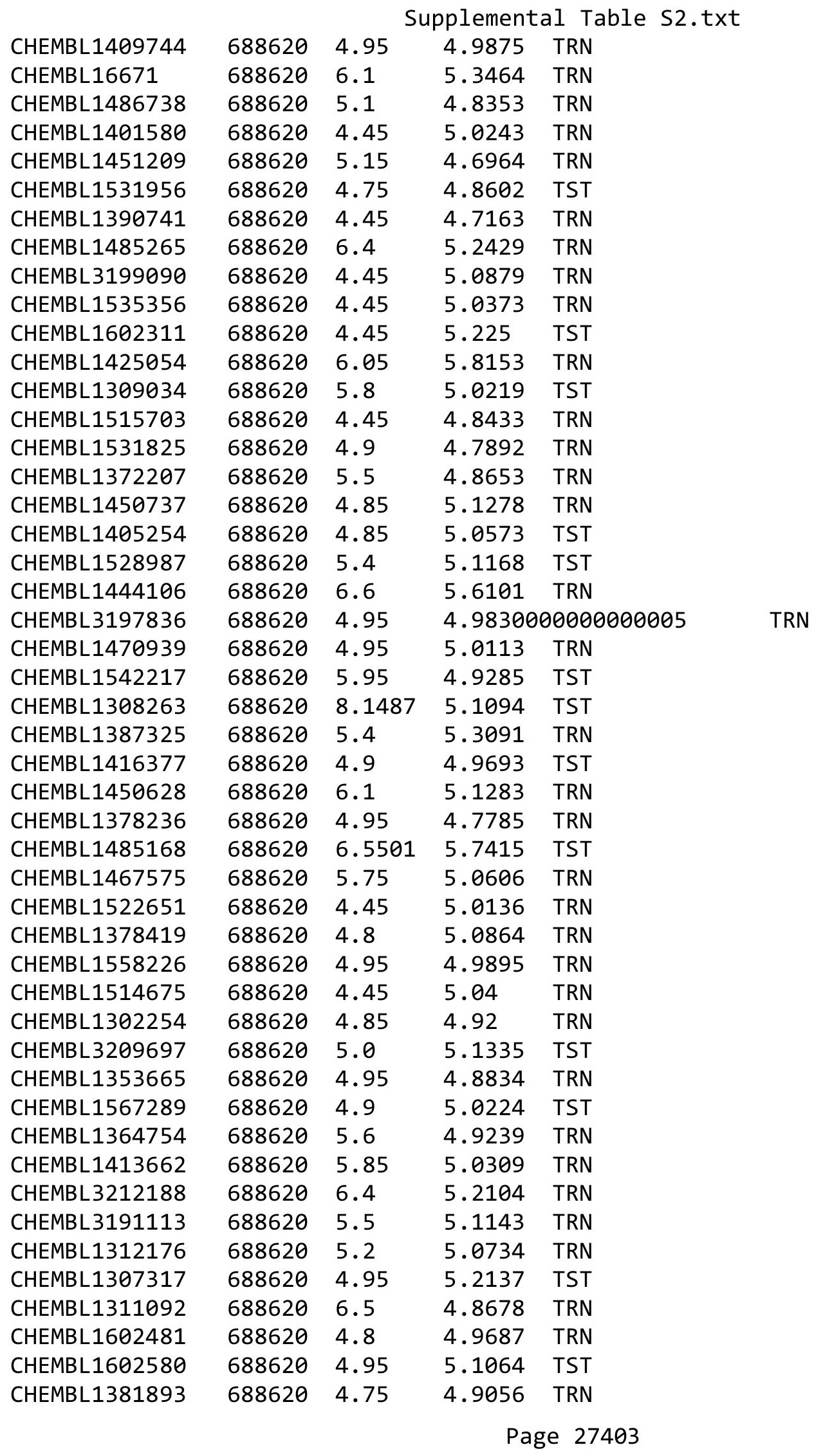




\begin{tabular}{|c|c|c|c|c|c|}
\hline & & \multicolumn{4}{|c|}{ Supplemental Table S2.txt } \\
\hline CHEMBL3193507 & 688620 & 4.55 & 4.9181 & TRN & \\
\hline CHEMBL1457693 & 688620 & 4.75 & 4.9311 & TST & \\
\hline CHEMBL1533035 & 688620 & 6.5501 & 4.9921 & TRN & \\
\hline CHEMBL1494675 & 688620 & 4.95 & 5.2977 & TST & \\
\hline CHEMBL1472925 & 688620 & 6.1 & 5.3574 & TRN & \\
\hline CHEMBL3199730 & 688620 & 4.8 & 5.2386 & TRN & \\
\hline CHEMBL1420257 & 688620 & 4.85 & 4.8756 & TRN & \\
\hline CHEMBL 3211363 & 688620 & 5.05 & 4.9729 & TRN & \\
\hline CHEMBL1503983 & 688620 & 4.45 & \multicolumn{2}{|c|}{ 4.9719999999999995 } & TRN \\
\hline CHEMBL1400146 & 688620 & 5.6 & 5.1127 & TST & \\
\hline CHEMBL 3198630 & 688620 & 5.0 & 5.1119 & TRN & \\
\hline CHEMBL1992943 & 688620 & 5.45 & 5.4462 & TRN & \\
\hline CHEMBL1534516 & 688620 & 5.65 & 5.0793 & TRN & \\
\hline CHEMBL1518159 & 688620 & 4.45 & 5.1573 & TRN & \\
\hline CHEMBL1608145 & 688620 & 4.45 & 4.82 & TRN & \\
\hline CHEMBL1521115 & 688620 & 5.15 & 5.5701 & TRN & \\
\hline CHEMBL1419080 & 688620 & 7.7496 & 4.9701 & TRN & \\
\hline CHEMBL1320149 & 688620 & 5.8 & 5.499 & TST & \\
\hline CHEMBL1525699 & 688620 & 5.15 & 5.4063 & TRN & \\
\hline CHEMBL 2002301 & 688620 & 5.8 & 5.4281 & TRN & \\
\hline CHEMBL1335522 & 688620 & 4.7 & 4.9771 & TST & \\
\hline CHEMBL1542511 & 688620 & 4.8 & 4.9923 & TRN & \\
\hline CHEMBL3199550 & 688620 & 5.4 & 5.5635 & TRN & \\
\hline CHEMBL1608584 & 688620 & 4.6 & 4.9439 & TRN & \\
\hline CHEMBL1165028 & 688620 & 4.9 & 5.034 & TRN & \\
\hline CHEMBL1360672 & 688620 & 5.4 & 5.007 & TRN & \\
\hline CHEMBL1360375 & 688620 & 4.45 & 4.7546 & TRN & \\
\hline CHEMBL1516459 & 688620 & 4.7 & 5.1553 & TST & \\
\hline CHEMBL1985486 & 688620 & 5.7 & 5.5362 & TRN & \\
\hline CHEMBL1327817 & 688620 & 4.8 & 5.2559 & TRN & \\
\hline CHEMBL1609019 & 688620 & 5.5 & 5.459 & TST & \\
\hline CHEMBL1487186 & 688620 & 4.9 & 5.0397 & TRN & \\
\hline CHEMBL1544094 & 688620 & 5.5 & 5.5443 & TRN & \\
\hline CHEMBL1487816 & 688620 & 4.45 & 5.4628 & TRN & \\
\hline CHEMBL1990383 & 688620 & 4.5 & 5.0668 & TRN & \\
\hline CHEMBL1493052 & 688620 & 5.15 & 5.1114 & TRN & \\
\hline CHEMBL3212376 & 688620 & 5.15 & 5.3845 & TRN & \\
\hline CHEMBL1469421 & 688620 & 4.9 & 5.1977 & TRN & \\
\hline CHEMBL1988657 & 688620 & 5.05 & 5.5528 & TRN & \\
\hline CHEMBL1531907 & 688620 & 4.95 & 5.0628 & TST & \\
\hline CHEMBL3195983 & 688620 & 4.45 & 5.2404 & TRN & \\
\hline CHEMBL1328145 & 688620 & 5.4 & 5.4652 & TRN & \\
\hline CHEMBL1605344 & 688620 & 4.95 & 4.9558 & TRN & \\
\hline CHEMBL1607703 & 688620 & 4.5 & 5.0619 & TRN & \\
\hline CHEMBL1392431 & 688620 & 4.95 & 4.9819 & TRN & \\
\hline CHEMBL1438983 & 688620 & 4.45 & 4.7385 & TST & \\
\hline CHEMBL1417591 & 688620 & 5.2 & 5.1807 & TST & \\
\hline CHEMBL1546353 & 688620 & 4.6 & 4.9478 & TST & \\
\hline
\end{tabular}




\begin{tabular}{|c|c|c|c|c|c|}
\hline \multicolumn{6}{|c|}{ Supplemental Table S2.txt } \\
\hline CHEMBL1375773 & 688620 & 6.25 & 5.0139 & TRN & \\
\hline CHEMBL1504573 & 688620 & 4.45 & 4.93 & TRN & \\
\hline CHEMBL1491920 & 688620 & 5.0 & 5.348 & TST & \\
\hline CHEMBL1322042 & 688620 & 4.75 & 5.2671 & TRN & \\
\hline CHEMBL1538169 & 688620 & 5.0 & 5.0425 & TRN & \\
\hline CHEMBL1331760 & 688620 & 5.0 & 4.8976 & TRN & \\
\hline CHEMBL1613717 & 688620 & 5.95 & 5.2014 & TRN & \\
\hline CHEMBL1433385 & 688620 & 4.55 & 5.2434 & TRN & \\
\hline CHEMBL1408074 & 688620 & 4.95 & 4.8407 & TRN & \\
\hline CHEMBL1510080 & 688620 & 5.0 & 5.2352 & TRN & \\
\hline CHEMBL1467422 & 688620 & 5.0 & 5.1645 & TRN & \\
\hline CHEMBL1460478 & 688620 & 5.6 & 5.57799 & 9999999999 & TRN \\
\hline CHEMBL1308454 & 688620 & 4.8 & 5.12 & TRN & \\
\hline CHEMBL1460654 & 688620 & 4.45 & 4.9394 & TRN & \\
\hline CHEMBL1365768 & 688620 & 4.8 & 5.1621 & TRN & \\
\hline CHEMBL3197643 & 688620 & 4.6 & 4.9812 & TRN & \\
\hline CHEMBL 2234807 & 688620 & 4.45 & 4.8863 & TRN & \\
\hline CHEMBL1391592 & 688620 & 4.65 & 4.957 & TRN & \\
\hline CHEMBL1344417 & 688620 & 6.35 & 5.5544 & TRN & \\
\hline CHEMBL1547031 & 688620 & 4.85 & 5.0311 & TRN & \\
\hline CHEMBL1342783 & 688620 & 4.45 & 5.0721 & TRN & \\
\hline CHEMBL1340499 & 688620 & 5.5 & 5.5526 & TRN & \\
\hline CHEMBL1581408 & 688620 & 5.1 & 5.2156 & TRN & \\
\hline CHEMBL1372908 & 688620 & 4.9 & 4.78100 & 0000000001 & TRN \\
\hline CHEMBL1609013 & 688620 & 4.85 & 5.1224 & TST & \\
\hline CHEMBL1537623 & 688620 & 5.25 & 5.3655 & TRN & \\
\hline CHEMBL1402084 & 688620 & 4.45 & 4.9257 & TST & \\
\hline CHEMBL1407865 & 688620 & 4.75 & 4.8984 & TRN & \\
\hline CHEMBL1605313 & 688620 & 4.95 & 5.1823 & TRN & \\
\hline CHEMBL1547694 & 688620 & 4.95 & 5.2328 & TRN & \\
\hline CHEMBL1408888 & 688620 & 4.95 & 5.0981 & TRN & \\
\hline CHEMBL3197460 & 688620 & 4.7 & 5.1195 & TRN & \\
\hline CHEMBL1487464 & 688620 & 4.75 & 5.0147 & TRN & \\
\hline CHEMBL1330401 & 688620 & 6.1 & 6.01 & TRN & \\
\hline CHEMBL1329140 & 688620 & 5.45 & 4.845 & TRN & \\
\hline CHEMBL1505653 & 688620 & 4.7 & 4.9106 & TRN & \\
\hline CHEMBL 1587080 & 688620 & 4.85 & 5.1298 & TRN & \\
\hline CHEMBL1526379 & 688620 & 4.85 & 5.0268 & TRN & \\
\hline CHEMBL 3191437 & 688620 & 4.9 & 4.9612 & TRN & \\
\hline CHEMBL1428192 & 688620 & 4.7 & 4.8033 & TRN & \\
\hline CHEMBL1507181 & 688620 & 5.55 & 5.3594 & TRN & \\
\hline CHEMBL1603362 & 688620 & 4.85 & 4.9319 & TRN & \\
\hline CHEMBL1312371 & 688620 & 4.45 & 4.7901 & TST & \\
\hline CHEMBL1546043 & 688620 & 4.85 & 5.0031 & TST & \\
\hline CHEMBL1587515 & 688620 & 4.85 & 4.9252 & TST & \\
\hline CHEMBL1565621 & 688620 & 4.45 & 5.1507 & TST & \\
\hline CHEMBL1495977 & 688620 & 6.8499 & 5.5342 & TRN & \\
\hline CHEMBL1379181 & 688620 & 5.35 & 5.4495 & TST & \\
\hline
\end{tabular}




\begin{tabular}{|c|c|c|c|c|}
\hline \multicolumn{5}{|c|}{ Supplemental Table S2.txt } \\
\hline CHEMBL3190353 & 688620 & 4.95 & 5.3489 & TRN \\
\hline CHEMBL1520403 & 688620 & 4.45 & 4.8571 & TRN \\
\hline CHEMBL1522934 & 688620 & 5.2 & 5.229 & TRN \\
\hline CHEMBL1342918 & 688620 & 4.5 & 4.8086 & TRN \\
\hline CHEMBL1575715 & 688620 & 4.45 & 5.2075 & TST \\
\hline CHEMBL1489148 & 688620 & 5.15 & 4.8966 & TRN \\
\hline CHEMBL1439437 & 688620 & 4.75 & 5.6902 & TRN \\
\hline CHEMBL1573636 & 688620 & 4.95 & 5.0101 & TRN \\
\hline CHEMBL1496886 & 688620 & 5.0 & 5.1176 & TRN \\
\hline CHEMBL1305600 & 688620 & 5.85 & 4.9518 & TRN \\
\hline CHEMBL3189991 & 688620 & 5.15 & 5.2185 & TRN \\
\hline CHEMBL1603364 & 688620 & 4.45 & 5.0227 & TRN \\
\hline CHEMBL1375397 & 688620 & 5.25 & 5.0898 & TRN \\
\hline CHEMBL1369664 & 688620 & 5.4 & 5.0265 & TST \\
\hline CHEMBL1307587 & 688620 & 5.1 & 5.0432 & TRN \\
\hline CHEMBL3192210 & 688620 & 6.5 & 6.1248 & TRN \\
\hline CHEMBL1342246 & 688620 & 4.55 & 5.0506 & TRN \\
\hline CHEMBL1391804 & 688620 & 4.45 & 5.0364 & TRN \\
\hline CHEMBL1460460 & 688620 & 5.15 & 5.0012 & TRN \\
\hline CHEMBL1336153 & 688620 & 4.8 & 5.0561 & TRN \\
\hline CHEMBL1969088 & 688620 & 4.75 & 4.9785 & TST \\
\hline CHEMBL1990300 & 688620 & 4.45 & 5.3014 & TST \\
\hline CHEMBL1407169 & 688620 & 4.45 & 4.9141 & TST \\
\hline CHEMBL1967497 & 688620 & 4.45 & 5.3366 & TRN \\
\hline CHEMBL3213431 & 688620 & 4.95 & 4.7998 & TRN \\
\hline CHEMBL3198938 & 688620 & 5.5 & 5.2201 & TST \\
\hline CHEMBL1453374 & 688620 & 4.5 & 5.021 & TRN \\
\hline CHEMBL1510082 & 688620 & 4.5 & 4.7869 & TRN \\
\hline CHEMBL1476225 & 688620 & 5.0 & 4.8508 & TRN \\
\hline CHEMBL1498477 & 688620 & 5.2 & 4.9822 & TRN \\
\hline CHEMBL1995910 & 688620 & 6.25 & 5.2993 & TRN \\
\hline CHEMBL475376 & 688620 & 4.65 & 4.8156 & TRN \\
\hline CHEMBL1530553 & 688620 & 4.8 & 4.7611 & TST \\
\hline CHEMBL3196499 & 688620 & 5.35 & 5.2371 & TRN \\
\hline CHEMBL1583663 & 688620 & 4.45 & 4.9606 & TST \\
\hline CHEMBL1306358 & 688620 & 5.0 & 5.062 & TRN \\
\hline CHEMBL1411777 & 688620 & 5.2 & 5.1949 & TRN \\
\hline CHEMBL1467800 & 688620 & 4.8 & 5.1692 & TRN \\
\hline CHEMBL1477834 & 688620 & 5.05 & 5.3304 & TRN \\
\hline CHEMBL1568237 & 688620 & 5.15 & 5.1207 & TRN \\
\hline CHEMBL1968089 & 688620 & 5.0 & 5.4144 & TRN \\
\hline CHEMBL1333617 & 688620 & 4.65 & 4.9112 & TST \\
\hline CHEMBL3195756 & 688620 & 5.35 & 5.6582 & TRN \\
\hline CHEMBL444236 & 688620 & 5.3 & 5.3996 & TST \\
\hline CHEMBL1349646 & 688620 & 5.6 & 5.1447 & TRN \\
\hline CHEMBL1445242 & 688620 & 6.3 & 5.1929 & TRN \\
\hline CHEMBL1467354 & 688620 & 4.9 & 4.8963 & TST \\
\hline CHEMBL1426511 & 688620 & 8.2518 & 5.024 & TRN \\
\hline
\end{tabular}




\begin{tabular}{|c|c|c|c|c|c|}
\hline \multicolumn{6}{|c|}{ Supplemental Table S2.txt } \\
\hline CHEMBL1313643 & 688620 & 5.1 & 5.1915 & TRN & \\
\hline CHEMBL1439337 & 688620 & 5.2 & 5.225 & TRN & \\
\hline CHEMBL1571292 & 688620 & 4.9 & 5.3756 & TRN & \\
\hline CHEMBL1588525 & 688620 & 5.75 & 6.0467 & TST & \\
\hline CHEMBL1576517 & 688620 & 6.0 & 5.7146 & TRN & \\
\hline CHEMBL1324593 & 688620 & 4.9 & 5.0005 & TRN & \\
\hline CHEMBL3195237 & 688620 & 5.55 & 5.6393 & TRN & \\
\hline CHEMBL1432997 & 688620 & 5.05 & 4.8785 & TST & \\
\hline CHEMBL1604221 & 688620 & 4.95 & 5.2492 & TRN & \\
\hline CHEMBL1541061 & 688620 & 5.0 & 4.9387 & TST & \\
\hline CHEMBL429335 & 688620 & 4.5 & 5.4111 & TRN & \\
\hline CHEMBL1492963 & 688620 & 5.0 & 4.9287 & TRN & \\
\hline CHEMBL1423536 & 688620 & 4.9 & 4.8855 & TRN & \\
\hline CHEMBL1337650 & 688620 & 5.9 & 4.9672 & TRN & \\
\hline CHEMBL1582705 & 688620 & 4.85 & 4.9495 & TRN & \\
\hline CHEMBL1300778 & 688620 & 6.95 & 5.1342 & TST & \\
\hline CHEMBL1494428 & 688620 & 4.95 & 5.0162 & TRN & \\
\hline CHEMBL1481775 & 688620 & 5.9 & 4.853 & TRN & \\
\hline CHEMBL468719 & 688620 & 4.5 & 5.3422 & TST & \\
\hline CHEMBL1531863 & 688620 & 5.15 & 4.9515 & TST & \\
\hline CHEMBL1331541 & 688620 & 5.3 & 5.2792 & TRN & \\
\hline CHEMBL1466899 & 688620 & 4.95 & 5.4445 & TRN & \\
\hline CHEMBL1997970 & 688620 & 5.35 & 5.6701 & TRN & \\
\hline CHEMBL1564594 & 688620 & 6.2 & 6.1789 & TST & \\
\hline CHEMBL1346498 & 688620 & 4.45 & 4.6789 & TRN & \\
\hline CHEMBL1502775 & 688620 & 4.75 & 4.9758 & TRN & \\
\hline CHEMBL1414734 & 688620 & 5.6 & 6.0623 & TST & \\
\hline CHEMBL3198558 & 688620 & 6.2 & 5.9337 & TRN & \\
\hline CHEMBL1605035 & 688620 & 5.0 & 5.2147 & TST & \\
\hline CHEMBL1390467 & 688620 & 4.85 & 5.0494 & TRN & \\
\hline CHEMBL1535361 & 688620 & 5.4 & 5.6224 & TRN & \\
\hline CHEMBL1471128 & 688620 & 5.5 & 5.0797 & TRN & \\
\hline CHEMBL1563704 & 688620 & 5.25 & 5.2444 & TRN & \\
\hline CHEMBL1604692 & 688620 & 5.2 & 5.3454 & TRN & \\
\hline CHEMBL 2002849 & 688620 & 6.05 & 5.0978 & TST & \\
\hline CHEMBL264141 & 688620 & 4.45 & 5.0243 & TRN & \\
\hline CHEMBL1467199 & 688620 & 4.45 & 5.1371 & TST & \\
\hline CHEMBL1456926 & 688620 & 5.4 & 5.2352 & TRN & \\
\hline CHEMBL1535162 & 688620 & 5.7 & 5.6783 & TST & \\
\hline CHEMBL1333755 & 688620 & 5.9 & 5.4345 & TST & \\
\hline CHEMBL1544131 & 688620 & 5.3 & 5.5903 & TST & \\
\hline CHEMBL3190871 & 688620 & 4.55 & 4.9438 & TRN & \\
\hline CHEMBL1501864 & 688620 & 4.95 & 4.64199 & 99999999995 & TRN \\
\hline CHEMBL1587043 & 688620 & 5.5 & 5.5391 & TRN & \\
\hline CHEMBL1303985 & 688620 & 4.95 & 4.9462 & TRN & \\
\hline CHEMBL1478564 & 688620 & 4.9 & 5.0177 & TRN & \\
\hline CHEMBL1343535 & 688620 & 5.1 & 4.7845 & TRN & \\
\hline CHEMBL1409076 & 688620 & 4.5 & 4.8507 & TRN & \\
\hline
\end{tabular}




\begin{tabular}{|c|c|c|c|c|}
\hline \multicolumn{5}{|c|}{ Supplemental Table S2.txt } \\
\hline CHEMBL1387333 & 688620 & 4.95 & 4.846 & TRN \\
\hline CHEMBL1324250 & 688620 & 4.8 & 4.8862 & TRN \\
\hline CHEMBL1420378 & 688620 & 5.2 & 5.0529 & TST \\
\hline CHEMBL1611725 & 688620 & 4.85 & 4.8552 & TRN \\
\hline CHEMBL3145301 & 688620 & 4.45 & 5.0888 & TRN \\
\hline CHEMBL1491929 & 688620 & 4.45 & 5.1316 & TRN \\
\hline CHEMBL1568551 & 688620 & 4.45 & 4.8074 & TST \\
\hline CHEMBL1497998 & 688620 & 4.6 & 5.0533 & TRN \\
\hline CHEMBL1539522 & 688620 & 4.55 & 5.2108 & TRN \\
\hline CHEMBL3196883 & 688620 & 6.5501 & 6.0151 & TRN \\
\hline CHEMBL1386745 & 688620 & 5.85 & 5.0545 & TRN \\
\hline CHEMBL1339829 & 688620 & 6.25 & 4.8784 & TRN \\
\hline CHEMBL1398361 & 688620 & 4.9 & 5.0128 & TRN \\
\hline CHEMBL1575588 & 688620 & 4.5 & 5.1858 & TRN \\
\hline CHEMBL1221601 & 688620 & 5.4 & 5.4734 & TST \\
\hline CHEMBL1423992 & 688620 & 5.9 & 5.3229 & TRN \\
\hline CHEMBL1465998 & 688620 & 4.95 & 5.1141 & TRN \\
\hline CHEMBL1461925 & 688620 & 4.45 & 4.9599 & TRN \\
\hline CHEMBL1304475 & 688620 & 6.0 & 5.1578 & TRN \\
\hline CHEMBL1464106 & 688620 & 6.35 & 5.6969 & TRN \\
\hline CHEMBL1416613 & 688620 & 4.85 & 5.1413 & TRN \\
\hline CHEMBL1361425 & 688620 & 4.9 & 5.0387 & TRN \\
\hline CHEMBL1401877 & 688620 & 4.85 & 4.8895 & TRN \\
\hline CHEMBL1346184 & 688620 & 4.7 & 5.0322 & TRN \\
\hline CHEMBL1468389 & 688620 & 5.6 & 4.9345 & TRN \\
\hline CHEMBL1367640 & 688620 & 5.35 & 5.178 & TST \\
\hline CHEMBL1600835 & 688620 & 4.9 & 5.2108 & TRN \\
\hline CHEMBL1505937 & 688620 & 5.0 & 5.1973 & TRN \\
\hline CHEMBL1420082 & 688620 & 5.05 & 5.2785 & TRN \\
\hline CHEMBL3193180 & 688620 & 4.6 & 4.9187 & TST \\
\hline CHEMBL1320210 & 688620 & 4.45 & 4.9696 & TRN \\
\hline CHEMBL1497707 & 688620 & 4.65 & 5.1271 & TRN \\
\hline CHEMBL1335002 & 688620 & 5.6 & 5.2326 & TRN \\
\hline CHEMBL1404842 & 688620 & 5.1 & 5.3421 & TRN \\
\hline CHEMBL 3195482 & 688620 & 4.95 & 5.1698 & TRN \\
\hline CHEMBL1524152 & 688620 & 4.45 & 5.1769 & TST \\
\hline CHEMBL 244746 & 688620 & 4.7 & 5.1123 & TRN \\
\hline CHEMBL1488721 & 688620 & 4.75 & 5.29 & TST \\
\hline CHEMBL1555884 & 688620 & 9.2218 & 4.633 & TST \\
\hline CHEMBL1380493 & 688620 & 4.45 & 4.9425 & TRN \\
\hline CHEMBL1466600 & 688620 & 5.45 & 5.1431 & TRN \\
\hline CHEMBL1568453 & 688620 & 5.35 & 4.8716 & TST \\
\hline CHEMBL1378197 & 688620 & 5.5 & 5.0501 & TST \\
\hline CHEMBL1559629 & 688620 & 4.45 & 5.1764 & TST \\
\hline CHEMBL1559300 & 688620 & 5.6 & 5.1363 & TRN \\
\hline CHEMBL1602888 & 688620 & 6.5501 & 5.6022 & TRN \\
\hline CHEMBL193888 & 688620 & 5.0 & 5.3495 & TRN \\
\hline CHEMBL1492594 & 688620 & 5.1 & 4.9458 & TRN \\
\hline
\end{tabular}




\begin{tabular}{|c|c|c|c|c|c|}
\hline \multicolumn{6}{|c|}{ Supplemental Table S2.txt } \\
\hline CHEMBL539507 & 688620 & 5.0 & 4.9187 & TST & \\
\hline CHEMBL1366958 & 688620 & 4.9 & 5.2828 & TRN & \\
\hline CHEMBL1572074 & 688620 & 6.35 & 5.1222 & TST & \\
\hline CHEMBL1378457 & 688620 & 4.6 & 4.9603 & TRN & \\
\hline CHEMBL1335802 & 688620 & 4.95 & 5.1637 & TST & \\
\hline CHEMBL3198269 & 688620 & 5.35 & 4.996 & TRN & \\
\hline CHEMBL1407257 & 688620 & 4.6 & 4.8904 & TRN & \\
\hline CHEMBL3191888 & 688620 & 4.9 & 5.5203 & TRN & \\
\hline CHEMBL1380294 & 688620 & 4.85 & 5.0856 & TST & \\
\hline CHEMBL1546196 & 688620 & 5.3 & 5.3755 & TRN & \\
\hline CHEMBL1507867 & 688620 & 5.0 & 4.9629 & TRN & \\
\hline CHEMBL1401082 & 688620 & 4.55 & 5.1726 & TST & \\
\hline CHEMBL1510389 & 688620 & 5.3 & 5.5609 & TRN & \\
\hline CHEMBL1484418 & 688620 & 6.7001 & 4.8376 & TRN & \\
\hline CHEMBL1305079 & 688620 & 5.8 & 5.2354 & TRN & \\
\hline CHEMBL1368433 & 688620 & 4.45 & 4.8105 & TRN & \\
\hline CHEMBL1453876 & 688620 & 4.45 & 4.97 & TST & \\
\hline CHEMBL1464853 & 688620 & 4.75 & 4.7466 & TST & \\
\hline CHEMBL1502142 & 688620 & 4.8 & 4.9755 & TST & \\
\hline CHEMBL493691 & 688620 & 4.75 & 4.777 & TRN & \\
\hline CHEMBL1594910 & 688620 & 5.4 & 4.9262 & TRN & \\
\hline CHEMBL1346977 & 688620 & 5.4 & 5.21299 & 9999999999 & TRN \\
\hline CHEMBL1348802 & 688620 & 5.7 & 5.1773 & TST & \\
\hline CHEMBL1341582 & 688620 & 4.75 & 5.3176 & TRN & \\
\hline CHEMBL3192335 & 688620 & 6.0 & 5.7923 & TRN & \\
\hline CHEMBL 2000750 & 688620 & 5.75 & 5.6291 & TRN & \\
\hline CHEMBL1431034 & 688620 & 4.45 & 4.8107 & TRN & \\
\hline CHEMBL1532862 & 688620 & 5.6 & 5.5719 & TRN & \\
\hline CHEMBL3191218 & 688620 & 6.4 & 6.3053 & TRN & \\
\hline CHEMBL1421583 & 688620 & 5.0 & 5.0436 & TRN & \\
\hline CHEMBL1543993 & 688620 & 4.95 & 5.1028 & TST & \\
\hline CHEMBL1597037 & 688620 & 4.95 & 4.9112 & TRN & \\
\hline CHEMBL1587671 & 688620 & 5.4 & 5.0001 & TRN & \\
\hline CHEMBL1448356 & 688620 & 4.9 & 4.7986 & TST & \\
\hline CHEMBL1301852 & 688620 & 4.8 & 5.1963 & TRN & \\
\hline CHEMBL1368441 & 688620 & 5.0 & 5.5725 & TRN & \\
\hline CHEMBL43612 & 688620 & 4.95 & 5.3003 & TST & \\
\hline CHEMBL1531686 & 688620 & 4.95 & 5.2076 & TST & \\
\hline CHEMBL1608957 & 688620 & 4.6 & 4.9583 & TRN & \\
\hline CHEMBL1559308 & 688620 & 5.6 & 5.4538 & TRN & \\
\hline CHEMBL1403896 & 688620 & 4.7 & 5.008 & TST & \\
\hline CHEMBL1599740 & 688620 & 4.95 & 5.0875 & TRN & \\
\hline CHEMBL1539019 & 688620 & 5.35 & 5.7266 & TRN & \\
\hline CHEMBL1501558 & 688620 & 5.4 & 5.5191 & TRN & \\
\hline CHEMBL1462036 & 688620 & 5.0 & 5.1468 & TRN & \\
\hline CHEMBL1527955 & 688620 & 4.9 & 5.0959 & TST & \\
\hline CHEMBL1539738 & 688620 & 6.8499 & 4.9805 & TRN & \\
\hline CHEMBL3193543 & 688620 & 4.45 & 5.6694 & TRN & \\
\hline
\end{tabular}




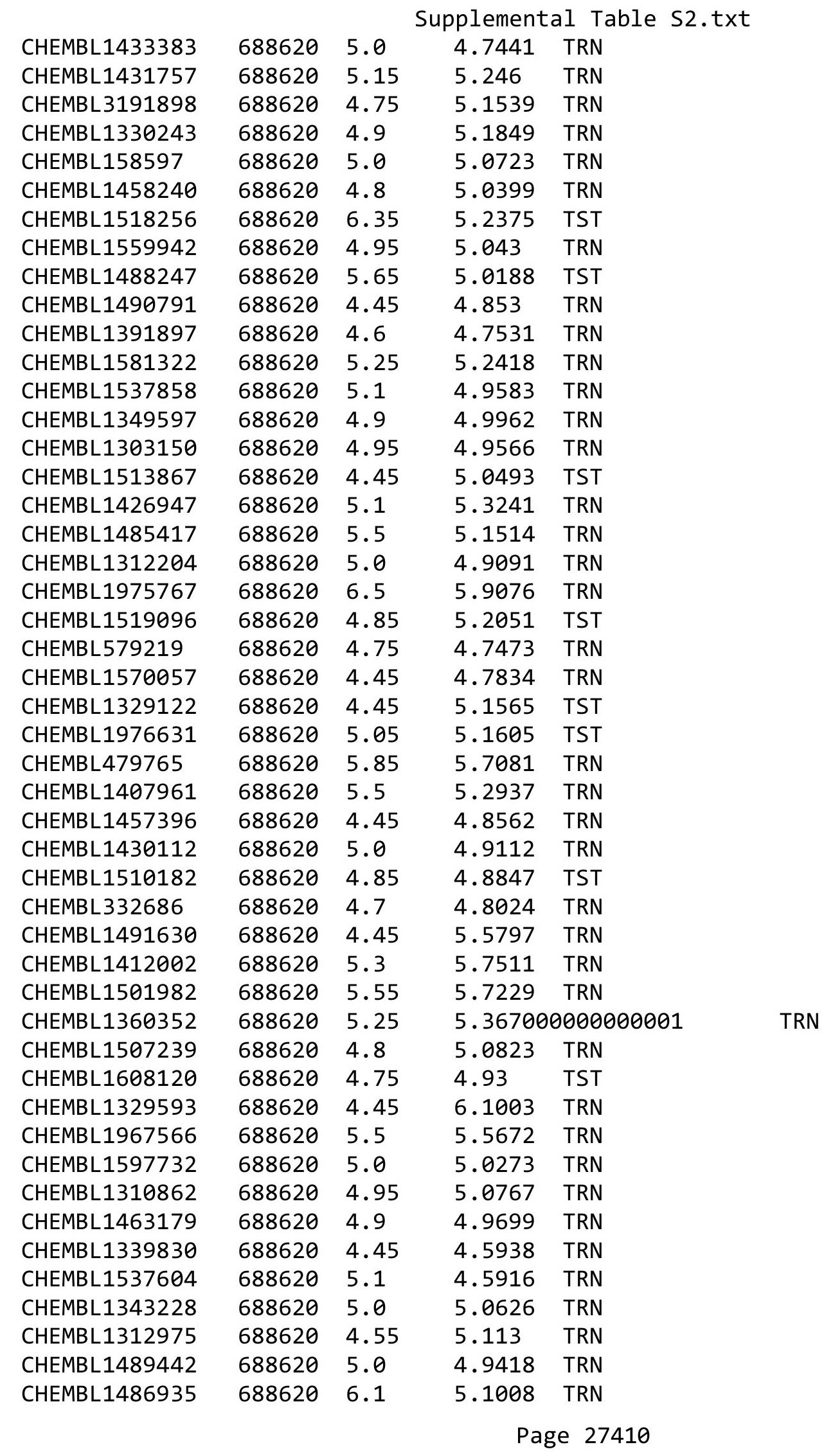




\begin{tabular}{|c|c|c|c|c|c|}
\hline \multicolumn{6}{|c|}{ Supplemental Table S2.txt } \\
\hline CHEMBL475541 & 688620 & 5.8 & 4.9755 & TRN & \\
\hline CHEMBL1600148 & 688620 & 4.9 & 5.5137 & TRN & \\
\hline CHEMBL1526068 & 688620 & 4.45 & 4.7465 & TRN & \\
\hline CHEMBL1550093 & 688620 & 4.45 & 5.0057 & TRN & \\
\hline CHEMBL1523600 & 688620 & 4.9 & 4.9381 & TST & \\
\hline CHEMBL584759 & 688620 & 6.0 & 5.7307 & TRN & \\
\hline CHEMBL1545253 & 688620 & 4.65 & 4.8811 & TRN & \\
\hline CHEMBL1598321 & 688620 & 4.75 & 5.0417 & TRN & \\
\hline CHEMBL1380755 & 688620 & 4.95 & 5.0702 & TST & \\
\hline CHEMBL1587549 & 688620 & 4.8 & 4.9346 & TRN & \\
\hline CHEMBL1347250 & 688620 & 4.95 & 4.8439 & TST & \\
\hline CHEMBL1487503 & 688620 & 6.0 & 5.0601 & TST & \\
\hline CHEMBL1334674 & 688620 & 5.15 & 5.4395 & TRN & \\
\hline CHEMBL1331509 & 688620 & 6.05 & 6.1954 & TRN & \\
\hline CHEMBL1583523 & 688620 & 4.45 & 5.1442 & TRN & \\
\hline CHEMBL1303110 & 688620 & 4.8 & 4.8358 & TST & \\
\hline CHEMBL1584615 & 688620 & 4.95 & 5.0196 & TRN & \\
\hline CHEMBL 3198460 & 688620 & 5.0 & 5.46899 & 9999999999 & TRN \\
\hline CHEMBL1523994 & 688620 & 4.8 & 5.2496 & TRN & \\
\hline CHEMBL1389520 & 688620 & 4.45 & 4.8427 & TRN & \\
\hline CHEMBL1459513 & 688620 & 4.95 & 5.1126 & TRN & \\
\hline CHEMBL1380424 & 688620 & 4.75 & 5.1663 & TRN & \\
\hline CHEMBL1336028 & 688620 & 4.8 & 5.0506 & TRN & \\
\hline CHEMBL1544239 & 688620 & 4.9 & 5.13299 & 9999999999 & TST \\
\hline CHEMBL1336081 & 688620 & 4.95 & 5.1001 & TRN & \\
\hline CHEMBL1378461 & 688620 & 4.45 & 4.9502 & TRN & \\
\hline CHEMBL1537460 & 688620 & 4.85 & 5.1283 & TRN & \\
\hline CHEMBL1350415 & 688620 & 4.8 & 5.0806 & TST & \\
\hline CHEMBL1530992 & 688620 & 4.75 & 4.9229 & TRN & \\
\hline CHEMBL3194521 & 688620 & 5.1 & 5.2715 & TRN & \\
\hline CHEMBL1997175 & 688620 & 5.95 & 5.6466 & TRN & \\
\hline CHEMBL1503912 & 688620 & 5.75 & 5.1904 & TRN & \\
\hline CHEMBL1366724 & 688620 & 4.45 & 5.0013 & TRN & \\
\hline CHEMBL1364139 & 688620 & 5.0 & 5.1674 & TRN & \\
\hline CHEMBL1402460 & 688620 & 4.9 & 4.9864 & TRN & \\
\hline CHEMBL1560266 & 688620 & 5.25 & 5.3204 & TRN & \\
\hline CHEMBL1498649 & 688620 & 4.9 & 5.0995 & TRN & \\
\hline CHEMBL1570920 & 688620 & 4.7 & 5.1621 & TST & \\
\hline CHEMBL1334768 & 688620 & 4.65 & 5.2527 & TRN & \\
\hline CHEMBL1574271 & 688620 & 4.7 & 4.7474 & TRN & \\
\hline CHEMBL1323024 & 688620 & 4.9 & 5.1003 & TST & \\
\hline CHEMBL1568135 & 688620 & 4.45 & 4.8765 & TRN & \\
\hline CHEMBL1452921 & 688620 & 5.05 & 5.0663 & TRN & \\
\hline CHEMBL1504328 & 688620 & 5.0 & 4.9286 & TRN & \\
\hline CHEMBL1450119 & 688620 & 5.2 & 5.3401 & TRN & \\
\hline CHEMBL1401344 & 688620 & 6.3 & 6.3136 & TRN & \\
\hline CHEMBL1403536 & 688620 & 6.5 & 4.8423 & TRN & \\
\hline CHEMBL1351502 & 688620 & 4.45 & 4.9893 & TRN & \\
\hline
\end{tabular}




\begin{tabular}{|c|c|c|c|c|c|}
\hline \multicolumn{6}{|c|}{ Supplemental Table S2.txt } \\
\hline CHEMBL1521414 & 688620 & 4.85 & 4.9436 & TRN & \\
\hline CHEMBL1415908 & 688620 & 5.3 & 5.1049 & TRN & \\
\hline CHEMBL1368609 & 688620 & 5.9 & 4.7946 & TST & \\
\hline CHEMBL1387822 & 688620 & 4.45 & 5.1064 & TRN & \\
\hline CHEMBL1462402 & 688620 & 5.0 & 5.022 & TST & \\
\hline CHEMBL1402257 & 688620 & 4.95 & 5.0781 & TST & \\
\hline CHEMBL1609319 & 688620 & 4.65 & 4.8238 & TRN & \\
\hline CHEMBL1471893 & 688620 & 4.45 & 4.8347 & TRN & \\
\hline CHEMBL1587870 & 688620 & 6.05 & 5.3825 & TRN & \\
\hline CHEMBL3191809 & 688620 & 5.7 & 5.1897 & TRN & \\
\hline CHEMBL1488674 & 688620 & 5.55 & 5.3105 & TRN & \\
\hline CHEMBL3197736 & 688620 & 5.35 & 4.8883 & TST & \\
\hline CHEMBL1437095 & 688620 & 4.75 & 4.7922 & TRN & \\
\hline CHEMBL1536282 & 688620 & 5.0 & 4.9542 & TST & \\
\hline CHEMBL1406596 & 688620 & 5.95 & 5.0379 & TST & \\
\hline CHEMBL1236872 & 688620 & 6.0 & 5.7765 & TRN & \\
\hline CHEMBL1351630 & 688620 & 5.4 & 5.074 & TRN & \\
\hline CHEMBL1357766 & 688620 & 4.75 & 5.1305 & TST & \\
\hline CHEMBL320247 & 688620 & 4.6 & 5.182 & TRN & \\
\hline CHEMBL3207540 & 688620 & 4.7 & 4.8416 & TRN & \\
\hline CHEMBL1457128 & 688620 & 5.45 & 5.1053 & TRN & \\
\hline CHEMBL1565600 & 688620 & 4.95 & 4.8585 & TST & \\
\hline CHEMBL1589428 & 688620 & 4.95 & 4.9275 & TRN & \\
\hline CHEMBL1444849 & 688620 & 4.45 & 4.9131 & TST & \\
\hline CHEMBL1567703 & 688620 & 4.95 & 4.7738 & TRN & \\
\hline CHEMBL1555729 & 688620 & 4.5 & 5.1166 & TRN & \\
\hline CHEMBL1544780 & 688620 & 4.45 & 5.1845 & TRN & \\
\hline CHEMBL1404122 & 688620 & 4.95 & 5.2619 & TRN & \\
\hline CHEMBL1398194 & 688620 & 4.6 & 5.003 & TRN & \\
\hline CHEMBL3196244 & 688620 & 4.45 & 5.1059 & TRN & \\
\hline CHEMBL1565408 & 688620 & 4.55 & 4.8869 & TRN & \\
\hline CHEMBL1430338 & 688620 & 4.9 & 5.2096 & TRN & \\
\hline CHEMBL1385598 & 688620 & 4.45 & 4.8411 & TRN & \\
\hline CHEMBL1508255 & 688620 & 5.4 & 4.9697 & TRN & \\
\hline CHEMBL1501896 & 688620 & 6.2 & 5.9668 & TRN & \\
\hline CHEMBL1411105 & 688620 & 5.0 & 5.3183 & TST & \\
\hline CHEMBL1523513 & 688620 & 4.75 & 4.96399 & 99999999995 & TRN \\
\hline CHEMBL1416355 & 688620 & 5.6 & 5.4903 & TRN & \\
\hline CHEMBL1348052 & 688620 & 4.85 & 4.9172 & TRN & \\
\hline CHEMBL 3213530 & 688620 & 5.5 & 5.1275 & TRN & \\
\hline CHEMBL1566487 & 688620 & 4.45 & 5.2569 & TRN & \\
\hline CHEMBL 2369295 & 688620 & 4.6 & 5.0613 & TRN & \\
\hline CHEMBL1463437 & 688620 & 5.9 & 4.9091 & TST & \\
\hline CHEMBL1495112 & 688620 & 5.3 & 4.8849 & TRN & \\
\hline CHEMBL1463966 & 688620 & 5.1 & 5.0858 & TRN & \\
\hline CHEMBL1495394 & 688620 & 4.85 & 5.141 & TRN & \\
\hline CHEMBL1482487 & 688620 & 4.95 & 4.9974 & TST & \\
\hline CHEMBL1585609 & 688620 & 5.5 & 5.3833 & TST & \\
\hline
\end{tabular}




\begin{tabular}{|c|c|c|c|c|c|}
\hline & & & & & \\
\hline CHEMBL1589003 & 688620 & 5.4 & 4.8988 & TRN & \\
\hline CHEMBL1557196 & 688620 & 4.45 & 4.9007 & TRN & \\
\hline CHEMBL37570 & 688620 & 5.4 & 5.1704 & TRN & \\
\hline CHEMBL1481472 & 688620 & 4.95 & 4.9187 & TRN & \\
\hline CHEMBL3196008 & 688620 & 5.05 & 5.1889 & TRN & \\
\hline CHEMBL1347781 & 688620 & 4.8 & 4.7768 & TRN & \\
\hline CHEMBL1506224 & 688620 & 5.1 & 5.2002 & TRN & \\
\hline CHEMBL1984787 & 688620 & 4.8 & 5.1713 & TRN & \\
\hline CHEMBL1555715 & 688620 & 5.05 & 5.3197 & TRN & \\
\hline CHEMBL1328169 & 688620 & 5.25 & 5.4871 & TRN & \\
\hline CHEMBL2094665 & 688620 & 5.45 & 5.0589 & TRN & \\
\hline CHEMBL3189945 & 688620 & 4.45 & 4.801 & TRN & \\
\hline CHEMBL1610866 & 688620 & 6.5501 & 5.1534 & TRN & \\
\hline CHEMBL1596984 & 688620 & 4.95 & 4.9717 & TRN & \\
\hline CHEMBL1390716 & 688620 & 6.2 & 5.9779 & TRN & \\
\hline CHEMBL1310124 & 688620 & 5.1 & 5.2092 & TST & \\
\hline CHEMBL3191268 & 688620 & 4.75 & 5.5765 & TRN & \\
\hline CHEMBL1405433 & 688620 & 4.65 & 4.8665 & TRN & \\
\hline CHEMBL1469489 & 688620 & 5.0 & 5.1879 & TRN & \\
\hline CHEMBL1548247 & 688620 & 5.0 & 5.1007 & TRN & \\
\hline CHEMBL1329146 & 688620 & 5.05 & 5.0791 & TST & \\
\hline CHEMBL1414821 & 688620 & 4.45 & 4.9934 & TST & \\
\hline CHEMBL1525175 & 688620 & 5.15 & 5.1391 & TRN & \\
\hline CHEMBL3193424 & 688620 & 4.95 & 5.1811 & TRN & \\
\hline CHEMBL1407635 & 688620 & 4.9 & 4.926 & TST & \\
\hline CHEMBL1605231 & 688620 & 4.6 & 4.9304 & TRN & \\
\hline CHEMBL1573380 & 688620 & 5.05 & 5.2428 & TRN & \\
\hline CHEMBL1596817 & 688620 & 4.7 & 5.1445 & TRN & \\
\hline CHEMBL3209024 & 688620 & 5.45 & 4.6078 & TRN & \\
\hline CHEMBL1610429 & 688620 & 6.05 & 5.6607 & TRN & \\
\hline CHEMBL1567660 & 688620 & 5.7 & 5.2879 & TST & \\
\hline CHEMBL3194113 & 688620 & 5.0 & 5.2584 & TRN & \\
\hline CHEMBL1379074 & 688620 & 4.45 & 4.7961 & TRN & \\
\hline CHEMBL1350780 & 688620 & 6.25 & 6.0128 & TST & \\
\hline CHEMBL1439833 & 688620 & 5.85 & 6.0095 & TRN & \\
\hline CHEMBL1575373 & 688620 & 4.85 & 4.8316 & TST & \\
\hline CHEMBL1329491 & 688620 & 4.75 & 4.9284 & TRN & \\
\hline CHEMBL1588770 & 688620 & 5.0 & 5.195 & TRN & \\
\hline CHEMBL1376574 & 688620 & 6.5501 & 5.1735 & TST & \\
\hline CHEMBL1549038 & 688620 & 4.45 & 4.8969 & TST & \\
\hline CHEMBL1478168 & 688620 & 5.5 & 5.2355 & TRN & \\
\hline CHEMBL1430145 & 688620 & 5.85 & 5.0229 & TRN & \\
\hline CHEMBL1536665 & 688620 & 5.85 & 5.6483 & TRN & \\
\hline CHEMBL1569724 & 688620 & 5.35 & 5.1571 & TRN & \\
\hline CHEMBL 270337 & 688620 & 4.85 & 5.1386 & TRN & \\
\hline CHEMBL1503795 & 688620 & 5.45 & 5.2308 & TST & \\
\hline CHEMBL1390930 & 688620 & 4.95 & 5.4165 & TRN & \\
\hline CHEMBL1369136 & 688620 & 4.85 & 4.90300 & 20000000005 & TRN \\
\hline & & & & 27413 & \\
\hline
\end{tabular}




\begin{tabular}{|c|c|c|c|c|}
\hline & & & pplement & al $\mathrm{Ta}$ \\
\hline CHEMBL1475088 & 688620 & 4.7 & 5.039 & TST \\
\hline CHEMBL1503598 & 688620 & 5.55 & 5.4312 & TRN \\
\hline CHEMBL1452885 & 688620 & 4.85 & 4.968 & TRN \\
\hline CHEMBL1420193 & 688620 & 4.85 & 5.0225 & TRN \\
\hline CHEMBL1472307 & 688620 & 6.15 & 4.9938 & TRN \\
\hline CHEMBL1409421 & 688620 & 4.85 & 4.7757 & TRN \\
\hline CHEMBL353021 & 688620 & 4.65 & 5.359 & TST \\
\hline CHEMBL1364432 & 688620 & 4.85 & 4.9059 & TRN \\
\hline CHEMBL1352348 & 688620 & 4.95 & 4.9411 & TRN \\
\hline CHEMBL1403734 & 688620 & 6.1 & 5.1103 & TRN \\
\hline CHEMBL1492972 & 688620 & 4.85 & 4.808 & TRN \\
\hline CHEMBL1375947 & 688620 & 4.65 & 4.5698 & TRN \\
\hline CHEMBL1600544 & 688620 & 4.45 & 5.2579 & TST \\
\hline CHEMBL1504332 & 688620 & 4.9 & 5.0924 & TRN \\
\hline CHEMBL1472328 & 688620 & 4.6 & 5.0222 & TRN \\
\hline CHEMBL1544478 & 688620 & 5.35 & 5.124 & TRN \\
\hline CHEMBL1327933 & 688620 & 4.85 & 4.7766 & TST \\
\hline CHEMBL1968739 & 688620 & 5.2 & 5.6034 & TRN \\
\hline CHEMBL1431865 & 688620 & 4.9 & 5.0163 & TRN \\
\hline CHEMBL1446268 & 688620 & 5.1 & 4.7537 & TRN \\
\hline CHEMBL2001393 & 688620 & 6.8 & 6.1199 & TRN \\
\hline CHEMBL1389542 & 688620 & 6.5501 & 6.2722 & TRN \\
\hline CHEMBL1324431 & 688620 & 5.2 & 5.0951 & TST \\
\hline CHEMBL1559226 & 688620 & 4.45 & 5.0785 & TRN \\
\hline CHEMBL1307114 & 688620 & 4.9 & 4.7174 & TRN \\
\hline CHEMBL1507012 & 688620 & 4.45 & 4.8536 & TRN \\
\hline CHEMBL1579863 & 688620 & 4.9 & 4.754 & TRN \\
\hline CHEMBL1314100 & 688620 & 5.65 & 5.1628 & TRN \\
\hline CHEMBL1483577 & 688620 & 5.8 & 5.4775 & TRN \\
\hline CHEMBL1404989 & 688620 & 4.45 & 5.0894 & TRN \\
\hline CHEMBL1542213 & 688620 & 4.45 & 5.1378 & TRN \\
\hline CHEMBL1605241 & 688620 & 4.45 & 5.0496 & TRN \\
\hline CHEMBL1519798 & 688620 & 4.45 & 5.0438 & TRN \\
\hline CHEMBL1565106 & 688620 & 4.45 & 5.2277 & TRN \\
\hline CHEMBL3195292 & 688620 & 4.95 & 5.1935 & TRN \\
\hline CHEMBL1413000 & 688620 & 6.7501 & 5.2028 & TST \\
\hline CHEMBL1559832 & 688620 & 5.6 & 4.9102 & TRN \\
\hline CHEMBL1529063 & 688620 & 4.65 & 4.8871 & TST \\
\hline CHEMBL1309220 & 688620 & 6.95 & 5.0882 & TST \\
\hline CHEMBL1327830 & 688620 & 7.0501 & 5.0204 & TRN \\
\hline CHEMBL1359157 & 688620 & 4.5 & 4.8098 & TST \\
\hline CHEMBL3193369 & 688620 & 5.6 & 5.3235 & TRN \\
\hline CHEMBL1509859 & 688620 & 4.95 & 4.9715 & TRN \\
\hline CHEMBL1312969 & 688620 & 5.65 & 5.5491 & TRN \\
\hline CHEMBL1449739 & 688620 & 5.9 & 5.0281 & TRN \\
\hline CHEMBL1526919 & 688620 & 5.0 & 5.0657 & TRN \\
\hline CHEMBL1506791 & 688620 & 6.2 & 5.941 & TST \\
\hline CHEMBL1382902 & 688620 & 5.25 & 5.0541 & TST \\
\hline
\end{tabular}




\begin{tabular}{|c|c|c|c|c|c|}
\hline \multicolumn{6}{|c|}{ Supplemental Table S2.txt } \\
\hline CHEMBL1489151 & 688620 & 4.45 & 5.0056 & TRN & \\
\hline CHEMBL1584765 & 688620 & 5.0 & 4.8969 & TRN & \\
\hline CHEMBL1511526 & 688620 & 5.0 & 4.8236 & TRN & \\
\hline CHEMBL1447782 & 688620 & 4.45 & 4.8032 & TRN & \\
\hline CHEMBL1425275 & 688620 & 5.0 & 4.9755 & TST & \\
\hline CHEMBL3209435 & 688620 & 5.15 & 5.2049 & TST & \\
\hline CHEMBL1461631 & 688620 & 4.8 & 5.3388 & TRN & \\
\hline CHEMBL1363063 & 688620 & 4.8 & 4.8757 & TRN & \\
\hline CHEMBL1386252 & 688620 & 6.0 & 5.4809 & TRN & \\
\hline CHEMBL1353608 & 688620 & 5.55 & 5.0787 & TST & \\
\hline CHEMBL1566795 & 688620 & 4.4 & 4.9341 & TRN & \\
\hline CHEMBL1322266 & 688620 & 7.0 & 5.0955 & TRN & \\
\hline CHEMBL1568201 & 688620 & 6.25 & 5.6551 & TRN & \\
\hline CHEMBL1539074 & 688620 & 5.85 & 5.494 & TRN & \\
\hline CHEMBL1542663 & 688620 & 4.75 & 5.3116 & TRN & \\
\hline CHEMBL1308522 & 688620 & 5.5 & 5.1162 & TRN & \\
\hline CHEMBL1441868 & 688620 & 4.8 & 5.1859 & TRN & \\
\hline CHEMBL1342663 & 688620 & 4.9 & 5.0775 & TST & \\
\hline CHEMBL1528851 & 688620 & 4.95 & 5.079 & TRN & \\
\hline CHEMBL1466481 & 688620 & 5.15 & 5.1161 & TRN & \\
\hline CHEMBL1529898 & 688620 & 4.95 & 5.0198 & TRN & \\
\hline CHEMBL1536376 & 688620 & 5.85 & 5.4013 & TRN & \\
\hline CHEMBL1549993 & 688620 & 4.45 & 4.86 & TST & \\
\hline CHEMBL1521136 & 688620 & 6.15 & 5.2483 & TRN & \\
\hline CHEMBL1312201 & 688620 & 4.55 & 5.0206 & TRN & \\
\hline CHEMBL1353943 & 688620 & 5.0 & 4.853 & TRN & \\
\hline CHEMBL1481869 & 688620 & 5.25 & 5.0552 & TST & \\
\hline CHEMBL1460004 & 688620 & 4.5 & $4.9430 e$ & 00000000005 & TRN \\
\hline CHEMBL1984107 & 688620 & 5.15 & 5.2482 & TRN & \\
\hline CHEMBL1411316 & 688620 & 4.65 & 4.8947 & TST & \\
\hline CHEMBL3189526 & 688620 & 4.6 & 5.1397 & TRN & \\
\hline CHEMBL1326470 & 688620 & 4.85 & 4.9317 & TST & \\
\hline CHEMBL3145380 & 688620 & 5.15 & 5.6078 & TRN & \\
\hline CHEMBL1372863 & 688620 & 4.85 & 5.2367 & TRN & \\
\hline CHEMBL1583833 & 688620 & 5.0 & 4.9846 & TRN & \\
\hline CHEMBL1345471 & 688620 & 5.0 & 4.8999 & TST & \\
\hline CHEMBL1576865 & 688620 & 4.8 & 5.12 & TRN & \\
\hline CHEMBL1327451 & 688620 & 4.95 & 4.7989 & TRN & \\
\hline CHEMBL1577312 & 688620 & 4.45 & 5.0996 & TRN & \\
\hline CHEMBL1503163 & 688620 & 4.75 & 4.8604 & TST & \\
\hline CHEMBL1604000 & 688620 & 4.95 & 5.0324 & TRN & \\
\hline CHEMBL1613374 & 688620 & 5.2 & 5.1562 & TRN & \\
\hline CHEMBL1459741 & 688620 & 4.45 & 5.0876 & TRN & \\
\hline CHEMBL1527838 & 688620 & 4.9 & 4.6933 & TRN & \\
\hline CHEMBL1580032 & 688620 & 5.35 & 5.0603 & TRN & \\
\hline CHEMBL1421925 & 688620 & 4.9 & 4.8763 & TRN & \\
\hline CHEMBL1465013 & 688620 & 5.95 & 5.2493 & TRN & \\
\hline CHEMBL1463850 & 688620 & 4.75 & 4.8849 & TRN & \\
\hline
\end{tabular}




\begin{tabular}{|c|c|c|c|c|c|}
\hline & & & & & \\
\hline CHEMBL1603584 & 688620 & 4.9 & 5.1632 & TRN & \\
\hline CHEMBL1305563 & 688620 & 4.6 & 4.7211 & TRN & \\
\hline CHEMBL1584184 & 688620 & 5.0 & 5.285 & TRN & \\
\hline CHEMBL1558403 & 688620 & 6.3 & 5.0098 & TRN & \\
\hline CHEMBL1374312 & 688620 & 5.5 & 5.2848 & TRN & \\
\hline CHEMBL1508787 & 688620 & 4.85 & 4.9995 & TRN & \\
\hline CHEMBL1383911 & 688620 & 4.45 & 4.9247 & TRN & \\
\hline CHEMBL1596152 & 688620 & 4.75 & 5.0028 & TST & \\
\hline CHEMBL1588369 & 688620 & 5.6 & 5.1665 & TRN & \\
\hline CHEMBL1307668 & 688620 & 4.5 & 4.9724 & TST & \\
\hline CHEMBL3191961 & 688620 & 5.0 & 5.2766 & TRN & \\
\hline CHEMBL1467294 & 688620 & 4.85 & 4.7854 & TST & \\
\hline CHEMBL3195200 & 688620 & 5.0 & 5.2733 & TRN & \\
\hline CHEMBL1536070 & 688620 & 4.75 & 4.7991 & TRN & \\
\hline CHEMBL3194061 & 688620 & 6.0 & 5.6257 & TRN & \\
\hline CHEMBL1520981 & 688620 & 4.8 & 5.0387 & TRN & \\
\hline CHEMBL1421626 & 688620 & 4.85 & 5.0345 & TST & \\
\hline CHEMBL1085358 & 688620 & 4.95 & 5.2597 & TST & \\
\hline CHEMBL1428986 & 688620 & 4.45 & 5.0234 & TRN & \\
\hline CHEMBL1442242 & 688620 & 5.15 & 4.9211 & TRN & \\
\hline CHEMBL1373924 & 688620 & 4.9 & $5.1670 e$ & 0000000001 & TRN \\
\hline CHEMBL1493171 & 688620 & 5.1 & 5.1346 & TRN & \\
\hline CHEMBL1361388 & 688620 & 4.5 & 4.8495 & TST & \\
\hline CHEMBL1462982 & 688620 & 5.3 & 5.0842 & TRN & \\
\hline CHEMBL1381688 & 688620 & 4.45 & 4.9161 & TRN & \\
\hline CHEMBL1361244 & 688620 & 4.95 & 5.1332 & TRN & \\
\hline CHEMBL1611137 & 688620 & 5.15 & 5.0456 & TRN & \\
\hline CHEMBL 260213 & 688620 & 4.85 & 5.2705 & TRN & \\
\hline CHEMBL1353969 & 688620 & 4.9 & 4.9328 & TRN & \\
\hline CHEMBL1400606 & 688620 & 4.45 & 4.88399 & 99999999995 & TRN \\
\hline CHEMBL1389786 & 688620 & 4.9 & 5.038 & TRN & \\
\hline CHEMBL1368718 & 688620 & 6.95 & 5.4289 & TRN & \\
\hline CHEMBL1605642 & 688620 & 4.5 & 4.8393 & TRN & \\
\hline CHEMBL1383140 & 688620 & 4.85 & 4.7946 & TST & \\
\hline CHEMBL1587513 & 688620 & 4.95 & 4.8411 & TRN & \\
\hline CHEMBL1399776 & 688620 & 4.7 & 4.8127 & TRN & \\
\hline CHEMBL1371066 & 688620 & 4.8 & 5.4919 & TRN & \\
\hline CHEMBL597047 & 688620 & 4.95 & 4.8859 & TST & \\
\hline CHEMBL1535989 & 688620 & 4.85 & 4.8787 & TST & \\
\hline CHEMBL3192251 & 688620 & 4.9 & 5.2733 & TRN & \\
\hline CHEMBL1605629 & 688620 & 6.0 & 5.2945 & TST & \\
\hline CHEMBL1347861 & 688620 & 4.85 & 5.3467 & TST & \\
\hline CHEMBL1558510 & 688620 & 4.95 & 5.1009 & TRN & \\
\hline CHEMBL1329966 & 688620 & 5.2 & 5.0124 & TST & \\
\hline CHEMBL1548507 & 688620 & 5.25 & 5.235 & TST & \\
\hline CHEMBL1584792 & 688620 & 4.75 & 4.9638 & TST & \\
\hline CHEMBL3392494 & 688620 & 5.95 & 5.9064 & TRN & \\
\hline CHEMBL3213255 & 688620 & 4.85 & 5.1738 & TRN & \\
\hline & & & & 27416 & \\
\hline
\end{tabular}




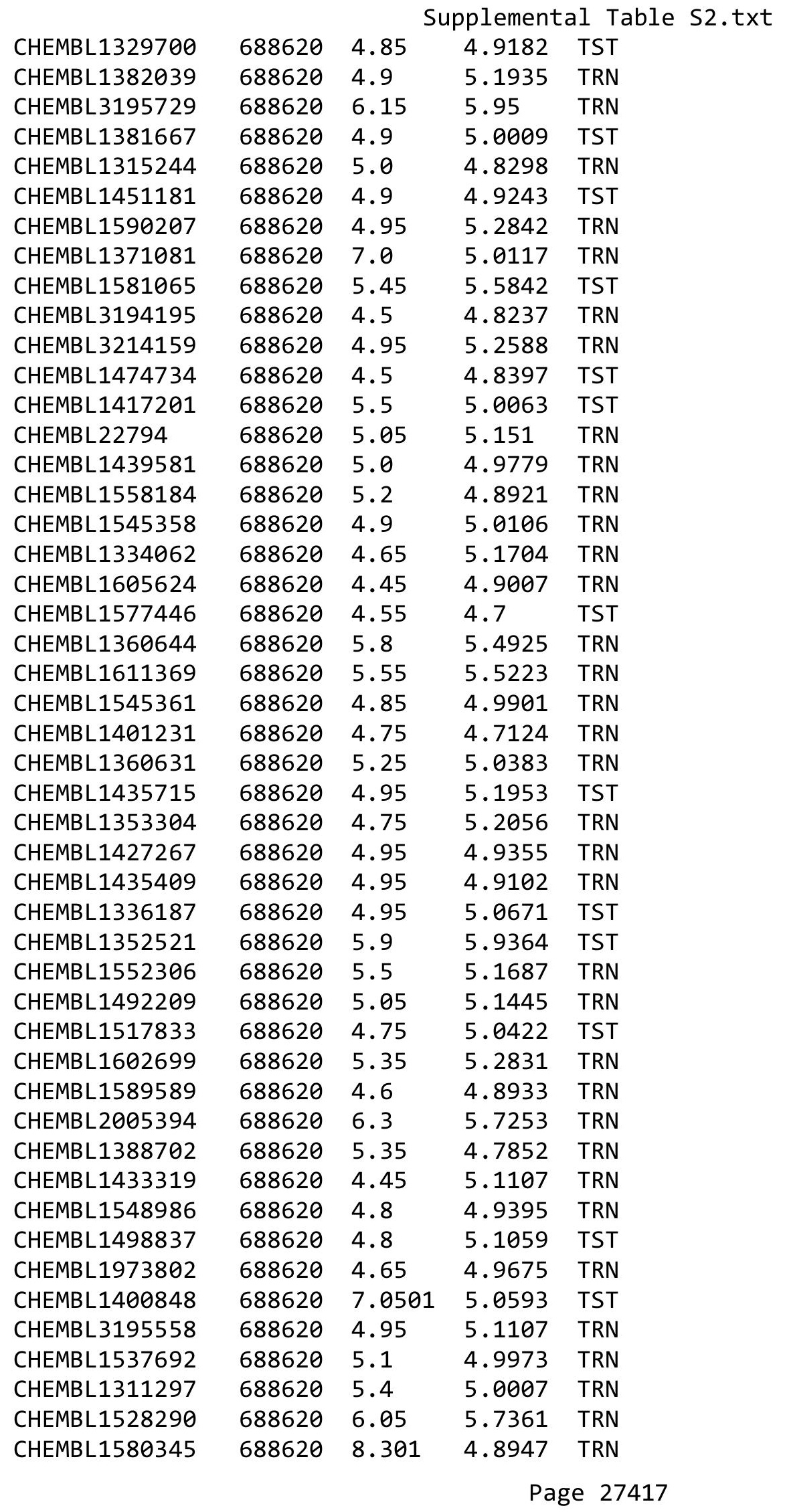




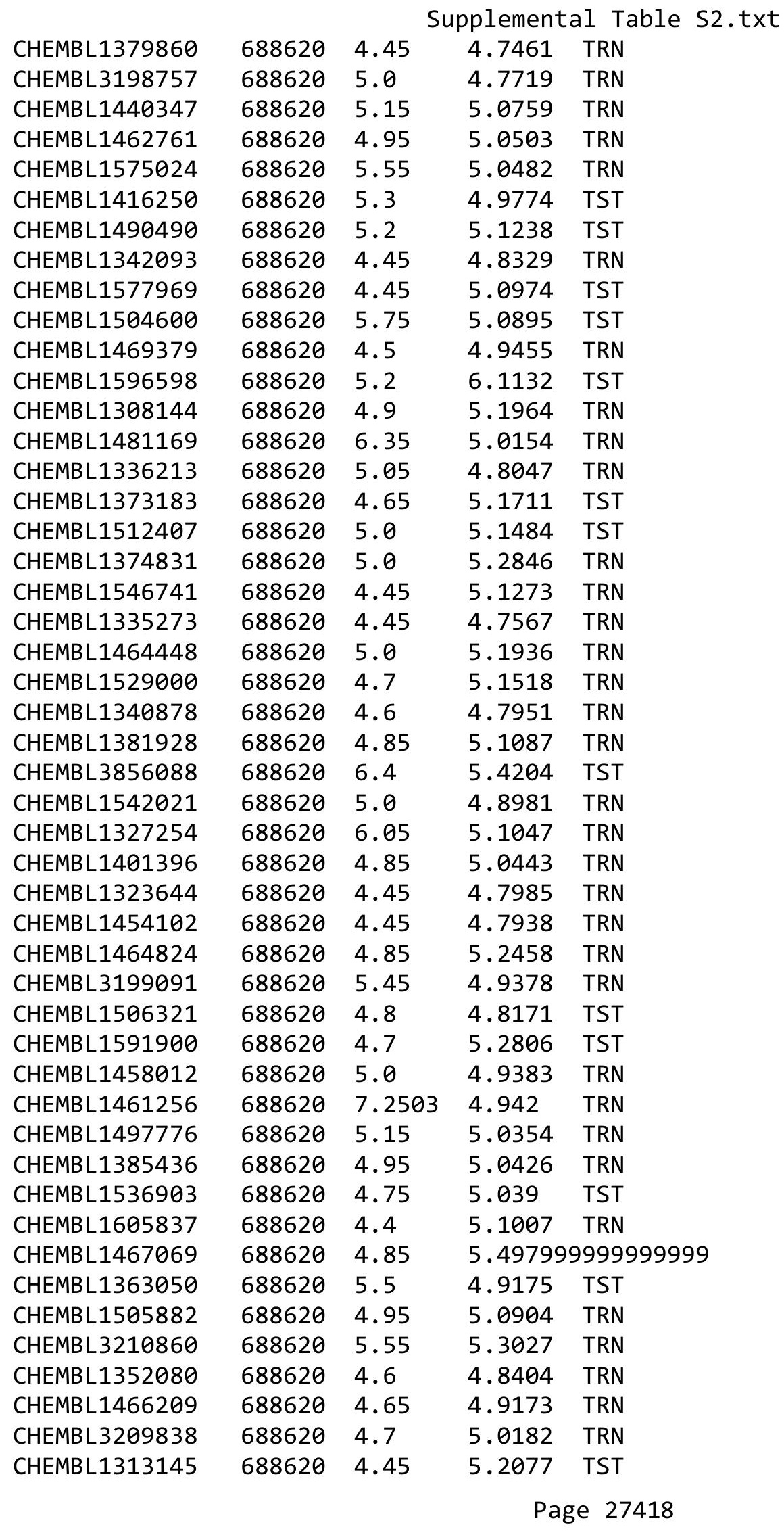




\begin{tabular}{|c|c|c|c|c|}
\hline \multicolumn{5}{|c|}{ Supplemental Table S2.txt } \\
\hline CHEMBL3207999 & 688620 & 4.85 & 4.8747 & TST \\
\hline CHEMBL1472289 & 688620 & 5.15 & 5.5191 & TRN \\
\hline CHEMBL3194953 & 688620 & 4.45 & 4.9897 & TST \\
\hline CHEMBL1612423 & 688620 & 5.0 & 5.2118 & TRN \\
\hline CHEMBL1410291 & 688620 & 5.15 & 5.0197 & TST \\
\hline CHEMBL1519512 & 688620 & 5.7 & 5.2916 & TRN \\
\hline CHEMBL1389144 & 688620 & 5.0 & 4.9753 & TST \\
\hline CHEMBL1508177 & 688620 & 5.1 & 5.0351 & TRN \\
\hline CHEMBL3193212 & 688620 & 4.9 & 5.0357 & TRN \\
\hline CHEMBL 226838 & 688620 & 5.75 & 5.1655 & TST \\
\hline CHEMBL1374155 & 688620 & 4.45 & 4.9105 & TRN \\
\hline CHEMBL3192138 & 688620 & 5.3 & 5.5375 & TRN \\
\hline CHEMBL1350179 & 688620 & 8.301 & 5.0649 & TST \\
\hline CHEMBL602730 & 688620 & 6.7001 & 5.8133 & TRN \\
\hline CHEMBL1596174 & 688620 & 5.45 & 4.9803 & TRN \\
\hline CHEMBL1990259 & 688620 & 5.6 & 5.1497 & TRN \\
\hline CHEMBL3191687 & 688620 & 5.8 & 5.6667 & TRN \\
\hline CHEMBL1549320 & 688620 & 4.45 & 4.7845 & TRN \\
\hline CHEMBL1606400 & 688620 & 6.3 & 5.0753 & TRN \\
\hline CHEMBL1381832 & 688620 & 5.45 & 5.357 & TRN \\
\hline CHEMBL1979306 & 688620 & 6.25 & 5.0977 & TST \\
\hline CHEMBL1584415 & 688620 & 5.15 & 4.9662 & TRN \\
\hline CHEMBL1375884 & 688620 & 5.2 & 5.3265 & TRN \\
\hline CHEMBL1498736 & 688620 & 4.45 & 4.979 & TRN \\
\hline CHEMBL1304557 & 688620 & 4.8 & 4.8508 & TST \\
\hline CHEMBL1401083 & 688620 & 4.9 & 5.1339 & TRN \\
\hline CHEMBL1593153 & 688620 & 6.05 & 5.0511 & TRN \\
\hline CHEMBL1332194 & 688620 & 6.2 & 5.0717 & TST \\
\hline CHEMBL1544911 & 688620 & 5.15 & 5.2438 & TRN \\
\hline CHEMBL1413252 & 688620 & 5.0 & 4.7964 & TST \\
\hline CHEMBL1346237 & 688620 & 4.9 & 4.9536 & TST \\
\hline CHEMBL119769 & 688620 & 4.45 & 5.3978 & TRN \\
\hline CHEMBL1517368 & 688620 & 4.9 & 4.7646 & TRN \\
\hline CHEMBL3207939 & 688620 & 4.45 & 5.0188 & TRN \\
\hline CHEMBL1304330 & 688620 & 4.7 & 4.8472 & TRN \\
\hline CHEMBL1494080 & 688620 & 5.35 & 5.3447 & TRN \\
\hline CHEMBL461579 & 688620 & 6.0 & 5.7363 & TST \\
\hline CHEMBL1583712 & 688620 & 4.75 & 5.1489 & TRN \\
\hline CHEMBL1384196 & 688620 & 4.95 & 5.1021 & TST \\
\hline CHEMBL1485579 & 688620 & 4.45 & 4.8576 & TRN \\
\hline CHEMBL3199687 & 688620 & 4.95 & 4.8326 & TRN \\
\hline CHEMBL1562036 & 688620 & 5.0 & 5.0661 & TRN \\
\hline CHEMBL3212543 & 688620 & 5.6 & 5.1604 & TST \\
\hline CHEMBL 3195884 & 688620 & 4.75 & 5.0029 & TRN \\
\hline CHEMBL1444727 & 688620 & 4.95 & 5.0379 & TRN \\
\hline CHEMBL1332557 & 688620 & 4.45 & 4.8936 & TRN \\
\hline CHEMBL1501809 & 688620 & 4.9 & 4.7176 & TRN \\
\hline CHEMBL1361285 & 688620 & 5.25 & 5.3629 & TRN \\
\hline
\end{tabular}




\begin{tabular}{|c|c|c|c|c|}
\hline \multicolumn{5}{|c|}{ Supplemental Table s2.txt } \\
\hline CHEMBL1502494 & 688620 & 4.7 & 4.9268 & TRN \\
\hline CHEMBL1582812 & 688620 & 4.9 & 4.7231 & TRN \\
\hline CHEMBL1464706 & 688620 & 4.65 & 5.1363 & TRN \\
\hline CHEMBL1427928 & 688620 & 5.75 & 4.9075 & TST \\
\hline CHEMBL1408460 & 688620 & 4.8 & 5.0156 & TRN \\
\hline CHEMBL1368699 & 688620 & 4.95 & 5.0258 & TRN \\
\hline CHEMBL1532337 & 688620 & 6.9 & 4.9864 & TRN \\
\hline CHEMBL1538386 & 688620 & 4.55 & 4.8355 & TRN \\
\hline CHEMBL1429992 & 688620 & 5.5 & 5.4189 & TRN \\
\hline CHEMBL1597123 & 688620 & 4.95 & 5.1212 & TRN \\
\hline CHEMBL1458938 & 688620 & 4.65 & 4.8428 & TRN \\
\hline CHEMBL1490834 & 688620 & 4.6 & 4.8679 & TST \\
\hline CHEMBL1441028 & 688620 & 5.2 & 5.1798 & TST \\
\hline CHEMBL1520782 & 688620 & 4.9 & 4.8101 & TRN \\
\hline CHEMBL1402567 & 688620 & 4.55 & 4.6516 & TRN \\
\hline CHEMBL1579846 & 688620 & 5.1 & 5.0226 & TRN \\
\hline CHEMBL1565019 & 688620 & 5.1 & 4.8707 & TRN \\
\hline CHEMBL3193511 & 688620 & 7.0501 & 5.0482 & TRN \\
\hline CHEMBL1542001 & 688620 & 5.15 & 5.0479 & TST \\
\hline CHEMBL1359989 & 688620 & 5.5 & 5.1909 & TRN \\
\hline CHEMBL1410585 & 688620 & 4.65 & 4.9354 & TST \\
\hline CHEMBL1536982 & 688620 & 5.6 & 5.1676 & TRN \\
\hline CHEMBL1446105 & 688620 & 4.5 & 5.077 & TRN \\
\hline CHEMBL1541141 & 688620 & 5.2 & 4.8935 & TST \\
\hline CHEMBL1580822 & 688620 & 4.85 & 4.8566 & TRN \\
\hline CHEMBL1369226 & 688620 & 5.35 & 5.8796 & TRN \\
\hline CHEMBL3199179 & 688620 & 4.45 & 4.9263 & TRN \\
\hline CHEMBL1438913 & 688620 & 4.45 & 4.8109 & TRN \\
\hline CHEMBL 1374220 & 688620 & 4.45 & 5.1417 & TST \\
\hline CHEMBL1450877 & 688620 & 4.5 & 5.3169 & TRN \\
\hline CHEMBL1325908 & 688620 & 4.7 & 4.8789 & TST \\
\hline CHEMBL1517737 & 688620 & 5.35 & 5.1309 & TRN \\
\hline CHEMBL1361541 & 688620 & 5.25 & 5.0188 & TRN \\
\hline CHEMBL1608602 & 688620 & 5.0 & 4.9099 & TST \\
\hline CHEMBL1587623 & 688620 & 4.95 & 5.1543 & TRN \\
\hline CHEMBL1351176 & 688620 & 4.9 & 4.948 & TRN \\
\hline CHEMBL1606110 & 688620 & 5.7 & 4.6417 & TRN \\
\hline CHEMBL1506479 & 688620 & 4.45 & 5.2444 & TST \\
\hline CHEMBL1322606 & 688620 & 5.2 & 4.9502 & TRN \\
\hline CHEMBL1478716 & 688620 & 4.75 & 5.0158 & TST \\
\hline CHEMBL1504284 & 688620 & 4.95 & 4.8541 & TRN \\
\hline CHEMBL3189233 & 688620 & 5.05 & 5.1337 & TRN \\
\hline CHEMBL48449 & 688620 & 6.0 & 5.8393 & TST \\
\hline CHEMBL1345130 & 688620 & 4.7 & 5.2989 & TST \\
\hline CHEMBL1349331 & 688620 & 5.0 & 5.2267 & TST \\
\hline CHEMBL1391912 & 688620 & 4.45 & 5.0657 & TST \\
\hline CHEMBL1606133 & 688620 & 4.9 & 4.8796 & TRN \\
\hline CHEMBL1463865 & 688620 & 4.75 & 4.8087 & TST \\
\hline
\end{tabular}




\begin{tabular}{|c|c|c|c|c|c|}
\hline & & & & & \\
\hline CHEMBL1976866 & 688620 & 6.0 & 5.3477 & TRN & \\
\hline CHEMBL3195343 & 688620 & 6.05 & 5.5199 & TST & \\
\hline CHEMBL1592216 & 688620 & 5.65 & 5.1736 & TRN & \\
\hline CHEMBL1382486 & 688620 & 4.95 & 4.9647 & TST & \\
\hline CHEMBL1411154 & 688620 & 5.15 & 5.1944 & TRN & \\
\hline CHEMBL1401945 & 688620 & 4.95 & 4.8864 & TRN & \\
\hline CHEMBL1432917 & 688620 & 5.2 & 5.1318 & TST & \\
\hline CHEMBL1412657 & 688620 & 5.0 & 5.0526 & TRN & \\
\hline CHEMBL1368447 & 688620 & 5.8 & 5.1299 & TST & \\
\hline CHEMBL 7747 & 688620 & 4.75 & 4.9627 & TRN & \\
\hline CHEMBL1449930 & 688620 & 4.75 & 5.159 & TRN & \\
\hline CHEMBL1526088 & 688620 & 4.95 & 4.773 & TST & \\
\hline CHEMBL1465700 & 688620 & 5.25 & 5.0252 & TRN & \\
\hline CHEMBL1300089 & 688620 & 4.85 & 4.8438 & TRN & \\
\hline CHEMBL1564737 & 688620 & 5.0 & 4.9043 & TRN & \\
\hline CHEMBL1365925 & 688620 & 4.45 & 5.2641 & TRN & \\
\hline CHEMBL1309604 & 688620 & 5.2 & 4.8784 & TRN & \\
\hline CHEMBL1613531 & 688620 & 4.9 & 5.3723 & TRN & \\
\hline CHEMBL1535078 & 688620 & 5.05 & 4.8409 & TRN & \\
\hline CHEMBL1336428 & 688620 & 5.7 & 4.9015 & TRN & \\
\hline CHEMBL1343490 & 688620 & 4.9 & 5.2774 & TST & \\
\hline CHEMBL1352163 & 688620 & 4.7 & 5.1496 & TST & \\
\hline CHEMBL1425103 & 688620 & 4.45 & 5.19799 & 99999999995 & TRN \\
\hline CHEMBL1481061 & 688620 & 5.6 & 5.49200 & 0000000001 & TST \\
\hline CHEMBL1518968 & 688620 & 5.45 & 6.1546 & TRN & \\
\hline CHEMBL1481593 & 688620 & 5.25 & 5.1629 & TST & \\
\hline CHEMBL1558990 & 688620 & 5.4 & 5.2921 & TST & \\
\hline CHEMBL1337009 & 688620 & 4.9 & 4.9287 & TRN & \\
\hline CHEMBL1602609 & 688620 & 4.9 & 5.1761 & TRN & \\
\hline CHEMBL3199494 & 688620 & 4.7 & 4.8701 & TST & \\
\hline CHEMBL1613457 & 688620 & 5.35 & 5.0465 & TRN & \\
\hline CHEMBL1384298 & 688620 & 4.45 & 4.6473 & TST & \\
\hline CHEMBL1462945 & 688620 & 5.2 & 5.0747 & TST & \\
\hline CHEMBL1540825 & 688620 & 4.85 & 4.9906 & TRN & \\
\hline CHEMBL1325769 & 688620 & 5.45 & 4.9714 & TST & \\
\hline CHEMBL1377571 & 688620 & 4.9 & 4.967 & TRN & \\
\hline CHEMBL1325683 & 688620 & 5.55 & 5.1376 & TRN & \\
\hline CHEMBL253989 & 688620 & 4.95 & 5.1994 & TST & \\
\hline CHEMBL1555998 & 688620 & 4.85 & 4.9833 & TRN & \\
\hline CHEMBL 3212028 & 688620 & 4.45 & 5.0469 & TRN & \\
\hline CHEMBL1390178 & 688620 & 4.95 & 5.0972 & TRN & \\
\hline CHEMBL3191063 & 688620 & 5.0 & 5.17399 & 99999999995 & TRN \\
\hline CHEMBL1335687 & 688620 & 5.5 & 5.1426 & TRN & \\
\hline CHEMBL1335888 & 688620 & 4.85 & 4.8893 & TRN & \\
\hline CHEMBL1332485 & 688620 & 4.45 & 4.9306 & TRN & \\
\hline CHEMBL1486335 & 688620 & 4.95 & 4.6911 & TRN & \\
\hline CHEMBL1548848 & 688620 & 4.45 & 4.7888 & TST & \\
\hline CHEMBL1522761 & 688620 & 8.2518 & 4.9987 & TRN & \\
\hline
\end{tabular}

Page 27421 


\begin{tabular}{|c|c|c|c|c|c|}
\hline \\
\hline CHEMBL1451954 & 688620 & 5.2 & 5.082 & TRN & \\
\hline CHEMBL1339860 & 688620 & 5.0 & 4.7715 & TRN & \\
\hline CHEMBL1306027 & 688620 & 5.4 & 5.4344 & TST & \\
\hline CHEMBL1345223 & 688620 & 4.95 & 5.1651 & TRN & \\
\hline CHEMBL1305893 & 688620 & 4.8 & 4.828 & TRN & \\
\hline CHEMBL1415460 & 688620 & 5.4 & 5.1268 & TST & \\
\hline CHEMBL1361740 & 688620 & 5.3 & 5.3944 & TST & \\
\hline CHEMBL1301371 & 688620 & 5.15 & 5.2912 & TRN & \\
\hline CHEMBL1536165 & 688620 & 5.0 & 5.1923 & TRN & \\
\hline CHEMBL1575765 & 688620 & 5.05 & 4.9739 & TRN & \\
\hline CHEMBL1454247 & 688620 & 4.55 & 5.7827 & TRN & \\
\hline CHEMBL1529767 & 688620 & 4.65 & 5.0019 & TRN & \\
\hline CHEMBL1319737 & 688620 & 4.75 & 4.9894 & TST & \\
\hline CHEMBL1417598 & 688620 & 5.0 & 5.0331 & TRN & \\
\hline CHEMBL1341568 & 688620 & 4.45 & 4.9566 & TRN & \\
\hline CHEMBL1565421 & 688620 & 5.55 & 5.0217 & TRN & \\
\hline CHEMBL1453730 & 688620 & 4.85 & 4.7402 & TRN & \\
\hline CHEMBL1400523 & 688620 & 4.45 & 4.7898 & TST & \\
\hline CHEMBL1520216 & 688620 & 4.45 & 4.8754 & TRN & \\
\hline CHEMBL1479214 & 688620 & 5.65 & 5.4061 & TRN & \\
\hline CHEMBL1447822 & 688620 & 4.95 & 5.1368 & TRN & \\
\hline CHEMBL1578269 & 688620 & 5.2 & 5.3816 & TRN & \\
\hline CHEMBL 277148 & 688620 & 6.0 & 5.053 & TRN & \\
\hline CHEMBL1602433 & 688620 & 4.65 & 5.4565 & TRN & \\
\hline CHEMBL1424422 & 688620 & 6.3 & 5.1588 & TRN & \\
\hline CHEMBL233549 & 688620 & 4.65 & 4.935 & TRN & \\
\hline CHEMBL1404968 & 688620 & 4.85 & 4.8538 & TST & \\
\hline CHEMBL1577707 & 688620 & 5.5 & 5.0314 & TRN & \\
\hline CHEMBL1342049 & 688620 & 4.95 & 4.881 & TRN & \\
\hline CHEMBL1387020 & 688620 & 5.8 & 4.9365 & TST & \\
\hline CHEMBL1416382 & 688620 & 4.45 & 5.1077 & TST & \\
\hline CHEMBL1334840 & 688620 & 5.2 & 5.2594 & TST & \\
\hline CHEMBL1332602 & 688620 & 5.4 & 5.6165 & TRN & \\
\hline CHEMBL1516992 & 688620 & 5.5 & 5.0991 & TRN & \\
\hline CHEMBL1988536 & 688620 & 5.2 & 4.973 & TRN & \\
\hline CHEMBL1454087 & 688620 & 5.0 & 4.9777 & TST & \\
\hline CHEMBL3196697 & 688620 & 5.55 & 5.5745 & TST & \\
\hline CHEMBL1403802 & 688620 & 5.55 & 5.2519 & TST & \\
\hline CHEMBL1540107 & 688620 & 6.7001 & 5.2361 & TRN & \\
\hline CHEMBL1420276 & 688620 & 4.85 & 5.0579 & TRN & \\
\hline CHEMBL1300444 & 688620 & 5.3 & 5.1576 & TRN & \\
\hline CHEMBL1550311 & 688620 & 4.5 & $4.9510 e$ & 00000000005 & TRN \\
\hline CHEMBL1598371 & 688620 & 4.45 & 4.9066 & TST & \\
\hline CHEMBL1497513 & 688620 & 5.05 & 4.8411 & TRN & \\
\hline CHEMBL3189916 & 688620 & 5.4 & 5.6933 & TRN & \\
\hline CHEMBL1577122 & 688620 & 4.9 & 4.9157 & TRN & \\
\hline CHEMBL1464494 & 688620 & 4.65 & 5.0222 & TST & \\
\hline CHEMBL1533620 & 688620 & 4.45 & 4.9608 & TST & \\
\hline & & & & 2 & \\
\hline
\end{tabular}




\begin{tabular}{|c|c|c|c|c|c|}
\hline \multicolumn{6}{|c|}{ Supplemental Table S2.txt } \\
\hline CHEMBL3196259 & 688620 & 4.5 & 5.1568 & TRN & \\
\hline CHEMBL1572484 & 688620 & 4.65 & 5.1081 & TST & \\
\hline CHEMBL1462350 & 688620 & 4.45 & 5.5889 & TRN & \\
\hline CHEMBL1534923 & 688620 & 5.1 & 5.1741 & TRN & \\
\hline CHEMBL1498999 & 688620 & 4.95 & 5.4098 & TRN & \\
\hline CHEMBL1536990 & 688620 & 4.8 & 4.7172 & TRN & \\
\hline CHEMBL1521466 & 688620 & 4.7 & 4.97 & TST & \\
\hline CHEMBL1608511 & 688620 & 4.9 & 5.1409 & TRN & \\
\hline CHEMBL3189276 & 688620 & 4.6 & 5.02 & TST & \\
\hline CHEMBL1345991 & 688620 & 6.5 & 5.8327 & TRN & \\
\hline CHEMBL1576347 & 688620 & 4.95 & 4.9383 & TST & \\
\hline CHEMBL1521028 & 688620 & 5.0 & 5.0679 & TRN & \\
\hline CHEMBL 2000196 & 688620 & 5.2 & 5.5033 & TRN & \\
\hline CHEMBL1353595 & 688620 & 6.3 & 5.28299 & 99999999995 & TRN \\
\hline CHEMBL1335977 & 688620 & 5.2 & 5.114 & TRN & \\
\hline CHEMBL1302115 & 688620 & 4.9 & 5.1081 & TRN & \\
\hline CHEMBL1415049 & 688620 & 4.95 & 4.8216 & TRN & \\
\hline CHEMBL1418442 & 688620 & 4.45 & 4.8919 & TST & \\
\hline CHEMBL1352171 & 688620 & 4.9 & 4.6916 & TRN & \\
\hline CHEMBL1524102 & 688620 & 5.5 & 4.9459 & TRN & \\
\hline CHEMBL1462695 & 688620 & 4.7 & 4.8642 & TRN & \\
\hline CHEMBL1431150 & 688620 & 7.1002 & 5.118 & TRN & \\
\hline CHEMBL1508175 & 688620 & 5.0 & 4.6271 & TRN & \\
\hline CHEMBL1487500 & 688620 & 4.75 & 5.3064 & TRN & \\
\hline CHEMBL1527484 & 688620 & 5.4 & 5.4199 & TST & \\
\hline CHEMBL3199899 & 688620 & 4.85 & 5.211 & TST & \\
\hline CHEMBL1482029 & 688620 & 4.45 & 4.6483 & TRN & \\
\hline CHEMBL1414955 & 688620 & 5.05 & 4.9501 & TRN & \\
\hline CHEMBL1393041 & 688620 & 4.95 & 6.3219 & TRN & \\
\hline CHEMBL1440068 & 688620 & 6.15 & 5.0732 & TRN & \\
\hline CHEMBL1605253 & 688620 & 4.95 & 4.9725 & TRN & \\
\hline CHEMBL1376258 & 688620 & 5.25 & 5.2669 & TRN & \\
\hline CHEMBL3199040 & 688620 & 5.2 & 4.7812 & TRN & \\
\hline CHEMBL1387058 & 688620 & 5.05 & 5.087 & TRN & \\
\hline CHEMBL1337473 & 688620 & 5.1 & 5.2091 & TRN & \\
\hline CHEMBL1462588 & 688620 & 5.9 & 5.1786 & TRN & \\
\hline CHEMBL1565105 & 688620 & 4.45 & 4.9608 & TRN & \\
\hline CHEMBL1423124 & 688620 & 4.45 & 4.9614 & TRN & \\
\hline CHEMBL3210132 & 688620 & 5.5 & 5.0665 & TST & \\
\hline CHEMBL1550432 & 688620 & 6.05 & 5.0087 & TRN & \\
\hline CHEMBL1510319 & 688620 & 5.05 & 5.1812 & TRN & \\
\hline CHEMBL1391097 & 688620 & 5.6 & 5.5814 & TRN & \\
\hline CHEMBL1597480 & 688620 & 4.45 & 4.9033 & TRN & \\
\hline CHEMBL1444032 & 688620 & 5.0 & 5.0046 & TRN & \\
\hline CHEMBL1431015 & 688620 & 5.3 & 5.30200 & 00000000005 & TRN \\
\hline CHEMBL1537422 & 688620 & 4.85 & 5.09 & TRN & \\
\hline CHEMBL3189164 & 688620 & 5.25 & 5.3818 & TRN & \\
\hline CHEMBL1400886 & 688620 & 4.95 & 4.8602 & TRN & \\
\hline
\end{tabular}




\begin{tabular}{|c|c|c|c|c|c|}
\hline \multicolumn{6}{|c|}{ Supplemental Table S2.txt } \\
\hline CHEMBL1425736 & 688620 & 4.8 & 4.8071 & TRN & \\
\hline CHEMBL1430265 & 688620 & 5.0 & 4.9056 & TRN & \\
\hline CHEMBL481854 & 688620 & 4.8 & 4.8607 & TRN & \\
\hline CHEMBL1455756 & 688620 & 4.9 & 5.4285 & TRN & \\
\hline CHEMBL96051 & 688620 & 5.8 & 5.0546 & TRN & \\
\hline CHEMBL1370851 & 688620 & 5.45 & 5.13399 & 99999999995 & TRN \\
\hline CHEMBL1563318 & 688620 & 4.75 & 4.7465 & TRN & \\
\hline CHEMBL1472014 & 688620 & 4.45 & 5.0894 & TRN & \\
\hline CHEMBL1566257 & 688620 & 4.95 & 5.155 & TRN & \\
\hline CHEMBL1400782 & 688620 & 5.35 & 5.0616 & TRN & \\
\hline CHEMBL1362495 & 688620 & 4.7 & 5.1144 & TST & \\
\hline CHEMBL1463433 & 688620 & 4.95 & 4.9724 & TRN & \\
\hline CHEMBL1338554 & 688620 & 4.9 & 5.136 & TRN & \\
\hline CHEMBL1562654 & 688620 & 4.7 & 4.7836 & TRN & \\
\hline CHEMBL1346090 & 688620 & 5.1 & 5.0512 & TRN & \\
\hline CHEMBL1480332 & 688620 & 4.65 & 5.1281 & TRN & \\
\hline CHEMBL1327018 & 688620 & 4.45 & 4.9795 & TRN & \\
\hline CHEMBL1351964 & 688620 & 4.45 & 4.6265 & TRN & \\
\hline CHEMBL1594633 & 688620 & 4.45 & 4.8882 & TST & \\
\hline CHEMBL1569557 & 688620 & 6.2 & 4.9727 & TRN & \\
\hline CHEMBL1597229 & 688620 & 4.45 & 4.9546 & TRN & \\
\hline CHEMBL3196730 & 688620 & 4.5 & 5.0381 & TRN & \\
\hline CHEMBL1543884 & 688620 & 5.0 & 5.1861 & TST & \\
\hline CHEMBL1449259 & 688620 & 4.95 & 4.7484 & TRN & \\
\hline CHEMBL1574914 & 688620 & 5.9 & 5.4585 & TRN & \\
\hline CHEMBL1349075 & 688620 & 4.45 & 5.1609 & TST & \\
\hline CHEMBL1510624 & 688620 & 4.85 & 4.8546 & TRN & \\
\hline CHEMBL1563580 & 688620 & 4.5 & 5.0042 & TRN & \\
\hline CHEMBL1559887 & 688620 & 4.45 & 4.9828 & TRN & \\
\hline CHEMBL1419721 & 688620 & 4.45 & 5.2363 & TRN & \\
\hline CHEMBL586024 & 688620 & 6.0 & 4.9234 & TRN & \\
\hline CHEMBL1305090 & 688620 & 4.45 & 4.9596 & TST & \\
\hline CHEMBL1479042 & 688620 & 4.45 & 4.9782 & TST & \\
\hline CHEMBL1305190 & 688620 & 5.4 & 4.735 & TRN & \\
\hline CHEMBL1342025 & 688620 & 4.6 & 4.8125 & TRN & \\
\hline CHEMBL488140 & 688620 & 5.45 & 5.3458 & TRN & \\
\hline CHEMBL1453214 & 688620 & 4.45 & 4.919 & TRN & \\
\hline CHEMBL 3196347 & 688620 & 5.4 & 5.3943 & TRN & \\
\hline CHEMBL 3210244 & 688620 & 4.8 & 5.0618 & TRN & \\
\hline CHEMBL1422969 & 688620 & 4.9 & 5.1144 & TRN & \\
\hline CHEMBL1522285 & 688620 & 4.75 & 4.7814 & TRN & \\
\hline CHEMBL1523643 & 688620 & 6.8499 & 5.1131 & TRN & \\
\hline CHEMBL1561941 & 688620 & 4.75 & 5.2558 & TRN & \\
\hline CHEMBL3194567 & 688620 & 5.2 & 5.0825 & TRN & \\
\hline CHEMBL1554842 & 688620 & 5.35 & 5.3304 & TRN & \\
\hline CHEMBL1299363 & 688620 & 5.35 & 5.2059 & TST & \\
\hline CHEMBL1523878 & 688620 & 4.95 & 4.9438 & TRN & \\
\hline CHEMBL1612448 & 688620 & 4.85 & 4.8501 & TRN & \\
\hline
\end{tabular}




\begin{tabular}{|c|c|c|c|c|}
\hline \multirow[b]{2}{*}{ CHEMBL1441920 } & \multicolumn{4}{|c|}{ Supplemental Table S2.txt } \\
\hline & 688620 & 6.0 & 4.8902 & TST \\
\hline CHEMBL1572263 & 688620 & 4.95 & 4.9391 & TRN \\
\hline CHEMBL 3196264 & 688620 & 4.6 & 4.9409 & TST \\
\hline CHEMBL1405705 & 688620 & 5.0 & 4.9366 & TRN \\
\hline CHEMBL1575331 & 688620 & 5.55 & 5.2894 & TRN \\
\hline CHEMBL1521659 & 688620 & 7.0 & 4.9914 & TRN \\
\hline CHEMBL1564714 & 688620 & 4.45 & 5.1087 & TRN \\
\hline CHEMBL1996464 & 688620 & 4.95 & 5.0603 & TRN \\
\hline CHEMBL1411551 & 688620 & 4.65 & 5.1731 & TST \\
\hline CHEMBL1472238 & 688620 & 5.2 & 5.2865 & TRN \\
\hline CHEMBL 1455538 & 688620 & 6.15 & 6.0728 & TRN \\
\hline CHEMBL1469277 & 688620 & 4.9 & 5.2024 & TRN \\
\hline CHEMBL1581631 & 688620 & 4.8 & 5.1928 & TRN \\
\hline CHEMBL1474988 & 688620 & 4.45 & 4.9071 & TST \\
\hline CHEMBL1545927 & 688620 & 4.9 & 5.1153 & TST \\
\hline CHEMBL1391431 & 688620 & 4.45 & 5.0285 & TST \\
\hline CHEMBL1492681 & 688620 & 4.75 & 5.0487 & TRN \\
\hline CHEMBL1594155 & 688620 & 5.7 & 5.0699 & TRN \\
\hline CHEMBL1339018 & 688620 & 4.45 & 5.0112 & TRN \\
\hline CHEMBL1604740 & 688620 & 4.8 & 5.0064 & TST \\
\hline CHEMBL1299886 & 688620 & 5.0 & 5.17 & TRN \\
\hline CHEMBL1506087 & 688620 & 4.75 & 4.9606 & TRN \\
\hline CHEMBL1343203 & 688620 & 5.15 & 4.993 & TRN \\
\hline CHEMBL1337570 & 688620 & 4.45 & 4.8143 & TRN \\
\hline CHEMBL1375286 & 688620 & 5.6 & 5.1431 & TRN \\
\hline CHEMBL1309143 & 688620 & 4.95 & 5.1354 & TST \\
\hline CHEMBL1452490 & 688620 & 4.45 & 4.8723 & TRN \\
\hline CHEMBL493863 & 688620 & 4.45 & 4.9361 & TST \\
\hline CHEMBL1505354 & 688620 & 4.45 & 5.1324 & TST \\
\hline CHEMBL1494433 & 688620 & 5.4 & 5.0811 & TRN \\
\hline CHEMBL1461517 & 688620 & 4.9 & 5.1902 & TRN \\
\hline CHEMBL1321375 & 688620 & 4.9 & 4.9242 & TRN \\
\hline CHEMBL1526892 & 688620 & 4.85 & 5.0 & TRN \\
\hline CHEMBL1513489 & 688620 & 5.5 & 5.1114 & TST \\
\hline CHEMBL1512595 & 688620 & 5.1 & 4.8584 & TRN \\
\hline CHEMBL1578619 & 688620 & 4.95 & 4.7545 & TRN \\
\hline CHEMBL1336011 & 688620 & 4.45 & 5.0733 & TRN \\
\hline CHEMBL1460644 & 688620 & 6.4 & 4.9922 & TRN \\
\hline CHEMBL1595633 & 688620 & 5.1 & 4.9997 & TRN \\
\hline CHEMBL1331252 & 688620 & 4.45 & 4.8506 & TRN \\
\hline CHEMBL1410577 & 688620 & 5.6 & 4.8928 & TRN \\
\hline CHEMBL3194266 & 688620 & 5.05 & 5.3375 & TRN \\
\hline CHEMBL1601912 & 688620 & 5.25 & 5.1142 & TST \\
\hline CHEMBL1424327 & 688620 & 4.45 & 5.2177 & TRN \\
\hline CHEMBL1545434 & 688620 & 4.75 & 5.1404 & TST \\
\hline CHEMBL1420204 & 688620 & 5.2 & 5.0615 & TRN \\
\hline CHEMBL1306981 & 688620 & 5.3 & 5.0686 & TRN \\
\hline CHEMBL108829 & 688620 & 4.45 & 4.949 & TST \\
\hline
\end{tabular}




\begin{tabular}{|c|c|c|c|c|}
\hline \multicolumn{5}{|c|}{ Supplemental Table S2.txt } \\
\hline CHEMBL1301983 & 688620 & 5.0 & 4.9257 & TRN \\
\hline CHEMBL1542726 & 688620 & 4.45 & 5.1228 & TRN \\
\hline CHEMBL1587252 & 688620 & 4.95 & 5.1439 & TRN \\
\hline CHEMBL1380120 & 688620 & 5.05 & 5.2255 & TRN \\
\hline CHEMBL1332254 & 688620 & 5.45 & 5.5059 & TRN \\
\hline CHEMBL1387835 & 688620 & 4.45 & 5.1378 & TST \\
\hline CHEMBL1303831 & 688620 & 4.45 & 5.026 & TST \\
\hline CHEMBL1405924 & 688620 & 4.9 & 4.9109 & TST \\
\hline CHEMBL1395792 & 688620 & 5.15 & 4.9869 & TRN \\
\hline CHEMBL1427523 & 688620 & 4.45 & 4.774 & TRN \\
\hline CHEMBL1469947 & 688620 & 4.85 & 5.0471 & TRN \\
\hline CHEMBL1142 & 688620 & 4.75 & 5.1183 & TST \\
\hline CHEMBL1300222 & 688620 & 4.8 & 4.8431 & TRN \\
\hline CHEMBL1335616 & 688620 & 4.95 & 5.0077 & TRN \\
\hline CHEMBL1441008 & 688620 & 4.7 & 4.8665 & TRN \\
\hline CHEMBL1976498 & 688620 & 4.45 & 5.1936 & TST \\
\hline CHEMBL1317999 & 688620 & 4.85 & 4.9033 & TRN \\
\hline CHEMBL1458493 & 688620 & 4.85 & 4.9356 & TST \\
\hline CHEMBL 3197737 & 688620 & 5.05 & 5.3436 & TRN \\
\hline CHEMBL1537171 & 688620 & 4.15 & 5.9775 & TRN \\
\hline CHEMBL1408817 & 688620 & 4.9 & 5.0509 & TRN \\
\hline CHEMBL1528342 & 688620 & 4.8 & 5.8589 & TRN \\
\hline CHEMBL1382236 & 688620 & 4.95 & 4.8643 & TRN \\
\hline CHEMBL1406262 & 688620 & 4.65 & 5.1068 & TRN \\
\hline CHEMBL1577986 & 688620 & 4.9 & 4.7928 & TRN \\
\hline CHEMBL3194023 & 688620 & 4.65 & 5.0726 & TRN \\
\hline CHEMBL1419847 & 688620 & 5.95 & 6.0582 & TRN \\
\hline CHEMBL1479150 & 688620 & 5.1 & 4.9287 & TST \\
\hline CHEMBL1303266 & 688620 & 6.15 & 5.0539 & TRN \\
\hline CHEMBL1462503 & 688620 & 6.6499 & 5.3875 & TRN \\
\hline CHEMBL1578061 & 688620 & 4.65 & 4.8574 & TRN \\
\hline CHEMBL1609461 & 688620 & 4.65 & 5.2791 & TST \\
\hline CHEMBL1563347 & 688620 & 5.25 & 5.1928 & TRN \\
\hline CHEMBL1978180 & 688620 & 5.35 & 4.9882 & TRN \\
\hline CHEMBL1341037 & 688620 & 4.95 & 5.0007 & TRN \\
\hline CHEMBL3197607 & 688620 & 4.9 & 4.9224 & TRN \\
\hline CHEMBL1510456 & 688620 & 5.45 & 5.1306 & TRN \\
\hline CHEMBL489738 & 688620 & 4.65 & 4.9387 & TRN \\
\hline CHEMBL1589633 & 688620 & 7.1002 & 5.1535 & TRN \\
\hline CHEMBL1378709 & 688620 & 4.5 & 4.9538 & TST \\
\hline CHEMBL1595220 & 688620 & 4.45 & 4.9604 & TST \\
\hline CHEMBL1362878 & 688620 & 5.35 & 5.042 & TRN \\
\hline CHEMBL1372307 & 688620 & 6.1 & 5.4573 & TST \\
\hline CHEMBL1431316 & 688620 & 4.9 & 5.0717 & TRN \\
\hline CHEMBL1901621 & 688620 & 4.9 & 4.7653 & TRN \\
\hline CHEMBL1345339 & 688620 & 4.85 & 5.1581 & TRN \\
\hline CHEMBL3196313 & 688620 & 4.75 & 5.2104 & TST \\
\hline CHEMBL1495765 & 688620 & 4.45 & 4.987 & TRN \\
\hline
\end{tabular}




\begin{tabular}{|c|c|c|c|c|}
\hline \multicolumn{5}{|c|}{ Supplemental Table S2.txt } \\
\hline CHEMBL1381628 & 688620 & 4.45 & 4.6542 & TRN \\
\hline CHEMBL3190723 & 688620 & 4.45 & 5.0112 & TRN \\
\hline CHEMBL1535472 & 688620 & 4.65 & 5.0848 & TRN \\
\hline CHEMBL1568811 & 688620 & 4.6 & 5.1979 & TRN \\
\hline CHEMBL1380683 & 688620 & 5.25 & 4.8995 & TRN \\
\hline CHEMBL1580272 & 688620 & 6.5501 & 4.7138 & TRN \\
\hline CHEMBL1416235 & 688620 & 4.85 & 4.977 & TRN \\
\hline CHEMBL1539141 & 688620 & 4.85 & 4.7973 & TRN \\
\hline CHEMBL1497750 & 688620 & 4.95 & 4.9173 & TRN \\
\hline CHEMBL1348070 & 688620 & 4.95 & 5.0107 & TRN \\
\hline CHEMBL1307553 & 688620 & 5.0 & 5.1408 & TST \\
\hline CHEMBL1550039 & 688620 & 4.45 & 5.1357 & TRN \\
\hline CHEMBL1398826 & 688620 & 6.15 & 5.0477 & TRN \\
\hline CHEMBL1507781 & 688620 & 5.2 & 4.9251 & TRN \\
\hline CHEMBL1504635 & 688620 & 4.95 & 5.0959 & TRN \\
\hline CHEMBL1418209 & 688620 & 4.95 & 4.9786 & TRN \\
\hline CHEMBL1604884 & 688620 & 6.05 & 6.0954 & TRN \\
\hline CHEMBL1380472 & 688620 & 5.2 & 5.1777 & TST \\
\hline CHEMBL1393620 & 688620 & 5.35 & 5.3003 & TRN \\
\hline CHEMBL1487290 & 688620 & 6.9 & 5.1054 & TRN \\
\hline CHEMBL3209244 & 688620 & 4.9 & 5.3234 & TRN \\
\hline CHEMBL1571040 & 688620 & 6.0 & 5.6233 & TRN \\
\hline CHEMBL1387650 & 688620 & 4.45 & 5.2431 & TST \\
\hline CHEMBL1455809 & 688620 & 6.5501 & 6.0561 & TRN \\
\hline CHEMBL1589658 & 688620 & 4.95 & 4.9949 & TRN \\
\hline CHEMBL1361076 & 688620 & 4.85 & 4.8477 & TRN \\
\hline CHEMBL1431639 & 688620 & 4.9 & 4.9787 & TRN \\
\hline CHEMBL1563650 & 688620 & 4.45 & 5.1795 & TRN \\
\hline CHEMBL1310883 & 688620 & 4.45 & 4.9309 & TRN \\
\hline CHEMBL1492738 & 688620 & 4.8 & 5.3245 & TRN \\
\hline CHEMBL1388345 & 688620 & 5.9 & 5.3381 & TRN \\
\hline CHEMBL3190418 & 688620 & 4.95 & 5.0127 & TRN \\
\hline CHEMBL1581510 & 688620 & 6.05 & 5.0828 & TRN \\
\hline CHEMBL3195009 & 688620 & 4.9 & 4.8894 & TST \\
\hline CHEMBL1608530 & 688620 & 4.8 & 4.7793 & TRN \\
\hline CHEMBL1463173 & 688620 & 4.75 & 5.1959 & TRN \\
\hline CHEMBL1569354 & 688620 & 8.3468 & 4.9767 & TST \\
\hline CHEMBL1442987 & 688620 & 4.8 & 4.8851 & TRN \\
\hline CHEMBL1518855 & 688620 & 4.9 & 5.0243 & TRN \\
\hline CHEMBL1436364 & 688620 & 4.45 & 5.0051 & TRN \\
\hline CHEMBL1405247 & 688620 & 4.9 & 4.9883 & TRN \\
\hline CHEMBL1608375 & 688620 & 4.6 & 4.7333 & TST \\
\hline CHEMBL1991959 & 688620 & 4.75 & 5.0781 & TRN \\
\hline CHEMBL 2002140 & 688620 & 5.05 & 5.2617 & TRN \\
\hline CHEMBL1457201 & 688620 & 4.45 & 4.9878 & TST \\
\hline CHEMBL1427576 & 688620 & 4.45 & 5.1137 & TST \\
\hline CHEMBL1544815 & 688620 & 4.9 & 4.9793 & TRN \\
\hline CHEMBL1478643 & 688620 & 5.0 & 5.1111 & TRN \\
\hline
\end{tabular}




\begin{tabular}{|c|c|c|c|c|c|}
\hline & & \multicolumn{4}{|c|}{ Supplemental Table s2.txt } \\
\hline CHEMBL1453002 & 688620 & 4.45 & 4.8094 & TRN & \\
\hline CHEMBL1458497 & 688620 & 4.45 & 5.0767 & TRN & \\
\hline CHEMBL1434411 & 688620 & 4.75 & 4.9393 & TRN & \\
\hline CHEMBL1452572 & 688620 & 4.7 & 5.0265 & TRN & \\
\hline CHEMBL1445601 & 688620 & 6.9 & 5.3608 & TRN & \\
\hline CHEMBL1326844 & 688620 & 6.35 & 4.9286 & TRN & \\
\hline CHEMBL1525390 & 688620 & 5.9 & 5.21200 & 0000000001 & TRN \\
\hline CHEMBL1413054 & 688620 & 4.9 & 5.0367 & TRN & \\
\hline CHEMBL1443791 & 688620 & 4.45 & 5.239 & TRN & \\
\hline CHEMBL1585716 & 688620 & 4.95 & 5.1098 & TRN & \\
\hline CHEMBL1378811 & 688620 & 5.0 & 4.9421 & TRN & \\
\hline CHEMBL1582999 & 688620 & 5.3 & 5.205 & TRN & \\
\hline CHEMBL3211892 & 688620 & 5.0 & 5.0104 & TST & \\
\hline CHEMBL1495766 & 688620 & 4.65 & 4.8608 & TRN & \\
\hline CHEMBL1582507 & 688620 & 4.65 & 4.8397 & TST & \\
\hline CHEMBL1417756 & 688620 & 4.95 & 4.9181 & TRN & \\
\hline CHEMBL600060 & 688620 & 6.8 & 5.8961 & TRN & \\
\hline CHEMBL1546653 & 688620 & 4.95 & 5.0018 & TRN & \\
\hline CHEMBL1333635 & 688620 & 5.1 & 5.0543 & TRN & \\
\hline CHEMBL3214061 & 688620 & 5.4 & 4.9626 & TRN & \\
\hline CHEMBL1573766 & 688620 & 5.5 & 5.8987 & TRN & \\
\hline CHEMBL1319850 & 688620 & 4.95 & 5.1129 & TRN & \\
\hline CHEMBL1487038 & 688620 & 4.45 & 5.1158 & TRN & \\
\hline CHEMBL1312031 & 688620 & 5.15 & 5.532 & TRN & \\
\hline CHEMBL1527393 & 688620 & 4.45 & 4.7362 & TRN & \\
\hline CHEMBL3190731 & 688620 & 4.65 & 4.9184 & TRN & \\
\hline CHEMBL1388295 & 688620 & 4.95 & 5.0607 & TRN & \\
\hline CHEMBL3194495 & 688620 & 4.75 & 4.8916 & TRN & \\
\hline CHEMBL1604844 & 688620 & 4.45 & 4.7913 & TRN & \\
\hline CHEMBL1977747 & 688620 & 6.95 & 5.8361 & TRN & \\
\hline CHEMBL1448294 & 688620 & 4.95 & 5.0652 & TRN & \\
\hline CHEMBL1455379 & 688620 & 4.45 & 5.0884 & TST & \\
\hline CHEMBL1980285 & 688620 & 5.35 & 5.1019 & TRN & \\
\hline CHEMBL1343662 & 688620 & 5.4 & 4.9202 & TRN & \\
\hline CHEMBL1573150 & 688620 & 4.7 & 4.8613 & TST & \\
\hline CHEMBL1348940 & 688620 & 4.45 & 5.1966 & TRN & \\
\hline CHEMBL1455170 & 688620 & 5.05 & 5.1208 & TST & \\
\hline CHEMBL1611134 & 688620 & 4.95 & 5.3045 & TST & \\
\hline CHEMBL1450885 & 688620 & 4.5 & 4.7852 & TRN & \\
\hline CHEMBL1582942 & 688620 & 4.7 & 4.7242 & TRN & \\
\hline CHEMBL465339 & 688620 & 5.95 & 5.3791 & TST & \\
\hline CHEMBL1413235 & 688620 & 4.45 & 4.7634 & TRN & \\
\hline CHEMBL1386719 & 688620 & 4.8 & 4.8536 & TRN & \\
\hline CHEMBL1410220 & 688620 & 4.8 & 4.731 & TRN & \\
\hline CHEMBL3197918 & 688620 & 4.45 & 4.8906 & TRN & \\
\hline CHEMBL1548069 & 688620 & 5.1 & 5.3174 & TRN & \\
\hline CHEMBL1500552 & 688620 & 4.45 & 4.9063 & TRN & \\
\hline CHEMBL195166 & 688620 & 4.85 & 5.087 & TRN & \\
\hline
\end{tabular}




\begin{tabular}{|c|c|c|c|c|}
\hline \multicolumn{5}{|c|}{ Supplemental Table S2.txt } \\
\hline CHEMBL1440017 & 688620 & 5.35 & 4.9356 & TRN \\
\hline CHEMBL1301377 & 688620 & 4.9 & 4.9298 & TRN \\
\hline CHEMBL1412820 & 688620 & 5.0 & 5.0349 & TRN \\
\hline CHEMBL1392187 & 688620 & 4.5 & 4.5809 & TRN \\
\hline CHEMBL1511596 & 688620 & 4.45 & 5.3392 & TRN \\
\hline CHEMBL1604553 & 688620 & 4.85 & 5.1672 & TST \\
\hline CHEMBL1531246 & 688620 & 4.45 & 4.9228 & TRN \\
\hline CHEMBL1368098 & 688620 & 5.0 & 5.2508 & TRN \\
\hline CHEMBL 28324 & 688620 & 4.95 & 4.9556 & TST \\
\hline CHEMBL3192082 & 688620 & 5.75 & 4.9863 & TRN \\
\hline CHEMBL1465276 & 688620 & 6.8 & 5.5993 & TST \\
\hline CHEMBL1462132 & 688620 & 6.9 & 5.1714 & TST \\
\hline CHEMBL1521149 & 688620 & 6.5 & 4.9986 & TRN \\
\hline CHEMBL1572468 & 688620 & 4.45 & 5.1095 & TRN \\
\hline CHEMBL1309029 & 688620 & 4.9 & 5.052 & TST \\
\hline CHEMBL3190495 & 688620 & 4.45 & 4.9305 & TRN \\
\hline CHEMBL1377773 & 688620 & 4.95 & 4.9921 & TRN \\
\hline CHEMBL1486042 & 688620 & 4.9 & 5.0483 & TRN \\
\hline CHEMBL1430435 & 688620 & 5.6 & 5.013 & TRN \\
\hline CHEMBL1506438 & 688620 & 5.05 & 5.1283 & TRN \\
\hline CHEMBL1505356 & 688620 & 4.9 & 4.8781 & TRN \\
\hline CHEMBL1580565 & 688620 & 5.2 & 4.9625 & TRN \\
\hline CHEMBL1309760 & 688620 & 4.9 & 4.9087 & TST \\
\hline CHEMBL1305421 & 688620 & 4.9 & 5.042 & TST \\
\hline CHEMBL3145036 & 688620 & 6.45 & 5.9936 & TST \\
\hline CHEMBL1461196 & 688620 & 6.9 & 6.0288 & TRN \\
\hline CHEMBL1427516 & 688620 & 4.95 & 4.9856 & TST \\
\hline CHEMBL1583979 & 688620 & 5.8 & 5.2468 & TRN \\
\hline CHEMBL1352534 & 688620 & 4.95 & 4.9915 & TRN \\
\hline CHEMBL240332 & 688620 & 5.5 & 5.5579 & TRN \\
\hline CHEMBL1541886 & 688620 & 4.9 & 4.7312 & TST \\
\hline CHEMBL1560080 & 688620 & 4.45 & 4.98 & TRN \\
\hline CHEMBL1304284 & 688620 & 4.75 & 4.9854 & TRN \\
\hline CHEMBL1543983 & 688620 & 4.95 & 5.1289 & TST \\
\hline CHEMBL1350350 & 688620 & 4.95 & 5.2526 & TRN \\
\hline CHEMBL1460869 & 688620 & 4.95 & 5.1659 & TRN \\
\hline CHEMBL1398828 & 688620 & 4.7 & 4.9568 & TRN \\
\hline CHEMBL1602406 & 688620 & 7.0501 & 4.9949 & TST \\
\hline CHEMBL1602395 & 688620 & 4.45 & 4.8235 & TRN \\
\hline CHEMBL3193377 & 688620 & 4.95 & 5.3796 & TRN \\
\hline CHEMBL1486684 & 688620 & 4.7 & 4.8965 & TRN \\
\hline CHEMBL1486810 & 688620 & 4.45 & 4.8515 & TRN \\
\hline CHEMBL3195067 & 688620 & 4.95 & 5.1544 & TRN \\
\hline CHEMBL1537886 & 688620 & 4.45 & 5.0347 & TRN \\
\hline CHEMBL1535572 & 688620 & 5.0 & 5.1567 & TRN \\
\hline CHEMBL1464925 & 688620 & 4.75 & 5.0472 & TRN \\
\hline CHEMBL3198247 & 688620 & 4.95 & 5.1436 & TRN \\
\hline CHEMBL1522246 & 688620 & 4.7 & 4.9194 & TRN \\
\hline
\end{tabular}




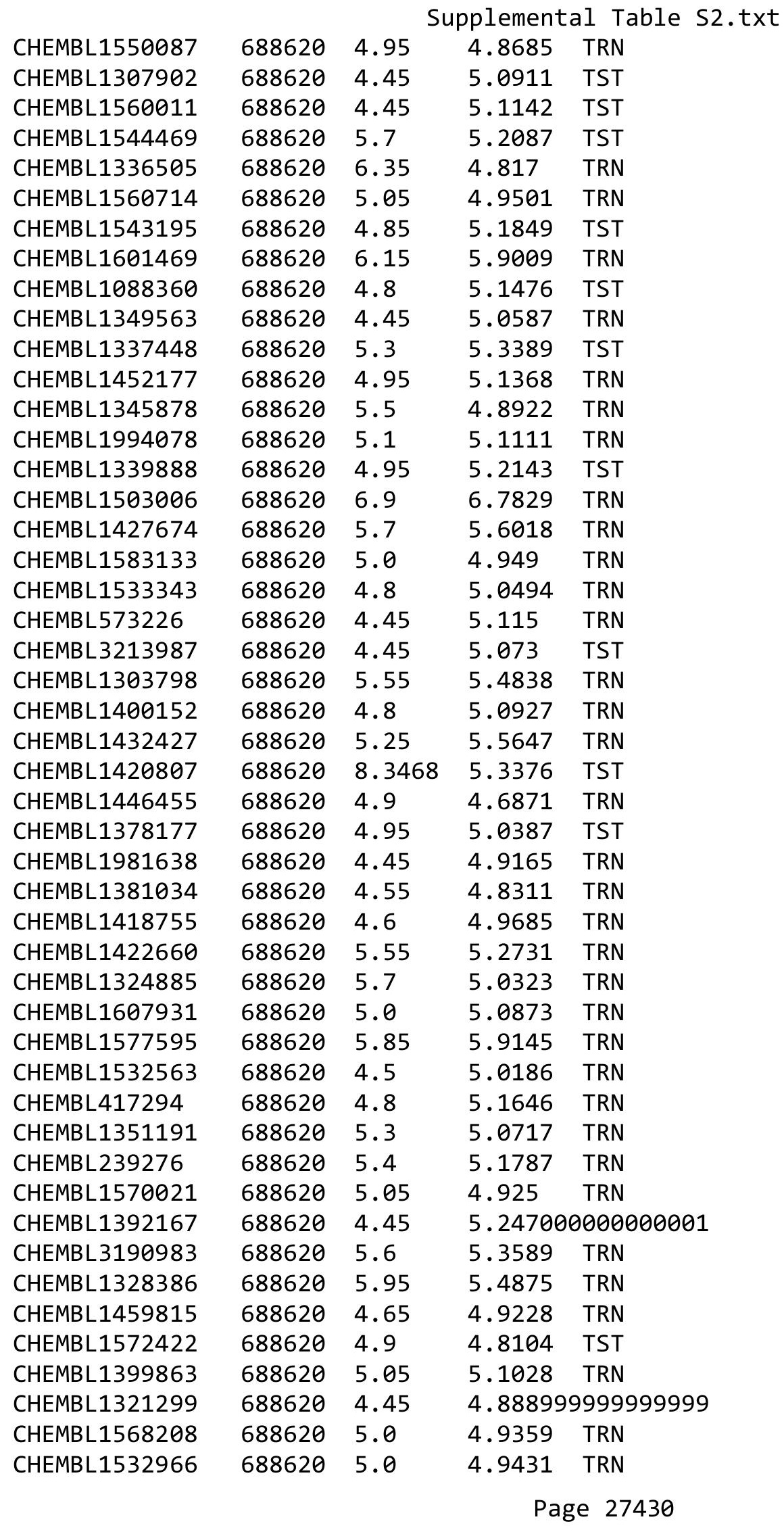




\begin{tabular}{|c|c|c|c|c|}
\hline \multicolumn{5}{|c|}{ Supplemental Table s2.txt } \\
\hline CHEMBL1396962 & 688620 & 4.45 & 4.9309 & TRN \\
\hline CHEMBL1423067 & 688620 & 4.85 & 4.9492 & TRN \\
\hline CHEMBL1496101 & 688620 & 4.8 & 4.849 & TRN \\
\hline CHEMBL1416195 & 688620 & 4.9 & 5.1081 & TST \\
\hline CHEMBL1417383 & 688620 & 4.8 & 5.157 & TST \\
\hline CHEMBL1381287 & 688620 & 6.45 & 5.8933 & TRN \\
\hline CHEMBL1589128 & 688620 & 5.0 & 5.1224 & TST \\
\hline CHEMBL1428316 & 688620 & 4.45 & 4.8349 & TRN \\
\hline CHEMBL1541866 & 688620 & 4.9 & 4.8062 & TRN \\
\hline CHEMBL1426027 & 688620 & 4.65 & 4.9353 & TST \\
\hline CHEMBL3209143 & 688620 & 5.05 & 4.9179 & TRN \\
\hline CHEMBL 3199129 & 688620 & 4.95 & 4.7608 & TST \\
\hline CHEMBL1383549 & 688620 & 4.75 & 4.7716 & TRN \\
\hline CHEMBL1502311 & 688620 & 6.0 & 5.2829 & TRN \\
\hline CHEMBL1332529 & 688620 & 4.75 & 5.0124 & TST \\
\hline CHEMBL1382556 & 688620 & 4.45 & 5.1157 & TST \\
\hline CHEMBL1450753 & 688620 & 5.25 & 5.5215 & TRN \\
\hline CHEMBL3195982 & 688620 & 4.45 & 4.9486 & TRN \\
\hline CHEMBL1312486 & 688620 & 5.4 & 5.121 & TRN \\
\hline CHEMBL 295316 & 688620 & 6.0 & 5.6531 & TST \\
\hline CHEMBL 2003973 & 688620 & 4.85 & 4.90600 & 0000000001 \\
\hline CHEMBL1488449 & 688620 & 5.15 & 5.182 & TRN \\
\hline CHEMBL1971727 & 688620 & 5.0 & 5.3583 & TRN \\
\hline CHEMBL1583426 & 688620 & 5.55 & 5.0295 & TRN \\
\hline CHEMBL1502372 & 688620 & 4.45 & 5.2055 & TST \\
\hline CHEMBL1341012 & 688620 & 4.45 & 4.5917 & TRN \\
\hline CHEMBL1369865 & 688620 & 5.55 & 5.3586 & TRN \\
\hline CHEMBL1468866 & 688620 & 5.15 & 5.2953 & TRN \\
\hline CHEMBL1382467 & 688620 & 4.45 & 4.9543 & TST \\
\hline CHEMBL1795374 & 688620 & 5.15 & 5.1102 & TRN \\
\hline CHEMBL1359349 & 688620 & 4.6 & 4.9481 & TRN \\
\hline CHEMBL3192844 & 688620 & 4.65 & 5.164 & TRN \\
\hline CHEMBL1429289 & 688620 & 4.65 & 4.938 & TRN \\
\hline CHEMBL1494527 & 688620 & 4.45 & 5.0216 & TRN \\
\hline CHEMBL1595139 & 688620 & 4.7 & 4.8751 & TST \\
\hline CHEMBL1404461 & 688620 & 4.55 & 5.1465 & TRN \\
\hline CHEMBL3194629 & 688620 & 4.6 & 4.7247 & TRN \\
\hline CHEMBL301100 & 688620 & 4.95 & 4.8862 & TRN \\
\hline CHEMBL1990545 & 688620 & 5.0 & 5.0273 & TRN \\
\hline CHEMBL579624 & 688620 & 4.9 & 4.9904 & TRN \\
\hline CHEMBL1351686 & 688620 & 4.95 & 5.4184 & TST \\
\hline CHEMBL1352201 & 688620 & 4.95 & 4.6163 & TRN \\
\hline CHEMBL1420756 & 688620 & 4.7 & 4.9868 & TRN \\
\hline CHEMBL1480032 & 688620 & 4.9 & 5.2177 & TRN \\
\hline CHEMBL1428996 & 688620 & 4.9 & 5.058 & TST \\
\hline CHEMBL1547757 & 688620 & 4.9 & 4.8832 & TST \\
\hline CHEMBL1415997 & 688620 & 4.65 & 4.8269 & TRN \\
\hline CHEMBL1446419 & 688620 & 4.8 & 4.8365 & TRN \\
\hline
\end{tabular}




\begin{tabular}{|c|c|c|c|c|c|}
\hline & & \multicolumn{4}{|c|}{ Supplemental Table S2.txt } \\
\hline CHEMBL1529936 & 688620 & 6.5 & 5.1299 & TRN & \\
\hline CHEMBL113414 & 688620 & 4.55 & 5.2078 & TRN & \\
\hline CHEMBL1469377 & 688620 & 5.6 & 4.9043 & TRN & \\
\hline CHEMBL1540341 & 688620 & 4.45 & 4.8474 & TRN & \\
\hline CHEMBL578502 & 688620 & 5.05 & 4.8576 & TRN & \\
\hline CHEMBL1612197 & 688620 & 4.45 & 4.7857 & TRN & \\
\hline CHEMBL1422105 & 688620 & 6.25 & 5.0689 & TST & \\
\hline CHEMBL1990071 & 688620 & 6.1 & 5.9018 & TRN & \\
\hline CHEMBL1336704 & 688620 & 4.45 & 4.8664 & TRN & \\
\hline CHEMBL1348823 & 688620 & 5.15 & 5.0646 & TRN & \\
\hline CHEMBL1393092 & 688620 & 5.25 & 4.9738 & TST & \\
\hline CHEMBL1497490 & 688620 & 4.65 & 4.9308 & TRN & \\
\hline CHEMBL 227400 & 688620 & 4.55 & 4.8257 & TRN & \\
\hline CHEMBL1318658 & 688620 & 5.5 & 5.1544 & TRN & \\
\hline CHEMBL585827 & 688620 & 5.9 & 5.7237 & TRN & \\
\hline CHEMBL1304663 & 688620 & 5.0 & 4.6719 & TRN & \\
\hline CHEMBL1523540 & 688620 & 4.9 & 5.0483 & TST & \\
\hline CHEMBL355159 & 688620 & 4.75 & 5.0433 & TRN & \\
\hline CHEMBL1505676 & 688620 & 4.45 & 4.797 & TRN & \\
\hline CHEMBL1554889 & 688620 & 4.95 & 5.1958 & TRN & \\
\hline CHEMBL1366499 & 688620 & 4.6 & 4.8541 & TRN & \\
\hline CHEMBL1430619 & 688620 & 4.8 & 5.0265 & TRN & \\
\hline CHEMBL1571055 & 688620 & 4.8 & 5.0091 & TST & \\
\hline CHEMBL1436984 & 688620 & 4.65 & 5.0783 & TST & \\
\hline CHEMBL1441394 & 688620 & 5.5 & 5.2639 & TRN & \\
\hline CHEMBL1303531 & 688620 & 5.25 & 5.024 & TRN & \\
\hline CHEMBL1411680 & 688620 & 5.15 & 5.0316 & TRN & \\
\hline CHEMBL1410787 & 688620 & 5.0 & 4.8002 & TRN & \\
\hline CHEMBL1996024 & 688620 & 4.85 & 4.8214 & TRN & \\
\hline CHEMBL1366017 & 688620 & 4.95 & 4.9256 & TRN & \\
\hline CHEMBL1372361 & 688620 & 4.75 & 5.093 & TRN & \\
\hline CHEMBL1557211 & 688620 & 4.8 & 5.2397 & TRN & \\
\hline CHEMBL1556267 & 688620 & 4.65 & 4.966 & TST & \\
\hline CHEMBL 2004056 & 688620 & 4.8 & 4.9773 & TRN & \\
\hline CHEMBL 3197786 & 688620 & 4.45 & 4.8742 & TRN & \\
\hline CHEMBL1381427 & 688620 & 4.6 & 5.3133 & TRN & \\
\hline CHEMBL1528186 & 688620 & 4.95 & 4.9903 & TST & \\
\hline CHEMBL1418007 & 688620 & 4.95 & 4.7991 & TST & \\
\hline CHEMBL1559266 & 688620 & 4.5 & 4.9638 & TRN & \\
\hline CHEMBL1336121 & 688620 & 5.2 & 5.3176 & TRN & \\
\hline CHEMBL3195827 & 688620 & 4.65 & 4.8844 & TST & \\
\hline CHEMBL1470325 & 688620 & 5.25 & 4.9736 & TRN & \\
\hline CHEMBL1542606 & 688620 & 4.85 & 4.8436 & TST & \\
\hline CHEMBL1329979 & 688620 & 4.75 & 4.9004 & TRN & \\
\hline CHEMBL1579781 & 688620 & 5.8 & 4.8454 & TST & \\
\hline CHEMBL579420 & 688620 & 4.75 & 5.0601 & TST & \\
\hline CHEMBL1450818 & 688620 & 6.0 & 5.24799 & 9999999999 & TRN \\
\hline CHEMBL1969721 & 688620 & 5.45 & 5.1312 & TST & \\
\hline
\end{tabular}




\begin{tabular}{|c|c|c|c|c|c|}
\hline \multicolumn{6}{|c|}{ Supplemental Table s2.txt } \\
\hline CHEMBL 3392444 & 688620 & 5.6 & 5.9597 & TRN & \\
\hline CHEMBL3192681 & 688620 & 5.05 & 5.184 & TST & \\
\hline CHEMBL1304798 & 688620 & 6.25 & 4.9648 & TRN & \\
\hline CHEMBL1364553 & 688620 & 4.85 & 5.2976 & TRN & \\
\hline CHEMBL1321276 & 688620 & 5.5 & 5.0469 & TRN & \\
\hline CHEMBL1309395 & 688620 & 5.55 & 5.0158 & TRN & \\
\hline CHEMBL3197029 & 688620 & 4.9 & 4.8913 & TRN & \\
\hline CHEMBL1526909 & 688620 & 5.15 & 5.2688 & TRN & \\
\hline CHEMBL1583263 & 688620 & 5.15 & 4.7316 & TRN & \\
\hline CHEMBL1327719 & 688620 & 5.6 & 4.8692 & TRN & \\
\hline CHEMBL1405542 & 688620 & 5.4 & 5.0017 & TRN & \\
\hline CHEMBL1579585 & 688620 & 4.45 & 4.8342 & TRN & \\
\hline CHEMBL1999019 & 688620 & 5.95 & 5.9589 & TRN & \\
\hline CHEMBL1518817 & 688620 & 5.15 & 5.0306 & TRN & \\
\hline CHEMBL1511250 & 688620 & 4.45 & 4.9308 & TRN & \\
\hline CHEMBL1350665 & 688620 & 4.55 & 4.6988 & TST & \\
\hline CHEMBL1599210 & 688620 & 4.9 & 4.9039 & TRN & \\
\hline CHEMBL1348432 & 688620 & 4.95 & 4.7838 & TRN & \\
\hline CHEMBL1417809 & 688620 & 5.25 & 4.9198 & TRN & \\
\hline CHEMBL1376584 & 688620 & 4.9 & 5.0988 & TRN & \\
\hline CHEMBL1342028 & 688620 & 5.8 & 5.1416 & TRN & \\
\hline CHEMBL1983075 & 688620 & 5.05 & 5.32299 & 99999999995 & TST \\
\hline CHEMBL1380852 & 688620 & 4.45 & 5.1538 & TRN & \\
\hline CHEMBL1455333 & 688620 & 4.8 & 4.9927 & TRN & \\
\hline CHEMBL1300668 & 688620 & 4.45 & 5.0055 & TRN & \\
\hline CHEMBL1543047 & 688620 & 5.15 & 5.4054 & TRN & \\
\hline CHEMBL3209657 & 688620 & 4.45 & 4.7626 & TRN & \\
\hline CHEMBL1406408 & 688620 & 5.1 & 4.8377 & TRN & \\
\hline CHEMBL3189656 & 688620 & 4.85 & 5.1374 & TRN & \\
\hline CHEMBL 1417354 & 688620 & 5.15 & 5.5705 & TRN & \\
\hline CHEMBL1439371 & 688620 & 5.45 & 4.9279 & TRN & \\
\hline CHEMBL1506508 & 688620 & 4.8 & 5.1205 & TRN & \\
\hline CHEMBL1382445 & 688620 & 5.4 & 5.4786 & TRN & \\
\hline CHEMBL1426109 & 688620 & 5.4 & 5.222 & TRN & \\
\hline CHEMBL1339656 & 688620 & 5.45 & 5.2898 & TRN & \\
\hline CHEMBL1453903 & 688620 & 4.85 & 5.1729 & TRN & \\
\hline CHEMBL1587113 & 688620 & 5.2 & 5.0098 & TRN & \\
\hline CHEMBL1508019 & 688620 & 5.15 & 4.9512 & TST & \\
\hline CHEMBL1494975 & 688620 & 5.3 & 5.044 & TRN & \\
\hline CHEMBL1464821 & 688620 & 4.75 & 5.2733 & TST & \\
\hline CHEMBL1378027 & 688620 & 4.45 & 4.9492 & TRN & \\
\hline CHEMBL1318951 & 688620 & 4.95 & 4.9709 & TRN & \\
\hline CHEMBL1545653 & 688620 & 4.8 & 5.1147 & TST & \\
\hline CHEMBL1369734 & 688620 & 4.9 & 5.0405 & TRN & \\
\hline CHEMBL1359299 & 688620 & 4.65 & 4.9211 & TRN & \\
\hline CHEMBL1323298 & 688620 & 4.45 & 5.2624 & TRN & \\
\hline CHEMBL1533469 & 688620 & 5.3 & 5.268 & TRN & \\
\hline CHEMBL1357718 & 688620 & 4.45 & 5.1642 & TST & \\
\hline
\end{tabular}




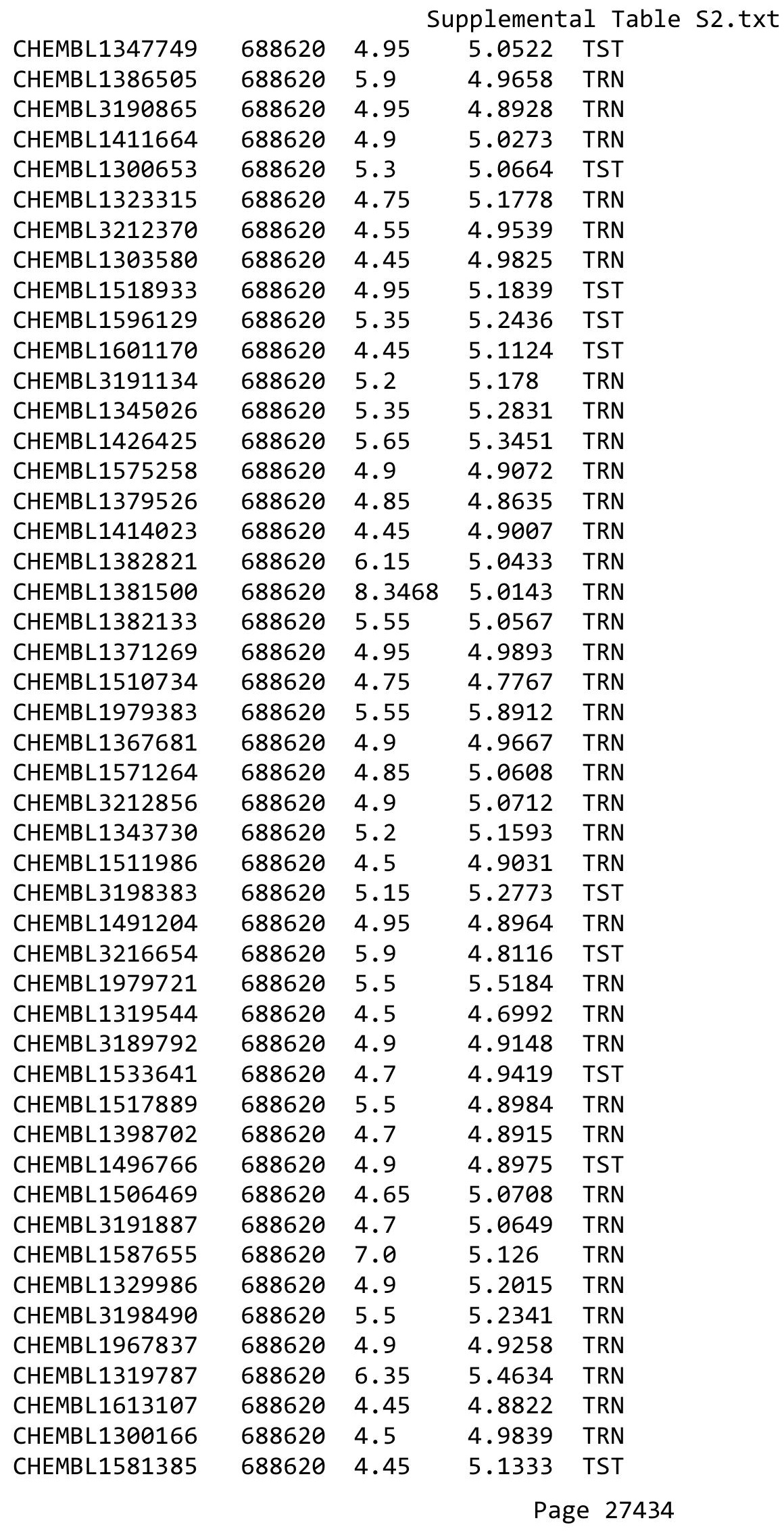




\begin{tabular}{|c|c|c|c|c|c|}
\hline \multicolumn{6}{|c|}{ Supplemental Table S2.txt } \\
\hline CHEMBL1498013 & 688620 & 4.65 & 4.809 & TRN & \\
\hline CHEMBL3192153 & 688620 & 4.9 & 5.0616 & TRN & \\
\hline CHEMBL1478939 & 688620 & 4.45 & 5.0316 & TRN & \\
\hline CHEMBL1530872 & 688620 & 4.65 & 4.7783 & TRN & \\
\hline CHEMBL1433012 & 688620 & 5.35 & 4.9808 & TRN & \\
\hline CHEMBL1550690 & 688620 & 4.9 & 4.8051 & TRN & \\
\hline CHEMBL1442391 & 688620 & 5.5 & 4.5923 & TRN & \\
\hline CHEMBL3196200 & 688620 & 5.35 & 5.2979 & TRN & \\
\hline CHEMBL1588204 & 688620 & 5.2 & 4.9124 & TRN & \\
\hline CHEMBL1344967 & 688620 & 5.0 & 4.9271 & TRN & \\
\hline CHEMBL1589388 & 688620 & 5.0 & 4.9333 & TRN & \\
\hline CHEMBL1434553 & 688620 & 5.5 & 4.9224 & TRN & \\
\hline CHEMBL1530409 & 688620 & 5.45 & 5.414 & TRN & \\
\hline CHEMBL1452029 & 688620 & 5.05 & 5.0797 & TRN & \\
\hline CHEMBL1534204 & 688620 & 5.2 & 5.6724 & TRN & \\
\hline CHEMBL1436507 & 688620 & 4.9 & 4.83899 & 99999999995 & TRN \\
\hline CHEMBL1443067 & 688620 & 5.75 & 4.9615 & TRN & \\
\hline CHEMBL1456311 & 688620 & 5.3 & 4.8123 & TRN & \\
\hline CHEMBL1983791 & 688620 & 5.0 & 4.9029 & TST & \\
\hline CHEMBL1584366 & 688620 & 4.6 & 5.0325 & TST & \\
\hline CHEMBL1585017 & 688620 & 5.0 & 4.9367 & TRN & \\
\hline CHEMBL1410436 & 688620 & 5.4 & 5.2174 & TRN & \\
\hline CHEMBL1370745 & 688620 & 5.1 & 5.4715 & TST & \\
\hline CHEMBL3189449 & 688620 & 5.3 & 5.2531 & TRN & \\
\hline CHEMBL1553855 & 688620 & 4.45 & 5.0052 & TST & \\
\hline CHEMBL1525429 & 688620 & 4.8 & 4.9027 & TRN & \\
\hline CHEMBL1409731 & 688620 & 5.5 & 5.2215 & TRN & \\
\hline CHEMBL1329715 & 688620 & 4.8 & 5.1393 & TRN & \\
\hline CHEMBL1419651 & 688620 & 5.5 & 4.8415 & TST & \\
\hline CHEMBL1366740 & 688620 & 6.5 & 4.9847 & TRN & \\
\hline CHEMBL1543875 & 688620 & 4.55 & 4.6714 & TRN & \\
\hline CHEMBL1574339 & 688620 & 5.2 & 5.3232 & TST & \\
\hline CHEMBL1599372 & 688620 & 7.0 & 5.7286 & TRN & \\
\hline CHEMBL1505359 & 688620 & 6.25 & 5.6529 & TRN & \\
\hline CHEMBL1375057 & 688620 & 5.6 & 5.3434 & TRN & \\
\hline CHEMBL1477061 & 688620 & 5.3 & 5.2503 & TST & \\
\hline CHEMBL 1557385 & 688620 & 4.45 & 5.0565 & TST & \\
\hline CHEMBL1477166 & 688620 & 6.8499 & 4.979 & TRN & \\
\hline CHEMBL1478613 & 688620 & 5.1 & 4.8376 & TRN & \\
\hline CHEMBL1987015 & 688620 & 5.15 & 5.0553 & TRN & \\
\hline CHEMBL1582504 & 688620 & 4.45 & 4.9274 & TRN & \\
\hline CHEMBL1312147 & 688620 & 5.25 & 5.0163 & TRN & \\
\hline CHEMBL1336237 & 688620 & 5.75 & 5.1348 & TRN & \\
\hline CHEMBL3189882 & 688620 & 5.25 & 5.2201 & TRN & \\
\hline CHEMBL1433384 & 688620 & 4.85 & 4.9641 & TRN & \\
\hline CHEMBL1597343 & 688620 & 5.2 & 5.0609 & TRN & \\
\hline CHEMBL1506974 & 688620 & 4.8 & 4.9453 & TST & \\
\hline CHEMBL1521074 & 688620 & 5.25 & 4.9281 & TST & \\
\hline
\end{tabular}




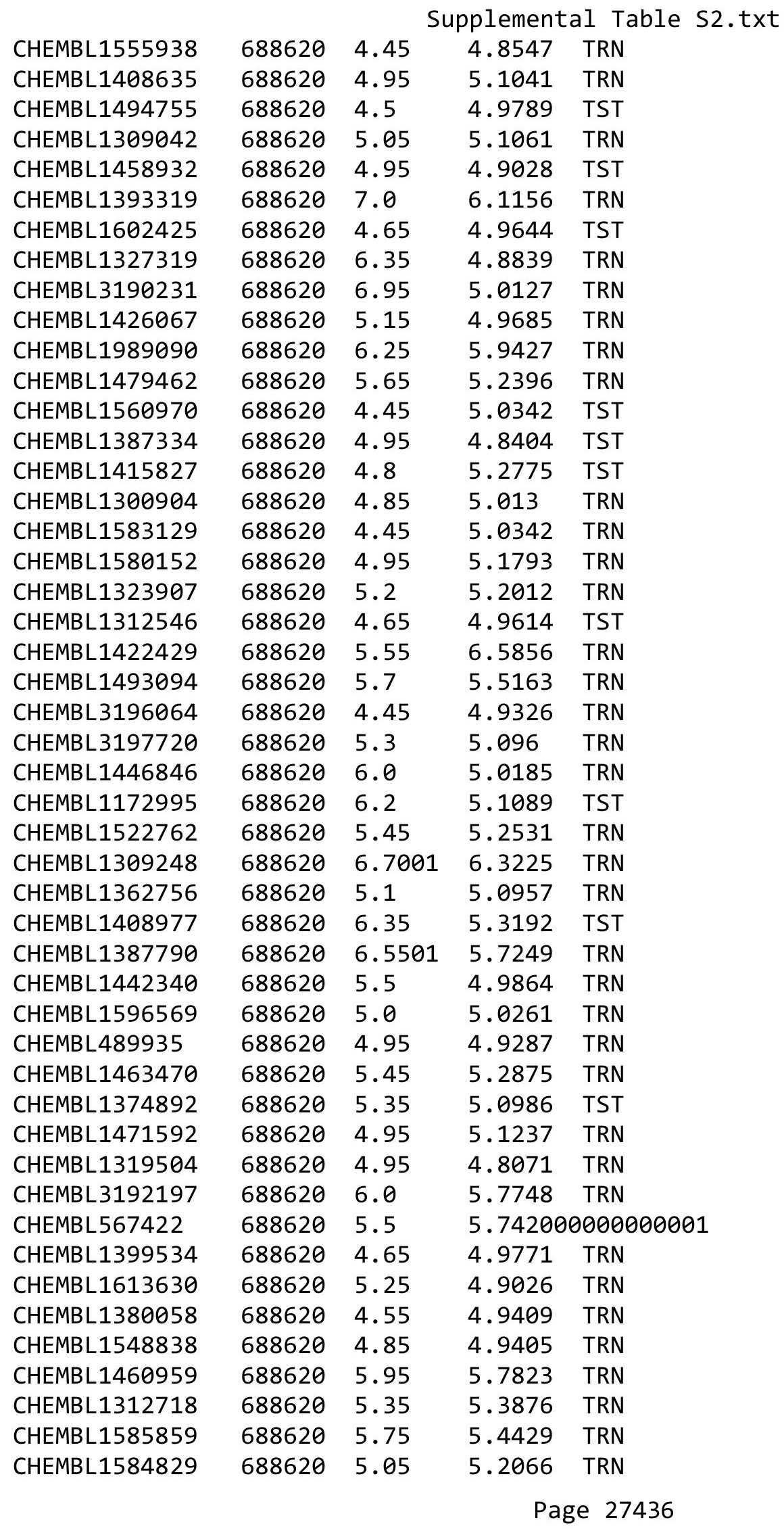




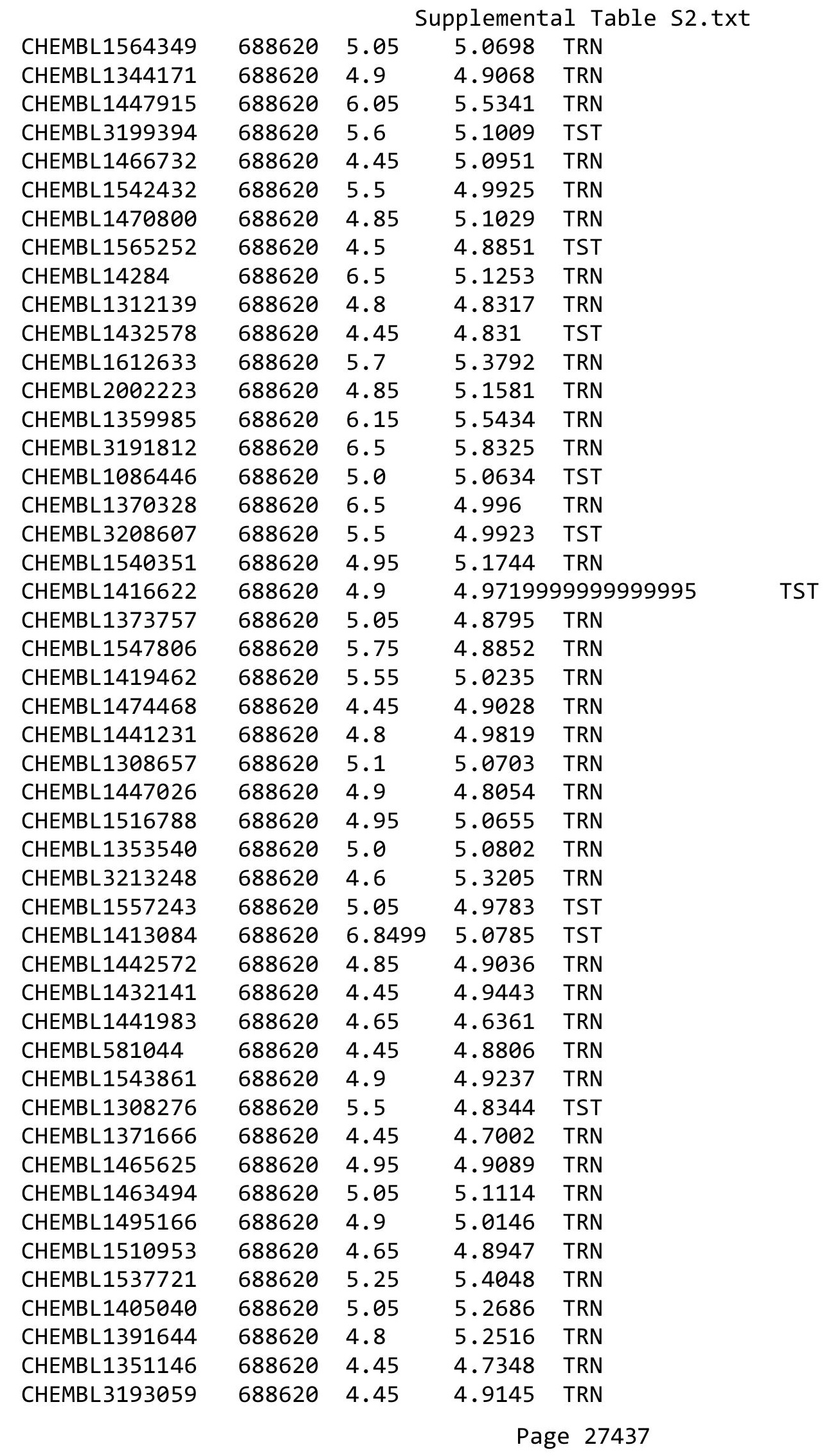




\begin{tabular}{|c|c|c|c|c|c|}
\hline \multicolumn{6}{|c|}{ Supplemental Table S2.txt } \\
\hline CHEMBL3199064 & 688620 & 5.75 & 5.5116 & TRN & \\
\hline CHEMBL 3199558 & 688620 & 4.8 & 4.8902 & TRN & \\
\hline CHEMBL1348219 & 688620 & 4.45 & 4.7675 & TST & \\
\hline CHEMBL1320046 & 688620 & 5.6 & 5.5419 & TRN & \\
\hline CHEMBL1311614 & 688620 & 4.75 & 4.7413 & TRN & \\
\hline CHEMBL1365027 & 688620 & 4.65 & 5.1731 & TRN & \\
\hline CHEMBL1541046 & 688620 & 4.45 & 4.8966 & TRN & \\
\hline CHEMBL1412163 & 688620 & 5.55 & 5.0694 & TST & \\
\hline CHEMBL1518629 & 688620 & 4.5 & 4.962 & TRN & \\
\hline CHEMBL1547687 & 688620 & 4.85 & 5.113 & TRN & \\
\hline CHEMBL1537304 & 688620 & 4.95 & 5.0568 & TRN & \\
\hline CHEMBL1385235 & 688620 & 4.95 & 4.9215 & TRN & \\
\hline CHEMBL1465696 & 688620 & 4.7 & 4.8801 & TRN & \\
\hline CHEMBL1542783 & 688620 & 4.65 & 4.8804 & TST & \\
\hline CHEMBL1464924 & 688620 & 4.8 & 5.1818 & TRN & \\
\hline CHEMBL1460627 & 688620 & 5.05 & 5.2793 & TRN & \\
\hline CHEMBL1511670 & 688620 & 4.85 & 4.9901 & TRN & \\
\hline CHEMBL1366644 & 688620 & 4.7 & 4.9468 & TRN & \\
\hline CHEMBL1306708 & 688620 & 4.7 & 5.1428 & TST & \\
\hline CHEMBL1479491 & 688620 & 4.95 & 4.9658 & TRN & \\
\hline CHEMBL1389653 & 688620 & 4.85 & 4.8125 & TST & \\
\hline CHEMBL1390300 & 688620 & 6.05 & 5.5579 & TRN & \\
\hline CHEMBL1385740 & 688620 & 4.85 & 4.9103 & TRN & \\
\hline CHEMBL1481422 & 688620 & 4.85 & 4.7489 & TRN & \\
\hline CHEMBL1566317 & 688620 & 5.25 & 4.9332 & TRN & \\
\hline CHEMBL1984680 & 688620 & 5.45 & 5.5879 & TRN & \\
\hline CHEMBL1384261 & 688620 & 4.85 & 5.016 & TRN & \\
\hline CHEMBL1331090 & 688620 & 5.45 & $5.1670 e$ & 0000000001 & TRN \\
\hline CHEMBL1497859 & 688620 & 4.45 & 5.3385 & TRN & \\
\hline CHEMBL3198449 & 688620 & 4.75 & 5.455 & TRN & \\
\hline CHEMBL1540744 & 688620 & 4.95 & 4.8484 & TRN & \\
\hline CHEMBL1480983 & 688620 & 5.05 & 5.3483 & TST & \\
\hline CHEMBL1528588 & 688620 & 5.85 & 5.079 & TST & \\
\hline CHEMBL1505749 & 688620 & 4.95 & 4.8255 & TRN & \\
\hline CHEMBL1549584 & 688620 & 4.9 & 4.9634 & TST & \\
\hline CHEMBL1523413 & 688620 & 4.85 & 5.065 & TRN & \\
\hline CHEMBL1486643 & 688620 & 4.95 & 4.9913 & TST & \\
\hline CHEMBL1462989 & 688620 & 4.6 & 5.0286 & TST & \\
\hline CHEMBL3192557 & 688620 & 5.75 & 5.7232 & TRN & \\
\hline CHEMBL3145285 & 688620 & 5.55 & 5.1913 & TST & \\
\hline CHEMBL1375938 & 688620 & 4.7 & 5.0252 & TST & \\
\hline CHEMBL1404819 & 688620 & 4.9 & 4.9671 & TRN & \\
\hline CHEMBL1299693 & 688620 & 5.65 & 5.126 & TST & \\
\hline CHEMBL1542654 & 688620 & 6.5 & 5.8134 & TRN & \\
\hline CHEMBL1596260 & 688620 & 4.75 & 5.1415 & TRN & \\
\hline CHEMBL1300618 & 688620 & 4.45 & 4.7217 & TRN & \\
\hline CHEMBL1321851 & 688620 & 5.1 & $5.1720 e$ & 0000000001 & TST \\
\hline CHEMBL1574211 & 688620 & 4.7 & 4.8044 & TRN & \\
\hline
\end{tabular}




\begin{tabular}{|c|c|c|c|c|}
\hline \multicolumn{5}{|c|}{ Supplemental Table S2.txt } \\
\hline CHEMBL1498470 & 688620 & 4.85 & 5.1013 & TRN \\
\hline CHEMBL1520051 & 688620 & 4.9 & 5.2877 & TRN \\
\hline CHEMBL1558327 & 688620 & 4.6 & 5.061 & TRN \\
\hline CHEMBL1468974 & 688620 & 4.8 & 4.9322 & TRN \\
\hline CHEMBL1489326 & 688620 & 5.0 & 4.9948 & TST \\
\hline CHEMBL1530735 & 688620 & 4.6 & 5.1455 & TRN \\
\hline CHEMBL1524531 & 688620 & 4.45 & 4.9747 & TRN \\
\hline CHEMBL1376319 & 688620 & 5.55 & 4.8446 & TRN \\
\hline CHEMBL1368497 & 688620 & 4.9 & 5.1406 & TRN \\
\hline CHEMBL1328136 & 688620 & 5.0 & 5.1259 & TRN \\
\hline CHEMBL1421652 & 688620 & 5.2 & 5.5002 & TRN \\
\hline CHEMBL1521109 & 688620 & 4.5 & 5.0845 & TRN \\
\hline CHEMBL1581454 & 688620 & 4.8 & 4.9638 & TST \\
\hline CHEMBL3209370 & 688620 & 4.75 & 4.7248 & TRN \\
\hline CHEMBL1447111 & 688620 & 5.0 & 5.1867 & TRN \\
\hline CHEMBL1361162 & 688620 & 4.45 & 5.0966 & TST \\
\hline CHEMBL1351837 & 688620 & 5.0 & 4.9724 & TRN \\
\hline CHEMBL1271635 & 688620 & 4.95 & 4.899 & TRN \\
\hline CHEMBL1375468 & 688620 & 4.85 & 5.1236 & TRN \\
\hline CHEMBL1966867 & 688620 & 5.3 & 5.0789 & TST \\
\hline CHEMBL1547468 & 688620 & 4.7 & 4.9933 & TST \\
\hline CHEMBL1300830 & 688620 & 6.2 & 6.1454 & TRN \\
\hline CHEMBL1352698 & 688620 & 6.3 & 6.16299 & 9999999999 \\
\hline CHEMBL1968458 & 688620 & 5.2 & 5.3113 & TRN \\
\hline CHEMBL1585456 & 688620 & 5.25 & 5.4964 & TRN \\
\hline CHEMBL1488257 & 688620 & 4.45 & 4.9204 & TRN \\
\hline CHEMBL 3197605 & 688620 & 4.7 & 4.9178 & TRN \\
\hline CHEMBL1475826 & 688620 & 5.75 & 5.4758 & TRN \\
\hline CHEMBL1410451 & 688620 & 5.1 & 4.908 & TRN \\
\hline CHEMBL1560247 & 688620 & 6.35 & 5.0313 & TST \\
\hline CHEMBL1573909 & 688620 & 5.0 & 4.9423 & TRN \\
\hline CHEMBL1399908 & 688620 & 4.95 & 5.1241 & TRN \\
\hline CHEMBL1578679 & 688620 & 4.45 & 4.7931 & TST \\
\hline CHEMBL1301474 & 688620 & 5.0 & 5.1446 & TRN \\
\hline CHEMBL1451170 & 688620 & 5.2 & 5.0804 & TST \\
\hline CHEMBL1610610 & 688620 & 4.45 & 4.7644 & TST \\
\hline CHEMBL1393714 & 688620 & 5.85 & 5.3787 & TRN \\
\hline CHEMBL1528240 & 688620 & 4.7 & 5.0051 & TRN \\
\hline CHEMBL1414496 & 688620 & 5.45 & 4.8678 & TRN \\
\hline CHEMBL1507866 & 688620 & 4.45 & 4.7841 & TRN \\
\hline CHEMBL1600576 & 688620 & 5.25 & 5.0023 & TRN \\
\hline CHEMBL1583200 & 688620 & 6.6499 & 5.1276 & TRN \\
\hline CHEMBL3191484 & 688620 & 5.05 & 5.1928 & TRN \\
\hline CHEMBL1308649 & 688620 & 4.9 & 5.3168 & TRN \\
\hline CHEMBL1529695 & 688620 & 6.2 & 5.4947 & TST \\
\hline CHEMBL1531352 & 688620 & 8.3468 & 5.0067 & TRN \\
\hline CHEMBL1585007 & 688620 & 5.0 & 5.226 & TRN \\
\hline CHEMBL1428095 & 688620 & 5.65 & 5.785 & TRN \\
\hline
\end{tabular}




\begin{tabular}{|c|c|c|c|c|}
\hline \multicolumn{5}{|c|}{ Supplemental Table } \\
\hline CHEMBL1353992 & 688620 & 6.0 & 5.3975 & TRN \\
\hline CHEMBL1601079 & 688620 & 4.8 & 5.0374 & TRN \\
\hline CHEMBL1602614 & 688620 & 5.1 & 5.2457 & TRN \\
\hline CHEMBL1422532 & 688620 & 4.95 & 4.9443 & TRN \\
\hline CHEMBL1345920 & 688620 & 4.45 & 4.9885 & TRN \\
\hline CHEMBL1509485 & 688620 & 4.95 & 4.6745 & TRN \\
\hline CHEMBL1481671 & 688620 & 4.45 & 4.977 & TRN \\
\hline CHEMBL1609520 & 688620 & 4.9 & 4.8283 & TRN \\
\hline CHEMBL1549149 & 688620 & 5.4 & 5.0244 & TRN \\
\hline CHEMBL1996281 & 688620 & 5.85 & 5.7799 & TRN \\
\hline CHEMBL1505228 & 688620 & 5.25 & 5.0168 & TRN \\
\hline CHEMBL1994510 & 688620 & 5.0 & 5.2656 & TRN \\
\hline CHEMBL1315056 & 688620 & 4.45 & 5.1687 & TRN \\
\hline CHEMBL1461972 & 688620 & 5.5 & 5.0466 & TRN \\
\hline CHEMBL1439052 & 688620 & 5.55 & 4.9836 & TRN \\
\hline CHEMBL1388614 & 688620 & 5.15 & 5.1336 & TST \\
\hline CHEMBL1455523 & 688620 & 5.1 & 5.1267 & TRN \\
\hline CHEMBL1414984 & 688620 & 4.45 & 4.8869 & TRN \\
\hline CHEMBL1373951 & 688620 & 5.4 & 4.9248 & TRN \\
\hline CHEMBL1497821 & 688620 & 4.75 & 4.9752 & TRN \\
\hline CHEMBL1383493 & 688620 & 4.85 & 5.1632 & TST \\
\hline CHEMBL1426040 & 688620 & 4.9 & 4.9781 & TRN \\
\hline CHEMBL1557122 & 688620 & 4.5 & 4.997 & TRN \\
\hline CHEMBL1406238 & 688620 & 6.25 & 5.6158 & TRN \\
\hline CHEMBL1322707 & 688620 & 4.95 & 4.9554 & TRN \\
\hline CHEMBL1604696 & 688620 & 4.65 & 5.0125 & TRN \\
\hline CHEMBL1432886 & 688620 & 5.85 & 5.4117 & TRN \\
\hline CHEMBL1333541 & 688620 & 5.8 & 5.2569 & TRN \\
\hline CHEMBL1602052 & 688620 & 4.75 & 5.0214 & TRN \\
\hline CHEMBL1302663 & 688620 & 4.65 & 5.0921 & TST \\
\hline CHEMBL1467130 & 688620 & 4.8 & 4.9996 & TRN \\
\hline CHEMBL1460748 & 688620 & 4.8 & 4.7286 & TRN \\
\hline CHEMBL3195449 & 688620 & 5.15 & 5.3768 & TRN \\
\hline CHEMBL1417898 & 688620 & 5.55 & 5.0885 & TST \\
\hline CHEMBL1391909 & 688620 & 4.65 & 4.9771 & TRN \\
\hline CHEMBL1376813 & 688620 & 4.8 & 4.8336 & TRN \\
\hline CHEMBL1327494 & 688620 & 4.65 & 5.6899 & TRN \\
\hline CHEMBL1445967 & 688620 & 5.15 & 5.6163 & TRN \\
\hline CHEMBL1561017 & 688620 & 4.9 & 5.0772 & TST \\
\hline CHEMBL1611812 & 688620 & 5.0 & 5.1524 & TST \\
\hline CHEMBL1566706 & 688620 & 4.8 & 4.6846 & TRN \\
\hline CHEMBL 38832 & 688620 & 4.45 & 5.0006 & TST \\
\hline CHEMBL1379675 & 688620 & 5.3 & 4.9934 & TRN \\
\hline CHEMBL1363507 & 688620 & 4.6 & 4.9132 & TRN \\
\hline CHEMBL1612588 & 688620 & 6.2 & 5.175 & TRN \\
\hline CHEMBL1974269 & 688620 & 5.0 & 4.8477 & TRN \\
\hline CHEMBL1484433 & 688620 & 4.9 & 4.8578 & TRN \\
\hline CHEMBL1536544 & 688620 & 4.9 & 5.0799 & TST \\
\hline
\end{tabular}




\begin{tabular}{|c|c|c|c|c|c|}
\hline \multicolumn{6}{|c|}{ Supplemental Table S2.txt } \\
\hline CHEMBL1351001 & 688620 & 5.2 & 4.8459 & TRN & \\
\hline CHEMBL1526906 & 688620 & 6.45 & 5.0206 & TRN & \\
\hline CHEMBL1964873 & 688620 & 5.55 & 5.5903 & TRN & \\
\hline CHEMBL1490500 & 688620 & 6.05 & 5.7112 & TRN & \\
\hline CHEMBL1302011 & 688620 & 5.2 & 4.7922 & TRN & \\
\hline CHEMBL1557752 & 688620 & 4.45 & 5.1552 & TRN & \\
\hline CHEMBL600686 & 688620 & 4.75 & 4.81 & TST & \\
\hline CHEMBL1565835 & 688620 & 5.5 & 5.0903 & TRN & \\
\hline CHEMBL1379833 & 688620 & 4.95 & 4.8237 & TRN & \\
\hline CHEMBL3192709 & 688620 & 5.05 & 4.9048 & TRN & \\
\hline CHEMBL1978989 & 688620 & 4.45 & 4.8398 & TRN & \\
\hline CHEMBL1487526 & 688620 & 5.15 & 4.9271 & TRN & \\
\hline CHEMBL 3192900 & 688620 & 4.75 & 4.9601 & TRN & \\
\hline CHEMBL1581719 & 688620 & 5.1 & 5.0428 & TRN & \\
\hline CHEMBL1525870 & 688620 & 4.8 & 4.8045 & TRN & \\
\hline CHEMBL3199367 & 688620 & 4.9 & 4.7935 & TRN & \\
\hline CHEMBL1582405 & 688620 & 6.15 & 5.1338 & TST & \\
\hline CHEMBL1538375 & 688620 & 4.45 & 5.0259 & TRN & \\
\hline CHEMBL1403484 & 688620 & 5.25 & 5.7582 & TST & \\
\hline CHEMBL1347529 & 688620 & 5.45 & 5.0358 & TRN & \\
\hline CHEMBL3213058 & 688620 & 4.9 & 4.7943 & TRN & \\
\hline CHEMBL114957 & 688620 & 4.5 & 5.1938 & TRN & \\
\hline CHEMBL1561736 & 688620 & 5.25 & $5.1220 e$ & 0000000001 & TRN \\
\hline CHEMBL1504876 & 688620 & 5.3 & 5.0973 & TRN & \\
\hline CHEMBL3191105 & 688620 & 4.7 & 4.8922 & TRN & \\
\hline CHEMBL1523883 & 688620 & 5.9 & 5.0351 & TRN & \\
\hline CHEMBL1597742 & 688620 & 5.5 & 5.1992 & TST & \\
\hline CHEMBL1427367 & 688620 & 4.45 & 5.2007 & TST & \\
\hline CHEMBL1528562 & 688620 & 5.0 & 5.0166 & TRN & \\
\hline CHEMBL1555679 & 688620 & 4.85 & 5.4258 & TRN & \\
\hline CHEMBL3211137 & 688620 & 4.8 & 5.7071 & TRN & \\
\hline CHEMBL1612940 & 688620 & 5.15 & 5.4501 & TRN & \\
\hline CHEMBL1497995 & 688620 & 4.7 & 4.9738 & TST & \\
\hline CHEMBL1447217 & 688620 & 4.7 & 5.1193 & TRN & \\
\hline CHEMBL1342205 & 688620 & 6.8499 & 5.098 & TRN & \\
\hline CHEMBL1310783 & 688620 & 4.95 & 5.0034 & TRN & \\
\hline CHEMBL1388976 & 688620 & 4.85 & 5.0471 & TST & \\
\hline CHEMBL1323961 & 688620 & 5.0 & 4.8971 & TRN & \\
\hline CHEMBL1446612 & 688620 & 4.7 & 4.9957 & TRN & \\
\hline CHEMBL3198619 & 688620 & 4.45 & 4.8294 & TST & \\
\hline CHEMBL1426268 & 688620 & 4.45 & 5.0706 & TRN & \\
\hline CHEMBL1521251 & 688620 & 4.95 & 5.1611 & TRN & \\
\hline CHEMBL1403180 & 688620 & 5.0 & 5.1561 & TRN & \\
\hline CHEMBL1597979 & 688620 & 6.4 & 5.1613 & TST & \\
\hline CHEMBL3145361 & 688620 & 6.35 & 6.1216 & TRN & \\
\hline CHEMBL1453054 & 688620 & 4.95 & 4.97 & TRN & \\
\hline CHEMBL1612234 & 688620 & 6.05 & 5.5758 & TST & \\
\hline CHEMBL1556469 & 688620 & 4.75 & 4.9919 & TST & \\
\hline
\end{tabular}




\begin{tabular}{|c|c|c|c|c|}
\hline & & & pplement & \\
\hline CHEMBL1429290 & 688620 & 5.5 & 5.0095 & TRN \\
\hline CHEMBL1437011 & 688620 & 5.1 & 5.0022 & TRN \\
\hline CHEMBL1517189 & 688620 & 4.9 & 4.9814 & TRN \\
\hline CHEMBL1480188 & 688620 & 5.75 & 4.8068 & TST \\
\hline CHEMBL1419521 & 688620 & 4.45 & 5.1402 & TRN \\
\hline CHEMBL 3193244 & 688620 & 4.95 & 4.9891 & TST \\
\hline CHEMBL1422459 & 688620 & 4.7 & 4.9786 & TST \\
\hline CHEMBL1425919 & 688620 & 5.0 & 5.1209 & TRN \\
\hline CHEMBL1412851 & 688620 & 4.9 & 5.0938 & TRN \\
\hline CHEMBL1342993 & 688620 & 5.5 & 5.3449 & TRN \\
\hline CHEMBL1329733 & 688620 & 4.55 & 4.8614 & TRN \\
\hline CHEMBL1583249 & 688620 & 5.3 & 4.961 & TRN \\
\hline CHEMBL1346038 & 688620 & 4.45 & 5.0626 & TRN \\
\hline CHEMBL405927 & 688620 & 4.95 & 5.1354 & TRN \\
\hline CHEMBL1319027 & 688620 & 4.8 & 5.3594 & TRN \\
\hline CHEMBL1452229 & 688620 & 4.65 & 5.1753 & TRN \\
\hline CHEMBL 3213780 & 688620 & 5.15 & 5.1381 & TST \\
\hline CHEMBL1588880 & 688620 & 5.35 & 5.4464 & TRN \\
\hline CHEMBL1558444 & 688620 & 4.65 & 4.8503 & TST \\
\hline CHEMBL1539609 & 688620 & 5.15 & 5.2142 & TRN \\
\hline CHEMBL1539018 & 688620 & 5.25 & 5.1332 & TST \\
\hline CHEMBL1446648 & 688620 & 5.1 & 4.974 & TRN \\
\hline CHEMBL1327592 & 688620 & 5.1 & 5.0883 & TRN \\
\hline CHEMBL1541012 & 688620 & 5.45 & 5.3057 & TRN \\
\hline CHEMBL1980184 & 688620 & 5.0 & 5.0254 & TRN \\
\hline CHEMBL1520479 & 688620 & 5.5 & 5.557 & TRN \\
\hline CHEMBL1326308 & 688620 & 4.95 & 5.0343 & TST \\
\hline CHEMBL1555899 & 688620 & 4.45 & 4.6657 & TRN \\
\hline CHEMBL1352295 & 688620 & 4.45 & 4.8818 & TRN \\
\hline CHEMBL1508614 & 688620 & 4.8 & 5.066 & TST \\
\hline CHEMBL1384946 & 688620 & 5.05 & 5.0744 & TRN \\
\hline CHEMBL1372612 & 688620 & 5.4 & 5.1378 & TRN \\
\hline CHEMBL1379768 & 688620 & 5.15 & 4.9713 & TRN \\
\hline CHEMBL1530278 & 688620 & 4.55 & 5.0666 & TRN \\
\hline CHEMBL1348836 & 688620 & 5.5 & 5.2847 & TRN \\
\hline CHEMBL3190644 & 688620 & 5.25 & 5.1451 & TST \\
\hline CHEMBL1509523 & 688620 & 6.2 & 5.6697 & TST \\
\hline CHEMBL124706 & 688620 & 4.7 & 4.8835 & TST \\
\hline CHEMBL1453237 & 688620 & 6.05 & 5.9358 & TRN \\
\hline CHEMBL1491145 & 688620 & 4.9 & 4.7824 & TRN \\
\hline CHEMBL1555491 & 688620 & 4.45 & 4.6671 & TRN \\
\hline CHEMBL1375300 & 688620 & 4.7 & 4.9474 & TRN \\
\hline CHEMBL3212362 & 688620 & 5.55 & 5.528 & TRN \\
\hline CHEMBL1586238 & 688620 & 4.9 & 5.0283 & TST \\
\hline CHEMBL1547979 & 688620 & 5.5 & 4.9881 & TST \\
\hline CHEMBL1457369 & 688620 & 5.1 & 5.3489 & TRN \\
\hline CHEMBL1576739 & 688620 & 4.75 & 5.0363 & TST \\
\hline CHEMBL1532673 & 688620 & 4.7 & 5.1474 & TST \\
\hline
\end{tabular}




\begin{tabular}{|c|c|c|c|c|c|}
\hline \multirow[b]{2}{*}{ CHEMBL1363191 } & \multicolumn{5}{|c|}{ Supplemental Table S2.txt } \\
\hline & 688620 & 6.6499 & 5.3885 & TST & \\
\hline CHEMBL1584564 & 688620 & 4.5 & 5.0426 & TRN & \\
\hline CHEMBL276139 & 688620 & 5.55 & 5.1018 & TST & \\
\hline CHEMBL1351501 & 688620 & 4.95 & 4.9189 & TRN & \\
\hline CHEMBL1536740 & 688620 & 6.25 & 6.3419 & TRN & \\
\hline CHEMBL1313310 & 688620 & 5.05 & 5.0705 & TRN & \\
\hline CHEMBL3191405 & 688620 & 5.9 & 4.7363 & TRN & \\
\hline CHEMBL1319952 & 688620 & 4.45 & 4.7271 & TRN & \\
\hline CHEMBL1440277 & 688620 & 4.9 & 4.922 & TRN & \\
\hline CHEMBL457504 & 688620 & 6.0 & 5.5902 & TRN & \\
\hline CHEMBL1492442 & 688620 & 4.6 & 4.9545 & TST & \\
\hline CHEMBL3198205 & 688620 & 5.65 & 5.3994 & TRN & \\
\hline CHEMBL1471051 & 688620 & 5.5 & 5.0113 & TRN & \\
\hline CHEMBL1330232 & 688620 & 4.55 & 4.9666 & TRN & \\
\hline CHEMBL1470218 & 688620 & 5.55 & 5.019 & TRN & \\
\hline CHEMBL1580176 & 688620 & 5.3 & 5.42700 & 00000000005 & TRN \\
\hline CHEMBL1308946 & 688620 & 5.3 & 5.4868 & TRN & \\
\hline CHEMBL 3197447 & 688620 & 5.25 & 5.456 & TRN & \\
\hline CHEMBL 3194747 & 688620 & 5.55 & 5.4909 & TRN & \\
\hline CHEMBL1568855 & 688620 & 5.0 & 5.3074 & TRN & \\
\hline CHEMBL 1443880 & 688620 & 4.45 & 4.9545 & TRN & \\
\hline CHEMBL1506464 & 688620 & 4.6 & 4.8968 & TRN & \\
\hline CHEMBL1465667 & 688620 & 5.35 & 5.1289 & TRN & \\
\hline CHEMBL1499699 & 688620 & 6.5 & 5.2683 & TST & \\
\hline CHEMBL1542083 & 688620 & 5.4 & 4.8977 & TRN & \\
\hline CHEMBL1381063 & 688620 & 4.6 & 4.8274 & TRN & \\
\hline CHEMBL1454668 & 688620 & 4.75 & 5.0002 & TRN & \\
\hline CHEMBL1451337 & 688620 & 4.75 & 4.9425 & TRN & \\
\hline CHEMBL1487813 & 688620 & 4.45 & 5.1016 & TRN & \\
\hline CHEMBL3191962 & 688620 & 6.3 & 5.5569 & TRN & \\
\hline CHEMBL3195100 & 688620 & 4.75 & 4.9176 & TRN & \\
\hline CHEMBL3199002 & 688620 & 4.95 & 5.0163 & TRN & \\
\hline CHEMBL1477281 & 688620 & 4.8 & 5.0346 & TST & \\
\hline CHEMBL1402847 & 688620 & 6.05 & 5.2104 & TRN & \\
\hline CHEMBL1307654 & 688620 & 5.0 & 5.0205 & TRN & \\
\hline CHEMBL1543517 & 688620 & 5.35 & 5.28700 & 0000000001 & TST \\
\hline CHEMBL1472428 & 688620 & 5.4 & 5.6343 & TRN & \\
\hline CHEMBL1369945 & 688620 & 4.9 & 4.909 & TRN & \\
\hline CHEMBL1458599 & 688620 & 5.25 & 5.3083 & TRN & \\
\hline CHEMBL1425283 & 688620 & 4.6 & 4.8668 & TRN & \\
\hline CHEMBL1412334 & 688620 & 4.45 & 4.7118 & TRN & \\
\hline CHEMBL1503602 & 688620 & 4.6 & 5.0239 & TRN & \\
\hline CHEMBL3195180 & 688620 & 4.45 & 4.8994 & TRN & \\
\hline CHEMBL3392458 & 688620 & 5.1 & 5.5274 & TST & \\
\hline CHEMBL1438793 & 688620 & 5.5 & 5.2605 & TST & \\
\hline CHEMBL1536914 & 688620 & 5.4 & 5.6879 & TST & \\
\hline CHEMBL1589786 & 688620 & 4.95 & 5.0776 & TRN & \\
\hline CHEMBL3199169 & 688620 & 5.45 & 5.4619 & TRN & \\
\hline
\end{tabular}




\begin{tabular}{|c|c|c|c|c|}
\hline & & & pplement & al $\mathrm{T}$ \\
\hline CHEMBL1408708 & 688620 & 5.2 & 5.1082 & TRN \\
\hline CHEMBL1317294 & 688620 & 4.8 & 5.1821 & TST \\
\hline CHEMBL1478962 & 688620 & 5.35 & 5.3073 & TRN \\
\hline CHEMBL1382120 & 688620 & 4.5 & 4.9236 & TRN \\
\hline CHEMBL 3197772 & 688620 & 4.8 & 4.9221 & TRN \\
\hline CHEMBL1975069 & 688620 & 5.1 & 4.8746 & TRN \\
\hline CHEMBL1353031 & 688620 & 4.85 & 5.025 & TRN \\
\hline CHEMBL3196075 & 688620 & 5.0 & 4.8602 & TRN \\
\hline CHEMBL1539967 & 688620 & 5.4 & 5.1821 & TST \\
\hline CHEMBL1312713 & 688620 & 5.4 & 5.0115 & TRN \\
\hline CHEMBL1389139 & 688620 & 4.85 & 5.0039 & TRN \\
\hline CHEMBL1430902 & 688620 & 5.8 & 5.2797 & TRN \\
\hline CHEMBL1981677 & 688620 & 5.2 & 5.0273 & TST \\
\hline CHEMBL1393047 & 688620 & 7.0501 & 5.7721 & TRN \\
\hline CHEMBL1321070 & 688620 & 4.45 & 5.038 & TST \\
\hline CHEMBL1579796 & 688620 & 4.9 & 4.7864 & TRN \\
\hline CHEMBL1306815 & 688620 & 5.4 & 5.3355 & TST \\
\hline CHEMBL1547141 & 688620 & 4.45 & 4.941 & TST \\
\hline CHEMBL3192757 & 688620 & 4.65 & 5.1794 & TRN \\
\hline CHEMBL3199263 & 688620 & 6.4 & 5.0499 & TRN \\
\hline CHEMBL1579490 & 688620 & 4.9 & 4.9336 & TRN \\
\hline CHEMBL1442260 & 688620 & 5.1 & 4.9761 & TRN \\
\hline CHEMBL1559004 & 688620 & 4.75 & 4.8939 & TRN \\
\hline CHEMBL1533117 & 688620 & 4.95 & 5.1199 & TRN \\
\hline CHEMBL1610067 & 688620 & 4.85 & 4.7584 & TRN \\
\hline CHEMBL3199295 & 688620 & 5.75 & 5.5027 & TST \\
\hline CHEMBL1533592 & 688620 & 5.5 & 4.9493 & TST \\
\hline CHEMBL1556651 & 688620 & 4.95 & 4.8574 & TRN \\
\hline CHEMBL1493137 & 688620 & 5.4 & 4.952 & TRN \\
\hline CHEMBL1587553 & 688620 & 4.9 & 5.065 & TST \\
\hline CHEMBL1345648 & 688620 & 4.95 & 5.216 & TST \\
\hline CHEMBL1586617 & 688620 & 4.7 & 4.9223 & TRN \\
\hline CHEMBL1311436 & 688620 & 4.95 & 4.6884 & TRN \\
\hline CHEMBL1462459 & 688620 & 4.65 & 4.8531 & TRN \\
\hline CHEMBL1430522 & 688620 & 6.15 & 5.2329 & TST \\
\hline CHEMBL1384984 & 688620 & 5.65 & 5.822 & TRN \\
\hline CHEMBL1455974 & 688620 & 4.95 & 4.8728 & TRN \\
\hline CHEMBL3039775 & 688620 & 5.5 & 5.2265 & TRN \\
\hline CHEMBL1459918 & 688620 & 6.0 & 5.6927 & TRN \\
\hline CHEMBL1303527 & 688620 & 4.45 & 4.9329 & TRN \\
\hline CHEMBL3199539 & 688620 & 4.9 & 5.4429 & TRN \\
\hline CHEMBL1305276 & 688620 & 4.8 & 4.7983 & TRN \\
\hline CHEMBL1505875 & 688620 & 4.75 & 4.8989 & TRN \\
\hline CHEMBL1360121 & 688620 & 4.45 & 5.1038 & TRN \\
\hline CHEMBL1569868 & 688620 & 5.05 & 5.0386 & TST \\
\hline CHEMBL1497561 & 688620 & 5.0 & 4.9117 & TRN \\
\hline CHEMBL1559414 & 688620 & 6.8 & 5.4471 & TRN \\
\hline CHEMBL1482986 & 688620 & 5.4 & 4.7383 & TST \\
\hline
\end{tabular}




\begin{tabular}{|c|c|c|c|c|}
\hline \multicolumn{5}{|c|}{ Supplemental Tabl } \\
\hline CHEMBL1433061 & 688620 & 6.15 & 5.0181 & TRN \\
\hline CHEMBL1595887 & 688620 & 4.6 & 4.7555 & TRN \\
\hline CHEMBL1556319 & 688620 & 4.45 & 4.9797 & TRN \\
\hline CHEMBL1559342 & 688620 & 5.1 & 5.0926 & TRN \\
\hline CHEMBL1523648 & 688620 & 4.6 & 5.0292 & TRN \\
\hline CHEMBL1308451 & 688620 & 4.95 & 5.0023 & TRN \\
\hline CHEMBL1468636 & 688620 & 4.95 & 4.9352 & TRN \\
\hline CHEMBL1451366 & 688620 & 4.95 & 5.0668 & TRN \\
\hline CHEMBL1597137 & 688620 & 5.25 & 5.0085 & TRN \\
\hline CHEMBL1531971 & 688620 & 4.95 & 4.9985 & TST \\
\hline CHEMBL1605586 & 688620 & 5.55 & 5.0664 & TRN \\
\hline CHEMBL 2007163 & 688620 & 4.75 & 4.787 & TRN \\
\hline CHEMBL1505991 & 688620 & 5.25 & 5.166 & TRN \\
\hline CHEMBL1500262 & 688620 & 4.7 & 5.2631 & TRN \\
\hline CHEMBL1411765 & 688620 & 4.9 & 5.1839 & TST \\
\hline CHEMBL1329327 & 688620 & 4.7 & 5.0244 & TRN \\
\hline CHEMBL1410897 & 688620 & 5.75 & 5.4406 & TRN \\
\hline CHEMBL1479740 & 688620 & 4.95 & 4.7939 & TRN \\
\hline CHEMBL1386065 & 688620 & 4.95 & 5.0014 & TRN \\
\hline CHEMBL1539097 & 688620 & 4.85 & 4.7014 & TRN \\
\hline CHEMBL1584746 & 688620 & 4.5 & 4.8458 & TRN \\
\hline CHEMBL1302330 & 688620 & 5.5 & 5.0803 & TRN \\
\hline CHEMBL1424264 & 688620 & 5.5 & 5.4745 & TRN \\
\hline CHEMBL1519538 & 688620 & 7.0 & 4.941 & TST \\
\hline CHEMBL1586766 & 688620 & 4.45 & 5.0397 & TRN \\
\hline CHEMBL1596288 & 688620 & 5.1 & 5.0836 & TST \\
\hline CHEMBL1592627 & 688620 & 4.45 & 5.1321 & TST \\
\hline CHEMBL1528944 & 688620 & 5.15 & 4.9915 & TRN \\
\hline CHEMBL1972739 & 688620 & 4.9 & 5.0578 & TRN \\
\hline CHEMBL1482781 & 688620 & 4.75 & 4.93 & TRN \\
\hline CHEMBL1588763 & 688620 & 4.95 & 4.987 & TRN \\
\hline CHEMBL1373096 & 688620 & 5.3 & 5.8306 & TRN \\
\hline CHEMBL 3190436 & 688620 & 4.75 & 4.875 & TRN \\
\hline CHEMBL1492800 & 688620 & 4.7 & 4.9856 & TRN \\
\hline CHEMBL1321310 & 688620 & 4.5 & 5.0503 & TRN \\
\hline CHEMBL1547350 & 688620 & 5.75 & 5.7726 & TRN \\
\hline CHEMBL3198206 & 688620 & 5.55 & 5.5901 & TRN \\
\hline CHEMBL1389469 & 688620 & 4.65 & 5.0153 & TRN \\
\hline CHEMBL1457476 & 688620 & 4.7 & 5.2205 & TRN \\
\hline CHEMBL1540705 & 688620 & 4.6 & 4.9093 & TRN \\
\hline CHEMBL1423969 & 688620 & 4.9 & 4.8149 & TRN \\
\hline CHEMBL1360510 & 688620 & 4.95 & 5.0168 & TRN \\
\hline CHEMBL1531549 & 688620 & 5.55 & 4.9679 & TST \\
\hline CHEMBL516952 & 688620 & 4.5 & 4.914 & TRN \\
\hline CHEMBL1528076 & 688620 & 4.45 & 4.9316 & TRN \\
\hline CHEMBL1332764 & 688620 & 5.65 & 5.2313 & TRN \\
\hline CHEMBL1600256 & 688620 & 4.65 & 5.0927 & TRN \\
\hline CHEMBL1312716 & 688620 & 5.65 & 5.2969 & TRN \\
\hline
\end{tabular}




\begin{tabular}{|c|c|c|c|c|c|}
\hline \multicolumn{6}{|c|}{ Supplemental Table s2.txt } \\
\hline CHEMBL1440814 & 688620 & 5.15 & 5.0638 & TST & \\
\hline CHEMBL 3193249 & 688620 & 6.25 & 5.2424 & TRN & \\
\hline CHEMBL1526659 & 688620 & 5.55 & 5.2515 & TRN & \\
\hline CHEMBL 327004 & 688620 & 3.15 & 5.1323 & TST & \\
\hline CHEMBL1581793 & 688620 & 4.45 & 5.0383 & TST & \\
\hline CHEMBL1590894 & 688620 & 4.45 & 5.0293 & TRN & \\
\hline CHEMBL3193901 & 688620 & 4.85 & 5.0466 & TRN & \\
\hline CHEMBL1437888 & 688620 & 5.0 & 4.7473 & TRN & \\
\hline CHEMBL1605643 & 688620 & 4.9 & 5.0849 & TST & \\
\hline CHEMBL1570371 & 688620 & 5.05 & 5.3164 & TRN & \\
\hline CHEMBL1530882 & 688620 & 4.85 & 4.9925 & TST & \\
\hline CHEMBL1308027 & 688620 & 5.6 & 5.7437 & TRN & \\
\hline CHEMBL3193994 & 688620 & 4.65 & 5.1929 & TRN & \\
\hline CHEMBL1586204 & 688620 & 4.45 & 5.0724 & TRN & \\
\hline CHEMBL1375000 & 688620 & 5.95 & 4.9978 & TRN & \\
\hline CHEMBL1461119 & 688620 & 4.8 & 5.2058 & TRN & \\
\hline CHEMBL1453327 & 688620 & 5.0 & 4.9434 & TST & \\
\hline CHEMBL1501764 & 688620 & 5.15 & 4.9979 & TST & \\
\hline CHEMBL1454395 & 688620 & 6.8 & 5.1851 & TRN & \\
\hline CHEMBL1508503 & 688620 & 4.65 & 4.6777 & TRN & \\
\hline CHEMBL1456192 & 688620 & 4.9 & 4.7495 & TRN & \\
\hline CHEMBL1999390 & 688620 & 5.5 & 5.659 & TRN & \\
\hline CHEMBL1359794 & 688620 & 4.7 & 4.8727 & TST & \\
\hline CHEMBL1555801 & 688620 & 4.5 & 4.86600 & 00000000005 & TRN \\
\hline CHEMBL3199467 & 688620 & 5.6 & 5.5691 & TST & \\
\hline CHEMBL1379026 & 688620 & 5.1 & 4.9503 & TRN & \\
\hline CHEMBL1968983 & 688620 & 6.3 & 6.1359 & TRN & \\
\hline CHEMBL1328233 & 688620 & 5.2 & 5.2875 & TRN & \\
\hline CHEMBL1577745 & 688620 & 5.9 & 4.8812 & TRN & \\
\hline CHEMBL1497645 & 688620 & 5.35 & 5.4488 & TST & \\
\hline CHEMBL1360730 & 688620 & 5.9 & 5.4889 & TRN & \\
\hline CHEMBL1539111 & 688620 & 4.9 & 4.9061 & TRN & \\
\hline CHEMBL587801 & 688620 & 4.8 & 5.0516 & TST & \\
\hline CHEMBL1495259 & 688620 & 4.8 & 4.7054 & TRN & \\
\hline CHEMBL1532698 & 688620 & 5.0 & 4.9252 & TRN & \\
\hline CHEMBL198759 & 688620 & 6.1 & 5.2864 & TST & \\
\hline CHEMBL1496732 & 688620 & 4.8 & 4.8324 & TST & \\
\hline CHEMBL1465362 & 688620 & 6.1 & 5.0387 & TRN & \\
\hline CHEMBL 3197815 & 688620 & 5.85 & 5.4106 & TRN & \\
\hline CHEMBL1439220 & 688620 & 4.75 & 5.0587 & TRN & \\
\hline CHEMBL1309002 & 688620 & 5.55 & 5.0879 & TST & \\
\hline CHEMBL1320263 & 688620 & 4.9 & 5.0241 & TRN & \\
\hline CHEMBL1480014 & 688620 & 5.3 & 5.1132 & TRN & \\
\hline CHEMBL601952 & 688620 & 4.45 & 4.8246 & TST & \\
\hline CHEMBL1417620 & 688620 & 5.25 & 5.0872 & TST & \\
\hline CHEMBL1354355 & 688620 & 4.8 & 4.8883 & TRN & \\
\hline CHEMBL1328078 & 688620 & 4.45 & 5.1191 & TST & \\
\hline CHEMBL1379072 & 688620 & 4.45 & 5.2663 & TRN & \\
\hline
\end{tabular}




\begin{tabular}{|c|c|c|c|c|}
\hline \multicolumn{5}{|c|}{ Supplemental Table s2.txt } \\
\hline CHEMBL1510876 & 688620 & 4.45 & 5.2349 & TST \\
\hline CHEMBL1468263 & 688620 & 4.9 & 4.7762 & TST \\
\hline CHEMBL1335768 & 688620 & 5.5 & 5.1595 & TRN \\
\hline CHEMBL1309332 & 688620 & 4.95 & 4.8673 & TRN \\
\hline CHEMBL1495231 & 688620 & 4.9 & 4.893 & TRN \\
\hline CHEMBL1577829 & 688620 & 4.9 & 4.875 & TRN \\
\hline CHEMBL505390 & 688620 & 4.45 & 5.0456 & TRN \\
\hline CHEMBL1449400 & 688620 & 4.6 & 5.178 & TST \\
\hline CHEMBL3195409 & 688620 & 5.35 & 5.6165 & TRN \\
\hline CHEMBL1442432 & 688620 & 5.0 & 4.9291 & TRN \\
\hline CHEMBL1377274 & 688620 & 4.5 & 5.0165 & TRN \\
\hline CHEMBL3145381 & 688620 & 6.05 & 5.9782 & TRN \\
\hline CHEMBL1979948 & 688620 & 4.65 & 5.2088 & TRN \\
\hline CHEMBL1386089 & 688620 & 5.9 & 5.2244 & TRN \\
\hline CHEMBL1565396 & 688620 & 4.75 & 5.0018 & TST \\
\hline CHEMBL1428528 & 688620 & 5.25 & 5.2215 & TRN \\
\hline CHEMBL1601258 & 688620 & 4.45 & 5.0017 & TST \\
\hline CHEMBL1467105 & 688620 & 4.45 & 5.0062 & TST \\
\hline CHEMBL1535919 & 688620 & 5.55 & 5.3765 & TRN \\
\hline CHEMBL1575829 & 688620 & 5.1 & 4.9312 & TRN \\
\hline CHEMBL1335623 & 688620 & 4.45 & 4.8936 & TST \\
\hline CHEMBL1570247 & 688620 & 4.75 & 4.9891 & TRN \\
\hline CHEMBL1443802 & 688620 & 4.45 & 4.4849 & TRN \\
\hline CHEMBL1474567 & 688620 & 5.45 & 5.0479 & TST \\
\hline CHEMBL1383282 & 688620 & 5.4 & 5.0531 & TST \\
\hline CHEMBL1365767 & 688620 & 5.55 & 5.2282 & TRN \\
\hline CHEMBL1415374 & 688620 & 4.6 & 4.7198 & TRN \\
\hline CHEMBL1418328 & 688620 & 4.45 & 5.1288 & TST \\
\hline CHEMBL1392807 & 688620 & 4.95 & 5.0375 & TST \\
\hline CHEMBL1560671 & 688620 & 4.95 & 4.9886 & TST \\
\hline CHEMBL1329243 & 688620 & 5.1 & 5.352 & TRN \\
\hline CHEMBL1480902 & 688620 & 4.65 & 4.9241 & TST \\
\hline CHEMBL1445733 & 688620 & 4.75 & 4.8783 & TST \\
\hline CHEMBL1305236 & 688620 & 4.45 & 5.0798 & TST \\
\hline CHEMBL1535429 & 688620 & 4.45 & 5.021 & TRN \\
\hline CHEMBL3214616 & 688620 & 5.0 & 5.4378 & TRN \\
\hline CHEMBL1383136 & 688620 & 5.0 & 5.1489 & TST \\
\hline CHEMBL3210489 & 688620 & 4.8 & 5.1286 & TST \\
\hline CHEMBL1509686 & 688620 & 5.2 & 5.3461 & TRN \\
\hline CHEMBL1571874 & 688620 & 4.65 & 4.9001 & TST \\
\hline CHEMBL1588256 & 688620 & 4.7 & 4.7852 & TRN \\
\hline CHEMBL1530387 & 688620 & 4.95 & 5.1942 & TST \\
\hline CHEMBL1324969 & 688620 & 5.05 & 5.0035 & TRN \\
\hline CHEMBL3196011 & 688620 & 5.0 & 5.1595 & TRN \\
\hline CHEMBL1556892 & 688620 & 4.85 & 5.03 & TRN \\
\hline CHEMBL1479161 & 688620 & 4.45 & 4.8951 & TST \\
\hline CHEMBL1329069 & 688620 & 4.9 & 4.9503 & TST \\
\hline CHEMBL 3195778 & 688620 & 5.3 & 5.5862 & TRN \\
\hline
\end{tabular}




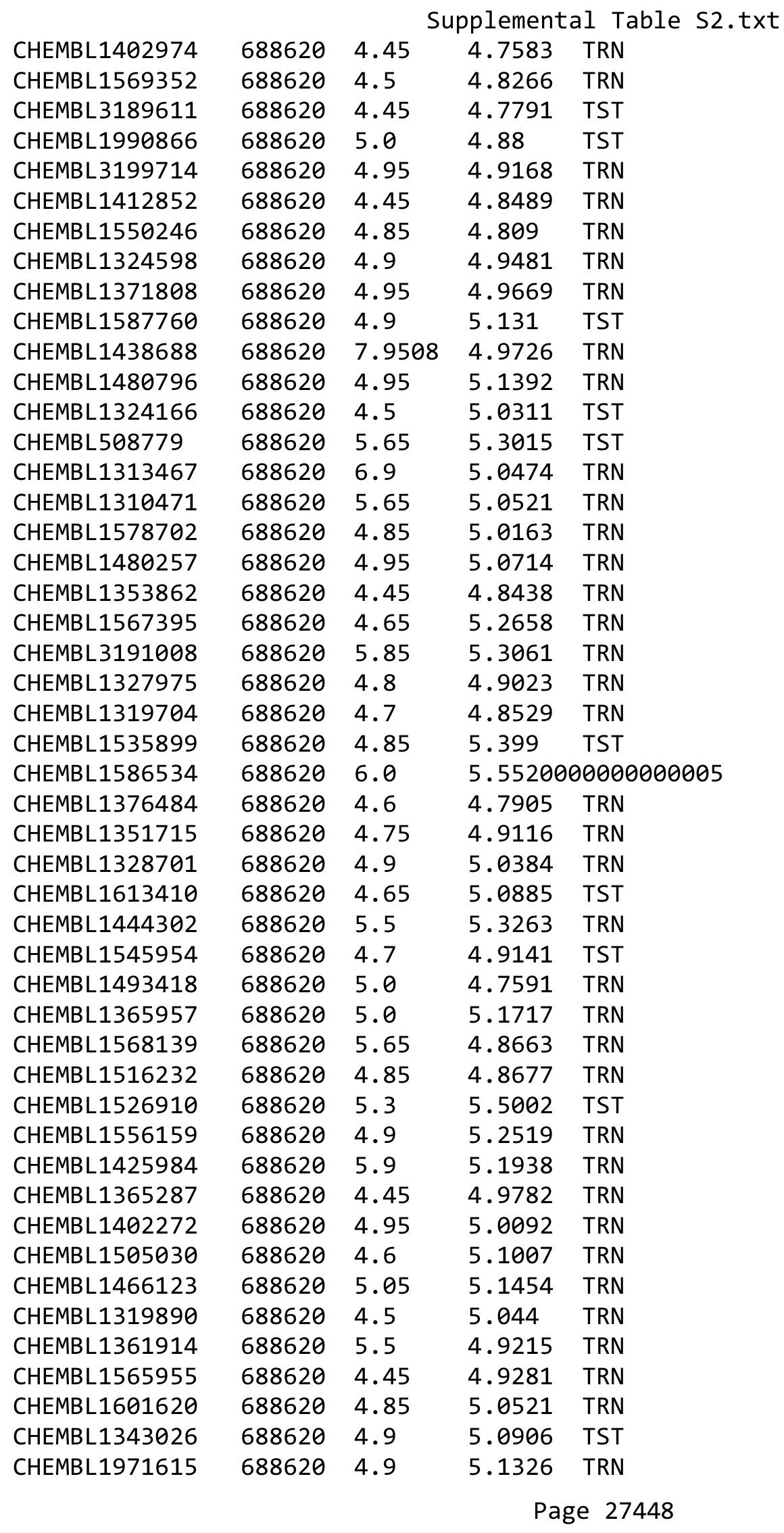




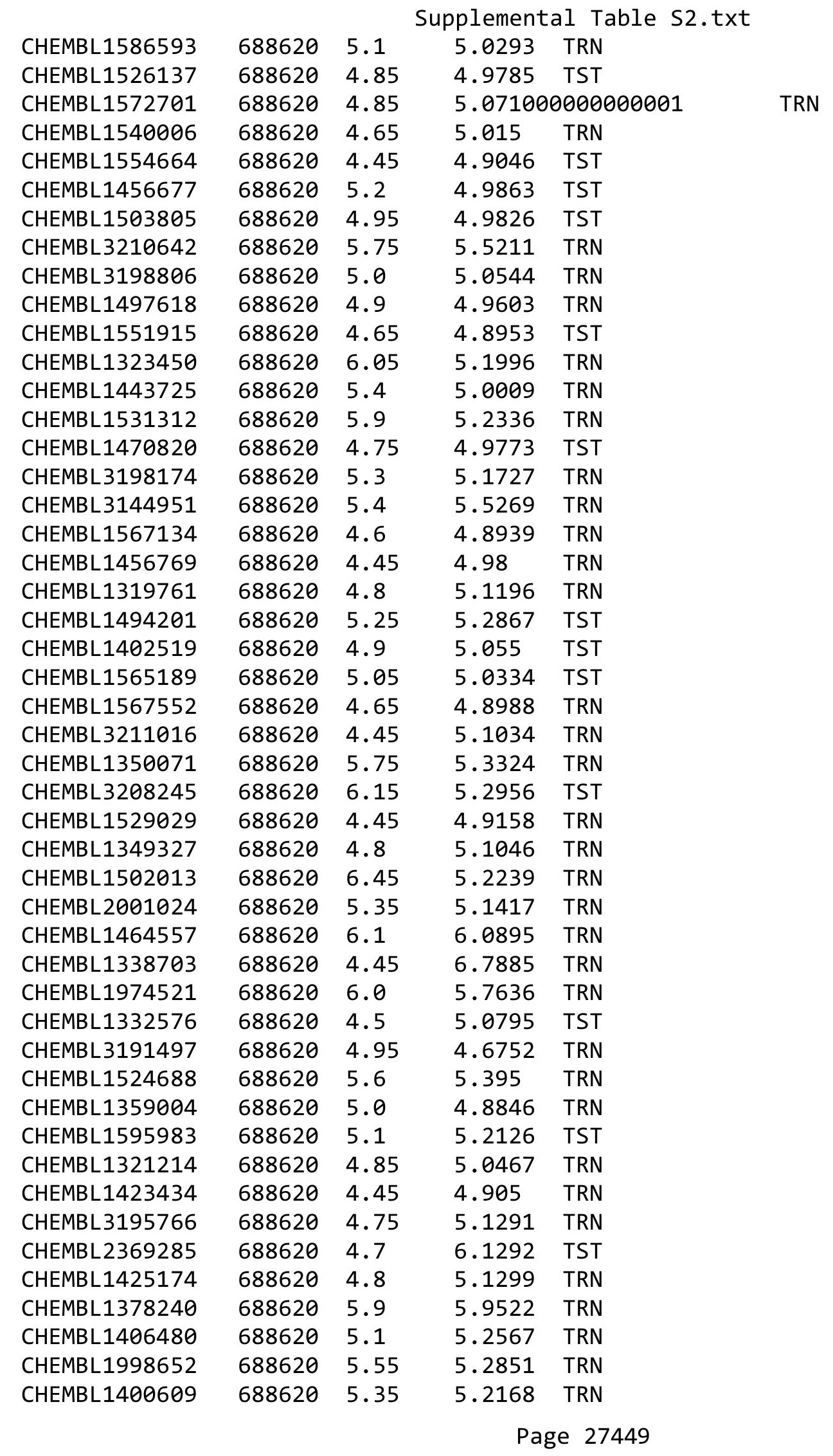




\begin{tabular}{|c|c|c|c|c|c|}
\hline \multicolumn{6}{|c|}{ Supplemental Table S2.txt } \\
\hline CHEMBL1586583 & 688620 & 4.45 & 4.9297 & TRN & \\
\hline CHEMBL1545117 & 688620 & 4.7 & 5.2198 & TRN & \\
\hline CHEMBL1535759 & 688620 & 6.0 & 5.4334 & TRN & \\
\hline CHEMBL1451974 & 688620 & 4.9 & 5.1551 & TRN & \\
\hline CHEMBL1501004 & 688620 & 4.7 & 4.6326 & TST & \\
\hline CHEMBL1370276 & 688620 & 5.1 & 5.0436 & TRN & \\
\hline CHEMBL1348117 & 688620 & 5.5 & 5.4731 & TRN & \\
\hline CHEMBL198918 & 688620 & 4.75 & 4.7649 & TRN & \\
\hline CHEMBL1319917 & 688620 & 5.0 & 5.2652 & TST & \\
\hline CHEMBL1477296 & 688620 & 4.45 & 5.0978 & TRN & \\
\hline CHEMBL1366959 & 688620 & 4.9 & 5.1154 & TRN & \\
\hline CHEMBL1353750 & 688620 & 5.45 & 5.2359 & TRN & \\
\hline CHEMBL1520944 & 688620 & 5.55 & 4.9767 & TRN & \\
\hline CHEMBL1533377 & 688620 & 4.85 & 5.16799 & 9999999999 & TRN \\
\hline CHEMBL1429187 & 688620 & 5.25 & 5.1729 & TST & \\
\hline CHEMBL1455101 & 688620 & 5.25 & 5.0299 & TRN & \\
\hline CHEMBL1613594 & 688620 & 5.0 & 5.07 & TRN & \\
\hline CHEMBL1361525 & 688620 & 4.75 & 5.0926 & TRN & \\
\hline CHEMBL1522288 & 688620 & 4.95 & 5.4932 & TRN & \\
\hline CHEMBL1302020 & 688620 & 4.95 & 5.11100 & 0000000001 & TRN \\
\hline CHEMBL1452449 & 688620 & 6.9 & 6.8692 & TRN & \\
\hline CHEMBL1321963 & 688620 & 5.2 & 5.2591 & TRN & \\
\hline CHEMBL1439864 & 688620 & 4.95 & 5.0409 & TST & \\
\hline CHEMBL1994910 & 688620 & 5.8 & 5.6044 & TRN & \\
\hline CHEMBL1379201 & 688620 & 5.4 & 5.024 & TRN & \\
\hline CHEMBL1506162 & 688620 & 5.0 & 4.8978 & TRN & \\
\hline CHEMBL1363361 & 688620 & 4.95 & 4.5007 & TST & \\
\hline CHEMBL1612112 & 688620 & 4.8 & 4.8693 & TRN & \\
\hline CHEMBL1336150 & 688620 & 4.9 & 5.044 & TRN & \\
\hline CHEMBL1608383 & 688620 & 5.4 & 5.8015 & TRN & \\
\hline CHEMBL1431752 & 688620 & 4.75 & 5.146 & TST & \\
\hline CHEMBL1574520 & 688620 & 4.9 & 4.8947 & TST & \\
\hline CHEMBL1327298 & 688620 & 4.8 & 5.7573 & TRN & \\
\hline CHEMBL1534714 & 688620 & 4.8 & 4.9891 & TRN & \\
\hline CHEMBL1586895 & 688620 & 5.1 & 5.022 & TRN & \\
\hline CHEMBL1451348 & 688620 & 4.45 & 4.9052 & TRN & \\
\hline CHEMBL1426505 & 688620 & 5.7 & 5.2567 & TRN & \\
\hline CHEMBL1501219 & 688620 & 4.9 & 5.1465 & TRN & \\
\hline CHEMBL1312242 & 688620 & 5.0 & 4.9109 & TRN & \\
\hline CHEMBL1560779 & 688620 & 5.0 & 5.0127 & TST & \\
\hline CHEMBL1423464 & 688620 & 5.05 & 5.1263 & TRN & \\
\hline CHEMBL1389418 & 688620 & 4.45 & 4.6405 & TRN & \\
\hline CHEMBL1308684 & 688620 & 5.0 & 5.0185 & TRN & \\
\hline CHEMBL1582137 & 688620 & 6.25 & 5.7561 & TRN & \\
\hline CHEMBL1422726 & 688620 & 5.9 & 5.6643 & TRN & \\
\hline CHEMBL98398 & 688620 & 5.35 & 4.9425 & TST & \\
\hline CHEMBL1976099 & 688620 & 6.45 & 5.879 & TRN & \\
\hline CHEMBL1352608 & 688620 & 4.9 & 4.9446 & TRN & \\
\hline
\end{tabular}




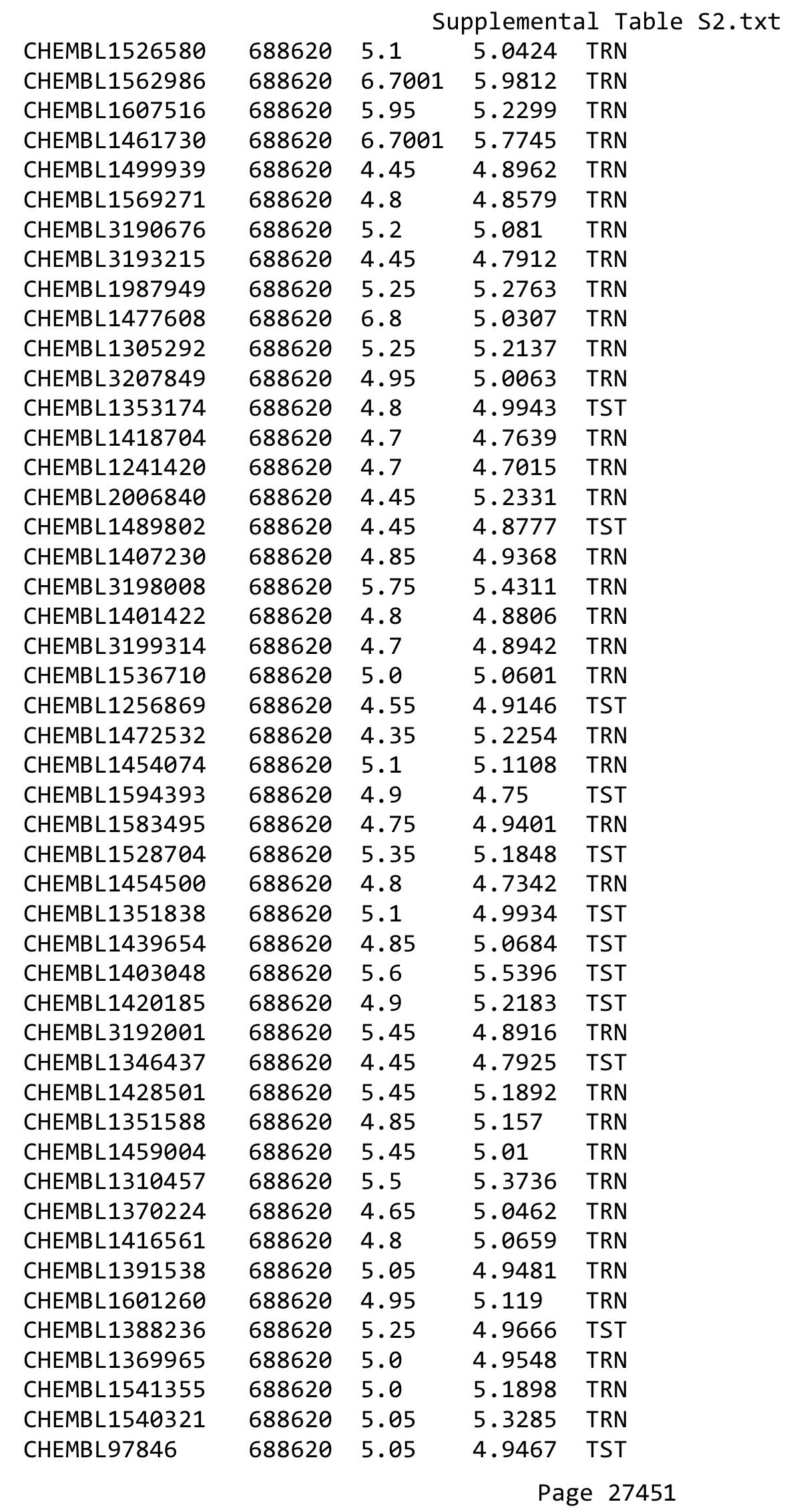




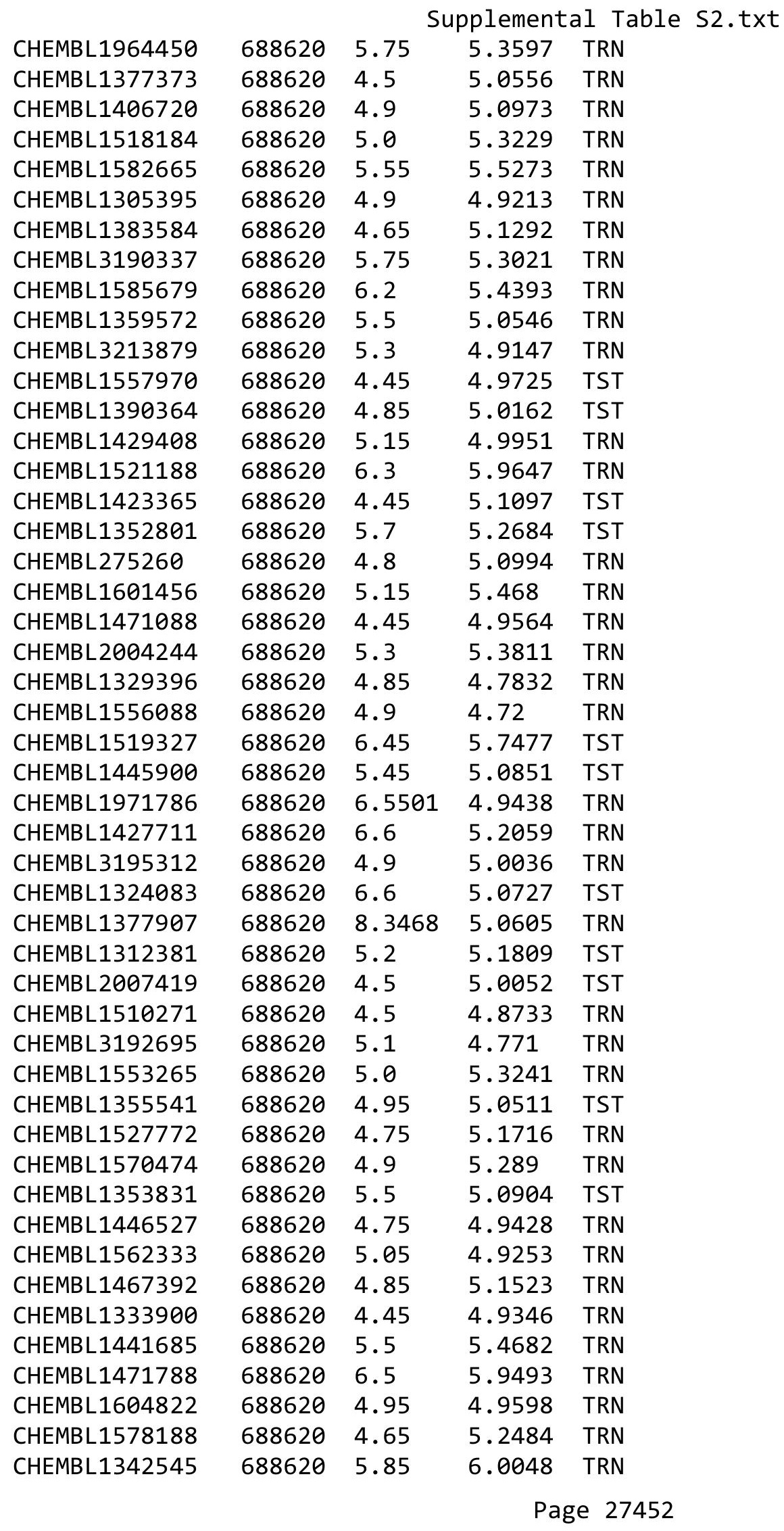




\begin{tabular}{|c|c|c|c|c|c|}
\hline \multirow[b]{2}{*}{ CHEMBL1429003 } & \multirow[b]{2}{*}{688620} & \\
\hline & & 6.0 & 5.4619 & TRN & \\
\hline CHEMBL1308537 & 688620 & 5.7 & 5.331 & TST & \\
\hline CHEMBL1588451 & 688620 & 4.45 & 4.9064 & TST & \\
\hline CHEMBL1971614 & 688620 & 5.4 & 5.1725 & TRN & \\
\hline CHEMBL1359377 & 688620 & 6.45 & 5.6414 & TRN & \\
\hline CHEMBL1528010 & 688620 & 4.9 & 5.0859 & TRN & \\
\hline CHEMBL1422650 & 688620 & 5.0 & 5.0504 & TST & \\
\hline CHEMBL1504486 & 688620 & 4.85 & 4.8093 & TST & \\
\hline CHEMBL1506432 & 688620 & 4.95 & 4.8658 & TRN & \\
\hline CHEMBL1537155 & 688620 & 6.45 & 4.9917 & TRN & \\
\hline CHEMBL1537812 & 688620 & 4.7 & \multicolumn{2}{|c|}{5.0169999999999995} & TRN \\
\hline CHEMBL1594465 & 688620 & 4.7 & 4.641 & TRN & \\
\hline CHEMBL3211527 & 688620 & 5.55 & 5.3375 & TST & \\
\hline CHEMBL1575809 & 688620 & 5.1 & 5.2412 & TST & \\
\hline CHEMBL1336714 & 688620 & 5.0 & 4.8592 & TRN & \\
\hline CHEMBL1336688 & 688620 & 5.25 & 4.9223 & TRN & \\
\hline CHEMBL1421783 & 688620 & 4.45 & 4.9071 & TRN & \\
\hline CHEMBL3194037 & 688620 & 4.45 & 4.9425 & TRN & \\
\hline CHEMBL1402439 & 688620 & 5.3 & 5.4077 & TRN & \\
\hline CHEMBL1530959 & 688620 & 4.95 & 5.118 & TST & \\
\hline CHEMBL1322216 & 688620 & 4.9 & 4.9966 & TRN & \\
\hline CHEMBL1504523 & 688620 & 5.85 & 5.1694 & TRN & \\
\hline CHEMBL72365 & 688620 & 6.0 & 4.9108 & TST & \\
\hline CHEMBL1453951 & 688620 & 4.85 & 4.8658 & TRN & \\
\hline CHEMBL3213496 & 688620 & 4.95 & 4.8135 & TRN & \\
\hline CHEMBL1301475 & 688620 & 4.95 & 5.051 & TST & \\
\hline CHEMBL 2001100 & 688620 & 6.7001 & 6.2518 & TRN & \\
\hline CHEMBL1418649 & 688620 & 4.7 & 4.9532 & TRN & \\
\hline CHEMBL1366258 & 688620 & 4.75 & 4.9006 & TRN & \\
\hline CHEMBL1330321 & 688620 & 5.5 & 4.8433 & TRN & \\
\hline CHEMBL1405919 & 688620 & 4.75 & \multicolumn{2}{|c|}{4.7989999999999995} & TST \\
\hline CHEMBL3189237 & 688620 & 5.0 & 5.1593 & TRN & \\
\hline CHEMBL1545804 & 688620 & 4.9 & 5.0567 & TRN & \\
\hline CHEMBL1412266 & 688620 & 4.5 & 5.1458 & TST & \\
\hline CHEMBL1574616 & 688620 & 4.95 & 4.864 & TRN & \\
\hline CHEMBL1557628 & 688620 & 5.85 & 5.3062 & TRN & \\
\hline CHEMBL1559106 & 688620 & 4.85 & 5.1844 & TST & \\
\hline CHEMBL1966108 & 688620 & 5.15 & 5.1164 & TRN & \\
\hline CHEMBL1465287 & 688620 & 4.85 & 5.0368 & TRN & \\
\hline CHEMBL3189564 & 688620 & 4.45 & 5.147 & TRN & \\
\hline CHEMBL1401293 & 688620 & 4.7 & 4.893 & TST & \\
\hline CHEMBL1333792 & 688620 & 4.95 & 5.0225 & TST & \\
\hline CHEMBL1605248 & 688620 & 5.05 & 5.5717 & TRN & \\
\hline CHEMBL1385214 & 688620 & 4.75 & 4.9625 & TRN & \\
\hline CHEMBL1602344 & 688620 & 4.8 & 4.6335 & TRN & \\
\hline CHEMBL1345660 & 688620 & 4.95 & 4.9666 & TRN & \\
\hline CHEMBL1353918 & 688620 & 5.1 & 4.8469 & TRN & \\
\hline \multirow[t]{2}{*}{ CHEMBL1418688 } & 688620 & 4.45 & 4.9203 & TST & \\
\hline & & \multicolumn{4}{|c|}{ Page 27453} \\
\hline
\end{tabular}




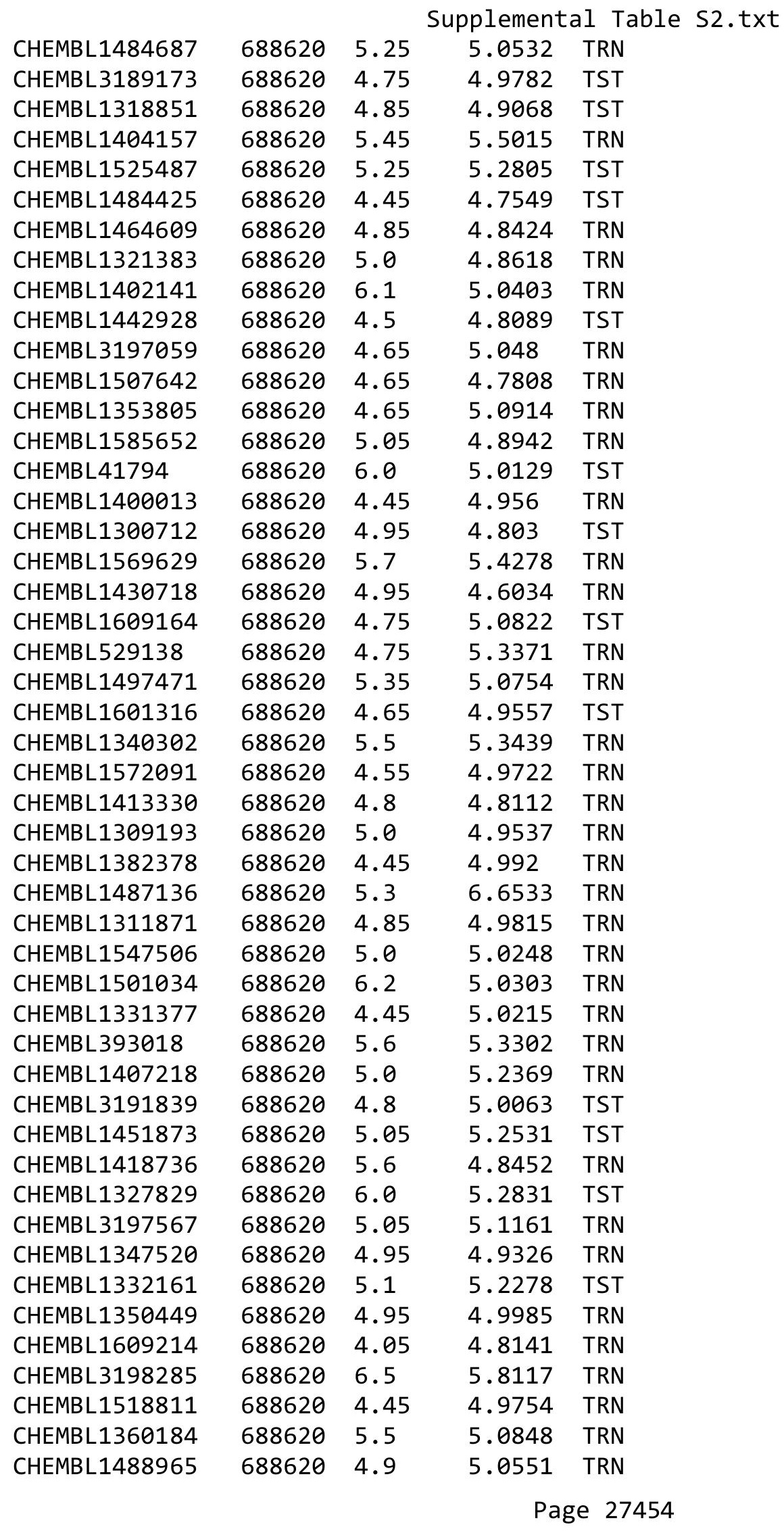




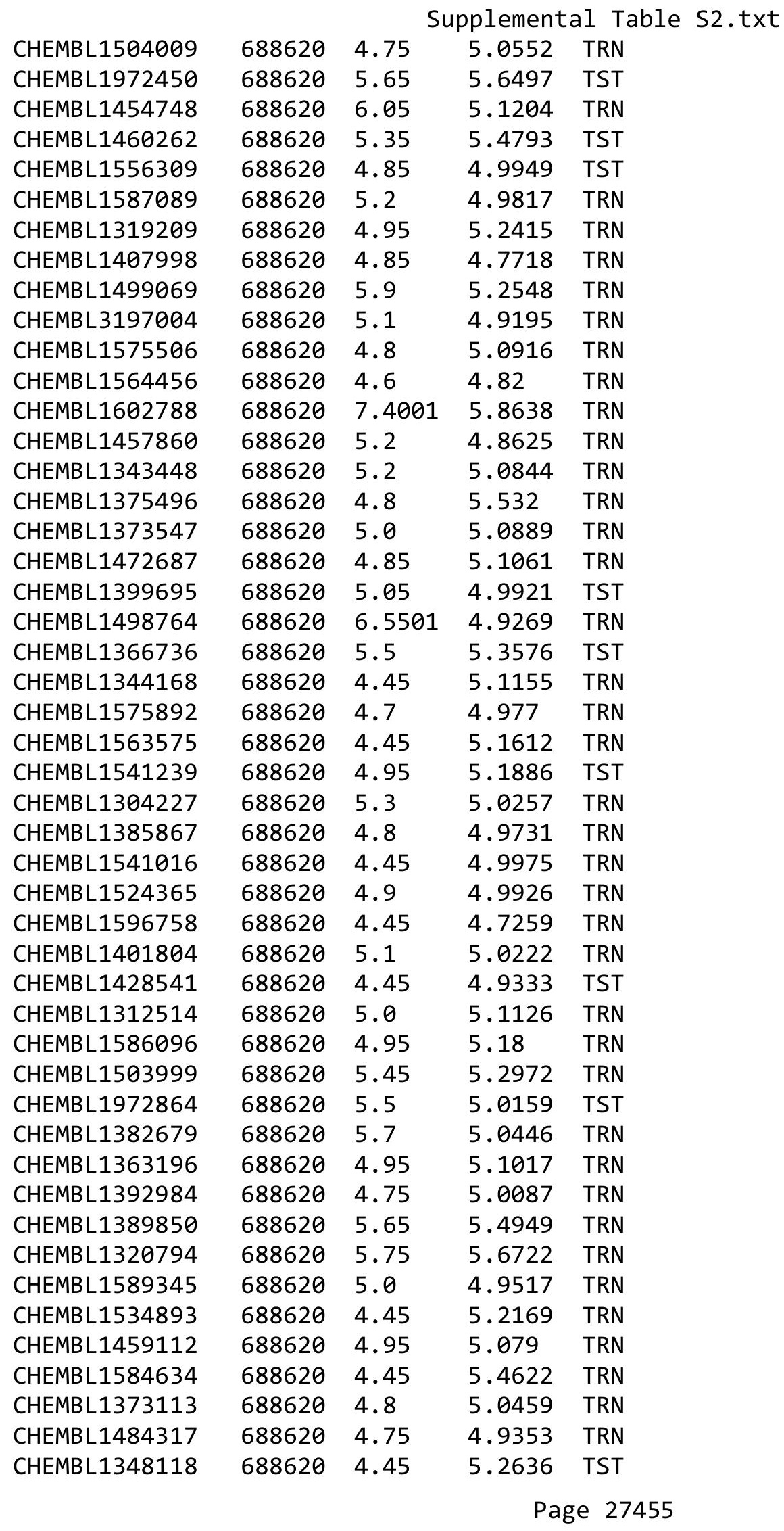




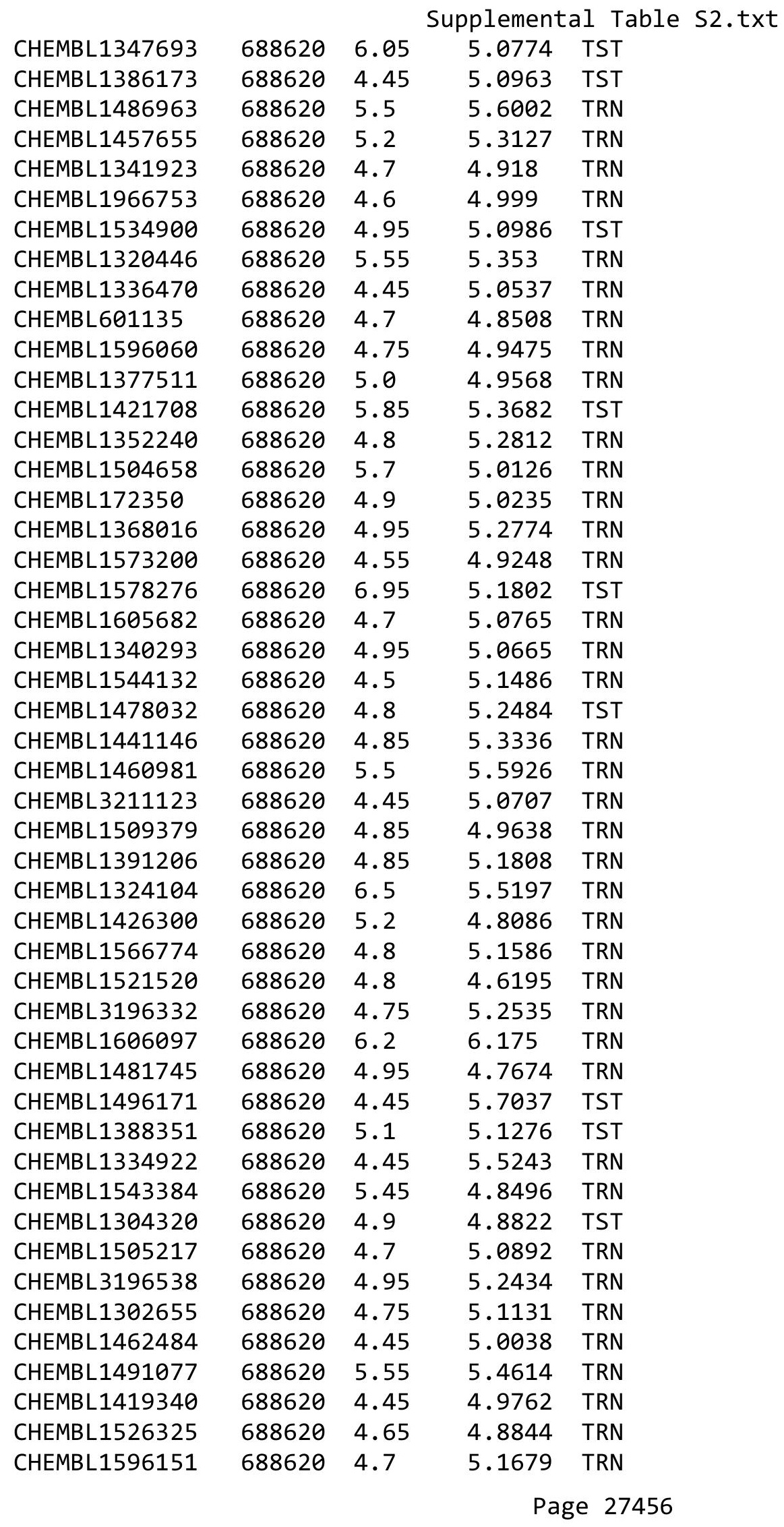




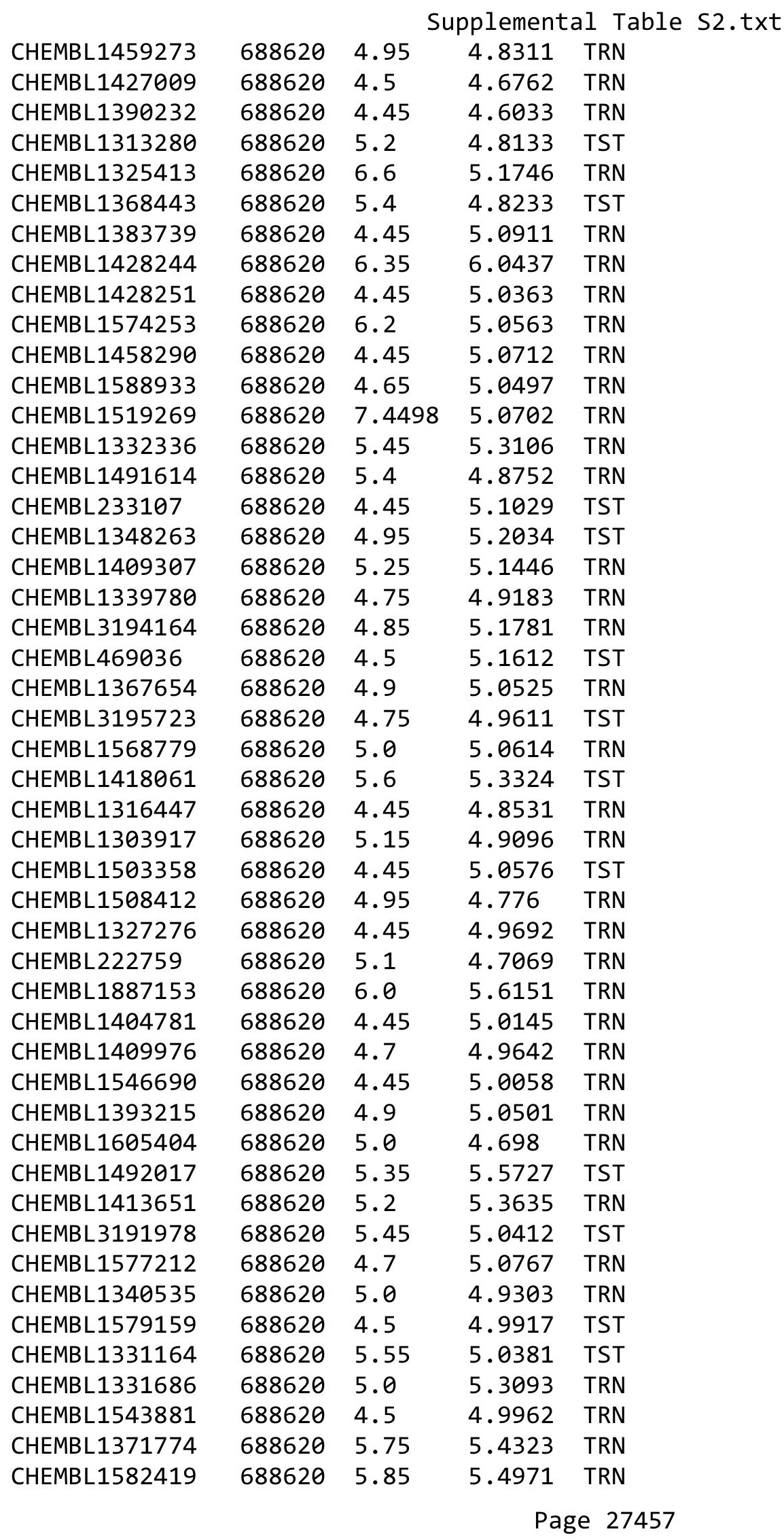




\begin{tabular}{|c|c|c|c|c|}
\hline \multicolumn{5}{|c|}{ Supplemental Table S2.txt } \\
\hline CHEMBL1572867 & 688620 & 5.55 & 4.8531 & TRN \\
\hline CHEMBL1538581 & 688620 & 4.8 & 5.1239 & TRN \\
\hline CHEMBL3208648 & 688620 & 4.55 & 5.0099 & TST \\
\hline CHEMBL1366403 & 688620 & 4.95 & 5.2046 & TRN \\
\hline CHEMBL1333224 & 688620 & 5.35 & 5.1657 & TRN \\
\hline CHEMBL1302699 & 688620 & 4.9 & 5.1324 & TRN \\
\hline CHEMBL1588463 & 688620 & 4.8 & 4.9701 & TRN \\
\hline CHEMBL1549775 & 688620 & 4.45 & 4.9721 & TRN \\
\hline CHEMBL1511784 & 688620 & 5.1 & 5.1666 & TRN \\
\hline CHEMBL1302039 & 688620 & 4.85 & 4.833 & TRN \\
\hline CHEMBL1299760 & 688620 & 5.0 & 4.9919 & TST \\
\hline CHEMBL1337912 & 688620 & 5.45 & 5.0451 & TRN \\
\hline CHEMBL3194202 & 688620 & 5.5 & 5.4741 & TRN \\
\hline CHEMBL1423466 & 688620 & 5.05 & 5.2032 & TRN \\
\hline CHEMBL406835 & 688620 & 5.2 & 5.2523 & TST \\
\hline CHEMBL1307201 & 688620 & 4.95 & 5.1984 & TRN \\
\hline CHEMBL1549357 & 688620 & 5.25 & 5.0497 & TRN \\
\hline CHEMBL1509504 & 688620 & 5.7 & 5.7839 & TRN \\
\hline CHEMBL1556394 & 688620 & 4.45 & 5.0732 & TRN \\
\hline CHEMBL1328854 & 688620 & 6.05 & 5.9157 & TST \\
\hline CHEMBL1323125 & 688620 & 5.35 & 5.0146 & TST \\
\hline CHEMBL1429784 & 688620 & 5.7 & 5.8374 & TST \\
\hline CHEMBL1404894 & 688620 & 6.1 & 5.4364 & TRN \\
\hline CHEMBL1416633 & 688620 & 4.9 & 5.251 & TRN \\
\hline CHEMBL3197716 & 688620 & 5.1 & 5.0781 & TST \\
\hline CHEMBL3192651 & 688620 & 6.5501 & 4.6477 & TRN \\
\hline CHEMBL1326523 & 688620 & 4.95 & 4.96899 & 9999999999 \\
\hline CHEMBL1599507 & 688620 & 5.75 & 4.9865 & TST \\
\hline CHEMBL1472240 & 688620 & 4.8 & 4.8781 & TRN \\
\hline CHEMBL1382059 & 688620 & 5.15 & 4.8104 & TRN \\
\hline CHEMBL1501118 & 688620 & 4.45 & 4.9498 & TST \\
\hline CHEMBL1301769 & 688620 & 4.45 & 4.8985 & TST \\
\hline CHEMBL 3191254 & 688620 & 5.15 & 5.1426 & TRN \\
\hline CHEMBL3210329 & 688620 & 4.45 & 5.1569 & TST \\
\hline CHEMBL1579977 & 688620 & 5.5 & 5.2755 & TRN \\
\hline CHEMBL1610649 & 688620 & 4.9 & 5.083 & TRN \\
\hline CHEMBL1480856 & 688620 & 4.95 & 5.0448 & TST \\
\hline CHEMBL1506827 & 688620 & 4.8 & 4.7302 & TRN \\
\hline CHEMBL1573158 & 688620 & 4.45 & 5.0107 & TST \\
\hline CHEMBL1551503 & 688620 & 4.45 & 4.7691 & TRN \\
\hline CHEMBL1422060 & 688620 & 6.15 & 5.0491 & TST \\
\hline CHEMBL1305953 & 688620 & 4.7 & 5.0515 & TRN \\
\hline CHEMBL1494548 & 688620 & 4.95 & 4.8907 & TRN \\
\hline CHEMBL1478805 & 688620 & 4.45 & 5.0249 & TRN \\
\hline CHEMBL1340964 & 688620 & 5.05 & 4.9355 & TST \\
\hline CHEMBL1325377 & 688620 & 4.45 & 5.0747 & TRN \\
\hline CHEMBL1528251 & 688620 & 4.55 & 4.9309 & TRN \\
\hline CHEMBL1468067 & 688620 & 5.85 & 5.0439 & TRN \\
\hline
\end{tabular}

TRN 


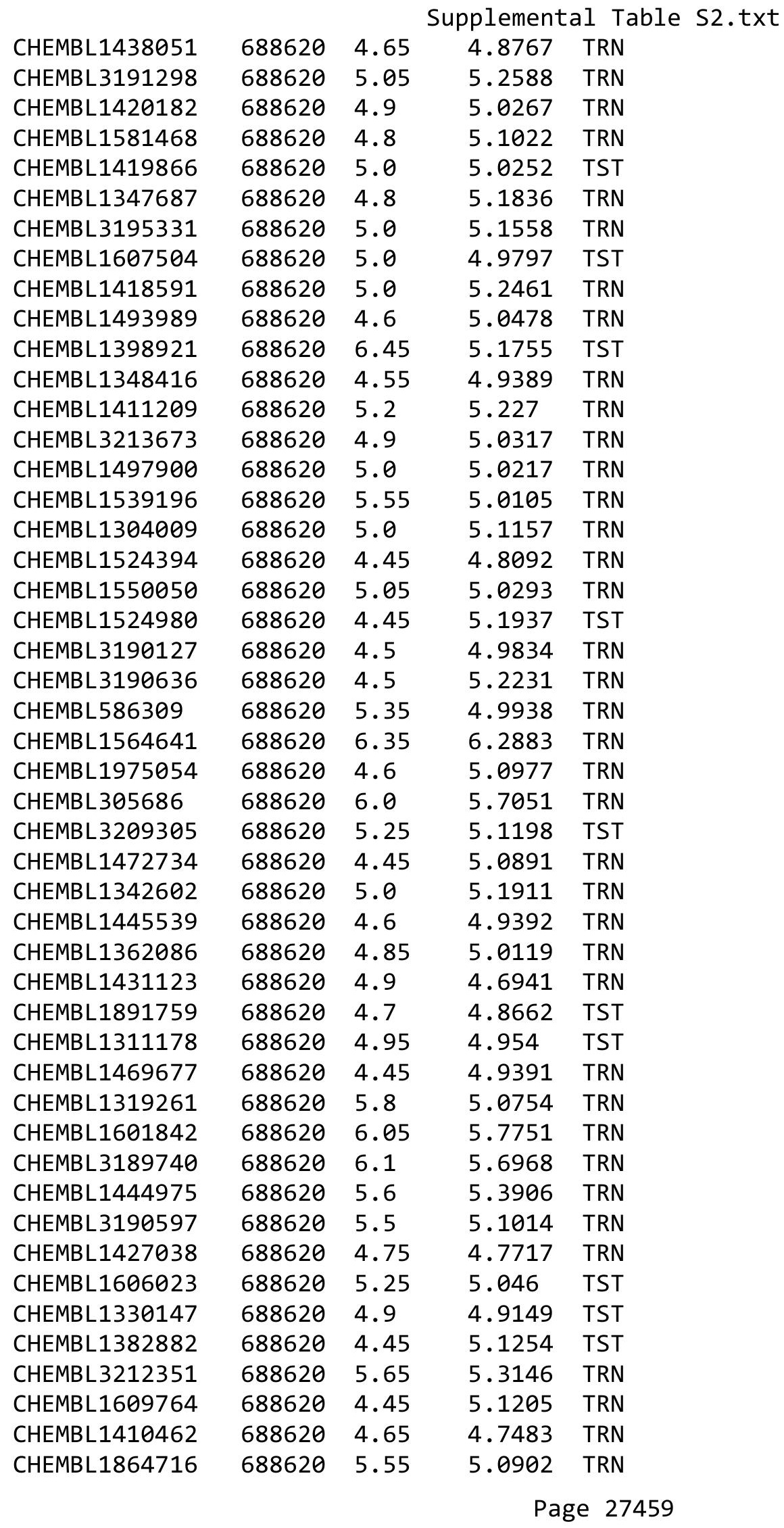




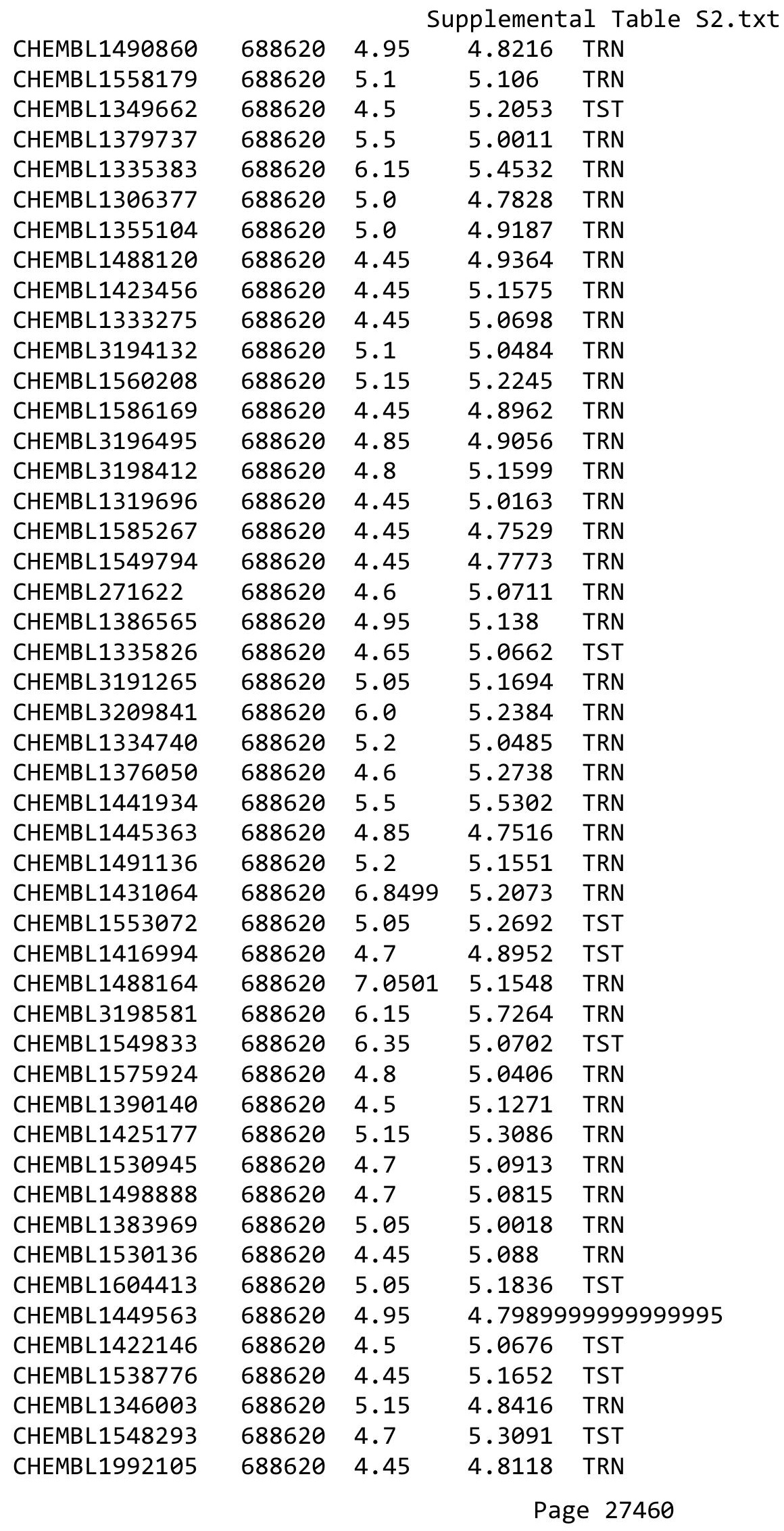

TRN 


\begin{tabular}{|c|c|c|c|c|}
\hline \multicolumn{5}{|c|}{ Supplemental Table S2.txt } \\
\hline CHEMBL1443812 & 688620 & 5.85 & 5.2794 & TRN \\
\hline CHEMBL1487850 & 688620 & 4.85 & 4.9524 & TRN \\
\hline CHEMBL1411417 & 688620 & 4.95 & 4.71 & TRN \\
\hline CHEMBL1479402 & 688620 & 4.75 & 4.9353 & TRN \\
\hline CHEMBL1390720 & 688620 & 4.95 & 5.045 & TRN \\
\hline CHEMBL1365457 & 688620 & 4.45 & 5.4467 & TST \\
\hline CHEMBL1585920 & 688620 & 4.45 & 4.8452 & TRN \\
\hline CHEMBL1485612 & 688620 & 5.2 & 5.4604 & TRN \\
\hline CHEMBL1378309 & 688620 & 5.65 & 5.064 & TRN \\
\hline CHEMBL1500908 & 688620 & 5.85 & 5.0796 & TRN \\
\hline CHEMBL1560973 & 688620 & 4.95 & 5.0827 & TRN \\
\hline CHEMBL1343351 & 688620 & 6.7001 & 5.0982 & TST \\
\hline CHEMBL1549471 & 688620 & 5.7 & 5.3107 & TRN \\
\hline CHEMBL3190482 & 688620 & 4.8 & 4.7859 & TST \\
\hline CHEMBL1390948 & 688620 & 4.8 & 4.9733 & TRN \\
\hline CHEMBL1508044 & 688620 & 4.95 & 4.9245 & TST \\
\hline CHEMBL1370612 & 688620 & 5.45 & 4.9929 & TRN \\
\hline CHEMBL1539616 & 688620 & 5.55 & 5.069 & TRN \\
\hline CHEMBL1468959 & 688620 & 6.1 & 5.0516 & TRN \\
\hline CHEMBL1388229 & 688620 & 5.05 & 5.1258 & TRN \\
\hline CHEMBL1403024 & 688620 & 5.05 & 5.1769 & TRN \\
\hline CHEMBL1991578 & 688620 & 4.75 & 5.0729 & TRN \\
\hline CHEMBL1588976 & 688620 & 4.8 & 5.0229 & TRN \\
\hline CHEMBL1499028 & 688620 & 5.25 & 4.9634 & TRN \\
\hline CHEMBL3195503 & 688620 & 4.7 & 4.8535 & TRN \\
\hline CHEMBL1333918 & 688620 & 6.6499 & 5.0054 & TRN \\
\hline CHEMBL1496421 & 688620 & 8.301 & 5.2382 & TRN \\
\hline CHEMBL1587852 & 688620 & 5.55 & 4.9999 & TRN \\
\hline CHEMBL1590402 & 688620 & 4.75 & 4.8791 & TRN \\
\hline CHEMBL3209931 & 688620 & 5.25 & 4.9886 & TRN \\
\hline CHEMBL1567499 & 688620 & 5.05 & 5.124 & TST \\
\hline CHEMBL1428042 & 688620 & 4.9 & 5.0649 & TRN \\
\hline CHEMBL 2002248 & 688620 & 5.35 & 5.1954 & TRN \\
\hline CHEMBL1381505 & 688620 & 5.55 & 4.9122 & TST \\
\hline CHEMBL1574883 & 688620 & 5.1 & 5.0993 & TST \\
\hline CHEMBL1504462 & 688620 & 4.8 & 5.0347 & TRN \\
\hline CHEMBL1441821 & 688620 & 4.85 & 5.1174 & TRN \\
\hline CHEMBL1508018 & 688620 & 4.55 & 4.9882 & TRN \\
\hline CHEMBL1586603 & 688620 & 7.3002 & 5.1158 & TRN \\
\hline CHEMBL1569274 & 688620 & 4.45 & 4.9885 & TST \\
\hline CHEMBL1461664 & 688620 & 4.75 & 4.8474 & TRN \\
\hline CHEMBL1576438 & 688620 & 4.7 & 4.919 & TRN \\
\hline CHEMBL1595191 & 688620 & 5.85 & 5.09399 & 9999999999 \\
\hline CHEMBL1320842 & 688620 & 4.6 & 4.9947 & TRN \\
\hline CHEMBL1560152 & 688620 & 5.4 & 5.1975 & TST \\
\hline CHEMBL1500106 & 688620 & 4.8 & 5.033 & TRN \\
\hline CHEMBL1569086 & 688620 & 4.45 & 4.8559 & TRN \\
\hline CHEMBL1471037 & 688620 & 4.45 & 5.2022 & TST \\
\hline
\end{tabular}




\begin{tabular}{|c|c|c|c|c|c|}
\hline & & \multicolumn{4}{|c|}{ Supplemental Table S2.txt } \\
\hline CHEMBL1568736 & 688620 & 8.3468 & 4.9952 & TST & \\
\hline CHEMBL1500805 & 688620 & 4.45 & 4.8293 & TRN & \\
\hline CHEMBL1313521 & 688620 & 5.55 & 4.8643 & TST & \\
\hline CHEMBL 3208717 & 688620 & 4.8 & 4.7431 & TRN & \\
\hline CHEMBL1369510 & 688620 & 5.15 & 4.7446 & TST & \\
\hline CHEMBL1544050 & 688620 & 4.45 & 4.9591 & TRN & \\
\hline CHEMBL1392500 & 688620 & 5.5 & 5.9026 & TRN & \\
\hline CHEMBL1304898 & 688620 & 5.3 & 5.1262 & TST & \\
\hline CHEMBL86931 & 688620 & 4.55 & 4.8622 & TST & \\
\hline CHEMBL1609982 & 688620 & 5.15 & 4.9368 & TRN & \\
\hline CHEMBL1343879 & 688620 & 6.3 & 5.8855 & TST & \\
\hline CHEMBL1421976 & 688620 & 4.65 & 5.0833 & TRN & \\
\hline CHEMBL1311943 & 688620 & 5.45 & 4.8912 & TRN & \\
\hline CHEMBL1575094 & 688620 & 5.85 & 5.5614 & TST & \\
\hline CHEMBL3195523 & 688620 & 5.15 & 5.3633 & TRN & \\
\hline CHEMBL1519408 & 688620 & 4.7 & 4.5081 & TRN & \\
\hline CHEMBL1494198 & 688620 & 5.45 & 5.44799 & 99999999995 & TRN \\
\hline CHEMBL1386044 & 688620 & 4.45 & 4.9582 & TRN & \\
\hline CHEMBL 3194340 & 688620 & 4.45 & 4.8167 & TRN & \\
\hline CHEMBL1347469 & 688620 & 4.45 & 5.2665 & TRN & \\
\hline CHEMBL1341408 & 688620 & 4.85 & 5.0496 & TRN & \\
\hline CHEMBL1409945 & 688620 & 4.95 & 4.9038 & TRN & \\
\hline CHEMBL1578503 & 688620 & 5.8 & 4.9561 & TRN & \\
\hline CHEMBL1531334 & 688620 & 4.45 & 5.2149 & TST & \\
\hline CHEMBL1607138 & 688620 & 4.45 & 5.1064 & TST & \\
\hline CHEMBL1568771 & 688620 & 4.7 & 5.1183 & TRN & \\
\hline CHEMBL1366981 & 688620 & 4.75 & 4.8106 & TRN & \\
\hline CHEMBL1311809 & 688620 & 4.45 & 5.0109 & TST & \\
\hline CHEMBL1456412 & 688620 & 5.9 & 5.251 & TST & \\
\hline CHEMBL1710 & 688620 & 4.7 & 4.8724 & TST & \\
\hline CHEMBL1491676 & 688620 & 4.45 & 4.9218 & TRN & \\
\hline CHEMBL1445029 & 688620 & 5.0 & 5.2871 & TRN & \\
\hline CHEMBL1324671 & 688620 & 4.75 & 5.0694 & TST & \\
\hline CHEMBL1461976 & 688620 & 5.45 & 5.2431 & TRN & \\
\hline CHEMBL1510817 & 688620 & 4.8 & 5.0893 & TST & \\
\hline CHEMBL3198403 & 688620 & 5.2 & 5.1395 & TST & \\
\hline CHEMBL1379946 & 688620 & 5.0 & 5.1199 & TRN & \\
\hline CHEMBL1547154 & 688620 & 6.05 & 5.0224 & TST & \\
\hline CHEMBL1414814 & 688620 & 5.25 & 5.2572 & TRN & \\
\hline CHEMBL1509297 & 688620 & 4.45 & 4.9534 & TRN & \\
\hline CHEMBL1542161 & 688620 & 5.8 & 5.0104 & TRN & \\
\hline CHEMBL1511640 & 688620 & 4.65 & 5.1931 & TRN & \\
\hline CHEMBL1524569 & 688620 & 4.95 & 5.0587 & TRN & \\
\hline CHEMBL1330201 & 688620 & 5.35 & 5.2779 & TRN & \\
\hline CHEMBL1416680 & 688620 & 5.8 & 5.0204 & TRN & \\
\hline CHEMBL1528965 & 688620 & 4.95 & 5.2793 & TRN & \\
\hline CHEMBL1328987 & 688620 & 5.95 & 5.8108 & TRN & \\
\hline CHEMBL1587402 & 688620 & 7.1002 & 5.1042 & TRN & \\
\hline
\end{tabular}




\begin{tabular}{|c|c|c|c|c|c|}
\hline \multicolumn{6}{|c|}{ Supplemental Table S2.txt } \\
\hline CHEMBL1300389 & 688620 & 5.25 & 5.0585 & TRN & \\
\hline CHEMBL3189905 & 688620 & 5.55 & 5.32600 & 00000000005 & TST \\
\hline CHEMBL1401880 & 688620 & 4.45 & 4.8409 & TRN & \\
\hline CHEMBL1445336 & 688620 & 4.5 & 4.9307 & TRN & \\
\hline CHEMBL1470628 & 688620 & 5.0 & 4.9415 & TRN & \\
\hline CHEMBL1351395 & 688620 & 4.45 & 5.0221 & TRN & \\
\hline CHEMBL1457961 & 688620 & 5.05 & 5.0827 & TRN & \\
\hline CHEMBL3194273 & 688620 & 4.45 & 4.9639 & TRN & \\
\hline CHEMBL1451721 & 688620 & 4.85 & 4.8767 & TRN & \\
\hline CHEMBL1343442 & 688620 & 5.2 & 4.9655 & TRN & \\
\hline CHEMBL1374945 & 688620 & 4.45 & 4.8934 & TRN & \\
\hline CHEMBL1463919 & 688620 & 5.0 & 5.119 & TRN & \\
\hline CHEMBL1425509 & 688620 & 4.9 & 5.6288 & TRN & \\
\hline CHEMBL1584229 & 688620 & 5.35 & 5.0197 & TRN & \\
\hline CHEMBL1465706 & 688620 & 5.25 & 5.63700 & 20000000005 & TRN \\
\hline CHEMBL1462297 & 688620 & 4.6 & 5.1155 & TRN & \\
\hline CHEMBL1425890 & 688620 & 4.45 & 5.2209 & TRN & \\
\hline CHEMBL1421593 & 688620 & 4.95 & 4.947 & TRN & \\
\hline CHEMBL3211198 & 688620 & 5.65 & 5.3063 & TRN & \\
\hline CHEMBL1420505 & 688620 & 4.95 & 4.9536 & TRN & \\
\hline CHEMBL1335202 & 688620 & 4.45 & 4.8354 & TRN & \\
\hline CHEMBL 2002420 & 688620 & 4.9 & 5.1098 & TRN & \\
\hline CHEMBL3199915 & 688620 & 5.05 & 5.3965 & TST & \\
\hline CHEMBL1343065 & 688620 & 5.45 & 5.0846 & TST & \\
\hline CHEMBL1385396 & 688620 & 5.55 & 4.9629 & TRN & \\
\hline CHEMBL1577010 & 688620 & 5.1 & 4.9086 & TRN & \\
\hline CHEMBL1408409 & 688620 & 4.45 & 5.0159 & TRN & \\
\hline CHEMBL1362856 & 688620 & 5.1 & 5.0747 & TRN & \\
\hline CHEMBL1572555 & 688620 & 4.95 & 5.4658 & TST & \\
\hline CHEMBL1603880 & 688620 & 4.45 & 4.9728 & TRN & \\
\hline CHEMBL1300981 & 688620 & 5.1 & 4.9991 & TRN & \\
\hline CHEMBL1543538 & 688620 & 5.2 & 5.0642 & TST & \\
\hline CHEMBL1378202 & 688620 & 5.25 & 5.2314 & TRN & \\
\hline CHEMBL272945 & 688620 & 5.25 & 4.8488 & TRN & \\
\hline CHEMBL1467837 & 688620 & 4.95 & 5.2445 & TRN & \\
\hline CHEMBL3194289 & 688620 & 4.45 & 4.917 & TRN & \\
\hline CHEMBL1319068 & 688620 & 5.1 & 5.0437 & TRN & \\
\hline CHEMBL1589133 & 688620 & 8.3468 & 5.1485 & TST & \\
\hline CHEMBL1510525 & 688620 & 5.6 & 5.4488 & TRN & \\
\hline CHEMBL3190551 & 688620 & 4.45 & 4.9535 & TRN & \\
\hline CHEMBL1511978 & 688620 & 4.7 & 5.044 & TST & \\
\hline CHEMBL1491278 & 688620 & 5.3 & 4.985 & TST & \\
\hline CHEMBL1507741 & 688620 & 5.45 & 5.5895 & TRN & \\
\hline CHEMBL1445321 & 688620 & 4.95 & 4.9137 & TRN & \\
\hline CHEMBL3144998 & 688620 & 5.25 & 5.2593 & TRN & \\
\hline CHEMBL1423004 & 688620 & 4.45 & 6.45 & TST & \\
\hline CHEMBL1456058 & 688620 & 4.95 & 4.9786 & TRN & \\
\hline CHEMBL1422974 & 688620 & 4.85 & 4.8474 & TST & \\
\hline
\end{tabular}




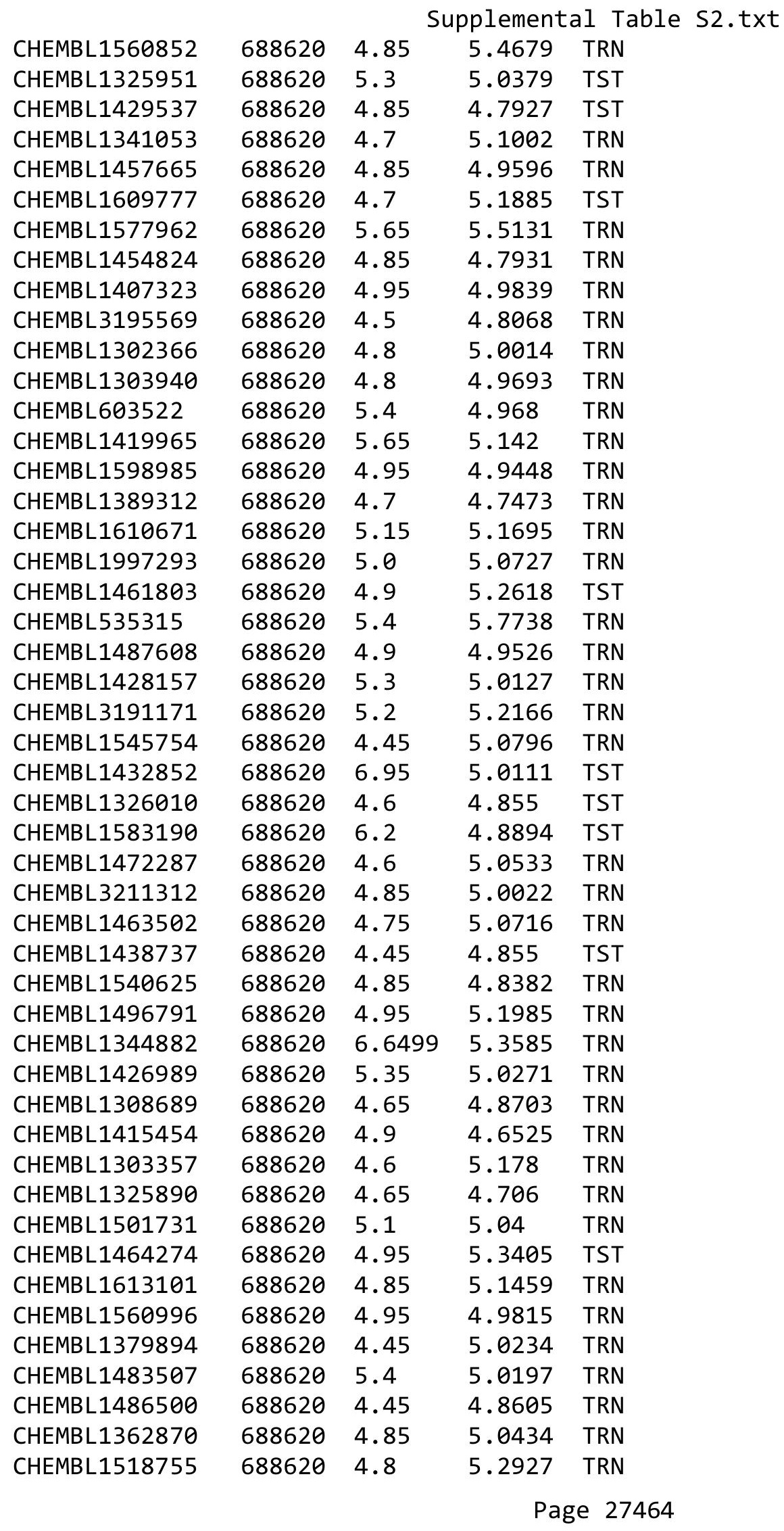




\begin{tabular}{|c|c|c|c|c|c|}
\hline \multicolumn{6}{|c|}{ Supplemental Table S2.txt } \\
\hline CHEMBL1334512 & 688620 & 4.9 & 5.0541 & TST & \\
\hline CHEMBL1585577 & 688620 & 4.45 & 4.8897 & TRN & \\
\hline CHEMBL1393687 & 688620 & 6.2 & 6.2373 & TRN & \\
\hline CHEMBL3190377 & 688620 & 4.95 & 4.8139 & TRN & \\
\hline CHEMBL1342335 & 688620 & 4.5 & 4.9334 & TRN & \\
\hline CHEMBL1558277 & 688620 & 4.95 & 4.909 & TRN & \\
\hline CHEMBL1342074 & 688620 & 4.9 & 4.7984 & TRN & \\
\hline CHEMBL 3196740 & 688620 & 4.75 & 4.8877 & TRN & \\
\hline CHEMBL1400664 & 688620 & 4.9 & 5.3566 & TRN & \\
\hline CHEMBL1588641 & 688620 & 4.95 & 5.0091 & TRN & \\
\hline CHEMBL1482237 & 688620 & 4.45 & 4.9865 & TST & \\
\hline CHEMBL1503130 & 688620 & 4.85 & 4.9473 & TST & \\
\hline CHEMBL1478676 & 688620 & 5.1 & 4.8255 & TST & \\
\hline CHEMBL1566362 & 688620 & 5.15 & 4.79899 & 99999999995 & TRN \\
\hline CHEMBL1547000 & 688620 & 6.5 & 6.3982 & TRN & \\
\hline CHEMBL1320646 & 688620 & 5.5 & 5.2818 & TRN & \\
\hline CHEMBL1308356 & 688620 & 6.0 & 4.8254 & TRN & \\
\hline CHEMBL1588293 & 688620 & 5.6 & 5.0338 & TST & \\
\hline CHEMBL1393552 & 688620 & 4.45 & 4.8222 & TRN & \\
\hline CHEMBL1548246 & 688620 & 4.6 & 5.0861 & TST & \\
\hline CHEMBL1509051 & 688620 & 7.0 & 5.56 & TRN & \\
\hline CHEMBL1392911 & 688620 & 5.0 & 5.3241 & TRN & \\
\hline CHEMBL1998184 & 688620 & 5.35 & 5.246 & TRN & \\
\hline CHEMBL1507040 & 688620 & 5.05 & 5.2197 & TRN & \\
\hline CHEMBL1468442 & 688620 & 6.15 & 5.22 & TRN & \\
\hline CHEMBL3195082 & 688620 & 4.5 & 5.2474 & TST & \\
\hline CHEMBL1981286 & 688620 & 4.9 & 5.1522 & TRN & \\
\hline CHEMBL1327690 & 688620 & 5.9 & 5.2085 & TRN & \\
\hline CHEMBL1550054 & 688620 & 4.85 & 4.9704 & TST & \\
\hline CHEMBL1458309 & 688620 & 5.15 & 5.0753 & TRN & \\
\hline CHEMBL3190627 & 688620 & 6.05 & 5.5339 & TRN & \\
\hline CHEMBL1587922 & 688620 & 5.85 & 5.1752 & TST & \\
\hline CHEMBL1318999 & 688620 & 4.9 & 5.2747 & TRN & \\
\hline CHEMBL1534078 & 688620 & 5.2 & 4.9027 & TST & \\
\hline CHEMBL1213281 & 688620 & 4.95 & 5.2569 & TRN & \\
\hline CHEMBL1531295 & 688620 & 5.25 & 5.0973 & TRN & \\
\hline CHEMBL 1415180 & 688620 & 4.6 & 4.9142 & TRN & \\
\hline CHEMBL1598377 & 688620 & 5.0 & 5.0187 & TRN & \\
\hline CHEMBL1500314 & 688620 & 4.45 & 5.0709 & TST & \\
\hline CHEMBL1507515 & 688620 & 4.9 & 5.2918 & TRN & \\
\hline CHEMBL1353124 & 688620 & 5.05 & 5.0985 & TST & \\
\hline CHEMBL1463491 & 688620 & 4.45 & 5.3002 & TST & \\
\hline CHEMBL1327132 & 688620 & 4.85 & 5.1986 & TST & \\
\hline CHEMBL1464462 & 688620 & 5.2 & 5.0706 & TRN & \\
\hline CHEMBL1323127 & 688620 & 7.0 & 6.1521 & TRN & \\
\hline CHEMBL546257 & 688620 & 4.45 & 5.5744 & TST & \\
\hline CHEMBL1550509 & 688620 & 5.15 & 4.8091 & TST & \\
\hline CHEMBL 2004657 & 688620 & 5.55 & 5.4998 & TRN & \\
\hline
\end{tabular}




\begin{tabular}{|c|c|c|c|c|}
\hline \multicolumn{5}{|c|}{ Supplemental Table } \\
\hline CHEMBL1598471 & 688620 & 5.55 & 5.0308 & TRN \\
\hline CHEMBL1301303 & 688620 & 5.1 & 5.0038 & TRN \\
\hline CHEMBL1463059 & 688620 & 4.8 & 5.1936 & TRN \\
\hline CHEMBL1432869 & 688620 & 5.2 & 5.1189 & TRN \\
\hline CHEMBL1325243 & 688620 & 4.95 & 5.2399 & TRN \\
\hline CHEMBL1348210 & 688620 & 4.45 & 5.1252 & TST \\
\hline CHEMBL1305470 & 688620 & 5.05 & 5.284 & TRN \\
\hline CHEMBL1330398 & 688620 & 4.9 & 5.2628 & TST \\
\hline CHEMBL1345724 & 688620 & 4.9 & 5.8644 & TST \\
\hline CHEMBL1571480 & 688620 & 5.15 & 5.0267 & TST \\
\hline CHEMBL1549675 & 688620 & 5.2 & 4.8964 & TST \\
\hline CHEMBL1988918 & 688620 & 4.45 & 4.902 & TRN \\
\hline CHEMBL1479301 & 688620 & 4.95 & 4.9843 & TRN \\
\hline CHEMBL1557507 & 688620 & 4.95 & 5.0438 & TRN \\
\hline CHEMBL1572591 & 688620 & 4.95 & 4.8279 & TRN \\
\hline CHEMBL1327412 & 688620 & 5.45 & 5.3635 & TRN \\
\hline CHEMBL1607458 & 688620 & 5.7 & 5.2542 & TRN \\
\hline CHEMBL1611675 & 688620 & 4.95 & 5.6001 & TRN \\
\hline CHEMBL1299525 & 688620 & 5.25 & 4.7845 & TRN \\
\hline CHEMBL1443182 & 688620 & 4.45 & 5.0539 & TRN \\
\hline CHEMBL1302442 & 688620 & 5.15 & 4.9246 & TRN \\
\hline CHEMBL1309246 & 688620 & 5.6 & 5.0946 & TRN \\
\hline CHEMBL1986380 & 688620 & 4.65 & 4.8655 & TRN \\
\hline CHEMBL1596221 & 688620 & 5.0 & 4.8641 & TRN \\
\hline CHEMBL1601376 & 688620 & 5.5 & 5.2419 & TRN \\
\hline CHEMBL1388475 & 688620 & 4.45 & 5.0891 & TST \\
\hline CHEMBL1382317 & 688620 & 5.2 & 5.1181 & TRN \\
\hline CHEMBL1460085 & 688620 & 6.15 & 5.8905 & TRN \\
\hline CHEMBL1479139 & 688620 & 5.0 & 4.893 & TST \\
\hline CHEMBL1377465 & 688620 & 4.55 & 5.1928 & TRN \\
\hline CHEMBL1443414 & 688620 & 4.65 & 5.2109 & TRN \\
\hline CHEMBL1440952 & 688620 & 6.0 & 5.8729 & TRN \\
\hline CHEMBL 3210788 & 688620 & 4.65 & 5.0346 & TRN \\
\hline CHEMBL1586039 & 688620 & 7.3002 & 5.2692 & TRN \\
\hline CHEMBL1586245 & 688620 & 4.7 & 4.7609 & TRN \\
\hline CHEMBL1501751 & 688620 & 6.1 & 5.3021 & TRN \\
\hline CHEMBL1602404 & 688620 & 4.45 & 5.2736 & TRN \\
\hline CHEMBL1351058 & 688620 & 4.45 & 4.8707 & TRN \\
\hline CHEMBL3196743 & 688620 & 5.7 & 5.3437 & TST \\
\hline CHEMBL1400201 & 688620 & 5.4 & 4.8199 & TRN \\
\hline CHEMBL1558402 & 688620 & 4.6 & 4.6138 & TRN \\
\hline CHEMBL1365700 & 688620 & 4.95 & 5.2294 & TST \\
\hline CHEMBL1971515 & 688620 & 5.4 & 5.5103 & TRN \\
\hline CHEMBL3210554 & 688620 & 5.0 & 5.5058 & TST \\
\hline CHEMBL3207668 & 688620 & 4.95 & 5.0991 & TST \\
\hline CHEMBL3197263 & 688620 & 5.15 & 4.9299 & TRN \\
\hline CHEMBL1522444 & 688620 & 5.0 & 4.9421 & TRN \\
\hline CHEMBL1564832 & 688620 & 4.45 & 5.0258 & TST \\
\hline
\end{tabular}




\begin{tabular}{|c|c|c|c|c|}
\hline \multicolumn{5}{|c|}{ Supplemental Table S2.txt } \\
\hline CHEMBL1321315 & 688620 & 5.0 & 5.0719 & TST \\
\hline CHEMBL3198703 & 688620 & 4.45 & 5.7265 & TRN \\
\hline CHEMBL1416576 & 688620 & 4.95 & 5.1421 & TRN \\
\hline CHEMBL1374282 & 688620 & 4.95 & 4.8377 & TRN \\
\hline CHEMBL 1353190 & 688620 & 4.95 & 5.091 & TRN \\
\hline CHEMBL1380716 & 688620 & 5.2 & 5.1198 & TRN \\
\hline CHEMBL1560300 & 688620 & 7.1002 & 4.8625 & TRN \\
\hline CHEMBL1507820 & 688620 & 4.75 & 5.3412 & TRN \\
\hline CHEMBL1414263 & 688620 & 4.8 & 4.8208 & TRN \\
\hline CHEMBL1408457 & 688620 & 5.05 & 5.3228 & TRN \\
\hline CHEMBL1366891 & 688620 & 6.1 & 5.0395 & TRN \\
\hline CHEMBL1447665 & 688620 & 5.45 & 5.4683 & TRN \\
\hline CHEMBL1544067 & 688620 & 5.9 & 4.9608 & TST \\
\hline CHEMBL1600637 & 688620 & 5.05 & 5.0552 & TRN \\
\hline CHEMBL1528303 & 688620 & 4.85 & 5.086 & TRN \\
\hline CHEMBL1576046 & 688620 & 4.8 & 4.9497 & TST \\
\hline CHEMBL1578596 & 688620 & 5.35 & 5.1994 & TRN \\
\hline CHEMBL1414672 & 688620 & 4.9 & 4.7342 & TRN \\
\hline CHEMBL1302407 & 688620 & 5.45 & 4.8665 & TRN \\
\hline CHEMBL1406305 & 688620 & 5.6 & 5.3415 & TRN \\
\hline CHEMBL1574212 & 688620 & 5.1 & 5.1 & TST \\
\hline CHEMBL1510170 & 688620 & 5.1 & 5.0283 & TRN \\
\hline CHEMBL1392814 & 688620 & 5.65 & 5.1105 & TST \\
\hline CHEMBL1540628 & 688620 & 5.05 & 4.9347 & TRN \\
\hline CHEMBL1544159 & 688620 & 5.05 & 5.1363 & TRN \\
\hline CHEMBL3207869 & 688620 & 5.2 & 5.0469 & TRN \\
\hline CHEMBL1589282 & 688620 & 4.45 & 4.9152 & TRN \\
\hline CHEMBL1453408 & 688620 & 4.85 & 4.6474 & TRN \\
\hline CHEMBL1565770 & 688620 & 4.8 & 4.9094 & TRN \\
\hline CHEMBL1504509 & 688620 & 5.55 & 4.9766 & TRN \\
\hline CHEMBL3190980 & 688620 & 5.0 & 5.2308 & TST \\
\hline CHEMBL1555802 & 688620 & 5.2 & 4.9498 & TST \\
\hline CHEMBL1983142 & 688620 & 5.6 & 5.268 & TRN \\
\hline CHEMBL1570869 & 688620 & 5.0 & 5.0771 & TST \\
\hline CHEMBL1602361 & 688620 & 5.0 & 4.7705 & TRN \\
\hline CHEMBL1533107 & 688620 & 5.4 & 5.2217 & TRN \\
\hline CHEMBL3210192 & 688620 & 4.95 & 4.8394 & TST \\
\hline CHEMBL1521533 & 688620 & 4.8 & 5.1205 & TRN \\
\hline CHEMBL1585209 & 688620 & 5.05 & 5.0596 & TRN \\
\hline CHEMBL1605224 & 688620 & 4.95 & 4.8101 & TRN \\
\hline CHEMBL1304506 & 688620 & 4.85 & 4.723 & TRN \\
\hline CHEMBL1572312 & 688620 & 4.45 & 4.8998 & TRN \\
\hline CHEMBL1410868 & 688620 & 4.45 & 4.9182 & TRN \\
\hline CHEMBL3208802 & 688620 & 4.9 & 4.8939 & TRN \\
\hline CHEMBL1306893 & 688620 & 5.15 & 4.8627 & TRN \\
\hline CHEMBL1468129 & 688620 & 4.55 & 5.0986 & TRN \\
\hline CHEMBL1445315 & 688620 & 5.1 & 5.1094 & TST \\
\hline CHEMBL1547641 & 688620 & 4.7 & 4.7445 & TST \\
\hline
\end{tabular}




\begin{tabular}{|c|c|c|c|c|}
\hline \multicolumn{5}{|c|}{ Supplemental Table S2.txt } \\
\hline CHEMBL1537378 & 688620 & 5.2 & 5.1324 & TST \\
\hline CHEMBL3208732 & 688620 & 5.95 & 5.2823 & TRN \\
\hline CHEMBL1432342 & 688620 & 4.45 & 5.08 & TRN \\
\hline CHEMBL1532795 & 688620 & 5.55 & 5.1337 & TRN \\
\hline CHEMBL1442312 & 688620 & 5.05 & 4.8464 & TRN \\
\hline CHEMBL1423956 & 688620 & 4.8 & 4.7836 & TRN \\
\hline CHEMBL1389941 & 688620 & 5.3 & 5.3706 & TRN \\
\hline CHEMBL1491847 & 688620 & 4.7 & 4.7647 & TRN \\
\hline CHEMBL1361890 & 688620 & 5.1 & 4.9588 & TRN \\
\hline CHEMBL1321604 & 688620 & 4.95 & 4.9695 & TRN \\
\hline CHEMBL1520301 & 688620 & 5.2 & 4.8509 & TRN \\
\hline CHEMBL1440993 & 688620 & 6.6499 & 5.1511 & TRN \\
\hline CHEMBL3211494 & 688620 & 5.1 & 4.9871 & TRN \\
\hline CHEMBL1377015 & 688620 & 5.25 & 5.4097 & TST \\
\hline CHEMBL3194096 & 688620 & 5.75 & 5.1654 & TST \\
\hline CHEMBL1563730 & 688620 & 5.2 & 4.9937 & TRN \\
\hline CHEMBL1329774 & 688620 & 4.55 & 5.1972 & TRN \\
\hline CHEMBL1459499 & 688620 & 4.95 & 5.0023 & TRN \\
\hline CHEMBL1444394 & 688620 & 5.85 & 4.8344 & TRN \\
\hline CHEMBL593120 & 688620 & 5.35 & 4.7977 & TRN \\
\hline CHEMBL1451615 & 688620 & 4.85 & 5.0043 & TRN \\
\hline CHEMBL1469708 & 688620 & 4.7 & 5.022 & TRN \\
\hline CHEMBL1378422 & 688620 & 6.0 & 4.9802 & TST \\
\hline CHEMBL1502265 & 688620 & 5.45 & 4.9897 & TRN \\
\hline CHEMBL1549893 & 688620 & 4.55 & 5.6255 & TST \\
\hline CHEMBL1457718 & 688620 & 5.3 & 5.0782 & TRN \\
\hline CHEMBL3209332 & 688620 & 5.15 & 5.2502 & TST \\
\hline CHEMBL1310052 & 688620 & 4.85 & 4.7978 & TRN \\
\hline CHEMBL3195536 & 688620 & 5.4 & 5.5421 & TRN \\
\hline CHEMBL1307766 & 688620 & 5.05 & 5.195 & TRN \\
\hline CHEMBL1327358 & 688620 & 4.95 & 4.9669 & TRN \\
\hline CHEMBL1541346 & 688620 & 5.2 & 4.7995 & TRN \\
\hline CHEMBL1420540 & 688620 & 4.75 & 4.9316 & TRN \\
\hline CHEMBL1572095 & 688620 & 4.6 & 4.6654 & TRN \\
\hline CHEMBL1607007 & 688620 & 4.8 & 4.8663 & TRN \\
\hline CHEMBL1465554 & 688620 & 5.4 & 5.0693 & TRN \\
\hline CHEMBL1316787 & 688620 & 4.65 & 4.9125 & TRN \\
\hline CHEMBL3213284 & 688620 & 5.0 & 5.1007 & TST \\
\hline CHEMBL1384345 & 688620 & 5.2 & 5.1673 & TRN \\
\hline CHEMBL1501483 & 688620 & 6.9 & 6.2871 & TRN \\
\hline CHEMBL1459971 & 688620 & 4.45 & 5.0359 & TRN \\
\hline CHEMBL1449961 & 688620 & 4.95 & 4.9556 & TRN \\
\hline CHEMBL1422148 & 688620 & 4.85 & 5.0111 & TST \\
\hline CHEMBL1586938 & 688620 & 5.55 & 5.3191 & TRN \\
\hline CHEMBL1579367 & 688620 & 4.9 & 4.6677 & TST \\
\hline CHEMBL1344875 & 688620 & 4.45 & 4.8976 & TRN \\
\hline CHEMBL1348209 & 688620 & 4.45 & 5.0771 & TRN \\
\hline CHEMBL1491185 & 688620 & 4.95 & 5.3142 & TRN \\
\hline
\end{tabular}




\begin{tabular}{|c|c|c|c|c|c|}
\hline & & \multicolumn{4}{|c|}{ Supplemental Table S2.txt } \\
\hline CHEMBL1367639 & 688620 & 5.1 & 4.9852 & TRN & \\
\hline CHEMBL1325684 & 688620 & 4.85 & 5.0864 & TRN & \\
\hline CHEMBL1431254 & 688620 & 5.0 & 4.7461 & TRN & \\
\hline CHEMBL1444507 & 688620 & 5.15 & 5.0153 & TRN & \\
\hline CHEMBL1427491 & 688620 & 5.25 & 4.9069 & TST & \\
\hline CHEMBL1385646 & 688620 & 4.7 & 5.0753 & TRN & \\
\hline CHEMBL1418464 & 688620 & 5.15 & 5.1536 & TST & \\
\hline CHEMBL1423314 & 688620 & 4.75 & 5.0598 & TRN & \\
\hline CHEMBL1496730 & 688620 & 6.35 & 5.0139 & TRN & \\
\hline CHEMBL1464525 & 688620 & 4.8 & 4.8907 & TST & \\
\hline CHEMBL1341087 & 688620 & 4.45 & 4.9527 & TST & \\
\hline CHEMBL1589770 & 688620 & 4.6 & 4.8448 & TRN & \\
\hline CHEMBL1365622 & 688620 & 4.95 & 4.8312 & TRN & \\
\hline CHEMBL1510714 & 688620 & 5.0 & 5.0583 & TST & \\
\hline CHEMBL1467999 & 688620 & 4.45 & 5.081 & TRN & \\
\hline CHEMBL1428017 & 688620 & 4.9 & 5.3275 & TST & \\
\hline CHEMBL1978651 & 688620 & 6.2 & 5.7002 & TST & \\
\hline CHEMBL1361988 & 688620 & 4.5 & 4.7341 & TRN & \\
\hline CHEMBL1334691 & 688620 & 4.9 & 5.2754 & TRN & \\
\hline CHEMBL1544103 & 688620 & 4.9 & 5.1813 & TRN & \\
\hline CHEMBL1400285 & 688620 & 4.45 & 4.9322 & TST & \\
\hline CHEMBL1391244 & 688620 & 5.1 & 5.2984 & TRN & \\
\hline CHEMBL1332061 & 688620 & 5.0 & 4.873 & TRN & \\
\hline CHEMBL1337227 & 688620 & 4.45 & 4.9461 & TRN & \\
\hline CHEMBL 3214147 & 688620 & 5.2 & 5.1466 & TST & \\
\hline CHEMBL1390350 & 688620 & 5.5 & 5.6731 & TRN & \\
\hline CHEMBL1997644 & 688620 & 5.75 & 5.6143 & TRN & \\
\hline CHEMBL1430861 & 688620 & 4.9 & 4.8929 & TRN & \\
\hline CHEMBL1320607 & 688620 & 4.85 & 5.0149 & TRN & \\
\hline CHEMBL1353250 & 688620 & 5.35 & 5.1406 & TRN & \\
\hline CHEMBL1320770 & 688620 & 5.5 & 4.9586 & TRN & \\
\hline CHEMBL1398777 & 688620 & 8.2518 & 5.1842 & TRN & \\
\hline CHEMBL1468776 & 688620 & 5.15 & 5.2287 & TRN & \\
\hline CHEMBL1392832 & 688620 & 4.95 & 5.1153 & TRN & \\
\hline CHEMBL1342016 & 688620 & 5.4 & 4.8799 & TRN & \\
\hline CHEMBL1980134 & 688620 & 4.8 & 4.9549 & TRN & \\
\hline CHEMBL1353155 & 688620 & 6.0 & 5.8531 & TRN & \\
\hline CHEMBL1549568 & 688620 & 5.85 & 5.1588 & TST & \\
\hline CHEMBL1981797 & 688620 & 5.55 & 5.5169 & TRN & \\
\hline CHEMBL1564256 & 688620 & 6.35 & 5.012 & TRN & \\
\hline CHEMBL1471011 & 688620 & 4.95 & 4.90600 & 0000000001 & TRN \\
\hline CHEMBL3199419 & 688620 & 5.5 & 5.3326 & TRN & \\
\hline CHEMBL1527216 & 688620 & 5.8 & 5.852 & TRN & \\
\hline CHEMBL1433972 & 688620 & 4.9 & 4.885 & TRN & \\
\hline CHEMBL1604680 & 688620 & 4.9 & 4.9139 & TRN & \\
\hline CHEMBL1603096 & 688620 & 4.95 & 4.8988 & TRN & \\
\hline CHEMBL1520552 & 688620 & 4.45 & 4.7149 & TRN & \\
\hline CHEMBL1588551 & 688620 & 5.25 & 5.0585 & TST & \\
\hline
\end{tabular}




\begin{tabular}{|c|c|c|c|c|}
\hline \multicolumn{5}{|c|}{ Supplemental Table s2.txt } \\
\hline CHEMBL1522007 & 688620 & 5.75 & 5.3123 & TRN \\
\hline CHEMBL 3191874 & 688620 & 6.0 & 4.7841 & TRN \\
\hline CHEMBL1538704 & 688620 & 4.9 & 5.0359 & TRN \\
\hline CHEMBL 3208801 & 688620 & 4.75 & 5.0157 & TRN \\
\hline CHEMBL3189229 & 688620 & 4.45 & 5.1862 & TRN \\
\hline CHEMBL1312648 & 688620 & 5.25 & 5.109 & TST \\
\hline CHEMBL1340573 & 688620 & 4.75 & 5.0331 & TST \\
\hline CHEMBL1566023 & 688620 & 5.65 & 5.5045 & TRN \\
\hline CHEMBL1460276 & 688620 & 4.8 & 4.9326 & TST \\
\hline CHEMBL1427959 & 688620 & 5.0 & 5.1784 & TRN \\
\hline CHEMBL1314094 & 688620 & 4.75 & 5.2317 & TRN \\
\hline CHEMBL3195017 & 688620 & 6.45 & 5.5487 & TRN \\
\hline CHEMBL1344825 & 688620 & 4.95 & 5.05 & TST \\
\hline CHEMBL3199673 & 688620 & 7.5003 & 6.4914 & TRN \\
\hline CHEMBL1339514 & 688620 & 4.9 & 4.8209 & TRN \\
\hline CHEMBL1567379 & 688620 & 4.45 & 4.8756 & TRN \\
\hline CHEMBL1500124 & 688620 & 4.75 & 5.1872 & TRN \\
\hline CHEMBL1462710 & 688620 & 4.85 & 4.9656 & TRN \\
\hline CHEMBL1582997 & 688620 & 5.55 & 5.32 & TST \\
\hline CHEMBL1353775 & 688620 & 5.3 & 5.1959 & TRN \\
\hline CHEMBL1516958 & 688620 & 4.8 & 5.0724 & TRN \\
\hline CHEMBL1489046 & 688620 & 5.05 & 5.0819 & TRN \\
\hline CHEMBL1467867 & 688620 & 6.05 & 5.6702 & TRN \\
\hline CHEMBL1444723 & 688620 & 5.4 & 4.7672 & TRN \\
\hline CHEMBL1454154 & 688620 & 4.8 & 5.2754 & TRN \\
\hline CHEMBL1531609 & 688620 & 4.8 & 5.1584 & TST \\
\hline CHEMBL3209273 & 688620 & 5.65 & 4.9217 & TRN \\
\hline CHEMBL1490625 & 688620 & 7.15 & 5.1035 & TRN \\
\hline CHEMBL1531757 & 688620 & 5.2 & 5.2545 & TRN \\
\hline CHEMBL1448912 & 688620 & 4.45 & 5.2661 & TRN \\
\hline CHEMBL1566193 & 688620 & 5.1 & 5.0957 & TST \\
\hline CHEMBL1550445 & 688620 & 4.45 & 4.7502 & TRN \\
\hline CHEMBL1514010 & 688620 & 4.45 & 5.3261 & TST \\
\hline CHEMBL1348126 & 688620 & 4.45 & 4.7798 & TRN \\
\hline CHEMBL1360741 & 688620 & 4.95 & 4.8858 & TRN \\
\hline CHEMBL496727 & 688620 & 4.85 & 5.074 & TRN \\
\hline CHEMBL1536012 & 688620 & 5.0 & 5.2018 & TRN \\
\hline CHEMBL1447473 & 688620 & 5.0 & 4.9288 & TRN \\
\hline CHEMBL3197603 & 688620 & 6.15 & 5.9182 & TRN \\
\hline CHEMBL1345313 & 688620 & 4.8 & 4.9802 & TRN \\
\hline CHEMBL1364107 & 688620 & 4.7 & 5.0822 & TST \\
\hline CHEMBL 306380 & 688620 & 4.9 & 5.144 & TRN \\
\hline CHEMBL199194 & 688620 & 5.45 & 5.21299 & 9999999999 \\
\hline CHEMBL1383123 & 688620 & 6.25 & 5.1432 & TRN \\
\hline CHEMBL1369569 & 688620 & 4.9 & 5.3607 & TST \\
\hline CHEMBL1350594 & 688620 & 5.9 & 5.5546 & TRN \\
\hline CHEMBL1468480 & 688620 & 4.45 & 4.931 & TRN \\
\hline CHEMBL3190945 & 688620 & 4.6 & 4.9482 & TRN \\
\hline
\end{tabular}




\begin{tabular}{|c|c|c|c|c|c|}
\hline & & \multicolumn{4}{|c|}{ Supplemental Table S2.txt } \\
\hline CHEMBL1623897 & 688620 & 5.15 & 4.6913 & TRN & \\
\hline CHEMBL1587597 & 688620 & 4.45 & 4.8778 & TRN & \\
\hline CHEMBL1555856 & 688620 & 4.75 & 5.1737 & TRN & \\
\hline CHEMBL1403026 & 688620 & 4.85 & 5.32799 & 9999999999 & TRN \\
\hline CHEMBL1460290 & 688620 & 4.6 & 4.9868 & TRN & \\
\hline CHEMBL3196073 & 688620 & 5.05 & 5.1228 & TRN & \\
\hline CHEMBL1404745 & 688620 & 5.45 & 5.2131 & TRN & \\
\hline CHEMBL1440964 & 688620 & 4.8 & 5.1602 & TRN & \\
\hline CHEMBL1500807 & 688620 & 5.2 & 5.1797 & TRN & \\
\hline CHEMBL1334299 & 688620 & 5.2 & 5.0288 & TRN & \\
\hline CHEMBL1465967 & 688620 & 4.9 & 5.0304 & TST & \\
\hline CHEMBL1490336 & 688620 & 6.15 & 5.5455 & TRN & \\
\hline CHEMBL428784 & 688620 & 6.6 & 5.5995 & TST & \\
\hline CHEMBL1564473 & 688620 & 4.65 & 4.6599 & TRN & \\
\hline CHEMBL1585257 & 688620 & 5.0 & 5.0115 & TST & \\
\hline CHEMBL1602636 & 688620 & 5.25 & 5.1335 & TRN & \\
\hline CHEMBL1458399 & 688620 & 5.0 & 5.234 & TST & \\
\hline CHEMBL1538753 & 688620 & 4.45 & 4.967 & TRN & \\
\hline CHEMBL1494906 & 688620 & 4.85 & 4.7786 & TST & \\
\hline CHEMBL1471479 & 688620 & 4.95 & 5.15 & TRN & \\
\hline CHEMBL1493434 & 688620 & 5.6 & 5.015 & TRN & \\
\hline CHEMBL1467319 & 688620 & 5.4 & 5.04 & TRN & \\
\hline CHEMBL1345109 & 688620 & 4.45 & 5.2267 & TRN & \\
\hline CHEMBL1417613 & 688620 & 4.9 & 5.0138 & TST & \\
\hline CHEMBL1341495 & 688620 & 5.1 & 4.9425 & TRN & \\
\hline CHEMBL1378219 & 688620 & 4.8 & 5.078 & TST & \\
\hline CHEMBL1511328 & 688620 & 4.95 & 5.3201 & TRN & \\
\hline CHEMBL1408788 & 688620 & 5.0 & 5.0148 & TRN & \\
\hline CHEMBL1423147 & 688620 & 5.0 & 4.9445 & TRN & \\
\hline CHEMBL1570985 & 688620 & 4.45 & 5.08899 & 99999999995 & TST \\
\hline CHEMBL1544254 & 688620 & 4.75 & 5.1176 & TRN & \\
\hline CHEMBL3209478 & 688620 & 4.95 & 5.0928 & TRN & \\
\hline CHEMBL1458443 & 688620 & 4.95 & 4.8359 & TRN & \\
\hline CHEMBL3208534 & 688620 & 5.25 & 5.229 & TRN & \\
\hline CHEMBL1478257 & 688620 & 4.9 & 5.039 & TRN & \\
\hline CHEMBL1465431 & 688620 & 6.5501 & 6.2579 & TRN & \\
\hline CHEMBL1564363 & 688620 & 4.95 & 5.1303 & TRN & \\
\hline CHEMBL1362757 & 688620 & 6.15 & 5.1482 & TST & \\
\hline CHEMBL1319026 & 688620 & 4.65 & 4.7736 & TST & \\
\hline CHEMBL491747 & 688620 & 4.5 & 4.8489 & TRN & \\
\hline CHEMBL1468744 & 688620 & 4.7 & 5.3114 & TRN & \\
\hline CHEMBL131199 & 688620 & 5.35 & 5.4132 & TST & \\
\hline CHEMBL3193338 & 688620 & 4.9 & 5.0718 & TST & \\
\hline CHEMBL1466644 & 688620 & 6.6499 & 6.2889 & TRN & \\
\hline CHEMBL3212390 & 688620 & 5.8 & 5.5872 & TST & \\
\hline CHEMBL1502187 & 688620 & 5.2 & 5.0618 & TRN & \\
\hline CHEMBL3195340 & 688620 & 4.5 & 4.9124 & TST & \\
\hline CHEMBL1409859 & 688620 & 4.7 & 5.0538 & TRN & \\
\hline
\end{tabular}




\begin{tabular}{|c|c|c|c|c|c|}
\hline \multicolumn{6}{|c|}{ Supplemental Table S2.txt } \\
\hline CHEMBL1448695 & 688620 & 4.95 & 4.6964 & TST & \\
\hline CHEMBL1548449 & 688620 & 5.4 & 5.1954 & TRN & \\
\hline CHEMBL1567859 & 688620 & 5.4 & 5.0223 & TRN & \\
\hline CHEMBL1489970 & 688620 & 4.95 & 5.1252 & TRN & \\
\hline CHEMBL1576630 & 688620 & 5.4 & 5.4193 & TRN & \\
\hline CHEMBL1418103 & 688620 & 5.4 & 5.0275 & TRN & \\
\hline CHEMBL1576784 & 688620 & 4.9 & 5.0189 & TST & \\
\hline CHEMBL1376078 & 688620 & 6.6499 & 5.1121 & TRN & \\
\hline CHEMBL1996136 & 688620 & 6.2 & 5.1464 & TRN & \\
\hline CHEMBL1546375 & 688620 & 5.35 & 5.1182 & TRN & \\
\hline CHEMBL1496106 & 688620 & 4.45 & 4.9553 & TRN & \\
\hline CHEMBL1390551 & 688620 & 5.2 & 5.1673 & TRN & \\
\hline CHEMBL1567103 & 688620 & 5.0 & 5.01 & TST & \\
\hline CHEMBL1531751 & 688620 & 6.6499 & 4.8194 & TST & \\
\hline CHEMBL 3193537 & 688620 & 6.5501 & 5.1904 & TRN & \\
\hline CHEMBL1545677 & 688620 & 5.0 & 5.2345 & TRN & \\
\hline CHEMBL95862 & 688620 & 5.05 & 5.0264 & TRN & \\
\hline CHEMBL1504925 & 688620 & 5.3 & 4.9865 & TST & \\
\hline CHEMBL1416690 & 688620 & 5.2 & 5.0074 & TRN & \\
\hline CHEMBL1524599 & 688620 & 5.0 & 4.715 & TST & \\
\hline CHEMBL1352543 & 688620 & 4.45 & 5.3244 & TRN & \\
\hline CHEMBL1584868 & 688620 & 6.1 & 5.0779 & TRN & \\
\hline CHEMBL1450104 & 688620 & 5.25 & 4.8206 & TST & \\
\hline CHEMBL1416700 & 688620 & 6.35 & 5.1224 & TST & \\
\hline CHEMBL1326813 & 688620 & 4.95 & 4.82100 & 0000000001 & TRN \\
\hline CHEMBL1449366 & 688620 & 5.15 & 5.0596 & TRN & \\
\hline CHEMBL1320469 & 688620 & 4.95 & 5.0178 & TRN & \\
\hline CHEMBL1510103 & 688620 & 5.6 & 5.1975 & TRN & \\
\hline CHEMBL1506216 & 688620 & 5.45 & 5.5346 & TRN & \\
\hline CHEMBL1549094 & 688620 & 4.9 & 4.8308 & TST & \\
\hline CHEMBL1501515 & 688620 & 4.95 & 5.0579 & TRN & \\
\hline CHEMBL1500983 & 688620 & 5.1 & 5.1135 & TRN & \\
\hline CHEMBL1986557 & 688620 & 4.7 & 4.8577 & TRN & \\
\hline CHEMBL1414047 & 688620 & 4.95 & 5.074 & TST & \\
\hline CHEMBL1415758 & 688620 & 5.95 & 4.9829 & TRN & \\
\hline CHEMBL1486949 & 688620 & 5.25 & 5.0785 & TST & \\
\hline CHEMBL505670 & 688620 & 6.0 & 5.3744 & TST & \\
\hline CHEMBL1610484 & 688620 & 4.45 & 4.8118 & TRN & \\
\hline CHEMBL1497643 & 688620 & 5.35 & 5.0458 & TST & \\
\hline CHEMBL 3197542 & 688620 & 5.35 & 5.2248 & TRN & \\
\hline CHEMBL1322273 & 688620 & 5.0 & 4.8779 & TRN & \\
\hline CHEMBL3191520 & 688620 & 5.35 & 5.2357 & TST & \\
\hline CHEMBL1301807 & 688620 & 4.95 & 4.9143 & TST & \\
\hline CHEMBL1506780 & 688620 & 4.45 & 5.1962 & TRN & \\
\hline CHEMBL1310070 & 688620 & 4.75 & 5.0398 & TRN & \\
\hline CHEMBL3195204 & 688620 & 4.45 & 5.3072 & TRN & \\
\hline CHEMBL1511095 & 688620 & 4.55 & 5.1493 & TRN & \\
\hline CHEMBL1333460 & 688620 & 5.0 & 4.9994 & TRN & \\
\hline
\end{tabular}




\begin{tabular}{|c|c|c|c|c|c|}
\hline \multicolumn{6}{|c|}{ Supplemental Table S2.txt } \\
\hline CHEMBL494668 & 688620 & 5.0 & 5.2805 & TST & \\
\hline CHEMBL1499568 & 688620 & 4.7 & 4.9844 & TRN & \\
\hline CHEMBL1577021 & 688620 & 4.75 & 5.1352 & TST & \\
\hline CHEMBL1433056 & 688620 & 4.8 & 5.0001 & TRN & \\
\hline CHEMBL148072 & 688620 & 4.95 & 5.0363 & TST & \\
\hline CHEMBL1443450 & 688620 & 4.6 & 4.8844 & TRN & \\
\hline CHEMBL1564542 & 688620 & 4.7 & 4.7418 & TRN & \\
\hline CHEMBL1458189 & 688620 & 4.45 & 4.9369 & TRN & \\
\hline CHEMBL1363376 & 688620 & 6.3 & 5.5616 & TRN & \\
\hline CHEMBL1510504 & 688620 & 4.95 & 4.85800 & 00000000005 & TRN \\
\hline CHEMBL1322812 & 688620 & 4.75 & 4.9468 & TRN & \\
\hline CHEMBL1562452 & 688620 & 5.05 & 5.0937 & TRN & \\
\hline CHEMBL3192838 & 688620 & 5.65 & 5.4126 & TRN & \\
\hline CHEMBL1423824 & 688620 & 4.9 & 4.8766 & TST & \\
\hline CHEMBL1162415 & 688620 & 4.45 & 5.0655 & TST & \\
\hline CHEMBL1576377 & 688620 & 4.65 & 4.9815 & TRN & \\
\hline CHEMBL3195937 & 688620 & 4.45 & 5.1528 & TRN & \\
\hline CHEMBL1976225 & 688620 & 4.9 & 5.3674 & TRN & \\
\hline CHEMBL3197175 & 688620 & 5.5 & 5.3775 & TRN & \\
\hline CHEMBL1545086 & 688620 & 4.45 & 4.8966 & TST & \\
\hline CHEMBL1467900 & 688620 & 6.5501 & 6.1105 & TRN & \\
\hline CHEMBL1402845 & 688620 & 5.3 & 5.2603 & TRN & \\
\hline CHEMBL1483593 & 688620 & 4.95 & 5.1339 & TRN & \\
\hline CHEMBL1483229 & 688620 & 4.95 & 4.9055 & TRN & \\
\hline CHEMBL1477220 & 688620 & 4.8 & 5.086 & TRN & \\
\hline CHEMBL1417414 & 688620 & 5.2 & 4.8257 & TRN & \\
\hline CHEMBL255073 & 688620 & 5.4 & 5.4196 & TRN & \\
\hline CHEMBL1528305 & 688620 & 4.9 & 4.7921 & TST & \\
\hline CHEMBL1603265 & 688620 & 4.75 & 4.9729 & TST & \\
\hline CHEMBL1525026 & 688620 & 4.8 & 5.1993 & TST & \\
\hline CHEMBL1465715 & 688620 & 4.45 & 5.0539 & TRN & \\
\hline CHEMBL1581360 & 688620 & 5.55 & 5.4018 & TRN & \\
\hline CHEMBL1426676 & 688620 & 4.9 & 5.0535 & TRN & \\
\hline CHEMBL1359029 & 688620 & 5.05 & 5.0349 & TST & \\
\hline CHEMBL1610965 & 688620 & 6.05 & 5.0951 & TST & \\
\hline CHEMBL1973122 & 688620 & 4.6 & 4.7955 & TRN & \\
\hline CHEMBL3195012 & 688620 & 5.25 & 5.5173 & TRN & \\
\hline CHEMBL1459033 & 688620 & 5.55 & 4.9096 & TRN & \\
\hline CHEMBL1328633 & 688620 & 4.95 & 4.9631 & TRN & \\
\hline CHEMBL1393437 & 688620 & 4.7 & 5.2497 & TST & \\
\hline CHEMBL1498127 & 688620 & 5.7 & 5.2512 & TRN & \\
\hline CHEMBL1352599 & 688620 & 4.9 & 5.1398 & TRN & \\
\hline CHEMBL1505644 & 688620 & 4.85 & 5.0378 & TRN & \\
\hline CHEMBL1421702 & 688620 & 4.85 & 5.037 & TRN & \\
\hline CHEMBL1521658 & 688620 & 4.7 & 5.0999 & TRN & \\
\hline CHEMBL1470305 & 688620 & 5.0 & 5.1238 & TST & \\
\hline CHEMBL1995280 & 688620 & 5.85 & 5.9675 & TRN & \\
\hline CHEMBL1598214 & 688620 & 4.75 & 4.9495 & TRN & \\
\hline
\end{tabular}




\begin{tabular}{|c|c|c|c|c|c|}
\hline \multicolumn{6}{|c|}{ Supplemental Table S2.txt } \\
\hline CHEMBL1576995 & 688620 & 4.7 & 5.2682 & TRN & \\
\hline CHEMBL1532732 & 688620 & 6.5501 & 5.6761 & TRN & \\
\hline CHEMBL1445070 & 688620 & 4.9 & 4.9218 & TRN & \\
\hline CHEMBL1325898 & 688620 & 4.8 & 4.8249 & TRN & \\
\hline CHEMBL1329654 & 688620 & 4.45 & 5.0293 & TRN & \\
\hline CHEMBL1353848 & 688620 & 8.3468 & 5.0423 & TST & \\
\hline CHEMBL1372272 & 688620 & 4.45 & 4.7471 & TRN & \\
\hline CHEMBL1345585 & 688620 & 5.65 & 5.2915 & TRN & \\
\hline CHEMBL585686 & 688620 & 6.3 & 4.8513 & TRN & \\
\hline CHEMBL1540318 & 688620 & 4.8 & 5.1189 & TRN & \\
\hline CHEMBL1322196 & 688620 & 4.45 & 4.8281 & TRN & \\
\hline CHEMBL3209278 & 688620 & 4.95 & 4.832 & TRN & \\
\hline CHEMBL1304689 & 688620 & 4.9 & 5.2363 & TST & \\
\hline CHEMBL1540045 & 688620 & 4.45 & 5.002 & TRN & \\
\hline CHEMBL1409593 & 688620 & 4.45 & 4.8836 & TRN & \\
\hline CHEMBL1578875 & 688620 & 4.8 & 4.9994 & TRN & \\
\hline CHEMBL3196369 & 688620 & 5.55 & 5.1781 & TRN & \\
\hline CHEMBL1970925 & 688620 & 5.7 & 5.2873 & TRN & \\
\hline CHEMBL1527645 & 688620 & 4.6 & 5.0634 & TRN & \\
\hline CHEMBL1987419 & 688620 & 6.15 & 5.7266 & TRN & \\
\hline CHEMBL1407846 & 688620 & 4.95 & 5.0358 & TST & \\
\hline CHEMBL1352390 & 688620 & 5.05 & 5.1534 & TRN & \\
\hline CHEMBL1557356 & 688620 & 4.9 & 4.9453 & TRN & \\
\hline CHEMBL1351106 & 688620 & 4.45 & 4.6604 & TRN & \\
\hline CHEMBL1964464 & 688620 & 6.4 & 5.7726 & TRN & \\
\hline CHEMBL1472144 & 688620 & 4.9 & 4.9469 & TRN & \\
\hline CHEMBL1471985 & 688620 & 4.5 & 5.1941 & TRN & \\
\hline CHEMBL1478496 & 688620 & 4.8 & 4.8048 & TST & \\
\hline CHEMBL1333549 & 688620 & 4.45 & 4.7165 & TST & \\
\hline CHEMBL1602767 & 688620 & 4.45 & 4.913 & TRN & \\
\hline CHEMBL1303276 & 688620 & 4.6 & 5.0604 & TRN & \\
\hline CHEMBL1368764 & 688620 & 4.5 & 4.9109 & TRN & \\
\hline CHEMBL1523264 & 688620 & 5.55 & 4.9076 & TST & \\
\hline CHEMBL1320044 & 688620 & 4.45 & 5.1263 & TST & \\
\hline CHEMBL1490539 & 688620 & 5.05 & 4.8858 & TRN & \\
\hline CHEMBL1421707 & 688620 & 6.6 & 4.9137 & TRN & \\
\hline CHEMBL1496110 & 688620 & 5.0 & 5.1675 & TRN & \\
\hline CHEMBL3193400 & 688620 & 5.15 & 5.4115 & TRN & \\
\hline CHEMBL1423708 & 688620 & 5.25 & 5.8317 & TST & \\
\hline CHEMBL1510671 & 688620 & 4.6 & 5.21700 & 00000000005 & TST \\
\hline CHEMBL1426461 & 688620 & 4.65 & 4.8843 & TST & \\
\hline CHEMBL1596191 & 688620 & 4.85 & 5.20799 & 9999999999 & TRN \\
\hline CHEMBL1462252 & 688620 & 4.85 & 4.9468 & TST & \\
\hline CHEMBL1600851 & 688620 & 4.6 & 5.2445 & TRN & \\
\hline CHEMBL3197968 & 688620 & 4.9 & 5.3805 & TRN & \\
\hline CHEMBL1381723 & 688620 & 5.0 & 5.1308 & TST & \\
\hline CHEMBL1393601 & 688620 & 4.45 & 5.1003 & TST & \\
\hline CHEMBL1490415 & 688620 & 4.95 & 5.0775 & TRN & \\
\hline
\end{tabular}




\begin{tabular}{|c|c|c|c|c|c|}
\hline \multicolumn{6}{|c|}{ Supplemental Table S2.txt } \\
\hline CHEMBL1534492 & 688620 & 4.9 & 5.2857 & TRN & \\
\hline CHEMBL1583677 & 688620 & 5.1 & 5.0729 & TRN & \\
\hline CHEMBL15177 & 688620 & 4.75 & 4.9883 & TST & \\
\hline CHEMBL1336833 & 688620 & 5.55 & 5.2954 & TRN & \\
\hline CHEMBL1363766 & 688620 & 4.45 & 4.8766 & TRN & \\
\hline CHEMBL1562608 & 688620 & 6.4 & 5.8819 & TRN & \\
\hline CHEMBL1547422 & 688620 & 5.35 & 4.9629 & TST & \\
\hline CHEMBL1384621 & 688620 & 4.45 & 5.0763 & TRN & \\
\hline CHEMBL1430433 & 688620 & 4.9 & 4.9825 & TRN & \\
\hline CHEMBL1329120 & 688620 & 5.1 & 4.953 & TRN & \\
\hline CHEMBL1378019 & 688620 & 4.95 & 5.0812 & TRN & \\
\hline CHEMBL 3207571 & 688620 & 5.0 & 5.1261 & TRN & \\
\hline CHEMBL1609200 & 688620 & 5.75 & 5.0868 & TRN & \\
\hline CHEMBL1518459 & 688620 & 4.9 & 4.9614 & TRN & \\
\hline CHEMBL1305436 & 688620 & 4.85 & 4.9016 & TRN & \\
\hline CHEMBL1430905 & 688620 & 4.5 & 4.9445 & TRN & \\
\hline CHEMBL1990716 & 688620 & 4.75 & 5.0873 & TRN & \\
\hline CHEMBL3209255 & 688620 & 4.65 & 5.4216 & TRN & \\
\hline CHEMBL1343019 & 688620 & 5.0 & 4.7232 & TRN & \\
\hline CHEMBL3191375 & 688620 & 5.55 & 5.3448 & TRN & \\
\hline CHEMBL1543801 & 688620 & 5.3 & 4.9618 & TRN & \\
\hline CHEMBL1537864 & 688620 & 6.15 & 5.1985 & TRN & \\
\hline CHEMBL1498364 & 688620 & 4.55 & 5.0369 & TRN & \\
\hline CHEMBL1464803 & 688620 & 4.45 & 4.9751 & TRN & \\
\hline CHEMBL1435313 & 688620 & 4.45 & 5.3217 & TRN & \\
\hline CHEMBL3207394 & 688620 & 5.55 & 4.9998 & TST & \\
\hline CHEMBL1300027 & 688620 & 4.9 & 4.9416 & TRN & \\
\hline CHEMBL1588920 & 688620 & 4.9 & 5.8101 & TRN & \\
\hline CHEMBL1303981 & 688620 & 4.55 & 4.8933 & TST & \\
\hline CHEMBL1612720 & 688620 & 4.8 & 4.8895 & TRN & \\
\hline CHEMBL1388339 & 688620 & 4.5 & 4.8869 & TRN & \\
\hline CHEMBL1566345 & 688620 & 4.95 & 4.9964 & TRN & \\
\hline CHEMBL1994148 & 688620 & 4.45 & 4.8747 & TRN & \\
\hline CHEMBL1421894 & 688620 & 4.85 & 5.0763 & TRN & \\
\hline CHEMBL463574 & 688620 & 5.45 & 5.0248 & TST & \\
\hline CHEMBL1388837 & 688620 & 4.75 & 5.0526 & TRN & \\
\hline CHEMBL1369547 & 688620 & 4.45 & 5.0318 & TRN & \\
\hline CHEMBL1971712 & 688620 & 5.0 & 4.9173 & TRN & \\
\hline CHEMBL1361579 & 688620 & 5.0 & 4.7717 & TRN & \\
\hline CHEMBL1608278 & 688620 & 6.6499 & $6.2570 e$ & 0000000001 & TRN \\
\hline CHEMBL 270605 & 688620 & 6.0 & 5.8888 & TRN & \\
\hline CHEMBL1381599 & 688620 & 5.4 & 5.1636 & TRN & \\
\hline CHEMBL1420853 & 688620 & 6.95 & 5.0911 & TRN & \\
\hline CHEMBL1450561 & 688620 & 4.7 & 4.967 & TRN & \\
\hline CHEMBL1435930 & 688620 & 4.9 & 4.7829 & TRN & \\
\hline CHEMBL1361967 & 688620 & 4.9 & 4.9372 & TRN & \\
\hline CHEMBL1461352 & 688620 & 6.25 & 5.9956 & TRN & \\
\hline CHEMBL3210611 & 688620 & 4.95 & 4.9591 & TRN & \\
\hline
\end{tabular}




\begin{tabular}{|c|c|c|c|c|c|}
\hline \multicolumn{6}{|c|}{ Supplemental Table S2.txt } \\
\hline CHEMBL1422680 & 688620 & 4.95 & 4.8228 & TRN & \\
\hline CHEMBL1404091 & 688620 & 4.7 & 4.8293 & TRN & \\
\hline CHEMBL1364855 & 688620 & 5.6 & 4.987 & TST & \\
\hline CHEMBL1348759 & 688620 & 4.9 & 4.9276 & TRN & \\
\hline CHEMBL1581997 & 688620 & 4.9 & 4.8684 & TRN & \\
\hline CHEMBL1600280 & 688620 & 4.45 & 4.9283 & TST & \\
\hline CHEMBL3195450 & 688620 & 4.45 & 5.1594 & TRN & \\
\hline CHEMBL1534369 & 688620 & 6.0 & 5.2527 & TRN & \\
\hline CHEMBL 3194882 & 688620 & 6.5 & 5.1507 & TST & \\
\hline CHEMBL3210912 & 688620 & 4.9 & 5.0782 & TRN & \\
\hline CHEMBL1506845 & 688620 & 5.0 & 4.8695 & TRN & \\
\hline CHEMBL1451003 & 688620 & 5.0 & 4.9503 & TRN & \\
\hline CHEMBL1538152 & 688620 & 4.75 & 4.7248 & TRN & \\
\hline CHEMBL1319865 & 688620 & 5.6 & 5.069 & TRN & \\
\hline CHEMBL 3192773 & 688620 & 5.0 & 4.5896 & TRN & \\
\hline CHEMBL1352199 & 688620 & 4.9 & 5.119 & TRN & \\
\hline CHEMBL1329566 & 688620 & 4.45 & 4.888 & TST & \\
\hline CHEMBL1335130 & 688620 & 4.45 & 4.9836 & TST & \\
\hline CHEMBL1977078 & 688620 & 5.6 & 5.175 & TRN & \\
\hline CHEMBL1299916 & 688620 & 4.45 & 4.8683 & TRN & \\
\hline CHEMBL3189177 & 688620 & 4.95 & 5.0457 & TRN & \\
\hline CHEMBL1305459 & 688620 & 6.5 & 5.1313 & TRN & \\
\hline CHEMBL1580951 & 688620 & 4.7 & 4.6898 & TRN & \\
\hline CHEMBL3197107 & 688620 & 4.95 & 5.0262 & TRN & \\
\hline CHEMBL1494847 & 688620 & 5.6 & 4.9332 & TRN & \\
\hline CHEMBL 3192642 & 688620 & 5.05 & 4.9914 & TRN & \\
\hline CHEMBL3197895 & 688620 & 4.45 & 5.05699 & 99999999995 & TRN \\
\hline CHEMBL1490730 & 688620 & 5.55 & 5.1727 & TRN & \\
\hline CHEMBL3194960 & 688620 & 5.6 & 5.1055 & TRN & \\
\hline CHEMBL1385241 & 688620 & 4.95 & 4.7854 & TRN & \\
\hline CHEMBL1477069 & 688620 & 4.45 & 4.6473 & TRN & \\
\hline CHEMBL1505968 & 688620 & 6.3 & 4.9716 & TRN & \\
\hline CHEMBL1528467 & 688620 & 5.65 & 5.2045 & TRN & \\
\hline CHEMBL 3190713 & 688620 & 5.05 & 4.7945 & TRN & \\
\hline CHEMBL1555433 & 688620 & 5.45 & 5.2562 & TRN & \\
\hline CHEMBL1323560 & 688620 & 4.45 & 5.1269 & TRN & \\
\hline CHEMBL3192616 & 688620 & 6.2 & 6.0242 & TRN & \\
\hline CHEMBL1454972 & 688620 & 4.45 & 5.1224 & TRN & \\
\hline CHEMBL 3197679 & 688620 & 5.4 & 5.3192 & TRN & \\
\hline CHEMBL1603755 & 688620 & 5.8 & 4.7799 & TRN & \\
\hline CHEMBL1327967 & 688620 & 5.4 & 4.9128 & TRN & \\
\hline CHEMBL3192438 & 688620 & 5.0 & 5.1862 & TRN & \\
\hline CHEMBL1441346 & 688620 & 4.45 & 4.9896 & TRN & \\
\hline CHEMBL1533776 & 688620 & 4.5 & 4.7693 & TRN & \\
\hline CHEMBL1568515 & 688620 & 4.45 & 4.9227 & TRN & \\
\hline CHEMBL1462836 & 688620 & 4.85 & 5.0663 & TRN & \\
\hline CHEMBL1480961 & 688620 & 4.9 & 5.0537 & TRN & \\
\hline CHEMBL1352336 & 688620 & 4.45 & 5.3957 & TST & \\
\hline
\end{tabular}




\begin{tabular}{|c|c|c|c|c|}
\hline \multicolumn{5}{|c|}{ Supplemental Table s2.txt } \\
\hline CHEMBL1577232 & 688620 & 4.45 & 5.1394 & TRN \\
\hline CHEMBL1332532 & 688620 & 4.8 & 4.9926 & TST \\
\hline CHEMBL1301132 & 688620 & 4.45 & 5.0729 & TRN \\
\hline CHEMBL1360480 & 688620 & 4.45 & 5.2759 & TST \\
\hline CHEMBL1426177 & 688620 & 4.45 & 4.8358 & TRN \\
\hline CHEMBL1488972 & 688620 & 4.8 & 5.2476 & TRN \\
\hline CHEMBL1390425 & 688620 & 4.45 & 5.0018 & TRN \\
\hline CHEMBL1437843 & 688620 & 4.7 & 4.8994 & TRN \\
\hline CHEMBL1997212 & 688620 & 5.3 & 5.1303 & TRN \\
\hline CHEMBL1982652 & 688620 & 4.6 & 4.9554 & TRN \\
\hline CHEMBL576607 & 688620 & 5.95 & 5.0124 & TRN \\
\hline CHEMBL1411172 & 688620 & 5.45 & 5.3219 & TRN \\
\hline CHEMBL1393740 & 688620 & 4.95 & 4.7847 & TRN \\
\hline CHEMBL1558076 & 688620 & 4.65 & 4.9837 & TST \\
\hline CHEMBL1328441 & 688620 & 4.45 & 4.8826 & TRN \\
\hline CHEMBL1341844 & 688620 & 4.9 & 4.9316 & TST \\
\hline CHEMBL3190398 & 688620 & 4.7 & 5.2392 & TRN \\
\hline CHEMBL1505913 & 688620 & 4.8 & 5.0797 & TRN \\
\hline CHEMBL1303315 & 688620 & 5.35 & 5.3102 & TRN \\
\hline CHEMBL1407655 & 688620 & 6.15 & 5.1772 & TRN \\
\hline CHEMBL1308842 & 688620 & 5.45 & 5.44600 & 0000000001 \\
\hline CHEMBL1368979 & 688620 & 4.9 & 4.6644 & TRN \\
\hline CHEMBL1376368 & 688620 & 6.45 & 5.1012 & TST \\
\hline CHEMBL1536701 & 688620 & 5.7 & 5.0712 & TRN \\
\hline CHEMBL1433185 & 688620 & 5.5 & 5.2448 & TRN \\
\hline CHEMBL1393417 & 688620 & 4.9 & 4.8853 & TST \\
\hline CHEMBL1367779 & 688620 & 4.45 & 4.9984 & TRN \\
\hline CHEMBL 3145367 & 688620 & 5.4 & 5.8739 & TRN \\
\hline CHEMBL1309653 & 688620 & 7.0 & 4.9243 & TRN \\
\hline CHEMBL54804 & 688620 & 5.4 & 5.5427 & TRN \\
\hline CHEMBL38508 & 688620 & 4.7 & 4.848 & TST \\
\hline CHEMBL1510952 & 688620 & 5.45 & 4.7599 & TST \\
\hline CHEMBL3195107 & 688620 & 5.4 & 5.1809 & TRN \\
\hline CHEMBL1478687 & 688620 & 4.9 & 5.2902 & TRN \\
\hline CHEMBL1519210 & 688620 & 5.7 & 5.2346 & TRN \\
\hline CHEMBL1469900 & 688620 & 4.6 & 5.3329 & TRN \\
\hline CHEMBL3209847 & 688620 & 4.9 & 5.1647 & TRN \\
\hline CHEMBL1568173 & 688620 & 4.45 & 4.8343 & TRN \\
\hline CHEMBL1447151 & 688620 & 5.25 & 4.9335 & TST \\
\hline CHEMBL1375520 & 688620 & 4.45 & 5.1498 & TRN \\
\hline CHEMBL1588407 & 688620 & 5.65 & 5.1504 & TST \\
\hline CHEMBL1374344 & 688620 & 4.45 & 5.064 & TRN \\
\hline CHEMBL1490194 & 688620 & 5.15 & 5.1169 & TRN \\
\hline CHEMBL1555397 & 688620 & 5.05 & 5.0064 & TST \\
\hline CHEMBL1465051 & 688620 & 5.6 & 5.6902 & TRN \\
\hline CHEMBL1538954 & 688620 & 4.85 & 5.1931 & TRN \\
\hline CHEMBL1392826 & 688620 & 4.45 & 4.8829 & TST \\
\hline CHEMBL3191401 & 688620 & 4.45 & 5.0057 & TRN \\
\hline
\end{tabular}




\begin{tabular}{|c|c|c|c|c|}
\hline & & & upplement & $\mathrm{T}$ \\
\hline CHEMBL1377160 & 688620 & 4.45 & 4.9004 & TST \\
\hline CHEMBL1490045 & 688620 & 5.0 & 5.2001 & TRN \\
\hline CHEMBL1342293 & 688620 & 6.3 & 6.1479 & TRN \\
\hline CHEMBL1382712 & 688620 & 4.45 & 5.1817 & TST \\
\hline CHEMBL1342041 & 688620 & 4.45 & 4.9655 & TRN \\
\hline CHEMBL1371664 & 688620 & 4.7 & 5.1379 & TRN \\
\hline CHEMBL3192188 & 688620 & 4.75 & 5.1234 & TRN \\
\hline CHEMBL1369352 & 688620 & 4.45 & 4.8094 & TST \\
\hline CHEMBL1582336 & 688620 & 5.3 & 5.1089 & TRN \\
\hline CHEMBL3199407 & 688620 & 5.15 & 5.0715 & TRN \\
\hline CHEMBL1333429 & 688620 & 5.1 & 4.9593 & TRN \\
\hline CHEMBL1536697 & 688620 & 4.45 & 5.0228 & TRN \\
\hline CHEMBL1459376 & 688620 & 4.75 & 4.8078 & TRN \\
\hline CHEMBL1304117 & 688620 & 4.85 & 5.1247 & TRN \\
\hline CHEMBL1578019 & 688620 & 4.9 & 4.8371 & TRN \\
\hline CHEMBL1611037 & 688620 & 4.45 & 5.0557 & TRN \\
\hline CHEMBL3190652 & 688620 & 6.8 & 5.3439 & TRN \\
\hline CHEMBL1224755 & 688620 & 5.2 & 5.3149 & TRN \\
\hline CHEMBL1459069 & 688620 & 4.45 & 4.9392 & TRN \\
\hline CHEMBL1402655 & 688620 & 4.75 & 5.0023 & TST \\
\hline CHEMBL1445687 & 688620 & 4.45 & 4.9284 & TRN \\
\hline CHEMBL1510552 & 688620 & 4.7 & 5.1707 & TRN \\
\hline CHEMBL1461561 & 688620 & 4.45 & 5.0953 & TRN \\
\hline CHEMBL1390765 & 688620 & 4.5 & 4.8022 & TRN \\
\hline CHEMBL1459202 & 688620 & 6.3 & 5.5902 & TRN \\
\hline CHEMBL1607302 & 688620 & 5.0 & 4.848 & TRN \\
\hline CHEMBL1420468 & 688620 & 4.9 & 4.8383 & TRN \\
\hline CHEMBL1421544 & 688620 & 5.55 & 5.4297 & TST \\
\hline CHEMBL1421170 & 688620 & 5.15 & 4.8655 & TRN \\
\hline CHEMBL3191731 & 688620 & 5.05 & 4.8515 & TRN \\
\hline CHEMBL1548372 & 688620 & 5.3 & 5.4935 & TST \\
\hline CHEMBL1413724 & 688620 & 5.2 & 4.9849 & TST \\
\hline CHEMBL1489443 & 688620 & 4.65 & 5.2344 & TRN \\
\hline CHEMBL1449195 & 688620 & 5.7 & 5.3276 & TRN \\
\hline CHEMBL166209 & 688620 & 4.85 & 5.1332 & TST \\
\hline CHEMBL1600552 & 688620 & 4.9 & 5.0191 & TST \\
\hline CHEMBL1500046 & 688620 & 6.8 & 4.9657 & TST \\
\hline CHEMBL1309957 & 688620 & 6.5 & 5.9338 & TRN \\
\hline CHEMBL1405962 & 688620 & 5.05 & 4.9285 & TRN \\
\hline CHEMBL1489281 & 688620 & 4.45 & 4.9247 & TRN \\
\hline CHEMBL1564662 & 688620 & 4.6 & 5.1363 & TRN \\
\hline CHEMBL1312523 & 688620 & 5.5 & 4.8654 & TRN \\
\hline CHEMBL1429318 & 688620 & 6.15 & 4.9852 & TST \\
\hline CHEMBL1425755 & 688620 & 5.05 & 5.2192 & TRN \\
\hline CHEMBL1980697 & 688620 & 4.95 & 5.2332 & TST \\
\hline CHEMBL1349282 & 688620 & 4.85 & 5.0041 & TRN \\
\hline CHEMBL1609022 & 688620 & 4.45 & 4.9203 & TRN \\
\hline CHEMBL1389010 & 688620 & 4.8 & 4.9987 & TRN \\
\hline
\end{tabular}




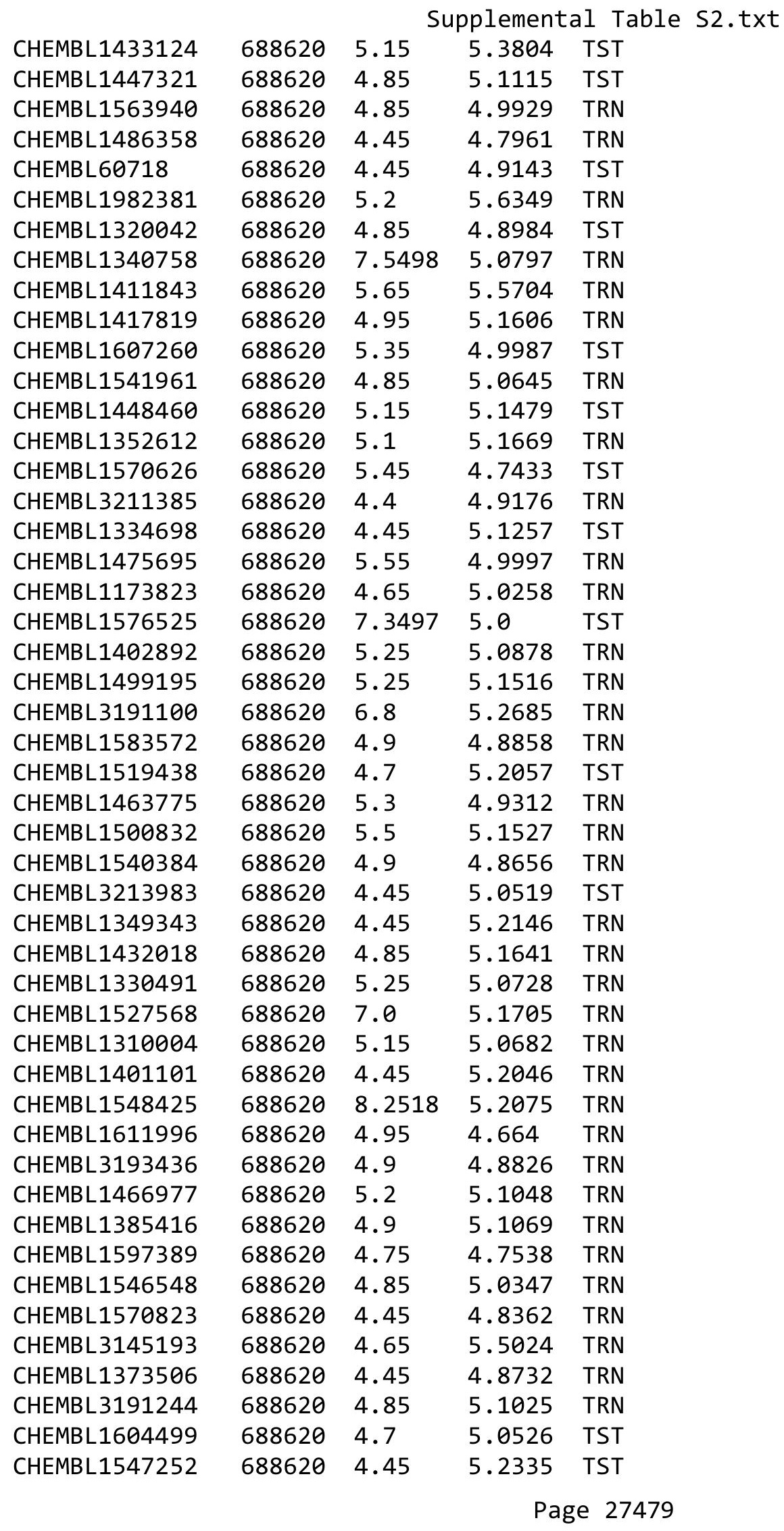




\begin{tabular}{|c|c|c|c|c|c|}
\hline \multicolumn{6}{|c|}{ Supplemental Table S2.txt } \\
\hline CHEMBL1976719 & 688620 & 5.2 & 5.1965 & TRN & \\
\hline CHEMBL1562890 & 688620 & 4.6 & 4.9918 & TRN & \\
\hline CHEMBL3214315 & 688620 & 4.65 & 5.0725 & TRN & \\
\hline CHEMBL1300900 & 688620 & 4.8 & 4.9672 & TRN & \\
\hline CHEMBL1409624 & 688620 & 5.25 & 4.8659 & TRN & \\
\hline CHEMBL3195431 & 688620 & 5.65 & 5.2557 & TRN & \\
\hline CHEMBL1308274 & 688620 & 4.5 & 5.0924 & TST & \\
\hline CHEMBL1308728 & 688620 & 4.9 & 4.8537 & TRN & \\
\hline CHEMBL1563221 & 688620 & 5.3 & 5.2491 & TRN & \\
\hline CHEMBL3208342 & 688620 & 4.75 & 4.9881 & TRN & \\
\hline CHEMBL1331439 & 688620 & 6.0 & 5.0489 & TST & \\
\hline CHEMBL3195980 & 688620 & 5.45 & 5.0988 & TST & \\
\hline CHEMBL 3190277 & 688620 & 5.85 & 5.3222 & TRN & \\
\hline CHEMBL1448599 & 688620 & 5.15 & 4.9708 & TRN & \\
\hline CHEMBL1549425 & 688620 & 4.45 & 4.937 & TRN & \\
\hline CHEMBL3190695 & 688620 & 5.0 & 5.0772 & TRN & \\
\hline CHEMBL507237 & 688620 & 4.65 & 4.9661 & TST & \\
\hline CHEMBL1589410 & 688620 & 5.0 & 5.5119 & TRN & \\
\hline CHEMBL1445305 & 688620 & 5.0 & 4.9906 & TRN & \\
\hline CHEMBL1965376 & 688620 & 6.25 & 5.8862 & TRN & \\
\hline CHEMBL1363804 & 688620 & 4.6 & 5.091 & TST & \\
\hline CHEMBL1357090 & 688620 & 5.15 & 5.001 & TRN & \\
\hline CHEMBL1342853 & 688620 & 5.55 & 5.0382 & TST & \\
\hline CHEMBL 3192184 & 688620 & 5.4 & 5.2415 & TRN & \\
\hline CHEMBL1445747 & 688620 & 4.85 & 5.5886 & TRN & \\
\hline CHEMBL1603247 & 688620 & 6.1 & 4.9099 & TRN & \\
\hline CHEMBL565657 & 688620 & 6.5 & 5.4967 & TST & \\
\hline CHEMBL1512990 & 688620 & 4.45 & 4.753 & TRN & \\
\hline CHEMBL1332241 & 688620 & 4.9 & 5.0559 & TRN & \\
\hline CHEMBL1327509 & 688620 & 5.2 & 4.8503 & TRN & \\
\hline CHEMBL1323575 & 688620 & 4.95 & 4.8553 & TST & \\
\hline CHEMBL1416469 & 688620 & 4.6 & 4.9651 & TST & \\
\hline CHEMBL1573599 & 688620 & 7.5498 & 5.00899 & 99999999995 & TRN \\
\hline CHEMBL1386535 & 688620 & 4.75 & 5.0258 & TRN & \\
\hline CHEMBL1466314 & 688620 & 5.45 & 4.9642 & TRN & \\
\hline CHEMBL1488126 & 688620 & 4.45 & 4.9138 & TRN & \\
\hline CHEMBL1389587 & 688620 & 5.6 & 5.428 & TST & \\
\hline CHEMBL3199170 & 688620 & 6.45 & 5.4448 & TRN & \\
\hline CHEMBL1463686 & 688620 & 7.2503 & 5.1143 & TRN & \\
\hline CHEMBL1337947 & 688620 & 6.0 & 5.6595 & TRN & \\
\hline CHEMBL3199727 & 688620 & 4.65 & 5.2615 & TRN & \\
\hline CHEMBL1481942 & 688620 & 5.0 & 6.1252 & TRN & \\
\hline CHEMBL1566927 & 688620 & 4.45 & 5.0298 & TST & \\
\hline CHEMBL1505940 & 688620 & 4.75 & 5.1064 & TRN & \\
\hline CHEMBL1457334 & 688620 & 4.9 & 5.1212 & TRN & \\
\hline CHEMBL1373888 & 688620 & 5.85 & 5.5424 & TRN & \\
\hline CHEMBL1517235 & 688620 & 5.0 & 4.6839 & TRN & \\
\hline CHEMBL1523141 & 688620 & 4.8 & 4.8897 & TRN & \\
\hline
\end{tabular}




\begin{tabular}{|c|c|c|c|c|}
\hline \multicolumn{5}{|c|}{ Supplemental Table S2.txt } \\
\hline CHEMBL1582928 & 688620 & 5.0 & 4.6897 & TRN \\
\hline CHEMBL1526336 & 688620 & 4.65 & 5.1571 & TST \\
\hline CHEMBL1508121 & 688620 & 5.35 & 5.2475 & TRN \\
\hline CHEMBL1402068 & 688620 & 6.15 & 5.1907 & TST \\
\hline CHEMBL1563747 & 688620 & 5.05 & 5.231 & TST \\
\hline CHEMBL1341878 & 688620 & 4.9 & 5.1391 & TRN \\
\hline CHEMBL1609122 & 688620 & 5.7 & 5.4906 & TRN \\
\hline CHEMBL1414618 & 688620 & 6.95 & 5.0701 & TRN \\
\hline CHEMBL1311519 & 688620 & 5.8 & 5.4015 & TRN \\
\hline CHEMBL1451642 & 688620 & 4.65 & 4.9228 & TST \\
\hline CHEMBL1429115 & 688620 & 5.0 & 4.9587 & TRN \\
\hline CHEMBL1526406 & 688620 & 5.2 & 4.8952 & TST \\
\hline CHEMBL1461945 & 688620 & 5.5 & 5.5112 & TRN \\
\hline CHEMBL1327549 & 688620 & 4.5 & 5.0008 & TST \\
\hline CHEMBL1546814 & 688620 & 4.9 & 5.0042 & TRN \\
\hline CHEMBL1384088 & 688620 & 4.9 & 5.1924 & TRN \\
\hline CHEMBL1489695 & 688620 & 4.95 & 4.9497 & TST \\
\hline CHEMBL1983843 & 688620 & 4.65 & 5.0471 & TRN \\
\hline CHEMBL1377334 & 688620 & 4.5 & 4.8686 & TRN \\
\hline CHEMBL1392034 & 688620 & 4.9 & 5.0008 & TST \\
\hline CHEMBL1396786 & 688620 & 4.4 & 5.1192 & TRN \\
\hline CHEMBL3189950 & 688620 & 5.0 & 4.9157 & TRN \\
\hline CHEMBL1412188 & 688620 & 5.5 & 5.2424 & TRN \\
\hline CHEMBL1608787 & 688620 & 4.95 & 4.8321 & TRN \\
\hline CHEMBL1538370 & 688620 & 4.9 & 4.9056 & TRN \\
\hline CHEMBL1595216 & 688620 & 6.8 & 4.9956 & TST \\
\hline CHEMBL1505364 & 688620 & 5.6 & 5.0596 & TRN \\
\hline CHEMBL 3208828 & 688620 & 5.25 & 5.1093 & TST \\
\hline CHEMBL1335696 & 688620 & 4.95 & 5.2388 & TRN \\
\hline CHEMBL1449307 & 688620 & 4.95 & 5.1455 & TRN \\
\hline CHEMBL1421020 & 688620 & 5.55 & 5.1673 & TRN \\
\hline CHEMBL1502716 & 688620 & 5.0 & 4.9219 & TST \\
\hline CHEMBL1441761 & 688620 & 4.6 & 4.9073 & TRN \\
\hline CHEMBL1557337 & 688620 & 4.65 & 4.8567 & TRN \\
\hline CHEMBL 3194627 & 688620 & 4.95 & 4.9914 & TST \\
\hline CHEMBL1516542 & 688620 & 5.8 & 5.2741 & TST \\
\hline CHEMBL1348553 & 688620 & 4.65 & 5.3273 & TRN \\
\hline CHEMBL1604728 & 688620 & 4.65 & 4.9658 & TRN \\
\hline CHEMBL1523605 & 688620 & 5.4 & 4.9238 & TST \\
\hline CHEMBL1481849 & 688620 & 4.95 & 4.7304 & TRN \\
\hline CHEMBL1311900 & 688620 & 4.9 & 5.3048 & TRN \\
\hline CHEMBL1530839 & 688620 & 5.3 & 5.1396 & TST \\
\hline CHEMBL1581874 & 688620 & 4.85 & 5.0163 & TRN \\
\hline CHEMBL1430674 & 688620 & 4.8 & 5.1657 & TRN \\
\hline CHEMBL1529050 & 688620 & 4.95 & 4.9837 & TRN \\
\hline CHEMBL1376995 & 688620 & 4.45 & 4.9213 & TRN \\
\hline CHEMBL1430405 & 688620 & 4.8 & 4.9737 & TRN \\
\hline CHEMBL1583281 & 688620 & 4.9 & 5.0397 & TST \\
\hline
\end{tabular}




\begin{tabular}{|c|c|c|c|c|c|}
\hline \multicolumn{6}{|c|}{ Supplemental Table S2.txt } \\
\hline CHEMBL1391921 & 688620 & 4.85 & 4.9702 & TRN & \\
\hline CHEMBL1964467 & 688620 & 5.0 & 5.21399 & 99999999995 & TRN \\
\hline CHEMBL1454627 & 688620 & 4.95 & 5.2558 & TRN & \\
\hline CHEMBL 3213347 & 688620 & 4.7 & 5.0669 & TST & \\
\hline CHEMBL1451592 & 688620 & 4.75 & 5.2001 & TRN & \\
\hline CHEMBL1480059 & 688620 & 4.85 & 5.0346 & TST & \\
\hline CHEMBL3210921 & 688620 & 6.1 & 5.01 & TST & \\
\hline CHEMBL1541608 & 688620 & 5.2 & 5.0149 & TST & \\
\hline CHEMBL1492643 & 688620 & 4.9 & 4.8344 & TRN & \\
\hline CHEMBL1409901 & 688620 & 5.1 & 5.1273 & TRN & \\
\hline CHEMBL1307593 & 688620 & 4.45 & 5.0646 & TRN & \\
\hline CHEMBL1544956 & 688620 & 4.95 & 5.3158 & TST & \\
\hline CHEMBL3195022 & 688620 & 5.1 & 5.2195 & TST & \\
\hline CHEMBL1574191 & 688620 & 5.55 & 4.9767 & TST & \\
\hline CHEMBL1323143 & 688620 & 4.75 & 5.0592 & TST & \\
\hline CHEMBL3194766 & 688620 & 4.6 & 4.9972 & TRN & \\
\hline CHEMBL1526536 & 688620 & 4.9 & 5.0869 & TRN & \\
\hline CHEMBL1548578 & 688620 & 5.2 & 4.96399 & 99999999995 & TRN \\
\hline CHEMBL1375051 & 688620 & 4.75 & 4.9985 & TST & \\
\hline CHEMBL1404911 & 688620 & 4.45 & 4.9787 & TRN & \\
\hline CHEMBL3211338 & 688620 & 4.8 & 5.0391 & TRN & \\
\hline CHEMBL1420323 & 688620 & 4.45 & 4.9409 & TRN & \\
\hline CHEMBL3198800 & 688620 & 5.0 & 5.0542 & TRN & \\
\hline CHEMBL1503613 & 688620 & 4.85 & 4.9062 & TRN & \\
\hline CHEMBL1328778 & 688620 & 5.0 & 4.9565 & TRN & \\
\hline CHEMBL1362538 & 688620 & 4.75 & 4.9738 & TRN & \\
\hline CHEMBL1427801 & 688620 & 5.0 & 5.4236 & TRN & \\
\hline CHEMBL260533 & 688620 & 4.95 & 5.0461 & TST & \\
\hline CHEMBL1547822 & 688620 & 5.55 & 5.0448 & TRN & \\
\hline CHEMBL1563651 & 688620 & 5.1 & 4.9987 & TRN & \\
\hline CHEMBL3189629 & 688620 & 5.6 & 5.0436 & TRN & \\
\hline CHEMBL1533586 & 688620 & 4.5 & 5.2143 & TST & \\
\hline CHEMBL1588449 & 688620 & 4.95 & 5.1408 & TRN & \\
\hline CHEMBL1560237 & 688620 & 6.0 & 5.5478 & TRN & \\
\hline CHEMBL1583587 & 688620 & 4.9 & 5.0044 & TRN & \\
\hline CHEMBL1403813 & 688620 & 4.65 & 4.7439 & TST & \\
\hline CHEMBL1388845 & 688620 & 5.8 & 5.8873 & TRN & \\
\hline CHEMBL3211585 & 688620 & 5.15 & 5.2154 & TRN & \\
\hline CHEMBL1451256 & 688620 & 5.15 & 5.1389 & TRN & \\
\hline CHEMBL1396030 & 688620 & 5.45 & 4.9845 & TRN & \\
\hline CHEMBL1998984 & 688620 & 5.45 & 5.513 & TRN & \\
\hline CHEMBL1499967 & 688620 & 4.9 & 5.0318 & TRN & \\
\hline CHEMBL1404628 & 688620 & 6.8499 & 5.1091 & TST & \\
\hline CHEMBL1323451 & 688620 & 4.95 & 5.0556 & TST & \\
\hline CHEMBL1573074 & 688620 & 4.95 & 5.1813 & TRN & \\
\hline CHEMBL1604508 & 688620 & 5.15 & 5.1005 & TRN & \\
\hline CHEMBL1526781 & 688620 & 4.85 & 4.9915 & TRN & \\
\hline CHEMBL1483682 & 688620 & 4.65 & 4.9111 & TRN & \\
\hline
\end{tabular}




\begin{tabular}{|c|c|c|c|c|}
\hline \multicolumn{5}{|c|}{ Supplemental Table S2.tx } \\
\hline CHEMBL1539815 & 688620 & 6.6499 & 5.1044 & TST \\
\hline CHEMBL1596220 & 688620 & 4.75 & 5.1407 & TRN \\
\hline CHEMBL1525321 & 688620 & 4.45 & 5.1867 & TST \\
\hline CHEMBL1345002 & 688620 & 4.8 & 5.0946 & TRN \\
\hline CHEMBL1388353 & 688620 & 4.45 & 5.0111 & TRN \\
\hline CHEMBL1348766 & 688620 & 5.35 & 5.0623 & TRN \\
\hline CHEMBL1302726 & 688620 & 5.25 & 4.995 & TST \\
\hline CHEMBL1421193 & 688620 & 4.45 & 4.8809 & TRN \\
\hline CHEMBL1603982 & 688620 & 5.45 & 5.3838 & TRN \\
\hline CHEMBL1496327 & 688620 & 5.15 & 5.1835 & TST \\
\hline CHEMBL1376943 & 688620 & 5.25 & 5.0098 & TRN \\
\hline CHEMBL3209586 & 688620 & 5.0 & 5.1314 & TRN \\
\hline CHEMBL1391945 & 688620 & 4.85 & 5.2038 & TST \\
\hline CHEMBL1597864 & 688620 & 5.0 & 4.8861 & TRN \\
\hline CHEMBL1518828 & 688620 & 4.8 & 5.1324 & TST \\
\hline CHEMBL1400797 & 688620 & 5.85 & 5.0233 & TRN \\
\hline CHEMBL1422850 & 688620 & 4.65 & 5.1743 & TST \\
\hline CHEMBL1570661 & 688620 & 4.95 & 5.0683 & TRN \\
\hline CHEMBL1372064 & 688620 & 5.2 & 4.8575 & TRN \\
\hline CHEMBL1599953 & 688620 & 5.05 & 4.9284 & TST \\
\hline CHEMBL1546125 & 688620 & 6.45 & 5.0225 & TRN \\
\hline CHEMBL1439276 & 688620 & 5.65 & 5.0932 & TRN \\
\hline CHEMBL1539339 & 688620 & 6.0 & 5.5907 & TRN \\
\hline CHEMBL1491524 & 688620 & 4.9 & 5.1947 & TRN \\
\hline CHEMBL1382786 & 688620 & 5.5 & 5.1022 & TST \\
\hline CHEMBL1310181 & 688620 & 5.25 & 5.0495 & TRN \\
\hline CHEMBL1478574 & 688620 & 4.9 & 4.7933 & TRN \\
\hline CHEMBL1419794 & 688620 & 5.75 & 5.36100 & 0000000001 \\
\hline CHEMBL1580578 & 688620 & 4.9 & 5.2807 & TST \\
\hline CHEMBL 1523817 & 688620 & 4.45 & 4.9048 & TST \\
\hline CHEMBL1470256 & 688620 & 4.95 & 5.4689 & TRN \\
\hline CHEMBL1516070 & 688620 & 5.0 & 4.8809 & TRN \\
\hline CHEMBL1403773 & 688620 & 5.2 & 4.8901 & TST \\
\hline CHEMBL1517758 & 688620 & 4.9 & 5.038 & TRN \\
\hline CHEMBL 3198085 & 688620 & 5.05 & 4.7509 & TST \\
\hline CHEMBL 3195828 & 688620 & 4.45 & 5.0726 & TRN \\
\hline CHEMBL1404485 & 688620 & 4.9 & 5.0365 & TRN \\
\hline CHEMBL1448681 & 688620 & 5.9 & 5.8277 & TRN \\
\hline CHEMBL1980600 & 688620 & 4.45 & 5.2714 & TST \\
\hline CHEMBL1448868 & 688620 & 4.75 & 5.2302 & TST \\
\hline CHEMBL1465298 & 688620 & 5.25 & 4.9414 & TST \\
\hline CHEMBL 3194780 & 688620 & 4.95 & 4.9546 & TRN \\
\hline CHEMBL1569374 & 688620 & 5.55 & 5.5091 & TRN \\
\hline CHEMBL1469600 & 688620 & 5.4 & 5.0585 & TST \\
\hline CHEMBL3194789 & 688620 & 4.7 & 4.9785 & TRN \\
\hline CHEMBL 3194550 & 688620 & 5.2 & 5.3366 & TRN \\
\hline CHEMBL1393899 & 688620 & 5.05 & 5.2076 & TRN \\
\hline CHEMBL1453079 & 688620 & 5.1 & 5.1731 & TRN \\
\hline
\end{tabular}




\begin{tabular}{|c|c|c|c|c|}
\hline \multicolumn{5}{|c|}{ Supplemental Table S2.txt } \\
\hline CHEMBL1563198 & 688620 & 4.5 & 4.8522 & TRN \\
\hline CHEMBL3189592 & 688620 & 4.95 & 4.9464 & TRN \\
\hline CHEMBL1577886 & 688620 & 4.5 & 4.9442 & TRN \\
\hline CHEMBL1398772 & 688620 & 5.2 & 5.0791 & TST \\
\hline CHEMBL 1440535 & 688620 & 4.45 & 5.1307 & TST \\
\hline CHEMBL1526174 & 688620 & 5.2 & 5.3181 & TST \\
\hline CHEMBL1606575 & 688620 & 4.45 & 4.6983 & TRN \\
\hline CHEMBL1451875 & 688620 & 4.9 & 5.0511 & TRN \\
\hline CHEMBL1427500 & 688620 & 4.85 & 5.0914 & TRN \\
\hline CHEMBL1601565 & 688620 & 4.9 & 4.9353 & TRN \\
\hline CHEMBL1327596 & 688620 & 5.2 & 4.9401 & TRN \\
\hline CHEMBL3191530 & 688620 & 4.85 & 4.9073 & TRN \\
\hline CHEMBL1561649 & 688620 & 4.75 & 5.974 & TRN \\
\hline CHEMBL1972500 & 688620 & 5.45 & 5.2307 & TRN \\
\hline CHEMBL355280 & 688620 & 5.3 & 5.1453 & TRN \\
\hline CHEMBL3194899 & 688620 & 4.45 & 4.7784 & TRN \\
\hline CHEMBL1344654 & 688620 & 4.75 & 4.9154 & TRN \\
\hline CHEMBL1503230 & 688620 & 4.9 & 4.7898 & TRN \\
\hline CHEMBL1487871 & 688620 & 5.65 & 5.5918 & TRN \\
\hline CHEMBL1303807 & 688620 & 5.3 & 5.1133 & TRN \\
\hline CHEMBL1472645 & 688620 & 4.95 & 5.0859 & TRN \\
\hline CHEMBL1524104 & 688620 & 4.85 & 5.1521 & TRN \\
\hline CHEMBL1401953 & 688620 & 5.9 & 5.3522 & TRN \\
\hline CHEMBL1502604 & 688620 & 4.45 & 4.7369 & TRN \\
\hline CHEMBL3144917 & 688620 & 4.45 & 4.7663 & TST \\
\hline CHEMBL1479250 & 688620 & 4.85 & 4.9987 & TRN \\
\hline CHEMBL3194416 & 688620 & 4.9 & 5.1372 & TRN \\
\hline CHEMBL1498124 & 688620 & 5.0 & 5.0569 & TST \\
\hline CHEMBL1504866 & 688620 & 5.2 & 5.1948 & TRN \\
\hline CHEMBL2004950 & 688620 & 5.15 & 5.0723 & TRN \\
\hline CHEMBL1442412 & 688620 & 4.45 & 4.942 & TST \\
\hline CHEMBL391123 & 688620 & 4.6 & 5.487 & TRN \\
\hline CHEMBL1581456 & 688620 & 4.75 & 4.9285 & TRN \\
\hline CHEMBL1366074 & 688620 & 5.9 & 5.374 & TRN \\
\hline CHEMBL1414717 & 688620 & 5.3 & 5.3159 & TRN \\
\hline CHEMBL193804 & 688620 & 4.8 & 4.9779 & TST \\
\hline CHEMBL1567097 & 688620 & 5.5 & 4.9343 & TRN \\
\hline CHEMBL3190531 & 688620 & 4.95 & 5.275 & TST \\
\hline CHEMBL1575293 & 688620 & 4.5 & 5.0892 & TRN \\
\hline CHEMBL1445275 & 688620 & 5.4 & 5.2219 & TST \\
\hline CHEMBL1378252 & 688620 & 5.45 & 5.027 & TRN \\
\hline CHEMBL296641 & 688620 & 5.65 & 4.867 & TST \\
\hline CHEMBL1499582 & 688620 & 4.9 & 5.2198 & TRN \\
\hline CHEMBL1505234 & 688620 & 4.8 & 5.0703 & TRN \\
\hline CHEMBL1391994 & 688620 & 5.0 & 4.9492 & TST \\
\hline CHEMBL1551399 & 688620 & 5.1 & 4.7053 & TRN \\
\hline CHEMBL1506502 & 688620 & 4.65 & 5.1141 & TRN \\
\hline CHEMBL1483744 & 688620 & 5.1 & 4.8927 & TRN \\
\hline
\end{tabular}




\begin{tabular}{|c|c|c|c|c|}
\hline \multicolumn{5}{|c|}{ Supplemental Table S2.txt } \\
\hline CHEMBL1585626 & 688620 & 5.4 & 5.1349 & TRN \\
\hline CHEMBL1453996 & 688620 & 6.5 & 5.789 & TST \\
\hline CHEMBL1378495 & 688620 & 5.45 & 4.9713 & TRN \\
\hline CHEMBL3190967 & 688620 & 6.45 & 6.2202 & TRN \\
\hline CHEMBL1601076 & 688620 & 4.55 & 5.3085 & TRN \\
\hline CHEMBL1378143 & 688620 & 4.95 & 5.0338 & TRN \\
\hline CHEMBL1416031 & 688620 & 4.75 & 4.8481 & TST \\
\hline CHEMBL1324781 & 688620 & 4.45 & 4.8813 & TRN \\
\hline CHEMBL1535992 & 688620 & 5.35 & 4.8143 & TRN \\
\hline CHEMBL1449094 & 688620 & 4.85 & 4.9941 & TST \\
\hline CHEMBL1584244 & 688620 & 5.55 & 5.1908 & TRN \\
\hline CHEMBL1508300 & 688620 & 5.25 & 5.1429 & TRN \\
\hline CHEMBL3193834 & 688620 & 4.45 & 5.435 & TST \\
\hline CHEMBL 3198547 & 688620 & 4.75 & 4.9607 & TST \\
\hline CHEMBL1478677 & 688620 & 4.45 & 4.9704 & TRN \\
\hline CHEMBL1432533 & 688620 & 6.0 & 5.6034 & TST \\
\hline CHEMBL3197653 & 688620 & 5.9 & 5.6495 & TST \\
\hline CHEMBL1341556 & 688620 & 5.2 & 4.8016 & TST \\
\hline CHEMBL1557433 & 688620 & 4.9 & 5.0213 & TRN \\
\hline CHEMBL1483432 & 688620 & 5.5 & 5.6583 & TRN \\
\hline CHEMBL1584766 & 688620 & 5.65 & 5.0229 & TST \\
\hline CHEMBL1459938 & 688620 & 4.45 & 5.0689 & TST \\
\hline CHEMBL1508080 & 688620 & 4.65 & 4.7995 & TST \\
\hline CHEMBL1503523 & 688620 & 4.45 & 4.9615 & TRN \\
\hline CHEMBL1326086 & 688620 & 5.0 & 5.0551 & TRN \\
\hline CHEMBL 233531 & 688620 & 5.45 & 5.8267 & TRN \\
\hline CHEMBL1376261 & 688620 & 4.45 & 5.0755 & TRN \\
\hline CHEMBL1432015 & 688620 & 4.65 & 5.0438 & TRN \\
\hline CHEMBL1519598 & 688620 & 4.9 & 5.0997 & TST \\
\hline CHEMBL1600994 & 688620 & 4.45 & 4.811 & TRN \\
\hline CHEMBL1307320 & 688620 & 5.2 & 5.0235 & TRN \\
\hline CHEMBL1566650 & 688620 & 5.45 & 5.0827 & TRN \\
\hline CHEMBL1583804 & 688620 & 4.45 & 4.9545 & TST \\
\hline CHEMBL1413309 & 688620 & 5.85 & 4.9041 & TRN \\
\hline CHEMBL1422320 & 688620 & 4.7 & 5.3044 & TST \\
\hline CHEMBL1384321 & 688620 & 5.05 & 4.9808 & TRN \\
\hline CHEMBL1502537 & 688620 & 4.9 & 5.2105 & TRN \\
\hline CHEMBL1493233 & 688620 & 4.85 & 4.7674 & TST \\
\hline CHEMBL1455159 & 688620 & 5.35 & 5.3725 & TRN \\
\hline CHEMBL1530982 & 688620 & 4.85 & 4.925 & TRN \\
\hline CHEMBL1404199 & 688620 & 4.9 & 4.8965 & TST \\
\hline CHEMBL3209649 & 688620 & 5.0 & 5.0459 & TRN \\
\hline CHEMBL1513241 & 688620 & 4.9 & 4.9095 & TRN \\
\hline CHEMBL1568834 & 688620 & 4.95 & 5.0993 & TRN \\
\hline CHEMBL1562942 & 688620 & 4.75 & 4.8868 & TST \\
\hline CHEMBL1564710 & 688620 & 4.8 & 5.0743 & TRN \\
\hline CHEMBL1574042 & 688620 & 4.9 & 5.0766 & TRN \\
\hline CHEMBL1501964 & 688620 & 4.45 & 4.8659 & TST \\
\hline
\end{tabular}




\begin{tabular}{|c|c|c|c|c|}
\hline \multicolumn{5}{|c|}{ Supplemental Table S2.txt } \\
\hline CHEMBL1336289 & 688620 & 4.8 & 4.9667 & TRN \\
\hline CHEMBL1369107 & 688620 & 6.15 & 5.0442 & TST \\
\hline CHEMBL1602159 & 688620 & 5.75 & 5.0062 & TRN \\
\hline CHEMBL1425463 & 688620 & 5.5 & 4.8231 & TRN \\
\hline CHEMBL1465007 & 688620 & 5.55 & 5.6937 & TST \\
\hline CHEMBL1431698 & 688620 & 4.95 & 4.8484 & TRN \\
\hline CHEMBL1313737 & 688620 & 5.3 & 5.0783 & TRN \\
\hline CHEMBL1438836 & 688620 & 5.6 & 5.9913 & TRN \\
\hline CHEMBL1468162 & 688620 & 5.0 & 5.1692 & TRN \\
\hline CHEMBL1423469 & 688620 & 4.5 & 5.0023 & TRN \\
\hline CHEMBL1354400 & 688620 & 4.85 & 4.9283 & TRN \\
\hline CHEMBL1454711 & 688620 & 4.95 & 4.9902 & TST \\
\hline CHEMBL1526633 & 688620 & 4.95 & 5.2459 & TST \\
\hline CHEMBL1503803 & 688620 & 7.0501 & 5.2897 & TST \\
\hline CHEMBL1317790 & 688620 & 4.85 & 5.0945 & TST \\
\hline CHEMBL1311588 & 688620 & 5.3 & 4.7914 & TST \\
\hline CHEMBL1989603 & 688620 & 5.15 & 5.2641 & TRN \\
\hline CHEMBL1330370 & 688620 & 5.05 & 5.0925 & TST \\
\hline CHEMBL1410338 & 688620 & 5.2 & 5.5267 & TRN \\
\hline CHEMBL1447988 & 688620 & 4.95 & 5.4009 & TRN \\
\hline CHEMBL1416621 & 688620 & 4.5 & 5.0714 & TRN \\
\hline CHEMBL1403816 & 688620 & 5.3 & 4.9218 & TST \\
\hline CHEMBL1586937 & 688620 & 4.95 & 4.9016 & TRN \\
\hline CHEMBL 3207775 & 688620 & 6.2 & 5.973 & TRN \\
\hline CHEMBL1549341 & 688620 & 5.5 & 5.2842 & TRN \\
\hline CHEMBL3392064 & 688620 & 4.7 & 4.9878 & TST \\
\hline CHEMBL1607324 & 688620 & 4.75 & 4.9487 & TRN \\
\hline CHEMBL1594276 & 688620 & 4.55 & 4.9428 & TRN \\
\hline CHEMBL3195273 & 688620 & 5.55 & 5.6231 & TRN \\
\hline CHEMBL1519291 & 688620 & 6.5 & 6.4094 & TRN \\
\hline CHEMBL3189196 & 688620 & 4.45 & 4.8626 & TRN \\
\hline CHEMBL1415579 & 688620 & 4.55 & 5.2304 & TRN \\
\hline CHEMBL1526693 & 688620 & 5.35 & 5.0368 & TRN \\
\hline CHEMBL1405539 & 688620 & 4.9 & 4.9408 & TST \\
\hline CHEMBL1343946 & 688620 & 5.35 & 4.8636 & TRN \\
\hline CHEMBL1519955 & 688620 & 5.05 & 5.6855 & TST \\
\hline CHEMBL1605291 & 688620 & 4.5 & 5.1526 & TST \\
\hline CHEMBL1312769 & 688620 & 4.45 & 4.998 & TRN \\
\hline CHEMBL1323987 & 688620 & 4.45 & 4.9618 & TRN \\
\hline CHEMBL1377790 & 688620 & 4.65 & 4.8292 & TRN \\
\hline CHEMBL3196534 & 688620 & 4.5 & 4.7992 & TRN \\
\hline CHEMBL1495495 & 688620 & 4.65 & 5.0311 & TRN \\
\hline CHEMBL1318856 & 688620 & 4.45 & 4.973 & TRN \\
\hline CHEMBL1441423 & 688620 & 4.65 & 5.0014 & TRN \\
\hline CHEMBL1502741 & 688620 & 5.35 & 4.9369 & TRN \\
\hline CHEMBL1311308 & 688620 & 4.85 & 4.7671 & TRN \\
\hline CHEMBL1542613 & 688620 & 5.0 & 4.9538 & TRN \\
\hline CHEMBL1318916 & 688620 & 4.45 & 4.8271 & TRN \\
\hline
\end{tabular}




\begin{tabular}{|c|c|c|c|c|}
\hline \multicolumn{5}{|c|}{ lemental Table s } \\
\hline CHEMBL1388186 & 688620 & 4.9 & 5.0358 & TST \\
\hline CHEMBL1375580 & 688620 & 5.2 & 5.3493 & TRN \\
\hline CHEMBL1509293 & 688620 & 5.6 & 5.0764 & TRN \\
\hline CHEMBL3189513 & 688620 & 5.25 & 5.1237 & TRN \\
\hline CHEMBL1367316 & 688620 & 5.5 & \multicolumn{2}{|c|}{5.422999999999999} \\
\hline CHEMBL1546935 & 688620 & 5.25 & 4.9792 & TRN \\
\hline CHEMBL3189969 & 688620 & 5.45 & 5.3171 & TRN \\
\hline CHEMBL1995296 & 688620 & 4.9 & 5.0155 & TRN \\
\hline CHEMBL1563281 & 688620 & 4.9 & 5.075 & TRN \\
\hline CHEMBL1310875 & 688620 & 5.2 & 5.2007 & TRN \\
\hline CHEMBL1387889 & 688620 & 5.0 & 4.9751 & TRN \\
\hline CHEMBL1091556 & 688620 & 6.25 & 5.5707 & TRN \\
\hline CHEMBL1393858 & 688620 & 4.95 & 5.1075 & TRN \\
\hline CHEMBL1589381 & 688620 & 5.0 & 4.8874 & TRN \\
\hline CHEMBL1345620 & 688620 & 6.1 & 5.4444 & TRN \\
\hline CHEMBL 1471602 & 688620 & 4.45 & 5.0069 & TST \\
\hline CHEMBL3189217 & 688620 & 5.55 & 5.655 & TRN \\
\hline CHEMBL1369467 & 688620 & 5.7 & 4.9861 & TRN \\
\hline CHEMBL1414184 & 688620 & 4.45 & 5.112 & TRN \\
\hline CHEMBL1470485 & 688620 & 5.75 & 5.4149 & TRN \\
\hline CHEMBL 1428363 & 688620 & 5.15 & 4.8621 & TRN \\
\hline CHEMBL1366322 & 688620 & 6.3 & 6.2069 & TST \\
\hline CHEMBL1580621 & 688620 & 4.8 & 5.0689 & TST \\
\hline CHEMBL1403377 & 688620 & 5.05 & 4.9944 & TRN \\
\hline CHEMBL1583901 & 688620 & 4.7 & 4.7368 & TRN \\
\hline CHEMBL1527994 & 688620 & 4.45 & 4.9678 & TRN \\
\hline CHEMBL1337420 & 688620 & 4.95 & 4.8397 & TRN \\
\hline CHEMBL1400959 & 688620 & 4.65 & 4.8837 & TRN \\
\hline CHEMBL1439992 & 688620 & 4.5 & 5.052 & TRN \\
\hline CHEMBL1500088 & 688620 & 5.35 & 5.1985 & TRN \\
\hline CHEMBL1560526 & 688620 & 5.0 & 5.3375 & TRN \\
\hline CHEMBL1360011 & 688620 & 4.85 & 5.289 & TRN \\
\hline CHEMBL1594742 & 688620 & 4.9 & 4.8609 & TRN \\
\hline CHEMBL1334950 & 688620 & 4.8 & 5.0665 & TST \\
\hline CHEMBL1389332 & 688620 & 6.95 & 5.5157 & TRN \\
\hline CHEMBL1522846 & 688620 & 5.4 & 5.0346 & TST \\
\hline CHEMBL1466055 & 688620 & 4.95 & 5.005 & TRN \\
\hline CHEMBL1347385 & 688620 & 4.45 & 4.7847 & TST \\
\hline CHEMBL1472294 & 688620 & 4.7 & 4.8457 & TST \\
\hline CHEMBL3194950 & 688620 & 4.5 & 5.1285 & TST \\
\hline CHEMBL3196795 & 688620 & 5.5 & 5.3325 & TRN \\
\hline CHEMBL1426565 & 688620 & 4.45 & 4.8376 & TRN \\
\hline CHEMBL1363166 & 688620 & 5.4 & 5.3441 & TST \\
\hline CHEMBL1521300 & 688620 & 4.45 & 5.314 & TRN \\
\hline CHEMBL3190226 & 688620 & 4.85 & 5.0632 & TRN \\
\hline CHEMBL1402529 & 688620 & 6.0 & 4.9212 & TRN \\
\hline CHEMBL1304565 & 688620 & 5.2 & 5.4493 & TRN \\
\hline CHEMBL1504022 & 688620 & 5.55 & 5.5008 & TRN \\
\hline
\end{tabular}




\begin{tabular}{|c|c|c|c|c|}
\hline \multicolumn{5}{|c|}{ splemental T } \\
\hline CHEMBL1500077 & 688620 & 4.8 & 4.8794 & TRN \\
\hline CHEMBL3213159 & 688620 & 4.45 & 5.1345 & TST \\
\hline CHEMBL2369244 & 688620 & 6.2 & 5.9214 & TRN \\
\hline CHEMBL1301159 & 688620 & 4.45 & 4.9806 & TRN \\
\hline CHEMBL1350902 & 688620 & 4.7 & 5.0197 & TRN \\
\hline CHEMBL1445206 & 688620 & 6.15 & 6.1958 & TRN \\
\hline CHEMBL1550657 & 688620 & 4.95 & 5.059 & TRN \\
\hline CHEMBL1380063 & 688620 & 5.45 & 5.3603 & TRN \\
\hline CHEMBL1444392 & 688620 & 4.95 & 4.928 & TRN \\
\hline CHEMBL1440162 & 688620 & 4.45 & 4.9051 & TRN \\
\hline CHEMBL1338441 & 688620 & 5.25 & 4.9901 & TRN \\
\hline CHEMBL1325844 & 688620 & 4.75 & 5.0148 & TST \\
\hline CHEMBL1991021 & 688620 & 4.45 & 4.7542 & TRN \\
\hline CHEMBL1329464 & 688620 & 5.6 & 5.436 & TRN \\
\hline CHEMBL1390623 & 688620 & 4.55 & 4.994 & TRN \\
\hline CHEMBL1502540 & 688620 & 5.4 & 4.8118 & TRN \\
\hline CHEMBL1382325 & 688620 & 4.8 & 4.9342 & TRN \\
\hline CHEMBL1322866 & 688620 & 4.45 & 4.879 & TST \\
\hline CHEMBL1579235 & 688620 & 6.0 & 5.2067 & TRN \\
\hline CHEMBL1435682 & 688620 & 5.6 & 5.1965 & TRN \\
\hline CHEMBL1505482 & 688620 & 5.1 & 5.2774 & TRN \\
\hline CHEMBL1521823 & 688620 & 6.5 & 5.0759 & TRN \\
\hline CHEMBL1346834 & 688620 & 4.95 & 5.0785 & TRN \\
\hline CHEMBL1347608 & 688620 & 4.45 & 5.0762 & TRN \\
\hline CHEMBL1478945 & 688620 & 4.85 & 5.13 & TRN \\
\hline CHEMBL1327628 & 688620 & 5.65 & 4.9105 & TRN \\
\hline CHEMBL1589224 & 688620 & 5.55 & 5.1214 & TST \\
\hline CHEMBL482642 & 688620 & 5.1 & 5.0493 & TST \\
\hline CHEMBL1604186 & 688620 & 4.85 & 4.7275 & TRN \\
\hline CHEMBL1369012 & 688620 & 5.15 & 5.0666 & TST \\
\hline CHEMBL1557651 & 688620 & 5.5 & 5.2138 & TST \\
\hline CHEMBL1501061 & 688620 & 6.1 & 6.0227 & TRN \\
\hline CHEMBL1394002 & 688620 & 5.15 & 5.0787 & TRN \\
\hline CHEMBL3194690 & 688620 & 4.45 & 5.1015 & TST \\
\hline CHEMBL1358334 & 688620 & 4.75 & 4.7965 & TRN \\
\hline CHEMBL3199006 & 688620 & 5.15 & 4.9612 & TRN \\
\hline CHEMBL1537457 & 688620 & 4.9 & 5.1225 & TRN \\
\hline CHEMBL1326424 & 688620 & 6.5501 & 5.1053 & TRN \\
\hline CHEMBL1390655 & 688620 & 4.75 & 5.1352 & TRN \\
\hline CHEMBL1388738 & 688620 & 5.2 & 5.1766 & TRN \\
\hline CHEMBL3191974 & 688620 & 4.55 & 4.9559 & TST \\
\hline CHEMBL1373622 & 688620 & 6.1 & 5.0232 & TST \\
\hline CHEMBL1537785 & 688620 & 4.45 & 5.0988 & TST \\
\hline CHEMBL1442080 & 688620 & 5.15 & 5.5243 & TRN \\
\hline CHEMBL1318957 & 688620 & 4.55 & 5.1137 & TRN \\
\hline CHEMBL1401681 & 688620 & 4.95 & 4.7992 & TST \\
\hline CHEMBL1569002 & 688620 & 5.35 & 5.0317 & TRN \\
\hline CHEMBL1380410 & 688620 & 5.3 & 5.2462 & TRN \\
\hline
\end{tabular}




\begin{tabular}{|c|c|c|c|c|c|}
\hline \multicolumn{6}{|c|}{ Supplemental Table S2.txt } \\
\hline CHEMBL1612811 & 688620 & 5.0 & 4.8763 & TRN & \\
\hline CHEMBL1497201 & 688620 & 5.1 & 5.5681 & TRN & \\
\hline CHEMBL1581231 & 688620 & 5.6 & 5.341 & TRN & \\
\hline CHEMBL 2007598 & 688620 & 4.95 & 5.0672 & TRN & \\
\hline CHEMBL1386475 & 688620 & 4.7 & 5.0734 & TRN & \\
\hline CHEMBL1541666 & 688620 & 5.0 & 5.4013 & TRN & \\
\hline CHEMBL1401582 & 688620 & 4.95 & 4.9174 & TST & \\
\hline CHEMBL1568341 & 688620 & 4.85 & $4.9860 e$ & 0000000001 & TRN \\
\hline CHEMBL 1608535 & 688620 & 5.25 & 4.8245 & TST & \\
\hline CHEMBL1518628 & 688620 & 5.0 & 5.1725 & TST & \\
\hline CHEMBL1586044 & 688620 & 4.9 & 5.0484 & TST & \\
\hline CHEMBL1407767 & 688620 & 4.45 & 5.1783 & TST & \\
\hline CHEMBL1501581 & 688620 & 6.4 & 4.9368 & TRN & \\
\hline CHEMBL1429966 & 688620 & 5.65 & 5.4343 & TRN & \\
\hline CHEMBL3195747 & 688620 & 6.2 & 5.8758 & TRN & \\
\hline CHEMBL1566373 & 688620 & 5.2 & 5.3186 & TRN & \\
\hline CHEMBL1609472 & 688620 & 5.2 & 5.2756 & TRN & \\
\hline CHEMBL3190727 & 688620 & 4.75 & 5.0276 & TRN & \\
\hline CHEMBL1408962 & 688620 & 5.45 & 5.1448 & TRN & \\
\hline CHEMBL1504515 & 688620 & 4.9 & 5.0752 & TST & \\
\hline CHEMBL1603956 & 688620 & 4.9 & 4.96399 & 99999999995 & TST \\
\hline CHEMBL3193100 & 688620 & 4.6 & 5.2319 & TRN & \\
\hline CHEMBL1564233 & 688620 & 4.9 & 5.0293 & TST & \\
\hline CHEMBL1584663 & 688620 & 4.95 & 5.2174 & TRN & \\
\hline CHEMBL3192880 & 688620 & 5.55 & 5.275 & TRN & \\
\hline CHEMBL1462767 & 688620 & 7.15 & 5.1003 & TST & \\
\hline CHEMBL1329600 & 688620 & 4.85 & 5.7154 & TRN & \\
\hline CHEMBL3213982 & 688620 & 4.6 & 5.2627 & TRN & \\
\hline CHEMBL1334574 & 688620 & 4.85 & 5.1276 & TST & \\
\hline CHEMBL1412262 & 688620 & 4.7 & 4.8061 & TRN & \\
\hline CHEMBL1345939 & 688620 & 6.35 & 6.5202 & TRN & \\
\hline CHEMBL1581300 & 688620 & 4.7 & 5.42 & TST & \\
\hline CHEMBL1537624 & 688620 & 5.15 & 4.8893 & TRN & \\
\hline CHEMBL1499668 & 688620 & 4.45 & 4.9833 & TRN & \\
\hline CHEMBL1362032 & 688620 & 5.0 & 4.7985 & TRN & \\
\hline CHEMBL1347027 & 688620 & 4.45 & 5.2002 & TRN & \\
\hline CHEMBL102714 & 688620 & 4.45 & 4.9704 & TST & \\
\hline CHEMBL3196722 & 688620 & 4.95 & $5.2120 e$ & 0000000001 & TRN \\
\hline CHEMBL1607563 & 688620 & 6.95 & 5.1851 & TRN & \\
\hline CHEMBL1409617 & 688620 & 4.95 & 5.2396 & TST & \\
\hline CHEMBL1415808 & 688620 & 5.25 & 5.1825 & TRN & \\
\hline CHEMBL1525546 & 688620 & 6.5 & 5.87299 & 9999999999 & TRN \\
\hline CHEMBL1327919 & 688620 & 5.5 & 5.1549 & TRN & \\
\hline CHEMBL1320111 & 688620 & 6.45 & 4.9449 & TRN & \\
\hline CHEMBL1339613 & 688620 & 4.45 & 4.7115 & TST & \\
\hline CHEMBL1438344 & 688620 & 4.85 & 4.97 & TRN & \\
\hline CHEMBL1530940 & 688620 & 4.95 & 5.0584 & TRN & \\
\hline CHEMBL1420460 & 688620 & 5.0 & 4.8804 & TRN & \\
\hline
\end{tabular}




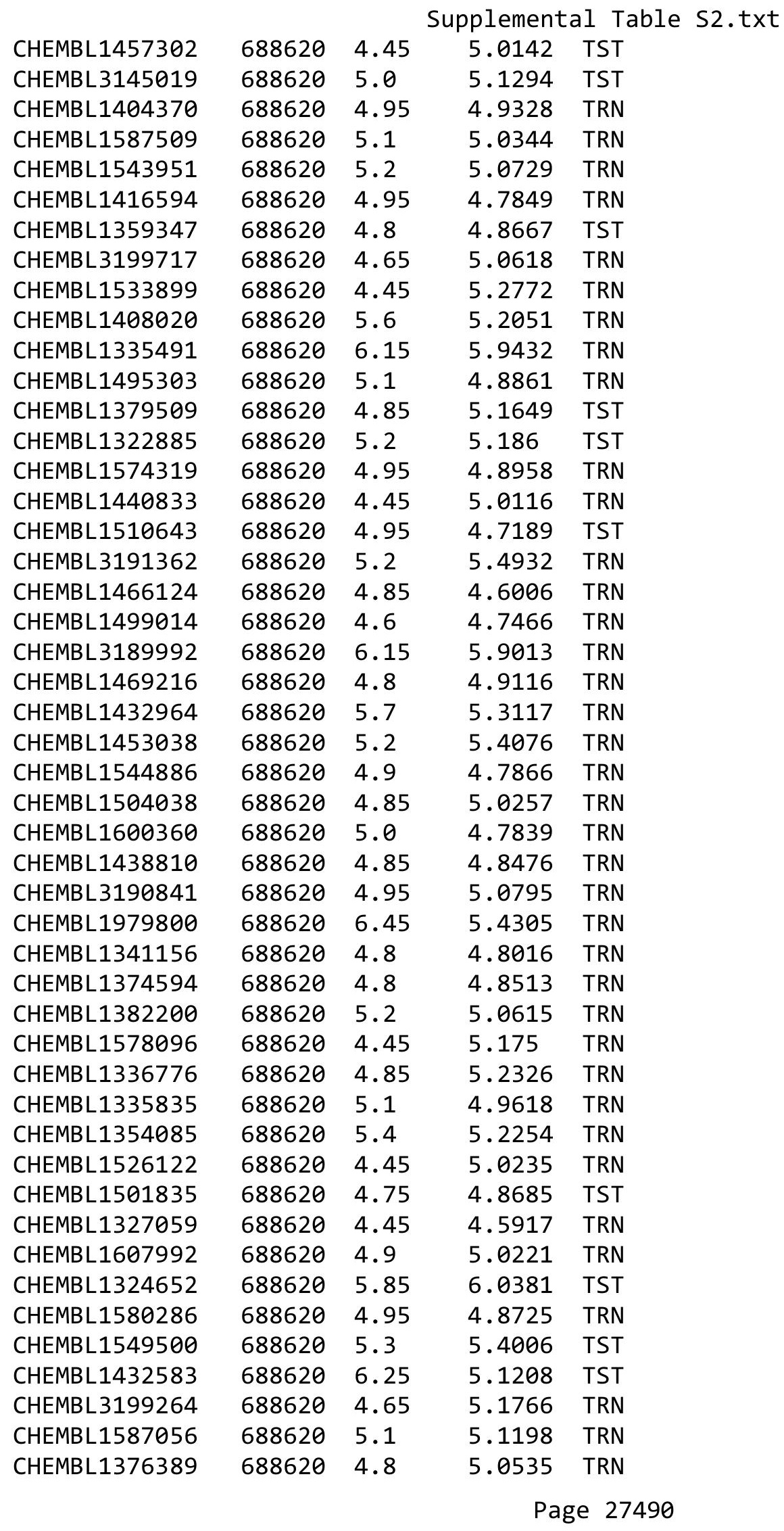




\begin{tabular}{|c|c|c|c|c|c|}
\hline \multicolumn{6}{|c|}{ Supplemental Table S2.txt } \\
\hline CHEMBL1387545 & 688620 & 5.05 & 5.1907 & TRN & \\
\hline CHEMBL1420658 & 688620 & 4.9 & 4.9835 & TRN & \\
\hline CHEMBL1353079 & 688620 & 5.15 & 5.4252 & TRN & \\
\hline CHEMBL 3209214 & 688620 & 5.05 & 4.9682 & TRN & \\
\hline CHEMBL1429109 & 688620 & 4.45 & 5.2844 & TRN & \\
\hline CHEMBL1458334 & 688620 & 4.75 & 4.9526 & TRN & \\
\hline CHEMBL3213872 & 688620 & 4.95 & 4.8937 & TRN & \\
\hline CHEMBL1533631 & 688620 & 5.3 & 5.088 & TST & \\
\hline CHEMBL1491806 & 688620 & 4.8 & 4.7205 & TRN & \\
\hline CHEMBL3185655 & 688620 & 7.0501 & 5.5625 & TRN & \\
\hline CHEMBL1607527 & 688620 & 5.2 & 4.7673 & TST & \\
\hline CHEMBL3195685 & 688620 & 5.25 & 5.065 & TRN & \\
\hline CHEMBL1511503 & 688620 & 4.95 & 4.9025 & TRN & \\
\hline CHEMBL1517873 & 688620 & 4.45 & 4.8763 & TRN & \\
\hline CHEMBL1544208 & 688620 & 4.85 & 4.8817 & TRN & \\
\hline CHEMBL1988303 & 688620 & 4.95 & 4.8597 & TRN & \\
\hline CHEMBL1507171 & 688620 & 4.85 & 4.8137 & TST & \\
\hline CHEMBL1572944 & 688620 & 5.3 & 5.0801 & TST & \\
\hline CHEMBL1511502 & 688620 & 4.95 & 4.9291 & TRN & \\
\hline CHEMBL1347147 & 688620 & 4.95 & 5.0911 & TRN & \\
\hline CHEMBL1380872 & 688620 & 4.85 & 5.0166 & TRN & \\
\hline CHEMBL1451381 & 688620 & 4.9 & 4.9196 & TRN & \\
\hline CHEMBL1526637 & 688620 & 4.8 & 5.1902 & TST & \\
\hline CHEMBL591412 & 688620 & 5.3 & 5.763 & TRN & \\
\hline CHEMBL1455885 & 688620 & 4.6 & 4.673 & TRN & \\
\hline CHEMBL1600550 & 688620 & 5.2 & 4.9219 & TRN & \\
\hline CHEMBL1407647 & 688620 & 5.2 & 5.0319 & TRN & \\
\hline CHEMBL 1465040 & 688620 & 5.5 & 5.5413 & TRN & \\
\hline CHEMBL1553153 & 688620 & 5.5 & 5.0136 & TRN & \\
\hline CHEMBL1364342 & 688620 & 4.9 & 5.0986 & TST & \\
\hline CHEMBL1360208 & 688620 & 4.8 & 4.6157 & TRN & \\
\hline CHEMBL1494130 & 688620 & 4.8 & 5.0066 & TRN & \\
\hline CHEMBL1565851 & 688620 & 5.3 & 5.5185 & TRN & \\
\hline CHEMBL1588657 & 688620 & 4.95 & 4.931 & TRN & \\
\hline CHEMBL1543125 & 688620 & 4.7 & 5.0627 & TST & \\
\hline CHEMBL1301109 & 688620 & 4.5 & 4.9621 & TRN & \\
\hline CHEMBL3194151 & 688620 & 4.45 & 5.32700 & 0000000001 & TST \\
\hline CHEMBL1565262 & 688620 & 4.85 & 5.1596 & TRN & \\
\hline CHEMBL1405119 & 688620 & 4.6 & 4.91100 & 00000000005 & TRN \\
\hline CHEMBL1575150 & 688620 & 4.95 & 4.7489 & TRN & \\
\hline CHEMBL1336743 & 688620 & 4.7 & 5.0683 & TRN & \\
\hline CHEMBL1481083 & 688620 & 4.65 & 5.4371 & TRN & \\
\hline CHEMBL1500735 & 688620 & 4.75 & 4.8568 & TST & \\
\hline CHEMBL578883 & 688620 & 4.95 & 5.2696 & TRN & \\
\hline CHEMBL1329500 & 688620 & 5.4 & 4.8638 & TRN & \\
\hline CHEMBL1533511 & 688620 & 4.95 & 4.5407 & TRN & \\
\hline CHEMBL1549666 & 688620 & 5.0 & 4.7557 & TRN & \\
\hline CHEMBL1299881 & 688620 & 5.15 & 5.046 & TRN & \\
\hline
\end{tabular}




\begin{tabular}{|c|c|c|c|c|c|}
\hline \multirow{3}{*}{$\begin{array}{l}\text { CHEMBL1507947 } \\
\text { CHEMBL1446899 }\end{array}$} & \multirow{3}{*}{$\begin{array}{l}688620 \\
688620\end{array}$} & \multicolumn{4}{|c|}{ Supplemental Table S2.txt } \\
\hline & & 4.95 & 5.1789 & 9999999999 & TST \\
\hline & & 6.25 & 5.7619 & TRN & \\
\hline CHEMBL1511950 & 688620 & 4.45 & 4.7628 & TRN & \\
\hline CHEMBL1575422 & 688620 & 4.7 & 4.9788 & TRN & \\
\hline CHEMBL1416243 & 688620 & 5.0 & 5.2616 & TRN & \\
\hline CHEMBL1571728 & 688620 & 5.4 & 5.1344 & TRN & \\
\hline CHEMBL1531311 & 688620 & 5.6 & 5.1349 & TRN & \\
\hline CHEMBL3198819 & 688620 & 4.8 & 5.1629 & TRN & \\
\hline CHEMBL1504229 & 688620 & 4.65 & 4.8826 & TRN & \\
\hline CHEMBL1380962 & 688620 & 6.15 & 4.9049 & TST & \\
\hline CHEMBL1353382 & 688620 & 5.0 & 5.1765 & TST & \\
\hline CHEMBL1395972 & 688620 & 4.85 & 5.62 & TST & \\
\hline CHEMBL1431785 & 688620 & 5.15 & 5.3701 & TRN & \\
\hline CHEMBL1523601 & 688620 & 4.95 & 5.0402 & TRN & \\
\hline CHEMBL1402633 & 688620 & 6.05 & 5.0423 & TST & \\
\hline CHEMBL1462190 & 688620 & 4.45 & 5.0823 & TRN & \\
\hline CHEMBL1321638 & 688620 & 6.15 & 5.9874 & TST & \\
\hline CHEMBL1547580 & 688620 & 4.95 & 4.7165 & TRN & \\
\hline CHEMBL1381793 & 688620 & 4.85 & 5.3632 & TRN & \\
\hline CHEMBL1434669 & 688620 & 4.85 & 5.0368 & TRN & \\
\hline CHEMBL1385716 & 688620 & 4.9 & 5.1312 & TRN & \\
\hline CHEMBL1380645 & 688620 & 4.45 & 4.8856 & TRN & \\
\hline CHEMBL1449795 & 688620 & 4.7 & 5.1256 & TRN & \\
\hline CHEMBL1386864 & 688620 & 4.9 & 4.7568 & TRN & \\
\hline CHEMBL1449846 & 688620 & 4.45 & 4.7631 & TRN & \\
\hline CHEMBL1377752 & 688620 & 4.95 & 5.0727 & TRN & \\
\hline CHEMBL1432314 & 688620 & 6.1 & 5.6142 & TST & \\
\hline CHEMBL1404060 & 688620 & 5.05 & 4.9214 & TRN & \\
\hline CHEMBL1581685 & 688620 & 5.0 & 5.079 & TRN & \\
\hline CHEMBL1489520 & 688620 & 5.4 & 5.0737 & TRN & \\
\hline CHEMBL1360972 & 688620 & 5.45 & 5.062 & TST & \\
\hline CHEMBL1482397 & 688620 & 4.45 & 4.8992 & TRN & \\
\hline CHEMBL1441473 & 688620 & 4.9 & 5.2065 & TRN & \\
\hline CHEMBL1328952 & 688620 & 5.4 & 5.2466 & TRN & \\
\hline CHEMBL1324727 & 688620 & 4.45 & 5.3528 & TST & \\
\hline CHEMBL1407812 & 688620 & 4.75 & 4.5287 & TRN & \\
\hline CHEMBL 1325158 & 688620 & 4.85 & 5.2136 & TRN & \\
\hline CHEMBL1324953 & 688620 & 5.3 & 5.0089 & TRN & \\
\hline CHEMBL1607420 & 688620 & 5.85 & 5.0417 & TRN & \\
\hline CHEMBL1382907 & 688620 & 6.9 & 5.3551 & TRN & \\
\hline CHEMBL 31782 & 688620 & 5.9 & 5.7852 & TRN & \\
\hline CHEMBL1565524 & 688620 & 5.05 & 5.0471 & TRN & \\
\hline CHEMBL1427387 & 688620 & 4.95 & 4.8898 & TRN & \\
\hline CHEMBL484663 & 688620 & 4.75 & 5.3335 & TRN & \\
\hline CHEMBL1386139 & 688620 & 4.85 & 5.2568 & TRN & \\
\hline CHEMBL1371142 & 688620 & 5.0 & 5.1121 & TST & \\
\hline CHEMBL1501062 & 688620 & 6.25 & 6.0627 & TRN & \\
\hline CHEMBL3198275 & 688620 & 5.2 & 5.1602 & TRN & \\
\hline
\end{tabular}




\begin{tabular}{|c|c|c|c|c|}
\hline \multicolumn{5}{|c|}{ Supplemental Table S2.txt } \\
\hline CHEMBL1500641 & 688620 & 6.0 & 5.6652 & TRN \\
\hline CHEMBL1486708 & 688620 & 5.2 & 5.113 & TST \\
\hline CHEMBL1526651 & 688620 & 4.9 & 5.12299 & 9999999999 \\
\hline CHEMBL1337529 & 688620 & 4.8 & 5.1063 & TRN \\
\hline CHEMBL1388969 & 688620 & 5.45 & 5.2556 & TRN \\
\hline CHEMBL1372142 & 688620 & 5.15 & 5.1376 & TST \\
\hline CHEMBL1533388 & 688620 & 6.0 & 5.2172 & TST \\
\hline CHEMBL1421836 & 688620 & 4.45 & 4.7505 & TST \\
\hline CHEMBL 2001904 & 688620 & 6.0 & 5.598 & TST \\
\hline CHEMBL1483138 & 688620 & 4.6 & 4.7416 & TRN \\
\hline CHEMBL1375181 & 688620 & 5.0 & 4.9765 & TST \\
\hline CHEMBL1539766 & 688620 & 5.05 & 5.1688 & TRN \\
\hline CHEMBL1309776 & 688620 & 4.95 & 5.1309 & TST \\
\hline CHEMBL1470378 & 688620 & 4.9 & 4.9042 & TST \\
\hline CHEMBL1561207 & 688620 & 4.5 & 5.2843 & TRN \\
\hline CHEMBL1429703 & 688620 & 4.95 & 4.9423 & TST \\
\hline CHEMBL1406986 & 688620 & 4.65 & 5.0879 & TRN \\
\hline CHEMBL1386185 & 688620 & 4.85 & 5.0108 & TRN \\
\hline CHEMBL 3190261 & 688620 & 5.3 & 5.6826 & TRN \\
\hline CHEMBL1564028 & 688620 & 5.0 & 4.8228 & TRN \\
\hline CHEMBL1432243 & 688620 & 4.7 & 5.0299 & TRN \\
\hline CHEMBL1547324 & 688620 & 4.45 & 4.7244 & TRN \\
\hline CHEMBL1416324 & 688620 & 5.35 & 5.0921 & TRN \\
\hline CHEMBL1418633 & 688620 & 4.45 & 5.0913 & TRN \\
\hline CHEMBL1352909 & 688620 & 4.9 & 5.0072 & TRN \\
\hline CHEMBL1464368 & 688620 & 4.75 & 5.3415 & TST \\
\hline CHEMBL1342910 & 688620 & 4.5 & 5.0696 & TST \\
\hline CHEMBL1309880 & 688620 & 4.9 & 5.1434 & TST \\
\hline CHEMBL1549088 & 688620 & 4.9 & 4.9708 & TRN \\
\hline CHEMBL1427060 & 688620 & 5.2 & 4.8546 & TRN \\
\hline CHEMBL1459385 & 688620 & 5.9 & 5.098 & TRN \\
\hline CHEMBL1469863 & 688620 & 4.45 & 5.3025 & TRN \\
\hline CHEMBL1410569 & 688620 & 6.15 & 5.1549 & TRN \\
\hline CHEMBL1545984 & 688620 & 5.3 & 5.3097 & TRN \\
\hline CHEMBL1545125 & 688620 & 4.7 & 5.0763 & TRN \\
\hline CHEMBL 2003831 & 688620 & 5.25 & 5.0205 & TST \\
\hline CHEMBL1462703 & 688620 & 4.45 & 4.9841 & TRN \\
\hline CHEMBL1299391 & 688620 & 4.7 & 4.9523 & TRN \\
\hline CHEMBL1527341 & 688620 & 5.0 & 5.1528 & TRN \\
\hline CHEMBL1605790 & 688620 & 4.95 & 5.0107 & TST \\
\hline CHEMBL1421265 & 688620 & 4.95 & 4.6555 & TRN \\
\hline CHEMBL1482438 & 688620 & 5.8 & 4.7472 & TRN \\
\hline CHEMBL1546727 & 688620 & 4.95 & 5.2327 & TST \\
\hline CHEMBL1535387 & 688620 & 4.95 & 4.9406 & TRN \\
\hline CHEMBL1479996 & 688620 & 6.5501 & 5.1547 & TRN \\
\hline CHEMBL1386947 & 688620 & 7.0 & 6.03 & TRN \\
\hline CHEMBL1445776 & 688620 & 5.3 & 5.2078 & TST \\
\hline CHEMBL1518412 & 688620 & 5.0 & 5.1154 & TRN \\
\hline
\end{tabular}




\begin{tabular}{|c|c|c|c|c|c|}
\hline & & \multicolumn{4}{|c|}{ Supplemental Table S2.txt } \\
\hline CHEMBL1446729 & 688620 & 8.2007 & 5.1088 & TST & \\
\hline CHEMBL3190346 & 688620 & 4.6 & 5.0263 & TRN & \\
\hline CHEMBL3211046 & 688620 & 4.45 & 5.5484 & TRN & \\
\hline CHEMBL1500382 & 688620 & 4.8 & 5.273 & TRN & \\
\hline CHEMBL1579067 & 688620 & 5.85 & 4.968 & TRN & \\
\hline CHEMBL1542148 & 688620 & 5.5 & 4.9746 & TRN & \\
\hline CHEMBL1432325 & 688620 & 4.75 & 4.8266 & TRN & \\
\hline CHEMBL1325170 & 688620 & 4.65 & 5.2685 & TST & \\
\hline CHEMBL1522980 & 688620 & 5.1 & 4.8294 & TRN & \\
\hline CHEMBL1545584 & 688620 & 4.95 & 4.9609 & TRN & \\
\hline CHEMBL1450467 & 688620 & 5.2 & 4.9677 & TRN & \\
\hline CHEMBL265686 & 688620 & 5.6 & 5.7682 & TRN & \\
\hline CHEMBL1451856 & 688620 & 4.45 & 4.9704 & TST & \\
\hline CHEMBL1966890 & 688620 & 5.55 & 5.3046 & TRN & \\
\hline CHEMBL1465947 & 688620 & 4.85 & 4.7537 & TRN & \\
\hline CHEMBL1319895 & 688620 & 5.05 & 4.9869 & TRN & \\
\hline CHEMBL1510138 & 688620 & 4.7 & 4.9485 & TRN & \\
\hline CHEMBL1432293 & 688620 & 4.95 & 4.9091 & TRN & \\
\hline CHEMBL1581855 & 688620 & 4.65 & 4.8496 & TRN & \\
\hline CHEMBL1508782 & 688620 & 5.15 & 4.9613 & TRN & \\
\hline CHEMBL3193095 & 688620 & 4.45 & 4.9357 & TRN & \\
\hline CHEMBL1383371 & 688620 & 6.15 & 5.87299 & 9999999999 & TRN \\
\hline CHEMBL3211510 & 688620 & 5.3 & 4.9426 & TRN & \\
\hline CHEMBL1319768 & 688620 & 6.1 & 5.1258 & TRN & \\
\hline CHEMBL1541933 & 688620 & 5.5 & 5.0498 & TRN & \\
\hline CHEMBL1464375 & 688620 & 4.65 & 5.2011 & TRN & \\
\hline CHEMBL454739 & 688620 & 4.8 & 5.106 & TST & \\
\hline CHEMBL1461038 & 688620 & 5.55 & 4.9514 & TST & \\
\hline CHEMBL1409840 & 688620 & 5.9 & 5.4869 & TRN & \\
\hline CHEMBL1412450 & 688620 & 4.45 & 4.7086 & TST & \\
\hline CHEMBL1503663 & 688620 & 6.4 & 4.9457 & TRN & \\
\hline CHEMBL1497658 & 688620 & 5.2 & 5.1118 & TRN & \\
\hline CHEMBL3195994 & 688620 & 4.9 & 5.0105 & TRN & \\
\hline CHEMBL2369184 & 688620 & 5.5 & 5.6412 & TRN & \\
\hline CHEMBL1431364 & 688620 & 4.8 & 5.1553 & TRN & \\
\hline CHEMBL1501707 & 688620 & 5.55 & 5.2395 & TST & \\
\hline CHEMBL1532645 & 688620 & 6.15 & 5.9798 & TRN & \\
\hline CHEMBL1520146 & 688620 & 4.5 & 4.9676 & TRN & \\
\hline CHEMBL1519109 & 688620 & 4.9 & 4.6799 & TST & \\
\hline CHEMBL1354188 & 688620 & 4.7 & 4.8205 & TST & \\
\hline CHEMBL1256686 & 688620 & 6.0 & 5.3575 & TST & \\
\hline CHEMBL1416425 & 688620 & 5.4 & 5.0576 & TRN & \\
\hline CHEMBL1569209 & 688620 & 4.9 & 4.9937 & TST & \\
\hline CHEMBL1412091 & 688620 & 5.4 & 5.3358 & TRN & \\
\hline CHEMBL1599521 & 688620 & 4.9 & 4.9895 & TRN & \\
\hline CHEMBL1534096 & 688620 & 4.95 & 4.9577 & TST & \\
\hline CHEMBL1350491 & 688620 & 4.6 & 4.7234 & TRN & \\
\hline CHEMBL3197803 & 688620 & 6.05 & 5.9071 & TRN & \\
\hline
\end{tabular}




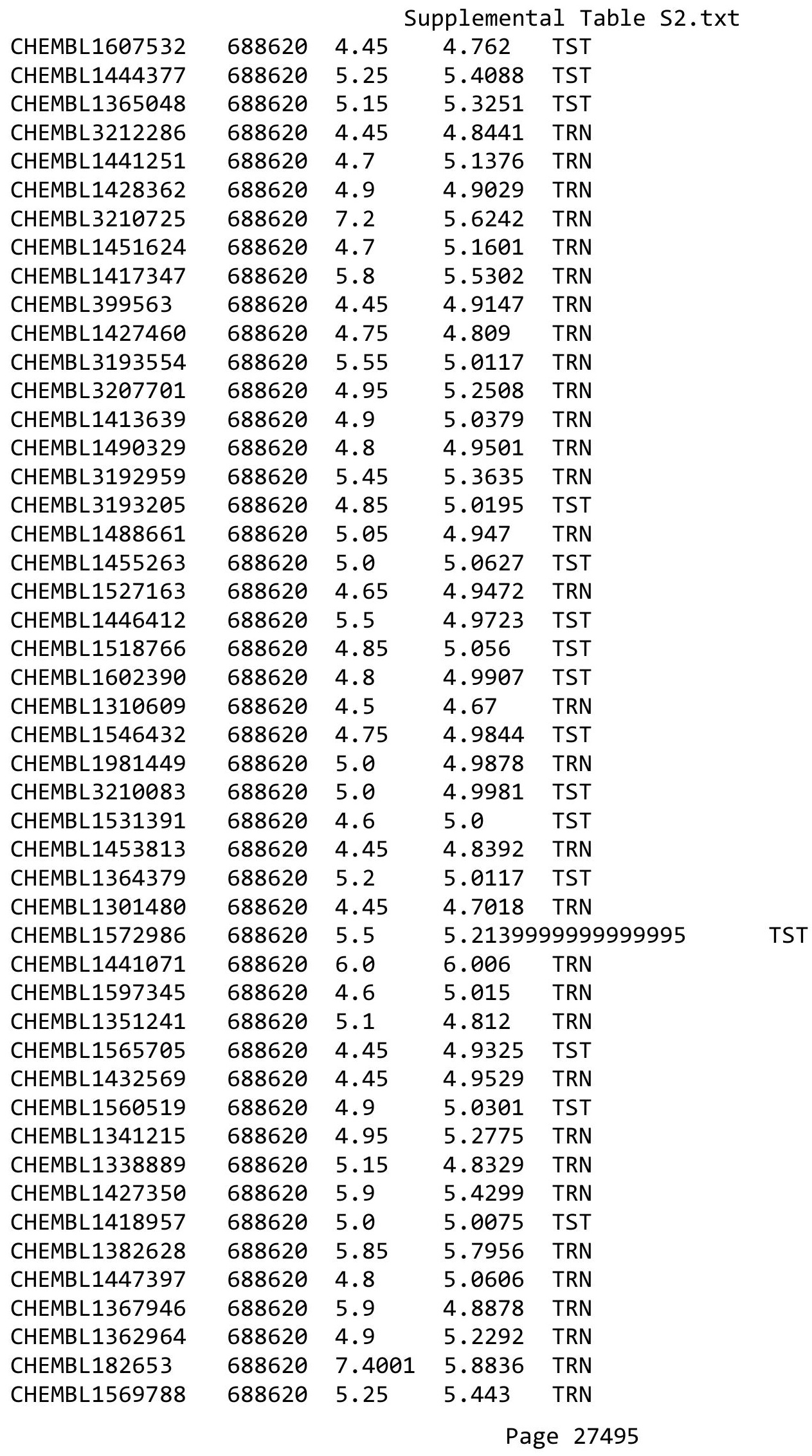




\begin{tabular}{|c|c|c|c|c|}
\hline \multicolumn{5}{|c|}{ Supplemental Table S2.txt } \\
\hline CHEMBL1391106 & 688620 & 5.55 & 5.0672 & TST \\
\hline CHEMBL1391381 & 688620 & 4.65 & 4.9632 & TRN \\
\hline CHEMBL1364510 & 688620 & 6.5 & 5.5324 & TST \\
\hline CHEMBL1993194 & 688620 & 5.6 & 5.5408 & TRN \\
\hline CHEMBL1442202 & 688620 & 4.65 & 4.8917 & TRN \\
\hline CHEMBL1373814 & 688620 & 4.8 & 5.0102 & TST \\
\hline CHEMBL1521144 & 688620 & 5.2 & 5.0597 & TST \\
\hline CHEMBL1443170 & 688620 & 5.3 & 5.0021 & TRN \\
\hline CHEMBL3194726 & 688620 & 6.25 & 5.5247 & TRN \\
\hline CHEMBL1530043 & 688620 & 5.65 & 4.9792 & TST \\
\hline CHEMBL1519843 & 688620 & 4.45 & 5.7421 & TRN \\
\hline CHEMBL1612061 & 688620 & 4.45 & 5.2337 & TST \\
\hline CHEMBL3193903 & 688620 & 4.9 & 5.1371 & TRN \\
\hline CHEMBL1492010 & 688620 & 5.05 & 4.994 & TRN \\
\hline CHEMBL1541379 & 688620 & 4.9 & 4.7071 & TRN \\
\hline CHEMBL609606 & 688620 & 4.45 & 5.3452 & TRN \\
\hline CHEMBL1608294 & 688620 & 5.15 & 5.0033 & TRN \\
\hline CHEMBL1407793 & 688620 & 4.8 & 4.7158 & TRN \\
\hline CHEMBL1517332 & 688620 & 4.5 & 5.0963 & TRN \\
\hline CHEMBL1410683 & 688620 & 4.8 & 5.0837 & TST \\
\hline CHEMBL1597356 & 688620 & 5.2 & 5.2332 & TRN \\
\hline CHEMBL3214547 & 688620 & 7.1002 & 5.1997 & TRN \\
\hline CHEMBL1368381 & 688620 & 4.8 & 4.8768 & TST \\
\hline CHEMBL3190843 & 688620 & 4.65 & 5.1081 & TRN \\
\hline CHEMBL1457884 & 688620 & 4.65 & 4.801 & TRN \\
\hline CHEMBL1490108 & 688620 & 5.15 & 4.9253 & TRN \\
\hline CHEMBL1302792 & 688620 & 5.85 & 4.8995 & TRN \\
\hline CHEMBL1421827 & 688620 & 4.45 & 4.8599 & TRN \\
\hline CHEMBL1476793 & 688620 & 5.7 & 5.0597 & TST \\
\hline CHEMBL1535225 & 688620 & 5.7 & 5.6765 & TRN \\
\hline CHEMBL1546767 & 688620 & 5.25 & 5.6445 & TRN \\
\hline CHEMBL1587190 & 688620 & 5.25 & 4.7393 & TRN \\
\hline CHEMBL1981103 & 688620 & 5.3 & 5.2316 & TST \\
\hline CHEMBL1369220 & 688620 & 4.95 & 5.2221 & TRN \\
\hline CHEMBL1578469 & 688620 & 4.9 & 5.0339 & TRN \\
\hline CHEMBL1589084 & 688620 & 7.1002 & 5.1015 & TST \\
\hline CHEMBL1323942 & 688620 & 4.85 & 5.1858 & TRN \\
\hline CHEMBL1577631 & 688620 & 4.85 & 4.7095 & TRN \\
\hline CHEMBL3212823 & 688620 & 4.95 & 5.1423 & TST \\
\hline CHEMBL1491050 & 688620 & 5.45 & 4.8786 & TRN \\
\hline CHEMBL3214566 & 688620 & 5.25 & 5.0781 & TRN \\
\hline CHEMBL1612888 & 688620 & 4.95 & 5.0397 & TST \\
\hline CHEMBL1464142 & 688620 & 4.9 & 4.9933 & TST \\
\hline CHEMBL3210321 & 688620 & 4.65 & 5.0656 & TRN \\
\hline CHEMBL1446234 & 688620 & 4.45 & 4.7109 & TRN \\
\hline CHEMBL1586557 & 688620 & 5.0 & 4.9751 & TRN \\
\hline CHEMBL1587831 & 688620 & 4.95 & 5.2321 & TST \\
\hline CHEMBL1322336 & 688620 & 5.9 & 5.2344 & TRN \\
\hline
\end{tabular}




\begin{tabular}{|c|c|c|c|c|c|}
\hline \multicolumn{6}{|c|}{ Supplemental Table S2.txt } \\
\hline CHEMBL1304946 & 688620 & 4.45 & 5.04 & TRN & \\
\hline CHEMBL3144948 & 688620 & 4.9 & 5.3505 & TST & \\
\hline CHEMBL1450728 & 688620 & 4.45 & 4.6717 & TRN & \\
\hline CHEMBL1521055 & 688620 & 4.45 & 4.9335 & TRN & \\
\hline CHEMBL1301140 & 688620 & 4.95 & 5.0264 & TRN & \\
\hline CHEMBL1498110 & 688620 & 4.45 & 5.0071 & TST & \\
\hline CHEMBL1338059 & 688620 & 4.85 & 5.0056 & TRN & \\
\hline CHEMBL1490308 & 688620 & 4.85 & 4.8619 & TST & \\
\hline CHEMBL1608180 & 688620 & 5.35 & 5.0169 & TRN & \\
\hline CHEMBL1492676 & 688620 & 4.45 & 5.1057 & TST & \\
\hline CHEMBL1965132 & 688620 & 5.9 & 5.5111 & TRN & \\
\hline CHEMBL1497243 & 688620 & 4.45 & 4.8627 & TRN & \\
\hline CHEMBL1414374 & 688620 & 4.8 & 5.1143 & TRN & \\
\hline CHEMBL1502296 & 688620 & 5.45 & 5.34 & TST & \\
\hline CHEMBL1977082 & 688620 & 4.45 & 4.7419 & TST & \\
\hline CHEMBL1390041 & 688620 & 6.1 & 5.0591 & TST & \\
\hline CHEMBL1310055 & 688620 & 5.35 & 5.0822 & TRN & \\
\hline CHEMBL1299672 & 688620 & 4.45 & 5.0208 & TRN & \\
\hline CHEMBL1308253 & 688620 & 5.6 & 4.928 & TST & \\
\hline CHEMBL1613433 & 688620 & 4.9 & 4.8242 & TRN & \\
\hline CHEMBL1390525 & 688620 & 4.85 & 5.1539 & TRN & \\
\hline CHEMBL1372217 & 688620 & 5.2 & 5.3084 & TRN & \\
\hline CHEMBL1459946 & 688620 & 4.6 & 5.0499 & TRN & \\
\hline CHEMBL1607067 & 688620 & 4.6 & 5.012 & TRN & \\
\hline CHEMBL570400 & 688620 & 5.2 & 4.9635 & TRN & \\
\hline CHEMBL1527494 & 688620 & 5.2 & 4.83899 & 99999999995 & TST \\
\hline CHEMBL1611371 & 688620 & 4.45 & 5.0593 & TRN & \\
\hline CHEMBL1450335 & 688620 & 4.9 & 4.9468 & TRN & \\
\hline CHEMBL1487078 & 688620 & 6.05 & 5.3602 & TRN & \\
\hline CHEMBL1584669 & 688620 & 4.75 & 4.9146 & TRN & \\
\hline CHEMBL1459812 & 688620 & 4.45 & 4.9377 & TRN & \\
\hline CHEMBL1346671 & 688620 & 4.8 & 4.878 & TST & \\
\hline CHEMBL1541341 & 688620 & 5.15 & 4.9721 & TRN & \\
\hline CHEMBL1583669 & 688620 & 4.5 & 5.0048 & TRN & \\
\hline CHEMBL1417979 & 688620 & 5.25 & 5.0722 & TST & \\
\hline CHEMBL243651 & 688620 & 4.45 & 4.7326 & TRN & \\
\hline CHEMBL1506109 & 688620 & 4.7 & 5.0676 & TRN & \\
\hline CHEMBL1559434 & 688620 & 4.9 & 5.0675 & TST & \\
\hline CHEMBL1561256 & 688620 & 5.4 & 4.9148 & TRN & \\
\hline CHEMBL1527880 & 688620 & 4.45 & 4.9153 & TRN & \\
\hline CHEMBL1469596 & 688620 & 4.45 & 4.9832 & TST & \\
\hline CHEMBL1406300 & 688620 & 5.6 & 4.8773 & TRN & \\
\hline CHEMBL3213149 & 688620 & 4.6 & 4.8175 & TRN & \\
\hline CHEMBL1345232 & 688620 & 4.9 & 5.0581 & TRN & \\
\hline CHEMBL1310240 & 688620 & 5.55 & 5.3486 & TRN & \\
\hline CHEMBL1307397 & 688620 & 4.7 & 4.8648 & TRN & \\
\hline CHEMBL1600765 & 688620 & 4.75 & 5.083 & TST & \\
\hline CHEMBL1571624 & 688620 & 5.2 & 5.0941 & TRN & \\
\hline
\end{tabular}




\begin{tabular}{|c|c|c|c|c|}
\hline \multicolumn{5}{|c|}{ Supplemental Table S2.txt } \\
\hline CHEMBL201325 & 688620 & 4.9 & 5.6903 & TRN \\
\hline CHEMBL1446039 & 688620 & 4.95 & 5.1941 & TRN \\
\hline CHEMBL1421686 & 688620 & 4.85 & 4.9174 & TST \\
\hline CHEMBL1385866 & 688620 & 5.0 & 4.8722 & TST \\
\hline CHEMBL 1477550 & 688620 & 4.45 & 5.0783 & TRN \\
\hline CHEMBL1366983 & 688620 & 5.55 & 4.9687 & TRN \\
\hline CHEMBL1454873 & 688620 & 5.2 & 4.954 & TRN \\
\hline CHEMBL1404950 & 688620 & 5.0 & 5.0418 & TST \\
\hline CHEMBL37708 & 688620 & 4.45 & 4.9942 & TST \\
\hline CHEMBL1369125 & 688620 & 4.45 & 4.6066 & TRN \\
\hline CHEMBL1450716 & 688620 & 5.55 & 5.1319 & TRN \\
\hline CHEMBL1393085 & 688620 & 4.85 & 4.8677 & TRN \\
\hline CHEMBL1520184 & 688620 & 4.65 & 5.1501 & TRN \\
\hline CHEMBL1443094 & 688620 & 4.95 & 5.1087 & TST \\
\hline CHEMBL1577609 & 688620 & 4.45 & 5.3211 & TRN \\
\hline CHEMBL1472375 & 688620 & 4.75 & 4.9223 & TRN \\
\hline CHEMBL1502148 & 688620 & 5.4 & 4.9151 & TRN \\
\hline CHEMBL1584879 & 688620 & 4.45 & 4.8171 & TRN \\
\hline CHEMBL1475194 & 688620 & 5.3 & 5.0103 & TRN \\
\hline CHEMBL1573972 & 688620 & 4.9 & 5.0919 & TRN \\
\hline CHEMBL1313475 & 688620 & 4.45 & 5.0892 & TST \\
\hline CHEMBL1498317 & 688620 & 4.9 & 5.0138 & TRN \\
\hline CHEMBL1455689 & 688620 & 5.15 & 5.4634 & TRN \\
\hline CHEMBL1428137 & 688620 & 4.6 & 5.2017 & TST \\
\hline CHEMBL1471241 & 688620 & 5.5 & 5.0331 & TRN \\
\hline CHEMBL1306262 & 688620 & 4.8 & 5.1592 & TST \\
\hline CHEMBL1996013 & 688620 & 6.0 & 5.6812 & TRN \\
\hline CHEMBL1546470 & 688620 & 4.65 & 5.033 & TST \\
\hline CHEMBL1361185 & 688620 & 4.8 & 5.1024 & TRN \\
\hline CHEMBL 1424857 & 688620 & 5.0 & 5.1247 & TST \\
\hline CHEMBL1496857 & 688620 & 4.45 & 5.09 & TST \\
\hline CHEMBL1509339 & 688620 & 4.45 & 5.1233 & TRN \\
\hline CHEMBL1415906 & 688620 & 4.6 & 5.1364 & TRN \\
\hline CHEMBL1506805 & 688620 & 4.75 & 5.0188 & TRN \\
\hline CHEMBL1501101 & 688620 & 5.2 & 5.2157 & TRN \\
\hline CHEMBL1406277 & 688620 & 6.3 & 4.9596 & TRN \\
\hline CHEMBL1534490 & 688620 & 5.2 & 5.073 & TST \\
\hline CHEMBL1344930 & 688620 & 5.1 & 5.13899 & 9999999999 \\
\hline CHEMBL1605277 & 688620 & 5.5 & 5.1405 & TRN \\
\hline CHEMBL1484856 & 688620 & 5.8 & 5.5604 & TST \\
\hline CHEMBL1543505 & 688620 & 4.95 & 4.8824 & TRN \\
\hline CHEMBL1386806 & 688620 & 4.5 & 4.914 & TRN \\
\hline CHEMBL1324074 & 688620 & 4.95 & 4.945 & TRN \\
\hline CHEMBL1568900 & 688620 & 5.5 & 5.1017 & TST \\
\hline CHEMBL1455289 & 688620 & 4.6 & 4.9966 & TRN \\
\hline CHEMBL1423082 & 688620 & 4.9 & 4.8374 & TRN \\
\hline CHEMBL1572875 & 688620 & 6.5501 & 4.9531 & TRN \\
\hline CHEMBL1497875 & 688620 & 5.05 & 5.148 & TST \\
\hline
\end{tabular}




\begin{tabular}{|c|c|c|c|c|c|}
\hline \multirow{2}{*}{ CHEMBL1455910 } & \multirow{2}{*}{688620} & \\
\hline & & 4.65 & \multicolumn{2}{|c|}{4.9030000000000005} & TRN \\
\hline CHEMBL3189508 & 688620 & 4.95 & 5.058 & TRN & \\
\hline CHEMBL1603582 & 688620 & 6.0 & 5.2754 & TRN & \\
\hline CHEMBL1334210 & 688620 & 4.85 & 5.2235 & TRN & \\
\hline CHEMBL1393234 & 688620 & 5.0 & 5.0638 & TRN & \\
\hline CHEMBL1415015 & 688620 & 4.45 & 4.8741 & TRN & \\
\hline CHEMBL1476181 & 688620 & 4.65 & 4.9919 & TRN & \\
\hline CHEMBL3190672 & 688620 & 5.45 & 5.263 & TRN & \\
\hline CHEMBL1545767 & 688620 & 4.9 & 5.0383 & TRN & \\
\hline CHEMBL1418096 & 688620 & 4.45 & 5.3404 & TRN & \\
\hline CHEMBL3189595 & 688620 & 5.55 & 5.4539 & TRN & \\
\hline CHEMBL1351465 & 688620 & 5.05 & 5.0541 & TRN & \\
\hline CHEMBL1365220 & 688620 & 4.7 & 5.1207 & TRN & \\
\hline CHEMBL1496007 & 688620 & 6.25 & 5.6657 & TRN & \\
\hline CHEMBL1346420 & 688620 & 4.45 & 4.9874 & TST & \\
\hline CHEMBL1352832 & 688620 & 4.75 & 4.7419 & TRN & \\
\hline CHEMBL1304854 & 688620 & 5.65 & \multicolumn{2}{|c|}{5.5520000000000005} & TRN \\
\hline CHEMBL1335780 & 688620 & 4.9 & 4.9733 & TRN & \\
\hline CHEMBL1517666 & 688620 & 4.75 & 4.9089 & TRN & \\
\hline CHEMBL1447077 & 688620 & 7.1002 & 5.0456 & TRN & \\
\hline CHEMBL1334826 & 688620 & 5.25 & 5.3315 & TRN & \\
\hline CHEMBL1543752 & 688620 & 4.45 & 4.6688 & TST & \\
\hline CHEMBL1442983 & 688620 & 4.45 & 5.0309 & TST & \\
\hline CHEMBL1400863 & 688620 & 6.2 & 5.0302 & TRN & \\
\hline CHEMBL1405946 & 688620 & 4.85 & 5.1211 & TRN & \\
\hline CHEMBL3189281 & 688620 & 5.9 & 5.106 & TST & \\
\hline CHEMBL1393851 & 688620 & 4.45 & 5.1936 & TRN & \\
\hline CHEMBL1405460 & 688620 & 4.45 & 4.9678 & TST & \\
\hline CHEMBL1458371 & 688620 & 4.9 & 4.9608 & TRN & \\
\hline CHEMBL3194964 & 688620 & 6.0 & 5.6773 & TRN & \\
\hline CHEMBL1321179 & 688620 & 5.45 & 4.9668 & TRN & \\
\hline CHEMBL1975959 & 688620 & 4.65 & 5.1575 & TST & \\
\hline CHEMBL3193581 & 688620 & 5.15 & 5.1584 & TRN & \\
\hline CHEMBL1313457 & 688620 & 4.95 & 4.835 & TRN & \\
\hline CHEMBL1540036 & 688620 & 4.7 & 4.8303 & TRN & \\
\hline CHEMBL1306199 & 688620 & 4.75 & 4.9119 & TRN & \\
\hline CHEMBL1447405 & 688620 & 6.25 & 5.0231 & TRN & \\
\hline CHEMBL1342926 & 688620 & 5.0 & 4.8362 & TRN & \\
\hline CHEMBL 2000340 & 688620 & 4.45 & 4.8855 & TRN & \\
\hline CHEMBL1970761 & 688620 & 4.75 & 5.02 & TST & \\
\hline CHEMBL1559726 & 688620 & 4.85 & 5.0368 & TST & \\
\hline CHEMBL1506622 & 688620 & 4.8 & 5.1015 & TRN & \\
\hline CHEMBL1390903 & 688620 & 5.1 & 5.1326 & TRN & \\
\hline CHEMBL1557254 & 688620 & 5.15 & 4.9754 & TRN & \\
\hline CHEMBL1368963 & 688620 & 5.2 & 4.838 & TRN & \\
\hline CHEMBL1597580 & 688620 & 5.2 & 5.0417 & TRN & \\
\hline CHEMBL1302352 & 688620 & 6.35 & 5.0074 & TRN & \\
\hline CHEMBL3192655 & 688620 & 4.95 & 5.3517 & TRN & \\
\hline
\end{tabular}




\begin{tabular}{|c|c|c|c|c|}
\hline \multicolumn{5}{|c|}{ Supplemental Table S2.txt } \\
\hline CHEMBL1406201 & 688620 & 4.7 & 4.8441 & TRN \\
\hline CHEMBL1341833 & 688620 & 4.65 & 4.8201 & TST \\
\hline CHEMBL1527400 & 688620 & 5.65 & 5.7971 & TRN \\
\hline CHEMBL 1498360 & 688620 & 5.35 & 5.0687 & TRN \\
\hline CHEMBL1520994 & 688620 & 4.9 & 4.9488 & TRN \\
\hline CHEMBL1550585 & 688620 & 5.35 & 4.9848 & TRN \\
\hline CHEMBL1343868 & 688620 & 4.75 & 4.9242 & TRN \\
\hline CHEMBL1494579 & 688620 & 5.0 & 4.7716 & TRN \\
\hline CHEMBL1419870 & 688620 & 6.0 & 5.269 & TRN \\
\hline CHEMBL1326145 & 688620 & 4.75 & 4.8851 & TRN \\
\hline CHEMBL1575487 & 688620 & 5.45 & 5.0217 & TST \\
\hline CHEMBL1431235 & 688620 & 7.0 & 5.0758 & TRN \\
\hline CHEMBL1331759 & 688620 & 4.75 & 5.019 & TRN \\
\hline CHEMBL1540632 & 688620 & 5.0 & 4.8782 & TRN \\
\hline CHEMBL1340713 & 688620 & 5.3 & 5.1861 & TST \\
\hline CHEMBL1312261 & 688620 & 4.95 & 4.8718 & TRN \\
\hline CHEMBL1984639 & 688620 & 5.25 & 5.6337 & TST \\
\hline CHEMBL1525220 & 688620 & 5.1 & 4.9675 & TRN \\
\hline CHEMBL1992486 & 688620 & 5.15 & 5.0133 & TST \\
\hline CHEMBL1364452 & 688620 & 5.05 & 5.1779 & TRN \\
\hline CHEMBL89445 & 688620 & 4.9 & 5.3688 & TRN \\
\hline CHEMBL1594321 & 688620 & 4.75 & 5.0893 & TRN \\
\hline CHEMBL1415705 & 688620 & 4.65 & 4.6242 & TST \\
\hline CHEMBL3192476 & 688620 & 8.3468 & 4.8545 & TRN \\
\hline CHEMBL1485246 & 688620 & 4.7 & 4.9591 & TRN \\
\hline CHEMBL1572605 & 688620 & 5.0 & 5.2074 & TST \\
\hline CHEMBL1424970 & 688620 & 4.9 & 5.1126 & TST \\
\hline CHEMBL1609044 & 688620 & 4.45 & 4.8705 & TRN \\
\hline CHEMBL3191830 & 688620 & 5.3 & 4.8593 & TRN \\
\hline CHEMBL1991126 & 688620 & 4.8 & 4.877 & TRN \\
\hline CHEMBL3194994 & 688620 & 4.85 & 4.7114 & TST \\
\hline CHEMBL1333193 & 688620 & 5.45 & 5.0911 & TRN \\
\hline CHEMBL1301075 & 688620 & 5.0 & 5.0089 & TRN \\
\hline CHEMBL1425837 & 688620 & 4.9 & 5.0192 & TRN \\
\hline CHEMBL512749 & 688620 & 5.6 & 5.4154 & TRN \\
\hline CHEMBL3194911 & 688620 & 4.95 & 4.9517 & TRN \\
\hline CHEMBL1605804 & 688620 & 5.75 & 5.1498 & TRN \\
\hline CHEMBL1481661 & 688620 & 4.45 & 5.1982 & TST \\
\hline CHEMBL1414330 & 688620 & 4.45 & 5.1836 & TRN \\
\hline CHEMBL1319024 & 688620 & 4.6 & 4.8036 & TRN \\
\hline CHEMBL1996523 & 688620 & 5.8 & 4.9779 & TRN \\
\hline CHEMBL1980050 & 688620 & 5.8 & 5.4312 & TRN \\
\hline CHEMBL1592920 & 688620 & 5.4 & 4.9356 & TST \\
\hline CHEMBL1365290 & 688620 & 4.9 & 5.2895 & TRN \\
\hline CHEMBL1407478 & 688620 & 4.45 & 4.8201 & TRN \\
\hline CHEMBL1492172 & 688620 & 4.95 & 4.8281 & TRN \\
\hline CHEMBL1511459 & 688620 & 5.1 & 5.1736 & TST \\
\hline CHEMBL1337898 & 688620 & 5.7 & 5.4859 & TRN \\
\hline
\end{tabular}




\begin{tabular}{|c|c|c|c|c|c|}
\hline \multicolumn{6}{|c|}{ Supplemental Table S2.txt } \\
\hline CHEMBL1452111 & 688620 & 5.75 & 5.2651 & TRN & \\
\hline CHEMBL1535314 & 688620 & 4.85 & 4.8498 & TRN & \\
\hline CHEMBL1558119 & 688620 & 4.45 & 4.8226 & TRN & \\
\hline CHEMBL1373489 & 688620 & 4.45 & 5.0389 & TRN & \\
\hline CHEMBL1336197 & 688620 & 5.5 & 5.2635 & TRN & \\
\hline CHEMBL1433049 & 688620 & 5.05 & 5.0561 & TRN & \\
\hline CHEMBL1487751 & 688620 & 5.0 & 5.0559 & TRN & \\
\hline CHEMBL1341560 & 688620 & 5.4 & 5.1471 & TRN & \\
\hline CHEMBL1430593 & 688620 & 5.5 & 5.0389 & TRN & \\
\hline CHEMBL1327047 & 688620 & 4.9 & 4.9238 & TST & \\
\hline CHEMBL1321091 & 688620 & 5.0 & 5.0124 & TRN & \\
\hline CHEMBL1349682 & 688620 & 6.0 & 5.6607 & TRN & \\
\hline CHEMBL1459350 & 688620 & 6.1 & 5.684 & TST & \\
\hline CHEMBL1342896 & 688620 & 6.8 & 5.9282 & TRN & \\
\hline CHEMBL1306290 & 688620 & 5.5 & 4.9717 & TST & \\
\hline CHEMBL1606479 & 688620 & 5.2 & 5.0133 & TRN & \\
\hline CHEMBL 3145116 & 688620 & 4.45 & 5.0085 & TRN & \\
\hline CHEMBL3193761 & 688620 & 4.85 & 5.101 & TST & \\
\hline CHEMBL1519982 & 688620 & 4.45 & 4.9835 & TRN & \\
\hline CHEMBL1431645 & 688620 & 4.8 & 4.9392 & TRN & \\
\hline CHEMBL1580415 & 688620 & 4.45 & 4.8443 & TRN & \\
\hline CHEMBL 3198533 & 688620 & 5.0 & 4.8959 & TST & \\
\hline CHEMBL1347611 & 688620 & 5.55 & 5.1069 & TRN & \\
\hline CHEMBL1525432 & 688620 & 4.95 & 5.0593 & TST & \\
\hline CHEMBL1500202 & 688620 & 4.9 & 4.94600 & 0000000001 & TRN \\
\hline CHEMBL1455637 & 688620 & 4.45 & 4.8531 & TST & \\
\hline CHEMBL1417810 & 688620 & 4.9 & 4.9602 & TRN & \\
\hline CHEMBL131921 & 688620 & 4.45 & 5.2487 & TRN & \\
\hline CHEMBL1504963 & 688620 & 4.45 & 5.0748 & TRN & \\
\hline CHEMBL1379620 & 688620 & 4.95 & 4.9109 & TRN & \\
\hline CHEMBL1389495 & 688620 & 5.85 & 6.0297 & TRN & \\
\hline CHEMBL1540333 & 688620 & 4.65 & 5.0519 & TRN & \\
\hline CHEMBL1345024 & 688620 & 4.8 & 5.1495 & TST & \\
\hline CHEMBL1497314 & 688620 & 5.05 & 5.0834 & TRN & \\
\hline CHEMBL1534505 & 688620 & 4.75 & 4.8546 & TST & \\
\hline CHEMBL1600668 & 688620 & 5.05 & 5.1423 & TRN & \\
\hline CHEMBL1451285 & 688620 & 4.95 & 4.9197 & TRN & \\
\hline CHEMBL1506679 & 688620 & 5.0 & 5.0616 & TST & \\
\hline CHEMBL1328230 & 688620 & 4.95 & 5.0098 & TRN & \\
\hline CHEMBL3194075 & 688620 & 4.7 & 4.9713 & TRN & \\
\hline CHEMBL 3192874 & 688620 & 5.25 & 5.0129 & TRN & \\
\hline CHEMBL1569160 & 688620 & 5.55 & 5.1334 & TRN & \\
\hline CHEMBL1369691 & 688620 & 4.8 & 4.8162 & TRN & \\
\hline CHEMBL1972519 & 688620 & 7.0 & 5.6908 & TRN & \\
\hline CHEMBL1471340 & 688620 & 6.6499 & 5.0066 & TRN & \\
\hline CHEMBL1588465 & 688620 & 5.25 & 5.1034 & TRN & \\
\hline CHEMBL1372776 & 688620 & 4.7 & 5.3871 & TST & \\
\hline CHEMBL1497272 & 688620 & 5.15 & 5.1637 & TRN & \\
\hline
\end{tabular}




\begin{tabular}{|c|c|c|c|c|c|}
\hline \multicolumn{6}{|c|}{ Supplemental Table S2.txt } \\
\hline CHEMBL3189259 & 688620 & 4.5 & 5.2778 & TRN & \\
\hline CHEMBL 3210043 & 688620 & 4.95 & 5.1589 & TRN & \\
\hline CHEMBL1535022 & 688620 & 4.45 & 4.7576 & TRN & \\
\hline CHEMBL1408441 & 688620 & 5.2 & 4.8148 & TST & \\
\hline CHEMBL1599965 & 688620 & 4.85 & 4.9174 & TST & \\
\hline CHEMBL1402545 & 688620 & 4.95 & 4.8271 & TRN & \\
\hline CHEMBL1366196 & 688620 & 4.65 & 5.0632 & TST & \\
\hline CHEMBL1308188 & 688620 & 4.45 & 4.9035 & TRN & \\
\hline CHEMBL478960 & 688620 & 5.5 & 4.8543 & TST & \\
\hline CHEMBL1299668 & 688620 & 5.45 & 5.188 & TRN & \\
\hline CHEMBL1388871 & 688620 & 4.95 & 5.0267 & TST & \\
\hline CHEMBL1567364 & 688620 & 6.7001 & 4.9504 & TRN & \\
\hline CHEMBL1449328 & 688620 & 5.6 & 5.1741 & TRN & \\
\hline CHEMBL1309774 & 688620 & 4.5 & 5.1168 & TRN & \\
\hline CHEMBL1312459 & 688620 & 4.65 & 5.0034 & TRN & \\
\hline CHEMBL1606209 & 688620 & 5.05 & 4.9671 & TRN & \\
\hline CHEMBL1391393 & 688620 & 5.4 & 4.9241 & TST & \\
\hline CHEMBL3195702 & 688620 & 5.45 & 5.5202 & TRN & \\
\hline CHEMBL1588842 & 688620 & 4.95 & 4.7883 & TRN & \\
\hline CHEMBL1600822 & 688620 & 4.65 & 4.8963 & TRN & \\
\hline CHEMBL1965973 & 688620 & 5.85 & 5.6095 & TRN & \\
\hline CHEMBL3211452 & 688620 & 4.45 & 5.5151 & TRN & \\
\hline CHEMBL1353297 & 688620 & 5.5 & 5.46899 & 9999999999 & TRN \\
\hline CHEMBL3197150 & 688620 & 5.25 & 5.1874 & TRN & \\
\hline CHEMBL1603873 & 688620 & 5.15 & 5.2887 & TRN & \\
\hline CHEMBL1985343 & 688620 & 4.65 & 4.8003 & TRN & \\
\hline CHEMBL1968206 & 688620 & 5.3 & 5.0535 & TRN & \\
\hline CHEMBL1611540 & 688620 & 4.95 & 5.0944 & TRN & \\
\hline CHEMBL 3145293 & 688620 & 5.2 & 5.3185 & TRN & \\
\hline CHEMBL1598401 & 688620 & 4.95 & 5.1811 & TRN & \\
\hline CHEMBL3194717 & 688620 & 6.6 & 5.4176 & TRN & \\
\hline CHEMBL1333377 & 688620 & 5.95 & 5.0102 & TRN & \\
\hline CHEMBL1990292 & 688620 & 5.85 & 5.7001 & TRN & \\
\hline CHEMBL1407561 & 688620 & 4.95 & 4.8957 & TRN & \\
\hline CHEMBL1499924 & 688620 & 4.9 & 5.2239 & TST & \\
\hline CHEMBL1400980 & 688620 & 6.6499 & 5.1526 & TRN & \\
\hline CHEMBL1452268 & 688620 & 4.9 & 5.178 & TRN & \\
\hline CHEMBL1528447 & 688620 & 4.9 & 4.998 & TRN & \\
\hline CHEMBL3391864 & 688620 & 5.6 & 5.3106 & TRN & \\
\hline CHEMBL1373189 & 688620 & 4.8 & 4.9771 & TRN & \\
\hline CHEMBL3209623 & 688620 & 5.8 & 5.3866 & TRN & \\
\hline CHEMBL1424109 & 688620 & 5.55 & 5.2129 & TRN & \\
\hline CHEMBL1577033 & 688620 & 4.9 & 5.0058 & TRN & \\
\hline CHEMBL472929 & 688620 & 5.0 & 5.3612 & TRN & \\
\hline CHEMBL1388539 & 688620 & 5.15 & 4.9897 & TST & \\
\hline CHEMBL1320389 & 688620 & 5.0 & 4.9941 & TRN & \\
\hline CHEMBL1321661 & 688620 & 4.45 & 4.928 & TRN & \\
\hline CHEMBL1498758 & 688620 & 4.8 & 4.842 & TRN & \\
\hline
\end{tabular}




\begin{tabular}{|c|c|c|c|c|c|}
\hline \multicolumn{6}{|c|}{ Supplemental Table s2.txt } \\
\hline CHEMBL 3207621 & 688620 & 4.6 & 5.06 & TRN & \\
\hline CHEMBL1324397 & 688620 & 4.95 & 4.8021 & TRN & \\
\hline CHEMBL1548695 & 688620 & 5.15 & 5.45299 & 9999999999 & TRN \\
\hline CHEMBL1504412 & 688620 & 4.9 & 4.8754 & TRN & \\
\hline CHEMBL1488342 & 688620 & 4.85 & 5.0657 & TST & \\
\hline CHEMBL1362678 & 688620 & 5.25 & 5.1995 & TST & \\
\hline CHEMBL1376777 & 688620 & 4.7 & 4.8258 & TRN & \\
\hline CHEMBL243250 & 688620 & 5.3 & 5.1906 & TRN & \\
\hline CHEMBL1411726 & 688620 & 4.45 & 5.391 & TRN & \\
\hline CHEMBL3211667 & 688620 & 5.05 & 4.9868 & TST & \\
\hline CHEMBL1557274 & 688620 & 4.9 & 4.9898 & TST & \\
\hline CHEMBL3210289 & 688620 & 5.0 & 5.1315 & TST & \\
\hline CHEMBL1423914 & 688620 & 5.15 & 5.7409 & TRN & \\
\hline CHEMBL1509740 & 688620 & 4.85 & 5.1754 & TST & \\
\hline CHEMBL1527103 & 688620 & 4.45 & 4.8607 & TRN & \\
\hline CHEMBL1588670 & 688620 & 5.5 & 4.9837 & TRN & \\
\hline CHEMBL1364853 & 688620 & 5.95 & 5.131 & TRN & \\
\hline CHEMBL3190132 & 688620 & 5.55 & 5.2872 & TRN & \\
\hline CHEMBL1376080 & 688620 & 4.65 & 5.092 & TRN & \\
\hline CHEMBL1546239 & 688620 & 4.75 & 4.7366 & TRN & \\
\hline CHEMBL1347101 & 688620 & 4.75 & 5.4846 & TST & \\
\hline CHEMBL1598578 & 688620 & 4.75 & 5.0684 & TRN & \\
\hline CHEMBL3216363 & 688620 & 5.7 & 5.26 & TRN & \\
\hline CHEMBL1604253 & 688620 & 4.85 & 5.3824 & TRN & \\
\hline CHEMBL1333720 & 688620 & 4.75 & 4.8923 & TRN & \\
\hline CHEMBL1432794 & 688620 & 5.35 & 5.309 & TRN & \\
\hline CHEMBL3194582 & 688620 & 4.9 & 4.8639 & TRN & \\
\hline CHEMBL1353251 & 688620 & 6.8499 & 4.9233 & TRN & \\
\hline CHEMBL1340610 & 688620 & 5.05 & 5.1002 & TRN & \\
\hline CHEMBL3199443 & 688620 & 5.65 & 5.3132 & TRN & \\
\hline CHEMBL1491686 & 688620 & 5.9 & 5.8589 & TST & \\
\hline CHEMBL3197364 & 688620 & 4.45 & 5.13700 & 00000000005 & TRN \\
\hline CHEMBL3198576 & 688620 & 6.35 & 5.8332 & TRN & \\
\hline CHEMBL 2094532 & 688620 & 5.7 & 5.7104 & TRN & \\
\hline CHEMBL1588471 & 688620 & 5.95 & 5.7814 & TRN & \\
\hline CHEMBL1317066 & 688620 & 4.8 & 4.8388 & TRN & \\
\hline CHEMBL3194300 & 688620 & 4.9 & 5.489 & TRN & \\
\hline CHEMBL1505652 & 688620 & 4.8 & 4.9983 & TST & \\
\hline CHEMBL1312876 & 688620 & 5.75 & 5.4417 & TRN & \\
\hline CHEMBL1346557 & 688620 & 4.9 & 5.1315 & TRN & \\
\hline CHEMBL1444167 & 688620 & 4.8 & 5.0043 & TRN & \\
\hline CHEMBL1308576 & 688620 & 5.15 & 4.8505 & TRN & \\
\hline CHEMBL1323248 & 688620 & 4.6 & 4.9506 & TST & \\
\hline CHEMBL1531501 & 688620 & 5.0 & 5.0741 & TRN & \\
\hline CHEMBL1439149 & 688620 & 5.0 & 4.8968 & TRN & \\
\hline CHEMBL1562869 & 688620 & 4.9 & 4.9153 & TRN & \\
\hline CHEMBL3189940 & 688620 & 4.45 & 4.8658 & TRN & \\
\hline CHEMBL1583510 & 688620 & 4.85 & 4.9259 & TRN & \\
\hline
\end{tabular}




\begin{tabular}{|c|c|c|c|c|c|}
\hline \multicolumn{6}{|c|}{ Supplemental Table S2.txt } \\
\hline CHEMBL1493812 & 688620 & 4.8 & 5.2016 & TRN & \\
\hline CHEMBL1576998 & 688620 & 6.6499 & 5.007 & TRN & \\
\hline CHEMBL1559578 & 688620 & 6.7001 & 5.0901 & TST & \\
\hline CHEMBL1337382 & 688620 & 5.2 & 5.25299 & 9999999999 & TRN \\
\hline CHEMBL1610037 & 688620 & 4.45 & 4.811 & TRN & \\
\hline CHEMBL1310186 & 688620 & 4.45 & 4.8392 & TRN & \\
\hline CHEMBL1348144 & 688620 & 4.9 & 5.1404 & TRN & \\
\hline CHEMBL1396795 & 688620 & 4.45 & 5.1076 & TRN & \\
\hline CHEMBL1563383 & 688620 & 5.05 & 5.2403 & TRN & \\
\hline CHEMBL1428562 & 688620 & 5.3 & 4.9245 & TRN & \\
\hline CHEMBL1972143 & 688620 & 5.5 & 5.5471 & TRN & \\
\hline CHEMBL1332167 & 688620 & 4.45 & 5.1574 & TRN & \\
\hline CHEMBL1367989 & 688620 & 4.95 & 4.959 & TRN & \\
\hline CHEMBL1581575 & 688620 & 4.55 & 5.1592 & TRN & \\
\hline CHEMBL1557023 & 688620 & 4.75 & 5.03600 & 00000000005 & TRN \\
\hline CHEMBL1391191 & 688620 & 6.0 & 5.678 & TRN & \\
\hline CHEMBL1424124 & 688620 & 4.9 & 5.081 & TRN & \\
\hline CHEMBL1530719 & 688620 & 5.05 & 5.2488 & TRN & \\
\hline CHEMBL1504139 & 688620 & 4.65 & 4.7377 & TST & \\
\hline CHEMBL1374590 & 688620 & 5.55 & 4.9971 & TST & \\
\hline CHEMBL1497481 & 688620 & 4.95 & 5.1422 & TRN & \\
\hline CHEMBL1709970 & 688620 & 6.5 & 4.5907 & TST & \\
\hline CHEMBL1461142 & 688620 & 5.3 & 5.2895 & TRN & \\
\hline CHEMBL1495363 & 688620 & 4.8 & 4.8556 & TRN & \\
\hline CHEMBL3196010 & 688620 & 4.7 & 4.9675 & TRN & \\
\hline CHEMBL1539354 & 688620 & 4.85 & 4.9565 & TRN & \\
\hline CHEMBL1503692 & 688620 & 5.35 & 4.9177 & TST & \\
\hline CHEMBL1531657 & 688620 & 6.1 & 5.1931 & TRN & \\
\hline CHEMBL1530170 & 688620 & 5.25 & 5.1671 & TRN & \\
\hline CHEMBL1336666 & 688620 & 4.6 & 5.2276 & TST & \\
\hline CHEMBL1562340 & 688620 & 5.35 & 4.9673 & TRN & \\
\hline CHEMBL1550866 & 688620 & 5.3 & 4.8693 & TST & \\
\hline CHEMBL1460800 & 688620 & 4.75 & 4.8736 & TRN & \\
\hline CHEMBL1323285 & 688620 & 4.45 & 5.1736 & TRN & \\
\hline CHEMBL1422002 & 688620 & 4.6 & 4.8728 & TRN & \\
\hline CHEMBL1374967 & 688620 & 4.45 & 5.2264 & TRN & \\
\hline CHEMBL1439065 & 688620 & 4.95 & 5.0116 & TRN & \\
\hline CHEMBL3193905 & 688620 & 4.95 & 5.051 & TRN & \\
\hline CHEMBL1532815 & 688620 & 6.2 & 6.3205 & TRN & \\
\hline CHEMBL1501645 & 688620 & 4.75 & 5.1846 & TST & \\
\hline CHEMBL1407461 & 688620 & 5.1 & 5.067 & TRN & \\
\hline CHEMBL1380123 & 688620 & 4.55 & 4.9035 & TRN & \\
\hline CHEMBL1521763 & 688620 & 4.7 & 5.0889 & TST & \\
\hline CHEMBL1459968 & 688620 & 4.85 & 4.9333 & TRN & \\
\hline CHEMBL1530090 & 688620 & 6.5 & 5.0569 & TRN & \\
\hline CHEMBL1488145 & 688620 & 6.45 & 5.0156 & TRN & \\
\hline CHEMBL1519186 & 688620 & 5.0 & 4.9964 & TST & \\
\hline CHEMBL1541363 & 688620 & 4.5 & 4.9441 & TRN & \\
\hline
\end{tabular}




\begin{tabular}{|c|c|c|c|c|}
\hline \multicolumn{5}{|c|}{ Supplemental Table S2.txt } \\
\hline CHEMBL1520396 & 688620 & 4.4 & 4.8546 & TRN \\
\hline CHEMBL3195158 & 688620 & 4.65 & 4.9144 & TST \\
\hline CHEMBL1402657 & 688620 & 4.85 & 5.0307 & TRN \\
\hline CHEMBL1589350 & 688620 & 4.55 & 5.2921 & TRN \\
\hline CHEMBL1409814 & 688620 & 4.95 & 5.0932 & TST \\
\hline CHEMBL1469862 & 688620 & 4.95 & 4.8983 & TRN \\
\hline CHEMBL1382863 & 688620 & 4.8 & 5.0604 & TST \\
\hline CHEMBL1272069 & 688620 & 4.65 & 5.3027 & TST \\
\hline CHEMBL1566907 & 688620 & 4.65 & 4.9969 & TRN \\
\hline CHEMBL1511310 & 688620 & 6.8499 & 5.1608 & TRN \\
\hline CHEMBL3190666 & 688620 & 5.45 & 5.1918 & TRN \\
\hline CHEMBL1339961 & 688620 & 4.85 & 4.9656 & TST \\
\hline CHEMBL1538563 & 688620 & 5.3 & 5.3635 & TRN \\
\hline CHEMBL1510625 & 688620 & 4.45 & 4.8402 & TRN \\
\hline CHEMBL1583161 & 688620 & 4.9 & 5.0153 & TRN \\
\hline CHEMBL1332930 & 688620 & 7.0 & 5.0841 & TST \\
\hline CHEMBL1405633 & 688620 & 5.05 & 5.2242 & TRN \\
\hline CHEMBL1428442 & 688620 & 5.6 & 5.0202 & TRN \\
\hline CHEMBL 3195621 & 688620 & 4.75 & 4.6928 & TRN \\
\hline CHEMBL1370995 & 688620 & 4.8 & 5.1797 & TRN \\
\hline CHEMBL1462967 & 688620 & 5.6 & 5.1994 & TRN \\
\hline CHEMBL1446929 & 688620 & 5.55 & 5.3694 & TST \\
\hline CHEMBL1360257 & 688620 & 5.35 & 5.0149 & TST \\
\hline CHEMBL1471899 & 688620 & 5.55 & 5.4986 & TRN \\
\hline CHEMBL1468340 & 688620 & 4.7 & 5.1408 & TRN \\
\hline CHEMBL3189343 & 688620 & 5.85 & 5.7965 & TRN \\
\hline CHEMBL1383298 & 688620 & 5.2 & 5.3435 & TRN \\
\hline CHEMBL1409773 & 688620 & 5.5 & 5.2172 & TRN \\
\hline CHEMBL1581221 & 688620 & 4.85 & 5.0267 & TRN \\
\hline CHEMBL1547090 & 688620 & 5.0 & 4.9809 & TST \\
\hline CHEMBL1448705 & 688620 & 4.85 & 4.6749 & TST \\
\hline CHEMBL1512190 & 688620 & 4.7 & 4.9539 & TRN \\
\hline CHEMBL1471046 & 688620 & 5.15 & 4.7856 & TRN \\
\hline CHEMBL1457235 & 688620 & 4.7 & 6.1036 & TRN \\
\hline CHEMBL1996490 & 688620 & 5.95 & 5.2558 & TRN \\
\hline CHEMBL1480580 & 688620 & 4.7 & 5.1211 & TRN \\
\hline CHEMBL1580075 & 688620 & 5.25 & 4.8154 & TRN \\
\hline CHEMBL1325777 & 688620 & 4.75 & 4.8932 & TST \\
\hline CHEMBL1413265 & 688620 & 4.95 & 5.0826 & TST \\
\hline CHEMBL1528712 & 688620 & 7.0501 & 5.1735 & TRN \\
\hline CHEMBL1324376 & 688620 & 5.0 & 5.2704 & TRN \\
\hline CHEMBL1493661 & 688620 & 4.5 & 4.9014 & TST \\
\hline CHEMBL1322521 & 688620 & 5.55 & 5.1609 & TRN \\
\hline CHEMBL1461413 & 688620 & 4.65 & 4.7453 & TST \\
\hline CHEMBL1331727 & 688620 & 4.65 & 4.9606 & TRN \\
\hline CHEMBL1530733 & 688620 & 4.45 & 5.0265 & TST \\
\hline CHEMBL1588539 & 688620 & 6.3 & 5.2365 & TRN \\
\hline CHEMBL1505721 & 688620 & 5.45 & 5.1155 & TRN \\
\hline
\end{tabular}




\begin{tabular}{|c|c|c|c|c|}
\hline \multicolumn{5}{|c|}{ Supplemental Table S2.txt } \\
\hline CHEMBL1489184 & 688620 & 5.35 & 4.9725 & TRN \\
\hline CHEMBL3199346 & 688620 & 4.75 & 4.9218 & TRN \\
\hline CHEMBL1427596 & 688620 & 4.9 & 5.1567 & TRN \\
\hline CHEMBL1584420 & 688620 & 4.85 & 4.9048 & TRN \\
\hline CHEMBL1539860 & 688620 & 5.6 & 5.4607 & TRN \\
\hline CHEMBL1522947 & 688620 & 4.8 & 4.9916 & TRN \\
\hline CHEMBL1405989 & 688620 & 5.15 & 5.0127 & TRN \\
\hline CHEMBL3193435 & 688620 & 4.45 & 4.7267 & TRN \\
\hline CHEMBL1467733 & 688620 & 5.05 & 4.9927 & TRN \\
\hline CHEMBL1549443 & 688620 & 5.0 & 5.0682 & TRN \\
\hline CHEMBL1539474 & 688620 & 4.45 & 5.093 & TST \\
\hline CHEMBL1460524 & 688620 & 4.8 & 4.9657 & TRN \\
\hline CHEMBL459939 & 688620 & 4.9 & 5.0131 & TRN \\
\hline CHEMBL1579058 & 688620 & 5.85 & 5.6935 & TRN \\
\hline CHEMBL1568968 & 688620 & 5.15 & 5.2258 & TRN \\
\hline CHEMBL1310706 & 688620 & 4.7 & 5.0207 & TST \\
\hline CHEMBL3193756 & 688620 & 4.7 & 4.9921 & TRN \\
\hline CHEMBL1432210 & 688620 & 4.9 & 4.7866 & TRN \\
\hline CHEMBL1968044 & 688620 & 5.8 & 5.6006 & TRN \\
\hline CHEMBL1366349 & 688620 & 5.0 & 5.0523 & TRN \\
\hline CHEMBL1350511 & 688620 & 4.5 & 5.1085 & TST \\
\hline CHEMBL1352001 & 688620 & 4.65 & 4.96 & TRN \\
\hline CHEMBL1480098 & 688620 & 5.0 & 4.9788 & TRN \\
\hline CHEMBL1561230 & 688620 & 6.3 & 4.9627 & TST \\
\hline CHEMBL1302119 & 688620 & 4.95 & 5.0214 & TST \\
\hline CHEMBL1479892 & 688620 & 4.5 & 5.1821 & TRN \\
\hline CHEMBL1607129 & 688620 & 5.5 & 5.1663 & TRN \\
\hline CHEMBL1583943 & 688620 & 6.25 & 5.8746 & TRN \\
\hline CHEMBL148296 & 688620 & 4.8 & 4.8915 & TST \\
\hline CHEMBL1343445 & 688620 & 5.5 & 5.2356 & TST \\
\hline CHEMBL1507266 & 688620 & 5.25 & 4.9576 & TRN \\
\hline CHEMBL1604131 & 688620 & 4.6 & 5.0202 & TST \\
\hline CHEMBL1517041 & 688620 & 4.8 & 4.9465 & TST \\
\hline CHEMBL3194293 & 688620 & 5.2 & 5.0714 & TRN \\
\hline CHEMBL1182777 & 688620 & 4.85 & 5.3077 & TST \\
\hline CHEMBL1076555 & 688620 & 4.95 & 5.6582 & TRN \\
\hline CHEMBL 1431345 & 688620 & 4.95 & 5.1795 & TRN \\
\hline CHEMBL1599847 & 688620 & 4.85 & 4.7303 & TRN \\
\hline CHEMBL1302280 & 688620 & 4.45 & 5.0934 & TRN \\
\hline CHEMBL1517234 & 688620 & 5.15 & 4.9033 & TRN \\
\hline CHEMBL1350810 & 688620 & 4.45 & 4.9751 & TRN \\
\hline CHEMBL1497078 & 688620 & 4.45 & 4.9091 & TRN \\
\hline CHEMBL1488464 & 688620 & 4.8 & 5.0527 & TRN \\
\hline CHEMBL1550802 & 688620 & 5.2 & 5.0588 & TRN \\
\hline CHEMBL1340645 & 688620 & 4.5 & 4.931 & TRN \\
\hline CHEMBL1545630 & 688620 & 5.2 & 4.8813 & TRN \\
\hline CHEMBL1528179 & 688620 & 5.0 & 4.9175 & TRN \\
\hline CHEMBL1414512 & 688620 & 4.9 & 5.1746 & TRN \\
\hline
\end{tabular}




\begin{tabular}{|c|c|c|c|c|c|}
\hline \multicolumn{6}{|c|}{ Supplemental Table S2.txt } \\
\hline CHEMBL1404138 & 688620 & 4.45 & 4.996 & TST & \\
\hline CHEMBL1518699 & 688620 & 5.2 & 5.3222 & TRN & \\
\hline CHEMBL3190429 & 688620 & 6.0 & 5.8326 & TRN & \\
\hline CHEMBL3191021 & 688620 & 5.15 & 4.849 & TRN & \\
\hline CHEMBL1511314 & 688620 & 5.9 & 4.9375 & TRN & \\
\hline CHEMBL1431022 & 688620 & 4.45 & 4.9988 & TRN & \\
\hline CHEMBL1462817 & 688620 & 4.45 & 4.9824 & TST & \\
\hline CHEMBL1556157 & 688620 & 4.85 & 4.8981 & TRN & \\
\hline CHEMBL1421192 & 688620 & 5.0 & 4.7594 & TRN & \\
\hline CHEMBL1339707 & 688620 & 4.75 & 4.9764 & TRN & \\
\hline CHEMBL 1445320 & 688620 & 4.45 & 4.9443 & TRN & \\
\hline CHEMBL1301234 & 688620 & 5.0 & 5.0773 & TRN & \\
\hline CHEMBL1604828 & 688620 & 4.45 & 5.25200 & 0000000001 & TST \\
\hline CHEMBL1500172 & 688620 & 4.9 & 4.9256 & TRN & \\
\hline CHEMBL1427365 & 688620 & 5.45 & 5.9959 & TRN & \\
\hline CHEMBL1371382 & 688620 & 4.45 & 5.1079 & TRN & \\
\hline CHEMBL1339044 & 688620 & 5.05 & 5.0472 & TRN & \\
\hline CHEMBL1368422 & 688620 & 4.95 & 5.0091 & TRN & \\
\hline CHEMBL1418466 & 688620 & 5.0 & 5.0591 & TRN & \\
\hline CHEMBL1568539 & 688620 & 4.95 & 4.784 & TRN & \\
\hline CHEMBL1386493 & 688620 & 4.45 & 4.9327 & TST & \\
\hline CHEMBL1547395 & 688620 & 5.0 & 4.6328 & TRN & \\
\hline CHEMBL1577735 & 688620 & 5.5 & 4.9309 & TRN & \\
\hline CHEMBL1589685 & 688620 & 4.45 & 4.9272 & TST & \\
\hline CHEMBL1498909 & 688620 & 4.85 & 4.9388 & TRN & \\
\hline CHEMBL1533731 & 688620 & 4.9 & 4.633 & TRN & \\
\hline CHEMBL1360902 & 688620 & 4.95 & 4.8987 & TRN & \\
\hline CHEMBL1478058 & 688620 & 4.9 & 5.1166 & TRN & \\
\hline CHEMBL1511871 & 688620 & 4.95 & 4.9807 & TRN & \\
\hline CHEMBL1310617 & 688620 & 5.25 & 5.4813 & TST & \\
\hline CHEMBL1309219 & 688620 & 4.45 & 4.9411 & TRN & \\
\hline CHEMBL1381905 & 688620 & 4.45 & 5.0295 & TST & \\
\hline CHEMBL1341586 & 688620 & 6.0 & 5.3691 & TRN & \\
\hline CHEMBL1450412 & 688620 & 4.9 & 5.1366 & TRN & \\
\hline CHEMBL1342715 & 688620 & 4.45 & 4.9668 & TST & \\
\hline CHEMBL3196833 & 688620 & 6.0 & 5.3992 & TRN & \\
\hline CHEMBL1428196 & 688620 & 5.0 & 5.4113 & TRN & \\
\hline CHEMBL1582712 & 688620 & 4.95 & 4.9844 & TST & \\
\hline CHEMBL1448070 & 688620 & 4.45 & 4.6763 & TRN & \\
\hline CHEMBL1576605 & 688620 & 5.75 & 5.1071 & TRN & \\
\hline CHEMBL1429035 & 688620 & 5.45 & 4.9727 & TRN & \\
\hline CHEMBL1444659 & 688620 & 4.95 & 5.0725 & TRN & \\
\hline CHEMBL1575624 & 688620 & 6.25 & 5.0974 & TRN & \\
\hline CHEMBL3196983 & 688620 & 4.45 & 5.3105 & TRN & \\
\hline CHEMBL1383419 & 688620 & 5.3 & 4.9682 & TST & \\
\hline CHEMBL1377679 & 688620 & 4.65 & 4.9598 & TRN & \\
\hline CHEMBL1312549 & 688620 & 4.65 & 4.9344 & TRN & \\
\hline CHEMBL1533621 & 688620 & 5.0 & 5.1437 & TRN & \\
\hline & & & & 27507 & \\
\hline
\end{tabular}




\begin{tabular}{|c|c|c|c|c|}
\hline \multicolumn{5}{|c|}{ Supplemental Table S2.txt } \\
\hline CHEMBL1506691 & 688620 & 4.95 & 4.9934 & TRN \\
\hline CHEMBL1998030 & 688620 & 5.1 & 5.1037 & TRN \\
\hline CHEMBL1451593 & 688620 & 4.8 & 5.0275 & TRN \\
\hline CHEMBL1545715 & 688620 & 5.9 & 5.3134 & TRN \\
\hline CHEMBL1496126 & 688620 & 4.8 & 4.8245 & TRN \\
\hline CHEMBL1447306 & 688620 & 5.95 & 5.1427 & TST \\
\hline CHEMBL1567422 & 688620 & 4.9 & 4.9669 & TRN \\
\hline CHEMBL1547074 & 688620 & 4.8 & 5.1396 & TRN \\
\hline CHEMBL1401257 & 688620 & 4.95 & 4.9373 & TRN \\
\hline CHEMBL1568128 & 688620 & 4.5 & 5.1405 & TRN \\
\hline CHEMBL1573479 & 688620 & 4.45 & 5.1165 & TST \\
\hline CHEMBL1547262 & 688620 & 5.7 & 5.2737 & TST \\
\hline CHEMBL3191062 & 688620 & 5.05 & 5.2366 & TRN \\
\hline CHEMBL1458893 & 688620 & 5.25 & 5.4504 & TRN \\
\hline CHEMBL1322082 & 688620 & 6.35 & 5.266 & TRN \\
\hline CHEMBL1438084 & 688620 & 6.5 & 5.7842 & TST \\
\hline CHEMBL1500903 & 688620 & 4.95 & 4.8978 & TRN \\
\hline CHEMBL1504526 & 688620 & 5.0 & 5.0847 & TST \\
\hline CHEMBL1560567 & 688620 & 4.65 & 5.0404 & TST \\
\hline CHEMBL569750 & 688620 & 5.45 & 4.9765 & TST \\
\hline CHEMBL1604458 & 688620 & 4.45 & 4.9922 & TRN \\
\hline CHEMBL1527613 & 688620 & 5.25 & 4.8896 & TRN \\
\hline CHEMBL1517297 & 688620 & 4.45 & 5.1026 & TRN \\
\hline CHEMBL1578430 & 688620 & 4.45 & 5.0373 & TRN \\
\hline CHEMBL1408170 & 688620 & 5.65 & 5.1139 & TRN \\
\hline CHEMBL1323328 & 688620 & 4.85 & 4.7913 & TRN \\
\hline CHEMBL3191233 & 688620 & 5.3 & 5.4056 & TRN \\
\hline CHEMBL1369885 & 688620 & 4.7 & 5.0034 & TRN \\
\hline CHEMBL3194368 & 688620 & 4.6 & 4.9961 & TRN \\
\hline CHEMBL1481390 & 688620 & 5.1 & 4.9713 & TST \\
\hline CHEMBL1335455 & 688620 & 4.45 & 5.3873 & TRN \\
\hline CHEMBL3210114 & 688620 & 5.2 & 5.135 & TST \\
\hline CHEMBL1468954 & 688620 & 5.0 & 4.8242 & TRN \\
\hline CHEMBL3213822 & 688620 & 4.8 & 5.4856 & TRN \\
\hline CHEMBL1309350 & 688620 & 4.45 & 5.1547 & TST \\
\hline CHEMBL3199094 & 688620 & 4.7 & 4.8066 & TRN \\
\hline CHEMBL1514639 & 688620 & 4.5 & 4.8205 & TST \\
\hline CHEMBL1467220 & 688620 & 4.8 & 4.8952 & TRN \\
\hline CHEMBL1432468 & 688620 & 5.0 & 5.4474 & TRN \\
\hline CHEMBL1480005 & 688620 & 4.85 & 5.1709 & TST \\
\hline CHEMBL1516593 & 688620 & 4.95 & 4.9542 & TRN \\
\hline CHEMBL 1301700 & 688620 & 4.8 & 4.8167 & TRN \\
\hline CHEMBL1459648 & 688620 & 4.8 & 5.1441 & TST \\
\hline CHEMBL1600508 & 688620 & 5.45 & 5.3887 & TRN \\
\hline CHEMBL1457209 & 688620 & 5.6 & 4.9525 & TRN \\
\hline CHEMBL1563491 & 688620 & 5.0 & 5.0724 & TST \\
\hline CHEMBL 2005042 & 688620 & 4.85 & 4.9359 & TRN \\
\hline CHEMBL1439668 & 688620 & 6.05 & 5.2345 & TST \\
\hline
\end{tabular}




\begin{tabular}{|c|c|c|c|c|c|}
\hline \multicolumn{6}{|c|}{ Supplemental Table S2.txt } \\
\hline CHEMBL1319428 & 688620 & 4.45 & 4.668 & TST & \\
\hline CHEMBL1313973 & 688620 & 5.2 & 5.5748 & TST & \\
\hline CHEMBL1415738 & 688620 & 4.8 & 4.9792 & TRN & \\
\hline CHEMBL1438005 & 688620 & 6.1 & 5.2156 & TST & \\
\hline CHEMBL1304169 & 688620 & 5.45 & 5.529 & TRN & \\
\hline CHEMBL1968402 & 688620 & 5.95 & 5.3868 & TRN & \\
\hline CHEMBL598695 & 688620 & 4.9 & 4.8262 & TST & \\
\hline CHEMBL1447990 & 688620 & 5.0 & 5.0357 & TST & \\
\hline CHEMBL1421896 & 688620 & 4.85 & 5.0717 & TST & \\
\hline CHEMBL1532278 & 688620 & 5.3 & 4.9537 & TRN & \\
\hline CHEMBL3193184 & 688620 & 4.75 & 4.862 & TRN & \\
\hline CHEMBL1596621 & 688620 & 6.0 & 5.0175 & TRN & \\
\hline CHEMBL1522333 & 688620 & 4.9 & 4.8509 & TRN & \\
\hline CHEMBL1591468 & 688620 & 4.45 & 4.8858 & TST & \\
\hline CHEMBL1312100 & 688620 & 4.9 & 5.0776 & TST & \\
\hline CHEMBL1333053 & 688620 & 5.0 & 5.0659 & TRN & \\
\hline CHEMBL1499267 & 688620 & 4.9 & 5.0651 & TST & \\
\hline CHEMBL1438622 & 688620 & 5.2 & 5.1252 & TST & \\
\hline CHEMBL 2007190 & 688620 & 4.45 & 4.768 & TRN & \\
\hline CHEMBL1991936 & 688620 & 5.1 & 4.6569 & TRN & \\
\hline CHEMBL1507998 & 688620 & 6.1 & 4.921 & TRN & \\
\hline CHEMBL1338548 & 688620 & 5.3 & 5.01399 & 9999999999 & TST \\
\hline CHEMBL1506351 & 688620 & 4.85 & 5.0918 & TRN & \\
\hline CHEMBL1538845 & 688620 & 4.45 & 4.8058 & TRN & \\
\hline CHEMBL1465477 & 688620 & 4.9 & 5.1678 & TST & \\
\hline CHEMBL1495012 & 688620 & 5.65 & 5.1822 & TRN & \\
\hline CHEMBL1584025 & 688620 & 4.8 & 4.6823 & TRN & \\
\hline CHEMBL1333085 & 688620 & 4.45 & 4.9941 & TRN & \\
\hline CHEMBL1441037 & 688620 & 5.15 & 5.06800 & 00000000005 & TRN \\
\hline CHEMBL1454840 & 688620 & 5.7 & 5.4136 & TRN & \\
\hline CHEMBL1374388 & 688620 & 5.85 & 5.7182 & TRN & \\
\hline CHEMBL1335411 & 688620 & 5.0 & 5.0011 & TRN & \\
\hline CHEMBL1300410 & 688620 & 5.55 & 5.48 & TRN & \\
\hline CHEMBL1424231 & 688620 & 5.05 & 4.9651 & TST & \\
\hline CHEMBL1483515 & 688620 & 4.5 & 4.8766 & TRN & \\
\hline CHEMBL1446966 & 688620 & 4.95 & 5.1665 & TRN & \\
\hline CHEMBL1241452 & 688620 & 4.6 & 4.9057 & TRN & \\
\hline CHEMBL1383843 & 688620 & 4.7 & 5.1094 & TRN & \\
\hline CHEMBL260503 & 688620 & 6.25 & 5.0342 & TRN & \\
\hline CHEMBL1414262 & 688620 & 5.1 & 5.0442 & TRN & \\
\hline CHEMBL1531308 & 688620 & 5.55 & 5.347 & TST & \\
\hline CHEMBL1534384 & 688620 & 5.0 & 5.0057 & TRN & \\
\hline CHEMBL3189620 & 688620 & 4.95 & 4.9256 & TRN & \\
\hline CHEMBL1336513 & 688620 & 5.6 & 5.2683 & TRN & \\
\hline CHEMBL1355965 & 688620 & 5.05 & 5.2487 & TST & \\
\hline CHEMBL531710 & 688620 & 5.6 & 5.4567 & TRN & \\
\hline CHEMBL1482484 & 688620 & 4.9 & 4.8914 & TRN & \\
\hline CHEMBL1594446 & 688620 & 5.0 & 4.8937 & TST & \\
\hline
\end{tabular}




\begin{tabular}{|c|c|c|c|c|}
\hline \multicolumn{5}{|c|}{ Supplemental Table S2.txt } \\
\hline CHEMBL1497721 & 688620 & 4.85 & 4.8951 & TRN \\
\hline CHEMBL1558021 & 688620 & 4.45 & 5.0906 & TRN \\
\hline CHEMBL1414771 & 688620 & 4.65 & 5.1489 & TRN \\
\hline CHEMBL3195375 & 688620 & 4.8 & 5.1649 & TRN \\
\hline CHEMBL3212081 & 688620 & 5.05 & 4.9203 & TRN \\
\hline CHEMBL1502572 & 688620 & 4.9 & 4.8613 & TRN \\
\hline CHEMBL1402410 & 688620 & 4.45 & 5.0116 & TST \\
\hline CHEMBL1339363 & 688620 & 4.75 & 5.0782 & TRN \\
\hline CHEMBL1573395 & 688620 & 4.45 & 4.7518 & TRN \\
\hline CHEMBL1362470 & 688620 & 4.45 & 4.9167 & TRN \\
\hline CHEMBL1507773 & 688620 & 4.9 & 4.9605 & TRN \\
\hline CHEMBL1327178 & 688620 & 6.8 & 5.0375 & TRN \\
\hline CHEMBL1595810 & 688620 & 5.1 & 4.9421 & TST \\
\hline CHEMBL1520309 & 688620 & 5.05 & 5.4036 & TRN \\
\hline CHEMBL1547237 & 688620 & 5.45 & 5.3034 & TRN \\
\hline CHEMBL1361936 & 688620 & 5.25 & 5.5008 & TRN \\
\hline CHEMBL1541545 & 688620 & 6.1 & 4.9477 & TST \\
\hline CHEMBL1427298 & 688620 & 5.45 & 5.4574 & TRN \\
\hline CHEMBL1389380 & 688620 & 4.8 & 4.8829 & TRN \\
\hline CHEMBL1427201 & 688620 & 5.25 & 4.9201 & TRN \\
\hline CHEMBL1401271 & 688620 & 4.7 & 5.1065 & TRN \\
\hline CHEMBL1513765 & 688620 & 4.8 & 4.7125 & TRN \\
\hline CHEMBL1326893 & 688620 & 4.45 & 4.9459 & TRN \\
\hline CHEMBL1571208 & 688620 & 4.45 & 4.9775 & TRN \\
\hline CHEMBL3194444 & 688620 & 5.15 & 5.0734 & TRN \\
\hline CHEMBL1392558 & 688620 & 5.3 & 5.1285 & TRN \\
\hline CHEMBL1318732 & 688620 & 4.9 & 5.0486 & TRN \\
\hline CHEMBL1308857 & 688620 & 4.95 & 5.1185 & TRN \\
\hline CHEMBL1468192 & 688620 & 5.3 & 5.8026 & TRN \\
\hline CHEMBL3197883 & 688620 & 6.5501 & 5.8438 & TRN \\
\hline CHEMBL1412318 & 688620 & 5.0 & 4.9441 & TRN \\
\hline CHEMBL1610039 & 688620 & 4.85 & 4.8279 & TRN \\
\hline CHEMBL1369192 & 688620 & 4.9 & 4.9161 & TRN \\
\hline CHEMBL3213747 & 688620 & 5.8 & 5.3609 & TST \\
\hline CHEMBL1594211 & 688620 & 4.45 & 5.012 & TRN \\
\hline CHEMBL1548611 & 688620 & 5.1 & 5.0125 & TST \\
\hline CHEMBL 1413888 & 688620 & 4.9 & 4.9939 & TRN \\
\hline CHEMBL1424911 & 688620 & 4.6 & 5.1642 & TRN \\
\hline CHEMBL1427178 & 688620 & 5.15 & 5.1464 & TRN \\
\hline CHEMBL1416149 & 688620 & 4.45 & 4.9057 & TST \\
\hline CHEMBL1431894 & 688620 & 5.4 & 5.3591 & TRN \\
\hline CHEMBL3193584 & 688620 & 4.8 & 4.8609 & TST \\
\hline CHEMBL1993488 & 688620 & 4.45 & 4.9128 & TRN \\
\hline CHEMBL1527249 & 688620 & 5.0 & 5.1874 & TRN \\
\hline CHEMBL1586705 & 688620 & 4.9 & 4.9314 & TST \\
\hline CHEMBL1326344 & 688620 & 4.45 & 5.0542 & TRN \\
\hline CHEMBL3197471 & 688620 & 4.9 & 5.3534 & TRN \\
\hline CHEMBL3190616 & 688620 & 4.95 & 5.5201 & TRN \\
\hline
\end{tabular}




\begin{tabular}{|c|c|c|c|c|c|}
\hline & & \multicolumn{4}{|c|}{ Supplemental Table s2.txt } \\
\hline CHEMBL1522950 & 688620 & 5.25 & 4.9369 & TRN & \\
\hline CHEMBL1360948 & 688620 & 4.85 & 4.8789 & TRN & \\
\hline CHEMBL1413631 & 688620 & 4.8 & 5.0747 & TRN & \\
\hline CHEMBL1343084 & 688620 & 6.25 & 5.0293 & TST & \\
\hline CHEMBL1573561 & 688620 & 4.65 & 4.92399 & 99999999995 & TRN \\
\hline CHEMBL1299454 & 688620 & 5.35 & 5.1887 & TST & \\
\hline CHEMBL1370829 & 688620 & 4.75 & 5.1801 & TRN & \\
\hline CHEMBL1574219 & 688620 & 5.1 & 5.0259 & TST & \\
\hline CHEMBL 3208083 & 688620 & 5.6 & 5.6121 & TRN & \\
\hline CHEMBL1510400 & 688620 & 4.5 & 4.9347 & TST & \\
\hline CHEMBL1597560 & 688620 & 5.55 & 4.9157 & TRN & \\
\hline CHEMBL1402436 & 688620 & 5.75 & 5.3454 & TRN & \\
\hline CHEMBL1407281 & 688620 & 5.2 & 4.9051 & TRN & \\
\hline CHEMBL1359849 & 688620 & 4.45 & 4.8859 & TRN & \\
\hline CHEMBL3189704 & 688620 & 5.65 & 5.2091 & TST & \\
\hline CHEMBL1997425 & 688620 & 5.35 & 5.5599 & TRN & \\
\hline CHEMBL1382575 & 688620 & 5.0 & 5.1401 & TRN & \\
\hline CHEMBL1372234 & 688620 & 4.45 & 4.9779 & TRN & \\
\hline CHEMBL1497624 & 688620 & 4.75 & 4.7919 & TRN & \\
\hline CHEMBL 2000008 & 688620 & 6.35 & 5.8381 & TRN & \\
\hline CHEMBL1426449 & 688620 & 5.0 & 5.2864 & TRN & \\
\hline CHEMBL3190458 & 688620 & 5.9 & 5.9287 & TRN & \\
\hline CHEMBL3195386 & 688620 & 4.9 & 4.8354 & TRN & \\
\hline CHEMBL1451647 & 688620 & 6.05 & 5.7267 & TRN & \\
\hline CHEMBL1306266 & 688620 & 6.2 & 5.4018 & TST & \\
\hline CHEMBL1445112 & 688620 & 4.5 & 5.1675 & TST & \\
\hline CHEMBL1494451 & 688620 & 5.25 & 4.8877 & TST & \\
\hline CHEMBL1345614 & 688620 & 4.9 & 5.143 & TRN & \\
\hline CHEMBL1484821 & 688620 & 4.45 & 5.0775 & TRN & \\
\hline CHEMBL1343687 & 688620 & 4.6 & 5.3256 & TRN & \\
\hline CHEMBL1993431 & 688620 & 6.4 & 5.9722 & TRN & \\
\hline CHEMBL1386171 & 688620 & 5.45 & 5.0136 & TRN & \\
\hline CHEMBL3193007 & 688620 & 4.75 & 5.4525 & TRN & \\
\hline CHEMBL1970867 & 688620 & 5.55 & 5.3094 & TRN & \\
\hline CHEMBL1323499 & 688620 & 4.95 & 5.0026 & TST & \\
\hline CHEMBL468341 & 688620 & 4.45 & 5.0843 & TST & \\
\hline CHEMBL1326635 & 688620 & 4.8 & 5.2558 & TRN & \\
\hline CHEMBL1360227 & 688620 & 4.8 & 4.8333 & TRN & \\
\hline CHEMBL1335391 & 688620 & 4.9 & 4.833 & TST & \\
\hline CHEMBL1343484 & 688620 & 4.9 & 5.0871 & TRN & \\
\hline CHEMBL1608887 & 688620 & 4.45 & 5.09 & TRN & \\
\hline CHEMBL1495938 & 688620 & 4.7 & 5.0212 & TST & \\
\hline CHEMBL1311849 & 688620 & 4.9 & 4.9528 & TST & \\
\hline CHEMBL1602389 & 688620 & 4.5 & 5.032 & TST & \\
\hline CHEMBL3198273 & 688620 & 4.45 & 4.9461 & TRN & \\
\hline CHEMBL1376863 & 688620 & 6.05 & 5.5377 & TST & \\
\hline CHEMBL1556683 & 688620 & 4.65 & 4.9234 & TRN & \\
\hline CHEMBL1459131 & 688620 & 4.8 & 5.2398 & TRN & \\
\hline
\end{tabular}




\begin{tabular}{|c|c|c|c|c|c|}
\hline \multirow[b]{2}{*}{ CHEMBL1417937 } & \multirow[b]{2}{*}{688620} & \multicolumn{4}{|c|}{ Supplemental Table S2.txt } \\
\hline & & 4.95 & 5.038 & TRN & \\
\hline CHEMBL1489771 & 688620 & 6.15 & 4.7326 & TRN & \\
\hline CHEMBL1351048 & 688620 & 5.55 & 5.2898 & TRN & \\
\hline CHEMBL1415612 & 688620 & 5.4 & 5.0354 & TRN & \\
\hline CHEMBL1421879 & 688620 & 4.45 & \multicolumn{2}{|c|}{4.7989999999999995} & TST \\
\hline CHEMBL1429403 & 688620 & 4.45 & 5.2459 & TRN & \\
\hline CHEMBL3191940 & 688620 & 4.65 & 5.053 & TST & \\
\hline CHEMBL1470274 & 688620 & 4.95 & 5.1029 & TRN & \\
\hline CHEMBL1489223 & 688620 & 4.45 & 5.432 & TRN & \\
\hline CHEMBL1340213 & 688620 & 5.05 & 4.7794 & TST & \\
\hline CHEMBL1485080 & 688620 & 5.0 & 5.0518 & TRN & \\
\hline CHEMBL1404356 & 688620 & 5.45 & 5.4174 & TRN & \\
\hline CHEMBL1300625 & 688620 & 5.35 & 4.8826 & TRN & \\
\hline CHEMBL3196341 & 688620 & 5.45 & 5.0132 & TST & \\
\hline CHEMBL1507774 & 688620 & 5.5 & 4.7626 & TRN & \\
\hline CHEMBL1976466 & 688620 & 5.0 & 4.8723 & TRN & \\
\hline CHEMBL1377462 & 688620 & 4.55 & 4.9856 & TST & \\
\hline CHEMBL1604770 & 688620 & 4.45 & 4.9369 & TRN & \\
\hline CHEMBL1352575 & 688620 & 5.95 & 5.1657 & TRN & \\
\hline CHEMBL1605019 & 688620 & 7.6003 & 5.1834 & TST & \\
\hline CHEMBL1556862 & 688620 & 6.2 & 5.1188 & TRN & \\
\hline CHEMBL3194808 & 688620 & 5.2 & 4.9805 & TRN & \\
\hline CHEMBL1530907 & 688620 & 4.45 & 5.1878 & TRN & \\
\hline CHEMBL1346846 & 688620 & 4.9 & 5.0601 & TRN & \\
\hline CHEMBL1559461 & 688620 & 5.0 & 5.5972 & TRN & \\
\hline CHEMBL1527885 & 688620 & 4.45 & 4.8121 & TST & \\
\hline CHEMBL1376736 & 688620 & 4.45 & 4.841 & TRN & \\
\hline CHEMBL585840 & 688620 & 4.8 & 5.0823 & TST & \\
\hline CHEMBL1334076 & 688620 & 4.45 & 4.9247 & TST & \\
\hline CHEMBL1452648 & 688620 & 4.65 & 5.0765 & TRN & \\
\hline CHEMBL1416689 & 688620 & 4.55 & 4.8401 & TRN & \\
\hline CHEMBL1464013 & 688620 & 5.25 & 4.9136 & TRN & \\
\hline CHEMBL1534851 & 688620 & 4.7 & 4.7403 & TRN & \\
\hline CHEMBL1459562 & 688620 & 5.25 & 5.2147 & TRN & \\
\hline CHEMBL1351347 & 688620 & 5.0 & 4.8172 & TRN & \\
\hline CHEMBL1547325 & 688620 & 5.35 & 4.9356 & TRN & \\
\hline CHEMBL1580658 & 688620 & 5.25 & 5.1783 & TRN & \\
\hline CHEMBL1427966 & 688620 & 4.9 & 5.1343 & TST & \\
\hline CHEMBL1567017 & 688620 & 5.35 & 5.033 & TRN & \\
\hline CHEMBL1532917 & 688620 & 4.85 & 5.1164 & TRN & \\
\hline CHEMBL1498313 & 688620 & 4.95 & 5.0012 & TRN & \\
\hline CHEMBL1308386 & 688620 & 4.8 & 5.0329 & TRN & \\
\hline CHEMBL1530871 & 688620 & 4.95 & 5.2951 & TRN & \\
\hline CHEMBL3195385 & 688620 & 5.15 & 5.0794 & TRN & \\
\hline CHEMBL404313 & 688620 & 4.95 & 4.953 & TRN & \\
\hline CHEMBL1470565 & 688620 & 5.2 & 5.1097 & TST & \\
\hline CHEMBL1594342 & 688620 & 4.45 & 5.0048 & TRN & \\
\hline CHEMBL1382720 & 688620 & 4.7 & 5.0286 & TRN & \\
\hline & & & $\mathrm{P}$ & 27512 & \\
\hline
\end{tabular}




\begin{tabular}{|c|c|c|c|c|c|}
\hline \multicolumn{6}{|c|}{ Supplemental Table S2.txt } \\
\hline CHEMBL1422397 & 688620 & 5.1 & 5.0341 & TRN & \\
\hline CHEMBL1478826 & 688620 & 5.85 & 5.5479 & TRN & \\
\hline CHEMBL3197978 & 688620 & 5.3 & 5.6531 & TRN & \\
\hline CHEMBL1364270 & 688620 & 5.0 & 5.2652 & TRN & \\
\hline CHEMBL3190188 & 688620 & 5.0 & 5.2364 & TRN & \\
\hline CHEMBL1493004 & 688620 & 4.85 & 4.9802 & TRN & \\
\hline CHEMBL1361644 & 688620 & 4.65 & 5.0378 & TRN & \\
\hline CHEMBL1973482 & 688620 & 5.4 & 5.2699 & TRN & \\
\hline CHEMBL1708334 & 688620 & 4.9 & 4.6098 & TRN & \\
\hline CHEMBL1431604 & 688620 & 5.05 & 5.0603 & TRN & \\
\hline CHEMBL3197908 & 688620 & 5.4 & 5.2477 & TRN & \\
\hline CHEMBL1463209 & 688620 & 4.75 & 4.8785 & TST & \\
\hline CHEMBL 277127 & 688620 & 4.85 & 5.16 & TST & \\
\hline CHEMBL1613127 & 688620 & 4.85 & 5.2623 & TRN & \\
\hline CHEMBL1578521 & 688620 & 4.45 & 4.8421 & TRN & \\
\hline CHEMBL1430808 & 688620 & 4.75 & 5.0121 & TRN & \\
\hline CHEMBL1574277 & 688620 & 4.45 & 5.0369 & TRN & \\
\hline CHEMBL1306673 & 688620 & 5.25 & 4.9789 & TRN & \\
\hline CHEMBL345124 & 688620 & 5.5 & 5.2826 & TST & \\
\hline CHEMBL1588196 & 688620 & 4.8 & 5.197 & TRN & \\
\hline CHEMBL1497473 & 688620 & 4.85 & 5.0863 & TST & \\
\hline CHEMBL3214269 & 688620 & 4.45 & 5.0501 & TST & \\
\hline CHEMBL1478035 & 688620 & 5.45 & 5.1859 & TRN & \\
\hline CHEMBL1423985 & 688620 & 4.6 & 4.9406 & TRN & \\
\hline CHEMBL1501127 & 688620 & 6.05 & 5.8142 & TST & \\
\hline CHEMBL1342598 & 688620 & 4.85 & 5.0133 & TRN & \\
\hline CHEMBL1546067 & 688620 & 6.1 & 4.9488 & TST & \\
\hline CHEMBL1982441 & 688620 & 5.2 & 5.5426 & TRN & \\
\hline CHEMBL1504016 & 688620 & 4.45 & 4.9648 & TRN & \\
\hline CHEMBL1374331 & 688620 & 5.2 & 4.8599 & TRN & \\
\hline CHEMBL1367757 & 688620 & 4.9 & 5.0279 & TRN & \\
\hline CHEMBL1611285 & 688620 & 4.45 & 5.016 & TRN & \\
\hline CHEMBL586135 & 688620 & 6.7501 & 6.1802 & TST & \\
\hline CHEMBL1444717 & 688620 & 5.35 & 5.1335 & TST & \\
\hline CHEMBL1367525 & 688620 & 5.0 & 4.8735 & TRN & \\
\hline CHEMBL1569728 & 688620 & 5.95 & $5.0280 e$ & 20000000005 & TRN \\
\hline CHEMBL1557678 & 688620 & 7.6003 & 5.6484 & TRN & \\
\hline CHEMBL1305944 & 688620 & 6.25 & 5.0818 & TST & \\
\hline CHEMBL1588282 & 688620 & 4.6 & 4.7024 & TRN & \\
\hline CHEMBL1412870 & 688620 & 4.45 & 4.9207 & TRN & \\
\hline CHEMBL1460252 & 688620 & 4.95 & 5.3173 & TST & \\
\hline CHEMBL1712082 & 688620 & 5.5 & 5.7283 & TRN & \\
\hline CHEMBL1311453 & 688620 & 5.0 & 4.8331 & TST & \\
\hline CHEMBL3194782 & 688620 & 6.25 & 5.595 & TRN & \\
\hline CHEMBL1368640 & 688620 & 4.7 & 4.974 & TST & \\
\hline CHEMBL1369929 & 688620 & 4.5 & 5.2635 & TST & \\
\hline CHEMBL1385174 & 688620 & 5.2 & 5.1539 & TRN & \\
\hline CHEMBL3207649 & 688620 & 4.95 & 4.9026 & TRN & \\
\hline
\end{tabular}




\begin{tabular}{|c|c|c|c|c|}
\hline & & & oplement & al \\
\hline CHEMBL1365959 & 688620 & 4.45 & 4.8775 & TRN \\
\hline CHEMBL 3207717 & 688620 & 4.7 & 5.1853 & TST \\
\hline CHEMBL1605879 & 688620 & 4.6 & 5.1911 & TRN \\
\hline CHEMBL1351567 & 688620 & 4.8 & 4.9991 & TRN \\
\hline CHEMBL1580356 & 688620 & 4.95 & 4.9389 & TRN \\
\hline CHEMBL1531579 & 688620 & 4.45 & 5.1114 & TST \\
\hline CHEMBL1563800 & 688620 & 5.05 & 4.9085 & TRN \\
\hline CHEMBL 3195389 & 688620 & 6.0 & 6.1747 & TRN \\
\hline CHEMBL1496892 & 688620 & 5.2 & 5.2602 & TRN \\
\hline CHEMBL1471767 & 688620 & 4.45 & 4.7965 & TRN \\
\hline CHEMBL1494865 & 688620 & 4.5 & 4.8082 & TRN \\
\hline CHEMBL 3198162 & 688620 & 5.3 & 5.0639 & TRN \\
\hline CHEMBL1441691 & 688620 & 4.75 & 5.0405 & TRN \\
\hline CHEMBL1381612 & 688620 & 5.5 & 4.8584 & TST \\
\hline CHEMBL 1505780 & 688620 & 5.15 & 5.1368 & TST \\
\hline CHEMBL 3193820 & 688620 & 5.7 & 5.3013 & TRN \\
\hline CHEMBL1559862 & 688620 & 4.85 & 5.2571 & TRN \\
\hline CHEMBL1341688 & 688620 & 4.9 & 5.0335 & TST \\
\hline CHEMBL1346518 & 688620 & 5.15 & 5.0808 & TST \\
\hline CHEMBL3198317 & 688620 & 4.45 & 4.9187 & TST \\
\hline CHEMBL1383052 & 688620 & 8.301 & 5.2208 & TST \\
\hline CHEMBL195506 & 688620 & 5.35 & 5.1483 & TRN \\
\hline CHEMBL1404547 & 688620 & 5.0 & 4.9801 & TRN \\
\hline CHEMBL1333828 & 688620 & 5.25 & 5.14 & TRN \\
\hline CHEMBL1302552 & 688620 & 5.6 & 4.974 & TRN \\
\hline CHEMBL1516681 & 688620 & 4.6 & 5.1178 & TST \\
\hline CHEMBL1477942 & 688620 & 4.95 & 5.0927 & TRN \\
\hline CHEMBL1594898 & 688620 & 5.55 & 4.9669 & TRN \\
\hline CHEMBL1370339 & 688620 & 5.8 & 5.1109 & TRN \\
\hline CHEMBL1416146 & 688620 & 4.5 & 4.7244 & TST \\
\hline CHEMBL1502711 & 688620 & 4.85 & 5.1066 & TRN \\
\hline CHEMBL1965415 & 688620 & 5.85 & 5.5164 & TRN \\
\hline CHEMBL1310196 & 688620 & 4.95 & 4.6554 & TRN \\
\hline CHEMBL1431619 & 688620 & 4.7 & 4.996 & TRN \\
\hline CHEMBL 3212023 & 688620 & 4.75 & 5.4134 & TST \\
\hline CHEMBL1485593 & 688620 & 5.0 & 4.805 & TRN \\
\hline CHEMBL1499083 & 688620 & 4.85 & 4.7632 & TRN \\
\hline CHEMBL1585654 & 688620 & 5.0 & 4.9137 & TRN \\
\hline CHEMBL1402883 & 688620 & 4.65 & 5.0546 & TRN \\
\hline CHEMBL3198361 & 688620 & 4.45 & 5.2119 & TST \\
\hline CHEMBL1540164 & 688620 & 4.95 & 4.9093 & TRN \\
\hline CHEMBL1580135 & 688620 & 5.5 & 5.2765 & TRN \\
\hline CHEMBL3195886 & 688620 & 4.45 & 4.8768 & TRN \\
\hline CHEMBL 3194222 & 688620 & 4.95 & 4.92 & TRN \\
\hline CHEMBL1456862 & 688620 & 4.45 & 4.8874 & TRN \\
\hline CHEMBL1386402 & 688620 & 4.9 & 4.97 & TRN \\
\hline CHEMBL1568487 & 688620 & 5.85 & 5.0893 & TST \\
\hline CHEMBL1488979 & 688620 & 4.6 & 5.1858 & TRN \\
\hline
\end{tabular}




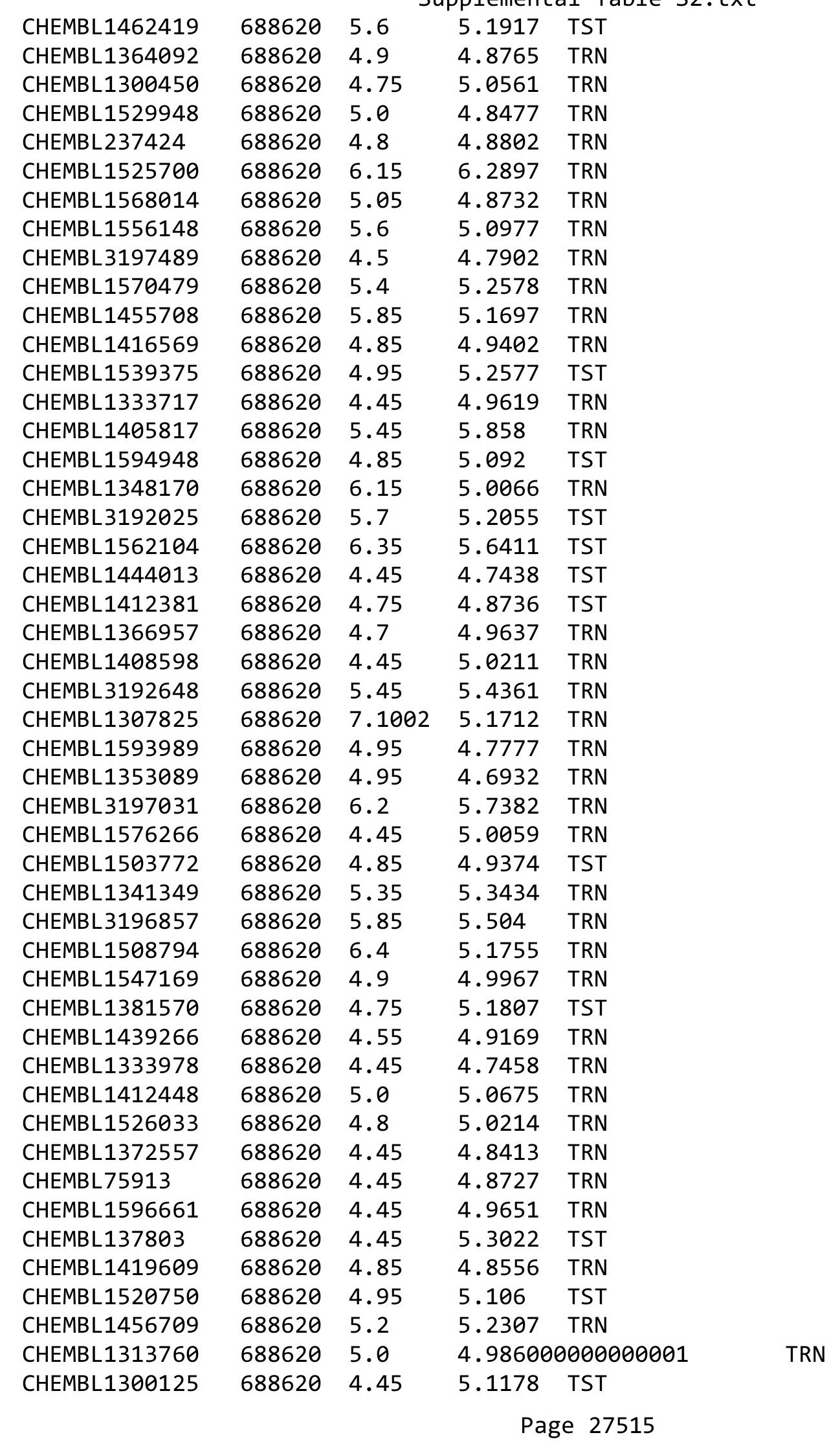




\begin{tabular}{|c|c|c|c|c|c|}
\hline \multicolumn{6}{|c|}{ Supplemental Table S2.txt } \\
\hline CHEMBL1375153 & 688620 & 4.45 & 4.6947 & TRN & \\
\hline CHEMBL77387 & 688620 & 4.9 & 4.8195 & TRN & \\
\hline CHEMBL1324573 & 688620 & 4.95 & 5.07 & TRN & \\
\hline CHEMBL1483208 & 688620 & 5.0 & 5.3903 & TRN & \\
\hline CHEMBL1573950 & 688620 & 4.95 & 4.8606 & TRN & \\
\hline CHEMBL3194601 & 688620 & 4.95 & 4.7696 & TRN & \\
\hline CHEMBL1606412 & 688620 & 5.9 & 5.58899 & 99999999995 & TRN \\
\hline CHEMBL1376396 & 688620 & 4.9 & 5.15600 & 0000000001 & TRN \\
\hline CHEMBL1313685 & 688620 & 5.2 & 5.1122 & TRN & \\
\hline CHEMBL1374222 & 688620 & 4.45 & 4.8814 & TST & \\
\hline CHEMBL1587786 & 688620 & 5.3 & 5.1947 & TRN & \\
\hline CHEMBL1534558 & 688620 & 4.95 & 5.1032 & TRN & \\
\hline CHEMBL104255 & 688620 & 4.45 & 4.8725 & TRN & \\
\hline CHEMBL1307384 & 688620 & 5.15 & 5.1025 & TRN & \\
\hline CHEMBL1402510 & 688620 & 5.75 & 6.7921 & TRN & \\
\hline CHEMBL1452253 & 688620 & 4.95 & 4.7095 & TRN & \\
\hline CHEMBL1373432 & 688620 & 4.6 & 5.0842 & TST & \\
\hline CHEMBL1386684 & 688620 & 5.1 & 5.4571 & TRN & \\
\hline CHEMBL1469313 & 688620 & 4.95 & 5.33899 & 99999999995 & TST \\
\hline CHEMBL1608698 & 688620 & 4.9 & 5.1082 & TRN & \\
\hline CHEMBL1405200 & 688620 & 4.9 & 4.8666 & TRN & \\
\hline CHEMBL3194146 & 688620 & 4.45 & 4.9301 & TRN & \\
\hline CHEMBL1441290 & 688620 & 4.9 & 4.9127 & TST & \\
\hline CHEMBL1384330 & 688620 & 4.45 & 4.7489 & TRN & \\
\hline CHEMBL1328324 & 688620 & 4.45 & 5.0301 & TST & \\
\hline CHEMBL1491092 & 688620 & 4.9 & 5.06800 & 00000000005 & TST \\
\hline CHEMBL1485781 & 688620 & 4.85 & 5.2024 & TRN & \\
\hline CHEMBL1410641 & 688620 & 4.45 & 4.9649 & TST & \\
\hline CHEMBL1505542 & 688620 & 4.8 & 5.053 & TRN & \\
\hline CHEMBL3194807 & 688620 & 6.35 & 5.9981 & TRN & \\
\hline CHEMBL1353528 & 688620 & 5.8 & 4.5729 & TRN & \\
\hline CHEMBL1400801 & 688620 & 5.1 & 4.957 & TRN & \\
\hline CHEMBL1518067 & 688620 & 4.85 & 5.0604 & TRN & \\
\hline CHEMBL1455336 & 688620 & 4.45 & 5.1568 & TST & \\
\hline CHEMBL3208922 & 688620 & 4.65 & 4.8282 & TRN & \\
\hline CHEMBL1608036 & 688620 & 4.9 & 4.8284 & TRN & \\
\hline CHEMBL1426881 & 688620 & 7.6498 & 4.9318 & TRN & \\
\hline CHEMBL1409914 & 688620 & 4.65 & 4.9895 & TST & \\
\hline CHEMBL 243664 & 688620 & 4.55 & 5.47 & TRN & \\
\hline CHEMBL1391041 & 688620 & 4.7 & 5.5181 & TST & \\
\hline CHEMBL1534607 & 688620 & 4.95 & 5.0985 & TST & \\
\hline CHEMBL1374616 & 688620 & 5.4 & 5.7923 & TRN & \\
\hline CHEMBL1410941 & 688620 & 4.95 & 5.4303 & TRN & \\
\hline CHEMBL1391098 & 688620 & 4.7 & 4.803 & TRN & \\
\hline CHEMBL 2001867 & 688620 & 4.65 & 4.9539 & TRN & \\
\hline CHEMBL1474771 & 688620 & 5.25 & 5.0613 & TST & \\
\hline CHEMBL1399643 & 688620 & 4.45 & 4.7625 & TRN & \\
\hline CHEMBL1507416 & 688620 & 4.95 & 5.5837 & TRN & \\
\hline
\end{tabular}




\begin{tabular}{|c|c|c|c|c|c|}
\hline \\
\hline CHEMBL1609978 & 688620 & 4.9 & 5.1249 & TST & \\
\hline CHEMBL1423636 & 688620 & 4.45 & 4.9344 & TST & \\
\hline CHEMBL3190730 & 688620 & 4.95 & 4.8777 & TRN & \\
\hline CHEMBL1606890 & 688620 & 5.1 & 5.0348 & TRN & \\
\hline CHEMBL1611511 & 688620 & 4.85 & 4.8682 & TRN & \\
\hline CHEMBL1582804 & 688620 & 4.45 & 4.8758 & TRN & \\
\hline CHEMBL1576495 & 688620 & 5.95 & 5.118 & TRN & \\
\hline CHEMBL1493405 & 688620 & 5.0 & 5.3223 & TRN & \\
\hline CHEMBL1462267 & 688620 & 4.8 & 5.0546 & TST & \\
\hline CHEMBL1365141 & 688620 & 5.0 & 4.901 & TRN & \\
\hline CHEMBL1986090 & 688620 & 6.35 & 5.555 & TRN & \\
\hline CHEMBL1531003 & 688620 & 4.95 & 5.26200 & 00000000005 & TST \\
\hline CHEMBL1344677 & 688620 & 6.6 & 5.4731 & TST & \\
\hline CHEMBL1360792 & 688620 & 5.2 & 5.4181 & TST & \\
\hline CHEMBL1481686 & 688620 & 5.6 & 5.3448 & TRN & \\
\hline CHEMBL1349183 & 688620 & 4.95 & 4.9541 & TRN & \\
\hline CHEMBL1322054 & 688620 & 4.95 & 5.2733 & TRN & \\
\hline CHEMBL1367932 & 688620 & 4.8 & 5.1005 & TST & \\
\hline CHEMBL1535379 & 688620 & 5.5 & 5.58899 & 99999999995 & TRN \\
\hline CHEMBL3190270 & 688620 & 4.75 & 4.9955 & TST & \\
\hline CHEMBL1342491 & 688620 & 6.35 & 6.2191 & TRN & \\
\hline CHEMBL1585594 & 688620 & 4.8 & 4.9635 & TRN & \\
\hline CHEMBL1312303 & 688620 & 5.0 & 5.2133 & TRN & \\
\hline CHEMBL1448292 & 688620 & 5.25 & 4.8847 & TRN & \\
\hline CHEMBL1556214 & 688620 & 5.8 & 5.3209 & TRN & \\
\hline CHEMBL1383583 & 688620 & 4.95 & 5.0462 & TST & \\
\hline CHEMBL1507125 & 688620 & 4.9 & 4.9944 & TRN & \\
\hline CHEMBL1505841 & 688620 & 4.8 & 5.1408 & TST & \\
\hline CHEMBL1349433 & 688620 & 4.75 & 5.0038 & TST & \\
\hline CHEMBL1455896 & 688620 & 5.7 & 5.1623 & TST & \\
\hline CHEMBL1352854 & 688620 & 5.35 & 5.5971 & TST & \\
\hline CHEMBL1582799 & 688620 & 4.95 & 4.9543 & TRN & \\
\hline CHEMBL1531725 & 688620 & 5.0 & 4.6468 & TRN & \\
\hline CHEMBL3207291 & 688620 & 4.45 & 5.1702 & TST & \\
\hline CHEMBL1411093 & 688620 & 5.25 & 5.2275 & TRN & \\
\hline CHEMBL1569090 & 688620 & 4.45 & 4.8853 & TRN & \\
\hline CHEMBL1323759 & 688620 & 5.0 & 5.0097 & TRN & \\
\hline CHEMBL1401373 & 688620 & 5.15 & 5.2283 & TST & \\
\hline CHEMBL1564487 & 688620 & 5.75 & 5.65 & TRN & \\
\hline CHEMBL1319955 & 688620 & 5.95 & 5.0838 & TRN & \\
\hline CHEMBL1428399 & 688620 & 4.85 & 4.9565 & TRN & \\
\hline CHEMBL1352019 & 688620 & 4.45 & 5.0807 & TRN & \\
\hline CHEMBL1583692 & 688620 & 4.45 & 5.042 & TRN & \\
\hline CHEMBL1336924 & 688620 & 4.85 & 4.8427 & TRN & \\
\hline CHEMBL 2016644 & 688620 & 5.95 & 5.5486 & TRN & \\
\hline CHEMBL1509811 & 688620 & 4.5 & 5.1363 & TRN & \\
\hline CHEMBL1568897 & 688620 & 7.6498 & 4.7236 & TRN & \\
\hline CHEMBL1508505 & 688620 & 4.9 & 4.7722 & TRN & \\
\hline
\end{tabular}




\begin{tabular}{|c|c|c|c|c|}
\hline \multicolumn{5}{|c|}{ Supplemental Table S2.txt } \\
\hline CHEMBL1607620 & 688620 & 4.85 & 4.9112 & TRN \\
\hline CHEMBL1451206 & 688620 & 4.9 & 5.0246 & TRN \\
\hline CHEMBL3193131 & 688620 & 4.95 & 5.0486 & TST \\
\hline CHEMBL1462124 & 688620 & 5.95 & 5.7256 & TRN \\
\hline CHEMBL1418430 & 688620 & 5.3 & 4.7491 & TRN \\
\hline CHEMBL1526722 & 688620 & 4.9 & 5.0836 & TRN \\
\hline CHEMBL3212907 & 688620 & 6.35 & 5.6779 & TRN \\
\hline CHEMBL1546398 & 688620 & 4.9 & 5.1039 & TRN \\
\hline CHEMBL1523068 & 688620 & 4.45 & 4.7713 & TRN \\
\hline CHEMBL1527529 & 688620 & 4.9 & 4.9316 & TRN \\
\hline CHEMBL1300338 & 688620 & 6.1 & 5.9625 & TRN \\
\hline CHEMBL1992001 & 688620 & 5.0 & 5.0497 & TRN \\
\hline CHEMBL1309253 & 688620 & 4.85 & 4.9592 & TRN \\
\hline CHEMBL1550446 & 688620 & 5.4 & 5.557 & TRN \\
\hline CHEMBL1313972 & 688620 & 6.15 & 4.9266 & TRN \\
\hline CHEMBL1553635 & 688620 & 8.2518 & 4.1601 & TST \\
\hline CHEMBL1450911 & 688620 & 4.9 & 4.9594 & TST \\
\hline CHEMBL1560595 & 688620 & 5.4 & 4.8939 & TST \\
\hline CHEMBL1387166 & 688620 & 4.45 & 4.773 & TRN \\
\hline CHEMBL1573956 & 688620 & 5.6 & 5.3926 & TRN \\
\hline CHEMBL1499711 & 688620 & 5.95 & 5.3968 & TRN \\
\hline CHEMBL1309540 & 688620 & 5.2 & 4.9659 & TRN \\
\hline CHEMBL1493497 & 688620 & 5.05 & 5.0709 & TRN \\
\hline CHEMBL1409032 & 688620 & 5.5 & 5.1033 & TRN \\
\hline CHEMBL1584782 & 688620 & 4.75 & 5.0283 & TRN \\
\hline CHEMBL1338209 & 688620 & 4.65 & 5.0891 & TRN \\
\hline CHEMBL1530349 & 688620 & 4.9 & 4.8729 & TRN \\
\hline CHEMBL1566829 & 688620 & 4.45 & 4.6787 & TRN \\
\hline CHEMBL1574553 & 688620 & 6.95 & 6.0012 & TST \\
\hline CHEMBL1492159 & 688620 & 4.65 & 5.1048 & TRN \\
\hline CHEMBL1322052 & 688620 & 6.25 & 5.7895 & TRN \\
\hline CHEMBL1310325 & 688620 & 4.45 & 4.7995 & TST \\
\hline CHEMBL1522486 & 688620 & 6.0 & 5.0852 & TRN \\
\hline CHEMBL1463222 & 688620 & 4.7 & 5.079 & TRN \\
\hline CHEMBL1426770 & 688620 & 6.6 & 4.9699 & TRN \\
\hline CHEMBL1409623 & 688620 & 5.45 & 4.9972 & TST \\
\hline CHEMBL1452588 & 688620 & 4.8 & 5.2861 & TRN \\
\hline CHEMBL1391830 & 688620 & 5.05 & 5.0982 & TRN \\
\hline CHEMBL1408729 & 688620 & 4.9 & 5.2264 & TRN \\
\hline CHEMBL1608050 & 688620 & 4.85 & 4.9163 & TST \\
\hline CHEMBL1471194 & 688620 & 5.35 & 5.0504 & TRN \\
\hline CHEMBL1519374 & 688620 & 5.15 & 4.8657 & TRN \\
\hline CHEMBL1462417 & 688620 & 4.95 & 5.0554 & TRN \\
\hline CHEMBL 3194835 & 688620 & 5.0 & 5.0358 & TRN \\
\hline CHEMBL1493343 & 688620 & 4.95 & 5.041 & TST \\
\hline CHEMBL1348898 & 688620 & 4.85 & 5.2112 & TST \\
\hline CHEMBL1509668 & 688620 & 4.45 & 4.9657 & TRN \\
\hline CHEMBL3190539 & 688620 & 5.0 & 5.1328 & TRN \\
\hline
\end{tabular}




\begin{tabular}{|c|c|c|c|c|c|}
\hline \\
\hline CHEMBL1530807 & 688620 & 4.7 & 4.7834 & TRN & \\
\hline CHEMBL1594268 & 688620 & 5.1 & 4.9063 & TRN & \\
\hline CHEMBL171632 & 688620 & 5.1 & 5.0193 & TST & \\
\hline CHEMBL1597489 & 688620 & 4.95 & 5.0003 & TST & \\
\hline CHEMBL1433353 & 688620 & 5.3 & 4.9215 & TRN & \\
\hline CHEMBL1459087 & 688620 & 4.45 & 4.914 & TRN & \\
\hline CHEMBL1561490 & 688620 & 5.3 & 4.9996 & TRN & \\
\hline CHEMBL1543426 & 688620 & 5.2 & 5.1665 & TRN & \\
\hline CHEMBL1496538 & 688620 & 4.9 & 4.9624 & TRN & \\
\hline CHEMBL1494120 & 688620 & 6.1 & 5.4977 & TRN & \\
\hline CHEMBL1543654 & 688620 & 4.45 & 4.9508 & TRN & \\
\hline CHEMBL1444471 & 688620 & 4.75 & 4.959 & TRN & \\
\hline CHEMBL1339931 & 688620 & 5.05 & 5.1963 & TST & \\
\hline CHEMBL1480712 & 688620 & 4.45 & 5.1221 & TRN & \\
\hline CHEMBL1790011 & 688620 & 4.9 & 4.9172 & TST & \\
\hline CHEMBL1589563 & 688620 & 6.35 & 5.5626 & TRN & \\
\hline CHEMBL1425453 & 688620 & 5.5 & 4.90300 & 00000000005 & TST \\
\hline CHEMBL1564582 & 688620 & 4.95 & 5.197 & TRN & \\
\hline CHEMBL1332854 & 688620 & 4.45 & 5.1609 & TST & \\
\hline CHEMBL1562304 & 688620 & 4.65 & 4.8819 & TRN & \\
\hline CHEMBL1429936 & 688620 & 6.8499 & 4.92399 & 99999999995 & TRN \\
\hline CHEMBL1974713 & 688620 & 4.75 & 4.9176 & TRN & \\
\hline CHEMBL1389153 & 688620 & 5.55 & 5.0916 & TRN & \\
\hline CHEMBL1569532 & 688620 & 4.8 & 4.9763 & TRN & \\
\hline CHEMBL3210602 & 688620 & 5.25 & 4.9212 & TST & \\
\hline CHEMBL1411785 & 688620 & 4.5 & 4.73600 & 3000000001 & TST \\
\hline CHEMBL1392092 & 688620 & 5.1 & 5.1236 & TRN & \\
\hline CHEMBL 3214622 & 688620 & 5.55 & 4.9364 & TRN & \\
\hline CHEMBL1499262 & 688620 & 4.9 & 5.1848 & TRN & \\
\hline CHEMBL1504670 & 688620 & 5.05 & 4.7363 & TRN & \\
\hline CHEMBL1427301 & 688620 & 5.4 & 5.1939 & TRN & \\
\hline CHEMBL1599035 & 688620 & 4.65 & 4.9339 & TST & \\
\hline CHEMBL1431140 & 688620 & 5.2 & 5.0763 & TRN & \\
\hline CHEMBL1414921 & 688620 & 4.95 & 4.9192 & TRN & \\
\hline CHEMBL1391413 & 688620 & 5.25 & 5.07 & TRN & \\
\hline CHEMBL1439138 & 688620 & 5.2 & 5.2546 & TRN & \\
\hline CHEMBL3189146 & 688620 & 4.9 & 5.1109 & TRN & \\
\hline CHEMBL1481273 & 688620 & 4.75 & 4.955 & TST & \\
\hline CHEMBL1605031 & 688620 & 4.45 & 5.0258 & TRN & \\
\hline CHEMBL1613404 & 688620 & 5.25 & 5.1522 & TRN & \\
\hline CHEMBL1373263 & 688620 & 4.7 & 4.9542 & TST & \\
\hline CHEMBL1560837 & 688620 & 4.75 & 4.9542 & TRN & \\
\hline CHEMBL1517768 & 688620 & 4.8 & 5.3162 & TST & \\
\hline CHEMBL3214114 & 688620 & 5.0 & 5.1573 & TRN & \\
\hline CHEMBL1459791 & 688620 & 4.9 & 5.1334 & TRN & \\
\hline CHEMBL1526085 & 688620 & 4.9 & 4.7776 & TST & \\
\hline CHEMBL175434 & 688620 & 5.0 & 4.6844 & TRN & \\
\hline CHEMBL1977384 & 688620 & 5.2 & 5.0278 & TRN & \\
\hline
\end{tabular}




\begin{tabular}{|c|c|c|c|c|}
\hline \multicolumn{5}{|c|}{ Supplemental Table S2.txt } \\
\hline CHEMBL1411210 & 688620 & 5.6 & 5.2114 & TST \\
\hline CHEMBL1430449 & 688620 & 4.45 & 4.8271 & TRN \\
\hline CHEMBL1582176 & 688620 & 5.15 & 4.9448 & TRN \\
\hline CHEMBL1397706 & 688620 & 4.85 & 5.0807 & TST \\
\hline CHEMBL1393095 & 688620 & 5.6 & 5.6173 & TRN \\
\hline CHEMBL1477920 & 688620 & 5.25 & 5.0905 & TST \\
\hline CHEMBL1420490 & 688620 & 5.8 & 5.0983 & TRN \\
\hline CHEMBL 3188020 & 688620 & 4.45 & 4.9144 & TRN \\
\hline CHEMBL1532984 & 688620 & 6.95 & 5.0767 & TST \\
\hline CHEMBL1500409 & 688620 & 5.95 & 5.5623 & TRN \\
\hline CHEMBL1603921 & 688620 & 4.5 & 4.9773 & TRN \\
\hline CHEMBL3191160 & 688620 & 6.1 & 6.0465 & TRN \\
\hline CHEMBL1449172 & 688620 & 5.0 & 5.1019 & TRN \\
\hline CHEMBL1560181 & 688620 & 5.25 & 5.4824 & TRN \\
\hline CHEMBL1570928 & 688620 & 4.9 & 4.9014 & TRN \\
\hline CHEMBL1463410 & 688620 & 4.7 & 4.9092 & TRN \\
\hline CHEMBL1442156 & 688620 & 5.2 & 5.1573 & TST \\
\hline CHEMBL1415508 & 688620 & 5.35 & 5.1209 & TRN \\
\hline CHEMBL1352653 & 688620 & 4.6 & 4.987 & TRN \\
\hline CHEMBL1442847 & 688620 & 5.25 & 4.7658 & TRN \\
\hline CHEMBL1492883 & 688620 & 4.95 & 5.0584 & TRN \\
\hline CHEMBL1536323 & 688620 & 4.85 & 5.0976 & TRN \\
\hline CHEMBL601757 & 688620 & 5.25 & 5.6073 & TRN \\
\hline CHEMBL1610341 & 688620 & 4.9 & 5.1724 & TST \\
\hline CHEMBL1419040 & 688620 & 5.5 & 4.768 & TRN \\
\hline CHEMBL1508850 & 688620 & 5.2 & 5.2756 & TRN \\
\hline CHEMBL1579164 & 688620 & 5.25 & 5.1122 & TRN \\
\hline CHEMBL1481367 & 688620 & 5.3 & 5.035 & TRN \\
\hline CHEMBL1543935 & 688620 & 4.9 & 5.4409 & TRN \\
\hline CHEMBL1465619 & 688620 & 4.95 & 5.0194 & TST \\
\hline CHEMBL1449107 & 688620 & 4.85 & 4.928 & TRN \\
\hline CHEMBL1581349 & 688620 & 5.2 & 5.1837 & TST \\
\hline CHEMBL1976304 & 688620 & 4.9 & 4.8913 & TST \\
\hline CHEMBL1435450 & 688620 & 4.85 & 5.0069 & TRN \\
\hline CHEMBL1586337 & 688620 & 4.6 & 5.0739 & TRN \\
\hline CHEMBL1486895 & 688620 & 4.45 & 4.8122 & TRN \\
\hline CHEMBL1301901 & 688620 & 4.45 & 4.9906 & TRN \\
\hline CHEMBL1314303 & 688620 & 5.0 & 4.8516 & TRN \\
\hline CHEMBL1390451 & 688620 & 4.65 & 4.9251 & TST \\
\hline CHEMBL1580526 & 688620 & 4.5 & 5.3716 & TST \\
\hline CHEMBL3189873 & 688620 & 5.1 & 5.0089 & TST \\
\hline CHEMBL1539595 & 688620 & 4.95 & 5.0572 & TRN \\
\hline CHEMBL1510644 & 688620 & 4.8 & 5.1606 & TRN \\
\hline CHEMBL1613388 & 688620 & 4.95 & 4.9122 & TRN \\
\hline CHEMBL1520832 & 688620 & 4.5 & 4.9982 & TRN \\
\hline CHEMBL1483523 & 688620 & 5.65 & 5.2151 & TRN \\
\hline CHEMBL1339426 & 688620 & 4.45 & 5.0049 & TRN \\
\hline CHEMBL1511004 & 688620 & 4.5 & 4.9306 & TRN \\
\hline
\end{tabular}




\begin{tabular}{|c|c|c|c|c|c|}
\hline \multicolumn{6}{|c|}{ Supplemental Table S2.txt } \\
\hline CHEMBL1307325 & 688620 & 3.95 & 4.9249 & TST & \\
\hline CHEMBL1569878 & 688620 & 4.45 & 4.8501 & TRN & \\
\hline CHEMBL1328035 & 688620 & 4.45 & 4.8602 & TRN & \\
\hline CHEMBL1407122 & 688620 & 5.0 & 4.9033 & TRN & \\
\hline CHEMBL1326531 & 688620 & 4.5 & 4.9343 & TRN & \\
\hline CHEMBL1607939 & 688620 & 5.35 & 5.0627 & TRN & \\
\hline CHEMBL3209359 & 688620 & 4.9 & 5.1448 & TRN & \\
\hline CHEMBL1380693 & 688620 & 4.85 & 4.9802 & TRN & \\
\hline CHEMBL1586284 & 688620 & 4.7 & 5.0355 & TST & \\
\hline CHEMBL1504915 & 688620 & 4.85 & 5.0761 & TRN & \\
\hline CHEMBL1532904 & 688620 & 4.5 & 5.1844 & TRN & \\
\hline CHEMBL1350951 & 688620 & 4.9 & 5.1016 & TRN & \\
\hline CHEMBL1329908 & 688620 & 4.5 & 5.0983 & TRN & \\
\hline CHEMBL1362497 & 688620 & 4.95 & 5.13399 & 99999999995 & TRN \\
\hline CHEMBL1401602 & 688620 & 4.45 & 4.8947 & TRN & \\
\hline CHEMBL1470512 & 688620 & 5.15 & 4.9204 & TRN & \\
\hline CHEMBL3198110 & 688620 & 4.95 & 4.9202 & TRN & \\
\hline CHEMBL1594566 & 688620 & 4.85 & 4.88399 & 99999999995 & TRN \\
\hline CHEMBL1587863 & 688620 & 5.6 & 5.7589 & TRN & \\
\hline CHEMBL1454677 & 688620 & 4.9 & 4.6713 & TRN & \\
\hline CHEMBL1471501 & 688620 & 6.1 & 5.7688 & TRN & \\
\hline CHEMBL1466818 & 688620 & 5.15 & 5.2773 & TRN & \\
\hline CHEMBL1573221 & 688620 & 6.0 & 4.7754 & TRN & \\
\hline CHEMBL1336242 & 688620 & 4.75 & 4.9143 & TRN & \\
\hline CHEMBL1581916 & 688620 & 4.65 & 5.152 & TRN & \\
\hline CHEMBL1516388 & 688620 & 6.0 & 5.6293 & TST & \\
\hline CHEMBL1423607 & 688620 & 5.45 & 5.1605 & TRN & \\
\hline CHEMBL1497566 & 688620 & 5.35 & 5.0478 & TST & \\
\hline CHEMBL1568523 & 688620 & 4.9 & 5.0411 & TRN & \\
\hline CHEMBL3212159 & 688620 & 4.45 & 5.0248 & TST & \\
\hline CHEMBL1558551 & 688620 & 6.05 & 5.7617 & TRN & \\
\hline CHEMBL475375 & 688620 & 4.45 & 4.948 & TRN & \\
\hline CHEMBL1607229 & 688620 & 4.45 & 5.1991 & TRN & \\
\hline CHEMBL1340731 & 688620 & 4.45 & 4.9993 & TRN & \\
\hline CHEMBL1337414 & 688620 & 5.05 & 4.9247 & TST & \\
\hline CHEMBL3190513 & 688620 & 5.25 & 5.5726 & TRN & \\
\hline CHEMBL1367245 & 688620 & 5.95 & 5.3925 & TRN & \\
\hline CHEMBL1595586 & 688620 & 4.5 & 4.8069 & TST & \\
\hline CHEMBL1564828 & 688620 & 5.0 & 5.0843 & TRN & \\
\hline CHEMBL1558724 & 688620 & 4.9 & 5.0722 & TRN & \\
\hline CHEMBL1372434 & 688620 & 4.75 & 4.9082 & TRN & \\
\hline CHEMBL1326420 & 688620 & 5.5 & 5.2093 & TRN & \\
\hline CHEMBL1459940 & 688620 & 4.9 & 4.9431 & TST & \\
\hline CHEMBL1548856 & 688620 & 7.6498 & 5.1047 & TST & \\
\hline CHEMBL1307370 & 688620 & 5.15 & 5.301 & TRN & \\
\hline CHEMBL1452438 & 688620 & 5.85 & 5.042 & TST & \\
\hline CHEMBL1500848 & 688620 & 5.0 & 5.0763 & TRN & \\
\hline CHEMBL 2006386 & 688620 & 4.45 & 4.8333 & TRN & \\
\hline
\end{tabular}




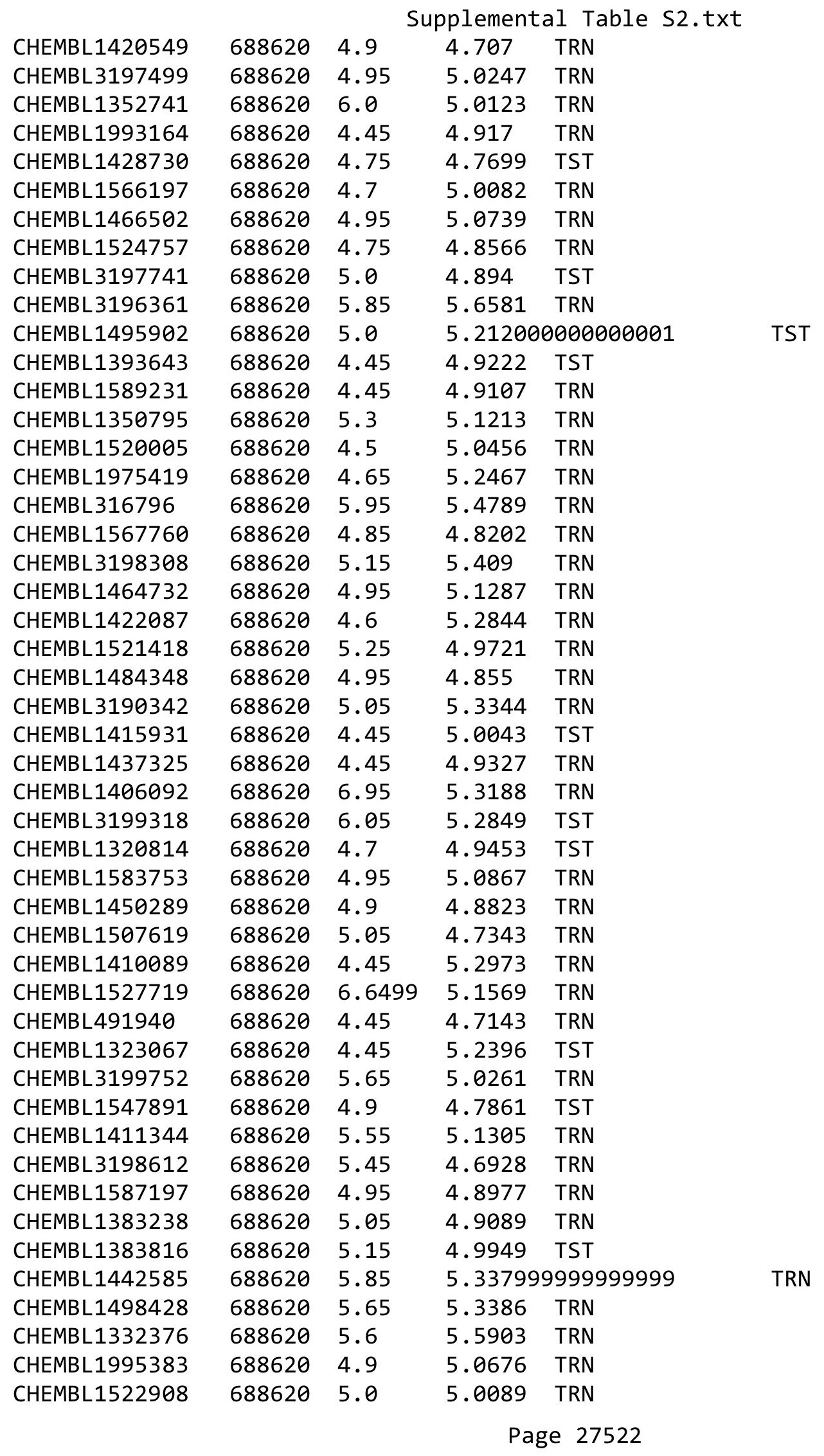




\begin{tabular}{|c|c|c|c|c|c|}
\hline \multicolumn{6}{|c|}{ Supplemental Table S2.txt } \\
\hline CHEMBL1308486 & 688620 & 5.1 & 4.8816 & TRN & \\
\hline CHEMBL1299834 & 688620 & 5.0 & 5.3878 & TRN & \\
\hline CHEMBL1370406 & 688620 & 4.95 & 4.555 & TRN & \\
\hline CHEMBL1557436 & 688620 & 4.45 & 5.0016 & TST & \\
\hline CHEMBL1386531 & 688620 & 4.65 & 4.9718 & TRN & \\
\hline CHEMBL1415303 & 688620 & 4.9 & 5.02 & TRN & \\
\hline CHEMBL3195162 & 688620 & 5.4 & 5.1858 & TRN & \\
\hline CHEMBL1447252 & 688620 & 4.45 & 5.0192 & TST & \\
\hline CHEMBL1606130 & 688620 & 4.5 & 4.9167 & TRN & \\
\hline CHEMBL3195837 & 688620 & 4.75 & 4.9169 & TRN & \\
\hline CHEMBL1572452 & 688620 & 7.0 & 5.0272 & TRN & \\
\hline CHEMBL1478256 & 688620 & 4.65 & 4.7305 & TRN & \\
\hline CHEMBL1485296 & 688620 & 5.65 & 5.5201 & TRN & \\
\hline CHEMBL1423743 & 688620 & 5.85 & 5.3349 & TRN & \\
\hline CHEMBL1497516 & 688620 & 4.65 & 5.1387 & TRN & \\
\hline CHEMBL1350184 & 688620 & 5.2 & 5.1891 & TST & \\
\hline CHEMBL1362734 & 688620 & 4.85 & 5.0662 & TST & \\
\hline CHEMBL1398827 & 688620 & 5.0 & 5.2126 & TRN & \\
\hline CHEMBL1345972 & 688620 & 4.65 & 4.9183 & TRN & \\
\hline CHEMBL1308291 & 688620 & 4.75 & 5.0421 & TRN & \\
\hline CHEMBL1308763 & 688620 & 5.0 & 4.9532 & TST & \\
\hline CHEMBL1500365 & 688620 & 4.45 & 4.9908 & TRN & \\
\hline CHEMBL3194852 & 688620 & 4.8 & $5.0680 e$ & 00000000005 & TRN \\
\hline CHEMBL1588042 & 688620 & 5.2 & 5.0372 & TRN & \\
\hline CHEMBL1538094 & 688620 & 5.05 & 5.1419 & TRN & \\
\hline CHEMBL1559318 & 688620 & 5.9 & 4.963 & TRN & \\
\hline CHEMBL1578958 & 688620 & 5.05 & 5.2402 & TRN & \\
\hline CHEMBL1304862 & 688620 & 5.0 & 4.9385 & TRN & \\
\hline CHEMBL1607104 & 688620 & 4.65 & 4.8713 & TRN & \\
\hline CHEMBL1504949 & 688620 & 4.9 & 5.0081 & TRN & \\
\hline CHEMBL1363033 & 688620 & 4.95 & 4.9853 & TRN & \\
\hline CHEMBL1569860 & 688620 & 5.1 & 5.7405 & TRN & \\
\hline CHEMBL1505939 & 688620 & 4.85 & 4.888 & TRN & \\
\hline CHEMBL1381360 & 688620 & 4.5 & 4.7733 & TST & \\
\hline CHEMBL1384173 & 688620 & 5.0 & 5.3749 & TRN & \\
\hline CHEMBL3189194 & 688620 & 4.95 & 5.2649 & TRN & \\
\hline CHEMBL3192922 & 688620 & 4.5 & 5.0308 & TRN & \\
\hline CHEMBL1560476 & 688620 & 4.75 & 4.7983 & TST & \\
\hline CHEMBL1378755 & 688620 & 4.45 & 4.6925 & TRN & \\
\hline CHEMBL1339047 & 688620 & 4.9 & 4.9395 & TST & \\
\hline CHEMBL1463504 & 688620 & 4.45 & 4.8933 & TRN & \\
\hline CHEMBL1402156 & 688620 & 4.45 & 5.1533 & TST & \\
\hline CHEMBL1399339 & 688620 & 5.5 & 5.5066 & TRN & \\
\hline CHEMBL1366133 & 688620 & 4.8 & 5.3556 & TST & \\
\hline CHEMBL3195168 & 688620 & 4.95 & 4.8518 & TRN & \\
\hline CHEMBL1490158 & 688620 & 4.65 & 5.0191 & TRN & \\
\hline CHEMBL1581989 & 688620 & 5.35 & 5.0738 & TRN & \\
\hline CHEMBL1477026 & 688620 & 5.65 & 5.2773 & TRN & \\
\hline
\end{tabular}




\begin{tabular}{|c|c|c|c|c|}
\hline \multicolumn{5}{|c|}{ Supplemental Table S2.txt } \\
\hline CHEMBL1485734 & 688620 & 5.2 & 5.2665 & TST \\
\hline CHEMBL3210985 & 688620 & 5.5 & 4.9381 & TRN \\
\hline CHEMBL1380521 & 688620 & 5.3 & 5.0565 & TRN \\
\hline CHEMBL1527056 & 688620 & 5.1 & 4.8065 & TRN \\
\hline CHEMBL1574247 & 688620 & 4.8 & 4.9988 & TRN \\
\hline CHEMBL1341505 & 688620 & 4.8 & 5.1399 & TRN \\
\hline CHEMBL1519589 & 688620 & 5.0 & 5.2942 & TRN \\
\hline CHEMBL1457111 & 688620 & 4.65 & 4.9922 & TRN \\
\hline CHEMBL1457048 & 688620 & 4.45 & 5.183 & TST \\
\hline CHEMBL3195672 & 688620 & 4.9 & 4.856 & TRN \\
\hline CHEMBL1308336 & 688620 & 5.7 & 5.8648 & TRN \\
\hline CHEMBL1448869 & 688620 & 4.95 & 5.1165 & TST \\
\hline CHEMBL1483261 & 688620 & 4.8 & 5.0933 & TRN \\
\hline CHEMBL1544400 & 688620 & 5.35 & 5.0624 & TRN \\
\hline CHEMBL3193898 & 688620 & 4.45 & 4.862 & TRN \\
\hline CHEMBL1424935 & 688620 & 5.1 & 5.0658 & TST \\
\hline CHEMBL1409835 & 688620 & 4.65 & 4.605 & TST \\
\hline CHEMBL1465435 & 688620 & 4.9 & 4.7317 & TRN \\
\hline CHEMBL1579011 & 688620 & 5.05 & 4.8786 & TRN \\
\hline CHEMBL1597943 & 688620 & 4.6 & 4.9936 & TRN \\
\hline CHEMBL1601509 & 688620 & 5.35 & 5.2214 & TRN \\
\hline CHEMBL1352133 & 688620 & 4.8 & 5.0329 & TRN \\
\hline CHEMBL1388015 & 688620 & 4.45 & 5.0018 & TRN \\
\hline CHEMBL1568614 & 688620 & 4.45 & 4.9693 & TST \\
\hline CHEMBL3198246 & 688620 & 6.45 & 5.5995 & TRN \\
\hline CHEMBL1579130 & 688620 & 6.0 & 5.6581 & TRN \\
\hline CHEMBL1485422 & 688620 & 5.35 & 5.1231 & TST \\
\hline CHEMBL1306097 & 688620 & 5.2 & 5.1734 & TRN \\
\hline CHEMBL1388220 & 688620 & 4.65 & 5.0939 & TRN \\
\hline CHEMBL1449869 & 688620 & 4.85 & 5.0741 & TRN \\
\hline CHEMBL1566417 & 688620 & 4.45 & 4.727 & TRN \\
\hline CHEMBL1456670 & 688620 & 5.1 & 5.1121 & TST \\
\hline CHEMBL1557108 & 688620 & 4.9 & 5.0127 & TRN \\
\hline CHEMBL1441046 & 688620 & 4.5 & 5.1673 & TRN \\
\hline CHEMBL1491661 & 688620 & 4.5 & 4.9427 & TRN \\
\hline CHEMBL1481154 & 688620 & 4.95 & 4.6591 & TST \\
\hline CHEMBL1437995 & 688620 & 5.1 & 5.1412 & TRN \\
\hline CHEMBL1580325 & 688620 & 6.1 & 5.0368 & TST \\
\hline CHEMBL1573261 & 688620 & 4.75 & 5.4078 & TRN \\
\hline CHEMBL1430138 & 688620 & 4.95 & 4.7743 & TST \\
\hline CHEMBL3145368 & 688620 & 6.15 & 5.7812 & TRN \\
\hline CHEMBL1576367 & 688620 & 7.4001 & 5.2263 & TRN \\
\hline CHEMBL1585888 & 688620 & 5.3 & 4.8084 & TRN \\
\hline CHEMBL1336488 & 688620 & 4.45 & 5.2459 & TRN \\
\hline CHEMBL3195924 & 688620 & 4.9 & 4.8793 & TST \\
\hline CHEMBL1412117 & 688620 & 4.95 & 4.7426 & TRN \\
\hline CHEMBL1603340 & 688620 & 5.0 & 5.1061 & TRN \\
\hline CHEMBL1327131 & 688620 & 6.3 & 5.1467 & TRN \\
\hline
\end{tabular}




\begin{tabular}{|c|c|c|c|c|}
\hline \multicolumn{5}{|c|}{ Supplemental Table S2.txt } \\
\hline CHEMBL1307919 & 688620 & 5.7 & 5.5005 & TRN \\
\hline CHEMBL1423670 & 688620 & 4.45 & 5.0289 & TRN \\
\hline CHEMBL1972922 & 688620 & 5.4 & 4.857 & TRN \\
\hline CHEMBL1430335 & 688620 & 4.45 & 5.0177 & TRN \\
\hline CHEMBL1332756 & 688620 & 5.85 & 5.8068 & TRN \\
\hline CHEMBL1519554 & 688620 & 5.45 & 5.1734 & TRN \\
\hline CHEMBL1303553 & 688620 & 4.5 & 5.0089 & TRN \\
\hline CHEMBL1517646 & 688620 & 5.0 & 5.0853 & TRN \\
\hline CHEMBL1426754 & 688620 & 4.9 & 5.307 & TRN \\
\hline CHEMBL1341682 & 688620 & 5.45 & 5.2013 & TST \\
\hline CHEMBL1466170 & 688620 & 4.95 & 5.022 & TRN \\
\hline CHEMBL1563702 & 688620 & 6.0 & 5.6327 & TRN \\
\hline CHEMBL1585691 & 688620 & 4.95 & 5.0179 & TST \\
\hline CHEMBL1366972 & 688620 & 5.25 & 4.8983 & TRN \\
\hline CHEMBL1393293 & 688620 & 4.7 & 4.9768 & TST \\
\hline CHEMBL1526473 & 688620 & 4.95 & 5.0007 & TRN \\
\hline CHEMBL1365812 & 688620 & 4.8 & 5.0506 & TRN \\
\hline CHEMBL1390999 & 688620 & 6.6 & 5.1986 & TRN \\
\hline CHEMBL1522807 & 688620 & 5.95 & 5.5476 & TRN \\
\hline CHEMBL 3210767 & 688620 & 5.35 & 5.141 & TRN \\
\hline CHEMBL1562072 & 688620 & 4.8 & 5.2369 & TRN \\
\hline CHEMBL 3214574 & 688620 & 5.1 & 4.7857 & TRN \\
\hline CHEMBL1487301 & 688620 & 6.7001 & 5.0171 & TST \\
\hline CHEMBL1330332 & 688620 & 5.45 & 5.1417 & TST \\
\hline CHEMBL 2003508 & 688620 & 5.7 & 5.1744 & TRN \\
\hline CHEMBL1581648 & 688620 & 4.95 & 4.792 & TRN \\
\hline CHEMBL3195177 & 688620 & 5.45 & 5.1829 & TRN \\
\hline CHEMBL1570127 & 688620 & 4.85 & 5.0091 & TRN \\
\hline CHEMBL1595601 & 688620 & 4.85 & 5.0694 & TRN \\
\hline CHEMBL1504916 & 688620 & 4.95 & 5.2236 & TRN \\
\hline CHEMBL1462352 & 688620 & 6.4 & 5.1144 & TST \\
\hline CHEMBL1462431 & 688620 & 4.9 & 5.4735 & TRN \\
\hline CHEMBL1343707 & 688620 & 4.45 & 4.8865 & TST \\
\hline CHEMBL1412171 & 688620 & 5.0 & 5.0037 & TRN \\
\hline CHEMBL1301188 & 688620 & 5.15 & 5.0166 & TST \\
\hline CHEMBL1572950 & 688620 & 5.0 & 4.9039 & TRN \\
\hline CHEMBL1369849 & 688620 & 4.9 & 4.9731 & TRN \\
\hline CHEMBL1359917 & 688620 & 4.65 & 4.9962 & TRN \\
\hline CHEMBL1451134 & 688620 & 5.7 & 5.2048 & TRN \\
\hline CHEMBL1412597 & 688620 & 5.0 & 5.3296 & TRN \\
\hline CHEMBL1595024 & 688620 & 4.8 & 5.2574 & TRN \\
\hline CHEMBL1570267 & 688620 & 4.9 & 5.1099 & TST \\
\hline CHEMBL1539817 & 688620 & 6.4 & 5.2004 & TRN \\
\hline CHEMBL 3208725 & 688620 & 4.7 & 4.9111 & TRN \\
\hline CHEMBL1480980 & 688620 & 5.45 & 5.1216 & TRN \\
\hline CHEMBL1543666 & 688620 & 4.55 & 4.9593 & TRN \\
\hline CHEMBL1366893 & 688620 & 4.95 & 5.0167 & TRN \\
\hline CHEMBL1482706 & 688620 & 8.301 & 5.2421 & TRN \\
\hline
\end{tabular}




\begin{tabular}{|c|c|c|c|c|c|}
\hline \multicolumn{6}{|c|}{ Supplemental Table S2.txt } \\
\hline CHEMBL1504565 & 688620 & 5.4 & 5.5535 & TRN & \\
\hline CHEMBL144686 & 688620 & 4.7 & 5.1476 & TRN & \\
\hline CHEMBL3213231 & 688620 & 4.95 & 5.17200 & 0000000001 & TST \\
\hline CHEMBL 3213441 & 688620 & 5.8 & 5.4345 & TRN & \\
\hline CHEMBL1430199 & 688620 & 4.8 & 5.1203 & TST & \\
\hline CHEMBL1559690 & 688620 & 6.6499 & 4.9012 & TST & \\
\hline CHEMBL1373552 & 688620 & 4.45 & 4.8348 & TRN & \\
\hline CHEMBL1326358 & 688620 & 4.8 & 5.4756 & TRN & \\
\hline CHEMBL1602931 & 688620 & 4.95 & 4.9646 & TRN & \\
\hline CHEMBL1597840 & 688620 & 4.65 & 4.9282 & TRN & \\
\hline CHEMBL1324032 & 688620 & 5.0 & 5.3648 & TST & \\
\hline CHEMBL1429373 & 688620 & 5.9 & 5.5793 & TRN & \\
\hline CHEMBL1569702 & 688620 & 5.0 & 5.3961 & TRN & \\
\hline CHEMBL1338229 & 688620 & 4.5 & 5.1151 & TST & \\
\hline CHEMBL1445505 & 688620 & 4.8 & 4.8663 & TRN & \\
\hline CHEMBL3196956 & 688620 & 5.8 & 5.0854 & TST & \\
\hline CHEMBL3194498 & 688620 & 5.15 & 4.8825 & TST & \\
\hline CHEMBL1601947 & 688620 & 5.25 & 5.1385 & TRN & \\
\hline CHEMBL1577938 & 688620 & 6.5 & 6.07799 & 7999999999 & TRN \\
\hline CHEMBL1451331 & 688620 & 4.45 & 5.0822 & TRN & \\
\hline CHEMBL1520897 & 688620 & 5.0 & 5.09 & TRN & \\
\hline CHEMBL1351643 & 688620 & 5.0 & 5.0371 & TRN & \\
\hline CHEMBL1366942 & 688620 & 5.85 & 4.7829 & TRN & \\
\hline CHEMBL3199399 & 688620 & 5.1 & 5.1865 & TRN & \\
\hline CHEMBL1422603 & 688620 & 4.45 & 4.9876 & TRN & \\
\hline CHEMBL1481035 & 688620 & 5.1 & 5.0674 & TRN & \\
\hline CHEMBL3199785 & 688620 & 4.45 & 5.1665 & TRN & \\
\hline CHEMBL3194213 & 688620 & 5.7 & 5.4982 & TRN & \\
\hline CHEMBL1313209 & 688620 & 4.95 & 4.9565 & TRN & \\
\hline CHEMBL1992492 & 688620 & 4.9 & 5.1481 & TRN & \\
\hline CHEMBL1450769 & 688620 & 4.45 & 5.0155 & TRN & \\
\hline CHEMBL1339995 & 688620 & 5.45 & 5.079 & TST & \\
\hline CHEMBL120734 & 688620 & 5.4 & 5.534 & TRN & \\
\hline CHEMBL1457624 & 688620 & 4.65 & 4.9107 & TRN & \\
\hline CHEMBL1574891 & 688620 & 5.65 & 5.0185 & TRN & \\
\hline CHEMBL1330129 & 688620 & 4.95 & 5.1202 & TRN & \\
\hline CHEMBL1599037 & 688620 & 4.8 & 5.0055 & TRN & \\
\hline CHEMBL1345335 & 688620 & 4.9 & 4.8373 & TRN & \\
\hline CHEMBL1490315 & 688620 & 4.9 & 5.2123 & TST & \\
\hline CHEMBL1465838 & 688620 & 4.7 & 5.024 & TRN & \\
\hline CHEMBL1481428 & 688620 & 4.45 & 5.0021 & TRN & \\
\hline CHEMBL1596507 & 688620 & 6.1 & 5.4532 & TRN & \\
\hline CHEMBL1528725 & 688620 & 4.95 & 4.896 & TRN & \\
\hline CHEMBL3207920 & 688620 & 4.95 & 4.8294 & TST & \\
\hline CHEMBL1533528 & 688620 & 4.45 & 4.9777 & TRN & \\
\hline CHEMBL1530968 & 688620 & 4.95 & 5.0645 & TRN & \\
\hline CHEMBL1313262 & 688620 & 4.8 & 5.2822 & TST & \\
\hline CHEMBL1329099 & 688620 & 4.8 & 4.9691 & TST & \\
\hline
\end{tabular}




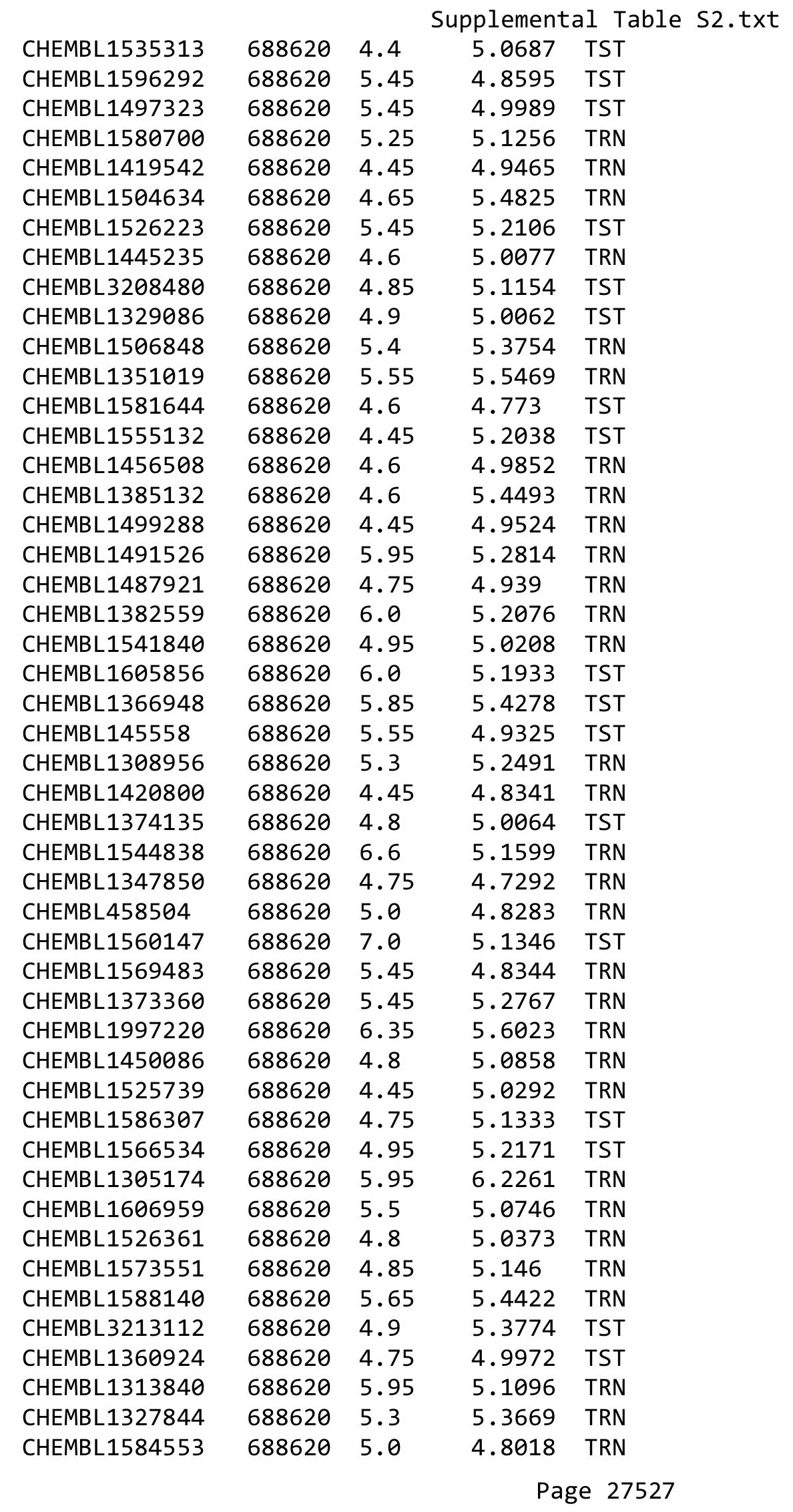




\begin{tabular}{|c|c|c|c|c|}
\hline \multicolumn{5}{|c|}{ Supplemental Table S2.txt } \\
\hline CHEMBL1479670 & 688620 & 5.0 & 4.7582 & TRN \\
\hline CHEMBL1303114 & 688620 & 4.95 & 5.0121 & TRN \\
\hline CHEMBL1483157 & 688620 & 4.65 & 4.8567 & TRN \\
\hline CHEMBL1313500 & 688620 & 5.55 & 5.1124 & TST \\
\hline CHEMBL1516799 & 688620 & 4.8 & 4.8374 & TRN \\
\hline CHEMBL1411398 & 688620 & 5.05 & 5.3652 & TRN \\
\hline CHEMBL1457939 & 688620 & 4.6 & 5.0129 & TST \\
\hline CHEMBL1351421 & 688620 & 4.85 & 5.0598 & TRN \\
\hline CHEMBL1391883 & 688620 & 6.4 & 5.1356 & TRN \\
\hline CHEMBL1559813 & 688620 & 5.15 & 5.2642 & TRN \\
\hline CHEMBL1991885 & 688620 & 5.4 & 5.3119 & TRN \\
\hline CHEMBL1409782 & 688620 & 5.25 & 5.0783 & TST \\
\hline CHEMBL1442517 & 688620 & 8.3468 & 5.3518 & TST \\
\hline CHEMBL1459148 & 688620 & 6.6499 & 4.8816 & TRN \\
\hline CHEMBL1533366 & 688620 & 4.95 & 5.2557 & TRN \\
\hline CHEMBL1520595 & 688620 & 4.75 & 4.8614 & TST \\
\hline CHEMBL1499622 & 688620 & 5.2 & 4.8395 & TST \\
\hline CHEMBL1466146 & 688620 & 5.15 & 4.9538 & TRN \\
\hline CHEMBL1603544 & 688620 & 4.85 & 5.0317 & TRN \\
\hline CHEMBL1460782 & 688620 & 4.9 & 4.9096 & TRN \\
\hline CHEMBL1386049 & 688620 & 6.35 & 5.9549 & TRN \\
\hline CHEMBL3195577 & 688620 & 4.95 & 5.0056 & TRN \\
\hline CHEMBL1407656 & 688620 & 6.2 & 6.3916 & TRN \\
\hline CHEMBL1548803 & 688620 & 5.35 & 5.3509 & TRN \\
\hline CHEMBL1589225 & 688620 & 4.45 & 5.0385 & TRN \\
\hline CHEMBL3207970 & 688620 & 5.0 & 4.9994 & TRN \\
\hline CHEMBL1335310 & 688620 & 5.9 & 5.0333 & TRN \\
\hline CHEMBL1323052 & 688620 & 5.45 & 5.4561 & TRN \\
\hline CHEMBL476190 & 688620 & 5.3 & 5.1504 & TRN \\
\hline CHEMBL1331076 & 688620 & 5.3 & 5.4146 & TRN \\
\hline CHEMBL1441858 & 688620 & 5.75 & 5.2687 & TST \\
\hline CHEMBL1509675 & 688620 & 4.45 & 4.8905 & TST \\
\hline CHEMBL1442633 & 688620 & 5.25 & 5.7145 & TRN \\
\hline CHEMBL1600246 & 688620 & 5.15 & 4.9836 & TST \\
\hline CHEMBL1384649 & 688620 & 7.15 & 5.8276 & TRN \\
\hline CHEMBL1569441 & 688620 & 6.05 & 5.1676 & TRN \\
\hline CHEMBL1608918 & 688620 & 4.45 & 5.1469 & TRN \\
\hline CHEMBL1302188 & 688620 & 5.5 & 4.9494 & TRN \\
\hline CHEMBL1319432 & 688620 & 4.8 & 4.6826 & TST \\
\hline CHEMBL1403448 & 688620 & 5.25 & 5.3814 & TST \\
\hline CHEMBL1448275 & 688620 & 5.65 & 6.2659 & TRN \\
\hline CHEMBL1447108 & 688620 & 4.9 & 5.0658 & TRN \\
\hline CHEMBL1407295 & 688620 & 8.301 & 4.7462 & TST \\
\hline CHEMBL1337293 & 688620 & 5.6 & 5.1771 & TRN \\
\hline CHEMBL1386512 & 688620 & 5.15 & 4.815 & TRN \\
\hline CHEMBL1547409 & 688620 & 4.7 & 4.6775 & TRN \\
\hline CHEMBL1543424 & 688620 & 5.1 & 4.9188 & TST \\
\hline CHEMBL1464997 & 688620 & 4.9 & 5.1976 & TRN \\
\hline
\end{tabular}




\begin{tabular}{|c|c|c|c|c|c|}
\hline \multirow[b]{2}{*}{ CHEMBL1596675 } & \multirow{2}{*}{688620} & \multicolumn{4}{|c|}{ supplemerlicas to } \\
\hline & & 4.95 & 5.1024 & TST & \\
\hline CHEMBL1501853 & 688620 & 5.05 & 4.941 & TRN & \\
\hline CHEMBL1493379 & 688620 & 4.5 & 5.1094 & TST & \\
\hline CHEMBL1566120 & 688620 & 5.6 & 4.9079 & TST & \\
\hline CHEMBL1416124 & 688620 & 5.6 & 5.73 & TST & \\
\hline CHEMBL 1457513 & 688620 & 5.15 & 4.9974 & TRN & \\
\hline CHEMBL1536196 & 688620 & 5.05 & 5.0738 & TRN & \\
\hline CHEMBL3197183 & 688620 & 5.35 & 5.0827 & TRN & \\
\hline CHEMBL3195339 & 688620 & 4.65 & 4.8255 & TRN & \\
\hline CHEMBL1364440 & 688620 & 4.45 & 4.7174 & TRN & \\
\hline CHEMBL 1587482 & 688620 & 5.15 & 5.1183 & TRN & \\
\hline CHEMBL1983243 & 688620 & 6.6 & 6.1651 & TRN & \\
\hline CHEMBL1529203 & 688620 & 5.2 & 5.2822 & TRN & \\
\hline CHEMBL1492540 & 688620 & 5.05 & 5.1457 & TST & \\
\hline CHEMBL1385760 & 688620 & 4.45 & 5.2291 & TRN & \\
\hline CHEMBL1549226 & 688620 & 7.0 & 5.1516 & TRN & \\
\hline CHEMBL1413306 & 688620 & 4.45 & 5.112 & TRN & \\
\hline CHEMBL1388019 & 688620 & 4.9 & 4.7488 & TRN & \\
\hline CHEMBL1429316 & 688620 & 4.7 & 5.0496 & TRN & \\
\hline CHEMBL1529430 & 688620 & 4.9 & 4.7744 & TRN & \\
\hline CHEMBL576656 & 688620 & 5.55 & 5.1588 & TRN & \\
\hline CHEMBL1312689 & 688620 & 4.85 & 5.0189 & TST & \\
\hline CHEMBL1597932 & 688620 & 4.45 & \multicolumn{2}{|c|}{5.0680000000000005} & TRN \\
\hline CHEMBL1361058 & 688620 & 4.7 & 4.794 & TRN & \\
\hline CHEMBL1451293 & 688620 & 5.7 & 5.5104 & TRN & \\
\hline CHEMBL1580127 & 688620 & 4.95 & 4.862 & TRN & \\
\hline CHEMBL1425605 & 688620 & 5.9 & 4.936 & TST & \\
\hline CHEMBL1609882 & 688620 & 4.75 & 5.1594 & TRN & \\
\hline CHEMBL1371946 & 688620 & 4.45 & \multicolumn{2}{|c|}{5.031000000000001} & TST \\
\hline CHEMBL1543087 & 688620 & 6.15 & 5.5373 & TRN & \\
\hline CHEMBL1583850 & 688620 & 5.5 & 5.2861 & TRN & \\
\hline CHEMBL1384903 & 688620 & 5.55 & 4.8808 & TST & \\
\hline CHEMBL1417334 & 688620 & 4.95 & 4.9984 & TRN & \\
\hline CHEMBL1608346 & 688620 & 5.4 & 5.2025 & TST & \\
\hline CHEMBL1548776 & 688620 & 5.2 & 4.8221 & TRN & \\
\hline CHEMBL1391629 & 688620 & 5.3 & 5.1971 & TRN & \\
\hline CHEMBL1427234 & 688620 & 4.45 & 5.0037 & TRN & \\
\hline CHEMBL1596491 & 688620 & 5.35 & 4.86 & TST & \\
\hline CHEMBL1336397 & 688620 & 5.15 & 4.9984 & TRN & \\
\hline CHEMBL1383763 & 688620 & 5.75 & 5.157 & TST & \\
\hline CHEMBL1377550 & 688620 & 4.8 & 5.3829 & TST & \\
\hline CHEMBL1447883 & 688620 & 5.35 & 5.3981 & TST & \\
\hline CHEMBL1360102 & 688620 & 4.45 & 4.8386 & TRN & \\
\hline CHEMBL1452795 & 688620 & 6.45 & 5.5059 & TST & \\
\hline CHEMBL1392742 & 688620 & 4.95 & 5.0707 & TRN & \\
\hline CHEMBL1427493 & 688620 & 6.1 & 5.2817 & TRN & \\
\hline CHEMBL1527349 & 688620 & 4.9 & 4.9382 & TST & \\
\hline CHEMBL600778 & 688620 & 5.7 & 5.8199 & TRN & \\
\hline & & & & 27529 & \\
\hline
\end{tabular}




\begin{tabular}{|c|c|c|c|c|c|}
\hline \multicolumn{6}{|c|}{ Supplemental Table S2.txt } \\
\hline CHEMBL1400058 & 688620 & 5.05 & 5.0776 & TST & \\
\hline CHEMBL1374672 & 688620 & 4.45 & 4.6314 & TRN & \\
\hline CHEMBL1340962 & 688620 & 4.45 & 4.9301 & TRN & \\
\hline CHEMBL1421664 & 688620 & 5.15 & 5.3266 & TRN & \\
\hline CHEMBL1582061 & 688620 & 6.15 & 5.1224 & TST & \\
\hline CHEMBL1597036 & 688620 & 5.0 & 5.0693 & TRN & \\
\hline CHEMBL3193332 & 688620 & 5.55 & 5.3868 & TRN & \\
\hline CHEMBL1524567 & 688620 & 4.95 & 5.0618 & TRN & \\
\hline CHEMBL1303438 & 688620 & 4.95 & 4.9857 & TRN & \\
\hline CHEMBL1467077 & 688620 & 4.45 & 5.0481 & TRN & \\
\hline CHEMBL1609564 & 688620 & 4.5 & 5.1863 & TST & \\
\hline CHEMBL1457427 & 688620 & 5.6 & 4.7955 & TRN & \\
\hline CHEMBL3193966 & 688620 & 5.2 & 5.5932 & TRN & \\
\hline CHEMBL453376 & 688620 & 4.45 & 5.5968 & TST & \\
\hline CHEMBL1431328 & 688620 & 5.05 & 4.7599 & TST & \\
\hline CHEMBL1558635 & 688620 & 5.35 & 5.3513 & TRN & \\
\hline CHEMBL1330109 & 688620 & 4.65 & 4.6116 & TRN & \\
\hline CHEMBL1391475 & 688620 & 4.45 & 4.95100 & 00000000005 & TST \\
\hline CHEMBL1437895 & 688620 & 5.25 & 5.1672 & TRN & \\
\hline CHEMBL1387918 & 688620 & 4.8 & 4.8365 & TRN & \\
\hline CHEMBL3195347 & 688620 & 4.9 & 5.0692 & TRN & \\
\hline CHEMBL1458833 & 688620 & 6.9 & 6.9138 & TRN & \\
\hline CHEMBL1580461 & 688620 & 4.5 & 4.8671 & TRN & \\
\hline CHEMBL1424721 & 688620 & 4.45 & 4.9295 & TST & \\
\hline CHEMBL1598364 & 688620 & 5.2 & 4.9308 & TST & \\
\hline CHEMBL3195098 & 688620 & 5.0 & 5.1953 & TST & \\
\hline CHEMBL1603817 & 688620 & 4.95 & 5.0807 & TRN & \\
\hline CHEMBL1989662 & 688620 & 4.75 & 5.1843 & TRN & \\
\hline CHEMBL1526409 & 688620 & 4.85 & 4.7258 & TRN & \\
\hline CHEMBL1310753 & 688620 & 4.6 & 5.1769 & TRN & \\
\hline CHEMBL1325856 & 688620 & 6.45 & 5.8715 & TRN & \\
\hline CHEMBL1312989 & 688620 & 4.85 & 5.1507 & TST & \\
\hline CHEMBL1540015 & 688620 & 5.55 & 4.9978 & TRN & \\
\hline CHEMBL1534475 & 688620 & 4.9 & 5.1356 & TST & \\
\hline CHEMBL1457353 & 688620 & 5.0 & 4.9545 & TST & \\
\hline CHEMBL1428566 & 688620 & 5.1 & 5.557 & TRN & \\
\hline CHEMBL1452248 & 688620 & 4.45 & 5.3539 & TRN & \\
\hline CHEMBL1412094 & 688620 & 5.05 & 5.0088 & TRN & \\
\hline CHEMBL1388972 & 688620 & 4.45 & 5.3191 & TRN & \\
\hline CHEMBL1367731 & 688620 & 4.8 & 5.125 & TRN & \\
\hline CHEMBL1431192 & 688620 & 5.4 & 5.3097 & TRN & \\
\hline CHEMBL1343348 & 688620 & 4.65 & 5.0875 & TST & \\
\hline CHEMBL1477595 & 688620 & 5.5 & 5.4042 & TRN & \\
\hline CHEMBL1496607 & 688620 & 4.8 & 5.0168 & TRN & \\
\hline CHEMBL1360475 & 688620 & 6.7001 & 5.1497 & TRN & \\
\hline CHEMBL1993020 & 688620 & 5.4 & 5.1869 & TRN & \\
\hline CHEMBL1602875 & 688620 & 5.8 & 4.9373 & TRN & \\
\hline CHEMBL1580804 & 688620 & 4.6 & 4.8774 & TST & \\
\hline
\end{tabular}




\begin{tabular}{|c|c|c|c|c|c|}
\hline \multicolumn{6}{|c|}{ Supplemental Table s2.txt } \\
\hline CHEMBL1459764 & 688620 & 4.95 & 4.9723 & TRN & \\
\hline CHEMBL 3197425 & 688620 & 5.0 & 5.0435 & TRN & \\
\hline CHEMBL1579819 & 688620 & 4.9 & 5.1196 & TRN & \\
\hline CHEMBL1329974 & 688620 & 4.45 & 4.8594 & TST & \\
\hline CHEMBL3195032 & 688620 & 5.15 & 5.3291 & TRN & \\
\hline CHEMBL1306384 & 688620 & 4.95 & 5.0157 & TRN & \\
\hline CHEMBL1444579 & 688620 & 4.95 & 5.3234 & TST & \\
\hline CHEMBL1458723 & 688620 & 5.0 & 5.0071 & TRN & \\
\hline CHEMBL1326508 & 688620 & 5.05 & 5.0997 & TRN & \\
\hline CHEMBL1589071 & 688620 & 4.75 & 4.9036 & TRN & \\
\hline CHEMBL1310508 & 688620 & 5.2 & 5.3193 & TRN & \\
\hline CHEMBL1561975 & 688620 & 4.85 & 4.989 & TST & \\
\hline CHEMBL1466267 & 688620 & 4.45 & 4.9196 & TRN & \\
\hline CHEMBL1560307 & 688620 & 4.45 & 5.2412 & TST & \\
\hline CHEMBL1452485 & 688620 & 4.7 & 5.2274 & TRN & \\
\hline CHEMBL1534263 & 688620 & 4.75 & 5.1412 & TRN & \\
\hline CHEMBL3213302 & 688620 & 4.45 & 5.1805 & TRN & \\
\hline CHEMBL1341776 & 688620 & 5.25 & 5.2922 & TRN & \\
\hline CHEMBL1526778 & 688620 & 4.45 & 5.1063 & TST & \\
\hline CHEMBL1546833 & 688620 & 5.0 & 5.0187 & TRN & \\
\hline CHEMBL1503310 & 688620 & 4.9 & 4.8379 & TRN & \\
\hline CHEMBL 3207373 & 688620 & 4.75 & 4.7134 & TRN & \\
\hline CHEMBL3198885 & 688620 & 4.9 & 4.9631 & TST & \\
\hline CHEMBL1501740 & 688620 & 4.45 & 5.1806 & TRN & \\
\hline CHEMBL1460815 & 688620 & 6.15 & 4.8781 & TRN & \\
\hline CHEMBL 2003521 & 688620 & 6.0 & 5.5044 & TRN & \\
\hline CHEMBL1545824 & 688620 & 5.15 & 5.3515 & TRN & \\
\hline CHEMBL1597726 & 688620 & 7.3497 & 5.2843 & TRN & \\
\hline CHEMBL1549881 & 688620 & 4.65 & 4.755 & TRN & \\
\hline CHEMBL1392403 & 688620 & 5.3 & 5.1871 & TRN & \\
\hline CHEMBL1311635 & 688620 & 4.75 & 5.04 & TST & \\
\hline CHEMBL1488374 & 688620 & 5.0 & 4.7073 & TRN & \\
\hline CHEMBL1502693 & 688620 & 5.5 & 5.0251 & TST & \\
\hline CHEMBL554041 & 688620 & 6.0 & 4.8468 & TST & \\
\hline CHEMBL1455361 & 688620 & 5.25 & 5.2835 & TRN & \\
\hline CHEMBL1419733 & 688620 & 6.2 & 5.853 & TRN & \\
\hline CHEMBL1336281 & 688620 & 4.45 & 4.9667 & TRN & \\
\hline CHEMBL1406140 & 688620 & 5.1 & 5.1046 & TRN & \\
\hline CHEMBL1607600 & 688620 & 7.0 & 5.1689 & TRN & \\
\hline CHEMBL1585761 & 688620 & 4.9 & 5.4591 & TRN & \\
\hline CHEMBL1340466 & 688620 & 5.2 & 5.3341 & TRN & \\
\hline CHEMBL1382683 & 688620 & 5.0 & 5.1707 & TRN & \\
\hline CHEMBL1391771 & 688620 & 4.75 & 5.0731 & TRN & \\
\hline CHEMBL1498389 & 688620 & 5.35 & 4.9453 & TST & \\
\hline CHEMBL1540477 & 688620 & 5.2 & 4.8682 & TRN & \\
\hline CHEMBL1306554 & 688620 & 6.1 & 4.9243 & TRN & \\
\hline CHEMBL1993199 & 688620 & 4.75 & 5.0346 & TST & \\
\hline CHEMBL1457695 & 688620 & 4.65 & $4.9460 e$ & 0000000001 & TRN \\
\hline & & & & 27531 & \\
\hline
\end{tabular}




\begin{tabular}{|c|c|c|c|c|c|}
\hline \\
\hline CHEMBL1571840 & 688620 & 4.9 & 5.047 & TRN & \\
\hline CHEMBL1320286 & 688620 & 4.45 & 5.2758 & TRN & \\
\hline CHEMBL1423318 & 688620 & 5.85 & 5.2392 & TRN & \\
\hline CHEMBL1446544 & 688620 & 4.9 & 4.8169 & TRN & \\
\hline CHEMBL1577255 & 688620 & 4.95 & 5.1196 & TRN & \\
\hline CHEMBL1299204 & 688620 & 5.05 & 4.8951 & TST & \\
\hline CHEMBL1573352 & 688620 & 5.2 & 4.9689 & TRN & \\
\hline CHEMBL1523561 & 688620 & 5.1 & 5.4425 & TST & \\
\hline CHEMBL3196651 & 688620 & 6.8 & 4.9709 & TRN & \\
\hline CHEMBL3199095 & 688620 & 5.5 & $4.9910 e$ & 00000000005 & TRN \\
\hline CHEMBL1301748 & 688620 & 4.95 & 4.7829 & TST & \\
\hline CHEMBL1303001 & 688620 & 5.55 & 5.4707 & TRN & \\
\hline CHEMBL3189289 & 688620 & 6.0 & 5.6783 & TRN & \\
\hline CHEMBL1311641 & 688620 & 4.45 & 5.1152 & TRN & \\
\hline CHEMBL1408585 & 688620 & 6.15 & 5.8758 & TRN & \\
\hline CHEMBL1344146 & 688620 & 4.5 & 4.9442 & TRN & \\
\hline CHEMBL1413870 & 688620 & 4.75 & 4.8843 & TRN & \\
\hline CHEMBL578716 & 688620 & 6.05 & 4.9927 & TST & \\
\hline CHEMBL1386681 & 688620 & 5.2 & 5.4073 & TRN & \\
\hline CHEMBL1604263 & 688620 & 4.45 & 4.9248 & TRN & \\
\hline CHEMBL1511207 & 688620 & 5.2 & 5.0349 & TST & \\
\hline CHEMBL1585936 & 688620 & 5.95 & 5.3407 & TRN & \\
\hline CHEMBL3195530 & 688620 & 5.8 & 5.3585 & TRN & \\
\hline CHEMBL1490987 & 688620 & 4.45 & 4.7092 & TRN & \\
\hline CHEMBL1606563 & 688620 & 4.45 & 4.905 & TRN & \\
\hline CHEMBL1435015 & 688620 & 5.5 & 4.9108 & TST & \\
\hline CHEMBL1442619 & 688620 & 4.95 & 4.9773 & TRN & \\
\hline CHEMBL1412285 & 688620 & 5.5 & 5.272 & TST & \\
\hline CHEMBL1420654 & 688620 & 4.95 & 4.8629 & TRN & \\
\hline CHEMBL1338806 & 688620 & 4.7 & 5.3721 & TRN & \\
\hline CHEMBL1547707 & 688620 & 4.5 & 5.269 & TRN & \\
\hline CHEMBL1386296 & 688620 & 5.55 & 5.0655 & TST & \\
\hline CHEMBL1547549 & 688620 & 4.75 & 4.9692 & TST & \\
\hline CHEMBL1580257 & 688620 & 4.95 & 5.1103 & TRN & \\
\hline CHEMBL1973307 & 688620 & 4.9 & 4.6963 & TRN & \\
\hline CHEMBL1580705 & 688620 & 5.0 & 4.9246 & TRN & \\
\hline CHEMBL1529845 & 688620 & 4.55 & 4.9514 & TRN & \\
\hline CHEMBL1344395 & 688620 & 5.0 & 4.8322 & TRN & \\
\hline CHEMBL3191307 & 688620 & 4.7 & $5.4510 e$ & 00000000005 & TRN \\
\hline CHEMBL1566615 & 688620 & 5.1 & 4.853 & TRN & \\
\hline CHEMBL1520803 & 688620 & 5.8 & 5.5147 & TRN & \\
\hline CHEMBL 3144885 & 688620 & 5.1 & 5.5069 & TRN & \\
\hline CHEMBL3214402 & 688620 & 5.05 & 5.0299 & TRN & \\
\hline CHEMBL1315760 & 688620 & 4.8 & 4.9095 & TRN & \\
\hline CHEMBL1414998 & 688620 & 4.75 & 4.9098 & TST & \\
\hline CHEMBL3209833 & 688620 & 4.65 & 5.1602 & TRN & \\
\hline CHEMBL 1460585 & 688620 & 4.95 & 4.9978 & TST & \\
\hline CHEMBL1537641 & 688620 & 5.0 & 4.9232 & TRN & \\
\hline
\end{tabular}




\begin{tabular}{|c|c|c|c|c|c|}
\hline \multicolumn{6}{|c|}{ Supplemental Table S2.txt } \\
\hline CHEMBL1578386 & 688620 & 5.45 & 4.8397 & TRN & \\
\hline CHEMBL1538638 & 688620 & 4.45 & 5.4099 & TST & \\
\hline CHEMBL1417355 & 688620 & 4.45 & 5.1289 & TRN & \\
\hline CHEMBL 3392457 & 688620 & 4.5 & 4.8945 & TRN & \\
\hline CHEMBL1523801 & 688620 & 4.95 & 5.0209 & TRN & \\
\hline CHEMBL1532545 & 688620 & 6.1 & 5.181 & TST & \\
\hline CHEMBL1339741 & 688620 & 6.1 & 5.1142 & TRN & \\
\hline CHEMBL1384576 & 688620 & 4.95 & 5.34399 & 9999999999 & TST \\
\hline CHEMBL1352417 & 688620 & 5.75 & 5.273 & TST & \\
\hline CHEMBL3191386 & 688620 & 5.05 & 5.0567 & TRN & \\
\hline CHEMBL1306092 & 688620 & 4.45 & 4.9104 & TRN & \\
\hline CHEMBL1376367 & 688620 & 5.0 & 4.7966 & TRN & \\
\hline CHEMBL1307717 & 688620 & 5.0 & 4.8821 & TRN & \\
\hline CHEMBL1429052 & 688620 & 6.15 & 5.9936 & TRN & \\
\hline CHEMBL1510928 & 688620 & 4.95 & 4.8035 & TRN & \\
\hline CHEMBL1377927 & 688620 & 6.0 & 5.5437 & TST & \\
\hline CHEMBL1453858 & 688620 & 4.8 & 5.3081 & TRN & \\
\hline CHEMBL1528974 & 688620 & 4.45 & 4.9701 & TRN & \\
\hline CHEMBL1408223 & 688620 & 5.05 & 4.9832 & TRN & \\
\hline CHEMBL1462856 & 688620 & 4.45 & 5.4099 & TST & \\
\hline CHEMBL1309281 & 688620 & 6.2 & 5.9453 & TRN & \\
\hline CHEMBL1339310 & 688620 & 6.7501 & 5.0826 & TRN & \\
\hline CHEMBL1611648 & 688620 & 5.0 & 4.9582 & TRN & \\
\hline CHEMBL1523627 & 688620 & 4.45 & 4.99100 & 00000000005 & TRN \\
\hline CHEMBL1505224 & 688620 & 4.95 & 4.9565 & TST & \\
\hline CHEMBL1578641 & 688620 & 4.45 & 4.7467 & TRN & \\
\hline CHEMBL1445515 & 688620 & 4.45 & 4.8349 & TRN & \\
\hline CHEMBL1580770 & 688620 & 5.0 & 5.0585 & TRN & \\
\hline CHEMBL1542189 & 688620 & 5.35 & 5.1259 & TRN & \\
\hline CHEMBL1488036 & 688620 & 4.45 & 5.0449 & TRN & \\
\hline CHEMBL1594657 & 688620 & 4.45 & 5.0326 & TRN & \\
\hline CHEMBL1424472 & 688620 & 5.15 & 5.0909 & TST & \\
\hline CHEMBL1386794 & 688620 & 4.95 & 4.9774 & TRN & \\
\hline CHEMBL1466011 & 688620 & 5.45 & 4.9491 & TST & \\
\hline CHEMBL1589649 & 688620 & 5.2 & 5.1133 & TRN & \\
\hline CHEMBL1349885 & 688620 & 4.8 & 5.1322 & TRN & \\
\hline CHEMBL1392050 & 688620 & 4.85 & 5.0193 & TRN & \\
\hline CHEMBL1417514 & 688620 & 5.35 & 5.0036 & TRN & \\
\hline CHEMBL1466487 & 688620 & 5.45 & 5.249 & TRN & \\
\hline CHEMBL1483021 & 688620 & 5.55 & 5.16799 & 9999999999 & TRN \\
\hline CHEMBL1599393 & 688620 & 4.8 & 5.1473 & TST & \\
\hline CHEMBL1486397 & 688620 & 4.45 & 4.9139 & TRN & \\
\hline CHEMBL1492417 & 688620 & 5.0 & 5.035 & TRN & \\
\hline CHEMBL1524122 & 688620 & 5.15 & 5.0473 & TST & \\
\hline CHEMBL3199536 & 688620 & 5.9 & 5.2615 & TRN & \\
\hline CHEMBL1440051 & 688620 & 4.9 & 5.1139 & TST & \\
\hline CHEMBL1545075 & 688620 & 5.55 & 4.9453 & TRN & \\
\hline CHEMBL1576836 & 688620 & 4.9 & 5.0187 & TRN & \\
\hline
\end{tabular}




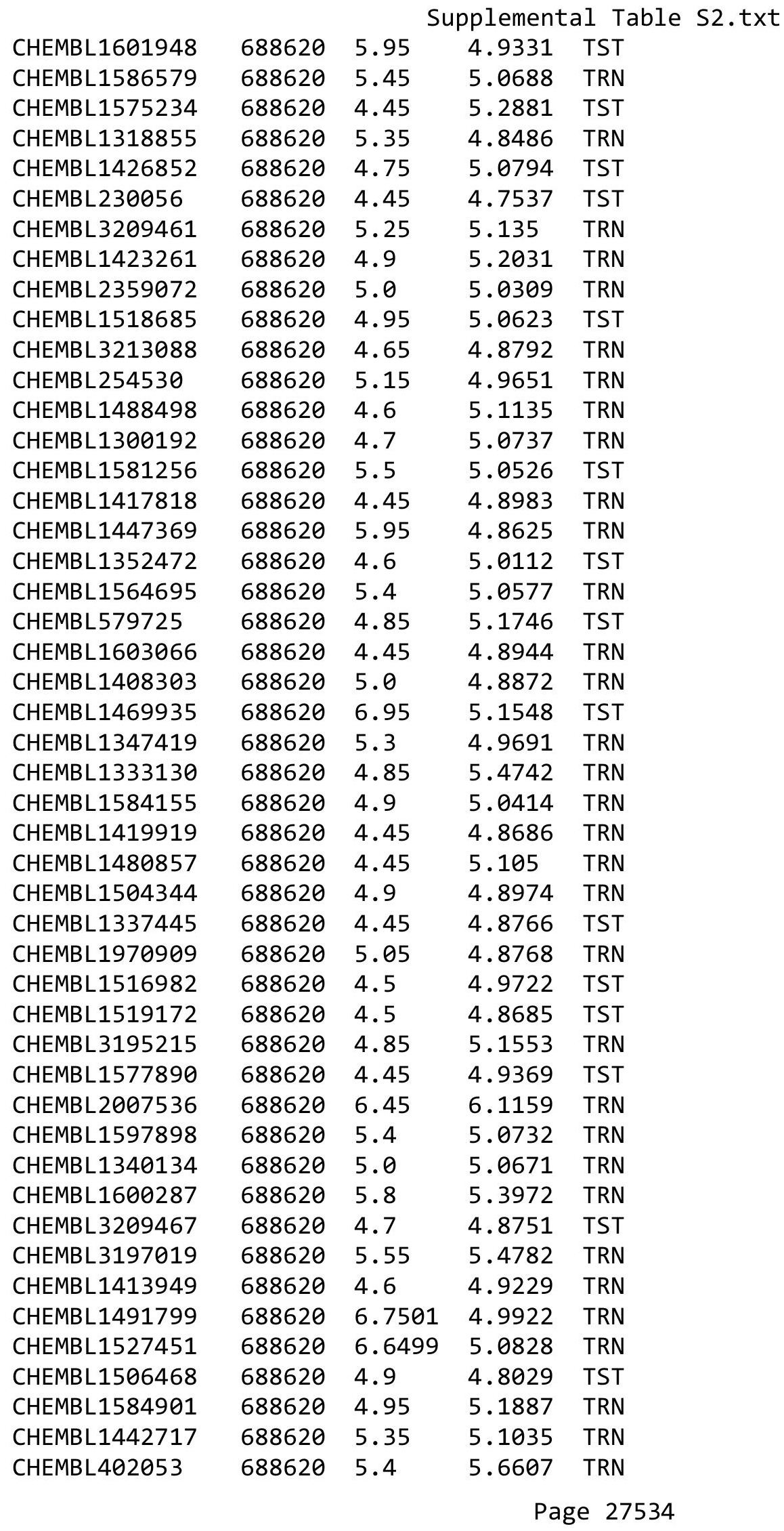




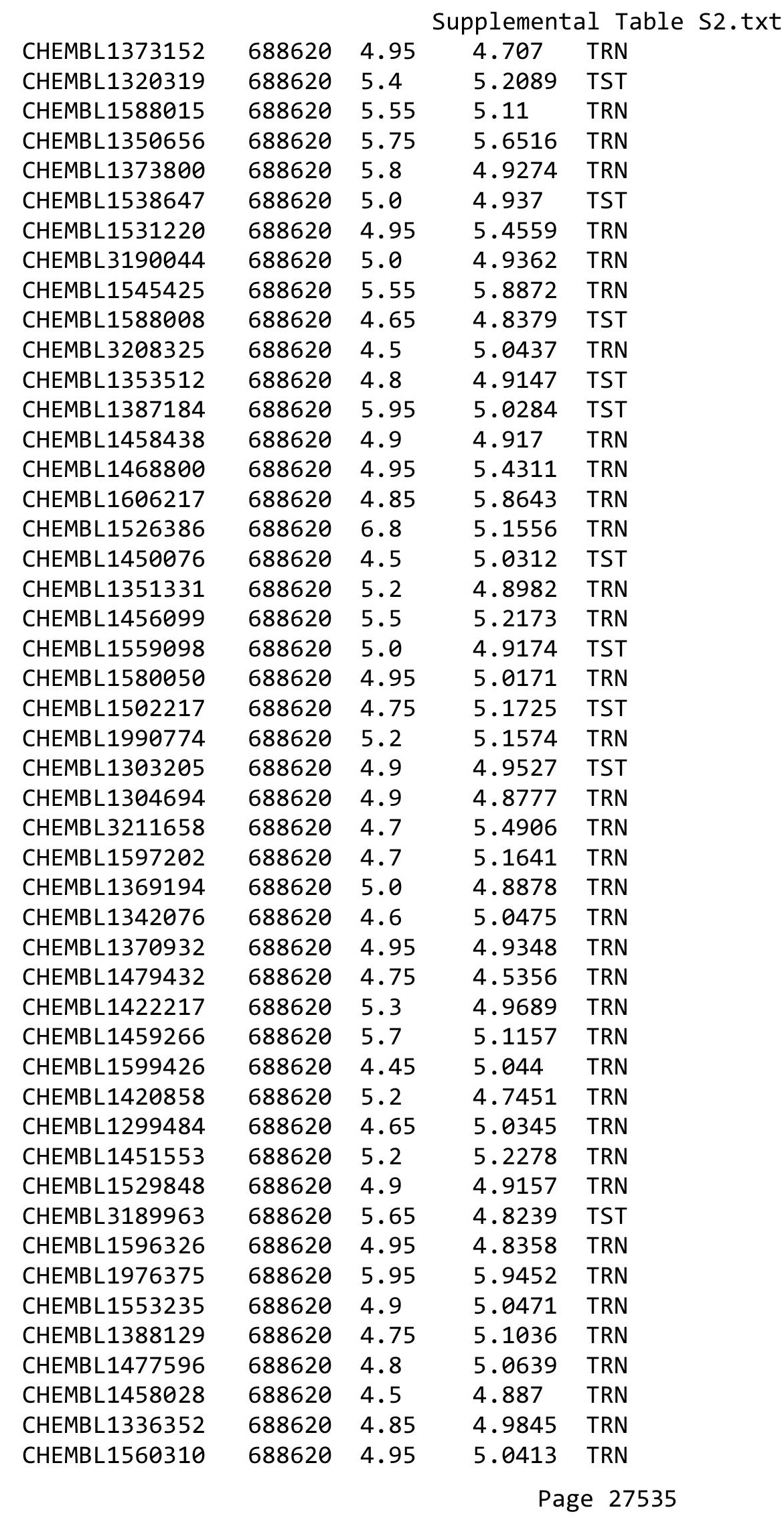




\begin{tabular}{|c|c|c|c|c|}
\hline & & & pplement & al $\mathrm{Ta}$ \\
\hline CHEMBL1387920 & 688620 & 4.45 & 5.0583 & TST \\
\hline CHEMBL1404345 & 688620 & 5.6 & 4.8923 & TRN \\
\hline CHEMBL1605749 & 688620 & 4.65 & 5.2392 & TST \\
\hline CHEMBL1353547 & 688620 & 5.15 & 4.9862 & TRN \\
\hline CHEMBL1522052 & 688620 & 5.15 & 4.8099 & TRN \\
\hline CHEMBL1425234 & 688620 & 4.45 & 5.0568 & TST \\
\hline CHEMBL1555066 & 688620 & 5.1 & 5.3053 & TST \\
\hline CHEMBL1599558 & 688620 & 4.95 & 5.0821 & TRN \\
\hline CHEMBL1501505 & 688620 & 4.95 & 4.6537 & TRN \\
\hline CHEMBL1608775 & 688620 & 4.8 & 5.1218 & TST \\
\hline CHEMBL1481243 & 688620 & 4.95 & 5.0882 & TRN \\
\hline CHEMBL1506910 & 688620 & 4.95 & 4.8358 & TST \\
\hline CHEMBL1603637 & 688620 & 4.85 & 5.0615 & TST \\
\hline CHEMBL602970 & 688620 & 4.9 & 4.8843 & TRN \\
\hline CHEMBL1602174 & 688620 & 4.5 & 5.1139 & TRN \\
\hline CHEMBL1306186 & 688620 & 4.95 & 4.9475 & TST \\
\hline CHEMBL1602401 & 688620 & 4.45 & 4.7331 & TST \\
\hline CHEMBL1382282 & 688620 & 5.15 & 5.4995 & TRN \\
\hline CHEMBL1330184 & 688620 & 5.1 & 5.0015 & TRN \\
\hline CHEMBL1571934 & 688620 & 4.55 & 4.9668 & TRN \\
\hline CHEMBL 3212185 & 688620 & 4.75 & 5.0375 & TRN \\
\hline CHEMBL1518040 & 688620 & 5.0 & 4.8658 & TST \\
\hline CHEMBL1334584 & 688620 & 4.55 & 4.8203 & TRN \\
\hline CHEMBL1311612 & 688620 & 4.45 & 5.034 & TST \\
\hline CHEMBL1598713 & 688620 & 4.45 & 4.8166 & TRN \\
\hline CHEMBL1408547 & 688620 & 6.0 & 4.9342 & TRN \\
\hline CHEMBL1336256 & 688620 & 4.45 & 4.9679 & TRN \\
\hline CHEMBL1562522 & 688620 & 4.85 & 4.9927 & TRN \\
\hline CHEMBL1493199 & 688620 & 4.95 & 4.6977 & TST \\
\hline CHEMBL1551567 & 688620 & 5.8 & 5.1281 & TRN \\
\hline CHEMBL 3191817 & 688620 & 5.5 & 5.5324 & TRN \\
\hline CHEMBL1445582 & 688620 & 4.6 & 4.9505 & TRN \\
\hline CHEMBL1549375 & 688620 & 5.15 & 4.7588 & TRN \\
\hline CHEMBL1503667 & 688620 & 5.7 & 5.1287 & TST \\
\hline CHEMBL1464829 & 688620 & 4.9 & 5.044 & TRN \\
\hline CHEMBL1323007 & 688620 & 4.45 & 4.8701 & TST \\
\hline CHEMBL3192395 & 688620 & 5.95 & 5.6112 & TRN \\
\hline CHEMBL1325262 & 688620 & 5.0 & 5.1035 & TST \\
\hline CHEMBL1468591 & 688620 & 4.95 & 5.1101 & TRN \\
\hline CHEMBL1555178 & 688620 & 5.75 & 5.1349 & TST \\
\hline CHEMBL1570481 & 688620 & 4.5 & 4.9797 & TST \\
\hline CHEMBL1493417 & 688620 & 4.45 & 5.0505 & TRN \\
\hline CHEMBL3196827 & 688620 & 4.85 & 5.2135 & TRN \\
\hline CHEMBL1425302 & 688620 & 4.45 & 4.9389 & TRN \\
\hline CHEMBL1321213 & 688620 & 4.95 & 5.2411 & TRN \\
\hline CHEMBL1561507 & 688620 & 6.25 & 5.7194 & TRN \\
\hline CHEMBL1341162 & 688620 & 7.4001 & 5.0946 & TST \\
\hline CHEMBL1438044 & 688620 & 4.95 & 5.2922 & TRN \\
\hline
\end{tabular}




\begin{tabular}{|c|c|c|c|c|c|}
\hline \multicolumn{6}{|c|}{ Supplemental Table S2.txt } \\
\hline CHEMBL1555936 & 688620 & 5.45 & 5.2262 & TRN & \\
\hline CHEMBL3211669 & 688620 & 4.95 & 4.9044 & TRN & \\
\hline CHEMBL1594554 & 688620 & 4.5 & 5.2954 & TRN & \\
\hline CHEMBL3198692 & 688620 & 5.0 & 5.3334 & TRN & \\
\hline CHEMBL1413495 & 688620 & 4.45 & 4.7526 & TST & \\
\hline CHEMBL1484357 & 688620 & 4.8 & 4.7558 & TRN & \\
\hline CHEMBL1506070 & 688620 & 4.7 & 4.9559 & TRN & \\
\hline CHEMBL1399683 & 688620 & 4.95 & 4.9023 & TRN & \\
\hline CHEMBL1460405 & 688620 & 4.8 & 4.9596 & TRN & \\
\hline CHEMBL1378904 & 688620 & 4.9 & 5.0016 & TRN & \\
\hline CHEMBL1406937 & 688620 & 6.1 & 5.0854 & TRN & \\
\hline CHEMBL1421699 & 688620 & 5.0 & 5.1068 & TRN & \\
\hline CHEMBL1484345 & 688620 & 4.45 & 4.92899 & 7999999999 & TRN \\
\hline CHEMBL1439319 & 688620 & 6.25 & 4.8322 & TST & \\
\hline CHEMBL1302758 & 688620 & 4.8 & 5.3946 & TRN & \\
\hline CHEMBL1375390 & 688620 & 4.75 & 4.9749 & TST & \\
\hline CHEMBL1312307 & 688620 & 4.75 & 5.2752 & TST & \\
\hline CHEMBL1336749 & 688620 & 4.85 & 5.0692 & TRN & \\
\hline CHEMBL1533171 & 688620 & 4.8 & 5.0186 & TRN & \\
\hline CHEMBL1335844 & 688620 & 5.1 & 5.0702 & TRN & \\
\hline CHEMBL1464037 & 688620 & 5.2 & 5.0623 & TRN & \\
\hline CHEMBL1353737 & 688620 & 5.55 & 5.6909 & TRN & \\
\hline CHEMBL1594188 & 688620 & 4.95 & 4.8101 & TRN & \\
\hline CHEMBL1351979 & 688620 & 7.0501 & 5.1465 & TRN & \\
\hline CHEMBL1387462 & 688620 & 5.0 & 4.8252 & TRN & \\
\hline CHEMBL1463767 & 688620 & 4.9 & 5.1843 & TRN & \\
\hline CHEMBL1572195 & 688620 & 5.5 & 4.9046 & TST & \\
\hline CHEMBL1431643 & 688620 & 4.45 & 4.8765 & TRN & \\
\hline CHEMBL1378712 & 688620 & 4.45 & 5.3865 & TRN & \\
\hline CHEMBL1536281 & 688620 & 5.0 & 5.3412 & TRN & \\
\hline CHEMBL1338757 & 688620 & 4.9 & 5.1289 & TST & \\
\hline CHEMBL3195641 & 688620 & 5.75 & 5.822 & TRN & \\
\hline CHEMBL1488603 & 688620 & 5.3 & 5.2457 & TST & \\
\hline CHEMBL1389077 & 688620 & 4.45 & 4.9237 & TST & \\
\hline CHEMBL1502173 & 688620 & 4.8 & 4.934 & TRN & \\
\hline CHEMBL1325348 & 688620 & 4.95 & 4.9315 & TRN & \\
\hline CHEMBL1607831 & 688620 & 4.8 & 5.17 & TST & \\
\hline CHEMBL1522973 & 688620 & 5.5 & 5.3158 & TRN & \\
\hline CHEMBL1528647 & 688620 & 5.55 & 4.9643 & TST & \\
\hline CHEMBL1533030 & 688620 & 4.45 & 5.1072 & TST & \\
\hline CHEMBL1547142 & 688620 & 5.45 & 5.0358 & TRN & \\
\hline CHEMBL1603581 & 688620 & 4.85 & 4.7576 & TST & \\
\hline CHEMBL1602015 & 688620 & 4.75 & 4.9558 & TRN & \\
\hline CHEMBL1537449 & 688620 & 5.6 & 5.41200 & 0000000001 & TRN \\
\hline CHEMBL1334793 & 688620 & 4.65 & 5.0469 & TRN & \\
\hline CHEMBL1382137 & 688620 & 4.95 & 5.0999 & TRN & \\
\hline CHEMBL1393912 & 688620 & 4.9 & 4.8036 & TST & \\
\hline CHEMBL1323954 & 688620 & 4.95 & 4.8523 & TRN & \\
\hline
\end{tabular}




\begin{tabular}{|c|c|c|c|c|}
\hline \multicolumn{5}{|c|}{ Supplemental Table S2.txt } \\
\hline CHEMBL1569974 & 688620 & 4.45 & 4.9529 & TRN \\
\hline CHEMBL388676 & 688620 & 6.0 & 5.6299 & TST \\
\hline CHEMBL1438100 & 688620 & 6.35 & 5.1182 & TRN \\
\hline CHEMBL 3209020 & 688620 & 4.95 & 5.0211 & TRN \\
\hline CHEMBL2003086 & 688620 & 4.9 & 5.3027 & TRN \\
\hline CHEMBL1458363 & 688620 & 4.7 & 4.8214 & TRN \\
\hline CHEMBL1400912 & 688620 & 5.05 & 4.8036 & TRN \\
\hline CHEMBL1449760 & 688620 & 4.45 & 4.9719 & TRN \\
\hline CHEMBL1584002 & 688620 & 5.75 & 5.1765 & TRN \\
\hline CHEMBL1595194 & 688620 & 4.75 & 6.1057 & TRN \\
\hline CHEMBL1441078 & 688620 & 4.5 & 5.0211 & TST \\
\hline CHEMBL1504873 & 688620 & 4.8 & 5.1728 & TRN \\
\hline CHEMBL 3210238 & 688620 & 4.95 & 5.1622 & TRN \\
\hline CHEMBL1530990 & 688620 & 5.5 & 5.1559 & TRN \\
\hline CHEMBL3194762 & 688620 & 4.45 & 4.9392 & TRN \\
\hline CHEMBL1570140 & 688620 & 5.15 & 4.9854 & TRN \\
\hline CHEMBL1343160 & 688620 & 5.25 & 5.0454 & TST \\
\hline CHEMBL1583479 & 688620 & 5.45 & 4.8064 & TRN \\
\hline CHEMBL1580233 & 688620 & 4.8 & 5.0106 & TST \\
\hline CHEMBL1545467 & 688620 & 8.3468 & 5.7477 & TST \\
\hline CHEMBL1468730 & 688620 & 4.95 & 5.1388 & TRN \\
\hline CHEMBL1447563 & 688620 & 5.45 & 5.0949 & TRN \\
\hline CHEMBL1352169 & 688620 & 4.95 & 5.0745 & TST \\
\hline CHEMBL1352471 & 688620 & 4.85 & 5.1312 & TRN \\
\hline CHEMBL1524866 & 688620 & 4.95 & 4.81 & TST \\
\hline CHEMBL1426234 & 688620 & 4.65 & 4.6811 & TRN \\
\hline CHEMBL1534949 & 688620 & 5.55 & 5.539 & TRN \\
\hline CHEMBL1342350 & 688620 & 4.75 & 5.0254 & TRN \\
\hline CHEMBL1401468 & 688620 & 5.0 & 5.2793 & TRN \\
\hline CHEMBL1444429 & 688620 & 5.2 & 4.8904 & TST \\
\hline CHEMBL1543567 & 688620 & 4.45 & 4.9844 & TRN \\
\hline CHEMBL1524332 & 688620 & 5.2 & 5.0032 & TRN \\
\hline CHEMBL1517782 & 688620 & 5.35 & 5.3734 & TRN \\
\hline CHEMBL1494996 & 688620 & 5.45 & 5.4974 & TRN \\
\hline CHEMBL1453625 & 688620 & 5.75 & 5.2661 & TRN \\
\hline CHEMBL1457420 & 688620 & 5.1 & 5.1159 & TRN \\
\hline CHEMBL1533506 & 688620 & 4.65 & 5.0138 & TRN \\
\hline CHEMBL1546301 & 688620 & 5.05 & 5.143 & TRN \\
\hline CHEMBL1999571 & 688620 & 6.2 & 5.691 & TRN \\
\hline CHEMBL1351764 & 688620 & 4.95 & 5.2442 & TRN \\
\hline CHEMBL1461618 & 688620 & 4.9 & 5.23 & TRN \\
\hline CHEMBL3191971 & 688620 & 4.55 & 5.0867 & TST \\
\hline CHEMBL1304952 & 688620 & 5.05 & 4.7565 & TRN \\
\hline CHEMBL1442709 & 688620 & 5.55 & 5.1593 & TRN \\
\hline CHEMBL1418389 & 688620 & 5.55 & 5.3476 & TRN \\
\hline CHEMBL1499937 & 688620 & 4.9 & 5.3361 & TRN \\
\hline CHEMBL1388783 & 688620 & 5.75 & 5.4964 & TRN \\
\hline CHEMBL1371600 & 688620 & 5.45 & 5.1641 & TRN \\
\hline
\end{tabular}




\begin{tabular}{|c|c|c|c|c|}
\hline & & & pplement & $\mathrm{a} \perp \mathrm{Ta}$ \\
\hline CHEMBL1468477 & 688620 & 4.5 & 5.305 & TST \\
\hline CHEMBL1462962 & 688620 & 4.5 & 5.0534 & TST \\
\hline CHEMBL1376392 & 688620 & 5.4 & 5.2752 & TST \\
\hline CHEMBL1605427 & 688620 & 4.45 & 4.8247 & TRN \\
\hline CHEMBL1558818 & 688620 & 4.6 & 5.0824 & TRN \\
\hline CHEMBL1302851 & 688620 & 5.15 & 4.9868 & TST \\
\hline CHEMBL1492002 & 688620 & 4.75 & 5.0258 & TST \\
\hline CHEMBL1383528 & 688620 & 4.8 & 4.8525 & TRN \\
\hline CHEMBL1970478 & 688620 & 4.65 & 5.1563 & TRN \\
\hline CHEMBL1407203 & 688620 & 5.15 & 4.9929 & TRN \\
\hline CHEMBL1324372 & 688620 & 6.2 & 5.11 & TRN \\
\hline CHEMBL1550385 & 688620 & 5.0 & 5.2018 & TRN \\
\hline CHEMBL1380326 & 688620 & 5.35 & 5.1282 & TRN \\
\hline CHEMBL1386406 & 688620 & 5.0 & 5.0824 & TRN \\
\hline CHEMBL1606260 & 688620 & 4.65 & 4.9602 & TRN \\
\hline CHEMBL1506843 & 688620 & 4.95 & 4.8846 & TRN \\
\hline CHEMBL1605770 & 688620 & 4.95 & 5.0384 & TRN \\
\hline CHEMBL3210159 & 688620 & 4.75 & 5.176 & TRN \\
\hline CHEMBL1425309 & 688620 & 5.05 & 5.2628 & TRN \\
\hline CHEMBL1998302 & 688620 & 4.95 & 5.0494 & TRN \\
\hline CHEMBL1420673 & 688620 & 4.85 & 5.1902 & TRN \\
\hline CHEMBL1547780 & 688620 & 4.45 & 4.9615 & TRN \\
\hline CHEMBL1510219 & 688620 & 4.75 & 4.9602 & TRN \\
\hline CHEMBL1360479 & 688620 & 4.9 & 5.1224 & TRN \\
\hline CHEMBL1406761 & 688620 & 5.2 & 4.9578 & TRN \\
\hline CHEMBL1501499 & 688620 & 6.5 & 5.0253 & TST \\
\hline CHEMBL1376611 & 688620 & 5.0 & 5.1688 & TRN \\
\hline CHEMBL1528476 & 688620 & 5.4 & 5.3627 & TRN \\
\hline CHEMBL1600434 & 688620 & 5.35 & 4.9848 & TRN \\
\hline CHEMBL180905 & 688620 & 4.5 & 5.2143 & TST \\
\hline CHEMBL1450615 & 688620 & 4.45 & 5.5565 & TRN \\
\hline CHEMBL3197277 & 688620 & 4.45 & 4.8947 & TRN \\
\hline CHEMBL1423161 & 688620 & 4.45 & 5.2514 & TST \\
\hline CHEMBL1587340 & 688620 & 4.6 & 5.1986 & TST \\
\hline CHEMBL1346348 & 688620 & 4.8 & 5.0787 & TST \\
\hline CHEMBL1488876 & 688620 & 4.9 & 4.8295 & TRN \\
\hline CHEMBL1546633 & 688620 & 4.45 & 4.8339 & TRN \\
\hline CHEMBL1469201 & 688620 & 5.55 & 4.9887 & TRN \\
\hline CHEMBL1579186 & 688620 & 6.0 & 5.6489 & TRN \\
\hline CHEMBL1346555 & 688620 & 4.95 & 5.1335 & TRN \\
\hline CHEMBL1497778 & 688620 & 4.5 & 5.0932 & TRN \\
\hline CHEMBL1490225 & 688620 & 5.25 & 5.1977 & TRN \\
\hline CHEMBL1331064 & 688620 & 5.4 & 5.3423 & TRN \\
\hline CHEMBL3209909 & 688620 & 4.75 & 4.8684 & TRN \\
\hline CHEMBL1447122 & 688620 & 4.85 & 5.1876 & TRN \\
\hline CHEMBL1379934 & 688620 & 4.8 & 4.7442 & TRN \\
\hline CHEMBL1570180 & 688620 & 4.95 & 5.1131 & TRN \\
\hline CHEMBL1344696 & 688620 & 5.45 & 5.8887 & TRN \\
\hline
\end{tabular}




\begin{tabular}{|c|c|c|c|c|}
\hline \multicolumn{5}{|c|}{ Supplemental Table S2.txt } \\
\hline CHEMBL1594263 & 688620 & 5.35 & 5.3461 & TRN \\
\hline CHEMBL1546468 & 688620 & 4.9 & 5.0087 & TST \\
\hline CHEMBL3194385 & 688620 & 5.05 & 5.0515 & TRN \\
\hline CHEMBL1337594 & 688620 & 4.8 & 5.2584 & TRN \\
\hline CHEMBL3191696 & 688620 & 4.45 & 5.1837 & TRN \\
\hline CHEMBL1399096 & 688620 & 5.2 & 5.0258 & TRN \\
\hline CHEMBL1387505 & 688620 & 5.2 & 4.7945 & TRN \\
\hline CHEMBL1597459 & 688620 & 5.1 & 4.8897 & TST \\
\hline CHEMBL1311858 & 688620 & 4.45 & 5.0003 & TRN \\
\hline CHEMBL3208702 & 688620 & 4.45 & 4.8184 & TRN \\
\hline CHEMBL1991440 & 688620 & 4.5 & 4.7396 & TRN \\
\hline CHEMBL1612254 & 688620 & 5.65 & 5.0399 & TRN \\
\hline CHEMBL1330251 & 688620 & 6.0 & 5.5493 & TRN \\
\hline CHEMBL493153 & 688620 & 4.9 & 5.2716 & TRN \\
\hline CHEMBL1347189 & 688620 & 4.45 & 5.0743 & TRN \\
\hline CHEMBL1596449 & 688620 & 5.25 & 4.7798 & TST \\
\hline CHEMBL1355644 & 688620 & 5.65 & 4.8728 & TRN \\
\hline CHEMBL1564313 & 688620 & 6.9 & 5.0976 & TST \\
\hline CHEMBL3210594 & 688620 & 4.95 & 4.824 & TST \\
\hline CHEMBL3198156 & 688620 & 6.05 & 5.8997 & TRN \\
\hline CHEMBL1548306 & 688620 & 4.45 & 5.0945 & TRN \\
\hline CHEMBL1417349 & 688620 & 4.85 & 4.915 & TST \\
\hline CHEMBL3196382 & 688620 & 5.7 & 5.3227 & TRN \\
\hline CHEMBL 3190540 & 688620 & 5.25 & 5.0483 & TRN \\
\hline CHEMBL1456451 & 688620 & 4.95 & 5.0574 & TRN \\
\hline CHEMBL3196451 & 688620 & 5.0 & 5.4218 & TRN \\
\hline CHEMBL1407673 & 688620 & 4.45 & 4.9874 & TST \\
\hline CHEMBL1416603 & 688620 & 4.9 & 4.6475 & TRN \\
\hline CHEMBL1300371 & 688620 & 5.5 & 5.1067 & TRN \\
\hline CHEMBL1477241 & 688620 & 6.0 & 4.811 & TRN \\
\hline CHEMBL1447130 & 688620 & 4.55 & 4.9918 & TRN \\
\hline CHEMBL1523974 & 688620 & 4.5 & 4.7756 & TRN \\
\hline CHEMBL1462468 & 688620 & 4.7 & 5.0406 & TST \\
\hline CHEMBL1379156 & 688620 & 4.95 & 4.915 & TRN \\
\hline CHEMBL1399797 & 688620 & 4.6 & 4.9487 & TRN \\
\hline CHEMBL1444938 & 688620 & 5.4 & 4.8233 & TRN \\
\hline CHEMBL1381680 & 688620 & 5.45 & 5.0278 & TRN \\
\hline CHEMBL1540319 & 688620 & 4.6 & 5.0228 & TRN \\
\hline CHEMBL1978908 & 688620 & 6.5501 & 6.0436 & TRN \\
\hline CHEMBL1417428 & 688620 & 6.0 & 5.0947 & TST \\
\hline CHEMBL1449081 & 688620 & 4.9 & 5.1242 & TST \\
\hline CHEMBL1369145 & 688620 & 4.75 & 5.3147 & TRN \\
\hline CHEMBL1483964 & 688620 & 4.95 & 4.9182 & TRN \\
\hline CHEMBL1560229 & 688620 & 4.9 & 4.8906 & TST \\
\hline CHEMBL1375831 & 688620 & 4.8 & 5.0153 & TST \\
\hline CHEMBL1489043 & 688620 & 4.65 & 4.8578 & TRN \\
\hline CHEMBL3196970 & 688620 & 5.7 & 5.706 & TRN \\
\hline CHEMBL1313842 & 688620 & 4.95 & 4.7783 & TRN \\
\hline
\end{tabular}




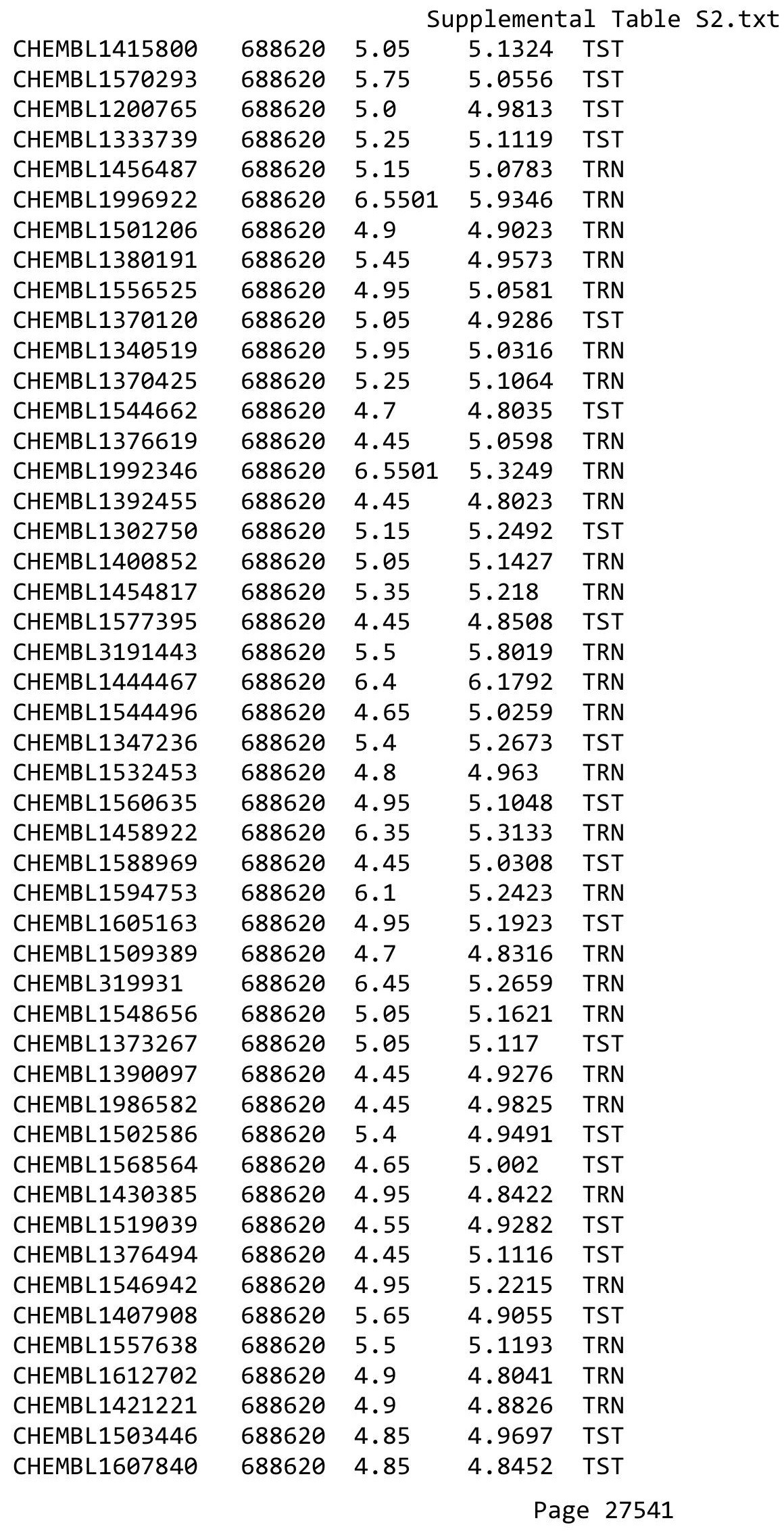




\begin{tabular}{|c|c|c|c|c|c|}
\hline \multicolumn{6}{|c|}{ Supplemental Table S2.txt } \\
\hline CHEMBL1487967 & 688620 & 5.15 & 5.6728 & TRN & \\
\hline CHEMBL1425524 & 688620 & 5.4 & 5.2118 & TRN & \\
\hline CHEMBL1541099 & 688620 & 4.65 & 4.8814 & TRN & \\
\hline CHEMBL1484242 & 688620 & 4.9 & 4.989 & TRN & \\
\hline CHEMBL 1485787 & 688620 & 4.9 & 5.0317 & TRN & \\
\hline CHEMBL1519953 & 688620 & 4.45 & 4.7637 & TRN & \\
\hline CHEMBL1339909 & 688620 & 5.25 & 5.3436 & TRN & \\
\hline CHEMBL1424065 & 688620 & 4.8 & 5.2852 & TRN & \\
\hline CHEMBL1345726 & 688620 & 4.45 & 5.1566 & TRN & \\
\hline CHEMBL1519022 & 688620 & 4.45 & 4.7317 & TRN & \\
\hline CHEMBL1424832 & 688620 & 4.45 & 4.9175 & TST & \\
\hline CHEMBL1458977 & 688620 & 5.5 & 5.55200 & 00000000005 & TRN \\
\hline CHEMBL1444459 & 688620 & 5.5 & 5.3328 & TST & \\
\hline CHEMBL1598705 & 688620 & 5.3 & 5.0805 & TRN & \\
\hline CHEMBL1425821 & 688620 & 5.0 & 5.0589 & TRN & \\
\hline CHEMBL1459638 & 688620 & 5.45 & 4.9678 & TST & \\
\hline CHEMBL1556767 & 688620 & 4.8 & 4.8182 & TRN & \\
\hline CHEMBL1522386 & 688620 & 4.5 & 5.1785 & TST & \\
\hline CHEMBL1329383 & 688620 & 5.45 & 4.8994 & TST & \\
\hline CHEMBL1540635 & 688620 & 5.6 & 5.2176 & TST & \\
\hline CHEMBL1460012 & 688620 & 5.45 & 5.0942 & TRN & \\
\hline CHEMBL3191232 & 688620 & 4.45 & 4.7973 & TST & \\
\hline CHEMBL1368088 & 688620 & 5.15 & 5.5322 & TRN & \\
\hline CHEMBL1594867 & 688620 & 5.3 & 5.1561 & TRN & \\
\hline CHEMBL1445052 & 688620 & 4.75 & 5.0372 & TRN & \\
\hline CHEMBL1344735 & 688620 & 5.05 & 5.2242 & TRN & \\
\hline CHEMBL1420146 & 688620 & 5.8 & 5.0544 & TRN & \\
\hline CHEMBL1407095 & 688620 & 4.8 & 5.6557 & TRN & \\
\hline CHEMBL1391765 & 688620 & 4.95 & 4.9039 & TRN & \\
\hline CHEMBL1359666 & 688620 & 7.15 & 5.0838 & TST & \\
\hline CHEMBL1574587 & 688620 & 5.25 & 5.182 & TST & \\
\hline CHEMBL 1354210 & 688620 & 4.8 & 5.1197 & TRN & \\
\hline CHEMBL1529289 & 688620 & 4.9 & 5.0099 & TRN & \\
\hline CHEMBL1571696 & 688620 & 4.85 & 5.1733 & TRN & \\
\hline CHEMBL1428320 & 688620 & 4.9 & 5.1703 & TRN & \\
\hline CHEMBL1461114 & 688620 & 4.45 & 5.3196 & TST & \\
\hline CHEMBL3211077 & 688620 & 5.2 & 5.1393 & TST & \\
\hline CHEMBL3214169 & 688620 & 5.45 & 5.2235 & TRN & \\
\hline CHEMBL1300711 & 688620 & 5.8 & 5.2873 & TRN & \\
\hline CHEMBL507264 & 688620 & 4.45 & 4.9021 & TST & \\
\hline CHEMBL1481910 & 688620 & 5.45 & 4.9668 & TST & \\
\hline CHEMBL3191827 & 688620 & 4.9 & 4.8306 & TRN & \\
\hline CHEMBL3208311 & 688620 & 6.6 & 5.0117 & TRN & \\
\hline CHEMBL3209803 & 688620 & 5.2 & 5.4235 & TRN & \\
\hline CHEMBL1544078 & 688620 & 5.4 & 5.1129 & TRN & \\
\hline CHEMBL1385552 & 688620 & 4.45 & 5.1822 & TRN & \\
\hline CHEMBL1371132 & 688620 & 4.7 & 5.273 & TRN & \\
\hline CHEMBL3194460 & 688620 & 4.9 & 5.2158 & TRN & \\
\hline
\end{tabular}




\begin{tabular}{|c|c|c|c|c|c|}
\hline \multicolumn{6}{|c|}{ Supplemental Table S2.txt } \\
\hline CHEMBL1995364 & 688620 & 5.8 & 5.5512 & TRN & \\
\hline CHEMBL3145322 & 688620 & 5.85 & 5.7598 & TRN & \\
\hline CHEMBL1386479 & 688620 & 4.95 & 5.0641 & TRN & \\
\hline CHEMBL1411385 & 688620 & 4.8 & 4.8891 & TST & \\
\hline CHEMBL1377978 & 688620 & 4.9 & 5.0334 & TST & \\
\hline CHEMBL1318455 & 688620 & 4.45 & 5.069 & TST & \\
\hline CHEMBL1354187 & 688620 & 4.45 & 5.16799 & 9999999999 & TRN \\
\hline CHEMBL1487666 & 688620 & 5.0 & 5.29299 & 9999999999 & TRN \\
\hline CHEMBL1330351 & 688620 & 5.95 & 5.2906 & TRN & \\
\hline CHEMBL1490873 & 688620 & 4.9 & 4.9489 & TRN & \\
\hline CHEMBL1988210 & 688620 & 5.45 & 5.0649 & TRN & \\
\hline CHEMBL1573167 & 688620 & 5.45 & 5.4531 & TRN & \\
\hline CHEMBL1471293 & 688620 & 4.45 & 4.9887 & TRN & \\
\hline CHEMBL1522112 & 688620 & 4.7 & 4.9253 & TST & \\
\hline CHEMBL1389769 & 688620 & 4.7 & 4.9558 & TRN & \\
\hline CHEMBL1361575 & 688620 & 4.9 & 5.1209 & TRN & \\
\hline CHEMBL1353878 & 688620 & 4.55 & 5.0809 & TRN & \\
\hline CHEMBL1588536 & 688620 & 6.25 & 5.5924 & TRN & \\
\hline CHEMBL1335204 & 688620 & 4.5 & 5.3613 & TRN & \\
\hline CHEMBL1613636 & 688620 & 4.65 & 4.8618 & TRN & \\
\hline CHEMBL1329915 & 688620 & 5.55 & 5.4524 & TRN & \\
\hline CHEMBL1538225 & 688620 & 4.45 & 4.8438 & TRN & \\
\hline CHEMBL1609946 & 688620 & 6.8 & 6.6122 & TRN & \\
\hline CHEMBL1415765 & 688620 & 6.7501 & 4.9463 & TRN & \\
\hline CHEMBL1521989 & 688620 & 5.4 & 4.9021 & TRN & \\
\hline CHEMBL1583656 & 688620 & 4.9 & 5.2199 & TRN & \\
\hline CHEMBL3190223 & 688620 & 4.85 & 4.9328 & TRN & \\
\hline CHEMBL3195093 & 688620 & 5.1 & 4.7802 & TRN & \\
\hline CHEMBL1416339 & 688620 & 4.8 & 5.1387 & TRN & \\
\hline CHEMBL1344075 & 688620 & 4.9 & 5.1528 & TRN & \\
\hline CHEMBL1589386 & 688620 & 4.6 & 4.8253 & TST & \\
\hline CHEMBL1491264 & 688620 & 5.25 & 5.114 & TRN & \\
\hline CHEMBL1469224 & 688620 & 4.9 & 4.8666 & TST & \\
\hline CHEMBL1409070 & 688620 & 4.6 & 5.2889 & TST & \\
\hline CHEMBL1336271 & 688620 & 5.8 & 4.7898 & TRN & \\
\hline CHEMBL1400818 & 688620 & 5.4 & 4.9712 & TRN & \\
\hline CHEMBL1452217 & 688620 & 5.0 & 4.9581 & TRN & \\
\hline CHEMBL1453722 & 688620 & 5.55 & 5.7369 & TRN & \\
\hline CHEMBL1307005 & 688620 & 8.1024 & 5.1611 & TRN & \\
\hline CHEMBL1601979 & 688620 & 4.8 & 4.9917 & TST & \\
\hline CHEMBL1462283 & 688620 & 5.8 & 5.4457 & TRN & \\
\hline CHEMBL1579670 & 688620 & 5.95 & 5.3782 & TRN & \\
\hline CHEMBL1389863 & 688620 & 4.6 & 4.9711 & TST & \\
\hline CHEMBL1612739 & 688620 & 5.2 & 5.0403 & TST & \\
\hline CHEMBL1409279 & 688620 & 4.95 & 4.9308 & TRN & \\
\hline CHEMBL1302479 & 688620 & 4.9 & 4.9231 & TRN & \\
\hline CHEMBL1329251 & 688620 & 6.2 & 5.4074 & TRN & \\
\hline CHEMBL3198276 & 688620 & 4.95 & 5.8885 & TRN & \\
\hline
\end{tabular}




\begin{tabular}{|c|c|c|c|c|c|}
\hline \multicolumn{6}{|c|}{ Supplemental Table S2.txt } \\
\hline CHEMBL1534523 & 688620 & 4.9 & 5.0444 & TRN & \\
\hline CHEMBL 3856094 & 688620 & 4.65 & 5.3478 & TST & \\
\hline CHEMBL1543834 & 688620 & 4.5 & 4.8133 & TRN & \\
\hline CHEMBL1308298 & 688620 & 4.95 & 5.1294 & TRN & \\
\hline CHEMBL1509954 & 688620 & 5.65 & 4.9052 & TRN & \\
\hline CHEMBL1361132 & 688620 & 4.85 & 5.2363 & TST & \\
\hline CHEMBL3196466 & 688620 & 4.9 & 5.1902 & TRN & \\
\hline CHEMBL3209626 & 688620 & 4.45 & 4.7476 & TRN & \\
\hline CHEMBL1469635 & 688620 & 5.15 & 4.9535 & TST & \\
\hline CHEMBL1378668 & 688620 & 4.45 & 5.1959 & TRN & \\
\hline CHEMBL1428391 & 688620 & 5.25 & 5.0537 & TST & \\
\hline CHEMBL1375342 & 688620 & 4.8 & 4.8815 & TRN & \\
\hline CHEMBL1602982 & 688620 & 4.45 & 5.064 & TRN & \\
\hline CHEMBL1450462 & 688620 & 5.5 & 5.4386 & TRN & \\
\hline CHEMBL1510089 & 688620 & 4.65 & 5.0206 & TRN & \\
\hline CHEMBL1532985 & 688620 & 4.95 & 4.9969 & TRN & \\
\hline CHEMBL1570993 & 688620 & 5.7 & 5.2937 & TRN & \\
\hline CHEMBL1301320 & 688620 & 4.75 & 4.9957 & TRN & \\
\hline CHEMBL1974362 & 688620 & 4.75 & 5.3817 & TRN & \\
\hline CHEMBL1361202 & 688620 & 5.4 & 5.59399 & 9999999999 & TRN \\
\hline CHEMBL1570557 & 688620 & 4.45 & 5.1299 & TST & \\
\hline CHEMBL1533617 & 688620 & 4.8 & 5.1391 & TRN & \\
\hline CHEMBL1992745 & 688620 & 5.7 & 5.8201 & TRN & \\
\hline CHEMBL 3208530 & 688620 & 5.3 & 5.1232 & TRN & \\
\hline CHEMBL1325606 & 688620 & 4.45 & 4.9957 & TRN & \\
\hline CHEMBL1519352 & 688620 & 4.9 & 4.8313 & TRN & \\
\hline CHEMBL1373222 & 688620 & 4.65 & 5.2181 & TST & \\
\hline CHEMBL1432377 & 688620 & 5.45 & 5.1549 & TRN & \\
\hline CHEMBL1562671 & 688620 & 5.2 & 5.0973 & TST & \\
\hline CHEMBL1556357 & 688620 & 5.6 & 5.4189 & TRN & \\
\hline CHEMBL578512 & 688620 & 7.4001 & 5.8607 & TRN & \\
\hline CHEMBL1514943 & 688620 & 4.85 & 5.1318 & TRN & \\
\hline CHEMBL3214189 & 688620 & 4.65 & 4.9463 & TRN & \\
\hline CHEMBL1504064 & 688620 & 4.45 & 4.9206 & TRN & \\
\hline CHEMBL1574826 & 688620 & 5.05 & 5.3572 & TRN & \\
\hline CHEMBL1312057 & 688620 & 4.75 & 4.8223 & TRN & \\
\hline CHEMBL1972348 & 688620 & 6.05 & 5.3563 & TRN & \\
\hline CHEMBL1418450 & 688620 & 4.85 & 4.9494 & TRN & \\
\hline CHEMBL1560426 & 688620 & 5.05 & 5.0838 & TRN & \\
\hline CHEMBL1379316 & 688620 & 4.75 & 4.9806 & TRN & \\
\hline CHEMBL1547444 & 688620 & 5.6 & 4.8089 & TST & \\
\hline CHEMBL1320715 & 688620 & 4.95 & 5.1289 & TST & \\
\hline CHEMBL1575428 & 688620 & 4.95 & 5.0618 & TRN & \\
\hline CHEMBL1390396 & 688620 & 4.8 & 4.8003 & TST & \\
\hline CHEMBL1309732 & 688620 & 4.45 & 4.9921 & TRN & \\
\hline CHEMBL1407588 & 688620 & 5.5 & 4.7705 & TRN & \\
\hline CHEMBL1385746 & 688620 & 4.95 & 4.7915 & TRN & \\
\hline CHEMBL1325633 & 688620 & 4.8 & 5.2102 & TST & \\
\hline
\end{tabular}




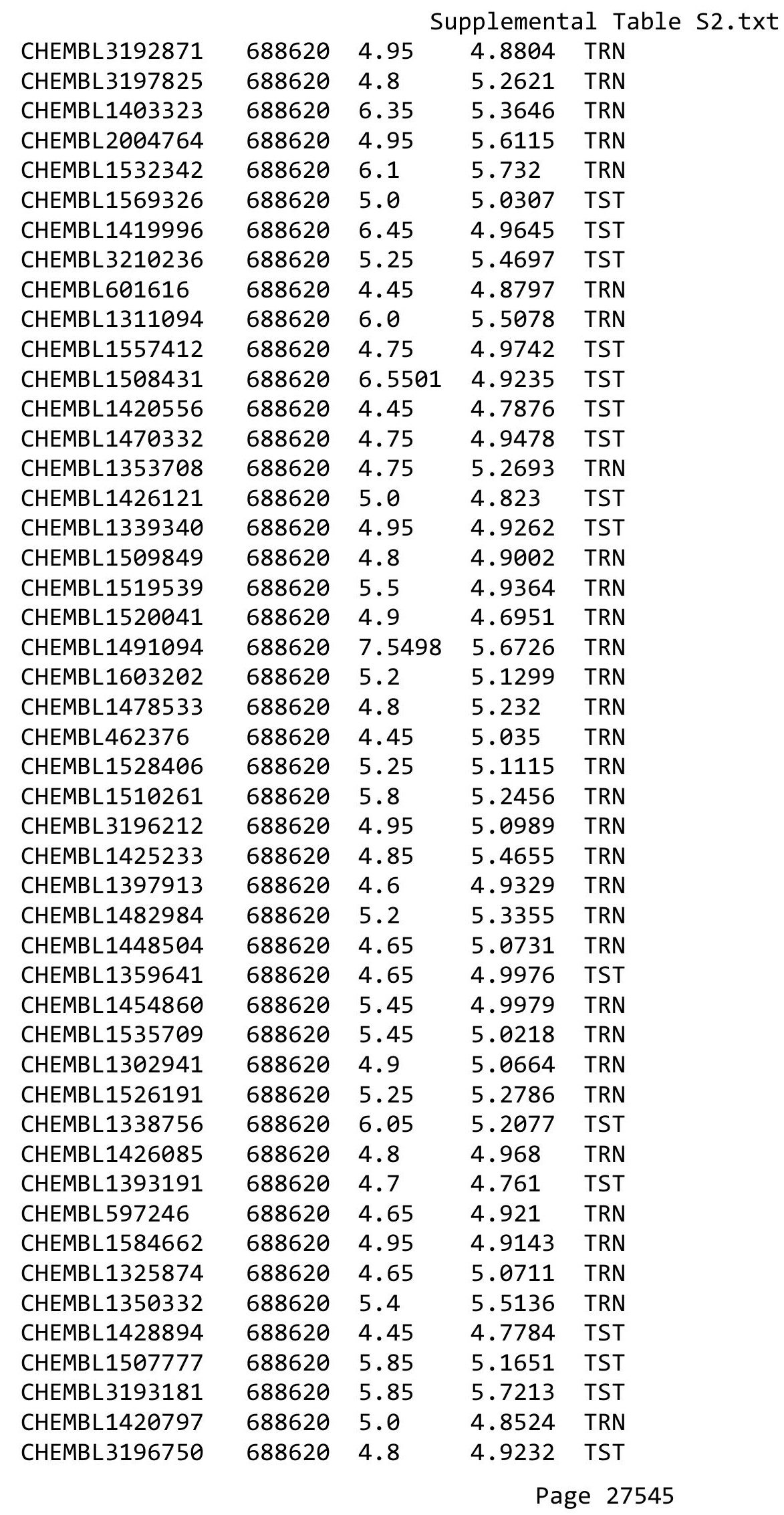




\begin{tabular}{|c|c|c|c|c|c|}
\hline \multicolumn{6}{|c|}{ Supplemental Table S2.txt } \\
\hline CHEMBL1380775 & 688620 & 4.65 & 5.1477 & TRN & \\
\hline CHEMBL1498673 & 688620 & 5.55 & 5.0185 & TRN & \\
\hline CHEMBL1319513 & 688620 & 6.0 & 5.5619 & TRN & \\
\hline CHEMBL1500102 & 688620 & 5.05 & 5.1104 & TRN & \\
\hline CHEMBL1541906 & 688620 & 6.5 & 5.0515 & TRN & \\
\hline CHEMBL1569358 & 688620 & 5.0 & 4.8798 & TRN & \\
\hline CHEMBL1536119 & 688620 & 4.8 & 4.9429 & TRN & \\
\hline CHEMBL1539466 & 688620 & 4.45 & 5.09 & TRN & \\
\hline CHEMBL3191471 & 688620 & 5.4 & 5.1117 & TRN & \\
\hline CHEMBL1422312 & 688620 & 5.2 & 5.1575 & TRN & \\
\hline CHEMBL90290 & 688620 & 4.45 & 4.8431 & TRN & \\
\hline CHEMBL1477234 & 688620 & 4.8 & 5.2068 & TRN & \\
\hline CHEMBL1458293 & 688620 & 6.45 & 4.9616 & TST & \\
\hline CHEMBL 3190060 & 688620 & 4.8 & 5.1363 & TRN & \\
\hline CHEMBL1456018 & 688620 & 4.45 & 4.9057 & TRN & \\
\hline CHEMBL1376929 & 688620 & 4.85 & 4.8283 & TST & \\
\hline CHEMBL1363774 & 688620 & 4.45 & 5.1135 & TRN & \\
\hline CHEMBL1550748 & 688620 & 5.3 & 5.1933 & TST & \\
\hline CHEMBL1409866 & 688620 & 5.25 & 4.887 & TRN & \\
\hline CHEMBL1379970 & 688620 & 5.2 & 6.1575 & TRN & \\
\hline CHEMBL1477676 & 688620 & 5.9 & 5.6195 & TRN & \\
\hline CHEMBL1509445 & 688620 & 4.65 & 4.9344 & TRN & \\
\hline CHEMBL1365229 & 688620 & 5.0 & 4.745 & TRN & \\
\hline CHEMBL1346710 & 688620 & 6.05 & 5.0575 & TRN & \\
\hline CHEMBL1463312 & 688620 & 4.95 & 4.855 & TRN & \\
\hline CHEMBL1493263 & 688620 & 4.65 & 4.9718 & TST & \\
\hline CHEMBL1302248 & 688620 & 4.85 & 5.0552 & TST & \\
\hline CHEMBL1312756 & 688620 & 4.45 & 5.0508 & TST & \\
\hline CHEMBL1417245 & 688620 & 5.15 & 5.0571 & TRN & \\
\hline CHEMBL1598810 & 688620 & 6.8499 & 5.063 & TRN & \\
\hline CHEMBL1427310 & 688620 & 5.2 & 5.0127 & TRN & \\
\hline CHEMBL1539204 & 688620 & 5.55 & 5.24700 & 0000000001 & TRN \\
\hline CHEMBL1461364 & 688620 & 4.65 & 4.9488 & TRN & \\
\hline CHEMBL3191684 & 688620 & 5.0 & 4.9203 & TST & \\
\hline CHEMBL3210334 & 688620 & 5.3 & 5.2695 & TST & \\
\hline CHEMBL1993070 & 688620 & 5.1 & 5.1074 & TRN & \\
\hline CHEMBL1386886 & 688620 & 6.95 & 4.9886 & TST & \\
\hline CHEMBL1528827 & 688620 & 5.9 & 5.6747 & TRN & \\
\hline CHEMBL1532224 & 688620 & 4.9 & 4.8986 & TRN & \\
\hline CHEMBL1502976 & 688620 & 5.5 & 4.9681 & TRN & \\
\hline CHEMBL1349387 & 688620 & 5.55 & 5.4349 & TRN & \\
\hline CHEMBL3212595 & 688620 & 4.65 & 4.9951 & TRN & \\
\hline CHEMBL1527398 & 688620 & 4.95 & 4.7754 & TRN & \\
\hline CHEMBL1416487 & 688620 & 4.6 & 4.9069 & TRN & \\
\hline CHEMBL1342630 & 688620 & 4.95 & 5.1436 & TRN & \\
\hline CHEMBL1428507 & 688620 & 4.65 & 4.6289 & TRN & \\
\hline CHEMBL1410009 & 688620 & 4.45 & 4.7995 & TRN & \\
\hline CHEMBL1439600 & 688620 & 5.1 & 5.2159 & TRN & \\
\hline
\end{tabular}




\begin{tabular}{|c|c|c|c|c|c|}
\hline \\
\hline CHEMBL3198003 & 688620 & 5.6 & 5.4739 & TRN & \\
\hline CHEMBL1599678 & 688620 & 5.6 & 5.2728 & TRN & \\
\hline CHEMBL1532915 & 688620 & 4.65 & 4.9004 & TRN & \\
\hline CHEMBL1339640 & 688620 & 4.8 & 4.6808 & TRN & \\
\hline CHEMBL1548136 & 688620 & 4.6 & 5.2262 & TRN & \\
\hline CHEMBL1335255 & 688620 & 5.65 & 5.2125 & TRN & \\
\hline CHEMBL1345798 & 688620 & 4.8 & 5.0526 & TRN & \\
\hline CHEMBL3193926 & 688620 & 4.7 & 4.9333 & TRN & \\
\hline CHEMBL1300111 & 688620 & 4.9 & 5.2991 & TRN & \\
\hline CHEMBL3213008 & 688620 & 4.95 & 4.7709 & TRN & \\
\hline CHEMBL3145107 & 688620 & 5.05 & 5.0066 & TRN & \\
\hline CHEMBL1300537 & 688620 & 5.15 & 4.9693 & TRN & \\
\hline CHEMBL3208970 & 688620 & 4.8 & 5.0065 & TRN & \\
\hline CHEMBL1312478 & 688620 & 6.9 & 5.183 & TRN & \\
\hline CHEMBL1376059 & 688620 & 4.65 & 5.3793 & TRN & \\
\hline CHEMBL1440378 & 688620 & 5.95 & 5.9841 & TRN & \\
\hline CHEMBL1511532 & 688620 & 5.15 & 5.0878 & TST & \\
\hline CHEMBL1587433 & 688620 & 5.45 & 4.9759 & TRN & \\
\hline CHEMBL1321112 & 688620 & 5.05 & 5.1719 & TRN & \\
\hline CHEMBL1403598 & 688620 & 4.9 & 5.0502 & TRN & \\
\hline CHEMBL1561338 & 688620 & 5.5 & 5.2464 & TST & \\
\hline CHEMBL1372086 & 688620 & 5.3 & 5.093 & TRN & \\
\hline CHEMBL1569169 & 688620 & 5.55 & 5.3197 & TST & \\
\hline CHEMBL1598631 & 688620 & 5.4 & 5.1374 & TST & \\
\hline CHEMBL1572788 & 688620 & 4.95 & 5.7482 & TRN & \\
\hline CHEMBL1379110 & 688620 & 5.15 & 5.2363 & TRN & \\
\hline CHEMBL1496534 & 688620 & 5.45 & 5.227 & TST & \\
\hline CHEMBL1549929 & 688620 & 4.5 & 4.9113 & TST & \\
\hline CHEMBL3198586 & 688620 & 5.2 & 5.0759 & TRN & \\
\hline CHEMBL1402453 & 688620 & 4.45 & 5.0056 & TRN & \\
\hline CHEMBL1544276 & 688620 & 5.45 & 5.2364 & TRN & \\
\hline CHEMBL3194705 & 688620 & 4.55 & 5.0872 & TST & \\
\hline CHEMBL1390049 & 688620 & 5.05 & 5.2542 & TRN & \\
\hline CHEMBL1585400 & 688620 & 5.1 & 5.3095 & TRN & \\
\hline CHEMBL1498396 & 688620 & 5.25 & 5.0354 & TRN & \\
\hline CHEMBL1467984 & 688620 & 5.2 & 5.222 & TRN & \\
\hline CHEMBL1528349 & 688620 & 5.7 & 5.3212 & TRN & \\
\hline CHEMBL1384228 & 688620 & 5.3 & 5.3495 & TRN & \\
\hline CHEMBL1328930 & 688620 & 4.5 & 5.2538 & TRN & \\
\hline CHEMBL1432870 & 688620 & 4.65 & 4.6734 & TRN & \\
\hline CHEMBL1385600 & 688620 & 4.5 & 4.973 & TST & \\
\hline CHEMBL1446439 & 688620 & 4.45 & 4.9637 & TST & \\
\hline CHEMBL1313491 & 688620 & 4.75 & $4.9830 e$ & 00000000005 & TRN \\
\hline CHEMBL1401243 & 688620 & 4.9 & 4.9968 & TRN & \\
\hline CHEMBL1472174 & 688620 & 4.5 & 5.0552 & TRN & \\
\hline CHEMBL1368715 & 688620 & 5.7 & 4.8787 & TRN & \\
\hline CHEMBL1572780 & 688620 & 4.9 & 5.2085 & TRN & \\
\hline CHEMBL521784 & 688620 & 4.8 & 5.0373 & TST & \\
\hline & & & & 27547 & \\
\hline
\end{tabular}




\begin{tabular}{|c|c|c|c|c|c|}
\hline \multicolumn{6}{|c|}{ Supplemental Table S2.txt } \\
\hline CHEMBL1460603 & 688620 & 4.95 & 4.9203 & TRN & \\
\hline CHEMBL1430096 & 688620 & 5.95 & 5.6708 & TRN & \\
\hline CHEMBL3198130 & 688620 & 5.0 & 4.9878 & TRN & \\
\hline CHEMBL210868 & 688620 & 4.45 & 4.9624 & TST & \\
\hline CHEMBL1442055 & 688620 & 4.95 & 5.03100 & 0000000001 & TST \\
\hline CHEMBL1416491 & 688620 & 4.45 & 5.0373 & TRN & \\
\hline CHEMBL1310005 & 688620 & 4.95 & 5.0211 & TRN & \\
\hline CHEMBL1503659 & 688620 & 5.0 & 5.4581 & TST & \\
\hline CHEMBL1522714 & 688620 & 4.95 & 4.9811 & TRN & \\
\hline CHEMBL1612916 & 688620 & 4.75 & 4.8571 & TST & \\
\hline CHEMBL3144902 & 688620 & 4.35 & 5.5636 & TRN & \\
\hline CHEMBL1504438 & 688620 & 5.05 & 5.0961 & TRN & \\
\hline CHEMBL1319277 & 688620 & 6.9 & 5.0439 & TRN & \\
\hline CHEMBL1497219 & 688620 & 4.6 & 4.8579 & TRN & \\
\hline CHEMBL1304476 & 688620 & 4.6 & 5.2309 & TRN & \\
\hline CHEMBL1443514 & 688620 & 5.2 & 4.9835 & TST & \\
\hline CHEMBL1392200 & 688620 & 5.75 & 5.8464 & TRN & \\
\hline CHEMBL1387205 & 688620 & 4.75 & 4.9739 & TST & \\
\hline CHEMBL1502000 & 688620 & 4.5 & 4.7621 & TRN & \\
\hline CHEMBL1469528 & 688620 & 5.05 & 5.0115 & TRN & \\
\hline CHEMBL1456584 & 688620 & 4.45 & 5.0602 & TRN & \\
\hline CHEMBL1462900 & 688620 & 5.2 & 5.2303 & TRN & \\
\hline CHEMBL1343828 & 688620 & 4.95 & 4.954 & TRN & \\
\hline CHEMBL1365126 & 688620 & 4.45 & 5.0913 & TST & \\
\hline CHEMBL1359180 & 688620 & 4.45 & 4.9071 & TST & \\
\hline CHEMBL1306124 & 688620 & 4.95 & 4.7769 & TRN & \\
\hline CHEMBL1601926 & 688620 & 4.8 & 4.8084 & TRN & \\
\hline CHEMBL1598279 & 688620 & 4.7 & 5.1219 & TST & \\
\hline CHEMBL1319612 & 688620 & 5.2 & 5.4529 & TRN & \\
\hline CHEMBL1507472 & 688620 & 4.6 & 4.9267 & TST & \\
\hline CHEMBL1306610 & 688620 & 4.95 & 5.1266 & TST & \\
\hline CHEMBL1543536 & 688620 & 6.5501 & 5.0275 & TST & \\
\hline CHEMBL1613046 & 688620 & 5.55 & 5.3529 & TRN & \\
\hline CHEMBL1422140 & 688620 & 5.55 & 5.53299 & 99999999995 & TRN \\
\hline CHEMBL1501109 & 688620 & 4.45 & 4.9904 & TRN & \\
\hline CHEMBL1461960 & 688620 & 5.85 & 5.6589 & TRN & \\
\hline CHEMBL1364051 & 688620 & 4.95 & 4.9745 & TRN & \\
\hline CHEMBL1402225 & 688620 & 6.95 & 5.7259 & TRN & \\
\hline CHEMBL1495905 & 688620 & 5.15 & 5.4616 & TRN & \\
\hline CHEMBL1529671 & 688620 & 5.9 & 5.6006 & TRN & \\
\hline CHEMBL1368243 & 688620 & 4.45 & 5.082 & TRN & \\
\hline CHEMBL1424249 & 688620 & 4.7 & 5.1766 & TRN & \\
\hline CHEMBL1511291 & 688620 & 5.65 & 5.3992 & TRN & \\
\hline CHEMBL1595444 & 688620 & 4.65 & 4.9206 & TRN & \\
\hline CHEMBL1522548 & 688620 & 4.9 & 5.0389 & TRN & \\
\hline CHEMBL1506663 & 688620 & 5.1 & 5.1396 & TRN & \\
\hline CHEMBL1402583 & 688620 & 4.95 & 4.8315 & TRN & \\
\hline CHEMBL1384179 & 688620 & 6.05 & 5.9556 & TRN & \\
\hline
\end{tabular}




\begin{tabular}{|c|c|c|c|c|c|}
\hline \\
\hline CHEMBL1308357 & 688620 & 4.8 & 4.7801 & TRN & \\
\hline CHEMBL1534916 & 688620 & 4.45 & 5.0315 & TRN & \\
\hline CHEMBL1394021 & 688620 & 4.95 & 5.0325 & TRN & \\
\hline CHEMBL1569380 & 688620 & 5.45 & 5.42899 & 9999999999 & TST \\
\hline CHEMBL1400142 & 688620 & 4.95 & 5.0698 & TST & \\
\hline CHEMBL1336199 & 688620 & 5.2 & 5.1298 & TRN & \\
\hline CHEMBL1387498 & 688620 & 5.55 & 5.0949 & TRN & \\
\hline CHEMBL1489385 & 688620 & 4.95 & 5.2513 & TRN & \\
\hline CHEMBL3211695 & 688620 & 4.9 & 5.0174 & TRN & \\
\hline CHEMBL1514903 & 688620 & 4.45 & 5.113 & TST & \\
\hline CHEMBL1368479 & 688620 & 4.95 & 5.2214 & TRN & \\
\hline CHEMBL1320125 & 688620 & 4.45 & 4.9416 & TRN & \\
\hline CHEMBL1501285 & 688620 & 4.45 & 4.7745 & TRN & \\
\hline CHEMBL1322285 & 688620 & 5.0 & 5.1493 & TRN & \\
\hline CHEMBL1459930 & 688620 & 4.45 & 4.8013 & TRN & \\
\hline CHEMBL1382028 & 688620 & 4.85 & 5.2427 & TRN & \\
\hline CHEMBL1390553 & 688620 & 6.95 & 4.9355 & TST & \\
\hline CHEMBL1507104 & 688620 & 4.6 & 4.8791 & TRN & \\
\hline CHEMBL1303463 & 688620 & 4.6 & 5.0733 & TRN & \\
\hline CHEMBL1597627 & 688620 & 6.45 & 5.8582 & TRN & \\
\hline CHEMBL1996315 & 688620 & 4.95 & 5.0377 & TRN & \\
\hline CHEMBL1414220 & 688620 & 5.35 & 4.7474 & TRN & \\
\hline CHEMBL3211326 & 688620 & 5.55 & 5.4975 & TRN & \\
\hline CHEMBL1445650 & 688620 & 6.0 & 6.1144 & TRN & \\
\hline CHEMBL 3192378 & 688620 & 4.85 & 4.8769 & TRN & \\
\hline CHEMBL1465015 & 688620 & 4.95 & 4.7988 & TST & \\
\hline CHEMBL1969298 & 688620 & 5.05 & 4.9985 & TRN & \\
\hline CHEMBL1405468 & 688620 & 5.15 & 4.9931 & TRN & \\
\hline CHEMBL1518635 & 688620 & 4.9 & 4.9975 & TRN & \\
\hline CHEMBL1524397 & 688620 & 5.9 & 5.1667 & TST & \\
\hline CHEMBL1481953 & 688620 & 4.95 & 4.9512 & TST & \\
\hline CHEMBL1536534 & 688620 & 5.65 & 5.1878 & TRN & \\
\hline CHEMBL1445414 & 688620 & 5.45 & 5.41799 & 9999999999 & TRN \\
\hline CHEMBL3189533 & 688620 & 6.05 & 5.1822 & TRN & \\
\hline CHEMBL 3189344 & 688620 & 5.5 & 5.6739 & TRN & \\
\hline CHEMBL1326919 & 688620 & 5.65 & 4.9388 & TRN & \\
\hline CHEMBL1557137 & 688620 & 4.9 & 4.7365 & TRN & \\
\hline CHEMBL1417507 & 688620 & 4.45 & 4.8414 & TRN & \\
\hline CHEMBL1379412 & 688620 & 4.95 & 5.1874 & TST & \\
\hline CHEMBL 1411376 & 688620 & 6.5 & 5.4139 & TRN & \\
\hline CHEMBL1530190 & 688620 & 5.0 & 5.1555 & TRN & \\
\hline CHEMBL1442937 & 688620 & 4.5 & 4.8974 & TRN & \\
\hline CHEMBL1561614 & 688620 & 4.95 & 4.9929 & TST & \\
\hline CHEMBL1591875 & 688620 & 4.45 & 4.7506 & TST & \\
\hline CHEMBL2000339 & 688620 & 4.8 & 5.2228 & TRN & \\
\hline CHEMBL1424499 & 688620 & 4.8 & 5.126 & TST & \\
\hline CHEMBL1519991 & 688620 & 4.6 & 4.9633 & TRN & \\
\hline CHEMBL1538774 & 688620 & 4.45 & 4.8956 & TRN & \\
\hline
\end{tabular}




\begin{tabular}{|c|c|c|c|c|}
\hline & & & pplement & a] \\
\hline CHEMBL1549883 & 688620 & 5.25 & 4.7497 & TRN \\
\hline CHEMBL1348539 & 688620 & 5.4 & 5.1692 & TRN \\
\hline CHEMBL1486491 & 688620 & 6.2 & 4.9177 & TRN \\
\hline CHEMBL1366480 & 688620 & 5.6 & 5.3047 & TST \\
\hline CHEMBL17201 & 688620 & 4.7 & 4.828 & TRN \\
\hline CHEMBL3209105 & 688620 & 4.8 & 5.2844 & TRN \\
\hline CHEMBL1431573 & 688620 & 4.45 & 5.5356 & TRN \\
\hline CHEMBL1503371 & 688620 & 4.8 & 4.9646 & TST \\
\hline CHEMBL1354600 & 688620 & 4.45 & 4.9002 & TRN \\
\hline CHEMBL186422 & 688620 & 5.2 & 5.1486 & TST \\
\hline CHEMBL1378357 & 688620 & 4.95 & 4.8429 & TRN \\
\hline CHEMBL1543807 & 688620 & 5.1 & 4.9984 & TST \\
\hline CHEMBL1425125 & 688620 & 4.45 & 5.4027 & TRN \\
\hline CHEMBL1465257 & 688620 & 5.5 & 5.183 & TRN \\
\hline CHEMBL1529387 & 688620 & 4.95 & 5.0327 & TRN \\
\hline CHEMBL3197980 & 688620 & 5.15 & 5.3949 & TRN \\
\hline CHEMBL1302791 & 688620 & 5.8 & 5.5191 & TRN \\
\hline CHEMBL1474098 & 688620 & 4.45 & 4.7406 & TRN \\
\hline CHEMBL1599496 & 688620 & 4.85 & 5.4261 & TRN \\
\hline CHEMBL1503503 & 688620 & 4.95 & 5.3152 & TRN \\
\hline CHEMBL1565112 & 688620 & 4.85 & 5.0444 & TRN \\
\hline CHEMBL1364411 & 688620 & 4.9 & 4.5794 & TST \\
\hline CHEMBL1440781 & 688620 & 4.75 & 5.1687 & TRN \\
\hline CHEMBL1612529 & 688620 & 5.35 & 5.1972 & TST \\
\hline CHEMBL1968376 & 688620 & 5.0 & 5.0577 & TRN \\
\hline CHEMBL1522234 & 688620 & 5.2 & 5.0243 & TRN \\
\hline CHEMBL1599416 & 688620 & 4.45 & 4.791 & TRN \\
\hline CHEMBL3210529 & 688620 & 5.0 & 5.1814 & TST \\
\hline CHEMBL1308164 & 688620 & 4.45 & 5.084 & TRN \\
\hline CHEMBL1431869 & 688620 & 5.2 & 5.113 & TST \\
\hline CHEMBL1449665 & 688620 & 5.05 & 5.0626 & TRN \\
\hline CHEMBL1334659 & 688620 & 5.2 & 5.0647 & TST \\
\hline CHEMBL1721986 & 688620 & 5.2 & 5.2805 & TRN \\
\hline CHEMBL1386901 & 688620 & 4.75 & 4.8195 & TRN \\
\hline CHEMBL1482328 & 688620 & 5.2 & 4.9322 & TST \\
\hline CHEMBL1990786 & 688620 & 5.5 & 5.4442 & TRN \\
\hline CHEMBL367741 & 688620 & 6.0 & 5.0294 & TST \\
\hline CHEMBL1307175 & 688620 & 6.5501 & 5.3107 & TST \\
\hline CHEMBL1423061 & 688620 & 5.3 & 5.0575 & TRN \\
\hline CHEMBL1445543 & 688620 & 4.95 & 4.9195 & TST \\
\hline CHEMBL1309127 & 688620 & 5.95 & 5.541 & TRN \\
\hline CHEMBL1546973 & 688620 & 4.45 & 4.8233 & TST \\
\hline CHEMBL1423084 & 688620 & 5.2 & 5.5788 & TST \\
\hline CHEMBL1489051 & 688620 & 4.95 & 4.9647 & TRN \\
\hline CHEMBL1503764 & 688620 & 5.0 & 5.0595 & TST \\
\hline CHEMBL1514819 & 688620 & 4.95 & 5.067 & TRN \\
\hline CHEMBL1404533 & 688620 & 5.0 & 5.0313 & TRN \\
\hline CHEMBL1300619 & 688620 & 4.85 & 4.6636 & TRN \\
\hline
\end{tabular}




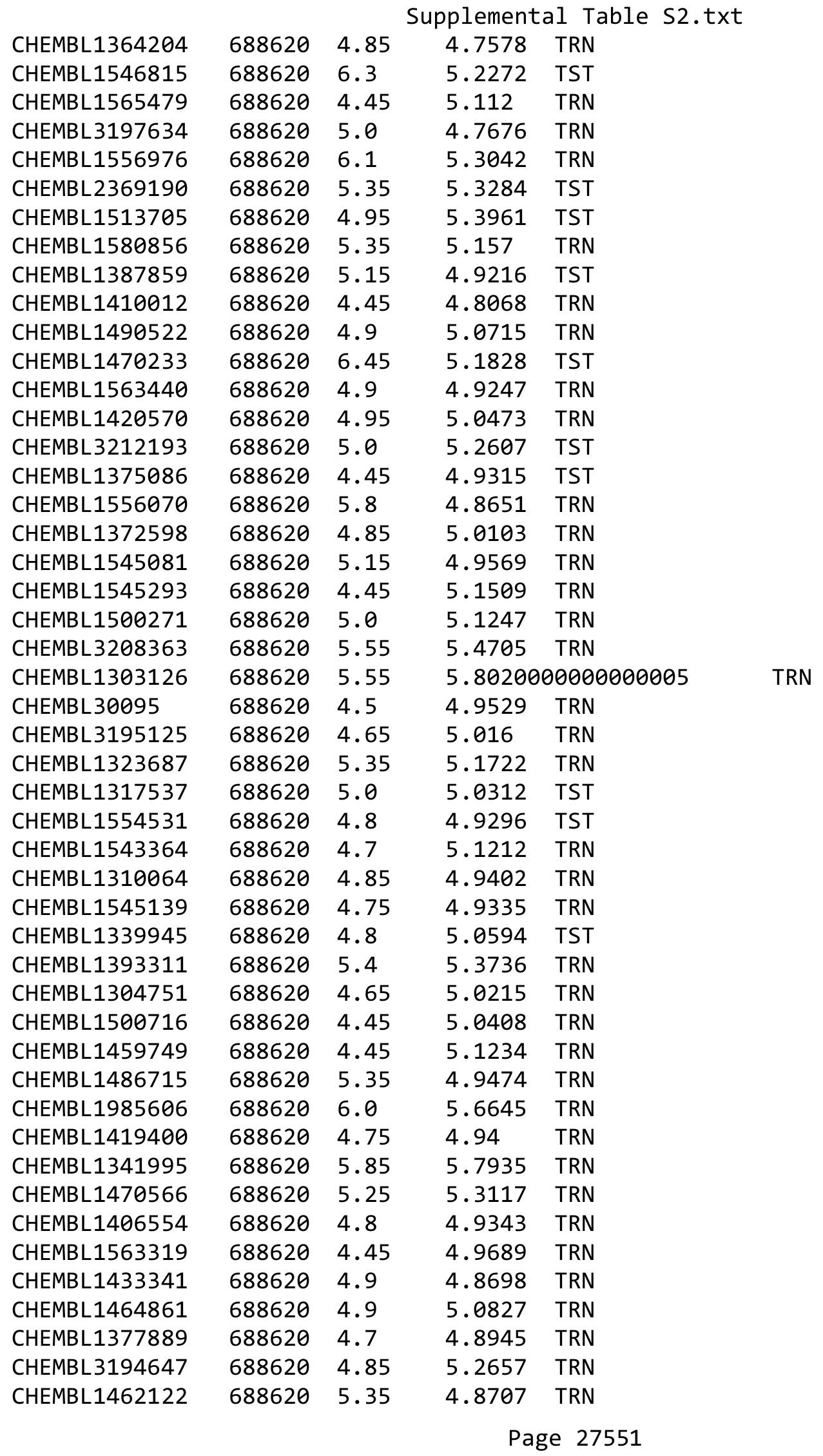




\begin{tabular}{|c|c|c|c|c|c|}
\hline \multirow[b]{2}{*}{ CHEMBL1991242 } & \multicolumn{5}{|c|}{ able S2. } \\
\hline & 688620 & 5.5 & 5.6465 & TRN & \\
\hline CHEMBL1477244 & 688620 & 5.05 & 5.0245 & TRN & \\
\hline CHEMBL1353619 & 688620 & 4.7 & 4.89199 & 99999999995 & TRN \\
\hline CHEMBL1371270 & 688620 & 5.3 & 4.7752 & TRN & \\
\hline CHEMBL1904956 & 688620 & 4.65 & 5.0555 & TRN & \\
\hline CHEMBL1480969 & 688620 & 4.7 & 5.0515 & TRN & \\
\hline CHEMBL1497698 & 688620 & 4.55 & 5.2431 & TRN & \\
\hline CHEMBL1438022 & 688620 & 4.45 & 4.8734 & TRN & \\
\hline CHEMBL1443504 & 688620 & 4.45 & 5.2995 & TST & \\
\hline CHEMBL1335967 & 688620 & 4.75 & 4.7704 & TRN & \\
\hline CHEMBL1598655 & 688620 & 4.8 & 4.8793 & TRN & \\
\hline CHEMBL1542122 & 688620 & 4.45 & 4.833 & TRN & \\
\hline CHEMBL1352972 & 688620 & 4.7 & 4.9083 & TRN & \\
\hline CHEMBL1518393 & 688620 & 5.55 & 4.8783 & TRN & \\
\hline CHEMBL1612348 & 688620 & 4.5 & 5.2014 & TRN & \\
\hline CHEMBL1584967 & 688620 & 4.6 & 4.7482 & TRN & \\
\hline CHEMBL1972666 & 688620 & 4.65 & 5.1599 & TST & \\
\hline CHEMBL1338954 & 688620 & 4.45 & 4.8443 & TRN & \\
\hline CHEMBL1429899 & 688620 & 7.0 & 4.8712 & TST & \\
\hline CHEMBL1423864 & 688620 & 5.15 & 5.055 & TRN & \\
\hline CHEMBL 243652 & 688620 & 4.45 & 4.7957 & TRN & \\
\hline CHEMBL1447305 & 688620 & 4.65 & 5.102 & TRN & \\
\hline CHEMBL1338090 & 688620 & 4.45 & 5.0788 & TRN & \\
\hline CHEMBL1305542 & 688620 & 4.6 & 4.9712 & TRN & \\
\hline CHEMBL1511676 & 688620 & 4.65 & 5.0363 & TRN & \\
\hline CHEMBL1563470 & 688620 & 4.85 & 4.9526 & TRN & \\
\hline CHEMBL1457990 & 688620 & 4.95 & 5.1999 & TST & \\
\hline CHEMBL1534728 & 688620 & 5.05 & 4.9308 & TRN & \\
\hline CHEMBL1430678 & 688620 & 6.5501 & 5.5008 & TRN & \\
\hline CHEMBL1601974 & 688620 & 5.25 & 4.7904 & TST & \\
\hline CHEMBL1574615 & 688620 & 4.9 & 4.9205 & TST & \\
\hline CHEMBL1543478 & 688620 & 5.0 & 4.9735 & TRN & \\
\hline CHEMBL1460532 & 688620 & 5.2 & 4.9188 & TST & \\
\hline CHEMBL1604540 & 688620 & 4.95 & 4.8815 & TRN & \\
\hline CHEMBL3193714 & 688620 & 5.2 & 5.0503 & TRN & \\
\hline CHEMBL1332928 & 688620 & 4.7 & 5.2946 & TRN & \\
\hline CHEMBL1429938 & 688620 & 4.45 & 5.1129 & TST & \\
\hline CHEMBL3192439 & 688620 & 5.35 & 5.3632 & TRN & \\
\hline CHEMBL1481917 & 688620 & 5.0 & 4.9781 & TRN & \\
\hline CHEMBL1352026 & 688620 & 7.0501 & 4.828 & TRN & \\
\hline CHEMBL1334083 & 688620 & 5.0 & 5.0861 & TRN & \\
\hline CHEMBL1500842 & 688620 & 4.95 & 5.023 & TRN & \\
\hline CHEMBL1299756 & 688620 & 4.55 & 5.332006 & 0000000001 & TST \\
\hline CHEMBL1300411 & 688620 & 4.85 & 5.1418 & TRN & \\
\hline CHEMBL1358310 & 688620 & 6.0 & 5.1088 & TRN & \\
\hline CHEMBL1318746 & 688620 & 7.3497 & 5.1726 & TRN & \\
\hline CHEMBL1470934 & 688620 & 5.5 & 5.2411 & TRN & \\
\hline CHEMBL1429554 & 688620 & 6.0 & 5.6994 & TRN & \\
\hline & & & & 27552 & \\
\hline
\end{tabular}




\begin{tabular}{|c|c|c|c|c|c|}
\hline \multicolumn{6}{|c|}{ Supplemental Table S2.txt } \\
\hline CHEMBL1313348 & 688620 & 5.35 & 5.0993 & TRN & \\
\hline CHEMBL1418334 & 688620 & 4.85 & 4.9664 & TRN & \\
\hline CHEMBL1986381 & 688620 & 5.6 & 5.3642 & TST & \\
\hline CHEMBL1461947 & 688620 & 4.85 & 4.8889 & TST & \\
\hline CHEMBL1589011 & 688620 & 4.85 & 5.1923 & TST & \\
\hline CHEMBL1310381 & 688620 & 4.9 & 4.9927 & TRN & \\
\hline CHEMBL1372734 & 688620 & 5.45 & 6.0358 & TRN & \\
\hline CHEMBL472839 & 688620 & 4.45 & 5.0754 & TRN & \\
\hline CHEMBL1487375 & 688620 & 4.8 & 5.0925 & TRN & \\
\hline CHEMBL3193528 & 688620 & 4.85 & 5.3349 & TRN & \\
\hline CHEMBL1613644 & 688620 & 4.8 & 5.0467 & TRN & \\
\hline CHEMBL1452089 & 688620 & 5.5 & 5.37 & TRN & \\
\hline CHEMBL1439662 & 688620 & 4.45 & 4.8159 & TST & \\
\hline CHEMBL1431565 & 688620 & 5.6 & 5.7492 & TRN & \\
\hline CHEMBL1458819 & 688620 & 4.8 & 4.9091 & TST & \\
\hline CHEMBL1439532 & 688620 & 4.6 & 4.843 & TRN & \\
\hline CHEMBL1518944 & 688620 & 4.45 & 5.1144 & TRN & \\
\hline CHEMBL1448507 & 688620 & 5.45 & 4.8652 & TRN & \\
\hline CHEMBL1460437 & 688620 & 4.45 & 5.0837 & TRN & \\
\hline CHEMBL1583472 & 688620 & 5.6 & 4.7607 & TRN & \\
\hline CHEMBL1510634 & 688620 & 5.05 & 5.0516 & TST & \\
\hline CHEMBL1424727 & 688620 & 5.1 & 4.9818 & TRN & \\
\hline CHEMBL1437924 & 688620 & 4.7 & 4.9931 & TST & \\
\hline CHEMBL1605598 & 688620 & 4.85 & 4.9854 & TRN & \\
\hline CHEMBL1539441 & 688620 & 5.0 & 4.9808 & TRN & \\
\hline CHEMBL1357724 & 688620 & 4.8 & 4.6722 & TRN & \\
\hline CHEMBL1508370 & 688620 & 5.2 & 5.4043 & TRN & \\
\hline CHEMBL1988310 & 688620 & 5.05 & 5.1585 & TRN & \\
\hline CHEMBL1598643 & 688620 & 4.95 & 4.7922 & TRN & \\
\hline CHEMBL1491271 & 688620 & 5.15 & 4.98600 & 0000000001 & TRN \\
\hline CHEMBL1422873 & 688620 & 4.95 & 5.0245 & TST & \\
\hline CHEMBL11709 & 688620 & 4.7 & 5.2393 & TRN & \\
\hline CHEMBL1540834 & 688620 & 5.0 & 4.9541 & TRN & \\
\hline CHEMBL1359321 & 688620 & 5.85 & 5.7975 & TRN & \\
\hline CHEMBL1428714 & 688620 & 4.7 & 5.3097 & TRN & \\
\hline CHEMBL1447142 & 688620 & 4.75 & 4.8941 & TRN & \\
\hline CHEMBL3208415 & 688620 & 6.1 & 5.8532 & TRN & \\
\hline CHEMBL1532249 & 688620 & 5.1 & 5.0792 & TRN & \\
\hline CHEMBL1587154 & 688620 & 4.8 & 5.0553 & TRN & \\
\hline CHEMBL1348360 & 688620 & 4.5 & 4.7508 & TRN & \\
\hline CHEMBL1459155 & 688620 & 5.2 & 5.2346 & TRN & \\
\hline CHEMBL1349747 & 688620 & 4.95 & 5.0273 & TST & \\
\hline CHEMBL1383757 & 688620 & 5.15 & 5.2403 & TST & \\
\hline CHEMBL1422789 & 688620 & 4.95 & 4.8246 & TRN & \\
\hline CHEMBL3193464 & 688620 & 5.0 & 4.8556 & TRN & \\
\hline CHEMBL1408929 & 688620 & 4.45 & 5.0543 & TRN & \\
\hline CHEMBL1510034 & 688620 & 5.0 & 4.8788 & TRN & \\
\hline CHEMBL1470302 & 688620 & 5.0 & 4.9318 & TRN & \\
\hline
\end{tabular}




\begin{tabular}{|c|c|c|c|c|}
\hline \multicolumn{5}{|c|}{ Supplemental Table S2.txt } \\
\hline CHEMBL1353259 & 688620 & 4.85 & 5.0911 & TRN \\
\hline CHEMBL1360382 & 688620 & 4.45 & 5.609 & TRN \\
\hline CHEMBL1996299 & 688620 & 5.6 & 4.9999 & TRN \\
\hline CHEMBL1556626 & 688620 & 4.95 & 5.0162 & TRN \\
\hline CHEMBL1334161 & 688620 & 4.65 & 5.0503 & TRN \\
\hline CHEMBL1549657 & 688620 & 4.95 & 4.6796 & TRN \\
\hline CHEMBL1609960 & 688620 & 4.85 & 4.9453 & TST \\
\hline CHEMBL1299540 & 688620 & 4.8 & 5.0843 & TRN \\
\hline CHEMBL1523950 & 688620 & 4.45 & 4.8511 & TST \\
\hline CHEMBL1607208 & 688620 & 6.5501 & 5.2948 & TST \\
\hline CHEMBL1570825 & 688620 & 4.9 & 5.2285 & TRN \\
\hline CHEMBL1609223 & 688620 & 4.9 & 5.1263 & TST \\
\hline CHEMBL1350361 & 688620 & 4.85 & 5.307 & TRN \\
\hline CHEMBL1484014 & 688620 & 5.0 & 4.7606 & TRN \\
\hline CHEMBL1351038 & 688620 & 4.85 & 5.1381 & TRN \\
\hline CHEMBL1981939 & 688620 & 4.85 & 4.8668 & TRN \\
\hline CHEMBL1510297 & 688620 & 4.85 & 5.078 & TRN \\
\hline CHEMBL1543036 & 688620 & 4.9 & 5.1264 & TRN \\
\hline CHEMBL1586643 & 688620 & 4.5 & 5.1489 & TST \\
\hline CHEMBL1350163 & 688620 & 5.1 & 4.919 & TST \\
\hline CHEMBL1478639 & 688620 & 4.85 & 5.2157 & TRN \\
\hline CHEMBL1567865 & 688620 & 4.9 & 5.01399 & 9999999999 \\
\hline CHEMBL236897 & 688620 & 6.15 & 5.5856 & TRN \\
\hline CHEMBL1390471 & 688620 & 4.45 & 4.6994 & TST \\
\hline CHEMBL1371453 & 688620 & 4.9 & 4.9673 & TRN \\
\hline CHEMBL1432981 & 688620 & 4.9 & 4.9917 & TRN \\
\hline CHEMBL1481332 & 688620 & 5.0 & 4.8238 & TRN \\
\hline CHEMBL1343306 & 688620 & 5.7 & 5.3506 & TRN \\
\hline CHEMBL1574035 & 688620 & 4.9 & 5.0417 & TST \\
\hline CHEMBL1989823 & 688620 & 4.7 & 5.0033 & TST \\
\hline CHEMBL1539689 & 688620 & 4.8 & 5.0324 & TRN \\
\hline CHEMBL1507597 & 688620 & 5.4 & 5.04 & TRN \\
\hline CHEMBL1491946 & 688620 & 4.45 & 5.4594 & TRN \\
\hline CHEMBL1573646 & 688620 & 5.9 & 5.0578 & TRN \\
\hline CHEMBL1465753 & 688620 & 4.95 & 5.1712 & TRN \\
\hline CHEMBL3193058 & 688620 & 4.85 & 4.8827 & TRN \\
\hline CHEMBL1430845 & 688620 & 4.45 & 4.9114 & TRN \\
\hline CHEMBL1565187 & 688620 & 5.55 & 5.0594 & TRN \\
\hline CHEMBL1529348 & 688620 & 4.75 & 4.9093 & TRN \\
\hline CHEMBL1429204 & 688620 & 4.45 & 5.0539 & TRN \\
\hline CHEMBL1352899 & 688620 & 5.95 & 4.9805 & TRN \\
\hline CHEMBL169272 & 688620 & 4.95 & 4.9614 & TRN \\
\hline CHEMBL1528100 & 688620 & 5.1 & 4.7994 & TRN \\
\hline CHEMBL1602453 & 688620 & 5.0 & 5.1635 & TRN \\
\hline CHEMBL1319037 & 688620 & 5.0 & 5.1832 & TRN \\
\hline CHEMBL1544371 & 688620 & 6.25 & 5.3853 & TRN \\
\hline CHEMBL227086 & 688620 & 4.9 & 5.2909 & TRN \\
\hline CHEMBL309016 & 688620 & 5.35 & 5.1501 & TRN \\
\hline
\end{tabular}




\begin{tabular}{|c|c|c|c|c|c|}
\hline \multicolumn{6}{|c|}{ Supplemental Table s2.txt } \\
\hline CHEMBL1463218 & 688620 & 5.0 & 5.1049 & TRN & \\
\hline CHEMBL1429331 & 688620 & 4.85 & 4.8699 & TRN & \\
\hline CHEMBL1466090 & 688620 & 5.0 & 5.2395 & TRN & \\
\hline CHEMBL1452652 & 688620 & 5.1 & 5.1242 & TRN & \\
\hline CHEMBL1345849 & 688620 & 4.45 & 4.7364 & TST & \\
\hline CHEMBL1339515 & 688620 & 6.7001 & 5.0273 & TST & \\
\hline CHEMBL1420988 & 688620 & 4.9 & 4.8861 & TST & \\
\hline CHEMBL1447458 & 688620 & 6.25 & 5.1338 & TST & \\
\hline CHEMBL1330902 & 688620 & 4.9 & 4.9635 & TST & \\
\hline CHEMBL1486676 & 688620 & 4.7 & 5.0974 & TST & \\
\hline CHEMBL1471907 & 688620 & 4.45 & 4.5907 & TRN & \\
\hline CHEMBL1600581 & 688620 & 7.1002 & 5.0133 & TRN & \\
\hline CHEMBL1404146 & 688620 & 4.95 & 4.8727 & TRN & \\
\hline CHEMBL1569608 & 688620 & 4.9 & 4.9831 & TRN & \\
\hline CHEMBL1449174 & 688620 & 4.7 & 4.8102 & TRN & \\
\hline CHEMBL1609546 & 688620 & 6.2 & 4.8809 & TRN & \\
\hline CHEMBL1366974 & 688620 & 5.05 & 5.2694 & TRN & \\
\hline CHEMBL1309045 & 688620 & 5.0 & 5.23600 & $\partial 000000001$ & TRN \\
\hline CHEMBL1527664 & 688620 & 4.95 & 4.9705 & TST & \\
\hline CHEMBL1485805 & 688620 & 4.45 & 4.90600 & 0000000001 & TRN \\
\hline CHEMBL1323512 & 688620 & 4.85 & 4.8858 & TST & \\
\hline CHEMBL1438073 & 688620 & 4.95 & 4.8611 & TRN & \\
\hline CHEMBL1305857 & 688620 & 4.65 & 4.97199 & 99999999995 & TST \\
\hline CHEMBL1362297 & 688620 & 5.05 & 5.0398 & TRN & \\
\hline CHEMBL317356 & 688620 & 6.5501 & 5.4808 & TRN & \\
\hline CHEMBL1453719 & 688620 & 4.95 & 5.0638 & TRN & \\
\hline CHEMBL1561445 & 688620 & 4.6 & 5.155 & TST & \\
\hline CHEMBL1581153 & 688620 & 4.8 & 5.1769 & TRN & \\
\hline CHEMBL1422346 & 688620 & 4.45 & 5.2126 & TRN & \\
\hline CHEMBL1526709 & 688620 & 4.85 & 5.3077 & TST & \\
\hline CHEMBL3210241 & 688620 & 4.8 & 4.8875 & TRN & \\
\hline CHEMBL1538614 & 688620 & 4.85 & 5.0524 & TRN & \\
\hline CHEMBL1996730 & 688620 & 5.0 & 5.2372 & TRN & \\
\hline CHEMBL1546571 & 688620 & 4.85 & 4.8445 & TRN & \\
\hline CHEMBL3209990 & 688620 & 4.65 & 5.1436 & TRN & \\
\hline CHEMBL1477271 & 688620 & 4.45 & 4.9439 & TST & \\
\hline CHEMBL1432038 & 688620 & 5.3 & 4.9642 & TRN & \\
\hline CHEMBL3199067 & 688620 & 4.9 & 4.8573 & TST & \\
\hline CHEMBL1519899 & 688620 & 4.9 & 5.0484 & TRN & \\
\hline CHEMBL1483475 & 688620 & 4.75 & 4.7215 & TRN & \\
\hline CHEMBL590666 & 688620 & 5.75 & 5.1002 & TRN & \\
\hline CHEMBL1537464 & 688620 & 4.75 & 5.0292 & TRN & \\
\hline CHEMBL1590262 & 688620 & 5.15 & 5.0055 & TRN & \\
\hline CHEMBL1508821 & 688620 & 4.7 & 5.046 & TRN & \\
\hline CHEMBL3196490 & 688620 & 4.6 & 5.1608 & TRN & \\
\hline CHEMBL1421817 & 688620 & 5.25 & 5.0341 & TRN & \\
\hline CHEMBL592106 & 688620 & 4.45 & 4.963 & TRN & \\
\hline CHEMBL1504742 & 688620 & 4.45 & 4.9292 & TST & \\
\hline
\end{tabular}




\begin{tabular}{|c|c|c|c|c|}
\hline \multicolumn{5}{|c|}{ Supplemental Table S2.txt } \\
\hline CHEMBL1427299 & 688620 & 5.45 & 5.2537 & TST \\
\hline CHEMBL1349081 & 688620 & 5.1 & 4.9779 & TRN \\
\hline CHEMBL1363560 & 688620 & 4.65 & 5.1537 & TRN \\
\hline CHEMBL 3196674 & 688620 & 4.9 & 5.3467 & TRN \\
\hline CHEMBL1313978 & 688620 & 4.45 & 4.8657 & TRN \\
\hline CHEMBL3198155 & 688620 & 5.1 & 5.0447 & TRN \\
\hline CHEMBL3192660 & 688620 & 4.95 & 5.1774 & TRN \\
\hline CHEMBL1451897 & 688620 & 4.45 & 4.8931 & TRN \\
\hline CHEMBL1716038 & 688620 & 4.9 & 4.7924 & TRN \\
\hline CHEMBL1544727 & 688620 & 4.9 & 4.8635 & TRN \\
\hline CHEMBL1498502 & 688620 & 4.95 & 4.8392 & TRN \\
\hline CHEMBL1381860 & 688620 & 6.35 & 5.1079 & TRN \\
\hline CHEMBL1524783 & 688620 & 5.35 & 4.8635 & TRN \\
\hline CHEMBL1348245 & 688620 & 5.55 & 5.803 & TST \\
\hline CHEMBL460508 & 688620 & 5.05 & 5.4077 & TRN \\
\hline CHEMBL1378877 & 688620 & 4.7 & 4.8983 & TRN \\
\hline CHEMBL1552163 & 688620 & 4.95 & 5.0304 & TRN \\
\hline CHEMBL1447404 & 688620 & 5.0 & 4.8173 & TRN \\
\hline CHEMBL1346533 & 688620 & 4.65 & 4.766 & TRN \\
\hline CHEMBL1454762 & 688620 & 4.5 & 5.0381 & TRN \\
\hline CHEMBL1341267 & 688620 & 5.65 & 5.0934 & TST \\
\hline CHEMBL1376262 & 688620 & 5.6 & 5.0695 & TST \\
\hline CHEMBL1345053 & 688620 & 4.45 & 4.8669 & TRN \\
\hline CHEMBL1380130 & 688620 & 4.75 & 4.8876 & TST \\
\hline CHEMBL1378812 & 688620 & 4.85 & 5.7664 & TST \\
\hline CHEMBL1983323 & 688620 & 4.7 & 5.1297 & TRN \\
\hline CHEMBL1528821 & 688620 & 5.1 & 4.8425 & TRN \\
\hline CHEMBL3192796 & 688620 & 4.75 & 5.0735 & TRN \\
\hline CHEMBL1580155 & 688620 & 4.5 & 5.1354 & TRN \\
\hline CHEMBL1562199 & 688620 & 5.0 & 5.1055 & TST \\
\hline CHEMBL1557668 & 688620 & 4.45 & 4.9062 & TRN \\
\hline CHEMBL3196240 & 688620 & 6.7501 & 6.6803 & TRN \\
\hline CHEMBL1337527 & 688620 & 5.3 & 5.206 & TRN \\
\hline CHEMBL1333680 & 688620 & 4.65 & 5.1484 & TRN \\
\hline CHEMBL1497352 & 688620 & 4.5 & 4.8159 & TRN \\
\hline CHEMBL467987 & 688620 & 4.9 & 5.1198 & TRN \\
\hline CHEMBL1608246 & 688620 & 4.95 & 4.9462 & TRN \\
\hline CHEMBL1558970 & 688620 & 4.95 & 4.9645 & TRN \\
\hline CHEMBL1312129 & 688620 & 5.1 & 4.8623 & TRN \\
\hline CHEMBL1384375 & 688620 & 6.95 & 5.1917 & TRN \\
\hline CHEMBL1453190 & 688620 & 4.45 & 5.23 & TRN \\
\hline CHEMBL1328572 & 688620 & 4.95 & 4.8507 & TST \\
\hline CHEMBL1583174 & 688620 & 4.75 & 5.0968 & TRN \\
\hline CHEMBL3192813 & 688620 & 4.7 & 5.0806 & TRN \\
\hline CHEMBL1318425 & 688620 & 4.8 & 4.9874 & TST \\
\hline CHEMBL1334629 & 688620 & 5.35 & 5.2837 & TST \\
\hline CHEMBL2369157 & 688620 & 6.2 & 5.7798 & TRN \\
\hline CHEMBL1371304 & 688620 & 4.8 & 4.801 & TST \\
\hline
\end{tabular}




\begin{tabular}{|c|c|c|c|c|c|}
\hline & & \multicolumn{4}{|c|}{ Supplemental Table S2.txt } \\
\hline CHEMBL1391703 & 688620 & 4.95 & 4.8817 & TRN & \\
\hline CHEMBL1980018 & 688620 & 5.05 & 4.8598 & TRN & \\
\hline CHEMBL1519501 & 688620 & 4.45 & 5.1994 & TRN & \\
\hline CHEMBL1569364 & 688620 & 4.75 & 5.1628 & TST & \\
\hline CHEMBL 3190411 & 688620 & 4.8 & 5.4544 & TRN & \\
\hline CHEMBL1467751 & 688620 & 5.35 & 5.1361 & TRN & \\
\hline CHEMBL1596037 & 688620 & 4.8 & 5.1563 & TST & \\
\hline CHEMBL 3210957 & 688620 & 4.45 & 5.1956 & TST & \\
\hline CHEMBL1422190 & 688620 & 5.0 & 4.8253 & TRN & \\
\hline CHEMBL1542776 & 688620 & 4.85 & 4.7519 & TRN & \\
\hline CHEMBL1504814 & 688620 & 4.6 & 4.8754 & TST & \\
\hline CHEMBL1548142 & 688620 & 5.65 & 5.4219 & TRN & \\
\hline CHEMBL1429487 & 688620 & 4.75 & 4.8523 & TRN & \\
\hline CHEMBL1557605 & 688620 & 4.8 & 5.2771 & TRN & \\
\hline CHEMBL1366020 & 688620 & 5.0 & 5.0288 & TRN & \\
\hline CHEMBL1362083 & 688620 & 4.95 & 5.0227 & TRN & \\
\hline CHEMBL1346788 & 688620 & 5.8 & 5.7342 & TRN & \\
\hline CHEMBL1483501 & 688620 & 5.7 & 5.042 & TRN & \\
\hline CHEMBL1486672 & 688620 & 4.95 & 5.414 & TRN & \\
\hline CHEMBL1445881 & 688620 & 4.95 & 5.1485 & TRN & \\
\hline CHEMBL1420393 & 688620 & 4.95 & 4.8862 & TRN & \\
\hline CHEMBL1336732 & 688620 & 4.5 & 5.0051 & TRN & \\
\hline CHEMBL1441560 & 688620 & 5.75 & 5.2155 & TST & \\
\hline CHEMBL1580920 & 688620 & 6.95 & 5.0385 & TRN & \\
\hline CHEMBL1392222 & 688620 & 6.3 & 5.0034 & TRN & \\
\hline CHEMBL1305487 & 688620 & 5.45 & 5.1837 & TST & \\
\hline CHEMBL1346849 & 688620 & 4.45 & 5.0497 & TST & \\
\hline CHEMBL1452038 & 688620 & 5.15 & 4.8229 & TST & \\
\hline CHEMBL1328547 & 688620 & 6.0 & 5.0149 & TRN & \\
\hline CHEMBL 2002262 & 688620 & 4.45 & 5.1775 & TST & \\
\hline CHEMBL1466082 & 688620 & 5.75 & 5.3722 & TRN & \\
\hline CHEMBL1511902 & 688620 & 5.3 & 5.1044 & TRN & \\
\hline CHEMBL1454300 & 688620 & 5.2 & 5.3908 & TRN & \\
\hline CHEMBL1551998 & 688620 & 4.9 & 5.0376 & TRN & \\
\hline CHEMBL1463482 & 688620 & 4.8 & 5.2843 & TST & \\
\hline CHEMBL1413351 & 688620 & 4.9 & 4.8274 & TST & \\
\hline CHEMBL1392602 & 688620 & 5.05 & 5.1319 & TRN & \\
\hline CHEMBL1390294 & 688620 & 4.65 & 5.1233 & TRN & \\
\hline CHEMBL1533719 & 688620 & 4.45 & 5.0447 & TST & \\
\hline CHEMBL 1536378 & 688620 & 4.75 & 5.045 & TRN & \\
\hline CHEMBL1597909 & 688620 & 4.95 & 5.0214 & TRN & \\
\hline CHEMBL 1402640 & 688620 & 5.0 & 4.9803 & TRN & \\
\hline CHEMBL1470728 & 688620 & 5.55 & 5.3235 & TST & \\
\hline CHEMBL1516884 & 688620 & 5.6 & 5.20200 & 0000000001 & TRN \\
\hline CHEMBL 3197127 & 688620 & 5.65 & 5.5134 & TST & \\
\hline CHEMBL1351173 & 688620 & 5.05 & 5.1524 & TRN & \\
\hline CHEMBL1523864 & 688620 & 5.4 & 5.4859 & TST & \\
\hline CHEMBL73090 & 688620 & 4.45 & 4.9657 & TRN & \\
\hline & & & & 27557 & \\
\hline
\end{tabular}




\begin{tabular}{|c|c|c|c|c|c|}
\hline \multirow[b]{2}{*}{ CHEMBL1503274 } & \multirow[b]{2}{*}{688620} & \multicolumn{4}{|c|}{ Supplemental Table s2.txt } \\
\hline & & 4.45 & \multicolumn{2}{|c|}{5.207999999999999} & TRN \\
\hline CHEMBL1431928 & 688620 & 5.35 & \multicolumn{2}{|c|}{5.617000000000001} & TRN \\
\hline CHEMBL1379003 & 688620 & 4.95 & 5.1157 & TRN & \\
\hline CHEMBL1417377 & 688620 & 5.15 & 4.917 & TRN & \\
\hline CHEMBL1585079 & 688620 & 5.25 & 4.926 & TRN & \\
\hline CHEMBL1538157 & 688620 & 5.45 & 5.4747 & TRN & \\
\hline CHEMBL 3212826 & 688620 & 4.45 & 4.6661 & TRN & \\
\hline CHEMBL149518 & 688620 & 5.1 & 4.9726 & TST & \\
\hline CHEMBL3211437 & 688620 & 4.85 & 5.0927 & TRN & \\
\hline CHEMBL3190594 & 688620 & 7.0 & 6.2398 & TRN & \\
\hline CHEMBL3194070 & 688620 & 5.0 & 5.4076 & TRN & \\
\hline CHEMBL1538339 & 688620 & 4.45 & 4.5372 & TRN & \\
\hline CHEMBL1502200 & 688620 & 4.45 & 4.8621 & TST & \\
\hline CHEMBL1478236 & 688620 & 4.85 & 4.7463 & TST & \\
\hline CHEMBL3210285 & 688620 & 4.95 & 4.8869 & TST & \\
\hline CHEMBL1504840 & 688620 & 4.95 & 5.4272 & TRN & \\
\hline CHEMBL3199782 & 688620 & 4.85 & 5.0034 & TST & \\
\hline CHEMBL1346982 & 688620 & 4.9 & 5.1484 & TST & \\
\hline CHEMBL595250 & 688620 & 5.15 & 5.0524 & TRN & \\
\hline CHEMBL1377589 & 688620 & 4.8 & \multicolumn{2}{|c|}{5.986000000000001} & TRN \\
\hline CHEMBL1415675 & 688620 & 4.95 & 4.7215 & TRN & \\
\hline CHEMBL1571989 & 688620 & 4.45 & 4.9395 & TRN & \\
\hline CHEMBL1603140 & 688620 & 6.05 & 4.8422 & TST & \\
\hline CHEMBL3190918 & 688620 & 4.45 & 5.3029 & TST & \\
\hline CHEMBL1323477 & 688620 & 5.05 & 5.2192 & TST & \\
\hline CHEMBL1478975 & 688620 & 5.3 & 5.1418 & TRN & \\
\hline CHEMBL1986355 & 688620 & 5.85 & 5.6865 & TST & \\
\hline CHEMBL1311543 & 688620 & 5.1 & 4.9019 & TRN & \\
\hline CHEMBL1369602 & 688620 & 6.05 & 5.2641 & TRN & \\
\hline CHEMBL1304022 & 688620 & 4.45 & 4.9462 & TRN & \\
\hline CHEMBL1361741 & 688620 & 5.4 & 5.0352 & TRN & \\
\hline CHEMBL1300217 & 688620 & 5.2 & 5.1372 & TST & \\
\hline CHEMBL1597531 & 688620 & 4.45 & 5.0408 & TRN & \\
\hline CHEMBL66854 & 688620 & 4.45 & 4.9121 & TST & \\
\hline CHEMBL1598091 & 688620 & 5.2 & 5.0458 & TRN & \\
\hline CHEMBL1988883 & 688620 & 4.9 & 5.2191 & TRN & \\
\hline CHEMBL1445318 & 688620 & 5.1 & 4.8857 & TRN & \\
\hline CHEMBL1574574 & 688620 & 5.45 & 4.9752 & TST & \\
\hline CHEMBL3192837 & 688620 & 4.7 & 4.9168 & TRN & \\
\hline CHEMBL1341130 & 688620 & 4.9 & 4.9515 & TST & \\
\hline CHEMBL1595402 & 688620 & 4.45 & 4.828 & TRN & \\
\hline CHEMBL602561 & 688620 & 4.45 & 5.0777 & TST & \\
\hline CHEMBL1352830 & 688620 & 4.9 & 4.9643 & TRN & \\
\hline CHEMBL1508957 & 688620 & 5.25 & 5.2329 & TST & \\
\hline CHEMBL1428739 & 688620 & 6.05 & 6.0149 & TRN & \\
\hline CHEMBL1547478 & 688620 & 5.55 & 5.0818 & TRN & \\
\hline CHEMBL1979530 & 688620 & 5.1 & 5.3016 & TRN & \\
\hline \multirow[t]{2}{*}{ CHEMBL1581503 } & 688620 & 5.1 & \multicolumn{2}{|c|}{ 4.928999999999999 } & TRN \\
\hline & & & & 2755 & \\
\hline
\end{tabular}




\begin{tabular}{|c|c|c|c|c|c|}
\hline \\
\hline CHEMBL1373639 & 688620 & 4.7 & 4.9831 & TRN & \\
\hline CHEMBL1545750 & 688620 & 5.0 & 4.902 & TRN & \\
\hline CHEMBL1450982 & 688620 & 5.2 & 5.0648 & TRN & \\
\hline CHEMBL1450616 & 688620 & 5.45 & 5.13899 & 9999999999 & TRN \\
\hline CHEMBL140130 & 688620 & 4.45 & 5.0052 & TRN & \\
\hline CHEMBL1495264 & 688620 & 4.8 & 4.6838 & TST & \\
\hline CHEMBL1550650 & 688620 & 4.85 & 4.898 & TRN & \\
\hline CHEMBL3192132 & 688620 & 4.85 & 4.8025 & TRN & \\
\hline CHEMBL1600673 & 688620 & 5.1 & 5.0621 & TRN & \\
\hline CHEMBL1577121 & 688620 & 4.8 & 4.8594 & TRN & \\
\hline CHEMBL1303669 & 688620 & 4.9 & 4.9111 & TRN & \\
\hline CHEMBL1326799 & 688620 & 5.0 & 4.9102 & TRN & \\
\hline CHEMBL1379553 & 688620 & 4.45 & 4.7603 & TST & \\
\hline CHEMBL1362984 & 688620 & 4.9 & 4.9799 & TRN & \\
\hline CHEMBL1562628 & 688620 & 4.9 & 4.9433 & TRN & \\
\hline CHEMBL3208483 & 688620 & 4.85 & 5.3569 & TST & \\
\hline CHEMBL1596056 & 688620 & 4.65 & 4.9595 & TRN & \\
\hline CHEMBL1582808 & 688620 & 4.65 & 5.0673 & TRN & \\
\hline CHEMBL1380633 & 688620 & 4.45 & 4.6323 & TST & \\
\hline CHEMBL3189492 & 688620 & 4.45 & 5.2643 & TRN & \\
\hline CHEMBL1388655 & 688620 & 4.8 & 4.8661 & TST & \\
\hline CHEMBL1594297 & 688620 & 4.95 & 4.9725 & TST & \\
\hline CHEMBL1492376 & 688620 & 5.95 & 5.5744 & TRN & \\
\hline CHEMBL1302572 & 688620 & 4.45 & 5.0826 & TRN & \\
\hline CHEMBL1508058 & 688620 & 5.65 & 5.3269 & TRN & \\
\hline CHEMBL1402035 & 688620 & 4.95 & 4.8942 & TRN & \\
\hline CHEMBL1579286 & 688620 & 5.55 & 5.4951 & TRN & \\
\hline CHEMBL 2006730 & 688620 & 6.45 & 6.1044 & TRN & \\
\hline CHEMBL1569078 & 688620 & 4.45 & 5.0669 & TRN & \\
\hline CHEMBL1543492 & 688620 & 5.8 & 4.9753 & TRN & \\
\hline CHEMBL1484168 & 688620 & 4.45 & 5.01 & TRN & \\
\hline CHEMBL 3209263 & 688620 & 4.85 & 5.216 & TRN & \\
\hline CHEMBL1309011 & 688620 & 5.05 & 5.2689 & TRN & \\
\hline CHEMBL1446764 & 688620 & 5.0 & 5.0065 & TST & \\
\hline CHEMBL1569929 & 688620 & 4.8 & 4.9848 & TRN & \\
\hline CHEMBL1504057 & 688620 & 6.1 & 5.676 & TRN & \\
\hline CHEMBL1479866 & 688620 & 5.0 & 4.9959 & TRN & \\
\hline CHEMBL 3194467 & 688620 & 6.05 & 5.5083 & TRN & \\
\hline CHEMBL1520567 & 688620 & 4.45 & 4.9326 & TRN & \\
\hline CHEMBL1506895 & 688620 & 4.9 & 5.24700 & 0000000001 & TRN \\
\hline CHEMBL1612007 & 688620 & 5.15 & 4.8407 & TRN & \\
\hline CHEMBL1504170 & 688620 & 4.85 & 4.9025 & TRN & \\
\hline CHEMBL3210899 & 688620 & 5.05 & 5.17299 & 9999999999 & TST \\
\hline CHEMBL1403985 & 688620 & 4.75 & 5.4899 & TRN & \\
\hline CHEMBL1545737 & 688620 & 5.3 & 4.8451 & TRN & \\
\hline CHEMBL1523637 & 688620 & 4.9 & 4.9785 & TRN & \\
\hline CHEMBL1342610 & 688620 & 5.5 & 4.9523 & TRN & \\
\hline CHEMBL1443155 & 688620 & 4.65 & 5.3458 & TRN & \\
\hline
\end{tabular}




\begin{tabular}{|c|c|c|c|c|c|}
\hline \multicolumn{6}{|c|}{ Supplemental Table S2.txt } \\
\hline CHEMBL1458127 & 688620 & 4.65 & 4.9673 & TST & \\
\hline CHEMBL3195689 & 688620 & 4.65 & 4.9175 & TRN & \\
\hline CHEMBL3195881 & 688620 & 5.0 & 5.1869 & TST & \\
\hline CHEMBL1450947 & 688620 & 4.85 & 5.605 & TRN & \\
\hline CHEMBL1378756 & 688620 & 4.65 & 5.0972 & TRN & \\
\hline CHEMBL1392677 & 688620 & 4.75 & 5.0092 & TRN & \\
\hline CHEMBL1499890 & 688620 & 4.55 & 4.8934 & TRN & \\
\hline CHEMBL1379910 & 688620 & 5.65 & 5.4397 & TRN & \\
\hline CHEMBL1377904 & 688620 & 4.95 & 5.1409 & TRN & \\
\hline CHEMBL1306580 & 688620 & 6.4 & 5.1173 & TRN & \\
\hline CHEMBL1408989 & 688620 & 4.45 & 5.0347 & TST & \\
\hline CHEMBL1545033 & 688620 & 4.55 & 4.7198 & TRN & \\
\hline CHEMBL1422132 & 688620 & 5.0 & 5.2072 & TRN & \\
\hline CHEMBL1330765 & 688620 & 4.45 & 5.0189 & TRN & \\
\hline CHEMBL 3195552 & 688620 & 4.45 & 5.0917 & TRN & \\
\hline CHEMBL1320326 & 688620 & 4.5 & 5.0651 & TRN & \\
\hline CHEMBL3192747 & 688620 & 5.35 & 5.2017 & TRN & \\
\hline CHEMBL1430878 & 688620 & 5.6 & 5.2062 & TST & \\
\hline CHEMBL1380931 & 688620 & 4.7 & 4.8081 & TRN & \\
\hline CHEMBL1595088 & 688620 & 4.7 & 4.8776 & TRN & \\
\hline CHEMBL1453835 & 688620 & 5.2 & 4.8867 & TST & \\
\hline CHEMBL1502519 & 688620 & 4.6 & 5.228 & TRN & \\
\hline CHEMBL1533538 & 688620 & 5.7 & 5.3331 & TRN & \\
\hline CHEMBL1575118 & 688620 & 4.8 & 4.7938 & TRN & \\
\hline CHEMBL1561385 & 688620 & 4.6 & 5.7415 & TST & \\
\hline CHEMBL1517119 & 688620 & 4.9 & 5.4358 & TRN & \\
\hline CHEMBL1605724 & 688620 & 6.05 & 5.9997 & TRN & \\
\hline CHEMBL3198062 & 688620 & 4.65 & 5.0928 & TRN & \\
\hline CHEMBL1541645 & 688620 & 4.75 & 4.9006 & TRN & \\
\hline CHEMBL1307864 & 688620 & 5.05 & 5.4563 & TRN & \\
\hline CHEMBL600895 & 688620 & 5.0 & 4.9628 & TRN & \\
\hline CHEMBL1586344 & 688620 & 4.95 & 4.7862 & TRN & \\
\hline CHEMBL1343068 & 688620 & 4.45 & 4.9488 & TRN & \\
\hline CHEMBL1583542 & 688620 & 4.7 & 4.6436 & TST & \\
\hline CHEMBL 3193493 & 688620 & 4.7 & 4.9099 & TRN & \\
\hline CHEMBL1566991 & 688620 & 5.0 & 5.0018 & TRN & \\
\hline CHEMBL1412818 & 688620 & 5.45 & 5.2941 & TRN & \\
\hline CHEMBL1405347 & 688620 & 4.7 & 4.63399 & 99999999995 & TRN \\
\hline CHEMBL1353139 & 688620 & 4.9 & 4.9894 & TST & \\
\hline CHEMBL602531 & 688620 & 4.45 & 4.9696 & TRN & \\
\hline CHEMBL1421134 & 688620 & 4.75 & 4.9611 & TRN & \\
\hline CHEMBL1542592 & 688620 & 4.85 & 5.1122 & TST & \\
\hline CHEMBL1379943 & 688620 & 5.75 & 5.2692 & TRN & \\
\hline CHEMBL1403339 & 688620 & 4.45 & 4.9098 & TRN & \\
\hline CHEMBL475754 & 688620 & 4.65 & 5.2619 & TRN & \\
\hline CHEMBL1436272 & 688620 & 4.45 & 4.8192 & TRN & \\
\hline CHEMBL1408386 & 688620 & 4.45 & 4.7297 & TRN & \\
\hline CHEMBL1533802 & 688620 & 4.9 & 5.0815 & TRN & \\
\hline
\end{tabular}




\begin{tabular}{|c|c|c|c|c|c|}
\hline \\
\hline CHEMBL1359540 & 688620 & 4.7 & 5.2995 & TRN & \\
\hline CHEMBL1351653 & 688620 & 4.45 & 5.1015 & TRN & \\
\hline CHEMBL1578922 & 688620 & 5.2 & 4.9852 & TST & \\
\hline CHEMBL3193379 & 688620 & 4.7 & 4.9722 & TRN & \\
\hline CHEMBL1499998 & 688620 & 6.05 & 4.8904 & TRN & \\
\hline CHEMBL1612299 & 688620 & 6.15 & 5.0982 & TRN & \\
\hline CHEMBL1431955 & 688620 & 4.95 & 5.0271 & TST & \\
\hline CHEMBL1607489 & 688620 & 4.7 & 5.0365 & TRN & \\
\hline CHEMBL1460201 & 688620 & 4.85 & 5.0685 & TST & \\
\hline CHEMBL1503254 & 688620 & 4.45 & 4.6321 & TRN & \\
\hline CHEMBL1538435 & 688620 & 5.45 & 6.039 & TRN & \\
\hline CHEMBL1406138 & 688620 & 4.45 & 5.1807 & TRN & \\
\hline CHEMBL1519536 & 688620 & 5.3 & 5.3552 & TRN & \\
\hline CHEMBL1389275 & 688620 & 5.6 & 5.58899 & 99999999995 & TRN \\
\hline CHEMBL1588217 & 688620 & 5.25 & 4.9674 & TRN & \\
\hline CHEMBL1432480 & 688620 & 4.85 & 5.1291 & TRN & \\
\hline CHEMBL3196621 & 688620 & 6.15 & 5.6126 & TRN & \\
\hline CHEMBL1422550 & 688620 & 5.05 & 4.8734 & TRN & \\
\hline CHEMBL1357855 & 688620 & 4.85 & 5.3452 & TRN & \\
\hline CHEMBL1371045 & 688620 & 6.1 & 5.4324 & TRN & \\
\hline CHEMBL1495025 & 688620 & 5.0 & 5.3816 & TRN & \\
\hline CHEMBL1537130 & 688620 & 5.4 & 5.2188 & TRN & \\
\hline CHEMBL1595094 & 688620 & 4.45 & 4.9786 & TRN & \\
\hline CHEMBL3194090 & 688620 & 4.7 & 4.9216 & TST & \\
\hline CHEMBL1490287 & 688620 & 4.95 & 5.3873 & TRN & \\
\hline CHEMBL1566941 & 688620 & 4.9 & 5.1446 & TRN & \\
\hline CHEMBL3198831 & 688620 & 4.85 & 4.9037 & TRN & \\
\hline CHEMBL1410990 & 688620 & 4.85 & 4.9441 & TRN & \\
\hline CHEMBL1547145 & 688620 & 5.95 & 5.513 & TRN & \\
\hline CHEMBL3193474 & 688620 & 4.95 & 5.0996 & TRN & \\
\hline CHEMBL1529957 & 688620 & 4.45 & 5.3157 & TRN & \\
\hline CHEMBL1976198 & 688620 & 4.65 & 4.8813 & TRN & \\
\hline CHEMBL 3197443 & 688620 & 5.0 & 5.1282 & TRN & \\
\hline CHEMBL1408111 & 688620 & 5.15 & 5.0722 & TST & \\
\hline CHEMBL1487529 & 688620 & 5.4 & 4.80699 & 99999999995 & TST \\
\hline CHEMBL1565999 & 688620 & 4.95 & 5.1969 & TRN & \\
\hline CHEMBL1308013 & 688620 & 6.25 & 5.3458 & TRN & \\
\hline CHEMBL1563176 & 688620 & 4.45 & 4.6296 & TRN & \\
\hline CHEMBL1352020 & 688620 & 5.05 & 4.9918 & TRN & \\
\hline CHEMBL1307732 & 688620 & 5.0 & 4.8638 & TST & \\
\hline CHEMBL1348501 & 688620 & 4.7 & 5.0676 & TST & \\
\hline CHEMBL1566760 & 688620 & 5.2 & 5.1695 & TRN & \\
\hline CHEMBL1339679 & 688620 & 4.9 & 5.5181 & TST & \\
\hline CHEMBL1452116 & 688620 & 5.65 & 5.6803 & TST & \\
\hline CHEMBL1418158 & 688620 & 4.95 & 5.1469 & TST & \\
\hline CHEMBL1494525 & 688620 & 4.7 & 5.1759 & TRN & \\
\hline CHEMBL1420985 & 688620 & 5.2 & 4.9893 & TRN & \\
\hline CHEMBL 2006997 & 688620 & 6.2 & 5.9957 & TRN & \\
\hline
\end{tabular}




\begin{tabular}{|c|c|c|c|c|}
\hline & & & pplement & al $\mathrm{T}$ \\
\hline CHEMBL3193006 & 688620 & 4.5 & 4.8947 & TRN \\
\hline CHEMBL1309235 & 688620 & 5.0 & 5.1039 & TRN \\
\hline CHEMBL1387758 & 688620 & 5.0 & 5.2665 & TRN \\
\hline CHEMBL1392918 & 688620 & 4.9 & 4.9886 & TRN \\
\hline CHEMBL1506907 & 688620 & 7.1002 & 5.1086 & TST \\
\hline CHEMBL1397452 & 688620 & 5.7 & 5.5523 & TST \\
\hline CHEMBL1423013 & 688620 & 4.9 & 4.815 & TRN \\
\hline CHEMBL1343361 & 688620 & 6.8499 & 5.1144 & TRN \\
\hline CHEMBL1381466 & 688620 & 4.8 & 4.9491 & TRN \\
\hline CHEMBL1328255 & 688620 & 5.4 & 5.5474 & TRN \\
\hline CHEMBL1322906 & 688620 & 5.2 & 5.2959 & TST \\
\hline CHEMBL1386650 & 688620 & 4.45 & 4.992 & TRN \\
\hline CHEMBL1594252 & 688620 & 5.0 & 5.2192 & TRN \\
\hline CHEMBL1443125 & 688620 & 5.85 & 5.4213 & TRN \\
\hline CHEMBL1372039 & 688620 & 4.6 & 5.1848 & TRN \\
\hline CHEMBL1313691 & 688620 & 5.05 & 4.9975 & TRN \\
\hline CHEMBL1378636 & 688620 & 6.2 & 5.6022 & TRN \\
\hline CHEMBL1338130 & 688620 & 4.85 & 4.8775 & TRN \\
\hline CHEMBL1346768 & 688620 & 4.9 & 5.0183 & TRN \\
\hline CHEMBL1360126 & 688620 & 5.0 & 5.0087 & TRN \\
\hline CHEMBL1570090 & 688620 & 4.65 & 4.9882 & TRN \\
\hline CHEMBL 3191030 & 688620 & 5.5 & 5.774 & TRN \\
\hline CHEMBL1492537 & 688620 & 5.4 & 4.8664 & TRN \\
\hline CHEMBL1519528 & 688620 & 5.0 & 5.1277 & TST \\
\hline CHEMBL1347156 & 688620 & 5.4 & 5.0906 & TRN \\
\hline CHEMBL1510772 & 688620 & 4.8 & 4.8686 & TRN \\
\hline CHEMBL3194398 & 688620 & 5.25 & 5.0096 & TRN \\
\hline CHEMBL1610253 & 688620 & 4.45 & 5.0855 & TRN \\
\hline CHEMBL1561495 & 688620 & 5.5 & 5.9489 & TRN \\
\hline CHEMBL1504570 & 688620 & 4.65 & 5.2098 & TRN \\
\hline CHEMBL1549605 & 688620 & 5.4 & 4.8229 & TST \\
\hline CHEMBL1441185 & 688620 & 5.0 & 5.1114 & TST \\
\hline CHEMBL1376302 & 688620 & 4.45 & 4.9696 & TRN \\
\hline CHEMBL3211290 & 688620 & 5.55 & 5.3665 & TRN \\
\hline CHEMBL3208135 & 688620 & 5.25 & 5.2616 & TST \\
\hline CHEMBL578944 & 688620 & 4.5 & 4.9439 & TRN \\
\hline CHEMBL1332415 & 688620 & 4.85 & 5.6126 & TRN \\
\hline CHEMBL1569904 & 688620 & 5.5 & 5.0599 & TRN \\
\hline CHEMBL1563358 & 688620 & 4.6 & 5.2519 & TRN \\
\hline CHEMBL1398895 & 688620 & 5.2 & 5.1269 & TST \\
\hline CHEMBL1432607 & 688620 & 4.95 & 5.1223 & TRN \\
\hline CHEMBL3214318 & 688620 & 5.4 & 4.9904 & TST \\
\hline CHEMBL1349863 & 688620 & 5.6 & 5.393 & TRN \\
\hline CHEMBL1361924 & 688620 & 4.45 & 4.9646 & TRN \\
\hline CHEMBL3193839 & 688620 & 5.65 & 5.3405 & TRN \\
\hline CHEMBL1970453 & 688620 & 5.45 & 5.5978 & TRN \\
\hline CHEMBL1446700 & 688620 & 4.95 & 4.9974 & TRN \\
\hline CHEMBL1469784 & 688620 & 4.45 & 5.1172 & TRN \\
\hline
\end{tabular}




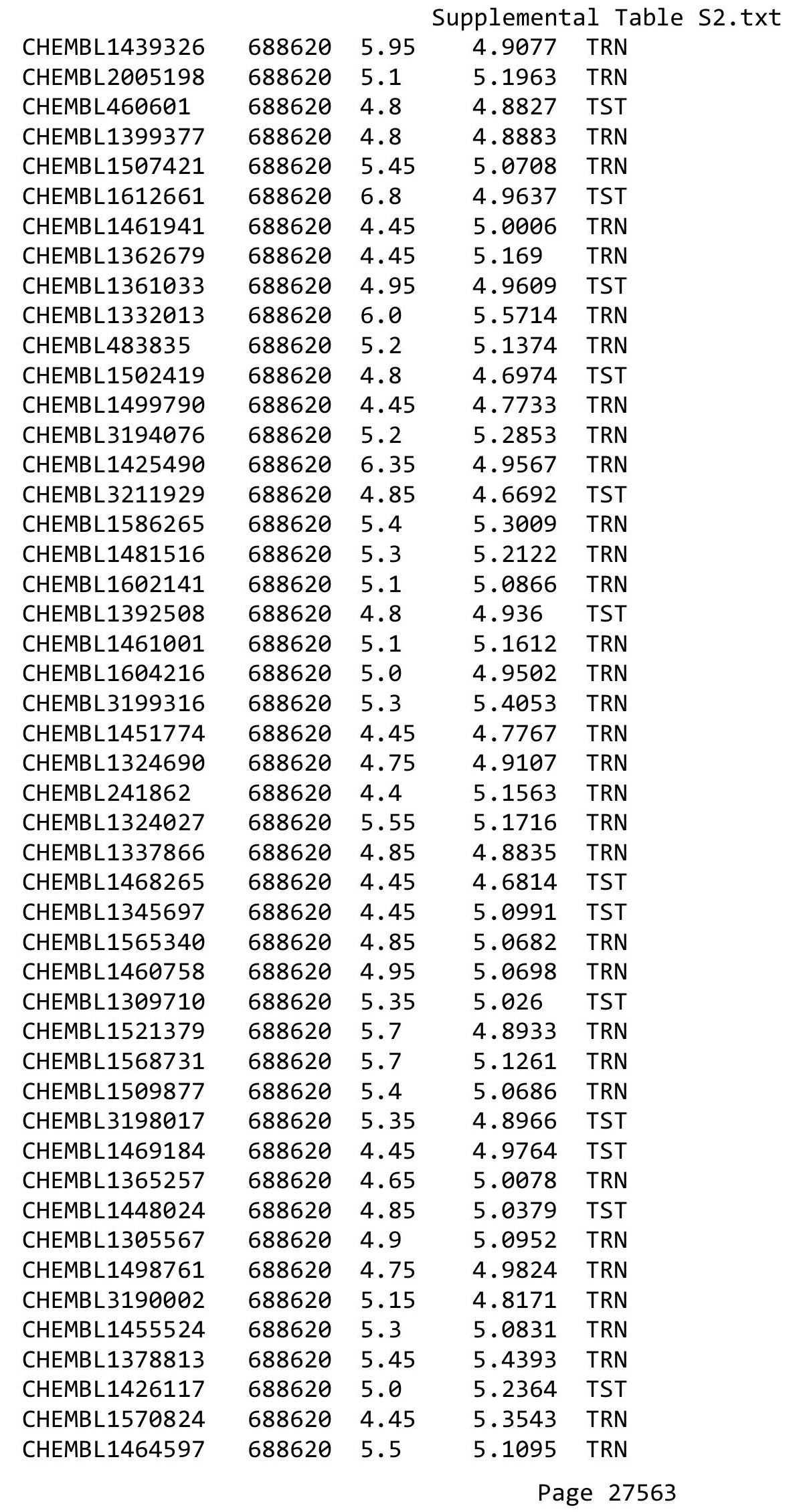




\begin{tabular}{|c|c|c|c|c|}
\hline \multicolumn{5}{|c|}{ Supplemental Table S2.txt } \\
\hline CHEMBL1430362 & 688620 & 5.15 & 5.0918 & TRN \\
\hline CHEMBL1399775 & 688620 & 4.5 & 4.7905 & TRN \\
\hline CHEMBL1511273 & 688620 & 5.2 & 4.9667 & TST \\
\hline CHEMBL1314376 & 688620 & 4.65 & 4.773 & TRN \\
\hline CHEMBL 1313550 & 688620 & 5.0 & 5.1166 & TRN \\
\hline CHEMBL1438274 & 688620 & 4.45 & 4.8839 & TRN \\
\hline CHEMBL1612850 & 688620 & 4.95 & 5.1766 & TRN \\
\hline CHEMBL1426200 & 688620 & 5.2 & 4.9401 & TRN \\
\hline CHEMBL1347040 & 688620 & 4.95 & 5.0677 & TST \\
\hline CHEMBL1319228 & 688620 & 4.9 & 5.0087 & TRN \\
\hline CHEMBL1430446 & 688620 & 4.8 & 5.0158 & TRN \\
\hline CHEMBL1387555 & 688620 & 5.0 & 4.9768 & TRN \\
\hline CHEMBL1331798 & 688620 & 4.45 & 4.9336 & TRN \\
\hline CHEMBL1406920 & 688620 & 6.15 & 6.1156 & TRN \\
\hline CHEMBL1474751 & 688620 & 4.8 & 4.8398 & TRN \\
\hline CHEMBL1516581 & 688620 & 4.75 & 5.1462 & TRN \\
\hline CHEMBL3197898 & 688620 & 5.25 & 4.9552 & TRN \\
\hline CHEMBL1409209 & 688620 & 6.6 & 5.5548 & TRN \\
\hline CHEMBL1474185 & 688620 & 4.45 & 4.8172 & TRN \\
\hline CHEMBL1348057 & 688620 & 4.45 & 4.8078 & TST \\
\hline CHEMBL1425018 & 688620 & 5.7 & 5.6416 & TRN \\
\hline CHEMBL1542378 & 688620 & 5.7 & 5.4305 & TRN \\
\hline CHEMBL1585542 & 688620 & 4.9 & 4.9295 & TRN \\
\hline CHEMBL1542690 & 688620 & 4.95 & 4.8934 & TRN \\
\hline CHEMBL1581070 & 688620 & 5.75 & 5.3213 & TRN \\
\hline CHEMBL1569750 & 688620 & 4.45 & 4.6037 & TRN \\
\hline CHEMBL1481410 & 688620 & 4.95 & 5.1833 & TST \\
\hline CHEMBL1553837 & 688620 & 4.9 & 5.1927 & TST \\
\hline CHEMBL1574218 & 688620 & 4.45 & 4.9934 & TST \\
\hline CHEMBL1589499 & 688620 & 4.85 & 4.9362 & TRN \\
\hline CHEMBL1546854 & 688620 & 4.75 & 5.218 & TRN \\
\hline CHEMBL1476258 & 688620 & 4.8 & 4.9924 & TRN \\
\hline CHEMBL1518334 & 688620 & 4.85 & 5.0638 & TST \\
\hline CHEMBL1430872 & 688620 & 4.45 & 4.914 & TRN \\
\hline CHEMBL1311732 & 688620 & 4.45 & 4.694 & TRN \\
\hline CHEMBL1484641 & 688620 & 5.4 & 4.9412 & TRN \\
\hline CHEMBL1310394 & 688620 & 5.0 & 5.1672 & TRN \\
\hline CHEMBL1386529 & 688620 & 4.5 & 5.1271 & TRN \\
\hline CHEMBL1509623 & 688620 & 5.2 & 5.3818 & TRN \\
\hline CHEMBL1424078 & 688620 & 4.95 & 5.2978 & TST \\
\hline CHEMBL1386622 & 688620 & 4.85 & 4.9268 & TST \\
\hline CHEMBL1485372 & 688620 & 4.95 & 5.2124 & TRN \\
\hline CHEMBL3190314 & 688620 & 5.3 & 5.1334 & TRN \\
\hline CHEMBL1607194 & 688620 & 5.0 & 5.0771 & TRN \\
\hline CHEMBL1409767 & 688620 & 4.9 & 4.8898 & TRN \\
\hline CHEMBL1482947 & 688620 & 5.0 & 5.1218 & TST \\
\hline CHEMBL 1440300 & 688620 & 6.05 & 5.5397 & TST \\
\hline CHEMBL1327153 & 688620 & 4.9 & 5.1453 & TST \\
\hline
\end{tabular}




\begin{tabular}{|c|c|c|c|c|c|}
\hline & & & & & \\
\hline CHEMBL1608459 & 688620 & 5.0 & 4.6473 & TRN & \\
\hline CHEMBL1431469 & 688620 & 5.5 & 4.94300 & 00000000005 & TRN \\
\hline CHEMBL3193515 & 688620 & 5.95 & 5.8967 & TRN & \\
\hline CHEMBL1428820 & 688620 & 5.6 & 5.1856 & TRN & \\
\hline CHEMBL3145281 & 688620 & 4.9 & 5.0252 & TRN & \\
\hline CHEMBL1573739 & 688620 & 5.0 & 5.0466 & TRN & \\
\hline CHEMBL1431063 & 688620 & 4.45 & 4.9376 & TRN & \\
\hline CHEMBL1506980 & 688620 & 4.8 & 4.8049 & TRN & \\
\hline CHEMBL1523685 & 688620 & 4.45 & 5.0267 & TST & \\
\hline CHEMBL1337611 & 688620 & 4.9 & 5.0157 & TRN & \\
\hline CHEMBL1486249 & 688620 & 4.95 & 5.0174 & TRN & \\
\hline CHEMBL1530295 & 688620 & 6.0 & 5.6811 & TST & \\
\hline CHEMBL1498144 & 688620 & 5.05 & 5.15 & TRN & \\
\hline CHEMBL1472521 & 688620 & 4.45 & 5.1224 & TRN & \\
\hline CHEMBL1998429 & 688620 & 4.6 & 4.6506 & TST & \\
\hline CHEMBL1382116 & 688620 & 4.5 & 4.8889 & TST & \\
\hline CHEMBL1334327 & 688620 & 4.9 & 4.856 & TRN & \\
\hline CHEMBL1401142 & 688620 & 5.5 & 4.98300 & 20000000005 & TRN \\
\hline CHEMBL1306923 & 688620 & 4.95 & 4.985 & TRN & \\
\hline CHEMBL 394242 & 688620 & 6.2 & 5.9009 & TRN & \\
\hline CHEMBL1481706 & 688620 & 4.9 & 4.84 & TRN & \\
\hline CHEMBL1467878 & 688620 & 6.05 & 6.1478 & TRN & \\
\hline CHEMBL1300140 & 688620 & 4.8 & 4.8768 & TRN & \\
\hline CHEMBL1321064 & 688620 & 5.2 & 5.55 & TRN & \\
\hline CHEMBL1424562 & 688620 & 4.8 & 5.1192 & TRN & \\
\hline CHEMBL1322548 & 688620 & 5.1 & 4.9302 & TRN & \\
\hline CHEMBL1571123 & 688620 & 4.65 & 5.4664 & TRN & \\
\hline CHEMBL1541540 & 688620 & 8.301 & 5.1969 & TST & \\
\hline CHEMBL1996189 & 688620 & 6.6499 & 4.8511 & TRN & \\
\hline CHEMBL1332678 & 688620 & 4.45 & 4.6357 & TST & \\
\hline CHEMBL1382542 & 688620 & 5.0 & 4.8078 & TRN & \\
\hline CHEMBL1373969 & 688620 & 4.9 & 4.8622 & TRN & \\
\hline CHEMBL1306274 & 688620 & 7.3002 & 4.994 & TRN & \\
\hline CHEMBL1560530 & 688620 & 4.9 & 5.2219 & TST & \\
\hline CHEMBL1603938 & 688620 & 5.0 & 4.8992 & TRN & \\
\hline CHEMBL1352996 & 688620 & 4.65 & 4.9866 & TST & \\
\hline CHEMBL1324203 & 688620 & 4.85 & 4.9954 & TST & \\
\hline CHEMBL1462043 & 688620 & 4.85 & 4.9088 & TRN & \\
\hline CHEMBL1527953 & 688620 & 5.45 & 5.1143 & TRN & \\
\hline CHEMBL1359770 & 688620 & 4.95 & 5.0091 & TRN & \\
\hline CHEMBL1418767 & 688620 & 5.45 & 4.9539 & TRN & \\
\hline CHEMBL3197109 & 688620 & 5.5 & 5.5145 & TRN & \\
\hline CHEMBL1533929 & 688620 & 4.8 & 5.0107 & TRN & \\
\hline CHEMBL3192910 & 688620 & 5.3 & 5.2101 & TRN & \\
\hline CHEMBL1304837 & 688620 & 4.75 & 4.9007 & TRN & \\
\hline CHEMBL1456847 & 688620 & 4.9 & 4.9692 & TRN & \\
\hline CHEMBL1562767 & 688620 & 5.25 & 4.9074 & TST & \\
\hline CHEMBL1403172 & 688620 & 4.7 & 5.0288 & TRN & \\
\hline & & & & 27565 & \\
\hline
\end{tabular}




\begin{tabular}{|c|c|c|c|c|c|}
\hline \multicolumn{6}{|c|}{ Supplemental Table s2.txt } \\
\hline CHEMBL1519160 & 688620 & 5.15 & 5.1243 & TRN & \\
\hline CHEMBL1523938 & 688620 & 4.95 & 5.1469 & TST & \\
\hline CHEMBL1442136 & 688620 & 4.45 & 4.5769 & TST & \\
\hline CHEMBL1420974 & 688620 & 4.95 & 5.1029 & TRN & \\
\hline CHEMBL1588056 & 688620 & 5.15 & 5.1925 & TRN & \\
\hline CHEMBL3199922 & 688620 & 4.55 & 4.8564 & TRN & \\
\hline CHEMBL1499840 & 688620 & 4.9 & 4.9461 & TRN & \\
\hline CHEMBL1324293 & 688620 & 4.95 & 5.0255 & TRN & \\
\hline CHEMBL1491777 & 688620 & 4.9 & 5.3008 & TRN & \\
\hline CHEMBL3209078 & 688620 & 5.8 & 5.206 & TRN & \\
\hline CHEMBL1349452 & 688620 & 4.85 & 4.8491 & TRN & \\
\hline CHEMBL1467527 & 688620 & 4.8 & 5.0256 & TRN & \\
\hline CHEMBL1571560 & 688620 & 6.05 & 4.9601 & TRN & \\
\hline CHEMBL1491703 & 688620 & 5.0 & 5.0188 & TST & \\
\hline CHEMBL1486366 & 688620 & 5.0 & 4.9546 & TRN & \\
\hline CHEMBL1301057 & 688620 & 5.3 & 5.1396 & TRN & \\
\hline CHEMBL1579191 & 688620 & 5.45 & 5.1106 & TRN & \\
\hline CHEMBL1547696 & 688620 & 4.6 & 4.927 & TRN & \\
\hline CHEMBL1348757 & 688620 & 4.85 & 4.9916 & TST & \\
\hline CHEMBL1363371 & 688620 & 8.301 & 5.09699 & 99999999995 & TRN \\
\hline CHEMBL1333172 & 688620 & 4.45 & 4.6962 & TRN & \\
\hline CHEMBL1429171 & 688620 & 5.1 & 4.9824 & TRN & \\
\hline CHEMBL3192851 & 688620 & 4.45 & 4.9059 & TRN & \\
\hline CHEMBL1490894 & 688620 & 4.5 & 5.0205 & TRN & \\
\hline CHEMBL1402963 & 688620 & 4.9 & 5.0609 & TRN & \\
\hline CHEMBL1493042 & 688620 & 5.4 & 5.426 & TRN & \\
\hline CHEMBL1984816 & 688620 & 5.3 & 5.2272 & TRN & \\
\hline CHEMBL1465603 & 688620 & 4.9 & 5.0456 & TRN & \\
\hline CHEMBL 3208249 & 688620 & 5.0 & 5.1656 & TRN & \\
\hline CHEMBL1349417 & 688620 & 4.85 & 5.0283 & TST & \\
\hline CHEMBL1468714 & 688620 & 6.0 & 4.7077 & TRN & \\
\hline CHEMBL1477846 & 688620 & 4.95 & 5.1769 & TST & \\
\hline CHEMBL3195224 & 688620 & 4.95 & 5.1936 & TRN & \\
\hline CHEMBL1534471 & 688620 & 4.45 & 5.0084 & TRN & \\
\hline CHEMBL1327816 & 688620 & 5.2 & 5.2868 & TRN & \\
\hline CHEMBL1323587 & 688620 & 4.9 & 5.0389 & TRN & \\
\hline CHEMBL1342404 & 688620 & 4.6 & 5.0594 & TRN & \\
\hline CHEMBL1333118 & 688620 & 5.0 & 4.8008 & TST & \\
\hline CHEMBL1599873 & 688620 & 5.2 & 5.2158 & TST & \\
\hline CHEMBL 2005497 & 688620 & 4.5 & 4.9286 & TST & \\
\hline CHEMBL1584281 & 688620 & 4.85 & 4.8951 & TRN & \\
\hline CHEMBL3197268 & 688620 & 4.95 & 5.0396 & TRN & \\
\hline CHEMBL3193555 & 688620 & 4.95 & 5.0452 & TRN & \\
\hline CHEMBL3198158 & 688620 & 5.2 & 5.2449 & TST & \\
\hline CHEMBL1565522 & 688620 & 4.7 & 4.9672 & TRN & \\
\hline CHEMBL1330308 & 688620 & 4.6 & 4.7963 & TRN & \\
\hline CHEMBL1534919 & 688620 & 4.9 & 5.1266 & TST & \\
\hline CHEMBL3212249 & 688620 & 4.9 & 5.069 & TRN & \\
\hline
\end{tabular}




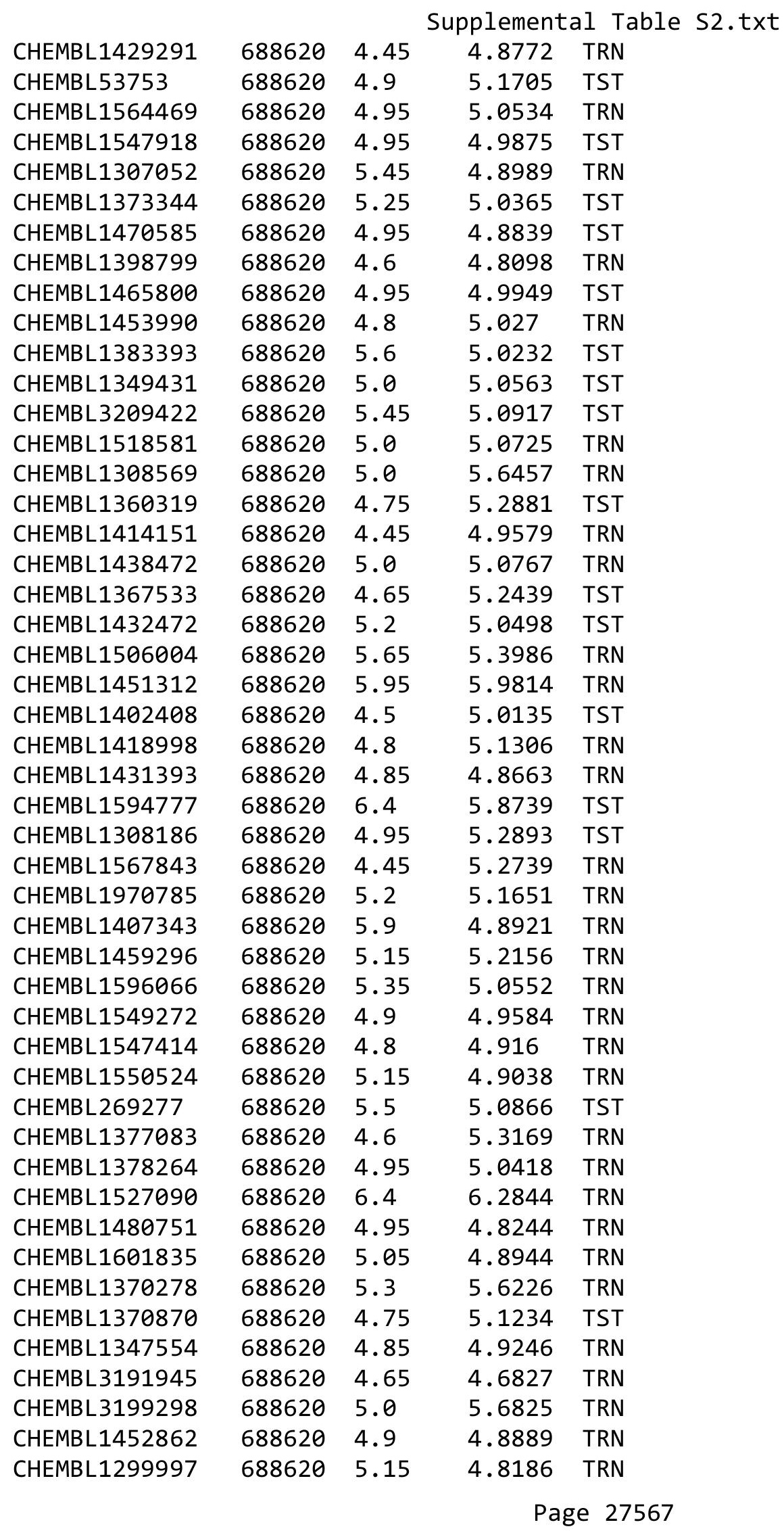




\begin{tabular}{|c|c|c|c|c|c|}
\hline \multicolumn{6}{|c|}{ Supplemental Table S2.txt } \\
\hline CHEMBL1502591 & 688620 & 4.85 & 4.809 & TST & \\
\hline CHEMBL1557451 & 688620 & 4.8 & 4.9488 & TRN & \\
\hline CHEMBL1348729 & 688620 & 4.95 & 4.9991 & TST & \\
\hline CHEMBL1414861 & 688620 & 4.85 & 5.0727 & TRN & \\
\hline CHEMBL1553349 & 688620 & 4.95 & 5.66299 & 9999999999 & TRN \\
\hline CHEMBL1544240 & 688620 & 4.9 & 4.9911 & TRN & \\
\hline CHEMBL1446681 & 688620 & 5.15 & 5.0982 & TST & \\
\hline CHEMBL1366055 & 688620 & 6.5 & 6.4371 & TRN & \\
\hline CHEMBL3191757 & 688620 & 5.15 & 5.36700 & 0000000001 & TRN \\
\hline CHEMBL1571017 & 688620 & 5.25 & 5.0046 & TRN & \\
\hline CHEMBL1383947 & 688620 & 5.6 & 5.3262 & TRN & \\
\hline CHEMBL1464684 & 688620 & 4.85 & 5.003 & TRN & \\
\hline CHEMBL1486319 & 688620 & 4.45 & 5.1529 & TST & \\
\hline CHEMBL1417987 & 688620 & 5.9 & 5.1261 & TRN & \\
\hline CHEMBL1553978 & 688620 & 4.45 & 4.6708 & TST & \\
\hline CHEMBL3189717 & 688620 & 6.15 & 6.0197 & TRN & \\
\hline CHEMBL3196684 & 688620 & 5.0 & 4.97199 & 99999999995 & TRN \\
\hline CHEMBL1526072 & 688620 & 5.1 & 4.9663 & TRN & \\
\hline CHEMBL 3212654 & 688620 & 4.45 & 5.2076 & TST & \\
\hline CHEMBL1461372 & 688620 & 4.45 & 4.7828 & TST & \\
\hline CHEMBL1387115 & 688620 & 4.7 & 4.7676 & TRN & \\
\hline CHEMBL1504080 & 688620 & 4.9 & 4.9795 & TST & \\
\hline CHEMBL1436110 & 688620 & 4.9 & 5.1678 & TRN & \\
\hline CHEMBL1986111 & 688620 & 4.45 & 4.9091 & TST & \\
\hline CHEMBL1349247 & 688620 & 4.45 & 5.0607 & TST & \\
\hline CHEMBL1501037 & 688620 & 5.05 & 5.2181 & TST & \\
\hline CHEMBL1509711 & 688620 & 5.9 & 5.21399 & 99999999995 & TRN \\
\hline CHEMBL1328840 & 688620 & 4.95 & 5.475 & TRN & \\
\hline CHEMBL1496372 & 688620 & 5.2 & 5.24 & TRN & \\
\hline CHEMBL1303391 & 688620 & 5.4 & 5.2386 & TRN & \\
\hline CHEMBL1611025 & 688620 & 5.3 & 4.827 & TST & \\
\hline CHEMBL3195792 & 688620 & 4.45 & 5.0528 & TRN & \\
\hline CHEMBL1586075 & 688620 & 4.45 & 4.7875 & TRN & \\
\hline CHEMBL3213956 & 688620 & 5.0 & 5.0074 & TRN & \\
\hline CHEMBL3197369 & 688620 & 5.55 & 5.6068 & TRN & \\
\hline CHEMBL1299904 & 688620 & 5.2 & 5.1344 & TST & \\
\hline CHEMBL1994877 & 688620 & 5.25 & 5.2793 & TRN & \\
\hline CHEMBL3194528 & 688620 & 4.95 & 5.3613 & TRN & \\
\hline CHEMBL1504913 & 688620 & 5.15 & 5.1229 & TRN & \\
\hline CHEMBL1310744 & 688620 & 4.95 & 4.5721 & TRN & \\
\hline CHEMBL1477452 & 688620 & 5.2 & 4.9988 & TRN & \\
\hline CHEMBL1541100 & 688620 & 4.9 & 4.9673 & TRN & \\
\hline CHEMBL1324698 & 688620 & 4.85 & 4.7369 & TST & \\
\hline CHEMBL1594512 & 688620 & 5.2 & 5.2216 & TRN & \\
\hline CHEMBL1574403 & 688620 & 5.2 & 4.933 & TRN & \\
\hline CHEMBL1610314 & 688620 & 4.95 & 4.8446 & TRN & \\
\hline CHEMBL1496207 & 688620 & 4.55 & 5.0018 & TST & \\
\hline CHEMBL1373171 & 688620 & 4.9 & 5.2861 & TRN & \\
\hline
\end{tabular}




\begin{tabular}{|c|c|c|c|c|}
\hline \multicolumn{5}{|c|}{ Supplemental Table } \\
\hline CHEMBL1600399 & 688620 & 5.85 & 5.1392 & TST \\
\hline CHEMBL1319755 & 688620 & 4.7 & 4.9149 & TRN \\
\hline CHEMBL1472135 & 688620 & 4.85 & 4.739 & TST \\
\hline CHEMBL1546603 & 688620 & 4.9 & 4.7713 & TRN \\
\hline CHEMBL1342948 & 688620 & 4.6 & 5.1514 & TRN \\
\hline CHEMBL3209924 & 688620 & 4.85 & 4.9102 & TST \\
\hline CHEMBL1609933 & 688620 & 4.45 & 5.0336 & TRN \\
\hline CHEMBL1366820 & 688620 & 4.45 & 5.1161 & TRN \\
\hline CHEMBL1421898 & 688620 & 4.9 & 5.2254 & TRN \\
\hline CHEMBL1299466 & 688620 & 4.9 & 4.8709 & TRN \\
\hline CHEMBL1509961 & 688620 & 4.8 & 5.13 & TST \\
\hline CHEMBL1564468 & 688620 & 4.8 & 5.2975 & TRN \\
\hline CHEMBL1491460 & 688620 & 4.5 & 4.9813 & TRN \\
\hline CHEMBL1562983 & 688620 & 4.85 & 4.6516 & TRN \\
\hline CHEMBL1559246 & 688620 & 4.45 & 5.1289 & TRN \\
\hline CHEMBL1524477 & 688620 & 4.95 & 4.9314 & TST \\
\hline CHEMBL1527350 & 688620 & 4.9 & 5.0139 & TST \\
\hline CHEMBL1506025 & 688620 & 4.8 & 4.8793 & TST \\
\hline CHEMBL1446061 & 688620 & 4.9 & 5.069 & TRN \\
\hline CHEMBL3194214 & 688620 & 6.3 & 5.7471 & TRN \\
\hline CHEMBL1461080 & 688620 & 4.5 & 5.1186 & TRN \\
\hline CHEMBL1510604 & 688620 & 4.45 & 4.9304 & TRN \\
\hline CHEMBL1337361 & 688620 & 6.45 & 6.2826 & TRN \\
\hline CHEMBL1302397 & 688620 & 4.6 & 5.0649 & TRN \\
\hline CHEMBL1338117 & 688620 & 4.85 & 4.9994 & TRN \\
\hline CHEMBL1599666 & 688620 & 4.45 & 5.0996 & TST \\
\hline CHEMBL1386104 & 688620 & 4.9 & 4.9591 & TRN \\
\hline CHEMBL1591074 & 688620 & 5.05 & 5.2735 & TST \\
\hline CHEMBL1535030 & 688620 & 5.15 & 5.1116 & TST \\
\hline CHEMBL1300364 & 688620 & 4.8 & 4.8779 & TRN \\
\hline CHEMBL1333734 & 688620 & 5.25 & 4.9246 & TRN \\
\hline CHEMBL1533964 & 688620 & 6.25 & 5.0641 & TST \\
\hline CHEMBL3193166 & 688620 & 4.45 & 5.3659 & TRN \\
\hline CHEMBL1497005 & 688620 & 4.8 & 5.329 & TST \\
\hline CHEMBL520107 & 688620 & 4.45 & 4.9121 & TST \\
\hline CHEMBL3207813 & 688620 & 5.45 & 5.1383 & TRN \\
\hline CHEMBL1612536 & 688620 & 5.65 & 5.2128 & TRN \\
\hline CHEMBL1341465 & 688620 & 4.95 & 5.1099 & TRN \\
\hline CHEMBL1538036 & 688620 & 5.4 & 5.1413 & TRN \\
\hline CHEMBL1557234 & 688620 & 5.35 & 5.1024 & TRN \\
\hline CHEMBL1444097 & 688620 & 4.95 & 5.1258 & TRN \\
\hline CHEMBL1321107 & 688620 & 5.4 & 4.9995 & TRN \\
\hline CHEMBL1372119 & 688620 & 4.95 & 4.9146 & TRN \\
\hline CHEMBL3209235 & 688620 & 5.0 & 4.9097 & TRN \\
\hline CHEMBL1586270 & 688620 & 4.85 & 4.8451 & TRN \\
\hline CHEMBL1588096 & 688620 & 4.45 & 5.0959 & TST \\
\hline CHEMBL1446191 & 688620 & 4.45 & 5.0184 & TRN \\
\hline CHEMBL1477052 & 688620 & 6.25 & 5.1782 & TRN \\
\hline
\end{tabular}




\begin{tabular}{|c|c|c|c|c|}
\hline \multicolumn{5}{|c|}{ splemental T } \\
\hline CHEMBL1332126 & 688620 & 5.4 & 5.0096 & TST \\
\hline CHEMBL1520671 & 688620 & 5.8 & 5.2145 & TRN \\
\hline CHEMBL1392817 & 688620 & 4.85 & 5.8931 & TRN \\
\hline CHEMBL1511224 & 688620 & 4.9 & 5.1346 & TST \\
\hline CHEMBL1452426 & 688620 & 5.35 & 5.2403 & TRN \\
\hline CHEMBL1597279 & 688620 & 5.0 & 4.8192 & TRN \\
\hline CHEMBL1468747 & 688620 & 4.45 & 5.1835 & TRN \\
\hline CHEMBL1538101 & 688620 & 4.9 & 4.8676 & TRN \\
\hline CHEMBL1535469 & 688620 & 4.45 & 4.8112 & TRN \\
\hline CHEMBL1415608 & 688620 & 5.4 & 5.1163 & TRN \\
\hline CHEMBL1449470 & 688620 & 5.15 & 5.2806 & TRN \\
\hline CHEMBL1569897 & 688620 & 4.65 & 4.9002 & TST \\
\hline CHEMBL1393226 & 688620 & 5.2 & 4.8786 & TRN \\
\hline CHEMBL1344848 & 688620 & 6.35 & 5.3602 & TRN \\
\hline CHEMBL1305334 & 688620 & 4.95 & 4.8524 & TRN \\
\hline CHEMBL1304443 & 688620 & 4.75 & 5.01 & TRN \\
\hline CHEMBL1318883 & 688620 & 4.7 & 5.0292 & TST \\
\hline CHEMBL1302640 & 688620 & 5.3 & 5.2583 & TRN \\
\hline CHEMBL1359847 & 688620 & 5.2 & 5.0969 & TRN \\
\hline CHEMBL1428029 & 688620 & 4.6 & 4.9078 & TRN \\
\hline CHEMBL1482808 & 688620 & 5.0 & 5.1304 & TRN \\
\hline CHEMBL1507705 & 688620 & 4.65 & 5.1029 & TRN \\
\hline CHEMBL1329291 & 688620 & 4.45 & 4.992 & TST \\
\hline CHEMBL1390987 & 688620 & 4.9 & 5.0813 & TST \\
\hline CHEMBL1458907 & 688620 & 4.5 & 5.0691 & TRN \\
\hline CHEMBL1464620 & 688620 & 6.7501 & 5.2273 & TRN \\
\hline CHEMBL1571514 & 688620 & 5.2 & 5.039 & TST \\
\hline CHEMBL1561928 & 688620 & 4.45 & 5.1861 & TST \\
\hline CHEMBL1390220 & 688620 & 5.0 & 5.1462 & TRN \\
\hline CHEMBL1595575 & 688620 & 4.5 & 5.053 & TRN \\
\hline CHEMBL1344579 & 688620 & 4.5 & 4.9385 & TRN \\
\hline CHEMBL1389625 & 688620 & 4.7 & 5.1225 & TST \\
\hline CHEMBL1492718 & 688620 & 4.75 & 4.8769 & TRN \\
\hline CHEMBL1467956 & 688620 & 4.95 & 4.6809 & TST \\
\hline CHEMBL1359298 & 688620 & 5.0 & 5.1106 & TRN \\
\hline CHEMBL1532649 & 688620 & 5.15 & 4.8037 & TRN \\
\hline CHEMBL1365774 & 688620 & 4.85 & 4.8017 & TST \\
\hline CHEMBL1468369 & 688620 & 4.95 & 5.1573 & TST \\
\hline CHEMBL1381051 & 688620 & 5.25 & 5.0456 & TRN \\
\hline CHEMBL1319249 & 688620 & 4.45 & 4.7995 & TRN \\
\hline CHEMBL1540520 & 688620 & 4.45 & 4.8996 & TRN \\
\hline CHEMBL252621 & 688620 & 5.0 & 4.9706 & TRN \\
\hline CHEMBL1439011 & 688620 & 4.7 & 5.0782 & TST \\
\hline CHEMBL1553484 & 688620 & 4.55 & 4.6713 & TRN \\
\hline CHEMBL1396172 & 688620 & 5.0 & 5.1245 & TRN \\
\hline CHEMBL1580774 & 688620 & 4.85 & 5.1107 & TRN \\
\hline CHEMBL1384915 & 688620 & 4.75 & 4.7527 & TRN \\
\hline CHEMBL1541511 & 688620 & 5.25 & 5.0041 & TST \\
\hline
\end{tabular}




\begin{tabular}{|c|c|c|c|c|c|}
\hline \\
\hline CHEMBL1367293 & 688620 & 4.7 & 5.1248 & TST & \\
\hline CHEMBL1994468 & 688620 & 4.45 & 4.9773 & TRN & \\
\hline CHEMBL1416858 & 688620 & 4.6 & 5.0823 & TRN & \\
\hline CHEMBL1579389 & 688620 & 5.2 & 6.2297 & TRN & \\
\hline CHEMBL1864436 & 688620 & 5.05 & 5.0607 & TST & \\
\hline CHEMBL1489769 & 688620 & 6.0 & 5.5774 & TST & \\
\hline CHEMBL1541291 & 688620 & 5.55 & 5.25899 & 99999999995 & TRN \\
\hline CHEMBL1527209 & 688620 & 4.45 & 4.9855 & TRN & \\
\hline CHEMBL3194291 & 688620 & 4.8 & 5.0678 & TST & \\
\hline CHEMBL1574364 & 688620 & 4.75 & 4.9282 & TST & \\
\hline CHEMBL1424783 & 688620 & 4.95 & 4.965 & TRN & \\
\hline CHEMBL1340111 & 688620 & 4.7 & 4.9876 & TST & \\
\hline CHEMBL1335212 & 688620 & 4.7 & 5.0701 & TRN & \\
\hline CHEMBL1429620 & 688620 & 4.95 & 5.2416 & TRN & \\
\hline CHEMBL1489349 & 688620 & 4.45 & 5.1007 & TRN & \\
\hline CHEMBL1550794 & 688620 & 4.9 & 4.8449 & TRN & \\
\hline CHEMBL3210411 & 688620 & 6.15 & 5.0538 & TRN & \\
\hline CHEMBL1328720 & 688620 & 4.95 & 5.0449 & TRN & \\
\hline CHEMBL1490187 & 688620 & 4.95 & 5.0715 & TRN & \\
\hline CHEMBL1438395 & 688620 & 4.45 & 4.968 & TRN & \\
\hline CHEMBL1575604 & 688620 & 4.7 & 4.8742 & TRN & \\
\hline CHEMBL1509397 & 688620 & 6.5 & 5.4195 & TST & \\
\hline CHEMBL1375478 & 688620 & 5.05 & 4.9522 & TST & \\
\hline CHEMBL1478602 & 688620 & 4.8 & 4.8476 & TRN & \\
\hline CHEMBL1536629 & 688620 & 4.95 & 4.7812 & TRN & \\
\hline CHEMBL1390840 & 688620 & 4.7 & 5.0002 & TST & \\
\hline CHEMBL1497577 & 688620 & 4.65 & 5.1047 & TST & \\
\hline CHEMBL1361220 & 688620 & 5.2 & 5.7554 & TRN & \\
\hline CHEMBL1406345 & 688620 & 4.45 & 4.8212 & TRN & \\
\hline CHEMBL1529150 & 688620 & 5.8 & 4.9114 & TRN & \\
\hline CHEMBL1440564 & 688620 & 4.45 & 5.1159 & TST & \\
\hline CHEMBL3209873 & 688620 & 4.45 & 5.148 & TST & \\
\hline CHEMBL1596226 & 688620 & 4.45 & 4.8481 & TST & \\
\hline CHEMBL 2236631 & 688620 & 4.45 & 4.7427 & TRN & \\
\hline CHEMBL1397979 & 688620 & 4.5 & 4.9781 & TRN & \\
\hline CHEMBL1429805 & 688620 & 5.1 & 4.9323 & TRN & \\
\hline CHEMBL1443953 & 688620 & 5.45 & 4.9228 & TRN & \\
\hline CHEMBL1427411 & 688620 & 5.15 & 4.9886 & TRN & \\
\hline CHEMBL1456624 & 688620 & 4.95 & 4.9437 & TRN & \\
\hline CHEMBL3197437 & 688620 & 5.3 & 4.8643 & TRN & \\
\hline CHEMBL1374920 & 688620 & 5.65 & 5.104 & TRN & \\
\hline CHEMBL1378451 & 688620 & 4.8 & 5.062 & TRN & \\
\hline CHEMBL2007057 & 688620 & 4.45 & 4.7514 & TRN & \\
\hline CHEMBL3208869 & 688620 & 5.0 & 5.1453 & TST & \\
\hline CHEMBL1571771 & 688620 & 4.45 & 4.9941 & TRN & \\
\hline CHEMBL1322563 & 688620 & 4.45 & 4.819 & TST & \\
\hline CHEMBL1480329 & 688620 & 4.45 & 5.2123 & TRN & \\
\hline CHEMBL1562432 & 688620 & 5.05 & 4.8447 & TST & \\
\hline
\end{tabular}




\begin{tabular}{|c|c|c|c|c|}
\hline \multicolumn{5}{|c|}{ Supplemental Table S2.txt } \\
\hline CHEMBL1323994 & 688620 & 4.9 & 5.0672 & TRN \\
\hline CHEMBL1532186 & 688620 & 4.7 & 4.871 & TRN \\
\hline CHEMBL3198523 & 688620 & 4.95 & 5.067 & TRN \\
\hline CHEMBL1399677 & 688620 & 5.0 & 5.0175 & TST \\
\hline CHEMBL1359829 & 688620 & 5.05 & 5.0739 & TRN \\
\hline CHEMBL1520291 & 688620 & 4.7 & 4.8977 & TRN \\
\hline CHEMBL1564343 & 688620 & 5.4 & 5.0134 & TST \\
\hline CHEMBL1549246 & 688620 & 4.95 & 4.9252 & TST \\
\hline CHEMBL1431443 & 688620 & 4.95 & 4.886 & TST \\
\hline CHEMBL1571977 & 688620 & 5.45 & 5.2072 & TST \\
\hline CHEMBL1484668 & 688620 & 5.95 & 5.2457 & TST \\
\hline CHEMBL1344871 & 688620 & 5.9 & 5.1157 & TRN \\
\hline CHEMBL1382205 & 688620 & 6.1 & 5.0674 & TST \\
\hline CHEMBL1546800 & 688620 & 4.8 & 5.1038 & TRN \\
\hline CHEMBL1419874 & 688620 & 5.6 & 5.0009 & TST \\
\hline CHEMBL1382789 & 688620 & 5.85 & 4.9299 & TRN \\
\hline CHEMBL1468455 & 688620 & 5.15 & 5.0152 & TRN \\
\hline CHEMBL1359344 & 688620 & 4.95 & 4.9995 & TST \\
\hline CHEMBL1490423 & 688620 & 4.9 & 5.1826 & TRN \\
\hline CHEMBL1457301 & 688620 & 5.5 & 5.1682 & TRN \\
\hline CHEMBL1438732 & 688620 & 4.45 & 4.8568 & TRN \\
\hline CHEMBL1361487 & 688620 & 4.45 & 4.9795 & TRN \\
\hline CHEMBL1378292 & 688620 & 4.5 & 5.0456 & TRN \\
\hline CHEMBL1612754 & 688620 & 5.2 & 5.2689 & TRN \\
\hline CHEMBL3193434 & 688620 & 4.85 & 5.0721 & TRN \\
\hline CHEMBL1602676 & 688620 & 6.25 & 4.8381 & TST \\
\hline CHEMBL1451753 & 688620 & 5.15 & 5.0255 & TRN \\
\hline CHEMBL1541244 & 688620 & 4.6 & 5.4324 & TRN \\
\hline CHEMBL1333278 & 688620 & 5.0 & 5.0971 & TST \\
\hline CHEMBL1300652 & 688620 & 4.7 & 5.0583 & TRN \\
\hline CHEMBL1608431 & 688620 & 5.3 & 5.0861 & TRN \\
\hline CHEMBL1366622 & 688620 & 4.45 & 5.2864 & TRN \\
\hline CHEMBL1420880 & 688620 & 4.45 & 5.055 & TRN \\
\hline CHEMBL1416799 & 688620 & 5.25 & 5.1013 & TRN \\
\hline CHEMBL1309252 & 688620 & 4.75 & 4.627 & TRN \\
\hline CHEMBL3197065 & 688620 & 5.3 & 5.7909 & TRN \\
\hline CHEMBL1315819 & 688620 & 4.7 & 4.89 & TRN \\
\hline CHEMBL1341756 & 688620 & 4.75 & 4.7086 & TRN \\
\hline CHEMBL1582505 & 688620 & 5.95 & 5.0658 & TST \\
\hline CHEMBL3194800 & 688620 & 5.1 & 4.8191 & TRN \\
\hline CHEMBL1599646 & 688620 & 4.55 & 5.1079 & TRN \\
\hline CHEMBL1558095 & 688620 & 6.9 & 7.5376 & TRN \\
\hline CHEMBL1528217 & 688620 & 4.9 & 5.1487 & TST \\
\hline CHEMBL1544486 & 688620 & 5.3 & 5.0362 & TRN \\
\hline CHEMBL1425472 & 688620 & 5.4 & 5.0432 & TRN \\
\hline CHEMBL1460496 & 688620 & 6.6499 & 6.1653 & TRN \\
\hline CHEMBL1363233 & 688620 & 4.9 & 5.2407 & TST \\
\hline CHEMBL1361068 & 688620 & 5.55 & 5.1601 & TRN \\
\hline
\end{tabular}




\begin{tabular}{|c|c|c|c|c|c|}
\hline \multicolumn{6}{|c|}{ Supplemental Table S2.txt } \\
\hline CHEMBL1497399 & 688620 & 4.85 & 4.9747 & TST & \\
\hline CHEMBL1446010 & 688620 & 4.65 & 4.9242 & TST & \\
\hline CHEMBL1345292 & 688620 & 5.0 & 4.8633 & TRN & \\
\hline CHEMBL1596823 & 688620 & 4.95 & 5.0517 & TRN & \\
\hline CHEMBL1472126 & 688620 & 4.95 & 4.6117 & TRN & \\
\hline CHEMBL1335288 & 688620 & 5.35 & 4.9814 & TRN & \\
\hline CHEMBL1378398 & 688620 & 4.85 & 4.8971 & TST & \\
\hline CHEMBL1529809 & 688620 & 4.45 & 4.7899 & TRN & \\
\hline CHEMBL1524838 & 688620 & 5.7 & 5.399 & TRN & \\
\hline CHEMBL1595294 & 688620 & 4.7 & 5.1051 & TRN & \\
\hline CHEMBL1421413 & 688620 & 4.85 & 4.8653 & TRN & \\
\hline CHEMBL1492687 & 688620 & 4.9 & 4.9588 & TRN & \\
\hline CHEMBL1335224 & 688620 & 4.8 & 4.6588 & TRN & \\
\hline CHEMBL1594989 & 688620 & 4.95 & 5.1844 & TST & \\
\hline CHEMBL1527607 & 688620 & 4.65 & 5.0827 & TST & \\
\hline CHEMBL1605678 & 688620 & 5.0 & 5.1241 & TRN & \\
\hline CHEMBL1971033 & 688620 & 5.7 & 5.6156 & TRN & \\
\hline CHEMBL 3199208 & 688620 & 4.45 & 4.9224 & TRN & \\
\hline CHEMBL1555595 & 688620 & 4.9 & 5.1907 & TRN & \\
\hline CHEMBL 3192749 & 688620 & 4.45 & 4.7473 & TRN & \\
\hline CHEMBL1426771 & 688620 & 5.0 & 4.9528 & TRN & \\
\hline CHEMBL1419303 & 688620 & 4.65 & 5.0815 & TST & \\
\hline CHEMBL1423081 & 688620 & 5.1 & 4.8013 & TRN & \\
\hline CHEMBL1449889 & 688620 & 6.15 & 5.0601 & TRN & \\
\hline CHEMBL1407280 & 688620 & 5.85 & 5.2123 & TRN & \\
\hline CHEMBL1595759 & 688620 & 5.7 & 5.5754 & TRN & \\
\hline CHEMBL1452227 & 688620 & 5.15 & 5.138 & TRN & \\
\hline CHEMBL3189767 & 688620 & 4.45 & 4.9112 & TRN & \\
\hline CHEMBL1467524 & 688620 & 5.35 & 5.25200 & 3000000001 & TRN \\
\hline CHEMBL 3213083 & 688620 & 4.45 & 4.8517 & TRN & \\
\hline CHEMBL1325480 & 688620 & 4.7 & 4.8366 & TRN & \\
\hline CHEMBL3197917 & 688620 & 4.7 & 4.984 & TRN & \\
\hline CHEMBL1329994 & 688620 & 5.1 & 4.8016 & TST & \\
\hline CHEMBL1522855 & 688620 & 5.2 & 5.0509 & TRN & \\
\hline CHEMBL1371874 & 688620 & 4.45 & 4.8154 & TRN & \\
\hline CHEMBL1324894 & 688620 & 5.65 & 5.4747 & TRN & \\
\hline CHEMBL1978383 & 688620 & 5.7 & 5.7019 & TRN & \\
\hline CHEMBL 3197680 & 688620 & 6.4 & 6.0642 & TRN & \\
\hline CHEMBL492116 & 688620 & 5.05 & 5.0084 & TRN & \\
\hline CHEMBL 3207693 & 688620 & 5.4 & 5.0201 & TRN & \\
\hline CHEMBL1528854 & 688620 & 5.0 & 4.8193 & TRN & \\
\hline CHEMBL1610058 & 688620 & 4.9 & 4.9336 & TST & \\
\hline CHEMBL1594536 & 688620 & 4.85 & 4.7876 & TRN & \\
\hline CHEMBL 3213163 & 688620 & 4.45 & 5.1116 & TST & \\
\hline CHEMBL1351599 & 688620 & 5.5 & 5.3441 & TRN & \\
\hline CHEMBL1329696 & 688620 & 4.9 & 4.8076 & TRN & \\
\hline CHEMBL1415670 & 688620 & 4.6 & 4.9603 & TRN & \\
\hline CHEMBL1448382 & 688620 & 4.85 & 4.817 & TRN & \\
\hline
\end{tabular}




\begin{tabular}{|c|c|c|c|c|c|}
\hline \\
\hline CHEMBL1705092 & 688620 & 5.5 & 5.4904 & TST & \\
\hline CHEMBL1529377 & 688620 & 4.45 & 4.8647 & TRN & \\
\hline CHEMBL1402356 & 688620 & 5.65 & 5.1961 & TRN & \\
\hline CHEMBL1605179 & 688620 & 5.45 & 5.1579 & TST & \\
\hline CHEMBL 2002465 & 688620 & 5.4 & 5.5284 & TRN & \\
\hline CHEMBL1545123 & 688620 & 4.75 & 5.1927 & TRN & \\
\hline CHEMBL1600352 & 688620 & 5.05 & 5.0023 & TRN & \\
\hline CHEMBL1299321 & 688620 & 4.45 & 5.3475 & TST & \\
\hline CHEMBL1300729 & 688620 & 6.6 & 6.256 & TRN & \\
\hline CHEMBL1562720 & 688620 & 4.45 & 4.8573 & TRN & \\
\hline CHEMBL1431705 & 688620 & 5.5 & 5.2993 & TRN & \\
\hline CHEMBL1418423 & 688620 & 4.6 & 5.0018 & TST & \\
\hline CHEMBL1403488 & 688620 & 4.75 & 4.8791 & TRN & \\
\hline CHEMBL1517779 & 688620 & 6.45 & 4.9091 & TST & \\
\hline CHEMBL1577126 & 688620 & 5.0 & 5.2542 & TRN & \\
\hline CHEMBL1565819 & 688620 & 4.85 & 4.9218 & TRN & \\
\hline CHEMBL1308266 & 688620 & 4.95 & 4.9632 & TRN & \\
\hline CHEMBL1537723 & 688620 & 5.15 & 5.2621 & TRN & \\
\hline CHEMBL1542333 & 688620 & 4.45 & 5.1646 & TRN & \\
\hline CHEMBL1411916 & 688620 & 6.1 & 5.0451 & TRN & \\
\hline CHEMBL1436964 & 688620 & 4.95 & 4.8122 & TRN & \\
\hline CHEMBL1458111 & 688620 & 5.95 & 5.3331 & TST & \\
\hline CHEMBL1463467 & 688620 & 4.95 & 4.9434 & TRN & \\
\hline CHEMBL1420379 & 688620 & 4.95 & 5.2388 & TRN & \\
\hline CHEMBL1557377 & 688620 & 7.1002 & 5.1501 & TRN & \\
\hline CHEMBL3210917 & 688620 & 4.95 & 4.9119 & TRN & \\
\hline CHEMBL1548183 & 688620 & 4.95 & 5.0039 & TRN & \\
\hline CHEMBL1964389 & 688620 & 6.15 & 5.53700 & 0000000001 & TRN \\
\hline CHEMBL1967775 & 688620 & 4.95 & 4.9935 & TST & \\
\hline CHEMBL1469838 & 688620 & 5.2 & 4.9664 & TRN & \\
\hline CHEMBL1402982 & 688620 & 4.45 & 4.8833 & TST & \\
\hline CHEMBL1344080 & 688620 & 4.85 & 5.1826 & TRN & \\
\hline CHEMBL1465741 & 688620 & 4.95 & 4.9472 & TRN & \\
\hline CHEMBL1577414 & 688620 & 6.3 & 5.2473 & TST & \\
\hline CHEMBL1533293 & 688620 & 4.7 & 5.1736 & TRN & \\
\hline CHEMBL3197230 & 688620 & 4.45 & 4.6846 & TRN & \\
\hline CHEMBL1438841 & 688620 & 4.65 & 4.9425 & TRN & \\
\hline CHEMBL1468438 & 688620 & 4.45 & 4.8254 & TRN & \\
\hline CHEMBL1312562 & 688620 & 5.15 & 5.3909 & TRN & \\
\hline CHEMBL1313191 & 688620 & 4.65 & 4.902 & TST & \\
\hline CHEMBL1424041 & 688620 & 5.35 & 5.1965 & TRN & \\
\hline CHEMBL1271764 & 688620 & 4.6 & 4.86 & TRN & \\
\hline CHEMBL1461037 & 688620 & 5.0 & 5.0157 & TRN & \\
\hline CHEMBL1490120 & 688620 & 4.8 & 4.8025 & TST & \\
\hline CHEMBL1583000 & 688620 & 4.75 & 4.8291 & TRN & \\
\hline CHEMBL1499036 & 688620 & 4.8 & 5.0075 & TRN & \\
\hline CHEMBL1467016 & 688620 & 5.15 & 5.4916 & TRN & \\
\hline CHEMBL1483857 & 688620 & 4.9 & 5.1798 & TRN & \\
\hline
\end{tabular}




\begin{tabular}{|c|c|c|c|c|}
\hline & & & upplemen & at \\
\hline CHEMBL1376146 & 688620 & 5.2 & 5.1649 & TST \\
\hline CHEMBL1376037 & 688620 & 4.7 & 4.5163 & TRN \\
\hline CHEMBL1456478 & 688620 & 5.25 & 5.3167 & TRN \\
\hline CHEMBL3199738 & 688620 & 4.95 & 4.9045 & TST \\
\hline CHEMBL1513578 & 688620 & 4.9 & 4.9749 & TRN \\
\hline CHEMBL580155 & 688620 & 4.9 & 5.1934 & TRN \\
\hline CHEMBL1371423 & 688620 & 4.45 & 4.8429 & TRN \\
\hline CHEMBL1981378 & 688620 & 5.6 & 5.6996 & TRN \\
\hline CHEMBL1583292 & 688620 & 5.8 & 6.0137 & TRN \\
\hline CHEMBL1416494 & 688620 & 4.9 & 4.9585 & TST \\
\hline CHEMBL3192650 & 688620 & 4.5 & 5.0022 & TRN \\
\hline CHEMBL1604833 & 688620 & 6.6 & 5.3623 & TRN \\
\hline CHEMBL1728993 & 688620 & 4.9 & 4.6364 & TRN \\
\hline CHEMBL1520217 & 688620 & 4.9 & 4.7685 & TRN \\
\hline CHEMBL1467841 & 688620 & 4.8 & 5.2522 & TRN \\
\hline CHEMBL3197286 & 688620 & 4.95 & 4.9823 & TST \\
\hline CHEMBL1389827 & 688620 & 4.85 & 5.2111 & TRN \\
\hline CHEMBL1541923 & 688620 & 5.5 & 5.1387 & TST \\
\hline CHEMBL1368739 & 688620 & 4.75 & 4.8871 & TRN \\
\hline CHEMBL1368833 & 688620 & 5.2 & 5.0785 & TRN \\
\hline CHEMBL1531349 & 688620 & 4.85 & 4.7063 & TRN \\
\hline CHEMBL1986785 & 688620 & 5.25 & 5.144 & TRN \\
\hline CHEMBL1410566 & 688620 & 5.15 & 5.0565 & TST \\
\hline CHEMBL3213303 & 688620 & 6.1 & 5.3112 & TRN \\
\hline CHEMBL3199452 & 688620 & 5.95 & 5.4671 & TRN \\
\hline CHEMBL1610040 & 688620 & 4.85 & 4.8554 & TRN \\
\hline CHEMBL1984719 & 688620 & 4.6 & 5.1504 & TRN \\
\hline CHEMBL1323795 & 688620 & 5.1 & 5.1141 & TRN \\
\hline CHEMBL1357018 & 688620 & 4.95 & 4.7866 & TRN \\
\hline CHEMBL1580652 & 688620 & 4.85 & 4.8845 & TRN \\
\hline CHEMBL1344163 & 688620 & 4.45 & 5.1523 & TRN \\
\hline CHEMBL1490442 & 688620 & 5.05 & 5.205 & TRN \\
\hline CHEMBL1453230 & 688620 & 5.6 & 4.928 & TST \\
\hline CHEMBL1407100 & 688620 & 4.75 & 4.8603 & TRN \\
\hline CHEMBL1585697 & 688620 & 4.85 & 4.9235 & TRN \\
\hline CHEMBL1459458 & 688620 & 5.0 & 5.1822 & TRN \\
\hline CHEMBL1343308 & 688620 & 4.7 & 5.0312 & TRN \\
\hline CHEMBL3197906 & 688620 & 5.15 & 5.2984 & TRN \\
\hline CHEMBL1409305 & 688620 & 4.75 & 5.1539 & TRN \\
\hline CHEMBL1597004 & 688620 & 4.65 & 4.8528 & TST \\
\hline CHEMBL1348299 & 688620 & 4.95 & 5.1057 & TRN \\
\hline CHEMBL1426004 & 688620 & 4.55 & 4.8109 & TRN \\
\hline CHEMBL3195487 & 688620 & 4.45 & 4.9274 & TRN \\
\hline CHEMBL1350373 & 688620 & 5.95 & 6.1731 & TRN \\
\hline CHEMBL 2007354 & 688620 & 4.6 & 5.0545 & TRN \\
\hline CHEMBL1395220 & 688620 & 4.95 & 5.0063 & TRN \\
\hline CHEMBL1323290 & 688620 & 5.45 & 5.2272 & TRN \\
\hline CHEMBL1521480 & 688620 & 5.6 & 5.1912 & TRN \\
\hline
\end{tabular}




\begin{tabular}{|c|c|c|c|c|c|}
\hline \multicolumn{6}{|c|}{ Supplemental Table S2.txt } \\
\hline CHEMBL1423858 & 688620 & 4.95 & 4.9435 & TRN & \\
\hline CHEMBL1459809 & 688620 & 5.8 & 5.4285 & TRN & \\
\hline CHEMBL1468765 & 688620 & 4.5 & 5.1874 & TRN & \\
\hline CHEMBL1562842 & 688620 & 4.9 & 5.1992 & TST & \\
\hline CHEMBL3198232 & 688620 & 4.85 & 5.3925 & TRN & \\
\hline CHEMBL1548606 & 688620 & 5.1 & 5.0562 & TRN & \\
\hline CHEMBL1568506 & 688620 & 4.95 & 4.9713 & TRN & \\
\hline CHEMBL3214435 & 688620 & 4.95 & 5.0264 & TRN & \\
\hline CHEMBL1321614 & 688620 & 5.15 & 5.2507 & TRN & \\
\hline CHEMBL1359279 & 688620 & 5.8 & 5.1474 & TRN & \\
\hline CHEMBL1570841 & 688620 & 4.45 & 4.8601 & TRN & \\
\hline CHEMBL1444864 & 688620 & 4.85 & 5.0534 & TST & \\
\hline CHEMBL3196037 & 688620 & 5.0 & 4.9569 & TRN & \\
\hline CHEMBL3192021 & 688620 & 5.9 & 5.8307 & TRN & \\
\hline CHEMBL1570763 & 688620 & 4.45 & 4.7951 & TRN & \\
\hline CHEMBL1364832 & 688620 & 5.5 & 5.0794 & TRN & \\
\hline CHEMBL1560637 & 688620 & 5.65 & 5.4914 & TRN & \\
\hline CHEMBL1363291 & 688620 & 5.7 & 5.1989 & TRN & \\
\hline CHEMBL1425561 & 688620 & 4.9 & 4.9617 & TRN & \\
\hline CHEMBL1601587 & 688620 & 4.75 & 4.8194 & TRN & \\
\hline CHEMBL3198420 & 688620 & 4.65 & 4.8431 & TRN & \\
\hline CHEMBL1256360 & 688620 & 4.9 & 5.0176 & TST & \\
\hline CHEMBL1491681 & 688620 & 4.9 & 5.3845 & TST & \\
\hline CHEMBL1485259 & 688620 & 4.45 & 4.8159 & TRN & \\
\hline CHEMBL1550406 & 688620 & 4.7 & 4.9984 & TRN & \\
\hline CHEMBL1586213 & 688620 & 4.45 & 4.9573 & TRN & \\
\hline CHEMBL1308586 & 688620 & 4.95 & 5.0314 & TRN & \\
\hline CHEMBL3198006 & 688620 & 5.6 & 4.8610 & 0000000001 & TRN \\
\hline CHEMBL1411527 & 688620 & 4.45 & 4.9981 & TRN & \\
\hline CHEMBL1540371 & 688620 & 4.9 & 4.9691 & TST & \\
\hline CHEMBL1321739 & 688620 & 4.7 & 4.8043 & TRN & \\
\hline CHEMBL1555662 & 688620 & 4.9 & 5.1412 & TST & \\
\hline CHEMBL1484071 & 688620 & 4.8 & 4.8696 & TST & \\
\hline CHEMBL1359000 & 688620 & 4.85 & 5.1051 & TRN & \\
\hline CHEMBL 258893 & 688620 & 6.0 & 5.0939 & 9999999999 & TST \\
\hline CHEMBL1328443 & 688620 & 4.45 & 5.09 & TRN & \\
\hline CHEMBL3192451 & 688620 & 5.35 & 4.8838 & TST & \\
\hline CHEMBL1454463 & 688620 & 4.65 & 4.8646 & TRN & \\
\hline CHEMBL1607666 & 688620 & 4.65 & 4.8498 & TRN & \\
\hline CHEMBL1393351 & 688620 & 6.0 & 5.4978 & TRN & \\
\hline CHEMBL1430042 & 688620 & 5.65 & 4.9491 & TRN & \\
\hline CHEMBL3190228 & 688620 & 4.9 & 5.136 & TRN & \\
\hline CHEMBL1603577 & 688620 & 5.55 & 5.2229 & TRN & \\
\hline CHEMBL1465267 & 688620 & 5.45 & 4.9856 & TRN & \\
\hline CHEMBL1500686 & 688620 & 4.65 & 4.8478 & TRN & \\
\hline CHEMBL3195300 & 688620 & 5.1 & 4.8983 & TRN & \\
\hline CHEMBL1363578 & 688620 & 4.8 & 5.1496 & TRN & \\
\hline CHEMBL1343620 & 688620 & 6.2 & 5.2541 & TRN & \\
\hline
\end{tabular}




\begin{tabular}{|c|c|c|c|c|c|}
\hline & & \multicolumn{4}{|c|}{ Supplemental Table S2.txt } \\
\hline CHEMBL1594220 & 688620 & 5.55 & 4.7173 & TRN & \\
\hline CHEMBL3199878 & 688620 & 4.9 & 5.0043 & TRN & \\
\hline CHEMBL1350239 & 688620 & 5.2 & 4.8488 & TRN & \\
\hline CHEMBL1493127 & 688620 & 5.2 & 4.95100 & 00000000005 & TRN \\
\hline CHEMBL3197665 & 688620 & 5.45 & 5.0616 & TRN & \\
\hline CHEMBL1526129 & 688620 & 4.95 & 4.8607 & TRN & \\
\hline CHEMBL1606362 & 688620 & 4.45 & 4.9921 & TST & \\
\hline CHEMBL1411215 & 688620 & 4.95 & 5.0663 & TRN & \\
\hline CHEMBL1389933 & 688620 & 5.8 & 5.4929 & TRN & \\
\hline CHEMBL1341443 & 688620 & 4.45 & 5.0843 & TRN & \\
\hline CHEMBL1338615 & 688620 & 4.9 & 4.8833 & TST & \\
\hline CHEMBL1520166 & 688620 & 4.8 & 4.8701 & TRN & \\
\hline CHEMBL1428366 & 688620 & 4.95 & 5.0957 & TST & \\
\hline CHEMBL1418741 & 688620 & 4.65 & 5.1746 & TRN & \\
\hline CHEMBL1340066 & 688620 & 5.8 & 4.8745 & TRN & \\
\hline CHEMBL3145377 & 688620 & 6.25 & 5.7523 & TRN & \\
\hline CHEMBL1413056 & 688620 & 5.25 & 4.9665 & TRN & \\
\hline CHEMBL602975 & 688620 & 4.6 & 4.74100 & 00000000005 & TST \\
\hline CHEMBL 3210060 & 688620 & 4.45 & 4.9679 & TRN & \\
\hline CHEMBL1442373 & 688620 & 4.75 & 4.7906 & TRN & \\
\hline CHEMBL1439938 & 688620 & 5.5 & 5.2891 & TRN & \\
\hline CHEMBL1425612 & 688620 & 5.0 & 4.9886 & TRN & \\
\hline CHEMBL592552 & 688620 & 4.65 & 4.7756 & TRN & \\
\hline CHEMBL1594557 & 688620 & 4.45 & 5.2223 & TRN & \\
\hline CHEMBL1568352 & 688620 & 4.95 & 5.1514 & TRN & \\
\hline CHEMBL3194969 & 688620 & 5.8 & 5.6031 & TRN & \\
\hline CHEMBL1530789 & 688620 & 5.35 & 5.5238 & TRN & \\
\hline CHEMBL3208691 & 688620 & 4.95 & 5.31 & TST & \\
\hline CHEMBL1417715 & 688620 & 4.95 & 5.1311 & TRN & \\
\hline CHEMBL3197750 & 688620 & 4.95 & 5.3323 & TRN & \\
\hline CHEMBL1308295 & 688620 & 4.75 & 4.707 & TST & \\
\hline CHEMBL1508531 & 688620 & 4.45 & 4.9515 & TRN & \\
\hline CHEMBL3212098 & 688620 & 5.3 & 5.1566 & TST & \\
\hline CHEMBL1455862 & 688620 & 5.1 & 5.1209 & TST & \\
\hline CHEMBL1492993 & 688620 & 6.9 & 5.0343 & TST & \\
\hline CHEMBL1974901 & 688620 & 6.05 & 5.894 & TRN & \\
\hline CHEMBL1576212 & 688620 & 5.2 & 4.9682 & TST & \\
\hline CHEMBL1469041 & 688620 & 4.7 & 4.7703 & TRN & \\
\hline CHEMBL1497133 & 688620 & 4.45 & 4.9491 & TST & \\
\hline CHEMBL3196108 & 688620 & 4.9 & 5.1743 & TRN & \\
\hline CHEMBL1550112 & 688620 & 4.45 & 5.0166 & TRN & \\
\hline CHEMBL3189285 & 688620 & 4.45 & 4.9591 & TST & \\
\hline CHEMBL1407491 & 688620 & 6.35 & 5.0742 & TST & \\
\hline CHEMBL1608266 & 688620 & 5.2 & 4.9473 & TRN & \\
\hline CHEMBL1365464 & 688620 & 4.85 & 5.2042 & TRN & \\
\hline CHEMBL1367691 & 688620 & 5.35 & 4.7127 & TST & \\
\hline CHEMBL1462428 & 688620 & 4.95 & 4.9487 & TST & \\
\hline CHEMBL1467936 & 688620 & 4.95 & 4.9715 & TRN & \\
\hline
\end{tabular}




\begin{tabular}{|c|c|c|c|c|c|}
\hline \multicolumn{6}{|c|}{ Supplemental Table S2.txt } \\
\hline CHEMBL1458452 & 688620 & 4.75 & 5.0053 & TRN & \\
\hline CHEMBL1599290 & 688620 & 6.2 & 5.5011 & TRN & \\
\hline CHEMBL1483734 & 688620 & 5.7 & 5.5213 & TRN & \\
\hline CHEMBL 3145303 & 688620 & 7.3002 & 7.2816 & TRN & \\
\hline CHEMBL1391919 & 688620 & 5.05 & 4.6425 & TRN & \\
\hline CHEMBL1351168 & 688620 & 4.45 & 4.85 & TRN & \\
\hline CHEMBL1427572 & 688620 & 4.9 & 4.8248 & TRN & \\
\hline CHEMBL1611102 & 688620 & 5.0 & 5.3231 & TST & \\
\hline CHEMBL1465694 & 688620 & 4.45 & 4.7641 & TST & \\
\hline CHEMBL1475029 & 688620 & 5.0 & 5.6107 & TST & \\
\hline CHEMBL1559095 & 688620 & 6.8499 & 5.2577 & TRN & \\
\hline CHEMBL1454753 & 688620 & 4.7 & 4.8567 & TRN & \\
\hline CHEMBL1465652 & 688620 & 4.5 & 4.7852 & TST & \\
\hline CHEMBL1460409 & 688620 & 4.75 & 5.1985 & TST & \\
\hline CHEMBL1347071 & 688620 & 5.05 & 5.3319 & TRN & \\
\hline CHEMBL1326215 & 688620 & 5.85 & 5.0472 & TST & \\
\hline CHEMBL85194 & 688620 & 4.9 & 5.2272 & TRN & \\
\hline CHEMBL1585187 & 688620 & 4.8 & 5.4299 & TRN & \\
\hline CHEMBL3192835 & 688620 & 4.8 & 5.1242 & TRN & \\
\hline CHEMBL1561936 & 688620 & 4.6 & 5.0145 & TRN & \\
\hline CHEMBL1520903 & 688620 & 4.85 & 5.005 & TRN & \\
\hline CHEMBL1557342 & 688620 & 4.85 & 5.1132 & TRN & \\
\hline CHEMBL1577116 & 688620 & 4.9 & 5.3293 & TRN & \\
\hline CHEMBL1485287 & 688620 & 6.2 & 5.13899 & 9999999999 & TRN \\
\hline CHEMBL1582160 & 688620 & 5.25 & 5.0865 & TST & \\
\hline CHEMBL3191087 & 688620 & 5.9 & 5.621 & TRN & \\
\hline CHEMBL1981923 & 688620 & 6.2 & 5.5232 & TRN & \\
\hline CHEMBL3198070 & 688620 & 6.1 & 5.7778 & TRN & \\
\hline CHEMBL1612168 & 688620 & 5.0 & 5.2456 & TRN & \\
\hline CHEMBL1409203 & 688620 & 4.95 & 5.1196 & TRN & \\
\hline CHEMBL1448617 & 688620 & 4.8 & 5.0308 & TRN & \\
\hline CHEMBL1345306 & 688620 & 4.7 & 5.2109 & TRN & \\
\hline CHEMBL1375572 & 688620 & 4.95 & 5.1563 & TST & \\
\hline CHEMBL2369228 & 688620 & 6.8 & 5.6348 & TRN & \\
\hline CHEMBL1555591 & 688620 & 5.9 & 5.5826 & TST & \\
\hline CHEMBL1336675 & 688620 & 4.95 & 5.5563 & TRN & \\
\hline CHEMBL3195574 & 688620 & 4.75 & 4.996 & TST & \\
\hline CHEMBL1607877 & 688620 & 4.45 & 4.6858 & TRN & \\
\hline CHEMBL3198191 & 688620 & 4.45 & 5.1647 & TRN & \\
\hline CHEMBL1385875 & 688620 & 4.45 & 5.1337 & TRN & \\
\hline CHEMBL1526131 & 688620 & 4.45 & 5.0195 & TRN & \\
\hline CHEMBL1596586 & 688620 & 4.9 & 4.9046 & TRN & \\
\hline CHEMBL1970152 & 688620 & 4.95 & 4.7843 & TRN & \\
\hline CHEMBL1387106 & 688620 & 5.4 & 5.1368 & TRN & \\
\hline CHEMBL1570637 & 688620 & 4.55 & 5.0345 & TST & \\
\hline CHEMBL3198105 & 688620 & 5.75 & 5.3138 & TRN & \\
\hline CHEMBL1529080 & 688620 & 4.8 & 4.9958 & TST & \\
\hline CHEMBL3195849 & 688620 & 5.55 & 5.2421 & TRN & \\
\hline
\end{tabular}




\begin{tabular}{|c|c|c|c|c|}
\hline \multicolumn{5}{|c|}{ Supplemental Table S2.txt } \\
\hline CHEMBL1551310 & 688620 & 4.45 & 4.9954 & TRN \\
\hline CHEMBL1404417 & 688620 & 4.95 & 4.8758 & TRN \\
\hline CHEMBL 3208410 & 688620 & 4.45 & 5.0878 & TRN \\
\hline CHEMBL1412396 & 688620 & 5.15 & 5.3355 & TRN \\
\hline CHEMBL 3192270 & 688620 & 5.0 & 5.1808 & TRN \\
\hline CHEMBL1499515 & 688620 & 5.0 & 5.2137 & TRN \\
\hline CHEMBL1372397 & 688620 & 4.95 & 5.0045 & TRN \\
\hline CHEMBL1385885 & 688620 & 4.6 & 5.2212 & TST \\
\hline CHEMBL1334795 & 688620 & 4.9 & 5.0124 & TRN \\
\hline CHEMBL1439385 & 688620 & 6.2 & 6.1112 & TRN \\
\hline CHEMBL1485632 & 688620 & 4.95 & 4.8489 & TRN \\
\hline CHEMBL1312049 & 688620 & 5.45 & 5.352 & TRN \\
\hline CHEMBL 3208475 & 688620 & 5.35 & 5.3376 & TRN \\
\hline CHEMBL 3192078 & 688620 & 5.4 & 5.3952 & TRN \\
\hline CHEMBL1421427 & 688620 & 6.3 & 5.4032 & TRN \\
\hline CHEMBL1592327 & 688620 & 4.75 & 5.0027 & TRN \\
\hline CHEMBL1321451 & 688620 & 4.95 & 4.8477 & TRN \\
\hline CHEMBL1604546 & 688620 & 5.5 & 5.1683 & TRN \\
\hline CHEMBL1604398 & 688620 & 4.95 & 4.8543 & TRN \\
\hline CHEMBL1604256 & 688620 & 4.45 & 5.1132 & TRN \\
\hline CHEMBL1453319 & 688620 & 5.0 & 5.0401 & TRN \\
\hline CHEMBL1306481 & 688620 & 4.95 & 5.2157 & TST \\
\hline CHEMBL1483193 & 688620 & 5.0 & 4.9901 & TST \\
\hline CHEMBL1379137 & 688620 & 4.95 & 4.8168 & TST \\
\hline CHEMBL1480050 & 688620 & 4.9 & 5.1198 & TRN \\
\hline CHEMBL1965786 & 688620 & 5.15 & 5.0355 & TRN \\
\hline CHEMBL1498969 & 688620 & 4.45 & 5.1555 & TRN \\
\hline CHEMBL1449446 & 688620 & 4.6 & 5.1164 & TRN \\
\hline CHEMBL1444670 & 688620 & 5.8 & 5.7728 & TRN \\
\hline CHEMBL1604630 & 688620 & 4.95 & 5.0573 & TRN \\
\hline CHEMBL1531932 & 688620 & 6.1 & 5.2756 & TST \\
\hline CHEMBL1308772 & 688620 & 4.7 & 4.9976 & TRN \\
\hline CHEMBL1448387 & 688620 & 6.0 & 5.0365 & TST \\
\hline CHEMBL1410367 & 688620 & 4.7 & 4.9845 & TST \\
\hline CHEMBL1500320 & 688620 & 5.15 & 5.442 & TST \\
\hline CHEMBL1572559 & 688620 & 4.75 & 4.9026 & TRN \\
\hline CHEMBL1404563 & 688620 & 5.35 & 5.1044 & TST \\
\hline CHEMBL1387042 & 688620 & 4.9 & 5.0089 & TRN \\
\hline CHEMBL1329016 & 688620 & 4.7 & 4.5165 & TRN \\
\hline CHEMBL1439031 & 688620 & 5.4 & 5.1475 & TRN \\
\hline CHEMBL1387641 & 688620 & 4.95 & 5.3628 & TRN \\
\hline CHEMBL1549509 & 688620 & 5.35 & 5.0031 & TST \\
\hline CHEMBL1312042 & 688620 & 5.55 & 5.0253 & TRN \\
\hline CHEMBL1607909 & 688620 & 5.75 & 5.3927 & TRN \\
\hline CHEMBL2003559 & 688620 & 4.95 & 5.0304 & TRN \\
\hline CHEMBL1326280 & 688620 & 5.0 & 4.8768 & TRN \\
\hline CHEMBL3190102 & 688620 & 4.45 & 5.1505 & TRN \\
\hline CHEMBL1585294 & 688620 & 4.75 & 5.1218 & TRN \\
\hline
\end{tabular}




\begin{tabular}{|c|c|c|c|c|c|}
\hline \multicolumn{6}{|c|}{ Supplemental Table S2.txt } \\
\hline CHEMBL1350636 & 688620 & 4.95 & 4.9691 & TRN & \\
\hline CHEMBL1460413 & 688620 & 4.9 & 5.1041 & TST & \\
\hline CHEMBL1416473 & 688620 & 4.95 & 4.9469 & TRN & \\
\hline CHEMBL1445652 & 688620 & 6.1 & 5.099 & TST & \\
\hline CHEMBL1455861 & 688620 & 5.9 & 5.4178 & TRN & \\
\hline CHEMBL1542164 & 688620 & 5.45 & 5.0611 & TRN & \\
\hline CHEMBL1591674 & 688620 & 4.45 & 4.7581 & TRN & \\
\hline CHEMBL1419975 & 688620 & 5.25 & 5.2093 & TRN & \\
\hline CHEMBL1576984 & 688620 & 5.5 & 4.7245 & TRN & \\
\hline CHEMBL1340729 & 688620 & 4.45 & 4.9571 & TRN & \\
\hline CHEMBL1558406 & 688620 & 5.4 & 5.3129 & TST & \\
\hline CHEMBL1420943 & 688620 & 4.65 & 4.9772 & TST & \\
\hline CHEMBL1425975 & 688620 & 4.6 & 5.6816 & TRN & \\
\hline CHEMBL1333712 & 688620 & 4.85 & 5.0932 & TRN & \\
\hline CHEMBL1564510 & 688620 & 4.6 & 5.16100 & 00000000005 & TST \\
\hline CHEMBL1333151 & 688620 & 5.05 & 5.2228 & TST & \\
\hline CHEMBL547285 & 688620 & 5.8 & 5.9026 & TRN & \\
\hline CHEMBL1591815 & 688620 & 5.0 & 4.8782 & TRN & \\
\hline CHEMBL1598909 & 688620 & 5.1 & 5.8324 & TRN & \\
\hline CHEMBL1540594 & 688620 & 5.0 & 4.9192 & TST & \\
\hline CHEMBL1598190 & 688620 & 5.2 & 5.1445 & TST & \\
\hline CHEMBL1301655 & 688620 & 6.5501 & 6.4803 & TRN & \\
\hline CHEMBL1509973 & 688620 & 4.5 & 4.8517 & TRN & \\
\hline CHEMBL1572269 & 688620 & 4.85 & 5.3196 & TRN & \\
\hline CHEMBL1567778 & 688620 & 5.85 & 5.103 & TRN & \\
\hline CHEMBL3213801 & 688620 & 4.65 & 4.9736 & TST & \\
\hline CHEMBL1984628 & 688620 & 5.05 & 5.0823 & TST & \\
\hline CHEMBL1371479 & 688620 & 5.4 & 5.1701 & TRN & \\
\hline CHEMBL1563148 & 688620 & 6.1 & 4.9791 & TRN & \\
\hline CHEMBL1470194 & 688620 & 4.75 & 4.8105 & TRN & \\
\hline CHEMBL1330840 & 688620 & 5.3 & 4.8785 & TRN & \\
\hline CHEMBL1307023 & 688620 & 4.95 & 5.182 & TRN & \\
\hline CHEMBL1496410 & 688620 & 5.2 & 5.0065 & TRN & \\
\hline CHEMBL1326615 & 688620 & 5.2 & 5.1107 & TRN & \\
\hline CHEMBL1524651 & 688620 & 4.45 & 5.1076 & TST & \\
\hline CHEMBL1306496 & 688620 & 4.95 & 5.0454 & TST & \\
\hline CHEMBL1351929 & 688620 & 4.9 & 5.0487 & TRN & \\
\hline CHEMBL1304480 & 688620 & 5.15 & 5.4089 & TRN & \\
\hline CHEMBL1582747 & 688620 & 4.95 & 4.8156 & TRN & \\
\hline CHEMBL1577657 & 688620 & 4.45 & 5.0833 & TRN & \\
\hline CHEMBL1517369 & 688620 & 5.0 & 5.0906 & TRN & \\
\hline CHEMBL1573159 & 688620 & 5.45 & 4.9934 & TRN & \\
\hline CHEMBL1432155 & 688620 & 4.9 & 4.9785 & TRN & \\
\hline CHEMBL1542491 & 688620 & 4.9 & 4.9865 & TST & \\
\hline CHEMBL1468262 & 688620 & 6.5 & 5.1088 & TRN & \\
\hline CHEMBL1504728 & 688620 & 5.65 & 5.5341 & TRN & \\
\hline CHEMBL1463461 & 688620 & 5.35 & 5.2274 & TST & \\
\hline CHEMBL1459790 & 688620 & 4.8 & 5.1773 & TRN & \\
\hline
\end{tabular}




\begin{tabular}{|c|c|c|c|c|}
\hline \multicolumn{5}{|c|}{ Supplemental Table S2.txt } \\
\hline CHEMBL 3190023 & 688620 & 4.75 & 4.8971 & TRN \\
\hline CHEMBL1497463 & 688620 & 4.8 & 5.6198 & TRN \\
\hline CHEMBL1612730 & 688620 & 4.85 & 4.9589 & TST \\
\hline CHEMBL1378922 & 688620 & 4.7 & 4.9661 & TST \\
\hline CHEMBL1371859 & 688620 & 4.75 & 5.1536 & TST \\
\hline CHEMBL1594474 & 688620 & 4.85 & 4.9432 & TRN \\
\hline CHEMBL1598139 & 688620 & 4.45 & 4.9763 & TRN \\
\hline CHEMBL1327470 & 688620 & 4.45 & 4.7335 & TRN \\
\hline CHEMBL1550064 & 688620 & 4.8 & 5.0067 & TRN \\
\hline CHEMBL1319582 & 688620 & 4.6 & 4.9566 & TRN \\
\hline CHEMBL3195173 & 688620 & 5.95 & 5.8511 & TRN \\
\hline CHEMBL1365226 & 688620 & 4.45 & 5.0169 & TRN \\
\hline CHEMBL1310221 & 688620 & 5.2 & 5.3388 & TRN \\
\hline CHEMBL1408625 & 688620 & 4.85 & 5.1053 & TRN \\
\hline CHEMBL3190868 & 688620 & 5.2 & 5.5911 & TRN \\
\hline CHEMBL1565547 & 688620 & 5.7 & 5.0928 & TRN \\
\hline CHEMBL1568419 & 688620 & 4.95 & 4.8748 & TRN \\
\hline CHEMBL1573697 & 688620 & 6.0 & 5.5253 & TRN \\
\hline CHEMBL1499073 & 688620 & 4.45 & 5.0474 & TRN \\
\hline CHEMBL1484970 & 688620 & 4.65 & 5.2673 & TST \\
\hline CHEMBL1379601 & 688620 & 4.9 & 5.0315 & TRN \\
\hline CHEMBL1491601 & 688620 & 4.45 & 5.1761 & TRN \\
\hline CHEMBL1434324 & 688620 & 4.5 & 5.0356 & TRN \\
\hline CHEMBL1974230 & 688620 & 4.45 & 4.853 & TRN \\
\hline CHEMBL1603171 & 688620 & 4.9 & 4.9119 & TRN \\
\hline CHEMBL1478787 & 688620 & 7.0 & 5.084 & TRN \\
\hline CHEMBL1358368 & 688620 & 4.75 & 4.7315 & TRN \\
\hline CHEMBL3198433 & 688620 & 6.6499 & 5.0973 & TST \\
\hline CHEMBL1413956 & 688620 & 6.1 & 5.0793 & TRN \\
\hline CHEMBL1382351 & 688620 & 4.45 & 5.4032 & TRN \\
\hline CHEMBL578943 & 688620 & 6.0 & 5.2892 & TRN \\
\hline CHEMBL1543494 & 688620 & 4.45 & 4.9344 & TRN \\
\hline CHEMBL1402215 & 688620 & 4.7 & 5.0034 & TRN \\
\hline CHEMBL1516527 & 688620 & 4.85 & 5.2272 & TST \\
\hline CHEMBL1322033 & 688620 & 4.5 & 4.9729 & TRN \\
\hline CHEMBL1580529 & 688620 & 6.1 & 4.9291 & TRN \\
\hline CHEMBL1309524 & 688620 & 4.7 & 4.9659 & TST \\
\hline CHEMBL1607857 & 688620 & 5.3 & 5.0726 & TST \\
\hline CHEMBL1521590 & 688620 & 4.45 & 5.069 & TRN \\
\hline CHEMBL1489503 & 688620 & 6.25 & 5.2298 & TRN \\
\hline CHEMBL1545502 & 688620 & 5.4 & 5.0474 & TRN \\
\hline CHEMBL1555743 & 688620 & 6.35 & 5.5936 & TRN \\
\hline CHEMBL1526182 & 688620 & 4.6 & 5.0315 & TST \\
\hline CHEMBL1386916 & 688620 & 5.1 & 5.1744 & TRN \\
\hline CHEMBL1504590 & 688620 & 5.7 & 5.2358 & TRN \\
\hline CHEMBL1417957 & 688620 & 4.95 & 4.7871 & TRN \\
\hline CHEMBL1328193 & 688620 & 4.75 & 4.8441 & TST \\
\hline CHEMBL1362462 & 688620 & 4.7 & 4.6646 & TRN \\
\hline
\end{tabular}




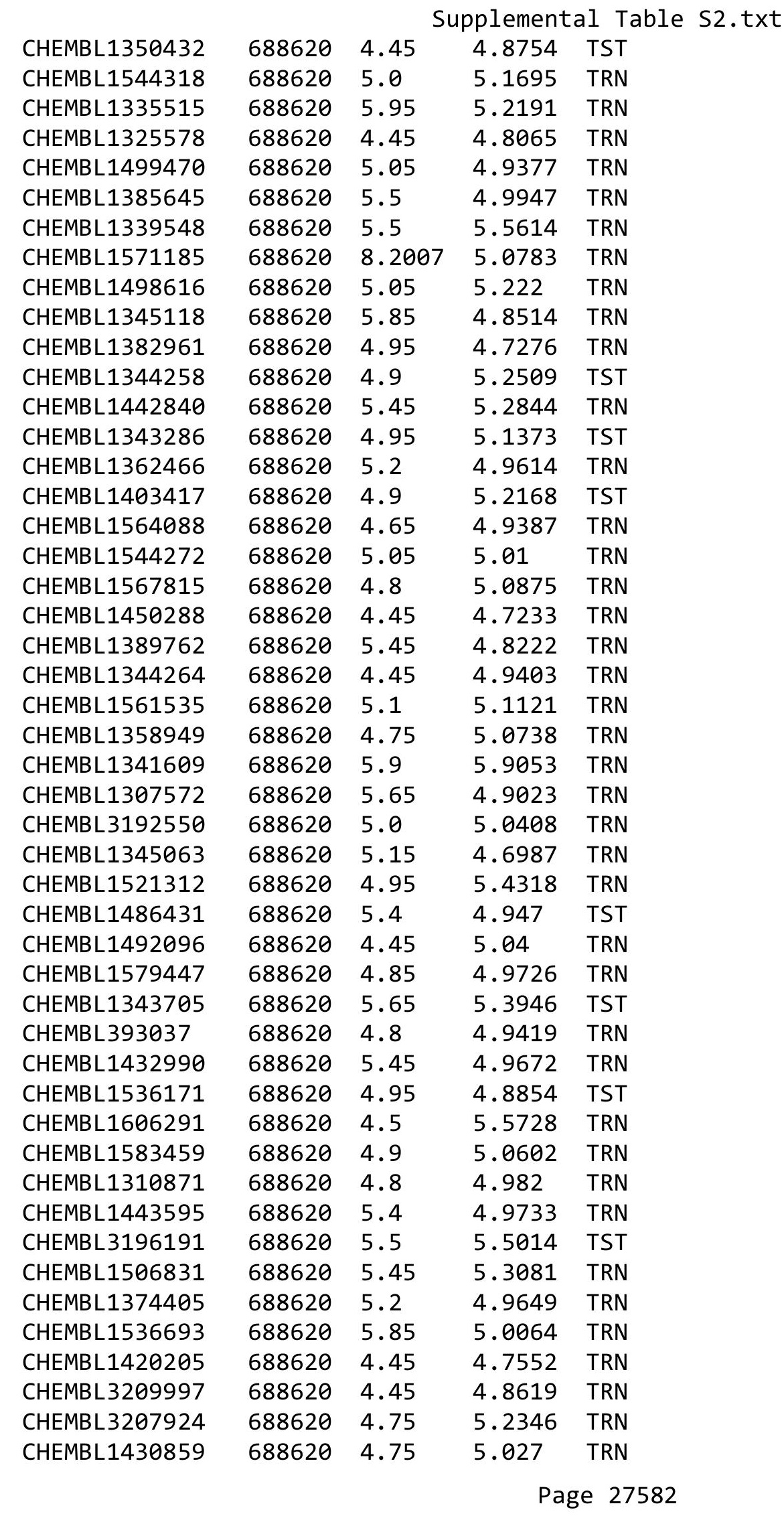




\begin{tabular}{|c|c|c|c|c|}
\hline \multicolumn{5}{|c|}{ Supplemental Table S2.txt } \\
\hline CHEMBL1550123 & 688620 & 4.55 & 5.3594 & TRN \\
\hline CHEMBL1489239 & 688620 & 4.45 & 4.9098 & TST \\
\hline CHEMBL1613609 & 688620 & 4.9 & 5.1642 & TRN \\
\hline CHEMBL1394070 & 688620 & 5.95 & 5.5921 & TRN \\
\hline CHEMBL1303653 & 688620 & 5.25 & 4.9649 & TRN \\
\hline CHEMBL489934 & 688620 & 4.45 & 4.8804 & TRN \\
\hline CHEMBL1488028 & 688620 & 5.85 & 5.0783 & TST \\
\hline CHEMBL1601977 & 688620 & 5.5 & 5.0876 & TRN \\
\hline CHEMBL1416928 & 688620 & 4.45 & 5.0619 & TST \\
\hline CHEMBL1310268 & 688620 & 4.45 & 5.1683 & TST \\
\hline CHEMBL1351050 & 688620 & 4.65 & 4.9398 & TRN \\
\hline CHEMBL1557217 & 688620 & 5.5 & 5.1303 & TRN \\
\hline CHEMBL1977369 & 688620 & 5.3 & 5.3408 & TRN \\
\hline CHEMBL 3192143 & 688620 & 5.7 & 5.7809 & TRN \\
\hline CHEMBL1300789 & 688620 & 4.95 & 5.0656 & TRN \\
\hline CHEMBL1536400 & 688620 & 4.95 & 5.0034 & TRN \\
\hline CHEMBL1350993 & 688620 & 5.2 & 4.9785 & TRN \\
\hline CHEMBL1510228 & 688620 & 5.8 & 5.4506 & TRN \\
\hline CHEMBL1427392 & 688620 & 5.3 & 5.1148 & TST \\
\hline CHEMBL3211207 & 688620 & 5.95 & 5.4072 & TRN \\
\hline CHEMBL1466466 & 688620 & 5.25 & 5.19600 & 0000000001 \\
\hline CHEMBL1476347 & 688620 & 4.9 & 4.8446 & TRN \\
\hline CHEMBL1544358 & 688620 & 5.3 & 5.1613 & TRN \\
\hline CHEMBL1385479 & 688620 & 4.45 & 4.7171 & TRN \\
\hline CHEMBL1467830 & 688620 & 4.45 & 4.8355 & TST \\
\hline CHEMBL3194414 & 688620 & 7.6003 & 4.9345 & TST \\
\hline CHEMBL1606289 & 688620 & 4.85 & 5.2151 & TRN \\
\hline CHEMBL1516659 & 688620 & 4.7 & 4.6321 & TRN \\
\hline CHEMBL1334513 & 688620 & 4.45 & 4.8531 & TST \\
\hline CHEMBL1549213 & 688620 & 5.25 & 4.8557 & TRN \\
\hline CHEMBL1452386 & 688620 & 4.45 & 5.0496 & TRN \\
\hline CHEMBL1455231 & 688620 & 5.1 & 5.1238 & TRN \\
\hline CHEMBL1602792 & 688620 & 4.95 & 5.0927 & TST \\
\hline CHEMBL1460199 & 688620 & 5.55 & 5.4844 & TRN \\
\hline CHEMBL1477949 & 688620 & 5.65 & 5.1229 & TRN \\
\hline CHEMBL1535538 & 688620 & 4.7 & 4.9021 & TRN \\
\hline CHEMBL1429711 & 688620 & 6.5501 & 5.9998 & TRN \\
\hline CHEMBL3197382 & 688620 & 6.0 & 5.5596 & TRN \\
\hline CHEMBL1517983 & 688620 & 5.2 & 4.7733 & TRN \\
\hline CHEMBL1320552 & 688620 & 4.85 & 5.3006 & TRN \\
\hline CHEMBL414890 & 688620 & 5.5 & 5.6504 & TST \\
\hline CHEMBL1432394 & 688620 & 4.45 & 4.9693 & TST \\
\hline CHEMBL1605329 & 688620 & 4.45 & 5.2343 & TST \\
\hline CHEMBL1341375 & 688620 & 5.7 & 5.0854 & TST \\
\hline CHEMBL1988684 & 688620 & 5.6 & 4.9399 & TST \\
\hline CHEMBL1453848 & 688620 & 4.8 & 4.8082 & TRN \\
\hline CHEMBL1544831 & 688620 & 6.25 & 5.2064 & TRN \\
\hline CHEMBL1607844 & 688620 & 4.7 & 4.9363 & TRN \\
\hline
\end{tabular}

TRN 


\begin{tabular}{|c|c|c|c|c|c|}
\hline \multicolumn{6}{|c|}{ Supplemental Table S2.txt } \\
\hline CHEMBL1349765 & 688620 & 4.75 & 5.0992 & TRN & \\
\hline CHEMBL1497162 & 688620 & 4.8 & 4.925 & TRN & \\
\hline CHEMBL1406772 & 688620 & 4.65 & 5.0931 & TST & \\
\hline CHEMBL1988056 & 688620 & 5.55 & 5.5085 & TRN & \\
\hline CHEMBL1549830 & 688620 & 5.35 & 5.20100 & 00000000005 & TRN \\
\hline CHEMBL1445748 & 688620 & 6.05 & 5.6722 & TRN & \\
\hline CHEMBL1335529 & 688620 & 6.0 & 5.0551 & TST & \\
\hline CHEMBL3197671 & 688620 & 5.9 & 5.684 & TRN & \\
\hline CHEMBL1599132 & 688620 & 5.25 & 5.2405 & TST & \\
\hline CHEMBL1502401 & 688620 & 5.5 & 5.0332 & TRN & \\
\hline CHEMBL1589357 & 688620 & 5.35 & 5.2297 & TRN & \\
\hline CHEMBL1351133 & 688620 & 4.95 & 4.9344 & TST & \\
\hline CHEMBL1341395 & 688620 & 4.95 & 4.9515 & TRN & \\
\hline CHEMBL1310859 & 688620 & 4.8 & 4.8073 & TRN & \\
\hline CHEMBL1485313 & 688620 & 4.8 & 4.8799 & TRN & \\
\hline CHEMBL1391982 & 688620 & 5.0 & 4.9698 & TRN & \\
\hline CHEMBL1523620 & 688620 & 5.1 & 4.6886 & TRN & \\
\hline CHEMBL1320586 & 688620 & 4.9 & 5.0359 & TRN & \\
\hline CHEMBL1598001 & 688620 & 4.9 & 5.3123 & TRN & \\
\hline CHEMBL3207486 & 688620 & 5.65 & 5.5279 & TRN & \\
\hline CHEMBL1496705 & 688620 & 4.9 & 5.1141 & TRN & \\
\hline CHEMBL1440609 & 688620 & 4.95 & 5.0314 & TST & \\
\hline CHEMBL1986259 & 688620 & 5.95 & 5.5437 & TRN & \\
\hline CHEMBL1390223 & 688620 & 4.45 & 4.8141 & TRN & \\
\hline CHEMBL1584860 & 688620 & 5.05 & 5.1704 & TRN & \\
\hline CHEMBL3193612 & 688620 & 4.8 & 4.8595 & TRN & \\
\hline CHEMBL1409398 & 688620 & 5.25 & 5.4595 & TRN & \\
\hline CHEMBL1506710 & 688620 & 5.2 & 4.8514 & TRN & \\
\hline CHEMBL1331465 & 688620 & 5.0 & 4.7948 & TRN & \\
\hline CHEMBL1318802 & 688620 & 4.85 & 5.1722 & TRN & \\
\hline CHEMBL1449960 & 688620 & 5.0 & 4.9926 & TRN & \\
\hline CHEMBL1530611 & 688620 & 5.0 & 5.2072 & TRN & \\
\hline CHEMBL1461395 & 688620 & 5.0 & 4.9421 & TRN & \\
\hline CHEMBL1493481 & 688620 & 6.05 & 5.6259 & TRN & \\
\hline CHEMBL1492491 & 688620 & 5.1 & 5.1457 & TRN & \\
\hline CHEMBL1483733 & 688620 & 5.0 & 5.0291 & TRN & \\
\hline CHEMBL1413612 & 688620 & 4.45 & 4.8527 & TRN & \\
\hline CHEMBL1352754 & 688620 & 5.65 & 5.2718 & TRN & \\
\hline CHEMBL3209719 & 688620 & 5.9 & 5.3145 & TRN & \\
\hline CHEMBL1542651 & 688620 & 4.45 & 5.1339 & TRN & \\
\hline CHEMBL1310422 & 688620 & 5.85 & 5.311 & TRN & \\
\hline CHEMBL1351473 & 688620 & 4.8 & 4.721 & TST & \\
\hline CHEMBL 2003595 & 688620 & 4.95 & 4.8575 & TRN & \\
\hline CHEMBL1333820 & 688620 & 4.45 & 5.1112 & TRN & \\
\hline CHEMBL1575194 & 688620 & 4.85 & 5.0447 & TRN & \\
\hline CHEMBL1561005 & 688620 & 5.95 & 4.8441 & TST & \\
\hline CHEMBL3195305 & 688620 & 5.55 & 4.9861 & TRN & \\
\hline CHEMBL1577294 & 688620 & 5.9 & 4.8644 & TRN & \\
\hline
\end{tabular}




\begin{tabular}{|c|c|c|c|c|c|}
\hline & & \multicolumn{4}{|c|}{ Supplemental Table S2.txt } \\
\hline CHEMBL1460061 & 688620 & 4.75 & 5.0306 & TRN & \\
\hline CHEMBL1469676 & 688620 & 4.7 & 4.8015 & TST & \\
\hline CHEMBL1597235 & 688620 & 5.6 & 5.0317 & TRN & \\
\hline CHEMBL1595900 & 688620 & 4.75 & 5.0229 & TRN & \\
\hline CHEMBL1495119 & 688620 & 4.85 & \multicolumn{2}{|c|}{5.531000000000001} & TRN \\
\hline CHEMBL1447433 & 688620 & 5.1 & 5.1452 & TST & \\
\hline CHEMBL1460351 & 688620 & 4.6 & 4.7005 & TRN & \\
\hline CHEMBL1573286 & 688620 & 5.2 & 5.1388 & TRN & \\
\hline CHEMBL1439301 & 688620 & 6.05 & 5.1617 & TRN & \\
\hline CHEMBL1390169 & 688620 & 5.5 & 5.1107 & TRN & \\
\hline CHEMBL1339273 & 688620 & 4.85 & 5.0772 & TRN & \\
\hline CHEMBL260311 & 688620 & 6.0 & 5.2373 & TRN & \\
\hline CHEMBL1450536 & 688620 & 4.7 & 5.3051 & TRN & \\
\hline CHEMBL1969464 & 688620 & 4.9 & 4.9658 & TRN & \\
\hline CHEMBL1365971 & 688620 & 4.95 & 4.9805 & TRN & \\
\hline CHEMBL1565449 & 688620 & 4.95 & 5.2192 & TRN & \\
\hline CHEMBL1544508 & 688620 & 5.2 & 4.782 & TRN & \\
\hline CHEMBL3194183 & 688620 & 5.05 & 5.1419 & TST & \\
\hline CHEMBL3213459 & 688620 & 5.1 & 5.2447 & TST & \\
\hline CHEMBL 3207360 & 688620 & 4.95 & 4.7864 & TRN & \\
\hline CHEMBL1538892 & 688620 & 6.5 & 6.2589 & TRN & \\
\hline CHEMBL1459825 & 688620 & 5.0 & 4.902 & TRN & \\
\hline CHEMBL3191398 & 688620 & 5.55 & 5.4516 & TRN & \\
\hline CHEMBL1446940 & 688620 & 4.7 & \multicolumn{2}{|c|}{4.8260000000000005} & TRN \\
\hline CHEMBL1501646 & 688620 & 4.95 & 5.001 & TRN & \\
\hline CHEMBL1329851 & 688620 & 6.3 & 5.1424 & TRN & \\
\hline CHEMBL3197454 & 688620 & 4.7 & 5.4644 & TRN & \\
\hline CHEMBL1482806 & 688620 & 5.0 & 5.7611 & TRN & \\
\hline CHEMBL1570860 & 688620 & 4.5 & 4.9195 & TRN & \\
\hline CHEMBL1495759 & 688620 & 5.85 & 5.1372 & TRN & \\
\hline CHEMBL1414895 & 688620 & 4.5 & 4.9117 & TST & \\
\hline CHEMBL1457925 & 688620 & 4.45 & 4.9966 & TRN & \\
\hline CHEMBL1558079 & 688620 & 4.6 & 5.0762 & TRN & \\
\hline CHEMBL1379191 & 688620 & 5.25 & 5.1637 & TRN & \\
\hline CHEMBL1533604 & 688620 & 6.15 & 6.1207 & TRN & \\
\hline CHEMBL1991311 & 688620 & 4.45 & 5.3137 & TRN & \\
\hline CHEMBL1509595 & 688620 & 4.45 & 4.9386 & TRN & \\
\hline CHEMBL1334472 & 688620 & 6.2 & 5.1766 & TST & \\
\hline CHEMBL1387670 & 688620 & 5.3 & 5.0131 & TRN & \\
\hline CHEMBL1352011 & 688620 & 4.85 & 4.9811 & TRN & \\
\hline CHEMBL1452858 & 688620 & 5.3 & 5.4358 & TRN & \\
\hline CHEMBL1432515 & 688620 & 4.95 & \multicolumn{2}{|c|}{5.0760000000000005} & TST \\
\hline CHEMBL1507756 & 688620 & 4.85 & 4.9489 & TRN & \\
\hline CHEMBL1579685 & 688620 & 4.75 & 5.0559 & TRN & \\
\hline CHEMBL1399368 & 688620 & 6.2 & 5.2308 & TST & \\
\hline CHEMBL1499646 & 688620 & 5.0 & 5.2181 & TRN & \\
\hline CHEMBL 3197544 & 688620 & 4.95 & 5.0667 & TRN & \\
\hline CHEMBL1580193 & 688620 & 5.45 & 5.2161 & TRN & \\
\hline
\end{tabular}




\begin{tabular}{|c|c|c|c|c|}
\hline \multicolumn{5}{|c|}{ Supplemental Table } \\
\hline CHEMBL1582866 & 688620 & 4.45 & 4.7439 & TRN \\
\hline CHEMBL3195167 & 688620 & 4.85 & 5.443 & TRN \\
\hline CHEMBL1338768 & 688620 & 4.7 & 5.0095 & TRN \\
\hline CHEMBL1524578 & 688620 & 4.7 & 5.112 & TRN \\
\hline CHEMBL1375571 & 688620 & 5.5 & 5.482 & TRN \\
\hline CHEMBL1539170 & 688620 & 4.95 & 5.0197 & TRN \\
\hline CHEMBL1610831 & 688620 & 4.45 & 4.7146 & TST \\
\hline CHEMBL 2005895 & 688620 & 6.25 & 5.6441 & TRN \\
\hline CHEMBL1303916 & 688620 & 5.2 & 5.091 & TRN \\
\hline CHEMBL1319760 & 688620 & 5.0 & 5.1665 & TRN \\
\hline CHEMBL1336569 & 688620 & 6.05 & 4.9881 & TRN \\
\hline CHEMBL1302868 & 688620 & 4.8 & 5.0425 & TRN \\
\hline CHEMBL1399919 & 688620 & 4.7 & 4.9924 & TST \\
\hline CHEMBL1390555 & 688620 & 6.15 & 4.8089 & TST \\
\hline CHEMBL1414907 & 688620 & 5.55 & 5.0286 & TRN \\
\hline CHEMBL1326847 & 688620 & 5.15 & 4.8965 & TRN \\
\hline CHEMBL1329511 & 688620 & 5.5 & 4.872 & TRN \\
\hline CHEMBL1584943 & 688620 & 4.75 & 4.7735 & TRN \\
\hline CHEMBL1595564 & 688620 & 4.65 & 5.1014 & TST \\
\hline CHEMBL1454186 & 688620 & 6.15 & 6.024 & TRN \\
\hline CHEMBL1393934 & 688620 & 5.05 & 5.0436 & TRN \\
\hline CHEMBL1526497 & 688620 & 4.8 & 4.9004 & TRN \\
\hline CHEMBL508112 & 688620 & 6.0 & 5.0565 & TRN \\
\hline CHEMBL 3194100 & 688620 & 4.9 & 4.8116 & TRN \\
\hline CHEMBL1558198 & 688620 & 5.05 & 4.9515 & TRN \\
\hline CHEMBL1310518 & 688620 & 5.0 & 5.1321 & TST \\
\hline CHEMBL1579380 & 688620 & 5.45 & 5.4637 & TRN \\
\hline CHEMBL1520621 & 688620 & 5.1 & 4.8296 & TRN \\
\hline CHEMBL1467985 & 688620 & 4.85 & 5.2921 & TST \\
\hline CHEMBL1420325 & 688620 & 5.35 & 5.1711 & TST \\
\hline CHEMBL1600941 & 688620 & 5.35 & 5.1368 & TRN \\
\hline CHEMBL1556253 & 688620 & 5.05 & 5.1298 & TRN \\
\hline CHEMBL1449624 & 688620 & 5.4 & 5.2596 & TST \\
\hline CHEMBL1460225 & 688620 & 4.45 & 4.7597 & TRN \\
\hline CHEMBL1383680 & 688620 & 4.65 & 5.0489 & TRN \\
\hline CHEMBL1998234 & 688620 & 4.8 & 4.9953 & TRN \\
\hline CHEMBL1311542 & 688620 & 5.3 & 5.3484 & TRN \\
\hline CHEMBL1504117 & 688620 & 4.45 & 4.9403 & TRN \\
\hline CHEMBL1516499 & 688620 & 4.9 & 4.9488 & TRN \\
\hline CHEMBL1611832 & 688620 & 4.45 & 4.7731 & TRN \\
\hline CHEMBL1471394 & 688620 & 4.9 & 5.0127 & TRN \\
\hline CHEMBL1430036 & 688620 & 4.95 & 5.0692 & TST \\
\hline CHEMBL1969034 & 688620 & 4.8 & 5.0114 & TRN \\
\hline CHEMBL1550045 & 688620 & 4.45 & 4.7628 & TRN \\
\hline CHEMBL1589240 & 688620 & 5.3 & 5.118 & TRN \\
\hline CHEMBL1430227 & 688620 & 4.5 & 4.968 & TRN \\
\hline CHEMBL1477219 & 688620 & 4.9 & 4.7123 & TRN \\
\hline CHEMBL 3145048 & 688620 & 5.95 & 5.8094 & TRN \\
\hline
\end{tabular}




\begin{tabular}{|c|c|c|c|c|}
\hline \multicolumn{5}{|c|}{ Supplemental Table S2.txt } \\
\hline CHEMBL1563401 & 688620 & 5.2 & 5.1903 & TRN \\
\hline CHEMBL1428181 & 688620 & 4.9 & 4.7036 & TRN \\
\hline CHEMBL1343572 & 688620 & 4.7 & 4.8096 & TRN \\
\hline CHEMBL1982869 & 688620 & 5.85 & 5.6311 & TRN \\
\hline CHEMBL3191422 & 688620 & 4.95 & 5.022 & TRN \\
\hline CHEMBL1399453 & 688620 & 4.8 & 4.9664 & TRN \\
\hline CHEMBL1329018 & 688620 & 4.8 & 4.9737 & TRN \\
\hline CHEMBL1381589 & 688620 & 4.7 & 5.0352 & TST \\
\hline CHEMBL334255 & 688620 & 6.0 & 5.5521 & TRN \\
\hline CHEMBL1486831 & 688620 & 6.35 & 5.1484 & TST \\
\hline CHEMBL1563725 & 688620 & 5.1 & 5.1685 & TRN \\
\hline CHEMBL1573581 & 688620 & 6.6 & 4.9765 & TRN \\
\hline CHEMBL1500227 & 688620 & 4.95 & 4.7323 & TRN \\
\hline CHEMBL1383585 & 688620 & 5.9 & 5.9067 & TRN \\
\hline CHEMBL1417527 & 688620 & 5.5 & 4.9558 & TRN \\
\hline CHEMBL1406873 & 688620 & 4.85 & 5.0 & TRN \\
\hline CHEMBL1481927 & 688620 & 6.15 & 5.0513 & TST \\
\hline CHEMBL1490527 & 688620 & 4.8 & 4.7993 & TRN \\
\hline CHEMBL1564636 & 688620 & 4.8 & 4.9101 & TRN \\
\hline CHEMBL3213317 & 688620 & 4.85 & 5.155 & TRN \\
\hline CHEMBL3190895 & 688620 & 4.8 & 4.8892 & TRN \\
\hline CHEMBL1481348 & 688620 & 4.85 & 5.0139 & TST \\
\hline CHEMBL1543577 & 688620 & 5.05 & 4.8911 & TRN \\
\hline CHEMBL3195037 & 688620 & 5.9 & 5.5721 & TRN \\
\hline CHEMBL1509351 & 688620 & 4.7 & 4.8887 & TST \\
\hline CHEMBL1576957 & 688620 & 4.95 & 5.1817 & TST \\
\hline CHEMBL1360146 & 688620 & 4.45 & 4.8568 & TRN \\
\hline CHEMBL1603973 & 688620 & 4.85 & 4.904 & TRN \\
\hline CHEMBL1349415 & 688620 & 4.45 & 4.9846 & TRN \\
\hline CHEMBL1551597 & 688620 & 4.5 & 4.6463 & TST \\
\hline CHEMBL1310176 & 688620 & 5.35 & 4.9281 & TST \\
\hline CHEMBL1503082 & 688620 & 5.3 & 4.9373 & TRN \\
\hline CHEMBL1583063 & 688620 & 5.45 & 5.1591 & TRN \\
\hline CHEMBL1468522 & 688620 & 4.9 & 4.6293 & TRN \\
\hline CHEMBL1335805 & 688620 & 4.7 & 5.0507 & TRN \\
\hline CHEMBL1377730 & 688620 & 4.95 & 5.1247 & TRN \\
\hline CHEMBL3192323 & 688620 & 4.9 & 5.3885 & TRN \\
\hline CHEMBL1429063 & 688620 & 4.65 & 5.0295 & TRN \\
\hline CHEMBL1398617 & 688620 & 5.25 & 5.3124 & TRN \\
\hline CHEMBL1452288 & 688620 & 6.0 & 6.1067 & TRN \\
\hline CHEMBL1520036 & 688620 & 4.95 & 5.0985 & TRN \\
\hline CHEMBL1511658 & 688620 & 7.4498 & 5.3495 & TST \\
\hline CHEMBL1341585 & 688620 & 5.35 & 4.9179 & TST \\
\hline CHEMBL1339810 & 688620 & 4.45 & 4.5173 & TRN \\
\hline CHEMBL1572297 & 688620 & 5.2 & 4.9771 & TST \\
\hline CHEMBL1522221 & 688620 & 5.55 & 5.0278 & TRN \\
\hline CHEMBL1382943 & 688620 & 4.45 & 5.1065 & TRN \\
\hline CHEMBL1410351 & 688620 & 5.3 & 5.1773 & TRN \\
\hline
\end{tabular}




\begin{tabular}{|c|c|c|c|c|}
\hline & & & upplement & $\mathrm{T}$ \\
\hline CHEMBL1337538 & 688620 & 4.65 & 4.9041 & TRN \\
\hline CHEMBL1383447 & 688620 & 5.5 & 4.7908 & TST \\
\hline CHEMBL1510554 & 688620 & 5.2 & 5.1215 & TST \\
\hline CHEMBL1496651 & 688620 & 4.9 & 5.2379 & TRN \\
\hline CHEMBL1375436 & 688620 & 4.65 & 5.043 & TRN \\
\hline CHEMBL1520867 & 688620 & 4.45 & 4.8946 & TRN \\
\hline CHEMBL 3193573 & 688620 & 4.95 & 5.1103 & TRN \\
\hline CHEMBL1383228 & 688620 & 5.0 & 4.8704 & TRN \\
\hline CHEMBL1524751 & 688620 & 5.55 & 5.0381 & TST \\
\hline CHEMBL1498693 & 688620 & 4.9 & 4.8033 & TRN \\
\hline CHEMBL1413413 & 688620 & 6.9 & 4.9929 & TST \\
\hline CHEMBL 3191930 & 688620 & 4.85 & 5.1157 & TST \\
\hline CHEMBL1320260 & 688620 & 4.45 & 4.9002 & TRN \\
\hline CHEMBL1452488 & 688620 & 5.05 & 4.8252 & TRN \\
\hline CHEMBL1493747 & 688620 & 6.9 & 5.2641 & TST \\
\hline CHEMBL1484272 & 688620 & 4.45 & 5.0109 & TRN \\
\hline CHEMBL1449793 & 688620 & 4.45 & 5.1855 & TRN \\
\hline CHEMBL1333913 & 688620 & 4.85 & 5.1033 & TRN \\
\hline CHEMBL1454344 & 688620 & 5.1 & 4.8607 & TRN \\
\hline CHEMBL1523844 & 688620 & 6.45 & 4.7886 & TST \\
\hline CHEMBL1582158 & 688620 & 4.9 & 4.8324 & TRN \\
\hline CHEMBL1459512 & 688620 & 4.45 & 5.2128 & TRN \\
\hline CHEMBL1605698 & 688620 & 4.6 & 5.0111 & TRN \\
\hline CHEMBL1362508 & 688620 & 5.3 & 5.4029 & TRN \\
\hline CHEMBL1366431 & 688620 & 5.4 & 5.1471 & TST \\
\hline CHEMBL1373418 & 688620 & 4.8 & 4.9712 & TRN \\
\hline CHEMBL1588710 & 688620 & 4.5 & 5.0269 & TRN \\
\hline CHEMBL1476170 & 688620 & 6.0 & 5.5678 & TST \\
\hline CHEMBL 3190853 & 688620 & 5.3 & 5.2412 & TRN \\
\hline CHEMBL1558960 & 688620 & 5.15 & 5.5559 & TRN \\
\hline CHEMBL1306725 & 688620 & 4.45 & 4.8642 & TRN \\
\hline CHEMBL1407457 & 688620 & 5.9 & 5.5425 & TRN \\
\hline CHEMBL1604129 & 688620 & 4.9 & 5.1199 & TRN \\
\hline CHEMBL1598562 & 688620 & 4.75 & 5.0683 & TRN \\
\hline CHEMBL1490060 & 688620 & 6.3 & 5.7449 & TST \\
\hline CHEMBL1549804 & 688620 & 4.75 & 5.0227 & TST \\
\hline CHEMBL1482193 & 688620 & 4.8 & 4.7191 & TRN \\
\hline CHEMBL1470236 & 688620 & 5.35 & 5.2654 & TST \\
\hline CHEMBL 212378 & 688620 & 4.9 & 5.1682 & TRN \\
\hline CHEMBL3199538 & 688620 & 5.4 & 5.3878 & TRN \\
\hline CHEMBL1470095 & 688620 & 4.75 & 4.9538 & TRN \\
\hline CHEMBL1367775 & 688620 & 4.7 & 4.9546 & TST \\
\hline CHEMBL1428045 & 688620 & 5.05 & 5.1915 & TRN \\
\hline CHEMBL1378232 & 688620 & 6.45 & 5.9889 & TRN \\
\hline CHEMBL1499873 & 688620 & 4.45 & 4.6342 & TRN \\
\hline CHEMBL1607065 & 688620 & 5.5 & 5.0023 & TST \\
\hline CHEMBL1418451 & 688620 & 5.2 & 5.4065 & TRN \\
\hline CHEMBL1407772 & 688620 & 5.0 & 5.1376 & TRN \\
\hline
\end{tabular}




\begin{tabular}{|c|c|c|c|c|c|}
\hline \\
\hline CHEMBL1386129 & 688620 & 6.3 & 5.9438 & TRN & \\
\hline CHEMBL1309801 & 688620 & 4.85 & 4.8466 & TRN & \\
\hline CHEMBL1530227 & 688620 & 4.65 & 5.1464 & TST & \\
\hline CHEMBL1561379 & 688620 & 5.1 & 5.0351 & TRN & \\
\hline CHEMBL1454295 & 688620 & 5.25 & 5.1953 & TRN & \\
\hline CHEMBL1561380 & 688620 & 4.9 & 4.8694 & TST & \\
\hline CHEMBL1469950 & 688620 & 5.3 & 5.2202 & TRN & \\
\hline CHEMBL1990184 & 688620 & 4.65 & 5.1401 & TRN & \\
\hline CHEMBL1605296 & 688620 & 4.95 & 4.9894 & TRN & \\
\hline CHEMBL1343697 & 688620 & 4.9 & 5.1723 & TST & \\
\hline CHEMBL1603583 & 688620 & 4.5 & 5.0319 & TRN & \\
\hline CHEMBL1378454 & 688620 & 6.25 & 5.41100 & 30000000005 & TRN \\
\hline CHEMBL1419587 & 688620 & 4.65 & 4.9355 & TRN & \\
\hline CHEMBL3210889 & 688620 & 5.9 & 5.4627 & TRN & \\
\hline CHEMBL1432330 & 688620 & 5.5 & 5.0803 & TRN & \\
\hline CHEMBL1410395 & 688620 & 5.15 & 5.146 & TRN & \\
\hline CHEMBL1388359 & 688620 & 4.45 & 5.1521 & TRN & \\
\hline CHEMBL1383379 & 688620 & 6.35 & 5.2603 & TRN & \\
\hline CHEMBL1484350 & 688620 & 4.45 & 4.8769 & TST & \\
\hline CHEMBL1490305 & 688620 & 4.45 & 5.0988 & TST & \\
\hline CHEMBL1481384 & 688620 & 4.65 & 5.1574 & TRN & \\
\hline CHEMBL1375312 & 688620 & 4.8 & 4.9969 & TRN & \\
\hline CHEMBL1405262 & 688620 & 5.9 & 5.3342 & TRN & \\
\hline CHEMBL1406731 & 688620 & 5.1 & 4.8519 & TRN & \\
\hline CHEMBL1365073 & 688620 & 4.8 & 4.9615 & TST & \\
\hline CHEMBL1529329 & 688620 & 4.85 & 5.1448 & TRN & \\
\hline CHEMBL1388611 & 688620 & 4.45 & 4.9704 & TRN & \\
\hline CHEMBL1494604 & 688620 & 4.9 & 4.9618 & TST & \\
\hline CHEMBL1504847 & 688620 & 4.85 & 5.0002 & TST & \\
\hline CHEMBL1590450 & 688620 & 5.1 & 4.8609 & TRN & \\
\hline CHEMBL1345029 & 688620 & 4.45 & 4.9042 & TST & \\
\hline CHEMBL1335742 & 688620 & 4.65 & 4.9233 & TRN & \\
\hline CHEMBL1391580 & 688620 & 6.05 & 4.8701 & TRN & \\
\hline CHEMBL1422053 & 688620 & 5.8 & 5.6974 & TRN & \\
\hline CHEMBL1430915 & 688620 & 5.0 & 5.2169 & TRN & \\
\hline CHEMBL1422903 & 688620 & 5.9 & 5.0669 & TRN & \\
\hline CHEMBL1431118 & 688620 & 4.95 & 4.8363 & TRN & \\
\hline CHEMBL1363796 & 688620 & 5.7 & 5.4833 & TST & \\
\hline CHEMBL1450937 & 688620 & 4.45 & 5.0111 & TST & \\
\hline CHEMBL1404077 & 688620 & 5.5 & 5.4966 & TRN & \\
\hline CHEMBL1422155 & 688620 & 4.45 & 5.1923 & TRN & \\
\hline CHEMBL1583683 & 688620 & 4.9 & 5.1252 & TRN & \\
\hline CHEMBL1519639 & 688620 & 4.45 & 5.0663 & TST & \\
\hline CHEMBL1485028 & 688620 & 5.55 & 4.7622 & TST & \\
\hline CHEMBL 8260 & 688620 & 6.0 & 4.9319 & TRN & \\
\hline CHEMBL1986027 & 688620 & 4.45 & 5.0651 & TST & \\
\hline CHEMBL1416808 & 688620 & 4.7 & 4.7775 & TRN & \\
\hline CHEMBL1608078 & 688620 & 5.45 & 5.3311 & TST & \\
\hline
\end{tabular}




\begin{tabular}{|c|c|c|c|c|c|}
\hline \multicolumn{6}{|c|}{ Supplemental Table S2.txt } \\
\hline CHEMBL1565500 & 688620 & 5.15 & 4.9218 & TRN & \\
\hline CHEMBL1453708 & 688620 & 5.0 & 4.6765 & TST & \\
\hline CHEMBL1546956 & 688620 & 4.45 & 5.3106 & TRN & \\
\hline CHEMBL1607320 & 688620 & 4.95 & 4.7065 & TRN & \\
\hline CHEMBL1529175 & 688620 & 5.45 & 4.9316 & TRN & \\
\hline CHEMBL1445370 & 688620 & 4.45 & 5.0035 & TST & \\
\hline CHEMBL1966612 & 688620 & 4.85 & 4.9329 & TST & \\
\hline CHEMBL1425752 & 688620 & 5.0 & 5.155 & TRN & \\
\hline CHEMBL1992589 & 688620 & 6.7001 & 6.1791 & TRN & \\
\hline CHEMBL1510098 & 688620 & 4.9 & 5.1615 & TST & \\
\hline CHEMBL1454990 & 688620 & 5.0 & 4.956 & TRN & \\
\hline CHEMBL1550417 & 688620 & 4.7 & 5.2127 & TST & \\
\hline CHEMBL1303598 & 688620 & 5.55 & 4.9753 & TRN & \\
\hline CHEMBL1531362 & 688620 & 4.7 & 5.1933 & TST & \\
\hline CHEMBL1345709 & 688620 & 5.4 & 5.1439 & TRN & \\
\hline CHEMBL1595854 & 688620 & 4.45 & 5.0601 & TST & \\
\hline CHEMBL1310861 & 688620 & 4.8 & 4.7163 & TST & \\
\hline CHEMBL1448216 & 688620 & 5.5 & 5.1785 & TST & \\
\hline CHEMBL1531900 & 688620 & 4.85 & 5.2645 & TRN & \\
\hline CHEMBL1384457 & 688620 & 5.6 & 5.7634 & TST & \\
\hline CHEMBL3197991 & 688620 & 5.3 & 5.3242 & TRN & \\
\hline CHEMBL1372447 & 688620 & 5.35 & 5.2945 & TRN & \\
\hline CHEMBL1418932 & 688620 & 4.9 & 5.1516 & TST & \\
\hline CHEMBL 3208266 & 688620 & 4.45 & 5.0273 & TRN & \\
\hline CHEMBL1578064 & 688620 & 4.45 & 4.8286 & TST & \\
\hline CHEMBL1378467 & 688620 & 5.45 & 5.0835 & TRN & \\
\hline CHEMBL1344052 & 688620 & 4.95 & 5.1547 & TRN & \\
\hline CHEMBL1508790 & 688620 & 5.05 & 5.2468 & TRN & \\
\hline CHEMBL1499364 & 688620 & 4.9 & 4.9338 & TRN & \\
\hline CHEMBL1304748 & 688620 & 6.9 & 5.0467 & TRN & \\
\hline CHEMBL1483942 & 688620 & 4.7 & 5.0473 & TST & \\
\hline CHEMBL1315710 & 688620 & 4.9 & 4.9291 & TRN & \\
\hline CHEMBL1365636 & 688620 & 5.75 & 4.909 & TRN & \\
\hline CHEMBL1421760 & 688620 & 5.35 & 5.0307 & TRN & \\
\hline CHEMBL1975006 & 688620 & 6.7001 & 6.1922 & TRN & \\
\hline CHEMBL1441532 & 688620 & 6.2 & 5.1416 & TRN & \\
\hline CHEMBL1430927 & 688620 & 4.55 & 4.7468 & TRN & \\
\hline CHEMBL1481166 & 688620 & 5.85 & 4.8505 & TST & \\
\hline CHEMBL1549643 & 688620 & 4.9 & 5.0171 & TRN & \\
\hline CHEMBL1455971 & 688620 & 4.45 & 4.8877 & TRN & \\
\hline CHEMBL600554 & 688620 & 4.45 & 5.32299 & 99999999995 & TRN \\
\hline CHEMBL1480782 & 688620 & 5.95 & 5.3064 & TRN & \\
\hline CHEMBL1451867 & 688620 & 4.9 & 4.8008 & TRN & \\
\hline CHEMBL1344561 & 688620 & 4.45 & 4.9819 & TRN & \\
\hline CHEMBL1386634 & 688620 & 4.5 & 4.8065 & TRN & \\
\hline CHEMBL1475884 & 688620 & 4.65 & 5.2103 & TRN & \\
\hline CHEMBL1537810 & 688620 & 6.25 & 5.8495 & TST & \\
\hline CHEMBL1491222 & 688620 & 6.25 & 5.7748 & TRN & \\
\hline
\end{tabular}




\begin{tabular}{|c|c|c|c|c|c|}
\hline \multicolumn{6}{|c|}{ Supplemental Table S2.txt } \\
\hline CHEMBL 3192348 & 688620 & 5.6 & 5.4902 & TRN & \\
\hline CHEMBL3207351 & 688620 & 4.85 & 5.0288 & TRN & \\
\hline CHEMBL1451636 & 688620 & 5.2 & 5.0332 & TRN & \\
\hline CHEMBL1306756 & 688620 & 4.45 & 5.3123 & TST & \\
\hline CHEMBL1468567 & 688620 & 5.2 & 4.8205 & TRN & \\
\hline CHEMBL1451743 & 688620 & 5.0 & 5.2636 & TRN & \\
\hline CHEMBL1349245 & 688620 & 4.9 & 4.9277 & TRN & \\
\hline CHEMBL1380078 & 688620 & 4.5 & 5.1814 & TST & \\
\hline CHEMBL1440069 & 688620 & 5.3 & 4.8991 & TRN & \\
\hline CHEMBL47986 & 688620 & 4.95 & 5.0435 & TST & \\
\hline CHEMBL1586704 & 688620 & 4.9 & 4.8137 & TRN & \\
\hline CHEMBL1611210 & 688620 & 4.7 & 4.893 & TRN & \\
\hline CHEMBL1310835 & 688620 & 4.5 & 5.0902 & TRN & \\
\hline CHEMBL3210988 & 688620 & 4.6 & 5.0256 & TRN & \\
\hline CHEMBL1490828 & 688620 & 5.1 & 5.0809 & TRN & \\
\hline CHEMBL1604587 & 688620 & 4.95 & 5.1445 & TRN & \\
\hline CHEMBL1392479 & 688620 & 4.45 & 5.2037 & TRN & \\
\hline CHEMBL1481765 & 688620 & 5.0 & 5.2121 & TRN & \\
\hline CHEMBL1543795 & 688620 & 4.95 & 5.3614 & TRN & \\
\hline CHEMBL1388680 & 688620 & 4.65 & 5.2441 & TRN & \\
\hline CHEMBL1382410 & 688620 & 5.35 & 5.1348 & TRN & \\
\hline CHEMBL1348468 & 688620 & 4.85 & 4.8205 & TRN & \\
\hline CHEMBL3209251 & 688620 & 4.9 & 4.8664 & TRN & \\
\hline CHEMBL1426120 & 688620 & 4.45 & 4.9244 & TST & \\
\hline CHEMBL1528564 & 688620 & 4.45 & $4.9830 e$ & 00000000005 & TRN \\
\hline CHEMBL1565451 & 688620 & 5.85 & 5.2421 & TRN & \\
\hline CHEMBL1508071 & 688620 & 4.45 & 5.0068 & TRN & \\
\hline CHEMBL1534404 & 688620 & 4.55 & 5.1249 & TRN & \\
\hline CHEMBL1369243 & 688620 & 4.85 & 4.9825 & TST & \\
\hline CHEMBL1524179 & 688620 & 5.95 & 5.055 & TRN & \\
\hline CHEMBL1399183 & 688620 & 4.45 & 5.0971 & TRN & \\
\hline CHEMBL1457441 & 688620 & 4.65 & 5.0957 & TRN & \\
\hline CHEMBL1301536 & 688620 & 6.2 & 5.8031 & TRN & \\
\hline CHEMBL451748 & 688620 & 4.7 & 5.1044 & TRN & \\
\hline CHEMBL1417449 & 688620 & 4.9 & 5.1051 & TRN & \\
\hline CHEMBL1527299 & 688620 & 4.45 & 5.1259 & TRN & \\
\hline CHEMBL1424097 & 688620 & 5.1 & 5.1966 & TRN & \\
\hline CHEMBL1304331 & 688620 & 4.8 & 4.9846 & TRN & \\
\hline CHEMBL1380535 & 688620 & 4.95 & 5.3275 & TRN & \\
\hline CHEMBL1330989 & 688620 & 4.9 & 4.9773 & TRN & \\
\hline CHEMBL1375858 & 688620 & 5.1 & 5.0477 & TRN & \\
\hline CHEMBL1995823 & 688620 & 6.5 & 5.983 & TRN & \\
\hline CHEMBL1520349 & 688620 & 4.8 & 5.2277 & TST & \\
\hline CHEMBL1408083 & 688620 & 6.15 & 5.1887 & TRN & \\
\hline CHEMBL1365498 & 688620 & 4.8 & 4.9403 & TRN & \\
\hline CHEMBL3199613 & 688620 & 4.45 & 5.0823 & TRN & \\
\hline CHEMBL1332649 & 688620 & 5.0 & 4.9213 & TST & \\
\hline CHEMBL1415155 & 688620 & 5.25 & 5.1716 & TRN & \\
\hline
\end{tabular}




\begin{tabular}{|c|c|c|c|c|c|}
\hline \multicolumn{6}{|c|}{ Supplemental Table S2.txt } \\
\hline CHEMBL1539115 & 688620 & 4.8 & 5.1742 & TRN & \\
\hline CHEMBL 3195248 & 688620 & 6.35 & 5.2624 & TST & \\
\hline CHEMBL1399130 & 688620 & 4.8 & 5.1067 & TRN & \\
\hline CHEMBL1441788 & 688620 & 4.5 & 5.1363 & TRN & \\
\hline CHEMBL3192272 & 688620 & 4.7 & 5.0144 & TRN & \\
\hline CHEMBL1437918 & 688620 & 5.55 & 4.9469 & TRN & \\
\hline CHEMBL1543235 & 688620 & 5.2 & 5.4543 & TRN & \\
\hline CHEMBL1302695 & 688620 & 6.0 & 5.3298 & TRN & \\
\hline CHEMBL1328382 & 688620 & 5.5 & 5.2079 & TRN & \\
\hline CHEMBL1481938 & 688620 & 4.8 & 5.1917 & TST & \\
\hline CHEMBL1456044 & 688620 & 4.7 & 5.0673 & TRN & \\
\hline CHEMBL1452480 & 688620 & 5.6 & 5.3452 & TST & \\
\hline CHEMBL1419049 & 688620 & 5.2 & 4.9672 & TRN & \\
\hline CHEMBL582980 & 688620 & 5.5 & 4.7986 & TRN & \\
\hline CHEMBL1399609 & 688620 & 4.35 & 4.9295 & TRN & \\
\hline CHEMBL3198975 & 688620 & 6.0 & $5.2810 e$ & 0000000001 & TRN \\
\hline CHEMBL1410187 & 688620 & 4.85 & 5.0975 & TRN & \\
\hline CHEMBL1581406 & 688620 & 4.7 & 4.92 & TRN & \\
\hline CHEMBL1468781 & 688620 & 4.45 & 5.0396 & TST & \\
\hline CHEMBL1416212 & 688620 & 6.5501 & 5.0638 & TST & \\
\hline CHEMBL1462873 & 688620 & 5.0 & 5.0581 & TRN & \\
\hline CHEMBL 3212802 & 688620 & 4.95 & 5.2451 & TRN & \\
\hline CHEMBL1483981 & 688620 & 6.7001 & 5.2371 & TST & \\
\hline CHEMBL1421545 & 688620 & 6.9 & $5.0710 e$ & 3000000001 & TST \\
\hline CHEMBL1598610 & 688620 & 5.6 & 5.2144 & TRN & \\
\hline CHEMBL1464228 & 688620 & 4.95 & 5.4942 & TST & \\
\hline CHEMBL1336134 & 688620 & 4.6 & 5.3299 & TST & \\
\hline CHEMBL1550518 & 688620 & 6.5501 & 6.5467 & TRN & \\
\hline CHEMBL1505868 & 688620 & 5.7 & 4.9175 & TRN & \\
\hline CHEMBL1443218 & 688620 & 4.8 & 5.1806 & TRN & \\
\hline CHEMBL1447028 & 688620 & 4.95 & 4.9691 & TRN & \\
\hline CHEMBL3189736 & 688620 & 5.0 & 4.7335 & TRN & \\
\hline CHEMBL1345326 & 688620 & 4.95 & 5.1126 & TRN & \\
\hline CHEMBL1457941 & 688620 & 4.95 & 5.2589 & TRN & \\
\hline CHEMBL1343248 & 688620 & 5.8 & 6.2143 & TRN & \\
\hline CHEMBL1401217 & 688620 & 5.55 & 5.1752 & TRN & \\
\hline CHEMBL3189738 & 688620 & 6.35 & 5.434 & TRN & \\
\hline CHEMBL1459644 & 688620 & 4.9 & 5.1237 & TRN & \\
\hline CHEMBL1343423 & 688620 & 5.25 & 5.0158 & TRN & \\
\hline CHEMBL1466824 & 688620 & 4.8 & 4.9793 & TRN & \\
\hline CHEMBL1607812 & 688620 & 5.3 & 4.9917 & TRN & \\
\hline CHEMBL3191541 & 688620 & 5.9 & 5.2743 & TRN & \\
\hline CHEMBL1348227 & 688620 & 4.45 & 4.7229 & TRN & \\
\hline CHEMBL1351901 & 688620 & 4.8 & 4.9573 & TRN & \\
\hline CHEMBL1327351 & 688620 & 4.5 & 4.7008 & TST & \\
\hline CHEMBL1361279 & 688620 & 5.75 & 4.8658 & TRN & \\
\hline CHEMBL1974389 & 688620 & 5.3 & 5.5325 & TRN & \\
\hline CHEMBL1438881 & 688620 & 4.95 & 5.2252 & TRN & \\
\hline
\end{tabular}




\begin{tabular}{|c|c|c|c|c|}
\hline \multicolumn{5}{|c|}{ Supplemental Table S2.txt } \\
\hline CHEMBL1506210 & 688620 & 4.45 & 4.8938 & TST \\
\hline CHEMBL1516549 & 688620 & 4.9 & 4.6729 & TRN \\
\hline CHEMBL1516772 & 688620 & 4.9 & 4.7952 & TRN \\
\hline CHEMBL1423629 & 688620 & 4.85 & 4.8539 & TRN \\
\hline CHEMBL1572380 & 688620 & 4.9 & 5.0209 & TRN \\
\hline CHEMBL1609124 & 688620 & 4.75 & 4.864 & TRN \\
\hline CHEMBL1582305 & 688620 & 5.3 & 5.0775 & TRN \\
\hline CHEMBL1581845 & 688620 & 4.45 & 4.9831 & TST \\
\hline CHEMBL1491474 & 688620 & 5.6 & 5.2421 & TST \\
\hline CHEMBL1385016 & 688620 & 4.95 & 5.1288 & TRN \\
\hline CHEMBL1504626 & 688620 & 4.45 & 5.0889 & TRN \\
\hline CHEMBL1344348 & 688620 & 4.65 & 4.9478 & TRN \\
\hline CHEMBL1573656 & 688620 & 4.85 & 5.0644 & TST \\
\hline CHEMBL1463659 & 688620 & 6.35 & 5.83 & TRN \\
\hline CHEMBL1307751 & 688620 & 4.95 & 4.7504 & TRN \\
\hline CHEMBL1572578 & 688620 & 6.7001 & 5.2368 & TRN \\
\hline CHEMBL1357562 & 688620 & 4.95 & 5.1774 & TRN \\
\hline CHEMBL1470910 & 688620 & 4.9 & 5.0067 & TRN \\
\hline CHEMBL1565290 & 688620 & 4.45 & 4.5766 & TST \\
\hline CHEMBL1529352 & 688620 & 4.5 & 4.9428 & TRN \\
\hline CHEMBL1468611 & 688620 & 4.85 & 5.4662 & TST \\
\hline CHEMBL1325220 & 688620 & 4.5 & 4.8816 & TRN \\
\hline CHEMBL1312321 & 688620 & 5.5 & 5.4343 & TRN \\
\hline CHEMBL1507630 & 688620 & 4.9 & 4.9966 & TRN \\
\hline CHEMBL1304773 & 688620 & 4.5 & 5.0045 & TRN \\
\hline CHEMBL1477402 & 688620 & 5.4 & 5.095 & TST \\
\hline CHEMBL1491053 & 688620 & 4.5 & 5.1731 & TRN \\
\hline CHEMBL1483759 & 688620 & 5.7 & 4.9742 & TST \\
\hline CHEMBL1576185 & 688620 & 4.45 & 5.0608 & TRN \\
\hline CHEMBL1422457 & 688620 & 5.6 & 5.3382 & TRN \\
\hline CHEMBL1558398 & 688620 & 4.9 & 4.9074 & TRN \\
\hline CHEMBL1423849 & 688620 & 4.85 & 5.0795 & TRN \\
\hline CHEMBL1573671 & 688620 & 4.8 & 5.0522 & TRN \\
\hline CHEMBL1383570 & 688620 & 4.8 & 5.1828 & TRN \\
\hline CHEMBL1311749 & 688620 & 5.1 & 5.059 & TRN \\
\hline CHEMBL1471798 & 688620 & 4.65 & 4.8881 & TRN \\
\hline CHEMBL1583357 & 688620 & 4.65 & 4.8533 & TRN \\
\hline CHEMBL1334814 & 688620 & 4.5 & 5.0779 & TRN \\
\hline CHEMBL1308836 & 688620 & 5.55 & 5.4311 & TST \\
\hline CHEMBL1583799 & 688620 & 6.1 & 5.7363 & TRN \\
\hline CHEMBL3193884 & 688620 & 4.75 & 4.8226 & TRN \\
\hline CHEMBL 1478241 & 688620 & 5.15 & 5.1116 & TST \\
\hline CHEMBL1459381 & 688620 & 4.5 & 4.8902 & TRN \\
\hline CHEMBL1422284 & 688620 & 5.35 & 5.0814 & TRN \\
\hline CHEMBL1541213 & 688620 & 6.1 & 5.2658 & TRN \\
\hline CHEMBL1486283 & 688620 & 5.65 & 5.1828 & TST \\
\hline CHEMBL1427431 & 688620 & 5.55 & 5.2239 & TRN \\
\hline CHEMBL1464980 & 688620 & 5.0 & 5.1269 & TST \\
\hline
\end{tabular}




\begin{tabular}{|c|c|c|c|c|c|}
\hline \multirow[b]{2}{*}{ CHEMBL1517732 } & \multicolumn{5}{|c|}{ Supplemental Table S2.txt } \\
\hline & 688620 & 4.45 & 4.7714 & TST & \\
\hline CHEMBL1506675 & 688620 & 4.65 & 4.8951 & TRN & \\
\hline CHEMBL1331069 & 688620 & 4.95 & 4.8642 & TRN & \\
\hline CHEMBL1491729 & 688620 & 5.75 & 5.1013 & TRN & \\
\hline CHEMBL1505962 & 688620 & 6.0 & 5.4075 & TRN & \\
\hline CHEMBL1517446 & 688620 & 5.65 & 5.42899 & 9999999999 & TRN \\
\hline CHEMBL1438930 & 688620 & 4.9 & 5.0644 & TRN & \\
\hline CHEMBL3194402 & 688620 & 4.8 & 4.9878 & TRN & \\
\hline CHEMBL1369671 & 688620 & 4.45 & 5.0017 & TRN & \\
\hline CHEMBL1420415 & 688620 & 4.55 & 4.7596 & TRN & \\
\hline CHEMBL1557920 & 688620 & 5.5 & 5.1552 & TST & \\
\hline CHEMBL1548251 & 688620 & 5.8 & 5.4419 & TRN & \\
\hline CHEMBL1486861 & 688620 & 5.3 & 5.0242 & TRN & \\
\hline CHEMBL3199896 & 688620 & 5.45 & 5.449 & TRN & \\
\hline CHEMBL1361056 & 688620 & 5.25 & 5.2771 & TRN & \\
\hline CHEMBL1487895 & 688620 & 4.75 & 4.796 & TST & \\
\hline CHEMBL1343462 & 688620 & 5.5 & 5.1838 & TRN & \\
\hline CHEMBL3199193 & 688620 & 7.4498 & 5.5327 & TRN & \\
\hline CHEMBL1370128 & 688620 & 6.5501 & 4.8817 & TST & \\
\hline CHEMBL1488001 & 688620 & 5.15 & 4.8554 & TRN & \\
\hline CHEMBL1384435 & 688620 & 5.15 & 4.9441 & TRN & \\
\hline CHEMBL1311587 & 688620 & 4.85 & 4.9086 & TST & \\
\hline CHEMBL1425434 & 688620 & 4.5 & 4.8394 & TRN & \\
\hline CHEMBL1596899 & 688620 & 4.9 & 5.0257 & TRN & \\
\hline CHEMBL1320417 & 688620 & 4.45 & 5.1112 & TRN & \\
\hline CHEMBL1575255 & 688620 & 4.7 & 5.0735 & TRN & \\
\hline CHEMBL1583290 & 688620 & 5.1 & 5.1078 & TRN & \\
\hline CHEMBL1344250 & 688620 & 4.45 & 5.1759 & TRN & \\
\hline CHEMBL1602709 & 688620 & 5.15 & 5.4072 & TRN & \\
\hline CHEMBL3196062 & 688620 & 5.55 & 5.1582 & TRN & \\
\hline CHEMBL1491406 & 688620 & 6.15 & 5.0093 & TST & \\
\hline CHEMBL1610307 & 688620 & 4.6 & 5.075 & TRN & \\
\hline CHEMBL1502443 & 688620 & 5.8 & 4.9063 & TRN & \\
\hline CHEMBL1367217 & 688620 & 4.9 & 5.2043 & TRN & \\
\hline CHEMBL1466549 & 688620 & 4.8 & 4.7857 & TRN & \\
\hline CHEMBL1426832 & 688620 & 4.95 & 4.6924 & TRN & \\
\hline CHEMBL 233347 & 688620 & 4.65 & 4.8123 & TRN & \\
\hline CHEMBL1600724 & 688620 & 5.85 & 5.0838 & TST & \\
\hline CHEMBL1305400 & 688620 & 8.3468 & 4.9531 & TRN & \\
\hline CHEMBL1545080 & 688620 & 5.25 & 4.9811 & TST & \\
\hline CHEMBL1339236 & 688620 & 4.95 & 5.2088 & TST & \\
\hline CHEMBL1378697 & 688620 & 4.95 & 5.1202 & TST & \\
\hline CHEMBL1487566 & 688620 & 4.5 & 5.046 & TRN & \\
\hline CHEMBL3190935 & 688620 & 5.05 & 5.0901 & TRN & \\
\hline CHEMBL1542349 & 688620 & 5.35 & 5.4279 & TRN & \\
\hline CHEMBL1316831 & 688620 & 5.25 & 5.3908 & TRN & \\
\hline CHEMBL 1450362 & 688620 & 6.0 & 5.0092 & TRN & \\
\hline CHEMBL1439176 & 688620 & 5.3 & 5.3362 & TRN & \\
\hline
\end{tabular}




\begin{tabular}{|c|c|c|c|c|}
\hline & & & pplemen & al $\mathrm{T}$ \\
\hline CHEMBL1576659 & 688620 & 5.0 & 5.1785 & TRN \\
\hline CHEMBL1337115 & 688620 & 4.8 & 4.8792 & TRN \\
\hline CHEMBL3191991 & 688620 & 5.75 & 5.5375 & TRN \\
\hline CHEMBL 3198574 & 688620 & 4.8 & 4.8362 & TRN \\
\hline CHEMBL1487132 & 688620 & 4.45 & 5.0545 & TRN \\
\hline CHEMBL1336246 & 688620 & 5.2 & 5.2466 & TRN \\
\hline CHEMBL3199850 & 688620 & 5.2 & 5.3888 & TRN \\
\hline CHEMBL1501238 & 688620 & 5.15 & 5.1382 & TRN \\
\hline CHEMBL1582353 & 688620 & 5.55 & 5.1694 & TRN \\
\hline CHEMBL1490574 & 688620 & 6.25 & 5.7227 & TRN \\
\hline CHEMBL1527891 & 688620 & 4.45 & 5.0439 & TRN \\
\hline CHEMBL1451111 & 688620 & 5.45 & 4.9531 & TRN \\
\hline CHEMBL1370177 & 688620 & 4.8 & 4.9789 & TRN \\
\hline CHEMBL1609585 & 688620 & 5.1 & 5.0385 & TRN \\
\hline CHEMBL1326124 & 688620 & 6.0 & 5.7871 & TRN \\
\hline CHEMBL1410250 & 688620 & 4.95 & 5.0906 & TRN \\
\hline CHEMBL1399127 & 688620 & 4.45 & 4.8071 & TST \\
\hline CHEMBL1311527 & 688620 & 4.45 & 5.0367 & TRN \\
\hline CHEMBL1392066 & 688620 & 4.55 & 5.1785 & TRN \\
\hline CHEMBL1342766 & 688620 & 5.75 & 5.4934 & TST \\
\hline CHEMBL1510589 & 688620 & 4.9 & 5.2056 & TST \\
\hline CHEMBL1526004 & 688620 & 5.25 & 5.1149 & TRN \\
\hline CHEMBL1521092 & 688620 & 4.85 & 5.2865 & TRN \\
\hline CHEMBL3198623 & 688620 & 4.45 & 4.877 & TRN \\
\hline CHEMBL1465725 & 688620 & 5.0 & 5.1187 & TRN \\
\hline CHEMBL1405942 & 688620 & 5.05 & 5.1969 & TRN \\
\hline CHEMBL1324181 & 688620 & 4.45 & 5.0103 & TST \\
\hline CHEMBL1351616 & 688620 & 4.85 & 4.8375 & TST \\
\hline CHEMBL1411732 & 688620 & 6.3 & 5.0036 & TST \\
\hline CHEMBL1360690 & 688620 & 4.9 & 5.1594 & TST \\
\hline CHEMBL1431532 & 688620 & 6.2 & 5.0079 & TRN \\
\hline CHEMBL1383955 & 688620 & 4.85 & 5.1153 & TST \\
\hline CHEMBL1350133 & 688620 & 4.5 & 4.8538 & TRN \\
\hline CHEMBL1353902 & 688620 & 4.9 & 5.228 & TRN \\
\hline CHEMBL1509402 & 688620 & 5.2 & 5.1298 & TST \\
\hline CHEMBL1439895 & 688620 & 4.8 & 5.1091 & TRN \\
\hline CHEMBL1998651 & 688620 & 4.45 & 4.9507 & TRN \\
\hline CHEMBL1556846 & 688620 & 5.6 & 5.2294 & TST \\
\hline CHEMBL1428437 & 688620 & 4.45 & 4.8488 & TRN \\
\hline CHEMBL1587562 & 688620 & 4.75 & 4.6878 & TRN \\
\hline CHEMBL3197520 & 688620 & 4.85 & 5.06 & TRN \\
\hline CHEMBL1548536 & 688620 & 5.2 & 5.1619 & TRN \\
\hline CHEMBL1377321 & 688620 & 4.45 & 5.1622 & TRN \\
\hline CHEMBL1461015 & 688620 & 4.85 & 5.2515 & TRN \\
\hline CHEMBL1447907 & 688620 & 6.8 & 5.1985 & TRN \\
\hline CHEMBL1430160 & 688620 & 4.55 & 4.9825 & TRN \\
\hline CHEMBL1403890 & 688620 & 4.45 & 4.734 & TRN \\
\hline CHEMBL1457085 & 688620 & 5.6 & 5.1021 & TRN \\
\hline
\end{tabular}




\begin{tabular}{|c|c|c|c|c|}
\hline & & & upplement & $\mathrm{T}$ \\
\hline CHEMBL1566790 & 688620 & 4.75 & 4.9042 & TRN \\
\hline CHEMBL1369628 & 688620 & 4.7 & 5.1159 & TRN \\
\hline CHEMBL1300391 & 688620 & 5.25 & 4.9287 & TRN \\
\hline CHEMBL1392852 & 688620 & 4.45 & 4.9949 & TRN \\
\hline CHEMBL1446437 & 688620 & 6.0 & 5.7617 & TST \\
\hline CHEMBL1586666 & 688620 & 4.9 & 5.0168 & TRN \\
\hline CHEMBL1593523 & 688620 & 5.05 & 4.9269 & TRN \\
\hline CHEMBL1594854 & 688620 & 5.6 & 5.1989 & TRN \\
\hline CHEMBL1361692 & 688620 & 5.8 & 5.1765 & TRN \\
\hline CHEMBL 3189878 & 688620 & 5.75 & 4.8376 & TRN \\
\hline CHEMBL1516627 & 688620 & 4.9 & 4.7652 & TRN \\
\hline CHEMBL1455904 & 688620 & 6.8 & 5.9035 & TRN \\
\hline CHEMBL 3189269 & 688620 & 5.7 & 5.3148 & TST \\
\hline CHEMBL1969232 & 688620 & 5.45 & 5.2227 & TRN \\
\hline CHEMBL1598433 & 688620 & 4.85 & 5.1352 & TRN \\
\hline CHEMBL 2004455 & 688620 & 5.05 & 4.9175 & TRN \\
\hline CHEMBL1424914 & 688620 & 5.15 & 5.0052 & TRN \\
\hline CHEMBL1606839 & 688620 & 4.45 & 4.6061 & TRN \\
\hline CHEMBL1374398 & 688620 & 5.35 & 5.1379 & TRN \\
\hline CHEMBL1367821 & 688620 & 4.45 & 5.0235 & TRN \\
\hline CHEMBL1530879 & 688620 & 4.6 & 5.0132 & TRN \\
\hline CHEMBL1464024 & 688620 & 5.25 & 5.4583 & TRN \\
\hline CHEMBL1400512 & 688620 & 4.95 & 4.9477 & TST \\
\hline CHEMBL1475642 & 688620 & 4.7 & 5.0136 & TRN \\
\hline CHEMBL1380857 & 688620 & 5.4 & 5.1322 & TRN \\
\hline CHEMBL3199920 & 688620 & 5.15 & 4.9509 & TRN \\
\hline CHEMBL1312363 & 688620 & 5.5 & 4.8739 & TST \\
\hline CHEMBL1511627 & 688620 & 4.75 & 5.1238 & TRN \\
\hline CHEMBL1607510 & 688620 & 4.7 & 5.0912 & TRN \\
\hline CHEMBL 3208408 & 688620 & 4.45 & 5.1845 & TRN \\
\hline CHEMBL1376153 & 688620 & 5.55 & 5.1916 & TST \\
\hline CHEMBL512216 & 688620 & 4.9 & 5.0767 & TST \\
\hline CHEMBL3210243 & 688620 & 5.2 & 5.2053 & TST \\
\hline CHEMBL1597146 & 688620 & 4.45 & 4.814 & TRN \\
\hline CHEMBL1597187 & 688620 & 5.0 & 5.0319 & TRN \\
\hline CHEMBL1523610 & 688620 & 4.95 & 4.8293 & TST \\
\hline CHEMBL1359879 & 688620 & 6.2 & 5.5241 & TRN \\
\hline CHEMBL1374390 & 688620 & 5.25 & 5.0815 & TRN \\
\hline CHEMBL601559 & 688620 & 4.95 & 5.1127 & TRN \\
\hline CHEMBL1471845 & 688620 & 4.9 & 5.3241 & TRN \\
\hline CHEMBL1503571 & 688620 & 4.75 & 5.0241 & TRN \\
\hline CHEMBL 1448630 & 688620 & 4.9 & 5.035 & TRN \\
\hline CHEMBL1587730 & 688620 & 5.25 & 5.1052 & TRN \\
\hline CHEMBL1465660 & 688620 & 5.25 & 5.2429 & TRN \\
\hline CHEMBL1319694 & 688620 & 4.7 & 4.9727 & TST \\
\hline CHEMBL1576979 & 688620 & 4.45 & 5.3384 & TRN \\
\hline CHEMBL1344112 & 688620 & 4.65 & 4.8465 & TRN \\
\hline CHEMBL1545598 & 688620 & 5.4 & 4.8837 & TRN \\
\hline
\end{tabular}




\begin{tabular}{|c|c|c|c|c|c|}
\hline \\
\hline CHEMBL1574206 & 688620 & 4.9 & 5.1484 & TST & \\
\hline CHEMBL1503012 & 688620 & 4.7 & 5.0263 & TRN & \\
\hline CHEMBL1477383 & 688620 & 4.85 & 4.9125 & TRN & \\
\hline CHEMBL1367587 & 688620 & 4.9 & 5.2707 & TRN & \\
\hline CHEMBL1309171 & 688620 & 4.95 & 5.0334 & TST & \\
\hline CHEMBL1346707 & 688620 & 4.95 & 5.1319 & TRN & \\
\hline CHEMBL1520478 & 688620 & 4.95 & 5.0351 & TRN & \\
\hline CHEMBL1519474 & 688620 & 5.45 & 4.7327 & TRN & \\
\hline CHEMBL1450224 & 688620 & 5.0 & 4.9785 & TRN & \\
\hline CHEMBL1533822 & 688620 & 5.7 & 5.2594 & TRN & \\
\hline CHEMBL1483133 & 688620 & 4.6 & 4.7089 & TRN & \\
\hline CHEMBL1555362 & 688620 & 4.5 & 4.8812 & TRN & \\
\hline CHEMBL1455633 & 688620 & 4.95 & 4.9423 & TST & \\
\hline CHEMBL1311628 & 688620 & 4.95 & 5.0578 & TRN & \\
\hline CHEMBL1496286 & 688620 & 4.45 & 4.98 & TRN & \\
\hline CHEMBL1463838 & 688620 & 4.45 & 5.0864 & TRN & \\
\hline CHEMBL1523463 & 688620 & 4.7 & 4.9779 & TRN & \\
\hline CHEMBL1457240 & 688620 & 4.65 & 5.0749 & TST & \\
\hline CHEMBL1575241 & 688620 & 5.55 & 5.0845 & TST & \\
\hline CHEMBL1399913 & 688620 & 5.9 & 5.0552 & TRN & \\
\hline CHEMBL2000686 & 688620 & 5.15 & 4.7422 & TRN & \\
\hline CHEMBL1353081 & 688620 & 4.55 & 4.9612 & TRN & \\
\hline CHEMBL1477248 & 688620 & 4.8 & 5.0167 & TRN & \\
\hline CHEMBL1380118 & 688620 & 5.0 & 5.635 & TRN & \\
\hline CHEMBL1497483 & 688620 & 5.25 & 4.9076 & TST & \\
\hline CHEMBL1484323 & 688620 & 5.05 & 4.7559 & TRN & \\
\hline CHEMBL3209573 & 688620 & 4.45 & 4.7719 & TRN & \\
\hline CHEMBL1383965 & 688620 & 5.9 & 5.0344 & TST & \\
\hline CHEMBL1489684 & 688620 & 5.05 & 5.1125 & TST & \\
\hline CHEMBL1402163 & 688620 & 4.45 & 5.0179 & TRN & \\
\hline CHEMBL531709 & 688620 & 4.8 & 4.9254 & TRN & \\
\hline CHEMBL1336568 & 688620 & 4.9 & 4.9723 & TRN & \\
\hline CHEMBL1577496 & 688620 & 4.65 & 4.8047 & TRN & \\
\hline CHEMBL3189244 & 688620 & 5.5 & 5.0859 & TST & \\
\hline CHEMBL1522418 & 688620 & 5.0 & 4.881 & TRN & \\
\hline CHEMBL1301054 & 688620 & 4.5 & 4.9764 & TRN & \\
\hline CHEMBL1596802 & 688620 & 4.45 & 4.8953 & TRN & \\
\hline CHEMBL1995503 & 688620 & 5.55 & 5.46399 & 99999999995 & TRN \\
\hline CHEMBL1326779 & 688620 & 5.4 & 5.3844 & TRN & \\
\hline CHEMBL1471460 & 688620 & 6.5501 & 5.6012 & TRN & \\
\hline CHEMBL1488712 & 688620 & 5.05 & 5.2231 & TRN & \\
\hline CHEMBL1583199 & 688620 & 5.05 & 5.2912 & TRN & \\
\hline CHEMBL3190891 & 688620 & 5.4 & 6.1913 & TRN & \\
\hline CHEMBL1488933 & 688620 & 4.75 & 5.0905 & TST & \\
\hline CHEMBL1418341 & 688620 & 5.0 & 4.6114 & TRN & \\
\hline CHEMBL3191835 & 688620 & 6.0 & 5.746 & TRN & \\
\hline CHEMBL1504003 & 688620 & 5.05 & 5.0565 & TRN & \\
\hline CHEMBL1339218 & 688620 & 5.55 & 5.1254 & TST & \\
\hline & & & & 7597 & \\
\hline
\end{tabular}




\begin{tabular}{|c|c|c|c|c|c|}
\hline \multicolumn{6}{|c|}{ Supplemental Table S2.txt } \\
\hline CHEMBL1575475 & 688620 & 6.35 & 5.5895 & TRN & \\
\hline CHEMBL1332341 & 688620 & 5.2 & 5.0151 & TRN & \\
\hline CHEMBL1534826 & 688620 & 4.8 & 4.8299 & TRN & \\
\hline CHEMBL1500042 & 688620 & 5.45 & 5.073 & TST & \\
\hline CHEMBL1473430 & 688620 & 4.85 & 5.0382 & TRN & \\
\hline CHEMBL1416756 & 688620 & 5.15 & 5.003 & TRN & \\
\hline CHEMBL1536942 & 688620 & 4.55 & 4.5934 & TRN & \\
\hline CHEMBL1580341 & 688620 & 5.5 & 5.2178 & TRN & \\
\hline CHEMBL1300952 & 688620 & 6.35 & 5.729 & TRN & \\
\hline CHEMBL1390273 & 688620 & 4.45 & 4.8847 & TST & \\
\hline CHEMBL1587708 & 688620 & 5.2 & 5.022 & TST & \\
\hline CHEMBL1613611 & 688620 & 6.0 & 5.5316 & TRN & \\
\hline CHEMBL1482717 & 688620 & 6.15 & 5.2666 & TRN & \\
\hline CHEMBL1483925 & 688620 & 8.3468 & 5.0899 & TRN & \\
\hline CHEMBL1431227 & 688620 & 4.95 & 4.9577 & TRN & \\
\hline CHEMBL1562798 & 688620 & 4.8 & 4.8588 & TST & \\
\hline CHEMBL1544646 & 688620 & 4.9 & 4.919 & TRN & \\
\hline CHEMBL1423254 & 688620 & 5.85 & 5.4785 & TRN & \\
\hline CHEMBL1366190 & 688620 & 4.95 & 5.0356 & TRN & \\
\hline CHEMBL1389343 & 688620 & 4.45 & 4.8103 & TRN & \\
\hline CHEMBL1996858 & 688620 & 4.45 & 5.2087 & TRN & \\
\hline CHEMBL1440883 & 688620 & 4.45 & 5.1892 & TRN & \\
\hline CHEMBL1332802 & 688620 & 4.45 & 4.73600 & 0000000001 & TRN \\
\hline CHEMBL1526966 & 688620 & 4.95 & 4.8819 & TRN & \\
\hline CHEMBL460517 & 688620 & 4.9 & 5.437 & TRN & \\
\hline CHEMBL1472023 & 688620 & 4.8 & 5.0635 & TRN & \\
\hline CHEMBL1411133 & 688620 & 4.6 & 5.1042 & TRN & \\
\hline CHEMBL1586780 & 688620 & 6.5 & 5.0704 & TST & \\
\hline CHEMBL1557191 & 688620 & 4.9 & 5.0858 & TRN & \\
\hline CHEMBL1606136 & 688620 & 4.75 & 4.8403 & TRN & \\
\hline CHEMBL1545965 & 688620 & 4.45 & 5.0311 & TRN & \\
\hline CHEMBL1533666 & 688620 & 5.5 & 5.0513 & TRN & \\
\hline CHEMBL1350248 & 688620 & 5.15 & 5.1976 & TRN & \\
\hline CHEMBL1519789 & 688620 & 4.6 & 5.0525 & TST & \\
\hline CHEMBL1575407 & 688620 & 5.05 & 5.0335 & TRN & \\
\hline CHEMBL1335043 & 688620 & 4.8 & 4.9474 & TRN & \\
\hline CHEMBL1884996 & 688620 & 7.0 & 6.0571 & TRN & \\
\hline CHEMBL1539501 & 688620 & 4.85 & 4.9485 & TRN & \\
\hline CHEMBL1361341 & 688620 & 6.45 & 6.2979 & TRN & \\
\hline CHEMBL1322584 & 688620 & 5.05 & 5.038 & TRN & \\
\hline CHEMBL1578087 & 688620 & 4.8 & 5.1368 & TRN & \\
\hline CHEMBL 1598020 & 688620 & 4.45 & 5.2666 & TRN & \\
\hline CHEMBL1589378 & 688620 & 4.95 & 5.3461 & TRN & \\
\hline CHEMBL 3199409 & 688620 & 5.0 & 5.2594 & TRN & \\
\hline CHEMBL1540547 & 688620 & 5.65 & 5.0245 & TRN & \\
\hline CHEMBL3208813 & 688620 & 4.7 & 5.0856 & TRN & \\
\hline CHEMBL3195327 & 688620 & 4.45 & 4.9494 & TRN & \\
\hline CHEMBL1964676 & 688620 & 5.4 & 5.1385 & TRN & \\
\hline
\end{tabular}




\begin{tabular}{|c|c|c|c|c|}
\hline \multicolumn{5}{|c|}{ Supplemental Table S2.txt } \\
\hline CHEMBL1993662 & 688620 & 5.35 & 5.5723 & TRN \\
\hline CHEMBL1480767 & 688620 & 4.85 & 5.0776 & TRN \\
\hline CHEMBL1404537 & 688620 & 4.9 & 4.9594 & TST \\
\hline CHEMBL1540765 & 688620 & 4.85 & 5.0053 & TRN \\
\hline CHEMBL1516588 & 688620 & 4.65 & 5.2151 & TRN \\
\hline CHEMBL1532281 & 688620 & 5.0 & 5.1524 & TST \\
\hline CHEMBL1426863 & 688620 & 5.25 & 5.0703 & TRN \\
\hline CHEMBL1421306 & 688620 & 4.5 & 4.8416 & TRN \\
\hline CHEMBL210329 & 688620 & 5.35 & 4.94 & TRN \\
\hline CHEMBL1544978 & 688620 & 5.25 & 5.1113 & TRN \\
\hline CHEMBL1405059 & 688620 & 5.9 & 5.6341 & TRN \\
\hline CHEMBL1964583 & 688620 & 4.8 & 5.3468 & TRN \\
\hline CHEMBL1458134 & 688620 & 4.9 & 5.1893 & TRN \\
\hline CHEMBL1556966 & 688620 & 7.5003 & 5.6374 & TST \\
\hline CHEMBL51773 & 688620 & 5.15 & 5.0719 & TRN \\
\hline CHEMBL1392705 & 688620 & 4.8 & 5.1026 & TRN \\
\hline CHEMBL1453546 & 688620 & 4.95 & 4.9987 & TRN \\
\hline CHEMBL1410663 & 688620 & 4.85 & 5.1884 & TRN \\
\hline CHEMBL1495502 & 688620 & 4.95 & 4.6639 & TRN \\
\hline CHEMBL1492488 & 688620 & 4.45 & 5.1032 & TRN \\
\hline CHEMBL1446704 & 688620 & 5.65 & 5.2307 & TRN \\
\hline CHEMBL1591336 & 688620 & 4.9 & 4.9339 & TRN \\
\hline CHEMBL3210202 & 688620 & 4.6 & 4.9328 & TRN \\
\hline CHEMBL1380011 & 688620 & 5.25 & 5.0485 & TRN \\
\hline CHEMBL1382936 & 688620 & 5.25 & 5.0075 & TRN \\
\hline CHEMBL1336098 & 688620 & 6.45 & 4.8585 & TRN \\
\hline CHEMBL1374486 & 688620 & 5.0 & 5.21 & TRN \\
\hline CHEMBL1465209 & 688620 & 4.95 & 4.9367 & TRN \\
\hline CHEMBL1496117 & 688620 & 5.5 & 5.0257 & TRN \\
\hline CHEMBL481577 & 688620 & 4.55 & 5.0571 & TRN \\
\hline CHEMBL1376445 & 688620 & 5.0 & 5.2892 & TST \\
\hline CHEMBL1596126 & 688620 & 5.25 & 4.9561 & TRN \\
\hline CHEMBL3191884 & 688620 & 5.0 & 5.1613 & TRN \\
\hline CHEMBL1391587 & 688620 & 5.0 & 5.0892 & TRN \\
\hline CHEMBL1374231 & 688620 & 4.45 & 5.1415 & TST \\
\hline CHEMBL1538919 & 688620 & 5.0 & 4.974 & TRN \\
\hline CHEMBL1383761 & 688620 & 4.45 & 4.8582 & TRN \\
\hline CHEMBL1489591 & 688620 & 5.0 & 5.3408 & TRN \\
\hline CHEMBL3191487 & 688620 & 4.95 & 4.8249 & TRN \\
\hline CHEMBL1384312 & 688620 & 5.2 & 4.9445 & TRN \\
\hline CHEMBL1335301 & 688620 & 4.95 & 4.9973 & TRN \\
\hline CHEMBL1310986 & 688620 & 4.45 & 5.3924 & TST \\
\hline CHEMBL1507022 & 688620 & 4.95 & 5.0872 & TST \\
\hline CHEMBL1521301 & 688620 & 4.45 & 5.1709 & TRN \\
\hline CHEMBL3392065 & 688620 & 5.9 & 5.1548 & TST \\
\hline CHEMBL1341932 & 688620 & 4.7 & 4.8269 & TRN \\
\hline CHEMBL1490832 & 688620 & 5.0 & 4.9247 & TRN \\
\hline CHEMBL1548195 & 688620 & 5.35 & 5.2066 & TRN \\
\hline
\end{tabular}




\begin{tabular}{|c|c|c|c|c|c|}
\hline \multicolumn{6}{|c|}{ Supplemental Table S2.txt } \\
\hline CHEMBL1467631 & 688620 & 5.8 & 5.439 & TRN & \\
\hline CHEMBL1585207 & 688620 & 5.2 & 5.1607 & TST & \\
\hline CHEMBL1998816 & 688620 & 4.9 & 5.0578 & TRN & \\
\hline CHEMBL1550237 & 688620 & 5.15 & 5.1762 & TRN & \\
\hline CHEMBL1589443 & 688620 & 5.3 & 5.1528 & TRN & \\
\hline CHEMBL1497625 & 688620 & 4.7 & 5.4477 & TRN & \\
\hline CHEMBL1353150 & 688620 & 4.45 & 5.0583 & TST & \\
\hline CHEMBL1381135 & 688620 & 4.75 & 5.157 & TRN & \\
\hline CHEMBL1508197 & 688620 & 5.0 & 4.9953 & TRN & \\
\hline CHEMBL1352268 & 688620 & 4.45 & 5.2018 & TST & \\
\hline CHEMBL1406488 & 688620 & 4.9 & 5.1916 & TRN & \\
\hline CHEMBL1415487 & 688620 & 6.6499 & 5.2983 & TST & \\
\hline CHEMBL 3195488 & 688620 & 4.75 & 5.2997 & TRN & \\
\hline CHEMBL1471740 & 688620 & 4.7 & 5.0376 & TRN & \\
\hline CHEMBL1502719 & 688620 & 4.5 & 4.8743 & TRN & \\
\hline CHEMBL1389145 & 688620 & 4.45 & 4.9566 & TRN & \\
\hline CHEMBL3211553 & 688620 & 4.45 & 4.9821 & TST & \\
\hline CHEMBL1579693 & 688620 & 5.25 & 5.6241 & TRN & \\
\hline CHEMBL1384916 & 688620 & 4.8 & 4.9111 & TRN & \\
\hline CHEMBL1340622 & 688620 & 4.45 & 5.1061 & TRN & \\
\hline CHEMBL1180 & 688620 & 5.4 & 4.8255 & TST & \\
\hline CHEMBL1470577 & 688620 & 4.45 & 5.1961 & TST & \\
\hline CHEMBL1587229 & 688620 & 5.4 & 4.9860 & 0000000001 & TRN \\
\hline CHEMBL1334044 & 688620 & 4.9 & 5.0245 & TRN & \\
\hline CHEMBL492267 & 688620 & 4.85 & 5.2093 & TST & \\
\hline CHEMBL1351752 & 688620 & 5.1 & 4.9905 & TRN & \\
\hline CHEMBL1359092 & 688620 & 5.65 & 4.9679 & TRN & \\
\hline CHEMBL1453690 & 688620 & 5.15 & 4.9658 & TRN & \\
\hline CHEMBL1479706 & 688620 & 5.6 & 5.0272 & TST & \\
\hline CHEMBL1479888 & 688620 & 5.05 & 4.6256 & TRN & \\
\hline CHEMBL1433223 & 688620 & 4.9 & 4.8524 & TRN & \\
\hline CHEMBL1468899 & 688620 & 5.55 & 5.2276 & TRN & \\
\hline CHEMBL503938 & 688620 & 6.35 & 5.2570 & 0000000001 & TST \\
\hline CHEMBL1391326 & 688620 & 4.45 & 4.94 & TST & \\
\hline CHEMBL 3207414 & 688620 & 4.9 & 5.144 & TRN & \\
\hline CHEMBL1508547 & 688620 & 5.15 & 5.1233 & TRN & \\
\hline CHEMBL1465951 & 688620 & 5.35 & 5.2109 & TRN & \\
\hline CHEMBL1519333 & 688620 & 5.75 & 5.5138 & TST & \\
\hline CHEMBL1499536 & 688620 & 5.4 & 5.1052 & TST & \\
\hline CHEMBL1526965 & 688620 & 5.55 & 5.2492 & TRN & \\
\hline CHEMBL1351105 & 688620 & 4.6 & 4.7538 & TST & \\
\hline CHEMBL1376387 & 688620 & 4.9 & 4.9989 & TRN & \\
\hline CHEMBL1314823 & 688620 & 6.3 & 5.9117 & TRN & \\
\hline CHEMBL1330725 & 688620 & 4.75 & 4.9803 & TRN & \\
\hline CHEMBL1347586 & 688620 & 6.05 & 4.7315 & TST & \\
\hline CHEMBL1577675 & 688620 & 4.85 & 4.9603 & TRN & \\
\hline CHEMBL1584187 & 688620 & 4.95 & 5.1541 & TST & \\
\hline CHEMBL1312226 & 688620 & 4.95 & 5.1008 & TST & \\
\hline
\end{tabular}




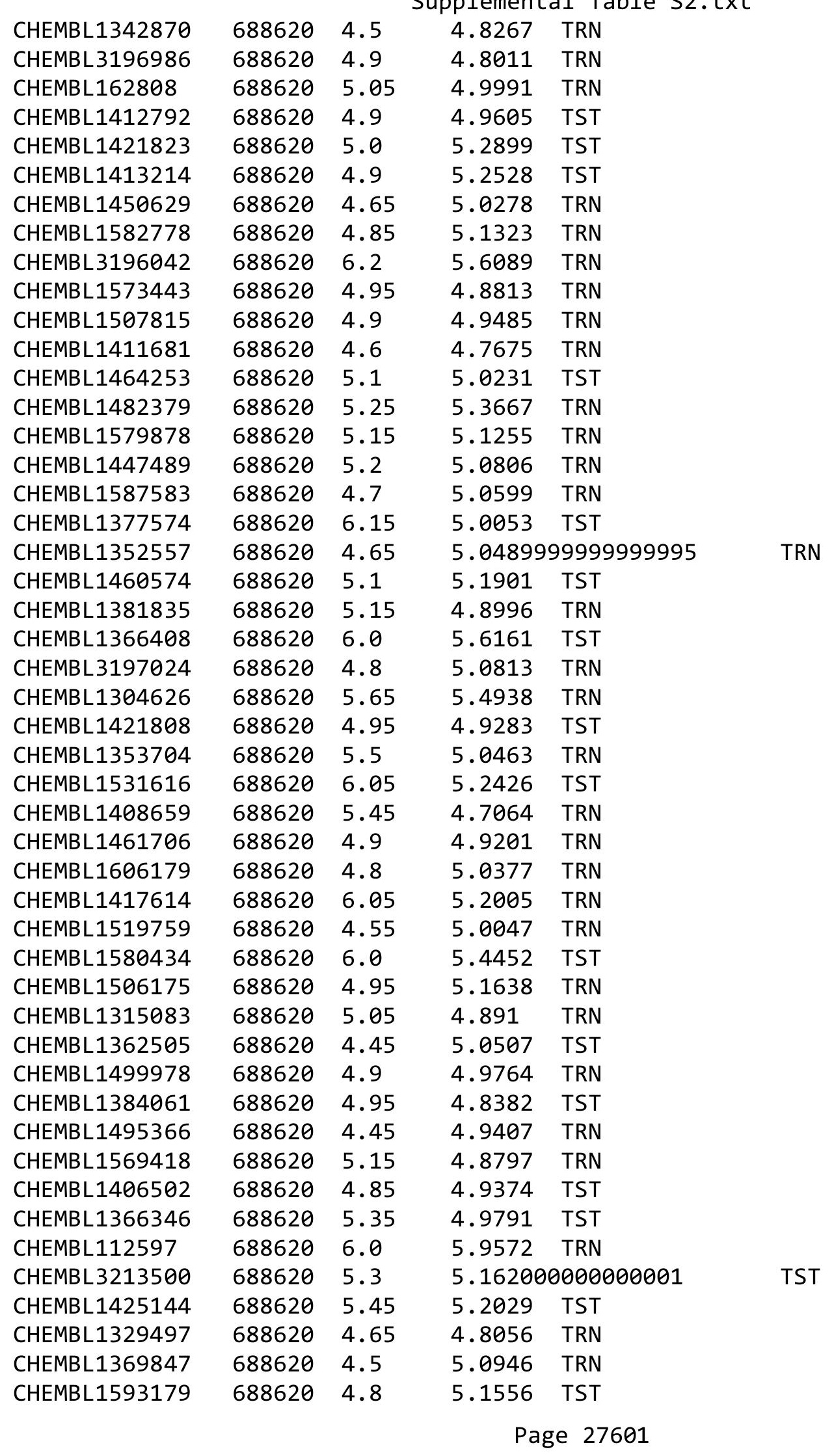




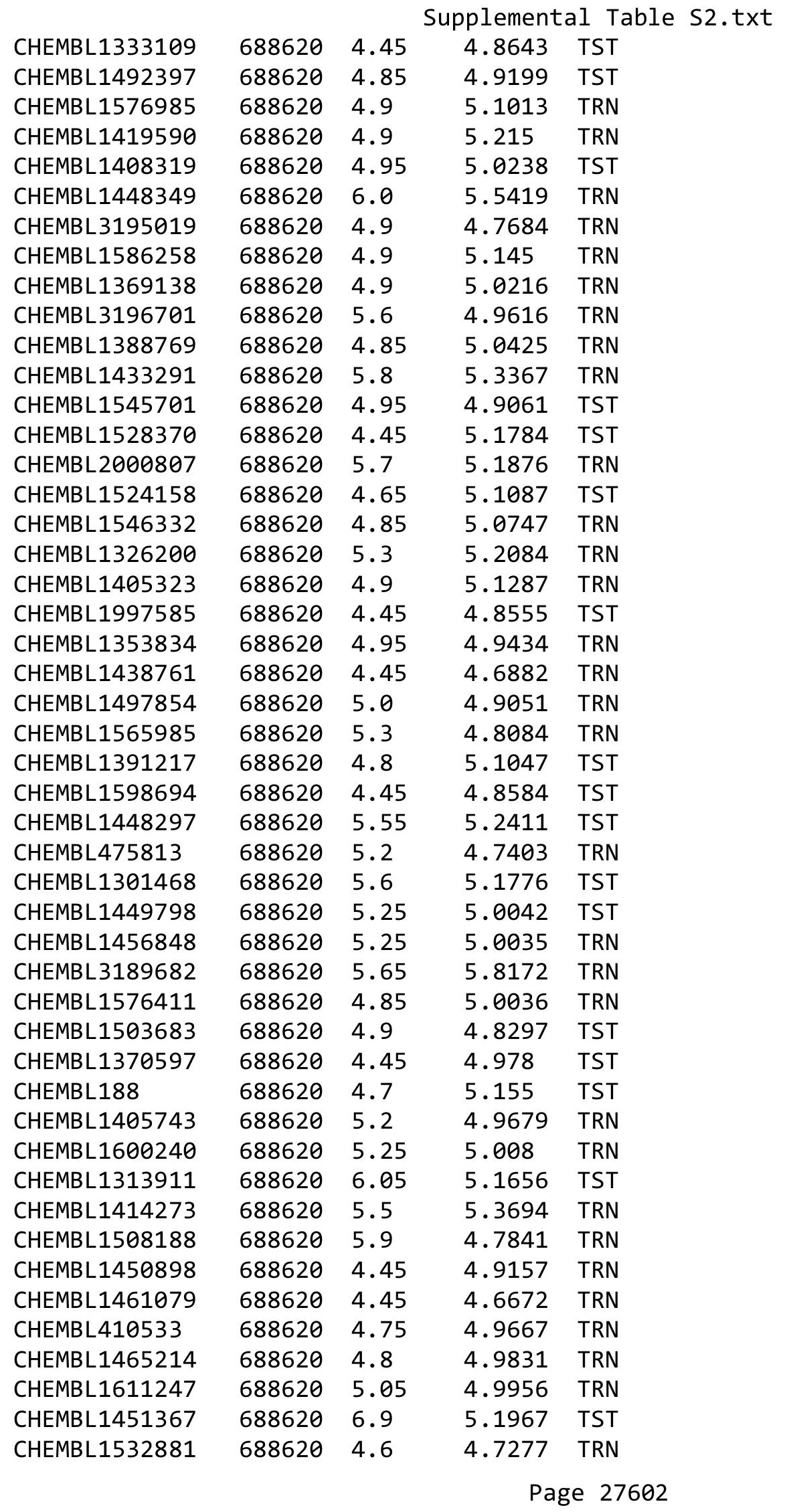




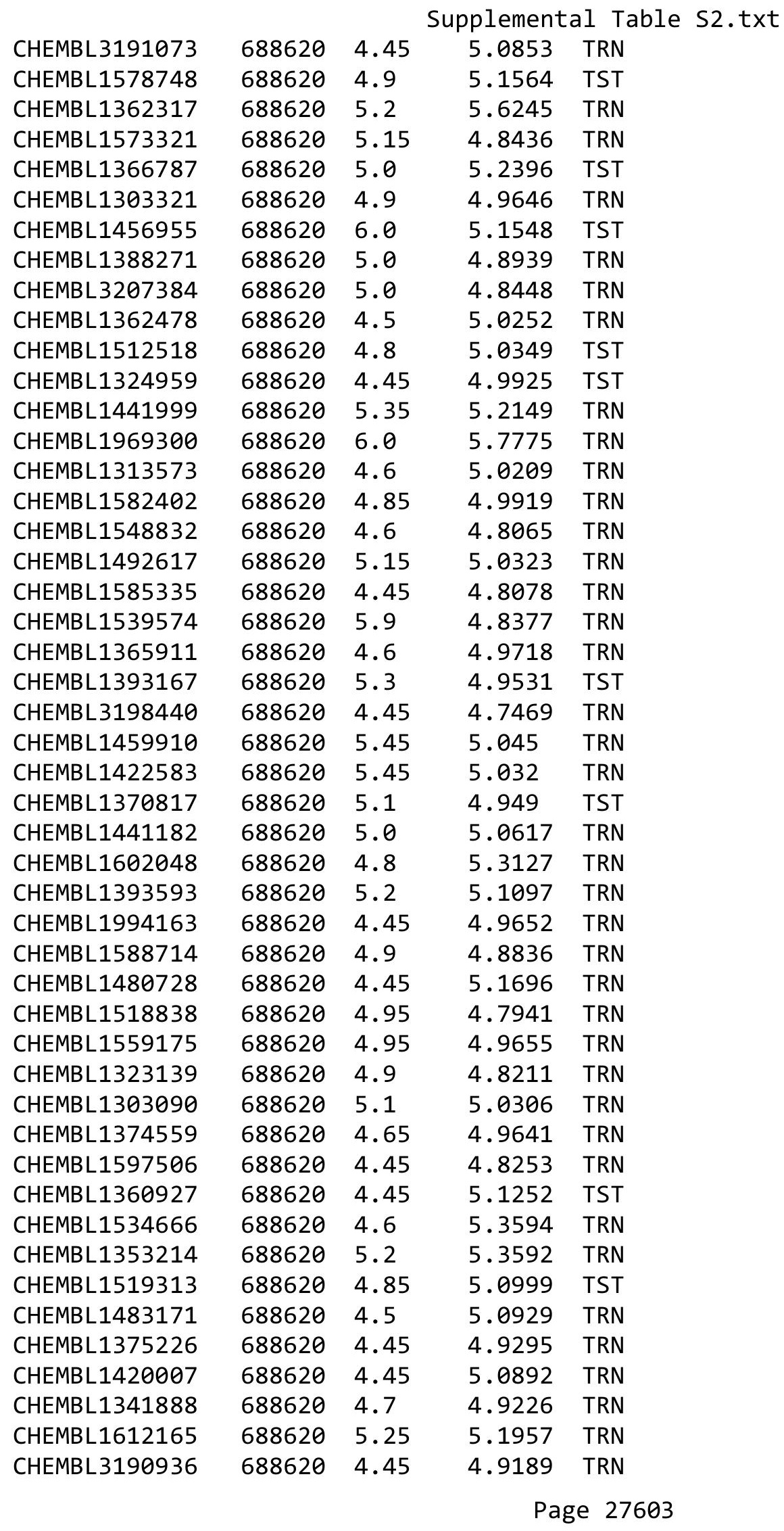




\begin{tabular}{|c|c|c|c|c|}
\hline \multicolumn{5}{|c|}{ Supplemental Table S2.txt } \\
\hline CHEMBL1391866 & 688620 & 5.85 & 5.4155 & TRN \\
\hline CHEMBL3189603 & 688620 & 5.1 & 4.9979 & TRN \\
\hline CHEMBL1483310 & 688620 & 5.05 & 5.1653 & TRN \\
\hline CHEMBL3194931 & 688620 & 5.0 & 4.824 & TST \\
\hline CHEMBL1346974 & 688620 & 4.95 & 4.6715 & TRN \\
\hline CHEMBL1502843 & 688620 & 4.9 & 5.0834 & TRN \\
\hline CHEMBL1313089 & 688620 & 5.25 & 5.2867 & TRN \\
\hline CHEMBL1458540 & 688620 & 4.55 & 5.0235 & TRN \\
\hline CHEMBL402069 & 688620 & 4.9 & 5.1457 & TST \\
\hline CHEMBL1351716 & 688620 & 4.75 & 4.8261 & TST \\
\hline CHEMBL 3193780 & 688620 & 4.6 & 4.9247 & TST \\
\hline CHEMBL1413839 & 688620 & 5.65 & 4.9353 & TRN \\
\hline CHEMBL1310202 & 688620 & 4.95 & 4.9837 & TRN \\
\hline CHEMBL1313595 & 688620 & 5.0 & 4.9715 & TST \\
\hline CHEMBL3211676 & 688620 & 4.95 & 5.0317 & TST \\
\hline CHEMBL1538643 & 688620 & 4.85 & 4.5814 & TST \\
\hline CHEMBL1555638 & 688620 & 5.2 & 5.1769 & TRN \\
\hline CHEMBL 2354875 & 688620 & 4.75 & 5.2437 & TST \\
\hline CHEMBL1421297 & 688620 & 4.95 & 4.916 & TRN \\
\hline CHEMBL1457383 & 688620 & 5.5 & 4.9249 & TRN \\
\hline CHEMBL1428225 & 688620 & 4.65 & 5.4537 & TRN \\
\hline CHEMBL1428731 & 688620 & 5.5 & 4.8545 & TRN \\
\hline CHEMBL1381088 & 688620 & 5.05 & 4.9765 & TST \\
\hline CHEMBL1490582 & 688620 & 4.7 & 4.7276 & TRN \\
\hline CHEMBL3198336 & 688620 & 5.15 & 5.0859 & TRN \\
\hline CHEMBL1453314 & 688620 & 4.95 & 5.0101 & TRN \\
\hline CHEMBL1381808 & 688620 & 4.45 & 4.7476 & TRN \\
\hline CHEMBL1606621 & 688620 & 4.95 & 5.1272 & TRN \\
\hline CHEMBL1413716 & 688620 & 5.1 & 5.0091 & TRN \\
\hline CHEMBL1308682 & 688620 & 5.45 & 5.4612 & TRN \\
\hline CHEMBL1538302 & 688620 & 5.75 & 5.1454 & TRN \\
\hline CHEMBL3198124 & 688620 & 4.75 & 4.7792 & TRN \\
\hline CHEMBL1411330 & 688620 & 4.85 & 5.0013 & TRN \\
\hline CHEMBL1414547 & 688620 & 4.45 & 5.1805 & TRN \\
\hline CHEMBL1493734 & 688620 & 5.1 & 4.9979 & TRN \\
\hline CHEMBL1562838 & 688620 & 6.6499 & 5.0831 & TRN \\
\hline CHEMBL3190946 & 688620 & 4.65 & 5.0557 & TRN \\
\hline CHEMBL465909 & 688620 & 4.5 & 5.1346 & TRN \\
\hline CHEMBL1971379 & 688620 & 6.4 & 5.9223 & TRN \\
\hline CHEMBL53628 & 688620 & 4.65 & 4.8552 & TRN \\
\hline CHEMBL363535 & 688620 & 5.0 & 5.234 & TST \\
\hline CHEMBL3193893 & 688620 & 5.25 & 5.3362 & TRN \\
\hline CHEMBL3213738 & 688620 & 5.35 & 5.3761 & TRN \\
\hline CHEMBL1365528 & 688620 & 5.0 & 5.074 & TRN \\
\hline CHEMBL1395497 & 688620 & 5.05 & 5.2709 & TRN \\
\hline CHEMBL1594771 & 688620 & 5.15 & 5.038 & TST \\
\hline CHEMBL1307506 & 688620 & 5.1 & 5.3542 & TST \\
\hline CHEMBL1452406 & 688620 & 4.45 & 5.085 & TRN \\
\hline
\end{tabular}




\begin{tabular}{|c|c|c|c|c|}
\hline & & & upplement & al $\mathrm{T}$ \\
\hline CHEMBL1546223 & 688620 & 4.45 & 4.7368 & TST \\
\hline CHEMBL1456801 & 688620 & 4.45 & 4.8718 & TST \\
\hline CHEMBL1545911 & 688620 & 5.55 & 5.4854 & TRN \\
\hline CHEMBL3196362 & 688620 & 6.25 & 5.1527 & TRN \\
\hline CHEMBL1444254 & 688620 & 5.5 & 4.9614 & TRN \\
\hline CHEMBL1974432 & 688620 & 6.45 & 5.9453 & TRN \\
\hline CHEMBL587919 & 688620 & 4.95 & 4.7258 & TST \\
\hline CHEMBL1499593 & 688620 & 4.95 & 5.3296 & TRN \\
\hline CHEMBL1990712 & 688620 & 4.95 & 5.153 & TRN \\
\hline CHEMBL1571157 & 688620 & 4.45 & 4.7702 & TRN \\
\hline CHEMBL1394829 & 688620 & 4.95 & 4.8736 & TRN \\
\hline CHEMBL1400972 & 688620 & 4.65 & 5.2108 & TRN \\
\hline CHEMBL1467868 & 688620 & 4.45 & 5.1589 & TRN \\
\hline CHEMBL1545588 & 688620 & 5.0 & 5.0032 & TRN \\
\hline CHEMBL1559721 & 688620 & 4.6 & 4.993 & TRN \\
\hline CHEMBL1570567 & 688620 & 5.85 & 5.3179 & TRN \\
\hline CHEMBL1419537 & 688620 & 4.65 & 4.8043 & TRN \\
\hline CHEMBL1319665 & 688620 & 6.0 & 5.2077 & TRN \\
\hline CHEMBL1556463 & 688620 & 4.85 & 4.9605 & TRN \\
\hline CHEMBL1457514 & 688620 & 4.45 & 5.1755 & TRN \\
\hline CHEMBL1563595 & 688620 & 4.45 & 5.0303 & TRN \\
\hline CHEMBL1375007 & 688620 & 4.65 & 4.7728 & TRN \\
\hline CHEMBL1381292 & 688620 & 4.65 & 5.2212 & TST \\
\hline CHEMBL1449640 & 688620 & 5.5 & 5.4838 & TRN \\
\hline CHEMBL3191331 & 688620 & 5.2 & 4.907 & TRN \\
\hline CHEMBL1447594 & 688620 & 5.0 & 5.1297 & TST \\
\hline CHEMBL1366577 & 688620 & 5.35 & 5.2744 & TRN \\
\hline CHEMBL1311003 & 688620 & 5.25 & 5.1322 & TST \\
\hline CHEMBL1455707 & 688620 & 4.65 & 4.8247 & TST \\
\hline CHEMBL1567827 & 688620 & 4.45 & 5.0573 & TRN \\
\hline CHEMBL1437994 & 688620 & 4.85 & 4.607 & TRN \\
\hline CHEMBL1584645 & 688620 & 4.9 & 5.2458 & TRN \\
\hline CHEMBL1451393 & 688620 & 4.45 & 4.9693 & TRN \\
\hline CHEMBL1490148 & 688620 & 4.75 & 4.7588 & TRN \\
\hline CHEMBL1419199 & 688620 & 5.6 & 5.2222 & TRN \\
\hline CHEMBL1509903 & 688620 & 5.15 & 5.0854 & TRN \\
\hline CHEMBL581471 & 688620 & 5.25 & 5.2156 & TST \\
\hline CHEMBL1408238 & 688620 & 5.05 & 5.2598 & TRN \\
\hline CHEMBL3199412 & 688620 & 4.6 & 5.136 & TRN \\
\hline CHEMBL1571499 & 688620 & 5.0 & 5.0356 & TRN \\
\hline CHEMBL1556798 & 688620 & 5.4 & 4.8731 & TRN \\
\hline CHEMBL1330053 & 688620 & 4.95 & 5.0675 & TST \\
\hline CHEMBL1966366 & 688620 & 4.5 & 5.0428 & TRN \\
\hline CHEMBL1417651 & 688620 & 4.9 & 4.8772 & TRN \\
\hline CHEMBL1466087 & 688620 & 4.75 & 5.3477 & TRN \\
\hline CHEMBL1608218 & 688620 & 4.45 & 4.9237 & TRN \\
\hline CHEMBL1300912 & 688620 & 4.9 & 4.9919 & TRN \\
\hline CHEMBL1560796 & 688620 & 4.45 & 5.2337 & TRN \\
\hline
\end{tabular}




\begin{tabular}{|c|c|c|c|c|c|}
\hline \multicolumn{6}{|c|}{ Supplemental Table S2.txt } \\
\hline CHEMBL1538927 & 688620 & 4.6 & 4.8261 & TRN & \\
\hline CHEMBL1299637 & 688620 & 6.5 & 5.5711 & TRN & \\
\hline CHEMBL1609155 & 688620 & 4.45 & 5.0214 & TRN & \\
\hline CHEMBL1215100 & 688620 & 5.0 & 4.9716 & TRN & \\
\hline CHEMBL1361410 & 688620 & 4.45 & 5.1673 & TST & \\
\hline CHEMBL1410296 & 688620 & 4.9 & 5.0308 & TRN & \\
\hline CHEMBL366563 & 688620 & 6.15 & 5.3426 & TST & \\
\hline CHEMBL1489757 & 688620 & 4.9 & 4.9263 & TRN & \\
\hline CHEMBL3197860 & 688620 & 5.3 & 5.1888 & TST & \\
\hline CHEMBL3195688 & 688620 & 4.85 & 5.2074 & TRN & \\
\hline CHEMBL1400881 & 688620 & 5.75 & 5.5516 & TRN & \\
\hline CHEMBL1319607 & 688620 & 5.45 & 4.9663 & TST & \\
\hline CHEMBL1460740 & 688620 & 4.45 & 4.8142 & TST & \\
\hline CHEMBL1539016 & 688620 & 5.0 & 5.1976 & TST & \\
\hline CHEMBL1555552 & 688620 & 4.55 & 5.0264 & TST & \\
\hline CHEMBL3209113 & 688620 & 4.45 & 4.7 & TRN & \\
\hline CHEMBL1997635 & 688620 & 5.35 & 5.2974 & TRN & \\
\hline CHEMBL1344634 & 688620 & 4.45 & 4.9325 & TRN & \\
\hline CHEMBL3190965 & 688620 & 5.75 & 5.1641 & TRN & \\
\hline CHEMBL1599360 & 688620 & 6.5501 & 5.2988 & TRN & \\
\hline CHEMBL1455309 & 688620 & 4.55 & 5.136 & TST & \\
\hline CHEMBL1343493 & 688620 & 4.95 & 5.0715 & TST & \\
\hline CHEMBL1529789 & 688620 & 5.3 & 4.8757 & TST & \\
\hline CHEMBL510515 & 688620 & 4.8 & 4.9524 & TRN & \\
\hline CHEMBL1375167 & 688620 & 4.9 & 5.0457 & TRN & \\
\hline CHEMBL1542586 & 688620 & 5.8 & 5.7076 & TRN & \\
\hline CHEMBL1479862 & 688620 & 4.45 & 4.8664 & TRN & \\
\hline CHEMBL1329461 & 688620 & 4.75 & 5.046 & TST & \\
\hline CHEMBL1611229 & 688620 & 5.6 & 5.1562 & TRN & \\
\hline CHEMBL3191755 & 688620 & 4.95 & 5.2673 & TRN & \\
\hline CHEMBL1532442 & 688620 & 4.45 & 5.0859 & TRN & \\
\hline CHEMBL3197173 & 688620 & 5.0 & 5.0914 & TRN & \\
\hline CHEMBL1362057 & 688620 & 4.95 & 4.8798 & TRN & \\
\hline CHEMBL1471396 & 688620 & 5.15 & $5.1610 e$ & 00000000005 & TRN \\
\hline CHEMBL1353758 & 688620 & 6.5 & 5.3005 & TRN & \\
\hline CHEMBL1409903 & 688620 & 4.5 & 4.7917 & TRN & \\
\hline CHEMBL1505221 & 688620 & 4.45 & 4.8209 & TST & \\
\hline CHEMBL1461974 & 688620 & 6.6499 & 4.8514 & TST & \\
\hline CHEMBL1489131 & 688620 & 4.45 & 4.8985 & TRN & \\
\hline CHEMBL1335766 & 688620 & 5.3 & 5.2898 & TRN & \\
\hline CHEMBL1449916 & 688620 & 6.0 & 5.9952 & TRN & \\
\hline CHEMBL1383820 & 688620 & 4.65 & 5.0648 & TST & \\
\hline CHEMBL1326249 & 688620 & 4.9 & 5.1344 & TST & \\
\hline CHEMBL1573815 & 688620 & 4.9 & 4.8658 & TRN & \\
\hline CHEMBL1340311 & 688620 & 6.05 & 5.1246 & TST & \\
\hline CHEMBL1502815 & 688620 & 4.95 & 5.0617 & TST & \\
\hline CHEMBL1330656 & 688620 & 5.15 & 4.9621 & TRN & \\
\hline CHEMBL1561496 & 688620 & 5.35 & 5.2204 & TRN & \\
\hline
\end{tabular}




\begin{tabular}{|c|c|c|c|c|}
\hline & & & pplement & al $\mathrm{T}$ \\
\hline CHEMBL1346478 & 688620 & 5.0 & 4.9157 & TST \\
\hline CHEMBL1455360 & 688620 & 4.75 & 5.1591 & TRN \\
\hline CHEMBL1610729 & 688620 & 6.95 & 5.3455 & TRN \\
\hline CHEMBL1544762 & 688620 & 5.95 & 5.3667 & TRN \\
\hline CHEMBL1303752 & 688620 & 5.05 & 5.1252 & TST \\
\hline CHEMBL1377406 & 688620 & 4.9 & 4.8794 & TRN \\
\hline CHEMBL1428170 & 688620 & 4.65 & 5.0741 & TRN \\
\hline CHEMBL1348256 & 688620 & 4.75 & 4.8988 & TRN \\
\hline CHEMBL1326896 & 688620 & 5.15 & 5.3131 & TRN \\
\hline CHEMBL1448592 & 688620 & 5.45 & 5.612 & TRN \\
\hline CHEMBL1518661 & 688620 & 5.0 & 5.1405 & TRN \\
\hline CHEMBL1383904 & 688620 & 5.55 & 5.0944 & TRN \\
\hline CHEMBL1332811 & 688620 & 4.85 & 4.9968 & TST \\
\hline CHEMBL1411542 & 688620 & 5.45 & 5.1354 & TRN \\
\hline CHEMBL1541893 & 688620 & 5.25 & 5.0609 & TST \\
\hline CHEMBL1455144 & 688620 & 6.1 & 5.0306 & TRN \\
\hline CHEMBL1395151 & 688620 & 4.6 & 4.7969 & TRN \\
\hline CHEMBL1362886 & 688620 & 4.8 & 5.0799 & TST \\
\hline CHEMBL1362928 & 688620 & 4.5 & 5.0916 & TST \\
\hline CHEMBL1302618 & 688620 & 4.45 & 4.954 & TST \\
\hline CHEMBL3209095 & 688620 & 4.45 & 4.942 & TRN \\
\hline CHEMBL3196791 & 688620 & 4.95 & 5.141 & TRN \\
\hline CHEMBL1364289 & 688620 & 5.05 & 5.3037 & TRN \\
\hline CHEMBL355612 & 688620 & 4.7 & 5.3793 & TRN \\
\hline CHEMBL1533753 & 688620 & 4.85 & 4.9877 & TST \\
\hline CHEMBL1567271 & 688620 & 5.55 & 5.2039 & TRN \\
\hline CHEMBL1508364 & 688620 & 5.25 & 4.8255 & TRN \\
\hline CHEMBL1499360 & 688620 & 4.9 & 4.8595 & TRN \\
\hline CHEMBL1584436 & 688620 & 4.45 & 5.1157 & TRN \\
\hline CHEMBL1588405 & 688620 & 8.2518 & 5.0298 & TRN \\
\hline CHEMBL1415513 & 688620 & 4.45 & 5.0219 & TST \\
\hline CHEMBL1495140 & 688620 & 4.45 & 5.0035 & TRN \\
\hline CHEMBL1325597 & 688620 & 4.45 & 5.0347 & TST \\
\hline CHEMBL1312820 & 688620 & 4.85 & 5.0615 & TRN \\
\hline CHEMBL1387593 & 688620 & 4.85 & 5.2187 & TRN \\
\hline CHEMBL1327939 & 688620 & 5.0 & 4.8773 & TRN \\
\hline CHEMBL1393403 & 688620 & 4.7 & 5.0492 & TRN \\
\hline CHEMBL1466186 & 688620 & 6.3 & 5.7181 & TRN \\
\hline CHEMBL1389481 & 688620 & 4.45 & 5.073 & TST \\
\hline CHEMBL1542632 & 688620 & 5.4 & 5.0862 & TST \\
\hline CHEMBL1397462 & 688620 & 4.9 & 4.7546 & TRN \\
\hline CHEMBL1507521 & 688620 & 4.85 & 5.3588 & TRN \\
\hline CHEMBL1432804 & 688620 & 5.2 & 5.067 & TRN \\
\hline CHEMBL1564201 & 688620 & 4.7 & 4.8438 & TRN \\
\hline CHEMBL1303945 & 688620 & 4.45 & 4.9028 & TRN \\
\hline CHEMBL1588790 & 688620 & 4.95 & 5.5138 & TRN \\
\hline CHEMBL1383881 & 688620 & 4.85 & 5.0565 & TST \\
\hline CHEMBL 3214255 & 688620 & 5.2 & 5.1045 & TRN \\
\hline
\end{tabular}




\begin{tabular}{|c|c|c|c|c|c|}
\hline \multicolumn{6}{|c|}{ Supplemental Table S2.txt } \\
\hline CHEMBL1359748 & 688620 & 4.75 & 4.9953 & TST & \\
\hline CHEMBL 2006757 & 688620 & 5.55 & 5.5031 & TRN & \\
\hline CHEMBL1528593 & 688620 & 5.3 & 5.2508 & TRN & \\
\hline CHEMBL1365827 & 688620 & 6.45 & 5.8907 & TST & \\
\hline CHEMBL1490721 & 688620 & 4.75 & 5.4881 & TST & \\
\hline CHEMBL1549308 & 688620 & 5.15 & 4.81 & TST & \\
\hline CHEMBL1600506 & 688620 & 5.6 & 5.6199 & TRN & \\
\hline CHEMBL2369208 & 688620 & 5.2 & 5.4428 & TRN & \\
\hline CHEMBL1549917 & 688620 & 4.6 & 5.1145 & TST & \\
\hline CHEMBL1979221 & 688620 & 5.8 & 5.6276 & TST & \\
\hline CHEMBL3197529 & 688620 & 5.2 & 5.0486 & TRN & \\
\hline CHEMBL1440386 & 688620 & 7.8508 & 4.9561 & TRN & \\
\hline CHEMBL1431944 & 688620 & 5.45 & 5.6055 & TRN & \\
\hline CHEMBL1612606 & 688620 & 7.0 & 5.25299 & 9999999999 & TRN \\
\hline CHEMBL1540767 & 688620 & 4.6 & 5.1303 & TRN & \\
\hline CHEMBL1489391 & 688620 & 4.9 & 5.038 & TRN & \\
\hline CHEMBL3190638 & 688620 & 4.75 & 4.9949 & TST & \\
\hline CHEMBL 2004956 & 688620 & 4.45 & 5.081 & TRN & \\
\hline CHEMBL1364640 & 688620 & 5.05 & 4.8549 & TRN & \\
\hline CHEMBL1540662 & 688620 & 4.6 & 5.1767 & TRN & \\
\hline CHEMBL1391788 & 688620 & 4.9 & 5.038 & TST & \\
\hline CHEMBL1359359 & 688620 & 4.8 & 4.9142 & TRN & \\
\hline CHEMBL1525468 & 688620 & 4.45 & 4.955 & TRN & \\
\hline CHEMBL1388157 & 688620 & 5.0 & 4.9232 & TRN & \\
\hline CHEMBL1565220 & 688620 & 4.85 & 5.0807 & TRN & \\
\hline CHEMBL1483794 & 688620 & 4.45 & 5.1706 & TRN & \\
\hline CHEMBL1612974 & 688620 & 4.6 & 4.9574 & TRN & \\
\hline CHEMBL1433339 & 688620 & 4.45 & 5.553 & TRN & \\
\hline CHEMBL1537369 & 688620 & 5.5 & 5.1546 & TRN & \\
\hline CHEMBL1609100 & 688620 & 6.0 & 5.9624 & TRN & \\
\hline CHEMBL514988 & 688620 & 4.6 & 5.1792 & TRN & \\
\hline CHEMBL1361949 & 688620 & 4.9 & 4.9102 & TRN & \\
\hline CHEMBL1494801 & 688620 & 4.45 & 5.1289 & TRN & \\
\hline CHEMBL1347962 & 688620 & 4.8 & 4.9807 & TRN & \\
\hline CHEMBL1365480 & 688620 & 5.65 & 5.4473 & TRN & \\
\hline CHEMBL1529379 & 688620 & 4.5 & 5.1224 & TRN & \\
\hline CHEMBL1334002 & 688620 & 5.7 & 5.254 & TST & \\
\hline CHEMBL1595400 & 688620 & 4.55 & 5.0367 & TRN & \\
\hline CHEMBL1349832 & 688620 & 4.6 & 5.3925 & TRN & \\
\hline CHEMBL1547229 & 688620 & 4.8 & 5.0573 & TRN & \\
\hline CHEMBL1421965 & 688620 & 4.45 & 4.984 & TRN & \\
\hline CHEMBL1502607 & 688620 & 4.95 & 5.0166 & TRN & \\
\hline CHEMBL1586817 & 688620 & 5.0 & 4.7946 & TRN & \\
\hline CHEMBL1477212 & 688620 & 5.4 & 5.101 & TRN & \\
\hline CHEMBL1489081 & 688620 & 5.8 & 5.3876 & TRN & \\
\hline CHEMBL1415229 & 688620 & 4.95 & 4.7117 & TRN & \\
\hline CHEMBL1566205 & 688620 & 6.2 & 5.5264 & TST & \\
\hline CHEMBL1400977 & 688620 & 4.45 & 4.9291 & TST & \\
\hline
\end{tabular}




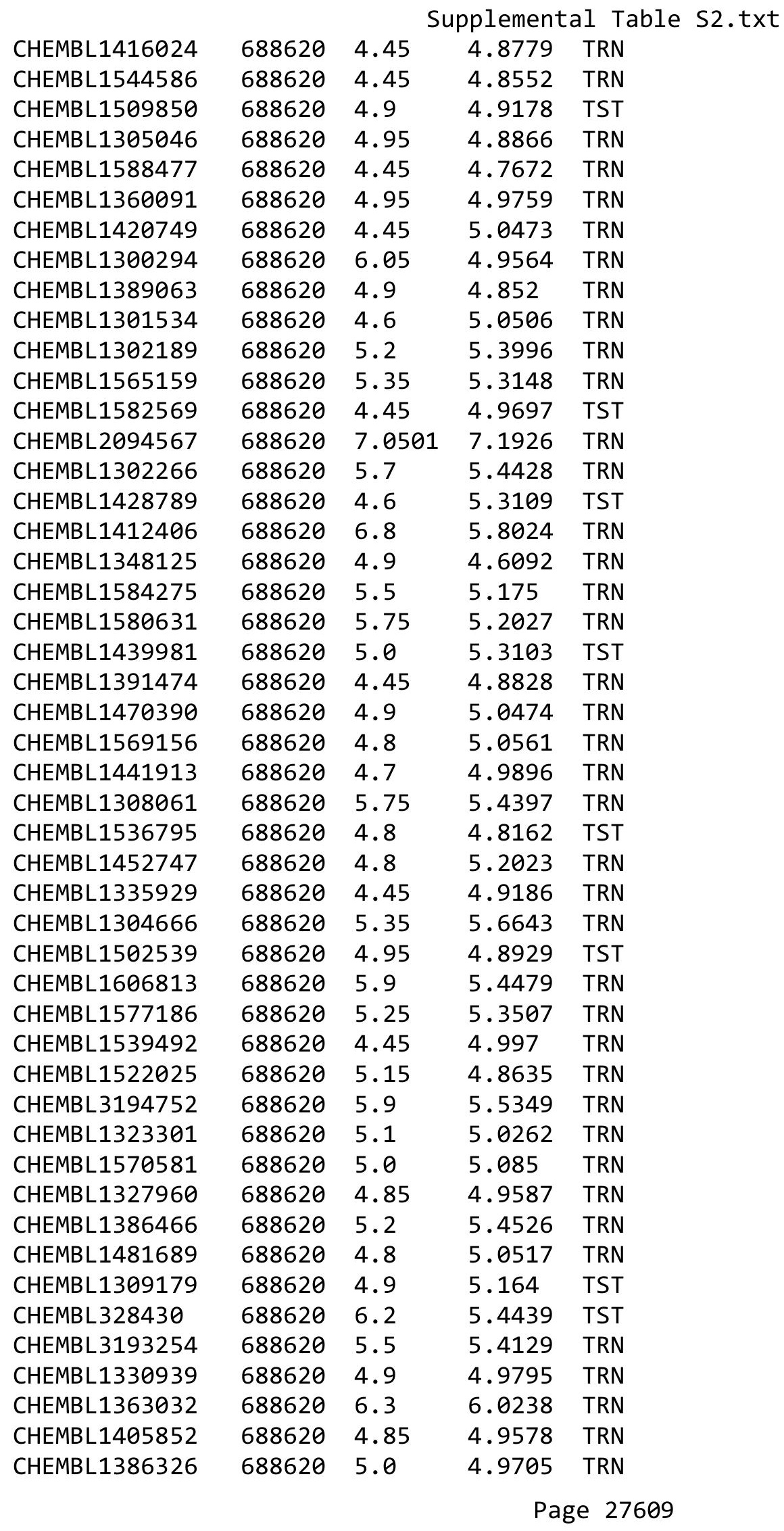




\begin{tabular}{|c|c|c|c|c|}
\hline \multicolumn{5}{|c|}{ Supplemental Table S2.txt } \\
\hline CHEMBL1387731 & 688620 & 5.65 & 5.4939 & TRN \\
\hline CHEMBL1313793 & 688620 & 4.75 & 4.8921 & TRN \\
\hline CHEMBL1405287 & 688620 & 7.15 & 5.0738 & TST \\
\hline CHEMBL1440762 & 688620 & 5.35 & 5.376 & TRN \\
\hline CHEMBL 1403450 & 688620 & 4.45 & 4.9385 & TRN \\
\hline CHEMBL1502481 & 688620 & 4.95 & 5.0916 & TRN \\
\hline CHEMBL1411508 & 688620 & 5.0 & 4.7022 & TRN \\
\hline CHEMBL1353770 & 688620 & 6.15 & 5.7239 & TST \\
\hline CHEMBL1517569 & 688620 & 5.0 & 5.1021 & TRN \\
\hline CHEMBL1559478 & 688620 & 4.85 & 4.9517 & TST \\
\hline CHEMBL1330718 & 688620 & 4.85 & 4.7846 & TRN \\
\hline CHEMBL1523674 & 688620 & 4.85 & 5.0812 & TST \\
\hline CHEMBL1986251 & 688620 & 6.25 & 5.5552 & TRN \\
\hline CHEMBL1603037 & 688620 & 4.85 & 5.2788 & TRN \\
\hline CHEMBL1359685 & 688620 & 5.6 & 5.0262 & TST \\
\hline CHEMBL3191525 & 688620 & 4.8 & 4.9589 & TST \\
\hline CHEMBL1462093 & 688620 & 4.45 & 4.9069 & TRN \\
\hline CHEMBL1605021 & 688620 & 6.2 & 5.6385 & TST \\
\hline CHEMBL1498585 & 688620 & 4.95 & 4.8924 & TRN \\
\hline CHEMBL1578058 & 688620 & 5.0 & 4.8101 & TRN \\
\hline CHEMBL1556834 & 688620 & 5.0 & 5.0702 & TRN \\
\hline CHEMBL1606040 & 688620 & 5.2 & 5.1683 & TRN \\
\hline CHEMBL1330311 & 688620 & 4.75 & 5.0127 & TRN \\
\hline CHEMBL1458022 & 688620 & 5.55 & 5.3075 & TST \\
\hline CHEMBL1322121 & 688620 & 4.75 & 4.8424 & TRN \\
\hline CHEMBL1588173 & 688620 & 5.25 & 5.0181 & TRN \\
\hline CHEMBL1313532 & 688620 & 4.95 & 4.9679 & TST \\
\hline CHEMBL1505474 & 688620 & 4.85 & 4.852 & TST \\
\hline CHEMBL3190968 & 688620 & 5.3 & 5.0674 & TRN \\
\hline CHEMBL1471872 & 688620 & 5.2 & 5.0173 & TRN \\
\hline CHEMBL1428963 & 688620 & 5.25 & 5.1115 & TST \\
\hline CHEMBL1458597 & 688620 & 4.95 & 5.1027 & TRN \\
\hline CHEMBL1347158 & 688620 & 6.3 & 5.1773 & TRN \\
\hline CHEMBL1494439 & 688620 & 5.25 & 4.9087 & TST \\
\hline CHEMBL1484951 & 688620 & 4.45 & 4.9683 & TRN \\
\hline CHEMBL 3194004 & 688620 & 4.45 & 5.1821 & TRN \\
\hline CHEMBL1309273 & 688620 & 5.1 & 5.0562 & TST \\
\hline CHEMBL1383818 & 688620 & 5.45 & 4.9437 & TRN \\
\hline CHEMBL1337039 & 688620 & 4.95 & 5.0954 & TRN \\
\hline CHEMBL3197475 & 688620 & 5.05 & 4.9336 & TRN \\
\hline CHEMBL1530880 & 688620 & 4.95 & 5.0118 & TRN \\
\hline CHEMBL1441426 & 688620 & 5.35 & 4.9419 & TRN \\
\hline CHEMBL1424732 & 688620 & 4.9 & 5.1755 & TST \\
\hline CHEMBL1338489 & 688620 & 4.85 & 4.9439 & TRN \\
\hline CHEMBL1507761 & 688620 & 4.45 & 5.015 & TRN \\
\hline CHEMBL1444554 & 688620 & 5.5 & 5.1981 & TRN \\
\hline CHEMBL1988500 & 688620 & 6.2 & 5.8706 & TRN \\
\hline CHEMBL1383684 & 688620 & 5.15 & 4.7852 & TST \\
\hline
\end{tabular}




\begin{tabular}{|c|c|c|c|c|}
\hline \multicolumn{5}{|c|}{ Supplemental Table S2.txt } \\
\hline CHEMBL1354837 & 688620 & 4.45 & 5.0728 & TST \\
\hline CHEMBL1425537 & 688620 & 5.7 & 5.0909 & TRN \\
\hline CHEMBL1495072 & 688620 & 5.7 & 6.359 & TRN \\
\hline CHEMBL1443211 & 688620 & 4.5 & 4.8941 & TRN \\
\hline CHEMBL1463844 & 688620 & 4.45 & 4.974 & TRN \\
\hline CHEMBL468167 & 688620 & 5.6 & 5.5927 & TST \\
\hline CHEMBL1407947 & 688620 & 5.25 & 4.9961 & TRN \\
\hline CHEMBL1543149 & 688620 & 6.0 & 5.8364 & TRN \\
\hline CHEMBL1471717 & 688620 & 4.8 & 5.1402 & TST \\
\hline CHEMBL1374937 & 688620 & 4.95 & 4.8949 & TRN \\
\hline CHEMBL1463755 & 688620 & 5.25 & 5.4604 & TRN \\
\hline CHEMBL1571383 & 688620 & 6.05 & 5.1429 & TRN \\
\hline CHEMBL1321507 & 688620 & 5.05 & 5.2993 & TRN \\
\hline CHEMBL1456393 & 688620 & 6.1 & 5.4571 & TRN \\
\hline CHEMBL1543919 & 688620 & 4.45 & 4.8605 & TRN \\
\hline CHEMBL1580641 & 688620 & 6.25 & 4.9652 & TRN \\
\hline CHEMBL1502346 & 688620 & 4.75 & 5.0704 & TST \\
\hline CHEMBL1986681 & 688620 & 4.65 & 4.8654 & TRN \\
\hline CHEMBL1380242 & 688620 & 5.55 & 4.9203 & TRN \\
\hline CHEMBL1398963 & 688620 & 4.9 & 5.144 & TRN \\
\hline CHEMBL1502732 & 688620 & 4.45 & 4.7221 & TRN \\
\hline CHEMBL1561673 & 688620 & 4.8 & 4.7416 & TST \\
\hline CHEMBL1490847 & 688620 & 4.7 & 5.1797 & TRN \\
\hline CHEMBL1553969 & 688620 & 4.65 & 5.0452 & TST \\
\hline CHEMBL1357385 & 688620 & 5.1 & 5.0733 & TRN \\
\hline CHEMBL1460176 & 688620 & 4.45 & 4.737 & TRN \\
\hline CHEMBL1364609 & 688620 & 5.3 & 5.0938 & TRN \\
\hline CHEMBL1399380 & 688620 & 5.95 & 5.1268 & TRN \\
\hline CHEMBL1463114 & 688620 & 4.45 & 4.9525 & TRN \\
\hline CHEMBL1538629 & 688620 & 4.45 & 4.9895 & TRN \\
\hline CHEMBL1470295 & 688620 & 5.0 & 5.1691 & TRN \\
\hline CHEMBL1608108 & 688620 & 5.25 & 4.8521 & TRN \\
\hline CHEMBL1333657 & 688620 & 4.95 & 4.9484 & TRN \\
\hline CHEMBL1580179 & 688620 & 4.8 & 4.9946 & TRN \\
\hline CHEMBL1359564 & 688620 & 4.85 & 4.8431 & TRN \\
\hline CHEMBL1582735 & 688620 & 5.7 & 5.4713 & TRN \\
\hline CHEMBL 1470543 & 688620 & 5.9 & 4.9037 & TST \\
\hline CHEMBL1472049 & 688620 & 4.45 & 4.9318 & TRN \\
\hline CHEMBL1403887 & 688620 & 4.9 & 4.8134 & TST \\
\hline CHEMBL1359871 & 688620 & 5.9 & 5.9257 & TST \\
\hline CHEMBL1487865 & 688620 & 4.9 & 4.8234 & TRN \\
\hline CHEMBL1431676 & 688620 & 5.65 & 5.7014 & TRN \\
\hline CHEMBL1317919 & 688620 & 4.9 & 4.9686 & TRN \\
\hline CHEMBL1499947 & 688620 & 4.45 & 4.8471 & TST \\
\hline CHEMBL1568088 & 688620 & 4.65 & 5.3114 & TST \\
\hline CHEMBL1319258 & 688620 & 5.3 & 5.0629 & TRN \\
\hline CHEMBL1505752 & 688620 & 5.0 & 5.2442 & TRN \\
\hline CHEMBL1522809 & 688620 & 5.55 & 5.4495 & TRN \\
\hline
\end{tabular}




\begin{tabular}{|c|c|c|c|c|}
\hline \multicolumn{5}{|c|}{ Supplemental Table s2.txt } \\
\hline CHEMBL1349307 & 688620 & 4.8 & 4.8684 & TRN \\
\hline CHEMBL3198095 & 688620 & 4.9 & 5.1601 & TRN \\
\hline CHEMBL1511264 & 688620 & 5.7 & 5.0092 & TST \\
\hline CHEMBL1503573 & 688620 & 4.95 & 5.0013 & TST \\
\hline CHEMBL1421602 & 688620 & 4.65 & 4.9382 & TRN \\
\hline CHEMBL1369656 & 688620 & 6.05 & 4.8999 & TST \\
\hline CHEMBL1458734 & 688620 & 4.65 & 5.1065 & TRN \\
\hline CHEMBL1448828 & 688620 & 5.5 & 4.9622 & TRN \\
\hline CHEMBL1323753 & 688620 & 4.65 & 4.9356 & TST \\
\hline CHEMBL1360576 & 688620 & 4.95 & 5.1304 & TRN \\
\hline CHEMBL3192625 & 688620 & 5.8 & 5.6969 & TRN \\
\hline CHEMBL3195160 & 688620 & 4.95 & 4.6492 & TRN \\
\hline CHEMBL1370302 & 688620 & 4.65 & 4.9546 & TST \\
\hline CHEMBL1490288 & 688620 & 5.05 & 5.1675 & TRN \\
\hline CHEMBL3208876 & 688620 & 4.45 & 4.9949 & TRN \\
\hline CHEMBL3212622 & 688620 & 5.65 & 5.2507 & TRN \\
\hline CHEMBL1430177 & 688620 & 4.95 & 4.7296 & TST \\
\hline CHEMBL1505511 & 688620 & 4.9 & 5.0116 & TST \\
\hline CHEMBL1342852 & 688620 & 4.45 & 4.7021 & TRN \\
\hline CHEMBL1585752 & 688620 & 5.35 & 5.1045 & TST \\
\hline CHEMBL1364886 & 688620 & 4.8 & 4.9135 & TST \\
\hline CHEMBL1432145 & 688620 & 4.95 & 5.0369 & TRN \\
\hline CHEMBL1418972 & 688620 & 5.9 & 4.8873 & TRN \\
\hline CHEMBL1403383 & 688620 & 4.85 & 5.3216 & TST \\
\hline CHEMBL1362248 & 688620 & 4.75 & 4.9293 & TST \\
\hline CHEMBL3198839 & 688620 & 4.45 & 4.9545 & TRN \\
\hline CHEMBL1462073 & 688620 & 4.45 & 4.8433 & TRN \\
\hline CHEMBL1599437 & 688620 & 4.45 & 5.251 & TRN \\
\hline CHEMBL3189885 & 688620 & 5.15 & 5.1611 & TRN \\
\hline CHEMBL1321902 & 688620 & 4.95 & 5.1444 & TRN \\
\hline CHEMBL1582746 & 688620 & 6.3 & 6.3082 & TRN \\
\hline CHEMBL1469643 & 688620 & 4.45 & 4.8103 & TRN \\
\hline CHEMBL1606355 & 688620 & 4.95 & 4.8425 & TRN \\
\hline CHEMBL1343155 & 688620 & 4.95 & 4.8869 & TRN \\
\hline CHEMBL1596329 & 688620 & 4.45 & 5.0649 & TRN \\
\hline CHEMBL251603 & 688620 & 4.95 & 4.7844 & TRN \\
\hline CHEMBL1531322 & 688620 & 7.15 & 5.1839 & TRN \\
\hline CHEMBL1425487 & 688620 & 5.1 & 5.1771 & TRN \\
\hline CHEMBL1483609 & 688620 & 4.8 & 5.053 & TRN \\
\hline CHEMBL1339949 & 688620 & 5.4 & 5.4124 & TRN \\
\hline CHEMBL1459165 & 688620 & 5.3 & 5.2323 & TST \\
\hline CHEMBL1431692 & 688620 & 4.9 & 5.29299 & 9999999999 \\
\hline CHEMBL131037 & 688620 & 5.3 & 5.2699 & TST \\
\hline CHEMBL1461043 & 688620 & 4.95 & 4.9871 & TRN \\
\hline CHEMBL1525276 & 688620 & 6.8 & 5.1911 & TST \\
\hline CHEMBL1337734 & 688620 & 4.65 & 5.0038 & TRN \\
\hline CHEMBL1324136 & 688620 & 7.0501 & 5.0545 & TST \\
\hline CHEMBL1373387 & 688620 & 5.05 & 5.3106 & TRN \\
\hline
\end{tabular}

TRN 


\begin{tabular}{|c|c|c|c|c|}
\hline \multicolumn{5}{|c|}{ Supplemental Table S2.txt } \\
\hline CHEMBL1432379 & 688620 & 5.55 & 4.9467 & TRN \\
\hline CHEMBL1399106 & 688620 & 4.45 & 6.7278 & TRN \\
\hline CHEMBL1392734 & 688620 & 4.45 & 4.9263 & TRN \\
\hline CHEMBL1440790 & 688620 & 5.9 & 5.7874 & TRN \\
\hline CHEMBL1611463 & 688620 & 4.8 & 5.169 & TRN \\
\hline CHEMBL1451525 & 688620 & 4.55 & 5.447 & TRN \\
\hline CHEMBL1433274 & 688620 & 5.45 & 5.4433 & TRN \\
\hline CHEMBL1401901 & 688620 & 4.9 & 5.025 & TRN \\
\hline CHEMBL1429207 & 688620 & 4.95 & 5.0145 & TRN \\
\hline CHEMBL1393745 & 688620 & 5.85 & 5.1479 & TRN \\
\hline CHEMBL 3194400 & 688620 & 5.8 & 5.4396 & TRN \\
\hline CHEMBL15063 & 688620 & 4.8 & 5.1184 & TRN \\
\hline CHEMBL3197201 & 688620 & 5.45 & 5.4308 & TRN \\
\hline CHEMBL1523492 & 688620 & 4.85 & 4.9667 & TRN \\
\hline CHEMBL1421247 & 688620 & 4.95 & 5.1785 & TST \\
\hline CHEMBL1996451 & 688620 & 5.6 & 5.0791 & TRN \\
\hline CHEMBL1513079 & 688620 & 5.15 & 5.3022 & TRN \\
\hline CHEMBL1534999 & 688620 & 5.2 & 5.0325 & TST \\
\hline CHEMBL 3144985 & 688620 & 5.05 & 4.913 & TST \\
\hline CHEMBL1384286 & 688620 & 4.95 & 5.1112 & TRN \\
\hline CHEMBL560020 & 688620 & 4.6 & 5.0744 & TST \\
\hline CHEMBL1300319 & 688620 & 6.45 & 5.7552 & TRN \\
\hline CHEMBL3195218 & 688620 & 5.0 & 5.0575 & TRN \\
\hline CHEMBL1360577 & 688620 & 5.4 & 5.2939 & TST \\
\hline CHEMBL1404633 & 688620 & 4.95 & 4.9314 & TRN \\
\hline CHEMBL1499881 & 688620 & 5.1 & 4.9397 & TRN \\
\hline CHEMBL1400298 & 688620 & 6.5501 & 5.7093 & TRN \\
\hline CHEMBL1985330 & 688620 & 5.3 & 5.5122 & TRN \\
\hline CHEMBL1372947 & 688620 & 4.5 & 4.916 & TRN \\
\hline CHEMBL1589423 & 688620 & 4.95 & 4.8896 & TRN \\
\hline CHEMBL1379163 & 688620 & 4.85 & 4.8032 & TRN \\
\hline CHEMBL1362088 & 688620 & 4.45 & 4.9112 & TRN \\
\hline CHEMBL1369767 & 688620 & 5.55 & 5.1967 & TST \\
\hline CHEMBL1967139 & 688620 & 4.45 & 5.0717 & TRN \\
\hline CHEMBL1309882 & 688620 & 4.75 & 4.8828 & TRN \\
\hline CHEMBL1599791 & 688620 & 4.9 & 5.1037 & TRN \\
\hline CHEMBL1363939 & 688620 & 4.5 & 4.8955 & TRN \\
\hline CHEMBL1359396 & 688620 & 4.5 & 5.0387 & TRN \\
\hline CHEMBL252789 & 688620 & 4.95 & 4.8188 & TRN \\
\hline CHEMBL1534035 & 688620 & 6.25 & 6.1775 & TST \\
\hline CHEMBL1428141 & 688620 & 4.65 & 4.9234 & TRN \\
\hline CHEMBL1492486 & 688620 & 4.75 & 5.1483 & TRN \\
\hline CHEMBL1568366 & 688620 & 5.25 & 5.0994 & TRN \\
\hline CHEMBL1431130 & 688620 & 4.85 & 4.9048 & TRN \\
\hline CHEMBL1362020 & 688620 & 4.85 & 4.9544 & TST \\
\hline CHEMBL1609713 & 688620 & 4.95 & 5.0052 & TRN \\
\hline CHEMBL1545669 & 688620 & 4.45 & 4.9293 & TRN \\
\hline CHEMBL1488999 & 688620 & 5.8 & 5.0513 & TST \\
\hline
\end{tabular}




\begin{tabular}{|c|c|c|c|c|c|}
\hline & & \multicolumn{4}{|c|}{ Supplemental Table s2.txt } \\
\hline CHEMBL1466706 & 688620 & 5.75 & 4.7586 & TRN & \\
\hline CHEMBL1313774 & 688620 & 5.2 & 5.2425 & TRN & \\
\hline CHEMBL1414416 & 688620 & 5.15 & 5.075 & TRN & \\
\hline CHEMBL1410701 & 688620 & 5.0 & 5.016 & TRN & \\
\hline CHEMBL3207718 & 688620 & 4.55 & 5.062 & TRN & \\
\hline CHEMBL1421570 & 688620 & 6.0 & 5.4238 & TRN & \\
\hline CHEMBL1350958 & 688620 & 5.65 & 5.0598 & TRN & \\
\hline CHEMBL1382246 & 688620 & 5.4 & 5.0236 & TST & \\
\hline CHEMBL1340191 & 688620 & 4.45 & 4.9688 & TRN & \\
\hline CHEMBL1422597 & 688620 & 4.95 & 5.1207 & TRN & \\
\hline CHEMBL1584597 & 688620 & 4.6 & 4.7574 & TRN & \\
\hline CHEMBL1556478 & 688620 & 4.45 & 4.9498 & TST & \\
\hline CHEMBL1300088 & 688620 & 4.95 & 4.9212 & TRN & \\
\hline CHEMBL1529876 & 688620 & 4.95 & 5.0466 & TRN & \\
\hline CHEMBL1608797 & 688620 & 4.45 & 5.2906 & TST & \\
\hline CHEMBL1592542 & 688620 & 6.0 & 5.3997 & TST & \\
\hline CHEMBL1384600 & 688620 & 4.95 & 4.9535 & TRN & \\
\hline CHEMBL1526248 & 688620 & 5.0 & 5.1954 & TRN & \\
\hline CHEMBL3192781 & 688620 & 5.45 & 5.0194 & TRN & \\
\hline CHEMBL1420598 & 688620 & 5.65 & \multicolumn{2}{|c|}{6.117999999999999} & TRN \\
\hline CHEMBL1549111 & 688620 & 4.85 & 5.1473 & TRN & \\
\hline CHEMBL1311158 & 688620 & 5.25 & 5.2422 & TRN & \\
\hline CHEMBL518923 & 688620 & 4.95 & 5.072 & TRN & \\
\hline CHEMBL1542737 & 688620 & 4.45 & 5.1265 & TRN & \\
\hline CHEMBL1380552 & 688620 & 4.5 & 4.9635 & TRN & \\
\hline CHEMBL1552100 & 688620 & 4.8 & 4.9387 & TRN & \\
\hline CHEMBL1602696 & 688620 & 4.45 & 5.04 & TRN & \\
\hline CHEMBL1549978 & 688620 & 5.65 & 5.1354 & TRN & \\
\hline CHEMBL1455950 & 688620 & 4.6 & \multicolumn{2}{|c|}{4.7989999999999995} & TST \\
\hline CHEMBL1407489 & 688620 & 5.7 & 5.2318 & TST & \\
\hline CHEMBL1588632 & 688620 & 4.45 & 4.9176 & TRN & \\
\hline CHEMBL1390669 & 688620 & 4.95 & 4.9064 & TRN & \\
\hline CHEMBL1446809 & 688620 & 5.75 & 4.9078 & TRN & \\
\hline CHEMBL1573566 & 688620 & 5.4 & 4.968 & TRN & \\
\hline CHEMBL1357381 & 688620 & 5.0 & 5.0652 & TRN & \\
\hline CHEMBL1416266 & 688620 & 6.25 & 5.3578 & TRN & \\
\hline CHEMBL1491251 & 688620 & 4.45 & 5.2175 & TRN & \\
\hline CHEMBL1502189 & 688620 & 4.6 & 5.0199 & TRN & \\
\hline CHEMBL1457519 & 688620 & 6.35 & 4.802 & TRN & \\
\hline CHEMBL1540114 & 688620 & 4.45 & 5.2517 & TRN & \\
\hline CHEMBL1562005 & 688620 & 4.85 & 5.0549 & TST & \\
\hline CHEMBL1347969 & 688620 & 5.15 & 4.9157 & TRN & \\
\hline CHEMBL1564731 & 688620 & 6.15 & 6.0439 & TRN & \\
\hline CHEMBL1512614 & 688620 & 4.45 & 4.7471 & TRN & \\
\hline CHEMBL1453439 & 688620 & 4.8 & 5.0222 & TRN & \\
\hline CHEMBL1309134 & 688620 & 5.45 & 5.315 & TST & \\
\hline CHEMBL1482007 & 688620 & 4.45 & 4.76399 & 9999999999 & TRN \\
\hline CHEMBL1352344 & 688620 & 6.05 & 5.2687 & TST & \\
\hline
\end{tabular}




\begin{tabular}{|c|c|c|c|c|}
\hline \multicolumn{5}{|c|}{ Supplemental Table S2.txt } \\
\hline CHEMBL1380970 & 688620 & 4.65 & 4.8365 & TRN \\
\hline CHEMBL1488694 & 688620 & 4.9 & 5.2149 & TRN \\
\hline CHEMBL1577704 & 688620 & 4.95 & 5.3467 & TST \\
\hline CHEMBL1374881 & 688620 & 4.7 & 5.1393 & TRN \\
\hline CHEMBL 1449230 & 688620 & 4.95 & 5.0126 & TST \\
\hline CHEMBL1611973 & 688620 & 4.9 & 4.9179 & TST \\
\hline CHEMBL1587675 & 688620 & 4.9 & 4.8973 & TRN \\
\hline CHEMBL1312255 & 688620 & 6.25 & 5.1943 & TRN \\
\hline CHEMBL1343688 & 688620 & 5.0 & 5.2202 & TRN \\
\hline CHEMBL1322110 & 688620 & 4.45 & 4.622 & TRN \\
\hline CHEMBL1478081 & 688620 & 4.45 & 5.098 & TRN \\
\hline CHEMBL1543921 & 688620 & 4.45 & 5.0197 & TRN \\
\hline CHEMBL1328774 & 688620 & 5.05 & 5.0329 & TRN \\
\hline CHEMBL1576173 & 688620 & 5.35 & 5.1198 & TRN \\
\hline CHEMBL1539231 & 688620 & 5.15 & 4.9852 & TRN \\
\hline CHEMBL1585628 & 688620 & 4.45 & 4.8548 & TRN \\
\hline CHEMBL1308457 & 688620 & 4.9 & 5.0198 & TRN \\
\hline CHEMBL1581030 & 688620 & 4.45 & 5.0029 & TRN \\
\hline CHEMBL1462318 & 688620 & 4.5 & 5.1484 & TRN \\
\hline CHEMBL1401755 & 688620 & 5.45 & 5.2869 & TRN \\
\hline CHEMBL1456415 & 688620 & 4.95 & 4.7606 & TRN \\
\hline CHEMBL1386897 & 688620 & 4.75 & 5.0762 & TRN \\
\hline CHEMBL1544721 & 688620 & 5.5 & 5.3644 & TRN \\
\hline CHEMBL1431166 & 688620 & 4.5 & 5.0422 & TRN \\
\hline CHEMBL1540432 & 688620 & 5.4 & 4.8762 & TRN \\
\hline CHEMBL1571734 & 688620 & 5.15 & 4.9606 & TRN \\
\hline CHEMBL1403741 & 688620 & 4.95 & 5.1319 & TRN \\
\hline CHEMBL3189837 & 688620 & 4.75 & 4.8668 & TRN \\
\hline CHEMBL1444739 & 688620 & 5.0 & 5.2095 & TRN \\
\hline CHEMBL 3213275 & 688620 & 4.95 & 4.9208 & TRN \\
\hline CHEMBL1462643 & 688620 & 4.9 & 5.1437 & TRN \\
\hline CHEMBL1485600 & 688620 & 5.0 & 4.9994 & TRN \\
\hline CHEMBL1350131 & 688620 & 4.45 & 4.8695 & TST \\
\hline CHEMBL1442527 & 688620 & 6.9 & 5.0301 & TRN \\
\hline CHEMBL1525557 & 688620 & 4.95 & 5.1459 & TRN \\
\hline CHEMBL1443337 & 688620 & 4.5 & 4.956 & TST \\
\hline CHEMBL 1455443 & 688620 & 4.7 & 5.3082 & TRN \\
\hline CHEMBL1351871 & 688620 & 5.15 & 4.9055 & TST \\
\hline CHEMBL1458027 & 688620 & 5.2 & 5.4715 & TRN \\
\hline CHEMBL1448627 & 688620 & 6.0 & 5.1894 & TST \\
\hline CHEMBL1457230 & 688620 & 4.85 & 5.0052 & TRN \\
\hline CHEMBL1589278 & 688620 & 5.85 & 5.1118 & TST \\
\hline CHEMBL 2001895 & 688620 & 5.15 & 5.1753 & TRN \\
\hline CHEMBL1430767 & 688620 & 4.75 & 4.8825 & TRN \\
\hline CHEMBL1558908 & 688620 & 4.45 & 4.9748 & TRN \\
\hline CHEMBL1487444 & 688620 & 5.2 & 5.2873 & TRN \\
\hline CHEMBL1500304 & 688620 & 4.75 & 5.1808 & TRN \\
\hline CHEMBL581152 & 688620 & 4.8 & 5.0278 & TRN \\
\hline
\end{tabular}




\begin{tabular}{|c|c|c|c|c|c|}
\hline \multirow[b]{2}{*}{ CHEMBL1605757 } & \multicolumn{5}{|c|}{ Supplemental Table S2.txt } \\
\hline & 688620 & 6.35 & 4.9307 & TRN & \\
\hline CHEMBL1398727 & 688620 & 4.55 & 4.83899 & 99999999995 & TRN \\
\hline CHEMBL1426267 & 688620 & 4.45 & 4.6432 & TRN & \\
\hline CHEMBL1568308 & 688620 & 5.65 & 5.3956 & TRN & \\
\hline CHEMBL3210389 & 688620 & 5.0 & 5.084 & TRN & \\
\hline CHEMBL 206778 & 688620 & 5.45 & 4.9796 & TRN & \\
\hline CHEMBL1311489 & 688620 & 4.45 & 4.7886 & TRN & \\
\hline CHEMBL1534605 & 688620 & 4.95 & 5.0173 & TST & \\
\hline CHEMBL1384148 & 688620 & 4.5 & 4.9377 & TRN & \\
\hline CHEMBL1586019 & 688620 & 4.95 & 5.3081 & TRN & \\
\hline CHEMBL1572873 & 688620 & 5.45 & 5.2252 & TST & \\
\hline CHEMBL1332668 & 688620 & 4.95 & 5.0923 & TST & \\
\hline CHEMBL1408078 & 688620 & 5.55 & 4.9634 & TRN & \\
\hline CHEMBL1513901 & 688620 & 4.65 & 4.9305 & TST & \\
\hline CHEMBL1416403 & 688620 & 4.5 & 5.0006 & TRN & \\
\hline CHEMBL1415400 & 688620 & 5.4 & 5.1304 & TRN & \\
\hline CHEMBL3190610 & 688620 & 5.6 & 5.4629 & TRN & \\
\hline CHEMBL1572620 & 688620 & 4.55 & 4.9535 & TRN & \\
\hline CHEMBL1976414 & 688620 & 4.65 & 5.0337 & TRN & \\
\hline CHEMBL1367324 & 688620 & 5.2 & 5.06 & TST & \\
\hline CHEMBL1569975 & 688620 & 6.5501 & 5.6959 & TRN & \\
\hline CHEMBL1412695 & 688620 & 5.0 & 5.1007 & TRN & \\
\hline CHEMBL1543118 & 688620 & 4.45 & 5.2243 & TRN & \\
\hline CHEMBL3191496 & 688620 & 5.35 & 5.1996 & TRN & \\
\hline CHEMBL1324034 & 688620 & 5.0 & 4.9343 & TRN & \\
\hline CHEMBL1480071 & 688620 & 4.95 & 4.998 & TST & \\
\hline CHEMBL1309997 & 688620 & 4.5 & 5.3207 & TRN & \\
\hline CHEMBL1408581 & 688620 & 5.05 & 5.0692 & TRN & \\
\hline CHEMBL3210881 & 688620 & 4.5 & 5.1205 & TST & \\
\hline CHEMBL1413518 & 688620 & 4.45 & 5.2578 & TRN & \\
\hline CHEMBL1404867 & 688620 & 4.6 & 5.0271 & TRN & \\
\hline CHEMBL1599300 & 688620 & 4.95 & 5.0597 & TRN & \\
\hline CHEMBL1579016 & 688620 & 4.75 & 4.9738 & TST & \\
\hline CHEMBL1423176 & 688620 & 5.8 & 5.4498 & TRN & \\
\hline CHEMBL1461831 & 688620 & 6.6 & 4.9793 & TRN & \\
\hline CHEMBL1566988 & 688620 & 5.7 & 5.3373 & TRN & \\
\hline CHEMBL1433127 & 688620 & 4.7 & 4.9431 & TST & \\
\hline CHEMBL1334906 & 688620 & 4.45 & 4.9181 & TST & \\
\hline CHEMBL1372741 & 688620 & 4.85 & 4.7015 & TRN & \\
\hline CHEMBL1358973 & 688620 & 4.8 & 4.9256 & TRN & \\
\hline CHEMBL1605018 & 688620 & 4.7 & 4.961 & TRN & \\
\hline CHEMBL1304383 & 688620 & 4.45 & 5.2651 & TRN & \\
\hline CHEMBL1539921 & 688620 & 5.0 & 5.0552 & TRN & \\
\hline CHEMBL1314906 & 688620 & 4.7 & 4.7009 & TRN & \\
\hline CHEMBL1364596 & 688620 & 5.9 & 4.9122 & TRN & \\
\hline CHEMBL1299770 & 688620 & 5.05 & 4.8015 & TRN & \\
\hline CHEMBL3196960 & 688620 & 5.7 & 5.4106 & TRN & \\
\hline CHEMBL1519945 & 688620 & 4.6 & 5.1061 & TRN & \\
\hline
\end{tabular}




\begin{tabular}{|c|c|c|c|c|}
\hline \multicolumn{5}{|c|}{ Supplemental Table S2.txt } \\
\hline CHEMBL1423015 & 688620 & 6.15 & 4.9274 & TRN \\
\hline CHEMBL1362371 & 688620 & 4.85 & 4.8937 & TRN \\
\hline CHEMBL1502367 & 688620 & 4.45 & 5.0361 & TST \\
\hline CHEMBL1604888 & 688620 & 4.45 & 4.8953 & TRN \\
\hline CHEMBL1391743 & 688620 & 5.55 & 5.0269 & TRN \\
\hline CHEMBL1574512 & 688620 & 5.0 & 5.2709 & TRN \\
\hline CHEMBL1997827 & 688620 & 4.95 & 4.9285 & TRN \\
\hline CHEMBL1464382 & 688620 & 4.5 & 5.0833 & TRN \\
\hline CHEMBL 3199548 & 688620 & 4.85 & 4.9626 & TST \\
\hline CHEMBL1398721 & 688620 & 4.6 & 4.6737 & TST \\
\hline CHEMBL1458395 & 688620 & 6.3 & 4.9804 & TRN \\
\hline CHEMBL 3197873 & 688620 & 5.2 & 5.5302 & TRN \\
\hline CHEMBL1533523 & 688620 & 5.15 & 5.1861 & TRN \\
\hline CHEMBL1391577 & 688620 & 5.3 & 5.0387 & TRN \\
\hline CHEMBL2369182 & 688620 & 4.95 & 5.1401 & TST \\
\hline CHEMBL1543735 & 688620 & 4.95 & 4.8104 & TRN \\
\hline CHEMBL1471170 & 688620 & 5.5 & 5.1449 & TRN \\
\hline CHEMBL1487659 & 688620 & 5.35 & 5.0046 & TRN \\
\hline CHEMBL1377620 & 688620 & 4.45 & 5.2576 & TRN \\
\hline CHEMBL1560795 & 688620 & 4.9 & 4.775 & TRN \\
\hline CHEMBL1443685 & 688620 & 4.6 & 5.1554 & TRN \\
\hline CHEMBL466930 & 688620 & 4.9 & 4.5839 & TST \\
\hline CHEMBL1304801 & 688620 & 4.45 & 5.1555 & TST \\
\hline CHEMBL1442881 & 688620 & 5.45 & 5.3812 & TRN \\
\hline CHEMBL1465173 & 688620 & 5.35 & 4.6363 & TST \\
\hline CHEMBL1453505 & 688620 & 4.95 & 5.0337 & TST \\
\hline CHEMBL3192551 & 688620 & 4.5 & 5.2122 & TRN \\
\hline CHEMBL1305239 & 688620 & 4.9 & 5.3585 & TRN \\
\hline CHEMBL1575246 & 688620 & 4.95 & 4.9816 & TRN \\
\hline CHEMBL1337016 & 688620 & 4.45 & 5.1178 & TRN \\
\hline CHEMBL1299217 & 688620 & 4.4 & 4.8264 & TRN \\
\hline CHEMBL1528258 & 688620 & 5.15 & 5.0935 & TRN \\
\hline CHEMBL1459717 & 688620 & 5.45 & 4.9996 & TRN \\
\hline CHEMBL1530208 & 688620 & 4.9 & 5.5083 & TRN \\
\hline CHEMBL1599746 & 688620 & 4.95 & 5.0636 & TRN \\
\hline CHEMBL1419176 & 688620 & 4.8 & 5.0006 & TRN \\
\hline CHEMBL1349577 & 688620 & 4.45 & 5.0637 & TRN \\
\hline CHEMBL1584228 & 688620 & 4.45 & 5.1145 & TST \\
\hline CHEMBL1539364 & 688620 & 4.75 & 4.9245 & TST \\
\hline CHEMBL3208658 & 688620 & 4.75 & 5.0167 & TRN \\
\hline CHEMBL3196900 & 688620 & 5.7 & 5.41 & TRN \\
\hline CHEMBL1576412 & 688620 & 4.7 & 5.077 & TST \\
\hline CHEMBL1338330 & 688620 & 4.65 & 5.1458 & TST \\
\hline CHEMBL1975982 & 688620 & 5.8 & 5.7366 & TRN \\
\hline CHEMBL1414873 & 688620 & 5.8 & 5.1194 & TRN \\
\hline CHEMBL1521135 & 688620 & 6.8499 & 5.1072 & TRN \\
\hline CHEMBL1546205 & 688620 & 4.45 & 4.8322 & TRN \\
\hline CHEMBL1334743 & 688620 & 5.8 & 5.0396 & TRN \\
\hline
\end{tabular}




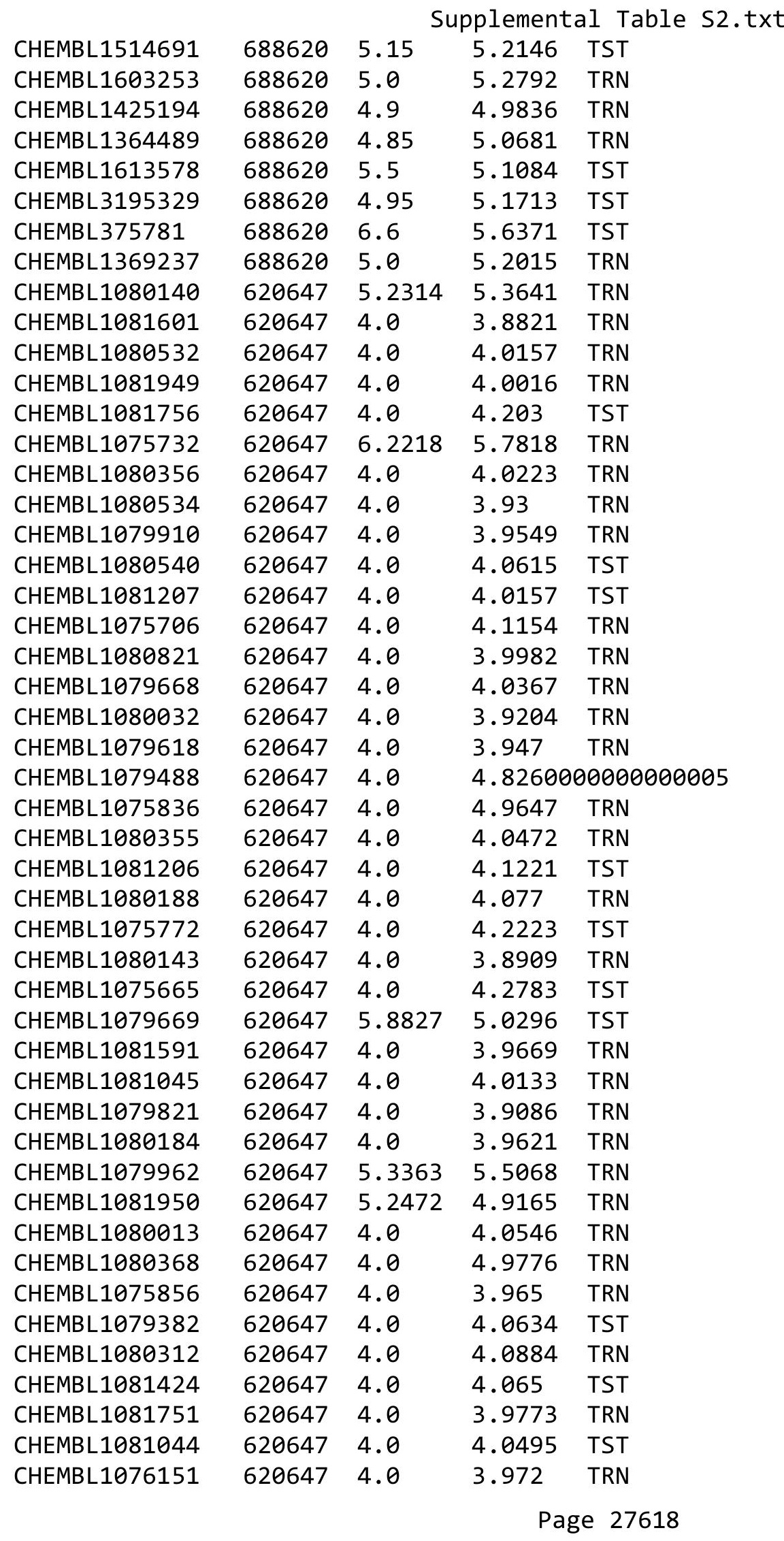




\begin{tabular}{|c|c|c|c|c|}
\hline \multicolumn{5}{|c|}{ Supplemental Table S2.txt } \\
\hline CHEMBL1081387 & 620647 & 4.0 & 4.0219 & TRN \\
\hline CHEMBL1080363 & 620647 & 4.0 & 3.8991 & TRN \\
\hline CHEMBL1081786 & 620647 & 5.1618 & 5.0123 & TRN \\
\hline CHEMBL1082090 & 620647 & 4.0 & 4.0756 & TRN \\
\hline CHEMBL1081750 & 620647 & 4.0 & 4.0063 & TRN \\
\hline CHEMBL1075894 & 620647 & 5.6038 & 5.2328 & TRN \\
\hline CHEMBL1081223 & 620647 & 4.0 & 3.9284 & TRN \\
\hline CHEMBL1081380 & 620647 & 4.0 & 4.0323 & TRN \\
\hline CHEMBL1079505 & 620647 & 4.0 & 3.9501 & TRN \\
\hline CHEMBL1075723 & 620647 & 5.9208 & 5.6593 & TRN \\
\hline CHEMBL1079449 & 620647 & 4.0 & 4.0095 & TRN \\
\hline CHEMBL1075682 & 620647 & 4.0 & 4.0292 & TRN \\
\hline CHEMBL1080369 & 620647 & 4.0 & 3.9313 & TRN \\
\hline CHEMBL1080366 & 620647 & 4.0 & 3.9397 & TRN \\
\hline CHEMBL1079965 & 620647 & 4.0 & 3.9792 & TRN \\
\hline CHEMBL1081224 & 620647 & 4.0 & 4.6077 & TRN \\
\hline CHEMBL1080033 & 620647 & 4.0 & 4.0735 & TRN \\
\hline CHEMBL1082117 & 620647 & 4.0 & 3.9588 & TRN \\
\hline CHEMBL1082137 & 620647 & 4.0 & 4.0107 & TRN \\
\hline CHEMBL1080187 & 620647 & 4.0 & 4.0942 & TRN \\
\hline CHEMBL1075835 & 620647 & 4.0 & 4.1128 & TRN \\
\hline CHEMBL1081764 & 620647 & 4.0 & 4.004 & TRN \\
\hline CHEMBL1080535 & 620647 & 4.0 & 3.9942 & TRN \\
\hline CHEMBL1080349 & 620647 & 4.0 & 3.8553 & TRN \\
\hline CHEMBL1079489 & 620647 & 4.0 & 5.2368 & TST \\
\hline CHEMBL1079925 & 620647 & 4.0 & 3.9609 & TRN \\
\hline CHEMBL1080172 & 620647 & 4.0 & 3.9705 & TRN \\
\hline CHEMBL1081763 & 620647 & 4.0 & 3.9785 & TRN \\
\hline CHEMBL1075683 & 620647 & 4.0 & 5.0541 & TRN \\
\hline CHEMBL1081730 & 620647 & 4.0 & 3.9559 & TRN \\
\hline CHEMBL1075893 & 620647 & 4.0 & 3.9797 & TRN \\
\hline CHEMBL1081241 & 620647 & 4.0 & 3.8438 & TST \\
\hline CHEMBL1079617 & 620647 & 4.0 & 3.9331 & TRN \\
\hline CHEMBL1080533 & 620647 & 4.0 & 4.0269 & TRN \\
\hline CHEMBL1079982 & 620647 & 4.0 & 3.903 & TRN \\
\hline CHEMBL1082116 & 620647 & 4.0 & 3.8969 & TRN \\
\hline CHEMBL1081951 & 620647 & 4.0 & 4.1622 & TRN \\
\hline CHEMBL1079984 & 620647 & 4.0 & 3.9616 & TRN \\
\hline CHEMBL1082115 & 620647 & 4.0 & 3.9655 & TRN \\
\hline CHEMBL1081410 & 620647 & 4.0 & 4.039 & TRN \\
\hline CHEMBL1080025 & 620647 & 4.0 & 3.9867 & TRN \\
\hline CHEMBL1075724 & 620647 & 5.8069 & 5.4781 & TRN \\
\hline CHEMBL1082089 & 620647 & 4.0 & 3.8292 & TRN \\
\hline CHEMBL1080026 & 620647 & 4.0 & 4.0266 & TRN \\
\hline CHEMBL1081602 & 620647 & 4.0 & 4.0269 & TRN \\
\hline CHEMBL1075704 & 620647 & 4.0 & 4.2279 & TRN \\
\hline CHEMBL1081962 & 620647 & 4.0 & 3.9229 & TRN \\
\hline CHEMBL1081926 & 620647 & 4.0 & 4.0359 & TRN \\
\hline
\end{tabular}




\begin{tabular}{|c|c|c|c|c|c|}
\hline \multirow[b]{2}{*}{ CHEMBL1079961 } & \multicolumn{5}{|c|}{ Supplemental Table S2.txt } \\
\hline & 620647 & 5.5918 & 5.5359 & TRN & \\
\hline CHEMBL1080365 & 620647 & 6.0088 & 5.5097 & TRN & \\
\hline CHEMBL1080708 & 620647 & 4.0 & 3.9855 & TRN & \\
\hline CHEMBL1081603 & 620647 & 4.0 & 4.0274 & TRN & \\
\hline CHEMBL1081391 & 620647 & 4.0 & 3.8623 & TRN & \\
\hline CHEMBL1081004 & 620647 & 4.0 & 3.9686 & TRN & \\
\hline CHEMBL1080361 & 620647 & 5.6383 & 5.351 & TST & \\
\hline CHEMBL1081003 & 620647 & 5.1965 & 5.1756 & TRN & \\
\hline CHEMBL1082131 & 620647 & 4.0 & 3.9823 & TRN & \\
\hline CHEMBL1080108 & 620647 & 4.0 & 4.0215 & TRN & \\
\hline CHEMBL1082114 & 620647 & 4.0 & 3.95600 & 00000000004 & TRN \\
\hline CHEMBL1079826 & 620647 & 4.0 & 4.0453 & TRN & \\
\hline CHEMBL1081729 & 620647 & 4.0 & 3.9103 & TRN & \\
\hline CHEMBL279053 & 620647 & 7.0 & 5.1422 & TST & \\
\hline CHEMBL1081963 & 620647 & 4.0 & 4.3216 & TST & \\
\hline CHEMBL1079677 & 620647 & 4.0 & 4.0634 & TRN & \\
\hline CHEMBL1081600 & 620647 & 4.0 & 3.9447 & TRN & \\
\hline CHEMBL1079981 & 620647 & 4.0 & 3.9214 & TRN & \\
\hline CHEMBL1080873 & 620647 & 4.0 & 3.9053 & TRN & \\
\hline CHEMBL1081964 & 620647 & 4.0 & 4.0085 & TRN & \\
\hline CHEMBL1075895 & 620647 & 5.9872 & 5.5213 & TRN & \\
\hline CHEMBL1079503 & 620647 & 4.0 & 3.9539 & TRN & \\
\hline CHEMBL1079504 & 620647 & 4.0 & 4.0157 & TRN & \\
\hline CHEMBL1079739 & 620647 & 4.0 & 4.0951 & TST & \\
\hline CHEMBL1075703 & 620647 & 4.0 & 3.9428 & TST & \\
\hline CHEMBL1076175 & 620647 & 4.0 & 3.9526 & TST & \\
\hline CHEMBL1080699 & 620647 & 4.1549 & 5.2919 & TST & \\
\hline CHEMBL1080173 & 620647 & 4.0 & 3.8998 & TST & \\
\hline CHEMBL1075725 & 620647 & 4.0 & 5.6962 & TST & \\
\hline CHEMBL1079983 & 620647 & 4.0 & 4.0243 & TST & \\
\hline CHEMBL1081749 & 620647 & 4.0 & 3.9862 & TST & \\
\hline CHEMBL1081046 & 620647 & 4.0 & 3.8787 & TST & \\
\hline CHEMBL1081771 & 620647 & 4.0 & 3.9066 & TST & \\
\hline CHEMBL210469 & 620647 & 4.0 & 3.8986 & TST & \\
\hline CHEMBL1079911 & 620647 & 4.0 & 3.9114 & TST & \\
\hline CHEMBL1075705 & 620647 & 4.0 & 4.728 & TST & \\
\hline CHEMBL1082118 & 620647 & 4.0 & 4.0556 & TST & \\
\hline CHEMBL1079646 & 620647 & 4.0 & 4.0534 & TST & \\
\hline CHEMBL1080168 & 620647 & 4.0 & 3.9405 & TST & \\
\hline CHEMBL340346 & 212403 & 5.699 & 5.2151 & TRN & \\
\hline CHEMBL127198 & 212403 & 4.4202 & 2.9193 & TST & \\
\hline CHEMBL108710 & 212403 & 4.9586 & 4.9394 & TRN & \\
\hline CHEMBL126867 & 212403 & 5.301 & 5.37799 & 9999999999 & TST \\
\hline CHEMBL127149 & 212403 & 4.9586 & 4.2861 & TRN & \\
\hline CHEMBL126817 & 212403 & 5.3979 & 4.8808 & TRN & \\
\hline CHEMBL124456 & 212403 & 3.0 & 2.8675 & TRN & \\
\hline CHEMBL126283 & 212403 & 5.2218 & 4.6429 & TRN & \\
\hline CHEMBL128952 & 212403 & 3.0 & 2.5031 & TRN & \\
\hline
\end{tabular}




\begin{tabular}{|c|c|c|c|c|c|}
\hline \multirow[b]{2}{*}{ CHEMBL414429 } & \multicolumn{5}{|c|}{ Supplemental Table S2.txt } \\
\hline & 212403 & 4.6576 & 3.9591 & TRN & \multirow{3}{*}{ TST } \\
\hline CHEMBL126353 & 212403 & 5.0 & \multicolumn{2}{|c|}{5.367000000000001} & \\
\hline CHEMBL127478 & 212403 & 4.8239 & 4.7729 & TRN & \\
\hline CHEMBL127291 & 212403 & 3.6021 & 3.9941 & TRN & \\
\hline CHEMBL338340 & 212403 & 3.6021 & 3.7888 & TRN & \\
\hline CHEMBL127280 & 212403 & 3.0 & 2.9969 & TRN & \\
\hline CHEMBL126511 & 212403 & 3.6021 & 4.1051 & TRN & \\
\hline CHEMBL340097 & 212403 & 4.4559 & 2.7194 & TST & \\
\hline CHEMBL127989 & 212403 & 3.6021 & 4.5196 & TRN & \\
\hline CHEMBL126646 & 212403 & 3.6021 & 2.9763 & TRN & \\
\hline CHEMBL126806 & 212403 & 3.6021 & 5.0174 & TST & \\
\hline CHEMBL126805 & 212403 & 3.6021 & 3.3626 & TST & \\
\hline CHEMBL126415 & 212403 & 5.0458 & 4.952 & TRN & \\
\hline CHEMBL126816 & 212403 & 5.0458 & 4.963 & TRN & \\
\hline CHEMBL126246 & 212403 & 5.301 & 5.0515 & TRN & \\
\hline CHEMBL339952 & 212403 & 3.6021 & 3.8778 & TRN & \\
\hline CHEMBL333333 & 212403 & 4.3188 & 4.6203 & TRN & \\
\hline CHEMBL545531 & 212403 & 5.0 & 4.2791 & TRN & \\
\hline CHEMBL334207 & 212403 & 3.0 & 2.8437 & TST & \\
\hline CHEMBL341096 & 212403 & 4.4559 & 4.7814 & TRN & \\
\hline CHEMBL127042 & 212403 & 5.5229 & 4.6822 & TST & \\
\hline CHEMBL124743 & 212403 & 3.6021 & 4.0159 & TRN & \\
\hline CHEMBL127466 & 212403 & 4.301 & 5.1568 & TRN & \\
\hline CHEMBL127192 & 212403 & 3.6021 & 4.0106 & TRN & \\
\hline CHEMBL341012 & 212403 & 3.301 & 3.2563 & TRN & \\
\hline CHEMBL125632 & 212403 & 4.699 & 4.3665 & TRN & \\
\hline CHEMBL127081 & 212403 & 3.6021 & 3.9394 & TRN & \\
\hline CHEMBL414243 & 212403 & 4.1675 & 4.6398 & TST & \\
\hline CHEMBL127990 & 212403 & 4.2596 & 3.7001 & TST & \\
\hline CHEMBL126945 & 212403 & 4.8861 & 4.7882 & TRN & \\
\hline CHEMBL126912 & 212403 & 3.0 & 3.5695 & TRN & \\
\hline CHEMBL127144 & 212403 & 5.301 & 5.047 & TRN & \\
\hline CHEMBL126249 & 212403 & 4.3188 & 4.3531 & TRN & \\
\hline CHEMBL127259 & 212403 & 5.5229 & 4.6121 & TRN & \\
\hline CHEMBL 125787 & 212403 & 4.4318 & 2.833 & TST & \\
\hline CHEMBL126434 & 212403 & 4.4815 & 2.7741 & TST & \\
\hline CHEMBL127154 & 212403 & 3.301 & 3.1855 & TRN & \\
\hline CHEMBL125687 & 212403 & 3.0 & 3.7819 & TRN & \\
\hline CHEMBL127003 & 212403 & 4.6778 & 5.1046 & TRN & \\
\hline CHEMBL435014 & 212403 & 3.6021 & 3.6399 & TRN & \\
\hline CHEMBL127390 & 212403 & 4.8539 & 4.4942 & TRN & \\
\hline CHEMBL125522 & 212403 & 3.6021 & 3.6742 & TST & \\
\hline CHEMBL125674 & 212403 & 4.2924 & 4.7806 & TRN & \\
\hline CHEMBL340827 & 212403 & 3.6021 & 3.70600 & 00000000004 & TRN \\
\hline CHEMBL126450 & 212403 & 3.6021 & 3.8559 & TRN & \\
\hline CHEMBL338765 & 212403 & 5.301 & 5.0564 & TRN & \\
\hline CHEMBL124975 & 212403 & 6.0 & 4.8849 & TST & \\
\hline CHEMBL544359 & 212403 & 4.4318 & 5.0067 & TST & \\
\hline & & & & 27621 & \\
\hline
\end{tabular}


Supplemental Table S2.txt

\begin{tabular}{|c|c|c|c|c|c|}
\hline CHEMBL129792 & 212403 & 3.6021 & 4.1169 & TRN & \\
\hline CHEMBL419775 & 212403 & 5.0458 & 4.7031 & TRN & \\
\hline CHEMBL567351 & 1447774 & 6.5686 & 6.5702 & TRN & \\
\hline CHEMBL3318914 & 1447774 & 6.2366 & 6.2401 & TRN & \\
\hline CHEMBL3318494 & 1447774 & 6.699 & 6.7162 & TRN & \\
\hline CHEMBL3318911 & 1447774 & 6.2366 & 6.2244 & TRN & \\
\hline CHEMBL3318819 & 1447774 & 6.3279 & 6.3151 & TRN & \\
\hline CHEMBL3319012 & 1447774 & 3.0 & 3.0099 & TRN & \\
\hline CHEMBL3318820 & 1447774 & 6.2291 & 6.2772 & TRN & \\
\hline CHEMBL3318927 & 1447774 & 3.0 & 3.0129 & TRN & \\
\hline CHEMBL3318811 & 1447774 & 6.1192 & 6.1119 & TRN & \\
\hline CHEMBL3318213 & 1447774 & 6.6198 & 6.5957 & TRN & \\
\hline CHEMBL3318496 & 1447774 & 5.9208 & 5.8338 & TRN & \\
\hline CHEMBL3318490 & 1447774 & 3.0 & 5.9153 & TST & \\
\hline CHEMBL3318806 & 1447774 & 6.2518 & 6.2692 & TRN & \\
\hline CHEMBL3318486 & 1447774 & 5.3768 & 6.0439 & TST & \\
\hline CHEMBL3318207 & 1447774 & 6.1361 & 5.5923 & TST & \\
\hline CHEMBL3318913 & 1447774 & 6.8697 & 6.8591 & TRN & \\
\hline CHEMBL3318915 & 1447774 & 5.8928 & 5.8747 & TRN & \\
\hline CHEMBL3319011 & 1447774 & 3.0 & 2.9982 & TRN & \\
\hline CHEMBL3318211 & 1447774 & 6.6383 & 6.6382 & TRN & \\
\hline CHEMBL3318497 & 1447774 & 5.8861 & 5.9084 & TRN & \\
\hline CHEMBL3319008 & 1447774 & 4.301 & 3.7766 & TST & \\
\hline CHEMBL3318498 & 1447774 & 5.9208 & 5.9697 & TRN & \\
\hline CHEMBL3318804 & 1447774 & 6.585 & 6.5881 & TRN & \\
\hline CHEMBL3318489 & 1447774 & 3.0 & 5.0991 & TST & \\
\hline CHEMBL3318206 & 1447774 & 6.4559 & 5.8715 & TST & \\
\hline CHEMBL3318916 & 1447774 & 6.5376 & 6.5482 & TRN & \\
\hline CHEMBL3318808 & 1447774 & 5.9318 & 5.8794 & TRN & \\
\hline CHEMBL3318805 & 1447774 & 3.301 & 3.2815 & TRN & \\
\hline CHEMBL3318491 & 1447774 & 5.0555 & 6.4413 & TST & \\
\hline CHEMBL3318814 & 1447774 & 4.699 & 4.7403 & TRN & \\
\hline CHEMBL3318816 & 1447774 & 6.0223 & 6.00899 & 99999999995 & TRN \\
\hline CHEMBL3318924 & 1447774 & 3.0 & 2.9056 & TST & \\
\hline CHEMBL3318923 & 1447774 & 4.0 & 3.9949 & TRN & \\
\hline CHEMBL3318499 & 1447774 & 5.1367 & 5.119 & TRN & \\
\hline CHEMBL3318922 & 1447774 & 6.699 & 6.6764 & TRN & \\
\hline CHEMBL3318921 & 1447774 & 6.5229 & 6.5395 & TRN & \\
\hline CHEMBL3318212 & 1447774 & 6.7959 & 6.8258 & TRN & \\
\hline CHEMBL3318821 & 1447774 & 6.6198 & 6.5774 & TRN & \\
\hline CHEMBL3318810 & 1447774 & 6.301 & 6.3223 & TRN & \\
\hline CHEMBL3318493 & 1447774 & 6.0969 & 6.0845 & TRN & \\
\hline CHEMBL3318487 & 1447774 & 5.0655 & 6.2831 & TST & \\
\hline CHEMBL3318920 & 1447774 & 6.5376 & 6.5203 & TRN & \\
\hline CHEMBL3318926 & 1447774 & 3.0 & 3.6036 & TST & \\
\hline CHEMBL3318210 & 1447774 & 5.4793 & 5.4868 & TRN & \\
\hline CHEMBL3318801 & 1447774 & 6.4949 & 6.5687 & TRN & \\
\hline CHEMBL3318815 & 1447774 & 6.6383 & 6.669 & TRN & \\
\hline
\end{tabular}


Supplemental Table S2.txt

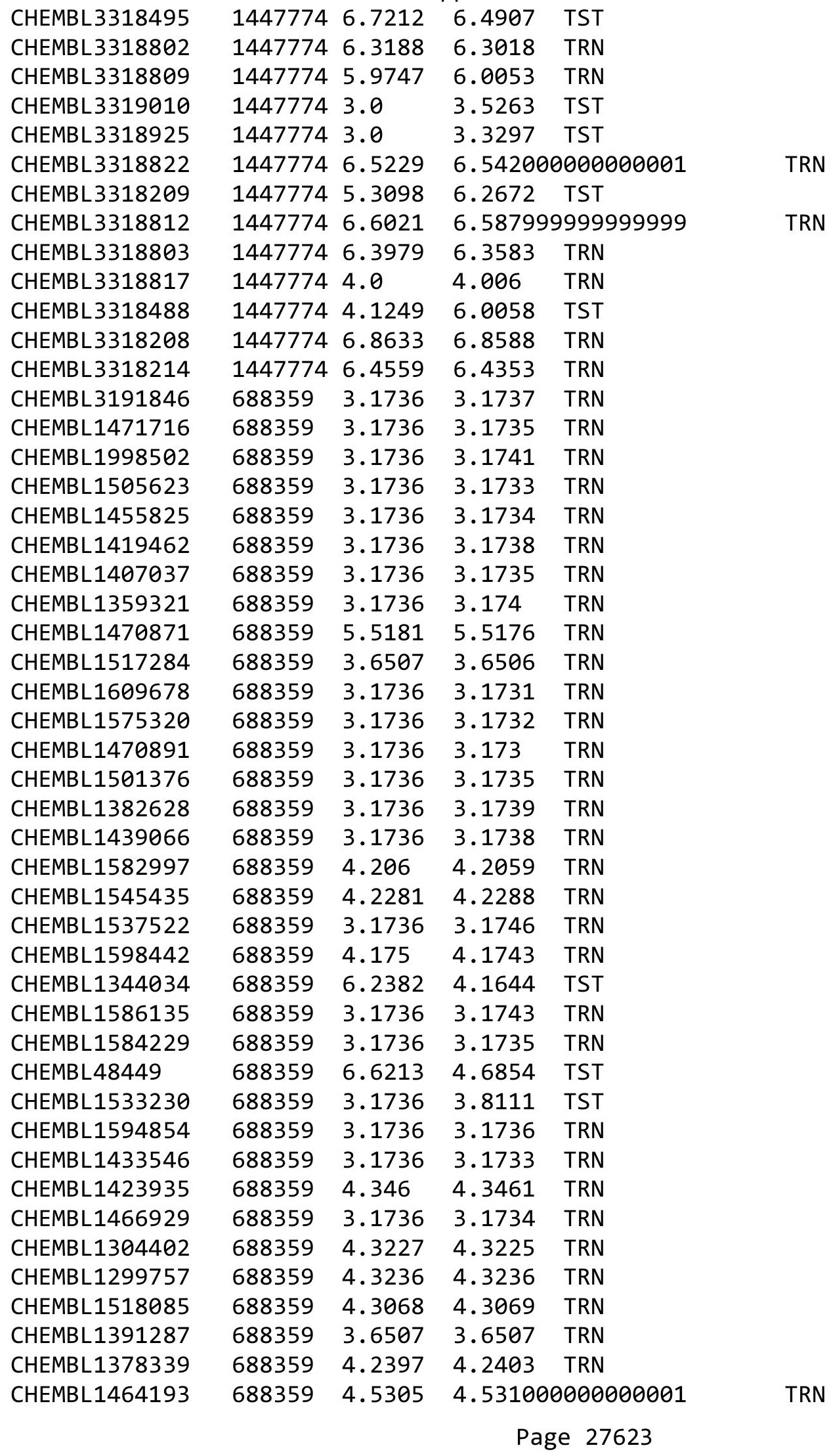




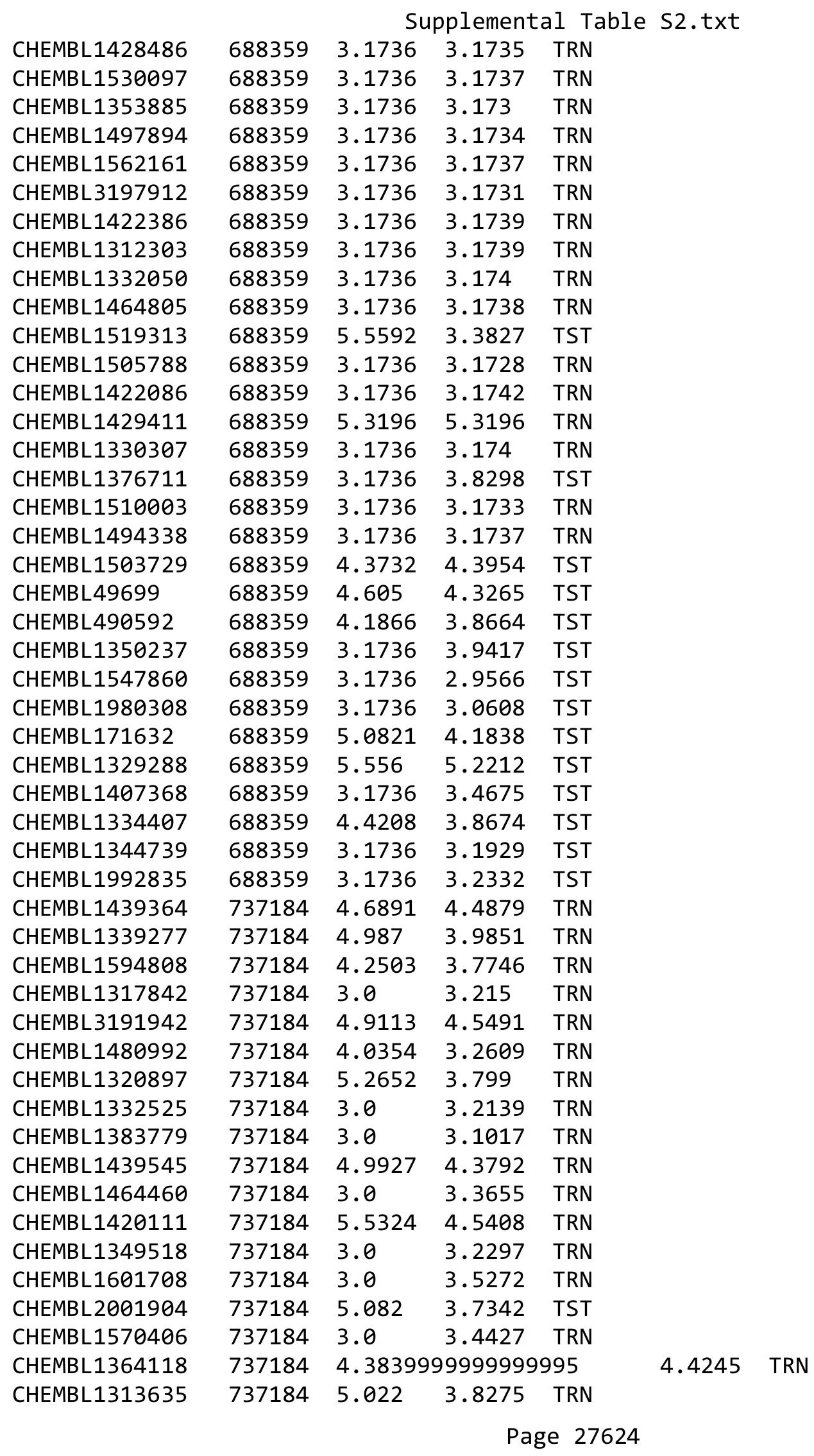




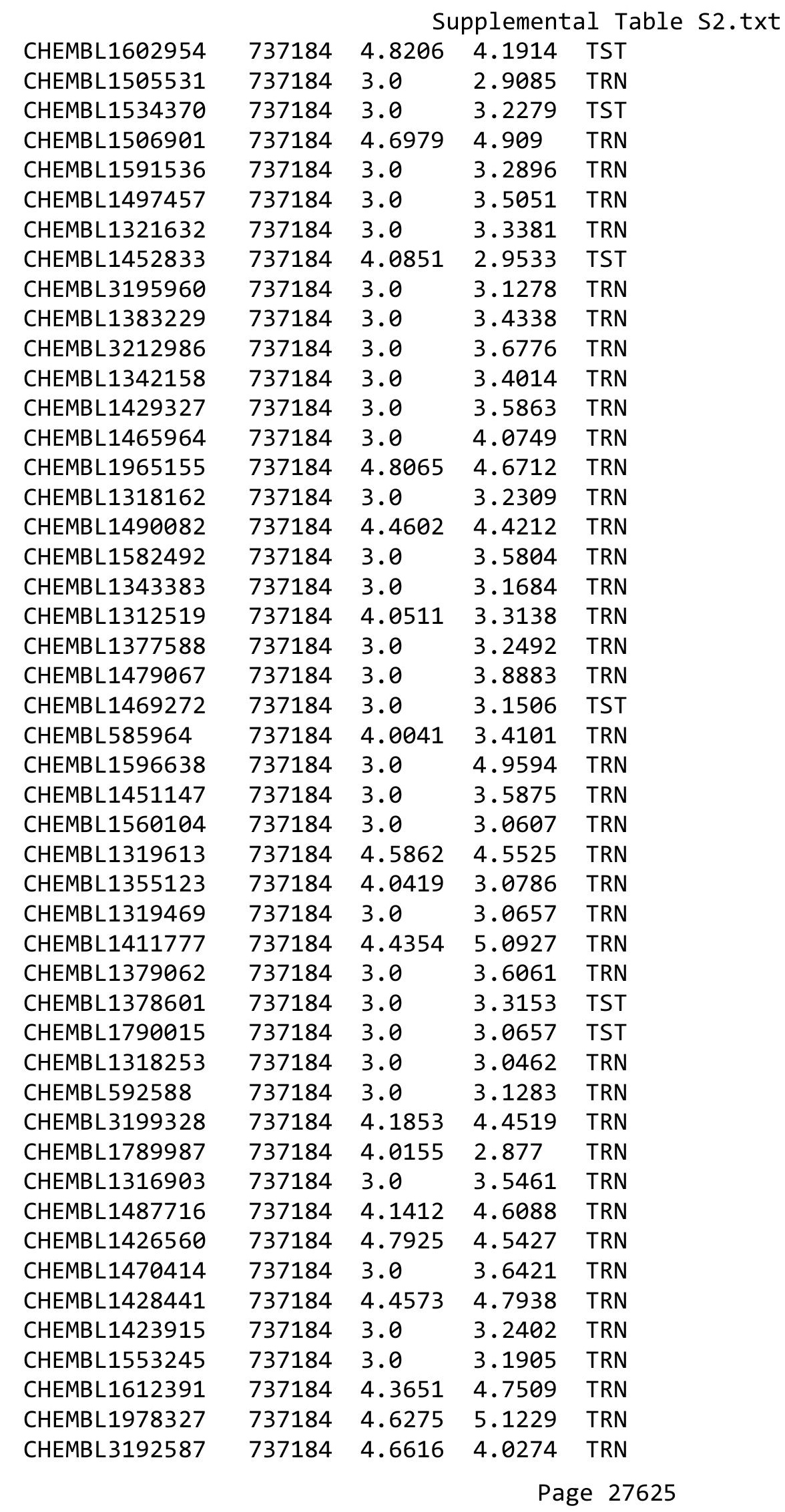




\begin{tabular}{|c|c|c|c|c|}
\hline \multicolumn{5}{|c|}{ Supplemental Table s2.txt } \\
\hline CHEMBL1572009 & 737184 & 3.0 & 3.3769 & TRN \\
\hline CHEMBL1333544 & 737184 & 3.0 & 3.5733 & TRN \\
\hline CHEMBL1985932 & 737184 & 4.8331 & 4.1866 & TRN \\
\hline CHEMBL3196705 & 737184 & 3.0 & 3.3597 & TRN \\
\hline CHEMBL1305247 & 737184 & 3.0 & 4.454 & TRN \\
\hline CHEMBL1423536 & 737184 & 3.0 & 3.1157 & TRN \\
\hline CHEMBL1353644 & 737184 & 4.8827 & 5.0777 & TRN \\
\hline CHEMBL1589193 & 737184 & 4.2926 & 3.909 & TRN \\
\hline CHEMBL3192559 & 737184 & 4.8333 & 3.9325 & TST \\
\hline CHEMBL1339518 & 737184 & 4.0095 & 3.3527 & TST \\
\hline CHEMBL1416798 & 737184 & 3.0 & 3.1929 & TRN \\
\hline CHEMBL1578367 & 737184 & 4.9884 & 4.4335 & TRN \\
\hline CHEMBL1482955 & 737184 & 3.0 & 4.0932 & TRN \\
\hline CHEMBL1542453 & 737184 & 6.1549 & 4.0274 & TRN \\
\hline CHEMBL1318903 & 737184 & 3.0 & 3.6214 & TRN \\
\hline CHEMBL1595086 & 737184 & 3.0 & 3.7759 & TRN \\
\hline CHEMBL3856090 & 737184 & 5.5751 & 4.2114 & TRN \\
\hline CHEMBL3210536 & 737184 & 4.499 & 4.3958 & TRN \\
\hline CHEMBL1991440 & 737184 & 4.8118 & 4.6445 & TRN \\
\hline CHEMBL1350188 & 737184 & 4.313 & 4.0471 & TRN \\
\hline CHEMBL1324692 & 737184 & 3.0 & 3.24600 & 00000000004 \\
\hline CHEMBL1563084 & 737184 & 4.9397 & 4.1588 & TRN \\
\hline CHEMBL1432423 & 737184 & 3.0 & 2.9143 & TST \\
\hline CHEMBL411502 & 737184 & 4.105 & 3.6266 & TRN \\
\hline CHEMBL1383109 & 737184 & 3.0 & 3.2745 & TRN \\
\hline CHEMBL1575292 & 737184 & 4.5504 & 4.4558 & TRN \\
\hline CHEMBL3190268 & 737184 & 5.6364 & 4.3731 & TRN \\
\hline CHEMBL1325618 & 737184 & 4.6169 & 4.1346 & TRN \\
\hline CHEMBL1596870 & 737184 & 3.0 & 3.7834 & TRN \\
\hline CHEMBL1422684 & 737184 & 3.0 & 3.5387 & TRN \\
\hline CHEMBL3210843 & 737184 & 3.0 & 3.253 & TST \\
\hline CHEMBL1993780 & 737184 & 5.3174 & 4.3295 & TRN \\
\hline CHEMBL589711 & 737184 & 3.0 & 3.1554 & TRN \\
\hline CHEMBL1445700 & 737184 & 3.0 & 2.888 & TRN \\
\hline CHEMBL1568319 & 737184 & 3.0 & 3.7749 & TST \\
\hline CHEMBL1367248 & 737184 & 4.9549 & 4.3674 & TRN \\
\hline CHEMBL1586498 & 737184 & 4.8748 & 4.7037 & TRN \\
\hline CHEMBL3213476 & 737184 & 3.0 & 3.6812 & TST \\
\hline CHEMBL1422657 & 737184 & 5.1397 & 4.1764 & TRN \\
\hline CHEMBL1599517 & 737184 & 3.0 & 3.3006 & TRN \\
\hline CHEMBL1602624 & 737184 & 4.6588 & 4.6689 & TRN \\
\hline CHEMBL1510003 & 737184 & 4.9716 & 3.8998 & TRN \\
\hline CHEMBL1561115 & 737184 & 4.2979 & 4.9727 & TRN \\
\hline CHEMBL1411577 & 737184 & 3.0 & 3.2848 & TRN \\
\hline CHEMBL1382280 & 737184 & 4.959 & 4.1812 & TRN \\
\hline CHEMBL1414701 & 737184 & 3.0 & 3.1759 & TRN \\
\hline CHEMBL1388052 & 737184 & 3.0 & 3.6063 & TST \\
\hline CHEMBL1369880 & 737184 & 3.0 & 3.2065 & TRN \\
\hline
\end{tabular}




\begin{tabular}{|c|c|c|c|c|}
\hline & & & pplement & at \\
\hline CHEMBL1485592 & 737184 & 3.0 & 3.4324 & TRN \\
\hline CHEMBL1970493 & 737184 & 3.0 & 3.7283 & TST \\
\hline CHEMBL1497097 & 737184 & 3.0 & 2.9084 & TRN \\
\hline CHEMBL1603147 & 737184 & 5.0846 & 4.1421 & TRN \\
\hline CHEMBL1483521 & 737184 & 3.0 & 3.2425 & TRN \\
\hline CHEMBL1461216 & 737184 & 5.1129 & 3.8987 & TRN \\
\hline CHEMBL1463019 & 737184 & 3.0 & 3.4528 & TRN \\
\hline CHEMBL1423236 & 737184 & 4.2156 & 2.9852 & TRN \\
\hline CHEMBL1307845 & 737184 & 4.0277 & 3.7517 & TRN \\
\hline CHEMBL1489703 & 737184 & 3.0 & 3.1414 & TRN \\
\hline CHEMBL1510325 & 737184 & 4.8052 & 4.5268 & TRN \\
\hline CHEMBL1441794 & 737184 & 5.3019 & 4.2862 & TRN \\
\hline CHEMBL3198496 & 737184 & 4.2276 & 4.6523 & TRN \\
\hline CHEMBL1582188 & 737184 & 4.2363 & 4.9037 & TRN \\
\hline CHEMBL1535072 & 737184 & 3.0 & 3.1038 & TRN \\
\hline CHEMBL1502154 & 737184 & 3.0 & 4.4677 & TRN \\
\hline CHEMBL3197066 & 737184 & 3.0 & 3.154 & TRN \\
\hline CHEMBL1577127 & 737184 & 3.0 & 2.8638 & TRN \\
\hline CHEMBL1547939 & 737184 & 3.0 & 3.4361 & TRN \\
\hline CHEMBL1469858 & 737184 & 5.2437 & 3.4881 & TST \\
\hline CHEMBL1527523 & 737184 & 3.0 & 3.175 & TST \\
\hline CHEMBL1326803 & 737184 & 4.6633 & 4.5151 & TST \\
\hline CHEMBL1562954 & 737184 & 3.0 & 3.4059 & TST \\
\hline CHEMBL1400038 & 737184 & 3.0 & 3.5493 & TST \\
\hline CHEMBL1610821 & 737184 & 3.0 & 2.9061 & TST \\
\hline CHEMBL1448744 & 737184 & 4.9549 & 4.4931 & TST \\
\hline CHEMBL1364684 & 737184 & 4.0092 & 3.21 & TST \\
\hline CHEMBL1573412 & 737184 & 3.0 & 3.5008 & TST \\
\hline CHEMBL1349451 & 737184 & 4.9015 & 4.3878 & TST \\
\hline CHEMBL1458352 & 737184 & 3.0 & 3.4563 & TST \\
\hline CHEMBL1583797 & 737184 & 4.8362 & 4.3586 & TST \\
\hline CHEMBL1407474 & 737184 & 4.6263 & 3.7342 & TST \\
\hline CHEMBL1563641 & 737184 & 3.0 & 3.6891 & TST \\
\hline CHEMBL1430103 & 737184 & 3.0 & 3.0416 & TST \\
\hline CHEMBL1480280 & 737184 & 3.0 & 3.2199 & TST \\
\hline CHEMBL1303289 & 737184 & 4.0659 & 3.4215 & TST \\
\hline CHEMBL1359526 & 737184 & 4.3162 & 3.1424 & TST \\
\hline CHEMBL1449357 & 737184 & 3.0 & 4.0161 & TST \\
\hline CHEMBL1334858 & 737184 & 3.0 & 3.0808 & TST \\
\hline CHEMBL1301276 & 737184 & 4.1244 & 3.2416 & TST \\
\hline CHEMBL1587391 & 737184 & 4.9205 & 4.7159 & TST \\
\hline CHEMBL1545487 & 737184 & 3.0 & 3.5445 & TST \\
\hline CHEMBL1783696 & 749421 & 4.8761 & 4.8455 & TRN \\
\hline CHEMBL1783546 & 749421 & 4.699 & 4.6965 & TRN \\
\hline CHEMBL1783672 & 749421 & 5.9586 & 5.9707 & TRN \\
\hline CHEMBL1783675 & 749421 & 5.6021 & 5.6513 & TRN \\
\hline CHEMBL1783577 & 749421 & 5.5686 & 5.5742 & TRN \\
\hline CHEMBL1783684 & 749421 & 4.5686 & 4.5745 & TRN \\
\hline
\end{tabular}




\begin{tabular}{|c|c|c|c|c|c|}
\hline & & \multicolumn{4}{|c|}{ Supplemental Table S2.txt } \\
\hline CHEMBL1783569 & 749421 & 5.4318 & 5.4298 & TRN & \\
\hline CHEMBL1783559 & 749421 & 5.3979 & 5.3911 & TRN & \\
\hline CHEMBL1783673 & 749421 & 5.585 & 5.5645 & TRN & \\
\hline CHEMBL1783689 & 749421 & 6.7212 & 6.6434 & TRN & \\
\hline CHEMBL1783549 & 749421 & 4.9208 & 5.0981 & TST & \\
\hline CHEMBL1783571 & 749421 & 5.585 & 5.5959 & TRN & \\
\hline CHEMBL1783580 & 749421 & 5.1549 & 5.1962 & TRN & \\
\hline CHEMBL1783573 & 749421 & 5.5086 & 5.5218 & TRN & \\
\hline CHEMBL1783686 & 749421 & 6.5086 & 6.4842 & TRN & \\
\hline CHEMBL1783567 & 749421 & 3.301 & 5.2956 & TST & \\
\hline CHEMBL1783669 & 749421 & 5.699 & 5.7134 & TRN & \\
\hline CHEMBL1783558 & 749421 & 4.4949 & 5.3609 & TST & \\
\hline CHEMBL1783682 & 749421 & 4.3979 & 4.4069 & TRN & \\
\hline CHEMBL 1783575 & 749421 & 5.1612 & 5.1515 & TRN & \\
\hline CHEMBL1783570 & 749421 & 5.7212 & 5.7 & TRN & \\
\hline CHEMBL1783562 & 749421 & 3.301 & 5.7188 & TST & \\
\hline CHEMBL1783563 & 749421 & 6.3279 & 6.3236 & TRN & \\
\hline CHEMBL1783555 & 749421 & 3.301 & 4.2315 & TST & \\
\hline CHEMBL 1783553 & 749421 & 3.301 & 3.3002 & TRN & \\
\hline CHEMBL1783698 & 749421 & 5.8239 & 5.8189 & TRN & \\
\hline CHEMBL1783681 & 749421 & 5.3665 & 5.3206 & TRN & \\
\hline CHEMBL1783691 & 749421 & 6.1549 & 6.28799 & 9999999999 & TRN \\
\hline CHEMBL1783572 & 749421 & 4.8633 & 4.8329 & TRN & \\
\hline CHEMBL1783693 & 749421 & 6.1367 & 6.1303 & TRN & \\
\hline CHEMBL1783560 & 749421 & 5.8239 & 5.7631 & TRN & \\
\hline CHEMBL1783699 & 749421 & 5.4202 & 5.4128 & TRN & \\
\hline CHEMBL1783712 & 749421 & 7.8239 & 5.4121 & TST & \\
\hline CHEMBL1783578 & 749421 & 5.1612 & 5.1486 & TRN & \\
\hline CHEMBL 1783548 & 749421 & 5.6021 & 5.6082 & TRN & \\
\hline CHEMBL1783676 & 749421 & 3.699 & 3.6878 & TRN & \\
\hline CHEMBL 1783700 & 749421 & 6.2366 & 6.2229 & TRN & \\
\hline CHEMBL1783707 & 749421 & 6.8539 & 6.9436 & TRN & \\
\hline CHEMBL1783711 & 749421 & 7.5229 & 5.1829 & TST & \\
\hline CHEMBL1783679 & 749421 & 4.8386 & 4.8195 & TRN & \\
\hline CHEMBL1783690 & 749421 & 5.7696 & 5.7656 & TRN & \\
\hline CHEMBL1783552 & 749421 & 4.4437 & 4.4473 & TRN & \\
\hline CHEMBL1783701 & 749421 & 6.6778 & 4.5297 & TST & \\
\hline CHEMBL1783551 & 749421 & 4.4559 & 5.1612 & TST & \\
\hline CHEMBL1783713 & 749421 & 7.0809 & 6.9171 & TRN & \\
\hline CHEMBL1783550 & 749421 & 4.2757 & 5.176 & TST & \\
\hline CHEMBL1783709 & 749421 & 6.9872 & 7.1415 & TRN & \\
\hline CHEMBL1783554 & 749421 & 4.6576 & 4.6677 & TRN & \\
\hline CHEMBL1783694 & 749421 & 5.0 & 5.0405 & TRN & \\
\hline CHEMBL1783687 & 749421 & 6.6383 & 6.6763 & TRN & \\
\hline CHEMBL1783557 & 749421 & 5.4949 & 5.4421 & TRN & \\
\hline CHEMBL1783685 & 749421 & 6.0269 & 6.0622 & TRN & \\
\hline CHEMBL1783674 & 749421 & 5.699 & 5.7256 & TRN & \\
\hline CHEMBL1783704 & 749421 & 4.8239 & 4.5389 & TST & \\
\hline
\end{tabular}


Supplemental Table S2.txt

\begin{tabular}{|c|c|c|c|c|c|}
\hline CHEMBL1783688 & 749421 & 6.8239 & 6.8503 & TRN & \\
\hline CHEMBL1783579 & 749421 & 4.9706 & 4.9577 & TRN & \\
\hline CHEMBL1783677 & 749421 & 5.0315 & 5.0044 & TRN & \\
\hline CHEMBL1783697 & 749421 & 5.6383 & 5.6508 & TRN & \\
\hline CHEMBL1783568 & 749421 & 5.5686 & 5.5705 & TRN & \\
\hline CHEMBL1783576 & 749421 & 3.3979 & 4.9812 & TST & \\
\hline CHEMBL1783678 & 749421 & 4.9469 & 5.0126 & TRN & \\
\hline CHEMBL1783566 & 749421 & 3.301 & 5.4302 & TST & \\
\hline CHEMBL1783545 & 749421 & 5.699 & 5.5952 & TRN & \\
\hline CHEMBL1783670 & 749421 & 6.3372 & 6.3271 & TRN & \\
\hline CHEMBL1783703 & 749421 & 4.5686 & 4.4924 & TST & \\
\hline CHEMBL1783710 & 749421 & 7.699 & 5.1257 & TST & \\
\hline CHEMBL1783708 & 749421 & 7.3468 & 7.1483 & TRN & \\
\hline CHEMBL1783680 & 749421 & 5.6021 & 5.6159 & TRN & \\
\hline CHEMBL1783581 & 749421 & 5.284 & 5.2457 & TRN & \\
\hline CHEMBL1783683 & 749421 & 4.3979 & 4.3945 & TRN & \\
\hline CHEMBL1783671 & 749421 & 5.4437 & 5.4206 & TRN & \\
\hline CHEMBL1783565 & 749421 & 3.301 & 5.2224 & TST & \\
\hline CHEMBL1783706 & 749421 & 3.699 & 4.7643 & TST & \\
\hline CHEMBL1783547 & 749421 & 4.8861 & 4.8739 & TRN & \\
\hline CHEMBL1783705 & 749421 & 4.8539 & 4.3875 & TST & \\
\hline CHEMBL1783695 & 749421 & 5.5376 & 5.5364 & TRN & \\
\hline CHEMBL1783561 & 749421 & 5.6383 & 5.8389 & TRN & \\
\hline CHEMBL1783574 & 749421 & 5.0044 & 5.0286 & TRN & \\
\hline CHEMBL1783668 & 749421 & 5.8239 & 5.8455 & TRN & \\
\hline CHEMBL 1783702 & 749421 & 4.8239 & 4.8863 & TST & \\
\hline CHEMBL1783556 & 749421 & 4.041 & 5.3341 & TST & \\
\hline CHEMBL1783564 & 749421 & 4.301 & 4.2997 & TRN & \\
\hline CHEMBL1783692 & 749421 & 6.6778 & 6.3801 & TST & \\
\hline CHEMBL81549 & 212394 & 3.301 & 3.3961 & TRN & \\
\hline CHEMBL 78652 & 212394 & 5.9586 & 5.5943 & TRN & \\
\hline CHEMBL 312223 & 212394 & 5.7696 & 5.7601 & TRN & \\
\hline CHEMBL81406 & 212394 & 5.5686 & 5.6194 & TRN & \\
\hline CHEMBL 78660 & 212394 & 5.3098 & 5.03600 & 00000000005 & TRN \\
\hline CHEMBL 78908 & 212394 & 5.1249 & 4.9908 & TRN & \\
\hline CHEMBL 78654 & 212394 & 3.301 & 4.7254 & TST & \\
\hline CHEMBL 81161 & 212394 & 5.4949 & 5.4898 & TRN & \\
\hline CHEMBL 78619 & 212394 & 5.1871 & 5.2195 & TRN & \\
\hline CHEMBL311983 & 212394 & 3.301 & 3.7686 & TST & \\
\hline CHEMBL 78873 & 212394 & 3.301 & 3.0844 & TRN & \\
\hline CHEMBL 77730 & 212394 & 4.6421 & 4.5976 & TRN & \\
\hline CHEMBL433320 & 212394 & 3.301 & 2.9741 & TRN & \\
\hline CHEMBL420390 & 212394 & 3.301 & 3.6733 & TRN & \\
\hline CHEMBL 78072 & 212394 & 5.0088 & 4.9704 & TRN & \\
\hline CHEMBL 78658 & 212394 & 3.301 & 3.1652 & TRN & \\
\hline CHEMBL 79010 & 212394 & 4.3969 & 4.1733 & TRN & \\
\hline CHEMBL 79071 & 212394 & 4.5952 & 4.5665 & TRN & \\
\hline CHEMBL309604 & 212394 & 4.9872 & 4.8778 & TRN & \\
\hline
\end{tabular}




\begin{tabular}{|c|c|c|c|c|c|}
\hline \multicolumn{6}{|c|}{ Supplemental Table S2.txt } \\
\hline CHEMBL 82482 & 212394 & 7.2218 & 7.4574 & TRN & \\
\hline CHEMBL79038 & 212394 & 6.3979 & 6.3804 & TRN & \\
\hline CHEMBL312814 & 212394 & 3.301 & 3.9384 & TRN & \\
\hline CHEMBL81497 & 212394 & 6.8861 & 6.9325 & TRN & \\
\hline CHEMBL78891 & 212394 & 3.301 & 3.2738 & TRN & \\
\hline CHEMBL311523 & 212394 & 4.3799 & 4.8218 & TRN & \\
\hline CHEMBL310393 & 212394 & 4.5482 & 5.1059 & TST & \\
\hline CHEMBL 312241 & 212394 & 4.3152 & 4.7433 & TST & \\
\hline CHEMBL420958 & 212394 & 6.2366 & 6.1819 & TRN & \\
\hline CHEMBL 81808 & 212394 & 5.7447 & 5.811 & TRN & \\
\hline CHEMBL82198 & 212394 & 5.6778 & 5.6493 & TRN & \\
\hline CHEMBL 78447 & 212394 & 5.3372 & 5.7818 & TRN & \\
\hline CHEMBL 78347 & 212394 & 3.301 & 4.6526 & TST & \\
\hline CHEMBL 79777 & 212394 & 3.301 & 4.0371 & TRN & \\
\hline CHEMBL 78431 & 212394 & 3.301 & 4.3398 & TST & \\
\hline CHEMBL310141 & 212394 & 7.2218 & 7.0511 & TRN & \\
\hline CHEMBL81277 & 212394 & 6.5086 & 6.9559 & TRN & \\
\hline CHEMBL 81108 & 212394 & 4.7282 & 4.5604 & TRN & \\
\hline CHEMBL 80883 & 212394 & 6.1079 & 5.8126 & TRN & \\
\hline CHEMBL 78604 & 212394 & 5.1427 & 4.2049 & TST & \\
\hline CHEMBL312681 & 212394 & 7.301 & 7.2988 & TRN & \\
\hline CHEMBL441261 & 212394 & 4.7825 & 5.5525 & TST & \\
\hline CHEMBL82306 & 212394 & 5.6198 & 5.7551 & TRN & \\
\hline CHEMBL 310882 & 212394 & 5.5686 & 5.2149 & TRN & \\
\hline CHEMBL 78779 & 212394 & 6.4949 & 6.4489 & TRN & \\
\hline CHEMBL312713 & 212394 & 5.6778 & 5.6285 & TRN & \\
\hline CHEMBL 80837 & 212394 & 7.0458 & 6.7085 & TRN & \\
\hline CHEMBL78936 & 212394 & 5.7696 & 5.7797 & TRN & \\
\hline CHEMBL 79072 & 212394 & 4.6073 & 4.6028 & TRN & \\
\hline CHEMBL82199 & 212394 & 5.8861 & 6.0279 & TRN & \\
\hline CHEMBL78834 & 212394 & 5.3098 & 5.4726 & TRN & \\
\hline CHEMBL311680 & 212394 & 6.0706 & 5.9976 & TRN & \\
\hline CHEMBL 78863 & 212394 & 5.7696 & 5.24299 & 9999999999 & TRN \\
\hline CHEMBL 82543 & 212394 & 3.301 & 3.2083 & TRN & \\
\hline CHEMBL 81550 & 212394 & 3.301 & 3.3012 & TRN & \\
\hline CHEMBL 78404 & 212394 & 3.301 & 3.4023 & TRN & \\
\hline CHEMBL 81870 & 212394 & 6.3468 & 6.0712 & TST & \\
\hline CHEMBL419100 & 212394 & 3.301 & 5.0364 & TST & \\
\hline CHEMBL 311437 & 212394 & 5.284 & 4.9701 & TST & \\
\hline CHEMBL 81234 & 212394 & 6.3565 & 5.6084 & TST & \\
\hline CHEMBL 78512 & 212394 & 3.301 & 4.7558 & TST & \\
\hline CHEMBL 82544 & 212394 & 5.2518 & 4.6147 & TST & \\
\hline CHEMBL82610 & 212394 & 5.9208 & 6.2732 & TST & \\
\hline CHEMBL77508 & 212394 & 6.9208 & 5.4226 & TST & \\
\hline CHEMBL3590279 & 1503506 & 3.301 & 3.375 & TRN & \\
\hline CHEMBL 3590280 & 1503506 & 3.301 & 3.0486 & TRN & \\
\hline CHEMBL 3590288 & 1503506 & 3.301 & 3.0639 & TST & \\
\hline CHEMBL3589442 & 1503506 & 3.301 & 3.9588 & TRN & \\
\hline
\end{tabular}


Supplemental Table S2.txt

\begin{tabular}{|c|c|c|c|c|c|}
\hline CHEMBL 3589431 & 1503506 & 4.3098 & 5.063 & TRN & \\
\hline CHEMBL 3589444 & 1503506 & 4.4815 & 5.3448 & TRN & \\
\hline CHEMBL2347404 & 1503506 & 5.7447 & 4.8253 & TRN & \\
\hline CHEMBL3589046 & 1503506 & 4.8239 & 5.1653 & TST & \\
\hline CHEMBL3590282 & 1503506 & 3.301 & 3.8607 & TRN & \\
\hline CHEMBL3589437 & 1503506 & 3.301 & 3.5667 & TRN & \\
\hline CHEMBL3589429 & 1503506 & 5.1805 & 5.4773 & TRN & \\
\hline CHEMBL3589456 & 1503506 & 3.301 & 3.3635 & TRN & \\
\hline CHEMBL3589436 & 1503506 & 6.1367 & 6.5564 & TRN & \\
\hline CHEMBL3589453 & 1503506 & 3.301 & 3.6964 & TRN & \\
\hline CHEMBL3590277 & 1503506 & 3.301 & 3.4251 & TRN & \\
\hline CHEMBL3590275 & 1503506 & 4.7696 & 4.1823 & TRN & \\
\hline CHEMBL3590286 & 1503506 & 5.6576 & 3.9503 & TST & \\
\hline CHEMBL 3589434 & 1503506 & 6.1367 & 5.8147 & TRN & \\
\hline CHEMBL3590285 & 1503506 & 3.301 & 3.9264 & TST & \\
\hline CHEMBL3589045 & 1503506 & 3.301 & 5.6281 & TST & \\
\hline CHEMBL3590276 & 1503506 & 5.8861 & 5.4203 & TRN & \\
\hline CHEMBL 3589438 & 1503506 & 3.301 & 3.7274 & TRN & \\
\hline CHEMBL3589451 & 1503506 & 4.3098 & 5.735 & TRN & \\
\hline CHEMBL3589447 & 1503506 & 3.301 & 2.9968 & TRN & \\
\hline CHEMBL3590284 & 1503506 & 6.0223 & 5.1016 & TRN & \\
\hline CHEMBL3589446 & 1503506 & 4.3468 & 4.0922 & TRN & \\
\hline CHEMBL 3589457 & 1503506 & 4.7447 & 4.0676 & TRN & \\
\hline CHEMBL3589454 & 1503506 & 3.301 & 2.8662 & TRN & \\
\hline CHEMBL3588866 & 1503506 & 5.6576 & 5.3359 & TRN & \\
\hline CHEMBL3589450 & 1503506 & 5.5086 & 4.8182 & TRN & \\
\hline CHEMBL3589449 & 1503506 & 3.301 & 4.1271 & TRN & \\
\hline CHEMBL 3589443 & 1503506 & 5.3279 & 5.007 & TRN & \\
\hline CHEMBL3590283 & 1503506 & 7.0458 & \multicolumn{2}{|c|}{5.5089999999999995} & TRN \\
\hline CHEMBL3589452 & 1503506 & 3.301 & 3.5817 & TRN & \\
\hline CHEMBL3589448 & 1503506 & 4.8239 & 3.0896 & TST & \\
\hline CHEMBL3589435 & 1503506 & 6.0315 & 6.3745 & TRN & \\
\hline CHEMBL3589439 & 1503506 & 3.301 & 2.6839 & TST & \\
\hline CHEMBL3589432 & 1503506 & 5.4559 & 4.4543 & TST & \\
\hline CHEMBL3589430 & 1503506 & 5.5686 & 5.5447 & TRN & \\
\hline CHEMBL3590278 & 1503506 & 3.301 & 3.0535 & TRN & \\
\hline CHEMBL3590287 & 1503506 & 3.301 & \multicolumn{2}{|c|}{3.3739999999999997} & TST \\
\hline CHEMBL 3590281 & 1503506 & 3.301 & 3.7415 & TRN & \\
\hline CHEMBL 3589441 & 1503506 & 3.301 & 3.2609 & TRN & \\
\hline CHEMBL 3589455 & 1503506 & 3.301 & 2.6443 & TST & \\
\hline CHEMBL2347539 & 1503506 & 6.2924 & 5.7445 & TRN & \\
\hline CHEMBL3589440 & 1503506 & 3.301 & 2.8427 & TST & \\
\hline CHEMBL 3589044 & 1503506 & 4.3188 & 3.7516 & TST & \\
\hline CHEMBL3589445 & 1503506 & 3.301 & 3.5799 & TRN & \\
\hline CHEMBL3589433 & 1503506 & 5.2757 & 5.6509 & TRN & \\
\hline CHEMBL3590289 & 1503506 & 5.2596 & 4.2362 & TST & \\
\hline CHEMBL362264 & 306551 & 6.6383 & 6.5277 & TRN & \\
\hline CHEMBL365634 & 306551 & 6.2596 & 6.3757 & TRN & \\
\hline
\end{tabular}

Page 27631 


\begin{tabular}{|c|c|c|c|c|c|}
\hline & & & & & \\
\hline CHEMBL186868 & 306551 & 8.4089 & 6.6121 & TST & \\
\hline CHEMBL184806 & 306551 & 5.5302 & 5.2871 & TRN & \\
\hline CHEMBL361053 & 306551 & 5.3979 & 5.6605 & TST & \\
\hline CHEMBL363118 & 306551 & 7.0969 & 6.7957 & TRN & \\
\hline CHEMBL183156 & 306551 & 5.3372 & 5.9426 & TRN & \\
\hline CHEMBL184837 & 306551 & 5.8827 & 6.1988 & TRN & \\
\hline CHEMBL185532 & 306551 & 5.7447 & 6.0276 & TRN & \\
\hline CHEMBL185446 & 306551 & 7.2218 & 6.9305 & TRN & \\
\hline CHEMBL182294 & 306551 & 6.8539 & 6.657 & TRN & \\
\hline CHEMBL363709 & 306551 & 5.2441 & 5.74799 & 9999999999 & TRN \\
\hline CHEMBL185502 & 306551 & 5.2291 & 5.9147 & TST & \\
\hline CHEMBL187201 & 306551 & 7.2218 & 7.0063 & TRN & \\
\hline CHEMBL182681 & 306551 & 5.3188 & 5.746 & TRN & \\
\hline CHEMBL182227 & 306551 & 6.585 & 6.364 & TRN & \\
\hline CHEMBL184829 & 306551 & 7.699 & 7.5585 & TRN & \\
\hline CHEMBL362719 & 306551 & 5.6576 & 5.4951 & TRN & \\
\hline CHEMBL184017 & 306551 & 6.8239 & 6.7819 & TRN & \\
\hline CHEMBL363236 & 306551 & 5.7212 & 5.9315 & TST & \\
\hline CHEMBL186615 & 306551 & 7.2218 & 7.2843 & TRN & \\
\hline CHEMBL365494 & 306551 & 5.2291 & 5.397 & TRN & \\
\hline CHEMBL365621 & 306551 & 5.7825 & 5.5844 & TRN & \\
\hline CHEMBL184334 & 306551 & 5.8239 & 5.5844 & TRN & \\
\hline CHEMBL184057 & 306551 & 6.699 & 7.0538 & TRN & \\
\hline CHEMBL 360874 & 306551 & 5.6716 & 6.2165 & TRN & \\
\hline CHEMBL183040 & 306551 & 6.3279 & 6.5016 & TRN & \\
\hline CHEMBL365659 & 306551 & 7.2218 & 6.687 & TRN & \\
\hline CHEMBL365402 & 306551 & 5.2518 & 5.5445 & TST & \\
\hline CHEMBL185604 & 306551 & 6.8539 & 6.3915 & TRN & \\
\hline CHEMBL184016 & 306551 & 7.0458 & 6.9653 & TRN & \\
\hline CHEMBL184154 & 306551 & 7.5229 & 7.4793 & TRN & \\
\hline CHEMBL185203 & 306551 & 7.0969 & 6.99700 & 3000000001 & TRN \\
\hline CHEMBL184416 & 306551 & 6.1549 & 5.8681 & TRN & \\
\hline CHEMBL184089 & 306551 & 6.0315 & 6.8664 & TRN & \\
\hline CHEMBL182574 & 306551 & 6.7959 & 6.3989 & TRN & \\
\hline CHEMBL365206 & 306551 & 5.1805 & 5.7394 & TST & \\
\hline CHEMBL359562 & 306551 & 6.0605 & 6.5123 & TRN & \\
\hline CHEMBL361512 & 306551 & 5.7696 & 5.9838 & TST & \\
\hline CHEMBL184960 & 306551 & 5.7878 & 6.8297 & TST & \\
\hline CHEMBL362033 & 306551 & 6.2518 & 6.0419 & TRN & \\
\hline CHEMBL361706 & 306551 & 5.1938 & 5.3132 & TRN & \\
\hline CHEMBL185531 & 306551 & 5.2757 & 5.5386 & TST & \\
\hline CHEMBL363097 & 306551 & 7.2218 & 6.9432 & TRN & \\
\hline CHEMBL183816 & 306551 & 5.1135 & 5.5521 & TST & \\
\hline CHEMBL183952 & 306551 & 6.9208 & 7.08 & TRN & \\
\hline CHEMBL183789 & 306551 & 5.9788 & 5.7263 & TST & \\
\hline CHEMBL367135 & 306551 & 6.5376 & 6.3378 & TRN & \\
\hline CHEMBL184470 & 306551 & 5.1249 & 5.5715 & TRN & \\
\hline CHEMBL185439 & 306551 & 6.6198 & 6.2793 & TRN & \\
\hline
\end{tabular}

Page 27632 
Page 27633 
Supplemental Table S2.txt

\begin{tabular}{|c|c|c|c|c|}
\hline CHEMBL 3361372 & 1459650 & 3.5751 & 3.5761 & TRN \\
\hline CHEMBL 1257903 & 1459650 & 3.4763 & 3.4745 & TRN \\
\hline CHEMBL 3361379 & 1459650 & 3.5654 & 3.5656 & TRN \\
\hline CHEMBL 3361394 & 1459650 & 3.6655 & 3.6639 & TRN \\
\hline CHEMBL 3361367 & 1459650 & 3.6091 & 3.6089 & TRN \\
\hline CHEMBL3361391 & 1459650 & 3.6904 & 3.6918 & TRN \\
\hline CHEMBL 3360789 & 1459650 & 5.5243 & 5.5247 & TRN \\
\hline CHEMBL 3361352 & 1459650 & 3.4622 & 3.9619 & TST \\
\hline CHEMBL 3361387 & 1459650 & 3.5421 & 3.5417 & TRN \\
\hline CHEMBL 3361349 & 1459650 & 3.4802 & 3.949 & TST \\
\hline CHEMBL 3361360 & 1459650 & 3.5186 & 3.3264 & TST \\
\hline CHEMBL 3360792 & 1459650 & 3.5513 & 3.5541 & TST \\
\hline CHEMBL 3361376 & 1459650 & 3.5017 & 3.3299 & TST \\
\hline CHEMBL 3361370 & 1459650 & 3.5186 & 3.7422 & TST \\
\hline CHEMBL 3361350 & 1459650 & 3.5361 & 2.6508 & TST \\
\hline CHEMBL 3361388 & 1459650 & 3.5817 & 4.7238 & TST \\
\hline CHEMBL 3361389 & 1459650 & 3.6904 & 4.8783 & TST \\
\hline CHEMBL 3361374 & 1459650 & 3.6091 & 3.6782 & TST \\
\hline CHEMBL 3353945 & 1451728 & 4.0 & 3.8195 & TRN \\
\hline CHEMBL 3354580 & 1451728 & 4.0 & 3.3888 & TRN \\
\hline CHEMBL 3353946 & 1451728 & 4.0 & 4.0745 & TRN \\
\hline CHEMBL 3353949 & 1451728 & 4.0 & 4.1373 & TRN \\
\hline CHEMBL 3354572 & 1451728 & 4.0 & 3.7016 & TST \\
\hline CHEMBL 3354582 & 1451728 & 4.0 & 3.9343 & TRN \\
\hline CHEMBL 3354597 & 1451728 & 4.0 & 4.0834 & TRN \\
\hline CHEMBL 3353943 & 1451728 & 4.0 & 3.9887 & TRN \\
\hline CHEMBL 3354587 & 1451728 & 4.0 & 5.4824 & TRN \\
\hline CHEMBL 3353938 & 1451728 & 7.7212 & 6.5122 & TRN \\
\hline CHEMBL 3353936 & 1451728 & 6.0 & 4.9001 & TST \\
\hline CHEMBL 3354571 & 1451728 & 4.0 & 4.0011 & TRN \\
\hline CHEMBL 3353929 & 1451728 & 4.0 & 4.7677 & TRN \\
\hline CHEMBL 3354598 & 1451728 & 4.0 & 3.8593 & TRN \\
\hline CHEMBL 3354586 & 1451728 & 4.0 & 5.5046 & TRN \\
\hline CHEMBL 3354601 & 1451728 & 4.0 & 3.5556 & TRN \\
\hline CHEMBL3353950 & 1451728 & 4.0 & 3.9901 & TRN \\
\hline CHEMBL 3354576 & 1451728 & 4.0 & 4.08 & TRN \\
\hline CHEMBL 3354596 & 1451728 & 4.0 & 4.0288 & TRN \\
\hline CHEMBL 3354574 & 1451728 & 4.0 & 3.4949 & TST \\
\hline CHEMBL 3353937 & 1451728 & 5.0 & 4.4314 & TST \\
\hline CHEMBL 3354594 & 1451728 & 4.0 & 4.2212 & TRN \\
\hline CHEMBL 3353939 & 1451728 & 4.0 & 4.78100 & 000000001 \\
\hline CHEMBL 3354600 & 1451728 & 4.0 & 3.7711 & TRN \\
\hline CHEMBL 3354602 & 1451728 & 4.0 & 3.8028 & TRN \\
\hline CHEMBL 3354577 & 1451728 & 4.0 & 4.00899 & 99999999995 \\
\hline CHEMBL 3354579 & 1451728 & 4.0 & 3.7651 & TRN \\
\hline CHEMBL 3353935 & 1451728 & 5.0 & 4.5399 & TST \\
\hline CHEMBL 3354583 & 1451728 & 4.0 & 3.4948 & TRN \\
\hline CHEMBL3353954 & 1451728 & 4.0 & 4.2134 & TRN \\
\hline
\end{tabular}


Supplemental Table S2.txt

\begin{tabular}{|c|c|c|c|c|}
\hline CHEMBL3353941 & 1451728 & 4.0 & 3.9399 & TRN \\
\hline HEMBL3353934 & 1451728 & 5.0 & 4.0198 & TST \\
\hline HEMBL3354590 & 451728 & 4.0 & $\partial 131$ & $\mathrm{~N}$ \\
\hline HEMBL3353931 & 451728 & 4.0 & 5976 & \\
\hline HEMBL3354589 & 451728 & 4.0 & .9389 & $\mathrm{RN}$ \\
\hline HEMBL3354585 & 451728 & 7.0655 & 6.1905 & 「RN \\
\hline HEMBL3353953 & 1451728 & 4.0 & 4.1971 & RN \\
\hline HEMBL3354581 & 451728 & 4.0 & 4.3412 & RN \\
\hline HEMBL3354591 & 1451728 & 4.0 & 3.8766 & RIN \\
\hline HEMBL3354588 & 451728 & 4.0 & .0546 & RN \\
\hline HEMBL 3354584 & 1451728 & 4.0 & 3.2441 & $\mathrm{RN}$ \\
\hline HEMBL3353955 & 1451728 & 4.0 & .4479 & RN \\
\hline HEMBL3353932 & 728 & 7.0706 & 5.3364 & RN \\
\hline HEMBL3353956 & 1451728 & 4.0 & 3.9958 & TRN \\
\hline HEMBL3354593 & 451728 & 4.0 & 3.762 & TRN \\
\hline HEMBL3353940 & 1728 & 7.9208 & 7.5579 & RN \\
\hline HEMBL439044 & 728 & 7.6778 & 218 & ST \\
\hline HEMBL3354575 & 728 & 4.0 & 4.3655 & TRN \\
\hline HEMBL3353944 & 1728 & 4.0 & 4.2262 & TRN \\
\hline HEMBL3354573 & 728 & 4.0 & 3.5969 & TST \\
\hline HEMBL3353930 & 728 & 4.0 & 2006 & 「RN \\
\hline HEMBL3 & 728 & 4.0 & 447 & RN \\
\hline HEMBL3354599 & 728 & 4.0 & 3.9283 & TRN \\
\hline HEMBL3353952 & 728 & 4.0 & 286 & TRN \\
\hline HEMBL3353948 & 728 & 4.0 & 4241 & TRN \\
\hline HEMBL3353942 & 728 & 4.0 & 1494 & TST \\
\hline HEMBL3 & 28 & 4.0 & 351 & TST \\
\hline HEMBL3354570 & 728 & 4.0 & 3.9093 & TST \\
\hline HEMBL3353951 & & 4.0 & 18 & TST \\
\hline HEMBL3352839 & 1451728 & 4.0 & .5149 & TST \\
\hline HEMBL3354592 & 728 & 7.14 & 3.6721 & TST \\
\hline CHEMBL3 & 28 & 4.0 & 184 & TST \\
\hline HEMBL3353933 & 728 & 4.0 & 5.2534 & TST \\
\hline HEMBL1086079 & & 9.8 & 6143 & TRN \\
\hline HEMBL1086080 & & 9.2 & 9.5142 & TRN \\
\hline HEMBL1085111 & & 9.5 & 9.4193 & TRN \\
\hline CHEMBL1 & & 10.2 & 66 & TRN \\
\hline CHEMBL1085112 & & 7.6 & 7.9063 & TRN \\
\hline CHEMBL1085113 & & 9.2 & 5829 & TRN \\
\hline CHEMBL1 & & 9.8 & 9.8959 & TRN \\
\hline CHEMBL1086324 & 63 & 9.6 & 9.2625 & TRN \\
\hline CHEMBL1086325 & 63 & 9.4 & 9.674 & TRN \\
\hline CHEMBL1086326 & 635521 & 10.1 & 9.7174 & TRN \\
\hline CHEMBL1085115 & 63 & 8.4 & 9385 & TRN \\
\hline CHEMBL1085368 & & 9.3 & 9.7032 & TST \\
\hline CHEMBL1086546 & 635521 & 6.8 & 6.925 & RIN \\
\hline CHEMBL1086547 & 635521 & 5.0 & 9.6997 & ST \\
\hline CHEMBL1085372 & 635521 & 9.5 & 9.7066 & TRN \\
\hline
\end{tabular}

Page 27635 


\begin{tabular}{|c|c|c|c|c|}
\hline \multicolumn{5}{|c|}{ Supplemental Table S2.txt } \\
\hline CHEMBL1085617 & 635521 & 9.8 & 9.5432 & TRN \\
\hline CHEMBL1085618 & 635521 & 8.1 & 7.5926 & TRN \\
\hline CHEMBL1085619 & 635521 & 8.7 & 8.9979 & TRN \\
\hline CHEMBL1084793 & 635521 & 9.1 & 9.2005 & TST \\
\hline CHEMBL1084794 & 635521 & 10.3 & 9.3875 & TST \\
\hline CHEMBL1086251 & 635521 & 8.3 & 10.113 & TST \\
\hline CHEMBL1086252 & 635521 & 10.0 & 10.1933 & TRN \\
\hline CHEMBL1086253 & 635521 & 8.9 & 8.8917 & TRN \\
\hline CHEMBL1085036 & 635521 & 9.0 & 9.5369 & TRN \\
\hline CHEMBL1085037 & 635521 & 9.9 & 9.6835 & TRN \\
\hline CHEMBL1085038 & 635521 & 9.6 & 9.11 & TRN \\
\hline CHEMBL1086476 & 635521 & 8.9 & 9.3424 & TRN \\
\hline CHEMBL1086477 & 635521 & 9.5 & 9.7149 & TRN \\
\hline CHEMBL1085585 & 635521 & 9.8 & 9.2949 & TRN \\
\hline CHEMBL1084071 & 635521 & 9.4 & 9.3724 & TRN \\
\hline CHEMBL1083575 & 635521 & 9.2 & 9.1752 & TRN \\
\hline CHEMBL1082509 & 635521 & 9.4 & 9.4856 & TRN \\
\hline CHEMBL1082510 & 635521 & 8.6 & 8.855 & TRN \\
\hline CHEMBL1085852 & 635521 & 7.4 & 7.5325 & TRN \\
\hline CHEMBL1084874 & 635521 & 8.8 & 8.6904 & TRN \\
\hline CHEMBL1083886 & 635521 & 9.9 & 9.6049 & TRN \\
\hline CHEMBL1084875 & 635521 & 8.8 & 8.3399 & TRN \\
\hline CHEMBL1085120 & 635521 & 10.0 & 9.1377 & TRN \\
\hline CHEMBL1084358 & 635521 & 9.1 & 9.1635 & TRN \\
\hline CHEMBL1084359 & 635521 & 8.4 & 8.5645 & TRN \\
\hline CHEMBL1083780 & 635521 & 8.7 & 8.3467 & TRN \\
\hline CHEMBL1083781 & 635521 & 9.7 & 9.4462 & TRN \\
\hline CHEMBL1083782 & 635521 & 9.4 & 9.035 & TRN \\
\hline CHEMBL1083481 & 635521 & 7.5 & 8.4803 & TRN \\
\hline CHEMBL1084711 & 635521 & 9.9 & 10.0695 & TRN \\
\hline CHEMBL1086572 & 635521 & 8.4 & 8.5708 & TRN \\
\hline CHEMBL1086573 & 635521 & 9.0 & 8.9882 & TRN \\
\hline CHEMBL1083173 & 635521 & 8.7 & 9.4903 & TRN \\
\hline CHEMBL1085879 & 635521 & 7.5 & 9.8426 & TST \\
\hline CHEMBL1086113 & 635521 & 10.0 & 9.6666 & TRN \\
\hline CHEMBL1086114 & 635521 & 8.3 & 9.92 & TST \\
\hline CHEMBL1085409 & 635521 & 7.8 & 9.9278 & TST \\
\hline CHEMBL1085651 & 635521 & 9.2 & 9.728 & TST \\
\hline CHEMBL1085658 & 635521 & 10.0 & 9.9297 & TST \\
\hline CHEMBL1084335 & 635521 & 8.2 & 9.6232 & TST \\
\hline CHEMBL1084336 & 635521 & 9.8 & 9.3955 & TST \\
\hline CHEMBL1084603 & 635521 & 9.7 & 9.4413 & TST \\
\hline CHEMBL1084604 & 635521 & 9.6 & 8.8739 & TST \\
\hline CHEMBL1082777 & 635521 & 9.5 & 9.1744 & TST \\
\hline CHEMBL1795397 & 752822 & 0.47 & 0.4964 & TRN \\
\hline CHEMBL1795398 & 752822 & 1.5 & 1.3128 & TRN \\
\hline CHEMBL596514 & 752822 & 0.52 & 0.5297 & TRN \\
\hline CHEMBL594211 & 752822 & 0.22 & 0.6478 & TRN \\
\hline
\end{tabular}




\begin{tabular}{|c|c|c|c|c|c|}
\hline \multicolumn{6}{|c|}{ Supplemental Table S2.txt } \\
\hline CHEMBL594135 & 752822 & 0.47 & 0.6121 & TRN & \\
\hline CHEMBL1600347 & 752822 & 0.77 & 0.6153 & TRN & \\
\hline CHEMBL1795399 & 752822 & 0.83 & 1.3979 & TRN & \\
\hline CHEMBL1795400 & 752822 & 1.4 & 1.2832 & TRN & \\
\hline CHEMBL1795401 & 752822 & 1.9 & 0.9563 & TRN & \\
\hline CHEMBL480626 & 752822 & 0.36 & 0.7359 & TRN & \\
\hline CHEMBL1795402 & 752822 & 1.9 & 2.122 & TRN & \\
\hline CHEMBL608690 & 752822 & 0.76 & 0.8186 & TRN & \\
\hline CHEMBL595366 & 752822 & 0.86 & 1.0191 & TRN & \\
\hline CHEMBL594650 & 752822 & 0.58 & 0.9259 & TRN & \\
\hline CHEMBL594196 & 752822 & 1.1 & 0.9725 & TRN & \\
\hline CHEMBL594920 & 752822 & 1.5 & 1.1452 & TRN & \\
\hline CHEMBL594921 & 752822 & 0.42 & 0.6377 & TRN & \\
\hline CHEMBL594087 & 752822 & 0.78 & 0.7082 & TRN & \\
\hline CHEMBL594424 & 752822 & 1.7 & 1.3902 & TRN & \\
\hline CHEMBL481210 & 752822 & 1.4 & 1.2901 & TST & \\
\hline CHEMBL520909 & 752822 & 1.2 & 1.4254 & TRN & \\
\hline CHEMBL1795403 & 752822 & 1.5 & 2.0756 & TRN & \\
\hline CHEMBL1795404 & 752822 & 1.5 & 1.8706 & TRN & \\
\hline CHEMBL1795405 & 752822 & 1.7 & 1.6927 & TRN & \\
\hline CHEMBL450947 & 752822 & 1.4 & 1.1916 & TRN & \\
\hline CHEMBL9225 & 752822 & 1.5 & 1.6976 & TRN & \\
\hline CHEMBL503990 & 752822 & 1.4 & 1.6799 & TRN & \\
\hline CHEMBL510600 & 752822 & 0.36 & 0.3664 & TRN & \\
\hline CHEMBL481993 & 752822 & 1.1 & 1.5248 & TRN & \\
\hline CHEMBL504414 & 752822 & 1.7 & 1.7559 & TRN & \\
\hline CHEMBL481409 & 752822 & 1.2 & 1.1271 & TRN & \\
\hline CHEMBL481036 & 752822 & 1.3 & 1.2258 & TST & \\
\hline CHEMBL453980 & 752822 & 1.6 & 1.5962 & TRN & \\
\hline CHEMBL480406 & 752822 & 1.3 & 1.7868 & TRN & \\
\hline CHEMBL445336 & 752822 & 0.97 & 1.1334 & TRN & \\
\hline CHEMBL481994 & 752822 & 1.3 & 1.0043 & TRN & \\
\hline CHEMBL481037 & 752822 & 1.1 & 0.9722 & TST & \\
\hline CHEMBL1795574 & 752822 & 2.1 & 1.795 & TRN & \\
\hline CHEMBL1795575 & 752822 & 2.2 & 1.926 & TRN & \\
\hline CHEMBL1795576 & 752822 & 2.4 & 1.8628 & TRN & \\
\hline CHEMBL1795582 & 752822 & 1.8 & 1.8449 & TRN & \\
\hline CHEMBL1795583 & 752822 & 1.7 & 1.7444 & TRN & \\
\hline CHEMBL1795585 & 752822 & 2.2 & 2.1397 & TRN & \\
\hline CHEMBL1795590 & 752822 & 2.1 & 1.689 & TRN & \\
\hline CHEMBL27134 & 752822 & 1.8 & 1.4951 & TRN & \\
\hline CHEMBL 279151 & 752822 & 1.8 & 1.7995 & TRN & \\
\hline CHEMBL1795594 & 752822 & 1.9 & 2.1034 & TRN & \\
\hline CHEMBL1795595 & 752822 & 2.5 & 2.1797 & TRN & \\
\hline CHEMBL1795596 & 752822 & 2.2 & 2.05400 & 00000000003 & TRN \\
\hline CHEMBL418971 & 752822 & 2.0 & 1.7656 & TRN & \\
\hline CHEMBL1797938 & 752822 & 1.1 & 1.0182 & TST & \\
\hline CHEMBL1797939 & 752822 & 1.8 & 0.9416 & TST & \\
\hline
\end{tabular}




\begin{tabular}{|c|c|c|c|c|c|}
\hline \multicolumn{6}{|c|}{ Supplemental Table S2.txt } \\
\hline CHEMBL1797940 & 752822 & 1.1 & 1.4167 & TST & \\
\hline CHEMBL1797941 & 752822 & 1.6 & 1.8458 & TST & \\
\hline CHEMBL1797942 & 752822 & 1.8 & 1.7778 & TRN & \\
\hline CHEMBL1797943 & 752822 & 1.4 & 1.4436 & TRN & \\
\hline CHEMBL447347 & 752822 & 1.3 & 1.1291 & TST & \\
\hline CHEMBL1797944 & 752822 & 1.2 & 0.9945 & TRN & \\
\hline CHEMBL1528970 & 752822 & 0.71 & 1.6476 & TST & \\
\hline CHEMBL1797945 & 752822 & 1.8 & 1.4175 & TST & \\
\hline CHEMBL1797946 & 752822 & 1.5 & 1.7682 & TST & \\
\hline CHEMBL1797947 & 752822 & 0.58 & 1.1982 & TST & \\
\hline CHEMBL1797948 & 752822 & 1.7 & 2.0103 & TST & \\
\hline CHEMBL1797949 & 752822 & 0.35 & 0.8477 & TST & \\
\hline CHEMBL1797950 & 752822 & 1.4 & 1.9843 & TST & \\
\hline CHEMBL1797951 & 752822 & 0.51 & 1.9783 & TST & \\
\hline CHEMBL1797952 & 752822 & 1.5 & 1.4261 & TST & \\
\hline CHEMBL95952 & 204599 & 7.0 & 7.1615 & TRN & \\
\hline CHEMBL99514 & 204599 & 8.3872 & 8.4246 & TRN & \\
\hline CHEMBL99300 & 204599 & 7.6021 & 7.7039 & TRN & \\
\hline CHEMBL95866 & 204599 & 6.7212 & 6.8736 & TRN & \\
\hline CHEMBL327722 & 204599 & 7.6778 & 7.9071 & TRN & \\
\hline CHEMBL99824 & 204599 & 8.1487 & 7.8843 & TRN & \\
\hline CHEMBL95372 & 204599 & 6.3188 & 6.50299 & 9999999999 & TRN \\
\hline CHEMBL97379 & 204599 & 7.0555 & 6.8506 & TRN & \\
\hline CHEMBL95458 & 204599 & 7.585 & 7.7117 & TRN & \\
\hline CHEMBL95410 & 204599 & 8.2218 & 8.0429 & TRN & \\
\hline CHEMBL318512 & 204599 & 8.4815 & 8.5571 & TRN & \\
\hline CHEMBL95588 & 204599 & 7.3665 & 7.4443 & TRN & \\
\hline CHEMBL95843 & 204599 & 8.0969 & 8.1322 & TRN & \\
\hline CHEMBL97248 & 204599 & 6.9208 & 6.8249 & TRN & \\
\hline CHEMBL99473 & 204599 & 7.6383 & 7.3426 & TRN & \\
\hline CHEMBL95409 & 204599 & 6.5229 & 6.8274 & TST & \\
\hline CHEMBL101260 & 204599 & 7.4318 & 7.392 & TRN & \\
\hline CHEMBL96030 & 204599 & 8.1427 & 8.2362 & TRN & \\
\hline CHEMBL97506 & 204599 & 8.0088 & 7.9584 & TRN & \\
\hline CHEMBL99449 & 204599 & 7.4089 & 8.0778 & TST & \\
\hline CHEMBL431270 & 204599 & 8.1079 & 8.1422 & TRN & \\
\hline CHEMBL100318 & 204599 & 7.7212 & 7.5335 & TRN & \\
\hline CHEMBL330421 & 204599 & 8.2518 & 8.0502 & TRN & \\
\hline CHEMBL319549 & 204599 & 8.0315 & 8.3041 & TRN & \\
\hline CHEMBL421752 & 204599 & 8.2007 & 8.1183 & TRN & \\
\hline CHEMBL328182 & 204599 & 7.6021 & 7.7505 & TRN & \\
\hline CHEMBL98478 & 204599 & 8.4437 & 8.5399 & TRN & \\
\hline CHEMBL95707 & 204599 & 6.6021 & 6.8538 & TST & \\
\hline CHEMBL99811 & 204599 & 8.0915 & 8.0723 & TRN & \\
\hline CHEMBL329690 & 204599 & 8.0555 & 8.0424 & TRN & \\
\hline CHEMBL95946 & 204599 & 7.8539 & 7.829 & TRN & \\
\hline CHEMBL95513 & 204599 & 7.1739 & 7.2176 & TRN & \\
\hline CHEMBL316858 & 204599 & 7.8239 & 8.1465 & TST & \\
\hline
\end{tabular}




\begin{tabular}{|c|c|c|c|c|c|}
\hline & & \multicolumn{4}{|c|}{ Supplemental Table s2.txt } \\
\hline CHEMBL100314 & 204599 & 7.7212 & 7.7348 & TRN & \\
\hline CHEMBL99450 & 204599 & 7.0132 & 7.2846 & TST & \\
\hline CHEMBL329483 & 204599 & 7.301 & 6.7538 & TST & \\
\hline CHEMBL319505 & 204599 & 8.0088 & 7.9663 & TRN & \\
\hline CHEMBL99804 & 204599 & 7.1135 & 7.3088 & TST & \\
\hline CHEMBL99522 & 204599 & 6.7696 & 6.5637 & TST & \\
\hline CHEMBL443496 & 204599 & 7.7212 & 7.6591 & TRN & \\
\hline CHEMBL319506 & 204599 & 8.0555 & 8.0244 & TRN & \\
\hline CHEMBL318402 & 204599 & 7.3279 & 7.3332 & TRN & \\
\hline CHEMBL327521 & 204599 & 7.6021 & 7.5413 & TRN & \\
\hline CHEMBL95403 & 204599 & 8.6383 & 8.3428 & TRN & \\
\hline CHEMBL317384 & 204599 & 7.1612 & 7.2113 & TST & \\
\hline CHEMBL414225 & 204599 & 6.7959 & 7.5788 & TST & \\
\hline CHEMBL431435 & 204599 & 7.6021 & 7.7694 & TRN & \\
\hline CHEMBL99860 & 204599 & 8.041 & 8.0643 & TRN & \\
\hline CHEMBL97093 & 204599 & 7.0757 & 6.8608 & TST & \\
\hline CHEMBL95833 & 204599 & 6.9208 & 7.3088 & TST & \\
\hline CHEMBL29925 & 204599 & 7.8539 & 7.9246 & TRN & \\
\hline CHEMBL99122 & 204599 & 6.1079 & 7.2156 & TST & \\
\hline CHEMBL1673312 & 723718 & 4.0 & 4.0014 & TRN & \\
\hline CHEMBL1673319 & 723718 & 4.0 & 4.01 & TRN & \\
\hline CHEMBL456574 & 723718 & 4.0 & 3.9492 & TRN & \\
\hline CHEMBL1673327 & 723718 & 4.0 & 5.38 & TST & \\
\hline CHEMBL1673320 & 723718 & 4.0 & 4.0023 & TRN & \\
\hline CHEMBL456170 & 723718 & 5.1871 & 5.2117 & TRN & \\
\hline CHEMBL456617 & 723718 & 5.6576 & 5.7057 & TRN & \\
\hline CHEMBL456618 & 723718 & 5.2676 & 5.3059 & TRN & \\
\hline CHEMBL458296 & 723718 & 5.4559 & 5.4643 & TRN & \\
\hline CHEMBL511686 & 723718 & 5.4949 & 5.4711 & TRN & \\
\hline CHEMBL1673330 & 723718 & 5.3372 & 5.3089 & TRN & \\
\hline CHEMBL460188 & 723718 & 5.3098 & 5.2112 & TRN & \\
\hline CHEMBL458932 & 723718 & 5.6021 & 5.66100 & 00000000005 & TRN \\
\hline CHEMBL1673333 & 723718 & 5.6198 & 5.621 & TRN & \\
\hline CHEMBL1673314 & 723718 & 4.0 & 3.9929 & TRN & \\
\hline CHEMBL455962 & 723718 & 5.5086 & 5.4887 & TRN & \\
\hline CHEMBL1673334 & 723718 & 5.3468 & 5.3562 & TRN & \\
\hline CHEMBL447757 & 723718 & 5.4559 & 5.4075 & TRN & \\
\hline CHEMBL1673317 & 723718 & 4.0 & 3.9926 & TRN & \\
\hline CHEMBL1423543 & 723718 & 4.0 & 5.0321 & TST & \\
\hline CHEMBL1503424 & 723718 & 5.0 & 4.9886 & TRN & \\
\hline CHEMBL1673336 & 723718 & 5.4437 & 5.4586 & TRN & \\
\hline CHEMBL1331520 & 723718 & 5.2596 & 5.25799 & 9999999999 & TRN \\
\hline CHEMBL1673321 & 723718 & 5.4202 & 5.4304 & TRN & \\
\hline CHEMBL1673325 & 723718 & 5.3872 & 5.3806 & TRN & \\
\hline CHEMBL513099 & 723718 & 4.0 & 3.9488 & TRN & \\
\hline CHEMBL458933 & 723718 & 5.4949 & 5.49700 & 0000000001 & TRN \\
\hline CHEMBL1673332 & 723718 & 4.0 & 4.7816 & TST & \\
\hline CHEMBL1673328 & 723718 & 4.0 & 5.4866 & TST & \\
\hline
\end{tabular}




\begin{tabular}{|c|c|c|c|c|c|}
\hline \multicolumn{6}{|c|}{ Supplemental Table S2.txt } \\
\hline CHEMBL1673318 & 723718 & 5.0 & 5.1427 & TST & \\
\hline CHEMBL1673313 & 723718 & 4.0 & 4.0055 & TRN & \\
\hline CHEMBL457662 & 723718 & 5.2757 & 5.1217 & TRN & \\
\hline CHEMBL509969 & 723718 & 5.3979 & 5.3738 & TRN & \\
\hline CHEMBL1673337 & 723718 & 4.0 & 4.3586 & TST & \\
\hline CHEMBL1673324 & 723718 & 4.0 & 3.6979 & TST & \\
\hline CHEMBL1673316 & 723718 & 5.4815 & 5.5007 & TRN & \\
\hline CHEMBL1673329 & 723718 & 5.2007 & 4.6324 & TST & \\
\hline CHEMBL1673323 & 723718 & 4.0 & 4.3746 & TST & \\
\hline CHEMBL456366 & 723718 & 5.2924 & 5.3388 & TRN & \\
\hline CHEMBL1673315 & 723718 & 5.4089 & 5.3849 & TRN & \\
\hline CHEMBL445832 & 723718 & 5.2518 & 5.2767 & TRN & \\
\hline CHEMBL458297 & 723718 & 5.3188 & 5.3538 & TRN & \\
\hline CHEMBL1673335 & 723718 & 4.0 & 5.61 & TST & \\
\hline CHEMBL1673311 & 723718 & 4.0 & 3.992 & TRN & \\
\hline CHEMBL1673326 & 723718 & 5.1549 & 4.5862 & TST & \\
\hline CHEMBL456327 & 723718 & 4.0 & 4.1868 & TRN & \\
\hline CHEMBL1673331 & 723718 & 5.3665 & 6.3548 & TST & \\
\hline CHEMBL457663 & 723718 & 5.6021 & 5.6417 & TRN & \\
\hline CHEMBL443679 & 723718 & 4.0 & 4.0105 & TRN & \\
\hline CHEMBL456826 & 723718 & 5.6021 & 5.5696 & TRN & \\
\hline CHEMBL1673322 & 723718 & 4.0 & 5.2611 & TST & \\
\hline CHEMBL404978 & 44489 & 5.3979 & 5.2514 & TRN & \\
\hline CHEMBL429765 & 44489 & 6.699 & 6.909 & TRN & \\
\hline CHEMBL 216710 & 44489 & 5.9208 & 5.34200 & 00000000005 & TRN \\
\hline CHEMBL412463 & 44489 & 4.5229 & 4.8869 & TRN & \\
\hline CHEMBL407854 & 44489 & 6.5528 & 6.2195 & TRN & \\
\hline CHEMBL405511 & 44489 & 6.4437 & 6.4805 & TRN & \\
\hline CHEMBL414069 & 44489 & 4.0 & 4.3299 & TRN & \\
\hline CHEMBL 275984 & 44489 & $5.0680 €$ & 00000000 & 4.5412 & TRN \\
\hline CHEMBL 264010 & 44489 & 7.5376 & 6.6791 & TRN & \\
\hline CHEMBL414503 & 44489 & 4.0 & 4.3622 & TRN & \\
\hline CHEMBL2371143 & 44489 & 6.8356 & 6.558 & TST & \\
\hline CHEMBL 384703 & 44489 & 4.0 & 4.0772 & TRN & \\
\hline CHEMBL408025 & 44489 & 4.0 & 4.1212 & TRN & \\
\hline CHEMBL20034 & 44489 & 6.6576 & 6.9312 & TST & \\
\hline CHEMBL262961 & 44489 & 4.3468 & 4.7862 & TST & \\
\hline CHEMBL 376040 & 44489 & 4.8539 & 4.3392 & TRN & \\
\hline CHEMBL 2371144 & 44489 & 6.041 & 6.5444 & TRN & \\
\hline CHEMBL 216101 & 44489 & 5.301 & 4.3959 & TRN & \\
\hline CHEMBL 268539 & 44489 & 6.6882 & 6.5907 & TRN & \\
\hline CHEMBL439085 & 44489 & 4.6198 & 4.8369 & TRN & \\
\hline CHEMBL438224 & 44489 & 5.0 & 5.1254 & TST & \\
\hline CHEMBL 269027 & 44489 & 5.0 & 5.5348 & TST & \\
\hline CHEMBL409205 & 44489 & 5.0 & 5.0041 & TRN & \\
\hline CHEMBL 386824 & 44489 & 5.1871 & 5.1682 & TRN & \\
\hline CHEMBL406587 & 44489 & 5.3468 & 4.352 & TRN & \\
\hline CHEMBL438008 & 44489 & 5.0 & 5.4223 & TRN & \\
\hline
\end{tabular}




\begin{tabular}{|c|c|c|c|c|c|}
\hline & & & & & \\
\hline CHEMBL267182 & 44489 & 5.0 & 5.3889 & TST & \\
\hline CHEMBL265906 & 44489 & 6.2076 & 6.6662 & TRN & \\
\hline CHEMBL404977 & 44489 & 4.6198 & 5.1173 & TRN & \\
\hline CHEMBL266666 & 44489 & 4.1549 & 4.1722 & TRN & \\
\hline CHEMBL407774 & 44489 & 5.5686 & 5.63 & TRN & \\
\hline CHEMBL267137 & 44489 & 5.0 & 5.2004 & TST & \\
\hline CHEMBL406459 & 44489 & 6.7986 & 6.2119 & TRN & \\
\hline CHEMBL274851 & 44489 & 6.3279 & 6.3659 & TRN & \\
\hline CHEMBL437079 & 44489 & 4.0 & 4.4864 & TRN & \\
\hline CHEMBL384581 & 44489 & 6.5229 & 6.5882 & TRN & \\
\hline CHEMBL265399 & 44489 & 5.0969 & 4.6657 & TRN & \\
\hline CHEMBL216229 & 44489 & 5.0 & 4.7477 & TRN & \\
\hline CHEMBL217867 & 44489 & 6.3098 & 6.7162 & TRN & \\
\hline CHEMBL266506 & 44489 & 4.5229 & 4.8696 & TRN & \\
\hline CHEMBL267406 & 44489 & 4.7447 & 4.6279 & TST & \\
\hline CHEMBL410450 & 44489 & 4.2924 & 4.1775 & TRN & \\
\hline CHEMBL405767 & 44489 & 4.4949 & 4.6033 & TRN & \\
\hline CHEMBL407401 & 44489 & 5.4685 & 5.2651 & TRN & \\
\hline CHEMBL407740 & 44489 & 5.5229 & 4.7325 & TRN & \\
\hline CHEMBL402699 & 44489 & 4.0 & 4.4261 & TRN & \\
\hline CHEMBL405694 & 44489 & 5.0 & 5.6499 & TRN & \\
\hline CHEMBL262749 & 44489 & 5.3468 & 5.3141 & TRN & \\
\hline CHEMBL407697 & 44489 & 5.0458 & 4.5238 & TST & \\
\hline CHEMBL269517 & 44489 & 4.0223 & 4.3714 & TRN & \\
\hline CHEMBL414492 & 44489 & 3.0 & 4.01399 & & TRN \\
\hline CHEMBL411804 & 44489 & 6.7696 & 6.5827 & TRN & \\
\hline CHEMBL411078 & 44489 & 5.3197 & 4.5829 & TST & \\
\hline CHEMBL263335 & 44489 & 3.0 & 3.9311 & TST & \\
\hline CHEMBL269328 & 44489 & 5.3691 & 4.9215 & TST & \\
\hline CHEMBL428096 & 44489 & 5.1549 & 4.1371 & TST & \\
\hline CHEMBL428655 & 44489 & 4.5229 & 5.8848 & TST & \\
\hline CHEMBL415812 & 44489 & 5.1612 & 4.6373 & TST & \\
\hline CHEMBL3913407 & 1528721 & 8.3188 & 9.0505 & TRN & \\
\hline CHEMBL3945706 & 1528721 & 9.3979 & 9.5317 & TRN & \\
\hline CHEMBL3911167 & 1528721 & 9.5528 & 8.7792 & TST & \\
\hline CHEMBL 3654529 & 1528721 & 8.4214 & 9.1652 & TRN & \\
\hline CHEMBL 3651161 & 1528721 & 6.5376 & 8.4956 & TST & \\
\hline CHEMBL3920734 & 1528721 & 9.6778 & 9.1552 & TRN & \\
\hline CHEMBL3924712 & 1528721 & 8.4012 & 8.8657 & TRN & \\
\hline CHEMBL3903939 & 1528721 & 9.4089 & 9.0888 & TRN & \\
\hline CHEMBL 3901540 & 1528721 & 8.1871 & 8.5984 & TRN & \\
\hline CHEMBL 3955424 & 1528721 & 8.3565 & 8.6123 & TST & \\
\hline CHEMBL3651169 & 1528721 & 8.0969 & 8.7425 & TST & \\
\hline CHEMBL3950136 & 1528721 & 7.0694 & 8.3898 & TRN & \\
\hline CHEMBL 3654461 & 1528721 & 8.8539 & 8.1289 & TRN & \\
\hline CHEMBL3963998 & 1528721 & 9.301 & 9.6803 & TRN & \\
\hline CHEMBL 3654527 & 1528721 & 8.3851 & 8.2118 & TRN & \\
\hline CHEMBL3910658 & 1528721 & 8.8894 & 8.8873 & TRN & \\
\hline
\end{tabular}

Page 27641 
Supplemental Table S2.txt

\begin{tabular}{|c|c|c|c|c|c|c|}
\hline CHEMBL3954166 & 1528721 & 6.0947 & 8.3138 & TST & & \\
\hline CHEMBL3896664 & 1528721 & 8.0106 & 8.1533 & TRN & & \\
\hline CHEMBL3889777 & 1528721 & 7.9788 & 7.6725 & TRN & & \\
\hline CHEMBL3936620 & 1528721 & 8.8601 & 8.8538 & TRN & & \\
\hline CHEMBL3919999 & 1528721 & 8.6326 & 8.6177 & TRN & & \\
\hline CHEMBL3954300 & 1528721 & 8.58 & 8.6464 & TRN & & \\
\hline CHEMBL3902144 & 1528721 & 9.2218 & 9.6109 & TRN & & \\
\hline CHEMBL 3893828 & 1528721 & 10.0 & 10.1284 & TRN & & \\
\hline CHEMBL3902755 & 1528721 & 8.7235 & 8.6522 & TRN & & \\
\hline CHEMBL3980991 & 1528721 & 8.1805 & 8.4785 & TRN & & \\
\hline CHEMBL 3654523 & 1528721 & \multicolumn{3}{|c|}{10.699000000000002} & 10.0476 & TRN \\
\hline CHEMBL 3654483 & 1528721 & 10.284 & 9.5602 & TST & & \\
\hline CHEMBL3896834 & 1528721 & 8.699 & 8.9444 & TRN & & \\
\hline CHEMBL 3654535 & 1528721 & 6.8861 & 7.9051 & TST & & \\
\hline CHEMBL3939122 & 1528721 & 8.4776 & 9.1108 & TRN & & \\
\hline CHEMBL3639533 & 1528721 & 8.5376 & 8.3247 & TRN & & \\
\hline CHEMBL3654533 & 1528721 & 9.585 & 9.4549 & TRN & & \\
\hline CHEMBL3939750 & 1528721 & 7.6916 & 7.7013 & TRN & & \\
\hline CHEMBL3914032 & 1528721 & 9.699 & 9.1659 & TRN & & \\
\hline CHEMBL3651159 & 1528721 & 6.9747 & 8.9181 & TST & & \\
\hline CHEMBL3897009 & 1528721 & 8.6271 & 8.7017 & TRN & & \\
\hline CHEMBL 3654525 & 1528721 & 9.3768 & 9.3422 & TRN & & \\
\hline CHEMBL3968663 & 1528721 & 9.2366 & 9.372 & TRN & & \\
\hline CHEMBL3909457 & 1528721 & 10.0 & 9.5751 & TRN & & \\
\hline CHEMBL3898065 & 1528721 & 8.7645 & 8.6645 & TRN & & \\
\hline CHEMBL3654528 & 1528721 & \multicolumn{3}{|c|}{ 7.752999999999999 } & 8.0796 & TRN \\
\hline CHEMBL3904527 & 1528721 & 6.0 & 6.6579 & TRN & & \\
\hline CHEMBL3975064 & 1528721 & 9.0915 & 9.2426 & TRN & & \\
\hline CHEMBL3982973 & 1528721 & 9.5686 & 9.2429 & TRN & & \\
\hline CHEMBL3933955 & 1528721 & 7.9586 & 8.0982 & TRN & & \\
\hline CHEMBL3903326 & 1528721 & 8.0362 & 7.7092 & TRN & & \\
\hline CHEMBL3654536 & 1528721 & 8.7747 & 8.9691 & TRN & & \\
\hline CHEMBL3933627 & 1528721 & 8.8447 & 9.2306 & TRN & & \\
\hline CHEMBL 3965270 & 1528721 & 9.0809 & 8.7388 & TRN & & \\
\hline CHEMBL3924097 & 1528721 & 8.7986 & 9.0914 & TRN & & \\
\hline CHEMBL3970666 & 1528721 & 9.6198 & 8.8934 & TRN & & \\
\hline CHEMBL3654462 & 1528721 & 8.585 & 8.3077 & TRN & & \\
\hline CHEMBL3926598 & 1528721 & 8.8633 & 8.9311 & TRN & & \\
\hline CHEMBL3969224 & 1528721 & 8.6198 & 9.2964 & TRN & & \\
\hline CHEMBL3943195 & 1528721 & 8.8601 & 9.1509 & TRN & & \\
\hline CHEMBL3897504 & 1528721 & 8.9208 & 8.8164 & TRN & & \\
\hline CHEMBL3980744 & 1528721 & 9.1805 & 9.2321 & TRN & & \\
\hline CHEMBL3983054 & 1528721 & 9.3979 & 9.5119 & TRN & & \\
\hline CHEMBL3912197 & 1528721 & 9.0458 & 8.9498 & TRN & & \\
\hline CHEMBL3920907 & 1528721 & 9.8861 & 8.9753 & TRN & & \\
\hline CHEMBL3921822 & 1528721 & 10.0 & 9.9413 & TRN & & \\
\hline CHEMBL3651160 & 1528721 & 7.1367 & 7.9486 & TST & & \\
\hline CHEMBL3938533 & 1528721 & 8.71 & 8.8016 & TRN & & \\
\hline
\end{tabular}


Supplemental Table S2.txt

\begin{tabular}{|c|c|c|c|c|c|c|}
\hline CHEMBL3913325 & 1528721 & 9.2757 & 9.2743 & TRN & & \\
\hline CHEMBL3651170 & 1528721 & 9.0969 & 8.8737 & TST & & \\
\hline CHEMBL3976620 & 1528721 & 7.0862 & 6.8249 & TRN & & \\
\hline CHEMBL3894104 & 1528721 & 9.8239 & 8.7634 & TRN & & \\
\hline CHEMBL3941387 & 1528721 & 8.6576 & 8.6053 & TRN & & \\
\hline CHEMBL3651175 & 1528721 & 8.8539 & 9.8302 & TST & & \\
\hline CHEMBL3959610 & 1528721 & 9.6778 & 8.9101 & TRN & & \\
\hline CHEMBL3971508 & 1528721 & 9.2147 & 8.7175 & TRN & & \\
\hline CHEMBL3925540 & 1528721 & 7.6882 & 7.7779 & TRN & & \\
\hline CHEMBL3985803 & 1528721 & 9.2924 & 9.4918 & TRN & & \\
\hline CHEMBL3911771 & 1528721 & 9.0132 & 8.3142 & TST & & \\
\hline CHEMBL3654482 & 1528721 & 9.283999 & 999999999 & 99 & 9.008 & TST $10-10$ \\
\hline CHEMBL3899493 & 1528721 & 8.6968 & 8.7031 & TST & & \\
\hline CHEMBL3919608 & 1528721 & 9.3188 & 9.119 & TST & & \\
\hline CHEMBL3935556 & 1528721 & 8.4828 & 8.0538 & TST & & \\
\hline CHEMBL3931213 & 1528721 & 10.5229 & 9.6408 & TST & & \\
\hline CHEMBL3902280 & 1528721 & 7.1192 & 7.2953 & TST & & \\
\hline CHEMBL3925058 & 1528721 & 9.6576 & 10.0179 & TST & & \\
\hline CHEMBL3654521 & 1528721 & 11.0 & 9.718 & TST & & \\
\hline CHEMBL3972703 & 1528721 & 8.8894 & 8.7521 & TST & & \\
\hline CHEMBL3799619 & 1573821 & 6.7447 & 6.8953 & TST & & \\
\hline CHEMBL3800425 & 1573821 & 5.4437 & 6.4711 & TRN & & \\
\hline CHEMBL3797233 & 1573821 & 5.8239 & 6.4443 & TRN & & \\
\hline CHEMBL3800234 & 1573821 & 6.8861 & 6.7806 & TRN & & \\
\hline CHEMBL3798094 & 1573821 & 7.1549 & 6.8698 & TRN & & \\
\hline CHEMBL3798513 & 1573821 & 5.6289 & 6.276 & TRN & & \\
\hline CHEMBL3799545 & 1573821 & 6.6576 & 6.6588 & TRN & & \\
\hline CHEMBL3798721 & 1573821 & 4.301 & 6.3175 & TRN & & \\
\hline CHEMBL3800396 & 1573821 & 4.301 & 5.4447 & TRN & & \\
\hline CHEMBL3799005 & 1573821 & 6.8539 & 6.7806 & TRN & & \\
\hline CHEMBL3416910 & 1573821 & 6.3279 & 6.347 & TRN & & \\
\hline CHEMBL3797938 & 1573821 & 5.8539 & 5.5967 & TRN & & \\
\hline CHEMBL3797956 & 1573821 & 4.301 & 5.5647 & TRN & & \\
\hline CHEMBL3800566 & 1573821 & 7.3979 & 7.1969 & TST & & \\
\hline CHEMBL3800477 & 1573821 & 6.3979 & 6.8792 & TST & & \\
\hline CHEMBL3416905 & 1573821 & 6.4202 & 6.5777 & TRN & & \\
\hline CHEMBL3798843 & 1573821 & 7.3979 & 7.3444 & TRN & & \\
\hline CHEMBL 3797388 & 1573821 & 6.585 & 6.4162 & TST & & \\
\hline CHEMBL 3800184 & 1573821 & 7.301 & 7.2859 & TRN & & \\
\hline CHEMBL3416891 & 1573821 & 6.3665 & 6.2763 & TRN & & \\
\hline CHEMBL3416909 & 1573821 & 6.0132 & 6.3393 & TST & & \\
\hline CHEMBL3799894 & 1573821 & 4.301 & 5.5123 & TST & & \\
\hline CHEMBL3798643 & 1573821 & \multicolumn{3}{|c|}{5.757000000000001} & 5.5708 & Tा \\
\hline CHEMBL3797833 & 1573821 & 6.699 & 6.5514 & TRN & & \\
\hline CHEMBL3416908 & 1573821 & 6.585 & 6.8164 & TRN & & \\
\hline CHEMBL3798733 & 1573821 & 6.9208 & 6.6176 & TRN & & \\
\hline CHEMBL3797227 & 1573821 & 6.6778 & 6.7806 & TRN & & \\
\hline CHEMBL 3800504 & 1573821 & 6.6021 & 7.1713 & TST & & \\
\hline
\end{tabular}


Supplemental Table S2.txt

\begin{tabular}{|c|c|c|c|c|}
\hline HEMB & 573821 & 6.4685 & & \\
\hline & 573821 & 6.1367 & .7806 & \\
\hline$-\sigma_{2}$ & 821 & & & \\
\hline AEMBL3 & 73821 & & & $2 \mathrm{~N}$ \\
\hline HEMBL37 & 573821 & 301 & & \\
\hline HEMBL3800588 & 573821 & 6.8861 & 1896 & \\
\hline HEMBL & 73821 & 565 & 858 & \\
\hline 346 & 73821 & & & \\
\hline HEMBL3 & 573821 & & 5763 & \\
\hline HEMBL3 & 573821 & & 333 & \\
\hline HEMBL37 & 573821 & & 28 & \\
\hline IEMBL & 821 & & 83 & \\
\hline AEMBL & & & & \\
\hline HEMBL3 & 573821 & 99 & 6.8399 & \\
\hline AEMBL3 & 821 & 778 & & \\
\hline AEMBL3 & 73821 & 7 & 96 & \\
\hline HEMBL & 21 & & & ות \\
\hline HEMBL & & & & \\
\hline HEMBL3 & 573821 & & 6.2776 & \\
\hline AEMBL3 & & & & \\
\hline HEMBL & 21 & & & Niv \\
\hline HEMBL & 21 & & & RN \\
\hline HEMBL; & & & & \\
\hline HEMBL3 & & 69 & & \\
\hline AEMBL3 & & & & $\Gamma \mathrm{RN}$ \\
\hline HEMBL3 & 21 & & & SI \\
\hline HEMBL & & & & RN \\
\hline HFMBI : & 21 & 96 & & \\
\hline HEMBL3 & & & & IRIN \\
\hline HEMBL37 & & & & I RIV \\
\hline HEMBL3 & 321 & & & ST \\
\hline HEMBL & & & & RN \\
\hline HEMBL & 21 & , & & $\Gamma R N$ \\
\hline HEMBL37 & & & & IRN \\
\hline HEMBL37 & 73821 & 6.6576 & & TRN \\
\hline HEMBL3 & 2. & 676 & 06 & TRN \\
\hline HFMRI & 1 & 2 & & RN \\
\hline HEMBL3 & & & & RN \\
\hline HEMBL3799721 & 573821 & 6.9586 & 7. & TRN \\
\hline AEMBL3 & 73821 & & & TST \\
\hline HEMBL3 & 73821 & 6 & 11 & DN \\
\hline CHEMBL 3 & & & 5.4435 & IST \\
\hline HEMBL3 & 573821 & 7.2218 & 6.8399 & RN \\
\hline HEMBL37 & 573821 & 6.8539 & 7.181 & PN \\
\hline 98 & & & 6.7 & $\mathrm{~N}$ \\
\hline HEMBL3 & 573821 & & 7.18 & \\
\hline HEMBL 37 & 57382 & .6576 & 5.6901 & \\
\hline CHEMBL3798639 & 1573821 & 7.2218 & 6.8399 & ГRN \\
\hline
\end{tabular}

Page 27644 
Supplemental Table S2.txt

\begin{tabular}{|c|c|c|c|c|}
\hline 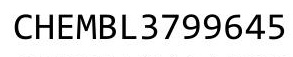 & & & & \\
\hline HEMBL 3414596 & 573821 & 6.301 & 347 & \\
\hline AEMBL3798466 & 73821 & 6.6576 & 1745 & \\
\hline 3549 & 73821 & & & \\
\hline IEMBL3797578 & 573821 & 969 & & \\
\hline AEMBL3416897 & 573821 & 6.7696 & 6511 & \\
\hline AEMBL3799762 & 573821 & 4.301 & .2848 & \\
\hline HEMBL3798398 & & & & \\
\hline IEMBL: & 573821 & 6.0969 & 3712 & \\
\hline IEMBL37 & 573821 & & & \\
\hline AEMBL3797247 & 573821 & 6.5528 & 5283 & \\
\hline AEMBL3800538 & 573821 & 6.6383 & & \\
\hline AEMBL3416911 & 573821 & & & \\
\hline AEMBL: & 821 & 96 & & \\
\hline AEMBL & 21 & 79 & & \\
\hline AEMBL3798562 & 573821 & 969 & 06 & \\
\hline AEMBL3797912 & 21 & & & \\
\hline HEMBL3800300 & 21 & 6. & & \\
\hline AEMBL3416937 & & & & \\
\hline 6907 & 21 & & & \\
\hline 9942 & 21 & 6. & & \\
\hline AEMBL3800326 & & & & \\
\hline AEMBL3 & 1 & & & \\
\hline 461 & & & & \\
\hline 5893 & & 6. & & \\
\hline 7735 & & & & \\
\hline IEMBL 3798428 & 21 & & & \\
\hline AEMBL3 & 1 & & & \\
\hline 970 & 1 & & & \\
\hline 9378 & & & & \\
\hline AEMBL3799958 & 21 & & & \\
\hline IEMBL 3799293 & 21 & 6. & 06 & \\
\hline & & 39 & & \\
\hline 4 & 1 & & & \\
\hline 6914 & 21 & & & RN \\
\hline AEMBL3800441 & 573821 & 7.0 & & RI \\
\hline AEMBL3799128 & 573821 & 586 & 806 & \\
\hline 3799811 & 57 & 19 & 037 & \\
\hline 542 & & & & \\
\hline HEMBL3797204 & & 6.4949 & & ST \\
\hline AEMBL3799605 & 573821 & 686 & & $\mathrm{R}$ \\
\hline 5915 & 1 & & & \\
\hline AEMBL3800274 & 5738 & & 421 & \\
\hline CHEMBL 3800494 & & & & RN \\
\hline AEMBL3798793 & 573821 & 7.0458 & .1896 & $\mathrm{~T}$ \\
\hline IEMBL3416889 & 573821 & 6.4318 & 2434 & s \\
\hline & & & & \\
\hline 9700 & & & & \\
\hline
\end{tabular}

Page 27645 
Supplemental Table S2.txt

\begin{tabular}{|c|c|c|c|c|}
\hline CHEMBL 3800426 & 1573821 & 4.3098 & 6.3175 & TRN \\
\hline CHEMBL3798194 & 1573821 & 5.8539 & 5.6283 & TRN \\
\hline CHEMBL 3800058 & 1573821 & 6.5528 & 7.0533 & TRN \\
\hline CHEMBL 3799702 & 1573821 & 6.8239 & 6.9615 & TRN \\
\hline CHEMBL3799719 & 1573821 & 6.2007 & 6.7806 & TRN \\
\hline CHEMBL 3416945 & 1573821 & 6.1612 & 5.8611 & TRN \\
\hline CHEMBL 3800498 & 1573821 & 7.301 & 6.4435 & TST \\
\hline CHEMBL3416906 & 1573821 & 6.3279 & 6.5354 & TRN \\
\hline CHEMBL3799797 & 1573821 & 4.301 & 5.6763 & TRN \\
\hline CHEMBL3798831 & 1573821 & 6.8861 & 6.276 & TRN \\
\hline CHEMBL 3416898 & 1573821 & 6.9208 & 6.347 & TRN \\
\hline CHEMBL3799411 & 1573821 & 6.4202 & 6.7806 & TRN \\
\hline CHEMBL3797810 & 1573821 & 5.9872 & 6.4985 & TST \\
\hline CHEMBL3799757 & 1573821 & 7.0458 & 6.1148 & TRN \\
\hline CHEMBL3798546 & 1573821 & 6.7212 & 6.9929 & TST \\
\hline CHEMBL3800248 & 1573821 & 6.6778 & 6.5534 & TRN \\
\hline CHEMBL3416904 & 1573821 & 6.7212 & 6.347 & TRN \\
\hline CHEMBL3798929 & 1573821 & 7.0 & 7.1241 & TRN \\
\hline CHEMBL3798261 & 1573821 & 6.7959 & 7.3318 & TST \\
\hline CHEMBL3799252 & 1573821 & 6.6778 & 6.5257 & TST \\
\hline CHEMBL3416901 & 1573821 & 6.8861 & 6.5953 & TRN \\
\hline CHEMBL3799839 & 1573821 & 6.0655 & 5.6283 & TRN \\
\hline CHEMBL3797934 & 1573821 & 6.5229 & 6.4648 & TST \\
\hline CHEMBL3798005 & 1573821 & 6.2518 & \multicolumn{2}{|c|}{5.906000000000001} \\
\hline CHEMBL 3416886 & 1573821 & 7.0458 & 6.7806 & TRN \\
\hline CHEMBL3798916 & 1573821 & 4.3098 & 6.4967 & TST \\
\hline CHEMBL3799550 & 1573821 & 6.6383 & 6.5534 & TRN \\
\hline CHEMBL3799535 & 1573821 & 7.0969 & 7.1896 & TST \\
\hline CHEMBL3797359 & 1573821 & 5.8239 & 6.5678 & TRN \\
\hline CHEMBL 3417035 & 1573821 & 7.0458 & 6.7806 & TRN \\
\hline CHEMBL 3800607 & 1573821 & 7.0 & 7.1432 & TST \\
\hline CHEMBL 3798860 & 1573821 & 6.4437 & 6.7806 & TRN \\
\hline CHEMBL3798267 & 1573821 & 5.699 & 6.2641 & TRN \\
\hline CHEMBL 3797473 & 1573821 & 6.6576 & 6.7806 & TRN \\
\hline CHEMBL 3797725 & 1573821 & 6.6778 & 6.4162 & TST \\
\hline CHEMBL3798058 & 1573821 & 7.301 & 6.8183 & TST \\
\hline CHEMBL3799705 & 1573821 & 7.0 & 7.0892 & TRN \\
\hline CHEMBL 3604232 & 1511354 & 5.2676 & 5.1964 & TRN \\
\hline CHEMBL 3604238 & 1511354 & 6.0862 & 6.3295 & TRN \\
\hline CHEMBL 3604240 & 1511354 & 6.2441 & 5.9012 & TRN \\
\hline CHEMBL1766759 & 1511354 & 4.0 & 4.7721 & TST \\
\hline CHEMBL3604214 & 1511354 & 6.585 & 6.7197 & TRN \\
\hline CHEMBL 3604273 & 1511354 & 6.9586 & 7.0226 & TRN \\
\hline CHEMBL3604228 & 1511354 & 4.0 & 5.074 & TST \\
\hline CHEMBL 3604244 & 1511354 & 4.0 & 4.2922 & TRN \\
\hline CHEMBL 3604247 & 1511354 & 6.3979 & 6.3125 & TRN \\
\hline CHEMBL 3604265 & 1511354 & 6.699 & 6.8236 & TST \\
\hline CHEMBL 3604271 & 1511354 & 6.6198 & 6.8536 & TRN \\
\hline
\end{tabular}

Page 27646 
Supplemental Table S2.txt

\begin{tabular}{|c|c|c|c|c|}
\hline CHEMBL3604213 & 1511354 & 5.585 & 5.5887 & TRN \\
\hline CHEMBL3604226 & 1511354 & 5.2147 & 5.5096 & TST \\
\hline CHEMBL 3604257 & 1511354 & 6.9586 & 7.1321 & TRN \\
\hline CHEMBL 3604222 & 1511354 & 4.0 & 5.8529 & TST \\
\hline CHEMBL 3604235 & 1511354 & 5.0 & 4.8462 & TRN \\
\hline CHEMBL3604242 & 1511354 & 6.3468 & 6.2308 & TRN \\
\hline CHEMBL3604270 & 1511354 & 6.8239 & 6.6313 & TRN \\
\hline CHEMBL 3604272 & 1511354 & 6.301 & 6.5545 & TST \\
\hline CHEMBL 3604255 & 1511354 & 5.5686 & 5.4428 & TRN \\
\hline CHEMBL3604219 & 1511354 & 5.1367 & 5.627999 & 9999999999 \\
\hline CHEMBL 3604236 & 1511354 & 5.9208 & 5.996 & TRN \\
\hline CHEMBL3604250 & 1511354 & 5.8861 & 5.7954 & TRN \\
\hline CHEMBL 3604246 & 1511354 & 5.5686 & 5.8672 & TRN \\
\hline CHEMBL3604224 & 1511354 & 5.585 & 5.169 & TST \\
\hline CHEMBL 3604264 & 1511354 & 6.6576 & 6.9163 & TRN \\
\hline CHEMBL3604216 & 1511354 & 4.0 & 4.0062 & TRN \\
\hline CHEMBL3604260 & 1511354 & 7.6021 & 7.5274 & TRN \\
\hline CHEMBL 3604229 & 1511354 & 6.1249 & 6.1356 & TRN \\
\hline CHEMBL3604221 & 1511354 & 4.0 & 5.8742 & TST \\
\hline CHEMBL 3604253 & 1511354 & 5.3279 & 4.5709 & TRN \\
\hline CHEMBL3604261 & 1511354 & 7.0 & 6.7167 & TRN \\
\hline CHEMBL 3604243 & 1511354 & 5.9586 & 5.8861 & TRN \\
\hline CHEMBL 3604225 & 1511354 & 5.5229 & 5.1045 & TRN \\
\hline CHEMBL 3604227 & 1511354 & 5.3372 & 5.7315 & TST \\
\hline CHEMBL 3604234 & 1511354 & 4.0 & 4.5362 & TRN \\
\hline CHEMBL3604233 & 1511354 & 6.0506 & 5.9342 & TRN \\
\hline CHEMBL3604220 & 1511354 & 4.0 & 5.3609 & TST \\
\hline CHEMBL3604215 & 1511354 & 6.4949 & 6.6332 & TRN \\
\hline CHEMBL 3604263 & 1511354 & 6.4437 & 6.7139 & TRN \\
\hline CHEMBL 3604248 & 1511354 & 6.1675 & 6.1098 & TRN \\
\hline CHEMBL3604251 & 1511354 & 5.3468 & 5.7651 & TRN \\
\hline CHEMBL2094423 & 1511354 & 6.3098 & 6.0932 & TRN \\
\hline CHEMBL3604230 & 1511354 & 5.9586 & 5.916 & TRN \\
\hline CHEMBL3604267 & 1511354 & 7.1487 & 6.9909 & TRN \\
\hline CHEMBL 3604252 & 1511354 & 5.5376 & 5.4392 & TRN \\
\hline CHEMBL3604262 & 1511354 & 6.585 & 6.4684 & TRN \\
\hline CHEMBL 3603845 & 1511354 & 6.1135 & 6.4004 & TRN \\
\hline CHEMBL3604254 & 1511354 & 5.4271 & 5.8108 & TRN \\
\hline CHEMBL 3604268 & 1511354 & 7.6198 & 7.5924 & TST \\
\hline CHEMBL 3604237 & 1511354 & 6.4559 & 6.1707 & TRN \\
\hline CHEMBL3604239 & 1511354 & 6.3188 & 6.2443 & TRN \\
\hline CHEMBL 3604245 & 1511354 & 6.7696 & 6.5854 & TRN \\
\hline CHEMBL 3604258 & 1511354 & 6.3188 & 6.188 & TRN \\
\hline CHEMBL3604231 & 1511354 & 4.0 & 4.5618 & TRN \\
\hline CHEMBL 3604218 & 1511354 & 6.2757 & 6.6418 & TRN \\
\hline CHEMBL3604249 & 1511354 & 5.6576 & 5.4821 & TRN \\
\hline CHEMBL 3604223 & 1511354 & 4.0 & 5.7469 & TST \\
\hline CHEMBL3604266 & 1511354 & 7.4559 & 7.1928 & TST \\
\hline
\end{tabular}


Supplemental Table S2.txt

\begin{tabular}{|c|c|c|c|c|}
\hline HEMBL $36 \ell$ & 511354 & 6.7696 & 6.7344 & TRN \\
\hline HEMBL3604217 & 511354 & 5.7696 & 6.6884 & \\
\hline HFMBI 3604241 & 511354 & 6.3872 & 3344 & \\
\hline HEMBL3604269 & 511354 & 7.2441 & 6.8109 & \\
\hline HEMBL3604259 & 511354 & 7.0969 & 8695 & \\
\hline HEMBL371133 & 25792 & 10.6021 & 10.6049 & \\
\hline HEMBL 200788 & 25792 & 10.6021 & 10.3263 & \\
\hline HEMBL 200482 & 25792 & 6.6383 & 6.4872 & RN \\
\hline HEMBL 200455 & 25792 & 8.7959 & 9.1612 & \\
\hline HEMBL 200545 & 25792 & 5.7447 & 6.5837 & ST \\
\hline HEMBL199488 & 25792 & 7.8861 & 8.1398 & \\
\hline AEMBL 200166 & 25792 & 9.0223 & 8661 & \\
\hline HEMBL 382 & 92 & 5.8239 & 6.39 & \\
\hline HEMBL 200531 & 325792 & 6.3098 & 6.2385 & \\
\hline HEMBL 200775 & 992 & 96 & 3611 & \\
\hline HEMBL3717 & 92 & 6.8239 & 7.4689 & ונכ \\
\hline HEMBL 200 & 92 & 10.6021 & 10.5401 & KIV \\
\hline HEMBL 200 & 92 & 7.4949 & 7.5754 & \\
\hline HEMBL414669 & 92 & 9.6021 & 9.0803 & \\
\hline HEMBL 200 & 92 & 4. & 169 & ST \\
\hline HEMBL199 & 92 & 5 & 1954 & ונ \\
\hline HEMBL200 & 92 & 6021 & 954 & $\mathrm{RN}$ \\
\hline HEMBL199 & 92 & 10.6021 & 0761 & \\
\hline HEMBL199214 & 92 & 10.6021 & 10.5049 & $\mathrm{TR}$ \\
\hline HEMBL 200 & & 10.6021 & 2539 & TRN \\
\hline HEMBL 200 & 92 & 7.8861 & 9238 & RN \\
\hline HEMBL 383 & 92 & 99 & 367 & RN \\
\hline HEMBL372 & 92 & 59 & 134 & ST \\
\hline HEMBL198859 & & 815 & 2903 & TRN \\
\hline HEMBL 200287 & 92 & 91 & 019 & IRN \\
\hline HEMBL 200 & 92 & 57 & 6.8242 & ST \\
\hline HEMBL $20 €$ & 92 & 76 & 843 & RN \\
\hline HEMBL426 & & 9. & 834 & TRN \\
\hline HEMBL199014 & 92 & 8.2676 & 815 & IRN \\
\hline HEMBL 372140 & 25792 & 5.8239 & 6.7006 & TST \\
\hline HEMBL 200 & 92 & 88 & 2442 & RN \\
\hline CHEMBL 19 & 2 & 24 & 806 & RN \\
\hline LHEMBL199487 & 92 & 7.8539 & 8.022 & TRN \\
\hline HEMBL198802 & 25792 & 10.6021 & 10.6042 & TRN \\
\hline HEMBL371059 & 92 & 4.9586 & 6.2139 & TST \\
\hline CHEMBL440035 & 92 & 239 & 9074 & RN \\
\hline CHEMBL200708 & 325792 & 9.5376 & 9.2406 & TRN \\
\hline CHEMBL370165 & 325792 & 10.6021 & 10.1089 & TRN \\
\hline CHEMBL200301 & 25792 & 7.7212 & 8.3345 & TRN \\
\hline LHEMBL 2007 & 92 & 9.2441 & 9.7561 & ונ \\
\hline CHEMBL372139 & 325792 & 6.3872 & 6.6755 & ST \\
\hline CHEMBL200543 & 325792 & 9.3279 & 9.4631 & RIV \\
\hline CHEMBL372410 & 325792 & 10.6021 & 10.6124 & RN \\
\hline
\end{tabular}

Page 27648 


\begin{tabular}{|c|c|c|c|c|c|}
\hline \multirow[b]{2}{*}{ CHEMBL198798 } & \multicolumn{5}{|c|}{ Supplemental Table S2.txt } \\
\hline & 325792 & 9.3468 & 9.3667 & TRN & \\
\hline CHEMBL381026 & 325792 & 8.0605 & 8.4847 & TRN & \\
\hline CHEMBL200167 & 325792 & 7.7959 & 7.3185 & TRN & \\
\hline CHEMBL 381190 & 325792 & 10.6021 & 10.1179 & TRN & \\
\hline CHEMBL200506 & 325792 & 9.0269 & 8.7588 & TRN & \\
\hline CHEMBL 200776 & 325792 & 2.8239 & 6.3559 & TST & \\
\hline CHEMBL435913 & 325792 & 9.1739 & 10.4458 & TRN & \\
\hline CHEMBL200289 & 325792 & 6.6778 & 6.7315 & TRN & \\
\hline CHEMBL197440 & 325792 & 8.2147 & 9.1029 & TRN & \\
\hline CHEMBL199358 & 325792 & 8.6383 & 8.667 & TRN & \\
\hline CHEMBL370786 & 325792 & 7.7447 & 7.5069 & TRN & \\
\hline CHEMBL200507 & 325792 & 8.8539 & 9.0177 & TRN & \\
\hline CHEMBL200596 & 325792 & 8.7959 & 9.3637 & TRN & \\
\hline CHEMBL 200529 & 325792 & 6.6383 & 6.5208 & TST & \\
\hline CHEMBL3194571 & 737456 & 4.8572 & 5.7756 & TRN & \\
\hline CHEMBL1437947 & 737456 & 5.1835 & 5.6514 & TRN & \\
\hline CHEMBL 2007593 & 737456 & 5.6784 & 6.0391 & TRN & \\
\hline CHEMBL1498210 & 737456 & 5.7784 & 5.5644 & TST & \\
\hline CHEMBL1323828 & 737456 & 7.301 & 6.3116 & TRN & \\
\hline CHEMBL3198952 & 737456 & 5.9361 & 5.952006 & 0000000001 & TRN \\
\hline CHEMBL1582888 & 737456 & 5.9962 & 5.417006 & 0000000001 & TST \\
\hline CHEMBL1532025 & 737456 & 6.2496 & 6.7227 & TRN & \\
\hline CHEMBL1369492 & 737456 & 5.7977 & 5.947 & TRN & \\
\hline CHEMBL1560901 & 737456 & 6.0954 & 6.7851 & TRN & \\
\hline CHEMBL1306983 & 737456 & 5.4507 & 5.606 & TRN & \\
\hline CHEMBL1716874 & 737456 & 5.9558 & 6.0734 & TRN & \\
\hline CHEMBL1566928 & 737456 & 7.301 & 5.6285 & TRN & \\
\hline CHEMBL1387413 & 737456 & 7.301 & 6.8368 & TRN & \\
\hline CHEMBL1370183 & 737456 & 5.3669 & 5.4071 & TRN & \\
\hline CHEMBL1442537 & 737456 & 6.2149 & 5.8873 & TRN & \\
\hline CHEMBL1497386 & 737456 & 6.0041 & 5.6614 & TST & \\
\hline CHEMBL1400236 & 737456 & 5.5084 & 5.62299 & 9999999999 & TRN \\
\hline CHEMBL1487918 & 737456 & 4.9204 & 5.6691 & TST & \\
\hline CHEMBL1517609 & 737456 & 5.7897 & 5.5477 & TST & \\
\hline CHEMBL1533415 & 737456 & 4.6325 & 5.6871 & TST & \\
\hline CHEMBL1386711 & 737456 & 6.276 & 5.8903 & TRN & \\
\hline CHEMBL1407436 & 737456 & 5.5858 & 5.5567 & TRN & \\
\hline CHEMBL1368962 & 737456 & 6.1146 & 6.076006 & 00000000005 & TRN \\
\hline CHEMBL1536628 & 737456 & 5.0555 & 5.6302 & TRN & \\
\hline CHEMBL1387336 & 737456 & 5.9214 & 6.0961 & TRN & \\
\hline CHEMBL1416442 & 737456 & 4.9577 & 5.5276 & TRN & \\
\hline CHEMBL1518827 & 737456 & 4.8151 & 5.6161 & TRN & \\
\hline CHEMBL1572785 & 737456 & 5.7409 & 5.3892 & TST & \\
\hline CHEMBL1457048 & 737456 & 5.6653 & 5.744 & TRN & \\
\hline CHEMBL1529781 & 737456 & 7.301 & 6.6922 & TRN & \\
\hline CHEMBL1444708 & 737456 & 6.0945 & 6.7532 & TRN & \\
\hline CHEMBL1981103 & 737456 & 5.5149 & 5.6167 & TST & \\
\hline CHEMBL1596753 & 737456 & 5.3049 & 5.8926 & TRN & \\
\hline
\end{tabular}


Supplemental Table S2.txt

\begin{tabular}{|c|c|c|c|c|}
\hline CHEMBL1612267 & 737456 & 5.7078 & 5.6866 & TST \\
\hline CHEMBL1608333 & 737456 & 5.5008 & 5.5814 & TRN \\
\hline CHEMBL1430125 & 737456 & 6.1041 & 5.4487 & TRN \\
\hline CHEMBL1526855 & 737456 & 5.2555 & 5.3738 & TRN \\
\hline CHEMBL1312928 & 737456 & 6.1283 & 6.6237 & TRN \\
\hline CHEMBL1466582 & 737456 & 5.5615 & 5.6509 & TST \\
\hline CHEMBL1494365 & 737456 & 5.9982 & 6.1895 & TRN \\
\hline CHEMBL1333032 & 737456 & 5.9348 & 6.6088 & TRN \\
\hline CHEMBL1536710 & 737456 & 5.6694 & 5.7813 & TRN \\
\hline CHEMBL1460894 & 737456 & 5.685 & 6.0934 & TRN \\
\hline CHEMBL193872 & 737456 & 5.9955 & 5.6806 & TST \\
\hline CHEMBL1523126 & 737456 & 5.8816 & 5.9898 & TRN \\
\hline CHEMBL1304179 & 737456 & 6.2415 & 5.7335 & TRN \\
\hline CHEMBL1570760 & 737456 & 5.6647 & 5.4552 & TRN \\
\hline CHEMBL1428840 & 737456 & 6.1186 & 5.607 & TRN \\
\hline CHEMBL1975147 & 737456 & 6.0465 & 6.0642 & TRN \\
\hline CHEMBL1367928 & 737456 & 7.301 & 6.7766 & TRN \\
\hline CHEMBL1595152 & 737456 & 5.8345 & 5.4312 & TRN \\
\hline CHEMBL1547464 & 737456 & 5.9509 & 5.8748 & TRN \\
\hline CHEMBL1412529 & 737456 & 5.8465 & 5.3863 & TRN \\
\hline CHEMBL1583901 & 737456 & 3.4948 & 5.53299 & 99999999995 \\
\hline CHEMBL1372770 & 737456 & 6.2513 & 6.11100 & 0000000001 \\
\hline CHEMBL1307717 & 737456 & 6.2031 & 5.6785 & TRN \\
\hline CHEMBL1970711 & 737456 & 5.7547 & 5.8299 & TRN \\
\hline CHEMBL3198175 & 737456 & 7.301 & 6.0029 & TRN \\
\hline CHEMBL1521989 & 737456 & 5.6103 & 5.5687 & TRN \\
\hline CHEMBL3209511 & 737456 & 5.8266 & 5.919 & TRN \\
\hline CHEMBL467373 & 737456 & 5.6509 & 5.5166 & TRN \\
\hline CHEMBL1463795 & 737456 & 5.5594 & 5.5731 & TST \\
\hline CHEMBL3196703 & 737456 & 5.5117 & 5.5925 & TRN \\
\hline CHEMBL1333832 & 737456 & 6.0318 & 5.6068 & TRN \\
\hline CHEMBL1464544 & 737456 & 6.0786 & 5.8849 & TRN \\
\hline CHEMBL1542492 & 737456 & 5.4146 & 5.4547 & TRN \\
\hline CHEMBL1351967 & 737456 & 5.8769 & 5.6022 & TRN \\
\hline CHEMBL1576905 & 737456 & 5.7045 & 5.5221 & TST \\
\hline CHEMBL1442788 & 737456 & 5.5659 & 5.5365 & TRN \\
\hline CHEMBL1369691 & 737456 & 5.6177 & 5.5284 & TRN \\
\hline CHEMBL1698464 & 737456 & 3.4948 & 5.1911 & TRN \\
\hline CHEMBL1708510 & 737456 & 7.301 & 6.0914 & TRN \\
\hline CHEMBL1550295 & 737456 & 5.7499 & 5.785 & TRN \\
\hline CHEMBL1407961 & 737456 & 5.4904 & 5.7951 & TRN \\
\hline CHEMBL1352624 & 737456 & 7.301 & 6.2316 & TRN \\
\hline CHEMBL1431610 & 737456 & 5.8631 & 5.7232 & TST \\
\hline CHEMBL1353925 & 737456 & 6.2545 & 5.7139 & TRN \\
\hline CHEMBL1487024 & 737456 & 6.249 & 6.7857 & TRN \\
\hline CHEMBL1424929 & 737456 & 6.2726 & 5.8343 & TRN \\
\hline CHEMBL1387749 & 737456 & 5.8211 & 6.3826 & TRN \\
\hline CHEMBL1388639 & 737456 & 5.5967 & 5.6302 & TRN \\
\hline
\end{tabular}

Page 27650 


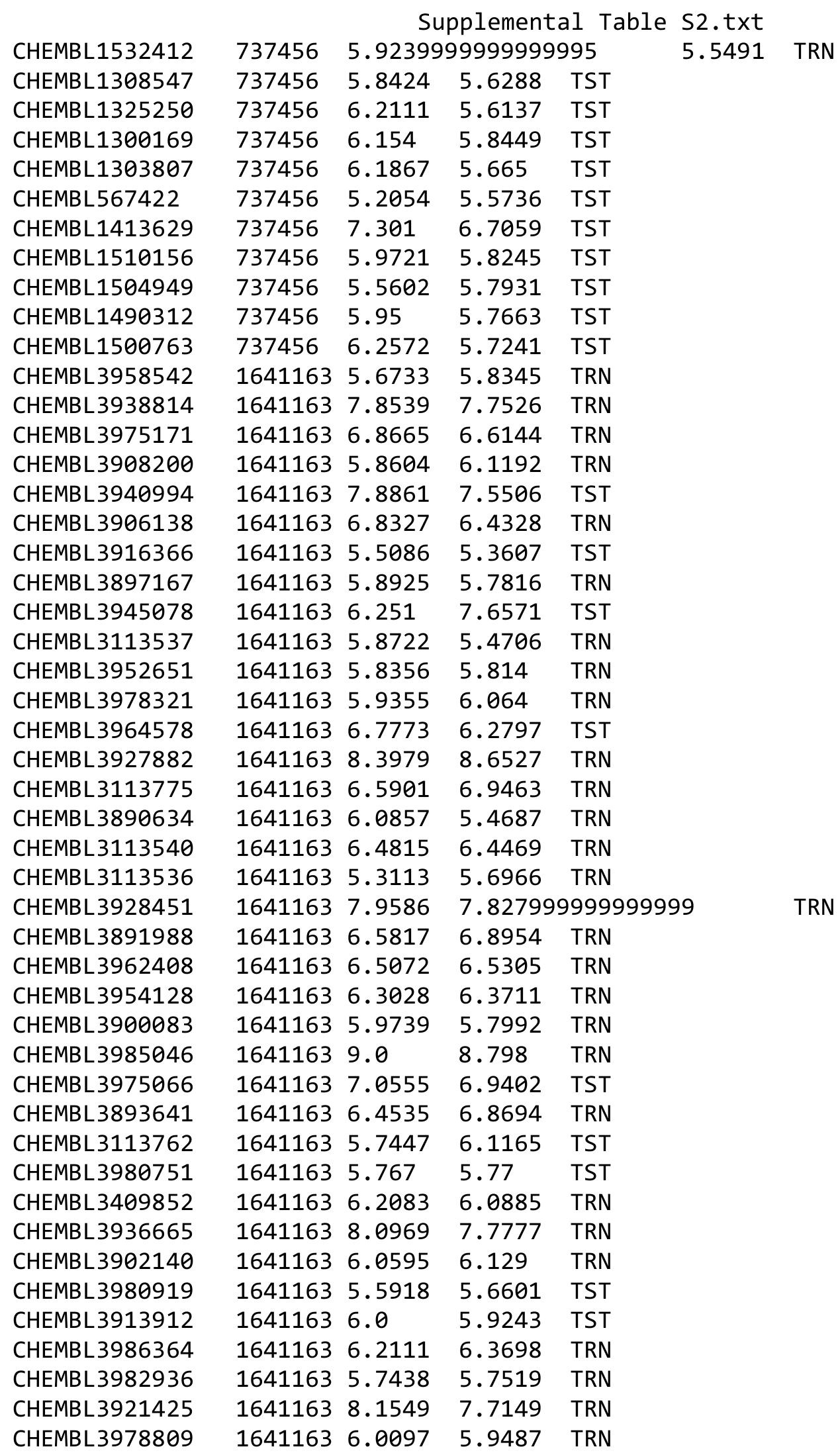

Page 27651 
Supplemental Table S2.txt

\begin{tabular}{|c|c|c|c|c|}
\hline HEMB I & 1163 & 7.4089 & & \\
\hline & 641163 & 6.0155 & .272 & \\
\hline-10 & & & 293 & \\
\hline HEMBL391 & 163 & 4 & 692 & \\
\hline AEMBL3938749 & 163 & 96 & 524 & \\
\hline HEMBL3954697 & 641163 & 7.5686 & 0698 & \\
\hline HEMBL; & & & 1006 & \\
\hline AFMBI 388 & & & & \\
\hline HEMBL3935599 & 163 & 5607 & .5688 & \\
\hline HEMBL3978443 & 63 & 229 & 3689 & \\
\hline HEMBL3899455 & 53 & 6.6861 & .4518 & \\
\hline IEMBL 394 & כ3 & 29 & 362 & \\
\hline AEMBL 396 & & & & \\
\hline HEMBL 398 & & 852 & 5.5208 & \\
\hline HEMBL393 & 53 & 6.0 & 1253 & \\
\hline AEMBL393 & כ & 6 & 5924 & \\
\hline HEMBL391 & 33 & & 263 & \\
\hline HEMBL 398 & & & 376 & \\
\hline HEMBL340 & & 6.0 & 5.8418 & \\
\hline AEMBL39 & 53 & 6. & & \\
\hline HEIMBLSS & 6 & 5. & 48 & NIV \\
\hline AEMBL3S & & & 18 & הות \\
\hline HEMBL3S & & & 38 & \\
\hline HFMBI 391 & & 8 . & 166 & \\
\hline HEMBL396 & & & & I RIV \\
\hline HEMBL39 & 6 & 3 . & 3413 & RN \\
\hline HEMBL3 & 3 & 6. & 33 & Niv \\
\hline HFMBI 36 & & & 36 & \\
\hline HEMBL391 & & & & $\ln$ \\
\hline HEMBL 391 & & & & Is \\
\hline HEMBL 389 & & & 18 & RN \\
\hline HEMBL3 & & & 69 & RN \\
\hline HEMBL39 & & 8 & 54 & -4 \\
\hline HEMBL3926196 & & & 5581 & $\mathrm{IR}$ \\
\hline HEMBL3935347 & & 6. & & TST \\
\hline HEMBL3S & & & 597 & ГST \\
\hline HFMRI $=$ & 53 & 6 & & ST \\
\hline HEMBL3 & & 5. & & RN \\
\hline HEMBL3939381 & & 6. & 194 & TST \\
\hline AEMBL 390 & & & 389 & TRN \\
\hline HEMBL 393 & 6 & & 1542 & \\
\hline CHEMBL394 & & & & RN \\
\hline HEMBL3951889 & 53 & 8.3979 & 8.2652 & RN \\
\hline HEMBL3941842 & $6=$ & 8.0969 & 1077 & TR \\
\hline $\mathrm{MRI}=$ & & & & RN \\
\hline HEMBL 39 & & & 2093 & \\
\hline CHEMBL390135 & & & 5.5528 & \\
\hline LHEMBL 3976348 & 1641163 & 7.4089 & 7.1215 & ГRN \\
\hline
\end{tabular}

Page 27652 
Supplemental Table S2.txt

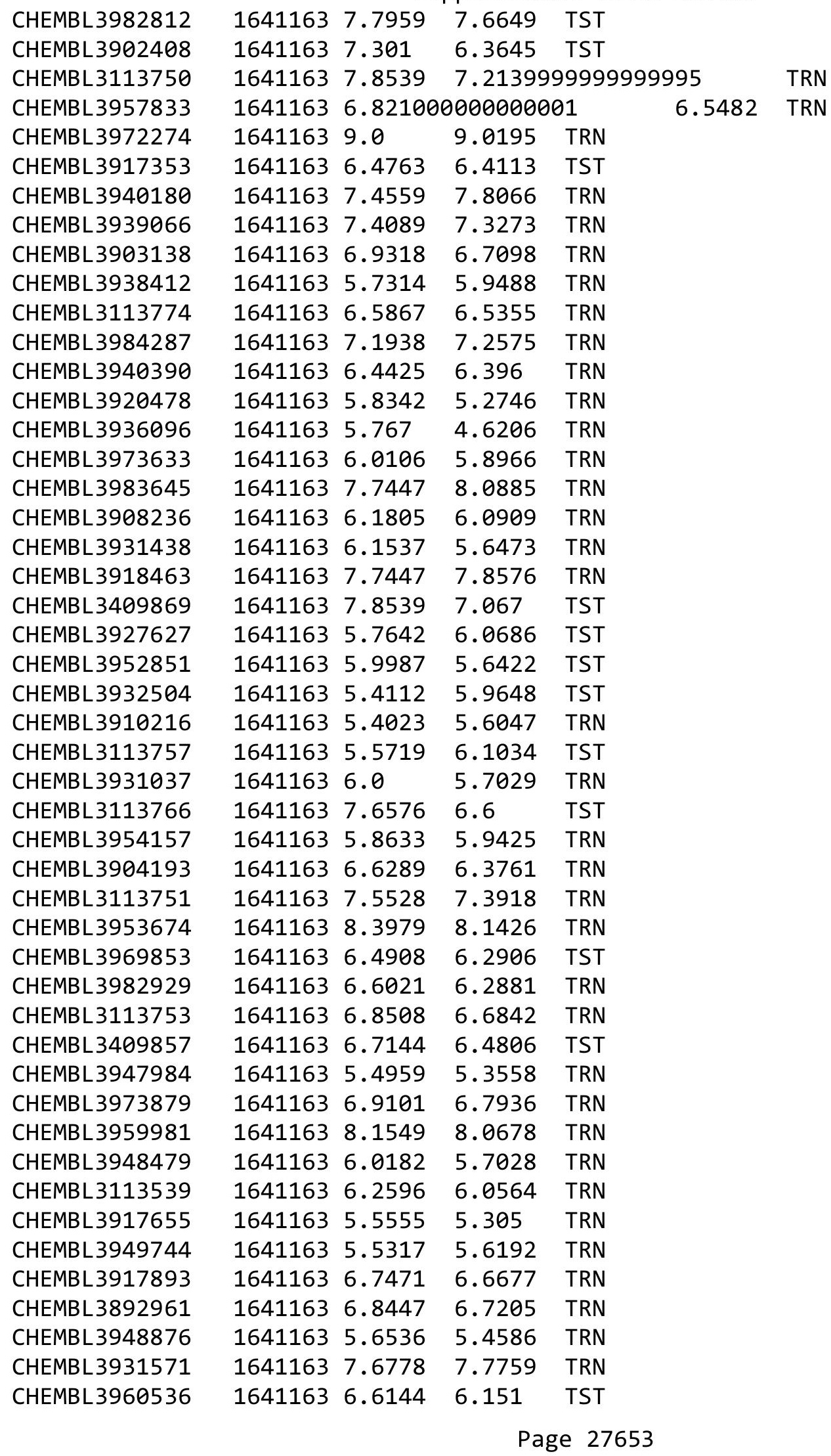


Supplemental Table S2.txt

\begin{tabular}{|c|c|c|c|c|c|}
\hline CHEMBL3918910 & 1641163 & 6.9172 & 7.348 & TRN & \\
\hline CHEMBL3955473 & 1641163 & 6.2557 & 6.4602 & TRN & \\
\hline CHEMBL3909991 & 1641163 & 6.6364 & 6.6012 & TRN & \\
\hline CHEMBL 3985834 & 1641163 & 8.1549 & 7.1709 & TST & \\
\hline CHEMBL3930793 & 1641163 & 6.064 & 5.87700 & 0000000001 & TRN \\
\hline CHEMBL 3968360 & 1641163 & 6.8097 & 7.0586 & TST & \\
\hline CHEMBL 3895685 & 1641163 & 6.9172 & 6.6391 & TST & \\
\hline CHEMBL 3940457 & 1641163 & 6.8153 & 6.8899 & TRN & \\
\hline CHEMBL 3889649 & 1641163 & 5.5931 & 5.57299 & 99999999995 & TRN \\
\hline CHEMBL3919895 & 1641163 & 8.0 & 7.3845 & TST & \\
\hline CHEMBL 3957444 & 1641163 & 8.2218 & 8.3554 & TRN & \\
\hline CHEMBL 3928054 & 1641163 & 5.8386 & 6.1518 & TST & \\
\hline CHEMBL3972041 & 1641163 & 6.7747 & 6.8735 & TRN & \\
\hline CHEMBL 3958111 & 1641163 & 8.0969 & 7.7629 & TST & \\
\hline CHEMBL3973182 & 1641163 & 6.4134 & 6.1939 & TRN & \\
\hline CHEMBL3956662 & 1641163 & 6.0264 & 6.159 & TST & \\
\hline CHEMBL3904636 & 1641163 & 5.9747 & 6.4616 & TRN & \\
\hline CHEMBL3910207 & 1641163 & 9.0 & 7.9736 & TST & \\
\hline CHEMBL 3945398 & 1641163 & 7.9208 & 7.7309 & TST & \\
\hline CHEMBL3913002 & 1641163 & 7.6383 & 7.6124 & TRN & \\
\hline CHEMBL 3974803 & 1641163 & 5.6077 & 6.1731 & TRN & \\
\hline CHEMBL3920976 & 1641163 & 6.2457 & 6.4152 & TRN & \\
\hline CHEMBL3894604 & 1641163 & 7.6778 & 7.49299 & 9999999999 & TRN \\
\hline CHEMBL 3955828 & 1641163 & 6.1068 & 6.4113 & TRN & \\
\hline CHEMBL 3904030 & 1641163 & 6.3925 & 6.3615 & TRN & \\
\hline CHEMBL 3929234 & 1641163 & \multicolumn{3}{|c|}{6.4510000000000005} & TRN \\
\hline CHEMBL 3909038 & 1641163 & 6.0835 & 5.3059 & TST & \\
\hline CHEMBL3964757 & 1641163 & 5.7693 & 5.6861 & TRN & \\
\hline CHEMBL 3890497 & 1641163 & 5.9547 & 6.1206 & TRN & \\
\hline CHEMBL3929583 & 1641163 & 5.7696 & 5.8876 & TRN & \\
\hline CHEMBL 3968171 & 1641163 & 7.1487 & 6.9235 & TRN & \\
\hline CHEMBL 3925639 & 1641163 & 5.7878 & 5.9468 & TRN & \\
\hline CHEMBL3921650 & 1641163 & 6.0711 & 6.8341 & TST & \\
\hline CHEMBL 3914248 & 1641163 & 7.6383 & 7.9635 & TRN & \\
\hline CHEMBL3977119 & 1641163 & 7.699 & 7.6046 & TRN & \\
\hline CHEMBL 3113548 & 1641163 & 6.6478 & 6.7433 & TRN & \\
\hline CHEMBL 3113741 & 1641163 & 7.585 & 7.3055 & TST & \\
\hline CHEMBL 3953208 & 1641163 & 6.6498 & 6.5605 & TRN & \\
\hline CHEMBL 3969627 & 1641163 & 6.6326 & 6.2724 & TRN & \\
\hline CHEMBL3409876 & 1641163 & 6.5406 & 6.5722 & TST & \\
\hline CHEMBL3934852 & 1641163 & 7.1308 & 7.2774 & TRN & \\
\hline CHEMBL3970006 & 1641163 & 6.6596 & 6.8199 & TRN & \\
\hline CHEMBL3930977 & 1641163 & 6.3458 & 6.4194 & TST & \\
\hline CHEMBL 3935470 & 1641163 & 6.2321 & 6.2248 & TRN & \\
\hline CHEMBL3986710 & 1641163 & 6.8729 & 6.6039 & TST & \\
\hline CHEMBL 3915484 & 1641163 & 6.2924 & 6.5479 & TRN & \\
\hline CHEMBL3926581 & 1641163 & 6.6517 & 6.5937 & TST & \\
\hline CHEMBL 3900701 & 1641163 & 5.9234 & 5.7113 & TRN & \\
\hline
\end{tabular}


Supplemental Table S2.txt

\begin{tabular}{|c|c|c|c|c|}
\hline CHEMBL3966965 & 1641163 & 8.5229 & 7.9932 & TRN \\
\hline CHEMBL3952476 & 1641163 & 5.819 & 6.1074 & TRN \\
\hline CHEMBL3986684 & 1641163 & 6.8633 & 7.1778 & TRN \\
\hline CHEMBL3892186 & 1641163 & 6.0 & 6.2969 & TRN \\
\hline CHEMBL3936905 & 1641163 & 6.098 & 6.2588 & TRN \\
\hline CHEMBL3901793 & 1641163 & 6.4597 & 6.3727 & TST \\
\hline CHEMBL3910868 & 1641163 & 7.0177 & 7.2527 & TRN \\
\hline CHEMBL3965358 & 1641163 & 7.9208 & 7.9451 & TRN \\
\hline CHEMBL3113748 & 1641163 & 7.8539 & 7.8055 & TRN \\
\hline CHEMBL3893390 & 1641163 & 8.2218 & 7.5053 & TST \\
\hline CHEMBL3900899 & 1641163 & 6.1898 & 6.2542 & TRN \\
\hline CHEMBL3962013 & 1641163 & 6.2741 & 6.492999 & 9999999999 \\
\hline CHEMBL3892988 & 1641163 & 5.8248 & 5.8742 & TRN \\
\hline CHEMBL3913204 & 1641163 & 6.4283 & 6.4043 & TRN \\
\hline CHEMBL3892317 & 1641163 & 5.9101 & 6.005 & TRN \\
\hline CHEMBL3920046 & 1641163 & 6.1029 & 6.1841 & TRN \\
\hline CHEMBL3943140 & 1641163 & 6.6778 & 6.7758 & TRN \\
\hline CHEMBL3947861 & 1641163 & 8.5229 & 8.1001 & TRN \\
\hline CHEMBL3986127 & 1641163 & 8.5229 & 8.2108 & TRN \\
\hline CHEMBL3971640 & 1641163 & 6.0 & 6.0962 & TRN \\
\hline CHEMBL3409872 & 1641163 & 7.699 & 7.4153 & TST \\
\hline CHEMBL3113534 & 1641163 & 5.4577 & 5.2897 & TRN \\
\hline CHEMBL3949346 & 1641163 & 3.8996 & 5.1429 & TRN \\
\hline CHEMBL3983793 & 1641163 & 7.2441 & 7.8079 & TRN \\
\hline CHEMBL3937786 & 1641163 & 6.4547 & 6.1159 & TRN \\
\hline CHEMBL3113538 & 1641163 & 6.6655 & 6.4221 & TRN \\
\hline CHEMBL3943538 & 1641163 & 6.1844 & 6.8925 & TST \\
\hline CHEMBL3933550 & 1641163 & 6.1457 & 6.6544 & TRN \\
\hline CHEMBL3954220 & 1641163 & 7.5686 & 7.6555 & TRN \\
\hline CHEMBL3913300 & 1641163 & 7.6576 & 7.3359 & TRN \\
\hline CHEMBL3918050 & 1641163 & 6.7799 & 6.6557 & TRN \\
\hline CHEMBL3925974 & 1641163 & 8.1549 & 7.9324 & TRN \\
\hline CHEMBL3985172 & 1641163 & 8.1549 & 8.2049 & TRN \\
\hline CHEMBL3933036 & 1641163 & 7.6021 & 7.6941 & TRN \\
\hline CHEMBL3906516 & 1641163 & 5.9208 & 6.181 & TRN \\
\hline CHEMBL3955148 & 1641163 & 7.1938 & 7.4275 & TRN \\
\hline CHEMBL3959670 & 1641163 & 6.8794 & 6.2938 & TST \\
\hline CHEMBL3945256 & 1641163 & 5.8041 & 5.9833 & TRN \\
\hline CHEMBL3917566 & 1641163 & 6.7852 & 6.6294 & TRN \\
\hline CHEMBL3898606 & 1641163 & 6.0 & 5.9493 & TST \\
\hline CHEMBL3937707 & 1641163 & 6.6234 & 6.6357 & TRN \\
\hline CHEMBL3917258 & 1641163 & 6.4401 & 6.4959 & TRN \\
\hline CHEMBL3951644 & 1641163 & 6.8447 & 6.6167 & TST \\
\hline CHEMBL3954609 & 1641163 & 6.7305 & 6.7684 & TRN \\
\hline CHEMBL3893831 & 1641163 & 6.2882 & 5.972 & TRN \\
\hline CHEMBL3953804 & 1641163 & 6.9788 & 8.4696 & TST \\
\hline CHEMBL3965518 & 1641163 & 5.7523 & 6.04 & TRN \\
\hline CHEMBL3923424 & 1641163 & 6.3665 & 6.3606 & TRN \\
\hline
\end{tabular}


Supplemental Table S2.txt

\begin{tabular}{|c|c|c|c|c|}
\hline CHEMBL 3895462 & 1641163 & 6.3883 & 6.2326 & TST \\
\hline CHEMBL3920348 & 1641163 & 6.0 & 5.2111 & TRN \\
\hline CHEMBL3113546 & 1641163 & 6.7721 & 6.5782 & TRN \\
\hline CHEMBL 3113770 & 1641163 & 8.699 & 7.7684 & TST \\
\hline CHEMBL 3909963 & 1641163 & 6.8268 & 6.1685 & TRN \\
\hline CHEMBL3113759 & 1641163 & 7.3979 & 6.4927 & TRN \\
\hline CHEMBL3409870 & 1641163 & 6.0 & 6.1767 & TST \\
\hline CHEMBL 3967832 & 1641163 & 6.4855 & 6.3038 & TRN \\
\hline CHEMBL3919179 & 1641163 & 6.0155 & 6.1133 & TRN \\
\hline CHEMBL3915167 & 1641163 & 6.6778 & 6.6847 & TRN \\
\hline CHEMBL3113535 & 1641163 & 5.358 & 5.6523 & TRN \\
\hline CHEMBL3954632 & 1641163 & 6.857 & 6.2695 & TST \\
\hline CHEMBL3927496 & 1641163 & 5.8539 & 6.5134 & TRN \\
\hline CHEMBL3951832 & 1641163 & 6.6498 & 6.4801 & TRN \\
\hline CHEMBL 3975065 & 1641163 & 5.3788 & 5.6156 & TRN \\
\hline CHEMBL 3924473 & 1641163 & 6.9508 & 6.9013 & TRN \\
\hline CHEMBL3911067 & 1641163 & 6.5575 & 6.1001 & TST \\
\hline CHEMBL3940216 & 1641163 & 6.8125 & 6.4259 & TST \\
\hline CHEMBL 3113755 & 1641163 & 7.7959 & 7.559 & TRN \\
\hline CHEMBL3113739 & 1641163 & 6.1918 & 6.3349 & TRN \\
\hline CHEMBL 3113742 & 1641163 & 8.699 & 7.4428 & TST \\
\hline CHEMBL3980990 & 1641163 & 5.2853 & 5.218 & TRN \\
\hline CHEMBL3969634 & 1641163 & 5.9923 & 6.0155 & TRN \\
\hline CHEMBL3929769 & 1641163 & 5.8824 & 6.004 & TRN \\
\hline CHEMBL 3948982 & 1641163 & 7.5528 & 7.4545 & TRN \\
\hline CHEMBL 3948062 & 1641163 & 5.8614 & 5.853 & TRN \\
\hline CHEMBL3963425 & 1641163 & 6.1911 & 6.3108 & TST \\
\hline CHEMBL3113760 & 1641163 & 6.27 & 6.2919 & TRN \\
\hline CHEMBL3970150 & 1641163 & 7.7696 & 7.8835 & TRN \\
\hline CHEMBL 3897884 & 1641163 & 8.2218 & 7.7991 & TST \\
\hline CHEMBL3934631 & 1641163 & 5.8447 & 5.8539 & TRN \\
\hline CHEMBL3983331 & 1641163 & 6.1838 & 5.9244 & TRN \\
\hline CHEMBL3113550 & 1641163 & 7.7696 & 7.8045 & TRN \\
\hline CHEMBL 3979268 & 1641163 & 8.699 & 8.4255 & TRN \\
\hline CHEMBL 3908623 & 1641163 & 6.9318 & 6.8743 & TRN \\
\hline CHEMBL3895491 & 1641163 & 6.6308 & 6.1951 & TST \\
\hline CHEMBL 3925582 & 1641163 & 6.02 & 6.4261 & TST \\
\hline CHEMBL3958622 & 1641163 & 7.5229 & 7.5828 & TRN \\
\hline CHEMBL 3113740 & 1641163 & 6.8125 & \multicolumn{2}{|c|}{6.497000000000001} \\
\hline CHEMBL 3902987 & 1641163 & 5.6893 & 6.159 & TST \\
\hline CHEMBL 3898298 & 1641163 & 5.6123 & 5.6931 & TRN \\
\hline CHEMBL 3909986 & 1641163 & 7.0706 & 6.8816 & TST \\
\hline CHEMBL3964349 & 1641163 & 6.1403 & 6.2219 & TRN \\
\hline CHEMBL 3113552 & 1641163 & 7.1135 & 7.1393 & TRN \\
\hline CHEMBL 3943558 & 1641163 & 6.4828 & 6.4936 & TRN \\
\hline CHEMBL 3969830 & 1641163 & 7.8239 & 7.5918 & TRN \\
\hline CHEMBL 3113761 & 1641163 & 5.8517 & 6.2701 & TST \\
\hline CHEMBL 3909846 & 1641163 & 6.9666 & 6.8697 & TRN \\
\hline
\end{tabular}

Page 27656 
Supplemental Table S2.txt

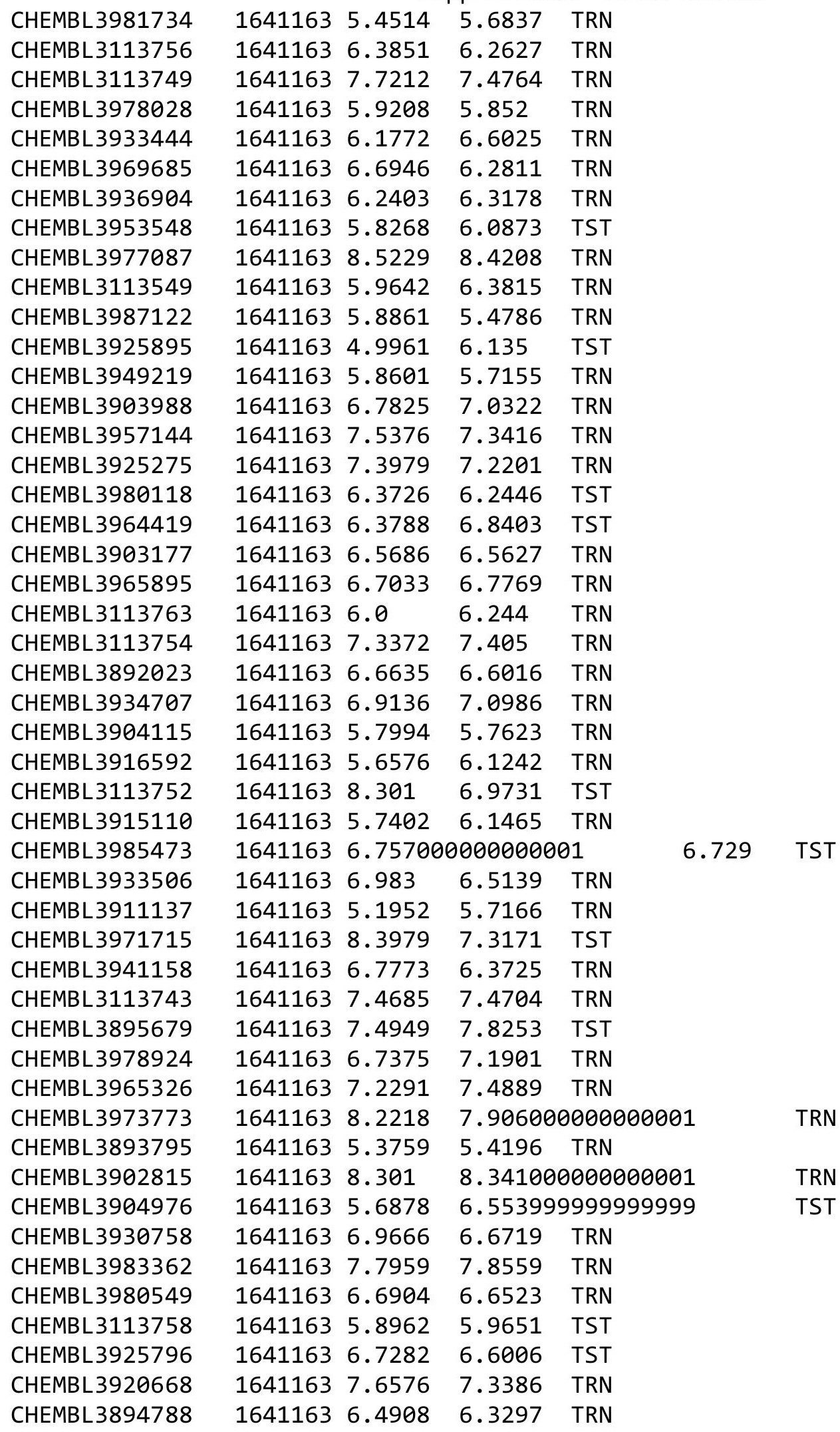

Page 27657 
Supplemental Table S2.txt

\begin{tabular}{|c|c|c|c|c|c|}
\hline CHEMBL 3943680 & 1641163 & 6.5482 & 5.8818 & TST & \\
\hline CHEMBL3942105 & 1641163 & 6.9245 & 6.7303 & TRN & \\
\hline CHEMBL3939364 & 1641163 & 5.9788 & \multicolumn{2}{|c|}{6.337000000000001} & TRN \\
\hline CHEMBL 3919889 & 1641163 & 6.7645 & 6.7368 & TRN & \\
\hline CHEMBL3964401 & 1641163 & 6.6696 & 6.234 & TST & \\
\hline CHEMBL 3957500 & 1641163 & 5.2716 & 5.624 & TRN & \\
\hline CHEMBL3912213 & 1641163 & 7.4089 & 7.2392 & TRN & \\
\hline CHEMBL3936509 & 1641163 & 5.9393 & 5.9894 & TRN & \\
\hline CHEMBL 3939214 & 1641163 & 5.8996 & 5.7855 & TRN & \\
\hline CHEMBL3983237 & 1641163 & 7.5376 & 7.5083 & TRN & \\
\hline CHEMBL 3981203 & 1641163 & 6.1308 & 6.1884 & TRN & \\
\hline CHEMBL3911666 & 1641163 & 6.0195 & 5.9836 & TRN & \\
\hline CHEMBL3938144 & 1641163 & 6.8477 & 6.7671 & TRN & \\
\hline CHEMBL3113744 & 1641163 & 7.6021 & 7.7408 & TRN & \\
\hline CHEMBL3930770 & 1641163 & 3.8962 & 4.3126 & TRN & \\
\hline CHEMBL3970401 & 1641163 & 7.0809 & 6.4702 & TST & \\
\hline CHEMBL3941481 & 1641163 & 7.4318 & 7.5374 & TST & \\
\hline CHEMBL3936553 & 1641163 & 8.0 & 7.7041 & TRN & \\
\hline CHEMBL3985508 & 1641163 & 7.0 & \multicolumn{2}{|c|}{6.797000000000001} & TST \\
\hline CHEMBL3969988 & 1641163 & 6.9957 & 6.7762 & TRN & \\
\hline CHEMBL3934682 & 1641163 & 7.9208 & 7.8364 & TRN & \\
\hline CHEMBL3922634 & 1641163 & 6.3696 & 8.0641 & TST & \\
\hline CHEMBL3969724 & 1641163 & 5.3902 & 5.3849 & TRN & \\
\hline CHEMBL3918728 & 1641163 & 6.3979 & 6.4068 & TRN & \\
\hline CHEMBL 3942476 & 1641163 & 5.7406 & 5.3509 & TST & \\
\hline CHEMBL3911828 & 1641163 & 8.1549 & 7.9751 & TRN & \\
\hline CHEMBL 3896893 & 1641163 & 6.0 & 5.494 & TST & \\
\hline CHEMBL3923606 & 1641163 & 6.8013 & 7.1535 & TRN & \\
\hline CHEMBL 3925745 & 1641163 & 5.8601 & 5.7974 & TRN & \\
\hline CHEMBL3897223 & 1641163 & 7.6021 & 7.2996 & TRN & \\
\hline CHEMBL 3922074 & 1641163 & 5.4763 & 5.9282 & TRN & \\
\hline CHEMBL3113545 & 1641163 & 6.8665 & 6.5689 & TRN & \\
\hline CHEMBL3926444 & 1641163 & 6.1772 & 6.4263 & TST & \\
\hline CHEMBL3949227 & 1641163 & 7.1249 & 6.7216 & TRN & \\
\hline CHEMBL3895495 & 1641163 & 6.0218 & 6.4712 & TRN & \\
\hline CHEMBL3980334 & 1641163 & 6.4145 & 6.9504 & TRN & \\
\hline CHEMBL3113746 & 1641163 & 8.5229 & 8.5173 & TRN & \\
\hline CHEMBL 3986272 & 1641163 & 6.983 & 7.268 & TRN & \\
\hline CHEMBL3919120 & 1641163 & 7.9208 & 7.9184 & TRN & \\
\hline CHEMBL3902382 & 1641163 & 7.5686 & 7.4476 & TRN & \\
\hline CHEMBL3957156 & 1641163 & 7.7959 & 7.3979 & TRN & \\
\hline CHEMBL3929739 & 1641163 & 7.301 & 7.6681 & TRN & \\
\hline CHEMBL3907804 & 1641163 & 5.2708 & 5.7016 & TRN & \\
\hline CHEMBL3943155 & 1641163 & 7.4685 & 7.1758 & TRN & \\
\hline CHEMBL3921925 & 1641163 & 6.0 & 5.6106 & TRN & \\
\hline CHEMBL3965481 & 1641163 & 7.6778 & 6.8684 & TST & \\
\hline CHEMBL3917482 & 1641163 & 5.8245 & 6.1869 & TRN & \\
\hline CHEMBL3113551 & 1641163 & 5.71 & 6.0709 & TRN & \\
\hline
\end{tabular}


Supplemental Table S2.txt

\begin{tabular}{|c|c|c|c|c|c|}
\hline CHEMBL3409860 & 1641163 & 6.0 & 5.9788 & TRN & \\
\hline CHEMBL3964922 & 1641163 & 5.4558 & 4.8079 & TRN & \\
\hline CHEMBL3914823 & 1641163 & 5.5272 & 5.5884 & TRN & \\
\hline CHEMBL3936973 & 1641163 & 6.0353 & 5.9057 & TST & \\
\hline CHEMBL3937008 & 1641163 & 8.699 & 8.831 & TRN & \\
\hline CHEMBL3113547 & 1641163 & 6.3883 & \multicolumn{2}{|c|}{6.497999999999999} & TRN \\
\hline CHEMBL3972122 & 1641163 & 6.5157 & 6.7903 & TRN & \\
\hline CHEMBL3941745 & 1641163 & 7.3768 & 7.6407 & TRN & \\
\hline CHEMBL3951985 & 1641163 & 6.0357 & 6.0538 & TRN & \\
\hline CHEMBL3985696 & 1641163 & 7.4815 & 7.3688 & TRN & \\
\hline CHEMBL3891082 & 1641163 & 7.6778 & 6.7917 & TST & \\
\hline CHEMBL3409871 & 1641163 & 8.699 & 7.4383 & TST & \\
\hline CHEMBL3986061 & 1641163 & 6.3768 & 6.7307 & TST & \\
\hline CHEMBL 3943446 & 1641163 & 5.2449 & 5.6569 & TRN & \\
\hline CHEMBL3924691 & 1641163 & 6.7721 & 6.6062 & TRN & \\
\hline CHEMBL3113745 & 1641163 & 8.0458 & 8.2655 & TRN & \\
\hline CHEMBL3986037 & 1641163 & 7.4089 & 7.1852 & TRN & \\
\hline CHEMBL3985659 & 1641163 & 6.2055 & 5.6692 & TST & \\
\hline CHEMBL3916581 & 1641163 & 6.6696 & 6.6437 & TRN & \\
\hline CHEMBL3917615 & 1641163 & 6.9031 & 6.7456 & TST & \\
\hline CHEMBL3983392 & 1641163 & 6.1624 & 5.8039 & TRN & \\
\hline CHEMBL3955491 & 1641163 & 5.7144 & 6.1814 & TRN & \\
\hline CHEMBL3985579 & 1641163 & 5.0284 & \multicolumn{2}{|c|}{5.093999999999999} & TRN \\
\hline CHEMBL 3973202 & 1641163 & 6.0 & 5.9569 & TRN & \\
\hline CHEMBL3903348 & 1641163 & 5.7496 & 6.1864 & TRN & \\
\hline CHEMBL3956786 & 1641163 & 6.6676 & 6.4245 & TRN & \\
\hline CHEMBL3933331 & 1641163 & 6.644 & 6.5157 & TRN & \\
\hline CHEMBL3917613 & 1641163 & 7.9586 & 8.0309 & TRN & \\
\hline CHEMBL3931687 & 1641163 & 6.9872 & 7.274 & TRN & \\
\hline CHEMBL3981188 & 1641163 & 6.0942 & 6.2557 & TST & \\
\hline CHEMBL3903190 & 1641163 & 8.2218 & 8.1631 & TRN & \\
\hline CHEMBL3971086 & 1641163 & 7.6383 & 7.6304 & TST & \\
\hline CHEMBL3946806 & 1641163 & 7.2441 & 7.2583 & TRN & \\
\hline CHEMBL 3113544 & 1641163 & 7.1805 & 7.0176 & TST & \\
\hline CHEMBL3962952 & 1641163 & 7.5528 & 7.4054 & TST & \\
\hline CHEMBL3931515 & 1641163 & 5.9586 & 5.9103 & TRN & \\
\hline CHEMBL3113771 & 1641163 & 7.4949 & 7.2016 & TST & \\
\hline CHEMBL3929633 & 1641163 & 5.1928 & 5.3304 & TST & \\
\hline CHEMBL3962071 & 1641163 & 7.6021 & \multicolumn{2}{|c|}{7.537000000000001} & TRN \\
\hline CHEMBL3952013 & 1641163 & 5.9788 & 5.6098 & TRN & \\
\hline CHEMBL 3890024 & 1641163 & 6.5058 & 6.32600 & 00000000005 & TRN \\
\hline CHEMBL3963602 & 1641163 & 6.4168 & 6.5924 & TRN & \\
\hline CHEMBL3906721 & 1641163 & 5.8268 & 5.8226 & TRN & \\
\hline CHEMBL3962237 & 1641163 & 6.8697 & 7.1645 & TRN & \\
\hline CHEMBL3113747 & 1641163 & 7.8539 & 7.6966 & TRN & \\
\hline CHEMBL 3927724 & 1641163 & 6.6498 & 6.5532 & TRN & \\
\hline CHEMBL3942056 & 1641163 & 5.6216 & 6.0197 & TRN & \\
\hline CHEMBL 3946040 & 1641163 & 6.7878 & 6.7175 & TRN & \\
\hline
\end{tabular}

Page 27659 
Supplemental Table S2.txt

\begin{tabular}{|c|c|c|c|c|c|}
\hline CHEMBL3927897 & 1641163 & 7.1675 & 7.1826 & TRN & \\
\hline CHEMBL3898822 & 1641163 & 6.0214 & 5.9329 & TRN & \\
\hline CHEMBL3916968 & 1641163 & 6.5768 & 6.461 & TRN & \\
\hline CHEMBL3902652 & 1641163 & 6.1457 & 6.0304 & TRN & \\
\hline CHEMBL3928080 & 1641163 & 5.59399 & 99999999 & 99 & 5.8429 \\
\hline CHEMBL3890906 & 1641163 & 6.8827 & 6.8545 & TRN & \\
\hline CHEMBL3894403 & 1641163 & 6.9431 & 7.2587 & TRN & \\
\hline CHEMBL3894979 & 1641163 & 6.6757 & 6.5687 & TRN & \\
\hline CHEMBL3899904 & 1641163 & 7.9208 & 7.7361 & TRN & \\
\hline CHEMBL3966605 & 1641163 & 6.1688 & 6.1183 & TRN & \\
\hline CHEMBL3916806 & 1641163 & 5.767 & 5.7965 & TRN & \\
\hline CHEMBL3946703 & 1641163 & 6.3316 & 6.5106 & TST & \\
\hline CHEMBL3948940 & 1641163 & 7.4559 & 7.4043 & TRN & \\
\hline CHEMBL3950159 & 1641163 & 6.5406 & 6.7186 & TRN & \\
\hline CHEMBL3975042 & 1641163 & 6.684 & 7.1055 & TST & \\
\hline CHEMBL3927062 & 1641163 & 6.1965 & 6.1301 & TST & \\
\hline CHEMBL3915976 & 1641163 & 5.4012 & 5.3393 & TST & \\
\hline CHEMBL3903513 & 1641163 & 5.9889 & 6.5828 & TST & \\
\hline CHEMBL3894400 & 1641163 & 7.3468 & 6.9827 & TST & \\
\hline CHEMBL3949230 & 1641163 & 8.301 & 7.7428 & TST & \\
\hline CHEMBL3222066 & 1332011 & 6.5376 & 6.4234 & TRN & \\
\hline CHEMBL3222071 & 1332011 & 5.2218 & 5.285 & TRN & \\
\hline CHEMBL3217872 & 1332011 & 5.6289 & 5.9181 & TRN & \\
\hline CHEMBL3222105 & 1332011 & 6.1024 & 5.6662 & TRN & \\
\hline CHEMBL3222067 & 1332011 & 5.8729 & 6.1774 & TRN & \\
\hline CHEMBL3217882 & 1332011 & 5.7423 & 5.7755 & TRN & \\
\hline CHEMBL3222060 & 1332011 & 5.6517 & 5.9968 & TRN & \\
\hline CHEMBL3217864 & 1332011 & 6.0757 & 5.9517 & TRN & \\
\hline CHEMBL3222082 & 1332011 & 6.1938 & 6.07 & TRN & \\
\hline CHEMBL 3222106 & 1332011 & 5.6383 & 5.3541 & TRN & \\
\hline CHEMBL3222086 & 1332011 & 6.6108 & 6.4503 & TRN & \\
\hline CHEMBL3217881 & 1332011 & 5.5243 & 5.3057 & TRN & \\
\hline CHEMBL3222095 & 1332011 & 6.5229 & 6.1602 & TST & \\
\hline CHEMBL 3222104 & 1332011 & 6.2076 & 5.443 & TRN & \\
\hline CHEMBL3222094 & 1332011 & 5.0315 & 5.4889 & TST & \\
\hline CHEMBL3222073 & 1332011 & 4.9586 & 5.522 & TRN & \\
\hline CHEMBL3217871 & 1332011 & 5.7878 & 5.8667 & TRN & \\
\hline CHEMBL3217877 & 1332011 & 4.0 & 4.4661 & TRN & \\
\hline CHEMBL3222089 & 1332011 & 7.3958 & 6.7191 & TRN & \\
\hline CHEMBL3222072 & 1332011 & 6.8539 & 6.475 & TRN & \\
\hline CHEMBL3217880 & 1332011 & 5.4921 & 5.1951 & TRN & \\
\hline CHEMBL3217874 & 1332011 & 5.5186 & 4.5552 & TRN & \\
\hline CHEMBL3217875 & 1332011 & 5.4486 & 4.5271 & TRN & \\
\hline CHEMBL3222063 & 1332011 & 5.3979 & 5.6788 & TRN & \\
\hline CHEMBL 3217800 & 1332011 & 6.7258 & 6.5363 & TRN & \\
\hline CHEMBL3222070 & 1332011 & 6.7212 & 6.5295 & TRN & \\
\hline CHEMBL3222099 & 1332011 & 5.9914 & 5.3858 & TRN & \\
\hline CHEMBL3222103 & 1332011 & 4.301 & 5.1605 & TRN & \\
\hline
\end{tabular}


Supplemental Table S2.txt

\begin{tabular}{|c|c|c|c|c|c|}
\hline CHEMBL 3222081 & 1332011 & 5.8477 & 6.2134 & TRN & \\
\hline CHEMBL3217870 & 1332011 & 5.0742 & 5.3249 & TRN & \\
\hline CHEMBL3222048 & 1332011 & 5.6716 & 6.2198 & TST & \\
\hline CHEMBL3222061 & 1332011 & 6.5376 & 6.4272 & TRN & \\
\hline CHEMBL3222096 & 1332011 & 6.1675 & 5.3389 & TST & \\
\hline CHEMBL3222077 & 1332011 & 5.7773 & 5.7486 & TRN & \\
\hline CHEMBL 3222087 & 1332011 & 6.1487 & 6.1845 & TRN & \\
\hline CHEMBL3222062 & 1332011 & 7.0 & 6.6436 & TRN & \\
\hline CHEMBL3217876 & 1332011 & 4.0 & 4.5398 & TRN & \\
\hline CHEMBL3222107 & 1332011 & 5.5391 & 5.3554 & TRN & \\
\hline CHEMBL 3222055 & 1332011 & 5.7747 & 5.9261 & TRN & \\
\hline CHEMBL3217866 & 1332011 & 6.6778 & 6.103 & TRN & \\
\hline CHEMBL3222069 & 1332011 & 5.2147 & 5.7938 & TRN & \\
\hline CHEMBL3222091 & 1332011 & 5.4101 & 5.8808 & TST & \\
\hline CHEMBL3222076 & 1332011 & 6.1367 & 6.4387 & TRN & \\
\hline CHEMBL 3222098 & 1332011 & 4.0 & 5.4899 & TRN & \\
\hline CHEMBL3222059 & 1332011 & 6.1308 & 5.9197 & TRN & \\
\hline CHEMBL3222050 & 1332011 & 5.6055 & 6.1346 & TST & \\
\hline CHEMBL3222088 & 1332011 & 6.1397 & 6.0356 & TRN & \\
\hline CHEMBL3222083 & 1332011 & 5.9666 & 6.0138 & TRN & \\
\hline CHEMBL3222085 & 1332011 & 6.1079 & 6.5827 & TRN & \\
\hline CHEMBL3222097 & 1332011 & 6.301 & 6.1312 & TST & \\
\hline CHEMBL3222101 & 1332011 & 5.5281 & 5.8057 & TST & \\
\hline CHEMBL3217868 & 1332011 & 5.9706 & 5.8357 & TRN & \\
\hline CHEMBL3222054 & 1332011 & 5.9318 & 6.0455 & TRN & \\
\hline CHEMBL3217867 & 1332011 & 6.8861 & 5.1317 & TRN & \\
\hline CHEMBL3222049 & 1332011 & 5.7235 & 6.2128 & TST & \\
\hline CHEMBL3222080 & 1332011 & 6.1487 & 6.2452 & TRN & \\
\hline CHEMBL3217879 & 1332011 & 4.0 & 4.8845 & TRN & \\
\hline CHEMBL3222079 & 1332011 & 5.6778 & 6.1595 & TRN & \\
\hline CHEMBL3222056 & 1332011 & 5.9788 & 5.8724 & TRN & \\
\hline CHEMBL3222078 & 1332011 & 4.7491 & 5.6729 & TRN & \\
\hline CHEMBL3217865 & 1332011 & 6.0088 & 5.7272 & TRN & \\
\hline CHEMBL3222068 & 1332011 & 5.9066 & 6.3301 & TRN & \\
\hline CHEMBL3217878 & 1332011 & 4.0 & 4.7927 & TRN & \\
\hline CHEMBL3222100 & 1332011 & 5.4095 & 5.8439 & TST & \\
\hline CHEMBL3222109 & 1332011 & 5.9957 & 5.6886 & TRN & \\
\hline CHEMBL3217873 & 1332011 & 5.5287 & 5.3337 & TRN & \\
\hline CHEMBL3222102 & 1332011 & 6.2007 & 5.548999 & 99999999995 & TRN \\
\hline CHEMBL3217869 & 1332011 & 5.2967 & 5.0967 & TRN & \\
\hline CHEMBL3222090 & 1332011 & 5.4881 & 5.5397 & TST & \\
\hline CHEMBL3222108 & 1332011 & 5.684 & 5.9751 & TRN & \\
\hline CHEMBL3222075 & 1332011 & 5.5686 & 5.7671 & TRN & \\
\hline CHEMBL3222110 & 1332011 & 6.3372 & 6.1733 & TRN & \\
\hline CHEMBL3222084 & 1332011 & 6.7212 & 6.5176 & TRN & \\
\hline CHEMBL3222064 & 1332011 & 5.5654 & 5.8574 & TRN & \\
\hline CHEMBL3217863 & 1332011 & 5.5302 & 5.5185 & TST & \\
\hline CHEMBL3222052 & 1332011 & 6.2076 & 6.041 & TST & \\
\hline
\end{tabular}


Supplemental Table S2.txt

\begin{tabular}{|c|c|c|c|c|}
\hline CHEMBL 3222047 & 1332011 & 5.4498 & 6.1805 & TST \\
\hline CHEMBL 3222057 & 1332011 & 5.4789 & 5.9059 & TST \\
\hline CHEMBL3222065 & 1332011 & 6.433 & 6.1831 & TST \\
\hline CHEMBL 3222093 & 1332011 & 5.5638 & 5.4266 & TST \\
\hline CHEMBL 3222053 & 1332011 & 6.2147 & 6.0235 & TST \\
\hline CHEMBL3222058 & 1332011 & 6.8239 & 6.3944 & TST \\
\hline CHEMBL 3222051 & 1332011 & 5.1918 & 6.053 & TST \\
\hline CHEMBL 3222074 & 1332011 & 6.4815 & 6.3566 & TST \\
\hline CHEMBL 3222092 & 1332011 & 5.5287 & 5.8504 & TST \\
\hline CHEMBL 2113204 & 326539 & 6.2924 & 6.1996 & TRN \\
\hline CHEMBL196974 & 326539 & 4.0 & 5.0201 & TST \\
\hline CHEMBL 2113203 & 326539 & 6.7545 & 6.8169 & TRN \\
\hline CHEMBL 2113189 & 326539 & 6.1367 & 6.3529 & TRN \\
\hline CHEMBL444879 & 326539 & 4.0 & 4.391 & TST \\
\hline CHEMBL200922 & 326539 & 4.0 & 3.9174 & TRN \\
\hline CHEMBL383149 & 326539 & 5.7959 & 4.692 & TST \\
\hline CHEMBL 2113205 & 326539 & 5.1624 & 5.1905 & TRN \\
\hline CHEMBL 2113194 & 326539 & 4.0 & 4.0472 & TRN \\
\hline CHEMBL198622 & 326539 & 6.2441 & 5.0319 & TST \\
\hline CHEMBL 2113207 & 326539 & 6.21399 & 999999999 & 6.2087 \\
\hline CHEMBL 2113202 & 326539 & 5.4425 & 5.5239 & TRN \\
\hline CHEMBL382515 & 326539 & 4.0 & 3.9449 & TRN \\
\hline CHEMBL199622 & 326539 & 4.0 & 4.0476 & TRN \\
\hline CHEMBL373167 & 326539 & 6.9393 & 5.4996 & TST \\
\hline CHEMBL 2113185 & 326539 & 6.8761 & 6.9554 & TRN \\
\hline CHEMBL 2113177 & 326539 & 6.2351 & 6.3787 & TRN \\
\hline CHEMBL 2113208 & 326539 & 6.2916 & 6.0986 & TRN \\
\hline CHEMBL198475 & 326539 & 4.0 & 3.9368 & TRN \\
\hline CHEMBL200329 & 326539 & 5.4928 & 5.4967 & TRN \\
\hline CHEMBL197378 & 326539 & 5.7959 & 5.1942 & TST \\
\hline CHEMBL 2113195 & 326539 & 5.8908 & 5.8281 & TRN \\
\hline CHEMBL200282 & 326539 & 4.0 & 4.0388 & TRN \\
\hline CHEMBL 2113201 & 326539 & 7.1871 & 7.0393 & TRN \\
\hline CHEMBL200403 & 326539 & 4.0 & 4.1 & TRN \\
\hline CHEMBL 2113214 & 326539 & 4.0 & 4.1847 & TRN \\
\hline CHEMBL200738 & 326539 & 4.0 & 4.1073 & TRN \\
\hline CHEMBL 2113181 & 326539 & 7.0269 & 7.002999 & 7999999999 \\
\hline CHEMBL381433 & 326539 & 6.4881 & 4.4821 & TST \\
\hline CHEMBL200682 & 326539 & 7.1549 & 5.9192 & TST \\
\hline CHEMBL199078 & 326539 & 4.0 & 3.8972 & TRN \\
\hline CHEMBL200415 & 326539 & 4.0 & 4.7833 & TST \\
\hline CHEMBL114302 & 326539 & 6.5229 & 5.6549 & TST \\
\hline CHEMBL 2113215 & 326539 & 6.3595 & 6.4176 & TRN \\
\hline CHEMBL200498 & 326539 & 4.0 & 4.0196 & TRN \\
\hline CHEMBL 200368 & 326539 & 5.7305 & 5.732 & TRN \\
\hline CHEMBL 2113216 & 326539 & 5.4283 & 5.3668 & TRN \\
\hline CHEMBL2113179 & 326539 & 6.2111 & 6.1802 & TRN \\
\hline CHEMBL200904 & 326539 & 4.0 & 4.834 & TST \\
\hline
\end{tabular}




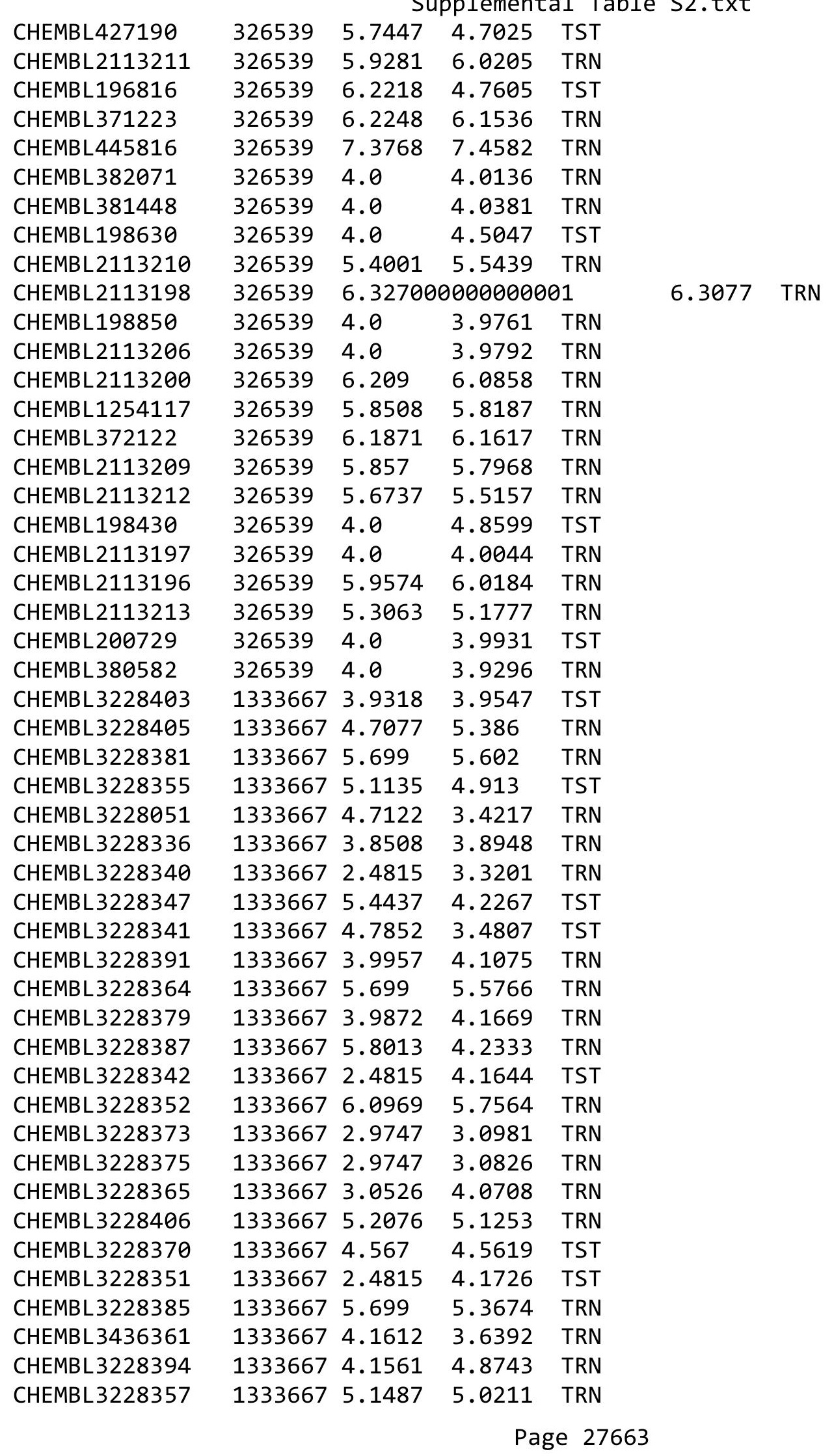


Supplemental Table S2.txt

\begin{tabular}{|c|c|c|c|c|}
\hline & & & 9 & \\
\hline HEMRI 3228368 & 33667 & 5,284 & & \\
\hline EMBL3228383 & & & & \\
\hline EMBL 3228374 & 33667 & 739 & 042 & \\
\hline HEMBL3228395 & 333667 & 757 & & \\
\hline AEMBL3228386 & 667 & & 692 & \\
\hline 90 & 667 & & & \\
\hline AEMBL3228389 & 667 & & & \\
\hline AEMBL3228398 & 333667 & 327 & 264 & \\
\hline HEMBL3228358 & 333667 & & 708 & \\
\hline IEMBL: & 667 & & 862 & \\
\hline EMBL & & & & \\
\hline AEMBL: & 667 & & & \\
\hline IEMBL: & 667 & & 256 & \\
\hline HEMBL; & 333667 & & & \\
\hline EMBL & 67 & & 27 & \\
\hline IEMBL & & & & \\
\hline AEMBL & 67 & & 85 & \\
\hline IEMBL & 67 & & & \\
\hline AEMBL3 & 567 & & 16 & \\
\hline 77 & 7 & & 794 & \\
\hline 71 & & & 69 & \\
\hline 93 & & & & \\
\hline 392 & & & & \\
\hline IEMBL: & 67 & & 06 & \\
\hline 397 & & & 86 & \\
\hline 28 & & & & \\
\hline & & & & \\
\hline 01 & & & & \\
\hline 28353 & 567 & & 764 & \\
\hline 60 & & & 33 & \\
\hline 59 & & & & KIN \\
\hline & & & & \\
\hline EMBL: & 57 & & & \\
\hline IEMBL 3228367 & 567 & & 09 & \\
\hline 347 & & & 89 & \\
\hline & & & & $m$ \\
\hline & & & & $\mathrm{RN}$ \\
\hline EMBL: & & & 296 & \\
\hline IEMBL: & & & 345 & \\
\hline 5459 & & & 196 & \\
\hline & & & 843 & RI \\
\hline IEMBL] & & & 9.4936 & \\
\hline EMBL: & 4 & & 765 & $\mathrm{~F}$ \\
\hline & & & & \\
\hline CHEMBL259181 & & & 6.38 & \\
\hline CHEMBL1590308 & & & 3.0209 & \\
\hline CHEMBL515416 & 954844 & 4.0382 & 4.0404 & \\
\hline
\end{tabular}

Page 27664 


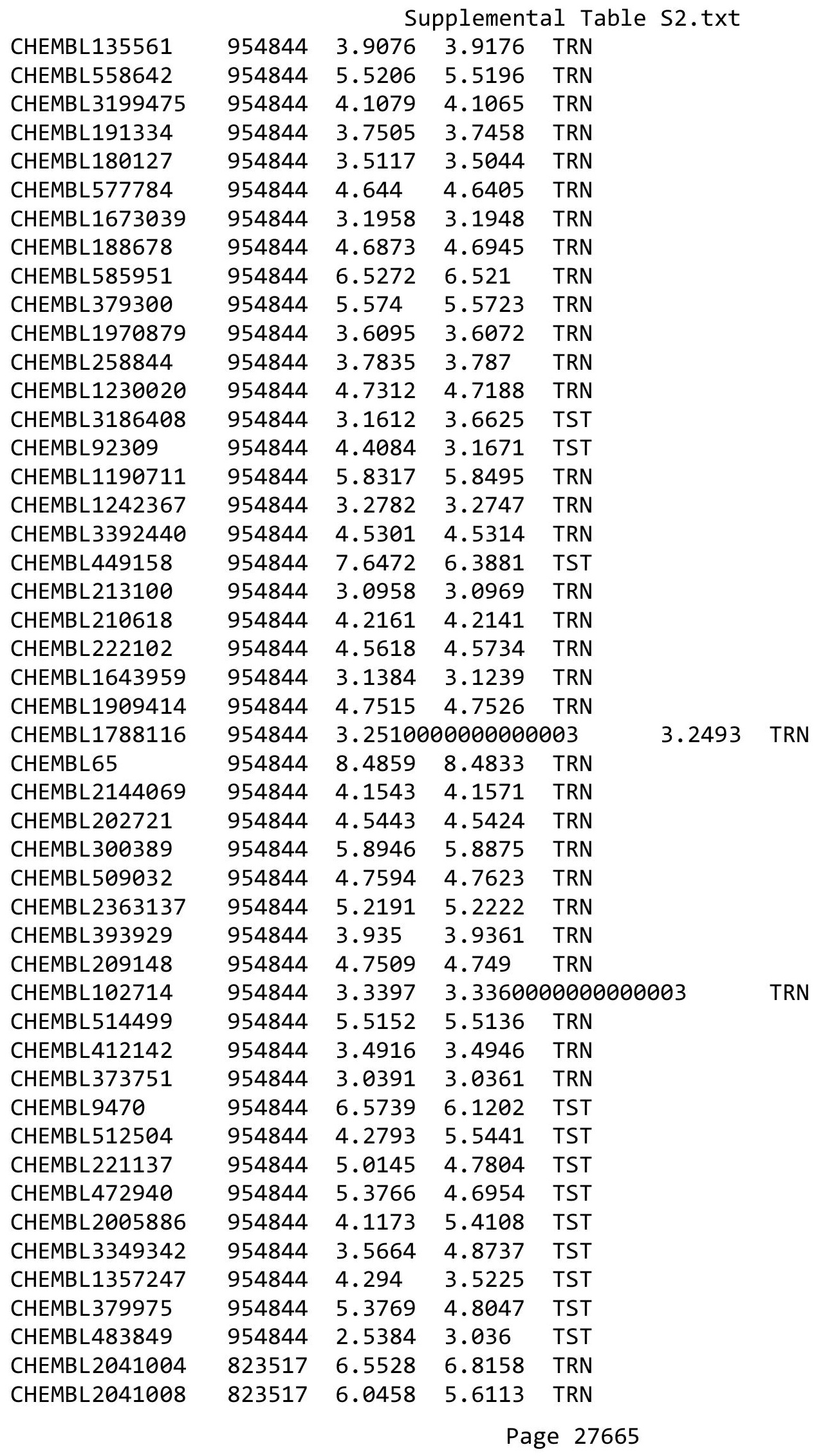


Supplemental Table S2.txt

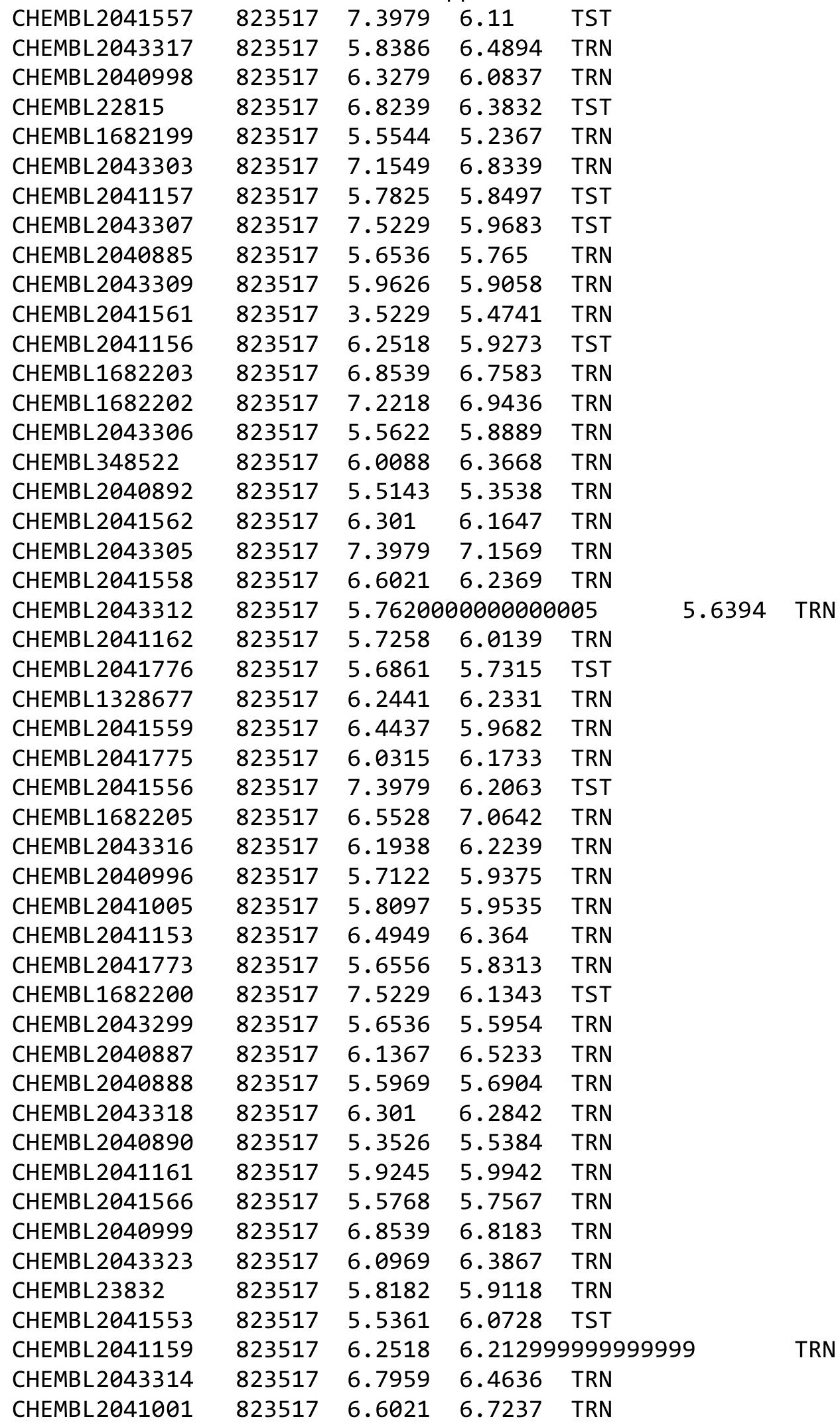

Page 27666 
Supplemental Table S2.txt

\begin{tabular}{|c|c|c|c|c|c|}
\hline CHEMBL 2041777 & 823517 & 6.0605 & 5.5062 & TRN & \\
\hline CHEMBL 2043304 & 823517 & 6.4437 & 6.3562 & TRN & \\
\hline CHEMBL 2041000 & 823517 & 6.2218 & 6.5796 & TRN & \\
\hline CHEMBL 2040995 & 823517 & 5.6459 & 5.9071 & TRN & \\
\hline CHEMBL 2043315 & 823517 & 6.2441 & 6.0768 & TRN & \\
\hline CHEMBL 2043300 & 823517 & 7.3979 & 5.9583 & TST & \\
\hline CHEMBL 2040884 & 823517 & 7.0969 & 7.1147 & TRN & \\
\hline CHEMBL 2043322 & 823517 & 6.6021 & 6.4943 & TRN & \\
\hline CHEMBL 2041155 & 823517 & 6.0177 & 6.3849 & TRN & \\
\hline CHEMBL 2043301 & 823517 & 6.8539 & 6.6407 & TRN & \\
\hline CHEMBL 2041006 & 823517 & 6.585 & 5.7448 & TST & \\
\hline CHEMBL 2041772 & 823517 & 5.9281 & 5.8516 & TRN & \\
\hline CHEMBL1682201 & 823517 & 7.301 & 6.6807 & TRN & \\
\hline CHEMBL1596993 & 823517 & 7.0458 & 6.7846 & TRN & \\
\hline CHEMBL 2041158 & 823517 & 6.5376 & 5.684 & TST & \\
\hline CHEMBL 2040860 & 823517 & 5.6253 & 5.19 & TRN & \\
\hline CHEMBL 2041163 & 823517 & 5.4473 & 5.6056 & TRN & \\
\hline CHEMBL 2040851 & 823517 & 6.1612 & 6.1235 & TRN & \\
\hline CHEMBL 2041002 & 823517 & 6.2147 & 6.432 & TRN & \\
\hline CHEMBL 2041568 & 823517 & 5.8794 & 5.1668 & TST & \\
\hline CHEMBL 2041563 & 823517 & 5.4698 & 5.3837 & TST & \\
\hline CHEMBL 2043308 & 823517 & 6.0506 & 5.9266 & TRN & \\
\hline CHEMBL1682207 & 823517 & 6.1549 & 6.3748 & TRN & \\
\hline CHEMBL 2041160 & 823517 & 6.3372 & 6.0722 & TRN & \\
\hline CHEMBL 2043321 & 823517 & 6.8239 & 6.9931 & TRN & \\
\hline CHEMBL 2040993 & 823517 & 6.1871 & 6.2063 & TRN & \\
\hline CHEMBL 2041778 & 823517 & 5.5969 & 5.5267 & TRN & \\
\hline CHEMBL 2040997 & 823517 & 5.9318 & 5.9767 & TRN & \\
\hline CHEMBL 2040886 & 823517 & 5.76200 & 00000000 & 05 & 5.9408 \\
\hline CHEMBL 2043320 & 823517 & 6.6576 & 6.8882 & TRN & \\
\hline CHEMBL 2041774 & 823517 & 5.7235 & 5.4132 & TRN & \\
\hline CHEMBL1682204 & 823517 & 6.8861 & 6.8455 & TRN & \\
\hline CHEMBL 2041321 & 823517 & 5.7852 & 5.9389 & TRN & \\
\hline CHEMBL 2041009 & 823517 & 5.7399 & 5.6326 & TRN & \\
\hline CHEMBL 2041560 & 823517 & 5.9666 & 5.9685 & TRN & \\
\hline CHEMBL2043319 & 823517 & 6.301 & 6.5332 & TRN & \\
\hline CHEMBL 2041152 & 823517 & 6.2147 & 5.6675 & TRN & \\
\hline CHEMBL 2040889 & 823517 & 5.9547 & 5.4666 & TST & \\
\hline CHEMBL 2041007 & 823517 & 5.7545 & 6.099 & TRN & \\
\hline CHEMBL 2043302 & 823517 & 6.8861 & 6.5185 & TRN & \\
\hline CHEMBL 2041154 & 823517 & 6.8239 & 5.8116 & TST & \\
\hline CHEMBL 2043310 & 823517 & 7.2218 & 6.7844 & TRN & \\
\hline CHEMBL 2043311 & 823517 & 5.7799 & 6.0215 & TRN & \\
\hline CHEMBL 2040893 & 823517 & 6.0088 & 5.811 & TRN & \\
\hline CHEMBL 2041771 & 823517 & 5.9788 & 5.8361 & TRN & \\
\hline CHEMBL1574420 & 823517 & 6.7959 & 6.1544 & TST & \\
\hline CHEMBL 2041554 & 823517 & 7.3979 & 6.3923 & TRN & \\
\hline CHEMBL 2040994 & 823517 & 5.9355 & 6.1708 & TRN & \\
\hline
\end{tabular}

Page 27667 
Supplemental Table S2.txt

\begin{tabular}{|c|c|c|c|}
\hline HEMBL2040891 & 823517 & 5.8697 & 5.7401 \\
\hline CHEMBL 2041567 & 823517 & 5.7773 & 5.801 \\
\hline CHEMBL 2041569 & 823517 & 5.6021 & 7967 \\
\hline AEMBL2041003 & 23517 & 5.7825 & 6.0466 \\
\hline HEMBL 23479 & 823517 & 6.6198 & 6.2379 \\
\hline HEMBL2041564 & 823517 & 5.3757 & 5.388 \\
\hline CHEMBL 2043313 & 823517 & 7.0969 & 6.0996 \\
\hline CHEMBL1682206 & 823517 & 6.3098 & 6.7523 \\
\hline HEMBL2041555 & 823517 & 7.5229 & 6.5336 \\
\hline HEMBL1682198 & 823517 & 6.0269 & 5.7712 \\
\hline HEMBL3652174 & 1527974 & 6.4559 & 6.7262 \\
\hline CHEMBL3652142 & 1527974 & 7.3979 & 7.5616 \\
\hline CHEMBL 3652167 & 1527974 & 6.7959 & 6.6041 \\
\hline CHEMBL365 & 1527974 & 7.1938 & 7.1339 \\
\hline HEMBL365 & 1527974 & 7.1249 & 7.0543 \\
\hline HEMBL3652127 & 1527974 & 7.3665 & 7.1419 \\
\hline CHEMBL 3652172 & 1527974 & 6.8539 & 6.7676 \\
\hline CHEMBL365 & 1527974 & 6.9586 & 7.0843 \\
\hline CHEMBL 365 & 1527974 & 7.6778 & 7.4341 \\
\hline HEMBL3652158 & 1527974 & 6.5436 & 7.1431 \\
\hline HEMBL3652153 & 1527974 & 7.2218 & 6.9491 \\
\hline CHEMBL 3639510 & 1527974 & 7.1871 & 7.1934 \\
\hline CHEMBL365 & 1527974 & 7.4685 & 7.4776 \\
\hline CHEMBL 365 & 1527974 & 5.7352 & 7.1367 \\
\hline HEMBL3652146 & 1527974 & 7.9586 & 7.7555 \\
\hline AEMBL3652130 & 1527974 & 6.3768 & 7.0327 \\
\hline CHEMBL 3652209 & 1527974 & 5.9586 & 6.6523 \\
\hline CHEMBL 365 & 1527974 & 7.6383 & 7.2621 \\
\hline CHEMBL 36 & 1527974 & 7.699 & 7.8259 \\
\hline CHEMBL 365 & 1527974 & 6.0132 & 6.2106 \\
\hline HEMBL3652128 & 1527974 & 7.3468 & 7.4358 \\
\hline CHEMBL 3652154 & 1527974 & 7.3565 & 7.0241 \\
\hline CHEMBL 365 & 1527974 & 809 & \\
\hline CHEMBL: & 1527974 & 88 & 7.1 \\
\hline CHEMBL 3652196 & 1527974 & 6.9586 & 6.8788 \\
\hline CHEMBL 3652187 & 1527974 & 6.4559 & 6.0553 \\
\hline CHEMBL 3652191 & 1527974 & 6.9208 & 6.9391 \\
\hline CHEMBL & 1527974 & & \\
\hline CHEMBL365 & 1527974 & 229 & 6.9018 \\
\hline CHEMBL 365 & 1527974 & 7.7447 & 7.4362 \\
\hline CHEMBL 3652147 & 1527974 & 6.6021 & 7.2657 \\
\hline CHEMBL 3652199 & 1527974 & 8.0 & 7. \\
\hline CHEMBL365 & 1527974 & & 7.2342 \\
\hline CHEMBL 3652195 & 1527974 & 7.3098 & 7.1818 \\
\hline CHEMBL 3652180 & 1527974 & 7.0605 & 7.0681 \\
\hline CHEMBL 3652166 & 1527974 & 7.0555 & 6.6657 \\
\hline CHEMBL 3652132 & 1527974 & 7.0506 & 7.1112 \\
\hline CHEMBL 3652205 & 1527974 & & 6.9514 \\
\hline
\end{tabular}

Page 27668 
Supplemental Table S2.txt

\begin{tabular}{|c|c|c|c|c|}
\hline HEMBL36 & 527974 & 6.7212 & & \\
\hline & 527974 & 7.5686 & & \\
\hline 2162 & 527974 & & & \\
\hline AEMBL3652155 & 527974 & $\partial 757$ & & \\
\hline AEMBL3 & 527974 & 7959 & & \\
\hline HEMBL3652188 & 527974 & 7.0757 & 3279 & \\
\hline AEMBL & 527974 & 686 & & \\
\hline EMBL & 527974 & & & \\
\hline AEMBL3652186 & 527974 & 3188 & & \\
\hline AEMBL3652122 & 527974 & 03 & & \\
\hline AEMBL3652120 & 527974 & 53 & & \\
\hline IEMBL & 527974 & & & \\
\hline IEMBL & 527974 & & & \\
\hline AEMBL; & 527974 & 468 & & \\
\hline AEMBL 3 & 527974 & & & \\
\hline AEMBL: & 527974 & 861 & & \\
\hline AEMBL & 527974 & & & \\
\hline AEMBL & 527974 & & & \\
\hline AEMBL & 527974 & 696 & & \\
\hline AEMBL: & 527974 & & & \\
\hline AEMBL & 527974 & 29 & & \\
\hline EMB & 527974 & & & \\
\hline IEMB & 527974 & 924 & & \\
\hline IEMBL & 527974 & & & \\
\hline IEMBL3 & 974 & 88 & & \\
\hline AEMBL: & 527974 & 7 & & \\
\hline IEMBL & 7974 & & & \\
\hline EMB & 527974 & 51 & & \\
\hline IEMBL & 974 & & & \\
\hline AEMBL36 & 74 & & & I \\
\hline AEMBL 3 & 527974 & 6 & & \\
\hline EME & 7974 & 3 & & \\
\hline 0 & 74 & & & $\mathrm{RN}$ \\
\hline AEMBL3 & 527974 & & & \\
\hline HEMBL365 & 527974 & & & \\
\hline IEMB & 74 & & & R \\
\hline JEMP & 74 & 29 & & \\
\hline HEMBL & 74 & 7. & & 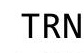 \\
\hline AEMBL 365 & 527974 & 7.14 & & \\
\hline IEMBL3 & 527974 & & & \\
\hline HEMBL & 527974 & & & \\
\hline HCMD - & 1527974 & 7.5229 & & \\
\hline HEMBL & 527974 & 7.3098 & 34 & $\mathrm{RI}$ \\
\hline AEMBL3 & 527974 & 5.5086 & 754 & \\
\hline AEMBL & 527974 & 7.1427 & & \\
\hline CHEMBL: & 1527974 & & & \\
\hline CHEMBL3652 & 527974 & 5.7825 & 6.6848 & \\
\hline CHEMBL365214 & 1527974 & 6.2596 & 6.5737 & \\
\hline
\end{tabular}

Page 27669 
Supplemental Table S2.txt

\begin{tabular}{|c|c|c|c|c|c|}
\hline CHEMBL3652141 & 1527974 & 7.5229 & \multicolumn{2}{|c|}{ 7.412999999999999 } & TRN \\
\hline CHEMBL3652123 & 1527974 & 7.3098 & 7.2576 & TRN & \\
\hline CHEMBL3652204 & 1527974 & 7.3665 & 6.8579 & TST & \\
\hline CHEMBL3652126 & 1527974 & 6.8239 & 7.3617 & TRN & \\
\hline CHEMBL3652201 & 1527974 & 6.1192 & 6.727 & TRN & \\
\hline CHEMBL 3652157 & 1527974 & 6.8861 & 7.3811 & TST & \\
\hline CHEMBL3652181 & 1527974 & 6.1427 & 6.1464 & TST & \\
\hline CHEMBL3652145 & 1527974 & 6.699 & 6.6942 & TST & \\
\hline CHEMBL 3652190 & 1527974 & 7.0605 & 7.1765 & TST & \\
\hline CHEMBL3652171 & 1527974 & 7.0655 & 7.2186 & TST & \\
\hline CHEMBL3652198 & 1527974 & 7.585 & 7.6809 & TST & \\
\hline CHEMBL3652135 & 1527974 & 6.3098 & 6.8698 & TST & \\
\hline CHEMBL3652189 & 1527974 & 6.1192 & 6.7129 & TST & \\
\hline CHEMBL3652118 & 1527974 & 7.0555 & 7.3782 & TST & \\
\hline CHEMBL3652185 & 1527974 & 7.4949 & 7.6441 & TST & \\
\hline CHEMBL3652163 & 1527974 & 7.2291 & 7.192 & TST & \\
\hline CHEMBL3652159 & 1527974 & 6.699 & 6.6563 & TST & \\
\hline CHEMBL1524916 & 688467 & 3.1003 & 3.0712 & TST & \\
\hline CHEMBL1333282 & 688467 & 3.1003 & 3.0314 & TRN & \\
\hline CHEMBL1462713 & 688467 & 5.1028 & 5.2605 & TRN & \\
\hline CHEMBL1308745 & 688467 & 3.1003 & 3.1296 & TRN & \\
\hline CHEMBL1492278 & 688467 & 3.1003 & 3.1204 & TRN & \\
\hline CHEMBL1328380 & 688467 & 3.1003 & 3.0559 & TRN & \\
\hline CHEMBL1300937 & 688467 & 3.1003 & 2.9885 & TRN & \\
\hline CHEMBL1407650 & 688467 & 3.1003 & 3.5209 & TST & \\
\hline CHEMBL3194048 & 688467 & 3.1003 & 3.1819 & TRN & \\
\hline CHEMBL1478352 & 688467 & 3.1003 & 3.0801 & TST & \\
\hline CHEMBL1505844 & 688467 & 4.258 & 3.6554 & TRN & \\
\hline CHEMBL1387238 & 688467 & 4.5885 & 4.4395 & TRN & \\
\hline CHEMBL1522046 & 688467 & 3.1003 & 3.0929 & TRN & \\
\hline CHEMBL3145293 & 688467 & 3.1003 & 3.1423 & TST & \\
\hline CHEMBL1613102 & 688467 & 3.1003 & 3.0425 & TRN & \\
\hline CHEMBL1439888 & 688467 & 4.6038 & 4.3428 & TRN & \\
\hline CHEMBL1579409 & 688467 & 3.1003 & 3.1425 & TRN & \\
\hline CHEMBL 2365639 & 688467 & 3.1003 & 3.0097 & TRN & \\
\hline CHEMBL1300045 & 688467 & 3.1003 & 3.1894 & TST & \\
\hline CHEMBL1492681 & 688467 & 3.1003 & 3.0687 & TST & \\
\hline CHEMBL1471858 & 688467 & 3.1003 & 3.3288 & TRN & \\
\hline CHEMBL1365995 & 688467 & 3.1003 & 3.0502 & TRN & \\
\hline CHEMBL1393451 & 688467 & 3.1003 & 3.0981 & TRN & \\
\hline CHEMBL1563536 & 688467 & 3.1003 & 3.1185 & TRN & \\
\hline CHEMBL1433290 & 688467 & 4.8722 & 4.3993 & TRN & \\
\hline CHEMBL1332678 & 688467 & 3.1003 & 3.0586 & TRN & \\
\hline CHEMBL1543543 & 688467 & 3.1003 & 4.1018 & TRN & \\
\hline CHEMBL1301738 & 688467 & 3.1003 & 3.0165 & TRN & \\
\hline CHEMBL1492457 & 688467 & 4.3057 & 4.2191 & TRN & \\
\hline CHEMBL1448381 & 688467 & 4.1985 & 3.9843 & TRN & \\
\hline CHEMBL1332063 & 688467 & 3.1003 & 3.0856 & TRN & \\
\hline
\end{tabular}

Page 27670 


\begin{tabular}{|c|c|c|c|c|c|}
\hline & & & & & \\
\hline CHEMBL1583115 & 688467 & 3.1003 & 3.1599 & TRN & \\
\hline CHEMBL1506506 & 688467 & 4.8422 & 4.863 & TRN & \\
\hline CHEMBL3210083 & 688467 & 3.1003 & 3.0567 & TRN & \\
\hline CHEMBL1540443 & 688467 & 4.0903 & 3.87100 & 00000000004 & TRN \\
\hline CHEMBL1603658 & 688467 & 3.1003 & 3.4549 & TRN & \\
\hline CHEMBL3194630 & 688467 & 3.1003 & 3.1334 & TRN & \\
\hline CHEMBL1333009 & 688467 & 3.1003 & 3.0326 & TRN & \\
\hline CHEMBL1532532 & 688467 & 4.6096 & 4.5234 & TRN & \\
\hline CHEMBL1519059 & 688467 & 3.1003 & 3.0855 & TRN & \\
\hline CHEMBL1439946 & 688467 & 3.1003 & 3.0774 & TRN & \\
\hline CHEMBL1321442 & 688467 & 3.1003 & 2.9762 & TRN & \\
\hline CHEMBL1583062 & 688467 & 3.1003 & 3.07800 & 00000000003 & TRN \\
\hline CHEMBL1421554 & 688467 & 3.1003 & 3.3089 & TRN & \\
\hline CHEMBL1558820 & 688467 & 4.7364 & 4.5087 & TRN & \\
\hline CHEMBL1563782 & 688467 & 3.1003 & 3.1426 & TRN & \\
\hline CHEMBL1606721 & 688467 & 3.1003 & 3.0448 & TRN & \\
\hline CHEMBL1449055 & 688467 & 3.1003 & 3.1012 & TRN & \\
\hline CHEMBL1427125 & 688467 & 3.1003 & 3.077 & TST & \\
\hline CHEMBL1432747 & 688467 & 3.1003 & 3.1022 & TST & \\
\hline CHEMBL1377287 & 688467 & 3.1003 & 3.0493 & TRN & \\
\hline CHEMBL1601494 & 688467 & 3.1003 & 3.1474 & TRN & \\
\hline CHEMBL3196561 & 688467 & 3.1003 & 3.10600 & 00000000003 & TST \\
\hline CHEMBL1427163 & 688467 & 3.1003 & 3.0373 & TRN & \\
\hline CHEMBL1414445 & 688467 & 4.9863 & 5.131 & TRN & \\
\hline CHEMBL1505466 & 688467 & 4.3001 & 4.249 & TRN & \\
\hline CHEMBL1609957 & 688467 & 3.1003 & 3.2575 & TRN & \\
\hline CHEMBL1507486 & 688467 & 3.1003 & 3.0359 & TST & \\
\hline CHEMBL1565229 & 688467 & 3.1003 & 3.1483 & TRN & \\
\hline CHEMBL1337316 & 688467 & 3.1003 & 3.2783 & TRN & \\
\hline CHEMBL1579471 & 688467 & 3.1003 & 3.2196 & TRN & \\
\hline CHEMBL1406161 & 688467 & 3.1003 & 3.9191 & TRN & \\
\hline CHEMBL1520457 & 688467 & 3.1003 & 3.1514 & TRN & \\
\hline CHEMBL 3195801 & 688467 & 4.3765 & 4.8302 & TRN & \\
\hline CHEMBL1320358 & 688467 & 3.1003 & 3.08100 & 00000000004 & TRN \\
\hline CHEMBL1419387 & 688467 & 3.1003 & 4.0147 & TRN & \\
\hline CHEMBL1567518 & 688467 & 4.8108 & 4.9076 & TRN & \\
\hline CHEMBL1575331 & 688467 & 3.1003 & 3.1909 & TRN & \\
\hline CHEMBL1411341 & 688467 & 3.1003 & 2.9908 & TST & \\
\hline CHEMBL1600071 & 688467 & 3.1003 & 2.998 & TST & \\
\hline CHEMBL 3192152 & 688467 & 3.1003 & 3.1443 & TRN & \\
\hline CHEMBL1507954 & 688467 & 4.6082 & 4.2832 & TRN & \\
\hline CHEMBL1543421 & 688467 & 3.1003 & 3.1634 & TRN & \\
\hline CHEMBL3195359 & 688467 & 3.1003 & 3.0012 & TST & \\
\hline CHEMBL1505538 & 688467 & 3.1003 & 3.1301 & TST & \\
\hline CHEMBL3189201 & 688467 & 4.9574 & 5.1351 & TRN & \\
\hline CHEMBL1468866 & 688467 & 3.1003 & 3.5793 & TRN & \\
\hline CHEMBL1344196 & 688467 & 3.1003 & 3.0523 & TRN & \\
\hline CHEMBL1428286 & 688467 & 4.5114 & 4.7195 & TRN & \\
\hline
\end{tabular}


Supplemental Table S2.txt

\begin{tabular}{|c|c|c|c|c|}
\hline 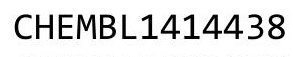 & & & & \\
\hline HEMBL1529358 & 38467 & 1003 & 99 & \\
\hline AEMBL1574032 & & 003 & 948 & \\
\hline 08 & & 003 & 232 & \\
\hline IEMBL 2369261 & & 1003 & & \\
\hline AEMBL1343936 & 88467 & 2975 & 13 & \\
\hline AEMBL1370692 & 88467 & .1003 & 0245 & \\
\hline AEMBL1511120 & & 414 & & \\
\hline EMBL1372206 & 67 & 003 & 082 & \\
\hline IEMBL1519242 & & 003 & 955 & \\
\hline AEMBL1304179 & 467 & 003 & 1291 & \\
\hline AEMBL1561769 & 67 & 003 & 1028 & \\
\hline AEMBL1352382 & & 003 & 734 & \\
\hline AEMBL1465049 & & 003 & 687 & \\
\hline JEMBL150 & & 217 & & \\
\hline AEMBL1480319 & & 003 & 523 & \\
\hline AEMBL1324127 & & 003 & & \\
\hline AEMBL141 & & 203 & 312 & \\
\hline AEMBL159 & & & 877 & \\
\hline IEMB & & & 123 & \\
\hline HEMBL137 & & 003 & .234 & \\
\hline AEMBL1342967 & & 03 & & \\
\hline AEMBL157 & & 47 & 98 & \\
\hline JFMRI 320 & & & 996 & \\
\hline 22 & & & 991 & \\
\hline רכת וסPMI & & 003 & 155 & \\
\hline IEMBL1472 & & 611 & & \\
\hline EMBL197 & & 203 & & \\
\hline 38 & & & 97 & \\
\hline 98 & & 03 & 053 & \\
\hline AEMBL1440953 & & 48 & & \\
\hline AEMBL1561316 & & 31 & 175 & \\
\hline 9 & & $\partial 3$ & & \\
\hline 36 & & 33 & 57 & \\
\hline HEMBL319 & & 23 & & \\
\hline AEMBL1999900 & & 03 & 662 & \\
\hline IEMBL601578 & & 303 & 359 & \\
\hline & & & & \\
\hline IFMn & & & 67 & \\
\hline HEMBL1539280 & & & & RN \\
\hline AEMBL1490883 & & 203 & .044 & $\mathrm{~F}$ \\
\hline-134 & & 03 & 855 & \\
\hline 44 & & & & \\
\hline HEMBL1366259 & & 97 & 5148 & \\
\hline AEMBL 2143919 & & .0917 & 9932 & RN \\
\hline MBL1425135 & & 983 & 019 & $1 \pi$ \\
\hline 321 & & & 9621 & \\
\hline & & & & \\
\hline
\end{tabular}

Page 27672 
Supplemental Table S2.txt

\begin{tabular}{|c|c|c|c|c|}
\hline CHEMBL1423417 & 688467 & 4.3872 & 4.388 & TRN \\
\hline CHEMBL1312030 & 688467 & 4.6662 & 4.533 & TRN \\
\hline CHEMBL1605172 & 688467 & 3.1003 & 3.0441 & TRN \\
\hline CHEMBL1341820 & 688467 & 3.1003 & 2.9808 & TRN \\
\hline CHEMBL1522598 & 688467 & 3.1003 & 3.0171 & TRN \\
\hline CHEMBL1457704 & 688467 & 3.1003 & 3.1231 & TRN \\
\hline CHEMBL1608186 & 688467 & 3.1003 & \multicolumn{2}{|c|}{ 3. 2969999999999997} \\
\hline CHEMBL1558616 & 688467 & 3.1003 & 3.168 & TRN \\
\hline CHEMBL1450472 & 688467 & 3.1003 & 3.0896 & TRN \\
\hline CHEMBL1565236 & 688467 & 4.4444 & 4.3765 & TRN \\
\hline CHEMBL1509978 & 688467 & 3.1003 & 3.1768 & TRN \\
\hline CHEMBL1335142 & 688467 & 3.1003 & 3.7859 & TRN \\
\hline CHEMBL1338594 & 688467 & 3.1003 & 3.0626 & TRN \\
\hline CHEMBL1447164 & 688467 & 5.0477 & 4.5366 & TRN \\
\hline CHEMBL533954 & 688467 & 3.1003 & 3.2177 & TRN \\
\hline CHEMBL1439119 & 688467 & 3.1003 & 3.0466 & TRN \\
\hline CHEMBL1516879 & 688467 & 3.1003 & 2.9635 & TRN \\
\hline CHEMBL581929 & 688467 & 3.1003 & \multicolumn{2}{|c|}{3.0580000000000003} \\
\hline CHEMBL1968355 & 688467 & 3.1003 & 3.0853 & TST \\
\hline CHEMBL1362098 & 688467 & 3.1003 & 3.0768 & TST \\
\hline CHEMBL1386273 & 688467 & 4.5887 & 4.4476 & TRN \\
\hline CHEMBL1334835 & 688467 & 3.1003 & 3.0166 & TRN \\
\hline CHEMBL1430993 & 688467 & 3.1003 & 3.0027 & TRN \\
\hline CHEMBL1478573 & 688467 & 4.2575 & 4.2881 & TRN \\
\hline CHEMBL1351131 & 688467 & 5.2165 & 4.7724 & TRN \\
\hline CHEMBL1526968 & 688467 & 3.1003 & 3.0494 & TRN \\
\hline CHEMBL1367765 & 688467 & 4.9512 & 4.4172 & TRN \\
\hline CHEMBL1604006 & 688467 & 3.1003 & 3.1608 & TRN \\
\hline CHEMBL1457789 & 688467 & 3.1003 & 3.0149 & TST \\
\hline CHEMBL1312906 & 688467 & 3.1003 & 2.998 & TRN \\
\hline CHEMBL1547693 & 688467 & 4.3499 & 4.1413 & TRN \\
\hline CHEMBL1488126 & 688467 & 3.1003 & 3.0234 & TRN \\
\hline CHEMBL1336097 & 688467 & 3.1003 & \multicolumn{2}{|c|}{ 3.2119999999999997 } \\
\hline CHEMBL 3210223 & 688467 & 3.1003 & 3.1614 & TRN \\
\hline CHEMBL1578636 & 688467 & 3.1003 & 3.1892 & TRN \\
\hline CHEMBL69086 & 688467 & 3.1003 & 3.0783 & TST \\
\hline CHEMBL3207839 & 688467 & 3.1003 & 3.4286 & TRN \\
\hline CHEMBL1484719 & 688467 & 3.1003 & 3.1005 & TRN \\
\hline CHEMBL1299851 & 688467 & 3.1003 & 3.031 & TRN \\
\hline CHEMBL1526833 & 688467 & 3.1003 & 3.1378 & TRN \\
\hline CHEMBL1339881 & 688467 & 3.1003 & 3.0633 & TRN \\
\hline CHEMBL1352206 & 688467 & 3.1003 & 3.1792 & TRN \\
\hline CHEMBL1381203 & 688467 & 3.1003 & 2.9856 & TRN \\
\hline CHEMBL1562550 & 688467 & 4.2314 & 4.2615 & TRN \\
\hline CHEMBL1306015 & 688467 & 3.1003 & 3.4373 & TRN \\
\hline CHEMBL1484427 & 688467 & 3.1003 & 3.0431 & TRN \\
\hline CHEMBL1597380 & 688467 & 3.1003 & 3.0652 & TRN \\
\hline CHEMBL1362807 & 688467 & 3.1003 & 3.1031 & TRN \\
\hline
\end{tabular}

Page 27673 


\begin{tabular}{|c|c|c|c|c|c|}
\hline \multicolumn{6}{|c|}{ Supplemental Table S2.txt } \\
\hline CHEMBL1321430 & 688467 & 5.0724 & 4.436 & TRN & \\
\hline CHEMBL1320697 & 688467 & 3.1003 & 3.1306 & TRN & \\
\hline CHEMBL1339272 & 688467 & 3.1003 & 2.9495 & TRN & \\
\hline CHEMBL 3189337 & 688467 & 3.1003 & 3.2221 & TRN & \\
\hline CHEMBL1312133 & 688467 & 3.1003 & 3.1455 & TRN & \\
\hline CHEMBL1579477 & 688467 & 3.1003 & 3.2164 & TRN & \\
\hline CHEMBL1438294 & 688467 & 3.1003 & 3.003 & TRN & \\
\hline CHEMBL1411662 & 688467 & 3.1003 & 3.1166 & TST & \\
\hline CHEMBL1346107 & 688467 & 4.07 & 3.1173 & TRN & \\
\hline CHEMBL1300069 & 688467 & 4.6148 & 4.4771 & TST & \\
\hline CHEMBL1390323 & 688467 & 3.1003 & 3.1389 & TRN & \\
\hline CHEMBL1531910 & 688467 & 4.6463 & 4.5651 & TRN & \\
\hline CHEMBL1604376 & 688467 & 4.6185 & 4.5439 & TRN & \\
\hline CHEMBL1353338 & 688467 & 3.1003 & 3.2621 & TRN & \\
\hline CHEMBL1449312 & 688467 & 3.1003 & 3.0517 & TST & \\
\hline CHEMBL546475 & 688467 & 3.1003 & 3.02699 & 99999999997 & TRN \\
\hline CHEMBL1414657 & 688467 & 5.0675 & 4.7742 & TRN & \\
\hline CHEMBL1454659 & 688467 & 3.1003 & 3.2265 & TRN & \\
\hline CHEMBL1351240 & 688467 & 3.1003 & 2.96 & TRN & \\
\hline CHEMBL3193904 & 688467 & 3.1003 & 3.0216 & TRN & \\
\hline CHEMBL1546304 & 688467 & 3.1003 & 3.0451 & TRN & \\
\hline CHEMBL1300592 & 688467 & 3.1003 & 3.1333 & TRN & \\
\hline CHEMBL1519736 & 688467 & 3.1003 & 3.0488 & TRN & \\
\hline CHEMBL1373371 & 688467 & 3.1003 & 3.0169 & TST & \\
\hline CHEMBL 3191374 & 688467 & 3.1003 & 3.1616 & TST & \\
\hline CHEMBL1382919 & 688467 & 3.1003 & 3.0584 & TRN & \\
\hline CHEMBL1453481 & 688467 & 3.1003 & 3.0474 & TRN & \\
\hline CHEMBL1578181 & 688467 & 4.7852 & 4.8847 & TRN & \\
\hline CHEMBL1329708 & 688467 & 3.1003 & 3.1012 & TRN & \\
\hline CHEMBL1432578 & 688467 & 3.1003 & 3.2896 & TRN & \\
\hline CHEMBL1440467 & 688467 & 3.1003 & 3.1798 & TRN & \\
\hline CHEMBL1608327 & 688467 & 3.1003 & 2.9567 & TST & \\
\hline CHEMBL1597754 & 688467 & 3.1003 & 3.7177 & TRN & \\
\hline CHEMBL1351640 & 688467 & 3.1003 & 3.1477 & TRN & \\
\hline CHEMBL1399673 & 688467 & 3.1003 & 3.0256 & TRN & \\
\hline CHEMBL1470921 & 688467 & 3.1003 & 3.1638 & TRN & \\
\hline CHEMBL 235260 & 688467 & 3.1003 & 3.2134 & TRN & \\
\hline CHEMBL1585187 & 688467 & 3.1003 & 3.1007 & TRN & \\
\hline CHEMBL1400006 & 688467 & 4.5827 & 4.6981 & TRN & \\
\hline CHEMBL1372549 & 688467 & 3.1003 & 3.1109 & TRN & \\
\hline CHEMBL1470283 & 688467 & 3.1003 & 3.0411 & TST & \\
\hline CHEMBL1463869 & 688467 & 3.1003 & 3.8242 & TRN & \\
\hline CHEMBL1348905 & 688467 & 3.1003 & 2.98 & TRN & \\
\hline CHEMBL1565213 & 688467 & 3.1003 & 3.2227 & TRN & \\
\hline CHEMBL1352697 & 688467 & 3.1003 & 3.0658 & TST & \\
\hline CHEMBL1532527 & 688467 & 4.6048 & 4.5216 & TRN & \\
\hline CHEMBL1310089 & 688467 & 3.1003 & 3.0699 & TRN & \\
\hline CHEMBL1420624 & 688467 & 3.1003 & 3.0617 & TST & \\
\hline
\end{tabular}




\begin{tabular}{|c|c|c|c|c|c|}
\hline \multirow{3}{*}{$\begin{array}{l}\text { CHEMBL1479296 } \\
\text { CHEMBL1459628 }\end{array}$} & \multirow{3}{*}{$\begin{array}{l}688467 \\
688467\end{array}$} & \multicolumn{4}{|c|}{ Supplemental Table S2.txt } \\
\hline & & 4.2742 & \multicolumn{2}{|c|}{4.2330000000000005} & \multirow[t]{2}{*}{ TRA } \\
\hline & & 3.1003 & 3.0154 & TRN & \\
\hline CHEMBL1471920 & 688467 & 4.4994 & 4.189 & TRN & \\
\hline CHEMBL1311094 & 688467 & 3.1003 & 3.0952 & TRN & \\
\hline CHEMBL1518205 & 688467 & 3.1003 & 3.0505 & TRN & \\
\hline CHEMBL1505656 & 688467 & 3.1003 & 3.0051 & TRN & \\
\hline CHEMBL3209698 & 688467 & 4.7342 & 4.6647 & TRN & \\
\hline CHEMBL1373790 & 688467 & 4.1929 & 4.0649 & TRN & \\
\hline CHEMBL1373843 & 688467 & 4.3776 & 4.3146 & TRN & \\
\hline CHEMBL1489593 & 688467 & 4.4339 & 4.2456 & TRN & \\
\hline CHEMBL1504012 & 688467 & 4.4605 & 4.7331 & TRN & \\
\hline CHEMBL3190105 & 688467 & 3.1003 & 3.0987 & TRN & \\
\hline CHEMBL1478894 & 688467 & 3.1003 & 3.053 & TST & \\
\hline CHEMBL1595850 & 688467 & 3.1003 & 3.0698 & TRN & \\
\hline CHEMBL1445372 & 688467 & 4.7031 & 4.3575 & TST & \\
\hline CHEMBL1336006 & 688467 & 3.1003 & 3.0269 & TRN & \\
\hline CHEMBL1407515 & 688467 & 4.0101 & 3.4766 & TRN & \\
\hline CHEMBL1345385 & 688467 & 3.1003 & 3.68 & TRN & \\
\hline CHEMBL1986690 & 688467 & 3.1003 & 3.5939 & TRN & \\
\hline CHEMBL1506760 & 688467 & 3.1003 & 2.995 & TRN & \\
\hline CHEMBL1306899 & 688467 & 3.1003 & 3.0212 & TRN & \\
\hline CHEMBL1557326 & 688467 & 4.6908 & 4.3571 & TRN & \\
\hline CHEMBL1601884 & 688467 & 3.1003 & 3.014 & TRN & \\
\hline CHEMBL1456983 & 688467 & 3.1003 & 3.0557 & TRN & \\
\hline CHEMBL1588102 & 688467 & 4.9404 & 4.7283 & TRN & \\
\hline CHEMBL1313434 & 688467 & 4.0467 & 3.5417 & TST & \\
\hline CHEMBL1458189 & 688467 & 3.1003 & 2.9759 & TRN & \\
\hline CHEMBL3209573 & 688467 & 4.8739 & 4.7936 & TRN & \\
\hline CHEMBL1430645 & 688467 & 3.1003 & 3.0458 & TST & \\
\hline CHEMBL3190678 & 688467 & 3.1003 & 3.048 & TST & \\
\hline CHEMBL1457449 & 688467 & 3.1003 & 3.2602 & TRN & \\
\hline CHEMBL1470470 & 688467 & 4.1476 & 3.8333 & TRN & \\
\hline CHEMBL1575265 & 688467 & 3.1003 & 2.9672 & TRN & \\
\hline CHEMBL1583907 & 688467 & 3.1003 & 3.7692 & TRN & \\
\hline CHEMBL1390367 & 688467 & 3.1003 & 2.9757 & TRN & \\
\hline CHEMBL1449791 & 688467 & 3.1003 & 2.99 & TRN & \\
\hline CHEMBL1306199 & 688467 & 3.1003 & 4.0779 & TRN & \\
\hline CHEMBL1538696 & 688467 & 3.1003 & 3.1213 & TRN & \\
\hline CHEMBL1542477 & 688467 & 4.2032 & 4.1919 & TRN & \\
\hline CHEMBL1598467 & 688467 & 3.1003 & 3.03899 & 99999999997 & TRN \\
\hline CHEMBL1389672 & 688467 & 3.1003 & 2.9622 & TRN & \\
\hline CHEMBL1581201 & 688467 & 3.1003 & 3.2773 & TRN & \\
\hline CHEMBL1329604 & 688467 & 4.9602 & 4.6722 & TRN & \\
\hline CHEMBL1418035 & 688467 & 4.2635 & 4.172 & TRN & \\
\hline CHEMBL1488374 & 688467 & 4.2655 & 3.7482 & TRN & \\
\hline CHEMBL1525574 & 688467 & 5.0622 & 5.2389 & TRN & \\
\hline CHEMBL1359239 & 688467 & 3.1003 & 3.3334 & TRN & \\
\hline CHEMBL3189704 & 688467 & 3.1003 & 3.0957 & TRN & \\
\hline
\end{tabular}

Page 27675 


\begin{tabular}{|c|c|c|c|c|c|c|}
\hline & & \multicolumn{5}{|c|}{ Supplemental Table S2.txt } \\
\hline CHEMBL1328108 & 688467 & 3.1003 & 2.9594 & TRN & & \\
\hline CHEMBL1584541 & 688467 & 3.1003 & 3.2333 & TRN & & \\
\hline CHEMBL1968356 & 688467 & 3.1003 & 3.1909 & TRN & & \\
\hline CHEMBL1488539 & 688467 & 4.1285 & 3.8384 & TRN & & \\
\hline CHEMBL1472502 & 688467 & 3.1003 & 3.0739 & TRN & & \\
\hline CHEMBL1425489 & 688467 & 3.1003 & 3.1017 & TST & & \\
\hline CHEMBL1324080 & 688467 & 3.1003 & 3.1441 & TRN & & \\
\hline CHEMBL1595702 & 688467 & 4.7645 & 4.474 & TRN & & \\
\hline CHEMBL1368233 & 688467 & 3.1003 & 3.1252 & TRN & & \\
\hline CHEMBL1544695 & 688467 & 3.1003 & 3.0992 & TRN & & \\
\hline CHEMBL1439502 & 688467 & 3.1003 & 3.0408 & TRN & & \\
\hline CHEMBL3197880 & 688467 & 3.1003 & 2.9564 & TRN & & \\
\hline CHEMBL1495320 & 688467 & 4.5885 & 4.5156 & TRN & & \\
\hline CHEMBL1478329 & 688467 & 3.1003 & 3.1647 & TRN & & \\
\hline CHEMBL1417370 & 688467 & 3.1003 & 3.0277 & TST & & \\
\hline CHEMBL1404571 & 688467 & 3.1003 & 3.0454 & TRN & & \\
\hline CHEMBL1508357 & 688467 & 3.1003 & 3.0852 & TST & & \\
\hline CHEMBL1560867 & 688467 & 3.1003 & 3.1161 & TRN & & \\
\hline CHEMBL1300026 & 688467 & 3.1003 & 3.0238 & TRN & & \\
\hline CHEMBL1472393 & 688467 & 4.7678 & 4.8178 & TRN & & \\
\hline CHEMBL1444824 & 688467 & 3.1003 & 3.2599 & TRN & & \\
\hline CHEMBL1579143 & 688467 & 3.1003 & 3.0072 & TST & & \\
\hline CHEMBL1386483 & 688467 & 3.1003 & 3.0982 & TST & & \\
\hline CHEMBL1495975 & 688467 & 3.1003 & 3.7216 & TRN & & \\
\hline CHEMBL3189578 & 688467 & 3.1003 & 3.0301 & TRN & & \\
\hline CHEMBL1563940 & 688467 & 3.1003 & 3.213 & TRN & & \\
\hline CHEMBL 2000686 & 688467 & 3.1003 & 3.0768 & TRN & & \\
\hline CHEMBL1426120 & 688467 & 3.1003 & 2.9982 & TRN & & \\
\hline CHEMBL1301961 & 688467 & 3.1003 & 3.0527 & TRN & & \\
\hline CHEMBL1557929 & 688467 & 3.1003 & 3.0968 & TRN & & \\
\hline CHEMBL1500181 & 688467 & 3.1003 & 2.9995 & TST & & \\
\hline CHEMBL1428087 & 688467 & 3.1003 & 3.3277 & TST & & \\
\hline CHEMBL1602811 & 688467 & 4.8775 & 4.6588 & TST & & \\
\hline CHEMBL1352863 & 688467 & 3.1003 & 3.0377 & TST & & \\
\hline CHEMBL1405757 & 688467 & 3.1003 & 3.0748 & TST & & \\
\hline CHEMBL1451889 & 688467 & 3.1003 & 4.0672 & TST & & \\
\hline CHEMBL1540811 & 688467 & $4.2810 e$ & 00000000 & $\partial 1$ & 4.5973 & TST \\
\hline CHEMBL1389115 & 688467 & 3.1003 & 3.0736 & TST & & \\
\hline CHEMBL1500513 & 688467 & 3.1003 & 2.9324 & TST & & \\
\hline CHEMBL1582123 & 688467 & 4.4035 & 4.5027 & TST & & \\
\hline CHEMBL3209557 & 688467 & 3.1003 & 3.1172 & TST & & \\
\hline CHEMBL1306879 & 688467 & 4.5343 & 4.2457 & TST & & \\
\hline CHEMBL1427319 & 688467 & 3.1003 & 3.3282 & TST & & \\
\hline CHEMBL1608778 & 688467 & 3.1003 & 3.1348 & TST & & \\
\hline CHEMBL3208420 & 688467 & 4.9488 & 4.9769 & TST & & \\
\hline CHEMBL1478908 & 688467 & 3.1003 & 3.0459 & TST & & \\
\hline CHEMBL1424266 & 688467 & 3.1003 & 3.082 & TST & & \\
\hline CHEMBL1372267 & 688467 & 3.1003 & 3.0923 & TST & & \\
\hline
\end{tabular}


Supplemental Table S2.txt

\begin{tabular}{|c|c|c|c|c|}
\hline CHEMBL1612392 & 688467 & 4.567 & 4.5936 & TST \\
\hline CHEMBL1468869 & 688467 & 4.9259 & 5.1592 & TST \\
\hline CHEMBL1528003 & 688467 & 3.1003 & 3.2915 & TST \\
\hline CHEMBL1531952 & 688467 & 3.1003 & 3.0631 & TST \\
\hline CHEMBL1324769 & 688467 & 3.1003 & 3.0619 & TST \\
\hline CHEMBL1461351 & 688467 & 4.7196 & 4.5838 & TST \\
\hline CHEMBL1426581 & 688467 & 4.7263 & 5.0344 & TST \\
\hline CHEMBL1600402 & 688467 & 3.1003 & 3.9733 & TST \\
\hline CHEMBL1606245 & 688467 & 3.1003 & 2.9714 & TST \\
\hline CHEMBL1564775 & 688467 & 3.1003 & 3.1799 & TST \\
\hline CHEMBL1526221 & 688467 & 3.1003 & 3.0428 & TST \\
\hline CHEMBL1521835 & 688467 & 3.1003 & 3.0629 & TST \\
\hline CHEMBL1398618 & 688467 & 4.61100 & 00000000 & 4.3616 \\
\hline CHEMBL1458535 & 688467 & 3.1003 & 3.034 & TST \\
\hline CHEMBL1385846 & 688467 & 3.1003 & 3.0788 & TST \\
\hline CHEMBL1528515 & 688467 & 3.1003 & 4.001 & TST \\
\hline CHEMBL1405306 & 688467 & 4.7744 & 4.6211 & TST \\
\hline CHEMBL1607599 & 688467 & 4.8318 & 4.4181 & TST \\
\hline CHEMBL1609070 & 688467 & 3.1003 & 3.0038 & TST \\
\hline CHEMBL1602928 & 688467 & 3.1003 & 2.996000 & 00000000004 \\
\hline CHEMBL1306142 & 688467 & 3.1003 & 3.1673 & TST \\
\hline CHEMBL1432295 & 688467 & 3.1003 & 3.0794 & TST \\
\hline CHEMBL1379482 & 688467 & 3.1003 & 3.1536 & TST \\
\hline CHEMBL1305056 & 688467 & 3.1003 & 2.9969 & TST \\
\hline CHEMBL1526244 & 688467 & 3.1003 & 2.9568 & TST \\
\hline CHEMBL1380816 & 688467 & 5.0096 & 4.2302 & TST \\
\hline CHEMBL566064 & 688467 & 4.7817 & 4.5131 & TST \\
\hline CHEMBL1325903 & 688467 & 3.1003 & 3.0167 & TST \\
\hline CHEMBL1334936 & 688467 & 3.1003 & 3.0543 & TST \\
\hline CHEMBL1409987 & 736835 & 3.0 & 3.9204 & TRN \\
\hline CHEMBL1722719 & 736835 & 5.5513 & 5.2432 & TRN \\
\hline CHEMBL1718018 & 736835 & 5.2941 & 5.1055 & TRN \\
\hline CHEMBL1492305 & 736835 & 5.7878 & 5.5246 & TRN \\
\hline CHEMBL408702 & 736835 & 3.0 & 3.55 & TST \\
\hline CHEMBL3193786 & 736835 & 5.5986 & 5.7039 & TRN \\
\hline CHEMBL1714966 & 736835 & 4.6778 & 4.6997 & TRN \\
\hline CHEMBL1589711 & 736835 & 4.4045 & 4.3141 & TRN \\
\hline CHEMBL1574614 & 736835 & 4.1778 & 3.5751 & TRN \\
\hline CHEMBL1373210 & 736835 & 5.5544 & 5.4464 & TRN \\
\hline CHEMBL1718472 & 736835 & 5.0292 & 4.8092 & TRN \\
\hline CHEMBL1411988 & 736835 & 3.0 & 3.9845 & TRN \\
\hline CHEMBL1713374 & 736835 & 3.0 & 3.5572 & TST \\
\hline CHEMBL1487024 & 736835 & 4.2306 & 4.7966 & TRN \\
\hline CHEMBL1715912 & 736835 & 3.0 & 2.9515 & TRN \\
\hline CHEMBL1734920 & 736835 & 3.0 & 2.615 & TRN \\
\hline CHEMBL601167 & 736835 & 6.011 & 5.1809 & TRN \\
\hline CHEMBL1704862 & 736835 & 6.0209 & 5.8939 & TRN \\
\hline CHEMBL1532025 & 736835 & 4.9172 & 4.7679 & TRN \\
\hline
\end{tabular}

Page 27677 


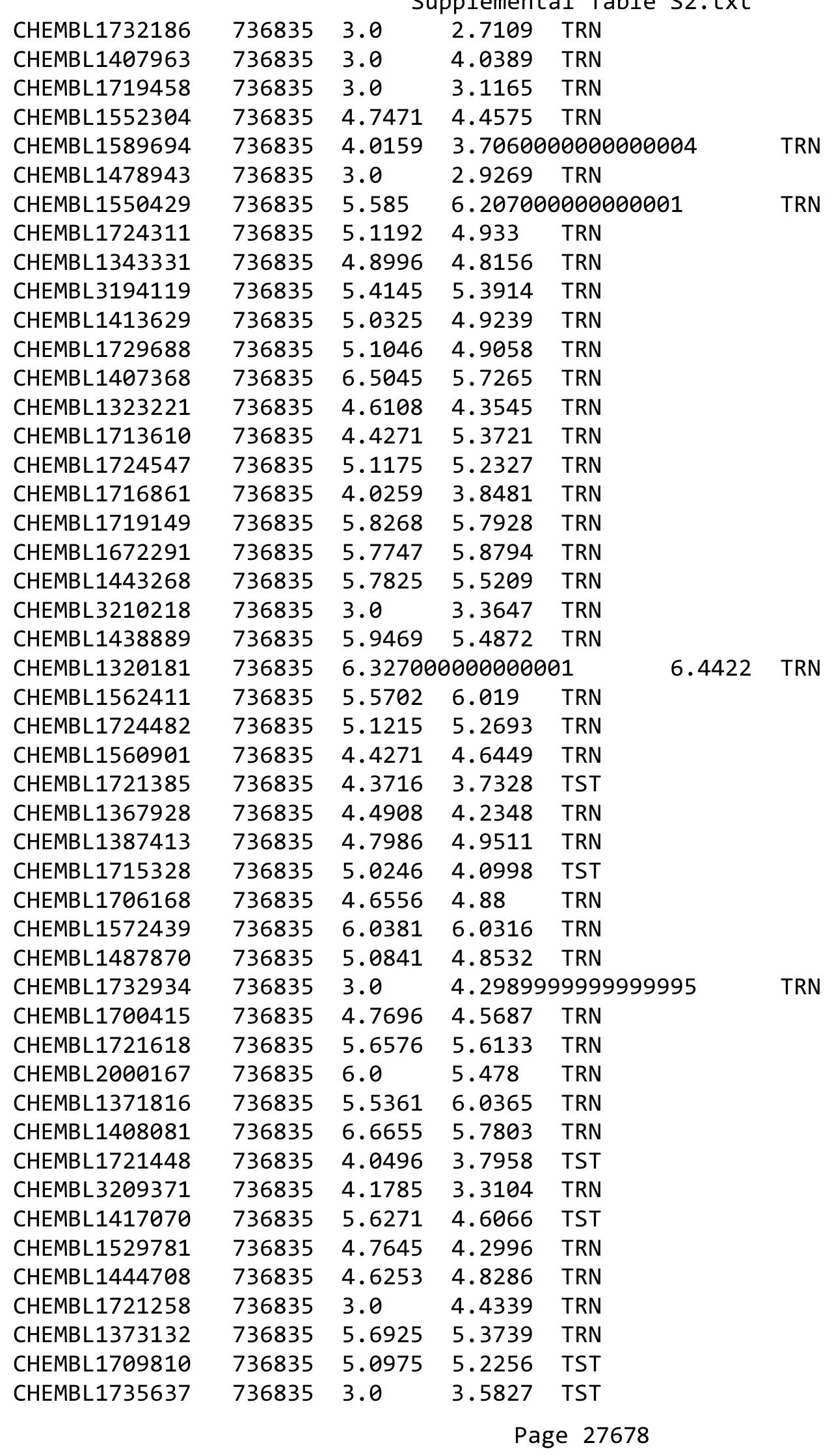




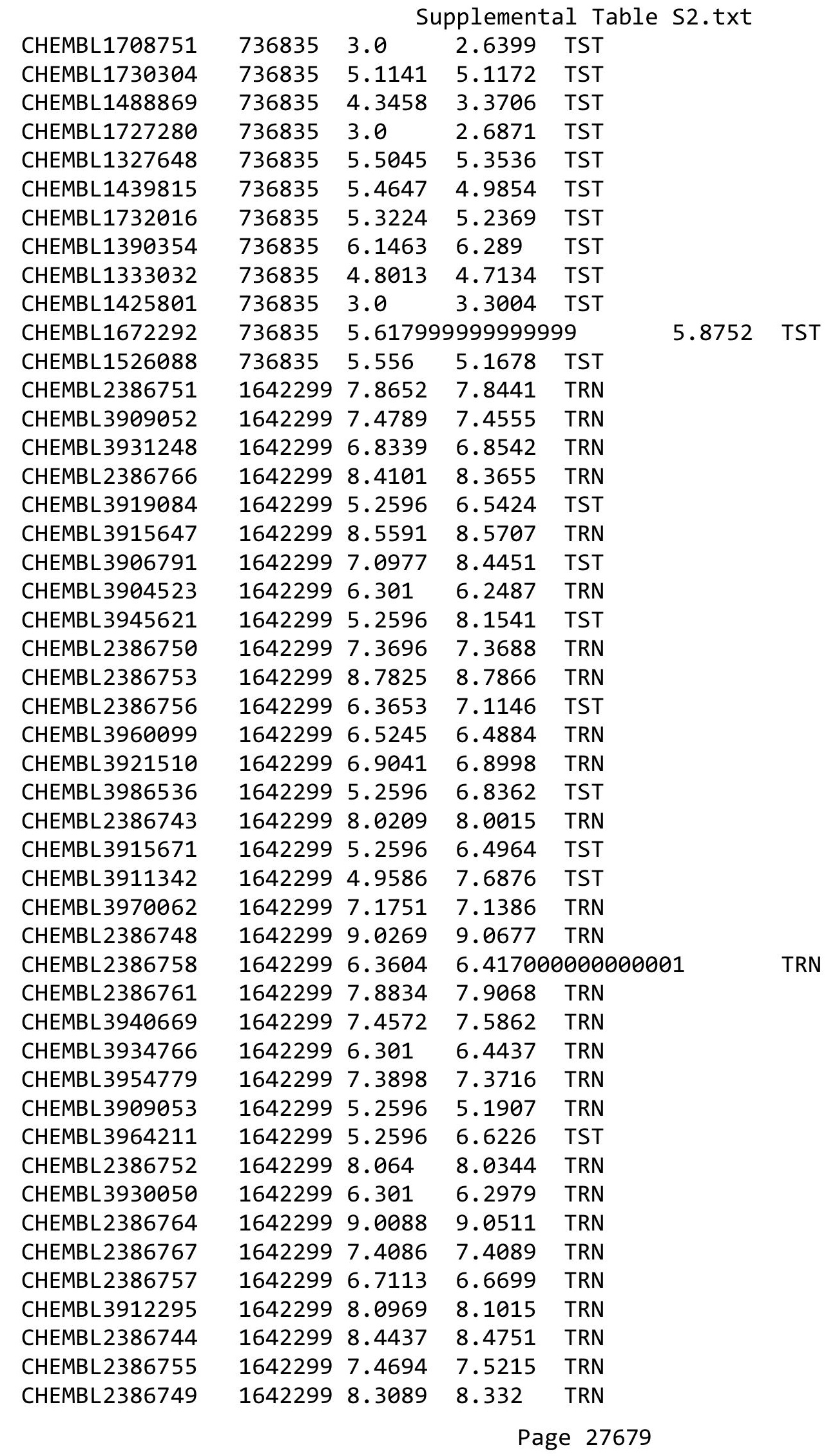


Supplemental Table S2.txt

\begin{tabular}{|c|c|c|c|c|}
\hline CHEMBL2386769 & 1642299 & 7.7385 & 7.7538 & TRN \\
\hline CHEMBL3913247 & 1642299 & 5.2596 & 7.3411 & TST \\
\hline CHEMBL2386770 & 1642299 & 9.7959 & 9.7342 & TRN \\
\hline CHEMBL3958753 & 1642299 & 5.2596 & 5.2212 & TRN \\
\hline CHEMBL3905538 & 1642299 & 8.3716 & 8.4405 & TRN \\
\hline CHEMBL 2386747 & 1642299 & 9.6576 & 9.5539 & TRN \\
\hline CHEMBL3900000 & 1642299 & 6.9083 & 6.8338 & TRN \\
\hline CHEMBL3957886 & 1642299 & 6.8462 & 6.8753 & TRN \\
\hline CHEMBL3983413 & 1642299 & 8.3526 & 7.2526 & TST \\
\hline CHEMBL3982462 & 1642299 & 7.2609 & 7.2351 & TRN \\
\hline CHEMBL2386768 & 1642299 & 7.4481 & 7.4813 & TRN \\
\hline CHEMBL3975006 & 1642299 & 5.2596 & 7.2575 & TST \\
\hline CHEMBL 2386759 & 1642299 & 7.5817 & 7.6287 & TRN \\
\hline CHEMBL3911303 & 1642299 & 5.4239 & 7.1969 & TST \\
\hline CHEMBL3971170 & 1642299 & 9.0044 & 9.0383 & TRN \\
\hline CHEMBL 2386760 & 1642299 & 8.2924 & 8.2096 & TRN \\
\hline CHEMBL2386765 & 1642299 & 8.2175 & 8.1715 & TRN \\
\hline CHEMBL 3893495 & 1642299 & 6.301 & 6.3531 & TRN \\
\hline CHEMBL3916163 & 1642299 & 7.3233 & 7.3482 & TRN \\
\hline CHEMBL 2386762 & 1642299 & 8.9469 & 8.9761 & TRN \\
\hline CHEMBL 2386754 & 1642299 & 8.2204 & 8.199 & TRN \\
\hline CHEMBL 2386763 & 1642299 & 8.7423 & 8.703 & TRN \\
\hline CHEMBL 3898860 & 1642299 & 7.7575 & 7.7478 & TRN \\
\hline CHEMBL3978290 & 1642299 & 5.2596 & 5.2466 & TRN \\
\hline CHEMBL3921110 & 1642299 & 6.8901 & 6.4147 & TST \\
\hline CHEMBL 3896497 & 1642299 & 5.2596 & 5.1757 & TST \\
\hline CHEMBL 3894571 & 1642299 & 9.4437 & 8.5089 & TST \\
\hline CHEMBL3987173 & 1642299 & 5.2596 & 7.1288 & TST \\
\hline CHEMBL3975059 & 1642299 & 6.301 & 6.7946 & TST \\
\hline CHEMBL195713 & 303261 & 6.0846 & 6.0869 & TRN \\
\hline CHEMBL365809 & 303261 & 3.0 & 2.7408 & TRN \\
\hline CHEMBL192039 & 303261 & 3.0 & 2.8822 & TRN \\
\hline CHEMBL191822 & 303261 & 7.4437 & 7.2179 & TRN \\
\hline CHEMBL365517 & 303261 & 6.284 & 6.2558 & TRN \\
\hline CHEMBL365392 & 303261 & 6.6576 & 7.1601 & TRN \\
\hline CHEMBL191625 & 303261 & 3.0 & 3.4137 & TRN \\
\hline CHEMBL370299 & 303261 & 4.857 & 4.5724 & TRN \\
\hline CHEMBL365161 & 303261 & 6.1331 & 5.3414 & TST \\
\hline CHEMBL90039 & 303261 & 3.0 & 2.9485 & TRN \\
\hline CHEMBL366205 & 303261 & 7.2716 & 7.0085 & TRN \\
\hline CHEMBL192252 & 303261 & 7.7905 & 7.8472 & TRN \\
\hline CHEMBL363186 & 303261 & 3.0 & 3.6026 & TST \\
\hline CHEMBL191513 & 303261 & 6.2366 & 6.6866 & TRN \\
\hline CHEMBL191688 & 303261 & 3.0 & 3.5674 & TST \\
\hline CHEMBL363855 & 303261 & 3.0 & 2.92100 & 00000000003 \\
\hline CHEMBL364734 & 303261 & 3.0 & 2.7147 & TRN \\
\hline CHEMBL362996 & 303261 & 8.2147 & 7.8992 & TRN \\
\hline CHEMBL192241 & 303261 & 7.8239 & 8.1455 & TRN \\
\hline
\end{tabular}

Page 27680 


\begin{tabular}{|c|c|c|c|c|c|}
\hline \multicolumn{6}{|c|}{ Supplemental Table s2.txt } \\
\hline CHEMBL190613 & 303261 & 3.0 & 3.6132 & TST & \\
\hline CHEMBL192589 & 303261 & 7.6635 & 7.7751 & TRN & \\
\hline CHEMBL190496 & 303261 & 3.0 & 2.8623 & TRN & \\
\hline CHEMBL 364588 & 303261 & 3.0 & 3.2441 & TRN & \\
\hline CHEMBL371858 & 303261 & 6.9245 & 6.8734 & TRN & \\
\hline CHEMBL 371371 & 303261 & 4.8041 & 3.5278 & TST & \\
\hline CHEMBL189988 & 303261 & 3.0 & 3.0008 & TRN & \\
\hline CHEMBL193180 & 303261 & 7.3197 & 7.2322 & TRN & \\
\hline CHEMBL 8320 & 303261 & 3.0 & 3.91399 & 99999999997 & TST \\
\hline CHEMBL192809 & 303261 & 3.0 & 3.18899 & 99999999996 & TRN \\
\hline CHEMBL193228 & 303261 & 8.3872 & 8.4336 & TRN & \\
\hline CHEMBL363919 & 303261 & 3.0 & 3.1884 & TST & \\
\hline CHEMBL365129 & 303261 & 3.0 & 3.0278 & TRN & \\
\hline CHEMBL191739 & 303261 & 8.0605 & 7.8593 & TRN & \\
\hline CHEMBL364729 & 303261 & 5.9851 & 6.035 & TST & \\
\hline CHEMBL365982 & 303261 & 3.0 & 2.9532 & TRN & \\
\hline CHEMBL435109 & 303261 & 7.1421 & 7.1266 & TRN & \\
\hline CHEMBL192712 & 303261 & 3.0 & 3.3183 & TST & \\
\hline CHEMBL189886 & 303261 & 6.9872 & 7.1339 & TRN & \\
\hline CHEMBL192474 & 303261 & 6.699 & 6.7057 & TRN & \\
\hline CHEMBL192595 & 303261 & 3.0 & 3.1934 & TRN & \\
\hline CHEMBL192648 & 303261 & 3.0 & 3.4557 & TRN & \\
\hline CHEMBL191800 & 303261 & 3.0 & 3.2932 & TST & \\
\hline CHEMBL 284028 & 303261 & 3.0 & 4.0808 & TST & \\
\hline CHEMBL192627 & 303261 & 7.2612 & 6.6587 & TST & \\
\hline CHEMBL191847 & 303261 & 7.9245 & 7.7806 & TRN & \\
\hline CHEMBL 371523 & 303261 & 5.4034 & 4.8988 & TRN & \\
\hline CHEMBL192180 & 303261 & 7.6216 & 7.6155 & TRN & \\
\hline CHEMBL192410 & 303261 & 6.4001 & 6.3002 & TRN & \\
\hline CHEMBL192139 & 303261 & 8.0223 & 8.0135 & TRN & \\
\hline CHEMBL425192 & 303261 & 3.0 & 2.9522 & TRN & \\
\hline CHEMBL191676 & 303261 & 5.6676 & 5.468 & TRN & \\
\hline CHEMBL193229 & 303261 & 7.75700 & 00000000 & 7.5134 & TRN \\
\hline CHEMBL192625 & 303261 & 7.3045 & 7.4126 & TRN & \\
\hline CHEMBL370059 & 303261 & 7.1938 & 7.0846 & TRN & \\
\hline CHEMBL193140 & 303261 & 6.9666 & 7.319 & TRN & \\
\hline CHEMBL192258 & 303261 & 5.3072 & 5.2772 & TRN & \\
\hline CHEMBL372856 & 303261 & 3.0 & 3.2131 & TRN & \\
\hline CHEMBL192657 & 303261 & 3.0 & 4.6641 & TST & \\
\hline CHEMBL189727 & 303261 & 3.0 & 3.7706 & TST & \\
\hline CHEMBL191796 & 303261 & 6.5735 & 7.4221 & TST & \\
\hline CHEMBL3654295 & 1528450 & 3.4318 & 3.50399 & 99999999996 & TRN \\
\hline CHEMBL3650896 & 1528450 & 5.3188 & 5.5694 & TRN & \\
\hline CHEMBL3650947 & 1528450 & 3.4318 & 4.1892 & TST & \\
\hline CHEMBL3650930 & 1528450 & 5.1871 & 5.2312 & TRN & \\
\hline CHEMBL3654281 & 1528450 & 5.5086 & 5.2507 & TRN & \\
\hline CHEMBL3650906 & 1528450 & 5.1675 & 5.16 & TRN & \\
\hline CHEMBL3650942 & 1528450 & 4.7447 & 4.9109 & TRN & \\
\hline
\end{tabular}


Supplemental Table S2.txt

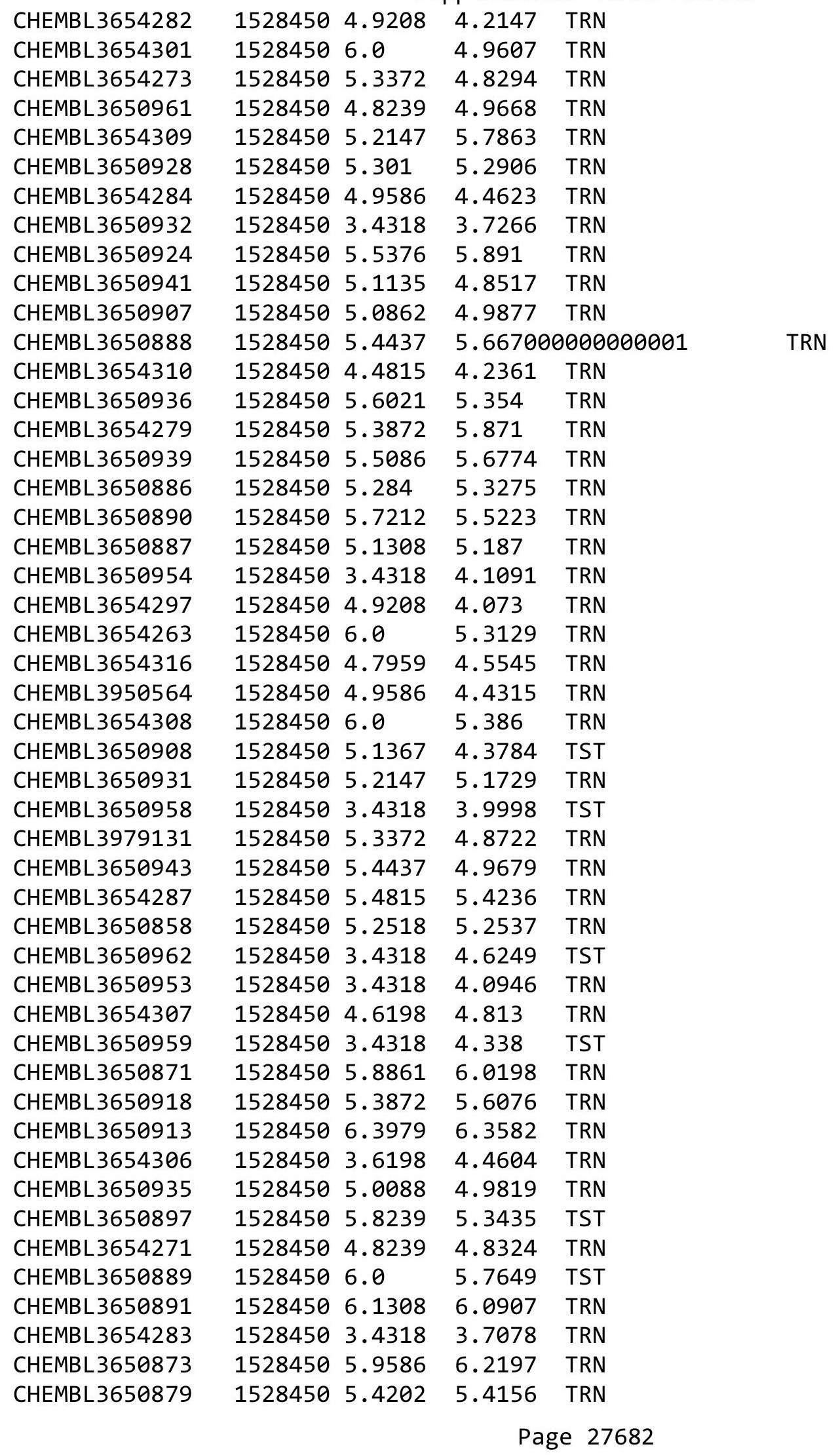


Supplemental Table S2.txt

\begin{tabular}{|c|c|c|c|c|}
\hline 5 & & & 4.7582 & \\
\hline & & 3.4318 & 3.7399 & \\
\hline EN & 50 & & & \\
\hline HEMBL & & & & \\
\hline AEMBL3654266 & 528450 & 18 & 4043 & \\
\hline HEMBL3654274 & 50 & & 2204 & \\
\hline 319 & & & 586 & \\
\hline AEMBL36 & & & & \\
\hline HEMBL3654289 & 528450 & 565 & 5619 & \\
\hline HEMBL3650914 & 528450 & & 1798 & \\
\hline HEMBL 365 & 50 & & & \\
\hline HEMBL & 50 & & 958 & \\
\hline AEMBL & & & & \\
\hline HEMBL3650895 & 528450 & & 4261 & \\
\hline HEMBL365 & 50 & & & \\
\hline HEMBL3 & 6 & 6 & 905 & וס \\
\hline HEMBL & 0 & & & RN \\
\hline HEMBL & 50 & & 447 & \\
\hline HEMBL3 & 50 & & & \\
\hline HEMBL365 & & & & $r$ \\
\hline HEMBL; & ש & & 78 & KIV \\
\hline HEM & & & 44 & RN \\
\hline HEMBL & 50 & & 178 & ST \\
\hline HEMBL3 & & & & \\
\hline HEMBL365 & 50 & & 97 & IRIN \\
\hline HEMBL3 & & & 99 & RN \\
\hline HFMP & & & & ST \\
\hline 17 & & & 21 & RN \\
\hline HEMBL3 & & & & IK \\
\hline HEMBL365 & 50 & & 154 & TRN \\
\hline AEMBL & & & 54 & 「RN \\
\hline HFM & & & & ГST \\
\hline וסMFנI & & & & 「RN \\
\hline HEMBL3 & & & & RN \\
\hline HEMBL 365 & 50 & & & RN \\
\hline $15 \mathrm{MPI}$ & 50 & & 21 & TRN \\
\hline 8 & & & 305 & TRN \\
\hline HEMBL3 & & & & 「RN \\
\hline HEMBL3 & $\theta$ & & 095 & TR \\
\hline 56 & & & 931 & RN \\
\hline HFMRI 3 & & & 994 & RN \\
\hline HEMBL3 & 50 & & 509 & ST \\
\hline HEMBL3654267 & 50 & & 9483 & TRN \\
\hline HEMBL 365 & 52 & & 195 & $=8$ \\
\hline CHEMBL3654276 & & & & ST \\
\hline HEMBL3 & 152 & & 8283 & \\
\hline CHEMBL3 & 152 & 5.3 & 5.2727 & ST \\
\hline CHEMBL3650885 & 1528450 & 3.4318 & 5.1051 & - \\
\hline
\end{tabular}

Page 27683 
Supplemental Table S2.txt

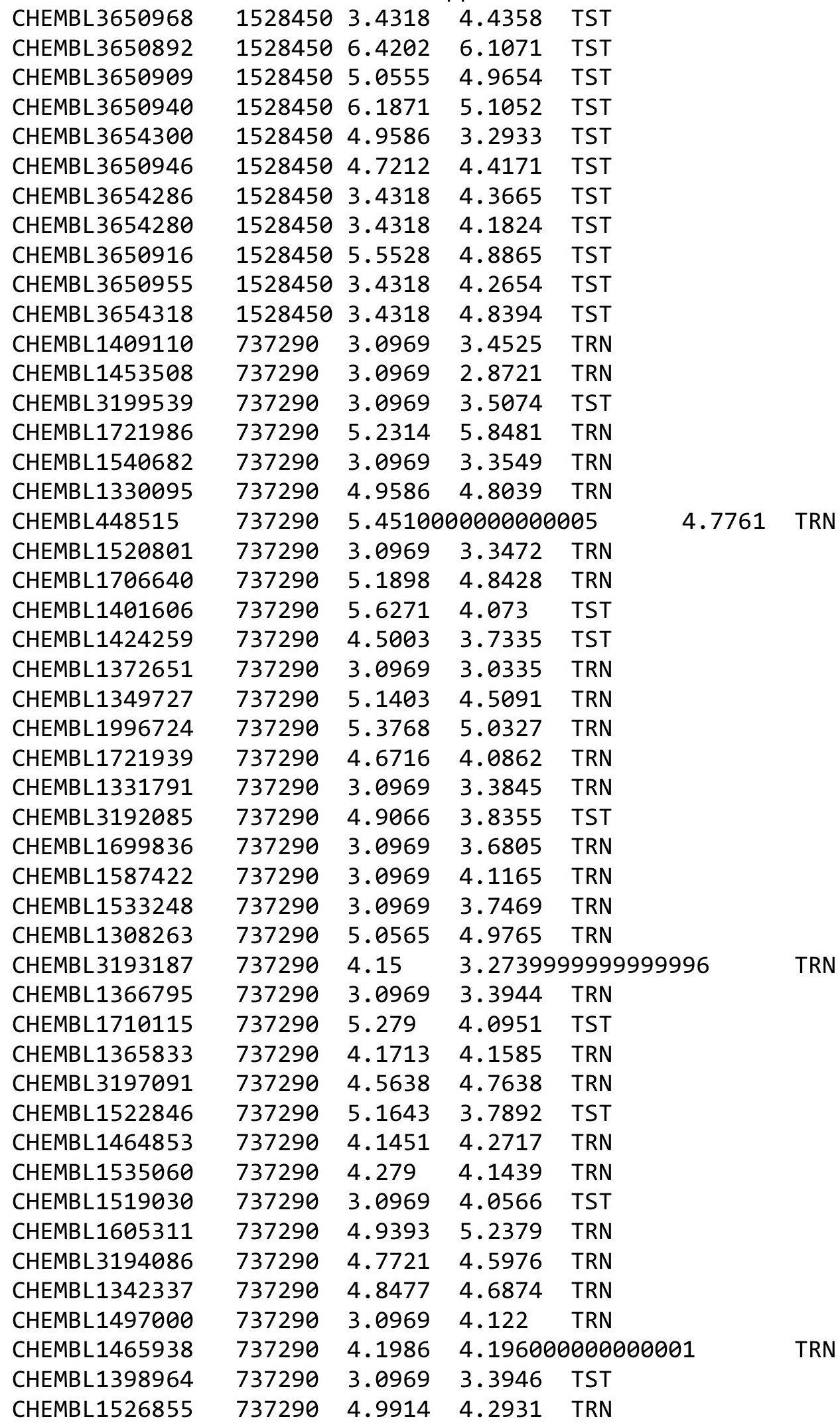

Page 27684 
Supplemental Table S2.txt

\begin{tabular}{|c|c|c|c|c|c|}
\hline CHEMBL1969046 & 737290 & 4.9586 & 4.7982 & TRN & \\
\hline CHEMBL1611371 & 737290 & 3.0969 & 4.08 & TST & \\
\hline CHEMBL1599965 & 737290 & 4.8697 & 4.0502 & TRN & \\
\hline CHEMBL1701224 & 737290 & 3.0969 & 3.1265 & TRN & \\
\hline CHEMBL1458873 & 737290 & 4.2565 & 4.0215 & TST & \\
\hline CHEMBL1376835 & 737290 & 5.153 & 4.2699 & TRN & \\
\hline CHEMBL3197637 & 737290 & 5.2388 & 5.3053 & TRN & \\
\hline CHEMBL1964361 & 737290 & 3.0969 & 4.103 & TST & \\
\hline CHEMBL1576324 & 737290 & 3.0969 & 3.7008 & TRN & \\
\hline CHEMBL1714002 & 737290 & 5.3107 & 4.9176 & TRN & \\
\hline CHEMBL1711303 & 737290 & 4.7055 & 5.1645 & TRN & \\
\hline CHEMBL1550490 & 737290 & 3.0969 & 4.8337 & TRN & \\
\hline CHEMBL1558210 & 737290 & 3.0969 & 3.6063 & TRN & \\
\hline CHEMBL1470476 & 737290 & 3.0969 & 3.2804 & TST & \\
\hline CHEMBL1442136 & 737290 & 3.0969 & 3.2206 & TRN & \\
\hline CHEMBL1302463 & 737290 & 3.0969 & 3.7268 & TRN & \\
\hline CHEMBL1545792 & 737290 & 3.0969 & 3.3688 & TRN & \\
\hline CHEMBL1479238 & 737290 & 5.1361 & 4.2823 & TST & \\
\hline CHEMBL456295 & 737290 & 4.9957 & 4.8392 & TRN & \\
\hline CHEMBL1372574 & 737290 & 4.5622 & 4.0354 & TRN & \\
\hline CHEMBL1704261 & 737290 & 5.5143 & 5.0543 & TRN & \\
\hline CHEMBL1336922 & 737290 & 4.7447 & 3.7332 & TRN & \\
\hline CHEMBL1329141 & 737290 & 3.0969 & 3.0944 & TRN & \\
\hline CHEMBL1315950 & 737290 & 4.8761 & 3.9008 & TST & \\
\hline CHEMBL1457825 & 737290 & 5.4306 & 4.7129 & TRN & \\
\hline CHEMBL 2028187 & 737290 & 4.3261 & 3.5532 & TRN & \\
\hline CHEMBL1416259 & 737290 & 3.0969 & 2.325 & TRN & \\
\hline CHEMBL1303693 & 737290 & 4.7235 & 4.4875 & TRN & \\
\hline CHEMBL1724454 & 737290 & 5.6819 & 4.1525 & TST & \\
\hline CHEMBL1337591 & 737290 & 3.0969 & 3.6251 & TRN & \\
\hline CHEMBL1420173 & 737290 & 3.0969 & 4.1229 & TRN & \\
\hline CHEMBL523200 & 737290 & 3.0969 & 3.50399 & 99999999996 & TRN \\
\hline CHEMBL1982305 & 737290 & 5.1681 & 5.099 & TRN & \\
\hline CHEMBL1344648 & 737290 & 3.0969 & 3.1096 & TRN & \\
\hline CHEMBL1385561 & 737290 & 4.8894 & 4.7556 & TRN & \\
\hline CHEMBL1484163 & 737290 & 4.8928 & 4.8393 & TRN & \\
\hline CHEMBL1964407 & 737290 & 4.51 & 3.7988 & TRN & \\
\hline CHEMBL1347591 & 737290 & 4.6478 & 4.9457 & TRN & \\
\hline CHEMBL1471595 & 737290 & 3.0969 & 3.3559 & TST & \\
\hline CHEMBL1305447 & 737290 & 4.9031 & 4.2406 & TST & \\
\hline CHEMBL1496503 & 737290 & 3.0969 & 3.4617 & TRN & \\
\hline CHEMBL1381676 & 737290 & 3.0969 & 3.6654 & TRN & \\
\hline CHEMBL1452254 & 737290 & 3.0969 & 3.4272 & TRN & \\
\hline CHEMBL1449694 & 737290 & 4.6615 & 3.6686 & TST & \\
\hline CHEMBL1440594 & 737290 & 4.6737 & 4.1831 & TRN & \\
\hline CHEMBL1556661 & 737290 & 3.0969 & 4.3375 & TRN & \\
\hline CHEMBL1492213 & 737290 & 4.6198 & 3.9569 & TRN & \\
\hline CHEMBL1612113 & 737290 & 5.0438 & 4.3828 & TRN & \\
\hline
\end{tabular}

Page 27685 
Supplemental Table S2.txt

\begin{tabular}{|c|c|c|c|c|}
\hline 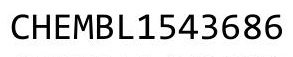 & & & & \\
\hline HEMBL1433120 & 290 & 1891 & 0964 & \\
\hline HEMBL1431126 & 37290 & 7212 & 2449 & \\
\hline 51 & & & 4012 & \\
\hline EMBL1 & 290 & 969 & 359 & \\
\hline AEMBL1509433 & 37290 & 7932 & 2648 & \\
\hline HEMBL1710429 & 37290 & 5.0128 & .7805 & \\
\hline HEMBL1421559 & & 979 & 0932 & \\
\hline IEMBL15 & 37290 & 969 & .1167 & \\
\hline IEMBL147 & 37290 & 969 & 137 & \\
\hline HEMBL1347253 & 37290 & 7447 & 9977 & \\
\hline HEMBL1698802 & 37290 & 4.1244 & 6721 & \\
\hline HEMBL1307207 & 90 & 969 & 8004 & \\
\hline AEME & 90 & 69 & 8004 & \\
\hline AEMBL15 & 90 & 969 & 2646 & \\
\hline AEMBL1329974 & 90 & 317 & 9763 & \\
\hline HEMBL1607313 & & 969 & & \\
\hline HEMBL 27 & $\theta$ & 76 & 57 & \\
\hline HEM & & 69 & 271 & \\
\hline HEMBL13 & 90 & 39 & 59 & \\
\hline HEMBL1342410 & & 852 & 778 & \\
\hline HEMBL141 & & 986 & & \\
\hline HEMBL14 & 90 & & & \\
\hline HEMBL13 & & & & \\
\hline 52 & 90 & 69 & & RN \\
\hline HEMBL13 & & 391 & & \\
\hline JEMBL14 & & 788 & 455 & ГRN \\
\hline HEMBL15 & 90 & 76 & 82 & \\
\hline HEM & 90 & 58 & 907 & RN \\
\hline HFME & & 69 & 254 & RN \\
\hline HEMBL 3195 & & & & ( \\
\hline HEMBL1576368 & & & 029 & TST \\
\hline HEMBL & & & & $\Gamma R$ \\
\hline$A F M$ & & & 97 & 「RN \\
\hline HEMBL16 & & & 7278 & RN \\
\hline HEMBL59212 & & & 9958 & IRN \\
\hline HEMBL157058 & 90 & 367 & 153 & ГRN \\
\hline $5 \Delta$ & 90 & 969 & 465 & TRN \\
\hline 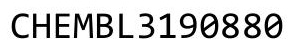 & & & & TRN \\
\hline HEMBL156 & & & & $\mathrm{RN}$ \\
\hline HEMBL145 & 90 & 962 & 851 & IRN \\
\hline HEMBL19 & 90 & 69 & 535 & \\
\hline 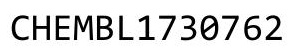 & & 449 & 872 & \\
\hline HEMBL15002 & & 969 & 7827 & \\
\hline HEMBL1580345 & & .7122 & 2543 & RN \\
\hline HEMBL2003651 & 90 & 5.2204 & 1884 & $N$ \\
\hline 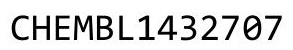 & & & & \\
\hline משת & & & & \\
\hline
\end{tabular}

Page 27686 


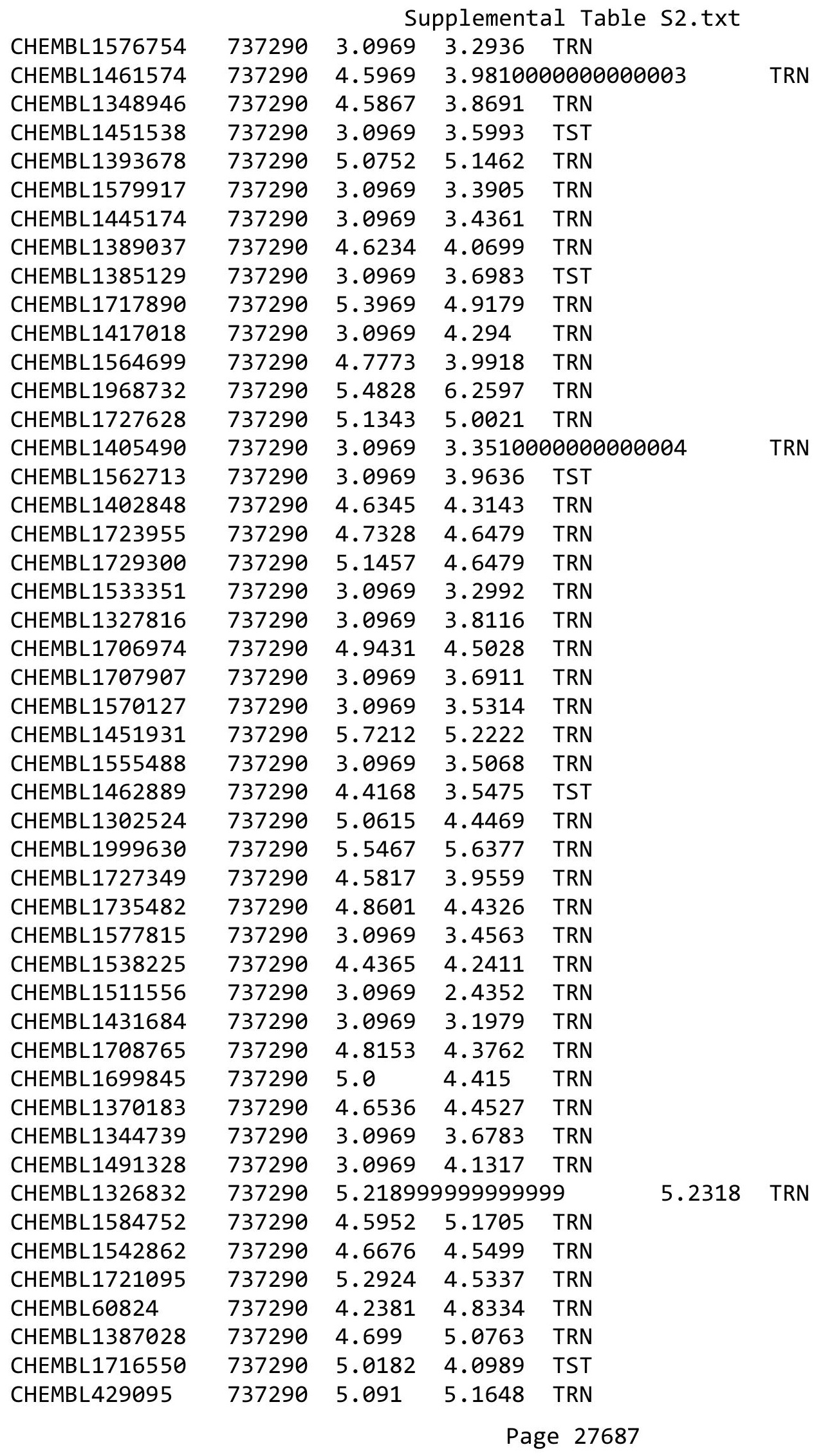


Supplemental Table S2.txt

\begin{tabular}{|c|c|c|c|c|c|}
\hline CHEMBL1451059 & 737290 & 4.2573 & 3.7283 & TRN & \\
\hline CHEMBL3195749 & 737290 & 4.2441 & 4.8602 & TRN & \\
\hline CHEMBL1440076 & 737290 & 3.0969 & 3.2077 & TRN & \\
\hline CHEMBL1335844 & 737290 & 4.2381 & 4.573 & TRN & \\
\hline CHEMBL1395907 & 737290 & 5.6216 & 5.434 & TRN & \\
\hline CHEMBL1469698 & 737290 & 4.5654 & 4.2111 & TRN & \\
\hline CHEMBL1321207 & 737290 & 5.2557 & 5.0306 & TRN & \\
\hline CHEMBL1445776 & 737290 & 5.1203 & 5.1608 & TRN & \\
\hline CHEMBL1487183 & 737290 & 4.4123 & 4.5935 & TST & \\
\hline CHEMBL1402473 & 737290 & 4.6021 & 4.0163 & TRN & \\
\hline CHEMBL1702945 & 737290 & 4.2226 & 3.5899 & TRN & \\
\hline CHEMBL1998302 & 737290 & 5.7878 & 5.0529 & TST & \\
\hline CHEMBL1301125 & 737290 & 3.0969 & 3.5532 & TST & \\
\hline CHEMBL1312974 & 737290 & 4.7258 & 3.5894 & TST & \\
\hline CHEMBL1342041 & 737290 & 4.2573 & 3.3273 & TST & \\
\hline CHEMBL1716008 & 737290 & 4.6345 & 3.9528 & TST & \\
\hline CHEMBL1730974 & 737290 & 3.0969 & 3.5226 & TST & \\
\hline CHEMBL1612983 & 737290 & 3.0969 & 2.7554 & TST & \\
\hline CHEMBL1464513 & 737290 & 5.2565 & 4.2112 & TST & \\
\hline CHEMBL1466196 & 737290 & 3.0969 & 4.0856 & TST & \\
\hline CHEMBL 2095095 & 737290 & 5.1831 & 4.9196 & TST & \\
\hline CHEMBL1366206 & 737290 & 5.6021 & 4.9388 & TST & \\
\hline CHEMBL1470135 & 737290 & 4.1062 & 4.2033 & TST & \\
\hline CHEMBL1385111 & 737290 & 4.6615 & 3.7768 & TST & \\
\hline CHEMBL1350020 & 737290 & 4.7328 & 3.9569 & TST & \\
\hline CHEMBL1301382 & 737290 & 3.0969 & 3.3831 & TST & \\
\hline CHEMBL1376029 & 737290 & 5.2434 & 4.3663 & TST & \\
\hline CHEMBL1703294 & 737290 & 3.0969 & 3.637 & TST & \\
\hline CHEMBL1491717 & 737290 & 3.0969 & 2.9815 & TST & \\
\hline CHEMBL1444565 & 737290 & 4.6517 & 4.8689 & TST & \\
\hline CHEMBL 2000517 & 737290 & 5.20200 & 000000000 & 4.8787 & TST \\
\hline CHEMBL1728280 & 737290 & 5.7375 & 5.0663 & TST & \\
\hline CHEMBL1728065 & 737290 & 4.1331 & 3.4932 & TST & \\
\hline CHEMBL 76796 & 210830 & 8.3979 & 8.8984 & TRN & \\
\hline CHEMBL298256 & 210830 & 8.0458 & 8.6612 & TRN & \\
\hline CHEMBL309395 & 210830 & 2.0 & 7.5291 & TST & \\
\hline CHEMBL 80930 & 210830 & 8.3979 & 8.2699 & TRN & \\
\hline CHEMBL75679 & 210830 & 8.699 & 9.0697 & TRN & \\
\hline CHEMBL448786 & 210830 & 9.3979 & 8.8638 & TRN & \\
\hline CHEMBL307427 & 210830 & 7.3565 & 8.5551 & TRN & \\
\hline CHEMBL311655 & 210830 & 10.0 & 8.8984 & TRN & \\
\hline CHEMBL308074 & 210830 & 7.5528 & 7.3877 & TRN & \\
\hline CHEMBL76070 & 210830 & 4.3372 & 7.338999 & 99999999995 & TST \\
\hline CHEMBL263454 & 210830 & 7.7959 & 10.3628 & TST & \\
\hline CHEMBL 76883 & 210830 & 9.1549 & 8.8984 & TRN & \\
\hline CHEMBL311043 & 210830 & 8.5229 & 7.6749 & TRN & \\
\hline CHEMBL312463 & 210830 & 7.0132 & 7.4065 & TRN & \\
\hline CHEMBL 76424 & 210830 & 8.699 & 11.5287 & TST & \\
\hline
\end{tabular}




\begin{tabular}{|c|c|c|c|c|c|}
\hline \multicolumn{6}{|c|}{ Supplemental Table S2.txt } \\
\hline CHEMBL263557 & 210830 & 7.5229 & 5.5932 & TRN & \\
\hline CHEMBL432172 & 210830 & 9.3979 & 9.7317 & TRN & \\
\hline CHEMBL307927 & 210830 & 6.0 & 10.3376 & TST & \\
\hline CHEMBL 308764 & 210830 & 7.9586 & 10.3376 & TST & \\
\hline CHEMBL78283 & 210830 & 8.0 & 8.0362 & TRN & \\
\hline CHEMBL77361 & 210830 & 5.5229 & 5.3502 & TRN & \\
\hline CHEMBL77183 & 210830 & 6.2924 & 10.3376 & TST & \\
\hline CHEMBL77998 & 210830 & 6.6198 & 7.1054 & TRN & \\
\hline CHEMBL 307597 & 210830 & 6.0 & 5.5743 & TRN & \\
\hline CHEMBL77949 & 210830 & 6.2147 & 9.6818 & TST & \\
\hline CHEMBL79655 & 210830 & 4.8239 & 4.9592 & TRN & \\
\hline CHEMBL77007 & 210830 & 8.0969 & 8.0231 & TRN & \\
\hline CHEMBL77326 & 210830 & 3.5935 & 7.7356 & TST & \\
\hline CHEMBL263244 & 210830 & 6.0458 & 5.4196 & TRN & \\
\hline CHEMBL76967 & 210830 & 2.0 & 4.5416 & TRN & \\
\hline CHEMBL307637 & 210830 & 7.3565 & 7.4143 & TRN & \\
\hline CHEMBL311482 & 210830 & 9.699 & 10.6058 & TRN & \\
\hline CHEMBL75972 & 210830 & 9.301 & 8.8984 & TRN & \\
\hline CHEMBL 306258 & 210830 & 7.0969 & 7.1883 & TRN & \\
\hline CHEMBL310760 & 210830 & 6.3565 & 6.5687 & TRN & \\
\hline CHEMBL307479 & 210830 & 5.2218 & 5.1215 & TRN & \\
\hline CHEMBL 75750 & 210830 & 9.3979 & 9.3846 & TRN & \\
\hline CHEMBL80502 & 210830 & 6.0 & 5.5932 & TRN & \\
\hline CHEMBL80878 & 210830 & 6.0862 & 5.7257 & TRN & \\
\hline CHEMBL43463 & 210830 & 3.9957 & 4.273 & TRN & \\
\hline CHEMBL 78173 & 210830 & 7.1549 & 7.2898 & TRN & \\
\hline CHEMBL 307374 & 210830 & 6.9393 & 9.2602 & TST & \\
\hline CHEMBL 308632 & 210830 & 8.5229 & 8.478 & TRN & \\
\hline CHEMBL75635 & 210830 & 8.301 & 11.3442 & TST & \\
\hline CHEMBL310412 & 210830 & 6.7447 & 6.4743 & TRN & \\
\hline CHEMBL 309830 & 210830 & 9.301 & 8.8443 & TRN & \\
\hline CHEMBL77043 & 210830 & 7.5229 & 9.9123 & TST & \\
\hline CHEMBL431969 & 210830 & 10.0 & 10.3512 & TRN & \\
\hline CHEMBL306622 & 210830 & 6.6778 & 7.0101 & TRN & \\
\hline CHEMBL312023 & 210830 & 6.5229 & 9.7555 & TST & \\
\hline CHEMBL42900 & 210830 & 9.301 & 8.2699 & TRN & \\
\hline CHEMBL75624 & 210830 & 7.0 & 11.1365 & TST & \\
\hline CHEMBL77074 & 210830 & 4.3872 & 5.32799 & 9999999999 & TRN \\
\hline CHEMBL406737 & 210830 & 6.1675 & 5.8185 & TRN & \\
\hline CHEMBL 308630 & 210830 & 8.3979 & 8.1799 & TRN & \\
\hline CHEMBL 3909892 & 1642520 & 5.994 & 6.6498 & TST & \\
\hline CHEMBL3963502 & 1642520 & 6.7932 & 6.6325 & TST & \\
\hline CHEMBL3969850 & 1642520 & 8.0969 & 7.462006 & 3000000001 & TRN \\
\hline CHEMBL3965744 & 1642520 & 6.301 & 6.6512 & TST & \\
\hline CHEMBL3920834 & 1642520 & 7.1249 & 6.6736 & TST & \\
\hline CHEMBL 3965234 & 1642520 & 6.8827 & 6.6105 & TRN & \\
\hline CHEMBL3891199 & 1642520 & 7.2441 & 6.6247 & TRN & \\
\hline CHEMBL3916931 & 1642520 & 6.6421 & 6.5686 & TRN & \\
\hline
\end{tabular}

Page 27689 
Supplemental Table S2.txt

\begin{tabular}{|c|c|c|c|c|c|}
\hline CHEMBL3986568 & 1642520 & 6.2899 & 6.7215 & TST & \\
\hline CHEMBL3963782 & 1642520 & 6.8962 & 6.7007 & TRN & \\
\hline CHEMBL3902915 & 1642520 & 6.5003 & 6.5736 & TRN & \\
\hline CHEMBL3896881 & 1642520 & 7.3565 & 7.2451 & TRN & \\
\hline CHEMBL 3902324 & 1642520 & 5.7525 & 6.8311 & TRN & \\
\hline CHEMBL3983016 & 1642520 & 6.0329 & 6.6295 & TST & \\
\hline CHEMBL3980921 & 1642520 & 6.1864 & 6.7042 & TRN & \\
\hline CHEMBL 3979128 & 1642520 & 7.3098 & 7.5058 & TRN & \\
\hline CHEMBL 3932347 & 1642520 & 6.6596 & 7.4166 & TRN & \\
\hline CHEMBL 3955383 & 1642520 & 6.767 & 6.6059 & TRN & \\
\hline CHEMBL 3948147 & 1642520 & 7.2924 & 6.6041 & TRN & \\
\hline CHEMBL3960001 & 1642520 & 6.4789 & 6.5686 & TRN & \\
\hline CHEMBL 3948646 & 1642520 & 6.4045 & 6.7136 & TST & \\
\hline CHEMBL3928529 & 1642520 & 5.9662 & 6.9226 & TRN & \\
\hline CHEMBL 3915823 & 1642520 & 6.5361 & 6.371 & TST & \\
\hline CHEMBL3937555 & 1642520 & 6.7721 & 7.1391 & TRN & \\
\hline CHEMBL3960522 & 1642520 & 6.5003 & 6.6352 & TRN & \\
\hline CHEMBL3913786 & 1642520 & 6.8268 & 6.66 & TST & \\
\hline CHEMBL 3923763 & 1642520 & 6.6271 & 6.6563 & TRN & \\
\hline CHEMBL 3939845 & 1642520 & 7.1675 & 6.5734 & TRN & \\
\hline CHEMBL 3928745 & 1642520 & 6.6696 & 6.5949 & TRN & \\
\hline CHEMBL3959571 & 1642520 & 6.3737 & 6.6546 & TRN & \\
\hline CHEMBL3911326 & 1642520 & 7.1308 & 6.7143 & TRN & \\
\hline CHEMBL 3933838 & 1642520 & 7.1805 & 6.6429 & TRN & \\
\hline CHEMBL 3956393 & 1642520 & 7.3468 & 7.4431 & TRN & \\
\hline CHEMBL 3903582 & 1642520 & 8.0 & 7.1566 & TRN & \\
\hline CHEMBL 3930385 & 1642520 & 6.6234 & 6.619 & TRN & \\
\hline CHEMBL3904656 & 1642520 & 7.0969 & 6.9379 & TRN & \\
\hline CHEMBL3906852 & 1642520 & 6.857 & 6.8417 & TST & \\
\hline CHEMBL 3932795 & 1642520 & 7.4089 & 6.6065 & TRN & \\
\hline CHEMBL3929333 & 1642520 & 6.6925 & 6.7131 & TRN & \\
\hline CHEMBL3911907 & 1642520 & 5.9311 & 6.5767 & TST & \\
\hline CHEMBL3954560 & 1642520 & 6.1811 & 6.5422 & TRN & \\
\hline CHEMBL 3943310 & 1642520 & 6.1959 & 6.5268 & TRN & \\
\hline CHEMBL3932134 & 1642520 & 7.0506 & \multicolumn{2}{|c|}{7.236000000000001} & TRN \\
\hline CHEMBL3966876 & 1642520 & 7.3468 & 6.9082 & TRN & \\
\hline CHEMBL 3922712 & 1642520 & 6.8928 & 6.7143 & TRN & \\
\hline CHEMBL3939288 & 1642520 & 6.8633 & 6.769 & TST & \\
\hline CHEMBL3926629 & 1642520 & \multicolumn{3}{|c|}{5.7589999999999995} & TRN \\
\hline CHEMBL3979369 & 1642520 & 6.8013 & 6.7409 & TRN & \\
\hline CHEMBL 3896809 & 1642520 & 5.6533 & 6.5173 & TRN & \\
\hline CHEMBL 3923095 & 1642520 & 7.1024 & 6.6917 & TRN & \\
\hline CHEMBL 3904060 & 1642520 & 7.3188 & 7.2792 & TRN & \\
\hline CHEMBL3935553 & 1642520 & 6.6402 & 6.6435 & TRN & \\
\hline CHEMBL 3956800 & 1642520 & 6.8962 & 6.4991 & TRN & \\
\hline CHEMBL 3957214 & 1642520 & 6.5258 & 6.5944 & TRN & \\
\hline CHEMBL3919153 & 1642520 & 6.8041 & 6.9127 & TRN & \\
\hline CHEMBL 3950435 & 1642520 & 7.3468 & 6.9968 & TRN & \\
\hline
\end{tabular}


Supplemental Table S2.txt

\begin{tabular}{|c|c|c|c|c|c|c|}
\hline CHEMBL3978636 & 1642520 & 7.0555 & \multicolumn{3}{|c|}{6.781000000000001} & TRN \\
\hline CHEMBL3933770 & 1642520 & 7.284 & 6.9965 & TRN & & \\
\hline CHEMBL3931023 & 1642520 & 6.6326 & 6.7452 & TST & & \\
\hline CHEMBL 3894142 & 1642520 & 7.0044 & 6.7751 & TRN & & \\
\hline CHEMBL 3930517 & 1642520 & 6.058 & 6.6481 & TST & & \\
\hline CHEMBL3963959 & 1642520 & 6.2874 & 6.977 & TRN & & \\
\hline CHEMBL3946672 & 1642520 & 7.7212 & 7.4996 & TRN & & \\
\hline CHEMBL3966709 & 1642520 & 6.8182 & 6.847 & TRN & & \\
\hline CHEMBL 3931982 & 1642520 & 5.3504 & 6.857 & TRN & & \\
\hline CHEMBL3896180 & 1642520 & 6.6198 & 6.6464 & TRN & & \\
\hline CHEMBL 3965125 & 1642520 & 6.0535 & 6.5763 & TRN & & \\
\hline CHEMBL 3936640 & 1642520 & 7.0706 & 6.621 & TRN & & \\
\hline CHEMBL3915303 & 1642520 & 7.4685 & 7.0197 & TRN & & \\
\hline CHEMBL3984023 & 1642520 & 7.5686 & 7.3957 & TRN & & \\
\hline CHEMBL3942809 & 1642520 & 6.9393 & 6.6833 & TRN & & \\
\hline CHEMBL3918525 & 1642520 & 7.2596 & 6.6098 & TRN & & \\
\hline CHEMBL3889992 & 1642520 & 7.4949 & 6.8278 & TRN & & \\
\hline CHEMBL3922037 & 1642520 & 6.3969 & \multicolumn{3}{|c|}{6.4670000000000005} & \\
\hline CHEMBL3931436 & 1642520 & 6.1871 & 6.956 & TRN & & \\
\hline CHEMBL3928136 & 1642520 & 7.4685 & 7.0192 & TRN & & \\
\hline CHEMBL 3955532 & 1642520 & 6.1871 & 6.6998 & TST & & \\
\hline CHEMBL3959648 & 1642520 & 7.1487 & 6.8516 & TRN & & \\
\hline CHEMBL3933307 & 1642520 & 6.0799 & 6.7097 & TRN & & \\
\hline CHEMBL3952520 & 1642520 & 6.3958 & 6.6957 & TST & & \\
\hline CHEMBL3895217 & 1642520 & 6.3288 & 6.6956 & TRN & & \\
\hline CHEMBL3903985 & 1642520 & 7.1192 & 6.5945 & TST & & \\
\hline CHEMBL3970904 & 1642520 & 8.0458 & 7.4491 & TRN & & \\
\hline CHEMBL3959546 & 1642520 & \multicolumn{3}{|c|}{6.752000000000001} & 6.6588 & \\
\hline CHEMBL 3924857 & 1642520 & 5.9991 & 6.6009 & TST & & \\
\hline CHEMBL 3893450 & 1642520 & 6.0526 & 6.6811 & TST & & \\
\hline CHEMBL3908102 & 1642520 & 7.0757 & 7.0321 & TRN & & \\
\hline CHEMBL 3941058 & 1642520 & 5.8038 & 6.8851 & TRN & & \\
\hline CHEMBL3912264 & 1642520 & 6.556 & 6.5049 & TRN & & \\
\hline CHEMBL3920324 & 1642520 & 6.4776 & 6.5865 & TRN & & \\
\hline CHEMBL3923197 & 1642520 & 6.7167 & 6.4495 & TRN & & \\
\hline CHEMBL3956696 & 1642520 & 7.0177 & 6.3874 & TST & & \\
\hline CHEMBL3931574 & 1642520 & 6.9469 & 6.7385 & TRN & & \\
\hline CHEMBL3932502 & 1642520 & 6.4597 & 6.6731 & TRN & & \\
\hline CHEMBL3976969 & 1642520 & 6.4622 & 6.5954 & TRN & & \\
\hline CHEMBL 3892438 & 1642520 & 7.6198 & 7.051 & TRN & & \\
\hline CHEMBL3911390 & 1642520 & 7.1079 & 7.4165 & TRN & & \\
\hline CHEMBL3963955 & 1642520 & 7.0655 & 6.8529 & TRN & & \\
\hline CHEMBL3959129 & 1642520 & 6.9914 & 6.9376 & TRN & & \\
\hline CHEMBL3935545 & 1642520 & 6.4989 & 6.95700 & 0000000001 & & TRN \\
\hline CHEMBL3909975 & 1642520 & 6.0883 & 6.6144 & TST & & \\
\hline CHEMBL3937017 & 1642520 & 6.9066 & 6.9542 & TRN & & \\
\hline CHEMBL3925590 & 1642520 & 6.6536 & 6.8881 & TRN & & \\
\hline CHEMBL3960486 & 1642520 & 6.5918 & 6.5187 & TRN & & \\
\hline
\end{tabular}


Supplemental Table S2.txt

\begin{tabular}{|c|c|c|c|c|}
\hline HEI & 20 & 634 & 03 & TF \\
\hline HEMBL3948064 & 642520 & 7.0915 & 7.1141 & \\
\hline HEMBI 393 & 520 & 1249 & 5074 & \\
\hline HEMBL3949822 & 642520 & 7.2076 & 005 & \\
\hline HEMBL3937113 & 642520 & 7.2291 & 0222 & \\
\hline HEMBL3941335 & 642520 & 7.6778 & 7.8959 & \\
\hline AEMBL389 & 520 & 6.9547 & 6921 & \\
\hline HEMBL3909522 & 520 & 7.8239 & .9013 & \\
\hline HEMBL3928358 & 520 & 7.4815 & 6.8833 & \\
\hline HEMBL3957877 & 520 & 6.6498 & 6.6103 & ST \\
\hline HEMBL3909108 & 520 & 7.3872 & 6.744 & \\
\hline HEMBL 394 & 520 & 6.983 & .4364 & \\
\hline HEMBL 396 & 520 & 079 & .2193 & \\
\hline HEMBL392 & 520 & 6.8297 & 6.6757 & \\
\hline HEMBL 390 & 520 & 6.3363 & 6.6712 & ST \\
\hline HEMBL 3706844 & 373 & 5.8861 & 5.4559 & \\
\hline HEMBL 20 & 23 & 6 & 65 & \\
\hline HEMBL 37 & & 8 & 1039 & \\
\hline HEMBL37e & & 528 & 5.3061 & \\
\hline HEMBL 211 & & 85 & 535 & \\
\hline HEMBL 21 & 3 & 518 & 4.5042 & \\
\hline HEMBL 37 & 3 & 979 & 5.3225 & \\
\hline HEMBL 21 & & 192 & 4.3171 & \\
\hline HEMBL 209 & & 2757 & 5.4844 & \\
\hline HEMBL 211 & 3 & 528 & 5.3478 & ST \\
\hline HEMBL37 & & 99 & 2028 & $\Gamma \mathrm{RN}$ \\
\hline HEMBL 21 & 3 & 861 & 42 & RN \\
\hline HEMBL 37 & & 696 & 5.5197 & RN \\
\hline HEMBL 212 & & 383 & 4.8225 & $\mathrm{RN}$ \\
\hline HEMBL 211 & 3 & 5383 & 5.7805 & TRN \\
\hline HEMBL 379 & & 372 & 4.5704 & RN \\
\hline HEMBL21 & & 318 & 5.5029 & RN \\
\hline HEMBL 2: & & 86 & 4.4736 & $\mathrm{RN}$ \\
\hline HEMBL 210189 & 23 & 198 & 4.419 & $\Gamma \mathrm{RN}$ \\
\hline HEMBL 379357 & 3 & 4.6021 & 4.4851 & $\Gamma \mathrm{RN}$ \\
\hline HEMBL438 & & 872 & 5.6943 & RN \\
\hline HEMBL3 & & 49 & 58 & RN \\
\hline HEMBL379 & & 4.8861 & 4.9358 & זRN \\
\hline HEMBL212209 & 73 & 5.5528 & 5.5233 & TRN \\
\hline HEMBL 211 & & & 5.4452 & TST \\
\hline CHEMBL 210 & ? & 4.1805 & 4.3304 & $\mathrm{RN}$ \\
\hline CHEMBL211 & & 4.8239 & 4.938 & RN \\
\hline CHEMBL211209 & 373 & 5.8861 & 5.7908 & TRN \\
\hline HEMBL378657 & 23 & 5.0223 & 4.914 & TRN \\
\hline CHEMBL379 & 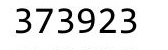 & 4.8861 & 5.3602 & TRN \\
\hline CHEMBL210244 & & 5.5376 & 5.54 & \\
\hline CHEMBL378830 & 373923 & 5.7447 & 5.6651 & \\
\hline CHEMBL379194 & 373923 & 4.6778 & 4.8372 & 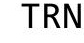 \\
\hline
\end{tabular}

Page 27692 


\begin{tabular}{|c|c|c|c|c|c|}
\hline \multicolumn{6}{|c|}{ Supplemental Table S2.txt } \\
\hline CHEMBL 208586 & 373923 & 5.2366 & 5.6243 & TST & \\
\hline CHEMBL 378643 & 373923 & 5.6576 & 5.2677 & TRN & \\
\hline CHEMBL 209334 & 373923 & 3.8861 & 4.4965 & TRN & \\
\hline CHEMBL 212031 & 373923 & 5.301 & 5.6101 & TST & \\
\hline CHEMBL 377763 & 373923 & 5.2007 & 5.4814 & TST & \\
\hline CHEMBL 212577 & 373923 & 4.4559 & 4.8267 & TRN & \\
\hline CHEMBL107955 & 373923 & 5.7696 & 5.5026 & TST & \\
\hline CHEMBL210386 & 373923 & 5.0458 & 5.481 & TST & \\
\hline CHEMBL380221 & 373923 & 5.0 & 5.0925 & TRN & \\
\hline CHEMBL 209586 & 373923 & 5.9586 & 5.7432 & TRN & \\
\hline CHEMBL 209841 & 373923 & 4.9788 & 5.4357 & TST & \\
\hline CHEMBL379957 & 373923 & 5.0809 & 5.371 & TST & \\
\hline CHEMBL380220 & 373923 & 5.6383 & 5.2489 & TST & \\
\hline CHEMBL 211549 & 373923 & 4.0969 & 4.6777 & TRN & \\
\hline CHEMBL 379958 & 373923 & 5.0 & 5.2391 & TRN & \\
\hline CHEMBL426501 & 373923 & 5.2924 & 4.7733 & TRN & \\
\hline CHEMBL379586 & 373923 & 5.0 & 5.5907 & TST & \\
\hline CHEMBL437307 & 373923 & 4.8239 & 4.8513 & TRN & \\
\hline CHEMBL 212538 & 373923 & 5.3372 & 5.4592 & TST & \\
\hline CHEMBL 212616 & 373923 & 4.8239 & 5.3691 & TST & \\
\hline CHEMBL 209910 & 373923 & 5.9208 & 5.6464 & TST & \\
\hline CHEMBL 373751 & 954761 & 3.5299 & 3.5323 & TRN & \\
\hline CHEMBL558642 & 954761 & 2.7647 & 2.7687 & TRN & \\
\hline CHEMBL 300389 & 954761 & 6.0268 & 6.0204 & TRN & \\
\hline CHEMBL1643959 & 954761 & 3.2271 & 3.2283 & TRN & \\
\hline CHEMBL202721 & 954761 & 5.7686 & 5.7759 & TRN & \\
\hline CHEMBL412142 & 954761 & 4.3411 & 4.338 & TRN & \\
\hline CHEMBL 240954 & 954761 & 2.929 & 3.83 & TST & \\
\hline CHEMBL392695 & 954761 & 4.2227 & 4.231 & TRN & \\
\hline CHEMBL 255342 & 954761 & 3.3538 & 3.3498 & TRN & \\
\hline CHEMBL1256459 & 954761 & 3.8093 & 3.80800 & 00000000003 & TRN \\
\hline CHEMBL 258844 & 954761 & 3.3254 & 3.3293 & TRN & \\
\hline CHEMBL1357247 & 954761 & 2.9546 & 2.9536 & TRN & \\
\hline CHEMBL1970879 & 954761 & 3.6289 & 3.6257 & TRN & \\
\hline CHEMBL1186585 & 954761 & 4.8785 & 4.87 & TRN & \\
\hline CHEMBL3349342 & 954761 & 4.0157 & 4.0157 & TRN & \\
\hline CHEMBL1404918 & 954761 & 2.6017 & 2.6031 & TRN & \\
\hline CHEMBL1516890 & 954761 & 4.0454 & 4.0447 & TRN & \\
\hline CHEMBL585951 & 954761 & 5.7014 & 5.6985 & TRN & \\
\hline CHEMBL449158 & 954761 & 5.7964 & 6.105 & TST & \\
\hline CHEMBL577784 & 954761 & 5.688 & 5.6812 & TRN & \\
\hline CHEMBL135561 & 954761 & 4.0209 & 4.0223 & TRN & \\
\hline CHEMBL192566 & 954761 & 7.2903 & 7.2174 & TST & \\
\hline CHEMBL 209148 & 954761 & 2.7797 & 2.7818 & TRN & \\
\hline CHEMBL 221137 & 954761 & 4.3646 & 4.2775 & TST & \\
\hline CHEMBL 3199475 & 954761 & 4.7744 & 4.7756 & TRN & \\
\hline CHEMBL 210618 & 954761 & 3.9546 & 3.9454 & TRN & \\
\hline CHEMBL92309 & 954761 & 2.0411 & 2.4502 & TST & \\
\hline
\end{tabular}


Supplemental Table S2.txt

\begin{tabular}{|c|c|c|c|c|c|}
\hline CHEMBL213100 & 954761 & 2.9766 & 2.9774 & TRN & \\
\hline CHEMBL483849 & 954761 & 1.8934 & 2.1373 & TST & \\
\hline CHEMBL1242367 & 954761 & 3.9629 & \multicolumn{2}{|c|}{3.9610000000000003} & TRN \\
\hline CHEMBL483847 & 954761 & 4.2032 & 4.199 & TRN & \\
\hline CHEMBL512504 & 954761 & 4.6794 & 4.6799 & TRN & \\
\hline CHEMBL188678 & 954761 & 3.9455 & 3.9562 & TRN & \\
\hline CHEMBL 3186408 & 954761 & 3.2492 & 4.0902 & TST & \\
\hline CHEMBL379975 & 954761 & 4.9572 & 4.9645 & TRN & \\
\hline CHEMBL 2363137 & 954761 & 5.0503 & 5.0456 & TRN & \\
\hline CHEMBL222102 & 954761 & 3.4799 & 3.4856 & TRN & \\
\hline CHEMBL1909414 & 954761 & 4.3313 & 4.3302 & TRN & \\
\hline CHEMBL189584 & 954761 & 4.6002 & 4.603 & TRN & \\
\hline CHEMBL65 & 954761 & 9.3685 & 9.368 & TRN & \\
\hline CHEMBL1190711 & 954761 & 4.6977 & 4.7004 & TRN & \\
\hline CHEMBL 2137530 & 954761 & 5.2902 & 5.3002 & TRN & \\
\hline CHEMBL509032 & 954761 & 6.1152 & 6.1213 & TRN & \\
\hline CHEMBL1230020 & 954761 & 3.0252 & 3.0206 & TRN & \\
\hline CHEMBL379300 & 954761 & 3.6631 & 3.6584 & TRN & \\
\hline CHEMBL1788116 & 954761 & 3.6951 & 3.6886 & TRN & \\
\hline CHEMBL3392440 & 954761 & 4.5659 & 4.5682 & TRN & \\
\hline CHEMBL472940 & 954761 & 2.6755 & 2.667 & TRN & \\
\hline CHEMBL1590308 & 954761 & 2.7389 & 3.5605 & TST & \\
\hline CHEMBL514499 & 954761 & 4.4508 & 4.4515 & TRN & \\
\hline CHEMBL 2005886 & 954761 & 2.9121 & 2.9135 & TRN & \\
\hline CHEMBL180127 & 954761 & 2.8609 & 2.8641 & TRN & \\
\hline CHEMBL220241 & 954761 & 3.8946 & 3.8945 & TRN & \\
\hline CHEMBL 2134202 & 954761 & 3.0748 & 3.0786 & TRN & \\
\hline CHEMBL399530 & 954761 & 4.6787 & 4.67 & TRN & \\
\hline CHEMBL102714 & 954761 & 3.4111 & 3.412 & TRN & \\
\hline CHEMBL1673039 & 954761 & 3.3162 & 4.0102 & TST & \\
\hline CHEMBL515416 & 954761 & 3.2953 & 3.9976 & TST & \\
\hline CHEMBL191334 & 954761 & 3.208 & 4.6269 & TST & \\
\hline CHEMBL217354 & 954761 & 6.7373 & 6.9313 & TST & \\
\hline CHEMBL 9470 & 954761 & 2.4868 & 4.4524 & TST & \\
\hline CHEMBL393929 & 954761 & 3.3304 & 4.672 & TST & \\
\hline CHEMBL 2144069 & 954761 & 4.7444 & 4.5783 & TST & \\
\hline CHEMBL573107 & 954761 & 5.5949 & 5.1017 & TST & \\
\hline CHEMBL259181 & 954761 & 4.2562 & 3.8595 & TST & \\
\hline CHEMBL3423184 & 1474899 & 4.8962 & 5.1372 & TRN & \\
\hline CHEMBL3423183 & 1474899 & 5.0555 & 5.1255 & TRN & \\
\hline CHEMBL3423153 & 1474899 & 4.2076 & 4.6784 & TRN & \\
\hline CHEMBL 3423177 & 1474899 & 5.1612 & 5.1823 & TRN & \\
\hline CHEMBL3423176 & 1474899 & 4.8447 & 5.0608 & TRN & \\
\hline CHEMBL3423164 & 1474899 & 5.0706 & 4.6883 & TST & \\
\hline CHEMBL 3423179 & 1474899 & 5.0915 & 5.1694 & TRN & \\
\hline CHEMBL3423188 & 1474899 & 5.2676 & 5.3204 & TRN & \\
\hline CHEMBL3423160 & 1474899 & 4.3107 & 4.3814 & TRN & \\
\hline CHEMBL3423162 & 1474899 & 5.9208 & 5.1808 & TRN & \\
\hline
\end{tabular}

Page 27694 
Supplemental Table S2.txt

\begin{tabular}{|c|c|c|c|c|c|}
\hline CHEMBL3423150 & 1474899 & 4.4763 & 4.6897 & TRN & \\
\hline CHEMBL3423165 & 1474899 & 5.1192 & 5.2269 & TST & \\
\hline CHEMBL3423189 & 1474899 & 5.0 & 4.9926 & TRN & \\
\hline CHEMBL 3423161 & 1474899 & 4.7399 & 4.6619 & TRN & \\
\hline CHEMBL 3423182 & 1474899 & 4.5834 & 5.0731 & TRN & \\
\hline CHEMBL 3423138 & 1474899 & 5.0223 & 4.8622 & TRN & \\
\hline CHEMBL3423151 & 1474899 & 4.4342 & 4.5272 & TRN & \\
\hline CHEMBL 3423145 & 1474899 & 3.0 & 3.8981 & TRN & \\
\hline CHEMBL 3087847 & 1474899 & 6.0 & 5.1525 & TRN & \\
\hline CHEMBL 3423143 & 1474899 & 4.0405 & 4.2446 & TST & \\
\hline CHEMBL 3423135 & 1474899 & 5.0862 & 4.7133 & TRN & \\
\hline CHEMBL3423146 & 1474899 & 4.2874 & 3.91899 & 99999999996 & TRN \\
\hline CHEMBL 3421648 & 1474899 & 4.5452 & 3.9215 & TRN & \\
\hline CHEMBL 3423144 & 1474899 & 3.0 & 4.0744 & TST & \\
\hline CHEMBL 3423175 & 1474899 & 5.0223 & 5.0537 & TRN & \\
\hline CHEMBL3423191 & 1474899 & 4.8894 & 5.077 & TRN & \\
\hline CHEMBL 3423140 & 1474899 & 4.7905 & 4.8435 & TST & \\
\hline CHEMBL 3423185 & 1474899 & 4.9872 & 5.1561 & TRN & \\
\hline CHEMBL 3423142 & 1474899 & 4.9914 & 4.76699 & 99999999995 & TST \\
\hline CHEMBL 3423149 & 1474899 & 3.0 & 4.1202 & TRN & \\
\hline CHEMBL3423155 & 1474899 & 4.4012 & 4.8196 & TST & \\
\hline CHEMBL 3423154 & 1474899 & 4.6198 & 4.631 & TST & \\
\hline CHEMBL3423166 & 1474899 & 4.9431 & 4.9605 & TST & \\
\hline CHEMBL3423181 & 1474899 & 5.0132 & 4.9386 & TRN & \\
\hline CHEMBL 3423147 & 1474899 & 4.4401 & 3.91300 & 20000000003 & TRN \\
\hline CHEMBL3423156 & 1474899 & 4.8356 & 4.7303 & TRN & \\
\hline CHEMBL 3423148 & 1474899 & 4.4584 & 3.8716 & TRN & \\
\hline CHEMBL3423169 & 1474899 & 5.1739 & 4.6686 & TST & \\
\hline CHEMBL 3423190 & 1474899 & 4.8996 & 5.1401 & TRN & \\
\hline CHEMBL 3423187 & 1474899 & 4.8794 & 5.0741 & TRN & \\
\hline CHEMBL3423172 & 1474899 & 4.8861 & 5.072 & TRN & \\
\hline CHEMBL 3423180 & 1474899 & 5.2676 & 4.9554 & TRN & \\
\hline CHEMBL 3423170 & 1474899 & 4.8041 & 5.1773 & TRN & \\
\hline CHEMBL3423157 & 1474899 & 6.2218 & 5.1148 & TRN & \\
\hline CHEMBL 3423171 & 1474899 & 4.9281 & 5.02 & TRN & \\
\hline CHEMBL3423141 & 1474899 & 4.6326 & 4.7097 & TST & \\
\hline CHEMBL 3423152 & 1474899 & 4.3098 & 4.6904 & TRN & \\
\hline CHEMBL 3423174 & 1474899 & 5.0 & 5.0243 & TRN & \\
\hline CHEMBL 3423186 & 1474899 & 5.301 & 5.1834 & TRN & \\
\hline CHEMBL 3423167 & 1474899 & 5.1308 & 4.9426 & TST & \\
\hline CHEMBL3423178 & 1474899 & 5.0706 & 5.0399 & TRN & \\
\hline CHEMBL 3423173 & 1474899 & 4.9788 & 5.0426 & TRN & \\
\hline CHEMBL 3423163 & 1474899 & 5.2518 & 5.0931 & TST & \\
\hline CHEMBL 3423159 & 1474899 & 4.8996 & 5.0054 & TRN & \\
\hline CHEMBL 3423139 & 1474899 & 4.5719 & 4.868 & TST & \\
\hline CHEMBL3423158 & 1474899 & 4.9172 & 4.893 & TRN & \\
\hline CHEMBL 3423168 & 1474899 & 5.0969 & 4.7897 & TST & \\
\hline CHEMBL354696 & 104172 & 5.1192 & 4.9186 & TRN & \\
\hline
\end{tabular}


Supplemental Table S2.txt

\begin{tabular}{|c|c|c|c|c|c|}
\hline CHEMBL166332 & 104172 & 6.3979 & 6.596 & TRN & \\
\hline CHEMBL168111 & 104172 & 5.0655 & 5.0433 & TRN & \\
\hline CHEMBL165431 & 104172 & 4.9586 & 5.1152 & TRN & \\
\hline CHEMBL164630 & 104172 & 5.3768 & 5.1331 & TRN & \\
\hline CHEMBL164285 & 104172 & 6.3979 & 6.6683 & TRN & \\
\hline CHEMBL351174 & 104172 & 4.9586 & 4.8704 & TRN & \\
\hline CHEMBL349462 & 104172 & 4.9586 & 6.1642 & TRN & \\
\hline CHEMBL163718 & 104172 & 4.9586 & 4.9306 & TRN & \\
\hline CHEMBL164697 & 104172 & 4.2366 & 5.1736 & TST & \\
\hline CHEMBL354267 & 104172 & 5.2218 & 5.6097 & TRN & \\
\hline CHEMBL350396 & 104172 & 8.0969 & 7.231 & TRN & \\
\hline CHEMBL355113 & 104172 & 8.1549 & 8.1399 & TRN & \\
\hline CHEMBL435256 & 104172 & 5.8539 & 5.1556 & TRN & \\
\hline CHEMBL167718 & 104172 & 5.2218 & 5.1982 & TRN & \\
\hline CHEMBL164496 & 104172 & 5.3979 & 5.0867 & TRN & \\
\hline CHEMBL165717 & 104172 & 8.0 & 7.3718 & TRN & \\
\hline CHEMBL435052 & 104172 & 5.2218 & 5.2992 & TRN & \\
\hline CHEMBL166179 & 104172 & 7.0 & 7.2775 & TRN & \\
\hline CHEMBL164006 & 104172 & 5.3979 & 5.716 & TRN & \\
\hline CHEMBL166218 & 104172 & 6.4202 & 6.1245 & TRN & \\
\hline CHEMBL351450 & 104172 & 4.9586 & 5.5498 & TRN & \\
\hline CHEMBL165549 & 104172 & 5.9208 & 5.91700 & 0000000001 & TRN \\
\hline CHEMBL445132 & 104172 & 5.0969 & 5.113 & TRN & \\
\hline CHEMBL164280 & 104172 & 3.699 & 4.3539 & TST & \\
\hline CHEMBL165121 & 104172 & 5.1135 & 4.8626 & TST & \\
\hline CHEMBL351848 & 104172 & 4.9586 & 4.8501 & TRN & \\
\hline CHEMBL164011 & 104172 & 4.9872 & 4.9811 & TRN & \\
\hline CHEMBL162040 & 104172 & 4.9355 & 4.6066 & TRN & \\
\hline CHEMBL164753 & 104172 & 7.0 & 6.9811 & TRN & \\
\hline CHEMBL165288 & 104172 & 5.3468 & 4.8845 & TST & \\
\hline CHEMBL351849 & 104172 & 4.9586 & 4.7099 & TRN & \\
\hline CHEMBL351741 & 104172 & 5.4559 & 5.7442 & TST & \\
\hline CHEMBL164503 & 104172 & 5.0177 & 4.814 & TRN & \\
\hline CHEMBL166333 & 104172 & 2.699 & 3.9443 & TRN & \\
\hline CHEMBL350051 & 104172 & 7.5229 & 7.0731 & TST & \\
\hline CHEMBL351212 & 104172 & 4.3279 & 3.8957 & TRN & \\
\hline CHEMBL350150 & 104172 & 5.8861 & 5.8697 & TRN & \\
\hline CHEMBL164511 & 104172 & 7.4559 & 7.1762 & TST & \\
\hline CHEMBL424382 & 104172 & 5.2218 & 5.9099 & TST & \\
\hline CHEMBL167896 & 104172 & 5.4437 & 5.5809 & TRN & \\
\hline CHEMBL165287 & 104172 & 5.3665 & 5.6393 & TRN & \\
\hline CHEMBL 349827 & 104172 & 5.699 & 4.984 & TRN & \\
\hline CHEMBL 348805 & 104172 & 5.2218 & 5.6647 & TST & \\
\hline CHEMBL350574 & 104172 & 5.8861 & 5.1265 & TRN & \\
\hline CHEMBL 351474 & 104172 & 3.3565 & 3.9572 & TRN & \\
\hline CHEMBL165965 & 104172 & 3.4168 & 5.5476 & TST & \\
\hline CHEMBL166810 & 104172 & 4.9586 & 4.2775 & TRN & \\
\hline CHEMBL168136 & 104172 & 5.0757 & 5.8537 & TRN & \\
\hline
\end{tabular}

Page 27696 


\begin{tabular}{|c|c|c|c|c|c|}
\hline \multicolumn{6}{|c|}{ Supplemental Table s2.txt } \\
\hline CHEMBL167037 & 104172 & 4.9586 & 5.4853 & TRN & \\
\hline CHEMBL165232 & 104172 & 5.0555 & 4.8165 & TRN & \\
\hline CHEMBL165216 & 104172 & 6.301 & 6.8786 & TST & \\
\hline CHEMBL349759 & 104172 & 5.0 & 5.6628 & TST & \\
\hline CHEMBL165622 & 104172 & 8.0 & 7.0265 & TST & \\
\hline CHEMBL168044 & 104172 & 3.8827 & 3.9748 & TRN & \\
\hline CHEMBL352047 & 104172 & 7.6021 & 7.2914 & TST & \\
\hline CHEMBL164559 & 104172 & 8.0969 & 7.8919 & TST & \\
\hline CHEMBL164956 & 104172 & 5.0044 & 5.1694 & TRN & \\
\hline CHEMBL354695 & 104172 & 5.0223 & 4.8885 & TRN & \\
\hline CHEMBL3236930 & 1337063 & 4.699 & 4.7346 & TRN & \\
\hline CHEMBL3236931 & 1337063 & 4.699 & 4.6879 & TRN & \\
\hline CHEMBL 2205146 & 1337063 & 8.0 & 7.8731 & TRN & \\
\hline CHEMBL 3237230 & 1337063 & 8.301 & 8.1921 & TRN & \\
\hline CHEMBL3236950 & 1337063 & 9.0 & 7.3719 & TST & \\
\hline CHEMBL3236948 & 1337063 & 8.2218 & 7.2728 & TST & \\
\hline CHEMBL3237232 & 1337063 & 8.2218 & 8.3072 & TRN & \\
\hline CHEMBL 3236960 & 1337063 & 8.3979 & 8.2043 & TRN & \\
\hline CHEMBL 3236958 & 1337063 & 8.699 & 8.8154 & TRN & \\
\hline CHEMBL3237235 & 1337063 & 7.1549 & 6.7967 & TST & \\
\hline CHEMBL3236936 & 1337063 & 6.9101 & 7.0158 & TST & \\
\hline CHEMBL3236946 & 1337063 & 7.6778 & 7.4697 & TRN & \\
\hline CHEMBL 3236952 & 1337063 & 7.8539 & 7.9994 & TST & \\
\hline CHEMBL 3237234 & 1337063 & 6.8633 & 6.6091 & TRN & \\
\hline CHEMBL3237233 & 1337063 & 8.2218 & 8.2314 & TRN & \\
\hline CHEMBL3236945 & 1337063 & 8.0969 & 8.076 & TRN & \\
\hline CHEMBL3236961 & 1337063 & 7.7447 & 7.7202 & TRN & \\
\hline CHEMBL 3236932 & 1337063 & 4.699 & 4.757 & TRN & \\
\hline CHEMBL 3237243 & 1337063 & 8.2218 & 8.308 & TRN & \\
\hline CHEMBL3236959 & 1337063 & 8.0969 & 8.4618 & TRN & \\
\hline CHEMBL3236929 & 1337063 & 9.0969 & 8.763 & TRN & \\
\hline CHEMBL 3237228 & 1337063 & 7.9586 & 8.0405 & TRN & \\
\hline CHEMBL 3237238 & 1337063 & 7.9586 & 7.9692 & TRN & \\
\hline CHEMBL3236947 & 1337063 & 7.7959 & 7.5407 & TRN & \\
\hline CHEMBL 3236943 & 1337063 & 8.0 & 8.1026 & TRN & \\
\hline CHEMBL3236951 & 1337063 & 8.5229 & 7.3679 & TST & \\
\hline CHEMBL3236940 & 1337063 & 6.1481 & 6.0663 & TRN & \\
\hline CHEMBL 3237240 & 1337063 & 8.0969 & 8.1955 & TRN & \\
\hline CHEMBL 2204469 & 1337063 & 8.699 & 8.5601 & TRN & \\
\hline CHEMBL3236938 & 1337063 & 6.2549 & 5.8277 & TST & \\
\hline CHEMBL3236928 & 1337063 & 6.1618 & 6.94799 & 99999999995 & TST \\
\hline CHEMBL3236949 & 1337063 & 8.3979 & 7.0599 & TST & \\
\hline CHEMBL3236953 & 1337063 & 6.9706 & 6.7321 & TST & \\
\hline CHEMBL 3236942 & 1337063 & 5.699 & 5.8492 & TRN & \\
\hline CHEMBL3236933 & 1337063 & 4.699 & 4.7975 & TRN & \\
\hline CHEMBL3236939 & 1337063 & 6.8297 & 6.9899 & TRN & \\
\hline CHEMBL 3237231 & 1337063 & 7.7696 & 8.2067 & TRN & \\
\hline CHEMBL 3237237 & 1337063 & 6.71 & 6.8068 & TST & \\
\hline
\end{tabular}


Supplemental Table S2.txt

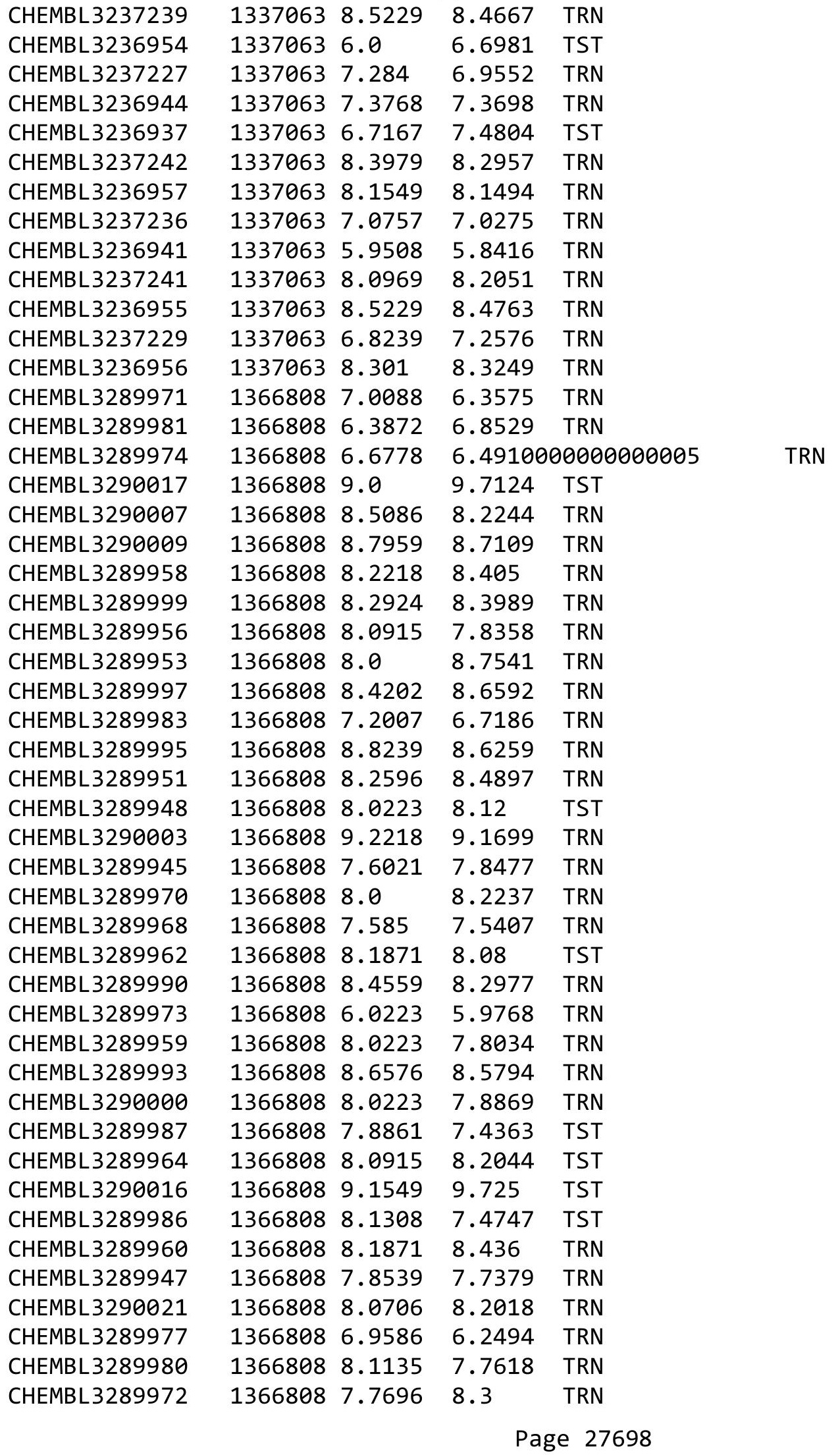


Supplemental Table S2.txt

\begin{tabular}{|c|c|c|c|c|}
\hline CHEMBL3290006 & 1366808 & 8.7696 & 8.9335 & TRN \\
\hline CHEMBL3289994 & 1366808 & 8.3098 & 8.203 & TRN \\
\hline CHEMBL3289975 & 1366808 & 6.0132 & 5.4681 & TST \\
\hline CHEMBL3290001 & 1366808 & 9.1549 & 8.962 & TRN \\
\hline CHEMBL3289946 & 1366808 & 7.9208 & 8.0418 & TRN \\
\hline CHEMBL3290013 & 1366808 & 8.585 & 8.6435 & TRN \\
\hline CHEMBL3289961 & 1366808 & 7.8539 & 7.5552 & TST \\
\hline CHEMBL3290014 & 1366808 & 9.0969 & 9.5545 & TRN \\
\hline CHEMBL3290015 & 1366808 & 8.6383 & 8.7998 & TST \\
\hline CHEMBL3289709 & 1366808 & 8.8861 & 8.4593 & TRN \\
\hline CHEMBL 3290020 & 1366808 & 8.041 & \multicolumn{2}{|c|}{8.392000000000001} \\
\hline CHEMBL3289991 & 1366808 & 8.4318 & 8.3227 & TRN \\
\hline CHEMBL3290004 & 1366808 & 8.7447 & 8.8223 & TRN \\
\hline CHEMBL3289989 & 1366808 & 5.2147 & 5.8537 & TST \\
\hline CHEMBL3290008 & 1366808 & 9.2218 & 9.012 & TRN \\
\hline CHEMBL3289955 & 1366808 & 7.8861 & 7.6291 & TRN \\
\hline CHEMBL3290005 & 1366808 & 8.5528 & 8.6242 & TRN \\
\hline CHEMBL3289976 & 1366808 & 5.5686 & 6.3662 & TST \\
\hline CHEMBL3289944 & 1366808 & 9.3979 & 8.6451 & TRN \\
\hline CHEMBL3289965 & 1366808 & 8.0757 & 8.4841 & TST \\
\hline CHEMBL3289954 & 1366808 & 8.8239 & 9.2349 & TRN \\
\hline CHEMBL3289969 & 1366808 & 6.5376 & 6.1446 & TRN \\
\hline CHEMBL3289949 & 1366808 & 8.6576 & 8.3826 & TST \\
\hline CHEMBL3289950 & 1366808 & 8.041 & 7.7385 & TRN \\
\hline CHEMBL3290010 & 1366808 & 8.2441 & 8.5125 & TRN \\
\hline CHEMBL3289984 & 1366808 & 7.9586 & 8.1672 & TRN \\
\hline CHEMBL3286432 & 1366808 & 7.8239 & 7.8357 & TRN \\
\hline CHEMBL3289978 & 1366808 & 9.1549 & 8.6099 & TRN \\
\hline CHEMBL3289952 & 1366808 & 9.0458 & 8.7343 & TRN \\
\hline CHEMBL3289967 & 1366808 & 5.3768 & 6.1374 & TRN \\
\hline CHEMBL3289982 & 1366808 & 6.7212 & 6.7271 & TRN \\
\hline CHEMBL3289998 & 1366808 & 8.4437 & 8.6371 & TRN \\
\hline CHEMBL 3289988 & 1366808 & 5.4815 & 5.2494 & TST \\
\hline CHEMBL3290002 & 1366808 & 8.7696 & 8.9123 & TRN \\
\hline CHEMBL3290012 & 1366808 & 9.2218 & 9.1082 & TRN \\
\hline CHEMBL3289708 & 1366808 & 8.0555 & 8.3345 & TRN \\
\hline CHEMBL3290019 & 1366808 & 8.0223 & 7.2322 & TST \\
\hline CHEMBL3289957 & 1366808 & 7.9586 & 8.0471 & TRN \\
\hline CHEMBL3289979 & 1366808 & 4.0 & 5.2514 & TRN \\
\hline CHEMBL3289966 & 1366808 & 8.1249 & 8.4893 & TST \\
\hline CHEMBL3289996 & 1366808 & 8.0458 & 7.9695 & TRN \\
\hline CHEMBL3290011 & 1366808 & 9.0458 & 8.6146 & TRN \\
\hline CHEMBL3289985 & 1366808 & 5.9208 & 5.20700 & 0000000001 \\
\hline CHEMBL3290018 & 1366808 & 8.1871 & 7.7034 & TST \\
\hline CHEMBL3289963 & 1366808 & 7.9208 & 8.0179 & TST \\
\hline CHEMBL3289992 & 1366808 & 8.6778 & 8.0266 & TST \\
\hline CHEMBL357710 & 184421 & 8.7696 & 8.7817 & TRN \\
\hline CHEMBL344534 & 184421 & 7.1367 & 7.147 & TRN \\
\hline
\end{tabular}


Supplemental Table S2.txt

\begin{tabular}{|c|c|c|c|c|}
\hline CHEMBL149549 & 184421 & 7.3872 & 7.3938 & TRN \\
\hline CHEMBL146302 & 184421 & 9.699 & 9.686 & TRN \\
\hline CHEMBL343471 & 184421 & 7.8665 & 7.8617 & TRN \\
\hline CHEMBL147217 & 184421 & 7.2518 & 7.2443 & TRN \\
\hline CHEMBL147161 & 184421 & 7.2924 & 7.2905 & TRN \\
\hline CHEMBL147312 & 184421 & 7.3665 & 7.3669 & TRN \\
\hline CHEMBL146577 & 184421 & 6.9101 & 6.9061 & TRN \\
\hline CHEMBL147364 & 184421 & 9.301 & 9.2957 & TRN \\
\hline CHEMBL342270 & 184421 & 9.0458 & 9.0448 & TRN \\
\hline CHEMBL146531 & 184421 & 6.4112 & 6.4061 & TRN \\
\hline CHEMBL146488 & 184421 & 6.8761 & 7.5529 & TST \\
\hline CHEMBL146086 & 184421 & 8.8539 & 8.8619 & TRN \\
\hline CHEMBL148891 & 184421 & 7.0362 & 7.0259 & TRN \\
\hline CHEMBL148044 & 184421 & 7.6778 & 7.6915 & TRN \\
\hline CHEMBL343009 & 184421 & 8.699 & 8.6907 & TRN \\
\hline CHEMBL147590 & 184421 & 8.4949 & 8.5034 & TRN \\
\hline CHEMBL146356 & 184421 & 8.6383 & 8.6367 & TRN \\
\hline CHEMBL146317 & 184421 & 8.1805 & 8.1921 & TRN \\
\hline CHEMBL146051 & 184421 & 7.0809 & 7.0877 & TRN \\
\hline CHEMBL145970 & 184421 & 7.5229 & 7.5312 & TRN \\
\hline CHEMBL147771 & 184421 & 7.1487 & 7.1494 & TRN \\
\hline CHEMBL147842 & 184421 & 8.7696 & 8.753 & TRN \\
\hline CHEMBL358519 & 184421 & 6.6655 & 6.6537 & TRN \\
\hline CHEMBL149287 & 184421 & 6.6946 & 6.6837 & TRN \\
\hline CHEMBL146670 & 184421 & 6.5214 & 6.5187 & TRN \\
\hline CHEMBL147379 & 184421 & 8.1367 & 8.1358 & TRN \\
\hline CHEMBL 344120 & 184421 & 8.8239 & 8.8266 & TRN \\
\hline CHEMBL149900 & 184421 & 7.8268 & 7.8239 & TRN \\
\hline CHEMBL344109 & 184421 & 6.6198 & 6.6126 & TST \\
\hline CHEMBL148030 & 184421 & 6.0985 & 6.097 & TRN \\
\hline CHEMBL146635 & 184421 & 7.3468 & 8.1701 & TST \\
\hline CHEMBL435481 & 184421 & 6.6383 & 6.6453 & TRN \\
\hline CHEMBL148043 & 184421 & 8.5229 & 7.4951 & TST \\
\hline CHEMBL359234 & 184421 & 6.9172 & 6.9122 & TRN \\
\hline CHEMBL145910 & 184421 & 7.9431 & 7.9457 & TRN \\
\hline CHEMBL149504 & 184421 & 7.1427 & 7.1406 & TRN \\
\hline CHEMBL342309 & 184421 & 6.8327 & 6.8396 & TRN \\
\hline CHEMBL356806 & 184421 & 9.301 & 9.3104 & TRN \\
\hline CHEMBL146075 & 184421 & 7.4089 & 7.4012 & TRN \\
\hline CHEMBL146390 & 184421 & 9.2218 & 9.215 & TRN \\
\hline CHEMBL357417 & 184421 & 7.0809 & 7.0969 & TRN \\
\hline CHEMBL358301 & 184421 & 7.585 & 8.4617 & TST \\
\hline CHEMBL356271 & 184421 & 8.585 & 7.7105 & TST \\
\hline CHEMBL146230 & 184421 & 9.0458 & 7.5406 & TST \\
\hline CHEMBL148574 & 184421 & 8.0809 & 8.3765 & TST \\
\hline CHEMBL358874 & 184421 & 7.9957 & 9.1782 & TST \\
\hline CHEMBL148737 & 184421 & 7.1938 & \multicolumn{2}{|c|}{7.2010000000000005} \\
\hline CHEMBL356161 & 184421 & 8.8861 & 8.3009 & TST \\
\hline
\end{tabular}

Page 27700 


\begin{tabular}{|c|c|c|c|c|c|}
\hline \multicolumn{6}{|c|}{ Supplemental Table s2.txt } \\
\hline CHEMBL148740 & 184421 & 8.0605 & 7.4788 & TST & \\
\hline CHEMBL147519 & 184421 & 6.5834 & 7.151 & TST & \\
\hline CHEMBL145983 & 184421 & 7.9469 & 7.9909 & TST & \\
\hline CHEMBL 2018736 & 813065 & 5.2596 & 5.2557 & TRN & \\
\hline CHEMBL 2018619 & 813065 & 5.8861 & 5.7701 & TRN & \\
\hline CHEMBL 2018737 & 813065 & 5.2441 & 5.2594 & TRN & \\
\hline CHEMBL569102 & 813065 & 5.699 & 5.5366 & TRN & \\
\hline CHEMBL 2018609 & 813065 & 5.3188 & 5.3708 & TST & \\
\hline CHEMBL 2018601 & 813065 & 3.699 & 3.905 & TRN & \\
\hline CHEMBL 2018734 & 813065 & 5.9586 & 6.0903 & TRN & \\
\hline CHEMBL 2018620 & 813065 & 5.0 & 5.0227 & TRN & \\
\hline CHEMBL 2018744 & 813065 & 3.699 & 5.1645 & TST & \\
\hline CHEMBL 2018603 & 813065 & 3.699 & 3.8415 & TRN & \\
\hline CHEMBL 2018605 & 813065 & 5.7959 & 5.7405 & TRN & \\
\hline CHEMBL 2018616 & 813065 & 4.9586 & 5.0225 & TRN & \\
\hline CHEMBL 2018606 & 813065 & 5.3098 & 4.9942 & TST & \\
\hline CHEMBL 2018595 & 813065 & 5.6021 & 5.41200 & 0000000001 & TRN \\
\hline CHEMBL 2018602 & 813065 & 4.9586 & 4.7293 & TRN & \\
\hline CHEMBL 2018729 & 813065 & 5.7447 & 5.3695 & TST & \\
\hline CHEMBL 2018608 & 813065 & 3.699 & 4.5251 & TST & \\
\hline CHEMBL 2018611 & 813065 & 5.3872 & 5.5366 & TRN & \\
\hline CHEMBL 2018738 & 813065 & 5.2518 & 5.2115 & TRN & \\
\hline CHEMBL 2018735 & 813065 & 6.0 & 5.9557 & TRN & \\
\hline CHEMBL 2018612 & 813065 & 5.6021 & 5.6751 & TRN & \\
\hline CHEMBL 2018599 & 813065 & 3.699 & 4.0044 & TRN & \\
\hline CHEMBL 2018624 & 813065 & 5.6576 & 5.7278 & TRN & \\
\hline CHEMBL 2018607 & 813065 & 4.8861 & 5.1513 & TST & \\
\hline CHEMBL 2018614 & 813065 & 5.7959 & 5.83799 & 9999999999 & TRN \\
\hline CHEMBL 2018622 & 813065 & 5.6778 & 5.7883 & TRN & \\
\hline CHEMBL 2018623 & 813065 & 5.9586 & 5.9229 & TRN & \\
\hline CHEMBL 2018615 & 813065 & 6.0 & 5.8132 & TRN & \\
\hline CHEMBL 2018733 & 813065 & 5.9586 & 5.9534 & TRN & \\
\hline CHEMBL 2018741 & 813065 & 3.699 & 5.2235 & TST & \\
\hline CHEMBL 2018726 & 813065 & 5.8539 & 6.0248 & TRN & \\
\hline CHEMBL 2018604 & 813065 & 5.6383 & 5.6071 & TRN & \\
\hline CHEMBL 2018621 & 813065 & 5.9586 & 5.8636 & TRN & \\
\hline CHEMBL 2018618 & 813065 & 5.4949 & 5.695 & TRN & \\
\hline CHEMBL 2018613 & 813065 & 5.585 & 5.5465 & TRN & \\
\hline CHEMBL 2018598 & 813065 & 5.6383 & 5.6751 & TRN & \\
\hline CHEMBL 2018617 & 813065 & 5.585 & 5.8389 & TRN & \\
\hline CHEMBL 2018742 & 813065 & 3.699 & 5.1019 & TST & \\
\hline CHEMBL 2018727 & 813065 & 5.7959 & 5.8712 & TRN & \\
\hline CHEMBL 2018732 & 813065 & 5.8861 & 5.8344 & TRN & \\
\hline CHEMBL 2018626 & 813065 & 5.8239 & 5.7163 & TRN & \\
\hline CHEMBL 2018597 & 813065 & 5.699 & 5.83799 & 9999999999 & TRN \\
\hline CHEMBL 2018610 & 813065 & 5.3872 & 5.3649 & TST & \\
\hline CHEMBL 2018739 & 813065 & 5.284 & 5.205 & TRN & \\
\hline CHEMBL 2018596 & 813065 & 4.8539 & 4.6276 & TRN & \\
\hline
\end{tabular}


Supplemental Table S2.txt

\begin{tabular}{|c|c|c|c|c|}
\hline HEMBL 20 & 13065 & .699 & 4.9853 &. \\
\hline HEMBL2018600 & 313065 & 4.9586 & 4.5019 & \\
\hline HEMBL2018728 & 3065 & 5198 & 5737 & \\
\hline HEMBL 2018730 & 3065 & 2596 & 3435 & אב \\
\hline HEMBL2018743 & 13065 & 3.699 & . 1842 & \\
\hline HEMBL 2018625 & 13065 & 5.8539 & .7166 & \\
\hline HEMBL 2018594 & 13065 & .6576 & .8389 & \\
\hline HEMBL2018731 & 13065 & .284 & 8284 & \\
\hline HEMBL 248938 & 58193 & 3.301 & 5.0922 & \\
\hline HEMBL400239 & 58193 & 6.3893 & .1749 & \\
\hline HEMBL 249738 & 458193 & 5.0835 & 7.6231 & \\
\hline HEMBL 251601 & 58193 & .0969 & 7.9722 & \\
\hline HEMBL 251375 & 193 & 202 & 7.7776 & RN \\
\hline HEMBL 251393 & 458193 & 8.3979 & 7.9758 & RN \\
\hline HEMBL 399086 & 3193 & 9458 & 2059 & \\
\hline HEMBL 250145 & 58193 & 969 & 7.6236 & \\
\hline HEMBL400471 & 193 & 3.301 & 9487 & \\
\hline HEMBL 399087 & 193 & 7.0223 & 1066 & \\
\hline HEMBL 248937 & 193 & 4.4685 & 6.2008 & \\
\hline HEMBL 250386 & 193 & 1559 & 104 & \\
\hline HEMBL400520 & 193 & 5.6635 & 6.0219 & RIV \\
\hline HEMBL 249141 & 193 & 7.2218 & 7.6694 & \\
\hline HEMBL 249140 & 193 & 7.5229 & 6.3135 & \\
\hline HEMBL401112 & 193 & 7.1427 & 6.2562 & \\
\hline HEMBL 249530 & 193 & 586 & 14 & $\mathrm{RN}$ \\
\hline HEMBL 251761 & 193 & 5778 & 5099 & RN \\
\hline HEMBL 248744 & 193 & 3.301 & $\partial 142$ & $\mathrm{RN}$ \\
\hline HEMBL 24 & 93 & 506 & 6.1876 & RN \\
\hline HEMBL249942 & 193 & 487 & 1498 & $\mathrm{RN}$ \\
\hline HEMBL404208 & 193 & 3861 & 59 & RN \\
\hline HEMBL 399234 & 193 & 318 & 3287 & RN \\
\hline HEMBL 251196 & 193 & .7959 & 7.9238 & RN \\
\hline CHEMBL 249 & 193 & 969 & 563 & RN \\
\hline LHEMBL401312 & 193 & 208 & 647 & RN \\
\hline HEMBL 250369 & 458193 & 7.7696 & 7.7841 & ГRN \\
\hline HEMBL445671 & 193 & 229 & 773 & ST \\
\hline HEMBL 249 & 93 & 188 & 18 & RN \\
\hline LHEMBL401056 & 8193 & 7.3468 & 7.8918 & $\mathrm{RN}$ \\
\hline LHEMBL400470 & 458193 & 4.7959 & 6.0783 & TRN \\
\hline HEMBL249337 & 58193 & 6.6021 & 8354 & IST \\
\hline HEMBL 250148 & 458193 & 7.4685 & 8394 & RN \\
\hline CHEMBL398647 & 458193 & 7.3098 & 6.1905 & $\mathrm{RN}$ \\
\hline CHEMBL249737 & 458193 & 6.7878 & 7.4843 & TST \\
\hline CHEMBL400240 & 458193 & 6.4559 & 7.2482 & TST \\
\hline CHEMBL399287 & 58193 & 549 & 6.3644 & RN \\
\hline CHEMBL249165 & 458193 & 7.4202 & 7.631 & \\
\hline CHEMBL249334 & 458193 & 7.3098 & 7.1422 & ST \\
\hline CHEMBL 398622 & 458193 & 7.8861 & 7.5054 & RN \\
\hline
\end{tabular}

Page 27702 


\begin{tabular}{|c|c|c|c|c|c|}
\hline \multicolumn{6}{|c|}{ Supplemental Table S2.txt } \\
\hline CHEMBL 249735 & 458193 & 6.0757 & 6.1319 & TRN & \\
\hline CHEMBL401111 & 458193 & 6.6021 & 6.1172 & TRN & \\
\hline CHEMBL442802 & 458193 & 8.699 & 6.4033 & TRN & \\
\hline CHEMBL 250183 & 458193 & 7.0506 & 7.6687 & TRN & \\
\hline CHEMBL398670 & 458193 & 7.7447 & 7.7539 & TRN & \\
\hline CHEMBL403350 & 458193 & 6.301 & 7.1244 & TST & \\
\hline CHEMBL 248537 & 458193 & 5.4685 & 6.2603 & TST & \\
\hline CHEMBL 249944 & 458193 & 5.9586 & 6.2839 & TST & \\
\hline CHEMBL 398621 & 458193 & 7.9586 & 7.4757 & TST & \\
\hline CHEMBL248219 & 458193 & 7.699 & 7.4271 & TST & \\
\hline CHEMBL 249736 & 458193 & 7.1487 & 6.3392 & TST & \\
\hline CHEMBL 249947 & 458193 & 6.5229 & 7.1081 & TST & \\
\hline CHEMBL399078 & 458193 & 7.3665 & 7.63899 & 9999999999 & TST \\
\hline CHEMBL44557 & 40286 & 8.6576 & 8.5822 & TRN & \\
\hline CHEMBL 298320 & 40286 & 5.041 & 5.0795 & TRN & \\
\hline CHEMBL552986 & 40286 & 8.4089 & 8.1513 & TRN & \\
\hline CHEMBL 240875 & 40286 & 6.7959 & 6.7817 & TRN & \\
\hline CHEMBL295428 & 40286 & 7.1024 & 7.0767 & TRN & \\
\hline CHEMBL555465 & 40286 & 8.6021 & 8.4102 & TRN & \\
\hline CHEMBL553293 & 40286 & 8.4949 & 7.8812 & TST & \\
\hline CHEMBL553843 & 40286 & 8.0706 & 8.1338 & TRN & \\
\hline CHEMBL130782 & 40286 & 7.585 & 7.648 & TST & \\
\hline CHEMBL554206 & 40286 & 8.28399 & 79999999 & 8.3146 & TRN \\
\hline CHEMBL543899 & 40286 & 8.6576 & 7.0665 & TST & \\
\hline CHEMBL43510 & 40286 & 5.9586 & 5.9558 & TRN & \\
\hline CHEMBL334421 & 40286 & 6.2291 & 6.1556 & TRN & \\
\hline CHEMBL133681 & 40286 & 4.0 & 5.1242 & TST & \\
\hline CHEMBL543781 & 40286 & 8.3188 & 8.3412 & TRN & \\
\hline CHEMBL 264751 & 40286 & 8.3768 & 8.4184 & TRN & \\
\hline CHEMBL288079 & 40286 & 6.1739 & 6.1825 & TRN & \\
\hline CHEMBL133005 & 40286 & 7.9586 & 7.9953 & TRN & \\
\hline CHEMBL133913 & 40286 & 7.7696 & 7.7306 & TRN & \\
\hline CHEMBL542958 & 40286 & 6.3279 & 6.3455 & TRN & \\
\hline CHEMBL41446 & 40286 & 6.5686 & 6.3746 & TST & \\
\hline CHEMBL336574 & 40286 & 7.5229 & 7.46399 & 99999999995 & TRN \\
\hline CHEMBL543659 & 40286 & 8.6021 & 8.604 & TRN & \\
\hline CHEMBL133339 & 40286 & 7.3372 & 6.9782 & TST & \\
\hline CHEMBL552543 & 40286 & 8.0315 & 7.3789 & TST & \\
\hline CHEMBL334753 & 40286 & 6.8861 & 6.8815 & TRN & \\
\hline CHEMBL133186 & 40286 & 5.699 & 5.5182 & TST & \\
\hline CHEMBL544601 & 40286 & 6.4685 & 6.4671 & TRN & \\
\hline CHEMBL130436 & 40286 & 9.2924 & 9.2897 & TRN & \\
\hline CHEMBL264259 & 40286 & 5.0 & 5.0121 & TRN & \\
\hline CHEMBL 21311 & 40286 & 5.0757 & 5.0356 & TRN & \\
\hline CHEMBL130517 & 40286 & 8.8539 & 8.8068 & TRN & \\
\hline CHEMBL44087 & 40286 & 8.1427 & 8.1755 & TRN & \\
\hline CHEMBL538732 & 40286 & 8.0458 & 7.6306 & TST & \\
\hline CHEMBL295005 & 40286 & 7.0269 & 7.0846 & TRN & \\
\hline
\end{tabular}




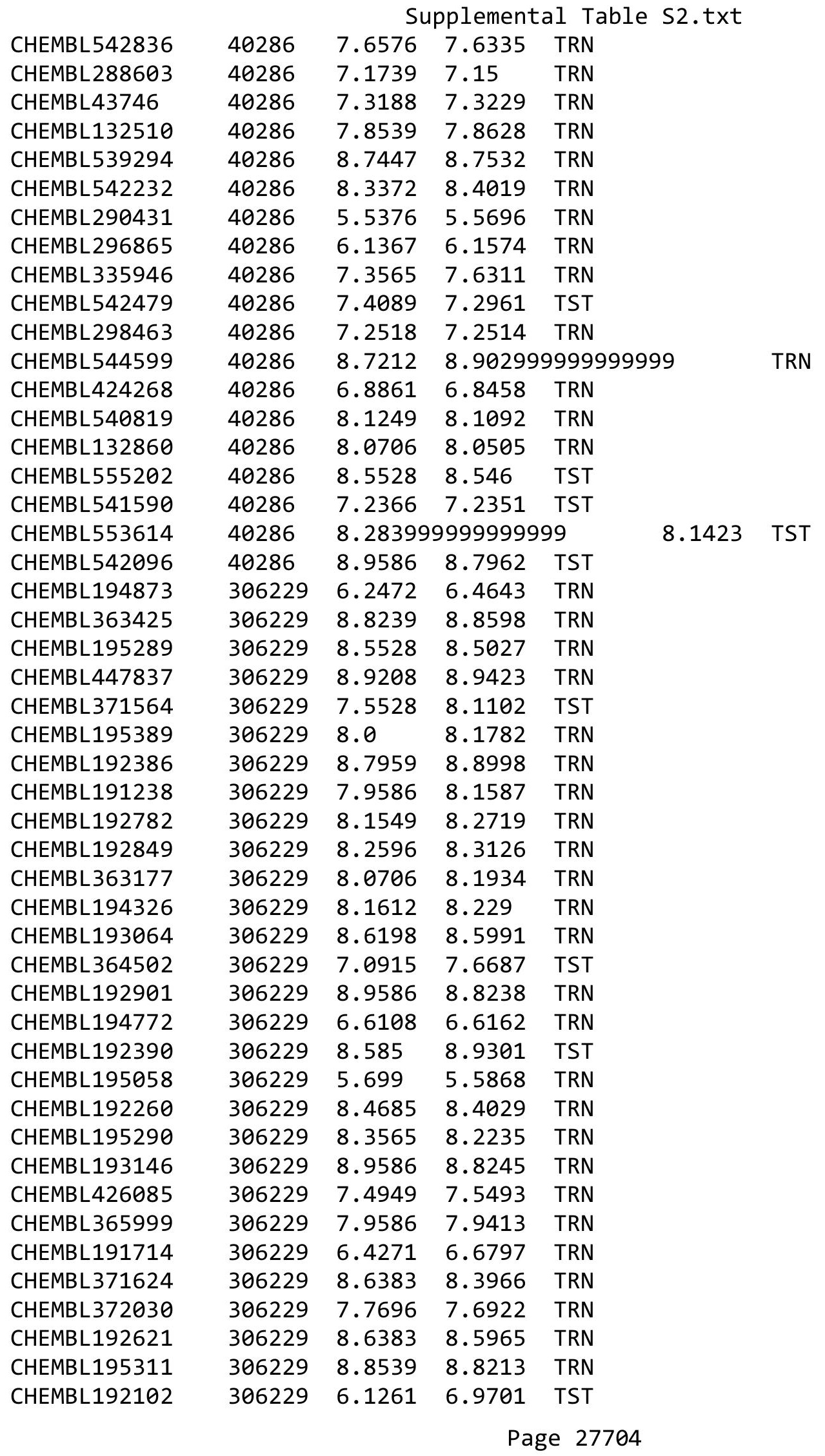




\begin{tabular}{|c|c|c|c|c|c|}
\hline \multirow[b]{2}{*}{ CHEMBL195807 } & \multicolumn{5}{|c|}{ Supplemental Table S2.txt } \\
\hline & 306229 & 8.2218 & 8.3237 & TRN & \\
\hline CHEMBL191759 & 306229 & 8.9208 & 8.8527 & TRN & \\
\hline CHEMBL192154 & 306229 & 8.5686 & 8.5099 & TRN & \\
\hline CHEMBL195788 & 306229 & 6.7011 & 7.9396 & TST & \\
\hline CHEMBL192876 & 306229 & 8.0458 & 8.158 & TRN & \\
\hline CHEMBL195217 & 306229 & 7.5229 & 7.2183 & TRN & \\
\hline CHEMBL192016 & 306229 & 8.2007 & 8.3652 & TRN & \\
\hline CHEMBL194936 & 306229 & 7.8861 & 7.8114 & TRN & \\
\hline CHEMBL371126 & 306229 & 8.2218 & 8.2115 & TST & \\
\hline CHEMBL195786 & 306229 & 6.9431 & 6.9094 & TRN & \\
\hline CHEMBL365941 & 306229 & 8.4685 & 8.5235 & TRN & \\
\hline CHEMBL427180 & 306229 & 7.5686 & 7.3941 & TST & \\
\hline CHEMBL193010 & 306229 & 6.6882 & 7.0007 & TST & \\
\hline CHEMBL426641 & 306229 & 8.6576 & 8.6008 & TRN & \\
\hline CHEMBL194762 & 306229 & 8.699 & 8.7637 & TRN & \\
\hline CHEMBL192218 & 306229 & 8.5229 & 8.7869 & TST & \\
\hline CHEMBL363367 & 306229 & 8.6383 & 8.4859 & TRN & \\
\hline CHEMBL195280 & 306229 & 8.2518 & 8.0773 & TRN & \\
\hline CHEMBL193726 & 306229 & 8.2366 & 7.9129 & TST & \\
\hline CHEMBL191715 & 306229 & 7.3565 & 7.315 & TRN & \\
\hline CHEMBL363633 & 306229 & 8.0 & 7.95100 & 00000000005 & TRN \\
\hline CHEMBL195039 & 306229 & 8.3468 & 8.6454 & TST & \\
\hline CHEMBL363634 & 306229 & 9.301 & 9.0713 & TRN & \\
\hline CHEMBL191716 & 306229 & 8.0757 & 7.8297 & TRN & \\
\hline CHEMBL191710 & 306229 & 8.4815 & 8.6284 & TRN & \\
\hline CHEMBL193727 & 306229 & 8.301 & 8.4307 & TRN & \\
\hline CHEMBL195208 & 306229 & 8.6021 & 8.7583 & TRN & \\
\hline CHEMBL194718 & 306229 & 6.2782 & 6.1837 & TRN & \\
\hline CHEMBL195154 & 306229 & 7.2366 & 7.5014 & TRN & \\
\hline CHEMBL44 & 306229 & 8.0132 & 7.8852 & TST & \\
\hline CHEMBL191808 & 306229 & 8.3979 & 8.2556 & TRN & \\
\hline CHEMBL191648 & 306229 & 8.1367 & 8.2203 & TRN & \\
\hline CHEMBL195878 & 306229 & 8.699 & 8.97299 & 9999999999 & TRN \\
\hline CHEMBL191901 & 306229 & 8.6021 & 8.4065 & TRN & \\
\hline CHEMBL192068 & 306229 & 7.9747 & 7.53700 & 0000000001 & TST \\
\hline CHEMBL191300 & 306229 & 7.8861 & 8.3422 & TST & \\
\hline CHEMBL192000 & 306229 & 8.6778 & 8.92799 & 9999999999 & TST \\
\hline CHEMBL364092 & 306229 & 8.5986 & 8.2145 & TST & \\
\hline CHEMBL 362966 & 306229 & 7.9208 & 8.1358 & TST & \\
\hline CHEMBL191974 & 306229 & 7.7878 & 7.7956 & TST & \\
\hline CHEMBL493436 & 498215 & 6.0 & 6.0625 & TRN & \\
\hline CHEMBL491934 & 498215 & 7.0 & 7.434 & TST & \\
\hline CHEMBL492112 & 498215 & 6.8 & 6.2208 & TST & \\
\hline CHEMBL490918 & 498215 & 6.7 & 6.6741 & TRN & \\
\hline CHEMBL524108 & 498215 & 6.6 & 7.05 & TRN & \\
\hline CHEMBL489741 & 498215 & 6.6 & 6.8899 & TRN & \\
\hline CHEMBL490696 & 498215 & 6.6 & 6.6913 & TRN & \\
\hline CHEMBL491369 & 498215 & 6.5 & 6.5265 & TRN & \\
\hline & & & & 27705 & \\
\hline
\end{tabular}




\begin{tabular}{|c|c|c|c|c|c|}
\hline \multirow[b]{2}{*}{ CHEMBL491713 } & \multirow[b]{2}{*}{498215} & \\
\hline & & 6.2 & 6.4444 & TRN & \\
\hline CHEMBL504419 & 498215 & 6.1 & 6.4925 & TRN & \\
\hline CHEMBL474645 & 498215 & 5.8 & 6.6388 & TRN & \\
\hline CHEMBL473020 & 498215 & 7.3 & 6.447 & TST & \\
\hline CHEMBL522967 & 498215 & 6.6 & 6.1947 & TRN & \\
\hline CHEMBL489919 & 498215 & 5.6 & 4.9879 & TRN & \\
\hline CHEMBL489931 & 498215 & 5.1 & 4.8568 & TRN & \\
\hline CHEMBL489932 & 498215 & 6.7 & 6.435 & TRN & \\
\hline CHEMBL521962 & 498215 & 7.7 & \multicolumn{2}{|c|}{7.428999999999999} & TRN \\
\hline CHEMBL491729 & 498215 & 7.0 & 6.8447 & TRN & \\
\hline CHEMBL491907 & 498215 & 7.2 & 6.9611 & TRN & \\
\hline CHEMBL491933 & 498215 & 7.4 & 7.7637 & TRN & \\
\hline CHEMBL491781 & 498215 & 7.3 & 6.5984 & TST & \\
\hline CHEMBL523157 & 498215 & 6.7 & 5.6828 & TST & \\
\hline CHEMBL492113 & 498215 & 7.0 & 6.3852 & TST & \\
\hline CHEMBL522647 & 498215 & 7.0 & 6.9702 & TRN & \\
\hline CHEMBL523319 & 498215 & 7.1 & 7.0128 & TRN & \\
\hline CHEMBL491740 & 498215 & 7.0 & 7.0192 & TRN & \\
\hline CHEMBL491741 & 498215 & 6.8 & 6.6797 & TRN & \\
\hline CHEMBL490917 & 498215 & 6.7 & 6.7661 & TRN & \\
\hline CHEMBL491370 & 498215 & 6.4 & 6.2438 & TRN & \\
\hline CHEMBL515918 & 498215 & 7.5 & 7.2005 & TRN & \\
\hline CHEMBL491766 & 498215 & 4.5 & 6.0081 & TRN & \\
\hline CHEMBL492123 & 498215 & 5.3 & 4.9496 & TRN & \\
\hline CHEMBL490558 & 498215 & 7.1 & 7.1057 & TRN & \\
\hline CHEMBL491552 & 498215 & 7.1 & 6.7276 & TRN & \\
\hline CHEMBL491553 & 498215 & 7.5 & 7.3839 & TRN & \\
\hline CHEMBL491728 & 498215 & 7.2 & 6.9353 & TRN & \\
\hline CHEMBL491730 & 498215 & 7.3 & 7.3611 & TRN & \\
\hline CHEMBL522120 & 498215 & 7.5 & 7.0324 & TRN & \\
\hline CHEMBL240177 & 498215 & 7.2 & 6.3042 & TST & \\
\hline CHEMBL540965 & 498215 & 7.2 & 6.1616 & TST & \\
\hline CHEMBL523112 & 498215 & 7.5 & 7.188 & TRN & \\
\hline CHEMBL255787 & 498215 & 7.4 & 7.2004 & TRN & \\
\hline CHEMBL490117 & 498215 & 7.2 & 6.9069 & TRN & \\
\hline CHEMBL492101 & 498215 & 7.1 & 7.1115 & TRN & \\
\hline CHEMBL489714 & 498215 & 7.0 & 6.8418 & TRN & \\
\hline CHEMBL523478 & 498215 & 6.5 & 6.6406 & TRN & \\
\hline CHEMBL493437 & 498215 & 5.7 & 6.3371 & TRN & \\
\hline CHEMBL475368 & 498215 & 5.5 & 6.0116 & TRN & \\
\hline CHEMBL522955 & 498215 & 7.2 & 7.0622 & TRN & \\
\hline CHEMBL491102 & 498215 & 7.2 & 6.6914 & TRN & \\
\hline CHEMBL491103 & 498215 & 6.1 & 6.4694 & TRN & \\
\hline CHEMBL489939 & 498215 & 6.4 & 6.7036 & TST & \\
\hline CHEMBL491916 & 498215 & 8.0 & 7.9076 & TST & \\
\hline CHEMBL490741 & 498215 & 8.0 & 7.8583 & TST & \\
\hline CHEMBL490912 & 498215 & 8.0 & 7.2531 & TST & \\
\hline CHEMBL489916 & 498215 & 7.5 & 7.2964 & TST & \\
\hline & & & & 27706 & \\
\hline
\end{tabular}




\begin{tabular}{|c|c|c|c|c|c|}
\hline \multicolumn{6}{|c|}{ Supplemental Table S2.txt } \\
\hline CHEMBL489917 & 498215 & 7.3 & 6.2327 & TST & \\
\hline CHEMBL490118 & 498215 & 7.2 & 6.7869 & TST & \\
\hline CHEMBL496427 & 523482 & 7.6383 & 7.3188 & TRN & \\
\hline CHEMBL502071 & 523482 & 7.5086 & 7.25899 & 99999999995 & TST \\
\hline CHEMBL524442 & 523482 & 7.0969 & 7.2593 & TST & \\
\hline CHEMBL520831 & 523482 & 7.699 & 7.4868 & TRN & \\
\hline CHEMBL467211 & 523482 & 7.0 & 7.7736 & TST & \\
\hline CHEMBL520679 & 523482 & 6.6383 & 6.3292 & TRN & \\
\hline CHEMBL503486 & 523482 & 8.1549 & 7.7198 & TST & \\
\hline CHEMBL496614 & 523482 & 6.585 & 6.32799 & 9999999999 & TRN \\
\hline CHEMBL496834 & 523482 & 6.2218 & 6.0772 & TRN & \\
\hline CHEMBL495581 & 523482 & 8.6198 & 8.317 & TRN & \\
\hline CHEMBL496198 & 523482 & 7.699 & 7.2242 & TRN & \\
\hline CHEMBL496607 & 523482 & 7.3979 & 7.7239 & TRN & \\
\hline CHEMBL495812 & 523482 & 7.9208 & 8.4629 & TRN & \\
\hline CHEMBL522557 & 523482 & 7.6021 & 7.4959 & TRN & \\
\hline CHEMBL508822 & 523482 & 7.1938 & 7.4773 & TST & \\
\hline CHEMBL496798 & 523482 & 7.0969 & 7.7555 & TRN & \\
\hline CHEMBL482856 & 523482 & 6.2596 & 6.4918 & TRN & \\
\hline CHEMBL497407 & 523482 & 6.699 & 6.8996 & TRN & \\
\hline CHEMBL495835 & 523482 & 6.699 & 7.0247 & TRN & \\
\hline CHEMBL457780 & 523482 & 7.3979 & 7.7451 & TST & \\
\hline CHEMBL525178 & 523482 & 7.0969 & 7.4334 & TRN & \\
\hline CHEMBL496442 & 523482 & 6.9586 & 6.9818 & TST & \\
\hline CHEMBL523754 & 523482 & 7.3979 & 7.8145 & TRN & \\
\hline CHEMBL497885 & 523482 & 7.0 & 6.9739 & TRN & \\
\hline CHEMBL496823 & 523482 & 8.8861 & 8.2554 & TRN & \\
\hline CHEMBL496592 & 523482 & 8.0458 & 7.6329 & TRN & \\
\hline CHEMBL496811 & 523482 & 6.8861 & 7.1508 & TRN & \\
\hline CHEMBL497405 & 523482 & 6.2924 & 6.5446 & TRN & \\
\hline CHEMBL451659 & 523482 & 7.301 & 7.5074 & TST & \\
\hline CHEMBL485449 & 523482 & 8.0 & 7.4792 & TRN & \\
\hline CHEMBL495602 & 523482 & 7.0 & 7.2448 & TRN & \\
\hline CHEMBL495868 & 523482 & 7.0969 & 6.95100 & 00000000005 & TRN \\
\hline CHEMBL522889 & 523482 & 6.3233 & 6.855 & TRN & \\
\hline CHEMBL496394 & 523482 & 9.0969 & 9.1727 & TRN & \\
\hline CHEMBL484700 & 523482 & 7.6021 & 7.5987 & TRN & \\
\hline CHEMBL498061 & 523482 & 7.0 & 7.6405 & TRN & \\
\hline CHEMBL496795 & 523482 & 7.0 & 7.4374 & TRN & \\
\hline CHEMBL450735 & 523482 & 8.0 & 8.0545 & TRN & \\
\hline CHEMBL484493 & 523482 & 8.301 & 8.0825 & TRN & \\
\hline CHEMBL498034 & 523482 & 8.301 & 7.2409 & TRN & \\
\hline CHEMBL496800 & 523482 & 8.8239 & 8.7345 & TRN & \\
\hline CHEMBL522738 & 523482 & 6.8239 & 7.2618 & TRN & \\
\hline CHEMBL497406 & 523482 & 7.0969 & 7.8152 & TST & \\
\hline CHEMBL452442 & 523482 & 6.9208 & 7.3445 & TST & \\
\hline CHEMBL497034 & 523482 & 9.301 & 8.1235 & TRN & \\
\hline CHEMBL495606 & 523482 & 8.0315 & 8.0126 & TRN & \\
\hline
\end{tabular}




\begin{tabular}{|c|c|c|c|c|c|}
\hline \\
\hline CHEMBL496023 & 523482 & 6.0 & 6.2712 & TRN & \\
\hline CHEMBL496062 & 523482 & 7.0 & 7.4334 & TRN & \\
\hline CHEMBL524618 & 523482 & 7.699 & 7.1933 & TRN & \\
\hline CHEMBL523898 & 523482 & 8.0 & 8.0676 & TRN & \\
\hline CHEMBL522565 & 523482 & 6.3768 & 7.0733 & TST & \\
\hline CHEMBL526114 & 523482 & 5.0 & 5.5608 & TST & \\
\hline CHEMBL484699 & 523482 & 8.301 & 7.9885 & TRN & \\
\hline CHEMBL496799 & 523482 & 8.9208 & 8.6221 & TRN & \\
\hline CHEMBL497409 & 523482 & 7.699 & 7.9699 & TRN & \\
\hline CHEMBL497408 & 523482 & 7.5229 & 7.2091 & TRN & \\
\hline CHEMBL523750 & 523482 & 6.2676 & 6.9136 & TST & \\
\hline CHEMBL496832 & 523482 & 6.6021 & 7.2339 & TRN & \\
\hline CHEMBL485450 & 523482 & 6.4437 & 6.4285 & TRN & \\
\hline CHEMBL495839 & 523482 & 7.6576 & 7.3359 & TRN & \\
\hline CHEMBL496037 & 523482 & 8.1549 & 8.6723 & TRN & \\
\hline CHEMBL495988 & 523482 & 8.0 & 8.0353 & TRN & \\
\hline CHEMBL467305 & 523482 & 8.0 & 8.2076 & TST & \\
\hline CHEMBL496622 & 523482 & 7.3979 & 7.599 & TRN & \\
\hline CHEMBL496036 & 523482 & 7.699 & 8.0455 & TST & \\
\hline CHEMBL525445 & 523482 & 5.0 & 7.1741 & TST & \\
\hline CHEMBL496025 & 523482 & 7.0 & 7.098 & TRN & \\
\hline CHEMBL500905 & 523482 & 7.6198 & 7.4769 & TRN & \\
\hline CHEMBL495618 & 523482 & 7.0 & 6.7775 & TRN & \\
\hline CHEMBL497205 & 523482 & 7.6778 & 7.3924 & TRN & \\
\hline CHEMBL496623 & 523482 & 8.2218 & 7.8618 & TST & \\
\hline CHEMBL496636 & 523482 & 6.6021 & 7.556 & TST & \\
\hline CHEMBL 221532 & 523482 & 9.3979 & 7.9278 & TST & \\
\hline CHEMBL496026 & 523482 & 7.0 & 6.8059 & TRN & \\
\hline CHEMBL498019 & 523482 & 7.301 & 7.8396 & TRN & \\
\hline CHEMBL189685 & 304131 & 6.5918 & 6.8518 & TRN & \\
\hline CHEMBL364810 & 304131 & 6.9208 & 7.3118 & TRN & \\
\hline CHEMBL193213 & 304131 & 6.1675 & 5.724 & TST & \\
\hline CHEMBL190213 & 304131 & 5.0 & 5.782 & TST & \\
\hline CHEMBL189944 & 304131 & 5.71 & 6.1026 & TRN & \\
\hline CHEMBL189224 & 304131 & 7.1135 & 7.0343 & TRN & \\
\hline CHEMBL192623 & 304131 & 5.0 & 5.3466 & TRN & \\
\hline CHEMBL435492 & 304131 & 6.6271 & 5.8203 & TST & \\
\hline CHEMBL192769 & 304131 & 6.6144 & 5.7743 & TRN & \\
\hline CHEMBL426273 & 304131 & 7.1135 & 6.7233 & TRN & \\
\hline CHEMBL370479 & 304131 & 6.7852 & 6.4175 & TRN & \\
\hline CHEMBL190844 & 304131 & 7.0269 & 6.7513 & TRN & \\
\hline CHEMBL425555 & 304131 & 6.8894 & 7.7292 & TRN & \\
\hline CHEMBL192839 & 304131 & 5.0 & 5.3228 & TRN & \\
\hline CHEMBL 363212 & 304131 & 7.0223 & 7.0209 & TRN & \\
\hline CHEMBL 371360 & 304131 & 7.7212 & 7.6477 & TRN & \\
\hline CHEMBL190830 & 304131 & 6.7328 & 6.9818 & TRN & \\
\hline CHEMBL 364746 & 304131 & 6.8327 & 6.38700 & 00000000005 & TRN \\
\hline CHEMBL192966 & 304131 & 7.6021 & 6.9091 & TRN & \\
\hline
\end{tabular}

Page 27708 


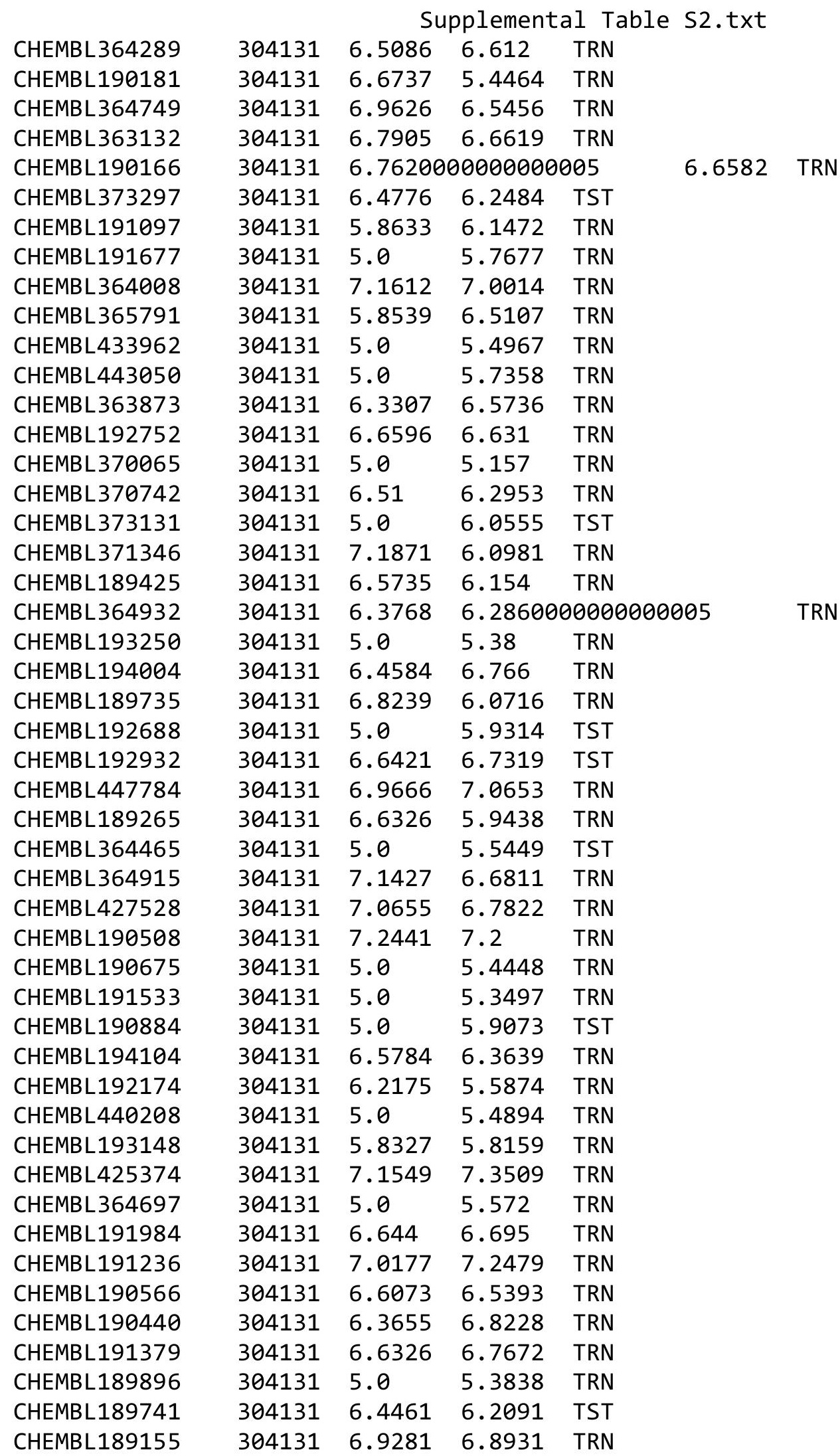

Page 27709 
Supplemental Table S2.txt

\begin{tabular}{|c|c|c|c|c|}
\hline CHEMBL 373308 & 304131 & 6.7878 & 6.8196 & TRN \\
\hline CHEMBL193099 & 304131 & 6.71 & 6.4877 & TRN \\
\hline CHEMBL191439 & 304131 & 6.6459 & 7.0073 & TRN \\
\hline CHEMBL192270 & 304131 & 6.8794 & 6.1523 & TRN \\
\hline CHEMBL371414 & 304131 & 6.7825 & 6.086 & TRN \\
\hline CHEMBL194054 & 304131 & 5.0 & 5.6452 & TRN \\
\hline CHEMBL189309 & 304131 & 6.6882 & 5.794 & TST \\
\hline CHEMBL189432 & 304131 & 6.251 & 6.4917 & TRN \\
\hline CHEMBL189897 & 304131 & 6.6861 & 6.9499 & TRN \\
\hline CHEMBL371179 & 304131 & 5.0 & 5.465 & TST \\
\hline CHEMBL192177 & 304131 & 5.0 & 5.7956 & TST \\
\hline CHEMBL189935 & 304131 & 5.0 & 5.5229 & TST \\
\hline CHEMBL371385 & 304131 & 7.1805 & 7.4432 & TRN \\
\hline CHEMBL190553 & 304131 & 6.8268 & 6.5527 & TST \\
\hline CHEMBL192488 & 304131 & 5.0 & 5.324 & TRN \\
\hline CHEMBL189728 & 304131 & 7.1938 & 7.0228 & TRN \\
\hline CHEMBL190421 & 304131 & 6.3478 & 6.3448 & TST \\
\hline CHEMBL 365028 & 304131 & 7.1427 & 7.3818 & TRN \\
\hline CHEMBL190304 & 304131 & 6.6576 & 5.3738 & TRN \\
\hline CHEMBL188141 & 304131 & 7.0132 & 6.91200 & 0000000001 \\
\hline CHEMBL362898 & 304131 & 5.8761 & 6.2767 & TST \\
\hline CHEMBL192852 & 304131 & 5.0 & 6.0046 & TST \\
\hline CHEMBL363653 & 304131 & 5.0 & 5.8384 & TST \\
\hline CHEMBL424814 & 304131 & 5.0 & 5.5324 & TST \\
\hline CHEMBL189930 & 304131 & 7.0506 & 6.6358 & TRN \\
\hline CHEMBL191741 & 304131 & 3.7033 & 5.5872 & TRN \\
\hline CHEMBL372916 & 304131 & 6.644 & 6.42700 & 00000000005 \\
\hline CHEMBL192070 & 304131 & 6.6819 & 6.0259 & TRN \\
\hline CHEMBL192772 & 304131 & 7.1487 & 7.119 & TST \\
\hline CHEMBL191578 & 304131 & 7.4202 & 7.4545 & TRN \\
\hline CHEMBL372258 & 304131 & 7.2924 & 7.2997 & TST \\
\hline CHEMBL192701 & 304131 & 6.0306 & 5.6247 & TST \\
\hline CHEMBL190499 & 304131 & 6.3655 & 6.0168 & TST \\
\hline CHEMBL55027 & 155808 & 2.699 & 2.5315 & TRN \\
\hline CHEMBL55988 & 155808 & 4.2284 & 2.9673 & TST \\
\hline CHEMBL55608 & 155808 & 2.699 & 3.1414 & TRN \\
\hline CHEMBL55353 & 155808 & 2.699 & 3.0929 & TST \\
\hline CHEMBL55140 & 155808 & 2.699 & 2.4678 & TRN \\
\hline CHEMBL55518 & 155808 & 2.699 & 2.6772 & TRN \\
\hline CHEMBL55889 & 155808 & 2.699 & 2.8895 & TRN \\
\hline CHEMBL55572 & 155808 & 2.699 & 4.8865 & TRN \\
\hline CHEMBL301572 & 155808 & 4.7352 & 3.9234 & TST \\
\hline CHEMBL 292224 & 155808 & 2.699 & 2.3516 & TST \\
\hline CHEMBL55959 & 155808 & 2.699 & 2.3429 & TRN \\
\hline CHEMBL431139 & 155808 & 3.983 & 4.0834 & TRN \\
\hline CHEMBL55886 & 155808 & 2.699 & 2.8881 & TRN \\
\hline CHEMBL54888 & 155808 & 4.3344 & 4.2112 & TRN \\
\hline CHEMBL54747 & 155808 & 2.699 & 3.1207 & TRN \\
\hline
\end{tabular}


Supplemental Table S2.txt

\begin{tabular}{|c|c|c|c|c|}
\hline CHEMBL56253 & 155808 & 2.699 & 2.3068 & כו \\
\hline CHEMBL58830 & 55808 & 2.699 & 2.3555 & \\
\hline CHEMBL5 5 & 55808 & 3.9872 & 9729 & \\
\hline HEMBL299443 & 55808 & 2.699 & 2.5801 & \\
\hline CHEMBL52620 & 55808 & 2.699 & 3544 & \\
\hline CHEMBL55582 & 55808 & 2.699 & 2.7704 & \\
\hline CHEMBL430963 & 55808 & 2.699 & 3.2371 & \\
\hline CHEMBL55358 & 55808 & 2.699 & 2.7615 & \\
\hline CHEMBL56255 & 155808 & 5.3188 & 5.2916 & \\
\hline CHEMBL 294192 & 55808 & 4.7696 & 4.8369 & \\
\hline CHEMBL 300361 & 155808 & 2.699 & 649 & \\
\hline CHEMBL417549 & 155808 & 3.9508 & 286 & \\
\hline CHEMBL 291727 & 155808 & 4.2976 & 495 & \\
\hline CHEMBL417198 & 155808 & 2.699 & 2.9149 & \\
\hline CHEMBL52306 & 155808 & 2.699 & 2.9705 & \\
\hline CHEMBL55221 & 155808 & 2.699 & 2. & \\
\hline CHEMBL2 & 155808 & 2.699 & 083 & \\
\hline CHEMBL: & 155808 & 5.6737 & 865 & \\
\hline CHEMBL 299988 & 155808 & 5.2573 & 5.1851 & \\
\hline CHEMBL 298547 & 155808 & 4.5735 & 865 & \\
\hline CHEMBL: & 155808 & 2.699 & 3.0421 & \\
\hline CHEMBL & 155808 & 2.699 & 242 & \\
\hline CHEMBL & 155808 & 2.699 & 2.3068 & \\
\hline CHEMBL55779 & 155808 & 2.699 & 2.3765 & \\
\hline CHEMBL293522 & 155808 & 2.699 & 394 & \\
\hline CHEMBL: & 155808 & 3.8861 & 95 & \\
\hline CHEMB & 155808 & 5.2815 & 65 & \\
\hline CHEMBL & 155808 & 2.699 & 038 & \\
\hline CHEMBL5 & 155808 & 4.6421 & 515 & $\Gamma R$ \\
\hline CHEMBL55464 & 155808 & 2.699 & 947 & \\
\hline CHEMBL 2 & 155808 & 2.699 & & \\
\hline $\mathrm{CHE}$ & 08 & 31 & 49 & \\
\hline $\mathrm{CHE}$ & 155 & 706 & 4.8865 & $\mathrm{TR}$ \\
\hline CHEMBL3 & 155808 & 3.7055 & 3.1722 & TR \\
\hline CHEMBL431735 & 155808 & 2.699 & 2.7773 & \\
\hline $\mathrm{CHE}$ & 155808 & & 374 & $\mathrm{~K}$ \\
\hline $\mathrm{CHE}$ & 155808 & 2. & 2.6326 & \\
\hline CHEMBL & 155808 & 2.699 & 2.4013 & $\mathrm{TR}$ \\
\hline CHEMBL417194 & 155808 & 2.699 & 2.5197 & TR \\
\hline CHEMBL52621 & 155808 & 2.699 & 2.6933 & $T$ \\
\hline CHEMBL52251 & 155808 & 4.8761 & 4.0286 & $1 \mathrm{R}$ \\
\hline CHEMBL56011 & 155808 & 3.699 & 3.4254 & \\
\hline CHEMBL56704 & 155808 & 2.699 & 2.3579 & TS \\
\hline CHEMBL54472 & 155808 & 2.699 & 2.421 & TS \\
\hline CHEMBL & 155808 & 4.1158 & 3.6313 & TR \\
\hline CHEMBL54056 & 155808 & 2.699 & 2.4906 & \\
\hline CHEMBL56556 & 155808 & 5.1135 & 4.954 & \\
\hline CHEMBL 300532 & 155808 & 2.699 & 2.6473 & \\
\hline
\end{tabular}

Page 27711 
Supplemental Table S2.txt

\begin{tabular}{|c|c|c|c|c|}
\hline CHEMBL294191 & 155808 & 2.699 & 2.8397 & TRN \\
\hline CHEMBL55856 & 155808 & 2.699 & 2.8237 & TRN \\
\hline CHEMBL55352 & 155808 & 2.699 & 3.2515 & TST \\
\hline CHEMBL301471 & 155808 & 2.699 & 2.8051 & TRN \\
\hline CHEMBL417932 & 155808 & 2.699 & 3.1036 & TRN \\
\hline CHEMBL54124 & 155808 & 2.699 & \multicolumn{2}{|c|}{2.6630000000000003} \\
\hline CHEMBL56254 & 155808 & 4.248 & 4.0286 & TRN \\
\hline CHEMBL54714 & 155808 & 4.9747 & 4.9567 & TRN \\
\hline CHEMBL55557 & 155808 & 2.699 & \multicolumn{2}{|c|}{2.4859999999999998} \\
\hline CHEMBL433833 & 155808 & 3.9872 & 4.2112 & TRN \\
\hline CHEMBL56073 & 155808 & 5.5376 & 5.2672 & TRN \\
\hline CHEMBL301247 & 155808 & 2.699 & 2.3549 & TRN \\
\hline CHEMBL301857 & 155808 & 2.699 & 2.8878 & TRN \\
\hline CHEMBL299563 & 155808 & 2.699 & 2.7407 & TST \\
\hline CHEMBL54344 & 155808 & 4.0453 & 3.5439 & TST \\
\hline CHEMBL434024 & 155808 & 2.699 & 2.8115 & TRN \\
\hline CHEMBL291736 & 155808 & 2.699 & 2.9874 & TRN \\
\hline CHEMBL55359 & 155808 & 3.8013 & 3.7884 & TRN \\
\hline CHEMBL300755 & 155808 & 2.699 & 2.6679 & TRN \\
\hline CHEMBL417419 & 155808 & 2.699 & 2.8466 & TRN \\
\hline CHEMBL299491 & 155808 & 4.2464 & 3.8846 & TRN \\
\hline CHEMBL434978 & 155808 & 2.699 & 2.6384 & TRN \\
\hline CHEMBL301244 & 155808 & 4.4743 & 4.7622 & TRN \\
\hline CHEMBL55837 & 155808 & 4.5406 & 4.8865 & TRN \\
\hline CHEMBL55222 & 155808 & 2.699 & 2.617 & TST \\
\hline CHEMBL55371 & 155808 & 2.699 & \multicolumn{2}{|c|}{2.7310000000000003} \\
\hline CHEMBL54004 & 155808 & 6.0809 & 4.8865 & TST \\
\hline CHEMBL56028 & 155808 & 4.5045 & 4.4302 & TRN \\
\hline CHEMBL301954 & 155808 & 2.699 & 2.9643 & TST \\
\hline CHEMBL55264 & 155808 & 5.3625 & 4.8865 & TST \\
\hline CHEMBL52137 & 155808 & 2.699 & 2.421 & TST \\
\hline CHEMBL596996 & 697223 & 7.4001 & 7.5277 & TRN \\
\hline CHEMBL1632195 & 697223 & 7.7212 & 6.8776 & TRN \\
\hline CHEMBL604164 & 697223 & 7.6819 & 7.4104 & TRN \\
\hline CHEMBL1632204 & 697223 & 6.5214 & 6.6754 & TRN \\
\hline CHEMBL1632660 & 697223 & 5.9626 & 6.0408 & TRN \\
\hline CHEMBL1632179 & 697223 & 7.4609 & 7.4969 & TRN \\
\hline CHEMBL1632670 & 697223 & 7.6615 & 7.3926 & TST \\
\hline CHEMBL1632202 & 697223 & 5.9208 & 6.4669 & TRN \\
\hline CHEMBL1632644 & 697223 & 5.7905 & 6.379 & TRN \\
\hline CHEMBL1632181 & 697223 & 7.7825 & 7.3632 & TRN \\
\hline CHEMBL1632674 & 697223 & 6.8013 & 7.4212 & TST \\
\hline CHEMBL1632185 & 697223 & 7.3706 & 7.414 & TRN \\
\hline CHEMBL1632180 & 697223 & 7.0501 & 7.1864 & TRN \\
\hline CHEMBL1632676 & 697223 & 8.9914 & 7.4276 & TST \\
\hline CHEMBL1632646 & 697223 & 6.8827 & 6.5437 & TRN \\
\hline CHEMBL1632648 & 697223 & 7.1203 & 6.5705 & TRN \\
\hline CHEMBL1630096 & 697223 & 7.4802 & 7.4742 & TST \\
\hline
\end{tabular}

Page 27712 
Supplemental Table S2.txt

\begin{tabular}{|c|c|c|c|c|c|c|}
\hline CHEMBL1632673 & 697223 & 7.5513 & 7.5166 & TST & & \\
\hline CHEMBL1632200 & 697223 & 7.3002 & 6.7185 & TRN & & \\
\hline CHEMBL1630093 & 697223 & 6.5702 & 6.8547 & TST & & \\
\hline CHEMBL1632178 & 697223 & 7.7212 & 7.4394 & TRN & & \\
\hline CHEMBL1630092 & 697223 & 8.4101 & 7.3294 & TST & & \\
\hline CHEMBL1632193 & 697223 & 7.6402 & 6.5772 & TST & & \\
\hline CHEMBL1632191 & 697223 & 6.2291 & 6.7216 & TRN & & \\
\hline CHEMBL1632652 & 697223 & 6.4306 & 6.5778 & TRN & & \\
\hline CHEMBL1632656 & 697223 & 6.7122 & 6.4858 & TRN & & \\
\hline CHEMBL1632645 & 697223 & 6.9208 & 6.4926 & TRN & & \\
\hline CHEMBL1632194 & 697223 & 7.0605 & 6.6111 & TRN & & \\
\hline CHEMBL1632198 & 697223 & 5.1367 & 6.5218 & TRN & & \\
\hline CHEMBL1632188 & 697223 & 7.3002 & 7.4146 & TRN & & \\
\hline CHEMBL1632668 & 697223 & 7.0101 & 6.8206 & TST & & \\
\hline CHEMBL1632659 & 697223 & 5.8297 & 6.0135 & TRN & & \\
\hline CHEMBL1632186 & 697223 & \multicolumn{3}{|c|}{7.4510000000000005} & 7.3169 & TRN \\
\hline CHEMBL1632201 & 697223 & 5.9031 & 6.5413 & TRN & & \\
\hline CHEMBL1632182 & 697223 & 6.6498 & 7.3402 & TRN & & \\
\hline CHEMBL1632671 & 697223 & 6.7212 & 7.2893 & TST & & \\
\hline CHEMBL1632199 & 697223 & 5.9031 & 6.2569 & TRN & & \\
\hline CHEMBL1632189 & 697223 & 5.9586 & 6.3691 & TRN & & \\
\hline CHEMBL1632664 & 697223 & 7.0501 & 6.1481 & TRN & & \\
\hline CHEMBL1632647 & 697223 & 6.3002 & 6.4416 & TRN & & \\
\hline CHEMBL599450 & 697223 & 7.58 & 7.3398 & TRN & & \\
\hline CHEMBL1632665 & 697223 & 6.0315 & 5.9726 & TRN & & \\
\hline CHEMBL1632655 & 697223 & 5.9393 & 6.3624 & TRN & & \\
\hline CHEMBL1632197 & 697223 & 7.5702 & 6.7054 & TRN & & \\
\hline CHEMBL599451 & 697223 & 7.4841 & 7.5362 & TRN & & \\
\hline CHEMBL1632666 & 697223 & 7.2007 & 6.1418 & TRN & & \\
\hline CHEMBL1632187 & 697223 & 5.9031 & 7.0095 & TRN & & \\
\hline CHEMBL1632677 & 697223 & 8.5214 & 7.6755 & TRN & & \\
\hline CHEMBL1632669 & 697223 & 6.9318 & 7.6273 & TRN & & \\
\hline CHEMBL1632650 & 697223 & 6.5003 & 6.4513 & TRN & & \\
\hline CHEMBL1632662 & 697223 & 6.2204 & 6.2216 & TST & & \\
\hline CHEMBL1632183 & 697223 & 7.3307 & 7.5628 & TST & & \\
\hline CHEMBL1632663 & 697223 & \multicolumn{3}{|c|}{5.752000000000001} & 6.0542 & TST \\
\hline CHEMBL1632177 & 697223 & 7.4101 & 7.1263 & TST & & \\
\hline CHEMBL 2012883 & 811468 & 7.5229 & 7.4294 & TRN & & \\
\hline CHEMBL487274 & 811468 & 6.0969 & 8.8737 & TST & & \\
\hline CHEMBL 2012880 & 811468 & 7.699 & 7.7558 & TRN & & \\
\hline CHEMBL1223526 & 811468 & 10.0 & 9.8355 & TRN & & \\
\hline CHEMBL 2012866 & 811468 & 7.0 & 6.9776 & TRN & & \\
\hline CHEMBL2012849 & 811468 & 6.0706 & 6.0001 & TRN & & \\
\hline CHEMBL 2012858 & 811468 & 8.301 & 8.383 & TRN & & \\
\hline CHEMBL 2012856 & 811468 & 8.0 & 7.8822 & TRN & & \\
\hline CHEMBL 2012879 & 811468 & 8.5229 & 8.3809 & TRN & & \\
\hline CHEMBL1223456 & 811468 & 8.0 & 9.0545 & TST & & \\
\hline CHEMBL 2012852 & 811468 & 8.0458 & 8.1462 & TRN & & \\
\hline
\end{tabular}

Page 27713 


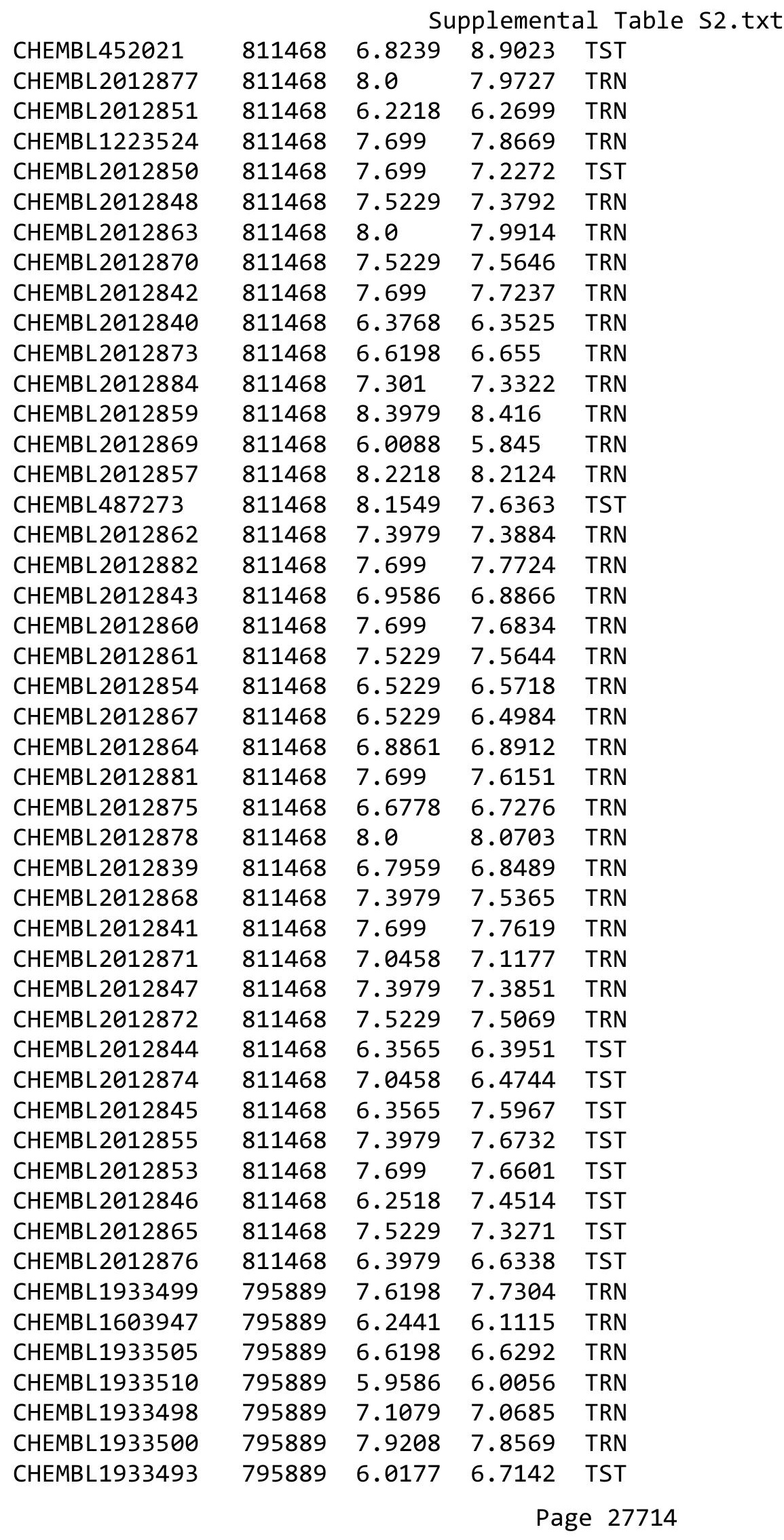


Supplemental Table S2.txt

\begin{tabular}{|c|c|c|c|c|}
\hline CHEMBL1933676 & 795889 & 6.699 & 6.6391 & TRN \\
\hline CHEMBL1933658 & 795889 & 5.699 & 5.4682 & TRN \\
\hline CHEMBL1933674 & 795889 & 6.1079 & 6.0092 & TRN \\
\hline CHEMBL1933502 & 795889 & 6.4685 & 6.4616 & TRN \\
\hline CHEMBL1933490 & 795889 & 6.9208 & 7.609 & TST \\
\hline CHEMBL1507203 & 795889 & 6.0223 & 6.3566 & TRN \\
\hline CHEMBL1933508 & 795889 & 6.8239 & 6.8035 & TRN \\
\hline CHEMBL1933666 & 795889 & 6.1487 & 6.1012 & TRN \\
\hline CHEMBL1933513 & 795889 & 5.8861 & 5.9396 & TRN \\
\hline CHEMBL1933655 & 795889 & 7.4949 & 7.4659 & TRN \\
\hline CHEMBL1933661 & 795889 & 8.0177 & 7.9646 & TRN \\
\hline CHEMBL1933516 & 795889 & 7.8239 & \multicolumn{2}{|c|}{7.8389999999999995} \\
\hline CHEMBL1933665 & 795889 & 5.3768 & 5.859 & TST \\
\hline CHEMBL1933507 & 795889 & 6.2518 & 6.0147 & TRN \\
\hline CHEMBL1933647 & 795889 & 7.5686 & 7.6375 & TRN \\
\hline CHEMBL215387 & 795889 & 8.5229 & 8.0362 & TST \\
\hline CHEMBL242655 & 795889 & 7.8539 & 7.9457 & TST \\
\hline CHEMBL1705444 & 795889 & 6.2924 & 5.9941 & TRN \\
\hline CHEMBL1933503 & 795889 & 7.2076 & 7.2081 & TRN \\
\hline CHEMBL1933512 & 795889 & 4.8861 & 4.9845 & TRN \\
\hline CHEMBL1933675 & 795889 & 5.9208 & 5.9885 & TRN \\
\hline CHEMBL1933670 & 795889 & 5.8539 & 5.9105 & TRN \\
\hline CHEMBL1933495 & 795889 & 6.3468 & 6.5978 & TST \\
\hline CHEMBL1933504 & 795889 & 5.6778 & 5.5315 & TRN \\
\hline CHEMBL1933496 & 795889 & 6.0223 & 6.5367 & TST \\
\hline CHEMBL1933671 & 795889 & 5.9208 & \multicolumn{2}{|c|}{5.497000000000001} \\
\hline CHEMBL1933677 & 795889 & 5.699 & 5.7846 & TRN \\
\hline CHEMBL1933669 & 795889 & 5.9208 & 5.9328 & TRN \\
\hline CHEMBL1933651 & 795889 & 8.7959 & 8.603 & TRN \\
\hline CHEMBL1933650 & 795889 & 7.2518 & 7.3622 & TRN \\
\hline CHEMBL1933667 & 795889 & 5.2218 & 5.2025 & TRN \\
\hline CHEMBL1933659 & 795889 & 7.7959 & 7.8086 & TRN \\
\hline CHEMBL1933489 & 795889 & 7.3363 & 7.3866 & TRN \\
\hline CHEMBL1933511 & 795889 & 6.8539 & 6.8566 & TRN \\
\hline CHEMBL1933497 & 795889 & 8.1739 & 8.212 & TRN \\
\hline CHEMBL1933653 & 795889 & 6.9208 & 6.9054 & TRN \\
\hline CHEMBL1933648 & 795889 & 8.1135 & 8.2219 & TRN \\
\hline CHEMBL1314245 & 795889 & 5.9586 & 5.9179 & TRN \\
\hline CHEMBL1890196 & 795889 & 6.2291 & 6.227 & TRN \\
\hline CHEMBL1933649 & 795889 & 7.9208 & 8.0022 & TRN \\
\hline CHEMBL1933494 & 795889 & 6.3098 & 6.9553 & TST \\
\hline CHEMBL1933515 & 795889 & 8.2676 & 8.0694 & TRN \\
\hline CHEMBL1933657 & 795889 & 6.4437 & 6.476 & TRN \\
\hline CHEMBL1933660 & 795889 & 5.2218 & 5.1089 & TRN \\
\hline CHEMBL1933663 & 795889 & 7.4559 & 7.3047 & TRN \\
\hline CHEMBL1933662 & 795889 & 6.6498 & 6.4695 & TRN \\
\hline CHEMBL1729370 & 795889 & 5.7212 & 5.6786 & TRN \\
\hline CHEMBL1933492 & 795889 & 6.4685 & 6.6477 & TST \\
\hline
\end{tabular}

Page 27715 


\begin{tabular}{|c|c|c|c|c|c|}
\hline & & & & & \\
\hline CHEMBL1933672 & 795889 & 6.2007 & 6.2444 & TRN & \\
\hline CHEMBL1933509 & 795889 & 4.301 & 5.006 & TRN & \\
\hline CHEMBL1933654 & 795889 & 6.8239 & 6.8624 & TRN & \\
\hline CHEMBL1933656 & 795889 & 7.7696 & 7.5739 & TRN & \\
\hline CHEMBL1933668 & 795889 & 7.6778 & 7.0346 & TST & \\
\hline CHEMBL 217758 & 795889 & 8.9586 & 7.2577 & TST & \\
\hline CHEMBL1933517 & 795889 & 7.7447 & 7.9955 & TRN & \\
\hline CHEMBL436774 & 795889 & 8.1549 & 7.1677 & TST & \\
\hline CHEMBL1933664 & 795889 & 6.0605 & 6.1299 & TRN & \\
\hline CHEMBL1933491 & 795889 & 7.6576 & 7.8751 & TRN & \\
\hline CHEMBL1933652 & 795889 & 5.7696 & 6.0878 & TRN & \\
\hline CHEMBL1933514 & 795889 & 6.3279 & 6.1817 & TST & \\
\hline CHEMBL1933673 & 795889 & 7.0362 & 5.9842 & TST & \\
\hline CHEMBL1933506 & 795889 & 5.6778 & 5.6668 & TST & \\
\hline CHEMBL242255 & 795889 & 8.7959 & 7.2745 & TST & \\
\hline CHEMBL1458 & 795889 & 7.284 & 6.44600 & 2000000001 & TST \\
\hline CHEMBL1933501 & 795889 & 6.3468 & 5.7535 & TST & \\
\hline CHEMBL 2058424 & 829593 & 5.9496 & 5.8965 & TRN & \\
\hline CHEMBL 2058413 & 829593 & 6.7825 & 6.816 & TRN & \\
\hline CHEMBL 2058154 & 829593 & 5.2583 & 4.9914 & TST & \\
\hline CHEMBL 2058419 & 829593 & 5.6847 & 5.6917 & TRN & \\
\hline CHEMBL404232 & 829593 & 7.4559 & 7.4279 & TRN & \\
\hline CHEMBL 2058410 & 829593 & 5.7062 & 5.6958 & TRN & \\
\hline CHEMBL 2058417 & 829593 & 7.5376 & 7.5209 & TRN & \\
\hline CHEMBL1982267 & 829593 & 5.5555 & 4.4768 & TST & \\
\hline CHEMBL 2058409 & 829593 & 5.2142 & 5.2368 & TRN & \\
\hline CHEMBL 2058429 & 829593 & 6.8153 & 6.8122 & TRN & \\
\hline CHEMBL 2058697 & 829593 & 6.2652 & 5.5653 & TST & \\
\hline CHEMBL 2058152 & 829593 & 5.2316 & 5.2212 & TRN & \\
\hline CHEMBL 2058418 & 829593 & 5.7212 & 5.6937 & TRN & \\
\hline CHEMBL2058151 & 829593 & 5.6078 & 5.2537 & TST & \\
\hline CHEMBL2058408 & 829593 & 5.2165 & 5.2599 & TRN & \\
\hline CHEMBL 2058706 & 829593 & 5.4089 & 5.0934 & TST & \\
\hline CHEMBL 2058407 & 829593 & 4.5822 & 4.6276 & TRN & \\
\hline CHEMBL 2058427 & 829593 & 7.0706 & 7.0163 & TRN & \\
\hline CHEMBL 2058428 & 829593 & 7.7447 & 7.8447 & TRN & \\
\hline CHEMBL 2058420 & 829593 & 7.284 & 7.2944 & TRN & \\
\hline CHEMBL 2058150 & 829593 & 4.8945 & 4.9226 & TRN & \\
\hline CHEMBL 2058423 & 829593 & 5.4881 & 5.51200 & 00000000005 & TRN \\
\hline CHEMBL 2058704 & 829593 & 5.9208 & 5.9329 & TRN & \\
\hline CHEMBL 2058703 & 829593 & 5.7447 & 5.5724 & TST & \\
\hline CHEMBL2058414 & 829593 & 5.9219 & 5.9144 & TRN & \\
\hline CHEMBL2058412 & 829593 & 6.4855 & 6.4625 & TRN & \\
\hline CHEMBL508657 & 829593 & 5.5122 & 5.4943 & TRN & \\
\hline CHEMBL541474 & 829593 & 4.8437 & 4.8138 & TRN & \\
\hline CHEMBL 2058153 & 829593 & 5.4338 & 5.4164 & TRN & \\
\hline CHEMBL 2058425 & 829593 & 5.9666 & 5.9722 & TRN & \\
\hline CHEMBL463249 & 829593 & 8.2518 & 8.1455 & TRN & \\
\hline
\end{tabular}

Page 27716 


\begin{tabular}{|c|c|c|c|c|}
\hline \multicolumn{5}{|c|}{ Supplemental Table S2.txt } \\
\hline CHEMBL1173331 & 829593 & 5.0969 & 4.9714 & TRN \\
\hline CHEMBL 2058700 & 829593 & 6.2733 & 6.1828 & TST \\
\hline CHEMBL2058415 & 829593 & 5.5879 & 5.5923 & TRN \\
\hline CHEMBL 2058694 & 829593 & 6.5735 & 6.0353 & TST \\
\hline CHEMBL 2058411 & 829593 & 5.819 & 5.8269 & TRN \\
\hline CHEMBL 2058698 & 829593 & 6.1694 & 5.9075 & TST \\
\hline CHEMBL512332 & 829593 & 7.0088 & 7.0016 & TRN \\
\hline CHEMBL1173525 & 829593 & 4.9148 & 4.9278 & TRN \\
\hline CHEMBL 2058696 & 829593 & 5.8145 & 5.8449 & TRN \\
\hline CHEMBL 2058701 & 829593 & 6.2027 & 5.851 & TST \\
\hline CHEMBL1170237 & 829593 & 6.6271 & 6.7437 & TRN \\
\hline CHEMBL 2058422 & 829593 & 5.2616 & 5.2311 & TRN \\
\hline CHEMBL 2058705 & 829593 & 5.3533 & 5.3411 & TRN \\
\hline CHEMBL 2058426 & 829593 & 6.2055 & 6.1716 & TRN \\
\hline CHEMBL 2058702 & 829593 & 4.8751 & 5.3089 & TST \\
\hline CHEMBL 2058421 & 829593 & 5.2353 & 5.2871 & TRN \\
\hline CHEMBL 2058699 & 829593 & 5.1467 & 5.4017 & TST \\
\hline CHEMBL 2058416 & 829593 & 6.58 & 6.6386 & TRN \\
\hline CHEMBL 2058695 & 829593 & 5.909 & 5.6066 & TST \\
\hline CHEMBL42388 & 39478 & 7.5229 & 7.3709 & TRN \\
\hline CHEMBL42948 & 39478 & 6.699 & 6.4127 & TRN \\
\hline CHEMBL51038 & 39478 & 5.2596 & 5.3707 & TRN \\
\hline CHEMBL50988 & 39478 & 7.0 & 6.9894 & TRN \\
\hline CHEMBL51163 & 39478 & 5.9586 & 5.8897 & TRN \\
\hline CHEMBL50937 & 39478 & 5.0915 & 5.2432 & TRN \\
\hline CHEMBL299226 & 39478 & 4.5918 & 4.5811 & TRN \\
\hline CHEMBL50591 & 39478 & 4.9586 & 4.9761 & TRN \\
\hline CHEMBL50129 & 39478 & 6.699 & 6.6699 & TRN \\
\hline CHEMBL50801 & 39478 & 5.8861 & 5.3958 & TST \\
\hline CHEMBL 300726 & 39478 & 6.4815 & 6.4128 & TRN \\
\hline CHEMBL51480 & 39478 & 6.7696 & 6.7951 & TRN \\
\hline CHEMBL43666 & 39478 & 6.5229 & 6.5636 & TRN \\
\hline CHEMBL54251 & 39478 & 5.7959 & 5.8739 & TRN \\
\hline CHEMBL50194 & 39478 & 9.0 & 6.9347 & TST \\
\hline CHEMBL51286 & 39478 & 7.699 & 7.7762 & TRN \\
\hline CHEMBL297904 & 39478 & 6.0 & 5.9808 & TRN \\
\hline CHEMBL 295832 & 39478 & 8.0 & 7.765 & TRN \\
\hline CHEMBL51113 & 39478 & 5.9208 & 5.9829 & TRN \\
\hline CHEMBL51110 & 39478 & 5.7959 & 5.7806 & TRN \\
\hline CHEMBL54143 & 39478 & 6.301 & 6.2969 & TRN \\
\hline CHEMBL415950 & 39478 & 5.1938 & 5.1286 & TRN \\
\hline CHEMBL 301503 & 39478 & 7.0458 & 6.3985 & TST \\
\hline CHEMBL50593 & 39478 & 6.0 & 6.059 & TRN \\
\hline CHEMBL262918 & 39478 & 7.1549 & 7.1538 & TRN \\
\hline CHEMBL51953 & 39478 & 5.8239 & 6.1221 & TST \\
\hline CHEMBL52094 & 39478 & 6.699 & 6.8636 & TRN \\
\hline CHEMBL 300699 & 39478 & 8.301 & 7.3806 & TST \\
\hline CHEMBL439744 & 39478 & 8.0458 & 8.1527 & TRN \\
\hline
\end{tabular}

Page 27717 


\begin{tabular}{|c|c|c|c|c|}
\hline \multicolumn{5}{|c|}{ Supplemental Table S2.txt } \\
\hline CHEMBL49921 & 39478 & 8.1549 & 6.1977 & TST \\
\hline CHEMBL50094 & 39478 & 7.3979 & 7.4292 & TRN \\
\hline CHEMBL51267 & 39478 & 6.6021 & 6.7176 & TRN \\
\hline CHEMBL299170 & 39478 & 8.1549 & 8.1406 & TRN \\
\hline CHEMBL54273 & 39478 & 7.5229 & 7.4869 & TRN \\
\hline CHEMBL416305 & 39478 & 7.5229 & 7.5147 & TRN \\
\hline CHEMBL301974 & 39478 & 7.699 & 7.7493 & TRN \\
\hline CHEMBL50354 & 39478 & 6.3979 & 6.3697 & TRN \\
\hline CHEMBL48873 & 39478 & 7.699 & 7.7231 & TRN \\
\hline CHEMBL43677 & 39478 & 7.699 & 7.6778 & TRN \\
\hline CHEMBL43173 & 39478 & 8.301 & 8.4268 & TRN \\
\hline CHEMBL299385 & 39478 & 6.699 & 6.6202 & TRN \\
\hline CHEMBL50557 & 39478 & 6.699 & 6.6942 & TRN \\
\hline CHEMBL49296 & 39478 & 6.0 & 5.8066 & TST \\
\hline CHEMBL50423 & 39478 & 6.0 & 6.1072 & TST \\
\hline CHEMBL51052 & 39478 & 6.699 & 6.3494 & TST \\
\hline CHEMBL49117 & 39478 & 6.0 & 5.8941 & TRN \\
\hline CHEMBL50401 & 39478 & 6.0969 & 5.3126 & TST \\
\hline CHEMBL433086 & 39478 & 5.3188 & 5.4348 & TST \\
\hline CHEMBL49404 & 39478 & 7.0 & 6.919 & TRN \\
\hline CHEMBL48401 & 39478 & 5.1675 & 5.1633 & TRN \\
\hline CHEMBL51307 & 39478 & 6.3979 & 6.3865 & TRN \\
\hline CHEMBL50645 & 39478 & 6.2757 & 6.3668 & TRN \\
\hline CHEMBL51259 & 39478 & 7.1549 & 7.2091 & TRN \\
\hline CHEMBL440477 & 39478 & 5.4318 & 5.6286 & TST \\
\hline CHEMBL50034 & 39478 & 7.301 & 7.2634 & TRN \\
\hline CHEMBL53673 & 39478 & 7.2218 & 7.1216 & TRN \\
\hline CHEMBL51512 & 39478 & 4.9957 & 5.0789 & TRN \\
\hline CHEMBL 297945 & 39478 & 5.9586 & 6.1201 & TST \\
\hline CHEMBL51244 & 39478 & 7.301 & 6.4283 & TST \\
\hline CHEMBL50726 & 39478 & 7.699 & 7.6078 & TRN \\
\hline CHEMBL50400 & 39478 & 5.9208 & 5.6965 & TST \\
\hline CHEMBL49702 & 39478 & 5.2924 & 5.2705 & TRN \\
\hline CHEMBL51937 & 39478 & 7.3979 & 7.4586 & TRN \\
\hline CHEMBL301601 & 39478 & 7.699 & 6.1487 & TST \\
\hline CHEMBL300472 & 39478 & 6.1549 & 6.1717 & TST \\
\hline CHEMBL50535 & 39478 & 7.301 & 7.152 & TRN \\
\hline CHEMBL300905 & 39478 & 6.301 & 6.1648 & TRN \\
\hline CHEMBL298999 & 39478 & 6.699 & 6.2495 & TST \\
\hline CHEMBL50829 & 39478 & 6.5229 & 6.5618 & TRN \\
\hline CHEMBL298414 & 39478 & 6.6198 & 6.8546 & TRN \\
\hline CHEMBL51507 & 39478 & 5.1805 & 4.8718 & TST \\
\hline CHEMBL295726 & 39478 & 6.301 & 6.2634 & TRN \\
\hline CHEMBL49938 & 39478 & 6.699 & 6.7277 & TRN \\
\hline CHEMBL50158 & 39478 & 7.0506 & 7.1172 & TRN \\
\hline CHEMBL51229 & 39478 & 7.0 & 6.7465 & TST \\
\hline CHEMBL416835 & 39478 & 5.4089 & 5.3209 & TRN \\
\hline CHEMBL301332 & 39478 & 5.0809 & 5.0998 & TRN \\
\hline
\end{tabular}




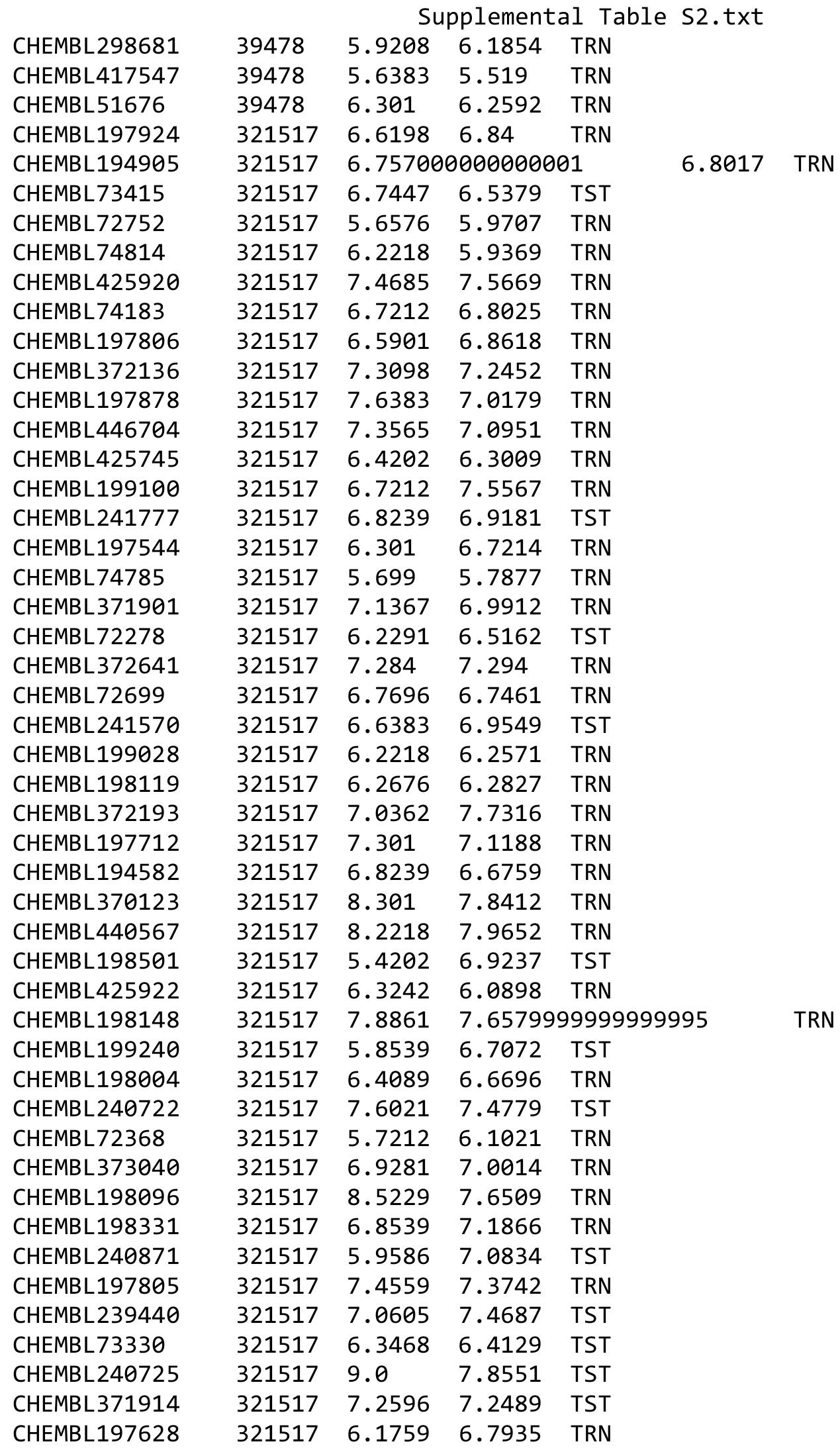

Page 27719 


\begin{tabular}{|c|c|c|c|c|c|c|}
\hline \multirow{2}{*}{ CHEMBL433987 } & \multirow{2}{*}{321517} & \\
\hline & & 7.1427 & 7.1298 & TRN & & \\
\hline CHEMBL 74579 & 321517 & 6.6778 & 6.2684 & TRN & & \\
\hline CHEMBL198250 & 321517 & 7.2676 & \multicolumn{3}{|c|}{7.372000000000001} & TRN \\
\hline CHEMBL372861 & 321517 & 6.4437 & 6.3533 & TRN & & \\
\hline CHEMBL198764 & 321517 & 7.2596 & 7.1935 & TRN & & \\
\hline CHEMBL307279 & 321517 & 6.8539 & 6.49 & TRN & & \\
\hline CHEMBL370444 & 321517 & 6.699 & 7.0812 & TST & & \\
\hline CHEMBL197841 & 321517 & 6.7959 & 6.7884 & TST & & \\
\hline CHEMBL371307 & 321517 & 7.585 & 7.4432 & TRN & & \\
\hline CHEMBL372815 & 321517 & 6.1904 & 6.9283 & TST & & \\
\hline CHEMBL369911 & 321517 & 6.4437 & 6.0162 & TRN & & \\
\hline CHEMBL197678 & 321517 & 6.3468 & 7.2752 & TST & & \\
\hline CHEMBL363415 & 321517 & 6.0605 & 6.4729 & TRN & & \\
\hline CHEMBL199069 & 321517 & 6.3747 & 6.5492 & TRN & & \\
\hline CHEMBL413566 & 321517 & 6.4559 & 6.0847 & TRN & & \\
\hline CHEMBL73491 & 321517 & 6.5528 & 6.9326 & TRN & & \\
\hline CHEMBL372491 & 305174 & 7.5528 & 7.636 & TRN & & \\
\hline CHEMBL426441 & 305174 & 9.3188 & 9.351 & TRN & & \\
\hline CHEMBL364585 & 305174 & 7.1024 & 7.4251 & TRN & & \\
\hline CHEMBL92955 & 305174 & 7.8539 & 7.8374 & TRN & & \\
\hline CHEMBL191729 & 305174 & 5.5735 & 5.1579 & TRN & & \\
\hline CHEMBL188714 & 305174 & 7.2676 & 7.3069 & TRN & & \\
\hline CHEMBL313231 & 305174 & \multicolumn{3}{|c|}{7.382000000000001} & 7.1755 & TST \\
\hline CHEMBL328102 & 305174 & 7.0044 & 7.2239 & TRN & & \\
\hline CHEMBL610243 & 305174 & 7.4949 & 7.6274 & TRN & & \\
\hline CHEMBL363455 & 305174 & 6.6198 & 6.539 & TST & & \\
\hline CHEMBL433379 & 305174 & 8.1079 & \multicolumn{3}{|c|}{8.181000000000001} & TRN \\
\hline CHEMBL313582 & 305174 & 6.857 & 7.0332 & TST & & \\
\hline CHEMBL92958 & 305174 & 6.9208 & 7.1844 & TRN & & \\
\hline CHEMBL92142 & 305174 & 6.6576 & 6.9726 & TRN & & \\
\hline CHEMBL185976 & 305174 & 6.9208 & 7.0506 & TRN & & \\
\hline CHEMBL86031 & 305174 & 7.0 & 7.0285 & TST & & \\
\hline CHEMBL188338 & 305174 & 6.0 & 6.2559 & TRN & & \\
\hline CHEMBL432376 & 305174 & 6.9208 & 7.0262 & TST & & \\
\hline CHEMBL92463 & 305174 & 7.585 & 7.8042 & TRN & & \\
\hline CHEMBL361869 & 305174 & 7.3665 & 7.2335 & TRN & & \\
\hline CHEMBL418955 & 305174 & 8.0809 & 8.0306 & TRN & & \\
\hline CHEMBL365904 & 305174 & 7.3979 & 7.5153 & TRN & & \\
\hline CHEMBL360832 & 305174 & 7.0458 & 6.9711 & TST & & \\
\hline CHEMBL189122 & 305174 & 8.2027 & 7.1558 & TRN & & \\
\hline CHEMBL329231 & 305174 & 9.2441 & 9.1912 & TRN & & \\
\hline CHEMBL189517 & 305174 & 6.9586 & 7.1765 & TRN & & \\
\hline CHEMBL362350 & 305174 & 6.4685 & 6.6068 & TST & & \\
\hline CHEMBL87014 & 305174 & 7.6576 & 7.5606 & TST & & \\
\hline CHEMBL87823 & 305174 & 7.301 & 6.9611 & TST & & \\
\hline CHEMBL330004 & 305174 & 7.301 & 7.289 & TRN & & \\
\hline CHEMBL189774 & 305174 & 7.5229 & 7.4588 & TRN & & \\
\hline CHEMBL92775 & 305174 & 6.9957 & 6.9803 & TRN & & \\
\hline
\end{tabular}

Page 27720 


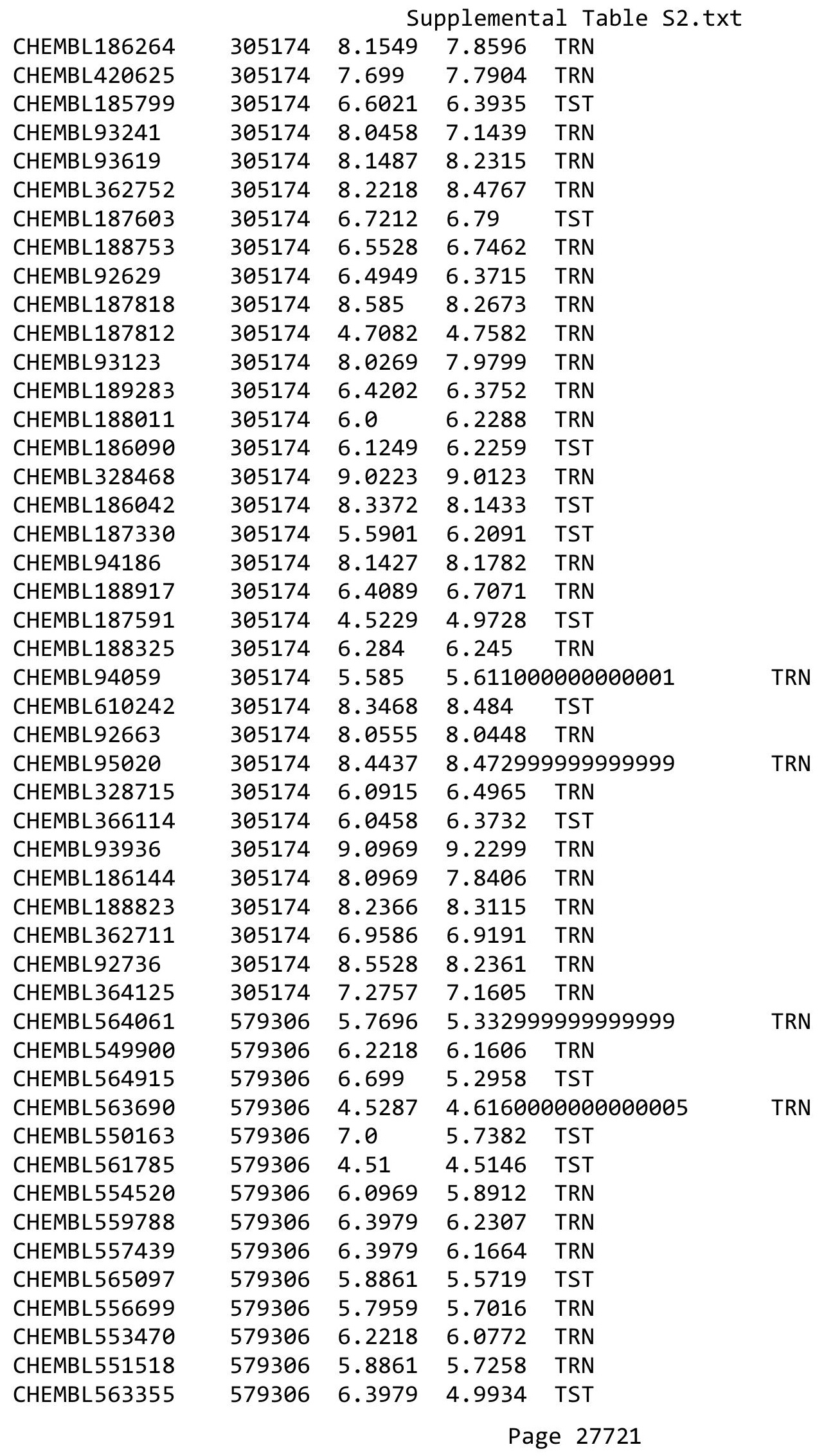




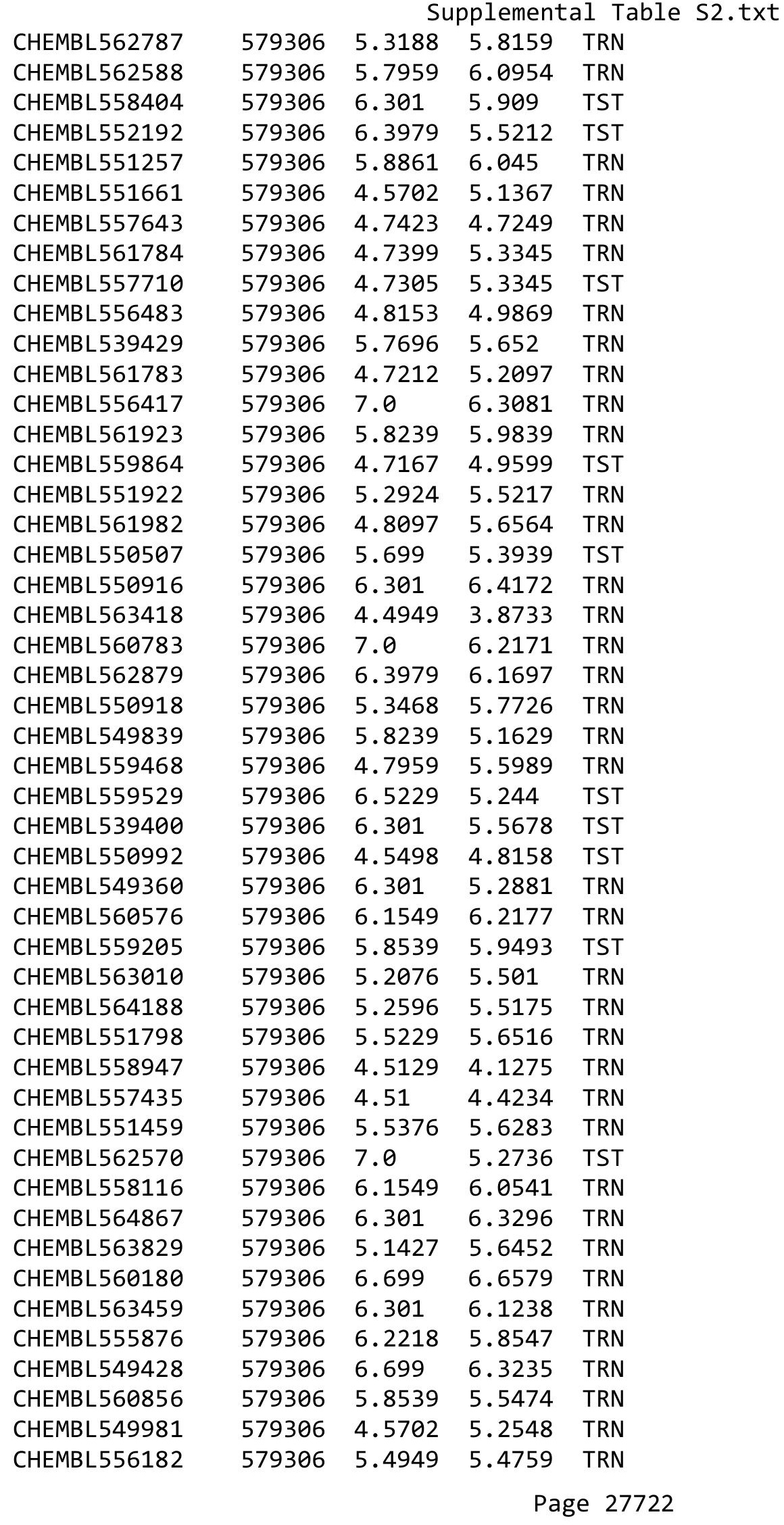




\begin{tabular}{|c|c|c|c|c|c|}
\hline \multicolumn{6}{|c|}{ Supplemental Table S2.txt } \\
\hline CHEMBL559924 & 579306 & 7.0 & 6.4557 & TST & \\
\hline CHEMBL3651909 & 1536256 & 8.5229 & 8.7059 & TRN & \\
\hline CHEMBL3651916 & 1536256 & 8.5229 & 8.6944 & TRN & \\
\hline CHEMBL3651953 & 1536256 & 8.699 & 8.5717 & TRN & \\
\hline CHEMBL3651975 & 1536256 & 8.5229 & 8.5004 & TRN & \\
\hline CHEMBL3652031 & 1536256 & 8.3979 & 8.4674 & TRN & \\
\hline CHEMBL 3651935 & 1536256 & 7.9208 & 8.0487 & TRN & \\
\hline CHEMBL3651899 & 1536256 & 9.0 & 8.7999 & TRN & \\
\hline CHEMBL3651977 & 1536256 & 8.301 & 8.2774 & TRN & \\
\hline CHEMBL3652017 & 1536256 & 8.699 & 8.6302 & TRN & \\
\hline CHEMBL3651976 & 1536256 & 8.1549 & 7.8112 & TST & \\
\hline CHEMBL 3651979 & 1536256 & 8.301 & 8.3231 & TRN & \\
\hline CHEMBL3651971 & 1536256 & 8.5229 & 8.5438 & TRN & \\
\hline CHEMBL3651913 & 1536256 & 6.0 & 5.7818 & TRN & \\
\hline CHEMBL3651993 & 1536256 & 8.5229 & 8.5407 & TRN & \\
\hline CHEMBL3651952 & 1536256 & 6.0 & 6.5569 & TST & \\
\hline CHEMBL3651997 & 1536256 & 8.3979 & 8.4328 & TRN & \\
\hline CHEMBL3651978 & 1536256 & 8.0458 & 8.1262 & TRN & \\
\hline CHEMBL3651910 & 1536256 & 7.9208 & 7.9505 & TRN & \\
\hline CHEMBL3651972 & 1536256 & 6.0 & 5.8019 & TRN & \\
\hline CHEMBL3652022 & 1536256 & 9.0 & 8.6664 & TRN & \\
\hline CHEMBL3651918 & 1536256 & 8.5229 & 8.4939 & TST & \\
\hline CHEMBL3651954 & 1536256 & 8.5229 & 8.4038 & TRN & \\
\hline CHEMBL3651904 & 1536256 & 8.699 & 8.859 & TRN & \\
\hline CHEMBL3651941 & 1536256 & 8.699 & 8.5623 & TRN & \\
\hline CHEMBL3651956 & 1536256 & 8.5229 & 8.5225 & TRN & \\
\hline CHEMBL 3651898 & 1536256 & 8.2218 & 8.1974 & TRN & \\
\hline CHEMBL3651938 & 1536256 & 8.699 & 8.6426 & TRN & \\
\hline CHEMBL3651947 & 1536256 & 6.0 & 6.5641 & TRN & \\
\hline CHEMBL3652001 & 1536256 & 8.2218 & 8.2598 & TST & \\
\hline CHEMBL3651914 & 1536256 & 8.1549 & 8.1406 & TRN & \\
\hline CHEMBL3651936 & 1536256 & 6.0 & 6.072 & TRN & \\
\hline CHEMBL3652009 & 1536256 & 9.0 & 9.1814 & TST & \\
\hline CHEMBL3651907 & 1536256 & 8.3979 & 8.6166 & TRN & \\
\hline CHEMBL3651906 & 1536256 & 8.2218 & 8.4261 & TRN & \\
\hline CHEMBL3652025 & 1536256 & 6.0 & 6.7859 & TRN & \\
\hline CHEMBL 3639508 & 1536256 & 7.9208 & 7.811 & TST & \\
\hline CHEMBL3652012 & 1536256 & 8.0458 & 7.9447 & TST & \\
\hline CHEMBL3651925 & 1536256 & 8.5229 & 8.7159 & TRN & \\
\hline CHEMBL3651970 & 1536256 & 8.3979 & 8.07200 & 0000000001 & TRN \\
\hline CHEMBL3652002 & 1536256 & 8.5229 & 8.7738 & TRN & \\
\hline CHEMBL 3651921 & 1536256 & 8.699 & 8.8556 & TST & \\
\hline CHEMBL3651922 & 1536256 & 8.699 & 8.8984 & TST & \\
\hline CHEMBL3651908 & 1536256 & 8.3979 & 8.5659 & TRN & \\
\hline CHEMBL3651989 & 1536256 & 6.0 & 5.6696 & TRN & \\
\hline CHEMBL3651980 & 1536256 & 8.1549 & 7.9558 & TST & \\
\hline CHEMBL 3651937 & 1536256 & 8.301 & 8.2987 & TRN & \\
\hline CHEMBL3651902 & 1536256 & 8.5229 & 8.4951 & TRN & \\
\hline
\end{tabular}

Page 27723 


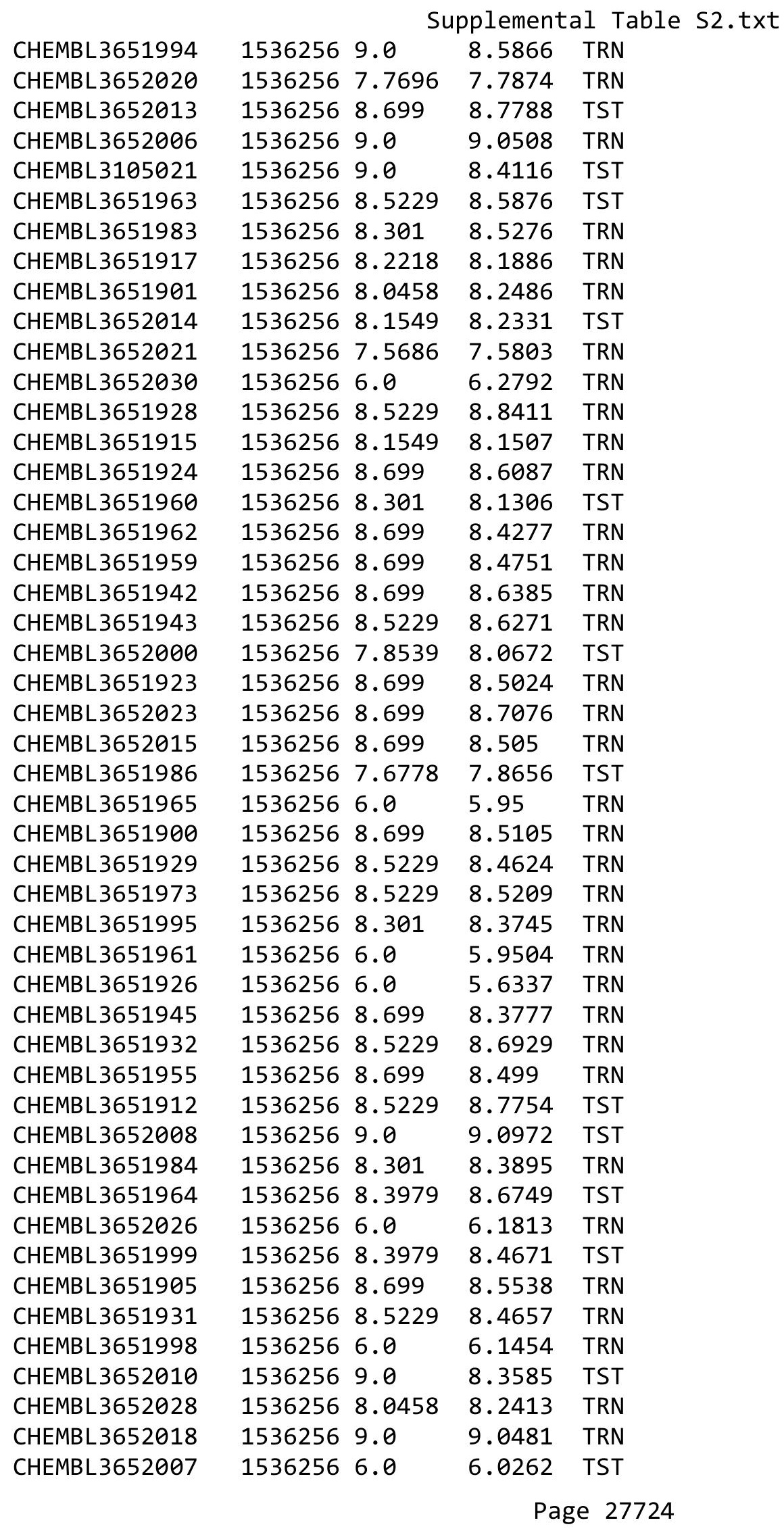




\begin{tabular}{|c|c|c|c|c|c|}
\hline \multicolumn{6}{|c|}{ Supplemental Table s2.txt } \\
\hline CHEMBL3652019 & 1536256 & 9.0 & 8.9207 & TRN & \\
\hline CHEMBL3651968 & 1536256 & 6.0 & 5.8491 & TRN & \\
\hline CHEMBL3651985 & 1536256 & 7.5376 & 7.8106 & TST & \\
\hline CHEMBL 3651920 & 1536256 & 9.0 & 8.6855 & TST & \\
\hline CHEMBL3651974 & 1536256 & 8.5229 & 8.5297 & TRN & \\
\hline CHEMBL3651957 & 1536256 & 8.3979 & 8.606 & TRN & \\
\hline CHEMBL3652003 & 1536256 & 8.699 & 9.0821 & TST & \\
\hline CHEMBL3651934 & 1536256 & 8.5229 & 8.5465 & TRN & \\
\hline CHEMBL3651939 & 1536256 & 8.699 & 8.5496 & TRN & \\
\hline CHEMBL3651903 & 1536256 & 8.699 & 8.6048 & TRN & \\
\hline CHEMBL3651933 & 1536256 & 8.301 & 8.2831 & TRN & \\
\hline CHEMBL3651930 & 1536256 & 8.2218 & 8.2607 & TRN & \\
\hline CHEMBL3651969 & 1536256 & 8.3979 & 8.5039 & TRN & \\
\hline CHEMBL 3651958 & 1536256 & 8.5229 & 8.5344 & TRN & \\
\hline CHEMBL3651944 & 1536256 & 8.0458 & 7.9776 & TRN & \\
\hline CHEMBL3652004 & 1536256 & 9.0 & \multicolumn{2}{|c|}{8.722000000000001} & TRN \\
\hline CHEMBL3652016 & 1536256 & 8.699 & 8.8025 & TRN & \\
\hline CHEMBL3651919 & 1536256 & 8.5229 & 8.7451 & TST & \\
\hline CHEMBL 3652005 & 1536256 & 7.9586 & 8.6843 & TST & \\
\hline CHEMBL3652029 & 1536256 & 8.1549 & 8.1345 & TST & \\
\hline CHEMBL1360733 & 1495400 & 3.2584 & 3.2415 & TRN & \\
\hline CHEMBL1539267 & 1495400 & 2.7769 & 2.5964 & TRN & \\
\hline CHEMBL1377679 & 1495400 & 2.7769 & 2.9441 & TST & \\
\hline CHEMBL1488495 & 1495400 & 2.7769 & 3.7127 & TRN & \\
\hline CHEMBL1406180 & 1495400 & 4.3467 & 3.6254 & TRN & \\
\hline CHEMBL1448654 & 1495400 & 2.7769 & 2.5594 & TRN & \\
\hline CHEMBL1312463 & 1495400 & 2.7769 & 2.7529 & TRN & \\
\hline CHEMBL1343994 & 1495400 & 3.8467 & 3.8198 & TRN & \\
\hline CHEMBL1302816 & 1495400 & 2.7769 & 3.1166 & TRN & \\
\hline CHEMBL1402600 & 1495400 & 2.7769 & 3.5219 & TRN & \\
\hline CHEMBL1407787 & 1495400 & 2.7769 & 3.3013 & TRN & \\
\hline CHEMBL1511190 & 1495400 & 4.2088 & 3.9282 & TST & \\
\hline CHEMBL1736964 & 1495400 & 4.6295 & 3.8147 & TRN & \\
\hline CHEMBL1301278 & 1495400 & 4.7641 & 4.1946 & TRN & \\
\hline CHEMBL1484749 & 1495400 & 2.7769 & 3.6198 & TRN & \\
\hline CHEMBL1613430 & 1495400 & 3.7355 & 3.4622 & TRN & \\
\hline CHEMBL1393575 & 1495400 & 2.7769 & 3.3981 & TRN & \\
\hline CHEMBL1302137 & 1495400 & 4.0902 & 3.5391 & TRN & \\
\hline CHEMBL1384852 & 1495400 & 2.7769 & 3.2619 & TRN & \\
\hline CHEMBL3189440 & 1495400 & 2.7769 & 2.782 & TRN & \\
\hline CHEMBL1867231 & 1495400 & 2.7769 & 3.2967 & TRN & \\
\hline CHEMBL3190427 & 1495400 & 3.9374 & 3.2134 & TRN & \\
\hline CHEMBL3560503 & 1495400 & 3.9394 & 3.7485 & TRN & \\
\hline CHEMBL1534889 & 1495400 & 4.2645 & 4.1891 & TRN & \\
\hline CHEMBL602722 & 1495400 & 3.2584 & 3.0029 & TRN & \\
\hline CHEMBL1353023 & 1495400 & 4.0414 & 3.4153 & TST & \\
\hline CHEMBL1544322 & 1495400 & 3.9873 & 3.193 & TRN & \\
\hline \multirow[t]{2}{*}{ CHEMBL1723213 } & 1495400 & 4.0837 & \multicolumn{2}{|c|}{ 3.1919999999999997 } & TRN \\
\hline & & & & 27725 & \\
\hline
\end{tabular}


Supplemental Table S2.txt

\begin{tabular}{|c|c|c|c|c|}
\hline HEMBL1589636 & 495400 & 2085 & 3.2942 & TRN \\
\hline ИГМР 154017 & 495400 & 2.7769 & 3.2126 & \\
\hline HEMBL $19{ }^{\circ}$ & 95400 & 2.7769 & 8699 & \\
\hline AEMBL1502645 & 400 & 2.7769 & 5547 & \\
\hline HEMBL1485821 & 495400 & 2.7769 & 5571 & \\
\hline HEMBL1338805 & 495400 & 4.2608 & 1361 & \\
\hline HEMBL1425516 & 400 & 2.7769 & 0024 & \\
\hline HEMBL1310797 & 495400 & 4.3271 & 2163 & \\
\hline HEMBL1323988 & 495400 & 2.7769 & 2.8975 & ГRN \\
\hline HEMBL1344706 & 495400 & 4.5641 & 9577 & \\
\hline HEMBL416556 & $\partial 0$ & 3.2584 & 4.0704 & \\
\hline AEMBL1445801 & $\partial 0$ & 4.1507 & .7914 & \\
\hline HEMBL1896589 & & 769 & 3719 & \\
\hline HEMBL1311018 & 495400 & 2.7769 & 2.8787 & IRIN \\
\hline HEMBL1508610 & 400 & 2.7769 & 3.1818 & I nIv \\
\hline HEMBL1579469 & 0 & 2. & 2.7784 & RIV \\
\hline HEMBL1541119 & & 2 . & 2.6332 & RN \\
\hline HEMBL1478459 & & 2.7769 & 3.2206 & RN \\
\hline HEMBL1510599 & 00 & 23 & 3.3422 & ISI \\
\hline HEMBL1549871 & & & 2.9072 & TS \\
\hline HEMBL1406568 & 0 & 4. & 3.4814 & SI \\
\hline HEMBL1 & & & 2.8978 & ST \\
\hline HEMBL1 & & 2.7769 & 3.5019 & TST \\
\hline HEMBL1 & & & 3387 & TST \\
\hline HEMBL1525497 & & 3.7 & 2.6891 & 15 \\
\hline HEMBL1 & & 2.7769 & 2.9011 & TST \\
\hline HEMBL1 & 0 & 769 & 607 & ST \\
\hline HEMBL 2 & & 6.2 & 5.7303 & TRN \\
\hline HEMBL1978271 & & 6 & 56 & IRIN \\
\hline HEMBL1967887 & 72 & 7. & . 9778 & TRN \\
\hline HEMBL 2 & 72 & 7 & 963 & TRN \\
\hline HEMBL & & 4. & 71 & TRN \\
\hline HEMBL 2 & & 6 . & 5.2326 & TRN \\
\hline HEMBL1994308 & & 5 . & 5.6253 & TRN \\
\hline HEMBL 2007097 & & 4 & 4.5651 & ГRN \\
\hline HEMBL1825138 & 2 & 4 & 1944 & ГST \\
\hline HEMPI 1 & & 4 & 4.4435 & TRN \\
\hline HEMBL1974328 & & 5.5 & 5.3641 & TRN \\
\hline HEMBL 243298 & & 6 & 159 & TRN \\
\hline HEMBL5 & & 4 & 738 & 「RN \\
\hline HEMBL1980435 & 72 & 4 . & 5.0219 & TRN \\
\hline CHEMBL 388311 & 72 & 5.8 & 6.275 & TRN \\
\hline HEMBL1998765 & & 5.7 & 5.1291 & TRN \\
\hline CHEMBL1964948 & & 6. & 523 & $\Gamma R$ \\
\hline SHEME & & 5 & & IRN \\
\hline CHEMBL1966204 & 809272 & 5.7 & 4.9177 & RIN \\
\hline CHEMBL1987430 & 809272 & 4.5 & 5.8086 & 「RN \\
\hline CHEMBL244378 & 809272 & 6.5 & 6.2675 & IRI \\
\hline
\end{tabular}

Page 27726 


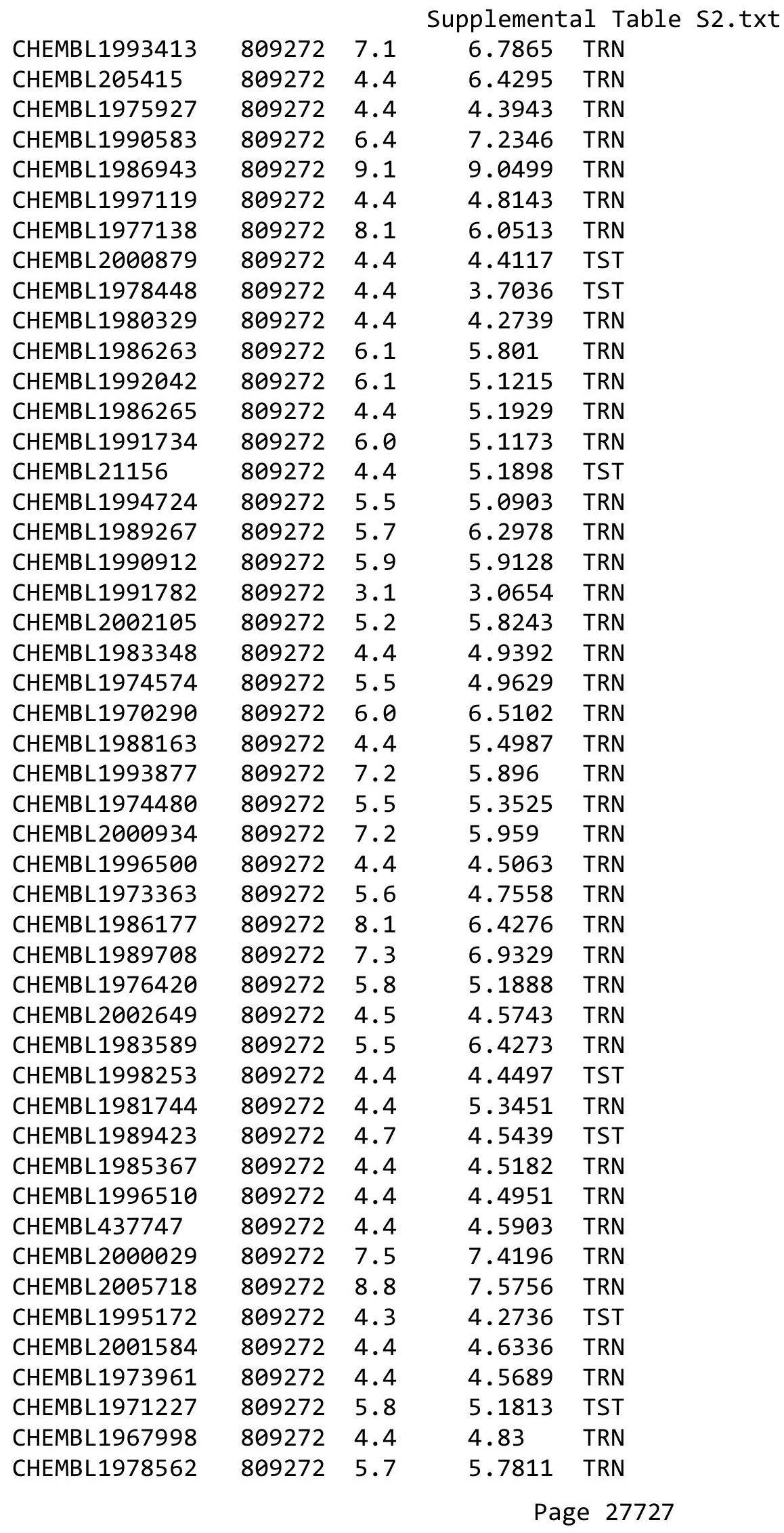




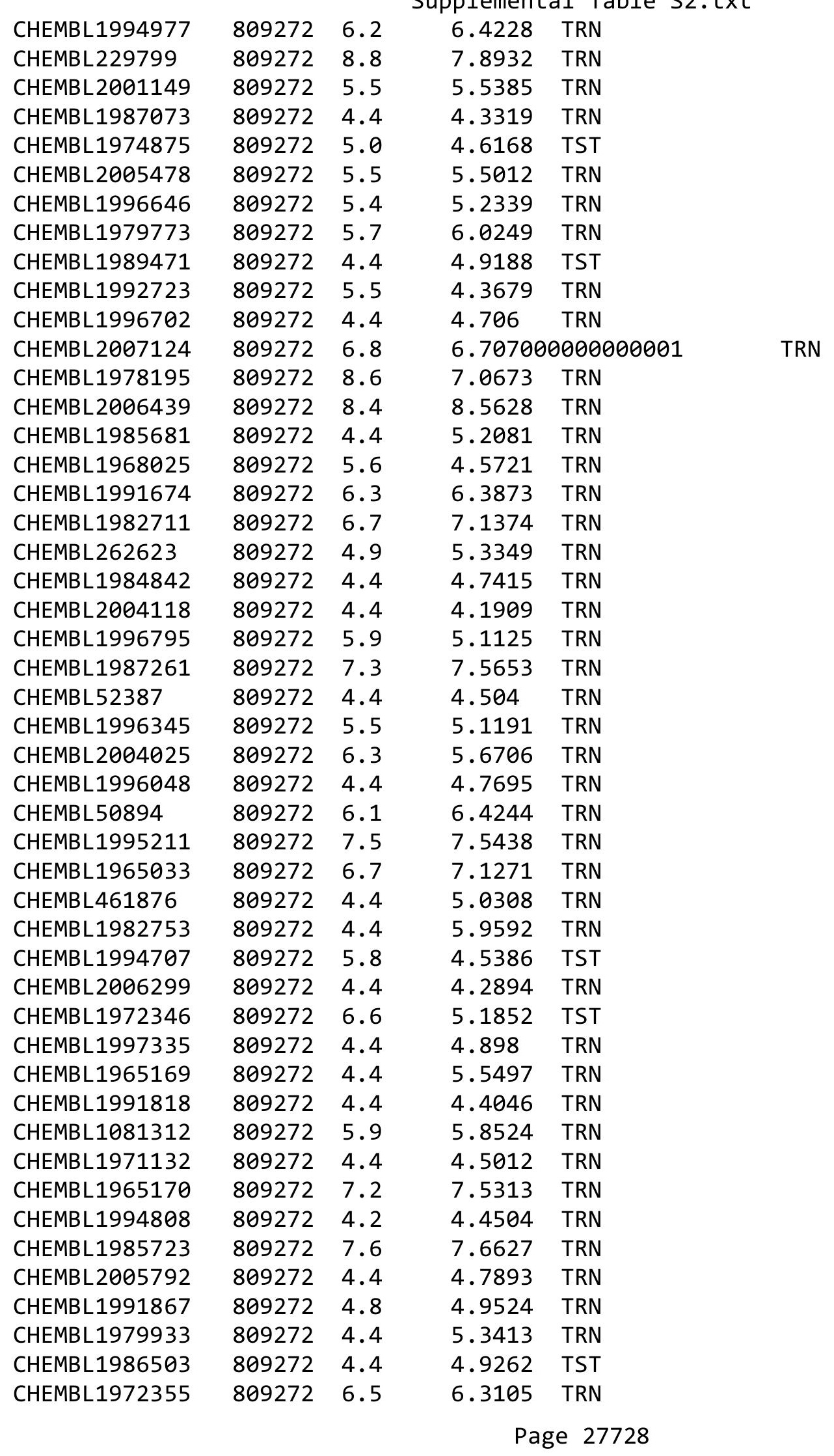




\begin{tabular}{|c|c|c|c|c|}
\hline & & & pl & \\
\hline CHEMBL226898 & 809272 & 7.9 & 6.7871 & TRN \\
\hline CHEMBL1997892 & 809272 & 6.8 & 6.2768 & TRN \\
\hline CHEMBL 2001641 & 809272 & 4.8 & 5.0532 & TRN \\
\hline CHEMBL1991377 & 809272 & 4.4 & 4.675 & TRN \\
\hline CHEMBL1976936 & 809272 & 6.1 & 6.1248 & TRN \\
\hline CHEMBL1997193 & 809272 & 5.9 & 5.9784 & TST \\
\hline CHEMBL1964902 & 809272 & 6.5 & 5.9827 & TRN \\
\hline CHEMBL1973868 & 809272 & 6.5 & 6.4714 & TRN \\
\hline CHEMBL1977128 & 809272 & 5.6 & 4.9798 & TRN \\
\hline CHEMBL1972462 & 809272 & 4.4 & 4.1214 & TRN \\
\hline CHEMBL1972988 & 809272 & 7.3 & 7.1164 & TRN \\
\hline CHEMBL399434 & 809272 & 5.6 & 4.754 & TST \\
\hline CHEMBL1965702 & 809272 & 8.7 & 7.9762 & TRN \\
\hline CHEMBL1983715 & 809272 & 6.6 & 5.7699 & TRN \\
\hline CHEMBL1984500 & 809272 & 3.1 & 3.5575 & TRN \\
\hline CHEMBL1966816 & 809272 & 4.4 & 5.0664 & TRN \\
\hline CHEMBL 2002992 & 809272 & 6.3 & 6.4858 & TRN \\
\hline CHEMBL1982700 & 809272 & 4.4 & 4.5964 & TRN \\
\hline CHEMBL10 & 809272 & 4.4 & 4.6341 & TRN \\
\hline CHEMBL 2005216 & 809272 & 7.0 & 6.0575 & TRN \\
\hline CHEMBL98350 & 809272 & 5.5 & 4.3521 & TST \\
\hline CHEMBL1980763 & 809272 & 4.4 & 4.2326 & TRN \\
\hline CHEMBL1977634 & 809272 & 6.0 & 6.2836 & TRN \\
\hline CHEMBL 2006456 & 809272 & 8.4 & 8.6204 & TRN \\
\hline CHEMBL1969156 & 809272 & 5.2 & 5.2881 & TRN \\
\hline CHEMBL375530 & 809272 & 5.7 & 4.637 & TST \\
\hline CHEMBL 2007479 & 809272 & 4.4 & 4.6711 & TRN \\
\hline CHEMBL1998953 & 809272 & 5.8 & 6.7405 & TRN \\
\hline CHEMBL1971606 & 809272 & 4.4 & 4.5439 & TRN \\
\hline CHEMBL1999120 & 809272 & 4.5 & 4.4421 & TRN \\
\hline CHEMBL1972220 & 809272 & 7.7 & 7.0335 & TRN \\
\hline CHEMBL1981215 & 809272 & 4.4 & 4.9897 & TRN \\
\hline CHEMBL 2003785 & 809272 & 4.9 & 4.5196 & TRN \\
\hline CHEMBL1973720 & 809272 & 8.3 & 8.6061 & TRN \\
\hline CHEMBL1999414 & 809272 & 7.1 & 6.876 & TRN \\
\hline CHEMBL1967336 & 809272 & 6.6 & 6.2172 & TRN \\
\hline CHEMBL 2001923 & 809272 & 4.4 & 4.5894 & TRN \\
\hline CHEMBL1983070 & 809272 & 4.4 & 4.539 & TRN \\
\hline CHEMBL 2003514 & 809272 & 4.4 & 4.5609 & TRN \\
\hline CHEMBL1970340 & 809272 & 6.3 & 5.8239 & TST \\
\hline CHEMBL1967992 & 809272 & 7.1 & 5.5232 & TRN \\
\hline CHEMBL1989043 & 809272 & 4.4 & 4.5701 & TRN \\
\hline CHEMBL1981671 & 809272 & 4.4 & 4.0324 & TRN \\
\hline CHEMBL 2006450 & 809272 & 7.8 & 8.2179 & TRN \\
\hline CHEMBL1967538 & 809272 & 4.6 & 4.8989 & TRN \\
\hline CHEMBL 2001987 & 809272 & 4.4 & 5.1936 & TRN \\
\hline CHEMBL1994555 & 809272 & 6.7 & 5.4114 & TRN \\
\hline CHEMBL1968515 & 809272 & 5.4 & 4.6367 & TST \\
\hline
\end{tabular}




\begin{tabular}{|c|c|c|c|c|c|}
\hline \\
\hline CHEMBL1164180 & 809272 & 4.4 & 5.0357 & TST & \\
\hline CHEMBL1975121 & 809272 & 4.7 & 4.0207 & TRN & \\
\hline CHEMBL1983640 & 809272 & 8.1 & 7.5247 & TRN & \\
\hline CHEMBL1997611 & 809272 & 5.7 & 5.131 & TRN & \\
\hline CHEMBL1980003 & 809272 & 4.9 & 4.412 & TRN & \\
\hline CHEMBL1971943 & 809272 & 6.7 & 6.4724 & TRN & \\
\hline CHEMBL 2002723 & 809272 & 5.6 & 6.0386 & TRN & \\
\hline CHEMBL1984686 & 809272 & 4.4 & 5.1072 & TRN & \\
\hline CHEMBL1973793 & 809272 & 4.4 & 4.8985 & TRN & \\
\hline CHEMBL1980178 & 809272 & 8.5 & 8.664 & TRN & \\
\hline CHEMBL1992073 & 809272 & 4.5 & 4.5285 & TRN & \\
\hline CHEMBL1990254 & 809272 & 4.4 & 4.8447 & TRN & \\
\hline CHEMBL1986143 & 809272 & 5.6 & 4.8126 & TRN & \\
\hline CHEMBL1972934 & 809272 & 5.0 & 5.5856 & TRN & \\
\hline CHEMBL2007559 & 809272 & 4.4 & 4.1414 & TRN & \\
\hline CHEMBL1992581 & 809272 & 4.4 & 5.2449 & TRN & \\
\hline CHEMBL 2004290 & 809272 & 6.7 & 6.9152 & TRN & \\
\hline CHEMBL1975921 & 809272 & 5.1 & 4.4579 & TRN & \\
\hline CHEMBL 2004033 & 809272 & 5.4 & 3.946 & TST & \\
\hline CHEMBL1975923 & 809272 & 5.7 & 4.9089 & TST & \\
\hline CHEMBL1984847 & 809272 & 4.4 & 4.9266 & TRN & \\
\hline CHEMBL1984402 & 809272 & 4.5 & 4.4455 & TRN & \\
\hline CHEMBL2005449 & 809272 & 4.4 & 4.7925 & TRN & \\
\hline CHEMBL1996576 & 809272 & 7.9 & 4.2295 & TST & \\
\hline CHEMBL1991678 & 809272 & 4.4 & 4.5758 & TRN & \\
\hline CHEMBL1987998 & 809272 & 4.4 & 4.5015 & TRN & \\
\hline CHEMBL1971534 & 809272 & 6.1 & 6.0448 & TRN & \\
\hline CHEMBL1990496 & 809272 & 4.4 & 4.4376 & TRN & \\
\hline CHEMBL1992363 & 809272 & 4.4 & 4.5888 & TRN & \\
\hline CHEMBL242865 & 809272 & 6.5 & 6.1098 & TRN & \\
\hline CHEMBL235157 & 809272 & 4.4 & 5.003 & TST & \\
\hline CHEMBL1982271 & 809272 & 8.8 & 8.8126 & TRN & \\
\hline CHEMBL2004159 & 809272 & 4.4 & 4.4289 & TRN & \\
\hline CHEMBL1978371 & 809272 & 6.4 & 5.375 & TST & \\
\hline CHEMBL2003952 & 809272 & 4.3 & 4.4833 & TRN & \\
\hline CHEMBL440084 & 809272 & 4.4 & 5.53299 & 99999999995 & TRN \\
\hline CHEMBL1998110 & 809272 & 4.4 & 4.6293 & TRN & \\
\hline CHEMBL1978166 & 809272 & 7.0 & 7.8601 & TRN & \\
\hline CHEMBL1981079 & 809272 & 7.5 & 7.7708 & TRN & \\
\hline CHEMBL 2000832 & 809272 & 5.5 & 4.4332 & TRN & \\
\hline CHEMBL2001451 & 809272 & 5.6 & 6.1136 & TRN & \\
\hline CHEMBL1990590 & 809272 & 4.4 & 4.5996 & TRN & \\
\hline CHEMBL1977814 & 809272 & 4.4 & 4.4161 & TRN & \\
\hline CHEMBL1974617 & 809272 & 5.2 & 5.4654 & TRN & \\
\hline CHEMBL86755 & 809272 & 4.4 & 4.0614 & TRN & \\
\hline CHEMBL1965660 & 809272 & 7.8 & 7.9054 & TRN & \\
\hline CHEMBL1972290 & 809272 & 7.7 & 7.9094 & TRN & \\
\hline CHEMBL1966175 & 809272 & 4.5 & 4.6183 & TRN & \\
\hline & & & & 27730 & \\
\hline
\end{tabular}




\begin{tabular}{|c|c|c|c|c|}
\hline & & & pplement & al $\mathrm{Ta}$ \\
\hline CHEMBL 2007375 & 809272 & 5.8 & 6.2258 & TRN \\
\hline CHEMBL1178727 & 809272 & 4.1 & 4.8145 & TST \\
\hline CHEMBL379975 & 809272 & 4.4 & 4.7356 & TST \\
\hline CHEMBL1967612 & 809272 & 4.2 & 4.123 & TST \\
\hline CHEMBL1973016 & 809272 & 4.4 & 4.68 & TRN \\
\hline CHEMBL1965387 & 809272 & 7.3 & 6.7321 & TRN \\
\hline CHEMBL2001539 & 809272 & 5.3 & 4.1732 & TST \\
\hline CHEMBL388978 & 809272 & 7.7 & 4.2114 & TST \\
\hline CHEMBL1997041 & 809272 & 4.3 & 5.609 & TRN \\
\hline CHEMBL1984548 & 809272 & 4.4 & 5.1615 & TRN \\
\hline CHEMBL550418 & 809272 & 5.9 & 5.4062 & TRN \\
\hline CHEMBL1986666 & 809272 & 4.4 & 5.1179 & TRN \\
\hline CHEMBL398951 & 809272 & 4.4 & 4.1509 & TST \\
\hline CHEMBL1971289 & 809272 & 6.2 & 5.131 & TST \\
\hline CHEMBL1988437 & 809272 & 4.7 & 5.2399 & TST \\
\hline CHEMBL 2007603 & 809272 & 7.1 & 6.0595 & TRN \\
\hline CHEMBL1985406 & 809272 & 5.8 & 5.5315 & TRN \\
\hline CHEMBL1988201 & 809272 & 5.9 & 5.1174 & TST \\
\hline CHEMBL1421720 & 809272 & 6.4 & 6.5116 & TRN \\
\hline CHEMBL1233887 & 809272 & 4.4 & 5.3287 & TRN \\
\hline CHEMBL1992607 & 809272 & 4.0 & 4.7836 & TRN \\
\hline CHEMBL2003689 & 809272 & 6.2 & 5.8889 & TRN \\
\hline CHEMBL576113 & 809272 & 4.4 & 4.8655 & TRN \\
\hline CHEMBL1996649 & 809272 & 6.3 & 6.5059 & TRN \\
\hline CHEMBL1986756 & 809272 & 4.4 & 5.3391 & TRN \\
\hline CHEMBL1972339 & 809272 & 7.9 & 7.6058 & TRN \\
\hline CHEMBL 3109278 & 809272 & 4.4 & 4.1524 & TRN \\
\hline CHEMBL1727312 & 809272 & 4.2 & 3.7307 & TRN \\
\hline CHEMBL1990223 & 809272 & 4.4 & 4.6967 & TRN \\
\hline CHEMBL1974998 & 809272 & 5.4 & 5.9873 & TRN \\
\hline CHEMBL 2006149 & 809272 & 5.8 & 6.0844 & TRN \\
\hline CHEMBL 2004438 & 809272 & 8.7 & 7.5027 & TRN \\
\hline CHEMBL1964382 & 809272 & 4.4 & 4.211 & TST \\
\hline CHEMBL101311 & 809272 & 5.5 & 5.4983 & TRN \\
\hline CHEMBL1981720 & 809272 & 6.9 & 6.2201 & TRN \\
\hline CHEMBL191003 & 809272 & 4.4 & 5.0346 & TRN \\
\hline CHEMBL 2002471 & 809272 & 6.0 & 5.2807 & TRN \\
\hline CHEMBL1973359 & 809272 & 6.9 & 5.9367 & TST \\
\hline CHEMBL1983595 & 809272 & 4.4 & 4.8521 & TRN \\
\hline CHEMBL1995740 & 809272 & 6.0 & 5.841 & TRN \\
\hline CHEMBL1988581 & 809272 & 7.3 & 5.6965 & TST \\
\hline CHEMBL1990162 & 809272 & 5.6 & 4.3037 & TRN \\
\hline CHEMBL1975500 & 809272 & 4.4 & 4.8393 & TRN \\
\hline CHEMBL2005699 & 809272 & 6.3 & 5.9524 & TRN \\
\hline CHEMBL 2006564 & 809272 & 4.4 & 5.3065 & TRN \\
\hline CHEMBL1979690 & 809272 & 4.4 & 4.8989 & TRN \\
\hline CHEMBL 234085 & 809272 & 5.8 & 5.2306 & TRN \\
\hline CHEMBL1965789 & 809272 & 5.5 & 4.9153 & TST \\
\hline
\end{tabular}




\begin{tabular}{|c|c|c|c|c|c|}
\hline & & & & & \\
\hline CHEMBL1978167 & 809272 & 4.4 & 5.6835 & TRN & \\
\hline CHEMBL418203 & 809272 & 8.7 & 5.0436 & TST & \\
\hline CHEMBL1998405 & 809272 & 5.6 & 4.3784 & TRN & \\
\hline CHEMBL243664 & 809272 & 6.2 & 5.4908 & TRN & \\
\hline CHEMBL225519 & 809272 & 8.0 & 6.1354 & TST & \\
\hline CHEMBL1994159 & 809272 & 4.5 & 4.9297 & TRN & \\
\hline CHEMBL1986658 & 809272 & 5.4 & 5.5656 & TRN & \\
\hline CHEMBL1976376 & 809272 & 6.6 & 6.0792 & TRN & \\
\hline CHEMBL1988622 & 809272 & 4.9 & 4.8409 & TRN & \\
\hline CHEMBL1983575 & 809272 & 6.2 & 6.4467 & TRN & \\
\hline CHEMBL1968868 & 809272 & 4.4 & 6.0166 & TRN & \\
\hline CHEMBL1971223 & 809272 & 5.6 & 6.2362 & TRN & \\
\hline CHEMBL1981047 & 809272 & 4.4 & 4.0763 & TRN & \\
\hline CHEMBL229968 & 809272 & 7.9 & 8.0572 & TRN & \\
\hline CHEMBL1996980 & 809272 & 8.8 & 9.0952 & TRN & \\
\hline CHEMBL1998470 & 809272 & 8.1 & 7.386 & TRN & \\
\hline CHEMBL1992354 & 809272 & 6.1 & 6.4527 & TRN & \\
\hline CHEMBL1976196 & 809272 & 5.8 & 5.52 & TST & \\
\hline CHEMBL1997197 & 809272 & 4.4 & 5.1594 & TRN & \\
\hline CHEMBL1983630 & 809272 & 4.6 & 4.1251 & TRN & \\
\hline CHEMBL1994669 & 809272 & 6.1 & 5.7156 & TRN & \\
\hline CHEMBL1975903 & 809272 & 4.4 & 5.0284 & TRN & \\
\hline CHEMBL1522508 & 809272 & 5.5 & 4.879 & TRN & \\
\hline CHEMBL458997 & 809272 & 4.4 & 3.6759 & TRN & \\
\hline CHEMBL1988805 & 809272 & 6.8 & 6.2949 & TRN & \\
\hline CHEMBL1969942 & 809272 & 6.9 & 6.06 & TRN & \\
\hline CHEMBL1982660 & 809272 & 4.4 & 4.3223 & TRN & \\
\hline CHEMBL1978567 & 809272 & 4.4 & 4.6293 & TRN & \\
\hline CHEMBL1977223 & 809272 & 6.8 & 5.8319 & TRN & \\
\hline CHEMBL1995765 & 809272 & 5.3 & 5.5015 & TRN & \\
\hline CHEMBL424872 & 809272 & 4.4 & 4.3576 & TRN & \\
\hline CHEMBL1984760 & 809272 & 4.4 & 4.1699 & TRN & \\
\hline CHEMBL1997846 & 809272 & 5.5 & 5.982 & TRN & \\
\hline CHEMBL360847 & 809272 & 4.4 & 4.044 & TRN & \\
\hline CHEMBL2007073 & 809272 & 6.4 & 6.2875 & TRN & \\
\hline CHEMBL1995811 & 809272 & 4.4 & 5.2161 & TRN & \\
\hline CHEMBL1992231 & 809272 & 4.4 & 4.3419 & TRN & \\
\hline CHEMBL1987240 & 809272 & 4.5 & 4.3169 & TRN & \\
\hline CHEMBL1983111 & 809272 & 4.4 & 5.3158 & TRN & \\
\hline CHEMBL1988141 & 809272 & 6.6 & 6.0384 & TST & \\
\hline CHEMBL1992937 & 809272 & 4.4 & 5.5351 & TRN & \\
\hline CHEMBL1977134 & 809272 & 7.6 & 7.08299 & 9999999999 & TRN \\
\hline CHEMBL1985206 & 809272 & 4.4 & 4.96899 & 9999999999 & TRN \\
\hline CHEMBL1991078 & 809272 & 4.4 & 5.3253 & TRN & \\
\hline CHEMBL1977749 & 809272 & 6.3 & 5.2051 & TST & \\
\hline CHEMBL 2001613 & 809272 & 5.0 & 5.0287 & TRN & \\
\hline CHEMBL261849 & 809272 & 4.4 & 4.9756 & TST & \\
\hline CHEMBL1983923 & 809272 & 4.4 & 3.5145 & TRN & \\
\hline & & & & 27732 & \\
\hline
\end{tabular}




\begin{tabular}{|c|c|c|c|c|c|}
\hline \\
\hline CHEMBL1993904 & 809272 & 8.6 & 8.4869 & TRN & \\
\hline CHEMBL1997275 & 809272 & 6.6 & 5.3493 & TRN & \\
\hline CHEMBL1994438 & 809272 & 7.9 & 7.6767 & TRN & \\
\hline CHEMBL1967513 & 809272 & 7.2 & 5.8227 & TRN & \\
\hline CHEMBL1980376 & 809272 & 5.5 & 5.6399 & TST & \\
\hline CHEMBL1988872 & 809272 & 5.6 & 5.3443 & TRN & \\
\hline CHEMBL 2000724 & 809272 & 4.4 & 4.9838 & TRN & \\
\hline CHEMBL1993634 & 809272 & 5.5 & 6.6961 & TRN & \\
\hline CHEMBL1982413 & 809272 & 5.7 & 5.8139 & TRN & \\
\hline CHEMBL2002182 & 809272 & 4.2 & 4.5391 & TRN & \\
\hline CHEMBL2003638 & 809272 & 5.9 & 5.7696 & TRN & \\
\hline CHEMBL1985042 & 809272 & 4.4 & 4.2964 & TRN & \\
\hline CHEMBL1987535 & 809272 & 7.1 & 6.9225 & TRN & \\
\hline CHEMBL1983393 & 809272 & 7.2 & 6.4439 & TRN & \\
\hline CHEMBL1981792 & 809272 & 7.0 & 5.4774 & TRN & \\
\hline CHEMBL 2002586 & 809272 & 4.4 & 5.0525 & TRN & \\
\hline CHEMBL 2006674 & 809272 & 4.4 & 5.042 & TST & \\
\hline CHEMBL1984236 & 809272 & 4.4 & 4.9978 & TST & \\
\hline CHEMBL383264 & 809272 & 6.5 & 5.5406 & TRN & \\
\hline CHEMBL1992371 & 809272 & 6.5 & 6.8081 & TRN & \\
\hline CHEMBL 2007421 & 809272 & 4.4 & 5.4211 & TRN & \\
\hline CHEMBL1973138 & 809272 & 4.4 & 4.4938 & TRN & \\
\hline CHEMBL1979970 & 809272 & 4.4 & 4.7446 & TRN & \\
\hline CHEMBL2002599 & 809272 & 7.0 & 6.8441 & TRN & \\
\hline CHEMBL1992673 & 809272 & 4.2 & 4.6563 & TRN & \\
\hline CHEMBL1969151 & 809272 & 7.8 & 8.3177 & TRN & \\
\hline CHEMBL1967252 & 809272 & 7.6 & 6.2848 & TST & \\
\hline CHEMBL1981492 & 809272 & 4.7 & 5.3217 & TST & \\
\hline CHEMBL1993335 & 809272 & 5.6 & 5.9345 & TST & \\
\hline CHEMBL1988692 & 809272 & 4.4 & 4.0972 & TST & \\
\hline CHEMBL 2007574 & 809272 & 8.9 & 8.0461 & TST & \\
\hline CHEMBL 2004637 & 809272 & 6.0 & 6.7946 & TST & \\
\hline CHEMBL1993374 & 809272 & 4.4 & 4.6674 & TST & \\
\hline CHEMBL1994318 & 809272 & 5.8 & 6.33899 & 99999999995 & TST \\
\hline CHEMBL1998680 & 809272 & 6.3 & 6.0781 & TST & \\
\hline CHEMBL592030 & 809272 & 4.4 & 5.9862 & TST & \\
\hline CHEMBL1970317 & 809272 & 5.8 & 6.6592 & TST & \\
\hline CHEMBL1999506 & 809272 & 5.6 & 6.0915 & TST & \\
\hline CHEMBL1967719 & 809272 & 5.7 & 5.472 & TST & \\
\hline CHEMBL 2002613 & 809272 & 7.5 & 4.82100 & 0000000001 & TST \\
\hline CHEMBL1605605 & 809272 & 5.6 & 5.5996 & TST & \\
\hline CHEMBL 2002736 & 809272 & 5.6 & 5.2942 & TST & \\
\hline CHEMBL1997007 & 809272 & 4.4 & 4.1524 & TST & \\
\hline CHEMBL1973936 & 809272 & 5.5 & 4.3764 & TST & \\
\hline CHEMBL1970352 & 809272 & 6.0 & 5.5489 & TST & \\
\hline CHEMBL1965631 & 809272 & 5.5 & 6.0479 & TST & \\
\hline CHEMBL1964444 & 809272 & 6.7 & 6.3058 & TST & \\
\hline CHEMBL 2002690 & 809272 & 4.4 & 5.34 & TST & \\
\hline
\end{tabular}




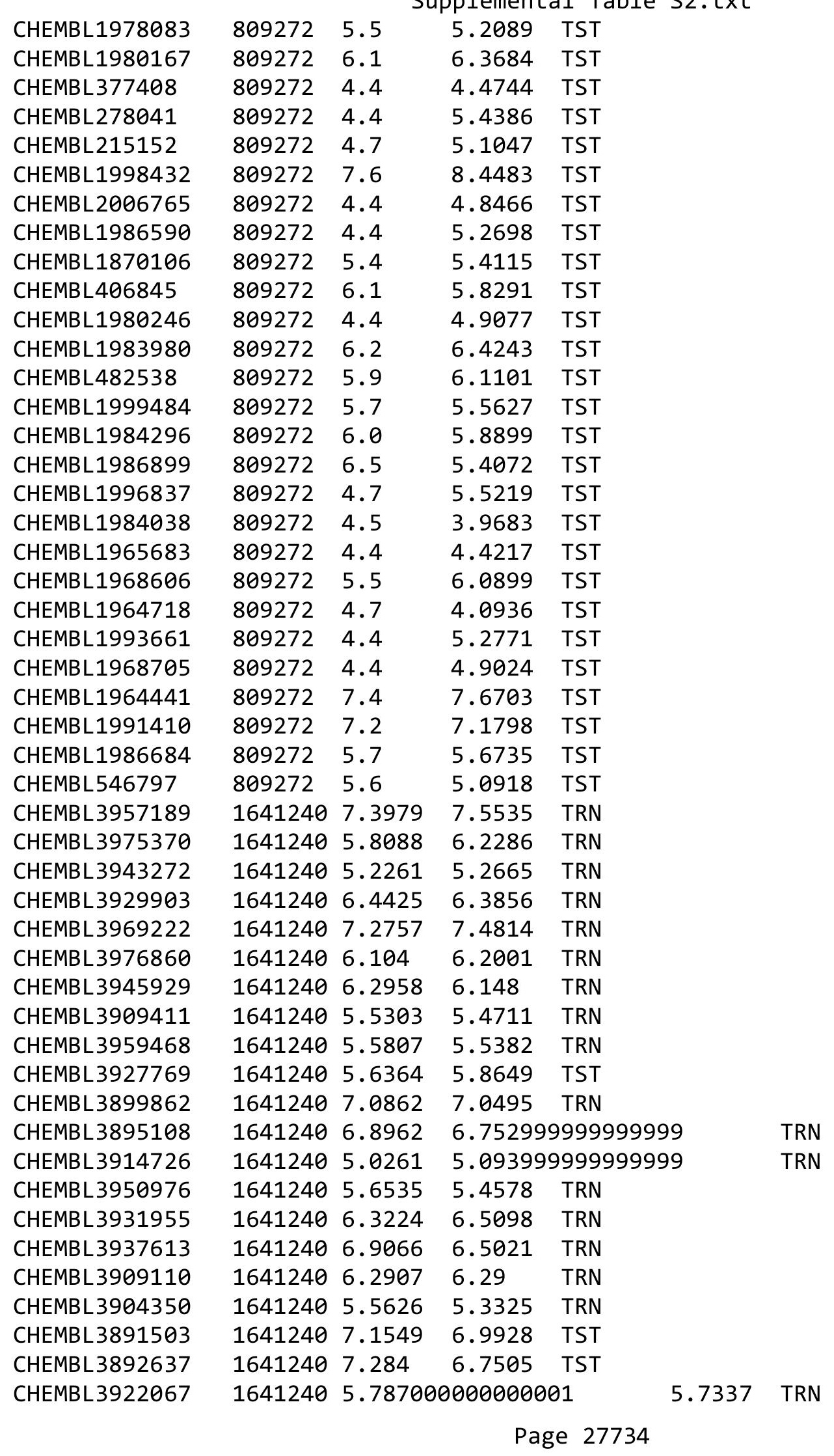


Supplemental Table S2.txt

\begin{tabular}{|c|c|c|c|c|c|}
\hline CHEMBL3939266 & 1641240 & 5.0618 & 5.4732 & TRN & \\
\hline CHEMBL3947045 & 1641240 & 5.9788 & 6.0467 & TRN & \\
\hline CHEMBL3892585 & 1641240 & 6.1871 & 6.27 & TRN & \\
\hline CHEMBL3944798 & 1641240 & 7.7447 & 8.0604 & TRN & \\
\hline CHEMBL3962309 & 1641240 & 5.3967 & 4.9186 & TST & \\
\hline CHEMBL3986051 & 1641240 & 5.2836 & 5.1248 & TRN & \\
\hline CHEMBL3946035 & 1641240 & 5.7908 & 5.4526 & TST & \\
\hline CHEMBL3987115 & 1641240 & 5.1163 & 5.2953 & TRN & \\
\hline CHEMBL3895793 & 1641240 & 8.0969 & 7.9841 & TST & \\
\hline CHEMBL3924734 & 1641240 & 6.5031 & 6.5121 & TRN & \\
\hline CHEMBL3919932 & 1641240 & 6.34200 & 000000000 & 6.32 & TRN \\
\hline CHEMBL3921461 & 1641240 & 5.1015 & 5.181 & TRN & \\
\hline CHEMBL3950656 & 1641240 & 8.699 & 8.423 & TST & \\
\hline CHEMBL3965265 & 1641240 & 7.0088 & 7.0307 & TRN & \\
\hline CHEMBL3925792 & 1641240 & 5.4238 & 5.2602 & TRN & \\
\hline CHEMBL3937006 & 1641240 & 5.6857 & 5.6841 & TRN & \\
\hline CHEMBL3898402 & 1641240 & 6.3665 & 5.9178 & TRN & \\
\hline CHEMBL 3951842 & 1641240 & 7.5376 & 7.3135 & TRN & \\
\hline CHEMBL3958335 & 1641240 & 5.183 & 5.3042 & TRN & \\
\hline CHEMBL3967276 & 1641240 & 6.9031 & 6.6005 & TRN & \\
\hline CHEMBL3940589 & 1641240 & 6.2874 & 6.1747 & TRN & \\
\hline CHEMBL 3944326 & 1641240 & 6.3595 & 6.0687 & TRN & \\
\hline CHEMBL3926826 & 1641240 & 6.6364 & 6.7196 & TRN & \\
\hline CHEMBL3951642 & 1641240 & 5.8359 & 6.1192 & TRN & \\
\hline CHEMBL3958889 & 1641240 & 5.3321 & 5.737999 & 99999999995 & TST \\
\hline CHEMBL3933655 & 1641240 & 6.567 & 6.7706 & TST & \\
\hline CHEMBL3928107 & 1641240 & 6.4461 & 6.2651 & TRN & \\
\hline CHEMBL3928663 & 1641240 & 5.6688 & 5.8227 & TRN & \\
\hline CHEMBL3911370 & 1641240 & 6.5935 & 6.5109 & TRN & \\
\hline CHEMBL3940329 & 1641240 & 5.38 & 5.3735 & TRN & \\
\hline CHEMBL3943097 & 1641240 & 8.0 & 6.6526 & TST & \\
\hline CHEMBL3939426 & 1641240 & 7.6383 & 7.1334 & TRN & \\
\hline CHEMBL3926861 & 1641240 & 6.3215 & 6.6344 & TRN & \\
\hline CHEMBL3955381 & 1641240 & 5.6421 & 5.7614 & TRN & \\
\hline CHEMBL3913349 & 1641240 & 5.6082 & 5.468999 & 9999999999 & TRN \\
\hline CHEMBL3924130 & 1641240 & 7.5376 & 6.5904 & TST & \\
\hline CHEMBL3929326 & 1641240 & 5.8179 & 5.7515 & TRN & \\
\hline CHEMBL3951738 & 1641240 & 6.8761 & 6.7876 & TST & \\
\hline CHEMBL3920995 & 1641240 & 6.3645 & 7.2483 & TST & \\
\hline CHEMBL3938382 & 1641240 & 5.9876 & 6.6749 & TST & \\
\hline CHEMBL3940306 & 1641240 & 5.6467 & 5.7826 & TRN & \\
\hline CHEMBL3943924 & 1641240 & 5.0922 & 5.3957 & TST & \\
\hline CHEMBL3916291 & 1641240 & 5.2303 & 5.3854 & TRN & \\
\hline CHEMBL3890299 & 1641240 & 8.301 & 7.8655 & TRN & \\
\hline CHEMBL3980233 & 1641240 & 5.4692 & 5.5236 & TRN & \\
\hline CHEMBL3958152 & 1641240 & 7.3098 & 7.2727 & TRN & \\
\hline CHEMBL 3979848 & 1641240 & 6.2125 & 6.2246 & TRN & \\
\hline CHEMBL3944795 & 1641240 & 6.7773 & 6.4121 & TST & \\
\hline
\end{tabular}




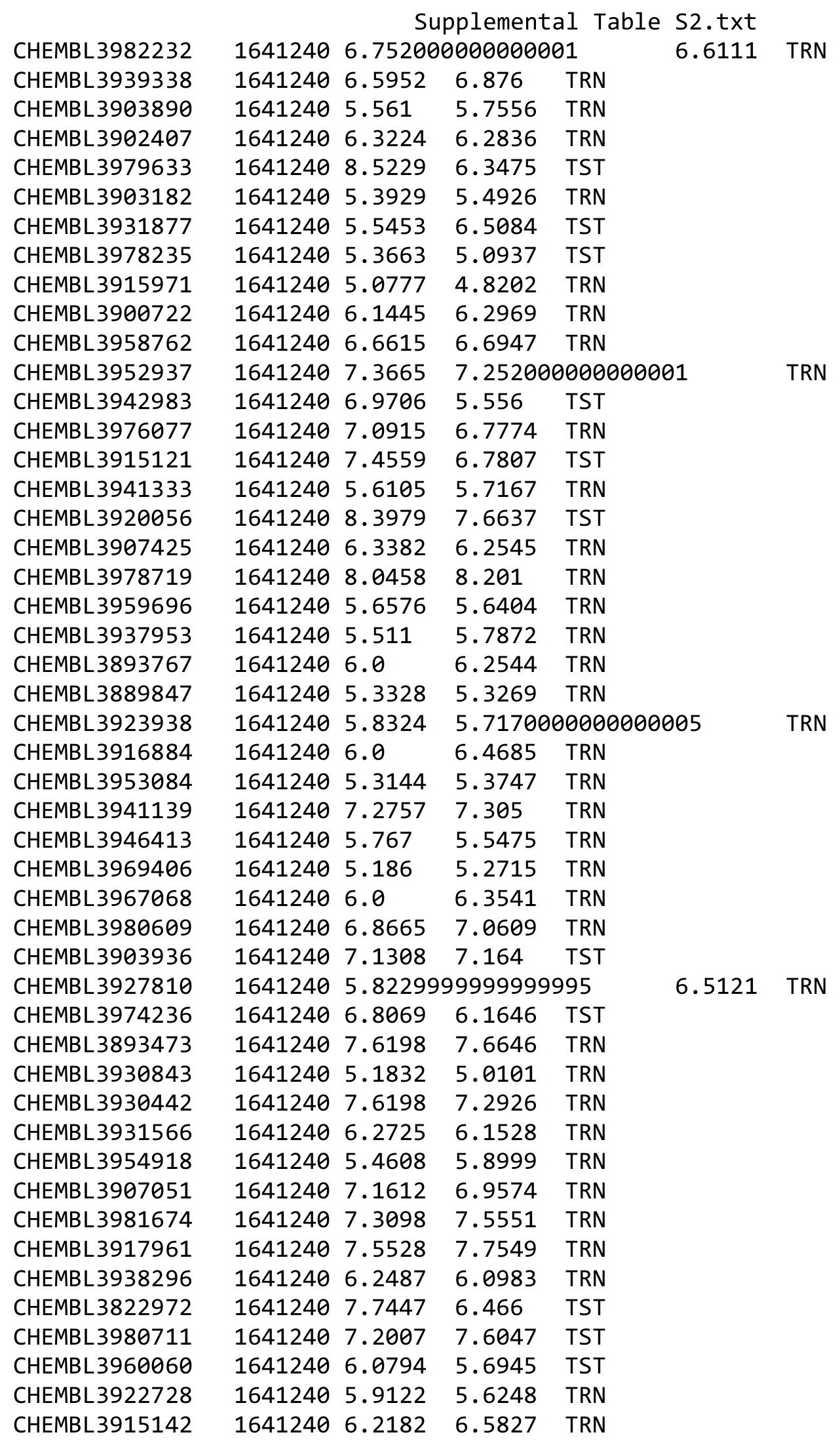

Page 27736 
Supplemental Table S2.txt

\begin{tabular}{|c|c|c|c|c|c|}
\hline CHEMBL 3897697 & 1641240 & 5.4207 & 5.3904 & TRN & \\
\hline CHEMBL 3903575 & 1641240 & 6.2815 & 6.2604 & TRN & \\
\hline CHEMBL 3898083 & 1641240 & 7.0 & 6.6969 & TST & \\
\hline CHEMBL3962911 & 1641240 & 6.3242 & 6.1578 & TRN & \\
\hline CHEMBL 3896123 & 1641240 & 5.4504 & 5.776 & TST & \\
\hline CHEMBL 3909791 & 1641240 & 6.1158 & 6.0191 & TRN & \\
\hline CHEMBL 3971885 & 1641240 & 6.1314 & 5.9356 & TRN & \\
\hline CHEMBL3950081 & 1641240 & 6.7011 & 6.5226 & TRN & \\
\hline CHEMBL 3953542 & 1641240 & 6.0 & 6.1551 & TRN & \\
\hline CHEMBL 3919293 & 1641240 & 6.5143 & 6.4245 & TRN & \\
\hline CHEMBL3969867 & 1641240 & 5.3837 & 5.3013 & TST & \\
\hline CHEMBL 3975532 & 1641240 & 6.5229 & 6.0488 & TST & \\
\hline CHEMBL 3937694 & 1641240 & 5.6889 & 5.7394 & TRN & \\
\hline CHEMBL 3925304 & 1641240 & 6.9957 & 6.5986 & TST & \\
\hline CHEMBL 3935363 & 1641240 & \multicolumn{2}{|c|}{6.3420000000000005} & 6.0294 & TRN \\
\hline CHEMBL 3904732 & 1641240 & 8.0 & 5.9739 & TST & \\
\hline CHEMBL 3946548 & 1641240 & 7.4815 & 7.1311 & TRN & \\
\hline CHEMBL 3909577 & 1641240 & 6.8633 & \multicolumn{2}{|c|}{6.6979999999999995} & TRN \\
\hline CHEMBL3353220 & 1641240 & 8.0969 & 6.1892 & TST & \\
\hline CHEMBL 3929293 & 1641240 & 7.9208 & 7.401 & TST & \\
\hline CHEMBL 3922946 & 1641240 & 6.098 & 5.9595 & TRN & \\
\hline CHEMBL 3892984 & 1641240 & 6.3605 & 5.4517 & TST & \\
\hline CHEMBL 3952668 & 1641240 & 5.1137 & 5.3596 & TRN & \\
\hline CHEMBL3953525 & 1641240 & 7.9208 & \multicolumn{2}{|c|}{7.632999999999999} & TST \\
\hline CHEMBL 3982737 & 1641240 & 5.6503 & 5.5246 & TST & \\
\hline CHEMBL 3955819 & 1641240 & 6.4855 & 6.5855 & TRN & \\
\hline CHEMBL 3955028 & 1641240 & 5.1345 & 5.2947 & TRN & \\
\hline CHEMBL3961117 & 1641240 & 6.5376 & 6.3084 & TRN & \\
\hline CHEMBL3901226 & 1641240 & 6.5214 & 6.3514 & TRN & \\
\hline CHEMBL 3918335 & 1641240 & 5.5164 & 5.3281 & TRN & \\
\hline CHEMBL 3902377 & 1641240 & 6.6003 & 6.8299 & TRN & \\
\hline CHEMBL3957910 & 1641240 & 5.301 & 5.7302 & TRN & \\
\hline CHEMBL3353219 & 1641240 & 9.0 & 7.5276 & TST & \\
\hline CHEMBL 3957438 & 1641240 & 5.6525 & 6.0499 & TST & \\
\hline CHEMBL 3947085 & 1641240 & 6.5058 & 6.4832 & TRN & \\
\hline CHEMBL3909778 & 1641240 & 7.4815 & 7.2791 & TRN & \\
\hline CHEMBL 3919594 & 1641240 & 6.8827 & 6.8581 & TRN & \\
\hline CHEMBL 3983893 & 1641240 & 6.9872 & 6.9108 & TRN & \\
\hline CHEMBL3969172 & 1641240 & 5.6164 & 5.6724 & TRN & \\
\hline CHEMBL 3962215 & 1641240 & 6.2248 & \multicolumn{2}{|c|}{5.877000000000001} & TST \\
\hline CHEMBL 3924141 & 1641240 & 5.432 & 5.2681 & TRN & \\
\hline CHEMBL 3940896 & 1641240 & 5.5286 & 5.767 & TRN & \\
\hline CHEMBL3889839 & 1641240 & 7.1192 & 6.9131 & TRN & \\
\hline CHEMBL3963416 & 1641240 & 6.0975 & 6.205 & TRN & \\
\hline CHEMBL 3905293 & 1641240 & 7.1192 & 6.5639 & TST & \\
\hline CHEMBL 3923236 & 1641240 & 5.657 & 5.5635 & TRN & \\
\hline CHEMBL 3964473 & 1641240 & 5.36600 & 00000000005 & 5.2545 & TRN \\
\hline CHEMBL3933884 & 1641240 & 5.6472 & \multicolumn{2}{|c|}{5.9270000000000005} & TRN \\
\hline
\end{tabular}

Page 27737 
Supplemental Table S2.txt

\begin{tabular}{|c|c|c|c|c|}
\hline CHEMBL3919571 & 1641240 & 7.1427 & 7.1531 & TRN \\
\hline CHEMBL3918045 & 1641240 & 6.3072 & 6.2443 & TRN \\
\hline CHEMBL3896014 & 1641240 & 6.1938 & 6.0446 & TRN \\
\hline CHEMBL61231 & 87054 & 8.14 & 8.1839 & TRN \\
\hline CHEMBL64799 & 87054 & 7.16 & 7.5029 & TRN \\
\hline CHEMBL62803 & 87054 & 8.86 & 8.4516 & TRN \\
\hline CHEMBL65518 & 87054 & 8.23 & \multicolumn{2}{|c|}{8.187000000000001} \\
\hline CHEMBL64100 & 87054 & 8.5 & 8.3543 & TRN \\
\hline CHEMBL64021 & 87054 & 6.54 & 6.6074 & TRN \\
\hline CHEMBL63631 & 87054 & 7.9 & 7.9739 & TRN \\
\hline CHEMBL64479 & 87054 & 8.19 & 8.2041 & TRN \\
\hline CHEMBL64334 & 87054 & 7.87 & 7.7299 & TRN \\
\hline CHEMBL60360 & 87054 & 7.78 & 6.9924 & TST \\
\hline CHEMBL440864 & 87054 & 7.17 & 6.915 & TRN \\
\hline CHEMBL294519 & 87054 & 7.44 & 7.516 & TRN \\
\hline CHEMBL64253 & 87054 & 7.8 & 7.8825 & TRN \\
\hline CHEMBL294502 & 87054 & 8.5 & 8.5405 & TRN \\
\hline CHEMBL62066 & 87054 & 8.27 & 8.4296 & TRN \\
\hline CHEMBL431172 & 87054 & 7.67 & 7.7123 & TRN \\
\hline CHEMBL304714 & 87054 & 8.44 & 8.3448 & TRN \\
\hline CHEMBL291882 & 87054 & 7.53 & 8.1711 & TST \\
\hline CHEMBL63632 & 87054 & 7.43 & 7.3162 & TST \\
\hline CHEMBL61070 & 87054 & 7.6 & 7.5896 & TRN \\
\hline CHEMBL64247 & 87054 & 7.88 & 7.7575 & TRN \\
\hline CHEMBL60620 & 87054 & 7.67 & 7.7811 & TRN \\
\hline CHEMBL60383 & 87054 & 7.8 & 7.6914 & TRN \\
\hline CHEMBL64408 & 87054 & 8.52 & 8.3731 & TRN \\
\hline CHEMBL291394 & 87054 & 8.2 & 8.0528 & TRN \\
\hline CHEMBL264761 & 87054 & 7.26 & 7.6715 & TRN \\
\hline CHEMBL59798 & 87054 & 8.03 & 8.1572 & TRN \\
\hline CHEMBL64775 & 87054 & 8.0 & 8.1543 & TRN \\
\hline CHEMBL432144 & 87054 & 7.56 & 7.5304 & TRN \\
\hline CHEMBL60509 & 87054 & 7.35 & 7.511 & TRN \\
\hline CHEMBL292275 & 87054 & 8.14 & 8.2515 & TRN \\
\hline CHEMBL302445 & 87054 & 7.57 & 7.5312 & TRN \\
\hline CHEMBL64667 & 87054 & 8.13 & 8.0475 & TRN \\
\hline CHEMBL62312 & 87054 & 7.98 & 7.6111 & TRN \\
\hline CHEMBL64773 & 87054 & 8.02 & 8.0302 & TRN \\
\hline CHEMBL62840 & 87054 & 8.3 & 7.8595 & TRN \\
\hline CHEMBL418691 & 87054 & 7.4 & 7.6046 & TRN \\
\hline CHEMBL64317 & 87054 & 7.69 & 8.1184 & TRN \\
\hline CHEMBL61396 & 87054 & 8.07 & 7.3754 & TST \\
\hline CHEMBL305313 & 87054 & 7.41 & 7.3532 & TRN \\
\hline CHEMBL63036 & 87054 & 7.28 & 7.1805 & TRN \\
\hline CHEMBL302886 & 87054 & 8.67 & 8.6701 & TRN \\
\hline CHEMBL62949 & 87054 & 8.1 & 8.3852 & TRN \\
\hline CHEMBL64658 & 87054 & 7.2 & 7.3948 & TRN \\
\hline CHEMBL305338 & 87054 & 8.0 & 7.8612 & TRN \\
\hline
\end{tabular}




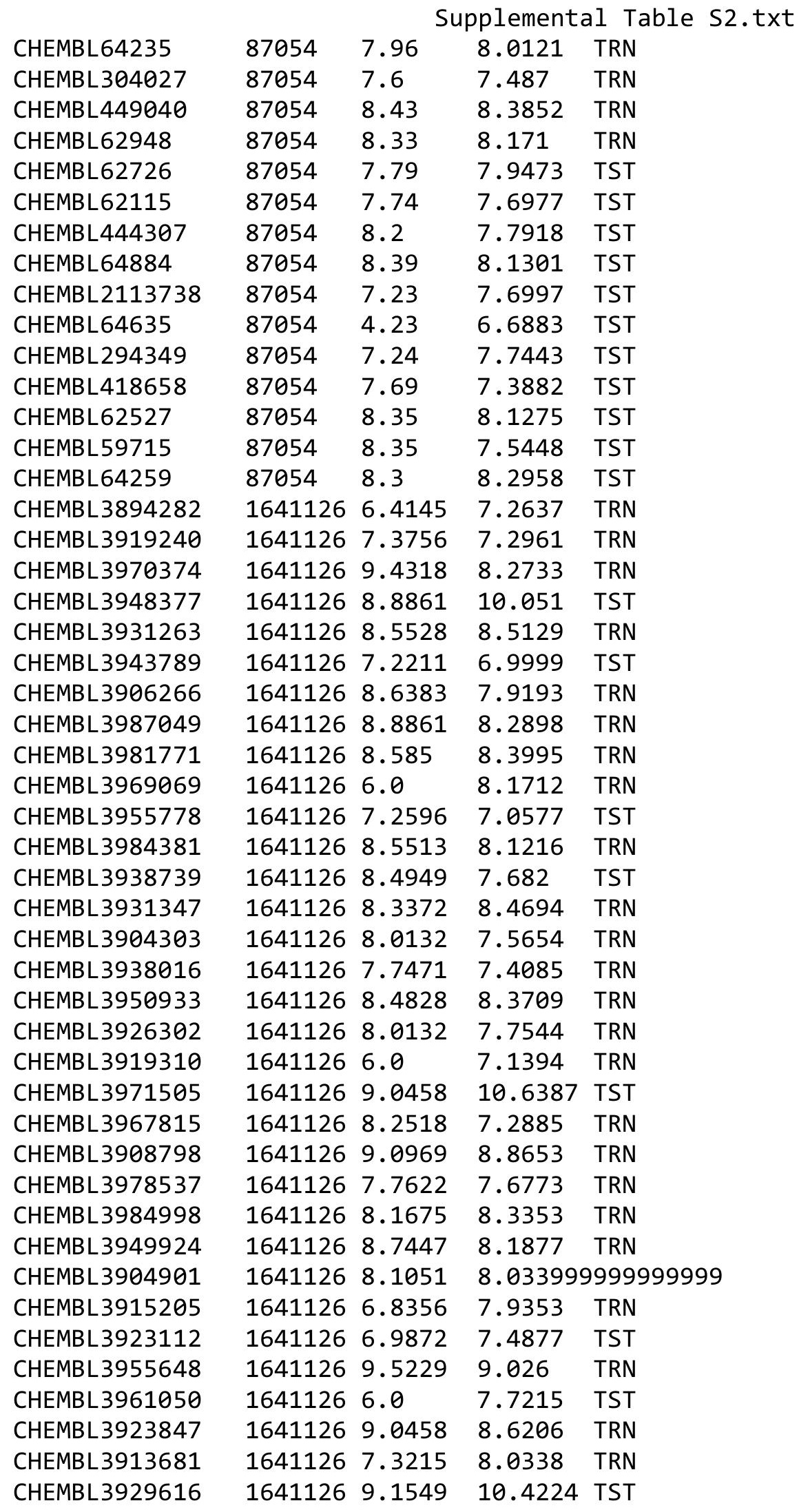


Supplemental Table S2.txt

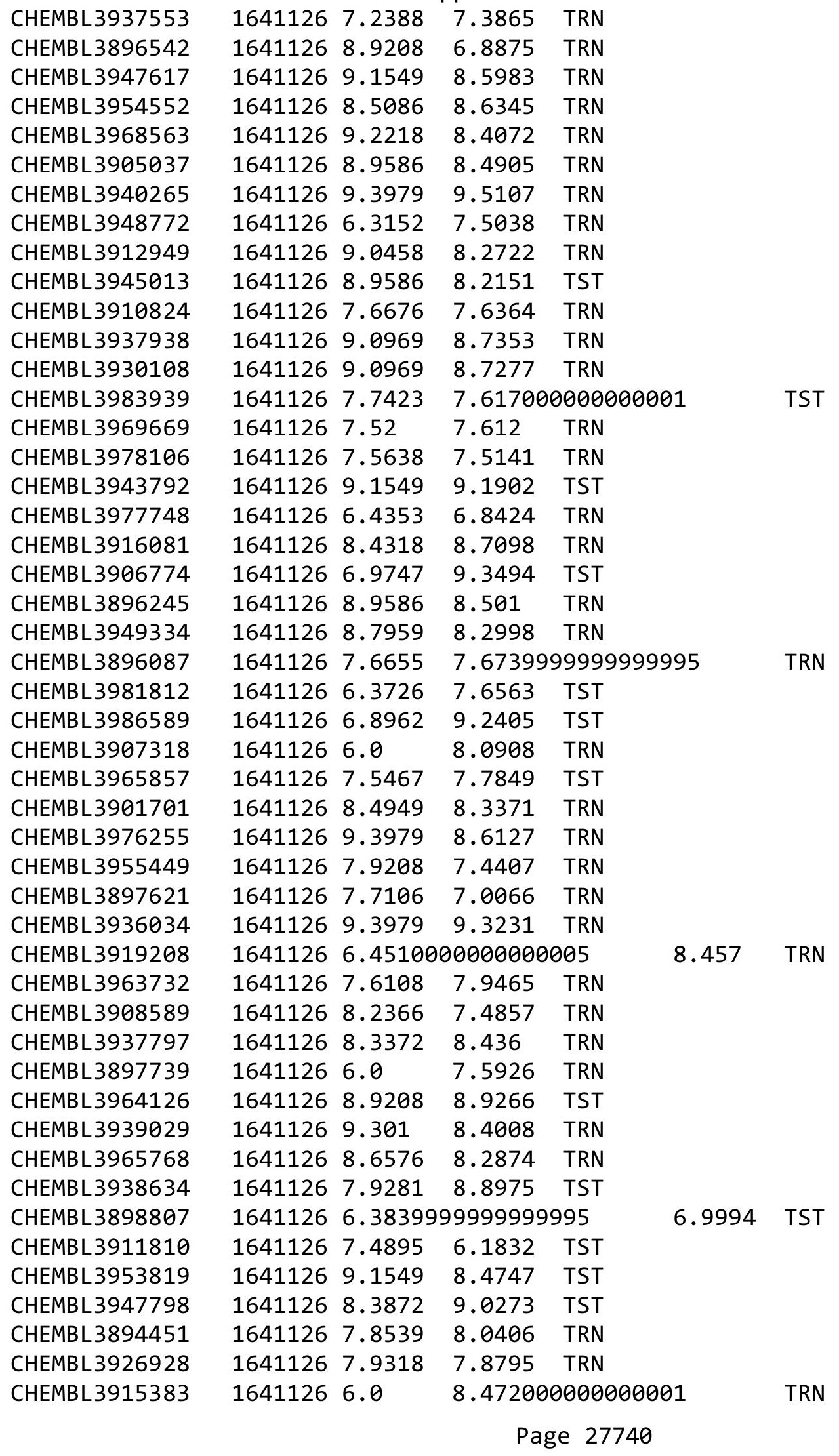


Supplemental Table S2.txt

\begin{tabular}{|c|c|c|c|c|c|}
\hline CHEMBL3984395 & 1641126 & 8.6021 & 8.8857 & TRN & \\
\hline CHEMBL3903729 & 1641126 & 6.0 & 7.3661 & TRN & \\
\hline CHEMBL3903409 & 1641126 & 7.1918 & 7.4046 & TRN & \\
\hline CHEMBL3943718 & 1641126 & 6.0 & 7.8567 & TRN & \\
\hline CHEMBL3935586 & 1641126 & 9.301 & 9.6337 & TRN & \\
\hline CHEMBL3971201 & 1641126 & 9.0 & 9.0499 & TRN & \\
\hline CHEMBL 3982104 & 1641126 & 6.8962 & 7.3179 & TRN & \\
\hline CHEMBL 3977071 & 1641126 & 7.8125 & 9.0192 & TST & \\
\hline CHEMBL 3928522 & 1641126 & 8.8239 & 8.6666 & TRN & \\
\hline CHEMBL3942412 & 1641126 & 6.4377 & 7.567 & TRN & \\
\hline CHEMBL3954131 & 1641126 & 8.8239 & 8.6068 & TRN & \\
\hline CHEMBL3911230 & 1641126 & 7.8601 & 7.8664 & TRN & \\
\hline CHEMBL3913064 & 1641126 & 9.0 & 7.9585 & TST & \\
\hline CHEMBL3969181 & 1641126 & 6.4763 & 6.9539 & TST & \\
\hline CHEMBL3935207 & 1641126 & 9.2218 & 9.1093 & TRN & \\
\hline CHEMBL3972811 & 1641126 & 9.2218 & 9.3443 & TRN & \\
\hline CHEMBL3932438 & 1641126 & 8.3872 & 7.6421 & TRN & \\
\hline CHEMBL3920742 & 1641126 & 8.2518 & 8.1998 & TRN & \\
\hline CHEMBL3973755 & 1641126 & 8.6198 & 8.4578 & TRN & \\
\hline CHEMBL3952320 & 1641126 & 8.9208 & 8.46600 & 0000000001 & TRN \\
\hline CHEMBL3966395 & 1641126 & 9.3979 & 9.6203 & TRN & \\
\hline CHEMBL3927224 & 1641126 & 6.0 & 7.6992 & TST & \\
\hline CHEMBL 3985358 & 1641126 & 6.0 & 8.0868 & TRN & \\
\hline CHEMBL3963270 & 1641126 & 7.1421 & 7.3739 & TRN & \\
\hline CHEMBL3982826 & 1641126 & 8.6198 & 7.557 & TRN & \\
\hline CHEMBL3965607 & 1641126 & 8.3125 & 7.9453 & TRN & \\
\hline CHEMBL3916468 & 1641126 & 9.0 & 8.7382 & TRN & \\
\hline CHEMBL3961044 & 1641126 & 6.9547 & 9.148 & TST & \\
\hline CHEMBL3921303 & 1641126 & 7.1267 & 8.734 & TST & \\
\hline CHEMBL3912740 & 1641126 & 7.2668 & 7.7263 & TRN & \\
\hline CHEMBL3970007 & 1641126 & 9.0 & 8.9367 & TRN & \\
\hline CHEMBL3900713 & 1641126 & 7.0518 & 7.809 & TST & \\
\hline CHEMBL3933429 & 1641126 & 8.1918 & 8.4135 & TST & \\
\hline CHEMBL3892129 & 1641126 & 6.0 & 7.9568 & TST & \\
\hline CHEMBL3956042 & 1641126 & 8.6021 & 9.0597 & TRN & \\
\hline CHEMBL3891799 & 1641126 & 7.2823 & 9.7334 & TST & \\
\hline CHEMBL3936963 & 1641126 & 8.4559 & \multicolumn{2}{|c|}{8.222000000000001} & TRN \\
\hline CHEMBL3981852 & 1641126 & 9.0 & 9.5569 & TRN & \\
\hline CHEMBL3958621 & 1641126 & 7.684 & 7.4708 & TST & \\
\hline CHEMBL3891969 & 1641126 & 7.9208 & 8.0111 & TRN & \\
\hline CHEMBL3948909 & 1641126 & 9.1549 & 9.0084 & TRN & \\
\hline CHEMBL3915750 & 1641126 & 9.0458 & 8.9177 & TRN & \\
\hline CHEMBL3892716 & 1641126 & 9.3979 & 9.0166 & TRN & \\
\hline CHEMBL3952010 & 1641126 & 8.5686 & 8.1264 & TRN & \\
\hline CHEMBL3936544 & 1641126 & 9.301 & 9.1752 & TRN & \\
\hline CHEMBL3902999 & 1641126 & 8.5528 & 8.9428 & TRN & \\
\hline CHEMBL3984657 & 1641126 & 8.5528 & 8.3002 & TRN & \\
\hline CHEMBL3931597 & 1641126 & 7.9666 & \multicolumn{2}{|c|}{8.197000000000001} & TRN \\
\hline
\end{tabular}

Page 27741 
Supplemental Table S2.txt

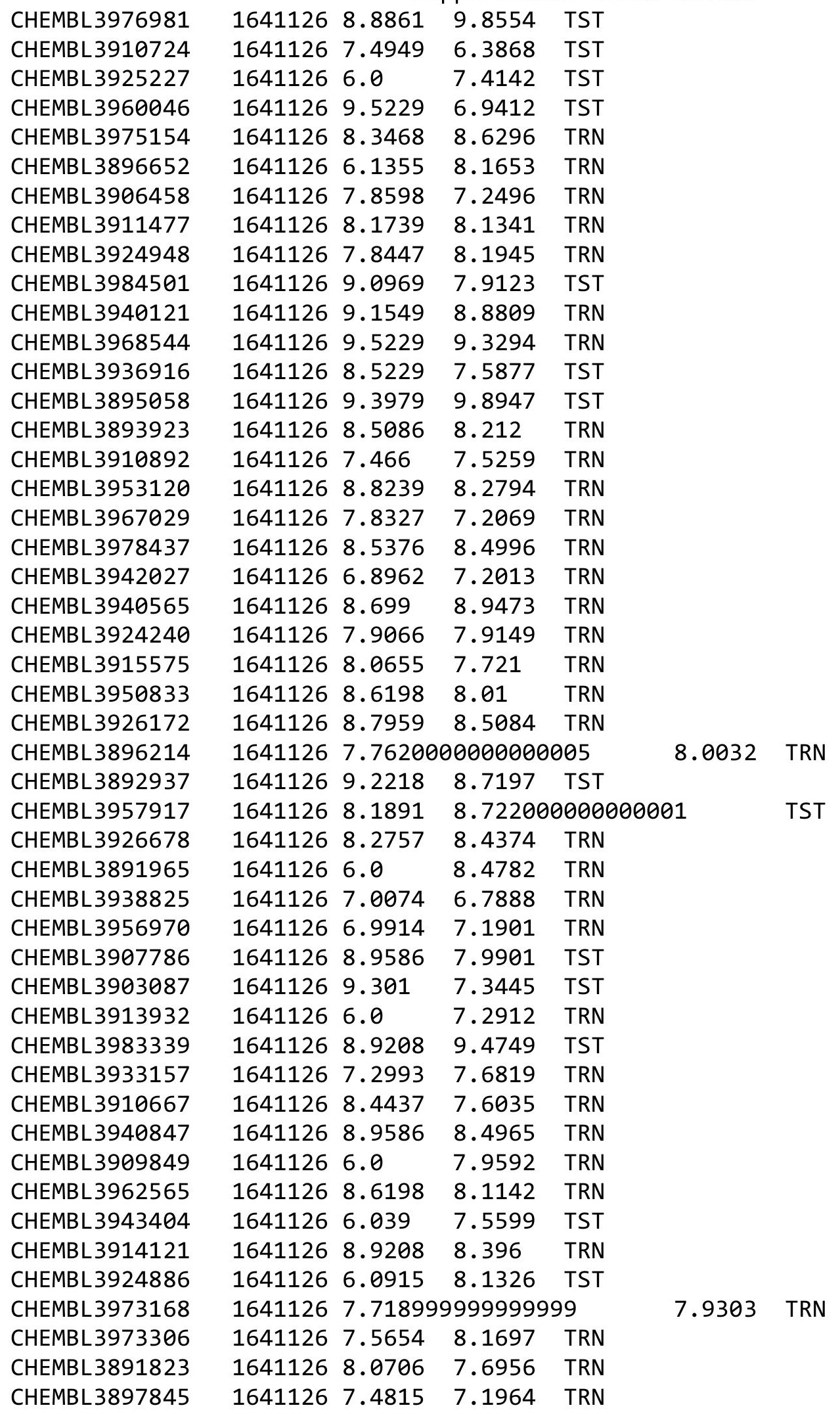

Page 27742 
Supplemental Table S2.txt

\begin{tabular}{|c|c|c|c|c|c|}
\hline CHEMBL 3898240 & 1641126 & 8.9208 & 9.0922 & TST & \\
\hline CHEMBL 3924200 & 1641126 & 8.6383 & 8.2082 & TRN & \\
\hline CHEMBL3921612 & 1641126 & 8.0044 & 7.1376 & TRN & \\
\hline CHEMBL3954737 & 1641126 & 8.0809 & 7.9117 & TST & \\
\hline CHEMBL 3969660 & 1641126 & 9.3979 & 8.9832 & TRN & \\
\hline CHEMBL3946743 & 1641126 & 7.4711 & 7.8639 & TST & \\
\hline CHEMBL3986965 & 1641126 & 8.6198 & 8.5991 & TRN & \\
\hline CHEMBL3920826 & 1641126 & 6.0 & 8.2616 & TRN & \\
\hline CHEMBL3931204 & 1641126 & 9.0 & 8.4586 & TRN & \\
\hline CHEMBL3964974 & 1641126 & 8.2798 & 8.2697 & TRN & \\
\hline CHEMBL3975353 & 1641126 & 8.9706 & 8.1762 & TRN & \\
\hline CHEMBL3979458 & 1641126 & 7.5784 & 7.2519 & TST & \\
\hline CHEMBL3973845 & 1641126 & 8.0757 & 7.9295 & TRN & \\
\hline CHEMBL3947047 & 1641126 & 8.2366 & 7.7188 & TST & \\
\hline CHEMBL 3982607 & 1641126 & 8.3565 & 8.8454 & TST & \\
\hline CHEMBL3897566 & 1641126 & 8.7773 & 8.1164 & TRN & \\
\hline CHEMBL3953009 & 1641126 & 8.4685 & 8.66 & TRN & \\
\hline CHEMBL3914482 & 1641126 & 9.5229 & 6.8887 & TST & \\
\hline CHEMBL 3983374 & 1641126 & 8.0177 & 7.78 & TST & \\
\hline CHEMBL 3947315 & 1641126 & 8.6383 & 8.2302 & TST & \\
\hline CHEMBL3925638 & 1641126 & 8.7696 & 7.8996 & TRN & \\
\hline CHEMBL 3894541 & 1641126 & 9.1549 & 9.7421 & TST & \\
\hline CHEMBL3926318 & 1641126 & 7.0555 & 7.7892 & TRN & \\
\hline CHEMBL 3897402 & 1641126 & 9.3979 & 8.5131 & TRN & \\
\hline CHEMBL 3979711 & 1641126 & 7.8601 & 7.9771 & TST & \\
\hline CHEMBL3940646 & 1641126 & 7.9208 & 7.3448 & TRN & \\
\hline CHEMBL 3900081 & 1641126 & 7.2798 & 7.9614 & TRN & \\
\hline CHEMBL3915593 & 1641126 & 8.6778 & 8.64299 & 9999999999 & TRN \\
\hline CHEMBL3934751 & 1641126 & 7.4067 & 8.3873 & TRN & \\
\hline CHEMBL 3964062 & 1641126 & 8.4437 & 9.0618 & TRN & \\
\hline CHEMBL3905016 & 1641126 & 8.9208 & 8.3575 & TRN & \\
\hline CHEMBL 3908472 & 1641126 & 9.2218 & 8.3291 & TRN & \\
\hline CHEMBL3963414 & 1641126 & 7.4179 & 7.189 & TST & \\
\hline CHEMBL3941741 & 1641126 & 9.0 & 7.6789 & TST & \\
\hline CHEMBL3978008 & 1641126 & 8.7696 & 8.3826 & TRN & \\
\hline CHEMBL3902111 & 1641126 & 7.8539 & 7.8568 & TRN & \\
\hline CHEMBL 3899689 & 1641126 & 8.8239 & 8.1926 & TRN & \\
\hline CHEMBL3973152 & 1641126 & 7.5952 & 7.3489 & TRN & \\
\hline CHEMBL3919444 & 1641126 & 6.7187 & 7.4268 & TST & \\
\hline CHEMBL3948729 & 1641126 & 8.3188 & 8.6326 & TRN & \\
\hline CHEMBL3953371 & 1641126 & 6.0269 & 7.5626 & TRN & \\
\hline CHEMBL 3947614 & 1641126 & 7.3526 & 8.2905 & TRN & \\
\hline CHEMBL3931735 & 1641126 & 7.556 & 7.4416 & TRN & \\
\hline CHEMBL3903227 & 1641126 & 9.0458 & 7.8202 & TRN & \\
\hline CHEMBL 3948938 & 1641126 & 9.301 & 9.3058 & TRN & \\
\hline CHEMBL3966874 & 1641126 & 7.553 & 7.8716 & TRN & \\
\hline CHEMBL 3908981 & 1641126 & 8.3665 & 8.5779 & TST & \\
\hline CHEMBL 3925852 & 1641126 & 8.8861 & 9.8515 & TST & \\
\hline
\end{tabular}


Supplemental Table S2.txt

\begin{tabular}{|c|c|c|c|c|c|c|}
\hline CHEMBL3954106 & 1641126 & 6.186 & 7.5804 & TST & & \\
\hline CHEMBL3902794 & 1641126 & 7.9281 & 7.7228 & TRN & & \\
\hline CHEMBL3911897 & 1641126 & $7.8210 e$ & 00000000 & 01 & 8.1436 & TRN \\
\hline CHEMBL 3936423 & 1641126 & 7.6003 & 7.5274 & TRN & & \\
\hline CHEMBL3979228 & 1641126 & 9.301 & 8.3954 & TRN & & \\
\hline CHEMBL3961859 & 1641126 & 9.0 & 7.6492 & TRN & & \\
\hline CHEMBL3924689 & 1641126 & 7.8327 & 7.5693 & TRN & & \\
\hline CHEMBL 3928134 & 1641126 & 6.0 & 7.4071 & TRN & & \\
\hline CHEMBL 3943323 & 1641126 & 6.7825 & 7.1808 & TRN & & \\
\hline CHEMBL3986313 & 1641126 & 6.0 & 7.29200 & 000000000 & & w \\
\hline CHEMBL3907091 & 1641126 & 9.2218 & 8.7214 & TRN & & \\
\hline CHEMBL3938617 & 1641126 & 7.0031 & 6.8928 & TST & & \\
\hline CHEMBL3986195 & 1641126 & 8.1367 & 8.1005 & TRN & & \\
\hline CHEMBL3916890 & 1641126 & 7.6108 & 7.8369 & TRN & & \\
\hline CHEMBL3924487 & 1641126 & 7.9318 & 7.7237 & TST & & \\
\hline CHEMBL3963793 & 1641126 & 7.2993 & 6.551 & TRN & & \\
\hline CHEMBL3925262 & 1641126 & 8.3372 & 7.7143 & TRN & & \\
\hline CHEMBL3892279 & 1641126 & 9.1549 & 8.2927 & TRN & & \\
\hline CHEMBL3907826 & 1641126 & 6.3757 & 6.8213 & TST & & \\
\hline CHEMBL3940673 & 1641126 & 7.6609 & 8.1019 & TRN & & \\
\hline CHEMBL3977937 & 1641126 & 7.4776 & 8.0985 & TRN & & \\
\hline CHEMBL3967339 & 1641126 & 8.2757 & 7.9595 & TRN & & \\
\hline CHEMBL3970261 & 1641126 & 7.284 & 7.0956 & TST & & \\
\hline CHEMBL3967620 & 1641126 & 9.0 & 8.9087 & TRN & & \\
\hline CHEMBL3911055 & 1641126 & \multicolumn{3}{|c|}{8.283999999999999} & 8.6786 & . \\
\hline CHEMBL3914126 & 1641126 & 7.426 & 7.5265 & TST & & \\
\hline CHEMBL 3957475 & 1641126 & 7.8327 & 7.9769 & TST & & \\
\hline CHEMBL3913726 & 1641126 & 6.5931 & 6.381 & TRN & & \\
\hline CHEMBL3965315 & 1641126 & 5.6421 & 6.7334 & TRN & & \\
\hline CHEMBL3933349 & 1641126 & 7.983 & 7.94 & TRN & & \\
\hline CHEMBL3964936 & 1641126 & 6.8447 & 7.725 & TRN & & \\
\hline CHEMBL3971035 & 1641126 & 7.098 & 7.2198 & TRN & & \\
\hline CHEMBL3910001 & 1641126 & 8.3565 & 8.1199 & TRN & & \\
\hline CHEMBL3910938 & 1641126 & 5.6392 & 8.0292 & TRN & & \\
\hline CHEMBL3978557 & 1641126 & 7.7305 & 7.4988 & TST & & \\
\hline CHEMBL3898461 & 1641126 & 9.3979 & 8.9732 & TRN & & \\
\hline CHEMBL3947227 & 1641126 & 8.5157 & 8.535 & TST & & \\
\hline CHEMBL3949841 & 1641126 & 7.9136 & 8.2717 & TST & & \\
\hline CHEMBL3944707 & 1641126 & 8.7959 & 9.3277 & TRN & & \\
\hline CHEMBL3903113 & 1641126 & 9.301 & 8.9935 & TRN & & \\
\hline CHEMBL3969022 & 1641126 & 8.9586 & 8.3518 & TRN & & \\
\hline CHEMBL3927086 & 1641126 & 7.7447 & 7.7252 & TRN & & \\
\hline CHEMBL3943392 & 1641126 & 7.8184 & 7.1386 & TRN & & \\
\hline CHEMBL3983583 & 1641126 & 8.6198 & 9.2012 & TRN & & \\
\hline CHEMBL3971316 & 1641126 & 7.7055 & 7.9213 & TST & & \\
\hline CHEMBL3920104 & 1641126 & 9.1549 & 9.1727 & TRN & & \\
\hline CHEMBL3939104 & 1641126 & 8.7959 & 8.0493 & TRN & & \\
\hline CHEMBL3908915 & 1641126 & 8.5086 & 8.0173 & TRN & & \\
\hline
\end{tabular}

Page 27744 
Supplemental Table S2.txt

\begin{tabular}{|c|c|c|c|c|}
\hline - & 126 & & & \\
\hline HEMBL3952207 & 641126 & & 8.2169 & \\
\hline 386 & & & 3915 & \\
\hline 16940 & 26 & 79 & 3919 & \\
\hline AEMBL3935193 & 641126 & 7.8268 & 2092 & \\
\hline AEMBL3939010 & 641126 & 8.585 & 5089 & \\
\hline HEMBL & 126 & 212 & 5006 & \\
\hline IEMBL: & 26 & 75 & 427 & \\
\hline AEMBL3937632 & 26 & & 434 & \\
\hline AEMBL3952798 & 126 & 9.3979 & 2929 & \\
\hline AEMBL3947632 & 126 & 8.3206 & 1394 & \\
\hline AEMBL397 & 26 & 979 & 528 & \\
\hline AEMBL3 & & & & \\
\hline AEMBL39 & & 696 & 502 & \\
\hline AEMBL3890482 & 26 & 18 & 5437 & \\
\hline HEMBL3920497 & & 8.2 & 73 & \\
\hline HEMBL3S & 26 & & 38 & \\
\hline HEMBL3S & & & & \\
\hline AEMBL3982793 & & & 5827 & \\
\hline AEMBL3900570 & 26 & 8 . & 92 & $\omega_{2}$ \\
\hline AEMBL3930162 & 26 & 55 & 03 & IRN \\
\hline HEMBL3S & 6 & 7. & 089 & RIN \\
\hline HEMBL3S & & & & \\
\hline 562 & & 6 & 5893 & $=$ \\
\hline AEMBL39 & 6 & 6 & 878 & RIN \\
\hline EMBL3S & & & 321 & ГRN \\
\hline AFMBL 38 & & & 551 & $\mathrm{RN}$ \\
\hline 54 & & & & RN \\
\hline AEMBL3S & 6 & & & ו \\
\hline HEMBL3S & 6 & & 06 & ГST \\
\hline AEMBL39 & & & 004 & $\mathrm{RN}$ \\
\hline AFMB 32 & & & 57 & RN \\
\hline 88 & & & 386 & RN \\
\hline HEMBL3933758 & & & & IRN \\
\hline HEMBL3922086 & 6 & & 639 & IST \\
\hline HEMBL3909027 & & & 542 & rRN \\
\hline 705 & & & & RN \\
\hline HEMBL3956636 & & & & TRN \\
\hline HEMBL3907749 & 26 & 8.7 & 8974 & TRN \\
\hline AEMBL394 & v. & & 924 & IST \\
\hline HEMBL3946050 & 16 & 7. & .796 & IST \\
\hline HEMBL 3913488 & & & & RN \\
\hline HEMBL3977991 & 26 & 6.0 & 133 & TRN \\
\hline HEMBL3928527 & 126 & 8.69 & 6696 & TRN \\
\hline IEMBL3933334 & & 9 & 127 & \\
\hline HEMBL393 & 16 & & & \\
\hline HEMBL3954406 & 10 & 8.4815 & 8.3479 & RN \\
\hline CHEMBL3905591 & 1641126 & 6.8729 & 7.0832 & RN \\
\hline
\end{tabular}

Page 27745 
Supplemental Table S2.txt

\begin{tabular}{|c|c|c|c|c|c|}
\hline CHEMBL3961631 & 1641126 & 8.9208 & 8.5494 & TRN & \\
\hline CHEMBL 3929728 & 1641126 & 7.1979 & 7.8075 & TRN & \\
\hline CHEMBL 3923246 & 1641126 & 8.4949 & 7.8575 & TRN & \\
\hline CHEMBL 3978986 & 1641126 & 8.5376 & 7.7305 & TRN & \\
\hline CHEMBL3968494 & 1641126 & 9.2518 & 7.8908 & TRN & \\
\hline CHEMBL 3923106 & 1641126 & 6.9957 & 7.5046 & TRN & \\
\hline CHEMBL3931319 & 1641126 & 8.0269 & 8.0921 & TRN & \\
\hline CHEMBL 3941714 & 1641126 & 6.4665 & 6.0077 & TRN & \\
\hline CHEMBL 3967474 & 1641126 & 8.28399 & 999999999 & 8.3071 & TRN \\
\hline CHEMBL3983936 & 1641126 & 5.6101 & 6.7073 & TRN & \\
\hline CHEMBL 3978252 & 1641126 & 8.2218 & 8.2559 & TST & \\
\hline CHEMBL 3966758 & 1641126 & 8.9208 & 8.5927 & TRN & \\
\hline CHEMBL 3967428 & 1641126 & 9.699 & 8.9512 & TRN & \\
\hline CHEMBL 3897771 & 1641126 & 8.5229 & 9.677999 & 9999999999 & TST \\
\hline CHEMBL3917818 & 1641126 & 7.7696 & 7.4973 & TRN & \\
\hline CHEMBL 3919880 & 1641126 & 8.2596 & 7.8887 & TRN & \\
\hline CHEMBL 3890615 & 1641126 & 6.0 & 7.1936 & TRN & \\
\hline CHEMBL 3932206 & 1641126 & 8.4437 & 8.1823 & TRN & \\
\hline CHEMBL 3893893 & 1641126 & 9.0 & 8.1438 & TRN & \\
\hline CHEMBL3935465 & 1641126 & 7.5058 & 6.8919 & TRN & \\
\hline CHEMBL3910615 & 1641126 & 8.3768 & 8.0677 & TRN & \\
\hline CHEMBL 3903622 & 1641126 & 7.8097 & 7.684 & TRN & \\
\hline CHEMBL 3949505 & 1641126 & 8.8539 & 8.6772 & TRN & \\
\hline CHEMBL 3961221 & 1641126 & 9.301 & 10.2485 & TST & \\
\hline CHEMBL 3922287 & 1641126 & 6.3161 & 7.0001 & TST & \\
\hline CHEMBL 3940704 & 1641126 & 7.5528 & 6.992999 & 9999999999 & TST \\
\hline CHEMBL 3942850 & 1641126 & 9.3979 & 8.2615 & TRN & \\
\hline CHEMBL 3954975 & 1641126 & 9.3979 & 9.4592 & TRN & \\
\hline CHEMBL 3965382 & 1641126 & 7.4989 & 7.245 & TRN & \\
\hline CHEMBL 3943257 & 1641126 & 8.0315 & 8.0494 & TRN & \\
\hline CHEMBL 3893370 & 1641126 & 7.5544 & 7.886 & TRN & \\
\hline CHEMBL 3942508 & 1641126 & 9.2147 & 8.3112 & TRN & \\
\hline CHEMBL3911976 & 1641126 & 6.0 & 6.4879 & TRN & \\
\hline CHEMBL 3981167 & 1641126 & 9.0 & 8.4122 & TRN & \\
\hline CHEMBL 3938032 & 1641126 & 7.7055 & 7.5297 & TRN & \\
\hline CHEMBL 3974074 & 1641126 & 9.5229 & 10.22200 & 00000000001 & בי \\
\hline CHEMBL 3895597 & 1641126 & 8.0 & 7.7076 & TRN & \\
\hline CHEMBL 3968296 & 1641126 & 7.6615 & 7.8224 & TRN & \\
\hline CHEMBL 3961120 & 1641126 & 9.301 & 8.5083 & TRN & \\
\hline CHEMBL 3939433 & 1641126 & 8.5376 & 9.1155 & TRN & \\
\hline CHEMBL 3925453 & 1641126 & 9.1549 & 8.2384 & TRN & \\
\hline CHEMBL 3890899 & 1641126 & 6.0 & 7.8056 & TRN & \\
\hline CHEMBL3923256 & 1641126 & 6.4498 & 7.3803 & TRN & \\
\hline CHEMBL 3982414 & 1641126 & 7.5622 & 7.4638 & TRN & \\
\hline CHEMBL3911158 & 1641126 & 8.6576 & 9.0028 & TRN & \\
\hline CHEMBL 3966374 & 1641126 & 6.4881 & 7.2811 & TST & \\
\hline CHEMBL 3925713 & 1641126 & 6.5544 & 7.9382 & TRN & \\
\hline CHEMBL 3930453 & 1641126 & 8.1308 & 6.9746 & TST & \\
\hline
\end{tabular}


Supplemental Table S2.txt

\begin{tabular}{|c|c|c|c|c|}
\hline CHEMBL3935256 & 1641126 & 6.0 & 8.9061 & TST \\
\hline CHEMBL3934415 & 1641126 & 7.8655 & 6.7613 & TRN \\
\hline CHEMBL3968853 & 1641126 & 9.301 & 8.7946 & TRN \\
\hline CHEMBL 3947004 & 1641126 & 7.4881 & \multicolumn{2}{|c|}{7.803999999999999} \\
\hline CHEMBL 3950434 & 1641126 & 6.9805 & 6.8473 & TRN \\
\hline CHEMBL3978065 & 1641126 & 7.5003 & 8.2783 & TRN \\
\hline CHEMBL3917853 & 1641126 & 7.9914 & \multicolumn{2}{|c|}{7.736000000000001} \\
\hline CHEMBL3911155 & 1641126 & 7.8153 & 7.1541 & TRN \\
\hline CHEMBL3972451 & 1641126 & 7.9281 & 9.0113 & TST \\
\hline CHEMBL3980973 & 1641126 & 9.0 & 8.081 & TRN \\
\hline CHEMBL3921012 & 1641126 & 8.0555 & 7.6175 & TRN \\
\hline CHEMBL3903262 & 1641126 & 9.2218 & 9.0168 & TRN \\
\hline CHEMBL3981751 & 1641126 & 9.5229 & 8.9273 & TRN \\
\hline CHEMBL 3943344 & 1641126 & 6.7773 & 6.763 & TST \\
\hline CHEMBL3968492 & 1641126 & 8.2518 & 8.1971 & TRN \\
\hline CHEMBL3968790 & 1641126 & 9.2218 & 9.77 & TST \\
\hline CHEMBL3975372 & 1641126 & 8.4089 & 7.7965 & TRN \\
\hline CHEMBL3914385 & 1641126 & 7.4001 & 8.4851 & TRN \\
\hline CHEMBL 3932542 & 1641126 & 8.3565 & 7.8336 & TST \\
\hline CHEMBL3958104 & 1641126 & 7.2426 & 7.2847 & TRN \\
\hline CHEMBL3925562 & 1641126 & 8.041 & 7.8252 & TRN \\
\hline CHEMBL3963426 & 1641126 & 8.5686 & 8.0277 & TRN \\
\hline CHEMBL3978086 & 1641126 & 9.3979 & 8.6735 & TST \\
\hline CHEMBL3985329 & 1641126 & 9.0862 & 8.621 & TRN \\
\hline CHEMBL3923316 & 1641126 & 7.4815 & 7.4176 & TRN \\
\hline CHEMBL3948847 & 1641126 & 6.3363 & 7.4427 & TRN \\
\hline CHEMBL3901658 & 1641126 & 8.4685 & 8.2338 & TRN \\
\hline CHEMBL3965910 & 1641126 & 9.5229 & 10.4894 & TST \\
\hline CHEMBL3938231 & 1641126 & 8.3098 & 9.3207 & TST \\
\hline CHEMBL3892239 & 1641126 & 8.8239 & 9.3844 & TST \\
\hline CHEMBL3925650 & 1641126 & 8.7471 & 7.9512 & TRN \\
\hline CHEMBL3944317 & 1641126 & 9.2218 & 7.9813 & TST \\
\hline CHEMBL3965795 & 1641126 & 9.3979 & 8.645 & TRN \\
\hline CHEMBL3891569 & 1641126 & 7.4306 & 7.218 & TST \\
\hline CHEMBL 3983240 & 1641126 & 8.7959 & 8.2563 & TRN \\
\hline CHEMBL3912792 & 1641126 & 6.0 & 7.7022 & TRN \\
\hline CHEMBL3973955 & 1641126 & 8.7959 & 8.7406 & TRN \\
\hline CHEMBL3976929 & 1641126 & 8.3665 & 8.2038 & TRN \\
\hline CHEMBL3907487 & 1641126 & 8.5086 & 7.5877 & TRN \\
\hline CHEMBL3932927 & 1641126 & 8.7696 & 8.1008 & TRN \\
\hline CHEMBL3973779 & 1641126 & 9.0458 & 10.0716 & TST \\
\hline CHEMBL172634 & 105136 & 4.9208 & 4.5252 & TRN \\
\hline CHEMBL170667 & 105136 & 4.8239 & 5.1955 & TRN \\
\hline CHEMBL169681 & 105136 & 4.2366 & 4.0876 & TRN \\
\hline CHEMBL353100 & 105136 & 4.0915 & 5.1012 & TST \\
\hline CHEMBL169039 & 105136 & 4.0 & 3.9901 & TRN \\
\hline CHEMBL354202 & 105136 & 4.0315 & 3.9382 & TRN \\
\hline CHEMBL169592 & 105136 & 3.9957 & 4.0473 & TRN \\
\hline
\end{tabular}

Page 27747 


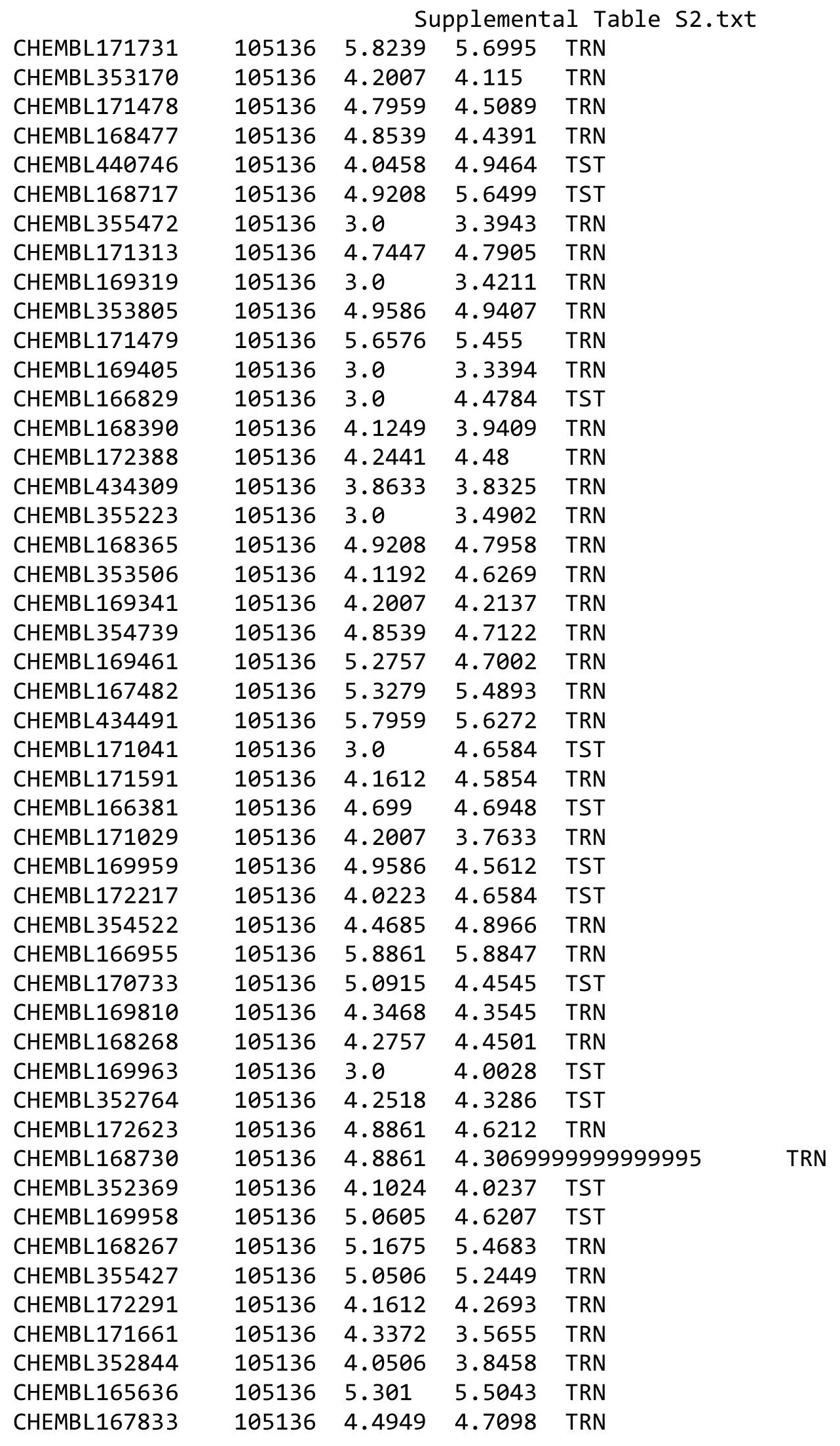

Page 27748 


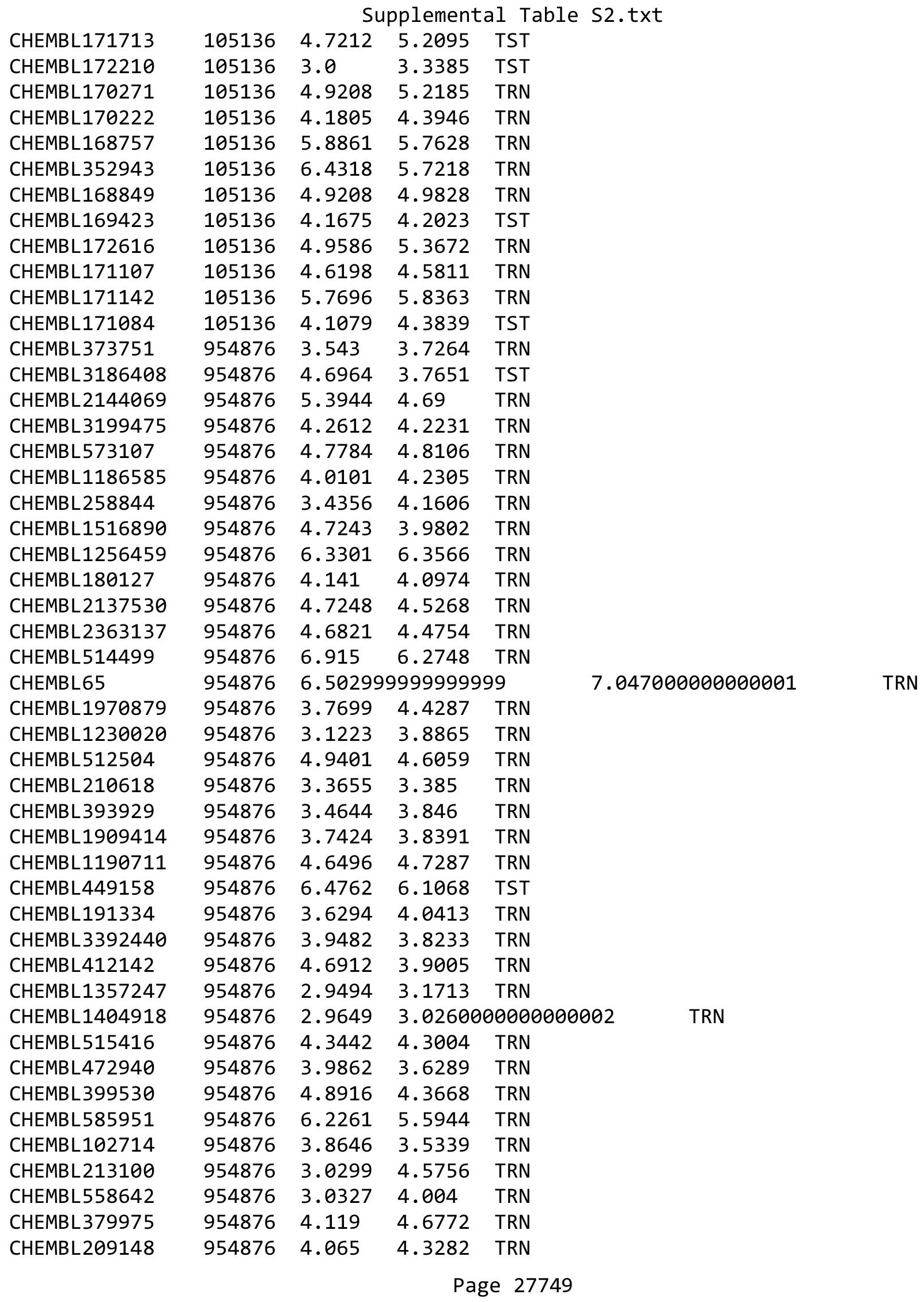




\begin{tabular}{|c|c|c|c|c|c|c|}
\hline & & \multicolumn{5}{|c|}{ Supplemental Table S2.txt } \\
\hline CHEMBL379300 & 954876 & 5.9466 & 5.8632 & TRN & & \\
\hline CHEMBL220241 & 954876 & 4.2011 & 4.5233 & TRN & & \\
\hline CHEMBL392695 & 954876 & 4.7786 & 4.7899 & TRN & & \\
\hline CHEMBL217354 & 954876 & 6.3716 & 5.4968 & TRN & & \\
\hline CHEMBL255342 & 954876 & 4.6953 & 3.6072 & TRN & & \\
\hline CHEMBL483849 & 954876 & 2.9421 & 2.5674 & TST & & \\
\hline CHEMBL577784 & 954876 & 5.5381 & 4.9202 & TRN & & \\
\hline CHEMBL1242367 & 954876 & 3.7502 & 4.0858 & TRN & & \\
\hline CHEMBL92309 & 954876 & 1.4836 & 3.0647 & TST & & \\
\hline CHEMBL9470 & 954876 & 5.9915 & 5.2941 & TST & & \\
\hline CHEMBL 2005886 & 954876 & 4.7787 & 5.0236 & TRN & & \\
\hline CHEMBL 259181 & 954876 & 3.9909 & 4.2682 & TRN & & \\
\hline CHEMBL509032 & 954876 & 5.7299 & 5.2303 & TRN & & \\
\hline CHEMBL1590308 & 954876 & 3.5485 & 3.4771 & TST & & \\
\hline CHEMBL3349342 & 954876 & 4.4093 & 4.7363 & TRN & & \\
\hline CHEMBL1788116 & 954876 & $5.7420 e$ & 00000000 & 01 & 4.2545 & TRN \\
\hline CHEMBL300389 & 954876 & 5.2336 & 6.0908 & TRN & & \\
\hline CHEMBL 2134202 & 954876 & 3.9715 & 4.1957 & TRN & & \\
\hline CHEMBL483847 & 954876 & 3.8158 & 4.1056 & TST & & \\
\hline CHEMBL202721 & 954876 & 4.0505 & 4.6657 & TST & & \\
\hline CHEMBL1673039 & 954876 & 3.7104 & 4.5618 & TST & & \\
\hline CHEMBL 188678 & 954876 & 3.9643 & 4.2597 & TST & & \\
\hline CHEMBL192566 & 954876 & 6.2965 & 7.0583 & TST & & \\
\hline CHEMBL1643959 & 954876 & 3.5391 & 3.7487 & TST & & \\
\hline CHEMBL135561 & 954876 & 4.1435 & 4.2608 & TST & & \\
\hline CHEMBL221137 & 954876 & 4.2378 & 4.4241 & TST & & \\
\hline CHEMBL189584 & 954876 & 4.3332 & 4.3861 & TST & & \\
\hline CHEMBL240954 & 954876 & 3.4138 & 3.6863 & TST & & \\
\hline CHEMBL222102 & 954876 & 4.1135 & 3.7598 & TST & & \\
\hline CHEMBL3924373 & 1640852 & 4.0 & 4.0653 & TRN & & \\
\hline CHEMBL3958453 & 1640852 & 4.0 & 4.7322 & TRN & & \\
\hline CHEMBL3981381 & 1640852 & 4.0 & 4.4335 & TRN & & \\
\hline CHEMBL3984932 & 1640852 & 5.0 & 4.7569 & TRN & & \\
\hline CHEMBL 3977240 & 1640852 & 5.0 & 5.1144 & TRN & & \\
\hline CHEMBL3944172 & 1640852 & 5.0 & 5.0903 & TRN & & \\
\hline CHEMBL3953123 & 1640852 & 4.0 & 4.3324 & TST & & \\
\hline CHEMBL3906012 & 1640852 & 4.0 & 4.0622 & TRN & & \\
\hline CHEMBL3979456 & 1640852 & 4.0 & 4.4973 & TRN & & \\
\hline CHEMBL3905460 & 1640852 & 4.0 & 4.737 & TRN & & \\
\hline CHEMBL3947801 & 1640852 & 5.0 & 4.6094 & TRN & & \\
\hline CHEMBL3697701 & 1640852 & 4.0 & 4.6013 & TST & & \\
\hline CHEMBL3897802 & 1640852 & 5.0 & 4.7912 & TRN & & \\
\hline CHEMBL3912738 & 1640852 & 5.0 & 4.9235 & TRN & & \\
\hline CHEMBL3935604 & 1640852 & 4.0 & 4.7992 & TST & & \\
\hline CHEMBL3897467 & 1640852 & 4.0 & 4.572 & TRN & & \\
\hline CHEMBL3973094 & 1640852 & 4.0 & 4.2445 & TRN & & \\
\hline CHEMBL3892326 & 1640852 & 4.0 & 4.8358 & TRN & & \\
\hline CHEMBL3943177 & 1640852 & 4.0 & 4.7645 & TRN & & \\
\hline
\end{tabular}


Supplemental Table S2.txt

\begin{tabular}{|c|c|c|}
\hline CHEMBL 3929233 & 1640852 & 4.0 \\
\hline CHEMBL3918948 & 1640852 & 4.0 \\
\hline CHEMBL 3899453 & 1640852 & 5.0 \\
\hline CHEMBL3905406 & 1640852 & 5.0 \\
\hline CHEMBL 3904057 & 1640852 & 4.0 \\
\hline CHEMBL 3894821 & 1640852 & 4.0 \\
\hline CHEMBL 3985375 & 1640852 & 4.0 \\
\hline CHEMBL 3906234 & 1640852 & 4.0 \\
\hline CHEMBL 3897132 & 1640852 & 5.0 \\
\hline CHEMBL3896353 & 1640852 & 4.0 \\
\hline CHEMBL 3947368 & 1640852 & 4.0 \\
\hline CHEMBL3974013 & 1640852 & 4.0 \\
\hline CHEMBL3920559 & 1640852 & 5.0 \\
\hline CHEMBL 3987145 & 1640852 & 5.0 \\
\hline CHEMBL3981050 & 1640852 & 4.0 \\
\hline CHEMBL 3942587 & 1640852 & 5.0 \\
\hline CHEMBL3911625 & 1640852 & 5.0 \\
\hline CHEMBL 3968210 & 1640852 & 4.0 \\
\hline CHEMBL 3956363 & 1640852 & 4.0 \\
\hline CHEMBL3896592 & 1640852 & 4.0 \\
\hline CHEMBL3964272 & 1640852 & 5.0 \\
\hline CHEMBL3976638 & 1640852 & 4.0 \\
\hline CHEMBL 3892970 & 1640852 & 5.0 \\
\hline CHEMBL 3947821 & 1640852 & 5.0 \\
\hline CHEMBL3976535 & 1640852 & 4.0 \\
\hline CHEMBL3904928 & 1640852 & 5.0 \\
\hline CHEMBL 3920312 & 1640852 & 4.0 \\
\hline CHEMBL3956560 & 1640852 & 5.0 \\
\hline CHEMBL 3948210 & 1640852 & 4.0 \\
\hline CHEMBL3981620 & 1640852 & 4.0 \\
\hline CHEMBL 3987098 & 1640852 & 5.5513 \\
\hline CHEMBL 3965541 & 1640852 & 5.0 \\
\hline CHEMBL3914798 & 1640852 & 4.0 \\
\hline CHEMBL 3953065 & 1640852 & 4.0 \\
\hline CHEMBL 3939180 & 1640852 & 5.0 \\
\hline CHEMBL3931880 & 1640852 & 5.3516 \\
\hline CHEMBL 3977053 & 1640852 & 4.0 \\
\hline CHEMBL 3894956 & 1640852 & 5.0 \\
\hline CHEMBL 3891778 & 1640852 & 4.0 \\
\hline CHEMBL 3914637 & 1640852 & 5.0 \\
\hline CHEMBL3920106 & 1640852 & 5.0 \\
\hline CHEMBL 3945471 & 1640852 & 5.5482 \\
\hline CHEMBL3902066 & 1640852 & 4.0 \\
\hline CHEMBL 3913924 & 1640852 & 5.0 \\
\hline CHEMBL 3937790 & 1640852 & 4.0 \\
\hline CHEMBL3944579 & 1640852 & 5.0 \\
\hline CHEMBL 3948438 & 1640852 & 4.0 \\
\hline CHEMBL389606€ & 164085 & 5.0 \\
\hline
\end{tabular}

\begin{tabular}{ll}
3.9032 & TRN \\
4.523 & TRN \\
4.5945 & TRN \\
4.4806 & TRN \\
4.2651 & TRN \\
4.0956 & TST \\
4.1449 & TRN \\
3.9729 & TRN \\
5.0415 & TRN \\
3.8457 & TRN \\
4.4812 & TRN \\
4.1863 & TRN \\
4.8346 & TRN \\
5.0343 & TRN \\
4.3428 & TRN \\
4.6784 & TRN \\
4.9475 & TRN \\
4.0428 & TRN \\
4.16 & TRN \\
4.5445 & TST \\
4.8268 & TRN \\
4.0897 & TST \\
5.0085 & TRN \\
4.4871 & TRN \\
3.8099 & TRN \\
5.0361 & TRN \\
4.0129 & TRN \\
4.9594 & TRN \\
3.8786 & TRN \\
3.8069 & TRN \\
4.8545 & TST \\
4.7187 & TRN \\
$\mathbf{3 . 8 2 3 5}$ & TST \\
4.2559 & TRN \\
5.0868 & TRN \\
4.8393 & TRN \\
4.8832 & TRN \\
4.6981 & TST \\
4.5872 & TRN \\
3.7987 & TRN \\
4.0842 & TRN \\
5.2068 & TRN \\
5.1777 & TRN \\
4.2897 & TRN \\
5.2112 & TRN \\
\hline .0853 & TST \\
\hline $1 R N$ \\
\hline
\end{tabular}

Page 27751 


\begin{tabular}{|c|c|c|c|c|c|}
\hline \\
\hline CHEMBL1086530 & 1640852 & 4.0 & 3.8408 & TST & \\
\hline CHEMBL3936454 & 1640852 & 5.0 & 4.9492 & TRN & \\
\hline CHEMBL3921886 & 1640852 & 4.0 & 4.0727 & TRN & \\
\hline CHEMBL3924146 & 1640852 & 4.0 & 3.8828 & TST & \\
\hline CHEMBL3931425 & 1640852 & 4.0 & 4.3781 & TST & \\
\hline CHEMBL3920880 & 1640852 & 5.0 & 4.6507 & TRN & \\
\hline CHEMBL1939972 & 1640852 & 4.0 & 4.2679 & TST & \\
\hline CHEMBL3932546 & 1640852 & 5.0 & 4.86100 & 0000000001 & TRN \\
\hline CHEMBL3922771 & 1640852 & 4.0 & 4.3344 & TRN & \\
\hline CHEMBL3951379 & 1640852 & 5.0 & 4.5546 & TRN & \\
\hline CHEMBL3968269 & 1640852 & 4.0 & 4.1031 & TRN & \\
\hline CHEMBL3898239 & 1640852 & 5.6021 & 5.1852 & TRN & \\
\hline CHEMBL3956711 & 1640852 & 5.6778 & 4.8044 & TRN & \\
\hline CHEMBL 3927494 & 1640852 & 5.0 & 4.6939 & TST & \\
\hline CHEMBL3894760 & 1640852 & 5.0 & 4.6253 & TST & \\
\hline CHEMBL3935137 & 1640852 & 4.0 & 4.7718 & TST & \\
\hline CHEMBL3900789 & 1640852 & 4.0 & 4.5457 & TST & \\
\hline CHEMBL3976217 & 1640852 & 5.0 & 4.8538 & TST & \\
\hline CHEMBL3908909 & 1640852 & 4.0 & 3.95399 & 99999999997 & TST \\
\hline CHEMBL3904770 & 1640852 & 4.0 & 4.2966 & TST & \\
\hline CHEMBL3941901 & 1640852 & 5.75200 & $\partial 0000000$ & 4.9441 & TST \\
\hline CHEMBL3329426 & 1459806 & 8.0 & 8.0055 & TRN & \\
\hline CHEMBL3329451 & 1459806 & 9.699 & 9.7056 & TRN & \\
\hline CHEMBL 329383 & 1459806 & 8.585 & 8.5923 & TRN & \\
\hline CHEMBL212995 & 1459806 & 8.9208 & 8.9259 & TRN & \\
\hline CHEMBL3329445 & 1459806 & 8.3979 & 8.4036 & TRN & \\
\hline CHEMBL292759 & 1459806 & 8.301 & 8.3032 & TRN & \\
\hline CHEMBL3329428 & 1459806 & 6.9281 & 6.9309 & TRN & \\
\hline CHEMBL3329425 & 1459806 & 8.7696 & 8.7685 & TRN & \\
\hline CHEMBL3329432 & 1459806 & 9.0 & 8.5005 & TST & \\
\hline CHEMBL3329453 & 1459806 & 9.5229 & 9.5286 & TRN & \\
\hline CHEMBL3329435 & 1459806 & 9.2757 & 9.274 & TRN & \\
\hline CHEMBL3329446 & 1459806 & 9.0315 & 9.0325 & TRN & \\
\hline CHEMBL177605 & 1459806 & 8.2757 & 8.2809 & TRN & \\
\hline CHEMBL3329444 & 1459806 & 7.2291 & 7.2283 & TRN & \\
\hline CHEMBL3329434 & 1459806 & 8.9208 & 8.9156 & TRN & \\
\hline CHEMBL1201756 & 1459806 & 9.6021 & 9.3591 & TST & \\
\hline CHEMBL29433 & 1459806 & 9.0969 & 9.0974 & TRN & \\
\hline CHEMBL3329440 & 1459806 & 9.0 & 8.998 & TRN & \\
\hline CHEMBL3329442 & 1459806 & 9.699 & 9.6978 & TRN & \\
\hline CHEMBL3331585 & 1459806 & 8.7959 & 8.7897 & TRN & \\
\hline CHEMBL433461 & 1459806 & 7.2596 & 7.2831 & TRN & \\
\hline CHEMBL361189 & 1459806 & 8.6198 & 8.6177 & TRN & \\
\hline CHEMBL3329427 & 1459806 & 7.0044 & 7.005 & TRN & \\
\hline CHEMBL3329430 & 1459806 & 9.699 & 9.6895 & TRN & \\
\hline CHEMBL3329429 & 1459806 & 9.301 & 9.3046 & TRN & \\
\hline CHEMBL179814 & 1459806 & 9.0 & 9.0095 & TRN & \\
\hline CHEMBL46071 & 1459806 & 7.9208 & 7.9068 & TRN & \\
\hline
\end{tabular}


Supplemental Table S2.txt

\begin{tabular}{|c|c|c|c|c|}
\hline EMBL 3329455 & 806 & 539 & 2857 & 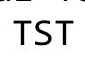 \\
\hline HEMRI 1081704 & 1459806 & 8.3979 & 8.3877 & \\
\hline IEMBL332943 & 9806 & 3979 & 1115 & \\
\hline IEMBL 3329437 & 459806 & 2441 & 2484 & \\
\hline HEMBL566213 & 459806 & 7.8861 & .881 & \\
\hline HEMBL3329450 & 806 & 458 & 0402 & \\
\hline EMBL3 & 806 & & 6957 & \\
\hline AEMBL179344 & 806 & 7.699 & 6878 & \\
\hline HEMBL193400 & 9806 & 9.5229 & .5134 & \\
\hline HEMBL127411 & 806 & 8.1427 & 8.1438 & \\
\hline HEMBL3329439 & 806 & 8.9208 & .9198 & \\
\hline IEMBL 3329448 & 806 & 8.0458 & .1058 & \\
\hline HEMBL571762 & 806 & 7.7959 & 7.794 & \\
\hline AEMBL3329454 & 806 & 8.0 & 8.1768 & \\
\hline AEMBL3329433 & 806 & 7.9586 & 7.9606 & \\
\hline 329441 & 806 & 9.3979 & 9.3921 & \\
\hline AEMBL & 06 & 7.9208 & 7.9168 & \\
\hline AEMBL3329443 & 806 & 8.4202 & 8.4189 & \\
\hline IEMBL 3329447 & 306 & 447 & & \\
\hline AEMBL367088 & 306 & 8.0088 & 09 & \\
\hline 29424 & 306 & 7.4949 & 47 & \\
\hline AEMBL & $\partial 6$ & 383 & 51 & \\
\hline 2752 & 306 & 8.5229 & 8.5208 & \\
\hline IEMBL & 306 & & 862 & \\
\hline HEMBL. & 306 & 9.0 & 8.1017 & TST \\
\hline EMBL & 306 & 8.8 & 11 & \\
\hline FMR & & & 41 & \\
\hline 537 & & & 263 & \\
\hline IEMBL & 06 & & & 15 \\
\hline IEMBL33294 & 306 & 8.9208 & 408 & $S$ \\
\hline EMBL & 306 & 9.5229 & & \\
\hline 8 & & 8. & & 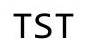 \\
\hline & & 9. & & \\
\hline IEMBL: & 06 & 8.85 & 51 & is \\
\hline AEMBL 20011 & 22 & 4. & 4.7688 & R \\
\hline IFMRI 19748 & 22 & 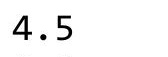 & 705 & \\
\hline & & 1 & 48 & KI \\
\hline & & 6.0 & & $\mathrm{RN}$ \\
\hline IEMBL1979773 & 22 & 4. & 4.3962 & TR \\
\hline EMBL: & 22 & & 5.1781 & $S$ \\
\hline 96702 & 22 & & 5.3889 & \\
\hline HEMBL 2 & & 4.5 & 4.5021 & RI \\
\hline EMBL: & & 4.5 & 5.1232 & RI \\
\hline IEMBL 2006439 & 22 & 4.5 & 5.1898 & $\mathrm{R}$ \\
\hline Not & & 5 . & 227 & \\
\hline CHEMBL1991674 & 809122 & 4.5 & 4.9645 & \\
\hline CHEMBL1982711 & 09122 & 6.0 & 5.3557 & \\
\hline CHEMBL262623 & 809122 & 4.5 & 4.5029 & 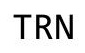 \\
\hline
\end{tabular}

Page 27753 


\begin{tabular}{|c|c|c|c|c|c|}
\hline & & & & & \\
\hline CHEMBL1984842 & 809122 & 4.5 & 4.4653 & TRN & \\
\hline CHEMBL 2004118 & 809122 & 5.6 & 5.1835 & TRN & \\
\hline CHEMBL1973516 & 809122 & 4.5 & 5.44 & TRN & \\
\hline CHEMBL1996345 & 809122 & 4.5 & 4.5648 & TRN & \\
\hline CHEMBL 2004025 & 809122 & 4.5 & 4.4529 & TRN & \\
\hline CHEMBL1996048 & 809122 & 4.5 & 4.7344 & TRN & \\
\hline CHEMBL50894 & 809122 & 4.5 & 4.6389 & TRN & \\
\hline CHEMBL1995211 & 809122 & 4.5 & 4.18199 & 99999999995 & TRN \\
\hline CHEMBL1965033 & 809122 & 4.5 & 4.4143 & TRN & \\
\hline CHEMBL461876 & 809122 & 4.5 & 4.4342 & TRN & \\
\hline CHEMBL1982753 & 809122 & 4.5 & 4.3679 & TRN & \\
\hline CHEMBL 2006299 & 809122 & 4.5 & 4.3007 & TRN & \\
\hline CHEMBL1972346 & 809122 & 6.4 & 5.6342 & TST & \\
\hline CHEMBL1997335 & 809122 & 6.3 & 6.1836 & TRN & \\
\hline CHEMBL1965169 & 809122 & 4.5 & 4.3715 & TRN & \\
\hline CHEMBL1081312 & 809122 & 5.8 & 5.3855 & TRN & \\
\hline CHEMBL1965170 & 809122 & 4.5 & 5.6854 & TRN & \\
\hline CHEMBL1994808 & 809122 & 4.5 & 4.3262 & TRN & \\
\hline CHEMBL 2005792 & 809122 & 4.5 & 4.459 & TRN & \\
\hline CHEMBL1991867 & 809122 & 4.4 & 4.538 & TRN & \\
\hline CHEMBL1972355 & 809122 & 5.7 & 5.80399 & 9999999999 & TRN \\
\hline CHEMBL1997892 & 809122 & 4.5 & 4.5445 & TRN & \\
\hline CHEMBL2001641 & 809122 & 4.5 & 4.2738 & TRN & \\
\hline CHEMBL1997193 & 809122 & 4.5 & 4.2261 & TST & \\
\hline CHEMBL1964902 & 809122 & 4.5 & 4.2694 & TRN & \\
\hline CHEMBL1973868 & 809122 & 4.5 & 4.7487 & TRN & \\
\hline CHEMBL1972462 & 809122 & 4.5 & 4.497 & TRN & \\
\hline CHEMBL1983715 & 809122 & 7.2 & 6.8296 & TRN & \\
\hline CHEMBL1984500 & 809122 & 3.2 & 3.5514 & TRN & \\
\hline CHEMBL 2002992 & 809122 & 4.5 & 4.3772 & TRN & \\
\hline CHEMBL1982700 & 809122 & 4.5 & 4.4447 & TRN & \\
\hline CHEMBL10 & 809122 & 4.5 & 4.3627 & TRN & \\
\hline CHEMBL1980763 & 809122 & 4.5 & 5.0993 & TRN & \\
\hline CHEMBL1977634 & 809122 & 4.5 & 4.3423 & TRN & \\
\hline CHEMBL1977931 & 809122 & 4.0 & 4.0217 & TRN & \\
\hline CHEMBL2007479 & 809122 & 4.5 & 4.3763 & TRN & \\
\hline CHEMBL1998953 & 809122 & 4.5 & 4.24 & TRN & \\
\hline CHEMBL1971606 & 809122 & 4.5 & 4.3442 & TRN & \\
\hline CHEMBL1971223 & 809122 & 4.5 & 4.5731 & TRN & \\
\hline CHEMBL1999120 & 809122 & 4.2 & 4.0825 & TST & \\
\hline CHEMBL1972220 & 809122 & 7.2 & 6.5322 & TRN & \\
\hline CHEMBL1981215 & 809122 & 4.5 & 4.7769 & TRN & \\
\hline CHEMBL 2003785 & 809122 & 4.0 & 4.29899 & 99999999995 & TRN \\
\hline CHEMBL1973720 & 809122 & 5.6 & 5.3466 & TRN & \\
\hline CHEMBL1999414 & 809122 & 6.2 & 6.3879 & TRN & \\
\hline CHEMBL1967336 & 809122 & 4.5 & 4.4652 & TRN & \\
\hline CHEMBL2001923 & 809122 & 4.5 & 4.4845 & TRN & \\
\hline CHEMBL1983070 & 809122 & 4.5 & 4.5379 & TRN & \\
\hline & & & & 27754 & \\
\hline
\end{tabular}




\begin{tabular}{|c|c|c|c|c|}
\hline & & & Supplemen & al $\mathrm{T}$ \\
\hline CHEMBL 2003514 & 809122 & 4.5 & 4.2647 & TRN \\
\hline CHEMBL1970340 & 809122 & 4.4 & 4.5331 & TRN \\
\hline CHEMBL1967992 & 809122 & 4.5 & 4.3903 & TRN \\
\hline CHEMBL1989043 & 809122 & 4.5 & 4.4096 & TRN \\
\hline CHEMBL 2006450 & 809122 & 4.5 & 4.3162 & TRN \\
\hline CHEMBL2001987 & 809122 & 4.5 & 4.7265 & TRN \\
\hline CHEMBL1994555 & 809122 & 4.5 & 4.7842 & TRN \\
\hline CHEMBL1164180 & 809122 & 4.5 & 4.6344 & TST \\
\hline CHEMBL1975121 & 809122 & 4.5 & 4.3267 & TRN \\
\hline CHEMBL1983640 & 809122 & 6.4 & 5.6392 & TRN \\
\hline CHEMBL1997611 & 809122 & 5.8 & 5.2526 & TST \\
\hline CHEMBL1971943 & 809122 & 4.5 & 4.4555 & TRN \\
\hline CHEMBL1984686 & 809122 & 4.5 & 4.5188 & TST \\
\hline CHEMBL1973793 & 809122 & 4.5 & 4.2736 & TRN \\
\hline CHEMBL1992073 & 809122 & 4.5 & 4.1971 & TRN \\
\hline CHEMBL1990254 & 809122 & 4.5 & 4.5936 & TRN \\
\hline CHEMBL1986143 & 809122 & 4.5 & 4.3786 & TRN \\
\hline CHEMBL2007559 & 809122 & 4.5 & 4.6824 & TRN \\
\hline CHEMBL1992581 & 809122 & 6.0 & 5.5246 & TRN \\
\hline CHEMBL 2004290 & 809122 & 6.2 & 5.9821 & TRN \\
\hline CHEMBL1975921 & 809122 & 4.4 & 4.4351 & TRN \\
\hline CHEMBL1975923 & 809122 & 4.8 & 4.8115 & TST \\
\hline CHEMBL 2004033 & 809122 & 5.5 & 4.8226 & TST \\
\hline CHEMBL1984847 & 809122 & 4.5 & 4.5327 & TRN \\
\hline CHEMBL 2005449 & 809122 & 4.5 & 4.7231 & TRN \\
\hline CHEMBL1996576 & 809122 & 4.5 & 4.4655 & TST \\
\hline CHEMBL1991678 & 809122 & 4.5 & 4.5193 & TRN \\
\hline CHEMBL1987998 & 809122 & 4.5 & 4.6062 & TRN \\
\hline CHEMBL1990496 & 809122 & 4.5 & 4.5343 & TRN \\
\hline CHEMBL242865 & 809122 & 6.4 & 5.8848 & TRN \\
\hline CHEMBL235157 & 809122 & 4.5 & 4.6829 & TST \\
\hline CHEMBL 2002480 & 809122 & 4.2 & 4.4783 & TRN \\
\hline CHEMBL 2004159 & 809122 & 4.5 & 4.2781 & TRN \\
\hline CHEMBL1978371 & 809122 & 4.5 & 5.0934 & TST \\
\hline CHEMBL440084 & 809122 & 4.5 & 4.5215 & TRN \\
\hline CHEMBL1998110 & 809122 & 4.5 & 4.3135 & TRN \\
\hline CHEMBL1978166 & 809122 & 6.4 & 6.4605 & TRN \\
\hline CHEMBL1972454 & 809122 & 4.1 & 4.7137 & TST \\
\hline CHEMBL1990590 & 809122 & 4.5 & 4.3468 & TRN \\
\hline CHEMBL1977814 & 809122 & 4.5 & 4.4537 & TST \\
\hline CHEMBL1974617 & 809122 & 4.7 & 4.5228 & TRN \\
\hline CHEMBL1965660 & 809122 & 4.5 & 4.8376 & TRN \\
\hline CHEMBL1992125 & 809122 & 5.7 & 5.4834 & TRN \\
\hline CHEMBL1966175 & 809122 & 4.5 & 4.2149 & TRN \\
\hline CHEMBL 2007375 & 809122 & 4.5 & 4.3386 & TRN \\
\hline CHEMBL379975 & 809122 & 5.6 & 4.7567 & TRN \\
\hline CHEMBL1973016 & 809122 & 4.5 & 4.4842 & TRN \\
\hline CHEMBL1965387 & 809122 & 4.5 & 4.5362 & TRN \\
\hline
\end{tabular}




\begin{tabular}{|c|c|c|c|c|c|}
\hline \\
\hline CHEMBL2001539 & 809122 & 4.2 & 4.2932 & TST & \\
\hline CHEMBL388978 & 809122 & 8.3 & 7.2696 & TST & \\
\hline CHEMBL1997041 & 809122 & 4.6 & 4.3106 & TRN & \\
\hline CHEMBL550418 & 809122 & 5.9 & 4.9577 & TRN & \\
\hline CHEMBL398951 & 809122 & 4.5 & 4.6273 & TRN & \\
\hline CHEMBL1971289 & 809122 & 4.5 & 4.592 & TRN & \\
\hline CHEMBL1988437 & 809122 & 5.7 & 5.8168 & TST & \\
\hline CHEMBL2007603 & 809122 & 4.5 & 4.5314 & TRN & \\
\hline CHEMBL1421720 & 809122 & 4.5 & 5.4561 & TRN & \\
\hline CHEMBL1233887 & 809122 & 4.5 & 4.3747 & TRN & \\
\hline CHEMBL1968130 & 809122 & 4.7 & 4.7166 & TST & \\
\hline CHEMBL 2003689 & 809122 & 4.5 & 4.335 & TRN & \\
\hline CHEMBL1996649 & 809122 & 6.2 & 6.1443 & TRN & \\
\hline CHEMBL1986756 & 809122 & 4.5 & 4.5776 & TRN & \\
\hline CHEMBL1949855 & 809122 & 4.9 & 4.749 & TRN & \\
\hline CHEMBL3109278 & 809122 & 4.6 & 4.3816 & TRN & \\
\hline CHEMBL1990223 & 809122 & 4.5 & 4.5354 & TRN & \\
\hline CHEMBL2004438 & 809122 & 4.5 & 4.5375 & TRN & \\
\hline CHEMBL1964382 & 809122 & 4.5 & 4.7964 & TST & \\
\hline CHEMBL101311 & 809122 & 4.5 & 4.8083 & TRN & \\
\hline CHEMBL191003 & 809122 & 4.5 & 4.9908 & TRN & \\
\hline CHEMBL1973359 & 809122 & 6.9 & 6.4775 & TST & \\
\hline CHEMBL1988581 & 809122 & 7.3 & 6.5764 & TST & \\
\hline CHEMBL2005699 & 809122 & 4.5 & 4.2594 & TRN & \\
\hline CHEMBL2006564 & 809122 & 6.8 & 6.2033 & TRN & \\
\hline CHEMBL1986943 & 809122 & 6.1 & 5.843 & TRN & \\
\hline CHEMBL1979690 & 809122 & 6.2 & 6.45799 & 9999999999 & TRN \\
\hline CHEMBL234085 & 809122 & 4.5 & 4.3113 & TRN & \\
\hline CHEMBL1978167 & 809122 & 4.5 & 4.4058 & TRN & \\
\hline CHEMBL418203 & 809122 & 4.5 & 4.9483 & TRN & \\
\hline CHEMBL225519 & 809122 & 4.5 & 4.7598 & TST & \\
\hline CHEMBL1976376 & 809122 & 5.6 & 4.6978 & TRN & \\
\hline CHEMBL1983575 & 809122 & 6.3 & 6.0619 & TRN & \\
\hline CHEMBL1968868 & 809122 & 4.5 & 4.6582 & TRN & \\
\hline CHEMBL 2007064 & 809122 & 4.5 & 4.8804 & TRN & \\
\hline CHEMBL1981047 & 809122 & 4.5 & 5.0304 & TRN & \\
\hline CHEMBL1998470 & 809122 & 4.5 & 4.6771 & TRN & \\
\hline CHEMBL1976196 & 809122 & 4.5 & 4.9833 & TRN & \\
\hline CHEMBL1997197 & 809122 & 4.5 & 4.4662 & TRN & \\
\hline CHEMBL1975903 & 809122 & 4.5 & 5.1241 & TRN & \\
\hline CHEMBL1983630 & 809122 & 4.0 & 4.1968 & TRN & \\
\hline CHEMBL1988805 & 809122 & 4.5 & 4.3263 & TRN & \\
\hline CHEMBL458997 & 809122 & 4.7 & 5.4626 & TRN & \\
\hline CHEMBL1969942 & 809122 & 4.5 & 4.6373 & TRN & \\
\hline CHEMBL1982660 & 809122 & 4.5 & 4.9702 & TRN & \\
\hline CHEMBL1978567 & 809122 & 4.5 & 4.3135 & TRN & \\
\hline CHEMBL1995765 & 809122 & 4.8 & 4.8067 & TST & \\
\hline CHEMBL1984760 & 809122 & 4.5 & 4.6819 & TRN & \\
\hline & & & & 7756 & \\
\hline
\end{tabular}




\begin{tabular}{|c|c|c|c|c|c|}
\hline \multicolumn{6}{|c|}{ Supplemental Table S2.txt } \\
\hline CHEMBL1997846 & 809122 & 4.5 & 4.8068 & TRN & \\
\hline CHEMBL424872 & 809122 & 4.5 & 4.1886 & TRN & \\
\hline CHEMBL360847 & 809122 & 4.5 & 4.891 & TRN & \\
\hline CHEMBL1995811 & 809122 & 5.9 & 5.4677 & TRN & \\
\hline CHEMBL1983111 & 809122 & 7.4 & 6.9668 & TRN & \\
\hline CHEMBL1988141 & 809122 & 5.6 & 4.7348 & TST & \\
\hline CHEMBL1992937 & 809122 & 4.5 & 4.4904 & TRN & \\
\hline CHEMBL1977134 & 809122 & 4.5 & 5.2198 & TRN & \\
\hline CHEMBL1985206 & 809122 & 4.5 & 4.5947 & TRN & \\
\hline CHEMBL1991078 & 809122 & 6.7 & 6.3743 & TRN & \\
\hline CHEMBL1977749 & 809122 & 6.1 & 5.1397 & TST & \\
\hline CHEMBL1982837 & 809122 & 6.3 & 5.4712 & TRN & \\
\hline CHEMBL1975212 & 809122 & 4.2 & 4.70100 & 00000000005 & TRN \\
\hline CHEMBL 2001613 & 809122 & 5.1 & 4.7054 & TRN & \\
\hline CHEMBL261849 & 809122 & 4.5 & 4.2799 & TST & \\
\hline CHEMBL1983923 & 809122 & 6.2 & 6.2144 & TRN & \\
\hline CHEMBL1993904 & 809122 & 4.5 & 4.6412 & TRN & \\
\hline CHEMBL1997275 & 809122 & 4.5 & 4.099 & TRN & \\
\hline CHEMBL1967513 & 809122 & 4.5 & 4.5666 & TRN & \\
\hline CHEMBL 2000724 & 809122 & 4.5 & 4.3069 & TRN & \\
\hline CHEMBL1982413 & 809122 & 4.5 & 4.8112 & TRN & \\
\hline CHEMBL1985042 & 809122 & 4.3 & 4.1776 & TST & \\
\hline CHEMBL1987535 & 809122 & 4.5 & 4.9523 & TRN & \\
\hline CHEMBL1983393 & 809122 & 4.5 & 4.5021 & TRN & \\
\hline CHEMBL1981792 & 809122 & 4.5 & 4.5712 & TRN & \\
\hline CHEMBL1985006 & 809122 & 6.0 & 5.3927 & TRN & \\
\hline CHEMBL 2002586 & 809122 & 4.5 & 4.4953 & TRN & \\
\hline CHEMBL 2006674 & 809122 & 4.5 & 4.5484 & TST & \\
\hline CHEMBL1992371 & 809122 & 4.5 & 4.8206 & TRN & \\
\hline CHEMBL383264 & 809122 & 4.5 & 5.2228 & TRN & \\
\hline CHEMBL1984236 & 809122 & 4.5 & 4.6303 & TST & \\
\hline CHEMBL 2007421 & 809122 & 4.5 & 4.6596 & TRN & \\
\hline CHEMBL1973138 & 809122 & 4.5 & 4.4927 & TRN & \\
\hline CHEMBL 2002599 & 809122 & 4.5 & 4.5769 & TRN & \\
\hline CHEMBL1969151 & 809122 & 5.6 & 5.2504 & TRN & \\
\hline CHEMBL1967252 & 809122 & 4.7 & 4.6831 & TRN & \\
\hline CHEMBL1993335 & 809122 & 4.5 & 4.9219 & TRN & \\
\hline CHEMBL 2007574 & 809122 & 4.5 & 4.662 & TRN & \\
\hline CHEMBL1988692 & 809122 & 4.5 & 4.6396 & TST & \\
\hline CHEMBL 2004637 & 809122 & 4.5 & 4.8794 & TRN & \\
\hline CHEMBL1993374 & 809122 & 4.5 & 4.3394 & TRN & \\
\hline CHEMBL1994318 & 809122 & 4.5 & 4.5176 & TRN & \\
\hline CHEMBL1998680 & 809122 & 4.5 & 4.3286 & TRN & \\
\hline CHEMBL592030 & 809122 & 4.5 & 4.6136 & TST & \\
\hline CHEMBL1999506 & 809122 & 4.5 & 4.3745 & TRN & \\
\hline CHEMBL1970317 & 809122 & 6.0 & 5.9591 & TRN & \\
\hline CHEMBL1605605 & 809122 & 4.5 & 4.4616 & TRN & \\
\hline CHEMBL429516 & 809122 & 5.5 & 5.2497 & TRN & \\
\hline
\end{tabular}




\begin{tabular}{|c|c|c|c|c|}
\hline \multicolumn{5}{|c|}{ Supplemental Tab } \\
\hline CHEMBL1997007 & 809122 & 4.5 & 4.9667 & TRN \\
\hline CHEMBL1970352 & 809122 & 4.5 & 4.8465 & TRN \\
\hline CHEMBL1964444 & 809122 & 4.5 & 4.5637 & TRN \\
\hline CHEMBL 2002690 & 809122 & 4.5 & 4.7729 & TRN \\
\hline CHEMBL1980167 & 809122 & 4.5 & 4.4846 & TRN \\
\hline CHEMBL 377408 & 809122 & 4.5 & 4.2265 & TRN \\
\hline CHEMBL278041 & 809122 & 4.5 & 4.4987 & TRN \\
\hline CHEMBL215152 & 809122 & 4.5 & 4.8707 & TRN \\
\hline CHEMBL 2006765 & 809122 & 6.1 & 5.5251 & TRN \\
\hline CHEMBL1986590 & 809122 & 4.5 & 4.1655 & TRN \\
\hline CHEMBL 1870106 & 809122 & 4.5 & 4.673 & TST \\
\hline CHEMBL406845 & 809122 & 4.5 & 5.0326 & TRN \\
\hline CHEMBL1980246 & 809122 & 4.5 & 4.6151 & TRN \\
\hline CHEMBL1998478 & 809122 & 5.5 & 4.5726 & TRN \\
\hline CHEMBL1983980 & 809122 & 5.6 & 5.569 & TRN \\
\hline CHEMBL1999484 & 809122 & 6.6 & 6.7656 & TRN \\
\hline CHEMBL1984296 & 809122 & 5.5 & 5.3991 & TRN \\
\hline CHEMBL1986899 & 809122 & 4.5 & 4.4219 & TRN \\
\hline CHEMBL1984038 & 809122 & 4.5 & 4.5285 & TRN \\
\hline CHEMBL1964718 & 809122 & 4.0 & 4.6387 & TST \\
\hline CHEMBL1993661 & 809122 & 6.9 & 6.897 & TRN \\
\hline CHEMBL1968705 & 809122 & 4.5 & 4.579 & TRN \\
\hline CHEMBL1991410 & 809122 & 4.5 & 4.273 & TRN \\
\hline CHEMBL1964441 & 809122 & 6.1 & 6.02 & TRN \\
\hline CHEMBL546797 & 809122 & 4.5 & 4.1813 & TRN \\
\hline CHEMBL1978271 & 809122 & 4.5 & 4.4463 & TRN \\
\hline CHEMBL 2007266 & 809122 & 4.5 & 4.6553 & TRN \\
\hline CHEMBL202721 & 809122 & 4.5 & 4.5449 & TRN \\
\hline CHEMBL 2000568 & 809122 & 4.5 & 4.6274 & TRN \\
\hline CHEMBL1994308 & 809122 & 4.5 & 4.5383 & TRN \\
\hline CHEMBL1974328 & 809122 & 4.7 & 4.7106 & TRN \\
\hline CHEMBL509032 & 809122 & 6.0 & 6.5097 & TRN \\
\hline CHEMBL388311 & 809122 & 7.7 & 7.2365 & TRN \\
\hline CHEMBL1964948 & 809122 & 4.5 & 4.3086 & TRN \\
\hline CHEMBL1973013 & 809122 & 4.5 & 4.6294 & TRN \\
\hline CHEMBL1987430 & 809122 & 4.5 & 4.5786 & TST \\
\hline CHEMBL1993413 & 809122 & 4.5 & 4.3157 & TST \\
\hline CHEMBL205415 & 809122 & 4.5 & 4.5768 & TST \\
\hline CHEMBL1975927 & 809122 & 6.7 & 5.7173 & TST \\
\hline CHEMBL1977138 & 809122 & 6.0 & 5.4242 & TST \\
\hline CHEMBL1978448 & 809122 & 4.5 & 4.565 & TST \\
\hline CHEMBL1980329 & 809122 & 4.5 & 5.7291 & TST \\
\hline CHEMBL 2004515 & 809122 & 5.1 & 4.6422 & TST \\
\hline CHEMBL1992042 & 809122 & 4.5 & 5.0091 & TST \\
\hline CHEMBL1986265 & 809122 & 4.5 & 4.4817 & TST \\
\hline CHEMBL1991734 & 809122 & 5.7 & 6.2463 & TST \\
\hline CHEMBL21156 & 809122 & 7.0 & 4.9722 & TST \\
\hline CHEMBL1994724 & 809122 & 4.5 & 4.5852 & TST \\
\hline
\end{tabular}




\begin{tabular}{|c|c|c|c|c|c|}
\hline \multicolumn{6}{|c|}{ Supplemental Table S2.txt } \\
\hline CHEMBL1989267 & 809122 & 6.2 & 5.8672 & TST & \\
\hline CHEMBL1991782 & 809122 & 3.2 & 3.0726 & TST & \\
\hline CHEMBL 2002105 & 809122 & 4.1 & 4.2893 & TST & \\
\hline CHEMBL1983348 & 809122 & 6.2 & 5.7271 & TST & \\
\hline CHEMBL1970290 & 809122 & 4.5 & 4.9193 & TST & \\
\hline CHEMBL1993877 & 809122 & 4.5 & 4.749 & TST & \\
\hline CHEMBL 2000934 & 809122 & 4.5 & 4.5577 & TST & \\
\hline CHEMBL1996500 & 809122 & 4.5 & 4.4398 & TST & \\
\hline CHEMBL1986177 & 809122 & 4.5 & 4.3546 & TST & \\
\hline CHEMBL1989708 & 809122 & 7.6 & 6.4441 & TST & \\
\hline CHEMBL1976420 & 809122 & 4.5 & 4.7722 & TST & \\
\hline CHEMBL1998253 & 809122 & 4.5 & 4.5633 & TST & \\
\hline CHEMBL1981744 & 809122 & 4.5 & 4.5407 & TST & \\
\hline CHEMBL1985367 & 809122 & 4.5 & 4.6614 & TST & \\
\hline CHEMBL1996510 & 809122 & 4.5 & 4.797 & TST & \\
\hline CHEMBL 2000029 & 809122 & 6.6 & 5.4078 & TST & \\
\hline CHEMBL1995172 & 809122 & 4.5 & 4.2548 & TST & \\
\hline CHEMBL 2001584 & 809122 & 4.5 & 4.5755 & TST & \\
\hline CHEMBL1973961 & 809122 & 4.5 & 4.2897 & TST & \\
\hline CHEMBL1967998 & 809122 & 6.0 & 6.3704 & TST & \\
\hline CHEMBL1978562 & 809122 & 4.5 & 4.1836 & TST & \\
\hline CHEMBL1994977 & 809122 & 4.5 & 4.3714 & TST & \\
\hline CHEMBL3949696 & 1640661 & 6.8239 & 6.7136 & TRN & \\
\hline CHEMBL3918240 & 1640661 & 3.699 & 3.8591 & TRN & \\
\hline CHEMBL3977113 & 1640661 & 6.7696 & 6.3425 & TST & \\
\hline CHEMBL3937649 & 1640661 & 6.585 & 6.3135 & TRN & \\
\hline CHEMBL3953237 & 1640661 & 6.6021 & 6.2063 & TRN & \\
\hline CHEMBL3953518 & 1640661 & 5.7986 & 6.1361 & TRN & \\
\hline CHEMBL3911474 & 1640661 & 6.1427 & 6.4498 & TRN & \\
\hline CHEMBL3944379 & 1640661 & 7.4318 & 7.3871 & TRN & \\
\hline CHEMBL3926420 & 1640661 & 3.699 & 4.3845 & TST & \\
\hline CHEMBL3975781 & 1640661 & 6.5229 & 6.4612 & TRN & \\
\hline CHEMBL3936466 & 1640661 & 6.3768 & 6.3124 & TRN & \\
\hline CHEMBL3945143 & 1640661 & 3.699 & 2.9344 & TRN & \\
\hline CHEMBL 3897532 & 1640661 & 5.5258 & 5.1626 & TRN & \\
\hline CHEMBL3961390 & 1640661 & 6.8539 & 5.8968 & TST & \\
\hline CHEMBL3938884 & 1640661 & 5.2147 & 4.9559 & TRN & \\
\hline CHEMBL3965989 & 1640661 & 6.2441 & 6.465 & TRN & \\
\hline CHEMBL3940518 & 1640661 & 5.4881 & 5.6036 & TRN & \\
\hline CHEMBL3967301 & 1640661 & 6.4437 & 6.7255 & TRN & \\
\hline CHEMBL3977889 & 1640661 & 3.699 & 4.0125 & TRN & \\
\hline CHEMBL3927472 & 1640661 & 6.9208 & 6.4583 & TRN & \\
\hline CHEMBL3960768 & 1640661 & 6.7447 & 7.0554 & TRN & \\
\hline CHEMBL3341992 & 1640661 & 6.7447 & 6.8154 & TST & \\
\hline CHEMBL 3912794 & 1640661 & 3.699 & 4.71899 & 9999999999 & TRN \\
\hline CHEMBL3928619 & 1640661 & 4.8239 & 4.73300 & 00000000005 & TRN \\
\hline CHEMBL 3943584 & 1640661 & 6.7447 & 6.75899 & 99999999995 & TRN \\
\hline CHEMBL3942876 & 1640661 & 6.3979 & 6.4219 & TRN & \\
\hline
\end{tabular}


Supplemental Table S2.txt

\begin{tabular}{|c|c|c|c|c|c|c|}
\hline CHEMBL 3944950 & 1640661 & 6.0605 & 6.5783 & TST & & \\
\hline CHEMBL 3925613 & 1640661 & 5.1898 & 5.5407 & TRN & & \\
\hline CHEMBL 3919780 & 1640661 & 6.8861 & 6.71399 & 99999999995 & TRN & \\
\hline CHEMBL 3907328 & 1640661 & 6.0223 & 6.3719 & TRN & & \\
\hline CHEMBL 3904821 & 1640661 & 5.699 & 6.5205 & TRN & & \\
\hline CHEMBL3920403 & 1640661 & 6.0044 & 5.8122 & TRN & & \\
\hline CHEMBL3970561 & 1640661 & 6.3372 & 5.5885 & TRN & & \\
\hline CHEMBL 3897429 & 1640661 & 6.3098 & 6.7761 & TRN & & \\
\hline CHEMBL 3922060 & 1640661 & 6.8539 & 6.273 & TRN & & \\
\hline CHEMBL 3934328 & 1640661 & 3.699 & 4.4366 & TRN & & \\
\hline CHEMBL3902996 & 1640661 & 6.5376 & 6.2391 & TST & & \\
\hline CHEMBL 3912049 & 1640661 & 6.3872 & 5.8075 & TRN & & \\
\hline CHEMBL 3940174 & 1640661 & 6.2676 & 6.6457 & TRN & & \\
\hline CHEMBL 3912013 & 1640661 & 6.9208 & 7.234 & TRN & & \\
\hline CHEMBL 3914255 & 1640661 & 5.8539 & 5.8921 & TRN & & \\
\hline CHEMBL 3973077 & 1640661 & 6.5086 & 6.8851 & TRN & & \\
\hline CHEMBL3950990 & 1640661 & 6.585 & 5.6893 & TRN & & \\
\hline CHEMBL 3890194 & 1640661 & 3.699 & 4.6965 & TRN & & \\
\hline CHEMBL 3916881 & 1640661 & 6.3665 & 6.5333 & TRN & & \\
\hline CHEMBL 3894054 & 1640661 & 5.9281 & 5.6884 & TRN & & \\
\hline CHEMBL 3927174 & 1640661 & 5.9393 & 5.4816 & TRN & & \\
\hline CHEMBL3951259 & 1640661 & 5.2426 & 5.7159 & TRN & & \\
\hline CHEMBL 3954057 & 1640661 & 5.8477 & 5.6754 & TST & & \\
\hline CHEMBL 3914757 & 1640661 & 4.8239 & 5.4078 & TRN & & \\
\hline CHEMBL 3917437 & 1640661 & 5.7447 & 4.0102 & TST & & \\
\hline CHEMBL 3910850 & 1640661 & 3.699 & 4.1793 & TRN & & \\
\hline CHEMBL 3941015 & 1640661 & 6.7696 & 7.0111 & TRN & & \\
\hline CHEMBL 3942271 & 1640661 & 3.699 & 5.7688 & TST & & \\
\hline CHEMBL3948908 & 1640661 & 6.4437 & 6.9499 & TRN & & \\
\hline CHEMBL 3915657 & 1640661 & 6.3872 & 6.0885 & TRN & & \\
\hline CHEMBL 3929431 & 1640661 & 6.6576 & 5.7929 & TST & & \\
\hline CHEMBL 3949552 & 1640661 & 5.9666 & 6.1579 & TST & & \\
\hline CHEMBL 3958760 & 1640661 & 6.5686 & 6.4795 & TST & & \\
\hline CHEMBL3962795 & 1640661 & 5.4248 & 4.4386 & TST & & \\
\hline CHEMBL3946219 & 1640661 & 6.9586 & \multicolumn{2}{|c|}{6.452000000000001} & TRN & \\
\hline CHEMBL 3926235 & 1640661 & 6.699 & 6.8737 & TRN & & \\
\hline CHEMBL 3944793 & 1640661 & 6.2757 & 6.0452 & TRN & & \\
\hline CHEMBL 3920546 & 1640661 & 6.6576 & 5.9792 & TST & & \\
\hline CHEMBL 3903025 & 1640661 & 5.7799 & \multicolumn{2}{|c|}{6.1370000000000005} & TRN & \\
\hline CHEMBL 3892406 & 1640661 & \multicolumn{3}{|c|}{5.757000000000001} & 111000000000001 & TRN \\
\hline CHEMBL 3982682 & 1640661 & 7.1612 & 6.4181 & TRN & & \\
\hline CHEMBL3966330 & 1640661 & 6.6576 & 6.0315 & TST & & \\
\hline CHEMBL 3943872 & 1640661 & 7.0555 & 7.4929 & TST & & \\
\hline CHEMBL 3891411 & 1640661 & 3.699 & 4.942 & TRN & & \\
\hline CHEMBL3921918 & 1640661 & 6.9586 & 6.928 & TRN & & \\
\hline CHEMBL3919469 & 1640661 & 3.699 & 3.3798 & TRN & & \\
\hline CHEMBL 3898158 & 1640661 & 7.0 & 7.0133 & TRN & & \\
\hline CHEMBL 3936134 & 1640661 & 5.3401 & 5.7129 & TST & & \\
\hline
\end{tabular}


Supplemental Table S2.txt

\begin{tabular}{|c|c|c|c|c|c|}
\hline CHEMBL3949110 & 1640661 & 6.7696 & 6.4058 & TRN & \\
\hline CHEMBL 3964588 & 1640661 & 6.585 & 6.5252 & TRN & \\
\hline CHEMBL3913084 & 1640661 & 6.3979 & 5.4693 & TRN & \\
\hline CHEMBL 3970081 & 1640661 & 5.8962 & 5.6789 & TRN & \\
\hline CHEMBL 3950415 & 1640661 & 3.699 & 3.96199 & 79999999997 & TRN \\
\hline CHEMBL 3981100 & 1640661 & 6.6778 & 6.9611 & TRN & \\
\hline CHEMBL 3931257 & 1640661 & 6.699 & 6.1311 & TST & \\
\hline CHEMBL3968977 & 1640661 & 5.6799 & 5.5649 & TRN & \\
\hline CHEMBL 3948223 & 1640661 & 6.7696 & 6.2954 & TRN & \\
\hline CHEMBL3922348 & 1640661 & 7.0809 & 6.653 & TST & \\
\hline CHEMBL 3939988 & 1640661 & 6.7959 & 6.7584 & TST & \\
\hline CHEMBL3932864 & 1640661 & 6.0655 & 5.9244 & TST & \\
\hline CHEMBL3943010 & 1640661 & 4.8239 & 6.1703 & TST & \\
\hline CHEMBL3902732 & 1640661 & 6.0132 & 5.4074 & TRN & \\
\hline CHEMBL3934493 & 1640661 & 5.6904 & 5.8155 & TRN & \\
\hline CHEMBL 3958355 & 1640661 & 6.6576 & 6.3249 & TRN & \\
\hline CHEMBL3934897 & 1640661 & 3.699 & 4.1886 & TRN & \\
\hline CHEMBL3972101 & 1640661 & 6.4685 & 6.3375 & TST & \\
\hline CHEMBL3920858 & 1640661 & 6.1024 & 5.6233 & TRN & \\
\hline CHEMBL3956885 & 1640661 & 3.699 & 4.3134 & TST & \\
\hline CHEMBL3942257 & 1640661 & 6.4089 & 6.3026 & TRN & \\
\hline CHEMBL 3940026 & 1640661 & 3.699 & 3.5754 & TRN & \\
\hline CHEMBL3900997 & 1640598 & 6.27 & 6.4019 & TRN & \\
\hline CHEMBL1087282 & 1640598 & 5.567 & 6.2563 & TST & \\
\hline CHEMBL3932009 & 1640598 & 5.699 & 5.7289 & TRN & \\
\hline CHEMBL3975330 & 1640598 & 5.767 & 6.7922 & TST & \\
\hline CHEMBL 3986610 & 1640598 & 7.2596 & 6.0794 & TRN & \\
\hline CHEMBL3904009 & 1640598 & 6.1713 & 6.1622 & TRN & \\
\hline CHEMBL3931249 & 1640598 & 6.5719 & 6.0914 & TRN & \\
\hline CHEMBL1080864 & 1640598 & 8.0458 & 7.7759 & TRN & \\
\hline CHEMBL1080382 & 1640598 & 8.2218 & 7.7959 & TRN & \\
\hline CHEMBL 3908286 & 1640598 & 6.6459 & 6.9545 & TRN & \\
\hline CHEMBL3908375 & 1640598 & 5.9935 & 6.2495 & TST & \\
\hline CHEMBL3890236 & 1640598 & 6.9281 & 6.4789 & TRN & \\
\hline CHEMBL3944612 & 1640598 & 6.4078 & 6.8474 & TRN & \\
\hline CHEMBL3922396 & 1640598 & 5.8416 & 5.2737 & TRN & \\
\hline CHEMBL3913491 & 1640598 & 7.3979 & \multicolumn{2}{|c|}{6.577000000000001} & TRN \\
\hline CHEMBL3902453 & 1640598 & 6.2464 & 6.8615 & TRN & \\
\hline CHEMBL1090422 & 1640598 & 7.0269 & 7.027 & TRN & \\
\hline CHEMBL3974061 & 1640598 & 7.4815 & 6.8372 & TRN & \\
\hline CHEMBL1081268 & 1640598 & 5.6778 & 6.4894 & TST & \\
\hline CHEMBL3909549 & 1640598 & 6.2147 & 6.3293 & TRN & \\
\hline CHEMBL1088176 & 1640598 & 7.1871 & 7.099 & TRN & \\
\hline CHEMBL1082868 & 1640598 & 6.6819 & 7.0246 & TRN & \\
\hline CHEMBL1081645 & 1640598 & 7.6091 & 7.416 & TRN & \\
\hline CHEMBL3929418 & 1640598 & 6.8962 & 6.8074 & TRN & \\
\hline CHEMBL3899372 & 1640598 & 5.6904 & 6.6656 & TRN & \\
\hline CHEMBL3978322 & 1640598 & 6.1024 & 5.09 & TRN & \\
\hline
\end{tabular}


Supplemental Table S2.txt

\begin{tabular}{|c|c|c|c|c|}
\hline CHEMBL3925848 & 1640598 & 6.1403 & 6.8102 & TRN \\
\hline CHEMBL3901810 & 1640598 & 5.1972 & 5.7788 & TST \\
\hline CHEMBL1076743 & 1640598 & 7.4437 & 7.3735 & TRN \\
\hline CHEMBL1087770 & 1640598 & 5.3516 & 5.5277 & TRN \\
\hline CHEMBL1087141 & 1640598 & 5.7011 & 5.608 & TRN \\
\hline CHEMBL 3962156 & 1640598 & 4.71 & 5.1998 & TST \\
\hline CHEMBL3958821 & 1640598 & 7.2924 & 7.4532 & TRN \\
\hline CHEMBL1087785 & 1640598 & 7.1367 & 6.8052 & TRN \\
\hline CHEMBL3980030 & 1640598 & 6.5768 & 6.1499 & TRN \\
\hline CHEMBL3927419 & 1640598 & 5.5051 & 6.0031 & TRN \\
\hline CHEMBL 3894305 & 1640598 & 7.1024 & 6.9799 & TST \\
\hline CHEMBL1076708 & 1640598 & 6.3979 & 7.0527 & TRN \\
\hline CHEMBL3895352 & 1640598 & 6.3536 & 6.0788 & TRN \\
\hline CHEMBL 3981793 & 1640598 & 5.5459 & 6.5059 & TST \\
\hline CHEMBL 3937270 & 1640598 & 5.8697 & 5.4325 & TST \\
\hline CHEMBL3940288 & 1640598 & 5.9788 & 6.3233 & TST \\
\hline CHEMBL3976411 & 1640598 & 6.0655 & 6.7775 & TST \\
\hline CHEMBL3936796 & 1640598 & 7.7212 & 7.1278 & TRN \\
\hline CHEMBL3946165 & 1640598 & 6.9706 & 6.66100 & 0000000005 \\
\hline CHEMBL 3986819 & 1640598 & 5.5702 & 6.3438 & TRN \\
\hline CHEMBL3909829 & 1640598 & 5.8508 & 5.8646 & TRN \\
\hline CHEMBL3922393 & 1640598 & 5.0535 & 6.4937 & TRN \\
\hline CHEMBL3896108 & 1640598 & 6.0931 & 6.3098 & TRN \\
\hline CHEMBL3929757 & 1640598 & 5.9706 & 6.5093 & TST \\
\hline CHEMBL 3927801 & 1640598 & 6.2534 & 7.2325 & TRN \\
\hline CHEMBL1087664 & 1640598 & 6.7144 & 7.08700 & 000000001 \\
\hline CHEMBL1080384 & 1640598 & 7.9208 & 7.7612 & TRN \\
\hline CHEMBL3911057 & 1640598 & 5.8268 & 6.4518 & TRN \\
\hline CHEMBL3955048 & 1640598 & 6.4271 & 5.5931 & TST \\
\hline CHEMBL 3918272 & 1640598 & 8.5376 & 6.9776 & TRN \\
\hline CHEMBL3941952 & 1640598 & 6.1512 & 6.4429 & TRN \\
\hline CHEMBL3918967 & 1640598 & 5.8013 & 5.0983 & TST \\
\hline CHEMBL1087651 & 1640598 & 6.4202 & 6.6505 & TRN \\
\hline CHEMBL1081271 & 1640598 & 6.1805 & 6.4321 & TRN \\
\hline CHEMBL3966554 & 1640598 & 5.9547 & 6.7083 & TRN \\
\hline CHEMBL1087142 & 1640598 & 6.3565 & 6.4321 & TRN \\
\hline CHEMBL3925876 & 1640598 & 5.8125 & 6.805 & TST \\
\hline CHEMBL3932998 & 1640598 & 5.6055 & 6.2527 & TRN \\
\hline CHEMBL3975047 & 1640598 & 7.1675 & 6.9738 & TRN \\
\hline CHEMBL3913545 & 1640598 & 5.6655 & 6.5725 & TRN \\
\hline CHEMBL3951737 & 1640598 & 6.6946 & 6.6798 & TRN \\
\hline CHEMBL3981078 & 1640598 & 6.9957 & 6.6289 & TRN \\
\hline CHEMBL3946353 & 1640598 & 5.7747 & 5.8403 & TRN \\
\hline CHEMBL3944313 & 1640598 & 5.8794 & 6.0362 & TST \\
\hline CHEMBL3968786 & 1640598 & 5.9706 & 5.1985 & TST \\
\hline CHEMBL3916874 & 1640598 & 6.5544 & 6.6448 & TRN \\
\hline CHEMBL3973776 & 1640598 & 7.2518 & 5.903 & TST \\
\hline CHEMBL3949207 & 1640598 & 6.2676 & 6.4051 & TRN \\
\hline
\end{tabular}


Supplemental Table S2.txt

\begin{tabular}{|c|c|c|c|c|c|c|}
\hline CHEMBL1082869 & 1640598 & 8.5229 & 7.9858 & TRN & & \\
\hline CHEMBL3978790 & 1640598 & 5.3605 & 6.6305 & TST & & \\
\hline CHEMBL1081654 & 1640598 & 5.9355 & 5.7748 & TRN & & \\
\hline CHEMBL3890343 & 1640598 & 6.2248 & 6.1532 & TST & & \\
\hline CHEMBL3906861 & 1640598 & 5.983 & 5.5095 & TRN & & \\
\hline CHEMBL3904549 & 1640598 & 7.3188 & 7.1113 & TRN & & \\
\hline CHEMBL3984678 & 1640598 & 7.7212 & 7.4812 & TRN & & \\
\hline CHEMBL3968471 & 1640598 & 5.2967 & 5.5609 & TRN & & \\
\hline CHEMBL 3897284 & 1640598 & 5.8327 & 6.1107 & TRN & & \\
\hline CHEMBL3930189 & 1640598 & 6.21899 & 99999999 & 99 & 6.1727 & TST \\
\hline CHEMBL1090066 & 1640598 & 7.4559 & 7.3998 & TRN & & \\
\hline CHEMBL1076723 & 1640598 & 6.4089 & 5.2248 & TRN & & \\
\hline CHEMBL3982822 & 1640598 & 5.5346 & 6.5503 & TST & & \\
\hline CHEMBL1080865 & 1640598 & 7.8861 & 7.3365 & TRN & & \\
\hline CHEMBL3975495 & 1640598 & 7.7212 & 6.6795 & TST & & \\
\hline CHEMBL3920176 & 1640598 & 6.0883 & 6.8207 & TRN & & \\
\hline CHEMBL3891818 & 1640598 & 6.8386 & 6.1422 & TST & & \\
\hline CHEMBL3981250 & 1640598 & 5.5599 & 5.9137 & TST & & \\
\hline CHEMBL3956992 & 1640598 & 5.9101 & 6.2076 & TRN & & \\
\hline CHEMBL3930934 & 1640598 & 6.6198 & 5.9181 & TRN & & \\
\hline CHEMBL3955061 & 1640598 & 5.6402 & 6.4487 & TRN & & \\
\hline CHEMBL1081269 & 1640598 & 6.0132 & 5.7748 & TRN & & \\
\hline CHEMBL3969302 & 1640598 & 7.4089 & 7.3578 & TRN & & \\
\hline CHEMBL3975379 & 1640598 & 6.4841 & 6.5729 & TRN & & \\
\hline CHEMBL3919701 & 1640598 & 6.3325 & 6.3937 & TRN & & \\
\hline CHEMBL1090423 & 1640598 & 7.7212 & 7.396 & TRN & & \\
\hline CHEMBL3979559 & 1640598 & 6.6655 & 6.7101 & TRN & & \\
\hline CHEMBL1080748 & 1640598 & 4.7773 & 5.3117 & TRN & & \\
\hline CHEMBL3981795 & 1640598 & 6.2262 & 6.9588 & TRN & & \\
\hline CHEMBL3931316 & 1640598 & 5.9431 & 4.9158 & TST & & \\
\hline CHEMBL1086158 & 1640598 & 7.699 & 7.6015 & TRN & & \\
\hline CHEMBL3983299 & 1640598 & 5.7747 & 6.0627 & TRN & & \\
\hline CHEMBL1081079 & 1640598 & 5.7496 & 5.3676 & TRN & & \\
\hline CHEMBL3906245 & 1640598 & 6.0857 & 6.3821 & TRN & & \\
\hline CHEMBL3898098 & 1640598 & 7.6778 & 7.2492 & TRN & & \\
\hline CHEMBL3922002 & 1640598 & 6.4609 & 6.8892 & TRN & & \\
\hline CHEMBL3959287 & 1640598 & 5.8182 & 6.1308 & TRN & & \\
\hline CHEMBL3892300 & 1640598 & 5.9508 & 6.4563 & TST & & \\
\hline CHEMBL3915773 & 1640598 & 7.4202 & 5.9047 & TST & & \\
\hline CHEMBL1080880 & 1640598 & 8.1675 & 7.5039 & TRN & & \\
\hline CHEMBL1088177 & 1640598 & 8.699 & 7.93 & TRN & & \\
\hline CHEMBL1087910 & 1640598 & 7.4089 & 7.5444 & TRN & & \\
\hline CHEMBL1081646 & 1640598 & 6.4318 & 6.3729 & TRN & & \\
\hline CHEMBL3956389 & 1640598 & 5.4861 & 6.8464 & TST & & \\
\hline CHEMBL3965613 & 1640598 & 6.3036 & 6.7542 & TRN & & \\
\hline CHEMBL1081270 & 1640598 & 6.1549 & 5.8674 & TRN & & \\
\hline CHEMBL3970356 & 1640598 & 5.6421 & 5.8494 & TRN & & \\
\hline CHEMBL3968409 & 1640598 & 6.6271 & 5.9971 & TST & & \\
\hline
\end{tabular}

Page 27763 
Supplemental Table S2.txt

\begin{tabular}{|c|c|c|c|c|c|}
\hline CHEMBL3941017 & 1640598 & 6.8794 & 6.3459 & TRN & \\
\hline CHEMBL1080881 & 1640598 & 6.6757 & 6.8024 & TRN & \\
\hline CHEMBL3914872 & 1640598 & 7.2007 & 6.8407 & TRN & \\
\hline CHEMBL 3976604 & 1640598 & 5.6308 & 6.3174 & TRN & \\
\hline CHEMBL 3924114 & 1640598 & 6.3179 & 5.80200 & 00000000005 & TST \\
\hline CHEMBL1087909 & 1640598 & 8.2366 & 7.5646 & TRN & \\
\hline CHEMBL3895726 & 1640598 & 5.9374 & 6.5689 & TRN & \\
\hline CHEMBL 3955296 & 1640598 & 7.4949 & 7.0577 & TRN & \\
\hline CHEMBL3905666 & 1640598 & 5.8239 & 5.5699 & TRN & \\
\hline CHEMBL1080684 & 1640598 & 6.3788 & 6.6916 & TRN & \\
\hline CHEMBL1086157 & 1640598 & 7.4815 & 7.1604 & TRN & \\
\hline CHEMBL 3892174 & 1640598 & 7.3188 & 7.7857 & TRN & \\
\hline CHEMBL1088178 & 1640598 & 8.5376 & 7.8398 & TRN & \\
\hline CHEMBL3894385 & 1640598 & 5.4123 & 4.837 & TST & \\
\hline CHEMBL 3892397 & 1640598 & 6.2865 & 6.0542 & TRN & \\
\hline CHEMBL1087139 & 1640598 & 6.0177 & 5.5738 & TRN & \\
\hline CHEMBL3950126 & 1640598 & 4.8761 & 6.8722 & TRN & \\
\hline CHEMBL 3968014 & 1640598 & 7.3468 & 6.9658 & TRN & \\
\hline CHEMBL3983474 & 1640598 & 7.2218 & 7.4232 & TRN & \\
\hline CHEMBL1090065 & 1640598 & 6.6234 & 6.7521 & TRN & \\
\hline CHEMBL 3986235 & 1640598 & 7.1612 & 6.7301 & TRN & \\
\hline CHEMBL 3912944 & 1640598 & 6.0424 & 6.1181 & TRN & \\
\hline CHEMBL1080383 & 1640598 & 7.9208 & 7.4084 & TRN & \\
\hline CHEMBL1087911 & 1640598 & 6.983 & 6.4106 & TRN & \\
\hline CHEMBL 3899042 & 1640598 & 6.5421 & 6.4342 & TST & \\
\hline CHEMBL3931810 & 1640598 & 5.7496 & 6.7498 & TST & \\
\hline CHEMBL 3958225 & 1640598 & 8.0362 & 7.4821 & TST & \\
\hline CHEMBL1081655 & 1640598 & 6.3565 & 6.0846 & TST & \\
\hline CHEMBL3914648 & 1640598 & 8.2218 & 6.7615 & TST & \\
\hline CHEMBL 3649718 & 1528687 & 5.4145 & 4.9779 & TST & \\
\hline CHEMBL 3649789 & 1528687 & 6.9586 & 6.9336 & TRN & \\
\hline CHEMBL 3649813 & 1528687 & 6.7696 & 6.6164 & TRN & \\
\hline CHEMBL 3649779 & 1528687 & 7.301 & 7.3793 & TRN & \\
\hline CHEMBL3649732 & 1528687 & 5.5784 & 5.6839 & TRN & \\
\hline CHEMBL 3649805 & 1528687 & 6.9208 & 6.9598 & TRN & \\
\hline CHEMBL3649726 & 1528687 & 4.3979 & 4.8699 & TRN & \\
\hline CHEMBL3649731 & 1528687 & 6.4089 & 6.5446 & TRN & \\
\hline CHEMBL 3649799 & 1528687 & 6.1135 & 5.9806 & TRN & \\
\hline CHEMBL3649713 & 1528687 & 4.3979 & 5.4624 & TST & \\
\hline CHEMBL 3649782 & 1528687 & 6.7447 & 6.649 & TRN & \\
\hline CHEMBL3649738 & 1528687 & 6.0315 & 5.9508 & TRN & \\
\hline CHEMBL3649735 & 1528687 & 5.5072 & 5.8012 & TST & \\
\hline CHEMBL 3649741 & 1528687 & 5.52 & 5.2136 & TRN & \\
\hline CHEMBL3649784 & 1528687 & 6.9586 & 6.9034 & TRN & \\
\hline CHEMBL3649740 & 1528687 & \multicolumn{3}{|c|}{5.4510000000000005} & $1 \mathrm{n}$ \\
\hline CHEMBL 3649769 & 1528687 & 5.8125 & 5.9326 & TST & \\
\hline CHEMBL 3649737 & 1528687 & 6.6383 & 6.5922 & TRN & \\
\hline CHEMBL3649714 & 1528687 & 4.3979 & 5.4765 & TST & \\
\hline
\end{tabular}


Supplemental Table S2.txt

\begin{tabular}{|c|c|c|c|c|}
\hline TLI & & 6.7212 & & \\
\hline & & 4.3979 & & \\
\hline HFMRI & 587 & & & \\
\hline 806 & 3687 & & & \\
\hline AEMBL3649773 & 528687 & 9626 & & \\
\hline HEMBL3649760 & 528687 & 5.7645 & 09 & \\
\hline 303 & 28687 & 6.2518 & & \\
\hline AEMBL & 8687 & & & \\
\hline HEMBL3649781 & 528687 & 6.9586 & .0452 & \\
\hline HEMBL3649753 & 528687 & 6.8861 & 3673 & \\
\hline HEMBL 364 & 528687 & 6.72 & 7673 & \\
\hline 46 & 3687 & 979 & 19 & \\
\hline AEMBL: & 687 & 979 & & \\
\hline HEMBL3649751 & 528687 & 6.2291 & 4346 & \\
\hline AEMBL3649801 & 528687 & 6.1249 & & \\
\hline AEMBL3 & 87 & & & \\
\hline AEMBL & 87 & 76 & & \\
\hline AEMBL. & 687 & 83 & & \\
\hline HFMBL $=$ & 528687 & 6 . & & \\
\hline AEMBL3 & & & & \\
\hline HEMBL & $3 /$ & 4. & & וכ \\
\hline HEM & & & & RN \\
\hline AEMBI & 87 & 5 & & \\
\hline 712 & & 4. & & 151 \\
\hline AEMBL3 & 3687 & 5 . & 19 & RN \\
\hline HEMBL & 887 & 6 & & RN \\
\hline HFM & 37 & & & KIV \\
\hline 25 & & & 31 & \\
\hline HEMBL & & & & | \\
\hline AEMBL3 & 528687 & 239 & 24 & TRN \\
\hline AEMBL & 87 & 29 & 57 & ובנ \\
\hline 3 & & & & RN \\
\hline 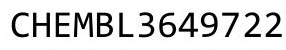 & & & & RN \\
\hline HEMBL3 & & & & RN \\
\hline HEMBL3653092 & 28687 & & & RN \\
\hline 302 & 37 & 7. & & TRN \\
\hline 0 & & & 45 & ГRN \\
\hline HEMBL3 & & & & TRN \\
\hline HEMBL3 & 87 & & & $\Gamma R$ \\
\hline 5 & & & & RN \\
\hline HEMBL; & & & & ГST \\
\hline & & & 758 & IST \\
\hline HEMBL3 & & & 1093 & $T R$ \\
\hline HEMBL3 & 87 & 7. & 87 & TR \\
\hline 4 & & & & \\
\hline HEMBL3 & -528081 & & 5.5174 & \\
\hline CHEMBL3 & .528687 & 7. & 7.1501 & \\
\hline CHEMBL3649770 & 1528687 & 7.0458 & 6.5687 & \\
\hline
\end{tabular}

Page 27765 
Supplemental Table S2.txt

\begin{tabular}{|c|c|c|c|c|c|}
\hline CHEMBL3649736 & 1528687 & 5.9706 & 6.7173 & TST & \\
\hline CHEMBL3649775 & 1528687 & 7.0969 & 7.2208 & TRN & \\
\hline CHEMBL3653090 & 1528687 & 6.3872 & 6.3913 & TRN & \\
\hline CHEMBL 3649778 & 1528687 & 7.301 & 7.3811 & TRN & \\
\hline CHEMBL3649739 & 1528687 & 5.7905 & 5.6934 & TRN & \\
\hline CHEMBL3653088 & 1528687 & 7.0 & 6.98 & TRN & \\
\hline CHEMBL3649728 & 1528687 & 5.8447 & 5.9416 & TRN & \\
\hline CHEMBL3649763 & 1528687 & 6.0362 & 6.1026 & TRN & \\
\hline CHEMBL 3649744 & 1528687 & 7.0 & 5.825 & TST & \\
\hline CHEMBL3649786 & 1528687 & 6.4949 & 6.5025 & TRN & \\
\hline CHEMBL3649716 & 1528687 & 5.9872 & 6.2349 & TST & \\
\hline CHEMBL3649717 & 1528687 & 5.9706 & 5.6914 & TST & \\
\hline CHEMBL3649727 & 1528687 & 5.9355 & 5.9586 & TRN & \\
\hline CHEMBL3649729 & 1528687 & 5.9666 & 6.1167 & TRN & \\
\hline CHEMBL3649790 & 1528687 & 6.2147 & 6.1759 & TRN & \\
\hline CHEMBL3649797 & 1528687 & 6.7696 & 6.8014 & TRN & \\
\hline CHEMBL3649757 & 1528687 & 7.1549 & 6.8671 & TRN & \\
\hline CHEMBL3653091 & 1528687 & 6.7447 & 6.8616 & TRN & \\
\hline CHEMBL 3649785 & 1528687 & 7.2218 & 7.1743 & TRN & \\
\hline CHEMBL3639486 & 1528687 & 7.0458 & 7.0205 & TRN & \\
\hline CHEMBL3649759 & 1528687 & 6.0315 & 6.3716 & TRN & \\
\hline CHEMBL3649812 & 1528687 & 6.0177 & 6.0872 & TRN & \\
\hline CHEMBL3649750 & 1528687 & 6.585 & 6.7184 & TRN & \\
\hline CHEMBL 3649743 & 1528687 & 7.301 & 6.0187 & TST & \\
\hline CHEMBL3649721 & 1528687 & 6.4318 & 6.4385 & TRN & \\
\hline CHEMBL3649796 & 1528687 & 6.8539 & 6.9797 & TRN & \\
\hline CHEMBL3649742 & 1528687 & 4.3979 & 6.7516 & TST & \\
\hline CHEMBL3649809 & 1528687 & 6.8539 & 6.8003 & TRN & \\
\hline CHEMBL 3649720 & 1528687 & 5.9788 & 7.0752 & TST & \\
\hline CHEMBL3649730 & 1528687 & 4.3979 & 4.471999 & 99999999995 & TRN \\
\hline CHEMBL3649715 & 1528687 & 4.3979 & 5.4067 & TST & \\
\hline CHEMBL3649791 & 1528687 & 6.9586 & 7.0134 & TRN & \\
\hline CHEMBL3649766 & 1528687 & 4.3979 & 4.5218 & TRN & \\
\hline CHEMBL3649765 & 1528687 & 6.9208 & 6.7496 & TRN & \\
\hline CHEMBL 3649807 & 1528687 & 6.7212 & 6.6588 & TRN & \\
\hline CHEMBL3649793 & 1528687 & 6.1079 & 6.0044 & TRN & \\
\hline CHEMBL3649761 & 1528687 & 6.7447 & 6.6283 & TRN & \\
\hline CHEMBL3649783 & 1528687 & 6.8539 & 6.8482 & TRN & \\
\hline CHEMBL 3649808 & 1528687 & 7.1549 & 7.0644 & TRN & \\
\hline CHEMBL 3649798 & 1528687 & 6.3098 & 5.9768 & TST & \\
\hline CHEMBL3649754 & 1528687 & 6.2076 & 5.8299 & TST & \\
\hline CHEMBL3950643 & 1642418 & 8.9208 & 8.1667 & TRN & \\
\hline CHEMBL3969426 & 1642418 & 7.82100 & 000000000 & 7.5584 & TRN \\
\hline CHEMBL 3943859 & 1642418 & 8.0177 & 7.8193 & TST & \\
\hline CHEMBL 3983188 & 1642418 & 9.2218 & 8.6262 & TRN & \\
\hline CHEMBL3985247 & 1642418 & 8.6198 & 8.6397 & TRN & \\
\hline CHEMBL3927161 & 1642418 & 7.20200 & 000000000 & 7.9221 & TRN \\
\hline CHEMBL3904806 & 1642418 & 7.6234 & 7.5461 & TRN & \\
\hline
\end{tabular}


Supplemental Table S2.txt

\begin{tabular}{|c|c|c|c|c|c|}
\hline CHEMBL 3964174 & 1642418 & 8.2076 & 8.3556 & TRN & \\
\hline CHEMBL3918125 & 1642418 & 6.0 & 7.6375 & TRN & \\
\hline CHEMBL3979440 & 1642418 & 7.5243 & 8.2826 & TRN & \\
\hline CHEMBL3959162 & 1642418 & 7.2628 & 8.5794 & TRN & \\
\hline CHEMBL 3927374 & 1642418 & 8.7212 & 8.231 & TST & \\
\hline CHEMBL3920735 & 1642418 & 9.0458 & 7.4117 & TRN & \\
\hline CHEMBL3965663 & 1642418 & 6.0 & 7.9788 & TRN & \\
\hline CHEMBL3936399 & 1642418 & 7.9355 & 7.8921 & TST & \\
\hline CHEMBL 3984784 & 1642418 & 7.8386 & 7.4553 & TRN & \\
\hline CHEMBL 3900080 & 1642418 & 6.8297 & 8.2783 & TST & \\
\hline CHEMBL3891036 & 1642418 & 8.1079 & 7.5527 & TRN & \\
\hline CHEMBL3939645 & 1642418 & 7.5751 & 8.34 & TRN & \\
\hline CHEMBL 3900272 & 1642418 & 7.8996 & 8.0649 & TRN & \\
\hline CHEMBL 3890370 & 1642418 & 7.8069 & 7.9954 & TRN & \\
\hline CHEMBL 3984516 & 1642418 & 8.1487 & 7.9068 & TRN & \\
\hline CHEMBL3953961 & 1642418 & 7.2197 & 7.6272 & TRN & \\
\hline CHEMBL 3972944 & 1642418 & 7.0097 & 8.4588 & TST & \\
\hline CHEMBL3949994 & 1642418 & 7.5654 & 7.522 & TRN & \\
\hline CHEMBL3969391 & 1642418 & 8.585 & 8.5608 & TRN & \\
\hline CHEMBL 3921388 & 1642418 & 8.9208 & 8.9891 & TST & \\
\hline CHEMBL 3971291 & 1642418 & 8.1938 & 7.6457 & TRN & \\
\hline CHEMBL3941234 & 1642418 & 7.6904 & 7.3436 & TRN & \\
\hline CHEMBL3889971 & 1642418 & 7.1707 & 7.4625 & TRN & \\
\hline CHEMBL 3967884 & 1642418 & 8.5528 & 8.8857 & TRN & \\
\hline CHEMBL 3934097 & 1642418 & 8.585 & 7.7368 & TRN & \\
\hline CHEMBL 3941737 & 1642418 & 7.9508 & 8.1125 & TST & \\
\hline CHEMBL 3895803 & 1642418 & 8.6021 & 8.1782 & TRN & \\
\hline CHEMBL3959126 & 1642418 & 7.8928 & 7.6698 & TRN & \\
\hline CHEMBL 3941844 & 1642418 & 6.8297 & 7.593 & TRN & \\
\hline CHEMBL3963976 & 1642418 & 9.4437 & 8.3927 & TRN & \\
\hline CHEMBL 3983890 & 1642418 & 6.9914 & 7.5585 & TRN & \\
\hline CHEMBL 3946300 & 1642418 & 9.0809 & 8.0296 & TRN & \\
\hline CHEMBL3945161 & 1642418 & 7.3788 & 7.3613 & TRN & \\
\hline CHEMBL 3920871 & 1642418 & 7.1209 & 7.4273 & TRN & \\
\hline CHEMBL3950121 & 1642418 & 8.9208 & 7.9418 & TRN & \\
\hline CHEMBL 3954584 & 1642418 & 7.5129 & 7.2479 & TRN & \\
\hline CHEMBL 3913245 & 1642418 & 8.301 & 7.4028 & TRN & \\
\hline CHEMBL3966063 & 1642418 & 8.7696 & 8.0766 & TRN & \\
\hline CHEMBL 3955890 & 1642418 & 6.9547 & 7.81 & TST & \\
\hline CHEMBL 3900242 & 1642418 & 7.4711 & 7.9994 & TRN & \\
\hline CHEMBL 3918422 & 1642418 & 7.8827 & 7.4004 & TST & \\
\hline CHEMBL 3986140 & 1642418 & 8.0809 & 7.7353 & TST & \\
\hline CHEMBL 3897844 & 1642418 & 10.6990 & 000000000 & 002 & 8.9403 \\
\hline CHEMBL 3979248 & 1642418 & 7.6073 & 8.2582 & TRN & \\
\hline CHEMBL 3894460 & 1642418 & 8.8239 & 8.4348 & TRN & \\
\hline CHEMBL3961594 & 1642418 & 8.5686 & 8.1205 & TRN & \\
\hline CHEMBL 3982223 & 1642418 & 8.301 & 7.6531 & TRN & \\
\hline CHEMBL 3949190 & 1642418 & 7.5528 & 7.7066 & TRN & \\
\hline
\end{tabular}

Page 27767 
Supplemental Table S2.txt

\begin{tabular}{|c|c|c|c|c|c|}
\hline CHEMBL3917341 & 1642418 & 8.3188 & 7.7158 & TST & \\
\hline CHEMBL3947968 & 1642418 & 7.4597 & 7.6079 & TRN & \\
\hline CHEMBL3926948 & 1642418 & 8.5686 & 7.5054 & TST & \\
\hline CHEMBL 3912028 & 1642418 & 7.1062 & 7.5342 & TST & \\
\hline CHEMBL3941792 & 1642418 & 7.3696 & 7.7094 & TST & \\
\hline CHEMBL 3975624 & 1642418 & 8.6778 & 8.4724 & TRN & \\
\hline CHEMBL3971314 & 1642418 & 7.76200 & 00000000 & 205 & 7.899 \\
\hline CHEMBL 3893644 & 1642418 & 7.767 & 7.7066 & TRN & \\
\hline CHEMBL 3974491 & 1642418 & 7.4881 & 7.5495 & TRN & \\
\hline CHEMBL3903655 & 1642418 & 7.5272 & 7.5872 & TRN & \\
\hline CHEMBL 3889718 & 1642418 & 7.8761 & 7.7086 & TRN & \\
\hline CHEMBL3930898 & 1642418 & 7.1018 & 7.6476 & TRN & \\
\hline CHEMBL3972315 & 1642418 & 8.9208 & 8.8337 & TRN & \\
\hline CHEMBL 3904631 & 1642418 & 6.3054 & 7.6582 & TRN & \\
\hline CHEMBL3894317 & 1642418 & 7.8297 & 8.6366 & TRN & \\
\hline CHEMBL3960398 & 1642418 & 8.0044 & 8.0565 & TRN & \\
\hline CHEMBL3974224 & 1642418 & 7.6216 & 7.6083 & TRN & \\
\hline CHEMBL3936384 & 1642418 & 7.2069 & 7.6582 & TST & \\
\hline CHEMBL 3927800 & 1642418 & 6.8928 & 8.4272 & TST & \\
\hline CHEMBL3899122 & 1642418 & 9.3979 & 8.0598 & TST & \\
\hline CHEMBL3918438 & 1642418 & 8.0223 & 7.7295 & TRN & \\
\hline CHEMBL3910251 & 1642418 & 8.2076 & 8.1461 & TRN & \\
\hline CHEMBL3891233 & 1642418 & 8.5528 & 8.6253 & TRN & \\
\hline CHEMBL 3948657 & 1642418 & 7.8297 & 7.5836 & TST & \\
\hline CHEMBL3961200 & 1642418 & 9.9208 & 8.1521 & TRN & \\
\hline CHEMBL3972651 & 1642418 & 7.8477 & 8.2509 & TRN & \\
\hline CHEMBL 3895718 & 1642418 & 6.1726 & 8.4442 & TST & \\
\hline CHEMBL3896754 & 1642418 & 7.7496 & 8.0071 & TRN & \\
\hline CHEMBL 3926328 & 1642418 & 7.2907 & 7.6655 & TST & \\
\hline CHEMBL3922161 & 1642418 & 7.2798 & 8.4023 & TST & \\
\hline CHEMBL 3894717 & 1642418 & 8.0 & 8.0229 & TRN & \\
\hline CHEMBL3895758 & 1642418 & 9.5229 & 7.9348 & TRN & \\
\hline CHEMBL3970393 & 1642418 & 6.2161 & 7.7087 & TRN & \\
\hline CHEMBL 3932816 & 1642418 & 8.9586 & 7.5974 & TST & \\
\hline CHEMBL3957982 & 1642418 & 7.5114 & 7.6818 & TRN & \\
\hline CHEMBL 3922474 & 1642418 & 8.8539 & 8.8324 & TRN & \\
\hline CHEMBL3983479 & 1642418 & 7.5436 & 8.3433 & TRN & \\
\hline CHEMBL3983618 & 1642418 & 8.0506 & 8.5006 & TRN & \\
\hline CHEMBL 3912291 & 1642418 & 6.8794 & 7.9111 & TRN & \\
\hline CHEMBL3953909 & 1642418 & 8.0315 & 7.8269 & TST & \\
\hline CHEMBL445346 & 558735 & 8.49 & 7.7362 & TRN & \\
\hline CHEMBL448335 & 558735 & 7.56 & 7.3711 & TRN & \\
\hline CHEMBL465922 & 558735 & 7.56 & 4.4563 & TST & \\
\hline CHEMBL524902 & 558735 & 6.87 & 6.1381 & TRN & \\
\hline CHEMBL504160 & 558735 & 6.84 & 6.3184 & TRN & \\
\hline CHEMBL511200 & 558735 & 6.75 & 3.6755 & TST & \\
\hline CHEMBL506373 & 558735 & 6.72 & 5.9873 & TRN & \\
\hline CHEMBL464057 & 558735 & 6.6 & 6.5723 & TRN & \\
\hline
\end{tabular}




\begin{tabular}{|c|c|c|c|c|c|}
\hline \multirow[b]{2}{*}{ CHEMBL517012 } & \multirow[b]{2}{*}{558735} & \multicolumn{4}{|c|}{ Supplemental Table S2.txt } \\
\hline & & 6.55 & 3.826 & TST & \\
\hline CHEMBL455306 & 558735 & 6.43 & 6.8966 & TRN & \\
\hline CHEMBL453712 & 558735 & 6.35 & 6.4734 & TRN & \\
\hline CHEMBL465950 & 558735 & 6.19 & 4.1982 & TST & \\
\hline CHEMBL464249 & 558735 & 6.16 & 6.0835 & TRN & \\
\hline CHEMBL465109 & 558735 & 5.84 & \multicolumn{2}{|c|}{5.4079999999999995} & TRN \\
\hline CHEMBL465454 & 558735 & 5.81 & 6.0849 & TRN & \\
\hline CHEMBL512408 & 558735 & 5.67 & 5.7607 & TRN & \\
\hline CHEMBL465455 & 558735 & 5.61 & 5.6014 & TRN & \\
\hline CHEMBL499800 & 558735 & 5.6 & 5.55 & TRN & \\
\hline CHEMBL465456 & 558735 & 5.58 & 3.6699 & TST & \\
\hline CHEMBL526140 & 558735 & 5.52 & 5.2303 & TRN & \\
\hline CHEMBL481576 & 558735 & 5.51 & 6.1185 & TRN & \\
\hline CHEMBL481577 & 558735 & 5.51 & 5.3294 & TRN & \\
\hline CHEMBL481578 & 558735 & 5.48 & 6.1271 & TRN & \\
\hline CHEMBL519785 & 558735 & 5.46 & 5.2994 & TRN & \\
\hline CHEMBL480795 & 558735 & 5.39 & 5.5093 & TRN & \\
\hline CHEMBL297914 & 558735 & 5.28 & 5.5326 & TRN & \\
\hline CHEMBL482376 & 558735 & 5.23 & 5.3856 & TRN & \\
\hline CHEMBL384903 & 558735 & 5.23 & \multicolumn{2}{|c|}{4.9639999999999995} & TST \\
\hline CHEMBL482377 & 558735 & 5.16 & 5.1183 & TRN & \\
\hline CHEMBL482378 & 558735 & 5.11 & 3.945 & TST & \\
\hline CHEMBL481781 & 558735 & 5.09 & 5.6221 & TRN & \\
\hline CHEMBL480414 & 558735 & 5.06 & 4.284 & TRN & \\
\hline CHEMBL443975 & 558735 & 5.03 & 5.1125 & TRN & \\
\hline CHEMBL480413 & 558735 & 4.99 & 5.0161 & TRN & \\
\hline CHEMBL480300 & 558735 & 4.96 & 4.6467 & TRN & \\
\hline CHEMBL501138 & 558735 & 4.95 & 5.3837 & TRN & \\
\hline CHEMBL480415 & 558735 & 4.95 & 4.7652 & TRN & \\
\hline CHEMBL447035 & 558735 & 4.93 & 4.817 & TRN & \\
\hline CHEMBL465926 & 558735 & 4.93 & 4.7886 & TRN & \\
\hline CHEMBL463870 & 558735 & 4.93 & 5.1781 & TRN & \\
\hline CHEMBL504665 & 558735 & 4.91 & 4.7857 & TRN & \\
\hline CHEMBL464033 & 558735 & 4.9 & 5.441 & TRN & \\
\hline CHEMBL464051 & 558735 & 4.87 & 4.9591 & TRN & \\
\hline CHEMBL506149 & 558735 & 4.87 & 4.8977 & TRN & \\
\hline CHEMBL464052 & 558735 & 4.86 & 4.9343 & TRN & \\
\hline CHEMBL463882 & 558735 & 4.82 & 4.9715 & TRN & \\
\hline CHEMBL465376 & 558735 & 4.82 & 5.2319 & TRN & \\
\hline CHEMBL468265 & 558735 & 4.8 & 4.76399 & 9999999999 & TRN \\
\hline CHEMBL501328 & 558735 & 4.76 & 4.5676 & TRN & \\
\hline CHEMBL467019 & 558735 & 4.75 & 4.5185 & TRN & \\
\hline CHEMBL467227 & 558735 & 4.73 & 4.5112 & TST & \\
\hline CHEMBL442581 & 558735 & 4.73 & 5.3141 & TRN & \\
\hline CHEMBL443771 & 558735 & 4.71 & 4.4047 & TRN & \\
\hline CHEMBL467228 & 558735 & 4.61 & 4.2291 & TST & \\
\hline CHEMBL454015 & 558735 & 4.57 & 4.6811 & TRN & \\
\hline \multirow[t]{2}{*}{ CHEMBL466611 } & 558735 & 4.55 & 5.4976 & TST & \\
\hline & & \multicolumn{4}{|c|}{ Page 27769} \\
\hline
\end{tabular}




\begin{tabular}{|c|c|c|c|c|c|}
\hline \multicolumn{6}{|c|}{ Supplemental Table S2.txt } \\
\hline CHEMBL466612 & 558735 & 4.52 & 4.9018 & TRN & \\
\hline CHEMBL466613 & 558735 & 4.52 & 4.5477 & TRN & \\
\hline CHEMBL466201 & 558735 & 4.51 & 4.776 & TRN & \\
\hline CHEMBL463866 & 558735 & 4.51 & 4.3244 & TRN & \\
\hline CHEMBL466000 & 558735 & 4.43 & 4.5021 & TRN & \\
\hline CHEMBL466204 & 558735 & 4.26 & 4.4086 & TST & \\
\hline CHEMBL468707 & 558735 & 4.26 & 3.9811 & TST & \\
\hline CHEMBL446913 & 558735 & 4.1 & 4.4608 & TST & \\
\hline CHEMBL449320 & 558735 & 4.03 & 4.0048 & TST & \\
\hline CHEMBL468913 & 558735 & 4.03 & 4.6577 & TST & \\
\hline CHEMBL503117 & 558735 & 3.98 & 4.4129 & TST & \\
\hline CHEMBL505582 & 558735 & 3.95 & 4.1417 & TST & \\
\hline CHEMBL499448 & 558735 & 3.81 & 5.7904 & TST & \\
\hline CHEMBL1631856 & 696215 & 7.4089 & 7.4149 & TRN & \\
\hline CHEMBL408229 & 696215 & 8.0458 & 8.0396 & TRN & \\
\hline CHEMBL1631855 & 696215 & 6.4559 & 7.206 & TST & \\
\hline CHEMBL401446 & 696215 & 7.4685 & 7.8963 & TST & \\
\hline CHEMBL1631860 & 696215 & 8.0969 & 8.1529 & TRN & \\
\hline CHEMBL1629865 & 696215 & 7.7447 & 7.7368 & TRN & \\
\hline CHEMBL1629860 & 696215 & 8.1549 & 8.1746 & TRN & \\
\hline CHEMBL1629851 & 696215 & 6.8928 & 6.91700 & 0000000001 & TRN \\
\hline CHEMBL1629853 & 696215 & 7.6383 & 7.6255 & TRN & \\
\hline CHEMBL1629858 & 696215 & 7.8539 & 7.86799 & 9999999999 & TRN \\
\hline CHEMBL1631874 & 696215 & 7.5376 & 7.5323 & TRN & \\
\hline CHEMBL1629857 & 696215 & 8.699 & 8.7311 & TRN & \\
\hline CHEMBL1631757 & 696215 & 8.301 & 8.287 & TRN & \\
\hline CHEMBL1631870 & 696215 & 7.3979 & 7.397 & TRN & \\
\hline CHEMBL1629852 & 696215 & 8.2218 & 8.231 & TRN & \\
\hline CHEMBL1629866 & 696215 & 8.2218 & 8.2521 & TRN & \\
\hline CHEMBL1631864 & 696215 & 8.3979 & 8.4086 & TRN & \\
\hline CHEMBL1629856 & 696215 & 8.699 & 8.6673 & TRN & \\
\hline CHEMBL1631869 & 696215 & 7.8861 & 7.9001 & TRN & \\
\hline CHEMBL1629854 & 696215 & 7.699 & 7.69799 & 99999999995 & TRN \\
\hline CHEMBL1629859 & 696215 & 8.0969 & 8.0873 & TRN & \\
\hline CHEMBL1631867 & 696215 & 7.7959 & 7.7789 & TRN & \\
\hline CHEMBL1629844 & 696215 & 8.301 & 8.3223 & TRN & \\
\hline CHEMBL411440 & 696215 & 7.585 & 7.2072 & TST & \\
\hline CHEMBL394287 & 696215 & 2.1938 & 8.5505 & TST & \\
\hline CHEMBL1631871 & 696215 & 6.5622 & 6.5483 & TRN & \\
\hline CHEMBL1631876 & 696215 & 8.699 & 8.7051 & TRN & \\
\hline CHEMBL1631861 & 696215 & 7.9208 & 7.9108 & TRN & \\
\hline CHEMBL1629845 & 696215 & 7.8861 & 7.9023 & TRN & \\
\hline CHEMBL1631875 & 696215 & 7.585 & 7.5791 & TRN & \\
\hline CHEMBL1629850 & 696215 & 7.7447 & 7.7493 & TRN & \\
\hline CHEMBL1631866 & 696215 & 6.9281 & 6.9337 & TRN & \\
\hline CHEMBL1629862 & 696215 & 8.3979 & 8.3533 & TRN & \\
\hline CHEMBL1629715 & 696215 & 8.0458 & 8.0499 & TRN & \\
\hline CHEMBL1629864 & 696215 & 8.3979 & 8.3895 & TRN & \\
\hline
\end{tabular}

Page 27770 


\begin{tabular}{|c|c|c|c|c|c|}
\hline \multicolumn{6}{|c|}{ Supplemental Table S2.txt } \\
\hline CHEMBL1629863 & 696215 & 8.0969 & 8.1055 & TRN & \\
\hline CHEMBL 261288 & 696215 & 7.9208 & 7.6219 & TST & \\
\hline CHEMBL1631854 & 696215 & 8.0969 & 8.1052 & TRN & \\
\hline CHEMBL1631865 & 696215 & 8.0 & 7.9992 & TRN & \\
\hline CHEMBL1631873 & 696215 & 7.2291 & 7.218999 & 9999999999 & TRN \\
\hline CHEMBL1629847 & 696215 & 8.0 & 7.9827 & TRN & \\
\hline CHEMBL1629855 & 696215 & 8.699 & 8.658 & TRN & \\
\hline CHEMBL1631858 & 696215 & 8.3979 & 8.3953 & TRN & \\
\hline CHEMBL1631857 & 696215 & 6.9208 & 6.9186 & TRN & \\
\hline CHEMBL1631868 & 696215 & 7.8861 & 7.859 & TRN & \\
\hline CHEMBL1631862 & 696215 & 7.1805 & 7.6677 & TST & \\
\hline CHEMBL1629846 & 696215 & 8.2218 & 8.0101 & TST & \\
\hline CHEMBL1631872 & 696215 & 7.8861 & 8.3722 & TST & \\
\hline CHEMBL1629848 & 696215 & 7.8539 & 7.6605 & TST & \\
\hline CHEMBL411095 & 696215 & 7.9208 & 7.7981 & TST & \\
\hline CHEMBL1631863 & 696215 & 8.0 & 8.1702 & TST & \\
\hline CHEMBL1629861 & 696215 & 8.0 & 7.7437 & TST & \\
\hline CHEMBL1629849 & 696215 & 7.0655 & 7.1301 & TST & \\
\hline CHEMBL1631859 & 696215 & 8.3979 & 8.2104 & TST & \\
\hline CHEMBL3704715 & 1528932 & 6.0 & 6.981 & TRN & \\
\hline CHEMBL3704688 & 1528932 & 8.857000 & 000000000 & 8.646 & TRN \\
\hline CHEMBL3704719 & 1528932 & 6.0 & 7.0709 & TRN & \\
\hline CHEMBL3704712 & 1528932 & 8.4101 & 8.5933 & TRN & \\
\hline CHEMBL3704705 & 1528932 & 6.0 & 6.361000 & 0000000001 & TRN \\
\hline CHEMBL3704676 & 1528932 & 6.0 & 6.9622 & TRN & \\
\hline CHEMBL3704657 & 1528932 & 9.1506 & 6.8436 & TST & \\
\hline CHEMBL3704735 & 1528932 & 6.0 & 5.8126 & TRN & \\
\hline CHEMBL3704691 & 1528932 & 8.6162 & 8.368 & TRN & \\
\hline CHEMBL3704733 & 1528932 & 6.0 & 5.8825 & TRN & \\
\hline CHEMBL3704661 & 1528932 & 9.0367 & 8.7132 & TST & \\
\hline CHEMBL3704675 & 1528932 & 9.1986 & 7.2667 & TST & \\
\hline CHEMBL 3704677 & 1528932 & 8.5638 & 9.5873 & TRN & \\
\hline CHEMBL3704694 & 1528932 & 6.0 & 6.9126 & TRN & \\
\hline CHEMBL3704701 & 1528932 & 6.0 & 6.6562 & TRN & \\
\hline CHEMBL 3704674 & 1528932 & 9.091000 & 000000000 & 7.2321 & TST \\
\hline CHEMBL3704680 & 1528932 & 8.3979 & 7.9296 & TRN & \\
\hline CHEMBL3704728 & 1528932 & 6.0 & 5.786000 & 00000000005 & TRN \\
\hline CHEMBL3704706 & 1528932 & 6.0 & 6.3811 & TST & \\
\hline CHEMBL3704696 & 1528932 & 6.0 & 5.8005 & TRN & \\
\hline CHEMBL3704659 & 1528932 & 8.6091 & 7.5694 & TST & \\
\hline CHEMBL3704658 & 1528932 & 9.2668 & 7.1332 & TST & \\
\hline CHEMBL3704739 & 1528932 & 10.3188 & 10.5106 & TRN & \\
\hline CHEMBL3704662 & 1528932 & 9.3546 & 8.1873 & TST & \\
\hline CHEMBL3704736 & 1528932 & 6.0 & 6.2712 & TRN & \\
\hline CHEMBL3704681 & 1528932 & 8.4763 & 8.5972 & TRN & \\
\hline CHEMBL 3704709 & 1528932 & 6.0 & 5.688 & TRN & \\
\hline CHEMBL3704734 & 1528932 & 6.0 & 7.5265 & TRN & \\
\hline CHEMBL3704665 & 1528932 & 8.4802 & 8.43 & TST & \\
\hline
\end{tabular}


Supplemental Table S2.txt

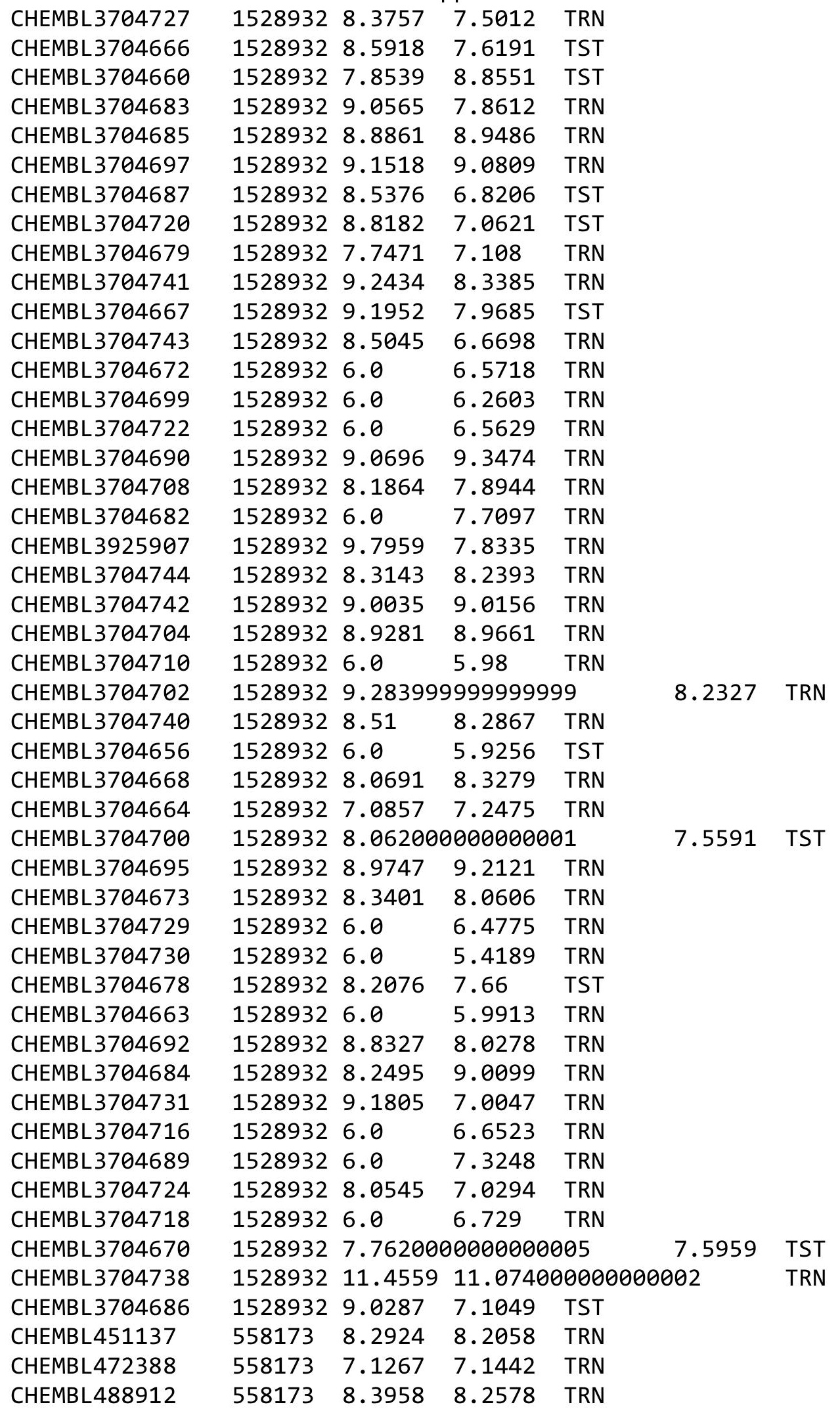

Page 27772 
Supplemental Table S2.txt

\begin{tabular}{|c|c|c|c|c|}
\hline 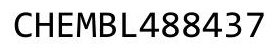 & 3 & 1 & 65 & TRN \\
\hline CHEMBL455425 & 58173 & 8.0506 & 8.3179 & TRN \\
\hline HEMBL508192 & 58173 & 7.0264 & .0059 & TII \\
\hline HEMBL462225 & 58173 & 8.0083 & 3.1853 & \\
\hline HEMBL454656 & 58173 & 7.5391 & .6469 & \\
\hline HEMBL452091 & 58173 & 8.3696 & 8.2195 & \\
\hline HEMBL527094 & 58173 & 7.3851 & 7.5448 & \\
\hline HEMBL443922 & 58173 & 9.4559 & 8.5587 & 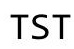 \\
\hline HEMBL488260 & 58173 & 7.5287 & 7.5285 & \\
\hline HEMBL488261 & 58173 & 8.2062 & 8.1592 & \\
\hline HEMBL455675 & 58173 & 8.3595 & 8.1888 & PO \\
\hline HEMBL453630 & 558173 & 7.2132 & 7.1907 & 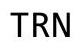 \\
\hline HEMBL447864 & 58173 & 7.7696 & 7.905 & RN \\
\hline HEMBL529660 & 58173 & 8.4237 & 8.4027 & \\
\hline HEMBL487222 & 58173 & 7.2457 & 7.3261 & . \\
\hline HEMBL455426 & 58173 & 8.4225 & 8.4609 & ST \\
\hline HEMBL449048 & 558173 & 7.1107 & 6.8524 & TRN \\
\hline HEMBL488911 & 58173 & 8.3019 & 8.4135 & TST \\
\hline LHEMBL461631 & 73 & 6.7282 & 7.3222 & SI \\
\hline HEMBL4 & 58173 & 8.4609 & 7.8938 & ST \\
\hline CHEMBL4 & 58173 & 7.5952 & 7.3809 & RN \\
\hline CHEMBL454657 & 58173 & 8.3458 & 8.2052 & RN \\
\hline HEMBL488435 & 73 & 8.3188 & 8.382 & RN \\
\hline HEMBL487221 & 58 & 7.6383 & 7.5979 & ST \\
\hline HEMBL4 & 73 & 7.767 & 7.8783 & RN \\
\hline CHEMBL 4 & 73 & 7.8508 & 8.0719 & RN \\
\hline CHEMBL462387 & .73 & 8.0362 & 8.0108 & $\mathrm{RN}$ \\
\hline CHEMBL505091 & 58 & 8.2418 & 1921 & TRN \\
\hline SHEMBL442923 & 58173 & 7.426 & 7.5342 & TRN \\
\hline HEMBL5 & 73 & 595 & 8.1249 & TRN \\
\hline CHEMBL 5 & 73 & 6.9393 & 7.6171 & TST \\
\hline CHEMBL488021 & 58173 & 8.1221 & 7.9758 & TRN \\
\hline CHEMBL488434 & 58173 & 8.0237 & 7.8952 & TRN \\
\hline HEMBL453880 & 58173 & 8.0128 & 8.1228 & $\lceil\mathrm{RN}$ \\
\hline CHEMBL4 & 73 & 7.8928 & 81 & $\Gamma \mathrm{RN}$ \\
\hline CHEMBL472389 & 73 & 6.4191 & 6.4938 & TRN \\
\hline CHEMBL487053 & 58173 & 8.4855 & 7.8113 & TST \\
\hline CHEMBL455184 & 58173 & 7.5058 & 7.6025 & TRN \\
\hline HEMBL462226 & 73 & 8.1255 & 8.0092 & RN \\
\hline CHEMBL507721 & 73 & 8.2573 & 8.0725 & TRN \\
\hline CHEMBL455511 & 558173 & 8.6271 & 8.3496 & TST \\
\hline CHEMBL487223 & 558173 & 7.4437 & 7.9703 & TRN \\
\hline CHEMBL507884 & 58173 & 7.6615 & 7.6547 & TRN \\
\hline CHEMBL488242 & 558173 & 7.857 & 7.9599 & I RIV \\
\hline CHEMBL507075 & 558173 & 7.5072 & 7.3723 & $\lceil\mathrm{RN}$ \\
\hline CHEMBL488060 & 558173 & 8.4841 & 8.2033 & $\Gamma \mathrm{RN}$ \\
\hline CHEMBL451178 & 58173 & 8.6144 & 8.5845 & TST \\
\hline CHEMBL451330 & 558173 & 8.3778 & 8.3177 & $\pi$ \\
\hline
\end{tabular}

Page 27773 


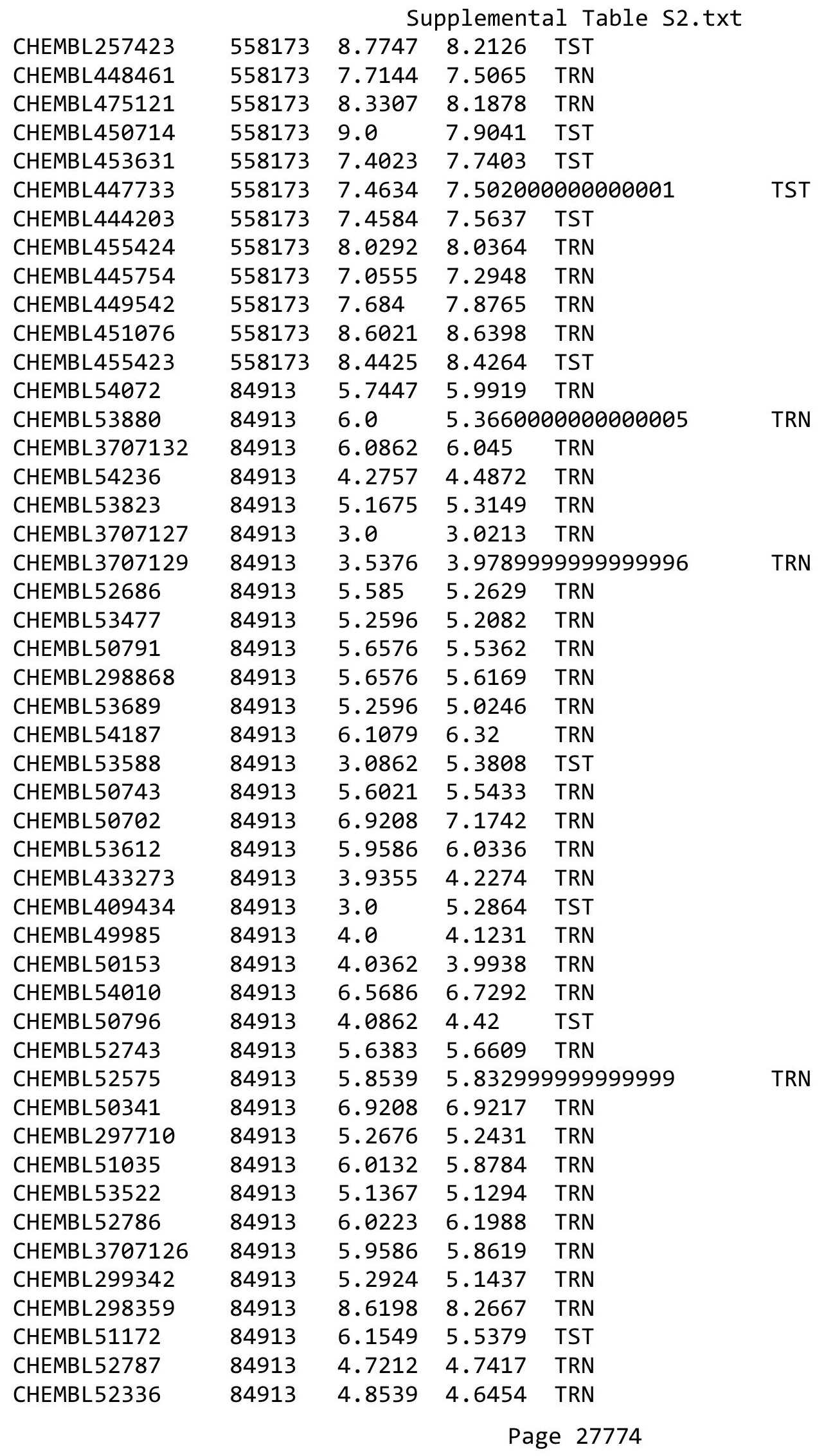




\begin{tabular}{|c|c|c|c|c|c|}
\hline \multicolumn{6}{|c|}{ Supplemental Table S2.txt } \\
\hline CHEMBL52061 & 84913 & 5.3098 & 5.3252 & TRN & \\
\hline CHEMBL51032 & 84913 & 5.6021 & 5.0465 & TRN & \\
\hline CHEMBL 300181 & 84913 & 5.9586 & 4.809 & TST & \\
\hline CHEMBL50939 & 84913 & 5.6383 & 5.5721 & TRN & \\
\hline CHEMBL445326 & 84913 & 5.2596 & 5.4271 & TRN & \\
\hline CHEMBL 301783 & 84913 & 6.7212 & 6.9532 & TRN & \\
\hline CHEMBL 3707130 & 84913 & 6.5086 & 6.1711 & TST & \\
\hline CHEMBL50043 & 84913 & 4.3188 & 4.2757 & TRN & \\
\hline CHEMBL53231 & 84913 & 5.9586 & 6.345 & TRN & \\
\hline CHEMBL50756 & 84913 & 6.1192 & 5.8104 & TST & \\
\hline CHEMBL3707131 & 84913 & 5.8861 & 6.2637 & TST & \\
\hline CHEMBL298961 & 84913 & 3.0 & 4.7667 & TST & \\
\hline CHEMBL301968 & 84913 & 4.5686 & 5.3457 & TST & \\
\hline CHEMBL52844 & 84913 & 5.2757 & 4.9066 & TST & \\
\hline CHEMBL416473 & 84913 & 4.0 & 4.8469 & TST & \\
\hline CHEMBL53341 & 84913 & 5.6576 & 5.4372 & TST & \\
\hline CHEMBL3963555 & 1641034 & 7.8239 & 7.5802 & TST & \\
\hline CHEMBL3973453 & 1641034 & 7.9586 & 6.2824 & TRN & \\
\hline CHEMBL 3942120 & 1641034 & 8.0223 & 7.7486 & TRN & \\
\hline CHEMBL3931093 & 1641034 & 9.0 & 9.2248 & TRN & \\
\hline CHEMBL 3986588 & 1641034 & 7.7447 & 7.8679 & TRN & \\
\hline CHEMBL3931935 & 1641034 & 6.0 & 6.716 & TRN & \\
\hline CHEMBL3957421 & 1641034 & 6.0 & 6.6857 & TRN & \\
\hline CHEMBL 3953229 & 1641034 & 8.699 & 9.1441 & TRN & \\
\hline CHEMBL3893196 & 1641034 & 7.6021 & 7.5434 & TRN & \\
\hline CHEMBL 3967735 & 1641034 & 6.0 & 7.25700 & 0000000001 & TRN \\
\hline CHEMBL 3894366 & 1641034 & 7.4089 & 7.975 & TST & \\
\hline CHEMBL3917056 & 1641034 & 8.1612 & 7.7946 & TRN & \\
\hline CHEMBL 3912503 & 1641034 & 6.0 & 7.2465 & TRN & \\
\hline CHEMBL3945787 & 1641034 & 7.7959 & 7.6402 & TRN & \\
\hline CHEMBL 3975439 & 1641034 & 8.0 & 7.7809 & TST & \\
\hline CHEMBL 3963994 & 1641034 & 7.7212 & 7.4244 & TRN & \\
\hline CHEMBL 3975090 & 1641034 & 7.6021 & 7.7375 & TRN & \\
\hline CHEMBL3937067 & 1641034 & 9.1805 & 9.0598 & TRN & \\
\hline CHEMBL3963319 & 1641034 & 6.699 & 7.2195 & TST & \\
\hline CHEMBL3910680 & 1641034 & 7.5086 & 7.4973 & TRN & \\
\hline CHEMBL3904312 & 1641034 & 8.4559 & 7.9868 & TRN & \\
\hline CHEMBL 3941925 & 1641034 & 8.6198 & 8.63600 & 0000000001 & TST \\
\hline CHEMBL3980246 & 1641034 & 7.7212 & 8.2531 & TRN & \\
\hline CHEMBL3968041 & 1641034 & 8.8861 & 8.802 & TRN & \\
\hline CHEMBL3958601 & 1641034 & 7.2757 & 7.2637 & TST & \\
\hline CHEMBL3962689 & 1641034 & 6.8861 & 7.026 & TRN & \\
\hline CHEMBL3955124 & 1641034 & 7.3565 & 7.3305 & TRN & \\
\hline CHEMBL3906872 & 1641034 & 7.6778 & 7.5112 & TST & \\
\hline CHEMBL3892296 & 1641034 & 8.6778 & 8.6541 & TRN & \\
\hline CHEMBL 3942424 & 1641034 & 6.0 & 6.7665 & TRN & \\
\hline CHEMBL3936356 & 1641034 & 8.3768 & 8.5838 & TST & \\
\hline CHEMBL3913397 & 1641034 & 8.301 & 7.775 & TRN & \\
\hline
\end{tabular}


Supplemental Table S2.txt

\begin{tabular}{|c|c|c|c|c|c|c|}
\hline CHEMBL3969811 & 1641034 & 7.4949 & 7.6934 & TRN & & \\
\hline CHEMBL3927252 & 1641034 & 9.4815 & 9.0699 & TRN & & \\
\hline CHEMBL3983303 & 1641034 & 8.2366 & 6.3448 & TRN & & \\
\hline CHEMBL3912192 & 1641034 & 8.3372 & 8.3252 & TRN & & \\
\hline CHEMBL 3922240 & 1641034 & 8.5686 & 8.6058 & TRN & & \\
\hline CHEMBL3911362 & 1641034 & 8.28399 & 999999999 & 99 & 7.8941 & TRN \\
\hline CHEMBL3949285 & 1641034 & 9.2147 & 9.1018 & TRN & & \\
\hline CHEMBL3972506 & 1641034 & 8.5528 & 8.1059 & TRN & & \\
\hline CHEMBL 3983344 & 1641034 & 8.0044 & 8.0298 & TRN & & \\
\hline CHEMBL3953550 & 1641034 & 8.4815 & 8.6797 & TRN & & \\
\hline CHEMBL 3952261 & 1641034 & 8.585 & 8.9443 & TRN & & \\
\hline CHEMBL3978202 & 1641034 & 8.9208 & 8.742 & TRN & & \\
\hline CHEMBL3978189 & 1641034 & 7.6198 & 7.8046 & TRN & & \\
\hline CHEMBL3917783 & 1641034 & 7.2518 & 7.3522 & TST & & \\
\hline CHEMBL3972067 & 1641034 & 7.699 & 8.109 & TRN & & \\
\hline CHEMBL3947889 & 1641034 & 8.1487 & 8.2385 & TRN & & \\
\hline CHEMBL3986686 & 1641034 & 7.1427 & 7.3762 & TRN & & \\
\hline CHEMBL3974989 & 1641034 & 8.699 & 8.5017 & TRN & & \\
\hline CHEMBL3947711 & 1641034 & 8.2676 & 7.7972 & TRN & & \\
\hline CHEMBL3960910 & 1641034 & 8.3279 & 8.5754 & TRN & & \\
\hline CHEMBL3925854 & 1641034 & 8.3565 & 8.5457 & TRN & & \\
\hline CHEMBL3944859 & 1641034 & 8.7959 & 8.8916 & TRN & & \\
\hline CHEMBL 3985243 & 1641034 & 8.8861 & 8.6028 & TRN & & \\
\hline CHEMBL3957937 & 1641034 & 8.2147 & 8.3645 & TRN & & \\
\hline CHEMBL3926748 & 1641034 & 7.5376 & 7.0702 & TRN & & \\
\hline CHEMBL3906687 & 1641034 & 8.301 & 7.9751 & TRN & & \\
\hline CHEMBL 3954894 & 1641034 & 9.699 & 9.2369 & TRN & & \\
\hline CHEMBL3920329 & 1641034 & 8.8239 & 8.5325 & TRN & & \\
\hline CHEMBL 3980041 & 1641034 & 6.0 & 6.9086 & TRN & & \\
\hline CHEMBL3959789 & 1641034 & 7.1612 & 5.9682 & TST & & \\
\hline CHEMBL3907774 & 1641034 & 7.9586 & 8.4551 & TRN & & \\
\hline CHEMBL 3978620 & 1641034 & 8.4559 & 8.1531 & TRN & & \\
\hline CHEMBL3956966 & 1641034 & 8.1192 & 7.5559 & TST & & \\
\hline CHEMBL 3908040 & 1641034 & 8.1249 & 7.9001 & TRN & & \\
\hline CHEMBL3923513 & 1641034 & 8.6198 & 9.0875 & TRN & & \\
\hline CHEMBL3919034 & 1641034 & 7.6576 & 7.7444 & TST & & \\
\hline CHEMBL3909146 & 1641034 & 8.6021 & 9.0261 & TRN & & \\
\hline CHEMBL3921365 & 1641034 & 6.0 & 6.7187 & TRN & & \\
\hline CHEMBL3899650 & 1641034 & 7.7959 & 7.3387 & TRN & & \\
\hline CHEMBL3905617 & 1641034 & 7.5376 & 7.1739 & TST & & \\
\hline CHEMBL3974904 & 1641034 & 6.7447 & 6.0952 & TRN & & \\
\hline CHEMBL3931293 & 1641034 & 7.0269 & 7.3536 & TST & & \\
\hline CHEMBL 3938277 & 1641034 & 7.7696 & 7.7354 & TST & & \\
\hline CHEMBL3900746 & 1641034 & 8.4815 & 7.8323 & TRN & & \\
\hline CHEMBL 3947782 & 1641034 & 7.5376 & 8.2725 & TRN & & \\
\hline CHEMBL3896215 & 1641034 & 7.7212 & 7.9921 & TST & & \\
\hline CHEMBL3945378 & 1641034 & 8.0969 & 7.9116 & TRN & & \\
\hline CHEMBL 3898916 & 1641034 & 6.8539 & 5.9818 & TRN & & \\
\hline
\end{tabular}

Page 27776 
Supplemental Table S2.txt

\begin{tabular}{|c|c|c|c|c|}
\hline HEM & 1034 & & & \\
\hline & 641034 & 7.2441 & 7.6782 & \\
\hline 14 & & & & \\
\hline AEMBL3931368 & & & & \\
\hline AEMBL3945740 & 034 & & & \\
\hline HEMBL3911142 & 641034 & 8.6021 & 3512 & \\
\hline HEMBL3902287 & 34 & & & \\
\hline IEMBL 3931435 & & 8 & & \\
\hline AEMBL3954819 & 034 & 6.0 & 6.8676 & \\
\hline HEMBL3984562 & 034 & 959 & 2633 & \\
\hline HEMBL3978777 & 34 & 7. & 5 & \\
\hline IEMBL395 & 34 & 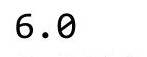 & 48 & \\
\hline AEMBL3936616 & & 8 & & \\
\hline HEMBL3950680 & 34 & & .9145 & \\
\hline AEMBL3911186 & 34 & 7 & & \\
\hline IEMBL397 & 7 & 8. & 05 & \\
\hline AEMBL39 & 34 & & & \\
\hline HEMBL 38 & & & & \\
\hline HEMBL 393 & & & 8362 & \\
\hline AEMBL39 & & & & \\
\hline HEIMBLSל & 64 & 8 & 28 & RIV \\
\hline AEMBL & & 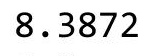 & & 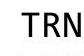 \\
\hline HEMBL3S & & 6. & & \\
\hline HFMBI 391 & & 7.88 & & \\
\hline AEMBL39 & & & & N \\
\hline HEMBL3S & 34 & 6 & & RN \\
\hline HEMBL3 & & & & ST \\
\hline HFMBI 3 & 34 & & & RN \\
\hline HEMBL3S & & & & iv \\
\hline HEMBL3918943 & & & & IRIV \\
\hline HEMBL3S & 6 & & 106 & RN \\
\hline HEMBL; & & 7. & 78 & RN \\
\hline HEMBL. & & 6 & 01 & $\mathrm{RN}$ \\
\hline HEMBL3981130 & & & 452 & IRN \\
\hline HEMBL3943946 & $c$ & & 366 & TRN \\
\hline HEMBL39 & & & 94 & \\
\hline HFMRI $=$ & & & & RN \\
\hline HEMBL3 & & 7.3279 & 2785 & $\Gamma \mathrm{RN}$ \\
\hline HEMBL3966840 & 34 & & 8776 & $\Gamma \mathrm{RN}$ \\
\hline IEMBL3S & 034 & & $\partial 69$ & RN \\
\hline HEMBL39 & 6 & & & \\
\hline CHEMBL39 & & & & TRN \\
\hline HEMBL3935688 & & & 8525 & $\Gamma \mathrm{RN}$ \\
\hline AEMBL3961357 & 03. & & 3214 & TRN \\
\hline 98 & & & & \\
\hline HEMBL39 & & 7. & 1276 & \\
\hline CHEMBL 3974289 & 164 & & 7.0391 & \\
\hline CHEMBL3942741 & 164103 & 8.7212 & 8.568 & ГRN \\
\hline
\end{tabular}

Page 27777 
Supplemental Table S2.txt

\begin{tabular}{|c|c|c|c|c|c|}
\hline CHEMBL3979623 & 1641034 & 8.2441 & 8.6967 & TRN & \\
\hline CHEMBL3972962 & 1641034 & 7.3872 & 7.6126 & TRN & \\
\hline CHEMBL3898818 & 1641034 & 8.3188 & 8.3724 & TRN & \\
\hline CHEMBL 3902428 & 1641034 & 8.0 & 7.3483 & TRN & \\
\hline CHEMBL3891947 & 1641034 & 8.7212 & 8.1607 & TRN & \\
\hline CHEMBL3898786 & 1641034 & 7.8861 & 8.1907 & TST & \\
\hline CHEMBL3894535 & 1641034 & 7.9586 & 8.0846 & TST & \\
\hline CHEMBL3923030 & 1641034 & 6.0 & 6.9065 & TRN & \\
\hline CHEMBL3956311 & 1641034 & 6.0 & 6.8776 & TRN & \\
\hline CHEMBL3949248 & 1641034 & 8.6198 & 7.9249 & TRN & \\
\hline CHEMBL3959692 & 1641034 & 8.4685 & 8.2502 & TST & \\
\hline CHEMBL3937326 & 1641034 & 7.5086 & 7.6206 & TRN & \\
\hline CHEMBL3936927 & 1641034 & 6.4202 & 6.2643 & TRN & \\
\hline CHEMBL3906210 & 1641034 & 8.0555 & 8.0992 & TRN & \\
\hline CHEMBL3983231 & 1641034 & 6.0 & 6.7916 & TRN & \\
\hline CHEMBL3894161 & 1641034 & 8.7447 & 8.9235 & TRN & \\
\hline CHEMBL3924572 & 1641034 & 8.3665 & 8.6354 & TRN & \\
\hline CHEMBL3897849 & 1641034 & 8.4089 & 8.0471 & TRN & \\
\hline CHEMBL3894516 & 1641034 & 8.7447 & 8.1825 & TRN & \\
\hline CHEMBL3902770 & 1641034 & 7.6778 & 7.4947 & TST & \\
\hline CHEMBL3902992 & 1641034 & 6.0 & 7.3038 & TRN & \\
\hline CHEMBL3903941 & 1641034 & 6.0 & 6.7418 & TRN & \\
\hline CHEMBL3912419 & 1641034 & 8.2441 & 7.944 & TRN & \\
\hline CHEMBL3936565 & 1641034 & 7.9586 & 8.2857 & TRN & \\
\hline CHEMBL3913693 & 1641034 & 7.9586 & 7.8783 & TRN & \\
\hline CHEMBL3918308 & 1641034 & 9.3979 & 9.0157 & TRN & \\
\hline CHEMBL3934440 & 1641034 & 7.7696 & 7.9227 & TRN & \\
\hline CHEMBL3892138 & 1641034 & 8.3098 & 8.462 & TRN & \\
\hline CHEMBL3941680 & 1641034 & 7.5686 & 7.5093 & TRN & \\
\hline CHEMBL3985119 & 1641034 & 8.1079 & 8.2561 & TRN & \\
\hline CHEMBL3934664 & 1641034 & 7.6778 & 7.9444 & TRN & \\
\hline CHEMBL3948605 & 1641034 & 7.8539 & 8.4922 & TST & \\
\hline CHEMBL3902123 & 1641034 & 8.2757 & 8.26799 & 7999999999 & TRN \\
\hline CHEMBL3956450 & 1641034 & 8.3665 & 8.7561 & TRN & \\
\hline CHEMBL3973017 & 1641034 & 7.4089 & 7.3608 & TRN & \\
\hline CHEMBL3969865 & 1641034 & 8.0223 & 7.7489 & TST & \\
\hline CHEMBL3904186 & 1641034 & 8.1612 & 8.0593 & TRN & \\
\hline CHEMBL3927827 & 1641034 & 8.2924 & 8.0576 & TST & \\
\hline CHEMBL3964133 & 1641034 & 8.1871 & 8.0527 & TRN & \\
\hline CHEMBL3972033 & 1641034 & 8.5528 & 8.2156 & TRN & \\
\hline CHEMBL3927649 & 1641034 & 8.9586 & 8.9546 & TRN & \\
\hline CHEMBL3929096 & 1641034 & 7.7959 & 7.9665 & TRN & \\
\hline CHEMBL3917030 & 1641034 & 7.7447 & 7.5922 & TRN & \\
\hline CHEMBL3965307 & 1641034 & 8.3565 & 7.9776 & TRN & \\
\hline CHEMBL3946758 & 1641034 & 8.1249 & 8.015 & TRN & \\
\hline CHEMBL3926894 & 1641034 & 8.7212 & 7.9409 & TRN & \\
\hline CHEMBL3973276 & 1641034 & 6.2007 & 6.8 & TRN & \\
\hline CHEMBL3927682 & 1641034 & 7.4202 & 7.7243 & TST & \\
\hline
\end{tabular}


Supplemental Table S2.txt

\begin{tabular}{|c|c|c|c|c|c|}
\hline CHEMBL3983856 & 1641034 & 7.3768 & \multicolumn{2}{|c|}{ 7.492999999999999 } & TRN \\
\hline CHEMBL3975399 & 1641034 & 8.4685 & 8.8295 & TRN & \\
\hline CHEMBL3889588 & 1641034 & 8.2924 & 8.2884 & TST & \\
\hline CHEMBL3971717 & 1641034 & 7.7212 & 7.7304 & TRN & \\
\hline CHEMBL3945676 & 1641034 & 8.1675 & 8.3442 & TRN & \\
\hline CHEMBL3965520 & 1641034 & 7.5528 & 7.7862 & TST & \\
\hline CHEMBL3953381 & 1641034 & 8.9208 & 8.2303 & TRN & \\
\hline CHEMBL3962300 & 1641034 & 7.585 & 7.7656 & TRN & \\
\hline CHEMBL3970198 & 1641034 & 7.5686 & 7.5306 & TRN & \\
\hline CHEMBL3963443 & 1641034 & 6.0 & 7.0492 & TRN & \\
\hline CHEMBL3963387 & 1641034 & 7.9208 & 7.801 & TRN & \\
\hline CHEMBL3949323 & 1641034 & 8.7212 & 8.2931 & TRN & \\
\hline CHEMBL3940782 & 1641034 & 8.6021 & 7.8613 & TRN & \\
\hline CHEMBL3890951 & 1641034 & 6.9208 & 6.9616 & TST & \\
\hline CHEMBL3955793 & 1641034 & 6.9208 & 7.2463 & TST & \\
\hline CHEMBL3980992 & 1641034 & 7.9586 & 7.8298 & TRN & \\
\hline CHEMBL3949242 & 1641034 & 8.0 & 7.9661 & TRN & \\
\hline CHEMBL3941241 & 1641034 & 6.0 & 6.676 & TRN & \\
\hline CHEMBL3951710 & 1641034 & 7.6021 & 7.5269 & TRN & \\
\hline CHEMBL3891030 & 1641034 & 8.041 & 8.5471 & TRN & \\
\hline CHEMBL3951230 & 1641034 & 8.3665 & 8.7111 & TRN & \\
\hline CHEMBL3973429 & 1641034 & 7.0969 & 7.7804 & TRN & \\
\hline CHEMBL3934943 & 1641034 & 7.8861 & 7.8896 & TRN & \\
\hline CHEMBL3924171 & 1641034 & 7.0506 & 6.1439 & TRN & \\
\hline CHEMBL 3896777 & 1641034 & 8.2596 & 8.1364 & TRN & \\
\hline CHEMBL3954249 & 1641034 & 8.3468 & 8.59 & TST & \\
\hline CHEMBL3973343 & 1641034 & 7.7696 & 8.0875 & TRN & \\
\hline CHEMBL3896461 & 1641034 & 7.699 & 7.6094 & TRN & \\
\hline CHEMBL3965965 & 1641034 & 8.4318 & 8.6487 & TRN & \\
\hline CHEMBL3941598 & 1641034 & 7.8539 & 7.6681 & TRN & \\
\hline CHEMBL3896784 & 1641034 & 6.0 & 6.9923 & TRN & \\
\hline CHEMBL3933458 & 1641034 & 7.2147 & 6.9883 & TRN & \\
\hline CHEMBL3979388 & 1641034 & 7.4089 & 7.9294 & TRN & \\
\hline CHEMBL3962051 & 1641034 & 8.4685 & 8.6202 & TST & \\
\hline CHEMBL3935532 & 1641034 & 7.8239 & 8.0 & TRN & \\
\hline CHEMBL3942459 & 1641034 & 8.0223 & 7.7333 & TRN & \\
\hline CHEMBL3929398 & 1641034 & 7.1487 & 7.2598 & TRN & \\
\hline CHEMBL3897798 & 1641034 & 8.6778 & 8.4949 & TRN & \\
\hline CHEMBL3970109 & 1641034 & 7.7696 & 7.1798 & TRN & \\
\hline CHEMBL3977496 & 1641034 & 6.5376 & 6.7064 & TRN & \\
\hline CHEMBL3917954 & 1641034 & 8.1739 & 7.9415 & TRN & \\
\hline CHEMBL 3899587 & 1641034 & 6.0 & 7.0639 & TST & \\
\hline CHEMBL3900724 & 1641034 & 6.1079 & 6.5638 & TRN & \\
\hline CHEMBL3922303 & 1641034 & 8.1024 & 7.4281 & TRN & \\
\hline CHEMBL3976587 & 1641034 & 7.8861 & 7.8439 & TRN & \\
\hline CHEMBL3909024 & 1641034 & 8.3372 & 8.3135 & TST & \\
\hline CHEMBL3975250 & 1641034 & 8.1487 & 7.7844 & TRN & \\
\hline CHEMBL3965670 & 1641034 & 8.2518 & 8.4701 & TST & \\
\hline
\end{tabular}


Supplemental Table S2.txt

\begin{tabular}{|c|c|c|c|c|}
\hline 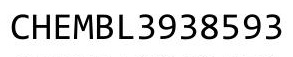 & & & & \\
\hline HEMBL3962451 & 1034 & 7.4089 & 9882 & \\
\hline HEMBL3967682 & 641034 & 6.0 & 8303 & \\
\hline 92 & & 5376 & & \\
\hline 73302 & 334 & 8.2147 & 443 & \\
\hline HEMBL3926516 & 641034 & 8.8861 & 7824 & \\
\hline HEMBL3900224 & 641034 & 8.3279 & 8.1244 & \\
\hline HEMBL3896798 & 34 & 7.1367 & 6249 & \\
\hline IEMBL: & 34 & 8.1308 & 9259 & \\
\hline IEMBL3S & 234 & 8.2518 & 578 & \\
\hline HEMBL3918854 & .034 & 8.2676 & 0456 & \\
\hline HEMBL3945964 & 034 & 8.0969 & 599 & \\
\hline HEMBL 391 & 34 & 7.9208 & 7997 & \\
\hline HEMBL3S & & 8.0458 & 283 & \\
\hline HEMBL3S & 34 & 6.0 & 41 & \\
\hline HEMBL39 & 34 & 8.4089 & 2889 & \\
\hline HEMBL3975088 & 34 & 76 & 5555 & \\
\hline HEMBL3\& & 34 & $\partial 8$ & 03 & \\
\hline HEMBL3S & & 6. & & \\
\hline HEMBL3S & & & & \\
\hline HEMBL 39 & & 57 & & RN \\
\hline HEMBL391 & 34 & 7.6778 & 84 & IST \\
\hline HEMBL393 & 34 & 8 . & 43 & RN \\
\hline HEMBL3\& & & 6. & & \\
\hline HEME & & 8 . & & RN \\
\hline HEMBL3S & & & & RN \\
\hline HEMBL3940644 & 34 & 7. & 944 & $R /$ \\
\hline HEMBL39 & 34 & 96 & 972 & RN \\
\hline HEM & & & 27 & RN \\
\hline HEMBL3S & & 39 & 672 & RN \\
\hline HEMBL 39 & & & & RN \\
\hline HEMBL3890660 & 34 & 7.0862 & 3405 & RN \\
\hline HEMBL3S & 334 & 676 & 355 & RN \\
\hline 1 & & 12 & 97 & RN \\
\hline HEMBL3S & & & 3757 & RN \\
\hline HEMBL3975255 & & 28 & 016 & ST \\
\hline HEMBL 391 & 34 & 7.6576 & & RN \\
\hline HEMBL39 & 6 & 89 & 746 & $\mathrm{RN}$ \\
\hline 6 & & & 873 & ST \\
\hline HEMBL39 & & 6.0 & & RN \\
\hline HEMBL3926817 & 34 & 8. & 629 & RN \\
\hline HEMBL 39 & 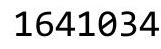 & 861 & 387 & RN \\
\hline HEMBL 3920091 & & & 518 & \\
\hline CHEMBL 3899634 & & & 965 & RN \\
\hline HEMBL 39 & & 8.1367 & .0848 & RN \\
\hline HEMBL3939331 & 6 & 7.4685 & 46 & RN \\
\hline-3 & & & & \\
\hline & & & & \\
\hline
\end{tabular}

Page 27780 
Supplemental Table S2.txt

\begin{tabular}{|c|c|c|c|c|}
\hline HEMB I & 1034 & 8.4815 & & \\
\hline & 641034 & 7.1805 & 9388 & \\
\hline 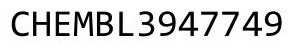 & & & & \\
\hline AEMBL3959556 & 034 & & & 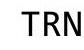 \\
\hline AEMBL3977129 & 034 & 528 & 3574 & \\
\hline HEMBL3967749 & 641034 & 9.1024 & 1103 & \\
\hline 5618 & & 08 & 037 & \\
\hline IFMBI 38 & & & & \\
\hline AEMBL3985597 & 034 & & 0128 & \\
\hline HEMBL3969516 & 034 & & . 9694 & \\
\hline HEMBL3944831 & $\partial 34$ & & .2357 & \\
\hline IEMBL39 & 34 & & 507 & \\
\hline AEMBL3S & & & & \\
\hline HEMBL391 & & & 0518 & \\
\hline HEMBL390 & 34 & & 9853 & \\
\hline IEMBL391 & 84 & & 8.4511 & \\
\hline HEMBL3S & 34 & & 137 & 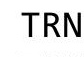 \\
\hline HEMBL3S & & & & \\
\hline HEMBL39 & & & 835 & \\
\hline AEMBL39 & & & 862 & \\
\hline HEIMBLSS & 34 & & 4 & t. \\
\hline HEMBL3 & & & 51 & 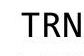 \\
\hline HEMBL3S & & & 82 & \\
\hline HEMBL3S & & & 7.8149 & \\
\hline HEMBL390 & & & & Tu \\
\hline HEMBL3S & 6 & & 243 & I RN \\
\hline HEMBL; & & & 71 & Niv \\
\hline$H F M B I=$ & & & 253 & \\
\hline HEMBL3S & & & 7.557 & r \\
\hline HEMBL 392 & & & 627 & I RIV \\
\hline HEMBL3S & 6 & & 548 & RN \\
\hline HEMBL; & & & 11 & ST \\
\hline HEMBL3 & & & 642 & $\mathrm{RN}$ \\
\hline HEMBL3981443 & & & 1636 & IRN \\
\hline HEMBL3933612 & 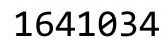 & & 3365 & TST \\
\hline HEMBL3\& & & & 34 & $\Gamma \mathrm{RN}$ \\
\hline HFMRI & & & 807 & RN \\
\hline HEMBL3 & & & & ST \\
\hline HEMBL3892562 & 34 & & 0828 & $\Gamma \mathrm{RN}$ \\
\hline IEMBL3S & & & 4749 & IRN \\
\hline HEMBL39 & ז & & 122 & \\
\hline CHEMBL39 & & & & RIV \\
\hline HEMBL3980369 & & & 7.6376 & $\Gamma \mathrm{RN}$ \\
\hline HEMBL3963480 & 034 & 8 . & 7.6988 & TST \\
\hline MBL3 & & & 7.7944 & \\
\hline HEMBL3S & & & 7.6753 & \\
\hline CHEMBL 3933671 & & & 7.0013 & \\
\hline CHEMBL397934e & 164103 & 8.8539 & 9.1582 & ГRN \\
\hline
\end{tabular}

Page 27781 
Supplemental Table S2.txt

\begin{tabular}{|c|c|c|c|c|c|}
\hline CHEMBL3916915 & 1641034 & 8.6021 & 8.3192 & TRN & \\
\hline CHEMBL3949040 & 1641034 & 9.1549 & \multicolumn{2}{|c|}{9.011000000000001} & TRN \\
\hline CHEMBL3935174 & 1641034 & 7.585 & 7.1251 & TRN & \\
\hline CHEMBL3937822 & 1641034 & 7.4559 & 7.6121 & TST & \\
\hline CHEMBL3937827 & 1641034 & 7.6778 & 7.4391 & TRN & \\
\hline CHEMBL3977017 & 1641034 & 8.585 & 8.6929 & TRN & \\
\hline CHEMBL3900189 & 1641034 & 7.1487 & 6.0426 & TRN & \\
\hline CHEMBL3943994 & 1641034 & 8.1079 & 7.9842 & TRN & \\
\hline CHEMBL3905358 & 1641034 & 7.585 & 7.3804 & TST & \\
\hline CHEMBL3902447 & 1641034 & 7.2147 & 6.9577 & TRN & \\
\hline CHEMBL3932581 & 1641034 & 7.699 & \multicolumn{2}{|c|}{7.763999999999999} & TST \\
\hline CHEMBL3962232 & 1641034 & 7.0757 & 7.2295 & TRN & \\
\hline CHEMBL3984960 & 1641034 & 8.585 & 8.1318 & TRN & \\
\hline CHEMBL3929124 & 1641034 & 8.5229 & 8.3565 & TRN & \\
\hline CHEMBL3951060 & 1641034 & 7.9586 & 7.9372 & TRN & \\
\hline CHEMBL3902256 & 1641034 & 7.1938 & 6.1944 & TRN & \\
\hline CHEMBL3934192 & 1641034 & 7.8239 & 8.0254 & TRN & \\
\hline CHEMBL3909751 & 1641034 & 7.6021 & 8.0059 & TRN & \\
\hline CHEMBL3916687 & 1641034 & 8.0 & 7.7887 & TRN & \\
\hline CHEMBL3900738 & 1641034 & 7.3565 & 7.5424 & TRN & \\
\hline CHEMBL3948921 & 1641034 & 8.3188 & 8.1875 & TRN & \\
\hline CHEMBL3928338 & 1641034 & 8.2441 & 8.4912 & TST & \\
\hline CHEMBL3975158 & 1641034 & 8.0044 & 8.2414 & TRN & \\
\hline CHEMBL3965485 & 1641034 & 7.0506 & 7.1419 & TRN & \\
\hline CHEMBL3931226 & 1641034 & 8.5086 & 8.3452 & TRN & \\
\hline CHEMBL3981338 & 1641034 & 8.0 & 8.3927 & TRN & \\
\hline CHEMBL3906460 & 1641034 & 8.0 & 7.475 & TRN & \\
\hline CHEMBL3903353 & 1641034 & 7.4949 & 7.3497 & TRN & \\
\hline CHEMBL3891204 & 1641034 & 7.284 & 7.7676 & TRN & \\
\hline CHEMBL3949461 & 1641034 & 7.8539 & 7.5719 & TRN & \\
\hline CHEMBL3957990 & 1641034 & 8.7959 & 8.5275 & TRN & \\
\hline CHEMBL 3985390 & 1641034 & 8.1612 & 7.725 & TRN & \\
\hline CHEMBL3971373 & 1641034 & 8.2757 & \multicolumn{2}{|c|}{8.187999999999999} & TRN \\
\hline CHEMBL3896712 & 1641034 & 6.5528 & 6.941 & TRN & \\
\hline CHEMBL3967880 & 1641034 & 8.3665 & 8.0137 & TRN & \\
\hline CHEMBL3907394 & 1641034 & 7.3188 & 7.4147 & TRN & \\
\hline CHEMBL 3904453 & 1641034 & 7.6576 & 7.0492 & TRN & \\
\hline CHEMBL3900631 & 1641034 & 8.1871 & 7.7645 & TRN & \\
\hline CHEMBL 3973060 & 1641034 & 7.7447 & 7.6522 & TST & \\
\hline CHEMBL3907503 & 1641034 & 8.0915 & 8.1477 & TRN & \\
\hline CHEMBL3973486 & 1641034 & 7.0223 & 7.0857 & TRN & \\
\hline CHEMBL 3904571 & 1641034 & \multicolumn{3}{|c|}{ 8. 283999999999999} & TRN \\
\hline CHEMBL3968423 & 1641034 & 6.0 & 6.7179 & TRN & \\
\hline CHEMBL 3923184 & 1641034 & 8.4815 & 8.1855 & TRN & \\
\hline CHEMBL3985603 & 1641034 & 7.9586 & 7.8521 & TRN & \\
\hline CHEMBL3902205 & 1641034 & 7.3372 & 7.7648 & TRN & \\
\hline CHEMBL 3897850 & 1641034 & 6.9208 & 5.9485 & TRN & \\
\hline CHEMBL3962117 & 1641034 & 8.1192 & 8.0832 & TRN & \\
\hline
\end{tabular}


Supplemental Table S2.txt

\begin{tabular}{|c|c|c|c|c|}
\hline CHEMBL3921442 & 1641034 & 8.4437 & 8.1861 & TRN \\
\hline CHEMBL3950399 & 1641034 & 7.6383 & 7.6759 & TST \\
\hline CHEMBL3920352 & 1641034 & 6.2596 & 6.1013 & TST \\
\hline CHEMBL3896566 & 1641034 & 8.8239 & 8.8567 & TST \\
\hline CHEMBL3942304 & 1641034 & 7.6778 & 8.2151 & TST \\
\hline CHEMBL3960109 & 1641034 & 8.1308 & 8.0448 & TST \\
\hline CHEMBL 3907944 & 1641034 & 7.9586 & 8.0782 & TST \\
\hline CHEMBL3972475 & 1641034 & 9.4949 & 9.2597 & TST \\
\hline CHEMBL3922488 & 1641034 & 7.6021 & 7.3211 & TST \\
\hline CHEMBL 3980241 & 1641034 & 6.0 & 6.8439 & TST \\
\hline CHEMBL 3953486 & 1641034 & 8.2757 & 8.4302 & TST \\
\hline CHEMBL 3940483 & 1641034 & 7.5528 & 7.8121 & TST \\
\hline CHEMBL 3899570 & 1641034 & 8.0655 & 8.3753 & TST \\
\hline CHEMBL3902431 & 1641034 & 7.5086 & 7.69600 & 6 \\
\hline CHEMBL 3905627 & 1641034 & 9.0269 & 9.0174 & TST \\
\hline CHEMBL 3905498 & 1641034 & 8.0915 & 8.252 & TST \\
\hline CHEMBL3922520 & 1641034 & 8.5376 & 7.9856 & TST \\
\hline CHEMBL 3980120 & 1641034 & 7.5229 & 7.9306 & TST \\
\hline CHEMBL 3947742 & 1641034 & 6.0 & 7.1283 & TST \\
\hline CHEMBL 3917774 & 1641034 & 8.4815 & 8.5807 & TST \\
\hline CHEMBL 3911874 & 1641034 & 7.699 & 7.7158 & TST \\
\hline CHEMBL3976885 & 1641034 & 7.2218 & 7.0818 & TST \\
\hline CHEMBL3946125 & 1641034 & 8.6021 & 8.1543 & TST \\
\hline CHEMBL 3941431 & 1641034 & 8.2076 & 8.0547 & TST \\
\hline CHEMBL 3986377 & 1641034 & 8.7959 & 8.7202 & TST \\
\hline CHEMBL 3955720 & 1641034 & 8.6778 & 8.6183 & TST \\
\hline CHEMBL3958797 & 1641034 & 7.7212 & 8.176 & TST \\
\hline CHEMBL3935408 & 1641034 & 7.699 & 8.0658 & TST \\
\hline CHEMBL3957659 & 1641034 & 8.2757 & 8.4296 & TST \\
\hline CHEMBL3906967 & 1641034 & 6.0 & 7.1203 & TST \\
\hline CHEMBL 3897648 & 1641034 & 7.6383 & 7.5003 & TST \\
\hline CHEMBL 3971898 & 1641034 & 7.6778 & 7.8148 & TST \\
\hline CHEMBL 3949195 & 1641034 & 7.0 & 6.7925 & TST \\
\hline CHEMBL 3962138 & 1641034 & 8.7696 & 8.2311 & TST \\
\hline CHEMBL3928091 & 1641034 & 7.6198 & 7.9121 & TST \\
\hline CHEMBL3907076 & 1641034 & 6.0 & 6.9311 & TST \\
\hline CHEMBL3907648 & 1641034 & 7.6576 & 7.6277 & TST \\
\hline CHEMBL 3983127 & 1641034 & 7.4815 & 7.79 & TST \\
\hline CHEMBL 3967397 & 1641034 & 8.2757 & 8.0865 & TST \\
\hline CHEMBL3963532 & 1641034 & 6.6383 & 7.5785 & TST \\
\hline CHEMBL 3908073 & 1641034 & 8.2291 & 8.043 & TST \\
\hline CHEMBL3975123 & 1641034 & 6.4437 & 7.3147 & TST \\
\hline CHEMBL1508723 & 737150 & 4.9101 & 4.444 & TRN \\
\hline CHEMBL 1450208 & 737150 & 5.0079 & 4.862 & TRN \\
\hline CHEMBL1733271 & 737150 & 4.9706 & 3.8957 & TRN \\
\hline CHEMBL1387990 & 737150 & 3.699 & 5.1817 & TST \\
\hline CHEMBL1727981 & 737150 & 6.0605 & 5.6464 & TRN \\
\hline CHEMBL1299637 & 737150 & 5.1701 & 5.3498 & TST \\
\hline
\end{tabular}


Supplemental Table S2.txt

\begin{tabular}{|c|c|c|c|c|c|}
\hline CHEMBL1387448 & 737150 & 3.699 & 3.4262 & TRN & \\
\hline CHEMBL1342760 & 737150 & 3.699 & 4.8316 & TRN & \\
\hline CHEMBL1332003 & 737150 & 3.699 & 3.657 & TRN & \\
\hline CHEMBL1706335 & 737150 & 6.1238 & 5.2275 & TST & \\
\hline CHEMBL1321508 & 737150 & 3.699 & 3.7876 & TRN & \\
\hline CHEMBL1700826 & 737150 & 3.699 & 3.9576 & TRN & \\
\hline CHEMBL1535050 & 737150 & 3.699 & 3.8357 & TRN & \\
\hline CHEMBL1384893 & 737150 & 3.699 & 4.4089 & TRN & \\
\hline CHEMBL1729147 & 737150 & 3.699 & 3.6105 & TRN & \\
\hline CHEMBL1569954 & 737150 & 6.0 & 4.5607 & TRN & \\
\hline CHEMBL1703685 & 737150 & 5.8665 & 5.4798 & TRN & \\
\hline CHEMBL1426966 & 737150 & 5.0862 & 4.9236 & TST & \\
\hline CHEMBL1717510 & 737150 & 3.699 & 3.6506 & TRN & \\
\hline CHEMBL1716673 & 737150 & 3.699 & 3.9014 & TRN & \\
\hline CHEMBL1302130 & 737150 & 5.6289 & 5.0634 & TST & \\
\hline CHEMBL1542558 & 737150 & 4.7447 & 4.46 & TRN & \\
\hline CHEMBL1349185 & 737150 & 3.699 & 3.6977 & TRN & \\
\hline CHEMBL1734357 & 737150 & 3.699 & 3.4753 & TRN & \\
\hline CHEMBL1417851 & 737150 & 8.4078 & 5.7681 & TST & \\
\hline CHEMBL1728008 & 737150 & 3.699 & 4.5607 & TRN & \\
\hline CHEMBL1472748 & 737150 & 3.699 & 4.6049 & TRN & \\
\hline CHEMBL1724688 & 737150 & 3.699 & 3.9424 & TRN & \\
\hline CHEMBL1521474 & 737150 & 3.699 & 3.7408 & TRN & \\
\hline CHEMBL1578700 & 737150 & 5.1818 & 5.2757 & TRN & \\
\hline CHEMBL1335978 & 737150 & 5.1302 & 5.1368 & TRN & \\
\hline CHEMBL1704929 & 737150 & 3.699 & 4.0087 & TRN & \\
\hline CHEMBL1720257 & 737150 & 5.2396 & 5.3752 & TRN & \\
\hline CHEMBL1325227 & 737150 & 3.699 & 4.6916 & TST & \\
\hline CHEMBL1568877 & 737150 & 5.3261 & 4.9612 & TRN & \\
\hline CHEMBL1427550 & 737150 & 3.699 & 4.3035 & TST & \\
\hline CHEMBL599890 & 737150 & 3.699 & 4.5319 & TST & \\
\hline CHEMBL1411639 & 737150 & 5.6757 & 5.4534 & TRN & \\
\hline CHEMBL1554526 & 737150 & 5.4976 & 4.8059 & TRN & \\
\hline CHEMBL1529741 & 737150 & 4.9031 & \multicolumn{2}{|c|}{5.207000000000001} & TRN \\
\hline CHEMBL1699128 & 737150 & 6.6091 & 6.3229 & TRN & \\
\hline CHEMBL552443 & 737150 & 3.699 & 4.4699 & TRN & \\
\hline CHEMBL1410618 & 737150 & 3.699 & 4.0457 & TRN & \\
\hline CHEMBL1485417 & 737150 & 5.8416 & 5.8833 & TRN & \\
\hline CHEMBL65374 & 737150 & 5.6576 & 5.28 & TRN & \\
\hline CHEMBL1327276 & 737150 & 5.3179 & 4.8102 & TST & \\
\hline CHEMBL1468596 & 737150 & 4.9914 & 5.3178 & TRN & \\
\hline CHEMBL1338507 & 737150 & 3.699 & 3.6363 & TRN & \\
\hline CHEMBL1732490 & 737150 & 7.4283 & 7.4538 & TRN & \\
\hline CHEMBL1698072 & 737150 & 3.699 & 5.0751 & TRN & \\
\hline CHEMBL1714566 & 737150 & 3.699 & 3.7731 & TRN & \\
\hline CHEMBL1405076 & 737150 & 3.699 & 3.7917 & TRN & \\
\hline CHEMBL1705298 & 737150 & 5.3893 & 5.5071 & TST & \\
\hline CHEMBL1537124 & 737150 & 5.2204 & 5.2213 & TRN & \\
\hline
\end{tabular}

Page 27784 


\begin{tabular}{|c|c|c|c|c|c|}
\hline \multicolumn{6}{|c|}{ Supplemental Table S2.txt } \\
\hline CHEMBL1360862 & 737150 & 4.9431 & 4.5513 & TRN & \\
\hline CHEMBL1714724 & 737150 & 3.699 & 3.6093 & TRN & \\
\hline CHEMBL1556990 & 737150 & 3.699 & 3.4031 & TRN & \\
\hline CHEMBL1732337 & 737150 & 6.6271 & 6.064 & TRN & \\
\hline CHEMBL1450407 & 737150 & 5.4145 & 5.6048 & TRN & \\
\hline CHEMBL1541475 & 737150 & 3.699 & 3.5251 & TRN & \\
\hline CHEMBL1712022 & 737150 & 3.699 & 4.2764 & TRN & \\
\hline CHEMBL1600776 & 737150 & 5.3726 & 5.2926 & TST & \\
\hline CHEMBL1726092 & 737150 & 3.699 & 3.6872 & TRN & \\
\hline CHEMBL1711273 & 737150 & 5.3556 & 5.1821 & TRN & \\
\hline CHEMBL1453730 & 737150 & 5.224 & 4.8663 & TST & \\
\hline CHEMBL1543504 & 737150 & 5.0883 & 5.2325 & TST & \\
\hline CHEMBL1380946 & 737150 & 3.699 & 4.1856 & TRN & \\
\hline CHEMBL1718809 & 737150 & 3.699 & 3.6455 & TRN & \\
\hline CHEMBL1708434 & 737150 & 3.699 & 4.069 & TRN & \\
\hline CHEMBL1484482 & 737150 & 5.2557 & 5.1923 & TRN & \\
\hline CHEMBL1595790 & 737150 & 8.4078 & 6.013 & TST & \\
\hline CHEMBL1733280 & 737150 & 5.3645 & 5.0756 & TRN & \\
\hline CHEMBL1325644 & 737150 & 3.699 & 4.0669 & TST & \\
\hline CHEMBL1705002 & 737150 & 7.433 & 7.4928 & TRN & \\
\hline CHEMBL3145330 & 737150 & 3.699 & 3.9755 & TST & \\
\hline CHEMBL1525546 & 737150 & 3.699 & 3.7002 & TST & \\
\hline CHEMBL1487136 & 737150 & 7.1007 & 6.7188 & TRN & \\
\hline CHEMBL1727369 & 737150 & 3.699 & 4.176 & TRN & \\
\hline CHEMBL1708215 & 737150 & 3.699 & 3.8518 & TRN & \\
\hline CHEMBL1729430 & 737150 & 4.8069 & 4.9428 & TST & \\
\hline CHEMBL1502127 & 737150 & 5.2062 & 5.5942 & TRN & \\
\hline CHEMBL1461631 & 737150 & 6.699 & 6.2972 & TRN & \\
\hline CHEMBL1581027 & 737150 & 3.699 & 3.4428 & TRN & \\
\hline CHEMBL3192230 & 737150 & 4.9626 & 4.957 & TRN & \\
\hline CHEMBL1735377 & 737150 & 3.699 & 4.1367 & TST & \\
\hline CHEMBL1529494 & 737150 & 4.9101 & 4.8491 & TRN & \\
\hline CHEMBL1482357 & 737150 & 3.699 & 4.2487 & TRN & \\
\hline CHEMBL1388356 & 737150 & 4.7878 & 4.71899 & 9999999999 & TST \\
\hline CHEMBL1525940 & 737150 & 3.699 & 4.1575 & TRN & \\
\hline CHEMBL1530557 & 737150 & 5.5017 & 5.4002 & TRN & \\
\hline CHEMBL1542483 & 737150 & 4.9066 & 4.5686 & TRN & \\
\hline CHEMBL1717116 & 737150 & 5.3665 & 5.3697 & TRN & \\
\hline CHEMBL1706800 & 737150 & 5.1662 & 5.5095 & TRN & \\
\hline CHEMBL1732890 & 737150 & 4.8761 & 4.9166 & TRN & \\
\hline CHEMBL1599782 & 737150 & 4.9547 & 4.9406 & TRN & \\
\hline CHEMBL1449663 & 737150 & 4.8729 & 4.6354 & TRN & \\
\hline CHEMBL1608707 & 737150 & 4.8861 & 4.5775 & TST & \\
\hline CHEMBL1719579 & 737150 & 3.699 & 4.6071 & TRN & \\
\hline CHEMBL1316316 & 737150 & 3.699 & 3.9376 & TRN & \\
\hline CHEMBL1730320 & 737150 & 3.699 & 3.8687 & TRN & \\
\hline CHEMBL1373066 & 737150 & 4.8097 & 4.3616 & TRN & \\
\hline CHEMBL1370066 & 737150 & 3.699 & 3.79600 & 00000000003 & TRN \\
\hline & & & & 27785 & \\
\hline
\end{tabular}


Supplemental Table S2.txt

\begin{tabular}{|c|c|c|c|c|c|}
\hline CHEMBL1382232 & 737150 & 3.699 & 3.4762 & TRN & \\
\hline CHEMBL1354394 & 737150 & 4.7055 & 4.7065 & TRN & \\
\hline CHEMBL1734509 & 737150 & 5.7375 & 5.7605 & TRN & \\
\hline CHEMBL1519988 & 737150 & 3.699 & 3.9331 & TRN & \\
\hline CHEMBL1716085 & 737150 & 3.699 & 3.4629 & TRN & \\
\hline CHEMBL1341697 & 737150 & 4.9872 & 5.1788 & TST & \\
\hline CHEMBL1718692 & 737150 & 3.699 & 3.8451 & TRN & \\
\hline CHEMBL1538154 & 737150 & 5.3288 & 5.3871 & TRN & \\
\hline CHEMBL1333987 & 737150 & 5.153 & 4.4711 & TST & \\
\hline CHEMBL1719472 & 737150 & 3.699 & 3.9216 & TRN & \\
\hline CHEMBL1597561 & 737150 & 7.341 & 6.33200 & 0000000001 & TST \\
\hline CHEMBL1700382 & 737150 & 3.699 & 3.78800 & 00000000003 & TRN \\
\hline CHEMBL1612423 & 737150 & 6.0 & 4.6071 & TRN & \\
\hline CHEMBL1434007 & 737150 & 3.699 & 3.4431 & TRN & \\
\hline CHEMBL1369425 & 737150 & 5.1186 & 5.5204 & TRN & \\
\hline CHEMBL1606820 & 737150 & 4.7825 & 4.2501 & TST & \\
\hline CHEMBL1706268 & 737150 & 5.056 & 5.098 & TRN & \\
\hline CHEMBL1700643 & 737150 & 4.9031 & 4.3799 & TRN & \\
\hline CHEMBL1731580 & 737150 & 3.699 & 4.3544 & TRN & \\
\hline CHEMBL1466495 & 737150 & 5.063 & 4.9284 & TST & \\
\hline CHEMBL1369879 & 737150 & 5.3737 & 5.1441 & TST & \\
\hline CHEMBL1384652 & 737150 & 5.2351 & 5.3263 & TST & \\
\hline CHEMBL1736760 & 737150 & 3.699 & 3.6728 & TRN & \\
\hline CHEMBL1562819 & 737150 & 5.2 & 5.2347 & TST & \\
\hline CHEMBL1405985 & 737150 & 5.3344 & 5.1727 & TRN & \\
\hline CHEMBL1299281 & 737150 & 5.3288 & 5.0822 & TRN & \\
\hline CHEMBL1532328 & 737150 & 5.5406 & 5.0381 & TRN & \\
\hline CHEMBL1333593 & 737150 & 5.1624 & 5.0756 & TRN & \\
\hline CHEMBL1320366 & 737150 & 3.699 & 3.378 & TRN & \\
\hline CHEMBL1481543 & 737150 & 7.1512 & 6.4969 & TRN & \\
\hline CHEMBL1729457 & 737150 & 3.699 & 3.7913 & TRN & \\
\hline CHEMBL1526705 & 737150 & 3.699 & 3.4008 & TRN & \\
\hline CHEMBL1323512 & 737150 & \multicolumn{2}{|c|}{5.202000000000001} & 5.6775 & TRN \\
\hline CHEMBL1480238 & 737150 & 6.6383 & 6.3469 & TRN & \\
\hline CHEMBL1611733 & 737150 & 5.4976 & 5.308 & TST & \\
\hline CHEMBL1700889 & 737150 & 4.8508 & 4.9249 & TRN & \\
\hline CHEMBL1730398 & 737150 & 3.699 & 3.4128 & TRN & \\
\hline CHEMBL1388113 & 737150 & 5.4921 & 5.0279 & TST & \\
\hline CHEMBL1603938 & 737150 & 3.699 & 3.56100 & 00000000004 & TRN \\
\hline CHEMBL1732865 & 737150 & 3.699 & 4.0383 & TRN & \\
\hline CHEMBL1713298 & 737150 & 7.6126 & 7.4426 & TRN & \\
\hline CHEMBL1732803 & 737150 & 5.4202 & 5.1994 & TST & \\
\hline CHEMBL1393375 & 737150 & 4.8794 & 5.0553 & TRN & \\
\hline CHEMBL1481689 & 737150 & 3.699 & 4.376 & TST & \\
\hline CHEMBL1710228 & 737150 & 3.699 & 3.6524 & TRN & \\
\hline CHEMBL1519375 & 737150 & 4.2029 & 4.9388 & TST & \\
\hline CHEMBL1586616 & 737150 & 5.2306 & 4.7435 & TST & \\
\hline CHEMBL1571150 & 737150 & 4.8386 & 4.7825 & TRN & \\
\hline
\end{tabular}




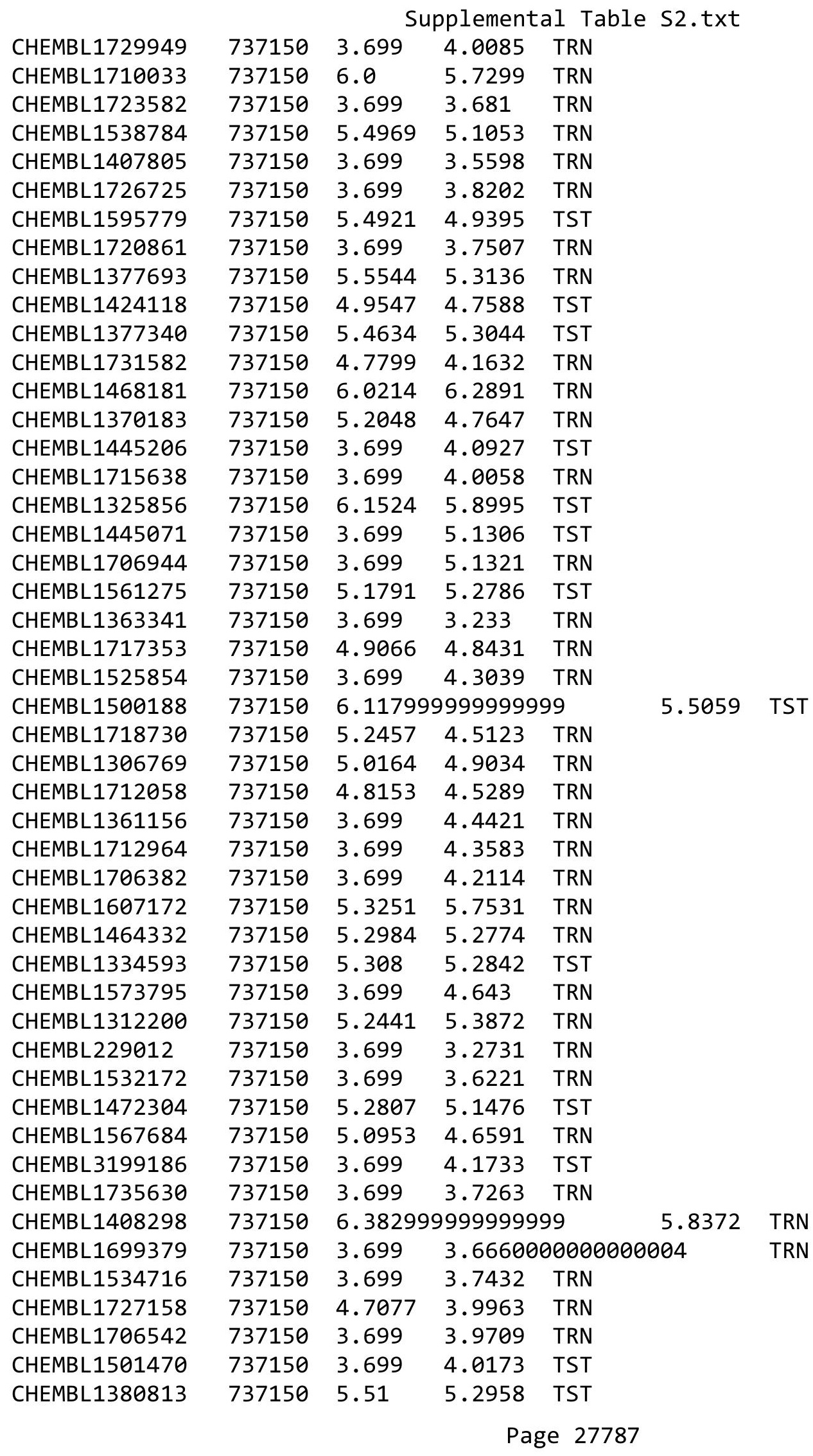


Supplemental Table S2.txt

\begin{tabular}{|c|c|c|c|c|c|}
\hline CHEMBL1488993 & 737150 & 3.699 & 3.9871 & TRN & \\
\hline CHEMBL1491541 & 737150 & 4.9586 & 4.9086 & TST & \\
\hline CHEMBL1529395 & 737150 & 5.3536 & 5.2481 & TRN & \\
\hline CHEMBL1736791 & 737150 & 3.699 & 4.3647 & TRN & \\
\hline CHEMBL1411903 & 737150 & 3.699 & 3.2473 & TRN & \\
\hline CHEMBL1433326 & 737150 & 3.699 & 3.6582 & TRN & \\
\hline CHEMBL1562608 & 737150 & 3.699 & 4.0171 & TRN & \\
\hline CHEMBL1372398 & 737150 & 5.3536 & 5.5883 & TRN & \\
\hline CHEMBL1524014 & 737150 & 6.7471 & 6.3411 & TRN & \\
\hline CHEMBL1708503 & 737150 & 5.5654 & 5.3077 & TRN & \\
\hline CHEMBL1487641 & 737150 & 3.699 & 3.6797 & TRN & \\
\hline CHEMBL1719980 & 737150 & 4.8794 & 4.4671 & TRN & \\
\hline CHEMBL1735926 & 737150 & 5.4855 & 5.695 & TRN & \\
\hline CHEMBL1308276 & 737150 & 5.426 & 5.2831 & TST & \\
\hline CHEMBL1424982 & 737150 & 3.699 & 3.3014 & TRN & \\
\hline CHEMBL1447125 & 737150 & 5.0246 & 5.1317 & TST & \\
\hline CHEMBL1299751 & 737150 & 5.3439 & 5.614 & TRN & \\
\hline CHEMBL1492752 & 737150 & 6.1475 & 5.2847 & TRN & \\
\hline CHEMBL1329930 & 737150 & 6.0555 & 5.9014 & TRN & \\
\hline CHEMBL1400601 & 737150 & 4.82100 & 000000000 & 4.6593 & TRN \\
\hline CHEMBL1392142 & 737150 & 8.4078 & 6.4442 & TST & \\
\hline CHEMBL1542713 & 737150 & 5.3382 & 4.8684 & TRN & \\
\hline CHEMBL1412853 & 737150 & 3.699 & 3.5816 & TRN & \\
\hline CHEMBL1387232 & 737150 & 4.7011 & 3.871000 & 00000000004 & TRN \\
\hline CHEMBL1721154 & 737150 & 3.699 & 3.6215 & TRN & \\
\hline CHEMBL1420187 & 737150 & 5.1871 & 5.4469 & TRN & \\
\hline CHEMBL67930 & 737150 & 3.699 & 4.5409 & TRN & \\
\hline CHEMBL1319304 & 737150 & 5.9281 & 6.0972 & TRN & \\
\hline CHEMBL1439726 & 737150 & 3.699 & 3.7911 & TRN & \\
\hline CHEMBL1698647 & 737150 & 3.699 & 3.5855 & TRN & \\
\hline CHEMBL1441295 & 737150 & 3.699 & 3.3995 & TRN & \\
\hline CHEMBL1709705 & 737150 & 6.2336 & 5.7511 & TRN & \\
\hline CHEMBL1401026 & 737150 & 5.6799 & 4.8915 & TST & \\
\hline CHEMBL1569988 & 737150 & \multicolumn{3}{|c|}{5.821000000000001} & TRN \\
\hline CHEMBL1333821 & 737150 & 5.7077 & 5.2376 & TST & \\
\hline CHEMBL1504170 & 737150 & 3.699 & 3.9376 & TRN & \\
\hline CHEMBL1528258 & 737150 & 3.699 & 4.5936 & TST & \\
\hline CHEMBL1731586 & 737150 & 5.27 & 4.3263 & TRN & \\
\hline CHEMBL1698552 & 737150 & 3.699 & 3.4186 & TRN & \\
\hline CHEMBL1703493 & 737150 & 3.699 & 4.1633 & TRN & \\
\hline CHEMBL1728408 & 737150 & 3.699 & 3.7073 & TRN & \\
\hline CHEMBL1525735 & 737150 & 5.5467 & 5.5972 & TRN & \\
\hline CHEMBL1411091 & 737150 & 3.699 & 4.0282 & TST & \\
\hline CHEMBL1481570 & 737150 & 3.699 & 3.7583 & TRN & \\
\hline CHEMBL1372308 & 737150 & 5.1791 & 5.1015 & TRN & \\
\hline CHEMBL1495977 & 737150 & 6.3354 & 6.1366 & TRN & \\
\hline CHEMBL1717950 & 737150 & 3.699 & 3.8069 & TRN & \\
\hline CHEMBL1703491 & 737150 & 3.699 & 5.6179 & TRN & \\
\hline
\end{tabular}


Supplemental Table S2.txt

\begin{tabular}{|c|c|c|c|c|}
\hline HEMBL172 & & 599 & 18 & TRI \\
\hline HFMBI 1709026 & 37150 & & 37625 & \\
\hline HEMBL17 & & & 9922 & \\
\hline AEMBL1433943 & 7150 & 1778 & 828 & \\
\hline HEMBL1489105 & 37150 & 9469 & 0152 & \\
\hline HEMBL1 & 50 & 721 & .8784 & \\
\hline AEMBL16 & & 2104 & .8853 & \\
\hline HEMBL1 & 50 & 53 & 3457 & \\
\hline HEMBL1305007 & 37150 & 99 & 4543 & \\
\hline HEMBL1723575 & 50 & .699 & .5408 & \\
\hline HEMBL17 & 50 & 295 & 8545 & \\
\hline HEMBL1 & & 861 & & RN \\
\hline HEMBL1 & 50 & 942 & 9516 & \\
\hline HEMBL17 & 50 & 599 & 801 & \\
\hline HEMBL17 & 50 & & & \\
\hline HEMBL1 & 50 & & 218 & \\
\hline HEMBL1 & & 878 & & RN \\
\hline HEMBL1 & 50 & 99 & 3348 & RN \\
\hline HEMBL1 & & & 107 & \\
\hline AEMBL14 & 50 & 99 & 2462 & וכ \\
\hline HEMBLI & 0 & $77 \varepsilon$ & 019 & SI \\
\hline HEMBL: & & & 05 & $\mathrm{RN}$ \\
\hline HEMBL1 & 50 & 666 & 988 & \\
\hline HEMBL: & & & & IST \\
\hline AEMBL1 & 50 & 027 & 3504 & |S| \\
\hline HEMBL1 & & 871 & 657 & ST \\
\hline AEME & & & & ST \\
\hline 54 & & & & IST \\
\hline AEMBL1 & & & & $|S|$ \\
\hline AEMBL1C & $\theta$ & 238 & 694 & TST \\
\hline HEMBLI & & 214 & 506 & ST \\
\hline$I 5 M$ & & 85 & & RN \\
\hline & & & & RN \\
\hline AEMBL2 & & & 31 & ГST \\
\hline AEMBL1: & & 045 & 371 & 「RN \\
\hline HEMBL2 & & 695 & 24 & 「RN \\
\hline & & & & 「RN \\
\hline HEMBL1 & & & & $\mathrm{RN}$ \\
\hline AEMBL3 & & 036 & 546 & 「RN \\
\hline IEMBL4 & & 397 & 2773 & RN \\
\hline HEMBL5 & & 395 & & \\
\hline & & 3.7714 & & RN \\
\hline HEMBL17 & & 1247 & & RN \\
\hline AEMBL3 & & 603 & 542 & TR \\
\hline 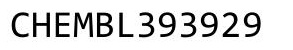 & & & 523 & \\
\hline CHEMBL 51 & & 7.6245 & 7.3627 & \\
\hline CHEMBL2363137 & & 5.7087 & 5.8548 & \\
\hline CHEMBL191334 & 954567 & 3.4657 & 3.3192 & ГRN \\
\hline
\end{tabular}

Page 27789 


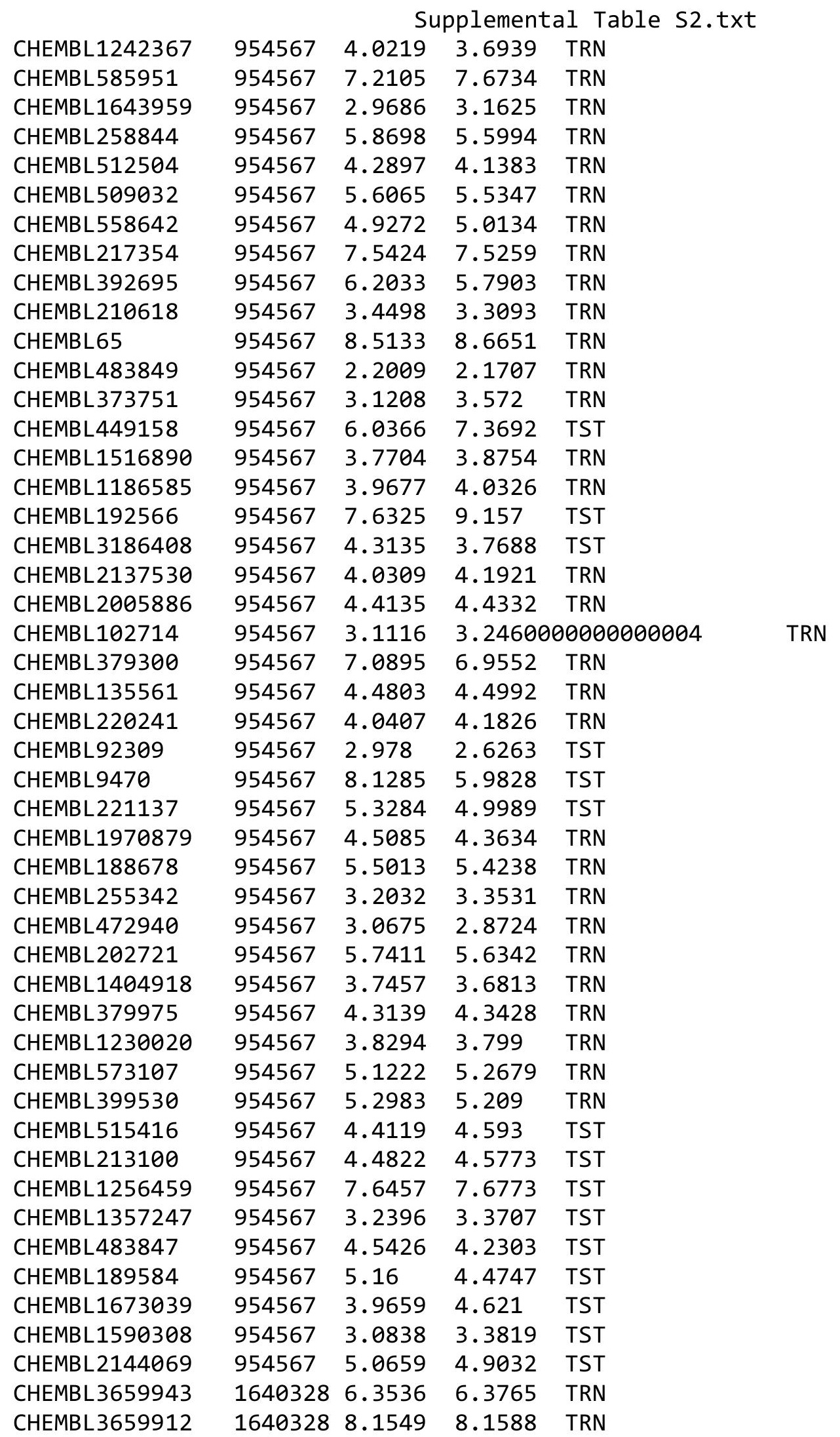

Page 27790 
Supplemental Table S2.txt

\begin{tabular}{|c|c|c|c|c|c|}
\hline CHEMBL3659949 & 1640328 & 6.6402 & 6.7591 & TRN & \\
\hline CHEMBL3659951 & 1640328 & 6.4389 & 6.4622 & TRN & \\
\hline CHEMBL3659934 & 1640328 & 6.9957 & 6.6921 & TRN & \\
\hline CHEMBL3659919 & 1640328 & 7.9208 & 7.9197 & TRN & \\
\hline CHEMBL3659917 & 1640328 & 7.9208 & 7.8858 & TRN & \\
\hline CHEMBL3659939 & 1640328 & \multicolumn{3}{|c|}{6.821000000000001} & TRN \\
\hline CHEMBL3659916 & 1640328 & 8.3979 & 7.5835 & TST & \\
\hline CHEMBL 3659958 & 1640328 & 7.6383 & 7.7368 & TST & \\
\hline CHEMBL 3659947 & 1640328 & 6.5436 & 6.6977 & TRN & \\
\hline CHEMBL3659932 & 1640328 & 6.1952 & 6.407 & TRN & \\
\hline CHEMBL3659921 & 1640328 & 6.8539 & 7.022 & TRN & \\
\hline CHEMBL3659941 & 1640328 & 6.5901 & 6.6248 & TRN & \\
\hline CHEMBL3659935 & 1640328 & 6.3655 & 6.6077 & TRN & \\
\hline CHEMBL3659925 & 1640328 & 6.6478 & 6.7457 & TRN & \\
\hline CHEMBL3659914 & 1640328 & 8.3979 & 7.8793 & TST & \\
\hline CHEMBL3659937 & 1640328 & 6.4634 & 6.5011 & TRN & \\
\hline CHEMBL3659956 & 1640328 & 6.3045 & 6.175 & TRN & \\
\hline CHEMBL3659961 & 1640328 & 6.5702 & 6.5529 & TRN & \\
\hline CHEMBL3659942 & 1640328 & 6.5406 & 6.6047 & TRN & \\
\hline CHEMBL3659964 & 1640328 & 8.0969 & 7.5785 & TST & \\
\hline CHEMBL3659962 & 1640328 & 5.7913 & 5.9312 & TRN & \\
\hline CHEMBL3659940 & 1640328 & 6.7328 & 6.568 & TRN & \\
\hline CHEMBL 3659945 & 1640328 & 6.5498 & 6.7041 & TRN & \\
\hline CHEMBL3659913 & 1640328 & 7.8239 & 7.737 & TRN & \\
\hline CHEMBL 3659960 & 1640328 & 6.7212 & 6.9159 & TRN & \\
\hline CHEMBL3659966 & 1640328 & 7.9586 & 7.9812 & TST & \\
\hline CHEMBL3659944 & 1640328 & 6.7696 & 6.5101 & TRN & \\
\hline CHEMBL3659965 & 1640328 & 7.7447 & 7.2313 & TST & \\
\hline CHEMBL3659952 & 1640328 & 6.2757 & 6.2271 & TRN & \\
\hline CHEMBL 3659923 & 1640328 & 7.3565 & 7.3454 & TRN & \\
\hline CHEMBL3659931 & 1640328 & 7.301 & 6.79899 & 99999999995 & 1. \\
\hline CHEMBL3659938 & 1640328 & 7.1549 & 7.0181 & TRN & \\
\hline CHEMBL3659959 & 1640328 & 6.5834 & 6.5607 & TST & \\
\hline CHEMBL3659910 & 1640328 & 8.1549 & 7.8754 & TST & \\
\hline CHEMBL 3659908 & 1640328 & 7.9586 & 7.5566 & TRN & \\
\hline CHEMBL3659906 & 1640328 & 6.5003 & 6.2023 & TRN & \\
\hline CHEMBL3659922 & 1640328 & 7.585 & 7.41100 & 20000000005 & \\
\hline CHEMBL3659915 & 1640328 & 8.301 & 7.6789 & TST & \\
\hline CHEMBL3659905 & 1640328 & 6.9747 & 6.894 & TST & \\
\hline CHEMBL3659955 & 1640328 & 6.2343 & 6.2408 & TRN & \\
\hline CHEMBL3659950 & 1640328 & 6.6716 & 6.7215 & TRN & \\
\hline CHEMBL3659957 & 1640328 & 6.3197 & 6.1497 & TRN & \\
\hline CHEMBL3659954 & 1640328 & 6.2976 & 6.2618 & TRN & \\
\hline CHEMBL3659930 & 1640328 & 6.2941 & 6.5363 & TRN & \\
\hline CHEMBL3659911 & 1640328 & 5.6861 & 5.6542 & TRN & \\
\hline CHEMBL3659907 & 1640328 & 4.8539 & 5.1943 & TST & \\
\hline CHEMBL3659953 & 1640328 & 6.2573 & 6.2139 & TRN & \\
\hline CHEMBL3659927 & 1640328 & 7.6198 & 7.7253 & TRN & \\
\hline
\end{tabular}

Page 27791 
Supplemental Table S2.txt

\begin{tabular}{|c|c|c|c|c|}
\hline CHEMBL 3659920 & 1640328 & 7.2441 & 7.3167 & TST \\
\hline CHEMBL 3659929 & 1640328 & 7.6021 & 7.1625 & TRN \\
\hline CHEMBL3659926 & 1640328 & 6.3224 & 6.3289 & TRN \\
\hline CHEMBL 3639587 & 1640328 & 6.6498 & 6.5196 & TST \\
\hline CHEMBL3659948 & 1640328 & 6.5017 & 6.4815 & TRN \\
\hline CHEMBL3659924 & 1640328 & 8.0458 & 7.9287 & TRN \\
\hline CHEMBL 3659967 & 1640328 & 8.301 & 8.0355 & TST \\
\hline CHEMBL3659936 & 1640328 & 6.5302 & 6.5838 & TRN \\
\hline CHEMBL 3659909 & 1640328 & 7.4949 & 8.0032 & TRN \\
\hline CHEMBL3659946 & 1640328 & \multicolumn{2}{|c|}{6.821000000000001} & 6.9425 \\
\hline CHEMBL3659928 & 1640328 & 7.5229 & 7.5636 & TRN \\
\hline CHEMBL 3659933 & 1640328 & 5.8365 & 6.3387 & TRN \\
\hline CHEMBL 3659963 & 1640328 & 8.3979 & 7.7121 & TST \\
\hline CHEMBL3659918 & 1640328 & 7.4559 & 7.3636 & TRN \\
\hline CHEMBL 2037262 & 820996 & 4.585 & 4.286006 & 00000000005 \\
\hline CHEMBL 2037167 & 820996 & 3.2596 & 3.3774 & TRN \\
\hline CHEMBL 2037245 & 820996 & 3.6778 & 4.3022 & TRN \\
\hline CHEMBL 2037246 & 820996 & 3.0 & 3.1225 & TRN \\
\hline CHEMBL 2037252 & 820996 & 3.0 & 2.7599 & TRN \\
\hline CHEMBL 2037247 & 820996 & 3.0 & 3.1214 & TRN \\
\hline CHEMBL 2037257 & 820996 & 5.3468 & 4.9621 & TRN \\
\hline CHEMBL1164403 & 820996 & 5.8239 & 4.096 & TST \\
\hline CHEMBL1093220 & 820996 & 3.0 & 3.4152 & TRN \\
\hline CHEMBL 2037240 & 820996 & 4.6576 & 4.4534 & TRN \\
\hline CHEMBL 2037250 & 820996 & 3.0 & 3.5454 & TRN \\
\hline CHEMBL 2037179 & 820996 & 5.7328 & 5.5154 & TRN \\
\hline CHEMBL 2037168 & 820996 & 3.3565 & 3.3868 & TRN \\
\hline CHEMBL 2037169 & 820996 & 4.7696 & 4.2053 & TRN \\
\hline CHEMBL 2037159 & 820996 & 3.0 & 3.9005 & TRN \\
\hline CHEMBL 2037269 & 820996 & 5.7696 & 4.7883 & TST \\
\hline CHEMBL 2037241 & 820996 & 4.2218 & 3.9422 & TRN \\
\hline CHEMBL 2037254 & 820996 & 3.0 & 3.2219 & TRN \\
\hline CHEMBL1092985 & 820996 & 4.6778 & 4.8915 & TRN \\
\hline CHEMBL 2037258 & 820996 & 3.0 & 3.6387 & TRN \\
\hline CHEMBL 2037260 & 820996 & 5.3979 & 5.2401 & TRN \\
\hline CHEMBL 2037164 & 820996 & 3.2218 & 2.6406 & TRN \\
\hline CHEMBL 2037175 & 820996 & 5.5935 & 5.3987 & TRN \\
\hline CHEMBL 2037249 & 820996 & 3.0 & 3.4009 & TST \\
\hline CHEMBL 2035004 & 820996 & 4.0 & 4.0829 & TRN \\
\hline CHEMBL 2037166 & 820996 & 4.7447 & 3.512 & TRN \\
\hline CHEMBL 2037178 & 820996 & 4.7447 & 5.3184 & TRN \\
\hline CHEMBL 2037160 & 820996 & 4.8239 & 3.9403 & TRN \\
\hline CHEMBL 2037248 & 820996 & 4.6576 & 4.0987 & TRN \\
\hline CHEMBL 2037244 & 820996 & 4.6778 & 3.9307 & TRN \\
\hline CHEMBL 2037264 & 820996 & 4.7959 & 4.744 & TST \\
\hline CHEMBL 2037253 & 820996 & 4.0 & 3.1577 & TST \\
\hline CHEMBL 2037174 & 820996 & 4.9586 & 4.4804 & TRN \\
\hline CHEMBL 2037177 & 820996 & 6.0706 & 5.2326 & TRN \\
\hline
\end{tabular}

Page 27792 


\begin{tabular}{|c|c|c|c|c|c|c|c|}
\hline \multicolumn{8}{|c|}{ Supplemental Table S2.txt } \\
\hline CHEMBL2037261 & 820996 & 3.0 & 4.0322 & TST & & & \\
\hline CHEMBL 2037243 & 820996 & 4.6383 & 2.9754 & TST & & & \\
\hline CHEMBL 2037165 & 820996 & 3.0 & 3.4518 & TRN & & & \\
\hline CHEMBL2037259 & 820996 & 5.1549 & 4.6848 & TST & & & \\
\hline CHEMBL2037173 & 820996 & 4.3468 & 4.0778 & TRN & & & \\
\hline CHEMBL2037161 & 820996 & 3.2366 & 4.0027 & TRN & & & \\
\hline CHEMBL2037256 & 820996 & 4.3565 & 3.65199 & 999999999 & 97 & TST & \\
\hline CHEMBL 2037263 & 820996 & 5.0969 & 5.2743 & TRN & & & \\
\hline CHEMBL2037251 & 820996 & 3.0 & 3.1193 & TST & & & \\
\hline CHEMBL 2037170 & 820996 & 3.0 & 2.8232 & TRN & & & \\
\hline CHEMBL 2037172 & 820996 & 3.0 & 4.1672 & TRN & & & \\
\hline CHEMBL 2037180 & 820996 & 6.0969 & 6.3374 & TRN & & & \\
\hline CHEMBL2037176 & 820996 & 5.4202 & 5.4814 & TRN & & & \\
\hline CHEMBL 2037242 & 820996 & 4.6383 & 3.1326 & TST & & & \\
\hline CHEMBL 2037163 & 820996 & 3.0 & 3.7444 & TRN & & & \\
\hline CHEMBL 2035005 & 820996 & 3.0 & 4.07100 & 000000000 & & TST & \\
\hline CHEMBL2037171 & 820996 & 4.301 & 4.397 & TRN & & & \\
\hline CHEMBL418899 & 820996 & 5.9586 & 4.9676 & TST & & & \\
\hline CHEMBL2037255 & 820996 & 4.2218 & 4.3815 & TRN & & & \\
\hline CHEMBL 2037239 & 820996 & 3.2676 & 3.7999 & TST & & & \\
\hline CHEMBL 2037162 & 820996 & 3.0 & 2.8349 & TRN & & & \\
\hline CHEMBL338492 & 29849 & 5.273 & 5.1025 & TRN & & & \\
\hline CHEMBL140020 & 29849 & 8.09700 & 00000000 & & 3.3839 & TST & \\
\hline CHEMBL138072 & 29849 & 5.42399 & 99999999 & 995 & 5.0262 & TRN & \\
\hline CHEMBL136870 & 29849 & 3.46199 & 99999999 & 997 & 3.1633 & TRN & \\
\hline CHEMBL612100 & 29849 & 6.33700 & 00000000 & & 6.2629 & TRN & \\
\hline CHEMBL139330 & 29849 & 6.181 & 6.2546 & TRN & & & \\
\hline CHEMBL140403 & 29849 & 2.947 & 3.125 & TRN & & & \\
\hline CHEMBL612098 & 29849 & 4.398 & 4.6289 & TRN & & & \\
\hline CHEMBL139908 & 29849 & 3.9 & 3.6749 & TST & & & \\
\hline CHEMBL54727 & 29849 & 6.456 & 6.36700 & 000000000 & & TRN & \\
\hline CHEMBL609671 & 29849 & 6.818 & 6.8154 & TRN & & & \\
\hline CHEMBL136145 & 29849 & 3.35699 & 99999999 & 998 & 3.11899 & 99999999998 & TRN \\
\hline CHEMBL137561 & 29849 & 5.54899 & 99999999 & 995 & 5.6524 & TRN & \\
\hline CHEMBL138988 & 29849 & 3.912 & 4.3891 & TRN & & & \\
\hline CHEMBL136526 & 29849 & 7.46899 & 99999999 & 99 & 7.3845 & TRN & \\
\hline CHEMBL334938 & 29849 & 1.936 & 4.7672 & TST & & & \\
\hline CHEMBL118539 & 29849 & 2.622 & 2.5957 & TRN & & & \\
\hline CHEMBL337142 & 29849 & 3.327 & 3.4144 & TRN & & & \\
\hline CHEMBL136294 & 29849 & 5.224 & 4.9376 & TRN & & & \\
\hline CHEMBL609672 & 29849 & 4.456 & 4.5492 & TRN & & & \\
\hline CHEMBL135086 & 29849 & 3.072 & 2.8451 & TRN & & & \\
\hline CHEMBL612099 & 29849 & 5.20100 & 00000000 & 005 & 5.2896 & TRN & \\
\hline CHEMBL342370 & 29849 & 2.68399 & 99999999 & 997 & 4.0301 & TST & \\
\hline CHEMBL136229 & 29849 & 3.088 & 3.0489 & TRN & & & \\
\hline CHEMBL137226 & 29849 & 3.0 & 2.7356 & TRN & & & \\
\hline CHEMBL136669 & 29849 & 4.16100 & 00000000 & 005 & 4.4788 & TRN & \\
\hline CHEMBL136916 & 29849 & 4.072 & 3.2807 & TST & & & \\
\hline
\end{tabular}




\begin{tabular}{|c|c|c|c|c|c|c|}
\hline & & \multicolumn{5}{|c|}{ Supplemental Table S2.txt } \\
\hline CHEMBL344196 & 29849 & 3.272 & 3.4661 & TRN & & \\
\hline CHEMBL136719 & 29849 & \multicolumn{3}{|c|}{ 4. 388999999999999} & 4.7568 & TRN \\
\hline CHEMBL136670 & 29849 & 3.123 & 3.5077 & TRN & & \\
\hline CHEMBL 342903 & 29849 & 2.762 & 4.4776 & TST & & \\
\hline CHEMBL134914 & 29849 & \multicolumn{3}{|c|}{2.9360000000000004} & 3.0149 & TST \\
\hline CHEMBL342902 & 29849 & 3.64 & 3.5214 & TST & & \\
\hline CHEMBL335108 & 29849 & 3.622 & 3.2516 & TRN & & \\
\hline CHEMBL609150 & 29849 & 6.959 & 6.9533 & TRN & & \\
\hline CHEMBL920 & 29849 & 2.521 & 2.659 & TRN & & \\
\hline CHEMBL136568 & 29849 & 2.821 & 2.7461 & TST & & \\
\hline CHEMBL344924 & 29849 & \multicolumn{3}{|c|}{ 3.2239999999999998 } & 3.4782 & TRN \\
\hline CHEMBL343319 & 29849 & 3.85 & 4.0436 & TRN & & \\
\hline CHEMBL60745 & 29849 & 6.108 & 6.1473 & TRN & & \\
\hline CHEMBL423352 & 29849 & 2.431 & 4.8393 & TST & & \\
\hline CHEMBL609149 & 29849 & 6.013 & 5.6381 & TRN & & \\
\hline CHEMBL135503 & 29849 & 2.535 & 2.5471 & TRN & & \\
\hline CHEMBL137560 & 29849 & \multicolumn{3}{|c|}{5.507000000000001} & 5.3751 & TRN \\
\hline CHEMBL 345031 & 29849 & \multicolumn{3}{|c|}{2.7539999999999996} & 5.0453 & \\
\hline CHEMBL609719 & 29849 & 2.291 & 4.2808 & TST & & \\
\hline CHEMBL136148 & 29849 & \multicolumn{3}{|c|}{3.2239999999999998} & 3.4625 & TIT \\
\hline CHEMBL335439 & 29849 & 2.09 & 4.5089 & TST & & \\
\hline CHEMBL344864 & 29849 & 2.417 & 5.0596 & TST & & \\
\hline CHEMBL 343344 & 29849 & 5.521 & 5.4851 & TRN & & \\
\hline CHEMBL422459 & 29849 & \multicolumn{3}{|c|}{6.0120000000000005} & 6.044 & \\
\hline CHEMBL139259 & 29849 & 3.161 & 4.8413 & TST & & \\
\hline CHEMBL139684 & 29849 & 4.056 & 3.7756 & TRN & & \\
\hline CHEMBL609718 & 29849 & 3.202 & 3.0572 & TRN & & \\
\hline CHEMBL1626784 & 29849 & 3.717 & 3.6152 & TRN & & \\
\hline CHEMBL609668 & 29849 & 5.77 & 5.6893 & TRN & & \\
\hline CHEMBL609409 & 29849 & 5.745 & 5.9657 & TRN & & \\
\hline CHEMBL89250 & 44654 & 5.5017 & 5.3993 & TST & & \\
\hline CHEMBL142900 & 44654 & 5.7447 & 5.8409 & TRN & & \\
\hline CHEMBL322704 & 44654 & 5.7825 & 5.7087 & TRN & & \\
\hline CHEMBL144756 & 44654 & 5.8861 & 5.7871 & TRN & & \\
\hline CHEMBL145311 & 44654 & 5.7825 & 5.7892 & TRN & & \\
\hline CHEMBL91163 & 44654 & 5.3372 & 5.5125 & TRN & & \\
\hline CHEMBL344072 & 44654 & 5.6478 & 5.5567 & TRN & & \\
\hline CHEMBL344274 & 44654 & 5.6882 & 5.7987 & TRN & & \\
\hline CHEMBL144088 & 44654 & 6.4437 & 6.5026 & TRN & & \\
\hline CHEMBL144303 & 44654 & 5.2007 & 5.1798 & TRN & & \\
\hline CHEMBL144411 & 44654 & 3.6021 & 3.9962 & TRN & & \\
\hline CHEMBL144208 & 44654 & 4.6676 & 4.1955 & TRN & & \\
\hline CHEMBL141831 & 44654 & 6.585 & 6.4656 & TRN & & \\
\hline CHEMBL359443 & 44654 & 6.585 & 6.7393 & TRN & & \\
\hline CHEMBL143452 & 44654 & 5.3468 & 5.2757 & TRN & & \\
\hline CHEMBL 343445 & 44654 & 4.3098 & 4.4671 & TST & & \\
\hline CHEMBL343238 & 44654 & 5.9508 & 5.9935 & TRN & & \\
\hline CHEMBL144757 & 44654 & 5.7447 & 4.4671 & TST & & \\
\hline
\end{tabular}




\begin{tabular}{|c|c|c|c|c|c|c|}
\hline \multirow[b]{2}{*}{ CHEMBL107707 } & \multicolumn{6}{|c|}{ Supplemental Table S2.txt } \\
\hline & 44654 & 5.7328 & 6.7456 & TST & & \\
\hline CHEMBL145490 & 44654 & 5.75700 & 00000000 & 01 & 5.8463 & TRN \\
\hline CHEMBL144827 & 44654 & 5.71 & 5.8047 & TRN & & \\
\hline CHEMBL423017 & 44654 & 5.9469 & 5.7862 & TRN & & \\
\hline CHEMBL300584 & 44654 & 7.3979 & 7.3663 & TRN & & \\
\hline CHEMBL34683 & 44654 & 5.5017 & 5.5125 & TRN & & \\
\hline CHEMBL145575 & 44654 & 5.2757 & 5.3798 & TRN & & \\
\hline CHEMBL144386 & 44654 & 5.71 & 5.6626 & TRN & & \\
\hline CHEMBL144848 & 44654 & 6.3768 & 6.2199 & TRN & & \\
\hline CHEMBL144984 & 44654 & 5.8697 & 5.8812 & TRN & & \\
\hline CHEMBL111417 & 44654 & 5.699 & 5.7633 & TRN & & \\
\hline CHEMBL144134 & 44654 & 5.8697 & 6.20799 & 9999999999 & & TST \\
\hline CHEMBL144334 & 44654 & 5.6778 & 5.7025 & TRN & & \\
\hline CHEMBL89977 & 44654 & 5.3565 & 5.3377 & TRN & & \\
\hline CHEMBL33505 & 44654 & 4.8539 & 4.518 & TST & & \\
\hline CHEMBL144999 & 44654 & 5.9586 & 5.8772 & TST & & \\
\hline CHEMBL144617 & 44654 & 6.2366 & 6.1625 & TRN & & \\
\hline CHEMBL146111 & 44654 & 5.7212 & 5.7862 & TRN & & \\
\hline CHEMBL33618 & 44654 & 5.2291 & 5.3993 & TST & & \\
\hline CHEMBL422120 & 44654 & 5.8539 & 5.8841 & TRN & & \\
\hline CHEMBL356077 & 44654 & 6.4318 & 6.4908 & TRN & & \\
\hline CHEMBL110044 & 44654 & 5.7696 & 5.8772 & TST & & \\
\hline CHEMBL144664 & 44654 & 6.4949 & 6.1867 & TRN & & \\
\hline CHEMBL144219 & 44654 & 5.7747 & 5.8498 & TRN & & \\
\hline CHEMBL444340 & 44654 & 5.8928 & 5.9054 & TRN & & \\
\hline CHEMBL109890 & 44654 & 5.3665 & 5.3457 & TRN & & \\
\hline CHEMBL109617 & 44654 & 5.7212 & 5.7871 & TRN & & \\
\hline CHEMBL14832 & 44654 & 5.9788 & 6.7456 & TST & & \\
\hline CHEMBL91898 & 44654 & 5.1249 & 4.518 & TST & & \\
\hline CHEMBL 345004 & 44654 & 7.7212 & 7.7412 & TRN & & \\
\hline CHEMBL444347 & 44654 & 5.7447 & 5.3377 & TST & & \\
\hline CHEMBL146602 & 44654 & 5.7959 & 6.20799 & 9999999999 & & TST \\
\hline CHEMBL 3900584 & 1641040 & 8.3279 & 8.0629 & TRN & & \\
\hline CHEMBL3969607 & 1641040 & 6.0 & 6.0842 & TST & & \\
\hline CHEMBL3894126 & 1641040 & 6.0969 & 6.2687 & TRN & & \\
\hline CHEMBL 3931784 & 1641040 & 6.0 & 5.9943 & TRN & & \\
\hline CHEMBL3981060 & 1641040 & 6.0 & 6.4718 & TRN & & \\
\hline CHEMBL3960335 & 1641040 & 7.1079 & 7.1379 & TST & & \\
\hline CHEMBL 3982356 & 1641040 & 6.0 & 5.9963 & TRN & & \\
\hline CHEMBL3982164 & 1641040 & 7.9208 & 7.1214 & TRN & & \\
\hline CHEMBL3954333 & 1641040 & 6.0 & 6.2921 & TRN & & \\
\hline CHEMBL 3950808 & 1641040 & 6.0 & 6.1244 & TRN & & \\
\hline CHEMBL3929453 & 1641040 & 6.2924 & 6.2332 & TRN & & \\
\hline CHEMBL 3952486 & 1641040 & 6.0 & 5.8903 & TRN & & \\
\hline CHEMBL3970202 & 1641040 & 8.5686 & 7.3439 & TRN & & \\
\hline CHEMBL3920842 & 1641040 & 6.0 & 5.9744 & TRN & & \\
\hline CHEMBL3895010 & 1641040 & 7.6778 & 6.675 & TRN & & \\
\hline CHEMBL3911736 & 1641040 & 6.0 & 7.1095 & TRN & & \\
\hline
\end{tabular}


Supplemental Table S2.txt

\begin{tabular}{|c|c|c|c|c|}
\hline CHEMBL3900427 & 1641040 & 6.0 & 6.2194 & TRN \\
\hline CHEMBL3937402 & 1641040 & 6.0 & 6.6943 & TRN \\
\hline CHEMBL3896645 & 1641040 & 6.0 & 6.0261 & TRN \\
\hline CHEMBL 3960023 & 1641040 & 7.7696 & 6.9329 & TRN \\
\hline CHEMBL 3899069 & 1641040 & 6.0 & 6.0646 & TRN \\
\hline CHEMBL 3982489 & 1641040 & 6.0 & 6.1893 & TST \\
\hline CHEMBL3961900 & 1641040 & 5.301 & 6.28 & TRN \\
\hline CHEMBL 3961290 & 1641040 & 8.4089 & 7.2559 & TRN \\
\hline CHEMBL3950307 & 1641040 & 6.0 & 6.1225 & TRN \\
\hline CHEMBL 3924184 & 1641040 & 7.4685 & \multicolumn{2}{|c|}{6.747000000000001} \\
\hline CHEMBL 3928008 & 1641040 & 6.0 & 6.0462 & TRN \\
\hline CHEMBL3891186 & 1641040 & 6.0 & 5.907 & TRN \\
\hline CHEMBL3959111 & 1641040 & 6.0 & 5.7509 & TRN \\
\hline CHEMBL3962711 & 1641040 & 6.0 & 6.2833 & TRN \\
\hline CHEMBL 3913429 & 1641040 & 6.0 & 6.0409 & TRN \\
\hline CHEMBL 3974380 & 1641040 & 6.0 & 5.9458 & TRN \\
\hline CHEMBL3963957 & 1641040 & 6.1739 & 6.5981 & TST \\
\hline CHEMBL3915549 & 1641040 & 6.0 & 5.6564 & TRN \\
\hline CHEMBL3900447 & 1641040 & 6.5229 & 7.3067 & TRN \\
\hline CHEMBL 3906736 & 1641040 & 6.0 & 5.8272 & TRN \\
\hline CHEMBL3982557 & 1641040 & 7.4815 & 6.9325 & TRN \\
\hline CHEMBL 3907494 & 1641040 & 6.2518 & 5.9605 & TRN \\
\hline CHEMBL 3897436 & 1641040 & 6.0 & 6.4191 & TRN \\
\hline CHEMBL 3956090 & 1641040 & 6.8239 & 6.8431 & TRN \\
\hline CHEMBL 3906896 & 1641040 & 6.0 & 5.7086 & TRN \\
\hline CHEMBL3943389 & 1641040 & 6.0 & 6.7683 & TST \\
\hline CHEMBL3931936 & 1641040 & 6.8239 & 6.7689 & TRN \\
\hline CHEMBL3921337 & 1641040 & 6.0 & 6.8103 & TRN \\
\hline CHEMBL3920851 & 1641040 & 6.0 & 5.6045 & TRN \\
\hline CHEMBL 3985335 & 1641040 & 6.0 & 6.2815 & TST \\
\hline CHEMBL3915215 & 1641040 & 6.0 & 7.2631 & TRN \\
\hline CHEMBL3921939 & 1641040 & 6.1427 & 5.9431 & TRN \\
\hline CHEMBL3972339 & 1641040 & 6.0 & 6.1 & TST \\
\hline CHEMBL3963730 & 1641040 & 5.8794 & 6.1066 & TRN \\
\hline CHEMBL3965966 & 1641040 & 5.9914 & 6.1488 & TRN \\
\hline CHEMBL3909861 & 1641040 & 6.0 & 5.8519 & TRN \\
\hline CHEMBL 3892956 & 1641040 & 6.0 & 5.9549 & TRN \\
\hline CHEMBL3953677 & 1641040 & 6.0 & 6.6271 & TRN \\
\hline CHEMBL 3904648 & 1641040 & 6.0 & 5.763 & TRN \\
\hline CHEMBL3906573 & 1641040 & 6.0 & 6.4888 & TST \\
\hline CHEMBL3925804 & 1641040 & 6.0 & 6.294 & TST \\
\hline CHEMBL3912428 & 1641040 & 6.0 & 6.3594 & TRN \\
\hline CHEMBL 3889968 & 1641040 & 7.4318 & 6.75299 & 9999999999 \\
\hline CHEMBL3893603 & 1641040 & 6.0 & 6.6981 & TRN \\
\hline CHEMBL3899911 & 1641040 & 6.0 & 6.0827 & TST \\
\hline CHEMBL3960010 & 1641040 & 6.0 & 6.1211 & TST \\
\hline CHEMBL 3925607 & 1641040 & 6.0 & 5.8653 & TST \\
\hline CHEMBL3908955 & 1641040 & 6.0 & 6.891 & TST \\
\hline
\end{tabular}


Supplemental Table S2.txt

\begin{tabular}{|c|c|c|c|c|c|}
\hline CHEMBL3899002 & 1641040 & 8.699 & 6.9551 & TST & \\
\hline CHEMBL 3983262 & 1641040 & 7.5086 & \multicolumn{2}{|c|}{6.861000000000001} & TST \\
\hline CHEMBL3905270 & 1641040 & 6.0 & 5.9233 & TST & \\
\hline CHEMBL 3898777 & 1641040 & 6.0 & 6.4272 & TST & \\
\hline CHEMBL1290393 & 687185 & 6.0315 & 6.0162 & TRN & \\
\hline CHEMBL1289741 & 687185 & 5.5421 & 5.4908 & TRN & \\
\hline CHEMBL1289848 & 687185 & 6.301 & 6.2267 & TRN & \\
\hline CHEMBL1290061 & 687185 & 4.8097 & 4.8087 & TRN & \\
\hline CHEMBL1290168 & 687185 & 5.8861 & 5.8258 & TRN & \\
\hline CHEMBL1289846 & 687185 & 6.2007 & 6.2627 & TRN & \\
\hline CHEMBL1290506 & 687185 & 5.1707 & 5.0164 & TRN & \\
\hline CHEMBL1290278 & 687185 & 3.301 & \multicolumn{2}{|c|}{3.2460000000000004} & TRN \\
\hline CHEMBL1256851 & 687185 & 6.1403 & 6.7835 & TST & \\
\hline CHEMBL1289065 & 687185 & 5.9872 & 6.0302 & TRN & \\
\hline CHEMBL1290394 & 687185 & 5.3279 & 5.1175 & TRN & \\
\hline CHEMBL1290277 & 687185 & 5.5735 & 5.5169 & TRN & \\
\hline CHEMBL1289739 & 687185 & 4.9508 & 4.9564 & TRN & \\
\hline CHEMBL1289414 & 687185 & 5.3002 & 5.3636 & TRN & \\
\hline CHEMBL1290616 & 687185 & 5.0092 & 5.0127 & TRN & \\
\hline CHEMBL1289849 & 687185 & 3.301 & 3.2022 & TRN & \\
\hline CHEMBL1289066 & 687185 & 5.6289 & 5.6784 & TRN & \\
\hline CHEMBL1289966 & 687185 & 4.4271 & 5.7489 & TST & \\
\hline CHEMBL1289413 & 687185 & 5.5751 & 5.6259 & TRN & \\
\hline CHEMBL1289297 & 687185 & 3.301 & 5.2441 & TST & \\
\hline CHEMBL1289742 & 687185 & 3.301 & \multicolumn{2}{|c|}{3.2460000000000004} & TRN \\
\hline CHEMBL1290615 & 687185 & 4.5003 & 4.5345 & TRN & \\
\hline CHEMBL1289636 & 687185 & 5.9666 & 5.3961 & TST & \\
\hline CHEMBL1289185 & 687185 & 5.2874 & 5.2657 & TRN & \\
\hline CHEMBL378104 & 687185 & 6.1308 & 5.7934 & TST & \\
\hline CHEMBL1289847 & 687185 & 6.041 & 5.9993 & TRN & \\
\hline CHEMBL1289635 & 687185 & 5.6144 & 5.02 & TST & \\
\hline CHEMBL1289740 & 687185 & 6.0706 & 6.0132 & TRN & \\
\hline CHEMBL1290062 & 687185 & 3.301 & 3.3209 & TRN & \\
\hline CHEMBL1289067 & 687185 & 5.5302 & 5.519 & TRN & \\
\hline CHEMBL1289182 & 687185 & 6.1549 & 6.3789 & TRN & \\
\hline CHEMBL1289184 & 687185 & 4.7852 & 4.901 & TRN & \\
\hline CHEMBL1289526 & 687185 & 5.8097 & 5.8473 & TRN & \\
\hline CHEMBL1289964 & 687185 & 4.757 & 4.7077 & TRN & \\
\hline CHEMBL1289634 & 687185 & 6.1367 & 6.1968 & TRN & \\
\hline CHEMBL1289967 & 687185 & 3.301 & 5.9731 & TST & \\
\hline CHEMBL1289296 & 687185 & 5.1427 & 5.0948 & TRN & \\
\hline CHEMBL1290617 & 687185 & 3.301 & \multicolumn{2}{|c|}{3.2880000000000003} & TRN \\
\hline CHEMBL1289633 & 687185 & 6.5086 & 6.4945 & TRN & \\
\hline CHEMBL1289412 & 687185 & 6.0555 & 5.8366 & TRN & \\
\hline CHEMBL1290733 & 687185 & 5.3179 & 5.3229 & TRN & \\
\hline CHEMBL1289965 & 687185 & 5.4572 & 5.4265 & TRN & \\
\hline CHEMBL1289529 & 687185 & 5.6216 & 5.6639 & TRN & \\
\hline CHEMBL1290735 & 687185 & 3.301 & 3.4958 & TRN & \\
\hline
\end{tabular}


Supplemental Table S2.txt

\begin{tabular}{|c|c|c|c|c|c|}
\hline CHEMBL1289064 & 687185 & 3.301 & \multicolumn{2}{|c|}{3.3960000000000004} & TRN \\
\hline CHEMBL1289415 & 687185 & 4.8153 & 4.8529 & TRN & \\
\hline CHEMBL1287826 & 687185 & 6.1739 & 5.9714 & TRN & \\
\hline CHEMBL1289527 & 687185 & 5.5607 & 5.6359 & TRN & \\
\hline CHEMBL1290614 & 687185 & 4.7878 & 4.9981 & TRN & \\
\hline CHEMBL1289295 & 687185 & 6.4318 & 6.5428 & TRN & \\
\hline CHEMBL1289411 & 687185 & 6.2596 & 5.7886 & TST & \\
\hline CHEMBL1289528 & 687185 & 5.4449 & 5.2234 & TST & \\
\hline CHEMBL1290167 & 687185 & 5.9788 & 5.2032 & TST & \\
\hline CHEMBL1290734 & 687185 & 6.0862 & 4.7836 & TST & \\
\hline CHEMBL1289637 & 687185 & 5.857 & 6.1159 & TST & \\
\hline CHEMBL1290505 & 687185 & 4.8327 & 5.5491 & TST & \\
\hline CHEMBL1289183 & 687185 & 6.2596 & 5.57 & TST & \\
\hline CHEMBL1290736 & 687185 & 3.8013 & 3.8448 & TST & \\
\hline CHEMBL 3952440 & 1641731 & 9.0458 & 9.0521 & TRN & \\
\hline CHEMBL3963812 & 1641731 & 8.1487 & 8.3544 & TST & \\
\hline CHEMBL 3984212 & 1641731 & 9.1549 & 9.1705 & TRN & \\
\hline CHEMBL3952900 & 1641731 & 8.4815 & 8.1519 & TST & \\
\hline CHEMBL 3892152 & 1641731 & 9.0969 & 9.0719 & TRN & \\
\hline CHEMBL 3983162 & 1641731 & 8.8539 & 9.102 & TRN & \\
\hline CHEMBL3890658 & 1641731 & 8.301 & 8.0726 & TST & \\
\hline CHEMBL3900366 & 1641731 & 9.301 & 9.1088 & TRN & \\
\hline CHEMBL 3973884 & 1641731 & 8.4815 & 9.2821 & TRN & \\
\hline CHEMBL 3901311 & 1641731 & 8.1612 & 8.1241 & TRN & \\
\hline CHEMBL3935476 & 1641731 & 10.1938 & 9.23 & TRN & \\
\hline CHEMBL3921088 & 1641731 & 8.5376 & 8.8213 & TRN & \\
\hline CHEMBL 3922003 & 1641731 & 9.1549 & 8.9104 & TRN & \\
\hline CHEMBL3918804 & 1641731 & 8.8539 & 8.7182 & TRN & \\
\hline CHEMBL 3984547 & 1641731 & 8.8861 & 9.039 & TRN & \\
\hline CHEMBL3925769 & 1641731 & 9.0969 & 9.7432 & TRN & \\
\hline CHEMBL3958720 & 1641731 & 8.7959 & 8.2925 & TST & \\
\hline CHEMBL 3918146 & 1641731 & 8.8861 & 8.7095 & TRN & \\
\hline CHEMBL 3897818 & 1641731 & 7.3279 & 8.5358 & TST & \\
\hline CHEMBL3957410 & 1641731 & 8.7212 & 8.4342 & TRN & \\
\hline CHEMBL 3950047 & 1641731 & 9.301 & 9.2717 & TRN & \\
\hline CHEMBL3918809 & 1641731 & 10.8861 & 9.4035 & TRN & \\
\hline CHEMBL 3959733 & 1641731 & 8.7447 & 8.2178 & TRN & \\
\hline CHEMBL3932539 & 1641731 & 9.301 & 8.0993 & TST & \\
\hline CHEMBL 3976479 & 1641731 & 9.1549 & 9.1362 & TRN & \\
\hline CHEMBL3979517 & 1641731 & 8.301 & 8.4312 & TRN & \\
\hline CHEMBL3930961 & 1641731 & 8.3468 & 8.3356 & TRN & \\
\hline CHEMBL 3899379 & 1641731 & 10.8861 & 9.6109 & TRN & \\
\hline CHEMBL3914737 & 1641731 & 8.585 & 8.9221 & TRN & \\
\hline CHEMBL 3893954 & 1641731 & 8.4559 & 7.849 & TST & \\
\hline CHEMBL 3905223 & 1641731 & 8.7696 & 8.3964 & TRN & \\
\hline CHEMBL3957898 & 1641731 & 8.4685 & 9.2827 & TRN & \\
\hline CHEMBL 3942251 & 1641731 & 9.1549 & 9.5767 & TRN & \\
\hline CHEMBL 3954161 & 1641731 & 9.0969 & 8.1141 & TST & \\
\hline
\end{tabular}


Supplemental Table S2.txt

\begin{tabular}{|c|c|c|c|c|}
\hline & 731 & 6.0 & & 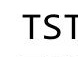 \\
\hline HEMBL 3950531 & 1641731 & 8.3872 & 2401 & \\
\hline 725 & 731 & & 2736 & \\
\hline 478 & 731 & & 501 & \\
\hline AEMBL & 731 & 549 & & \\
\hline AEMBL3917707 & 641731 & 8.8539 & 3134 & \\
\hline AEMBL3902696 & 641731 & 8.2757 & 9.6141 & \\
\hline 58479 & 731 & & & \\
\hline 332 & 731 & 8.3768 & & \\
\hline AEMBL: & 731 & 938 & & \\
\hline AEMBL3965179 & 1641731 & 9.699 & 177 & \\
\hline AEMBL3951572 & 731 & 7.7447 & & \\
\hline AEMBL3899209 & 731 & 9.0 & & \\
\hline AEMBL & 731 & 9.699 & & \\
\hline AEMBL. & 731 & & & \\
\hline HEMBL: & 731 & 8. & & \\
\hline AEMBL & & 7. & & \\
\hline AEMBL. & 31 & 8. & & \\
\hline AEMBL & 731 & 8.699 & & \\
\hline AEMBL & 731 & 9.699 & & \\
\hline AEMBL & & 8 . & & \\
\hline 373 & & 10.8861 & & $\mathrm{TR}_{\mathrm{T}}$ \\
\hline HEMBL & 16 & 9. & & RI \\
\hline 937 & 731 & 60 & & RN \\
\hline 312 & 731 & 8.0809 & & TRN \\
\hline AEMBL & & & & Th \\
\hline AEMBL & & 9.09 & & TS \\
\hline 589 & 731 & 0 & & TS \\
\hline AFM & 731 & 9 & & וכו \\
\hline 587 & 731 & 6.0 & & $\mathrm{TR}$ \\
\hline & & & & m \\
\hline 432 & 164 & 8.9586 & & $\mathrm{TR}$ \\
\hline 904 & 16 & 8 . & & T \\
\hline 900 & 31 & 9 & & \\
\hline & 164 & & & TR \\
\hline & 731 & 9.0969 & & TR \\
\hline HEMBL & 731 & 9.301 & & 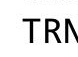 \\
\hline 420 & 731 & 8 . & 01 & 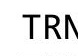 \\
\hline & 16 & & & ГRN \\
\hline & 164 & 8.4437 & & TRN \\
\hline HEMBL3 & 731 & 8.4685 & & TS \\
\hline 5724 & 164 & 9.3979 & & 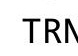 \\
\hline 715 & 164 & 8.0915 & & . \\
\hline & 164 & 9.0 & & TST \\
\hline HEMBL3 & 1641731 & 8.95 & 7.7955 & TST \\
\hline AEMBL. & 164173 & 10.8861 & 9.8144 & $\mathrm{TR}$ \\
\hline & & 9.35 & & $\mathrm{R}$ \\
\hline & רב & & & \\
\hline
\end{tabular}

Page 27799 
Supplemental Table S2.txt

\begin{tabular}{|c|c|c|c|c|c|}
\hline CHEMBL3939643 & 1641731 & 9.3979 & 10.0949 & TRN & \\
\hline CHEMBL3915526 & 1641731 & 9.1549 & 9.7929 & TRN & \\
\hline CHEMBL3980308 & 1641731 & 9.3979 & 9.3324 & TRN & \\
\hline CHEMBL316305 & 42810 & 4.301 & 5.4651 & TRN & \\
\hline CHEMBL90179 & 42810 & 4.301 & 4.897 & TST & \\
\hline CHEMBL 92544 & 42810 & 5.699 & 5.5408 & TRN & \\
\hline CHEMBL88339 & 42810 & 4.301 & 4.6453 & TST & \\
\hline CHEMBL 330000 & 42810 & 4.301 & 4.3079 & TRN & \\
\hline CHEMBL313226 & 42810 & 4.301 & 4.1289 & TRN & \\
\hline CHEMBL177993 & 42810 & 4.301 & 5.5654 & TST & \\
\hline CHEMBL91360 & 42810 & 5.699 & 5.511 & TRN & \\
\hline CHEMBL93626 & 42810 & 5.699 & 5.4481 & TRN & \\
\hline CHEMBL264268 & 42810 & 6.0 & 5.4867 & TRN & \\
\hline CHEMBL328316 & 42810 & 4.301 & 5.2338 & TRN & \\
\hline CHEMBL91033 & 42810 & 5.699 & 5.486000 & 0000000001 & TRN \\
\hline CHEMBL90860 & 42810 & 5.699 & 5.5065 & TRN & \\
\hline CHEMBL90826 & 42810 & 4.301 & 4.7948 & TRN & \\
\hline CHEMBL330746 & 42810 & 4.301 & 4.4879 & TST & \\
\hline CHEMBL91212 & 42810 & 5.699 & 5.3226 & TRN & \\
\hline CHEMBL 90233 & 42810 & 4.301 & 4.5536 & TST & \\
\hline CHEMBL314000 & 42810 & 4.301 & 4.529 & TST & \\
\hline CHEMBL1160615 & 42810 & 4.301 & 4.7992 & TST & \\
\hline CHEMBL314378 & 42810 & 5.699 & 5.5945 & TRN & \\
\hline CHEMBL330111 & 42810 & 4.301 & 5.3949 & TRN & \\
\hline CHEMBL 80562 & 42810 & 4.301 & 5.5172 & TRN & \\
\hline CHEMBL327629 & 42810 & 6.0969 & 5.5849 & TRN & \\
\hline CHEMBL316276 & 42810 & 5.699 & 5.2625 & TRN & \\
\hline CHEMBL328701 & 42810 & 5.301 & 5.3478 & TRN & \\
\hline CHEMBL312530 & 42810 & 5.699 & 5.6529 & TRN & \\
\hline CHEMBL 75924 & 42810 & 5.699 & 5.4876 & TRN & \\
\hline CHEMBL90628 & 42810 & 6.0 & 5.6108 & TRN & \\
\hline CHEMBL89964 & 42810 & 5.301 & 5.2382 & TRN & \\
\hline CHEMBL90454 & 42810 & 6.301 & 5.6174 & TRN & \\
\hline CHEMBL330230 & 42810 & 4.301 & 4.1875 & TRN & \\
\hline CHEMBL3706627 & 42810 & 4.301 & 5.6991 & TRN & \\
\hline CHEMBL90361 & 42810 & 4.301 & 4.4592 & TRN & \\
\hline CHEMBL 88743 & 42810 & 4.301 & 4.6169 & TRN & \\
\hline CHEMBL 88428 & 42810 & 4.301 & 4.2494 & TRN & \\
\hline CHEMBL280074 & 42810 & 5.1549 & 4.8317 & TRN & \\
\hline CHEMBL91378 & 42810 & 5.3979 & 5.4523 & TRN & \\
\hline CHEMBL 80754 & 42810 & 5.8239 & 5.5702 & TRN & \\
\hline CHEMBL 90229 & 42810 & 5.5229 & 5.3949 & TRN & \\
\hline CHEMBL445628 & 42810 & 4.301 & 4.7145 & TST & \\
\hline CHEMBL539688 & 42810 & 4.301 & 5.1976 & TRN & \\
\hline CHEMBL 88585 & 42810 & 4.301 & 4.5198 & TRN & \\
\hline CHEMBL93892 & 42810 & 6.2218 & 5.4026 & TRN & \\
\hline CHEMBL 88491 & 42810 & 5.699 & 5.63 & TRN & \\
\hline CHEMBL92288 & 42810 & 6.2218 & 5.4424 & TRN & \\
\hline
\end{tabular}




\begin{tabular}{|c|c|c|c|c|c|}
\hline \multicolumn{6}{|c|}{ Supplemental Table S2.txt } \\
\hline CHEMBL90082 & 42810 & 6.0 & 5.6056 & TRN & \\
\hline CHEMBL88694 & 42810 & 4.301 & 5.4696 & TRN & \\
\hline CHEMBL433154 & 42810 & 5.301 & 5.4242 & TRN & \\
\hline CHEMBL 90549 & 42810 & 6.0 & 5.4549 & TRN & \\
\hline CHEMBL 90300 & 42810 & 5.5229 & 5.7541 & TRN & \\
\hline CHEMBL314092 & 42810 & 4.301 & 4.899 & TST & \\
\hline CHEMBL 327843 & 42810 & 5.301 & 5.3691 & TRN & \\
\hline CHEMBL314739 & 42810 & 5.699 & 5.5235 & TRN & \\
\hline CHEMBL330026 & 42810 & 6.0 & 4.6916 & TRN & \\
\hline CHEMBL88813 & 42810 & 5.699 & 5.3861 & TRN & \\
\hline CHEMBL328678 & 42810 & 5.5229 & 5.4805 & TRN & \\
\hline CHEMBL90706 & 42810 & 5.6021 & 5.21399 & 99999999995 & TRN \\
\hline CHEMBL 88788 & 42810 & 4.301 & 4.1642 & TRN & \\
\hline CHEMBL80713 & 42810 & 6.301 & 5.6686 & TRN & \\
\hline CHEMBL90696 & 42810 & 4.301 & 5.1467 & TRN & \\
\hline CHEMBL328027 & 42810 & 5.301 & 5.3351 & TRN & \\
\hline CHEMBL90941 & 42810 & 6.2218 & 5.614 & TRN & \\
\hline CHEMBL90707 & 42810 & 4.301 & 4.5816 & TST & \\
\hline CHEMBL91116 & 42810 & 4.301 & 4.4003 & TRN & \\
\hline CHEMBL 328700 & 42810 & 4.301 & 5.3265 & TRN & \\
\hline CHEMBL90763 & 42810 & 4.301 & 4.4698 & TST & \\
\hline CHEMBL91169 & 42810 & 6.0 & 5.4801 & TST & \\
\hline CHEMBL329380 & 42810 & 6.0 & 5.3498 & TST & \\
\hline CHEMBL329676 & 42810 & 4.301 & 5.6421 & TST & \\
\hline CHEMBL90099 & 42810 & 5.699 & 5.4655 & TST & \\
\hline CHEMBL90028 & 42810 & 4.301 & 4.4581 & TST & \\
\hline CHEMBL90891 & 42810 & 4.301 & 4.5165 & TST & \\
\hline CHEMBL420571 & 42810 & 6.0 & 5.5117 & TST & \\
\hline CHEMBL 329440 & 42810 & 4.301 & 5.3634 & TST & \\
\hline CHEMBL1277214 & 685143 & 6.4868 & 6.5841 & TRN & \\
\hline CHEMBL1277212 & 685143 & 5.2813 & 5.4251 & TRN & \\
\hline CHEMBL1277582 & 685143 & 6.7825 & 6.8899 & TRN & \\
\hline CHEMBL1276221 & 685143 & 5.6625 & 5.7862 & TRN & \\
\hline CHEMBL1278111 & 685143 & 6.6289 & 6.5976 & TRN & \\
\hline CHEMBL1277124 & 685143 & 6.4763 & 6.2919 & TRN & \\
\hline CHEMBL1277123 & 685143 & 6.3516 & 6.5364 & TRN & \\
\hline CHEMBL1276946 & 685143 & 6.7825 & 6.9199 & TRN & \\
\hline CHEMBL1278017 & 685143 & 6.5331 & 6.6405 & TRN & \\
\hline CHEMBL1277852 & 685143 & 7.3279 & 7.3762 & TRN & \\
\hline CHEMBL1276222 & 685143 & 6.4685 & 6.3939 & TRN & \\
\hline CHEMBL1277487 & 685143 & 3.5229 & 3.4577 & TRN & \\
\hline CHEMBL 1278110 & 685143 & 6.24799 & 79999999 & 6.0633 & TRN \\
\hline CHEMBL1277398 & 685143 & 6.5867 & 6.5415 & TRN & \\
\hline CHEMBL1277307 & 685143 & 5.9179 & 5.74 & TRN & \\
\hline CHEMBL1276858 & 685143 & 6.2882 & 6.2186 & TRN & \\
\hline CHEMBL1276162 & 685143 & 6.6676 & 6.7127 & TRN & \\
\hline CHEMBL1277399 & 685143 & 6.6289 & 6.8041 & TRN & \\
\hline CHEMBL1277488 & 685143 & 3.5229 & 3.6702 & TRN & \\
\hline
\end{tabular}

Page 27801 


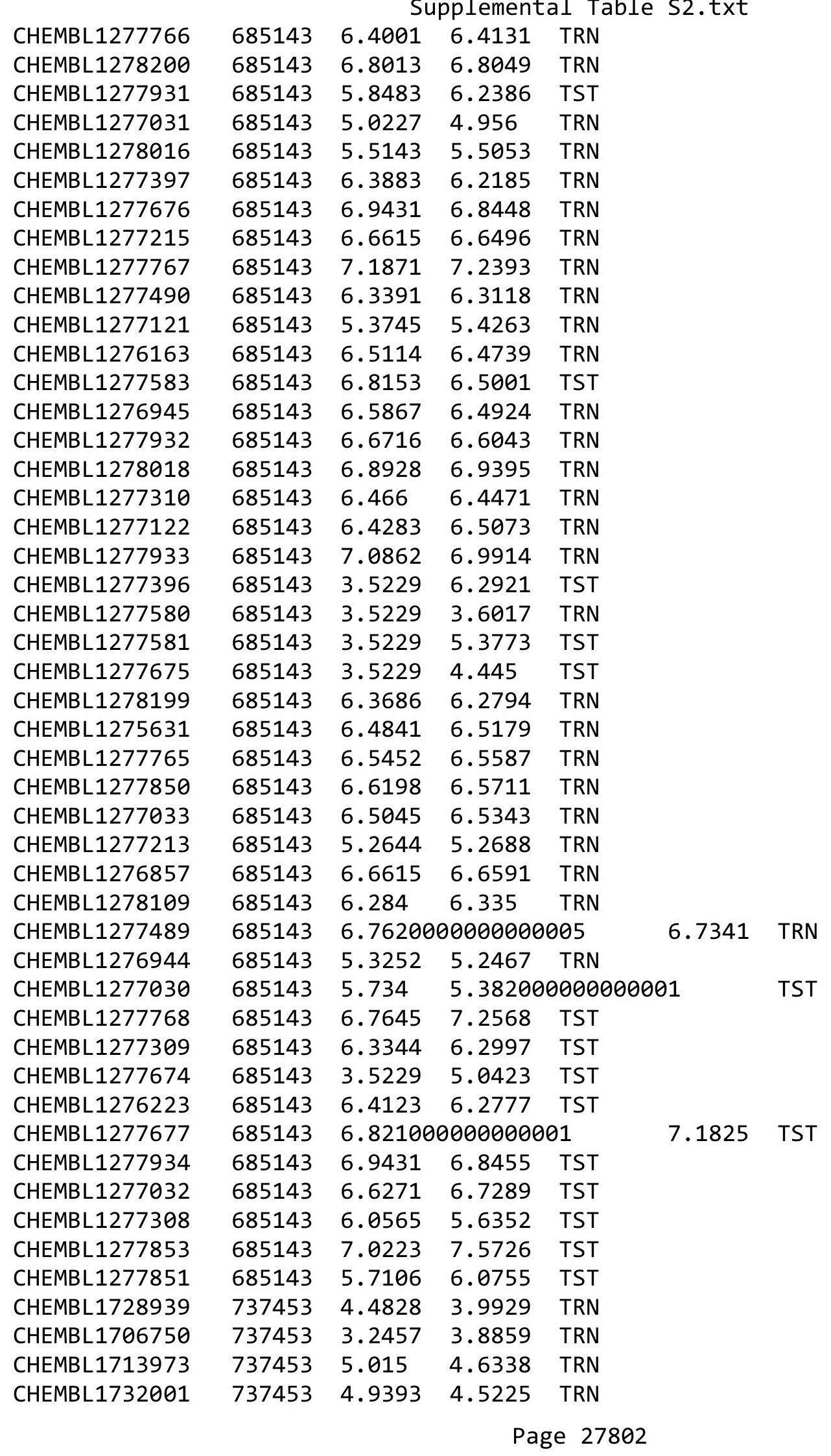


Supplemental Table S2.txt

\begin{tabular}{|c|c|c|c|c|}
\hline 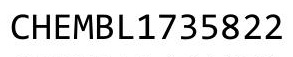 & & & & \\
\hline HEMBL1404231 & 37453 & 3.2457 & 5937 & \\
\hline HEMBL1402286 & 3 & 39 & 85 & \\
\hline 39 & & & & \\
\hline AEMBL1600114 & 3 & & & \\
\hline AEMBL1712282 & 37453 & 3.2457 & 595 & \\
\hline HEMBL1728381 & 37453 & 3.2457 & 4376 & \\
\hline HEMBL1705892 & 37 & & 4008 & \\
\hline HEMBL1722076 & 3 & 46 & 336 & \\
\hline HEMBL1729929 & 3 & 57 & & \\
\hline HEMBL1719047 & 37 & 5.2526 & .9679 & \\
\hline HEMBL1310699 & 37 & .2457 & 3.8122 & \\
\hline HEMBL1722566 & 3 & 2083 & 5.4115 & \\
\hline HEMBL17 & 3 & 57 & & \\
\hline JEMBL14 & 3 & & & \\
\hline HEMBL1713480 & 53 & 4. & 4.801 & \\
\hline AEMBL1715245 & & & & \\
\hline HEMBL17 & 3 & 3. & 78 & \\
\hline L17 & 3 & 57 & & \\
\hline AEMBL17 & 3 & & & \\
\hline HEMBL1699680 & 3 & & & \\
\hline AEMBL1709589 & & & & \\
\hline HEMBL15 & 3 & 48 & 32 & \\
\hline HEM & & 91 & 41 & \\
\hline 1 & 3 & & & \\
\hline L17 & & & & ST \\
\hline IEMBL17 & & & & RN \\
\hline HEMBL17 & 3 & & & \\
\hline HEN & P & & & \\
\hline L14 & 3 & & 13 & RN \\
\hline AEMBL1334484 & & & & ST \\
\hline HEMBL1728154 & & & & RN \\
\hline AEMBL1 & & & & \\
\hline 0 & 3 & & & ST \\
\hline 99 & 3 & & & RN \\
\hline AEMBL1731392 & & & & RN \\
\hline AEMBL1548870 & 3 & & $\partial 21$ & ST \\
\hline 7 & 3 & & 63 & I \\
\hline & 3 & & & RIN \\
\hline HEMBL14 & & & 4.4984 & ST \\
\hline AEMBL1530437 & 37 & & 4.8076 & RN \\
\hline IEMBL17 & 3 & & & \\
\hline רית & & & & \\
\hline HEMBL3189251 & & & 4.2816 & SI \\
\hline HEMBL1736103 & 3 & & .5651 & RN \\
\hline IEMBL14947 & 37 & 33 & 5348 & \\
\hline & & & & \\
\hline & 7374 & & & \\
\hline
\end{tabular}

Page 27803 
Supplemental Table S2.txt

\begin{tabular}{|c|c|c|c|c|c|c|}
\hline CHEMBL1703530 & 737453 & 4.6073 & 4.058 & TRN & & \\
\hline CHEMBL1729181 & 737453 & 4.9706 & 4.7697 & TST & & \\
\hline CHEMBL3190104 & 737453 & 4.6696 & 4.2085 & TST & & \\
\hline CHEMBL1728000 & 737453 & 4.7423 & 4.263 & TRN & & \\
\hline CHEMBL1546396 & 737453 & 4.7645 & 4.7738 & TRN & & \\
\hline CHEMBL1719138 & 737453 & 3.2457 & 3.2276 & TRN & & \\
\hline CHEMBL1518888 & 737453 & 3.2457 & 3.9311 & TRN & & \\
\hline CHEMBL1711885 & 737453 & 4.5346 & 3.3412 & TRN & & \\
\hline CHEMBL1383746 & 737453 & 3.2457 & 3.7247 & TRN & & \\
\hline CHEMBL1719957 & 737453 & 4.6596 & 4.4316 & TRN & & \\
\hline CHEMBL1733814 & 737453 & 3.2457 & 4.4535 & TST & & \\
\hline CHEMBL1725449 & 737453 & 5.0414 & 4.8605 & TRN & & \\
\hline CHEMBL1727351 & 737453 & 3.2457 & 3.6447 & TRN & & \\
\hline CHEMBL1703238 & 737453 & 4.6326 & 4.063 & TRN & & \\
\hline CHEMBL1399979 & 737453 & 5.3242 & 5.101 & TRN & & \\
\hline CHEMBL1585333 & 737453 & 3.2457 & 3.9626 & TST & & \\
\hline CHEMBL1700238 & 737453 & 3.2457 & 3.9065 & TRN & & \\
\hline CHEMBL1530272 & 737453 & 4.9355 & 4.6388 & TST & & \\
\hline CHEMBL1526223 & 737453 & 3.2457 & 4.4604 & TST & & \\
\hline CHEMBL1706851 & 737453 & 4.757 & 4.2406 & TRN & & \\
\hline CHEMBL1720079 & 737453 & 4.5171 & 4.4245 & TRN & & \\
\hline CHEMBL1721038 & 737453 & 4.71899 & 99999999 & 99 & 4.9895 & TRN \\
\hline CHEMBL1707912 & 737453 & 3.2457 & 3.6175 & TRN & & \\
\hline CHEMBL1518374 & 737453 & 5.2277 & 4.2081 & TRN & & \\
\hline CHEMBL1360146 & 737453 & 3.2457 & 4.2951 & TST & & \\
\hline CHEMBL1700723 & 737453 & 3.2457 & 3.4554 & TRN & & \\
\hline CHEMBL1736753 & 737453 & 4.7167 & 4.2367 & TRN & & \\
\hline CHEMBL1361703 & 737453 & 4.644 & 4.5298 & TRN & & \\
\hline CHEMBL1509648 & 1301882 & 4.9729 & 4.686 & TRN & & \\
\hline CHEMBL1966224 & 1301882 & 5.9682 & 5.5487 & TRN & & \\
\hline CHEMBL1560629 & 1301882 & 6.0887 & 5.1835 & TRN & & \\
\hline CHEMBL1509308 & 1301882 & 3.437 & 4.522 & TST & & \\
\hline CHEMBL1459786 & 1301882 & 5.5242 & 5.0182 & TRN & & \\
\hline CHEMBL1578953 & 1301882 & 5.0098 & 4.7654 & TRN & & \\
\hline CHEMBL1329826 & 1301882 & \multicolumn{3}{|c|}{5.7589999999999995} & 6.0002 & TRN \\
\hline CHEMBL2004928 & 1301882 & 3.437 & 4.8076 & TRN & & \\
\hline CHEMBL1429479 & 1301882 & 5.6985 & 4.4137 & TRN & & \\
\hline CHEMBL1349474 & 1301882 & 5.1904 & 4.6203 & TRN & & \\
\hline CHEMBL1709354 & 1301882 & 5.4203 & 5.1261 & TRN & & \\
\hline CHEMBL484640 & 1301882 & 5.0273 & 5.6389 & TRN & & \\
\hline CHEMBL1715550 & 1301882 & 5.3072 & 5.0025 & TRN & & \\
\hline CHEMBL1731995 & 1301882 & 5.1912 & 5.4457 & TRN & & \\
\hline CHEMBL278037 & 1301882 & 3.437 & 4.9905 & TRN & & \\
\hline CHEMBL3193946 & 1301882 & 4.8455 & 4.6818 & TRN & & \\
\hline CHEMBL1385808 & 1301882 & 5.4269 & 5.6179 & TST & & \\
\hline CHEMBL175266 & 1301882 & 6.6739 & 5.6436 & TRN & & \\
\hline CHEMBL1555959 & 1301882 & 3.437 & 4.5782 & TRN & & \\
\hline CHEMBL1727228 & 1301882 & 4.5337 & 4.7886 & TST & & \\
\hline
\end{tabular}


Supplemental Table S2.txt

\begin{tabular}{|c|c|c|c|c|}
\hline CHEMBL1271266 & 1301882 & 5.564 & 5.1256 & TRN \\
\hline CHEMBL1606907 & 1301882 & 4.9953 & 4.6719 & TRN \\
\hline CHEMBL1594376 & 1301882 & 5.8684 & 5.6139 & TRN \\
\hline CHEMBL3195623 & 1301882 & 4.9228 & 4.8874 & TRN \\
\hline CHEMBL1706577 & 1301882 & 5.4149 & 5.21899 & 9999999999 \\
\hline CHEMBL1730974 & 1301882 & 6.1411 & 5.2774 & TRN \\
\hline CHEMBL255881 & 1301882 & 6.3451 & 5.8904 & TRN \\
\hline CHEMBL1471337 & 1301882 & 4.8092 & 5.1134 & TRN \\
\hline CHEMBL1727349 & 1301882 & 4.8102 & 5.2379 & TRN \\
\hline CHEMBL82242 & 1301882 & 5.584 & 5.5626 & TRN \\
\hline CHEMBL1321116 & 1301882 & 3.4375 & 5.2261 & TST \\
\hline CHEMBL1576140 & 1301882 & 5.6225 & 5.6884 & TRN \\
\hline CHEMBL3192179 & 1301882 & 4.6185 & 5.2482 & TRN \\
\hline CHEMBL1501635 & 1301882 & 3.9145 & 5.1083 & TST \\
\hline CHEMBL1574133 & 1301882 & 4.8254 & 4.5102 & TRN \\
\hline CHEMBL1732979 & 1301882 & 5.4589 & 4.9558 & TST \\
\hline CHEMBL1866510 & 1301882 & 3.4374 & 4.9101 & TRN \\
\hline CHEMBL1417168 & 1301882 & 5.7457 & \multicolumn{2}{|c|}{5.0680000000000005} \\
\hline CHEMBL1994094 & 1301882 & 5.6747 & 5.5124 & TRN \\
\hline CHEMBL1323000 & 1301882 & 4.5841 & 4.8137 & TRN \\
\hline CHEMBL1481914 & 1301882 & 4.8551 & 4.9084 & TRN \\
\hline CHEMBL172350 & 1301882 & 5.7364 & 5.4713 & TRN \\
\hline CHEMBL1443059 & 1301882 & 5.0392 & 4.5677 & TRN \\
\hline CHEMBL1557426 & 1301882 & 3.4374 & 4.8126 & TRN \\
\hline CHEMBL1484234 & 1301882 & 5.0855 & 5.0845 & TST \\
\hline CHEMBL1486827 & 1301882 & 3.4374 & 5.7547 & TRN \\
\hline CHEMBL1324051 & 1301882 & 5.3145 & 5.313 & TRN \\
\hline CHEMBL1493191 & 1301882 & 5.5759 & 5.4321 & TRN \\
\hline CHEMBL1723511 & 1301882 & 6.4328 & 5.6685 & TRN \\
\hline CHEMBL1560833 & 1301882 & 5.1614 & 5.1826 & TRN \\
\hline CHEMBL 3193134 & 1301882 & 5.9901 & 5.5772 & TRN \\
\hline CHEMBL1374603 & 1301882 & 5.6728 & 5.1665 & TRN \\
\hline CHEMBL1173475 & 1301882 & 6.3024 & 6.018 & TRN \\
\hline CHEMBL1403497 & 1301882 & 6.1606 & 4.9171 & TRN \\
\hline CHEMBL1461772 & 1301882 & 5.3583 & 5.0723 & TRN \\
\hline CHEMBL1447917 & 1301882 & 5.8035 & 4.5136 & TRN \\
\hline CHEMBL1893276 & 1301882 & 5.0189 & 4.8216 & TST \\
\hline CHEMBL1976219 & 1301882 & 4.5405 & 4.6922 & TRN \\
\hline CHEMBL1709145 & 1301882 & 5.4041 & 4.5869 & TRN \\
\hline CHEMBL1985664 & 1301882 & 6.1617 & 5.8332 & TRN \\
\hline CHEMBL1706454 & 1301882 & 5.6426 & 5.4368 & TRN \\
\hline CHEMBL1718398 & 1301882 & 4.869 & 5.4614 & TST \\
\hline CHEMBL1349475 & 1301882 & 5.0578 & 5.5253 & TRN \\
\hline CHEMBL1966984 & 1301882 & 5.6834 & 6.0808 & TRN \\
\hline CHEMBL1540637 & 1301882 & 4.8386 & 5.6998 & TRN \\
\hline CHEMBL1735454 & 1301882 & 4.9653 & 5.2181 & TRN \\
\hline CHEMBL1426749 & 1301882 & 5.1017 & 4.8782 & TRN \\
\hline CHEMBL1465049 & 1301882 & 3.4374 & 4.2915 & TRN \\
\hline
\end{tabular}

Page 27805 
Supplemental Table S2.txt

\begin{tabular}{|c|c|c|c|c|c|}
\hline CHEMBL3195409 & 1301882 & 4.9823 & 5.296 & TRN & \\
\hline CHEMBL164 & 1301882 & 6.1204 & 6.6507 & TRN & \\
\hline CHEMBL1392911 & 1301882 & 4.5347 & 4.8546 & TST & \\
\hline CHEMBL1964793 & 1301882 & 3.4373 & 4.9035 & TRN & \\
\hline CHEMBL163316 & 1301882 & 5.7203 & 5.4146 & TRN & \\
\hline CHEMBL1469743 & 1301882 & 5.7421 & 4.9334 & TST & \\
\hline CHEMBL1984240 & 1301882 & 5.4872 & 5.606 & TRN & \\
\hline CHEMBL1424694 & 1301882 & 6.1004 & 6.183 & TRN & \\
\hline CHEMBL1721855 & 1301882 & 5.2601 & 4.8093 & TRN & \\
\hline CHEMBL3191780 & 1301882 & 5.3239 & 5.5271 & TRN & \\
\hline CHEMBL1346055 & 1301882 & 5.3714 & 5.7467 & TRN & \\
\hline CHEMBL151 & 1301882 & 5.9751 & 5.4457 & TRN & \\
\hline CHEMBL1560775 & 1301882 & 5.38899 & 79999999 & 99 & 4.912 \\
\hline CHEMBL1315784 & 1301882 & 4.8739 & 5.3113 & TRN & \\
\hline CHEMBL1362112 & 1301882 & 4.9598 & 5.1231 & TRN & \\
\hline CHEMBL1730762 & 1301882 & 3.4378 & 5.2839 & TRN & \\
\hline CHEMBL1488474 & 1301882 & 5.9702 & 6.0545 & TRN & \\
\hline CHEMBL1531320 & 1301882 & 4.9453 & 4.9207 & TRN & \\
\hline CHEMBL1310972 & 1301882 & 3.4373 & 4.4788 & TRN & \\
\hline CHEMBL1555751 & 1301882 & 5.3221 & 5.6855 & TST & \\
\hline CHEMBL405110 & 1301882 & 3.4374 & 5.1647 & TRN & \\
\hline CHEMBL1561877 & 1301882 & 4.8972 & 4.615 & TRN & \\
\hline CHEMBL1325440 & 1301882 & 5.6424 & 5.1912 & TRN & \\
\hline CHEMBL1986342 & 1301882 & 6.1295 & 5.5917 & TRN & \\
\hline CHEMBL1340344 & 1301882 & 5.3989 & 5.052 & TRN & \\
\hline CHEMBL3189823 & 1301882 & 4.9482 & 5.4008 & TRN & \\
\hline CHEMBL1732657 & 1301882 & 3.4371 & 5.0866 & TST & \\
\hline CHEMBL1424486 & 1301882 & 3.4373 & 4.503 & TRN & \\
\hline CHEMBL3187659 & 1301882 & 3.4373 & 4.5811 & TRN & \\
\hline CHEMBL1725798 & 1301882 & 3.4368 & 4.7106 & TRN & \\
\hline CHEMBL1335254 & 1301882 & 4.62 & 4.5807 & TRN & \\
\hline CHEMBL 3197564 & 1301882 & 4.6449 & 4.4408 & TRN & \\
\hline CHEMBL1314787 & 1301882 & 4.7633 & 5.0492 & TRN & \\
\hline CHEMBL1737002 & 1301882 & 5.3482 & 5.0592 & TRN & \\
\hline CHEMBL1464280 & 1301882 & 5.6218 & 5.8099 & TST & \\
\hline CHEMBL234338 & 1301882 & 6.4674 & 5.2699 & TRN & \\
\hline CHEMBL1315592 & 1301882 & 5.2278 & 4.9066 & TRN & \\
\hline CHEMBL1600440 & 1301882 & 5.8972 & 4.9003 & TRN & \\
\hline CHEMBL515252 & 1301882 & 5.3735 & 5.6266 & TRN & \\
\hline CHEMBL1728023 & 1301882 & 6.4222 & 5.7654 & TRN & \\
\hline CHEMBL1533230 & 1301882 & 5.5137 & 5.7674 & TST & \\
\hline CHEMBL1336927 & 1301882 & 4.7308 & 4.6137 & TRN & \\
\hline CHEMBL222759 & 1301882 & 4.7378 & 4.6573 & TRN & \\
\hline CHEMBL1508847 & 1301882 & 6.4234 & 6.2014 & TRN & \\
\hline CHEMBL1604163 & 1301882 & 4.4373 & 4.7111 & TRN & \\
\hline CHEMBL1567396 & 1301882 & 6.24 & 5.4903 & TRN & \\
\hline CHEMBL1350188 & 1301882 & 5.2761 & 5.4547 & TRN & \\
\hline CHEMBL1704223 & 1301882 & 4.8179 & 4.9406 & TRN & \\
\hline
\end{tabular}

Page 27806 
Supplemental Table S2.txt

\begin{tabular}{|c|c|c|c|c|c|c|}
\hline CHEMBL136344 & 1301882 & 5.0179 & 5.1556 & TRN & & \\
\hline CHEMBL1731349 & 1301882 & 4.6574 & 5.0996 & TST & & \\
\hline CHEMBL3196993 & 1301882 & 6.0329 & 5.7644 & TRN & & \\
\hline CHEMBL1463181 & 1301882 & 4.8494 & 5.5137 & TRN & & \\
\hline CHEMBL3193049 & 1301882 & 3.4373 & 4.7957 & TRN & & \\
\hline CHEMBL1373577 & 1301882 & 5.0526 & 4.7289 & TRN & & \\
\hline CHEMBL1601846 & 1301882 & 6.61299 & 99999999 & 995 & 6.5715 & TRN \\
\hline CHEMBL3195177 & 1301882 & 5.251 & 5.2536 & TRN & & \\
\hline CHEMBL1561729 & 1301882 & 5.5453 & 5.3373 & TRN & & \\
\hline CHEMBL483206 & 1301882 & 5.3285 & 5.4811 & TRN & & \\
\hline CHEMBL1368108 & 1301882 & 5.228 & 5.4603 & TST & & \\
\hline CHEMBL1443351 & 1301882 & 3.9144 & 4.8261 & TRN & & \\
\hline CHEMBL1342436 & 1301882 & 4.7971 & 4.9801 & TST & & \\
\hline CHEMBL1598766 & 1301882 & 4.7913 & 4.9825 & TST & & \\
\hline CHEMBL 3186253 & 1301882 & 5.3507 & 5.1324 & TRN & & \\
\hline CHEMBL607979 & 1301882 & 6.1577 & 5.6194 & TRN & & \\
\hline CHEMBL1982107 & 1301882 & 5.7142 & 5.4598 & TRN & & \\
\hline CHEMBL1408747 & 1301882 & 5.6094 & 5.5108 & TRN & & \\
\hline CHEMBL1734083 & 1301882 & 6.3679 & 5.0181 & TST & & \\
\hline CHEMBL1408535 & 1301882 & 3.4375 & 4.5203 & TRN & & \\
\hline CHEMBL1700270 & 1301882 & 5.0027 & 5.2208 & TRN & & \\
\hline CHEMBL1375795 & 1301882 & 5.09399 & 99999999 & 99 & 5.2895 & TRN \\
\hline CHEMBL1732315 & 1301882 & 5.716 & 4.7917 & TRN & & \\
\hline CHEMBL523844 & 1301882 & 5.1336 & 4.6769 & TRN & & \\
\hline CHEMBL1362935 & 1301882 & 5.978 & 5.8316 & TRN & & \\
\hline CHEMBL1613004 & 1301882 & 5.8303 & 5.6849 & TRN & & \\
\hline CHEMBL1510349 & 1301882 & 5.3262 & 5.4834 & TST & & \\
\hline CHEMBL1704267 & 1301882 & 5.0658 & 5.3799 & TRN & & \\
\hline CHEMBL1310907 & 1301882 & 3.4373 & 4.8387 & TRN & & \\
\hline CHEMBL1601394 & 1301882 & 5.225 & 5.5346 & TRN & & \\
\hline CHEMBL3196837 & 1301882 & 5.5487 & 5.0852 & TRN & & \\
\hline CHEMBL1985649 & 1301882 & 3.9144 & 4.7281 & TST & & \\
\hline CHEMBL3194385 & 1301882 & 5.347 & 5.5298 & TRN & & \\
\hline CHEMBL1320897 & 1301882 & 5.3128 & 5.0035 & TRN & & \\
\hline CHEMBL66966 & 1301882 & 6.5619 & 5.8766 & TRN & & \\
\hline CHEMBL1257003 & 1301882 & 6.1239 & 6.3472 & TRN & & \\
\hline CHEMBL1468796 & 1301882 & 5.9014 & 5.7082 & TRN & & \\
\hline CHEMBL3199191 & 1301882 & 5.5232 & 5.3854 & TRN & & \\
\hline CHEMBL56393 & 1301882 & 7.0994 & 6.6269 & TRN & & \\
\hline CHEMBL1429070 & 1301882 & 5.8668 & 5.1536 & TRN & & \\
\hline CHEMBL3197557 & 1301882 & 5.6108 & 5.6881 & TRN & & \\
\hline CHEMBL 3193326 & 1301882 & 3.4374 & 5.5971 & TRN & & \\
\hline CHEMBL1527520 & 1301882 & 6.1225 & 5.9765 & TRN & & \\
\hline CHEMBL224916 & 1301882 & 5.6566 & 5.4626 & TRN & & \\
\hline CHEMBL1399979 & 1301882 & 5.1294 & 4.715 & TRN & & \\
\hline CHEMBL1333249 & 1301882 & 5.5902 & 4.6012 & TRN & & \\
\hline CHEMBL1997747 & 1301882 & 3.4373 & 4.5835 & TRN & & \\
\hline CHEMBL1407474 & 1301882 & 6.2076 & 6.0122 & TRN & & \\
\hline
\end{tabular}


Supplemental Table S2.txt

\begin{tabular}{|c|c|c|c|c|c|}
\hline CHEMBL1409344 & 1301882 & 3.4369 & 4.8094 & TRN & \\
\hline CHEMBL 246446 & 1301882 & 5.7169 & 5.5069 & TRN & \\
\hline CHEMBL469424 & 1301882 & 5.5872 & 5.4763 & TRN & \\
\hline CHEMBL3192715 & 1301882 & 5.4722 & 5.5735 & TRN & \\
\hline CHEMBL1482883 & 1301882 & 5.0196 & 4.8641 & TRN & \\
\hline CHEMBL1401747 & 1301882 & 5.9215 & 5.692 & TRN & \\
\hline CHEMBL1485960 & 1301882 & 5.8099 & 4.8365 & TRN & \\
\hline CHEMBL1458486 & 1301882 & 4.8002 & 4.5501 & TRN & \\
\hline CHEMBL1877709 & 1301882 & 6.0017 & 5.1348 & TRN & \\
\hline CHEMBL1419228 & 1301882 & 5.0614 & 5.6098 & TRN & \\
\hline CHEMBL1413866 & 1301882 & 5.2125 & 5.5081 & TRN & \\
\hline CHEMBL1503050 & 1301882 & 5.1303 & 5.4888 & TST & \\
\hline CHEMBL1411344 & 1301882 & $5.6560 e$ & $\partial 0000000$ & $\partial 1$ & 4.6302 \\
\hline CHEMBL1460436 & 1301882 & 4.7164 & 4.7006 & TST & \\
\hline CHEMBL3192541 & 1301882 & 4.8687 & 5.4634 & TRN & \\
\hline CHEMBL1427047 & 1301882 & 5.1948 & 4.6095 & TRN & \\
\hline CHEMBL1364584 & 1301882 & 5.0931 & 4.6609 & TRN & \\
\hline CHEMBL1700996 & 1301882 & 6.0731 & 5.4321 & TRN & \\
\hline CHEMBL1482554 & 1301882 & 4.6321 & 4.8144 & TRN & \\
\hline CHEMBL1409603 & 1301882 & 5.545 & 4.8831 & TRN & \\
\hline CHEMBL156383 & 1301882 & 5.4913 & 5.3549 & TST & \\
\hline CHEMBL1323674 & 1301882 & 5.6178 & 5.6158 & TRN & \\
\hline CHEMBL1320230 & 1301882 & 5.7326 & 6.0101 & TRN & \\
\hline CHEMBL463563 & 1301882 & 5.3042 & 5.3095 & TRN & \\
\hline CHEMBL1996376 & 1301882 & 5.1312 & 5.0159 & TRN & \\
\hline CHEMBL3194876 & 1301882 & 6.0948 & 5.5261 & TRN & \\
\hline CHEMBL1302308 & 1301882 & 5.8105 & 6.1564 & TRN & \\
\hline CHEMBL3193581 & 1301882 & 4.8559 & 4.9581 & TRN & \\
\hline CHEMBL1980844 & 1301882 & 6.5419 & 4.8129 & TST & \\
\hline CHEMBL1374016 & 1301882 & 5.1353 & 4.6346 & TRN & \\
\hline CHEMBL3191022 & 1301882 & 6.3679 & 5.978 & TRN & \\
\hline CHEMBL1459125 & 1301882 & 5.1792 & 4.8703 & TRN & \\
\hline CHEMBL1972037 & 1301882 & 5.9052 & 5.8514 & TRN & \\
\hline CHEMBL444478 & 1301882 & 5.8517 & 5.6117 & TRN & \\
\hline CHEMBL156174 & 1301882 & 5.6688 & 4.9485 & TRN & \\
\hline CHEMBL 290914 & 1301882 & 5.3551 & 5.4871 & TST & \\
\hline CHEMBL1469229 & 1301882 & 5.0118 & 5.1699 & TST & \\
\hline CHEMBL1301673 & 1301882 & 5.4877 & 5.7118 & TST & \\
\hline CHEMBL1464053 & 1301882 & 4.8576 & 4.6082 & TST & \\
\hline CHEMBL1713097 & 1301882 & 3.4373 & 5.1242 & TST & \\
\hline CHEMBL1709241 & 1301882 & 3.4367 & 4.7793 & TST & \\
\hline CHEMBL1429677 & 1301882 & 5.2774 & 5.5044 & TST & \\
\hline CHEMBL3186591 & 1301882 & 5.4407 & 5.3654 & TST & \\
\hline CHEMBL1522218 & 1301882 & 5.7929 & 4.8333 & TST & \\
\hline CHEMBL1400929 & 1301882 & 5.267 & 5.3805 & TST & \\
\hline CHEMBL1715667 & 1301882 & 4.8011 & 5.0573 & TST & \\
\hline CHEMBL 3190268 & 1301882 & 6.7523 & 4.7722 & TST & \\
\hline CHEMBL1354766 & 1301882 & 4.4488 & 4.6094 & TST & \\
\hline
\end{tabular}


Supplemental Table S2.txt

\begin{tabular}{|c|c|c|c|c|c|c|}
\hline CHEMBL1968928 & 1301882 & 6.7196 & 5.9489 & TST & & \\
\hline CHEMBL1967046 & 1301882 & 5.93 & 4.8937 & TST & & \\
\hline CHEMBL1499658 & 1301882 & 5.4186 & 5.2472 & TST & & \\
\hline CHEMBL3191063 & 1301882 & 5.5996 & 5.3842 & TST & & \\
\hline CHEMBL1381868 & 1301882 & 4.9831 & 5.2909 & TST & & \\
\hline CHEMBL1501392 & 1301882 & 6.3896 & 5.5401 & TST & & \\
\hline CHEMBL1722566 & 1301882 & 5.5926 & 5.1278 & TST & & \\
\hline CHEMBL1546656 & 1301882 & 5.077 & 4.9156 & TST & & \\
\hline CHEMBL1582771 & 1301882 & \multicolumn{3}{|c|}{5.757000000000001} & 5.011 & ST \\
\hline CHEMBL1981657 & 1301882 & 5.8094 & 5.4746 & TST & & \\
\hline CHEMBL1493010 & 1301882 & 5.064 & 5.4567 & TST & & \\
\hline CHEMBL1575767 & 1301882 & 5.5616 & 5.9187 & TST & & \\
\hline CHEMBL1311198 & 1301882 & 3.4373 & 5.0027 & TST & & \\
\hline CHEMBL1360585 & 1301882 & 5.4876 & 5.809 & TST & & \\
\hline CHEMBL1573731 & 1301882 & 4.9827 & 5.6361 & TST & & \\
\hline CHEMBL3194109 & 1301882 & 4.8487 & 5.0353 & TST & & \\
\hline CHEMBL1373655 & 1301882 & 6.1342 & 6.0458 & TST & & \\
\hline CHEMBL68096 & 1301882 & 5.2919 & 5.0389 & TST & & \\
\hline CHEMBL1701533 & 1301882 & 4.4928 & 4.9384 & TST & & \\
\hline CHEMBL1976786 & 688471 & 5.9508 & 5.7206 & TRN & & \\
\hline CHEMBL1362507 & 688471 & 5.8462 & 5.6519 & TRN & & \\
\hline CHEMBL300389 & 688471 & 7.1308 & 6.5005 & TST & & \\
\hline CHEMBL3192855 & 688471 & 6.1314 & 5.3959 & TRN & & \\
\hline CHEMBL1423192 & 688471 & 6.8996 & 6.1321 & TRN & & \\
\hline CHEMBL1998521 & 688471 & 6.6536 & 6.4641 & TRN & & \\
\hline CHEMBL1572139 & 688471 & 5.9126 & 5.8724 & TRN & & \\
\hline CHEMBL1451921 & 688471 & 6.5391 & 6.4217 & TRN & & \\
\hline CHEMBL1324061 & 688471 & 5.6625 & 4.6916 & TRN & & \\
\hline CHEMBL1505209 & 688471 & 5.9755 & 5.7815 & TRN & & \\
\hline CHEMBL1586489 & 688471 & 3.9208 & 5.41 & TRN & & \\
\hline CHEMBL1313520 & 688471 & 5.9274 & 6.6435 & TRN & & \\
\hline CHEMBL1606583 & 688471 & 4.9709 & 4.8669 & TRN & & \\
\hline CHEMBL1468323 & 688471 & 6.6326 & 6.6568 & TRN & & \\
\hline CHEMBL1525789 & 688471 & 5.9208 & 5.7278 & TRN & & \\
\hline CHEMBL1322272 & 688471 & 5.8242 & 5.3259 & TRN & & \\
\hline CHEMBL1432420 & 688471 & 3.9208 & 5.8773 & TRN & & \\
\hline CHEMBL1524034 & 688471 & 6.5302 & 6.6441 & TRN & & \\
\hline CHEMBL1368103 & 688471 & 7.2924 & 6.8508 & TRN & & \\
\hline CHEMBL3211308 & 688471 & 6.2388 & 6.467000 & 000006 & 0005 & \\
\hline CHEMBL1300558 & 688471 & 3.9208 & 5.6991 & TRN & & \\
\hline CHEMBL1339289 & 688471 & 3.9208 & 5.5945 & TRN & & \\
\hline CHEMBL1372889 & 688471 & 6.8962 & 6.9676 & TRN & & \\
\hline CHEMBL1602385 & 688471 & 6.9547 & 6.8887 & TRN & & \\
\hline CHEMBL1392228 & 688471 & 6.3645 & 6.5243 & TRN & & \\
\hline CHEMBL1408486 & 688471 & 5.9714 & 5.9924 & TRN & & \\
\hline CHEMBL1576870 & 688471 & 6.3279 & 6.7853 & TRN & & \\
\hline CHEMBL222409 & 688471 & 6.6421 & 6.7766 & TRN & & \\
\hline & & & & & & \\
\hline
\end{tabular}

Page 27809 
Supplemental Table S2.txt

\begin{tabular}{|c|c|c|c|c|}
\hline CHEMBL460601 & 688471 & 6.9872 & 6.9249 & TRN \\
\hline CHEMBL517645 & 688471 & 6.3655 & 6.6348 & TRN \\
\hline CHEMBL1333930 & 688471 & 7.0088 & 6.445 & TRN \\
\hline CHEMBL1379970 & 688471 & 6.4895 & 6.8885 & TRN \\
\hline CHEMBL1586862 & 688471 & 5.7338 & 5.2986 & TRN \\
\hline CHEMBL304291 & 688471 & 6.5719 & 6.933 & TST \\
\hline CHEMBL1500581 & 688471 & 6.0173 & 5.2157 & TRN \\
\hline CHEMBL1459109 & 688471 & 6.4908 & 6.2633 & TRN \\
\hline CHEMBL1406361 & 688471 & 6.3883 & 6.3033 & TRN \\
\hline CHEMBL1306460 & 688471 & 3.9208 & 5.2218 & TST \\
\hline CHEMBL1360484 & 688471 & 6.6402 & 6.6245 & TRN \\
\hline CHEMBL1567841 & 688471 & 5.6187 & 4.8564 & TRN \\
\hline CHEMBL1447219 & 688471 & 5.0779 & 5.197 & TST \\
\hline CHEMBL1414112 & 688471 & 6.1209 & 5.5196 & TRN \\
\hline CHEMBL1312738 & 688471 & 6.8539 & 6.8782 & TST \\
\hline CHEMBL1405749 & 688471 & 6.9469 & 6.7348 & TRN \\
\hline CHEMBL1493731 & 688471 & 5.9763 & 5.3346 & TRN \\
\hline CHEMBL3198912 & 688471 & 6.2534 & 5.9477 & TRN \\
\hline CHEMBL1371056 & 688471 & 6.0315 & 5.8268 & TRN \\
\hline CHEMBL1440954 & 688471 & 6.6003 & 6.6464 & TRN \\
\hline CHEMBL1567269 & 688471 & 5.4148 & 5.8035 & TRN \\
\hline CHEMBL1513325 & 688471 & 5.7675 & 5.6316 & TRN \\
\hline CHEMBL1536981 & 688471 & 7.6778 & 7.3671 & TRN \\
\hline CHEMBL3192138 & 688471 & 8.0969 & 7.3921 & TRN \\
\hline CHEMBL1332878 & 688471 & 6.057 & 6.2206 & TRN \\
\hline CHEMBL1580848 & 688471 & 6.2857 & 6.09200 & 00000000005 \\
\hline CHEMBL3195389 & 688471 & 7.0655 & 7.0839 & TRN \\
\hline CHEMBL1541017 & 688471 & 6.2832 & 6.1263 & TRN \\
\hline CHEMBL1307769 & 688471 & 6.6696 & 6.8809 & TRN \\
\hline CHEMBL1371507 & 688471 & 6.2668 & 6.1282 & TRN \\
\hline CHEMBL267099 & 688471 & 6.5986 & 6.8054 & TST \\
\hline CHEMBL261115 & 688471 & 3.9208 & 5.3654 & TRN \\
\hline CHEMBL1324125 & 688471 & 6.6655 & 6.599 & TRN \\
\hline CHEMBL1347346 & 688471 & 7.2366 & 7.0311 & TRN \\
\hline CHEMBL1500190 & 688471 & 4.4202 & 5.8105 & TRN \\
\hline CHEMBL1572278 & 688471 & 6.0155 & 5.9668 & TRN \\
\hline CHEMBL1331904 & 688471 & 6.3242 & 6.1182 & TRN \\
\hline CHEMBL1455468 & 688471 & 6.6308 & 6.4554 & TRN \\
\hline CHEMBL1357620 & 688471 & 7.2076 & 7.1549 & TST \\
\hline CHEMBL1563201 & 688471 & 6.1864 & 5.925 & TRN \\
\hline CHEMBL1476264 & 688471 & 6.1445 & 5.9003 & TRN \\
\hline CHEMBL1305287 & 688471 & 6.0458 & 6.1579 & TRN \\
\hline CHEMBL1342336 & 688471 & 7.4685 & 7.1539 & TRN \\
\hline CHEMBL1432507 & 688471 & 6.5768 & 6.6229 & TRN \\
\hline CHEMBL1562712 & 688471 & 6.0044 & 5.6546 & TRN \\
\hline CHEMBL1521023 & 688471 & 7.1739 & 6.9071 & TRN \\
\hline CHEMBL1560237 & 688471 & 5.9169 & 6.2448 & TST \\
\hline CHEMBL1572214 & 688471 & 6.3478 & 6.2965 & TST \\
\hline
\end{tabular}

Page 27810 
Supplemental Table S2.txt

\begin{tabular}{|c|c|c|c|c|}
\hline CHEMBL1537509 & 688471 & 7.2924 & 6.8401 & TST \\
\hline CHEMBL1562033 & 688471 & 5.9045 & 5.7558 & TRN \\
\hline CHEMBL251785 & 688471 & 6.2048 & 6.7123 & TRN \\
\hline CHEMBL1358782 & 688471 & 5.9133 & 5.9549 & TRN \\
\hline CHEMBL1307091 & 688471 & 7.3565 & 6.9572 & TRN \\
\hline CHEMBL1386228 & 688471 & 3.9208 & 5.9267 & TRN \\
\hline CHEMBL1459841 & 688471 & 6.1772 & 4.7997 & TRN \\
\hline CHEMBL1576251 & 688471 & 6.6778 & 6.6058 & TRN \\
\hline CHEMBL1567568 & 688471 & 6.0477 & 5.7858 & TRN \\
\hline CHEMBL1488760 & 688471 & 6.2381 & 6.3756 & TRN \\
\hline CHEMBL600060 & 688471 & 6.2306 & 6.1813 & TRN \\
\hline CHEMBL1331514 & 688471 & 3.9208 & 5.5838 & TRN \\
\hline CHEMBL1562575 & 688471 & 7.8239 & 7.392 & TRN \\
\hline CHEMBL1340058 & 688471 & 6.1215 & 5.4457 & TRN \\
\hline CHEMBL1321427 & 688471 & 6.6946 & 6.312 & TRN \\
\hline CHEMBL1359872 & 688471 & 6.2233 & 6.2747 & TRN \\
\hline CHEMBL486504 & 688471 & 7.0555 & 6.8357 & TRN \\
\hline CHEMBL1327496 & 688471 & 6.0357 & 5.3202 & TRN \\
\hline CHEMBL1381392 & 688471 & 5.7951 & 5.7105 & TRN \\
\hline CHEMBL1467877 & 688471 & 5.5855 & 5.4194 & TRN \\
\hline CHEMBL1996189 & 688471 & 6.0511 & 5.3743 & TRN \\
\hline CHEMBL1537098 & 688471 & 6.9747 & 6.8043 & TRN \\
\hline CHEMBL3185655 & 688471 & 7.2291 & 7.1806 & TRN \\
\hline CHEMBL1392142 & 688471 & 6.9914 & 6.8052 & TRN \\
\hline CHEMBL1884996 & 688471 & 7.0757 & 6.4689 & TRN \\
\hline CHEMBL1396209 & 688471 & 5.7891 & 6.1335 & TRN \\
\hline CHEMBL1451935 & 688471 & 5.9034 & 5.9501 & TRN \\
\hline CHEMBL3191808 & 688471 & 5.7474 & 5.1967 & TRN \\
\hline CHEMBL1518647 & 688471 & 6.3947 & 6.4592 & TRN \\
\hline CHEMBL1391313 & 688471 & 5.9504 & 5.968 & TRN \\
\hline CHEMBL1495092 & 688471 & 7.301 & 6.7594 & TST \\
\hline CHEMBL1994623 & 688471 & 6.0311 & 5.3286 & TRN \\
\hline CHEMBL1587117 & 688471 & 7.1427 & 7.2857 & TRN \\
\hline CHEMBL1321290 & 688471 & 6.426 & 6.0294 & TRN \\
\hline CHEMBL1476215 & 688471 & 6.1451 & 6.0032 & TRN \\
\hline CHEMBL19980 & 688471 & 7.1079 & 7.1466 & TST \\
\hline CHEMBL1447284 & 688471 & 3.9208 & 5.2721 & TRN \\
\hline CHEMBL1537452 & 688471 & 6.4535 & 6.4309 & TRN \\
\hline CHEMBL1305304 & 688471 & 6.5751 & 6.7054 & TRN \\
\hline CHEMBL1374715 & 688471 & 5.7972 & \multicolumn{2}{|c|}{5.502000000000001} \\
\hline CHEMBL1329221 & 688471 & 6.0857 & 6.1547 & TRN \\
\hline CHEMBL1530673 & 688471 & 6.0752 & 5.2216 & TST \\
\hline CHEMBL1462938 & 688471 & 8.0458 & \multicolumn{2}{|c|}{8.232999999999999} \\
\hline CHEMBL1402510 & 688471 & 6.585 & 6.7688 & TRN \\
\hline CHEMBL1332139 & 688471 & 6.5498 & 6.4752 & TRN \\
\hline CHEMBL1483593 & 688471 & 6.8447 & 6.9693 & TRN \\
\hline CHEMBL563577 & 688471 & 5.9151 & 5.4447 & TRN \\
\hline CHEMBL290077 & 688471 & 6.7011 & 6.9051 & TST \\
\hline
\end{tabular}


Supplemental Table S2.txt

\begin{tabular}{|c|c|c|c|c|c|}
\hline CHEMBL1420319 & 688471 & 6.0953 & 6.3473 & TRN & \\
\hline CHEMBL3189712 & 688471 & 5.9314 & 6.0216 & TRN & \\
\hline CHEMBL1316831 & 688471 & 6.8041 & 6.8286 & TST & \\
\hline CHEMBL1324197 & 688471 & 6.2933 & 6.6437 & TRN & \\
\hline CHEMBL1323668 & 688471 & 6.5086 & 6.0473 & TRN & \\
\hline CHEMBL1597778 & 688471 & 5.9551 & 6.1865 & TRN & \\
\hline CHEMBL1431151 & 688471 & 5.5203 & 5.4688 & TRN & \\
\hline CHEMBL3193098 & 688471 & 6.2211 & 5.6597 & TRN & \\
\hline CHEMBL1384292 & 688471 & 6.5884 & 6.5918 & TRN & \\
\hline CHEMBL193627 & 688471 & 5.5025 & 5.2469 & TST & \\
\hline CHEMBL1579258 & 688471 & 5.8864 & 5.609 & TRN & \\
\hline CHEMBL1349428 & 688471 & 5.3763 & 6.0501 & TRN & \\
\hline CHEMBL1584985 & 688471 & 6.2277 & 5.9753 & TRN & \\
\hline CHEMBL 373137 & 688471 & 7.0177 & 7.03799 & 7999999999 & TRN \\
\hline CHEMBL579318 & 688471 & 6.8962 & 6.7084 & TRN & \\
\hline CHEMBL1421170 & 688471 & 6.5229 & 5.9495 & TRN & \\
\hline CHEMBL1503006 & 688471 & 3.9208 & 5.0134 & TRN & \\
\hline CHEMBL1585825 & 688471 & 3.9208 & 4.9172 & TRN & \\
\hline CHEMBL1329237 & 688471 & 5.9176 & 6.3021 & TRN & \\
\hline CHEMBL1415899 & 688471 & 3.9208 & 4.8217 & TRN & \\
\hline CHEMBL1372163 & 688471 & 5.9821 & 6.0955 & TRN & \\
\hline CHEMBL1355541 & 688471 & 7.0809 & 6.9856 & TST & \\
\hline CHEMBL1389580 & 688471 & 5.937 & 5.4479 & TRN & \\
\hline CHEMBL1605021 & 688471 & 6.0645 & 5.7274 & TST & \\
\hline CHEMBL 259103 & 688471 & 6.0114 & 6.5288 & TST & \\
\hline CHEMBL1528660 & 688471 & 6.9031 & 6.7679 & TST & \\
\hline CHEMBL1984876 & 688471 & 6.1463 & 5.8581 & TST & \\
\hline CHEMBL585591 & 688471 & 6.1574 & 6.2685 & TST & \\
\hline CHEMBL1428735 & 688471 & 6.58 & 6.3861 & TST & \\
\hline CHEMBL1422161 & 688471 & 5.8891 & 5.439 & TST & \\
\hline CHEMBL1376166 & 688471 & 6.3002 & 6.1249 & TST & \\
\hline CHEMBL3191453 & 688471 & 6.0467 & 5.8142 & TST & \\
\hline CHEMBL1527380 & 688471 & 6.2573 & 5.9398 & TST & \\
\hline CHEMBL1323774 & 688471 & 6.9666 & 6.6284 & TST & \\
\hline CHEMBL1479301 & 688471 & 6.6402 & 6.9203 & TST & \\
\hline CHEMBL1567944 & 688471 & 7.5229 & 7.0717 & TST & \\
\hline CHEMBL1555935 & 688471 & 8.301 & 7.4872 & TST & \\
\hline CHEMBL1327749 & 688471 & 6.0123 & 5.847 & TST & \\
\hline CHEMBL3199311 & 688471 & 3.9208 & 5.2198 & TST & \\
\hline CHEMBL1333449 & 688471 & 6.0496 & 5.3831 & TST & \\
\hline CHEMBL598263 & 688471 & 7.041 & 6.8917 & TST & \\
\hline CHEMBL1603960 & 688471 & 3.9208 & 4.7491 & TST & \\
\hline CHEMBL1453996 & 688471 & 6.8729 & 7.0112 & TST & \\
\hline CHEMBL1423927 & 688471 & 6.0773 & 5.6885 & TST & \\
\hline CHEMBL 1473676 & 688471 & 7.0362 & 6.8853 & TST & \\
\hline CHEMBL1490293 & 688471 & 6.6345 & \multicolumn{2}{|c|}{6.582000000000001} & TST \\
\hline CHEMBL1376974 & 688471 & 7.1308 & 7.3085 & TST & \\
\hline CHEMBL1970422 & 688471 & 6.6234 & 6.7966 & TST & \\
\hline
\end{tabular}


Supplemental Table S2.txt

\begin{tabular}{|c|c|c|c|c|c|}
\hline CHEMBL1540099 & 688471 & 6.7033 & \multicolumn{2}{|c|}{6.593999999999999} & TST \\
\hline CHEMBL1595169 & 688471 & 7.0605 & 6.8535 & TST & \\
\hline CHEMBL1076199 & 619938 & 6.3363 & 6.5194 & TRN & \\
\hline CHEMBL1086730 & 619938 & 4.0 & 5.6743 & TRN & \\
\hline CHEMBL1080294 & 619938 & 4.0 & 4.1684 & TRN & \\
\hline CHEMBL1076201 & 619938 & 6.4389 & 6.5576 & TRN & \\
\hline CHEMBL1087524 & 619938 & 4.0 & 5.0684 & TRN & \\
\hline CHEMBL1076476 & 619938 & 4.0 & 4.2726 & TRN & \\
\hline CHEMBL1088028 & 619938 & 5.2696 & 5.0466 & TRN & \\
\hline CHEMBL1076469 & 619938 & 5.9169 & 6.1629 & TRN & \\
\hline CHEMBL1076193 & 619938 & 6.9706 & 6.0976 & TRN & \\
\hline CHEMBL1076200 & 619938 & 6.2782 & 6.5571 & TRN & \\
\hline CHEMBL1080930 & 619938 & 4.0 & 4.0366 & TRN & \\
\hline CHEMBL1076533 & 619938 & 5.2099 & 5.0252 & TRN & \\
\hline CHEMBL1088153 & 619938 & 6.0182 & 6.5992 & TST & \\
\hline CHEMBL1076471 & 619938 & 6.2218 & 6.2837 & TRN & \\
\hline CHEMBL1076432 & 619938 & 7.4089 & 7.39 & TRN & \\
\hline CHEMBL1076436 & 619938 & 7.3279 & 7.5614 & TRN & \\
\hline CHEMBL1080299 & 619938 & 6.3098 & 6.4034 & TRN & \\
\hline CHEMBL1076195 & 619938 & 5.9727 & 5.8219 & TRN & \\
\hline CHEMBL1076478 & 619938 & 6.2211 & 6.4186 & TRN & \\
\hline CHEMBL1079946 & 619938 & 5.0135 & 4.8128 & TRN & \\
\hline CHEMBL1076197 & 619938 & 5.8511 & 5.6292 & TRN & \\
\hline CHEMBL1076472 & 619938 & 6.0443 & 6.4615 & TRN & \\
\hline CHEMBL1079422 & 619938 & 6.1871 & 5.8759 & TRN & \\
\hline CHEMBL1087127 & 619938 & 7.6778 & 7.5986 & TRN & \\
\hline CHEMBL1087128 & 619938 & 6.6946 & 6.3028 & TRN & \\
\hline CHEMBL1087002 & 619938 & 5.1443 & 5.0601 & TRN & \\
\hline CHEMBL1081090 & 619938 & 5.3576 & 4.9025 & TRN & \\
\hline CHEMBL1076468 & 619938 & 6.4001 & 6.3865 & TRN & \\
\hline CHEMBL1087636 & 619938 & 5.8901 & 5.7734 & TRN & \\
\hline CHEMBL1076465 & 619938 & 5.8788 & 5.7451 & TRN & \\
\hline CHEMBL1079945 & 619938 & 7.1079 & 6.6907 & TRN & \\
\hline CHEMBL1076470 & 619938 & 6.3585 & 6.2703 & TRN & \\
\hline CHEMBL1076433 & 619938 & 7.3279 & 7.5996 & TST & \\
\hline CHEMBL1088429 & 619938 & 5.9136 & 5.567 & TRN & \\
\hline CHEMBL1076473 & 619938 & 6.1314 & 6.2332 & TRN & \\
\hline CHEMBL1087649 & 619938 & 4.0 & 4.092 & TRN & \\
\hline CHEMBL1086731 & 619938 & 8.3979 & 8.9248 & TST & \\
\hline CHEMBL1088027 & 619938 & 4.0 & 4.2722 & TRN & \\
\hline CHEMBL1076475 & 619938 & 6.2807 & 5.2805 & TRN & \\
\hline CHEMBL1076466 & 619938 & 5.7796 & 5.85 & TRN & \\
\hline CHEMBL1076198 & 619938 & 6.2549 & 6.6145 & TRN & \\
\hline CHEMBL1081436 & 619938 & 5.1184 & 4.7876 & TST & \\
\hline CHEMBL1076196 & 619938 & 5.8133 & 5.4125 & TRN & \\
\hline CHEMBL1075628 & 619938 & 6.6038 & 7.231 & TST & \\
\hline CHEMBL1087638 & 619938 & 5.7701 & 5.8698 & TRN & \\
\hline CHEMBL1076203 & 619938 & 6.9318 & 6.6461 & TRN & \\
\hline
\end{tabular}

Page 27813 


\begin{tabular}{|c|c|c|c|c|c|}
\hline \multirow[b]{2}{*}{ CHEMBL1087513 } & \multicolumn{5}{|c|}{ Supplemental Table S2.txt } \\
\hline & 619938 & 4.0 & 3.951 & TRN & \\
\hline CHEMBL1076477 & 619938 & 6.0372 & 6.5708 & TST & \\
\hline CHEMBL1076437 & 619938 & 7.2441 & 7.6626 & TST & \\
\hline CHEMBL1079424 & 619938 & 4.0 & 4.1246 & TST & \\
\hline CHEMBL 1076480 & 619938 & 6.2175 & 4.9043 & TST & \\
\hline CHEMBL1076194 & 619938 & 5.8969 & 5.4346 & TST & \\
\hline CHEMBL1076202 & 619938 & 5.9126 & 6.2252 & TST & \\
\hline CHEMBL1080475 & 619938 & 7.2518 & 7.0451 & TST & \\
\hline CHEMBL1076474 & 619938 & 5.8608 & 5.9608 & TST & \\
\hline CHEMBL1086860 & 619938 & 7.2518 & 7.397 & TST & \\
\hline CHEMBL3601127 & 1509388 & 5.3848 & 5.5786 & TRN & \\
\hline CHEMBL3601239 & 1509388 & 4.5578 & 4.59 & TST & \\
\hline CHEMBL3601238 & 1509388 & 5.2615 & 4.9667 & TRN & \\
\hline CHEMBL3601716 & 1509388 & 5.2193 & 5.4159 & TRN & \\
\hline CHEMBL3601242 & 1509388 & 5.392 & 5.484 & TRN & \\
\hline CHEMBL3601226 & 1509388 & 5.6826 & 5.9232 & TRN & \\
\hline CHEMBL3601710 & 1509388 & 5.0025 & 4.7997 & TRN & \\
\hline CHEMBL3601706 & 1509388 & 5.6696 & 5.70100 & 00000000005 & TRN \\
\hline CHEMBL3601117 & 1509388 & 4.8808 & 4.9277 & TRN & \\
\hline CHEMBL3601705 & 1509388 & 6.3382 & 5.8629 & TRN & \\
\hline CHEMBL3601121 & 1509388 & 5.0773 & 4.98300 & 00000000005 & TRN \\
\hline CHEMBL 3601125 & 1509388 & 4.5741 & 4.9748 & TRN & \\
\hline CHEMBL3601111 & 1509388 & 4.9743 & 4.9672 & TRN & \\
\hline CHEMBL3601707 & 1509388 & 5.1073 & 4.6205 & TRN & \\
\hline CHEMBL3601722 & 1509388 & 4.4853 & 4.7209 & TST & \\
\hline CHEMBL3601718 & 1509388 & 5.2087 & 5.3196 & TRN & \\
\hline CHEMBL3601243 & 1509388 & 4.9574 & 4.9674 & TRN & \\
\hline CHEMBL3601711 & 1509388 & 5.5455 & 5.5027 & TRN & \\
\hline CHEMBL 3601236 & 1509388 & 5.05699 & 99999999 & 5.151 & TRN \\
\hline CHEMBL3601712 & 1509388 & 4.957 & 5.5064 & TRN & \\
\hline CHEMBL3601861 & 1509388 & 5.1758 & 5.0949 & TRN & \\
\hline CHEMBL3601112 & 1509388 & 4.7291 & 4.7265 & TRN & \\
\hline CHEMBL3601115 & 1509388 & 3.301 & 4.1009 & TRN & \\
\hline CHEMBL 3601723 & 1509388 & 5.5245 & 5.3059 & TST & \\
\hline CHEMBL3601726 & 1509388 & 4.9013 & 5.0921 & TST & \\
\hline CHEMBL3601228 & 1509388 & 5.71399 & 99999999 & 6.1447 & TRN \\
\hline CHEMBL3601704 & 1509388 & 5.3958 & 5.3415 & TRN & \\
\hline CHEMBL3601107 & 1509388 & 5.3591 & 5.3352 & TRN & \\
\hline CHEMBL3601235 & 1509388 & 3.301 & 3.4703 & TRN & \\
\hline CHEMBL3601230 & 1509388 & 5.5491 & 5.1703 & TRN & \\
\hline CHEMBL3601713 & 1509388 & 5.2566 & 5.3061 & TST & \\
\hline CHEMBL3601122 & 1509388 & 5.1195 & 4.9481 & TRN & \\
\hline CHEMBL3600393 & 1509388 & 5.2769 & 5.5388 & TRN & \\
\hline CHEMBL 3601234 & 1509388 & 3.301 & 3.2463 & TRN & \\
\hline CHEMBL3601120 & 1509388 & 5.0544 & 5.0335 & TRN & \\
\hline CHEMBL3601231 & 1509388 & 4.8631 & 5.3078 & TRN & \\
\hline CHEMBL3601123 & 1509388 & 4.6238 & 4.4057 & TRN & \\
\hline CHEMBL3601244 & 1509388 & 5.3982 & 5.2812 & TST & \\
\hline
\end{tabular}


Supplemental Table S2.txt

\begin{tabular}{|c|c|c|c|c|c|}
\hline CHEMBL3601727 & 1509388 & 5.3079 & 4.9278 & TST & \\
\hline CHEMBL3601119 & 1509388 & 5.2238 & 5.0655 & TRN & \\
\hline CHEMBL3601714 & 1509388 & 5.0511 & 4.9817 & TRN & \\
\hline CHEMBL3601118 & 1509388 & 3.301 & 3.8925 & TRN & \\
\hline CHEMBL3601229 & 1509388 & 5.4597 & 5.7492 & TRN & \\
\hline CHEMBL3601113 & 1509388 & 5.2678 & 5.1813 & TRN & \\
\hline CHEMBL3601223 & 1509388 & 5.5161 & 5.3846 & TRN & \\
\hline CHEMBL3601237 & 1509388 & 5.6334 & 5.0535 & TRN & \\
\hline CHEMBL3601233 & 1509388 & 4.6496 & 4.7451 & TRN & \\
\hline CHEMBL3601728 & 1509388 & 5.2926 & 5.1692 & TRN & \\
\hline CHEMBL 3601724 & 1509388 & 3.301 & 4.1546 & TST & \\
\hline CHEMBL 3601114 & 1509388 & 5.1656 & 5.0212 & TRN & \\
\hline CHEMBL3601110 & 1509388 & 4.6611 & 4.4838 & TRN & \\
\hline CHEMBL3601106 & 1509388 & 5.5036 & 5.4088 & TRN & \\
\hline CHEMBL3601725 & 1509388 & 5.5402 & 5.2252 & TST & \\
\hline CHEMBL3601708 & 1509388 & 5.5198 & 4.9699 & TRN & \\
\hline CHEMBL3601232 & 1509388 & 5.3474 & 5.0227 & TRN & \\
\hline CHEMBL3601116 & 1509388 & 4.952 & 4.9888 & TST & \\
\hline CHEMBL3601227 & 1509388 & 5.8074 & 5.9945 & TST & \\
\hline CHEMBL3601108 & 1509388 & 4.9274 & 5.2117 & TST & \\
\hline CHEMBL3601709 & 1509388 & 5.1686 & 5.2467 & TST & \\
\hline CHEMBL 3601224 & 1509388 & 5.2793 & 5.1871 & TST & \\
\hline CHEMBL 3601715 & 1509388 & 5.5197 & 5.4481 & TST & \\
\hline CHEMBL3601109 & 1509388 & 3.301 & 3.3028 & TST & \\
\hline CHEMBL181220 & 306735 & 7.5686 & 7.2154 & TRN & \\
\hline CHEMBL361639 & 306735 & 6.5686 & 6.6132 & TRN & \\
\hline CHEMBL3706765 & 306735 & 8.0 & 7.9264 & TRN & \\
\hline CHEMBL369336 & 306735 & 6.585 & 5.6488 & TRN & \\
\hline CHEMBL181743 & 306735 & 6.3768 & 6.2035 & TRN & \\
\hline CHEMBL426595 & 306735 & 4.0 & 4.3035 & TRN & \\
\hline CHEMBL425166 & 306735 & 6.5229 & 3.85399 & 99999999996 & TST \\
\hline CHEMBL178611 & 306735 & 6.041 & 6.1258 & TRN & \\
\hline CHEMBL361315 & 306735 & 7.8239 & 7.6928 & TRN & \\
\hline CHEMBL362645 & 306735 & 7.5528 & 7.5258 & TRN & \\
\hline CHEMBL179335 & 306735 & 8.2218 & 8.0028 & TRN & \\
\hline CHEMBL360042 & 306735 & 7.2076 & 7.3218 & TRN & \\
\hline CHEMBL180783 & 306735 & 4.0 & 4.8303 & TRN & \\
\hline CHEMBL360734 & 306735 & 4.0 & 4.9152 & TST & \\
\hline CHEMBL178613 & 306735 & 8.0 & 7.74 & TRN & \\
\hline CHEMBL181028 & 306735 & 6.9586 & 6.9348 & TRN & \\
\hline CHEMBL52 & 306735 & 6.9586 & 3.0877 & TST & \\
\hline CHEMBL181340 & 306735 & 4.6198 & 4.3426 & TRN & \\
\hline CHEMBL181450 & 306735 & 4.0 & 3.9757 & TRN & \\
\hline CHEMBL263232 & 306735 & 6.8447 & 6.9187 & TRN & \\
\hline CHEMBL362689 & 306735 & 7.9586 & 7.9777 & TRN & \\
\hline CHEMBL180979 & 306735 & 5.8239 & 6.084 & TRN & \\
\hline CHEMBL433557 & 306735 & 7.4318 & 7.5392 & TRN & \\
\hline CHEMBL180052 & 306735 & 7.9208 & 8.0439 & TRN & \\
\hline
\end{tabular}

Page 27815 


\begin{tabular}{|c|c|c|c|c|c|}
\hline & & \multicolumn{4}{|c|}{ Supplemental Table S2.txt } \\
\hline CHEMBL180917 & 306735 & 5.4191 & 4.2521 & TST & \\
\hline CHEMBL180256 & 306735 & 6.9586 & 7.1121 & TRN & \\
\hline CHEMBL178920 & 306735 & 7.8861 & 8.0795 & TRN & \\
\hline CHEMBL427319 & 306735 & 7.3279 & 7.3781 & TRN & \\
\hline CHEMBL360222 & 306735 & 5.4283 & 5.4648 & TRN & \\
\hline CHEMBL426423 & 306735 & 8.0969 & 8.4299 & TRN & \\
\hline CHEMBL182243 & 306735 & 4.0 & 3.8984 & TRN & \\
\hline CHEMBL425695 & 306735 & 6.3565 & 6.2183 & TRN & \\
\hline CHEMBL181409 & 306735 & 7.4949 & 7.4361 & TRN & \\
\hline CHEMBL359834 & 306735 & 5.7959 & 5.6371 & TRN & \\
\hline CHEMBL360987 & 306735 & 6.3468 & 6.2774 & TRN & \\
\hline CHEMBL433554 & 306735 & 5.4685 & 5.9953 & TRN & \\
\hline CHEMBL368254 & 306735 & 7.6021 & 7.568 & TRN & \\
\hline CHEMBL179844 & 306735 & 5.5045 & 5.3862 & TRN & \\
\hline CHEMBL179959 & 306735 & 7.9586 & 8.0437 & TRN & \\
\hline CHEMBL180838 & 306735 & 7.3768 & 7.1309 & TRN & \\
\hline CHEMBL360890 & 306735 & 5.5129 & 5.5759 & TRN & \\
\hline CHEMBL181993 & 306735 & 6.1079 & 6.1058 & TRN & \\
\hline CHEMBL178139 & 306735 & 8.0 & 8.1949 & TRN & \\
\hline CHEMBL433952 & 306735 & 6.9586 & 7.0501 & TRN & \\
\hline CHEMBL425336 & 306735 & 7.3279 & 7.0648 & TRN & \\
\hline CHEMBL180947 & 306735 & 5.8539 & 3.4123 & TST & \\
\hline CHEMBL181128 & 306735 & 6.2757 & 6.3209 & TST & \\
\hline CHEMBL 369787 & 306735 & 6.6271 & 5.579 & TST & \\
\hline CHEMBL178178 & 306735 & 6.5528 & 6.3966 & TST & \\
\hline CHEMBL181939 & 306735 & 4.0 & 5.4515 & TST & \\
\hline CHEMBL180769 & 306735 & 7.0506 & 7.1797 & TST & \\
\hline CHEMBL181837 & 306735 & 7.1192 & 6.2509 & TST & \\
\hline CHEMBL181226 & 306735 & 7.9586 & 7.4816 & TST & \\
\hline CHEMBL178575 & 306735 & 7.5229 & 7.6215 & TST & \\
\hline CHEMBL178495 & 306735 & 6.0362 & 5.7586 & TST & \\
\hline CHEMBL67054 & 45347 & 5.7447 & 5.74200 & 0000000001 & TRN \\
\hline CHEMBL 303871 & 45347 & 5.6021 & 5.6013 & TRN & \\
\hline CHEMBL 304154 & 45347 & 5.7212 & 5.251 & TRN & \\
\hline CHEMBL 304544 & 45347 & 3.0 & 2.935 & TST & \\
\hline CHEMBL69553 & 45347 & 5.2291 & 5.2999 & TRN & \\
\hline CHEMBL442366 & 45347 & 4.699 & 4.905 & TRN & \\
\hline CHEMBL68428 & 45347 & 5.3188 & 5.1716 & TRN & \\
\hline CHEMBL68637 & 45347 & 5.0706 & 4.9343 & TRN & \\
\hline CHEMBL65936 & 45347 & 5.0969 & 5.0483 & TRN & \\
\hline CHEMBL439755 & 45347 & 5.6383 & 5.2229 & TRN & \\
\hline CHEMBL68915 & 45347 & 3.0 & 3.8559 & TRN & \\
\hline CHEMBL69991 & 45347 & 6.1549 & 6.24 & TRN & \\
\hline CHEMBL69096 & 45347 & 5.3188 & 5.0388 & TRN & \\
\hline CHEMBL 304838 & 45347 & 6.1938 & 6.1662 & TRN & \\
\hline CHEMBL305066 & 45347 & 6.2218 & 6.3522 & TRN & \\
\hline CHEMBL66504 & 45347 & 6.0 & 5.5034 & TRN & \\
\hline CHEMBL303194 & 45347 & 3.0 & 2.6897 & TRN & \\
\hline
\end{tabular}




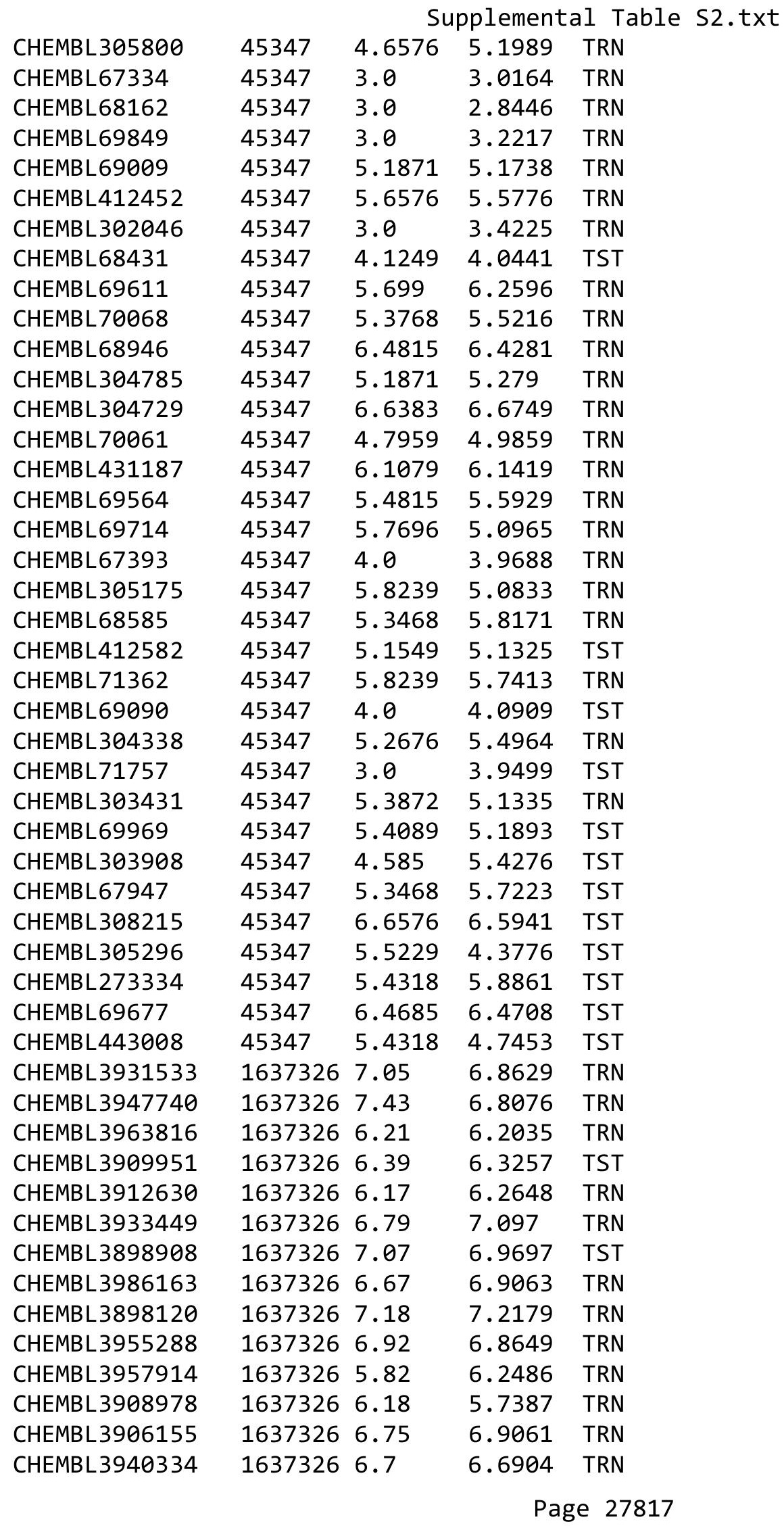


Supplemental Table S2.txt

\begin{tabular}{|c|c|c|c|c|c|}
\hline CHEMBL3958153 & 1637326 & 7.07 & 7.2722 & TRN & \\
\hline CHEMBL3925254 & 1637326 & 6.92 & 6.5832 & TRN & \\
\hline CHEMBL3907600 & 1637326 & 6.65 & 6.7112 & TRN & \\
\hline CHEMBL3954368 & 1637326 & 5.74 & 5.9509 & TRN & \\
\hline CHEMBL3951714 & 1637326 & 6.79 & 6.745 & TRN & \\
\hline CHEMBL3965364 & 1637326 & 5.92 & 5.7319 & TRN & \\
\hline CHEMBL3969446 & 1637326 & 7.37 & 7.4529 & TRN & \\
\hline CHEMBL3951126 & 1637326 & 7.12 & 7.4528 & TRN & \\
\hline CHEMBL3933015 & 1637326 & 5.0 & 5.3545 & TRN & \\
\hline CHEMBL3898881 & 1637326 & 7.39 & 7.4624 & TRN & \\
\hline CHEMBL3901644 & 1637326 & 6.62 & 6.6568 & TRN & \\
\hline CHEMBL3944665 & 1637326 & 5.0 & 6.1703 & TST & \\
\hline CHEMBL3947293 & 1637326 & 6.48 & 6.7582 & TRN & \\
\hline CHEMBL3947826 & 1637326 & 6.97 & 6.0667 & TST & \\
\hline CHEMBL3985692 & 1637326 & 6.95 & 7.0329 & TST & \\
\hline CHEMBL3947990 & 1637326 & 7.19 & 6.7751 & TST & \\
\hline CHEMBL3925306 & 1637326 & 7.55 & 7.79799 & & TRN \\
\hline CHEMBL3951245 & 1637326 & 6.91 & 6.9635 & TST & \\
\hline CHEMBL3948623 & 1637326 & 6.46 & 6.8006 & TRN & \\
\hline CHEMBL3892018 & 1637326 & 7.15 & 7.2775 & TRN & \\
\hline CHEMBL3987037 & 1637326 & 7.08 & 7.3136 & TRN & \\
\hline CHEMBL3921313 & 1637326 & 6.46 & 6.4217 & TRN & \\
\hline CHEMBL3927327 & 1637326 & 6.68 & 6.779 & TRN & \\
\hline CHEMBL3976280 & 1637326 & 7.31 & 7.4487 & TRN & \\
\hline CHEMBL3973820 & 1637326 & 7.0 & 7.028 & TRN & \\
\hline CHEMBL3918011 & 1637326 & 6.59 & 6.5182 & TRN & \\
\hline CHEMBL3915235 & 1637326 & 6.91 & 6.6074 & TRN & \\
\hline CHEMBL3965673 & 1637326 & 5.0 & 5.6424 & TRN & \\
\hline CHEMBL3968094 & 1637326 & 5.0 & 5.9577 & TRN & \\
\hline CHEMBL3918751 & 1637326 & 7.27 & 7.2379 & TRN & \\
\hline CHEMBL3956164 & 1637326 & 6.86 & 6.8891 & TRN & \\
\hline CHEMBL3908829 & 1637326 & 7.69 & 6.8997 & TRN & \\
\hline CHEMBL3911573 & 1637326 & 7.26 & 7.2024 & TRN & \\
\hline CHEMBL3969879 & 1637326 & 6.05 & 6.0287 & TRN & \\
\hline CHEMBL3972564 & 1637326 & 6.14 & 5.9046 & TRN & \\
\hline CHEMBL3927875 & 1637326 & 7.54 & 7.4219 & TRN & \\
\hline CHEMBL3930634 & 1637326 & 5.0 & 5.902 & TRN & \\
\hline CHEMBL3901627 & 1637326 & 6.86 & 6.8924 & TST & \\
\hline CHEMBL3904329 & 1637326 & 6.69 & 6.8823 & TRN & \\
\hline CHEMBL3969408 & 1637326 & 5.91 & 5.3097 & TRN & \\
\hline CHEMBL3985853 & 1637326 & 7.14 & 7.3834 & TRN & \\
\hline CHEMBL3908326 & 1637326 & 7.01 & 7.38 & TRN & \\
\hline CHEMBL3918092 & 1637326 & 7.61 & 7.5199 & TRN & \\
\hline CHEMBL3964675 & 1637326 & 7.12 & 6.7495 & TRN & \\
\hline CHEMBL3955706 & 1637326 & 7.44 & 7.5203 & TRN & \\
\hline CHEMBL3937533 & 1637326 & 7.04 & 6.8957 & TRN & \\
\hline CHEMBL 3962814 & 1637326 & 6.76 & 6.7902 & TRN & \\
\hline CHEMBL3931674 & 1637326 & 6.87 & 7.3687 & TRN & \\
\hline
\end{tabular}




\begin{tabular}{|c|c|c|c|c|}
\hline \multicolumn{5}{|c|}{ Supplemental Table S2.txt } \\
\hline CHEMBL3976219 & 1637326 & 6.47 & 6.6726 & TRN \\
\hline CHEMBL 3924872 & 1637326 & 6.82 & 6.568 & TRN \\
\hline CHEMBL 3908529 & 1637326 & 7.36 & 7.598 & TRN \\
\hline CHEMBL 3962805 & 1637326 & 6.49 & 6.6521 & TRN \\
\hline CHEMBL 3960128 & 1637326 & 6.34 & 6.8607 & TST \\
\hline CHEMBL3909565 & 1637326 & 6.79 & 7.0381 & TRN \\
\hline CHEMBL 3948321 & 1637326 & 7.22 & 7.1934 & TRN \\
\hline CHEMBL 3985750 & 1637326 & 6.78 & 6.7382 & TRN \\
\hline CHEMBL 3983115 & 1637326 & 6.35 & 6.6734 & TRN \\
\hline CHEMBL3926311 & 1637326 & 5.0 & 6.0453 & TRN \\
\hline CHEMBL3926406 & 1637326 & 7.23 & 7.3786 & TRN \\
\hline CHEMBL 3979490 & 1637326 & 7.28 & 6.9012 & TST \\
\hline CHEMBL3898355 & 1637326 & 7.14 & 7.2152 & TST \\
\hline CHEMBL 3940725 & 1637326 & 6.49 & 6.239 & TRN \\
\hline CHEMBL3973531 & 1637326 & 6.66 & 6.9784 & TRN \\
\hline CHEMBL3913757 & 1637326 & 7.28 & 7.4866 & TRN \\
\hline CHEMBL3961210 & 1637326 & 7.47 & 7.2628 & TRN \\
\hline CHEMBL3936765 & 1637326 & 6.4 & 6.3661 & TRN \\
\hline CHEMBL3951156 & 1637326 & 6.68 & 6.6231 & TRN \\
\hline CHEMBL3979170 & 1637326 & 7.38 & 7.2686 & TST \\
\hline CHEMBL3921618 & 1637326 & 7.86 & 7.6158 & TRN \\
\hline CHEMBL3969815 & 1637326 & 7.04 & 7.1376 & TRN \\
\hline CHEMBL3961872 & 1637326 & 7.39 & 7.0204 & TST \\
\hline CHEMBL 3985222 & 1637326 & 7.78 & 7.4365 & TRN \\
\hline CHEMBL 3974664 & 1637326 & 7.05 & 6.7965 & TRN \\
\hline CHEMBL3972173 & 1637326 & 6.2 & 6.6418 & TRN \\
\hline CHEMBL3919173 & 1637326 & 7.96 & 7.5851 & TRN \\
\hline CHEMBL 3956737 & 1637326 & 5.0 & 5.591 & TRN \\
\hline CHEMBL 3966022 & 1637326 & 6.75 & 6.7443 & TRN \\
\hline CHEMBL3968499 & 1637326 & 7.6 & 7.5249 & TRN \\
\hline CHEMBL3912505 & 1637326 & 6.29 & 6.1496 & TRN \\
\hline CHEMBL 3915158 & 1637326 & 6.0 & 5.4718 & TRN \\
\hline CHEMBL3950262 & 1637326 & 6.63 & 6.5333 & TRN \\
\hline CHEMBL 3949470 & 1637326 & 7.23 & 7.3641 & TRN \\
\hline CHEMBL3893008 & 1637326 & 7.35 & 7.3477 & TRN \\
\hline CHEMBL 3889493 & 1637326 & 7.14 & 6.6511 & TRN \\
\hline CHEMBL 3984548 & 1637326 & 7.18 & 7.1637 & TRN \\
\hline CHEMBL3920908 & 1637326 & 7.16 & 6.9073 & TST \\
\hline CHEMBL 3939278 & 1637326 & 7.31 & 7.2989 & TRN \\
\hline CHEMBL3974693 & 1637326 & 7.14 & 7.061 & TRN \\
\hline CHEMBL3972208 & 1637326 & 6.31 & 6.0958 & TRN \\
\hline CHEMBL3950907 & 1637326 & 7.0 & 6.8754 & TRN \\
\hline CHEMBL3931421 & 1637326 & 7.39 & 7.2449 & TRN \\
\hline CHEMBL 3923296 & 1637326 & 7.68 & 7.5121 & TRN \\
\hline CHEMBL3918495 & 1637326 & 7.69 & 7.4748 & TRN \\
\hline CHEMBL3945369 & 1637326 & 5.96 & 5.4295 & TRN \\
\hline CHEMBL3961267 & 1637326 & 6.76 & 6.6758 & TRN \\
\hline CHEMBL3984039 & 1637326 & 7.97 & 7.6163 & TRN \\
\hline
\end{tabular}




\begin{tabular}{|c|c|c|c|c|c|}
\hline \multicolumn{6}{|c|}{ Supplemental Table S2.txt } \\
\hline CHEMBL3928627 & 1637326 & 6.23 & 5.7009 & TST & \\
\hline CHEMBL 3908877 & 1637326 & 7.07 & 7.1312 & TST & \\
\hline CHEMBL 3907488 & 1637326 & 6.53 & 6.4738 & TST & \\
\hline CHEMBL 3929803 & 1637326 & 7.16 & 7.0841 & TRN & \\
\hline CHEMBL 3970430 & 1637326 & 7.6 & 7.3572 & TRN & \\
\hline CHEMBL3969475 & 1637326 & 6.87 & 6.8416 & TRN & \\
\hline CHEMBL3963728 & 1637326 & 6.04 & 5.7568 & TST & \\
\hline CHEMBL 3944224 & 1637326 & 7.24 & 6.8307 & TRN & \\
\hline CHEMBL 3909318 & 1637326 & 6.72 & 6.9136 & TRN & \\
\hline CHEMBL3982668 & 1637326 & 7.31 & 7.0316 & TRN & \\
\hline CHEMBL 3980232 & 1637326 & 7.53 & 7.4063 & TST & \\
\hline CHEMBL 3937633 & 1637326 & 7.58 & 7.5825 & TRN & \\
\hline CHEMBL 3955563 & 1637326 & 7.59 & 7.2756 & TRN & \\
\hline CHEMBL 3890607 & 1637326 & 7.92 & 7.5781 & TRN & \\
\hline CHEMBL 3893373 & 1637326 & 7.13 & 6.9021 & TRN & \\
\hline CHEMBL 3954298 & 1637326 & 7.08 & 7.1965 & TRN & \\
\hline CHEMBL3900620 & 1637326 & 7.06 & 6.693 & TRN & \\
\hline CHEMBL3983996 & 1637326 & 7.72 & 7.6201 & TRN & \\
\hline CHEMBL3935124 & 1637326 & 6.54 & 6.73 & TRN & \\
\hline CHEMBL 3973645 & 1637326 & 5.0 & 5.2594 & TST & \\
\hline CHEMBL 3971073 & 1637326 & 6.59 & 6.6354 & TRN & \\
\hline CHEMBL3957264 & 1637326 & 7.0 & 7.3694 & TRN & \\
\hline CHEMBL3969096 & 1637326 & 6.12 & 5.7519 & TRN & \\
\hline CHEMBL 3905212 & 1637326 & 7.1 & 6.9032 & TST & \\
\hline CHEMBL 3897034 & 1637326 & 6.79 & 6.8236 & TRN & \\
\hline CHEMBL3979885 & 1637326 & 6.98 & 6.9934 & TRN & \\
\hline CHEMBL3982334 & 1637326 & 6.16 & 5.9659 & TRN & \\
\hline CHEMBL3919730 & 1637326 & 7.7 & 7.7052 & TRN & \\
\hline CHEMBL3922453 & 1637326 & 7.47 & 7.5093 & TRN & \\
\hline CHEMBL3959345 & 1637326 & 7.33 & 7.5308 & TRN & \\
\hline CHEMBL3959201 & 1637326 & 7.15 & 6.8942 & TST & \\
\hline CHEMBL 3915233 & 1637326 & 5.0 & 6.06 & TRN & \\
\hline CHEMBL3912569 & 1637326 & 7.67 & 7.4982 & TRN & \\
\hline CHEMBL3975954 & 1637326 & 6.86 & 6.9742 & TRN & \\
\hline CHEMBL 3966748 & 1637326 & 7.43 & 7.5498 & TST & \\
\hline CHEMBL3929648 & 1637326 & 7.17 & 7.4258 & TRN & \\
\hline CHEMBL3926964 & 1637326 & 5.0 & 5.6662 & TRN & \\
\hline CHEMBL3891619 & 1637326 & 6.71 & 6.7736 & TRN & \\
\hline CHEMBL 3986661 & 1637326 & 6.6 & 6.33299 & 9999999999 & TRN \\
\hline CHEMBL 3943043 & 1637326 & 7.26 & 7.1627 & TRN & \\
\hline CHEMBL3904745 & 1637326 & 7.02 & 6.9183 & TRN & \\
\hline CHEMBL3965614 & 1637326 & 7.24 & 7.0015 & TRN & \\
\hline CHEMBL3968009 & 1637326 & 7.24 & 7.1879 & TST & \\
\hline CHEMBL 3906122 & 1637326 & 7.06 & 6.9549 & TST & \\
\hline CHEMBL 3900268 & 1637326 & 5.0 & 5.5349 & TRN & \\
\hline CHEMBL3951728 & 1637326 & 6.61 & 6.9892 & TRN & \\
\hline CHEMBL 3962554 & 1637326 & 7.04 & 7.0294 & TRN & \\
\hline CHEMBL3913970 & 1637326 & 7.01 & 6.7569 & TST & \\
\hline
\end{tabular}




$$
\text { Supplemental Table S2.txt }
$$

$\begin{array}{lllll}\text { CHEMBL3972979 } & 1637326 & 7.37 & 7.0239 & \text { TRN } \\ \text { CHEMBL3975447 } & 1637326 & 7.62 & 7.5436 & \text { TRN } \\ \text { CHEMBL3911516 } & 1637326 & 6.57 & 6.6141 & \text { TRN } \\ \text { CHEMBL3958756 } & 1637326 & 6.23 & 6.2866 & \text { TRN } \\ \text { CHEMBL3956120 } & 1637326 & 6.83 & 6.5616 & \text { TRN } \\ \text { CHEMBL3907551 } & 1637326 & 6.34 & 6.0823 & \text { TRN } \\ \text { CHEMBL3904777 } & 1637326 & 6.59 & 6.4088 & \text { TST } \\ \text { CHEMBL3975007 } & 1637326 & 6.64 & 6.6126 & \text { TRN } \\ \text { CHEMBL3972517 } & 1637326 & 7.11 & 7.1834 & \text { TRN } \\ \text { CHEMBL3928956 } & 1637326 & 5.0 & 5.7411 & \text { TRN } \\ \text { CHEMBL3919270 } & 1637326 & 6.14 & 6.3384 & \text { TRN } \\ \text { CHEMBL3941705 } & 1637326 & 6.16 & 6.4111 & \text { TRN } \\ \text { CHEMBL3982570 } & 1637326 & 6.1 & 6.1003 & \text { TRN } \\ \text { CHEMBL3920007 } & 1637326 & 7.09 & 7.0744 & \text { TRN } \\ \text { CHEMBL3922698 } & 1637326 & 7.33 & 7.6431 & \text { TRN } \\ \text { CHEMBL3957533 } & 1637326 & 7.69 & 7.4792 & \text { TRN } \\ \text { CHEMBL3969373 } & 1637326 & 7.52 & 7.4404 & \text { TRN } \\ \text { CHEMBL3905485 } & 1637326 & 7.31 & 7.2974 & \text { TRN } \\ \text { CHEMBL3904674 } & 1637326 & 7.47 & 7.5494 & \text { TRN } \\ \text { CHEMBL3945845 } & 1637326 & 7.01 & 6.4456 & \text { TRN } \\ \text { CHEMBL3951694 } & 1637326 & 7.23 & 7.5531 & \text { TRN } \\ \text { CHEMBL3929914 } & 1637326 & 6.86 & 6.6098 & \text { TST } \\ \text { CHEMBL3971277 } & 1637326 & 7.24 & 7.3111 & \text { TRN } \\ \text { CHEMBL3891892 } & 1637326 & 7.64 & 7.251 & \text { TRN } \\ \text { CHEMBL3985498 } & 1637326 & 6.62 & 6.8668 & \text { TRN } \\ \text { CHEMBL3912831 } & 1637326 & 6.99 & 7.1807 & \text { TRN } \\ \text { CHEMBL3931154 } & 1637326 & 6.86 & 7.1788 & \text { TRN } \\ \text { CHEMBL3893718 } & 1637326 & 7.22 & 7.4041 & \text { TRN } \\ \text { CHEMBL3973321 } & 1637326 & 7.46 & 7.1678 & \text { TRN } \\ \text { CHEMBL3960327 } & 1637326 & 7.08 & 7.4169 & \text { TRN } \\ \text { CHEMBL3956571 } & 1637326 & 6.9 & 6.4311 & \text { TRN } \\ \text { CHEMBML3969824 } & 1637326 & 7.17 & 6.8062 & \text { TRN } \\ \text { CHEMBL3907314 } & 1637326 & 8.08 & 7.4987 & \text { TRN } \\ \text { CHEMB392258 } & 1637326 & 7.49 & 7.2392 & \text { TRN } \\ \text { CHEMBL3904561 } & 1637326 & 7.07 & 6.9186 & \text { TST } \\ \text { CHEMBEB } 3937326 & 7.42 & 7.3924 & \text { TRN }\end{array}$

Page 27821 


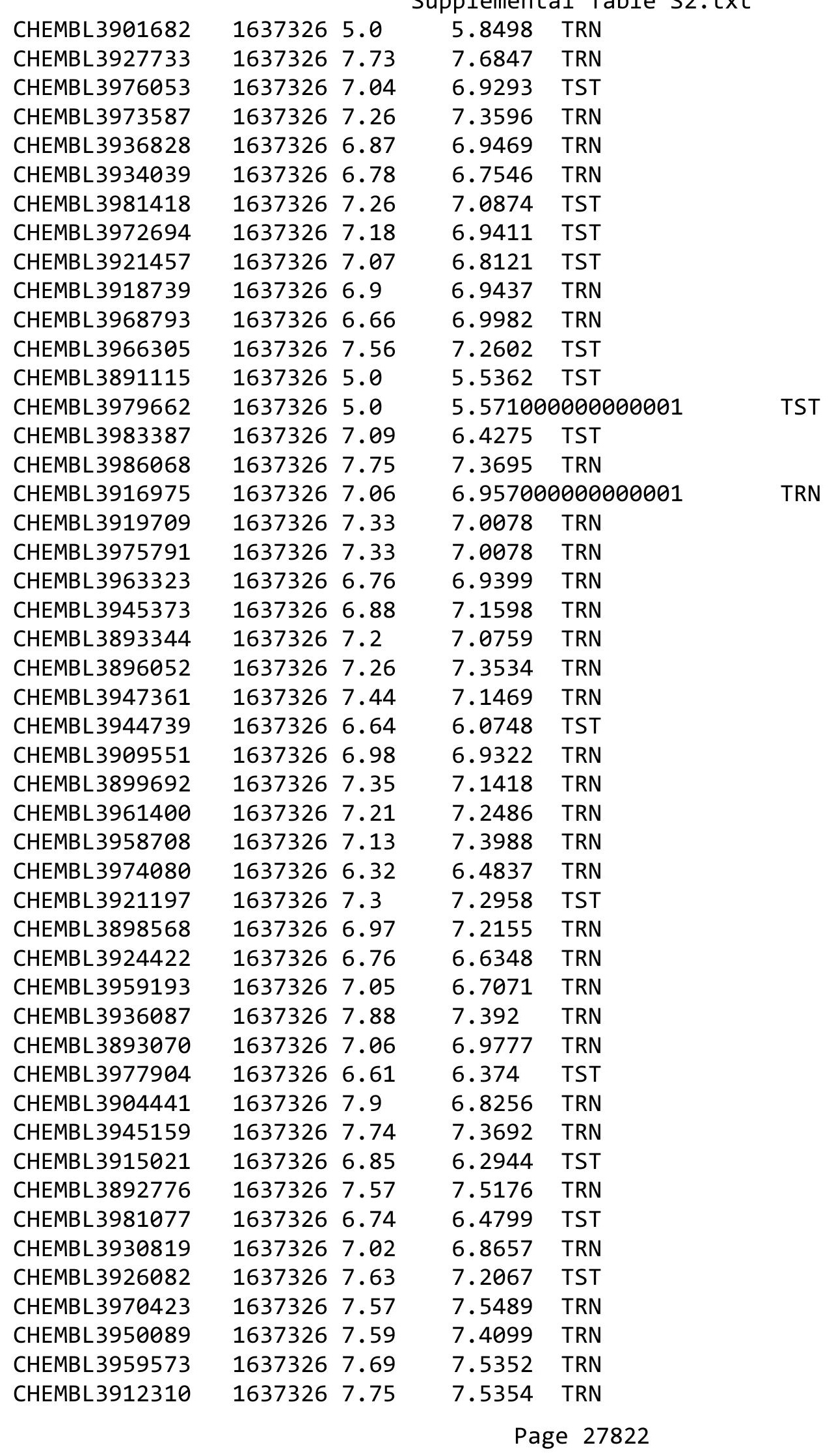




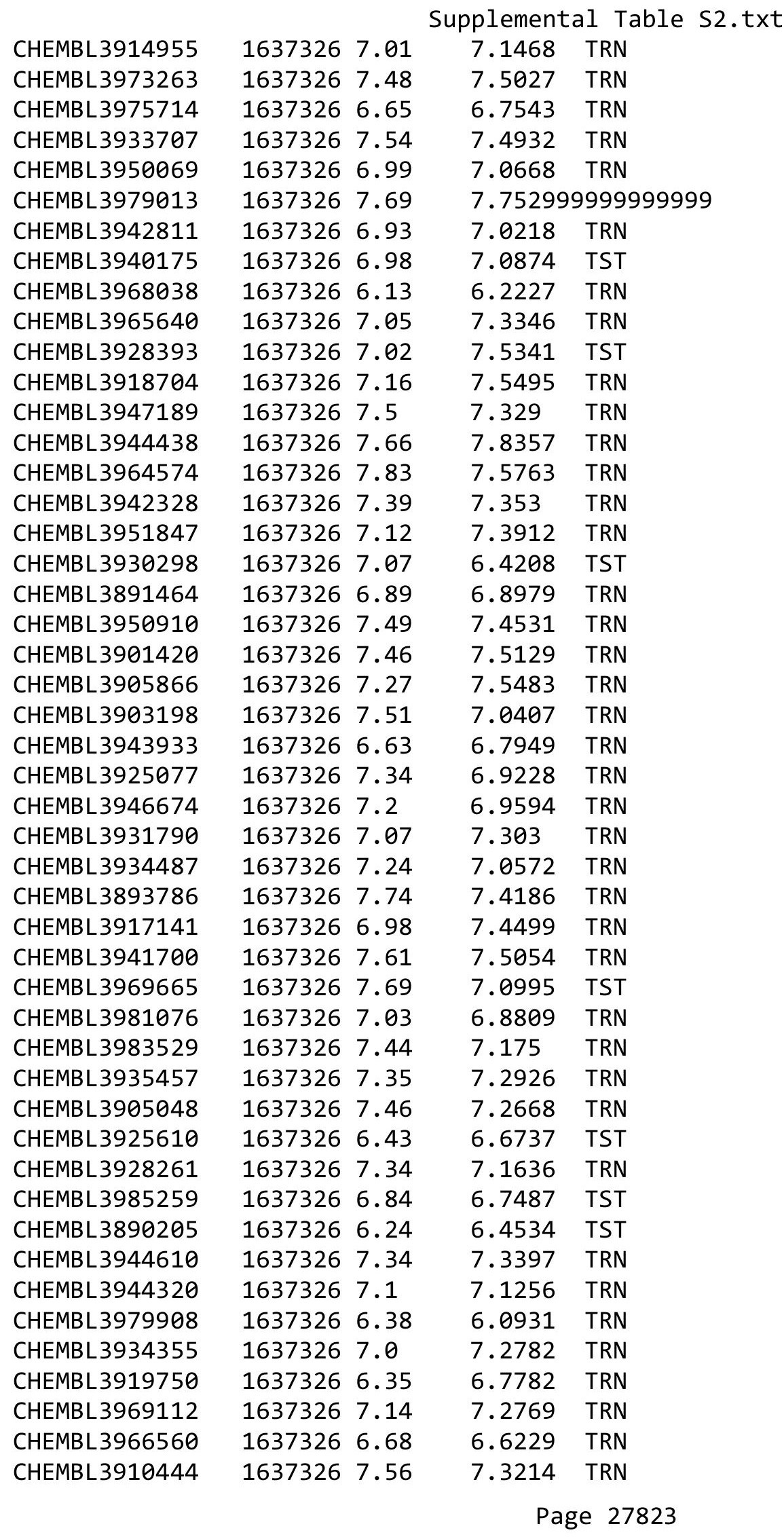

TRN 


\begin{tabular}{|c|c|c|c|c|c|}
\hline \multirow[b]{2}{*}{ CHEMBL3907642 } & \\
\hline & 1637326 & 7.14 & 6.7594 & TRN & \\
\hline CHEMBL3973929 & 1637326 & 7.18 & 7.4715 & TRN & \\
\hline CHEMBL3972617 & 1637326 & 6.71 & 6.7642 & TRN & \\
\hline CHEMBL3908149 & 1637326 & 7.57 & 7.2661 & TRN & \\
\hline CHEMBL 3943080 & 1637326 & 6.58 & 6.6982 & TRN & \\
\hline CHEMBL3904294 & 1637326 & 7.63 & 7.3474 & TRN & \\
\hline CHEMBL3907063 & 1637326 & 7.43 & $7.4910 e$ & 00000000005 & TRN \\
\hline CHEMBL3896623 & 1637326 & 7.17 & 7.1018 & TRN & \\
\hline CHEMBL3893950 & 1637326 & 7.2 & 7.1451 & TRN & \\
\hline CHEMBL3955745 & 1637326 & 6.93 & 6.7543 & TRN & \\
\hline CHEMBL3953117 & 1637326 & 6.61 & 6.4177 & TST & \\
\hline CHEMBL3951360 & 1637326 & 6.78 & 6.9998 & TRN & \\
\hline CHEMBL3930158 & 1637326 & 6.52 & 6.601 & TRN & \\
\hline CHEMBL3911746 & 1637326 & 7.97 & 6.7496 & TST & \\
\hline CHEMBL3917295 & 1637326 & 7.23 & 7.4687 & TRN & \\
\hline CHEMBL3902110 & 1637326 & 6.95 & 6.9432 & TRN & \\
\hline CHEMBL3904814 & 1637326 & 5.0 & 6.2277 & TST & \\
\hline CHEMBL3911948 & 1637326 & 6.17 & 6.2246 & TST & \\
\hline CHEMBL3928239 & 1637326 & 7.11 & 7.2945 & TRN & \\
\hline CHEMBL3979028 & 1637326 & 6.7 & 6.5918 & TRN & \\
\hline CHEMBL3890378 & 1637326 & 6.96 & 7.199 & TRN & \\
\hline CHEMBL3932363 & 1637326 & 7.39 & 6.8998 & TST & \\
\hline CHEMBL3932756 & 1637326 & 7.28 & 7.119 & TRN & \\
\hline CHEMBL3919479 & 1637326 & 7.53 & 7.5445 & TRN & \\
\hline CHEMBL3968818 & 1637326 & 6.95 & 7.0849 & TRN & \\
\hline CHEMBL3966316 & 1637326 & 6.57 & 6.5702 & TRN & \\
\hline CHEMBL3940940 & 1637326 & 6.57 & 6.6052 & TST & \\
\hline CHEMBL3982107 & 1637326 & 7.4 & 7.5614 & TRN & \\
\hline CHEMBL3979670 & 1637326 & 7.2 & 7.4828 & TRN & \\
\hline CHEMBL3911738 & 1637326 & 6.9 & 7.0655 & TRN & \\
\hline CHEMBL3951090 & 1637326 & 7.02 & 7.3158 & TRN & \\
\hline CHEMBL3960571 & 1637326 & 7.37 & 7.3151 & TRN & \\
\hline CHEMBL3949508 & 1637326 & 6.72 & 7.0399 & TRN & \\
\hline CHEMBL3901612 & 1637326 & 7.96 & 7.9195 & TRN & \\
\hline CHEMBL3974206 & 1637326 & 6.87 & 6.9091 & TST & \\
\hline CHEMBL3889711 & 1637326 & 6.6 & 6.7537 & TRN & \\
\hline CHEMBL3927585 & 1637326 & 6.44 & 6.7334 & TRN & \\
\hline CHEMBL3946103 & 1637326 & 7.48 & 7.7441 & TRN & \\
\hline CHEMBL3936421 & 1637326 & 6.52 & 6.5196 & TRN & \\
\hline CHEMBL3901119 & 1637326 & 7.65 & 7.0507 & TST & \\
\hline CHEMBL3919884 & 1637326 & 7.26 & 7.273 & TST & \\
\hline CHEMBL3942606 & 1637326 & 7.1 & 6.9453 & TST & \\
\hline CHEMBL3945277 & 1637326 & 7.19 & 6.955 & TRN & \\
\hline CHEMBL3897523 & 1637326 & 6.0 & 6.1499 & TRN & \\
\hline CHEMBL3907327 & 1637326 & 7.08 & $6.6610 e$ & 00000000005 & TRN \\
\hline CHEMBL3956579 & 1637326 & 6.23 & 6.5402 & TST & \\
\hline CHEMBL3959260 & 1637326 & 6.96 & 6.6202 & TRN & \\
\hline CHEMBL3890852 & 1637326 & 7.07 & 6.9709 & TST & \\
\hline & & & & 27824 & \\
\hline
\end{tabular}




\begin{tabular}{|c|c|c|c|c|c|}
\hline \\
\hline CHEMBL3893642 & 1637326 & 7.41 & 7.2264 & TRN & \\
\hline CHEMBL3950156 & 1637326 & 7.24 & 7.1233 & TRN & \\
\hline CHEMBL3952866 & 1637326 & 6.87 & 6.8026 & TST & \\
\hline CHEMBL3925114 & 1637326 & 7.0 & 7.0068 & TRN & \\
\hline CHEMBL3897155 & 1637326 & 7.31 & 7.1853 & TST & \\
\hline CHEMBL3937972 & 1637326 & 7.27 & 7.1471 & TRN & \\
\hline CHEMBL3935177 & 1637326 & 6.86 & 6.9424 & TRN & \\
\hline CHEMBL3962492 & 1637326 & 7.32 & 7.2771 & TRN & \\
\hline CHEMBL3903823 & 1637326 & 7.11 & 7.0022 & TRN & \\
\hline CHEMBL3964096 & 1637326 & 7.34 & 7.1637 & TST & \\
\hline CHEMBL3948755 & 1637326 & 6.65 & 6.7394 & TST & \\
\hline CHEMBL3892155 & 1637326 & 7.42 & 7.3207 & TRN & \\
\hline CHEMBL3987162 & 1637326 & 6.39 & 5.7463 & TRN & \\
\hline CHEMBL3921441 & 1637326 & 7.41 & 7.4624 & TRN & \\
\hline CHEMBL3905015 & 1637326 & 6.96 & 6.7373 & TRN & \\
\hline CHEMBL3921817 & 1637326 & 7.39 & 7.33899 & 99999999995 & TRN \\
\hline CHEMBL3927219 & 1637326 & 7.01 & 6.9982 & TRN & \\
\hline CHEMBL3902434 & 1637326 & 7.03 & 7.1441 & TRN & \\
\hline CHEMBL3927158 & 1637326 & 6.06 & 5.9323 & TRN & \\
\hline CHEMBL3985182 & 1637326 & 6.2 & 6.256 & TRN & \\
\hline CHEMBL3933442 & 1637326 & 7.01 & 7.1875 & TRN & \\
\hline CHEMBL3934080 & 1637326 & 7.32 & 7.5321 & TRN & \\
\hline CHEMBL3895443 & 1637326 & 6.98 & 7.2279 & TRN & \\
\hline CHEMBL3904736 & 1637326 & 6.08 & 6.466 & TRN & \\
\hline CHEMBL3914473 & 1637326 & 5.0 & 5.9022 & TRN & \\
\hline CHEMBL3898926 & 1637326 & 6.72 & 7.1267 & TRN & \\
\hline CHEMBL3952277 & 1637326 & 7.05 & 7.2181 & TRN & \\
\hline CHEMBL3926245 & 1637326 & 7.02 & 6.2906 & TST & \\
\hline CHEMBL3978617 & 1637326 & 7.13 & 7.5353 & TRN & \\
\hline CHEMBL3966071 & 1637326 & 7.04 & 7.0444 & TST & \\
\hline CHEMBL3966200 & 1637326 & 7.22 & 7.3203 & TRN & \\
\hline CHEMBL 3940672 & 1637326 & 7.49 & 7.1311 & TST & \\
\hline CHEMBL3979328 & 1637326 & 7.5 & 7.4483 & TRN & \\
\hline CHEMBL3983918 & 1637326 & 7.47 & 7.0927 & TST & \\
\hline CHEMBL3975193 & 1637326 & 6.85 & 6.2699 & TRN & \\
\hline CHEMBL3924172 & 1637326 & 6.77 & 6.7493 & TRN & \\
\hline CHEMBL3921469 & 1637326 & 7.18 & 7.3532 & TRN & \\
\hline CHEMBL3900551 & 1637326 & 6.21 & 6.1873 & TRN & \\
\hline CHEMBL3897783 & 1637326 & 7.4 & 7.4659 & TRN & \\
\hline CHEMBL3891525 & 1637326 & 7.23 & 7.0978 & TRN & \\
\hline CHEMBL3935838 & 1637326 & 6.78 & 6.7752 & TST & \\
\hline CHEMBL3977010 & 1637326 & 7.33 & 7.1976 & TRN & \\
\hline CHEMBL3967761 & 1637326 & 7.42 & 7.3142 & TRN & \\
\hline CHEMBL3893556 & 1637326 & 6.0 & 6.0154 & TRN & \\
\hline CHEMBL3896249 & 1637326 & 7.95 & 7.2696 & TRN & \\
\hline CHEMBL3952789 & 1637326 & 5.78 & 6.2814 & TRN & \\
\hline CHEMBL3955385 & 1637326 & 6.52 & 6.1302 & TRN & \\
\hline CHEMBL3977708 & 1637326 & 6.43 & 6.1676 & TRN & \\
\hline
\end{tabular}


Supplemental Table S2.txt

\begin{tabular}{|c|c|c|c|c|c|}
\hline CHEMBL3980069 & 1637326 & 7.7 & \multicolumn{2}{|c|}{ 7.712000000000001 } & TRN \\
\hline CHEMBL3946938 & 1637326 & 7.11 & 7.2722 & TRN & \\
\hline CHEMBL3941337 & 1637326 & 5.0 & 5.2084 & TRN & \\
\hline CHEMBL 3983585 & 1637326 & 5.0 & 4.9726 & TRN & \\
\hline CHEMBL 3918638 & 1637326 & 7.63 & 7.0078 & TRN & \\
\hline CHEMBL 3920637 & 1637326 & 7.57 & \multicolumn{2}{|c|}{7.337000000000001} & TRN \\
\hline CHEMBL3917908 & 1637326 & 7.19 & 7.3464 & TRN & \\
\hline CHEMBL3980712 & 1637326 & 5.0 & 5.0567 & TRN & \\
\hline CHEMBL 3978349 & 1637326 & 6.74 & 6.9064 & TST & \\
\hline CHEMBL3976721 & 1637326 & 6.4 & 5.9974 & TRN & \\
\hline CHEMBL 3974273 & 1637326 & 6.22 & 6.1565 & TRN & \\
\hline CHEMBL 3898255 & 1637326 & 6.17 & \multicolumn{2}{|c|}{6.0360000000000005} & TST \\
\hline CHEMBL 3927794 & 1637326 & 6.2 & 5.7623 & TST & \\
\hline CHEMBL 3953833 & 1637326 & 6.22 & 6.1098 & TRN & \\
\hline CHEMBL 3964043 & 1637326 & 6.51 & 6.7647 & TRN & \\
\hline CHEMBL 3945658 & 1637326 & 6.08 & 5.4418 & TRN & \\
\hline CHEMBL3948306 & 1637326 & 5.0 & 4.7894 & TRN & \\
\hline CHEMBL 3984035 & 1637326 & 7.01 & 6.4922 & TST & \\
\hline CHEMBL 3986725 & 1637326 & 6.75 & 6.6196 & TST & \\
\hline CHEMBL 3896142 & 1637326 & 7.47 & 7.1624 & TST & \\
\hline CHEMBL 3908707 & 1637326 & 7.37 & 7.1729 & TRN & \\
\hline CHEMBL3941227 & 1637326 & 6.68 & 6.4721 & TST & \\
\hline CHEMBL3943917 & 1637326 & 6.46 & 6.2431 & TRN & \\
\hline CHEMBL3979972 & 1637326 & 7.52 & 6.6079 & TRN & \\
\hline CHEMBL3982399 & 1637326 & 6.55 & 6.4925 & TRN & \\
\hline CHEMBL 3932817 & 1637326 & 6.61 & 6.3241 & TST & \\
\hline CHEMBL3930088 & 1637326 & 6.99 & 6.8117 & TST & \\
\hline CHEMBL 3972445 & 1637326 & 5.0 & 5.2858 & TRN & \\
\hline CHEMBL 3969747 & 1637326 & 5.0 & 6.2346 & TST & \\
\hline CHEMBL3918426 & 1637326 & 5.0 & 7.0644 & TST & \\
\hline CHEMBL3906938 & 1637326 & 7.41 & 6.7506 & TRN & \\
\hline CHEMBL3956028 & 1637326 & 5.0 & 4.9915 & TRN & \\
\hline CHEMBL 3964762 & 1637326 & 6.7 & 6.4002 & TRN & \\
\hline CHEMBL 3948234 & 1637326 & 5.0 & 6.8672 & TST & \\
\hline CHEMBL3932022 & 1637326 & 7.78 & 6.9498 & TST & \\
\hline CHEMBL3957473 & 1637326 & 5.0 & 6.9749 & TRN & \\
\hline CHEMBL3950496 & 1637326 & 6.85 & 7.1936 & TRN & \\
\hline CHEMBL3902961 & 1637326 & 6.63 & 6.9162 & TRN & \\
\hline CHEMBL 3905633 & 1637326 & 6.0 & 6.8484 & TST & \\
\hline CHEMBL3937212 & 1637326 & 6.9 & 6.5474 & TST & \\
\hline CHEMBL3966929 & 1637326 & 7.08 & 6.9982 & TRN & \\
\hline CHEMBL3922100 & 1637326 & 6.86 & 6.4945 & TST & \\
\hline CHEMBL3906284 & 1637326 & 7.44 & 7.4624 & TRN & \\
\hline CHEMBL3921787 & 1637326 & 6.54 & 6.0477 & TRN & \\
\hline CHEMBL 3951171 & 1637326 & 7.74 & 7.0056 & TRN & \\
\hline CHEMBL 3983694 & 1637326 & 5.0 & 6.032 & TRN & \\
\hline CHEMBL3981207 & 1637326 & 6.7 & 6.9112 & TRN & \\
\hline CHEMBL3986631 & 1637326 & 6.42 & 5.8438 & TRN & \\
\hline
\end{tabular}




\begin{tabular}{|c|c|c|c|c|c|}
\hline \multirow[b]{2}{*}{ CHEMBL3969667 } & \\
\hline & 1637326 & 7.11 & 6.9719 & TRN & \\
\hline CHEMBL3933908 & 1637326 & 6.32 & 6.1122 & TRN & \\
\hline CHEMBL3936673 & 1637326 & 6.26 & 6.0598 & TRN & \\
\hline CHEMBL3980417 & 1637326 & 6.27 & 6.5832 & TRN & \\
\hline CHEMBL3921190 & 1637326 & 6.1 & 6.6462 & TRN & \\
\hline CHEMBL3920274 & 1637326 & 5.0 & 5.4042 & TST & \\
\hline CHEMBL3953771 & 1637326 & 6.86 & \multicolumn{2}{|c|}{6.5520000000000005} & TST \\
\hline CHEMBL3950292 & 1637326 & 6.45 & 6.2736 & TRN & \\
\hline CHEMBL3959787 & 1637326 & 5.0 & 5.1725 & TRN & \\
\hline CHEMBL3986861 & 1637326 & 6.47 & 6.5253 & TST & \\
\hline CHEMBL3891816 & 1637326 & 6.06 & 5.8278 & TST & \\
\hline CHEMBL3927140 & 1637326 & 5.71 & 6.3427 & TRN & \\
\hline CHEMBL3929849 & 1637326 & 6.1 & 5.6641 & TRN & \\
\hline CHEMBL3966941 & 1637326 & 6.02 & 5.8911 & TST & \\
\hline CHEMBL3939018 & 1637326 & 6.75 & 6.5234 & TST & \\
\hline CHEMBL3912757 & 1637326 & 7.11 & 6.6132 & TRN & \\
\hline CHEMBL3915450 & 1637326 & 6.95 & 6.2756 & TRN & \\
\hline CHEMBL3956493 & 1637326 & 6.81 & 6.9541 & TRN & \\
\hline CHEMBL3964931 & 1637326 & 6.44 & 6.1413 & TRN & \\
\hline CHEMBL3918956 & 1637326 & 6.49 & 6.0477 & TRN & \\
\hline CHEMBL3894754 & 1637326 & 5.0 & 5.8918 & TRN & \\
\hline CHEMBL3963296 & 1637326 & 5.0 & 5.9814 & TRN & \\
\hline CHEMBL 3890187 & 1637326 & 5.0 & 5.6512 & TST & \\
\hline CHEMBL3978313 & 1637326 & 6.02 & 6.3275 & TRN & \\
\hline CHEMBL3889604 & 1637326 & 6.91 & \multicolumn{2}{|c|}{6.922000000000001} & TRN \\
\hline CHEMBL3939332 & 1637326 & 6.75 & 6.9052 & TRN & \\
\hline CHEMBL3912250 & 1637326 & 6.78 & 6.9296 & TRN & \\
\hline CHEMBL3901265 & 1637326 & 6.72 & 6.7796 & TRN & \\
\hline CHEMBL3903973 & 1637326 & 7.93 & 7.7727 & TRN & \\
\hline CHEMBL3957928 & 1637326 & 5.0 & 5.9412 & TRN & \\
\hline CHEMBL3960591 & 1637326 & 6.37 & 6.3285 & TST & \\
\hline CHEMBL3899721 & 1637326 & 6.03 & 5.8786 & TRN & \\
\hline CHEMBL3934772 & 1637326 & 6.25 & 6.0512 & TRN & \\
\hline CHEMBL3909752 & 1637326 & 6.61 & 6.6545 & TRN & \\
\hline CHEMBL3906945 & 1637326 & 7.12 & 6.7206 & TRN & \\
\hline CHEMBL3954396 & 1637326 & 7.76 & 7.5433 & TRN & \\
\hline CHEMBL3944937 & 1637326 & 5.0 & 5.7179 & TRN & \\
\hline CHEMBL3895267 & 1637326 & 6.98 & 6.5923 & TRN & \\
\hline CHEMBL3892529 & 1637326 & 7.85 & 7.761 & TRN & \\
\hline CHEMBL3935597 & 1637326 & 7.65 & 7.5619 & TRN & \\
\hline CHEMBL3932893 & 1637326 & 5.0 & 5.8346 & TST & \\
\hline CHEMBL3952706 & 1637326 & 5.0 & 5.8937 & TST & \\
\hline CHEMBL3939860 & 1637326 & 7.04 & 6.9531 & TST & \\
\hline CHEMBL3976275 & 1637326 & 7.64 & 7.3082 & TRN & \\
\hline CHEMBL3978754 & 1637326 & 7.58 & 6.9723 & TST & \\
\hline CHEMBL3942716 & 1637326 & 7.07 & 7.1805 & TRN & \\
\hline CHEMBL3982718 & 1637326 & 5.0 & 5.8927 & TRN & \\
\hline \multirow[t]{2}{*}{ CHEMBL3892005 } & 1637326 & 6.15 & \multicolumn{2}{|c|}{5.9479999999999995} & TST \\
\hline & & & & 27827 & \\
\hline
\end{tabular}




\begin{tabular}{|c|c|c|c|c|}
\hline \multicolumn{5}{|c|}{ Supplemental Table S2.txt } \\
\hline CHEMBL 3894762 & 1637326 & 7.39 & 6.5731 & TST \\
\hline CHEMBL 3896514 & 1637326 & 6.61 & 6.5212 & TST \\
\hline CHEMBL3906253 & 1637326 & 6.42 & 6.0122 & TRN \\
\hline CHEMBL 3946877 & 1637326 & 5.0 & 5.4549 & TST \\
\hline CHEMBL 3944241 & 1637326 & 6.98 & 6.3787 & TST \\
\hline CHEMBL 3947664 & 1637326 & 6.71 & 6.6728 & TRN \\
\hline CHEMBL 3899151 & 1637326 & 7.68 & 7.6056 & TRN \\
\hline CHEMBL3960877 & 1637326 & 7.43 & 7.4691 & TST \\
\hline CHEMBL3958209 & 1637326 & 7.74 & 7.6628 & TRN \\
\hline CHEMBL3933492 & 1637326 & 5.8 & 5.3646 & TRN \\
\hline CHEMBL 3982416 & 1637326 & 5.3 & 5.2211 & TRN \\
\hline CHEMBL3984969 & 1637326 & 6.2 & 5.8178 & TRN \\
\hline CHEMBL3953206 & 1637326 & 6.2 & 5.8982 & TRN \\
\hline CHEMBL3946591 & 1637326 & 5.0 & 6.1536 & TST \\
\hline CHEMBL3942179 & 1637326 & 6.29 & 6.5261 & TRN \\
\hline CHEMBL3930685 & 1637326 & 5.0 & 5.9359 & TST \\
\hline CHEMBL3910555 & 1637326 & 7.26 & 7.3683 & TRN \\
\hline CHEMBL3918036 & 1637326 & 6.21 & 5.5341 & TRN \\
\hline CHEMBL3926088 & 1637326 & 6.09 & 5.4097 & TRN \\
\hline CHEMBL3948043 & 1637326 & 5.0 & 7.0078 & TRN \\
\hline CHEMBL3972657 & 1637326 & 5.0 & 6.1353 & TST \\
\hline CHEMBL 3918892 & 1637326 & 6.16 & 5.7137 & TST \\
\hline CHEMBL3966660 & 1637326 & 5.0 & 5.1871 & TST \\
\hline CHEMBL 3899891 & 1637326 & 5.0 & 6.0854 & TST \\
\hline CHEMBL 3890118 & 1637326 & 5.0 & 6.4376 & TST \\
\hline CHEMBL3950169 & 1637326 & 7.32 & 7.1599 & TST \\
\hline CHEMBL 3952885 & 1637326 & 5.0 & 5.8557 & TST \\
\hline CHEMBL 3890870 & 1637326 & 6.09 & 6.2982 & TST \\
\hline CHEMBL3893659 & 1637326 & 6.14 & 4.8151 & TST \\
\hline CHEMBL3928923 & 1637326 & 6.25 & 6.8044 & TST \\
\hline CHEMBL3938712 & 1637326 & 5.0 & 5.4348 & TST \\
\hline CHEMBL 3975295 & 1637326 & 5.0 & 5.5367 & TST \\
\hline CHEMBL 3977791 & 1637326 & 5.0 & 5.651 & TST \\
\hline CHEMBL3916904 & 1637326 & 5.0 & 5.0378 & TST \\
\hline CHEMBL3974131 & 1637326 & 5.0 & 5.6981 & TST \\
\hline CHEMBL3925322 & 1637326 & 6.26 & 6.1529 & TST \\
\hline CHEMBL3922592 & 1637326 & 5.0 & 4.3897 & TST \\
\hline CHEMBL 3985007 & 1637326 & 5.0 & 5.2291 & TST \\
\hline CHEMBL3982466 & 1637326 & 5.0 & 4.9042 & TST \\
\hline CHEMBL3910921 & 1637326 & 6.63 & 7.1471 & TST \\
\hline CHEMBL3908141 & 1637326 & 5.0 & 4.2998 & TST \\
\hline CHEMBL 3971947 & 1637326 & 6.08 & 6.1475 & TST \\
\hline CHEMBL3960102 & 1637326 & 5.0 & 5.4202 & TST \\
\hline CHEMBL3891736 & 1637326 & 6.31 & 6.2334 & TST \\
\hline CHEMBL3932123 & 1637326 & 5.0 & 5.9305 & TST \\
\hline CHEMBL3952488 & 1637326 & 7.63 & 5.9034 & TST \\
\hline CHEMBL3664612 & 1527871 & 6.4156 & 6.5313 & TRN \\
\hline CHEMBL3660028 & 1527871 & 6.8416 & 7.0268 & TRN \\
\hline
\end{tabular}


Supplemental Table S2.txt

\begin{tabular}{|c|c|c|c|c|c|}
\hline CHEMBL 3664613 & 1527871 & 6.7867 & 6.8973 & TRN & \\
\hline CHEMBL 3664620 & 1527871 & 7.0386 & 6.9116 & TRN & \\
\hline CHEMBL 3660072 & 1527871 & 5.0 & 5.3383 & TST & \\
\hline CHEMBL 3660092 & 1527871 & 6.3569 & 6.2691 & TRN & \\
\hline CHEMBL3660051 & 1527871 & 5.0 & 5.1003 & TRN & \\
\hline CHEMBL3664623 & 1527871 & 6.0 & 5.9709 & TRN & \\
\hline CHEMBL 3660059 & 1527871 & 5.7642 & 5.6122 & TRN & \\
\hline CHEMBL 3660077 & 1527871 & 6.8477 & 6.8687 & TRN & \\
\hline CHEMBL 3664630 & 1527871 & 6.8489 & 6.5394 & TRN & \\
\hline CHEMBL3660037 & 1527871 & 6.0 & 6.74 & TST & \\
\hline CHEMBL3660020 & 1527871 & 5.3748 & 5.3034 & TRN & \\
\hline CHEMBL 3660008 & 1527871 & 6.0931 & 6.1745 & TRN & \\
\hline CHEMBL3660043 & 1527871 & 6.7399 & 6.569 & TRN & \\
\hline CHEMBL 3664627 & 1527871 & 6.0 & 6.0218 & TRN & \\
\hline CHEMBL3660057 & 1527871 & 5.7545 & 5.9698 & TRN & \\
\hline CHEMBL3660029 & 1527871 & 7.1135 & 7.1653 & TRN & \\
\hline CHEMBL3660075 & 1527871 & 7.2596 & 7.1254 & TRN & \\
\hline CHEMBL3944365 & 1527871 & 6.0 & 5.2134 & TST & \\
\hline CHEMBL3664615 & 1527871 & 6.523 & 6.6668 & TRN & \\
\hline CHEMBL3660069 & 1527871 & 7.1024 & 6.8991 & TRN & \\
\hline CHEMBL3660081 & 1527871 & 6.9788 & 6.8511 & TRN & \\
\hline CHEMBL3660091 & 1527871 & 6.0 & 6.2802 & TRN & \\
\hline CHEMBL 3660084 & 1527871 & 6.2993 & 6.1385 & TRN & \\
\hline CHEMBL3660027 & 1527871 & 6.3002 & 6.16 & TRN & \\
\hline CHEMBL 3660046 & 1527871 & 5.1265 & 5.1266 & TST & \\
\hline CHEMBL3660058 & 1527871 & 5.0 & 5.1513 & TRN & \\
\hline CHEMBL3660067 & 1527871 & 5.0 & 5.0213 & TRN & \\
\hline CHEMBL 3660079 & 1527871 & 6.7144 & 6.9749 & TRN & \\
\hline CHEMBL3664625 & 1527871 & 6.4514 & 6.6097 & TRN & \\
\hline CHEMBL3660056 & 1527871 & 5.5427 & 5.9167 & TRN & \\
\hline CHEMBL 3660070 & 1527871 & 5.7003 & 4.7686 & TST & \\
\hline CHEMBL 3664622 & 1527871 & 6.8069 & 6.9403 & TRN & \\
\hline CHEMBL 3660073 & 1527871 & 5.8573 & \multicolumn{2}{|c|}{6.1339999999999995} & TRN \\
\hline CHEMBL3664631 & 1527871 & 6.0215 & 6.0916 & TRN & \\
\hline CHEMBL 3660063 & 1527871 & 7.1612 & 6.9427 & TRN & \\
\hline CHEMBL3660026 & 1527871 & 5.8684 & 5.8767 & TRN & \\
\hline CHEMBL3660049 & 1527871 & 6.3915 & 6.4775 & TRN & \\
\hline CHEMBL 3660030 & 1527871 & 6.0 & 5.8686 & TRN & \\
\hline CHEMBL3660039 & 1527871 & 6.0 & 6.3607 & TST & \\
\hline CHEMBL 3660009 & 1527871 & 6.0 & 5.7556 & TRN & \\
\hline CHEMBL3664632 & 1527871 & 6.2957 & 6.3303 & TRN & \\
\hline CHEMBL3660087 & 1527871 & 6.2958 & 6.6079 & TST & \\
\hline CHEMBL3660019 & 1527871 & 6.2503 & 6.2737 & TRN & \\
\hline CHEMBL3660023 & 1527871 & 7.3098 & 7.1082 & TRN & \\
\hline CHEMBL 3660054 & 1527871 & 6.3152 & 6.3951 & TRN & \\
\hline CHEMBL3660078 & 1527871 & 5.9851 & 6.114 & TRN & \\
\hline CHEMBL3664616 & 1527871 & 6.7775 & 6.6291 & TRN & \\
\hline CHEMBL3660024 & 1527871 & 7.7696 & 7.4427 & TRN & \\
\hline
\end{tabular}

Page 27829 
Supplemental Table S2.txt

\begin{tabular}{|c|c|c|c|c|c|}
\hline CHEMBL 3660032 & 1527871 & 6.4908 & 6.6532 & TRN & \\
\hline CHEMBL3660089 & 1527871 & 6.1796 & 6.2006 & TRN & \\
\hline CHEMBL 3660082 & 1527871 & 6.8477 & 6.8715 & TRN & \\
\hline CHEMBL 3660074 & 1527871 & 5.8935 & 5.5311 & TRN & \\
\hline CHEMBL3660011 & 1527871 & 5.0 & 5.9164 & TST & \\
\hline CHEMBL3660071 & 1527871 & 5.0489 & 5.6942 & TST & \\
\hline CHEMBL 3660042 & 1527871 & 5.8938 & 6.5078 & TST & \\
\hline CHEMBL 3660018 & 1527871 & 6.7235 & 6.5143 & TRN & \\
\hline CHEMBL 3660041 & 1527871 & 7.585 & 7.3509 & TST & \\
\hline CHEMBL3660006 & 1527871 & 5.9559 & 6.1138 & TRN & \\
\hline CHEMBL3660016 & 1527871 & 6.0 & 5.7124 & TRN & \\
\hline CHEMBL 3664624 & 1527871 & 6.3674 & 6.604 & TRN & \\
\hline CHEMBL3660068 & 1527871 & 6.2306 & 6.3795 & TRN & \\
\hline CHEMBL 3664611 & 1527871 & 6.3105 & 6.3111 & TRN & \\
\hline CHEMBL3660015 & 1527871 & 6.289 & 5.9867 & TST & \\
\hline CHEMBL3660014 & 1527871 & 6.2441 & 6.5058 & TRN & \\
\hline CHEMBL3660048 & 1527871 & 6.0 & 5.9903 & TRN & \\
\hline CHEMBL3660097 & 1527871 & 6.0 & 6.1308 & TRN & \\
\hline CHEMBL3660047 & 1527871 & 5.761 & 5.2804 & TST & \\
\hline CHEMBL3664628 & 1527871 & 6.0 & 7.4605 & TST & \\
\hline CHEMBL3664633 & 1527871 & 6.4414 & 6.8528 & TST & \\
\hline CHEMBL3660095 & 1527871 & 6.3883 & 6.482 & TRN & \\
\hline CHEMBL 3660060 & 1527871 & 6.9957 & 6.5678 & TST & \\
\hline CHEMBL3660053 & 1527871 & 6.3696 & 6.2378 & TRN & \\
\hline CHEMBL 3660025 & 1527871 & 7.2924 & 6.9106 & TST & \\
\hline CHEMBL3664626 & 1527871 & 6.0 & 5.9142 & TRN & \\
\hline CHEMBL 3660007 & 1527871 & 5.0 & 5.5746 & TST & \\
\hline CHEMBL 3660094 & 1527871 & 6.7185 & 6.7972 & TRN & \\
\hline CHEMBL3660076 & 1527871 & 5.9344 & 6.0268 & TRN & \\
\hline CHEMBL 3664617 & 1527871 & 7.0655 & 7.1336 & TRN & \\
\hline CHEMBL 3660093 & 1527871 & 7.1831 & 6.9313 & TRN & \\
\hline CHEMBL3660061 & 1527871 & 6.4908 & 7.3501 & TST & \\
\hline CHEMBL3660066 & 1527871 & 7.1739 & 7.2611 & TRN & \\
\hline CHEMBL3660055 & 1527871 & 6.6904 & 6.1228 & TST & \\
\hline CHEMBL 3660090 & 1527871 & 6.0 & 5.75799 & 9999999999 & TRN \\
\hline CHEMBL 3660052 & 1527871 & 5.0 & 4.9305 & TRN & \\
\hline CHEMBL3664621 & 1527871 & 6.0 & 6.1105 & TRN & \\
\hline CHEMBL 3660086 & 1527871 & 6.0 & 5.9409 & TRN & \\
\hline CHEMBL3660033 & 1527871 & 6.8447 & 6.7238 & TST & \\
\hline CHEMBL 3660050 & 1527871 & 6.0 & 6.1865 & TRN & \\
\hline CHEMBL3664618 & 1527871 & 6.6529 & 6.7564 & TRN & \\
\hline CHEMBL3660064 & 1527871 & 6.8996 & 6.9715 & TRN & \\
\hline CHEMBL 3660045 & 1527871 & 5.0 & 6.1168 & TST & \\
\hline CHEMBL3660080 & 1527871 & 7.1367 & 6.9291 & TRN & \\
\hline CHEMBL 3660034 & 1527871 & 6.2328 & 6.2119 & TRN & \\
\hline CHEMBL3660021 & 1527871 & 6.7721 & 6.3647 & TRN & \\
\hline CHEMBL3660012 & 1527871 & 5.9809 & 6.0439 & TST & \\
\hline CHEMBL3660062 & 1527871 & 6.7595 & 7.0121 & TST & \\
\hline
\end{tabular}

Page 27830 
Supplemental Table S2.txt

\begin{tabular}{|c|c|c|c|c|}
\hline CHEMBL3660065 & 1527871 & 7.0223 & 7.1035 & TRN \\
\hline CHEMBL3660096 & 1527871 & 7.5952 & 7.5664 & TRN \\
\hline CHEMBL3660035 & 1527871 & 6.0 & 6.3133 & TST \\
\hline CHEMBL 3664614 & 1527871 & 6.0 & 5.9657 & TRN \\
\hline CHEMBL3664629 & 1527871 & 7.1163 & 7.1818 & TST \\
\hline CHEMBL3660013 & 1527871 & 5.2539 & 6.4031 & TST \\
\hline CHEMBL3664619 & 1527871 & 6.0 & 6.1418 & TRN \\
\hline CHEMBL149835 & 154524 & 8.59 & 8.5964 & TRN \\
\hline CHEMBL355924 & 154524 & 5.84 & 5.8394 & TRN \\
\hline CHEMBL342514 & 154524 & 6.46 & 6.4536 & TRN \\
\hline CHEMBL147323 & 154524 & 6.89 & 6.893 & TRN \\
\hline CHEMBL146341 & 154524 & 6.79 & 6.7942 & TRN \\
\hline CHEMBL342533 & 154524 & 6.17 & 6.1883 & TRN \\
\hline CHEMBL149113 & 154524 & 6.26 & 6.26 & TRN \\
\hline CHEMBL359285 & 154524 & 8.59 & 8.5862 & TRN \\
\hline CHEMBL146650 & 154524 & 8.58 & 8.5846 & TRN \\
\hline CHEMBL148540 & 154524 & 6.63 & 6.6313 & TRN \\
\hline CHEMBL149715 & 154524 & 6.77 & 6.7767 & TRN \\
\hline CHEMBL422487 & 154524 & 5.99 & 5.996 & TRN \\
\hline CHEMBL148664 & 154524 & 7.14 & 6.9743 & TST \\
\hline CHEMBL148663 & 154524 & 5.79 & 5.7386 & TST \\
\hline CHEMBL147935 & 154524 & 8.9 & 8.8984 & TRN \\
\hline CHEMBL148459 & 154524 & 8.72 & 8.7221 & TRN \\
\hline CHEMBL146806 & 154524 & 7.56 & 7.5534 & TRN \\
\hline CHEMBL147294 & 154524 & 6.01 & 6.0064 & TRN \\
\hline CHEMBL344986 & 154524 & 6.27 & 6.2707 & TRN \\
\hline CHEMBL358325 & 154524 & 8.66 & 8.6548 & TRN \\
\hline CHEMBL146663 & 154524 & 5.99 & 5.9875 & TRN \\
\hline CHEMBL146301 & 154524 & 9.01 & 9.0078 & TRN \\
\hline CHEMBL148950 & 154524 & 8.85 & 8.8172 & TRN \\
\hline CHEMBL146133 & 154524 & 6.57 & 6.5821 & TRN \\
\hline CHEMBL343210 & 154524 & 9.05 & 9.0511 & TRN \\
\hline CHEMBL148341 & 154524 & 7.04 & 6.9634 & TST \\
\hline CHEMBL147095 & 154524 & 9.07 & 9.0751 & TRN \\
\hline CHEMBL146029 & 154524 & 6.93 & 6.9325 & TRN \\
\hline CHEMBL343260 & 154524 & 6.95 & 6.9479 & TRN \\
\hline CHEMBL148254 & 154524 & 5.86 & 5.8515 & TRN \\
\hline CHEMBL424126 & 154524 & 6.14 & 6.1382 & TRN \\
\hline CHEMBL147090 & 154524 & 9.06 & 9.0877 & TRN \\
\hline CHEMBL146231 & 154524 & 8.36 & 8.3584 & TRN \\
\hline CHEMBL358379 & 154524 & 8.96 & 8.9213 & TRN \\
\hline CHEMBL149064 & 154524 & 6.38 & 6.3774 & TRN \\
\hline CHEMBL446629 & 154524 & 9.16 & 9.166 & TRN \\
\hline CHEMBL147480 & 154524 & 6.45 & 6.45 & TRN \\
\hline CHEMBL149647 & 154524 & 8.7 & 8.3093 & TST \\
\hline CHEMBL147648 & 154524 & 6.43 & 6.435 & TRN \\
\hline CHEMBL265551 & 154524 & 6.88 & 6.8762 & TRN \\
\hline CHEMBL147212 & 154524 & 5.62 & 5.6101 & TRN \\
\hline
\end{tabular}




\begin{tabular}{|c|c|c|c|c|c|}
\hline \multicolumn{6}{|c|}{ Supplemental Table S2.txt } \\
\hline CHEMBL148797 & 154524 & 8.75 & 8.7482 & TRN & \\
\hline CHEMBL149876 & 154524 & 9.11 & 9.1093 & TRN & \\
\hline CHEMBL356784 & 154524 & 6.33 & 6.3284 & TRN & \\
\hline CHEMBL356382 & 154524 & 8.96 & 8.9831 & TRN & \\
\hline CHEMBL356707 & 154524 & 7.91 & 7.9174 & TRN & \\
\hline CHEMBL341899 & 154524 & 6.43 & 6.425 & TRN & \\
\hline CHEMBL356773 & 154524 & 6.8 & 6.61799 & 9999999999 & TST \\
\hline CHEMBL357759 & 154524 & 6.1 & 6.4269 & TST & \\
\hline CHEMBL146864 & 154524 & 6.92 & 6.4565 & TST & \\
\hline CHEMBL146320 & 154524 & 6.97 & 6.6832 & TST & \\
\hline CHEMBL343215 & 154524 & 6.02 & 6.4906 & TST & \\
\hline CHEMBL342292 & 154524 & 8.32 & 8.0478 & TST & \\
\hline CHEMBL146369 & 154524 & 6.84 & 6.1804 & TST & \\
\hline CHEMBL147384 & 154524 & 8.8 & 9.1502 & TST & \\
\hline CHEMBL149782 & 154524 & 7.03 & 6.6666 & TST & \\
\hline CHEMBL147049 & 154524 & 5.86 & 5.9113 & TST & \\
\hline CHEMBL147819 & 154524 & 6.12 & 6.2924 & TST & \\
\hline CHEMBL 365780 & 304924 & 6.9586 & 6.9617 & TRN & \\
\hline CHEMBL 22310 & 304924 & 7.3188 & 5.6643 & TST & \\
\hline CHEMBL193887 & 304924 & 6.1487 & 6.1476 & TRN & \\
\hline CHEMBL195173 & 304924 & 7.2218 & 7.2101 & TRN & \\
\hline CHEMBL195862 & 304924 & 5.3768 & 5.3606 & TRN & \\
\hline CHEMBL195755 & 304924 & 7.2518 & 7.2596 & TRN & \\
\hline CHEMBL 362930 & 304924 & 5.1024 & 5.0992 & TRN & \\
\hline CHEMBL191812 & 304924 & 6.6198 & 6.6128 & TRN & \\
\hline CHEMBL195905 & 304924 & 7.0223 & 7.016 & TRN & \\
\hline CHEMBL191823 & 304924 & 5.4318 & 5.4321 & TRN & \\
\hline CHEMBL191858 & 304924 & 6.6198 & 6.6326 & TRN & \\
\hline CHEMBL192781 & 304924 & 5.9586 & 5.9838 & TRN & \\
\hline CHEMBL192980 & 304924 & 6.2924 & 6.4623 & TRN & \\
\hline CHEMBL192117 & 304924 & 7.5686 & 7.5711 & TRN & \\
\hline CHEMBL369888 & 304924 & 6.1135 & 6.1295 & TRN & \\
\hline CHEMBL 370240 & 304924 & 7.0 & 6.9708 & TRN & \\
\hline CHEMBL 365996 & 304924 & 5.699 & 5.6881 & TRN & \\
\hline CHEMBL192425 & 304924 & 7.1249 & 7.1116 & TRN & \\
\hline CHEMBL195739 & 304924 & 6.8539 & 6.7321 & TST & \\
\hline CHEMBL370033 & 304924 & 6.8539 & 6.8412 & TRN & \\
\hline CHEMBL 372472 & 304924 & 6.8239 & 6.8283 & TRN & \\
\hline CHEMBL195205 & 304924 & 6.9586 & 6.9691 & TRN & \\
\hline CHEMBL364057 & 304924 & 6.9586 & 6.9391 & TRN & \\
\hline CHEMBL263326 & 304924 & 6.8239 & 6.82100 & 0000000001 & TRN \\
\hline CHEMBL370734 & 304924 & 6.3188 & 6.3269 & TRN & \\
\hline CHEMBL194437 & 304924 & 6.3768 & 6.231 & TRN & \\
\hline CHEMBL191769 & 304924 & 7.0655 & 7.0802 & TRN & \\
\hline CHEMBL192421 & 304924 & 7.0 & 7.0223 & TRN & \\
\hline CHEMBL366031 & 304924 & 6.8539 & 6.8465 & TRN & \\
\hline CHEMBL370072 & 304924 & 8.5229 & 8.5305 & TRN & \\
\hline CHEMBL192983 & 304924 & 6.0141 & 5.7895 & TST & \\
\hline
\end{tabular}




\begin{tabular}{|c|c|c|c|c|c|}
\hline \multicolumn{6}{|c|}{ Supplemental Table S2.txt } \\
\hline CHEMBL191652 & 304924 & 4.2676 & 4.2668 & TRN & \\
\hline CHEMBL191514 & 304924 & 6.4089 & 6.4007 & TRN & \\
\hline CHEMBL195667 & 304924 & 7.1612 & 7.644 & TST & \\
\hline CHEMBL363584 & 304924 & 7.4318 & 7.428 & TRN & \\
\hline CHEMBL 364093 & 304924 & 5.5528 & 5.5685 & TRN & \\
\hline CHEMBL194489 & 304924 & 6.2218 & 6.068 & TRN & \\
\hline CHEMBL191354 & 304924 & 6.6021 & 6.6067 & TRN & \\
\hline CHEMBL195378 & 304924 & 8.2218 & 8.219 & TRN & \\
\hline CHEMBL363175 & 304924 & 6.3565 & 6.3385 & TRN & \\
\hline CHEMBL195270 & 304924 & 5.4318 & 5.41 & TRN & \\
\hline CHEMBL192449 & 304924 & 6.2366 & 6.2353 & TRN & \\
\hline CHEMBL192365 & 304924 & 6.4437 & 6.4278 & TRN & \\
\hline CHEMBL190454 & 304924 & 6.7696 & 6.7753 & TRN & \\
\hline CHEMBL371846 & 304924 & 6.9586 & 6.9706 & TRN & \\
\hline CHEMBL191906 & 304924 & 6.4318 & 6.4192 & TRN & \\
\hline CHEMBL192396 & 304924 & 5.8239 & 6.84 & TST & \\
\hline CHEMBL190979 & 304924 & 7.0088 & 7.032 & TRN & \\
\hline CHEMBL362976 & 304924 & 5.9586 & 5.9648 & TRN & \\
\hline CHEMBL552788 & 304924 & 5.7696 & 5.9046 & TST & \\
\hline CHEMBL370079 & 304924 & 5.4437 & 5.5976 & TRN & \\
\hline CHEMBL191933 & 304924 & 6.9208 & 6.3976 & TST & \\
\hline CHEMBL 365575 & 304924 & 6.5528 & 6.1302 & TST & \\
\hline CHEMBL195443 & 304924 & 6.8861 & 6.6057 & TST & \\
\hline CHEMBL 366173 & 304924 & 5.9586 & 5.6979 & TST & \\
\hline CHEMBL189881 & 304924 & 7.1938 & 6.6819 & TST & \\
\hline CHEMBL362973 & 304924 & 5.8539 & 5.7108 & TST & \\
\hline CHEMBL 365953 & 304924 & 6.9586 & 6.5713 & TST & \\
\hline CHEMBL 278729 & 304924 & 6.8239 & 7.1303 & TST & \\
\hline CHEMBL425375 & 304924 & 6.8861 & 5.6144 & TST & \\
\hline CHEMBL11037 & 51459 & 2.6 & 2.558000 & 00000000003 & TRN \\
\hline CHEMBL275329 & 51459 & 1.9 & 1.8977 & TRN & \\
\hline CHEMBL429032 & 51459 & 0.46 & 0.457999 & 999999999996 & TRN \\
\hline CHEMBL11220 & 51459 & 2.4 & 2.4121 & TRN & \\
\hline CHEMBL 268964 & 51459 & 3.46 & 3.2816 & TRN & \\
\hline CHEMBL11033 & 51459 & 2.0 & 1.9756 & TRN & \\
\hline CHEMBL268701 & 51459 & 2.7 & 2.6964 & TRN & \\
\hline CHEMBL 273953 & 51459 & 0.0 & -0.0101 & TRN & \\
\hline CHEMBL 276401 & 51459 & 2.46 & 2.469 & TRN & \\
\hline CHEMBL 268963 & 51459 & 1.1 & 1.1122 & TRN & \\
\hline CHEMBL9069 & 51459 & 2.6 & 2.3023 & TST & \\
\hline CHEMBL10995 & 51459 & 3.1 & 3.1411 & TRN & \\
\hline CHEMBL11439 & 51459 & 1.7 & 1.7066 & TRN & \\
\hline CHEMBL 275263 & 51459 & 3.12 & 3.1434 & TRN & \\
\hline CHEMBL62350 & 51459 & 2.52 & 2.5115 & TRN & \\
\hline CHEMBL11120 & 51459 & 2.26 & 2.2332 & TRN & \\
\hline CHEMBL11240 & 51459 & 1.1 & 1.1544 & TRN & \\
\hline CHEMBL11127 & 51459 & 3.1 & 3.1089 & TRN & \\
\hline CHEMBL11635 & 51459 & 2.82 & 2.8763 & TRN & \\
\hline
\end{tabular}




\begin{tabular}{|c|c|c|c|c|}
\hline \multicolumn{5}{|c|}{ Supplemental Table S2.txt } \\
\hline CHEMBL11636 & 51459 & 1.65 & 1.6557 & TRN \\
\hline CHEMBL 273267 & 51459 & 2.46 & 2.4218 & TRN \\
\hline CHEMBL11048 & 51459 & 1.3 & 1.3255 & TRN \\
\hline CHEMBL 276227 & 51459 & 2.0 & 2.2548 & TRN \\
\hline CHEMBL11288 & 51459 & 2.3 & 2.3168 & TRN \\
\hline CHEMBL10937 & 51459 & 2.19 & 2.1924 & TRN \\
\hline CHEMBL11385 & 51459 & 1.3 & 1.2908 & TRN \\
\hline CHEMBL 273508 & 51459 & 0.3 & 0.3044 & TRN \\
\hline CHEMBL11146 & 51459 & 0.4 & 0.3985 & TRN \\
\hline CHEMBL10579 & 51459 & 1.52 & 1.7763 & TST \\
\hline CHEMBL 27047 & 51459 & 2.7 & 2.7152 & TRN \\
\hline CHEMBL11271 & 51459 & 2.89 & 2.9024 & TRN \\
\hline CHEMBL 269218 & 51459 & 3.1 & 3.0519 & TRN \\
\hline CHEMBL406993 & 51459 & 2.0 & 1.9571 & TRN \\
\hline CHEMBL415971 & 51459 & 3.82 & 2.3557 & TST \\
\hline CHEMBL10984 & 51459 & 2.15 & 2.0216 & TRN \\
\hline CHEMBL 273370 & 51459 & 1.1 & 1.0505 & TRN \\
\hline CHEMBL11342 & 51459 & 3.0 & 3.0521 & TST \\
\hline CHEMBL11163 & 51459 & 2.7 & 2.6824 & TRN \\
\hline CHEMBL415248 & 51459 & 2.0 & 1.9998 & TRN \\
\hline CHEMBL416884 & 51459 & 2.1 & 2.1815 & TRN \\
\hline CHEMBL 276603 & 51459 & 2.7 & 2.8379 & TRN \\
\hline CHEMBL 276830 & 51459 & 2.76 & 2.7417 & TRN \\
\hline CHEMBL158507 & 51459 & 3.15 & 2.6045 & TST \\
\hline CHEMBL10873 & 51459 & 2.4 & 2.1519 & TST \\
\hline CHEMBL 274778 & 51459 & 0.7 & 0.645 & TRN \\
\hline CHEMBL10895 & 51459 & 2.6 & 2.6013 & TRN \\
\hline CHEMBL 268026 & 51459 & 3.1 & 3.0252 & TRN \\
\hline CHEMBL11054 & 51459 & 2.22 & 1.755 & TST \\
\hline CHEMBL11332 & 51459 & 2.74 & 2.0713 & TST \\
\hline CHEMBL11410 & 51459 & 3.1 & 2.9021 & TST \\
\hline CHEMBL11000 & 51459 & 2.1 & 2.1643 & TST \\
\hline CHEMBL11077 & 51459 & 2.4 & 2.3867 & TST \\
\hline CHEMBL11348 & 51459 & 2.52 & 2.5218 & TST \\
\hline CHEMBL 269633 & 51459 & 1.89 & 1.66 & TST \\
\hline CHEMBL 275793 & 51459 & 2.26 & 1.841 & TST \\
\hline CHEMBL 2041180 & 823545 & 7.699 & 7.7422 & TRN \\
\hline CHEMBL 2043011 & 823545 & 8.1427 & 8.16 & TRN \\
\hline CHEMBL 2043327 & 823545 & 6.9208 & 7.5992 & TST \\
\hline CHEMBL2041182 & 823545 & 8.4949 & 8.5632 & TRN \\
\hline CHEMBL 2041167 & 823545 & 7.6778 & 7.7094 & TRN \\
\hline CHEMBL2041169 & 823545 & 8.4559 & 8.4334 & TRN \\
\hline CHEMBL 2043010 & 823545 & 8.4559 & 8.0107 & TST \\
\hline CHEMBL 2041166 & 823545 & 7.2147 & 7.1983 & TRN \\
\hline CHEMBL2040896 & 823545 & 7.1192 & 7.0991 & TRN \\
\hline CHEMBL 2041173 & 823545 & 7.3279 & 7.2142 & TST \\
\hline CHEMBL 2041177 & 823545 & 7.8239 & 7.8075 & TRN \\
\hline CHEMBL 2043328 & 823545 & 7.2147 & 7.2368 & TRN \\
\hline
\end{tabular}


Supplemental Table S2.txt

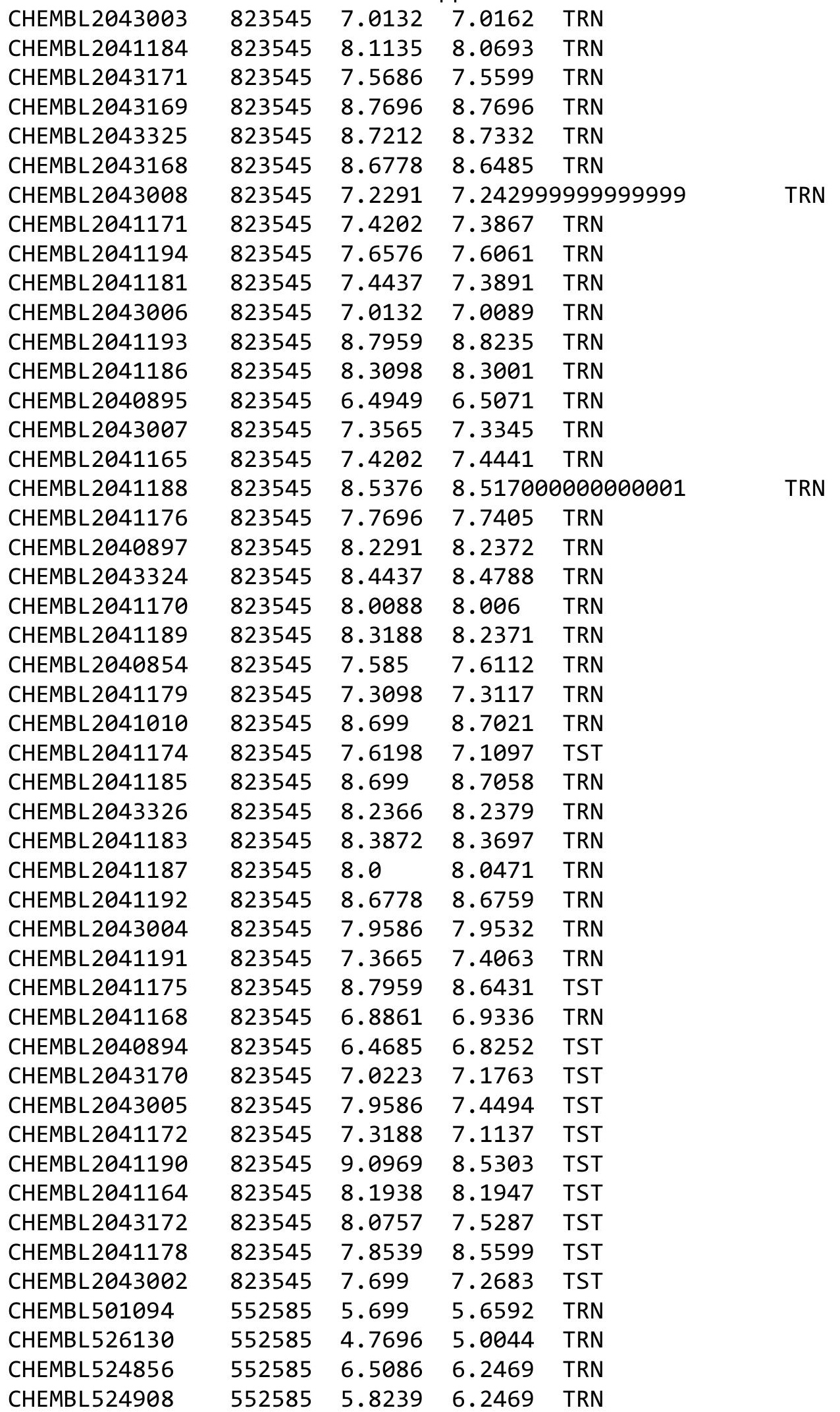

Page 27835 
Supplemental Table S2.txt

\begin{tabular}{|c|c|c|c|c|}
\hline CHEMBL504493 & 552585 & 6.3872 & 6.2469 & TRN \\
\hline CHEMBL526861 & 552585 & 5.5686 & 5.4563 & TRN \\
\hline CHEMBL527072 & 552585 & 5.0 & 5.4406 & TRN \\
\hline CHEMBL525583 & 552585 & 6.4949 & 6.8665 & TST \\
\hline CHEMBL454229 & 552585 & 5.6576 & 5.6839 & TRN \\
\hline CHEMBL498954 & 552585 & 2.6021 & 4.6663 & TST \\
\hline CHEMBL505899 & 552585 & 6.9586 & 6.8416 & TRN \\
\hline CHEMBL501395 & 552585 & 6.1938 & 6.5404 & TRN \\
\hline CHEMBL507649 & 552585 & 6.1739 & 6.2581 & TRN \\
\hline CHEMBL504269 & 552585 & 4.4685 & 4.763 & TRN \\
\hline CHEMBL504266 & 552585 & 6.3188 & 6.4274 & TRN \\
\hline CHEMBL506740 & 552585 & 5.3468 & 5.1339 & TRN \\
\hline CHEMBL524509 & 552585 & 5.2147 & 5.3743 & TRN \\
\hline CHEMBL505681 & 552585 & 3.6383 & 4.0905 & TRN \\
\hline CHEMBL511030 & 552585 & 5.699 & 5.5209 & TRN \\
\hline CHEMBL526187 & 552585 & 6.4949 & 6.2469 & TRN \\
\hline CHEMBL506836 & 552585 & 4.7447 & 4.7337 & TRN \\
\hline CHEMBL505609 & 552585 & 6.4949 & 6.6724 & TRN \\
\hline CHEMBL525594 & 552585 & 3.6383 & 3.6363 & TRN \\
\hline CHEMBL499766 & 552585 & 6.5086 & 6.4789 & TRN \\
\hline CHEMBL499790 & 552585 & 5.284 & 4.3349 & TST \\
\hline CHEMBL499121 & 552585 & 5.7328 & 6.3212 & TST \\
\hline CHEMBL451424 & 552585 & 6.2366 & 6.3584 & TRN \\
\hline CHEMBL508398 & 552585 & 5.3188 & 4.7933 & TRN \\
\hline CHEMBL524825 & 552585 & 4.0555 & 4.0761 & TRN \\
\hline CHEMBL500475 & 552585 & 7.3665 & 7.50799 & 9999999999 \\
\hline CHEMBL510066 & 552585 & 5.9208 & 5.1138 & TRN \\
\hline CHEMBL525624 & 552585 & 5.9208 & 5.4406 & TRN \\
\hline CHEMBL526337 & 552585 & 6.0 & 6.2469 & TRN \\
\hline CHEMBL503205 & 552585 & 4.6576 & 4.7933 & TRN \\
\hline CHEMBL508564 & 552585 & 6.6383 & 6.2469 & TRN \\
\hline CHEMBL502881 & 552585 & 3.7447 & 3.9801 & TRN \\
\hline CHEMBL526348 & 552585 & 2.6021 & 3.7913 & TRN \\
\hline CHEMBL501558 & 552585 & 5.0555 & 4.7173 & TST \\
\hline CHEMBL504423 & 552585 & 7.2291 & 6.9577 & TRN \\
\hline CHEMBL505622 & 552585 & 6.3665 & 6.3452 & TRN \\
\hline CHEMBL508486 & 552585 & 5.1135 & 5.2086 & TRN \\
\hline CHEMBL504837 & 552585 & 6.6576 & 6.6014 & TRN \\
\hline CHEMBL506623 & 552585 & 6.6198 & 6.9191 & TRN \\
\hline CHEMBL499501 & 552585 & 3.9208 & 4.1044 & TRN \\
\hline CHEMBL501031 & 552585 & 4.9586 & 4.6146 & TRN \\
\hline CHEMBL508411 & 552585 & 5.2441 & 4.1155 & TST \\
\hline CHEMBL524476 & 552585 & 4.7375 & 5.1012 & TRN \\
\hline CHEMBL526381 & 552585 & 6.5528 & 6.8293 & TST \\
\hline CHEMBL526683 & 552585 & 4.9586 & 5.459 & TST \\
\hline CHEMBL508377 & 552585 & 6.3098 & 6.1948 & TRN \\
\hline CHEMBL526174 & 552585 & 7.3565 & 7.2952 & TST \\
\hline CHEMBL526300 & 552585 & 5.9208 & 5.7417 & TRN \\
\hline
\end{tabular}

Page 27836 


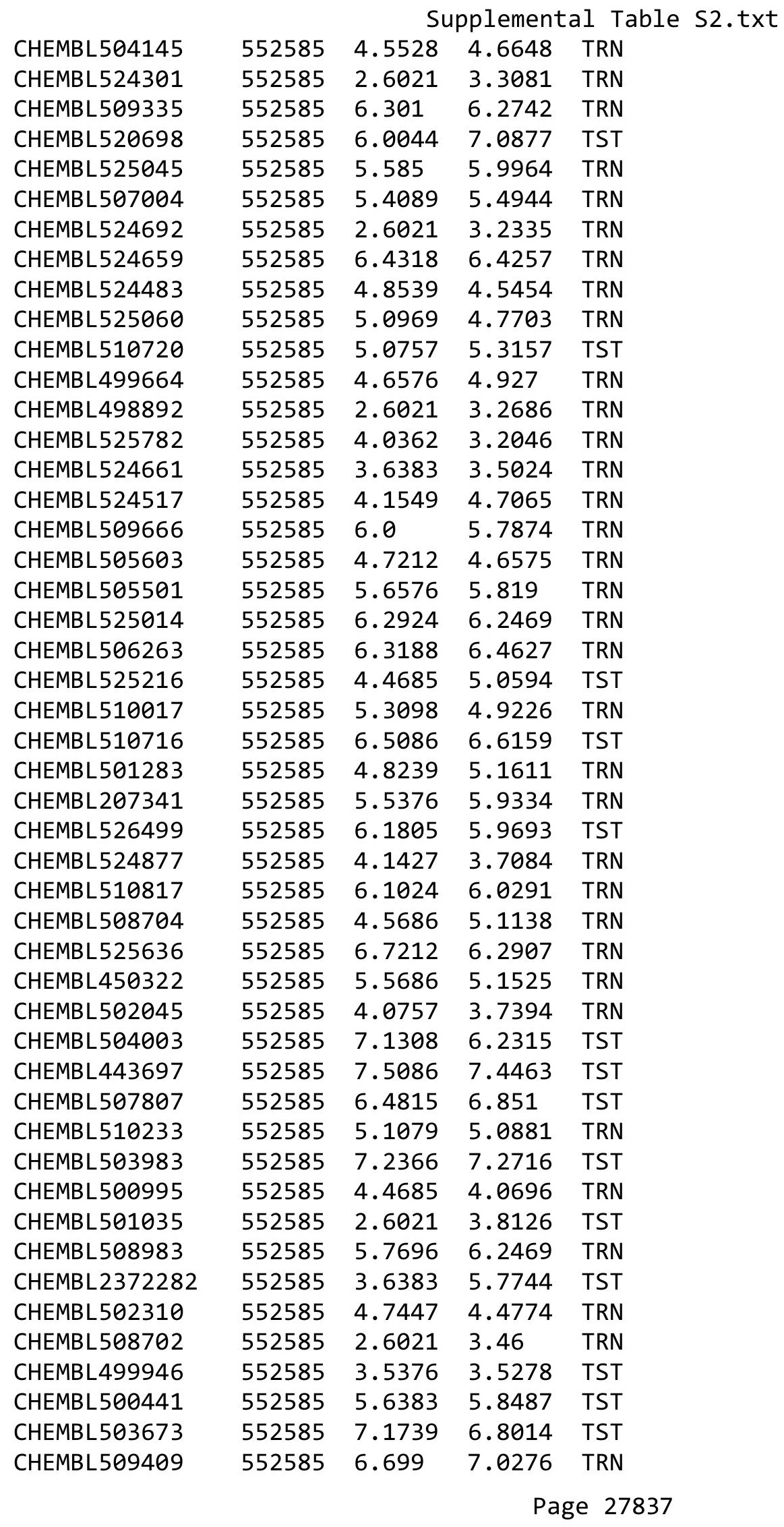




\begin{tabular}{|c|c|c|c|c|c|}
\hline \\
\hline CHEMBL508902 & 552585 & 5.4815 & 5.8814 & TST & \\
\hline CHEMBL504855 & 552585 & 6.699 & 6.6695 & TRN & \\
\hline CHEMBL446284 & 552585 & 6.7696 & 6.572 & TRN & \\
\hline CHEMBL504336 & 552585 & 5.8861 & 5.9132 & TST & \\
\hline CHEMBL444687 & 552585 & 3.5686 & 3.2967 & TRN & \\
\hline CHEMBL527080 & 552585 & 5.3468 & 5.3184 & TRN & \\
\hline CHEMBL507073 & 552585 & 4.5086 & 4.5317 & TRN & \\
\hline CHEMBL525587 & 552585 & 2.6021 & 3.2504 & TRN & \\
\hline CHEMBL525232 & 552585 & 5.0044 & 4.8641 & TST & \\
\hline CHEMBL525431 & 552585 & 5.284 & 5.4547 & TST & \\
\hline CHEMBL501266 & 552585 & 3.6383 & 3.7213 & TRN & \\
\hline CHEMBL508491 & 552585 & 5.0177 & 4.5239 & TRN & \\
\hline CHEMBL527084 & 552585 & 5.5686 & 5.63899 & 9999999999 & TRN \\
\hline CHEMBL505689 & 552585 & 5.0 & 5.586 & TRN & \\
\hline CHEMBL526336 & 552585 & 5.9208 & 5.152 & TRN & \\
\hline CHEMBL508126 & 552585 & 3.6383 & 3.8721 & TRN & \\
\hline CHEMBL504226 & 552585 & 5.4202 & 5.4944 & TRN & \\
\hline CHEMBL504919 & 552585 & 5.6778 & 5.9702 & TRN & \\
\hline CHEMBL503489 & 552585 & 6.6383 & 6.5429 & TRN & \\
\hline CHEMBL506644 & 552585 & 6.0 & 4.1675 & TRN & \\
\hline CHEMBL524297 & 552585 & 5.8861 & 5.5844 & TST & \\
\hline CHEMBL504095 & 552585 & 3.6383 & 3.2702 & TRN & \\
\hline CHEMBL442891 & 552585 & 3.6383 & 3.5424 & TRN & \\
\hline CHEMBL524718 & 552585 & 5.4815 & 5.9759 & TST & \\
\hline CHEMBL525018 & 552585 & 6.3468 & 6.4627 & TRN & \\
\hline CHEMBL444514 & 552585 & 4.699 & 5.0676 & TST & \\
\hline CHEMBL451944 & 552585 & 5.3768 & 5.0686 & TRN & \\
\hline CHEMBL500788 & 552585 & 5.6576 & 5.5309 & TRN & \\
\hline CHEMBL506195 & 552585 & 6.9586 & 6.7931 & TST & \\
\hline CHEMBL499402 & 552585 & 6.0 & 4.927 & TRN & \\
\hline CHEMBL503730 & 552585 & 5.3372 & 5.2828 & TRN & \\
\hline CHEMBL503191 & 552585 & 5.0757 & 5.0044 & TRN & \\
\hline CHEMBL526373 & 552585 & 6.0757 & 6.7335 & TST & \\
\hline CHEMBL525635 & 552585 & 6.3872 & 6.4627 & TRN & \\
\hline CHEMBL503219 & 552585 & 4.6576 & 3.8039 & TST & \\
\hline CHEMBL510473 & 552585 & 5.284 & 5.8147 & TRN & \\
\hline CHEMBL527054 & 552585 & 4.585 & 4.2574 & TRN & \\
\hline CHEMBL525614 & 552585 & 7.0655 & 6.6741 & TRN & \\
\hline CHEMBL486090 & 552585 & 6.9872 & 7.0593 & TST & \\
\hline CHEMBL509774 & 552585 & 5.0269 & 4.8274 & TST & \\
\hline CHEMBL525265 & 552585 & 7.3372 & 7.1498 & TRN & \\
\hline CHEMBL506645 & 552585 & 3.6383 & 3.8573 & TRN & \\
\hline CHEMBL505790 & 552585 & 6.0809 & 6.2469 & TRN & \\
\hline CHEMBL525040 & 552585 & 5.699 & 6.2469 & TRN & \\
\hline CHEMBL1766837 & 741534 & 5.3391 & 5.3444 & TRN & \\
\hline CHEMBL1766862 & 741534 & 5.8794 & 5.8314 & TRN & \\
\hline CHEMBL1766841 & 741534 & 3.4948 & 5.2211 & TST & \\
\hline CHEMBL1766840 & 741534 & 6.1675 & 6.1968 & TRN & \\
\hline
\end{tabular}


Supplemental Table S2.txt

\begin{tabular}{|c|c|c|c|c|c|}
\hline CHEMBL1766856 & 741534 & 5.7212 & 5.7393 & TRN & \\
\hline CHEMBL1766857 & 741534 & 5.7258 & 5.7763 & TRN & \\
\hline CHEMBL1766851 & 741534 & 5.4737 & 5.4423 & TRN & \\
\hline CHEMBL1765108 & 741534 & 5.5272 & 5.5211 & TRN & \\
\hline CHEMBL1766868 & 741534 & 3.4948 & 3.5146 & TRN & \\
\hline CHEMBL1766842 & 741534 & 5.6655 & 5.6501 & TRN & \\
\hline CHEMBL1766875 & 741534 & 3.4948 & 3.5568 & TST & \\
\hline CHEMBL1766853 & 741534 & 5.7773 & 5.7565 & TRN & \\
\hline CHEMBL1766839 & 741534 & 5.857 & \multicolumn{2}{|c|}{5.832000000000001} & TRN \\
\hline CHEMBL1766832 & 741534 & 3.4948 & 4.438 & TST & \\
\hline CHEMBL1766861 & 741534 & 5.6655 & 5.6369 & TRN & \\
\hline CHEMBL1766865 & 741534 & 5.4425 & 5.4561 & TRN & \\
\hline CHEMBL1766870 & 741534 & 5.6517 & 5.6435 & TRN & \\
\hline CHEMBL1766858 & 741534 & 5.4698 & 5.5271 & TRN & \\
\hline CHEMBL1766863 & 741534 & 3.4948 & 3.47 & TRN & \\
\hline CHEMBL1766860 & 741534 & 5.5317 & \multicolumn{2}{|c|}{5.5489999999999995} & TRN \\
\hline CHEMBL1766843 & 741534 & 5.4868 & 5.5284 & TRN & \\
\hline CHEMBL1766874 & 741534 & 6.0605 & 6.0401 & TRN & \\
\hline CHEMBL1766876 & 741534 & 3.4948 & 3.2383 & TST & \\
\hline CHEMBL1766866 & 741534 & 3.4948 & 3.4991 & TRN & \\
\hline CHEMBL1766850 & 741534 & 5.7282 & 5.7281 & TRN & \\
\hline CHEMBL1412368 & 741534 & 5.7747 & 5.6306 & TRN & \\
\hline CHEMBL1766854 & 741534 & 6.1487 & 6.1764 & TRN & \\
\hline CHEMBL1766833 & 741534 & 3.4948 & 3.4586 & TRN & \\
\hline CHEMBL1766880 & 741534 & 3.4948 & 3.4857 & TRN & \\
\hline CHEMBL1766845 & 741534 & 5.4828 & 5.5147 & TRN & \\
\hline CHEMBL1766849 & 741534 & 5.4868 & 5.4655 & TRN & \\
\hline CHEMBL1766844 & 741534 & 5.1107 & 5.0084 & TST & \\
\hline CHEMBL1766872 & 741534 & 5.5884 & 4.8472 & TST & \\
\hline CHEMBL1766834 & 741534 & 5.1146 & 5.4952 & TST & \\
\hline CHEMBL1766846 & 741534 & 5.4908 & 5.4892 & TRN & \\
\hline CHEMBL1766867 & 741534 & 3.4948 & 3.5265 & TRN & \\
\hline CHEMBL1766878 & 741534 & 3.4948 & 3.5269 & TRN & \\
\hline CHEMBL1766838 & 741534 & 5.8794 & 5.8253 & TRN & \\
\hline CHEMBL1766855 & 741534 & 5.7595 & 5.7739 & TRN & \\
\hline CHEMBL1766836 & 741534 & 5.6925 & 5.5267 & TST & \\
\hline CHEMBL1766869 & 741534 & 5.5086 & 5.5196 & TRN & \\
\hline CHEMBL1766848 & 741534 & 5.5272 & 5.5271 & TRN & \\
\hline CHEMBL1766877 & 741534 & 3.4948 & 3.4698 & TRN & \\
\hline CHEMBL1766852 & 741534 & 4.9359 & 4.9507 & TRN & \\
\hline CHEMBL1766871 & 741534 & 5.5467 & 5.5519 & TRN & \\
\hline CHEMBL1766847 & 741534 & 5.4622 & 5.5572 & TRN & \\
\hline CHEMBL1766859 & 741534 & 5.9245 & 5.6432 & TST & \\
\hline CHEMBL1766864 & 741534 & 5.4498 & 6.2398 & TST & \\
\hline CHEMBL1766873 & 741534 & 5.4498 & 4.9231 & TST & \\
\hline CHEMBL1766835 & 741534 & 5.5272 & 4.408 & TST & \\
\hline CHEMBL1766879 & 741534 & 3.4948 & 3.3531 & TST & \\
\hline CHEMBL466426 & 1592867 & 4.4888 & 4.6665 & TST & \\
\hline
\end{tabular}


Supplemental Table S2.txt

\begin{tabular}{|c|c|c|c|c|}
\hline HEMBL474899 & 592867 & 5.1798 & 5.2516 & . \\
\hline & 592867 & & & \\
\hline HFMRI 363 & 867 & & & \\
\hline HEMBL1872842 & 867 & & & \\
\hline HEMBL45843 & 592867 & 872 & 5815 & \\
\hline HEMBL3431191 & 867 & 4.4908 & .6421 & \\
\hline AEMBL1 & 367 & & 7691 & \\
\hline AEMBL 2 & & & 3559 & ל \\
\hline HEMBL1836562 & 592867 & 5.4225 & 6035 & \\
\hline HEMBL3431411 & 867 & 4. & 2153 & \\
\hline HEMBL4 & 867 & & 6779 & \\
\hline HEMBL: & 67 & & 1951 & \\
\hline HEMBL & & & 173 & \\
\hline HEMBL1 & 867 & & 3.4201 & \\
\hline HEMBL3 & 367 & & 5201 & \\
\hline HEMBLS & b/ & & 398 & RN \\
\hline HEMBL; & & & 988 & RN \\
\hline HEMBL 2 & 67 & & 821 & \\
\hline HEMBL3 & & & 3866 & \\
\hline HEMBL 2 & 67 & 6. & 044 & I KIV \\
\hline HEMBL: & 67 & & 13 & ST \\
\hline HEMBL & & & & $\mathrm{RN}$ \\
\hline HEMBL & & & 539 & \\
\hline HEMBL3 & & & 767 & TST \\
\hline HEMBL 2 & 67 & 5 . & 56 & RN \\
\hline HEMBL & & & & RN \\
\hline HEMBL & & & 31 & 「RN \\
\hline HEME & & & 509 & RN \\
\hline HEMBL & & & & IRIN \\
\hline HEMBL5 & 67 & 4. & & RN \\
\hline HEMBL & & & 76 & ST \\
\hline HFM & & & & 「RN \\
\hline וסMFנI & & & & TST \\
\hline HEMBL3 & & & 658 & 「RN \\
\hline HEMBL3 & 67 & & & RN \\
\hline HEMBL & 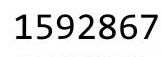 & & 781 & TRN \\
\hline (זM & & & & ST \\
\hline HEMBL] & & & 373 & TST \\
\hline HEMBL 3 & 367 & & 917 & TRN \\
\hline ILTIDL & & & & RN \\
\hline HEMBL3 & & & 569 & TRN \\
\hline HEMBL2 & & & 595 & TRN \\
\hline HEMBL1 & & & 4.2941 & TRN \\
\hline CHEMBL2 & 367 & & 475 & TR \\
\hline LHEMBL & & & & \\
\hline HEMBL3 & & 7.8861 & 7.8104 & \\
\hline CHEMBL 2 & 367 & 4.7894 & 4.9289 & RN \\
\hline CHEMBL3431272 & 1592867 & 7.0 & 6.7422 & TRN \\
\hline
\end{tabular}

Page 27840 
Supplemental Table S2.txt

\begin{tabular}{|c|c|c|c|c|}
\hline 94 & & & & 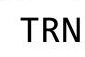 \\
\hline HEMBL 2326941 & 592867 & 7.699 & & \\
\hline & & 7122 & & \\
\hline 381 & 867 & 8271 & & \\
\hline IEMBL3431099 & 592867 & 5.684 & & \\
\hline IEMBL 394474 & 592867 & 4.8216 & 565 & \\
\hline IEMBL3431105 & 592867 & 2757 & 514 & \\
\hline & 67 & 6021 & & \\
\hline IEMBL & 592867 & 8861 & 3838 & \\
\hline AEMBL1197424 & 592867 & 3.4948 & 5365 & \\
\hline AEMBL2323246 & 38230 & 4559 & 644 & \\
\hline IEMBL 2323260 & 30 & 576 & 953 & \\
\hline EMBL2 & & & & RN \\
\hline IEMBL23 & 0 & & & \\
\hline IEMBL 2323041 & 30 & 229 & 23 & \\
\hline IEMBL 2323254 & 30 & 576 & 7022 & ST \\
\hline IEMBL23 & 30 & 376 & 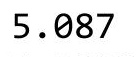 & SI \\
\hline IEMBL23 & & & & RN \\
\hline IEMBL2 & $\theta$ & & & \\
\hline IEMBL23 & 0 & & & \\
\hline IEMBL 2323052 & 30 & 36 & 56 & KIV \\
\hline IEMBL2: & 0 & 19 & 97 & RN \\
\hline EMBL 23 & & & 27 & \\
\hline 48 & & & & \\
\hline IEMBL 2 & & & & iv \\
\hline EMBL23 & $\theta$ & 9 & 18 & RN \\
\hline EMBL2: & 0 & 19 & $\partial 2$ & RN \\
\hline 89 & & & 82 & \\
\hline 76 & & & & 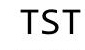 \\
\hline IEMBL2 & 0 & 9 & 1 & RN \\
\hline IEMBL2 & $\theta$ & & 96 & RN \\
\hline EMBL 2 & & & 59 & RN \\
\hline & & & & 10 \\
\hline EMBL2323039 & & & & RN \\
\hline EMBL23 & $\theta$ & 9 & 25 & RN \\
\hline EMBL2 & 0 & 59 & 95 & RN \\
\hline 42 & & & & RN \\
\hline & & & 484 & ST \\
\hline AEMBL2323273 & 82 & & & TRN \\
\hline MBL2 & ש & & 92 & TST \\
\hline IEMBL2: & 0 & 8 & 062 & RN \\
\hline & & & & RN \\
\hline AEMBL2323275 & 8230 & & 4.6027 & $\mathrm{RN}$ \\
\hline EMBL2323060 & 8230 & 9969 & 5.5945 & TST \\
\hline 45 & a & & 364 & RIV \\
\hline CHEMBL2323282 & 38230 & & 4.6167 & I \\
\hline CHEMBL2323279 & 38230 & 3.3979 & 4.6322 & SI \\
\hline CHEMBL232324 & 38230 & 5.5229 & 5.3772 & TRN \\
\hline
\end{tabular}

Page 27841 


\begin{tabular}{|c|c|c|c|c|}
\hline & & & oplement & al $\mathrm{T}$ \\
\hline CHEMBL 2323053 & 938230 & 4.8239 & 5.4131 & TRN \\
\hline CHEMBL 2323257 & 938230 & 3.3979 & 4.5905 & TST \\
\hline CHEMBL1729263 & 938230 & 4.7212 & 4.7763 & TST \\
\hline CHEMBL2323049 & 938230 & 5.4949 & 5.4364 & TRN \\
\hline CHEMBL2323046 & 938230 & 5.1675 & 5.0552 & TRN \\
\hline CHEMBL2323058 & 938230 & 5.1805 & 5.4061 & TRN \\
\hline CHEMBL 2323255 & 938230 & 3.3979 & 4.739 & TST \\
\hline CHEMBL2323269 & 938230 & 3.3979 & 4.4533 & TRN \\
\hline CHEMBL 2323280 & 938230 & 3.3979 & 4.5573 & TST \\
\hline CHEMBL2323264 & 938230 & 5.4685 & 5.3933 & TRN \\
\hline CHEMBL2323270 & 938230 & 5.0706 & 5.1722 & TRN \\
\hline CHEMBL2321891 & 938230 & 5.4685 & 5.3007 & TRN \\
\hline CHEMBL2323277 & 938230 & 4.5086 & 4.4414 & TST \\
\hline CHEMBL2323057 & 938230 & 6.301 & 5.879 & TRN \\
\hline CHEMBL 2323050 & 938230 & 5.0969 & 5.1625 & TRN \\
\hline CHEMBL2323258 & 938230 & 5.0605 & 5.0622 & TST \\
\hline CHEMBL 2323044 & 938230 & 5.585 & 5.3415 & TRN \\
\hline CHEMBL2323043 & 938230 & 5.9586 & 5.6768 & TRN \\
\hline CHEMBL2323035 & 938230 & 5.6778 & 5.9365 & TRN \\
\hline CHEMBL 2323278 & 938230 & 3.3979 & 4.6741 & TST \\
\hline CHEMBL 2323034 & 938230 & 5.3565 & 6.0802 & TRN \\
\hline CHEMBL 2323281 & 938230 & 4.5376 & 4.6766 & TRN \\
\hline CHEMBL2323272 & 938230 & 5.3979 & 5.407 & TRN \\
\hline CHEMBL2323059 & 938230 & 6.1249 & 5.2071 & TRN \\
\hline CHEMBL2323247 & 938230 & 5.6198 & 6.3177 & TRN \\
\hline CHEMBL2323252 & 938230 & 3.3979 & 4.742 & TST \\
\hline CHEMBL 2323253 & 938230 & 4.5376 & 4.7256 & TST \\
\hline CHEMBL 2323047 & 938230 & 5.2676 & 5.5803 & TRN \\
\hline CHEMBL2323056 & 938230 & 4.8386 & 4.971 & TRN \\
\hline CHEMBL 2323251 & 938230 & 5.7696 & 6.1145 & TRN \\
\hline CHEMBL 2323274 & 938230 & 5.9208 & 5.3739 & TRN \\
\hline CHEMBL2323036 & 938230 & 5.4815 & 6.0785 & TST \\
\hline CHEMBL42146 & 140683 & 7.4318 & 7.4297 & TRN \\
\hline CHEMBL 295427 & 140683 & 4.2757 & 4.2757 & TRN \\
\hline CHEMBL 297310 & 140683 & 5.5376 & 5.5392 & TRN \\
\hline CHEMBL290321 & 140683 & 4.5086 & 4.5145 & TRN \\
\hline CHEMBL42057 & 140683 & 5.3565 & 6.8241 & TST \\
\hline CHEMBL 296577 & 140683 & 4.4685 & 4.4693 & TRN \\
\hline CHEMBL 298284 & 140683 & 5.0315 & 5.0329 & TRN \\
\hline CHEMBL43848 & 140683 & 4.9586 & 4.96 & TRN \\
\hline CHEMBL42430 & 140683 & 4.7696 & 4.7698 & TRN \\
\hline CHEMBL 296068 & 140683 & 5.6778 & 5.6785 & TRN \\
\hline CHEMBL291148 & 140683 & 7.0223 & 7.0217 & TRN \\
\hline CHEMBL42694 & 140683 & 5.7447 & 5.7418 & TRN \\
\hline CHEMBL41791 & 140683 & 5.0088 & 5.0065 & TRN \\
\hline CHEMBL40976 & 140683 & 7.6383 & 7.6415 & TRN \\
\hline CHEMBL44079 & 140683 & 3.0 & 2.9994 & TRN \\
\hline CHEMBL288855 & 140683 & 8.1549 & 8.0137 & TST \\
\hline
\end{tabular}




\begin{tabular}{|c|c|c|c|c|c|}
\hline & & & & & \\
\hline CHEMBL42329 & 140683 & 6.2007 & 6.2034 & TRN & \\
\hline CHEMBL42071 & 140683 & 5.8539 & 5.3601 & TST & \\
\hline CHEMBL289167 & 140683 & 5.3665 & 5.3651 & TRN & \\
\hline CHEMBL41538 & 140683 & 3.0 & 4.5906 & TST & \\
\hline CHEMBL290747 & 140683 & 5.5528 & 5.5524 & TRN & \\
\hline CHEMBL43875 & 140683 & 3.0 & 5.54899 & 99999999995 & TST \\
\hline CHEMBL41399 & 140683 & 6.1938 & 6.1923 & TRN & \\
\hline CHEMBL42482 & 140683 & 5.8539 & 5.8513 & TRN & \\
\hline CHEMBL43918 & 140683 & 3.0 & 4.7575 & TST & \\
\hline CHEMBL289756 & 140683 & 3.0 & 2.9964 & TRN & \\
\hline CHEMBL553334 & 140683 & 6.0 & 6.0013 & TRN & \\
\hline CHEMBL295084 & 140683 & 5.4815 & 5.4831 & TRN & \\
\hline CHEMBL40745 & 140683 & 6.8861 & 6.8885 & TRN & \\
\hline CHEMBL42176 & 140683 & 6.6576 & 6.65600 & 0000000001 & TRN \\
\hline CHEMBL417710 & 140683 & 4.8861 & 4.8877 & TRN & \\
\hline CHEMBL41341 & 140683 & 6.3979 & 6.3952 & TRN & \\
\hline CHEMBL42350 & 140683 & 5.8239 & 5.82600 & 30000000005 & TRN \\
\hline CHEMBL291149 & 140683 & 7.0862 & 7.0835 & TRN & \\
\hline CHEMBL442545 & 140683 & 4.8239 & 4.574 & TST & \\
\hline CHEMBL42466 & 140683 & 6.8239 & 6.8246 & TRN & \\
\hline CHEMBL296558 & 140683 & 3.0 & 3.8793 & TST & \\
\hline CHEMBL282672 & 140683 & 5.0088 & 5.0095 & TRN & \\
\hline CHEMBL44260 & 140683 & 5.7447 & 5.7493 & TRN & \\
\hline CHEMBL41340 & 140683 & 6.5376 & 6.0373 & TST & \\
\hline CHEMBL40755 & 140683 & 4.699 & 4.7002 & TRN & \\
\hline CHEMBL41180 & 140683 & 5.5229 & 5.5235 & TRN & \\
\hline CHEMBL43869 & 140683 & 4.7959 & 4.7935 & TRN & \\
\hline CHEMBL295995 & 140683 & 6.8239 & 6.8266 & TRN & \\
\hline CHEMBL289779 & 140683 & 6.1367 & 4.5721 & TST & \\
\hline CHEMBL41691 & 140683 & 7.3468 & 7.3495 & TRN & \\
\hline CHEMBL288904 & 140683 & 4.2147 & 5.4185 & TST & \\
\hline CHEMBL 288384 & 140683 & 6.1079 & 6.1059 & TRN & \\
\hline CHEMBL41460 & 140683 & 7.5376 & 7.5355 & TRN & \\
\hline CHEMBL42248 & 140683 & 7.1938 & 7.1903 & TRN & \\
\hline CHEMBL291161 & 140683 & 6.6576 & 6.0338 & TST & \\
\hline CHEMBL42915 & 140683 & 7.4815 & 7.3756 & TST & \\
\hline CHEMBL 284028 & 140683 & 6.8861 & 6.8914 & TRN & \\
\hline CHEMBL43122 & 140683 & 5.3665 & 5.3652 & TRN & \\
\hline CHEMBL296521 & 140683 & 5.5086 & 5.5102 & TRN & \\
\hline CHEMBL42307 & 140683 & 5.3979 & 5.3979 & TRN & \\
\hline CHEMBL40708 & 140683 & 6.7696 & 6.8834 & TST & \\
\hline CHEMBL288839 & 140683 & 7.1367 & 7.1384 & TRN & \\
\hline CHEMBL41295 & 140683 & 6.7959 & 6.7933 & TRN & \\
\hline CHEMBL43846 & 140683 & 7.5229 & 7.5181 & TRN & \\
\hline CHEMBL41501 & 140683 & 5.2676 & 5.2644 & TRN & \\
\hline CHEMBL44018 & 140683 & 5.4437 & 5.4438 & TRN & \\
\hline CHEMBL43910 & 140683 & 3.0 & 2.9986 & TRN & \\
\hline CHEMBL40652 & 140683 & 7.5376 & 7.54 & TRN & \\
\hline
\end{tabular}




\begin{tabular}{|c|c|c|c|c|c|}
\hline & & \multicolumn{4}{|c|}{ Supplemental Table S2.txt } \\
\hline CHEMBL282003 & 140683 & 6.5528 & 6.5532 & TRN & \\
\hline CHEMBL297881 & 140683 & 8.3279 & 8.3287 & TRN & \\
\hline CHEMBL295179 & 140683 & 3.0 & 5.1545 & TST & \\
\hline CHEMBL40623 & 140683 & 7.9208 & 7.2143 & TST & \\
\hline CHEMBL43318 & 140683 & 5.4685 & 5.9863 & TST & \\
\hline CHEMBL291170 & 140683 & 5.4815 & 5.9221 & TST & \\
\hline CHEMBL40555 & 140683 & 3.0 & 3.0027 & TRN & \\
\hline CHEMBL42367 & 140683 & 4.7696 & 4.7702 & TRN & \\
\hline CHEMBL291169 & 140683 & 6.041 & 4.5822 & TST & \\
\hline CHEMBL43800 & 140683 & 4.6198 & 4.6197 & TRN & \\
\hline CHEMBL42426 & 140683 & 8.0605 & 8.0611 & TRN & \\
\hline CHEMBL40649 & 140683 & 5.7212 & 5.7206 & TRN & \\
\hline CHEMBL41291 & 140683 & 6.9586 & 6.9561 & TRN & \\
\hline CHEMBL22720 & 140683 & 5.4815 & 5.482 & TRN & \\
\hline CHEMBL298232 & 140683 & 4.3979 & 3.6838 & TST & \\
\hline CHEMBL41939 & 140683 & 4.7212 & 4.7164 & TRN & \\
\hline CHEMBL21641 & 140683 & 5.7447 & 5.7417 & TRN & \\
\hline CHEMBL295154 & 140683 & 7.2757 & 6.705 & TST & \\
\hline CHEMBL42805 & 140683 & 5.1308 & 5.1326 & TRN & \\
\hline CHEMBL40193 & 140683 & 3.0 & 3.0008 & TRN & \\
\hline CHEMBL418509 & 478938 & 8.07 & 7.8437 & TRN & \\
\hline CHEMBL260055 & 478938 & 7.66 & 6.8303 & TRN & \\
\hline CHEMBL411899 & 478938 & 6.97 & 7.2657 & TRN & \\
\hline CHEMBL 259188 & 478938 & 5.38 & 5.1163 & TRN & \\
\hline CHEMBL261793 & 478938 & 6.74 & 5.0818 & TRN & \\
\hline CHEMBL 225786 & 478938 & 3.94 & 4.5735 & TRN & \\
\hline CHEMBL261327 & 478938 & 6.15 & 6.6317 & TRN & \\
\hline CHEMBL 265440 & 478938 & 5.93 & 5.5949 & TRN & \\
\hline CHEMBL410084 & 478938 & 6.01 & 7.5194 & TRN & \\
\hline CHEMBL258627 & 478938 & 7.06 & 5.4925 & TRN & \\
\hline CHEMBL258946 & 478938 & 5.89 & 5.2515 & TRN & \\
\hline CHEMBL 265688 & 478938 & 4.33 & 5.9529 & TRN & \\
\hline CHEMBL265689 & 478938 & 7.8 & 7.7665 & TRN & \\
\hline CHEMBL261664 & 478938 & 6.46 & 6.9316 & TRN & \\
\hline CHEMBL412078 & 478938 & 6.37 & 5.1146 & TRN & \\
\hline CHEMBL 258660 & 478938 & 3.48 & 5.5223 & TRN & \\
\hline CHEMBL261887 & 478938 & 6.21 & 5.5653 & TRN & \\
\hline CHEMBL410465 & 478938 & 6.91 & 6.58200 & 0000000001 & TRN \\
\hline CHEMBL 260645 & 478938 & 7.16 & 6.3061 & TRN & \\
\hline CHEMBL265930 & 478938 & 6.8 & 6.9258 & TRN & \\
\hline CHEMBL411710 & 478938 & 6.6 & 6.5031 & TRN & \\
\hline CHEMBL408449 & 478938 & 6.09 & 5.8056 & TRN & \\
\hline CHEMBL408710 & 478938 & 7.09 & 6.69 & TRN & \\
\hline CHEMBL411065 & 478938 & 6.75 & 6.6462 & TRN & \\
\hline CHEMBL259866 & 478938 & 8.32 & 7.8871 & TRN & \\
\hline CHEMBL 259301 & 478938 & 6.61 & 6.3696 & TRN & \\
\hline CHEMBL 259303 & 478938 & 6.7 & 6.6877 & TRN & \\
\hline CHEMBL 259189 & 478938 & 6.55 & 6.606 & TRN & \\
\hline
\end{tabular}




\begin{tabular}{|c|c|c|c|c|c|}
\hline \multirow{3}{*}{$\begin{array}{l}\text { CHEMBL412113 } \\
\text { CHEMBL411687 }\end{array}$} & \multirow{3}{*}{$\begin{array}{l}478938 \\
478938\end{array}$} & \multicolumn{4}{|c|}{ Supplemental Table S2.txt } \\
\hline & & 6.48 & \multicolumn{2}{|c|}{6.7010000000000005} & TRN \\
\hline & & 6.44 & 6.4801 & TRN & \\
\hline CHEMBL259759 & 478938 & 6.65 & 6.7359 & TRN & \\
\hline CHEMBL261528 & 478938 & 6.55 & 6.0342 & TRN & \\
\hline CHEMBL261530 & 478938 & 6.45 & 6.1054 & TRN & \\
\hline CHEMBL258626 & 478938 & 5.75 & 5.8663 & TRN & \\
\hline CHEMBL260348 & 478938 & 5.82 & 6.1678 & TRN & \\
\hline CHEMBL411306 & 478938 & 5.62 & 5.9188 & TRN & \\
\hline CHEMBL409320 & 478938 & 7.11 & 6.5205 & TRN & \\
\hline CHEMBL258947 & 478938 & 4.48 & 4.8223 & TRN & \\
\hline CHEMBL439437 & 478938 & 3.41 & 4.965 & TST & \\
\hline CHEMBL262874 & 478938 & 3.71 & 5.3236 & TST & \\
\hline CHEMBL403715 & 478938 & 3.47 & 4.49100 & 00000000005 & TST \\
\hline CHEMBL328824 & 478938 & 4.11 & 5.2632 & TST & \\
\hline CHEMBL 258982 & 478938 & 3.94 & 4.8153 & TST & \\
\hline CHEMBL410476 & 478938 & 5.28 & 5.4774 & TRN & \\
\hline CHEMBL99203 & 478938 & 3.64 & 4.9024 & TST & \\
\hline CHEMBL265928 & 478938 & 4.0 & 5.4962 & TST & \\
\hline CHEMBL405374 & 478938 & 3.63 & 5.039 & TST & \\
\hline CHEMBL 258662 & 478938 & 4.84 & 4.9147 & TRN & \\
\hline CHEMBL258879 & 478938 & 3.35 & 3.9467 & TRN & \\
\hline CHEMBL440414 & 478938 & 4.83 & 5.3167 & TRN & \\
\hline CHEMBL408715 & 478938 & 4.46 & 4.7149 & TRN & \\
\hline CHEMBL260646 & 478938 & 4.49 & 3.9699 & TRN & \\
\hline CHEMBL405642 & 478938 & 4.04 & 5.0135 & TST & \\
\hline CHEMBL262072 & 478938 & 4.79 & 4.8645 & TRN & \\
\hline CHEMBL263651 & 478938 & 6.75 & 6.9634 & TRN & \\
\hline CHEMBL407963 & 478938 & 5.34 & 5.9348 & TRN & \\
\hline CHEMBL259960 & 478938 & 3.69 & 3.7818 & TRN & \\
\hline CHEMBL 260406 & 478938 & 1.94 & 4.1223 & TRN & \\
\hline CHEMBL408942 & 478938 & 3.24 & 4.5626 & TRN & \\
\hline CHEMBL405093 & 478938 & 4.38 & 5.0437 & TST & \\
\hline CHEMBL408943 & 478938 & 3.72 & 3.6611 & TRN & \\
\hline CHEMBL407471 & 478938 & 3.84 & 4.482 & TST & \\
\hline CHEMBL259961 & 478938 & 5.06 & 4.1417 & TRN & \\
\hline CHEMBL408881 & 478938 & 4.2 & 5.1916 & TST & \\
\hline CHEMBL429510 & 478938 & 4.09 & 4.3333 & TRN & \\
\hline CHEMBL260688 & 478938 & 8.56 & 7.629 & TRN & \\
\hline CHEMBL260497 & 478938 & 5.94 & 6.318 & TRN & \\
\hline CHEMBL260689 & 478938 & 5.32 & 5.5022 & TRN & \\
\hline CHEMBL408045 & 478938 & 3.79 & 3.7025 & TRN & \\
\hline CHEMBL261796 & 478938 & 4.87 & 5.2277 & TRN & \\
\hline CHEMBL261797 & 478938 & 4.2 & 3.7332 & TRN & \\
\hline CHEMBL411688 & 478938 & 4.92 & 4.4128 & TRN & \\
\hline CHEMBL261798 & 478938 & 4.28 & 5.3673 & TST & \\
\hline CHEMBL259986 & 478938 & 3.66 & 5.0017 & TST & \\
\hline CHEMBL 259774 & 478938 & 3.92 & 4.8701 & TST & \\
\hline CHEMBL409354 & 478938 & 6.09 & 6.0158 & TRN & \\
\hline
\end{tabular}




\begin{tabular}{|c|c|c|c|c|}
\hline \multicolumn{5}{|c|}{ Supplemental Table S2.txt } \\
\hline CHEMBL411114 & 478938 & 5.54 & 5.6683 & TRN \\
\hline CHEMBL407159 & 478938 & 5.28 & 5.0796 & TRN \\
\hline CHEMBL 294755 & 478938 & 6.34 & 5.6532 & TRN \\
\hline CHEMBL59168 & 478938 & 4.92 & 5.2624 & TRN \\
\hline CHEMBL540448 & 478938 & 5.2 & 5.0337 & TRN \\
\hline CHEMBL 263131 & 478938 & 4.04 & 4.5147 & TRN \\
\hline CHEMBL410665 & 478938 & 5.87 & 5.5027 & TRN \\
\hline CHEMBL 258880 & 478938 & 3.56 & 4.9149 & TST \\
\hline CHEMBL 388931 & 478938 & 3.64 & 4.0885 & TRN \\
\hline CHEMBL410477 & 478938 & 3.94 & 4.4408 & TRN \\
\hline CHEMBL412274 & 478938 & 5.32 & 5.9389 & TRN \\
\hline CHEMBL 260882 & 478938 & 7.48 & 8.1589 & TRN \\
\hline CHEMBL406191 & 478938 & 4.24 & 4.2588 & TRN \\
\hline CHEMBL 259044 & 478938 & 4.67 & 4.3251 & TRN \\
\hline CHEMBL411438 & 478938 & 5.2 & 4.862 & TRN \\
\hline CHEMBL 259045 & 478938 & 5.81 & 4.8808 & TRN \\
\hline CHEMBL60662 & 478938 & 5.77 & 5.5716 & TRN \\
\hline CHEMBL 260407 & 478938 & 4.86 & 4.8438 & TRN \\
\hline CHEMBL 259868 & 478938 & 5.68 & 5.0792 & TRN \\
\hline CHEMBL406643 & 478938 & 4.75 & 4.4679 & TRN \\
\hline CHEMBL 262083 & 478938 & 4.49 & 4.2844 & TRN \\
\hline CHEMBL427558 & 478938 & 6.51 & 6.6988 & TRN \\
\hline CHEMBL 260167 & 478938 & 3.59 & 3.8844 & TRN \\
\hline CHEMBL18115 & 478938 & 4.44 & 4.3588 & TRN \\
\hline CHEMBL 260057 & 478938 & 3.04 & 4.2931 & TST \\
\hline CHEMBL 388757 & 478938 & 4.97 & 4.7496 & TST \\
\hline CHEMBL404779 & 478938 & 4.87 & 4.4317 & TST \\
\hline CHEMBL394171 & 478938 & 7.67 & 7.3344 & TST \\
\hline CHEMBL429511 & 478938 & 5.74 & 5.4495 & TST \\
\hline CHEMBL 258729 & 478938 & 2.76 & 7.3508 & TST \\
\hline CHEMBL438046 & 478938 & 6.48 & 7.8666 & TST \\
\hline CHEMBL 259855 & 478938 & 3.61 & 7.9815 & TST \\
\hline CHEMBL260281 & 478938 & 2.13 & 7.4695 & TST \\
\hline CHEMBL261226 & 478938 & 5.44 & 7.1007 & TST \\
\hline CHEMBL 260570 & 478938 & 8.26 & 7.7352 & TST \\
\hline CHEMBL 261227 & 478938 & 6.74 & 7.7479 & TST \\
\hline CHEMBL408670 & 478938 & 5.52 & 7.2021 & TST \\
\hline CHEMBL 3431610 & 1479039 & 5.1927 & 5.5372 & TRN \\
\hline CHEMBL3431784 & 1479039 & 3.0 & 4.0405 & TST \\
\hline CHEMBL3431921 & 1479039 & 5.277 & 5.1448 & TRN \\
\hline CHEMBL 3431594 & 1479039 & 3.0 & 3.1446 & TRN \\
\hline CHEMBL 3431461 & 1479039 & 6.6946 & 5.8672 & TRN \\
\hline CHEMBL3431714 & 1479039 & 3.0 & 3.4875 & TRN \\
\hline CHEMBL3431872 & 1479039 & 3.0 & 3.4749 & TRN \\
\hline CHEMBL3431589 & 1479039 & 3.0 & 3.35 & TST \\
\hline CHEMBL 3431893 & 1479039 & 6.2234 & 6.0904 & TRN \\
\hline CHEMBL 3431795 & 1479039 & 4.2823 & 4.9254 & TRN \\
\hline CHEMBL 3431732 & 1479039 & 3.0 & 4.052 & TST \\
\hline
\end{tabular}


Supplemental Table S2.txt

\begin{tabular}{|c|c|c|c|c|}
\hline CHEMBL 3431513 & 1479039 & 3.0 & 4.8174 & TST \\
\hline CHEMBL 3431863 & 1479039 & 4.1115 & 3.716 & TRN \\
\hline CHEMBL 3431534 & 1479039 & 3.0 & 2.9459 & TRN \\
\hline CHEMBL3431640 & 1479039 & 4.3623 & 3.097 & TRN \\
\hline CHEMBL3431540 & 1479039 & 4.5589 & 3.3942 & TRN \\
\hline CHEMBL 3431551 & 1479039 & 5.2855 & 5.4737 & TRN \\
\hline CHEMBL 3431632 & 1479039 & 6.2715 & 5.76399 & 9999999999 \\
\hline CHEMBL 3431750 & 1479039 & 3.0 & 3.1959 & TRN \\
\hline CHEMBL 3431464 & 1479039 & 3.0 & 3.2295 & TRN \\
\hline CHEMBL3431661 & 1479039 & 6.0304 & 5.6638 & TRN \\
\hline CHEMBL 3431783 & 1479039 & 3.0 & 3.8191 & TRN \\
\hline CHEMBL 3431644 & 1479039 & 3.0 & 3.4443 & TST \\
\hline CHEMBL 3431878 & 1479039 & 4.5187 & 3.4032 & TRN \\
\hline CHEMBL 3431664 & 1479039 & 3.0 & 3.1936 & TRN \\
\hline CHEMBL3431781 & 1479039 & 3.0 & 4.7746 & TST \\
\hline CHEMBL 3431747 & 1479039 & 3.0 & 2.9341 & TRN \\
\hline CHEMBL 3431842 & 1479039 & 3.0 & 4.5603 & TST \\
\hline CHEMBL 3431895 & 1479039 & 4.7535 & 4.419 & TRN \\
\hline CHEMBL 3431675 & 1479039 & 3.0 & 3.0126 & TRN \\
\hline CHEMBL3431548 & 1479039 & 6.0048 & 5.5141 & TRN \\
\hline CHEMBL3431792 & 1479039 & 5.7608 & 5.5606 & TRN \\
\hline CHEMBL 3431690 & 1479039 & 5.1682 & 6.7385 & TRN \\
\hline CHEMBL 3431680 & 1479039 & 5.7389 & 6.0352 & TRN \\
\hline CHEMBL 3431766 & 1479039 & 6.2908 & 3.6993 & TST \\
\hline CHEMBL 3431686 & 1479039 & 6.0224 & 6.48 & TST \\
\hline CHEMBL3431897 & 1479039 & 5.5642 & 5.1773 & TRN \\
\hline CHEMBL 3431749 & 1479039 & 3.0 & 3.2082 & TRN \\
\hline CHEMBL 3431614 & 1479039 & 3.0 & 3.0895 & TRN \\
\hline CHEMBL 3431583 & 1479039 & 3.0 & 3.3874 & TRN \\
\hline CHEMBL 3431685 & 1479039 & 6.3579 & 5.797006 & 3000000001 \\
\hline CHEMBL 3431744 & 1479039 & 3.0 & 3.1624 & TRN \\
\hline CHEMBL 3431791 & 1479039 & 3.0 & 3.4283 & TRN \\
\hline CHEMBL 3431512 & 1479039 & 6.13 & 5.5852 & TRN \\
\hline CHEMBL 3431603 & 1479039 & 5.16 & 5.6178 & TRN \\
\hline CHEMBL 3431777 & 1479039 & 3.0 & 3.6206 & TST \\
\hline CHEMBL3431785 & 1479039 & 4.0002 & 4.4909 & TST \\
\hline CHEMBL 3431825 & 1479039 & 5.9356 & 5.9841 & TRN \\
\hline CHEMBL 3431809 & 1479039 & 3.0 & 3.1853 & TRN \\
\hline CHEMBL 3431658 & 1479039 & 3.0 & 3.003 & TST \\
\hline CHEMBL 3431620 & 1479039 & 4.4091 & 3.6158 & TRN \\
\hline CHEMBL3431869 & 1479039 & 5.3811 & 3.5337 & TRN \\
\hline CHEMBL 3431571 & 1479039 & 3.0 & 3.3724 & TRN \\
\hline CHEMBL3431480 & 1479039 & 4.1951 & 3.4107 & TRN \\
\hline CHEMBL 3431847 & 1479039 & 4.0182 & 3.6542 & TRN \\
\hline CHEMBL 3431914 & 1479039 & 5.5832 & 4.4882 & TRN \\
\hline CHEMBL3431767 & 1479039 & 5.0952 & 5.1871 & TRN \\
\hline CHEMBL3431579 & 1479039 & 3.0 & 3.2824 & TRN \\
\hline CHEMBL 3431663 & 1479039 & 4.0261 & 3.5082 & TRN \\
\hline
\end{tabular}

Page 27847 
Supplemental Table S2.txt

\begin{tabular}{|c|c|c|c|c|}
\hline CHEMBL 3431808 & 1479039 & 4.1454 & 3.5294 & TRN \\
\hline CHEMBL3431776 & 1479039 & 3.0 & 3.3956 & TST \\
\hline CHEMBL3431618 & 1479039 & 3.0 & 3.2585 & TRN \\
\hline CHEMBL 3431857 & 1479039 & 5.2475 & 3.5113 & TRN \\
\hline CHEMBL3431830 & 1479039 & 4.9196 & 3.883 & TRN \\
\hline CHEMBL3431799 & 1479039 & 3.0 & 3.7898 & TST \\
\hline CHEMBL3431569 & 1479039 & 3.0 & 3.2203 & TRN \\
\hline CHEMBL3431491 & 1479039 & 3.0 & 3.3814 & TRN \\
\hline CHEMBL3431759 & 1479039 & 3.0 & 3.2787 & TRN \\
\hline CHEMBL3431558 & 1479039 & 3.0 & 3.4749 & TRN \\
\hline CHEMBL3431557 & 1479039 & 3.0 & 3.33100 & 00000000004 \\
\hline CHEMBL3431888 & 1479039 & 6.2061 & 5.9368 & TRN \\
\hline CHEMBL3431556 & 1479039 & 3.0 & 3.51 & TRN \\
\hline CHEMBL3431650 & 1479039 & 4.5273 & 2.9373 & TST \\
\hline CHEMBL3431906 & 1479039 & 3.0 & 3.2571 & TRN \\
\hline CHEMBL 2216778 & 1479039 & 5.46700 & 00000000 & 4.5079 \\
\hline CHEMBL3431470 & 1479039 & 6.1797 & 5.8651 & TRN \\
\hline CHEMBL3431760 & 1479039 & 3.0 & 3.3986 & TRN \\
\hline CHEMBL3431837 & 1479039 & 4.306 & 3.9142 & TRN \\
\hline CHEMBL3431727 & 1479039 & 5.9206 & 5.8453 & TRN \\
\hline CHEMBL3431577 & 1479039 & 4.6461 & 4.5684 & TRN \\
\hline CHEMBL3431692 & 1479039 & 3.0 & 3.8257 & TST \\
\hline CHEMBL3431666 & 1479039 & 3.0 & 3.3149 & TRN \\
\hline CHEMBL3431920 & 1479039 & 6.086 & 5.7753 & TRN \\
\hline CHEMBL3431586 & 1479039 & 4.2857 & 3.3168 & TST \\
\hline CHEMBL3431739 & 1479039 & 3.0 & 4.032 & TST \\
\hline CHEMBL3431709 & 1479039 & 3.0 & 3.2687 & TST \\
\hline CHEMBL 3431604 & 1479039 & 5.5665 & 5.9832 & TRN \\
\hline CHEMBL3431819 & 1479039 & 6.3497 & 5.974 & TRN \\
\hline CHEMBL3431864 & 1479039 & 3.0 & 3.3216 & TRN \\
\hline CHEMBL3431505 & 1479039 & 3.0 & 3.7962 & TRN \\
\hline CHEMBL3431489 & 1479039 & 3.0 & 3.1704 & TRN \\
\hline CHEMBL3431612 & 1479039 & 5.041 & 5.706 & TRN \\
\hline CHEMBL3431856 & 1479039 & 3.0 & 3.7435 & TRN \\
\hline CHEMBL3431605 & 1479039 & 5.2628 & 4.4917 & TRN \\
\hline CHEMBL3431713 & 1479039 & 3.0 & 3.1705 & TRN \\
\hline CHEMBL3431844 & 1479039 & 5.5893 & 4.7694 & TST \\
\hline CHEMBL 3431554 & 1479039 & 5.046 & 5.3132 & TRN \\
\hline CHEMBL3431533 & 1479039 & 6.1712 & 4.4813 & TST \\
\hline CHEMBL3431917 & 1479039 & 3.0 & 4.5341 & TRN \\
\hline CHEMBL3431877 & 1479039 & 3.0 & 3.5066 & TRN \\
\hline CHEMBL3431751 & 1479039 & 3.0 & 3.3382 & TRN \\
\hline CHEMBL3431733 & 1479039 & 3.0 & 3.8102 & TST \\
\hline CHEMBL3431570 & 1479039 & 3.0 & 3.4727 & TRN \\
\hline CHEMBL3431606 & 1479039 & 5.4521 & 5.3064 & TRN \\
\hline CHEMBL3431839 & 1479039 & 5.7736 & 4.8792 & TRN \\
\hline CHEMBL3431754 & 1479039 & 5.8436 & 5.6984 & TRN \\
\hline CHEMBL3431488 & 1479039 & 3.0 & 3.3827 & TRN \\
\hline
\end{tabular}


Supplemental Table S2.txt

\begin{tabular}{|c|c|c|c|c|}
\hline CHEMBL3431654 & 1479039 & 4.1071 & 3.2748 & TRN \\
\hline CHEMBL3431495 & 1479039 & 3.0 & 3.2789 & TRN \\
\hline CHEMBL3431796 & 1479039 & 4.4324 & 5.2773 & TRN \\
\hline CHEMBL3431850 & 1479039 & 3.0 & 3.8085 & TRN \\
\hline CHEMBL3431483 & 1479039 & 3.0 & 3.3456 & TRN \\
\hline CHEMBL3431490 & 1479039 & 3.0 & 3.0176 & TRN \\
\hline CHEMBL3431563 & 1479039 & 3.0 & 3.0921 & TRN \\
\hline CHEMBL3431706 & 1479039 & 3.0 & 3.7554 & TST \\
\hline CHEMBL3431771 & 1479039 & 6.5864 & 6.0539 & TRN \\
\hline CHEMBL3431694 & 1479039 & 3.0 & 3.8538 & TST \\
\hline CHEMBL 3431843 & 1479039 & 5.9043 & 4.9672 & TST \\
\hline CHEMBL3431827 & 1479039 & 5.8071 & 5.954 & TRN \\
\hline CHEMBL3431813 & 1479039 & 3.0 & 5.1083 & TST \\
\hline CHEMBL3431916 & 1479039 & 4.4451 & 4.376 & TRN \\
\hline CHEMBL3431823 & 1479039 & 4.0804 & 3.6593 & TST \\
\hline CHEMBL3431494 & 1479039 & 3.0 & 3.2641 & TRN \\
\hline CHEMBL3431693 & 1479039 & 3.0 & 3.8429 & TST \\
\hline CHEMBL3431855 & 1479039 & 5.0914 & 3.7204 & TRN \\
\hline CHEMBL3431891 & 1479039 & 5.7535 & 5.2501 & TRN \\
\hline CHEMBL3431866 & 1479039 & 4.2235 & 3.5604 & TRN \\
\hline CHEMBL3431615 & 1479039 & 3.0 & 3.1974 & TRN \\
\hline CHEMBL3431746 & 1479039 & 3.0 & 3.0494 & TRN \\
\hline CHEMBL3431487 & 1479039 & 3.0 & 3.406 & TRN \\
\hline CHEMBL3431667 & 1479039 & 5.1179 & 3.4971 & TRN \\
\hline CHEMBL3431717 & 1479039 & 5.4374 & 5.85 & TRN \\
\hline CHEMBL3431624 & 1479039 & 6.0036 & 5.79 & TRN \\
\hline CHEMBL3431898 & 1479039 & 5.9294 & 5.5007 & TRN \\
\hline CHEMBL3431511 & 1479039 & 6.1247 & 5.8574 & TRN \\
\hline CHEMBL3431677 & 1479039 & 5.9663 & 6.151 & TRN \\
\hline CHEMBL3431657 & 1479039 & 3.0 & 3.2225 & TST \\
\hline CHEMBL3431925 & 1479039 & 5.2745 & 5.2281 & TRN \\
\hline CHEMBL 3431740 & 1479039 & 4.6605 & 5.6345 & TST \\
\hline CHEMBL3431912 & 1479039 & 5.3411 & 5.22 & TRN \\
\hline CHEMBL3431672 & 1479039 & 3.0 & 3.1788 & TRN \\
\hline CHEMBL3431529 & 1479039 & 3.0 & 3.2036 & TRN \\
\hline CHEMBL3431894 & 1479039 & 4.5377 & 4.242 & TRN \\
\hline CHEMBL3431860 & 1479039 & 3.0 & 3.7846 & TRN \\
\hline CHEMBL3431816 & 1479039 & 5.0447 & 3.9559 & TRN \\
\hline CHEMBL3431629 & 1479039 & 4.5768 & 4.67399 & 99999999995 \\
\hline CHEMBL3431598 & 1479039 & 3.0 & 3.1214 & TRN \\
\hline CHEMBL3431702 & 1479039 & 3.0 & 3.1601 & TRN \\
\hline CHEMBL3431835 & 1479039 & 5.0917 & 4.9645 & TRN \\
\hline CHEMBL3431886 & 1479039 & 6.2077 & 5.7362 & TRN \\
\hline CHEMBL3431838 & 1479039 & 5.0049 & 4.8915 & TRN \\
\hline CHEMBL3431492 & 1479039 & 3.0 & 3.0895 & TRN \\
\hline CHEMBL3431801 & 1479039 & 3.0 & 3.9825 & TST \\
\hline CHEMBL3431635 & 1479039 & 6.0824 & 6.0547 & TRN \\
\hline CHEMBL3431874 & 1479039 & 3.0 & 3.7353 & TRN \\
\hline
\end{tabular}




\begin{tabular}{|c|c|c|c|c|c|}
\hline \multicolumn{6}{|c|}{ Supplemental Table S2.txt } \\
\hline CHEMBL3431602 & 1479039 & 5.4342 & 5.3748 & TRN & \\
\hline CHEMBL3431831 & 1479039 & 3.0 & 3.4751 & TRN & \\
\hline CHEMBL3431904 & 1479039 & 3.0 & 3.4222 & TRN & \\
\hline CHEMBL3431892 & 1479039 & 5.5272 & 5.8492 & TRN & \\
\hline CHEMBL3431712 & 1479039 & 5.6065 & 5.9365 & TRN & \\
\hline CHEMBL3431772 & 1479039 & 3.0 & 3.1021 & TRN & \\
\hline CHEMBL3431546 & 1479039 & 4.3747 & 5.2753 & TRN & \\
\hline CHEMBL3431875 & 1479039 & 3.0 & 3.6282 & TRN & \\
\hline CHEMBL3431617 & 1479039 & 3.0 & 3.2151 & TRN & \\
\hline CHEMBL3431723 & 1479039 & 5.1361 & 3.7014 & TST & \\
\hline CHEMBL3431599 & 1479039 & 3.0 & 3.5369 & TRN & \\
\hline CHEMBL3431859 & 1479039 & 3.0 & 3.3248 & TRN & \\
\hline CHEMBL3431501 & 1479039 & 3.0 & 3.886 & TRN & \\
\hline CHEMBL 3431478 & 1479039 & 5.7074 & 4.2966 & TRN & \\
\hline CHEMBL3431761 & 1479039 & 3.0 & 3.1159 & TRN & \\
\hline CHEMBL3431637 & 1479039 & 3.0 & 2.9353 & TRN & \\
\hline CHEMBL3431652 & 1479039 & 3.0 & 5.1892 & TST & \\
\hline CHEMBL3431753 & 1479039 & 6.2211 & 6.1424 & TRN & \\
\hline CHEMBL3431817 & 1479039 & 3.0 & 3.6962 & TST & \\
\hline CHEMBL3431497 & 1479039 & 3.0 & 3.137 & TRN & \\
\hline CHEMBL3431515 & 1479039 & 3.0 & 2.9175 & TRN & \\
\hline CHEMBL3431778 & 1479039 & 4.4987 & 3.577 & TST & \\
\hline CHEMBL3431885 & 1479039 & 5.5527 & 6.1069 & TRN & \\
\hline CHEMBL3431867 & 1479039 & 3.0 & 3.97600 & 00000000004 & TRN \\
\hline CHEMBL3431908 & 1479039 & 3.0 & 4.1775 & TRN & \\
\hline CHEMBL3431716 & 1479039 & 3.0 & 3.3319 & TRN & \\
\hline CHEMBL3431527 & 1479039 & 3.0 & 3.5651 & TRN & \\
\hline CHEMBL3431818 & 1479039 & 5.5914 & 5.7389 & TST & \\
\hline CHEMBL3431655 & 1479039 & 4.0926 & 3.4336 & TRN & \\
\hline CHEMBL 3431482 & 1479039 & 3.0 & 2.9932 & TRN & \\
\hline CHEMBL3431880 & 1479039 & 5.9171 & 5.9392 & TRN & \\
\hline CHEMBL3431476 & 1479039 & 3.0 & 3.1402 & TRN & \\
\hline CHEMBL3431592 & 1479039 & 3.0 & 3.1709 & TRN & \\
\hline CHEMBL3431752 & 1479039 & 6.2752 & 6.5424 & TRN & \\
\hline CHEMBL 3431542 & 1479039 & 3.0 & 3.4273 & TRN & \\
\hline CHEMBL3431788 & 1479039 & 4.8094 & 4.7156 & TRN & \\
\hline CHEMBL3431769 & 1479039 & 3.0 & 3.2946 & TRN & \\
\hline CHEMBL3431636 & 1479039 & 3.0 & 3.0604 & TST & \\
\hline CHEMBL3431710 & 1479039 & 5.0051 & 3.3834 & TST & \\
\hline CHEMBL3431509 & 1479039 & 3.0 & 3.5335 & TRN & \\
\hline CHEMBL3431647 & 1479039 & 4.4138 & 4.4939 & TRN & \\
\hline CHEMBL3431538 & 1479039 & 4.5722 & 5.3562 & TST & \\
\hline CHEMBL3431576 & 1479039 & 4.9291 & 4.7024 & TRN & \\
\hline CHEMBL3431807 & 1479039 & 3.0 & 3.555 & TRN & \\
\hline CHEMBL3431477 & 1479039 & 3.0 & 4.0458 & TRN & \\
\hline CHEMBL3431793 & 1479039 & 5.5713 & 5.3754 & TRN & \\
\hline CHEMBL3431829 & 1479039 & 5.7566 & 5.0578 & TRN & \\
\hline CHEMBL3431555 & 1479039 & 3.0 & 4.5357 & TST & \\
\hline
\end{tabular}




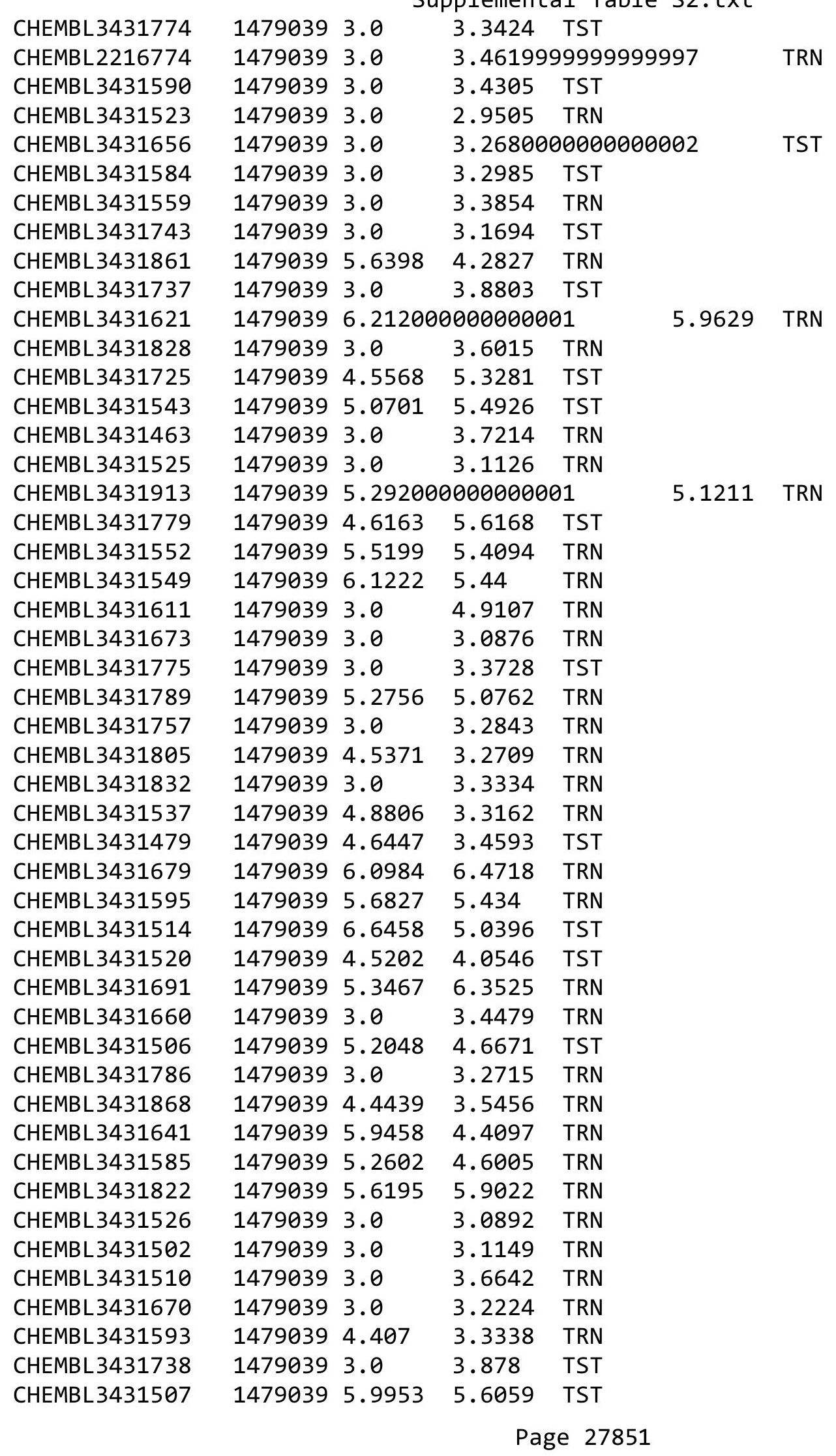


Supplemental Table S2.txt

\begin{tabular}{|c|c|c|c|c|c|}
\hline CHEMBL3431653 & 1479039 & 3.0 & 3.4449 & TRN & \\
\hline CHEMBL3431500 & 1479039 & 3.0 & 3.4789 & TRN & \\
\hline CHEMBL3431700 & 1479039 & 3.0 & 3.08100 & 00000000004 & TRN \\
\hline CHEMBL 3431797 & 1479039 & 5.5597 & 5.7591 & TST & \\
\hline CHEMBL3431814 & 1479039 & 3.0 & 3.6275 & TRN & \\
\hline CHEMBL3431918 & 1479039 & 3.0 & 3.9628 & TRN & \\
\hline CHEMBL3431553 & 1479039 & 4.7072 & 5.8934 & TRN & \\
\hline CHEMBL 3431687 & 1479039 & 5.8705 & 6.108 & TST & \\
\hline CHEMBL3431485 & 1479039 & 3.0 & 3.1044 & TRN & \\
\hline CHEMBL3431472 & 1479039 & 3.0 & 4.7197 & TRN & \\
\hline CHEMBL3431518 & 1479039 & 5.3068 & 4.6094 & TRN & \\
\hline CHEMBL3431567 & 1479039 & 3.0 & 2.9791 & TRN & \\
\hline CHEMBL3431544 & 1479039 & 6.8731 & 5.1476 & TRN & \\
\hline CHEMBL 3431634 & 1479039 & 6.6284 & 6.0665 & TRN & \\
\hline CHEMBL3431755 & 1479039 & 4.1506 & 3.4018 & TRN & \\
\hline CHEMBL3431508 & 1479039 & 3.0 & 3.3386 & TST & \\
\hline CHEMBL3431745 & 1479039 & 3.0 & 3.1903 & TRN & \\
\hline CHEMBL3431903 & 1479039 & 3.0 & 4.3668 & TRN & \\
\hline CHEMBL3431699 & 1479039 & 3.0 & 3.4511 & TRN & \\
\hline CHEMBL 2216779 & 1479039 & 3.0 & 4.6857 & TRN & \\
\hline CHEMBL 3431580 & 1479039 & 5.2096 & 5.1566 & TST & \\
\hline CHEMBL3431517 & 1479039 & 4.0289 & 3.01899 & 99999999997 & TRN \\
\hline CHEMBL3431609 & 1479039 & 3.0 & 3.31 & TST & \\
\hline CHEMBL3431561 & 1479039 & 3.0 & 3.3347 & TRN & \\
\hline CHEMBL3431762 & 1479039 & 3.0 & 3.4777 & TST & \\
\hline CHEMBL3431539 & 1479039 & 3.0 & 2.8411 & TST & \\
\hline CHEMBL3431575 & 1479039 & 4.0853 & 4.61 & TRN & \\
\hline CHEMBL3431851 & 1479039 & 3.0 & 3.5745 & TRN & \\
\hline CHEMBL3431901 & 1479039 & 4.3379 & 3.3352 & TRN & \\
\hline CHEMBL 3431734 & 1479039 & 3.0 & 3.6878 & TST & \\
\hline CHEMBL3431910 & 1479039 & 3.0 & 3.1988 & TST & \\
\hline CHEMBL3431848 & 1479039 & 5.2131 & 3.858 & TRN & \\
\hline CHEMBL3431879 & 1479039 & 6.0668 & 6.2808 & TRN & \\
\hline CHEMBL 3431468 & 1479039 & 3.0 & 2.734 & TRN & \\
\hline CHEMBL3431587 & 1479039 & 5.6423 & 5.358 & TRN & \\
\hline CHEMBL3431905 & 1479039 & 3.0 & 3.3194 & TRN & \\
\hline CHEMBL3431572 & 1479039 & 3.0 & 3.0775 & TRN & \\
\hline CHEMBL3431578 & 1479039 & 3.0 & 3.2714 & TRN & \\
\hline CHEMBL3431622 & 1479039 & 6.2574 & 5.6513 & TRN & \\
\hline CHEMBL3431899 & 1479039 & 5.8827 & 5.4456 & TRN & \\
\hline CHEMBL3431688 & 1479039 & 3.0 & 3.552 & TRN & \\
\hline CHEMBL3431600 & 1479039 & 3.0 & 3.3955 & TRN & \\
\hline CHEMBL3431887 & 1479039 & 5.8632 & 5.1656 & TRN & \\
\hline CHEMBL3431503 & 1479039 & 4.4796 & 3.5525 & TRN & \\
\hline CHEMBL3431519 & 1479039 & 3.0 & 3.0513 & TRN & \\
\hline CHEMBL3431882 & 1479039 & 5.9285 & 5.7372 & TRN & \\
\hline CHEMBL3431804 & 1479039 & 3.0 & 3.5105 & TRN & \\
\hline CHEMBL3431719 & 1479039 & 5.4984 & 5.591 & TRN & \\
\hline
\end{tabular}


Supplemental Table S2.txt

\begin{tabular}{|c|c|c|c|c|}
\hline CHEMBL3431616 & 1479039 & 3.0 & 3.2052 & TRN \\
\hline CHEMBL3431674 & 1479039 & 3.0 & 3.0557 & TRN \\
\hline CHEMBL3431633 & 1479039 & 5.6628 & 4.7916 & TST \\
\hline CHEMBL 2216777 & 1479039 & 5.4552 & 6.1287 & TRN \\
\hline CHEMBL 3431689 & 1479039 & 5.6556 & 6.25 & TRN \\
\hline CHEMBL3431907 & 1479039 & 5.5979 & 4.373 & TST \\
\hline CHEMBL 3431560 & 1479039 & 3.0 & 3.1313 & TRN \\
\hline CHEMBL3431865 & 1479039 & 3.0 & 3.1742 & TRN \\
\hline CHEMBL3431780 & 1479039 & 3.0 & 3.4684 & TRN \\
\hline CHEMBL 3431671 & 1479039 & 5.6331 & 5.879 & TST \\
\hline CHEMBL 3431708 & 1479039 & 3.0 & 3.4382 & TST \\
\hline CHEMBL 3431651 & 1479039 & 4.1371 & 3.4063 & TRN \\
\hline CHEMBL 3431541 & 1479039 & 4.3455 & 3.9781 & TST \\
\hline CHEMBL 3431659 & 1479039 & 4.7638 & 4.6252 & TRN \\
\hline CHEMBL 3431469 & 1479039 & 3.0 & 2.8492 & TRN \\
\hline CHEMBL3431466 & 1479039 & 3.0 & 2.9561 & TRN \\
\hline CHEMBL3431473 & 1479039 & 3.0 & 2.9113 & TRN \\
\hline CHEMBL 3431678 & 1479039 & 6.2089 & 6.0856 & TRN \\
\hline CHEMBL 3431607 & 1479039 & 3.0 & 2.9972 & TST \\
\hline CHEMBL3431646 & 1479039 & 5.7635 & 5.7605 & TST \\
\hline CHEMBL 3431765 & 1479039 & 5.8183 & 5.4938 & TRN \\
\hline CHEMBL3431695 & 1479039 & 3.0 & 3.2074 & TST \\
\hline CHEMBL3431929 & 1479039 & 3.0 & 4.0809 & TRN \\
\hline CHEMBL 3431724 & 1479039 & 6.1978 & 5.7307 & TST \\
\hline CHEMBL 3431883 & 1479039 & 5.9624 & 6.00899 & 99999999995 \\
\hline CHEMBL3431573 & 1479039 & 5.7449 & 5.41200 & 0000000001 \\
\hline CHEMBL3431486 & 1479039 & 3.0 & 3.5103 & TRN \\
\hline CHEMBL 3431528 & 1479039 & 3.0 & 3.3765 & TRN \\
\hline CHEMBL 3431628 & 1479039 & 5.5767 & 4.6056 & TST \\
\hline CHEMBL 3431741 & 1479039 & 4.0792 & 3.3722 & TRN \\
\hline CHEMBL 3431484 & 1479039 & 3.0 & 3.1805 & TRN \\
\hline CHEMBL3431922 & 1479039 & 5.4485 & 5.9019 & TRN \\
\hline CHEMBL3431919 & 1479039 & 6.2774 & 4.6449 & TRN \\
\hline CHEMBL 3431871 & 1479039 & 3.0 & 3.7427 & TST \\
\hline CHEMBL 3431481 & 1479039 & 3.0 & 3.2053 & TRN \\
\hline CHEMBL3431810 & 1479039 & 3.0 & 3.5781 & TRN \\
\hline CHEMBL3431698 & 1479039 & 3.0 & 3.4235 & TRN \\
\hline CHEMBL3431928 & 1479039 & 5.5516 & 4.7707 & TRN \\
\hline CHEMBL 3431736 & 1479039 & 3.0 & 3.5977 & TST \\
\hline CHEMBL3431591 & 1479039 & 3.0 & 3.4359 & TRN \\
\hline CHEMBL 3431597 & 1479039 & 3.0 & 3.2847 & TRN \\
\hline CHEMBL 3431460 & 1479039 & 3.0 & 3.4522 & TRN \\
\hline CHEMBL3431881 & 1479039 & 5.3705 & 5.3019 & TRN \\
\hline CHEMBL 3431763 & 1479039 & 5.7583 & 5.2627 & TRN \\
\hline CHEMBL 3431474 & 1479039 & 3.0 & 2.9412 & TRN \\
\hline CHEMBL 3431721 & 1479039 & 6.0738 & 5.6546 & TRN \\
\hline CHEMBL3431566 & 1479039 & 3.0 & 3.0153 & TRN \\
\hline CHEMBL 3431715 & 1479039 & 3.0 & 3.0057 & TRN \\
\hline
\end{tabular}


Supplemental Table S2.txt

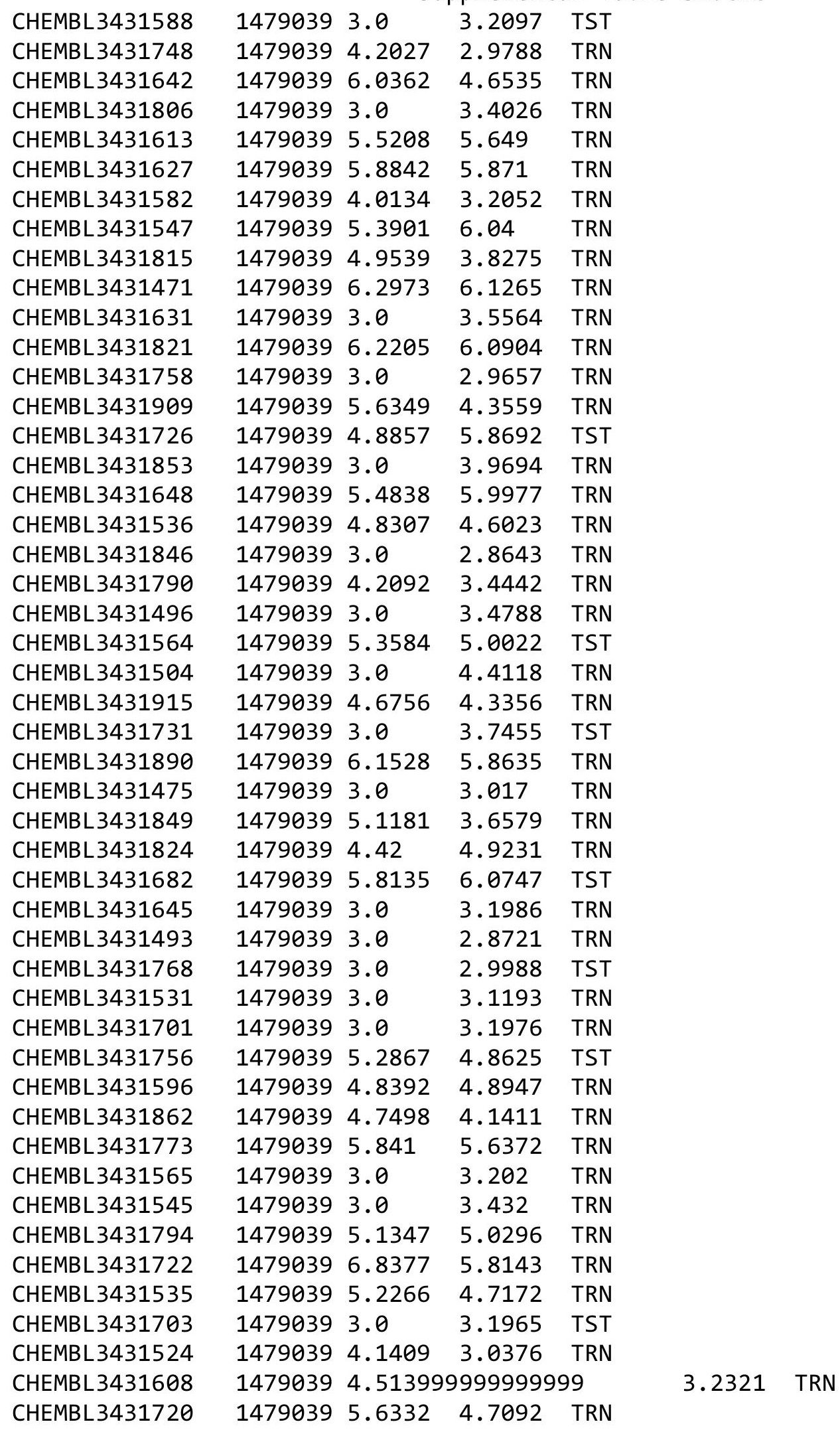

Page 27854 
Supplemental Table S2.txt

\begin{tabular}{|c|c|c|c|c|c|c|}
\hline CHEMBL3431729 & 1479039 & 4.1025 & 3.9814 & TST & & \\
\hline CHEMBL3431668 & 1479039 & 5.91299 & 99999999 & 99 & 5.4001 & TST \\
\hline CHEMBL3431462 & 1479039 & 3.0 & 3.7567 & TST & & \\
\hline CHEMBL 3431852 & 1479039 & 4.4619 & 3.8027 & TRN & & \\
\hline CHEMBL 3431638 & 1479039 & 6.3734 & 5.806 & TRN & & \\
\hline CHEMBL3431649 & 1479039 & 5.8607 & 5.7333 & TRN & & \\
\hline CHEMBL3431911 & 1479039 & 3.0 & 3.6045 & TST & & \\
\hline CHEMBL3431550 & 1479039 & 5.4168 & 6.0392 & TRN & & \\
\hline CHEMBL 3431800 & 1479039 & 3.0 & 3.6175 & TST & & \\
\hline CHEMBL3431530 & 1479039 & 3.0 & 3.4537 & TRN & & \\
\hline CHEMBL3431787 & 1479039 & 3.0 & 3.0139 & TRN & & \\
\hline CHEMBL3431902 & 1479039 & 3.0 & 3.0887 & TRN & & \\
\hline CHEMBL3431581 & 1479039 & 3.0 & 3.1764 & TRN & & \\
\hline CHEMBL 3431707 & 1479039 & 3.0 & 3.8614 & TST & & \\
\hline CHEMBL3431623 & 1479039 & 6.1011 & 6.142 & TRN & & \\
\hline CHEMBL3431924 & 1479039 & 6.0389 & 5.8294 & TRN & & \\
\hline CHEMBL3431728 & 1479039 & 6.3092 & 6.0076 & TRN & & \\
\hline CHEMBL3431735 & 1479039 & 3.0 & 3.7529 & TST & & \\
\hline CHEMBL3431811 & 1479039 & 4.9573 & 4.8074 & TST & & \\
\hline CHEMBL3431643 & 1479039 & 4.4494 & 3.7565 & TRN & & \\
\hline CHEMBL3431601 & 1479039 & 6.1262 & 3.6864 & TRN & & \\
\hline CHEMBL3431798 & 1479039 & 4.3298 & 4.3772 & TST & & \\
\hline CHEMBL3431626 & 1479039 & 5.6723 & 6.1465 & TRN & & \\
\hline CHEMBL3431876 & 1479039 & 3.0 & 3.4632 & TRN & & \\
\hline CHEMBL3431465 & 1479039 & 3.0 & 3.0985 & TRN & & \\
\hline CHEMBL3431836 & 1479039 & 4.4058 & 3.7627 & TRN & & \\
\hline CHEMBL3431676 & 1479039 & 5.6683 & 5.5119 & TRN & & \\
\hline CHEMBL3431711 & 1479039 & 5.6171 & 5.6329 & TRN & & \\
\hline CHEMBL 3431870 & 1479039 & 3.0 & 3.7783 & TRN & & \\
\hline CHEMBL 3431884 & 1479039 & 5.9459 & 5.824 & TRN & & \\
\hline CHEMBL3431927 & 1479039 & \multicolumn{3}{|c|}{5.247999999999999} & 4.8481 & RN \\
\hline CHEMBL3431840 & 1479039 & 3.0 & 4.1523 & TST & & \\
\hline CHEMBL3431697 & 1479039 & 3.0 & 3.2814 & TRN & & \\
\hline CHEMBL3431521 & 1479039 & 4.2746 & 4.8964 & TST & & \\
\hline CHEMBL3431532 & 1479039 & 6.2018 & 4.6551 & TST & & \\
\hline CHEMBL3431718 & 1479039 & 5.6403 & 5.9552 & TRN & & \\
\hline CHEMBL3431562 & 1479039 & 3.0 & 2.9517 & TRN & & \\
\hline CHEMBL3431820 & 1479039 & 3.0 & 5.7084 & TRN & & \\
\hline CHEMBL3431705 & 1479039 & 3.0 & 3.6645 & TST & & \\
\hline CHEMBL3431639 & 1479039 & 4.985 & 4.1009 & TST & & \\
\hline CHEMBL3431826 & 1479039 & 5.3921 & 4.8573 & TRN & & \\
\hline CHEMBL3431742 & 1479039 & 3.0 & 3.0795 & TST & & \\
\hline CHEMBL3431812 & 1479039 & 3.0 & 3.7651 & TRN & & \\
\hline CHEMBL3431858 & 1479039 & 4.7102 & 3.7449 & TRN & & \\
\hline CHEMBL3431619 & 1479039 & 3.0 & 3.2647 & TRN & & \\
\hline CHEMBL3431467 & 1479039 & 3.0 & 2.7316 & TRN & & \\
\hline CHEMBL3431889 & 1479039 & 6.02 & 6.2417 & TRN & & \\
\hline CHEMBL3431696 & 1479039 & 3.0 & 3.5768 & TST & & \\
\hline
\end{tabular}


Supplemental Table S2.txt

\begin{tabular}{|c|c|c|c|c|}
\hline CHEMBL3431522 & 1479039 & 3.0 & 4.2862 & TST \\
\hline CHEMBL3431662 & 1479039 & 5.0169 & 5.6579 & TST \\
\hline CHEMBL3431665 & 1479039 & 3.0 & \multicolumn{2}{|c|}{3.2030000000000003} \\
\hline CHEMBL3431873 & 1479039 & 3.0 & 3.5003 & TRN \\
\hline CHEMBL3431681 & 1479039 & 5.6555 & 5.9393 & TST \\
\hline CHEMBL3431782 & 1479039 & 3.0 & 4.0726 & TRN \\
\hline CHEMBL 3431770 & 1479039 & 3.0 & 4.1097 & TST \\
\hline CHEMBL 3431730 & 1479039 & 3.0 & 3.9003 & TST \\
\hline CHEMBL3431896 & 1479039 & 5.3069 & 5.269 & TRN \\
\hline CHEMBL3431764 & 1479039 & 6.3985 & 5.5558 & TRN \\
\hline CHEMBL3431625 & 1479039 & 4.4889 & 5.699 & TST \\
\hline CHEMBL3431854 & 1479039 & 3.0 & 3.753 & TRN \\
\hline CHEMBL 3431926 & 1479039 & 6.164 & 5.6666 & TRN \\
\hline CHEMBL3431630 & 1479039 & 3.0 & 5.0127 & TST \\
\hline CHEMBL 3431574 & 1479039 & 5.4457 & 5.3485 & TRN \\
\hline CHEMBL3431516 & 1479039 & 3.0 & 3.315 & TRN \\
\hline CHEMBL3431845 & 1479039 & 5.2295 & 3.6129 & TST \\
\hline CHEMBL3431669 & 1479039 & 5.7279 & 5.4659 & TST \\
\hline CHEMBL 3431923 & 1479039 & 5.8159 & 6.1994 & TST \\
\hline CHEMBL 3431568 & 1479039 & 3.0 & 3.2036 & TRN \\
\hline CHEMBL 3431841 & 1479039 & 5.0541 & 4.4686 & TST \\
\hline CHEMBL3930593 & 1640604 & 7.4089 & 7.2345 & TST \\
\hline CHEMBL1938786 & 1640604 & 7.6778 & 7.0767 & TRN \\
\hline CHEMBL 3923698 & 1640604 & 7.9586 & 7.8697 & TRN \\
\hline CHEMBL 3985647 & 1640604 & 7.1675 & 6.5755 & TRN \\
\hline CHEMBL1933148 & 1640604 & 7.9586 & 7.9182 & TRN \\
\hline CHEMBL3910706 & 1640604 & 5.1549 & 5.9398 & TRN \\
\hline CHEMBL 3916626 & 1640604 & 8.5229 & 8.5545 & TRN \\
\hline CHEMBL1938769 & 1640604 & 5.7696 & 6.8566 & TST \\
\hline CHEMBL3919317 & 1640604 & 7.8539 & 7.5582 & TRN \\
\hline CHEMBL 3967861 & 1640604 & 5.6021 & 6.5734 & TRN \\
\hline CHEMBL3907067 & 1640604 & 8.0969 & 7.9516 & TRN \\
\hline CHEMBL3979890 & 1640604 & 8.1192 & 7.5278 & TRN \\
\hline CHEMBL3905749 & 1640604 & 6.0 & 6.5619 & TRN \\
\hline CHEMBL3911905 & 1640604 & 7.8861 & 7.6095 & TRN \\
\hline CHEMBL 3948495 & 1640604 & 6.9586 & 7.2006 & TRN \\
\hline CHEMBL3948994 & 1640604 & 6.0458 & 5.9556 & TRN \\
\hline CHEMBL 3969237 & 1640604 & 7.5686 & 7.2003 & TRN \\
\hline CHEMBL 3985027 & 1640604 & 9.0506 & 9.8447 & TRN \\
\hline CHEMBL3906949 & 1640604 & 7.7447 & 7.265 & TRN \\
\hline CHEMBL 3927732 & 1640604 & 6.1739 & 6.1626 & TRN \\
\hline CHEMBL1938771 & 1640604 & 5.4815 & 6.907 & TST \\
\hline CHEMBL1938792 & 1640604 & 7.5935 & 7.3743 & TRN \\
\hline CHEMBL 3915806 & 1640604 & 7.7696 & 7.3812 & TRN \\
\hline CHEMBL 3952734 & 1640604 & 7.2924 & 7.1901 & TRN \\
\hline CHEMBL3951696 & 1640604 & 7.7212 & 7.0672 & TST \\
\hline CHEMBL3952605 & 1640604 & 7.9586 & 7.3484 & TRN \\
\hline CHEMBL1938770 & 1640604 & 6.3665 & 6.8538 & TST \\
\hline
\end{tabular}


Supplemental Table S2.txt

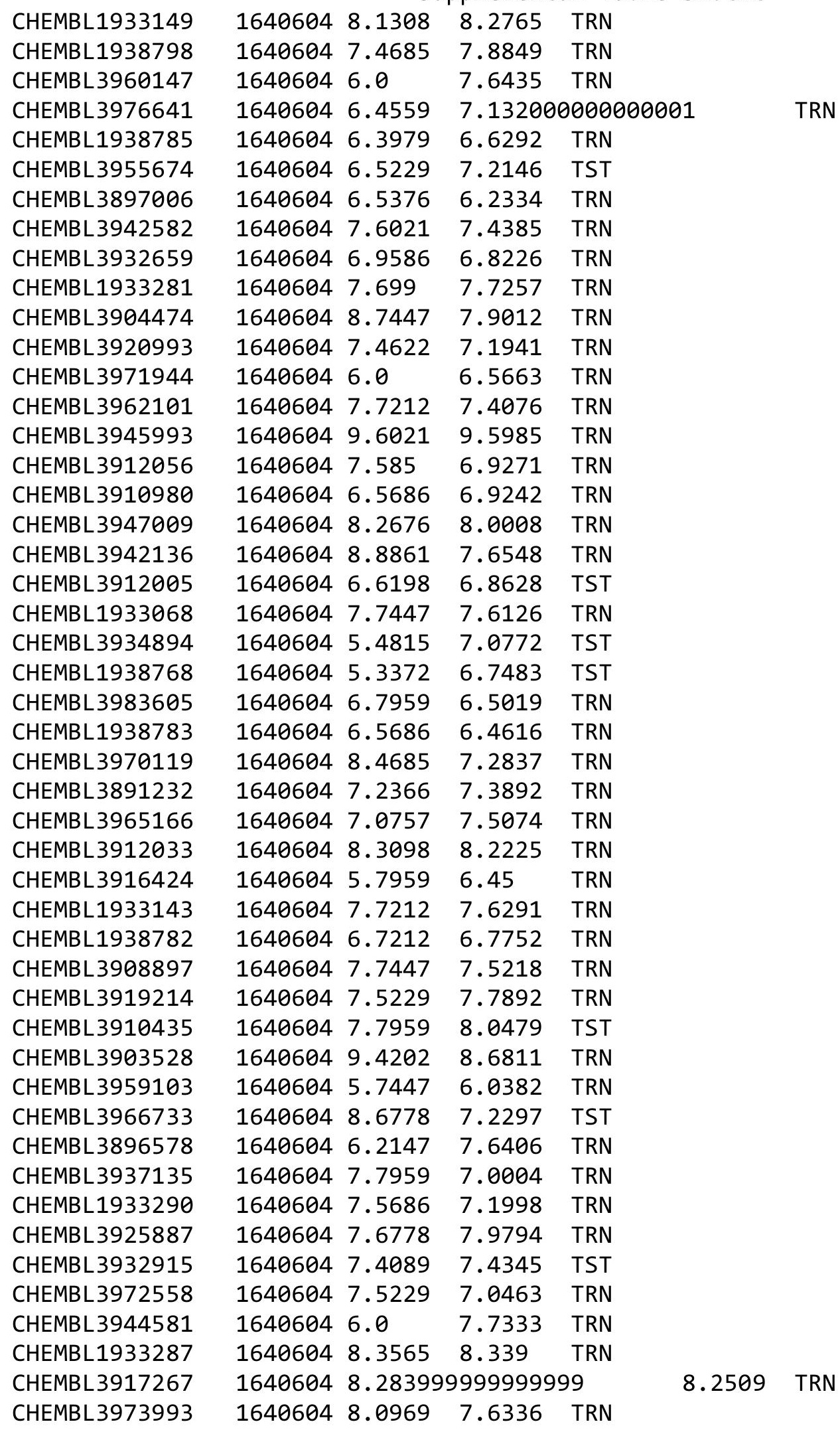

Page 27857 
Supplemental Table S2.txt

\begin{tabular}{|c|c|c|c|c|}
\hline 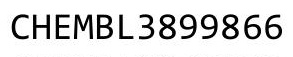 & & & & \\
\hline HEMBL3906539 & 40604 & 7.6021 & 7264 & \\
\hline HEMBL3 & 640604 & 7.3979 & & \\
\hline IEM & 604 & & 28 & \\
\hline EMBL3 & 604 & 7.2676 & 6709 & \\
\hline HEMBL3961193 & 640604 & 7.0706 & 0154 & \\
\hline HEMBL3951802 & 640604 & 9.1135 & .7702 & \\
\hline HEMBL3941501 & 504 & & 3121 & \\
\hline 0099 & 504 & & 7234 & \\
\hline IEMBL 3C & 504 & & .7507 & \\
\hline HEMBL3919152 & 640604 & 6.301 & 5.92 & \\
\hline HEMBL3924810 & 604 & 7.0177 & 1973 & \\
\hline HEMBL3933561 & 604 & 6. & 9763 & \\
\hline HEMBL19 & 04 & 7. & 5229 & \\
\hline HEMBL3S & 04 & & $\partial 195$ & \\
\hline HEMBL 39 & 640604 & 7. & 6231 & \\
\hline HEMBL3918100 & 504 & 8. & & \\
\hline HEMBL19 & 24 & 5 . & 91 & \\
\hline HEMBL3S & & & 16 & \\
\hline HEMBL & & & 5938 & \\
\hline HEMBL1S & 04 & 7. & 5372 & \\
\hline HEMBL3943871 & 04 & & & \\
\hline HEMBL39 & 24 & & 58 & \\
\hline HEMBL1S & & & 37 & \\
\hline 337 & 24 & & 307 & RN \\
\hline HEMBL 39 & 04 & & & RN \\
\hline AEMBL3978178 & 04 & 7. & 8005 & \\
\hline HEMBL3S & 24 & & 11 & RN \\
\hline HEM & 4 & & 75 & RN \\
\hline 155 & 24 & & 48 & RN \\
\hline HEMBL19 & 34 & & & $\mathrm{RN}$ \\
\hline HEMBL3939161 & 04 & & 1039 & TRN \\
\hline HEMBL3 & & & 81 & $\mathrm{RN}$ \\
\hline 6 & 4 & 9 & & ST \\
\hline HEMBL1S & 24 & & & RN \\
\hline HEMBL3938374 & 640 & & & TST \\
\hline HEMBL3973806 & 640604 & & 292 & TRN \\
\hline 372 & 24 & 8 & 77 & IS \\
\hline 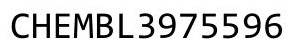 & & & 376 & TRN \\
\hline HEMBL3S & & & & RN \\
\hline HEMBL3950889 & 640604 & 8.0862 & 9882 & TRN \\
\hline HEMBL1S & 04 & & 7.4991 & RN \\
\hline HEMBL 39 & & & & \\
\hline CHEMBL 3908561 & & & & TRN \\
\hline HEMBL3943709 & 1640604 & 6.9666 & .4897 & ST \\
\hline HEMBL3955947 & 640604 & 9.2218 & .5221 & RN \\
\hline EM & & & & \\
\hline 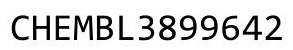 & & & & \\
\hline
\end{tabular}

Page 27858 
Supplemental Table S2.txt

\begin{tabular}{|c|c|c|c|c|}
\hline IE & 34 & & & \\
\hline HEMPI 2071400 & 640604 & 7.6383 & .3239 & \\
\hline 9149 & 504 & & & \\
\hline EMB & 604 & 605 & 87 & \\
\hline AEMBL3927200 & 604 & 386 & 88 & \\
\hline HEMBL3974341 & 640604 & 7.0605 & 1475 & \\
\hline 142 & 504 & 318 & & \\
\hline 800 & & & & \\
\hline AEMBL39 & 604 & 3861 & 229 & \\
\hline HEMBL3958213 & 604 & 437 & 535 & \\
\hline HEMBL3949208 & 504 & 5.1135 & 5786 & \\
\hline EMBL39 & 04 & 088 & 3519 & \\
\hline IEMBL3 & & & & \\
\hline AEMBL3959915 & 04 & 291 & 8438 & \\
\hline HEMBL391 & 504 & & 5077 & \\
\hline AEMBL19 & 04 & 18 & 05 & \\
\hline AEMBL3 & $\partial 4$ & 97 & 47 & \\
\hline HEMBL1S & & 586 & 573 & \\
\hline HEMBL3\& & 04 & 6.2676 & 7.23 & \\
\hline AEMBL3S & 04 & 192 & & \\
\hline HEMBI & 04 & 65 & 38 & \\
\hline AEMBL & 4 & 78 & 77 & \\
\hline HEMBL: & & 76 & & \\
\hline 41 & & 05 & & \\
\hline AEMBL3S & & 32 & & RN \\
\hline HEMBL: & 34 & 212 & 93 & \\
\hline HEMBL3 & 4 & 41 & 13 & \\
\hline$A F M B \mid=$ & & 24 & 106 & RN \\
\hline AEMBL3 & & & & \\
\hline HEMBL3956539 & 24 & & 076 & I RN \\
\hline HEMBL3S & 64 & & 837 & \\
\hline $\mathrm{HFMB} \mid 1$ & 4 & & 54 & Niv \\
\hline HEMBL3 & & 6 & 146 & RN \\
\hline HEMBL3898985 & 34 & 6 & 3712 & TRN \\
\hline HEMBL 393726 & 640 & 7. & 7.1434 & TST \\
\hline HEMBL1S & 34 & 47 & 136 & $x^{2}+2>$ \\
\hline HᄃMP = & & & & ST \\
\hline HEMBL3 & & & 3791 & RN \\
\hline HEMBL3941636 & 84 & 696 & 7297 & $\Gamma \mathrm{RN}$ \\
\hline EMBL] & 24 & 872 & 2778 & IST \\
\hline HEMBL39 & $\partial 4$ & 386 & .0253 & \\
\hline HEMBL 39 & & & 7.3228 & RN \\
\hline HEMBL395 & 604 & 8.2076 & 8.4831 & TRN \\
\hline HEMBL3900064 & 640604 & & 2933 & ГRN \\
\hline MBL3 & & & 44 & \\
\hline HEMBL39 & 64 & 1 & & \\
\hline CHEMBL38926 & 164 & .8539 & 7. 2801 & \\
\hline CHEMBL3965433 & 1640604 & 5.3872 & 6.2916 & ГRN \\
\hline
\end{tabular}

Page 27859 
Supplemental Table S2.txt

\begin{tabular}{|c|c|c|c|c|}
\hline CHEMBL 3946668 & 1640604 & 8.6021 & 8.0587 & TRN \\
\hline CHEMBL 3980088 & 1640604 & 6.9031 & 6.4855 & TRN \\
\hline CHEMBL3977541 & 1640604 & 8.0862 & 7.8707 & TST \\
\hline CHEMBL 3937497 & 1640604 & 7.6198 & 7.9294 & TRN \\
\hline CHEMBL 3947149 & 1640604 & 6.7447 & 6.9679 & TRN \\
\hline CHEMBL 3921354 & 1640604 & 8.3979 & 7.6043 & TRN \\
\hline CHEMBL3973596 & 1640604 & 5.2007 & 6.1073 & TST \\
\hline CHEMBL 3896482 & 1640604 & 6.8239 & 6.4516 & TST \\
\hline CHEMBL1933288 & 1640604 & 6.0 & 7.5612 & TRN \\
\hline CHEMBL 3921790 & 1640604 & 7.9586 & 7.26399 & 9999999999 \\
\hline CHEMBL 3983084 & 1640604 & 6.8125 & 6.4888 & TRN \\
\hline CHEMBL1933279 & 1640604 & 8.0458 & 7.778 & TRN \\
\hline CHEMBL 3980724 & 1640604 & 8.7212 & 8.0744 & TRN \\
\hline CHEMBL3941595 & 1640604 & 6.7959 & 7.063 & TST \\
\hline CHEMBL1938794 & 1640604 & 7.3665 & 7.4235 & TRN \\
\hline CHEMBL3910239 & 1640604 & 5.7447 & 7.1421 & TST \\
\hline CHEMBL 3908302 & 1640604 & 8.4437 & 9.1588 & TRN \\
\hline CHEMBL3963988 & 1640604 & 8.7447 & 8.6294 & TRN \\
\hline CHEMBL 3898040 & 1640604 & 7.3372 & 7.0739 & TRN \\
\hline CHEMBL3920136 & 1640604 & 7.585 & 7.261 & TRN \\
\hline CHEMBL1938796 & 1640604 & 7.0315 & 7.102 & TRN \\
\hline CHEMBL 3938082 & 1640604 & 8.0 & 7.6305 & TRN \\
\hline CHEMBL 3902177 & 1640604 & 5.6383 & 6.8195 & TRN \\
\hline CHEMBL 3958165 & 1640604 & 6.4949 & 7.2912 & TRN \\
\hline CHEMBL3952950 & 1640604 & 8.3665 & 7.1621 & TRN \\
\hline CHEMBL3912437 & 1640604 & 7.3565 & 6.9888 & TST \\
\hline CHEMBL 3949573 & 1640604 & 8.0339 & 7.311 & TRN \\
\hline CHEMBL3964720 & 1640604 & 7.0506 & 7.1833 & TRN \\
\hline CHEMBL3939884 & 1640604 & 6.0 & 7.69799 & 99999999995 \\
\hline CHEMBL 3966940 & 1640604 & 7.2218 & 6.1555 & TRN \\
\hline CHEMBL3931737 & 1640604 & 7.9586 & 6.8135 & TST \\
\hline CHEMBL1938799 & 1640604 & 7.2757 & 7.5476 & TST \\
\hline CHEMBL 3905379 & 1640604 & 6.8539 & 6.0171 & TRN \\
\hline CHEMBL3908811 & 1640604 & 6.0 & 7.7972 & TRN \\
\hline CHEMBL 3914275 & 1640604 & 6.9747 & 6.5299 & TRN \\
\hline CHEMBL1938776 & 1640604 & 7.3468 & 6.7683 & TST \\
\hline CHEMBL1938795 & 1640604 & 6.2676 & 6.9981 & TRN \\
\hline CHEMBL3968264 & 1640604 & 7.9626 & 7.6849 & TST \\
\hline CHEMBL3965519 & 1640604 & 8.699 & 8.4067 & TRN \\
\hline CHEMBL 3893525 & 1640604 & 8.0458 & 7.0439 & TST \\
\hline CHEMBL3966062 & 1640604 & 6.8239 & 6.6895 & TST \\
\hline CHEMBL3913615 & 1640604 & 6.9393 & 7.388 & TST \\
\hline CHEMBL3890669 & 1640604 & 7.3872 & 6.6748 & TRN \\
\hline CHEMBL3981684 & 1640604 & 8.2924 & 7.66200 & 0000000001 \\
\hline CHEMBL1511717 & 954320 & 6.3855 & 6.3004 & TRN \\
\hline CHEMBL1547425 & 954320 & 5.4679 & 6.0232 & TRN \\
\hline CHEMBL 2360906 & 954320 & 4.001 & 5.1706 & TRN \\
\hline CHEMBL 3214461 & 954320 & 5.4216 & 4.9076 & TRN \\
\hline
\end{tabular}




\begin{tabular}{|c|c|c|c|c|c|}
\hline \multirow[b]{2}{*}{ CHEMBL1602148 } & \multicolumn{5}{|c|}{ Supplemental Table S2.txt } \\
\hline & 954320 & 5.8024 & 6.1147 & TRN & \\
\hline CHEMBL1162428 & 954320 & 5.604 & 5.6286 & TRN & \\
\hline CHEMBL1599156 & 954320 & 5.1998 & 5.3141 & TRN & \\
\hline CHEMBL2361506 & 954320 & 5.2706 & 5.2096 & TRN & \\
\hline CHEMBL1379356 & 954320 & 5.3583 & 5.432 & TRN & \\
\hline CHEMBL1423790 & 954320 & 6.1758 & 6.0049 & TRN & \\
\hline CHEMBL3211970 & 954320 & 4.0013 & 4.5764 & TRN & \\
\hline CHEMBL1499063 & 954320 & 6.1551 & 6.086 & TRN & \\
\hline CHEMBL1605615 & 954320 & 5.5134 & 5.87299 & 9999999999 & TRN \\
\hline CHEMBL1698898 & 954320 & 5.3522 & 5.6613 & TRN & \\
\hline CHEMBL1331469 & 954320 & 5.0287 & 5.28799 & 9999999999 & TRN \\
\hline CHEMBL2357494 & 954320 & 6.13399 & 99999999 & 5.4609 & \\
\hline CHEMBL1703181 & 954320 & 5.2902 & 5.4517 & TRN & \\
\hline CHEMBL3194231 & 954320 & 3.5237 & 4.9226 & TRN & \\
\hline CHEMBL 2143258 & 954320 & 6.1872 & 6.5905 & TRN & \\
\hline CHEMBL1558546 & 954320 & 5.7005 & 4.8363 & TST & \\
\hline CHEMBL261687 & 954320 & 6.1743 & 5.8142 & TRN & \\
\hline CHEMBL1359255 & 954320 & 5.4585 & 5.8411 & TRN & \\
\hline CHEMBL1367707 & 954320 & 6.4607 & 5.9249 & TRN & \\
\hline CHEMBL1705485 & 954320 & 5.3326 & 5.9156 & TRN & \\
\hline CHEMBL2360698 & 954320 & 5.4919 & 4.9958 & TRN & \\
\hline CHEMBL1428644 & 954320 & 3.5241 & 4.6492 & TRN & \\
\hline CHEMBL1536976 & 954320 & 5.6315 & 5.9478 & TST & \\
\hline CHEMBL3213883 & 954320 & 5.7918 & 5.5514 & TRN & \\
\hline CHEMBL2132933 & 954320 & 5.1244 & 5.3358 & TRN & \\
\hline CHEMBL1604713 & 954320 & 5.5099 & 5.5509 & TST & \\
\hline CHEMBL1562679 & 954320 & 5.5293 & 5.9117 & TRN & \\
\hline CHEMBL1886420 & 954320 & 5.9285 & 5.9581 & TST & \\
\hline CHEMBL1533231 & 954320 & 5.6824 & 5.4812 & TRN & \\
\hline CHEMBL1508812 & 954320 & 5.1501 & 5.6209 & TRN & \\
\hline CHEMBL1463562 & 954320 & 4.863 & 5.481 & TRN & \\
\hline CHEMBL1463960 & 954320 & 5.4781 & 4.4567 & TRN & \\
\hline CHEMBL579919 & 954320 & 4.4785 & 5.1766 & TRN & \\
\hline CHEMBL 2138173 & 954320 & 5.1526 & 5.0683 & TRN & \\
\hline CHEMBL 2136532 & 954320 & 5.4445 & 5.1559 & TRN & \\
\hline CHEMBL2354461 & 954320 & 5.4466 & 5.4292 & TRN & \\
\hline CHEMBL1490416 & 954320 & 5.9496 & 5.4499 & TRN & \\
\hline CHEMBL1407270 & 954320 & 5.9201 & 6.0396 & TRN & \\
\hline CHEMBL1466922 & 954320 & 6.2295 & 6.0019 & TRN & \\
\hline CHEMBL1870655 & 954320 & 4.9555 & 5.5303 & TRN & \\
\hline CHEMBL1704437 & 954320 & 5.0637 & 5.1158 & TST & \\
\hline CHEMBL1566565 & 954320 & 6.1357 & 5.8442 & TRN & \\
\hline CHEMBL1473677 & 954320 & 5.4843 & 5.7003 & TRN & \\
\hline CHEMBL3193006 & 954320 & 5.9416 & 6.1011 & TRN & \\
\hline CHEMBL1391385 & 954320 & 5.7149 & 5.3172 & TRN & \\
\hline CHEMBL1547381 & 954320 & 5.0048 & 5.5825 & TRN & \\
\hline CHEMBL1545571 & 954320 & 7.0613 & 6.4292 & TRN & \\
\hline CHEMBL1491982 & 954320 & 5.6256 & 5.5839 & TRN & \\
\hline
\end{tabular}

Page 27861 


\begin{tabular}{|c|c|c|c|c|c|c|}
\hline & & \multicolumn{5}{|c|}{ Supplemental Table S2.txt } \\
\hline CHEMBL1438255 & 954320 & 5.7359 & 5.1818 & TRN & & \\
\hline CHEMBL 2355777 & 954320 & 6.3142 & 5.944 & TRN & & \\
\hline CHEMBL3210912 & 954320 & 5.5496 & 4.3406 & TRN & & \\
\hline CHEMBL1364248 & 954320 & 5.3542 & 5.4134 & TRN & & \\
\hline CHEMBL1887240 & 954320 & 5.6885 & 6.0891 & TRN & & \\
\hline CHEMBL1410154 & 954320 & 5.4414 & 5.65600 & 0000000001 & & TRN \\
\hline CHEMBL1722433 & 954320 & 5.2261 & 5.7662 & TRN & & \\
\hline CHEMBL1541755 & 954320 & 5.4641 & 4.6907 & TRN & & \\
\hline CHEMBL1549077 & 954320 & 5.4628 & 5.8905 & TST & & \\
\hline CHEMBL1569653 & 954320 & 6.4284 & 6.4042 & TRN & & \\
\hline CHEMBL1376491 & 954320 & 5.4118 & 6.0215 & TRN & & \\
\hline CHEMBL 2361355 & 954320 & 5.17299 & 99999999 & & 5.141 & TRN \\
\hline CHEMBL3190925 & 954320 & 5.9348 & 5.1968 & TRN & & \\
\hline CHEMBL 2357051 & 954320 & 5.1402 & 5.4903 & TST & & \\
\hline CHEMBL1300561 & 954320 & 5.5259 & 5.4309 & TRN & & \\
\hline CHEMBL3212150 & 954320 & 5.7115 & 6.2632 & TRN & & \\
\hline CHEMBL 2354450 & 954320 & 5.9674 & 5.61 & TRN & & \\
\hline CHEMBL1423730 & 954320 & 5.8213 & 5.63299 & 9999999999 & & TRN \\
\hline CHEMBL1501007 & 954320 & 5.8542 & 5.8445 & TRN & & \\
\hline CHEMBL1479715 & 954320 & 5.3919 & 5.771 & TRN & & \\
\hline CHEMBL 2359354 & 954320 & 5.3643 & 4.6279 & TRN & & \\
\hline CHEMBL1432152 & 954320 & 4.4781 & 5.4802 & TRN & & \\
\hline CHEMBL1715558 & 954320 & 5.7077 & 6.1343 & TRN & & \\
\hline CHEMBL1895912 & 954320 & 5.5781 & 5.8491 & TRN & & \\
\hline CHEMBL1380028 & 954320 & 6.3476 & 6.171 & TRN & & \\
\hline CHEMBL 2360290 & 954320 & 5.2135 & 5.1448 & TRN & & \\
\hline CHEMBL1887682 & 954320 & 5.5879 & 5.0352 & TRN & & \\
\hline CHEMBL1487563 & 954320 & 6.2078 & 5.7703 & TRN & & \\
\hline CHEMBL170012 & 954320 & 5.9914 & 5.9343 & TRN & & \\
\hline CHEMBL525826 & 954320 & 5.3567 & 5.8331 & TRN & & \\
\hline CHEMBL3194978 & 954320 & $5.4220 e$ & 00000000 & & 5.106 & TST \\
\hline CHEMBL1597959 & 954320 & 3.5245 & 5.1748 & TRN & & \\
\hline CHEMBL1472129 & 954320 & 5.7135 & 5.24299 & 9999999999 & & TRN \\
\hline CHEMBL3191063 & 954320 & 5.3817 & 5.7351 & TRN & & \\
\hline CHEMBL1873712 & 954320 & 5.5583 & 5.8327 & TRN & & \\
\hline CHEMBL1582580 & 954320 & 5.495 & 6.0243 & TRN & & \\
\hline CHEMBL 2359853 & 954320 & 5.6254 & 5.2765 & TRN & & \\
\hline CHEMBL1718277 & 954320 & 5.0207 & 5.6372 & TRN & & \\
\hline CHEMBL3190051 & 954320 & 6.4296 & 6.0882 & TST & & \\
\hline CHEMBL1526328 & 954320 & 5.6015 & 5.0657 & TRN & & \\
\hline CHEMBL591598 & 954320 & 5.3441 & 5.4703 & TRN & & \\
\hline CHEMBL1454429 & 954320 & 5.9974 & 6.0747 & TRN & & \\
\hline CHEMBL1699232 & 954320 & 3.5244 & 5.0337 & TRN & & \\
\hline CHEMBL3195298 & 954320 & 5.6641 & 5.0647 & TRN & & \\
\hline CHEMBL1871423 & 954320 & 5.4378 & 5.5397 & TRN & & \\
\hline CHEMBL3196571 & 954320 & 6.0988 & 4.9794 & TRN & & \\
\hline CHEMBL 2354809 & 954320 & 5.0903 & 5.0823 & TRN & & \\
\hline CHEMBL1382433 & 954320 & 4.6519 & 5.9811 & TST & & \\
\hline
\end{tabular}


Supplemental Table S2.txt

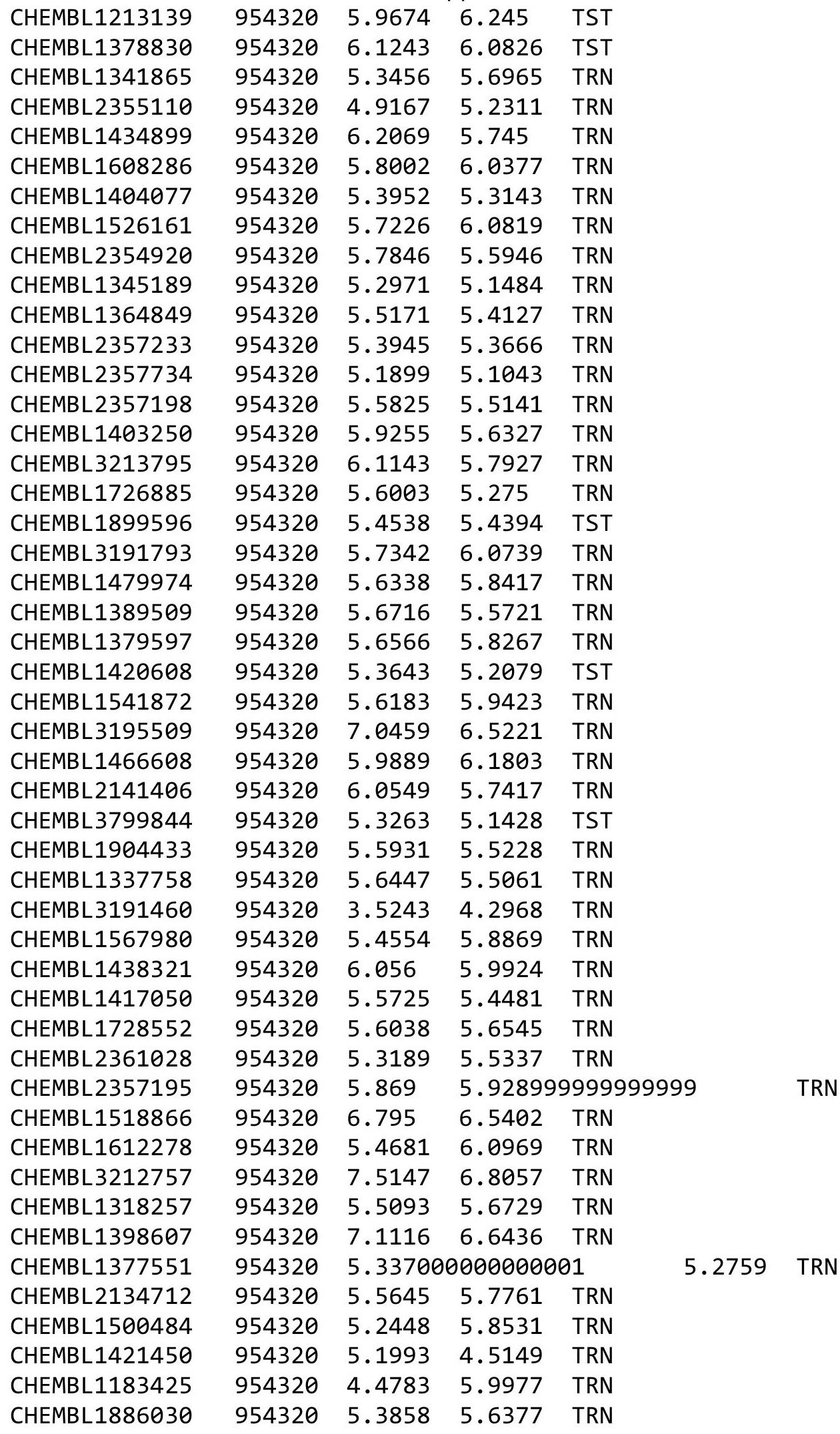

Page 27863 


\begin{tabular}{|c|c|c|c|c|c|c|}
\hline & & \multicolumn{4}{|c|}{ Supplemental Table s2.txt } & \multirow[b]{2}{*}{ TRN } \\
\hline CHEMBL590666 & 954320 & 5.75799 & 99999999 & 99 & 5.6229 & \\
\hline CHEMBL1468992 & 954320 & 5.2914 & 4.9821 & TST & & \\
\hline CHEMBL1462723 & 954320 & 5.004 & 5.2506 & TST & & \\
\hline CHEMBL2354481 & 954320 & 5.6607 & 5.1622 & TRN & & \\
\hline CHEMBL2355180 & 954320 & 5.7562 & 5.39 & TRN & & \\
\hline CHEMBL1708460 & 954320 & 5.9024 & 5.2533 & TRN & & \\
\hline CHEMBL154103 & 954320 & 4.2864 & 4.9559 & TRN & & \\
\hline CHEMBL2358935 & 954320 & 5.6107 & 5.3583 & TRN & & \\
\hline CHEMBL358290 & 954320 & 5.5911 & 5.5512 & TRN & & \\
\hline CHEMBL1429050 & 954320 & 3.5241 & 5.1368 & TRN & & \\
\hline CHEMBL1333983 & 954320 & \multicolumn{3}{|c|}{6.8870000000000005} & 6.5464 & TRN \\
\hline CHEMBL1534795 & 954320 & 6.1579 & 6.0324 & TRN & & \\
\hline CHEMBL1346716 & 954320 & 5.1489 & 4.7521 & TST & & \\
\hline CHEMBL1304172 & 954320 & 5.5322 & 6.0924 & TRN & & \\
\hline CHEMBL1375754 & 954320 & \multicolumn{3}{|c|}{5.968999999999999} & 5.7183 & TRN \\
\hline CHEMBL1718535 & 954320 & 6.4936 & 5.3721 & TRN & & \\
\hline CHEMBL1378576 & 954320 & 5.3512 & 5.8753 & TRN & & \\
\hline CHEMBL1350323 & 954320 & 5.474 & 5.9032 & TRN & & \\
\hline CHEMBL1703117 & 954320 & 5.151 & 5.4466 & TRN & & \\
\hline CHEMBL11608 & 954320 & 6.7503 & 6.2411 & TRN & & \\
\hline CHEMBL441948 & 954320 & 6.4927 & 6.4824 & TST & & \\
\hline CHEMBL1557071 & 954320 & 6.5276 & 5.7737 & TRN & & \\
\hline CHEMBL1997990 & 954320 & 6.1888 & 5.4397 & TRN & & \\
\hline CHEMBL530698 & 954320 & 7.1044 & 6.806 & TRN & & \\
\hline CHEMBL3197751 & 954320 & 6.9737 & 6.6908 & TRN & & \\
\hline CHEMBL1345740 & 954320 & 4.4785 & 5.2098 & TRN & & \\
\hline CHEMBL3197611 & 954320 & 5.8083 & 6.0211 & TRN & & \\
\hline CHEMBL1536693 & 954320 & 5.7908 & 5.7894 & TRN & & \\
\hline CHEMBL1538734 & 954320 & 3.5242 & 5.3866 & TRN & & \\
\hline CHEMBL1602292 & 954320 & 6.8545 & 6.1049 & TRN & & \\
\hline CHEMBL1449416 & 954320 & 5.8918 & 5.7543 & TRN & & \\
\hline CHEMBL3190696 & 954320 & 7.3714 & 6.805 & TRN & & \\
\hline CHEMBL1582087 & 954320 & 5.7597 & 5.4197 & TRN & & \\
\hline CHEMBL1449262 & 954320 & 5.0839 & 5.62 & TRN & & \\
\hline CHEMBL1576496 & 954320 & 6.2717 & 4.9754 & TRN & & \\
\hline CHEMBL1391510 & 954320 & 5.5476 & 5.1382 & TRN & & \\
\hline CHEMBL1531312 & 954320 & 5.6457 & 5.862 & TRN & & \\
\hline CHEMBL1592934 & 954320 & 5.3967 & 5.9745 & TST & & \\
\hline CHEMBL1447789 & 954320 & 5.3141 & 5.1987 & TST & & \\
\hline CHEMBL2356557 & 954320 & 5.6579 & 99999999 & 995 & 5.1635 & TRN \\
\hline CHEMBL1305977 & 954320 & 5.5991 & 5.4267 & TRN & & \\
\hline CHEMBL168337 & 954320 & 6.261 & 5.4671 & TRN & & \\
\hline CHEMBL2138994 & 954320 & 5.6196 & 5.2121 & TRN & & \\
\hline CHEMBL1305696 & 954320 & 5.3114 & 5.529 & TST & & \\
\hline CHEMBL1408579 & 954320 & 6.2479 & 5.7166 & TRN & & \\
\hline CHEMBL1525315 & 954320 & 5.7298 & 6.2966 & TRN & & \\
\hline CHEMBL1492904 & 954320 & 5.9751 & 6.1723 & TRN & & \\
\hline CHEMBL1595732 & 954320 & 5.8837 & 6.2383 & TRN & & \\
\hline
\end{tabular}




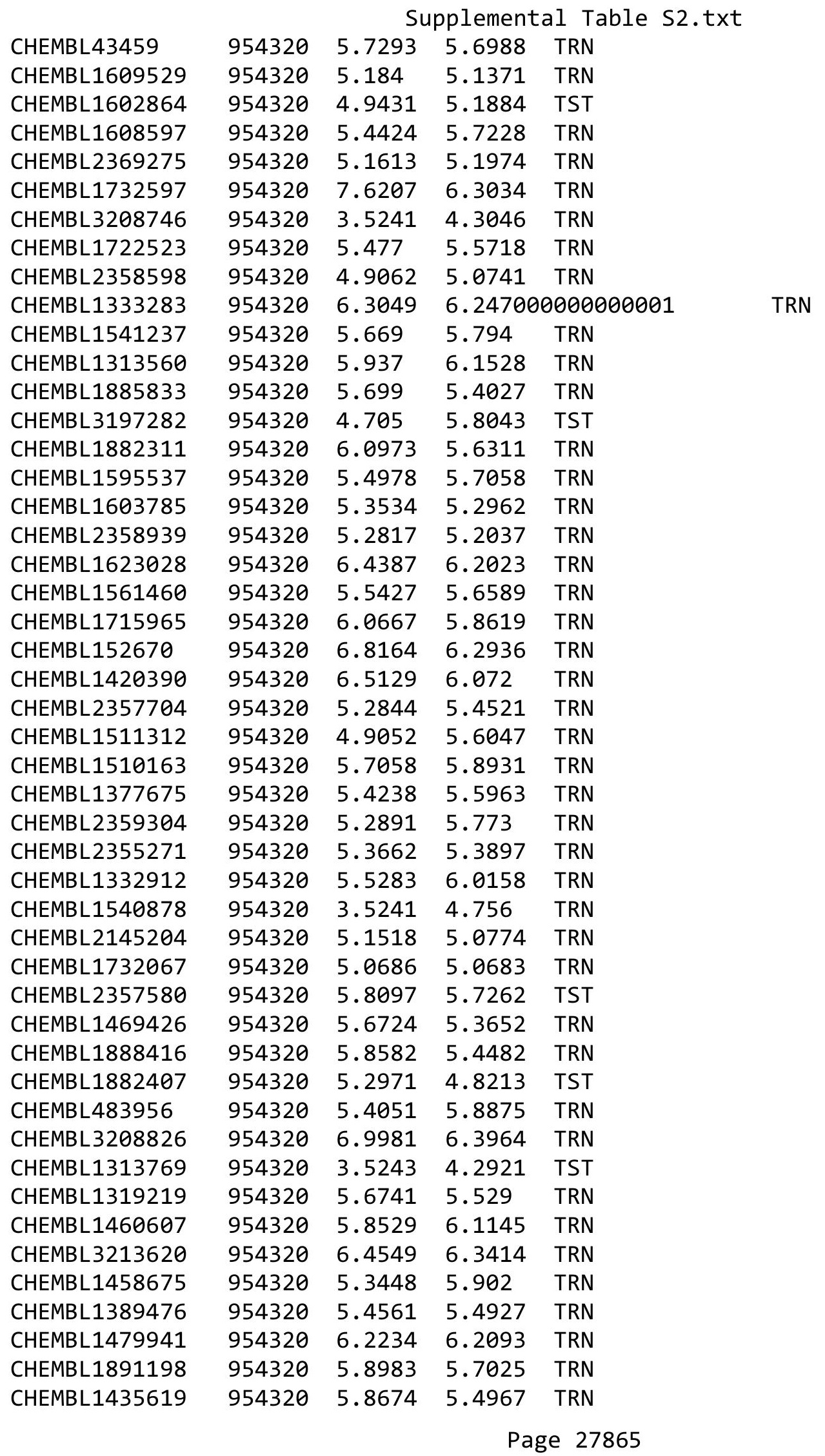


Supplemental Table S2.txt

\begin{tabular}{|c|c|c|c|c|c|c|}
\hline CHEMBL2356880 & 954320 & 5.6975 & 5.4493 & TRN & & \\
\hline CHEMBL1537381 & 954320 & 6.23799 & 99999999 & 995 & 6.2431 & TRN \\
\hline CHEMBL1320254 & 954320 & 6.1822 & 6.6059 & TRN & & \\
\hline CHEMBL2361837 & 954320 & 5.5363 & 5.2791 & TRN & & \\
\hline CHEMBL1602445 & 954320 & 5.7082 & 5.6815 & TRN & & \\
\hline CHEMBL1995645 & 954320 & 3.5239 & 5.2967 & TRN & & \\
\hline CHEMBL1531127 & 954320 & 5.8636 & 6.0123 & TRN & & \\
\hline CHEMBL1449587 & 954320 & 5.2466 & 5.7294 & TST & & \\
\hline CHEMBL1323911 & 954320 & 5.2062 & 5.4361 & TRN & & \\
\hline CHEMBL1542890 & 954320 & 6.3024 & 5.6434 & TRN & & \\
\hline CHEMBL3197538 & 954320 & 5.5714 & 5.6164 & TRN & & \\
\hline CHEMBL1539325 & 954320 & 6.0826 & 6.0934 & TST & & \\
\hline CHEMBL1370193 & 954320 & 5.586 & 5.7142 & TRN & & \\
\hline CHEMBL1725501 & 954320 & 5.3486 & 5.2791 & TRN & & \\
\hline CHEMBL2359184 & 954320 & 5.9245 & 5.5376 & TRN & & \\
\hline CHEMBL345735 & 954320 & 4.9809 & 4.8859 & TRN & & \\
\hline CHEMBL1379139 & 954320 & 6.5229 & 5.2924 & TRN & & \\
\hline CHEMBL2360891 & 954320 & 6.1228 & 5.9458 & TRN & & \\
\hline CHEMBL1448326 & 954320 & 5.6194 & 5.6191 & TRN & & \\
\hline CHEMBL1335190 & 954320 & 7.4364 & 6.75700 & 0000000001 & & \\
\hline CHEMBL1621012 & 954320 & 5.2311 & 5.8153 & TST & & \\
\hline CHEMBL1368074 & 954320 & 5.4489 & 5.6827 & TST & & \\
\hline CHEMBL1340446 & 954320 & 5.6586 & 6.0398 & TRN & & \\
\hline CHEMBL2356479 & 954320 & 5.6853 & 5.3864 & TRN & & \\
\hline CHEMBL546344 & 954320 & 4.7166 & 5.5935 & TRN & & \\
\hline CHEMBL598204 & 954320 & 5.8268 & 5.6469 & TST & & \\
\hline CHEMBL1303784 & 954320 & 6.2256 & 6.0982 & TRN & & \\
\hline CHEMBL 3191126 & 954320 & 3.5242 & 5.659 & TRN & & \\
\hline CHEMBL406341 & 954320 & 6.9707 & 6.9201 & TST & & \\
\hline CHEMBL1446878 & 954320 & 5.3024 & 5.5138 & TRN & & \\
\hline CHEMBL1603110 & 954320 & 5.7675 & 5.6077 & TRN & & \\
\hline CHEMBL1734759 & 954320 & 6.3057 & 6.3353 & TRN & & \\
\hline CHEMBL1560683 & 954320 & 5.5294 & 5.6443 & TRN & & \\
\hline CHEMBL2362576 & 954320 & 5.5382 & \multicolumn{3}{|c|}{5.457999999999999} & \\
\hline CHEMBL1872433 & 954320 & 6.3079 & 6.1225 & TRN & & \\
\hline CHEMBL3198735 & 954320 & 5.6651 & 5.1363 & TRN & & \\
\hline CHEMBL1511007 & 954320 & 4.9035 & 4.7586 & TRN & & \\
\hline CHEMBL2362944 & 954320 & 5.3206 & 5.7989 & TRN & & \\
\hline CHEMBL1366348 & 954320 & 5.6289 & 5.7189 & TST & & \\
\hline CHEMBL1540947 & 954320 & 4.8365 & 5.3202 & TST & & \\
\hline CHEMBL1720591 & 954320 & 5.7411 & 6.0498 & TRN & & \\
\hline CHEMBL1542557 & 954320 & 4.9428 & 5.2392 & TRN & & \\
\hline CHEMBL1463068 & 954320 & 6.9028 & 6.4764 & TRN & & \\
\hline CHEMBL1304117 & 954320 & 6.5756 & 6.0869 & TRN & & \\
\hline CHEMBL1429767 & 954320 & 5.8586 & 5.3908 & TRN & & \\
\hline CHEMBL1342198 & 954320 & 5.3241 & 5.919 & TRN & & \\
\hline CHEMBL1733489 & 954320 & 5.419 & 5.5482 & TRN & & \\
\hline CHEMBL1325494 & 954320 & 6.5953 & 6.1975 & TRN & & \\
\hline
\end{tabular}

Page 27866 


\begin{tabular}{|c|c|c|c|c|c|}
\hline \multirow[b]{2}{*}{ CHEMBL2356177 } & & \multicolumn{4}{|c|}{ Supplemental Table s2.txt } \\
\hline & 954320 & 5.226 & 5.0422 & TRN & \\
\hline CHEMBL 2356944 & 954320 & 5.8122 & \multicolumn{2}{|c|}{5.5360000000000005} & TRN \\
\hline CHEMBL1476474 & 954320 & 5.4501 & \multicolumn{2}{|c|}{5.803999999999999} & TRN \\
\hline CHEMBL1610758 & 954320 & 5.4176 & 5.4739 & TST & \\
\hline CHEMBL1436462 & 954320 & 5.5376 & 5.4849 & TRN & \\
\hline CHEMBL1363380 & 954320 & 4.9812 & 5.4269 & TST & \\
\hline CHEMBL1383417 & 954320 & 4.8309 & \multicolumn{2}{|c|}{4.803999999999999} & TRN \\
\hline CHEMBL1735124 & 954320 & 6.8923 & 6.6229 & TRN & \\
\hline CHEMBL2361315 & 954320 & 5.519 & 5.7095 & TRN & \\
\hline CHEMBL3193114 & 954320 & 3.5242 & 4.1319 & TRN & \\
\hline CHEMBL1305907 & 954320 & 5.6682 & 6.2427 & TRN & \\
\hline CHEMBL1501805 & 954320 & 6.4782 & 6.2592 & TRN & \\
\hline CHEMBL1870898 & 954320 & 7.8239 & 5.3494 & TRN & \\
\hline CHEMBL1451277 & 954320 & 5.9048 & 5.9126 & TST & \\
\hline CHEMBL1378332 & 954320 & 5.5758 & 5.7995 & TRN & \\
\hline CHEMBL 2359412 & 954320 & 4.9865 & 4.474 & TRN & \\
\hline CHEMBL1888052 & 954320 & 5.93 & 5.6223 & TRN & \\
\hline CHEMBL1597672 & 954320 & 5.7496 & 5.9087 & TRN & \\
\hline CHEMBL2356408 & 954320 & 5.4222 & 5.4007 & TRN & \\
\hline CHEMBL1700180 & 954320 & 5.5558 & 5.716 & TRN & \\
\hline CHEMBL1556845 & 954320 & 5.9842 & 5.7548 & TRN & \\
\hline CHEMBL1729231 & 954320 & 6.0624 & 6.0071 & TRN & \\
\hline CHEMBL560832 & 954320 & 3.5242 & 4.5848 & TST & \\
\hline CHEMBL1421659 & 954320 & 6.473 & 5.9887 & TRN & \\
\hline CHEMBL1348375 & 954320 & 5.4351 & 5.8661 & TST & \\
\hline CHEMBL1724146 & 954320 & 6.7233 & 6.1652 & TRN & \\
\hline CHEMBL1880660 & 954320 & 5.8383 & 4.5029 & TST & \\
\hline CHEMBL2355229 & 954320 & 5.5161 & 5.9125 & TRN & \\
\hline CHEMBL1736439 & 954320 & 5.9087 & 5.9694 & TRN & \\
\hline CHEMBL1898588 & 954320 & 6.7222 & 6.6234 & TST & \\
\hline CHEMBL524376 & 954320 & 7.1981 & 6.8652 & TRN & \\
\hline CHEMBL1905908 & 954320 & 6.0381 & 4.6264 & TRN & \\
\hline CHEMBL2131436 & 954320 & 5.6036 & 5.3327 & TRN & \\
\hline CHEMBL3193664 & 954320 & 6.303 & 5.6724 & TRN & \\
\hline CHEMBL1605900 & 954320 & 6.1366 & 5.8708 & TST & \\
\hline CHEMBL1878125 & 954320 & 3.5242 & 4.6262 & TRN & \\
\hline CHEMBL553503 & 954320 & 5.1848 & 5.1052 & TST & \\
\hline CHEMBL1529081 & 954320 & 5.9772 & 6.0348 & TST & \\
\hline CHEMBL1302888 & 954320 & 5.6759 & 5.6612 & TRN & \\
\hline CHEMBL1725080 & 954320 & 6.5303 & 5.8355 & TRN & \\
\hline CHEMBL1589671 & 954320 & 5.8027 & 5.5169 & TST & \\
\hline CHEMBL3211097 & 954320 & 6.4458 & 6.4619 & TRN & \\
\hline CHEMBL1312140 & 954320 & 6.3623 & 6.0941 & TRN & \\
\hline CHEMBL1606897 & 954320 & 5.2682 & 5.6734 & TRN & \\
\hline CHEMBL1490462 & 954320 & 5.4451 & 5.5771 & TRN & \\
\hline CHEMBL 2355781 & 954320 & 6.0471 & 5.6396 & TRN & \\
\hline CHEMBL3195378 & 954320 & 5.8928 & 5.49799 & 9999999999 & TRN \\
\hline CHEMBL589061 & 954320 & 4.8258 & 4.4451 & TRN & \\
\hline & & & & 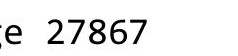 & \\
\hline
\end{tabular}


Supplemental Table S2.txt

\begin{tabular}{|c|c|c|c|c|c|}
\hline CHEMBL1453263 & 954320 & 6.4098 & 6.0177 & TRN & \\
\hline CHEMBL1528135 & 954320 & 5.7781 & 5.5017 & TRN & \\
\hline CHEMBL1423849 & 954320 & 5.6517 & 5.5716 & TRN & \\
\hline CHEMBL1879995 & 954320 & 6.5626 & 6.4993 & TST & \\
\hline CHEMBL 2358672 & 954320 & 4.9964 & 5.1376 & TRN & \\
\hline CHEMBL1469275 & 954320 & 5.9397 & 6.192 & TRN & \\
\hline CHEMBL1508576 & 954320 & 5.9352 & 5.8312 & TRN & \\
\hline CHEMBL 2356751 & 954320 & 5.1324 & 5.1322 & TRN & \\
\hline CHEMBL 2135019 & 954320 & 5.3914 & 5.3527 & TRN & \\
\hline CHEMBL1589413 & 954320 & 5.9292 & 5.3769 & TST & \\
\hline CHEMBL1486681 & 954320 & 4.9902 & 4.3567 & TST & \\
\hline CHEMBL1589612 & 954320 & 3.52399 & 999999999 & 4.8516 & TST \\
\hline CHEMBL1735835 & 954320 & 5.1324 & 5.3328 & TST & \\
\hline CHEMBL1557646 & 954320 & 5.2452 & 5.6399 & TST & \\
\hline CHEMBL1878997 & 954320 & 5.2858 & 4.2925 & TST & \\
\hline CHEMBL1512974 & 954320 & 5.2474 & 5.4875 & TST & \\
\hline CHEMBL1873269 & 954320 & 5.8517 & 5.9695 & TST & \\
\hline CHEMBL1487478 & 954320 & 5.4448 & 5.6116 & TST & \\
\hline CHEMBL3195694 & 954320 & 5.8422 & 5.4026 & TST & \\
\hline CHEMBL 1579150 & 954320 & 7.148 & 5.2024 & TST & \\
\hline CHEMBL 2356536 & 954320 & 5.539 & 5.2571 & TST & \\
\hline CHEMBL 2356254 & 954320 & 5.2112 & 5.1665 & TST & \\
\hline CHEMBL1416014 & 954320 & 5.73 & 5.8474 & TST & \\
\hline CHEMBL1532210 & 954320 & 5.1166 & 4.766999 & 99999999995 & 1 \\
\hline CHEMBL1371471 & 954320 & 6.1709 & 5.6999 & TST & \\
\hline CHEMBL1506119 & 954320 & 5.9161 & 5.8386 & TST & \\
\hline CHEMBL1332279 & 954320 & 5.2685 & 5.2602 & TST & \\
\hline CHEMBL1398016 & 954320 & 4.0016 & 5.9519 & TST & \\
\hline CHEMBL1300980 & 954320 & 6.6167 & 6.0744 & TST & \\
\hline CHEMBL1329321 & 954320 & 4.8989 & 5.2255 & TST & \\
\hline CHEMBL 2355518 & 954320 & 5.416 & 5.1959 & TST & \\
\hline CHEMBL 2356494 & 954320 & 5.8374 & 5.8149 & TST & \\
\hline CHEMBL1467587 & 954320 & 5.459 & 6.0875 & TST & \\
\hline CHEMBL1401155 & 954320 & 5.6966 & 5.3737 & TST & \\
\hline CHEMBL313833 & 954320 & \multicolumn{3}{|c|}{6.2139999999999995} & TS \\
\hline CHEMBL1418373 & 954320 & 5.4632 & 6.0908 & TST & \\
\hline CHEMBL1393484 & 954320 & 6.8634 & 6.6734 & TST & \\
\hline CHEMBL1542918 & 954320 & 6.2569 & 6.0476 & TST & \\
\hline CHEMBL1576416 & 954320 & 6.9265 & 6.4229 & TST & \\
\hline CHEMBL1728498 & 954320 & 5.71 & 4.9647 & TST & \\
\hline CHEMBL1873950 & 954320 & \multicolumn{3}{|c|}{5.712000000000001} & נו \\
\hline CHEMBL1429444 & 954320 & 6.1204 & 5.791 & TST & \\
\hline CHEMBL1353406 & 954320 & 5.5613 & 5.4082 & TST & \\
\hline CHEMBL3211702 & 954320 & 3.5244 & 4.8742 & TST & \\
\hline CHEMBL1224310 & 954320 & 5.848 & 5.9185 & TST & \\
\hline CHEMBL1343298 & 954320 & 7.1641 & 6.3198 & TST & \\
\hline CHEMBL39947 & 954320 & 5.1176 & 5.853 & TST & \\
\hline CHEMBL3190656 & 954320 & 5.3719 & 5.5745 & TST & \\
\hline
\end{tabular}


Supplemental Table S2.txt

\begin{tabular}{|c|c|c|c|c|}
\hline CHEMBL 2360359 & 954320 & 5.5007 & 5.2241 & TST \\
\hline CHEMBL1500127 & 954320 & 5.9944 & 5.8558 & TST \\
\hline CHEMBL1411785 & 954320 & 6.8047 & 6.0776 & TST \\
\hline CHEMBL1415470 & 954320 & 3.5243 & 6.3423 & TST \\
\hline CHEMBL1589687 & 954320 & 5.0813 & 5.49 & TST \\
\hline CHEMBL1256191 & 954320 & 6.1235 & 6.1091 & TST \\
\hline CHEMBL1558163 & 954320 & 5.5036 & 5.3401 & TST \\
\hline CHEMBL1519667 & 954320 & 6.1156 & 6.0708 & TST \\
\hline CHEMBL1477268 & 954320 & 5.8351 & 5.9562 & TST \\
\hline CHEMBL1886930 & 954320 & 5.6765 & 6.2051 & TST \\
\hline CHEMBL 2359610 & 954320 & 5.7201 & 5.5101 & TST \\
\hline CHEMBL1451121 & 954320 & 7.8239 & 5.5302 & TST \\
\hline CHEMBL3212402 & 954320 & 6.5381 & 5.9261 & TST \\
\hline CHEMBL3193382 & 954320 & 3.5237 & 5.2418 & TST \\
\hline CHEMBL1351105 & 1495332 & 5.7945 & 5.8491 & TRN \\
\hline CHEMBL1548635 & 1495332 & 5.7426 & 6.9123 & TRN \\
\hline CHEMBL1348393 & 1495332 & 6.2967 & 5.8389 & TRN \\
\hline CHEMBL1327816 & 1495332 & 5.8778 & 6.1333 & TRN \\
\hline CHEMBL1312953 & 1495332 & 6.7055 & 7.4649 & TRN \\
\hline CHEMBL1560590 & 1495332 & 5.8038 & 5.7864 & TRN \\
\hline CHEMBL1570920 & 1495332 & 5.6844 & 6.3495 & TRN \\
\hline CHEMBL1499932 & 1495332 & \multicolumn{3}{|c|}{6.4510000000000005} \\
\hline CHEMBL1536954 & 1495332 & 6.1403 & 6.58200 & 0000000001 \\
\hline CHEMBL1540682 & 1495332 & 7.0809 & 6.029 & TRN \\
\hline CHEMBL601757 & 1495332 & 6.6799 & 5.6039 & TRN \\
\hline CHEMBL1496329 & 1495332 & 6.699 & 5.7013 & TRN \\
\hline CHEMBL1540555 & 1495332 & 6.7825 & 6.5486 & TRN \\
\hline CHEMBL3189845 & 1495332 & 6.3401 & 5.879 & TST \\
\hline CHEMBL1308547 & 1495332 & 9.0 & 7.7836 & TRN \\
\hline CHEMBL1313588 & 1495332 & 5.7657 & 5.4231 & TRN \\
\hline CHEMBL1452795 & 1495332 & 6.061 & 6.3318 & TRN \\
\hline CHEMBL935 & 1495332 & 7.2596 & 7.2082 & TRN \\
\hline CHEMBL1422349 & 1495332 & 6.9508 & 6.5137 & TRN \\
\hline CHEMBL1390000 & 1495332 & 7.2518 & 7.1247 & TRN \\
\hline CHEMBL1607320 & 1495332 & 6.8013 & 6.2122 & TRN \\
\hline CHEMBL1487260 & 1495332 & 4.301 & 6.2436 & TRN \\
\hline CHEMBL1337933 & 1495332 & 5.7828 & 5.7695 & TRN \\
\hline CHEMBL1587254 & 1495332 & 5.6842 & 6.1742 & TRN \\
\hline CHEMBL1968355 & 1495332 & 6.4306 & 6.2642 & TST \\
\hline CHEMBL1382884 & 1495332 & 6.1518 & 7.3864 & TRN \\
\hline CHEMBL1445372 & 1495332 & 6.2596 & 5.8543 & TRN \\
\hline CHEMBL1604567 & 1495332 & 6.2503 & 5.8174 & TST \\
\hline CHEMBL1542851 & 1495332 & 6.0414 & 6.4628 & TRN \\
\hline CHEMBL1522486 & 1495332 & 4.301 & 6.1376 & TRN \\
\hline CHEMBL117108 & 1495332 & 5.6494 & 6.1748 & TRN \\
\hline CHEMBL1599370 & 1495332 & 7.0605 & 6.4634 & TRN \\
\hline CHEMBL1521960 & 1495332 & 8.3979 & 7.521 & TRN \\
\hline CHEMBL1309888 & 1495332 & 6.1681 & 6.022 & TRN \\
\hline
\end{tabular}


Supplemental Table S2.txt

\begin{tabular}{|c|c|c|c|c|c|}
\hline CHEMBL1563483 & 1495332 & 5.7752 & 7.2167 & TST & \\
\hline CHEMBL1480470 & 1495332 & 5.8697 & 6.6589 & TST & \\
\hline CHEMBL1790002 & 1495332 & 6.1549 & 6.7283 & TRN & \\
\hline CHEMBL1545699 & 1495332 & 5.357 & 6.1218 & TRN & \\
\hline CHEMBL1327020 & 1495332 & 5.8918 & 6.2343 & TRN & \\
\hline CHEMBL1327934 & 1495332 & 9.0 & 7.5748 & TRN & \\
\hline CHEMBL1419943 & 1495332 & 6.7212 & 6.2164 & TST & \\
\hline CHEMBL1540089 & 1495332 & 5.791 & 5.6765 & TRN & \\
\hline CHEMBL1485865 & 1495332 & 8.5229 & 7.7945 & TRN & \\
\hline CHEMBL1546470 & 1495332 & 5.7144 & 6.3873 & TRN & \\
\hline CHEMBL1561248 & 1495332 & 6.0367 & 5.822999 & 99999999995 & TRN \\
\hline CHEMBL1468507 & 1495332 & 5.8413 & 5.845 & TRN & \\
\hline CHEMBL1881681 & 1495332 & 5.8351 & 5.9859 & TRN & \\
\hline CHEMBL1429621 & 1495332 & 6.5376 & 6.2038 & TRN & \\
\hline CHEMBL1341106 & 1495332 & 6.9101 & 6.8711 & TRN & \\
\hline CHEMBL1325945 & 1495332 & 6.5918 & 5.9076 & TRN & \\
\hline CHEMBL1300710 & 1495332 & 5.5382 & 6.1713 & TRN & \\
\hline CHEMBL3192842 & 1495332 & 6.1662 & 6.7764 & TRN & \\
\hline CHEMBL1422429 & 1495332 & 9.0 & 7.9136 & TRN & \\
\hline CHEMBL1723567 & 1495332 & 6.1871 & 6.307 & TRN & \\
\hline CHEMBL1451428 & 1495332 & 5.9784 & 7.1679 & TRN & \\
\hline CHEMBL1428409 & 1495332 & 5.739 & 5.8334 & TRN & \\
\hline CHEMBL1507162 & 1495332 & 6.4089 & 6.735 & TRN & \\
\hline CHEMBL1318943 & 1495332 & 6.0259 & 6.0932 & TRN & \\
\hline CHEMBL1386970 & 1495332 & 8.5229 & 7.1661 & TRN & \\
\hline CHEMBL599924 & 1495332 & 4.301 & 5.7258 & TRN & \\
\hline CHEMBL1304378 & 1495332 & 6.7122 & 7.1934 & TRN & \\
\hline CHEMBL1427221 & 1495332 & 5.9 & 5.4191 & TRN & \\
\hline CHEMBL533293 & 1495332 & 9.0 & 7.5472 & TRN & \\
\hline CHEMBL1378479 & 1495332 & 6.0862 & 5.9221 & TRN & \\
\hline CHEMBL1478310 & 1495332 & 6.7167 & 6.4841 & TRN & \\
\hline CHEMBL3189714 & 1495332 & 6.6126 & 6.7635 & TRN & \\
\hline CHEMBL1362565 & 1495332 & 5.7305 & 5.9028 & TRN & \\
\hline CHEMBL 29711 & 1495332 & 6.8665 & 6.9592 & TST & \\
\hline CHEMBL1458786 & 1495332 & 6.3768 & 6.3346 & TRN & \\
\hline CHEMBL1360792 & 1495332 & 6.4935 & 6.2082 & TRN & \\
\hline CHEMBL1399107 & 1495332 & 6.9031 & 6.862999 & 99999999995 & TRN \\
\hline CHEMBL1539018 & 1495332 & 6.1518 & 6.3579 & TRN & \\
\hline CHEMBL1338349 & 1495332 & 5.7194 & 5.6755 & TRN & \\
\hline CHEMBL1497104 & 1495332 & 6.266 & 6.0328 & TRN & \\
\hline CHEMBL1310332 & 1495332 & 5.6576 & 5.4228 & TRN & \\
\hline CHEMBL1449336 & 1495332 & 6.5969 & 6.4672 & TRN & \\
\hline CHEMBL1337040 & 1495332 & 6.75700 & \multirow{2}{*}{\multicolumn{3}{|c|}{$\begin{array}{ccc}0.0892 & \text { ISI } \\
5.843999999999999 & \text { TRN }\end{array}$}} \\
\hline CHEMBL1348145 & 1495332 & 5.5196 & & & \\
\hline CHEMBL1448592 & 1495332 & 7.4437 & 7.5653 & TRN & \\
\hline CHEMBL1494256 & 1495332 & 5.4729 & 5.4537 & TRN & \\
\hline CHEMBL1508680 & 1495332 & 6.6882 & 6.5855 & TRN & \\
\hline CHEMBL1537417 & 1495332 & 6.7645 & 7.0929 & TRN & \\
\hline
\end{tabular}

Page 27870 
Supplemental Table S2.txt

\begin{tabular}{|c|c|c|c|c|c|}
\hline CHEMBL1390452 & 1495332 & 5.6904 & 6.3085 & TRN & \\
\hline CHEMBL1516515 & 1495332 & 5.9574 & 5.7793 & TRN & \\
\hline CHEMBL1413661 & 1495332 & 6.2255 & 5.8625 & TRN & \\
\hline CHEMBL1408395 & 1495332 & 5.6923 & 6.4487 & TST & \\
\hline CHEMBL1358722 & 1495332 & 9.0 & 6.8986 & TST & \\
\hline CHEMBL1497797 & 1495332 & 5.5498 & 5.9994 & TRN & \\
\hline CHEMBL1502014 & 1495332 & 6.2652 & 6.6883 & TRN & \\
\hline CHEMBL1400660 & 1495332 & 6.056 & 6.0033 & TRN & \\
\hline CHEMBL1382301 & 1495332 & 7.9208 & 6.649 & TRN & \\
\hline CHEMBL1442788 & 1495332 & 6.2534 & 5.7769 & TRN & \\
\hline CHEMBL465423 & 1495332 & 5.934 & 6.5078 & TST & \\
\hline CHEMBL1482215 & 1495332 & 6.4855 & 5.8751 & TRN & \\
\hline CHEMBL1610831 & 1495332 & 6.15799 & 99999999 & 995 & 6.1886 \\
\hline CHEMBL1541441 & 1495332 & 4.301 & 5.9038 & TRN & \\
\hline CHEMBL1522827 & 1495332 & 6.9914 & 6.5287 & TRN & \\
\hline CHEMBL1382698 & 1495332 & 6.3716 & 5.5894 & TRN & \\
\hline CHEMBL1526405 & 1495332 & 6.5686 & 6.7023 & TRN & \\
\hline CHEMBL1448895 & 1495332 & 6.5072 & 6.5467 & TRN & \\
\hline CHEMBL1450647 & 1495332 & 6.8827 & 6.5868 & TRN & \\
\hline CHEMBL1531383 & 1495332 & 5.9462 & 6.2301 & TRN & \\
\hline CHEMBL1736169 & 1495332 & 5.9784 & 5.8162 & TRN & \\
\hline CHEMBL1565385 & 1495332 & 6.3696 & 6.34 & TRN & \\
\hline CHEMBL1730783 & 1495332 & 6.7375 & 6.1118 & TRN & \\
\hline CHEMBL229150 & 1495332 & 6.8794 & 6.0724 & TRN & \\
\hline CHEMBL1500867 & 1495332 & 5.697 & 5.5691 & TRN & \\
\hline CHEMBL328834 & 1495332 & 6.7645 & 6.3983 & TST & \\
\hline CHEMBL1334062 & 1495332 & 4.301 & 5.0226 & TRN & \\
\hline CHEMBL1500966 & 1495332 & 5.671 & 6.5559 & TRN & \\
\hline CHEMBL533602 & 1495332 & 5.9151 & 5.9805 & TST & \\
\hline CHEMBL465226 & 1495332 & 6.0482 & 6.6484 & TST & \\
\hline CHEMBL1341132 & 1495332 & 6.4737 & 5.9124 & TRN & \\
\hline CHEMBL1611990 & 1495332 & 6.6925 & 6.0337 & TRN & \\
\hline CHEMBL1499792 & 1495332 & 7.9586 & 7.8202 & TRN & \\
\hline CHEMBL1572087 & 1495332 & 6.0809 & 6.5916 & TRN & \\
\hline CHEMBL1523566 & 1495332 & 5.7062 & 6.1134 & TRN & \\
\hline CHEMBL1573754 & 1495332 & 6.2541 & 7.939 & TRN & \\
\hline CHEMBL1463885 & 1495332 & 6.1085 & 6.0671 & TST & \\
\hline CHEMBL1572001 & 1495332 & 6.0555 & 5.5232 & TRN & \\
\hline CHEMBL388978 & 1495332 & 9.0 & 7.2907 & TST & \\
\hline CHEMBL1347071 & 1495332 & 8.5229 & 7.7742 & TST & \\
\hline CHEMBL1428407 & 1495332 & 5.8011 & 5.8341 & TST & \\
\hline CHEMBL1384094 & 1495332 & 6.9666 & 6.1738 & TST & \\
\hline CHEMBL588038 & 1495332 & 6.2291 & 5.7662 & TST & \\
\hline CHEMBL1418463 & 1495332 & 6.6861 & 6.5081 & TST & \\
\hline CHEMBL1472411 & 1495332 & 6.3757 & 5.7799 & TST & \\
\hline CHEMBL1518664 & 1495332 & 6.104 & 6.1746 & TST & \\
\hline CHEMBL3210018 & 1495332 & 5.8077 & 6.4836 & TST & \\
\hline CHEMBL1578962 & 1495332 & 6.0921 & 6.2707 & TST & \\
\hline
\end{tabular}

Page 27871 
Supplemental Table S2.txt

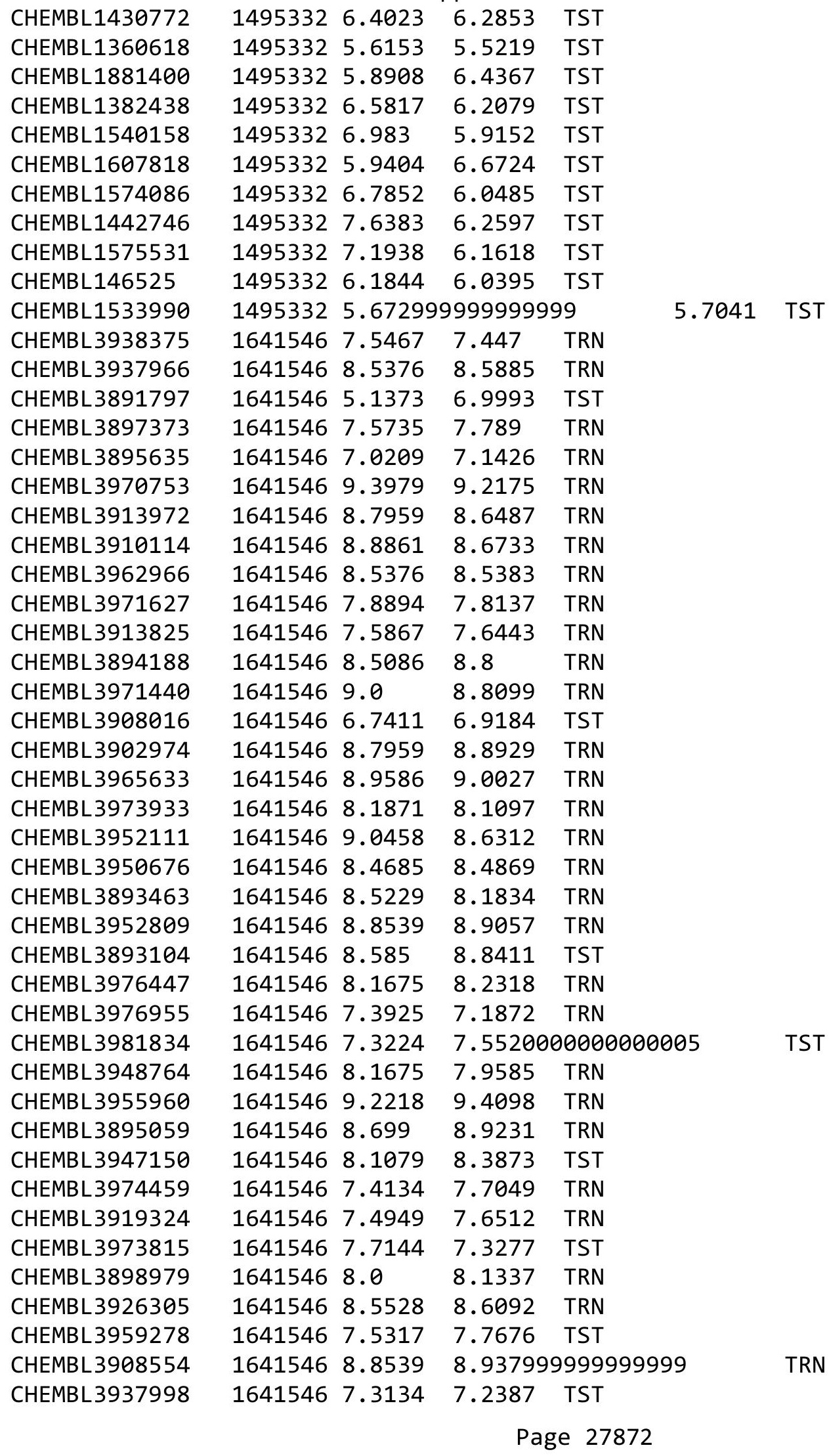


Supplemental Table S2.txt

\begin{tabular}{|c|c|c|c|c|c|}
\hline CHEMBL3980947 & 1641546 & 9.1308 & 9.0883 & TRN & \\
\hline CHEMBL3904830 & 1641546 & 8.9586 & 9.1251 & TRN & \\
\hline CHEMBL3962806 & 1641546 & 6.9208 & 7.6079 & TST & \\
\hline CHEMBL3906344 & 1641546 & 7.7932 & 8.0098 & TRN & \\
\hline CHEMBL 3973477 & 1641546 & 9.0458 & 8.6722 & TRN & \\
\hline CHEMBL 3948443 & 1641546 & 8.8239 & 8.828 & TRN & \\
\hline CHEMBL 3917225 & 1641546 & 8.2924 & 8.4094 & TRN & \\
\hline CHEMBL 3950477 & 1641546 & 8.6021 & 8.8774 & TRN & \\
\hline CHEMBL 3908654 & 1641546 & 8.8239 & 8.8454 & TRN & \\
\hline CHEMBL 3890449 & 1641546 & 8.7447 & 8.7799 & TRN & \\
\hline CHEMBL 3902076 & 1641546 & 8.2676 & 8.2688 & TRN & \\
\hline CHEMBL3927120 & 1641546 & 7.9666 & 7.5217 & TST & \\
\hline CHEMBL 3903132 & 1641546 & 9.0 & 8.68799 & 9999999999 & TRN \\
\hline CHEMBL 3949245 & 1641546 & 9.2218 & 9.1098 & TRN & \\
\hline CHEMBL3937992 & 1641546 & 8.0555 & 8.1785 & TRN & \\
\hline CHEMBL 3932872 & 1641546 & 8.2076 & 8.4819 & TRN & \\
\hline CHEMBL3914230 & 1641546 & 9.0969 & 8.9152 & TRN & \\
\hline CHEMBL3970199 & 1641546 & 7.8962 & 7.8706 & TRN & \\
\hline CHEMBL 3947677 & 1641546 & 8.5686 & 8.6494 & TRN & \\
\hline CHEMBL 3908041 & 1641546 & 8.9586 & 8.5893 & TST & \\
\hline CHEMBL 3960345 & 1641546 & 7.8153 & 7.847 & TRN & \\
\hline CHEMBL3935967 & 1641546 & 6.5017 & 6.8126 & TST & \\
\hline CHEMBL 3922952 & 1641546 & 9.0458 & 9.1721 & TRN & \\
\hline CHEMBL 3904724 & 1641546 & 6.9469 & 8.0464 & TST & \\
\hline CHEMBL 3975637 & 1641546 & 8.9208 & 8.7952 & TRN & \\
\hline CHEMBL 3966377 & 1641546 & 8.5686 & 8.5124 & TRN & \\
\hline CHEMBL3979006 & 1641546 & 9.0 & 9.0937 & TRN & \\
\hline CHEMBL 3890269 & 1641546 & 8.699 & 8.6835 & TRN & \\
\hline CHEMBL 3968517 & 1641546 & 9.3979 & 9.2631 & TRN & \\
\hline CHEMBL3917597 & 1641546 & 8.8539 & 8.7341 & TRN & \\
\hline CHEMBL 3968748 & 1641546 & 8.7447 & 8.6634 & TRN & \\
\hline CHEMBL3909521 & 1641546 & 7.3458 & 7.3078 & TRN & \\
\hline CHEMBL 3978473 & 1641546 & 7.8665 & 7.704 & TRN & \\
\hline CHEMBL 3978732 & 1641546 & 8.7696 & 8.5445 & TRN & \\
\hline CHEMBL 3930557 & 1641546 & 8.0315 & 8.2999 & TRN & \\
\hline CHEMBL3936498 & 1641546 & 7.9208 & 8.0912 & TST & \\
\hline CHEMBL3984506 & 1641546 & 8.5086 & 8.5042 & TRN & \\
\hline CHEMBL3979722 & 1641546 & 7.4271 & 7.2102 & TST & \\
\hline CHEMBL 3905117 & 1641546 & 8.6198 & 8.4849 & TRN & \\
\hline CHEMBL 3917445 & 1641546 & 8.7959 & 8.706 & TST & \\
\hline CHEMBL3959106 & 1641546 & 9.2218 & 9.2605 & TRN & \\
\hline CHEMBL3963996 & 1641546 & 9.0458 & 8.6498 & TST & \\
\hline CHEMBL3921606 & 1641546 & 7.9706 & 8.1901 & TRN & \\
\hline CHEMBL 3899000 & 1641546 & 8.5229 & 8.3806 & TRN & \\
\hline CHEMBL 3944050 & 1641546 & 8.1549 & 8.0938 & TRN & \\
\hline CHEMBL 3893589 & 1641546 & 8.1675 & 7.8983 & TST & \\
\hline CHEMBL3945386 & 1641546 & 9.2218 & 8.8218 & TST & \\
\hline CHEMBL 3967607 & 1641546 & 6.5952 & 7.2563 & TST & \\
\hline
\end{tabular}


Supplemental Table S2.txt

\begin{tabular}{|c|c|c|c|c|}
\hline 240 & 641546 & 8.8239 & 9.0242 & TRI \\
\hline HEMBL3986979 & 641546 & 8.301 & 8.125 & \\
\hline HEMBL & 541546 & 1549 & & N \\
\hline HEMBL394 & 541546 & 9.0969 & 952 & \\
\hline HEMBL3966650 & 641546 & 7.1574 & .2491 & ST \\
\hline HEMBL 584676 & 369322 & 4.8735 & 4.8793 & \\
\hline HEMBL586 & 322 & 6.0 & .1544 & \\
\hline HEMBL 599885 & 322 & 4.8567 & .0022 & 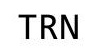 \\
\hline HEMBL527131 & 369322 & 5.1198 & 5.0326 & \\
\hline HEMBL581240 & 322 & 5.5186 & 5.2817 & \\
\hline JEMBL202 & 322 & 5.2958 & 5.3211 & \\
\hline HEMBL537 & 22 & 5.3439 & .4411 & RN \\
\hline HEMBL53e & & 883 & .609 & \\
\hline HEMBL591395 & 322 & 4.8861 & 5.1819 & 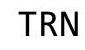 \\
\hline HEMBL 534288 & 322 & 5.3595 & 5.2553 & \\
\hline HEMBL599 & 22 & 6. & 5.3874 & \\
\hline HEMBL59 & 22 & 06 & .2937 & RN \\
\hline HEMBL 20 & 322 & 5.0778 & .7524 & $\mathrm{RN}$ \\
\hline HEMBL531 & 322 & 5.104 & 4.9761 & TST \\
\hline HEMBL601 & & 5. & 5.3974 & 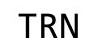 \\
\hline HEMBL5 & 22 & 5. & 64 & RIV \\
\hline HEMBL5 & & 52 & 46 & RN \\
\hline HEMBL1C & 22 & 5. & 5.3449 & RN \\
\hline HEMBL606 & & 5 . & 8799 & $\Gamma \mathrm{RN}$ \\
\hline HEMBL589 & & 5.0 & 5.0977 & IRIN \\
\hline HEMBL5 & 22 & & 798 & 「RN \\
\hline HEME & & & 45 & $\mathrm{RN}$ \\
\hline HEMBL & 22 & 4. & 347 & RN \\
\hline HEMBL58e & & & & IRIN \\
\hline HEMBL 589236 & 322 & 5.2373 & 5.0494 & TRN \\
\hline HEMBL5 & 22 & 82 & 18 & RN \\
\hline HFM & & 16 & 06 & RN \\
\hline HEMBL 5 & & 5 . & 5.227 & TRN \\
\hline HEMBL526 & & 4.8368 & 0527 & TRN \\
\hline HEMBL 548 & 22 & 6. & 5.5843 & ГRN \\
\hline HEMBLI & 22 & 382 & 9776 & ГST \\
\hline HEM & & 5 . & 37 & TRN \\
\hline HEMBL 202 & & 4.5 & 5.2407 & TRN \\
\hline HEMBL490 & 322 & 6.2 & 4591 & TRN \\
\hline HEMBL & & & & 「RN \\
\hline HEMBL5 & & 52 & 5.2025 & TRN \\
\hline HEMBL 5 & 322 & 4.7652 & 5.4961 & 「RN \\
\hline HEMBL603 & & 4.8511 & 5.2954 & TRN \\
\hline CHEMBL605 & 22 & 5. & 71 & TR \\
\hline 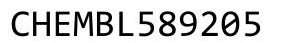 & & & & \\
\hline HEMBL5 & & 7.2924 & 5.6042 & \\
\hline CHEMBL533855 & 322 & 6.3468 & 5.7945 & \\
\hline CHEMBL589723 & 1369322 & 5.2596 & 5.1343 & 15 \\
\hline
\end{tabular}

Page 27874 
Supplemental Table S2.txt

\begin{tabular}{|c|c|c|c|c|}
\hline CHEMBL530149 & 1369322 & 5.5171 & 5.1201 & TRN \\
\hline CHEMBL592332 & 1369322 & 5.1226 & 5.4744 & TRN \\
\hline CHEMBL601492 & 1369322 & 5.2449 & 5.1414 & TRN \\
\hline CHEMBL529640 & 1369322 & 5.1152 & 4.9585 & TRN \\
\hline CHEMBL535556 & 1369322 & 5.0 & 5.3479 & TRN \\
\hline CHEMBL580249 & 1369322 & 5.0 & 4.5244 & TRN \\
\hline CHEMBL591887 & 1369322 & 4.8179 & 5.1702 & TRN \\
\hline CHEMBL583555 & 1369322 & 5.3449 & 5.4843 & TST \\
\hline CHEMBL607308 & 1369322 & 5.3107 & 5.4272 & TRN \\
\hline CHEMBL537087 & 1369322 & 5.4078 & 5.2316 & TRN \\
\hline CHEMBL591362 & 1369322 & 5.2596 & 5.3474 & TRN \\
\hline CHEMBL582070 & 1369322 & 4.9087 & 5.3351 & TRN \\
\hline CHEMBL591890 & 1369322 & 6.2441 & 5.0644 & TST \\
\hline CHEMBL579459 & 1369322 & 4.7515 & 4.7264 & TST \\
\hline CHEMBL589920 & 1369322 & 5.3215 & 5.1068 & TRN \\
\hline CHEMBL601325 & 1369322 & 5.2933 & 5.5699 & TST \\
\hline CHEMBL532597 & 1369322 & 5.2596 & 5.3525 & TRN \\
\hline CHEMBL602764 & 1369322 & 5.1555 & 5.0725 & TRN \\
\hline CHEMBL585983 & 1369322 & 4.7997 & 5.4452 & TRN \\
\hline CHEMBL590944 & 1369322 & 4.8431 & 4.9272 & TRN \\
\hline CHEMBL578952 & 1369322 & 5.16299 & 999999999 & 4.9543 \\
\hline CHEMBL581489 & 1369322 & 4.8468 & 4.5926 & TRN \\
\hline CHEMBL580381 & 1369322 & 5.1518 & 5.3912 & TRN \\
\hline CHEMBL529984 & 1369322 & 5.3778 & 5.2825 & TRN \\
\hline CHEMBL584841 & 1369322 & 6.0 & 5.0717 & TRN \\
\hline CHEMBL1738986 & 1369322 & 4.9234 & 5.371 & TRN \\
\hline CHEMBL582420 & 1369322 & 5.0 & 4.8524 & TRN \\
\hline CHEMBL588155 & 1369322 & 4.7282 & 5.2908 & TRN \\
\hline CHEMBL534190 & 1369322 & 4.9382 & 5.2788 & TRN \\
\hline CHEMBL600444 & 1369322 & 5.5302 & 5.2144 & TRN \\
\hline CHEMBL589916 & 1369322 & 5.0 & 5.0815 & TRN \\
\hline CHEMBL601567 & 1369322 & 5.1746 & 5.1754 & TRN \\
\hline CHEMBL584235 & 1369322 & 6.0757 & 5.5995 & TRN \\
\hline CHEMBL600374 & 1369322 & 5.3778 & 5.537000 & 3000000001 \\
\hline CHEMBL586344 & 1369322 & 4.7338 & 5.3713 & TST \\
\hline CHEMBL601566 & 1369322 & 3.6021 & 5.2364 & TST \\
\hline CHEMBL589922 & 1369322 & 4.8179 & 5.1551 & TRN \\
\hline CHEMBL578933 & 1369322 & 4.9226 & 5.1252 & TRN \\
\hline CHEMBL597855 & 1369322 & 3.6021 & 4.572 & TRN \\
\hline CHEMBL582552 & 1369322 & 5.4425 & 5.4859 & TRN \\
\hline CHEMBL536421 & 1369322 & 4.9062 & 4.7284 & TRN \\
\hline CHEMBL587288 & 1369322 & 4.8167 & 4.5983 & TRN \\
\hline CHEMBL592125 & 1369322 & 4.8976 & 5.3912 & TRN \\
\hline CHEMBL 2028057 & 1369322 & 6.0 & 5.1005 & TRN \\
\hline CHEMBL548469 & 1369322 & 7.0 & 5.6884 & TRN \\
\hline CHEMBL549208 & 1369322 & 5.2373 & 5.1467 & TRN \\
\hline CHEMBL604982 & 1369322 & 5.5302 & 5.6101 & TRN \\
\hline CHEMBL1545915 & 1369322 & 5.4535 & 5.0505 & TRN \\
\hline
\end{tabular}


Supplemental Table S2.txt

\begin{tabular}{|c|c|c|c|c|c|}
\hline CHEMBL592786 & 1369322 & 4.8996 & 4.973 & TRN & \\
\hline CHEMBL1623028 & 1369322 & 6.1024 & 5.3887 & TRN & \\
\hline CHEMBL600906 & 1369322 & 5.6198 & 5.0098 & TRN & \\
\hline CHEMBL 2028066 & 1369322 & 4.7491 & 5.2184 & TST & \\
\hline CHEMBL586933 & 1369322 & 5.2487 & 5.0335 & TRN & \\
\hline CHEMBL597262 & 1369322 & 4.9944 & 5.2384 & TRN & \\
\hline CHEMBL588516 & 1369322 & 4.8013 & 4.8367 & TRN & \\
\hline CHEMBL587892 & 1369322 & 4.782 & 5.3454 & TRN & \\
\hline CHEMBL525692 & 1369322 & 5.0 & 4.9026 & TRN & \\
\hline CHEMBL581349 & 1369322 & 6.0 & 5.2644 & TRN & \\
\hline CHEMBL582119 & 1369322 & 4.8567 & 5.0839 & TST & \\
\hline CHEMBL533017 & 1369322 & 4.6373 & 4.88399 & 99999999995 & TRN \\
\hline CHEMBL598881 & 1369322 & 4.9727 & 5.2075 & TST & \\
\hline CHEMBL 2028059 & 1369322 & 5.0 & 5.0326 & TRN & \\
\hline CHEMBL591183 & 1369322 & 6.0 & 5.6833 & TRN & \\
\hline CHEMBL589060 & 1369322 & 5.4425 & 4.9879 & TRN & \\
\hline CHEMBL580876 & 1369322 & 5.0 & 5.0275 & TRN & \\
\hline CHEMBL527541 & 1369322 & 4.8179 & 4.9483 & TRN & \\
\hline CHEMBL577445 & 1369322 & 5.0 & 5.3005 & TRN & \\
\hline CHEMBL532155 & 1369322 & 5.2716 & 5.3623 & TRN & \\
\hline CHEMBL592550 & 1369322 & 4.8941 & 5.2237 & TRN & \\
\hline CHEMBL590182 & 1369322 & 4.9996 & 4.9504 & TRN & \\
\hline CHEMBL577011 & 1369322 & 5.3487 & 5.16299 & 9999999999 & TRN \\
\hline CHEMBL532525 & 1369322 & 4.8775 & 5.2935 & TRN & \\
\hline CHEMBL532510 & 1369322 & 4.8517 & 5.4695 & TRN & \\
\hline CHEMBL 2028055 & 1369322 & 5.466 & 5.1253 & TRN & \\
\hline CHEMBL587485 & 1369322 & 5.0 & 5.0358 & TRN & \\
\hline CHEMBL578508 & 1369322 & 5.0372 & 4.8164 & TRN & \\
\hline CHEMBL319952 & 1369322 & 4.9727 & 5.4466 & TRN & \\
\hline CHEMBL537505 & 1369322 & 5.6108 & 4.6721 & TRN & \\
\hline CHEMBL578030 & 1369322 & 4.8111 & 5.6213 & TRN & \\
\hline CHEMBL534283 & 1369322 & 6.6021 & 5.638 & TST & \\
\hline CHEMBL600439 & 1369322 & 4.7632 & 5.1487 & TST & \\
\hline CHEMBL525519 & 1369322 & 5.3372 & 5.2801 & TRN & \\
\hline CHEMBL591147 & 1369322 & 4.9034 & 5.1564 & TRN & \\
\hline CHEMBL 2028045 & 1369322 & 4.8567 & 5.5293 & TRN & \\
\hline CHEMBL459199 & 1369322 & 5.04 & 5.1356 & TRN & \\
\hline CHEMBL590680 & 1369322 & 5.1029 & 5.0891 & TRN & \\
\hline CHEMBL584655 & 1369322 & 4.9034 & 5.4825 & TRN & \\
\hline CHEMBL605751 & 1369322 & 6.1192 & 5.665 & TRN & \\
\hline CHEMBL533917 & 1369322 & 6.3279 & 5.7427 & TRN & \\
\hline CHEMBL600356 & 1369322 & 5.4868 & 5.5826 & TST & \\
\hline CHEMBL529968 & 1369322 & 5.4134 & 5.4182 & TRN & \\
\hline CHEMBL588855 & 1369322 & 5.1931 & 5.5754 & TRN & \\
\hline CHEMBL529874 & 1369322 & 7.2676 & 5.3269 & TST & \\
\hline CHEMBL95606 & 1369322 & 4.8511 & 5.3261 & TST & \\
\hline CHEMBL597248 & 1369322 & 5.6737 & 5.5785 & TRN & \\
\hline CHEMBL586026 & 1369322 & 5.2907 & 5.4063 & TST & \\
\hline
\end{tabular}


Supplemental Table S2.txt

\begin{tabular}{|c|c|c|c|c|c|}
\hline CHEMBL601786 & 1369322 & 6.8539 & 5.3682 & TRN & \\
\hline CHEMBL 2028050 & 1369322 & 5.52 & 5.3887 & TRN & \\
\hline CHEMBL 2028067 & 1369322 & 5.2457 & 5.3342 & TRN & \\
\hline CHEMBL527234 & 1369322 & 4.7997 & 5.0386 & TRN & \\
\hline CHEMBL587410 & 1369322 & 3.6021 & 5.0051 & TST & \\
\hline CHEMBL602946 & 1369322 & 7.0 & 5.7267 & TRN & \\
\hline CHEMBL582547 & 1369322 & 4.9169 & 5.5685 & TRN & \\
\hline CHEMBL534612 & 1369322 & 5.3242 & 5.5978 & TRN & \\
\hline CHEMBL547193 & 1369322 & 4.7959 & 5.0002 & TRN & \\
\hline CHEMBL579331 & 1369322 & 5.3595 & 5.3981 & TRN & \\
\hline CHEMBL532015 & 1369322 & 6.1871 & 5.1265 & TRN & \\
\hline CHEMBL 2028064 & 1369322 & 6.3279 & 5.3942 & TST & \\
\hline CHEMBL602179 & 1369322 & 4.7924 & 5.1557 & TRN & \\
\hline CHEMBL589224 & 1369322 & 6.1871 & 4.6871 & TST & \\
\hline CHEMBL600174 & 1369322 & 4.8368 & 5.3226 & TRN & \\
\hline CHEMBL601156 & 1369322 & 5.3143 & 5.2613 & TST & \\
\hline CHEMBL582286 & 1369322 & 4.6523 & 5.1758 & TRN & \\
\hline CHEMBL581860 & 1369322 & 5.857 & 5.6532 & TRN & \\
\hline CHEMBL580388 & 1369322 & 4.7395 & 4.8971 & TST & \\
\hline CHEMBL601612 & 1369322 & 5.3778 & 5.1065 & TST & \\
\hline CHEMBL 2028060 & 1369322 & 4.9226 & 5.232 & TRN & \\
\hline CHEMBL601158 & 1369322 & 4.8533 & 4.9105 & TRN & \\
\hline CHEMBL548338 & 1369322 & 6.0 & 5.5366 & TRN & \\
\hline CHEMBL601825 & 1369322 & 4.8579 & 4.8609 & TRN & \\
\hline CHEMBL600549 & 1369322 & 4.8972 & 4.9938 & TRN & \\
\hline CHEMBL600030 & 1369322 & 5.0 & 5.2332 & TRN & \\
\hline CHEMBL1594640 & 1369322 & 3.6021 & 5.1263 & TRN & \\
\hline CHEMBL1198307 & 1369322 & 5.3449 & 5.4313 & TRN & \\
\hline CHEMBL602312 & 1369322 & 6.6021 & 5.6294 & TRN & \\
\hline CHEMBL546162 & 1369322 & 4.762 & 5.6211 & TRN & \\
\hline CHEMBL532560 & 1369322 & 6.2366 & 5.6979 & TRN & \\
\hline CHEMBL586704 & 1369322 & 5.5229 & 5.2305 & TRN & \\
\hline CHEMBL549216 & 1369322 & 5.0 & 5.2635 & TRN & \\
\hline CHEMBL547488 & 1369322 & 5.5406 & 5.2938 & TRN & \\
\hline CHEMBL586442 & 1369322 & 4.7809 & 4.76399 & 9999999999 & TRN \\
\hline CHEMBL587022 & 1369322 & 4.8837 & 5.2891 & TST & \\
\hline CHEMBL525826 & 1369322 & 5.3883 & 5.4166 & TRN & \\
\hline CHEMBL584240 & 1369322 & 5.8539 & 5.3458 & TRN & \\
\hline CHEMBL592044 & 1369322 & 4.8242 & 5.3447 & TST & \\
\hline CHEMBL548334 & 1369322 & 5.1391 & 5.0428 & TST & \\
\hline CHEMBL530438 & 1369322 & 5.1637 & 5.4018 & TST & \\
\hline CHEMBL600904 & 1369322 & 6.3565 & 5.5111 & TRN & \\
\hline CHEMBL581475 & 1369322 & 4.8775 & 4.8579 & TRN & \\
\hline CHEMBL602366 & 1369322 & 5.3696 & 5.0789 & TRN & \\
\hline CHEMBL586178 & 1369322 & 4.8996 & 4.82600 & 00000000005 & TRN \\
\hline CHEMBL525106 & 1369322 & 5.8013 & 5.5474 & TRN & \\
\hline CHEMBL588859 & 1369322 & 5.2487 & 5.4826 & TRN & \\
\hline CHEMBL547269 & 1369322 & 6.4815 & 5.2849 & TRN & \\
\hline
\end{tabular}

Page 27877 
Supplemental Table S2.txt

\begin{tabular}{|c|c|c|c|c|c|}
\hline CHEMBL10835 & 1369322 & 6.6778 & 5.3631 & TRN & \\
\hline CHEMBL 2028063 & 1369322 & 6.2757 & 5.3731 & TRN & \\
\hline CHEMBL524973 & 1369322 & 7.0 & 5.7149 & TRN & \\
\hline CHEMBL125044 & 1369322 & 5.0372 & 5.2177 & TRN & \\
\hline CHEMBL531222 & 1369322 & 5.1367 & 4.8879 & TRN & \\
\hline CHEMBL 2028051 & 1369322 & 4.743 & 5.1709 & TRN & \\
\hline CHEMBL600235 & 1369322 & 4.8925 & 5.6317 & TRN & \\
\hline CHEMBL580188 & 1369322 & 5.2048 & 4.8612 & TRN & \\
\hline CHEMBL586962 & 1369322 & 5.2269 & 5.52 & TRN & \\
\hline CHEMBL261095 & 1369322 & 5.3778 & 5.0054 & TRN & \\
\hline CHEMBL1437888 & 1369322 & 6.3098 & 5.8137 & TRN & \\
\hline CHEMBL585966 & 1369322 & 4.9952 & 4.9825 & TRN & \\
\hline CHEMBL531060 & 1369322 & 5.5186 & 5.1578 & TRN & \\
\hline CHEMBL587923 & 1369322 & 6.4815 & 5.65600 & 0000000001 & TRN \\
\hline CHEMBL601378 & 1369322 & 4.9226 & 5.4188 & TRN & \\
\hline CHEMBL533563 & 1369322 & 4.6592 & 4.9703 & TST & \\
\hline CHEMBL577874 & 1369322 & 5.2449 & 5.3503 & TRN & \\
\hline CHEMBL586000 & 1369322 & 4.8306 & 5.4311 & TRN & \\
\hline CHEMBL596852 & 1369322 & 5.0904 & 5.4131 & TRN & \\
\hline CHEMBL582478 & 1369322 & 5.0 & 5.5783 & TRN & \\
\hline CHEMBL590914 & 1369322 & 5.4622 & 5.5089 & TRN & \\
\hline CHEMBL596856 & 1369322 & 4.8425 & 5.2602 & TRN & \\
\hline CHEMBL600132 & 1369322 & 5.4425 & 4.9865 & TST & \\
\hline CHEMBL581187 & 1369322 & 6.3188 & 5.5925 & TRN & \\
\hline CHEMBL590201 & 1369322 & 4.9087 & 5.2084 & TRN & \\
\hline CHEMBL600305 & 1369322 & 4.7716 & 4.8011 & TRN & \\
\hline CHEMBL609036 & 1369322 & 4.8063 & 5.5442 & TRN & \\
\hline CHEMBL530308 & 1369322 & 4.9817 & 5.5866 & TST & \\
\hline CHEMBL524930 & 1369322 & 7.0 & 5.2862 & TRN & \\
\hline CHEMBL580757 & 1369322 & 4.8894 & 5.0213 & TRN & \\
\hline CHEMBL530978 & 1369322 & 4.8431 & 5.1453 & TRN & \\
\hline CHEMBL547614 & 1369322 & 4.8013 & 4.6751 & TST & \\
\hline CHEMBL597857 & 1369322 & 5.1319 & 5.3469 & TRN & \\
\hline CHEMBL592338 & 1369322 & 4.751 & 5.2391 & TRN & \\
\hline CHEMBL580353 & 1369322 & 5.4935 & 5.348 & TRN & \\
\hline CHEMBL601806 & 1369322 & 4.8775 & 5.245 & TST & \\
\hline CHEMBL600706 & 1369322 & 3.6021 & 4.7437 & TRN & \\
\hline CHEMBL528533 & 1369322 & 5.3675 & 5.2311 & TRN & \\
\hline CHEMBL582486 & 1369322 & 5.9914 & 5.077 & TST & \\
\hline CHEMBL603943 & 1369322 & 5.0 & 4.9292 & TRN & \\
\hline CHEMBL601348 & 1369322 & 4.8167 & 4.8144 & TST & \\
\hline CHEMBL585686 & 1369322 & 6.6596 & 5.7985 & TRN & \\
\hline CHEMBL590212 & 1369322 & 5.4089 & 5.7612 & TRN & \\
\hline CHEMBL583682 & 1369322 & 5.1163 & 4.9011 & TRN & \\
\hline CHEMBL528492 & 1369322 & 4.8539 & 4.9446 & TRN & \\
\hline CHEMBL 2028061 & 1369322 & 4.8768 & 5.1053 & TRN & \\
\hline CHEMBL583844 & 1369322 & 4.8894 & 5.0708 & TST & \\
\hline CHEMBL581874 & 1369322 & 4.8983 & 5.4725 & TRN & \\
\hline
\end{tabular}


Supplemental Table S2.txt

\begin{tabular}{|c|c|c|c|c|c|}
\hline CHEMBL338094 & 1369322 & 4.9978 & 5.1449 & TRN & \\
\hline CHEMBL582079 & 1369322 & 5.3372 & 5.3087 & TRN & \\
\hline CHEMBL602552 & 1369322 & 4.8368 & 5.1206 & TRN & \\
\hline CHEMBL547266 & 1369322 & 5.8539 & 5.4826 & TRN & \\
\hline CHEMBL578294 & 1369322 & 4.8179 & 5.6093 & TRN & \\
\hline CHEMBL592808 & 1369322 & 4.8788 & 5.3689 & TRN & \\
\hline CHEMBL599886 & 1369322 & 4.9183 & 5.1878 & TST & \\
\hline CHEMBL590686 & 1369322 & 6.3372 & 5.195 & TRN & \\
\hline CHEMBL1616787 & 1369322 & 4.7997 & 5.675 & TRN & \\
\hline CHEMBL533598 & 1369322 & 5.857 & 5.3883 & TRN & \\
\hline CHEMBL608855 & 1369322 & 4.8176 & 5.2988 & TST & \\
\hline CHEMBL532141 & 1369322 & 7.0 & 5.7309 & TRN & \\
\hline CHEMBL580159 & 1369322 & 5.3215 & 5.1595 & TRN & \\
\hline CHEMBL528245 & 1369322 & 4.8861 & 5.466 & TRN & \\
\hline CHEMBL601814 & 1369322 & 5.0372 & 5.4118 & TRN & \\
\hline CHEMBL529603 & 1369322 & 5.0 & 5.0224 & TRN & \\
\hline CHEMBL606252 & 1369322 & 4.8847 & 5.3738 & TRN & \\
\hline CHEMBL601743 & 1369322 & 5.0 & 5.2158 & TRN & \\
\hline CHEMBL585431 & 1369322 & 4.9867 & 4.9256 & TRN & \\
\hline CHEMBL579294 & 1369322 & 5.4522 & 4.9233 & TRN & \\
\hline CHEMBL589946 & 1369322 & 5.0 & 5.1886 & TRN & \\
\hline CHEMBL 2028058 & 1369322 & 5.1163 & 5.2438 & TRN & \\
\hline CHEMBL 2028046 & 1369322 & 4.9727 & 5.4423 & TRN & \\
\hline CHEMBL528734 & 1369322 & 4.9987 & 4.834 & TRN & \\
\hline CHEMBL526587 & 1369322 & 5.0835 & 4.8087 & TRN & \\
\hline CHEMBL546994 & 1369322 & 4.7817 & 4.7676 & TRN & \\
\hline CHEMBL548374 & 1369322 & 4.7421 & 5.2116 & TRN & \\
\hline CHEMBL546168 & 1369322 & 3.6021 & 4.9449 & TRN & \\
\hline CHEMBL577440 & 1369322 & 5.0835 & 5.1303 & TRN & \\
\hline CHEMBL598279 & 1369322 & 5.3215 & 5.7263 & TRN & \\
\hline CHEMBL606159 & 1369322 & 4.8511 & \multicolumn{2}{|c|}{5.372000000000001} & TRN \\
\hline CHEMBL582767 & 1369322 & 5.2269 & 5.9205 & TST & \\
\hline CHEMBL590933 & 1369322 & 5.4283 & \multicolumn{2}{|c|}{5.787999999999999} & TRN \\
\hline CHEMBL577014 & 1369322 & 5.2 & \multicolumn{2}{|c|}{5.662999999999999} & TRN \\
\hline CHEMBL587104 & 1369322 & 4.9226 & 5.0775 & TRN & \\
\hline CHEMBL 2028056 & 1369322 & 5.0835 & 5.2172 & TRN & \\
\hline CHEMBL 2021322 & 1369322 & 4.8179 & \multicolumn{2}{|c|}{5.2139999999999995} & TRN \\
\hline CHEMBL590159 & 1369322 & 4.7129 & 5.0171 & TRN & \\
\hline CHEMBL527620 & 1369322 & 5.1555 & 5.1792 & TRN & \\
\hline CHEMBL603686 & 1369322 & 4.7924 & 4.9735 & TST & \\
\hline CHEMBL547443 & 1369322 & 6.3872 & 5.6394 & TRN & \\
\hline CHEMBL588501 & 1369322 & 6.1938 & 5.9592 & TRN & \\
\hline CHEMBL592123 & 1369322 & 5.5302 & 5.6767 & TRN & \\
\hline CHEMBL580516 & 1369322 & 4.9978 & 5.3082 & TRN & \\
\hline CHEMBL588481 & 1369322 & 5.6635 & 5.6551 & TRN & \\
\hline CHEMBL 2028047 & 1369322 & 4.757 & 5.7066 & TRN & \\
\hline CHEMBL586033 & 1369322 & 4.8996 & 5.3893 & TRN & \\
\hline CHEMBL 2028054 & 1369322 & 4.9087 & 4.9749 & TST & \\
\hline
\end{tabular}


Supplemental Table S2.txt

\begin{tabular}{|c|c|c|c|c|c|c|}
\hline CHEMBL548399 & 1369322 & 4.6908 & 4.5977 & TRN & & \\
\hline CHEMBL590919 & 1369322 & 5.6108 & 5.4584 & TRN & & \\
\hline CHEMBL607975 & 1369322 & 5.4425 & 5.0094 & TRN & & \\
\hline CHEMBL 2028048 & 1369322 & 4.782 & 4.8572 & TRN & & \\
\hline CHEMBL1623897 & 1369322 & 5.0 & 4.9977 & TRN & & \\
\hline CHEMBL589422 & 1369322 & 4.8996 & 5.3459 & TST & & \\
\hline CHEMBL607688 & 1369322 & 4.8955 & 5.4721 & TRN & & \\
\hline CHEMBL602580 & 1369322 & 6.8861 & 5.8949 & TST & & \\
\hline CHEMBL602413 & 1369322 & 5.6576 & 5.3986 & TRN & & \\
\hline CHEMBL580140 & 1369322 & 5.7282 & 5.428 & TRN & & \\
\hline CHEMBL596652 & 1369322 & 4.8431 & 5.1441 & TRN & & \\
\hline CHEMBL581194 & 1369322 & 5.1675 & 5.4729 & TRN & & \\
\hline CHEMBL584237 & 1369322 & 4.8013 & 4.9725 & TRN & & \\
\hline CHEMBL533999 & 1369322 & 4.9062 & 5.0369 & TRN & & \\
\hline CHEMBL591641 & 1369322 & 5.1494 & 5.2623 & TRN & & \\
\hline CHEMBL602234 & 1369322 & 5.3449 & 5.7915 & TRN & & \\
\hline CHEMBL535730 & 1369322 & 6.2147 & 5.2626 & TST & & \\
\hline CHEMBL 2028068 & 1369322 & 6.1192 & 5.5714 & TST & & \\
\hline CHEMBL584829 & 1369322 & 5.4134 & 5.335 & TRN & & \\
\hline CHEMBL527730 & 1369322 & 4.7881 & 5.1315 & TRN & & \\
\hline CHEMBL609628 & 1369322 & 4.8179 & 5.3908 & TRN & & \\
\hline CHEMBL533399 & 1369322 & 6.2076 & 5.8012 & TST & & \\
\hline CHEMBL587371 & 1369322 & 5.4789 & 5.621 & TRN & & \\
\hline CHEMBL 2028049 & 1369322 & 5.3556 & 4.967 & TRN & & \\
\hline CHEMBL581225 & 1369322 & 6.1739 & 5.4318 & TST & & \\
\hline CHEMBL602586 & 1369322 & 6.2007 & 5.7645 & TST & & \\
\hline CHEMBL1744512 & 1369322 & 7.0 & 5.2007 & TST & & \\
\hline CHEMBL1237255 & 1369322 & 4.7997 & 5.711 & TRN & & \\
\hline CHEMBL529348 & 1369322 & 6.4089 & 5.6564 & TRN & & \\
\hline CHEMBL601528 & 1369322 & 5.05399 & 999999999 & 99 & 5.4237 & TRN \\
\hline CHEMBL586888 & 1369322 & 5.2848 & 5.4886 & TRN & & \\
\hline CHEMBL601534 & 1369322 & 6.585 & 5.5322 & TST & & \\
\hline CHEMBL579105 & 1369322 & 5.2958 & 5.1537 & TRN & & \\
\hline CHEMBL580819 & 1369322 & 5.4318 & 5.2399 & TRN & & \\
\hline CHEMBL609156 & 1369322 & 4.8729 & 4.6767 & TRN & & \\
\hline CHEMBL590675 & 1369322 & 6.2924 & 5.4933 & TRN & & \\
\hline CHEMBL528437 & 1369322 & 5.38399 & 999999999 & 995 & 5.3584 & TST \\
\hline CHEMBL585839 & 1369322 & 4.8179 & 5.1927 & TST & & \\
\hline CHEMBL529919 & 1369322 & 3.6021 & 4.9394 & TST & & \\
\hline CHEMBL546531 & 1369322 & 5.2933 & 5.907 & TST & & \\
\hline CHEMBL591128 & 1369322 & 4.9034 & 5.2096 & TST & & \\
\hline CHEMBL533921 & 1369322 & 4.7632 & 5.5903 & TST & & \\
\hline CHEMBL582495 & 1369322 & 5.3696 & 5.7983 & TST & & \\
\hline CHEMBL584015 & 1369322 & 6.7696 & 5.4261 & TST & & \\
\hline CHEMBL 206540 & 1369322 & 4.8277 & 4.6748 & TST & & \\
\hline CHEMBL591393 & 1369322 & 5.4698 & 5.1848 & TST & & \\
\hline CHEMBL534589 & 1369322 & 4.8468 & 4.9723 & TST & & \\
\hline CHEMBL577012 & 1369322 & 5.0835 & 5.1145 & TST & & \\
\hline
\end{tabular}




\begin{tabular}{|c|c|c|c|c|c|c|}
\hline \multicolumn{7}{|c|}{ Supplemental Table S2.txt } \\
\hline CHEMBL1740701 & 1369322 & 5.05399 & 99999999 & 99 & 4.9604 & TST \\
\hline CHEMBL590683 & 1369322 & 5.4283 & 5.1978 & TST & & \\
\hline CHEMBL547825 & 1369322 & 5.3215 & 5.5765 & TST & & \\
\hline CHEMBL545880 & 1369322 & 5.4698 & 5.6946 & TST & & \\
\hline CHEMBL596643 & 1369322 & 5.0835 & 5.0991 & TST & & \\
\hline CHEMBL588732 & 1369322 & 4.8891 & 5.2946 & TST & & \\
\hline CHEMBL548209 & 1369322 & 6.0969 & 5.5946 & TST & & \\
\hline CHEMBL611070 & 1369322 & 4.8462 & 5.3397 & TST & & \\
\hline CHEMBL546799 & 1369322 & 4.8179 & 5.9969 & TST & & \\
\hline CHEMBL582180 & 1369322 & 5.0 & 5.6933 & TST & & \\
\hline CHEMBL592305 & 1369322 & 4.8617 & 5.0976 & TST & & \\
\hline CHEMBL534319 & 1369322 & 6.301 & 5.7166 & TST & & \\
\hline CHEMBL526981 & 1369322 & 4.8739 & 4.985 & TST & & \\
\hline CHEMBL579760 & 1369322 & 5.2933 & 5.1991 & TST & & \\
\hline CHEMBL601580 & 1369322 & 4.8013 & 5.3657 & TST & & \\
\hline CHEMBL604389 & 1369322 & 4.8474 & 5.0871 & TST & & \\
\hline CHEMBL602211 & 1369322 & 7.1871 & 5.4233 & TST & & \\
\hline CHEMBL532079 & 1369322 & 5.1549 & 5.3079 & TST & & \\
\hline CHEMBL 2028053 & 1369322 & 5.2299 & 4.7335 & TST & & \\
\hline CHEMBL600488 & 1369322 & 4.8775 & 5.0415 & TST & & \\
\hline CHEMBL602409 & 1369322 & 4.9952 & 5.1142 & TST & & \\
\hline CHEMBL579300 & 1369322 & 5.05699 & 79999999 & 995 & 5.4322 & TST \\
\hline CHEMBL602940 & 1369322 & 5.4318 & 5.4071 & TST & & \\
\hline CHEMBL597444 & 1369322 & 4.7997 & 5.3207 & TST & & \\
\hline CHEMBL2028062 & 1369322 & 5.2757 & 5.4077 & TST & & \\
\hline CHEMBL2028052 & 1369322 & 4.6021 & 4.7332 & TST & & \\
\hline CHEMBL590435 & 1369322 & 4.7338 & 4.8602 & TST & & \\
\hline CHEMBL529773 & 1369322 & 5.1409 & 4.7847 & TST & & \\
\hline CHEMBL3922203 & 1640395 & 8.2076 & 8.0401 & TRN & & \\
\hline CHEMBL3967396 & 1640395 & 8.6576 & 7.0325 & TRN & & \\
\hline CHEMBL3920175 & 1640395 & 6.0 & 6.6869 & TRN & & \\
\hline CHEMBL3938709 & 1640395 & 7.8729 & 8.1926 & TST & & \\
\hline CHEMBL3925696 & 1640395 & 8.4559 & 8.5649 & TRN & & \\
\hline CHEMBL3900602 & 1640395 & 8.2757 & 8.5618 & TRN & & \\
\hline CHEMBL3895650 & 1640395 & 8.8239 & 8.9951 & TRN & & \\
\hline CHEMBL3954855 & 1640395 & 8.5086 & 8.2224 & TRN & & \\
\hline CHEMBL3952884 & 1640395 & 8.8861 & 8.5156 & TRN & & \\
\hline CHEMBL3892455 & 1640395 & 6.0 & 7.0013 & TRN & & \\
\hline CHEMBL3980058 & 1640395 & 7.9872 & 7.8325 & TRN & & \\
\hline CHEMBL3932567 & 1640395 & 8.1675 & 8.006 & TRN & & \\
\hline CHEMBL3933370 & 1640395 & 8.1079 & 8.4273 & TRN & & \\
\hline CHEMBL3967229 & 1640395 & 7.9706 & 7.8795 & TST & & \\
\hline CHEMBL3911489 & 1640395 & 8.6021 & 8.0558 & TRN & & \\
\hline CHEMBL3894685 & 1640395 & 8.4318 & 8.3096 & TST & & \\
\hline CHEMBL3965397 & 1640395 & 8.2596 & 6.8336 & TRN & & \\
\hline CHEMBL3917045 & 1640395 & 7.7352 & 7.96200 & 0000000001 & & TST \\
\hline CHEMBL3951566 & 1640395 & 8.7696 & 9.0353 & TRN & & \\
\hline CHEMBL3923273 & 1640395 & 8.1871 & 7.6572 & TRN & & \\
\hline
\end{tabular}

Page 27881 
Supplemental Table S2.txt

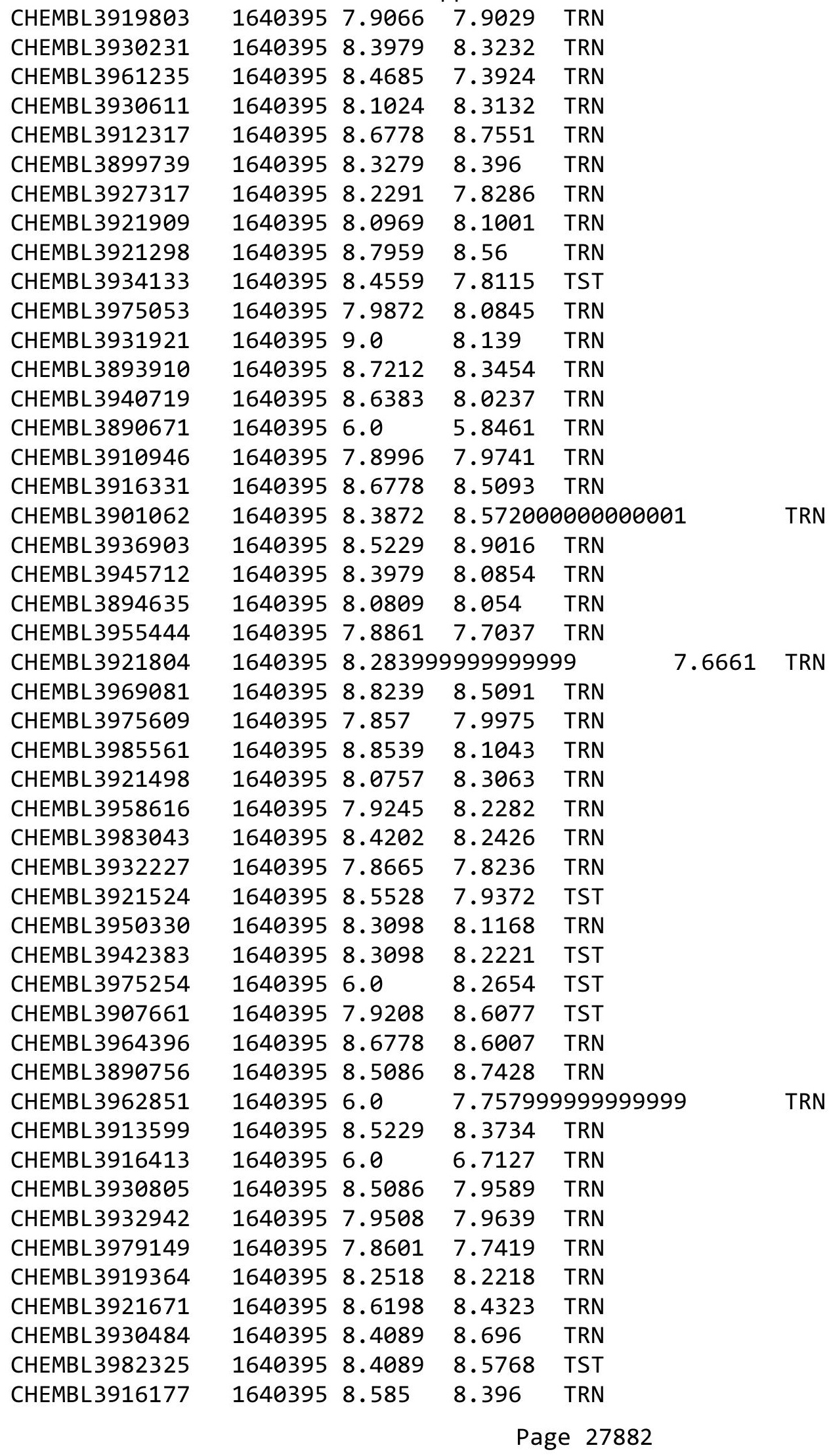


Supplemental Table S2.txt

\begin{tabular}{|c|c|c|c|c|}
\hline HEMB I & & .7212 & & \\
\hline HEMPI 2070711 & & 8.6576 & .0801 & \\
\hline 2 & & 208 & & \\
\hline HEMBL 391 & & 3565 & & Ne \\
\hline AEMBL3920819 & 395 & 355 & & \\
\hline HEMBL3955139 & 540395 & 7.7799 & 8932 & \\
\hline 31 & & & & \\
\hline AEMBL3S & & & & \\
\hline HEMBL 389 & 95 & 3872 & 7822 & \\
\hline HEMBL395 & 395 & 871 & .454 & \\
\hline HEMBL 388 & 64 & 8. & 8.7534 & \\
\hline IEMBL3C & 95 & & 5766 & \\
\hline AEMBL3S & & & & \\
\hline HEMBL39 & 64 & & 7.7892 & \\
\hline AEMBL39 & 54 & & .5499 & \\
\hline AEMBL393 & 04 & 6. & 1754 & \\
\hline HEMBL3S & 64 & & 1479 & \\
\hline HEMBL3\& & & & 5022 & \\
\hline HEMBL39 & & & 7.7681 & \\
\hline AEMBL3S & & & & $\mathrm{T}$ \\
\hline HEMBL= & 64 & & 68 & $\mathrm{IRIV}$ \\
\hline AEMBL: & & & 79 & ודת \\
\hline HEMBL & & 366 & 87 & \\
\hline HFMBI 30 & & 6 & 3756 & Tu \\
\hline AEMBL39 & & & & TRN \\
\hline HEMBL3S & 62 & & 103 & $\cdot$ \\
\hline HEMBL3 & 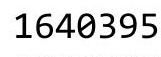 & & 992 & ST \\
\hline HFMBI 36 & 5 & 6 & 405 & \\
\hline HEMBL39 & & & & IRIN \\
\hline HEMBL 396 & 64 & & 465 & I RIV \\
\hline HEMBL3S & 62 & & 7181 & SI \\
\hline HEMBL & $54+2+2>$ & & 095 & ST \\
\hline HEMBL3 & & 8 & 193 & RN \\
\hline HEMBL 390 & 64 & & 6.9076 & IRN \\
\hline HEMBL3917913 & 64 & & 8.2965 & TRN \\
\hline HEMBL3 & $61+10$ & 6 & 5282 & $\Gamma \mathrm{RN}$ \\
\hline HFMRI $=2$ & 61 & & 292 & IST \\
\hline HEMBL3 & & & 122 & $\Gamma \mathrm{RN}$ \\
\hline HEMBL391 & ( & & 8.4707 & TST \\
\hline AEMBL39 & 64 & & 372 & $\Gamma \mathrm{RN}$ \\
\hline HEMBL3S & $64-2+2>0$ & 96 & 487 & \\
\hline CHEMBL 39 & & & 8.5649 & RN \\
\hline HEMBL39 & 95 & & 8.7744 & RN \\
\hline HEMBL 394 & 64 & 8.4685 & 8.3879 & TRN \\
\hline MPI 3 & & & 8.7207 & $\mathrm{~N}$ \\
\hline HEMBL 39 & 64 & & 7.4021 & \\
\hline CHEMBL 398 & & & 8.8304 & \\
\hline LHEMBL 3907387 & 1640395 & 8.4559 & 8.5462 & \\
\hline
\end{tabular}

Page 27883 
Supplemental Table S2.txt

\begin{tabular}{|c|c|c|c|c|}
\hline CHEMBL3960714 & 1640395 & 7.8327 & 8.0221 & TST \\
\hline CHEMBL3977528 & 1640395 & 8.4949 & 8.3806 & TRN \\
\hline CHEMBL3910861 & 1640395 & 7.71 & 7.8382 & TRN \\
\hline CHEMBL3985658 & 1640395 & 6.0 & 6.3622 & TRN \\
\hline CHEMBL3929214 & 1640395 & 8.8239 & 8.4591 & TRN \\
\hline CHEMBL3918091 & 1640395 & 8.6021 & 8.5677 & TRN \\
\hline CHEMBL3894325 & 1640395 & 8.9208 & 9.1282 & TRN \\
\hline CHEMBL3982186 & 1640395 & 6.0 & 6.0263 & TRN \\
\hline CHEMBL3986164 & 1640395 & 7.8297 & 8.3855 & TST \\
\hline CHEMBL3922545 & 1640395 & 8.7696 & 8.4699 & TRN \\
\hline CHEMBL3964637 & 1640395 & 8.5528 & 7.9777 & TST \\
\hline CHEMBL3898899 & 1640395 & 8.5686 & 8.5812 & TRN \\
\hline CHEMBL3920482 & 1640395 & 8.4559 & 8.7658 & TRN \\
\hline CHEMBL3915943 & 1640395 & 7.9957 & 8.2569 & TRN \\
\hline CHEMBL3973967 & 1640395 & 7.8729 & 8.2573 & TRN \\
\hline CHEMBL3972875 & 1640395 & 8.6383 & 8.2594 & TST \\
\hline CHEMBL3907463 & 1640395 & 8.3979 & 8.522 & TRN \\
\hline CHEMBL3933220 & 1640395 & 8.1487 & 7.9924 & TRN \\
\hline CHEMBL3929809 & 1640395 & 8.7212 & 8.7027 & TRN \\
\hline CHEMBL3946151 & 1640395 & 7.8041 & 8.1818 & TST \\
\hline CHEMBL3910788 & 1640395 & 9.0 & 8.7603 & TRN \\
\hline CHEMBL3979090 & 1640395 & 8.6198 & 8.4915 & TRN \\
\hline CHEMBL3949797 & 1640395 & 6.0 & 6.2248 & TRN \\
\hline CHEMBL3943030 & 1640395 & 8.585 & 8.4611 & TRN \\
\hline CHEMBL3958553 & 1640395 & 8.0177 & 8.4868 & TST \\
\hline CHEMBL3984669 & 1640395 & 8.0177 & 7.9855 & TRN \\
\hline CHEMBL3925504 & 1640395 & 8.3468 & 8.5295 & TRN \\
\hline CHEMBL3895062 & 1640395 & 8.4685 & 8.3516 & TST \\
\hline CHEMBL3942368 & 1640395 & 8.5086 & 8.5322 & TRN \\
\hline CHEMBL3927743 & 1640395 & 8.2007 & 8.5659 & TST \\
\hline CHEMBL3906868 & 1640395 & 6.0 & 7.07 & TRN \\
\hline CHEMBL3978080 & 1640395 & 6.0 & 6.8768 & TRN \\
\hline CHEMBL3909749 & 1640395 & 8.1024 & 7.6169 & TRN \\
\hline CHEMBL3926706 & 1640395 & 8.699 & 8.342 & TRN \\
\hline CHEMBL3944025 & 1640395 & 8.5229 & 7.9976 & TRN \\
\hline CHEMBL3970139 & 1640395 & 7.9431 & 8.3392 & TRN \\
\hline CHEMBL3944126 & 1640395 & 8.7212 & 8.9131 & TRN \\
\hline CHEMBL3913368 & 1640395 & 8.7959 & 8.3136 & TRN \\
\hline CHEMBL3973778 & 1640395 & 7.8477 & \multicolumn{2}{|c|}{8.033999999999999} \\
\hline CHEMBL3974154 & 1640395 & 8.4559 & 7.561 & TST \\
\hline CHEMBL3921623 & 1640395 & 8.301 & 8.1216 & TRN \\
\hline CHEMBL 3894977 & 1640395 & 8.2218 & 8.3088 & TRN \\
\hline CHEMBL3923977 & 1640395 & 8.2924 & 7.9958 & TST \\
\hline CHEMBL3904913 & 1640395 & 8.2757 & 7.876 & TRN \\
\hline CHEMBL3916085 & 1640395 & 8.6021 & \multicolumn{2}{|c|}{8.562999999999999} \\
\hline CHEMBL3960042 & 1640395 & 7.7799 & 6.7046 & TRN \\
\hline CHEMBL 3948840 & 1640395 & 8.1079 & 8.047 & TRN \\
\hline CHEMBL3931002 & 1640395 & 8.6383 & 8.4446 & TST \\
\hline
\end{tabular}


Supplemental Table S2.txt

\begin{tabular}{|c|c|c|c|c|c|}
\hline CHEMBL3954542 & 1640395 & 7.8416 & 8.7194 & TST & \\
\hline CHEMBL3970900 & 1640395 & 7.9788 & 7.3092 & TST & \\
\hline CHEMBL3938304 & 1640395 & 8.3098 & 8.536 & TRN & \\
\hline CHEMBL3893606 & 1640395 & 8.4815 & 7.6361 & TRN & \\
\hline CHEMBL3969630 & 1640395 & 8.1249 & 8.3499 & TRN & \\
\hline CHEMBL3947435 & 1640395 & 7.9872 & 7.7686 & TRN & \\
\hline CHEMBL3985083 & 1640395 & 8.4089 & 8.9472 & TST & \\
\hline CHEMBL3904774 & 1640395 & 8.6021 & 9.3204 & TRN & \\
\hline CHEMBL3919724 & 1640395 & 8.4685 & 8.8503 & TRN & \\
\hline CHEMBL3977107 & 1640395 & 8.3872 & 8.5154 & TRN & \\
\hline CHEMBL3906640 & 1640395 & 7.8827 & 7.1171 & TST & \\
\hline CHEMBL3984250 & 1640395 & 8.4318 & 7.8153 & TRN & \\
\hline CHEMBL3967272 & 1640395 & 8.1739 & 8.2152 & TRN & \\
\hline CHEMBL3911855 & 1640395 & 8.7959 & 8.04 & TRN & \\
\hline CHEMBL3904136 & 1640395 & 8.8539 & 8.3088 & TRN & \\
\hline CHEMBL3954117 & 1640395 & 8.7959 & 9.2356 & TST & \\
\hline CHEMBL3908786 & 1640395 & 8.2291 & 8.2681 & TST & \\
\hline CHEMBL3979121 & 1640395 & 8.0862 & 7.7154 & TST & \\
\hline CHEMBL3978710 & 1640395 & 8.3098 & 8.7298 & TRN & \\
\hline CHEMBL 3898245 & 1640395 & 8.3665 & 7.8431 & TST & \\
\hline CHEMBL3899111 & 1640395 & 8.4318 & 8.3857 & TRN & \\
\hline CHEMBL3896926 & 1640395 & 7.8153 & 7.5596 & TRN & \\
\hline CHEMBL3984144 & 1640395 & 8.8239 & 7.7204 & TRN & \\
\hline CHEMBL3899732 & 1640395 & 8.0506 & 8.2671 & TST & \\
\hline CHEMBL3963839 & 1640395 & 8.3279 & 8.3493 & TRN & \\
\hline CHEMBL3963776 & 1640395 & 8.0315 & 8.3886 & TRN & \\
\hline CHEMBL3891526 & 1640395 & 8.0044 & 8.4008 & TST & \\
\hline CHEMBL3951845 & 1640395 & 8.8239 & 8.6619 & TRN & \\
\hline CHEMBL3958699 & 1640395 & 8.4815 & 7.7696 & TRN & \\
\hline CHEMBL3948919 & 1640395 & 8.0458 & 8.2994 & TRN & \\
\hline CHEMBL3956057 & 1640395 & 8.3665 & 8.2983 & TRN & \\
\hline CHEMBL 3897707 & 1640395 & 8.0506 & 8.4032 & TST & \\
\hline CHEMBL3958925 & 1640395 & 8.3872 & 8.2884 & TRN & \\
\hline CHEMBL3925715 & 1640395 & 8.1549 & 7.643 & TRN & \\
\hline CHEMBL3947515 & 1640395 & 8.5686 & 8.5746 & TRN & \\
\hline CHEMBL3900923 & 1640395 & 6.0 & 7.7912 & TRN & \\
\hline CHEMBL3890901 & 1640395 & 8.6778 & 8.9402 & TRN & \\
\hline CHEMBL3926949 & 1640395 & 8.585 & 8.0259 & TRN & \\
\hline CHEMBL3949542 & 1640395 & 8.585 & 8.6503 & TRN & \\
\hline CHEMBL3975864 & 1640395 & 8.8539 & 8.8304 & TRN & \\
\hline CHEMBL3947516 & 1640395 & 8.7212 & 8.3544 & TRN & \\
\hline CHEMBL 3958424 & 1640395 & 8.3188 & 8.2535 & TRN & \\
\hline CHEMBL3944351 & 1640395 & 8.1739 & 8.34700 & 0000000001 & TRN \\
\hline CHEMBL3954291 & 1640395 & 8.1675 & 9.4205 & TST & \\
\hline CHEMBL3965150 & 1640395 & 8.699 & 8.4942 & TRN & \\
\hline CHEMBL3945316 & 1640395 & 8.1938 & 7.8491 & TRN & \\
\hline CHEMBL3916960 & 1640395 & 8.5086 & 8.0754 & TRN & \\
\hline CHEMBL3907969 & 1640395 & $7.7620 e$ & 30000000 & 8.0279 & TST \\
\hline
\end{tabular}


Supplemental Table S2.txt

\begin{tabular}{|c|c|c|c|c|}
\hline HEN & 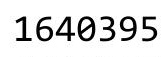 & .8861 & 8.7951 & \\
\hline 8389 & & 8.7212 & 8.4081 & \\
\hline 38 & & 706 & & \\
\hline HEMBL393 & & 2007 & 3122 & 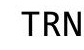 \\
\hline AEMBL3937513 & 395 & 7.9706 & 3184 & \\
\hline HEMBL3972570 & 640395 & 6.0 & 0474 & \\
\hline HEMBL396 & & 768 & 8583 & \\
\hline AFMBI 390 & & & 5578 & RN \\
\hline AEMBL3985780 & 95 & 9.0 & 9143 & \\
\hline HEMBL3973484 & 395 & 747 & 9838 & \\
\hline AEMBL3921401 & 64 & 655 & 5751 & \\
\hline IEMBL394 & 04 & 76 & 3319 & \\
\hline AEMBL39 & & & & \\
\hline HEMBL3907144 & 64 & & 5223 & \\
\hline HEMBL393 & 64 & 079 & 437 & \\
\hline AEMBL3906014 & 64 & 8 . & 904 & \\
\hline HEMBL397 & o & 96 & 3862 & \\
\hline HEMBL 398 & & & 953 & \\
\hline HEMBL3894985 & & 959 & 9554 & \\
\hline HEMBL398 & & 06 & 636 & \\
\hline HEIMBLSS & 64 & 96 & 462 & Niv \\
\hline HEMBL3S & & 68 & 942 & ודת \\
\hline HEMBL3\& & & 595 & 228 & \\
\hline 711 & & 6 . & 945 & \\
\hline HEMBL 394 & & 15 & & I RIV \\
\hline HEMBL 39 & 62 & 8. & 647 & | \\
\hline HEMBL3S & 62 & & 223 & ST \\
\hline HFMBI $3 c$ & 5 & 6. & 949 & RN \\
\hline HEMBL392 & & 8.2366 & & 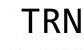 \\
\hline HEMBL3964745 & 64 & & 535 & I RIV \\
\hline HEMBL39 & 64 & & 319 & ST \\
\hline HEMBL3 & & 79 & 859 & ST \\
\hline HEMBL; & & 61 & 651 & $\mathrm{RN}$ \\
\hline HEMBL3933731 & 64 & & 1786 & IR \\
\hline HEMBL 3938159 & 64 & 308 & 2938 & TRN \\
\hline HEMBL39 & $6 \Delta$ & 327 & 356 & RN \\
\hline HFMRI 3 & P & 6 . & 301 & RN \\
\hline HEMBL3 & & & 085 & $\Gamma \mathrm{RN}$ \\
\hline HEMBL3913307 & 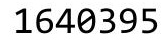 & 8.2676 & 1609 & TST \\
\hline HEMBL391 & 64 & 372 & 7281 & $\Gamma \mathrm{RN}$ \\
\hline HEMBL395 & 64 & 815 & 1703 & \\
\hline CHEMBL390 & & & 7875 & RIV \\
\hline HEMBL3970825 & 95 & 8.2924 & 8.0967 & RN \\
\hline AEMBL3964228 & 64 & 8.4559 & 3093 & TRN \\
\hline $1=2$ & & & 7835 & \\
\hline HEMBL 39 & & 279 & 0588 & \\
\hline CHEMBL3918132 & & .5686 & 8.2626 & \\
\hline CHEMBL3905782 & 1640395 & 7.9031 & 8.4418 & ГRN \\
\hline
\end{tabular}

Page 27886 
Supplemental Table S2.txt

\begin{tabular}{|c|c|c|c|c|}
\hline CHEMBL3976685 & 1640395 & 8.699 & 8.2155 & TST \\
\hline CHEMBL3939971 & 1640395 & 8.9208 & 9.3794 & TRN \\
\hline CHEMBL3903828 & 1640395 & 6.0 & 6.8586 & TRN \\
\hline CHEMBL3965267 & 1640395 & 8.7696 & 8.4467 & TRN \\
\hline CHEMBL 3901471 & 1640395 & 8.7447 & 8.2757 & TRN \\
\hline CHEMBL 3892868 & 1640395 & 8.3665 & 8.2442 & TRN \\
\hline CHEMBL3916358 & 1640395 & 8.2076 & 8.3668 & TRN \\
\hline CHEMBL3905839 & 1640395 & 7.8297 & 8.1662 & TRN \\
\hline CHEMBL3894101 & 1640395 & 8.041 & 6.8058 & TST \\
\hline CHEMBL 3978447 & 1640395 & 8.1805 & 7.6483 & TST \\
\hline CHEMBL 3922141 & 1640395 & 8.1249 & 7.9721 & TRN \\
\hline CHEMBL3913330 & 1640395 & 8.0 & 7.83899 & 99999999995 \\
\hline CHEMBL 3923561 & 1640395 & 8.7212 & 8.1463 & TRN \\
\hline CHEMBL3969303 & 1640395 & 6.0 & 6.0383 & TRN \\
\hline CHEMBL 3982472 & 1640395 & 8.6198 & 8.7779 & TRN \\
\hline CHEMBL 3925564 & 1640395 & 8.7696 & 8.3122 & TRN \\
\hline CHEMBL3976210 & 1640395 & 8.2147 & 7.84 & TST \\
\hline CHEMBL 3922192 & 1640395 & 8.2518 & 7.8686 & TRN \\
\hline CHEMBL 3973052 & 1640395 & 8.0757 & 7.9277 & TST \\
\hline CHEMBL3899639 & 1640395 & 7.6345 & 8.1381 & TRN \\
\hline CHEMBL3917015 & 1640395 & 8.8861 & 8.3277 & TST \\
\hline CHEMBL3932150 & 1640395 & 8.1487 & 8.4643 & TRN \\
\hline CHEMBL3953153 & 1640395 & 7.7959 & 6.7732 & TRN \\
\hline CHEMBL 3945364 & 1640395 & 8.8861 & 8.52799 & 9999999999 \\
\hline CHEMBL 3898650 & 1640395 & 8.0223 & 8.1877 & TRN \\
\hline CHEMBL 3897893 & 1640395 & 8.7447 & 8.6851 & TRN \\
\hline CHEMBL3921521 & 1640395 & 8.6778 & 8.5226 & TRN \\
\hline CHEMBL 3925280 & 1640395 & 8.2147 & 8.5615 & TRN \\
\hline CHEMBL3945757 & 1640395 & 8.6576 & 7.4339 & TST \\
\hline CHEMBL3924892 & 1640395 & 7.7352 & 8.2141 & TRN \\
\hline CHEMBL3948008 & 1640395 & 8.0 & 8.1117 & TRN \\
\hline CHEMBL3982117 & 1640395 & 8.3665 & 8.2367 & TRN \\
\hline CHEMBL 3959143 & 1640395 & 8.7447 & 8.6384 & TRN \\
\hline CHEMBL3891636 & 1640395 & 8.3188 & 7.7762 & TRN \\
\hline CHEMBL3945971 & 1640395 & 8.6021 & 8.4428 & TRN \\
\hline CHEMBL 3899443 & 1640395 & 7.8996 & 8.3153 & TRN \\
\hline CHEMBL3945662 & 1640395 & 7.9281 & 7.8207 & TRN \\
\hline CHEMBL 3971692 & 1640395 & 6.0 & 6.7588 & TRN \\
\hline CHEMBL3948470 & 1640395 & 7.8069 & 6.3466 & TRN \\
\hline CHEMBL3979646 & 1640395 & 8.1079 & 8.4589 & TRN \\
\hline CHEMBL 3908748 & 1640395 & 8.6198 & 8.8064 & TRN \\
\hline CHEMBL3923081 & 1640395 & 7.7645 & 7.7918 & TST \\
\hline CHEMBL3968003 & 1640395 & 8.301 & 8.1363 & TRN \\
\hline CHEMBL3898909 & 1640395 & 8.3468 & 7.5257 & TST \\
\hline CHEMBL3903389 & 1640395 & 8.6576 & 8.6094 & TRN \\
\hline CHEMBL 3894314 & 1640395 & 7.8153 & 7.5729 & TST \\
\hline CHEMBL3892469 & 1640395 & 8.1739 & 8.3866 & TST \\
\hline CHEMBL3900682 & 1640395 & 6.0 & 7.6968 & TRN \\
\hline
\end{tabular}


Supplemental Table S2.txt

\begin{tabular}{|c|c|c|c|c|}
\hline W & & & & \\
\hline & & 8.3872 & .0256 & \\
\hline SII & & & & \\
\hline AEMBL3977447 & & 1871 & & \\
\hline AEMBL3908695 & 395 & 2518 & . & \\
\hline HEMBL3894173 & 640395 & 8.1871 & .9988 & \\
\hline HEMBL3944682 & & 8861 & & \\
\hline IEMBL 3899651 & & & & RN \\
\hline AEMBL3955569 & 95 & 7878 & 3.343 & \\
\hline AEMBL3924238 & 395 & 8.2441 & 3.2948 & \\
\hline HEMBL3901404 & 64 & 8.9208 & 8.7 & \\
\hline IEMBL 3911443 & oc & 729 & .1585 & \\
\hline AEMBL3977923 & & & & \\
\hline HEMBL3939758 & 95 & 6 . & 6.0 & \\
\hline AEMBL3985506 & 64 & & & \\
\hline AEMBL3915841 & 64 & 6 & 96 & \\
\hline AEMBL3927958 & 64 & 28 & 93 & \\
\hline HEMBL 394 & & & 63 & \\
\hline AEMBL3942281 & & & 8.8192 & \\
\hline AEMBL389 & 64 & & & \\
\hline HEMIBL396 & 64 & 51 & 7.7 & Intv \\
\hline AEMBL39 & $\partial^{2}+2+2$ & & 96 & RN \\
\hline AEMBL39 & & & 45 & \\
\hline AFMRI 394 & & & & \\
\hline IEMBL 396 & & & & I RIV \\
\hline HEMBL 39 & 62 & & 72 & RN \\
\hline HEMBL3 & & & & וד \\
\hline HFMBI 36 & & & 52 & RN \\
\hline HEMBL 395 & & & & $\ln$ \\
\hline HEMBL3986533 & & 8. & 58 & IK \\
\hline HEMBL 395 & 64 & & 6.2 & RN \\
\hline HEMBL3 & & & 24 & RN \\
\hline AEMBL3 & & & 44 & 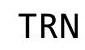 \\
\hline HEMBL3915905 & & & 8.9505 & is \\
\hline HEMBL3930748 & 64 & 15 & 7.9345 & TRN \\
\hline AEMBL39 & $6 \Delta+2-1$ & & 35 & ST \\
\hline HFMRI $=$ & & & & \\
\hline HEMBL 397 & & & 54 & IRN \\
\hline HEMBL3890249 & ( & 086 & .1924 & TRN \\
\hline IEMBL391 & 64 & & 42 & IRN \\
\hline HEMBL 397 & 64 & & 61 & \\
\hline HEMBL3958754 & & & 7.8221 & RN \\
\hline HEMBL3962443 & 164 & 6. & 8.2211 & TST \\
\hline AEMBL3897642 & 395 & 8.7212 & .0784 & TS \\
\hline $\mathrm{MB} \mid 3$ & & & 05 & TR \\
\hline HEMBL 39 & & & 3.4204 & \\
\hline CHEMBL 3910394 & & 8.3979 & 8.3954 & \\
\hline HEMBL3981512 & 1640395 & 8.6198 & 8.144 & IST \\
\hline
\end{tabular}

Page 27888 
Supplemental Table S2.txt

\begin{tabular}{|c|c|c|c|c|}
\hline CHEMBL3949459 & 1640395 & 8.1739 & 8.1295 & TRN \\
\hline CHEMBL3907110 & 1640395 & 6.0 & 6.4915 & TRN \\
\hline CHEMBL3925285 & 1640395 & 8.585 & 8.5122 & TRN \\
\hline CHEMBL3932139 & 1640395 & 8.3098 & 8.2996 & TRN \\
\hline CHEMBL3931009 & 1640395 & 8.3468 & 8.1747 & TRN \\
\hline CHEMBL3928568 & 1640395 & 8.6198 & 8.4709 & TRN \\
\hline CHEMBL3957076 & 1640395 & 8.4318 & 8.3301 & TRN \\
\hline CHEMBL 3947754 & 1640395 & 8.4437 & 8.4785 & TRN \\
\hline CHEMBL3911840 & 1640395 & 8.3565 & 8.5103 & TRN \\
\hline CHEMBL3985428 & 1640395 & 8.1675 & 8.3818 & TRN \\
\hline CHEMBL3951721 & 1640395 & 8.2757 & 8.7414 & TST \\
\hline CHEMBL3923198 & 1640395 & 8.4559 & 8.7176 & TRN \\
\hline CHEMBL 3952777 & 1640395 & 8.3872 & 7.9468 & TRN \\
\hline CHEMBL 3895223 & 1640395 & 8.7212 & 8.138 & TRN \\
\hline CHEMBL3933455 & 1640395 & 8.9586 & 8.1944 & TST \\
\hline CHEMBL3986395 & 1640395 & 7.9788 & 7.8097 & TRN \\
\hline CHEMBL3953652 & 1640395 & 7.8697 & 8.2924 & TST \\
\hline CHEMBL3901313 & 1640395 & 8.8861 & 8.721 & TRN \\
\hline CHEMBL3953324 & 1640395 & 8.0605 & 8.0164 & TST \\
\hline CHEMBL3895880 & 1640395 & 8.2757 & 8.6956 & TST \\
\hline CHEMBL3926478 & 1640395 & 8.585 & 8.5335 & TRN \\
\hline CHEMBL3914366 & 1640395 & 8.2518 & 8.004 & TST \\
\hline CHEMBL3944786 & 1640395 & 8.5229 & 7.6521 & TRN \\
\hline CHEMBL3933738 & 1640395 & 8.0132 & 7.9111 & TRN \\
\hline CHEMBL3934549 & 1640395 & 8.2291 & 8.519 & TST \\
\hline CHEMBL 3898438 & 1640395 & 8.2147 & 7.1329 & TRN \\
\hline CHEMBL3979501 & 1640395 & 8.3188 & 7.6809 & TST \\
\hline CHEMBL3911745 & 1640395 & 8.3372 & 7.1493 & TRN \\
\hline CHEMBL3896511 & 1640395 & 8.3665 & 8.7337 & TRN \\
\hline CHEMBL3909263 & 1640395 & 8.2076 & 8.1598 & TST \\
\hline CHEMBL3900811 & 1640395 & 8.1612 & 8.0513 & TST \\
\hline CHEMBL3955122 & 1640395 & 9.0458 & 8.8499 & TRN \\
\hline CHEMBL3949865 & 1640395 & 8.2757 & 7.9692 & TRN \\
\hline CHEMBL 3922334 & 1640395 & 8.4437 & 8.1582 & TRN \\
\hline CHEMBL3952217 & 1640395 & 6.0 & 6.1819 & TRN \\
\hline CHEMBL3910634 & 1640395 & 9.0 & 8.4018 & TRN \\
\hline CHEMBL 3943142 & 1640395 & 7.8268 & 7.8543 & TRN \\
\hline CHEMBL3950681 & 1640395 & 8.8539 & 8.1983 & TRN \\
\hline CHEMBL3960161 & 1640395 & 8.0969 & 8.4271 & TRN \\
\hline CHEMBL3938123 & 1640395 & 8.3188 & \multicolumn{2}{|c|}{8.017000000000001} \\
\hline CHEMBL3896950 & 1640395 & 7.9706 & 8.5982 & TST \\
\hline CHEMBL 3957487 & 1640395 & 7.9208 & 8.1898 & TRN \\
\hline CHEMBL3912015 & 1640395 & 6.0 & 7.6951 & TRN \\
\hline CHEMBL 3893544 & 1640395 & 7.9547 & 7.6762 & TST \\
\hline CHEMBL3918227 & 1640395 & 8.7696 & 8.5326 & TRN \\
\hline CHEMBL3937449 & 1640395 & 8.0915 & 7.7438 & TRN \\
\hline CHEMBL3951199 & 1640395 & 6.0 & 8.1839 & TST \\
\hline CHEMBL 3960922 & 1640395 & 7.9626 & 7.6673 & TRN \\
\hline
\end{tabular}

Page 27889 
Supplemental Table S2.txt

\begin{tabular}{|c|c|c|c|c|c|}
\hline CHEMBL 3976033 & 1640395 & 8.1549 & 8.0354 & TRN & \\
\hline CHEMBL3918010 & 1640395 & 8.585 & 9.17799 & 7999999999 & TST \\
\hline CHEMBL3946289 & 1640395 & 8.8861 & 8.6629 & TRN & \\
\hline CHEMBL 3906440 & 1640395 & 6.0 & 7.8274 & TRN & \\
\hline CHEMBL3986991 & 1640395 & 7.8761 & 8.3823 & TRN & \\
\hline CHEMBL3931392 & 1640395 & 8.585 & 7.9372 & TRN & \\
\hline CHEMBL3910792 & 1640395 & 6.0 & 7.0343 & TRN & \\
\hline CHEMBL3909960 & 1640395 & 8.6198 & 7.9721 & TRN & \\
\hline CHEMBL3914626 & 1640395 & 8.9208 & 8.7414 & TRN & \\
\hline CHEMBL3983233 & 1640395 & 8.3565 & 8.5083 & TRN & \\
\hline CHEMBL3964752 & 1640395 & 7.9626 & 8.2934 & TST & \\
\hline CHEMBL3962545 & 1640395 & 8.0 & 7.9136 & TST & \\
\hline CHEMBL3931897 & 1640395 & 8.4318 & 8.5904 & TRN & \\
\hline CHEMBL3930769 & 1640395 & 7.7721 & 8.1272 & TST & \\
\hline CHEMBL3956425 & 1640395 & 8.7696 & 8.9081 & TRN & \\
\hline CHEMBL3911139 & 1640395 & 8.3468 & 8.7095 & TRN & \\
\hline CHEMBL3918080 & 1640395 & 8.0655 & 8.7939 & TST & \\
\hline CHEMBL3921676 & 1640395 & 8.3565 & 8.4282 & TST & \\
\hline CHEMBL3914855 & 1640395 & 6.0 & 7.4414 & TRN & \\
\hline CHEMBL 3893244 & 1640395 & 8.3768 & 8.326 & TRN & \\
\hline CHEMBL3904178 & 1640395 & 7.7747 & 8.0524 & TST & \\
\hline CHEMBL3942019 & 1640395 & 6.0 & 6.6513 & TRN & \\
\hline CHEMBL 3902828 & 1640395 & 6.0 & 7.9601 & TRN & \\
\hline CHEMBL3945657 & 1640395 & 8.5376 & 8.4206 & TRN & \\
\hline CHEMBL3906816 & 1640395 & 8.6383 & 8.6014 & TRN & \\
\hline CHEMBL3944265 & 1640395 & 8.4949 & 8.1094 & TST & \\
\hline CHEMBL 3963235 & 1640395 & 8.1612 & 8.0725 & TRN & \\
\hline CHEMBL3947682 & 1640395 & 8.2596 & 8.4028 & TRN & \\
\hline CHEMBL3913033 & 1640395 & 7.8182 & 8.0944 & TRN & \\
\hline CHEMBL3969520 & 1640395 & 8.4437 & 8.3268 & TRN & \\
\hline CHEMBL3950419 & 1640395 & 8.4437 & 8.1771 & TST & \\
\hline CHEMBL 3904448 & 1640395 & 8.8239 & \multicolumn{2}{|c|}{8.488999999999999} & TRN \\
\hline CHEMBL 3933351 & 1640395 & 6.0 & 7.9284 & TRN & \\
\hline CHEMBL3940559 & 1640395 & 8.8239 & 8.8574 & TST & \\
\hline CHEMBL3945366 & 1640395 & 7.7696 & 8.2776 & TRN & \\
\hline CHEMBL3936270 & 1640395 & 7.7986 & 7.9306 & TST & \\
\hline CHEMBL 3927074 & 1640395 & 6.0 & 8.082 & TRN & \\
\hline CHEMBL3947291 & 1640395 & 8.699 & 8.3964 & TRN & \\
\hline CHEMBL3956207 & 1640395 & 8.2757 & 8.2338 & TRN & \\
\hline CHEMBL3965928 & 1640395 & 8.5528 & 8.5436 & TRN & \\
\hline CHEMBL 3898994 & 1640395 & 8.2076 & 7.6524 & TRN & \\
\hline CHEMBL 3889975 & 1640395 & 8.7447 & 8.5558 & TRN & \\
\hline CHEMBL3946552 & 1640395 & 8.6383 & 8.4769 & TRN & \\
\hline CHEMBL3890485 & 1640395 & 7.9508 & 7.8715 & TRN & \\
\hline CHEMBL 3942848 & 1640395 & 7.7122 & 7.7252 & TRN & \\
\hline CHEMBL 3961444 & 1640395 & 7.9666 & 7.4684 & TRN & \\
\hline CHEMBL3953510 & 1640395 & 8.1675 & 8.193 & TRN & \\
\hline CHEMBL3914088 & 1640395 & 7.6968 & 7.8137 & TST & \\
\hline
\end{tabular}

Page 27890 
Supplemental Table S2.txt

\begin{tabular}{|c|c|c|c|c|c|c|}
\hline CHEMBL3921381 & 1640395 & 8.4318 & 7.9313 & TRN & & \\
\hline CHEMBL3921034 & 1640395 & 8.6021 & 8.8688 & TRN & & \\
\hline CHEMBL3924106 & 1640395 & 7.8633 & 7.805 & TRN & & \\
\hline CHEMBL3924209 & 1640395 & 6.0 & 7.2969 & TST & & \\
\hline CHEMBL3931792 & 1640395 & 8.6383 & 8.4036 & TRN & & \\
\hline CHEMBL3938325 & 1640395 & 8.1739 & 8.2202 & TST & & \\
\hline CHEMBL3914423 & 1640395 & 6.0 & 6.4555 & TRN & & \\
\hline CHEMBL3928195 & 1640395 & 8.4815 & 8.453 & TRN & & \\
\hline CHEMBL3941116 & 1640395 & 8.0315 & 7.9298 & TRN & & \\
\hline CHEMBL3956976 & 1640395 & 8.2924 & 7.9809 & TRN & & \\
\hline CHEMBL3943293 & 1640395 & 8.6778 & 7.9128 & TRN & & \\
\hline CHEMBL3938824 & 1640395 & 8.4815 & 7.966 & TRN & & \\
\hline CHEMBL3986782 & 1640395 & 8.3468 & 7.7776 & TRN & & \\
\hline CHEMBL3938766 & 1640395 & 8.2076 & 8.3482 & TRN & & \\
\hline CHEMBL3978920 & 1640395 & 7.8477 & 8.0567 & TRN & & \\
\hline CHEMBL3923602 & 1640395 & 6.0 & 7.6078 & TRN & & \\
\hline CHEMBL3949946 & 1640395 & 8.3468 & 8.6435 & TRN & & \\
\hline CHEMBL3981918 & 1640395 & 8.7212 & 8.0613 & TST & & \\
\hline CHEMBL3922765 & 1640395 & 8.4949 & 7.9527 & TRN & & \\
\hline CHEMBL3971988 & 1640395 & 8.1549 & 6.9528 & TRN & & \\
\hline CHEMBL3952898 & 1640395 & 6.0 & 6.5758 & TRN & & \\
\hline CHEMBL3964003 & 1640395 & 8.2218 & 8.4342 & TST & & \\
\hline CHEMBL3892080 & 1640395 & 8.4437 & 8.195 & TRN & & \\
\hline CHEMBL3956735 & 1640395 & 8.5376 & 8.4511 & TRN & & \\
\hline CHEMBL3940327 & 1640395 & 8.1739 & 8.512 & TRN & & \\
\hline CHEMBL3925452 & 1640395 & 8.3872 & 8.2462 & TST & & \\
\hline CHEMBL3953139 & 1640395 & 7.7328 & 7.5674 & TST & & \\
\hline CHEMBL3912832 & 1640395 & 8.2757 & 7.8834 & TRN & & \\
\hline CHEMBL3940416 & 1640395 & 8.1249 & 7.9635 & TRN & & \\
\hline CHEMBL3961364 & 1640395 & 8.0915 & 7.2732 & TRN & & \\
\hline CHEMBL3902784 & 1640395 & 8.1871 & 8.2165 & TRN & & \\
\hline CHEMBL3912558 & 1640395 & 8.4815 & 8.4823 & TRN & & \\
\hline CHEMBL3919786 & 1640395 & 6.0 & 6.5541 & TST & & \\
\hline CHEMBL3922598 & 1640395 & 8.1367 & 7.9464 & TRN & & \\
\hline CHEMBL3965765 & 1640395 & 7.8539 & 7.6878 & TST & & \\
\hline CHEMBL3981248 & 1640395 & 8.1549 & 7.8118 & TRN & & \\
\hline CHEMBL3928275 & 1640395 & 8.1675 & 7.9727 & TRN & & \\
\hline CHEMBL3896676 & 1640395 & 7.75700 & 0000000 & 01 & 8.3554 & TRN \\
\hline CHEMBL 3900741 & 1640395 & 7.9355 & 7.7438 & TST & & \\
\hline CHEMBL3923865 & 1640395 & 8.5528 & 8.529 & TRN & & \\
\hline CHEMBL3978605 & 1640395 & 8.6778 & 8.5694 & TRN & & \\
\hline CHEMBL3916338 & 1640395 & 8.7959 & 8.5997 & TRN & & \\
\hline CHEMBL3975890 & 1640395 & 6.0 & 7.0892 & TRN & & \\
\hline CHEMBL 3949424 & 1640395 & 7.7077 & 7.6348 & TRN & & \\
\hline CHEMBL3896270 & 1640395 & 8.3872 & 7.726 & TRN & & \\
\hline CHEMBL3907139 & 1640395 & 8.28399 & 999999995 & 99 & 8.5449 & TST \\
\hline CHEMBL 3918207 & 1640395 & 8.6021 & 8.6217 & TRN & & \\
\hline CHEMBL3947585 & 1640395 & 8.0915 & 7.7851 & TST & & \\
\hline
\end{tabular}


Supplemental Table S2.txt

\begin{tabular}{|c|c|c|c|c|c|}
\hline CHEMBL3900998 & 1640395 & 8.7447 & 9.0698 & TRN & \\
\hline CHEMBL3901331 & 1640395 & 8.0362 & 9.001 & TST & \\
\hline CHEMBL3958605 & 1640395 & 7.8827 & 8.4027 & TST & \\
\hline CHEMBL 3890090 & 1640395 & 8.2291 & 7.8571 & TRN & \\
\hline CHEMBL 3966609 & 1640395 & 7.8327 & 8.7752 & TST & \\
\hline CHEMBL3971510 & 1640395 & 8.3979 & 8.411 & TRN & \\
\hline CHEMBL3937950 & 1640395 & 8.1805 & 8.4009 & TRN & \\
\hline CHEMBL3970494 & 1640395 & 7.82100 & 300000000 & 8.2217 & TST \\
\hline CHEMBL3932579 & 1640395 & 8.0809 & 8.1736 & TRN & \\
\hline CHEMBL 3982704 & 1640395 & 6.0 & 6.957999 & 9999999999 & TRI \\
\hline CHEMBL3949889 & 1640395 & 8.5528 & 8.234 & TRN & \\
\hline CHEMBL3932666 & 1640395 & 8.5376 & 8.1009 & TRN & \\
\hline CHEMBL3908153 & 1640395 & 8.8239 & 8.7624 & TRN & \\
\hline CHEMBL3962078 & 1640395 & 7.8697 & 8.059 & TRN & \\
\hline CHEMBL 3953618 & 1640395 & 8.585 & 7.9992 & TST & \\
\hline CHEMBL 3898036 & 1640395 & 7.8416 & 8.1229 & TRN & \\
\hline CHEMBL3966110 & 1640395 & 8.2924 & 7.9431 & TST & \\
\hline CHEMBL 3903800 & 1640395 & 8.5528 & 9.181000 & 0000000001 & \\
\hline CHEMBL 3949690 & 1640395 & 8.3279 & 7.8786 & TRN & \\
\hline CHEMBL 3924758 & 1640395 & 8.7696 & 8.2707 & TST & \\
\hline CHEMBL3906410 & 1640395 & 8.4815 & 8.4906 & TRN & \\
\hline CHEMBL3937122 & 1640395 & 6.0 & 6.3872 & TRN & \\
\hline CHEMBL3952321 & 1640395 & 8.585 & 9.0222 & TRN & \\
\hline CHEMBL 3930757 & 1640395 & 7.8697 & 8.1129 & TST & \\
\hline CHEMBL 3982521 & 1640395 & 8.2441 & 8.4772 & TRN & \\
\hline CHEMBL3965756 & 1640395 & 7.7959 & 8.3031 & TST & \\
\hline CHEMBL3974716 & 1640395 & 8.5528 & 8.6672 & TRN & \\
\hline CHEMBL3891376 & 1640395 & 8.2147 & 8.2432 & TST & \\
\hline CHEMBL3954007 & 1640395 & 8.1487 & 8.4747 & TRN & \\
\hline CHEMBL3983419 & 1640395 & 8.2007 & 8.256 & TRN & \\
\hline CHEMBL3984391 & 1640395 & 8.8239 & 8.6422 & TRN & \\
\hline CHEMBL3910109 & 1640395 & 8.4685 & 8.3875 & TST & \\
\hline CHEMBL3903294 & 1640395 & 8.5686 & 7.7878 & TST & \\
\hline CHEMBL 3924274 & 1640395 & 8.3468 & 8.2147 & TRN & \\
\hline CHEMBL 3927607 & 1640395 & 8.4815 & 7.9494 & TRN & \\
\hline CHEMBL3914863 & 1640395 & 6.0 & 7.0495 & TRN & \\
\hline CHEMBL 3945719 & 1640395 & 8.7212 & 8.8514 & TRN & \\
\hline CHEMBL 3977494 & 1640395 & 8.699 & 8.3269 & TST & \\
\hline CHEMBL 3945681 & 1640395 & 8.7447 & 8.6998 & TRN & \\
\hline CHEMBL 3902044 & 1640395 & 7.9431 & \multicolumn{2}{|c|}{7.742000000000001} & TRN \\
\hline CHEMBL 3931480 & 1640395 & 8.1675 & 8.4172 & TST & \\
\hline CHEMBL 3980604 & 1640395 & 8.4685 & 8.2608 & TST & \\
\hline CHEMBL 3895603 & 1640395 & 8.7212 & 8.1336 & TRN & \\
\hline CHEMBL 3974591 & 1640395 & 6.0 & 6.8179 & TRN & \\
\hline CHEMBL 3984056 & 1640395 & 8.0362 & 7.8067 & TRN & \\
\hline CHEMBL 3914563 & 1640395 & 8.5686 & 8.7054 & TRN & \\
\hline CHEMBL 3904661 & 1640395 & 6.0 & 6.3868 & TRN & \\
\hline CHEMBL 3956279 & 1640395 & 7.8297 & 7.9846 & TRN & \\
\hline
\end{tabular}

Page 27892 
Supplemental Table S2.txt

\begin{tabular}{|c|c|c|c|c|}
\hline CHEMBL3923585 & 1640395 & 8.6021 & 8.2771 & TRN \\
\hline CHEMBL3961524 & 1640395 & 8.0362 & 7.9982 & TST \\
\hline CHEMBL 3944259 & 1640395 & 8.28399 & 99999999 & 8.5076 \\
\hline CHEMBL 3936231 & 1640395 & 8.7447 & 8.8191 & TST \\
\hline CHEMBL 3899030 & 1640395 & 8.4815 & 6.881 & TST \\
\hline CHEMBL 3969084 & 1640395 & 7.9281 & 8.2 & TRN \\
\hline CHEMBL3970854 & 1640395 & 8.7696 & 8.5659 & TRN \\
\hline CHEMBL 3963368 & 1640395 & 8.7959 & 8.3268 & TRN \\
\hline CHEMBL 252377 & 459936 & 6.9393 & 6.6674 & TST \\
\hline CHEMBL 253192 & 459936 & 7.6778 & 7.6834 & TRN \\
\hline CHEMBL400186 & 459936 & 6.4647 & 6.4525 & TRN \\
\hline CHEMBL398709 & 459936 & 7.5686 & 7.5727 & TRN \\
\hline CHEMBL252376 & 459936 & 6.8356 & 6.8419 & TRN \\
\hline CHEMBL253836 & 459936 & 7.4949 & 7.4949 & TRN \\
\hline CHEMBL427716 & 459936 & 7.4089 & 7.4187 & TRN \\
\hline CHEMBL 252577 & 459936 & 6.6536 & 6.6454 & TRN \\
\hline CHEMBL253617 & 459936 & 6.8962 & 6.9 & TRN \\
\hline CHEMBL252983 & 459936 & 5.58 & 5.5852 & TRN \\
\hline CHEMBL 254248 & 459936 & 7.6576 & 7.6667 & TRN \\
\hline CHEMBL 399732 & 459936 & 5.7799 & 5.7714 & TRN \\
\hline CHEMBL401370 & 459936 & 7.1308 & 7.1352 & TRN \\
\hline CHEMBL254458 & 459936 & 7.4559 & 7.4514 & TRN \\
\hline CHEMBL 254042 & 459936 & 7.699 & 7.6835 & TRN \\
\hline CHEMBL399530 & 459936 & 6.5528 & 7.9043 & TST \\
\hline CHEMBL 254043 & 459936 & 7.585 & 7.58799 & \\
\hline CHEMBL428236 & 459936 & 7.4559 & 7.45 & TRN \\
\hline CHEMBL 253618 & 459936 & 6.6216 & 6.6293 & TRN \\
\hline CHEMBL428763 & 459936 & 7.2441 & 7.0716 & TST \\
\hline CHEMBL254249 & 459936 & 7.8539 & 7.8474 & TRN \\
\hline CHEMBL 252124 & 459936 & 7.5528 & 7.5484 & TRN \\
\hline CHEMBL 254457 & 459936 & 7.4437 & 7.4259 & TRN \\
\hline CHEMBL252165 & 459936 & 8.2218 & 8.2253 & TRN \\
\hline CHEMBL 254037 & 459936 & 6.5884 & 6.886 & TST \\
\hline CHEMBL 253401 & 459936 & 7.5528 & 7.5519 & TRN \\
\hline CHEMBL429841 & 459936 & 6.0391 & 6.0422 & TRN \\
\hline CHEMBL253616 & 459936 & 7.7447 & 7.7422 & TRN \\
\hline CHEMBL429307 & 459936 & 6.6364 & 6.6361 & TRN \\
\hline CHEMBL399583 & 459936 & 8.0969 & 8.0916 & TRN \\
\hline CHEMBL253193 & 459936 & 7.8539 & 7.8585 & TRN \\
\hline CHEMBL 365617 & 459936 & 7.6021 & 7.6058 & TRN \\
\hline CHEMBL438695 & 459936 & 7.8239 & 7.8245 & TRN \\
\hline CHEMBL 252779 & 459936 & 6.0 & 6.0033 & TRN \\
\hline CHEMBL437015 & 459936 & 7.4089 & 7.4092 & TRN \\
\hline CHEMBL438873 & 459936 & 7.585 & 7.6113 & TRN \\
\hline CHEMBL 251974 & 459936 & 6.2218 & 7.0595 & TST \\
\hline CHEMBL400778 & 459936 & 7.8539 & 7.8453 & TRN \\
\hline CHEMBL 253400 & 459936 & 7.7212 & 7.7221 & TRN \\
\hline CHEMBL 398710 & 459936 & 6.8477 & 6.841 & TRN \\
\hline
\end{tabular}




\begin{tabular}{|c|c|c|c|c|}
\hline & & & plemen & \\
\hline CHEMBL252329 & 459936 & 5.8069 & 5.8087 & TRN \\
\hline CHEMBL 252780 & 459936 & 6.3655 & 6.3691 & TRN \\
\hline CHEMBL399980 & 459936 & 7.4089 & 7.4138 & TRN \\
\hline CHEMBL253399 & 459936 & 7.1938 & 7.1862 & TRN \\
\hline CHEMBL 252328 & 459936 & 6.2676 & 7.1432 & TST \\
\hline CHEMBL 252576 & 459936 & 7.4318 & 7.6953 & TST \\
\hline CHEMBL253185 & 459936 & 7.9586 & 8.1393 & TST \\
\hline CHEMBL399531 & 459936 & 6.1379 & 6.2981 & TST \\
\hline CHEMBL 253837 & 459936 & 7.8861 & 7.1528 & TST \\
\hline CHEMBL 252370 & 459936 & 8.2218 & 8.5703 & TST \\
\hline CHEMBL 252984 & 459936 & 5.8894 & 6.2422 & TST \\
\hline CHEMBL400187 & 459936 & 7.5376 & 7.6154 & TST \\
\hline CHEMBL398346 & 459936 & 7.6778 & 7.6957 & TST \\
\hline CHEMBL1359614 & 809424 & 5.2487 & 5.2603 & TRN \\
\hline CHEMBL1364192 & 809424 & 5.4089 & 5.4452 & TRN \\
\hline CHEMBL1364175 & 809424 & 5.5751 & 5.5923 & TRN \\
\hline CHEMBL1314093 & 809424 & 6.1574 & 6.1226 & TRN \\
\hline CHEMBL1466912 & 809424 & 5.3862 & 5.3781 & TRN \\
\hline CHEMBL1484595 & 809424 & 5.52 & 5.4064 & TST \\
\hline CHEMBL1433062 & 809424 & 6.0794 & 6.0291 & TRN \\
\hline CHEMBL1467623 & 809424 & 5.7773 & 5.7642 & TRN \\
\hline CHEMBL1971786 & 809424 & 4.6635 & 4.6108 & TRN \\
\hline CHEMBL1405203 & 809424 & 6.0259 & 5.8887 & TRN \\
\hline CHEMBL1964442 & 809424 & 5.8097 & 5.8313 & TRN \\
\hline CHEMBL1331791 & 809424 & 4.618 & 4.6279 & TRN \\
\hline CHEMBL1993173 & 809424 & 5.6108 & 5.5324 & TRN \\
\hline CHEMBL1438892 & 809424 & 5.6108 & 5.6515 & TRN \\
\hline CHEMBL1976599 & 809424 & 5.6234 & 5.6222 & TRN \\
\hline CHEMBL1331139 & 809424 & 6.0013 & 5.974 & TRN \\
\hline CHEMBL1344075 & 809424 & 6.0283 & 6.0569 & TRN \\
\hline CHEMBL1408579 & 809424 & 5.9508 & 5.974 & TRN \\
\hline CHEMBL1991440 & 809424 & 5.3872 & 5.3778 & TRN \\
\hline CHEMBL1470628 & 809424 & 5.8665 & 5.8538 & TRN \\
\hline CHEMBL1721094 & 809424 & 5.5817 & 5.5489 & TRN \\
\hline CHEMBL1360394 & 809424 & 5.3063 & 5.3032 & TRN \\
\hline CHEMBL1434855 & 809424 & 5.5935 & 5.6092 & TRN \\
\hline CHEMBL1370165 & 809424 & 6.4522 & 6.4538 & TRN \\
\hline CHEMBL1509369 & 809424 & 5.1445 & 5.1573 & TRN \\
\hline CHEMBL1973855 & 809424 & 5.1798 & 5.1591 & TRN \\
\hline CHEMBL1345966 & 809424 & 5.2874 & 5.2681 & TRN \\
\hline CHEMBL1540317 & 809424 & 6.2464 & 6.2498 & TRN \\
\hline CHEMBL1410244 & 809424 & 6.4672 & 6.4977 & TRN \\
\hline CHEMBL1580036 & 809424 & 5.9872 & 6.0013 & TRN \\
\hline CHEMBL1383966 & 809424 & 5.5229 & 5.5533 & TRN \\
\hline CHEMBL1505300 & 809424 & 5.9172 & 5.9497 & TRN \\
\hline CHEMBL1971015 & 809424 & 5.6162 & 5.5831 & TRN \\
\hline CHEMBL1385949 & 809424 & 6.567 & 6.5459 & TRN \\
\hline CHEMBL1304345 & 809424 & 5.7423 & 5.7561 & TRN \\
\hline
\end{tabular}




\begin{tabular}{|c|c|c|c|c|c|c|}
\hline & & \multicolumn{5}{|c|}{ Supplemental Table S2.txt } \\
\hline CHEMBL1367604 & 809424 & 5.8477 & 5.8613 & TRN & & \\
\hline CHEMBL1893949 & 809424 & 5.5114 & 5.4982 & TRN & & \\
\hline CHEMBL1412602 & 809424 & 5.5129 & 5.1256 & TST & & \\
\hline CHEMBL1331149 & 809424 & 6.466 & 6.449 & TRN & & \\
\hline CHEMBL1982391 & 809424 & 5.4685 & 5.4839 & TRN & & \\
\hline CHEMBL1966746 & 809424 & 5.5171 & 5.5323 & TRN & & \\
\hline CHEMBL1976414 & 809424 & 5.5143 & \multicolumn{3}{|c|}{5.542000000000001} & TRN \\
\hline CHEMBL1343331 & 809424 & \multicolumn{3}{|c|}{4.9830000000000005} & 5.0008 & TRN \\
\hline CHEMBL1724282 & 809424 & 6.2644 & 6.2064 & TRN & & \\
\hline CHEMBL1984990 & 809424 & 4.8069 & 4.7988 & TRN & & \\
\hline CHEMBL1965710 & 809424 & 4.8508 & 4.8392 & TRN & & \\
\hline CHEMBL1478082 & 809424 & 6.1085 & 6.0982 & TRN & & \\
\hline CHEMBL1518926 & 809424 & 5.5072 & 5.485 & TRN & & \\
\hline CHEMBL1528944 & 809424 & 5.9101 & 5.5218 & TST & & \\
\hline CHEMBL1423213 & 809424 & 4.2848 & 4.2465 & TRN & & \\
\hline CHEMBL1991021 & 809424 & 5.7328 & 5.7059 & TRN & & \\
\hline CHEMBL1456747 & 809424 & 5.4921 & 5.4493 & TST & & \\
\hline CHEMBL1417141 & 809424 & 5.4342 & 5.5278 & TRN & & \\
\hline CHEMBL1533277 & 809424 & 5.3391 & 5.3485 & TRN & & \\
\hline CHEMBL1353918 & 809424 & 6.4647 & 6.4509 & TRN & & \\
\hline CHEMBL1271266 & 809424 & 6.3143 & 6.3031 & TRN & & \\
\hline CHEMBL1489399 & 809424 & 6.1308 & 6.1234 & TRN & & \\
\hline CHEMBL1714422 & 809424 & 5.6038 & 5.6105 & TRN & & \\
\hline CHEMBL1985932 & 809424 & 5.3197 & 5.3574 & TRN & & \\
\hline CHEMBL1608180 & 809424 & 5.7905 & 5.7661 & TRN & & \\
\hline CHEMBL1986392 & 809424 & 5.056 & 5.0644 & TRN & & \\
\hline CHEMBL1731009 & 809424 & 5.8239 & 5.7915 & TRN & & \\
\hline CHEMBL1569105 & 809424 & 5.8633 & 5.8439 & TRN & & \\
\hline CHEMBL1461216 & 809424 & 6.2933 & 6.322 & TRN & & \\
\hline CHEMBL1982044 & 809424 & 5.6402 & 5.6251 & TRN & & \\
\hline CHEMBL1586977 & 809424 & 4.5702 & 4.5884 & TRN & & \\
\hline CHEMBL1993643 & 809424 & 5.3696 & 5.3699 & TRN & & \\
\hline CHEMBL1340607 & 809424 & 6.1427 & 6.0223 & TRN & & \\
\hline CHEMBL1725497 & 809424 & 5.3925 & 5.4024 & TRN & & \\
\hline CHEMBL1672291 & 809424 & 5.52 & 5.5153 & TRN & & \\
\hline CHEMBL1426299 & 809424 & 6.4698 & 6.29 & TRN & & \\
\hline CHEMBL1480960 & 809424 & 5.2676 & 5.2449 & TRN & & \\
\hline CHEMBL1302298 & 809424 & 5.1831 & 5.1868 & TRN & & \\
\hline CHEMBL1477633 & 809424 & 5.4949 & 5.4515 & TRN & & \\
\hline CHEMBL1383849 & 809424 & 5.1605 & 5.1448 & TRN & & \\
\hline CHEMBL1407021 & 809424 & 4.9666 & 4.9868 & TRN & & \\
\hline CHEMBL1304265 & 809424 & 5.3716 & 5.3834 & TRN & & \\
\hline CHEMBL1893914 & 809424 & 5.5045 & 5.5135 & TRN & & \\
\hline CHEMBL1485717 & 809424 & 6.0915 & 6.2193 & TRN & & \\
\hline CHEMBL1535692 & 809424 & 5.4089 & 5.4058 & TRN & & \\
\hline CHEMBL1595181 & 809424 & 5.8069 & 6.0224 & TST & & \\
\hline CHEMBL1502703 & 809424 & 5.5702 & 5.9427 & TST & & \\
\hline CHEMBL1733383 & 809424 & 5.1759 & 5.1611 & TRN & & \\
\hline
\end{tabular}


Supplemental Table S2.txt

\begin{tabular}{|c|c|c|c|c|c|}
\hline CHEMBL1314584 & 809424 & 6.0947 & 6.1116 & TRN & \\
\hline CHEMBL1605157 & 809424 & 5.75200 & 00000000 & & 5.756 \\
\hline CHEMBL1334491 & 809424 & 5.9872 & 6.0159 & TRN & \\
\hline CHEMBL1412803 & 809424 & 5.5114 & 5.42 & TST & \\
\hline CHEMBL1489711 & 809424 & 5.2449 & 5.2543 & TRN & \\
\hline CHEMBL1445488 & 809424 & 6.2604 & 5.6473 & TST & \\
\hline CHEMBL1537922 & 809424 & 6.091 & 6.0772 & TRN & \\
\hline CHEMBL1405311 & 809424 & 5.6402 & 5.6222 & TRN & \\
\hline CHEMBL1463248 & 809424 & 6.7878 & 6.8126 & TRN & \\
\hline CHEMBL1511981 & 809424 & 5.8962 & 5.91200 & 0000000001 & \\
\hline CHEMBL1432675 & 809424 & 5.9666 & 5.944 & TRN & \\
\hline CHEMBL1421470 & 809424 & 6.3028 & 6.3314 & TRN & \\
\hline CHEMBL1224683 & 809424 & 6.1433 & 6.1188 & TRN & \\
\hline CHEMBL1329712 & 809424 & 6.1152 & 6.0997 & TRN & \\
\hline CHEMBL1330962 & 809424 & 4.5719 & 4.5742 & TRN & \\
\hline CHEMBL1721577 & 809424 & 5.1096 & 5.5505 & TST & \\
\hline CHEMBL220259 & 809424 & 5.4647 & 5.511 & TRN & \\
\hline CHEMBL1453902 & 809424 & 5.8827 & 5.8798 & TRN & \\
\hline CHEMBL1566674 & 809424 & 5.3979 & 5.3914 & TRN & \\
\hline CHEMBL1387238 & 809424 & 5.5031 & 5.4815 & TRN & \\
\hline CHEMBL1419452 & 809424 & 5.3788 & 5.4134 & TRN & \\
\hline CHEMBL1381413 & 809424 & 6.4647 & 6.5067 & TRN & \\
\hline CHEMBL1528986 & 809424 & 5.6038 & 5.6234 & TRN & \\
\hline CHEMBL1303831 & 809424 & 4.4157 & 4.363 & TRN & \\
\hline CHEMBL1487101 & 809424 & 5.8861 & 6.0019 & TRN & \\
\hline CHEMBL1550032 & 809424 & 5.8069 & 5.7503 & TRN & \\
\hline CHEMBL1429265 & 809424 & 5.4634 & 5.433 & TRN & \\
\hline CHEMBL1545441 & 809424 & 6.1226 & 6.1254 & TRN & \\
\hline CHEMBL1585855 & 809424 & 5.3363 & 5.374 & TRN & \\
\hline CHEMBL1349800 & 809424 & 5.9066 & 6.1077 & TST & \\
\hline CHEMBL1406679 & 809424 & 5.1537 & 5.1652 & TRN & \\
\hline CHEMBL1996666 & 809424 & 5.7144 & 5.6711 & TRN & \\
\hline CHEMBL1460292 & 809424 & 3.0969 & 3.102 & TRN & \\
\hline CHEMBL3145017 & 809424 & 5.4437 & 5.4521 & TRN & \\
\hline CHEMBL1301519 & 809424 & 5.6696 & 5.6839 & TRN & \\
\hline CHEMBL1531641 & 809424 & 5.2204 & 5.246 & TRN & \\
\hline CHEMBL1888077 & 809424 & 6.0329 & 5.5388 & TST & \\
\hline CHEMBL1597485 & 809424 & 5.8794 & 5.888 & TRN & \\
\hline CHEMBL1584150 & 809424 & 5.6038 & 5.9718 & TST & \\
\hline CHEMBL1888617 & 809424 & 5.308 & 5.3629 & TRN & \\
\hline CHEMBL1733061 & 809424 & 5.8962 & 6.5586 & TST & \\
\hline CHEMBL358290 & 809424 & 5.4989 & 5.4858 & TRN & \\
\hline CHEMBL1594597 & 809424 & 4.5952 & 4.9443 & TST & \\
\hline CHEMBL1569991 & 809424 & 6.2441 & 6.5803 & TST & \\
\hline CHEMBL1350887 & 809424 & 6.1451 & 6.1511 & TRN & \\
\hline CHEMBL1993711 & 809424 & 5.4112 & 5.4093 & TRN & \\
\hline CHEMBL1735536 & 809424 & 5.8297 & 5.4988 & TST & \\
\hline CHEMBL1430499 & 809424 & 5.3655 & 5.3872 & TRN & \\
\hline
\end{tabular}

Page 27896 


\begin{tabular}{|c|c|c|c|c|c|}
\hline & & & Premertes & & \\
\hline CHEMBL1540065 & 809424 & 6.301 & 6.347 & TRN & \\
\hline CHEMBL1506538 & 809424 & 5.9508 & 6.0537 & TRN & \\
\hline CHEMBL1308781 & 809424 & 4.1343 & 4.1644 & TRN & \\
\hline CHEMBL1517266 & 809424 & 5.2967 & 5.3058 & TRN & \\
\hline CHEMBL1451261 & 809424 & 5.7167 & 5.734 & TRN & \\
\hline CHEMBL1504939 & 809424 & 6.4134 & 6.3708 & TRN & \\
\hline CHEMBL1529185 & 809424 & 5.8794 & 5.88299 & 9999999999 & TRN \\
\hline CHEMBL1398814 & 809424 & 5.3372 & 5.3789 & TRN & \\
\hline CHEMBL1973036 & 809424 & 5.1215 & 5.1249 & TST & \\
\hline CHEMBL1500616 & 809424 & 5.5186 & 5.4796 & TST & \\
\hline CHEMBL1523808 & 809424 & 5.1805 & 5.3571 & TST & \\
\hline CHEMBL1586360 & 809424 & 5.9431 & 6.0603 & TST & \\
\hline CHEMBL1985091 & 809424 & 5.2984 & 5.2304 & TST & \\
\hline CHEMBL1515727 & 809424 & 5.1791 & 5.8069 & TST & \\
\hline CHEMBL1421970 & 809424 & 6.5058 & 6.3623 & TST & \\
\hline CHEMBL1875123 & 809424 & 5.2993 & 5.4708 & TST & \\
\hline CHEMBL1996139 & 809424 & 5.5467 & 5.206 & TST & \\
\hline CHEMBL1898589 & 809424 & 5.7011 & 5.49299 & 9999999999 & TST \\
\hline CHEMBL1547640 & 809424 & 5.3645 & 5.3872 & TST & \\
\hline CHEMBL1564440 & 809424 & 5.5361 & 5.7296 & TST & \\
\hline CHEMBL1381758 & 809424 & 5.8894 & 6.0746 & TST & \\
\hline CHEMBL1506021 & 809424 & 5.4535 & 4.9672 & TST & \\
\hline CHEMBL1503182 & 809424 & 5.82100 & 00000000 & 6.1929 & TST \\
\hline CHEMBL1529345 & 809424 & 5.3696 & 5.1261 & TST & \\
\hline CHEMBL1368444 & 809424 & 5.4306 & 5.3424 & TST & \\
\hline CHEMBL1407203 & 809424 & 5.8962 & 5.8879 & TST & \\
\hline CHEMBL1971404 & 809424 & 5.8665 & 5.6369 & TST & \\
\hline CHEMBL1991426 & 809424 & 5.5421 & 5.7298 & TST & \\
\hline CHEMBL1986343 & 809424 & 5.9136 & 5.2485 & TST & \\
\hline CHEMBL1487426 & 809424 & 3.0969 & 3.8797 & TST & \\
\hline CHEMBL1608642 & 809424 & 6.4802 & 6.2505 & TST & \\
\hline CHEMBL1310336 & 809424 & 5.5638 & 5.7884 & TST & \\
\hline CHEMBL1558648 & 809424 & 5.9872 & 6.229 & TST & \\
\hline CHEMBL1460464 & 809424 & 4.1314 & 3.99399 & 99999999998 & TST \\
\hline CHEMBL3314908 & 1452895 & 5.644 & 5.5535 & TRN & \\
\hline CHEMBL3314902 & 1452895 & 6.0255 & 5.84 & TRN & \\
\hline CHEMBL3314872 & 1452895 & 6.0186 & 5.6404 & TRN & \\
\hline CHEMBL3314878 & 1452895 & 5.0462 & 2.5399 & TST & \\
\hline CHEMBL3314909 & 1452895 & 4.8729 & 4.9033 & TRN & \\
\hline CHEMBL3314876 & 1452895 & 6.7328 & 6.9388 & TRN & \\
\hline CHEMBL3314929 & 1452895 & 4.5214 & 4.3725 & TRN & \\
\hline CHEMBL3314887 & 1452895 & 6.0097 & 5.7573 & TRN & \\
\hline CHEMBL3314895 & 1452895 & 6.0269 & 6.1302 & TRN & \\
\hline CHEMBL3314911 & 1452895 & 6.8508 & 6.6203 & TRN & \\
\hline CHEMBL3314918 & 1452895 & 5.3478 & 5.4338 & TRN & \\
\hline CHEMBL3314896 & 1452895 & 5.8729 & 6.0984 & TRN & \\
\hline CHEMBL 3314888 & 1452895 & 6.7905 & 6.4745 & TRN & \\
\hline CHEMBL3314884 & 1452895 & 4.8962 & 3.4094 & TST & \\
\hline
\end{tabular}


Supplemental Table S2.txt

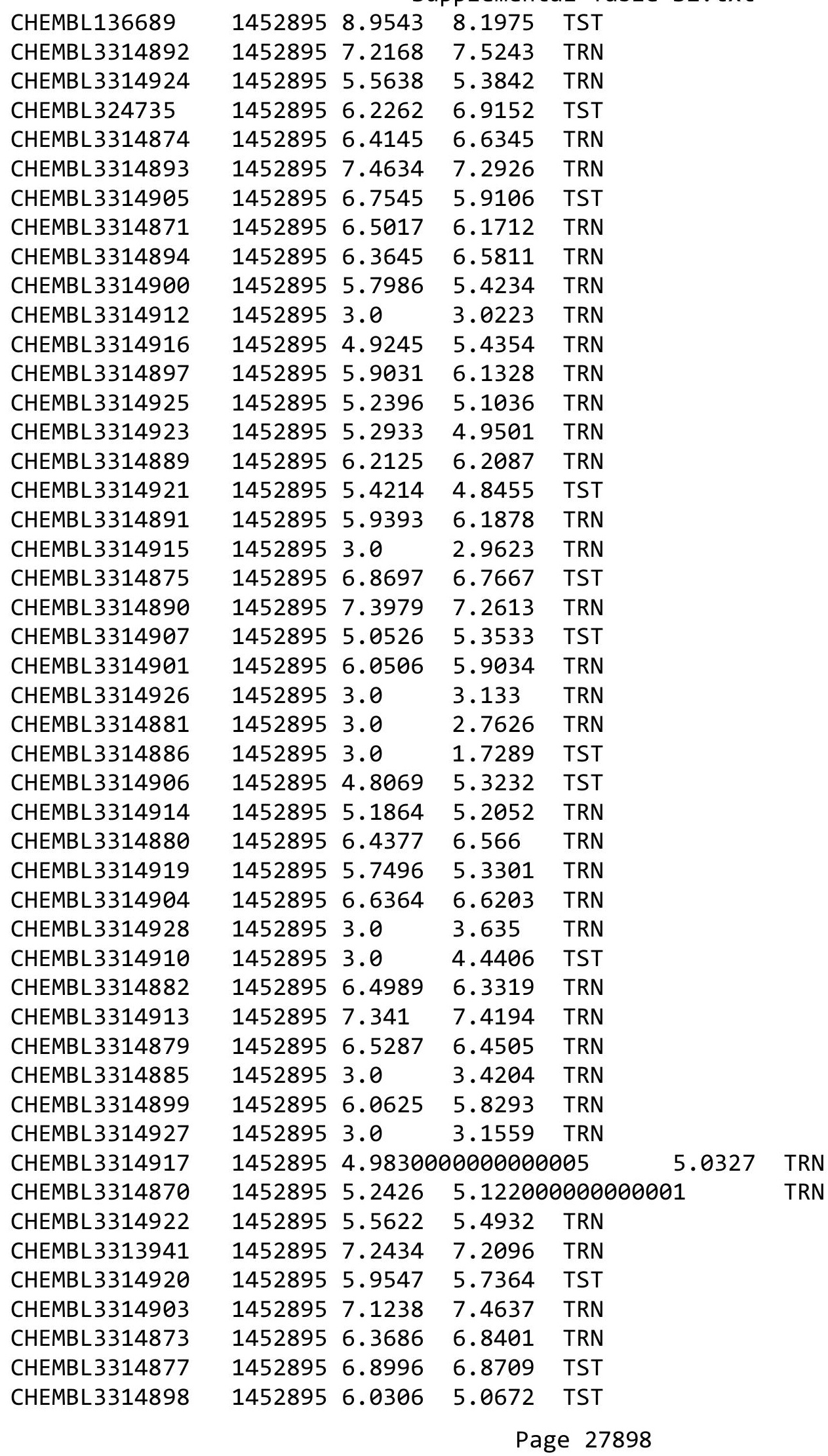


Supplemental Table S2.txt

\begin{tabular}{|c|c|c|c|c|c|}
\hline CHEMBL 3314883 & 1452895 & 6.4921 & 6.5881 & TST & \\
\hline CHEMBL3314930 & 1452895 & 5.6108 & 4.2699 & TST & \\
\hline CHEMBL3682108 & 1528100 & 7.1296 & 6.8139 & TRN & \\
\hline CHEMBL 3682078 & 1528100 & 5.5751 & 6.4033 & TRN & \\
\hline CHEMBL3672181 & 1528100 & 6.0 & 6.2764 & TRN & \\
\hline CHEMBL3682110 & 1528100 & 8.1046 & 8.2223 & TRN & \\
\hline CHEMBL 3677125 & 1528100 & 6.0716 & 5.8889 & TRN & \\
\hline CHEMBL 3682080 & 1528100 & 7.0462 & 6.5333 & TRN & \\
\hline CHEMBL 3682101 & 1528100 & 7.3002 & 6.6533 & TRN & \\
\hline CHEMBL3682084 & 1528100 & 7.3737 & 6.9835 & TRN & \\
\hline CHEMBL3898664 & 1528100 & 6.0 & 5.8292 & TST & \\
\hline CHEMBL3682112 & 1528100 & 6.0 & 5.8806 & TST & \\
\hline CHEMBL3682036 & 1528100 & 6.2255 & 5.7555 & TST & \\
\hline CHEMBL3911714 & 1528100 & 6.5317 & 6.1358 & TRN & \\
\hline CHEMBL3682012 & 1528100 & 6.0857 & 5.5771 & TRN & \\
\hline CHEMBL3677038 & 1528100 & 7.055 & 7.0214 & TRN & \\
\hline CHEMBL3984418 & 1528100 & 6.0 & 5.8992 & TRN & \\
\hline CHEMBL 3677065 & 1528100 & 6.4711 & 6.5287 & TRN & \\
\hline CHEMBL3682131 & 1528100 & 6.1457 & 6.5642 & TRN & \\
\hline CHEMBL3682070 & 1528100 & 8.0904 & 8.2003 & TRN & \\
\hline CHEMBL3682136 & 1528100 & 6.4737 & 6.8235 & TRN & \\
\hline CHEMBL3677081 & 1528100 & 7.2161 & 7.3425 & TRN & \\
\hline CHEMBL 3894206 & 1528100 & 6.0 & 6.362 & TRN & \\
\hline CHEMBL3677058 & 1528100 & 7.1791 & \multicolumn{2}{|c|}{6.9639999999999995} & TRN \\
\hline CHEMBL 3889462 & 1528100 & 6.5768 & 6.8737 & TRN & \\
\hline CHEMBL3682125 & 1528100 & 7.1135 & 7.1936 & TRN & \\
\hline CHEMBL 3682015 & 1528100 & 6.7178 & 6.2698 & TRN & \\
\hline CHEMBL3953121 & 1528100 & 7.2306 & 6.9195 & TRN & \\
\hline CHEMBL3677139 & 1528100 & 7.6198 & 7.1876 & TRN & \\
\hline CHEMBL 3682018 & 1528100 & 4.8297 & \multicolumn{2}{|c|}{5.792999999999999} & TRN \\
\hline CHEMBL 3677140 & 1528100 & 6.0 & 6.3795 & TST & \\
\hline CHEMBL 3925382 & 1528100 & 4.7471 & 6.2712 & TRN & \\
\hline CHEMBL 3682130 & 1528100 & 6.1302 & 6.6642 & TRN & \\
\hline CHEMBL3677100 & 1528100 & 5.6421 & 6.0482 & TRN & \\
\hline CHEMBL 3682053 & 1528100 & 6.4202 & 6.2313 & TST & \\
\hline CHEMBL3980857 & 1528100 & 6.5482 & 6.1923 & TRN & \\
\hline CHEMBL3941584 & 1528100 & 6.0 & 6.0352 & TRN & \\
\hline CHEMBL 3682047 & 1528100 & 6.5607 & \multicolumn{2}{|c|}{6.127999999999999} & TST \\
\hline CHEMBL3682109 & 1528100 & 7.1073 & 7.9577 & TRN & \\
\hline CHEMBL 3677116 & 1528100 & 6.5702 & 6.9637 & TRN & \\
\hline CHEMBL3682071 & 1528100 & 7.1385 & 7.7472 & TRN & \\
\hline CHEMBL3908964 & 1528100 & 6.0 & 6.0135 & TRN & \\
\hline CHEMBL3682096 & 1528100 & 6.0 & 5.7084 & TST & \\
\hline CHEMBL3672198 & 1528100 & 6.4535 & 6.0133 & TRN & \\
\hline CHEMBL3682056 & 1528100 & 7.2277 & 6.6997 & TRN & \\
\hline CHEMBL3682088 & 1528100 & 6.5591 & 6.3784 & TRN & \\
\hline CHEMBL3682050 & 1528100 & 6.3152 & 6.1417 & TRN & \\
\hline CHEMBL3677066 & 1528100 & 6.6596 & \multicolumn{2}{|c|}{6.247999999999999} & TRN \\
\hline
\end{tabular}

Page 27899 
Supplemental Table S2.txt

\begin{tabular}{|c|c|c|c|c|c|}
\hline CHEMBL 3677050 & 1528100 & 7.3224 & 6.9351 & TRN & \\
\hline CHEMBL 3902890 & 1528100 & 7.3872 & 7.0235 & TRN & \\
\hline CHEMBL 3937291 & 1528100 & 6.0 & 5.7917 & TST & \\
\hline CHEMBL 3682134 & 1528100 & 7.3768 & 7.2365 & TRN & \\
\hline CHEMBL 3911367 & 1528100 & 7.1772 & 5.9387 & TRN & \\
\hline CHEMBL 3682124 & 1528100 & 7.7447 & 8.338 & TRN & \\
\hline CHEMBL 3677040 & 1528100 & 6.3575 & 5.7319 & TST & \\
\hline CHEMBL 3914229 & 1528100 & 6.0 & 6.7132 & TST & \\
\hline CHEMBL 3677090 & 1528100 & 7.1945 & 7.1357 & TRN & \\
\hline CHEMBL 3682065 & 1528100 & 7.3696 & 7.0382 & TRN & \\
\hline CHEMBL 3889664 & 1528100 & 6.4498 & 6.0848 & TRN & \\
\hline CHEMBL 3682119 & 1528100 & 5.9914 & 5.7386 & TST & \\
\hline CHEMBL 3677060 & 1528100 & 6.6162 & 6.4605 & TRN & \\
\hline CHEMBL 3682127 & 1528100 & 6.7496 & 7.0922 & TRN & \\
\hline CHEMBL 3677057 & 1528100 & 7.3344 & 7.036000 & 30000000005 & TRN \\
\hline CHEMBL 3677113 & 1528100 & 6.426 & 6.3044 & TRN & \\
\hline CHEMBL 3682126 & 1528100 & 6.0 & 6.8019 & TRN & \\
\hline CHEMBL 3672188 & 1528100 & 6.2434 & 5.8803 & TST & \\
\hline CHEMBL 3672218 & 1528100 & 6.6676 & 6.5935 & TRN & \\
\hline CHEMBL 3677135 & 1528100 & 6.153 & 6.1067 & TRN & \\
\hline CHEMBL 3677082 & 1528100 & 6.2526 & 6.0693 & TST & \\
\hline CHEMBL 3672206 & 1528100 & 5.9431 & 6.1053 & TRN & \\
\hline CHEMBL 3983796 & 1528100 & 7.0521 & 6.9159 & TRN & \\
\hline CHEMBL 3677105 & 1528100 & 7.0462 & 6.8123 & TRN & \\
\hline CHEMBL 3682035 & 1528100 & 6.857 & 6.9417 & TST & \\
\hline CHEMBL 3920649 & 1528100 & 6.7696 & 5.9139 & TRN & \\
\hline CHEMBL 3906448 & 1528100 & 6.0 & 7.3741 & TST & \\
\hline CHEMBL 3936803 & 1528100 & 6.0 & 5.6246 & TRN & \\
\hline CHEMBL 3677064 & 1528100 & 7.8508 & 7.3184 & TRN & \\
\hline CHEMBL 3677207 & 1528100 & 6.0 & 6.1412 & TRN & \\
\hline CHEMBL 3956178 & 1528100 & 6.5986 & 6.3189 & TRN & \\
\hline CHEMBL 3677117 & 1528100 & 6.7212 & 6.2629 & TRN & \\
\hline CHEMBL 3672154 & 1528100 & 7.0269 & 7.0245 & TRN & \\
\hline CHEMBL3915330 & 1528100 & 6.0 & 6.4094 & TRN & \\
\hline CHEMBL 3682095 & 1528100 & 6.5482 & 6.5692 & TST & \\
\hline CHEMBL 3984142 & 1528100 & 6.3645 & 6.3743 & TRN & \\
\hline CHEMBL 3934405 & 1528100 & 6.0 & 6.4663 & TRN & \\
\hline CHEMBL 3677034 & 1528100 & 6.6596 & 6.7211 & TRN & \\
\hline CHEMBL 3677099 & 1528100 & 6.9666 & 6.8559 & TST & \\
\hline CHEMBL 3677015 & 1528100 & 7.4698 & 6.8209 & TRN & \\
\hline CHEMBL 3672214 & 1528100 & 6.7905 & 6.9723 & TRN & \\
\hline CHEMBL 3677091 & 1528100 & 7.0039 & 7.1449 & TRN & \\
\hline CHEMBL 3682098 & 1528100 & 6.2581 & 6.4185 & TRN & \\
\hline CHEMBL 3672173 & 1528100 & 6.5114 & 5.9211 & TST & \\
\hline CHEMBL 3677118 & 1528100 & 6.1583 & 5.7517 & TRN & \\
\hline CHEMBL 3948460 & 1528100 & 7.16299 & 999999999 & 6.1858 & TRN \\
\hline CHEMBL 3677016 & 1528100 & 6.8447 & 6.3103 & TST & \\
\hline CHEMBL 3979480 & 1528100 & 6.0 & 6.7264 & TRN & \\
\hline
\end{tabular}


Supplemental Table S2.txt

\begin{tabular}{|c|c|c|c|c|c|c|}
\hline CHEMBL 3682030 & 1528100 & 6.3595 & 6.6313 & TST & & \\
\hline CHEMBL 3677132 & 1528100 & 7.38399 & 999999999 & 995 & 7.1678 & TRI \\
\hline CHEMBL 3682097 & 1528100 & 4.6021 & 5.6177 & TST & & \\
\hline CHEMBL 3672203 & 1528100 & 6.5467 & 6.3482 & TST & & \\
\hline CHEMBL 3677041 & 1528100 & 7.6198 & 6.9823 & TST & & \\
\hline CHEMBL 3677086 & 1528100 & 6.6099 & 6.4623 & TRN & & \\
\hline CHEMBL3949499 & 1528100 & 5.8601 & 5.649 & TRN & & \\
\hline CHEMBL3914966 & 1528100 & 6.0 & 6.0569 & TRN & & \\
\hline CHEMBL 3682033 & 1528100 & 6.0857 & \multicolumn{3}{|c|}{6.747000000000001} & $\mathrm{TC}$ \\
\hline CHEMBL 3682105 & 1528100 & 6.9431 & 7.314 & TRN & & \\
\hline CHEMBL 3672229 & 1528100 & 5.6021 & 5.9227 & TST & & \\
\hline CHEMBL 3955504 & 1528100 & 6.6904 & 6.0143 & TST & & \\
\hline CHEMBL 3677045 & 1528100 & 7.6861 & 7.4781 & TRN & & \\
\hline CHEMBL 3677101 & 1528100 & 6.0 & 6.1466 & TRN & & \\
\hline CHEMBL 3682121 & 1528100 & 6.0706 & 5.8844 & TST & & \\
\hline CHEMBL 3939273 & 1528100 & 7.38299 & \multicolumn{2}{|c|}{9999999999} & 6.7865 & \\
\hline CHEMBL 3939172 & 1528100 & 6.0 & 5.7503 & TRN & & \\
\hline CHEMBL 3682079 & 1528100 & 6.2418 & \multicolumn{3}{|c|}{6.127999999999999} & \\
\hline CHEMBL 3893404 & 1528100 & 6.0 & 6.0986 & TRN & & \\
\hline CHEMBL 3672142 & 1528100 & 5.71899 & \multicolumn{2}{|c|}{9999999999} & 5.9199 & \\
\hline CHEMBL 3682064 & 1528100 & 7.6757 & 6.8341 & TRN & & \\
\hline CHEMBL 3677061 & 1528100 & 6.1221 & 6.5927 & TRN & & \\
\hline CHEMBL 3682100 & 1528100 & 7.3979 & 6.3811 & TRN & & \\
\hline CHEMBL 3682051 & 1528100 & 7.5317 & 6.6845 & TST & & \\
\hline CHEMBL 3889647 & 1528100 & 5.7799 & 6.0437 & TRN & & \\
\hline CHEMBL 3677078 & 1528100 & 6.2104 & 6.6274 & TST & & \\
\hline CHEMBL 3682049 & 1528100 & 7.1118 & 6.5703 & TST & & \\
\hline CHEMBL 3677047 & 1528100 & 6.2041 & 6.1458 & TRN & & \\
\hline CHEMBL 3677120 & 1528100 & 7.1904 & 6.6736 & TRN & & \\
\hline CHEMBL 3682042 & 1528100 & 5.8386 & 6.3142 & TST & & \\
\hline CHEMBL 3677001 & 1528100 & 6.2692 & 6.3376 & TRN & & \\
\hline CHEMBL 3677007 & 1528100 & 6.6055 & 6.2754 & TST & & \\
\hline CHEMBL 3677071 & 1528100 & 6.6162 & 6.9267 & TRN & & \\
\hline CHEMBL 3682045 & 1528100 & 6.0177 & 6.318 & TST & & \\
\hline CHEMBL 3677062 & 1528100 & 7.1649 & 6.8879 & TRN & & \\
\hline CHEMBL 3682090 & 1528100 & 6.3872 & \multicolumn{3}{|c|}{6.5520000000000005} & \\
\hline CHEMBL3677059 & 1528100 & \multicolumn{3}{|c|}{7.382000000000001} & 7.0697 & \\
\hline CHEMBL 3682066 & 1528100 & 7.0701 & 6.7758 & TRN & & \\
\hline CHEMBL 3682133 & 1528100 & 6.1373 & \multicolumn{3}{|c|}{6.662000000000001} & 78 \\
\hline CHEMBL 3682028 & 1528100 & 6.059 & 6.5089 & TST & & \\
\hline CHEMBL 3903440 & 1528100 & 5.8153 & 6.1604 & TRN & & \\
\hline CHEMBL 3682114 & 1528100 & 6.7144 & 6.8066 & TRN & & \\
\hline CHEMBL 3677122 & 1528100 & 6.1884 & 6.5301 & TST & & \\
\hline CHEMBL3677076 & 1528100 & 5.7471 & 5.9839 & TST & & \\
\hline CHEMBL 3682040 & 1528100 & 5.2782 & 5.8611 & TST & & \\
\hline CHEMBL 3677077 & 1528100 & 6.0747 & 6.0002 & TST & & \\
\hline CHEMBL 3677049 & 1528100 & 6.6073 & 6.3947 & TRN & & \\
\hline CHEMBL 3677114 & 1528100 & 5.5952 & 5.8657 & TRN & & \\
\hline
\end{tabular}

Page 27901 
Supplemental Table S2.txt

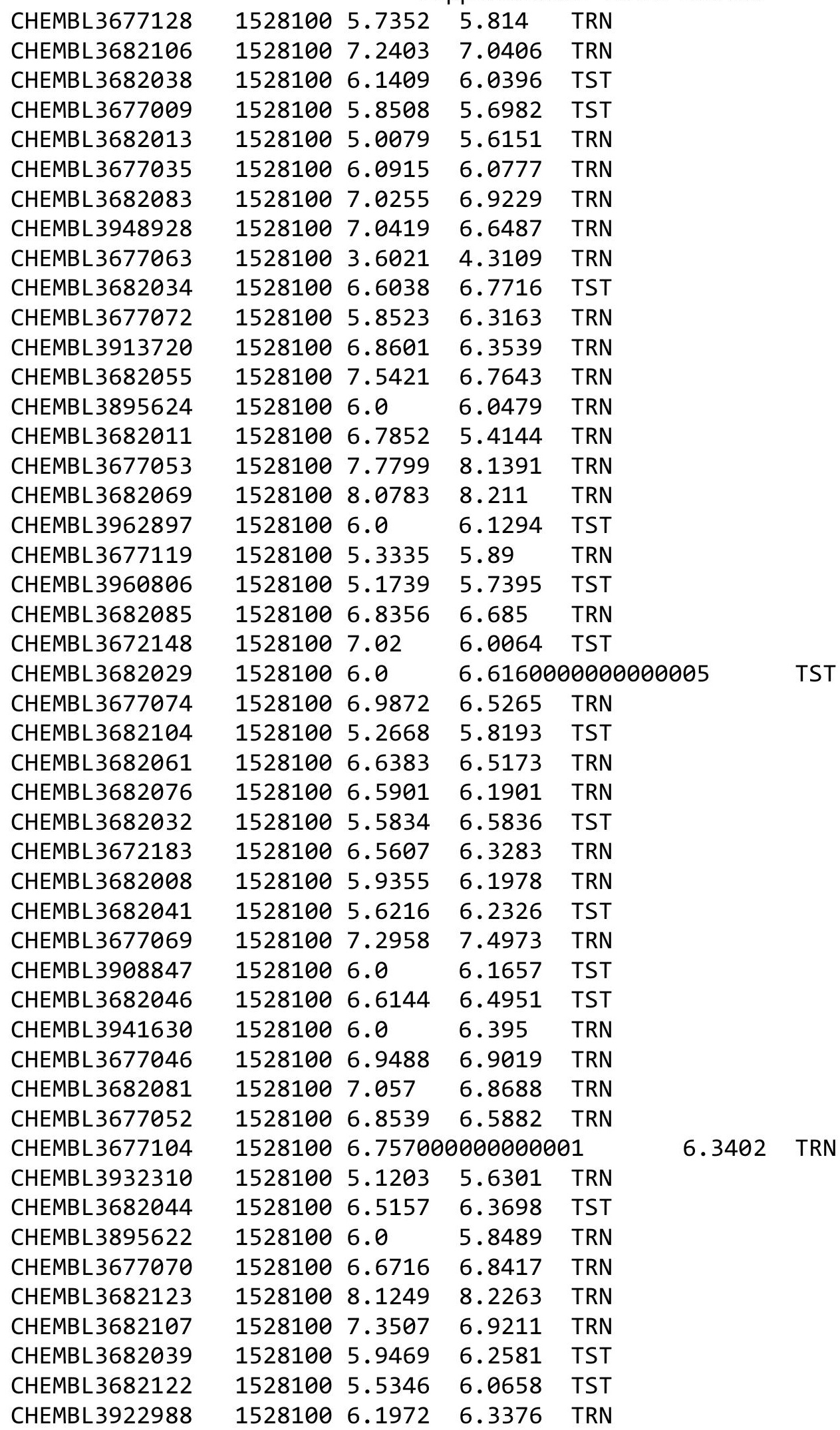

Page 27902 


\begin{tabular}{|c|c|c|c|c|c|c|}
\hline \multicolumn{7}{|c|}{ Supplemental Table S2.txt } \\
\hline CHEMBL3889619 & 1528100 & 6.0 & 6.1041 & TRN & & \\
\hline CHEMBL3909387 & 1528100 & 7.4089 & 6.2492 & TRN & & \\
\hline CHEMBL3911319 & 1528100 & 6.0 & 6.4939 & TRN & & \\
\hline CHEMBL3926617 & 1528100 & 4.9031 & 5.5432 & TRN & & \\
\hline CHEMBL3682068 & 1528100 & 7.2062 & 6.9091 & TRN & & \\
\hline CHEMBL3677051 & 1528100 & 6.5287 & 6.3239 & TRN & & \\
\hline CHEMBL3682059 & 1528100 & 6.4401 & 6.7153 & TRN & & \\
\hline CHEMBL3682006 & 1528100 & 7.8861 & 7.8683 & TRN & & \\
\hline CHEMBL 3677054 & 1528100 & $7.7620 e$ & 0000000 & 005 & 7.6676 & TRN \\
\hline CHEMBL3682016 & 1528100 & 6.7645 & 6.81 & TRN & & \\
\hline CHEMBL3677037 & 1528100 & 6.8371 & 6.7597 & TRN & & \\
\hline CHEMBL 3904820 & 1528100 & 7.1765 & 5.9739 & TRN & & \\
\hline CHEMBL3682057 & 1528100 & 5.8013 & 6.652 & TRN & & \\
\hline CHEMBL 3677044 & 1528100 & 6.3778 & 6.4476 & TRN & & \\
\hline CHEMBL3677103 & 1528100 & 6.5638 & 6.5147 & TST & & \\
\hline CHEMBL3967026 & 1528100 & 6.0 & 5.9033 & TST & & \\
\hline CHEMBL3677003 & 1528100 & 6.2233 & 6.1931 & TRN & & \\
\hline CHEMBL 3677083 & 1528100 & 5.9508 & 6.001 & TST & & \\
\hline CHEMBL 3682102 & 1528100 & 6.51 & 6.8161 & TRN & & \\
\hline CHEMBL3682077 & 1528100 & 6.5719 & 6.4494 & TRN & & \\
\hline CHEMBL3893024 & 1528100 & 6.0 & 6.4738 & TRN & & \\
\hline CHEMBL 3682072 & 1528100 & 6.644 & 6.3394 & TRN & & \\
\hline CHEMBL3672215 & 1528100 & 6.0 & 6.0466 & TRN & & \\
\hline CHEMBL 3677080 & 1528100 & 7.0565 & 7.1414 & TST & & \\
\hline CHEMBL3682058 & 1528100 & 7.1051 & 6.1761 & TRN & & \\
\hline CHEMBL3902129 & 1528100 & 6.6478 & 6.66299 & 9999999999 & & TRN \\
\hline CHEMBL3672219 & 1528100 & 6.7471 & 6.0386 & TST & & \\
\hline CHEMBL 3677126 & 1528100 & 5.983 & 6.5381 & TST & & \\
\hline CHEMBL 3682129 & 1528100 & 6.8125 & 6.7778 & TRN & & \\
\hline CHEMBL3682037 & 1528100 & 6.1343 & 6.165 & TST & & \\
\hline CHEMBL 3672230 & 1528100 & 6.8312 & 6.8292 & TST & & \\
\hline CHEMBL3682060 & 1528100 & 6.7282 & 6.9353 & TRN & & \\
\hline CHEMBL3682099 & 1528100 & 6.4389 & 6.6996 & TRN & & \\
\hline CHEMBL 3682074 & 1528100 & 6.7375 & 6.3375 & TRN & & \\
\hline CHEMBL3677068 & 1528100 & 7.1367 & 7.1896 & TRN & & \\
\hline CHEMBL3677073 & 1528100 & 6.1113 & 6.2527 & TRN & & \\
\hline CHEMBL3677039 & 1528100 & 6.4647 & 6.3648 & TRN & & \\
\hline CHEMBL3677115 & 1528100 & 3.6021 & 4.7542 & TRN & & \\
\hline CHEMBL 3915347 & 1528100 & 6.0 & 7.0107 & TRN & & \\
\hline CHEMBL3682063 & 1528100 & 6.7825 & 6.666 & TRN & & \\
\hline CHEMBL3677031 & 1528100 & 6.475 & 6.1479 & TRN & & \\
\hline CHEMBL3899804 & 1528100 & 6.0 & 6.0554 & TRN & & \\
\hline CHEMBL3919859 & 1528100 & 5.5421 & 6.0986 & TRN & & \\
\hline CHEMBL 3962702 & 1528100 & 6.7799 & 6.1358 & TRN & & \\
\hline CHEMBL3970266 & 1528100 & 6.0 & 6.2511 & TRN & & \\
\hline CHEMBL3945628 & 1528100 & 3.6021 & 4.85 & TRN & & \\
\hline CHEMBL3923961 & 1528100 & 7.2668 & 5.9489 & TRN & & \\
\hline CHEMBL3672185 & 1528100 & 6.2233 & 6.1598 & TST & & \\
\hline
\end{tabular}


Supplemental Table S2.txt

\begin{tabular}{|c|c|c|c|c|c|}
\hline CHEMBL3934162 & 1528100 & 6.4868 & 6.0808 & TRN & \\
\hline CHEMBL3682142 & 1528100 & 7.0061 & 6.135 & TST & \\
\hline CHEMBL3682014 & 1528100 & 5.1299 & 5.1764 & TRN & \\
\hline CHEMBL3677067 & 1528100 & 5.0088 & 6.3861 & TRN & \\
\hline CHEMBL3682067 & 1528100 & 7.2125 & 6.9674 & TRN & \\
\hline CHEMBL3677079 & 1528100 & 7.3298 & 7.2797 & TST & \\
\hline CHEMBL3672106 & 1528100 & 5.02 & 5.7778 & TRN & \\
\hline CHEMBL3682137 & 1528100 & 6.7932 & 6.9209 & TRN & \\
\hline CHEMBL 3945687 & 1528100 & 6.0 & 6.3197 & TRN & \\
\hline CHEMBL3677127 & 1528100 & \multicolumn{2}{|c|}{4.9830000000000005} & 5.3676 & TRN \\
\hline CHEMBL3682089 & 1528100 & 7.7011 & 8.3144 & TRN & \\
\hline CHEMBL3920782 & 1528100 & 3.6021 & 5.4056 & TRN & \\
\hline CHEMBL 3672210 & 1528100 & 6.8268 & 7.0474 & TST & \\
\hline CHEMBL 3894813 & 1528100 & 6.0 & 6.1705 & TRN & \\
\hline CHEMBL3677075 & 1528100 & 6.5591 & 6.2651 & TRN & \\
\hline CHEMBL3677013 & 1528100 & 7.5017 & 7.3904 & TRN & \\
\hline CHEMBL3682111 & 1528100 & 6.4895 & 6.7133 & TRN & \\
\hline CHEMBL3672169 & 1528100 & 5.3696 & 5.9009 & TRN & \\
\hline CHEMBL3913515 & 1528100 & 7.426 & 7.9867 & TRN & \\
\hline CHEMBL3677056 & 1528100 & 7.4698 & 7.2318 & TRN & \\
\hline CHEMBL3913641 & 1528100 & 6.0 & 6.5264 & TRN & \\
\hline CHEMBL3677094 & 1528100 & 7.6345 & 7.8502 & TRN & \\
\hline CHEMBL3677036 & 1528100 & 7.7721 & 6.8999 & TRN & \\
\hline CHEMBL 3677004 & 1528100 & 6.2351 & 6.263 & TRN & \\
\hline CHEMBL3682043 & 1528100 & 6.3063 & 6.2849 & TST & \\
\hline CHEMBL3682094 & 1528100 & 6.6253 & 6.3588 & TRN & \\
\hline CHEMBL3672097 & 1528100 & 6.5287 & 5.9237 & TRN & \\
\hline CHEMBL3682073 & 1528100 & 6.4802 & 6.7064 & TRN & \\
\hline CHEMBL 3682027 & 1528100 & 5.6737 & 6.5619 & TST & \\
\hline CHEMBL3897455 & 1528100 & 6.0 & 6.5638 & TRN & \\
\hline CHEMBL3682075 & 1528100 & 6.983 & 6.3375 & TRN & \\
\hline CHEMBL3677092 & 1528100 & 6.1681 & 5.7805 & TST & \\
\hline CHEMBL3677055 & 1528100 & 7.0799 & 7.3842 & TRN & \\
\hline CHEMBL3971372 & 1528100 & 5.6799 & 5.6784 & TRN & \\
\hline CHEMBL3682103 & 1528100 & 6.8861 & 6.4692 & TRN & \\
\hline CHEMBL3682113 & 1528100 & 6.0 & 5.9064 & TST & \\
\hline CHEMBL3682031 & 1528100 & $5.3820 e$ & 000000000 & 6.539 & TST \\
\hline CHEMBL 3682048 & 1528100 & 6.3372 & 6.1056 & TST & \\
\hline CHEMBL 3682062 & 1528100 & 6.1278 & 6.1213 & TRN & \\
\hline CHEMBL 3682017 & 1528100 & 6.1079 & 5.912999 & э999999999 & TRN \\
\hline CHEMBL3672202 & 1528100 & 6.0273 & 6.2567 & TRN & \\
\hline CHEMBL3682135 & 1528100 & 7.4685 & 7.1424 & TRN & \\
\hline CHEMBL3672207 & 1528100 & 6.8996 & 6.9036 & TRN & \\
\hline CHEMBL 3682054 & 1528100 & 7.4737 & 6.7286 & TST & \\
\hline CHEMBL3928964 & 1528100 & 6.0 & 6.0984 & TRN & \\
\hline CHEMBL3924306 & 1528100 & 6.0 & 6.3137 & TRN & \\
\hline CHEMBL3677106 & 1528100 & 6.5376 & 6.5502 & TRN & \\
\hline CHEMBL3682082 & 1528100 & 7.3215 & 6.8506 & TRN & \\
\hline
\end{tabular}




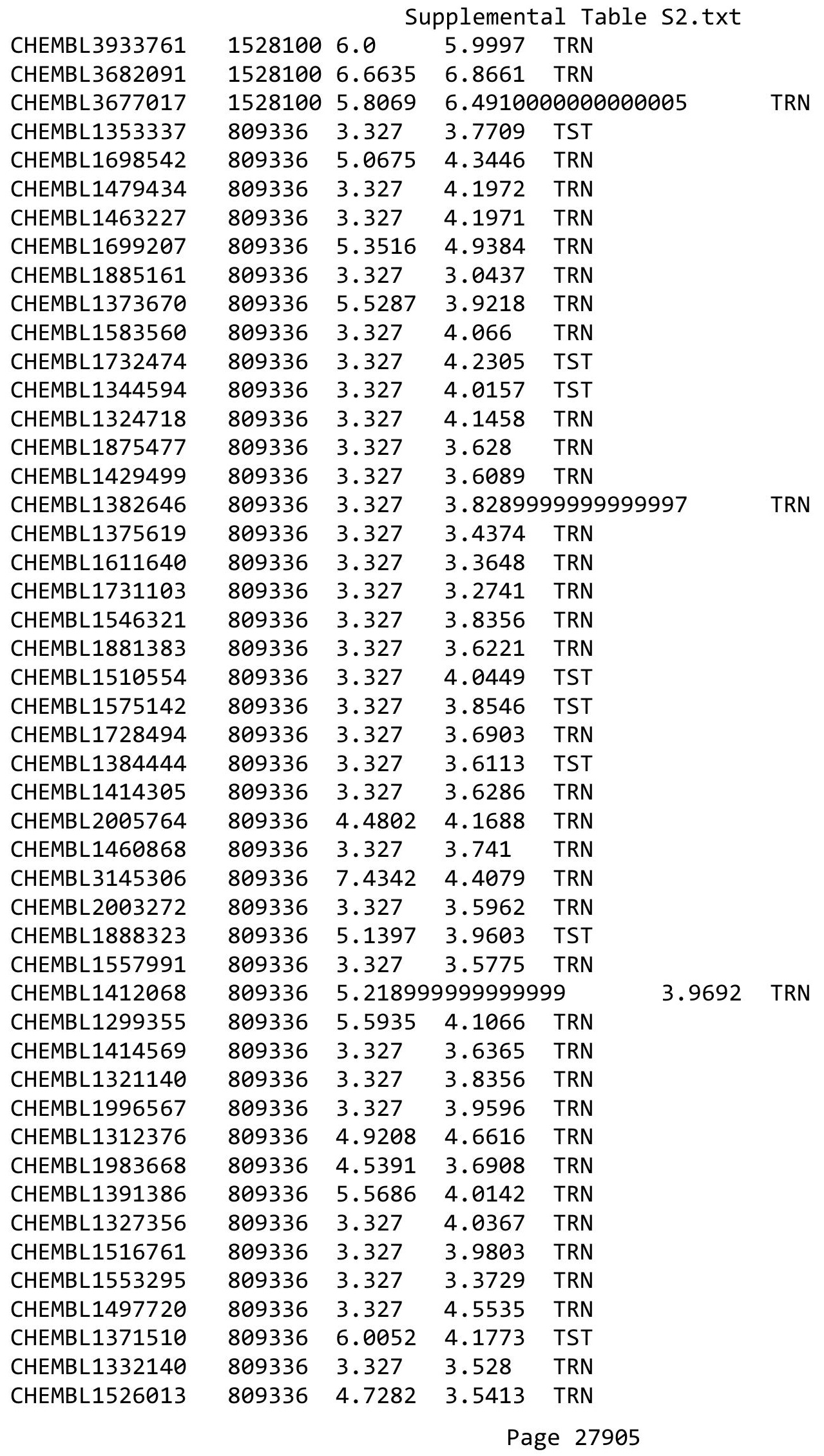




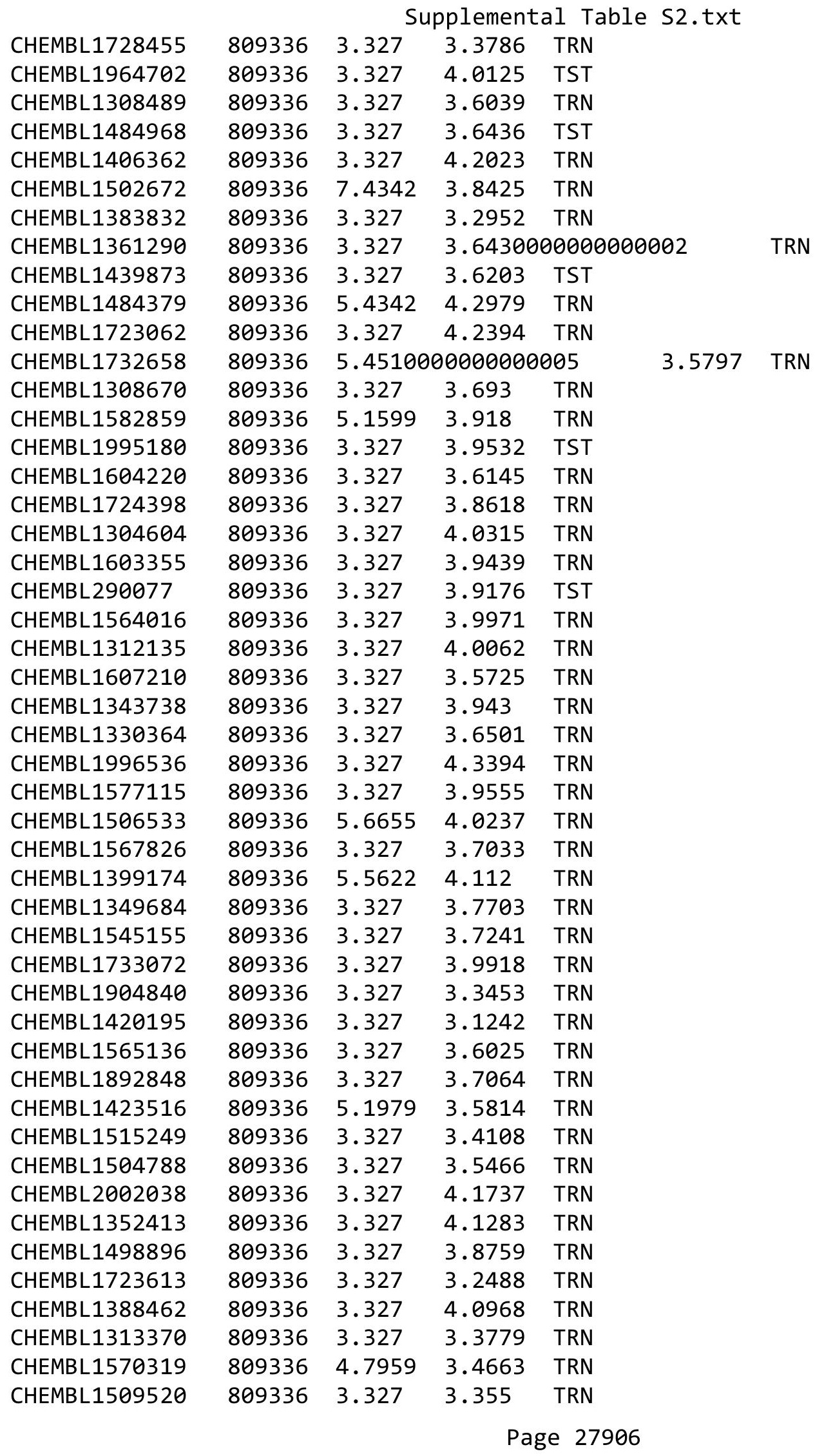




\begin{tabular}{|c|c|c|c|c|}
\hline & & & oplement & al Ta \\
\hline CHEMBL1459793 & 809336 & 3.327 & 3.5462 & TST \\
\hline CHEMBL1699713 & 809336 & 5.2118 & 4.4227 & TRN \\
\hline CHEMBL1536902 & 809336 & 3.327 & 3.9598 & TRN \\
\hline CHEMBL 2005790 & 809336 & 3.327 & 3.8038 & TRN \\
\hline CHEMBL1983899 & 809336 & 3.327 & 3.9882 & TRN \\
\hline CHEMBL1591701 & 809336 & 4.6345 & 4.3523 & TRN \\
\hline CHEMBL1324348 & 809336 & 3.327 & 3.6055 & TST \\
\hline CHEMBL1392211 & 809336 & 3.327 & 3.6636 & TRN \\
\hline CHEMBL1336833 & 809336 & 3.327 & 3.4422 & TST \\
\hline CHEMBL1879838 & 809336 & 3.327 & 3.7588 & TRN \\
\hline CHEMBL1349192 & 809336 & 3.327 & 3.9083 & TRN \\
\hline CHEMBL1429819 & 809336 & 3.327 & 3.6989 & TRN \\
\hline CHEMBL1458175 & 809336 & 5.5406 & 4.3848 & TRN \\
\hline CHEMBL1707714 & 809336 & 3.327 & 4.1306 & TST \\
\hline CHEMBL 3144894 & 809336 & 3.327 & 3.4748 & TRN \\
\hline CHEMBL1344377 & 809336 & 3.327 & 3.4054 & TRN \\
\hline CHEMBL1711254 & 809336 & 3.327 & 4.3173 & TRN \\
\hline CHEMBL1344304 & 809336 & 3.327 & 3.8936 & TRN \\
\hline CHEMBL1446271 & 809336 & 3.327 & 4.6935 & TRN \\
\hline CHEMBL1723672 & 809336 & 3.327 & 3.466 & TRN \\
\hline CHEMBL1411742 & 809336 & 3.327 & 3.4474 & TRN \\
\hline CHEMBL1725775 & 809336 & 3.327 & 3.7444 & TRN \\
\hline CHEMBL1568515 & 809336 & 3.327 & 3.8 & TRN \\
\hline CHEMBL1455085 & 809336 & 5.2899 & 3.6802 & TRN \\
\hline CHEMBL1442928 & 809336 & 3.327 & 4.6019 & TRN \\
\hline CHEMBL1709601 & 809336 & 3.327 & 3.5312 & TST \\
\hline CHEMBL1471894 & 809336 & 3.327 & 3.2313 & TRN \\
\hline CHEMBL1965196 & 809336 & 3.327 & 3.4972 & TRN \\
\hline CHEMBL1443681 & 809336 & 3.327 & 4.2189 & TRN \\
\hline CHEMBL1467874 & 809336 & 4.475 & 3.864 & TRN \\
\hline CHEMBL1530938 & 809336 & 3.327 & 3.6273 & TST \\
\hline CHEMBL1501932 & 809336 & 5.1046 & 4.5005 & TRN \\
\hline CHEMBL1970082 & 809336 & 3.327 & 4.183 & TRN \\
\hline CHEMBL1887983 & 809336 & 3.327 & 3.8092 & TRN \\
\hline CHEMBL1501720 & 809336 & 5.3288 & 4.2351 & TST \\
\hline CHEMBL1589282 & 809336 & 7.4342 & 4.5493 & TRN \\
\hline CHEMBL1393828 & 809336 & 5.2449 & 3.6501 & TRN \\
\hline CHEMBL1715050 & 809336 & 3.327 & 3.5019 & TRN \\
\hline CHEMBL1420948 & 809336 & 3.327 & 4.3797 & TRN \\
\hline CHEMBL1561118 & 809336 & 3.327 & 3.6557 & TRN \\
\hline CHEMBL1452200 & 809336 & 3.327 & 3.8347 & TRN \\
\hline CHEMBL1468661 & 809336 & 3.327 & 4.3363 & TRN \\
\hline CHEMBL 3145244 & 809336 & 5.2147 & 4.6387 & TRN \\
\hline CHEMBL1979527 & 809336 & 5.4056 & 4.4329 & TRN \\
\hline CHEMBL1887152 & 809336 & 3.327 & 4.0237 & TST \\
\hline CHEMBL1611234 & 809336 & 3.327 & 3.8786 & TRN \\
\hline CHEMBL1588126 & 809336 & 3.327 & 3.4418 & TRN \\
\hline CHEMBL1549986 & 809336 & 5.3809 & 4.8921 & TRN \\
\hline
\end{tabular}




\begin{tabular}{|c|c|c|c|c|c|}
\hline \multicolumn{6}{|c|}{ Supplemental Table S2.txt } \\
\hline CHEMBL1992166 & 809336 & 3.327 & 4.2082 & TST & \\
\hline CHEMBL1299452 & 809336 & 3.327 & 3.7513 & TRN & \\
\hline CHEMBL1545744 & 809336 & 3.327 & 3.4485 & TRN & \\
\hline CHEMBL1560765 & 809336 & 3.327 & 3.8608 & TRN & \\
\hline CHEMBL 1417320 & 809336 & 7.4342 & 4.9007 & TRN & \\
\hline CHEMBL1878533 & 809336 & 3.327 & 3.7576 & TRN & \\
\hline CHEMBL1573287 & 809336 & 3.327 & 4.0211 & TRN & \\
\hline CHEMBL1723182 & 809336 & 5.4437 & 3.6304 & TRN & \\
\hline CHEMBL1966751 & 809336 & 5.3316 & 4.6527 & TRN & \\
\hline CHEMBL1529498 & 809336 & 3.327 & 4.3559 & TRN & \\
\hline CHEMBL1998555 & 809336 & 3.327 & 4.0526 & TRN & \\
\hline CHEMBL1428709 & 809336 & 3.327 & 4.1327 & TRN & \\
\hline CHEMBL1443801 & 809336 & 3.327 & 4.57 & TRN & \\
\hline CHEMBL1703698 & 809336 & 3.327 & 3.3302 & TRN & \\
\hline CHEMBL1572223 & 809336 & 3.327 & 3.9904 & TRN & \\
\hline CHEMBL1720346 & 809336 & 7.4342 & 3.6156 & TRN & \\
\hline CHEMBL1371231 & 809336 & 3.327 & 3.694 & TRN & \\
\hline CHEMBL1299931 & 809336 & 3.327 & 4.2687 & TRN & \\
\hline CHEMBL1407214 & 809336 & 3.327 & 4.1406 & TRN & \\
\hline CHEMBL1366275 & 809336 & 4.6126 & 3.5482 & TRN & \\
\hline CHEMBL1583989 & 809336 & 3.327 & 3.8572 & TRN & \\
\hline CHEMBL1608859 & 809336 & 3.327 & 3.53899 & 999999 & TRN \\
\hline CHEMBL1302298 & 809336 & 3.327 & 3.6117 & TRN & \\
\hline CHEMBL1507745 & 809336 & 3.327 & 3.8681 & TRN & \\
\hline CHEMBL399632 & 809336 & 3.327 & 4.2927 & TRN & \\
\hline CHEMBL1458155 & 809336 & 3.327 & 3.2155 & TRN & \\
\hline CHEMBL1317462 & 809336 & 3.327 & 3.9284 & TRN & \\
\hline CHEMBL1301113 & 809336 & 3.327 & 4.1971 & TST & \\
\hline CHEMBL1442304 & 809336 & 3.327 & 3.905 & TRN & \\
\hline CHEMBL1389188 & 809336 & 3.327 & 4.3795 & TRN & \\
\hline CHEMBL1967673 & 809336 & 3.327 & 4.2021 & TRN & \\
\hline CHEMBL565862 & 809336 & 3.327 & 4.1296 & TRN & \\
\hline CHEMBL582701 & 809336 & 3.327 & 3.8202 & TRN & \\
\hline CHEMBL1429338 & 809336 & 7.4342 & 4.266 & TRN & \\
\hline CHEMBL1583398 & 809336 & 3.327 & 4.0381 & TRN & \\
\hline CHEMBL1302934 & 809336 & 3.327 & 3.79600 & 00000000003 & TRN \\
\hline CHEMBL 1381340 & 809336 & 3.327 & 4.1035 & TRN & \\
\hline CHEMBL1904654 & 809336 & 3.327 & 3.8248 & TRN & \\
\hline CHEMBL1707911 & 809336 & 7.4342 & 3.8561 & TRN & \\
\hline CHEMBL1602999 & 809336 & 3.327 & 4.4409 & TST & \\
\hline CHEMBL1512198 & 809336 & 3.327 & 3.7594 & TST & \\
\hline CHEMBL1549225 & 809336 & 3.327 & 3.5631 & TRN & \\
\hline CHEMBL1509762 & 809336 & 5.3372 & 4.5778 & TRN & \\
\hline CHEMBL1718088 & 809336 & 3.327 & 4.2162 & TST & \\
\hline CHEMBL1401190 & 809336 & 3.327 & 3.4921 & TRN & \\
\hline CHEMBL1413942 & 809336 & 3.327 & 3.7114 & TRN & \\
\hline CHEMBL1978150 & 809336 & 7.4342 & 3.6919 & TRN & \\
\hline CHEMBL1313525 & 809336 & 3.327 & 4.4082 & TRN & \\
\hline
\end{tabular}




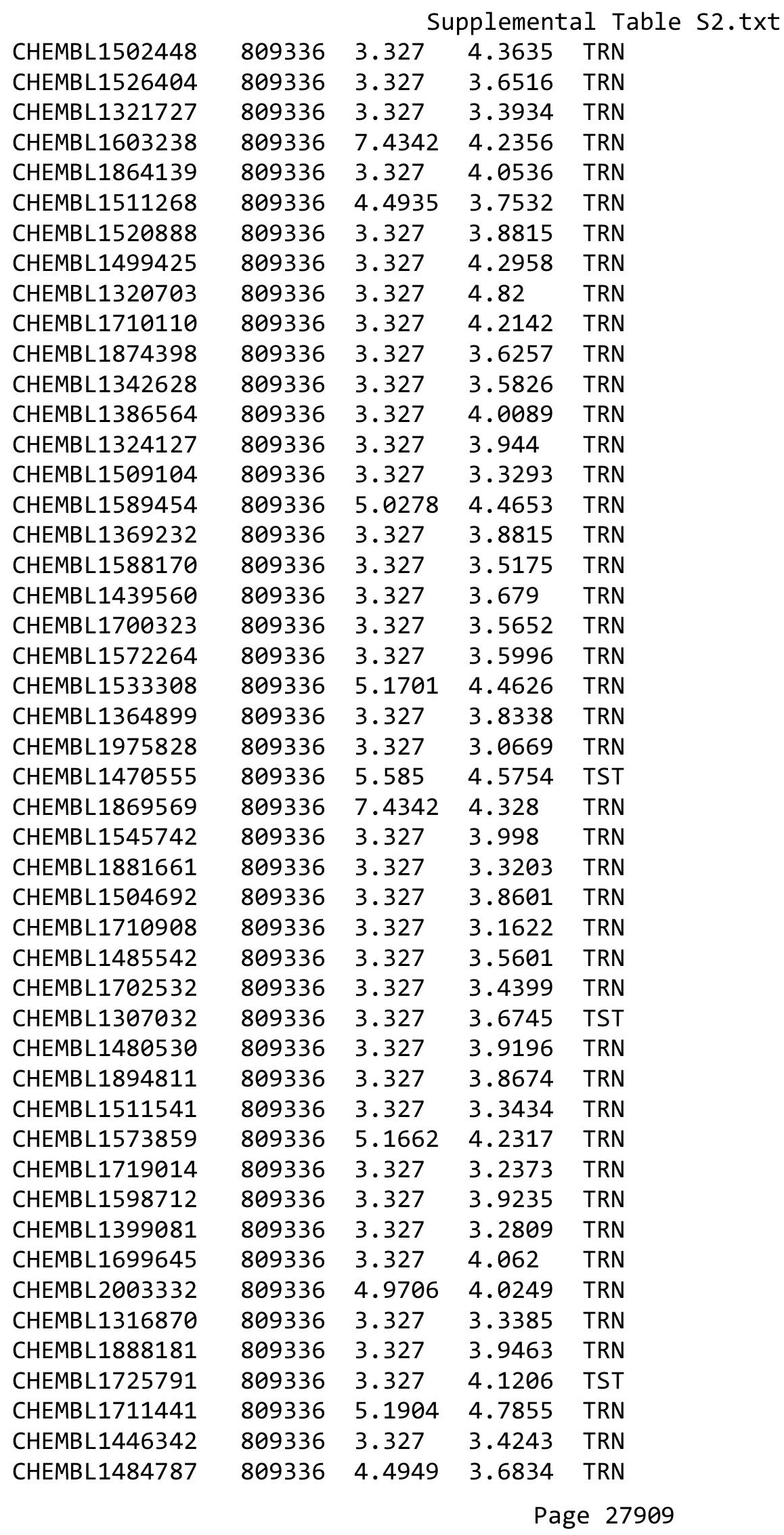




\begin{tabular}{|c|c|c|c|c|}
\hline & & & oplement & al Ta \\
\hline CHEMBL1608409 & 809336 & 3.327 & 3.6114 & TRN \\
\hline CHEMBL1352375 & 809336 & 3.327 & 3.6359 & TRN \\
\hline CHEMBL1493661 & 809336 & 5.5591 & 3.9871 & TRN \\
\hline CHEMBL1370400 & 809336 & 3.327 & 4.0713 & TRN \\
\hline CHEMBL1464772 & 809336 & 3.327 & 3.1964 & TRN \\
\hline CHEMBL1304518 & 809336 & 3.327 & 3.2564 & TRN \\
\hline CHEMBL1710576 & 809336 & 3.327 & 3.8767 & TRN \\
\hline CHEMBL1340878 & 809336 & 4.7932 & 4.0277 & TRN \\
\hline CHEMBL1710738 & 809336 & 3.327 & 3.408 & TRN \\
\hline CHEMBL1458284 & 809336 & 5.7986 & 4.425 & TRN \\
\hline CHEMBL1503652 & 809336 & 3.327 & 4.3703 & TRN \\
\hline CHEMBL1553543 & 809336 & 3.327 & 3.2179 & TRN \\
\hline CHEMBL1346842 & 809336 & 3.327 & 3.6869 & TRN \\
\hline CHEMBL1441618 & 809336 & 3.327 & 3.9117 & TRN \\
\hline CHEMBL1384559 & 809336 & 3.327 & 4.0404 & TRN \\
\hline CHEMBL1486792 & 809336 & 3.327 & 3.8209 & TRN \\
\hline CHEMBL1385113 & 809336 & 3.327 & 3.8019 & TRN \\
\hline CHEMBL1386414 & 809336 & 3.327 & 3.2784 & TRN \\
\hline CHEMBL1990092 & 809336 & 3.327 & 3.4151 & TRN \\
\hline CHEMBL1877686 & 809336 & 3.327 & 3.7583 & TRN \\
\hline CHEMBL1527203 & 809336 & 3.327 & 3.7637 & TRN \\
\hline CHEMBL1717188 & 809336 & 3.327 & 3.5597 & TRN \\
\hline CHEMBL1977611 & 809336 & 5.308 & 4.562 & TST \\
\hline CHEMBL1466605 & 809336 & 3.327 & 3.6822 & TRN \\
\hline CHEMBL1351355 & 809336 & 3.327 & 3.5232 & TRN \\
\hline CHEMBL1529768 & 809336 & 3.327 & 4.4846 & TST \\
\hline CHEMBL1534293 & 809336 & 3.327 & 4.1138 & TRN \\
\hline CHEMBL1993617 & 809336 & 3.327 & 4.0498 & TRN \\
\hline CHEMBL1540243 & 809336 & 3.327 & 3.6887 & TRN \\
\hline CHEMBL1307886 & 809336 & 3.327 & 4.2587 & TRN \\
\hline CHEMBL1390405 & 809336 & 3.327 & 4.0687 & TRN \\
\hline CHEMBL1442604 & 809336 & 4.5901 & 3.9093 & TRN \\
\hline CHEMBL1996766 & 809336 & 3.327 & 3.4221 & TST \\
\hline CHEMBL1506402 & 809336 & 3.327 & 4.0192 & TRN \\
\hline CHEMBL1541183 & 809336 & 3.327 & 3.665 & TRN \\
\hline CHEMBL1339456 & 809336 & 3.327 & 3.313 & TRN \\
\hline CHEMBL1988767 & 809336 & 4.4157 & 4.0996 & TRN \\
\hline CHEMBL1524366 & 809336 & 3.327 & 3.9997 & TRN \\
\hline CHEMBL1311578 & 809336 & 3.327 & 4.1073 & TRN \\
\hline CHEMBL1527434 & 809336 & 3.327 & 3.8434 & TRN \\
\hline CHEMBL1481422 & 809336 & 3.327 & 3.4153 & TRN \\
\hline CHEMBL1871578 & 809336 & 3.327 & 3.7577 & TRN \\
\hline CHEMBL1601531 & 809336 & 3.327 & 3.1709 & TRN \\
\hline CHEMBL1339626 & 809336 & 7.4342 & 4.8448 & TRN \\
\hline CHEMBL1558763 & 809336 & 3.327 & 3.4266 & TRN \\
\hline CHEMBL601994 & 809336 & 3.327 & 3.9453 & TST \\
\hline CHEMBL1460452 & 809336 & 3.327 & 3.7349 & TRN \\
\hline CHEMBL1577332 & 809336 & 3.327 & 4.0212 & TRN \\
\hline
\end{tabular}




\begin{tabular}{|c|c|c|c|c|c|}
\hline & & \multicolumn{4}{|c|}{ Supplemental Table S2.txt } \\
\hline CHEMBL1343832 & 809336 & 3.327 & 3.2941 & TRN & \\
\hline CHEMBL1698302 & 809336 & 3.327 & 3.5107 & TRN & \\
\hline CHEMBL1699070 & 809336 & 5.5421 & 4.7306 & TRN & \\
\hline CHEMBL1715921 & 809336 & 3.327 & 4.1287 & TRN & \\
\hline CHEMBL1385288 & 809336 & 3.327 & 3.8711 & TRN & \\
\hline CHEMBL1989074 & 809336 & 3.327 & 4.1793 & TST & \\
\hline CHEMBL1305431 & 809336 & 3.327 & 4.24100 & 00000000005 & TRN \\
\hline CHEMBL1500116 & 809336 & 4.7167 & 3.9996 & TRN & \\
\hline CHEMBL1577182 & 809336 & 3.327 & 3.5083 & TRN & \\
\hline CHEMBL1559794 & 809336 & 3.327 & 3.5089 & TRN & \\
\hline CHEMBL1540150 & 809336 & 3.327 & 3.8453 & TRN & \\
\hline CHEMBL1735745 & 809336 & 3.327 & 3.5035 & TRN & \\
\hline CHEMBL1384182 & 809336 & 7.4342 & 4.7728 & TRN & \\
\hline CHEMBL1489517 & 809336 & 6.2147 & 4.0287 & TRN & \\
\hline CHEMBL1479892 & 809336 & 3.327 & 3.609 & TRN & \\
\hline CHEMBL1903664 & 809336 & 3.327 & 3.8337 & TRN & \\
\hline CHEMBL1500419 & 809336 & 3.327 & 4.2681 & TST & \\
\hline CHEMBL1421539 & 809336 & 3.327 & 3.5193 & TRN & \\
\hline CHEMBL1399067 & 809336 & 3.327 & 3.2628 & TRN & \\
\hline CHEMBL1510258 & 809336 & 3.327 & 3.7083 & TRN & \\
\hline CHEMBL1386423 & 809336 & 3.327 & 4.129 & TST & \\
\hline CHEMBL1487187 & 809336 & 3.327 & 3.4525 & TRN & \\
\hline CHEMBL1557508 & 809336 & 4.8894 & 4.0214 & TRN & \\
\hline CHEMBL1428733 & 809336 & 3.327 & 3.7839 & TRN & \\
\hline CHEMBL1521600 & 809336 & 3.327 & 3.8649 & TRN & \\
\hline CHEMBL1540674 & 809336 & 3.327 & 3.3587 & TRN & \\
\hline CHEMBL1563028 & 809336 & 3.327 & 3.8098 & TRN & \\
\hline CHEMBL1596383 & 809336 & 3.327 & 3.2485 & TRN & \\
\hline CHEMBL1577226 & 809336 & 3.327 & 4.1562 & TRN & \\
\hline CHEMBL1445253 & 809336 & 3.327 & 3.7145 & TRN & \\
\hline CHEMBL1870218 & 809336 & 3.327 & 4.1016 & TRN & \\
\hline CHEMBL1730846 & 809336 & 3.327 & 4.123 & TRN & \\
\hline CHEMBL1564012 & 809336 & 7.4342 & 4.4034 & TRN & \\
\hline CHEMBL1302939 & 809336 & 3.327 & 3.4023 & TRN & \\
\hline CHEMBL1451142 & 809336 & 3.327 & 4.1783 & TRN & \\
\hline CHEMBL1568876 & 809336 & 3.327 & 4.2112 & TRN & \\
\hline CHEMBL1708045 & 809336 & 3.327 & 4.3001 & TST & \\
\hline CHEMBL1510057 & 809336 & 3.327 & 4.2717 & TRN & \\
\hline CHEMBL1981572 & 809336 & 3.327 & 3.8472 & TRN & \\
\hline CHEMBL1495550 & 809336 & 7.4342 & 4.2946 & TST & \\
\hline CHEMBL1411251 & 809336 & 3.327 & 3.84800 & 00000000003 & TRN \\
\hline CHEMBL1899444 & 809336 & 3.327 & 3.4452 & TST & \\
\hline CHEMBL1605856 & 809336 & 3.327 & 3.4391 & TRN & \\
\hline CHEMBL1503834 & 809336 & 5.2984 & 3.8309 & TST & \\
\hline CHEMBL1985863 & 809336 & 3.327 & 4.0634 & TRN & \\
\hline CHEMBL1453993 & 809336 & 3.327 & 4.1287 & TRN & \\
\hline CHEMBL1558773 & 809336 & 3.327 & 3.8534 & TST & \\
\hline CHEMBL1410321 & 809336 & 5.4271 & 3.784 & TRN & \\
\hline
\end{tabular}




\begin{tabular}{|c|c|c|c|c|c|c|}
\hline & & \multicolumn{5}{|c|}{ Supplemental Table S2.txt } \\
\hline CHEMBL1983775 & 809336 & 3.327 & 3.6741 & TST & & \\
\hline CHEMBL1409493 & 809336 & 3.327 & 3.6098 & TRN & & \\
\hline CHEMBL 2002815 & 809336 & 3.327 & 4.1848 & TRN & & \\
\hline CHEMBL1401879 & 809336 & 3.327 & 3.6382 & TRN & & \\
\hline CHEMBL1403753 & 809336 & 3.327 & 3.6443 & TRN & & \\
\hline CHEMBL1545385 & 809336 & 5.4597 & 4.3965 & TRN & & \\
\hline CHEMBL1335827 & 809336 & 3.327 & 4.1527 & TRN & & \\
\hline CHEMBL1701597 & 809336 & 3.327 & 4.0266 & TRN & & \\
\hline CHEMBL1522964 & 809336 & 3.327 & 3.3095 & TRN & & \\
\hline CHEMBL1568079 & 809336 & 3.327 & 3.7134 & TRN & & \\
\hline CHEMBL1891811 & 809336 & 3.327 & 3.3662 & TRN & & \\
\hline CHEMBL1449516 & 809336 & 3.327 & 3.6522 & TRN & & \\
\hline CHEMBL 2002522 & 809336 & 4.6108 & 4.3645 & TRN & & \\
\hline CHEMBL1546406 & 809336 & 3.327 & 3.7882 & TRN & & \\
\hline CHEMBL1343599 & 809336 & 3.327 & 4.2567 & TRN & & \\
\hline CHEMBL1548552 & 809336 & 5.1871 & 3.3479 & TRN & & \\
\hline CHEMBL579621 & 809336 & 6.0088 & 4.7105 & TRN & & \\
\hline CHEMBL1419816 & 809336 & 7.4342 & 3.7296 & TRN & & \\
\hline CHEMBL1461925 & 809336 & 4.9586 & 4.2095 & TRN & & \\
\hline CHEMBL1330414 & 809336 & 3.327 & 3.6242 & TRN & & \\
\hline CHEMBL1489218 & 809336 & 7.4342 & 3.9461 & TRN & & \\
\hline CHEMBL1377280 & 809336 & 3.327 & 3.7265 & TRN & & \\
\hline CHEMBL1578207 & 809336 & 3.327 & 3.8106 & TRN & & \\
\hline CHEMBL1508389 & 809336 & 4.9245 & 4.3384 & TST & & \\
\hline CHEMBL1327923 & 809336 & $5.7570 e$ & 00000000 & $\partial 1$ & 4.0034 & TRN \\
\hline CHEMBL1409619 & 809336 & 5.5654 & 4.3685 & TRN & & \\
\hline CHEMBL1427197 & 809336 & 3.327 & 3.7009 & TRN & & \\
\hline CHEMBL1556353 & 809336 & 3.327 & 3.4445 & TRN & & \\
\hline CHEMBL1306905 & 809336 & 3.327 & 3.7096 & TRN & & \\
\hline CHEMBL1350251 & 809336 & 3.327 & 3.903 & TRN & & \\
\hline CHEMBL1472016 & 809336 & 7.4342 & 4.0319 & TRN & & \\
\hline CHEMBL1307329 & 809336 & 3.327 & 3.7918 & TRN & & \\
\hline CHEMBL1559175 & 809336 & 5.3152 & 3.997 & TRN & & \\
\hline CHEMBL1726318 & 809336 & 3.6271 & 4.1839 & TRN & & \\
\hline CHEMBL1535443 & 809336 & 5.3242 & 4.7543 & TRN & & \\
\hline CHEMBL1510100 & 809336 & 4.5622 & 4.0203 & TRN & & \\
\hline CHEMBL1532749 & 809336 & 3.327 & 4.199 & TRN & & \\
\hline CHEMBL1430859 & 809336 & 3.327 & 3.6503 & TRN & & \\
\hline CHEMBL1539071 & 809336 & 3.327 & 3.6391 & TRN & & \\
\hline CHEMBL1883622 & 809336 & 3.327 & 4.1547 & TST & & \\
\hline CHEMBL1380641 & 809336 & 3.327 & 3.8072 & TRN & & \\
\hline CHEMBL1415345 & 809336 & 3.327 & 3.443 & TRN & & \\
\hline CHEMBL1386528 & 809336 & 3.327 & 3.4158 & TRN & & \\
\hline CHEMBL 1388416 & 809336 & 3.327 & 3.4276 & TRN & & \\
\hline CHEMBL1872930 & 809336 & 3.327 & 3.3149 & TRN & & \\
\hline CHEMBL1582790 & 809336 & 3.327 & 3.4631 & TRN & & \\
\hline CHEMBL1318567 & 809336 & 7.4342 & 3.7009 & TRN & & \\
\hline CHEMBL1370360 & 809336 & 3.327 & 3.5879 & TRN & & \\
\hline
\end{tabular}




\begin{tabular}{|c|c|c|c|c|}
\hline \multicolumn{5}{|c|}{ Supplemental Tabl } \\
\hline CHEMBL1587306 & 809336 & 4.5114 & 4.0304 & TRN \\
\hline CHEMBL1462418 & 809336 & 5.0434 & 4.7287 & TRN \\
\hline CHEMBL1701573 & 809336 & 3.327 & 3.8047 & TRN \\
\hline CHEMBL1341868 & 809336 & 3.327 & 3.9549 & TRN \\
\hline CHEMBL1446075 & 809336 & 3.327 & 3.5886 & TRN \\
\hline CHEMBL1256362 & 809336 & 3.327 & 3.6928 & TST \\
\hline CHEMBL1987295 & 809336 & 3.327 & 4.1928 & TRN \\
\hline CHEMBL1395930 & 809336 & 3.327 & 3.6223 & TRN \\
\hline CHEMBL1470702 & 809336 & 3.327 & 4.2747 & TRN \\
\hline CHEMBL1719191 & 809336 & 3.327 & 3.3098 & TRN \\
\hline CHEMBL1313600 & 809336 & 3.327 & 4.0308 & TRN \\
\hline CHEMBL1376663 & 809336 & 3.327 & 4.4114 & TRN \\
\hline CHEMBL1430478 & 809336 & 3.327 & 3.6175 & TRN \\
\hline CHEMBL1602641 & 809336 & 3.327 & 3.3474 & TRN \\
\hline CHEMBL1545363 & 809336 & 5.4168 & 3.8896 & TST \\
\hline CHEMBL1577208 & 809336 & 3.327 & 3.6819 & TRN \\
\hline CHEMBL1448716 & 809336 & 3.327 & 3.7307 & TRN \\
\hline CHEMBL1447016 & 809336 & 7.4342 & 4.2074 & TST \\
\hline CHEMBL1503606 & 809336 & 3.327 & 3.7108 & TRN \\
\hline CHEMBL1500525 & 809336 & 3.327 & 3.4514 & TRN \\
\hline CHEMBL1312615 & 809336 & 3.327 & 4.1556 & TRN \\
\hline CHEMBL1423919 & 809336 & 4.9586 & 4.2296 & TRN \\
\hline CHEMBL1353508 & 809336 & 3.327 & 4.2166 & TST \\
\hline CHEMBL1377025 & 809336 & 3.327 & 4.2837 & TRN \\
\hline CHEMBL1716105 & 809336 & 3.327 & 3.9867 & TST \\
\hline CHEMBL1388117 & 809336 & 3.327 & 4.4911 & TST \\
\hline CHEMBL1874188 & 809336 & 3.327 & 3.6113 & TRN \\
\hline CHEMBL1597620 & 809336 & 3.327 & 3.7444 & TRN \\
\hline CHEMBL1386013 & 809336 & 3.327 & 4.2774 & TST \\
\hline CHEMBL1730260 & 809336 & 3.327 & 3.3799 & TRN \\
\hline CHEMBL1888652 & 809336 & 3.327 & 3.3616 & TRN \\
\hline CHEMBL1380417 & 809336 & 4.7878 & 4.0533 & TRN \\
\hline CHEMBL1374633 & 809336 & 3.327 & 3.6164 & TRN \\
\hline CHEMBL1490809 & 809336 & 3.327 & 4.1224 & TRN \\
\hline CHEMBL1488101 & 809336 & 4.3862 & 4.0576 & TRN \\
\hline CHEMBL1505907 & 809336 & 3.327 & 3.4212 & TRN \\
\hline CHEMBL1866538 & 809336 & 3.327 & 3.7751 & TRN \\
\hline CHEMBL1906557 & 809336 & 3.327 & 4.0013 & TRN \\
\hline CHEMBL1528669 & 809336 & 7.4342 & 3.5902 & TRN \\
\hline CHEMBL1975484 & 809336 & 3.327 & 3.9057 & TRN \\
\hline CHEMBL1447555 & 809336 & 3.327 & 3.2764 & TRN \\
\hline CHEMBL1428209 & 809336 & 3.327 & 3.7133 & TRN \\
\hline CHEMBL1388565 & 809336 & 5.699 & 4.2944 & TRN \\
\hline CHEMBL1596504 & 809336 & 3.327 & 4.566 & TST \\
\hline CHEMBL1344220 & 809336 & 3.327 & 4.1346 & TRN \\
\hline CHEMBL1370330 & 809336 & 3.327 & 3.7346 & TRN \\
\hline CHEMBL1365314 & 809336 & 3.327 & 3.715 & TRN \\
\hline CHEMBL1471897 & 809336 & 3.327 & 3.6608 & TRN \\
\hline
\end{tabular}




\begin{tabular}{|c|c|c|c|c|c|}
\hline & & \multicolumn{4}{|c|}{ Supplemental Table s2.txt } \\
\hline CHEMBL1343195 & 809336 & 3.327 & 4.0015 & TRN & \\
\hline CHEMBL1580050 & 809336 & 3.327 & 3.9372 & TST & \\
\hline CHEMBL1601483 & 809336 & 3.327 & 4.0499 & TST & \\
\hline CHEMBL236059 & 809336 & 3.327 & 3.7235 & TRN & \\
\hline CHEMBL1421353 & 809336 & 4.9586 & 3.6269 & TRN & \\
\hline CHEMBL1470207 & 809336 & 3.327 & 4.4433 & TST & \\
\hline CHEMBL1459637 & 809336 & 3.327 & 4.0254 & TRN & \\
\hline CHEMBL1992918 & 809336 & 3.327 & 3.7904 & TST & \\
\hline CHEMBL1331093 & 809336 & 3.327 & 3.9566 & TRN & \\
\hline CHEMBL1550694 & 809336 & 3.327 & 4.5425 & TRN & \\
\hline CHEMBL1420688 & 809336 & 3.327 & 3.3452 & TRN & \\
\hline CHEMBL 2002003 & 809336 & 3.327 & 4.3714 & TST & \\
\hline CHEMBL1899719 & 809336 & 3.327 & 3.1801 & TRN & \\
\hline CHEMBL1575690 & 809336 & 4.699 & 4.1148 & TRN & \\
\hline CHEMBL1442335 & 809336 & 4.4089 & 4.0965 & TRN & \\
\hline CHEMBL1395588 & 809336 & 3.327 & 3.5672 & TRN & \\
\hline CHEMBL1887958 & 809336 & 3.327 & 3.571 & TRN & \\
\hline CHEMBL1446255 & 809336 & 3.327 & 3.4413 & TRN & \\
\hline CHEMBL1698159 & 809336 & 3.327 & 3.7779 & TRN & \\
\hline CHEMBL1579621 & 809336 & 3.327 & 3.8292 & TRN & \\
\hline CHEMBL1534572 & 809336 & 3.327 & 3.5421 & TRN & \\
\hline CHEMBL1549531 & 809336 & 3.327 & 4.4685 & TRN & \\
\hline CHEMBL1364242 & 809336 & 4.7852 & 3.9071 & TRN & \\
\hline CHEMBL1504102 & 809336 & 3.327 & 4.1125 & TRN & \\
\hline CHEMBL1310406 & 809336 & 3.327 & 3.4177 & TRN & \\
\hline CHEMBL1305899 & 809336 & 3.327 & 3.54399 & 99999999996 & TRN \\
\hline CHEMBL1462114 & 809336 & 4.3354 & 3.9019 & TST & \\
\hline CHEMBL1360428 & 809336 & 3.327 & 3.302 & TST & \\
\hline CHEMBL1367530 & 809336 & 3.327 & 3.5298 & TRN & \\
\hline CHEMBL1558111 & 809336 & 3.327 & 4.3225 & TRN & \\
\hline CHEMBL1312858 & 809336 & 4.6198 & 4.2025 & TRN & \\
\hline CHEMBL1900655 & 809336 & 3.327 & 4.1853 & TRN & \\
\hline CHEMBL1987735 & 809336 & 7.4342 & 3.7465 & TRN & \\
\hline CHEMBL 2000414 & 809336 & 3.327 & 3.8438 & TRN & \\
\hline CHEMBL1334133 & 809336 & 4.8827 & 4.3277 & TRN & \\
\hline CHEMBL1609782 & 809336 & 3.327 & 3.4065 & TRN & \\
\hline CHEMBL 2006470 & 809336 & 3.327 & 3.9837 & TRN & \\
\hline CHEMBL1710757 & 809336 & 4.4597 & 4.7366 & TRN & \\
\hline CHEMBL1732994 & 809336 & 3.327 & 3.9208 & TRN & \\
\hline CHEMBL1503247 & 809336 & 3.327 & 3.0137 & TRN & \\
\hline CHEMBL1563699 & 809336 & 7.4342 & 4.3093 & TRN & \\
\hline CHEMBL1389843 & 809336 & 7.4342 & 4.7288 & TRN & \\
\hline CHEMBL1411304 & 809336 & 3.327 & 4.228 & TRN & \\
\hline CHEMBL1353853 & 809336 & 3.327 & 4.2661 & TST & \\
\hline CHEMBL1406404 & 809336 & 3.327 & 3.8925 & TST & \\
\hline CHEMBL1450691 & 809336 & 3.327 & 4.04 & TST & \\
\hline CHEMBL1424877 & 809336 & 3.327 & 4.4178 & TRN & \\
\hline CHEMBL1401975 & 809336 & 3.327 & 4.1478 & TRN & \\
\hline
\end{tabular}




\begin{tabular}{|c|c|c|c|c|c|}
\hline & & \multicolumn{4}{|c|}{ Supplemental Table s2.txt } \\
\hline CHEMBL1432493 & 809336 & 3.327 & 3.8354 & TRN & \\
\hline CHEMBL1403387 & 809336 & 3.327 & 3.6997 & TRN & \\
\hline CHEMBL2006275 & 809336 & 3.327 & 3.9647 & TRN & \\
\hline CHEMBL1347512 & 809336 & 3.327 & 3.9583 & TRN & \\
\hline CHEMBL1453985 & 809336 & 4.6308 & 4.3274 & TRN & \\
\hline CHEMBL1365298 & 809336 & 3.327 & 3.81399 & 99999999996 & TRN \\
\hline CHEMBL245265 & 809336 & 4.4584 & 3.9788 & TRN & \\
\hline CHEMBL1448881 & 809336 & 5.6655 & 3.6831 & TRN & \\
\hline CHEMBL 2004640 & 809336 & 3.327 & 3.2352 & TRN & \\
\hline CHEMBL1412335 & 809336 & 3.327 & 3.3766 & TRN & \\
\hline CHEMBL1704208 & 809336 & 3.327 & 3.88199 & 99999999997 & TRN \\
\hline CHEMBL1600733 & 809336 & 3.327 & 4.2191 & TRN & \\
\hline CHEMBL1734352 & 809336 & 3.327 & 3.9502 & TRN & \\
\hline CHEMBL1469608 & 809336 & 3.327 & 4.1355 & TRN & \\
\hline CHEMBL1997174 & 809336 & 3.327 & 4.6737 & TRN & \\
\hline CHEMBL1546612 & 809336 & 3.327 & 3.5906 & TRN & \\
\hline CHEMBL1968526 & 809336 & 7.4342 & 3.4404 & TST & \\
\hline CHEMBL1477639 & 809336 & 3.327 & 3.9156 & TRN & \\
\hline CHEMBL1305513 & 809336 & 3.327 & 3.7353 & TRN & \\
\hline CHEMBL1548099 & 809336 & 3.327 & 3.7894 & TRN & \\
\hline CHEMBL1872619 & 809336 & 3.327 & 3.5628 & TRN & \\
\hline CHEMBL1715110 & 809336 & 3.327 & 3.1905 & TRN & \\
\hline CHEMBL 235843 & 809336 & 3.327 & 3.9613 & TRN & \\
\hline CHEMBL1540130 & 809336 & 3.327 & 4.6218 & TRN & \\
\hline CHEMBL1606173 & 809336 & 3.327 & 4.1652 & TRN & \\
\hline CHEMBL1716799 & 809336 & 3.327 & 3.3328 & TRN & \\
\hline CHEMBL1393211 & 809336 & 3.327 & 3.6596 & TRN & \\
\hline CHEMBL1577167 & 809336 & 3.327 & 3.2591 & TRN & \\
\hline CHEMBL1496607 & 809336 & 5.2434 & 3.9558 & TRN & \\
\hline CHEMBL1497158 & 809336 & 3.327 & 3.431 & TST & \\
\hline CHEMBL1503528 & 809336 & 7.4342 & 3.8407 & TRN & \\
\hline CHEMBL1535377 & 809336 & 3.327 & 3.9703 & TRN & \\
\hline CHEMBL1411141 & 809336 & 3.327 & 3.2222 & TRN & \\
\hline CHEMBL1346004 & 809336 & 5.4034 & 3.502 & TRN & \\
\hline CHEMBL1368214 & 809336 & 3.327 & 4.1245 & TRN & \\
\hline CHEMBL1480837 & 809336 & 3.327 & 3.5534 & TRN & \\
\hline CHEMBL1709676 & 809336 & 4.5768 & 3.4284 & TRN & \\
\hline CHEMBL1393086 & 809336 & 3.327 & 3.4747 & TRN & \\
\hline CHEMBL1407488 & 809336 & 5.1079 & 3.671006 & 00000000003 & TRN \\
\hline CHEMBL1400492 & 809336 & 5.2628 & 3.8885 & TRN & \\
\hline CHEMBL1402112 & 809336 & 3.327 & 3.5979 & TRN & \\
\hline CHEMBL1493417 & 809336 & 5.21899 & 79999999ऽ & 4.5459 & TRN \\
\hline CHEMBL1487747 & 809336 & 3.327 & 3.8514 & TRN & \\
\hline CHEMBL1971410 & 809336 & 3.327 & 4.1331 & TRN & \\
\hline CHEMBL1539526 & 809336 & 4.644 & 4.3454 & TST & \\
\hline CHEMBL1590902 & 809336 & 3.327 & 3.4569 & TST & \\
\hline CHEMBL1369524 & 809336 & 3.327 & 4.1302 & TRN & \\
\hline CHEMBL1532970 & 809336 & 3.327 & 3.7422 & TRN & \\
\hline
\end{tabular}




\begin{tabular}{|c|c|c|c|c|c|c|}
\hline & & \multicolumn{5}{|c|}{ Supplemental Table S2.txt } \\
\hline CHEMBL1317088 & 809336 & 3.327 & 3.6754 & TRN & & \\
\hline CHEMBL1418504 & 809336 & 3.327 & 4.4103 & TRN & & \\
\hline CHEMBL1736945 & 809336 & 3.327 & 3.8153 & TRN & & \\
\hline CHEMBL1310211 & 809336 & 5.3915 & 4.2756 & TRN & & \\
\hline CHEMBL1526913 & 809336 & 3.327 & 4.0373 & TST & & \\
\hline CHEMBL1409442 & 809336 & 3.327 & 3.7145 & TRN & & \\
\hline CHEMBL1349459 & 809336 & 5.2984 & 4.2134 & TRN & & \\
\hline CHEMBL1550137 & 809336 & 3.327 & 3.5046 & TRN & & \\
\hline CHEMBL 2002641 & 809336 & 3.327 & 4.1269 & TRN & & \\
\hline CHEMBL1548881 & 809336 & 7.4342 & 3.9597 & TRN & & \\
\hline CHEMBL1458095 & 809336 & 3.327 & 3.7189 & TRN & & \\
\hline CHEMBL1539444 & 809336 & 3.327 & 4.0522 & TRN & & \\
\hline CHEMBL1418574 & 809336 & 3.327 & 3.5221 & TRN & & \\
\hline CHEMBL1371902 & 809336 & 6.1409 & 4.2612 & TST & & \\
\hline CHEMBL1501751 & 809336 & 4.4535 & 3.9109 & TRN & & \\
\hline CHEMBL1486410 & 809336 & 3.327 & 3.4183 & TRN & & \\
\hline CHEMBL1519404 & 809336 & 3.327 & 4.1702 & TRN & & \\
\hline CHEMBL1449957 & 809336 & 3.327 & 3.8967 & TRN & & \\
\hline CHEMBL1994316 & 809336 & 3.327 & 4.673 & TRN & & \\
\hline CHEMBL1577205 & 809336 & 5.5986 & 4.2218 & TRN & & \\
\hline CHEMBL1874757 & 809336 & 3.327 & 3.0956 & TST & & \\
\hline CHEMBL1981949 & 809336 & 3.327 & 4.2171 & TRN & & \\
\hline CHEMBL1742219 & 809336 & 3.327 & 4.4227 & TST & & \\
\hline CHEMBL 2006634 & 809336 & 3.327 & 3.8077 & TRN & & \\
\hline CHEMBL1482357 & 809336 & 3.327 & 3.4599 & TRN & & \\
\hline CHEMBL1416981 & 809336 & 5.284 & 4.476 & TST & & \\
\hline CHEMBL1561297 & 809336 & 3.327 & 3.8061 & TRN & & \\
\hline CHEMBL1373134 & 809336 & 3.327 & 3.8798 & TRN & & \\
\hline CHEMBL1986785 & 809336 & 3.327 & 4.1632 & TST & & \\
\hline CHEMBL1459324 & 809336 & 5.21899 & 99999999 & 99 & 3.9595 & TRN \\
\hline CHEMBL1715025 & 809336 & 3.327 & 3.6906 & TRN & & \\
\hline CHEMBL1455113 & 809336 & 5.1618 & 4.249 & TRN & & \\
\hline CHEMBL1558725 & 809336 & 3.327 & 3.6432 & TRN & & \\
\hline CHEMBL1708473 & 809336 & 3.327 & 3.5823 & TRN & & \\
\hline CHEMBL1380341 & 809336 & 3.327 & 4.1433 & TRN & & \\
\hline CHEMBL1526754 & 809336 & 3.327 & 4.1048 & TRN & & \\
\hline CHEMBL1489089 & 809336 & 7.4342 & 3.909 & TRN & & \\
\hline CHEMBL1453885 & 809336 & 3.327 & 3.5619 & TRN & & \\
\hline CHEMBL1323917 & 809336 & 4.8539 & 4.2926 & TRN & & \\
\hline CHEMBL1905755 & 809336 & 3.327 & 3.3529 & TRN & & \\
\hline CHEMBL1510679 & 809336 & 5.6038 & 4.5234 & TRN & & \\
\hline CHEMBL1466865 & 809336 & 3.327 & 4.0764 & TRN & & \\
\hline CHEMBL1999547 & 809336 & 3.327 & 4.1015 & TRN & & \\
\hline CHEMBL1422860 & 809336 & 3.327 & 4.0062 & TST & & \\
\hline CHEMBL1319234 & 809336 & 3.327 & 2.987 & TRN & & \\
\hline CHEMBL1546999 & 809336 & 3.327 & 4.4548 & TST & & \\
\hline CHEMBL1522372 & 809336 & 4.3575 & 3.9116 & TRN & & \\
\hline CHEMBL1301647 & 809336 & 5.3726 & 4.5093 & TST & & \\
\hline
\end{tabular}




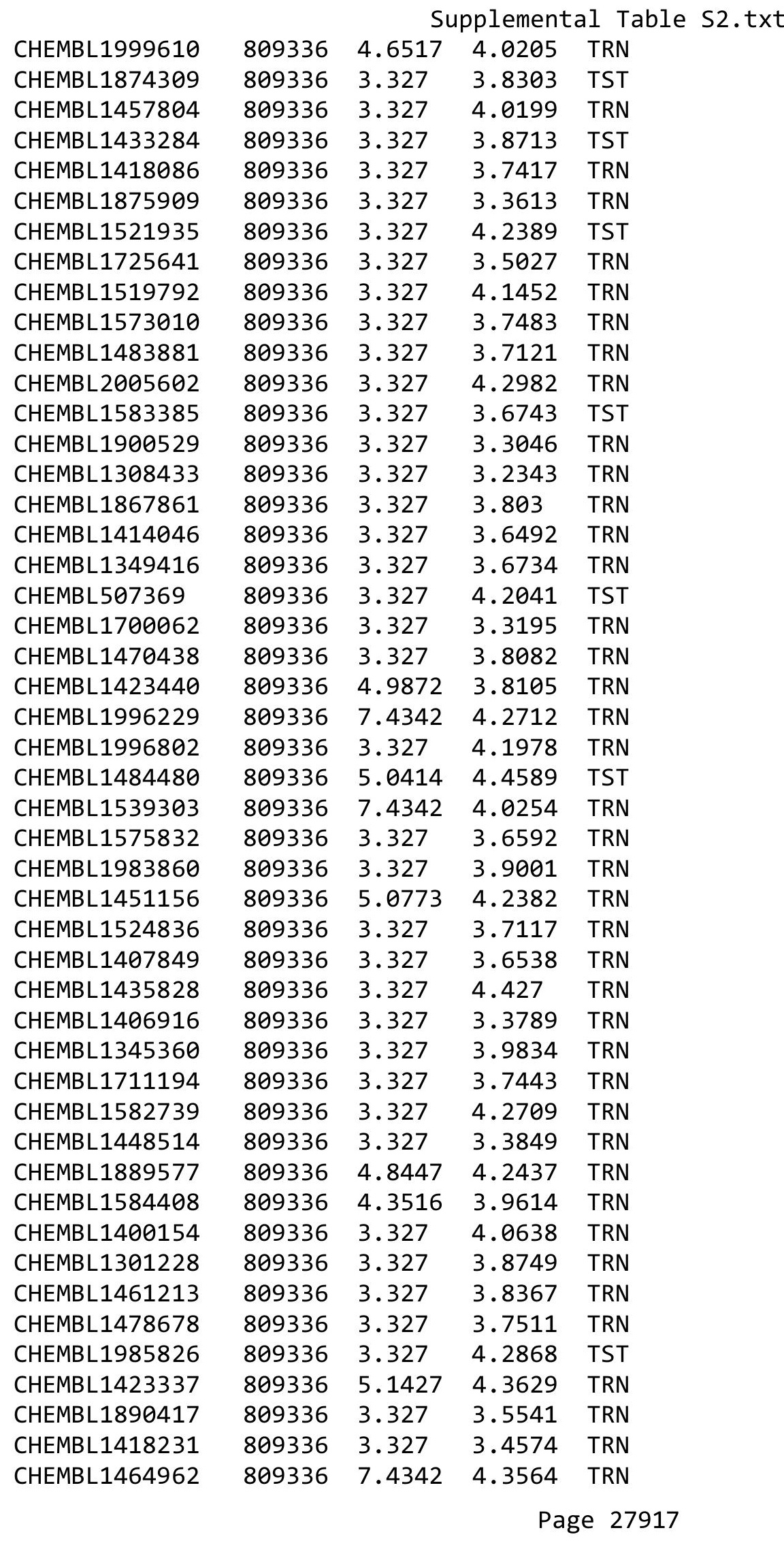




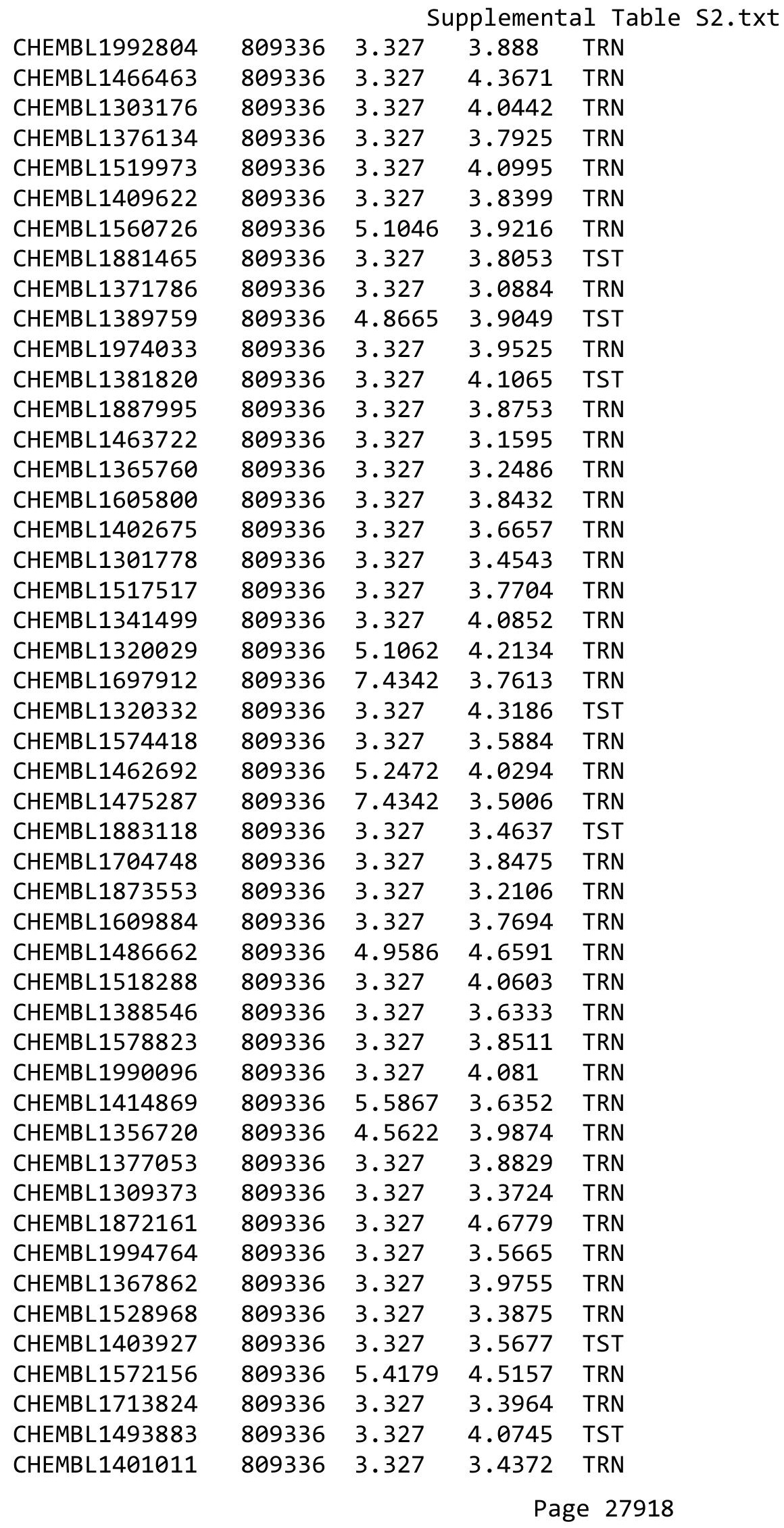




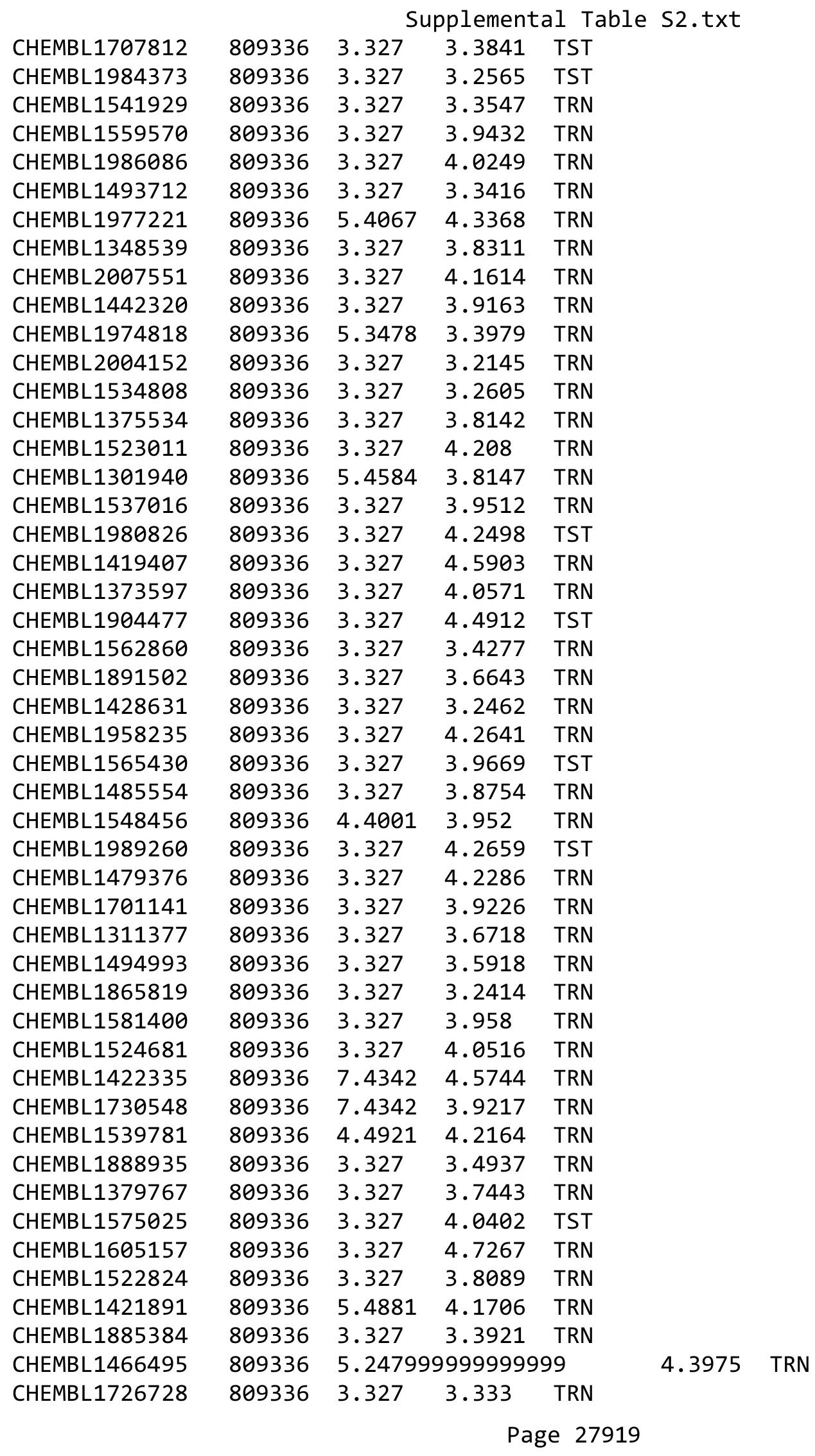




\begin{tabular}{|c|c|c|c|c|}
\hline & & & oplement & al Ta \\
\hline CHEMBL579967 & 809336 & 3.327 & 4.3723 & TRN \\
\hline CHEMBL1724527 & 809336 & 3.327 & 4.4106 & TRN \\
\hline CHEMBL1348506 & 809336 & 4.8794 & 4.2962 & TRN \\
\hline CHEMBL1336902 & 809336 & 3.327 & 3.3238 & TRN \\
\hline CHEMBL1602136 & 809336 & 3.327 & 4.0681 & TST \\
\hline CHEMBL1307386 & 809336 & 3.327 & 4.0201 & TRN \\
\hline CHEMBL1378628 & 809336 & 3.327 & 3.6119 & TRN \\
\hline CHEMBL1430624 & 809336 & 3.327 & 3.9537 & TRN \\
\hline CHEMBL1407565 & 809336 & 3.327 & 3.6492 & TRN \\
\hline CHEMBL1497417 & 809336 & 3.327 & 4.3093 & TST \\
\hline CHEMBL1429539 & 809336 & 3.327 & 4.053 & TRN \\
\hline CHEMBL1214033 & 809336 & 5.2874 & 4.3025 & TST \\
\hline CHEMBL1377693 & 809336 & 3.327 & 3.833 & TRN \\
\hline CHEMBL1443529 & 809336 & 3.327 & 4.2248 & TRN \\
\hline CHEMBL274499 & 809336 & 3.327 & 3.5948 & TRN \\
\hline CHEMBL1970627 & 809336 & 3.327 & 4.0395 & TRN \\
\hline CHEMBL1577217 & 809336 & 3.327 & 4.6612 & TST \\
\hline CHEMBL1484743 & 809336 & 3.327 & 3.8285 & TRN \\
\hline CHEMBL1359231 & 809336 & 3.327 & 3.4432 & TRN \\
\hline CHEMBL1906080 & 809336 & 3.327 & 3.4958 & TRN \\
\hline CHEMBL1543180 & 809336 & 3.327 & 3.2603 & TRN \\
\hline CHEMBL1569905 & 809336 & 3.327 & 3.5906 & TRN \\
\hline CHEMBL1385804 & 809336 & 3.327 & 3.6699 & TRN \\
\hline CHEMBL1523577 & 809336 & 5.4168 & 4.2545 & TST \\
\hline CHEMBL1431045 & 809336 & 3.327 & 3.8056 & TST \\
\hline CHEMBL1467660 & 809336 & 7.4342 & 3.9733 & TRN \\
\hline CHEMBL1733837 & 809336 & 3.327 & 3.9428 & TRN \\
\hline CHEMBL1568987 & 809336 & 3.327 & 4.3118 & TRN \\
\hline CHEMBL1728659 & 809336 & 3.327 & 3.9318 & TRN \\
\hline CHEMBL1733654 & 809336 & 3.327 & 3.3334 & TST \\
\hline CHEMBL488803 & 809336 & 7.4342 & 4.6585 & TRN \\
\hline CHEMBL1461578 & 809336 & 3.327 & 4.6118 & TRN \\
\hline CHEMBL1490486 & 809336 & 3.327 & 4.7081 & TRN \\
\hline CHEMBL1301337 & 809336 & 3.327 & 3.8894 & TST \\
\hline CHEMBL1426795 & 809336 & 3.327 & 4.2547 & TST \\
\hline CHEMBL 2005840 & 809336 & 3.327 & 3.8914 & TRN \\
\hline CHEMBL1563559 & 809336 & 5.0048 & 4.0547 & TRN \\
\hline CHEMBL1578622 & 809336 & 3.327 & 3.8987 & TRN \\
\hline CHEMBL1475698 & 809336 & 3.327 & 3.8109 & TST \\
\hline CHEMBL1540390 & 809336 & 3.327 & 3.8011 & TRN \\
\hline CHEMBL1303437 & 809336 & 3.327 & 3.9492 & TRN \\
\hline CHEMBL1975512 & 809336 & 3.327 & 3.6546 & TRN \\
\hline CHEMBL1398866 & 809336 & 3.327 & 4.3632 & TRN \\
\hline CHEMBL1418166 & 809336 & 3.327 & 3.7463 & TRN \\
\hline CHEMBL1373053 & 809336 & 4.3726 & 3.2807 & TRN \\
\hline CHEMBL1455161 & 809336 & 3.327 & 3.2778 & TST \\
\hline CHEMBL1519192 & 809336 & 7.4342 & 3.5318 & TRN \\
\hline CHEMBL1485894 & 809336 & 3.327 & 3.8146 & TRN \\
\hline
\end{tabular}




\begin{tabular}{|c|c|c|c|c|c|}
\hline & & \multicolumn{4}{|c|}{ Supplemental Table s2.txt } \\
\hline CHEMBL1731923 & 809336 & 5.2343 & 3.9992 & TRN & \\
\hline CHEMBL1323621 & 809336 & 3.327 & 3.9273 & TRN & \\
\hline CHEMBL1343586 & 809336 & 7.4342 & 4.5473 & TRN & \\
\hline CHEMBL1733230 & 809336 & 3.327 & 3.1526 & TRN & \\
\hline CHEMBL1498408 & 809336 & 3.327 & 4.0366 & TRN & \\
\hline CHEMBL1726591 & 809336 & 3.327 & 4.4751 & TRN & \\
\hline CHEMBL1349183 & 809336 & 3.327 & 3.7703 & TRN & \\
\hline CHEMBL1964667 & 809336 & 3.327 & \multicolumn{2}{|c|}{4.6080000000000005} & TST \\
\hline CHEMBL1537326 & 809336 & 3.327 & 3.9169 & TRN & \\
\hline CHEMBL1430256 & 809336 & 3.327 & 3.8496 & TST & \\
\hline CHEMBL1299959 & 809336 & 3.327 & 3.6364 & TRN & \\
\hline CHEMBL1577735 & 809336 & 3.327 & 3.822 & TRN & \\
\hline CHEMBL1735078 & 809336 & 3.327 & 3.593 & TRN & \\
\hline CHEMBL1382689 & 809336 & 3.327 & 3.7527 & TRN & \\
\hline CHEMBL1474802 & 809336 & 3.327 & 3.552 & TRN & \\
\hline CHEMBL1470951 & 809336 & 7.4342 & 3.5735 & TST & \\
\hline CHEMBL493062 & 809336 & 4.9957 & 4.555 & TRN & \\
\hline CHEMBL1372192 & 809336 & 3.327 & 3.7905 & TST & \\
\hline CHEMBL1877350 & 809336 & 3.327 & 3.4276 & TST & \\
\hline CHEMBL1705012 & 809336 & 3.327 & 3.2313 & TRN & \\
\hline CHEMBL1988535 & 809336 & 3.327 & 4.106 & TRN & \\
\hline CHEMBL1299512 & 809336 & 3.327 & 3.8419 & TST & \\
\hline CHEMBL1538757 & 809336 & 7.4342 & 4.1299 & TRN & \\
\hline CHEMBL1897451 & 809336 & 3.327 & 3.7455 & TRN & \\
\hline CHEMBL1413464 & 809336 & 5.0114 & 3.7851 & TRN & \\
\hline CHEMBL1516953 & 809336 & 3.327 & 4.4202 & TST & \\
\hline CHEMBL1537666 & 809336 & 3.327 & 3.6078 & TRN & \\
\hline CHEMBL1344412 & 809336 & 5.4868 & 4.2237 & TRN & \\
\hline CHEMBL1712227 & 809336 & 3.327 & 3.3519 & TRN & \\
\hline CHEMBL1975511 & 809336 & 3.327 & 3.2368 & TRN & \\
\hline CHEMBL1713997 & 809336 & 5.0009 & 4.805 & TRN & \\
\hline CHEMBL1438361 & 809336 & 3.327 & 3.4118 & TRN & \\
\hline CHEMBL1470866 & 809336 & 3.327 & 3.7611 & TRN & \\
\hline CHEMBL1505398 & 809336 & 3.327 & 4.1998 & TST & \\
\hline CHEMBL1539096 & 809336 & 3.327 & 3.923 & TRN & \\
\hline CHEMBL1710923 & 809336 & 3.327 & 3.388 & TRN & \\
\hline CHEMBL1494460 & 809336 & 7.4342 & 4.4134 & TRN & \\
\hline CHEMBL1979293 & 809336 & 3.327 & 3.7849 & TST & \\
\hline CHEMBL1531179 & 809336 & 3.327 & 3.9418 & TRN & \\
\hline CHEMBL1990571 & 809336 & 3.327 & 3.8966 & TST & \\
\hline CHEMBL1544854 & 809336 & 3.327 & 3.36899 & 99999999998 & TRN \\
\hline CHEMBL1480560 & 809336 & 5.4486 & 4.2787 & TRN & \\
\hline CHEMBL1505242 & 809336 & 3.327 & 3.8335 & TRN & \\
\hline CHEMBL1506841 & 809336 & 3.327 & 3.7187 & TST & \\
\hline CHEMBL1606959 & 809336 & 3.327 & 3.27600 & 00000000002 & TRN \\
\hline CHEMBL1892675 & 809336 & 3.327 & 3.9201 & TRN & \\
\hline CHEMBL1558416 & 809336 & 3.327 & 3.79699 & 99999999997 & TRN \\
\hline CHEMBL1559371 & 809336 & 3.327 & 3.8316 & TST & \\
\hline
\end{tabular}




\begin{tabular}{|c|c|c|c|c|c|}
\hline & & \multicolumn{4}{|c|}{ Supplemental Table S2.txt } \\
\hline CHEMBL1365079 & 809336 & 3.327 & 3.8044 & TRN & \\
\hline CHEMBL1479108 & 809336 & 3.327 & 4.1368 & TRN & \\
\hline CHEMBL1332343 & 809336 & 3.327 & 4.0419 & TRN & \\
\hline CHEMBL1545197 & 809336 & 3.327 & 3.9161 & TRN & \\
\hline CHEMBL1413726 & 809336 & 3.327 & 3.8388 & TRN & \\
\hline CHEMBL1376862 & 809336 & 3.327 & 4.3119 & TRN & \\
\hline CHEMBL1492583 & 809336 & 4.4711 & 4.1499 & TRN & \\
\hline CHEMBL1975457 & 809336 & 3.327 & 4.22199 & 99999999995 & TRN \\
\hline CHEMBL1426832 & 809336 & 3.327 & 4.1355 & TRN & \\
\hline CHEMBL1325638 & 809336 & 3.327 & 3.6984 & TRN & \\
\hline CHEMBL1456653 & 809336 & 3.327 & 4.4958 & TRN & \\
\hline CHEMBL1452064 & 809336 & 5.4168 & 4.2372 & TRN & \\
\hline CHEMBL1698491 & 809336 & 3.327 & 3.3371 & TRN & \\
\hline CHEMBL1489194 & 809336 & 3.327 & 4.0154 & TRN & \\
\hline CHEMBL1703980 & 809336 & 3.327 & 3.681 & TRN & \\
\hline CHEMBL1570445 & 809336 & 3.327 & 3.6202 & TRN & \\
\hline CHEMBL1321837 & 809336 & 5.1403 & 4.2333 & TRN & \\
\hline CHEMBL1309071 & 809336 & 3.327 & 3.8739 & TRN & \\
\hline CHEMBL1500567 & 809336 & 3.327 & 3.9734 & TRN & \\
\hline CHEMBL1509653 & 809336 & 3.327 & 4.525 & TRN & \\
\hline CHEMBL1386981 & 809336 & 3.327 & 3.9859 & TST & \\
\hline CHEMBL1708151 & 809336 & 3.327 & 4.1307 & TST & \\
\hline CHEMBL1606891 & 809336 & 5.0958 & 4.2681 & TRN & \\
\hline CHEMBL1429300 & 809336 & 3.327 & 3.4322 & TRN & \\
\hline CHEMBL1724629 & 809336 & 3.327 & 3.7887 & TRN & \\
\hline CHEMBL1794099 & 809336 & 3.327 & 3.678 & TRN & \\
\hline CHEMBL1408399 & 809336 & 3.327 & 4.379 & TST & \\
\hline CHEMBL1545472 & 809336 & 3.327 & 4.0309 & TRN & \\
\hline CHEMBL1438765 & 809336 & 3.327 & 3.9838 & TRN & \\
\hline CHEMBL1974381 & 809336 & 6.1385 & 4.58 & TRN & \\
\hline CHEMBL1594237 & 809336 & 3.327 & 3.5398 & TRN & \\
\hline CHEMBL1723695 & 809336 & 3.327 & 3.605 & TST & \\
\hline CHEMBL1362550 & 809336 & 3.327 & 3.5372 & TRN & \\
\hline CHEMBL1537400 & 809336 & 3.327 & 3.8016 & TST & \\
\hline CHEMBL516954 & 809336 & 3.327 & 4.2275 & TRN & \\
\hline CHEMBL1711135 & 809336 & 3.327 & 4.2905 & TRN & \\
\hline CHEMBL1314028 & 809336 & 5.3936 & 4.0208 & TRN & \\
\hline CHEMBL1698099 & 809336 & 3.327 & 3.7105 & TRN & \\
\hline CHEMBL1359668 & 809336 & 3.327 & 3.9715 & TST & \\
\hline CHEMBL1571584 & 809336 & 3.327 & 3.7764 & TRN & \\
\hline CHEMBL1443043 & 809336 & 3.327 & 4.1839 & TRN & \\
\hline CHEMBL 1482223 & 809336 & 3.327 & 3.5647 & TRN & \\
\hline CHEMBL1369775 & 809336 & 3.327 & 3.6384 & TRN & \\
\hline CHEMBL1557071 & 809336 & 3.327 & 3.9712 & TRN & \\
\hline CHEMBL1338083 & 809336 & 3.327 & 4.1192 & TST & \\
\hline CHEMBL1571286 & 809336 & 3.327 & 4.2624 & TRN & \\
\hline CHEMBL1531482 & 809336 & 3.327 & 4.0949 & TST & \\
\hline CHEMBL1506420 & 809336 & 4.9355 & 4.5624 & TRN & \\
\hline
\end{tabular}




\begin{tabular}{|c|c|c|c|c|c|}
\hline & & \multicolumn{4}{|c|}{ Supplemental Table S2.txt } \\
\hline CHEMBL1382229 & 809336 & 4.3788 & 3.6715 & TRN & \\
\hline CHEMBL1731729 & 809336 & 3.327 & 4.1035 & TRN & \\
\hline CHEMBL1876295 & 809336 & 3.327 & 3.2359 & TRN & \\
\hline CHEMBL1564146 & 809336 & 3.327 & 4.2728 & TRN & \\
\hline CHEMBL1892065 & 809336 & 3.327 & 3.4232 & TRN & \\
\hline CHEMBL1405338 & 809336 & 3.327 & 3.264 & TRN & \\
\hline CHEMBL1450131 & 809336 & 3.327 & 3.4292 & TRN & \\
\hline CHEMBL1469037 & 809336 & 3.327 & 3.8561 & TRN & \\
\hline CHEMBL1609832 & 809336 & 5.0915 & 3.9086 & TRN & \\
\hline CHEMBL1326065 & 809336 & 3.327 & 3.9305 & TRN & \\
\hline CHEMBL 2000543 & 809336 & 3.327 & 3.8067 & TRN & \\
\hline CHEMBL1976940 & 809336 & 3.327 & 4.5429 & TRN & \\
\hline CHEMBL1478737 & 809336 & 3.327 & 3.2938 & TRN & \\
\hline CHEMBL1875872 & 809336 & 3.327 & 3.1816 & TRN & \\
\hline CHEMBL1426270 & 809336 & 3.327 & 4.0147 & TRN & \\
\hline CHEMBL1438670 & 809336 & 4.8928 & 3.6893 & TRN & \\
\hline CHEMBL1409450 & 809336 & 3.327 & 3.681 & TRN & \\
\hline CHEMBL1716557 & 809336 & 3.327 & 3.2231 & TRN & \\
\hline CHEMBL1568265 & 809336 & 4.6478 & 4.24100 & 00000000005 & TST \\
\hline CHEMBL1361917 & 809336 & 4.7747 & 4.4305 & TRN & \\
\hline CHEMBL1357212 & 809336 & 3.327 & 3.5448 & TRN & \\
\hline CHEMBL1714612 & 809336 & 3.327 & 4.2421 & TRN & \\
\hline CHEMBL1500670 & 809336 & 3.327 & 3.8894 & TRN & \\
\hline CHEMBL1462518 & 809336 & 5.0726 & 4.4445 & TRN & \\
\hline CHEMBL1430148 & 809336 & 3.327 & 3.4171 & TRN & \\
\hline CHEMBL1306981 & 809336 & 3.327 & 4.2034 & TRN & \\
\hline CHEMBL1393492 & 809336 & 4.6925 & 4.3383 & TRN & \\
\hline CHEMBL1431871 & 809336 & 3.327 & 3.3101 & TRN & \\
\hline CHEMBL1699018 & 809336 & 4.4868 & 4.4762 & TRN & \\
\hline CHEMBL1599431 & 809336 & 5.3242 & 4.4934 & TRN & \\
\hline CHEMBL1456116 & 809336 & 3.327 & 3.7868 & TRN & \\
\hline CHEMBL1401174 & 809336 & 3.327 & 4.3778 & TRN & \\
\hline CHEMBL1394369 & 809336 & 3.327 & 3.4152 & TRN & \\
\hline CHEMBL1712408 & 809336 & 4.4365 & 3.8989 & TRN & \\
\hline CHEMBL1328875 & 809336 & 3.327 & 4.0911 & TRN & \\
\hline CHEMBL1332874 & 809336 & 3.327 & 3.9501 & TRN & \\
\hline CHEMBL1985295 & 809336 & 5.3251 & 3.6577 & TRN & \\
\hline CHEMBL1354456 & 809336 & 3.327 & 4.1744 & TRN & \\
\hline CHEMBL1593302 & 809336 & 3.327 & 3.4416 & TRN & \\
\hline CHEMBL1708485 & 809336 & 4.3862 & 3.6289 & TRN & \\
\hline CHEMBL1890665 & 809336 & 3.327 & 4.0307 & TRN & \\
\hline CHEMBL1702440 & 809336 & 3.327 & 4.319 & TRN & \\
\hline CHEMBL1421652 & 809336 & 3.327 & 3.7284 & TRN & \\
\hline CHEMBL1319274 & 809336 & 3.327 & 4.4872 & TRN & \\
\hline CHEMBL1509029 & 809336 & 3.327 & 4.0444 & TRN & \\
\hline CHEMBL1309395 & 809336 & 3.327 & 3.9223 & TRN & \\
\hline CHEMBL1332300 & 809336 & 3.327 & 3.8581 & TRN & \\
\hline CHEMBL1704238 & 809336 & 5.4134 & 4.6944 & TRN & \\
\hline
\end{tabular}




\begin{tabular}{|c|c|c|c|c|c|c|}
\hline & & \multicolumn{5}{|c|}{ Supplemental Table S2.txt } \\
\hline CHEMBL1729811 & 809336 & 3.327 & 3.638 & TRN & & \\
\hline CHEMBL1533222 & 809336 & 5.6799 & 3.5978 & TRN & & \\
\hline CHEMBL1362378 & 809336 & 3.327 & 3.5655 & TRN & & \\
\hline CHEMBL1603027 & 809336 & 3.327 & 4.2187 & TRN & & \\
\hline CHEMBL1361846 & 809336 & 3.327 & 4.0981 & TRN & & \\
\hline CHEMBL1868573 & 809336 & 3.327 & 3.2706 & TRN & & \\
\hline CHEMBL1343603 & 809336 & 3.327 & 4.3079 & TRN & & \\
\hline CHEMBL1569153 & 809336 & \multicolumn{3}{|c|}{5.617999999999999} & 3.9476 & TST \\
\hline CHEMBL1711726 & 809336 & 3.327 & 3.9441 & TRN & & \\
\hline CHEMBL1568411 & 809336 & 3.327 & 3.6645 & TRN & & \\
\hline CHEMBL1429351 & 809336 & 3.327 & 4.0231 & TRN & & \\
\hline CHEMBL1454950 & 809336 & 3.327 & 3.7537 & TST & & \\
\hline CHEMBL1430681 & 809336 & 3.327 & 4.1808 & TST & & \\
\hline CHEMBL1573714 & 809336 & 3.327 & 3.9801 & TRN & & \\
\hline CHEMBL1416158 & 809336 & 3.327 & 3.9245 & TRN & & \\
\hline CHEMBL1342544 & 809336 & 3.327 & 4.0819 & TRN & & \\
\hline CHEMBL1458718 & 809336 & 3.327 & 3.9744 & TRN & & \\
\hline CHEMBL1386745 & 809336 & 3.327 & 3.7601 & TRN & & \\
\hline CHEMBL1412955 & 809336 & 3.327 & 4.0688 & TRN & & \\
\hline CHEMBL1421097 & 809336 & 3.327 & 3.889 & TRN & & \\
\hline CHEMBL1308594 & 809336 & 5.3872 & 4.1471 & TRN & & \\
\hline CHEMBL1461858 & 809336 & 4.4134 & 4.3739 & TRN & & \\
\hline CHEMBL1350767 & 809336 & 3.327 & 3.2769 & TST & & \\
\hline CHEMBL1742190 & 809336 & 3.327 & 3.2463 & TRN & & \\
\hline CHEMBL1364945 & 809336 & 3.327 & 3.9568 & TST & & \\
\hline CHEMBL1597140 & 809336 & 3.327 & 3.9215 & TRN & & \\
\hline CHEMBL1708730 & 809336 & 3.327 & 3.6719 & TRN & & \\
\hline CHEMBL1465482 & 809336 & 3.327 & 4.4116 & TRN & & \\
\hline CHEMBL1312383 & 809336 & 3.327 & 3.705 & TRN & & \\
\hline CHEMBL1350574 & 809336 & 3.327 & 3.5579 & TRN & & \\
\hline CHEMBL1511951 & 809336 & 7.4342 & 3.6821 & TRN & & \\
\hline CHEMBL1344002 & 809336 & 5.0061 & 4.1159 & TST & & \\
\hline CHEMBL1389073 & 809336 & 4.6126 & 4.6877 & TRN & & \\
\hline CHEMBL1607556 & 809336 & 5.3915 & 4.1025 & TRN & & \\
\hline CHEMBL1302523 & 809336 & \multicolumn{3}{|c|}{5.718999999999999} & 4.394 & $1 \mathrm{nN}$ \\
\hline CHEMBL1984510 & 809336 & 3.327 & 3.8833 & TRN & & \\
\hline CHEMBL1879609 & 809336 & 3.327 & 3.8988 & TRN & & \\
\hline CHEMBL1456097 & 809336 & 3.327 & 3.1542 & TRN & & \\
\hline CHEMBL1584067 & 809336 & 5.2573 & 4.1457 & TRN & & \\
\hline CHEMBL1530471 & 809336 & 4.6364 & 4.5319 & TRN & & \\
\hline CHEMBL1379439 & 809336 & 3.327 & 3.3538 & TRN & & \\
\hline CHEMBL1421707 & 809336 & 3.327 & 4.5134 & TRN & & \\
\hline CHEMBL1403593 & 809336 & 5.0137 & 4.379 & TRN & & \\
\hline CHEMBL1437929 & 809336 & 7.4342 & 4.194 & TST & & \\
\hline CHEMBL1328328 & 809336 & 5.3575 & 4.4616 & TRN & & \\
\hline CHEMBL1511721 & 809336 & 3.327 & 4.0461 & TST & & \\
\hline CHEMBL1340535 & 809336 & 4.7773 & 4.2512 & TRN & & \\
\hline CHEMBL1736615 & 809336 & 4.7235 & 3.7782 & TRN & & \\
\hline
\end{tabular}

Page 27924 


\begin{tabular}{|c|c|c|c|c|}
\hline & & & oplement & al $\mathrm{Tc}$ \\
\hline CHEMBL1471602 & 809336 & 3.327 & 3.98 & TRN \\
\hline CHEMBL1388057 & 809336 & 3.327 & 3.7317 & TST \\
\hline CHEMBL1342559 & 809336 & 4.6696 & 3.8978 & TRN \\
\hline CHEMBL1501584 & 809336 & 3.327 & 3.5565 & TRN \\
\hline CHEMBL1306028 & 809336 & 3.327 & 3.9082 & TRN \\
\hline CHEMBL1466899 & 809336 & 3.327 & 4.8495 & TRN \\
\hline CHEMBL1707960 & 809336 & 7.4342 & 4.4417 & TST \\
\hline CHEMBL1395368 & 809336 & 3.327 & 3.8042 & TRN \\
\hline CHEMBL1492417 & 809336 & 3.327 & 3.8304 & TRN \\
\hline CHEMBL1548104 & 809336 & 3.327 & 4.2803 & TST \\
\hline CHEMBL1478939 & 809336 & 3.327 & 4.2665 & TRN \\
\hline CHEMBL548691 & 809336 & 3.327 & 3.8363 & TRN \\
\hline CHEMBL1386092 & 809336 & 3.327 & 4.2127 & TST \\
\hline CHEMBL1610675 & 809336 & 7.4342 & 4.0387 & TRN \\
\hline CHEMBL1523379 & 809336 & 3.327 & 3.5313 & TRN \\
\hline CHEMBL1520997 & 809336 & 3.327 & 3.5349 & TRN \\
\hline CHEMBL1515236 & 809336 & 3.327 & 3.1472 & TRN \\
\hline CHEMBL1417161 & 809336 & 3.327 & 3.2172 & TRN \\
\hline CHEMBL1570708 & 809336 & 3.327 & 4.0549 & TRN \\
\hline CHEMBL1995109 & 809336 & 3.327 & 3.859 & TRN \\
\hline CHEMBL1592570 & 809336 & 3.327 & 3.2286 & TRN \\
\hline CHEMBL1322948 & 809336 & 5.6308 & 4.4104 & TRN \\
\hline CHEMBL1343918 & 809336 & 3.327 & 4.1063 & TRN \\
\hline CHEMBL1403507 & 809336 & 3.327 & 4.4365 & TRN \\
\hline CHEMBL1313479 & 809336 & 6.0 & 4.2475 & TRN \\
\hline CHEMBL1877846 & 809336 & 3.327 & 3.5266 & TRN \\
\hline CHEMBL1470409 & 809336 & 3.327 & 3.7367 & TRN \\
\hline CHEMBL1892819 & 809336 & 3.327 & 3.6571 & TRN \\
\hline CHEMBL1364015 & 809336 & 3.327 & 4.6062 & TRN \\
\hline CHEMBL1596758 & 809336 & 3.327 & 3.7805 & TRN \\
\hline CHEMBL1447644 & 809336 & 3.327 & 4.158 & TRN \\
\hline CHEMBL1330067 & 809336 & 3.327 & 4.0976 & TRN \\
\hline CHEMBL1518424 & 809336 & 3.327 & 3.0884 & TRN \\
\hline CHEMBL1389939 & 809336 & 3.327 & 3.1437 & TRN \\
\hline CHEMBL1481185 & 809336 & 4.684 & 3.8171 & TRN \\
\hline CHEMBL1573665 & 809336 & 3.327 & 3.7917 & TRN \\
\hline CHEMBL1411649 & 809336 & 3.327 & 3.508 & TRN \\
\hline CHEMBL1711327 & 809336 & 3.327 & 4.5375 & TRN \\
\hline CHEMBL1712433 & 809336 & 3.327 & 3.3424 & TRN \\
\hline CHEMBL1577691 & 809336 & 3.327 & 3.2708 & TRN \\
\hline CHEMBL1422869 & 809336 & 3.327 & 4.2882 & TRN \\
\hline CHEMBL1491493 & 809336 & 3.327 & 3.4518 & TRN \\
\hline CHEMBL1405032 & 809336 & 3.327 & 3.8342 & TRN \\
\hline CHEMBL1714214 & 809336 & 3.327 & 3.1245 & TRN \\
\hline CHEMBL1384298 & 809336 & 5.2255 & 4.3389 & TRN \\
\hline CHEMBL1456403 & 809336 & 3.327 & 4.1403 & TST \\
\hline CHEMBL1986734 & 809336 & 3.327 & 4.0158 & TRN \\
\hline CHEMBL1353236 & 809336 & 3.327 & 3.1547 & TRN \\
\hline
\end{tabular}




\begin{tabular}{|c|c|c|c|c|c|}
\hline & & \multicolumn{4}{|c|}{ Supplemental Table s2.txt } \\
\hline CHEMBL1329711 & 809336 & 3.327 & 3.8326 & TRN & \\
\hline CHEMBL1350499 & 809336 & 3.327 & 3.7013 & TRN & \\
\hline CHEMBL1894417 & 809336 & 5.5258 & 3.5853 & TRN & \\
\hline CHEMBL1505728 & 809336 & 3.327 & 4.197 & TST & \\
\hline CHEMBL1504622 & 809336 & 5.2381 & 3.8492 & TRN & \\
\hline CHEMBL1393746 & 809336 & 3.327 & 3.4477 & TRN & \\
\hline CHEMBL1400385 & 809336 & 6.2958 & 3.9219 & TRN & \\
\hline CHEMBL1430628 & 809336 & 5.3893 & 4.2274 & TST & \\
\hline CHEMBL1570188 & 809336 & 3.327 & 3.9476 & TRN & \\
\hline CHEMBL1528052 & 809336 & 3.327 & 3.7805 & TRN & \\
\hline CHEMBL1332851 & 809336 & 4.4101 & 4.0452 & TRN & \\
\hline CHEMBL1344221 & 809336 & 5.1694 & 3.6067 & TRN & \\
\hline CHEMBL1340114 & 809336 & 5.7328 & 4.5663 & TRN & \\
\hline CHEMBL1380203 & 809336 & 3.327 & 3.2502 & TRN & \\
\hline CHEMBL1448446 & 809336 & 3.327 & 3.4071 & TRN & \\
\hline CHEMBL1586984 & 809336 & 3.327 & 3.8318 & TRN & \\
\hline CHEMBL1418321 & 809336 & 3.327 & 3.8054 & TRN & \\
\hline CHEMBL1504649 & 809336 & 3.327 & 4.0409 & TRN & \\
\hline CHEMBL1713500 & 809336 & 3.327 & 3.7607 & TRN & \\
\hline CHEMBL1589370 & 809336 & 3.327 & 4.4128 & TRN & \\
\hline CHEMBL1461547 & 809336 & 3.327 & 4.4066 & TRN & \\
\hline CHEMBL1360430 & 809336 & 3.327 & 3.9138 & TRN & \\
\hline CHEMBL1975008 & 809336 & 3.327 & 3.8398 & TST & \\
\hline CHEMBL1976163 & 809336 & 3.327 & 3.43899 & 99999999996 & TRN \\
\hline CHEMBL1875137 & 809336 & 3.327 & 3.9021 & TRN & \\
\hline CHEMBL1544367 & 809336 & 3.327 & 3.8554 & TRN & \\
\hline CHEMBL1559323 & 809336 & 3.327 & 3.8695 & TRN & \\
\hline CHEMBL1526763 & 809336 & 7.4342 & 4.0748 & TRN & \\
\hline CHEMBL1736939 & 809336 & 3.327 & 3.3232 & TRN & \\
\hline CHEMBL1715901 & 809336 & 7.4342 & 3.4112 & TRN & \\
\hline CHEMBL1380999 & 809336 & 3.327 & 4.1886 & TRN & \\
\hline CHEMBL1976321 & 809336 & 3.327 & 3.9893 & TRN & \\
\hline CHEMBL1307289 & 809336 & 3.327 & 4.0662 & TST & \\
\hline CHEMBL1361352 & 809336 & 3.327 & 3.6447 & TRN & \\
\hline CHEMBL1497550 & 809336 & 5.1637 & 4.2565 & TRN & \\
\hline CHEMBL1446935 & 809336 & 7.4342 & 4.4148 & TRN & \\
\hline CHEMBL255068 & 809336 & 3.327 & 3.9161 & TRN & \\
\hline CHEMBL1325114 & 809336 & 3.327 & 3.7784 & TRN & \\
\hline CHEMBL1368669 & 809336 & 3.327 & 3.9299 & TST & \\
\hline CHEMBL1992255 & 809336 & 3.327 & 4.4615 & TST & \\
\hline CHEMBL1576123 & 809336 & 5.9431 & 4.4196 & TRN & \\
\hline CHEMBL1408146 & 809336 & 5.3655 & 4.2887 & TRN & \\
\hline CHEMBL1577837 & 809336 & 3.327 & 3.57800 & 00000000003 & TRN \\
\hline CHEMBL1870822 & 809336 & 3.327 & 4.0714 & TRN & \\
\hline CHEMBL1472223 & 809336 & 3.327 & 4.1367 & TRN & \\
\hline CHEMBL1304709 & 809336 & 3.327 & 4.3135 & TST & \\
\hline CHEMBL1502712 & 809336 & 3.327 & 4.4843 & TRN & \\
\hline CHEMBL1609933 & 809336 & 3.327 & 3.6439 & TRN & \\
\hline
\end{tabular}




\begin{tabular}{|c|c|c|c|c|c|}
\hline & & \multicolumn{4}{|c|}{ Supplemental Table S2.txt } \\
\hline CHEMBL1469717 & 809336 & 3.327 & 4.0552 & TRN & \\
\hline CHEMBL1380082 & 809336 & 3.327 & 3.8648 & TRN & \\
\hline CHEMBL1505415 & 809336 & 3.327 & 3.8676 & TRN & \\
\hline CHEMBL1458493 & 809336 & 3.327 & 3.5065 & TRN & \\
\hline CHEMBL1720301 & 809336 & 3.327 & 4.184 & TST & \\
\hline CHEMBL1341582 & 809336 & 7.4342 & 4.5803 & TRN & \\
\hline CHEMBL1557730 & 809336 & 3.327 & 4.2017 & TST & \\
\hline CHEMBL1406376 & 809336 & 3.327 & 4.1809 & TRN & \\
\hline CHEMBL1603812 & 809336 & 4.7905 & 4.2208 & TRN & \\
\hline CHEMBL1463504 & 809336 & 7.4342 & 4.4516 & TRN & \\
\hline CHEMBL1864216 & 809336 & 3.327 & 3.9346 & TRN & \\
\hline CHEMBL1458398 & 809336 & 7.4342 & 4.0734 & TRN & \\
\hline CHEMBL1373829 & 809336 & 3.327 & 4.4082 & TRN & \\
\hline CHEMBL1586817 & 809336 & 3.327 & 4.047 & TRN & \\
\hline CHEMBL1731772 & 809336 & 3.327 & 4.2624 & TST & \\
\hline CHEMBL1714053 & 809336 & 3.327 & 3.4928 & TST & \\
\hline CHEMBL1529222 & 809336 & 5.0026 & 3.7253 & TRN & \\
\hline CHEMBL1326395 & 809336 & 5.1451 & 3.8031 & TRN & \\
\hline CHEMBL1369099 & 809336 & 3.327 & 4.1316 & TRN & \\
\hline CHEMBL1403977 & 809336 & 3.327 & 3.7793 & TRN & \\
\hline CHEMBL1888682 & 809336 & 3.327 & 3.5926 & TRN & \\
\hline CHEMBL1498125 & 809336 & 4.8297 & 4.0496 & TRN & \\
\hline CHEMBL1599981 & 809336 & 4.9788 & 4.4772 & TRN & \\
\hline CHEMBL1382321 & 809336 & 3.327 & 4.0795 & TST & \\
\hline CHEMBL1903930 & 809336 & 4.857 & 4.1128 & TST & \\
\hline CHEMBL1873436 & 809336 & 5.6946 & 3.8445 & TRN & \\
\hline CHEMBL1444243 & 809336 & 7.4342 & 4.4857 & TRN & \\
\hline CHEMBL1411122 & 809336 & 3.327 & 3.3677 & TRN & \\
\hline CHEMBL1472267 & 809336 & 3.327 & 4.2548 & TRN & \\
\hline CHEMBL1875657 & 809336 & 3.327 & 3.3013 & TRN & \\
\hline CHEMBL1725853 & 809336 & 3.327 & 4.2938 & TST & \\
\hline CHEMBL1491621 & 809336 & 3.327 & 4.3088 & TRN & \\
\hline CHEMBL1587395 & 809336 & 3.327 & 4.5498 & TST & \\
\hline CHEMBL1588406 & 809336 & 3.327 & 3.7006 & TRN & \\
\hline CHEMBL1863862 & 809336 & 3.327 & 3.4328 & TRN & \\
\hline CHEMBL1358911 & 809336 & 3.327 & 3.4483 & TRN & \\
\hline CHEMBL1984169 & 809336 & 3.327 & 3.3934 & TRN & \\
\hline CHEMBL1511045 & 809336 & 3.327 & 4.1214 & TRN & \\
\hline CHEMBL1548041 & 809336 & 3.327 & 3.5204 & TRN & \\
\hline CHEMBL1563771 & 809336 & 3.327 & 3.8619 & TRN & \\
\hline CHEMBL1541174 & 809336 & 4.4023 & 4.2708 & TRN & \\
\hline CHEMBL1464557 & 809336 & 3.327 & 3.7331 & TRN & \\
\hline CHEMBL 2005619 & 809336 & 3.327 & 4.6453 & TST & \\
\hline CHEMBL1449928 & 809336 & 3.327 & 3.50100 & 00000000003 & TST \\
\hline CHEMBL1469111 & 809336 & 3.327 & 4.0536 & TRN & \\
\hline CHEMBL1698581 & 809336 & 3.327 & 3.3696 & TRN & \\
\hline CHEMBL1301825 & 809336 & 3.327 & 4.2156 & TRN & \\
\hline CHEMBL1330258 & 809336 & 7.4342 & 4.4358 & TRN & \\
\hline
\end{tabular}




\begin{tabular}{|c|c|c|c|c|c|c|}
\hline & & \multicolumn{5}{|c|}{ Supplemental Table S2.txt } \\
\hline CHEMBL1399164 & 809336 & 4.5935 & 3.931 & TRN & & \\
\hline CHEMBL605752 & 809336 & 3.327 & 4.338 & TST & & \\
\hline CHEMBL1489947 & 809336 & 3.327 & 3.3791 & TRN & & \\
\hline CHEMBL1439222 & 809336 & 3.327 & 3.725 & TRN & & \\
\hline CHEMBL1876097 & 809336 & 4.6308 & 4.1999 & TST & & \\
\hline CHEMBL1890943 & 809336 & 7.4342 & 3.8387 & TRN & & \\
\hline CHEMBL1463889 & 809336 & 3.327 & 3.7091 & TST & & \\
\hline CHEMBL1383937 & 809336 & 3.327 & 4.1701 & TST & & \\
\hline CHEMBL1348983 & 809336 & 3.327 & 4.5315 & TRN & & \\
\hline CHEMBL1411720 & 809336 & 3.327 & 4.0473 & TRN & & \\
\hline CHEMBL1965884 & 809336 & 3.327 & 3.8308 & TRN & & \\
\hline CHEMBL1598653 & 809336 & 3.327 & 3.6982 & TST & & \\
\hline CHEMBL1472456 & 809336 & 3.327 & 4.2958 & TRN & & \\
\hline CHEMBL1897450 & 809336 & 3.327 & 3.35 & TRN & & \\
\hline CHEMBL1582765 & 809336 & 3.327 & 4.2058 & TST & & \\
\hline CHEMBL1304685 & 809336 & 4.8827 & 3.7763 & TRN & & \\
\hline CHEMBL1471140 & 809336 & 3.327 & 3.8507 & TRN & & \\
\hline CHEMBL1566464 & 809336 & 4.8962 & 4.4847 & TST & & \\
\hline CHEMBL1361071 & 809336 & 5.0926 & 4.3622 & TST & & \\
\hline CHEMBL1557059 & 809336 & 3.327 & 4.1266 & TST & & \\
\hline CHEMBL1870358 & 809336 & 3.327 & 3.7466 & TRN & & \\
\hline CHEMBL1466914 & 809336 & 3.327 & 3.68 & TRN & & \\
\hline CHEMBL1716414 & 809336 & 5.0017 & 4.7269 & TRN & & \\
\hline CHEMBL1343816 & 809336 & 3.327 & 3.71100 & 20000 & 003 & TRN \\
\hline CHEMBL1731983 & 809336 & 3.327 & 3.3136 & TRN & & \\
\hline CHEMBL1447812 & 809336 & 3.327 & 3.8451 & TRN & & \\
\hline CHEMBL1380796 & 809336 & 4.98300 & 30000000 & 205 & 4.093 & TRN \\
\hline CHEMBL1479354 & 809336 & 3.327 & 3.8319 & TRN & & \\
\hline CHEMBL1978211 & 809336 & 3.327 & 3.7707 & TRN & & \\
\hline CHEMBL1305020 & 809336 & 4.7122 & 3.8997 & TRN & & \\
\hline CHEMBL1588455 & 809336 & 5.32700 & 00000000 & $\partial 1$ & 4.5648 & TRN \\
\hline CHEMBL1561657 & 809336 & 3.327 & 3.7794 & TRN & & \\
\hline CHEMBL1460794 & 809336 & 3.327 & 3.7407 & TRN & & \\
\hline CHEMBL1489935 & 809336 & 4.5607 & 4.3478 & TRN & & \\
\hline CHEMBL1699154 & 809336 & 3.327 & 4.1164 & TRN & & \\
\hline CHEMBL1303082 & 809336 & 3.327 & 3.8628 & TRN & & \\
\hline CHEMBL1540293 & 809336 & 3.327 & 3.6188 & TRN & & \\
\hline CHEMBL1483550 & 809336 & 5.3556 & 4.6683 & TRN & & \\
\hline CHEMBL1709644 & 809336 & 5.9245 & 3.5032 & TRN & & \\
\hline CHEMBL1310482 & 809336 & 3.327 & 4.1697 & TST & & \\
\hline CHEMBL1994261 & 809336 & 3.327 & 3.5089 & TRN & & \\
\hline CHEMBL1717982 & 809336 & 3.327 & 3.27 & TRN & & \\
\hline CHEMBL1889401 & 809336 & 7.4342 & 4.7615 & TRN & & \\
\hline CHEMBL1467207 & 809336 & 3.327 & 3.8264 & TRN & & \\
\hline CHEMBL1510844 & 809336 & 3.327 & 3.54399 & 99999 & 996 & TRN \\
\hline CHEMBL1574884 & 809336 & 5.1002 & 3.9871 & TRN & & \\
\hline CHEMBL1412427 & 809336 & 4.4698 & 4.0192 & TRN & & \\
\hline CHEMBL1520053 & 809336 & 4.6073 & 4.1644 & TST & & \\
\hline
\end{tabular}




\begin{tabular}{|c|c|c|c|c|}
\hline & & \multicolumn{3}{|c|}{ Supplemental Table S2.txt } \\
\hline CHEMBL1729254 & 809336 & 7.4342 & 4.0004 & TST \\
\hline CHEMBL1459418 & 809336 & 3.327 & 3.6558 & TRN \\
\hline CHEMBL1605776 & 809336 & 5.3288 & 4.289 & TRN \\
\hline CHEMBL1556611 & 809336 & 3.327 & 3.4579 & TRN \\
\hline CHEMBL1320678 & 809336 & 3.327 & 4.2225 & TST \\
\hline CHEMBL1573401 & 809336 & 3.327 & 4.0023 & TRN \\
\hline CHEMBL1320393 & 809336 & 7.4342 & 4.4047 & TRN \\
\hline CHEMBL1386206 & 809336 & 3.327 & 4.2055 & TRN \\
\hline CHEMBL1367000 & 809336 & 3.327 & 3.1274 & TRN \\
\hline CHEMBL1409074 & 809336 & 3.327 & 4.2303 & TRN \\
\hline CHEMBL1611775 & 809336 & 3.327 & 3.8594 & TRN \\
\hline CHEMBL1573421 & 809336 & 5.2204 & 4.5873 & TRN \\
\hline CHEMBL1383459 & 809336 & 3.327 & 3.6727 & TRN \\
\hline CHEMBL1450032 & 809336 & 3.327 & 3.7769 & TRN \\
\hline CHEMBL1549488 & 809336 & 3.327 & 3.4525 & TRN \\
\hline CHEMBL1568582 & 809336 & 4.3298 & 4.3611 & TRN \\
\hline CHEMBL1510007 & 809336 & 3.327 & 3.8057 & TST \\
\hline CHEMBL1966166 & 809336 & 5.3925 & 4.0343 & TRN \\
\hline CHEMBL1410268 & 809336 & 3.327 & 3.8465 & TRN \\
\hline CHEMBL1303495 & 809336 & 5.2565 & 3.3974 & TRN \\
\hline CHEMBL1376420 & 809336 & 7.4342 & 4.0196 & TRN \\
\hline CHEMBL1371272 & 809336 & 3.327 & 3.3767 & TRN \\
\hline CHEMBL1439946 & 809336 & 3.327 & 3.6299 & TRN \\
\hline CHEMBL1893985 & 809336 & 3.327 & 3.5898 & TST \\
\hline CHEMBL1485638 & 809336 & 3.327 & 3.8644 & TRN \\
\hline CHEMBL1546025 & 809336 & 3.327 & 3.9528 & TRN \\
\hline CHEMBL1414912 & 809336 & 3.327 & 3.8981 & TRN \\
\hline CHEMBL1367360 & 809336 & 3.327 & 3.9633 & TRN \\
\hline CHEMBL1547545 & 809336 & 3.327 & 4.2622 & TRN \\
\hline CHEMBL1990055 & 809336 & 3.327 & 4.1373 & TRN \\
\hline CHEMBL1483664 & 809336 & 3.327 & 3.4838 & TRN \\
\hline CHEMBL1416865 & 809336 & 3.327 & 3.4094 & TRN \\
\hline CHEMBL1377770 & 809336 & 5.3625 & 4.2363 & TRN \\
\hline CHEMBL1311995 & 809336 & 3.327 & 3.6637 & TST \\
\hline CHEMBL1729347 & 809336 & 3.327 & 3.4752 & TRN \\
\hline CHEMBL1541239 & 809336 & 3.327 & 4.3753 & TST \\
\hline CHEMBL1530277 & 809336 & 3.327 & 3.5657 & TRN \\
\hline CHEMBL1710207 & 809336 & 3.327 & 3.7366 & TRN \\
\hline CHEMBL1971946 & 809336 & 3.327 & 4.2203 & TRN \\
\hline CHEMBL1715061 & 809336 & 3.327 & 3.9295 & TRN \\
\hline CHEMBL1559894 & 809336 & 3.327 & 3.7868 & TRN \\
\hline CHEMBL1576910 & 809336 & 3.327 & 3.8614 & TRN \\
\hline CHEMBL1300114 & 809336 & 5.5258 & 3.9705 & TST \\
\hline CHEMBL254071 & 809336 & 3.327 & 3.9632 & TRN \\
\hline CHEMBL1454341 & 809336 & 3.327 & 3.7235 & TRN \\
\hline CHEMBL1351559 & 809336 & 3.327 & 3.722 & TRN \\
\hline CHEMBL1410862 & 809336 & 3.327 & 3.9909 & TRN \\
\hline CHEMBL1572346 & 809336 & 4.5214 & 4.3932 & TRN \\
\hline
\end{tabular}

Page 27929 


\begin{tabular}{|c|c|c|c|c|c|}
\hline & & \multicolumn{4}{|c|}{ Supplemental Table S2.txt } \\
\hline CHEMBL1872585 & 809336 & 3.327 & 4.2725 & TRN & \\
\hline CHEMBL1371722 & 809336 & 3.327 & 4.0665 & TRN & \\
\hline CHEMBL1607098 & 809336 & 3.327 & 3.8109 & TRN & \\
\hline CHEMBL1600649 & 809336 & 5.1938 & 3.7486 & TRN & \\
\hline CHEMBL1896141 & 809336 & 3.327 & 3.5624 & TRN & \\
\hline CHEMBL1432687 & 809336 & 7.4342 & 4.2854 & TRN & \\
\hline CHEMBL1485456 & 809336 & 3.327 & 3.8264 & TRN & \\
\hline CHEMBL1345541 & 809336 & 7.4342 & 4.1763 & TRN & \\
\hline CHEMBL1333325 & 809336 & 5.2757 & 3.7644 & TRN & \\
\hline CHEMBL1383372 & 809336 & 3.327 & 3.6093 & TRN & \\
\hline CHEMBL1886994 & 809336 & 3.327 & 3.3929 & TRN & \\
\hline CHEMBL1386394 & 809336 & 3.327 & 3.2544 & TRN & \\
\hline CHEMBL1735984 & 809336 & 3.327 & 4.1813 & TRN & \\
\hline CHEMBL1328164 & 809336 & 4.9586 & 4.2768 & TRN & \\
\hline CHEMBL1967756 & 809336 & 3.327 & 4.2776 & TRN & \\
\hline CHEMBL1904763 & 809336 & 3.327 & 3.5351 & TRN & \\
\hline CHEMBL1717845 & 809336 & 3.327 & 4.2574 & TRN & \\
\hline CHEMBL1492295 & 809336 & 3.327 & 3.6104 & TRN & \\
\hline CHEMBL1600229 & 809336 & 5.5058 & 4.6241 & TRN & \\
\hline CHEMBL1448689 & 809336 & 3.327 & 4.0702 & TRN & \\
\hline CHEMBL1573703 & 809336 & 3.327 & 3.3701 & TRN & \\
\hline CHEMBL1405942 & 809336 & 3.327 & 4.4804 & TRN & \\
\hline CHEMBL1611972 & 809336 & 3.327 & 3.6669 & TRN & \\
\hline CHEMBL1539584 & 809336 & 3.327 & 3.992 & TRN & \\
\hline CHEMBL1886668 & 809336 & 3.327 & 2.8007 & TRN & \\
\hline CHEMBL1974913 & 809336 & 3.327 & 4.747 & TRN & \\
\hline CHEMBL1442046 & 809336 & 7.4342 & 3.7474 & TRN & \\
\hline CHEMBL1904355 & 809336 & 3.327 & 3.6554 & TRN & \\
\hline CHEMBL1464771 & 809336 & 3.327 & 3.557 & TRN & \\
\hline CHEMBL1518781 & 809336 & 3.327 & 4.2743 & TRN & \\
\hline CHEMBL1479188 & 809336 & 3.327 & 4.5025 & TST & \\
\hline CHEMBL1365431 & 809336 & 3.327 & 4.0888 & TRN & \\
\hline CHEMBL1323094 & 809336 & 3.327 & 3.4287 & TRN & \\
\hline CHEMBL1453075 & 809336 & 3.327 & 3.3491 & TRN & \\
\hline CHEMBL1509203 & 809336 & 3.327 & 4.0484 & TRN & \\
\hline CHEMBL1560907 & 809336 & 3.327 & 3.7464 & TRN & \\
\hline CHEMBL1894266 & 809336 & 3.327 & 4.0693 & TRN & \\
\hline CHEMBL1611094 & 809336 & 3.327 & 3.9872 & TRN & \\
\hline CHEMBL1877673 & 809336 & 3.327 & 3.8288 & TRN & \\
\hline CHEMBL1452608 & 809336 & 4.8069 & 3.9452 & TRN & \\
\hline CHEMBL1735370 & 809336 & 5.5243 & 3.9629 & TRN & \\
\hline CHEMBL1444763 & 809336 & 3.327 & 4.0945 & TRN & \\
\hline CHEMBL1388885 & 809336 & 5.21399 & 79999999 & 995 & 3.7236 \\
\hline CHEMBL1607637 & 809336 & 5.4034 & 3.5966 & TRN & \\
\hline CHEMBL1462394 & 809336 & 3.327 & 3.1874 & TRN & \\
\hline CHEMBL1302890 & 809336 & 3.327 & 3.5637 & TST & \\
\hline CHEMBL1354394 & 809336 & 5.3054 & 4.3936 & TST & \\
\hline CHEMBL604100 & 809336 & 5.3757 & 4.0019 & TRN & \\
\hline
\end{tabular}




\begin{tabular}{|c|c|c|c|c|c|}
\hline & & \multicolumn{4}{|c|}{ Supplemental Table S2.txt } \\
\hline CHEMBL1863675 & 809336 & 3.327 & 3.023 & TRN & \\
\hline CHEMBL1594700 & 809336 & 3.327 & 3.8628 & TRN & \\
\hline CHEMBL1443298 & 809336 & 3.327 & 3.7999 & TRN & \\
\hline CHEMBL1521778 & 809336 & 5.2924 & 4.2799 & TRN & \\
\hline CHEMBL 1887166 & 809336 & 7.4342 & 3.9569 & TRN & \\
\hline CHEMBL1504948 & 809336 & 5.0218 & 4.0981 & TRN & \\
\hline CHEMBL1385236 & 809336 & 3.327 & 3.5129 & TRN & \\
\hline CHEMBL1514369 & 809336 & 3.327 & 3.1858 & TRN & \\
\hline CHEMBL1323940 & 809336 & 3.327 & 3.7439 & TST & \\
\hline CHEMBL1976917 & 809336 & 4.9914 & 4.4458 & TRN & \\
\hline CHEMBL1352502 & 809336 & 3.327 & 3.6483 & TRN & \\
\hline CHEMBL1906017 & 809336 & 3.327 & 3.9201 & TST & \\
\hline CHEMBL1389157 & 809336 & 3.327 & 3.93600 & 00000000004 & TRN \\
\hline CHEMBL1500018 & 809336 & 3.327 & 3.9691 & TRN & \\
\hline CHEMBL1505493 & 809336 & 5.209 & 4.2407 & TRN & \\
\hline CHEMBL1435209 & 809336 & 3.327 & 4.1084 & TRN & \\
\hline CHEMBL1452280 & 809336 & 3.327 & 4.0114 & TRN & \\
\hline CHEMBL1415544 & 809336 & 3.327 & 3.5469 & TRN & \\
\hline CHEMBL1724228 & 809336 & 3.327 & 4.2924 & TRN & \\
\hline CHEMBL1982381 & 809336 & 7.4342 & 4.578 & TRN & \\
\hline CHEMBL1353259 & 809336 & 7.4342 & 3.9596 & TRN & \\
\hline CHEMBL1422936 & 809336 & 3.327 & 4.4391 & TRN & \\
\hline CHEMBL1339815 & 809336 & 3.327 & 4.0016 & TRN & \\
\hline CHEMBL1894795 & 809336 & 3.327 & 3.426 & TRN & \\
\hline CHEMBL1366743 & 809336 & 3.327 & 4.1065 & TRN & \\
\hline CHEMBL1971705 & 809336 & 7.4342 & 4.7066 & TRN & \\
\hline CHEMBL1310645 & 809336 & 3.327 & 3.3937 & TRN & \\
\hline CHEMBL1510050 & 809336 & 4.4425 & 3.8564 & TRN & \\
\hline CHEMBL1302244 & 809336 & 3.327 & 3.3373 & TRN & \\
\hline CHEMBL1478318 & 809336 & 7.4342 & 4.0276 & TRN & \\
\hline CHEMBL1976769 & 809336 & 3.327 & 3.7997 & TRN & \\
\hline CHEMBL1466793 & 809336 & 3.327 & 3.7698 & TRN & \\
\hline CHEMBL1322166 & 809336 & 3.327 & 3.779 & TST & \\
\hline CHEMBL1986726 & 809336 & 3.327 & 4.0938 & TST & \\
\hline CHEMBL1562790 & 809336 & 3.327 & 3.7299 & TRN & \\
\hline CHEMBL1601295 & 809336 & 3.327 & 3.5779 & TRN & \\
\hline CHEMBL1561865 & 809336 & 3.327 & 4.2106 & TRN & \\
\hline CHEMBL1604210 & 809336 & 3.327 & 4.3968 & TRN & \\
\hline CHEMBL1451481 & 809336 & 3.327 & 3.2909 & TRN & \\
\hline CHEMBL1371629 & 809336 & 5.2373 & 4.1649 & TRN & \\
\hline CHEMBL1455809 & 809336 & 3.327 & 3.8834 & TRN & \\
\hline CHEMBL1891903 & 809336 & 7.4342 & 4.0762 & TRN & \\
\hline CHEMBL1483077 & 809336 & 7.4342 & 4.1742 & TST & \\
\hline CHEMBL1533024 & 809336 & 4.6144 & 3.8631 & TRN & \\
\hline CHEMBL1892879 & 809336 & 5.475 & 4.2235 & TRN & \\
\hline CHEMBL1967399 & 809336 & 3.327 & 3.475 & TRN & \\
\hline CHEMBL1716755 & 809336 & 3.327 & 3.5347 & TRN & \\
\hline CHEMBL1990569 & 809336 & 4.8601 & 4.0566 & TRN & \\
\hline
\end{tabular}




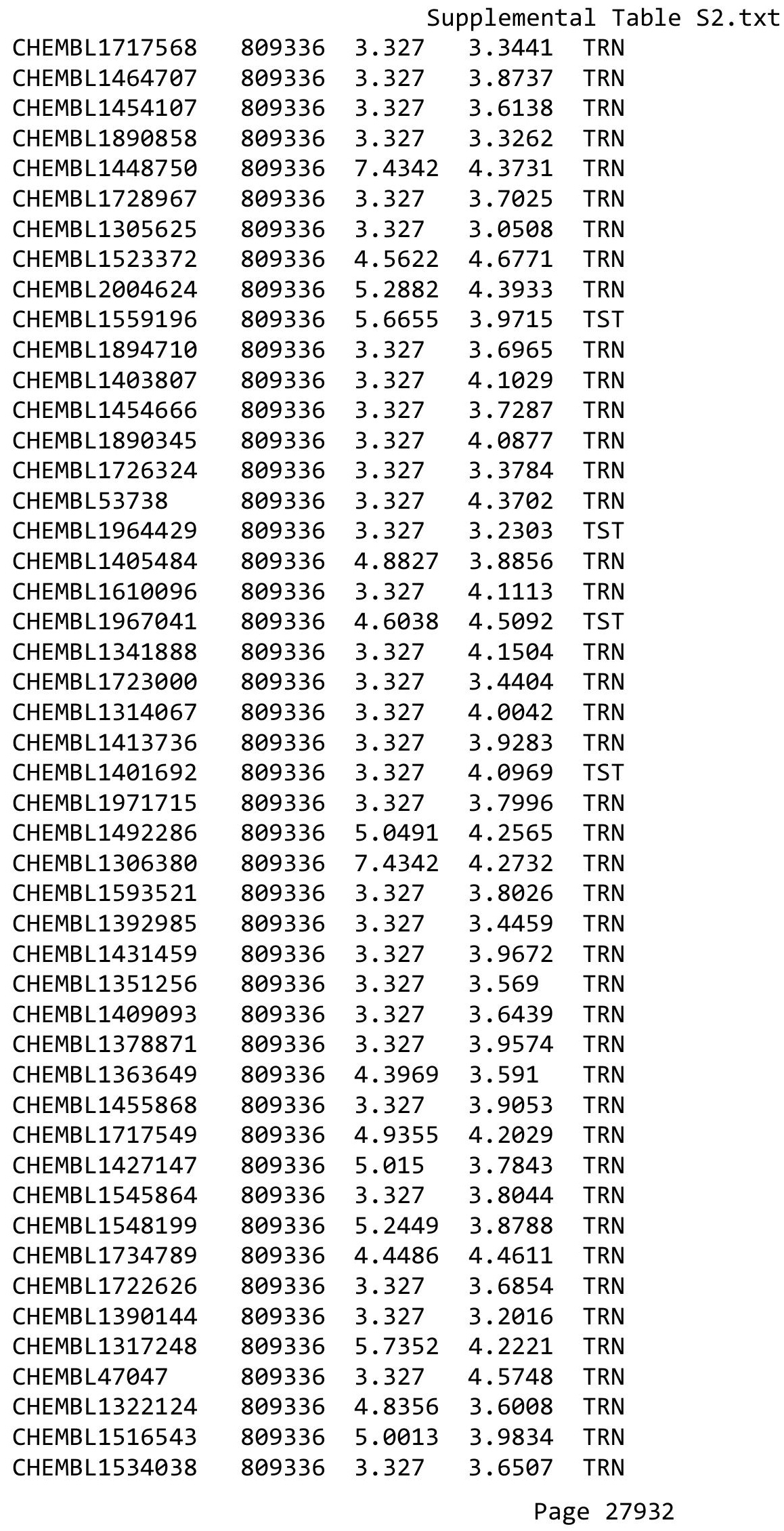




\begin{tabular}{|c|c|c|c|c|c|}
\hline & & \multicolumn{4}{|c|}{ Supplemental Table S2.txt } \\
\hline CHEMBL1609057 & 809336 & 3.327 & 3.8001 & TRN & \\
\hline CHEMBL1426192 & 809336 & 4.7852 & 3.428 & TRN & \\
\hline CHEMBL1536683 & 809336 & 7.4342 & 3.5007 & TRN & \\
\hline CHEMBL1465250 & 809336 & 4.7878 & 4.4348 & TRN & \\
\hline CHEMBL1307629 & 809336 & 3.327 & 3.5312 & TRN & \\
\hline CHEMBL1726441 & 809336 & 4.7773 & 4.6875 & TRN & \\
\hline CHEMBL1491923 & 809336 & 4.4353 & 3.8816 & TRN & \\
\hline CHEMBL1470679 & 809336 & 3.327 & 3.7926 & TRN & \\
\hline CHEMBL1549656 & 809336 & 3.327 & 3.9432 & TST & \\
\hline CHEMBL1489121 & 809336 & 3.327 & 3.842 & TRN & \\
\hline CHEMBL1594409 & 809336 & 3.327 & 4.428 & TRN & \\
\hline CHEMBL1964936 & 809336 & 3.327 & 3.4149 & TRN & \\
\hline CHEMBL1430122 & 809336 & 3.327 & 4.0193 & TRN & \\
\hline CHEMBL1545743 & 809336 & 4.5768 & 4.1232 & TRN & \\
\hline CHEMBL1462154 & 809336 & 3.327 & 3.59899 & 99999999998 & TRN \\
\hline CHEMBL1467065 & 809336 & 3.327 & 3.75699 & 99999999997 & TST \\
\hline CHEMBL1526909 & 809336 & 3.327 & 3.4557 & TRN & \\
\hline CHEMBL1409324 & 809336 & 3.327 & 4.2031 & TST & \\
\hline CHEMBL1478027 & 809336 & 3.327 & 3.9065 & TRN & \\
\hline CHEMBL1730368 & 809336 & 3.327 & 3.3297 & TRN & \\
\hline CHEMBL1303685 & 809336 & 3.327 & 3.5472 & TRN & \\
\hline CHEMBL1324073 & 809336 & 3.327 & 3.6855 & TRN & \\
\hline CHEMBL1964398 & 809336 & 5.3487 & 4.0852 & TRN & \\
\hline CHEMBL1971446 & 809336 & 3.327 & 3.4808 & TST & \\
\hline CHEMBL1544198 & 809336 & 3.327 & 3.9741 & TRN & \\
\hline CHEMBL1516685 & 809336 & 5.2358 & 4.2872 & TRN & \\
\hline CHEMBL1466828 & 809336 & 3.327 & 3.2132 & TRN & \\
\hline CHEMBL1451651 & 809336 & 3.327 & 3.3627 & TRN & \\
\hline CHEMBL 2007120 & 809336 & 3.327 & 4.1147 & TRN & \\
\hline CHEMBL1965976 & 809336 & 4.3595 & 4.0657 & TRN & \\
\hline CHEMBL1342653 & 809336 & 3.327 & 3.7888 & TRN & \\
\hline CHEMBL1904453 & 809336 & 5.4622 & 4.2662 & TST & \\
\hline CHEMBL1721075 & 809336 & 3.327 & 3.7899 & TRN & \\
\hline CHEMBL1572432 & 809336 & 3.327 & 3.2944 & TRN & \\
\hline CHEMBL1733884 & 809336 & 3.327 & 3.1662 & TRN & \\
\hline CHEMBL1889769 & 809336 & 3.327 & 3.4441 & TRN & \\
\hline CHEMBL1389929 & 809336 & 3.327 & 4.2277 & TST & \\
\hline CHEMBL1610382 & 809336 & 7.4342 & 3.7359 & TRN & \\
\hline CHEMBL1307359 & 809336 & 3.327 & 4.0354 & TRN & \\
\hline CHEMBL1373496 & 809336 & 3.327 & 3.9782 & TST & \\
\hline CHEMBL1305430 & 809336 & 4.6383 & 4.5115 & TRN & \\
\hline CHEMBL 1706502 & 809336 & 3.327 & 3.7765 & TRN & \\
\hline CHEMBL1389773 & 809336 & 3.327 & 3.6265 & TRN & \\
\hline CHEMBL1713532 & 809336 & 3.327 & 3.6229 & TRN & \\
\hline CHEMBL1707844 & 809336 & 3.327 & 3.4661 & TRN & \\
\hline CHEMBL1446098 & 809336 & 3.327 & 3.9735 & TRN & \\
\hline CHEMBL1428268 & 809336 & 7.4342 & 4.2822 & TST & \\
\hline CHEMBL1413263 & 809336 & 3.327 & 4.1598 & TRN & \\
\hline
\end{tabular}




\begin{tabular}{|c|c|c|c|c|c|}
\hline & & \multicolumn{4}{|c|}{ Supplemental Table S2.txt } \\
\hline CHEMBL1335494 & 809336 & 3.327 & 4.5175 & TRN & \\
\hline CHEMBL1720731 & 809336 & 3.327 & 3.6335 & TST & \\
\hline CHEMBL1572190 & 809336 & 3.327 & 3.6127 & TRN & \\
\hline CHEMBL1985679 & 809336 & 3.327 & 3.7786 & TRN & \\
\hline CHEMBL1583719 & 809336 & 5.2248 & 4.5437 & TRN & \\
\hline CHEMBL1727878 & 809336 & 3.327 & 3.3523 & TRN & \\
\hline CHEMBL1302687 & 809336 & 3.327 & 3.134 & TRN & \\
\hline CHEMBL1355070 & 809336 & 3.327 & 3.342 & TRN & \\
\hline CHEMBL1870778 & 809336 & 3.327 & 3.4963 & TRN & \\
\hline CHEMBL1454472 & 809336 & 3.327 & 4.0426 & TRN & \\
\hline CHEMBL1567636 & 809336 & 5.4248 & 3.6792 & TRN & \\
\hline CHEMBL1609619 & 809336 & 3.327 & 4.3546 & TRN & \\
\hline CHEMBL1387503 & 809336 & 3.327 & 3.4291 & TRN & \\
\hline CHEMBL1588913 & 809336 & 4.9872 & 4.1625 & TRN & \\
\hline CHEMBL1994655 & 809336 & 5.4737 & 4.255 & TRN & \\
\hline CHEMBL1576383 & 809336 & 3.327 & 4.2627 & TRN & \\
\hline CHEMBL1451816 & 809336 & 3.327 & 4.0032 & TRN & \\
\hline CHEMBL1490454 & 809336 & 3.327 & 3.9273 & TRN & \\
\hline CHEMBL458114 & 809336 & 5.5935 & 4.6575 & TRN & \\
\hline CHEMBL1484914 & 809336 & 3.327 & 3.6819 & TRN & \\
\hline CHEMBL1548706 & 809336 & 3.327 & 4.5632 & TRN & \\
\hline CHEMBL1387734 & 809336 & 3.327 & 4.0634 & TRN & \\
\hline CHEMBL1596199 & 809336 & 3.327 & 3.1964 & TRN & \\
\hline CHEMBL1465349 & 809336 & 3.327 & 3.5611 & TRN & \\
\hline CHEMBL1519061 & 809336 & 3.327 & 3.25100 & 00000000003 & TRN \\
\hline CHEMBL 2005182 & 809336 & 5.3645 & 3.9658 & TRN & \\
\hline CHEMBL1311234 & 809336 & 3.327 & 3.715 & TRN & \\
\hline CHEMBL1733976 & 809336 & 3.327 & 4.4966 & TRN & \\
\hline CHEMBL1537866 & 809336 & 3.327 & 3.6157 & TRN & \\
\hline CHEMBL1462179 & 809336 & 4.5129 & 4.6083 & TRN & \\
\hline CHEMBL1482606 & 809336 & 3.327 & 4.0836 & TRN & \\
\hline CHEMBL1731931 & 809336 & 3.327 & 3.8377 & TST & \\
\hline CHEMBL 1486020 & 809336 & 3.327 & 3.5369 & TRN & \\
\hline CHEMBL1518362 & 809336 & 3.327 & 4.3719 & TRN & \\
\hline CHEMBL1400207 & 809336 & 3.327 & 3.2837 & TRN & \\
\hline CHEMBL1443994 & 809336 & 3.327 & 3.9503 & TRN & \\
\hline CHEMBL1422326 & 809336 & 4.6757 & 4.0723 & TRN & \\
\hline CHEMBL1461296 & 809336 & 3.327 & 3.3096 & TRN & \\
\hline CHEMBL1427638 & 809336 & 3.327 & 4.6383 & TRN & \\
\hline CHEMBL1894626 & 809336 & 3.327 & 3.5115 & TRN & \\
\hline CHEMBL1526005 & 809336 & 3.327 & 3.7442 & TRN & \\
\hline CHEMBL1974644 & 809336 & 5.2441 & 3.8131 & TST & \\
\hline CHEMBL1461975 & 809336 & 3.327 & 3.8945 & TST & \\
\hline CHEMBL1551917 & 809336 & 3.327 & 4.4829 & TRN & \\
\hline CHEMBL1352235 & 809336 & 5.2284 & 3.7727 & TRN & \\
\hline CHEMBL1539574 & 809336 & 3.327 & 3.2541 & TRN & \\
\hline CHEMBL1883373 & 809336 & 3.327 & 3.7921 & TRN & \\
\hline CHEMBL1408292 & 809336 & 4.8996 & 4.4461 & TRN & \\
\hline
\end{tabular}

Page 27934 


\begin{tabular}{|c|c|c|c|c|}
\hline \multicolumn{5}{|c|}{ Supplemental Table } \\
\hline CHEMBL1881506 & 809336 & 3.327 & 4.3145 & TRN \\
\hline CHEMBL1710436 & 809336 & 3.327 & 4.2886 & TRN \\
\hline CHEMBL1335865 & 809336 & 7.4342 & 3.7163 & TRN \\
\hline CHEMBL1583628 & 809336 & 4.8601 & 4.3279 & TST \\
\hline CHEMBL1967050 & 809336 & 3.327 & 4.2573 & TRN \\
\hline CHEMBL1541746 & 809336 & 3.327 & 3.9097 & TRN \\
\hline CHEMBL1704588 & 809336 & 5.5346 & 4.5357 & TRN \\
\hline CHEMBL1483134 & 809336 & 3.327 & 3.7584 & TST \\
\hline CHEMBL1718457 & 809336 & 3.327 & 3.7534 & TRN \\
\hline CHEMBL 1485786 & 809336 & 3.327 & 4.2474 & TST \\
\hline CHEMBL1311851 & 809336 & 3.327 & 3.8097 & TRN \\
\hline CHEMBL1519756 & 809336 & 3.327 & 4.1877 & TRN \\
\hline CHEMBL1453613 & 809336 & 3.327 & 3.5478 & TRN \\
\hline CHEMBL1469767 & 809336 & 3.327 & 3.8008 & TRN \\
\hline CHEMBL1467253 & 809336 & 3.327 & 3.8161 & TRN \\
\hline CHEMBL1999645 & 809336 & 3.327 & 3.5726 & TST \\
\hline CHEMBL1343279 & 809336 & 3.327 & 4.2258 & TRN \\
\hline CHEMBL1308291 & 809336 & 4.4078 & 3.8102 & TRN \\
\hline CHEMBL1580963 & 809336 & 3.327 & 4.2308 & TRN \\
\hline CHEMBL1353110 & 809336 & 5.1302 & 4.1442 & TRN \\
\hline CHEMBL1391337 & 809336 & 4.7352 & 4.3219 & TRN \\
\hline CHEMBL1462218 & 809336 & 4.9957 & 3.8 & TRN \\
\hline CHEMBL1715787 & 809336 & 3.327 & 3.3763 & TRN \\
\hline CHEMBL1345007 & 809336 & 3.327 & 3.22 & TRN \\
\hline CHEMBL1403574 & 809336 & 3.327 & 3.0757 & TRN \\
\hline CHEMBL1549532 & 809336 & 4.7545 & 4.1162 & TRN \\
\hline CHEMBL1723007 & 809336 & 3.327 & 3.5436 & TRN \\
\hline CHEMBL1704445 & 809336 & 3.327 & 4.7374 & TRN \\
\hline CHEMBL1325579 & 809336 & 3.327 & 3.8057 & TRN \\
\hline CHEMBL3144954 & 809336 & 4.6517 & 4.2744 & TST \\
\hline CHEMBL1466769 & 809336 & 3.327 & 3.6347 & TRN \\
\hline CHEMBL1603709 & 809336 & 7.4342 & 4.2822 & TRN \\
\hline CHEMBL1882047 & 809336 & 3.327 & 3.7002 & TRN \\
\hline CHEMBL1863899 & 809336 & 3.327 & 3.205 & TRN \\
\hline CHEMBL1306608 & 809336 & 4.7375 & 4.0371 & TRN \\
\hline CHEMBL1094498 & 809336 & 3.327 & 4.453 & TRN \\
\hline CHEMBL1559259 & 809336 & 6.0665 & 4.0971 & TRN \\
\hline CHEMBL1472387 & 809336 & 3.327 & 3.7511 & TRN \\
\hline CHEMBL1980967 & 809336 & 3.327 & 4.2115 & TRN \\
\hline CHEMBL1708220 & 809336 & 3.327 & 3.477 & TRN \\
\hline CHEMBL 2000650 & 809336 & 3.327 & 3.5152 & TRN \\
\hline CHEMBL49520 & 809336 & 3.327 & 3.9408 & TRN \\
\hline CHEMBL1983302 & 809336 & 3.327 & 3.9959 & TRN \\
\hline CHEMBL 200965 & 809336 & 5.2596 & 4.4498 & TRN \\
\hline CHEMBL1700503 & 809336 & 3.327 & 3.6851 & TRN \\
\hline CHEMBL1459511 & 809336 & 3.327 & 4.4597 & TRN \\
\hline CHEMBL1979256 & 809336 & 3.327 & 4.0249 & TRN \\
\hline CHEMBL 2000006 & 809336 & 3.327 & 3.3267 & TRN \\
\hline
\end{tabular}




\begin{tabular}{|c|c|c|c|c|}
\hline & & & oplement & al Ta \\
\hline CHEMBL1516419 & 809336 & 3.327 & 4.1226 & TRN \\
\hline CHEMBL1600188 & 809336 & 3.327 & 3.7511 & TRN \\
\hline CHEMBL1527705 & 809336 & 4.8697 & 3.8714 & TRN \\
\hline CHEMBL1602008 & 809336 & 3.327 & 3.7648 & TRN \\
\hline CHEMBL1451237 & 809336 & 3.327 & 3.5037 & TRN \\
\hline CHEMBL1320148 & 809336 & 5.7747 & 4.4992 & TRN \\
\hline CHEMBL1369403 & 809336 & 3.327 & 4.2749 & TRN \\
\hline CHEMBL1965280 & 809336 & 5.2757 & 3.91 & TRN \\
\hline CHEMBL1528725 & 809336 & 3.327 & 3.5747 & TRN \\
\hline CHEMBL1879384 & 809336 & 3.327 & 4.1872 & TRN \\
\hline CHEMBL1966716 & 809336 & 3.327 & 3.8336 & TST \\
\hline CHEMBL1359784 & 809336 & 4.5702 & 4.034 & TST \\
\hline CHEMBL1578253 & 809336 & 3.327 & 3.9937 & TST \\
\hline CHEMBL1401343 & 809336 & 3.327 & 3.5979 & TST \\
\hline CHEMBL1709546 & 809336 & 5.5498 & 3.7247 & TST \\
\hline CHEMBL1462834 & 809336 & 3.327 & 4.1957 & TST \\
\hline CHEMBL1544694 & 809336 & 3.327 & 4.1424 & TST \\
\hline CHEMBL1714444 & 809336 & 3.327 & 3.9384 & TST \\
\hline CHEMBL1547595 & 809336 & 3.327 & 3.917 & TST \\
\hline CHEMBL1362871 & 809336 & 3.327 & 4.3253 & TST \\
\hline CHEMBL1410245 & 809336 & 3.327 & 3.5276 & TST \\
\hline CHEMBL1987891 & 809336 & 3.327 & 4.1945 & TST \\
\hline CHEMBL1448380 & 809336 & 3.327 & 3.9181 & TST \\
\hline CHEMBL1540435 & 809336 & 4.5317 & 4.2756 & TST \\
\hline CHEMBL1872450 & 809336 & 3.327 & 3.8164 & TST \\
\hline CHEMBL1466608 & 809336 & 3.327 & 3.6945 & TST \\
\hline CHEMBL1400754 & 809336 & 3.327 & 3.9986 & TST \\
\hline CHEMBL1364137 & 809336 & 3.327 & 4.4153 & TST \\
\hline CHEMBL1326848 & 809336 & 3.327 & 3.8724 & TST \\
\hline CHEMBL1970751 & 809336 & 3.327 & 3.3801 & TST \\
\hline CHEMBL1387446 & 809336 & 3.327 & 3.8645 & TST \\
\hline CHEMBL1728240 & 809336 & 3.327 & 4.0914 & TST \\
\hline CHEMBL1469811 & 809336 & 3.327 & 4.2179 & TST \\
\hline CHEMBL1904030 & 809336 & 3.327 & 3.6462 & TST \\
\hline CHEMBL1422205 & 809336 & 3.327 & 4.2995 & TST \\
\hline CHEMBL1419090 & 809336 & 3.327 & 3.7333 & TST \\
\hline CHEMBL1725722 & 809336 & 3.327 & 3.7117 & TST \\
\hline CHEMBL1900007 & 809336 & 3.327 & 4.1184 & TST \\
\hline CHEMBL1347041 & 809336 & 3.327 & 3.517 & TST \\
\hline CHEMBL 2000334 & 809336 & 3.327 & 4.025 & TST \\
\hline CHEMBL1479410 & 809336 & 3.327 & 4.2034 & TST \\
\hline CHEMBL491820 & 809336 & 5.1007 & 4.0118 & TST \\
\hline CHEMBL1874305 & 809336 & 3.327 & 3.9667 & TST \\
\hline CHEMBL1331062 & 809336 & 3.327 & 3.9164 & TST \\
\hline CHEMBL1967062 & 809336 & 3.327 & 3.7557 & TST \\
\hline CHEMBL1370822 & 809336 & 3.327 & 3.8779 & TST \\
\hline CHEMBL1604593 & 809336 & 3.327 & 3.5778 & TST \\
\hline CHEMBL1504475 & 809336 & 7.4342 & 4.8209 & TST \\
\hline
\end{tabular}




\begin{tabular}{|c|c|c|c|c|}
\hline & & & oplement & al $\mathrm{Tc}$ \\
\hline CHEMBL1457805 & 809336 & 3.327 & 3.6018 & TST \\
\hline CHEMBL1418327 & 809336 & 3.327 & 4.1132 & TST \\
\hline CHEMBL1329616 & 809336 & 4.8447 & 4.4817 & TST \\
\hline CHEMBL1700989 & 809336 & 3.327 & 3.3388 & TST \\
\hline CHEMBL1308965 & 809336 & 3.327 & 4.2641 & TST \\
\hline CHEMBL1589496 & 809336 & 4.4377 & 4.3506 & TST \\
\hline CHEMBL1339445 & 809336 & 3.327 & 4.4603 & TST \\
\hline CHEMBL1448457 & 809336 & 3.327 & 4.1069 & TST \\
\hline CHEMBL1375673 & 809336 & 3.327 & 3.7027 & TST \\
\hline CHEMBL1444799 & 809336 & 3.327 & 3.2764 & TST \\
\hline CHEMBL1499721 & 809336 & 3.327 & 4.2949 & TST \\
\hline CHEMBL1470078 & 809336 & 4.9747 & 3.48 & TST \\
\hline CHEMBL1579924 & 809336 & 4.6517 & 4.3916 & TST \\
\hline CHEMBL1368180 & 809336 & 3.327 & 3.9017 & TST \\
\hline CHEMBL1500468 & 809336 & 7.4342 & 4.0041 & TST \\
\hline CHEMBL1988441 & 809336 & 3.327 & 3.4689 & TST \\
\hline CHEMBL1329882 & 809336 & 3.327 & 3.9795 & TST \\
\hline CHEMBL1432138 & 809336 & 7.4342 & 4.5047 & TST \\
\hline CHEMBL1992678 & 809336 & 3.327 & 3.7087 & TST \\
\hline CHEMBL1991442 & 809336 & 4.7167 & 4.2321 & TST \\
\hline CHEMBL 2000442 & 809336 & 3.327 & 4.269 & TST \\
\hline CHEMBL1973493 & 809336 & 3.327 & 4.7094 & TST \\
\hline CHEMBL1877793 & 809336 & 3.327 & 3.7692 & TST \\
\hline CHEMBL1391209 & 809336 & 5.0701 & 3.5984 & TST \\
\hline CHEMBL1493739 & 809336 & 3.327 & 3.3094 & TST \\
\hline CHEMBL1478277 & 809336 & 3.327 & 3.6478 & TST \\
\hline CHEMBL1430340 & 809336 & 3.327 & 4.2846 & TST \\
\hline CHEMBL1583000 & 809336 & 3.327 & 4.5504 & TST \\
\hline CHEMBL1585233 & 809336 & 3.327 & 3.9009 & TST \\
\hline CHEMBL1550439 & 809336 & 3.327 & 3.702 & TST \\
\hline CHEMBL1561527 & 809336 & 3.327 & 3.8691 & TST \\
\hline CHEMBL1413143 & 809336 & 4.5867 & 4.2417 & TST \\
\hline CHEMBL1466708 & 809336 & 3.327 & 4.3365 & TST \\
\hline CHEMBL1452263 & 809336 & 3.327 & 3.3196 & TST \\
\hline CHEMBL1509034 & 809336 & 5.7328 & 4.0333 & TST \\
\hline CHEMBL1904249 & 809336 & 3.327 & 3.4275 & TST \\
\hline CHEMBL1550586 & 809336 & 3.327 & 3.8153 & TST \\
\hline CHEMBL1580579 & 809336 & 3.327 & 3.3814 & TST \\
\hline CHEMBL1525088 & 809336 & 3.327 & 3.3917 & TST \\
\hline CHEMBL1543476 & 809336 & 3.327 & 3.4163 & TST \\
\hline CHEMBL 2005894 & 809336 & 3.327 & 4.3476 & TST \\
\hline CHEMBL1398879 & 809336 & 4.8861 & 3.9972 & TST \\
\hline CHEMBL1325211 & 809336 & 3.327 & 3.8656 & TST \\
\hline CHEMBL1878235 & 809336 & 3.327 & 3.1673 & TST \\
\hline CHEMBL1457141 & 809336 & 3.327 & 4.3316 & TST \\
\hline CHEMBL1318357 & 809336 & 4.7033 & 4.0194 & TST \\
\hline CHEMBL1317849 & 809336 & 3.327 & 3.3028 & TST \\
\hline CHEMBL1409229 & 809336 & 3.327 & 4.1122 & TST \\
\hline
\end{tabular}




\begin{tabular}{|c|c|c|c|c|}
\hline & & & oplement & al Ta \\
\hline CHEMBL1379461 & 809336 & 3.327 & 4.2229 & TST \\
\hline CHEMBL1736441 & 809336 & 3.327 & 4.4204 & TST \\
\hline CHEMBL1456300 & 809336 & 4.7496 & 4.3674 & TST \\
\hline CHEMBL1573332 & 809336 & 3.327 & 3.1476 & TST \\
\hline CHEMBL1702337 & 809336 & 3.327 & 3.9789 & TST \\
\hline CHEMBL1359436 & 809336 & 3.327 & 3.397 & TST \\
\hline CHEMBL1735667 & 809336 & 3.327 & 3.8339 & TST \\
\hline CHEMBL1613653 & 809336 & 3.327 & 3.6691 & TST \\
\hline CHEMBL1970761 & 809336 & 3.327 & 3.9674 & TST \\
\hline CHEMBL1700097 & 809336 & 3.327 & 3.4437 & TST \\
\hline CHEMBL1569011 & 809336 & 4.5867 & 4.5417 & TST \\
\hline CHEMBL1568043 & 809336 & 3.327 & 3.9959 & TST \\
\hline CHEMBL1375451 & 809336 & 6.2636 & 4.2496 & TST \\
\hline CHEMBL1378498 & 809336 & 3.327 & 4.3496 & TST \\
\hline CHEMBL1606762 & 809336 & 3.327 & 3.4369 & TST \\
\hline CHEMBL1429233 & 809336 & 3.327 & 4.2669 & TST \\
\hline CHEMBL1704086 & 809336 & 5.1524 & 4.8356 & TST \\
\hline CHEMBL1322928 & 809336 & 3.327 & 3.8221 & TST \\
\hline CHEMBL1903884 & 809336 & 3.327 & 4.3083 & TST \\
\hline CHEMBL1424762 & 809336 & 3.327 & 3.8673 & TST \\
\hline CHEMBL1715726 & 809336 & 3.327 & 4.3723 & TST \\
\hline CHEMBL1529357 & 809336 & 4.5436 & 3.9152 & TST \\
\hline CHEMBL1546530 & 809336 & 4.7878 & 3.8834 & TST \\
\hline CHEMBL1605046 & 809336 & 3.327 & 3.7369 & TST \\
\hline CHEMBL1442865 & 809336 & 3.327 & 4.0851 & TST \\
\hline CHEMBL1613198 & 809336 & 3.327 & 3.5235 & TST \\
\hline CHEMBL458112 & 809336 & 5.2269 & 4.2336 & TST \\
\hline CHEMBL1734867 & 809336 & 3.327 & 3.6771 & TST \\
\hline CHEMBL1416986 & 809336 & 3.327 & 3.7834 & TST \\
\hline CHEMBL1712230 & 809336 & 3.327 & 4.1403 & TST \\
\hline CHEMBL1582516 & 809336 & 3.327 & 3.8942 & TST \\
\hline CHEMBL1712394 & 809336 & 3.327 & 4.0736 & TST \\
\hline CHEMBL1706945 & 809336 & 3.327 & 3.673 & TST \\
\hline CHEMBL1480465 & 809336 & 3.327 & 4.3461 & TST \\
\hline CHEMBL1362168 & 809336 & 4.8125 & 4.1447 & TST \\
\hline CHEMBL1612213 & 809336 & 3.327 & 3.6122 & TST \\
\hline CHEMBL1581165 & 809336 & 3.327 & 3.705 & TST \\
\hline CHEMBL578162 & 809336 & 3.327 & 4.2837 & TST \\
\hline CHEMBL1438154 & 809336 & 3.327 & 3.4986 & TST \\
\hline CHEMBL1369993 & 809336 & 3.327 & 3.4619 & TST \\
\hline CHEMBL1708852 & 809336 & 4.7282 & 4.5212 & TST \\
\hline CHEMBL1326080 & 809336 & 3.327 & 3.908 & TST \\
\hline CHEMBL1887005 & 809336 & 3.327 & 3.3534 & TST \\
\hline CHEMBL1391473 & 809336 & 3.327 & 4.27 & TST \\
\hline CHEMBL1362082 & 809336 & 3.327 & 4.1875 & TST \\
\hline CHEMBL1899747 & 809336 & 3.327 & 4.1692 & TST \\
\hline CHEMBL1307438 & 809336 & 3.327 & 4.0801 & TST \\
\hline CHEMBL1981398 & 809336 & 5.4802 & 4.069 & TST \\
\hline
\end{tabular}




\begin{tabular}{|c|c|c|c|c|c|}
\hline & & \multicolumn{4}{|c|}{ Supplemental Table S2.txt } \\
\hline CHEMBL1397756 & 809336 & 3.327 & 4.1328 & TST & \\
\hline CHEMBL1703252 & 809336 & 3.327 & 3.7381 & TST & \\
\hline CHEMBL 2001421 & 809336 & 3.327 & 3.45600 & 00000000004 & TST \\
\hline CHEMBL1380457 & 809336 & 3.327 & 3.9121 & TST & \\
\hline CHEMBL1712381 & 809336 & 3.327 & 3.4327 & TST & \\
\hline CHEMBL1377734 & 809336 & 7.4342 & 3.4504 & TST & \\
\hline CHEMBL1403377 & 809336 & 3.327 & 3.2097 & TST & \\
\hline CHEMBL1705299 & 809336 & 3.327 & 3.3459 & TST & \\
\hline CHEMBL 2001857 & 809336 & 5.0757 & 4.2952 & TST & \\
\hline CHEMBL1502167 & 809336 & 7.4342 & 3.3152 & TST & \\
\hline CHEMBL1578488 & 809336 & 3.327 & 4.2587 & TST & \\
\hline CHEMBL1323512 & 809336 & 5.2396 & 4.8209 & TST & \\
\hline CHEMBL1580715 & 809336 & 4.8125 & 3.9564 & TST & \\
\hline CHEMBL1383148 & 809336 & 3.327 & 3.8312 & TST & \\
\hline CHEMBL1332469 & 809336 & 3.327 & 3.63 & TST & \\
\hline CHEMBL1370968 & 809336 & 3.327 & 4.14199 & 99999999995 & TST \\
\hline CHEMBL1402044 & 809336 & 3.327 & 4.2318 & TST & \\
\hline CHEMBL1371225 & 809336 & 3.327 & 4.0051 & TST & \\
\hline CHEMBL1887973 & 809336 & 3.327 & 3.6342 & TST & \\
\hline CHEMBL1365924 & 809336 & 3.327 & 3.7916 & TST & \\
\hline CHEMBL1377330 & 809336 & 5.1537 & 4.1002 & TST & \\
\hline CHEMBL1545575 & 809336 & 3.327 & 3.4882 & TST & \\
\hline CHEMBL1527787 & 809336 & 3.327 & 3.7866 & TST & \\
\hline CHEMBL1519513 & 809336 & 5.2958 & 4.1255 & TST & \\
\hline CHEMBL1610880 & 809336 & 3.327 & 3.5691 & TST & \\
\hline CHEMBL1474580 & 809336 & 4.6289 & 4.2958 & TST & \\
\hline CHEMBL1433943 & 809336 & 4.8356 & 3.95399 & 99999999997 & TST \\
\hline CHEMBL1461473 & 809336 & 3.327 & 3.8054 & TST & \\
\hline CHEMBL1327017 & 809336 & 3.327 & 4.0502 & TST & \\
\hline CHEMBL1469381 & 809336 & 3.327 & 3.7722 & TST & \\
\hline CHEMBL1613291 & 809336 & 3.327 & 4.0134 & TST & \\
\hline CHEMBL1457468 & 809336 & 3.327 & 3.4828 & TST & \\
\hline CHEMBL1494767 & 809336 & 3.327 & 4.5581 & TST & \\
\hline CHEMBL1440842 & 809336 & 7.4342 & 4.2065 & TST & \\
\hline CHEMBL1988039 & 809336 & 3.327 & 4.0956 & TST & \\
\hline CHEMBL1526794 & 809336 & 3.327 & 3.5283 & TST & \\
\hline CHEMBL1407268 & 809336 & 3.327 & 3.7147 & TST & \\
\hline CHEMBL1734544 & 809336 & 6.1226 & 4.6161 & TST & \\
\hline CHEMBL1508635 & 809336 & 7.4342 & 3.2908 & TST & \\
\hline CHEMBL1604103 & 809336 & 3.327 & 4.5707 & TST & \\
\hline CHEMBL1355120 & 809336 & 3.327 & 3.7105 & TST & \\
\hline CHEMBL1458769 & 809336 & 3.327 & 4.0507 & TST & \\
\hline CHEMBL1567718 & 809336 & 3.327 & 3.9979 & TST & \\
\hline CHEMBL1385580 & 809336 & 3.327 & 3.6981 & TST & \\
\hline CHEMBL1570103 & 809336 & 3.327 & 3.9234 & TST & \\
\hline CHEMBL1464293 & 809336 & 3.327 & 3.4987 & TST & \\
\hline CHEMBL1407258 & 809336 & 4.5436 & 3.9169 & TST & \\
\hline CHEMBL1310715 & 809336 & 4.8182 & 3.7204 & TST & \\
\hline
\end{tabular}




\begin{tabular}{|c|c|c|c|c|c|}
\hline \multirow{3}{*}{$\begin{array}{l}\text { CHEMBL1473316 } \\
\text { CHFMBI } 1386484\end{array}$} & & \multicolumn{4}{|c|}{ Supplemental Table S2.txt } \\
\hline & 809336 & 7.4342 & \multicolumn{2}{|c|}{3.9139999999999997} & TST \\
\hline & 809336 & 3.327 & 4.0071 & TST & \\
\hline CHEMBL1998821 & 809336 & 3.327 & 3.5997 & TST & \\
\hline CHEMBL1459678 & 809336 & 3.327 & 3.6762 & TST & \\
\hline CHEMBL1534844 & 809336 & 3.327 & 3.6988 & TST & \\
\hline CHEMBL1449721 & 809336 & 5.3635 & 3.8946 & TST & \\
\hline CHEMBL1370144 & 809336 & 3.327 & \multicolumn{2}{|c|}{3.4989999999999997} & TST \\
\hline CHEMBL1428092 & 809336 & 3.327 & 3.5895 & TST & \\
\hline CHEMBL1455852 & 809336 & 3.327 & 4.0696 & TST & \\
\hline CHEMBL1377960 & 809336 & 3.327 & 3.5974 & TST & \\
\hline CHEMBL1900473 & 809336 & 3.327 & 3.2217 & TST & \\
\hline CHEMBL1373367 & 809336 & 3.327 & 4.5375 & TST & \\
\hline CHEMBL1414980 & 809336 & 3.327 & 3.8958 & TST & \\
\hline CHEMBL1578625 & 809336 & 3.327 & 3.6604 & TST & \\
\hline CHEMBL1508157 & 809336 & 3.327 & 4.0447 & TST & \\
\hline CHEMBL1361498 & 809336 & 7.4342 & 3.8098 & TST & \\
\hline CHEMBL1478769 & 809336 & 3.327 & 4.0682 & TST & \\
\hline CHEMBL1897551 & 809336 & 4.4622 & 3.6848 & TST & \\
\hline CHEMBL1424031 & 809336 & 3.327 & 4.3164 & TST & \\
\hline CHEMBL1509469 & 809336 & 3.327 & 4.1338 & TST & \\
\hline CHEMBL1883660 & 809336 & 7.4342 & 4.1417 & TST & \\
\hline CHEMBL1556371 & 809336 & 3.327 & 3.5932 & TST & \\
\hline CHEMBL1524620 & 809336 & 3.327 & 4.3581 & TST & \\
\hline CHEMBL1313624 & 809336 & 3.327 & 4.1549 & TST & \\
\hline CHEMBL1901013 & 809336 & 3.327 & 3.4709 & TST & \\
\hline CHEMBL1886696 & 809336 & 3.327 & 3.4562 & TST & \\
\hline CHEMBL1736883 & 809336 & 4.4134 & 3.8884 & TST & \\
\hline CHEMBL1345630 & 809336 & 3.327 & 4.4561 & TST & \\
\hline CHEMBL1975607 & 809336 & 3.327 & 3.3546 & TST & \\
\hline CHEMBL1988099 & 809336 & 3.327 & 3.7728 & TST & \\
\hline CHEMBL1412020 & 809336 & 3.327 & 3.7215 & TST & \\
\hline CHEMBL1524084 & 809336 & 3.327 & 3.4558 & TST & \\
\hline CHEMBL1869204 & 809336 & 3.327 & 3.4636 & TST & \\
\hline CHEMBL1527480 & 809336 & 4.5058 & 3.7481 & TST & \\
\hline CHEMBL1470406 & 809336 & 5.2204 & 3.7999 & TST & \\
\hline CHEMBL 2000538 & 809336 & 3.327 & 3.3386 & TST & \\
\hline CHEMBL1698481 & 809336 & 3.327 & 3.7645 & TST & \\
\hline CHEMBL1301531 & 809336 & 3.327 & 3.8348 & TST & \\
\hline CHEMBL1399679 & 809336 & 3.327 & 3.5957 & TST & \\
\hline CHEMBL1349774 & 809336 & 3.327 & 3.6446 & TST & \\
\hline CHEMBL1467043 & 809336 & 3.327 & 3.5818 & TST & \\
\hline CHEMBL1334115 & 809336 & 3.327 & 3.83100 & 00000000004 & TST \\
\hline CHEMBL1873302 & 809336 & 3.327 & 4.1622 & TST & \\
\hline CHEMBL1540040 & 809336 & 5.3134 & 3.7932 & TST & \\
\hline CHEMBL3645597 & 1527970 & 6.3979 & 6.4455 & TRN & \\
\hline CHEMBL 3645657 & 1527970 & 8.2218 & 8.4012 & TRN & \\
\hline CHEMBL 3645588 & 1527970 & 8.5229 & 8.3909 & TRN & \\
\hline CHEMBL 3645753 & 1527970 & 7.6021 & 7.5789 & TRN & \\
\hline
\end{tabular}

Page 27940 
Supplemental Table S2.txt

\begin{tabular}{|c|c|c|c|c|}
\hline HEM & 527970 & .8239 & 8.8271 & \\
\hline HEMBL 3645727 & 527970 & 8.5229 & 8.6982 & \\
\hline 575 & 27970 & 979 & & \\
\hline AEMBL & & & & $\mathrm{MI}$ \\
\hline AEMBL 364 & 527970 & & 267 & \\
\hline HEMBL3645691 & 527970 & 8.3468 & 4089 & \\
\hline HEMBL; & 970 & 8.0 & 586 & \\
\hline AEMBL: & & 36 & & \\
\hline HEMBL36 & 70 & 6.0 & & \\
\hline HEMBL 364 & 527970 & & 8144 & \\
\hline HEMBL 3645734 & 970 & 9.2218 & 1244 & \\
\hline IEMBL36 & 70 & 6.0 & 176 & \\
\hline AEMBL3 & & 9 & & \\
\hline HEMBL36 & 70 & 815 & 1624 & \\
\hline AEMBL36 & 70 & 8.6021 & 4571 & \\
\hline AEMBL364 & 70 & 5. & 24 & \\
\hline AEMBL3 & 80 & 7. & 591 & \\
\hline HEMBL36 & & 6 . & & \\
\hline HEMBL36 & 70 & & & \\
\hline AEMBL36 & & & & \\
\hline AEMBL3 & $\theta$ & & 45 & 1SI \\
\hline AEMBL: & & & & ודים \\
\hline HEMBL; & & & & \\
\hline 580 & & & & RN \\
\hline AEMBL36 & & & & I RIV \\
\hline HEMBL3 & $\theta$ & 6 & & RN \\
\hline HEMBL & & & & וד וכ \\
\hline HFMBI : & 70 & 49 & & RN \\
\hline HEMBL3 & & 2596 & & 1 \\
\hline HEMBL 364 & & & & 15 \\
\hline HEMBL36 & $\theta$ & 7. & 104 & ГST \\
\hline HEMBL & & 8 & 69 & TRN \\
\hline HEMBL3 & & 7. & & ST \\
\hline HEMBL36 & & 6.301 & & TST \\
\hline HEMBL3645674 & & 8.6021 & & TRN \\
\hline HEMBL36 & & 8 & 33 & RN \\
\hline HFMRI & & 6 . & & RN \\
\hline HEMBL & & & & RN \\
\hline HEMBL $36 \angle$ & 70 & 7.2 & 3173 & TRN \\
\hline AEMBL36 & 52 & & & TRN \\
\hline HEMBL36 & & 371 & 275 & \\
\hline CHEMBL 36 & & & & RN \\
\hline HEMBL36 & 70 & 7.6021 & 692 & ST \\
\hline HEMBL 364 & 70 & 8.1549 & .724 & TRN \\
\hline $\mathrm{MPI}=$ & & & & 13 \\
\hline HEMBL36 & & 3979 & & \\
\hline HEMBL 36 & & 8.6021 & .5513 & \\
\hline CHEMBL3645609 & 1527970 & 8.5229 & 8.6332 & \\
\hline
\end{tabular}

Page 27941 
Supplemental Table S2.txt

\begin{tabular}{|c|c|c|c|c|}
\hline CHEMBL3645666 & 1527970 & 8.699 & 8.5453 & TRN \\
\hline CHEMBL 3645647 & 1527970 & 7.8239 & 7.8613 & TRN \\
\hline CHEMBL3645654 & 1527970 & 8.3979 & 8.6203 & TRN \\
\hline CHEMBL 3645760 & 1527970 & 8.0 & 7.9722 & TRN \\
\hline CHEMBL3645584 & 1527970 & 7.1871 & 7.1347 & TRN \\
\hline CHEMBL3645631 & 1527970 & 8.1871 & 8.4039 & TRN \\
\hline CHEMBL 3645685 & 1527970 & 6.0 & 6.69 & TRN \\
\hline CHEMBL 3645742 & 1527970 & 8.0 & \multicolumn{2}{|c|}{7.9479999999999995} \\
\hline CHEMBL3645664 & 1527970 & 8.301 & 8.1573 & TRN \\
\hline CHEMBL3645670 & 1527970 & 8.0 & 8.8675 & TRN \\
\hline CHEMBL3645615 & 1527970 & 9.0458 & 8.9644 & TRN \\
\hline CHEMBL3645715 & 1527970 & 8.5229 & 8.6918 & TRN \\
\hline CHEMBL3645766 & 1527970 & 8.0969 & 8.0885 & TRN \\
\hline CHEMBL3639446 & 1527970 & 7.1549 & 7.3463 & TST \\
\hline CHEMBL 3645683 & 1527970 & 6.0 & 6.2512 & TRN \\
\hline CHEMBL 3645711 & 1527970 & 8.0969 & 7.7863 & TRN \\
\hline CHEMBL 3645718 & 1527970 & 8.699 & 8.9029 & TRN \\
\hline CHEMBL3645608 & 1527970 & 6.0 & 7.8029 & TRN \\
\hline CHEMBL 3645761 & 1527970 & 7.1249 & 7.2932 & TST \\
\hline CHEMBL 3645643 & 1527970 & 7.301 & 7.4007 & TST \\
\hline CHEMBL 3645622 & 1527970 & 6.0 & 6.6461 & TRN \\
\hline CHEMBL 3645732 & 1527970 & 8.2076 & 8.3386 & TST \\
\hline CHEMBL 3645578 & 1527970 & 7.4559 & 7.3048 & TST \\
\hline CHEMBL3645636 & 1527970 & 9.0 & 8.4873 & TRN \\
\hline CHEMBL3645612 & 1527970 & 6.0 & 7.2648 & TRN \\
\hline CHEMBL 3645733 & 1527970 & 8.0 & 8.2559 & TST \\
\hline CHEMBL 3645606 & 1527970 & 9.0 & 8.953 & TRN \\
\hline CHEMBL 3645642 & 1527970 & 6.0223 & 6.2311 & TST \\
\hline CHEMBL 3645624 & 1527970 & 8.4202 & 7.3252 & TRN \\
\hline CHEMBL3645714 & 1527970 & 8.0458 & 7.8808 & TRN \\
\hline CHEMBL 3645610 & 1527970 & 6.0 & 6.3996 & TRN \\
\hline CHEMBL 3645678 & 1527970 & 7.3468 & 7.313 & TRN \\
\hline CHEMBL 3645603 & 1527970 & 7.3979 & 6.7758 & TST \\
\hline CHEMBL 3645627 & 1527970 & 8.7696 & 8.4525 & TRN \\
\hline CHEMBL3645675 & 1527970 & 8.0969 & 8.064 & TRN \\
\hline CHEMBL 3645729 & 1527970 & 9.0458 & 6.5654 & TRN \\
\hline CHEMBL3645668 & 1527970 & 8.301 & 7.2648 & TRN \\
\hline CHEMBL3645703 & 1527970 & 8.0969 & 8.4566 & TRN \\
\hline CHEMBL3645605 & 1527970 & 8.0969 & 7.9733 & TRN \\
\hline CHEMBL3645738 & 1527970 & 9.0 & 8.3536 & TRN \\
\hline CHEMBL3645677 & 1527970 & 7.8239 & 7.7596 & TRN \\
\hline CHEMBL3645750 & 1527970 & 7.4559 & 7.5279 & TST \\
\hline CHEMBL3645630 & 1527970 & 8.0969 & 8.0888 & TRN \\
\hline CHEMBL3645701 & 1527970 & 8.8539 & 8.6492 & TRN \\
\hline CHEMBL3645639 & 1527970 & 6.0 & 6.7927 & TRN \\
\hline CHEMBL3645619 & 1527970 & 6.0 & 6.5463 & TRN \\
\hline CHEMBL 3645704 & 1527970 & 8.2596 & 8.2041 & TRN \\
\hline CHEMBL3645702 & 1527970 & 8.2218 & 8.4227 & TRN \\
\hline
\end{tabular}


Supplemental Table S2.txt

\begin{tabular}{|c|c|c|c|c|}
\hline HEN & 527970 & 3565 & & \\
\hline & 527970 & 8.0969 & 7.9823 & \\
\hline & 70 & & & \\
\hline AEMBL & & 6021 & & \\
\hline AEMBL 36 & 527970 & 549 & & \\
\hline HEMBL3645638 & 527970 & 8.699 & 6688 & \\
\hline & 970 & 9586 & & \\
\hline 24 & & & & \\
\hline AEMBL36 & 70 & & 2628 & \\
\hline HEMBL 364 & 527970 & 99 & 8204 & \\
\hline AEMBL364 & 970 & 8.4559 & 0941 & \\
\hline IEMBL36 & 70 & 229 & 1652 & \\
\hline AEMBL3 & & & & \\
\hline HEMBL36 & 70 & 3539 & 8.6559 & \\
\hline AEMBL36 & 70 & 229 & & \\
\hline AEMBL364 & 70 & 5 & 45 & \\
\hline HEMBL36 & 80 & & 507 & \\
\hline HEMBL36 & & & & \\
\hline HEMBL3E & 70 & 8 . & 8637 & \\
\hline AEMBL36 & & 8 . & & \\
\hline HEMBL= & $\theta$ & 7 & 55 & Niv \\
\hline AEMBL: & & & 89 & 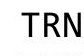 \\
\hline HEMBL; & & & 74 & \\
\hline 98 & & 10.5229 & & \\
\hline AEMBL36 & & & & 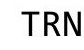 \\
\hline HEMBL & $\theta$ & & 16 & RN \\
\hline HEMBL; & & & & 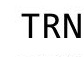 \\
\hline HFMBI : & 70 & 7. & 551 & \\
\hline HEMBL36 & & & & TIV \\
\hline HEMBL 364 & & & 836 & I RIV \\
\hline HEMBL36 & & 8 . & 286 & RN \\
\hline HEMBL & & 6 & 83 & RN \\
\hline HEMBL3 & & 7. & 186 & ST \\
\hline HEMBL36 & & & & Is \\
\hline HEMBL 364 & $\theta$ & 8.5528 & 3237 & TRN \\
\hline HEMBL36 & $\theta$ & 021 & 5974 & 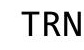 \\
\hline HFMRI & & 7. & & ST \\
\hline HEMBL & & 7. & 242 & $\mathrm{~K}$ \\
\hline HEMBL364 & 70 & 7.8239 & 7325 & $\mathrm{TR}$ \\
\hline EMBL & E & 71 & 607 & RN \\
\hline HEMBL36 & & 39 & 162 & \\
\hline HEMBL 3 & & 7.0458 & 7.2138 & ST \\
\hline HEMBL36 & 70 & 6.0 & 0818 & RN \\
\hline AEMBL36 & 70 & 8.699 & 2781 & TR \\
\hline 1. & & 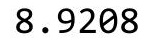 & 9674 & \\
\hline HEMBL36 & & 18 & 2863 & \\
\hline HEMBL 36 & & 7.8539 & 6.8728 & \\
\hline CHEMBL3645764 & 1527970 & 7.3979 & 7.5142 & ГST \\
\hline
\end{tabular}

Page 27943 
Supplemental Table S2.txt

\begin{tabular}{|c|c|c|c|c|}
\hline CHEMBL3645697 & 1527970 & 8.8239 & 8.9504 & TRN \\
\hline CHEMBL3645712 & 1527970 & 8.0 & 7.76 & TRN \\
\hline CHEMBL3645651 & 1527970 & 6.1871 & 6.4161 & TST \\
\hline CHEMBL 3645705 & 1527970 & 8.5528 & 8.4804 & TRN \\
\hline CHEMBL3645706 & 1527970 & 8.5229 & 8.625 & TRN \\
\hline CHEMBL 3645582 & 1527970 & 6.5229 & 6.7389 & TRN \\
\hline CHEMBL3645728 & 1527970 & 7.1871 & 7.2096 & TST \\
\hline CHEMBL 3645707 & 1527970 & 8.301 & 8.6001 & TRN \\
\hline CHEMBL3645756 & 1527970 & 7.699 & 7.7536 & TST \\
\hline CHEMBL 3645634 & 1527970 & 5.9031 & 6.11799 & 999999999 \\
\hline CHEMBL 3645650 & 1527970 & 9.0458 & 8.6863 & TRN \\
\hline CHEMBL3645626 & 1527970 & 8.6021 & 8.4466 & TRN \\
\hline CHEMBL 3645614 & 1527970 & 8.2218 & 7.9493 & TRN \\
\hline CHEMBL 3645743 & 1527970 & 7.6021 & 7.6516 & TST \\
\hline CHEMBL 3645629 & 1527970 & 8.8539 & 8.512 & TRN \\
\hline CHEMBL 3645652 & 1527970 & 8.6021 & 6.9657 & TRN \\
\hline CHEMBL3645690 & 1527970 & 8.2596 & 8.014 & TRN \\
\hline CHEMBL 3645767 & 1527970 & 7.4559 & 7.5548 & TST \\
\hline CHEMBL 3645708 & 1527970 & 8.3468 & 8.1005 & TRN \\
\hline CHEMBL 3645589 & 1527970 & 6.0 & 6.4032 & TRN \\
\hline CHEMBL 3645577 & 1527970 & 8.2218 & 6.2687 & TRN \\
\hline CHEMBL3645641 & 1527970 & 7.699 & 7.7954 & TRN \\
\hline CHEMBL 3645607 & 1527970 & 8.4559 & 8.1934 & TRN \\
\hline CHEMBL 3645598 & 1527970 & 7.1871 & 7.1721 & TRN \\
\hline CHEMBL 3645757 & 1527970 & 7.2596 & 7.4238 & TST \\
\hline CHEMBL 3645673 & 1527970 & 8.0 & 8.3459 & TST \\
\hline CHEMBL3645684 & 1527970 & 8.0969 & 8.1173 & TST \\
\hline CHEMBL 3645723 & 1527970 & 8.8861 & 8.5073 & TST \\
\hline CHEMBL 3645747 & 1527970 & 7.5229 & 7.5389 & TST \\
\hline CHEMBL3717532 & 1536984 & 5.4815 & 5.5935 & TRN \\
\hline CHEMBL3716598 & 1536984 & 5.3872 & 5.16 & TST \\
\hline CHEMBL 3716544 & 1536984 & 6.2596 & 6.2226 & TST \\
\hline CHEMBL3717295 & 1536984 & 6.284 & 6.3022 & TRN \\
\hline CHEMBL3715825 & 1536984 & 5.8861 & 5.8826 & TRN \\
\hline CHEMBL 3717030 & 1536984 & 6.0 & 6.0483 & TRN \\
\hline CHEMBL3718105 & 1536984 & 5.6778 & 5.6934 & TRN \\
\hline CHEMBL3718575 & 1536984 & 4.8861 & 4.90600 & 000000001 \\
\hline CHEMBL3716936 & 1536984 & 5.0655 & 5.1411 & TRN \\
\hline CHEMBL3715919 & 1536984 & 5.3565 & 5.4062 & TRN \\
\hline CHEMBL3718268 & 1536984 & 6.1192 & 6.0423 & TRN \\
\hline CHEMBL 3716048 & 1536984 & 5.2441 & 5.3194 & TRN \\
\hline CHEMBL3718368 & 1536984 & 5.5376 & 5.4102 & TST \\
\hline CHEMBL3718019 & 1536984 & 5.3979 & 5.3672 & TRN \\
\hline CHEMBL3716143 & 1536984 & 4.8539 & 5.0316 & TST \\
\hline CHEMBL 3715388 & 1536984 & 6.3098 & 6.5049 & TST \\
\hline CHEMBL 3718407 & 1536984 & 5.7447 & 5.9811 & TRN \\
\hline CHEMBL3718661 & 1536984 & 5.1487 & 5.3502 & TRN \\
\hline CHEMBL 3716274 & 1536984 & 5.2366 & 4.9311 & TRN \\
\hline
\end{tabular}

Page 27944 
Supplemental Table S2.txt

\begin{tabular}{|c|c|c|c|c|}
\hline HEMB & & 6.1487 & & \\
\hline & & 4.3279 & & \\
\hline EM $>>$ & 84 & & & \\
\hline IEMBL & & & & \\
\hline AEMBL3719067 & 536984 & 1192 & 6771 & \\
\hline HEMBL3 & 84 & 5.8239 & .6881 & \\
\hline 121 & & & $\partial 399$ & \\
\hline AEMBL3 & & & 5394 & \\
\hline HEMBL3716727 & 536984 & 5.4089 & .2905 & \\
\hline HEMBL3718783 & 536984 & 6.1427 & 1941 & \\
\hline HEMBL3 & 984 & & .311 & \\
\hline IEMBL & & & 2064 & \\
\hline HEMBL; & & & 6354 & \\
\hline HEMBL3 & 84 & 6.1079 & 6.1734 & \\
\hline HEMBL3 & & & 6197 & \\
\hline HEMBL; & 4 & & 5244 & RIV \\
\hline HEMBL & & & 9564 & RN \\
\hline HEMBL. & & & 7826 & \\
\hline HFMBI 3 & 84 & & 2366 & \\
\hline AEMBL3 & 34 & & 944 & I KIV \\
\hline HEMBL & 34 & & 768 & ГRN \\
\hline HEM & & & 998 & TIV \\
\hline HEMBL & & & 887 & $\mathrm{RN}$ \\
\hline HEMBL & & & 485 & I RIV \\
\hline AEMBL3 & & & 919 & IRN \\
\hline HEMBL & & & 643 & 「RN \\
\hline HEME & & & & וכב \\
\hline 96 & & 6. & 952 & TST \\
\hline HEMBL3 & & & 93 & is \\
\hline HEMBL3 & 34 & 76 & 794 & TST \\
\hline AEMBL & & & 437 & IST \\
\hline 9 & & & & ГST \\
\hline 412 & & & 574 & TST \\
\hline HEMBL3 & & & 223 & TST \\
\hline HEMBL3 & 84 & & 6771 & ГST \\
\hline HEMRI & & & 522 & TST \\
\hline 0 & & & 323 & TRN \\
\hline HEMBLS & & & 5.2358 & TRN \\
\hline HEMBL4 & & & 228 & TRN \\
\hline 0 & & & 542 & 「RN \\
\hline HEMBL3 & & & 889 & TRN \\
\hline HEMBL5 & & & 985 & 「RN \\
\hline HEMBL 2 & & & 1849 & TRN \\
\hline HEMBL2 & 1 & & 407 & TR \\
\hline CHEMPI 2 & & & & RN \\
\hline HEMBLI & & & 5474 & \\
\hline CHEMBL1 & 955061 & 3.6579 & 3.7276 & RN \\
\hline CHEMBL180127 & 955061 & 4.4329 & 4.3975 & IR \\
\hline
\end{tabular}

Page 27945 


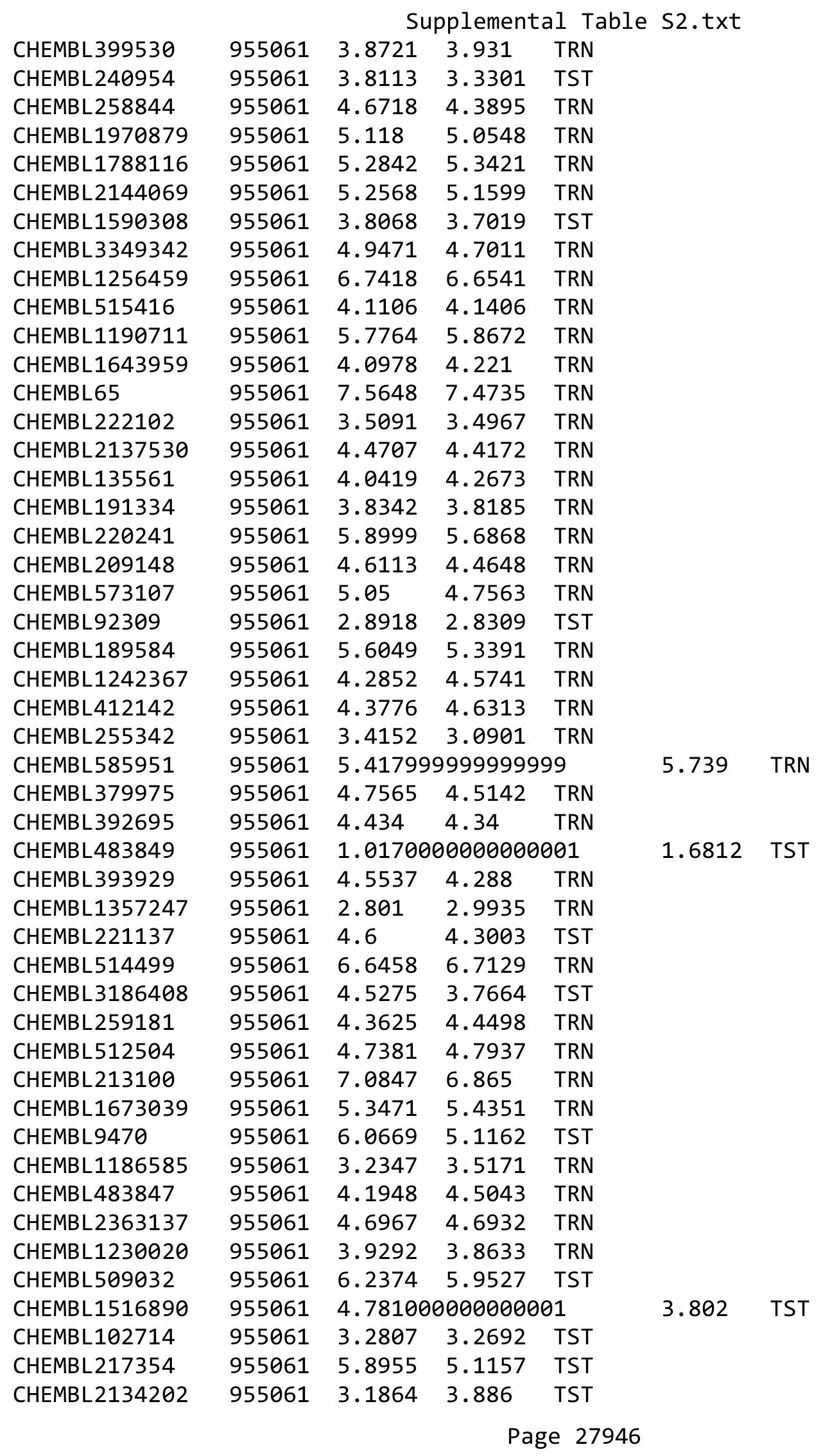


Supplemental Table S2.txt

\begin{tabular}{|c|c|c|c|c|}
\hline CHEMBL 3392440 & 955061 & 4.1268 & 3.9352 & TST \\
\hline CHEMBL210618 & 955061 & 4.4747 & 3.3932 & TST \\
\hline CHEMBL379300 & 955061 & 6.3141 & \multicolumn{2}{|c|}{5.997000000000001} \\
\hline CHEMBL449158 & 955061 & 5.9558 & 6.4667 & TST \\
\hline CHEMBL 1808450 & 759897 & 6.3372 & 6.3789 & TRN \\
\hline CHEMBL1807223 & 759897 & 7.0555 & 6.5924 & TRN \\
\hline CHEMBL1807224 & 759897 & 6.1675 & 7.2641 & TRN \\
\hline CHEMBL1808273 & 759897 & 4.6021 & 5.4534 & TST \\
\hline CHEMBL1808451 & 759897 & 6.1135 & 6.3705 & TRN \\
\hline CHEMBL1808156 & 759897 & 4.8239 & \multicolumn{2}{|c|}{5.428999999999999} \\
\hline CHEMBL1808459 & 759897 & 6.6778 & 5.8498 & TRN \\
\hline CHEMBL1807231 & 759897 & 7.8861 & 5.9404 & TRN \\
\hline CHEMBL1808448 & 759897 & 6.0555 & 6.0361 & TST \\
\hline CHEMBL1808275 & 759897 & 4.6021 & 5.4129 & TRN \\
\hline CHEMBL1808282 & 759897 & 5.9586 & 6.5664 & TRN \\
\hline CHEMBL1808446 & 759897 & 4.6021 & 6.0784 & TST \\
\hline CHEMBL1807235 & 759897 & 5.2924 & 5.8493 & TRN \\
\hline CHEMBL1808447 & 759897 & 6.3565 & 6.0542 & TST \\
\hline CHEMBL1808288 & 759897 & 5.699 & 6.0077 & TST \\
\hline CHEMBL1807221 & 759897 & 5.7447 & 6.1242 & TRN \\
\hline CHEMBL1808453 & 759897 & 6.5086 & 6.5261 & TRN \\
\hline CHEMBL1808460 & 759897 & 6.0506 & 6.0727 & TRN \\
\hline CHEMBL1808159 & 759897 & 5.3979 & 5.4008 & TRN \\
\hline CHEMBL1808461 & 759897 & 4.6021 & 5.7183 & TRN \\
\hline CHEMBL1807228 & 759897 & 7.3279 & 7.1558 & TRN \\
\hline CHEMBL1808158 & 759897 & 4.8239 & 5.3938 & TRN \\
\hline CHEMBL1808278 & 759897 & 6.0362 & 5.4923 & TRN \\
\hline CHEMBL 1807220 & 759897 & 6.6576 & 6.2604 & TRN \\
\hline CHEMBL1808280 & 759897 & 6.5528 & 6.5081 & TRN \\
\hline CHEMBL1807234 & 759897 & 5.1079 & 5.8416 & TRN \\
\hline CHEMBL1808157 & 759897 & 4.8239 & 5.2693 & TRN \\
\hline CHEMBL1807222 & 759897 & 7.9208 & 6.7728 & TRN \\
\hline CHEMBL1807225 & 759897 & 7.7212 & 7.6638 & TRN \\
\hline CHEMBL1807230 & 759897 & 6.2076 & 6.8244 & TRN \\
\hline CHEMBL1807233 & 759897 & 5.8539 & 6.0231 & TST \\
\hline CHEMBL1807227 & 759897 & 6.7959 & 7.2983 & TRN \\
\hline CHEMBL1808443 & 759897 & 4.6021 & 6.1395 & TST \\
\hline CHEMBL1807232 & 759897 & 5.4949 & 6.1391 & TST \\
\hline CHEMBL1807229 & 759897 & 7.0555 & 6.9332 & TRN \\
\hline CHEMBL1808283 & 759897 & 6.1549 & \multicolumn{2}{|c|}{5.9670000000000005} \\
\hline CHEMBL1808289 & 759897 & 4.6021 & 6.1909 & TST \\
\hline CHEMBL1808276 & 759897 & 6.6021 & 5.5745 & TRN \\
\hline CHEMBL1808457 & 759897 & 7.2076 & 6.4119 & TRN \\
\hline CHEMBL1808281 & 759897 & 6.5528 & 6.3102 & TRN \\
\hline CHEMBL1808462 & 759897 & 5.7696 & 5.7765 & TRN \\
\hline CHEMBL1808286 & 759897 & 6.0506 & 6.0746 & TRN \\
\hline CHEMBL1808454 & 759897 & 6.8861 & 6.6395 & TRN \\
\hline CHEMBL1808455 & 759897 & 6.5528 & 6.6479 & TRN \\
\hline
\end{tabular}

Page 27947 


\begin{tabular}{|c|c|c|c|c|c|c|}
\hline \multirow[b]{2}{*}{ CHEMBL1808285 } & \multicolumn{6}{|c|}{ Supplemental Table S2.txt } \\
\hline & 759897 & 6.0 & 5.7209 & TRN & & \\
\hline CHEMBL1808445 & 759897 & 4.6021 & 6.0337 & TST & & \\
\hline CHEMBL1808449 & 759897 & 5.9586 & 6.3795 & TRN & & \\
\hline CHEMBL1808452 & 759897 & 6.3188 & 6.4412 & TRN & & \\
\hline CHEMBL1807226 & 759897 & 6.8539 & 7.1169 & TRN & & \\
\hline CHEMBL1808279 & 759897 & 6.6576 & 6.4481 & TRN & & \\
\hline CHEMBL1808456 & 759897 & 7.1135 & 6.5106 & TRN & & \\
\hline CHEMBL1808277 & 759897 & 6.4202 & 5.6247 & TST & & \\
\hline CHEMBL1808274 & 759897 & 4.6021 & 5.346 & TST & & \\
\hline CHEMBL1808458 & 759897 & 7.0757 & 6.4532 & TST & & \\
\hline CHEMBL1808444 & 759897 & 4.6021 & 6.4389 & TST & & \\
\hline CHEMBL300389 & 955006 & 6.6947 & 6.6763 & TRN & & \\
\hline CHEMBL210618 & 955006 & 3.8111 & 3.8239 & TRN & & \\
\hline CHEMBL92309 & 955006 & 3.4629 & 2.7654 & TST & & \\
\hline CHEMBL 240954 & 955006 & 3.2415 & 3.2614 & TST & & \\
\hline CHEMBL 2134202 & 955006 & \multicolumn{3}{|c|}{3.0660000000000003} & 3.1595 & TRN \\
\hline CHEMBL3392440 & 955006 & 3.653 & 3.5373 & TRN & & \\
\hline CHEMBL1590308 & 955006 & 4.2709 & 2.5665 & TST & & \\
\hline CHEMBL558642 & 955006 & 2.8841 & 2.925 & TRN & & \\
\hline CHEMBL102714 & 955006 & 3.2038 & 3.2881 & TRN & & \\
\hline CHEMBL1404918 & 955006 & 3.2878 & 3.2758 & TRN & & \\
\hline CHEMBL 258844 & 955006 & 3.8785 & 3.8459 & TRN & & \\
\hline CHEMBL 2363137 & 955006 & 4.8567 & 4.8072 & TRN & & \\
\hline CHEMBL 222102 & 955006 & 3.2078 & 3.425 & TRN & & \\
\hline CHEMBL1186585 & 955006 & 3.4756 & 3.5123 & TRN & & \\
\hline CHEMBL3349342 & 955006 & 6.3219 & 6.3112 & TRN & & \\
\hline CHEMBL515416 & 955006 & 4.7008 & 4.745 & TRN & & \\
\hline CHEMBL 220241 & 955006 & 4.5198 & 4.5503 & TRN & & \\
\hline CHEMBL399530 & 955006 & 5.0733 & 5.1233 & TRN & & \\
\hline CHEMBL1256459 & 955006 & 6.9026 & 6.9546 & TRN & & \\
\hline CHEMBL1242367 & 955006 & 3.2412 & 3.1262 & TRN & & \\
\hline CHEMBL392695 & 955006 & 5.1879 & 5.1265 & TRN & & \\
\hline CHEMBL188678 & 955006 & 4.7988 & 4.4051 & TRN & & \\
\hline CHEMBL1643959 & 955006 & 2.9913 & 2.907 & TRN & & \\
\hline CHEMBL65 & 955006 & 8.4295 & 8.4082 & TRN & & \\
\hline CHEMBL 2005886 & 955006 & 4.8903 & 4.9057 & TRN & & \\
\hline CHEMBL189584 & 955006 & 3.885 & 4.0199 & TRN & & \\
\hline CHEMBL 2144069 & 955006 & 4.7843 & 4.9387 & TRN & & \\
\hline CHEMBL379975 & 955006 & 4.9739 & 4.8939 & TRN & & \\
\hline CHEMBL577784 & 955006 & 5.8223 & 5.8934 & TRN & & \\
\hline CHEMBL1909414 & 955006 & 5.4965 & 5.4313 & TRN & & \\
\hline CHEMBL1970879 & 955006 & 4.9443 & 4.9755 & TRN & & \\
\hline CHEMBL573107 & 955006 & 5.6894 & 5.7388 & TRN & & \\
\hline CHEMBL 373751 & 955006 & 3.20300 & 30000000 & 203 & 3.3928 & TRN \\
\hline CHEMBL213100 & 955006 & 4.511 & 4.3923 & TRN & & \\
\hline CHEMBL180127 & 955006 & 3.7988 & 3.8055 & TRN & & \\
\hline CHEMBL 3186408 & 955006 & 3.24600 & 00000000 & 204 & 3.7689 & TST \\
\hline CHEMBL221137 & 955006 & 4.7573 & 4.9891 & TST & & \\
\hline
\end{tabular}




\begin{tabular}{|c|c|c|c|c|}
\hline \multicolumn{5}{|c|}{ Supplemental Table S2.txt } \\
\hline CHEMBL3199475 & 955006 & 4.9486 & 4.8433 & TRN \\
\hline CHEMBL 209148 & 955006 & 4.489 & 4.5602 & TRN \\
\hline CHEMBL483849 & 955006 & 3.032 & 2.0213 & TST \\
\hline CHEMBL259181 & 955006 & 4.7093 & 4.8927 & TRN \\
\hline CHEMBL 1357247 & 955006 & 3.2708 & 3.2455 & TRN \\
\hline CHEMBL1788116 & 955006 & 4.2489 & 4.2593 & TRN \\
\hline CHEMBL1230020 & 955006 & 4.5628 & 4.5116 & TRN \\
\hline CHEMBL509032 & 955006 & 5.6845 & 5.6488 & TRN \\
\hline CHEMBL192566 & 955006 & 8.5253 & 9.1306 & TST \\
\hline CHEMBL483847 & 955006 & 4.2242 & 4.1353 & TRN \\
\hline CHEMBL255342 & 955006 & 3.4295 & 3.2376 & TRN \\
\hline CHEMBL 2137530 & 955006 & 4.8795 & 4.8853 & TRN \\
\hline CHEMBL449158 & 955006 & 6.1545 & 6.6405 & TST \\
\hline CHEMBL202721 & 955006 & 5.2224 & 5.2409 & TRN \\
\hline CHEMBL1516890 & 955006 & 4.7824 & 4.7114 & TRN \\
\hline CHEMBL1190711 & 955006 & 5.5751 & 5.5772 & TRN \\
\hline CHEMBL393929 & 955006 & 5.0636 & 5.1067 & TRN \\
\hline CHEMBL514499 & 955006 & 6.9023 & 6.8825 & TRN \\
\hline CHEMBL472940 & 955006 & 3.9046 & 4.0227 & TRN \\
\hline CHEMBL191334 & 955006 & 5.4138 & 4.5241 & TST \\
\hline CHEMBL379300 & 955006 & 6.0985 & 6.2335 & TST \\
\hline CHEMBL1673039 & 955006 & 3.7724 & 3.9977 & TST \\
\hline CHEMBL135561 & 955006 & 4.1449 & 4.6856 & TST \\
\hline CHEMBL512504 & 955006 & 7.0539 & 4.4469 & TST \\
\hline CHEMBL217354 & 955006 & 6.5675 & 7.3073 & TST \\
\hline CHEMBL 9470 & 955006 & 6.3853 & 6.2004 & TST \\
\hline CHEMBL412142 & 955006 & 6.2304 & 3.8574 & TST \\
\hline CHEMBL585951 & 955006 & 6.3217 & 6.4493 & TST \\
\hline CHEMBL1964290 & 809156 & 4.2 & 5.1932 & TRN \\
\hline CHEMBL 2003768 & 809156 & 5.7 & 5.3285 & TRN \\
\hline CHEMBL 213505 & 809156 & 6.9 & 6.7623 & TRN \\
\hline CHEMBL1982880 & 809156 & 4.2 & 4.2465 & TRN \\
\hline CHEMBL1987034 & 809156 & 7.0 & 7.2479 & TRN \\
\hline CHEMBL1993941 & 809156 & 6.5 & 6.4609 & TRN \\
\hline CHEMBL 377383 & 809156 & 4.2 & 4.376 & TRN \\
\hline CHEMBL578061 & 809156 & 4.9 & 5.0647 & TRN \\
\hline CHEMBL 2005886 & 809156 & 6.7 & 6.2342 & TRN \\
\hline CHEMBL1682345 & 809156 & 7.3 & 6.9046 & TRN \\
\hline CHEMBL1973142 & 809156 & 5.3 & 5.2014 & TRN \\
\hline CHEMBL1973145 & 809156 & 5.3 & 5.6721 & TRN \\
\hline CHEMBL1982924 & 809156 & 5.3 & 4.8894 & TRN \\
\hline CHEMBL2005936 & 809156 & 6.0 & 5.9797 & TRN \\
\hline CHEMBL1807515 & 809156 & 6.3 & 6.4786 & TRN \\
\hline CHEMBL1971141 & 809156 & 4.2 & 4.1916 & TRN \\
\hline CHEMBL1995813 & 809156 & 6.3 & 6.4827 & TRN \\
\hline CHEMBL1979718 & 809156 & 6.9 & 5.2218 & TRN \\
\hline CHEMBL206236 & 809156 & 6.0 & 5.5207 & TRN \\
\hline CHEMBL1562756 & 809156 & 4.2 & 5.1769 & TST \\
\hline
\end{tabular}




\begin{tabular}{|c|c|c|c|c|}
\hline & & & pplement & \\
\hline CHEMBL 244378 & 809156 & 6.4 & 5.8922 & TRN \\
\hline CHEMBL 2001957 & 809156 & 4.2 & 4.2044 & TRN \\
\hline CHEMBL1969372 & 809156 & 4.2 & 4.0245 & TRN \\
\hline CHEMBL1990583 & 809156 & 4.2 & 5.4629 & TRN \\
\hline CHEMBL1986943 & 809156 & 7.0 & 6.49 & TRN \\
\hline CHEMBL 2006263 & 809156 & 4.2 & 5.2186 & TST \\
\hline CHEMBL1993584 & 809156 & 6.3 & 5.5946 & TRN \\
\hline CHEMBL1986263 & 809156 & 5.5 & 5.6902 & TRN \\
\hline CHEMBL 2000114 & 809156 & 6.1 & 5.4349 & TRN \\
\hline CHEMBL 210618 & 809156 & 5.5 & 4.1914 & TRN \\
\hline CHEMBL1975647 & 809156 & 4.2 & 4.4486 & TRN \\
\hline CHEMBL1968380 & 809156 & 4.2 & 4.0785 & TRN \\
\hline CHEMBL1964644 & 809156 & 4.2 & 4.4827 & TRN \\
\hline CHEMBL1981782 & 809156 & 7.8 & 7.0523 & TRN \\
\hline CHEMBL1977681 & 809156 & 4.2 & 5.0323 & TRN \\
\hline CHEMBL1970142 & 809156 & 7.5 & 7.0655 & TRN \\
\hline CHEMBL1990912 & 809156 & 4.2 & 4.6271 & TRN \\
\hline CHEMBL1988163 & 809156 & 6.3 & 5.9667 & TRN \\
\hline CHEMBL1995592 & 809156 & 5.9 & 5.597 & TST \\
\hline CHEMBL 2006493 & 809156 & 4.2 & 4.654 & TST \\
\hline CHEMBL1982541 & 809156 & 6.3 & 4.9591 & TRN \\
\hline CHEMBL1996923 & 809156 & 4.2 & 4.9378 & TST \\
\hline CHEMBL1983449 & 809156 & 6.7 & 5.9986 & TRN \\
\hline CHEMBL1992323 & 809156 & 4.2 & 4.6014 & TRN \\
\hline CHEMBL1969735 & 809156 & 4.2 & 4.13 & TRN \\
\hline CHEMBL 2003524 & 809156 & 6.2 & 4.6815 & TST \\
\hline CHEMBL 2002649 & 809156 & 5.3 & 6.6419 & TRN \\
\hline CHEMBL437747 & 809156 & 4.2 & 4.8901 & TRN \\
\hline CHEMBL1995172 & 809156 & 4.2 & 4.8318 & TST \\
\hline CHEMBL507936 & 809156 & 5.2 & 4.8379 & TRN \\
\hline CHEMBL104264 & 809156 & 7.8 & 6.3266 & TRN \\
\hline CHEMBL1994321 & 809156 & 7.7 & 7.8402 & TRN \\
\hline CHEMBL1997129 & 809156 & 6.1 & 5.8565 & TRN \\
\hline CHEMBL1964307 & 809156 & 6.3 & 6.441 & TRN \\
\hline CHEMBL 2000508 & 809156 & 4.2 & 4.2251 & TRN \\
\hline CHEMBL1971694 & 809156 & 4.2 & 4.9404 & TST \\
\hline CHEMBL 2001547 & 809156 & 4.2 & 4.15 & TRN \\
\hline CHEMBL 210928 & 809156 & 4.2 & 4.2018 & TRN \\
\hline CHEMBL1986603 & 809156 & 4.2 & 4.6568 & TST \\
\hline CHEMBL1972840 & 809156 & 6.7 & 7.1781 & TRN \\
\hline CHEMBL1977148 & 809156 & 4.2 & 5.5411 & TRN \\
\hline CHEMBL 2003286 & 809156 & 5.2 & 5.5018 & TRN \\
\hline CHEMBL1992306 & 809156 & 5.4 & 5.5771 & TRN \\
\hline CHEMBL 2002165 & 809156 & 6.7 & 6.8627 & TRN \\
\hline CHEMBL 2001668 & 809156 & 5.5 & 4.521 & TST \\
\hline CHEMBL1979318 & 809156 & 4.2 & 4.8307 & TRN \\
\hline CHEMBL 206382 & 809156 & 4.2 & 5.3601 & TRN \\
\hline CHEMBL1998585 & 809156 & 7.6 & 8.2283 & TRN \\
\hline
\end{tabular}




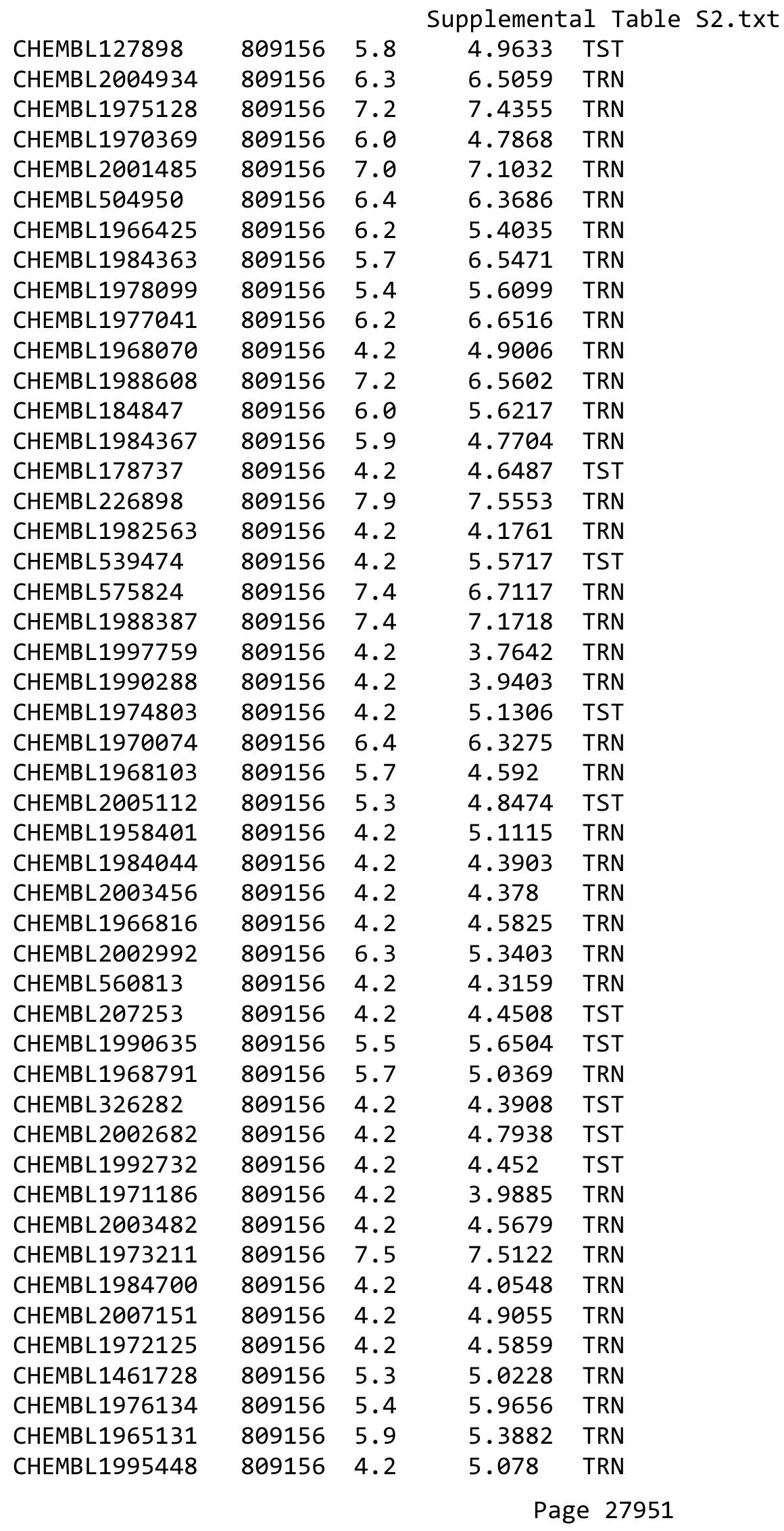




\begin{tabular}{|c|c|c|c|c|}
\hline & & & pplement & al $\mathrm{Ta}$ \\
\hline CHEMBL1972158 & 809156 & 6.6 & 6.8434 & TRN \\
\hline CHEMBL1974457 & 809156 & 4.2 & 4.2812 & TRN \\
\hline CHEMBL2006580 & 809156 & 4.2 & 4.6716 & TRN \\
\hline CHEMBL 2006581 & 809156 & 4.2 & 4.3193 & TRN \\
\hline CHEMBL2006481 & 809156 & 4.2 & 4.9274 & TRN \\
\hline CHEMBL1979855 & 809156 & 6.8 & 4.6742 & TRN \\
\hline CHEMBL1970340 & 809156 & 6.9 & 5.8053 & TRN \\
\hline CHEMBL2005186 & 809156 & 4.2 & 4.9718 & TRN \\
\hline CHEMBL1995927 & 809156 & 4.2 & 4.6595 & TST \\
\hline CHEMBL1975534 & 809156 & 6.1 & 5.5861 & TRN \\
\hline CHEMBL1993424 & 809156 & 4.2 & 5.5209 & TRN \\
\hline CHEMBL1966703 & 809156 & 4.2 & 4.6269 & TST \\
\hline CHEMBL1969561 & 809156 & 6.7 & 6.7527 & TRN \\
\hline CHEMBL1997023 & 809156 & 4.2 & 4.816 & TST \\
\hline CHEMBL1964687 & 809156 & 7.3 & 7.3194 & TRN \\
\hline CHEMBL1971943 & 809156 & 7.1 & 6.0256 & TRN \\
\hline CHEMBL1999918 & 809156 & 6.8 & 5.9316 & TRN \\
\hline CHEMBL1974254 & 809156 & 6.6 & 6.3465 & TRN \\
\hline CHEMBL1988537 & 809156 & 6.1 & 5.7036 & TST \\
\hline CHEMBL1969049 & 809156 & 5.6 & 6.3927 & TRN \\
\hline CHEMBL 2005828 & 809156 & 5.9 & 5.8744 & TRN \\
\hline CHEMBL 2002240 & 809156 & 4.2 & 4.1275 & TRN \\
\hline CHEMBL1991143 & 809156 & 4.2 & 4.7219 & TST \\
\hline CHEMBL1998611 & 809156 & 5.7 & 5.5555 & TRN \\
\hline CHEMBL485556 & 809156 & 4.2 & 4.4036 & TST \\
\hline CHEMBL1975900 & 809156 & 7.2 & 6.7058 & TRN \\
\hline CHEMBL 255822 & 809156 & 5.4 & 5.642 & TRN \\
\hline CHEMBL1972221 & 809156 & 5.2 & 4.2427 & TRN \\
\hline CHEMBL 2006778 & 809156 & 6.3 & 6.4675 & TRN \\
\hline CHEMBL378627 & 809156 & 4.2 & 4.3119 & TRN \\
\hline CHEMBL1996979 & 809156 & 4.2 & 4.6856 & TRN \\
\hline CHEMBL1997025 & 809156 & 4.2 & 4.4197 & TRN \\
\hline CHEMBL1968406 & 809156 & 7.8 & 7.5922 & TRN \\
\hline CHEMBL1982476 & 809156 & 7.2 & 7.2619 & TRN \\
\hline CHEMBL1984274 & 809156 & 4.2 & 4.9926 & TST \\
\hline CHEMBL1998545 & 809156 & 4.2 & 5.3811 & TRN \\
\hline CHEMBL1986869 & 809156 & 4.2 & 4.9175 & TRN \\
\hline CHEMBL 2006010 & 809156 & 5.2 & 4.5019 & TRN \\
\hline CHEMBL1682558 & 809156 & 4.2 & 4.7088 & TRN \\
\hline CHEMBL1990496 & 809156 & 4.3 & 4.3622 & TRN \\
\hline CHEMBL1997623 & 809156 & 4.2 & 5.8958 & TRN \\
\hline CHEMBL 2002479 & 809156 & 5.8 & 5.8681 & TRN \\
\hline CHEMBL1993166 & 809156 & 6.3 & 6.1836 & TRN \\
\hline CHEMBL1967094 & 809156 & 5.9 & 5.2083 & TRN \\
\hline CHEMBL1966035 & 809156 & 4.2 & 4.8025 & TRN \\
\hline CHEMBL 2003341 & 809156 & 6.0 & 5.8025 & TRN \\
\hline CHEMBL1992644 & 809156 & 5.6 & 4.8659 & TRN \\
\hline CHEMBL1992645 & 809156 & 4.2 & 4.462 & TST \\
\hline
\end{tabular}




\begin{tabular}{|c|c|c|c|c|}
\hline \multicolumn{5}{|c|}{ Supplemental Table S2.txt } \\
\hline CHEMBL1982992 & 809156 & 4.2 & 4.5541 & TRN \\
\hline CHEMBL1999590 & 809156 & 4.2 & 4.3196 & TST \\
\hline CHEMBL1981079 & 809156 & 4.2 & 5.2862 & TRN \\
\hline CHEMBL1972276 & 809156 & 4.2 & 4.8551 & TRN \\
\hline CHEMBL1980489 & 809156 & 6.5 & 5.9446 & TRN \\
\hline CHEMBL1967116 & 809156 & 8.0 & 7.105 & TRN \\
\hline CHEMBL 2000832 & 809156 & 5.6 & 4.6942 & TRN \\
\hline CHEMBL1977814 & 809156 & 4.2 & 4.6587 & TST \\
\hline CHEMBL513846 & 809156 & 5.7 & 4.5763 & TRN \\
\hline CHEMBL1970709 & 809156 & 7.3 & 6.2533 & TRN \\
\hline CHEMBL1965660 & 809156 & 4.2 & 5.5982 & TRN \\
\hline CHEMBL1998112 & 809156 & 4.2 & 3.9665 & TRN \\
\hline CHEMBL1969126 & 809156 & 4.2 & 4.3029 & TRN \\
\hline CHEMBL1980896 & 809156 & 4.2 & 4.9276 & TRN \\
\hline CHEMBL1975208 & 809156 & 4.2 & 4.39 & TRN \\
\hline CHEMBL1970104 & 809156 & 6.3 & 6.5198 & TRN \\
\hline CHEMBL1991429 & 809156 & 4.2 & 3.9927 & TRN \\
\hline CHEMBL1964777 & 809156 & 4.2 & 4.9993 & TRN \\
\hline CHEMBL1971149 & 809156 & 4.2 & 4.2042 & TRN \\
\hline CHEMBL1999714 & 809156 & 4.2 & 4.654 & TRN \\
\hline CHEMBL1987533 & 809156 & 4.2 & 4.5743 & TRN \\
\hline CHEMBL1994040 & 809156 & 4.2 & 4.0373 & TRN \\
\hline CHEMBL 388978 & 809156 & 8.3 & 8.6655 & TST \\
\hline CHEMBL398951 & 809156 & 4.2 & 5.0836 & TST \\
\hline CHEMBL1982506 & 809156 & 6.3 & 4.6338 & TST \\
\hline CHEMBL2004716 & 809156 & 7.6 & 7.4334 & TRN \\
\hline CHEMBL1968127 & 809156 & 4.2 & 4.1813 & TRN \\
\hline CHEMBL1975233 & 809156 & 4.3 & 4.4779 & TRN \\
\hline CHEMBL1985406 & 809156 & 4.2 & 4.4792 & TRN \\
\hline CHEMBL 207400 & 809156 & 4.2 & 4.631 & TST \\
\hline CHEMBL2000894 & 809156 & 5.7 & 5.4088 & TST \\
\hline CHEMBL1982135 & 809156 & 4.2 & 5.1142 & TRN \\
\hline CHEMBL1976090 & 809156 & 6.3 & 6.7204 & TRN \\
\hline CHEMBL1993243 & 809156 & 7.1 & 5.9675 & TRN \\
\hline CHEMBL1992922 & 809156 & 6.2 & 5.6828 & TRN \\
\hline CHEMBL2004771 & 809156 & 5.2 & 5.0119 & TRN \\
\hline CHEMBL399021 & 809156 & 6.6 & 4.9606 & TRN \\
\hline CHEMBL1997597 & 809156 & 5.5 & 4.9853 & TRN \\
\hline CHEMBL1969537 & 809156 & 6.4 & 5.7422 & TST \\
\hline CHEMBL1976093 & 809156 & 4.2 & 4.1378 & TRN \\
\hline CHEMBL210032 & 809156 & 4.2 & 3.7498 & TRN \\
\hline CHEMBL1996543 & 809156 & 5.3 & 5.6055 & TRN \\
\hline CHEMBL508928 & 809156 & 6.0 & 5.8395 & TRN \\
\hline CHEMBL1991356 & 809156 & 4.2 & 4.5183 & TST \\
\hline CHEMBL1983309 & 809156 & 4.2 & 4.3994 & TRN \\
\hline CHEMBL 2004892 & 809156 & 4.2 & 4.9297 & TRN \\
\hline CHEMBL1999126 & 809156 & 4.2 & 4.7832 & TST \\
\hline CHEMBL1997503 & 809156 & 4.2 & 4.2198 & TST \\
\hline
\end{tabular}




\begin{tabular}{|c|c|c|c|c|c|}
\hline \\
\hline CHEMBL116070 & 809156 & 4.2 & 4.8839 & TRN & \\
\hline CHEMBL1990821 & 809156 & 4.2 & 4.9368 & TST & \\
\hline CHEMBL1970314 & 809156 & 4.2 & 4.3496 & TRN & \\
\hline CHEMBL2004872 & 809156 & 5.4 & 5.7373 & TRN & \\
\hline CHEMBL1727312 & 809156 & 4.2 & 4.2766 & TRN & \\
\hline CHEMBL1969879 & 809156 & 4.2 & 4.4403 & TRN & \\
\hline CHEMBL1981720 & 809156 & 5.4 & 4.3649 & TRN & \\
\hline CHEMBL419932 & 809156 & 6.0 & 6.2164 & TRN & \\
\hline CHEMBL262433 & 809156 & 6.0 & 6.6516 & TRN & \\
\hline CHEMBL306380 & 809156 & 6.3 & 7.0685 & TRN & \\
\hline CHEMBL1966722 & 809156 & 5.8 & 4.9249 & TST & \\
\hline CHEMBL1976328 & 809156 & 7.0 & 6.215 & TRN & \\
\hline CHEMBL1975500 & 809156 & 4.2 & 4.2092 & TRN & \\
\hline CHEMBL394619 & 809156 & 6.8 & 6.78299 & 99999999995 & TRN \\
\hline CHEMBL1964399 & 809156 & 5.5 & 5.82299 & 99999999995 & TRN \\
\hline CHEMBL1996831 & 809156 & 4.2 & 4.292 & TST & \\
\hline CHEMBL1965988 & 809156 & 7.7 & 7.7137 & TRN & \\
\hline CHEMBL418203 & 809156 & 4.2 & 4.8041 & TST & \\
\hline CHEMBL1989646 & 809156 & 6.1 & 6.7563 & TRN & \\
\hline CHEMBL1682357 & 809156 & 7.3 & 6.4057 & TRN & \\
\hline CHEMBL225519 & 809156 & 5.7 & 5.784 & TRN & \\
\hline CHEMBL209534 & 809156 & 4.2 & 4.2142 & TRN & \\
\hline CHEMBL1978200 & 809156 & 4.2 & 4.2511 & TRN & \\
\hline CHEMBL1970522 & 809156 & 5.7 & 5.0067 & TRN & \\
\hline CHEMBL1990415 & 809156 & 4.2 & 4.2385 & TRN & \\
\hline CHEMBL1966087 & 809156 & 5.3 & 5.365 & TRN & \\
\hline CHEMBL1964692 & 809156 & 7.9 & 7.0494 & TRN & \\
\hline CHEMBL1996931 & 809156 & 5.8 & 5.4203 & TRN & \\
\hline CHEMBL1964413 & 809156 & 8.4 & 6.2322 & TRN & \\
\hline CHEMBL1973483 & 809156 & 4.2 & 4.4715 & TRN & \\
\hline CHEMBL1984432 & 809156 & 7.8 & 6.5372 & TRN & \\
\hline CHEMBL1970735 & 809156 & 4.2 & 3.8441 & TRN & \\
\hline CHEMBL219722 & 809156 & 5.5 & 6.2596 & TRN & \\
\hline CHEMBL1997340 & 809156 & 5.3 & 4.9159 & TRN & \\
\hline CHEMBL 2004365 & 809156 & 4.2 & 4.9861 & TST & \\
\hline CHEMBL1522508 & 809156 & 4.2 & 3.9849 & TRN & \\
\hline CHEMBL1989474 & 809156 & 4.2 & 4.5509 & TRN & \\
\hline CHEMBL1090360 & 809156 & 4.2 & 3.5906 & TRN & \\
\hline CHEMBL210887 & 809156 & 4.2 & 4.2727 & TST & \\
\hline CHEMBL458997 & 809156 & 5.4 & 5.6031 & TRN & \\
\hline CHEMBL227271 & 809156 & 8.1 & 7.6637 & TRN & \\
\hline CHEMBL1971021 & 809156 & 6.0 & 6.1652 & TRN & \\
\hline CHEMBL583144 & 809156 & 6.1 & 5.3319 & TRN & \\
\hline CHEMBL1974310 & 809156 & 4.2 & 5.1446 & TRN & \\
\hline CHEMBL1982660 & 809156 & 4.2 & 5.2099 & TRN & \\
\hline CHEMBL1994693 & 809156 & 5.4 & 6.0838 & TRN & \\
\hline CHEMBL1982957 & 809156 & 5.9 & 5.9585 & TRN & \\
\hline CHEMBL1725279 & 809156 & 6.9 & 6.4746 & TST & \\
\hline & & & & 27954 & \\
\hline
\end{tabular}




\begin{tabular}{|c|c|c|c|c|c|}
\hline \\
\hline CHEMBL1975138 & 809156 & 4.2 & 4.7603 & TST & \\
\hline CHEMBL424872 & 809156 & 4.2 & 4.4537 & TRN & \\
\hline CHEMBL 2006836 & 809156 & 4.3 & 4.6012 & TST & \\
\hline CHEMBL1971947 & 809156 & 6.8 & 7.1054 & TRN & \\
\hline CHEMBL412142 & 809156 & 5.5 & 4.6005 & TST & \\
\hline CHEMBL1980704 & 809156 & 6.3 & 5.0996 & TST & \\
\hline CHEMBL 2003271 & 809156 & 5.9 & 5.2525 & TRN & \\
\hline CHEMBL1966808 & 809156 & 4.2 & 5.0362 & TST & \\
\hline CHEMBL 2004447 & 809156 & 4.2 & 4.9245 & TRN & \\
\hline CHEMBL1983111 & 809156 & 6.9 & 7.1953 & TST & \\
\hline CHEMBL1973860 & 809156 & 4.2 & 4.7377 & TRN & \\
\hline CHEMBL260135 & 809156 & 4.2 & 5.1467 & TRN & \\
\hline CHEMBL220241 & 809156 & 8.5 & 6.1587 & TRN & \\
\hline CHEMBL 2004544 & 809156 & 4.2 & 5.046 & TST & \\
\hline CHEMBL1982610 & 809156 & 4.2 & 4.7654 & TST & \\
\hline CHEMBL1989569 & 809156 & 5.6 & 4.671 & TRN & \\
\hline CHEMBL1986996 & 809156 & 5.2 & 5.4112 & TST & \\
\hline CHEMBL1999496 & 809156 & 4.2 & 4.5922 & TRN & \\
\hline CHEMBL 2006933 & 809156 & 6.5 & 6.3014 & TST & \\
\hline CHEMBL1988300 & 809156 & 5.5 & 5.70200 & 0000000001 & TRN \\
\hline CHEMBL1991078 & 809156 & 7.0 & 6.416 & TRN & \\
\hline CHEMBL1987359 & 809156 & 5.4 & 4.7815 & TST & \\
\hline CHEMBL 2000685 & 809156 & 7.0 & 6.6462 & TRN & \\
\hline CHEMBL1985311 & 809156 & 5.4 & 6.3389 & TRN & \\
\hline CHEMBL1989265 & 809156 & 4.2 & 4.739 & TRN & \\
\hline CHEMBL1969502 & 809156 & 7.5 & 6.5485 & TRN & \\
\hline CHEMBL1965910 & 809156 & 5.5 & 4.8758 & TRN & \\
\hline CHEMBL1682553 & 809156 & 6.5 & 6.3467 & TRN & \\
\hline CHEMBL1971430 & 809156 & 4.2 & 4.488 & TRN & \\
\hline CHEMBL1997764 & 809156 & 4.2 & 4.4427 & TRN & \\
\hline CHEMBL1983963 & 809156 & 6.8 & 6.7493 & TRN & \\
\hline CHEMBL 2000271 & 809156 & 6.5 & 6.2673 & TRN & \\
\hline CHEMBL1985092 & 809156 & 6.6 & 6.1483 & TST & \\
\hline CHEMBL 2004692 & 809156 & 5.2 & 4.9314 & TST & \\
\hline CHEMBL1996234 & 809156 & 4.2 & 4.8904 & TRN & \\
\hline CHEMBL1991434 & 809156 & 4.2 & 4.8276 & TST & \\
\hline CHEMBL1967544 & 809156 & 6.5 & 6.1889 & TRN & \\
\hline CHEMBL 223367 & 809156 & 6.7 & 5.7014 & TST & \\
\hline CHEMBL340384 & 809156 & 6.2 & 6.164 & TST & \\
\hline CHEMBL1996587 & 809156 & 4.2 & 4.1783 & TRN & \\
\hline CHEMBL1964804 & 809156 & 5.9 & 5.4557 & TRN & \\
\hline CHEMBL443962 & 809156 & 4.2 & 4.6917 & TST & \\
\hline CHEMBL 2000354 & 809156 & 5.5 & 5.1698 & TRN & \\
\hline CHEMBL1965507 & 809156 & 4.2 & 5.2714 & TRN & \\
\hline CHEMBL274064 & 809156 & 4.2 & 4.4818 & TRN & \\
\hline CHEMBL1967564 & 809156 & 4.2 & 4.1849 & TRN & \\
\hline CHEMBL 2000071 & 809156 & 6.1 & 5.4725 & TRN & \\
\hline CHEMBL1979176 & 809156 & 4.2 & 4.5462 & TRN & \\
\hline
\end{tabular}




\begin{tabular}{|c|c|c|c|c|}
\hline \multicolumn{5}{|c|}{ Supplemental Table S2.txt } \\
\hline CHEMBL1970317 & 809156 & 7.0 & 6.5041 & TRN \\
\hline CHEMBL 2000408 & 809156 & 4.2 & 4.2105 & TRN \\
\hline CHEMBL248757 & 809156 & 4.2 & 5.2429 & TST \\
\hline CHEMBL1978014 & 809156 & 4.2 & 4.6527 & TRN \\
\hline CHEMBL1994538 & 809156 & 4.2 & 4.3064 & TRN \\
\hline CHEMBL1983195 & 809156 & 4.2 & 4.5122 & TST \\
\hline CHEMBL1975490 & 809156 & 5.7 & 5.6375 & TRN \\
\hline CHEMBL1964444 & 809156 & 4.2 & 4.6588 & TRN \\
\hline CHEMBL 2006567 & 809156 & 4.2 & 4.1031 & TRN \\
\hline CHEMBL1986139 & 809156 & 4.2 & 4.3785 & TRN \\
\hline CHEMBL1980540 & 809156 & 4.2 & 4.1266 & TRN \\
\hline CHEMBL1979883 & 809156 & 7.4 & 7.7343 & TRN \\
\hline CHEMBL491758 & 809156 & 8.6 & 5.2611 & TRN \\
\hline CHEMBL549730 & 809156 & 4.2 & 5.2505 & TRN \\
\hline CHEMBL1970189 & 809156 & 4.2 & 4.788 & TRN \\
\hline CHEMBL1996791 & 809156 & 6.1 & 5.7256 & TRN \\
\hline CHEMBL371206 & 809156 & 7.1 & 7.3778 & TRN \\
\hline CHEMBL1974664 & 809156 & 4.2 & 5.5558 & TST \\
\hline CHEMBL1974288 & 809156 & 5.2 & 6.2191 & TRN \\
\hline CHEMBL196363 & 809156 & 7.7 & 7.4539 & TRN \\
\hline CHEMBL1190711 & 809156 & 4.2 & 4.2219 & TRN \\
\hline CHEMBL1990346 & 809156 & 6.6 & 6.2589 & TRN \\
\hline CHEMBL1968705 & 809156 & 4.2 & 5.3273 & TRN \\
\hline CHEMBL404367 & 809156 & 6.4 & 6.316 & TRN \\
\hline CHEMBL1966343 & 809156 & 5.7 & 6.1625 & TRN \\
\hline CHEMBL1967887 & 809156 & 4.2 & 6.0773 & TRN \\
\hline CHEMBL 2000568 & 809156 & 4.2 & 4.4706 & TRN \\
\hline CHEMBL 2000335 & 809156 & 7.9 & 7.9847 & TRN \\
\hline CHEMBL1977604 & 809156 & 4.2 & 4.6249 & TRN \\
\hline CHEMBL1974328 & 809156 & 6.9 & 5.8333 & TRN \\
\hline CHEMBL509032 & 809156 & 6.0 & 6.5884 & TRN \\
\hline CHEMBL1973808 & 809156 & 5.4 & 5.0411 & TRN \\
\hline CHEMBL 2000429 & 809156 & 4.2 & 4.0262 & TRN \\
\hline CHEMBL1992555 & 809156 & 4.2 & 5.2839 & TST \\
\hline CHEMBL1992342 & 809156 & 5.7 & 5.1623 & TRN \\
\hline CHEMBL1988173 & 809156 & 4.2 & 5.3659 & TST \\
\hline CHEMBL535331 & 809156 & 4.2 & 4.6141 & TRN \\
\hline CHEMBL1989805 & 809156 & 4.2 & 4.897 & TST \\
\hline CHEMBL1965423 & 809156 & 4.2 & 4.0284 & TRN \\
\hline CHEMBL1982980 & 809156 & 4.2 & 4.3945 & TST \\
\hline CHEMBL1983025 & 809156 & 7.4 & 7.7065 & TRN \\
\hline CHEMBL205415 & 809156 & 6.2 & 6.7365 & TRN \\
\hline CHEMBL1977135 & 809156 & 5.6 & 5.5819 & TRN \\
\hline CHEMBL 2001920 & 809156 & 5.2 & 5.4599 & TRN \\
\hline CHEMBL 2002322 & 809156 & 4.2 & 4.5892 & TRN \\
\hline CHEMBL1241473 & 809156 & 6.8 & 6.7983 & TRN \\
\hline CHEMBL 2002323 & 809156 & 4.2 & 4.7463 & TRN \\
\hline CHEMBL1978448 & 809156 & 4.2 & 5.1425 & TST \\
\hline
\end{tabular}




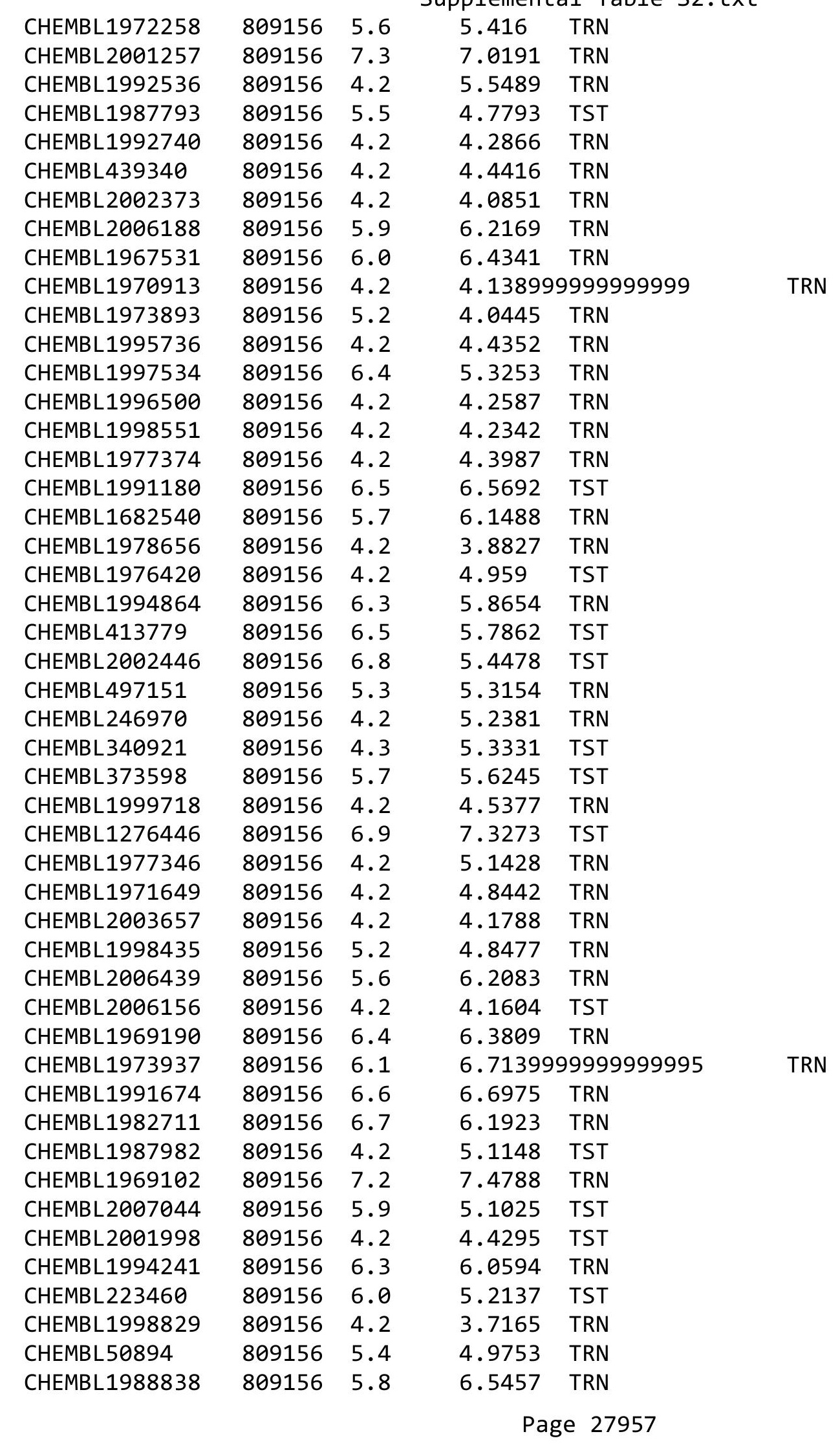




\begin{tabular}{|c|c|c|c|c|c|}
\hline \\
\hline CHEMBL1981725 & 809156 & 4.2 & 4.5836 & TRN & \\
\hline CHEMBL375284 & 809156 & 6.3 & 5.5347 & TRN & \\
\hline CHEMBL1982866 & 809156 & 4.2 & 4.5196 & TRN & \\
\hline CHEMBL1968926 & 809156 & 4.2 & 4.67399 & 99999999995 & TRN \\
\hline CHEMBL462120 & 809156 & 5.3 & 4.7649 & TST & \\
\hline CHEMBL1984206 & 809156 & 4.2 & 4.3566 & TRN & \\
\hline CHEMBL1991577 & 809156 & 4.2 & 4.7504 & TRN & \\
\hline CHEMBL1965570 & 809156 & 5.9 & 6.1687 & TRN & \\
\hline CHEMBL 2007592 & 809156 & 4.2 & 4.3687 & TST & \\
\hline CHEMBL 210963 & 809156 & 4.2 & 4.0216 & TRN & \\
\hline CHEMBL1082440 & 809156 & 4.2 & 5.9447 & TST & \\
\hline CHEMBL1614705 & 809156 & 4.2 & 4.5144 & TRN & \\
\hline CHEMBL1984633 & 809156 & 5.9 & 6.1607 & TRN & \\
\hline CHEMBL 2007372 & 809156 & 4.2 & 4.1921 & TRN & \\
\hline CHEMBL1965845 & 809156 & 7.4 & 7.0683 & TRN & \\
\hline CHEMBL1982167 & 809156 & 4.2 & 3.8397 & TRN & \\
\hline CHEMBL 2006715 & 809156 & 4.2 & 3.8668 & TRN & \\
\hline CHEMBL1986597 & 809156 & 5.3 & 4.7571 & TRN & \\
\hline CHEMBL1971017 & 809156 & 5.6 & 5.6839 & TRN & \\
\hline CHEMBL1990482 & 809156 & 5.5 & 4.9742 & TRN & \\
\hline CHEMBL1990904 & 809156 & 4.2 & 3.958 & TRN & \\
\hline CHEMBL 2005475 & 809156 & 4.2 & 4.8863 & TRN & \\
\hline CHEMBL 2000104 & 809156 & 4.2 & 4.5639 & TRN & \\
\hline CHEMBL402846 & 809156 & 6.3 & 6.3249 & TRN & \\
\hline CHEMBL1997349 & 809156 & 4.2 & 5.0724 & TST & \\
\hline CHEMBL183844 & 809156 & 4.2 & 5.3092 & TRN & \\
\hline CHEMBL220057 & 809156 & 6.3 & 6.671 & TRN & \\
\hline CHEMBL1682545 & 809156 & 6.3 & 5.2248 & TRN & \\
\hline CHEMBL383541 & 809156 & 6.2 & 6.4198 & TRN & \\
\hline CHEMBL 2001224 & 809156 & 4.2 & 4.7102 & TRN & \\
\hline CHEMBL10 & 809156 & 4.2 & 4.6619 & TRN & \\
\hline CHEMBL1976732 & 809156 & 4.2 & 4.5056 & TRN & \\
\hline CHEMBL1969506 & 809156 & 4.2 & 4.7844 & TRN & \\
\hline CHEMBL1964937 & 809156 & 6.5 & 6.5699 & TRN & \\
\hline CHEMBL1980163 & 809156 & 4.2 & 4.1924 & TRN & \\
\hline CHEMBL590109 & 809156 & 4.2 & 7.1966 & TST & \\
\hline CHEMBL1970879 & 809156 & 4.2 & 4.8108 & TRN & \\
\hline CHEMBL1989856 & 809156 & 5.9 & 4.8753 & TST & \\
\hline CHEMBL 2005899 & 809156 & 4.2 & 5.5192 & TRN & \\
\hline CHEMBL1682552 & 809156 & 6.3 & 5.8829 & TRN & \\
\hline CHEMBL259850 & 809156 & 5.3 & 4.4287 & TRN & \\
\hline CHEMBL1996155 & 809156 & 5.5 & 5.0994 & TRN & \\
\hline CHEMBL229799 & 809156 & 7.1 & 7.3831 & TRN & \\
\hline CHEMBL105739 & 809156 & 6.9 & 6.0195 & TRN & \\
\hline CHEMBL203673 & 809156 & 5.6 & 5.6535 & TRN & \\
\hline CHEMBL1969523 & 809156 & 4.2 & 6.1018 & TRN & \\
\hline CHEMBL207995 & 809156 & 4.2 & 4.4884 & TRN & \\
\hline CHEMBL1988995 & 809156 & 4.2 & 4.3019 & TRN & \\
\hline
\end{tabular}




\begin{tabular}{|c|c|c|c|c|c|}
\hline & & \multicolumn{4}{|c|}{ Supplemental Table S2.txt } \\
\hline CHEMBL2001923 & 809156 & 4.2 & 4.5533 & TRN & \\
\hline CHEMBL1986781 & 809156 & 4.2 & 3.6302 & TRN & \\
\hline CHEMBL526133 & 809156 & 5.7 & 6.2593 & TRN & \\
\hline CHEMBL1981045 & 809156 & 4.2 & 4.1279 & TRN & \\
\hline CHEMBL387971 & 809156 & 4.4 & 4.8412 & TST & \\
\hline CHEMBL1979057 & 809156 & 4.2 & 5.5039 & TRN & \\
\hline CHEMBL1992796 & 809156 & 4.2 & 4.8712 & TST & \\
\hline CHEMBL1999428 & 809156 & 5.9 & 5.8044 & TRN & \\
\hline CHEMBL223257 & 809156 & 5.3 & 5.4646 & TST & \\
\hline CHEMBL1967560 & 809156 & 4.2 & 4.0824 & TRN & \\
\hline CHEMBL211378 & 809156 & 5.8 & 5.434 & TRN & \\
\hline CHEMBL1516890 & 809156 & 5.6 & 5.6596 & TRN & \\
\hline CHEMBL1982465 & 809156 & 7.2 & 7.1079 & TRN & \\
\hline CHEMBL 2003420 & 809156 & 4.2 & 4.7067 & TRN & \\
\hline CHEMBL1984586 & 809156 & 4.2 & 4.9355 & TRN & \\
\hline CHEMBL1999774 & 809156 & 4.2 & 4.4209 & TRN & \\
\hline CHEMBL1972659 & 809156 & 5.7 & 4.6525 & TST & \\
\hline CHEMBL1973395 & 809156 & 6.4 & 5.522 & TRN & \\
\hline CHEMBL272453 & 809156 & 8.1 & 6.7775 & TRN & \\
\hline CHEMBL1970217 & 809156 & 6.4 & 6.5204 & TRN & \\
\hline CHEMBL1971801 & 809156 & 4.2 & 4.5786 & TRN & \\
\hline CHEMBL1968850 & 809156 & 4.2 & 4.8441 & TRN & \\
\hline CHEMBL 2005528 & 809156 & 5.8 & 4.9538 & TST & \\
\hline CHEMBL185569 & 809156 & 5.8 & 5.3759 & TRN & \\
\hline CHEMBL1969843 & 809156 & 5.5 & 5.7764 & TRN & \\
\hline CHEMBL 2007002 & 809156 & 4.2 & 4.0613 & TRN & \\
\hline CHEMBL1987007 & 809156 & 4.2 & 4.3674 & TRN & \\
\hline CHEMBL1969588 & 809156 & 7.1 & 6.7932 & TRN & \\
\hline CHEMBL1984711 & 809156 & 4.2 & 4.3274 & TRN & \\
\hline CHEMBL1990212 & 809156 & 4.2 & 3.9212 & TRN & \\
\hline CHEMBL1979252 & 809156 & 7.3 & 6.7036 & TRN & \\
\hline CHEMBL 2004290 & 809156 & 7.2 & 6.1979 & TRN & \\
\hline CHEMBL1986499 & 809156 & 6.4 & 6.5139 & 9999999999 & TRN \\
\hline CHEMBL1972937 & 809156 & 4.2 & 4.7499 & TRN & \\
\hline CHEMBL1972250 & 809156 & 5.5 & 4.896 & TST & \\
\hline CHEMBL2000393 & 809156 & 5.7 & 5.6142 & TST & \\
\hline CHEMBL 2004072 & 809156 & 5.3 & 4.4361 & TRN & \\
\hline CHEMBL2004311 & 809156 & 6.5 & 6.3167 & TRN & \\
\hline CHEMBL1992634 & 809156 & 4.2 & 4.3821 & TRN & \\
\hline CHEMBL1242373 & 809156 & 7.4 & 7.5284 & TRN & \\
\hline CHEMBL56543 & 809156 & 4.2 & 5.2374 & TRN & \\
\hline CHEMBL316264 & 809156 & 4.2 & 4.5758 & TRN & \\
\hline CHEMBL1991678 & 809156 & 4.2 & 4.2856 & TRN & \\
\hline CHEMBL2001239 & 809156 & 5.6 & 5.3171 & TST & \\
\hline CHEMBL 2001288 & 809156 & 5.5 & 5.3557 & TRN & \\
\hline CHEMBL 260092 & 809156 & 6.7 & 6.976 & TRN & \\
\hline CHEMBL1999811 & 809156 & 5.9 & 5.5419 & TST & \\
\hline CHEMBL1965495 & 809156 & 5.3 & 5.5426 & TRN & \\
\hline
\end{tabular}




\begin{tabular}{|c|c|c|c|c|}
\hline & & & pplement & al $\mathrm{Ta}$ \\
\hline CHEMBL1985074 & 809156 & 4.2 & 4.5729 & TST \\
\hline CHEMBL2000481 & 809156 & 5.6 & 5.5233 & TRN \\
\hline CHEMBL1991725 & 809156 & 6.0 & 5.9715 & TRN \\
\hline CHEMBL1992242 & 809156 & 5.6 & 4.4948 & TRN \\
\hline CHEMBL 2007296 & 809156 & 5.4 & 5.5843 & TRN \\
\hline CHEMBL396523 & 809156 & 6.2 & 6.0202 & TRN \\
\hline CHEMBL 2007138 & 809156 & 3.8 & 4.1539 & TRN \\
\hline CHEMBL208637 & 809156 & 4.2 & 3.9142 & TRN \\
\hline CHEMBL1970300 & 809156 & 5.2 & 5.3778 & TRN \\
\hline CHEMBL1986530 & 809156 & 4.2 & 4.2954 & TST \\
\hline CHEMBL1999321 & 809156 & 4.2 & 4.7272 & TRN \\
\hline CHEMBL1968590 & 809156 & 5.3 & 5.4198 & TRN \\
\hline CHEMBL1999749 & 809156 & 4.2 & 3.8145 & TRN \\
\hline CHEMBL2005375 & 809156 & 4.2 & 4.0004 & TRN \\
\hline CHEMBL1984191 & 809156 & 4.2 & 4.5867 & TRN \\
\hline CHEMBL1983006 & 809156 & 4.2 & 4.0364 & TRN \\
\hline CHEMBL1972183 & 809156 & 4.2 & 4.5684 & TRN \\
\hline CHEMBL1971029 & 809156 & 4.2 & 6.058 & TRN \\
\hline CHEMBL1995391 & 809156 & 3.8 & 4.8183 & TRN \\
\hline CHEMBL383527 & 809156 & 4.2 & 5.9217 & TRN \\
\hline CHEMBL394790 & 809156 & 6.7 & 6.2981 & TRN \\
\hline CHEMBL226471 & 809156 & 6.0 & 4.6434 & TRN \\
\hline CHEMBL1974702 & 809156 & 4.2 & 4.9246 & TRN \\
\hline CHEMBL1996111 & 809156 & 6.6 & 6.6984 & TRN \\
\hline CHEMBL1965589 & 809156 & 4.2 & 4.178 & TRN \\
\hline CHEMBL1998193 & 809156 & 4.2 & 4.1903 & TRN \\
\hline CHEMBL474432 & 809156 & 7.4 & 5.5636 & TST \\
\hline CHEMBL1988153 & 809156 & 4.2 & 4.2173 & TRN \\
\hline CHEMBL1972584 & 809156 & 5.9 & 5.1419 & TRN \\
\hline CHEMBL1999556 & 809156 & 5.7 & 5.3824 & TRN \\
\hline CHEMBL1988437 & 809156 & 5.6 & 6.1238 & TST \\
\hline CHEMBL1968245 & 809156 & 5.9 & 6.2084 & TRN \\
\hline CHEMBL1998121 & 809156 & 8.7 & 8.1845 & TRN \\
\hline CHEMBL1979577 & 809156 & 8.1 & 7.8337 & TRN \\
\hline CHEMBL1985566 & 809156 & 5.7 & 4.1784 & TRN \\
\hline CHEMBL52387 & 809156 & 4.2 & 4.8882 & TST \\
\hline CHEMBL379835 & 809156 & 4.2 & 4.3295 & TST \\
\hline CHEMBL1980802 & 809156 & 4.2 & 5.1365 & TST \\
\hline CHEMBL1979357 & 809156 & 5.9 & 5.7637 & TRN \\
\hline CHEMBL1996817 & 809156 & 6.3 & 5.6455 & TRN \\
\hline CHEMBL2004355 & 809156 & 5.7 & 4.5268 & TRN \\
\hline CHEMBL468280 & 809156 & 4.2 & 4.705 & TST \\
\hline CHEMBL1990884 & 809156 & 5.2 & 5.6072 & TST \\
\hline CHEMBL3109278 & 809156 & 6.4 & 6.7179 & TRN \\
\hline CHEMBL256835 & 809156 & 4.2 & 4.0929 & TRN \\
\hline CHEMBL1980142 & 809156 & 4.2 & 4.2632 & TRN \\
\hline CHEMBL41783 & 809156 & 4.2 & 4.4526 & TRN \\
\hline CHEMBL2004438 & 809156 & 6.4 & 5.7775 & TRN \\
\hline
\end{tabular}




\begin{tabular}{|c|c|c|c|c|c|}
\hline \multirow[b]{2}{*}{ CHEMBL 2006276} & \multirow[b]{2}{*}{809156} & \\
\hline & & 5.2 & 4.5195 & TRN & \\
\hline CHEMBL 271381 & 809156 & 6.8 & 6.7472 & TRN & \\
\hline CHEMBL2006785 & 809156 & 4.2 & \multicolumn{2}{|c|}{4.7589999999999995} & TRN \\
\hline CHEMBL1982466 & 809156 & 7.4 & 6.806 & TRN & \\
\hline CHEMBL1995740 & 809156 & 5.7 & 5.0104 & TRN & \\
\hline CHEMBL1996390 & 809156 & 4.2 & 4.5712 & TRN & \\
\hline CHEMBL234085 & 809156 & 4.4 & 4.8659 & TRN & \\
\hline CHEMBL1995832 & 809156 & 4.2 & 4.1043 & TRN & \\
\hline CHEMBL1998414 & 809156 & 5.4 & \multicolumn{2}{|c|}{5.1160000000000005} & TRN \\
\hline CHEMBL1969042 & 809156 & 6.2 & 6.0869 & TST & \\
\hline CHEMBL 2000345 & 809156 & 6.3 & 6.2943 & TRN & \\
\hline CHEMBL1999931 & 809156 & 7.0 & 6.8335 & TRN & \\
\hline CHEMBL1991640 & 809156 & 4.2 & \multicolumn{2}{|c|}{4.656000000000001} & TST \\
\hline CHEMBL1375418 & 809156 & 4.2 & 4.242 & TRN & \\
\hline CHEMBL 302449 & 809156 & 7.3 & 7.0129 & TST & \\
\hline CHEMBL 2007064 & 809156 & 6.8 & 6.5919 & TRN & \\
\hline CHEMBL1981047 & 809156 & 4.2 & 5.5457 & TST & \\
\hline CHEMBL229968 & 809156 & 7.6 & 7.4936 & TRN & \\
\hline CHEMBL1976240 & 809156 & 7.6 & 7.108 & TRN & \\
\hline CHEMBL1979093 & 809156 & 6.8 & 6.8323 & TRN & \\
\hline CHEMBL1968151 & 809156 & 4.2 & 4.8587 & TST & \\
\hline CHEMBL1381197 & 809156 & 4.2 & 3.8744 & TRN & \\
\hline CHEMBL1987009 & 809156 & 6.1 & 5.7531 & TRN & \\
\hline CHEMBL379218 & 809156 & 7.2 & 6.7386 & TRN & \\
\hline CHEMBL2003817 & 809156 & 4.2 & 4.6734 & TRN & \\
\hline CHEMBL336961 & 809156 & 4.2 & 4.1674 & TRN & \\
\hline CHEMBL1994830 & 809156 & 4.2 & 4.4661 & TRN & \\
\hline CHEMBL1987054 & 809156 & 7.0 & 7.479 & TRN & \\
\hline CHEMBL1970083 & 809156 & 7.6 & 7.4265 & TRN & \\
\hline CHEMBL226403 & 809156 & 6.0 & 4.6061 & TRN & \\
\hline CHEMBL2005631 & 809156 & 7.2 & 7.2551 & TRN & \\
\hline CHEMBL1994938 & 809156 & 7.2 & 6.0752 & TRN & \\
\hline CHEMBL1977223 & 809156 & 5.3 & 5.5183 & TRN & \\
\hline CHEMBL1825138 & 809156 & 5.8 & 5.57 & TST & \\
\hline CHEMBL1236126 & 809156 & 4.2 & 4.2779 & TST & \\
\hline CHEMBL1966279 & 809156 & 4.2 & 5.3206 & TRN & \\
\hline CHEMBL1997846 & 809156 & 6.3 & 6.2299 & TRN & \\
\hline CHEMBL2004419 & 809156 & 4.2 & 4.1012 & TRN & \\
\hline CHEMBL1991728 & 809156 & 6.5 & 6.3583 & TRN & \\
\hline CHEMBL1975787 & 809156 & 5.6 & 5.4933 & TRN & \\
\hline CHEMBL2002407 & 809156 & 5.6 & 5.2022 & TRN & \\
\hline CHEMBL1972489 & 809156 & 4.2 & 4.4123 & TRN & \\
\hline CHEMBL1994074 & 809156 & 4.2 & 4.3747 & TRN & \\
\hline CHEMBL1992937 & 809156 & 4.2 & 5.28299 & 99999999995 & TST \\
\hline CHEMBL1990541 & 809156 & 5.6 & 5.0883 & TST & \\
\hline CHEMBL1972119 & 809156 & 4.2 & 4.284 & TRN & \\
\hline CHEMBL1986328 & 809156 & 4.2 & 4.3962 & TST & \\
\hline \multirow[t]{2}{*}{ CHEMBL95692 } & 809156 & 4.2 & 4.4182 & TRN & \\
\hline & & \multicolumn{4}{|c|}{ Page 27961} \\
\hline
\end{tabular}




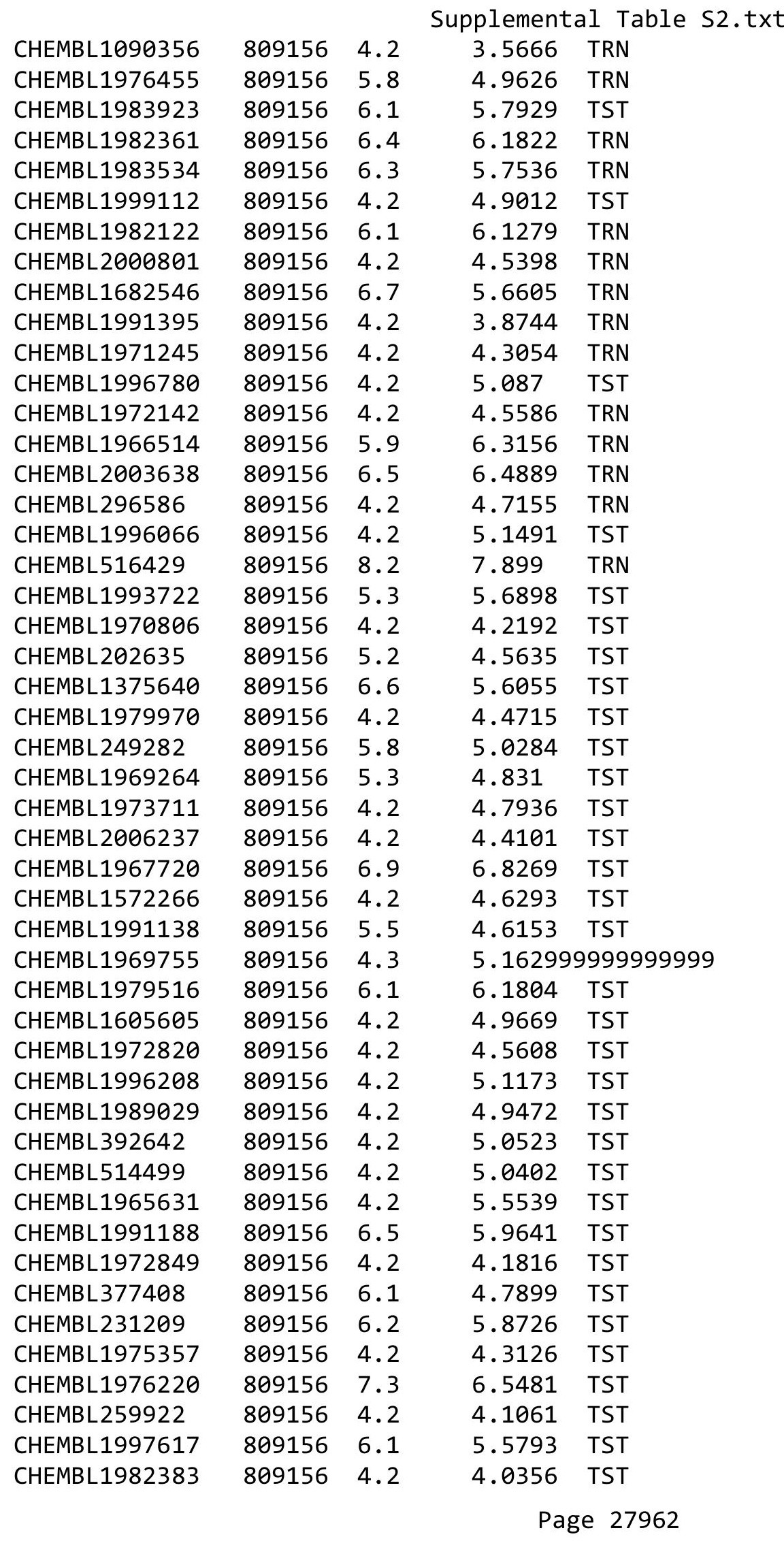




\begin{tabular}{|c|c|c|c|c|}
\hline \multicolumn{5}{|c|}{ Supplemental Table S2.txt } \\
\hline CHEMBL17370 & 809156 & 5.3 & 4.8668 & TST \\
\hline CHEMBL1987910 & 809156 & 4.2 & 5.2984 & TST \\
\hline CHEMBL1983932 & 809156 & 4.2 & 4.7786 & TST \\
\hline CHEMBL1997822 & 809156 & 4.2 & 5.6836 & TST \\
\hline CHEMBL1991285 & 809156 & 4.2 & 4.6046 & TST \\
\hline CHEMBL1984038 & 809156 & 4.2 & 4.1722 & TST \\
\hline CHEMBL 243088 & 809156 & 5.5 & 5.2571 & TST \\
\hline CHEMBL1993661 & 809156 & 7.0 & 7.0747 & TST \\
\hline CHEMBL1974416 & 809156 & 4.2 & 4.6457 & TST \\
\hline CHEMBL 2004615 & 809156 & 6.0 & 5.3048 & TST \\
\hline CHEMBL1984039 & 809156 & 4.2 & 4.6069 & TST \\
\hline CHEMBL1997872 & 809156 & 4.2 & 4.1805 & TST \\
\hline CHEMBL3650725 & 1535647 & 8.5229 & 8.5173 & TRN \\
\hline CHEMBL 3650706 & 1535647 & 8.5229 & 8.7298 & TRN \\
\hline CHEMBL3650712 & 1535647 & 7.5229 & 7.8525 & TRN \\
\hline CHEMBL3650693 & 1535647 & 8.5229 & 8.5447 & TRN \\
\hline CHEMBL 3650754 & 1535647 & 8.5229 & 8.4084 & TRN \\
\hline CHEMBL3650755 & 1535647 & 8.5229 & 8.4514 & TRN \\
\hline CHEMBL3650698 & 1535647 & 8.5229 & 8.4574 & TRN \\
\hline CHEMBL3650753 & 1535647 & 8.5229 & 8.3979 & TRN \\
\hline CHEMBL3650704 & 1535647 & 8.5229 & 8.2765 & TRN \\
\hline CHEMBL 3650705 & 1535647 & 7.5229 & 7.7624 & TRN \\
\hline CHEMBL3650733 & 1535647 & 7.5229 & 7.5361 & TRN \\
\hline CHEMBL 3650717 & 1535647 & 8.5229 & 8.6181 & TRN \\
\hline CHEMBL 3650710 & 1535647 & 7.5229 & 8.0054 & TST \\
\hline CHEMBL 3650724 & 1535647 & 8.5229 & 8.5079 & TRN \\
\hline CHEMBL 3650718 & 1535647 & 8.5229 & 8.5722 & TRN \\
\hline CHEMBL3650699 & 1535647 & 8.5229 & 8.5821 & TST \\
\hline CHEMBL 3650723 & 1535647 & 7.5229 & 7.4145 & TRN \\
\hline CHEMBL 3965652 & 1535647 & 6.5229 & 6.9275 & TRN \\
\hline CHEMBL3650739 & 1535647 & 7.5229 & 7.8869 & TRN \\
\hline CHEMBL 3650745 & 1535647 & 7.5229 & 7.4623 & TRN \\
\hline CHEMBL3650691 & 1535647 & 8.5229 & 8.4393 & TRN \\
\hline CHEMBL 3650731 & 1535647 & 8.5229 & 8.5568 & TRN \\
\hline CHEMBL3650728 & 1535647 & 8.5229 & 8.2341 & TRN \\
\hline CHEMBL3650697 & 1535647 & 8.5229 & 8.6254 & TST \\
\hline CHEMBL3650707 & 1535647 & 7.5229 & 7.715 & TST \\
\hline CHEMBL3650692 & 1535647 & 8.5229 & 8.4847 & TRN \\
\hline CHEMBL3953136 & 1535647 & 7.5229 & 7.6202 & TST \\
\hline CHEMBL3650711 & 1535647 & 8.5229 & 7.6374 & TRN \\
\hline CHEMBL3650750 & 1535647 & 7.5229 & 7.5705 & TRN \\
\hline CHEMBL3650741 & 1535647 & 8.5229 & 8.3768 & TRN \\
\hline CHEMBL3650719 & 1535647 & 8.5229 & 8.712 & TRN \\
\hline CHEMBL 3984422 & 1535647 & 8.5229 & 7.9809 & TRN \\
\hline CHEMBL3650708 & 1535647 & 7.5229 & 7.7324 & TRN \\
\hline CHEMBL3650701 & 1535647 & 8.5229 & 8.5887 & TRN \\
\hline CHEMBL 3925468 & 1535647 & 8.5229 & 8.0278 & TST \\
\hline CHEMBL3892112 & 1535647 & 6.0458 & 7.4858 & TST \\
\hline
\end{tabular}


Supplemental Table S2.txt

\begin{tabular}{|c|c|c|c|c|c|}
\hline CHEMBL3650738 & 1535647 & 8.5229 & 8.3106 & TRN & \\
\hline CHEMBL3650744 & 1535647 & 8.5229 & 8.464 & TRN & \\
\hline CHEMBL3639495 & 1535647 & 8.5229 & 8.7087 & TRN & \\
\hline CHEMBL3650751 & 1535647 & 8.5229 & 8.3531 & TRN & \\
\hline CHEMBL3650737 & 1535647 & 8.5229 & 8.4877 & TRN & \\
\hline CHEMBL3650735 & 1535647 & 8.5229 & 8.4445 & TRN & \\
\hline CHEMBL3650726 & 1535647 & 8.5229 & 8.5318 & TRN & \\
\hline CHEMBL3650702 & 1535647 & 8.5229 & 8.7022 & TRN & \\
\hline CHEMBL3650727 & 1535647 & 8.5229 & 8.6976 & TRN & \\
\hline CHEMBL3650729 & 1535647 & 7.5229 & 8.0633 & TRN & \\
\hline CHEMBL3650690 & 1535647 & 8.5229 & 8.5141 & TRN & \\
\hline CHEMBL3650716 & 1535647 & 8.5229 & 8.6415 & TST & \\
\hline CHEMBL3650703 & 1535647 & 7.5229 & 7.9594 & TST & \\
\hline CHEMBL3650749 & 1535647 & 8.5229 & 8.1512 & TST & \\
\hline CHEMBL3650740 & 1535647 & 7.5229 & 8.3434 & TST & \\
\hline CHEMBL3650722 & 1535647 & 6.5229 & 7.6427 & TST & \\
\hline CHEMBL3650730 & 1535647 & 8.5229 & 8.3342 & TST & \\
\hline CHEMBL3650743 & 1535647 & 7.5229 & 8.1098 & TST & \\
\hline CHEMBL1964290 & 809238 & 5.4 & 5.8907 & TRN & \\
\hline CHEMBL2003768 & 809238 & 4.0 & 3.7925 & TRN & \\
\hline CHEMBL213505 & 809238 & 4.0 & 4.09399 & 9999999999 & TRN \\
\hline CHEMBL1982880 & 809238 & 4.0 & 4.1962 & TRN & \\
\hline CHEMBL1993941 & 809238 & 4.0 & 4.1312 & TRN & \\
\hline CHEMBL1980435 & 809238 & 7.2 & 7.5308 & TRN & \\
\hline CHEMBL377383 & 809238 & 4.0 & 4.2115 & TRN & \\
\hline CHEMBL1973142 & 809238 & 5.4 & 5.93 & TRN & \\
\hline CHEMBL1973145 & 809238 & 4.0 & 3.9816 & TRN & \\
\hline CHEMBL1982924 & 809238 & 5.1 & 4.2669 & TRN & \\
\hline CHEMBL1964948 & 809238 & 4.5 & 4.47 & TRN & \\
\hline CHEMBL1971141 & 809238 & 4.0 & 4.2254 & TRN & \\
\hline CHEMBL1995813 & 809238 & 7.3 & 7.7262 & TRN & \\
\hline CHEMBL1979718 & 809238 & 4.0 & 4.1826 & TRN & \\
\hline CHEMBL206236 & 809238 & 4.0 & 4.0333 & TRN & \\
\hline CHEMBL523823 & 809238 & 4.0 & 4.4366 & TST & \\
\hline CHEMBL244378 & 809238 & 7.1 & 7.3259 & TRN & \\
\hline CHEMBL1990583 & 809238 & 4.0 & 4.8668 & TRN & \\
\hline CHEMBL1986943 & 809238 & 8.0 & 8.2683 & TRN & \\
\hline CHEMBL 2006263 & 809238 & 4.0 & 4.5327 & TST & \\
\hline CHEMBL1993584 & 809238 & 4.0 & 4.0772 & TRN & \\
\hline CHEMBL2000114 & 809238 & 5.3 & 5.7198 & TRN & \\
\hline CHEMBL210618 & 809238 & 4.0 & 4.6255 & TRN & \\
\hline CHEMBL1971172 & 809238 & 6.5 & 6.7638 & TRN & \\
\hline CHEMBL1975647 & 809238 & 7.0 & \multicolumn{2}{|c|}{6.742000000000001} & TRN \\
\hline CHEMBL1968380 & 809238 & 4.0 & 3.6964 & TRN & \\
\hline CHEMBL1991734 & 809238 & 7.1 & 6.1906 & TST & \\
\hline CHEMBL1990912 & 809238 & 6.8 & 6.2526 & TRN & \\
\hline CHEMBL1991782 & 809238 & 5.7 & 3.7993 & TRN & \\
\hline CHEMBL1988163 & 809238 & 7.3 & 7.3656 & TRN & \\
\hline
\end{tabular}




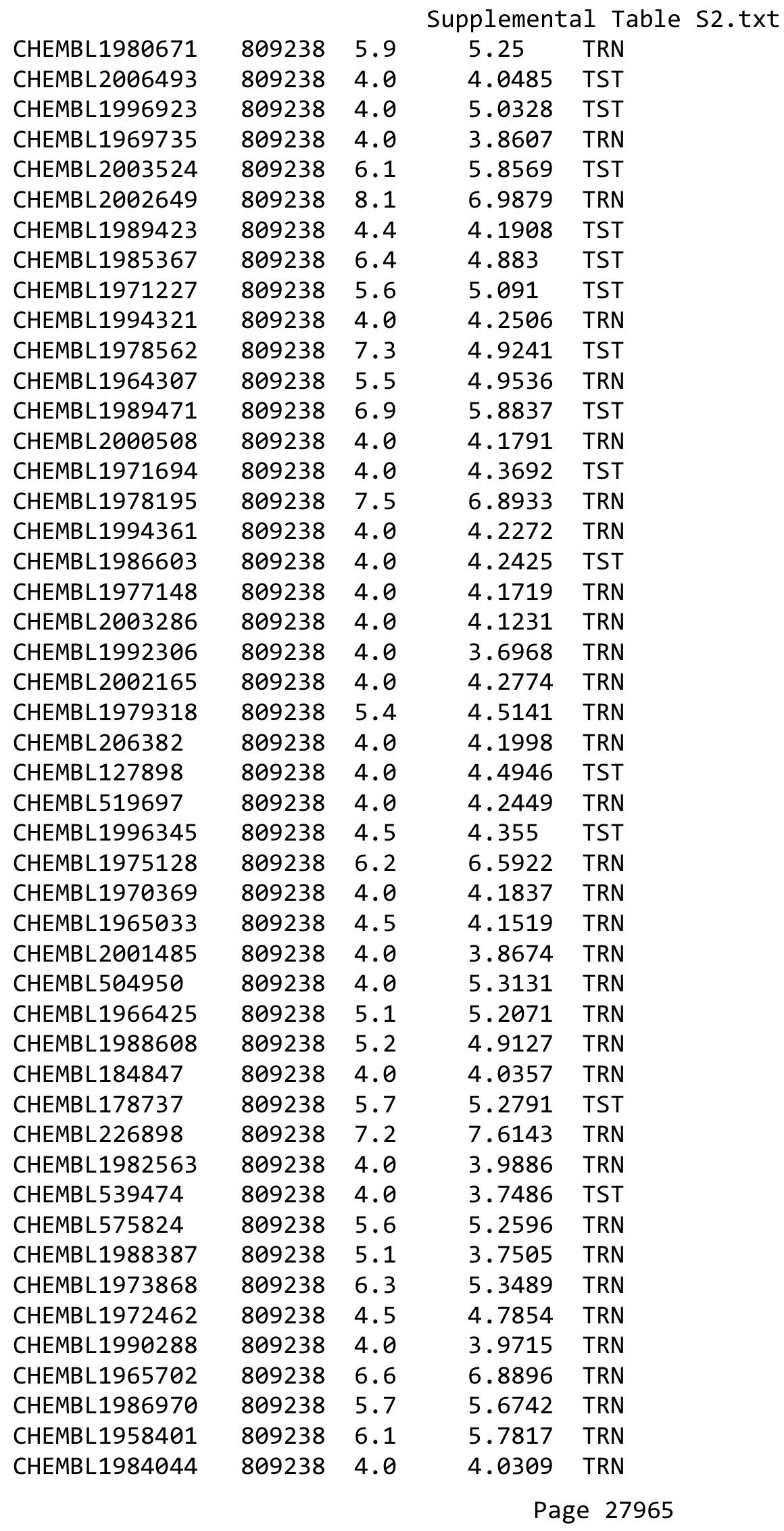




\begin{tabular}{|c|c|c|c|c|}
\hline \multicolumn{5}{|c|}{ Supplemental Table S2.txt } \\
\hline CHEMBL1972584 & 809238 & 4.0 & 5.0304 & TRN \\
\hline CHEMBL1982700 & 809238 & 4.5 & 5.0273 & TST \\
\hline CHEMBL326282 & 809238 & 4.0 & 4.0142 & TST \\
\hline CHEMBL1992732 & 809238 & 4.0 & 3.8572 & TST \\
\hline CHEMBL1971186 & 809238 & 4.0 & 4.555 & TRN \\
\hline CHEMBL 2003482 & 809238 & 4.2 & 5.2064 & TRN \\
\hline CHEMBL 2006456 & 809238 & 7.2 & 7.5668 & TRN \\
\hline CHEMBL1969156 & 809238 & 4.2 & 4.4898 & TRN \\
\hline CHEMBL1973211 & 809238 & 4.0 & 4.1241 & TRN \\
\hline CHEMBL1999120 & 809238 & 4.8 & 4.8272 & TST \\
\hline CHEMBL1976134 & 809238 & 5.6 & 5.7367 & TRN \\
\hline CHEMBL1965131 & 809238 & 5.4 & 5.9342 & TRN \\
\hline CHEMBL1981215 & 809238 & 4.5 & 5.0849 & TRN \\
\hline CHEMBL1974457 & 809238 & 4.0 & 5.1284 & TRN \\
\hline CHEMBL 2006580 & 809238 & 4.0 & 3.8351 & TRN \\
\hline CHEMBL 280074 & 809238 & 5.2 & 5.4799 & TST \\
\hline CHEMBL 2006581 & 809238 & 4.0 & 4.1489 & TRN \\
\hline CHEMBL1979855 & 809238 & 4.0 & 3.9568 & TRN \\
\hline CHEMBL1970340 & 809238 & 4.2 & 4.473 & TRN \\
\hline CHEMBL 2005186 & 809238 & 4.0 & 4.3569 & TRN \\
\hline CHEMBL1995927 & 809238 & 4.0 & 4.3662 & TST \\
\hline CHEMBL 2006450 & 809238 & 6.0 & 5.7094 & TRN \\
\hline CHEMBL 2001987 & 809238 & 4.5 & 5.0 & TRN \\
\hline CHEMBL1994555 & 809238 & 6.7 & 6.4987 & TST \\
\hline CHEMBL1997023 & 809238 & 4.0 & 3.7825 & TST \\
\hline CHEMBL1971943 & 809238 & 4.2 & 5.0087 & TRN \\
\hline CHEMBL1969049 & 809238 & 4.0 & 4.2454 & TRN \\
\hline CHEMBL 2005828 & 809238 & 4.0 & 4.3655 & TRN \\
\hline CHEMBL1991143 & 809238 & 4.0 & 4.1756 & TST \\
\hline CHEMBL1998611 & 809238 & 5.7 & 6.3769 & TRN \\
\hline CHEMBL1975900 & 809238 & 4.0 & 4.382 & TRN \\
\hline CHEMBL255822 & 809238 & 4.0 & 4.4609 & TRN \\
\hline CHEMBL 2006778 & 809238 & 4.0 & 4.0087 & TRN \\
\hline CHEMBL378627 & 809238 & 4.0 & 4.0923 & TRN \\
\hline CHEMBL1996979 & 809238 & 4.1 & 4.6113 & TRN \\
\hline CHEMBL1997025 & 809238 & 4.0 & 3.4181 & TRN \\
\hline CHEMBL1968406 & 809238 & 4.0 & 4.3647 & TRN \\
\hline CHEMBL1975921 & 809238 & 7.3 & 5.2384 & TRN \\
\hline CHEMBL1982476 & 809238 & 4.0 & 4.0984 & TRN \\
\hline CHEMBL1975923 & 809238 & 4.8 & 5.4472 & TST \\
\hline CHEMBL 2005449 & 809238 & 7.5 & 5.0421 & TRN \\
\hline CHEMBL 2006010 & 809238 & 4.0 & 4.3185 & TRN \\
\hline CHEMBL1682558 & 809238 & 4.0 & 3.8192 & TRN \\
\hline CHEMBL1990496 & 809238 & 4.1 & 3.9435 & TRN \\
\hline CHEMBL1993166 & 809238 & 5.8 & 5.7495 & TRN \\
\hline CHEMBL1967094 & 809238 & 4.0 & 3.6941 & TRN \\
\hline CHEMBL 2003341 & 809238 & 4.0 & 4.0884 & TRN \\
\hline CHEMBL1992645 & 809238 & 4.0 & 4.2229 & TST \\
\hline
\end{tabular}




\begin{tabular}{|c|c|c|c|c|c|}
\hline \\
\hline CHEMBL1998110 & 809238 & 4.5 & 4.5037 & TRN & \\
\hline CHEMBL1999590 & 809238 & 4.0 & 3.8864 & TST & \\
\hline CHEMBL1981079 & 809238 & 5.9 & 6.5497 & TRN & \\
\hline CHEMBL1978166 & 809238 & 5.9 & 5.2269 & TRN & \\
\hline CHEMBL1980489 & 809238 & 4.0 & 4.0139 & TRN & \\
\hline CHEMBL 2000832 & 809238 & 7.6 & 6.8794 & TRN & \\
\hline CHEMBL1967116 & 809238 & 4.0 & 3.8607 & TRN & \\
\hline CHEMBL1977814 & 809238 & 4.2 & 4.7169 & TST & \\
\hline CHEMBL513846 & 809238 & 4.0 & 4.8073 & TRN & \\
\hline CHEMBL1974617 & 809238 & 6.5 & 5.9066 & TRN & \\
\hline CHEMBL1965660 & 809238 & 6.5 & 6.9039 & TRN & \\
\hline CHEMBL1998112 & 809238 & 4.0 & 3.8216 & TRN & \\
\hline CHEMBL1969126 & 809238 & 4.0 & 3.8181 & TRN & \\
\hline CHEMBL1980896 & 809238 & 4.0 & 4.2652 & TRN & \\
\hline CHEMBL1975208 & 809238 & 4.0 & 3.467 & TST & \\
\hline CHEMBL1991429 & 809238 & 4.0 & 3.7422 & TRN & \\
\hline CHEMBL1967612 & 809238 & 4.3 & 4.7332 & TST & \\
\hline CHEMBL1971149 & 809238 & 4.0 & 3.83699 & 99999999997 & TRN \\
\hline CHEMBL1999714 & 809238 & 4.0 & 4.3142 & TRN & \\
\hline CHEMBL1994040 & 809238 & 4.0 & 3.9927 & TRN & \\
\hline CHEMBL388978 & 809238 & 8.4 & 8.0301 & TST & \\
\hline CHEMBL2004716 & 809238 & 4.0 & 4.1194 & TRN & \\
\hline CHEMBL1975233 & 809238 & 4.0 & 4.9269 & TRN & \\
\hline CHEMBL1421720 & 809238 & 5.8 & 5.6819 & TRN & \\
\hline CHEMBL2002553 & 809238 & 4.0 & 3.9813 & TST & \\
\hline CHEMBL1982135 & 809238 & 4.0 & 3.9373 & TRN & \\
\hline CHEMBL1976090 & 809238 & 6.0 & 5.5956 & TRN & \\
\hline CHEMBL2004771 & 809238 & 4.0 & 4.56 & TRN & \\
\hline CHEMBL1992922 & 809238 & 6.7 & 6.7869 & TRN & \\
\hline CHEMBL1997597 & 809238 & 5.2 & 5.2714 & TRN & \\
\hline CHEMBL1976093 & 809238 & 4.0 & 4.459 & TRN & \\
\hline CHEMBL1996543 & 809238 & 4.0 & 4.5286 & TRN & \\
\hline CHEMBL1975256 & 809238 & 5.3 & 4.9099 & TST & \\
\hline CHEMBL1949855 & 809238 & 5.1 & 5.0663 & TRN & \\
\hline CHEMBL1999126 & 809238 & 4.0 & 3.4574 & TST & \\
\hline CHEMBL1997503 & 809238 & 4.0 & 3.5829 & TST & \\
\hline CHEMBL116070 & 809238 & 6.2 & 5.8827 & TRN & \\
\hline CHEMBL1990821 & 809238 & 4.0 & 3.7661 & TST & \\
\hline CHEMBL 2004871 & 809238 & 4.0 & 4.0076 & TRN & \\
\hline CHEMBL 2004872 & 809238 & 4.0 & 4.2142 & TRN & \\
\hline CHEMBL1727312 & 809238 & 3.9 & 4.39 & TRN & \\
\hline CHEMBL1990223 & 809238 & 4.5 & 4.4897 & TRN & \\
\hline CHEMBL1969879 & 809238 & 4.0 & 3.5084 & TRN & \\
\hline CHEMBL1964382 & 809238 & 4.5 & 4.9838 & TST & \\
\hline CHEMBL101311 & 809238 & 5.9 & 5.5386 & TRN & \\
\hline CHEMBL1981720 & 809238 & 6.8 & 6.5177 & TRN & \\
\hline CHEMBL419932 & 809238 & 4.0 & 3.9125 & TRN & \\
\hline CHEMBL2005699 & 809238 & 4.5 & 4.2029 & TRN & \\
\hline & & & & 2796 & \\
\hline
\end{tabular}




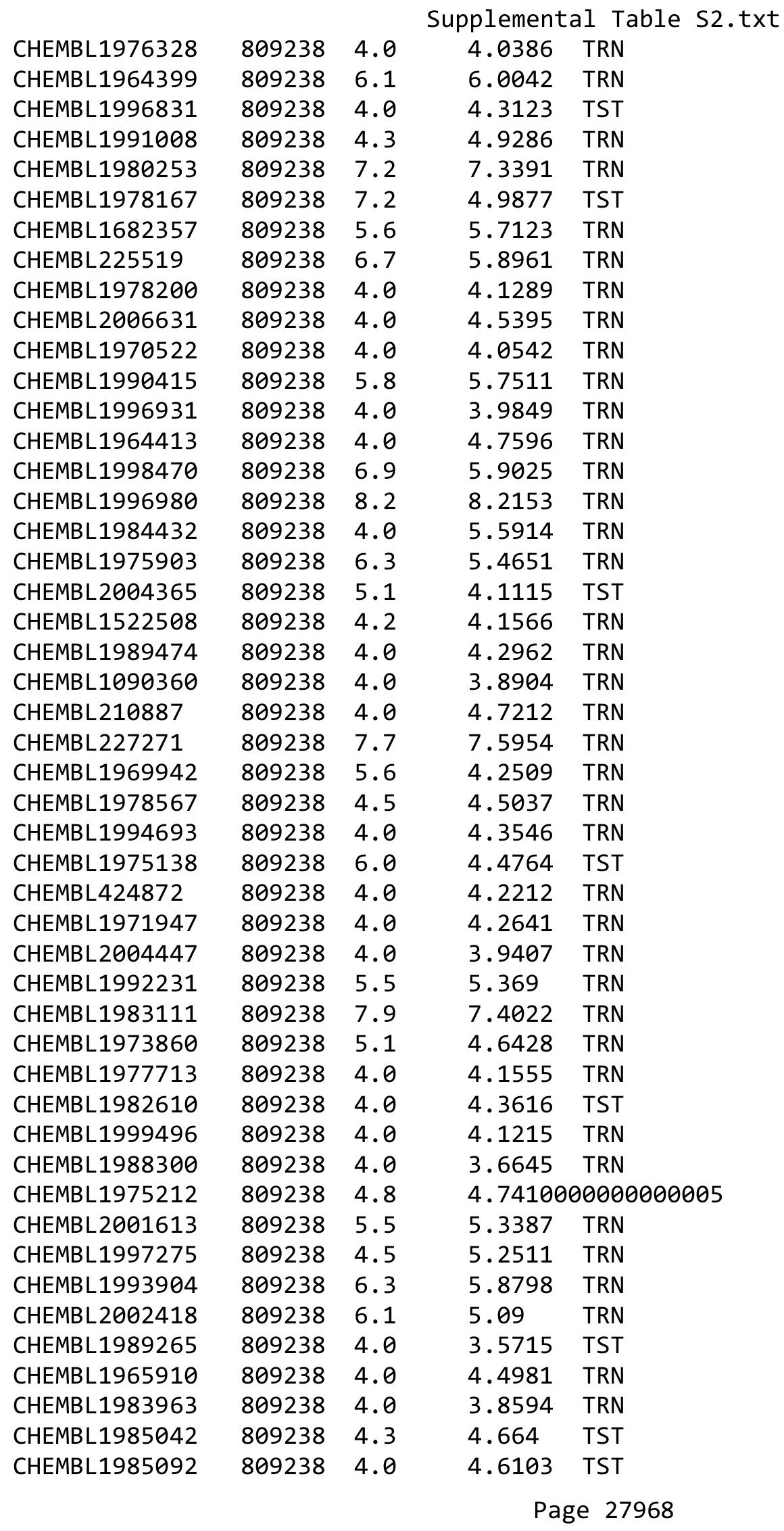




\begin{tabular}{|c|c|c|c|c|c|}
\hline \multicolumn{6}{|c|}{ Supplemental Table S2.txt } \\
\hline CHEMBL1981410 & 809238 & 4.0 & 4.0948 & TRN & \\
\hline CHEMBL383264 & 809238 & 7.1 & 5.6797 & TRN & \\
\hline CHEMBL 2007421 & 809238 & 7.3 & 5.2269 & TST & \\
\hline CHEMBL1991434 & 809238 & 4.0 & 4.1558 & TRN & \\
\hline CHEMBL1973138 & 809238 & 4.5 & 4.1506 & TRN & \\
\hline CHEMBL340384 & 809238 & 5.7 & 6.2794 & TST & \\
\hline CHEMBL1969151 & 809238 & 8.0 & 7.7903 & TRN & \\
\hline CHEMBL1996587 & 809238 & 4.0 & 3.7056 & TRN & \\
\hline CHEMBL1981492 & 809238 & 4.4 & 4.4958 & TRN & \\
\hline CHEMBL1988692 & 809238 & 6.0 & 4.4467 & TRN & \\
\hline CHEMBL592030 & 809238 & 5.8 & 6.6841 & TST & \\
\hline CHEMBL 2000071 & 809238 & 6.4 & 6.3978 & TRN & \\
\hline CHEMBL1979176 & 809238 & 4.0 & 4.4492 & TRN & \\
\hline CHEMBL 2002613 & 809238 & 6.8 & 7.3712 & TRN & \\
\hline CHEMBL 2002736 & 809238 & 5.8 & 5.2963 & TRN & \\
\hline CHEMBL1983195 & 809238 & 4.0 & 4.1274 & TST & \\
\hline CHEMBL1964444 & 809238 & 6.5 & 5.6944 & TRN & \\
\hline CHEMBL1989957 & 809238 & 4.0 & 4.3685 & TRN & \\
\hline CHEMBL1980540 & 809238 & 4.0 & 3.8439 & TRN & \\
\hline CHEMBL 278041 & 809238 & 4.5 & 4.6032 & TRN & \\
\hline CHEMBL1984162 & 809238 & 5.3 & 4.4319 & TRN & \\
\hline CHEMBL1998432 & 809238 & 6.9 & 7.2723 & TRN & \\
\hline CHEMBL1870106 & 809238 & 4.5 & 5.1439 & TRN & \\
\hline CHEMBL1996791 & 809238 & 5.6 & 5.83700 & 2000000001 & TRN \\
\hline CHEMBL371206 & 809238 & 4.0 & 4.7933 & TRN & \\
\hline CHEMBL1974664 & 809238 & 6.2 & 4.7733 & TST & \\
\hline CHEMBL1970104 & 809238 & 6.4 & 6.4795 & TRN & \\
\hline CHEMBL482538 & 809238 & 5.6 & 5.4469 & TRN & \\
\hline CHEMBL1984296 & 809238 & 6.0 & 5.5522 & TST & \\
\hline CHEMBL196363 & 809238 & 4.0 & 4.2592 & TRN & \\
\hline CHEMBL1996837 & 809238 & 5.1 & 5.2568 & TRN & \\
\hline CHEMBL1190711 & 809238 & 6.9 & 5.6442 & TRN & \\
\hline CHEMBL1964441 & 809238 & 4.5 & 4.4555 & TRN & \\
\hline CHEMBL546797 & 809238 & 4.5 & 5.0057 & TRN & \\
\hline CHEMBL404367 & 809238 & 4.0 & 4.578 & TRN & \\
\hline CHEMBL1966343 & 809238 & 6.0 & 5.9476 & TRN & \\
\hline CHEMBL1967887 & 809238 & 7.0 & 6.9699 & TRN & \\
\hline CHEMBL 2000568 & 809238 & 5.5 & 4.8957 & TRN & \\
\hline CHEMBL 2000335 & 809238 & 5.3 & 5.4682 & TRN & \\
\hline CHEMBL 2007097 & 809238 & 5.1 & 4.7362 & TRN & \\
\hline CHEMBL243298 & 809238 & 6.1 & 6.57700 & 0000000001 & TRN \\
\hline CHEMBL1973808 & 809238 & 4.0 & 4.1805 & TRN & \\
\hline CHEMBL 2000429 & 809238 & 4.0 & 3.9815 & TRN & \\
\hline CHEMBL1972576 & 809238 & 4.0 & 4.5483 & TRN & \\
\hline CHEMBL1992555 & 809238 & 4.0 & 3.9621 & TRN & \\
\hline CHEMBL1988173 & 809238 & 6.5 & 4.4045 & TST & \\
\hline CHEMBL535331 & 809238 & 4.0 & 4.0818 & TRN & \\
\hline CHEMBL1989805 & 809238 & 5.3 & 4.5083 & TST & \\
\hline
\end{tabular}




\begin{tabular}{|c|c|c|c|c|}
\hline & & & 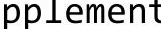 & al Ta \\
\hline CHEMBL1982980 & 809238 & 4.0 & 3.8449 & TST \\
\hline CHEMBL1983025 & 809238 & 4.0 & 4.8175 & TRN \\
\hline CHEMBL1975927 & 809238 & 4.5 & 6.1022 & TRN \\
\hline CHEMBL 2002322 & 809238 & 5.4 & 6.0805 & TRN \\
\hline CHEMBL 2002323 & 809238 & 4.0 & 4.4679 & TST \\
\hline CHEMBL 2000879 & 809238 & 4.7 & 4.5972 & TST \\
\hline CHEMBL 2005548 & 809238 & 4.0 & 3.8309 & TRN \\
\hline CHEMBL 2001704 & 809238 & 4.4 & 4.7883 & TST \\
\hline CHEMBL1987793 & 809238 & 4.0 & 3.9876 & TST \\
\hline CHEMBL21156 & 809238 & 4.5 & 4.1748 & TST \\
\hline CHEMBL1992740 & 809238 & 5.6 & 6.3098 & TRN \\
\hline CHEMBL1989267 & 809238 & 6.1 & 4.3093 & TRN \\
\hline CHEMBL 2002373 & 809238 & 4.0 & 4.1271 & TRN \\
\hline CHEMBL439340 & 809238 & 4.0 & 3.5836 & TRN \\
\hline CHEMBL1974574 & 809238 & 5.6 & 5.0621 & TST \\
\hline CHEMBL 2006188 & 809238 & 4.0 & 4.3726 & TRN \\
\hline CHEMBL1973893 & 809238 & 6.3 & 6.4602 & TRN \\
\hline CHEMBL1995736 & 809238 & 4.0 & 4.084 & TRN \\
\hline CHEMBL1985095 & 809238 & 6.1 & 6.0707 & TST \\
\hline CHEMBL1996500 & 809238 & 4.4 & 4.0107 & TRN \\
\hline CHEMBL1682540 & 809238 & 5.8 & 5.7767 & TRN \\
\hline CHEMBL413779 & 809238 & 4.0 & 5.3958 & TST \\
\hline CHEMBL497151 & 809238 & 4.0 & 4.5985 & TRN \\
\hline CHEMBL 2000029 & 809238 & 8.1 & 6.9992 & TRN \\
\hline CHEMBL1973961 & 809238 & 4.4 & 4.8638 & TRN \\
\hline CHEMBL1980497 & 809238 & 5.3 & 5.2441 & TRN \\
\hline CHEMBL1994977 & 809238 & 4.5 & 4.1905 & TRN \\
\hline CHEMBL373598 & 809238 & 4.0 & 4.9357 & TST \\
\hline CHEMBL 2001149 & 809238 & 5.5 & 5.7324 & TRN \\
\hline CHEMBL1999718 & 809238 & 4.0 & 4.3849 & TRN \\
\hline CHEMBL1987073 & 809238 & 7.7 & 7.6412 & TRN \\
\hline CHEMBL1996646 & 809238 & 4.5 & 4.61 & TRN \\
\hline CHEMBL1979773 & 809238 & 4.5 & 4.6731 & TRN \\
\hline CHEMBL1977346 & 809238 & 6.6 & 6.5104 & TRN \\
\hline CHEMBL1996702 & 809238 & 8.0 & 7.0537 & TRN \\
\hline CHEMBL1998435 & 809238 & 4.0 & 4.5732 & TRN \\
\hline CHEMBL1969190 & 809238 & 4.0 & 4.093 & TRN \\
\hline CHEMBL1973937 & 809238 & 4.0 & 4.2246 & TRN \\
\hline CHEMBL 2002099 & 809238 & 4.5 & 4.8461 & TRN \\
\hline CHEMBL1982711 & 809238 & 6.3 & 6.9043 & TRN \\
\hline CHEMBL1987982 & 809238 & 4.0 & 4.4781 & TST \\
\hline CHEMBL1969102 & 809238 & 4.0 & 3.8091 & TRN \\
\hline CHEMBL2004118 & 809238 & 5.5 & 4.8733 & TRN \\
\hline CHEMBL1682346 & 809238 & 5.9 & 6.5109 & TRN \\
\hline CHEMBL1994241 & 809238 & 4.0 & 5.1346 & TRN \\
\hline CHEMBL 2007044 & 809238 & 4.0 & 5.0434 & TST \\
\hline CHEMBL2001998 & 809238 & 4.0 & 4.409 & TST \\
\hline CHEMBL50894 & 809238 & 7.9 & 6.9082 & TRN \\
\hline
\end{tabular}




\begin{tabular}{|c|c|c|c|c|c|}
\hline \multicolumn{6}{|c|}{ Supplemental Table S2.txt } \\
\hline CHEMBL1995211 & 809238 & 7.0 & 6.6458 & TRN & \\
\hline CHEMBL1988838 & 809238 & 6.4 & 6.5873 & TRN & \\
\hline CHEMBL1981725 & 809238 & 4.0 & 4.5125 & TRN & \\
\hline CHEMBL1965169 & 809238 & 8.1 & 4.953 & TST & \\
\hline CHEMBL1081312 & 809238 & 5.9 & 5.597 & TRN & \\
\hline CHEMBL1965170 & 809238 & 4.5 & 4.3087 & TRN & \\
\hline CHEMBL 2005792 & 809238 & 4.2 & 4.2707 & TRN & \\
\hline CHEMBL1984206 & 809238 & 4.0 & 4.0397 & TRN & \\
\hline CHEMBL462120 & 809238 & 4.0 & 4.7748 & TST & \\
\hline CHEMBL1991577 & 809238 & 4.0 & 3.7835 & TRN & \\
\hline CHEMBL 2007592 & 809238 & 4.0 & 3.5985 & TRN & \\
\hline CHEMBL1997892 & 809238 & 4.5 & 4.0814 & TRN & \\
\hline CHEMBL1976936 & 809238 & 5.5 & 5.6742 & TRN & \\
\hline CHEMBL210963 & 809238 & 4.0 & 4.0157 & TRN & \\
\hline CHEMBL1984633 & 809238 & 4.0 & 4.2327 & TRN & \\
\hline CHEMBL1965845 & 809238 & 6.2 & 6.1631 & TRN & \\
\hline CHEMBL1983715 & 809238 & 7.6 & 6.9727 & TRN & \\
\hline CHEMBL402846 & 809238 & 4.0 & 4.4408 & TRN & \\
\hline CHEMBL1682545 & 809238 & 4.0 & 4.6885 & TRN & \\
\hline CHEMBL1976732 & 809238 & 4.0 & 3.8903 & TRN & \\
\hline CHEMBL1980163 & 809238 & 4.0 & 4.0647 & TRN & \\
\hline CHEMBL1989856 & 809238 & 4.0 & 3.8328 & TST & \\
\hline CHEMBL1972568 & 809238 & 4.0 & 4.2497 & TRN & \\
\hline CHEMBL 259850 & 809238 & 5.0 & 4.8361 & TRN & \\
\hline CHEMBL105739 & 809238 & 4.0 & 4.5235 & TRN & \\
\hline CHEMBL203673 & 809238 & 4.0 & 4.2173 & TRN & \\
\hline CHEMBL 2003785 & 809238 & 5.3 & 4.9779 & TST & \\
\hline CHEMBL1981045 & 809238 & 4.0 & 4.7922 & TRN & \\
\hline CHEMBL387971 & 809238 & 4.0 & 3.9432 & TST & \\
\hline CHEMBL1975418 & 809238 & 6.5 & 6.4251 & TRN & \\
\hline CHEMBL1992796 & 809238 & 4.0 & 4.2853 & TST & \\
\hline CHEMBL1968515 & 809238 & 5.3 & 4.6248 & TST & \\
\hline CHEMBL1164180 & 809238 & 4.4 & 4.5839 & TST & \\
\hline CHEMBL 223257 & 809238 & 4.0 & 4.7569 & TST & \\
\hline CHEMBL1997611 & 809238 & 5.9 & 5.1902 & TST & \\
\hline CHEMBL1516890 & 809238 & 5.0 & 5.37799 & 7999999999 & TRN \\
\hline CHEMBL 2001751 & 809238 & 6.7 & 6.9737 & TRN & \\
\hline CHEMBL1984586 & 809238 & 4.0 & 3.7274 & TRN & \\
\hline CHEMBL1999774 & 809238 & 4.0 & 3.9562 & TST & \\
\hline CHEMBL1972659 & 809238 & 4.0 & 4.0543 & TST & \\
\hline CHEMBL1973395 & 809238 & 6.5 & 6.2399 & TRN & \\
\hline CHEMBL1984686 & 809238 & 6.8 & 5.1353 & TRN & \\
\hline CHEMBL1969843 & 809238 & 5.0 & 5.2116 & TRN & \\
\hline CHEMBL 2007002 & 809238 & 5.8 & 5.6017 & TRN & \\
\hline CHEMBL1992073 & 809238 & 4.5 & 4.3735 & TRN & \\
\hline CHEMBL484390 & 809238 & 4.0 & 3.9587 & TRN & \\
\hline CHEMBL 2007559 & 809238 & 4.5 & 5.3732 & TRN & \\
\hline CHEMBL2004290 & 809238 & 4.2 & 4.1797 & TRN & \\
\hline
\end{tabular}




\begin{tabular}{|c|c|c|c|c|c|}
\hline \multicolumn{6}{|c|}{ Supplemental Table S2.txt } \\
\hline CHEMBL 2000393 & 809238 & 5.8 & 5.3932 & TST & \\
\hline CHEMBL 2004072 & 809238 & 4.0 & 4.4697 & TRN & \\
\hline CHEMBL1242373 & 809238 & 4.0 & 4.2222 & TRN & \\
\hline CHEMBL 2000433 & 809238 & 4.0 & 3.9006 & TST & \\
\hline CHEMBL56543 & 809238 & 4.0 & 4.3394 & TRN & \\
\hline CHEMBL1984402 & 809238 & 5.5 & 3.9917 & TRN & \\
\hline CHEMBL1988075 & 809238 & 4.0 & 4.1627 & TRN & \\
\hline CHEMBL2001239 & 809238 & 5.2 & 5.54 & TRN & \\
\hline CHEMBL 2001288 & 809238 & 5.1 & 5.646 & TRN & \\
\hline CHEMBL1992363 & 809238 & 7.5 & 7.7385 & TRN & \\
\hline CHEMBL1999811 & 809238 & 5.1 & 4.6256 & TRN & \\
\hline CHEMBL235157 & 809238 & 4.5 & 4.8792 & TST & \\
\hline CHEMBL 2000481 & 809238 & 4.0 & 4.8083 & TRN & \\
\hline CHEMBL1992242 & 809238 & 4.0 & 4.0815 & TRN & \\
\hline CHEMBL1982271 & 809238 & 7.9 & 7.855 & TRN & \\
\hline CHEMBL 2004159 & 809238 & 4.5 & 4.4179 & TRN & \\
\hline CHEMBL1986530 & 809238 & 4.0 & 4.2162 & TST & \\
\hline CHEMBL1999321 & 809238 & 4.0 & 4.0216 & TRN & \\
\hline CHEMBL1968590 & 809238 & 4.0 & 3.8938 & TRN & \\
\hline CHEMBL 2005375 & 809238 & 4.0 & 3.7667 & TRN & \\
\hline CHEMBL1972183 & 809238 & 4.0 & 3.7002 & TRN & \\
\hline CHEMBL1974702 & 809238 & 4.0 & 5.2084 & TRN & \\
\hline CHEMBL474432 & 809238 & 4.0 & 4.6801 & TST & \\
\hline CHEMBL1965387 & 809238 & 4.5 & 4.2098 & TRN & \\
\hline CHEMBL 2001539 & 809238 & 5.2 & 5.0352 & TST & \\
\hline CHEMBL550418 & 809238 & 7.8 & 6.6499 & TRN & \\
\hline CHEMBL1986666 & 809238 & 6.6 & 6.5223 & TRN & \\
\hline CHEMBL1971289 & 809238 & 7.2 & 5.694 & TRN & \\
\hline CHEMBL1999556 & 809238 & 6.8 & 6.6893 & TRN & \\
\hline CHEMBL1988437 & 809238 & 4.2 & 4.4593 & TRN & \\
\hline CHEMBL1998121 & 809238 & 5.6 & 5.5425 & TRN & \\
\hline CHEMBL1992607 & 809238 & 4.3 & 5.0771 & TRN & \\
\hline CHEMBL1991800 & 809238 & 4.0 & 4.1136 & TRN & \\
\hline CHEMBL1985566 & 809238 & 4.0 & 5.0339 & TRN & \\
\hline CHEMBL 2003689 & 809238 & 4.5 & 4.2662 & TRN & \\
\hline CHEMBL379835 & 809238 & 4.0 & 3.97600 & 00000000004 & TST \\
\hline CHEMBL1980802 & 809238 & 4.0 & 4.7549 & TST & \\
\hline CHEMBL1996649 & 809238 & 4.5 & 4.6087 & TRN & \\
\hline CHEMBL1979554 & 809238 & 4.0 & 4.2096 & TRN & \\
\hline CHEMBL1986756 & 809238 & 4.5 & 5.0952 & TRN & \\
\hline CHEMBL3197315 & 809238 & 4.0 & 3.9955 & TST & \\
\hline CHEMBL468280 & 809238 & 4.0 & 3.9341 & TST & \\
\hline CHEMBL1990884 & 809238 & 4.0 & 3.8655 & TRN & \\
\hline CHEMBL3109278 & 809238 & 4.5 & 4.5657 & TRN & \\
\hline CHEMBL1970006 & 809238 & 4.0 & 4.7098 & TST & \\
\hline CHEMBL 2006276 & 809238 & 4.1 & 5.4659 & TRN & \\
\hline CHEMBL191003 & 809238 & 9.3 & 6.4543 & TRN & \\
\hline CHEMBL2006785 & 809238 & 4.0 & 4.0497 & TRN & \\
\hline
\end{tabular}




\begin{tabular}{|c|c|c|c|c|}
\hline & & & Supplement & al $\mathrm{T}$ \\
\hline CHEMBL1973359 & 809238 & 6.9 & 6.676 & TST \\
\hline CHEMBL1995740 & 809238 & 7.7 & 7.3605 & TRN \\
\hline CHEMBL1979690 & 809238 & 7.0 & 6.6144 & TRN \\
\hline CHEMBL1995832 & 809238 & 4.0 & 4.119 & TRN \\
\hline CHEMBL 2000345 & 809238 & 4.0 & 4.7847 & TRN \\
\hline CHEMBL1983575 & 809238 & 6.5 & 6.0084 & TRN \\
\hline CHEMBL1375418 & 809238 & 4.0 & 3.9894 & TRN \\
\hline CHEMBL 302449 & 809238 & 7.8 & 7.1662 & TST \\
\hline CHEMBL1981047 & 809238 & 5.9 & 5.7567 & TRN \\
\hline CHEMBL229968 & 809238 & 7.9 & 8.0702 & TRN \\
\hline CHEMBL1976196 & 809238 & 4.5 & 5.0345 & TST \\
\hline CHEMBL1976240 & 809238 & 5.2 & 4.6907 & TRN \\
\hline CHEMBL1987948 & 809238 & 7.0 & 7.1457 & TRN \\
\hline CHEMBL1983630 & 809238 & 4.6 & 5.0882 & TRN \\
\hline CHEMBL1979093 & 809238 & 4.0 & 3.9797 & TRN \\
\hline CHEMBL336961 & 809238 & 4.0 & 5.5419 & TRN \\
\hline CHEMBL1970083 & 809238 & 4.0 & 3.6004 & TRN \\
\hline CHEMBL1994938 & 809238 & 4.0 & 4.2369 & TRN \\
\hline CHEMBL1977223 & 809238 & 8.2 & 8.5199 & TRN \\
\hline CHEMBL1236126 & 809238 & 4.0 & 4.1391 & TRN \\
\hline CHEMBL1997846 & 809238 & 4.4 & 4.6701 & TRN \\
\hline CHEMBL2004419 & 809238 & 4.0 & 3.9119 & TRN \\
\hline CHEMBL1992937 & 809238 & 6.5 & 6.4525 & TRN \\
\hline CHEMBL1972119 & 809238 & 4.0 & 3.8631 & TRN \\
\hline CHEMBL95692 & 809238 & 4.0 & 4.0544 & TRN \\
\hline CHEMBL1976455 & 809238 & 6.6 & 6.6252 & TRN \\
\hline CHEMBL1983923 & 809238 & 4.2 & 4.5025 & TRN \\
\hline CHEMBL1983534 & 809238 & 4.0 & 4.8281 & TRN \\
\hline CHEMBL1982361 & 809238 & 4.0 & 3.8972 & TRN \\
\hline CHEMBL 2000801 & 809238 & 4.1 & 3.8843 & TRN \\
\hline CHEMBL1991395 & 809238 & 4.0 & 4.1064 & TRN \\
\hline CHEMBL1971245 & 809238 & 4.0 & 4.9138 & TRN \\
\hline CHEMBL1987648 & 809238 & 4.0 & 3.9643 & TRN \\
\hline CHEMBL1972142 & 809238 & 4.2 & 4.0074 & TRN \\
\hline CHEMBL1966514 & 809238 & 4.0 & 4.0866 & TRN \\
\hline CHEMBL 2003638 & 809238 & 7.9 & 7.7302 & TRN \\
\hline CHEMBL1983393 & 809238 & 4.5 & 4.6495 & TRN \\
\hline CHEMBL516429 & 809238 & 6.5 & 6.5372 & TRN \\
\hline CHEMBL1972152 & 809238 & 4.1 & 4.3408 & TST \\
\hline CHEMBL1970806 & 809238 & 4.0 & 3.944 & TRN \\
\hline CHEMBL1992371 & 809238 & 8.2 & 7.0957 & TRN \\
\hline CHEMBL1979970 & 809238 & 7.2 & 6.8794 & TRN \\
\hline CHEMBL1967252 & 809238 & 6.9 & 6.9043 & TRN \\
\hline CHEMBL1993374 & 809238 & 6.4 & 5.4412 & TST \\
\hline CHEMBL1969264 & 809238 & 4.0 & 4.2803 & TRN \\
\hline CHEMBL2006237 & 809238 & 4.0 & 4.1293 & TRN \\
\hline CHEMBL2005509 & 809238 & 8.2 & 8.1182 & TRN \\
\hline CHEMBL1572266 & 809238 & 4.0 & 4.0969 & TST \\
\hline
\end{tabular}




\begin{tabular}{|c|c|c|c|c|c|}
\hline \multicolumn{6}{|c|}{ Supplemental Table s2.txt } \\
\hline CHEMBL1979516 & 809238 & 4.0 & 3.9528 & TRN & \\
\hline CHEMBL1972820 & 809238 & 4.0 & 4.3792 & TST & \\
\hline CHEMBL1605605 & 809238 & 5.5 & 4.8487 & TRN & \\
\hline CHEMBL1989029 & 809238 & 4.0 & 3.9501 & TRN & \\
\hline CHEMBL392642 & 809238 & 5.8 & 5.8785 & TRN & \\
\hline CHEMBL1980167 & 809238 & 4.5 & 5.5374 & TST & \\
\hline CHEMBL1972849 & 809238 & 4.0 & 3.5788 & TRN & \\
\hline CHEMBL1975357 & 809238 & 4.0 & 4.1492 & TST & \\
\hline CHEMBL 259922 & 809238 & 4.0 & 3.6694 & TST & \\
\hline CHEMBL1997617 & 809238 & 4.0 & 4.5175 & TRN & \\
\hline CHEMBL1969301 & 809238 & 4.0 & 3.9469 & TRN & \\
\hline CHEMBL1987910 & 809238 & 4.0 & 3.9716 & TRN & \\
\hline CHEMBL1983932 & 809238 & 5.2 & 5.2425 & TRN & \\
\hline CHEMBL1983980 & 809238 & 5.6 & 5.5188 & TRN & \\
\hline CHEMBL1966069 & 809238 & 5.1 & 5.71 & TRN & \\
\hline CHEMBL1986899 & 809238 & 4.5 & 4.774 & TRN & \\
\hline CHEMBL243088 & 809238 & 6.4 & 6.5697 & TRN & \\
\hline CHEMBL202721 & 809238 & 4.5 & 3.9798 & TRN & \\
\hline CHEMBL1987034 & 809238 & 8.1 & 7.5821 & TRN & \\
\hline CHEMBL 2005886 & 809238 & 4.0 & 5.0165 & TRN & \\
\hline CHEMBL1682345 & 809238 & 6.1 & 6.0218 & TRN & \\
\hline CHEMBL481491 & 809238 & 4.0 & 3.8714 & TST & \\
\hline CHEMBL388311 & 809238 & 9.2 & 7.2324 & TRN & \\
\hline CHEMBL1998765 & 809238 & 5.8 & 4.4989 & TRN & \\
\hline CHEMBL 2005936 & 809238 & 6.4 & 6.7072 & TRN & \\
\hline CHEMBL1987430 & 809238 & 4.5 & 5.3031 & TRN & \\
\hline CHEMBL1562756 & 809238 & 4.0 & 4.9644 & TST & \\
\hline CHEMBL1993413 & 809238 & 4.4 & 4.7392 & TRN & \\
\hline CHEMBL1969372 & 809238 & 4.0 & 4.3634 & TRN & \\
\hline CHEMBL 2001957 & 809238 & 4.0 & 4.0784 & TRN & \\
\hline CHEMBL1986263 & 809238 & 7.9 & 6.9132 & TRN & \\
\hline CHEMBL1986265 & 809238 & 4.5 & 4.3348 & TRN & \\
\hline CHEMBL1964644 & 809238 & 4.0 & 4.9417 & TRN & \\
\hline CHEMBL1981782 & 809238 & 5.1 & 4.2216 & TRN & \\
\hline CHEMBL1970142 & 809238 & 4.0 & 3.9919 & TRN & \\
\hline CHEMBL1977681 & 809238 & 5.2 & 4.2978 & TRN & \\
\hline CHEMBL 2002105 & 809238 & 6.0 & 5.5335 & TRN & \\
\hline CHEMBL1983348 & 809238 & 7.7 & 6.4295 & TRN & \\
\hline CHEMBL1995592 & 809238 & 5.9 & 5.41 & TST & \\
\hline CHEMBL1986177 & 809238 & 4.5 & 4.3622 & TRN & \\
\hline CHEMBL1992323 & 809238 & 4.0 & 4.0845 & TRN & \\
\hline CHEMBL1983449 & 809238 & 4.2 & 4.1319 & TRN & \\
\hline CHEMBL1983589 & 809238 & 6.4 & 6.13899 & э999999999 & TRN \\
\hline CHEMBL1996510 & 809238 & 6.1 & 4.8998 & TST & \\
\hline CHEMBL 2005718 & 809238 & 7.2 & 7.1517 & TRN & \\
\hline CHEMBL437747 & 809238 & 6.8 & 6.0411 & TRN & \\
\hline CHEMBL507936 & 809238 & 4.0 & 3.9571 & TRN & \\
\hline CHEMBL 2001584 & 809238 & 4.5 & 4.2493 & TRN & \\
\hline
\end{tabular}




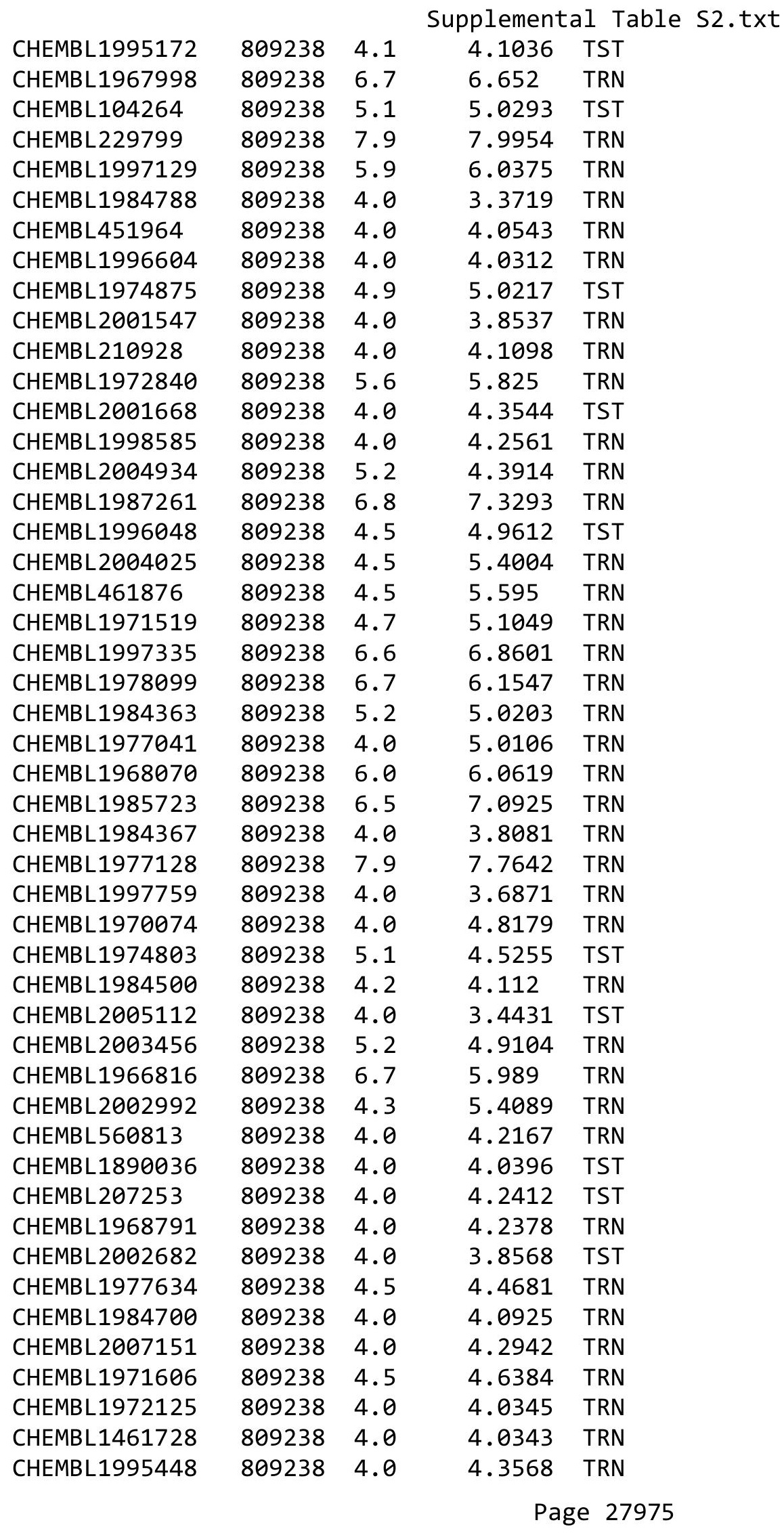




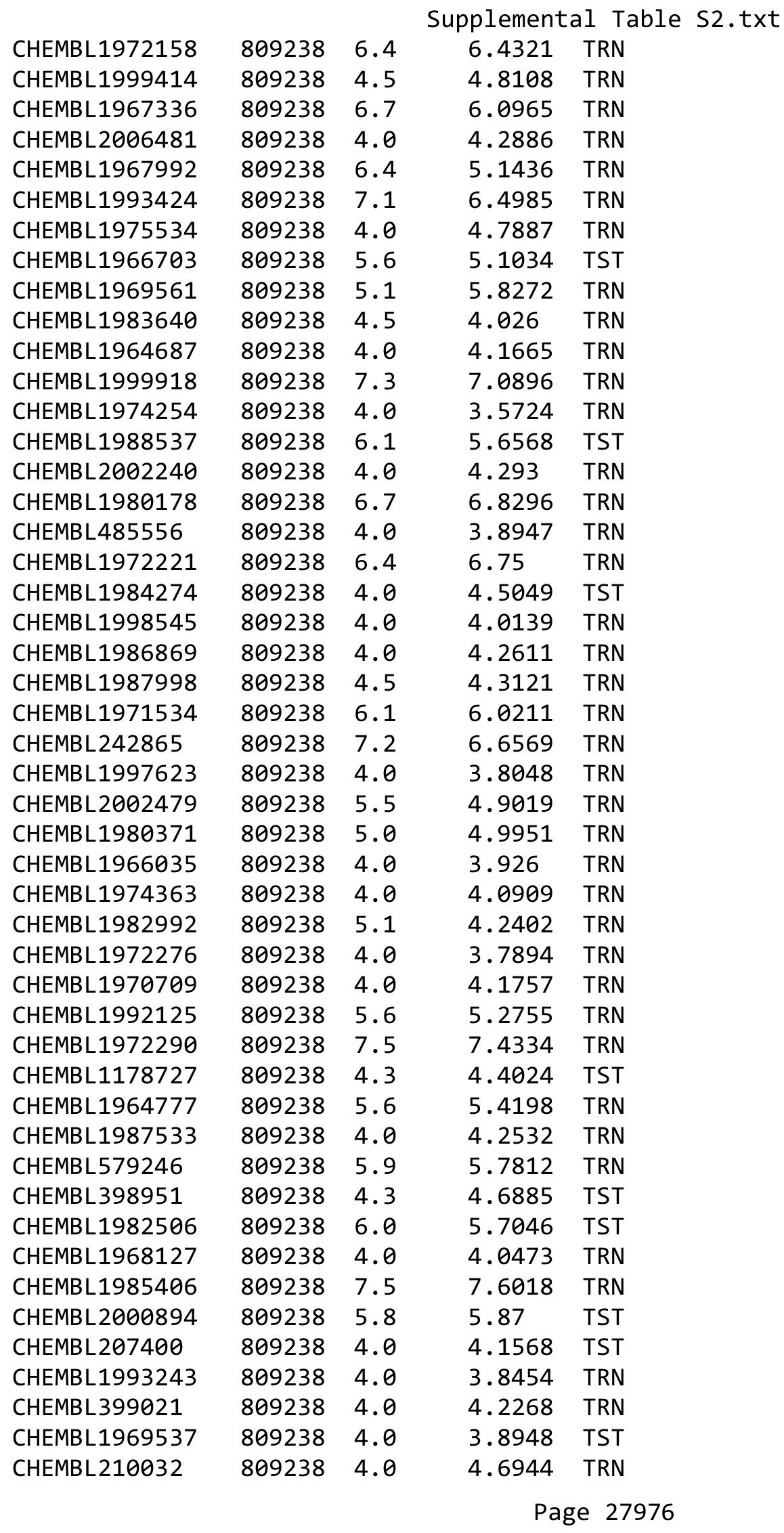




\begin{tabular}{|c|c|c|c|c|}
\hline & & & Supplement & \\
\hline CHEMBL508928 & 809238 & 4.0 & 4.6234 & TRN \\
\hline CHEMBL1991356 & 809238 & 5.1 & 4.2044 & TST \\
\hline CHEMBL1983309 & 809238 & 4.0 & 4.5216 & TRN \\
\hline CHEMBL 2004892 & 809238 & 5.3 & 5.3791 & TRN \\
\hline CHEMBL1972339 & 809238 & 6.8 & 7.1454 & TRN \\
\hline CHEMBL1970314 & 809238 & 4.0 & 4.1281 & TRN \\
\hline CHEMBL262433 & 809238 & 4.0 & 3.9407 & TRN \\
\hline CHEMBL306380 & 809238 & 4.0 & 4.8684 & TRN \\
\hline CHEMBL1983595 & 809238 & 7.6 & 7.4997 & TRN \\
\hline CHEMBL1966722 & 809238 & 6.1 & 4.7103 & TST \\
\hline CHEMBL1975500 & 809238 & 7.0 & 7.1654 & TRN \\
\hline CHEMBL1988581 & 809238 & 7.4 & 6.7639 & TST \\
\hline CHEMBL394619 & 809238 & 4.0 & 4.3224 & TRN \\
\hline CHEMBL 2006564 & 809238 & 6.3 & 5.8529 & TRN \\
\hline CHEMBL411903 & 809238 & 4.0 & 4.1042 & TRN \\
\hline CHEMBL1965988 & 809238 & 4.0 & 4.7105 & TRN \\
\hline CHEMBL418203 & 809238 & 7.6 & 6.7316 & TST \\
\hline CHEMBL1989646 & 809238 & 6.3 & 6.4309 & TRN \\
\hline CHEMBL209534 & 809238 & 4.0 & 4.2347 & TRN \\
\hline CHEMBL1966087 & 809238 & 4.0 & 4.2261 & TRN \\
\hline CHEMBL1964692 & 809238 & 4.0 & 4.0372 & TRN \\
\hline CHEMBL1973483 & 809238 & 4.0 & 4.4931 & TRN \\
\hline CHEMBL219722 & 809238 & 5.4 & 4.9463 & TRN \\
\hline CHEMBL1970735 & 809238 & 4.0 & 4.0678 & TRN \\
\hline CHEMBL1997340 & 809238 & 4.0 & 4.0409 & TRN \\
\hline CHEMBL458997 & 809238 & 5.5 & 5.8864 & TRN \\
\hline CHEMBL1988805 & 809238 & 5.6 & 5.1908 & TST \\
\hline CHEMBL1971021 & 809238 & 4.0 & 3.8578 & TRN \\
\hline CHEMBL1974310 & 809238 & 6.6 & 6.4947 & TRN \\
\hline CHEMBL583144 & 809238 & 4.0 & 4.751 & TRN \\
\hline CHEMBL1982660 & 809238 & 5.8 & 5.5723 & TRN \\
\hline CHEMBL1982957 & 809238 & 7.2 & 7.0866 & TRN \\
\hline CHEMBL1725279 & 809238 & 6.0 & 6.7258 & TST \\
\hline CHEMBL2006836 & 809238 & 4.0 & 3.5192 & TST \\
\hline CHEMBL412142 & 809238 & 4.0 & 4.7836 & TST \\
\hline CHEMBL 2003271 & 809238 & 5.6 & 5.9042 & TRN \\
\hline CHEMBL1980704 & 809238 & 4.0 & 3.8991 & TST \\
\hline CHEMBL1966808 & 809238 & 4.0 & 3.7168 & TRN \\
\hline CHEMBL260135 & 809238 & 5.5 & 5.6524 & TRN \\
\hline CHEMBL 220241 & 809238 & 4.0 & 3.7376 & TRN \\
\hline CHEMBL 2004544 & 809238 & 4.2 & 4.4526 & TST \\
\hline CHEMBL1988141 & 809238 & 6.5 & 6.0183 & TST \\
\hline CHEMBL1977134 & 809238 & 4.5 & 4.2349 & TRN \\
\hline CHEMBL1970873 & 809238 & 5.3 & 4.4409 & TRN \\
\hline CHEMBL1985206 & 809238 & 6.4 & 4.8361 & TST \\
\hline CHEMBL 2006933 & 809238 & 7.0 & 6.1329 & TST \\
\hline CHEMBL1991078 & 809238 & 7.9 & 7.6781 & TRN \\
\hline CHEMBL1987359 & 809238 & 4.0 & 4.1909 & TST \\
\hline
\end{tabular}




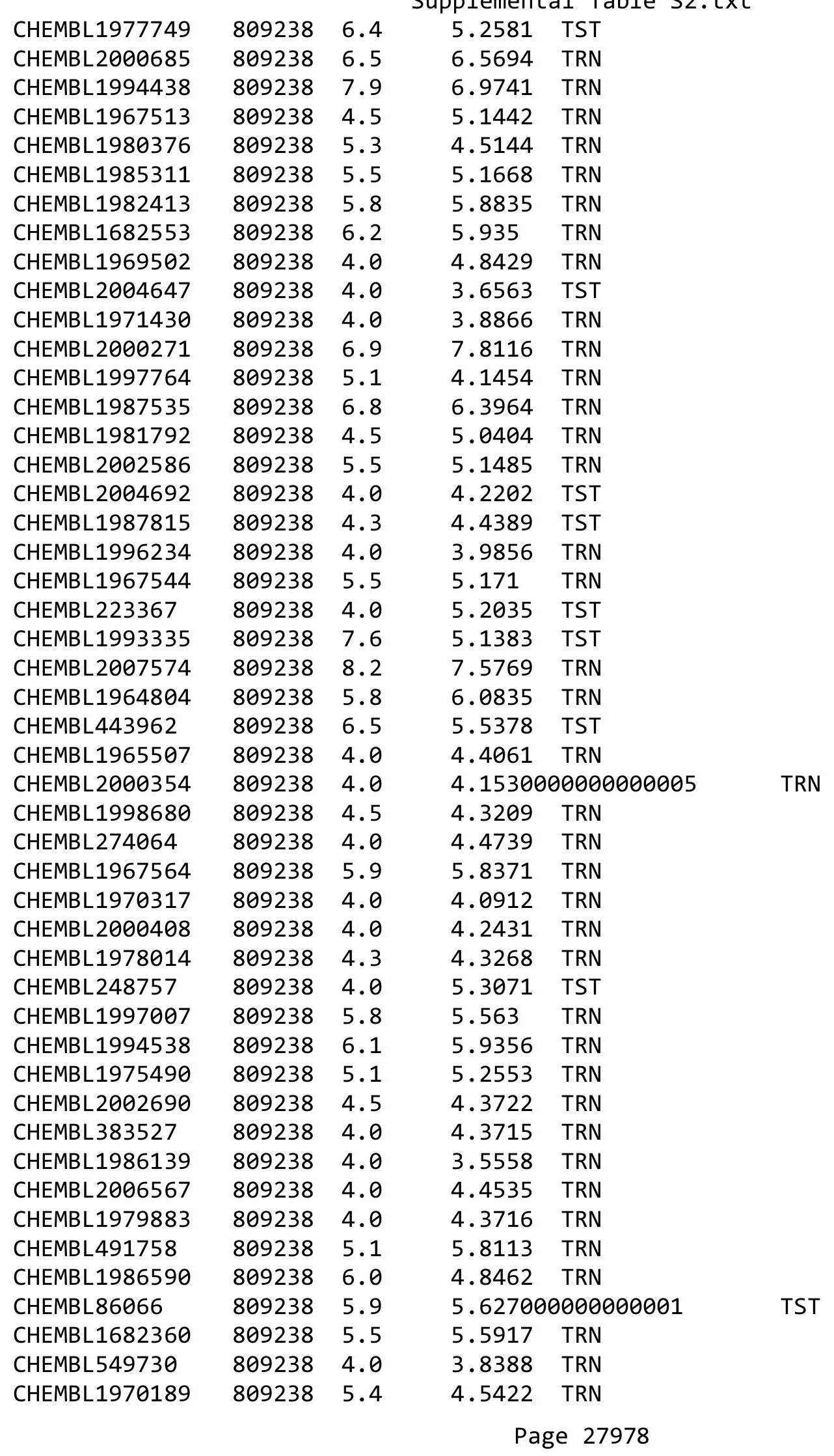




\begin{tabular}{|c|c|c|c|c|c|}
\hline \multicolumn{6}{|c|}{ Supplemental Table S2.txt } \\
\hline CHEMBL406845 & 809238 & 5.5 & 4.6796 & TRN & \\
\hline CHEMBL1974288 & 809238 & 5.2 & 4.6503 & TRN & \\
\hline CHEMBL1964718 & 809238 & 4.3 & 4.8186 & TST & \\
\hline CHEMBL1991410 & 809238 & 4.4 & 4.9786 & TRN & \\
\hline CHEMBL1968705 & 809238 & 4.2 & 4.4642 & TRN & \\
\hline CHEMBL1986684 & 809238 & 6.2 & 4.3956 & TST & \\
\hline CHEMBL1978271 & 809238 & 4.5 & 4.1611 & TRN & \\
\hline CHEMBL 2007266 & 809238 & 4.5 & 4.2968 & TRN & \\
\hline CHEMBL1994308 & 809238 & 4.5 & 4.5418 & TRN & \\
\hline CHEMBL1977604 & 809238 & 4.0 & 3.562 & TST & \\
\hline CHEMBL1974328 & 809238 & 6.5 & 5.8553 & TRN & \\
\hline CHEMBL1988717 & 809238 & 4.0 & 4.0617 & TRN & \\
\hline CHEMBL509032 & 809238 & 7.1 & 6.8707 & TRN & \\
\hline CHEMBL1992342 & 809238 & 5.1 & 5.3891 & TRN & \\
\hline CHEMBL1973013 & 809238 & 7.6 & 6.2009 & TST & \\
\hline CHEMBL1966204 & 809238 & 8.2 & 8.0578 & TRN & \\
\hline CHEMBL1965423 & 809238 & 4.0 & 3.8426 & TRN & \\
\hline CHEMBL205415 & 809238 & 4.2 & 4.6504 & TRN & \\
\hline CHEMBL1977135 & 809238 & 4.0 & 4.1192 & TRN & \\
\hline CHEMBL 2001920 & 809238 & 4.0 & 4.7855 & TRN & \\
\hline CHEMBL1977138 & 809238 & 7.9 & 6.1569 & TST & \\
\hline CHEMBL1241473 & 809238 & 7.6 & 8.3626 & TRN & \\
\hline CHEMBL1978448 & 809238 & 4.2 & 3.6352 & TST & \\
\hline CHEMBL2004513 & 809238 & 5.1 & 4.581 & TRN & \\
\hline CHEMBL1972258 & 809238 & 4.0 & 4.2589 & TRN & \\
\hline CHEMBL 2001257 & 809238 & 4.0 & 4.2089 & TRN & \\
\hline CHEMBL 2004515 & 809238 & 5.5 & 5.1381 & TRN & \\
\hline CHEMBL1980329 & 809238 & 4.5 & 5.4311 & TRN & \\
\hline CHEMBL1971785 & 809238 & 4.2 & 4.6058 & TST & \\
\hline CHEMBL1992042 & 809238 & 4.5 & 5.11600 & 00000000005 & TRN \\
\hline CHEMBL1992536 & 809238 & 4.3 & 4.3003 & TRN & \\
\hline CHEMBL1994724 & 809238 & 4.5 & 5.0013 & TRN & \\
\hline CHEMBL1967531 & 809238 & 4.0 & 4.4247 & TRN & \\
\hline CHEMBL1970913 & 809238 & 6.0 & 5.8438 & TRN & \\
\hline CHEMBL1997534 & 809238 & 6.0 & 6.0224 & TRN & \\
\hline CHEMBL1993877 & 809238 & 7.0 & 6.0309 & TRN & \\
\hline CHEMBL1977374 & 809238 & 4.0 & 3.52 & TRN & \\
\hline CHEMBL1998551 & 809238 & 4.0 & 3.4656 & TRN & \\
\hline CHEMBL2005352 & 809238 & 5.6 & 5.6566 & TRN & \\
\hline CHEMBL1991180 & 809238 & 5.2 & 4.8712 & TST & \\
\hline CHEMBL1978656 & 809238 & 4.0 & 3.8698 & TRN & \\
\hline CHEMBL1976420 & 809238 & 4.6 & 5.9427 & TST & \\
\hline CHEMBL1981744 & 809238 & 4.5 & 4.4508 & TRN & \\
\hline CHEMBL1994864 & 809238 & 4.1 & 4.3235 & TRN & \\
\hline CHEMBL 2002446 & 809238 & 4.0 & 4.2332 & TST & \\
\hline CHEMBL246970 & 809238 & 5.6 & 5.9192 & TRN & \\
\hline CHEMBL340921 & 809238 & 5.7 & 5.728 & TST & \\
\hline CHEMBL 2005478 & 809238 & 5.5 & 5.3911 & TST & \\
\hline
\end{tabular}




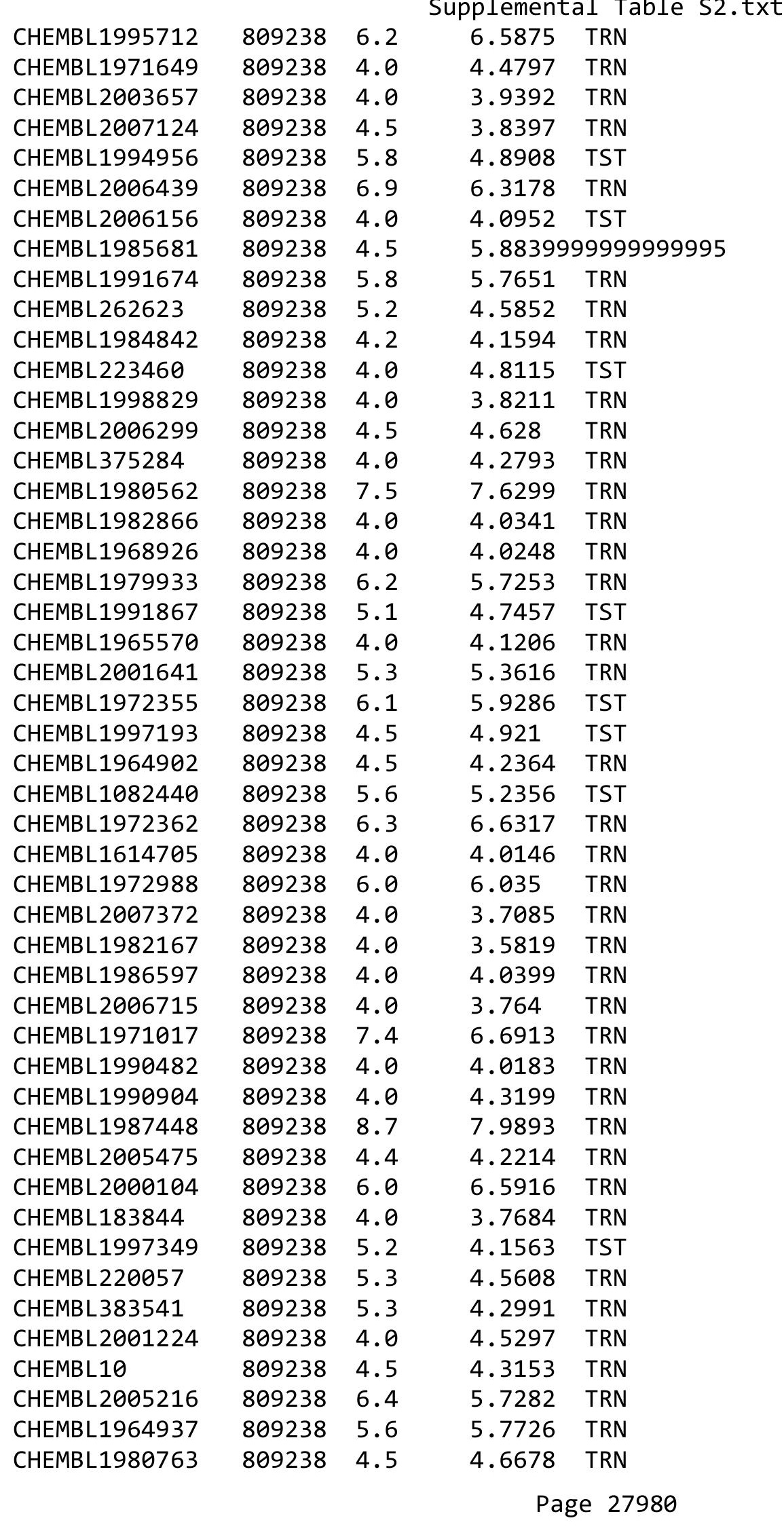




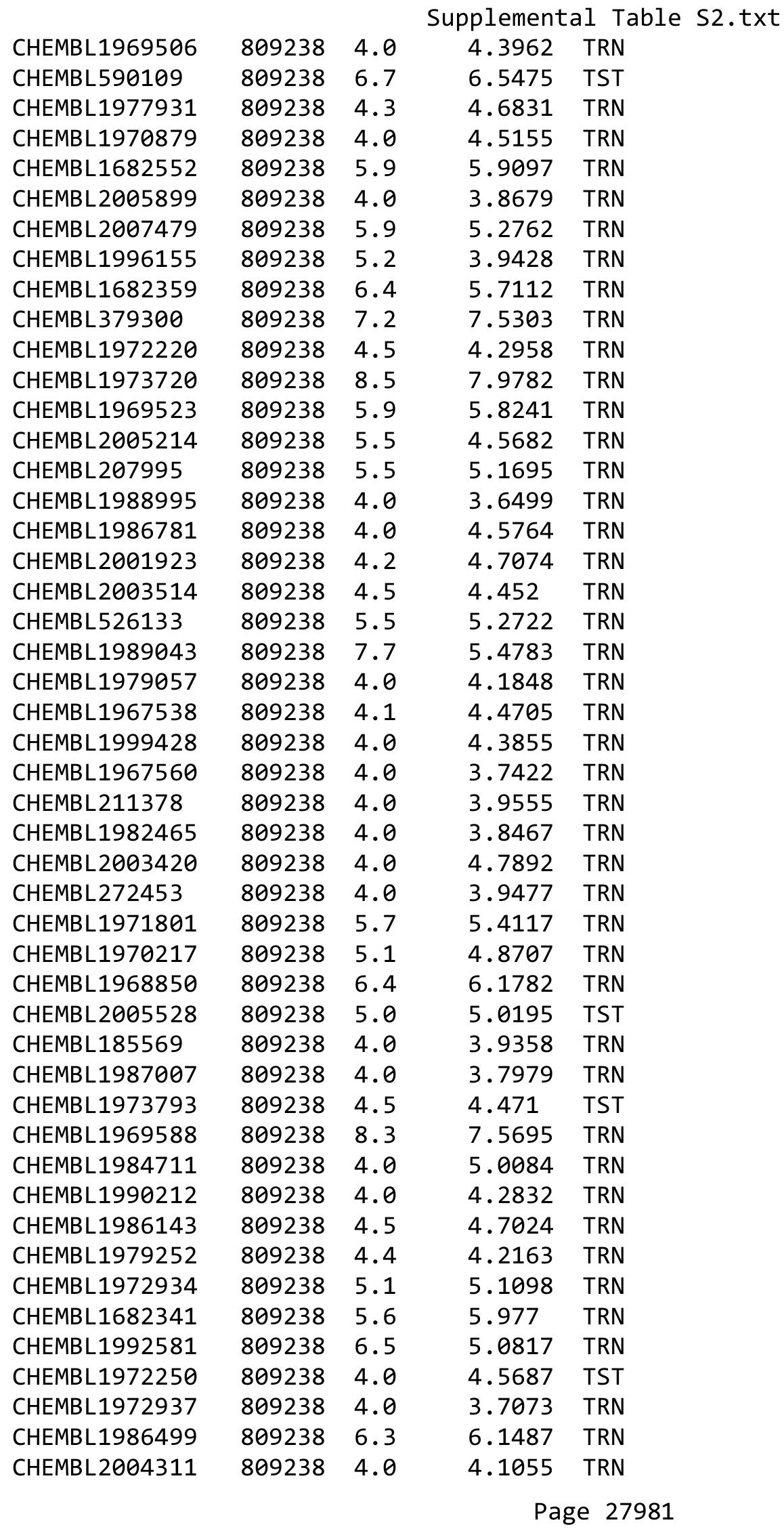




\begin{tabular}{|c|c|c|c|c|c|}
\hline & & & & & \\
\hline CHEMBL1992634 & 809238 & 6.6 & 6.0447 & TRN & \\
\hline CHEMBL316264 & 809238 & 4.0 & 4.1602 & TRN & \\
\hline CHEMBL1996576 & 809238 & 4.5 & 4.4987 & TST & \\
\hline CHEMBL1991678 & 809238 & 4.4 & 4.0368 & TRN & \\
\hline CHEMBL1988594 & 809238 & 4.0 & 4.2072 & TRN & \\
\hline CHEMBL260092 & 809238 & 4.0 & $4.2860 €$ & 00000000005 & TRN \\
\hline CHEMBL1965495 & 809238 & 6.0 & 5.9722 & TRN & \\
\hline CHEMBL1985074 & 809238 & 4.0 & 4.6232 & TST & \\
\hline CHEMBL1982874 & 809238 & 4.0 & 4.0619 & TRN & \\
\hline CHEMBL1991725 & 809238 & 4.0 & 5.4056 & TRN & \\
\hline CHEMBL 2007296 & 809238 & 5.3 & 4.3209 & TRN & \\
\hline CHEMBL396523 & 809238 & 6.8 & 7.2495 & TRN & \\
\hline CHEMBL208637 & 809238 & 4.0 & 4.0057 & TRN & \\
\hline CHEMBL1978371 & 809238 & 4.5 & 5.5489 & TST & \\
\hline CHEMBL 2003952 & 809238 & 4.3 & 4.4285 & TRN & \\
\hline CHEMBL1970203 & 809238 & 4.0 & 4.3785 & TRN & \\
\hline CHEMBL1999749 & 809238 & 4.0 & 3.8164 & TRN & \\
\hline CHEMBL1983006 & 809238 & 4.0 & 4.7166 & TRN & \\
\hline CHEMBL1984191 & 809238 & 4.0 & 4.4237 & TRN & \\
\hline CHEMBL1971029 & 809238 & 7.2 & 7.1833 & TRN & \\
\hline CHEMBL394790 & 809238 & 4.0 & 4.2812 & TRN & \\
\hline CHEMBL226471 & 809238 & 4.0 & 4.6467 & TRN & \\
\hline CHEMBL1966175 & 809238 & 4.5 & 3.766 & TRN & \\
\hline CHEMBL1996111 & 809238 & 5.8 & 5.7159 & TRN & \\
\hline CHEMBL 2007375 & 809238 & 4.5 & 5.2641 & TRN & \\
\hline CHEMBL1965589 & 809238 & 4.0 & 4.3121 & TRN & \\
\hline CHEMBL1998193 & 809238 & 4.0 & 4.7104 & TRN & \\
\hline CHEMBL379975 & 809238 & 6.4 & 5.347 & TST & \\
\hline CHEMBL1973016 & 809238 & 4.5 & 4.3994 & TRN & \\
\hline CHEMBL1988153 & 809238 & 5.6 & 5.3559 & TRN & \\
\hline CHEMBL1968245 & 809238 & 4.0 & 4.2913 & TRN & \\
\hline CHEMBL1233887 & 809238 & 4.5 & 5.1893 & TST & \\
\hline CHEMBL1979577 & 809238 & 4.0 & 4.372 & TRN & \\
\hline CHEMBL1988201 & 809238 & 5.5 & 5.2308 & TST & \\
\hline CHEMBL52387 & 809238 & 6.7 & 5.8626 & TST & \\
\hline CHEMBL1979357 & 809238 & 4.3 & 4.3118 & TRN & \\
\hline CHEMBL1996817 & 809238 & 6.6 & 6.978 & TRN & \\
\hline CHEMBL 2004355 & 809238 & 4.0 & 4.3251 & TRN & \\
\hline CHEMBL256835 & 809238 & 4.0 & 3.8289 & 99999999997 & TRN \\
\hline CHEMBL1980142 & 809238 & 4.0 & 4.1176 & TRN & \\
\hline CHEMBL 2004438 & 809238 & 4.2 & 3.8154 & TRN & \\
\hline CHEMBL41783 & 809238 & 6.0 & 6.1854 & TRN & \\
\hline CHEMBL271381 & 809238 & 4.0 & 3.74 & TRN & \\
\hline CHEMBL1982466 & 809238 & 4.0 & 4.0544 & TRN & \\
\hline CHEMBL1990162 & 809238 & 8.3 & 7.8666 & TRN & \\
\hline CHEMBL1996390 & 809238 & 4.0 & 5.3027 & TRN & \\
\hline CHEMBL1992220 & 809238 & 8.2 & 8.2121 & TRN & \\
\hline CHEMBL 234085 & 809238 & 4.4 & 3.5485 & TRN & \\
\hline & & & & 27982 & \\
\hline
\end{tabular}




\begin{tabular}{|c|c|c|c|c|c|}
\hline \multicolumn{6}{|c|}{ Supplemental Table S2.txt } \\
\hline CHEMBL1998414 & 809238 & 4.0 & 4.1552 & TRN & \\
\hline CHEMBL1969042 & 809238 & 5.3 & 5.3481 & TST & \\
\hline CHEMBL1999931 & 809238 & 8.0 & 8.0584 & TRN & \\
\hline CHEMBL1976376 & 809238 & 4.5 & 4.38 & TRN & \\
\hline CHEMBL1991640 & 809238 & 5.9 & 4.3915 & TST & \\
\hline CHEMBL1968868 & 809238 & 5.9 & 4.8275 & TRN & \\
\hline CHEMBL 2007064 & 809238 & 4.0 & 4.9816 & TRN & \\
\hline CHEMBL1997197 & 809238 & 6.9 & 5.2493 & TRN & \\
\hline CHEMBL1968151 & 809238 & 4.0 & 3.8862 & TRN & \\
\hline CHEMBL1381197 & 809238 & 4.0 & 3.7238 & TRN & \\
\hline CHEMBL1987009 & 809238 & 4.0 & 4.5519 & TRN & \\
\hline CHEMBL 2003817 & 809238 & 5.5 & 5.5665 & TRN & \\
\hline CHEMBL379218 & 809238 & 6.9 & 7.63899 & 9999999999 & TRN \\
\hline CHEMBL1994830 & 809238 & 5.9 & 5.8115 & TST & \\
\hline CHEMBL1987054 & 809238 & 5.6 & 4.3059 & TST & \\
\hline CHEMBL226403 & 809238 & 4.0 & 4.6703 & TST & \\
\hline CHEMBL 2005631 & 809238 & 4.0 & 4.1327 & TST & \\
\hline CHEMBL1995765 & 809238 & 5.2 & 5.0315 & TST & \\
\hline CHEMBL1966279 & 809238 & 4.0 & 4.3784 & TST & \\
\hline CHEMBL1984760 & 809238 & 6.0 & 5.2577 & TST & \\
\hline CHEMBL1991728 & 809238 & 5.7 & 6.0768 & TST & \\
\hline CHEMBL360847 & 809238 & 4.5 & 5.2282 & TST & \\
\hline CHEMBL1995811 & 809238 & 8.0 & 7.4385 & TST & \\
\hline CHEMBL1975787 & 809238 & 6.9 & 6.8451 & TST & \\
\hline CHEMBL 2002407 & 809238 & 5.6 & 4.9858 & TST & \\
\hline CHEMBL1995916 & 809238 & 4.3 & 4.3038 & TST & \\
\hline CHEMBL1972489 & 809238 & 4.0 & 3.9948 & TST & \\
\hline CHEMBL1994074 & 809238 & 4.0 & 4.823 & TST & \\
\hline CHEMBL451401 & 809238 & 4.5 & 5.2179 & TST & \\
\hline CHEMBL1968930 & 809238 & 8.9 & 7.8186 & TST & \\
\hline CHEMBL536151 & 809238 & 4.0 & 4.2822 & TST & \\
\hline CHEMBL1090356 & 809238 & 4.0 & 4.2155 & TST & \\
\hline CHEMBL1986328 & 809238 & 4.0 & 4.1817 & TST & \\
\hline CHEMBL261849 & 809238 & 4.5 & 4.7803 & TST & \\
\hline CHEMBL1982122 & 809238 & 4.0 & 4.7044 & TST & \\
\hline CHEMBL1999112 & 809238 & 4.0 & 4.0529 & TST & \\
\hline CHEMBL1682546 & 809238 & 4.0 & 4.9162 & TST & \\
\hline CHEMBL1996780 & 809238 & 5.3 & 5.2626 & TST & \\
\hline CHEMBL1996066 & 809238 & 4.0 & 4.5405 & TST & \\
\hline CHEMBL 296586 & 809238 & 5.8 & 6.0542 & TST & \\
\hline CHEMBL1993722 & 809238 & 5.4 & 4.9489 & TST & \\
\hline CHEMBL 2006674 & 809238 & 9.5 & 5.3504 & TST & \\
\hline CHEMBL1984236 & 809238 & 5.9 & 4.4744 & TST & \\
\hline CHEMBL202635 & 809238 & 4.0 & 4.5418 & TST & \\
\hline CHEMBL 2002599 & 809238 & 4.5 & 5.8525 & TST & \\
\hline CHEMBL1375640 & 809238 & 4.0 & 5.1304 & TST & \\
\hline CHEMBL249282 & 809238 & 4.0 & 4.335 & TST & \\
\hline CHEMBL1994318 & 809238 & 4.5 & 4.8 & TST & \\
\hline
\end{tabular}




\begin{tabular}{|c|c|c|c|c|c|}
\hline \\
\hline CHEMBL1973711 & 809238 & 5.3 & 3.8957 & TST & \\
\hline CHEMBL1967720 & 809238 & 4.0 & 4.3409 & TST & \\
\hline CHEMBL1969755 & 809238 & 4.0 & 4.0566 & TST & \\
\hline CHEMBL1991138 & 809238 & 4.0 & 4.0352 & TST & \\
\hline CHEMBL1996208 & 809238 & 4.2 & 4.1271 & TST & \\
\hline CHEMBL514499 & 809238 & 4.0 & 3.588 & TST & \\
\hline CHEMBL1970352 & 809238 & 5.7 & 5.6923 & TST & \\
\hline CHEMBL1965631 & 809238 & 7.0 & 7.7374 & TST & \\
\hline CHEMBL1980144 & 809238 & 4.0 & 3.9911 & TST & \\
\hline CHEMBL1991188 & 809238 & 5.6 & 5.13200 & $\partial 000000001$ & TST \\
\hline CHEMBL 377408 & 809238 & 4.0 & 4.2265 & TST & \\
\hline CHEMBL215152 & 809238 & 4.2 & 3.9914 & TST & \\
\hline CHEMBL231209 & 809238 & 4.0 & 4.4586 & TST & \\
\hline CHEMBL2006765 & 809238 & 6.9 & 6.1229 & TST & \\
\hline CHEMBL1976220 & 809238 & 4.0 & 4.4015 & TST & \\
\hline CHEMBL1982383 & 809238 & 4.0 & 3.6715 & TST & \\
\hline CHEMBL17370 & 809238 & 4.0 & 3.9642 & TST & \\
\hline CHEMBL1980246 & 809238 & 6.4 & 5.4906 & TST & \\
\hline CHEMBL1999484 & 809238 & 8.1 & 7.2422 & TST & \\
\hline CHEMBL1997822 & 809238 & 4.0 & 4.03 & TST & \\
\hline CHEMBL1991285 & 809238 & 4.0 & 4.6163 & TST & \\
\hline CHEMBL1984038 & 809238 & 4.2 & 4.9963 & TST & \\
\hline CHEMBL1974416 & 809238 & 5.3 & 4.5056 & TST & \\
\hline CHEMBL1984039 & 809238 & 4.0 & 3.8237 & TST & \\
\hline CHEMBL2004615 & 809238 & 5.1 & 4.8467 & TST & \\
\hline CHEMBL1997872 & 809238 & 4.0 & 3.8606 & TST & \\
\hline CHEMBL150645 & 149384 & 7.7773 & 7.6579 & TRN & \\
\hline CHEMBL152553 & 149384 & 6.8097 & 6.8041 & TRN & \\
\hline CHEMBL150556 & 149384 & 7.5817 & 7.6031 & TRN & \\
\hline CHEMBL153249 & 149384 & 7.4425 & 7.38700 & 00000000005 & TRN \\
\hline CHEMBL346687 & 149384 & 7.4597 & 7.4854 & TRN & \\
\hline CHEMBL153402 & 149384 & 6.4437 & 7.0793 & TST & \\
\hline CHEMBL151138 & 149384 & 6.4089 & 7.1418 & TST & \\
\hline CHEMBL 348703 & 149384 & 7.7328 & 7.7418 & TRN & \\
\hline CHEMBL152883 & 149384 & 6.7873 & 6.8039 & TRN & \\
\hline CHEMBL356005 & 149384 & 7.7033 & 7.7104 & TRN & \\
\hline CHEMBL155453 & 149384 & 6.3809 & 6.3504 & TRN & \\
\hline CHEMBL152266 & 149384 & 7.6819 & 7.705 & TRN & \\
\hline CHEMBL359359 & 149384 & 7.3107 & 7.3959 & TRN & \\
\hline CHEMBL422502 & 149384 & 8.0132 & 7.9992 & TRN & \\
\hline CHEMBL357111 & 149384 & 7.9136 & 7.9861 & TRN & \\
\hline CHEMBL 346634 & 149384 & 7.5751 & 7.4653 & TRN & \\
\hline CHEMBL152861 & 149384 & 7.2644 & 7.2828 & TRN & \\
\hline CHEMBL152882 & 149384 & 7.7959 & 7.7949 & TRN & \\
\hline CHEMBL152886 & 149384 & 8.0177 & 7.9389 & TRN & \\
\hline CHEMBL152862 & 149384 & 6.5388 & 6.5348 & TRN & \\
\hline CHEMBL357254 & 149384 & 7.5867 & 7.6053 & TRN & \\
\hline CHEMBL152286 & 149384 & 7.7122 & 7.7742 & TRN & \\
\hline
\end{tabular}




\begin{tabular}{|c|c|c|c|c|c|c|}
\hline \multirow[b]{2}{*}{ CHEMBL153797 } & \multicolumn{6}{|c|}{ Supplemental Table S2.txt } \\
\hline & 149384 & 7.0862 & 7.0484 & TRN & & \\
\hline CHEMBL356238 & 149384 & 7.0937 & 7.066 & TRN & & \\
\hline CHEMBL152884 & 149384 & 6.6657 & 6.53799 & 99999 & 99 & TST \\
\hline CHEMBL152635 & 149384 & 7.1343 & 7.6132 & TST & & \\
\hline CHEMBL152059 & 149384 & 7.20200 & 000000006 & $\partial 1$ & 7.1353 & TRN \\
\hline CHEMBL152793 & 149384 & 6.8268 & 7.6035 & TST & & \\
\hline CHEMBL124723 & 149384 & 9.0458 & 9.015 & TRN & & \\
\hline CHEMBL152570 & 149384 & 7.3665 & 7.7744 & TST & & \\
\hline CHEMBL346177 & 149384 & 6.5842 & 6.5897 & TRN & & \\
\hline CHEMBL356249 & 149384 & 7.6055 & 7.6039 & TRN & & \\
\hline CHEMBL152620 & 149384 & 8.301 & 8.3445 & TRN & & \\
\hline CHEMBL357756 & 149384 & 7.7825 & 7.7242 & TRN & & \\
\hline CHEMBL152875 & 149384 & 6.4023 & 7.4668 & TST & & \\
\hline CHEMBL422682 & 149384 & 7.6968 & 6.8032 & TST & & \\
\hline CHEMBL153137 & 149384 & 7.2581 & 7.3426 & TRN & & \\
\hline CHEMBL150702 & 149384 & 7.2366 & 7.2648 & TRN & & \\
\hline CHEMBL153430 & 149384 & 7.9431 & 7.9336 & TRN & & \\
\hline CHEMBL345958 & 149384 & 7.3363 & 7.4248 & TRN & & \\
\hline CHEMBL152229 & 149384 & 7.4179 & 6.4764 & TST & & \\
\hline CHEMBL150355 & 149384 & 7.7258 & 7.7588 & TRN & & \\
\hline CHEMBL153507 & 149384 & 8.0555 & 8.0373 & TRN & & \\
\hline CHEMBL151044 & 149384 & 7.3969 & 7.4299 & TRN & & \\
\hline CHEMBL153755 & 149384 & 8.6576 & 8.7132 & TRN & & \\
\hline CHEMBL150301 & 149384 & 7.34200 & $00000000 t$ & 205 & 7.311 & TRN \\
\hline CHEMBL355935 & 149384 & 7.4225 & 7.3597 & TRN & & \\
\hline CHEMBL152251 & 149384 & 7.7799 & 7.845 & TRN & & \\
\hline CHEMBL152845 & 149384 & 6.558 & 7.2444 & TST & & \\
\hline CHEMBL151908 & 149384 & 7.7282 & 7.7145 & TRN & & \\
\hline CHEMBL151514 & 149384 & 8.2291 & 8.0787 & TRN & & \\
\hline CHEMBL357028 & 149384 & 6.9504 & 7.5139 & TST & & \\
\hline CHEMBL421970 & 149384 & 7.1713 & 7.3176 & TST & & \\
\hline CHEMBL152392 & 149384 & 7.1302 & 7.233 & TRN & & \\
\hline CHEMBL345264 & 149384 & 6.6676 & 6.7684 & TRN & & \\
\hline CHEMBL347524 & 149384 & 6.3665 & 6.9711 & TST & & \\
\hline CHEMBL153000 & 149384 & 6.4976 & 7.7288 & TST & & \\
\hline CHEMBL149751 & 149384 & 7.6946 & 7.8325 & TST & & \\
\hline CHEMBL356811 & 149384 & 8.1249 & 8.1322 & TRN & & \\
\hline CHEMBL152052 & 149384 & 6.8474 & 6.767 & TRN & & \\
\hline CHEMBL357948 & 149384 & 7.9914 & 8.0576 & TST & & \\
\hline CHEMBL1336098 & 688487 & 3.4506 & 3.3707 & TRN & & \\
\hline CHEMBL1995800 & 688487 & 3.4506 & 4.0025 & TRN & & \\
\hline CHEMBL1581332 & 688487 & 5.0305 & 4.6057 & TRN & & \\
\hline CHEMBL1374954 & 688487 & 3.4506 & 4.7989 & TRN & & \\
\hline CHEMBL1485064 & 688487 & 4.8725 & 4.5746 & TRN & & \\
\hline CHEMBL1350193 & 688487 & 3.4506 & 3.3763 & TRN & & \\
\hline CHEMBL3208904 & 688487 & 3.4506 & 3.56699 & 99999 & 997 & TRN \\
\hline CHEMBL1602800 & 688487 & 5.34399 & 99999999 & & 5.1118 & TRN \\
\hline CHEMBL1302519 & 688487 & 4.6476 & 5.3651 & TRN & & \\
\hline
\end{tabular}




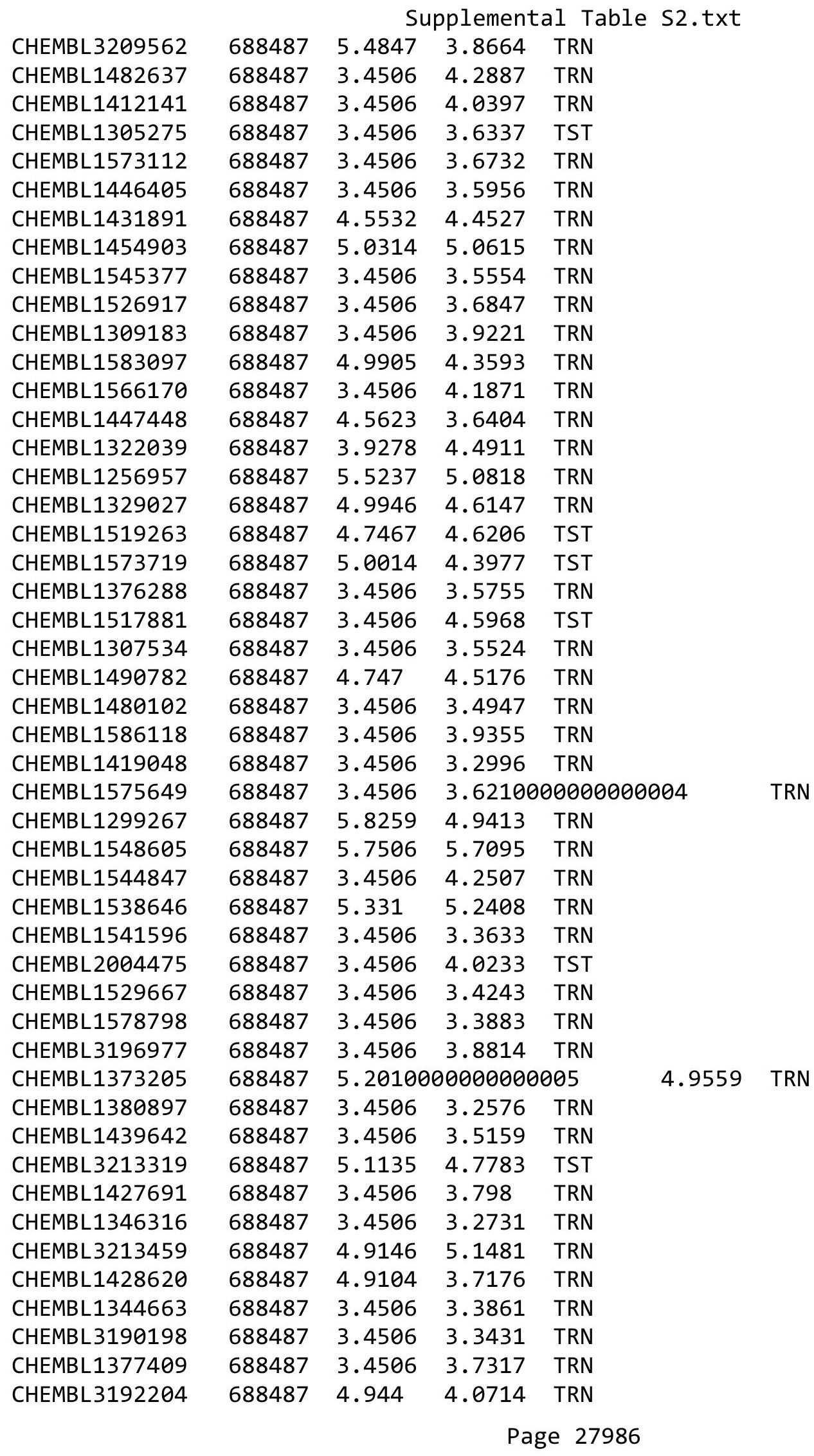




\begin{tabular}{|c|c|c|c|c|c|}
\hline & & \multicolumn{4}{|c|}{ Supplemental Table s2.txt } \\
\hline CHEMBL1431189 & 688487 & 3.4506 & 4.2448 & TRN & \\
\hline CHEMBL1303340 & 688487 & 3.4506 & 3.8476 & TRN & \\
\hline CHEMBL1366987 & 688487 & 4.9095 & 4.4791 & TRN & \\
\hline CHEMBL1418821 & 688487 & 4.8155 & 4.1709 & TRN & \\
\hline CHEMBL1505552 & 688487 & 3.9278 & 4.2659 & TRN & \\
\hline CHEMBL1431391 & 688487 & 3.4506 & 3.6466 & TRN & \\
\hline CHEMBL65374 & 688487 & 3.4506 & 3.9238 & TRN & \\
\hline CHEMBL1335334 & 688487 & 3.4506 & 3.5618 & TST & \\
\hline CHEMBL1311742 & 688487 & 5.1266 & 4.655 & TRN & \\
\hline CHEMBL1595361 & 688487 & 5.0586 & 5.2511 & TRN & \\
\hline CHEMBL1378687 & 688487 & 3.4506 & 4.5348 & TST & \\
\hline CHEMBL1342462 & 688487 & 5.6139 & 5.4093 & TRN & \\
\hline CHEMBL1345141 & 688487 & 4.4048 & 4.2067 & TRN & \\
\hline CHEMBL1452524 & 688487 & 3.4506 & 3.6788 & TST & \\
\hline CHEMBL3194195 & 688487 & 5.1396 & 4.6716 & TRN & \\
\hline CHEMBL1343823 & 688487 & 3.4506 & 4.0625 & TST & \\
\hline CHEMBL1392858 & 688487 & 4.8975 & 4.7802 & TRN & \\
\hline CHEMBL1537587 & 688487 & 3.4506 & 3.6586 & TRN & \\
\hline CHEMBL1331489 & 688487 & 3.4506 & 3.2617 & TRN & \\
\hline CHEMBL1388940 & 688487 & 3.4506 & 4.0774 & TST & \\
\hline CHEMBL1461853 & 688487 & 3.9278 & 3.8556 & TST & \\
\hline CHEMBL3198532 & 688487 & 3.4506 & 3.6537 & TST & \\
\hline CHEMBL1504701 & 688487 & 3.4506 & 4.8085 & TST & \\
\hline CHEMBL1411218 & 688487 & 3.4506 & 3.9932 & TST & \\
\hline CHEMBL1386851 & 688487 & 3.4506 & 4.1159 & TST & \\
\hline CHEMBL1348298 & 688487 & 3.4506 & 4.5022 & TST & \\
\hline CHEMBL1426686 & 688487 & 3.4506 & 3.7306 & TST & \\
\hline CHEMBL3197361 & 688487 & 3.4506 & 4.3934 & TST & \\
\hline CHEMBL1506914 & 688487 & 3.4506 & 4.09399 & 9999999999 & TST \\
\hline CHEMBL1471202 & 688487 & 4.4048 & 4.5392 & TST & \\
\hline CHEMBL1547757 & 688487 & 5.0315 & 4.7984 & TST & \\
\hline CHEMBL3935738 & 1528171 & 8.0555 & 8.2384 & TRN & \\
\hline CHEMBL 3673014 & 1528171 & 6.0 & 6.1137 & TRN & \\
\hline CHEMBL3673016 & 1528171 & 6.0 & 6.0172 & TRN & \\
\hline CHEMBL3673002 & 1528171 & 6.0 & 5.9027 & TRN & \\
\hline CHEMBL 3673027 & 1528171 & 6.0 & 6.0712 & TST & \\
\hline CHEMBL3918071 & 1528171 & 8.1367 & 8.2146 & TRN & \\
\hline CHEMBL3959892 & 1528171 & 7.7399 & 7.7858 & TRN & \\
\hline CHEMBL 3672999 & 1528171 & 6.0 & 5.96 & TRN & \\
\hline CHEMBL3942310 & 1528171 & 7.5467 & 7.6243 & TST & \\
\hline CHEMBL3908142 & 1528171 & 7.5376 & 7.5037 & TRN & \\
\hline CHEMBL3672991 & 1528171 & 6.0 & 5.943 & TRN & \\
\hline CHEMBL3968339 & 1528171 & 8.7959 & 8.7983 & TRN & \\
\hline CHEMBL3953501 & 1528171 & 8.4949 & 8.3874 & TRN & \\
\hline CHEMBL3949788 & 1528171 & 8.28399 & 99999999 & 8.1843 & TRN \\
\hline CHEMBL3889470 & 1528171 & 8.1249 & 8.1406 & TRN & \\
\hline CHEMBL3672948 & 1528171 & 6.0 & 5.8776 & TRN & \\
\hline CHEMBL3673026 & 1528171 & 6.0 & 5.8989 & TST & \\
\hline
\end{tabular}




\begin{tabular}{|c|c|c|c|c|c|}
\hline \multicolumn{6}{|c|}{ Supplemental Table S2.txt } \\
\hline CHEMBL3672997 & 1528171 & 6.0 & 5.91 & TRN & \\
\hline CHEMBL 3672975 & 1528171 & 5.6825 & 5.8035 & TRN & \\
\hline CHEMBL3673019 & 1528171 & 6.0 & 6.0696 & TRN & \\
\hline CHEMBL 3937657 & 1528171 & 8.0223 & 8.0766 & TRN & \\
\hline CHEMBL3672996 & 1528171 & 6.0 & 6.0597 & TRN & \\
\hline CHEMBL3907918 & 1528171 & 7.9788 & 7.8357 & TRN & \\
\hline CHEMBL3672998 & 1528171 & 8.699 & 8.6378 & TRN & \\
\hline CHEMBL3978596 & 1528171 & 7.1878 & 7.1394 & TRN & \\
\hline CHEMBL 3970300 & 1528171 & 7.0701 & 6.893 & TRN & \\
\hline CHEMBL3672982 & 1528171 & 8.3665 & 8.3603 & TRN & \\
\hline CHEMBL 3672983 & 1528171 & 8.8239 & 8.6608 & TRN & \\
\hline CHEMBL 3673025 & 1528171 & 6.0 & 6.1387 & TST & \\
\hline CHEMBL3982016 & 1528171 & 7.6289 & 7.6405 & TRN & \\
\hline CHEMBL 3672985 & 1528171 & 7.7852 & 7.7748 & TRN & \\
\hline CHEMBL3673005 & 1528171 & 6.0 & 6.0426 & TRN & \\
\hline CHEMBL3672980 & 1528171 & 8.5376 & 8.6213 & TRN & \\
\hline CHEMBL3962712 & 1528171 & 7.3809 & 7.44 & TRN & \\
\hline CHEMBL3672967 & 1528171 & 6.0 & 6.1935 & TST & \\
\hline CHEMBL3672959 & 1528171 & 6.0 & 6.0485 & TRN & \\
\hline CHEMBL3952952 & 1528171 & 8.0132 & 7.6791 & TRN & \\
\hline CHEMBL3898640 & 1528171 & 8.2676 & 8.2889 & TRN & \\
\hline CHEMBL3672962 & 1528171 & 6.0 & 6.2125 & TST & \\
\hline CHEMBL 3673007 & 1528171 & 6.0 & 5.8208 & TRN & \\
\hline CHEMBL 3673022 & 1528171 & 6.0 & 5.996 & TRN & \\
\hline CHEMBL3672954 & 1528171 & 6.0 & 5.9936 & TRN & \\
\hline CHEMBL3672956 & 1528171 & 6.0 & 6.3317 & TST & \\
\hline CHEMBL3944115 & 1528171 & 6.8526 & 6.9519 & TRN & \\
\hline CHEMBL3948104 & 1528171 & 7.5867 & 8.1416 & TST & \\
\hline CHEMBL 3958528 & 1528171 & 7.5952 & 7.5796 & TRN & \\
\hline CHEMBL3944200 & 1528171 & 8.8539 & 8.9489 & TRN & \\
\hline CHEMBL 3914844 & 1528171 & 7.0737 & 7.068 & TST & \\
\hline CHEMBL3941658 & 1528171 & 7.8386 & 7.7774 & TST & \\
\hline CHEMBL 3673028 & 1528171 & 6.0 & 8.1439 & TST & \\
\hline CHEMBL 3672994 & 1528171 & 6.0 & 6.01399 & 9999999999 & TRN \\
\hline CHEMBL3970091 & 1528171 & 8.1249 & 8.2049 & TRN & \\
\hline CHEMBL 3981464 & 1528171 & 8.3188 & 8.3604 & TRN & \\
\hline CHEMBL3911357 & 1528171 & 8.1308 & 8.1402 & TRN & \\
\hline CHEMBL3672973 & 1528171 & 6.0 & 6.2614 & TST & \\
\hline CHEMBL3672989 & 1528171 & 6.0 & 6.0346 & TRN & \\
\hline CHEMBL3673035 & 1528171 & 6.0 & 6.4478 & TST & \\
\hline CHEMBL3974007 & 1528171 & 7.6946 & 7.6734 & TRN & \\
\hline CHEMBL3672966 & 1528171 & 6.0 & 6.404 & TST & \\
\hline CHEMBL3973594 & 1528171 & 7.38399 & 99999999 & 7.6509 & TST \\
\hline CHEMBL 3672946 & 1528171 & 6.0 & 6.2853 & TST & \\
\hline CHEMBL3672979 & 1528171 & 6.0 & 6.03700 & 0000000001 & TRN \\
\hline CHEMBL3673039 & 1528171 & 6.0 & 6.2191 & TRN & \\
\hline CHEMBL3672958 & 1528171 & 6.0 & 6.03600 & 00000000005 & TRN \\
\hline CHEMBL3673012 & 1528171 & 6.0 & 5.9885 & TRN & \\
\hline
\end{tabular}


Supplemental Table S2.txt

\begin{tabular}{|c|c|c|c|c|c|}
\hline CHEMBL 3935827 & 1528171 & 8.1549 & 7.9683 & TRN & \\
\hline CHEMBL3672987 & 1528171 & 6.0 & 5.9937 & TRN & \\
\hline CHEMBL3672952 & 1528171 & 6.0 & 6.0245 & TRN & \\
\hline CHEMBL3672976 & 1528171 & 8.6198 & 8.6154 & TRN & \\
\hline CHEMBL3673001 & 1528171 & 6.0 & 6.0445 & TRN & \\
\hline CHEMBL3673042 & 1528171 & 6.0 & 5.9735 & TRN & \\
\hline CHEMBL3672977 & 1528171 & 6.0 & 6.0787 & TRN & \\
\hline CHEMBL3898894 & 1528171 & 8.1739 & 8.3489 & TRN & \\
\hline CHEMBL3672950 & 1528171 & 6.0 & 5.8763 & TRN & \\
\hline CHEMBL3673044 & 1528171 & 6.0 & 5.9653 & TRN & \\
\hline CHEMBL 3898424 & 1528171 & 8.0555 & 8.1153 & TRN & \\
\hline CHEMBL 3673034 & 1528171 & 6.0 & 6.3233 & TST & \\
\hline CHEMBL3673004 & 1528171 & 8.5086 & 8.5448 & TRN & \\
\hline CHEMBL3672986 & 1528171 & 6.0 & \multicolumn{2}{|c|}{6.122000000000001} & TRN \\
\hline CHEMBL3920284 & 1528171 & 7.3179 & 7.5933 & TST & \\
\hline CHEMBL3672971 & 1528171 & 7.8539 & 7.4697 & TST & \\
\hline CHEMBL3971126 & 1528171 & 7.2907 & 6.8507 & TST & \\
\hline CHEMBL 3672984 & 1528171 & 7.5528 & 7.5581 & TRN & \\
\hline CHEMBL3969821 & 1528171 & 8.585 & 8.7291 & TRN & \\
\hline CHEMBL3931156 & 1528171 & 8.0969 & 8.0276 & TRN & \\
\hline CHEMBL3893232 & 1528171 & 8.2007 & 7.8935 & TST & \\
\hline CHEMBL3983785 & 1528171 & 8.8861 & 8.7793 & TRN & \\
\hline CHEMBL3958742 & 1528171 & 8.0315 & 7.7586 & TST & \\
\hline CHEMBL3959004 & 1528171 & 8.3768 & 7.1756 & TST & \\
\hline CHEMBL3982218 & 1528171 & 8.7212 & 8.726 & TRN & \\
\hline CHEMBL3671527 & 1528897 & 7.3468 & 7.7717 & TRN & \\
\hline CHEMBL3671519 & 1528897 & 7.4089 & 7.2741 & TRN & \\
\hline CHEMBL 3671528 & 1528897 & 6.7033 & \multicolumn{2}{|c|}{7.0520000000000005} & TRN \\
\hline CHEMBL3671521 & 1528897 & 6.8928 & 7.4103 & TRN & \\
\hline CHEMBL3671506 & 1528897 & 7.6021 & 7.7825 & TRN & \\
\hline CHEMBL3671576 & 1528897 & 7.3468 & 7.0844 & TRN & \\
\hline CHEMBL 3671550 & 1528897 & 7.4437 & 7.7393 & TST & \\
\hline CHEMBL 3671478 & 1528897 & 7.8239 & 7.3802 & TST & \\
\hline CHEMBL3671538 & 1528897 & 7.6778 & 7.3228 & TRN & \\
\hline CHEMBL3671536 & 1528897 & 7.1549 & 7.1806 & TRN & \\
\hline CHEMBL3671573 & 1528897 & 7.8539 & 6.7571 & TRN & \\
\hline CHEMBL3676365 & 1528897 & 7.3872 & 7.6142 & TRN & \\
\hline CHEMBL3676346 & 1528897 & 6.0487 & 6.7162 & TRN & \\
\hline CHEMBL3671511 & 1528897 & 7.699 & 7.4482 & TRN & \\
\hline CHEMBL3676356 & 1528897 & 6.4935 & 8.2575 & TST & \\
\hline CHEMBL3671507 & 1528897 & 7.585 & 7.6862 & TRN & \\
\hline CHEMBL3671515 & 1528897 & 7.2291 & 7.7178 & TRN & \\
\hline CHEMBL3676359 & 1528897 & 7.3979 & 7.5581 & TRN & \\
\hline CHEMBL3671508 & 1528897 & 7.0088 & 7.364 & TRN & \\
\hline CHEMBL 3671578 & 1528897 & 6.9031 & 7.6447 & TST & \\
\hline CHEMBL3676357 & 1528897 & 8.3979 & 8.2032 & TRN & \\
\hline CHEMBL3671568 & 1528897 & 6.0 & 6.572 & TST & \\
\hline CHEMBL3676354 & 1528897 & 7.8861 & 8.3 & TRN & \\
\hline
\end{tabular}


Supplemental Table S2.txt

\begin{tabular}{|c|c|c|c|c|c|}
\hline CHEMBL 3671567 & 1528897 & 5.7091 & 6.3569 & TRN & \\
\hline CHEMBL 3671560 & 1528897 & 6.5302 & 7.6693 & TST & \\
\hline CHEMBL 3671563 & 1528897 & 7.4437 & 7.2516 & TRN & \\
\hline CHEMBL 3671581 & 1528897 & 7.7447 & 8.0175 & TRN & \\
\hline CHEMBL3676352 & 1528897 & 7.3768 & 6.9401 & TRN & \\
\hline CHEMBL 3676387 & 1528897 & 7.699 & 7.1883 & TST & \\
\hline CHEMBL 3676366 & 1528897 & 6.6716 & 7.4238 & TRN & \\
\hline CHEMBL 3676379 & 1528897 & 7.2441 & 7.1386 & TRN & \\
\hline CHEMBL 3671501 & 1528897 & 7.6383 & 7.5281 & TRN & \\
\hline CHEMBL3671542 & 1528897 & 6.9914 & 7.5817 & TRN & \\
\hline CHEMBL 3676373 & 1528897 & 6.6536 & 7.1521 & TST & \\
\hline CHEMBL 3671534 & 1528897 & 6.5884 & 7.0714 & TRN & \\
\hline CHEMBL 3671548 & 1528897 & 6.4101 & 6.865 & TST & \\
\hline CHEMBL 3676386 & 1528897 & 7.1675 & 7.7067 & TRN & \\
\hline CHEMBL3676378 & 1528897 & 7.6383 & 7.4587 & TST & \\
\hline CHEMBL 3671499 & 1528897 & 8.301 & 7.6963 & TRN & \\
\hline CHEMBL 3676388 & 1528897 & 7.0605 & 7.3898 & TRN & \\
\hline CHEMBL 3671554 & 1528897 & 7.585 & 8.0448 & TRN & \\
\hline CHEMBL 3671585 & 1528897 & 6.3778 & 7.6283 & TRN & \\
\hline CHEMBL 3671540 & 1528897 & 6.8069 & 7.2358 & TRN & \\
\hline CHEMBL 3671577 & 1528897 & 7.4949 & 7.0907 & TRN & \\
\hline CHEMBL 3676355 & 1528897 & 8.0458 & 7.6491 & TRN & \\
\hline CHEMBL 3671513 & 1528897 & 7.7212 & 7.8597 & TRN & \\
\hline CHEMBL 3671571 & 1528897 & 7.9208 & 6.872999 & و999999999 & TRN \\
\hline CHEMBL 3671490 & 1528897 & 8.5229 & 7.9518 & TRN & \\
\hline CHEMBL 3671537 & 1528897 & 6.1858 & 6.9596 & TRN & \\
\hline CHEMBL 3671561 & 1528897 & 7.7696 & 7.3814 & TST & \\
\hline CHEMBL 3671579 & 1528897 & 6.0057 & 6.9884 & TRN & \\
\hline CHEMBL 3671500 & 1528897 & 8.5229 & 7.9737 & TRN & \\
\hline CHEMBL 3671479 & 1528897 & 8.5229 & 7.2878 & TST & \\
\hline CHEMBL 3671480 & 1528897 & 7.2518 & 7.8557 & TST & \\
\hline CHEMBL 3676345 & 1528897 & 7.7212 & 7.0329 & TRN & \\
\hline CHEMBL 3676343 & 1528897 & 6.75700 & 00000000 & 7.3003 & TRN \\
\hline CHEMBL 3676392 & 1528897 & 6.0195 & 7.5839 & TST & \\
\hline CHEMBL 3671529 & 1528897 & 7.0506 & 7.3092 & TRN & \\
\hline CHEMBL 3671493 & 1528897 & 8.0 & 7.6164 & TRN & \\
\hline CHEMBL 3676367 & 1528897 & 7.9208 & 7.1538 & TRN & \\
\hline CHEMBL 3671476 & 1528897 & 7.3279 & 7.3388 & TST & \\
\hline CHEMBL 3671555 & 1528897 & 7.5376 & 7.4728 & TRN & \\
\hline CHEMBL 3671475 & 1528897 & 8.5229 & 7.4993 & TST & \\
\hline CHEMBL 3676370 & 1528897 & 7.6778 & 7.3531 & TRN & \\
\hline CHEMBL 3676389 & 1528897 & 7.7447 & 7.4966 & TRN & \\
\hline CHEMBL 3676349 & 1528897 & 7.0969 & 7.6327 & TRN & \\
\hline CHEMBL 3671558 & 1528897 & 7.0269 & 6.9557 & TST & \\
\hline CHEMBL 3671488 & 1528897 & 7.2291 & 7.5496 & TRN & \\
\hline CHEMBL 3671543 & 1528897 & 6.5918 & 7.2615 & TRN & \\
\hline CHEMBL 3676372 & 1528897 & 7.1249 & 7.1148 & TRN & \\
\hline CHEMBL 3671533 & 1528897 & 8.0458 & 7.4141 & TRN & \\
\hline
\end{tabular}


Supplemental Table S2.txt

\begin{tabular}{|c|c|c|c|c|}
\hline 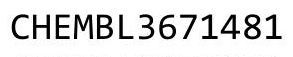 & & & & \\
\hline HEMBL3676350 & 528897 & $\partial 991$ & 7.1673 & \\
\hline HEMBL 367 & 528897 & 7.7959 & 5439 & \\
\hline IEMBL & 897 & 088 & & \\
\hline 1497 & 28897 & 3979 & & \\
\hline HEMBL3676394 & 528897 & 6.8268 & 2504 & \\
\hline HEMBL3671570 & 528897 & 8.1549 & .9667 & \\
\hline HEMBL3671523 & 528897 & 7212 & 8364 & \\
\hline 5341 & 528897 & 8.301 & .996 & \\
\hline IEMBL & 897 & 7.8539 & 8919 & \\
\hline HEMBL3671491 & 528897 & 8.699 & 6932 & \\
\hline HEMBL3676338 & 528897 & 6.0343 & 2915 & \\
\hline HEMBL3671564 & 528897 & 561 & 7869 & \\
\hline HEMBL36 & 528897 & 85 & 3095 & \\
\hline HEMBL & 397 & 99 & 505 & \\
\hline HEMBL36 & 897 & 85 & 2121 & \\
\hline HEMBL3671492 & 528897 & 458 & 9695 & \\
\hline HEMBL; & 397 & 25 & 709 & \\
\hline HEMBL & 97 & 768 & & \\
\hline HEMBL & 97 & 861 & & \\
\hline HEMBL36 & 397 & 212 & 865 & \\
\hline HEMBL3671525 & 897 & 437 & & \\
\hline HEMBL & 97 & 098 & 672 & \\
\hline HEMBL & & 86 & 48 & \\
\hline 531 & 97 & 565 & 533 & RN \\
\hline HEMBL36 & 97 & 861 & 9986 & RN \\
\hline AEMBL36 & 397 & 675 & 3121 & RN \\
\hline HEMBL3 & 397 & 979 & 3547 & $\mathrm{RN}$ \\
\hline HEM & 97 & 79 & 327 & RN \\
\hline 74 & & 198 & 5023 & ST \\
\hline HEMBL36 & 97 & 996 & 064 & \\
\hline HEMBL 3671484 & 897 & 8.2218 & 5885 & ST \\
\hline HEMBL3 & 397 & 239 & 095 & RN \\
\hline 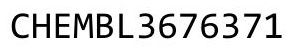 & 97 & & 06 & RN \\
\hline HEMBL3 & & 39 & 251 & ST \\
\hline HEMBL3671580 & 397 & 208 & & RN \\
\hline HEMBL3671505 & 897 & 7.6021 & 3405 & RN \\
\hline HEMBL3E & 397 & 914 & 167 & RIV \\
\hline HIM & & & & SI \\
\hline HEMBL36 & & 447 & 7.2282 & RN \\
\hline HEMBL3671562 & 528897 & 7.3279 & 429 & ST \\
\hline HEMBL36 & 397 & 12 & 964 & RN \\
\hline HEMBL 36 & 1528897 & & 7.1958 & \\
\hline CHEMBL 3671524 & & & .2572 & RN \\
\hline HEMBL3676340 & & 7.6576 & 7.5941 & RN \\
\hline HEMBL3671503 & 1528897 & 7.0177 & 7931 & RN \\
\hline CHEMBL 36715 & & & & \\
\hline סגריב יחנזו & & & & \\
\hline
\end{tabular}

Page 27991 
Supplemental Table S2.txt

\begin{tabular}{|c|c|c|c|c|}
\hline CHEMBL 3671520 & 1528897 & 7.6198 & 7.3102 & TRN \\
\hline CHEMBL 3676347 & 1528897 & 6.2457 & 6.9094 & TRN \\
\hline CHEMBL3671516 & 1528897 & 6.9626 & 7.4585 & TST \\
\hline CHEMBL3671495 & 1528897 & 8.301 & 7.5357 & TRN \\
\hline CHEMBL3671504 & 1528897 & 7.0458 & 8.0032 & TRN \\
\hline CHEMBL 3671545 & 1528897 & 6.4881 & 6.9616 & TRN \\
\hline CHEMBL3676351 & 1528897 & 5.0 & 6.6893 & TRN \\
\hline CHEMBL3676369 & 1528897 & 7.7959 & 7.7062 & TRN \\
\hline CHEMBL3671512 & 1528897 & 7.5376 & 7.7079 & TRN \\
\hline CHEMBL3676362 & 1528897 & 7.8539 & 8.1931 & TRN \\
\hline CHEMBL3671535 & 1528897 & 6.8013 & \multicolumn{2}{|c|}{7.547999999999999} \\
\hline CHEMBL 3671518 & 1528897 & 7.4949 & 7.4438 & TRN \\
\hline CHEMBL 3671565 & 1528897 & 7.1192 & 6.9941 & TRN \\
\hline CHEMBL3671557 & 1528897 & 7.3979 & 7.7748 & TRN \\
\hline CHEMBL3671496 & 1528897 & 8.699 & 7.8087 & TRN \\
\hline CHEMBL3676391 & 1528897 & 6.6091 & 7.4603 & TST \\
\hline CHEMBL3671530 & 1528897 & 6.9031 & 7.3057 & TRN \\
\hline CHEMBL3676339 & 1528897 & 7.8539 & 7.5702 & TRN \\
\hline CHEMBL3671498 & 1528897 & 8.699 & 7.3432 & TRN \\
\hline CHEMBL3671572 & 1528897 & 7.4949 & 7.0029 & TRN \\
\hline CHEMBL3639752 & 1528897 & 7.9208 & 7.3912 & TRN \\
\hline CHEMBL3676361 & 1528897 & 7.8861 & 7.9174 & TRN \\
\hline CHEMBL3671509 & 1528897 & 7.041 & 7.4611 & TRN \\
\hline CHEMBL3676385 & 1528897 & 7.585 & 7.9946 & TRN \\
\hline CHEMBL 3671514 & 1528897 & 7.4559 & 7.4968 & TRN \\
\hline CHEMBL 3671574 & 1528897 & 7.6021 & 6.7916 & TST \\
\hline CHEMBL3671575 & 1528897 & 6.7077 & 6.6961 & TST \\
\hline CHEMBL3671549 & 1528897 & 7.1079 & 7.1667 & TRN \\
\hline CHEMBL3671517 & 1528897 & 7.8539 & 7.2671 & TRN \\
\hline CHEMBL 3676368 & 1528897 & 7.5528 & 7.4598 & TRN \\
\hline CHEMBL 3671532 & 1528897 & 6.8665 & 7.3139 & TRN \\
\hline CHEMBL3671494 & 1528897 & 8.0969 & 7.2265 & TRN \\
\hline CHEMBL 3671559 & 1528897 & 6.8928 & 6.7548 & TST \\
\hline CHEMBL3676364 & 1528897 & 8.1549 & 7.564 & TRN \\
\hline CHEMBL 3671510 & 1528897 & 7.4437 & 7.3445 & TRN \\
\hline CHEMBL3671569 & 1528897 & 6.4342 & 6.7243 & TST \\
\hline CHEMBL3676348 & 1528897 & 7.1871 & 7.3781 & TST \\
\hline CHEMBL3676381 & 1528897 & 7.0088 & 7.7604 & TRN \\
\hline CHEMBL3671486 & 1528897 & 8.699 & 7.4171 & TRN \\
\hline CHEMBL 3671556 & 1528897 & 7.1612 & 7.83 & TST \\
\hline CHEMBL3676360 & 1528897 & 8.0458 & 7.6681 & TRN \\
\hline CHEMBL 3676384 & 1528897 & 8.0969 & 8.1083 & TST \\
\hline CHEMBL3676342 & 1528897 & 6.0575 & 7.4245 & TST \\
\hline CHEMBL3671544 & 1528897 & 6.6003 & 7.3328 & TST \\
\hline CHEMBL3671539 & 1528897 & 7.0506 & 7.37 & TST \\
\hline CHEMBL336704 & 207997 & 3.5229 & 3.5371 & TRN \\
\hline CHEMBL130443 & 207997 & 7.0 & 6.9859 & TRN \\
\hline CHEMBL336977 & 207997 & 5.4935 & 5.2079 & TRN \\
\hline
\end{tabular}




\begin{tabular}{|c|c|c|c|c|c|}
\hline \multicolumn{6}{|c|}{ Supplemental Table S2.txt } \\
\hline CHEMBL336273 & 207997 & 3.0 & 5.4591 & TST & \\
\hline CHEMBL335076 & 207997 & 6.0 & 6.2501 & TRN & \\
\hline CHEMBL133006 & 207997 & 4.7484 & 4.7594 & TRN & \\
\hline CHEMBL130808 & 207997 & 3.5229 & 5.1897 & TST & \\
\hline CHEMBL335187 & 207997 & 6.1427 & 6.1699 & TRN & \\
\hline CHEMBL77076 & 207997 & 3.0 & 3.3212 & TRN & \\
\hline CHEMBL131436 & 207997 & 3.5229 & 3.5359 & TRN & \\
\hline CHEMBL133069 & 207997 & 3.0 & 4.4468 & TST & \\
\hline CHEMBL341487 & 207997 & 5.0969 & 5.0385 & TRN & \\
\hline CHEMBL337678 & 207997 & 6.0506 & 5.9628 & TRN & \\
\hline CHEMBL130067 & 207997 & 5.0 & 4.9446 & TRN & \\
\hline CHEMBL131831 & 207997 & 5.0 & 5.0037 & TRN & \\
\hline CHEMBL338322 & 207997 & 5.0655 & 5.0757 & TRN & \\
\hline CHEMBL336768 & 207997 & 3.5229 & 3.3374 & TRN & \\
\hline CHEMBL133623 & 207997 & 5.1175 & 5.1451 & TRN & \\
\hline CHEMBL75084 & 207997 & 6.7959 & 6.9207 & TRN & \\
\hline CHEMBL335484 & 207997 & 6.699 & 6.6019 & TRN & \\
\hline CHEMBL133174 & 207997 & 3.5229 & 3.5898 & TRN & \\
\hline CHEMBL130346 & 207997 & 8.3979 & 8.3558 & TRN & \\
\hline CHEMBL129926 & 207997 & 3.5229 & 3.81100 & 00000000004 & TRN \\
\hline CHEMBL131326 & 207997 & 6.5229 & 6.7306 & TST & \\
\hline CHEMBL128685 & 207997 & 4.5544 & 4.5936 & TRN & \\
\hline CHEMBL133110 & 207997 & 3.0 & 5.3048 & TST & \\
\hline CHEMBL131472 & 207997 & 3.5229 & 4.2092 & TST & \\
\hline CHEMBL127554 & 207997 & 6.9586 & 6.9311 & TRN & \\
\hline CHEMBL131473 & 207997 & 5.5528 & 5.561 & TRN & \\
\hline CHEMBL337214 & 207997 & 3.5229 & 3.4334 & TRN & \\
\hline CHEMBL130228 & 207997 & 3.5229 & 3.5904 & TRN & \\
\hline CHEMBL131554 & 207997 & 3.5229 & 3.5296 & TRN & \\
\hline CHEMBL130603 & 207997 & 4.9469 & 4.9537 & TRN & \\
\hline CHEMBL444600 & 207997 & 5.1561 & 4.9149 & TRN & \\
\hline CHEMBL133456 & 207997 & 3.5229 & 4.8607 & TST & \\
\hline CHEMBL130537 & 207997 & 5.3979 & 5.4721 & TRN & \\
\hline CHEMBL339732 & 207997 & 4.8239 & 4.8579 & TRN & \\
\hline CHEMBL131250 & 207997 & 5.284 & 5.2997 & TRN & \\
\hline CHEMBL133404 & 207997 & 5.9208 & 5.8986 & TRN & \\
\hline CHEMBL131190 & 207997 & 6.8239 & 6.0761 & TST & \\
\hline CHEMBL133383 & 207997 & 4.7282 & 4.7781 & TRN & \\
\hline CHEMBL132042 & 207997 & 3.5229 & 3.528 & TRN & \\
\hline CHEMBL131521 & 207997 & 4.699 & 3.7979 & TST & \\
\hline CHEMBL130202 & 207997 & 3.0 & 5.185 & TST & \\
\hline CHEMBL133273 & 207997 & 3.5229 & 3.46100 & 00000000003 & TRN \\
\hline CHEMBL129894 & 207997 & 3.0 & 3.929 & TST & \\
\hline CHEMBL338952 & 207997 & 5.1487 & 5.1228 & TRN & \\
\hline CHEMBL130447 & 207997 & 5.0969 & 3.6151 & TST & \\
\hline CHEMBL130178 & 207997 & 5.3979 & 5.2983 & TRN & \\
\hline CHEMBL436370 & 207997 & 5.0605 & 5.0698 & TRN & \\
\hline CHEMBL130371 & 207997 & 4.8861 & 4.9418 & TRN & \\
\hline
\end{tabular}


Supplemental Table S2.txt

\begin{tabular}{|c|c|c|c|c|c|}
\hline CHEMBL127553 & 207997 & 5.5229 & 5.5572 & TRN & \\
\hline CHEMBL335186 & 207997 & 3.5229 & 3.4446 & TRN & \\
\hline CHEMBL133007 & 207997 & 4.5467 & 4.5633 & TRN & \\
\hline CHEMBL131400 & 207997 & 4.699 & 4.7497 & TRN & \\
\hline CHEMBL339164 & 207997 & 8.3979 & 8.3369 & TRN & \\
\hline CHEMBL412136 & 207997 & 7.0 & 7.0562 & TRN & \\
\hline CHEMBL132051 & 207997 & 5.9208 & 5.8685 & TRN & \\
\hline CHEMBL133683 & 207997 & 4.6271 & 4.6058 & TRN & \\
\hline CHEMBL338615 & 207997 & 4.4318 & 4.4892 & TRN & \\
\hline CHEMBL130897 & 207997 & 5.699 & 5.7449 & TRN & \\
\hline CHEMBL131884 & 207997 & 3.5229 & 3.5104 & TRN & \\
\hline CHEMBL132151 & 207997 & 6.0458 & 5.9392 & TRN & \\
\hline CHEMBL424264 & 207997 & 8.3979 & 8.4304 & TRN & \\
\hline CHEMBL336144 & 207997 & 6.5229 & 6.5849 & TRN & \\
\hline CHEMBL335491 & 207997 & 6.0088 & 6.0316 & TRN & \\
\hline CHEMBL133125 & 207997 & 5.9586 & 6.0017 & TRN & \\
\hline CHEMBL335755 & 207997 & 5.5086 & 4.9032 & TST & \\
\hline CHEMBL422079 & 207997 & 5.4815 & 5.4785 & TRN & \\
\hline CHEMBL337278 & 207997 & 5.6778 & 5.661006 & 00000000005 & TRN \\
\hline CHEMBL131947 & 207997 & 5.4559 & 5.4581 & TRN & \\
\hline CHEMBL336074 & 207997 & 4.7235 & 4.7425 & TRN & \\
\hline CHEMBL131878 & 207997 & 5.3372 & 5.3899 & TRN & \\
\hline CHEMBL423521 & 207997 & 5.0 & 4.9703 & TRN & \\
\hline CHEMBL335406 & 207997 & 6.2366 & 6.2527 & TRN & \\
\hline CHEMBL132845 & 207997 & 3.5229 & 2.5584 & TST & \\
\hline CHEMBL130702 & 207997 & 4.7011 & 3.9934 & TST & \\
\hline CHEMBL127389 & 207997 & 3.5229 & 3.4608 & TRN & \\
\hline CHEMBL130812 & 207997 & 5.6778 & 5.6636 & TRN & \\
\hline CHEMBL335171 & 207997 & 5.0 & 5.0262 & TRN & \\
\hline CHEMBL340945 & 207997 & 5.2007 & 5.1699 & TRN & \\
\hline CHEMBL131490 & 207997 & 4.6904 & 4.4635 & TRN & \\
\hline CHEMBL132855 & 207997 & 7.2218 & 7.2516 & TRN & \\
\hline CHEMBL130100 & 207997 & 6.5229 & 6.5811 & TRN & \\
\hline CHEMBL128284 & 207997 & 5.9586 & 5.915 & TRN & \\
\hline CHEMBL130815 & 207997 & 5.3915 & 5.388 & TRN & \\
\hline CHEMBL338869 & 207997 & 5.3565 & 5.4288 & TST & \\
\hline CHEMBL131056 & 207997 & 6.0 & 5.3452 & TST & \\
\hline CHEMBL130166 & 207997 & 5.0969 & 5.7421 & TST & \\
\hline CHEMBL130120 & 207997 & 5.0 & 4.746 & TST & \\
\hline CHEMBL131601 & 207997 & 5.284 & 5.3797 & TST & \\
\hline CHEMBL130287 & 207997 & 4.7825 & 4.9779 & TST & \\
\hline CHEMBL133009 & 207997 & 5.3716 & 4.4987 & TST & \\
\hline CHEMBL339692 & 207997 & 5.699 & 6.9861 & TST & \\
\hline CHEMBL131559 & 207997 & 3.5229 & 6.1572 & TST & \\
\hline CHEMBL199641 & 329662 & 2.73 & 3.8658 & TST & \\
\hline CHEMBL437135 & 329662 & 2.07 & 2.0786 & TRN & \\
\hline CHEMBL 373246 & 329662 & 3.78 & \multicolumn{2}{|c|}{3.7910000000000004} & TST \\
\hline CHEMBL425928 & 329662 & 2.4 & 3.2975 & TST & \\
\hline
\end{tabular}




\begin{tabular}{|c|c|c|c|c|c|}
\hline CHEMBL199401 & 329662 & 3.0 & \multicolumn{2}{|c|}{3.7689999999999997} & TST \\
\hline CHEMBL199804 & 329662 & 4.29 & 4.2925 & TRN & \\
\hline CHEMBL382762 & 329662 & 3.79 & 4.0463 & TST & \\
\hline CHEMBL154793 & 329662 & 3.34 & 4.1 & TST & \\
\hline CHEMBL372487 & 329662 & 4.61 & 4.6838 & TRN & \\
\hline CHEMBL190043 & 329662 & 4.34 & \multicolumn{2}{|c|}{4.4830000000000005} & TRN \\
\hline CHEMBL371117 & 329662 & 4.91 & 4.8905 & TRN & \\
\hline CHEMBL353091 & 329662 & 4.53 & 4.5495 & TRN & \\
\hline CHEMBL202764 & 329662 & 4.21 & 4.2872 & TRN & \\
\hline CHEMBL201031 & 329662 & 3.11 & 5.0524 & TRN & \\
\hline CHEMBL200051 & 329662 & 4.28 & 5.0524 & TRN & \\
\hline CHEMBL381905 & 329662 & 5.94 & 5.0524 & TRN & \\
\hline CHEMBL199336 & 329662 & 5.89 & 5.0524 & TRN & \\
\hline CHEMBL192510 & 329662 & 3.23 & 3.4859 & TRN & \\
\hline CHEMBL193218 & 329662 & 3.72 & 3.6694 & TRN & \\
\hline CHEMBL363868 & 329662 & 5.52 & 5.0524 & TRN & \\
\hline CHEMBL192401 & 329662 & 3.62 & 3.4859 & TRN & \\
\hline CHEMBL370513 & 329662 & 3.75 & 3.6694 & TRN & \\
\hline CHEMBL426628 & 329662 & 5.49 & 5.0524 & TRN & \\
\hline CHEMBL191837 & 329662 & 5.35 & 5.0524 & TRN & \\
\hline CHEMBL377287 & 329662 & 4.91 & 4.8592 & TRN & \\
\hline CHEMBL191683 & 329662 & 3.0 & 2.9489 & TRN & \\
\hline CHEMBL434163 & 329662 & 3.43 & 3.4575 & TRN & \\
\hline CHEMBL371140 & 329662 & 3.85 & 3.8936 & TRN & \\
\hline CHEMBL364312 & 329662 & 4.09 & \multicolumn{2}{|c|}{3.9810000000000003} & TRN \\
\hline CHEMBL201171 & 329662 & 4.34 & 4.2442 & TRN & \\
\hline CHEMBL169721 & 329662 & 4.68 & 4.8871 & TRN & \\
\hline CHEMBL365188 & 329662 & 3.96 & 3.9104 & TRN & \\
\hline CHEMBL301920 & 329662 & 3.27 & 3.5613 & TST & \\
\hline CHEMBL371659 & 329662 & 4.3 & 4.169 & TRN & \\
\hline CHEMBL197659 & 329662 & 5.0 & 4.8621 & TRN & \\
\hline CHEMBL49614 & 329662 & 4.73 & 4.8213 & TRN & \\
\hline CHEMBL199555 & 329662 & 4.13 & 4.1233 & TRN & \\
\hline CHEMBL199864 & 329662 & 3.98 & 4.3775 & TRN & \\
\hline CHEMBL199863 & 329662 & 4.31 & 4.3775 & TRN & \\
\hline CHEMBL372745 & 329662 & 3.52 & 3.5159 & TRN & \\
\hline CHEMBL380690 & 329662 & 3.79 & 3.778 & TRN & \\
\hline CHEMBL51191 & 329662 & 3.3 & 3.927 & TRN & \\
\hline CHEMBL201588 & 329662 & 3.62 & 4.0655 & TRN & \\
\hline CHEMBL48487 & 329662 & 4.89 & 4.9186 & TRN & \\
\hline CHEMBL45797 & 329662 & 4.87 & 4.3775 & TRN & \\
\hline CHEMBL49407 & 329662 & 4.56 & 3.927 & TRN & \\
\hline CHEMBL199915 & 329662 & 4.31 & 4.0655 & TRN & \\
\hline CHEMBL198339 & 329662 & 5.12 & 4.3775 & TST & \\
\hline CHEMBL295546 & 329662 & 5.02 & 4.3775 & TST & \\
\hline CHEMBL299218 & 329662 & 4.53 & 4.2191 & TST & \\
\hline CHEMBL190411 & 329662 & 4.71 & 4.3957 & TST & \\
\hline CHEMBL201125 & 329662 & 4.99 & 4.6495 & TST & \\
\hline
\end{tabular}




\begin{tabular}{|c|c|c|c|c|c|c|}
\hline \multicolumn{7}{|c|}{ Supplemental Table S2.txt } \\
\hline CHEMBL49393 & 329662 & 4.29 & 4.2484 & TST & & \\
\hline CHEMBL380808 & 329662 & 3.76 & 3.6146 & TST & & \\
\hline CHEMBL135561 & 954388 & 4.5666 & 4.5641 & TRN & & \\
\hline CHEMBL189584 & 954388 & 4.1896 & 4.2003 & TRN & & \\
\hline CHEMBL1357247 & 954388 & 3.735 & 3.7443 & TRN & & \\
\hline CHEMBL222102 & 954388 & 3.8583 & 3.8816 & TRN & & \\
\hline CHEMBL1788116 & 954388 & 4.82100 & 00000000 & & 4.809 & TRN \\
\hline CHEMBL1590308 & 954388 & 2.5242 & 3.4431 & TST & & \\
\hline CHEMBL 210618 & 954388 & 4.6423 & 4.6389 & TRN & & \\
\hline CHEMBL240954 & 954388 & 3.6525 & 3.483 & TST & & \\
\hline CHEMBL 2134202 & 954388 & 3.7696 & 3.7629 & TRN & & \\
\hline CHEMBL449158 & 954388 & 6.2587 & 6.0199 & TST & & \\
\hline CHEMBL300389 & 954388 & 6.2002 & 6.1964 & TRN & & \\
\hline CHEMBL3349342 & 954388 & 3.6997 & 3.7014 & TRN & & \\
\hline CHEMBL379975 & 954388 & 4.3395 & 4.3398 & TRN & & \\
\hline CHEMBL217354 & 954388 & 5.3076 & 5.3004 & TRN & & \\
\hline CHEMBL373751 & 954388 & 3.363 & 3.3948 & TRN & & \\
\hline CHEMBL1190711 & 954388 & 4.4643 & 4.4726 & TRN & & \\
\hline CHEMBL209148 & 954388 & 2.6371 & 2.6347 & TRN & & \\
\hline CHEMBL512504 & 954388 & 4.4644 & 4.4705 & TRN & & \\
\hline CHEMBL3199475 & 954388 & 4.897 & 4.8954 & TRN & & \\
\hline CHEMBL509032 & 954388 & 4.71899 & 99999999 & 99 & 4.7049 & TRN \\
\hline CHEMBL3392440 & 954388 & 3.6549 & 3.6565 & TRN & & \\
\hline CHEMBL483847 & 954388 & 3.9268 & 3.9262 & TRN & & \\
\hline CHEMBL483849 & 954388 & 2.4347 & 2.5157 & TST & & \\
\hline CHEMBL191334 & 954388 & 5.1312 & 5.1483 & TRN & & \\
\hline CHEMBL577784 & 954388 & 4.3482 & 4.3499 & TRN & & \\
\hline CHEMBL192566 & 954388 & 6.8322 & 6.2577 & TST & & \\
\hline CHEMBL573107 & 954388 & 4.2053 & 4.1991 & TRN & & \\
\hline CHEMBL 1242367 & 954388 & 3.2284 & 3.2165 & TRN & & \\
\hline CHEMBL1643959 & 954388 & 2.9829 & 2.9745 & TRN & & \\
\hline CHEMBL 2005886 & 954388 & 3.84899 & 99999999 & 998 & 3.8478 & TRN \\
\hline CHEMBL102714 & 954388 & 3.1435 & 3.1446 & TRN & & \\
\hline CHEMBL220241 & 954388 & 4.1525 & 4.1638 & TRN & & \\
\hline CHEMBL 379300 & 954388 & 5.7293 & 5.711 & TRN & & \\
\hline CHEMBL 2137530 & 954388 & 4.9086 & 4.926 & TRN & & \\
\hline CHEMBL258844 & 954388 & 4.9388 & 4.9239 & TRN & & \\
\hline CHEMBL514499 & 954388 & 4.4551 & 4.4529 & TRN & & \\
\hline CHEMBL392695 & 954388 & 4.2582 & 4.2771 & TRN & & \\
\hline CHEMBL 9470 & 954388 & 5.8617 & 4.8062 & TST & & \\
\hline CHEMBL259181 & 954388 & 3.0805 & 3.0886 & TRN & & \\
\hline CHEMBL221137 & 954388 & 4.6823 & 4.2791 & TST & & \\
\hline CHEMBL1970879 & 954388 & 3.3024 & 3.3096 & TRN & & \\
\hline CHEMBL92309 & 954388 & 3.4823 & 2.8824 & TST & & \\
\hline CHEMBL515416 & 954388 & 4.7795 & 4.7763 & TRN & & \\
\hline CHEMBL1230020 & 954388 & 4.2856 & 4.2952 & TRN & & \\
\hline CHEMBL412142 & 954388 & 4.2875 & 4.2727 & TRN & & \\
\hline CHEMBL202721 & 954388 & 4.5611 & 4.5507 & TRN & & \\
\hline
\end{tabular}




\begin{tabular}{|c|c|c|c|c|c|}
\hline & & & & & \\
\hline CHEMBL65 & 954388 & 6.8257 & 6.8426 & TRN & \\
\hline CHEMBL472940 & 954388 & 2.7165 & 2.7092 & TRN & \\
\hline CHEMBL255342 & 954388 & 3.6151 & 3.5799 & TRN & \\
\hline CHEMBL213100 & 954388 & 3.2477 & 3.2533 & TRN & \\
\hline CHEMBL585951 & 954388 & 6.205 & 6.2097 & TRN & \\
\hline CHEMBL399530 & 954388 & 3.92 & 3.9136 & TRN & \\
\hline CHEMBL1516890 & 954388 & 3.864 & 3.85100 & 00000000004 & TRN \\
\hline CHEMBL188678 & 954388 & 4.2985 & 4.2843 & TRN & \\
\hline CHEMBL558642 & 954388 & 3.6861 & 3.6817 & TRN & \\
\hline CHEMBL1404918 & 954388 & 2.8104 & 2.8238 & TRN & \\
\hline CHEMBL1256459 & 954388 & 4.8226 & 4.8425 & TST & \\
\hline CHEMBL1909414 & 954388 & 3.6149 & 4.1169 & TST & \\
\hline CHEMBL1673039 & 954388 & 3.8292 & 4.0129 & TST & \\
\hline CHEMBL1186585 & 954388 & 3.3953 & 4.1135 & TST & \\
\hline CHEMBL 3186408 & 954388 & 3.0336 & 3.7017 & TST & \\
\hline CHEMBL2144069 & 954388 & 3.4819 & 4.228 & TST & \\
\hline CHEMBL180127 & 954388 & 3.0077 & 3.7638 & TST & \\
\hline CHEMBL2363137 & 954388 & 5.0721 & 4.4188 & TST & \\
\hline CHEMBL393929 & 954388 & 3.9772 & 4.0559 & TST & \\
\hline CHEMBL3651594 & 1535209 & 4.4353 & 4.1527 & TRN & \\
\hline CHEMBL 3655333 & 1535209 & 4.4012 & 4.1669 & TRN & \\
\hline CHEMBL3655321 & 1535209 & 4.7375 & 4.3687 & TRN & \\
\hline CHEMBL3651586 & 1535209 & 5.9031 & 5.5915 & TRN & \\
\hline CHEMBL3651585 & 1535209 & 5.0458 & 5.4898 & TRN & \\
\hline CHEMBL3655329 & 1535209 & 3.3979 & 4.128 & TRN & \\
\hline CHEMBL3655322 & 1535209 & 4.6091 & 4.1862 & TRN & \\
\hline CHEMBL 3651582 & 1535209 & 3.301 & 4.2191 & TRN & \\
\hline CHEMBL3651593 & 1535209 & 5.4949 & 5.3133 & TRN & \\
\hline CHEMBL 3655323 & 1535209 & 3.3979 & 4.3206 & TRN & \\
\hline CHEMBL3651597 & 1535209 & 4.5331 & 4.678 & TRN & \\
\hline CHEMBL 3651600 & 1535209 & 4.3936 & 4.1546 & TRN & \\
\hline CHEMBL3651598 & 1535209 & 4.7399 & 4.436 & TRN & \\
\hline CHEMBL 3655327 & 1535209 & 5.3768 & 4.6933 & TRN & \\
\hline CHEMBL 3655331 & 1535209 & 4.4841 & 4.3178 & TRN & \\
\hline CHEMBL3651577 & 1535209 & 3.3979 & 4.2678 & TRN & \\
\hline CHEMBL3655326 & 1535209 & 3.3979 & 3.7813 & TRN & \\
\hline CHEMBL 3651589 & 1535209 & 5.6198 & 5.6248 & TRN & \\
\hline CHEMBL3651563 & 1535209 & 3.0 & 4.2154 & TST & \\
\hline CHEMBL 3651590 & 1535209 & 5.4089 & 5.6137 & TRN & \\
\hline CHEMBL3651583 & 1535209 & 5.1549 & 4.505 & TRN & \\
\hline CHEMBL 3651576 & 1535209 & 3.3979 & 4.1892 & TRN & \\
\hline CHEMBL 3651568 & 1535209 & 3.301 & 4.2764 & TST & \\
\hline CHEMBL 3651567 & 1535209 & 3.3768 & 4.1164 & TRN & \\
\hline CHEMBL 3655334 & 1535209 & 4.7399 & 4.5987 & TRN & \\
\hline CHEMBL3651561 & 1535209 & 4.1192 & 4.3101 & TST & \\
\hline CHEMBL 3655332 & 1535209 & 4.6108 & 4.5105 & TRN & \\
\hline CHEMBL 3651579 & 1535209 & 3.0 & 4.1694 & TST & \\
\hline CHEMBL3651588 & 1535209 & 5.3979 & 5.4197 & TRN & \\
\hline
\end{tabular}

Page 27997 
Supplemental Table S2.txt

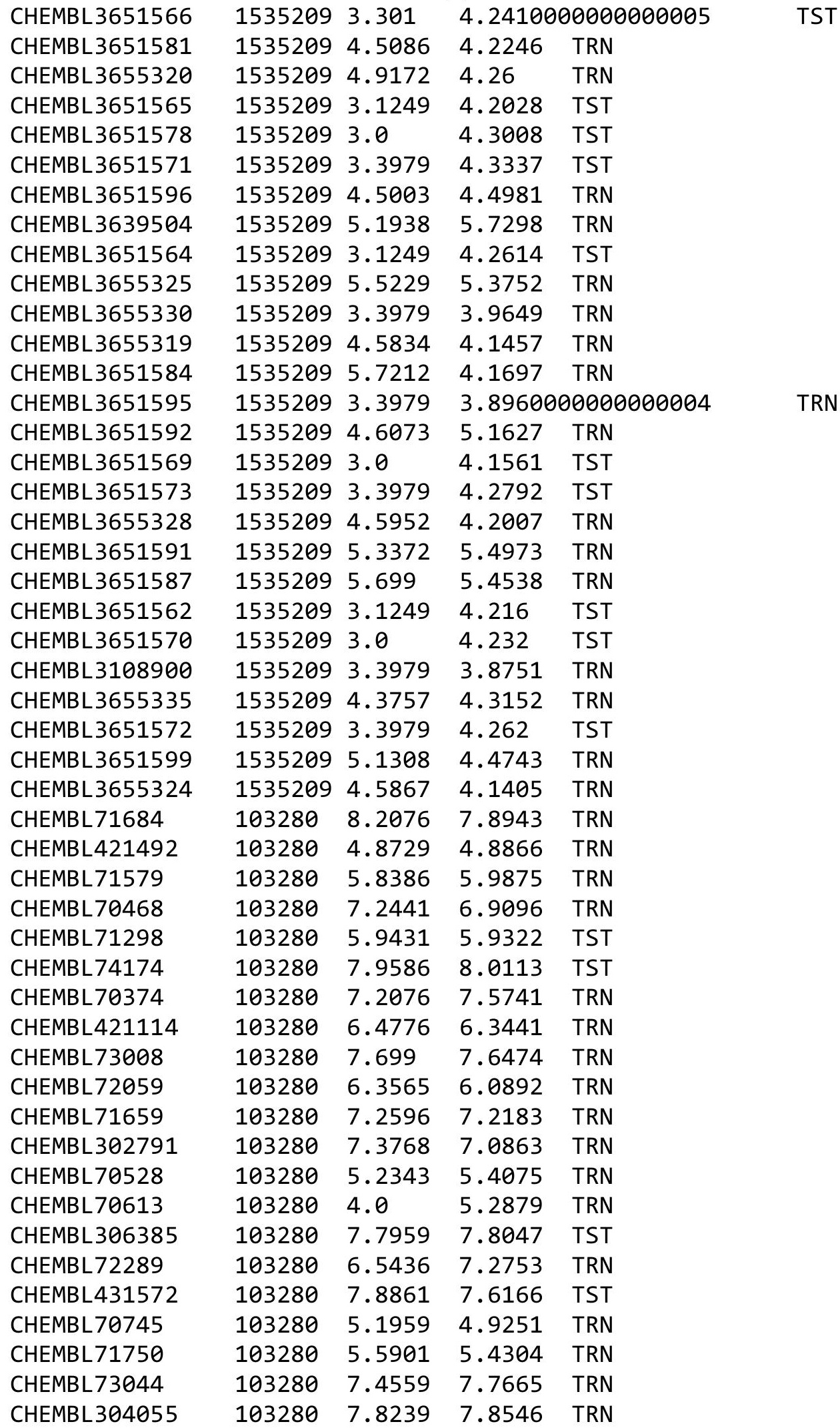

Page 27998 


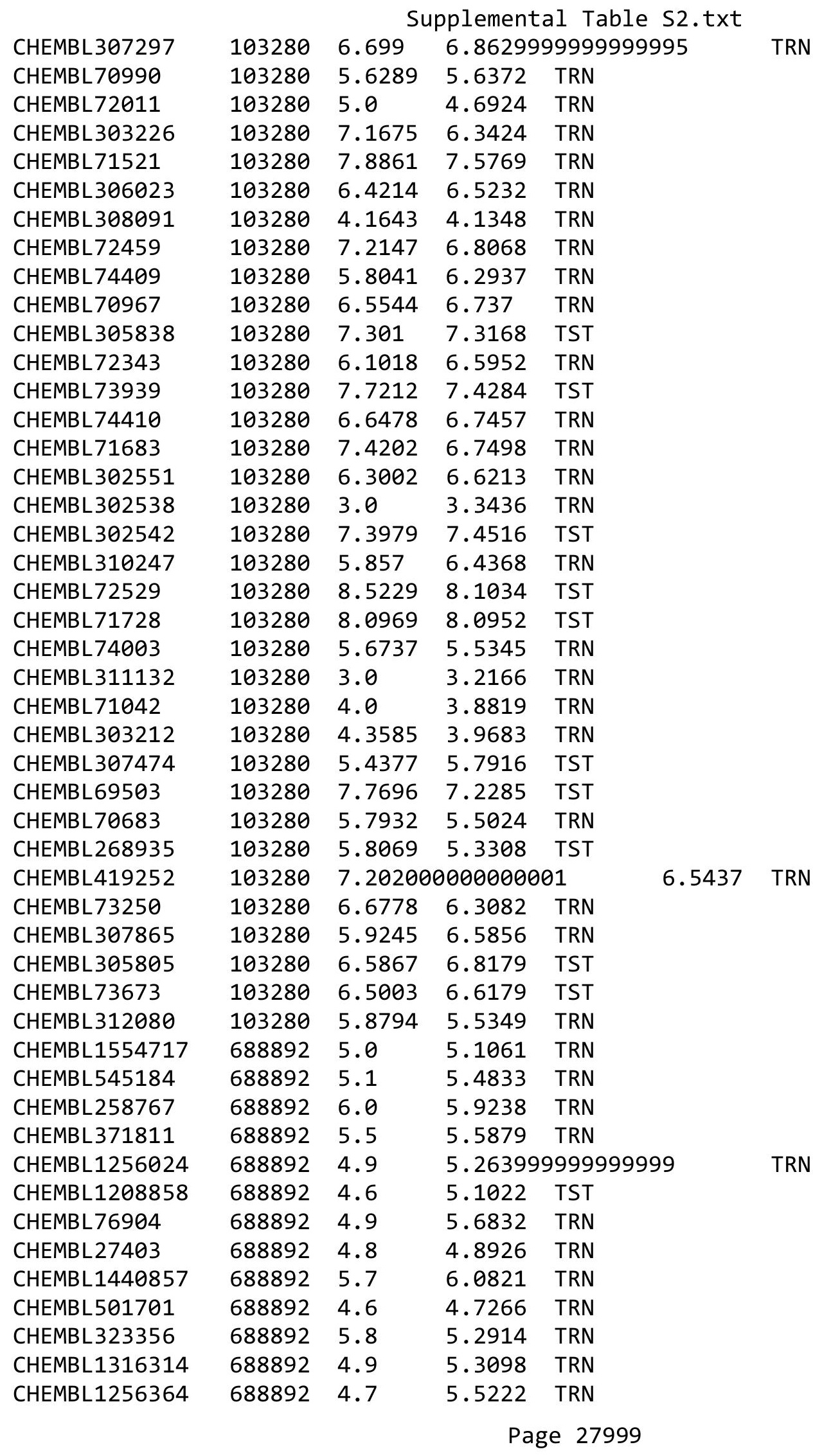




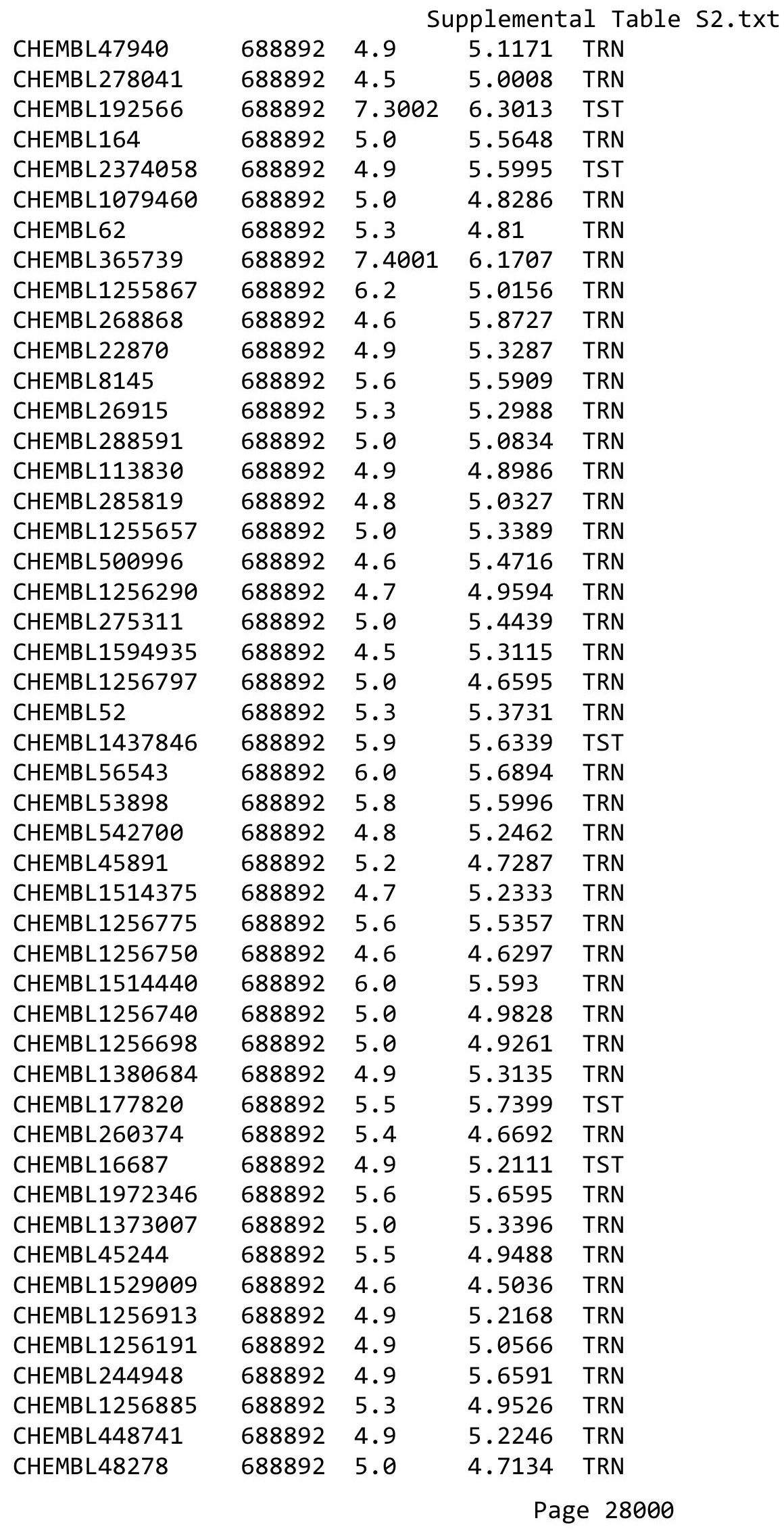




\begin{tabular}{|c|c|c|c|c|c|}
\hline \multicolumn{6}{|c|}{ splemental } \\
\hline CHEMBL587714 & 688892 & 4.9 & 5.0315 & TRN & \\
\hline CHEMBL1521453 & 688892 & 5.3 & 5.6863 & TST & \\
\hline CHEMBL1365553 & 688892 & 6.3 & 5.8969 & TRN & \\
\hline CHEMBL2374259 & 688892 & 4.9 & 4.9413 & TRN & \\
\hline CHEMBL1335406 & 688892 & 4.9 & 5.0558 & TRN & \\
\hline CHEMBL 26320 & 688892 & 4.9 & 4.8254 & TRN & \\
\hline CHEMBL19439 & 688892 & 6.1 & 5.3656 & TRN & \\
\hline CHEMBL319244 & 688892 & 6.6 & 5.9041 & TRN & \\
\hline CHEMBL1527722 & 688892 & 6.9 & 5.3367 & TRN & \\
\hline CHEMBL297784 & 688892 & 6.0 & 5.1334 & TRN & \\
\hline CHEMBL188 & 688892 & 4.9 & 5.1653 & TRN & \\
\hline CHEMBL391997 & 688892 & 5.0 & 4.6579 & TRN & \\
\hline CHEMBL328710 & 688892 & 7.2 & 6.6196 & TRN & \\
\hline CHEMBL109037 & 688892 & 4.9 & 5.2194 & TRN & \\
\hline CHEMBL30432 & 688892 & 5.0 & 5.2001 & TST & \\
\hline CHEMBL405358 & 688892 & 7.1002 & 5.9662 & TRN & \\
\hline CHEMBL1256910 & 688892 & 5.4 & 5.6084 & TRN & \\
\hline CHEMBL402063 & 688892 & 5.1 & 5.5833 & TRN & \\
\hline CHEMBL 290943 & 688892 & 6.8 & 5.3462 & TST & \\
\hline CHEMBL1257041 & 688892 & 5.0 & 4.9973 & TRN & \\
\hline CHEMBL1256687 & 688892 & 4.6 & 5.0363 & TRN & \\
\hline CHEMBL35482 & 688892 & 6.4 & 6.0492 & TRN & \\
\hline CHEMBL1256876 & 688892 & 5.0 & 5.3233 & TRN & \\
\hline CHEMBL1256751 & 688892 & 4.9 & 4.7624 & TRN & \\
\hline CHEMBL13647 & 688892 & 5.1 & 5.1095 & TRN & \\
\hline CHEMBL1315457 & 688892 & 5.6 & 5.5155 & TST & \\
\hline CHEMBL 25236 & 688892 & 4.9 & 4.9012 & TRN & \\
\hline CHEMBL 293749 & 688892 & 5.9 & 5.6303 & TRN & \\
\hline CHEMBL1256759 & 688892 & 5.5 & 5.4396 & TRN & \\
\hline CHEMBL596674 & 688892 & 5.6 & 5.4883 & TRN & \\
\hline CHEMBL1473612 & 688892 & 4.9 & 5.2877 & TST & \\
\hline CHEMBL1255778 & 688892 & 4.6 & 5.2746 & TRN & \\
\hline CHEMBL1256666 & 688892 & 5.0 & 5.3704 & TRN & \\
\hline CHEMBL1256180 & 688892 & 5.3 & 5.473 & TRN & \\
\hline CHEMBL1725279 & 688892 & 5.3 & 5.6768 & TRN & \\
\hline CHEMBL2374063 & 688892 & 5.6 & 5.8507 & TST & \\
\hline CHEMBL1257083 & 688892 & 6.6 & 5.0107 & TRN & \\
\hline CHEMBL539027 & 688892 & 5.1 & 5.1141 & TRN & \\
\hline CHEMBL40998 & 688892 & 5.1 & 5.4638 & TRN & \\
\hline CHEMBL1256873 & 688892 & 5.4 & 5.4913 & TST & \\
\hline CHEMBL68534 & 688892 & 5.5 & 5.4971 & TRN & \\
\hline CHEMBL1256737 & 688892 & 5.0 & 4.97199 & 99999999995 & TRN \\
\hline CHEMBL268609 & 688892 & 5.0 & 5.559 & TRN & \\
\hline CHEMBL67311 & 688892 & 4.9 & 5.0503 & TST & \\
\hline CHEMBL399491 & 688892 & 5.4 & 5.0935 & TST & \\
\hline CHEMBL 336467 & 688892 & 5.4 & 5.6574 & TST & \\
\hline CHEMBL 299052 & 688892 & 4.5 & 5.388 & TRN & \\
\hline CHEMBL258893 & 688892 & 5.7 & 5.8051 & TRN & \\
\hline
\end{tabular}




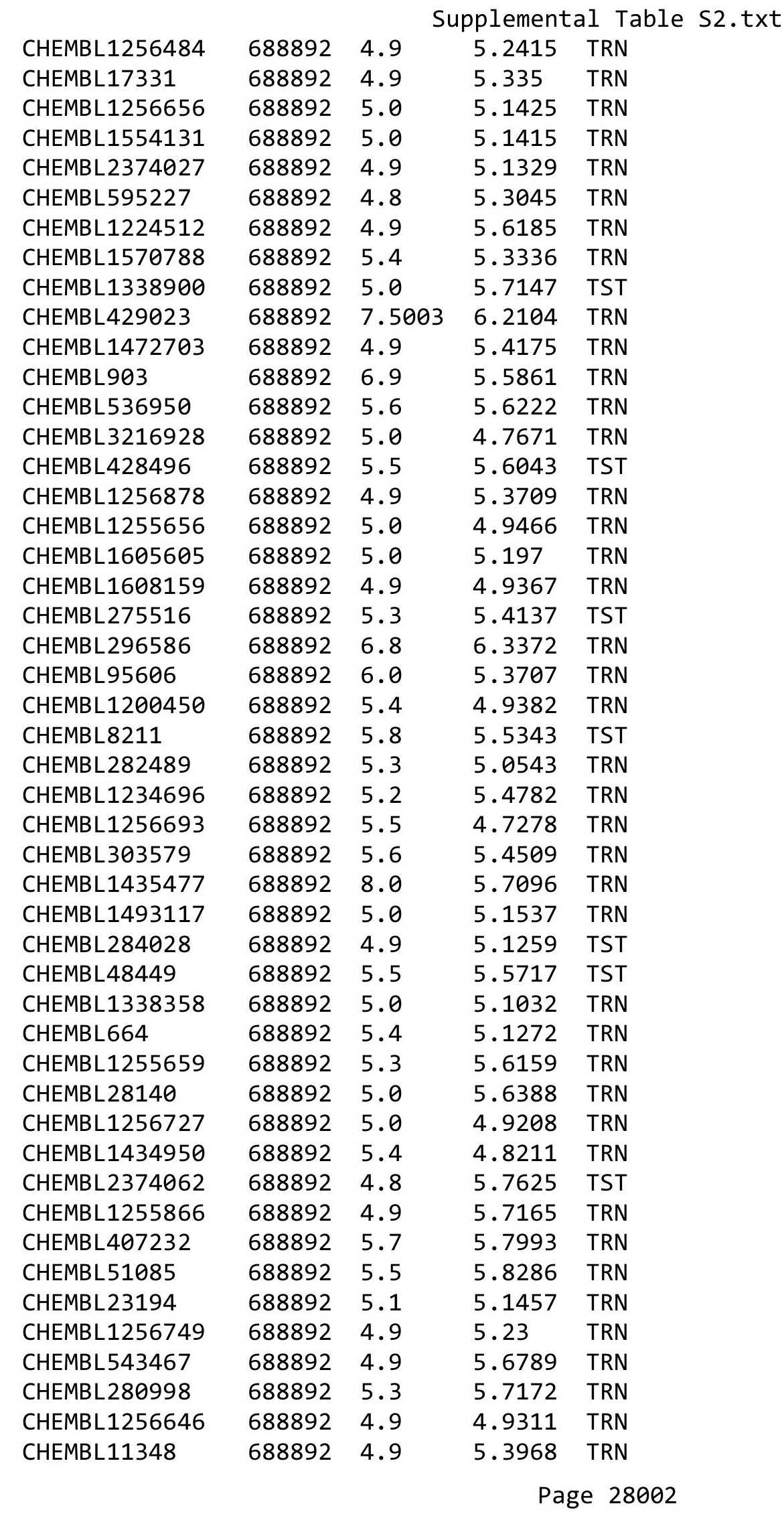




\begin{tabular}{|c|c|c|c|c|c|}
\hline \multicolumn{6}{|c|}{ splemental labıe s } \\
\hline CHEMBL 78150 & 688892 & 5.8 & 5.6397 & TRN & \\
\hline CHEMBL 262083 & 688892 & 5.4 & 5.2523 & TRN & \\
\hline CHEMBL1366616 & 688892 & 4.6 & 4.9181 & TRN & \\
\hline CHEMBL 65 & 688892 & 6.9 & 6.7612 & TRN & \\
\hline CHEMBL123 & 688892 & 5.0 & 5.7063 & TRN & \\
\hline CHEMBL520992 & 688892 & 5.0 & 4.7568 & TRN & \\
\hline CHEMBL554311 & 688892 & 5.0 & 5.5146 & TRN & \\
\hline CHEMBL66654 & 688892 & 6.0 & 5.7604 & TRN & \\
\hline CHEMBL372052 & 688892 & 4.9 & 5.6503 & TRN & \\
\hline CHEMBL1448979 & 688892 & 8.3979 & 6.0403 & TRN & \\
\hline CHEMBL556001 & 688892 & 5.0 & 5.5047 & TRN & \\
\hline CHEMBL1257013 & 688892 & 5.4 & 5.1324 & TRN & \\
\hline CHEMBL1256869 & 688892 & 4.9 & 5.2042 & TRN & \\
\hline CHEMBL 322970 & 688892 & 6.7001 & 5.8222 & TRN & \\
\hline CHEMBL1256660 & 688892 & 4.6 & 4.75 & TRN & \\
\hline CHEMBL1355963 & 688892 & 4.9 & 5.7029 & TST & \\
\hline CHEMBL1256647 & 688892 & 4.9 & 4.298 & TRN & \\
\hline CHEMBL1256686 & 688892 & 5.5 & 5.24799 & 9999999999 & TST \\
\hline CHEMBL19612 & 688892 & 5.2 & 5.165 & TRN & \\
\hline CHEMBL44 & 688892 & 5.8 & 5.7335 & TRN & \\
\hline CHEMBL604119 & 688892 & 5.0 & 4.9116 & TST & \\
\hline CHEMBL 288174 & 688892 & 5.3 & 5.0246 & TRN & \\
\hline CHEMBL576349 & 688892 & 5.1 & 6.2712 & TRN & \\
\hline CHEMBL1256654 & 688892 & 6.0 & 5.5281 & TRN & \\
\hline CHEMBL1336166 & 688892 & 5.8 & 5.1945 & TRN & \\
\hline CHEMBL1256678 & 688892 & 5.7 & 5.2617 & TRN & \\
\hline CHEMBL 28626 & 688892 & 5.5 & 5.7243 & TRN & \\
\hline CHEMBL1322702 & 688892 & 4.9 & 4.8827 & TRN & \\
\hline CHEMBL 542493 & 688892 & 5.0 & 5.1137 & TRN & \\
\hline CHEMBL1284 & 688892 & 5.0 & 5.36799 & 9999999999 & TRN \\
\hline CHEMBL 270299 & 688892 & 6.1 & 5.7462 & TST & \\
\hline CHEMBL13790 & 688892 & 5.5 & 5.3411 & TRN & \\
\hline CHEMBL1256659 & 688892 & 5.0 & 5.048 & TRN & \\
\hline CHEMBL 310798 & 688892 & 4.7 & 5.4709 & TRN & \\
\hline CHEMBL544115 & 688892 & 5.6 & 4.845 & TRN & \\
\hline CHEMBL1396661 & 688892 & 4.9 & 5.3379 & TRN & \\
\hline CHEMBL1256147 & 688892 & 4.7 & 5.2976 & TRN & \\
\hline CHEMBL153036 & 688892 & 6.0 & 5.3969 & TRN & \\
\hline CHEMBL112816 & 688892 & 5.2 & 5.3794 & TRN & \\
\hline CHEMBL1237212 & 688892 & 4.9 & 5.3656 & TST & \\
\hline CHEMBL445102 & 688892 & 5.0 & 4.7964 & TRN & \\
\hline CHEMBL355496 & 688892 & 6.6 & 6.0336 & TRN & \\
\hline CHEMBL1256663 & 688892 & 5.0 & 4.8403 & TRN & \\
\hline CHEMBL 34241 & 688892 & 5.6 & 5.9671 & TRN & \\
\hline CHEMBL 8080 & 688892 & 5.0 & 5.2171 & TST & \\
\hline CHEMBL 34730 & 688892 & 4.6 & 5.2319 & TRN & \\
\hline CHEMBL 279556 & 688892 & 4.6 & 4.9733 & TRN & \\
\hline CHEMBL541585 & 688892 & 5.5 & 4.7218 & TRN & \\
\hline
\end{tabular}




\begin{tabular}{|c|c|c|c|c|c|}
\hline \multirow[b]{2}{*}{ CHEMBL1256995 } & \multicolumn{5}{|c|}{ plemental } \\
\hline & 688892 & 4.8 & 5.0005 & TRN & \\
\hline CHEMBL1255936 & 688892 & 5.6 & 5.5881 & TRN & \\
\hline CHEMBL1255649 & 688892 & 5.9 & 5.1109 & TRN & \\
\hline CHEMBL1318166 & 688892 & 5.3 & 5.3524 & TST & \\
\hline CHEMBL18132 & 688892 & 5.0 & 5.17200 & 0000000001 & TRN \\
\hline CHEMBL1476170 & 688892 & 8.3979 & 5.7686 & TRN & \\
\hline CHEMBL1590378 & 688892 & 4.9 & 4.9488 & TRN & \\
\hline CHEMBL1256661 & 688892 & 4.8 & 5.1642 & TRN & \\
\hline CHEMBL1256911 & 688892 & 5.6 & 4.7684 & TRN & \\
\hline CHEMBL275938 & 688892 & 5.5 & 5.5466 & TRN & \\
\hline CHEMBL441282 & 688892 & 5.1 & 5.0407 & TRN & \\
\hline CHEMBL1405759 & 688892 & 5.0 & 5.4424 & TRN & \\
\hline CHEMBL126077 & 688892 & 6.0 & 5.982 & TRN & \\
\hline CHEMBL1567944 & 688892 & 7.2 & 5.8007 & TRN & \\
\hline CHEMBL1355710 & 688892 & 5.6 & 5.1916 & TRN & \\
\hline CHEMBL1436882 & 688892 & 4.8 & 5.25700 & 0000000001 & TRN \\
\hline CHEMBL1526455 & 688892 & 5.0 & 4.979 & TRN & \\
\hline CHEMBL1415777 & 688892 & 5.1 & 5.358 & TRN & \\
\hline CHEMBL567175 & 688892 & 4.8 & 4.9438 & TRN & \\
\hline CHEMBL517986 & 688892 & 5.0 & 5.2804 & TRN & \\
\hline CHEMBL1357558 & 688892 & 4.9 & 4.69300 & 00000000005 & TRN \\
\hline CHEMBL 274438 & 688892 & 5.0 & 5.3146 & TRN & \\
\hline CHEMBL553503 & 688892 & 5.0 & 5.1855 & TRN & \\
\hline CHEMBL1480136 & 688892 & 5.3 & 5.3593 & TRN & \\
\hline CHEMBL276727 & 688892 & 5.5 & 5.4147 & TRN & \\
\hline CHEMBL 28 & 688892 & 6.3 & 5.6215 & TRN & \\
\hline CHEMBL 299613 & 688892 & 5.0 & 5.3148 & TRN & \\
\hline CHEMBL541543 & 688892 & 5.1 & 4.8812 & TST & \\
\hline CHEMBL 225230 & 688892 & 4.9 & 5.0339 & TRN & \\
\hline CHEMBL102714 & 688892 & 4.8 & 5.2992 & TRN & \\
\hline CHEMBL1367076 & 688892 & 6.5 & 5.8812 & TRN & \\
\hline CHEMBL1554098 & 688892 & 6.4 & 5.66299 & 9999999999 & TST \\
\hline CHEMBL1412842 & 688892 & 5.2 & 5.5893 & TRN & \\
\hline CHEMBL 250711 & 688892 & 6.3 & 5.2534 & TRN & \\
\hline CHEMBL14276 & 688892 & 4.8 & 5.227 & TRN & \\
\hline CHEMBL288096 & 688892 & 5.0 & 4.8189 & TRN & \\
\hline CHEMBL1490919 & 688892 & 4.8 & 5.3946 & TST & \\
\hline CHEMBL376505 & 688892 & 5.9 & 5.83799 & 9999999999 & TST \\
\hline CHEMBL1600780 & 688892 & 5.1 & 5.0957 & TRN & \\
\hline CHEMBL1456417 & 688892 & 5.0 & 5.5811 & TRN & \\
\hline CHEMBL73188 & 688892 & 5.0 & 5.5825 & TST & \\
\hline CHEMBL1523894 & 688892 & 4.9 & 5.45299 & 9999999999 & TST \\
\hline CHEMBL1515691 & 688892 & 7.6003 & 5.9797 & TST & \\
\hline CHEMBL546257 & 688892 & 5.0 & 5.1905 & TRN & \\
\hline CHEMBL 294590 & 688892 & 5.0 & 4.8651 & TRN & \\
\hline CHEMBL 347862 & 688892 & 5.3 & 5.4382 & TRN & \\
\hline CHEMBL 21260 & 688892 & 7.4001 & 6.1843 & TRN & \\
\hline CHEMBL1255940 & 688892 & 5.2 & 5.6717 & TRN & \\
\hline
\end{tabular}




\begin{tabular}{|c|c|c|c|c|}
\hline & & & & al Tabl \\
\hline CHEMBL1527442 & 688892 & 4.6 & 5.0057 & TST \\
\hline CHEMBL559612 & 688892 & 4.9 & 4.9373 & TST \\
\hline CHEMBL56393 & 688892 & 4.5 & 5.4824 & TRN \\
\hline CHEMBL1593815 & 688892 & 5.3 & 5.3075 & TRN \\
\hline CHEMBL513116 & 688892 & 4.7 & 4.9758 & TRN \\
\hline CHEMBL 289277 & 688892 & 4.9 & 5.6367 & TRN \\
\hline CHEMBL1453208 & 688892 & 5.0 & 5.3789 & TRN \\
\hline CHEMBL1559663 & 688892 & 5.5 & 5.723 & TST \\
\hline CHEMBL1255737 & 688892 & 5.5 & 5.438 & TRN \\
\hline CHEMBL1528565 & 688892 & 5.0 & 4.8924 & TRN \\
\hline CHEMBL574181 & 688892 & 4.7 & 5.0344 & TRN \\
\hline CHEMBL429095 & 688892 & 5.9 & 5.9768 & TRN \\
\hline CHEMBL98350 & 688892 & 5.0 & 5.4067 & TRN \\
\hline CHEMBL1324022 & 688892 & 5.0 & 5.1506 & TRN \\
\hline CHEMBL402468 & 688892 & 5.4 & 6.1086 & TRN \\
\hline CHEMBL104264 & 688892 & 5.0 & 5.239 & TRN \\
\hline CHEMBL34704 & 688892 & 4.9 & 5.6443 & TST \\
\hline CHEMBL416657 & 688892 & 5.0 & 5.0254 & TRN \\
\hline CHEMBL1515334 & 688892 & 4.9 & 4.9305 & TRN \\
\hline CHEMBL 320820 & 688892 & 5.0 & 5.2848 & TST \\
\hline CHEMBL1513654 & 688892 & 4.9 & 4.9268 & TRN \\
\hline CHEMBL101168 & 688892 & 6.0 & 5.5335 & TRN \\
\hline CHEMBL1461491 & 688892 & 5.0 & 5.2923 & TST \\
\hline CHEMBL250892 & 688892 & 5.2 & 5.4393 & TST \\
\hline CHEMBL1554789 & 688892 & 5.3 & 5.2025 & TST \\
\hline CHEMBL1598680 & 688892 & 4.9 & 5.6539 & TST \\
\hline CHEMBL24983 & 688892 & 4.9 & 5.5718 & TST \\
\hline CHEMBL15192 & 688892 & 5.8 & 5.9943 & TST \\
\hline CHEMBL60518 & 688892 & 5.7 & 4.6881 & TST \\
\hline CHEMBL3186408 & 688892 & 5.0 & 5.6628 & TST \\
\hline CHEMBL129795 & 688892 & 5.5 & 5.6414 & TST \\
\hline CHEMBL1398031 & 688892 & 5.0 & 5.3341 & TST \\
\hline CHEMBL1161525 & 688892 & 5.5 & 5.2538 & TST \\
\hline CHEMBL310310 & 688892 & 4.9 & 4.9959 & TST \\
\hline CHEMBL429711 & 688892 & 5.5 & 5.6238 & TST \\
\hline CHEMBL60718 & 688892 & 5.0 & 5.41299 & 9999999999 \\
\hline CHEMBL408982 & 688892 & 5.6 & 5.3683 & TST \\
\hline CHEMBL1331383 & 688892 & 5.0 & 4.9102 & TST \\
\hline CHEMBL1255837 & 688892 & 5.0 & 5.3818 & TST \\
\hline CHEMBL1255755 & 688892 & 7.0 & 5.5957 & TST \\
\hline CHEMBL3392050 & 688892 & 4.9 & 5.431 & TST \\
\hline CHEMBL539947 & 688892 & 5.0 & 5.6367 & TST \\
\hline CHEMBL110739 & 688892 & 5.9 & 5.3891 & TST \\
\hline CHEMBL428768 & 688892 & 5.0 & 5.2209 & TST \\
\hline CHEMBL85139 & 688892 & 6.5 & 5.4217 & TST \\
\hline CHEMBL1329033 & 688892 & 5.0 & 5.2702 & TST \\
\hline CHEMBL1522486 & 688892 & 5.6 & 5.5264 & TST \\
\hline CHEMBL63154 & 688892 & 5.1 & 5.2944 & TST \\
\hline
\end{tabular}




\begin{tabular}{|c|c|c|c|c|}
\hline \multicolumn{5}{|c|}{ Supplemental Table S2.txt } \\
\hline CHEMBL1413371 & 688892 & 5.4 & 5.197 & TST \\
\hline CHEMBL 375270 & 688892 & 5.8 & 5.7019 & TST \\
\hline CHEMBL1526543 & 688892 & 4.9 & 5.3241 & TST \\
\hline CHEMBL 24510 & 688892 & 5.7 & 4.9954 & TST \\
\hline CHEMBL1595524 & 688892 & 4.9 & 5.4785 & TST \\
\hline CHEMBL165 & 688892 & 4.9 & 5.6704 & TST \\
\hline CHEMBL365809 & 688892 & 5.0 & 5.5442 & TST \\
\hline CHEMBL1256754 & 688892 & 5.4 & 5.251 & TST \\
\hline CHEMBL1355762 & 688892 & 4.9 & 5.6905 & TST \\
\hline CHEMBL269733 & 688892 & 5.4 & 5.50799 & 9999999999 \\
\hline CHEMBL3692602 & 1528523 & 4.0 & 4.1689 & TRN \\
\hline CHEMBL 3692642 & 1528523 & 5.301 & 5.2461 & TRN \\
\hline CHEMBL3692605 & 1528523 & 4.0 & 4.1956 & TRN \\
\hline CHEMBL3692608 & 1528523 & 4.0 & 4.1702 & TRN \\
\hline CHEMBL3688140 & 1528523 & 4.0 & 3.8499 & TRN \\
\hline CHEMBL3692620 & 1528523 & 4.0 & 3.8228 & TRN \\
\hline CHEMBL3692601 & 1528523 & 4.0 & 4.3144 & TRN \\
\hline CHEMBL3910908 & 1528523 & 4.0 & 4.561 & TRN \\
\hline CHEMBL 3692578 & 1528523 & 4.0 & 4.1662 & TRN \\
\hline CHEMBL 3688160 & 1528523 & 4.0 & 4.1356 & TRN \\
\hline CHEMBL3692603 & 1528523 & 4.0 & 3.9954 & TRN \\
\hline CHEMBL 3688147 & 1528523 & 4.0 & 3.898 & TST \\
\hline CHEMBL3949727 & 1528523 & 5.2366 & 5.5526 & TST \\
\hline CHEMBL3692691 & 1528523 & 5.0555 & 4.8168 & TRN \\
\hline CHEMBL 3692647 & 1528523 & 4.0 & 5.1599 & TST \\
\hline CHEMBL3692623 & 1528523 & 4.0 & 4.1037 & TRN \\
\hline CHEMBL 3688163 & 1528523 & 4.0 & 3.9612 & TRN \\
\hline CHEMBL 3692593 & 1528523 & 4.0 & 4.0448 & TRN \\
\hline CHEMBL3692609 & 1528523 & 4.0 & 4.3295 & TRN \\
\hline CHEMBL 3688142 & 1528523 & 4.0 & 3.8368 & TRN \\
\hline CHEMBL3692604 & 1528523 & 4.0 & 4.1839 & TRN \\
\hline CHEMBL3692639 & 1528523 & 5.4437 & 5.369 & TRN \\
\hline CHEMBL 3688164 & 1528523 & 4.0 & 3.8403 & TRN \\
\hline CHEMBL3692630 & 1528523 & 5.1549 & 5.2339 & TRN \\
\hline CHEMBL3692631 & 1528523 & 4.0 & 4.6275 & TST \\
\hline CHEMBL3692613 & 1528523 & 4.0 & 4.0158 & TRN \\
\hline CHEMBL3692597 & 1528523 & 4.0 & 4.0359 & TRN \\
\hline CHEMBL 3688154 & 1528523 & 4.0 & 3.9718 & TRN \\
\hline CHEMBL 3692653 & 1528523 & 4.0 & 4.1935 & TST \\
\hline CHEMBL3692591 & 1528523 & 4.0 & 3.7469 & TRN \\
\hline CHEMBL3688141 & 1528523 & 4.0 & 4.1054 & TRN \\
\hline CHEMBL3692638 & 1528523 & 4.0 & 5.0059 & TST \\
\hline CHEMBL3688155 & 1528523 & 4.0 & 4.0995 & TRN \\
\hline CHEMBL 3692580 & 1528523 & 4.0 & 4.0936 & TST \\
\hline CHEMBL 3692643 & 1528523 & 4.0 & 5.1923 & TST \\
\hline CHEMBL3915725 & 1528523 & 5.3768 & 5.6385 & TST \\
\hline CHEMBL3688156 & 1528523 & 4.0 & 3.8476 & TRN \\
\hline CHEMBL3688159 & 1528523 & 4.0 & 4.0768 & TRN \\
\hline
\end{tabular}


Supplemental Table S2.txt

\begin{tabular}{|c|c|c|c|c|}
\hline CHEMBL 3943688 & 1528523 & 5.9208 & 5.6836 & TRN \\
\hline CHEMBL 3692690 & 1528523 & 5.2147 & 4.7188 & TRN \\
\hline CHEMBL3692625 & 1528523 & 4.0 & 4.0795 & TRN \\
\hline CHEMBL 3688158 & 1528523 & 4.0 & 3.6307 & TRN \\
\hline CHEMBL 3692644 & 1528523 & 4.0 & 5.0052 & TST \\
\hline CHEMBL 3692649 & 1528523 & 4.0 & 4.5785 & TST \\
\hline CHEMBL 3692579 & 1528523 & 4.0 & 4.2533 & TST \\
\hline CHEMBL 3952684 & 1528523 & 5.5376 & 5.2554 & TRN \\
\hline CHEMBL 3977713 & 1528523 & 4.0 & 4.1942 & TST \\
\hline CHEMBL3688148 & 1528523 & 4.0 & 3.957 & TRN \\
\hline CHEMBL 3692583 & 1528523 & 4.0 & 4.0882 & TRN \\
\hline CHEMBL 3692566 & 1528523 & 4.0 & 3.823 & TRN \\
\hline CHEMBL 3940445 & 1528523 & 4.0 & 4.9267 & TST \\
\hline CHEMBL 3688161 & 1528523 & 4.0 & 4.0975 & TRN \\
\hline CHEMBL3692677 & 1528523 & 4.0 & 4.1456 & TRN \\
\hline CHEMBL 3692633 & 1528523 & 4.0 & 4.6531 & TST \\
\hline CHEMBL3688149 & 1528523 & 4.0 & 4.0888 & TRN \\
\hline CHEMBL3951915 & 1528523 & 4.0 & 4.4312 & TST \\
\hline CHEMBL 3692571 & 1528523 & 4.0 & 3.9082 & TRN \\
\hline CHEMBL3692645 & 1528523 & 4.0 & 5.0391 & TST \\
\hline CHEMBL 3639914 & 1528523 & 4.0 & 4.0061 & TRN \\
\hline CHEMBL 3688165 & 1528523 & 4.0 & 3.7959 & TRN \\
\hline CHEMBL 3934360 & 1528523 & 4.0 & 4.7253 & TST \\
\hline CHEMBL 3692598 & 1528523 & 4.0 & 4.1882 & TRN \\
\hline CHEMBL 3692584 & 1528523 & 4.0 & 4.0831 & TRN \\
\hline CHEMBL 3692632 & 1528523 & 4.0 & 5.1359 & TST \\
\hline CHEMBL 3692646 & 1528523 & 4.0 & 4.7463 & TST \\
\hline CHEMBL3692582 & 1528523 & 4.0 & 4.0417 & TRN \\
\hline CHEMBL 3692688 & 1528523 & 5.5376 & 5.4093 & TRN \\
\hline CHEMBL 3692567 & 1528523 & 4.0 & 3.7756 & TRN \\
\hline CHEMBL 3692595 & 1528523 & 4.0 & 3.8546 & TRN \\
\hline CHEMBL 3692612 & 1528523 & 4.0 & 4.0067 & TRN \\
\hline CHEMBL 3692637 & 1528523 & 4.0 & 5.1948 & TST \\
\hline CHEMBL 3907512 & 1528523 & 4.0 & 4.5008 & TST \\
\hline CHEMBL3692592 & 1528523 & 4.0 & 3.8945 & TRN \\
\hline CHEMBL 3692585 & 1528523 & 4.0 & 4.0807 & TRN \\
\hline CHEMBL3935456 & 1528523 & 4.0 & 4.2517 & TRN \\
\hline CHEMBL 3692635 & 1528523 & 4.0 & 4.3799 & TST \\
\hline CHEMBL 3692568 & 1528523 & 5.1192 & 4.8908 & TRN \\
\hline CHEMBL 3692590 & 1528523 & 4.0 & 3.9432 & TRN \\
\hline CHEMBL 3930432 & 1528523 & 5.7447 & 4.8834 & TRN \\
\hline CHEMBL3688152 & 1528523 & 4.0 & 4.1127 & TRN \\
\hline CHEMBL 3692628 & 1528523 & 4.0 & 3.8391 & TRN \\
\hline CHEMBL3692569 & 1528523 & 4.0 & 3.8486 & TRN \\
\hline CHEMBL 3692607 & 1528523 & 4.0 & 4.0221 & TRN \\
\hline CHEMBL 3692668 & 1528523 & 4.0 & 4.3463 & TRN \\
\hline CHEMBL3688153 & 1528523 & 4.0 & 3.9095 & TRN \\
\hline CHEMBL 3692574 & 1528523 & 4.0 & 4.0665 & TRN \\
\hline
\end{tabular}


Supplemental Table S2.txt

\begin{tabular}{|c|c|c|c|c|c|}
\hline CHEMBL 3692624 & 1528523 & 4.0 & 4.3106 & TRN & \\
\hline CHEMBL 3692614 & 1528523 & 4.0 & 4.119 & TRN & \\
\hline CHEMBL3692611 & 1528523 & 4.0 & 4.0983 & TRN & \\
\hline CHEMBL3692599 & 1528523 & 4.0 & 3.9173 & TRN & \\
\hline CHEMBL 3688144 & 1528523 & 4.0 & 3.8127 & TRN & \\
\hline CHEMBL 3692641 & 1528523 & 5.2076 & 5.1943 & TST & \\
\hline CHEMBL3932719 & 1528523 & 5.2924 & 5.6935 & TST & \\
\hline CHEMBL 3692573 & 1528523 & 4.0 & 4.05 & TRN & \\
\hline CHEMBL 3945309 & 1528523 & 4.0 & 4.0757 & TRN & \\
\hline CHEMBL3692576 & 1528523 & 4.0 & 4.6571 & TST & \\
\hline CHEMBL 3692600 & 1528523 & 4.0 & 4.0472 & TRN & \\
\hline CHEMBL3944406 & 1528523 & 5.6198 & 5.6892 & TRN & \\
\hline CHEMBL 3692594 & 1528523 & 4.0 & 3.8114 & TRN & \\
\hline CHEMBL 3688151 & 1528523 & 4.0 & 4.0646 & TRN & \\
\hline CHEMBL 3692572 & 1528523 & 4.0 & 4.1051 & TRN & \\
\hline CHEMBL3692616 & 1528523 & 4.0 & 3.8787 & TRN & \\
\hline CHEMBL3692581 & 1528523 & 4.0 & 4.1223 & TRN & \\
\hline CHEMBL 3692588 & 1528523 & 4.0 & 3.8997 & TRN & \\
\hline CHEMBL 3688145 & 1528523 & 4.0 & 4.4684 & TRN & \\
\hline CHEMBL3692596 & 1528523 & 4.0 & 3.847 & TRN & \\
\hline CHEMBL3897135 & 1528523 & 5.0434 & 4.8721 & TST & \\
\hline CHEMBL 3692587 & 1528523 & 4.0 & 4.3495 & TRN & \\
\hline CHEMBL 3692575 & 1528523 & 4.0 & 4.4169 & TRN & \\
\hline CHEMBL 3692629 & 1528523 & 4.0 & 4.1665 & TRN & \\
\hline CHEMBL3692650 & 1528523 & 4.0 & 4.7052 & TST & \\
\hline CHEMBL3692610 & 1528523 & 4.0 & 4.1877 & TRN & \\
\hline CHEMBL 3688150 & 1528523 & 4.0 & 3.7992 & TRN & \\
\hline CHEMBL 3980730 & 1528523 & 4.0 & 4.7073 & TST & \\
\hline CHEMBL 3941794 & 1528523 & 4.0 & \multicolumn{2}{|c|}{ 4. 3919999999999995} & TRN \\
\hline CHEMBL3890376 & 1528523 & 5.1838 & 4.6747 & TRN & \\
\hline CHEMBL3958525 & 1528523 & 5.6576 & 5.5997 & TRN & \\
\hline CHEMBL 3688143 & 1528523 & 4.0 & 3.9483 & TRN & \\
\hline CHEMBL 3692615 & 1528523 & 4.0 & 3.9174 & TRN & \\
\hline CHEMBL 3932819 & 1528523 & 4.0 & 4.5306 & TRN & \\
\hline CHEMBL3918370 & 1528523 & 5.5686 & 5.7992 & TST & \\
\hline CHEMBL3692586 & 1528523 & 4.0 & 3.9361 & TRN & \\
\hline CHEMBL 3692648 & 1528523 & 4.0 & 4.3732 & TST & \\
\hline CHEMBL 3692654 & 1528523 & 4.0 & 4.2375 & TST & \\
\hline CHEMBL 3692656 & 1528523 & 5.0458 & 4.5883 & TRN & \\
\hline CHEMBL 3692570 & 1528523 & 4.0 & 4.1945 & TRN & \\
\hline CHEMBL 3688146 & 1528523 & 4.0 & 3.8605 & TRN & \\
\hline CHEMBL 3688162 & 1528523 & 4.0 & 3.6855 & TRN & \\
\hline CHEMBL 84877 & 96910 & 8.0458 & 8.0328 & TRN & \\
\hline CHEMBL321862 & 96910 & 8.301 & 8.3209 & TRN & \\
\hline CHEMBL 84046 & 96910 & 8.2218 & 8.0795 & TRN & \\
\hline CHEMBL313466 & 96910 & 7.9586 & 8.0441 & TRN & \\
\hline CHEMBL107183 & 96910 & 6.6198 & 6.5778 & TRN & \\
\hline CHEMBL106457 & 96910 & 8.6198 & 8.0479 & TRN & \\
\hline
\end{tabular}

Page 28008 


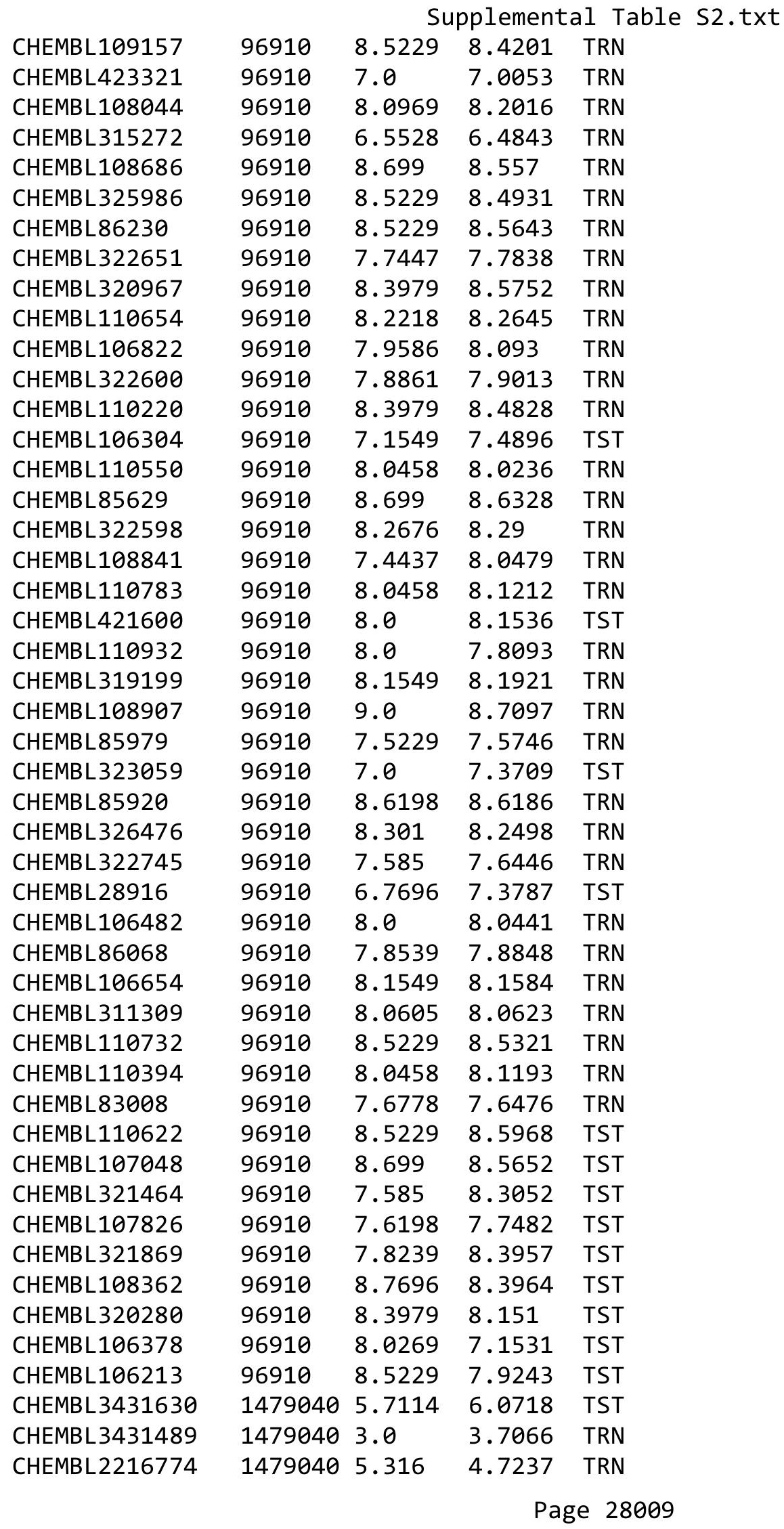


Supplemental Table S2.txt

\begin{tabular}{|c|c|c|c|c|}
\hline CHEMBL3431927 & 1479040 & 3.0 & 3.3787 & TRN \\
\hline CHEMBL3431692 & 1479040 & 5.6863 & 6.0485 & TST \\
\hline CHEMBL3431573 & 1479040 & 5.2009 & 5.2831 & TRN \\
\hline CHEMBL3431928 & 1479040 & 3.0 & 3.4133 & TRN \\
\hline CHEMBL3431680 & 1479040 & 3.0 & 3.6897 & TRN \\
\hline CHEMBL3431505 & 1479040 & 3.0 & 3.6529 & TRN \\
\hline CHEMBL3431915 & 1479040 & 6.2566 & 5.8379 & TRN \\
\hline CHEMBL3431786 & 1479040 & 3.0 & 3.4472 & TRN \\
\hline CHEMBL3431929 & 1479040 & 5.8413 & 5.2375 & TRN \\
\hline CHEMBL3431857 & 1479040 & 4.32 & 3.589 & TRN \\
\hline CHEMBL3431685 & 1479040 & 3.0 & \multicolumn{2}{|c|}{3.5669999999999997} \\
\hline CHEMBL3431657 & 1479040 & 3.0 & 3.5029 & TST \\
\hline CHEMBL3431656 & 1479040 & 3.0 & 3.5614 & TST \\
\hline CHEMBL 3431480 & 1479040 & 4.8416 & 3.7023 & TRN \\
\hline CHEMBL 3431517 & 1479040 & 3.0 & 3.5867 & TRN \\
\hline CHEMBL3431556 & 1479040 & 3.0 & 3.7023 & TRN \\
\hline CHEMBL3431776 & 1479040 & 5.5049 & 6.441 & TST \\
\hline CHEMBL 2216778 & 1479040 & 3.0 & 3.6552 & TST \\
\hline CHEMBL3431675 & 1479040 & 3.0 & 3.3653 & TRN \\
\hline CHEMBL3431837 & 1479040 & 3.0 & 3.3637 & TRN \\
\hline CHEMBL 3431473 & 1479040 & 4.3228 & 3.4802 & TRN \\
\hline CHEMBL3431626 & 1479040 & 3.0 & 3.5074 & TRN \\
\hline CHEMBL3431724 & 1479040 & 3.0 & 3.4479 & TST \\
\hline CHEMBL3431872 & 1479040 & 4.2296 & 3.6926 & TRN \\
\hline CHEMBL 3431774 & 1479040 & 5.9875 & 6.1068 & TST \\
\hline CHEMBL 3431790 & 1479040 & 4.6285 & 4.5041 & TRN \\
\hline CHEMBL3431625 & 1479040 & 3.0 & 3.185 & TST \\
\hline CHEMBL3431493 & 1479040 & 4.7604 & 3.6752 & TRN \\
\hline CHEMBL 3431644 & 1479040 & 3.0 & 3.6268 & TST \\
\hline CHEMBL3431919 & 1479040 & 5.7071 & 5.3268 & TRN \\
\hline CHEMBL3431761 & 1479040 & 4.2881 & 3.6125 & TRN \\
\hline CHEMBL3431561 & 1479040 & 3.0 & 3.9731 & TRN \\
\hline CHEMBL3431595 & 1479040 & 5.4617 & 5.3245 & TRN \\
\hline CHEMBL 3431713 & 1479040 & 4.9194 & 3.6002 & TRN \\
\hline CHEMBL3431924 & 1479040 & 3.0 & 3.265 & TRN \\
\hline CHEMBL3431840 & 1479040 & 3.0 & 3.6935 & TST \\
\hline CHEMBL3431894 & 1479040 & 6.1066 & 5.7979 & TRN \\
\hline CHEMBL3431566 & 1479040 & 4.6141 & 4.418 & TRN \\
\hline CHEMBL3431835 & 1479040 & 3.0 & \multicolumn{2}{|c|}{3.4739999999999998} \\
\hline CHEMBL3431605 & 1479040 & 6.4872 & 6.4904 & TRN \\
\hline CHEMBL 3431477 & 1479040 & 3.0 & 3.8711 & TRN \\
\hline CHEMBL3431785 & 1479040 & 3.0 & 3.545 & TST \\
\hline CHEMBL3431661 & 1479040 & 3.0 & 3.6522 & TRN \\
\hline CHEMBL3431769 & 1479040 & 4.8517 & 3.4429 & TRN \\
\hline CHEMBL 3431621 & 1479040 & 3.0 & 3.339 & TRN \\
\hline CHEMBL 3431730 & 1479040 & 6.1979 & 6.2098 & TST \\
\hline CHEMBL3431568 & 1479040 & 4.9181 & 4.9074 & TRN \\
\hline CHEMBL 3431722 & 1479040 & 3.0 & 3.4079 & TRN \\
\hline
\end{tabular}


Supplemental Table S2.txt

\begin{tabular}{|c|c|c|c|c|c|}
\hline CHEMBL 3431500 & 1479040 & 3.0 & 3.6458 & TRN & \\
\hline CHEMBL 3431822 & 1479040 & 3.0 & 3.655 & TRN & \\
\hline CHEMBL3431663 & 1479040 & 4.3099 & 4.3889 & TRN & \\
\hline CHEMBL3431611 & 1479040 & 4.0237 & 5.0739 & TRN & \\
\hline CHEMBL 3431617 & 1479040 & 5.0372 & 4.18199 & 79999999995 & TRN \\
\hline CHEMBL3431515 & 1479040 & 4.4008 & 4.7716 & TRN & \\
\hline CHEMBL 3431874 & 1479040 & 3.0 & 3.4897 & TRN & \\
\hline CHEMBL 3431643 & 1479040 & 4.6135 & 4.5825 & TRN & \\
\hline CHEMBL3431618 & 1479040 & 5.1338 & 3.7315 & TRN & \\
\hline CHEMBL3431565 & 1479040 & 4.8559 & 4.4834 & TRN & \\
\hline CHEMBL 3431873 & 1479040 & 3.0 & 3.8363 & TRN & \\
\hline CHEMBL 3431538 & 1479040 & 3.0 & 3.6162 & TST & \\
\hline CHEMBL3431719 & 1479040 & 3.0 & 3.3 & TRN & \\
\hline CHEMBL3431522 & 1479040 & 5.5185 & 5.86700 & 3000000001 & \\
\hline CHEMBL3431486 & 1479040 & 4.6512 & 3.6332 & TRN & \\
\hline CHEMBL 3431672 & 1479040 & 3.0 & 3.4088 & TRN & \\
\hline CHEMBL3431559 & 1479040 & 4.00899 & 99999999 & 3.5763 & \\
\hline CHEMBL3431628 & 1479040 & 5.9711 & 6.0848 & TST & \\
\hline CHEMBL3431771 & 1479040 & 3.0 & 3.4917 & TRN & \\
\hline CHEMBL3431582 & 1479040 & 4.2407 & 4.525 & TRN & \\
\hline CHEMBL3431571 & 1479040 & 4.5254 & 4.5312 & TRN & \\
\hline CHEMBL 3431504 & 1479040 & 3.0 & 4.1643 & TRN & \\
\hline CHEMBL3431845 & 1479040 & 3.0 & 3.5582 & TST & \\
\hline CHEMBL3431483 & 1479040 & 4.0746 & 3.722 & TRN & \\
\hline CHEMBL3431709 & 1479040 & 4.3038 & 4.1729 & TST & \\
\hline CHEMBL3431864 & 1479040 & 3.0 & 3.7335 & TRN & \\
\hline CHEMBL 3431810 & 1479040 & 5.08 & 4.6689 & TRN & \\
\hline CHEMBL 3431748 & 1479040 & 3.0 & 3.55 & TRN & \\
\hline CHEMBL3431552 & 1479040 & 5.5534 & 5.5881 & TRN & \\
\hline CHEMBL3431813 & 1479040 & 3.0 & 4.812 & TST & \\
\hline CHEMBL3431839 & 1479040 & 4.6708 & 4.9501 & TRN & \\
\hline CHEMBL3431623 & 1479040 & 3.0 & 3.5167 & TRN & \\
\hline CHEMBL3431603 & 1479040 & 4.7309 & 4.3901 & TRN & \\
\hline CHEMBL3431637 & 1479040 & 3.0 & 3.47399 & 99999999998 & \\
\hline CHEMBL3431655 & 1479040 & 4.7445 & 3.6893 & TRN & \\
\hline CHEMBL3431805 & 1479040 & 4.9758 & 4.631 & TRN & \\
\hline CHEMBL 2216779 & 1479040 & 6.1311 & 5.591 & TRN & \\
\hline CHEMBL3431503 & 1479040 & 4.8244 & 4.3387 & TRN & \\
\hline CHEMBL3431648 & 1479040 & 3.0 & 3.4103 & TRN & \\
\hline CHEMBL3431729 & 1479040 & 5.5506 & 6.0493 & TST & \\
\hline CHEMBL3431920 & 1479040 & 4.4172 & 3.2893 & TRN & \\
\hline CHEMBL3431590 & 1479040 & 3.0 & 3.7471 & TST & \\
\hline CHEMBL3431516 & 1479040 & 4.212 & 4.5183 & TRN & \\
\hline CHEMBL3431511 & 1479040 & 3.0 & 3.3954 & TRN & \\
\hline CHEMBL3431847 & 1479040 & 4.6388 & 3.6357 & TRN & \\
\hline CHEMBL3431904 & 1479040 & 4.6585 & 3.5504 & TRN & \\
\hline CHEMBL3431897 & 1479040 & 5.5564 & 5.5468 & TRN & \\
\hline CHEMBL3431743 & 1479040 & 4.7201 & 4.4186 & TST & \\
\hline
\end{tabular}


Supplemental Table S2.txt

\begin{tabular}{|c|c|c|c|c|c|}
\hline CHEMBL3431539 & 1479040 & 4.024 & 3.7456 & TST & \\
\hline CHEMBL 3431827 & 1479040 & 3.0 & 3.4401 & TRN & \\
\hline CHEMBL 3431629 & 1479040 & 5.6404 & 5.9808 & TST & \\
\hline CHEMBL 3431788 & 1479040 & 5.2646 & 5.3782 & TRN & \\
\hline CHEMBL3431577 & 1479040 & 5.26399 & 999999999 & 4.7094 & TRN \\
\hline CHEMBL 3431907 & 1479040 & 5.35 & 4.7431 & TST & \\
\hline CHEMBL3431651 & 1479040 & 4.6379 & 3.8239 & TRN & \\
\hline CHEMBL3431912 & 1479040 & 5.8156 & 5.6342 & TRN & \\
\hline CHEMBL 3431676 & 1479040 & 5.5878 & 5.5311 & TRN & \\
\hline CHEMBL 3431863 & 1479040 & 5.2055 & 4.1934 & TRN & \\
\hline CHEMBL3431576 & 1479040 & 3.0 & 4.0496 & TRN & \\
\hline CHEMBL 3431604 & 1479040 & 5.6912 & 5.0425 & TRN & \\
\hline CHEMBL 3431885 & 1479040 & 4.4238 & 3.342 & TRN & \\
\hline CHEMBL 3431612 & 1479040 & 4.5509 & 5.2211 & TRN & \\
\hline CHEMBL 3431584 & 1479040 & 4.2172 & 3.8809 & TST & \\
\hline CHEMBL3431791 & 1479040 & 3.0 & 3.3641 & TRN & \\
\hline CHEMBL 3431745 & 1479040 & 3.0 & 3.633 & TRN & \\
\hline CHEMBL 3431555 & 1479040 & 5.4907 & 5.0132 & TST & \\
\hline CHEMBL 3431808 & 1479040 & 4.776 & 4.84 & TRN & \\
\hline CHEMBL 3431836 & 1479040 & 3.0 & 3.2843 & TRN & \\
\hline CHEMBL 3431701 & 1479040 & 3.0 & 3.6813 & TRN & \\
\hline CHEMBL 3431508 & 1479040 & 5.0936 & 3.6544 & TST & \\
\hline CHEMBL 3431635 & 1479040 & 3.0 & 3.4297 & TRN & \\
\hline CHEMBL 3431494 & 1479040 & 4.7258 & 4.3626 & TRN & \\
\hline CHEMBL 3431465 & 1479040 & 4.4287 & 3.4705 & TRN & \\
\hline CHEMBL 3431902 & 1479040 & 4.7333 & 3.8137 & TRN & \\
\hline CHEMBL3431492 & 1479040 & 4.6701 & 3.7582 & TRN & \\
\hline CHEMBL 3431689 & 1479040 & 3.0 & 3.8895 & TRN & \\
\hline CHEMBL 3431844 & 1479040 & 5.6096 & 5.4952 & TST & \\
\hline CHEMBL3431899 & 1479040 & 6.1638 & 6.1368 & TRN & \\
\hline CHEMBL 3431723 & 1479040 & 3.0 & 3.6247 & TST & \\
\hline CHEMBL 3431698 & 1479040 & 5.0003 & 4.6115 & TRN & \\
\hline CHEMBL3431557 & 1479040 & 4.7832 & 4.5811 & TRN & \\
\hline CHEMBL3431512 & 1479040 & 3.0 & $3.28800 e$ & 30000000003 & TRN \\
\hline CHEMBL 3431693 & 1479040 & 3.0 & 4.0776 & TST & \\
\hline CHEMBL 3431759 & 1479040 & 3.0 & 3.5921 & TRN & \\
\hline CHEMBL3431592 & 1479040 & 3.0 & 4.2441 & TRN & \\
\hline CHEMBL 3431703 & 1479040 & 3.0 & 3.6264 & TST & \\
\hline CHEMBL 3431823 & 1479040 & 3.0 & 3.4963 & TST & \\
\hline CHEMBL 3431497 & 1479040 & 3.0 & 3.5955 & TRN & \\
\hline CHEMBL 3431806 & 1479040 & 4.4974 & 4.5226 & TRN & \\
\hline CHEMBL 3431585 & 1479040 & 5.539 & 5.4934 & TRN & \\
\hline CHEMBL 3431854 & 1479040 & 4.3814 & 3.6472 & TRN & \\
\hline CHEMBL 3431484 & 1479040 & 5.3213 & 3.6107 & TRN & \\
\hline CHEMBL 3431921 & 1479040 & 3.0 & 3.2817 & TRN & \\
\hline CHEMBL 3431649 & 1479040 & 3.0 & 3.2556 & TRN & \\
\hline CHEMBL 3431832 & 1479040 & 3.0 & 3.4575 & TRN & \\
\hline CHEMBL3431558 & 1479040 & 4.2297 & 4.4561 & TRN & \\
\hline
\end{tabular}

Page 28012 
Supplemental Table S2.txt

\begin{tabular}{|c|c|c|c|c|}
\hline HEMB & 479040 & 642 & 4.2758 & TS \\
\hline & 479040 & 4.0073 & 3.6625 & \\
\hline IFMRI & 9040 & 3.0 & 1623 & \\
\hline AEMBL 3 & 9040 & 973 & & \\
\hline AEMBL3431911 & 479040 & 3.0 & $\partial 278$ & \\
\hline HEMBL3431587 & 479040 & 5.0119 & .4619 & \\
\hline HEMBL3 & 9040 & 3.0 & 3282 & \\
\hline AEMBL3 & 9040 & 1 & & \\
\hline HEMBL3431720 & 479040 & 5.8687 & 119 & \\
\hline HEMBL3431816 & 479040 & 3.0 & 3453 & \\
\hline HEMBL3 & 9040 & 4.5337 & 5733 & \\
\hline AEMBL & 9040 & 162 & 583 & \\
\hline HEMBL; & 9040 & 218 & 328 & \\
\hline HEMBL3. & 479040 & 3.0 & 2762 & \\
\hline HEMBL3 & 9040 & 4.8227 & & \\
\hline HEMBL; & 9040 & 3. & 19 & \\
\hline HEMBL & 040 & 5 . & & RIV \\
\hline HEMBL; & 040 & 3. & & \\
\hline HEMBL & 9040 & 3 . & 831 & \\
\hline AEMBL3 & 040 & 4. & & RIN \\
\hline HEMBL; & 1640 & 3 & & $2 \mathrm{~N}$ \\
\hline HEME & 040 & & & RN \\
\hline HEMBL & 9040 & & 94 & RN \\
\hline HEMBL & 9040 & 3 . & & TRN \\
\hline AEMBL3 & 40 & 4. & 75 & RN \\
\hline HEMBL & 040 & 5 . & & RN \\
\hline HEME & 40 & & & $\mathrm{RN}$ \\
\hline HEME & 40 & 58 & 74 & RN \\
\hline HEMBL & 9040 & 6. & & $\mid$ \\
\hline HEMBL3 & 9040 & 3 & & TRN \\
\hline HEMBL. & 040 & 3 & & $\mathrm{RN}$ \\
\hline HFN & 10 & 4 & & 「RN \\
\hline נ & & & & 「RN \\
\hline HEMBL3 & 040 & 62 & & 「RN \\
\hline HEMBL3 & 9040 & 5.7892 & 653 & ГST \\
\hline HEMRI & 040 & 4. & 84 & ГST \\
\hline 2 & & & 03 & TRN \\
\hline HEMBL3 & & 3 . & & TRN \\
\hline HEMBL3 & 9040 & 3. & 82 & TRN \\
\hline 0 & 040 & & & RN \\
\hline HEMBL; & 9040 & 4. & 36 & TRN \\
\hline HEMBL3 & & 3. & 3.4589 & 「RN \\
\hline HEMBL3 & 9040 & 3. & 4004 & TRN \\
\hline HEMBL & 9040 & 3 . & 719 & TR \\
\hline 7 & & 4. & & \\
\hline HEMBL3 & 1479040 & 3.0 & .9739 & \\
\hline CHEMBL3 & 1479040 & 5.823 & 5.0603 & $\mathrm{~N}$ \\
\hline CHEMBL3431820 & 1479040 & 3.0 & 3.3753 & $\mathrm{~K}$ \\
\hline
\end{tabular}

Page 28013 
Supplemental Table S2.txt

\begin{tabular}{|c|c|c|c|c|c|}
\hline CHEMBL3431763 & 1479040 & 5.3515 & \multicolumn{2}{|c|}{5.2010000000000005} & TRN \\
\hline CHEMBL3431746 & 1479040 & 3.0 & 3.615 & TRN & \\
\hline CHEMBL3431910 & 1479040 & 3.0 & 3.6477 & TST & \\
\hline CHEMBL3431768 & 1479040 & 3.0 & 3.7872 & TST & \\
\hline CHEMBL3431687 & 1479040 & 3.0 & 3.6635 & TST & \\
\hline CHEMBL3431507 & 1479040 & 3.0 & 3.2773 & TST & \\
\hline CHEMBL3431563 & 1479040 & 4.6147 & 3.6865 & TRN & \\
\hline CHEMBL3431519 & 1479040 & 4.709 & 4.8813 & TRN & \\
\hline CHEMBL3431678 & 1479040 & 3.0 & 3.5657 & TRN & \\
\hline CHEMBL3431546 & 1479040 & 4.4946 & 5.3235 & TRN & \\
\hline CHEMBL3431870 & 1479040 & 3.0 & 4.373 & TRN & \\
\hline CHEMBL3431640 & 1479040 & 3.0 & 3.6972 & TRN & \\
\hline CHEMBL3431472 & 1479040 & 3.0 & 4.3284 & TRN & \\
\hline CHEMBL3431636 & 1479040 & 3.0 & 3.6612 & TST & \\
\hline CHEMBL3431599 & 1479040 & 4.7125 & 4.3177 & TRN & \\
\hline CHEMBL3431736 & 1479040 & 6.3296 & 6.6604 & TST & \\
\hline CHEMBL3431909 & 1479040 & 6.237 & 5.5901 & TRN & \\
\hline CHEMBL3431751 & 1479040 & 5.3245 & 3.7915 & TRN & \\
\hline CHEMBL3431922 & 1479040 & 4.1285 & 3.2704 & TRN & \\
\hline CHEMBL3431821 & 1479040 & 3.0 & 3.327 & TRN & \\
\hline CHEMBL3431543 & 1479040 & 3.0 & 3.5238 & TST & \\
\hline CHEMBL3431598 & 1479040 & 4.7657 & 3.8869 & TRN & \\
\hline CHEMBL3431594 & 1479040 & 3.0 & 3.8603 & TRN & \\
\hline CHEMBL3431569 & 1479040 & 4.5179 & 4.3449 & TRN & \\
\hline CHEMBL3431665 & 1479040 & 4.4955 & 3.675 & TRN & \\
\hline CHEMBL3431609 & 1479040 & 4.3267 & 4.5235 & TST & \\
\hline CHEMBL3431784 & 1479040 & 3.0 & 3.282 & TST & \\
\hline CHEMBL3431717 & 1479040 & 3.0 & 3.4494 & TRN & \\
\hline CHEMBL3431613 & 1479040 & 4.9224 & 5.5404 & TRN & \\
\hline CHEMBL3431490 & 1479040 & 5.1805 & 4.3474 & TRN & \\
\hline CHEMBL3431732 & 1479040 & 5.1459 & 5.4121 & TST & \\
\hline CHEMBL3431849 & 1479040 & 4.7742 & 3.7058 & TRN & \\
\hline CHEMBL3431506 & 1479040 & 4.9673 & 5.0627 & TST & \\
\hline CHEMBL3431523 & 1479040 & 3.0 & 3.4879 & TRN & \\
\hline CHEMBL3431876 & 1479040 & 5.2926 & 3.7191 & TRN & \\
\hline CHEMBL3431650 & 1479040 & 3.0 & 3.5847 & TST & \\
\hline CHEMBL3431811 & 1479040 & 5.8962 & 5.172000 & 0000000001 & TST \\
\hline CHEMBL2216777 & 1479040 & 5.5528 & 4.896 & TRN & \\
\hline CHEMBL3431535 & 1479040 & 5.6713 & 5.795 & TRN & \\
\hline CHEMBL3431862 & 1479040 & 4.3488 & 3.8409 & TRN & \\
\hline CHEMBL3431572 & 1479040 & 4.71 & 4.7318 & TRN & \\
\hline CHEMBL3431583 & 1479040 & 4.3548 & 4.3719 & TRN & \\
\hline CHEMBL3431463 & 1479040 & 3.0 & 3.4149 & TRN & \\
\hline CHEMBL3431694 & 1479040 & 5.5733 & 5.2473 & TST & \\
\hline CHEMBL3431632 & 1479040 & 3.0 & 3.2699 & TST & \\
\hline CHEMBL3431758 & 1479040 & 3.0 & 3.5987 & TRN & \\
\hline CHEMBL3431903 & 1479040 & 4.9486 & 4.0292 & TRN & \\
\hline CHEMBL3431706 & 1479040 & 3.0 & 3.7584 & TST & \\
\hline
\end{tabular}


Supplemental Table S2.txt

\begin{tabular}{|c|c|c|c|c|c|}
\hline CHEMBL3431775 & 1479040 & 5.8077 & 6.1586 & TST & \\
\hline CHEMBL3431567 & 1479040 & 3.0 & 3.8238 & TRN & \\
\hline CHEMBL3431831 & 1479040 & 3.0 & 3.3308 & TRN & \\
\hline CHEMBL3431513 & 1479040 & 3.0 & 3.5114 & TST & \\
\hline CHEMBL3431588 & 1479040 & 3.0 & 4.2147 & TST & \\
\hline CHEMBL 3431754 & 1479040 & 3.0 & 3.3807 & TRN & \\
\hline CHEMBL 3431638 & 1479040 & 3.0 & 3.2973 & TRN & \\
\hline CHEMBL 3431721 & 1479040 & 4.3878 & 3.2388 & TRN & \\
\hline CHEMBL 3431925 & 1479040 & 3.0 & 3.2564 & TRN & \\
\hline CHEMBL3431631 & 1479040 & 3.0 & 3.6518 & TRN & \\
\hline CHEMBL 3431537 & 1479040 & 4.1585 & 4.7555 & TRN & \\
\hline CHEMBL 3431777 & 1479040 & 6.26399 & 99999999 & 99 & 6.6135 \\
\hline CHEMBL3431578 & 1479040 & 4.1827 & 4.4002 & TRN & \\
\hline CHEMBL 3431478 & 1479040 & 6.2703 & 5.3475 & TRN & \\
\hline CHEMBL3431765 & 1479040 & 5.3602 & 5.5363 & TRN & \\
\hline CHEMBL 3431653 & 1479040 & 4.7683 & 3.6674 & TRN & \\
\hline CHEMBL3431856 & 1479040 & 4.207 & 3.6008 & TRN & \\
\hline CHEMBL3431596 & 1479040 & 4.7547 & 5.5177 & TRN & \\
\hline CHEMBL 3431750 & 1479040 & 3.0 & 3.6763 & TRN & \\
\hline CHEMBL 3431738 & 1479040 & 6.1542 & 6.5013 & TST & \\
\hline CHEMBL3431893 & 1479040 & 4.2826 & 3.3737 & TRN & \\
\hline CHEMBL3431744 & 1479040 & 3.0 & 3.5543 & TRN & \\
\hline CHEMBL3431901 & 1479040 & 4.7032 & 3.7927 & TRN & \\
\hline CHEMBL 3431853 & 1479040 & 4.2519 & 3.6642 & TRN & \\
\hline CHEMBL3431691 & 1479040 & 3.0 & 3.7478 & TRN & \\
\hline CHEMBL3431739 & 1479040 & 6.3256 & 6.7271 & TST & \\
\hline CHEMBL 3431712 & 1479040 & 3.0 & 3.449 & TRN & \\
\hline CHEMBL 3431800 & 1479040 & 6.2674 & 6.3676 & TST & \\
\hline CHEMBL 3431807 & 1479040 & 4.5414 & 4.6913 & TRN & \\
\hline CHEMBL3431799 & 1479040 & 6.2948 & 6.3814 & TST & \\
\hline CHEMBL 3431586 & 1479040 & 4.6768 & 3.4939 & TST & \\
\hline CHEMBL3431755 & 1479040 & 4.5791 & 4.5382 & TRN & \\
\hline CHEMBL3431614 & 1479040 & 3.0 & 3.824 & TRN & \\
\hline CHEMBL 3431574 & 1479040 & 5.2895 & 5.3493 & TRN & \\
\hline CHEMBL 3431474 & 1479040 & 4.1055 & 3.4958 & TRN & \\
\hline CHEMBL3431865 & 1479040 & 4.3025 & 3.6126 & TRN & \\
\hline CHEMBL3431467 & 1479040 & 3.0 & 3.5249 & TRN & \\
\hline CHEMBL3431887 & 1479040 & 3.0 & 3.2463 & TRN & \\
\hline CHEMBL 3431779 & 1479040 & 3.0 & 3.2619 & TST & \\
\hline CHEMBL3431622 & 1479040 & 3.0 & 3.2321 & TRN & \\
\hline CHEMBL3431884 & 1479040 & 3.0 & 3.2875 & TRN & \\
\hline CHEMBL3431652 & 1479040 & 3.0 & 3.4856 & TST & \\
\hline CHEMBL3431783 & 1479040 & 3.0 & 3.8295 & TRN & \\
\hline CHEMBL 3431479 & 1479040 & 5.2151 & 4.6128 & TST & \\
\hline CHEMBL3431892 & 1479040 & 4.8593 & 3.3395 & TRN & \\
\hline CHEMBL3431547 & 1479040 & 4.9411 & 5.2539 & TRN & \\
\hline CHEMBL3431711 & 1479040 & 3.0 & 3.1985 & TRN & \\
\hline CHEMBL3431715 & 1479040 & 3.0 & 3.6083 & TRN & \\
\hline
\end{tabular}


Supplemental Table S2.txt

\begin{tabular}{|c|c|c|c|c|c|c|}
\hline CHEMBL 3431858 & 1479040 & 4.0897 & 4.3771 & TRN & & \\
\hline CHEMBL 3431549 & 1479040 & 6.0149 & 5.9851 & TRN & & \\
\hline CHEMBL 3431550 & 1479040 & 5.6085 & 5.8278 & TRN & & \\
\hline CHEMBL 3431798 & 1479040 & 3.0 & 3.3762 & TST & & \\
\hline CHEMBL 3431639 & 1479040 & 4.3612 & 4.655 & TST & & \\
\hline CHEMBL3431501 & 1479040 & 3.0 & 3.9872 & TRN & & \\
\hline CHEMBL 3431778 & 1479040 & 6.2322 & 6.2555 & TST & & \\
\hline CHEMBL 3431481 & 1479040 & 4.4759 & 3.6558 & TRN & & \\
\hline CHEMBL 3431464 & 1479040 & 3.0 & 3.58 & TRN & & \\
\hline CHEMBL 3431852 & 1479040 & 3.0 & 3.8421 & TRN & & \\
\hline CHEMBL 3431878 & 1479040 & 4.2755 & 3.5138 & TRN & & \\
\hline CHEMBL 3431880 & 1479040 & 3.0 & 3.3079 & TRN & & \\
\hline CHEMBL 3431553 & 1479040 & 3.0 & 4.4567 & TRN & & \\
\hline CHEMBL 3431764 & 1479040 & 5.7004 & 5.5355 & TRN & & \\
\hline CHEMBL 3431716 & 1479040 & 4.4155 & 3.7045 & TRN & & \\
\hline CHEMBL 3431542 & 1479040 & 4.71899 & 999999999 & 99 & 4.5325 & TRN \\
\hline CHEMBL 3431705 & 1479040 & 3.0 & 3.5774 & TST & & \\
\hline CHEMBL 3431846 & 1479040 & 3.0 & 3.5377 & TRN & & \\
\hline CHEMBL 3431913 & 1479040 & 5.7653 & 5.7271 & TRN & & \\
\hline CHEMBL 3431528 & 1479040 & 3.0 & 3.7329 & TRN & & \\
\hline CHEMBL 3431658 & 1479040 & 4.6163 & 3.5631 & TST & & \\
\hline CHEMBL 3431917 & 1479040 & 4.4721 & 5.001 & TRN & & \\
\hline CHEMBL 3431520 & 1479040 & 5.7396 & 6.2761 & TST & & \\
\hline CHEMBL 3431521 & 1479040 & 4.5893 & 4.1525 & TST & & \\
\hline CHEMBL 3431527 & 1479040 & 4.3791 & 4.4278 & TRN & & \\
\hline CHEMBL 3431662 & 1479040 & 3.0 & 3.2035 & TST & & \\
\hline CHEMBL 3431601 & 1479040 & 4.065 & 4.1335 & TRN & & \\
\hline CHEMBL 3431908 & 1479040 & 3.0 & 4.1053 & TRN & & \\
\hline CHEMBL 3431926 & 1479040 & 3.0 & 3.3875 & TRN & & \\
\hline CHEMBL 3431866 & 1479040 & 4.4856 & 4.2905 & TRN & & \\
\hline CHEMBL 3431485 & 1479040 & 3.0 & 3.6419 & TRN & & \\
\hline CHEMBL 3431877 & 1479040 & 4.2231 & 3.4246 & TRN & & \\
\hline CHEMBL 3431879 & 1479040 & 3.0 & 3.4014 & TRN & & \\
\hline CHEMBL 3431668 & 1479040 & 5.3917 & 5.1677 & TST & & \\
\hline CHEMBL 3431564 & 1479040 & 3.0 & 3.9314 & TST & & \\
\hline CHEMBL 3431890 & 1479040 & 3.0 & 3.2604 & TRN & & \\
\hline CHEMBL 3431850 & 1479040 & 6.1635 & 4.6561 & TRN & & \\
\hline CHEMBL 3431697 & 1479040 & 4.2054 & 3.6572 & TRN & & \\
\hline CHEMBL 3431502 & 1479040 & 3.0 & 4.7109 & TRN & & \\
\hline CHEMBL 3431753 & 1479040 & 3.0 & 3.6122 & TRN & & \\
\hline CHEMBL 3431889 & 1479040 & 3.0 & 3.3351 & TRN & & \\
\hline CHEMBL 3431819 & 1479040 & 4.0068 & 3.6185 & TRN & & \\
\hline CHEMBL 3431762 & 1479040 & 3.0 & 3.8732 & TST & & \\
\hline CHEMBL 3431848 & 1479040 & 5.7294 & 3.6783 & TRN & & \\
\hline CHEMBL 3431533 & 1479040 & 3.0 & 3.5566 & TST & & \\
\hline CHEMBL 3431619 & 1479040 & 3.0 & 3.5332 & TRN & & \\
\hline CHEMBL 3431770 & 1479040 & 3.0 & 3.7335 & TST & & \\
\hline CHEMBL 3431773 & 1479040 & 3.0 & 3.1479 & TRN & & \\
\hline
\end{tabular}


Supplemental Table S2.txt

\begin{tabular}{|c|c|c|c|c|c|}
\hline CHEMBL3431914 & 1479040 & 6.2379 & 4.9981 & TRN & \\
\hline CHEMBL3431725 & 1479040 & 3.0 & 4.0806 & TST & \\
\hline CHEMBL3431534 & 1479040 & 3.0 & 3.7064 & TRN & \\
\hline CHEMBL3431728 & 1479040 & 3.0 & 3.2961 & TRN & \\
\hline CHEMBL3431633 & 1479040 & 5.2587 & 5.37200 & 0000000001 & TST \\
\hline CHEMBL3431487 & 1479040 & 4.4184 & 3.59899 & 99999999998 & TRN \\
\hline CHEMBL3431461 & 1479040 & 3.0 & 3.1954 & TRN & \\
\hline CHEMBL3431688 & 1479040 & 4.2654 & 3.6476 & TRN & \\
\hline CHEMBL3431659 & 1479040 & 5.5966 & 4.7449 & TRN & \\
\hline CHEMBL3431468 & 1479040 & 3.0 & 3.4548 & TRN & \\
\hline CHEMBL3431554 & 1479040 & 5.6522 & 5.7516 & TRN & \\
\hline CHEMBL3431606 & 1479040 & 6.2283 & 6.4591 & TRN & \\
\hline CHEMBL3431471 & 1479040 & 3.0 & 3.3462 & TRN & \\
\hline CHEMBL3431602 & 1479040 & 6.5441 & 6.5688 & TRN & \\
\hline CHEMBL3431740 & 1479040 & 3.0 & 3.2181 & TST & \\
\hline CHEMBL3431792 & 1479040 & 3.0 & 3.3601 & TRN & \\
\hline CHEMBL3431714 & 1479040 & 4.9868 & 4.4201 & TRN & \\
\hline CHEMBL 3431825 & 1479040 & 4.5461 & 4.013 & TRN & \\
\hline CHEMBL3431597 & 1479040 & 4.6294 & 4.0957 & TRN & \\
\hline CHEMBL3431843 & 1479040 & 5.8669 & 5.6045 & TST & \\
\hline CHEMBL3431752 & 1479040 & 3.0 & 3.5852 & TRN & \\
\hline CHEMBL3431696 & 1479040 & 4.7588 & 3.6642 & TST & \\
\hline CHEMBL3431686 & 1479040 & 3.0 & 3.6544 & TST & \\
\hline CHEMBL3431510 & 1479040 & 4.6416 & 3.6487 & TRN & \\
\hline CHEMBL3431462 & 1479040 & 6.2103 & 6.4351 & TST & \\
\hline CHEMBL3431731 & 1479040 & 6.0074 & 6.0761 & TST & \\
\hline CHEMBL3431654 & 1479040 & 4.8392 & 3.7112 & TRN & \\
\hline CHEMBL3431496 & 1479040 & 4.67 & 4.4708 & TRN & \\
\hline CHEMBL3431742 & 1479040 & 4.4665 & 3.7169 & TST & \\
\hline CHEMBL3431647 & 1479040 & 5.4626 & 5.3803 & TRN & \\
\hline CHEMBL 3431741 & 1479040 & 4.5269 & 4.2579 & TRN & \\
\hline CHEMBL3431673 & 1479040 & 4.3386 & 3.4153 & TRN & \\
\hline CHEMBL3431789 & 1479040 & 5.5531 & 5.6382 & TRN & \\
\hline CHEMBL3431695 & 1479040 & 3.0 & 3.7487 & TST & \\
\hline CHEMBL3431916 & 1479040 & 6.5064 & 6.0656 & TRN & \\
\hline CHEMBL3431842 & 1479040 & 3.0 & 3.6248 & TST & \\
\hline CHEMBL3431760 & 1479040 & 4.2962 & 3.6889 & TRN & \\
\hline CHEMBL3431615 & 1479040 & 3.0 & 3.6245 & TRN & \\
\hline CHEMBL3431495 & 1479040 & 3.0 & 3.6818 & TRN & \\
\hline CHEMBL3431812 & 1479040 & 3.0 & 3.4391 & TRN & \\
\hline CHEMBL3431682 & 1479040 & 4.0763 & 3.6907 & TST & \\
\hline CHEMBL3431541 & 1479040 & 3.0 & 3.7717 & TST & \\
\hline CHEMBL3431526 & 1479040 & 3.0 & 4.476 & TRN & \\
\hline CHEMBL3431826 & 1479040 & 4.6839 & 4.9694 & TRN & \\
\hline CHEMBL3431524 & 1479040 & 4.7763 & 4.7675 & TRN & \\
\hline CHEMBL3431891 & 1479040 & 3.0 & 3.2431 & TRN & \\
\hline CHEMBL 3431645 & 1479040 & 3.0 & 3.6601 & TRN & \\
\hline CHEMBL3431667 & 1479040 & 5.2033 & 5.0044 & TRN & \\
\hline
\end{tabular}


Supplemental Table S2.txt

\begin{tabular}{|c|c|c|c|c|}
\hline CHEMBL3431923 & 1479040 & 3.0 & 3.3381 & TRN \\
\hline CHEMBL3431600 & 1479040 & 4.468 & 4.129 & TRN \\
\hline CHEMBL3431735 & 1479040 & 6.4116 & 6.6391 & TST \\
\hline CHEMBL3431851 & 1479040 & 5.4343 & 3.5785 & TRN \\
\hline CHEMBL3431575 & 1479040 & 3.0 & 3.84 & TRN \\
\hline CHEMBL3431787 & 1479040 & 3.0 & 3.4304 & TRN \\
\hline CHEMBL3431466 & 1479040 & 4.3929 & 3.4913 & TRN \\
\hline CHEMBL3431581 & 1479040 & 4.1381 & 3.5751 & TRN \\
\hline CHEMBL3431918 & 1479040 & 5.6351 & 5.6047 & TRN \\
\hline CHEMBL3431610 & 1479040 & 4.3806 & 4.2398 & TRN \\
\hline CHEMBL3431460 & 1479040 & 3.0 & 3.8194 & TRN \\
\hline CHEMBL3431707 & 1479040 & 3.0 & 3.7274 & TST \\
\hline CHEMBL3431475 & 1479040 & 4.7007 & 3.5067 & TRN \\
\hline CHEMBL3431544 & 1479040 & 3.0 & 3.6737 & TRN \\
\hline CHEMBL3431679 & 1479040 & 3.0 & 3.5662 & TRN \\
\hline CHEMBL3431545 & 1479040 & 4.4003 & 4.6511 & TRN \\
\hline CHEMBL3431664 & 1479040 & 3.0 & 3.4482 & TRN \\
\hline CHEMBL3431896 & 1479040 & 5.7105 & 5.4955 & TRN \\
\hline CHEMBL3431734 & 1479040 & 5.7013 & 6.3201 & TST \\
\hline CHEMBL3431491 & 1479040 & 5.5622 & 4.5833 & TRN \\
\hline CHEMBL3431677 & 1479040 & 3.0 & 3.5688 & TRN \\
\hline CHEMBL3431869 & 1479040 & 3.0 & 4.5985 & TRN \\
\hline CHEMBL3431804 & 1479040 & 3.0 & 3.77 & TRN \\
\hline CHEMBL3431782 & 1479040 & 3.0 & 3.9681 & TRN \\
\hline CHEMBL3431793 & 1479040 & 5.8024 & 5.9704 & TRN \\
\hline CHEMBL3431641 & 1479040 & 5.2947 & 5.5184 & TRN \\
\hline CHEMBL3431591 & 1479040 & 3.0 & 3.9882 & TRN \\
\hline CHEMBL3431540 & 1479040 & 4.3673 & 4.5222 & TRN \\
\hline CHEMBL3431871 & 1479040 & 3.0 & 3.5771 & TST \\
\hline CHEMBL3431829 & 1479040 & 4.7486 & 4.9255 & TRN \\
\hline CHEMBL3431855 & 1479040 & 5.1838 & 4.445 & TRN \\
\hline CHEMBL3431824 & 1479040 & 3.0 & 3.258 & TRN \\
\hline CHEMBL3431669 & 1479040 & 3.0 & 3.5678 & TST \\
\hline CHEMBL3431488 & 1479040 & 4.7444 & 3.6568 & TRN \\
\hline CHEMBL3431797 & 1479040 & 3.0 & 3.2282 & TST \\
\hline CHEMBL3431749 & 1479040 & 3.0 & 3.5239 & TRN \\
\hline CHEMBL3431886 & 1479040 & 3.0 & 3.2595 & TST \\
\hline CHEMBL3431548 & 1479040 & 5.8625 & 5.8856 & TRN \\
\hline CHEMBL3431905 & 1479040 & 4.808 & 3.6558 & TRN \\
\hline CHEMBL3431818 & 1479040 & 3.0 & 3.2822 & TST \\
\hline CHEMBL3431815 & 1479040 & 3.0 & 3.2856 & TRN \\
\hline CHEMBL3431607 & 1479040 & 3.0 & 3.8045 & TST \\
\hline CHEMBL3431796 & 1479040 & 5.7313 & 4.58 & TRN \\
\hline CHEMBL3431801 & 1479040 & 6.7135 & 6.7113 & TST \\
\hline CHEMBL3431660 & 1479040 & 4.6735 & 3.6739 & TRN \\
\hline CHEMBL3431616 & 1479040 & 4.0531 & 3.6011 & TRN \\
\hline CHEMBL3431737 & 1479040 & 6.1924 & 6.7817 & TST \\
\hline CHEMBL3431470 & 1479040 & 3.0 & 3.2175 & TRN \\
\hline
\end{tabular}


Supplemental Table S2.txt

\begin{tabular}{|c|c|c|c|c|}
\hline CHEMBL 3431795 & 1479040 & 3.0 & 4.4158 & TRN \\
\hline CHEMBL 3431514 & 1479040 & 4.2628 & 3.9117 & TST \\
\hline CHEMBL3431726 & 1479040 & 3.0 & 3.3692 & TST \\
\hline CHEMBL3431532 & 1479040 & 3.0 & 3.8008 & TST \\
\hline CHEMBL 3431772 & 1479040 & 4.7915 & 3.5707 & TRN \\
\hline CHEMBL 3431898 & 1479040 & 6.234 & 5.9189 & TRN \\
\hline CHEMBL3431702 & 1479040 & 3.0 & 3.5592 & TRN \\
\hline CHEMBL3431700 & 1479040 & 4.0891 & 3.4765 & TRN \\
\hline CHEMBL3431867 & 1479040 & 3.0 & 3.4955 & TRN \\
\hline CHEMBL3431589 & 1479040 & 4.8927 & 4.2777 & TST \\
\hline CHEMBL3431767 & 1479040 & 5.2553 & 5.4601 & TRN \\
\hline CHEMBL3431895 & 1479040 & 4.8203 & 4.1703 & TRN \\
\hline CHEMBL 3431841 & 1479040 & 3.0 & 3.5416 & TST \\
\hline CHEMBL3431476 & 1479040 & 4.2421 & 4.1701 & TRN \\
\hline CHEMBL 3431868 & 1479040 & 4.615 & 4.2573 & TRN \\
\hline CHEMBL3431781 & 1479040 & 3.0 & 3.6788 & TST \\
\hline CHEMBL3431859 & 1479040 & 4.7226 & 4.5935 & TRN \\
\hline CHEMBL 3431681 & 1479040 & 3.0 & 3.3588 & TST \\
\hline CHEMBL3431579 & 1479040 & 4.4358 & 4.61600 & 00000000005 \\
\hline CHEMBL 3431646 & 1479040 & 3.0 & 3.32899 & 99999999997 \\
\hline CHEMBL3431580 & 1479040 & 4.1393 & 4.1715 & TST \\
\hline CHEMBL3431828 & 1479040 & 3.0 & 3.3761 & TRN \\
\hline CHEMBL 3431560 & 1479040 & 3.0 & 3.6931 & TRN \\
\hline CHEMBL3431671 & 1479040 & 3.0 & 3.4423 & TST \\
\hline CHEMBL3431838 & 1479040 & 3.0 & 3.3463 & TRN \\
\hline CHEMBL 3431794 & 1479040 & 5.7095 & 5.7255 & TRN \\
\hline CHEMBL 3431708 & 1479040 & 4.3249 & 3.6017 & TST \\
\hline CHEMBL3431666 & 1479040 & 5.1379 & 4.388 & TRN \\
\hline CHEMBL3431627 & 1479040 & 3.0 & 3.3227 & TRN \\
\hline CHEMBL3431670 & 1479040 & 4.3692 & 3.7516 & TRN \\
\hline CHEMBL 2043144 & 823387 & 6.301 & 6.2994 & TRN \\
\hline CHEMBL2042986 & 823387 & 5.2924 & 5.2712 & TRN \\
\hline CHEMBL2042836 & 823387 & 6.1549 & 6.0964 & TRN \\
\hline CHEMBL 2042838 & 823387 & 5.8539 & 5.895 & TRN \\
\hline CHEMBL 2043140 & 823387 & 6.1549 & 6.4221 & TST \\
\hline CHEMBL2043138 & 823387 & 5.8239 & 5.7289 & TRN \\
\hline CHEMBL 2042987 & 823387 & 5.8239 & 5.6048 & TST \\
\hline CHEMBL 2042706 & 823387 & 5.8539 & 5.6457 & TRN \\
\hline CHEMBL 2042704 & 823387 & 4.301 & 4.3982 & TRN \\
\hline CHEMBL 2043146 & 823387 & 7.3372 & 6.44799 & 99999999995 \\
\hline CHEMBL 2042543 & 823387 & 5.7447 & 6.1366 & TST \\
\hline CHEMBL2042539 & 823387 & 6.0458 & 6.0694 & TRN \\
\hline CHEMBL2042988 & 823387 & 6.0969 & 6.0838 & TRN \\
\hline CHEMBL2043133 & 823387 & 6.1549 & 6.1511 & TRN \\
\hline CHEMBL 2043131 & 823387 & 6.0458 & 6.0439 & TRN \\
\hline CHEMBL 2042541 & 823387 & 6.2218 & 6.2621 & TRN \\
\hline CHEMBL2043136 & 823387 & 6.0 & 5.9702 & TRN \\
\hline CHEMBL2042834 & 823387 & 6.2218 & 6.2994 & TRN \\
\hline
\end{tabular}

Page 28019 
Supplemental Table S2.txt

\begin{tabular}{|c|c|c|c|c|}
\hline CHEMBL 2042989 & 823387 & 5.6576 & 5.7397 & TRN \\
\hline CHEMBL 2043135 & 823387 & 6.0969 & 6.1756 & TRN \\
\hline CHEMBL 2043129 & 823387 & 5.7212 & 5.6345 & TRN \\
\hline CHEMBL 2042705 & 823387 & 6.2218 & 5.957999 & 9999999999 \\
\hline CHEMBL 2042835 & 823387 & 5.6576 & 5.5698 & TRN \\
\hline CHEMBL 2042709 & 823387 & 5.6198 & 5.6759 & TRN \\
\hline CHEMBL 2043145 & 823387 & 5.8861 & 5.8188 & TRN \\
\hline CHEMBL 2043137 & 823387 & 6.0969 & 6.1337 & TRN \\
\hline CHEMBL 2042701 & 823387 & 4.301 & 4.3856 & TRN \\
\hline CHEMBL 2042700 & 823387 & 5.6198 & 5.4998 & TRN \\
\hline CHEMBL 2042544 & 823387 & 6.0969 & 6.0548 & TRN \\
\hline CHEMBL 2042984 & 823387 & 5.9208 & 6.175 & TRN \\
\hline CHEMBL 2043132 & 823387 & 6.0458 & 6.2339 & TST \\
\hline CHEMBL 2042548 & 823387 & 6.5229 & 6.4207 & TRN \\
\hline CHEMBL 2042382 & 823387 & 5.6778 & 5.6819 & TRN \\
\hline CHEMBL 2042837 & 823387 & 6.0458 & 6.0162 & TRN \\
\hline CHEMBL 2042833 & 823387 & 5.8539 & 5.8734 & TRN \\
\hline CHEMBL 2042698 & 823387 & 5.9208 & 5.9564 & TRN \\
\hline CHEMBL 2043130 & 823387 & 5.7212 & 5.7735 & TRN \\
\hline CHEMBL 2042699 & 823387 & 6.1549 & 6.1427 & TRN \\
\hline CHEMBL 2043139 & 823387 & 6.2218 & 6.3144 & TRN \\
\hline CHEMBL 2043134 & 823387 & 5.9586 & 6.5008 & TST \\
\hline CHEMBL 2043147 & 823387 & 8.0458 & 6.361006 & 2000000001 \\
\hline CHEMBL 2043143 & 823387 & 6.0 & 6.0438 & TRN \\
\hline CHEMBL 2042832 & 823387 & 5.6021 & 5.6056 & TRN \\
\hline CHEMBL 2042839 & 823387 & 5.8539 & 5.7657 & TRN \\
\hline CHEMBL 2042549 & 823387 & 5.699 & 5.7205 & TRN \\
\hline CHEMBL 2042708 & 823387 & 6.0969 & 6.0187 & TRN \\
\hline CHEMBL 2042707 & 823387 & 5.8539 & 5.7415 & TST \\
\hline CHEMBL 2043142 & 823387 & 5.8861 & 5.8732 & TRN \\
\hline CHEMBL 2042703 & 823387 & 6.1549 & 6.1887 & TRN \\
\hline CHEMBL 2042985 & 823387 & 6.1549 & 6.1053 & TRN \\
\hline CHEMBL 2042547 & 823387 & 4.301 & 6.1396 & TST \\
\hline CHEMBL 2043141 & 823387 & 4.301 & 4.2977 & TRN \\
\hline CHEMBL 2042540 & 823387 & 6.0 & 6.034 & TRN \\
\hline CHEMBL 2042542 & 823387 & 6.1549 & 6.2312 & TST \\
\hline CHEMBL 2042550 & 823387 & 5.9586 & 5.7322 & TST \\
\hline CHEMBL 2042702 & 823387 & 5.6021 & 5.3364 & TST \\
\hline CHEMBL 2042546 & 823387 & 6.0969 & 5.81 & TST \\
\hline CHEMBL 2042545 & 823387 & 5.7959 & 5.2792 & TST \\
\hline CHEMBL591500 & 613511 & 8.12 & 8.1246 & TRN \\
\hline CHEMBL592188 & 613511 & 7.9 & 7.9047 & TRN \\
\hline CHEMBL591011 & 613511 & 8.37 & 8.2742 & TRN \\
\hline CHEMBL591248 & 613511 & 7.75 & 7.7287 & TRN \\
\hline CHEMBL591249 & 613511 & 8.0 & 7.9863 & TRN \\
\hline CHEMBL591250 & 613511 & 8.03 & 8.0527 & TRN \\
\hline CHEMBL592663 & 613511 & 8.27 & 8.2784 & TRN \\
\hline CHEMBL592379 & 613511 & 8.31 & 8.2308 & TRN \\
\hline
\end{tabular}




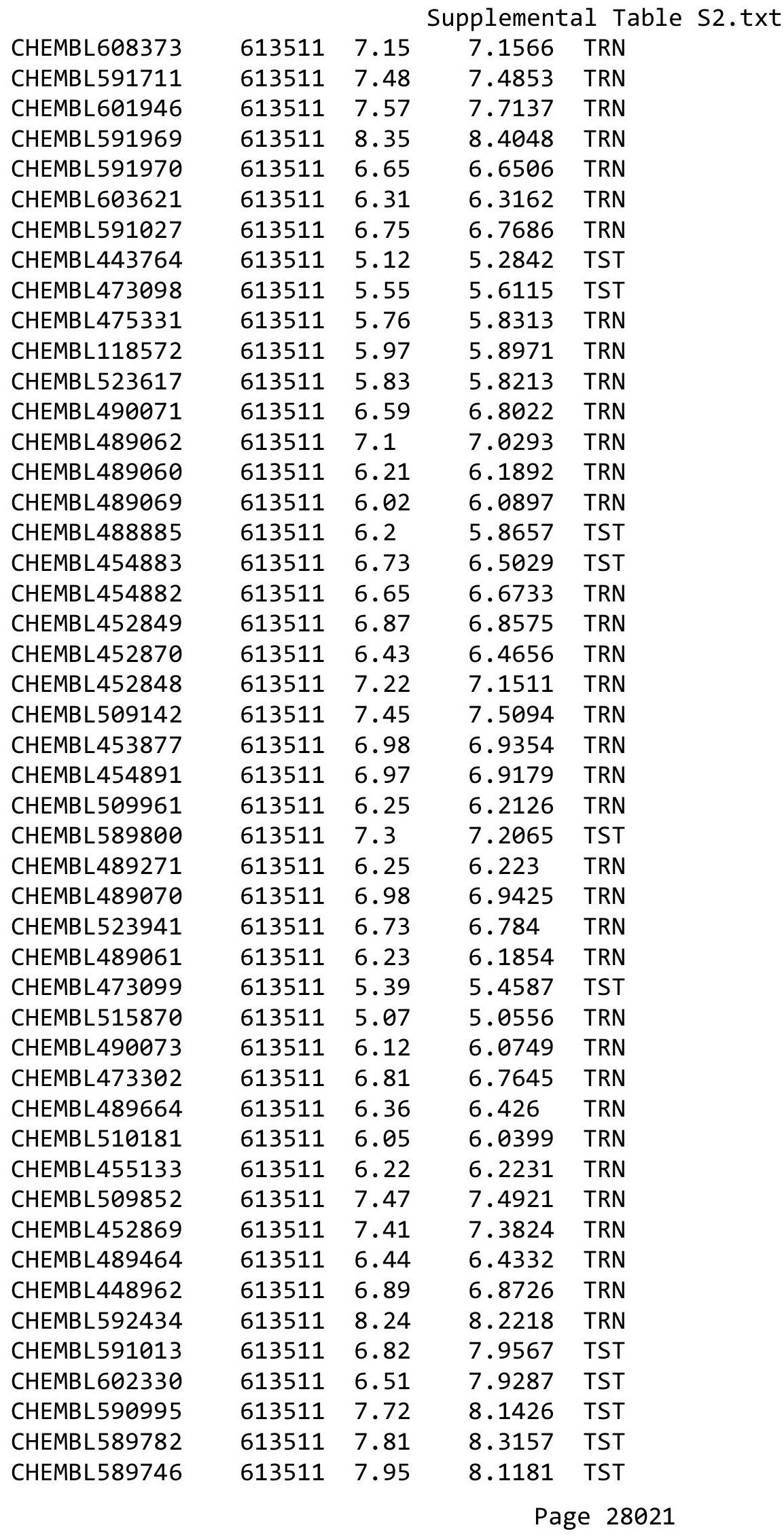




\begin{tabular}{|c|c|c|c|c|c|}
\hline \multicolumn{6}{|c|}{ Supplemental Table S2.txt } \\
\hline CHEMBL591496 & 613511 & 8.09 & 7.848 & TST & \\
\hline CHEMBL452847 & 613511 & 8.12 & 7.4873 & TST & \\
\hline CHEMBL454890 & 613511 & 7.05 & 7.0498 & TST & \\
\hline CHEMBL260374 & 613511 & 7.2 & 6.0515 & TST & \\
\hline CHEMBL24057 & 1506084 & 5.3737 & 5.6935 & TRN & \\
\hline CHEMBL165542 & 1506084 & 5.1752 & 5.232 & TRN & \\
\hline CHEMBL279660 & 1506084 & 4.9136 & 4.9695 & TRN & \\
\hline CHEMBL3594018 & 1506084 & 5.4237 & 5.5003 & TRN & \\
\hline CHEMBL185172 & 1506084 & 5.6596 & 5.4917 & TST & \\
\hline CHEMBL3594013 & 1506084 & 6.0706 & 5.7933 & TRN & \\
\hline CHEMBL229102 & 1506084 & 6.284 & 5.6238 & TST & \\
\hline CHEMBL181480 & 1506084 & 5.8356 & 5.8056 & TST & \\
\hline CHEMBL1170755 & 1506084 & 5.5834 & 5.5109 & TRN & \\
\hline CHEMBL537055 & 1506084 & 4.6234 & 4.8728 & TST & \\
\hline CHEMBL1081887 & 1506084 & 4.8041 & 4.1465 & TRN & \\
\hline CHEMBL1081886 & 1506084 & 4.5768 & 4.1465 & TRN & \\
\hline CHEMBL1852582 & 1506084 & 3.9031 & 4.0266 & TRN & \\
\hline CHEMBL88670 & 1506084 & 4.8928 & 5.1018 & TST & \\
\hline CHEMBL3594195 & 1506084 & 5.2725 & 5.2953 & TRN & \\
\hline CHEMBL3594009 & 1506084 & 5.9136 & 5.98799 & 99999999995 & TRN \\
\hline CHEMBL1963649 & 1506084 & 3.1624 & 2.9029 & TRN & \\
\hline CHEMBL 22629 & 1506084 & 5.0 & 4.8043 & TRN & \\
\hline CHEMBL3594014 & 1506084 & 6.1192 & 6.2538 & TRN & \\
\hline CHEMBL1170548 & 1506084 & 5.4976 & 5.3791 & TRN & \\
\hline CHEMBL1081709 & 1506084 & 4.6402 & 4.1465 & TRN & \\
\hline CHEMBL102740 & 1506084 & 5.3372 & 4.1989 & TST & \\
\hline CHEMBL 249456 & 1506084 & 6.1024 & 5.3974 & TST & \\
\hline CHEMBL1087975 & 1506084 & 3.4989 & 4.5099 & TST & \\
\hline CHEMBL1851728 & 1506084 & 3.8182 & 4.0088 & TRN & \\
\hline CHEMBL586743 & 1506084 & 4.7122 & 4.7312 & TRN & \\
\hline CHEMBL283745 & 1506084 & 5.34200 & 00000000 & 5.0719 & TRN \\
\hline CHEMBL89159 & 1506084 & 4.3851 & 4.28600 & 00000000005 & TRN \\
\hline CHEMBL 9053 & 1506084 & 5.0026 & 5.1956 & TRN & \\
\hline CHEMBL3594083 & 1506084 & 5.1391 & 5.5384 & TRN & \\
\hline CHEMBL3594082 & 1506084 & 5.3307 & 5.5384 & TRN & \\
\hline CHEMBL185175 & 1506084 & 3.7825 & 3.7585 & TRN & \\
\hline CHEMBL535436 & 1506084 & 4.6696 & 4.6119 & TRN & \\
\hline CHEMBL183814 & 1506084 & 4.9666 & 4.8545 & TST & \\
\hline CHEMBL1080776 & 1506084 & 5.0164 & 4.1465 & TRN & \\
\hline CHEMBL142952 & 1506084 & 4.2684 & 4.3298 & TRN & \\
\hline CHEMBL365916 & 1506084 & 5.2807 & 5.2074 & TST & \\
\hline CHEMBL 9185 & 1506084 & 5.5186 & 5.256 & TST & \\
\hline CHEMBL3594197 & 1506084 & 4.5719 & 5.2652 & TST & \\
\hline CHEMBL537516 & 1506084 & 4.7986 & 4.7694 & TRN & \\
\hline CHEMBL3594081 & 1506084 & 5.7352 & 5.7886 & TRN & \\
\hline CHEMBL3594008 & 1506084 & 5.6576 & 5.5306 & TRN & \\
\hline CHEMBL9531 & 1506084 & 4.2351 & 4.3349 & TRN & \\
\hline CHEMBL3594012 & 1506084 & 5.5406 & 5.5484 & TRN & \\
\hline
\end{tabular}


Supplemental Table S2.txt

\begin{tabular}{|c|c|c|c|c|}
\hline CHEMBL3594196 & 1506084 & 5.3002 & 5.1677 & TRN \\
\hline CHEMBL535664 & 1506084 & 5.0339 & 5.0343 & TRN \\
\hline CHEMBL3593840 & 1506084 & 5.5867 & 5.6446 & TRN \\
\hline CHEMBL1170985 & 1506084 & 5.567 & 5.597 & TRN \\
\hline CHEMBL137195 & 1506084 & 5.3595 & 5.5384 & TRN \\
\hline CHEMBL424711 & 1506084 & 5.0044 & 5.3028 & TST \\
\hline CHEMBL 3594010 & 1506084 & 5.5086 & 5.7334 & TRN \\
\hline CHEMBL 3594007 & 1506084 & 4.9747 & 4.9759 & TRN \\
\hline CHEMBL22998 & 1506084 & 4.752 & 5.3976 & TST \\
\hline CHEMBL69590 & 1506084 & 5.1518 & 5.2882 & TST \\
\hline CHEMBL3594017 & 1506084 & 6.6198 & 6.3766 & TRN \\
\hline CHEMBL9391 & 1506084 & 4.3737 & 4.4283 & TRN \\
\hline CHEMBL1962539 & 1506084 & 3.5751 & 2.9029 & TRN \\
\hline CHEMBL1169964 & 1506084 & 5.6968 & 5.2065 & TRN \\
\hline CHEMBL9341 & 1506084 & 4.752 & 4.9626 & TRN \\
\hline CHEMBL1232046 & 1506084 & 5.4935 & 5.3515 & TRN \\
\hline CHEMBL269032 & 1506084 & 6.6021 & 6.4178 & TRN \\
\hline CHEMBL284933 & 1506084 & 5.1568 & 5.0108 & TRN \\
\hline CHEMBL3594016 & 1506084 & 6.6383 & 6.544 & TRN \\
\hline CHEMBL535205 & 1506084 & 4.9872 & 4.8982 & TRN \\
\hline CHEMBL3594080 & 1506084 & 5.9431 & 5.9704 & TRN \\
\hline CHEMBL1081708 & 1506084 & 2.0 & 4.1465 & TRN \\
\hline CHEMBL1963636 & 1506084 & 2.0 & 2.355 & TRN \\
\hline CHEMBL8892 & 1506084 & 5.1918 & 4.8778 & TST \\
\hline CHEMBL1851600 & 1506084 & 4.9747 & 4.8804 & TRN \\
\hline CHEMBL3594015 & 1506084 & 4.6737 & 4.8406 & TRN \\
\hline CHEMBL185063 & 1506084 & 3.6383 & 3.6397 & TRN \\
\hline CHEMBL9490 & 1506084 & 4.4609 & 4.6411 & TRN \\
\hline CHEMBL3593841 & 1506084 & 5.4672 & 5.2949 & TRN \\
\hline CHEMBL1852874 & 1506084 & 5.1586 & 5.2663 & TRN \\
\hline CHEMBL9025 & 1506084 & 4.9508 & 5.2489 & TST \\
\hline CHEMBL9126 & 1506084 & 5.5114 & 5.5737 & TST \\
\hline CHEMBL88596 & 1506084 & 5.0899 & 5.3369 & TST \\
\hline CHEMBL1963648 & 1506084 & 2.0 & 2.4294 & TRN \\
\hline CHEMBL9121 & 1506084 & 5.025 & 4.6583 & TST \\
\hline CHEMBL3594011 & 1506084 & 6.2518 & 6.425 & TRN \\
\hline CHEMBL3115839 & 1290966 & 4.0 & 4.5589 & TRN \\
\hline CHEMBL 3116012 & 1290966 & 5.7212 & 6.5089 & TRN \\
\hline CHEMBL3115824 & 1290966 & 8.699 & 8.7717 & TRN \\
\hline CHEMBL 3116024 & 1290966 & 7.3979 & 7.1168 & TRN \\
\hline CHEMBL3116008 & 1290966 & 6.0 & 6.1294 & TRN \\
\hline CHEMBL3116026 & 1290966 & 7.301 & 7.13399 & 99999999995 \\
\hline CHEMBL3116025 & 1290966 & 7.301 & 6.3086 & TRN \\
\hline CHEMBL 2408315 & 1290966 & 6.3665 & 6.1451 & TRN \\
\hline CHEMBL3115820 & 1290966 & 7.301 & 8.0166 & TRN \\
\hline CHEMBL3115996 & 1290966 & 3.699 & 4.6968 & TRN \\
\hline CHEMBL 2408321 & 1290966 & 7.0 & 7.0011 & TRN \\
\hline CHEMBL3116009 & 1290966 & 4.9208 & 5.8649 & TRN \\
\hline
\end{tabular}

Page 28023 
Supplemental Table S2.txt

\begin{tabular}{|c|c|c|c|c|c|}
\hline CHEMBL 3115808 & 1290966 & 7.3979 & 8.0281 & TRN & \\
\hline CHEMBL3115837 & 1290966 & 3.699 & 5.1004 & TRN & \\
\hline CHEMBL3116021 & 1290966 & 3.699 & 3.4195 & TRN & \\
\hline CHEMBL3115812 & 1290966 & 3.699 & 3.3995 & TRN & \\
\hline CHEMBL3116006 & 1290966 & 5.9586 & 5.4455 & TST & \\
\hline CHEMBL3112624 & 1290966 & 3.699 & 6.5118 & TST & \\
\hline CHEMBL3115830 & 1290966 & 8.0 & 8.1895 & TRN & \\
\hline CHEMBL3116028 & 1290966 & 6.3768 & 6.6288 & TRN & \\
\hline CHEMBL3116018 & 1290966 & 4.0 & 4.5745 & TRN & \\
\hline CHEMBL3115806 & 1290966 & 7.5229 & 7.7203 & TRN & \\
\hline CHEMBL3115834 & 1290966 & 8.301 & 7.8441 & TRN & \\
\hline CHEMBL3115832 & 1290966 & 8.699 & 8.4085 & TRN & \\
\hline CHEMBL3116001 & 1290966 & 6.3872 & 6.1007 & TRN & \\
\hline CHEMBL2408322 & 1290966 & 5.7212 & 5.4411 & TRN & \\
\hline CHEMBL3115810 & 1290966 & 3.699 & 3.0836 & TRN & \\
\hline CHEMBL3116014 & 1290966 & 4.0 & 6.1361 & TST & \\
\hline CHEMBL3116027 & 1290966 & 6.7696 & 6.437 & TRN & \\
\hline CHEMBL3115811 & 1290966 & 3.699 & 3.6408 & TRN & \\
\hline CHEMBL3115801 & 1290966 & 8.3979 & 8.332 & TRN & \\
\hline CHEMBL3115995 & 1290966 & 5.1549 & 5.4172 & TRN & \\
\hline CHEMBL3116010 & 1290966 & 6.3979 & 6.1943 & TRN & \\
\hline CHEMBL3115998 & 1290966 & 5.9586 & 5.0136 & TRN & \\
\hline CHEMBL 3116000 & 1290966 & 3.699 & 6.3414 & TST & \\
\hline CHEMBL3115819 & 1290966 & 6.9208 & 7.1997 & TST & \\
\hline CHEMBL 2408320 & 1290966 & 6.9208 & 5.8313 & TRN & \\
\hline CHEMBL3115823 & 1290966 & 8.301 & 7.1911 & TRN & \\
\hline CHEMBL3115826 & 1290966 & 8.5229 & 8.4055 & TRN & \\
\hline CHEMBL 2408323 & 1290966 & 6.8239 & 6.4213 & TRN & \\
\hline CHEMBL3115827 & 1290966 & 8.699 & 8.8861 & TRN & \\
\hline CHEMBL3115813 & 1290966 & 3.699 & 3.6968 & TRN & \\
\hline CHEMBL3116005 & 1290966 & 3.699 & 5.5615 & TST & \\
\hline CHEMBL3116007 & 1290966 & 5.4202 & 5.5428 & TRN & \\
\hline CHEMBL3115828 & 1290966 & 7.5229 & 7.5836 & TRN & \\
\hline CHEMBL3115833 & 1290966 & 8.3979 & 8.1756 & TRN & \\
\hline CHEMBL3115803 & 1290966 & 8.301 & 7.8782 & TRN & \\
\hline CHEMBL3115818 & 1290966 & 5.0 & 6.2556 & TST & \\
\hline CHEMBL3116029 & 1290966 & 6.699 & 6.0971 & TRN & \\
\hline CHEMBL 3115821 & 1290966 & 8.699 & \multicolumn{2}{|c|}{8.722000000000001} & TRN \\
\hline CHEMBL3115815 & 1290966 & 3.699 & 4.1068 & TRN & \\
\hline CHEMBL 2408330 & 1290966 & 3.699 & 3.5476 & TRN & \\
\hline CHEMBL3116019 & 1290966 & 3.301 & 3.1467 & TRN & \\
\hline CHEMBL3116003 & 1290966 & 6.301 & 5.9634 & TRN & \\
\hline CHEMBL3116015 & 1290966 & 3.699 & 6.0461 & TST & \\
\hline CHEMBL3115814 & 1290966 & 3.699 & 3.1015 & TST & \\
\hline CHEMBL3115817 & 1290966 & 7.1549 & 7.2826 & TST & \\
\hline CHEMBL3116016 & 1290966 & 3.699 & 5.9731 & TST & \\
\hline CHEMBL3115836 & 1290966 & 4.0 & 4.8301 & TRN & \\
\hline CHEMBL3116023 & 1290966 & 6.4202 & 7.2595 & TRN & \\
\hline
\end{tabular}

Page 28024 
Supplemental Table S2.txt

\begin{tabular}{|c|c|c|c|c|c|}
\hline CHEMBL3115997 & 1290966 & 6.0458 & 5.7639 & TRN & \\
\hline CHEMBL3116013 & 1290966 & 5.1549 & 6.2991 & TST & \\
\hline CHEMBL3116020 & 1290966 & 3.301 & 3.5526 & TRN & \\
\hline CHEMBL3115829 & 1290966 & 7.699 & 8.2302 & TRN & \\
\hline CHEMBL3115831 & 1290966 & 8.3979 & 8.4359 & TRN & \\
\hline CHEMBL3115999 & 1290966 & 5.2147 & 6.3338 & TST & \\
\hline CHEMBL 2408335 & 1290966 & 5.1487 & 5.6921 & TRN & \\
\hline CHEMBL3115805 & 1290966 & 8.301 & 8.3105 & TRN & \\
\hline CHEMBL3116011 & 1290966 & 7.0458 & 6.59 & TRN & \\
\hline CHEMBL3115809 & 1290966 & 3.699 & 3.2863 & TRN & \\
\hline CHEMBL3116022 & 1290966 & 6.6383 & \multicolumn{2}{|c|}{6.7860000000000005} & TRN \\
\hline CHEMBL3115822 & 1290966 & 8.0 & 8.0509 & TST & \\
\hline CHEMBL3115802 & 1290966 & 8.0 & 8.2891 & TST & \\
\hline CHEMBL 3116004 & 1290966 & 6.9208 & 6.0097 & TRN & \\
\hline CHEMBL3115835 & 1290966 & 8.0 & \multicolumn{2}{|c|}{8.197000000000001} & TST \\
\hline CHEMBL3115994 & 1290966 & 5.8239 & 5.9934 & TRN & \\
\hline CHEMBL3116017 & 1290966 & 6.3979 & 6.3985 & TRN & \\
\hline CHEMBL1548889 & 1290966 & 3.699 & 5.104 & TST & \\
\hline CHEMBL3115816 & 1290966 & 6.699 & 6.6026 & TST & \\
\hline CHEMBL2094282 & 1290966 & 6.6576 & 6.0086 & TRN & \\
\hline CHEMBL3115825 & 1290966 & 8.301 & 8.4416 & TST & \\
\hline CHEMBL3115804 & 1290966 & 7.699 & 7.4374 & TST & \\
\hline CHEMBL3115807 & 1290966 & 7.2218 & 8.0911 & TST & \\
\hline CHEMBL3116002 & 1290966 & 4.0 & 5.2216 & TRN & \\
\hline CHEMBL3112622 & 1290966 & 6.699 & 7.1846 & TST & \\
\hline CHEMBL1474325 & 688340 & 4.55 & 5.445 & TRN & \\
\hline CHEMBL1589017 & 688340 & 4.45 & 5.01 & TRN & \\
\hline CHEMBL1417952 & 688340 & 4.5 & 5.479 & TRN & \\
\hline CHEMBL1421034 & 688340 & 5.35 & 4.6488 & TRN & \\
\hline CHEMBL1592521 & 688340 & 5.5 & 4.8506 & TRN & \\
\hline CHEMBL1540993 & 688340 & 4.4 & 5.1005 & TRN & \\
\hline CHEMBL3193428 & 688340 & 4.5 & 5.0035 & TRN & \\
\hline CHEMBL1317027 & 688340 & 4.55 & 4.7464 & TRN & \\
\hline CHEMBL1423254 & 688340 & 5.0 & 5.2918 & TRN & \\
\hline CHEMBL3214317 & 688340 & 4.4 & 5.0721 & TRN & \\
\hline CHEMBL3193052 & 688340 & 4.65 & 4.9817 & TRN & \\
\hline CHEMBL1385620 & 688340 & 5.15 & 4.9203 & TRN & \\
\hline CHEMBL1310290 & 688340 & 4.55 & 4.7736 & TRN & \\
\hline CHEMBL1373836 & 688340 & 6.1 & 5.0459 & TRN & \\
\hline CHEMBL1417605 & 688340 & 5.0 & \multicolumn{2}{|c|}{5.287999999999999} & TRN \\
\hline CHEMBL1342989 & 688340 & 4.55 & 4.9076 & TRN & \\
\hline CHEMBL1324616 & 688340 & 4.4 & 4.9033 & TST & \\
\hline CHEMBL1611155 & 688340 & 4.55 & 4.9469 & TRN & \\
\hline CHEMBL1465935 & 688340 & 4.55 & 5.2857 & TST & \\
\hline CHEMBL1300008 & 688340 & 4.45 & 4.5997 & TRN & \\
\hline CHEMBL1462216 & 688340 & 6.15 & 5.6866 & TST & \\
\hline CHEMBL1411720 & 688340 & 5.0 & 5.0543 & TST & \\
\hline CHEMBL1552120 & 688340 & 4.8 & 5.2156 & TRN & \\
\hline
\end{tabular}




\begin{tabular}{|c|c|c|c|c|c|}
\hline \multicolumn{6}{|c|}{ Supplemental Table S2.tx } \\
\hline CHEMBL1394868 & 688340 & 4.55 & 5.0003 & TRN & \\
\hline CHEMBL1453257 & 688340 & 4.55 & 4.833 & TRN & \\
\hline CHEMBL1470012 & 688340 & 5.05 & 5.2189 & TRN & \\
\hline CHEMBL1539407 & 688340 & 5.0 & 5.0859 & TRN & \\
\hline CHEMBL1422131 & 688340 & 4.35 & 4.9947 & TRN & \\
\hline CHEMBL3191137 & 688340 & 4.8 & 4.7494 & TRN & \\
\hline CHEMBL1460107 & 688340 & 5.35 & 4.885 & TRN & \\
\hline CHEMBL1513393 & 688340 & 6.0 & 5.1081 & TRN & \\
\hline CHEMBL 3193893 & 688340 & 6.95 & 4.8322 & TST & \\
\hline CHEMBL1367236 & 688340 & 5.0 & 5.1444 & TST & \\
\hline CHEMBL1552557 & 688340 & 4.6 & 5.0937 & TRN & \\
\hline CHEMBL1323798 & 688340 & 4.4 & 5.1784 & TRN & \\
\hline CHEMBL1386973 & 688340 & 4.5 & 4.676 & TRN & \\
\hline CHEMBL 3196591 & 688340 & 4.4 & 4.794 & TRN & \\
\hline CHEMBL1594468 & 688340 & 4.6 & 4.6774 & TST & \\
\hline CHEMBL1429169 & 688340 & 4.4 & 5.2918 & TRN & \\
\hline CHEMBL1496620 & 688340 & 4.65 & 4.8201 & TST & \\
\hline CHEMBL1512334 & 688340 & 4.35 & 5.2420 & 0000000001 & TRN \\
\hline CHEMBL1999959 & 688340 & 4.4 & 4.8641 & TRN & \\
\hline CHEMBL1485461 & 688340 & 4.95 & 5.3383 & TST & \\
\hline CHEMBL3211574 & 688340 & 4.35 & 5.1873 & TST & \\
\hline CHEMBL1303265 & 688340 & 5.5 & 5.2077 & TST & \\
\hline CHEMBL1481333 & 688340 & 4.4 & 4.9361 & TST & \\
\hline CHEMBL1610181 & 688340 & 4.7 & 4.8889 & TRN & \\
\hline CHEMBL1498209 & 688340 & 6.4 & 5.2582 & TRN & \\
\hline CHEMBL1564646 & 688340 & 7.0 & 5.2424 & TRN & \\
\hline CHEMBL1456545 & 688340 & 4.4 & 5.0065 & TRN & \\
\hline CHEMBL1318358 & 688340 & 4.4 & 5.1502 & TST & \\
\hline CHEMBL1502860 & 688340 & 5.35 & 4.7410 & 20000000005 & TRN \\
\hline CHEMBL1501377 & 688340 & 4.6 & 4.6548 & TST & \\
\hline CHEMBL1486184 & 688340 & 4.45 & 5.0436 & TST & \\
\hline CHEMBL1538323 & 688340 & 5.15 & 5.1794 & TRN & \\
\hline CHEMBL1360991 & 688340 & 4.65 & 4.8502 & TRN & \\
\hline CHEMBL1571433 & 688340 & 4.6 & 4.9481 & TRN & \\
\hline CHEMBL1414933 & 688340 & 7.0 & 4.8578 & TRN & \\
\hline CHEMBL1447783 & 688340 & 4.55 & 5.1236 & TRN & \\
\hline CHEMBL1416306 & 688340 & 4.55 & 4.9081 & TRN & \\
\hline CHEMBL1521598 & 688340 & 6.1 & 5.6147 & TRN & \\
\hline CHEMBL1603321 & 688340 & 4.85 & 4.94 & TRN & \\
\hline CHEMBL1578838 & 688340 & 5.05 & 5.3334 & TRN & \\
\hline CHEMBL1277150 & 688340 & 4.4 & 4.6179 & TRN & \\
\hline CHEMBL1485657 & 688340 & 4.3 & 5.1326 & TRN & \\
\hline CHEMBL1555174 & 688340 & 4.4 & 4.7423 & TRN & \\
\hline CHEMBL1380479 & 688340 & 7.0 & 5.1671 & TST & \\
\hline CHEMBL1315134 & 688340 & 4.7 & 4.9776 & TRN & \\
\hline CHEMBL1591866 & 688340 & 6.0 & 5.3361 & TRN & \\
\hline CHEMBL1433231 & 688340 & 4.85 & 4.6955 & TRN & \\
\hline CHEMBL1514274 & 688340 & 5.3 & 5.1545 & TRN & \\
\hline
\end{tabular}




\begin{tabular}{|c|c|c|c|c|c|}
\hline \multicolumn{6}{|c|}{ Supplemental Table S2.txt } \\
\hline CHEMBL18132 & 688340 & 4.45 & 4.6615 & TST & \\
\hline CHEMBL1578037 & 688340 & 4.95 & 5.3681 & TRN & \\
\hline CHEMBL1461797 & 688340 & 4.55 & 4.6479 & TRN & \\
\hline CHEMBL1331921 & 688340 & 5.75 & 5.1172 & TRN & \\
\hline CHEMBL1486687 & 688340 & 5.0 & 4.90600 & 0000000001 & TST \\
\hline CHEMBL1488743 & 688340 & 4.45 & 4.8672 & TRN & \\
\hline CHEMBL1535634 & 688340 & 7.0 & 5.1832 & TRN & \\
\hline CHEMBL1611336 & 688340 & 5.15 & 4.8953 & TST & \\
\hline CHEMBL1341037 & 688340 & 4.5 & 5.1279 & TRN & \\
\hline CHEMBL1487470 & 688340 & 6.1 & 5.1427 & TRN & \\
\hline CHEMBL1550190 & 688340 & 4.8 & 5.0684 & TRN & \\
\hline CHEMBL1578207 & 688340 & 4.4 & 5.1186 & TRN & \\
\hline CHEMBL1489166 & 688340 & 4.55 & 4.5111 & TRN & \\
\hline CHEMBL1345993 & 688340 & 4.65 & 4.9693 & TRN & \\
\hline CHEMBL1342069 & 688340 & 4.45 & 5.09699 & 99999999995 & TST \\
\hline CHEMBL1577539 & 688340 & 4.5 & 5.15799 & 99999999995 & TRN \\
\hline CHEMBL1412750 & 688340 & 4.4 & 4.7412 & TST & \\
\hline CHEMBL1497924 & 688340 & 5.05 & 4.6832 & TST & \\
\hline CHEMBL1387566 & 688340 & 7.0501 & 5.2736 & TRN & \\
\hline CHEMBL1556282 & 688340 & 4.7 & 4.6616 & TRN & \\
\hline CHEMBL3039775 & 688340 & 4.55 & 4.8039 & TRN & \\
\hline CHEMBL167869 & 688340 & 4.4 & 5.0248 & TRN & \\
\hline CHEMBL1405543 & 688340 & 4.4 & 5.0286 & TRN & \\
\hline CHEMBL1411343 & 688340 & 5.0 & 4.8284 & TRN & \\
\hline CHEMBL1600131 & 688340 & 4.65 & 5.2805 & TST & \\
\hline CHEMBL1528697 & 688340 & 6.2 & 5.033 & TRN & \\
\hline CHEMBL1536547 & 688340 & 5.1 & 5.0391 & TRN & \\
\hline CHEMBL1367421 & 688340 & 5.3 & 4.1647 & TST & \\
\hline CHEMBL1596626 & 688340 & 4.5 & 4.6973 & TRN & \\
\hline CHEMBL1601605 & 688340 & 4.6 & 4.775 & TRN & \\
\hline CHEMBL1466887 & 688340 & 4.6 & 4.9385 & TRN & \\
\hline CHEMBL1517137 & 688340 & 4.95 & 5.1737 & TST & \\
\hline CHEMBL1415919 & 688340 & 4.9 & 5.2536 & TRN & \\
\hline CHEMBL1308229 & 688340 & 4.5 & 5.5113 & TRN & \\
\hline CHEMBL1492354 & 688340 & 6.15 & 5.2687 & TRN & \\
\hline CHEMBL1539677 & 688340 & 4.7 & 5.3614 & TRN & \\
\hline CHEMBL1569119 & 688340 & 6.25 & 5.2462 & TST & \\
\hline CHEMBL1315399 & 688340 & 4.55 & 4.9072 & TRN & \\
\hline CHEMBL1471190 & 688340 & 4.4 & 4.7883 & TRN & \\
\hline CHEMBL1389107 & 688340 & 4.45 & 4.7984 & TRN & \\
\hline CHEMBL1345309 & 688340 & 4.5 & 5.2436 & TRN & \\
\hline CHEMBL1597897 & 688340 & 4.45 & 4.9118 & TRN & \\
\hline CHEMBL1443119 & 688340 & 6.05 & 4.9702 & TRN & \\
\hline CHEMBL1439060 & 688340 & 4.5 & 4.7026 & TRN & \\
\hline CHEMBL1301417 & 688340 & 5.15 & 4.7598 & TST & \\
\hline CHEMBL1530883 & 688340 & 6.0 & 4.8583 & TRN & \\
\hline CHEMBL1328213 & 688340 & 4.95 & 4.7286 & TST & \\
\hline CHEMBL1375536 & 688340 & 4.4 & 5.0086 & TRN & \\
\hline
\end{tabular}




\begin{tabular}{|c|c|c|c|c|}
\hline \multicolumn{5}{|c|}{ Supplemental Table S2.txt } \\
\hline CHEMBL1346204 & 688340 & 4.7 & 5.0031 & TRN \\
\hline CHEMBL1409288 & 688340 & 5.0 & 5.2922 & TST \\
\hline CHEMBL1416989 & 688340 & 3.25 & 4.7898 & TRN \\
\hline CHEMBL1555696 & 688340 & 5.55 & 5.1382 & TRN \\
\hline CHEMBL1521215 & 688340 & 5.25 & 4.7942 & TRN \\
\hline CHEMBL1316810 & 688340 & 4.55 & 4.8148 & TRN \\
\hline CHEMBL1347774 & 688340 & 4.0 & 5.2516 & TRN \\
\hline CHEMBL1417159 & 688340 & 5.45 & 5.28100 & 0000000001 \\
\hline CHEMBL1576649 & 688340 & 4.8 & 4.815 & TST \\
\hline CHEMBL1538862 & 688340 & 6.8499 & 5.1908 & TRN \\
\hline CHEMBL1466712 & 688340 & 5.0 & 4.3546 & TST \\
\hline CHEMBL1520439 & 688340 & 6.95 & 5.2167 & TST \\
\hline CHEMBL1601302 & 688340 & 4.4 & 5.0473 & TRN \\
\hline CHEMBL1458469 & 688340 & 4.6 & 5.2017 & TRN \\
\hline CHEMBL1564558 & 688340 & 5.15 & 5.0765 & TRN \\
\hline CHEMBL3193094 & 688340 & 4.6 & 4.8213 & TRN \\
\hline CHEMBL1983839 & 688340 & 4.7 & 4.9153 & TRN \\
\hline CHEMBL1545791 & 688340 & 5.6 & 4.8907 & TRN \\
\hline CHEMBL1516627 & 688340 & 4.4 & 4.7222 & TRN \\
\hline CHEMBL1473184 & 688340 & 4.6 & 5.2434 & TRN \\
\hline CHEMBL1531087 & 688340 & 4.95 & 5.0206 & TST \\
\hline CHEMBL1561204 & 688340 & 4.6 & 4.9017 & TRN \\
\hline CHEMBL1496554 & 688340 & 4.4 & 4.7837 & TRN \\
\hline CHEMBL1391697 & 688340 & 5.2 & 5.147 & TRN \\
\hline CHEMBL1325813 & 688340 & 4.65 & 4.6602 & TRN \\
\hline CHEMBL1427161 & 688340 & 4.65 & 5.2943 & TRN \\
\hline CHEMBL1312996 & 688340 & 4.55 & 4.7583 & TRN \\
\hline CHEMBL1313909 & 688340 & 4.65 & 4.9607 & TRN \\
\hline CHEMBL1549735 & 688340 & 4.4 & 5.0734 & TST \\
\hline CHEMBL1378036 & 688340 & 4.45 & 4.3556 & TRN \\
\hline CHEMBL1596779 & 688340 & 4.4 & 4.8153 & TST \\
\hline CHEMBL1339859 & 688340 & 4.6 & 5.0241 & TRN \\
\hline CHEMBL1557217 & 688340 & 4.4 & 5.0369 & TRN \\
\hline CHEMBL1471170 & 688340 & 4.7 & 5.0505 & TRN \\
\hline CHEMBL1568298 & 688340 & 4.5 & 5.0506 & TRN \\
\hline CHEMBL1405830 & 688340 & 4.9 & 5.052 & TRN \\
\hline CHEMBL1398027 & 688340 & 5.75 & 5.1184 & TST \\
\hline CHEMBL3209170 & 688340 & 5.45 & 5.0117 & TST \\
\hline CHEMBL3192968 & 688340 & 4.95 & 5.3415 & TST \\
\hline CHEMBL1510417 & 688340 & 4.5 & 4.9484 & TST \\
\hline CHEMBL3198632 & 688340 & 4.7 & 4.4025 & TRN \\
\hline CHEMBL1350028 & 688340 & 4.5 & 4.7972 & TRN \\
\hline CHEMBL1432606 & 688340 & 6.45 & 5.0802 & TRN \\
\hline CHEMBL1389034 & 688340 & 4.65 & 4.8851 & TRN \\
\hline CHEMBL1379310 & 688340 & 6.8499 & 5.1146 & TRN \\
\hline CHEMBL1603604 & 688340 & 4.65 & 5.0634 & TST \\
\hline CHEMBL1334940 & 688340 & 4.65 & 5.2683 & TRN \\
\hline CHEMBL1446172 & 688340 & 5.05 & 4.6028 & TRN \\
\hline
\end{tabular}




\begin{tabular}{|c|c|c|c|c|c|}
\hline \\
\hline CHEMBL1563317 & 688340 & 5.4 & 5.0597 & TRN & \\
\hline CHEMBL1446409 & 688340 & 5.0 & 5.2372 & TRN & \\
\hline CHEMBL1550675 & 688340 & 4.45 & 5.0823 & TRN & \\
\hline CHEMBL1477203 & 688340 & 7.4001 & 5.1544 & TRN & \\
\hline CHEMBL1547183 & 688340 & 4.45 & 5.6407 & TRN & \\
\hline CHEMBL1538696 & 688340 & 4.6 & 4.9509 & TST & \\
\hline CHEMBL1427630 & 688340 & 4.6 & 4.8088 & TRN & \\
\hline CHEMBL1570956 & 688340 & 5.9 & 5.0485 & TRN & \\
\hline CHEMBL1545624 & 688340 & 5.5 & 5.5465 & TRN & \\
\hline CHEMBL3198242 & 688340 & 4.65 & 5.0192 & TRN & \\
\hline CHEMBL1506515 & 688340 & 5.0 & 4.9192 & TRN & \\
\hline CHEMBL1568766 & 688340 & 4.4 & 4.8633 & TRN & \\
\hline CHEMBL1394014 & 688340 & 5.0 & 5.1377 & TST & \\
\hline CHEMBL1476054 & 688340 & 6.9 & 5.0128 & TRN & \\
\hline CHEMBL1436029 & 688340 & 5.85 & 5.3795 & TRN & \\
\hline CHEMBL1343400 & 688340 & 5.15 & 5.1607 & TRN & \\
\hline CHEMBL1611535 & 688340 & 4.55 & 4.5509 & TRN & \\
\hline CHEMBL1553755 & 688340 & 4.55 & 4.7827 & TST & \\
\hline CHEMBL1427879 & 688340 & 4.8 & 4.9851 & TRN & \\
\hline CHEMBL1427217 & 688340 & 5.8 & 5.0822 & TRN & \\
\hline CHEMBL1502624 & 688340 & 6.4 & 5.1124 & TRN & \\
\hline CHEMBL1972621 & 688340 & 4.6 & 5.1049 & TST & \\
\hline CHEMBL1527067 & 688340 & 5.2 & 5.1157 & TST & \\
\hline CHEMBL1477000 & 688340 & 4.4 & 5.2467 & TRN & \\
\hline CHEMBL1509961 & 688340 & 5.45 & 5.0769 & TRN & \\
\hline CHEMBL1477188 & 688340 & 4.65 & 4.9063 & TRN & \\
\hline CHEMBL1353707 & 688340 & 4.55 & 4.744 & TRN & \\
\hline CHEMBL1404286 & 688340 & 4.6 & 4.8804 & TRN & \\
\hline CHEMBL1330769 & 688340 & 5.15 & 4.8413 & TRN & \\
\hline CHEMBL1490082 & 688340 & 4.65 & 5.0569 & TST & \\
\hline CHEMBL1430005 & 688340 & 4.55 & 4.87 & TRN & \\
\hline CHEMBL1490960 & 688340 & 4.5 & 4.4298 & TST & \\
\hline CHEMBL1461676 & 688340 & 5.15 & 5.1987 & TRN & \\
\hline CHEMBL1424214 & 688340 & 4.85 & 5.44600 & 0000000001 & TRN \\
\hline CHEMBL1471672 & 688340 & 6.25 & 5.0262 & TRN & \\
\hline CHEMBL1449354 & 688340 & 4.5 & 4.6205 & TRN & \\
\hline CHEMBL1374351 & 688340 & 5.4 & 5.0303 & TRN & \\
\hline CHEMBL1543835 & 688340 & 4.4 & 4.9135 & TRN & \\
\hline CHEMBL3193196 & 688340 & 5.0 & 5.1566 & TST & \\
\hline CHEMBL1484779 & 688340 & 4.5 & 4.8141 & TRN & \\
\hline CHEMBL1578362 & 688340 & 6.1 & 4.9881 & TRN & \\
\hline CHEMBL1389259 & 688340 & 7.0 & 5.1782 & TRN & \\
\hline CHEMBL1401784 & 688340 & 5.15 & 4.9449 & TRN & \\
\hline CHEMBL3191443 & 688340 & 4.45 & 4.945 & TRN & \\
\hline CHEMBL3197063 & 688340 & 4.55 & 4.8634 & TRN & \\
\hline CHEMBL1531830 & 688340 & 4.7 & 4.7153 & TRN & \\
\hline CHEMBL3392066 & 688340 & 7.0 & 5.1156 & TRN & \\
\hline CHEMBL1609066 & 688340 & 5.75 & 5.4993 & TRN & \\
\hline
\end{tabular}




\begin{tabular}{|c|c|c|c|c|c|}
\hline \\
\hline CHEMBL3191370 & 688340 & 3.0 & 5.0731 & TST & \\
\hline CHEMBL1371586 & 688340 & 4.55 & 4.7639 & TRN & \\
\hline CHEMBL1516127 & 688340 & 6.1 & 5.1462 & TRN & \\
\hline CHEMBL1567171 & 688340 & 5.3 & 5.2867 & TST & \\
\hline CHEMBL1511237 & 688340 & 4.95 & 5.4054 & TRN & \\
\hline CHEMBL1526152 & 688340 & 4.5 & 4.9382 & TRN & \\
\hline CHEMBL1484167 & 688340 & 4.9 & 4.8106 & TST & \\
\hline CHEMBL1427154 & 688340 & 4.4 & 4.8966 & TRN & \\
\hline CHEMBL1608375 & 688340 & 4.75 & 4.9144 & TRN & \\
\hline CHEMBL1345218 & 688340 & 5.85 & 4.7644 & TRN & \\
\hline CHEMBL1442925 & 688340 & 5.15 & 5.3883 & TRN & \\
\hline CHEMBL1416095 & 688340 & 4.25 & 5.153 & TRN & \\
\hline CHEMBL1467060 & 688340 & 5.45 & 4.9878 & TST & \\
\hline CHEMBL1394100 & 688340 & 4.3 & 5.1504 & TRN & \\
\hline CHEMBL1998606 & 688340 & 4.4 & 4.8049 & TRN & \\
\hline CHEMBL505057 & 688340 & 4.65 & 5.1095 & TST & \\
\hline CHEMBL1302334 & 688340 & 5.35 & 4.8748 & TST & \\
\hline CHEMBL 3189165 & 688340 & 4.75 & 4.9079 & TRN & \\
\hline CHEMBL1474337 & 688340 & 5.2 & 4.9766 & TST & \\
\hline CHEMBL1366605 & 688340 & 7.0 & 4.9569 & TRN & \\
\hline CHEMBL1324526 & 688340 & 5.8 & 5.035 & TRN & \\
\hline CHEMBL1484706 & 688340 & 5.5 & 5.3003 & TRN & \\
\hline CHEMBL1526126 & 688340 & 4.45 & 4.7217 & TRN & \\
\hline CHEMBL1455222 & 688340 & 4.5 & 5.0344 & TRN & \\
\hline CHEMBL3190410 & 688340 & 5.05 & 4.8718 & TRN & \\
\hline CHEMBL1442334 & 688340 & 4.55 & 5.0148 & TRN & \\
\hline CHEMBL1480681 & 688340 & 4.4 & 5.2118 & TRN & \\
\hline CHEMBL1416698 & 688340 & 4.4 & 5.3689 & TRN & \\
\hline CHEMBL1571382 & 688340 & 5.65 & 4.8308 & TST & \\
\hline CHEMBL3198405 & 688340 & 6.4 & 5.38200 & 0000000001 & TRN \\
\hline CHEMBL1586425 & 688340 & 6.45 & 5.3686 & TST & \\
\hline CHEMBL1335170 & 688340 & 4.6 & 4.7895 & TRN & \\
\hline CHEMBL1343643 & 688340 & 4.35 & 5.0608 & TST & \\
\hline CHEMBL1982713 & 688340 & 5.4 & 4.8706 & TRN & \\
\hline CHEMBL1568196 & 688340 & 5.35 & 5.2113 & TST & \\
\hline CHEMBL1487400 & 688340 & 5.15 & 5.3694 & TRN & \\
\hline CHEMBL 3194456 & 688340 & 5.35 & 5.0285 & TRN & \\
\hline CHEMBL1419946 & 688340 & 4.9 & 4.9967 & TRN & \\
\hline CHEMBL1530043 & 688340 & 4.5 & 5.4059 & TRN & \\
\hline CHEMBL1608407 & 688340 & 4.6 & 4.9429 & TST & \\
\hline CHEMBL1317990 & 688340 & 4.4 & 5.2221 & TRN & \\
\hline CHEMBL1545295 & 688340 & 5.05 & 5.2956 & TRN & \\
\hline CHEMBL1322656 & 688340 & 4.4 & 4.7748 & TRN & \\
\hline CHEMBL 3197246 & 688340 & 4.4 & 4.8588 & TRN & \\
\hline CHEMBL1520346 & 688340 & 5.5 & 4.8886 & TRN & \\
\hline CHEMBL1484059 & 688340 & 4.7 & 4.9733 & TRN & \\
\hline CHEMBL1332221 & 688340 & 5.2 & 4.9217 & TRN & \\
\hline CHEMBL1365516 & 688340 & 4.55 & 4.8133 & TST & \\
\hline
\end{tabular}




\begin{tabular}{|c|c|c|c|c|}
\hline & & & & \\
\hline CHEMBL1346062 & 688340 & 4.4 & 4.7777 & TRN \\
\hline CHEMBL1565308 & 688340 & 6.1 & 5.66299 & 9999999999 \\
\hline CHEMBL1312117 & 688340 & 4.5 & 5.2283 & TRN \\
\hline CHEMBL1319525 & 688340 & 5.2 & 5.0496 & TRN \\
\hline CHEMBL1415146 & 688340 & 5.4 & 5.5118 & TRN \\
\hline CHEMBL1473548 & 688340 & 4.4 & 5.1306 & TRN \\
\hline CHEMBL1542026 & 688340 & 5.65 & 5.4493 & TRN \\
\hline CHEMBL3191714 & 688340 & 5.8 & 5.1491 & TRN \\
\hline CHEMBL1383756 & 688340 & 4.35 & 5.2188 & TRN \\
\hline CHEMBL1588519 & 688340 & 6.15 & 5.5083 & TST \\
\hline CHEMBL1306051 & 688340 & 5.0 & 5.0452 & TRN \\
\hline CHEMBL1463952 & 688340 & 4.35 & 5.0122 & TST \\
\hline CHEMBL1448671 & 688340 & 5.4 & 4.6143 & TRN \\
\hline CHEMBL1976388 & 688340 & 5.2 & 4.9213 & TRN \\
\hline CHEMBL3211252 & 688340 & 4.4 & 4.8281 & TRN \\
\hline CHEMBL1598900 & 688340 & 7.0 & 5.1565 & TRN \\
\hline CHEMBL1419273 & 688340 & 4.4 & 4.9112 & TRN \\
\hline CHEMBL1349264 & 688340 & 4.8 & 5.2517 & TRN \\
\hline CHEMBL1553481 & 688340 & 7.0501 & 5.3757 & TRN \\
\hline CHEMBL3191063 & 688340 & 4.85 & 4.8703 & TRN \\
\hline CHEMBL1479725 & 688340 & 4.55 & 4.9169 & TST \\
\hline CHEMBL1543583 & 688340 & 4.85 & 4.3923 & TST \\
\hline CHEMBL1380970 & 688340 & 4.55 & 4.9858 & TST \\
\hline CHEMBL1307070 & 688340 & 5.25 & 5.3017 & TRN \\
\hline CHEMBL1507474 & 688340 & 4.6 & 4.7859 & TST \\
\hline CHEMBL1319221 & 688340 & 5.5 & 5.17 & TST \\
\hline CHEMBL1526855 & 688340 & 4.6 & 5.0052 & TST \\
\hline CHEMBL1468838 & 688340 & 4.6 & 4.65 & TRN \\
\hline CHEMBL1555493 & 688340 & 5.35 & 4.9725 & TST \\
\hline CHEMBL1450826 & 688340 & 5.25 & 4.8541 & TST \\
\hline CHEMBL3210613 & 688340 & 4.7 & 4.4385 & TRN \\
\hline CHEMBL1381742 & 688340 & 5.05 & 5.1945 & TRN \\
\hline CHEMBL1970872 & 688340 & 4.65 & 4.5813 & TRN \\
\hline CHEMBL1517325 & 688340 & 4.65 & 4.6186 & TRN \\
\hline CHEMBL1437995 & 688340 & 5.75 & 5.1534 & TRN \\
\hline CHEMBL1612133 & 688340 & 4.4 & 4.6237 & TRN \\
\hline CHEMBL1477665 & 688340 & 4.5 & 4.9158 & TST \\
\hline CHEMBL1585410 & 688340 & 4.45 & 4.9478 & TST \\
\hline CHEMBL1533641 & 688340 & 4.6 & 4.9529 & TRN \\
\hline CHEMBL1425435 & 688340 & 4.4 & 4.8264 & TST \\
\hline CHEMBL1420254 & 688340 & 6.15 & 5.1375 & TRN \\
\hline CHEMBL3211277 & 688340 & 4.6 & 4.9817 & TST \\
\hline CHEMBL1422722 & 688340 & 5.65 & 5.3937 & TRN \\
\hline CHEMBL1357845 & 688340 & 4.55 & 5.1506 & TRN \\
\hline CHEMBL1541239 & 688340 & 4.45 & 4.9458 & TRN \\
\hline CHEMBL 3195734 & 688340 & 4.5 & 4.698 & TRN \\
\hline CHEMBL1488926 & 688340 & 4.95 & 4.775 & TST \\
\hline CHEMBL1580845 & 688340 & 4.75 & 4.9523 & TRN \\
\hline
\end{tabular}

TRN 


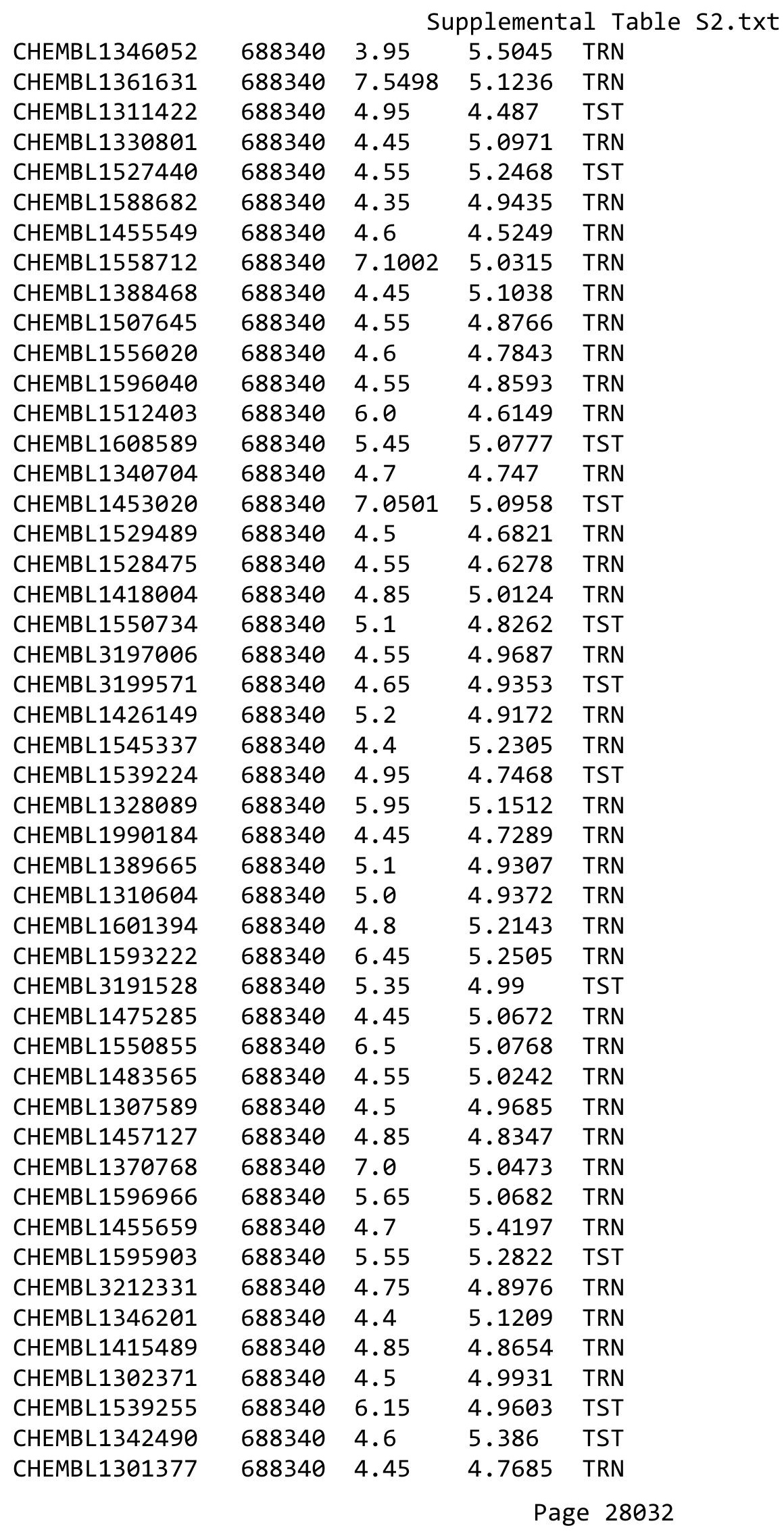




\begin{tabular}{|c|c|c|c|c|c|}
\hline \multicolumn{6}{|c|}{ Supplemental Table S2.txt } \\
\hline CHEMBL1515342 & 688340 & 4.85 & 4.8707 & TRN & \\
\hline CHEMBL 259840 & 688340 & 4.4 & 5.2384 & TRN & \\
\hline CHEMBL1965155 & 688340 & 4.55 & 4.8185 & TRN & \\
\hline CHEMBL1314038 & 688340 & 4.0 & 5.1412 & TRN & \\
\hline CHEMBL1517880 & 688340 & 4.6 & 5.0805 & TRN & \\
\hline CHEMBL1582933 & 688340 & 6.2 & 4.7699 & TRN & \\
\hline CHEMBL1522033 & 688340 & 4.4 & 4.9902 & TRN & \\
\hline CHEMBL1524188 & 688340 & 4.35 & 5.0493 & TST & \\
\hline CHEMBL1594017 & 688340 & 5.2 & 5.0677 & TST & \\
\hline CHEMBL1429861 & 688340 & 5.45 & 4.5684 & TRN & \\
\hline CHEMBL 2005497 & 688340 & 4.4 & 4.8408 & TRN & \\
\hline CHEMBL1588640 & 688340 & 7.0 & 5.205 & TST & \\
\hline CHEMBL1523242 & 688340 & 5.25 & 4.7851 & TST & \\
\hline CHEMBL3208553 & 688340 & 4.4 & 4.9765 & TRN & \\
\hline CHEMBL1504160 & 688340 & 5.05 & 4.89199 & 99999999995 & TRN \\
\hline CHEMBL1466135 & 688340 & 4.45 & 4.7678 & TST & \\
\hline CHEMBL1461180 & 688340 & 4.75 & 4.885 & TRN & \\
\hline CHEMBL1528674 & 688340 & 4.95 & 4.8801 & TRN & \\
\hline CHEMBL1327720 & 688340 & 4.75 & 5.0029 & TRN & \\
\hline CHEMBL1379854 & 688340 & 6.2 & 5.3835 & TRN & \\
\hline CHEMBL1574448 & 688340 & 4.9 & 5.0132 & TRN & \\
\hline CHEMBL1534361 & 688340 & 5.3 & 5.3079 & TRN & \\
\hline CHEMBL1315904 & 688340 & 5.3 & 4.7178 & TST & \\
\hline CHEMBL1373933 & 688340 & 6.1 & 4.9638 & TST & \\
\hline CHEMBL1574747 & 688340 & 6.4 & 5.5692 & TRN & \\
\hline CHEMBL1332890 & 688340 & 4.5 & 4.6871 & TRN & \\
\hline CHEMBL1442207 & 688340 & 4.55 & 4.9318 & TST & \\
\hline CHEMBL1347832 & 688340 & 4.75 & 4.8894 & TRN & \\
\hline CHEMBL1323213 & 688340 & 4.8 & 5.2263 & TST & \\
\hline CHEMBL1468942 & 688340 & 4.95 & 5.4191 & TRN & \\
\hline CHEMBL3193515 & 688340 & 4.65 & 4.8261 & TRN & \\
\hline CHEMBL3192810 & 688340 & 4.4 & 4.9048 & TRN & \\
\hline CHEMBL1325348 & 688340 & 4.45 & 4.8357 & TRN & \\
\hline CHEMBL1466123 & 688340 & 5.45 & 5.0638 & TRN & \\
\hline CHEMBL1568686 & 688340 & 5.6 & 5.13 & TST & \\
\hline CHEMBL1552790 & 688340 & 7.0501 & 5.3378 & TRN & \\
\hline CHEMBL1400393 & 688340 & 7.0 & 5.2895 & TST & \\
\hline CHEMBL1597292 & 688340 & 4.75 & 5.0014 & TRN & \\
\hline CHEMBL1384761 & 688340 & 9.0458 & 5.3575 & TRN & \\
\hline CHEMBL3189512 & 688340 & 4.5 & 4.8926 & TRN & \\
\hline CHEMBL3197903 & 688340 & 4.6 & 4.6978 & TRN & \\
\hline CHEMBL1443968 & 688340 & 4.45 & 4.8609 & TST & \\
\hline CHEMBL1348345 & 688340 & 4.5 & 5.1085 & TRN & \\
\hline CHEMBL1586326 & 688340 & 4.5 & 4.7376 & TST & \\
\hline CHEMBL1594666 & 688340 & 5.6 & 5.1913 & TRN & \\
\hline CHEMBL1425719 & 688340 & 5.35 & 5.3872 & TRN & \\
\hline CHEMBL1494638 & 688340 & 4.4 & 4.9691 & TST & \\
\hline CHEMBL3207660 & 688340 & 4.55 & 5.0681 & TST & \\
\hline
\end{tabular}




\begin{tabular}{|c|c|c|c|c|}
\hline \multicolumn{5}{|c|}{ Supplemental Table S2.txt } \\
\hline CHEMBL1510329 & 688340 & 5.05 & 5.0064 & TRN \\
\hline CHEMBL1479634 & 688340 & 7.0 & 5.2653 & TRN \\
\hline CHEMBL1522797 & 688340 & 7.0 & 5.1908 & TRN \\
\hline CHEMBL1598223 & 688340 & 4.55 & 5.0749 & TRN \\
\hline CHEMBL1300732 & 688340 & 4.6 & 5.3961 & TST \\
\hline CHEMBL1561993 & 688340 & 4.4 & 4.8979 & TST \\
\hline CHEMBL1547658 & 688340 & 5.7 & 4.8462 & TRN \\
\hline CHEMBL1307888 & 688340 & 6.1 & 5.0588 & TRN \\
\hline CHEMBL1510876 & 688340 & 4.5 & 4.6092 & TST \\
\hline CHEMBL1424391 & 688340 & 4.9 & 5.2441 & TRN \\
\hline CHEMBL3212392 & 688340 & 4.5 & 4.9132 & TRN \\
\hline CHEMBL3191932 & 688340 & 4.75 & 4.9323 & TRN \\
\hline CHEMBL1467962 & 688340 & 4.0 & 4.9403 & TST \\
\hline CHEMBL1549128 & 688340 & 5.85 & 4.6266 & TST \\
\hline CHEMBL1560242 & 688340 & 5.05 & 5.1461 & TRN \\
\hline CHEMBL1500453 & 688340 & 4.45 & 5.0859 & TST \\
\hline CHEMBL1572113 & 688340 & 4.6 & 5.0307 & TST \\
\hline CHEMBL1383099 & 688340 & 5.75 & 5.0005 & TRN \\
\hline CHEMBL1589643 & 688340 & 4.4 & 5.0113 & TRN \\
\hline CHEMBL1343906 & 688340 & 4.5 & 4.9475 & TRN \\
\hline CHEMBL1424181 & 688340 & 4.65 & 4.6943 & TRN \\
\hline CHEMBL1357952 & 688340 & 4.55 & 4.6864 & TRN \\
\hline CHEMBL1516758 & 688340 & 4.45 & 5.1853 & TST \\
\hline CHEMBL1333319 & 688340 & 4.55 & 4.7281 & TRN \\
\hline CHEMBL1317249 & 688340 & 4.85 & 4.7451 & TRN \\
\hline CHEMBL1584170 & 688340 & 4.45 & 4.9701 & TST \\
\hline CHEMBL89671 & 688340 & 4.4 & 5.0071 & TRN \\
\hline CHEMBL1516370 & 688340 & 5.4 & 5.3349 & TRN \\
\hline CHEMBL1607464 & 688340 & 4.65 & 4.6478 & TRN \\
\hline CHEMBL 3194882 & 688340 & 6.15 & 5.0634 & TRN \\
\hline CHEMBL1607184 & 688340 & 4.65 & 4.723 & TST \\
\hline CHEMBL1528412 & 688340 & 5.25 & 4.8996 & TST \\
\hline CHEMBL3213165 & 688340 & 4.6 & 4.9431 & TST \\
\hline CHEMBL1301270 & 688340 & 6.45 & 4.9044 & TRN \\
\hline CHEMBL1508016 & 688340 & 5.05 & 4.9272 & TST \\
\hline CHEMBL1307647 & 688340 & 4.4 & 5.0503 & TRN \\
\hline CHEMBL1371286 & 688340 & 4.45 & 4.9259 & TRN \\
\hline CHEMBL1439862 & 688340 & 4.65 & 5.4731 & TRN \\
\hline CHEMBL1363334 & 688340 & 4.3 & 5.1111 & TST \\
\hline CHEMBL1501581 & 688340 & 5.05 & 5.192 & TRN \\
\hline CHEMBL1604493 & 688340 & 4.5 & 5.0906 & TST \\
\hline CHEMBL1458746 & 688340 & 4.7 & 4.6498 & TRN \\
\hline CHEMBL1587197 & 688340 & 5.0 & 4.926 & TRN \\
\hline CHEMBL1546118 & 688340 & 4.35 & 5.2054 & TRN \\
\hline CHEMBL1579325 & 688340 & 5.05 & 5.2357 & TRN \\
\hline CHEMBL1442821 & 688340 & 4.7 & 4.7777 & TRN \\
\hline CHEMBL1505413 & 688340 & 4.4 & 4.8962 & TRN \\
\hline CHEMBL 1437025 & 688340 & 6.8499 & 5.3207 & TRN \\
\hline
\end{tabular}

Page 28034 


\begin{tabular}{|c|c|c|c|c|}
\hline \multicolumn{5}{|c|}{ Supplemental Table S2.txt } \\
\hline CHEMBL1402142 & 688340 & 5.5 & 5.0438 & TRN \\
\hline CHEMBL1441404 & 688340 & 6.25 & 5.1945 & TST \\
\hline CHEMBL1398686 & 688340 & 6.0 & 4.9576 & TRN \\
\hline CHEMBL1365290 & 688340 & 4.65 & 4.6374 & TRN \\
\hline CHEMBL1533434 & 688340 & 5.35 & 5.151 & TRN \\
\hline CHEMBL1543349 & 688340 & 4.75 & 4.8245 & TST \\
\hline CHEMBL1584033 & 688340 & 3.45 & 4.9311 & TRN \\
\hline CHEMBL240836 & 688340 & 4.5 & 4.7397 & TRN \\
\hline CHEMBL 37537 & 688340 & 4.4 & 4.975 & TST \\
\hline CHEMBL1425018 & 688340 & 6.1 & 5.1463 & TRN \\
\hline CHEMBL1379541 & 688340 & 3.35 & 5.1547 & TRN \\
\hline CHEMBL1570277 & 688340 & 4.4 & 4.9013 & TST \\
\hline CHEMBL1425478 & 688340 & 4.55 & 4.9764 & TRN \\
\hline CHEMBL1423975 & 688340 & 4.4 & 5.3854 & TST \\
\hline CHEMBL1457700 & 688340 & 4.6 & 4.7832 & TRN \\
\hline CHEMBL1351180 & 688340 & 4.75 & 4.8356 & TRN \\
\hline CHEMBL1301960 & 688340 & 4.5 & 4.7511 & TRN \\
\hline CHEMBL1465577 & 688340 & 5.2 & 5.4026 & TRN \\
\hline CHEMBL1358071 & 688340 & 5.5 & 5.4542 & TRN \\
\hline CHEMBL1548232 & 688340 & 5.0 & 5.0762 & TRN \\
\hline CHEMBL1301219 & 688340 & 4.4 & 4.8878 & TST \\
\hline CHEMBL1324036 & 688340 & 4.5 & 4.8778 & TRN \\
\hline CHEMBL1385223 & 688340 & 4.5 & 4.7246 & TRN \\
\hline CHEMBL1399167 & 688340 & 7.0 & 5.3618 & TRN \\
\hline CHEMBL1542993 & 688340 & 5.2 & 5.4289 & TRN \\
\hline CHEMBL1389020 & 688340 & 4.55 & 4.9998 & TRN \\
\hline CHEMBL1512333 & 688340 & 4.6 & 5.2049 & TRN \\
\hline CHEMBL1576658 & 688340 & 6.1 & 5.0068 & TST \\
\hline CHEMBL1559143 & 688340 & 4.8 & 4.8983 & TST \\
\hline CHEMBL1489221 & 688340 & 4.45 & 5.0673 & TST \\
\hline CHEMBL1329615 & 688340 & 6.45 & 5.2445 & TRN \\
\hline CHEMBL1506262 & 688340 & 4.4 & 5.3266 & TST \\
\hline CHEMBL1343562 & 688340 & 4.0 & 5.1578 & TRN \\
\hline CHEMBL 3145001 & 688340 & 5.4 & 4.955 & TRN \\
\hline CHEMBL1303737 & 688340 & 4.75 & 4.7836 & TST \\
\hline CHEMBL1401040 & 688340 & 4.55 & 5.2334 & TRN \\
\hline CHEMBL1576746 & 688340 & 5.4 & 5.032 & TRN \\
\hline CHEMBL 3856090 & 688340 & 5.45 & 5.2706 & TRN \\
\hline CHEMBL1549081 & 688340 & 5.0 & 4.7457 & TRN \\
\hline CHEMBL1314677 & 688340 & 4.75 & 4.7866 & TRN \\
\hline CHEMBL1422046 & 688340 & 5.0 & 4.8449 & TRN \\
\hline CHEMBL1468734 & 688340 & 4.4 & 4.7969 & TRN \\
\hline CHEMBL1413453 & 688340 & 5.2 & 4.7325 & TRN \\
\hline CHEMBL1301390 & 688340 & 5.05 & 4.874 & TRN \\
\hline CHEMBL1477090 & 688340 & 4.65 & 4.9694 & TRN \\
\hline CHEMBL1453758 & 688340 & 5.45 & 4.8951 & TRN \\
\hline CHEMBL1304384 & 688340 & 4.75 & 4.8832 & TRN \\
\hline CHEMBL1332596 & 688340 & 5.35 & 5.3731 & TRN \\
\hline
\end{tabular}




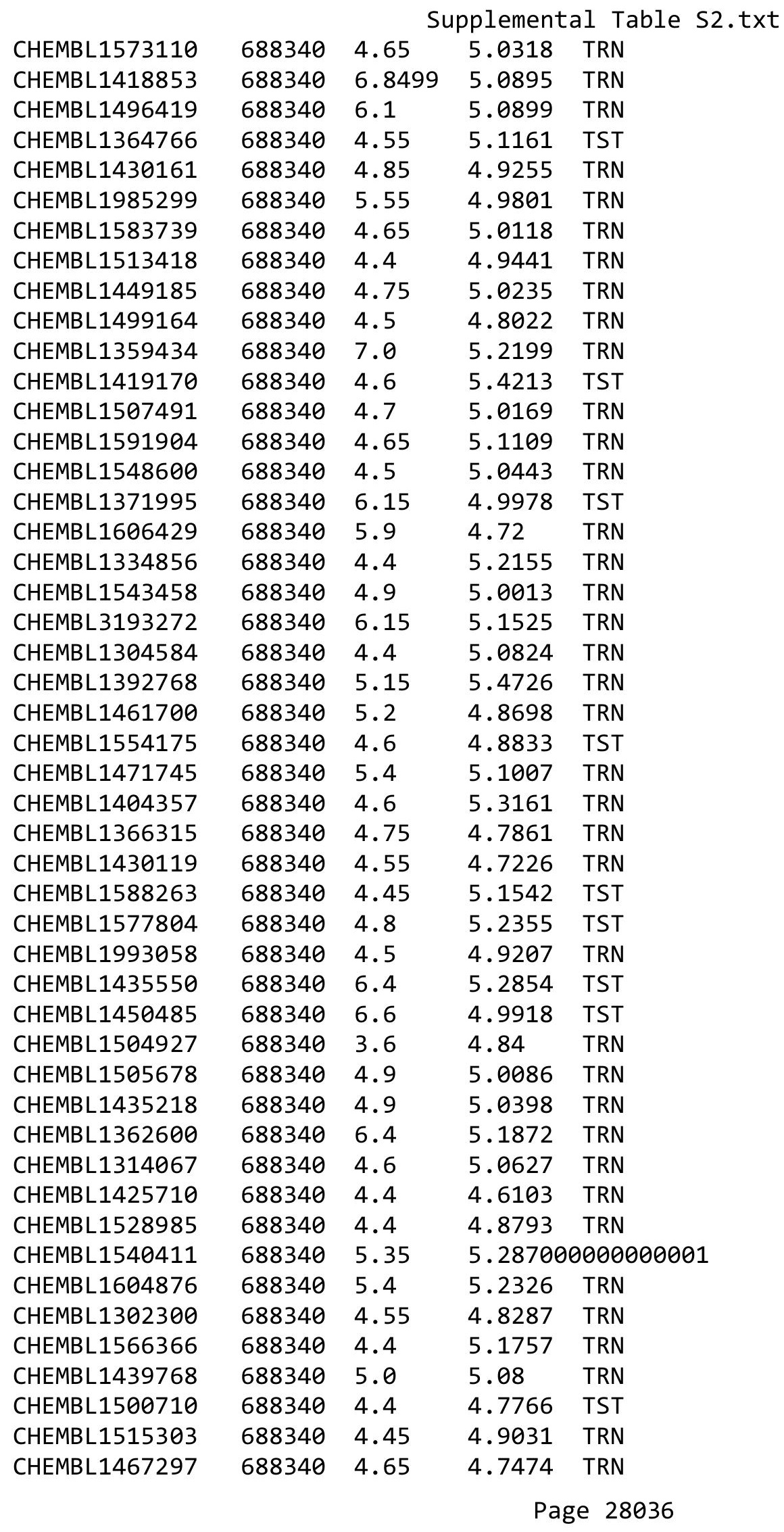




\begin{tabular}{|c|c|c|c|c|}
\hline \multicolumn{5}{|c|}{ Supplemental Table S2.txt } \\
\hline CHEMBL1301527 & 688340 & 5.15 & 5.1232 & TST \\
\hline CHEMBL1463259 & 688340 & 5.15 & 5.313 & TRN \\
\hline CHEMBL1584065 & 688340 & 5.55 & 5.0649 & TST \\
\hline CHEMBL1341388 & 688340 & 4.6 & 5.0466 & TRN \\
\hline CHEMBL1446100 & 688340 & 4.55 & 5.1505 & TRN \\
\hline CHEMBL1457077 & 688340 & 4.9 & 4.9275 & TRN \\
\hline CHEMBL1390030 & 688340 & 4.55 & 5.0922 & TST \\
\hline CHEMBL1409512 & 688340 & 4.75 & 5.2943 & TRN \\
\hline CHEMBL1410351 & 688340 & 5.2 & 4.9952 & TRN \\
\hline CHEMBL1553613 & 688340 & 4.95 & 5.2258 & TRN \\
\hline CHEMBL1501908 & 688340 & 5.2 & 5.2765 & TRN \\
\hline CHEMBL1412223 & 688340 & 4.55 & 4.9348 & TST \\
\hline CHEMBL1503477 & 688340 & 4.65 & 4.7933 & TRN \\
\hline CHEMBL1496701 & 688340 & 4.3 & 4.6989 & TRN \\
\hline CHEMBL1579766 & 688340 & 4.85 & 4.8856 & TRN \\
\hline CHEMBL1333967 & 688340 & 4.5 & 4.6246 & TST \\
\hline CHEMBL1372844 & 688340 & 4.65 & 4.8646 & TRN \\
\hline CHEMBL1442806 & 688340 & 6.15 & 4.7902 & TRN \\
\hline CHEMBL1387292 & 688340 & 4.5 & 4.9684 & TRN \\
\hline CHEMBL1353227 & 688340 & 4.6 & 4.6853 & TRN \\
\hline CHEMBL1548623 & 688340 & 5.0 & 5.4333 & TRN \\
\hline CHEMBL1469526 & 688340 & 4.75 & 4.9741 & TST \\
\hline CHEMBL1582742 & 688340 & 5.5 & 4.8819 & TST \\
\hline CHEMBL1589109 & 688340 & 4.5 & 4.8736 & TRN \\
\hline CHEMBL1390230 & 688340 & 4.85 & 5.0148 & TRN \\
\hline CHEMBL1555070 & 688340 & 4.45 & 5.2069 & TRN \\
\hline CHEMBL 305978 & 688340 & 4.5 & 4.7891 & TRN \\
\hline CHEMBL1464962 & 688340 & 4.4 & 4.7672 & TRN \\
\hline CHEMBL1429586 & 688340 & 4.7 & 4.654 & TST \\
\hline CHEMBL1436200 & 688340 & 4.85 & 5.5657 & TRN \\
\hline CHEMBL3197689 & 688340 & 4.5 & 4.9521 & TRN \\
\hline CHEMBL1330516 & 688340 & 5.0 & 4.7016 & TRN \\
\hline CHEMBL1570678 & 688340 & 6.3 & 4.7176 & TRN \\
\hline CHEMBL1540557 & 688340 & 5.7 & 4.8937 & TRN \\
\hline CHEMBL3197151 & 688340 & 5.8 & 4.9287 & TST \\
\hline CHEMBL1479179 & 688340 & 4.55 & 5.0882 & TRN \\
\hline CHEMBL1476157 & 688340 & 7.0 & 5.5078 & TRN \\
\hline CHEMBL1580889 & 688340 & 4.5 & 4.7515 & TRN \\
\hline CHEMBL1476201 & 688340 & 4.4 & 5.2709 & TRN \\
\hline CHEMBL1367086 & 688340 & 4.35 & 4.7546 & TST \\
\hline CHEMBL1610729 & 688340 & 5.0 & 5.5706 & TRN \\
\hline CHEMBL3212304 & 688340 & 4.45 & 4.6213 & TRN \\
\hline CHEMBL1501269 & 688340 & 4.5 & 4.7417 & TRN \\
\hline CHEMBL1406018 & 688340 & 4.55 & 5.1103 & TRN \\
\hline CHEMBL1400649 & 688340 & 4.35 & 5.2093 & TST \\
\hline CHEMBL1536678 & 688340 & 4.4 & 5.1619 & TRN \\
\hline CHEMBL1495935 & 688340 & 6.1 & 5.1746 & TRN \\
\hline CHEMBL1455791 & 688340 & 5.9 & 4.9492 & TRN \\
\hline
\end{tabular}




\begin{tabular}{|c|c|c|c|c|}
\hline \multicolumn{5}{|c|}{ Supplemental Table S2.txt } \\
\hline CHEMBL1424620 & 688340 & 5.35 & 5.2258 & TRN \\
\hline CHEMBL1521190 & 688340 & 4.45 & 4.9367 & TRN \\
\hline CHEMBL1405111 & 688340 & 5.0 & 4.8792 & TRN \\
\hline CHEMBL1548363 & 688340 & 4.6 & 4.9913 & TST \\
\hline CHEMBL1509803 & 688340 & 6.0 & 4.9854 & TST \\
\hline CHEMBL1424161 & 688340 & 4.4 & 4.8971 & TRN \\
\hline CHEMBL1351788 & 688340 & 5.2 & 5.2546 & TRN \\
\hline CHEMBL1437493 & 688340 & 3.1 & 4.897 & TRN \\
\hline CHEMBL1358948 & 688340 & 5.2 & 5.0972 & TRN \\
\hline CHEMBL1429979 & 688340 & 4.5 & 4.9576 & TRN \\
\hline CHEMBL1603810 & 688340 & 4.0 & 5.1759 & TRN \\
\hline CHEMBL1365962 & 688340 & 4.4 & 5.3146 & TRN \\
\hline CHEMBL1462701 & 688340 & 4.55 & 5.2294 & TRN \\
\hline CHEMBL1524172 & 688340 & 4.5 & 4.9566 & TRN \\
\hline CHEMBL1539741 & 688340 & 4.5 & 5.1532 & TST \\
\hline CHEMBL1439255 & 688340 & 4.65 & 4.7957 & TRN \\
\hline CHEMBL1504889 & 688340 & 5.8 & 5.0875 & TRN \\
\hline CHEMBL1473519 & 688340 & 4.45 & 5.0038 & TST \\
\hline CHEMBL1525518 & 688340 & 5.3 & 5.0473 & TST \\
\hline CHEMBL1390593 & 688340 & 4.55 & 4.4622 & TRN \\
\hline CHEMBL1447616 & 688340 & 4.0 & 5.0626 & TRN \\
\hline CHEMBL1545855 & 688340 & 4.55 & 4.8199 & TRN \\
\hline CHEMBL1470853 & 688340 & 5.8 & 5.1181 & TRN \\
\hline CHEMBL 3207890 & 688340 & 4.6 & 5.0519 & TRN \\
\hline CHEMBL1505608 & 688340 & 4.9 & 4.823 & TRN \\
\hline CHEMBL1412002 & 688340 & 4.55 & 4.3863 & TRN \\
\hline CHEMBL164 & 688340 & 6.35 & 5.3624 & TRN \\
\hline CHEMBL1503787 & 688340 & 6.3 & 5.1242 & TRN \\
\hline CHEMBL3213388 & 688340 & 5.3 & 5.1892 & TST \\
\hline CHEMBL1486011 & 688340 & 4.65 & 4.9434 & TRN \\
\hline CHEMBL1359936 & 688340 & 4.4 & 5.2461 & TST \\
\hline CHEMBL1509444 & 688340 & 6.0 & 5.3276 & TRN \\
\hline CHEMBL1376002 & 688340 & 7.0 & 5.2352 & TRN \\
\hline CHEMBL1395469 & 688340 & 4.5 & 5.1155 & TRN \\
\hline CHEMBL1426949 & 688340 & 4.4 & 5.0288 & TRN \\
\hline CHEMBL1576814 & 688340 & 4.6 & 4.9939 & TRN \\
\hline CHEMBL1462614 & 688340 & 4.45 & 4.9119 & TRN \\
\hline CHEMBL1446575 & 688340 & 5.3 & 4.9616 & TRN \\
\hline CHEMBL1397345 & 688340 & 9.5229 & 5.3886 & TRN \\
\hline CHEMBL1560136 & 688340 & 4.5 & 4.7852 & TRN \\
\hline CHEMBL1510148 & 688340 & 4.85 & 5.1835 & TST \\
\hline CHEMBL1379542 & 688340 & 4.55 & 5.0405 & TST \\
\hline CHEMBL1385887 & 688340 & 4.85 & 4.843 & TST \\
\hline CHEMBL1350559 & 688340 & 5.15 & 4.9682 & TST \\
\hline CHEMBL1431332 & 688340 & 4.55 & 4.8466 & TRN \\
\hline CHEMBL1506031 & 688340 & 4.85 & 4.8669 & TRN \\
\hline CHEMBL1391256 & 688340 & 5.5 & 4.672 & TST \\
\hline CHEMBL1532477 & 688340 & 4.55 & 4.837 & TRN \\
\hline
\end{tabular}




\begin{tabular}{|c|c|c|c|c|}
\hline \multicolumn{5}{|c|}{ Supplemental Table s2.txt } \\
\hline CHEMBL3194122 & 688340 & 4.4 & 5.0123 & TRN \\
\hline CHEMBL1509653 & 688340 & 4.65 & 4.9927 & TRN \\
\hline CHEMBL 334707 & 688340 & 4.5 & 4.6105 & TRN \\
\hline CHEMBL1478601 & 688340 & 5.05 & 5.3953 & TRN \\
\hline CHEMBL1483946 & 688340 & 5.25 & 4.7899 & TRN \\
\hline CHEMBL1560670 & 688340 & 6.45 & 5.3147 & TRN \\
\hline CHEMBL1488542 & 688340 & 4.4 & 4.7515 & TST \\
\hline CHEMBL1597187 & 688340 & 4.6 & 4.8405 & TRN \\
\hline CHEMBL1432071 & 688340 & 7.0 & 5.224 & TST \\
\hline CHEMBL3212016 & 688340 & 6.45 & 4.8294 & TRN \\
\hline CHEMBL1495484 & 688340 & 6.0 & 4.9433 & TRN \\
\hline CHEMBL1340690 & 688340 & 5.0 & 5.1327 & TRN \\
\hline CHEMBL1321234 & 688340 & 5.0 & 5.1193 & TRN \\
\hline CHEMBL1357349 & 688340 & 7.0 & 5.2084 & TRN \\
\hline CHEMBL1504311 & 688340 & 4.4 & 4.8719 & TRN \\
\hline CHEMBL1428178 & 688340 & 6.1 & 4.8782 & TST \\
\hline CHEMBL1585745 & 688340 & 5.9 & 4.9945 & TRN \\
\hline CHEMBL42355 & 688340 & 4.35 & 4.9457 & TRN \\
\hline CHEMBL1386730 & 688340 & 5.2 & 5.3333 & TRN \\
\hline CHEMBL1594182 & 688340 & 4.4 & 4.9066 & TST \\
\hline CHEMBL1329087 & 688340 & 4.45 & 5.4783 & TRN \\
\hline CHEMBL 272465 & 688340 & 5.45 & 4.9565 & TST \\
\hline CHEMBL428064 & 688340 & 4.95 & 4.7216 & TST \\
\hline CHEMBL1347778 & 688340 & 7.15 & 5.0815 & TRN \\
\hline CHEMBL1469967 & 688340 & 4.65 & 4.6513 & TRN \\
\hline CHEMBL1568783 & 688340 & 4.6 & 4.84399 & 9999999999 \\
\hline CHEMBL1394024 & 688340 & 4.5 & 4.7891 & TRN \\
\hline CHEMBL1398414 & 688340 & 5.2 & 5.3647 & TRN \\
\hline CHEMBL1328158 & 688340 & 4.55 & 4.6428 & TRN \\
\hline CHEMBL3193064 & 688340 & 4.75 & 5.0839 & TRN \\
\hline CHEMBL1577846 & 688340 & 6.4 & 5.2341 & TRN \\
\hline CHEMBL1982025 & 688340 & 4.5 & 4.9996 & TRN \\
\hline CHEMBL1533626 & 688340 & 4.6 & 4.9751 & TRN \\
\hline CHEMBL1566124 & 688340 & 6.7501 & 5.1129 & TST \\
\hline CHEMBL1329228 & 688340 & 5.2 & 5.0563 & TRN \\
\hline CHEMBL1470702 & 688340 & 4.6 & 5.0484 & TST \\
\hline CHEMBL1429833 & 688340 & 4.6 & 5.0981 & TRN \\
\hline CHEMBL1524454 & 688340 & 4.45 & 4.655 & TRN \\
\hline CHEMBL3207983 & 688340 & 4.45 & 4.765 & TRN \\
\hline CHEMBL1998516 & 688340 & 5.1 & 4.8177 & TRN \\
\hline CHEMBL1491040 & 688340 & 4.7 & 4.8733 & TST \\
\hline CHEMBL1578546 & 688340 & 4.85 & 4.7161 & TRN \\
\hline CHEMBL1516682 & 688340 & 4.8 & 4.7011 & TRN \\
\hline CHEMBL1471595 & 688340 & 4.85 & 4.9246 & TST \\
\hline CHEMBL1571430 & 688340 & 5.05 & 4.6404 & TST \\
\hline CHEMBL1403337 & 688340 & 5.2 & 4.822 & TST \\
\hline CHEMBL3210921 & 688340 & 5.2 & 4.8445 & TRN \\
\hline CHEMBL1598879 & 688340 & 4.6 & 4.8249 & TRN \\
\hline
\end{tabular}




\begin{tabular}{|c|c|c|c|c|}
\hline \multicolumn{5}{|c|}{ Supplemental Table S2.txt } \\
\hline CHEMBL1372767 & 688340 & 4.5 & 5.3232 & TRN \\
\hline CHEMBL1501293 & 688340 & 7.0501 & 5.1894 & TST \\
\hline CHEMBL1578397 & 688340 & 5.5 & 4.9534 & TRN \\
\hline CHEMBL1515359 & 688340 & 5.0 & 5.1284 & TRN \\
\hline CHEMBL1562346 & 688340 & 4.4 & 5.052 & TRN \\
\hline CHEMBL1346653 & 688340 & 4.5 & 4.9158 & TRN \\
\hline CHEMBL1365814 & 688340 & 4.4 & 4.877 & TRN \\
\hline CHEMBL3190421 & 688340 & 4.75 & 4.7209 & TRN \\
\hline CHEMBL1301350 & 688340 & 4.65 & 4.6977 & TRN \\
\hline CHEMBL1332012 & 688340 & 5.95 & 4.9665 & TST \\
\hline CHEMBL1557043 & 688340 & 4.4 & 4.4762 & TRN \\
\hline CHEMBL1498525 & 688340 & 4.4 & 4.855 & TRN \\
\hline CHEMBL1377263 & 688340 & 4.45 & 4.6864 & TRN \\
\hline CHEMBL1520414 & 688340 & 4.55 & 5.0665 & TRN \\
\hline CHEMBL3191119 & 688340 & 4.95 & 4.8222 & TST \\
\hline CHEMBL1551448 & 688340 & 5.45 & 5.0941 & TRN \\
\hline CHEMBL1299980 & 688340 & 5.1 & 5.1122 & TST \\
\hline CHEMBL1451956 & 688340 & 5.3 & 5.0579 & TRN \\
\hline CHEMBL 234338 & 688340 & 5.5 & 5.1193 & TRN \\
\hline CHEMBL1500388 & 688340 & 4.55 & 5.4422 & TRN \\
\hline CHEMBL1475749 & 688340 & 6.0 & 4.9801 & TRN \\
\hline CHEMBL1527207 & 688340 & 4.4 & 4.9831 & TRN \\
\hline CHEMBL 3213621 & 688340 & 4.45 & 4.9785 & TRN \\
\hline CHEMBL1372501 & 688340 & 5.05 & 5.0108 & TST \\
\hline CHEMBL1566591 & 688340 & 4.35 & 5.1003 & TRN \\
\hline CHEMBL1577378 & 688340 & 5.15 & 5.4135 & TST \\
\hline CHEMBL1426426 & 688340 & 4.95 & 5.4501 & TRN \\
\hline CHEMBL1505423 & 688340 & 4.65 & 4.9541 & TRN \\
\hline CHEMBL1387587 & 688340 & 4.35 & 5.0727 & TRN \\
\hline CHEMBL1445638 & 688340 & 4.8 & 5.2418 & TRN \\
\hline CHEMBL1558306 & 688340 & 4.45 & 4.9458 & TRN \\
\hline CHEMBL1605504 & 688340 & 4.7 & 5.3765 & TRN \\
\hline CHEMBL1605420 & 688340 & 5.5 & 4.7705 & TST \\
\hline CHEMBL1482554 & 688340 & 4.9 & 4.6938 & TRN \\
\hline CHEMBL1466282 & 688340 & 6.1 & 5.0463 & TRN \\
\hline CHEMBL1413787 & 688340 & 4.4 & 4.8894 & TRN \\
\hline CHEMBL1506744 & 688340 & 4.6 & 5.4179 & TRN \\
\hline CHEMBL1426034 & 688340 & 7.0 & 5.0764 & TST \\
\hline CHEMBL 3213916 & 688340 & 6.0 & 5.0721 & TRN \\
\hline CHEMBL 3207592 & 688340 & 4.4 & 5.2164 & TST \\
\hline CHEMBL1358935 & 688340 & 4.3 & 5.4366 & TRN \\
\hline CHEMBL1544745 & 688340 & 6.25 & 5.2521 & TRN \\
\hline CHEMBL1470065 & 688340 & 4.4 & 4.7205 & TST \\
\hline CHEMBL1474275 & 688340 & 6.05 & 5.3049 & TRN \\
\hline CHEMBL1557074 & 688340 & 5.25 & 5.394 & TST \\
\hline CHEMBL1371114 & 688340 & 4.8 & 4.6414 & TRN \\
\hline CHEMBL1565621 & 688340 & 5.7 & 5.3588 & TRN \\
\hline CHEMBL1498282 & 688340 & 5.2 & 4.8832 & TRN \\
\hline
\end{tabular}




\begin{tabular}{|c|c|c|c|c|c|}
\hline \multicolumn{6}{|c|}{ Supplemental Table S2.txt } \\
\hline CHEMBL1340709 & 688340 & 5.6 & 5.2345 & TST & \\
\hline CHEMBL1359029 & 688340 & 6.15 & 4.9644 & TRN & \\
\hline CHEMBL1383333 & 688340 & 4.85 & 4.9642 & TRN & \\
\hline CHEMBL1449667 & 688340 & 4.35 & 4.7577 & TST & \\
\hline CHEMBL1560787 & 688340 & 5.0 & 4.8796 & TRN & \\
\hline CHEMBL1400888 & 688340 & 4.4 & 5.1018 & TST & \\
\hline CHEMBL1460226 & 688340 & 5.7 & 5.2334 & TST & \\
\hline CHEMBL1997568 & 688340 & 4.6 & 4.8027 & TRN & \\
\hline CHEMBL1519862 & 688340 & 4.8 & 4.802 & TRN & \\
\hline CHEMBL1346853 & 688340 & 4.85 & 4.6965 & TST & \\
\hline CHEMBL1422471 & 688340 & 4.8 & 4.6365 & TRN & \\
\hline CHEMBL1389843 & 688340 & 4.55 & 4.6649 & TRN & \\
\hline CHEMBL1307978 & 688340 & 4.5 & 4.9196 & TRN & \\
\hline CHEMBL1241671 & 688340 & 5.3 & 4.7236 & TST & \\
\hline CHEMBL1356184 & 688340 & 5.05 & 4.8083 & TST & \\
\hline CHEMBL1300510 & 688340 & 4.5 & 4.7217 & TRN & \\
\hline CHEMBL1518855 & 688340 & 4.75 & 4.84699 & 99999999995 & TRN \\
\hline CHEMBL1988210 & 688340 & 5.5 & 5.1096 & TRN & \\
\hline CHEMBL1413956 & 688340 & 4.5 & 5.0317 & TRN & \\
\hline CHEMBL1541691 & 688340 & 4.6 & 4.9479 & TRN & \\
\hline CHEMBL3195428 & 688340 & 6.5501 & 4.8631 & TRN & \\
\hline CHEMBL1439051 & 688340 & 4.5 & 4.6608 & TRN & \\
\hline CHEMBL256098 & 688340 & 4.45 & 4.8874 & TRN & \\
\hline CHEMBL1315631 & 688340 & 7.0 & 5.4614 & TRN & \\
\hline CHEMBL1385051 & 688340 & 4.45 & 5.0537 & TRN & \\
\hline CHEMBL1350429 & 688340 & 4.4 & 5.0905 & TRN & \\
\hline CHEMBL1573529 & 688340 & 6.0 & 4.8489 & TRN & \\
\hline CHEMBL1334890 & 688340 & 5.55 & 5.0719 & TST & \\
\hline CHEMBL3193265 & 688340 & 5.95 & 5.032 & TRN & \\
\hline CHEMBL1368221 & 688340 & 5.4 & 5.1126 & TRN & \\
\hline CHEMBL1439211 & 688340 & 7.1002 & 5.4628 & TRN & \\
\hline CHEMBL1427315 & 688340 & 5.25 & 5.6189 & TRN & \\
\hline CHEMBL1581395 & 688340 & 6.15 & 4.8996 & TST & \\
\hline CHEMBL1393901 & 688340 & 4.8 & 4.4833 & TRN & \\
\hline CHEMBL1374841 & 688340 & 4.5 & 4.9132 & TRN & \\
\hline CHEMBL1598875 & 688340 & 4.4 & 4.8917 & TST & \\
\hline CHEMBL1560210 & 688340 & 5.05 & 4.95100 & 00000000005 & TRN \\
\hline CHEMBL1375615 & 688340 & 4.55 & 4.7592 & TST & \\
\hline CHEMBL1430793 & 688340 & 4.4 & 4.6974 & TRN & \\
\hline CHEMBL1301115 & 688340 & 5.15 & 5.0546 & TRN & \\
\hline CHEMBL1612018 & 688340 & 4.55 & 4.7567 & TRN & \\
\hline CHEMBL1372293 & 688340 & 6.05 & 5.1763 & TST & \\
\hline CHEMBL1466134 & 688340 & 4.65 & 4.7523 & TRN & \\
\hline CHEMBL1331097 & 688340 & 4.75 & 4.7879 & TRN & \\
\hline CHEMBL1369742 & 688340 & 4.75 & 5.0965 & TRN & \\
\hline CHEMBL162808 & 688340 & 4.7 & 4.9104 & TRN & \\
\hline CHEMBL1437800 & 688340 & 5.25 & 5.4273 & TRN & \\
\hline CHEMBL1316169 & 688340 & 5.15 & 5.1419 & TST & \\
\hline
\end{tabular}




\begin{tabular}{|c|c|c|c|c|c|}
\hline & \\
\hline CHEMBL1341594 & 688340 & 4.5 & 4.4734 & TST & \\
\hline CHEMBL1318564 & 688340 & 4.6 & 4.734 & TST & \\
\hline CHEMBL1342983 & 688340 & 4.6 & 4.8046 & TRN & \\
\hline CHEMBL1609454 & 688340 & 5.1 & 4.8008 & TRN & \\
\hline CHEMBL1436869 & 688340 & 4.5 & 5.0642 & TRN & \\
\hline CHEMBL1381723 & 688340 & 4.75 & 5.2344 & TRN & \\
\hline CHEMBL1595759 & 688340 & 4.55 & 4.4988 & TRN & \\
\hline CHEMBL1442042 & 688340 & 6.1 & 5.0077 & TRN & \\
\hline CHEMBL1412611 & 688340 & 4.7 & 5.07 & TST & \\
\hline CHEMBL1305597 & 688340 & 4.8 & 4.944 & TST & \\
\hline CHEMBL1554772 & 688340 & 4.4 & 5.53 & TST & \\
\hline CHEMBL1364569 & 688340 & 4.0 & 4.5721 & TRN & \\
\hline CHEMBL1370976 & 688340 & 4.5 & 4.8023 & TRN & \\
\hline CHEMBL 3191141 & 688340 & 4.4 & 4.7698 & TRN & \\
\hline CHEMBL1304640 & 688340 & 4.05 & 4.8333 & TRN & \\
\hline CHEMBL1511864 & 688340 & 4.7 & 5.1078 & TRN & \\
\hline CHEMBL1469804 & 688340 & 5.15 & 4.9114 & TRN & \\
\hline CHEMBL1326946 & 688340 & 5.15 & 4.8695 & TRN & \\
\hline CHEMBL1373517 & 688340 & 6.1 & 5.08 & TRN & \\
\hline CHEMBL 3190570 & 688340 & 4.55 & 4.874 & TRN & \\
\hline CHEMBL1364630 & 688340 & 5.25 & 4.8843 & TST & \\
\hline CHEMBL1526715 & 688340 & 4.4 & 4.8324 & TRN & \\
\hline CHEMBL562949 & 688340 & 5.5 & 4.9396 & TRN & \\
\hline CHEMBL1589124 & 688340 & 4.5 & 4.6467 & TRN & \\
\hline CHEMBL 203671 & 688340 & 4.55 & 4.6508 & TRN & \\
\hline CHEMBL1393035 & 688340 & 5.15 & 5.2426 & TST & \\
\hline CHEMBL1551177 & 688340 & 4.6 & 4.9968 & TRN & \\
\hline CHEMBL1388689 & 688340 & 5.05 & 4.9121 & TRN & \\
\hline CHEMBL1546979 & 688340 & 4.6 & 5.3686 & TRN & \\
\hline CHEMBL1325152 & 688340 & 4.5 & 4.7123 & TST & \\
\hline CHEMBL1609096 & 688340 & 4.8 & $5.0310 e$ & 0000000001 & TST \\
\hline CHEMBL1984479 & 688340 & 5.25 & 5.1211 & TRN & \\
\hline CHEMBL1984884 & 688340 & 4.55 & 4.6523 & TRN & \\
\hline CHEMBL1538535 & 688340 & 4.45 & 4.9549 & TRN & \\
\hline CHEMBL1410109 & 688340 & 4.55 & 4.913 & TST & \\
\hline CHEMBL1407211 & 688340 & 5.15 & 5.3784 & TST & \\
\hline CHEMBL1466297 & 688340 & 4.55 & 4.8358 & TRN & \\
\hline CHEMBL1338730 & 688340 & 5.1 & 4.8627 & TRN & \\
\hline CHEMBL 3195342 & 688340 & 4.55 & 4.8593 & TRN & \\
\hline CHEMBL1603092 & 688340 & 5.05 & 4.921 & TRN & \\
\hline CHEMBL1377314 & 688340 & 6.45 & 5.0816 & TRN & \\
\hline CHEMBL1595644 & 688340 & 4.5 & 5.1884 & TRN & \\
\hline CHEMBL3197887 & 688340 & 4.75 & 4.9512 & TRN & \\
\hline CHEMBL1482471 & 688340 & 7.0501 & 5.4832 & TRN & \\
\hline CHEMBL1430424 & 688340 & 6.5501 & 5.2627 & TRN & \\
\hline CHEMBL1530719 & 688340 & 4.45 & 4.7572 & TRN & \\
\hline CHEMBL1406109 & 688340 & 5.1 & 5.0591 & TRN & \\
\hline CHEMBL1486109 & 688340 & 4.6 & 4.8232 & TRN & \\
\hline & & & & 3042 & \\
\hline
\end{tabular}




\begin{tabular}{|c|c|c|c|c|c|}
\hline & & & & & \\
\hline CHEMBL1485923 & 688340 & 5.5 & 4.7559 & TRN & \\
\hline CHEMBL3392417 & 688340 & 6.0 & 5.2938 & TRN & \\
\hline CHEMBL1994371 & 688340 & 4.8 & 4.8051 & TRN & \\
\hline CHEMBL1315642 & 688340 & 4.5 & 4.919 & TRN & \\
\hline CHEMBL1531304 & 688340 & 5.45 & 4.8097 & TRN & \\
\hline CHEMBL1372733 & 688340 & 4.45 & 5.1656 & TRN & \\
\hline CHEMBL1389861 & 688340 & 6.6 & 5.2652 & TRN & \\
\hline CHEMBL1383731 & 688340 & 4.7 & 5.6 & TRN & \\
\hline CHEMBL3197153 & 688340 & 4.6 & 4.89199 & 99999999995 & TRN \\
\hline CHEMBL1316338 & 688340 & 4.55 & 4.9051 & TRN & \\
\hline CHEMBL1513664 & 688340 & 4.65 & 5.0415 & TRN & \\
\hline CHEMBL1464786 & 688340 & 4.5 & 4.5694 & TRN & \\
\hline CHEMBL1326211 & 688340 & 5.2 & 5.0724 & TRN & \\
\hline CHEMBL1528787 & 688340 & 4.5 & 4.9446 & TRN & \\
\hline CHEMBL1306092 & 688340 & 4.85 & 4.6856 & TRN & \\
\hline CHEMBL1301297 & 688340 & 4.5 & 4.8422 & TRN & \\
\hline CHEMBL1334930 & 688340 & 4.4 & 5.2284 & TST & \\
\hline CHEMBL1400463 & 688340 & 5.05 & 5.1103 & TST & \\
\hline CHEMBL1512641 & 688340 & 4.5 & 4.796 & TST & \\
\hline CHEMBL1448049 & 688340 & 4.45 & 4.8339 & TRN & \\
\hline CHEMBL1530230 & 688340 & 6.2 & 5.1692 & TRN & \\
\hline CHEMBL1311347 & 688340 & 4.95 & 5.38299 & 9999999999 & TST \\
\hline CHEMBL1459180 & 688340 & 5.0 & 5.1334 & TST & \\
\hline CHEMBL1425336 & 688340 & 4.55 & 5.0584 & TRN & \\
\hline CHEMBL1328571 & 688340 & 4.55 & 5.4818 & TRN & \\
\hline CHEMBL1452391 & 688340 & 4.55 & 4.6301 & TRN & \\
\hline CHEMBL1534240 & 688340 & 4.4 & 4.8916 & TRN & \\
\hline CHEMBL1365242 & 688340 & 5.35 & 4.9361 & TST & \\
\hline CHEMBL1552032 & 688340 & 4.65 & 4.9993 & TRN & \\
\hline CHEMBL1566873 & 688340 & 6.15 & 5.0421 & TRN & \\
\hline CHEMBL1319619 & 688340 & 4.55 & 4.8851 & TRN & \\
\hline CHEMBL1459233 & 688340 & 5.2 & 5.1329 & TRN & \\
\hline CHEMBL1456352 & 688340 & 4.95 & 5.0566 & TST & \\
\hline CHEMBL1569172 & 688340 & 5.0 & 5.4477 & TRN & \\
\hline CHEMBL1375999 & 688340 & 4.95 & 5.348 & TRN & \\
\hline CHEMBL1335960 & 688340 & 5.35 & 5.2233 & TRN & \\
\hline CHEMBL1351286 & 688340 & 4.75 & 5.2627 & TST & \\
\hline CHEMBL1372470 & 688340 & 5.6 & 4.9528 & TRN & \\
\hline CHEMBL1536977 & 688340 & 4.4 & 4.9752 & TST & \\
\hline CHEMBL1457430 & 688340 & 5.05 & 5.0754 & TRN & \\
\hline CHEMBL1546463 & 688340 & 4.65 & 4.7676 & TST & \\
\hline CHEMBL1469724 & 688340 & 6.1 & 5.0571 & TRN & \\
\hline CHEMBL1396369 & 688340 & 4.65 & 5.1459 & TRN & \\
\hline CHEMBL1430674 & 688340 & 4.55 & 4.9586 & TRN & \\
\hline CHEMBL1501874 & 688340 & 4.65 & 4.843 & TRN & \\
\hline CHEMBL1567415 & 688340 & 4.4 & 4.8753 & TST & \\
\hline CHEMBL1397015 & 688340 & 5.3 & 5.0103 & TRN & \\
\hline CHEMBL1339694 & 688340 & 4.75 & 4.71899 & 9999999999 & TRN \\
\hline & & & & 28043 & \\
\hline
\end{tabular}




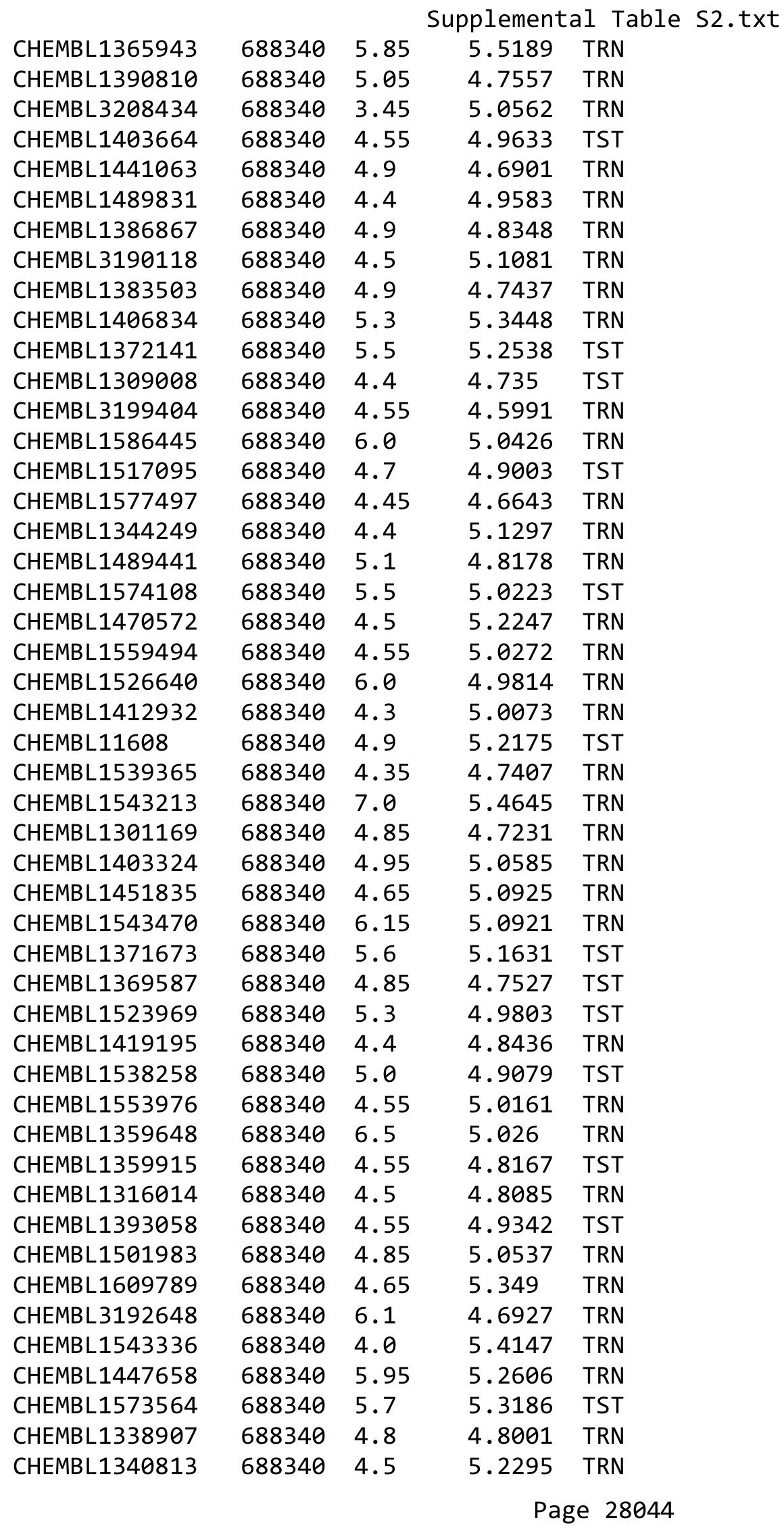




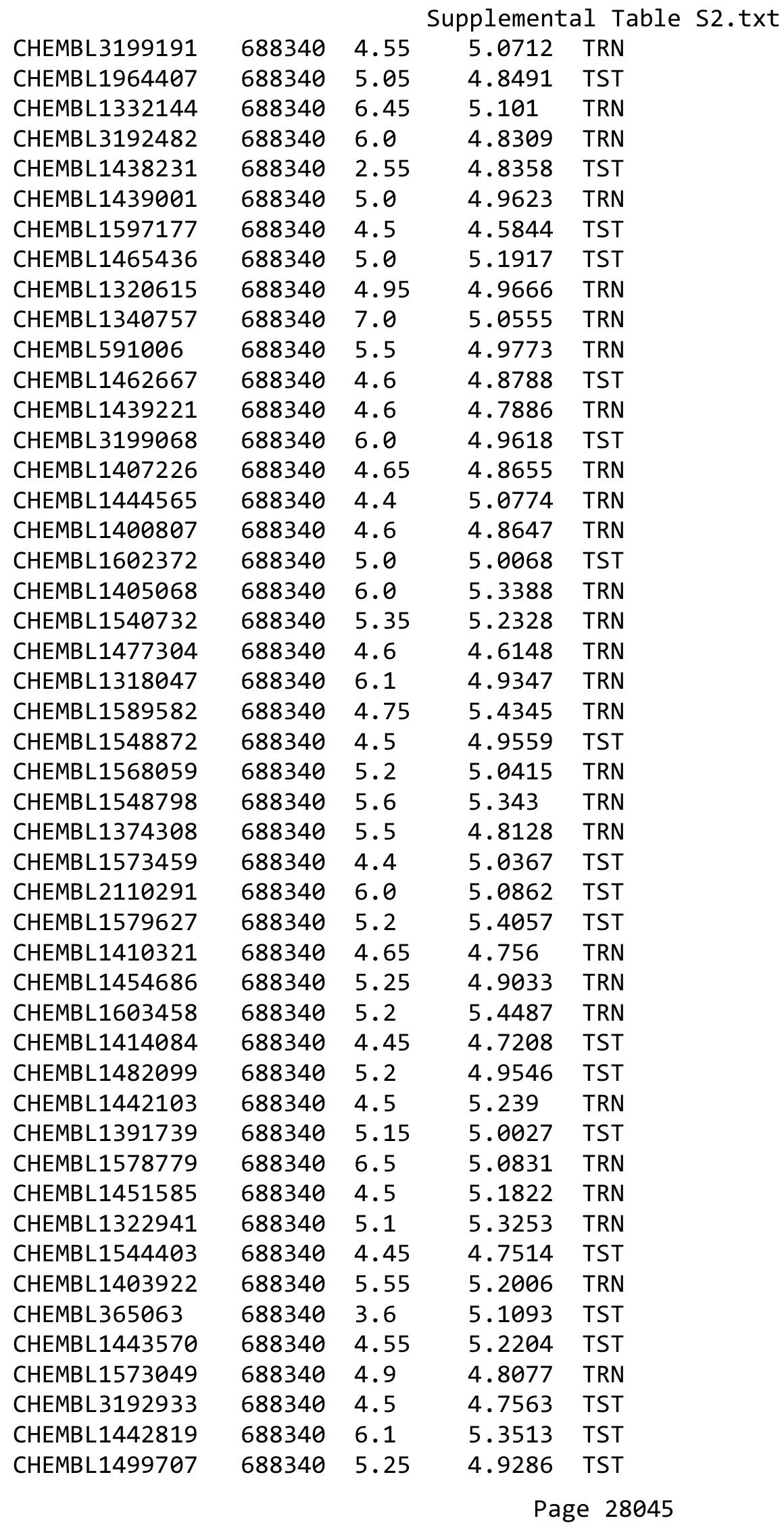




\begin{tabular}{|c|c|c|c|c|}
\hline \multicolumn{5}{|c|}{ Supplemental Table S2.txt } \\
\hline CHEMBL1523042 & 688340 & 2.4 & 5.606 & TRN \\
\hline CHEMBL3210959 & 688340 & 5.2 & 4.8935 & TRN \\
\hline CHEMBL1445539 & 688340 & 6.8499 & 5.1616 & TRN \\
\hline CHEMBL1328700 & 688340 & 4.0 & 5.2368 & TRN \\
\hline CHEMBL1490689 & 688340 & 5.05 & 4.7519 & TST \\
\hline CHEMBL1588342 & 688340 & 6.15 & 4.7272 & TRN \\
\hline CHEMBL 3190125 & 688340 & 4.85 & 5.1916 & TRN \\
\hline CHEMBL1345397 & 688340 & 5.0 & 5.2295 & TRN \\
\hline CHEMBL1339294 & 688340 & 4.4 & 4.9699 & TRN \\
\hline CHEMBL1432902 & 688340 & 4.55 & 4.8344 & TRN \\
\hline CHEMBL 3145114 & 688340 & 5.6 & 5.1408 & TRN \\
\hline CHEMBL1531768 & 688340 & 5.8 & 5.4125 & TRN \\
\hline CHEMBL3191577 & 688340 & 4.55 & 4.9164 & TRN \\
\hline CHEMBL1560808 & 688340 & 5.35 & 5.2753 & TST \\
\hline CHEMBL1334062 & 688340 & 5.8 & 5.1361 & TRN \\
\hline CHEMBL3194760 & 688340 & 5.05 & 5.0939 & TST \\
\hline CHEMBL1534987 & 688340 & 4.4 & 4.7488 & TRN \\
\hline CHEMBL1413486 & 688340 & 4.55 & 5.0426 & TRN \\
\hline CHEMBL1544621 & 688340 & 5.45 & 5.2798 & TRN \\
\hline CHEMBL1612314 & 688340 & 5.35 & 4.9771 & TRN \\
\hline CHEMBL1578344 & 688340 & 4.4 & 5.5798 & TRN \\
\hline CHEMBL1403726 & 688340 & 7.0 & 5.3066 & TST \\
\hline CHEMBL1525922 & 688340 & 5.2 & 5.2139 & TRN \\
\hline CHEMBL1456070 & 688340 & 4.55 & 4.7052 & TRN \\
\hline CHEMBL1520880 & 688340 & 6.15 & 4.8592 & TST \\
\hline CHEMBL1365920 & 688340 & 4.85 & 4.9496 & TRN \\
\hline CHEMBL1432513 & 688340 & 5.0 & 4.9127 & TRN \\
\hline CHEMBL1447917 & 688340 & 4.55 & 4.7208 & TRN \\
\hline CHEMBL1569755 & 688340 & 4.85 & 4.9769 & TST \\
\hline CHEMBL1549021 & 688340 & 4.7 & 4.8093 & TST \\
\hline CHEMBL1460664 & 688340 & 6.95 & 4.6499 & TST \\
\hline CHEMBL1428270 & 688340 & 4.4 & 5.3501 & TRN \\
\hline CHEMBL1547399 & 688340 & 4.55 & 4.7744 & TRN \\
\hline CHEMBL3392035 & 688340 & 4.4 & 4.8669 & TRN \\
\hline CHEMBL1445490 & 688340 & 5.2 & 5.2703 & TRN \\
\hline CHEMBL1457209 & 688340 & 4.5 & 4.7746 & TRN \\
\hline CHEMBL1492305 & 688340 & 6.0 & 4.939 & TRN \\
\hline CHEMBL1331365 & 688340 & 7.9508 & 5.5392 & TRN \\
\hline CHEMBL1405726 & 688340 & 6.15 & 4.9088 & TRN \\
\hline CHEMBL1500884 & 688340 & 4.6 & 5.0524 & TST \\
\hline CHEMBL1544859 & 688340 & 4.85 & 5.1127 & TRN \\
\hline CHEMBL1531013 & 688340 & 4.65 & 5.44 & TRN \\
\hline CHEMBL1405722 & 688340 & 4.75 & 5.1238 & TRN \\
\hline CHEMBL1602882 & 688340 & 6.2 & 5.2125 & TRN \\
\hline CHEMBL1509802 & 688340 & 4.35 & 4.9165 & TST \\
\hline CHEMBL1537025 & 688340 & 4.6 & 5.2767 & TRN \\
\hline CHEMBL1467020 & 688340 & 6.45 & 5.0974 & TRN \\
\hline CHEMBL1554884 & 688340 & 4.5 & 5.0248 & TST \\
\hline
\end{tabular}




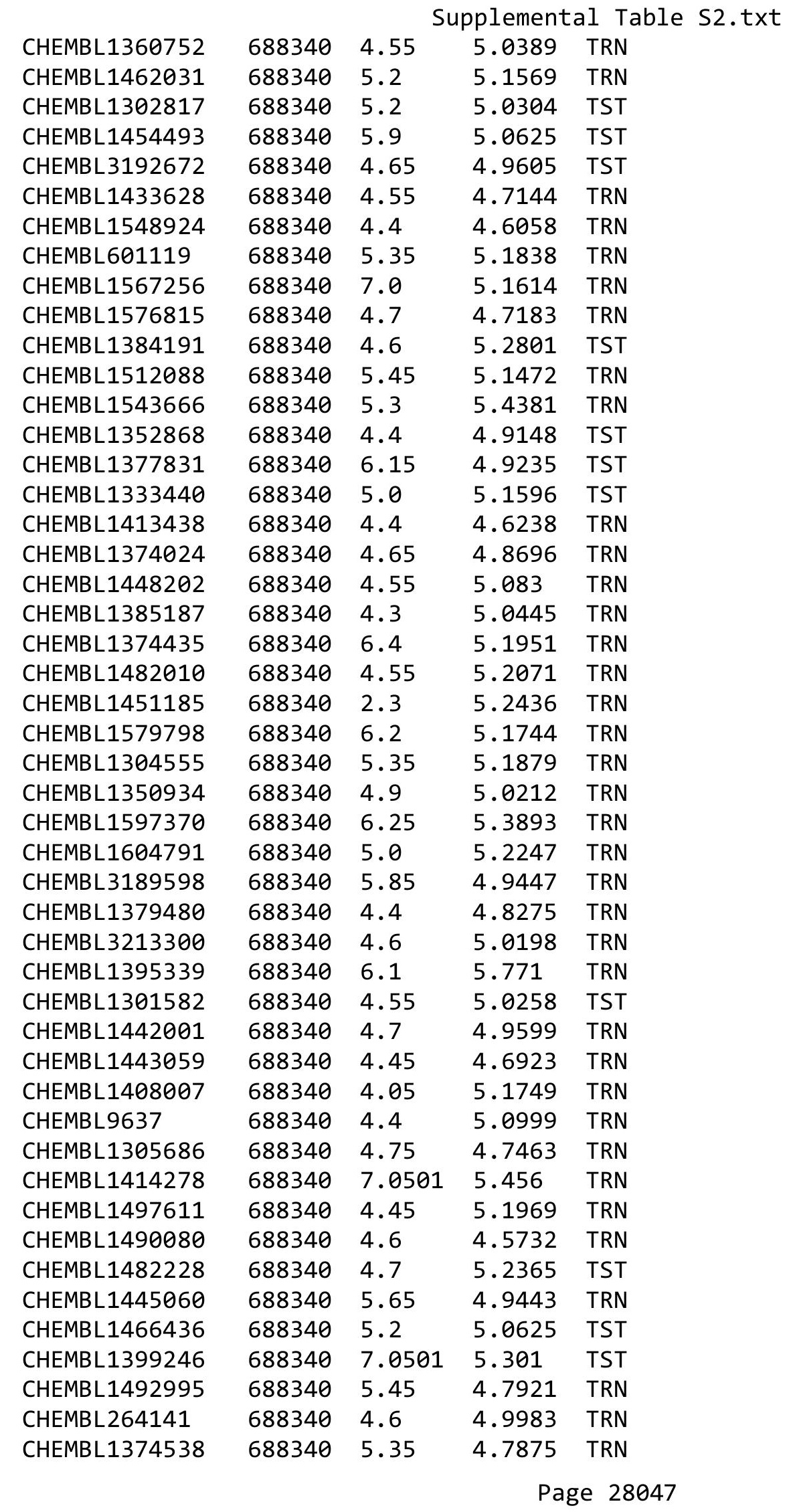




\begin{tabular}{|c|c|c|c|c|c|}
\hline \multicolumn{6}{|c|}{ Supplemental Table S2.txt } \\
\hline CHEMBL1732085 & 688340 & 5.65 & 4.7935 & TST & \\
\hline CHEMBL1562324 & 688340 & 4.85 & 4.8241 & TRN & \\
\hline CHEMBL1483767 & 688340 & 5.75 & 5.1417 & TRN & \\
\hline CHEMBL1556767 & 688340 & 6.05 & 5.4191 & TRN & \\
\hline CHEMBL1449842 & 688340 & 4.8 & 5.2066 & TRN & \\
\hline CHEMBL1474107 & 688340 & 5.4 & 5.1115 & TRN & \\
\hline CHEMBL1585055 & 688340 & 7.15 & 5.1695 & TRN & \\
\hline CHEMBL1563980 & 688340 & 4.4 & 5.0638 & TRN & \\
\hline CHEMBL1594854 & 688340 & 4.85 & 4.8408 & TRN & \\
\hline CHEMBL1304473 & 688340 & 4.4 & 4.7306 & TRN & \\
\hline CHEMBL 3209451 & 688340 & 4.4 & 4.8932 & TRN & \\
\hline CHEMBL1393639 & 688340 & 4.65 & 4.8504 & TRN & \\
\hline CHEMBL1973626 & 688340 & 4.45 & 4.9778 & TST & \\
\hline CHEMBL1331190 & 688340 & 4.65 & 4.7819 & TRN & \\
\hline CHEMBL1505987 & 688340 & 4.75 & 5.3256 & TRN & \\
\hline CHEMBL1591163 & 688340 & 5.05 & 5.1281 & TRN & \\
\hline CHEMBL1706577 & 688340 & 5.25 & 4.7726 & TRN & \\
\hline CHEMBL1391475 & 688340 & 4.8 & 4.8257 & TRN & \\
\hline CHEMBL1590596 & 688340 & 4.55 & 5.0564 & TRN & \\
\hline CHEMBL1326909 & 688340 & 4.7 & 5.2885 & TRN & \\
\hline CHEMBL1379395 & 688340 & 6.7001 & 5.4234 & TRN & \\
\hline CHEMBL1349578 & 688340 & 4.65 & 5.185 & TRN & \\
\hline CHEMBL1444217 & 688340 & 7.0501 & 4.46899 & 7999999999 & TRN \\
\hline CHEMBL1432363 & 688340 & 4.4 & 5.056 & TRN & \\
\hline CHEMBL1541628 & 688340 & 5.2 & 4.7383 & TRN & \\
\hline CHEMBL1316899 & 688340 & 6.35 & 5.0534 & TST & \\
\hline CHEMBL1300367 & 688340 & 5.25 & 5.3268 & TST & \\
\hline CHEMBL1311485 & 688340 & 4.95 & 5.2422 & TRN & \\
\hline CHEMBL1530972 & 688340 & 4.8 & 5.0621 & TRN & \\
\hline CHEMBL 3194745 & 688340 & 4.5 & 4.9878 & TRN & \\
\hline CHEMBL1399698 & 688340 & 4.4 & 4.7389 & TRN & \\
\hline CHEMBL1359154 & 688340 & 4.6 & 4.7026 & TST & \\
\hline CHEMBL1376258 & 688340 & 4.65 & 5.0651 & TRN & \\
\hline CHEMBL1324834 & 688340 & 4.6 & 4.6309 & TRN & \\
\hline CHEMBL1420617 & 688340 & 5.0 & 5.5647 & TRN & \\
\hline CHEMBL1438372 & 688340 & 4.55 & 4.7222 & TRN & \\
\hline CHEMBL1587333 & 688340 & 4.4 & 4.8598 & TRN & \\
\hline CHEMBL1507935 & 688340 & 4.7 & 5.0882 & TRN & \\
\hline CHEMBL1458098 & 688340 & 5.05 & 4.8308 & TRN & \\
\hline CHEMBL1326116 & 688340 & 5.2 & 5.12299 & 9999999999 & TST \\
\hline CHEMBL1548159 & 688340 & 4.4 & 5.0297 & TST & \\
\hline CHEMBL1499658 & 688340 & 4.5 & 5.035 & TRN & \\
\hline CHEMBL1334407 & 688340 & 5.05 & 4.5914 & TRN & \\
\hline CHEMBL1427447 & 688340 & 4.45 & 4.8243 & TRN & \\
\hline CHEMBL1310407 & 688340 & 4.7 & 4.7909 & TST & \\
\hline CHEMBL1607424 & 688340 & 4.2 & 5.4607 & TRN & \\
\hline CHEMBL1437477 & 688340 & 4.65 & 4.8977 & TRN & \\
\hline CHEMBL1587496 & 688340 & 4.6 & 4.8454 & TRN & \\
\hline
\end{tabular}




\begin{tabular}{|c|c|c|c|c|c|}
\hline \multicolumn{6}{|c|}{ Supplemental Table s2.txt } \\
\hline CHEMBL3191730 & 688340 & 5.05 & 5.1198 & TRN & \\
\hline CHEMBL1459869 & 688340 & 4.4 & 5.1791 & TRN & \\
\hline CHEMBL1573697 & 688340 & 4.5 & 4.9065 & TRN & \\
\hline CHEMBL1978354 & 688340 & 4.9 & 4.9703 & TRN & \\
\hline CHEMBL1304574 & 688340 & 5.2 & 5.1017 & TRN & \\
\hline CHEMBL1608253 & 688340 & 6.1 & 5.1375 & TRN & \\
\hline CHEMBL1613476 & 688340 & 6.0 & 5.0933 & TST & \\
\hline CHEMBL1454269 & 688340 & 4.8 & 4.6967 & TRN & \\
\hline CHEMBL1551847 & 688340 & 7.15 & 5.3557 & TST & \\
\hline CHEMBL1434491 & 688340 & 4.5 & 4.869 & TST & \\
\hline CHEMBL1543689 & 688340 & 4.65 & 4.5883 & TRN & \\
\hline CHEMBL1302868 & 688340 & 4.55 & 5.0616 & TRN & \\
\hline CHEMBL1472524 & 688340 & 4.65 & 4.8523 & TRN & \\
\hline CHEMBL1500933 & 688340 & 5.15 & 4.97 & TST & \\
\hline CHEMBL1431091 & 688340 & 4.55 & 4.7815 & TRN & \\
\hline CHEMBL1331729 & 688340 & 5.2 & 5.025 & TRN & \\
\hline CHEMBL1497660 & 688340 & 4.5 & 5.003 & TRN & \\
\hline CHEMBL1323027 & 688340 & 4.65 & 4.865 & TRN & \\
\hline CHEMBL1417287 & 688340 & 4.6 & 4.9044 & TRN & \\
\hline CHEMBL1982032 & 688340 & 4.5 & 4.7304 & TST & \\
\hline CHEMBL1498949 & 688340 & 3.45 & 5.0797 & TRN & \\
\hline CHEMBL1379606 & 688340 & 4.55 & 4.82100 & 0000000001 & TRN \\
\hline CHEMBL1998967 & 688340 & 4.75 & 5.1017 & TRN & \\
\hline CHEMBL1326644 & 688340 & 5.0 & 5.1184 & TRN & \\
\hline CHEMBL1484014 & 688340 & 4.5 & 4.7916 & TRN & \\
\hline CHEMBL1337583 & 688340 & 4.35 & 4.6938 & TRN & \\
\hline CHEMBL1584595 & 688340 & 4.55 & 4.9739 & TRN & \\
\hline CHEMBL3212127 & 688340 & 4.65 & 4.7592 & TRN & \\
\hline CHEMBL1368226 & 688340 & 5.8 & 5.0616 & TST & \\
\hline CHEMBL1470016 & 688340 & 4.75 & 5.0982 & TST & \\
\hline CHEMBL1413764 & 688340 & 4.4 & 5.0507 & TRN & \\
\hline CHEMBL1440196 & 688340 & 4.7 & 4.897 & TRN & \\
\hline CHEMBL1361231 & 688340 & 7.6003 & 5.1514 & TST & \\
\hline CHEMBL1394361 & 688340 & 4.85 & 4.9452 & TRN & \\
\hline CHEMBL3197308 & 688340 & 4.6 & 4.8524 & TRN & \\
\hline CHEMBL1384216 & 688340 & 4.5 & 4.6312 & TRN & \\
\hline CHEMBL1538815 & 688340 & 4.4 & 5.02800 & 00000000005 & TST \\
\hline CHEMBL1416774 & 688340 & 5.2 & 5.3668 & TST & \\
\hline CHEMBL1994838 & 688340 & 5.25 & 5.1435 & TRN & \\
\hline CHEMBL1361455 & 688340 & 5.65 & 4.865 & TRN & \\
\hline CHEMBL1345482 & 688340 & 4.55 & 5.1419 & TST & \\
\hline CHEMBL1531551 & 688340 & 6.15 & 5.34200 & 20000000005 & TRN \\
\hline CHEMBL3199587 & 688340 & 6.1 & 4.9648 & TST & \\
\hline CHEMBL1429386 & 688340 & 5.8 & 5.1593 & TRN & \\
\hline CHEMBL1323786 & 688340 & 4.55 & 5.1249 & TST & \\
\hline CHEMBL1602732 & 688340 & 6.1 & 5.32100 & 0000000001 & TRN \\
\hline CHEMBL1611907 & 688340 & 4.55 & 4.4033 & TRN & \\
\hline CHEMBL1544178 & 688340 & 4.4 & 4.9903 & TST & \\
\hline
\end{tabular}




\begin{tabular}{|c|c|c|c|c|c|}
\hline \multicolumn{6}{|c|}{ Supplemental Table S2.txt } \\
\hline CHEMBL3192511 & 688340 & 4.4 & 4.8667 & TRN & \\
\hline CHEMBL1391424 & 688340 & 4.5 & 4.8832 & TRN & \\
\hline CHEMBL3191825 & 688340 & 5.35 & 4.8923 & TST & \\
\hline CHEMBL1321098 & 688340 & 5.3 & 4.9603 & TST & \\
\hline CHEMBL1395843 & 688340 & 4.4 & 4.6804 & TRN & \\
\hline CHEMBL1366770 & 688340 & 4.5 & 4.9517 & TRN & \\
\hline CHEMBL1712181 & 688340 & 5.45 & 4.8707 & TST & \\
\hline CHEMBL1309157 & 688340 & 4.5 & 4.8789 & TRN & \\
\hline CHEMBL3192400 & 688340 & 6.1 & $4.9910 e$ & 00000000005 & TRN \\
\hline CHEMBL1412765 & 688340 & 6.8 & $5.1560 e$ & 0000000001 & TRN \\
\hline CHEMBL1547122 & 688340 & 6.9 & 4.9925 & TST & \\
\hline CHEMBL1501353 & 688340 & 4.45 & 5.2252 & TRN & \\
\hline CHEMBL1608662 & 688340 & 4.65 & 4.6481 & TRN & \\
\hline CHEMBL 3207720 & 688340 & 4.45 & 4.9058 & TST & \\
\hline CHEMBL1413442 & 688340 & 7.0 & 5.4552 & TRN & \\
\hline CHEMBL1451016 & 688340 & 4.7 & $5.3370 e$ & 0000000001 & TRN \\
\hline CHEMBL1447861 & 688340 & 7.0501 & 5.1321 & TRN & \\
\hline CHEMBL1304979 & 688340 & 5.35 & 4.8869 & TRN & \\
\hline CHEMBL1507261 & 688340 & 4.5 & 4.7692 & TRN & \\
\hline CHEMBL1523513 & 688340 & 4.4 & 4.9588 & TRN & \\
\hline CHEMBL1361080 & 688340 & 4.6 & 4.9349 & TRN & \\
\hline CHEMBL3213265 & 688340 & 4.45 & 4.9193 & TRN & \\
\hline CHEMBL1504587 & 688340 & 6.35 & 5.1931 & TRN & \\
\hline CHEMBL1572059 & 688340 & 4.55 & 5.1649 & TRN & \\
\hline CHEMBL1602697 & 688340 & 5.1 & 4.7201 & TST & \\
\hline CHEMBL1535715 & 688340 & 5.25 & 5.3486 & TRN & \\
\hline CHEMBL1464162 & 688340 & 6.1 & 5.2356 & TST & \\
\hline CHEMBL1602182 & 688340 & 4.4 & 4.981 & TST & \\
\hline CHEMBL1379897 & 688340 & 4.5 & 4.7555 & TRN & \\
\hline CHEMBL1491561 & 688340 & 4.5 & 5.2212 & TRN & \\
\hline CHEMBL1502283 & 688340 & 6.5 & 5.0664 & TRN & \\
\hline CHEMBL1361295 & 688340 & 5.6 & 5.2581 & TST & \\
\hline CHEMBL3191089 & 688340 & 5.1 & 4.8018 & TRN & \\
\hline CHEMBL1350577 & 688340 & 5.2 & 5.4883 & TST & \\
\hline CHEMBL1421846 & 688340 & 6.0 & 4.8064 & TRN & \\
\hline CHEMBL1329208 & 688340 & 5.15 & 5.7242 & TRN & \\
\hline CHEMBL1527767 & 688340 & 7.0 & 5.4047 & TST & \\
\hline CHEMBL1482593 & 688340 & 6.15 & 4.8364 & TRN & \\
\hline CHEMBL1305178 & 688340 & 4.35 & 5.4794 & TST & \\
\hline CHEMBL1537631 & 688340 & 6.7001 & 5.001 & TST & \\
\hline CHEMBL1506088 & 688340 & 4.55 & 4.5609 & TST & \\
\hline CHEMBL1443559 & 688340 & 4.65 & 4.5814 & TST & \\
\hline CHEMBL1410519 & 688340 & 5.15 & 4.9557 & TRN & \\
\hline CHEMBL1424762 & 688340 & 5.45 & 4.9973 & TST & \\
\hline CHEMBL1602745 & 688340 & 4.6 & 4.83899 & 99999999995 & TRN \\
\hline CHEMBL3208102 & 688340 & 6.05 & 5.2428 & TRN & \\
\hline CHEMBL1364184 & 688340 & 5.3 & 4.8962 & TST & \\
\hline CHEMBL1340228 & 688340 & 4.95 & 4.893 & TRN & \\
\hline
\end{tabular}




\begin{tabular}{|c|c|c|c|c|}
\hline \multicolumn{5}{|c|}{ Supplemental Table S2.txt } \\
\hline CHEMBL1421519 & 688340 & 6.9 & 5.1995 & TRN \\
\hline CHEMBL1463825 & 688340 & 5.2 & 5.0511 & TST \\
\hline CHEMBL1515422 & 688340 & 4.55 & 4.7456 & TRN \\
\hline CHEMBL1486016 & 688340 & 4.85 & 4.8171 & TRN \\
\hline CHEMBL1448898 & 688340 & 5.85 & 5.0985 & TRN \\
\hline CHEMBL1564401 & 688340 & 4.55 & 4.8048 & TRN \\
\hline CHEMBL1367216 & 688340 & 5.3 & 5.2129 & TRN \\
\hline CHEMBL1352717 & 688340 & 4.6 & 4.5593 & TRN \\
\hline CHEMBL1603215 & 688340 & 6.15 & 5.575 & TRN \\
\hline CHEMBL1324256 & 688340 & 6.1 & 4.8842 & TST \\
\hline CHEMBL1373013 & 688340 & 5.0 & 5.2307 & TRN \\
\hline CHEMBL1524323 & 688340 & 4.5 & 4.8422 & TRN \\
\hline CHEMBL1384502 & 688340 & 4.4 & 5.0428 & TRN \\
\hline CHEMBL1600821 & 688340 & 4.65 & 5.0856 & TST \\
\hline CHEMBL1610239 & 688340 & 6.95 & 5.0683 & TRN \\
\hline CHEMBL1519067 & 688340 & 6.95 & 5.0908 & TRN \\
\hline CHEMBL1299668 & 688340 & 4.6 & 4.9975 & TRN \\
\hline CHEMBL1389338 & 688340 & 4.65 & 5.1116 & TRN \\
\hline CHEMBL1524927 & 688340 & 4.45 & 4.8842 & TRN \\
\hline CHEMBL3189712 & 688340 & 4.55 & 4.8147 & TST \\
\hline CHEMBL1571808 & 688340 & 4.45 & 4.9768 & TRN \\
\hline CHEMBL1603637 & 688340 & 4.4 & 4.6053 & TST \\
\hline CHEMBL1344643 & 688340 & 5.35 & 5.0601 & TRN \\
\hline CHEMBL1521366 & 688340 & 6.95 & 5.0431 & TRN \\
\hline CHEMBL1342351 & 688340 & 6.95 & 4.6309 & TST \\
\hline CHEMBL3210497 & 688340 & 5.1 & 5.0821 & TST \\
\hline CHEMBL1529774 & 688340 & 4.9 & 5.0271 & TRN \\
\hline CHEMBL1453410 & 688340 & 5.25 & 4.8345 & TRN \\
\hline CHEMBL498373 & 688340 & 4.55 & 5.3114 & TRN \\
\hline CHEMBL1337991 & 688340 & 5.95 & 4.8173 & TST \\
\hline CHEMBL1317564 & 688340 & 4.65 & 4.8265 & TRN \\
\hline CHEMBL1453532 & 688340 & 5.65 & 5.2958 & TRN \\
\hline CHEMBL1389827 & 688340 & 4.6 & 5.2305 & TRN \\
\hline CHEMBL1332004 & 688340 & 5.7 & 5.3146 & TRN \\
\hline CHEMBL1322220 & 688340 & 4.55 & 4.4118 & TRN \\
\hline CHEMBL1320458 & 688340 & 7.0 & 5.2148 & TRN \\
\hline CHEMBL1521262 & 688340 & 4.4 & 4.7884 & TRN \\
\hline CHEMBL1485901 & 688340 & 4.35 & 4.9916 & TRN \\
\hline CHEMBL1501307 & 688340 & 5.05 & 5.1016 & TST \\
\hline CHEMBL1405165 & 688340 & 6.25 & 5.1787 & TRN \\
\hline CHEMBL3187596 & 688340 & 5.2 & 4.915 & TRN \\
\hline CHEMBL1543504 & 688340 & 4.9 & 5.0969 & TST \\
\hline CHEMBL133576 & 688340 & 4.8 & 4.8014 & TST \\
\hline CHEMBL1487025 & 688340 & 4.4 & 5.2543 & TRN \\
\hline CHEMBL547101 & 688340 & 5.3 & 5.1861 & TST \\
\hline CHEMBL1499839 & 688340 & 4.4 & 4.8407 & TRN \\
\hline CHEMBL1397463 & 688340 & 6.0 & 4.9677 & TRN \\
\hline CHEMBL1608266 & 688340 & 5.05 & 4.7957 & TRN \\
\hline
\end{tabular}




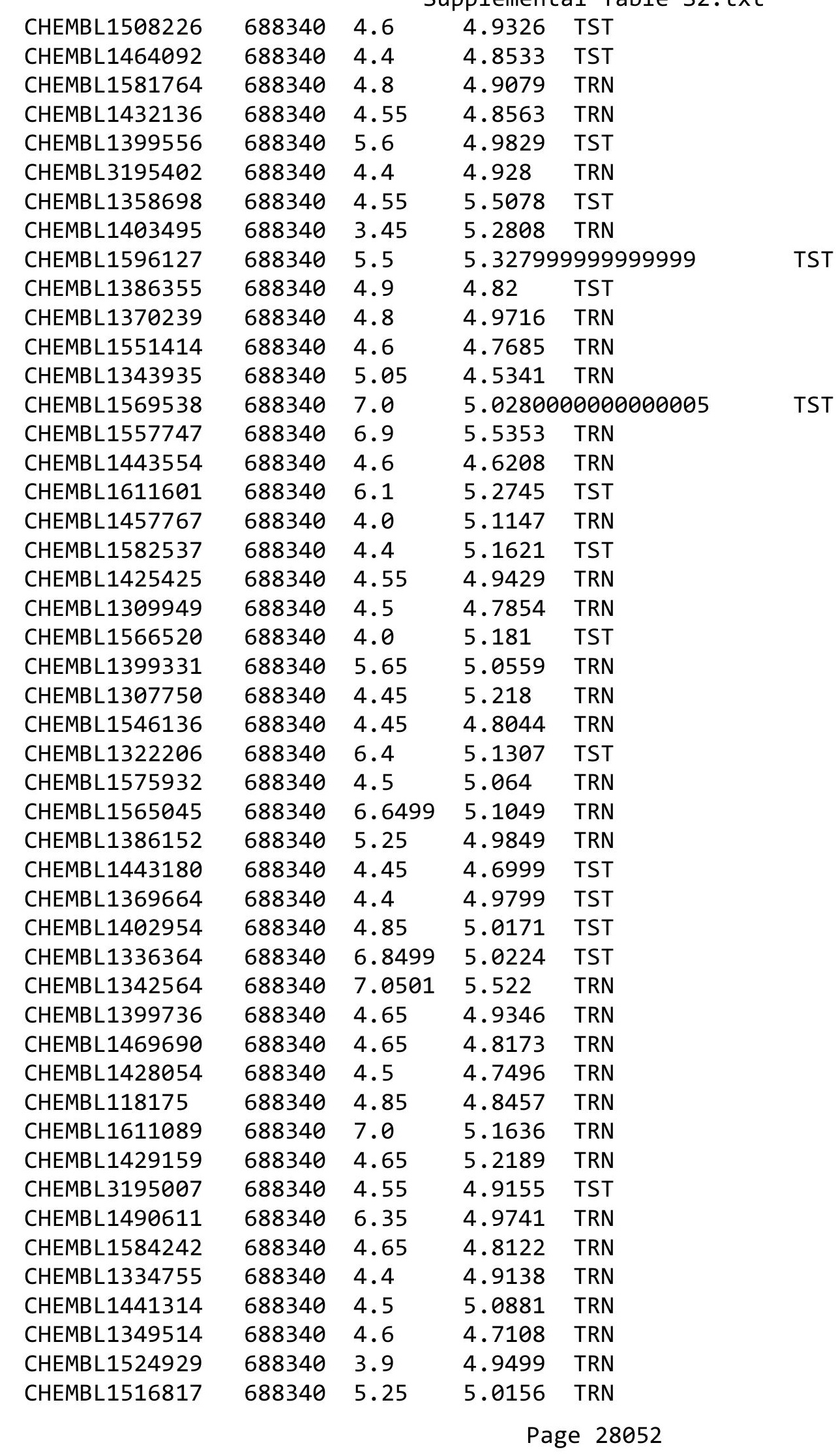




\begin{tabular}{|c|c|c|c|c|c|}
\hline \\
\hline CHEMBL1433049 & 688340 & 4.5 & 4.7967 & TRN & \\
\hline CHEMBL1484314 & 688340 & 4.95 & 5.0572 & TST & \\
\hline CHEMBL1467690 & 688340 & 4.55 & 5.0118 & TRN & \\
\hline CHEMBL601952 & 688340 & 4.75 & 4.8468 & TRN & \\
\hline CHEMBL1405750 & 688340 & 4.5 & 4.8225 & TRN & \\
\hline CHEMBL1586426 & 688340 & 5.15 & 5.4324 & TRN & \\
\hline CHEMBL1434892 & 688340 & 4.45 & 5.5356 & TRN & \\
\hline CHEMBL1326845 & 688340 & 5.2 & 5.1378 & TST & \\
\hline CHEMBL1562661 & 688340 & 5.15 & 5.4633 & TRN & \\
\hline CHEMBL1338325 & 688340 & 4.55 & 5.1046 & TRN & \\
\hline CHEMBL1475965 & 688340 & 7.0 & 5.0355 & TRN & \\
\hline CHEMBL3144972 & 688340 & 5.1 & 5.2355 & TRN & \\
\hline CHEMBL1489645 & 688340 & 4.55 & 4.7046 & TRN & \\
\hline CHEMBL1398645 & 688340 & 4.55 & 4.6574 & TST & \\
\hline CHEMBL1468981 & 688340 & 5.1 & $5.1110 e$ & 0000000001 & TRN \\
\hline CHEMBL1503625 & 688340 & 5.6 & 4.9455 & TRN & \\
\hline CHEMBL1599881 & 688340 & 4.6 & $4.8210 e$ & 0000000001 & TST \\
\hline CHEMBL1390303 & 688340 & 4.35 & 4.913 & TRN & \\
\hline CHEMBL1444250 & 688340 & 4.7 & 4.9577 & TRN & \\
\hline CHEMBL1991710 & 688340 & 4.55 & 4.8452 & TRN & \\
\hline CHEMBL1417848 & 688340 & 4.5 & 4.7909 & TRN & \\
\hline CHEMBL1468796 & 688340 & 5.0 & 5.1132 & TRN & \\
\hline CHEMBL1438582 & 688340 & 4.5 & 5.0543 & TRN & \\
\hline CHEMBL1332130 & 688340 & 5.0 & 4.7521 & TRN & \\
\hline CHEMBL1535280 & 688340 & 5.4 & 5.2869 & TRN & \\
\hline CHEMBL1450669 & 688340 & 4.0 & 4.8445 & TST & \\
\hline CHEMBL1540240 & 688340 & 5.2 & 4.9611 & TRN & \\
\hline CHEMBL1403286 & 688340 & 5.0 & 5.1239 & TRN & \\
\hline CHEMBL1383622 & 688340 & 4.75 & 4.5677 & TRN & \\
\hline CHEMBL1456251 & 688340 & 5.05 & 5.0553 & TRN & \\
\hline CHEMBL1530786 & 688340 & 4.7 & 4.84699 & 99999999995 & TRN \\
\hline CHEMBL1393159 & 688340 & 5.4 & 5.005 & TRN & \\
\hline CHEMBL1416224 & 688340 & 6.4 & 5.2592 & TST & \\
\hline CHEMBL1350240 & 688340 & 4.5 & 4.7069 & TRN & \\
\hline CHEMBL1504321 & 688340 & 6.95 & 5.5202 & TRN & \\
\hline CHEMBL1465240 & 688340 & 4.4 & 4.6651 & TRN & \\
\hline CHEMBL3196671 & 688340 & 4.6 & 5.0958 & TRN & \\
\hline CHEMBL1434555 & 688340 & 5.4 & 5.1971 & TRN & \\
\hline CHEMBL1512349 & 688340 & 6.15 & 5.1228 & TRN & \\
\hline CHEMBL1505552 & 688340 & 4.4 & 4.9271 & TRN & \\
\hline CHEMBL 3145085 & 688340 & 5.05 & 5.005 & TRN & \\
\hline CHEMBL1378305 & 688340 & 6.0 & 5.3691 & TRN & \\
\hline CHEMBL1398290 & 688340 & 4.6 & 4.7988 & TRN & \\
\hline CHEMBL1554731 & 688340 & 4.5 & 4.8021 & TRN & \\
\hline CHEMBL1396987 & 688340 & 4.55 & 5.2485 & TRN & \\
\hline CHEMBL1389226 & 688340 & 4.4 & 5.0076 & TRN & \\
\hline CHEMBL1505041 & 688340 & 3.95 & 4.5531 & TRN & \\
\hline CHEMBL1580363 & 688340 & 5.3 & 5.2067 & TST & \\
\hline
\end{tabular}




\begin{tabular}{|c|c|c|c|c|}
\hline & & & pplemen & al $\mathrm{T}$ \\
\hline CHEMBL1541306 & 688340 & 5.2 & 5.1597 & TRN \\
\hline CHEMBL3189877 & 688340 & 4.5 & 4.7507 & TRN \\
\hline CHEMBL1412478 & 688340 & 4.65 & 5.0908 & TRN \\
\hline CHEMBL1405353 & 688340 & 4.55 & 4.8772 & TRN \\
\hline CHEMBL1612531 & 688340 & 4.5 & 5.1838 & TRN \\
\hline CHEMBL1500807 & 688340 & 4.35 & 5.1135 & TST \\
\hline CHEMBL1352624 & 688340 & 4.85 & 4.6654 & TRN \\
\hline CHEMBL514612 & 688340 & 4.65 & 4.6589 & TRN \\
\hline CHEMBL1596594 & 688340 & 5.9 & 4.6316 & TRN \\
\hline CHEMBL1443497 & 688340 & 5.1 & 4.8829 & TRN \\
\hline CHEMBL1608924 & 688340 & 5.1 & 5.0056 & TST \\
\hline CHEMBL3212055 & 688340 & 6.95 & 5.1981 & TRN \\
\hline CHEMBL1319774 & 688340 & 5.35 & 5.1445 & TRN \\
\hline CHEMBL1345754 & 688340 & 5.1 & 4.7226 & TRN \\
\hline CHEMBL1447082 & 688340 & 6.5 & 5.0687 & TRN \\
\hline CHEMBL1558301 & 688340 & 4.4 & 4.809 & TRN \\
\hline CHEMBL1570159 & 688340 & 6.05 & 5.0807 & TST \\
\hline CHEMBL1546183 & 688340 & 4.6 & 4.7822 & TRN \\
\hline CHEMBL1513205 & 688340 & 5.15 & 4.6097 & TRN \\
\hline CHEMBL1329406 & 688340 & 5.1 & 5.1736 & TRN \\
\hline CHEMBL3209691 & 688340 & 4.5 & 5.2371 & TRN \\
\hline CHEMBL1553644 & 688340 & 4.6 & 5.1805 & TRN \\
\hline CHEMBL1415923 & 688340 & 4.55 & 5.5836 & TST \\
\hline CHEMBL1388048 & 688340 & 6.5501 & 4.9449 & TRN \\
\hline CHEMBL585628 & 688340 & 5.45 & 4.8045 & TRN \\
\hline CHEMBL1530571 & 688340 & 4.65 & 4.9598 & TRN \\
\hline CHEMBL1320301 & 688340 & 7.0 & 5.0462 & TST \\
\hline CHEMBL1466218 & 688340 & 5.0 & 5.0869 & TST \\
\hline CHEMBL1305248 & 688340 & 4.4 & 4.8416 & TRN \\
\hline CHEMBL1349942 & 688340 & 4.75 & 5.1989 & TRN \\
\hline CHEMBL1354971 & 688340 & 7.0 & 5.1851 & TRN \\
\hline CHEMBL1577766 & 688340 & 4.65 & 5.0973 & TRN \\
\hline CHEMBL1427339 & 688340 & 4.95 & 5.0085 & TRN \\
\hline CHEMBL1532181 & 688340 & 5.15 & 4.8442 & TRN \\
\hline CHEMBL1598833 & 688340 & 4.45 & 4.6935 & TST \\
\hline CHEMBL1321900 & 688340 & 4.45 & 5.0238 & TST \\
\hline CHEMBL1502148 & 688340 & 5.2 & 5.1246 & TRN \\
\hline CHEMBL1412159 & 688340 & 4.3 & 4.9359 & TRN \\
\hline CHEMBL1445831 & 688340 & 4.95 & 5.1377 & TRN \\
\hline CHEMBL1302217 & 688340 & 4.5 & 4.9695 & TRN \\
\hline CHEMBL1528570 & 688340 & 5.1 & 4.8787 & TRN \\
\hline CHEMBL1386656 & 688340 & 4.75 & 4.8751 & TRN \\
\hline CHEMBL1475073 & 688340 & 4.4 & 5.2344 & TRN \\
\hline CHEMBL1518026 & 688340 & 4.6 & 4.8739 & TRN \\
\hline CHEMBL1494857 & 688340 & 5.2 & 5.2838 & TRN \\
\hline CHEMBL1369410 & 688340 & 4.6 & 4.7557 & TRN \\
\hline CHEMBL1307247 & 688340 & 4.55 & 5.1157 & TRN \\
\hline CHEMBL1431996 & 688340 & 4.5 & 4.6715 & TRN \\
\hline
\end{tabular}




\begin{tabular}{|c|c|c|c|c|c|}
\hline \\
\hline CHEMBL1517909 & 688340 & 4.7 & 4.8569 & TRN & \\
\hline CHEMBL1721986 & 688340 & 4.95 & 4.9287 & TRN & \\
\hline CHEMBL1521410 & 688340 & 4.4 & 4.7841 & TST & \\
\hline CHEMBL1609381 & 688340 & 4.35 & 4.9428 & TRN & \\
\hline CHEMBL1369499 & 688340 & 4.4 & 5.2036 & TRN & \\
\hline CHEMBL3210158 & 688340 & 4.0 & 5.3427 & TRN & \\
\hline CHEMBL1454393 & 688340 & 4.4 & 4.9503 & TRN & \\
\hline CHEMBL1338973 & 688340 & 4.7 & 5.1447 & TRN & \\
\hline CHEMBL3212478 & 688340 & 4.5 & 4.8118 & TRN & \\
\hline CHEMBL1407524 & 688340 & 4.65 & 5.1339 & TRN & \\
\hline CHEMBL1498783 & 688340 & 4.65 & 5.1102 & TST & \\
\hline CHEMBL1411470 & 688340 & 4.85 & 5.3528 & TST & \\
\hline CHEMBL1418488 & 688340 & 4.55 & 5.1783 & TST & \\
\hline CHEMBL1542301 & 688340 & 4.7 & 4.90300 & 00000000005 & TRN \\
\hline CHEMBL1496719 & 688340 & 5.4 & 4.809 & TST & \\
\hline CHEMBL1515138 & 688340 & 4.55 & 5.3274 & TRN & \\
\hline CHEMBL1384834 & 688340 & 6.2 & 5.0401 & TRN & \\
\hline CHEMBL1415513 & 688340 & 4.5 & 4.868 & TRN & \\
\hline CHEMBL1470721 & 688340 & 4.85 & 4.7732 & TST & \\
\hline CHEMBL400144 & 688340 & 4.6 & 4.8776 & TRN & \\
\hline CHEMBL3190473 & 688340 & 4.45 & 4.9897 & TST & \\
\hline CHEMBL1441677 & 688340 & 4.5 & 4.9996 & TST & \\
\hline CHEMBL1314077 & 688340 & 4.5 & 4.723 & TRN & \\
\hline CHEMBL1497543 & 688340 & 7.4498 & 4.7064 & TST & \\
\hline CHEMBL1598188 & 688340 & 4.4 & 5.3134 & TST & \\
\hline CHEMBL1372136 & 688340 & 4.8 & 4.7096 & TRN & \\
\hline CHEMBL1402586 & 688340 & 4.5 & 4.9616 & TST & \\
\hline CHEMBL1531835 & 688340 & 4.45 & 4.6728 & TRN & \\
\hline CHEMBL1504776 & 688340 & 4.55 & 5.1419 & TRN & \\
\hline CHEMBL1429637 & 688340 & 6.15 & 4.8139 & TRN & \\
\hline CHEMBL1567221 & 688340 & 4.85 & 5.1601 & TRN & \\
\hline CHEMBL1583292 & 688340 & 4.5 & 4.9129 & TRN & \\
\hline CHEMBL1595943 & 688340 & 5.05 & 4.8721 & TRN & \\
\hline CHEMBL1506756 & 688340 & 4.55 & 4.6559 & TRN & \\
\hline CHEMBL1417216 & 688340 & 4.9 & 5.1339 & TRN & \\
\hline CHEMBL1468211 & 688340 & 5.05 & 5.278 & TST & \\
\hline CHEMBL1441312 & 688340 & 4.6 & 5.1095 & TST & \\
\hline CHEMBL1516829 & 688340 & 4.55 & 4.8606 & TST & \\
\hline CHEMBL1343476 & 688340 & 7.6498 & 4.9951 & TRN & \\
\hline CHEMBL1493478 & 688340 & 4.55 & 4.8146 & TRN & \\
\hline CHEMBL1388295 & 688340 & 4.5 & 4.8628 & TRN & \\
\hline CHEMBL1369875 & 688340 & 4.4 & 5.1207 & TRN & \\
\hline CHEMBL1604142 & 688340 & 4.4 & 4.706 & TRN & \\
\hline CHEMBL1326671 & 688340 & 7.0501 & 5.1917 & TST & \\
\hline CHEMBL1576594 & 688340 & 4.6 & 4.9062 & TRN & \\
\hline CHEMBL1556919 & 688340 & 5.5 & 5.3957 & TRN & \\
\hline CHEMBL1400907 & 688340 & 4.85 & 4.865 & TRN & \\
\hline CHEMBL1408300 & 688340 & 4.65 & 4.9197 & TRN & \\
\hline
\end{tabular}




\begin{tabular}{|c|c|c|c|c|}
\hline \multicolumn{5}{|c|}{ Supplemental Table S2.txt } \\
\hline CHEMBL1300312 & 688340 & 4.55 & 4.9725 & TRN \\
\hline CHEMBL3207328 & 688340 & 6.0 & 4.9751 & TRN \\
\hline CHEMBL1475691 & 688340 & 5.15 & 5.1565 & TST \\
\hline CHEMBL1593333 & 688340 & 4.85 & 4.8699 & TRN \\
\hline CHEMBL1346637 & 688340 & 4.55 & 4.9508 & TST \\
\hline CHEMBL1582767 & 688340 & 4.45 & 5.1909 & TRN \\
\hline CHEMBL1492423 & 688340 & 5.05 & 5.1606 & TST \\
\hline CHEMBL1566541 & 688340 & 7.0 & 5.2704 & TRN \\
\hline CHEMBL1308735 & 688340 & 6.95 & 5.0817 & TST \\
\hline CHEMBL1414370 & 688340 & 4.75 & 5.0326 & TRN \\
\hline CHEMBL3199030 & 688340 & 4.45 & 4.9194 & TST \\
\hline CHEMBL1448249 & 688340 & 5.2 & 4.966 & TRN \\
\hline CHEMBL1486258 & 688340 & 4.4 & 4.7236 & TRN \\
\hline CHEMBL1407057 & 688340 & 5.55 & 5.1173 & TST \\
\hline CHEMBL1318214 & 688340 & 5.9 & 5.0283 & TRN \\
\hline CHEMBL1453942 & 688340 & 4.55 & 4.6276 & TRN \\
\hline CHEMBL1389841 & 688340 & 4.6 & 5.0699 & TRN \\
\hline CHEMBL1326280 & 688340 & 6.4 & 5.1266 & TRN \\
\hline CHEMBL1461084 & 688340 & 5.0 & 4.9349 & TST \\
\hline CHEMBL1513962 & 688340 & 4.5 & 5.0762 & TRN \\
\hline CHEMBL1301947 & 688340 & 4.5 & 5.1589 & TRN \\
\hline CHEMBL1445465 & 688340 & 5.1 & 5.1098 & TRN \\
\hline CHEMBL1367938 & 688340 & 4.5 & 5.0002 & TRN \\
\hline CHEMBL1341267 & 688340 & 4.6 & 4.8894 & TRN \\
\hline CHEMBL1340894 & 688340 & 5.2 & 5.0615 & TST \\
\hline CHEMBL1578567 & 688340 & 7.0 & 5.4147 & TST \\
\hline CHEMBL1494077 & 688340 & 4.0 & 5.0042 & TRN \\
\hline CHEMBL1482177 & 688340 & 4.6 & 4.8955 & TRN \\
\hline CHEMBL1471353 & 688340 & 4.6 & 4.6989 & TRN \\
\hline CHEMBL1333164 & 688340 & 6.5 & 5.2381 & TRN \\
\hline CHEMBL1574857 & 688340 & 6.15 & 4.962 & TRN \\
\hline CHEMBL3209959 & 688340 & 6.1 & 5.098 & TRN \\
\hline CHEMBL1360673 & 688340 & 5.25 & 5.2178 & TST \\
\hline CHEMBL1510455 & 688340 & 4.65 & 5.0599 & TRN \\
\hline CHEMBL3192970 & 688340 & 4.55 & 4.7851 & TST \\
\hline CHEMBL1305529 & 688340 & 5.5 & 5.2606 & TRN \\
\hline CHEMBL1532690 & 688340 & 4.0 & 5.0071 & TST \\
\hline CHEMBL1367140 & 688340 & 7.8996 & 5.3389 & TST \\
\hline CHEMBL1564801 & 688340 & 5.2 & 4.7808 & TST \\
\hline CHEMBL1439149 & 688340 & 4.7 & 4.9217 & TST \\
\hline CHEMBL1490818 & 688340 & 5.1 & 4.8986 & TRN \\
\hline CHEMBL1976677 & 688340 & 4.5 & 4.8354 & TRN \\
\hline CHEMBL1565888 & 688340 & 5.0 & 5.3038 & TRN \\
\hline CHEMBL1336564 & 688340 & 4.45 & 5.1182 & TRN \\
\hline CHEMBL1416301 & 688340 & 4.45 & 4.8717 & TRN \\
\hline CHEMBL1397979 & 688340 & 4.5 & 5.7768 & TRN \\
\hline CHEMBL449392 & 688340 & 7.0 & 5.0048 & TST \\
\hline CHEMBL1422573 & 688340 & 4.55 & 4.6337 & TRN \\
\hline
\end{tabular}




\begin{tabular}{|c|c|c|c|c|c|}
\hline & & \multicolumn{4}{|c|}{ Supplemental Table s2.txt } \\
\hline CHEMBL1565759 & 688340 & 5.55 & 5.6948 & TRN & \\
\hline CHEMBL1423220 & 688340 & 4.5 & 5.1755 & TRN & \\
\hline CHEMBL1556497 & 688340 & 7.0 & 5.2361 & TRN & \\
\hline CHEMBL1538099 & 688340 & 4.8 & 4.8175 & TST & \\
\hline CHEMBL574954 & 688340 & 5.1 & 5.0755 & TRN & \\
\hline CHEMBL1551566 & 688340 & 4.4 & 5.2876 & TRN & \\
\hline CHEMBL1460721 & 688340 & 4.85 & 4.9636 & TRN & \\
\hline CHEMBL1530097 & 688340 & 5.05 & 4.9233 & TST & \\
\hline CHEMBL1551097 & 688340 & 7.0 & 5.1903 & TRN & \\
\hline CHEMBL1501935 & 688340 & 4.55 & 5.1537 & TRN & \\
\hline CHEMBL1514157 & 688340 & 5.0 & 4.6976 & TRN & \\
\hline CHEMBL3192924 & 688340 & 4.85 & 5.0616 & TRN & \\
\hline CHEMBL1540040 & 688340 & 4.55 & 4.8412 & TST & \\
\hline CHEMBL1443506 & 688340 & 4.4 & 4.9174 & TST & \\
\hline CHEMBL1590690 & 688340 & 4.5 & 5.037 & TRN & \\
\hline CHEMBL1345598 & 688340 & 4.6 & 4.7432 & TST & \\
\hline CHEMBL1368326 & 688340 & 4.8 & 4.8107 & TRN & \\
\hline CHEMBL1404673 & 688340 & 4.65 & 4.9166 & TRN & \\
\hline CHEMBL1313900 & 688340 & 6.1 & 4.8484 & TST & \\
\hline CHEMBL1442312 & 688340 & 4.5 & 5.0131 & TRN & \\
\hline CHEMBL1438115 & 688340 & 4.5 & 4.9085 & TRN & \\
\hline CHEMBL1566704 & 688340 & 4.5 & 4.9811 & TRN & \\
\hline CHEMBL1401847 & 688340 & 4.4 & 4.9835 & TST & \\
\hline CHEMBL1523038 & 688340 & 5.35 & 4.6743 & TRN & \\
\hline CHEMBL 212414 & 688340 & 5.0 & 5.1914 & TRN & \\
\hline CHEMBL1576300 & 688340 & 5.2 & 5.0272 & TRN & \\
\hline CHEMBL1498431 & 688340 & 4.4 & 4.8811 & TRN & \\
\hline CHEMBL1610555 & 688340 & 4.4 & 5.1304 & TRN & \\
\hline CHEMBL 3190268 & 688340 & 6.15 & 4.99100 & 00000000005 & TRN \\
\hline CHEMBL1538036 & 688340 & 4.4 & 4.7785 & TRN & \\
\hline CHEMBL1473093 & 688340 & 4.6 & 4.8981 & TRN & \\
\hline CHEMBL1592328 & 688340 & 5.75 & 5.1113 & TST & \\
\hline CHEMBL1408654 & 688340 & 4.4 & 4.8248 & TRN & \\
\hline CHEMBL1486139 & 688340 & 5.25 & 4.9295 & TRN & \\
\hline CHEMBL1549772 & 688340 & 5.15 & 5.5082 & TRN & \\
\hline CHEMBL1382710 & 688340 & 5.95 & 5.2948 & TST & \\
\hline CHEMBL1536945 & 688340 & 4.4 & 4.7448 & TRN & \\
\hline CHEMBL81782 & 688340 & 4.55 & 4.5031 & TRN & \\
\hline CHEMBL1992631 & 688340 & 4.55 & 5.0247 & TRN & \\
\hline CHEMBL1571050 & 688340 & 5.3 & 5.1159 & TST & \\
\hline CHEMBL1603442 & 688340 & 4.75 & 5.1999 & TRN & \\
\hline CHEMBL1309448 & 688340 & 4.55 & 4.791 & TRN & \\
\hline CHEMBL1533140 & 688340 & 4.4 & 5.2202 & TRN & \\
\hline CHEMBL1388376 & 688340 & 5.15 & 5.1005 & TST & \\
\hline CHEMBL1554012 & 688340 & 4.4 & 4.9787 & TRN & \\
\hline CHEMBL1530877 & 688340 & 6.0 & 5.2541 & TRN & \\
\hline CHEMBL1270169 & 688340 & 4.55 & 4.8256 & TRN & \\
\hline CHEMBL1345360 & 688340 & 4.6 & 4.8195 & TRN & \\
\hline
\end{tabular}




\begin{tabular}{|c|c|c|c|c|}
\hline & & & pplement & al Ta \\
\hline CHEMBL1460499 & 688340 & 5.25 & 5.0823 & TST \\
\hline CHEMBL1379816 & 688340 & 5.15 & 5.1059 & TST \\
\hline CHEMBL1457650 & 688340 & 3.95 & 5.1933 & TRN \\
\hline CHEMBL1369046 & 688340 & 4.85 & 5.7212 & TST \\
\hline CHEMBL1451402 & 688340 & 4.45 & 5.1948 & TRN \\
\hline CHEMBL1539905 & 688340 & 4.9 & 4.5482 & TRN \\
\hline CHEMBL3145289 & 688340 & 5.4 & 4.9859 & TST \\
\hline CHEMBL1379918 & 688340 & 4.4 & 5.0165 & TRN \\
\hline CHEMBL1589054 & 688340 & 4.4 & 5.2357 & TST \\
\hline CHEMBL3212541 & 688340 & 4.6 & 5.0354 & TRN \\
\hline CHEMBL3199240 & 688340 & 4.65 & 5.0118 & TRN \\
\hline CHEMBL1319089 & 688340 & 4.65 & 5.1246 & TRN \\
\hline CHEMBL1337183 & 688340 & 4.4 & 4.9048 & TRN \\
\hline CHEMBL1383916 & 688340 & 6.15 & 5.2407 & TRN \\
\hline CHEMBL1432135 & 688340 & 4.5 & 4.8835 & TRN \\
\hline CHEMBL1309704 & 688340 & 4.4 & 5.2075 & TRN \\
\hline CHEMBL1501761 & 688340 & 5.3 & 4.968 & TST \\
\hline CHEMBL1518655 & 688340 & 4.8 & 5.0765 & TST \\
\hline CHEMBL1427721 & 688340 & 4.95 & 5.5044 & TRN \\
\hline CHEMBL1302785 & 688340 & 4.4 & 4.6958 & TRN \\
\hline CHEMBL1391414 & 688340 & 4.55 & 5.2564 & TST \\
\hline CHEMBL1522953 & 688340 & 4.75 & 4.9282 & TRN \\
\hline CHEMBL 246655 & 688340 & 4.45 & 4.9224 & TRN \\
\hline CHEMBL1557386 & 688340 & 4.4 & 4.7519 & TRN \\
\hline CHEMBL1310309 & 688340 & 4.6 & 4.8828 & TRN \\
\hline CHEMBL1476805 & 688340 & 6.5 & 5.1317 & TRN \\
\hline CHEMBL1502563 & 688340 & 4.9 & 4.7696 & TRN \\
\hline CHEMBL1552460 & 688340 & 4.0 & 4.9941 & TRN \\
\hline CHEMBL1534470 & 688340 & 5.2 & 4.8047 & TRN \\
\hline CHEMBL3195772 & 688340 & 4.85 & 4.9115 & TRN \\
\hline CHEMBL1417920 & 688340 & 7.0 & 5.1349 & TRN \\
\hline CHEMBL1611608 & 688340 & 5.0 & 5.1832 & TRN \\
\hline CHEMBL1330453 & 688340 & 4.65 & 4.9149 & TRN \\
\hline CHEMBL1302643 & 688340 & 4.7 & 4.9572 & TST \\
\hline CHEMBL1308445 & 688340 & 4.3 & 5.1507 & TST \\
\hline CHEMBL1387880 & 688340 & 5.0 & 5.4172 & TST \\
\hline CHEMBL1569544 & 688340 & 4.4 & 4.8648 & TRN \\
\hline CHEMBL1546364 & 688340 & 6.8499 & 5.4951 & TRN \\
\hline CHEMBL1093246 & 688340 & 5.05 & 5.0371 & TRN \\
\hline CHEMBL1463865 & 688340 & 6.15 & 4.9788 & TST \\
\hline CHEMBL1432713 & 688340 & 5.65 & 5.365 & TST \\
\hline CHEMBL460347 & 688340 & 4.65 & 4.8736 & TST \\
\hline CHEMBL1165270 & 688340 & 4.6 & 5.1754 & TST \\
\hline CHEMBL1606000 & 688340 & 5.65 & 5.3529 & TRN \\
\hline CHEMBL1322434 & 688340 & 4.85 & 5.0723 & TRN \\
\hline CHEMBL1548326 & 688340 & 4.55 & 5.099 & TRN \\
\hline CHEMBL1478490 & 688340 & 4.75 & 4.7201 & TRN \\
\hline CHEMBL1543371 & 688340 & 4.5 & 4.9053 & TRN \\
\hline
\end{tabular}




\begin{tabular}{|c|c|c|c|c|c|}
\hline \\
\hline CHEMBL1415172 & 688340 & 4.9 & 4.9958 & TRN & \\
\hline CHEMBL1573287 & 688340 & 4.95 & 4.5864 & TRN & \\
\hline CHEMBL1536618 & 688340 & 5.25 & 5.3679 & TRN & \\
\hline CHEMBL1408536 & 688340 & 5.05 & 5.1158 & TRN & \\
\hline CHEMBL1392415 & 688340 & 4.35 & 4.8365 & TRN & \\
\hline CHEMBL1360276 & 688340 & 5.25 & 4.9862 & TRN & \\
\hline CHEMBL1610151 & 688340 & 7.0 & 5.2329 & TST & \\
\hline CHEMBL1481671 & 688340 & 4.85 & 5.1355 & TRN & \\
\hline CHEMBL3197879 & 688340 & 4.65 & 4.8446 & TRN & \\
\hline CHEMBL1546267 & 688340 & 6.9 & 5.2503 & TRN & \\
\hline CHEMBL1442730 & 688340 & 4.55 & 4.7327 & TRN & \\
\hline CHEMBL1533772 & 688340 & 4.4 & 4.7297 & TRN & \\
\hline CHEMBL224869 & 688340 & 4.6 & 5.0126 & TST & \\
\hline CHEMBL1344422 & 688340 & 4.55 & 4.7947 & TRN & \\
\hline CHEMBL3194731 & 688340 & 5.05 & 4.9552 & TRN & \\
\hline CHEMBL1312820 & 688340 & 4.85 & 5.3899 & TRN & \\
\hline CHEMBL1377693 & 688340 & 4.35 & 4.9879 & TRN & \\
\hline CHEMBL1303733 & 688340 & 4.65 & 4.672 & TRN & \\
\hline CHEMBL1358216 & 688340 & 4.0 & 4.9887 & TST & \\
\hline CHEMBL1603303 & 688340 & 4.65 & 5.0471 & TRN & \\
\hline CHEMBL1306895 & 688340 & 5.85 & 4.8229 & TRN & \\
\hline CHEMBL1377156 & 688340 & 4.6 & 5.055 & TRN & \\
\hline CHEMBL1596636 & 688340 & 4.35 & $4.4460 e$ & 0000000001 & TRN \\
\hline CHEMBL1364057 & 688340 & 5.35 & 5.0949 & TRN & \\
\hline CHEMBL1532143 & 688340 & 4.6 & 5.1475 & TST & \\
\hline CHEMBL1493432 & 688340 & 4.65 & 4.9746 & TST & \\
\hline CHEMBL1404686 & 688340 & 4.65 & 4.6753 & TRN & \\
\hline CHEMBL1433855 & 688340 & 4.5 & 4.8078 & TRN & \\
\hline CHEMBL1587712 & 688340 & 4.0 & 5.1496 & TRN & \\
\hline CHEMBL3199359 & 688340 & 4.4 & 5.0018 & TRN & \\
\hline CHEMBL1541836 & 688340 & 6.0 & 5.2277 & TRN & \\
\hline CHEMBL1542485 & 688340 & 5.2 & 5.0457 & TRN & \\
\hline CHEMBL1564289 & 688340 & 5.05 & 5.7343 & TRN & \\
\hline CHEMBL1368345 & 688340 & 4.5 & 4.632 & TRN & \\
\hline CHEMBL1481328 & 688340 & 5.5 & 4.996 & TRN & \\
\hline CHEMBL1422731 & 688340 & 5.3 & 5.1386 & TST & \\
\hline CHEMBL1449895 & 688340 & 4.95 & 4.4283 & TRN & \\
\hline CHEMBL1438764 & 688340 & 4.55 & 5.125 & TRN & \\
\hline CHEMBL1588333 & 688340 & 5.0 & 5.0682 & TRN & \\
\hline CHEMBL1333932 & 688340 & 5.85 & 5.4126 & TRN & \\
\hline CHEMBL1389537 & 688340 & 4.4 & 5.1154 & TST & \\
\hline CHEMBL1547092 & 688340 & 5.4 & 4.8111 & TRN & \\
\hline CHEMBL1388431 & 688340 & 4.65 & 5.0765 & TRN & \\
\hline CHEMBL1443134 & 688340 & 6.5 & 5.2423 & TST & \\
\hline CHEMBL1384559 & 688340 & 4.8 & 4.7999 & TRN & \\
\hline CHEMBL1567916 & 688340 & 4.65 & 5.1222 & TRN & \\
\hline CHEMBL187266 & 688340 & 4.75 & 4.8051 & TRN & \\
\hline CHEMBL1985649 & 688340 & 4.95 & 5.0631 & TST & \\
\hline
\end{tabular}




\begin{tabular}{|c|c|c|c|c|c|}
\hline \\
\hline CHEMBL1313638 & 688340 & 4.4 & 5.1914 & TST & \\
\hline CHEMBL1526101 & 688340 & 5.95 & 5.5106 & TRN & \\
\hline CHEMBL1482224 & 688340 & 4.4 & 5.1468 & TRN & \\
\hline CHEMBL1568791 & 688340 & 5.35 & 4.9918 & TRN & \\
\hline CHEMBL1477505 & 688340 & 5.35 & 4.9598 & TST & \\
\hline CHEMBL1493277 & 688340 & 4.8 & 4.9269 & TRN & \\
\hline CHEMBL1315502 & 688340 & 5.05 & 4.9902 & TRN & \\
\hline CHEMBL1305969 & 688340 & 4.55 & 4.9002 & TST & \\
\hline CHEMBL3191762 & 688340 & 4.95 & 5.0741 & TRN & \\
\hline CHEMBL1472228 & 688340 & 4.75 & 5.3411 & TRN & \\
\hline CHEMBL1501902 & 688340 & 5.45 & 5.206 & TRN & \\
\hline CHEMBL1603474 & 688340 & 5.5 & 5.0364 & TRN & \\
\hline CHEMBL1342914 & 688340 & 4.85 & 4.9607 & TRN & \\
\hline CHEMBL1356719 & 688340 & 5.35 & 4.9428 & TRN & \\
\hline CHEMBL1508378 & 688340 & 4.65 & 5.1251 & TRN & \\
\hline CHEMBL1307516 & 688340 & 4.75 & 5.0066 & TRN & \\
\hline CHEMBL1430450 & 688340 & 4.75 & 4.8955 & TST & \\
\hline CHEMBL1409603 & 688340 & 4.55 & 5.307 & TRN & \\
\hline CHEMBL1325292 & 688340 & 7.0 & 4.7646 & TRN & \\
\hline CHEMBL1492114 & 688340 & 5.5 & 5.0326 & TRN & \\
\hline CHEMBL1466360 & 688340 & 4.0 & 5.1684 & TST & \\
\hline CHEMBL1494334 & 688340 & 4.45 & 4.5424 & TST & \\
\hline CHEMBL1564153 & 688340 & 5.0 & 4.8068 & TRN & \\
\hline CHEMBL1337635 & 688340 & 4.4 & 4.7836 & TRN & \\
\hline CHEMBL1407037 & 688340 & 4.6 & 4.9704 & TRN & \\
\hline CHEMBL1542479 & 688340 & 5.1 & 5.0379 & TRN & \\
\hline CHEMBL1350249 & 688340 & 5.15 & 4.7519 & TRN & \\
\hline CHEMBL1418723 & 688340 & 5.6 & 5.0233 & TST & \\
\hline CHEMBL527307 & 688340 & 6.2 & 5.1438 & TST & \\
\hline CHEMBL1548374 & 688340 & 5.3 & 4.834 & TRN & \\
\hline CHEMBL1978364 & 688340 & 5.1 & 4.6634 & TRN & \\
\hline CHEMBL 1408875 & 688340 & 5.5 & 5.2678 & TRN & \\
\hline CHEMBL 3208494 & 688340 & 6.45 & 4.9082 & TRN & \\
\hline CHEMBL119171 & 688340 & 4.6 & 5.2864 & TST & \\
\hline CHEMBL1384255 & 688340 & 4.4 & $5.2810 e$ & 0000000001 & TRN \\
\hline CHEMBL1526008 & 688340 & 4.65 & 4.8666 & TRN & \\
\hline CHEMBL1446210 & 688340 & 4.4 & 5.1731 & TRN & \\
\hline CHEMBL 3194385 & 688340 & 4.95 & 5.1192 & TRN & \\
\hline CHEMBL1529320 & 688340 & 5.35 & 4.7762 & TST & \\
\hline CHEMBL1626797 & 688340 & 6.8499 & 4.9528 & TRN & \\
\hline CHEMBL1461987 & 688340 & 5.45 & 5.2376 & TRN & \\
\hline CHEMBL1602270 & 688340 & 4.6 & 5.0045 & TST & \\
\hline CHEMBL3197411 & 688340 & 4.5 & 5.007 & TRN & \\
\hline CHEMBL1486131 & 688340 & 5.65 & 4.9403 & TRN & \\
\hline CHEMBL1594184 & 688340 & 4.75 & 5.1262 & TST & \\
\hline CHEMBL1997220 & 688340 & 4.6 & 4.7501 & TRN & \\
\hline CHEMBL1505060 & 688340 & 4.5 & 5.0918 & TRN & \\
\hline CHEMBL 3197651 & 688340 & 6.2 & 4.7692 & TRN & \\
\hline
\end{tabular}




\begin{tabular}{|c|c|c|c|c|c|}
\hline & & & & & \\
\hline CHEMBL1453697 & 688340 & 5.1 & 5.1915 & TST & \\
\hline CHEMBL1560052 & 688340 & 4.55 & 4.9553 & TRN & \\
\hline CHEMBL1463947 & 688340 & 7.0 & 4.7285 & TRN & \\
\hline CHEMBL1476838 & 688340 & 4.6 & 4.6724 & TRN & \\
\hline CHEMBL1302041 & 688340 & 4.5 & 4.9721 & TST & \\
\hline CHEMBL1426938 & 688340 & 4.4 & 5.0523 & TRN & \\
\hline CHEMBL1362782 & 688340 & 4.25 & 5.0247 & TRN & \\
\hline CHEMBL1310541 & 688340 & 4.95 & 5.1392 & TRN & \\
\hline CHEMBL1345467 & 688340 & 4.65 & 4.5909 & TRN & \\
\hline CHEMBL1545084 & 688340 & 7.0 & 5.0942 & TRN & \\
\hline CHEMBL1455346 & 688340 & 6.5 & 5.3709 & TST & \\
\hline CHEMBL3207786 & 688340 & 5.5 & 4.8691 & TST & \\
\hline CHEMBL1540384 & 688340 & 4.5 & 4.4295 & TRN & \\
\hline CHEMBL1554180 & 688340 & 7.0 & 5.2906 & TRN & \\
\hline CHEMBL1426496 & 688340 & 5.45 & 4.8586 & TRN & \\
\hline CHEMBL3195535 & 688340 & 4.8 & 4.9302 & TRN & \\
\hline CHEMBL3145113 & 688340 & 4.5 & 4.9683 & TST & \\
\hline CHEMBL1439292 & 688340 & 4.5 & 4.8446 & TST & \\
\hline CHEMBL1301238 & 688340 & 4.5 & 4.9763 & TRN & \\
\hline CHEMBL1453703 & 688340 & 5.95 & 5.2551 & TRN & \\
\hline CHEMBL1486833 & 688340 & 4.4 & 5.3059 & TST & \\
\hline CHEMBL1608659 & 688340 & 5.95 & 5.17700 & 00000000005 & TRN \\
\hline CHEMBL1312087 & 688340 & 5.0 & 4.9416 & TST & \\
\hline CHEMBL1515695 & 688340 & 4.65 & 5.3495 & TRN & \\
\hline CHEMBL1580367 & 688340 & 4.45 & 5.2508 & TRN & \\
\hline CHEMBL1594374 & 688340 & 6.1 & 5.3495 & TST & \\
\hline CHEMBL1381590 & 688340 & 4.45 & 4.92899 & 9999999999 & TRN \\
\hline CHEMBL1518155 & 688340 & 4.6 & 4.777 & TRN & \\
\hline CHEMBL1339345 & 688340 & 5.5 & 5.1932 & TRN & \\
\hline CHEMBL1353690 & 688340 & 4.55 & 4.8109 & TRN & \\
\hline CHEMBL1436778 & 688340 & 6.0 & 4.9514 & TRN & \\
\hline CHEMBL1347554 & 688340 & 4.9 & 5.2311 & TRN & \\
\hline CHEMBL1389438 & 688340 & 4.8 & 5.062 & TRN & \\
\hline CHEMBL1505324 & 688340 & 5.55 & 4.8928 & TRN & \\
\hline CHEMBL1485168 & 688340 & 4.4 & 4.6167 & TST & \\
\hline CHEMBL1383093 & 688340 & 5.2 & 5.2243 & TRN & \\
\hline CHEMBL1428156 & 688340 & 4.95 & 5.303 & TST & \\
\hline CHEMBL1477154 & 688340 & 4.55 & 4.4279 & TRN & \\
\hline CHEMBL1336434 & 688340 & 5.55 & 5.4221 & TRN & \\
\hline CHEMBL1983311 & 688340 & 6.95 & 4.8769 & TRN & \\
\hline CHEMBL1511451 & 688340 & 5.85 & 5.1001 & TST & \\
\hline CHEMBL1490736 & 688340 & 7.5498 & 5.3796 & TRN & \\
\hline CHEMBL1589096 & 688340 & 4.4 & 4.9513 & TST & \\
\hline CHEMBL1573477 & 688340 & 4.5 & 5.3935 & TRN & \\
\hline CHEMBL1540134 & 688340 & 7.0 & 4.9176 & TST & \\
\hline CHEMBL1516860 & 688340 & 4.5 & 4.7667 & TRN & \\
\hline CHEMBL1329235 & 688340 & 6.0 & 4.5631 & TRN & \\
\hline CHEMBL1423479 & 688340 & 4.5 & 5.2463 & TRN & \\
\hline
\end{tabular}




\begin{tabular}{|c|c|c|c|c|}
\hline \multicolumn{5}{|c|}{ Supplemental Table S2.txt } \\
\hline CHEMBL3198972 & 688340 & 4.35 & 5.0161 & TST \\
\hline CHEMBL1345446 & 688340 & 5.4 & 4.8021 & TST \\
\hline CHEMBL3196418 & 688340 & 4.95 & 5.2597 & TRN \\
\hline CHEMBL1344490 & 688340 & 6.95 & 5.5117 & TRN \\
\hline CHEMBL3194058 & 688340 & 4.5 & 4.7876 & TRN \\
\hline CHEMBL1402043 & 688340 & 4.7 & 4.9396 & TRN \\
\hline CHEMBL1541426 & 688340 & 4.85 & 4.6799 & TRN \\
\hline CHEMBL1448982 & 688340 & 4.4 & 4.5151 & TRN \\
\hline CHEMBL1433124 & 688340 & 4.6 & 4.9648 & TRN \\
\hline CHEMBL1406596 & 688340 & 6.1 & 5.0921 & TRN \\
\hline CHEMBL1502701 & 688340 & 5.2 & 4.8937 & TRN \\
\hline CHEMBL3192820 & 688340 & 4.9 & 5.0274 & TRN \\
\hline CHEMBL1494543 & 688340 & 6.15 & 5.0779 & TRN \\
\hline CHEMBL1531149 & 688340 & 4.95 & 5.1356 & TST \\
\hline CHEMBL 252332 & 688340 & 4.5 & 4.452 & TRN \\
\hline CHEMBL3195688 & 688340 & 5.05 & 5.0318 & TRN \\
\hline CHEMBL3210692 & 688340 & 5.1 & 4.9297 & TRN \\
\hline CHEMBL1501799 & 688340 & 4.6 & 4.8189 & TRN \\
\hline CHEMBL1577443 & 688340 & 4.55 & 5.0669 & TRN \\
\hline CHEMBL1311405 & 688340 & 4.4 & 4.5847 & TST \\
\hline CHEMBL1510038 & 688340 & 4.5 & 5.0621 & TRN \\
\hline CHEMBL3193536 & 688340 & 4.55 & 4.7162 & TRN \\
\hline CHEMBL3193435 & 688340 & 7.0 & 4.8284 & TRN \\
\hline CHEMBL1300679 & 688340 & 4.5 & 4.9638 & TRN \\
\hline CHEMBL1429677 & 688340 & 5.45 & 5.3066 & TRN \\
\hline CHEMBL1346396 & 688340 & 4.6 & 4.8228 & TRN \\
\hline CHEMBL1350159 & 688340 & 6.9 & 5.0595 & TST \\
\hline CHEMBL1604803 & 688340 & 4.5 & 4.8172 & TRN \\
\hline CHEMBL1605106 & 688340 & 4.3 & 4.9396 & TRN \\
\hline CHEMBL3193888 & 688340 & 4.5 & 4.7154 & TRN \\
\hline CHEMBL1367973 & 688340 & 4.45 & 4.9549 & TRN \\
\hline CHEMBL1479325 & 688340 & 4.55 & 4.666 & TRN \\
\hline CHEMBL1428953 & 688340 & 4.55 & 5.0203 & TRN \\
\hline CHEMBL1384436 & 688340 & 4.55 & 4.7813 & TRN \\
\hline CHEMBL1487262 & 688340 & 7.0501 & 5.1859 & TRN \\
\hline CHEMBL1562431 & 688340 & 5.05 & 5.1478 & TRN \\
\hline CHEMBL1447211 & 688340 & 4.8 & 4.8973 & TRN \\
\hline CHEMBL1361661 & 688340 & 6.15 & 5.2012 & TRN \\
\hline CHEMBL1479316 & 688340 & 4.5 & 4.8272 & TRN \\
\hline CHEMBL1586803 & 688340 & 4.8 & 5.059 & TRN \\
\hline CHEMBL1539508 & 688340 & 4.65 & 5.2888 & TRN \\
\hline CHEMBL1495387 & 688340 & 6.15 & 5.3351 & TRN \\
\hline CHEMBL 3214025 & 688340 & 4.55 & 4.9914 & TRN \\
\hline CHEMBL1432959 & 688340 & 5.45 & 4.9878 & TRN \\
\hline CHEMBL1418233 & 688340 & 5.1 & 4.9613 & TST \\
\hline CHEMBL1510624 & 688340 & 4.5 & 5.2992 & TRN \\
\hline CHEMBL1546767 & 688340 & 4.5 & 4.6542 & TRN \\
\hline CHEMBL1527345 & 688340 & 5.15 & 5.2651 & TST \\
\hline
\end{tabular}




\begin{tabular}{|c|c|c|c|c|}
\hline \multicolumn{5}{|c|}{ Supplemental Table s2.txt } \\
\hline CHEMBL1388310 & 688340 & 4.5 & 4.9328 & TRN \\
\hline CHEMBL1299540 & 688340 & 4.75 & 4.9428 & TRN \\
\hline CHEMBL1400432 & 688340 & 4.65 & 5.0247 & TST \\
\hline CHEMBL1500500 & 688340 & 7.5003 & 4.7505 & TRN \\
\hline CHEMBL1300382 & 688340 & 4.7 & 5.1796 & TST \\
\hline CHEMBL3198007 & 688340 & 4.4 & 4.8518 & TRN \\
\hline CHEMBL1314992 & 688340 & 4.65 & 5.2285 & TRN \\
\hline CHEMBL1541656 & 688340 & 4.4 & 4.928 & TRN \\
\hline CHEMBL1380723 & 688340 & 5.35 & 5.0976 & TRN \\
\hline CHEMBL1351479 & 688340 & 4.6 & 4.8111 & TRN \\
\hline CHEMBL1573632 & 688340 & 4.55 & 5.2826 & TRN \\
\hline CHEMBL1549707 & 688340 & 4.4 & 4.7007 & TRN \\
\hline CHEMBL1348498 & 688340 & 7.0 & 5.0579 & TRN \\
\hline CHEMBL1307562 & 688340 & 7.0 & 5.6404 & TRN \\
\hline CHEMBL1384567 & 688340 & 4.8 & 4.9284 & TST \\
\hline CHEMBL1500909 & 688340 & 4.9 & 4.6227 & TRN \\
\hline CHEMBL1545808 & 688340 & 4.4 & 5.0348 & TRN \\
\hline CHEMBL1381676 & 688340 & 4.75 & 4.9832 & TST \\
\hline CHEMBL1385529 & 688340 & 4.65 & 5.1261 & TRN \\
\hline CHEMBL1483188 & 688340 & 4.45 & 5.562 & TST \\
\hline CHEMBL1609313 & 688340 & 5.2 & 5.3475 & TRN \\
\hline CHEMBL1388927 & 688340 & 4.8 & 4.8155 & TRN \\
\hline CHEMBL1448992 & 688340 & 4.55 & 4.78 & TRN \\
\hline CHEMBL1612483 & 688340 & 5.05 & 4.5757 & TRN \\
\hline CHEMBL1456007 & 688340 & 4.55 & 4.9168 & TRN \\
\hline CHEMBL1499266 & 688340 & 4.45 & 5.1008 & TRN \\
\hline CHEMBL1340951 & 688340 & 4.6 & 4.8886 & TST \\
\hline CHEMBL1910223 & 688340 & 4.55 & 5.0616 & TRN \\
\hline CHEMBL1541529 & 688340 & 7.0501 & 5.5283 & TRN \\
\hline CHEMBL392866 & 688340 & 4.4 & 5.4765 & TRN \\
\hline CHEMBL1427602 & 688340 & 5.3 & 4.848 & TRN \\
\hline CHEMBL1362414 & 688340 & 4.55 & 5.2982 & TRN \\
\hline CHEMBL1373558 & 688340 & 4.65 & 5.0602 & TRN \\
\hline CHEMBL1499696 & 688340 & 4.45 & 4.6543 & TST \\
\hline CHEMBL 2001294 & 688340 & 5.2 & 4.7037 & TRN \\
\hline CHEMBL1601599 & 688340 & 5.05 & 4.6542 & TRN \\
\hline CHEMBL1413518 & 688340 & 4.65 & 5.046 & TRN \\
\hline CHEMBL1577676 & 688340 & 3.0 & 5.2056 & TRN \\
\hline CHEMBL1380847 & 688340 & 4.6 & 4.5945 & TRN \\
\hline CHEMBL162783 & 688340 & 5.7 & 5.093 & TRN \\
\hline CHEMBL1369226 & 688340 & 4.9 & 5.12799 & 9999999999 \\
\hline CHEMBL1544323 & 688340 & 4.5 & 5.1572 & TST \\
\hline CHEMBL3212741 & 688340 & 5.05 & 5.3713 & TRN \\
\hline CHEMBL1367991 & 688340 & 4.35 & 4.7652 & TST \\
\hline CHEMBL1330044 & 688340 & 4.35 & 5.1025 & TRN \\
\hline CHEMBL1346436 & 688340 & 4.8 & 5.2437 & TST \\
\hline CHEMBL1301914 & 688340 & 5.35 & 4.6923 & TST \\
\hline CHEMBL1476574 & 688340 & 4.05 & 4.978 & TRN \\
\hline
\end{tabular}




\begin{tabular}{|c|c|c|c|c|c|}
\hline & & \multicolumn{4}{|c|}{ Supplemental Table S2.txt } \\
\hline CHEMBL1572945 & 688340 & 4.35 & 5.5928 & TRN & \\
\hline CHEMBL1375933 & 688340 & 4.4 & 5.2211 & TST & \\
\hline CHEMBL3214101 & 688340 & 6.1 & 5.16 & TST & \\
\hline CHEMBL1539664 & 688340 & 7.0 & 5.0513 & TRN & \\
\hline CHEMBL1493224 & 688340 & 5.0 & 4.6064 & TRN & \\
\hline CHEMBL1564456 & 688340 & 7.5498 & 5.2765 & TRN & \\
\hline CHEMBL1495248 & 688340 & 5.25 & 5.0429 & TRN & \\
\hline CHEMBL1436080 & 688340 & 4.95 & 5.118 & TRN & \\
\hline CHEMBL 3145185 & 688340 & 5.1 & 4.898 & TST & \\
\hline CHEMBL1514647 & 688340 & 4.6 & 5.0005 & TRN & \\
\hline CHEMBL1526945 & 688340 & 5.2 & 4.992 & TRN & \\
\hline CHEMBL1559365 & 688340 & 5.05 & 5.121 & TRN & \\
\hline CHEMBL1422855 & 688340 & 7.1002 & 5.5379 & TRN & \\
\hline CHEMBL1313426 & 688340 & 7.0 & 5.1376 & TRN & \\
\hline CHEMBL1601936 & 688340 & 4.85 & 5.0041 & TRN & \\
\hline CHEMBL1583684 & 688340 & 4.3 & 4.8758 & TST & \\
\hline CHEMBL1315239 & 688340 & 6.5 & 5.0114 & TRN & \\
\hline CHEMBL1603914 & 688340 & 6.45 & 5.4125 & TRN & \\
\hline CHEMBL1329731 & 688340 & 2.75 & 4.9684 & TRN & \\
\hline CHEMBL1329933 & 688340 & 6.1 & 5.3564 & TRN & \\
\hline CHEMBL1429362 & 688340 & 4.45 & 5.1587 & TRN & \\
\hline CHEMBL1414618 & 688340 & 5.05 & 5.0029 & TRN & \\
\hline CHEMBL1541516 & 688340 & 4.0 & 5.1479 & TST & \\
\hline CHEMBL1555623 & 688340 & 4.7 & 4.9116 & TRN & \\
\hline CHEMBL1567025 & 688340 & 4.6 & 5.1921 & TRN & \\
\hline CHEMBL1486517 & 688340 & 4.4 & 5.2519 & TST & \\
\hline CHEMBL1445265 & 688340 & 4.95 & 5.5315 & TRN & \\
\hline CHEMBL1363706 & 688340 & 6.0 & 4.9577 & TRN & \\
\hline CHEMBL1465469 & 688340 & 4.65 & 4.9611 & TRN & \\
\hline CHEMBL260028 & 688340 & 4.95 & 4.6719 & TRN & \\
\hline CHEMBL1442560 & 688340 & 4.4 & 4.9811 & TRN & \\
\hline CHEMBL1568140 & 688340 & 5.0 & 5.0825 & TST & \\
\hline CHEMBL1581578 & 688340 & 5.1 & 4.9429 & TRN & \\
\hline CHEMBL1400257 & 688340 & 4.6 & 5.1046 & TRN & \\
\hline CHEMBL1403189 & 688340 & 5.1 & 5.1427 & TST & \\
\hline CHEMBL1607897 & 688340 & 4.45 & 4.6868 & TST & \\
\hline CHEMBL1427620 & 688340 & 4.85 & 4.8148 & TRN & \\
\hline CHEMBL1425567 & 688340 & 4.4 & 4.7387 & TST & \\
\hline CHEMBL1313899 & 688340 & 5.2 & 5.0332 & TRN & \\
\hline CHEMBL1423032 & 688340 & 4.5 & 4.9535 & TRN & \\
\hline CHEMBL1429428 & 688340 & 6.1 & 5.1058 & TRN & \\
\hline CHEMBL1410931 & 688340 & 4.55 & 5.1997 & TST & \\
\hline CHEMBL3209306 & 688340 & 4.8 & 4.9152 & TRN & \\
\hline CHEMBL 1606110 & 688340 & 5.35 & 4.83899 & 99999999995 & TRN \\
\hline CHEMBL1421953 & 688340 & 4.5 & 5.085 & TRN & \\
\hline CHEMBL1490056 & 688340 & 4.6 & 4.92399 & 99999999995 & TST \\
\hline CHEMBL1510092 & 688340 & 5.3 & 4.9133 & TRN & \\
\hline CHEMBL1589421 & 688340 & 4.05 & 4.9628 & TRN & \\
\hline
\end{tabular}




\begin{tabular}{|c|c|c|c|c|c|}
\hline \\
\hline CHEMBL1518029 & 688340 & 5.0 & 5.1838 & TST & \\
\hline CHEMBL1587252 & 688340 & 4.4 & 4.901 & TRN & \\
\hline CHEMBL1500607 & 688340 & 6.15 & 5.0509 & TRN & \\
\hline CHEMBL3199337 & 688340 & 4.65 & 4.6505 & TRN & \\
\hline CHEMBL1584768 & 688340 & 4.4 & 5.0765 & TST & \\
\hline CHEMBL1321993 & 688340 & 5.4 & 4.8701 & TRN & \\
\hline CHEMBL1567595 & 688340 & 4.65 & 4.5658 & TRN & \\
\hline CHEMBL1587545 & 688340 & 5.95 & 4.8909 & TST & \\
\hline CHEMBL1540328 & 688340 & 4.6 & 4.7726 & TST & \\
\hline CHEMBL1399834 & 688340 & 5.15 & 5.1396 & TRN & \\
\hline CHEMBL3208880 & 688340 & 4.45 & 4.8462 & TRN & \\
\hline CHEMBL1375166 & 688340 & 5.2 & 5.2247 & TST & \\
\hline CHEMBL1547145 & 688340 & 4.4 & 4.8588 & TRN & \\
\hline CHEMBL1475012 & 688340 & 4.6 & 5.0626 & TRN & \\
\hline CHEMBL1533196 & 688340 & 5.05 & 5.21299 & 9999999999 & TST \\
\hline CHEMBL1561605 & 688340 & 4.65 & 4.7583 & TRN & \\
\hline CHEMBL1526800 & 688340 & 4.5 & 4.7816 & TRN & \\
\hline CHEMBL1439632 & 688340 & 4.4 & 4.8226 & TRN & \\
\hline CHEMBL1606671 & 688340 & 4.5 & 4.702 & TRN & \\
\hline CHEMBL1551613 & 688340 & 6.15 & 5.2143 & TST & \\
\hline CHEMBL1725507 & 688340 & 4.4 & 5.20100 & 00000000005 & TRN \\
\hline CHEMBL1595235 & 688340 & 5.55 & 4.8417 & TRN & \\
\hline CHEMBL1475126 & 688340 & 4.5 & 5.1822 & TST & \\
\hline CHEMBL1301614 & 688340 & 4.95 & 5.0965 & TRN & \\
\hline CHEMBL1566373 & 688340 & 4.0 & 5.0881 & TST & \\
\hline CHEMBL1580450 & 688340 & 4.4 & 5.0127 & TRN & \\
\hline CHEMBL1502852 & 688340 & 5.2 & 4.699 & TST & \\
\hline CHEMBL1597442 & 688340 & 5.35 & 5.1441 & TRN & \\
\hline CHEMBL1430184 & 688340 & 5.45 & 4.8379 & TRN & \\
\hline CHEMBL1430903 & 688340 & 3.1 & 4.9132 & TRN & \\
\hline CHEMBL1385254 & 688340 & 6.1 & 4.8764 & TRN & \\
\hline CHEMBL1579353 & 688340 & 6.6 & 5.2444 & TRN & \\
\hline CHEMBL1365368 & 688340 & 6.25 & 5.3639 & TRN & \\
\hline CHEMBL1399172 & 688340 & 4.5 & 5.0266 & TRN & \\
\hline CHEMBL1309217 & 688340 & 4.4 & 5.0573 & TRN & \\
\hline CHEMBL3189405 & 688340 & 4.75 & 5.2456 & TRN & \\
\hline CHEMBL1559281 & 688340 & 5.3 & 5.28299 & 99999999995 & TST \\
\hline CHEMBL1360864 & 688340 & 5.2 & 5.1209 & TRN & \\
\hline CHEMBL1399663 & 688340 & 4.55 & 4.8521 & TRN & \\
\hline CHEMBL1312576 & 688340 & 5.7 & 4.8402 & TST & \\
\hline CHEMBL1613351 & 688340 & 5.25 & 4.9729 & TRN & \\
\hline CHEMBL1424118 & 688340 & 4.7 & 4.836 & TRN & \\
\hline CHEMBL1432405 & 688340 & 4.55 & 4.8019 & TST & \\
\hline CHEMBL1481501 & 688340 & 4.5 & 5.1287 & TRN & \\
\hline CHEMBL1411120 & 688340 & 4.8 & 4.9673 & TRN & \\
\hline CHEMBL1321020 & 688340 & 4.6 & 4.9125 & TRN & \\
\hline CHEMBL1427872 & 688340 & 5.25 & 5.4339 & TRN & \\
\hline CHEMBL1579637 & 688340 & 4.7 & 4.8787 & TST & \\
\hline
\end{tabular}




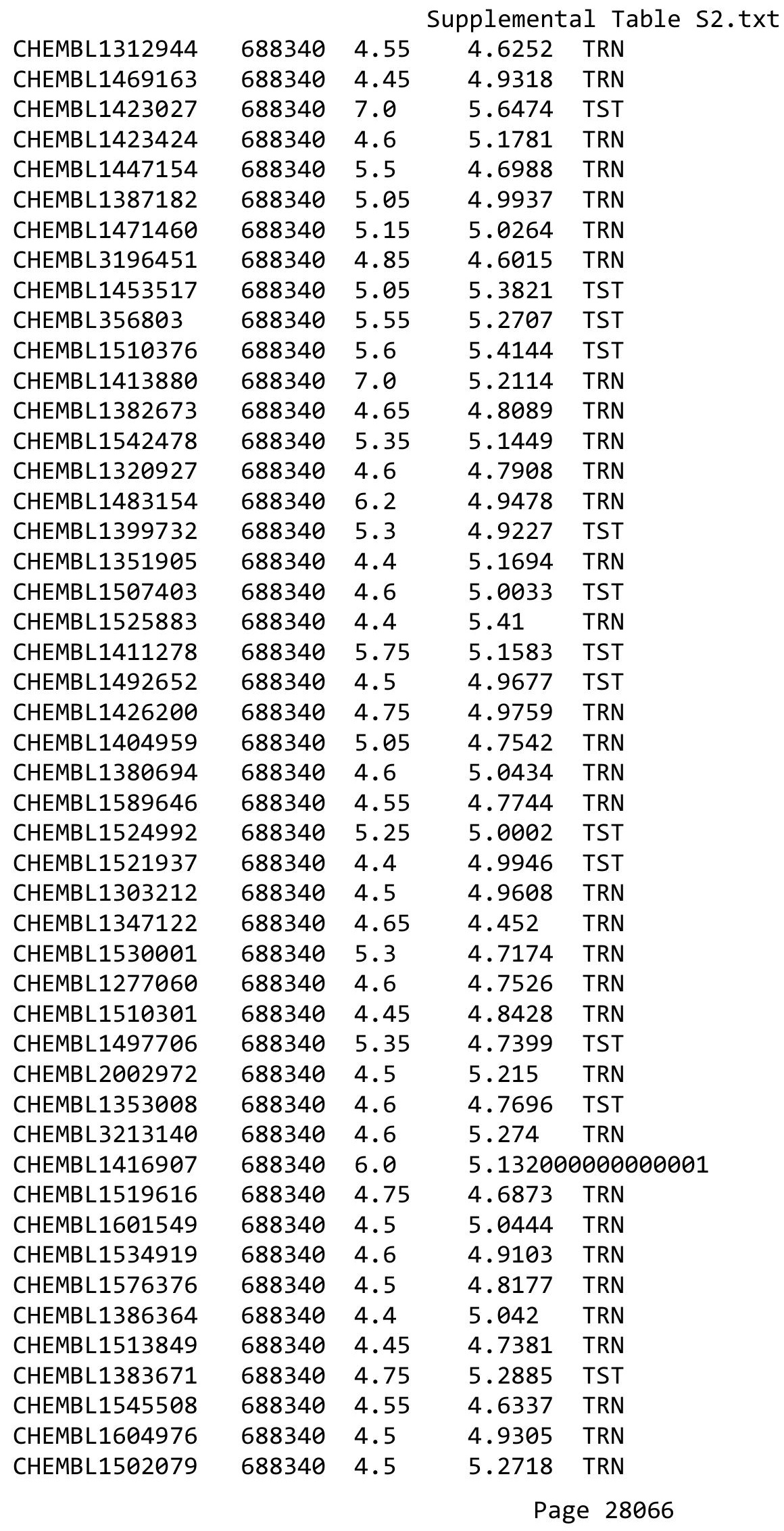




\begin{tabular}{|c|c|c|c|c|}
\hline \multicolumn{5}{|c|}{ Supplemental Table S2.txt } \\
\hline CHEMBL562334 & 688340 & 4.9 & 5.0012 & TRN \\
\hline CHEMBL1343325 & 688340 & 4.55 & 4.9951 & TST \\
\hline CHEMBL1488436 & 688340 & 4.65 & 4.8112 & TRN \\
\hline CHEMBL1324734 & 688340 & 5.25 & 5.4978 & TRN \\
\hline CHEMBL1547555 & 688340 & 4.45 & 5.1385 & TRN \\
\hline CHEMBL1416164 & 688340 & 4.45 & 4.6156 & TRN \\
\hline CHEMBL1366062 & 688340 & 4.55 & 4.9478 & TST \\
\hline CHEMBL1487564 & 688340 & 4.65 & 4.7845 & TRN \\
\hline CHEMBL1444995 & 688340 & 5.9 & 4.922 & TRN \\
\hline CHEMBL1572785 & 688340 & 5.0 & 4.9388 & TST \\
\hline CHEMBL1462927 & 688340 & 4.6 & 4.6812 & TST \\
\hline CHEMBL1528771 & 688340 & 4.4 & 5.065 & TST \\
\hline CHEMBL1445433 & 688340 & 5.8 & 5.6206 & TRN \\
\hline CHEMBL1448203 & 688340 & 5.6 & 4.7749 & TST \\
\hline CHEMBL1474222 & 688340 & 4.55 & 5.0248 & TST \\
\hline CHEMBL1327663 & 688340 & 5.05 & 5.3845 & TST \\
\hline CHEMBL1444791 & 688340 & 6.35 & 5.0041 & TRN \\
\hline CHEMBL1319116 & 688340 & 4.55 & 4.5603 & TRN \\
\hline CHEMBL1570908 & 688340 & 5.3 & 4.9149 & TST \\
\hline CHEMBL592124 & 688340 & 4.45 & 4.8817 & TRN \\
\hline CHEMBL1326069 & 688340 & 5.0 & 5.2785 & TST \\
\hline CHEMBL 3198005 & 688340 & 4.6 & 4.857 & TRN \\
\hline CHEMBL1541349 & 688340 & 4.5 & 5.1582 & TRN \\
\hline CHEMBL1489380 & 688340 & 4.55 & 4.9116 & TRN \\
\hline CHEMBL1531786 & 688340 & 4.45 & 5.3713 & TRN \\
\hline CHEMBL1585997 & 688340 & 4.5 & 4.4967 & TRN \\
\hline CHEMBL1321713 & 688340 & 4.4 & 4.6946 & TRN \\
\hline CHEMBL1585191 & 688340 & 4.6 & 4.8635 & TRN \\
\hline CHEMBL59026 & 688340 & 7.0 & 5.1141 & TRN \\
\hline CHEMBL1505944 & 688340 & 6.95 & 5.2956 & TRN \\
\hline CHEMBL1494188 & 688340 & 4.5 & 4.8331 & TRN \\
\hline CHEMBL1400334 & 688340 & 4.4 & 4.7134 & TRN \\
\hline CHEMBL1569171 & 688340 & 6.5501 & 4.8866 & TST \\
\hline CHEMBL1542240 & 688340 & 4.6 & 5.1745 & TST \\
\hline CHEMBL1342018 & 688340 & 7.0 & 5.032 & TRN \\
\hline CHEMBL1561861 & 688340 & 4.55 & 4.7204 & TST \\
\hline CHEMBL1402641 & 688340 & 5.95 & 5.069 & TST \\
\hline CHEMBL1465892 & 688340 & 4.65 & 4.7771 & TRN \\
\hline CHEMBL 2004475 & 688340 & 4.85 & 4.8419 & TST \\
\hline CHEMBL1385174 & 688340 & 4.95 & 5.3504 & TRN \\
\hline CHEMBL1391036 & 688340 & 4.6 & 5.1716 & TRN \\
\hline CHEMBL1567482 & 688340 & 4.45 & 5.0183 & TRN \\
\hline CHEMBL1420838 & 688340 & 4.5 & 4.7331 & TRN \\
\hline CHEMBL1511979 & 688340 & 4.6 & 5.0692 & TRN \\
\hline CHEMBL3198727 & 688340 & 4.0 & 4.9302 & TRN \\
\hline CHEMBL1545022 & 688340 & 5.15 & 5.2453 & TST \\
\hline CHEMBL1556956 & 688340 & 4.85 & 4.4734 & TRN \\
\hline CHEMBL1341584 & 688340 & 6.35 & 5.0573 & TRN \\
\hline
\end{tabular}




\begin{tabular}{|c|c|c|c|c|}
\hline \multicolumn{5}{|c|}{ Supplemental Table S2.txt } \\
\hline CHEMBL1323790 & 688340 & 5.2 & 5.1712 & TRN \\
\hline CHEMBL1448258 & 688340 & 4.45 & 5.0301 & TRN \\
\hline CHEMBL1463839 & 688340 & 4.9 & 5.4851 & TST \\
\hline CHEMBL1399060 & 688340 & 5.0 & 5.7517 & TRN \\
\hline CHEMBL1996030 & 688340 & 5.35 & 5.1496 & TST \\
\hline CHEMBL1429044 & 688340 & 4.4 & 5.0886 & TST \\
\hline CHEMBL578883 & 688340 & 5.05 & 5.471 & TRN \\
\hline CHEMBL1550006 & 688340 & 5.05 & 5.098 & TST \\
\hline CHEMBL1299315 & 688340 & 4.4 & 4.9947 & TST \\
\hline CHEMBL1438294 & 688340 & 7.0 & 4.9487 & TRN \\
\hline CHEMBL1411616 & 688340 & 7.0 & 5.1346 & TST \\
\hline CHEMBL1571901 & 688340 & 6.1 & 4.7834 & TRN \\
\hline CHEMBL3214204 & 688340 & 5.15 & 5.0454 & TST \\
\hline CHEMBL1466332 & 688340 & 4.3 & 5.4852 & TRN \\
\hline CHEMBL1470135 & 688340 & 4.5 & 4.7506 & TRN \\
\hline CHEMBL1384563 & 688340 & 5.25 & 5.0238 & TRN \\
\hline CHEMBL1302203 & 688340 & 4.4 & 4.966 & TRN \\
\hline CHEMBL1599688 & 688340 & 5.4 & 5.1958 & TRN \\
\hline CHEMBL1582116 & 688340 & 4.55 & 5.0647 & TRN \\
\hline CHEMBL1359066 & 688340 & 4.55 & 4.6309 & TRN \\
\hline CHEMBL1487959 & 688340 & 4.55 & 4.6883 & TRN \\
\hline CHEMBL1556103 & 688340 & 4.6 & 4.9942 & TST \\
\hline CHEMBL1598189 & 688340 & 6.0 & 5.0335 & TRN \\
\hline CHEMBL1423686 & 688340 & 7.0501 & 4.9179 & TST \\
\hline CHEMBL1305152 & 688340 & 5.25 & 4.9486 & TST \\
\hline CHEMBL1541360 & 688340 & 4.55 & 4.8925 & TRN \\
\hline CHEMBL1480383 & 688340 & 3.85 & 4.7825 & TRN \\
\hline CHEMBL1566722 & 688340 & 5.4 & 4.709 & TRN \\
\hline CHEMBL1574979 & 688340 & 4.55 & 4.965 & TRN \\
\hline CHEMBL1557972 & 688340 & 4.8 & 4.8068 & TRN \\
\hline CHEMBL1466991 & 688340 & 4.6 & 4.8301 & TRN \\
\hline CHEMBL1532094 & 688340 & 7.0501 & 4.8067 & TST \\
\hline CHEMBL1313449 & 688340 & 4.85 & 4.9565 & TRN \\
\hline CHEMBL1573752 & 688340 & 4.55 & 4.9726 & TRN \\
\hline CHEMBL1579533 & 688340 & 6.95 & 5.2451 & TRN \\
\hline CHEMBL1537019 & 688340 & 6.5501 & 4.6203 & TRN \\
\hline CHEMBL1500968 & 688340 & 4.4 & 4.9653 & TRN \\
\hline CHEMBL1487357 & 688340 & 6.05 & 4.8361 & TRN \\
\hline CHEMBL1373090 & 688340 & 5.15 & 5.2376 & TRN \\
\hline CHEMBL546170 & 688340 & 4.4 & 4.4319 & TST \\
\hline CHEMBL1596171 & 688340 & 5.55 & 4.7202 & TRN \\
\hline CHEMBL1427649 & 688340 & 4.55 & 4.6253 & TRN \\
\hline CHEMBL1335651 & 688340 & 6.1 & 5.3301 & TRN \\
\hline CHEMBL1546297 & 688340 & 5.6 & 4.9344 & TRN \\
\hline CHEMBL1451930 & 688340 & 5.05 & 5.2992 & TRN \\
\hline CHEMBL1404047 & 688340 & 4.7 & 4.942 & TST \\
\hline CHEMBL1339703 & 688340 & 5.75 & 5.0192 & TRN \\
\hline CHEMBL1966283 & 688340 & 5.05 & 5.2259 & TST \\
\hline
\end{tabular}




\begin{tabular}{|c|c|c|c|c|}
\hline \multicolumn{5}{|c|}{ Supplemental Table s2.txt } \\
\hline CHEMBL1473590 & 688340 & 4.7 & 4.7376 & TRN \\
\hline CHEMBL1413229 & 688340 & 6.1 & 5.0577 & TST \\
\hline CHEMBL489695 & 688340 & 4.35 & 4.8539 & TRN \\
\hline CHEMBL1469355 & 688340 & 4.4 & 4.9552 & TRN \\
\hline CHEMBL1448933 & 688340 & 4.65 & 5.0726 & TST \\
\hline CHEMBL1346896 & 688340 & 5.75 & 5.1572 & TRN \\
\hline CHEMBL1362335 & 688340 & 4.8 & 4.8723 & TRN \\
\hline CHEMBL1389329 & 688340 & 4.8 & 5.2816 & TRN \\
\hline CHEMBL1544867 & 688340 & 4.65 & 5.159 & TRN \\
\hline CHEMBL1584173 & 688340 & 4.55 & 4.8043 & TRN \\
\hline CHEMBL 3194388 & 688340 & 4.4 & 5.2298 & TRN \\
\hline CHEMBL1417122 & 688340 & 4.55 & 4.7678 & TRN \\
\hline CHEMBL1432981 & 688340 & 4.5 & 4.487 & TRN \\
\hline CHEMBL1455176 & 688340 & 5.05 & 5.2189 & TRN \\
\hline CHEMBL1352386 & 688340 & 6.5 & 5.0583 & TRN \\
\hline CHEMBL1356266 & 688340 & 4.45 & 4.9536 & TRN \\
\hline CHEMBL1343313 & 688340 & 6.0 & 4.7625 & TST \\
\hline CHEMBL1320844 & 688340 & 4.8 & 4.88 & TRN \\
\hline CHEMBL1501896 & 688340 & 5.0 & 5.3168 & TRN \\
\hline CHEMBL1464387 & 688340 & 5.1 & 5.1432 & TRN \\
\hline CHEMBL1572968 & 688340 & 5.15 & 4.8618 & TRN \\
\hline CHEMBL3198782 & 688340 & 4.45 & 4.817 & TRN \\
\hline CHEMBL3189290 & 688340 & 4.55 & 4.9065 & TRN \\
\hline CHEMBL1484902 & 688340 & 5.2 & 5.0167 & TST \\
\hline CHEMBL1968928 & 688340 & 5.05 & 5.1616 & TRN \\
\hline CHEMBL3194528 & 688340 & 4.65 & 4.6777 & TRN \\
\hline CHEMBL1364967 & 688340 & 4.6 & 4.8273 & TRN \\
\hline CHEMBL1368207 & 688340 & 5.2 & 4.6534 & TRN \\
\hline CHEMBL1423216 & 688340 & 4.5 & 4.9522 & TRN \\
\hline CHEMBL1544507 & 688340 & 7.0 & 5.2504 & TRN \\
\hline CHEMBL1547221 & 688340 & 5.4 & 4.9741 & TST \\
\hline CHEMBL1469574 & 688340 & 5.2 & 4.5608 & TRN \\
\hline CHEMBL1331229 & 688340 & 4.3 & 4.9854 & TRN \\
\hline CHEMBL1557816 & 688340 & 4.55 & 4.8829 & TST \\
\hline CHEMBL1311602 & 688340 & 5.05 & 5.0719 & TRN \\
\hline CHEMBL1415277 & 688340 & 5.05 & 4.8973 & TST \\
\hline CHEMBL1995296 & 688340 & 4.5 & 4.9272 & TST \\
\hline CHEMBL1450108 & 688340 & 4.55 & 4.5834 & TRN \\
\hline CHEMBL1524953 & 688340 & 5.05 & 5.2186 & TRN \\
\hline CHEMBL1321679 & 688340 & 5.0 & 4.8076 & TRN \\
\hline CHEMBL1557408 & 688340 & 7.0501 & 5.4691 & TRN \\
\hline CHEMBL1366810 & 688340 & 4.8 & 4.6946 & TRN \\
\hline CHEMBL1362047 & 688340 & 4.45 & 5.0048 & TRN \\
\hline CHEMBL1543416 & 688340 & 4.5 & 4.6558 & TRN \\
\hline CHEMBL1427047 & 688340 & 4.6 & 4.9697 & TRN \\
\hline CHEMBL1344492 & 688340 & 6.8499 & 5.4163 & TRN \\
\hline CHEMBL1494449 & 688340 & 4.4 & 5.0224 & TRN \\
\hline CHEMBL592184 & 688340 & 4.5 & 5.0008 & TST \\
\hline
\end{tabular}




\begin{tabular}{|c|c|c|c|c|}
\hline & & & upplement & al $\mathrm{Ta}$ \\
\hline CHEMBL1517697 & 688340 & 5.85 & 4.8131 & TRN \\
\hline CHEMBL1402230 & 688340 & 4.6 & 4.5861 & TRN \\
\hline CHEMBL1565570 & 688340 & 4.05 & 4.9465 & TRN \\
\hline CHEMBL3194711 & 688340 & 4.4 & 4.9442 & TST \\
\hline CHEMBL1548238 & 688340 & 5.15 & 4.9916 & TRN \\
\hline CHEMBL1462474 & 688340 & 4.45 & 5.1488 & TST \\
\hline CHEMBL1550629 & 688340 & 4.55 & 4.8164 & TRN \\
\hline CHEMBL1303745 & 688340 & 4.75 & 4.8702 & TRN \\
\hline CHEMBL1578345 & 688340 & 4.6 & 4.61 & TRN \\
\hline CHEMBL1404071 & 688340 & 4.55 & 4.8362 & TRN \\
\hline CHEMBL1532571 & 688340 & 4.55 & 4.9511 & TRN \\
\hline CHEMBL1407355 & 688340 & 4.55 & 4.9372 & TRN \\
\hline CHEMBL1501434 & 688340 & 6.4 & 5.086 & TST \\
\hline CHEMBL1323907 & 688340 & 4.55 & 5.0959 & TRN \\
\hline CHEMBL1548870 & 688340 & 4.4 & 4.8878 & TRN \\
\hline CHEMBL1425814 & 688340 & 7.0 & 5.1829 & TRN \\
\hline CHEMBL1384874 & 688340 & 5.45 & 5.1481 & TRN \\
\hline CHEMBL1517916 & 688340 & 4.85 & 5.0369 & TST \\
\hline CHEMBL1561123 & 688340 & 4.45 & 4.8992 & TST \\
\hline CHEMBL1580272 & 688340 & 4.4 & 4.6833 & TRN \\
\hline CHEMBL3207466 & 688340 & 5.45 & 4.6897 & TRN \\
\hline CHEMBL1606938 & 688340 & 4.6 & 4.6868 & TRN \\
\hline CHEMBL1493910 & 688340 & 4.4 & 4.6588 & TRN \\
\hline CHEMBL1502296 & 688340 & 4.6 & 5.0803 & TST \\
\hline CHEMBL1390501 & 688340 & 4.95 & 5.5924 & TRN \\
\hline CHEMBL1453370 & 688340 & 5.25 & 5.2529 & TRN \\
\hline CHEMBL1425856 & 688340 & 4.7 & 4.9819 & TRN \\
\hline CHEMBL1418990 & 688340 & 4.5 & 5.8338 & TRN \\
\hline CHEMBL1343529 & 688340 & 4.65 & 4.7074 & TRN \\
\hline CHEMBL1571821 & 688340 & 5.1 & 5.0644 & TRN \\
\hline CHEMBL3198489 & 688340 & 4.65 & 4.8406 & TRN \\
\hline CHEMBL1305534 & 688340 & 5.05 & 5.0605 & TRN \\
\hline CHEMBL1428857 & 688340 & 4.5 & 5.0144 & TRN \\
\hline CHEMBL1482591 & 688340 & 5.2 & 5.0824 & TST \\
\hline CHEMBL1311488 & 688340 & 4.7 & 4.912 & TRN \\
\hline CHEMBL1611750 & 688340 & 5.2 & 5.0541 & TRN \\
\hline CHEMBL1513413 & 688340 & 4.4 & 5.1394 & TRN \\
\hline CHEMBL1527848 & 688340 & 4.5 & 4.7091 & TST \\
\hline CHEMBL3192162 & 688340 & 4.75 & 4.9 & TRN \\
\hline CHEMBL3192994 & 688340 & 5.3 & 5.2023 & TRN \\
\hline CHEMBL1393628 & 688340 & 4.5 & 4.9026 & TRN \\
\hline CHEMBL1423490 & 688340 & 4.5 & 4.7669 & TRN \\
\hline CHEMBL1331740 & 688340 & 4.45 & 4.6297 & TRN \\
\hline CHEMBL1497015 & 688340 & 5.3 & 5.4768 & TST \\
\hline CHEMBL1344381 & 688340 & 4.4 & 4.7324 & TRN \\
\hline CHEMBL1494137 & 688340 & 4.4 & 5.3088 & TST \\
\hline CHEMBL1313798 & 688340 & 4.95 & 4.9653 & TST \\
\hline CHEMBL1530839 & 688340 & 5.2 & 5.0968 & TRN \\
\hline
\end{tabular}




\begin{tabular}{|c|c|c|c|c|c|}
\hline \multicolumn{6}{|c|}{ Supplemental Table S2.txt } \\
\hline CHEMBL1565897 & 688340 & 4.65 & 4.9646 & TST & \\
\hline CHEMBL1597262 & 688340 & 4.7 & 5.0808 & TRN & \\
\hline CHEMBL1385385 & 688340 & 4.45 & 4.9044 & TST & \\
\hline CHEMBL1370836 & 688340 & 4.55 & 4.8047 & TRN & \\
\hline CHEMBL1422723 & 688340 & 5.8 & 5.2499 & TRN & \\
\hline CHEMBL1563559 & 688340 & 4.4 & 4.9455 & TRN & \\
\hline CHEMBL1362714 & 688340 & 4.75 & 5.1807 & TRN & \\
\hline CHEMBL1468225 & 688340 & 4.5 & 4.9456 & TRN & \\
\hline CHEMBL1460520 & 688340 & 7.0501 & 5.2588 & TST & \\
\hline CHEMBL1335687 & 688340 & 4.55 & 4.7935 & TRN & \\
\hline CHEMBL3192796 & 688340 & 4.4 & 5.0409 & TRN & \\
\hline CHEMBL3198881 & 688340 & 5.3 & 5.2774 & TRN & \\
\hline CHEMBL1542151 & 688340 & 5.15 & 4.8333 & TRN & \\
\hline CHEMBL 299853 & 688340 & 5.3 & 4.7094 & TRN & \\
\hline CHEMBL1472574 & 688340 & 4.8 & 4.8637 & TRN & \\
\hline CHEMBL1469926 & 688340 & 4.45 & 5.0211 & TRN & \\
\hline CHEMBL1532497 & 688340 & 6.0 & 5.3519 & TST & \\
\hline CHEMBL 1457785 & 688340 & 5.15 & 4.9899 & TST & \\
\hline CHEMBL1375207 & 688340 & 5.25 & 4.7283 & TST & \\
\hline CHEMBL1306461 & 688340 & 4.45 & 4.6425 & TRN & \\
\hline CHEMBL1519151 & 688340 & 6.1 & 5.0081 & TRN & \\
\hline CHEMBL1383031 & 688340 & 5.7 & 5.4153 & TRN & \\
\hline CHEMBL1356680 & 688340 & 6.0 & 5.1296 & TST & \\
\hline CHEMBL315348 & 688340 & 4.55 & 4.6083 & TRN & \\
\hline CHEMBL1528126 & 688340 & 5.2 & 4.7496 & TST & \\
\hline CHEMBL1386699 & 688340 & 6.25 & 4.9732 & TRN & \\
\hline CHEMBL1351610 & 688340 & 4.85 & 4.7476 & TST & \\
\hline CHEMBL1470284 & 688340 & 4.45 & 5.4282 & TRN & \\
\hline CHEMBL1348113 & 688340 & 4.4 & 5.2131 & TRN & \\
\hline CHEMBL 3145314 & 688340 & 4.75 & 4.8603 & TRN & \\
\hline CHEMBL1458870 & 688340 & 5.05 & 5.064 & TRN & \\
\hline CHEMBL3199418 & 688340 & 5.5 & 5.0526 & TRN & \\
\hline CHEMBL1567827 & 688340 & 4.6 & 4.5346 & TRN & \\
\hline CHEMBL1606327 & 688340 & 5.3 & 5.5189 & TRN & \\
\hline CHEMBL1408919 & 688340 & 4.45 & 4.6374 & TRN & \\
\hline CHEMBL1391945 & 688340 & 4.6 & 4.7665 & TST & \\
\hline CHEMBL1320874 & 688340 & 5.9 & 5.043 & TRN & \\
\hline CHEMBL1347917 & 688340 & 6.05 & 4.7749 & TRN & \\
\hline CHEMBL3194820 & 688340 & 4.8 & 4.7678 & TRN & \\
\hline CHEMBL1361173 & 688340 & 4.55 & 4.8264 & TRN & \\
\hline CHEMBL1560522 & 688340 & 4.55 & 4.8496 & TRN & \\
\hline CHEMBL1334484 & 688340 & 4.6 & 4.7286 & TST & \\
\hline CHEMBL1508680 & 688340 & 4.5 & 4.9897 & TST & \\
\hline CHEMBL1416868 & 688340 & 5.2 & 5.38299 & 9999999999 & TRN \\
\hline CHEMBL1411116 & 688340 & 4.55 & 4.7986 & TRN & \\
\hline CHEMBL1531574 & 688340 & 4.55 & 4.9484 & TRN & \\
\hline CHEMBL1392253 & 688340 & 6.2 & 5.2761 & TST & \\
\hline CHEMBL1440473 & 688340 & 4.65 & 4.7956 & TRN & \\
\hline
\end{tabular}




\begin{tabular}{|c|c|c|c|c|c|}
\hline \multicolumn{6}{|c|}{ Supplemental Table S2.txt } \\
\hline CHEMBL1507432 & 688340 & 4.35 & 5.5008 & TST & \\
\hline CHEMBL1449587 & 688340 & 5.2 & 5.1234 & TST & \\
\hline CHEMBL1430278 & 688340 & 4.5 & 5.03100 & 0000000001 & TRN \\
\hline CHEMBL1545874 & 688340 & 4.55 & 5.1031 & TRN & \\
\hline CHEMBL1373595 & 688340 & 5.0 & 4.7093 & TRN & \\
\hline CHEMBL1583782 & 688340 & 4.6 & 4.7963 & TRN & \\
\hline CHEMBL1589600 & 688340 & 6.95 & 4.898 & TST & \\
\hline CHEMBL1416821 & 688340 & 4.5 & 5.1984 & TRN & \\
\hline CHEMBL1484734 & 688340 & 4.4 & 5.1832 & TRN & \\
\hline CHEMBL1447124 & 688340 & 4.65 & 4.9576 & TST & \\
\hline CHEMBL1579342 & 688340 & 4.4 & 5.4231 & TRN & \\
\hline CHEMBL1308435 & 688340 & 4.4 & 4.8517 & TST & \\
\hline CHEMBL1407009 & 688340 & 4.4 & 4.9923 & TRN & \\
\hline CHEMBL 2373678 & 688340 & 6.0 & 5.0772 & TST & \\
\hline CHEMBL1417833 & 688340 & 6.8 & 5.1734 & TRN & \\
\hline CHEMBL1518374 & 688340 & 5.05 & 5.1524 & TRN & \\
\hline CHEMBL1458759 & 688340 & 5.4 & 5.2204 & TRN & \\
\hline CHEMBL1579774 & 688340 & 7.0501 & 4.8596 & TST & \\
\hline CHEMBL 1425680 & 688340 & 6.0 & 5.1244 & TRN & \\
\hline CHEMBL1306141 & 688340 & 6.1 & 5.0087 & TRN & \\
\hline CHEMBL3196999 & 688340 & 5.35 & 5.54 & TRN & \\
\hline CHEMBL3192083 & 688340 & 4.75 & 4.9917 & TRN & \\
\hline CHEMBL1417102 & 688340 & 4.35 & 5.2717 & TRN & \\
\hline CHEMBL1458563 & 688340 & 5.45 & 5.1186 & TRN & \\
\hline CHEMBL3190233 & 688340 & 4.6 & 4.9366 & TRN & \\
\hline CHEMBL1467229 & 688340 & 4.55 & 4.898 & TRN & \\
\hline CHEMBL1590171 & 688340 & 4.85 & 5.0602 & TRN & \\
\hline CHEMBL1482275 & 688340 & 4.45 & 4.7405 & TRN & \\
\hline CHEMBL1485014 & 688340 & 5.05 & 4.9919 & TRN & \\
\hline CHEMBL1441370 & 688340 & 4.95 & 4.5142 & TRN & \\
\hline CHEMBL1426992 & 688340 & 4.5 & 4.6402 & TRN & \\
\hline CHEMBL1355244 & 688340 & 4.0 & 5.2183 & TRN & \\
\hline CHEMBL1437436 & 688340 & 5.45 & 5.1548 & TST & \\
\hline CHEMBL1438756 & 688340 & 5.2 & 5.0059 & TRN & \\
\hline CHEMBL1561563 & 688340 & 4.55 & 4.8688 & TRN & \\
\hline CHEMBL1300164 & 688340 & 4.5 & 4.7286 & TRN & \\
\hline CHEMBL1377708 & 688340 & 4.45 & 4.9 & TRN & \\
\hline CHEMBL1557617 & 688340 & 4.6 & 4.6788 & TST & \\
\hline CHEMBL3191500 & 688340 & 4.7 & 5.1294 & TST & \\
\hline CHEMBL1344816 & 688340 & 4.5 & 4.82600 & 00000000005 & TRN \\
\hline CHEMBL1498132 & 688340 & 4.4 & 4.7622 & TST & \\
\hline CHEMBL1336464 & 688340 & 5.05 & 5.4059 & TST & \\
\hline CHEMBL1325726 & 688340 & 4.35 & 5.1684 & TST & \\
\hline CHEMBL1490685 & 688340 & 5.05 & 4.8393 & TST & \\
\hline CHEMBL1503568 & 688340 & 4.65 & 4.9864 & TRN & \\
\hline CHEMBL 2001950 & 688340 & 5.75 & 4.7651 & TRN & \\
\hline CHEMBL1314482 & 688340 & 4.5 & 5.0611 & TRN & \\
\hline CHEMBL1585735 & 688340 & 4.65 & 4.8809 & TRN & \\
\hline
\end{tabular}




\begin{tabular}{|c|c|c|c|c|}
\hline \multicolumn{5}{|c|}{ Supplemental Table S2.txt } \\
\hline CHEMBL1339797 & 688340 & 4.5 & 4.9321 & TRN \\
\hline CHEMBL1589689 & 688340 & 4.4 & 4.7506 & TRN \\
\hline CHEMBL1330075 & 688340 & 6.15 & 4.7189 & TST \\
\hline CHEMBL1313507 & 688340 & 4.8 & 4.8478 & TST \\
\hline CHEMBL1319963 & 688340 & 4.5 & 5.135 & TST \\
\hline CHEMBL1435502 & 688340 & 6.95 & 5.358 & TRN \\
\hline CHEMBL1581312 & 688340 & 4.0 & 4.8406 & TST \\
\hline CHEMBL1418613 & 688340 & 4.55 & 4.8326 & TST \\
\hline CHEMBL1310149 & 688340 & 5.4 & 5.1126 & TST \\
\hline CHEMBL1467040 & 688340 & 4.55 & 4.75 & TST \\
\hline CHEMBL1598397 & 688340 & 5.65 & 5.0023 & TRN \\
\hline CHEMBL1989853 & 688340 & 4.5 & 4.8974 & TRN \\
\hline CHEMBL1402442 & 688340 & 4.65 & 4.7132 & TRN \\
\hline CHEMBL 3145028 & 688340 & 4.55 & 4.9883 & TRN \\
\hline CHEMBL1601462 & 688340 & 6.1 & 5.3943 & TST \\
\hline CHEMBL1472580 & 688340 & 4.65 & 4.9191 & TRN \\
\hline CHEMBL1437147 & 688340 & 4.65 & 4.8389 & TRN \\
\hline CHEMBL577589 & 688340 & 5.0 & 5.0624 & TST \\
\hline CHEMBL1606232 & 688340 & 4.9 & 4.9996 & TST \\
\hline CHEMBL1513929 & 688340 & 4.65 & 4.5115 & TST \\
\hline CHEMBL3194569 & 688340 & 4.5 & 5.146 & TRN \\
\hline CHEMBL1502369 & 688340 & 5.2 & 5.303 & TRN \\
\hline CHEMBL1493936 & 688340 & 5.4 & 4.7209 & TRN \\
\hline CHEMBL1353528 & 688340 & 6.1 & 4.8757 & TRN \\
\hline CHEMBL1512653 & 688340 & 4.5 & 5.3828 & TST \\
\hline CHEMBL1370055 & 688340 & 5.2 & 5.414 & TST \\
\hline CHEMBL1584070 & 688340 & 4.45 & 4.8994 & TST \\
\hline CHEMBL1591604 & 688340 & 4.0 & 5.194 & TST \\
\hline CHEMBL1405515 & 688340 & 5.1 & 4.9601 & TRN \\
\hline CHEMBL1501050 & 688340 & 4.55 & 4.9397 & TRN \\
\hline CHEMBL1494157 & 688340 & 4.7 & 5.1265 & TRN \\
\hline CHEMBL584905 & 688340 & 5.2 & 5.1751 & TRN \\
\hline CHEMBL1556323 & 688340 & 4.6 & 4.5478 & TRN \\
\hline CHEMBL1494156 & 688340 & 5.1 & 5.1964 & TRN \\
\hline CHEMBL1481815 & 688340 & 4.35 & 4.9317 & TRN \\
\hline CHEMBL1536844 & 688340 & 5.3 & 5.0199 & TST \\
\hline CHEMBL1525811 & 688340 & 4.5 & 5.157 & TST \\
\hline CHEMBL1537923 & 688340 & 5.25 & 5.3172 & TRN \\
\hline CHEMBL1362778 & 688340 & 6.0 & 5.3358 & TRN \\
\hline CHEMBL1612236 & 688340 & 4.85 & 4.7783 & TST \\
\hline CHEMBL1407056 & 688340 & 4.55 & 4.9626 & TRN \\
\hline CHEMBL1373731 & 688340 & 4.95 & 5.1605 & TST \\
\hline CHEMBL1555222 & 688340 & 4.6 & 4.9372 & TRN \\
\hline CHEMBL1376101 & 688340 & 4.65 & 5.1502 & TRN \\
\hline CHEMBL1990357 & 688340 & 4.4 & 5.0751 & TRN \\
\hline CHEMBL1499762 & 688340 & 4.6 & 5.0299 & TRN \\
\hline CHEMBL1593900 & 688340 & 4.6 & 5.2822 & TRN \\
\hline CHEMBL1230640 & 688340 & 4.8 & 4.7661 & TRN \\
\hline
\end{tabular}




\begin{tabular}{|c|c|c|c|c|}
\hline \multicolumn{5}{|c|}{ Supplemental Table } \\
\hline CHEMBL1310673 & 688340 & 5.55 & 5.0171 & TST \\
\hline CHEMBL1981928 & 688340 & 4.5 & 5.1284 & TRN \\
\hline CHEMBL1598011 & 688340 & 6.15 & 4.8158 & TRN \\
\hline CHEMBL 3208674 & 688340 & 5.0 & 5.154 & TST \\
\hline CHEMBL1423933 & 688340 & 4.4 & 4.5187 & TST \\
\hline CHEMBL1563095 & 688340 & 4.45 & 5.546 & TRN \\
\hline CHEMBL1424340 & 688340 & 4.85 & 4.973 & TRN \\
\hline CHEMBL1362370 & 688340 & 4.4 & 5.0013 & TRN \\
\hline CHEMBL1464176 & 688340 & 5.0 & 5.2763 & TRN \\
\hline CHEMBL1441686 & 688340 & 5.2 & 5.3537 & TST \\
\hline CHEMBL1468094 & 688340 & 6.5 & 5.1152 & TST \\
\hline CHEMBL1430755 & 688340 & 4.65 & 4.7305 & TRN \\
\hline CHEMBL1451398 & 688340 & 4.55 & 4.8085 & TRN \\
\hline CHEMBL3196463 & 688340 & 4.65 & 4.7538 & TRN \\
\hline CHEMBL1584818 & 688340 & 5.0 & 4.6778 & TRN \\
\hline CHEMBL527584 & 688340 & 4.95 & 4.6126 & TRN \\
\hline CHEMBL1424929 & 688340 & 5.55 & 5.0408 & TRN \\
\hline CHEMBL1536878 & 688340 & 5.1 & 4.9396 & TRN \\
\hline CHEMBL1312523 & 688340 & 4.5 & 4.9195 & TST \\
\hline CHEMBL1546249 & 688340 & 4.45 & 4.5719 & TRN \\
\hline CHEMBL1532544 & 688340 & 5.35 & 4.9024 & TST \\
\hline CHEMBL1411986 & 688340 & 5.4 & 4.9314 & TST \\
\hline CHEMBL1473822 & 688340 & 4.55 & 4.8999 & TST \\
\hline CHEMBL1334834 & 688340 & 6.25 & 5.1032 & TRN \\
\hline CHEMBL1318711 & 688340 & 5.15 & 5.4345 & TRN \\
\hline CHEMBL1350436 & 688340 & 4.4 & 4.9816 & TRN \\
\hline CHEMBL1402157 & 688340 & 4.95 & 5.2511 & TRN \\
\hline CHEMBL1613367 & 688340 & 5.3 & 5.2918 & TRN \\
\hline CHEMBL1533021 & 688340 & 6.15 & 5.4046 & TRN \\
\hline CHEMBL1976638 & 688340 & 5.35 & 4.9194 & TST \\
\hline CHEMBL1601997 & 688340 & 4.8 & 4.9449 & TST \\
\hline CHEMBL1480968 & 688340 & 4.4 & 4.6441 & TRN \\
\hline CHEMBL1335404 & 688340 & 6.05 & 5.1497 & TRN \\
\hline CHEMBL1602864 & 688340 & 4.6 & 4.7894 & TRN \\
\hline CHEMBL1439879 & 688340 & 4.45 & 4.8104 & TRN \\
\hline CHEMBL1987816 & 688340 & 4.55 & 4.9672 & TRN \\
\hline CHEMBL1549833 & 688340 & 6.15 & 4.9476 & TST \\
\hline CHEMBL1473351 & 688340 & 5.0 & 5.0911 & TRN \\
\hline CHEMBL1579831 & 688340 & 5.25 & 5.0094 & TRN \\
\hline CHEMBL1588287 & 688340 & 4.45 & 4.7057 & TST \\
\hline CHEMBL1512445 & 688340 & 5.95 & 5.1474 & TRN \\
\hline CHEMBL1530025 & 688340 & 4.6 & 4.7521 & TRN \\
\hline CHEMBL1531992 & 688340 & 4.55 & 5.1184 & TRN \\
\hline CHEMBL1599905 & 688340 & 4.65 & 4.5982 & TST \\
\hline CHEMBL1561696 & 688340 & 5.2 & 5.0113 & TRN \\
\hline CHEMBL1597775 & 688340 & 4.4 & 4.8197 & TRN \\
\hline CHEMBL1311121 & 688340 & 6.3 & 5.2881 & TST \\
\hline CHEMBL1384470 & 688340 & 4.4 & 4.6333 & TRN \\
\hline
\end{tabular}




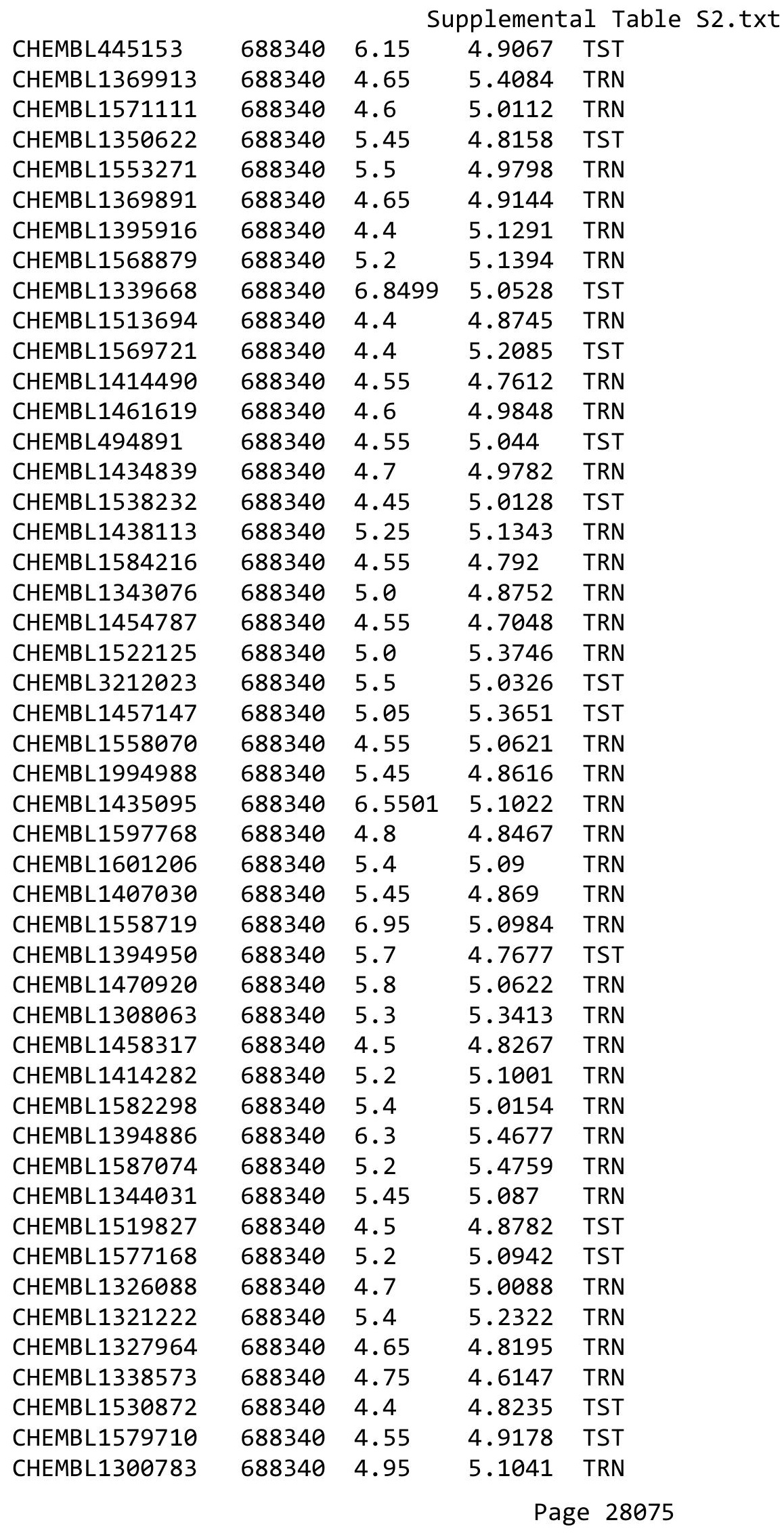




\begin{tabular}{|c|c|c|c|c|}
\hline \multicolumn{5}{|r|}{ al rable } \\
\hline CHEMBL1516942 & 688340 & 4.4 & 4.8746 & TRN \\
\hline CHEMBL1574639 & 688340 & 4.65 & 4.7631 & TRN \\
\hline CHEMBL1490369 & 688340 & 5.65 & 5.0933 & TRN \\
\hline CHEMBL 1402030 & 688340 & 4.55 & 5.0236 & TRN \\
\hline CHEMBL576349 & 688340 & 4.4 & 5.1055 & TRN \\
\hline CHEMBL1419663 & 688340 & 4.45 & 4.9988 & TST \\
\hline CHEMBL1334092 & 688340 & 4.5 & 4.5392 & TRN \\
\hline CHEMBL1472189 & 688340 & 5.0 & 5.2763 & TRN \\
\hline CHEMBL1300890 & 688340 & 4.4 & 5.1346 & TRN \\
\hline CHEMBL1519274 & 688340 & 6.15 & 5.2011 & TST \\
\hline CHEMBL1447830 & 688340 & 5.6 & 4.9706 & TRN \\
\hline CHEMBL267373 & 688340 & 6.6499 & 5.397 & TRN \\
\hline CHEMBL1313982 & 688340 & 4.95 & 4.7628 & TST \\
\hline CHEMBL1445488 & 688340 & 5.2 & 4.8168 & TRN \\
\hline CHEMBL1528726 & 688340 & 4.55 & 4.9162 & TRN \\
\hline CHEMBL1404841 & 688340 & 4.6 & 4.5648 & TRN \\
\hline CHEMBL1560698 & 688340 & 4.6 & 4.8162 & TRN \\
\hline CHEMBL1329125 & 688340 & 5.0 & 5.4078 & TRN \\
\hline CHEMBL1337571 & 688340 & 6.45 & 5.3607 & TRN \\
\hline CHEMBL1521693 & 688340 & 4.55 & 4.8533 & TST \\
\hline CHEMBL1309505 & 688340 & 5.2 & 5.1821 & TRN \\
\hline CHEMBL1500855 & 688340 & 7.0 & 4.8833 & TRN \\
\hline CHEMBL1613199 & 688340 & 4.45 & 4.8657 & TRN \\
\hline CHEMBL 3212642 & 688340 & 4.65 & 5.0748 & TRN \\
\hline CHEMBL1360937 & 688340 & 5.3 & 5.4086 & TRN \\
\hline CHEMBL1378385 & 688340 & 4.85 & 4.77 & TRN \\
\hline CHEMBL1524890 & 688340 & 5.05 & 4.9031 & TRN \\
\hline CHEMBL1569625 & 688340 & 4.45 & 4.7462 & TRN \\
\hline CHEMBL1367450 & 688340 & 4.95 & 5.3849 & TST \\
\hline CHEMBL1404230 & 688340 & 6.8 & 5.2471 & TRN \\
\hline CHEMBL1610961 & 688340 & 4.85 & 4.9002 & TRN \\
\hline CHEMBL1448452 & 688340 & 4.5 & 5.2418 & TRN \\
\hline CHEMBL1519229 & 688340 & 4.5 & 4.8221 & TRN \\
\hline CHEMBL1346180 & 688340 & 6.15 & 5.0633 & TRN \\
\hline CHEMBL 3195488 & 688340 & 5.25 & 5.0217 & TRN \\
\hline CHEMBL1467455 & 688340 & 4.6 & 5.0048 & TST \\
\hline CHEMBL1325219 & 688340 & 5.5 & 5.0592 & TST \\
\hline CHEMBL1386639 & 688340 & 7.699 & 5.2024 & TRN \\
\hline CHEMBL1602562 & 688340 & 4.3 & 4.816 & TRN \\
\hline CHEMBL1605161 & 688340 & 4.4 & 5.0365 & TRN \\
\hline CHEMBL1338816 & 688340 & 7.5003 & 5.2257 & TRN \\
\hline CHEMBL1537727 & 688340 & 4.4 & 5.2312 & TRN \\
\hline CHEMBL3199461 & 688340 & 4.4 & 5.1142 & TRN \\
\hline CHEMBL1431096 & 688340 & 6.45 & 5.38299 & 9999999999 \\
\hline CHEMBL1474359 & 688340 & 6.1 & 5.2983 & TRN \\
\hline CHEMBL450948 & 688340 & 4.6 & 4.9861 & TRN \\
\hline CHEMBL1426985 & 688340 & 4.45 & 4.7512 & TRN \\
\hline CHEMBL1397108 & 688340 & 4.55 & 4.9123 & TST \\
\hline
\end{tabular}




\begin{tabular}{|c|c|c|c|c|c|}
\hline \multicolumn{6}{|c|}{ Supplemental Table S2.txt } \\
\hline CHEMBL1471276 & 688340 & 4.6 & 4.79 & TRN & \\
\hline CHEMBL1593514 & 688340 & 4.45 & 5.2006 & TRN & \\
\hline CHEMBL3193808 & 688340 & 4.9 & 4.9166 & TST & \\
\hline CHEMBL1302941 & 688340 & 5.35 & 5.6162 & TRN & \\
\hline CHEMBL1519283 & 688340 & 6.45 & 5.2334 & TST & \\
\hline CHEMBL261123 & 688340 & 4.5 & 4.7653 & TRN & \\
\hline CHEMBL 3189280 & 688340 & 4.45 & 4.732 & TST & \\
\hline CHEMBL1561413 & 688340 & 6.15 & 5.0531 & TRN & \\
\hline CHEMBL1543320 & 688340 & 4.85 & 5.3548 & TRN & \\
\hline CHEMBL1542839 & 688340 & 5.2 & 4.8855 & TRN & \\
\hline CHEMBL1355655 & 688340 & 4.55 & 4.91 & TRN & \\
\hline CHEMBL1598713 & 688340 & 4.65 & 4.921 & TRN & \\
\hline CHEMBL1329689 & 688340 & 5.5 & 4.7999 & TST & \\
\hline CHEMBL1454948 & 688340 & 4.65 & 5.3352 & TRN & \\
\hline CHEMBL1565649 & 688340 & 4.5 & 5.1737 & TRN & \\
\hline CHEMBL1513100 & 688340 & 4.55 & $5.1610 e$ & 00000000005 & TRN \\
\hline CHEMBL1360734 & 688340 & 4.85 & 4.7656 & TRN & \\
\hline CHEMBL 3198829 & 688340 & 5.55 & 5.1489 & TRN & \\
\hline CHEMBL3194929 & 688340 & 4.6 & 5.1393 & TRN & \\
\hline CHEMBL1503724 & 688340 & 4.6 & 5.0963 & TRN & \\
\hline CHEMBL1384270 & 688340 & 5.2 & 4.7292 & TST & \\
\hline CHEMBL1419812 & 688340 & 4.4 & 5.0636 & TRN & \\
\hline CHEMBL1303883 & 688340 & 6.2 & 5.188 & TRN & \\
\hline CHEMBL1382182 & 688340 & 4.65 & 5.0326 & TST & \\
\hline CHEMBL1302176 & 688340 & 5.2 & 4.9862 & TST & \\
\hline CHEMBL1481411 & 688340 & 4.35 & 5.1806 & TRN & \\
\hline CHEMBL1454997 & 688340 & 4.65 & 4.8893 & TRN & \\
\hline CHEMBL1306664 & 688340 & 5.9 & 5.4612 & TRN & \\
\hline CHEMBL1431858 & 688340 & 4.5 & 5.0444 & TRN & \\
\hline CHEMBL1984703 & 688340 & 4.9 & 4.7562 & TRN & \\
\hline CHEMBL1312235 & 688340 & 4.5 & 4.4751 & TRN & \\
\hline CHEMBL1580249 & 688340 & 5.15 & 4.8205 & TRN & \\
\hline CHEMBL1385413 & 688340 & 5.3 & 4.8248 & TRN & \\
\hline CHEMBL1535609 & 688340 & 4.55 & 5.0037 & TRN & \\
\hline CHEMBL1395490 & 688340 & 4.4 & 5.1357 & TRN & \\
\hline CHEMBL1393881 & 688340 & 5.05 & 4.9645 & TRN & \\
\hline CHEMBL1333033 & 688340 & 4.35 & 5.1658 & TRN & \\
\hline CHEMBL1494451 & 688340 & 5.15 & 4.7658 & TST & \\
\hline CHEMBL1375375 & 688340 & 4.8 & 4.8573 & TRN & \\
\hline CHEMBL1363368 & 688340 & 4.65 & 5.0569 & TRN & \\
\hline CHEMBL1357216 & 688340 & 5.0 & 5.2084 & TRN & \\
\hline CHEMBL1577826 & 688340 & 5.05 & 4.9015 & TST & \\
\hline CHEMBL1318210 & 688340 & 4.6 & 4.8208 & TRN & \\
\hline CHEMBL1406151 & 688340 & 4.5 & 4.7024 & TRN & \\
\hline CHEMBL1474082 & 688340 & 4.35 & 5.2629 & TRN & \\
\hline CHEMBL1477748 & 688340 & 4.4 & 5.1801 & TRN & \\
\hline CHEMBL1421327 & 688340 & 4.6 & 4.6258 & TRN & \\
\hline CHEMBL1424310 & 688340 & 6.2 & 5.0931 & TRN & \\
\hline
\end{tabular}




\begin{tabular}{|c|c|c|c|c|c|}
\hline & & \multicolumn{4}{|c|}{ Supplemental Table S2.txt } \\
\hline CHEMBL1301250 & 688340 & 5.45 & 4.9827 & TST & \\
\hline CHEMBL1433459 & 688340 & 5.1 & 4.9624 & TRN & \\
\hline CHEMBL3198921 & 688340 & 5.45 & 4.9687 & TRN & \\
\hline CHEMBL1453649 & 688340 & 4.5 & 4.9257 & TRN & \\
\hline CHEMBL1404361 & 688340 & 4.5 & 4.9587 & TRN & \\
\hline CHEMBL1414095 & 688340 & 7.0 & 5.6052 & TST & \\
\hline CHEMBL 2001396 & 688340 & 5.75 & 4.9024 & TRN & \\
\hline CHEMBL1438071 & 688340 & 4.55 & 4.4919 & TRN & \\
\hline CHEMBL1344712 & 688340 & 5.2 & 4.7769 & TRN & \\
\hline CHEMBL1481771 & 688340 & 5.55 & 4.9784 & TST & \\
\hline CHEMBL1364573 & 688340 & 4.5 & 4.6917 & TST & \\
\hline CHEMBL1347010 & 688340 & 7.4498 & 5.4895 & TRN & \\
\hline CHEMBL1402297 & 688340 & 6.45 & 5.178 & TRN & \\
\hline CHEMBL1527083 & 688340 & 6.45 & 5.5168 & TST & \\
\hline CHEMBL1385654 & 688340 & 5.0 & 4.8938 & TRN & \\
\hline CHEMBL3195665 & 688340 & 4.45 & 5.4193 & TRN & \\
\hline CHEMBL1423537 & 688340 & 4.7 & 4.7676 & TRN & \\
\hline CHEMBL1367847 & 688340 & 5.9 & 5.29706 & 0000000001 & TRN \\
\hline CHEMBL3212972 & 688340 & 4.5 & 4.8191 & TRN & \\
\hline CHEMBL1318300 & 688340 & 4.5 & 4.9376 & TRN & \\
\hline CHEMBL1547605 & 688340 & 4.55 & 4.8013 & TRN & \\
\hline CHEMBL1427994 & 688340 & 7.0 & 5.3911 & TST & \\
\hline CHEMBL1429766 & 688340 & 5.05 & 5.1196 & TRN & \\
\hline CHEMBL1533166 & 688340 & 4.6 & 4.7095 & TRN & \\
\hline CHEMBL1482199 & 688340 & 4.5 & 4.8232 & TST & \\
\hline CHEMBL3195133 & 688340 & 4.35 & 5.0332 & TRN & \\
\hline CHEMBL1427635 & 688340 & 5.2 & 5.1929 & TST & \\
\hline CHEMBL1380715 & 688340 & 5.25 & 5.1333 & TST & \\
\hline CHEMBL1590478 & 688340 & 3.0 & 5.2023 & TST & \\
\hline CHEMBL1316857 & 688340 & 4.5 & 5.0828 & TRN & \\
\hline CHEMBL1546601 & 688340 & 5.65 & 4.9195 & TRN & \\
\hline CHEMBL151146 & 688340 & 4.5 & 4.968 & TRN & \\
\hline CHEMBL1411403 & 688340 & 4.6 & 4.6479 & TRN & \\
\hline CHEMBL1351958 & 688340 & 4.5 & 5.0115 & TRN & \\
\hline CHEMBL1417476 & 688340 & 4.4 & 5.0431 & TST & \\
\hline CHEMBL582290 & 688340 & 4.4 & 5.1494 & TRN & \\
\hline CHEMBL3191969 & 688340 & 4.4 & 4.8068 & TRN & \\
\hline CHEMBL1568537 & 688340 & 4.5 & 4.7514 & TRN & \\
\hline CHEMBL1577761 & 688340 & 6.05 & 5.4559 & TRN & \\
\hline CHEMBL 2007438 & 688340 & 4.65 & 5.0286 & TRN & \\
\hline CHEMBL1503613 & 688340 & 3.95 & 5.1137 & TRN & \\
\hline CHEMBL1500272 & 688340 & 4.35 & 5.0999 & TRN & \\
\hline CHEMBL1323774 & 688340 & 4.6 & 4.6347 & TRN & \\
\hline CHEMBL1423551 & 688340 & 4.55 & 4.9469 & TRN & \\
\hline CHEMBL1351425 & 688340 & 4.5 & 4.8902 & TRN & \\
\hline CHEMBL1446088 & 688340 & 4.9 & 5.2158 & TRN & \\
\hline CHEMBL1426910 & 688340 & 4.45 & 5.0606 & TST & \\
\hline CHEMBL1534986 & 688340 & 4.65 & 4.744 & TRN & \\
\hline
\end{tabular}




\begin{tabular}{|c|c|c|c|c|c|}
\hline \multicolumn{6}{|c|}{ Supplemental Table S2.txt } \\
\hline CHEMBL1502359 & 688340 & 4.65 & 4.7741 & TST & \\
\hline CHEMBL3198600 & 688340 & 4.75 & 5.1964 & TRN & \\
\hline CHEMBL1310638 & 688340 & 4.6 & 4.7662 & TST & \\
\hline CHEMBL1307882 & 688340 & 4.5 & 4.8704 & TST & \\
\hline CHEMBL1365572 & 688340 & 7.0 & 5.2783 & TST & \\
\hline CHEMBL1257234 & 688340 & 4.5 & 4.8433 & TRN & \\
\hline CHEMBL3210442 & 688340 & 4.45 & 4.8345 & TST & \\
\hline CHEMBL1419657 & 688340 & 4.55 & 5.104 & TRN & \\
\hline CHEMBL1598380 & 688340 & 6.15 & 5.0684 & TST & \\
\hline CHEMBL1319440 & 688340 & 5.2 & 4.9577 & TST & \\
\hline CHEMBL1328104 & 688340 & 4.45 & 4.8037 & TRN & \\
\hline CHEMBL1359216 & 688340 & 5.5 & 4.8741 & TST & \\
\hline CHEMBL1374335 & 688340 & 4.6 & 4.6583 & TRN & \\
\hline CHEMBL 3189262 & 688340 & 4.55 & 4.7804 & TRN & \\
\hline CHEMBL1416655 & 688340 & 4.6 & 4.8466 & TRN & \\
\hline CHEMBL1318330 & 688340 & 5.2 & 4.7689 & TRN & \\
\hline CHEMBL1383812 & 688340 & 4.5 & 4.9058 & TST & \\
\hline CHEMBL1575524 & 688340 & 5.25 & 5.4064 & TRN & \\
\hline CHEMBL1352950 & 688340 & 4.8 & 5.2867 & TST & \\
\hline CHEMBL1461474 & 688340 & 6.25 & 5.3889 & TRN & \\
\hline CHEMBL3191389 & 688340 & 4.85 & 4.845 & TRN & \\
\hline CHEMBL1588455 & 688340 & 5.2 & 5.1269 & TRN & \\
\hline CHEMBL1588128 & 688340 & 4.95 & 5.0319 & TRN & \\
\hline CHEMBL1610480 & 688340 & 4.6 & 4.8113 & TRN & \\
\hline CHEMBL1329552 & 688340 & 5.45 & 5.0334 & TRN & \\
\hline CHEMBL1446425 & 688340 & 6.45 & 4.9805 & TST & \\
\hline CHEMBL1317226 & 688340 & 4.4 & 5.2581 & TRN & \\
\hline CHEMBL1348898 & 688340 & 5.15 & 5.3415 & TRN & \\
\hline CHEMBL1469705 & 688340 & 4.45 & 4.7595 & TST & \\
\hline CHEMBL1413158 & 688340 & 5.35 & 5.4109 & TST & \\
\hline CHEMBL3210415 & 688340 & 5.85 & 4.9113 & TRN & \\
\hline CHEMBL1535540 & 688340 & 4.4 & 5.039 & TRN & \\
\hline CHEMBL1333760 & 688340 & 4.45 & 4.8635 & TRN & \\
\hline CHEMBL1324944 & 688340 & 4.7 & 4.9294 & TRN & \\
\hline CHEMBL1483264 & 688340 & 6.05 & 5.36299 & 99999999995 & TRN \\
\hline CHEMBL1381318 & 688340 & 4.55 & 4.9556 & TRN & \\
\hline CHEMBL1523648 & 688340 & 7.0 & 5.2613 & TRN & \\
\hline CHEMBL1405112 & 688340 & 4.4 & 4.8209 & TRN & \\
\hline CHEMBL1556541 & 688340 & 5.6 & 5.204 & TRN & \\
\hline CHEMBL1570612 & 688340 & 4.4 & 4.8668 & TRN & \\
\hline CHEMBL1452027 & 688340 & 4.6 & 4.8792 & TST & \\
\hline CHEMBL1608424 & 688340 & 4.5 & 4.7016 & TRN & \\
\hline CHEMBL1545801 & 688340 & 4.95 & 4.8913 & TRN & \\
\hline CHEMBL1608893 & 688340 & 4.45 & 4.8527 & TRN & \\
\hline CHEMBL1473694 & 688340 & 4.6 & 5.1256 & TRN & \\
\hline CHEMBL1305050 & 688340 & 5.3 & 4.9136 & TRN & \\
\hline CHEMBL1583445 & 688340 & 5.3 & 5.3787 & TST & \\
\hline CHEMBL1513299 & 688340 & 4.4 & 4.8495 & TST & \\
\hline
\end{tabular}




\begin{tabular}{|c|c|c|c|c|c|}
\hline & & \multicolumn{4}{|c|}{ Supplemental Table S2.txt } \\
\hline CHEMBL1577153 & 688340 & 7.0501 & 5.1214 & TST & \\
\hline CHEMBL1516044 & 688340 & 5.2 & 4.9604 & TST & \\
\hline CHEMBL1350132 & 688340 & 4.55 & 5.0254 & TRN & \\
\hline CHEMBL1597979 & 688340 & 5.4 & 5.2394 & TRN & \\
\hline CHEMBL1416244 & 688340 & 4.6 & 4.9627 & TRN & \\
\hline CHEMBL1394791 & 688340 & 5.65 & 5.4055 & TRN & \\
\hline CHEMBL1535916 & 688340 & 4.65 & 5.0834 & TST & \\
\hline CHEMBL1573731 & 688340 & 6.25 & 4.909 & TRN & \\
\hline CHEMBL1559469 & 688340 & 5.15 & 5.2124 & TST & \\
\hline CHEMBL1319030 & 688340 & 4.4 & 4.7911 & TST & \\
\hline CHEMBL1312507 & 688340 & 4.55 & 4.9743 & TST & \\
\hline CHEMBL1325513 & 688340 & 4.65 & 4.896 & TRN & \\
\hline CHEMBL1376983 & 688340 & 6.0 & 5.4899 & TST & \\
\hline CHEMBL1565444 & 688340 & 4.55 & 4.7075 & TRN & \\
\hline CHEMBL1518778 & 688340 & 4.6 & 4.9229 & TRN & \\
\hline CHEMBL1343939 & 688340 & 4.75 & 4.8815 & TST & \\
\hline CHEMBL1429069 & 688340 & 4.9 & 4.7098 & TRN & \\
\hline CHEMBL1565341 & 688340 & 5.0 & 5.10800 & 00000000005 & TRN \\
\hline CHEMBL1333993 & 688340 & 4.65 & 4.6134 & TRN & \\
\hline CHEMBL1525775 & 688340 & 4.65 & 4.6005 & TRN & \\
\hline CHEMBL1380892 & 688340 & 6.15 & 5.244 & TRN & \\
\hline CHEMBL1594156 & 688340 & 5.5 & 4.9738 & TST & \\
\hline CHEMBL1365324 & 688340 & 4.45 & 4.9316 & TST & \\
\hline CHEMBL1567134 & 688340 & 4.55 & 4.8644 & TRN & \\
\hline CHEMBL1485442 & 688340 & 6.45 & 4.9517 & TST & \\
\hline CHEMBL481049 & 688340 & 7.4001 & 5.1466 & TRN & \\
\hline CHEMBL1447137 & 688340 & 4.6 & 4.7758 & TRN & \\
\hline CHEMBL1345037 & 688340 & 4.7 & 4.9794 & TRN & \\
\hline CHEMBL1331415 & 688340 & 4.85 & 4.7729 & TRN & \\
\hline CHEMBL3208980 & 688340 & 5.9 & 4.7038 & TRN & \\
\hline CHEMBL3195177 & 688340 & 4.5 & 4.8601 & TRN & \\
\hline CHEMBL1427520 & 688340 & 4.75 & 4.8122 & TRN & \\
\hline CHEMBL1533014 & 688340 & 5.45 & 5.3455 & TRN & \\
\hline CHEMBL1537135 & 688340 & 4.7 & 5.1669 & TRN & \\
\hline CHEMBL1486420 & 688340 & 4.3 & 4.726 & TST & \\
\hline CHEMBL1165723 & 688340 & 4.8 & 4.8375 & TRN & \\
\hline CHEMBL1594105 & 688340 & 5.45 & 4.9432 & TRN & \\
\hline CHEMBL1308055 & 688340 & 4.55 & 4.7642 & TST & \\
\hline CHEMBL1522966 & 688340 & 4.55 & 5.2994 & TRN & \\
\hline CHEMBL1399767 & 688340 & 4.8 & 4.8535 & TRN & \\
\hline CHEMBL1322906 & 688340 & 4.6 & 4.8983 & TST & \\
\hline CHEMBL1374987 & 688340 & 4.75 & 4.776 & TST & \\
\hline CHEMBL1590832 & 688340 & 4.7 & 4.9134 & TRN & \\
\hline CHEMBL551883 & 688340 & 4.5 & 4.7322 & TST & \\
\hline CHEMBL1370800 & 688340 & 4.85 & 5.0275 & TST & \\
\hline CHEMBL1372102 & 688340 & 4.65 & 4.9803 & TST & \\
\hline CHEMBL1494755 & 688340 & 5.4 & 5.0538 & TRN & \\
\hline CHEMBL1328921 & 688340 & 5.15 & 5.0363 & TRN & \\
\hline
\end{tabular}




\begin{tabular}{|c|c|c|c|c|}
\hline \multicolumn{5}{|c|}{ Supplemental Table S2.txt } \\
\hline CHEMBL1575014 & 688340 & 4.4 & 5.0864 & TRN \\
\hline CHEMBL3198798 & 688340 & 5.0 & 5.0669 & TST \\
\hline CHEMBL1420076 & 688340 & 4.35 & 5.1938 & TRN \\
\hline CHEMBL1574206 & 688340 & 4.45 & 4.9684 & TST \\
\hline CHEMBL1599238 & 688340 & 5.55 & 5.2128 & TRN \\
\hline CHEMBL1450217 & 688340 & 4.45 & 5.1447 & TST \\
\hline CHEMBL1310844 & 688340 & 4.55 & 5.2014 & TRN \\
\hline CHEMBL1350637 & 688340 & 5.0 & 4.7101 & TRN \\
\hline CHEMBL1369631 & 688340 & 5.6 & 4.7272 & TRN \\
\hline CHEMBL1465016 & 688340 & 5.7 & 5.0686 & TRN \\
\hline CHEMBL1405445 & 688340 & 5.45 & 5.0794 & TST \\
\hline CHEMBL1506241 & 688340 & 4.9 & 4.7921 & TRN \\
\hline CHEMBL1342752 & 688340 & 6.15 & 5.265 & TST \\
\hline CHEMBL1420640 & 688340 & 5.05 & 5.04 & TRN \\
\hline CHEMBL1512382 & 688340 & 4.45 & 5.0988 & TST \\
\hline CHEMBL1325810 & 688340 & 6.45 & 5.2434 & TRN \\
\hline CHEMBL1550662 & 688340 & 4.85 & 5.0347 & TRN \\
\hline CHEMBL1451599 & 688340 & 4.85 & 5.2009 & TRN \\
\hline CHEMBL1575378 & 688340 & 4.75 & 5.1281 & TST \\
\hline CHEMBL1596753 & 688340 & 4.65 & 4.6477 & TRN \\
\hline CHEMBL1511276 & 688340 & 4.85 & 5.0156 & TRN \\
\hline CHEMBL1528932 & 688340 & 5.3 & 4.9532 & TST \\
\hline CHEMBL1409150 & 688340 & 5.2 & 5.2365 & TST \\
\hline CHEMBL1970118 & 688340 & 4.45 & 4.9593 & TRN \\
\hline CHEMBL3191860 & 688340 & 4.55 & 5.4132 & TRN \\
\hline CHEMBL1310569 & 688340 & 4.4 & 4.8679 & TST \\
\hline CHEMBL1443701 & 688340 & 4.55 & 4.7893 & TRN \\
\hline CHEMBL1502716 & 688340 & 4.55 & 4.5838 & TST \\
\hline CHEMBL1299352 & 688340 & 4.4 & 5.0353 & TST \\
\hline CHEMBL1572912 & 688340 & 4.4 & 5.2652 & TRN \\
\hline CHEMBL1599175 & 688340 & 4.6 & 4.6949 & TRN \\
\hline CHEMBL 3235884 & 688340 & 4.4 & 4.928 & TRN \\
\hline CHEMBL1584338 & 688340 & 5.15 & 5.1026 & TST \\
\hline CHEMBL1523660 & 688340 & 4.5 & 4.9498 & TRN \\
\hline CHEMBL1598695 & 688340 & 4.45 & 5.1448 & TRN \\
\hline CHEMBL1326229 & 688340 & 4.45 & 4.6898 & TRN \\
\hline CHEMBL1360607 & 688340 & 4.55 & 5.0492 & TST \\
\hline CHEMBL1489465 & 688340 & 5.4 & 5.4148 & TRN \\
\hline CHEMBL1549631 & 688340 & 4.45 & 5.0601 & TRN \\
\hline CHEMBL1334633 & 688340 & 5.5 & 5.1002 & TRN \\
\hline CHEMBL1512656 & 688340 & 4.4 & 5.2854 & TRN \\
\hline CHEMBL1514952 & 688340 & 7.0 & 5.4645 & TRN \\
\hline CHEMBL1531305 & 688340 & 4.65 & 5.0045 & TRN \\
\hline CHEMBL1394210 & 688340 & 5.35 & 5.1305 & TRN \\
\hline CHEMBL1601650 & 688340 & 4.5 & 4.8536 & TST \\
\hline CHEMBL1312303 & 688340 & 4.95 & 4.9075 & TRN \\
\hline CHEMBL1573569 & 688340 & 4.85 & 4.7734 & TRN \\
\hline CHEMBL1498402 & 688340 & 4.4 & 5.1895 & TST \\
\hline
\end{tabular}




\begin{tabular}{|c|c|c|c|c|}
\hline \multicolumn{5}{|c|}{ Supplemental Table S2.txt } \\
\hline CHEMBL1404493 & 688340 & 6.0 & 4.6263 & TRN \\
\hline CHEMBL3198108 & 688340 & 4.75 & 4.9803 & TRN \\
\hline CHEMBL3197711 & 688340 & 4.4 & 4.7349 & TST \\
\hline CHEMBL1606433 & 688340 & 4.55 & 4.9223 & TST \\
\hline CHEMBL1428143 & 688340 & 4.45 & 5.4759 & TST \\
\hline CHEMBL1356956 & 688340 & 6.15 & 5.4633 & TRN \\
\hline CHEMBL1405810 & 688340 & 4.4 & 4.7526 & TST \\
\hline CHEMBL1346814 & 688340 & 4.8 & 5.0931 & TRN \\
\hline CHEMBL1466164 & 688340 & 4.5 & 4.3899 & TRN \\
\hline CHEMBL1475222 & 688340 & 4.35 & 5.3457 & TRN \\
\hline CHEMBL1301677 & 688340 & 6.0 & 4.8937 & TRN \\
\hline CHEMBL1579947 & 688340 & 7.0 & 5.1672 & TRN \\
\hline CHEMBL1965791 & 688340 & 4.4 & 4.8987 & TRN \\
\hline CHEMBL1339902 & 688340 & 4.75 & 5.0534 & TRN \\
\hline CHEMBL1443462 & 688340 & 5.5 & 5.056 & TRN \\
\hline CHEMBL1491210 & 688340 & 4.5 & 4.8271 & TRN \\
\hline CHEMBL1334865 & 688340 & 6.0 & 5.1004 & TST \\
\hline CHEMBL1428248 & 688340 & 5.7 & 5.0222 & TRN \\
\hline CHEMBL1347030 & 688340 & 4.9 & 4.8344 & TRN \\
\hline CHEMBL1488985 & 688340 & 4.95 & 5.5104 & TRN \\
\hline CHEMBL1382223 & 688340 & 7.0501 & 5.13 & TRN \\
\hline CHEMBL1579973 & 688340 & 5.0 & 4.3929 & TRN \\
\hline CHEMBL3209171 & 688340 & 4.4 & 5.0136 & TRN \\
\hline CHEMBL1344103 & 688340 & 4.5 & 4.6144 & TRN \\
\hline CHEMBL1320170 & 688340 & 5.25 & 4.9273 & TRN \\
\hline CHEMBL1331262 & 688340 & 6.4 & 5.1552 & TST \\
\hline CHEMBL1588239 & 688340 & 6.1 & 5.3927 & TRN \\
\hline CHEMBL1987136 & 688340 & 4.9 & 4.981 & TRN \\
\hline CHEMBL1310972 & 688340 & 4.55 & 4.7123 & TRN \\
\hline CHEMBL1341838 & 688340 & 4.6 & 5.0448 & TRN \\
\hline CHEMBL1605205 & 688340 & 5.15 & 5.5198 & TRN \\
\hline CHEMBL1333831 & 688340 & 4.55 & 4.812 & TRN \\
\hline CHEMBL1404802 & 688340 & 4.5 & 4.8646 & TST \\
\hline CHEMBL1375407 & 688340 & 4.55 & 4.8471 & TST \\
\hline CHEMBL1369834 & 688340 & 4.95 & 4.9105 & TRN \\
\hline CHEMBL3209342 & 688340 & 5.3 & 4.5983 & TRN \\
\hline CHEMBL 1445840 & 688340 & 4.4 & 4.9667 & TRN \\
\hline CHEMBL1602302 & 688340 & 6.35 & 5.402 & TRN \\
\hline CHEMBL1534825 & 688340 & 5.7 & 5.5717 & TRN \\
\hline CHEMBL1550873 & 688340 & 6.8499 & 5.1623 & TRN \\
\hline CHEMBL1465049 & 688340 & 4.5 & 4.6225 & TRN \\
\hline CHEMBL3145033 & 688340 & 4.5 & 5.0771 & TST \\
\hline CHEMBL1591932 & 688340 & 5.5 & 5.2458 & TRN \\
\hline CHEMBL1402669 & 688340 & 4.55 & 4.835 & TRN \\
\hline CHEMBL1613243 & 688340 & 4.4 & 4.7544 & TRN \\
\hline CHEMBL1530296 & 688340 & 4.7 & 5.0603 & TRN \\
\hline CHEMBL1321044 & 688340 & 7.0 & 5.1978 & TRN \\
\hline CHEMBL1588210 & 688340 & 4.55 & 4.8051 & TRN \\
\hline
\end{tabular}




\begin{tabular}{|c|c|c|c|c|c|}
\hline \multicolumn{6}{|c|}{ Supplemental Table S2.txt } \\
\hline CHEMBL1350599 & 688340 & 5.75 & 5.0112 & TRN & \\
\hline CHEMBL1304438 & 688340 & 5.9 & 5.1364 & TST & \\
\hline CHEMBL1456530 & 688340 & 4.55 & 5.072 & TRN & \\
\hline CHEMBL1307565 & 688340 & 6.1 & 5.7923 & TRN & \\
\hline CHEMBL1448440 & 688340 & 4.4 & 4.9141 & TRN & \\
\hline CHEMBL3212689 & 688340 & 5.6 & 5.0494 & TST & \\
\hline CHEMBL1434930 & 688340 & 4.6 & 4.8835 & TRN & \\
\hline CHEMBL1388870 & 688340 & 5.1 & 4.8176 & TRN & \\
\hline CHEMBL1540982 & 688340 & 4.55 & 4.8336 & TRN & \\
\hline CHEMBL1492565 & 688340 & 4.65 & 4.9419 & TRN & \\
\hline CHEMBL1349631 & 688340 & 4.4 & 4.7228 & TRN & \\
\hline CHEMBL1509034 & 688340 & 5.0 & 4.869 & TRN & \\
\hline CHEMBL1393965 & 688340 & 4.75 & 4.9761 & TST & \\
\hline CHEMBL1511195 & 688340 & 6.9 & 5.5801 & TRN & \\
\hline CHEMBL1542181 & 688340 & 5.2 & 5.2068 & TRN & \\
\hline CHEMBL1345026 & 688340 & 4.8 & 4.9917 & TRN & \\
\hline CHEMBL1526325 & 688340 & 4.6 & 4.9105 & TRN & \\
\hline CHEMBL1584562 & 688340 & 4.8 & 4.9066 & TRN & \\
\hline CHEMBL1562087 & 688340 & 5.0 & 5.2046 & TST & \\
\hline CHEMBL1609866 & 688340 & 4.6 & 4.9796 & TRN & \\
\hline CHEMBL1487054 & 688340 & 6.1 & 5.0952 & TRN & \\
\hline CHEMBL1560144 & 688340 & 4.5 & 4.7609 & TRN & \\
\hline CHEMBL1313681 & 688340 & 5.25 & 5.0824 & TRN & \\
\hline CHEMBL1508593 & 688340 & 4.6 & 5.0532 & TRN & \\
\hline CHEMBL1311868 & 688340 & 4.55 & 4.8519 & TRN & \\
\hline CHEMBL3208443 & 688340 & 4.6 & 4.8652 & TRN & \\
\hline CHEMBL1539624 & 688340 & 4.5 & 4.757 & TRN & \\
\hline CHEMBL1493511 & 688340 & 5.2 & 5.4273 & TRN & \\
\hline CHEMBL1439560 & 688340 & 6.8499 & 5.0068 & TST & \\
\hline CHEMBL1512684 & 688340 & 4.7 & 5.0219 & TRN & \\
\hline CHEMBL1477316 & 688340 & 4.35 & 5.0044 & TRN & \\
\hline CHEMBL1299527 & 688340 & 5.6 & 4.88399 & 99999999995 & TRN \\
\hline CHEMBL1610987 & 688340 & 5.15 & 4.8548 & TST & \\
\hline CHEMBL1523475 & 688340 & 4.55 & 4.9582 & TRN & \\
\hline CHEMBL 2007218 & 688340 & 5.5 & 5.0425 & TRN & \\
\hline CHEMBL1554509 & 688340 & 4.55 & 5.095 & TRN & \\
\hline CHEMBL1489113 & 688340 & 5.0 & 5.0306 & TRN & \\
\hline CHEMBL1594882 & 688340 & 5.05 & 5.2575 & TRN & \\
\hline CHEMBL1312846 & 688340 & 5.0 & 5.2052 & TRN & \\
\hline CHEMBL1563705 & 688340 & 4.5 & 4.9768 & TST & \\
\hline CHEMBL1445420 & 688340 & 5.9 & 5.0902 & TST & \\
\hline CHEMBL1337580 & 688340 & 4.35 & 5.1839 & TRN & \\
\hline CHEMBL1471102 & 688340 & 4.5 & 5.0937 & TRN & \\
\hline CHEMBL1479448 & 688340 & 5.2 & 5.2906 & TST & \\
\hline CHEMBL1347567 & 688340 & 5.4 & 5.0812 & TST & \\
\hline CHEMBL1597130 & 688340 & 4.5 & 5.0814 & TRN & \\
\hline CHEMBL1611650 & 688340 & 4.4 & 4.8395 & TST & \\
\hline CHEMBL1570827 & 688340 & 5.15 & 4.824 & TRN & \\
\hline
\end{tabular}




\begin{tabular}{|c|c|c|c|c|}
\hline \multicolumn{5}{|c|}{ Supplemental Table S2.txt } \\
\hline CHEMBL1523090 & 688340 & 4.7 & 4.9188 & TRN \\
\hline CHEMBL1541487 & 688340 & 4.45 & 4.6868 & TST \\
\hline CHEMBL1530785 & 688340 & 5.9 & 5.4432 & TRN \\
\hline CHEMBL1545947 & 688340 & 5.45 & 5.4488 & TST \\
\hline CHEMBL1560141 & 688340 & 5.1 & 4.856 & TRN \\
\hline CHEMBL1397288 & 688340 & 5.0 & 4.8732 & TRN \\
\hline CHEMBL1492023 & 688340 & 3.95 & 5.0041 & TST \\
\hline CHEMBL3211676 & 688340 & 4.4 & 4.9379 & TRN \\
\hline CHEMBL1387920 & 688340 & 4.6 & 5.3542 & TST \\
\hline CHEMBL1338970 & 688340 & 5.35 & 4.8419 & TRN \\
\hline CHEMBL1355885 & 688340 & 4.55 & 4.7918 & TST \\
\hline CHEMBL1542752 & 688340 & 4.55 & 4.5664 & TST \\
\hline CHEMBL1593198 & 688340 & 4.65 & 5.5044 & TRN \\
\hline CHEMBL1374487 & 688340 & 4.5 & 4.8809 & TRN \\
\hline CHEMBL3187659 & 688340 & 4.6 & 4.8789 & TRN \\
\hline CHEMBL1589087 & 688340 & 4.9 & 4.7857 & TRN \\
\hline CHEMBL1488270 & 688340 & 4.6 & 5.1432 & TRN \\
\hline CHEMBL1517881 & 688340 & 4.85 & 4.9524 & TRN \\
\hline CHEMBL1564327 & 688340 & 4.35 & 5.4285 & TRN \\
\hline CHEMBL1379132 & 688340 & 5.2 & 4.9568 & TST \\
\hline CHEMBL1456189 & 688340 & 5.2 & 5.035 & TRN \\
\hline CHEMBL1456171 & 688340 & 5.75 & 5.4872 & TRN \\
\hline CHEMBL1457578 & 688340 & 6.1 & 5.273 & TRN \\
\hline CHEMBL1590936 & 688340 & 4.4 & 4.8897 & TRN \\
\hline CHEMBL3197963 & 688340 & 4.85 & 4.3933 & TST \\
\hline CHEMBL1319601 & 688340 & 4.9 & 4.7624 & TST \\
\hline CHEMBL1354163 & 688340 & 4.45 & 5.0773 & TRN \\
\hline CHEMBL1398790 & 688340 & 4.55 & 4.6935 & TRN \\
\hline CHEMBL1574176 & 688340 & 4.55 & 4.9625 & TRN \\
\hline CHEMBL1563902 & 688340 & 4.6 & 5.0269 & TRN \\
\hline CHEMBL1537036 & 688340 & 4.4 & 5.1994 & TRN \\
\hline CHEMBL1463019 & 688340 & 5.25 & 5.0805 & TRN \\
\hline CHEMBL1444456 & 688340 & 4.45 & 5.0385 & TRN \\
\hline CHEMBL1544909 & 688340 & 4.55 & 5.2041 & TRN \\
\hline CHEMBL1544325 & 688340 & 6.1 & 5.2019 & TRN \\
\hline CHEMBL3195793 & 688340 & 4.55 & 4.9059 & TRN \\
\hline CHEMBL3194962 & 688340 & 5.0 & 4.8655 & TRN \\
\hline CHEMBL1379102 & 688340 & 4.45 & 5.4933 & TRN \\
\hline CHEMBL1457254 & 688340 & 6.5 & 5.3178 & TST \\
\hline CHEMBL1564280 & 688340 & 3.4 & 5.0306 & TRN \\
\hline CHEMBL1549036 & 688340 & 5.2 & 4.9674 & TST \\
\hline CHEMBL1341815 & 688340 & 4.8 & 4.8826 & TRN \\
\hline CHEMBL1603337 & 688340 & 5.2 & 4.9748 & TST \\
\hline CHEMBL1611853 & 688340 & 4.55 & 4.9418 & TRN \\
\hline CHEMBL1562072 & 688340 & 7.6003 & 5.2677 & TRN \\
\hline CHEMBL1426759 & 688340 & 5.0 & 5.0262 & TRN \\
\hline CHEMBL1533230 & 688340 & 5.45 & 5.4059 & TRN \\
\hline CHEMBL1353221 & 688340 & 5.5 & 4.9461 & TST \\
\hline
\end{tabular}




\begin{tabular}{|c|c|c|c|c|c|}
\hline \multicolumn{6}{|c|}{ Supplemental Table s2.txt } \\
\hline CHEMBL1509312 & 688340 & 5.35 & 5.3256 & TRN & \\
\hline CHEMBL1495121 & 688340 & 4.8 & 5.0369 & TRN & \\
\hline CHEMBL1320175 & 688340 & 5.5 & 4.9349 & TRN & \\
\hline CHEMBL3192296 & 688340 & 4.5 & 5.1405 & TRN & \\
\hline CHEMBL1542238 & 688340 & 5.2 & 5.3816 & TRN & \\
\hline CHEMBL1555752 & 688340 & 4.85 & 5.0697 & TRN & \\
\hline CHEMBL1379852 & 688340 & 4.5 & 4.6993 & TRN & \\
\hline CHEMBL1428621 & 688340 & 5.2 & 5.1072 & TST & \\
\hline CHEMBL1347594 & 688340 & 4.55 & 4.8477 & TRN & \\
\hline CHEMBL1466996 & 688340 & 4.45 & 5.0258 & TST & \\
\hline CHEMBL1599440 & 688340 & 7.1002 & 5.1226 & TRN & \\
\hline CHEMBL3199879 & 688340 & 4.55 & 4.6944 & TRN & \\
\hline CHEMBL1530121 & 688340 & 6.0 & 4.8525 & TST & \\
\hline CHEMBL1573558 & 688340 & 5.0 & 5.1259 & TRN & \\
\hline CHEMBL3144995 & 688340 & 4.6 & 5.2495 & TRN & \\
\hline CHEMBL1477039 & 688340 & 5.15 & 4.9958 & TRN & \\
\hline CHEMBL3198468 & 688340 & 5.2 & 5.0714 & TRN & \\
\hline CHEMBL1341432 & 688340 & 4.7 & 4.9323 & TRN & \\
\hline CHEMBL1579064 & 688340 & 5.2 & 5.1323 & TRN & \\
\hline CHEMBL3213697 & 688340 & 4.4 & 4.8918 & TRN & \\
\hline CHEMBL1507788 & 688340 & 4.5 & 5.2973 & TRN & \\
\hline CHEMBL1332873 & 688340 & 5.5 & 4.6779 & TRN & \\
\hline CHEMBL1433525 & 688340 & 4.6 & 5.1387 & TRN & \\
\hline CHEMBL1598087 & 688340 & 3.45 & 4.9789 & TRN & \\
\hline CHEMBL1505353 & 688340 & 5.3 & 4.8619 & TST & \\
\hline CHEMBL3212209 & 688340 & 4.45 & 4.8053 & TRN & \\
\hline CHEMBL1606497 & 688340 & 4.65 & 5.0672 & TRN & \\
\hline CHEMBL1528618 & 688340 & 5.5 & 4.8222 & TRN & \\
\hline CHEMBL1530431 & 688340 & 4.55 & 5.0301 & TRN & \\
\hline CHEMBL1523710 & 688340 & 4.6 & 4.9035 & TRN & \\
\hline CHEMBL1578946 & 688340 & 4.6 & 4.9388 & TRN & \\
\hline CHEMBL1488814 & 688340 & 4.65 & 4.9681 & TST & \\
\hline CHEMBL1508080 & 688340 & 4.5 & 4.8018 & TRN & \\
\hline CHEMBL1448096 & 688340 & 5.8 & 5.1095 & TRN & \\
\hline CHEMBL1509648 & 688340 & 4.65 & 4.6311 & TRN & \\
\hline CHEMBL1537829 & 688340 & 4.7 & 5.0581 & TST & \\
\hline CHEMBL1409614 & 688340 & 4.4 & 5.4144 & TRN & \\
\hline CHEMBL1303371 & 688340 & 5.4 & 4.9589 & TST & \\
\hline CHEMBL1364413 & 688340 & 6.5 & 5.1211 & TRN & \\
\hline CHEMBL1372732 & 688340 & 4.65 & 4.9113 & TST & \\
\hline CHEMBL1533549 & 688340 & 4.95 & 4.8302 & TRN & \\
\hline CHEMBL1605551 & 688340 & 5.0 & 5.1437 & TRN & \\
\hline CHEMBL1585431 & 688340 & 4.55 & 5.0331 & TRN & \\
\hline CHEMBL1536614 & 688340 & 6.05 & 4.8218 & TRN & \\
\hline CHEMBL1539797 & 688340 & 6.15 & 5.1286 & TRN & \\
\hline CHEMBL1384587 & 688340 & 6.15 & 4.6945 & TST & \\
\hline CHEMBL1325859 & 688340 & 4.75 & 5.16799 & 9999999999 & TRN \\
\hline CHEMBL1378851 & 688340 & 7.0501 & 5.0773 & TRN & \\
\hline
\end{tabular}




\begin{tabular}{|c|c|c|c|c|c|}
\hline \\
\hline CHEMBL1970082 & 688340 & 5.6 & 4.7309 & TRN & \\
\hline CHEMBL1480522 & 688340 & 4.6 & 4.878 & TRN & \\
\hline CHEMBL1407945 & 688340 & 5.85 & 5.1954 & TRN & \\
\hline CHEMBL1389287 & 688340 & 6.15 & 4.9881 & TRN & \\
\hline CHEMBL1420895 & 688340 & 4.45 & 5.053 & TST & \\
\hline CHEMBL1374946 & 688340 & 4.95 & 4.9993 & TST & \\
\hline CHEMBL3193713 & 688340 & 4.4 & 4.7511 & TST & \\
\hline CHEMBL1449284 & 688340 & 4.4 & 4.624 & TRN & \\
\hline CHEMBL1398357 & 688340 & 4.5 & 4.6976 & TRN & \\
\hline CHEMBL1518422 & 688340 & 5.55 & 4.9223 & TRN & \\
\hline CHEMBL1532953 & 688340 & 5.3 & 4.7287 & TRN & \\
\hline CHEMBL1456595 & 688340 & 4.55 & 4.8043 & TRN & \\
\hline CHEMBL1379602 & 688340 & 4.6 & 5.2206 & TRN & \\
\hline CHEMBL1455994 & 688340 & 5.25 & 5.1174 & TST & \\
\hline CHEMBL1471999 & 688340 & 4.95 & 4.9913 & TST & \\
\hline CHEMBL1421457 & 688340 & 6.5501 & 5.1512 & TST & \\
\hline CHEMBL1596583 & 688340 & 5.05 & 5.1605 & TST & \\
\hline CHEMBL1487131 & 688340 & 5.25 & 4.7534 & TRN & \\
\hline CHEMBL1524521 & 688340 & 4.4 & 4.907 & TRN & \\
\hline CHEMBL1364909 & 688340 & 5.55 & 5.1029 & TRN & \\
\hline CHEMBL1309726 & 688340 & 4.4 & 5.2662 & TRN & \\
\hline CHEMBL1095207 & 688340 & 4.6 & 4.9291 & TRN & \\
\hline CHEMBL1568035 & 688340 & 5.45 & 5.0234 & TRN & \\
\hline CHEMBL1583128 & 688340 & 4.4 & 5.2629 & TST & \\
\hline CHEMBL1984001 & 688340 & 5.6 & 4.8677 & TRN & \\
\hline CHEMBL1417481 & 688340 & 4.75 & 4.6824 & TST & \\
\hline CHEMBL1546396 & 688340 & 6.05 & 5.0048 & TRN & \\
\hline CHEMBL1213050 & 688340 & 4.5 & 5.1184 & TST & \\
\hline CHEMBL1522257 & 688340 & 5.45 & 4.997 & TST & \\
\hline CHEMBL1532572 & 688340 & 4.45 & 5.2305 & TST & \\
\hline CHEMBL3192575 & 688340 & 4.4 & 4.6066 & TRN & \\
\hline CHEMBL3196941 & 688340 & 6.0 & 4.9715 & TRN & \\
\hline CHEMBL1395464 & 688340 & 4.55 & 5.1615 & TRN & \\
\hline CHEMBL3214426 & 688340 & 4.95 & 4.54899 & 99999999995 & TRN \\
\hline CHEMBL393037 & 688340 & 4.4 & 4.9745 & TRN & \\
\hline CHEMBL1550516 & 688340 & 5.15 & 5.0893 & TST & \\
\hline CHEMBL1345540 & 688340 & 5.35 & 4.9009 & TRN & \\
\hline CHEMBL1428067 & 688340 & 4.5 & 5.1198 & TRN & \\
\hline CHEMBL1442559 & 688340 & 4.5 & 5.16200 & 2000000001 & TRN \\
\hline CHEMBL1443860 & 688340 & 5.5 & 4.7389 & TRN & \\
\hline CHEMBL1414667 & 688340 & 4.5 & 4.7656 & TRN & \\
\hline CHEMBL1321022 & 688340 & 4.45 & 5.1109 & TRN & \\
\hline CHEMBL1514082 & 688340 & 4.55 & 4.9555 & TRN & \\
\hline CHEMBL3194947 & 688340 & 5.35 & 4.9976 & TRN & \\
\hline CHEMBL1484382 & 688340 & 5.5 & 5.6524 & TRN & \\
\hline CHEMBL1499921 & 688340 & 4.6 & 5.0288 & TRN & \\
\hline CHEMBL1491855 & 688340 & 6.5 & 5.1051 & TST & \\
\hline CHEMBL1397359 & 688340 & 4.55 & 5.1811 & TRN & \\
\hline
\end{tabular}




\begin{tabular}{|c|c|c|c|c|}
\hline \multicolumn{5}{|c|}{ Supplemental Table S2.txt } \\
\hline CHEMBL1465122 & 688340 & 5.0 & 5.0073 & TST \\
\hline CHEMBL1415322 & 688340 & 6.15 & 5.5206 & TST \\
\hline CHEMBL3194284 & 688340 & 6.3 & 4.8112 & TRN \\
\hline CHEMBL 2006607 & 688340 & 4.5 & 5.0153 & TRN \\
\hline CHEMBL3195827 & 688340 & 4.65 & 4.9342 & TRN \\
\hline CHEMBL1508086 & 688340 & 5.5 & 4.9168 & TRN \\
\hline CHEMBL1562812 & 688340 & 6.8499 & 5.0677 & TST \\
\hline CHEMBL1515505 & 688340 & 4.6 & 4.8857 & TST \\
\hline CHEMBL1417748 & 688340 & 4.65 & 4.7435 & TRN \\
\hline CHEMBL1535216 & 688340 & 4.55 & 4.9932 & TST \\
\hline CHEMBL1404289 & 688340 & 4.35 & 5.1424 & TST \\
\hline CHEMBL1455463 & 688340 & 5.2 & 5.1198 & TST \\
\hline CHEMBL290914 & 688340 & 5.6 & 4.9704 & TST \\
\hline CHEMBL1997422 & 688340 & 4.5 & 4.9213 & TRN \\
\hline CHEMBL1553553 & 688340 & 5.55 & 4.8247 & TST \\
\hline CHEMBL1527832 & 688340 & 4.55 & 4.7051 & TST \\
\hline CHEMBL1341036 & 688340 & 4.35 & 4.8445 & TST \\
\hline CHEMBL1564536 & 688340 & 4.4 & 4.9663 & TST \\
\hline CHEMBL1424046 & 688340 & 7.0 & 4.8899 & TRN \\
\hline CHEMBL1328497 & 688340 & 5.95 & 4.6311 & TRN \\
\hline CHEMBL1352264 & 688340 & 4.4 & 5.3063 & TRN \\
\hline CHEMBL1312745 & 688340 & 4.4 & 5.2892 & TRN \\
\hline CHEMBL1410594 & 688340 & 4.5 & 4.695 & TRN \\
\hline CHEMBL1399840 & 688340 & 5.6 & 5.5337 & TRN \\
\hline CHEMBL1486302 & 688340 & 4.4 & 5.3399 & TRN \\
\hline CHEMBL1576788 & 688340 & 4.5 & 4.9698 & TRN \\
\hline CHEMBL1574903 & 688340 & 5.45 & 5.0744 & TST \\
\hline CHEMBL1334020 & 688340 & 4.6 & 5.0292 & TRN \\
\hline CHEMBL1562735 & 688340 & 4.5 & 5.1799 & TST \\
\hline CHEMBL1353217 & 688340 & 4.9 & 5.1853 & TRN \\
\hline CHEMBL1378754 & 688340 & 5.85 & 5.2195 & TRN \\
\hline CHEMBL1502471 & 688340 & 4.35 & 5.3944 & TRN \\
\hline CHEMBL1388714 & 688340 & 5.3 & 4.9335 & TST \\
\hline CHEMBL1309643 & 688340 & 4.6 & 4.5721 & TRN \\
\hline CHEMBL1385597 & 688340 & 6.25 & 5.0397 & TRN \\
\hline CHEMBL1608844 & 688340 & 4.9 & 5.1428 & TRN \\
\hline CHEMBL1579818 & 688340 & 4.45 & 4.507 & TRN \\
\hline CHEMBL1556246 & 688340 & 6.7001 & 5.1097 & TST \\
\hline CHEMBL1303220 & 688340 & 4.4 & 5.3478 & TRN \\
\hline CHEMBL1502646 & 688340 & 4.85 & 5.4002 & TRN \\
\hline CHEMBL 205040 & 688340 & 4.4 & 5.1378 & TRN \\
\hline CHEMBL1501573 & 688340 & 4.45 & 4.8736 & TST \\
\hline CHEMBL1518941 & 688340 & 4.65 & 4.8881 & TRN \\
\hline CHEMBL1477384 & 688340 & 4.8 & 4.9708 & TST \\
\hline CHEMBL1594055 & 688340 & 6.35 & 5.1154 & TRN \\
\hline CHEMBL39839 & 688340 & 4.2 & 5.2744 & TST \\
\hline CHEMBL1435637 & 688340 & 5.7 & 4.9998 & TRN \\
\hline CHEMBL1586973 & 688340 & 4.55 & 5.4022 & TRN \\
\hline
\end{tabular}




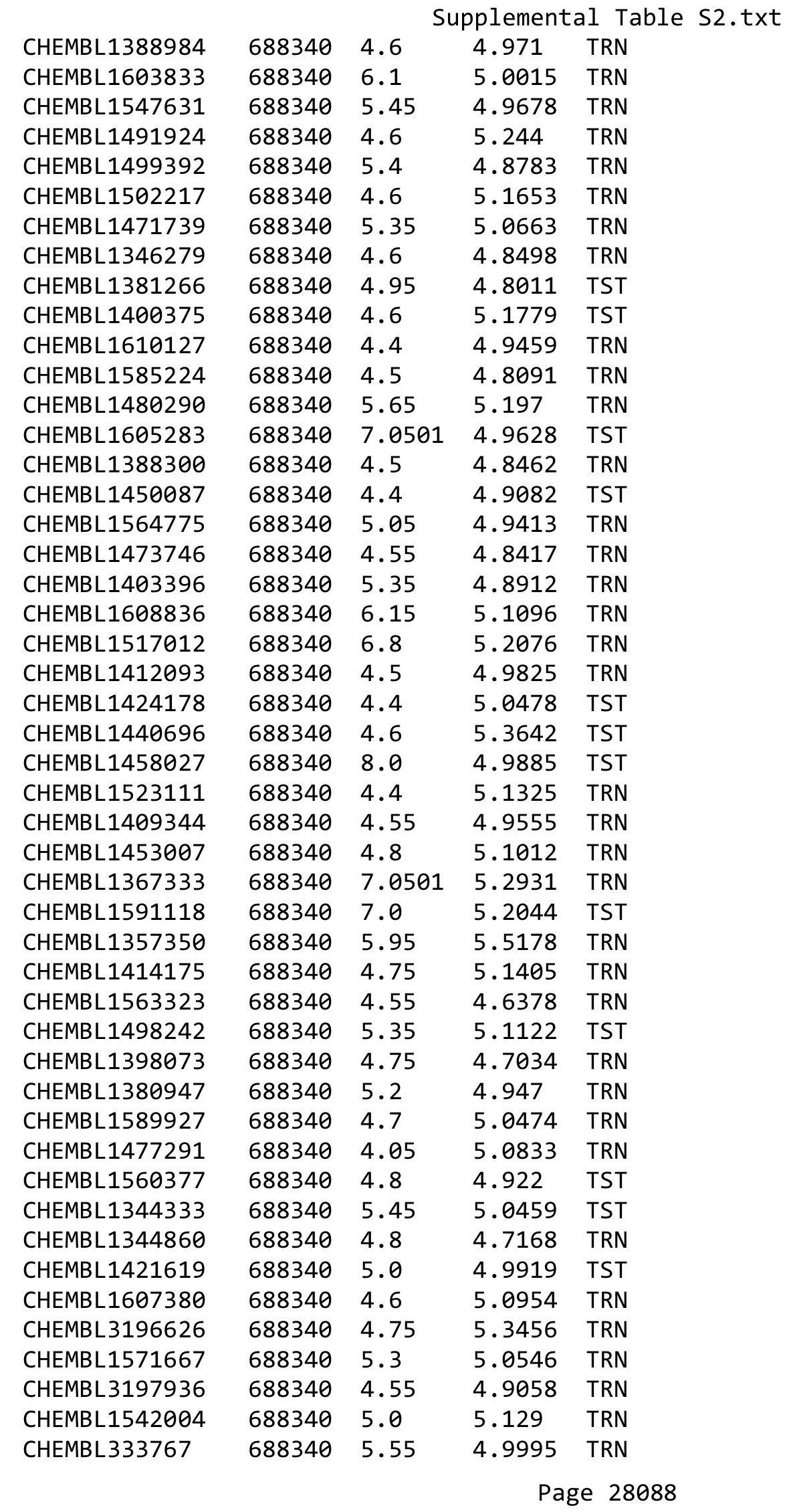




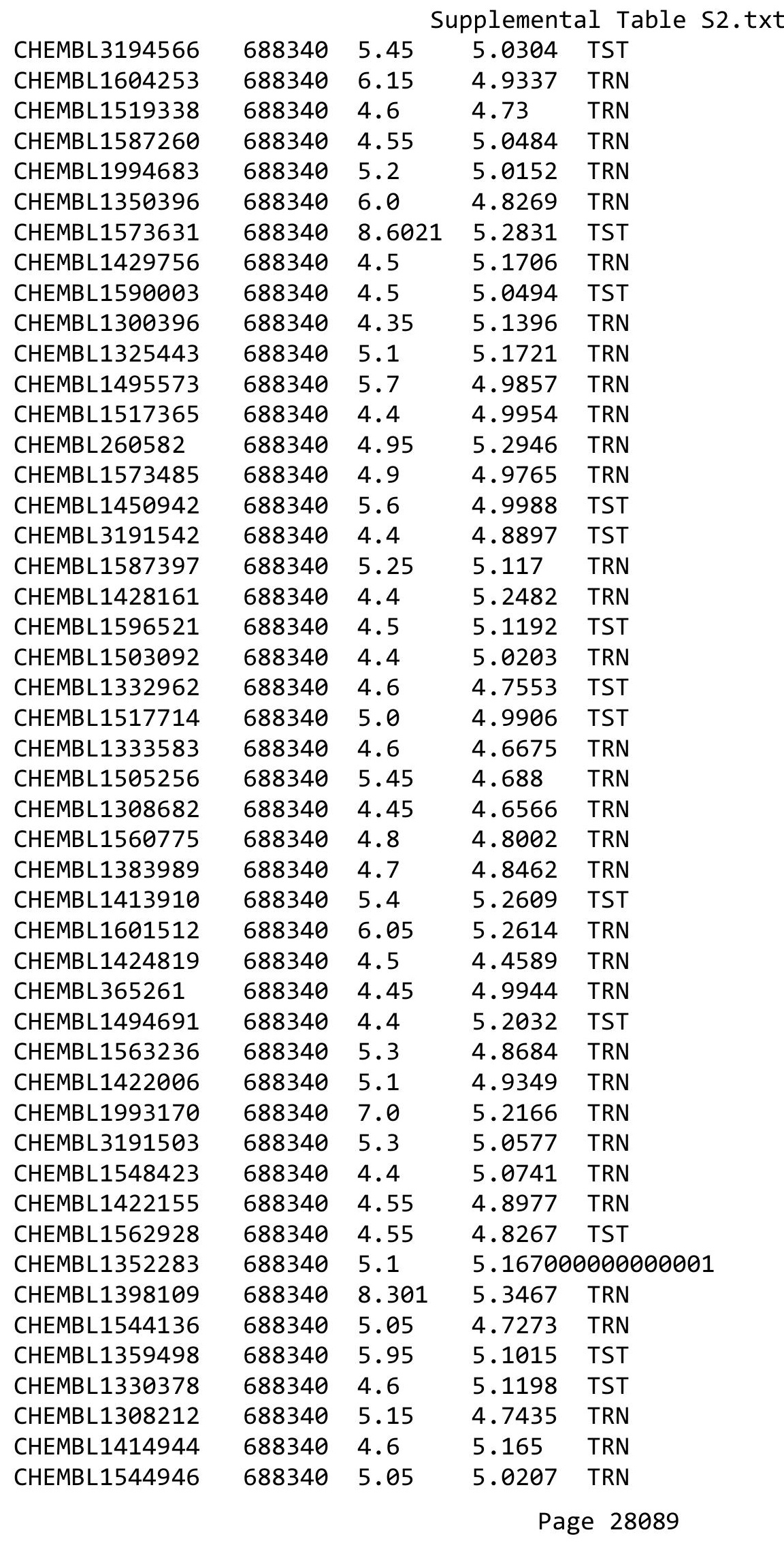




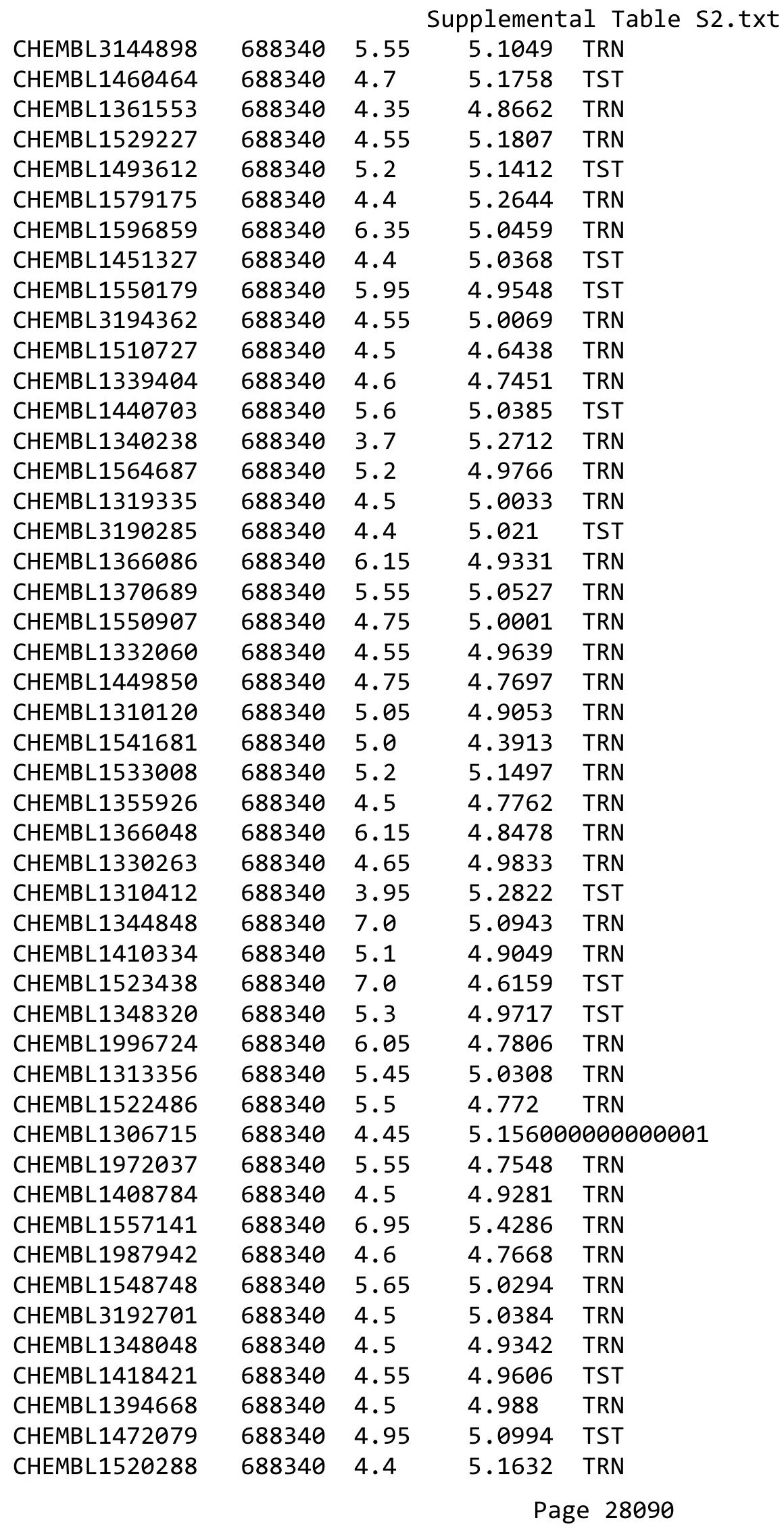




\begin{tabular}{|c|c|c|c|c|}
\hline \multicolumn{5}{|c|}{ Supplemental Table S2.txt } \\
\hline CHEMBL1361695 & 688340 & 5.35 & 5.2665 & TST \\
\hline CHEMBL1457049 & 688340 & 4.4 & 5.0167 & TRN \\
\hline CHEMBL1382320 & 688340 & 4.65 & 5.0219 & TRN \\
\hline CHEMBL1439046 & 688340 & 5.0 & 5.2604 & TRN \\
\hline CHEMBL571296 & 688340 & 4.6 & 5.0134 & TRN \\
\hline CHEMBL305469 & 688340 & 5.25 & 4.9179 & TRN \\
\hline CHEMBL1567670 & 688340 & 5.2 & 5.1337 & TRN \\
\hline CHEMBL1348764 & 688340 & 4.4 & 5.2939 & TST \\
\hline CHEMBL1581050 & 688340 & 4.0 & 5.0691 & TRN \\
\hline CHEMBL1301285 & 688340 & 5.55 & 4.7655 & TST \\
\hline CHEMBL1415665 & 688340 & 4.4 & 4.8946 & TRN \\
\hline CHEMBL1540721 & 688340 & 4.5 & 5.4154 & TRN \\
\hline CHEMBL1544505 & 688340 & 4.85 & 4.7589 & TRN \\
\hline CHEMBL1417591 & 688340 & 6.8 & 5.2485 & TST \\
\hline CHEMBL1469275 & 688340 & 5.55 & 4.7812 & TRN \\
\hline CHEMBL3213398 & 688340 & 4.65 & 5.1893 & TRN \\
\hline CHEMBL1555876 & 688340 & 4.45 & 4.8345 & TRN \\
\hline CHEMBL1374926 & 688340 & 4.5 & 4.6893 & TRN \\
\hline CHEMBL1546874 & 688340 & 5.3 & 5.1898 & TRN \\
\hline CHEMBL1418181 & 688340 & 7.0501 & 5.1531 & TRN \\
\hline CHEMBL3925157 & 688340 & 4.85 & 4.5752 & TRN \\
\hline CHEMBL1350310 & 688340 & 4.55 & 4.8998 & TRN \\
\hline CHEMBL1480252 & 688340 & 4.8 & 4.98 & TRN \\
\hline CHEMBL1529041 & 688340 & 4.85 & 5.2975 & TRN \\
\hline CHEMBL1447037 & 688340 & 5.2 & 4.9216 & TRN \\
\hline CHEMBL1531336 & 688340 & 6.05 & 5.2636 & TST \\
\hline CHEMBL1360170 & 688340 & 4.6 & 4.7628 & TRN \\
\hline CHEMBL1481733 & 688340 & 5.2 & 4.9621 & TST \\
\hline CHEMBL1501635 & 688340 & 4.6 & 4.8596 & TRN \\
\hline CHEMBL1593626 & 688340 & 4.55 & 4.8885 & TRN \\
\hline CHEMBL1613240 & 688340 & 4.75 & 5.255 & TST \\
\hline CHEMBL1581849 & 688340 & 4.4 & 5.1762 & TRN \\
\hline CHEMBL1986557 & 688340 & 4.45 & 4.8166 & TRN \\
\hline CHEMBL1351373 & 688340 & 7.0 & 5.1125 & TST \\
\hline CHEMBL1335841 & 688340 & 7.0501 & 4.697 & TST \\
\hline CHEMBL1493950 & 688340 & 4.55 & 4.9557 & TRN \\
\hline CHEMBL1556080 & 688340 & 6.2 & 4.956 & TST \\
\hline CHEMBL1536339 & 688340 & 5.15 & 5.1128 & TRN \\
\hline CHEMBL1528901 & 688340 & 5.15 & 5.1093 & TRN \\
\hline CHEMBL3207399 & 688340 & 4.45 & 4.9206 & TRN \\
\hline CHEMBL1597879 & 688340 & 5.5 & 5.3897 & TRN \\
\hline CHEMBL1496602 & 688340 & 4.4 & 5.1699 & TST \\
\hline CHEMBL1387909 & 688340 & 6.95 & 5.2764 & TRN \\
\hline CHEMBL1320617 & 688340 & 5.5 & 4.9592 & TST \\
\hline CHEMBL1344470 & 688340 & 5.25 & 5.045 & TST \\
\hline CHEMBL1413018 & 688340 & 7.0 & 5.4442 & TRN \\
\hline CHEMBL1307971 & 688340 & 4.55 & 4.7626 & TST \\
\hline CHEMBL1483896 & 688340 & 4.4 & 5.351 & TST \\
\hline
\end{tabular}




\begin{tabular}{|c|c|c|c|c|c|}
\hline \multicolumn{6}{|c|}{ plement } \\
\hline CHEMBL1331063 & 688340 & 4.4 & 4.8451 & TST & \\
\hline CHEMBL1572087 & 688340 & 4.8 & 4.6318 & TST & \\
\hline CHEMBL1475596 & 688340 & 4.55 & 5.25200 & 0000000001 & TRN \\
\hline CHEMBL1394090 & 688340 & 4.4 & 5.2278 & TRN & \\
\hline CHEMBL1357378 & 688340 & 5.0 & 5.0126 & TST & \\
\hline CHEMBL1449397 & 688340 & 4.35 & 5.5905 & TRN & \\
\hline CHEMBL1613468 & 688340 & 5.2 & 4.9212 & TST & \\
\hline CHEMBL1340204 & 688340 & 4.45 & 5.0731 & TRN & \\
\hline CHEMBL1334962 & 688340 & 4.4 & 4.8433 & TRN & \\
\hline CHEMBL1461772 & 688340 & 5.5 & 4.7112 & TRN & \\
\hline CHEMBL1540209 & 688340 & 4.6 & 4.7176 & TRN & \\
\hline CHEMBL1519097 & 688340 & 5.75 & 5.2475 & TRN & \\
\hline CHEMBL1556706 & 688340 & 4.0 & 5.1967 & TRN & \\
\hline CHEMBL1400469 & 688340 & 4.75 & 5.2176 & TRN & \\
\hline CHEMBL1364831 & 688340 & 4.45 & 5.1152 & TST & \\
\hline CHEMBL1556879 & 688340 & 6.6 & 5.4235 & TRN & \\
\hline CHEMBL1364180 & 688340 & 4.55 & 4.7837 & TRN & \\
\hline CHEMBL1568085 & 688340 & 6.45 & 5.1938 & TST & \\
\hline CHEMBL1587043 & 688340 & 4.4 & 5.1149 & TRN & \\
\hline CHEMBL1554900 & 688340 & 5.0 & 5.0215 & TRN & \\
\hline CHEMBL1328116 & 688340 & 4.55 & 4.8366 & TRN & \\
\hline CHEMBL1342157 & 688340 & 4.4 & 4.8718 & TRN & \\
\hline CHEMBL1421489 & 688340 & 5.2 & 5.3607 & TST & \\
\hline CHEMBL1487397 & 688340 & 4.6 & 5.2015 & TRN & \\
\hline CHEMBL1323467 & 688340 & 4.35 & 4.6847 & TRN & \\
\hline CHEMBL1424982 & 688340 & 4.6 & 4.7818 & TRN & \\
\hline CHEMBL1968842 & 688340 & 7.0 & 5.0172 & TRN & \\
\hline CHEMBL1530933 & 688340 & 6.15 & 5.476 & TRN & \\
\hline CHEMBL1340440 & 688340 & 4.45 & 4.5857 & TRN & \\
\hline CHEMBL3213891 & 688340 & 4.4 & 5.0354 & TRN & \\
\hline CHEMBL1586589 & 688340 & 4.7 & 4.9041 & TRN & \\
\hline CHEMBL1433185 & 688340 & 4.65 & 4.6683 & TRN & \\
\hline CHEMBL1343411 & 688340 & 4.6 & 4.9846 & TRN & \\
\hline CHEMBL1324866 & 688340 & 4.55 & 5.13299 & 9999999999 & TST \\
\hline CHEMBL1610739 & 688340 & 4.8 & 4.8085 & TRN & \\
\hline CHEMBL1576739 & 688340 & 6.35 & 4.6602 & TRN & \\
\hline CHEMBL1592884 & 688340 & 4.4 & 5.3158 & TRN & \\
\hline CHEMBL1397916 & 688340 & 5.2 & 5.1077 & TRN & \\
\hline CHEMBL1466181 & 688340 & 4.4 & 4.9756 & TRN & \\
\hline CHEMBL1399302 & 688340 & 5.3 & 5.3021 & TST & \\
\hline CHEMBL1455912 & 688340 & 4.55 & 4.735 & TRN & \\
\hline CHEMBL1514913 & 688340 & 4.5 & 4.6853 & TRN & \\
\hline CHEMBL66953 & 688340 & 6.25 & 5.3156 & TST & \\
\hline CHEMBL3198162 & 688340 & 6.15 & 5.0407 & TST & \\
\hline CHEMBL1465211 & 688340 & 4.55 & 4.8654 & TRN & \\
\hline CHEMBL1478182 & 688340 & 4.0 & 5.4662 & TST & \\
\hline CHEMBL1420301 & 688340 & 4.7 & 5.0453 & TRN & \\
\hline CHEMBL1424931 & 688340 & 4.45 & 5.1317 & TRN & \\
\hline
\end{tabular}




\begin{tabular}{|c|c|c|c|c|c|}
\hline \multirow[b]{2}{*}{ CHEMBL1321907 } & \multirow[b]{2}{*}{688340} & \\
\hline & & 4.4 & 5.3262 & TST & \\
\hline CHEMBL1367174 & 688340 & 4.4 & 4.9914 & TRN & \\
\hline CHEMBL1482852 & 688340 & 5.25 & 4.6123 & TRN & \\
\hline CHEMBL1364957 & 688340 & 5.2 & 4.7782 & TRN & \\
\hline CHEMBL1467520 & 688340 & 5.8 & 4.8729 & TRN & \\
\hline CHEMBL1410994 & 688340 & 5.4 & 5.0282 & TST & \\
\hline CHEMBL1465213 & 688340 & 4.75 & 5.0151 & TRN & \\
\hline CHEMBL1465974 & 688340 & 4.4 & 5.0177 & TRN & \\
\hline CHEMBL1498161 & 688340 & 4.4 & 4.9953 & TRN & \\
\hline CHEMBL1539720 & 688340 & 4.4 & 4.9923 & TST & \\
\hline CHEMBL1459655 & 688340 & 4.4 & 5.2625 & TST & \\
\hline CHEMBL1482363 & 688340 & 6.15 & 5.1184 & TRN & \\
\hline CHEMBL1495238 & 688340 & 4.45 & 4.7837 & TRN & \\
\hline CHEMBL1527992 & 688340 & 4.85 & 5.0028 & TRN & \\
\hline CHEMBL1417027 & 688340 & 4.4 & 5.2372 & TST & \\
\hline CHEMBL1438192 & 688340 & 5.7 & 5.0052 & TRN & \\
\hline CHEMBL1560181 & 688340 & 4.45 & 5.0062 & TRN & \\
\hline CHEMBL1377441 & 688340 & 5.25 & 5.1109 & TRN & \\
\hline CHEMBL3210767 & 688340 & 7.0 & 5.1012 & TRN & \\
\hline CHEMBL1539477 & 688340 & 5.7 & 4.9605 & TST & \\
\hline CHEMBL1513668 & 688340 & 4.45 & 5.4928 & TRN & \\
\hline CHEMBL1722566 & 688340 & 5.0 & 4.626 & TRN & \\
\hline CHEMBL1590291 & 688340 & 5.4 & 5.2038 & TRN & \\
\hline CHEMBL1508014 & 688340 & 6.5 & 5.0375 & TRN & \\
\hline CHEMBL1500836 & 688340 & 5.9 & 5.256 & TRN & \\
\hline CHEMBL3208258 & 688340 & 4.6 & 4.7606 & TST & \\
\hline CHEMBL1460452 & 688340 & 4.6 & 5.0884 & TRN & \\
\hline CHEMBL1355301 & 688340 & 4.45 & 4.9615 & TRN & \\
\hline CHEMBL1599396 & 688340 & 4.85 & 4.6699 & TRN & \\
\hline CHEMBL1301598 & 688340 & 4.5 & 5.0221 & TRN & \\
\hline CHEMBL1306283 & 688340 & 5.85 & 4.7852 & TRN & \\
\hline CHEMBL1389101 & 688340 & 5.0 & 5.2782 & TRN & \\
\hline CHEMBL1507906 & 688340 & 5.2 & 5.2302 & TRN & \\
\hline CHEMBL1536290 & 688340 & 4.6 & 4.8765 & TRN & \\
\hline CHEMBL1312717 & 688340 & 4.6 & 4.9743 & TRN & \\
\hline CHEMBL1338643 & 688340 & 5.0 & 5.0248 & TRN & \\
\hline CHEMBL3144948 & 688340 & 4.4 & $5.0760 e$ & 20000000005 & TST \\
\hline CHEMBL1576122 & 688340 & 5.15 & 5.2529 & TRN & \\
\hline CHEMBL1336153 & 688340 & 5.2 & 4.7379 & TRN & \\
\hline CHEMBL3209045 & 688340 & 4.45 & 4.6286 & TRN & \\
\hline CHEMBL533082 & 688340 & 6.15 & $4.8610 e$ & 2000000001 & TRN \\
\hline CHEMBL1438837 & 688340 & 4.5 & 5.4773 & TRN & \\
\hline CHEMBL1586520 & 688340 & 4.4 & 5.4657 & TST & \\
\hline CHEMBL1978564 & 688340 & 4.45 & 4.7506 & TRN & \\
\hline CHEMBL1607452 & 688340 & 4.55 & 4.6837 & TRN & \\
\hline CHEMBL1364979 & 688340 & 4.85 & 4.7958 & TST & \\
\hline CHEMBL1377646 & 688340 & 6.5 & 5.0932 & TRN & \\
\hline CHEMBL1360361 & 688340 & 7.0 & 5.2107 & TST & \\
\hline & & & & 805 & \\
\hline
\end{tabular}




\begin{tabular}{|c|c|c|c|c|c|}
\hline \\
\hline CHEMBL1501322 & 688340 & 5.2 & 5.218 & TST & \\
\hline CHEMBL1376870 & 688340 & 5.5 & 5.2309 & TRN & \\
\hline CHEMBL1502989 & 688340 & 6.35 & 5.2097 & TRN & \\
\hline CHEMBL3196071 & 688340 & 4.4 & 4.7704 & TRN & \\
\hline CHEMBL1560447 & 688340 & 4.95 & 4.92 & TRN & \\
\hline CHEMBL1544291 & 688340 & 4.65 & 5.1669 & TRN & \\
\hline CHEMBL1418560 & 688340 & 4.5 & 5.36700 & $\partial 000000001$ & TST \\
\hline CHEMBL1366618 & 688340 & 6.45 & 5.5738 & TRN & \\
\hline CHEMBL1462707 & 688340 & 4.45 & 4.6963 & TRN & \\
\hline CHEMBL1434792 & 688340 & 4.4 & 4.732 & TRN & \\
\hline CHEMBL3199539 & 688340 & 4.4 & 4.7723 & TRN & \\
\hline CHEMBL1580068 & 688340 & 4.45 & 4.9677 & TST & \\
\hline CHEMBL1494960 & 688340 & 5.35 & 5.3115 & TRN & \\
\hline CHEMBL1325710 & 688340 & 5.6 & 5.3239 & TRN & \\
\hline CHEMBL172439 & 688340 & 5.55 & 4.9918 & TRN & \\
\hline CHEMBL1516690 & 688340 & 6.95 & 4.8233 & TRN & \\
\hline CHEMBL1573698 & 688340 & 5.25 & 5.0795 & TST & \\
\hline CHEMBL1460175 & 688340 & 5.55 & 5.1229 & TRN & \\
\hline CHEMBL1469493 & 688340 & 5.45 & 5.065 & TRN & \\
\hline CHEMBL1558826 & 688340 & 5.0 & 5.1671 & TRN & \\
\hline CHEMBL1502466 & 688340 & 4.55 & 4.7247 & TRN & \\
\hline CHEMBL1499434 & 688340 & 7.6003 & 5.0396 & TRN & \\
\hline CHEMBL1508325 & 688340 & 4.45 & 4.6502 & TRN & \\
\hline CHEMBL1425142 & 688340 & 4.5 & 4.7877 & TRN & \\
\hline CHEMBL1595160 & 688340 & 7.5498 & 4.7785 & TST & \\
\hline CHEMBL1549952 & 688340 & 5.4 & 5.2692 & TST & \\
\hline CHEMBL1476545 & 688340 & 4.65 & 4.7438 & TRN & \\
\hline CHEMBL1348916 & 688340 & 4.95 & 5.13700 & 00000000005 & TRN \\
\hline CHEMBL3196370 & 688340 & 7.0 & 4.9454 & TRN & \\
\hline CHEMBL1361191 & 688340 & 4.7 & 5.0507 & TRN & \\
\hline CHEMBL1400130 & 688340 & 4.55 & 4.8641 & TST & \\
\hline CHEMBL1313904 & 688340 & 4.5 & 4.84399 & 9999999999 & TST \\
\hline CHEMBL1517760 & 688340 & 4.45 & 4.8511 & TRN & \\
\hline CHEMBL1358522 & 688340 & 5.7 & 5.1651 & TST & \\
\hline CHEMBL1500424 & 688340 & 4.95 & 5.066 & TST & \\
\hline CHEMBL1299711 & 688340 & 4.5 & 4.942 & TRN & \\
\hline CHEMBL1390278 & 688340 & 4.45 & 5.1348 & TRN & \\
\hline CHEMBL1389315 & 688340 & 4.75 & 4.877 & TRN & \\
\hline CHEMBL3197991 & 688340 & 4.6 & 4.7523 & TRN & \\
\hline CHEMBL1479704 & 688340 & 5.3 & 5.4287 & TRN & \\
\hline CHEMBL1490458 & 688340 & 4.9 & 4.5963 & TST & \\
\hline CHEMBL1400660 & 688340 & 4.4 & 5.1454 & TST & \\
\hline CHEMBL3207597 & 688340 & 6.6 & 5.0043 & TRN & \\
\hline CHEMBL1563265 & 688340 & 4.55 & 4.782 & TRN & \\
\hline CHEMBL1430762 & 688340 & 4.0 & 5.1279 & TST & \\
\hline CHEMBL1401424 & 688340 & 4.4 & 4.7078 & TRN & \\
\hline CHEMBL1538928 & 688340 & 4.8 & 4.9471 & TRN & \\
\hline CHEMBL1525784 & 688340 & 5.15 & 5.0643 & TST & \\
\hline
\end{tabular}




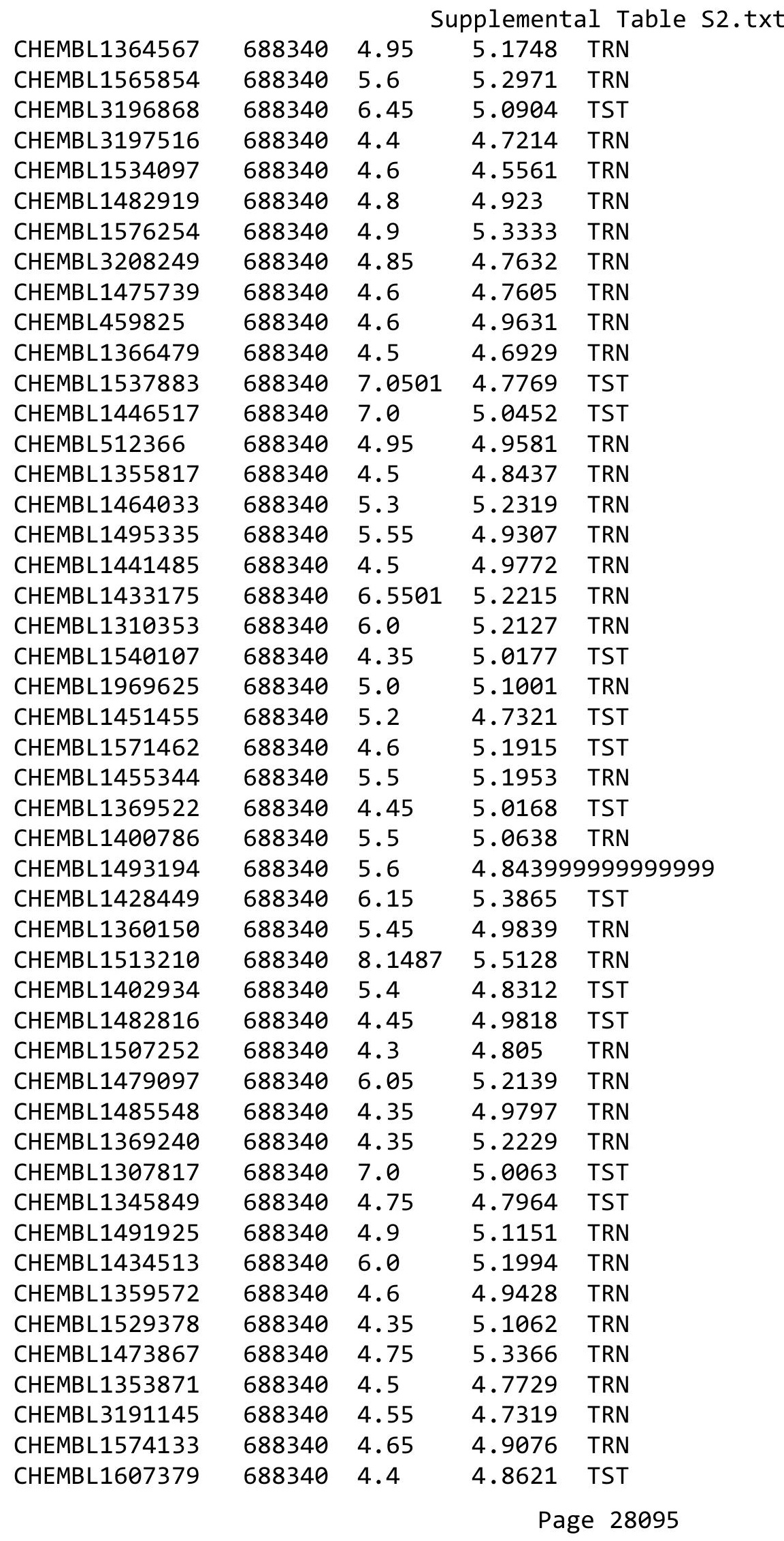




\begin{tabular}{|c|c|c|c|c|c|}
\hline \\
\hline CHEMBL1424451 & 688340 & 4.4 & 4.8358 & TST & \\
\hline CHEMBL1569702 & 688340 & 5.1 & 5.3958 & TRN & \\
\hline CHEMBL1520238 & 688340 & 4.85 & 4.5638 & TRN & \\
\hline CHEMBL1366858 & 688340 & 4.55 & 5.075 & TRN & \\
\hline CHEMBL1427504 & 688340 & 4.65 & 4.9718 & TRN & \\
\hline CHEMBL1484476 & 688340 & 6.25 & 5.046 & TRN & \\
\hline CHEMBL1427893 & 688340 & 7.0501 & 5.1249 & TRN & \\
\hline CHEMBL1557668 & 688340 & 4.85 & 5.0492 & TRN & \\
\hline CHEMBL1341524 & 688340 & 7.0 & 5.3629 & TST & \\
\hline CHEMBL1347927 & 688340 & 5.3 & 4.9481 & TST & \\
\hline CHEMBL1480813 & 688340 & 4.55 & 5.4036 & TRN & \\
\hline CHEMBL1333889 & 688340 & 4.5 & 4.4286 & TRN & \\
\hline CHEMBL1497848 & 688340 & 4.4 & 4.9985 & TRN & \\
\hline CHEMBL1417498 & 688340 & 5.6 & 5.4606 & TRN & \\
\hline CHEMBL1542511 & 688340 & 4.65 & 4.8426 & TRN & \\
\hline CHEMBL1553639 & 688340 & 4.6 & 5.0592 & TRN & \\
\hline CHEMBL1586078 & 688340 & 4.85 & 4.8724 & TRN & \\
\hline CHEMBL1327581 & 688340 & 4.5 & 5.24200 & 0000000001 & TRN \\
\hline CHEMBL1310031 & 688340 & 4.55 & 5.0042 & TST & \\
\hline CHEMBL1479450 & 688340 & 4.55 & 4.7901 & TRN & \\
\hline CHEMBL1463629 & 688340 & 4.6 & 4.71899 & 7999999999 & TRN \\
\hline CHEMBL1505297 & 688340 & 4.4 & 5.3677 & TRN & \\
\hline CHEMBL1443590 & 688340 & 5.2 & 5.2335 & TRN & \\
\hline CHEMBL1516794 & 688340 & 5.6 & 4.9532 & TRN & \\
\hline CHEMBL493863 & 688340 & 4.85 & 4.6096 & TST & \\
\hline CHEMBL1603078 & 688340 & 4.5 & 5.3686 & TST & \\
\hline CHEMBL1355595 & 688340 & 5.2 & 5.1535 & TRN & \\
\hline CHEMBL3199065 & 688340 & 4.4 & 4.9558 & TST & \\
\hline CHEMBL1516283 & 688340 & 4.7 & 4.8868 & TRN & \\
\hline CHEMBL448868 & 688340 & 4.4 & 5.266 & TRN & \\
\hline CHEMBL1353979 & 688340 & 4.55 & 5.1132 & TRN & \\
\hline CHEMBL1610002 & 688340 & 4.8 & 4.9163 & TRN & \\
\hline CHEMBL1448366 & 688340 & 4.65 & 4.9163 & TST & \\
\hline CHEMBL1432260 & 688340 & 3.8 & 5.0382 & TST & \\
\hline CHEMBL1578780 & 688340 & 4.4 & 5.4504 & TRN & \\
\hline CHEMBL1321454 & 688340 & 7.0 & 5.2732 & TRN & \\
\hline CHEMBL1491730 & 688340 & 4.35 & 4.882 & TRN & \\
\hline CHEMBL1382865 & 688340 & 4.4 & 5.1082 & TST & \\
\hline CHEMBL1502576 & 688340 & 4.85 & 4.6447 & TRN & \\
\hline CHEMBL1338299 & 688340 & 4.85 & 4.8385 & TST & \\
\hline CHEMBL1578448 & 688340 & 4.65 & 5.1256 & TRN & \\
\hline CHEMBL1383384 & 688340 & 7.0 & 4.9913 & TRN & \\
\hline CHEMBL1479971 & 688340 & 4.45 & 5.0464 & TRN & \\
\hline CHEMBL1344702 & 688340 & 4.55 & 4.8574 & TRN & \\
\hline CHEMBL1558950 & 688340 & 4.5 & 4.8668 & TST & \\
\hline CHEMBL1431176 & 688340 & 6.6 & 5.0633 & TRN & \\
\hline CHEMBL3193042 & 688340 & 7.0 & 5.1974 & TRN & \\
\hline CHEMBL1548732 & 688340 & 5.2 & 5.0443 & TRN & \\
\hline
\end{tabular}




\begin{tabular}{|c|c|c|c|c|}
\hline \multicolumn{5}{|c|}{ Supplemental Table S2.txt } \\
\hline CHEMBL1485893 & 688340 & 5.35 & 5.2945 & TRN \\
\hline CHEMBL1512764 & 688340 & 4.6 & 5.0328 & TRN \\
\hline CHEMBL561936 & 688340 & 4.4 & 4.7966 & TRN \\
\hline CHEMBL1471131 & 688340 & 2.95 & 5.2876 & TST \\
\hline CHEMBL3191982 & 688340 & 5.05 & 4.9491 & TRN \\
\hline CHEMBL1305188 & 688340 & 4.4 & 4.8469 & TRN \\
\hline CHEMBL2369186 & 688340 & 4.5 & 4.8921 & TST \\
\hline CHEMBL1441099 & 688340 & 4.6 & 4.798 & TST \\
\hline CHEMBL1569100 & 688340 & 5.2 & 4.8686 & TRN \\
\hline CHEMBL1401936 & 688340 & 6.6499 & 5.2359 & TRN \\
\hline CHEMBL1327942 & 688340 & 4.55 & 5.0116 & TRN \\
\hline CHEMBL1443784 & 688340 & 4.4 & 5.0815 & TST \\
\hline CHEMBL1340285 & 688340 & 5.05 & 5.072 & TRN \\
\hline CHEMBL1320005 & 688340 & 5.9 & 5.1613 & TST \\
\hline CHEMBL 275177 & 688340 & 4.7 & 4.7642 & TST \\
\hline CHEMBL1401676 & 688340 & 7.0501 & 4.9195 & TRN \\
\hline CHEMBL1467771 & 688340 & 4.4 & 4.8839 & TRN \\
\hline CHEMBL1504842 & 688340 & 5.5 & 5.2032 & TST \\
\hline CHEMBL1529000 & 688340 & 4.4 & 4.9259 & TST \\
\hline CHEMBL1359249 & 688340 & 7.0 & 5.2278 & TRN \\
\hline CHEMBL1323785 & 688340 & 4.35 & 4.8526 & TRN \\
\hline CHEMBL1461339 & 688340 & 4.0 & 5.1511 & TRN \\
\hline CHEMBL1533128 & 688340 & 4.55 & 5.114 & TRN \\
\hline CHEMBL1409623 & 688340 & 4.55 & 5.2639 & TRN \\
\hline CHEMBL1465115 & 688340 & 4.55 & 4.762 & TRN \\
\hline CHEMBL1347156 & 688340 & 7.4498 & 4.9859 & TST \\
\hline CHEMBL1417547 & 688340 & 4.6 & 5.2692 & TRN \\
\hline CHEMBL1309493 & 688340 & 4.55 & 4.74 & TST \\
\hline CHEMBL1511600 & 688340 & 8.1487 & 5.3307 & TRN \\
\hline CHEMBL1407772 & 688340 & 6.4 & 5.1631 & TST \\
\hline CHEMBL1412013 & 688340 & 4.45 & 4.6945 & TRN \\
\hline CHEMBL1463258 & 688340 & 4.4 & 5.0139 & TST \\
\hline CHEMBL1307014 & 688340 & 4.5 & 4.8147 & TRN \\
\hline CHEMBL1439735 & 688340 & 4.4 & 5.1829 & TRN \\
\hline CHEMBL1416508 & 688340 & 3.45 & 5.1976 & TRN \\
\hline CHEMBL1477589 & 688340 & 4.65 & 4.8336 & TRN \\
\hline CHEMBL1344433 & 688340 & 6.35 & 5.1232 & TRN \\
\hline CHEMBL1334336 & 688340 & 4.45 & 5.2133 & TST \\
\hline CHEMBL1546039 & 688340 & 4.6 & 4.9993 & TRN \\
\hline CHEMBL1339581 & 688340 & 4.45 & 4.8255 & TST \\
\hline CHEMBL1604401 & 688340 & 4.55 & 5.0572 & TRN \\
\hline CHEMBL1325370 & 688340 & 4.6 & 5.1619 & TRN \\
\hline CHEMBL 2003304 & 688340 & 4.95 & 4.829 & TRN \\
\hline CHEMBL3210775 & 688340 & 6.5 & 4.87 & TRN \\
\hline CHEMBL1537420 & 688340 & 4.5 & 4.5672 & TRN \\
\hline CHEMBL1442142 & 688340 & 4.8 & 4.6413 & TRN \\
\hline CHEMBL1594622 & 688340 & 5.0 & 5.2497 & TRN \\
\hline CHEMBL1412133 & 688340 & 5.25 & 4.7795 & TRN \\
\hline
\end{tabular}




\begin{tabular}{|c|c|c|c|c|c|}
\hline \multicolumn{6}{|c|}{ Supplemental Table S2.txt } \\
\hline CHEMBL1399430 & 688340 & 4.6 & 4.8224 & TRN & \\
\hline CHEMBL1342736 & 688340 & 5.25 & 4.4024 & TRN & \\
\hline CHEMBL1528757 & 688340 & 4.5 & 4.9617 & TST & \\
\hline CHEMBL3196632 & 688340 & 6.05 & 4.8008 & TRN & \\
\hline CHEMBL1389452 & 688340 & 4.45 & 5.0234 & TRN & \\
\hline CHEMBL1574403 & 688340 & 2.9 & 4.9686 & TST & \\
\hline CHEMBL1450648 & 688340 & 4.45 & 4.5579 & TRN & \\
\hline CHEMBL1966984 & 688340 & 6.0 & 5.0747 & TST & \\
\hline CHEMBL1499754 & 688340 & 5.4 & 5.0035 & TRN & \\
\hline CHEMBL1605081 & 688340 & 4.45 & 4.757 & TRN & \\
\hline CHEMBL1402108 & 688340 & 4.45 & 5.1675 & TST & \\
\hline CHEMBL1361219 & 688340 & 5.4 & 5.2962 & TRN & \\
\hline CHEMBL1446342 & 688340 & 4.4 & 5.1161 & TRN & \\
\hline CHEMBL1328930 & 688340 & 4.5 & 4.8274 & TRN & \\
\hline CHEMBL1596318 & 688340 & 4.55 & 4.8523 & TRN & \\
\hline CHEMBL1428886 & 688340 & 4.8 & $5.1320 e$ & 0000000001 & TRN \\
\hline CHEMBL1606568 & 688340 & 4.5 & 4.7384 & TRN & \\
\hline CHEMBL1536839 & 688340 & 6.1 & 5.4288 & TRN & \\
\hline CHEMBL1362899 & 688340 & 4.55 & 4.9007 & TRN & \\
\hline CHEMBL1541863 & 688340 & 4.6 & 5.0932 & TRN & \\
\hline CHEMBL3192144 & 688340 & 5.75 & 4.6312 & TRN & \\
\hline CHEMBL1422199 & 688340 & 4.4 & 5.0292 & TRN & \\
\hline CHEMBL1333929 & 688340 & 4.4 & 4.7451 & TRN & \\
\hline CHEMBL1312828 & 688340 & 4.45 & 5.0846 & TRN & \\
\hline CHEMBL1408111 & 688340 & 4.5 & 5.0073 & TRN & \\
\hline CHEMBL1454195 & 688340 & 5.15 & 4.7588 & TRN & \\
\hline CHEMBL3198581 & 688340 & 6.1 & 4.71899 & 9999999999 & TRN \\
\hline CHEMBL 1478588 & 688340 & 4.4 & 4.7807 & TST & \\
\hline CHEMBL1497192 & 688340 & 3.65 & 4.703 & TRN & \\
\hline CHEMBL1594723 & 688340 & 4.75 & 4.8856 & TST & \\
\hline CHEMBL1423248 & 688340 & 5.0 & 5.282 & TST & \\
\hline CHEMBL1317607 & 688340 & 5.25 & 4.984 & TST & \\
\hline CHEMBL1424408 & 688340 & 4.4 & 4.7709 & TRN & \\
\hline CHEMBL1992547 & 688340 & 4.55 & 4.9274 & TRN & \\
\hline CHEMBL1390040 & 688340 & 4.35 & 5.1295 & TRN & \\
\hline CHEMBL1402628 & 688340 & 4.6 & 4.7059 & TRN & \\
\hline CHEMBL1561998 & 688340 & 5.2 & 4.9875 & TST & \\
\hline CHEMBL1998639 & 688340 & 5.05 & 4.8739 & TRN & \\
\hline CHEMBL1478628 & 688340 & 4.5 & 4.7779 & TRN & \\
\hline CHEMBL1499802 & 688340 & 5.1 & 5.5397 & TST & \\
\hline CHEMBL1576392 & 688340 & 5.6 & 5.0681 & TRN & \\
\hline CHEMBL1300408 & 688340 & 5.05 & 5.066 & TRN & \\
\hline CHEMBL1555117 & 688340 & 4.65 & 5.0028 & TST & \\
\hline CHEMBL1454606 & 688340 & 4.45 & 5.1166 & TST & \\
\hline CHEMBL1494931 & 688340 & 4.8 & 4.8545 & TRN & \\
\hline CHEMBL 3145017 & 688340 & 4.5 & 5.0006 & TRN & \\
\hline CHEMBL1447055 & 688340 & 4.9 & 4.7322 & TRN & \\
\hline CHEMBL1392393 & 688340 & 4.45 & 4.9202 & TRN & \\
\hline
\end{tabular}




\begin{tabular}{|c|c|c|c|c|c|}
\hline \multicolumn{6}{|c|}{ Supplemental Table S2.txt } \\
\hline CHEMBL1353886 & 688340 & 5.4 & 4.8647 & TRN & \\
\hline CHEMBL1557093 & 688340 & 4.65 & 4.8966 & TRN & \\
\hline CHEMBL1414424 & 688340 & 6.5 & 5.4999 & TST & \\
\hline CHEMBL1423359 & 688340 & 4.35 & 4.7709 & TST & \\
\hline CHEMBL3190881 & 688340 & 4.55 & 4.9055 & TRN & \\
\hline CHEMBL1554899 & 688340 & 4.55 & 4.8218 & TRN & \\
\hline CHEMBL1565762 & 688340 & 4.85 & 4.9265 & TRN & \\
\hline CHEMBL3195986 & 688340 & 4.45 & 4.8435 & TRN & \\
\hline CHEMBL1527772 & 688340 & 6.2 & 4.6239 & TRN & \\
\hline CHEMBL1425960 & 688340 & 4.7 & 5.0685 & TRN & \\
\hline CHEMBL1565415 & 688340 & 5.5 & 5.0087 & TRN & \\
\hline CHEMBL1471412 & 688340 & 4.65 & 5.1576 & TRN & \\
\hline CHEMBL1321082 & 688340 & 4.8 & 5.2959 & TST & \\
\hline CHEMBL1408272 & 688340 & 6.15 & 5.2384 & TRN & \\
\hline CHEMBL1528413 & 688340 & 4.5 & 5.0427 & TRN & \\
\hline CHEMBL1415210 & 688340 & 4.6 & 5.0721 & TRN & \\
\hline CHEMBL1573647 & 688340 & 4.75 & 4.7324 & TRN & \\
\hline CHEMBL1309045 & 688340 & 4.4 & 4.7491 & TRN & \\
\hline CHEMBL1416788 & 688340 & 5.0 & 4.982 & TRN & \\
\hline CHEMBL1344803 & 688340 & 5.55 & 5.0148 & TRN & \\
\hline CHEMBL1599617 & 688340 & 6.5501 & 5.5282 & TRN & \\
\hline CHEMBL1546125 & 688340 & 4.95 & 5.087 & TST & \\
\hline CHEMBL3198816 & 688340 & 4.55 & 4.7748 & TRN & \\
\hline CHEMBL1495333 & 688340 & 3.65 & 5.2721 & TRN & \\
\hline CHEMBL1976499 & 688340 & 5.1 & 4.7327 & TRN & \\
\hline CHEMBL1482989 & 688340 & 4.55 & 4.9547 & TRN & \\
\hline CHEMBL1499596 & 688340 & 4.85 & 5.0184 & TRN & \\
\hline CHEMBL1547247 & 688340 & 4.5 & 4.5791 & TRN & \\
\hline CHEMBL1531756 & 688340 & 5.45 & 5.08899 & 99999999995 & TRN \\
\hline CHEMBL1603529 & 688340 & 7.0 & 5.4014 & TRN & \\
\hline CHEMBL1554618 & 688340 & 4.55 & 5.1115 & TRN & \\
\hline CHEMBL3197284 & 688340 & 4.4 & 5.1387 & TST & \\
\hline CHEMBL1468351 & 688340 & 4.4 & 5.112 & TRN & \\
\hline CHEMBL1385481 & 688340 & 4.55 & 5.0749 & TST & \\
\hline CHEMBL1485195 & 688340 & 4.6 & 5.3028 & TST & \\
\hline CHEMBL1478904 & 688340 & 5.2 & 5.4999 & TRN & \\
\hline CHEMBL1586766 & 688340 & 4.6 & 4.5833 & TRN & \\
\hline CHEMBL1379048 & 688340 & 4.55 & 4.9978 & TRN & \\
\hline CHEMBL1374516 & 688340 & 5.75 & 5.2735 & TRN & \\
\hline CHEMBL1508508 & 688340 & 4.6 & 4.6364 & TRN & \\
\hline CHEMBL1551591 & 688340 & 4.55 & 4.8903 & TRN & \\
\hline CHEMBL1340288 & 688340 & 4.45 & 4.7048 & TRN & \\
\hline CHEMBL1485793 & 688340 & 5.0 & 4.4394 & TST & \\
\hline CHEMBL1533248 & 688340 & 4.5 & 4.8657 & TRN & \\
\hline CHEMBL1378836 & 688340 & 4.55 & 5.2158 & TRN & \\
\hline CHEMBL1351487 & 688340 & 4.45 & 4.9679 & TST & \\
\hline CHEMBL1970824 & 688340 & 4.6 & 4.7738 & TRN & \\
\hline CHEMBL1432090 & 688340 & 4.75 & 5.0692 & TST & \\
\hline
\end{tabular}




\begin{tabular}{|c|c|c|c|c|c|}
\hline \multicolumn{6}{|c|}{ Supplemental Table S2.txt } \\
\hline CHEMBL3199237 & 688340 & 4.75 & 4.8815 & TRN & \\
\hline CHEMBL1313459 & 688340 & 4.55 & 4.902 & TRN & \\
\hline CHEMBL1386109 & 688340 & 5.0 & 5.0244 & TRN & \\
\hline CHEMBL1521801 & 688340 & 5.2 & 5.2397 & TST & \\
\hline CHEMBL1481270 & 688340 & 6.15 & 5.1198 & TRN & \\
\hline CHEMBL1320542 & 688340 & 5.45 & 5.16200 & 0000000001 & TRN \\
\hline CHEMBL 3193734 & 688340 & 5.65 & 5.0544 & TRN & \\
\hline CHEMBL1419162 & 688340 & 4.4 & 5.1853 & TST & \\
\hline CHEMBL1425232 & 688340 & 4.55 & 5.0932 & TRN & \\
\hline CHEMBL1613394 & 688340 & 6.0 & 4.8964 & TRN & \\
\hline CHEMBL1505305 & 688340 & 5.0 & 4.4548 & TST & \\
\hline CHEMBL1403321 & 688340 & 4.6 & 4.8882 & TRN & \\
\hline CHEMBL1399952 & 688340 & 4.5 & 4.897 & TRN & \\
\hline CHEMBL1583756 & 688340 & 6.35 & 5.1211 & TRN & \\
\hline CHEMBL1581799 & 688340 & 4.5 & 5.0961 & TRN & \\
\hline CHEMBL1596712 & 688340 & 6.15 & 5.0193 & TST & \\
\hline CHEMBL596631 & 688340 & 4.6 & 5.0733 & TST & \\
\hline CHEMBL1313972 & 688340 & 6.15 & 4.7908 & TST & \\
\hline CHEMBL1367360 & 688340 & 6.95 & 5.20799 & 9999999999 & TST \\
\hline CHEMBL1504591 & 688340 & 4.6 & 5.087 & TRN & \\
\hline CHEMBL1434031 & 688340 & 4.4 & 4.7381 & TRN & \\
\hline CHEMBL1358982 & 688340 & 4.9 & 4.7567 & TRN & \\
\hline CHEMBL1307207 & 688340 & 4.4 & 5.155 & TRN & \\
\hline CHEMBL1310780 & 688340 & 5.0 & 5.0251 & TST & \\
\hline CHEMBL1556041 & 688340 & 4.4 & 4.9713 & TRN & \\
\hline CHEMBL1363807 & 688340 & 5.15 & 5.416 & TRN & \\
\hline CHEMBL1356102 & 688340 & 4.8 & 5.2163 & TRN & \\
\hline CHEMBL1484173 & 688340 & 4.3 & 4.8735 & TST & \\
\hline CHEMBL1575026 & 688340 & 5.0 & 5.1532 & TRN & \\
\hline CHEMBL1388860 & 688340 & 4.55 & 4.931 & TRN & \\
\hline CHEMBL1515143 & 688340 & 4.6 & 5.1544 & TRN & \\
\hline CHEMBL1423990 & 688340 & 4.75 & 5.0196 & TRN & \\
\hline CHEMBL1433546 & 688340 & 5.8 & 4.9827 & TRN & \\
\hline CHEMBL1441590 & 688340 & 4.4 & 5.0021 & TST & \\
\hline CHEMBL1581504 & 688340 & 6.5501 & 5.2744 & TRN & \\
\hline CHEMBL1385947 & 688340 & 5.45 & 5.0851 & TRN & \\
\hline CHEMBL3194798 & 688340 & 4.65 & 4.8826 & TRN & \\
\hline CHEMBL1549056 & 688340 & 5.05 & 4.8357 & TRN & \\
\hline CHEMBL1351837 & 688340 & 4.5 & 5.0342 & TRN & \\
\hline CHEMBL1379103 & 688340 & 4.6 & 5.2572 & TST & \\
\hline CHEMBL1396295 & 688340 & 4.85 & 5.2005 & TRN & \\
\hline CHEMBL3193810 & 688340 & 4.7 & 5.0431 & TRN & \\
\hline CHEMBL1425932 & 688340 & 4.5 & 4.7398 & TRN & \\
\hline CHEMBL1354473 & 688340 & 4.6 & 5.1653 & TRN & \\
\hline CHEMBL1527416 & 688340 & 4.7 & 5.0384 & TST & \\
\hline CHEMBL1496954 & 688340 & 4.4 & 4.8246 & TRN & \\
\hline CHEMBL3194610 & 688340 & 4.4 & 4.8018 & TRN & \\
\hline CHEMBL1316124 & 688340 & 4.75 & 5.1957 & TRN & \\
\hline
\end{tabular}




\begin{tabular}{|c|c|c|c|c|}
\hline & & & pplement & al Table \\
\hline CHEMBL199405 & 688340 & 4.5 & 4.7924 & TRN \\
\hline CHEMBL1538210 & 688340 & 4.7 & 4.9225 & TRN \\
\hline CHEMBL1365415 & 688340 & 4.35 & 4.8262 & TRN \\
\hline CHEMBL1599351 & 688340 & 4.6 & 5.0428 & TRN \\
\hline CHEMBL1421223 & 688340 & 4.4 & 4.9919 & TST \\
\hline CHEMBL1349096 & 688340 & 4.45 & 5.1899 & TRN \\
\hline CHEMBL1452952 & 688340 & 5.45 & 4.7678 & TRN \\
\hline CHEMBL 2000264 & 688340 & 4.6 & 4.7869 & TST \\
\hline CHEMBL3207381 & 688340 & 5.15 & 5.1377 & TRN \\
\hline CHEMBL1317969 & 688340 & 4.65 & 4.7557 & TRN \\
\hline CHEMBL1535361 & 688340 & 4.65 & 4.7387 & TRN \\
\hline CHEMBL1386432 & 688340 & 4.9 & 5.2667 & TRN \\
\hline CHEMBL1305498 & 688340 & 5.0 & 5.5179 & TST \\
\hline CHEMBL1583883 & 688340 & 4.6 & 4.9588 & TST \\
\hline CHEMBL1603364 & 688340 & 5.05 & 5.052 & TRN \\
\hline CHEMBL1503940 & 688340 & 5.5 & 5.0636 & TST \\
\hline CHEMBL1532258 & 688340 & 7.5003 & 5.546 & TRN \\
\hline CHEMBL1415308 & 688340 & 4.4 & 4.6421 & TRN \\
\hline CHEMBL1537531 & 688340 & 5.35 & 5.1923 & TST \\
\hline CHEMBL1588697 & 688340 & 4.45 & 4.9248 & TRN \\
\hline CHEMBL1595534 & 688340 & 7.0501 & 5.2305 & TRN \\
\hline CHEMBL1504489 & 688340 & 4.3 & 4.9336 & TRN \\
\hline CHEMBL1410176 & 688340 & 4.4 & 4.856 & TST \\
\hline CHEMBL1459962 & 688340 & 4.6 & 4.8694 & TRN \\
\hline CHEMBL1461273 & 688340 & 4.65 & 4.7463 & TST \\
\hline CHEMBL1606004 & 688340 & 5.4 & 4.8773 & TRN \\
\hline CHEMBL1463970 & 688340 & 4.4 & 5.0867 & TST \\
\hline CHEMBL1540269 & 688340 & 7.0501 & 5.1582 & TST \\
\hline CHEMBL3213812 & 688340 & 4.4 & 4.9197 & TRN \\
\hline CHEMBL1514983 & 688340 & 4.45 & 5.2766 & TRN \\
\hline CHEMBL1580172 & 688340 & 2.7 & 5.1437 & TRN \\
\hline CHEMBL1339069 & 688340 & 4.4 & 4.505 & TRN \\
\hline CHEMBL1400298 & 688340 & 5.0 & 4.6788 & TRN \\
\hline CHEMBL3189704 & 688340 & 5.1 & 4.7039 & TST \\
\hline CHEMBL1492946 & 688340 & 5.0 & 4.7925 & TRN \\
\hline CHEMBL1359851 & 688340 & 4.5 & 5.5073 & TRN \\
\hline CHEMBL3198918 & 688340 & 5.5 & 5.2905 & TRN \\
\hline CHEMBL1417822 & 688340 & 7.0 & 5.3931 & TRN \\
\hline CHEMBL1455009 & 688340 & 1.25 & 5.2321 & TST \\
\hline CHEMBL1522183 & 688340 & 4.4 & 5.0362 & TRN \\
\hline CHEMBL1362766 & 688340 & 6.15 & 5.1036 & TST \\
\hline CHEMBL1307241 & 688340 & 5.75 & 5.3842 & TRN \\
\hline CHEMBL1421731 & 688340 & 5.0 & 4.6633 & TRN \\
\hline CHEMBL502315 & 688340 & 6.2 & 4.8639 & TRN \\
\hline CHEMBL1383057 & 688340 & 4.45 & 5.1276 & TRN \\
\hline CHEMBL1595045 & 688340 & 4.4 & 5.1225 & TRN \\
\hline CHEMBL1594358 & 688340 & 4.75 & 4.8028 & TST \\
\hline CHEMBL1591449 & 688340 & 4.05 & 5.1869 & TRN \\
\hline
\end{tabular}




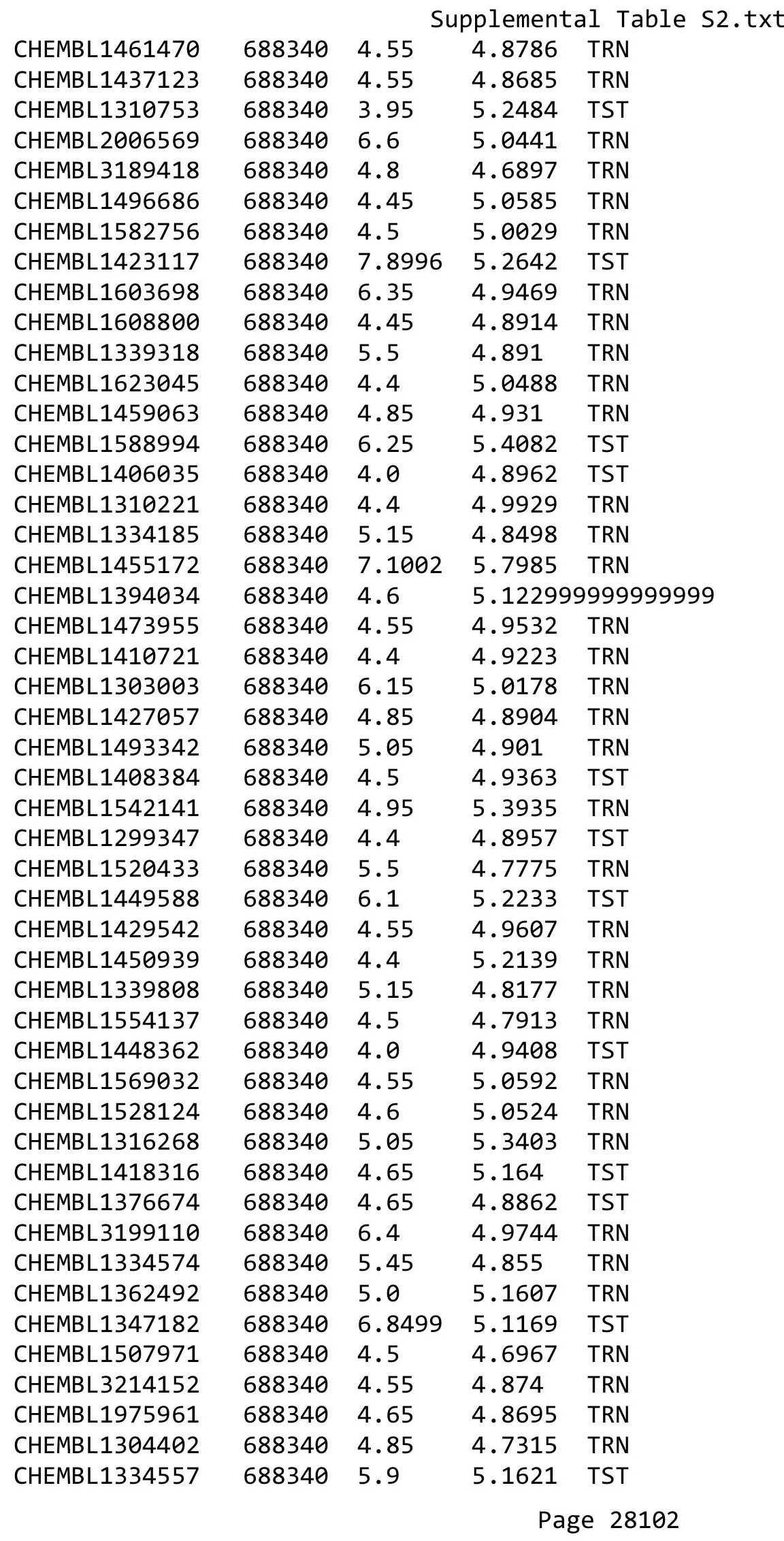




\begin{tabular}{|c|c|c|c|c|c|}
\hline & & & & & \\
\hline CHEMBL1465619 & 688340 & 4.5 & 5.0336 & TRN & \\
\hline CHEMBL1597146 & 688340 & 4.65 & 4.9003 & TRN & \\
\hline CHEMBL3209087 & 688340 & 4.55 & 4.9307 & TRN & \\
\hline CHEMBL1389297 & 688340 & 4.4 & 4.8695 & TRN & \\
\hline CHEMBL3199405 & 688340 & 4.7 & 4.9832 & TST & \\
\hline CHEMBL1556329 & 688340 & 4.4 & 5.2748 & TST & \\
\hline CHEMBL1299757 & 688340 & 5.45 & 4.6131 & TRN & \\
\hline CHEMBL1588565 & 688340 & 5.25 & 5.4787 & TRN & \\
\hline CHEMBL1590634 & 688340 & 4.45 & 5.3888 & TRN & \\
\hline CHEMBL1598524 & 688340 & 3.55 & 5.3962 & TST & \\
\hline CHEMBL1349475 & 688340 & 6.0 & 4.8025 & TRN & \\
\hline CHEMBL1585138 & 688340 & 4.5 & 4.9151 & TRN & \\
\hline CHEMBL1570915 & 688340 & 4.4 & 4.6196 & TRN & \\
\hline CHEMBL1412953 & 688340 & 4.35 & 5.1979 & TRN & \\
\hline CHEMBL1586339 & 688340 & 4.8 & 4.9929 & TRN & \\
\hline CHEMBL1431891 & 688340 & 6.95 & 5.1134 & TRN & \\
\hline CHEMBL 2002849 & 688340 & 4.55 & 4.8752 & TRN & \\
\hline CHEMBL1541431 & 688340 & 4.6 & 4.5756 & TRN & \\
\hline CHEMBL1455893 & 688340 & 5.3 & 5.3841 & TRN & \\
\hline CHEMBL1546837 & 688340 & 4.4 & 5.0149 & TST & \\
\hline CHEMBL1519033 & 688340 & 5.05 & 5.1886 & TRN & \\
\hline CHEMBL1603878 & 688340 & 5.0 & 5.0912 & TRN & \\
\hline CHEMBL38739 & 688340 & 6.2 & 5.059 & TST & \\
\hline CHEMBL1436425 & 688340 & 4.6 & 5.2499 & TRN & \\
\hline CHEMBL1551351 & 688340 & 4.45 & 4.9354 & TRN & \\
\hline CHEMBL1440656 & 688340 & 4.5 & 4.8852 & TST & \\
\hline CHEMBL1389687 & 688340 & 4.4 & 4.76 & TRN & \\
\hline CHEMBL1581314 & 688340 & 4.45 & 4.7351 & TRN & \\
\hline CHEMBL3192151 & 688340 & 4.0 & 5.2085 & TST & \\
\hline CHEMBL1425679 & 688340 & 4.55 & 5.5056 & TRN & \\
\hline CHEMBL1343777 & 688340 & 5.45 & 5.0697 & TST & \\
\hline CHEMBL1307754 & 688340 & 5.4 & 4.8827 & TRN & \\
\hline CHEMBL1594831 & 688340 & 5.0 & 5.2523 & TRN & \\
\hline CHEMBL1387355 & 688340 & 4.5 & 4.8047 & TRN & \\
\hline CHEMBL1579857 & 688340 & 6.1 & 5.3106 & TRN & \\
\hline CHEMBL1469728 & 688340 & 4.55 & 4.706 & TRN & \\
\hline CHEMBL1509954 & 688340 & 5.6 & 5.0759 & TST & \\
\hline CHEMBL1487907 & 688340 & 4.65 & 4.8281 & TRN & \\
\hline CHEMBL1545677 & 688340 & 4.5 & 4.9211 & TST & \\
\hline CHEMBL1459351 & 688340 & 4.7 & 4.88 & TRN & \\
\hline CHEMBL1496820 & 688340 & 5.25 & 4.8719 & TST & \\
\hline CHEMBL1484570 & 688340 & 5.4 & 5.0901 & TRN & \\
\hline CHEMBL1425630 & 688340 & 5.3 & 5.2329 & TRN & \\
\hline CHEMBL1580116 & 688340 & 4.6 & 4.6705 & TST & \\
\hline CHEMBL1332125 & 688340 & 4.65 & 5.0628 & TST & \\
\hline CHEMBL1306398 & 688340 & 5.0 & 5.0209 & TRN & \\
\hline CHEMBL1461931 & 688340 & 5.0 & 4.9952 & TRN & \\
\hline CHEMBL1328988 & 688340 & 4.5 & 4.79899 & 99999999995 & TRN \\
\hline & & & & 28103 & \\
\hline
\end{tabular}




\begin{tabular}{|c|c|c|c|c|c|}
\hline \multicolumn{6}{|c|}{ Supplemental Table S2.txt } \\
\hline CHEMBL1452712 & 688340 & 4.75 & 4.7927 & TRN & \\
\hline CHEMBL3195881 & 688340 & 6.25 & 4.8824 & TST & \\
\hline CHEMBL1446729 & 688340 & 4.4 & 4.8476 & TRN & \\
\hline CHEMBL1508131 & 688340 & 5.6 & 5.03100 & 0000000001 & TRN \\
\hline CHEMBL1413250 & 688340 & 7.0 & 5.0763 & TST & \\
\hline CHEMBL1395553 & 688340 & 4.3 & 5.3121 & TRN & \\
\hline CHEMBL1466985 & 688340 & 5.15 & 5.3559 & TST & \\
\hline CHEMBL1527581 & 688340 & 5.6 & 5.2493 & TST & \\
\hline CHEMBL1442239 & 688340 & 4.65 & 5.1959 & TRN & \\
\hline CHEMBL529615 & 688340 & 6.2 & 5.0278 & TRN & \\
\hline CHEMBL1502391 & 688340 & 6.95 & 5.6068 & TRN & \\
\hline CHEMBL3195136 & 688340 & 3.95 & 5.0572 & TST & \\
\hline CHEMBL1408363 & 688340 & 5.9 & 5.1023 & TRN & \\
\hline CHEMBL3209336 & 688340 & 4.7 & 4.7867 & TST & \\
\hline CHEMBL1544708 & 688340 & 6.4 & 5.2149 & TRN & \\
\hline CHEMBL1385653 & 688340 & 4.4 & 4.8148 & TRN & \\
\hline CHEMBL3208404 & 688340 & 6.5 & 5.0107 & TRN & \\
\hline CHEMBL1307398 & 688340 & 6.5 & 4.9375 & TST & \\
\hline CHEMBL1543895 & 688340 & 4.6 & 4.8965 & TRN & \\
\hline CHEMBL1429713 & 688340 & 5.3 & 4.9815 & TRN & \\
\hline CHEMBL1425967 & 688340 & 5.5 & 5.0517 & TRN & \\
\hline CHEMBL1519235 & 688340 & 6.1 & 5.1751 & TRN & \\
\hline CHEMBL1584902 & 688340 & 4.6 & 4.7995 & TRN & \\
\hline CHEMBL1334671 & 688340 & 4.95 & 4.8 & TRN & \\
\hline CHEMBL3196537 & 688340 & 4.5 & 5.2022 & TRN & \\
\hline CHEMBL1447737 & 688340 & 5.05 & 5.2374 & TST & \\
\hline CHEMBL1497254 & 688340 & 6.1 & 5.4497 & TRN & \\
\hline CHEMBL1595628 & 688340 & 5.2 & 5.3141 & TRN & \\
\hline CHEMBL1486752 & 688340 & 6.05 & 5.1977 & TST & \\
\hline CHEMBL1441303 & 688340 & 5.15 & 4.9916 & TST & \\
\hline CHEMBL1331884 & 688340 & 4.55 & 4.9059 & TRN & \\
\hline CHEMBL1534378 & 688340 & 4.6 & 5.34399 & & TRN \\
\hline CHEMBL1558160 & 688340 & 4.85 & 5.0651 & TRN & \\
\hline CHEMBL1352318 & 688340 & 5.05 & 5.0737 & TST & \\
\hline CHEMBL1323237 & 688340 & 6.05 & 5.0992 & TST & \\
\hline CHEMBL1508492 & 688340 & 4.95 & 5.2231 & TST & \\
\hline CHEMBL1462808 & 688340 & 4.8 & 4.9286 & TRN & \\
\hline CHEMBL1503478 & 688340 & 4.55 & 4.9508 & TST & \\
\hline CHEMBL1423524 & 688340 & 4.5 & 4.8797 & TRN & \\
\hline CHEMBL1366472 & 688340 & 4.8 & 5.1945 & TRN & \\
\hline CHEMBL1314930 & 688340 & 7.0 & 5.102 & TST & \\
\hline CHEMBL1529498 & 688340 & 5.0 & 5.3799 & TRN & \\
\hline CHEMBL1588665 & 688340 & 4.95 & 5.2454 & TRN & \\
\hline CHEMBL1565468 & 688340 & 4.35 & 4.9059 & TRN & \\
\hline CHEMBL1415710 & 688340 & 4.6 & 5.0262 & TRN & \\
\hline CHEMBL1311651 & 688340 & 4.4 & 4.8563 & TRN & \\
\hline CHEMBL1337947 & 688340 & 4.85 & 4.7431 & TRN & \\
\hline CHEMBL1428105 & 688340 & 4.55 & 4.7067 & TRN & \\
\hline
\end{tabular}




\begin{tabular}{|c|c|c|c|c|}
\hline \multicolumn{5}{|c|}{ Supplemental Table S2.txt } \\
\hline CHEMBL1404467 & 688340 & 4.6 & 5.3972 & TRN \\
\hline CHEMBL1376806 & 688340 & 4.3 & 4.915 & TRN \\
\hline CHEMBL3199283 & 688340 & 4.55 & 5.0225 & TRN \\
\hline CHEMBL1518271 & 688340 & 4.6 & 4.9873 & TRN \\
\hline CHEMBL2001904 & 688340 & 4.65 & 4.7607 & TST \\
\hline CHEMBL1340352 & 688340 & 4.4 & 5.101 & TST \\
\hline CHEMBL1459193 & 688340 & 8.8861 & 5.6124 & TRN \\
\hline CHEMBL1400016 & 688340 & 5.15 & 5.4339 & TRN \\
\hline CHEMBL1486353 & 688340 & 5.2 & 4.9607 & TST \\
\hline CHEMBL1472068 & 688340 & 4.65 & 5.2114 & TRN \\
\hline CHEMBL1414406 & 688340 & 4.5 & 4.7654 & TRN \\
\hline CHEMBL1484258 & 688340 & 5.15 & 5.0311 & TRN \\
\hline CHEMBL1338677 & 688340 & 5.15 & 4.7348 & TRN \\
\hline CHEMBL1428789 & 688340 & 4.5 & 5.0836 & TRN \\
\hline CHEMBL1574764 & 688340 & 5.85 & 5.1008 & TST \\
\hline CHEMBL1354360 & 688340 & 4.4 & 4.8122 & TRN \\
\hline CHEMBL1977596 & 688340 & 5.15 & 4.7907 & TRN \\
\hline CHEMBL1509944 & 688340 & 4.45 & 4.7229 & TST \\
\hline CHEMBL1534393 & 688340 & 4.75 & 4.7895 & TRN \\
\hline CHEMBL3193781 & 688340 & 4.5 & 4.995 & TRN \\
\hline CHEMBL1445956 & 688340 & 6.5501 & 5.2749 & TRN \\
\hline CHEMBL1325377 & 688340 & 4.75 & 4.8049 & TRN \\
\hline CHEMBL1575246 & 688340 & 4.6 & 4.7305 & TRN \\
\hline CHEMBL1972029 & 688340 & 4.55 & 4.6365 & TRN \\
\hline CHEMBL1506160 & 688340 & 4.4 & 5.0998 & TRN \\
\hline CHEMBL1322784 & 688340 & 4.8 & 4.867 & TRN \\
\hline CHEMBL1471603 & 688340 & 7.0 & 5.0395 & TST \\
\hline CHEMBL1456316 & 688340 & 6.7001 & 4.9631 & TST \\
\hline CHEMBL1342500 & 688340 & 5.5 & 5.2157 & TRN \\
\hline CHEMBL3199097 & 688340 & 5.05 & 5.0808 & TRN \\
\hline CHEMBL1384323 & 688340 & 4.7 & 5.1174 & TRN \\
\hline CHEMBL1330510 & 688340 & 4.45 & 4.5046 & TRN \\
\hline CHEMBL1475576 & 688340 & 7.0 & 5.2411 & TST \\
\hline CHEMBL1333309 & 688340 & 4.0 & 4.9878 & TST \\
\hline CHEMBL1388372 & 688340 & 4.8 & 4.7826 & TST \\
\hline CHEMBL1522155 & 688340 & 4.4 & 5.1396 & TRN \\
\hline CHEMBL1427155 & 688340 & 5.65 & 4.9706 & TRN \\
\hline CHEMBL1593286 & 688340 & 4.85 & 5.0095 & TRN \\
\hline CHEMBL1530400 & 688340 & 6.1 & 5.1632 & TRN \\
\hline CHEMBL1441106 & 688340 & 7.0 & 5.2994 & TRN \\
\hline CHEMBL1436039 & 688340 & 4.5 & 4.843 & TRN \\
\hline CHEMBL3199638 & 688340 & 4.6 & 4.993 & TST \\
\hline CHEMBL1352596 & 688340 & 6.95 & 5.433 & TST \\
\hline CHEMBL1561787 & 688340 & 9.2218 & 5.0785 & TRN \\
\hline CHEMBL1449926 & 688340 & 2.3 & 4.7524 & TST \\
\hline CHEMBL 244090 & 688340 & 4.5 & 4.8162 & TST \\
\hline CHEMBL1401229 & 688340 & 4.4 & 4.9026 & TRN \\
\hline CHEMBL1577952 & 688340 & 4.85 & 4.7451 & TRN \\
\hline
\end{tabular}




\begin{tabular}{|c|c|c|c|c|c|}
\hline & & & & & \\
\hline CHEMBL1609550 & 688340 & 5.5 & 4.9361 & TRN & \\
\hline CHEMBL1370763 & 688340 & 6.0 & 5.401 & TRN & \\
\hline CHEMBL1507356 & 688340 & 6.05 & 5.3955 & TST & \\
\hline CHEMBL1423852 & 688340 & 5.4 & 4.8141 & TRN & \\
\hline CHEMBL1496836 & 688340 & 6.9 & 5.0601 & TRN & \\
\hline CHEMBL1433190 & 688340 & 4.4 & 4.9131 & TRN & \\
\hline CHEMBL1390039 & 688340 & 7.0 & 5.0191 & TRN & \\
\hline CHEMBL1473426 & 688340 & 4.45 & 5.1804 & TRN & \\
\hline CHEMBL1445560 & 688340 & 6.5 & 5.0461 & TRN & \\
\hline CHEMBL1491894 & 688340 & 4.6 & 4.84399 & 9999999999 & TRN \\
\hline CHEMBL1366820 & 688340 & 4.55 & 4.8106 & TRN & \\
\hline CHEMBL1428894 & 688340 & 4.6 & 4.6656 & TRN & \\
\hline CHEMBL1521676 & 688340 & 4.6 & 4.6536 & TRN & \\
\hline CHEMBL1421596 & 688340 & 4.45 & 5.0278 & TRN & \\
\hline CHEMBL1966224 & 688340 & 5.45 & 4.89 & TRN & \\
\hline CHEMBL1367603 & 688340 & 4.55 & 4.6452 & TRN & \\
\hline CHEMBL1559613 & 688340 & 7.2503 & 5.2311 & TRN & \\
\hline CHEMBL1373897 & 688340 & 5.5 & 4.7555 & TRN & \\
\hline CHEMBL1369037 & 688340 & 4.65 & 5.192 & TRN & \\
\hline CHEMBL1345825 & 688340 & 4.7 & 4.6609 & TRN & \\
\hline CHEMBL 1402385 & 688340 & 4.65 & 4.7474 & TRN & \\
\hline CHEMBL1612112 & 688340 & 5.45 & 4.9309 & TRN & \\
\hline CHEMBL1484021 & 688340 & 5.85 & 4.9246 & TRN & \\
\hline CHEMBL3197122 & 688340 & 4.4 & 4.9852 & TRN & \\
\hline CHEMBL1324935 & 688340 & 4.65 & 4.7178 & TRN & \\
\hline CHEMBL1413473 & 688340 & 4.5 & 5.2053 & TRN & \\
\hline CHEMBL1400008 & 688340 & 7.4498 & 5.2449 & TRN & \\
\hline CHEMBL1540373 & 688340 & 4.55 & 4.9239 & TRN & \\
\hline CHEMBL1491556 & 688340 & 4.4 & 4.9704 & TRN & \\
\hline CHEMBL1454039 & 688340 & 5.4 & 4.7184 & TRN & \\
\hline CHEMBL1299975 & 688340 & 5.2 & 5.1042 & TRN & \\
\hline CHEMBL1539165 & 688340 & 4.5 & 4.7901 & TRN & \\
\hline CHEMBL1387106 & 688340 & 6.15 & 5.3974 & TST & \\
\hline CHEMBL1539737 & 688340 & 6.15 & 5.5376 & TRN & \\
\hline CHEMBL1581309 & 688340 & 5.35 & 4.9307 & TST & \\
\hline CHEMBL1532269 & 688340 & 5.5 & 5.2654 & TST & \\
\hline CHEMBL1532193 & 688340 & 4.4 & 4.877 & TST & \\
\hline CHEMBL3209792 & 688340 & 4.6 & 4.5688 & TRN & \\
\hline CHEMBL1352659 & 688340 & 4.5 & 4.7146 & TRN & \\
\hline CHEMBL1432199 & 688340 & 5.75 & 4.9465 & TRN & \\
\hline CHEMBL1310162 & 688340 & 4.6 & 5.1498 & TRN & \\
\hline CHEMBL1453802 & 688340 & 7.0 & 5.1113 & TRN & \\
\hline CHEMBL1561995 & 688340 & 4.65 & 4.8958 & TRN & \\
\hline CHEMBL1494232 & 688340 & 3.95 & 5.5444 & TRN & \\
\hline CHEMBL1567416 & 688340 & 4.4 & 5.1293 & TST & \\
\hline CHEMBL1213771 & 688340 & 5.25 & 5.1178 & TRN & \\
\hline CHEMBL1506520 & 688340 & 6.0 & 5.1 & TRN & \\
\hline CHEMBL1308201 & 688340 & 4.75 & 4.8536 & TST & \\
\hline
\end{tabular}




\begin{tabular}{|c|c|c|c|c|}
\hline \multicolumn{5}{|c|}{ Supplemental Table S2.txt } \\
\hline CHEMBL1477236 & 688340 & 4.7 & 4.6792 & TRN \\
\hline CHEMBL1346172 & 688340 & 5.45 & 5.1794 & TRN \\
\hline CHEMBL1566772 & 688340 & 4.7 & 5.0754 & TST \\
\hline CHEMBL1313759 & 688340 & 5.0 & 4.6096 & TRN \\
\hline CHEMBL1430376 & 688340 & 4.6 & 4.8267 & TRN \\
\hline CHEMBL1590494 & 688340 & 4.4 & 4.9568 & TRN \\
\hline CHEMBL1428364 & 688340 & 4.35 & 5.3753 & TRN \\
\hline CHEMBL1418116 & 688340 & 4.7 & 5.0531 & TRN \\
\hline CHEMBL1427552 & 688340 & 5.2 & 5.3028 & TST \\
\hline CHEMBL1563251 & 688340 & 4.75 & 4.6523 & TRN \\
\hline CHEMBL1977226 & 688340 & 5.25 & 4.9156 & TRN \\
\hline CHEMBL1425682 & 688340 & 4.55 & 4.9891 & TRN \\
\hline CHEMBL1301037 & 688340 & 4.45 & 4.5815 & TRN \\
\hline CHEMBL1341586 & 688340 & 7.0 & 5.0491 & TRN \\
\hline CHEMBL1599131 & 688340 & 4.55 & 4.84 & TRN \\
\hline CHEMBL1511296 & 688340 & 5.5 & 5.1798 & TST \\
\hline CHEMBL1542217 & 688340 & 5.1 & 5.1389 & TRN \\
\hline CHEMBL1489664 & 688340 & 4.4 & 5.1948 & TST \\
\hline CHEMBL578585 & 688340 & 4.55 & 5.0781 & TRN \\
\hline CHEMBL1572662 & 688340 & 5.7 & 4.935 & TRN \\
\hline CHEMBL1486047 & 688340 & 4.4 & 5.1378 & TRN \\
\hline CHEMBL1466868 & 688340 & 5.05 & 4.9067 & TRN \\
\hline CHEMBL1441583 & 688340 & 4.5 & 4.6388 & TRN \\
\hline CHEMBL1421377 & 688340 & 5.1 & 4.8628 & TST \\
\hline CHEMBL1313495 & 688340 & 4.75 & 4.6455 & TRN \\
\hline CHEMBL1530402 & 688340 & 4.55 & 4.6789 & TRN \\
\hline CHEMBL1392606 & 688340 & 4.4 & 4.7722 & TRN \\
\hline CHEMBL1433962 & 688340 & 6.0 & 5.0674 & TRN \\
\hline CHEMBL1393891 & 688340 & 4.75 & 5.136 & TRN \\
\hline CHEMBL1396915 & 688340 & 4.85 & 4.9451 & TRN \\
\hline CHEMBL1395854 & 688340 & 4.7 & 5.1791 & TRN \\
\hline CHEMBL 3198040 & 688340 & 4.6 & 4.9202 & TST \\
\hline CHEMBL504791 & 688340 & 4.4 & 4.8999 & TRN \\
\hline CHEMBL1550444 & 688340 & 5.3 & 4.9456 & TRN \\
\hline CHEMBL1524251 & 688340 & 4.45 & 5.2059 & TRN \\
\hline CHEMBL1495072 & 688340 & 6.0 & 4.5847 & TRN \\
\hline CHEMBL3198658 & 688340 & 4.5 & 4.6673 & TRN \\
\hline CHEMBL1335321 & 688340 & 5.4 & 5.0938 & TRN \\
\hline CHEMBL1550959 & 688340 & 4.5 & 4.9871 & TRN \\
\hline CHEMBL1424574 & 688340 & 3.9 & 5.1679 & TRN \\
\hline CHEMBL1583457 & 688340 & 5.1 & 5.3479 & TRN \\
\hline CHEMBL1541118 & 688340 & 3.9 & 5.3513 & TRN \\
\hline CHEMBL1509590 & 688340 & 4.55 & 4.8068 & TST \\
\hline CHEMBL1373095 & 688340 & 5.15 & 4.9936 & TRN \\
\hline CHEMBL1319471 & 688340 & 6.1 & 5.1345 & TST \\
\hline CHEMBL1350329 & 688340 & 5.05 & 4.9711 & TST \\
\hline CHEMBL1336843 & 688340 & 7.0501 & 5.3551 & TRN \\
\hline CHEMBL1452808 & 688340 & 4.5 & 4.6243 & TRN \\
\hline
\end{tabular}




\begin{tabular}{|c|c|c|c|c|c|}
\hline \\
\hline CHEMBL1410280 & 688340 & 4.7 & 5.2237 & TRN & \\
\hline CHEMBL1357086 & 688340 & 5.15 & 4.9847 & TST & \\
\hline CHEMBL1605938 & 688340 & 5.4 & 5.1929 & TRN & \\
\hline CHEMBL3144987 & 688340 & 5.45 & 4.8796 & TST & \\
\hline CHEMBL1500619 & 688340 & 4.4 & 4.84 & TRN & \\
\hline CHEMBL3207561 & 688340 & 6.8 & 5.0833 & TRN & \\
\hline CHEMBL1965758 & 688340 & 5.2 & 5.0109 & TRN & \\
\hline CHEMBL1381495 & 688340 & 4.4 & 4.9061 & TRN & \\
\hline CHEMBL1548829 & 688340 & 5.15 & 5.4002 & TRN & \\
\hline CHEMBL1484544 & 688340 & 4.65 & 4.9649 & TRN & \\
\hline CHEMBL1355450 & 688340 & 5.2 & 4.8918 & TRN & \\
\hline CHEMBL1482686 & 688340 & 6.45 & 4.9398 & TST & \\
\hline CHEMBL1431004 & 688340 & 4.5 & 4.5933 & TRN & \\
\hline CHEMBL1330600 & 688340 & 4.4 & 4.8623 & TRN & \\
\hline CHEMBL1422319 & 688340 & 5.45 & 5.36299 & 99999999995 & TRN \\
\hline CHEMBL1452711 & 688340 & 4.55 & 4.6784 & TRN & \\
\hline CHEMBL1590643 & 688340 & 4.4 & 5.1255 & TST & \\
\hline CHEMBL1523489 & 688340 & 4.55 & 5.2952 & TRN & \\
\hline CHEMBL1314032 & 688340 & 4.5 & 5.011 & TRN & \\
\hline CHEMBL1505545 & 688340 & 5.0 & 5.029 & TRN & \\
\hline CHEMBL1434141 & 688340 & 4.5 & 4.9239 & TRN & \\
\hline CHEMBL1518329 & 688340 & 4.0 & 5.3472 & TRN & \\
\hline CHEMBL1209491 & 688340 & 4.5 & 5.1985 & TRN & \\
\hline CHEMBL1332486 & 688340 & 7.0 & 4.8647 & TRN & \\
\hline CHEMBL1340612 & 688340 & 5.15 & 4.9468 & TRN & \\
\hline CHEMBL1367790 & 688340 & 4.35 & 5.0971 & TST & \\
\hline CHEMBL1481047 & 688340 & 5.2 & 4.8257 & TST & \\
\hline CHEMBL3196882 & 688340 & 5.0 & 4.7532 & TRN & \\
\hline CHEMBL1494805 & 688340 & 5.55 & 5.0384 & TRN & \\
\hline CHEMBL3214359 & 688340 & 4.4 & 4.9195 & TST & \\
\hline CHEMBL1534433 & 688340 & 4.4 & 4.6112 & TRN & \\
\hline CHEMBL1539359 & 688340 & 4.5 & 4.6398 & TRN & \\
\hline CHEMBL1335022 & 688340 & 7.5003 & 5.1028 & TRN & \\
\hline CHEMBL1599325 & 688340 & 5.5 & 5.4012 & TRN & \\
\hline CHEMBL1324722 & 688340 & 4.55 & 5.1915 & TRN & \\
\hline CHEMBL1322001 & 688340 & 4.5 & 4.895 & TRN & \\
\hline CHEMBL1511804 & 688340 & 4.55 & 4.7839 & TRN & \\
\hline CHEMBL1472736 & 688340 & 4.8 & 4.878 & TRN & \\
\hline CHEMBL1475797 & 688340 & 5.2 & 5.3144 & TST & \\
\hline CHEMBL1547578 & 688340 & 4.45 & 5.012 & TRN & \\
\hline CHEMBL1511469 & 688340 & 5.85 & 5.2831 & TRN & \\
\hline CHEMBL1539847 & 688340 & 5.05 & 4.8729 & TRN & \\
\hline CHEMBL1488028 & 688340 & 5.25 & 5.2391 & TST & \\
\hline CHEMBL1376550 & 688340 & 4.65 & 5.0001 & TRN & \\
\hline CHEMBL1606258 & 688340 & 4.45 & 4.8338 & TRN & \\
\hline CHEMBL1479070 & 688340 & 4.35 & 5.5491 & TRN & \\
\hline CHEMBL1493114 & 688340 & 4.7 & 5.2573 & TRN & \\
\hline CHEMBL1394761 & 688340 & 4.7 & 5.1144 & TRN & \\
\hline
\end{tabular}




\begin{tabular}{|c|c|c|c|c|c|}
\hline & & & & & \\
\hline CHEMBL1557795 & 688340 & 7.0 & 5.2013 & TST & \\
\hline CHEMBL1316631 & 688340 & 5.1 & 5.2057 & TRN & \\
\hline CHEMBL1418951 & 688340 & 4.4 & 4.8677 & TST & \\
\hline CHEMBL1556998 & 688340 & 4.7 & 4.927 & TRN & \\
\hline CHEMBL3209767 & 688340 & 4.35 & 5.33899 & 99999999995 & TST \\
\hline CHEMBL1392405 & 688340 & 4.75 & 4.6105 & TRN & \\
\hline CHEMBL1376417 & 688340 & 6.15 & 4.9847 & TRN & \\
\hline CHEMBL1548491 & 688340 & 5.15 & 5.1764 & TRN & \\
\hline CHEMBL1440435 & 688340 & 7.0501 & 5.5414 & TRN & \\
\hline CHEMBL1518074 & 688340 & 5.45 & 5.28299 & 99999999995 & TRN \\
\hline CHEMBL3194845 & 688340 & 5.15 & 4.9379 & TST & \\
\hline CHEMBL1484071 & 688340 & 4.4 & 5.0483 & TRN & \\
\hline CHEMBL1528024 & 688340 & 4.4 & 5.3761 & TRN & \\
\hline CHEMBL1458660 & 688340 & 4.4 & 4.8942 & TRN & \\
\hline CHEMBL1607330 & 688340 & 5.0 & 5.1299 & TST & \\
\hline CHEMBL1342486 & 688340 & 4.45 & 5.2099 & TRN & \\
\hline CHEMBL1488416 & 688340 & 5.3 & 5.2587 & TRN & \\
\hline CHEMBL1417859 & 688340 & 4.5 & 4.621 & TRN & \\
\hline CHEMBL1426590 & 688340 & 6.1 & 5.3861 & TRN & \\
\hline CHEMBL1449916 & 688340 & 4.95 & 4.8159 & TRN & \\
\hline CHEMBL1354257 & 688340 & 5.2 & 5.36100 & 0000000001 & TRN \\
\hline CHEMBL1313896 & 688340 & 7.0 & 5.3042 & TST & \\
\hline CHEMBL3195858 & 688340 & 4.4 & 5.0675 & TRN & \\
\hline CHEMBL1549265 & 688340 & 6.15 & 4.848 & TRN & \\
\hline CHEMBL1476225 & 688340 & 4.4 & 4.5417 & TRN & \\
\hline CHEMBL1391135 & 688340 & 6.45 & 5.3767 & TST & \\
\hline CHEMBL1427627 & 688340 & 4.4 & 5.2289 & TST & \\
\hline CHEMBL1394407 & 688340 & 4.6 & 5.0205 & TST & \\
\hline CHEMBL1438956 & 688340 & 4.95 & 4.877 & TRN & \\
\hline CHEMBL1611995 & 688340 & 4.45 & 5.5356 & TRN & \\
\hline CHEMBL1312214 & 688340 & 4.6 & 4.7547 & TRN & \\
\hline CHEMBL1412385 & 688340 & 4.5 & 4.8107 & TRN & \\
\hline CHEMBL1356387 & 688340 & 6.8499 & 5.175 & TRN & \\
\hline CHEMBL1578513 & 688340 & 5.2 & 5.0635 & TRN & \\
\hline CHEMBL1452063 & 688340 & 4.75 & 4.9982 & TRN & \\
\hline CHEMBL1534876 & 688340 & 4.45 & 4.8437 & TST & \\
\hline CHEMBL1445684 & 688340 & 4.6 & 4.9662 & TST & \\
\hline CHEMBL1448097 & 688340 & 6.95 & 4.8902 & TRN & \\
\hline CHEMBL1303867 & 688340 & 5.05 & 5.5511 & TRN & \\
\hline CHEMBL1414675 & 688340 & 4.8 & 5.0207 & TRN & \\
\hline CHEMBL1590965 & 688340 & 5.05 & 5.2115 & TRN & \\
\hline CHEMBL1569142 & 688340 & 4.4 & 4.9585 & TST & \\
\hline CHEMBL1548333 & 688340 & 4.75 & 4.9241 & TRN & \\
\hline CHEMBL1469187 & 688340 & 4.4 & 5.0137 & TRN & \\
\hline CHEMBL1552901 & 688340 & 4.45 & 5.105 & TRN & \\
\hline CHEMBL1420798 & 688340 & 4.85 & 5.0229 & TRN & \\
\hline CHEMBL1367594 & 688340 & 4.5 & 4.6864 & TRN & \\
\hline CHEMBL1416259 & 688340 & 4.4 & 4.607 & TRN & \\
\hline
\end{tabular}




\begin{tabular}{|c|c|c|c|c|}
\hline \multicolumn{5}{|c|}{ Supplemental Table S2.txt } \\
\hline CHEMBL1312167 & 688340 & 4.65 & 5.2727 & TST \\
\hline CHEMBL1878162 & 688340 & 4.6 & 4.8289 & TST \\
\hline CHEMBL3190261 & 688340 & 4.4 & 4.6943 & TRN \\
\hline CHEMBL1427113 & 688340 & 4.6 & 4.9623 & TRN \\
\hline CHEMBL1425091 & 688340 & 4.5 & 4.8954 & TRN \\
\hline CHEMBL1556606 & 688340 & 6.3 & 5.0535 & TRN \\
\hline CHEMBL1334833 & 688340 & 5.45 & 4.9182 & TRN \\
\hline CHEMBL1530220 & 688340 & 4.45 & 4.9092 & TST \\
\hline CHEMBL1555257 & 688340 & 6.8499 & 5.3708 & TRN \\
\hline CHEMBL1375268 & 688340 & 5.85 & 4.9243 & TRN \\
\hline CHEMBL1411253 & 688340 & 4.7 & 4.8117 & TRN \\
\hline CHEMBL1512831 & 688340 & 4.65 & 5.1695 & TRN \\
\hline CHEMBL570400 & 688340 & 4.45 & 4.5965 & TRN \\
\hline CHEMBL1365457 & 688340 & 6.1 & 5.0816 & TRN \\
\hline CHEMBL3189635 & 688340 & 4.4 & 4.8537 & TRN \\
\hline CHEMBL1585056 & 688340 & 7.0 & 5.0732 & TRN \\
\hline CHEMBL3193238 & 688340 & 7.0 & 5.1158 & TRN \\
\hline CHEMBL3196832 & 688340 & 4.5 & 4.7769 & TRN \\
\hline CHEMBL1470310 & 688340 & 5.3 & 5.1775 & TST \\
\hline CHEMBL1586568 & 688340 & 4.45 & 5.3167 & TRN \\
\hline CHEMBL1453916 & 688340 & 4.9 & 4.9613 & TRN \\
\hline CHEMBL1367321 & 688340 & 5.95 & 5.2092 & TST \\
\hline CHEMBL1424638 & 688340 & 4.8 & 4.8109 & TRN \\
\hline CHEMBL1504992 & 688340 & 5.2 & 5.3079 & TRN \\
\hline CHEMBL1329874 & 688340 & 1.85 & 4.968 & TST \\
\hline CHEMBL1425512 & 688340 & 4.55 & 4.8317 & TRN \\
\hline CHEMBL1555042 & 688340 & 4.5 & 5.2967 & TRN \\
\hline CHEMBL1452795 & 688340 & 5.0 & 5.063 & TST \\
\hline CHEMBL1551632 & 688340 & 6.15 & 5.3064 & TRN \\
\hline CHEMBL1528737 & 688340 & 5.3 & 5.0322 & TRN \\
\hline CHEMBL1380934 & 688340 & 4.4 & 4.5342 & TRN \\
\hline CHEMBL1513846 & 688340 & 4.85 & 4.7598 & TRN \\
\hline CHEMBL1600455 & 688340 & 6.8499 & 5.0553 & TRN \\
\hline CHEMBL1427210 & 688340 & 5.3 & 4.8196 & TRN \\
\hline CHEMBL1599893 & 688340 & 4.6 & 4.8234 & TRN \\
\hline CHEMBL1478219 & 688340 & 5.95 & 5.4727 & TRN \\
\hline CHEMBL1449110 & 688340 & 4.65 & 4.9989 & TRN \\
\hline CHEMBL1388088 & 688340 & 5.2 & 5.0998 & TRN \\
\hline CHEMBL1600203 & 688340 & 4.4 & 4.6849 & TRN \\
\hline CHEMBL1313028 & 688340 & 4.2 & 5.0245 & TRN \\
\hline CHEMBL1330670 & 688340 & 6.95 & 4.7515 & TRN \\
\hline CHEMBL3208621 & 688340 & 5.2 & 5.1399 & TST \\
\hline CHEMBL1554607 & 688340 & 6.95 & 5.2614 & TRN \\
\hline CHEMBL3198838 & 688340 & 4.6 & 5.0416 & TRN \\
\hline CHEMBL3199665 & 688340 & 4.45 & 4.8925 & TRN \\
\hline CHEMBL1372438 & 688340 & 4.6 & 4.8704 & TRN \\
\hline CHEMBL1329490 & 688340 & 4.4 & 4.9344 & TRN \\
\hline CHEMBL3196182 & 688340 & 4.5 & 4.8453 & TST \\
\hline
\end{tabular}




\begin{tabular}{|c|c|c|c|c|c|}
\hline \\
\hline CHEMBL1428066 & 688340 & 6.4 & 5.409 & TST & \\
\hline CHEMBL1309844 & 688340 & 4.55 & 4.8351 & TRN & \\
\hline CHEMBL1597116 & 688340 & 4.6 & 5.3144 & TRN & \\
\hline CHEMBL1605353 & 688340 & 4.45 & 4.9469 & TST & \\
\hline CHEMBL1323615 & 688340 & 4.45 & 4.9544 & TRN & \\
\hline CHEMBL1603778 & 688340 & 5.3 & 5.186 & TST & \\
\hline CHEMBL1564358 & 688340 & 5.2 & 5.1611 & TRN & \\
\hline CHEMBL1593561 & 688340 & 6.1 & 4.8477 & TRN & \\
\hline CHEMBL1488792 & 688340 & 4.4 & 5.1032 & TRN & \\
\hline CHEMBL1508653 & 688340 & 5.6 & 5.0767 & TST & \\
\hline CHEMBL1316396 & 688340 & 4.5 & 4.9392 & TRN & \\
\hline CHEMBL1981464 & 688340 & 4.55 & 4.8015 & TRN & \\
\hline CHEMBL1320746 & 688340 & 4.25 & 5.4751 & TRN & \\
\hline CHEMBL1992834 & 688340 & 5.75 & 4.9003 & TRN & \\
\hline CHEMBL406557 & 688340 & 4.5 & 4.7321 & TRN & \\
\hline CHEMBL1415575 & 688340 & 5.85 & 4.8988 & TRN & \\
\hline CHEMBL1403589 & 688340 & 4.6 & 5.0225 & TRN & \\
\hline CHEMBL1541299 & 688340 & 4.7 & 4.8344 & TRN & \\
\hline CHEMBL1465200 & 688340 & 4.35 & 5.3116 & TRN & \\
\hline CHEMBL3145067 & 688340 & 4.4 & 5.1263 & TRN & \\
\hline CHEMBL1376849 & 688340 & 4.9 & 4.9648 & TRN & \\
\hline CHEMBL1544412 & 688340 & 4.8 & 4.7635 & TRN & \\
\hline CHEMBL1561199 & 688340 & 4.5 & 5.226 & TRN & \\
\hline CHEMBL1363572 & 688340 & 4.4 & 5.0078 & TST & \\
\hline CHEMBL1536689 & 688340 & 4.45 & 5.1168 & TRN & \\
\hline CHEMBL1584337 & 688340 & 4.6 & 5.0646 & TRN & \\
\hline CHEMBL1511929 & 688340 & 4.45 & 4.95100 & 00000000005 & TRN \\
\hline CHEMBL1588705 & 688340 & 4.55 & 4.6631 & TRN & \\
\hline CHEMBL1320557 & 688340 & 4.45 & 5.0598 & TST & \\
\hline CHEMBL1418418 & 688340 & 4.55 & 5.0777 & TRN & \\
\hline CHEMBL2007318 & 688340 & 4.45 & 5.1077 & TRN & \\
\hline CHEMBL1520007 & 688340 & 4.5 & 5.0783 & TRN & \\
\hline CHEMBL1314718 & 688340 & 7.9508 & 4.9106 & TST & \\
\hline CHEMBL1582533 & 688340 & 6.15 & 5.0653 & TRN & \\
\hline CHEMBL1370148 & 688340 & 6.15 & 5.0581 & TRN & \\
\hline CHEMBL1427261 & 688340 & 5.7 & 5.1344 & TRN & \\
\hline CHEMBL1270217 & 688340 & 4.6 & 4.6897 & TRN & \\
\hline CHEMBL1610804 & 688340 & 5.75 & 5.3951 & TRN & \\
\hline CHEMBL1392000 & 688340 & 4.95 & 5.1716 & TRN & \\
\hline CHEMBL1350898 & 688340 & 7.0501 & 5.2199 & TRN & \\
\hline CHEMBL233302 & 688340 & 4.6 & 4.657 & TRN & \\
\hline CHEMBL 213432 & 688340 & 5.75 & 4.9351 & TRN & \\
\hline CHEMBL1476881 & 688340 & 4.4 & 5.1413 & TRN & \\
\hline CHEMBL1413591 & 688340 & 5.7 & 5.2874 & TST & \\
\hline CHEMBL1606890 & 688340 & 4.45 & 4.9309 & TRN & \\
\hline CHEMBL3145161 & 688340 & 4.8 & 5.1365 & TRN & \\
\hline CHEMBL1555751 & 688340 & 6.05 & 5.2727 & TRN & \\
\hline CHEMBL1532623 & 688340 & 4.55 & 4.7451 & TRN & \\
\hline
\end{tabular}




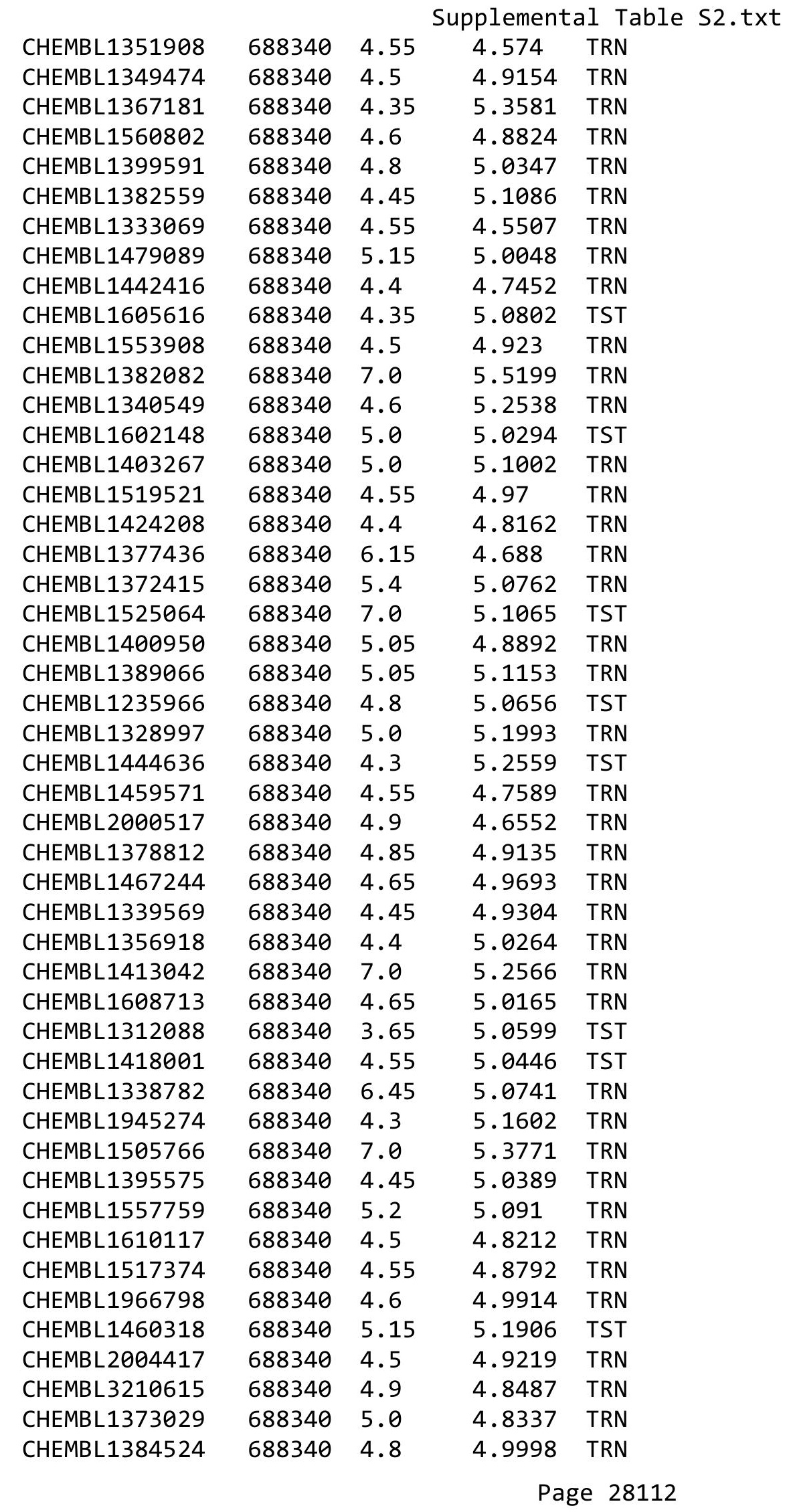




\begin{tabular}{|c|c|c|c|c|c|}
\hline \\
\hline CHEMBL26655 & 688340 & 4.5 & 4.9832 & TST & \\
\hline CHEMBL1439225 & 688340 & 4.65 & 4.7257 & TST & \\
\hline CHEMBL3208482 & 688340 & 4.55 & 5.0069 & TRN & \\
\hline CHEMBL1367899 & 688340 & 4.65 & 5.0948 & TRN & \\
\hline CHEMBL3198837 & 688340 & 4.6 & 4.9082 & TRN & \\
\hline CHEMBL1585164 & 688340 & 4.6 & 4.879 & TRN & \\
\hline CHEMBL1462205 & 688340 & 4.8 & 4.8829 & TRN & \\
\hline CHEMBL1533505 & 688340 & 4.4 & 5.0172 & TRN & \\
\hline CHEMBL1424918 & 688340 & 3.95 & 4.8987 & TRN & \\
\hline CHEMBL1547457 & 688340 & 4.65 & 4.8126 & TRN & \\
\hline CHEMBL1402056 & 688340 & 4.85 & 5.2138 & TST & \\
\hline CHEMBL1471957 & 688340 & 4.55 & 4.8041 & TRN & \\
\hline CHEMBL1432333 & 688340 & 4.6 & 4.9659 & TRN & \\
\hline CHEMBL1463277 & 688340 & 4.55 & 5.32600 & 00000000005 & TRN \\
\hline CHEMBL1348290 & 688340 & 6.15 & 4.8 & TST & \\
\hline CHEMBL1516397 & 688340 & 7.0 & 5.5438 & TRN & \\
\hline CHEMBL1542907 & 688340 & 4.4 & 5.1653 & TRN & \\
\hline CHEMBL3195485 & 688340 & 4.6 & 4.9299 & TRN & \\
\hline CHEMBL1403497 & 688340 & 5.5 & 4.9313 & TRN & \\
\hline CHEMBL1308955 & 688340 & 4.4 & 4.93199 & 99999999995 & TST \\
\hline CHEMBL1309927 & 688340 & 5.2 & 5.3219 & TRN & \\
\hline CHEMBL1561230 & 688340 & 4.5 & 4.9695 & TRN & \\
\hline CHEMBL1544616 & 688340 & 4.6 & 5.1296 & TRN & \\
\hline CHEMBL1540555 & 688340 & 5.2 & 4.9447 & TST & \\
\hline CHEMBL1513075 & 688340 & 4.55 & 5.1459 & TRN & \\
\hline CHEMBL1366888 & 688340 & 4.4 & 4.8596 & TST & \\
\hline CHEMBL1504890 & 688340 & 5.3 & 5.0214 & TST & \\
\hline CHEMBL1421311 & 688340 & 5.6 & 4.6767 & TST & \\
\hline CHEMBL1436453 & 688340 & 5.05 & 5.4445 & TRN & \\
\hline CHEMBL1327690 & 688340 & 4.75 & 4.7672 & TRN & \\
\hline CHEMBL1381216 & 688340 & 4.55 & 4.8019 & TRN & \\
\hline CHEMBL1496557 & 688340 & 6.15 & 5.2215 & TRN & \\
\hline CHEMBL3192616 & 688340 & 4.7 & 4.7639 & TRN & \\
\hline CHEMBL1600674 & 688340 & 4.55 & 4.9013 & TRN & \\
\hline CHEMBL1350245 & 688340 & 6.15 & 5.0145 & TRN & \\
\hline CHEMBL1530638 & 688340 & 6.5 & 4.96899 & 9999999999 & TST \\
\hline CHEMBL1420189 & 688340 & 4.6 & 4.7511 & TRN & \\
\hline CHEMBL1517913 & 688340 & 4.95 & 4.5351 & TRN & \\
\hline CHEMBL3190860 & 688340 & 4.65 & 4.9161 & TST & \\
\hline CHEMBL3199756 & 688340 & 5.1 & 5.2762 & TRN & \\
\hline CHEMBL1503232 & 688340 & 4.6 & 4.7058 & TRN & \\
\hline CHEMBL1348074 & 688340 & 5.35 & 5.0113 & TST & \\
\hline CHEMBL1611001 & 688340 & 5.05 & 4.6432 & TST & \\
\hline CHEMBL1466557 & 688340 & 7.0501 & 5.232 & TRN & \\
\hline CHEMBL1557061 & 688340 & 5.4 & 5.528 & TRN & \\
\hline CHEMBL1433062 & 688340 & 5.45 & 5.2371 & TST & \\
\hline CHEMBL1299311 & 688340 & 7.0 & 4.8997 & TST & \\
\hline CHEMBL1503134 & 688340 & 4.55 & 4.904 & TST & \\
\hline
\end{tabular}




\begin{tabular}{|c|c|c|c|c|}
\hline & & & pplement & al $\mathrm{T}$ \\
\hline CHEMBL1391390 & 688340 & 4.4 & 4.7749 & TRN \\
\hline CHEMBL1526088 & 688340 & 4.4 & 4.9051 & TRN \\
\hline CHEMBL1359796 & 688340 & 4.65 & 4.6656 & TRN \\
\hline CHEMBL1400925 & 688340 & 4.6 & 4.5343 & TRN \\
\hline CHEMBL1459413 & 688340 & 4.6 & 4.7797 & TST \\
\hline CHEMBL1517192 & 688340 & 4.65 & 4.9895 & TRN \\
\hline CHEMBL1497513 & 688340 & 4.55 & 5.095 & TRN \\
\hline CHEMBL1348847 & 688340 & 4.45 & 4.7236 & TRN \\
\hline CHEMBL1562896 & 688340 & 5.0 & 5.0683 & TRN \\
\hline CHEMBL1332541 & 688340 & 4.35 & 5.0795 & TST \\
\hline CHEMBL1394311 & 688340 & 4.05 & 5.2459 & TST \\
\hline CHEMBL 3208710 & 688340 & 4.4 & 5.2012 & TST \\
\hline CHEMBL1528969 & 688340 & 7.0 & 4.8369 & TRN \\
\hline CHEMBL1452270 & 688340 & 4.4 & 4.6883 & TRN \\
\hline CHEMBL1315954 & 688340 & 7.0 & 5.1795 & TRN \\
\hline CHEMBL1556470 & 688340 & 6.8499 & 5.1692 & TST \\
\hline CHEMBL1340335 & 688340 & 6.0 & 5.1731 & TRN \\
\hline CHEMBL1603332 & 688340 & 4.85 & 4.9481 & TRN \\
\hline CHEMBL 3196583 & 688340 & 5.25 & 5.4831 & TRN \\
\hline CHEMBL1361578 & 688340 & 4.4 & 5.3646 & TRN \\
\hline CHEMBL1547738 & 688340 & 4.5 & 4.7667 & TST \\
\hline CHEMBL1580173 & 688340 & 4.55 & 4.9889 & TRN \\
\hline CHEMBL1321790 & 688340 & 4.6 & 4.8432 & TRN \\
\hline CHEMBL1422445 & 688340 & 6.1 & 5.1909 & TRN \\
\hline CHEMBL1464457 & 688340 & 4.4 & 4.8844 & TRN \\
\hline CHEMBL1304536 & 688340 & 5.6 & 5.1969 & TRN \\
\hline CHEMBL1491043 & 688340 & 6.25 & 4.9654 & TRN \\
\hline CHEMBL1370513 & 688340 & 4.75 & 4.6618 & TRN \\
\hline CHEMBL1304408 & 688340 & 4.85 & 4.2556 & TRN \\
\hline CHEMBL1538209 & 688340 & 4.65 & 5.1517 & TRN \\
\hline CHEMBL1590574 & 688340 & 4.6 & 5.0506 & TRN \\
\hline CHEMBL1456571 & 688340 & 4.95 & 4.9343 & TRN \\
\hline CHEMBL 3198003 & 688340 & 4.7 & 5.0181 & TRN \\
\hline CHEMBL 3193225 & 688340 & 4.9 & 4.7412 & TRN \\
\hline CHEMBL 3195780 & 688340 & 4.4 & 4.942 & TRN \\
\hline CHEMBL 3145204 & 688340 & 5.5 & 5.0195 & TRN \\
\hline CHEMBL1383603 & 688340 & 4.8 & 4.7684 & TRN \\
\hline CHEMBL1594557 & 688340 & 4.4 & 4.5175 & TRN \\
\hline CHEMBL1465422 & 688340 & 5.5 & 4.8857 & TRN \\
\hline CHEMBL1330714 & 688340 & 4.8 & 4.8336 & TRN \\
\hline CHEMBL1406715 & 688340 & 4.55 & 4.9457 & TST \\
\hline CHEMBL1577723 & 688340 & 5.2 & 5.0101 & TRN \\
\hline CHEMBL1965687 & 688340 & 4.85 & 4.9956 & TRN \\
\hline CHEMBL1315872 & 688340 & 4.65 & 5.0752 & TST \\
\hline CHEMBL1417651 & 688340 & 6.1 & 5.1606 & TRN \\
\hline CHEMBL1311955 & 688340 & 4.4 & 4.9342 & TST \\
\hline CHEMBL1414565 & 688340 & 5.5 & 5.2667 & TRN \\
\hline CHEMBL598054 & 688340 & 6.25 & 5.0052 & TRN \\
\hline
\end{tabular}




\begin{tabular}{|c|c|c|c|c|}
\hline \multicolumn{5}{|c|}{ Supplemental Table S2.txt } \\
\hline CHEMBL1500203 & 688340 & 4.75 & 5.0444 & TRN \\
\hline CHEMBL1489629 & 688340 & 5.55 & 4.9823 & TRN \\
\hline CHEMBL1583713 & 688340 & 6.1 & 5.4128 & TRN \\
\hline CHEMBL1965298 & 688340 & 4.45 & 4.6336 & TRN \\
\hline CHEMBL1427457 & 688340 & 6.1 & 5.0111 & TRN \\
\hline CHEMBL1474542 & 688340 & 4.7 & 4.9593 & TRN \\
\hline CHEMBL1373099 & 688340 & 4.45 & 5.0137 & TRN \\
\hline CHEMBL1300318 & 688340 & 6.1 & 4.6506 & TRN \\
\hline CHEMBL1347310 & 688340 & 4.5 & 5.2618 & TST \\
\hline CHEMBL1495242 & 688340 & 5.6 & 4.9127 & TST \\
\hline CHEMBL1466628 & 688340 & 4.75 & 5.0824 & TRN \\
\hline CHEMBL1307329 & 688340 & 7.0 & 4.9276 & TRN \\
\hline CHEMBL1553966 & 688340 & 6.9 & 5.0377 & TST \\
\hline CHEMBL1502351 & 688340 & 4.7 & 4.9323 & TRN \\
\hline CHEMBL1556534 & 688340 & 5.05 & 4.7399 & TRN \\
\hline CHEMBL1392739 & 688340 & 4.4 & 5.3484 & TST \\
\hline CHEMBL1513476 & 688340 & 4.4 & 4.9575 & TRN \\
\hline CHEMBL1535710 & 688340 & 5.45 & 5.0007 & TRN \\
\hline CHEMBL1338406 & 688340 & 4.6 & 4.7166 & TRN \\
\hline CHEMBL1530236 & 688340 & 4.45 & 5.2396 & TRN \\
\hline CHEMBL1477569 & 688340 & 5.1 & 5.1494 & TRN \\
\hline CHEMBL1523854 & 688340 & 5.15 & 5.0034 & TRN \\
\hline CHEMBL1468534 & 688340 & 5.0 & 5.234 & TRN \\
\hline CHEMBL1457303 & 688340 & 5.0 & 5.1024 & TRN \\
\hline CHEMBL1368096 & 688340 & 4.55 & 5.106 & TRN \\
\hline CHEMBL1402032 & 688340 & 4.85 & 4.9795 & TST \\
\hline CHEMBL3192256 & 688340 & 5.1 & 4.776 & TRN \\
\hline CHEMBL1589731 & 688340 & 4.5 & 4.7524 & TST \\
\hline CHEMBL1420834 & 688340 & 5.2 & 5.2448 & TST \\
\hline CHEMBL3195305 & 688340 & 4.7 & 5.3065 & TRN \\
\hline CHEMBL1335857 & 688340 & 4.6 & 5.1958 & TRN \\
\hline CHEMBL1304169 & 688340 & 4.8 & 5.0939 & TST \\
\hline CHEMBL1415851 & 688340 & 6.05 & 4.9331 & TST \\
\hline CHEMBL1546043 & 688340 & 4.55 & 4.6448 & TRN \\
\hline CHEMBL1508745 & 688340 & 4.65 & 4.5946 & TRN \\
\hline CHEMBL1339178 & 688340 & 4.5 & 4.8442 & TST \\
\hline CHEMBL1448818 & 688340 & 4.95 & 4.9373 & TRN \\
\hline CHEMBL1351718 & 688340 & 7.0501 & 4.9602 & TRN \\
\hline CHEMBL1340099 & 688340 & 4.55 & 5.3183 & TRN \\
\hline CHEMBL1545530 & 688340 & 4.55 & 4.9395 & TRN \\
\hline CHEMBL1598554 & 688340 & 6.25 & 4.9546 & TRN \\
\hline CHEMBL1495622 & 688340 & 4.5 & 4.9124 & TRN \\
\hline CHEMBL1522821 & 688340 & 4.65 & 4.6888 & TRN \\
\hline CHEMBL1428563 & 688340 & 4.45 & 5.0366 & TST \\
\hline CHEMBL1540395 & 688340 & 5.05 & 4.8918 & TRN \\
\hline CHEMBL1404913 & 688340 & 4.55 & 4.9556 & TRN \\
\hline CHEMBL3191015 & 688340 & 6.1 & 5.0289 & TRN \\
\hline CHEMBL1376622 & 688340 & 5.2 & 5.0004 & TST \\
\hline
\end{tabular}




\begin{tabular}{|c|c|c|c|c|}
\hline & & & pplement & $\mathrm{a} \perp \mathrm{Ta}$ \\
\hline CHEMBL1467991 & 688340 & 4.4 & 5.0722 & TST \\
\hline CHEMBL1504924 & 688340 & 5.3 & 4.9658 & TRN \\
\hline CHEMBL1327103 & 688340 & 6.0 & 5.3841 & TRN \\
\hline CHEMBL1374183 & 688340 & 6.1 & 5.0981 & TRN \\
\hline CHEMBL1530442 & 688340 & 5.1 & 5.5477 & TRN \\
\hline CHEMBL1580345 & 688340 & 6.5 & 5.106 & TRN \\
\hline CHEMBL229760 & 688340 & 4.6 & 4.8493 & TST \\
\hline CHEMBL1439173 & 688340 & 5.2 & 4.931 & TRN \\
\hline CHEMBL1426598 & 688340 & 5.0 & 5.157 & TRN \\
\hline CHEMBL1528116 & 688340 & 5.05 & 4.8737 & TRN \\
\hline CHEMBL1547914 & 688340 & 4.55 & 5.1629 & TRN \\
\hline CHEMBL1329465 & 688340 & 4.5 & 4.8389 & TRN \\
\hline CHEMBL1598475 & 688340 & 4.35 & 4.9589 & TRN \\
\hline CHEMBL1407468 & 688340 & 6.0 & 5.2833 & TST \\
\hline CHEMBL1447770 & 688340 & 4.5 & 5.4387 & TRN \\
\hline CHEMBL1420849 & 688340 & 4.4 & 4.7357 & TST \\
\hline CHEMBL1314256 & 688340 & 4.7 & 4.7801 & TRN \\
\hline CHEMBL1461132 & 688340 & 4.45 & 4.8534 & TRN \\
\hline CHEMBL1530244 & 688340 & 5.0 & 5.2143 & TRN \\
\hline CHEMBL1555092 & 688340 & 4.5 & 5.3251 & TRN \\
\hline CHEMBL1547311 & 688340 & 4.65 & 4.8638 & TRN \\
\hline CHEMBL1581350 & 688340 & 4.5 & 4.7255 & TRN \\
\hline CHEMBL1424734 & 688340 & 5.4 & 5.1856 & TRN \\
\hline CHEMBL1483458 & 688340 & 4.75 & 5.0073 & TRN \\
\hline CHEMBL1371027 & 688340 & 5.4 & 4.8248 & TRN \\
\hline CHEMBL1996730 & 688340 & 4.9 & 4.8774 & TRN \\
\hline CHEMBL1356645 & 688340 & 4.55 & 4.747 & TRN \\
\hline CHEMBL 294264 & 688340 & 4.5 & 5.0895 & TRN \\
\hline CHEMBL1548264 & 688340 & 4.55 & 5.3632 & TRN \\
\hline CHEMBL1544699 & 688340 & 4.9 & 4.7829 & TST \\
\hline CHEMBL1383987 & 688340 & 4.4 & 4.8731 & TST \\
\hline CHEMBL1424547 & 688340 & 6.15 & 5.1924 & TRN \\
\hline CHEMBL1398187 & 688340 & 4.55 & 5.0644 & TRN \\
\hline CHEMBL1505715 & 688340 & 5.7 & 4.9719 & TST \\
\hline CHEMBL1492110 & 688340 & 4.6 & 4.9398 & TRN \\
\hline CHEMBL1587107 & 688340 & 7.0 & 5.244 & TRN \\
\hline CHEMBL1432507 & 688340 & 4.5 & 4.7906 & TRN \\
\hline CHEMBL1562097 & 688340 & 4.4 & 5.2046 & TRN \\
\hline CHEMBL1456505 & 688340 & 4.5 & 4.6916 & TRN \\
\hline CHEMBL1448837 & 688340 & 4.55 & 5.0028 & TRN \\
\hline CHEMBL1599536 & 688340 & 4.65 & 5.0274 & TRN \\
\hline CHEMBL1489693 & 688340 & 4.9 & 4.8475 & TRN \\
\hline CHEMBL1332871 & 688340 & 4.4 & 5.0418 & TRN \\
\hline CHEMBL1414159 & 688340 & 4.55 & 4.9101 & TRN \\
\hline CHEMBL1371386 & 688340 & 5.2 & 4.6132 & TRN \\
\hline CHEMBL1376482 & 688340 & 5.15 & 5.4566 & TRN \\
\hline CHEMBL1589575 & 688340 & 5.4 & 5.1502 & TRN \\
\hline CHEMBL1347944 & 688340 & 4.6 & 4.8367 & TRN \\
\hline
\end{tabular}




\begin{tabular}{|c|c|c|c|c|}
\hline & & & upplemen & al $\mathrm{T}$ \\
\hline CHEMBL1494139 & 688340 & 6.95 & 5.1004 & TRN \\
\hline CHEMBL1353026 & 688340 & 4.4 & 5.494 & TRN \\
\hline CHEMBL1332837 & 688340 & 4.6 & 5.1325 & TST \\
\hline CHEMBL1369656 & 688340 & 5.35 & 5.0778 & TST \\
\hline CHEMBL1383849 & 688340 & 4.45 & 5.0579 & TRN \\
\hline CHEMBL1529669 & 688340 & 4.5 & 5.0332 & TRN \\
\hline CHEMBL1429257 & 688340 & 4.4 & 4.9776 & TRN \\
\hline CHEMBL1349136 & 688340 & 5.45 & 5.5527 & TST \\
\hline CHEMBL1396736 & 688340 & 6.05 & 5.4543 & TRN \\
\hline CHEMBL1490789 & 688340 & 4.55 & 4.9214 & TST \\
\hline CHEMBL1399884 & 688340 & 4.5 & 4.8093 & TRN \\
\hline CHEMBL1481817 & 688340 & 4.6 & 4.9999 & TRN \\
\hline CHEMBL1589019 & 688340 & 4.4 & 5.1629 & TRN \\
\hline CHEMBL1973780 & 688340 & 6.15 & 4.875 & TRN \\
\hline CHEMBL1325233 & 688340 & 4.5 & 5.263 & TRN \\
\hline CHEMBL1436803 & 688340 & 4.45 & 4.8905 & TRN \\
\hline CHEMBL1479477 & 688340 & 5.2 & 4.9056 & TST \\
\hline CHEMBL1486451 & 688340 & 5.05 & 4.811 & TRN \\
\hline CHEMBL1531320 & 688340 & 4.7 & 5.0451 & TRN \\
\hline CHEMBL1359279 & 688340 & 5.05 & 5.0254 & TRN \\
\hline CHEMBL1531153 & 688340 & 4.4 & 4.9593 & TRN \\
\hline CHEMBL1558223 & 688340 & 4.85 & 5.2766 & TRN \\
\hline CHEMBL1391426 & 688340 & 4.5 & 4.9966 & TRN \\
\hline CHEMBL1473059 & 688340 & 5.45 & 4.8966 & TRN \\
\hline CHEMBL1307600 & 688340 & 4.7 & 5.1111 & TRN \\
\hline CHEMBL1398030 & 688340 & 4.4 & 5.4367 & TRN \\
\hline CHEMBL1580534 & 688340 & 4.7 & 4.7437 & TRN \\
\hline CHEMBL1370358 & 688340 & 4.5 & 4.9444 & TRN \\
\hline CHEMBL1599723 & 688340 & 4.85 & 4.6474 & TRN \\
\hline CHEMBL1556277 & 688340 & 4.95 & 4.8215 & TRN \\
\hline CHEMBL1459715 & 688340 & 4.6 & 5.0832 & TRN \\
\hline CHEMBL1364984 & 688340 & 4.4 & 4.4966 & TRN \\
\hline CHEMBL1597330 & 688340 & 5.35 & 5.0458 & TST \\
\hline CHEMBL1325366 & 688340 & 4.6 & 5.1077 & TRN \\
\hline CHEMBL3195120 & 688340 & 4.95 & 4.8426 & TRN \\
\hline CHEMBL1528784 & 688340 & 4.5 & 5.0125 & TRN \\
\hline CHEMBL1531805 & 688340 & 4.35 & 4.9568 & TRN \\
\hline CHEMBL1396147 & 688340 & 4.75 & 4.6797 & TRN \\
\hline CHEMBL1557038 & 688340 & 4.4 & 5.2131 & TST \\
\hline CHEMBL1384097 & 688340 & 4.35 & 5.2904 & TST \\
\hline CHEMBL1487722 & 688340 & 4.85 & 5.0739 & TRN \\
\hline CHEMBL1587105 & 688340 & 5.35 & 5.3278 & TRN \\
\hline CHEMBL1553517 & 688340 & 4.5 & 4.7678 & TST \\
\hline CHEMBL1426723 & 688340 & 4.95 & 5.0658 & TRN \\
\hline CHEMBL1480656 & 688340 & 6.1 & 4.99 & TRN \\
\hline CHEMBL1488022 & 688340 & 4.45 & 4.7465 & TRN \\
\hline CHEMBL1346570 & 688340 & 4.45 & 4.9718 & TRN \\
\hline CHEMBL1561181 & 688340 & 5.15 & 4.9135 & TRN \\
\hline
\end{tabular}




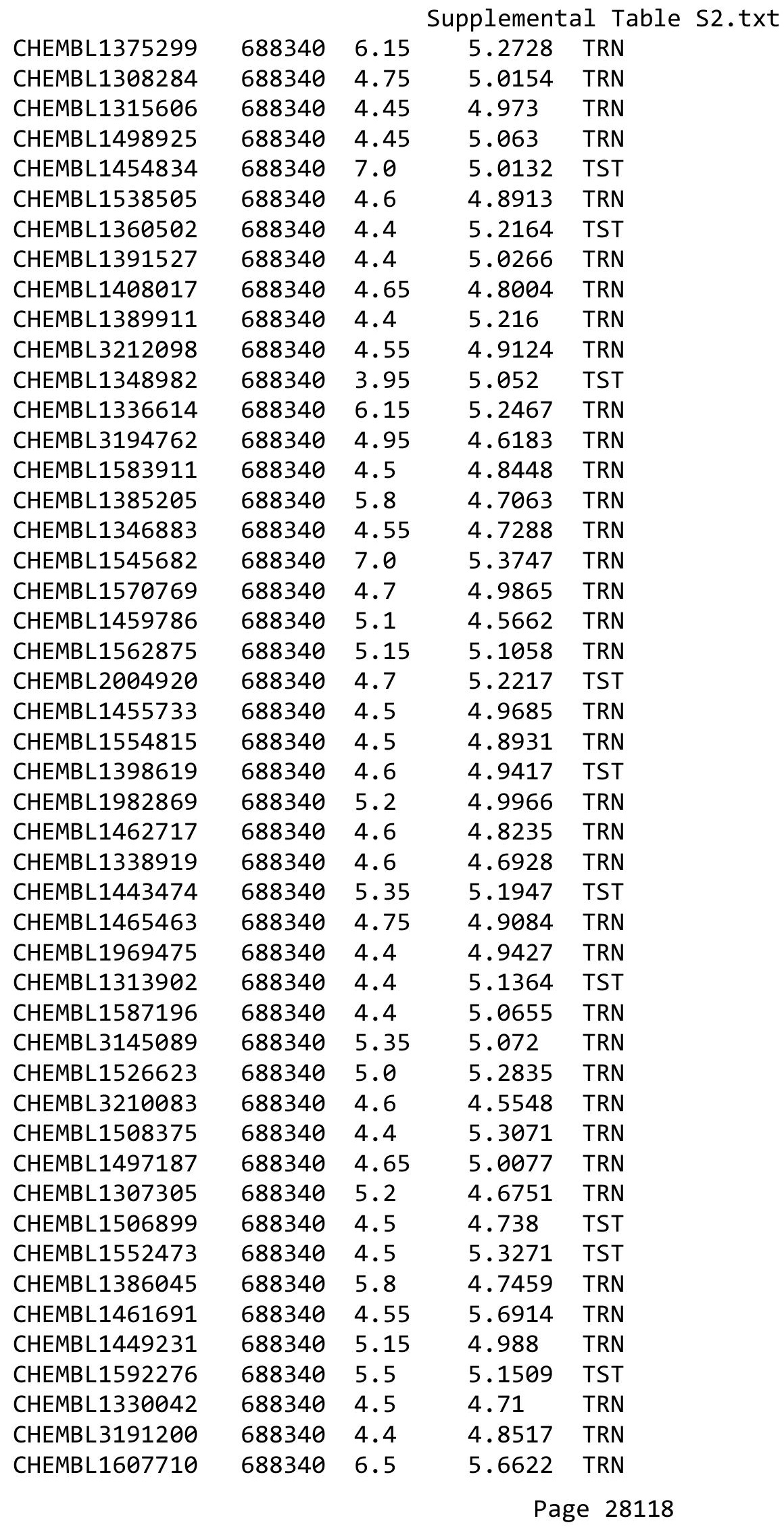




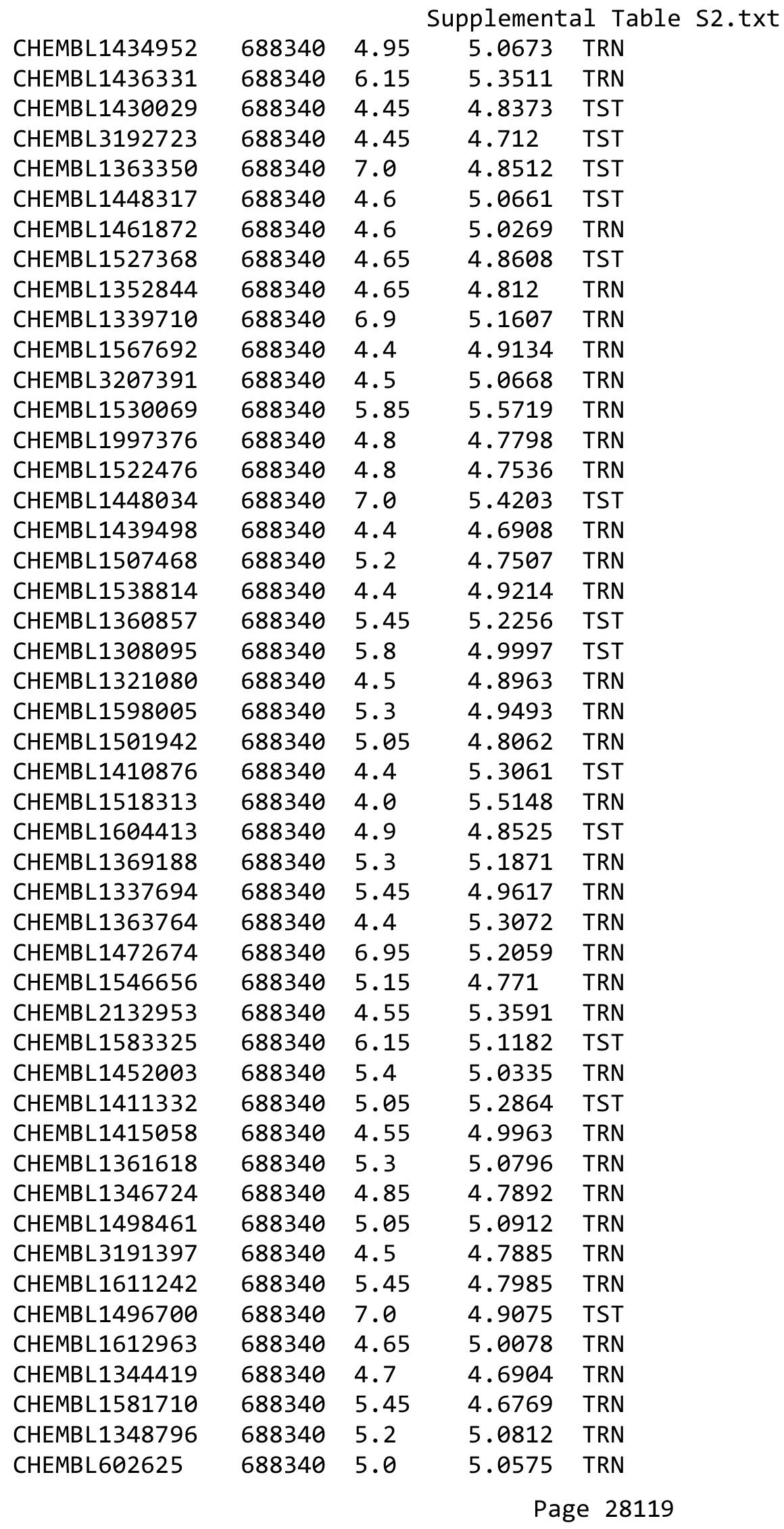




\begin{tabular}{|c|c|c|c|c|}
\hline \multicolumn{5}{|c|}{ Supplemental Table } \\
\hline CHEMBL1400056 & 688340 & 4.45 & 4.8319 & TRN \\
\hline CHEMBL1513919 & 688340 & 4.5 & 5.187 & TRN \\
\hline CHEMBL1557725 & 688340 & 6.15 & 5.3449 & TRN \\
\hline CHEMBL1432862 & 688340 & 5.75 & 5.4495 & TRN \\
\hline CHEMBL1469314 & 688340 & 4.4 & 4.9893 & TRN \\
\hline CHEMBL1469712 & 688340 & 6.15 & 5.2838 & TRN \\
\hline CHEMBL3214086 & 688340 & 7.3002 & 4.9692 & TST \\
\hline CHEMBL1545798 & 688340 & 4.95 & 5.273 & TRN \\
\hline CHEMBL1417350 & 688340 & 4.7 & 5.0593 & TRN \\
\hline CHEMBL1567262 & 688340 & 4.55 & 5.2788 & TST \\
\hline CHEMBL1558835 & 688340 & 7.0501 & 4.737 & TST \\
\hline CHEMBL 3194858 & 688340 & 5.5 & 5.1429 & TST \\
\hline CHEMBL1408861 & 688340 & 4.4 & 5.2506 & TRN \\
\hline CHEMBL1446910 & 688340 & 5.5 & 5.3729 & TRN \\
\hline CHEMBL1558953 & 688340 & 7.0 & 5.5043 & TRN \\
\hline CHEMBL8260 & 688340 & 4.8 & 5.1049 & TRN \\
\hline CHEMBL1326231 & 688340 & 4.7 & 5.0484 & TST \\
\hline CHEMBL3145149 & 688340 & 4.9 & 5.1687 & TRN \\
\hline CHEMBL1495774 & 688340 & 4.45 & 4.5426 & TRN \\
\hline CHEMBL1472493 & 688340 & 5.4 & 4.8642 & TRN \\
\hline CHEMBL1519988 & 688340 & 5.05 & 5.223 & TRN \\
\hline CHEMBL3190902 & 688340 & 2.8 & 5.3621 & TST \\
\hline CHEMBL558842 & 688340 & 5.5 & 5.0139 & TST \\
\hline CHEMBL1340197 & 688340 & 4.65 & 5.2212 & TRN \\
\hline CHEMBL1366319 & 688340 & 5.2 & 4.9403 & TRN \\
\hline CHEMBL1324733 & 688340 & 5.95 & 4.8476 & TRN \\
\hline CHEMBL1361858 & 688340 & 4.65 & 5.0829 & TRN \\
\hline CHEMBL1313195 & 688340 & 4.9 & 4.9823 & TST \\
\hline CHEMBL1555503 & 688340 & 4.55 & 4.7194 & TRN \\
\hline CHEMBL1535375 & 688340 & 6.0 & 4.901 & TRN \\
\hline CHEMBL1305523 & 688340 & 4.55 & 4.7247 & TRN \\
\hline CHEMBL1332349 & 688340 & 5.2 & 4.959 & TRN \\
\hline CHEMBL1585567 & 688340 & 4.35 & 5.0543 & TRN \\
\hline CHEMBL1432717 & 688340 & 4.4 & 4.5316 & TRN \\
\hline CHEMBL1426027 & 688340 & 4.55 & 4.9286 & TST \\
\hline CHEMBL1316977 & 688340 & 4.0 & 4.8839 & TRN \\
\hline CHEMBL1507149 & 688340 & 4.55 & 4.7503 & TRN \\
\hline CHEMBL1587954 & 688340 & 5.85 & 4.9974 & TRN \\
\hline CHEMBL1536572 & 688340 & 5.05 & 5.1842 & TRN \\
\hline CHEMBL1335976 & 688340 & 4.55 & 5.0011 & TRN \\
\hline CHEMBL1511554 & 688340 & 6.1 & 5.0562 & TST \\
\hline CHEMBL1443884 & 688340 & 4.55 & 4.9072 & TRN \\
\hline CHEMBL601757 & 688340 & 6.95 & 5.4376 & TRN \\
\hline CHEMBL1407373 & 688340 & 4.7 & 4.9327 & TRN \\
\hline CHEMBL1380017 & 688340 & 5.0 & 4.9982 & TST \\
\hline CHEMBL1586361 & 688340 & 5.35 & 5.1492 & TST \\
\hline CHEMBL1525081 & 688340 & 4.6 & 4.7369 & TRN \\
\hline CHEMBL1541898 & 688340 & 4.45 & 5.0894 & TRN \\
\hline
\end{tabular}




\begin{tabular}{|c|c|c|c|c|c|}
\hline \multicolumn{6}{|c|}{ Supplemental Table S2.txt } \\
\hline CHEMBL1490942 & 688340 & 4.45 & 4.7736 & TRN & \\
\hline CHEMBL1340439 & 688340 & 4.4 & 5.3072 & TST & \\
\hline CHEMBL1307271 & 688340 & 6.25 & 4.5881 & TRN & \\
\hline CHEMBL3191048 & 688340 & 4.4 & 5.0667 & TRN & \\
\hline CHEMBL1391686 & 688340 & 5.45 & 4.9424 & TRN & \\
\hline CHEMBL1318729 & 688340 & 4.85 & 5.1831 & TST & \\
\hline CHEMBL1575218 & 688340 & 4.55 & 5.50700 & 0000000001 & TRN \\
\hline CHEMBL1519896 & 688340 & 4.6 & 4.9383 & TRN & \\
\hline CHEMBL1302116 & 688340 & 4.45 & 5.1619 & TRN & \\
\hline CHEMBL1415103 & 688340 & 7.5498 & 4.7507 & TRN & \\
\hline CHEMBL1482397 & 688340 & 5.5 & 5.5668 & TST & \\
\hline CHEMBL1591211 & 688340 & 4.6 & 4.7387 & TRN & \\
\hline CHEMBL1565218 & 688340 & 4.35 & 4.9615 & TST & \\
\hline CHEMBL192600 & 688340 & 5.1 & 5.0124 & TRN & \\
\hline CHEMBL1430336 & 688340 & 4.55 & 4.9954 & TRN & \\
\hline CHEMBL1582801 & 688340 & 5.05 & 5.3894 & TRN & \\
\hline CHEMBL3213441 & 688340 & 4.4 & 4.7952 & TRN & \\
\hline CHEMBL1400452 & 688340 & 4.55 & 4.7772 & TST & \\
\hline CHEMBL1456632 & 688340 & 5.2 & 4.8251 & TRN & \\
\hline CHEMBL1997797 & 688340 & 4.4 & 5.1193 & TRN & \\
\hline CHEMBL1337232 & 688340 & 4.65 & 5.5163 & TRN & \\
\hline CHEMBL1494460 & 688340 & 4.5 & 4.7257 & TRN & \\
\hline CHEMBL1371229 & 688340 & 5.45 & 5.436 & TRN & \\
\hline CHEMBL1314354 & 688340 & 5.0 & 5.1089 & TRN & \\
\hline CHEMBL3189334 & 688340 & 4.9 & 4.6097 & TRN & \\
\hline CHEMBL3189468 & 688340 & 4.8 & 4.6786 & TRN & \\
\hline CHEMBL1373179 & 688340 & 4.25 & 5.0682 & TRN & \\
\hline CHEMBL1538501 & 688340 & 6.45 & 5.2532 & TRN & \\
\hline CHEMBL1445168 & 688340 & 4.4 & 5.0329 & TRN & \\
\hline CHEMBL1352698 & 688340 & 6.15 & 4.9103 & TRN & \\
\hline CHEMBL1350949 & 688340 & 5.45 & 5.0367 & TRN & \\
\hline CHEMBL1581471 & 688340 & 4.65 & 4.9554 & TRN & \\
\hline CHEMBL1486241 & 688340 & 4.5 & 5.0622 & TRN & \\
\hline CHEMBL1425927 & 688340 & 5.55 & 4.9356 & TRN & \\
\hline CHEMBL1320295 & 688340 & 6.1 & 5.2233 & TRN & \\
\hline CHEMBL1495170 & 688340 & 4.55 & 4.8705 & TST & \\
\hline CHEMBL1556957 & 688340 & 5.15 & 5.345 & TRN & \\
\hline CHEMBL1391963 & 688340 & 4.8 & 4.4575 & TRN & \\
\hline CHEMBL1509416 & 688340 & 4.4 & 5.1174 & TST & \\
\hline CHEMBL3197649 & 688340 & 7.0 & 5.0204 & TST & \\
\hline CHEMBL3209553 & 688340 & 4.4 & 5.0281 & TRN & \\
\hline CHEMBL1310655 & 688340 & 4.6 & 4.9634 & TRN & \\
\hline CHEMBL1601028 & 688340 & 5.7 & 5.2508 & TST & \\
\hline CHEMBL1329229 & 688340 & 5.5 & 5.2532 & TRN & \\
\hline CHEMBL1453393 & 688340 & 4.6 & 4.9344 & TRN & \\
\hline CHEMBL1349800 & 688340 & 4.4 & 5.1376 & TST & \\
\hline CHEMBL1524779 & 688340 & 5.15 & 4.8252 & TRN & \\
\hline CHEMBL1277149 & 688340 & 4.6 & 4.6899 & TRN & \\
\hline
\end{tabular}




\begin{tabular}{|c|c|c|c|c|c|}
\hline \multicolumn{6}{|c|}{ Supplemental Table S2.txt } \\
\hline CHEMBL1607263 & 688340 & 4.95 & 4.7434 & TRN & \\
\hline CHEMBL1539356 & 688340 & 4.5 & 5.2625 & TRN & \\
\hline CHEMBL3392058 & 688340 & 4.6 & 5.0713 & TST & \\
\hline CHEMBL1588325 & 688340 & 4.75 & 5.1324 & TRN & \\
\hline CHEMBL1418483 & 688340 & 4.55 & 4.6368 & TST & \\
\hline CHEMBL1350495 & 688340 & 3.95 & 4.9578 & TRN & \\
\hline CHEMBL1390497 & 688340 & 4.45 & 4.8941 & TRN & \\
\hline CHEMBL1344418 & 688340 & 5.25 & 4.7878 & TRN & \\
\hline CHEMBL1540981 & 688340 & 4.95 & 5.3713 & TRN & \\
\hline CHEMBL1352328 & 688340 & 4.45 & 4.999 & TRN & \\
\hline CHEMBL1595383 & 688340 & 5.85 & 5.107 & TRN & \\
\hline CHEMBL1320523 & 688340 & 4.6 & 4.9021 & TST & \\
\hline CHEMBL1589264 & 688340 & 4.05 & 5.2256 & TST & \\
\hline CHEMBL1439785 & 688340 & 5.0 & 5.4288 & TRN & \\
\hline CHEMBL1503795 & 688340 & 5.45 & 5.0803 & TST & \\
\hline CHEMBL1542342 & 688340 & 4.0 & 5.2677 & TRN & \\
\hline CHEMBL1519409 & 688340 & 4.4 & 4.8563 & TRN & \\
\hline CHEMBL1346664 & 688340 & 4.45 & 4.798 & TRN & \\
\hline CHEMBL1460006 & 688340 & 4.75 & 4.8479 & TRN & \\
\hline CHEMBL1321417 & 688340 & 6.1 & 5.1981 & TRN & \\
\hline CHEMBL1398721 & 688340 & 5.3 & 4.8935 & TRN & \\
\hline CHEMBL1395187 & 688340 & 6.7001 & 5.147 & TRN & \\
\hline CHEMBL1564658 & 688340 & 4.75 & 4.865 & TRN & \\
\hline CHEMBL 2007180 & 688340 & 5.45 & 4.8625 & TRN & \\
\hline CHEMBL1449202 & 688340 & 5.2 & 5.4005 & TRN & \\
\hline CHEMBL1566153 & 688340 & 4.4 & 4.7933 & TRN & \\
\hline CHEMBL1608460 & 688340 & 4.6 & 4.7257 & TRN & \\
\hline CHEMBL1545414 & 688340 & 4.65 & 5.4039 & TRN & \\
\hline CHEMBL1387836 & 688340 & 4.45 & 4.9037 & TST & \\
\hline CHEMBL1532208 & 688340 & 5.3 & 5.1696 & TST & \\
\hline CHEMBL1524562 & 688340 & 4.65 & 5.229 & TST & \\
\hline CHEMBL1505273 & 688340 & 4.35 & 5.0312 & TST & \\
\hline CHEMBL1329587 & 688340 & 5.05 & 5.1813 & TRN & \\
\hline CHEMBL1331138 & 688340 & 5.4 & 5.0702 & TRN & \\
\hline CHEMBL1305424 & 688340 & 5.7 & 5.0205 & TRN & \\
\hline CHEMBL1519057 & 688340 & 4.45 & 4.931 & TRN & \\
\hline CHEMBL1496529 & 688340 & 4.8 & 4.9868 & TRN & \\
\hline CHEMBL1551449 & 688340 & 4.55 & 5.2404 & TST & \\
\hline CHEMBL1433523 & 688340 & 7.0 & 5.0439 & TST & \\
\hline CHEMBL1602539 & 688340 & 4.35 & 5.1367 & TRN & \\
\hline CHEMBL1338469 & 688340 & 4.6 & 5.0808 & TRN & \\
\hline CHEMBL1392610 & 688340 & 5.45 & 4.9504 & TST & \\
\hline CHEMBL1541513 & 688340 & 6.1 & 5.4077 & TRN & \\
\hline CHEMBL1511397 & 688340 & 5.1 & 4.6893 & TRN & \\
\hline CHEMBL1414730 & 688340 & 4.5 & 5.20700 & 0000000001 & TRN \\
\hline CHEMBL1497680 & 688340 & 4.8 & 5.2127 & TRN & \\
\hline CHEMBL1327270 & 688340 & 4.5 & 4.5493 & TRN & \\
\hline CHEMBL1510742 & 688340 & 4.5 & 4.9872 & TRN & \\
\hline
\end{tabular}




\begin{tabular}{|c|c|c|c|c|}
\hline \multicolumn{5}{|c|}{ Supplemental Table S2.txt } \\
\hline CHEMBL1574224 & 688340 & 6.5 & 5.1122 & TST \\
\hline CHEMBL1578776 & 688340 & 5.5 & 4.868 & TRN \\
\hline CHEMBL1983530 & 688340 & 4.6 & 5.1532 & TST \\
\hline CHEMBL1384090 & 688340 & 4.6 & 4.5889 & TRN \\
\hline CHEMBL1505062 & 688340 & 4.55 & 4.9585 & TRN \\
\hline CHEMBL1601357 & 688340 & 4.4 & 5.5625 & TST \\
\hline CHEMBL1335945 & 688340 & 4.5 & 4.8776 & TST \\
\hline CHEMBL1402115 & 688340 & 5.0 & 5.1174 & TRN \\
\hline CHEMBL1338820 & 688340 & 5.15 & 5.192 & TRN \\
\hline CHEMBL1521318 & 688340 & 7.0 & 5.2943 & TRN \\
\hline CHEMBL1382549 & 688340 & 5.0 & 5.1 & TST \\
\hline CHEMBL1309545 & 688340 & 4.65 & 4.9332 & TRN \\
\hline CHEMBL1506843 & 688340 & 4.55 & 4.6806 & TRN \\
\hline CHEMBL1404223 & 688340 & 6.8 & 5.2268 & TST \\
\hline CHEMBL1352473 & 688340 & 4.55 & 4.8847 & TRN \\
\hline CHEMBL1477093 & 688340 & 4.6 & 4.8865 & TRN \\
\hline CHEMBL1359636 & 688340 & 4.4 & 4.8758 & TRN \\
\hline CHEMBL1397075 & 688340 & 4.65 & 5.1427 & TST \\
\hline CHEMBL1538679 & 688340 & 5.2 & 5.4064 & TST \\
\hline CHEMBL1494338 & 688340 & 5.45 & 4.8628 & TRN \\
\hline CHEMBL1496749 & 688340 & 4.55 & 4.5443 & TRN \\
\hline CHEMBL1360482 & 688340 & 4.9 & 4.8658 & TRN \\
\hline CHEMBL1534587 & 688340 & 7.0 & 5.046 & TST \\
\hline CHEMBL1322428 & 688340 & 5.0 & 4.9359 & TRN \\
\hline CHEMBL3192822 & 688340 & 5.5 & 4.8226 & TRN \\
\hline CHEMBL1333669 & 688340 & 3.1 & 5.5282 & TRN \\
\hline CHEMBL1464060 & 688340 & 5.1 & 4.8626 & TRN \\
\hline CHEMBL1591269 & 688340 & 5.6 & $5.2920 e$ & 0000000001 \\
\hline CHEMBL1606767 & 688340 & 4.4 & 4.7974 & TRN \\
\hline CHEMBL1350614 & 688340 & 4.7 & 5.0772 & TRN \\
\hline CHEMBL1348725 & 688340 & 5.45 & 5.1229 & TST \\
\hline CHEMBL1339153 & 688340 & 4.45 & 4.8194 & TRN \\
\hline CHEMBL1596998 & 688340 & 7.0 & 5.1614 & TST \\
\hline CHEMBL1353247 & 688340 & 8.1487 & 5.1485 & TRN \\
\hline CHEMBL2373682 & 688340 & 4.75 & 4.7182 & TST \\
\hline CHEMBL1541304 & 688340 & 5.2 & 5.3806 & TRN \\
\hline CHEMBL1271117 & 688340 & 4.55 & 4.7035 & TRN \\
\hline CHEMBL1353595 & 688340 & 7.0 & 5.4433 & TRN \\
\hline CHEMBL1343836 & 688340 & 5.25 & 5.4135 & TRN \\
\hline CHEMBL1493528 & 688340 & 5.1 & 4.9028 & TST \\
\hline CHEMBL1406968 & 688340 & 3.95 & 5.2737 & TRN \\
\hline CHEMBL1424468 & 688340 & 4.5 & 4.7733 & TRN \\
\hline CHEMBL3190452 & 688340 & 4.7 & 5.0236 & TRN \\
\hline CHEMBL1558581 & 688340 & 5.4 & 5.2563 & TRN \\
\hline CHEMBL3190459 & 688340 & 4.55 & 5.0476 & TRN \\
\hline CHEMBL177987 & 688340 & 6.7001 & 5.0476 & TST \\
\hline CHEMBL1532036 & 688340 & 4.45 & 4.6441 & TRN \\
\hline CHEMBL1344158 & 688340 & 4.95 & 4.9195 & TRN \\
\hline
\end{tabular}




\begin{tabular}{|c|c|c|c|c|c|}
\hline \multicolumn{6}{|c|}{ Supplemental Table S2.txt } \\
\hline CHEMBL1312514 & 688340 & 5.4 & 5.2823 & TRN & \\
\hline CHEMBL1491637 & 688340 & 7.0501 & 4.774 & TRN & \\
\hline CHEMBL1329065 & 688340 & 5.15 & 4.9909 & TRN & \\
\hline CHEMBL1892270 & 688340 & 4.55 & 4.8225 & TRN & \\
\hline CHEMBL1524480 & 688340 & 5.2 & 4.9048 & TRN & \\
\hline CHEMBL1518897 & 688340 & 4.4 & 4.7366 & TRN & \\
\hline CHEMBL1979954 & 688340 & 4.5 & 5.1156 & TST & \\
\hline CHEMBL1520615 & 688340 & 4.5 & 4.7426 & TST & \\
\hline CHEMBL1565328 & 688340 & 4.5 & 4.8787 & TRN & \\
\hline CHEMBL1458049 & 688340 & 5.0 & 5.0515 & TST & \\
\hline CHEMBL1505955 & 688340 & 4.55 & 4.9197 & TRN & \\
\hline CHEMBL1401818 & 688340 & 4.45 & 4.6835 & TRN & \\
\hline CHEMBL1418493 & 688340 & 4.55 & 4.9057 & TRN & \\
\hline CHEMBL1372788 & 688340 & 7.5498 & 4.96899 & 9999999999 & TST \\
\hline CHEMBL1347387 & 688340 & 4.5 & 4.8085 & TRN & \\
\hline CHEMBL1419967 & 688340 & 4.8 & 4.8118 & TST & \\
\hline CHEMBL1565290 & 688340 & 4.8 & 4.7031 & TRN & \\
\hline CHEMBL1314100 & 688340 & 5.3 & 4.9103 & TST & \\
\hline CHEMBL1300431 & 688340 & 4.7 & 4.8883 & TRN & \\
\hline CHEMBL3196117 & 688340 & 4.8 & 4.476 & TRN & \\
\hline CHEMBL1445930 & 688340 & 4.9 & 5.1542 & TRN & \\
\hline CHEMBL1425029 & 688340 & 4.5 & 5.20200 & 0000000001 & TST \\
\hline CHEMBL1356435 & 688340 & 4.75 & 4.7744 & TRN & \\
\hline CHEMBL1321360 & 688340 & 5.65 & 5.4749 & TRN & \\
\hline CHEMBL1573987 & 688340 & 4.7 & 4.7964 & TRN & \\
\hline CHEMBL1402267 & 688340 & 4.85 & 4.9061 & TST & \\
\hline CHEMBL1584978 & 688340 & 5.2 & 4.7955 & TST & \\
\hline CHEMBL1555191 & 688340 & 5.15 & 5.1164 & TRN & \\
\hline CHEMBL1383610 & 688340 & 4.55 & 5.0671 & TRN & \\
\hline CHEMBL1510239 & 688340 & 6.95 & 5.1428 & TST & \\
\hline CHEMBL1520409 & 688340 & 4.5 & 4.8759 & TRN & \\
\hline CHEMBL1360203 & 688340 & 4.65 & 4.7251 & TRN & \\
\hline CHEMBL1330880 & 688340 & 5.15 & 5.088 & TRN & \\
\hline CHEMBL1537393 & 688340 & 4.6 & 4.934 & TRN & \\
\hline CHEMBL1446166 & 688340 & 4.45 & 4.8814 & TRN & \\
\hline CHEMBL3210904 & 688340 & 4.95 & 5.0104 & TST & \\
\hline CHEMBL1432742 & 688340 & 4.55 & 5.1675 & TRN & \\
\hline CHEMBL1525423 & 688340 & 6.05 & 5.8786 & TRN & \\
\hline CHEMBL1402596 & 688340 & 4.55 & 5.1268 & TRN & \\
\hline CHEMBL1564665 & 688340 & 5.65 & 5.2138 & TRN & \\
\hline CHEMBL1303739 & 688340 & 5.2 & 5.12 & TST & \\
\hline CHEMBL1400828 & 688340 & 5.4 & 4.755 & TRN & \\
\hline CHEMBL1310108 & 688340 & 4.85 & 4.8894 & TRN & \\
\hline CHEMBL1340155 & 688340 & 4.4 & 4.7685 & TRN & \\
\hline CHEMBL1407766 & 688340 & 4.65 & 4.9305 & TRN & \\
\hline CHEMBL1583185 & 688340 & 4.95 & 5.3433 & TST & \\
\hline CHEMBL1576369 & 688340 & 6.1 & 5.0007 & TRN & \\
\hline CHEMBL1544876 & 688340 & 4.55 & 4.9009 & TRN & \\
\hline
\end{tabular}




\begin{tabular}{|c|c|c|c|c|}
\hline \multicolumn{5}{|c|}{ Supplemental Table S2.txt } \\
\hline CHEMBL1600772 & 688340 & 3.95 & 4.4853 & TRN \\
\hline CHEMBL1582620 & 688340 & 4.45 & 5.0648 & TRN \\
\hline CHEMBL3199234 & 688340 & 4.4 & 5.2054 & TRN \\
\hline CHEMBL1385524 & 688340 & 4.8 & 4.9307 & TRN \\
\hline CHEMBL3197749 & 688340 & 4.5 & 5.1107 & TST \\
\hline CHEMBL1414071 & 688340 & 7.0 & 5.1051 & TRN \\
\hline CHEMBL1343094 & 688340 & 4.6 & 4.8276 & TST \\
\hline CHEMBL1461389 & 688340 & 4.6 & 4.7804 & TRN \\
\hline CHEMBL1378397 & 688340 & 4.4 & 5.1697 & TST \\
\hline CHEMBL1524533 & 688340 & 4.4 & 4.8818 & TRN \\
\hline CHEMBL1403888 & 688340 & 4.55 & 4.7544 & TRN \\
\hline CHEMBL3196918 & 688340 & 4.4 & 4.7595 & TST \\
\hline CHEMBL1319039 & 688340 & 5.55 & 5.1253 & TRN \\
\hline CHEMBL1586967 & 688340 & 6.15 & 5.3397 & TRN \\
\hline CHEMBL1382458 & 688340 & 6.45 & 5.2704 & TRN \\
\hline CHEMBL1488116 & 688340 & 5.35 & 5.3831 & TRN \\
\hline CHEMBL1517216 & 688340 & 5.35 & 5.3368 & TRN \\
\hline CHEMBL1610680 & 688340 & 5.45 & 4.8893 & TRN \\
\hline CHEMBL1401396 & 688340 & 4.5 & 5.0665 & TRN \\
\hline CHEMBL1545468 & 688340 & 4.9 & 4.6492 & TRN \\
\hline CHEMBL1481383 & 688340 & 4.55 & 4.9049 & TRN \\
\hline CHEMBL1343591 & 688340 & 6.8 & 5.2453 & TRN \\
\hline CHEMBL1600433 & 688340 & 4.85 & 4.5464 & TRN \\
\hline CHEMBL1392212 & 688340 & 5.15 & 4.9716 & TRN \\
\hline CHEMBL1422078 & 688340 & 4.6 & 4.623 & TRN \\
\hline CHEMBL1367262 & 688340 & 4.4 & 4.5426 & TRN \\
\hline CHEMBL1388113 & 688340 & 5.0 & 4.8346 & TST \\
\hline CHEMBL1380057 & 688340 & 4.55 & 4.8206 & TST \\
\hline CHEMBL1511162 & 688340 & 4.6 & 4.8412 & TRN \\
\hline CHEMBL1588027 & 688340 & 4.6 & 4.7656 & TRN \\
\hline CHEMBL1548982 & 688340 & 5.3 & 5.2344 & TST \\
\hline CHEMBL1563601 & 688340 & 5.65 & 5.3112 & TST \\
\hline CHEMBL1408577 & 688340 & 4.4 & 4.8404 & TST \\
\hline CHEMBL1340514 & 688340 & 4.7 & 4.7829 & TRN \\
\hline CHEMBL 235891 & 688340 & 4.9 & 4.8608 & TRN \\
\hline CHEMBL1364092 & 688340 & 5.2 & 5.1893 & TRN \\
\hline CHEMBL1558194 & 688340 & 4.2 & 5.2485 & TRN \\
\hline CHEMBL1439269 & 688340 & 6.15 & 4.8301 & TRN \\
\hline CHEMBL1402051 & 688340 & 4.55 & 4.7992 & TRN \\
\hline CHEMBL1392663 & 688340 & 4.4 & 4.9665 & TRN \\
\hline CHEMBL1606521 & 688340 & 4.45 & 5.0201 & TRN \\
\hline CHEMBL1471805 & 688340 & 7.15 & 5.0066 & TST \\
\hline CHEMBL1352156 & 688340 & 4.5 & 4.8621 & TRN \\
\hline CHEMBL1406058 & 688340 & 5.0 & 5.3145 & TST \\
\hline CHEMBL1328499 & 688340 & 4.4 & 5.0529 & TST \\
\hline CHEMBL1436529 & 688340 & 4.6 & 5.3763 & TST \\
\hline CHEMBL1381087 & 688340 & 4.6 & 4.8548 & TRN \\
\hline CHEMBL1397584 & 688340 & 4.5 & 4.9447 & TRN \\
\hline
\end{tabular}




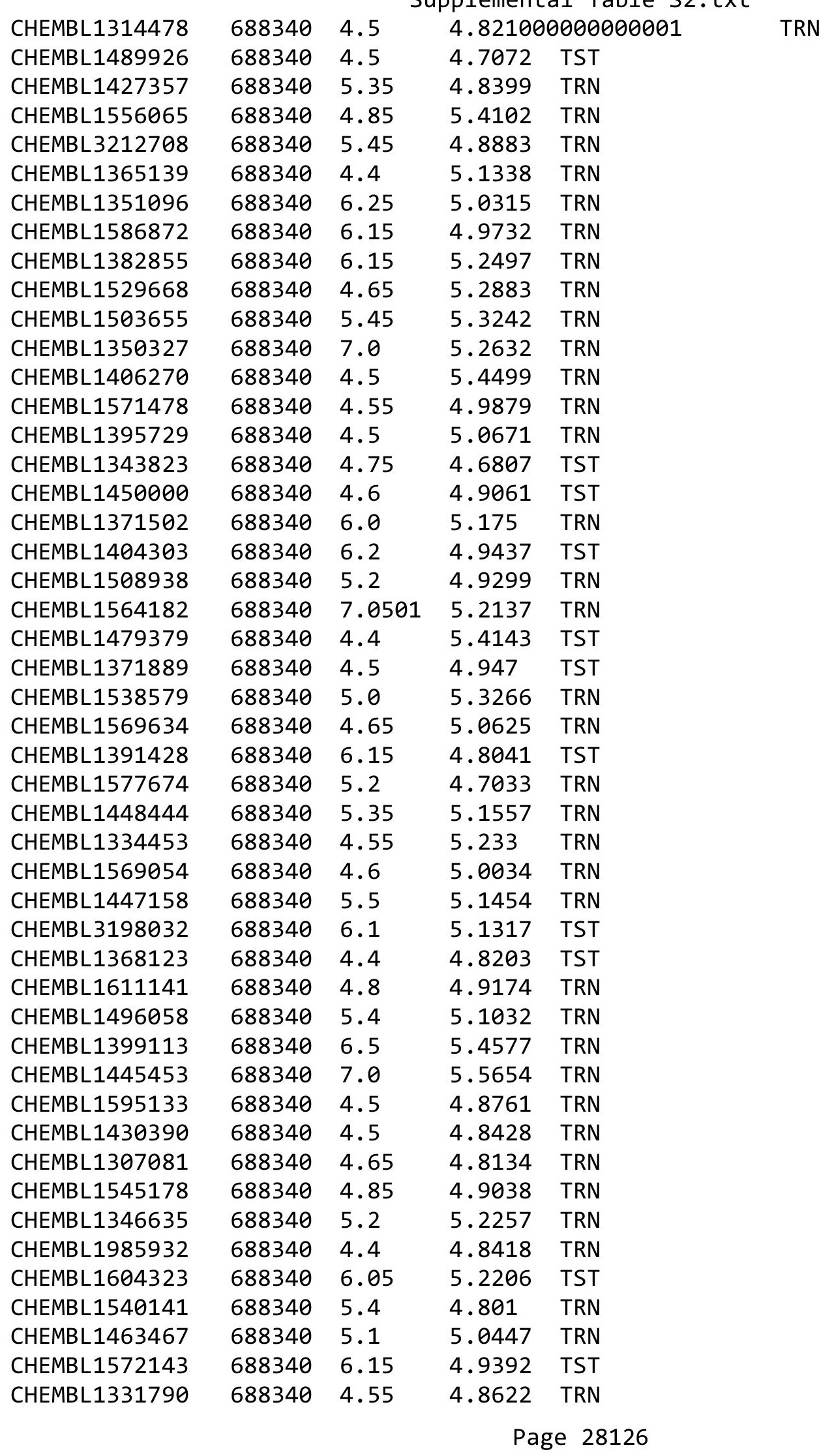




\begin{tabular}{|c|c|c|c|c|}
\hline \multicolumn{5}{|c|}{ Supplemental Table S2.txt } \\
\hline CHEMBL1388271 & 688340 & 4.5 & 4.67 & TRN \\
\hline CHEMBL1999678 & 688340 & 7.0 & 4.8576 & TRN \\
\hline CHEMBL1578235 & 688340 & 4.6 & 4.9498 & TRN \\
\hline CHEMBL1401022 & 688340 & 5.0 & 5.1419 & TRN \\
\hline CHEMBL1513470 & 688340 & 7.0 & 5.5081 & TRN \\
\hline CHEMBL1373607 & 688340 & 4.65 & 4.8055 & TRN \\
\hline CHEMBL1553004 & 688340 & 6.95 & 5.1534 & TRN \\
\hline CHEMBL1516503 & 688340 & 5.2 & 5.1938 & TRN \\
\hline CHEMBL1429093 & 688340 & 5.05 & 5.1896 & TST \\
\hline CHEMBL1585621 & 688340 & 5.35 & 4.9935 & TST \\
\hline CHEMBL1346794 & 688340 & 4.9 & 4.8804 & TRN \\
\hline CHEMBL1270410 & 688340 & 4.6 & 4.6429 & TRN \\
\hline CHEMBL1324793 & 688340 & 5.85 & 5.2385 & TRN \\
\hline CHEMBL1304363 & 688340 & 5.2 & 4.7159 & TRN \\
\hline CHEMBL1449571 & 688340 & 5.25 & 5.3035 & TRN \\
\hline CHEMBL1362388 & 688340 & 5.45 & 5.3078 & TRN \\
\hline CHEMBL1417935 & 688340 & 4.9 & 5.0444 & TRN \\
\hline CHEMBL1346908 & 688340 & 5.05 & 4.9299 & TRN \\
\hline CHEMBL1307925 & 688340 & 5.95 & 4.8962 & TST \\
\hline CHEMBL1546332 & 688340 & 4.55 & 5.0397 & TRN \\
\hline CHEMBL1355280 & 688340 & 4.7 & 4.8767 & TRN \\
\hline CHEMBL1530054 & 688340 & 4.55 & 5.12 & TRN \\
\hline CHEMBL1300726 & 688340 & 4.5 & 4.8706 & TRN \\
\hline CHEMBL1445370 & 688340 & 4.0 & 5.0354 & TST \\
\hline CHEMBL1344487 & 688340 & 6.15 & 5.1756 & TST \\
\hline CHEMBL1570359 & 688340 & 4.6 & 5.0033 & TRN \\
\hline CHEMBL1509790 & 688340 & 4.6 & 4.959 & TRN \\
\hline CHEMBL1598791 & 688340 & 4.55 & 4.9671 & TST \\
\hline CHEMBL2007273 & 688340 & 7.0 & 5.0599 & TST \\
\hline CHEMBL1435948 & 688340 & 4.85 & 5.5292 & TRN \\
\hline CHEMBL1397073 & 688340 & 6.15 & 5.1437 & TRN \\
\hline CHEMBL1454848 & 688340 & 4.4 & 4.8919 & TST \\
\hline CHEMBL1558389 & 688340 & 4.6 & 4.8121 & TST \\
\hline CHEMBL1302802 & 688340 & 4.55 & 4.7572 & TRN \\
\hline CHEMBL1476902 & 688340 & 7.0 & 5.0469 & TRN \\
\hline CHEMBL3209051 & 688340 & 5.4 & 5.0233 & TST \\
\hline CHEMBL1309244 & 688340 & 4.55 & 5.0483 & TRN \\
\hline CHEMBL1406511 & 688340 & 7.0 & 4.7704 & TST \\
\hline CHEMBL1530853 & 688340 & 5.0 & 4.8851 & TST \\
\hline CHEMBL 3189251 & 688340 & 4.4 & 4.9717 & TRN \\
\hline CHEMBL1563456 & 688340 & 5.0 & 5.4657 & TRN \\
\hline CHEMBL1314778 & 688340 & 4.5 & 5.0332 & TRN \\
\hline CHEMBL1431081 & 688340 & 4.55 & 4.8762 & TST \\
\hline CHEMBL1443410 & 688340 & 4.65 & 5.0378 & TST \\
\hline CHEMBL3208271 & 688340 & 4.65 & 5.0305 & TRN \\
\hline CHEMBL1299329 & 688340 & 4.55 & 4.9302 & TRN \\
\hline CHEMBL1505637 & 688340 & 5.45 & 5.1747 & TRN \\
\hline CHEMBL1387024 & 688340 & 4.4 & 4.8137 & TST \\
\hline
\end{tabular}




\begin{tabular}{|c|c|c|c|c|}
\hline & & & pplemen & al $\mathrm{T}$ \\
\hline CHEMBL1351964 & 688340 & 5.5 & 4.9553 & TRN \\
\hline CHEMBL1334591 & 688340 & 4.6 & 4.944 & TRN \\
\hline CHEMBL1451464 & 688340 & 4.6 & 4.8798 & TRN \\
\hline CHEMBL1335645 & 688340 & 4.35 & 5.5363 & TST \\
\hline CHEMBL1964676 & 688340 & 6.0 & 4.9531 & TST \\
\hline CHEMBL 3208718 & 688340 & 5.15 & 4.9824 & TST \\
\hline CHEMBL1571648 & 688340 & 5.05 & 4.662 & TST \\
\hline CHEMBL1331573 & 688340 & 5.2 & 4.8341 & TRN \\
\hline CHEMBL1370844 & 688340 & 4.8 & 4.8734 & TRN \\
\hline CHEMBL1449629 & 688340 & 5.9 & 4.9838 & TRN \\
\hline CHEMBL1386015 & 688340 & 4.7 & 4.9734 & TRN \\
\hline CHEMBL1370729 & 688340 & 5.8 & 5.0462 & TST \\
\hline CHEMBL1590564 & 688340 & 5.75 & 5.2816 & TRN \\
\hline CHEMBL1510479 & 688340 & 5.45 & 4.8492 & TRN \\
\hline CHEMBL1451448 & 688340 & 6.25 & 5.1788 & TST \\
\hline CHEMBL1534086 & 688340 & 5.0 & 5.1005 & TRN \\
\hline CHEMBL3192686 & 688340 & 5.85 & 5.3189 & TRN \\
\hline CHEMBL1350077 & 688340 & 6.45 & 5.0338 & TST \\
\hline CHEMBL1452260 & 688340 & 5.7 & 4.8928 & TST \\
\hline CHEMBL1582997 & 688340 & 5.45 & 4.7158 & TRN \\
\hline CHEMBL1584374 & 688340 & 5.5 & 4.9449 & TRN \\
\hline CHEMBL1332066 & 688340 & 4.5 & 4.5242 & TRN \\
\hline CHEMBL1497780 & 688340 & 7.0 & 5.4121 & TRN \\
\hline CHEMBL1451077 & 688340 & 5.0 & 5.1714 & TST \\
\hline CHEMBL1537303 & 688340 & 4.0 & 5.0287 & TST \\
\hline CHEMBL1368546 & 688340 & 5.2 & 4.7215 & TST \\
\hline CHEMBL1466032 & 688340 & 4.5 & 4.7826 & TRN \\
\hline CHEMBL1368409 & 688340 & 5.15 & 4.9138 & TST \\
\hline CHEMBL1330258 & 688340 & 4.5 & 4.6211 & TRN \\
\hline CHEMBL1430166 & 688340 & 4.8 & 4.9661 & TST \\
\hline CHEMBL1451101 & 688340 & 4.55 & 4.8176 & TRN \\
\hline CHEMBL1536992 & 688340 & 5.5 & 4.9895 & TST \\
\hline CHEMBL1514058 & 688340 & 4.45 & 5.042 & TST \\
\hline CHEMBL1492976 & 688340 & 4.25 & 5.4745 & TST \\
\hline CHEMBL1413892 & 688340 & 4.8 & 4.8437 & TRN \\
\hline CHEMBL1532819 & 688340 & 5.5 & 4.6464 & TRN \\
\hline CHEMBL1520133 & 688340 & 4.55 & 4.7105 & TRN \\
\hline CHEMBL1480292 & 688340 & 5.4 & 5.235 & TRN \\
\hline CHEMBL1508974 & 688340 & 5.5 & 5.2513 & TRN \\
\hline CHEMBL 3198133 & 688340 & 7.0 & 5.0376 & TRN \\
\hline CHEMBL1331605 & 688340 & 4.5 & 4.9889 & TRN \\
\hline CHEMBL1444220 & 688340 & 4.55 & 4.9562 & TRN \\
\hline CHEMBL1431648 & 688340 & 4.5 & 4.9838 & TRN \\
\hline CHEMBL1404996 & 688340 & 4.35 & 4.9077 & TST \\
\hline CHEMBL1509160 & 688340 & 6.15 & 5.1268 & TST \\
\hline CHEMBL1447865 & 688340 & 4.7 & 5.0731 & TRN \\
\hline CHEMBL1525188 & 688340 & 4.5 & 5.4441 & TRN \\
\hline CHEMBL1595372 & 688340 & 4.4 & 5.0299 & TRN \\
\hline
\end{tabular}




\begin{tabular}{|c|c|c|c|c|c|}
\hline \\
\hline CHEMBL1490280 & 688340 & 4.5 & 4.9644 & TRN & \\
\hline CHEMBL1418828 & 688340 & 4.7 & 5.4576 & TST & \\
\hline CHEMBL1453830 & 688340 & 4.4 & 4.7427 & TRN & \\
\hline CHEMBL1332948 & 688340 & 5.2 & 5.3324 & TST & \\
\hline CHEMBL1377847 & 688340 & 5.25 & 5.7154 & TRN & \\
\hline CHEMBL1574887 & 688340 & 4.45 & 4.865 & TRN & \\
\hline CHEMBL1553444 & 688340 & 7.0 & 5.2386 & TST & \\
\hline CHEMBL1339640 & 688340 & 4.55 & 4.7885 & TRN & \\
\hline CHEMBL1515780 & 688340 & 5.55 & 5.0758 & TRN & \\
\hline CHEMBL1314029 & 688340 & 4.6 & 5.1871 & TRN & \\
\hline CHEMBL1429681 & 688340 & 5.4 & 5.2683 & TRN & \\
\hline CHEMBL1451092 & 688340 & 6.45 & 5.3475 & TRN & \\
\hline CHEMBL1573585 & 688340 & 4.7 & 5.1355 & TRN & \\
\hline CHEMBL1353059 & 688340 & 5.25 & 5.0728 & TRN & \\
\hline CHEMBL1479775 & 688340 & 4.05 & 5.3855 & TST & \\
\hline CHEMBL1606409 & 688340 & 4.5 & 4.9378 & TRN & \\
\hline CHEMBL1388045 & 688340 & 6.6 & 4.9442 & TST & \\
\hline CHEMBL1374950 & 688340 & 4.45 & 4.91 & TRN & \\
\hline CHEMBL1413943 & 688340 & 5.15 & 5.3521 & TRN & \\
\hline CHEMBL1337827 & 688340 & 4.6 & 4.6143 & TRN & \\
\hline CHEMBL1439869 & 688340 & 4.85 & 5.4859 & TST & \\
\hline CHEMBL1423121 & 688340 & 4.6 & 4.8807 & TRN & \\
\hline CHEMBL1384027 & 688340 & 5.45 & 4.8939 & TRN & \\
\hline CHEMBL1405958 & 688340 & 4.65 & 4.6023 & TRN & \\
\hline CHEMBL1315592 & 688340 & 6.1 & 5.08899 & 99999999995 & TRN \\
\hline CHEMBL1373232 & 688340 & 4.4 & 4.8655 & TRN & \\
\hline CHEMBL1471737 & 688340 & 5.15 & 4.8966 & TRN & \\
\hline CHEMBL1402084 & 688340 & 4.5 & 4.6737 & TRN & \\
\hline CHEMBL1396332 & 688340 & 4.4 & 5.6162 & TRN & \\
\hline CHEMBL1587728 & 688340 & 4.5 & 4.71 & TRN & \\
\hline CHEMBL1536629 & 688340 & 4.4 & 5.0328 & TRN & \\
\hline CHEMBL1428836 & 688340 & 7.0501 & 5.2176 & TRN & \\
\hline CHEMBL1531388 & 688340 & 4.4 & 4.8205 & TRN & \\
\hline CHEMBL1528694 & 688340 & 5.8 & 5.501 & TRN & \\
\hline CHEMBL1607765 & 688340 & 6.15 & 5.501 & TRN & \\
\hline CHEMBL1466075 & 688340 & 4.65 & 4.6373 & TRN & \\
\hline CHEMBL1429154 & 688340 & 5.2 & 5.1061 & TST & \\
\hline CHEMBL1452132 & 688340 & 5.05 & 4.6376 & TRN & \\
\hline CHEMBL 2000619 & 688340 & 5.1 & 4.8472 & TRN & \\
\hline CHEMBL1353334 & 688340 & 5.15 & 5.2927 & TRN & \\
\hline CHEMBL1380344 & 688340 & 5.45 & 5.33200 & $\partial 000000001$ & TRN \\
\hline CHEMBL1477631 & 688340 & 5.0 & 5.3894 & TRN & \\
\hline CHEMBL 2369228 & 688340 & 5.0 & 5.1152 & TST & \\
\hline CHEMBL1439069 & 688340 & 4.4 & 4.7368 & TRN & \\
\hline CHEMBL1343888 & 688340 & 5.3 & 5.4446 & TST & \\
\hline CHEMBL1327509 & 688340 & 6.95 & 4.8106 & TRN & \\
\hline CHEMBL1540556 & 688340 & 4.4 & 4.7154 & TRN & \\
\hline CHEMBL1487716 & 688340 & 4.4 & 5.165 & TRN & \\
\hline
\end{tabular}




\begin{tabular}{|c|c|c|c|c|c|}
\hline \\
\hline CHEMBL3196392 & 688340 & 4.4 & 5.0352 & TST & \\
\hline CHEMBL1422344 & 688340 & 5.55 & 5.1151 & TST & \\
\hline CHEMBL1541780 & 688340 & 4.8 & 4.7013 & TRN & \\
\hline CHEMBL1609517 & 688340 & 4.4 & 4.4542 & TRN & \\
\hline CHEMBL1505890 & 688340 & 4.9 & 5.4337 & TRN & \\
\hline CHEMBL1366536 & 688340 & 4.4 & 5.2069 & TRN & \\
\hline CHEMBL1313042 & 688340 & 4.5 & 4.9541 & TRN & \\
\hline CHEMBL1528644 & 688340 & 6.05 & 4.88899 & 9999999999 & TRN \\
\hline CHEMBL1601473 & 688340 & 6.1 & 4.9899 & TRN & \\
\hline CHEMBL195705 & 688340 & 4.6 & 5.0529 & TRN & \\
\hline CHEMBL1316578 & 688340 & 4.0 & 5.3866 & TRN & \\
\hline CHEMBL1415319 & 688340 & 5.25 & 4.7685 & TRN & \\
\hline CHEMBL1326606 & 688340 & 5.45 & 4.9339 & TST & \\
\hline CHEMBL1510264 & 688340 & 4.55 & 5.0496 & TRN & \\
\hline CHEMBL1993103 & 688340 & 4.4 & 5.0026 & TRN & \\
\hline CHEMBL549640 & 688340 & 4.7 & 5.0329 & TRN & \\
\hline CHEMBL1422419 & 688340 & 4.65 & 4.8413 & TST & \\
\hline CHEMBL1313968 & 688340 & 5.05 & 4.9531 & TRN & \\
\hline CHEMBL1355894 & 688340 & 4.5 & 4.9576 & TRN & \\
\hline CHEMBL1308760 & 688340 & 5.2 & 4.9984 & TRN & \\
\hline CHEMBL1424343 & 688340 & 4.65 & 4.8099 & TRN & \\
\hline CHEMBL1418786 & 688340 & 4.55 & 4.513 & TRN & \\
\hline CHEMBL1413056 & 688340 & 4.7 & 4.8233 & TRN & \\
\hline CHEMBL1505809 & 688340 & 4.45 & 4.7912 & TRN & \\
\hline CHEMBL1998946 & 688340 & 4.5 & 4.8707 & TRN & \\
\hline CHEMBL1335351 & 688340 & 4.75 & 5.0585 & TRN & \\
\hline CHEMBL3189342 & 688340 & 5.85 & 5.0172 & TRN & \\
\hline CHEMBL1418959 & 688340 & 5.2 & 5.0479 & TRN & \\
\hline CHEMBL1519331 & 688340 & 6.95 & 5.2621 & TRN & \\
\hline CHEMBL1371819 & 688340 & 4.05 & 4.9723 & TST & \\
\hline CHEMBL1537044 & 688340 & 3.95 & 5.0613 & TST & \\
\hline CHEMBL1343533 & 688340 & 6.15 & 5.2653 & TRN & \\
\hline CHEMBL1371320 & 688340 & 4.4 & 4.8091 & TRN & \\
\hline CHEMBL3199125 & 688340 & 5.2 & 4.6309 & TRN & \\
\hline CHEMBL1302615 & 688340 & 4.75 & 5.0235 & TRN & \\
\hline CHEMBL1452246 & 688340 & 5.5 & 5.4008 & TST & \\
\hline CHEMBL1343559 & 688340 & 4.65 & 5.2012 & TST & \\
\hline CHEMBL1588058 & 688340 & 4.45 & 4.6747 & TRN & \\
\hline CHEMBL1373096 & 688340 & 4.4 & 4.5257 & TRN & \\
\hline CHEMBL3195091 & 688340 & 5.05 & 5.095 & TRN & \\
\hline CHEMBL1591943 & 688340 & 4.65 & 4.8509 & TRN & \\
\hline CHEMBL1380147 & 688340 & 5.2 & 4.9104 & TST & \\
\hline CHEMBL1361744 & 688340 & 4.55 & 4.8968 & TRN & \\
\hline CHEMBL1330308 & 688340 & 4.5 & 4.9929 & TRN & \\
\hline CHEMBL1977877 & 688340 & 5.1 & 5.0182 & TRN & \\
\hline CHEMBL1302388 & 688340 & 4.55 & 5.0977 & TST & \\
\hline CHEMBL1549491 & 688340 & 5.45 & 5.3016 & TRN & \\
\hline CHEMBL1373655 & 688340 & 5.5 & 4.7395 & TRN & \\
\hline
\end{tabular}




\begin{tabular}{|c|c|c|c|c|c|}
\hline \\
\hline CHEMBL1460884 & 688340 & 5.4 & 4.9349 & TRN & \\
\hline CHEMBL1526055 & 688340 & 4.4 & 4.8205 & TST & \\
\hline CHEMBL1395123 & 688340 & 4.5 & 4.9686 & TRN & \\
\hline CHEMBL1400349 & 688340 & 4.4 & 5.2245 & TRN & \\
\hline CHEMBL1512113 & 688340 & 6.15 & 5.1564 & TRN & \\
\hline CHEMBL1305645 & 688340 & 5.65 & 5.2028 & TRN & \\
\hline CHEMBL1521268 & 688340 & 6.15 & 5.1303 & TRN & \\
\hline CHEMBL1390942 & 688340 & 6.15 & 5.5481 & TRN & \\
\hline CHEMBL1470346 & 688340 & 5.5 & 4.7087 & TRN & \\
\hline CHEMBL1412950 & 688340 & 4.65 & 4.8141 & TRN & \\
\hline CHEMBL1418039 & 688340 & 5.45 & 4.9615 & TRN & \\
\hline CHEMBL1351599 & 688340 & 4.55 & 4.5368 & TRN & \\
\hline CHEMBL1333935 & 688340 & 4.55 & 5.3232 & TRN & \\
\hline CHEMBL1602624 & 688340 & 4.55 & 4.8397 & TRN & \\
\hline CHEMBL1416750 & 688340 & 5.1 & 5.24200 & $\partial 000000001$ & TRN \\
\hline CHEMBL1342666 & 688340 & 4.7 & 5.0693 & TRN & \\
\hline CHEMBL1571442 & 688340 & 4.65 & 4.8228 & TRN & \\
\hline CHEMBL1586917 & 688340 & 4.7 & 4.732 & TRN & \\
\hline CHEMBL1492406 & 688340 & 4.45 & 5.2646 & TRN & \\
\hline CHEMBL1396250 & 688340 & 5.4 & 5.45299 & 9999999999 & TST \\
\hline CHEMBL1454198 & 688340 & 5.65 & 5.3316 & TST & \\
\hline CHEMBL1312031 & 688340 & 4.4 & 4.7405 & TRN & \\
\hline CHEMBL1325244 & 688340 & 5.15 & 5.1799 & TRN & \\
\hline CHEMBL1561043 & 688340 & 4.85 & 4.723 & TRN & \\
\hline CHEMBL1608130 & 688340 & 4.55 & 5.0305 & TRN & \\
\hline CHEMBL1401798 & 688340 & 4.45 & 4.7455 & TRN & \\
\hline CHEMBL47940 & 688340 & 4.8 & 4.7928 & TST & \\
\hline CHEMBL1554633 & 688340 & 4.5 & 4.871 & TRN & \\
\hline CHEMBL1507703 & 688340 & 7.4001 & 5.1927 & TRN & \\
\hline CHEMBL1496473 & 688340 & 4.8 & 5.37799 & 9999999999 & TST \\
\hline CHEMBL1573194 & 688340 & 4.7 & 4.9236 & TRN & \\
\hline CHEMBL1425225 & 688340 & 5.3 & 5.0382 & TRN & \\
\hline CHEMBL1531162 & 688340 & 4.65 & 5.0908 & TRN & \\
\hline CHEMBL1503165 & 688340 & 4.65 & 4.9082 & TRN & \\
\hline CHEMBL1307523 & 688340 & 4.5 & 4.8802 & TRN & \\
\hline CHEMBL1364458 & 688340 & 4.9 & 4.9472 & TST & \\
\hline CHEMBL1343856 & 688340 & 4.4 & 4.8746 & TRN & \\
\hline CHEMBL1542862 & 688340 & 4.45 & 4.8739 & TRN & \\
\hline CHEMBL1459732 & 688340 & 5.75 & 5.2307 & TRN & \\
\hline CHEMBL1455458 & 688340 & 4.55 & 5.0359 & TST & \\
\hline CHEMBL1565660 & 688340 & 4.3 & 4.9475 & TRN & \\
\hline CHEMBL1461905 & 688340 & 5.15 & 5.1465 & TRN & \\
\hline CHEMBL1335502 & 688340 & 4.5 & 4.9296 & TRN & \\
\hline CHEMBL1362945 & 688340 & 5.2 & 5.2368 & TRN & \\
\hline CHEMBL242711 & 688340 & 4.05 & 4.9144 & TRN & \\
\hline CHEMBL1498917 & 688340 & 6.7001 & 5.2419 & TRN & \\
\hline CHEMBL1561094 & 688340 & 4.0 & 4.8849 & TRN & \\
\hline CHEMBL1530664 & 688340 & 5.25 & 5.1111 & TRN & \\
\hline
\end{tabular}




\begin{tabular}{|c|c|c|c|c|c|}
\hline \multicolumn{6}{|c|}{ Supplemental Table S2.txt } \\
\hline CHEMBL1442668 & 688340 & 4.6 & 4.6446 & TRN & \\
\hline CHEMBL1461754 & 688340 & 5.95 & 4.9336 & TRN & \\
\hline CHEMBL1982991 & 688340 & 5.1 & 5.0189 & TRN & \\
\hline CHEMBL3196326 & 688340 & 4.6 & 4.6611 & TRN & \\
\hline CHEMBL1300612 & 688340 & 4.5 & 5.0987 & TST & \\
\hline CHEMBL3208617 & 688340 & 4.85 & 5.0725 & TRN & \\
\hline CHEMBL1496229 & 688340 & 7.0 & 5.3256 & TRN & \\
\hline CHEMBL1424821 & 688340 & 4.4 & 5.3789 & TRN & \\
\hline CHEMBL1529628 & 688340 & 5.2 & 5.5808 & TRN & \\
\hline CHEMBL1518085 & 688340 & 6.35 & 4.67899 & 9999999999 & TRN \\
\hline CHEMBL1539114 & 688340 & 4.45 & 5.0309 & TRN & \\
\hline CHEMBL1596904 & 688340 & 6.15 & 5.0221 & TRN & \\
\hline CHEMBL1421545 & 688340 & 5.95 & 4.7774 & TRN & \\
\hline CHEMBL1568805 & 688340 & 4.75 & 4.9228 & TST & \\
\hline CHEMBL1382255 & 688340 & 7.0501 & 5.6577 & TST & \\
\hline CHEMBL1498595 & 688340 & 4.7 & 5.1578 & TST & \\
\hline CHEMBL1412315 & 688340 & 4.6 & 4.6388 & TRN & \\
\hline CHEMBL 3210057 & 688340 & 4.75 & 4.8175 & TRN & \\
\hline CHEMBL1589780 & 688340 & 5.3 & 5.4251 & TRN & \\
\hline CHEMBL1469276 & 688340 & 3.0 & 5.2426 & TRN & \\
\hline CHEMBL1511142 & 688340 & 4.95 & 5.0011 & TRN & \\
\hline CHEMBL1371697 & 688340 & 4.4 & 4.8356 & TRN & \\
\hline CHEMBL1485691 & 688340 & 4.45 & 4.8583 & TST & \\
\hline CHEMBL1551588 & 688340 & 4.5 & 4.9375 & TRN & \\
\hline CHEMBL1323902 & 688340 & 4.9 & 4.9349 & TRN & \\
\hline CHEMBL1325945 & 688340 & 5.25 & 5.3529 & TRN & \\
\hline CHEMBL1492547 & 688340 & 4.0 & 5.3122 & TST & \\
\hline CHEMBL3190333 & 688340 & 4.45 & 4.9373 & TRN & \\
\hline CHEMBL1369173 & 688340 & 4.4 & 5.1098 & TRN & \\
\hline CHEMBL1400685 & 688340 & 7.0 & 5.2081 & TRN & \\
\hline CHEMBL1552773 & 688340 & 5.0 & 5.1469 & TRN & \\
\hline CHEMBL3193923 & 688340 & 5.7 & 4.7199 & TRN & \\
\hline CHEMBL1377774 & 688340 & 4.35 & 4.6503 & TRN & \\
\hline CHEMBL3210208 & 688340 & 4.75 & 5.1652 & TST & \\
\hline CHEMBL1574128 & 688340 & 4.6 & 5.3191 & TST & \\
\hline CHEMBL1570808 & 688340 & 4.6 & 4.9194 & TRN & \\
\hline CHEMBL1480067 & 688340 & 4.45 & 4.761 & TRN & \\
\hline CHEMBL1578446 & 688340 & 4.75 & 5.1638 & TRN & \\
\hline CHEMBL3195227 & 688340 & 5.3 & 5.046 & TST & \\
\hline CHEMBL1501558 & 688340 & 4.4 & 4.6493 & TRN & \\
\hline CHEMBL1419335 & 688340 & 4.6 & 4.9777 & TRN & \\
\hline CHEMBL1539518 & 688340 & 5.5 & 4.7779 & TRN & \\
\hline CHEMBL1516893 & 688340 & 5.35 & 5.365 & TRN & \\
\hline CHEMBL1360523 & 688340 & 4.8 & 4.7733 & TRN & \\
\hline CHEMBL1416960 & 688340 & 5.4 & 5.0175 & TRN & \\
\hline CHEMBL1387357 & 688340 & 4.55 & 5.1561 & TRN & \\
\hline CHEMBL582722 & 688340 & 4.45 & 4.7981 & TST & \\
\hline CHEMBL1526977 & 688340 & 5.2 & 5.0221 & TRN & \\
\hline
\end{tabular}




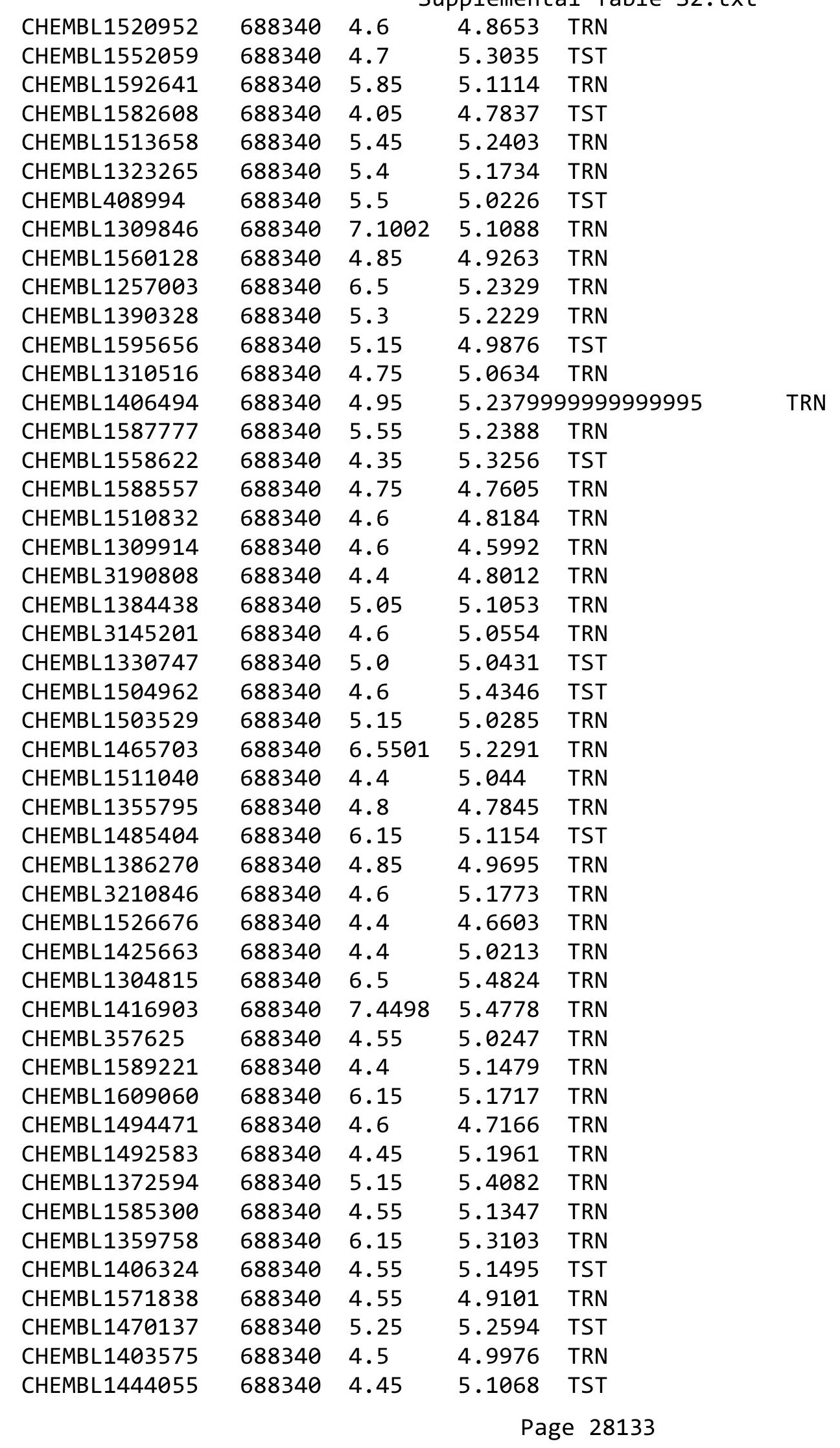




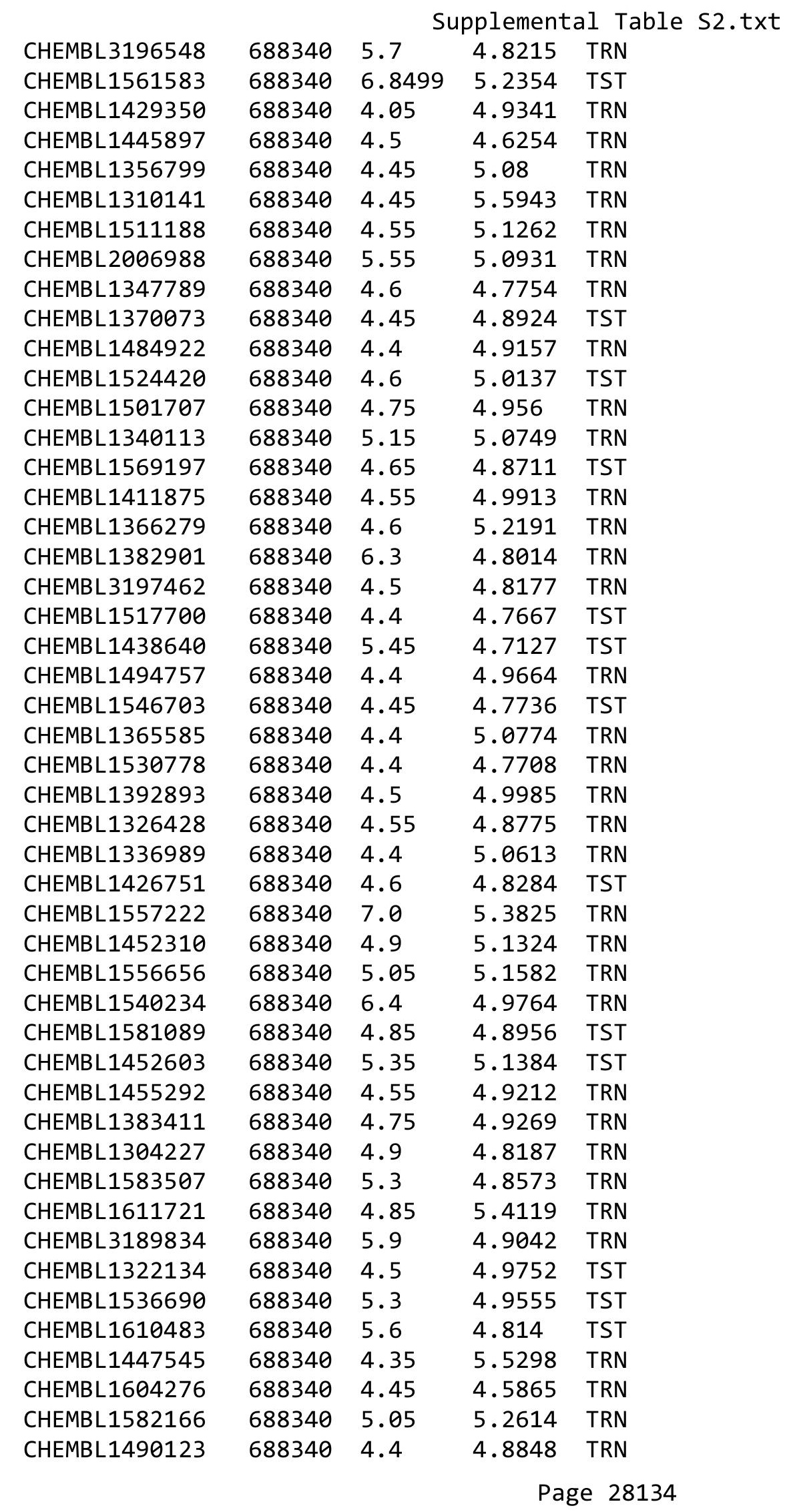




\begin{tabular}{|c|c|c|c|c|}
\hline \multicolumn{5}{|c|}{ Supplemental Table S2.txt } \\
\hline CHEMBL1593350 & 688340 & 4.4 & 5.4527 & TRN \\
\hline CHEMBL1409337 & 688340 & 4.5 & 4.949 & TRN \\
\hline CHEMBL1359999 & 688340 & 5.25 & 4.9032 & TRN \\
\hline CHEMBL1368508 & 688340 & 4.55 & 5.3778 & TRN \\
\hline CHEMBL1603748 & 688340 & 4.45 & 5.153 & TRN \\
\hline CHEMBL1530941 & 688340 & 5.9 & 5.2125 & TST \\
\hline CHEMBL1322701 & 688340 & 4.55 & 5.0244 & TRN \\
\hline CHEMBL1469948 & 688340 & 4.55 & 5.1483 & TRN \\
\hline CHEMBL1573530 & 688340 & 4.0 & 5.3977 & TST \\
\hline CHEMBL1303204 & 688340 & 4.6 & 5.0 & TRN \\
\hline CHEMBL1299698 & 688340 & 7.0501 & 5.0712 & TRN \\
\hline CHEMBL1429463 & 688340 & 4.5 & 4.9745 & TRN \\
\hline CHEMBL1584229 & 688340 & 5.3 & 4.9385 & TRN \\
\hline CHEMBL1342477 & 688340 & 6.25 & 5.186 & TRN \\
\hline CHEMBL3208346 & 688340 & 4.0 & 5.1538 & TRN \\
\hline CHEMBL1390343 & 688340 & 4.5 & 4.9234 & TRN \\
\hline CHEMBL1443383 & 688340 & 4.4 & 4.9668 & TRN \\
\hline CHEMBL1521130 & 688340 & 4.55 & 4.6173 & TRN \\
\hline CHEMBL1385003 & 688340 & 6.5501 & 4.9512 & TRN \\
\hline CHEMBL3392453 & 688340 & 4.35 & 5.2955 & TRN \\
\hline CHEMBL1433317 & 688340 & 4.45 & 4.9346 & TRN \\
\hline CHEMBL1435721 & 688340 & 6.9 & 5.2111 & TRN \\
\hline CHEMBL1338569 & 688340 & 7.4001 & 5.606 & TRN \\
\hline CHEMBL1455838 & 688340 & 7.0 & 4.9555 & TRN \\
\hline CHEMBL1446089 & 688340 & 4.6 & 4.7757 & TRN \\
\hline CHEMBL1515345 & 688340 & 4.55 & 5.1278 & TRN \\
\hline CHEMBL1318526 & 688340 & 4.75 & 4.873 & TRN \\
\hline CHEMBL1353189 & 688340 & 5.45 & 4.5945 & TRN \\
\hline CHEMBL1612608 & 688340 & 4.95 & 4.9787 & TST \\
\hline CHEMBL1419451 & 688340 & 5.05 & 5.1632 & TST \\
\hline CHEMBL1455976 & 688340 & 5.45 & 5.0697 & TRN \\
\hline CHEMBL1429225 & 688340 & 4.55 & 4.7981 & TST \\
\hline CHEMBL1406670 & 688340 & 5.2 & 5.0614 & TST \\
\hline CHEMBL1521974 & 688340 & 4.4 & 5.2087 & TRN \\
\hline CHEMBL1499667 & 688340 & 4.05 & 5.1533 & TST \\
\hline CHEMBL1408524 & 688340 & 5.2 & 4.717 & TST \\
\hline CHEMBL1987884 & 688340 & 4.55 & 4.6342 & TRN \\
\hline CHEMBL1507831 & 688340 & 4.45 & 5.2101 & TRN \\
\hline CHEMBL1548993 & 688340 & 8.1024 & 5.4912 & TST \\
\hline CHEMBL1313485 & 688340 & 6.25 & 4.8428 & TRN \\
\hline CHEMBL1414376 & 688340 & 5.4 & 4.7822 & TRN \\
\hline CHEMBL1379810 & 688340 & 6.15 & 5.1971 & TRN \\
\hline CHEMBL1543963 & 688340 & 5.25 & 5.0494 & TRN \\
\hline CHEMBL1991875 & 688340 & 4.45 & 4.8468 & TRN \\
\hline CHEMBL1393857 & 688340 & 4.8 & 4.7802 & TRN \\
\hline CHEMBL1371913 & 688340 & 5.3 & 5.3504 & TRN \\
\hline CHEMBL1311299 & 688340 & 5.2 & 5.3517 & TRN \\
\hline CHEMBL1303118 & 688340 & 4.85 & 5.008 & TRN \\
\hline
\end{tabular}




\begin{tabular}{|c|c|c|c|c|c|}
\hline & & & & & \\
\hline CHEMBL1521578 & 688340 & 5.5 & 5.1172 & TRN & \\
\hline CHEMBL1480727 & 688340 & 6.1 & 4.9158 & TRN & \\
\hline CHEMBL1505227 & 688340 & 4.85 & 4.8822 & TST & \\
\hline CHEMBL1332033 & 688340 & 4.45 & 4.5456 & TST & \\
\hline CHEMBL1473146 & 688340 & 4.65 & 4.9782 & TRN & \\
\hline CHEMBL1332048 & 688340 & 4.55 & 5.0316 & TRN & \\
\hline CHEMBL57978 & 688340 & 5.3 & 4.9818 & TST & \\
\hline CHEMBL1444727 & 688340 & 5.0 & 5.0724 & TST & \\
\hline CHEMBL1346503 & 688340 & 6.25 & 4.9258 & TRN & \\
\hline CHEMBL3192475 & 688340 & 4.9 & 5.0267 & TRN & \\
\hline CHEMBL1318651 & 688340 & 6.0 & 4.6907 & TRN & \\
\hline CHEMBL1596628 & 688340 & 4.7 & 5.3018 & TRN & \\
\hline CHEMBL1370817 & 688340 & 4.5 & 4.6709 & TRN & \\
\hline CHEMBL1531383 & 688340 & 5.2 & 5.0441 & TRN & \\
\hline CHEMBL1425268 & 688340 & 4.6 & 4.7571 & TRN & \\
\hline CHEMBL1601945 & 688340 & 6.5501 & 5.2258 & TRN & \\
\hline CHEMBL3208447 & 688340 & 4.55 & 5.1734 & TRN & \\
\hline CHEMBL1341022 & 688340 & 4.55 & 4.9198 & TRN & \\
\hline CHEMBL1513420 & 688340 & 4.55 & 4.9972 & TST & \\
\hline CHEMBL1611199 & 688340 & 4.4 & 4.9264 & TRN & \\
\hline CHEMBL1575767 & 688340 & 5.9 & 5.1004 & TRN & \\
\hline CHEMBL1336738 & 688340 & 6.0 & 4.7528 & TRN & \\
\hline CHEMBL1587606 & 688340 & 4.75 & 4.5962 & TRN & \\
\hline CHEMBL1419848 & 688340 & 5.75 & 4.9598 & TST & \\
\hline CHEMBL1586610 & 688340 & 4.4 & 4.8339 & TRN & \\
\hline CHEMBL1343819 & 688340 & 4.85 & 4.7784 & TST & \\
\hline CHEMBL1566280 & 688340 & 4.85 & 4.6899 & TRN & \\
\hline CHEMBL1438031 & 688340 & 5.45 & 4.8564 & TRN & \\
\hline CHEMBL1354004 & 688340 & 4.55 & 5.0566 & TST & \\
\hline CHEMBL1350364 & 688340 & 4.6 & 5.1034 & TRN & \\
\hline CHEMBL1562201 & 688340 & 4.55 & 4.9269 & TRN & \\
\hline CHEMBL1397806 & 688340 & 5.35 & 4.8995 & TRN & \\
\hline CHEMBL1395435 & 688340 & 6.1 & 5.5548 & TRN & \\
\hline CHEMBL3213729 & 688340 & 4.5 & 5.1866 & TRN & \\
\hline CHEMBL1556570 & 688340 & 4.4 & 4.9826 & TRN & \\
\hline CHEMBL1479900 & 688340 & 4.6 & 5.1894 & TRN & \\
\hline CHEMBL1570793 & 688340 & 4.35 & 5.409 & TRN & \\
\hline CHEMBL1454775 & 688340 & 4.8 & 5.0182 & TRN & \\
\hline CHEMBL1601402 & 688340 & 4.55 & 4.9134 & TRN & \\
\hline CHEMBL1500890 & 688340 & 4.4 & 4.9077 & TRN & \\
\hline CHEMBL1344120 & 688340 & 4.7 & 5.3632 & TRN & \\
\hline CHEMBL1455666 & 688340 & 5.55 & 5.0447 & TRN & \\
\hline CHEMBL1431625 & 688340 & 4.95 & 5.1393 & TRN & \\
\hline CHEMBL1350338 & 688340 & 5.05 & 5.2595 & TRN & \\
\hline CHEMBL1501819 & 688340 & 5.6 & 5.4181 & TST & \\
\hline CHEMBL1322848 & 688340 & 5.45 & 5.12299 & 9999999999 & TRN \\
\hline CHEMBL1489176 & 688340 & 4.9 & 4.9443 & TRN & \\
\hline CHEMBL1305918 & 688340 & 4.55 & 5.30399 & 9999999999 & TRN \\
\hline & & & & 28136 & \\
\hline
\end{tabular}




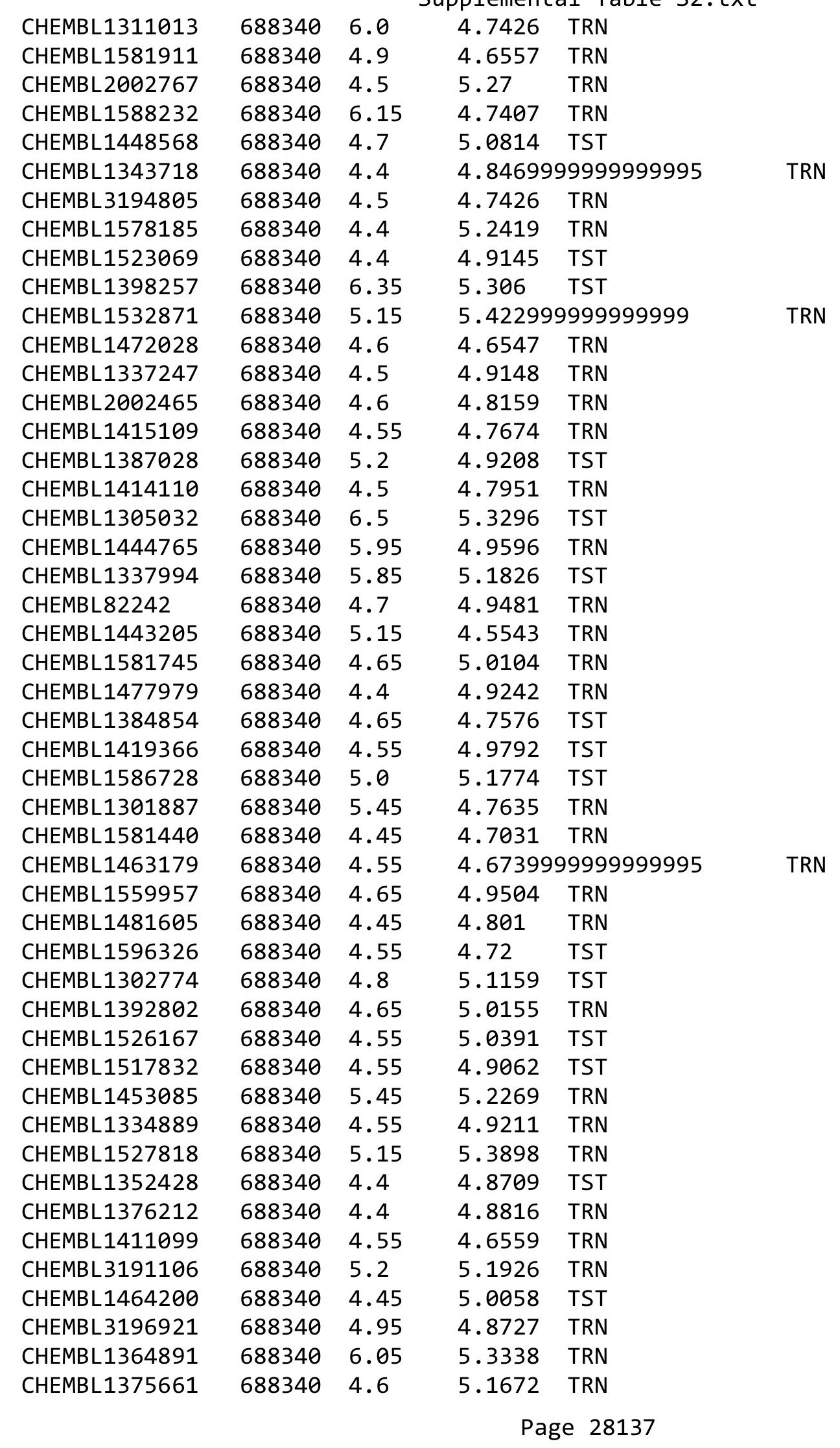




\begin{tabular}{|c|c|c|c|c|}
\hline \multicolumn{5}{|c|}{ pplemental T } \\
\hline CHEMBL3199225 & 688340 & 4.6 & 4.9122 & TST \\
\hline CHEMBL1350756 & 688340 & 4.55 & 4.957 & TST \\
\hline CHEMBL1513500 & 688340 & 5.55 & 5.2578 & TRN \\
\hline CHEMBL1565142 & 688340 & 4.9 & 5.4616 & TST \\
\hline CHEMBL1316929 & 688340 & 4.4 & 4.9923 & TRN \\
\hline CHEMBL1387261 & 688340 & 6.2 & 5.3309 & TRN \\
\hline CHEMBL1552723 & 688340 & 4.4 & 4.7628 & TRN \\
\hline CHEMBL 252352 & 688340 & 4.4 & 4.8101 & TRN \\
\hline CHEMBL1532104 & 688340 & 4.8 & 5.1128 & TRN \\
\hline CHEMBL1323252 & 688340 & 4.55 & 4.8173 & TRN \\
\hline CHEMBL1495819 & 688340 & 6.05 & 5.1918 & TST \\
\hline CHEMBL1451681 & 688340 & 4.8 & 4.8081 & TRN \\
\hline CHEMBL1310332 & 688340 & 4.55 & 4.9358 & TST \\
\hline CHEMBL1344825 & 688340 & 4.5 & 5.0168 & TST \\
\hline CHEMBL1395528 & 688340 & 4.45 & 5.1068 & TRN \\
\hline CHEMBL1500967 & 688340 & 4.65 & 5.5574 & TRN \\
\hline CHEMBL1350202 & 688340 & 4.4 & 4.6074 & TRN \\
\hline CHEMBL1540428 & 688340 & 5.45 & 5.0939 & TRN \\
\hline CHEMBL1485293 & 688340 & 4.0 & 4.9216 & TRN \\
\hline CHEMBL1337806 & 688340 & 4.55 & 4.9001 & TRN \\
\hline CHEMBL1333181 & 688340 & 4.75 & 5.1758 & TRN \\
\hline CHEMBL1502810 & 688340 & 5.85 & 4.9227 & TRN \\
\hline CHEMBL1408087 & 688340 & 7.0 & 5.5747 & TRN \\
\hline CHEMBL 2001211 & 688340 & 4.4 & 5.1897 & TRN \\
\hline CHEMBL1323000 & 688340 & 4.85 & 5.1815 & TST \\
\hline CHEMBL1589440 & 688340 & 4.4 & 5.1477 & TST \\
\hline CHEMBL1390397 & 688340 & 6.2 & 4.9886 & TRN \\
\hline CHEMBL1314965 & 688340 & 4.55 & 5.0782 & TRN \\
\hline CHEMBL1366870 & 688340 & 4.45 & 4.6067 & TRN \\
\hline CHEMBL1381550 & 688340 & 6.0 & 5.4436 & TRN \\
\hline CHEMBL1587982 & 688340 & 6.6 & 5.2758 & TST \\
\hline CHEMBL1315792 & 688340 & 5.15 & 4.8347 & TRN \\
\hline CHEMBL1387667 & 688340 & 4.45 & 4.8206 & TRN \\
\hline CHEMBL1581915 & 688340 & 4.5 & 4.8286 & TRN \\
\hline CHEMBL1301113 & 688340 & 4.4 & 5.2004 & TST \\
\hline CHEMBL3196998 & 688340 & 6.45 & 4.6929 & TRN \\
\hline CHEMBL1335454 & 688340 & 4.5 & 5.0731 & TST \\
\hline CHEMBL3190372 & 688340 & 4.65 & 5.2221 & TRN \\
\hline CHEMBL1469717 & 688340 & 4.8 & 4.7265 & TRN \\
\hline CHEMBL1468458 & 688340 & 4.6 & 4.6987 & TRN \\
\hline CHEMBL3193284 & 688340 & 5.0 & 4.7516 & TRN \\
\hline CHEMBL3193994 & 688340 & 5.35 & 4.9932 & TST \\
\hline CHEMBL3198445 & 688340 & 4.6 & 4.8328 & TST \\
\hline CHEMBL1989750 & 688340 & 5.3 & 5.1632 & TRN \\
\hline CHEMBL1494549 & 688340 & 5.0 & 4.9861 & TST \\
\hline CHEMBL1556301 & 688340 & 4.45 & 5.0451 & TRN \\
\hline CHEMBL1407114 & 688340 & 4.6 & 5.1698 & TRN \\
\hline CHEMBL1355780 & 688340 & 5.25 & 5.2613 & TRN \\
\hline
\end{tabular}




\begin{tabular}{|c|c|c|c|c|}
\hline \multicolumn{5}{|c|}{ Supplemental Table S2.txt } \\
\hline CHEMBL1305653 & 688340 & 4.6 & 4.7553 & TST \\
\hline CHEMBL1490151 & 688340 & 5.5 & 5.3496 & TRN \\
\hline CHEMBL 317115 & 688340 & 5.0 & 4.626 & TRN \\
\hline CHEMBL1322624 & 688340 & 4.45 & 4.9034 & TRN \\
\hline CHEMBL1443166 & 688340 & 4.75 & 5.0715 & TRN \\
\hline CHEMBL1541839 & 688340 & 5.2 & 4.9063 & TRN \\
\hline CHEMBL1335027 & 688340 & 3.45 & 4.8734 & TST \\
\hline CHEMBL1584523 & 688340 & 4.8 & 4.7385 & TRN \\
\hline CHEMBL1362442 & 688340 & 5.25 & 5.1208 & TRN \\
\hline CHEMBL1441632 & 688340 & 5.2 & 5.1444 & TRN \\
\hline CHEMBL3197755 & 688340 & 4.55 & 5.0853 & TST \\
\hline CHEMBL1542526 & 688340 & 4.55 & 5.1101 & TRN \\
\hline CHEMBL1544713 & 688340 & 4.6 & 4.79 & TRN \\
\hline CHEMBL1468130 & 688340 & 4.75 & 5.0173 & TRN \\
\hline CHEMBL1388666 & 688340 & 4.6 & 4.6563 & TRN \\
\hline CHEMBL1443805 & 688340 & 5.2 & 4.8176 & TST \\
\hline CHEMBL1415219 & 688340 & 6.1 & 5.246 & TRN \\
\hline CHEMBL1305738 & 688340 & 4.95 & 4.9503 & TRN \\
\hline CHEMBL1329911 & 688340 & 4.85 & 4.7677 & TRN \\
\hline CHEMBL1369958 & 688340 & 4.65 & 4.7977 & TRN \\
\hline CHEMBL1412733 & 688340 & 4.95 & 5.1518 & TRN \\
\hline CHEMBL1569992 & 688340 & 5.45 & 5.1576 & TRN \\
\hline CHEMBL1581454 & 688340 & 4.5 & 4.6221 & TRN \\
\hline CHEMBL1354590 & 688340 & 5.0 & 4.9284 & TRN \\
\hline CHEMBL1334980 & 688340 & 4.55 & 5.0125 & TRN \\
\hline CHEMBL1427726 & 688340 & 4.4 & 5.1648 & TST \\
\hline CHEMBL1482738 & 688340 & 4.4 & 4.8622 & TRN \\
\hline CHEMBL1317567 & 688340 & 6.1 & 5.1455 & TRN \\
\hline CHEMBL1452116 & 688340 & 4.4 & 4.9012 & TRN \\
\hline CHEMBL1433995 & 688340 & 4.65 & 4.8785 & TRN \\
\hline CHEMBL1311270 & 688340 & 4.5 & 5.0124 & TRN \\
\hline CHEMBL1405727 & 688340 & 4.6 & 5.0805 & TRN \\
\hline CHEMBL1401009 & 688340 & 4.0 & 5.2034 & TRN \\
\hline CHEMBL1338790 & 688340 & 4.4 & 5.482 & TRN \\
\hline CHEMBL3209551 & 688340 & 4.35 & 5.1263 & TST \\
\hline CHEMBL1384136 & 688340 & 5.5 & 4.8901 & TST \\
\hline CHEMBL1588187 & 688340 & 5.25 & 5.1571 & TRN \\
\hline CHEMBL1305329 & 688340 & 4.4 & 4.6072 & TRN \\
\hline CHEMBL 2095095 & 688340 & 5.2 & 4.5777 & TRN \\
\hline CHEMBL1302682 & 688340 & 4.55 & 5.0297 & TRN \\
\hline CHEMBL 3193430 & 688340 & 4.85 & 5.1437 & TRN \\
\hline CHEMBL1460692 & 688340 & 4.4 & 4.8426 & TRN \\
\hline CHEMBL1462973 & 688340 & 4.8 & 4.8231 & TST \\
\hline CHEMBL1580193 & 688340 & 7.4498 & 4.8988 & TRN \\
\hline CHEMBL1568803 & 688340 & 4.55 & 4.8189 & TRN \\
\hline CHEMBL1536107 & 688340 & 5.05 & 4.7755 & TRN \\
\hline CHEMBL1583598 & 688340 & 4.55 & 4.981 & TRN \\
\hline CHEMBL1429730 & 688340 & 6.2 & 5.2965 & TRN \\
\hline
\end{tabular}




\begin{tabular}{|c|c|c|c|c|}
\hline \multicolumn{5}{|c|}{ Supplemental Table S2.txt } \\
\hline CHEMBL1358863 & 688340 & 4.4 & 4.7718 & TRN \\
\hline CHEMBL1452720 & 688340 & 5.95 & 5.3495 & TRN \\
\hline CHEMBL1373628 & 688340 & 5.15 & 4.9301 & TRN \\
\hline CHEMBL1545104 & 688340 & 4.5 & 4.6143 & TRN \\
\hline CHEMBL1610409 & 688340 & 4.4 & 4.7636 & TRN \\
\hline CHEMBL1506956 & 688340 & 4.45 & 4.732 & TST \\
\hline CHEMBL1445579 & 688340 & 5.05 & 5.2366 & TRN \\
\hline CHEMBL1587886 & 688340 & 4.35 & 5.3103 & TRN \\
\hline CHEMBL1510325 & 688340 & 4.65 & 4.9693 & TRN \\
\hline CHEMBL1607274 & 688340 & 4.5 & 5.1578 & TRN \\
\hline CHEMBL447111 & 688340 & 4.45 & 4.7653 & TST \\
\hline CHEMBL1495198 & 688340 & 4.75 & 5.1723 & TST \\
\hline CHEMBL3212733 & 688340 & 4.4 & 5.3065 & TRN \\
\hline CHEMBL1602205 & 688340 & 5.0 & 5.3121 & TST \\
\hline CHEMBL1311173 & 688340 & 4.55 & 5.2749 & TRN \\
\hline CHEMBL1304004 & 688340 & 5.3 & 5.0553 & TRN \\
\hline CHEMBL1531417 & 688340 & 5.25 & 5.4393 & TRN \\
\hline CHEMBL1498780 & 688340 & 4.55 & 4.8046 & TRN \\
\hline CHEMBL1330995 & 688340 & 4.05 & 5.4225 & TRN \\
\hline CHEMBL1391287 & 688340 & 5.45 & 4.4409 & TRN \\
\hline CHEMBL1483320 & 688340 & 5.0 & 5.6028 & TRN \\
\hline CHEMBL1502016 & 688340 & 4.3 & 5.1647 & TST \\
\hline CHEMBL1486503 & 688340 & 4.45 & 4.8964 & TRN \\
\hline CHEMBL1299421 & 688340 & 4.55 & 4.789 & TRN \\
\hline CHEMBL1524046 & 688340 & 4.5 & 4.9987 & TRN \\
\hline CHEMBL1567396 & 688340 & 5.9 & 5.2489 & TRN \\
\hline CHEMBL1465581 & 688340 & 4.5 & 4.8656 & TRN \\
\hline CHEMBL1561360 & 688340 & 4.4 & 5.1115 & TRN \\
\hline CHEMBL1495149 & 688340 & 5.25 & 5.0107 & TST \\
\hline CHEMBL1996555 & 688340 & 5.45 & 5.0448 & TRN \\
\hline CHEMBL1517882 & 688340 & 5.2 & 5.3631 & TRN \\
\hline CHEMBL 1467330 & 688340 & 7.7496 & 5.3864 & TRN \\
\hline CHEMBL1416256 & 688340 & 4.5 & 5.0 & TRN \\
\hline CHEMBL1549502 & 688340 & 5.7 & 5.0149 & TST \\
\hline CHEMBL1433082 & 688340 & 5.3 & 4.9537 & TRN \\
\hline CHEMBL1567495 & 688340 & 5.45 & 5.0341 & TRN \\
\hline CHEMBL443510 & 688340 & 5.15 & 4.8859 & TST \\
\hline CHEMBL1510344 & 688340 & 4.6 & 4.7178 & TRN \\
\hline CHEMBL1350628 & 688340 & 4.55 & 4.9039 & TST \\
\hline CHEMBL1507299 & 688340 & 4.7 & 5.141 & TRN \\
\hline CHEMBL1542730 & 688340 & 4.55 & 5.0726 & TRN \\
\hline CHEMBL1371233 & 688340 & 6.05 & 5.2227 & TRN \\
\hline CHEMBL1566165 & 688340 & 5.45 & 5.2046 & TRN \\
\hline CHEMBL1607308 & 688340 & 5.0 & 5.3837 & TST \\
\hline CHEMBL1513994 & 688340 & 5.05 & 5.4334 & TRN \\
\hline CHEMBL3208059 & 688340 & 5.35 & 4.7636 & TRN \\
\hline CHEMBL1332997 & 688340 & 5.0 & 5.0999 & TRN \\
\hline CHEMBL530049 & 688340 & 5.3 & 4.6678 & TST \\
\hline
\end{tabular}




\begin{tabular}{|c|c|c|c|c|}
\hline \multicolumn{5}{|c|}{ Supplemental Table S2.txt } \\
\hline CHEMBL1426761 & 688340 & 4.6 & 5.083 & TRN \\
\hline CHEMBL1542813 & 688340 & 4.55 & 4.8733 & TRN \\
\hline CHEMBL1383123 & 688340 & 5.15 & 5.3812 & TRN \\
\hline CHEMBL1339141 & 688340 & 7.0501 & 5.0768 & TST \\
\hline CHEMBL1389486 & 688340 & 5.6 & 5.1194 & TRN \\
\hline CHEMBL1608016 & 688340 & 4.4 & 5.0352 & TRN \\
\hline CHEMBL1384527 & 688340 & 4.45 & 4.8945 & TRN \\
\hline CHEMBL1511748 & 688340 & 4.5 & 4.7212 & TRN \\
\hline CHEMBL1381289 & 688340 & 4.5 & 4.9085 & TRN \\
\hline CHEMBL1607747 & 688340 & 7.0 & 5.235 & TRN \\
\hline CHEMBL1342358 & 688340 & 7.0 & 4.9237 & TST \\
\hline CHEMBL1325986 & 688340 & 4.55 & 4.9965 & TST \\
\hline CHEMBL1412244 & 688340 & 4.85 & 4.9621 & TST \\
\hline CHEMBL1539800 & 688340 & 4.75 & 4.8002 & TRN \\
\hline CHEMBL1474553 & 688340 & 6.0 & 4.966 & TRN \\
\hline CHEMBL1423325 & 688340 & 5.4 & 5.1689 & TRN \\
\hline CHEMBL1301862 & 688340 & 4.55 & 4.7919 & TRN \\
\hline CHEMBL1573798 & 688340 & 5.35 & 5.3036 & TRN \\
\hline CHEMBL1371245 & 688340 & 4.85 & 5.0173 & TST \\
\hline CHEMBL1583586 & 688340 & 5.8 & 4.8603 & TRN \\
\hline CHEMBL1303276 & 688340 & 5.05 & 5.169 & TRN \\
\hline CHEMBL1461193 & 688340 & 4.6 & 5.0946 & TST \\
\hline CHEMBL1451409 & 688340 & 6.1 & 4.671 & TST \\
\hline CHEMBL1337872 & 688340 & 4.5 & 4.8443 & TRN \\
\hline CHEMBL1430493 & 688340 & 4.55 & 4.79 & TRN \\
\hline CHEMBL1481065 & 688340 & 4.5 & 4.7565 & TRN \\
\hline CHEMBL1454773 & 688340 & 4.6 & 4.8187 & TRN \\
\hline CHEMBL1576107 & 688340 & 4.5 & 4.9114 & TRN \\
\hline CHEMBL3199661 & 688340 & 4.4 & 4.6961 & TRN \\
\hline CHEMBL1366214 & 688340 & 4.95 & 5.1813 & TRN \\
\hline CHEMBL1460173 & 688340 & 5.3 & 5.2394 & TRN \\
\hline CHEMBL1347766 & 688340 & 7.0 & 5.2005 & TST \\
\hline CHEMBL1475029 & 688340 & 5.05 & 4.9461 & TST \\
\hline CHEMBL1497173 & 688340 & 4.0 & 5.2468 & TRN \\
\hline CHEMBL1338029 & 688340 & 6.1 & 5.2746 & TST \\
\hline CHEMBL1380261 & 688340 & 6.25 & 4.7954 & TRN \\
\hline CHEMBL1982868 & 688340 & 4.6 & 4.8055 & TRN \\
\hline CHEMBL1541353 & 688340 & 4.4 & 4.6771 & TRN \\
\hline CHEMBL1373969 & 688340 & 4.4 & 5.1124 & TRN \\
\hline CHEMBL1423810 & 688340 & 4.55 & 4.6307 & TRN \\
\hline CHEMBL1359257 & 688340 & 7.0 & 5.2122 & TST \\
\hline CHEMBL1508395 & 688340 & 5.45 & 5.3677 & TRN \\
\hline CHEMBL1447316 & 688340 & 5.5 & 4.8396 & TST \\
\hline CHEMBL1313793 & 688340 & 4.6 & 4.9258 & TRN \\
\hline CHEMBL1393987 & 688340 & 4.65 & 4.691 & TRN \\
\hline CHEMBL1411636 & 688340 & 4.4 & 4.8506 & TRN \\
\hline CHEMBL1500164 & 688340 & 4.8 & 4.8419 & TRN \\
\hline CHEMBL1454174 & 688340 & 5.15 & 5.0964 & TRN \\
\hline
\end{tabular}




\begin{tabular}{|c|c|c|c|c|c|}
\hline \multicolumn{6}{|c|}{ Supplemental Table S2.txt } \\
\hline CHEMBL1578471 & 688340 & 4.65 & 4.9511 & TST & \\
\hline CHEMBL1555589 & 688340 & 4.65 & 5.0476 & TRN & \\
\hline CHEMBL1574830 & 688340 & 4.55 & 5.0727 & TST & \\
\hline CHEMBL1533079 & 688340 & 4.55 & 4.8565 & TRN & \\
\hline CHEMBL1556308 & 688340 & 4.55 & 4.6902 & TRN & \\
\hline CHEMBL1319867 & 688340 & 4.8 & 4.8069 & TRN & \\
\hline CHEMBL1545716 & 688340 & 4.35 & 5.2158 & TRN & \\
\hline CHEMBL1474676 & 688340 & 4.35 & 5.2452 & TRN & \\
\hline CHEMBL1993491 & 688340 & 4.45 & 5.2684 & TST & \\
\hline CHEMBL1580465 & 688340 & 4.65 & 4.7823 & TRN & \\
\hline CHEMBL1443798 & 688340 & 4.5 & 4.859 & TST & \\
\hline CHEMBL1397083 & 688340 & 4.45 & 4.8407 & TRN & \\
\hline CHEMBL1422647 & 688340 & 5.1 & 4.7447 & TST & \\
\hline CHEMBL1494117 & 688340 & 4.55 & 4.8081 & TRN & \\
\hline CHEMBL1340051 & 688340 & 4.5 & 4.6775 & TRN & \\
\hline CHEMBL1467161 & 688340 & 4.55 & 4.9262 & TRN & \\
\hline CHEMBL3197257 & 688340 & 5.2 & 4.9995 & TRN & \\
\hline CHEMBL1301785 & 688340 & 4.6 & 4.8473 & TRN & \\
\hline CHEMBL1549773 & 688340 & 5.2 & 5.4639 & TRN & \\
\hline CHEMBL1498624 & 688340 & 6.8499 & 5.3779 & TRN & \\
\hline CHEMBL1361845 & 688340 & 4.5 & 5.1404 & TRN & \\
\hline CHEMBL3212524 & 688340 & 7.0 & 5.0208 & TRN & \\
\hline CHEMBL1426071 & 688340 & 4.6 & 5.053 & TRN & \\
\hline CHEMBL1473768 & 688340 & 3.45 & 5.4883 & TRN & \\
\hline CHEMBL1473081 & 688340 & 4.7 & 4.8873 & TRN & \\
\hline CHEMBL1385538 & 688340 & 4.5 & 5.034 & TRN & \\
\hline CHEMBL1311814 & 688340 & 4.65 & 4.5869 & TRN & \\
\hline CHEMBL1578157 & 688340 & 4.4 & 4.5869 & TST & \\
\hline CHEMBL1493764 & 688340 & 7.4001 & 4.5351 & TST & \\
\hline CHEMBL1594376 & 688340 & 5.5 & 5.044 & TRN & \\
\hline CHEMBL3193164 & 688340 & 4.75 & 4.9694 & TRN & \\
\hline CHEMBL1460194 & 688340 & 4.4 & 4.9233 & TRN & \\
\hline CHEMBL1567693 & 688340 & 6.0 & 5.66100 & 00000000005 & TST \\
\hline CHEMBL1381158 & 688340 & 5.35 & 5.059 & TRN & \\
\hline CHEMBL1556317 & 688340 & 4.4 & 5.2219 & TST & \\
\hline CHEMBL1569989 & 688340 & 4.45 & 4.6588 & TRN & \\
\hline CHEMBL1562290 & 688340 & 5.2 & 5.0984 & TST & \\
\hline CHEMBL1565873 & 688340 & 4.4 & 4.787 & TST & \\
\hline CHEMBL1406589 & 688340 & 7.0 & 5.0462 & TRN & \\
\hline CHEMBL1612453 & 688340 & 4.4 & 5.2928 & TST & \\
\hline CHEMBL1596920 & 688340 & 5.15 & 5.117 & TST & \\
\hline CHEMBL550826 & 688340 & 6.1 & 4.5793 & TRN & \\
\hline CHEMBL1493703 & 688340 & 4.4 & 5.0223 & TRN & \\
\hline CHEMBL1469748 & 688340 & 4.6 & 5.1308 & TRN & \\
\hline CHEMBL1386893 & 688340 & 6.9 & 5.1041 & TRN & \\
\hline CHEMBL1466395 & 688340 & 5.05 & 5.0531 & TRN & \\
\hline CHEMBL1415800 & 688340 & 4.95 & 4.8175 & TST & \\
\hline CHEMBL1579441 & 688340 & 4.55 & 5.0625 & TRN & \\
\hline
\end{tabular}




\begin{tabular}{|c|c|c|c|c|}
\hline \multicolumn{5}{|c|}{ Supplemental Table s2.txt } \\
\hline CHEMBL1523164 & 688340 & 4.7 & 4.9262 & TRN \\
\hline CHEMBL1411862 & 688340 & 6.15 & 5.2281 & TRN \\
\hline CHEMBL1375461 & 688340 & 5.25 & 4.9399 & TRN \\
\hline CHEMBL1353547 & 688340 & 4.4 & 5.1285 & TRN \\
\hline CHEMBL1327521 & 688340 & 5.2 & 4.6525 & TRN \\
\hline CHEMBL1597650 & 688340 & 4.65 & 5.1161 & TRN \\
\hline CHEMBL1556887 & 688340 & 5.45 & 4.9925 & TRN \\
\hline CHEMBL1606023 & 688340 & 7.0501 & 5.0747 & TST \\
\hline CHEMBL1543610 & 688340 & 4.75 & 4.9103 & TRN \\
\hline CHEMBL1502833 & 688340 & 5.15 & 5.3144 & TRN \\
\hline CHEMBL1517608 & 688340 & 4.4 & 4.8198 & TRN \\
\hline CHEMBL1494618 & 688340 & 3.5 & 5.1006 & TRN \\
\hline CHEMBL1607022 & 688340 & 4.45 & 4.9125 & TRN \\
\hline CHEMBL1515153 & 688340 & 4.7 & 4.8205 & TRN \\
\hline CHEMBL1389701 & 688340 & 4.35 & 5.309 & TRN \\
\hline CHEMBL1331558 & 688340 & 4.7 & 5.1742 & TST \\
\hline CHEMBL1462597 & 688340 & 4.6 & 5.0941 & TRN \\
\hline CHEMBL1530824 & 688340 & 4.55 & 4.8743 & TRN \\
\hline CHEMBL1410143 & 688340 & 6.1 & 5.1101 & TST \\
\hline CHEMBL1385263 & 688340 & 6.1 & 5.0264 & TST \\
\hline CHEMBL1512320 & 688340 & 4.5 & 4.9654 & TRN \\
\hline CHEMBL1524983 & 688340 & 5.15 & 5.295 & TRN \\
\hline CHEMBL1533229 & 688340 & 4.65 & 5.0039 & TRN \\
\hline CHEMBL1459596 & 688340 & 6.15 & 5.3647 & TRN \\
\hline CHEMBL3198496 & 688340 & 4.85 & 4.8363 & TRN \\
\hline CHEMBL1558934 & 688340 & 4.55 & 4.5579 & TRN \\
\hline CHEMBL1440240 & 688340 & 4.8 & 5.1941 & TRN \\
\hline CHEMBL1590032 & 688340 & 5.9 & 5.3057 & TST \\
\hline CHEMBL1399397 & 688340 & 5.2 & 5.1113 & TRN \\
\hline CHEMBL1567609 & 688340 & 4.6 & 4.8064 & TRN \\
\hline CHEMBL1417764 & 688340 & 4.4 & 4.9346 & TRN \\
\hline CHEMBL1408973 & 688340 & 5.5 & 4.8697 & TRN \\
\hline CHEMBL1536196 & 688340 & 4.6 & 4.9408 & TST \\
\hline CHEMBL1562936 & 688340 & 5.2 & 5.2846 & TRN \\
\hline CHEMBL1471607 & 688340 & 4.55 & 4.8391 & TRN \\
\hline CHEMBL1363824 & 688340 & 5.45 & 5.2015 & TRN \\
\hline CHEMBL1312404 & 688340 & 5.05 & 5.0934 & TST \\
\hline CHEMBL1537839 & 688340 & 5.2 & 5.4574 & TRN \\
\hline CHEMBL1449981 & 688340 & 4.35 & 5.2303 & TRN \\
\hline CHEMBL1497417 & 688340 & 5.45 & 5.0387 & TRN \\
\hline CHEMBL1514178 & 688340 & 4.4 & 5.1272 & TRN \\
\hline CHEMBL1550264 & 688340 & 4.6 & 4.9184 & TRN \\
\hline CHEMBL1314357 & 688340 & 5.3 & 5.4358 & TRN \\
\hline CHEMBL1521831 & 688340 & 5.7 & 5.1873 & TRN \\
\hline CHEMBL3856095 & 688340 & 4.55 & 5.2609 & TRN \\
\hline CHEMBL1312995 & 688340 & 6.45 & 4.9501 & TRN \\
\hline CHEMBL3193909 & 688340 & 4.6 & 4.7695 & TRN \\
\hline CHEMBL1307436 & 688340 & 5.0 & 5.191 & TST \\
\hline
\end{tabular}




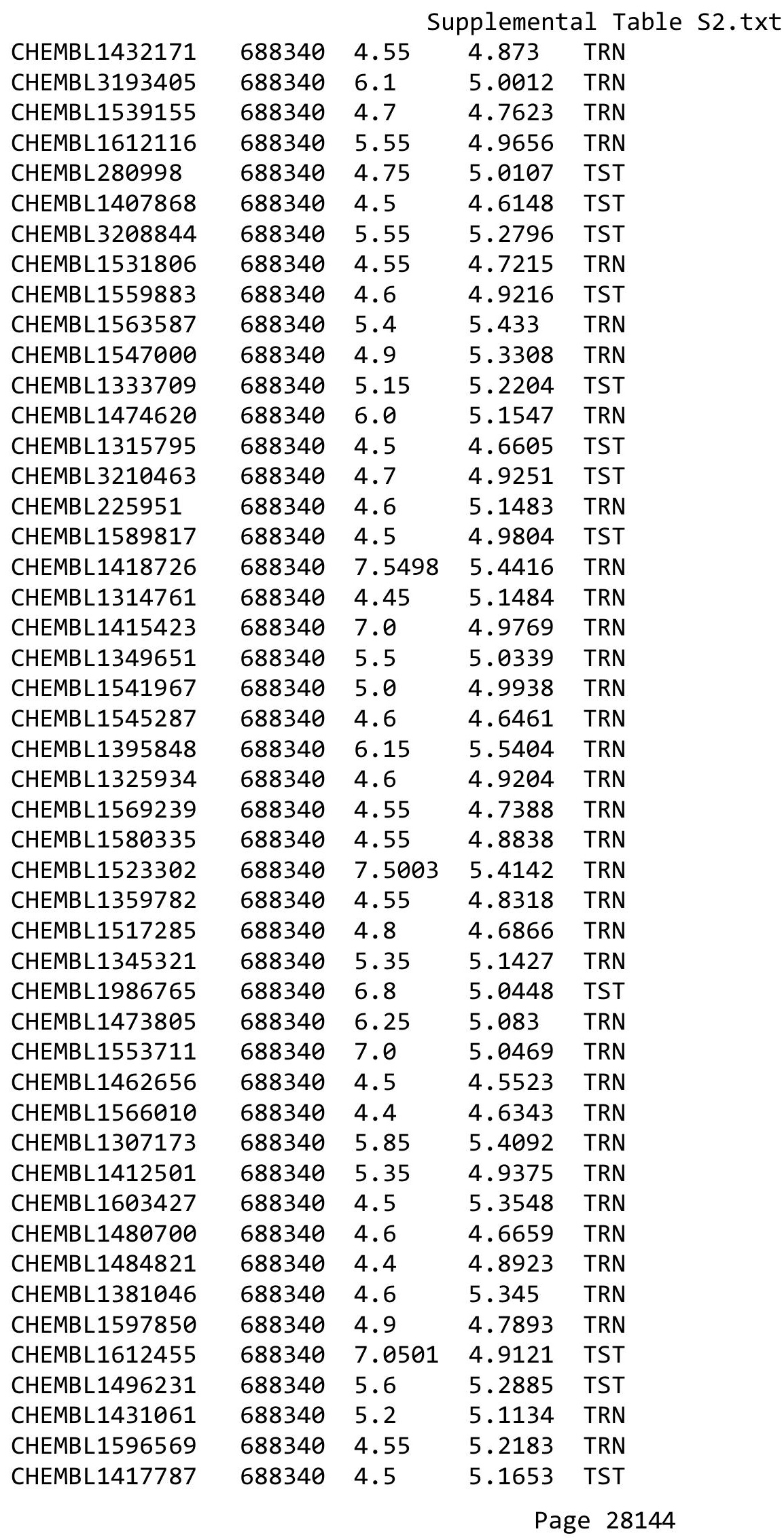




\begin{tabular}{|c|c|c|c|c|c|}
\hline \\
\hline CHEMBL1562277 & 688340 & 5.3 & 4.9837 & TRN & \\
\hline CHEMBL1541331 & 688340 & 3.15 & 5.0464 & TST & \\
\hline CHEMBL1486562 & 688340 & 4.6 & 4.9161 & TRN & \\
\hline CHEMBL1328839 & 688340 & 4.5 & 5.0416 & TRN & \\
\hline CHEMBL1416105 & 688340 & 5.45 & 5.6178 & TRN & \\
\hline CHEMBL1586104 & 688340 & 4.55 & 4.5603 & TRN & \\
\hline CHEMBL1417924 & 688340 & 4.6 & 4.7783 & TRN & \\
\hline CHEMBL1526188 & 688340 & 4.65 & 4.4855 & TRN & \\
\hline CHEMBL1322279 & 688340 & 6.0 & 5.1539 & TRN & \\
\hline CHEMBL1509576 & 688340 & 4.4 & 5.0218 & TST & \\
\hline CHEMBL1564060 & 688340 & 7.0 & 5.2028 & TST & \\
\hline CHEMBL1340017 & 688340 & 4.55 & 4.9271 & TRN & \\
\hline CHEMBL1583391 & 688340 & 4.55 & 4.9851 & TST & \\
\hline CHEMBL3209062 & 688340 & 4.85 & 4.6372 & TRN & \\
\hline CHEMBL1487329 & 688340 & 4.85 & 5.0889 & TST & \\
\hline CHEMBL3196584 & 688340 & 4.6 & 4.5003 & TRN & \\
\hline CHEMBL1558195 & 688340 & 5.25 & 5.1179 & TRN & \\
\hline CHEMBL1419788 & 688340 & 5.55 & 5.1175 & TST & \\
\hline CHEMBL1460215 & 688340 & 4.85 & 4.7265 & TRN & \\
\hline CHEMBL1340517 & 688340 & 4.45 & 5.0334 & TRN & \\
\hline CHEMBL1369866 & 688340 & 6.1 & 5.2519 & TST & \\
\hline CHEMBL1570296 & 688340 & 4.9 & 5.1362 & TST & \\
\hline CHEMBL1364029 & 688340 & 5.55 & 5.2837 & TRN & \\
\hline CHEMBL1483496 & 688340 & 6.0 & 5.2558 & TRN & \\
\hline CHEMBL1591346 & 688340 & 4.6 & 5.0558 & TRN & \\
\hline CHEMBL1403894 & 688340 & 4.65 & 5.7075 & TRN & \\
\hline CHEMBL1562246 & 688340 & 4.4 & 4.9063 & TRN & \\
\hline CHEMBL1994048 & 688340 & 4.55 & 4.9073 & TRN & \\
\hline CHEMBL1447974 & 688340 & 4.55 & 4.7897 & TST & \\
\hline CHEMBL1471712 & 688340 & 4.35 & 4.93 & TST & \\
\hline CHEMBL1416603 & 688340 & 6.8499 & 5.1081 & TRN & \\
\hline CHEMBL1372886 & 688340 & 6.0 & 5.1686 & TST & \\
\hline CHEMBL1518073 & 688340 & 5.0 & 5.21899 & 9999999999 & TRN \\
\hline CHEMBL1389990 & 688340 & 4.4 & 4.9167 & TRN & \\
\hline CHEMBL1549894 & 688340 & 5.3 & 4.6752 & TRN & \\
\hline CHEMBL1438901 & 688340 & 4.6 & 5.5481 & TRN & \\
\hline CHEMBL1480999 & 688340 & 6.45 & 5.1851 & TRN & \\
\hline CHEMBL1520161 & 688340 & 4.45 & 5.1718 & TRN & \\
\hline CHEMBL1561981 & 688340 & 4.45 & 5.1663 & TRN & \\
\hline CHEMBL1387731 & 688340 & 4.45 & 4.6889 & TRN & \\
\hline CHEMBL1389769 & 688340 & 4.35 & 4.9693 & TRN & \\
\hline CHEMBL1312376 & 688340 & 4.55 & 4.919 & TRN & \\
\hline CHEMBL1443379 & 688340 & 5.05 & 4.8944 & TST & \\
\hline CHEMBL1513927 & 688340 & 6.45 & 5.3553 & TRN & \\
\hline CHEMBL1533325 & 688340 & 6.05 & 5.0605 & TRN & \\
\hline CHEMBL1495745 & 688340 & 4.8 & 5.0821 & TRN & \\
\hline CHEMBL1385672 & 688340 & 5.05 & 5.025 & TRN & \\
\hline CHEMBL1549439 & 688340 & 7.6003 & 5.3699 & TRN & \\
\hline
\end{tabular}




\begin{tabular}{|c|c|c|c|c|}
\hline \multicolumn{5}{|c|}{ Supplemental Tab } \\
\hline CHEMBL1382759 & 688340 & 4.5 & 4.7805 & TST \\
\hline CHEMBL1602212 & 688340 & 4.4 & 5.1076 & TRN \\
\hline CHEMBL1504215 & 688340 & 6.0 & 5.0314 & TRN \\
\hline CHEMBL3193203 & 688340 & 4.95 & 4.6894 & TRN \\
\hline CHEMBL1490260 & 688340 & 5.05 & 5.1333 & TST \\
\hline CHEMBL1346873 & 688340 & 4.4 & 5.1983 & TST \\
\hline CHEMBL1559877 & 688340 & 4.4 & 5.0636 & TRN \\
\hline CHEMBL1314018 & 688340 & 6.35 & 5.2573 & TRN \\
\hline CHEMBL1584293 & 688340 & 5.4 & 5.0156 & TRN \\
\hline CHEMBL1470112 & 688340 & 4.95 & 4.7879 & TRN \\
\hline CHEMBL1484312 & 688340 & 4.55 & 4.6992 & TRN \\
\hline CHEMBL1517567 & 688340 & 4.6 & 5.0572 & TRN \\
\hline CHEMBL1498296 & 688340 & 5.5 & 5.3024 & TST \\
\hline CHEMBL1590676 & 688340 & 4.85 & 5.0946 & TRN \\
\hline CHEMBL1313866 & 688340 & 5.2 & 4.6819 & TRN \\
\hline CHEMBL1574883 & 688340 & 5.0 & 4.6428 & TRN \\
\hline CHEMBL578675 & 688340 & 6.0 & 4.8786 & TRN \\
\hline CHEMBL 3191374 & 688340 & 4.4 & 4.422 & TRN \\
\hline CHEMBL1515030 & 688340 & 4.65 & 4.7204 & TRN \\
\hline CHEMBL1413672 & 688340 & 4.75 & 4.8145 & TRN \\
\hline CHEMBL1406051 & 688340 & 5.15 & 5.0247 & TRN \\
\hline CHEMBL3207976 & 688340 & 5.05 & 5.1575 & TST \\
\hline CHEMBL1587791 & 688340 & 4.6 & 4.7171 & TRN \\
\hline CHEMBL1368891 & 688340 & 4.65 & 4.3677 & TRN \\
\hline CHEMBL1991599 & 688340 & 4.85 & 5.0256 & TRN \\
\hline CHEMBL1997174 & 688340 & 6.35 & 5.0296 & TRN \\
\hline CHEMBL1334247 & 688340 & 4.35 & 4.8849 & TST \\
\hline CHEMBL 3197038 & 688340 & 4.4 & 5.2036 & TST \\
\hline CHEMBL 3213762 & 688340 & 5.15 & 4.7152 & TRN \\
\hline CHEMBL1430372 & 688340 & 5.4 & 4.758 & TST \\
\hline CHEMBL1475104 & 688340 & 4.5 & 5.1851 & TRN \\
\hline CHEMBL1578880 & 688340 & 4.6 & 4.9043 & TRN \\
\hline CHEMBL1398363 & 688340 & 5.05 & 4.9965 & TRN \\
\hline CHEMBL1374531 & 688340 & 4.45 & 4.6468 & TST \\
\hline CHEMBL1440470 & 688340 & 5.9 & 4.9425 & TST \\
\hline CHEMBL3214217 & 688340 & 6.95 & 5.5384 & TRN \\
\hline CHEMBL1579823 & 688340 & 5.25 & 4.7926 & TRN \\
\hline CHEMBL1394747 & 688340 & 4.65 & 5.0714 & TRN \\
\hline CHEMBL1414567 & 688340 & 5.15 & 5.3018 & TRN \\
\hline CHEMBL1517324 & 688340 & 5.6 & 5.2415 & TST \\
\hline CHEMBL1563338 & 688340 & 6.1 & 5.1953 & TST \\
\hline CHEMBL1381264 & 688340 & 4.5 & 4.6402 & TST \\
\hline CHEMBL1402902 & 688340 & 4.95 & 4.7672 & TRN \\
\hline CHEMBL1499231 & 688340 & 5.2 & 5.224 & TRN \\
\hline CHEMBL1482027 & 688340 & 5.35 & 4.961 & TRN \\
\hline CHEMBL 275938 & 688340 & 7.4498 & 5.0456 & TST \\
\hline CHEMBL1464853 & 688340 & 4.75 & 4.7534 & TST \\
\hline CHEMBL1538504 & 688340 & 4.55 & 4.9856 & TRN \\
\hline
\end{tabular}




\begin{tabular}{|c|c|c|c|c|c|}
\hline \multirow{3}{*}{$\begin{array}{l}\text { CHEMBL1406588 } \\
\text { CHEMBL } 1408684\end{array}$} & \multirow{3}{*}{$\begin{array}{l}688340 \\
688340\end{array}$} & \multicolumn{4}{|c|}{ Supplemental Table s2.txt } \\
\hline & & 5.15 & 4.94600 & 0000000001 & TRN \\
\hline & & 5.8 & 5.2054 & TRN & \\
\hline CHEMBL3212679 & 688340 & 5.2 & 4.8313 & TST & \\
\hline CHEMBL1385164 & 688340 & 5.2 & 4.8157 & TRN & \\
\hline CHEMBL1396666 & 688340 & 4.55 & 4.8503 & TRN & \\
\hline CHEMBL1591950 & 688340 & 4.55 & 5.2058 & TRN & \\
\hline CHEMBL1348503 & 688340 & 5.45 & 4.8948 & TRN & \\
\hline CHEMBL1499615 & 688340 & 7.0 & 5.2322 & TRN & \\
\hline CHEMBL1495685 & 688340 & 4.55 & 4.749 & TRN & \\
\hline CHEMBL1534077 & 688340 & 6.15 & 5.1562 & TRN & \\
\hline CHEMBL1446626 & 688340 & 4.4 & 5.0827 & TRN & \\
\hline CHEMBL1517295 & 688340 & 5.85 & 5.4002 & TRN & \\
\hline CHEMBL1453566 & 688340 & 7.0 & 5.0444 & TST & \\
\hline CHEMBL3199127 & 688340 & 4.4 & 4.961 & TRN & \\
\hline CHEMBL 1346787 & 688340 & 4.6 & 5.6234 & TRN & \\
\hline CHEMBL1546440 & 688340 & 4.8 & 4.9079 & TRN & \\
\hline CHEMBL1528739 & 688340 & 5.0 & 4.7612 & TST & \\
\hline CHEMBL1299420 & 688340 & 5.05 & 4.7779 & TST & \\
\hline CHEMBL1518557 & 688340 & 4.65 & 4.6422 & TRN & \\
\hline CHEMBL1594325 & 688340 & 4.4 & 4.5835 & TRN & \\
\hline CHEMBL1335383 & 688340 & 4.85 & 5.0866 & TRN & \\
\hline CHEMBL1349727 & 688340 & 4.4 & 4.8407 & TRN & \\
\hline CHEMBL1494096 & 688340 & 4.95 & 4.8219 & TRN & \\
\hline CHEMBL3193786 & 688340 & 4.5 & 4.874 & TRN & \\
\hline CHEMBL1531237 & 688340 & 4.55 & 5.0908 & TRN & \\
\hline CHEMBL1502053 & 688340 & 4.6 & 4.8939 & TRN & \\
\hline CHEMBL1423932 & 688340 & 4.7 & 4.9723 & TRN & \\
\hline CHEMBL1484110 & 688340 & 4.4 & 5.1922 & TRN & \\
\hline CHEMBL1451917 & 688340 & 4.95 & 4.9295 & TST & \\
\hline CHEMBL1489241 & 688340 & 5.4 & 5.0509 & TRN & \\
\hline CHEMBL1597905 & 688340 & 6.2 & 5.2632 & TST & \\
\hline CHEMBL1341875 & 688340 & 7.0 & 5.2598 & TST & \\
\hline CHEMBL1387415 & 688340 & 6.2 & 5.0031 & TRN & \\
\hline CHEMBL1599897 & 688340 & 4.55 & 5.126 & TRN & \\
\hline CHEMBL1308927 & 688340 & 7.0501 & 5.0461 & TST & \\
\hline CHEMBL1344164 & 688340 & 4.95 & 5.2909 & TRN & \\
\hline CHEMBL1476105 & 688340 & 4.5 & 5.0223 & TST & \\
\hline CHEMBL1463691 & 688340 & 4.65 & 4.8565 & TRN & \\
\hline CHEMBL1468123 & 688340 & 4.4 & 4.7407 & TRN & \\
\hline CHEMBL1407991 & 688340 & 4.4 & 4.9971 & TRN & \\
\hline CHEMBL3191647 & 688340 & 4.55 & 4.9132 & TRN & \\
\hline CHEMBL 1386600 & 688340 & 5.2 & 5.3083 & TST & \\
\hline CHEMBL1597481 & 688340 & 4.5 & 4.4356 & TRN & \\
\hline CHEMBL3197786 & 688340 & 4.6 & 4.6847 & TRN & \\
\hline CHEMBL1397411 & 688340 & 5.1 & 5.3328 & TST & \\
\hline CHEMBL1462574 & 688340 & 4.5 & 4.8476 & TST & \\
\hline CHEMBL1479096 & 688340 & 4.65 & 5.5347 & TRN & \\
\hline CHEMBL1586806 & 688340 & 4.8 & 4.6859 & TST & \\
\hline
\end{tabular}




\begin{tabular}{|c|c|c|c|c|}
\hline \multirow[b]{2}{*}{ CHEMBL3190868 } & \multicolumn{4}{|c|}{ Supplemental Ta } \\
\hline & 688340 & 4.5 & 4.9625 & TRN \\
\hline CHEMBL1609070 & 688340 & 4.6 & 4.7142 & TRN \\
\hline CHEMBL1419733 & 688340 & 4.5 & 4.4504 & TRN \\
\hline CHEMBL1381757 & 688340 & 4.5 & 4.7761 & TRN \\
\hline CHEMBL3196161 & 688340 & 5.75 & 5.0587 & TRN \\
\hline CHEMBL1342372 & 688340 & 6.95 & 5.4843 & TRN \\
\hline CHEMBL1500530 & 688340 & 4.55 & 4.8639 & TST \\
\hline CHEMBL1392500 & 688340 & 4.6 & 4.9749 & TRN \\
\hline CHEMBL1582887 & 688340 & 4.55 & 5.4507 & TST \\
\hline CHEMBL1330304 & 688340 & 4.45 & 4.676 & TST \\
\hline CHEMBL1510748 & 688340 & 6.25 & 5.6191 & TST \\
\hline CHEMBL1411997 & 688340 & 5.3 & 5.145 & TRN \\
\hline CHEMBL1305014 & 688340 & 4.4 & 4.6733 & TRN \\
\hline CHEMBL1406745 & 688340 & 4.55 & 4.6032 & TRN \\
\hline CHEMBL1584841 & 688340 & 5.15 & 5.2707 & TRN \\
\hline CHEMBL1585845 & 688340 & 4.4 & 4.7287 & TRN \\
\hline CHEMBL3191856 & 688340 & 5.35 & 4.5549 & TRN \\
\hline CHEMBL1327184 & 688340 & 4.65 & 4.9689 & TRN \\
\hline CHEMBL1572853 & 688340 & 4.45 & 4.9078 & TST \\
\hline CHEMBL 2007077 & 688340 & 4.85 & 4.9799 & TST \\
\hline CHEMBL1566953 & 688340 & 4.45 & 5.1404 & TST \\
\hline CHEMBL1521026 & 688340 & 4.65 & 4.9385 & TRN \\
\hline CHEMBL3145143 & 688340 & 6.1 & 4.9636 & TST \\
\hline CHEMBL1329871 & 688340 & 4.45 & 5.3952 & TRN \\
\hline CHEMBL1585544 & 688340 & 3.95 & 5.0419 & TST \\
\hline CHEMBL1489362 & 688340 & 4.9 & 5.0382 & TST \\
\hline CHEMBL3198952 & 688340 & 4.4 & 5.2074 & TRN \\
\hline CHEMBL1426340 & 688340 & 6.05 & 4.5568 & TRN \\
\hline CHEMBL1547330 & 688340 & 7.0 & 5.4323 & TST \\
\hline CHEMBL1453871 & 688340 & 4.5 & 4.8521 & TRN \\
\hline CHEMBL1329464 & 688340 & 5.1 & 5.1456 & TST \\
\hline CHEMBL1371119 & 688340 & 4.5 & 4.9427 & TRN \\
\hline CHEMBL1562926 & 688340 & 5.25 & 5.2301 & TRN \\
\hline CHEMBL1556256 & 688340 & 4.5 & 4.8467 & TRN \\
\hline CHEMBL 3194449 & 688340 & 4.6 & 5.1377 & TST \\
\hline CHEMBL1469360 & 688340 & 5.55 & 5.3338 & TST \\
\hline CHEMBL1558345 & 688340 & 7.0 & 5.2469 & TRN \\
\hline CHEMBL1365308 & 688340 & 6.15 & 5.2077 & TRN \\
\hline CHEMBL1522796 & 688340 & 5.0 & 4.6503 & TST \\
\hline CHEMBL1553446 & 688340 & 4.55 & 5.0876 & TRN \\
\hline CHEMBL1368258 & 688340 & 4.7 & 4.8772 & TRN \\
\hline CHEMBL3194421 & 688340 & 4.45 & 5.1897 & TRN \\
\hline CHEMBL1319267 & 688340 & 4.65 & 5.2083 & TRN \\
\hline CHEMBL1431380 & 688340 & 4.5 & 4.7716 & TST \\
\hline CHEMBL1552776 & 688340 & 4.5 & 4.9704 & TRN \\
\hline CHEMBL1433931 & 688340 & 4.55 & 4.8953 & TRN \\
\hline CHEMBL1503422 & 688340 & 7.1002 & 5.4619 & TRN \\
\hline CHEMBL1375099 & 688340 & 4.4 & 4.8826 & TRN \\
\hline
\end{tabular}




\begin{tabular}{|c|c|c|c|c|c|}
\hline \\
\hline CHEMBL1611797 & 688340 & 4.7 & 5.086 & TRN & \\
\hline CHEMBL1514581 & 688340 & 4.4 & 5.01 & TRN & \\
\hline CHEMBL1423924 & 688340 & 5.0 & 5.0967 & TRN & \\
\hline CHEMBL1573999 & 688340 & 5.95 & 5.2862 & TRN & \\
\hline CHEMBL1510732 & 688340 & 5.95 & 5.1865 & TST & \\
\hline CHEMBL1501588 & 688340 & 5.4 & 5.0779 & TRN & \\
\hline CHEMBL1351618 & 688340 & 4.7 & 4.9341 & TRN & \\
\hline CHEMBL1543251 & 688340 & 4.6 & 4.9772 & TRN & \\
\hline CHEMBL1315948 & 688340 & 4.55 & 4.6349 & TRN & \\
\hline CHEMBL1498069 & 688340 & 4.4 & 5.2092 & TST & \\
\hline CHEMBL1346953 & 688340 & 7.0 & 5.1955 & TRN & \\
\hline CHEMBL1302533 & 688340 & 4.4 & 5.0563 & TRN & \\
\hline CHEMBL1516970 & 688340 & 6.4 & 5.0802 & TST & \\
\hline CHEMBL1309959 & 688340 & 5.2 & 5.3826 & TRN & \\
\hline CHEMBL1359529 & 688340 & 4.45 & 4.9598 & TRN & \\
\hline CHEMBL1445336 & 688340 & 4.8 & 4.6028 & TRN & \\
\hline CHEMBL1348265 & 688340 & 4.6 & 5.0344 & TST & \\
\hline CHEMBL1571895 & 688340 & 6.2 & $5.3670 e$ & 0000000001 & TST \\
\hline CHEMBL1603514 & 688340 & 6.3 & 4.9238 & TST & \\
\hline CHEMBL1370536 & 688340 & 4.8 & 4.7867 & TRN & \\
\hline CHEMBL1479427 & 688340 & 4.55 & 4.7239 & TRN & \\
\hline CHEMBL1494662 & 688340 & 4.7 & 5.1643 & TRN & \\
\hline CHEMBL1429975 & 688340 & 4.4 & 4.7687 & TRN & \\
\hline CHEMBL1425675 & 688340 & 4.5 & 4.6915 & TRN & \\
\hline CHEMBL1566396 & 688340 & 4.4 & 5.4397 & TRN & \\
\hline CHEMBL1391393 & 688340 & 4.85 & 4.6588 & TST & \\
\hline CHEMBL1431245 & 688340 & 5.05 & 4.8349 & TRN & \\
\hline CHEMBL1497892 & 688340 & 5.15 & 4.9272 & TST & \\
\hline CHEMBL1314898 & 688340 & 4.4 & 5.13899 & 9999999999 & TRN \\
\hline CHEMBL1431955 & 688340 & 5.05 & 5.102 & TRN & \\
\hline CHEMBL1304480 & 688340 & 5.25 & 5.2498 & TST & \\
\hline CHEMBL1602990 & 688340 & 4.4 & 5.1051 & TRN & \\
\hline CHEMBL1417212 & 688340 & 4.75 & 4.9018 & TRN & \\
\hline CHEMBL1981063 & 688340 & 4.5 & 4.9848 & TRN & \\
\hline CHEMBL1301164 & 688340 & 4.85 & 4.859 & TRN & \\
\hline CHEMBL1322518 & 688340 & 4.5 & 4.9423 & TST & \\
\hline CHEMBL1468403 & 688340 & 4.8 & 4.9947 & TRN & \\
\hline CHEMBL1381585 & 688340 & 4.85 & 5.1906 & TST & \\
\hline CHEMBL1329453 & 688340 & 4.55 & 4.7582 & TRN & \\
\hline CHEMBL1422562 & 688340 & 4.4 & 5.3787 & TRN & \\
\hline CHEMBL1460901 & 688340 & 4.4 & 5.0845 & TRN & \\
\hline CHEMBL1440706 & 688340 & 4.65 & 5.1149 & TRN & \\
\hline CHEMBL1368408 & 688340 & 5.2 & 4.8924 & TST & \\
\hline CHEMBL3190181 & 688340 & 5.8 & 4.6547 & TRN & \\
\hline CHEMBL1585097 & 688340 & 5.45 & 4.8018 & TRN & \\
\hline CHEMBL1567873 & 688340 & 4.55 & 5.0148 & TST & \\
\hline CHEMBL1613639 & 688340 & 4.45 & 4.8634 & TRN & \\
\hline CHEMBL1394648 & 688340 & 4.6 & 4.959 & TRN & \\
\hline
\end{tabular}




\begin{tabular}{|c|c|c|c|c|}
\hline \multicolumn{5}{|c|}{ Supplemental Table S2.txt } \\
\hline CHEMBL1548834 & 688340 & 4.55 & 4.5291 & TRN \\
\hline CHEMBL1386626 & 688340 & 4.4 & 5.2758 & TRN \\
\hline CHEMBL1504072 & 688340 & 5.05 & 5.2004 & TRN \\
\hline CHEMBL1316331 & 688340 & 3.95 & 5.3746 & TST \\
\hline CHEMBL1522777 & 688340 & 4.9 & 4.9884 & TST \\
\hline CHEMBL3193134 & 688340 & 5.25 & 4.76 & TRN \\
\hline CHEMBL1397261 & 688340 & 4.55 & 5.0392 & TRN \\
\hline CHEMBL1384172 & 688340 & 5.0 & 4.9107 & TRN \\
\hline CHEMBL1317084 & 688340 & 4.4 & 4.8744 & TRN \\
\hline CHEMBL1567882 & 688340 & 4.5 & 4.9915 & TST \\
\hline CHEMBL1521636 & 688340 & 4.4 & 4.9371 & TRN \\
\hline CHEMBL15594 & 688340 & 4.4 & 5.0137 & TRN \\
\hline CHEMBL1319003 & 688340 & 5.2 & 4.8813 & TST \\
\hline CHEMBL1361868 & 688340 & 4.4 & 5.3117 & TST \\
\hline CHEMBL1523224 & 688340 & 4.6 & 4.7064 & TRN \\
\hline CHEMBL1556580 & 688340 & 5.0 & 5.1561 & TRN \\
\hline CHEMBL1454357 & 688340 & 4.55 & 4.9843 & TRN \\
\hline CHEMBL1593005 & 688340 & 6.5 & 5.4861 & TRN \\
\hline CHEMBL1438567 & 688340 & 4.6 & 4.9578 & TRN \\
\hline CHEMBL1454734 & 688340 & 5.6 & 5.0964 & TRN \\
\hline CHEMBL1363689 & 688340 & 4.75 & 5.0521 & TRN \\
\hline CHEMBL1387692 & 688340 & 4.4 & 5.1449 & TST \\
\hline CHEMBL1523626 & 688340 & 5.05 & 4.7766 & TRN \\
\hline CHEMBL1536210 & 688340 & 4.95 & 5.0947 & TRN \\
\hline CHEMBL1490112 & 688340 & 5.55 & 5.1681 & TST \\
\hline CHEMBL1365889 & 688340 & 4.5 & 5.0115 & TRN \\
\hline CHEMBL1365022 & 688340 & 2.2 & 5.1183 & TST \\
\hline CHEMBL1311395 & 688340 & 4.65 & 4.7602 & TRN \\
\hline CHEMBL1399743 & 688340 & 7.0 & 4.9877 & TST \\
\hline CHEMBL1307382 & 688340 & 6.5501 & 4.997 & TST \\
\hline CHEMBL1400376 & 688340 & 4.55 & 4.8632 & TRN \\
\hline CHEMBL1457139 & 688340 & 4.45 & 4.5842 & TRN \\
\hline CHEMBL1347308 & 688340 & 6.6 & 5.1167 & TST \\
\hline CHEMBL1300410 & 688340 & 4.5 & 4.8176 & TRN \\
\hline CHEMBL1489861 & 688340 & 4.85 & 4.7523 & TRN \\
\hline CHEMBL1325176 & 688340 & 5.0 & 4.4418 & TRN \\
\hline CHEMBL1546132 & 688340 & 4.65 & 4.8943 & TRN \\
\hline CHEMBL1419328 & 688340 & 4.4 & 4.9228 & TRN \\
\hline CHEMBL1580359 & 688340 & 6.1 & 5.0161 & TRN \\
\hline CHEMBL1373986 & 688340 & 5.65 & 5.6866 & TRN \\
\hline CHEMBL1342921 & 688340 & 4.85 & 4.717 & TRN \\
\hline CHEMBL1449968 & 688340 & 4.7 & 4.5403 & TRN \\
\hline CHEMBL1587655 & 688340 & 5.25 & 4.7513 & TST \\
\hline CHEMBL1971478 & 688340 & 4.0 & 4.9831 & TRN \\
\hline CHEMBL1522018 & 688340 & 4.6 & 4.8297 & TRN \\
\hline CHEMBL1357144 & 688340 & 6.7501 & 5.129 & TRN \\
\hline CHEMBL1082898 & 688340 & 5.45 & 5.475 & TRN \\
\hline CHEMBL1553253 & 688340 & 4.35 & 5.2665 & TRN \\
\hline
\end{tabular}




\begin{tabular}{|c|c|c|c|c|}
\hline \multicolumn{5}{|c|}{ Supplemental Tab } \\
\hline CHEMBL1493379 & 688340 & 4.6 & 4.8774 & TRN \\
\hline CHEMBL1387843 & 688340 & 4.8 & 5.0018 & TST \\
\hline CHEMBL1566081 & 688340 & 4.5 & 4.9288 & TST \\
\hline CHEMBL1354270 & 688340 & 4.6 & 4.7472 & TRN \\
\hline CHEMBL1330307 & 688340 & 4.55 & 4.6674 & TRN \\
\hline CHEMBL1530059 & 688340 & 7.0501 & 5.437 & TRN \\
\hline CHEMBL1532058 & 688340 & 4.45 & 5.3195 & TRN \\
\hline CHEMBL1586008 & 688340 & 4.65 & 5.2321 & TST \\
\hline CHEMBL1473428 & 688340 & 4.6 & 4.629 & TRN \\
\hline CHEMBL1590005 & 688340 & 4.85 & 5.1486 & TRN \\
\hline CHEMBL1255831 & 688340 & 4.85 & 5.3839 & TST \\
\hline CHEMBL1485390 & 688340 & 7.6003 & 5.2528 & TRN \\
\hline CHEMBL1516057 & 688340 & 4.65 & 4.9225 & TST \\
\hline CHEMBL1539327 & 688340 & 4.5 & 4.987 & TRN \\
\hline CHEMBL1608934 & 688340 & 4.35 & 5.1369 & TRN \\
\hline CHEMBL1319608 & 688340 & 4.55 & 4.9573 & TRN \\
\hline CHEMBL1344907 & 688340 & 5.65 & 5.0453 & TST \\
\hline CHEMBL1455281 & 688340 & 4.65 & 4.8292 & TRN \\
\hline CHEMBL1395168 & 688340 & 6.15 & 5.3994 & TRN \\
\hline CHEMBL1444164 & 688340 & 4.7 & 5.2123 & TRN \\
\hline CHEMBL1410227 & 688340 & 5.15 & 4.9175 & TST \\
\hline CHEMBL1412548 & 688340 & 4.4 & 5.0104 & TRN \\
\hline CHEMBL1525631 & 688340 & 4.4 & 4.9502 & TRN \\
\hline CHEMBL1337330 & 688340 & 4.75 & 5.1314 & TRN \\
\hline CHEMBL3197170 & 688340 & 6.25 & 5.2134 & TST \\
\hline CHEMBL1381221 & 688340 & 6.9 & 5.3602 & TRN \\
\hline CHEMBL1554818 & 688340 & 4.6 & 4.9025 & TRN \\
\hline CHEMBL1515534 & 688340 & 3.85 & 4.9852 & TRN \\
\hline CHEMBL1573325 & 688340 & 4.3 & 5.2657 & TRN \\
\hline CHEMBL1449222 & 688340 & 4.5 & 4.7639 & TRN \\
\hline CHEMBL1438222 & 688340 & 4.55 & 4.7237 & TRN \\
\hline CHEMBL1582111 & 688340 & 5.5 & 4.8692 & TRN \\
\hline CHEMBL1576508 & 688340 & 4.55 & 5.1553 & TST \\
\hline CHEMBL1306901 & 688340 & 4.65 & 5.2094 & TST \\
\hline CHEMBL1320613 & 688340 & 6.15 & 4.9313 & TST \\
\hline CHEMBL1594238 & 688340 & 4.5 & 5.1246 & TRN \\
\hline CHEMBL590927 & 688340 & 4.6 & 4.6077 & TRN \\
\hline CHEMBL1384815 & 688340 & 4.6 & 4.9607 & TRN \\
\hline CHEMBL1427405 & 688340 & 7.0501 & 5.3445 & TRN \\
\hline CHEMBL1534133 & 688340 & 5.5 & 5.0677 & TRN \\
\hline CHEMBL1338673 & 688340 & 4.4 & 4.5335 & TRN \\
\hline CHEMBL1489760 & 688340 & 4.65 & 4.8486 & TRN \\
\hline CHEMBL3191584 & 688340 & 7.0 & 5.2159 & TST \\
\hline CHEMBL1581101 & 688340 & 4.6 & 5.3175 & TRN \\
\hline CHEMBL3199194 & 688340 & 6.05 & 5.1278 & TST \\
\hline CHEMBL1340336 & 688340 & 4.4 & 4.7504 & TRN \\
\hline CHEMBL1300015 & 688340 & 4.55 & 4.6685 & TRN \\
\hline CHEMBL1315020 & 688340 & 4.5 & 5.2368 & TST \\
\hline
\end{tabular}




\begin{tabular}{|c|c|c|c|c|}
\hline \multicolumn{5}{|c|}{ Iemen } \\
\hline CHEMBL1372534 & 688340 & 4.6 & 5.2296 & TST \\
\hline CHEMBL1400136 & 688340 & 4.7 & 4.8956 & TST \\
\hline CHEMBL1579917 & 688340 & 5.0 & 4.7642 & TRN \\
\hline CHEMBL1566246 & 688340 & 4.35 & 5.1692 & TRN \\
\hline CHEMBL1589407 & 688340 & 4.75 & 4.5905 & TRN \\
\hline CHEMBL1307669 & 688340 & 5.1 & 4.3584 & TRN \\
\hline CHEMBL3199655 & 688340 & 4.7 & 5.0132 & TRN \\
\hline CHEMBL1534204 & 688340 & 4.35 & 5.0332 & TRN \\
\hline CHEMBL1527529 & 688340 & 4.65 & 4.9465 & TRN \\
\hline CHEMBL1391233 & 688340 & 4.55 & 5.0935 & TRN \\
\hline CHEMBL1580316 & 688340 & 4.55 & 4.8603 & TRN \\
\hline CHEMBL1575600 & 688340 & 5.35 & 5.0585 & TST \\
\hline CHEMBL1521959 & 688340 & 4.35 & 5.1991 & TRN \\
\hline CHEMBL1307634 & 688340 & 4.65 & 4.9293 & TRN \\
\hline CHEMBL1445625 & 688340 & 4.85 & 5.0066 & TRN \\
\hline CHEMBL3197024 & 688340 & 5.1 & 4.5861 & TRN \\
\hline CHEMBL1480576 & 688340 & 4.7 & 5.2157 & TST \\
\hline CHEMBL 1475400 & 688340 & 4.55 & 4.853 & TRN \\
\hline CHEMBL1586704 & 688340 & 5.2 & 5.1312 & TST \\
\hline CHEMBL1394247 & 688340 & 4.6 & 5.3861 & TRN \\
\hline CHEMBL1468708 & 688340 & 4.5 & 4.6185 & TRN \\
\hline CHEMBL3198908 & 688340 & 4.55 & 4.8036 & TRN \\
\hline CHEMBL1365292 & 688340 & 5.25 & 5.0045 & TST \\
\hline CHEMBL1544639 & 688340 & 4.4 & 5.2394 & TST \\
\hline CHEMBL1375489 & 688340 & 7.5003 & 5.02800 & 00000000005 \\
\hline CHEMBL1334461 & 688340 & 5.3 & 5.1566 & TRN \\
\hline CHEMBL1526143 & 688340 & 4.45 & 4.8017 & TRN \\
\hline CHEMBL1321629 & 688340 & 5.4 & 5.4418 & TRN \\
\hline CHEMBL1508531 & 688340 & 6.1 & 5.0703 & TRN \\
\hline CHEMBL1587849 & 688340 & 4.55 & 4.8935 & TRN \\
\hline CHEMBL1449836 & 688340 & 5.1 & 4.6204 & TRN \\
\hline CHEMBL1379059 & 688340 & 4.0 & 5.0701 & TST \\
\hline CHEMBL1536772 & 688340 & 4.55 & 4.9973 & TST \\
\hline CHEMBL3196900 & 688340 & 4.5 & 5.1905 & TRN \\
\hline CHEMBL1409569 & 688340 & 6.0 & 5.1714 & TRN \\
\hline CHEMBL1451145 & 688340 & 7.0 & 5.3079 & TST \\
\hline CHEMBL209453 & 688340 & 4.45 & 4.8586 & TRN \\
\hline CHEMBL1551105 & 688340 & 7.0 & 5.0002 & TST \\
\hline CHEMBL1522726 & 688340 & 5.05 & 4.8667 & TRN \\
\hline CHEMBL3213956 & 688340 & 4.8 & 4.9025 & TRN \\
\hline CHEMBL1613006 & 688340 & 6.15 & 5.2629 & TST \\
\hline CHEMBL1402494 & 688340 & 5.4 & 5.1092 & TRN \\
\hline CHEMBL1299502 & 688340 & 4.45 & 5.0577 & TST \\
\hline CHEMBL1376450 & 688340 & 4.4 & 5.0771 & TRN \\
\hline CHEMBL3195470 & 688340 & 4.8 & 4.8935 & TRN \\
\hline CHEMBL1378626 & 688340 & 3.55 & 5.4171 & TRN \\
\hline CHEMBL1326485 & 688340 & 4.8 & 4.9122 & TRN \\
\hline CHEMBL1389600 & 688340 & 5.5 & 5.1771 & TRN \\
\hline
\end{tabular}




\begin{tabular}{|c|c|c|c|c|}
\hline \multicolumn{5}{|c|}{ Supplemental Table S2.txt } \\
\hline CHEMBL1337325 & 688340 & 5.05 & 4.8596 & TRN \\
\hline CHEMBL1433778 & 688340 & 4.4 & 5.0207 & TRN \\
\hline CHEMBL1353508 & 688340 & 4.65 & 4.9695 & TST \\
\hline CHEMBL1507274 & 688340 & 6.9 & 5.1508 & TRN \\
\hline CHEMBL1542340 & 688340 & 4.6 & 5.0112 & TRN \\
\hline CHEMBL1345724 & 688340 & 4.55 & 4.8275 & TRN \\
\hline CHEMBL1543785 & 688340 & 6.3 & 4.8869 & TRN \\
\hline CHEMBL1308151 & 688340 & 4.45 & 5.0223 & TRN \\
\hline CHEMBL1400653 & 688340 & 4.7 & 4.9445 & TRN \\
\hline CHEMBL1353367 & 688340 & 4.35 & 5.0141 & TST \\
\hline CHEMBL1450052 & 688340 & 4.45 & 4.7726 & TRN \\
\hline CHEMBL1445386 & 688340 & 5.65 & 4.7777 & TST \\
\hline CHEMBL1445244 & 688340 & 3.45 & 5.2005 & TST \\
\hline CHEMBL1345888 & 688340 & 4.55 & 4.5518 & TRN \\
\hline CHEMBL1520896 & 688340 & 4.55 & 5.2506 & TRN \\
\hline CHEMBL1396552 & 688340 & 4.5 & 4.7502 & TST \\
\hline CHEMBL1418018 & 688340 & 5.2 & 5.1002 & TRN \\
\hline CHEMBL1510626 & 688340 & 6.45 & 5.2198 & TRN \\
\hline CHEMBL1316502 & 688340 & 4.4 & 4.8661 & TRN \\
\hline CHEMBL1347831 & 688340 & 4.55 & 4.6424 & TRN \\
\hline CHEMBL1399610 & 688340 & 4.4 & 5.2355 & TST \\
\hline CHEMBL1552359 & 688340 & 5.15 & 4.9456 & TRN \\
\hline CHEMBL1400446 & 688340 & 4.65 & 4.9914 & TRN \\
\hline CHEMBL1458206 & 688340 & 4.4 & 5.3823 & TST \\
\hline CHEMBL1506181 & 688340 & 6.3 & 4.7892 & TRN \\
\hline CHEMBL1371262 & 688340 & 4.5 & 4.9152 & TST \\
\hline CHEMBL1356219 & 688340 & 5.2 & 4.9745 & TST \\
\hline CHEMBL1382266 & 688340 & 4.45 & 4.7273 & TRN \\
\hline CHEMBL1548117 & 688340 & 5.4 & 5.3053 & TST \\
\hline CHEMBL1426209 & 688340 & 5.2 & 5.5632 & TST \\
\hline CHEMBL1380516 & 688340 & 3.5 & 4.987 & TRN \\
\hline CHEMBL1541889 & 688340 & 4.45 & 4.9375 & TRN \\
\hline CHEMBL1521827 & 688340 & 4.55 & 4.8898 & TST \\
\hline CHEMBL1468161 & 688340 & 4.05 & 5.0437 & TRN \\
\hline CHEMBL1569681 & 688340 & 3.05 & 4.8966 & TRN \\
\hline CHEMBL547483 & 688340 & 4.4 & 4.8603 & TST \\
\hline CHEMBL3193785 & 688340 & 5.45 & 4.9753 & TRN \\
\hline CHEMBL1498786 & 688340 & 7.0501 & 5.0964 & TST \\
\hline CHEMBL1344568 & 688340 & 5.55 & 5.0769 & TRN \\
\hline CHEMBL1479187 & 688340 & 7.0 & 5.1419 & TST \\
\hline CHEMBL1213606 & 688340 & 5.6 & 5.1046 & TST \\
\hline CHEMBL3196395 & 688340 & 5.95 & 4.914 & TRN \\
\hline CHEMBL1448944 & 688340 & 4.4 & 4.9773 & TRN \\
\hline CHEMBL1521846 & 688340 & 6.5 & 5.2232 & TST \\
\hline CHEMBL286204 & 688340 & 4.65 & 5.0911 & TRN \\
\hline CHEMBL1452993 & 688340 & 5.45 & 5.2626 & TST \\
\hline CHEMBL1406995 & 688340 & 4.55 & 4.7842 & TRN \\
\hline CHEMBL1580214 & 688340 & 4.6 & 4.6732 & TRN \\
\hline
\end{tabular}




\begin{tabular}{|c|c|c|c|c|c|}
\hline \\
\hline CHEMBL1502312 & 688340 & 6.2 & 5.0009 & TRN & \\
\hline CHEMBL1492209 & 688340 & 4.4 & 5.2458 & TRN & \\
\hline CHEMBL1529322 & 688340 & 5.3 & 5.0526 & TRN & \\
\hline CHEMBL1536896 & 688340 & 5.15 & 4.97 & TRN & \\
\hline CHEMBL1413112 & 688340 & 4.6 & 4.9825 & TRN & \\
\hline CHEMBL1409380 & 688340 & 4.4 & 4.6738 & TRN & \\
\hline CHEMBL1498882 & 688340 & 6.15 & 5.0003 & TRN & \\
\hline CHEMBL1413316 & 688340 & 4.4 & 5.0354 & TRN & \\
\hline CHEMBL1517980 & 688340 & 5.4 & 5.0573 & TRN & \\
\hline CHEMBL1450092 & 688340 & 4.45 & 5.1163 & TRN & \\
\hline CHEMBL1390126 & 688340 & 4.6 & 4.9471 & TST & \\
\hline CHEMBL1309398 & 688340 & 5.05 & 4.8557 & TST & \\
\hline CHEMBL1526651 & 688340 & 4.65 & 4.6787 & TRN & \\
\hline CHEMBL1393905 & 688340 & 4.5 & 4.7828 & TST & \\
\hline CHEMBL1399257 & 688340 & 4.55 & 5.1211 & TRN & \\
\hline CHEMBL1470038 & 688340 & 4.5 & 4.8226 & TRN & \\
\hline CHEMBL3212538 & 688340 & 4.4 & 5.1769 & TRN & \\
\hline CHEMBL1463427 & 688340 & 4.6 & 4.6184 & TRN & \\
\hline CHEMBL1602644 & 688340 & 4.75 & 5.3768 & TRN & \\
\hline CHEMBL1525363 & 688340 & 5.05 & 5.569 & TRN & \\
\hline CHEMBL1331501 & 688340 & 4.55 & 4.9699 & TRN & \\
\hline CHEMBL527454 & 688340 & 7.0 & 5.2839 & TRN & \\
\hline CHEMBL1394643 & 688340 & 4.6 & 4.7964 & TRN & \\
\hline CHEMBL1374298 & 688340 & 5.2 & 4.7902 & TST & \\
\hline CHEMBL3191432 & 688340 & 4.8 & 4.7902 & TRN & \\
\hline CHEMBL3194893 & 688340 & 4.45 & 5.2286 & TRN & \\
\hline CHEMBL1383456 & 688340 & 5.2 & 5.1811 & TST & \\
\hline CHEMBL1415703 & 688340 & 4.45 & 4.637 & TST & \\
\hline CHEMBL1417050 & 688340 & 5.0 & 5.0851 & TST & \\
\hline CHEMBL1419809 & 688340 & 4.4 & 4.9604 & TRN & \\
\hline CHEMBL1413210 & 688340 & 5.85 & 5.2984 & TST & \\
\hline CHEMBL1504175 & 688340 & 4.4 & 4.9049 & TRN & \\
\hline CHEMBL1469800 & 688340 & 5.2 & 5.2335 & TRN & \\
\hline CHEMBL1442148 & 688340 & 4.4 & 4.7492 & TRN & \\
\hline CHEMBL1398012 & 688340 & 4.7 & 4.6349 & TRN & \\
\hline CHEMBL1253586 & 688340 & 4.5 & $5.0310 e$ & 0000000001 & TRN \\
\hline CHEMBL1394552 & 688340 & 4.4 & 4.7759 & TRN & \\
\hline CHEMBL1300571 & 688340 & 5.9 & 4.874 & TST & \\
\hline CHEMBL1538367 & 688340 & 4.5 & 5.1091 & TRN & \\
\hline CHEMBL1507969 & 688340 & 5.45 & 4.978 & TRN & \\
\hline CHEMBL1407306 & 688340 & 4.75 & 4.9784 & TRN & \\
\hline CHEMBL1541279 & 688340 & 5.15 & 5.1543 & TST & \\
\hline CHEMBL3192078 & 688340 & 5.45 & 4.7781 & TRN & \\
\hline CHEMBL1492833 & 688340 & 5.0 & 5.0255 & TST & \\
\hline CHEMBL1559629 & 688340 & 6.0 & 4.9956 & TST & \\
\hline CHEMBL1446689 & 688340 & 5.4 & 5.3978 & TRN & \\
\hline CHEMBL1544660 & 688340 & 6.15 & 4.5861 & TRN & \\
\hline CHEMBL3213551 & 688340 & 4.4 & 4.6351 & TRN & \\
\hline & & & & 2815 & \\
\hline
\end{tabular}




\begin{tabular}{|c|c|c|c|c|c|}
\hline \multicolumn{6}{|c|}{ Supplemental Table S2.txt } \\
\hline CHEMBL1506256 & 688340 & 5.4 & 5.2438 & TRN & \\
\hline CHEMBL1520060 & 688340 & 5.6 & 5.0089 & TST & \\
\hline CHEMBL1548521 & 688340 & 5.3 & 5.2681 & TRN & \\
\hline CHEMBL1545601 & 688340 & 4.75 & 5.0064 & TRN & \\
\hline CHEMBL1525606 & 688340 & 4.45 & 4.8827 & TRN & \\
\hline CHEMBL1354200 & 688340 & 4.6 & 4.6221 & TRN & \\
\hline CHEMBL1374440 & 688340 & 4.5 & 4.9302 & TRN & \\
\hline CHEMBL1399826 & 688340 & 7.0 & 5.0557 & TRN & \\
\hline CHEMBL1335995 & 688340 & 5.05 & 4.8242 & TRN & \\
\hline CHEMBL1325782 & 688340 & 4.6 & 4.8444 & TST & \\
\hline CHEMBL1979800 & 688340 & 4.9 & 4.7796 & TRN & \\
\hline CHEMBL1469872 & 688340 & 5.2 & 4.6169 & TRN & \\
\hline CHEMBL1437658 & 688340 & 4.6 & 5.1515 & TRN & \\
\hline CHEMBL1495410 & 688340 & 4.4 & 5.0532 & TST & \\
\hline CHEMBL1377845 & 688340 & 6.45 & 5.2197 & TRN & \\
\hline CHEMBL1319461 & 688340 & 4.6 & 4.9125 & TRN & \\
\hline CHEMBL1471854 & 688340 & 6.15 & 5.3657 & TST & \\
\hline CHEMBL1586840 & 688340 & 4.6 & 4.9124 & TRN & \\
\hline CHEMBL1582178 & 688340 & 4.4 & 5.2065 & TST & \\
\hline CHEMBL1612972 & 688340 & 5.05 & 5.095 & TST & \\
\hline CHEMBL394197 & 688340 & 4.85 & 4.8337 & TRN & \\
\hline CHEMBL1305272 & 688340 & 6.0 & 5.0228 & TRN & \\
\hline CHEMBL1388002 & 688340 & 6.8 & 4.9925 & TST & \\
\hline CHEMBL1553387 & 688340 & 4.55 & 4.7268 & TRN & \\
\hline CHEMBL1570727 & 688340 & 4.5 & 4.71 & TRN & \\
\hline CHEMBL1572814 & 688340 & 4.7 & 5.0852 & TRN & \\
\hline CHEMBL1589632 & 688340 & 5.15 & 5.291 & TRN & \\
\hline CHEMBL1376327 & 688340 & 3.9 & 5.002 & TRN & \\
\hline CHEMBL1337277 & 688340 & 6.1 & $4.8180 e$ & 00000000005 & TRN \\
\hline CHEMBL1380467 & 688340 & 5.75 & 5.1385 & TST & \\
\hline CHEMBL1501071 & 688340 & 4.35 & 4.9181 & TST & \\
\hline CHEMBL1366079 & 688340 & 6.45 & 5.3535 & TST & \\
\hline CHEMBL1518249 & 688340 & 5.25 & 4.9772 & TRN & \\
\hline CHEMBL1522738 & 688340 & 4.5 & 4.5841 & TRN & \\
\hline CHEMBL1341081 & 688340 & 6.95 & 5.1292 & TRN & \\
\hline CHEMBL1431438 & 688340 & 4.5 & 5.2574 & TRN & \\
\hline CHEMBL1594943 & 688340 & 4.4 & 4.7787 & TRN & \\
\hline CHEMBL1321406 & 688340 & 4.8 & 4.6523 & TRN & \\
\hline CHEMBL1304755 & 688340 & 4.5 & 4.6998 & TRN & \\
\hline CHEMBL1386860 & 688340 & 4.55 & 5.5359 & TRN & \\
\hline CHEMBL1464899 & 688340 & 4.85 & 4.9927 & TST & \\
\hline CHEMBL1497677 & 688340 & 6.05 & 5.0913 & TRN & \\
\hline CHEMBL72628 & 688340 & 4.85 & 5.0061 & TRN & \\
\hline CHEMBL1307998 & 688340 & 6.5 & 5.3501 & TRN & \\
\hline CHEMBL1520825 & 688340 & 5.15 & 4.8587 & TST & \\
\hline CHEMBL1311615 & 688340 & 4.6 & 4.9739 & TRN & \\
\hline CHEMBL1347423 & 688340 & 4.55 & 4.9681 & TRN & \\
\hline CHEMBL1598455 & 688340 & 4.55 & 4.8295 & TRN & \\
\hline
\end{tabular}




\begin{tabular}{|c|c|c|c|c|c|}
\hline \multicolumn{6}{|c|}{ Supplemental Table S2.txt } \\
\hline CHEMBL1319811 & 688340 & 4.55 & 5.0702 & TRN & \\
\hline CHEMBL1465326 & 688340 & 6.8499 & 5.4225 & TRN & \\
\hline CHEMBL1347686 & 688340 & 5.2 & 4.6345 & TST & \\
\hline CHEMBL1375286 & 688340 & 4.5 & 4.7431 & TRN & \\
\hline CHEMBL3191785 & 688340 & 4.55 & 4.8028 & TRN & \\
\hline CHEMBL1421530 & 688340 & 4.5 & 4.6645 & TRN & \\
\hline CHEMBL1448310 & 688340 & 5.0 & 5.1556 & TST & \\
\hline CHEMBL1471380 & 688340 & 5.2 & 5.0696 & TST & \\
\hline CHEMBL1493952 & 688340 & 3.45 & 5.1059 & TST & \\
\hline CHEMBL1371533 & 688340 & 4.55 & 4.8738 & TRN & \\
\hline CHEMBL1543574 & 688340 & 4.55 & 4.5221 & TRN & \\
\hline CHEMBL1481522 & 688340 & 5.95 & 5.2065 & TRN & \\
\hline CHEMBL1303387 & 688340 & 4.55 & 5.0207 & TST & \\
\hline CHEMBL1401471 & 688340 & 7.0 & 5.268 & TRN & \\
\hline CHEMBL3198742 & 688340 & 4.6 & 5.3641 & TST & \\
\hline CHEMBL1583832 & 688340 & 4.55 & 5.0206 & TRN & \\
\hline CHEMBL1491101 & 688340 & 6.0 & 4.9683 & TST & \\
\hline CHEMBL3190142 & 688340 & 4.45 & 4.7257 & TRN & \\
\hline CHEMBL1399193 & 688340 & 4.55 & 5.1686 & TRN & \\
\hline CHEMBL1323803 & 688340 & 7.0501 & 5.2409 & TRN & \\
\hline CHEMBL1424701 & 688340 & 4.4 & 5.0514 & TRN & \\
\hline CHEMBL1468919 & 688340 & 5.0 & 5.1104 & TST & \\
\hline CHEMBL1447529 & 688340 & 4.4 & 4.6718 & TRN & \\
\hline CHEMBL1433553 & 688340 & 9.5229 & 5.195 & TRN & \\
\hline CHEMBL1476116 & 688340 & 4.55 & 4.7975 & TRN & \\
\hline CHEMBL3195865 & 688340 & 5.15 & 5.1144 & TRN & \\
\hline CHEMBL1438996 & 688340 & 4.9 & 5.0508 & TRN & \\
\hline CHEMBL1322346 & 688340 & 7.0 & 5.6097 & TRN & \\
\hline CHEMBL1478064 & 688340 & 4.7 & 5.0103 & TRN & \\
\hline CHEMBL1589211 & 688340 & 5.45 & 4.7108 & TRN & \\
\hline CHEMBL1501051 & 688340 & 5.2 & 5.062 & TST & \\
\hline CHEMBL1399315 & 688340 & 4.5 & 4.7523 & TRN & \\
\hline CHEMBL1346341 & 688340 & 5.05 & 4.8912 & TST & \\
\hline CHEMBL1312225 & 688340 & 7.0 & 5.40799 & 99999999995 & TRN \\
\hline CHEMBL1422456 & 688340 & 4.8 & 4.8312 & TRN & \\
\hline CHEMBL1466971 & 688340 & 4.45 & 5.0954 & TRN & \\
\hline CHEMBL1602010 & 688340 & 5.15 & 5.1985 & TST & \\
\hline CHEMBL1585178 & 688340 & 4.5 & 4.6279 & TRN & \\
\hline CHEMBL1478026 & 688340 & 6.1 & 4.9407 & TRN & \\
\hline CHEMBL1328795 & 688340 & 4.55 & 5.2118 & TRN & \\
\hline CHEMBL3193530 & 688340 & 4.4 & 4.9125 & TRN & \\
\hline CHEMBL1568971 & 688340 & 4.6 & 4.7257 & TRN & \\
\hline CHEMBL1334684 & 688340 & 5.5 & 4.9164 & TRN & \\
\hline CHEMBL1505858 & 688340 & 4.4 & 4.9501 & TST & \\
\hline CHEMBL1395180 & 688340 & 4.6 & 5.3185 & TRN & \\
\hline CHEMBL3197594 & 688340 & 4.45 & 4.7817 & TRN & \\
\hline CHEMBL1401410 & 688340 & 5.1 & 4.9083 & TRN & \\
\hline CHEMBL1506656 & 688340 & 4.55 & 5.0296 & TRN & \\
\hline
\end{tabular}




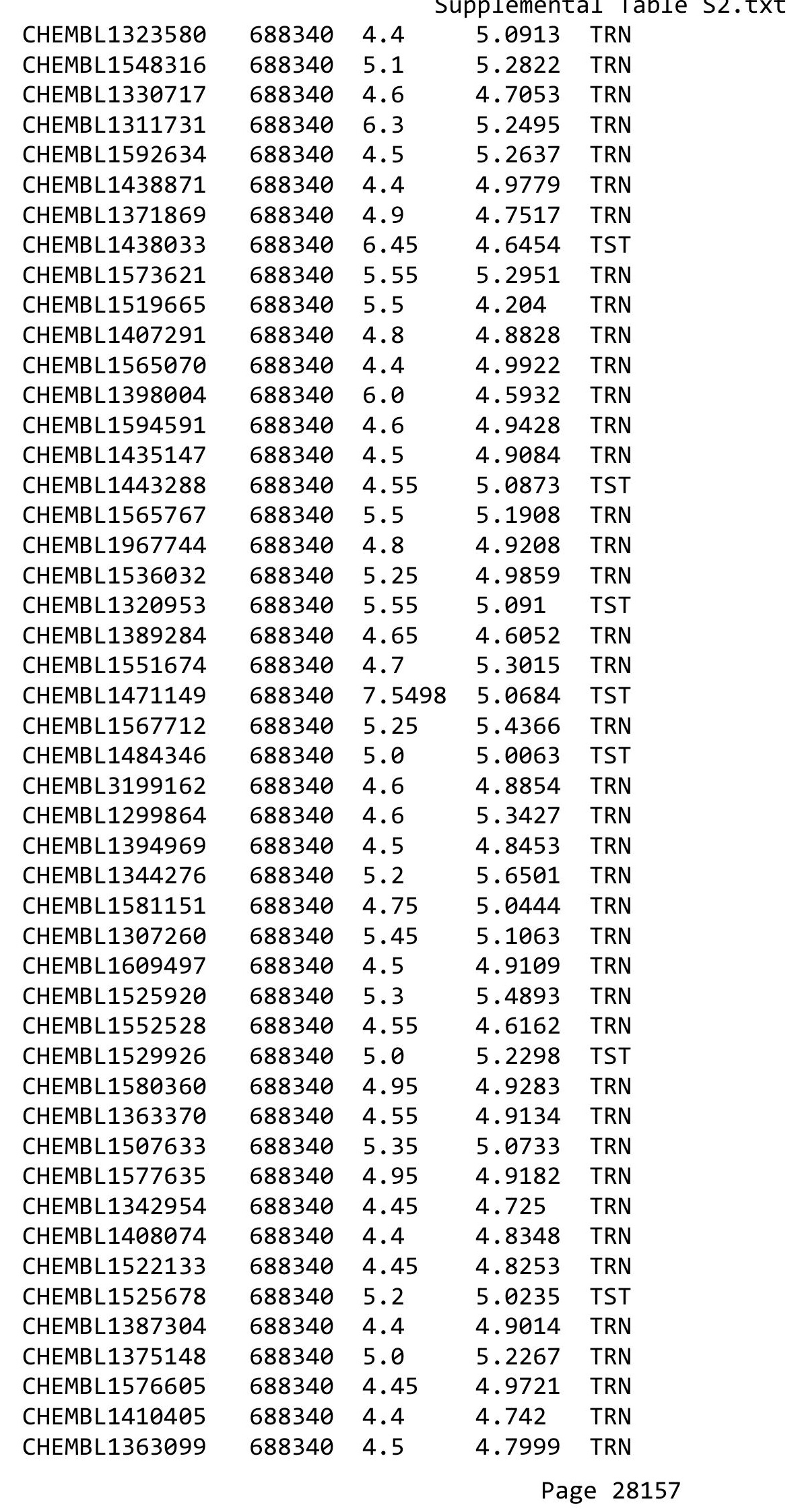




\begin{tabular}{|c|c|c|c|c|}
\hline \multicolumn{5}{|c|}{ Supplemental Table S2.txt } \\
\hline CHEMBL3192963 & 688340 & 6.95 & 4.9124 & TRN \\
\hline CHEMBL1451688 & 688340 & 6.05 & 5.2445 & TRN \\
\hline CHEMBL1525547 & 688340 & 4.9 & 4.697 & TRN \\
\hline CHEMBL1451433 & 688340 & 5.35 & 5.0414 & TRN \\
\hline CHEMBL1576273 & 688340 & 4.6 & 4.8483 & TRN \\
\hline CHEMBL1306522 & 688340 & 6.15 & 5.0751 & TRN \\
\hline CHEMBL3194359 & 688340 & 5.3 & 5.1557 & TRN \\
\hline CHEMBL1379133 & 688340 & 6.95 & 4.9835 & TRN \\
\hline CHEMBL1405256 & 688340 & 8.2007 & 5.2141 & TST \\
\hline CHEMBL1372796 & 688340 & 4.4 & 5.2453 & TRN \\
\hline CHEMBL1537365 & 688340 & 7.0 & 4.9669 & TRN \\
\hline CHEMBL1672292 & 688340 & 4.5 & 4.8746 & TRN \\
\hline CHEMBL 2000342 & 688340 & 5.15 & 5.0293 & TST \\
\hline CHEMBL1331688 & 688340 & 5.0 & 5.0793 & TST \\
\hline CHEMBL1460032 & 688340 & 4.5 & 4.9751 & TRN \\
\hline CHEMBL1299586 & 688340 & 5.5 & 5.0801 & TST \\
\hline CHEMBL1429293 & 688340 & 4.65 & 4.7346 & TRN \\
\hline CHEMBL1505749 & 688340 & 4.6 & 4.7742 & TRN \\
\hline CHEMBL1568055 & 688340 & 4.55 & 5.149 & TRN \\
\hline CHEMBL1495001 & 688340 & 4.55 & 4.7655 & TRN \\
\hline CHEMBL1600301 & 688340 & 4.95 & 5.0688 & TRN \\
\hline CHEMBL1426874 & 688340 & 4.55 & 5.004 & TRN \\
\hline CHEMBL1394812 & 688340 & 6.0 & 5.3664 & TRN \\
\hline CHEMBL3194022 & 688340 & 4.65 & 4.8512 & TRN \\
\hline CHEMBL1526785 & 688340 & 5.35 & 4.7178 & TRN \\
\hline CHEMBL1456462 & 688340 & 4.6 & 4.8907 & TRN \\
\hline CHEMBL1349705 & 688340 & 4.45 & 4.9491 & TRN \\
\hline CHEMBL1509542 & 688340 & 5.05 & 5.2457 & TST \\
\hline CHEMBL3191076 & 688340 & 4.6 & 5.0095 & TRN \\
\hline CHEMBL3209391 & 688340 & 4.4 & 5.1201 & TRN \\
\hline CHEMBL1330794 & 688340 & 4.75 & 4.6907 & TST \\
\hline CHEMBL1550256 & 688340 & 5.0 & 5.2171 & TRN \\
\hline CHEMBL1512217 & 688340 & 4.4 & 4.9883 & TRN \\
\hline CHEMBL1361208 & 688340 & 6.7001 & 5.0278 & TRN \\
\hline CHEMBL1537245 & 688340 & 5.4 & 4.7808 & TRN \\
\hline CHEMBL1515306 & 688340 & 4.4 & 5.0264 & TRN \\
\hline CHEMBL1456911 & 688340 & 5.2 & 4.9701 & TRN \\
\hline CHEMBL1577860 & 688340 & 4.55 & 5.1589 & TRN \\
\hline CHEMBL1348173 & 688340 & 4.4 & 4.7701 & TST \\
\hline CHEMBL1433259 & 688340 & 4.45 & 5.4159 & TRN \\
\hline CHEMBL1443309 & 688340 & 4.8 & 5.3422 & TRN \\
\hline CHEMBL1459273 & 688340 & 4.8 & 4.8218 & TRN \\
\hline CHEMBL1347633 & 688340 & 4.55 & 4.9817 & TST \\
\hline CHEMBL1341877 & 688340 & 5.65 & 5.295 & TRN \\
\hline CHEMBL1325796 & 688340 & 4.45 & 5.237 & TST \\
\hline CHEMBL1568603 & 688340 & 7.0 & 4.9838 & TST \\
\hline CHEMBL1440291 & 688340 & 4.8 & 4.4442 & TRN \\
\hline CHEMBL1600709 & 688340 & 4.45 & 5.1535 & TRN \\
\hline
\end{tabular}




\begin{tabular}{|c|c|c|c|c|c|}
\hline \\
\hline CHEMBL3192555 & 688340 & 5.5 & 4.6531 & TRN & \\
\hline CHEMBL1524678 & 688340 & 4.55 & 4.7969 & TRN & \\
\hline CHEMBL1559785 & 688340 & 4.5 & 4.6877 & TST & \\
\hline CHEMBL1597685 & 688340 & 4.55 & 4.9014 & TRN & \\
\hline CHEMBL1568124 & 688340 & 4.9 & 4.7285 & TRN & \\
\hline CHEMBL1300534 & 688340 & 4.7 & 4.7674 & TRN & \\
\hline CHEMBL1565049 & 688340 & 5.55 & 5.2047 & TRN & \\
\hline CHEMBL1404321 & 688340 & 4.45 & 5.1384 & TRN & \\
\hline CHEMBL1412640 & 688340 & 7.0 & 5.316 & TRN & \\
\hline CHEMBL1323981 & 688340 & 5.35 & 4.948 & TST & \\
\hline CHEMBL1568469 & 688340 & 4.4 & 5.1125 & TRN & \\
\hline CHEMBL1609356 & 688340 & 5.0 & 5.4492 & TRN & \\
\hline CHEMBL1430659 & 688340 & 4.45 & 4.9083 & TRN & \\
\hline CHEMBL3195570 & 688340 & 4.6 & 5.1008 & TRN & \\
\hline CHEMBL1460025 & 688340 & 4.7 & 5.0154 & TRN & \\
\hline CHEMBL1417413 & 688340 & 5.5 & 5.4524 & TRN & \\
\hline CHEMBL1395928 & 688340 & 3.9 & 5.0341 & TRN & \\
\hline CHEMBL1466205 & 688340 & 4.4 & 4.7389 & TST & \\
\hline CHEMBL1417521 & 688340 & 4.5 & 4.5355 & TRN & \\
\hline CHEMBL1362082 & 688340 & 4.6 & 4.8608 & TRN & \\
\hline CHEMBL1478713 & 688340 & 7.0 & 5.5299 & TRN & \\
\hline CHEMBL1568684 & 688340 & 4.65 & 5.1153 & TRN & \\
\hline CHEMBL1347385 & 688340 & 4.4 & 4.70100 & 00000000005 & TRN \\
\hline CHEMBL1376746 & 688340 & 5.0 & 4.9037 & TRN & \\
\hline CHEMBL 2005873 & 688340 & 4.45 & 4.7179 & TST & \\
\hline CHEMBL1356027 & 688340 & 5.35 & 5.1541 & TRN & \\
\hline CHEMBL1601208 & 688340 & 4.9 & 5.0561 & TRN & \\
\hline CHEMBL1466666 & 688340 & 4.75 & 5.17200 & 0000000001 & TRN \\
\hline CHEMBL1551131 & 688340 & 4.45 & 5.0273 & TRN & \\
\hline CHEMBL1511058 & 688340 & 5.6 & 4.7644 & TRN & \\
\hline CHEMBL1487849 & 688340 & 4.85 & 4.7938 & TRN & \\
\hline CHEMBL1466186 & 688340 & 4.6 & 4.8593 & TRN & \\
\hline CHEMBL3192541 & 688340 & 5.8 & 5.1 & TRN & \\
\hline CHEMBL1517233 & 688340 & 4.7 & 4.9716 & TRN & \\
\hline CHEMBL1434377 & 688340 & 4.8 & 4.7433 & TRN & \\
\hline CHEMBL1592351 & 688340 & 5.15 & 5.3256 & TRN & \\
\hline CHEMBL1529619 & 688340 & 6.7001 & 5.3594 & TRN & \\
\hline CHEMBL1430209 & 688340 & 5.2 & 5.2046 & TRN & \\
\hline CHEMBL1362927 & 688340 & 5.2 & 4.8519 & TRN & \\
\hline CHEMBL1417557 & 688340 & 4.35 & 5.3007 & TRN & \\
\hline CHEMBL1432020 & 688340 & 7.0501 & 5.3227 & TST & \\
\hline CHEMBL1359274 & 688340 & 4.55 & 5.3536 & TRN & \\
\hline CHEMBL1605526 & 688340 & 4.5 & 4.8829 & TRN & \\
\hline CHEMBL1514155 & 688340 & 6.35 & 5.0087 & TRN & \\
\hline CHEMBL1544074 & 688340 & 4.45 & 4.8017 & TRN & \\
\hline CHEMBL1433872 & 688340 & 4.8 & 5.1224 & TST & \\
\hline CHEMBL1472349 & 688340 & 7.0 & 5.0953 & TRN & \\
\hline CHEMBL1498364 & 688340 & 4.45 & 4.7676 & TRN & \\
\hline
\end{tabular}




\begin{tabular}{|c|c|c|c|c|c|}
\hline \multicolumn{6}{|c|}{ Supplemental Table S2.txt } \\
\hline CHEMBL1577298 & 688340 & 4.6 & 5.0912 & TRN & \\
\hline CHEMBL1336438 & 688340 & 4.95 & 5.0081 & TRN & \\
\hline CHEMBL1378470 & 688340 & 4.4 & 4.9754 & TST & \\
\hline CHEMBL1326803 & 688340 & 4.5 & 4.7432 & TRN & \\
\hline CHEMBL1474069 & 688340 & 4.6 & 4.9027 & TRN & \\
\hline CHEMBL1421887 & 688340 & 4.95 & 4.9765 & TRN & \\
\hline CHEMBL1486191 & 688340 & 6.2 & 5.0207 & TRN & \\
\hline CHEMBL1405706 & 688340 & 4.65 & 5.0804 & TST & \\
\hline CHEMBL1499130 & 688340 & 4.4 & 5.3071 & TRN & \\
\hline CHEMBL3197916 & 688340 & 4.55 & 4.7594 & TRN & \\
\hline CHEMBL1422553 & 688340 & 4.3 & 4.8784 & TST & \\
\hline CHEMBL1390521 & 688340 & 6.25 & 5.5884 & TRN & \\
\hline CHEMBL3190886 & 688340 & 4.45 & 4.8397 & TRN & \\
\hline CHEMBL1992276 & 688340 & 5.5 & 4.9466 & TRN & \\
\hline CHEMBL1299454 & 688340 & 4.35 & 4.791 & TRN & \\
\hline CHEMBL1378546 & 688340 & 5.25 & 4.7094 & TRN & \\
\hline CHEMBL1483348 & 688340 & 4.55 & 4.6777 & TRN & \\
\hline CHEMBL 602718 & 688340 & 4.4 & 4.6443 & TRN & \\
\hline CHEMBL1531566 & 688340 & 4.8 & $4.9910 e$ & 00000000005 & TRN \\
\hline CHEMBL1321272 & 688340 & 5.1 & 4.9466 & TST & \\
\hline CHEMBL1308663 & 688340 & 5.2 & 5.2957 & TRN & \\
\hline CHEMBL1319744 & 688340 & 4.35 & 4.8488 & TRN & \\
\hline CHEMBL3196391 & 688340 & 5.4 & 5.0315 & TRN & \\
\hline CHEMBL3196532 & 688340 & 6.45 & 4.9619 & TST & \\
\hline CHEMBL3198412 & 688340 & 5.0 & 5.0289 & TRN & \\
\hline CHEMBL1380221 & 688340 & 4.4 & 5.1035 & TRN & \\
\hline CHEMBL1583406 & 688340 & 4.4 & 4.853 & TRN & \\
\hline CHEMBL1357435 & 688340 & 4.45 & 5.6021 & TST & \\
\hline CHEMBL1323245 & 688340 & 4.6 & 4.7922 & TRN & \\
\hline CHEMBL1612809 & 688340 & 4.85 & 4.9346 & TRN & \\
\hline CHEMBL1611594 & 688340 & 5.25 & 5.5374 & TRN & \\
\hline CHEMBL1595211 & 688340 & 6.1 & 4.9653 & TST & \\
\hline CHEMBL1460377 & 688340 & 4.4 & 4.9207 & TRN & \\
\hline CHEMBL1541308 & 688340 & 6.2 & 5.1368 & TRN & \\
\hline CHEMBL391997 & 688340 & 4.4 & 5.0321 & TST & \\
\hline CHEMBL3197567 & 688340 & 4.35 & 4.8271 & TRN & \\
\hline CHEMBL1385646 & 688340 & 4.4 & 5.0674 & TST & \\
\hline CHEMBL1301521 & 688340 & 5.4 & 4.7784 & TRN & \\
\hline CHEMBL1323844 & 688340 & 6.0 & 4.7429 & TRN & \\
\hline CHEMBL1573757 & 688340 & 6.2 & 5.1446 & TRN & \\
\hline CHEMBL1434622 & 688340 & 5.2 & 4.7185 & TRN & \\
\hline CHEMBL65374 & 688340 & 4.65 & 5.1834 & TRN & \\
\hline CHEMBL1512560 & 688340 & 7.5498 & 5.3447 & TRN & \\
\hline CHEMBL1495043 & 688340 & 4.55 & 5.006 & TRN & \\
\hline CHEMBL1308296 & 688340 & 4.5 & 4.7909 & TRN & \\
\hline CHEMBL 3197435 & 688340 & 4.75 & 5.0002 & TRN & \\
\hline CHEMBL1502942 & 688340 & 4.75 & 5.2932 & TRN & \\
\hline CHEMBL1580672 & 688340 & 4.4 & 5.0083 & TRN & \\
\hline
\end{tabular}




\begin{tabular}{|c|c|c|c|c|c|}
\hline \multicolumn{6}{|c|}{ Supplemental Table S2.txt } \\
\hline CHEMBL1384377 & 688340 & 4.55 & 5.3588 & TRN & \\
\hline CHEMBL1378735 & 688340 & 4.45 & 4.7103 & TRN & \\
\hline CHEMBL1507941 & 688340 & 5.25 & 4.8495 & TST & \\
\hline CHEMBL1318103 & 688340 & 5.6 & 5.0219 & TRN & \\
\hline CHEMBL1560046 & 688340 & 5.2 & 5.0353 & TST & \\
\hline CHEMBL1343163 & 688340 & 4.65 & 4.8315 & TRN & \\
\hline CHEMBL1421043 & 688340 & 4.65 & 4.9052 & TRN & \\
\hline CHEMBL1444086 & 688340 & 4.5 & 4.9737 & TRN & \\
\hline CHEMBL1377992 & 688340 & 4.55 & 4.7548 & TST & \\
\hline CHEMBL1438614 & 688340 & 5.6 & 4.9997 & TRN & \\
\hline CHEMBL1416496 & 688340 & 5.5 & 4.9695 & TRN & \\
\hline CHEMBL1388202 & 688340 & 5.5 & 4.6517 & TRN & \\
\hline CHEMBL1438738 & 688340 & 4.65 & 4.8877 & TRN & \\
\hline CHEMBL1449141 & 688340 & 4.75 & 5.1052 & TRN & \\
\hline CHEMBL1376523 & 688340 & 6.95 & 5.6126 & TRN & \\
\hline CHEMBL1564189 & 688340 & 6.3 & 5.2921 & TRN & \\
\hline CHEMBL1433294 & 688340 & 4.5 & 4.8448 & TST & \\
\hline CHEMBL1441018 & 688340 & 4.05 & 5.3294 & TST & \\
\hline CHEMBL 3145108 & 688340 & 4.4 & 5.24299 & 7999999999 & TRN \\
\hline CHEMBL 3198743 & 688340 & 6.5 & 4.9323 & TRN & \\
\hline CHEMBL1412190 & 688340 & 4.5 & 4.5581 & TRN & \\
\hline CHEMBL1420321 & 688340 & 4.8 & 4.6012 & TST & \\
\hline CHEMBL1543965 & 688340 & 4.6 & 4.7405 & TRN & \\
\hline CHEMBL1470074 & 688340 & 5.2 & 5.4048 & TRN & \\
\hline CHEMBL1321156 & 688340 & 5.4 & 4.7823 & TRN & \\
\hline CHEMBL1488973 & 688340 & 4.5 & 5.0668 & TST & \\
\hline CHEMBL1348115 & 688340 & 4.6 & 4.8581 & TRN & \\
\hline CHEMBL1463683 & 688340 & 4.55 & 4.7055 & TRN & \\
\hline CHEMBL1995645 & 688340 & 4.75 & 5.012 & TRN & \\
\hline CHEMBL1467696 & 688340 & 4.95 & 5.1823 & TRN & \\
\hline CHEMBL1364080 & 688340 & 4.45 & 4.9255 & TRN & \\
\hline CHEMBL1478546 & 688340 & 4.4 & 4.9841 & TRN & \\
\hline CHEMBL372629 & 688340 & 4.7 & 4.765 & TST & \\
\hline CHEMBL1555603 & 688340 & 6.5 & 5.2489 & TRN & \\
\hline CHEMBL1578953 & 688340 & 4.5 & 4.7181 & TRN & \\
\hline CHEMBL1552902 & 688340 & 4.5 & 4.8655 & TRN & \\
\hline CHEMBL1583593 & 688340 & 5.4 & 5.2651 & TRN & \\
\hline CHEMBL1345839 & 688340 & 4.9 & 5.0942 & TRN & \\
\hline CHEMBL1991234 & 688340 & 4.8 & 4.7204 & TRN & \\
\hline CHEMBL1455044 & 688340 & 4.85 & 5.0851 & TRN & \\
\hline CHEMBL1383103 & 688340 & 4.5 & 5.0749 & TRN & \\
\hline CHEMBL1597344 & 688340 & 4.95 & 5.0705 & TRN & \\
\hline CHEMBL1481557 & 688340 & 5.8 & 5.2826 & TST & \\
\hline CHEMBL1525867 & 688340 & 4.55 & 5.1392 & TRN & \\
\hline CHEMBL1334710 & 688340 & 4.65 & 4.9482 & TRN & \\
\hline CHEMBL1526817 & 688340 & 7.0 & 5.1754 & TST & \\
\hline CHEMBL1502267 & 688340 & 4.45 & 4.8263 & TRN & \\
\hline CHEMBL1524972 & 688340 & 4.9 & 4.8042 & TRN & \\
\hline
\end{tabular}




\begin{tabular}{|c|c|c|c|c|c|}
\hline \\
\hline CHEMBL1598442 & 688340 & 5.4 & 4.8482 & TRN & \\
\hline CHEMBL1481798 & 688340 & 4.0 & 5.0586 & TRN & \\
\hline CHEMBL1392177 & 688340 & 5.05 & 5.2143 & TST & \\
\hline CHEMBL3194431 & 688340 & 4.95 & 4.8558 & TRN & \\
\hline CHEMBL1440687 & 688340 & 4.5 & 5.0507 & TRN & \\
\hline CHEMBL1410271 & 688340 & 4.6 & 4.8629 & TRN & \\
\hline CHEMBL1426749 & 688340 & 5.2 & 4.8462 & TRN & \\
\hline CHEMBL1412005 & 688340 & 5.15 & 4.8867 & TST & \\
\hline CHEMBL1573589 & 688340 & 6.35 & 5.0575 & TRN & \\
\hline CHEMBL1361619 & 688340 & 4.05 & 5.0857 & TRN & \\
\hline CHEMBL1993788 & 688340 & 4.45 & 4.7448 & TRN & \\
\hline CHEMBL1496434 & 688340 & 4.75 & 5.2077 & TRN & \\
\hline CHEMBL2003806 & 688340 & 4.75 & 4.7791 & TRN & \\
\hline CHEMBL1545300 & 688340 & 6.1 & 4.8798 & TRN & \\
\hline CHEMBL1429630 & 688340 & 5.2 & 4.9326 & TRN & \\
\hline CHEMBL1558081 & 688340 & 4.6 & 5.0656 & TRN & \\
\hline CHEMBL1399339 & 688340 & 5.6 & 5.2948 & TRN & \\
\hline CHEMBL1588368 & 688340 & 6.25 & 5.0318 & TRN & \\
\hline CHEMBL1351460 & 688340 & 4.8 & 5.0329 & TST & \\
\hline CHEMBL1319647 & 688340 & 6.4 & 4.9536 & TST & \\
\hline CHEMBL3193544 & 688340 & 4.55 & 5.0567 & TST & \\
\hline CHEMBL1304265 & 688340 & 4.7 & 5.0287 & TRN & \\
\hline CHEMBL1329055 & 688340 & 4.45 & 5.1424 & TRN & \\
\hline CHEMBL1417546 & 688340 & 5.0 & 5.1443 & TRN & \\
\hline CHEMBL1523916 & 688340 & 4.4 & 5.0963 & TST & \\
\hline CHEMBL1476925 & 688340 & 4.4 & 5.4954 & TST & \\
\hline CHEMBL1549825 & 688340 & 5.4 & 4.6516 & TRN & \\
\hline CHEMBL1363577 & 688340 & 4.25 & 5.5808 & TRN & \\
\hline CHEMBL1448322 & 688340 & 4.5 & 4.7297 & TRN & \\
\hline CHEMBL1466301 & 688340 & 4.6 & 5.0397 & TRN & \\
\hline CHEMBL1384904 & 688340 & 4.4 & 4.9165 & TRN & \\
\hline CHEMBL1413228 & 688340 & 4.35 & 5.29799 & 9999999999 & TRN \\
\hline CHEMBL1380145 & 688340 & 4.5 & 4.9434 & TRN & \\
\hline CHEMBL1329140 & 688340 & 4.6 & 4.69 & TST & \\
\hline CHEMBL1495928 & 688340 & 5.95 & 4.9936 & TRN & \\
\hline CHEMBL3191655 & 688340 & 4.45 & 4.5654 & TRN & \\
\hline CHEMBL1583472 & 688340 & 7.0 & 5.3914 & TRN & \\
\hline CHEMBL1480945 & 688340 & 5.1 & 4.6659 & TST & \\
\hline CHEMBL1509804 & 688340 & 4.8 & 4.9465 & TRN & \\
\hline CHEMBL1500349 & 688340 & 5.15 & 5.1809 & TRN & \\
\hline CHEMBL1335622 & 688340 & 5.55 & 4.8693 & TRN & \\
\hline CHEMBL1599034 & 688340 & 4.0 & 5.2904 & TRN & \\
\hline CHEMBL1491358 & 688340 & 6.15 & 5.5654 & TRN & \\
\hline CHEMBL1573782 & 688340 & 4.5 & 4.9259 & TRN & \\
\hline CHEMBL1517774 & 688340 & 5.0 & 4.7924 & TRN & \\
\hline CHEMBL1351967 & 688340 & 7.0501 & 4.5296 & TRN & \\
\hline CHEMBL1608355 & 688340 & 4.65 & 4.5228 & TRN & \\
\hline CHEMBL1578599 & 688340 & 5.15 & 5.3886 & TRN & \\
\hline & & & & $281 \epsilon$ & \\
\hline
\end{tabular}




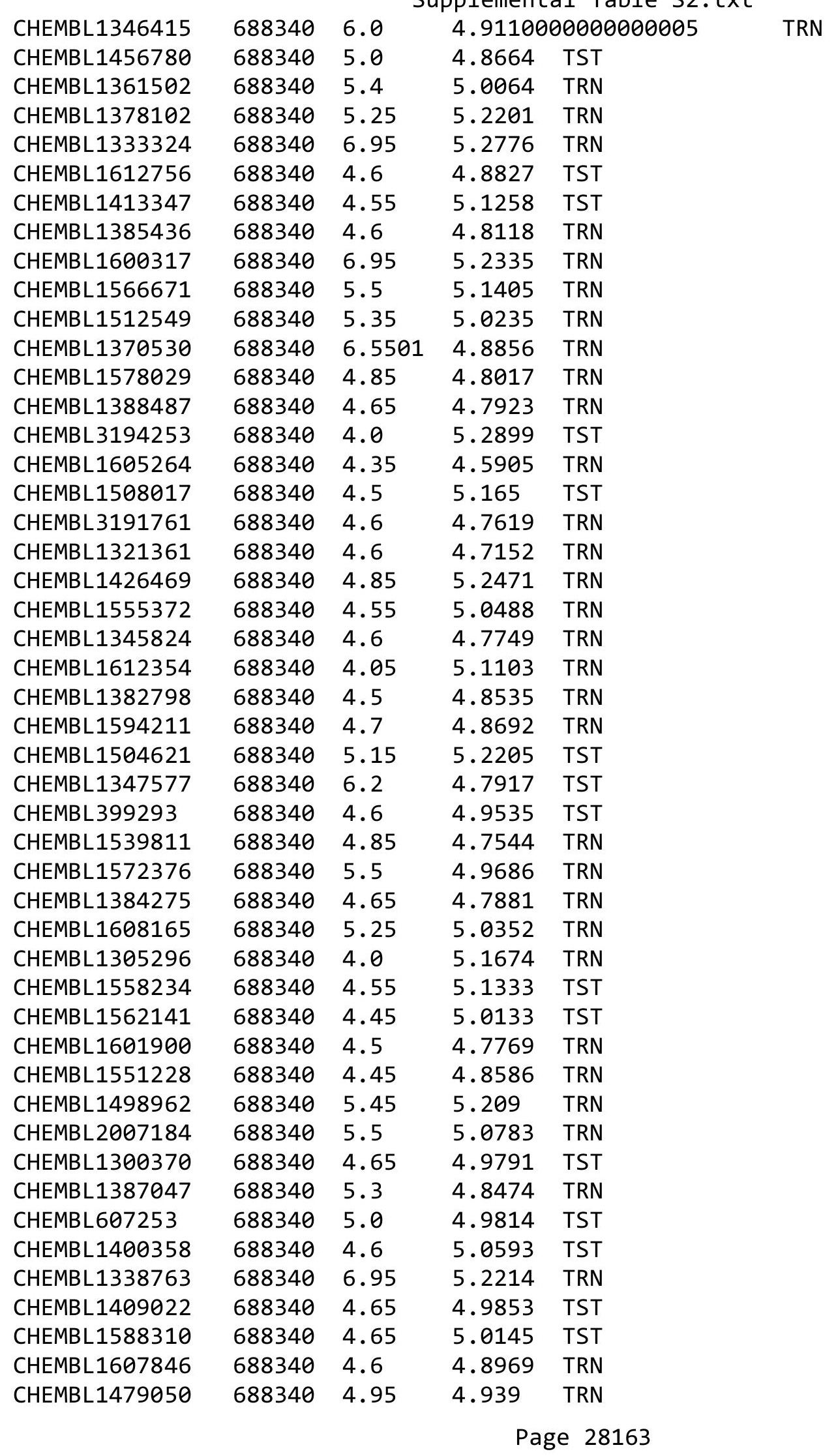




\begin{tabular}{|c|c|c|c|c|}
\hline \multicolumn{5}{|c|}{ Supplemental Table S2.txt } \\
\hline CHEMBL1390522 & 688340 & 4.0 & 5.2062 & TST \\
\hline CHEMBL1491726 & 688340 & 5.0 & 5.3523 & TRN \\
\hline CHEMBL1582279 & 688340 & 4.4 & 5.1157 & TRN \\
\hline CHEMBL 2000577 & 688340 & 5.0 & 4.9909 & TRN \\
\hline CHEMBL3190594 & 688340 & 4.55 & 4.7863 & TRN \\
\hline CHEMBL1371693 & 688340 & 4.55 & 4.7505 & TRN \\
\hline CHEMBL1453782 & 688340 & 4.55 & 4.7728 & TRN \\
\hline CHEMBL1576284 & 688340 & 4.85 & 5.0198 & TRN \\
\hline CHEMBL1327639 & 688340 & 6.5 & 5.0516 & TRN \\
\hline CHEMBL3189548 & 688340 & 6.5501 & 4.5885 & TST \\
\hline CHEMBL1443017 & 688340 & 5.35 & 5.1516 & TRN \\
\hline CHEMBL1578568 & 688340 & 5.3 & 4.9831 & TRN \\
\hline CHEMBL1465164 & 688340 & 4.75 & 4.8387 & TRN \\
\hline CHEMBL1485310 & 688340 & 4.4 & 4.7832 & TRN \\
\hline CHEMBL1330857 & 688340 & 6.15 & 5.1576 & TST \\
\hline CHEMBL1335363 & 688340 & 4.5 & 4.7675 & TRN \\
\hline CHEMBL1398276 & 688340 & 5.65 & 5.3381 & TRN \\
\hline CHEMBL1457798 & 688340 & 5.15 & 5.0871 & TST \\
\hline CHEMBL1994910 & 688340 & 5.7 & 4.9125 & TRN \\
\hline CHEMBL1604163 & 688340 & 4.85 & 4.6425 & TRN \\
\hline CHEMBL1349662 & 688340 & 8.0506 & 4.9329 & TRN \\
\hline CHEMBL1609438 & 688340 & 5.75 & 5.2823 & TST \\
\hline CHEMBL1518568 & 688340 & 4.0 & 5.0515 & TST \\
\hline CHEMBL1415125 & 688340 & 7.0 & 5.2476 & TRN \\
\hline CHEMBL1473251 & 688340 & 7.3497 & 5.3565 & TST \\
\hline CHEMBL1489464 & 688340 & 5.9 & 5.5084 & TRN \\
\hline CHEMBL1582656 & 688340 & 5.55 & 5.0282 & TRN \\
\hline CHEMBL1378469 & 688340 & 6.0 & 4.9152 & TST \\
\hline CHEMBL1582242 & 688340 & 4.4 & 4.9019 & TRN \\
\hline CHEMBL1545948 & 688340 & 4.75 & 5.0088 & TRN \\
\hline CHEMBL1359920 & 688340 & 6.35 & 4.8886 & TRN \\
\hline CHEMBL193769 & 688340 & 4.5 & 4.9069 & TRN \\
\hline CHEMBL1346219 & 688340 & 5.2 & 4.9585 & TRN \\
\hline CHEMBL1383856 & 688340 & 4.65 & 4.8036 & TRN \\
\hline CHEMBL1360224 & 688340 & 4.5 & 4.9416 & TRN \\
\hline CHEMBL1408390 & 688340 & 4.4 & 5.0289 & TRN \\
\hline CHEMBL1449832 & 688340 & 4.65 & 5.0634 & TRN \\
\hline CHEMBL1585417 & 688340 & 7.5003 & 5.0396 & TRN \\
\hline CHEMBL1598910 & 688340 & 4.6 & 4.7689 & TRN \\
\hline CHEMBL3194157 & 688340 & 4.45 & 4.9909 & TST \\
\hline CHEMBL1451772 & 688340 & 4.8 & 4.467 & TRN \\
\hline CHEMBL1386115 & 688340 & 5.1 & 5.0906 & TRN \\
\hline CHEMBL1545242 & 688340 & 5.25 & 5.0683 & TST \\
\hline CHEMBL1547115 & 688340 & 5.5 & 4.8628 & TRN \\
\hline CHEMBL1519538 & 688340 & 5.4 & 5.3362 & TRN \\
\hline CHEMBL1398061 & 688340 & 5.2 & 4.9897 & TST \\
\hline CHEMBL1452158 & 688340 & 4.45 & 4.9323 & TRN \\
\hline CHEMBL1557350 & 688340 & 3.95 & 5.4195 & TRN \\
\hline
\end{tabular}




\begin{tabular}{|c|c|c|c|c|}
\hline \multicolumn{5}{|c|}{ Supplemental Table S2.txt } \\
\hline CHEMBL1436679 & 688340 & 5.35 & 5.0645 & TRN \\
\hline CHEMBL3190813 & 688340 & 5.55 & 4.8536 & TRN \\
\hline CHEMBL1421490 & 688340 & 4.4 & 5.0614 & TRN \\
\hline CHEMBL1328207 & 688340 & 4.5 & 5.224 & TST \\
\hline CHEMBL1533303 & 688340 & 4.5 & 4.8664 & TST \\
\hline CHEMBL1514442 & 688340 & 6.1 & 4.9302 & TST \\
\hline CHEMBL1385916 & 688340 & 6.15 & 5.5017 & TRN \\
\hline CHEMBL1490317 & 688340 & 4.35 & 5.318 & TRN \\
\hline CHEMBL1346468 & 688340 & 4.45 & 4.3963 & TRN \\
\hline CHEMBL1543474 & 688340 & 4.4 & 5.0858 & TRN \\
\hline CHEMBL1399171 & 688340 & 5.5 & 5.1225 & TST \\
\hline CHEMBL1594861 & 688340 & 4.45 & 4.6766 & TRN \\
\hline CHEMBL3196589 & 688340 & 4.4 & 4.7818 & TRN \\
\hline CHEMBL1338027 & 688340 & 4.45 & 4.8144 & TRN \\
\hline CHEMBL1416130 & 688340 & 4.6 & 5.0037 & TRN \\
\hline CHEMBL1519727 & 688340 & 5.1 & 5.0545 & TRN \\
\hline CHEMBL1330122 & 688340 & 4.45 & 4.835 & TRN \\
\hline CHEMBL1318943 & 688340 & 4.65 & 4.7009 & TRN \\
\hline CHEMBL1353445 & 688340 & 5.35 & 5.018 & TST \\
\hline CHEMBL1353489 & 688340 & 4.7 & 4.6617 & TRN \\
\hline CHEMBL1576354 & 688340 & 4.55 & 5.1478 & TRN \\
\hline CHEMBL1484214 & 688340 & 4.55 & 4.6985 & TRN \\
\hline CHEMBL198630 & 688340 & 4.45 & 5.3021 & TRN \\
\hline CHEMBL1375459 & 688340 & 4.4 & 5.2714 & TRN \\
\hline CHEMBL1356731 & 688340 & 6.45 & 5.1252 & TRN \\
\hline CHEMBL1497915 & 688340 & 4.4 & 4.8775 & TRN \\
\hline CHEMBL1531895 & 688340 & 4.4 & 4.6971 & TRN \\
\hline CHEMBL1527252 & 688340 & 5.4 & 5.1525 & TST \\
\hline CHEMBL1427972 & 688340 & 4.55 & 4.4292 & TRN \\
\hline CHEMBL1482988 & 688340 & 4.5 & 4.9428 & TRN \\
\hline CHEMBL1404753 & 688340 & 4.4 & 4.8931 & TST \\
\hline CHEMBL1453603 & 688340 & 4.6 & 5.008 & TST \\
\hline CHEMBL1531037 & 688340 & 4.6 & 4.7517 & TRN \\
\hline CHEMBL1317560 & 688340 & 4.0 & 5.3184 & TRN \\
\hline CHEMBL1558543 & 688340 & 4.8 & 5.0211 & TRN \\
\hline CHEMBL1519313 & 688340 & 4.6 & 5.0744 & TST \\
\hline CHEMBL 1316327 & 688340 & 4.45 & 5.1507 & TRN \\
\hline CHEMBL3197949 & 688340 & 6.0 & 4.9066 & TRN \\
\hline CHEMBL1565819 & 688340 & 5.2 & 4.7273 & TRN \\
\hline CHEMBL1384171 & 688340 & 4.5 & 4.9876 & TRN \\
\hline CHEMBL1386841 & 688340 & 6.95 & 5.2609 & TRN \\
\hline CHEMBL1968356 & 688340 & 5.5 & 5.0936 & TST \\
\hline CHEMBL1540863 & 688340 & 4.75 & 5.7465 & TST \\
\hline CHEMBL3195871 & 688340 & 4.6 & 4.8093 & TST \\
\hline CHEMBL1560810 & 688340 & 4.4 & 5.3999 & TRN \\
\hline CHEMBL3213606 & 688340 & 4.6 & 4.7764 & TRN \\
\hline CHEMBL1493353 & 688340 & 4.4 & 4.6444 & TRN \\
\hline CHEMBL1985759 & 688340 & 4.95 & 5.0055 & TRN \\
\hline
\end{tabular}




\begin{tabular}{|c|c|c|c|c|}
\hline & & & upplement & al $\mathrm{T}$ \\
\hline CHEMBL1403442 & 688340 & 4.4 & 4.6484 & TRN \\
\hline CHEMBL1317636 & 688340 & 4.6 & 4.9955 & TRN \\
\hline CHEMBL1391158 & 688340 & 4.95 & 5.0057 & TRN \\
\hline CHEMBL1472878 & 688340 & 4.4 & 4.8552 & TRN \\
\hline CHEMBL1481257 & 688340 & 4.4 & 5.0403 & TST \\
\hline CHEMBL3145010 & 688340 & 4.8 & 5.2445 & TRN \\
\hline CHEMBL1428455 & 688340 & 5.55 & 5.1155 & TRN \\
\hline CHEMBL3190624 & 688340 & 5.1 & 5.3688 & TRN \\
\hline CHEMBL1339889 & 688340 & 5.2 & 4.9419 & TRN \\
\hline CHEMBL1584995 & 688340 & 5.4 & 5.5058 & TRN \\
\hline CHEMBL1380748 & 688340 & 4.55 & 5.2508 & TRN \\
\hline CHEMBL3196684 & 688340 & 4.6 & 4.8382 & TRN \\
\hline CHEMBL1312334 & 688340 & 4.45 & 4.6957 & TST \\
\hline CHEMBL1478158 & 688340 & 4.75 & 4.9444 & TRN \\
\hline CHEMBL1495396 & 688340 & 7.0 & 5.1993 & TST \\
\hline CHEMBL3190671 & 688340 & 4.5 & 5.2048 & TST \\
\hline CHEMBL1449476 & 688340 & 6.1 & 5.35 & TRN \\
\hline CHEMBL1456279 & 688340 & 4.45 & 5.3588 & TRN \\
\hline CHEMBL1517787 & 688340 & 5.65 & 5.0302 & TRN \\
\hline CHEMBL1518359 & 688340 & 4.55 & 4.744 & TRN \\
\hline CHEMBL1510650 & 688340 & 5.2 & 5.2452 & TRN \\
\hline CHEMBL1437961 & 688340 & 4.7 & 5.1672 & TRN \\
\hline CHEMBL1571560 & 688340 & 4.8 & 4.4382 & TST \\
\hline CHEMBL1482623 & 688340 & 5.2 & 5.7217 & TRN \\
\hline CHEMBL1477352 & 688340 & 7.0 & 5.0886 & TRN \\
\hline CHEMBL56393 & 688340 & 6.3 & 5.1107 & TRN \\
\hline CHEMBL1381017 & 688340 & 4.4 & 5.4412 & TRN \\
\hline CHEMBL3193110 & 688340 & 4.55 & 4.9434 & TRN \\
\hline CHEMBL1315061 & 688340 & 4.8 & 5.4828 & TRN \\
\hline CHEMBL1382468 & 688340 & 4.5 & 4.8411 & TST \\
\hline CHEMBL1413807 & 688340 & 6.0 & 5.0302 & TRN \\
\hline CHEMBL1339102 & 688340 & 4.4 & 5.5398 & TRN \\
\hline CHEMBL1302308 & 688340 & 6.0 & 5.1517 & TRN \\
\hline CHEMBL1481874 & 688340 & 5.2 & 5.0027 & TRN \\
\hline CHEMBL1381510 & 688340 & 4.5 & 5.4274 & TRN \\
\hline CHEMBL1309335 & 688340 & 5.25 & 5.2948 & TRN \\
\hline CHEMBL1384365 & 688340 & 4.5 & 4.8227 & TRN \\
\hline CHEMBL1585109 & 688340 & 4.8 & 5.0858 & TRN \\
\hline CHEMBL1410665 & 688340 & 4.4 & 5.263 & TRN \\
\hline CHEMBL1987820 & 688340 & 5.65 & 4.8018 & TRN \\
\hline CHEMBL1539228 & 688340 & 6.1 & 4.9951 & TST \\
\hline CHEMBL1490468 & 688340 & 6.1 & 5.4383 & TRN \\
\hline CHEMBL1315243 & 688340 & 4.65 & 4.9191 & TRN \\
\hline CHEMBL1546532 & 688340 & 4.4 & 5.3203 & TST \\
\hline CHEMBL1509303 & 688340 & 4.7 & 4.8763 & TST \\
\hline CHEMBL1360750 & 688340 & 5.45 & 5.4365 & TST \\
\hline CHEMBL3209496 & 688340 & 4.55 & 4.815 & TRN \\
\hline CHEMBL1372459 & 688340 & 4.5 & 4.8217 & TRN \\
\hline
\end{tabular}




\begin{tabular}{|c|c|c|c|c|}
\hline \multicolumn{5}{|c|}{ Supplemental Table S2.txt } \\
\hline CHEMBL1507162 & 688340 & 4.55 & 4.8049 & TRN \\
\hline CHEMBL1469332 & 688340 & 4.4 & 4.7675 & TST \\
\hline CHEMBL1455101 & 688340 & 4.5 & 5.0851 & TRN \\
\hline CHEMBL1462993 & 688340 & 4.55 & 4.5909 & TRN \\
\hline CHEMBL1473629 & 688340 & 4.4 & 4.5878 & TRN \\
\hline CHEMBL1344305 & 688340 & 4.4 & 4.7709 & TRN \\
\hline CHEMBL1562046 & 688340 & 4.75 & 4.8262 & TRN \\
\hline CHEMBL1583260 & 688340 & 5.05 & 4.7064 & TRN \\
\hline CHEMBL1518016 & 688340 & 4.45 & 4.6998 & TRN \\
\hline CHEMBL1362580 & 688340 & 4.55 & 4.8028 & TRN \\
\hline CHEMBL538146 & 688340 & 4.7 & 5.2787 & TST \\
\hline CHEMBL1345787 & 688340 & 4.6 & 4.7398 & TRN \\
\hline CHEMBL1326588 & 688340 & 5.45 & 5.1184 & TRN \\
\hline CHEMBL1569713 & 688340 & 6.1 & 5.2692 & TST \\
\hline CHEMBL3196386 & 688340 & 4.55 & 4.6657 & TST \\
\hline CHEMBL1557098 & 688340 & 4.6 & 4.8436 & TRN \\
\hline CHEMBL1468698 & 688340 & 5.25 & 4.9783 & TRN \\
\hline CHEMBL1431104 & 688340 & 4.8 & 4.9841 & TST \\
\hline CHEMBL1347561 & 688340 & 6.2 & 4.9384 & TST \\
\hline CHEMBL1359411 & 688340 & 6.05 & 5.2519 & TST \\
\hline CHEMBL1523806 & 688340 & 5.05 & 5.3011 & TRN \\
\hline CHEMBL1416845 & 688340 & 4.4 & 4.868 & TRN \\
\hline CHEMBL1339695 & 688340 & 4.5 & 4.9797 & TRN \\
\hline CHEMBL1606978 & 688340 & 4.55 & 4.8328 & TRN \\
\hline CHEMBL3192270 & 688340 & 5.2 & 4.6009 & TRN \\
\hline CHEMBL1543654 & 688340 & 4.45 & 4.975 & TRN \\
\hline CHEMBL1504661 & 688340 & 5.0 & 5.3457 & TST \\
\hline CHEMBL1484695 & 688340 & 4.8 & 5.0708 & TRN \\
\hline CHEMBL1559061 & 688340 & 4.6 & 4.6817 & TRN \\
\hline CHEMBL1320915 & 688340 & 4.4 & 4.7549 & TRN \\
\hline CHEMBL1612672 & 688340 & 5.0 & 4.8475 & TRN \\
\hline CHEMBL1339474 & 688340 & 5.3 & 5.2926 & TRN \\
\hline CHEMBL1608028 & 688340 & 6.45 & 4.843 & TST \\
\hline CHEMBL1470056 & 688340 & 4.6 & 4.6929 & TRN \\
\hline CHEMBL1511661 & 688340 & 4.55 & 5.1492 & TRN \\
\hline CHEMBL483325 & 688340 & 7.5003 & 4.999 & TRN \\
\hline CHEMBL3208475 & 688340 & 4.7 & 4.9531 & TRN \\
\hline CHEMBL1327914 & 688340 & 4.7 & 5.1409 & TRN \\
\hline CHEMBL1601496 & 688340 & 4.5 & 4.7604 & TRN \\
\hline CHEMBL1337928 & 688340 & 4.7 & 4.7336 & TST \\
\hline CHEMBL1382652 & 688340 & 5.5 & 4.6995 & TRN \\
\hline CHEMBL1418678 & 688340 & 5.3 & 4.9541 & TRN \\
\hline CHEMBL1610677 & 688340 & 5.35 & 4.8619 & TRN \\
\hline CHEMBL1501298 & 688340 & 6.35 & 4.8885 & TRN \\
\hline CHEMBL1389045 & 688340 & 7.0 & 5.2792 & TRN \\
\hline CHEMBL1583198 & 688340 & 4.55 & 4.7958 & TRN \\
\hline CHEMBL1594460 & 688340 & 5.95 & 5.2187 & TRN \\
\hline CHEMBL1512670 & 688340 & 6.05 & 5.0907 & TRN \\
\hline
\end{tabular}




\begin{tabular}{|c|c|c|c|c|c|}
\hline \multicolumn{6}{|c|}{ Supplemental Table S2.txt } \\
\hline CHEMBL1322783 & 688340 & 4.4 & 4.7305 & TRN & \\
\hline CHEMBL1535453 & 688340 & 4.95 & 4.9772 & TRN & \\
\hline CHEMBL1365370 & 688340 & 5.5 & 5.1378 & TRN & \\
\hline CHEMBL1303798 & 688340 & 4.35 & 4.9884 & TST & \\
\hline CHEMBL1452360 & 688340 & 5.0 & 5.3592 & TST & \\
\hline CHEMBL1407084 & 688340 & 4.4 & 4.8712 & TRN & \\
\hline CHEMBL1610801 & 688340 & 4.65 & 4.9475 & TST & \\
\hline CHEMBL1438771 & 688340 & 4.6 & 4.7632 & TRN & \\
\hline CHEMBL1460284 & 688340 & 5.15 & 5.4012 & TRN & \\
\hline CHEMBL1468845 & 688340 & 4.4 & 4.6212 & TRN & \\
\hline CHEMBL 2000340 & 688340 & 4.9 & 5.0302 & TRN & \\
\hline CHEMBL1323132 & 688340 & 4.8 & 5.0748 & TRN & \\
\hline CHEMBL1970527 & 688340 & 5.35 & 4.8522 & TRN & \\
\hline CHEMBL1325997 & 688340 & 5.25 & 5.444 & TST & \\
\hline CHEMBL1442059 & 688340 & 4.45 & 4.6555 & TRN & \\
\hline CHEMBL1304445 & 688340 & 4.85 & 4.8739 & TRN & \\
\hline CHEMBL242112 & 688340 & 4.7 & 5.0322 & TRN & \\
\hline CHEMBL1538884 & 688340 & 7.1002 & 5.3375 & TST & \\
\hline CHEMBL1323442 & 688340 & 4.4 & 5.1016 & TRN & \\
\hline CHEMBL1544622 & 688340 & 4.7 & 4.817 & TRN & \\
\hline CHEMBL1453687 & 688340 & 4.4 & 5.4188 & TRN & \\
\hline CHEMBL1386982 & 688340 & 5.1 & 5.5058 & TRN & \\
\hline CHEMBL1429871 & 688340 & 4.7 & 4.9301 & TST & \\
\hline CHEMBL1468287 & 688340 & 6.0 & 4.8939 & TST & \\
\hline CHEMBL1336127 & 688340 & 4.4 & 5.1214 & TRN & \\
\hline CHEMBL1995550 & 688340 & 4.7 & 4.8815 & TRN & \\
\hline CHEMBL1330671 & 688340 & 4.75 & 4.9224 & TRN & \\
\hline CHEMBL1460426 & 688340 & 4.95 & 5.6115 & TRN & \\
\hline CHEMBL1583321 & 688340 & 4.85 & 4.6221 & TST & \\
\hline CHEMBL1612775 & 688340 & 5.7 & 5.2709 & TRN & \\
\hline CHEMBL1363366 & 688340 & 6.15 & 4.9054 & TRN & \\
\hline CHEMBL1315210 & 688340 & 7.5498 & 4.5553 & TRN & \\
\hline CHEMBL1601344 & 688340 & 4.55 & 4.55399 & 9999999999 & TRN \\
\hline CHEMBL1521270 & 688340 & 7.0 & 5.2147 & TST & \\
\hline CHEMBL1604322 & 688340 & 4.5 & 5.004 & TRN & \\
\hline CHEMBL1503381 & 688340 & 4.5 & 4.8812 & TST & \\
\hline CHEMBL1390647 & 688340 & 4.4 & 4.8807 & TRN & \\
\hline CHEMBL3189368 & 688340 & 6.95 & 4.8667 & TRN & \\
\hline CHEMBL3192257 & 688340 & 4.7 & 4.9499 & TST & \\
\hline CHEMBL1450946 & 688340 & 5.6 & 5.3665 & TRN & \\
\hline CHEMBL1518183 & 688340 & 5.0 & 4.9593 & TRN & \\
\hline CHEMBL1221925 & 688340 & 4.8 & 5.1205 & TRN & \\
\hline CHEMBL1391464 & 688340 & 4.65 & 4.7231 & TRN & \\
\hline CHEMBL1309254 & 688340 & 5.05 & 5.0928 & TRN & \\
\hline CHEMBL1581494 & 688340 & 4.65 & 4.9809 & TST & \\
\hline CHEMBL1488668 & 688340 & 4.65 & 4.8716 & TRN & \\
\hline CHEMBL1477741 & 688340 & 4.8 & 4.8346 & TRN & \\
\hline CHEMBL1422509 & 688340 & 4.65 & 4.9359 & TRN & \\
\hline
\end{tabular}




\begin{tabular}{|c|c|c|c|c|c|}
\hline \multicolumn{6}{|c|}{ Supplemental Table s2.txt } \\
\hline CHEMBL1519722 & 688340 & 7.0 & 5.1676 & TRN & \\
\hline CHEMBL1462639 & 688340 & 6.15 & 4.9536 & TST & \\
\hline CHEMBL1405784 & 688340 & 6.1 & 5.103 & TRN & \\
\hline CHEMBL1358230 & 688340 & 5.35 & 5.4747 & TST & \\
\hline CHEMBL1318654 & 688340 & 4.55 & 4.9217 & TRN & \\
\hline CHEMBL3210449 & 688340 & 4.95 & 5.4098 & TST & \\
\hline CHEMBL1592993 & 688340 & 6.25 & 4.7718 & TRN & \\
\hline CHEMBL1543232 & 688340 & 4.55 & 5.0406 & TST & \\
\hline CHEMBL1493660 & 688340 & 4.6 & 5.3885 & TST & \\
\hline CHEMBL1557472 & 688340 & 5.0 & 5.3381 & TST & \\
\hline CHEMBL1601578 & 688340 & 4.5 & 5.1722 & TRN & \\
\hline CHEMBL1407268 & 688340 & 5.0 & 4.5827 & TRN & \\
\hline CHEMBL1400764 & 688340 & 4.5 & 4.5465 & TRN & \\
\hline CHEMBL 3192856 & 688340 & 4.5 & 5.0094 & TRN & \\
\hline CHEMBL1489007 & 688340 & 5.15 & 4.9467 & TRN & \\
\hline CHEMBL1333441 & 688340 & 4.85 & 4.8555 & TST & \\
\hline CHEMBL1429058 & 688340 & 6.0 & 5.3204 & TRN & \\
\hline CHEMBL1432518 & 688340 & 7.0501 & 5.1192 & TRN & \\
\hline CHEMBL1362526 & 688340 & 4.45 & 4.7178 & TRN & \\
\hline CHEMBL3209766 & 688340 & 5.6 & 5.1318 & TST & \\
\hline CHEMBL1492510 & 688340 & 5.1 & 4.6429 & TST & \\
\hline CHEMBL1387163 & 688340 & 4.45 & 5.0472 & TRN & \\
\hline CHEMBL1307301 & 688340 & 4.45 & 4.921 & TRN & \\
\hline CHEMBL1463676 & 688340 & 5.0 & 5.2508 & TST & \\
\hline CHEMBL1394004 & 688340 & 4.4 & 5.4006 & TRN & \\
\hline CHEMBL1427197 & 688340 & 5.95 & 4.9682 & TST & \\
\hline CHEMBL1421507 & 688340 & 4.9 & 5.4094 & TRN & \\
\hline CHEMBL1491707 & 688340 & 5.2 & 4.95100 & 00000000005 & \\
\hline CHEMBL1451727 & 688340 & 4.7 & 5.2158 & TST & \\
\hline CHEMBL3189865 & 688340 & 5.1 & 4.7709 & TRN & \\
\hline CHEMBL1466865 & 688340 & 4.55 & 4.7605 & TRN & \\
\hline CHEMBL1521201 & 688340 & 7.0 & 5.3221 & TRN & \\
\hline CHEMBL1600957 & 688340 & 6.3 & 5.4657 & TRN & \\
\hline CHEMBL1570758 & 688340 & 4.6 & 5.1184 & TRN & \\
\hline CHEMBL1394026 & 688340 & 4.45 & 4.9706 & TRN & \\
\hline CHEMBL1533383 & 688340 & 5.05 & 5.2148 & TRN & \\
\hline CHEMBL1330585 & 688340 & 4.9 & 4.9892 & TRN & \\
\hline CHEMBL1546048 & 688340 & 5.35 & 4.9824 & TRN & \\
\hline CHEMBL1608157 & 688340 & 4.45 & 4.9731 & TRN & \\
\hline CHEMBL1497504 & 688340 & 4.35 & 5.0748 & TRN & \\
\hline CHEMBL1490983 & 688340 & 6.7001 & 5.1215 & TRN & \\
\hline CHEMBL1611211 & 688340 & 7.0 & 5.3719 & TRN & \\
\hline CHEMBL1544691 & 688340 & 4.55 & 4.8897 & TRN & \\
\hline CHEMBL3195384 & 688340 & 4.6 & 5.0325 & TRN & \\
\hline CHEMBL1497539 & 688340 & 4.85 & 4.8969 & TRN & \\
\hline CHEMBL1563280 & 688340 & 7.0 & 5.1316 & TRN & \\
\hline CHEMBL1580208 & 688340 & 5.55 & 5.0347 & TST & \\
\hline CHEMBL1335117 & 688340 & 4.55 & 4.9243 & TRN & \\
\hline
\end{tabular}




\begin{tabular}{|c|c|c|c|c|}
\hline & & & pplement & al $\mathrm{T}$ \\
\hline CHEMBL1315946 & 688340 & 4.6 & 5.1961 & TRN \\
\hline CHEMBL1349711 & 688340 & 5.5 & 5.1836 & TST \\
\hline CHEMBL1559741 & 688340 & 4.9 & 5.0332 & TRN \\
\hline CHEMBL1335299 & 688340 & 4.4 & 4.9674 & TST \\
\hline CHEMBL1517418 & 688340 & 4.4 & 4.8423 & TRN \\
\hline CHEMBL1449869 & 688340 & 6.05 & 5.1326 & TRN \\
\hline CHEMBL1488035 & 688340 & 6.15 & 5.0082 & TRN \\
\hline CHEMBL1532407 & 688340 & 4.45 & 4.5652 & TRN \\
\hline CHEMBL 3193391 & 688340 & 4.85 & 4.7584 & TRN \\
\hline CHEMBL1329997 & 688340 & 6.15 & 4.7383 & TST \\
\hline CHEMBL1472261 & 688340 & 4.5 & 4.6335 & TRN \\
\hline CHEMBL1353969 & 688340 & 5.25 & 4.8734 & TRN \\
\hline CHEMBL1534224 & 688340 & 4.85 & 4.8748 & TRN \\
\hline CHEMBL1584748 & 688340 & 4.55 & 5.0267 & TST \\
\hline CHEMBL1313870 & 688340 & 4.6 & 4.8254 & TST \\
\hline CHEMBL1458396 & 688340 & 4.5 & 4.8553 & TRN \\
\hline CHEMBL1549120 & 688340 & 4.6 & 4.8642 & TRN \\
\hline CHEMBL1453311 & 688340 & 4.95 & 4.8837 & TRN \\
\hline CHEMBL1405976 & 688340 & 4.55 & 5.2438 & TST \\
\hline CHEMBL1362864 & 688340 & 4.55 & 5.0089 & TRN \\
\hline CHEMBL1313995 & 688340 & 4.55 & 5.1677 & TRN \\
\hline CHEMBL1612428 & 688340 & 5.1 & 5.5095 & TRN \\
\hline CHEMBL1509244 & 688340 & 5.35 & 5.1734 & TRN \\
\hline CHEMBL1308058 & 688340 & 5.1 & 4.7541 & TRN \\
\hline CHEMBL1427873 & 688340 & 4.6 & 4.83 & TRN \\
\hline CHEMBL1513542 & 688340 & 4.4 & 4.7346 & TRN \\
\hline CHEMBL3193168 & 688340 & 4.4 & 4.8853 & TRN \\
\hline CHEMBL1475242 & 688340 & 4.5 & 5.0128 & TRN \\
\hline CHEMBL1386409 & 688340 & 4.45 & 5.0656 & TRN \\
\hline CHEMBL1327367 & 688340 & 5.45 & 4.9056 & TST \\
\hline CHEMBL1536653 & 688340 & 4.7 & 5.0105 & TRN \\
\hline CHEMBL 1457711 & 688340 & 6.1 & 4.8394 & TRN \\
\hline CHEMBL1427913 & 688340 & 4.55 & 4.7148 & TRN \\
\hline CHEMBL1417408 & 688340 & 4.65 & 5.2711 & TST \\
\hline CHEMBL3213353 & 688340 & 4.55 & 5.1272 & TRN \\
\hline CHEMBL1309130 & 688340 & 7.0501 & 5.1957 & TRN \\
\hline CHEMBL3192607 & 688340 & 4.65 & 5.035 & TRN \\
\hline CHEMBL1517853 & 688340 & 6.0 & 5.1418 & TRN \\
\hline CHEMBL1388399 & 688340 & 4.45 & 4.7948 & TST \\
\hline CHEMBL1351571 & 688340 & 5.45 & 4.8788 & TRN \\
\hline CHEMBL1365061 & 688340 & 4.85 & 4.7746 & TST \\
\hline CHEMBL1519448 & 688340 & 6.2 & 5.0449 & TRN \\
\hline CHEMBL1491192 & 688340 & 4.45 & 5.0211 & TST \\
\hline CHEMBL1564032 & 688340 & 7.0501 & 4.8884 & TRN \\
\hline CHEMBL1421902 & 688340 & 4.6 & 4.827 & TRN \\
\hline CHEMBL1469048 & 688340 & 5.5 & 4.8373 & TST \\
\hline CHEMBL1419960 & 688340 & 5.05 & 5.3877 & TRN \\
\hline CHEMBL1417260 & 688340 & 6.35 & 5.4139 & TRN \\
\hline
\end{tabular}




\begin{tabular}{|c|c|c|c|c|}
\hline \multicolumn{5}{|c|}{ Supplemental Table s2.txt } \\
\hline CHEMBL1554488 & 688340 & 4.35 & 5.4581 & TRN \\
\hline CHEMBL1600876 & 688340 & 4.4 & 4.628 & TST \\
\hline CHEMBL1302354 & 688340 & 6.4 & 5.2765 & TRN \\
\hline CHEMBL1309332 & 688340 & 4.55 & 4.8721 & TRN \\
\hline CHEMBL1391725 & 688340 & 5.2 & 4.8177 & TRN \\
\hline CHEMBL1582743 & 688340 & 6.5 & 5.0159 & TST \\
\hline CHEMBL1548164 & 688340 & 5.75 & 5.0179 & TRN \\
\hline CHEMBL1464237 & 688340 & 4.55 & 4.6978 & TRN \\
\hline CHEMBL1587845 & 688340 & 5.7 & 5.2357 & TRN \\
\hline CHEMBL1409954 & 688340 & 4.45 & 5.0555 & TRN \\
\hline CHEMBL1310767 & 688340 & 5.3 & 4.9717 & TRN \\
\hline CHEMBL1589602 & 688340 & 5.05 & 4.9995 & TRN \\
\hline CHEMBL1352429 & 688340 & 4.8 & 4.8088 & TRN \\
\hline CHEMBL1385363 & 688340 & 5.3 & 5.1607 & TRN \\
\hline CHEMBL 7257 & 688340 & 4.5 & 5.106 & TRN \\
\hline CHEMBL1416762 & 688340 & 4.55 & 5.1312 & TRN \\
\hline CHEMBL1498144 & 688340 & 4.55 & 4.6968 & TRN \\
\hline CHEMBL1596938 & 688340 & 5.35 & 4.8621 & TST \\
\hline CHEMBL1438625 & 688340 & 6.1 & 5.4653 & TRN \\
\hline CHEMBL1707818 & 688340 & 4.85 & 4.8379 & TST \\
\hline CHEMBL1334064 & 688340 & 7.0501 & 5.3528 & TST \\
\hline CHEMBL1364429 & 688340 & 4.6 & 5.3287 & TRN \\
\hline CHEMBL1466718 & 688340 & 5.4 & 5.0491 & TST \\
\hline CHEMBL1428136 & 688340 & 4.6 & 5.4844 & TRN \\
\hline CHEMBL1356226 & 688340 & 4.4 & 5.0045 & TST \\
\hline CHEMBL1452122 & 688340 & 5.25 & 5.1938 & TRN \\
\hline CHEMBL1416282 & 688340 & 6.1 & 5.124 & TST \\
\hline CHEMBL1369957 & 688340 & 6.1 & 4.672 & TST \\
\hline CHEMBL1473579 & 688340 & 4.75 & 4.9491 & TRN \\
\hline CHEMBL1368934 & 688340 & 4.5 & 5.1776 & TRN \\
\hline CHEMBL1492290 & 688340 & 6.4 & 5.4246 & TRN \\
\hline CHEMBL1360063 & 688340 & 5.2 & 5.2927 & TRN \\
\hline CHEMBL1973042 & 688340 & 5.05 & 4.9249 & TRN \\
\hline CHEMBL1609552 & 688340 & 4.9 & 5.1891 & TRN \\
\hline CHEMBL1348716 & 688340 & 8.699 & 5.0167 & TST \\
\hline CHEMBL142868 & 688340 & 4.55 & 4.9708 & TRN \\
\hline CHEMBL1503781 & 688340 & 5.0 & 5.0899 & TST \\
\hline CHEMBL1551917 & 688340 & 4.45 & 4.9104 & TRN \\
\hline CHEMBL1592706 & 688340 & 6.0 & 5.1153 & TRN \\
\hline CHEMBL1447016 & 688340 & 4.55 & 4.8223 & TRN \\
\hline CHEMBL1342604 & 688340 & 4.55 & 5.1357 & TRN \\
\hline CHEMBL1612081 & 688340 & 4.6 & 4.6515 & TRN \\
\hline CHEMBL1425909 & 688340 & 4.5 & 4.9393 & TST \\
\hline CHEMBL1323243 & 688340 & 4.85 & 4.8306 & TST \\
\hline CHEMBL1594102 & 688340 & 4.5 & 4.6121 & TRN \\
\hline CHEMBL11475 & 688340 & 6.1 & 5.0987 & TST \\
\hline CHEMBL496729 & 688340 & 4.4 & 4.9818 & TRN \\
\hline CHEMBL1383822 & 688340 & 4.45 & 4.9038 & TRN \\
\hline
\end{tabular}




\begin{tabular}{|c|c|c|c|c|}
\hline \multicolumn{5}{|c|}{ Supplemental Table S2.txt } \\
\hline CHEMBL1503135 & 688340 & 4.55 & 5.0289 & TRN \\
\hline CHEMBL1525995 & 688340 & 4.8 & 4.8803 & TST \\
\hline CHEMBL1410986 & 688340 & 4.95 & 5.3034 & TRN \\
\hline CHEMBL1309171 & 688340 & 4.4 & 4.7238 & TRN \\
\hline CHEMBL1531785 & 688340 & 4.35 & 4.8812 & TRN \\
\hline CHEMBL591126 & 688340 & 4.4 & 4.544 & TRN \\
\hline CHEMBL2311905 & 688340 & 4.8 & 4.9862 & TRN \\
\hline CHEMBL1486792 & 688340 & 4.4 & 4.9207 & TRN \\
\hline CHEMBL1564035 & 688340 & 4.4 & 5.0384 & TST \\
\hline CHEMBL1592592 & 688340 & 4.7 & 4.9866 & TRN \\
\hline CHEMBL3196342 & 688340 & 4.4 & 4.6863 & TRN \\
\hline CHEMBL2028179 & 688340 & 5.0 & 5.062 & TST \\
\hline CHEMBL1300404 & 688340 & 4.35 & 5.2957 & TRN \\
\hline CHEMBL1465949 & 688340 & 5.2 & 5.6885 & TRN \\
\hline CHEMBL1447011 & 688340 & 4.45 & 5.0949 & TRN \\
\hline CHEMBL1605058 & 688340 & 4.4 & 5.5818 & TRN \\
\hline CHEMBL1336637 & 688340 & 5.0 & 5.3732 & TRN \\
\hline CHEMBL1995823 & 688340 & 4.6 & 5.1565 & TRN \\
\hline CHEMBL1463594 & 688340 & 4.6 & 4.7214 & TRN \\
\hline CHEMBL1586072 & 688340 & 4.9 & 4.9266 & TRN \\
\hline CHEMBL1533020 & 688340 & 5.6 & 5.1731 & TST \\
\hline CHEMBL 252978 & 688340 & 4.8 & 4.8964 & TRN \\
\hline CHEMBL1324009 & 688340 & 6.2 & 5.3996 & TRN \\
\hline CHEMBL1587882 & 688340 & 4.6 & 4.9074 & TRN \\
\hline CHEMBL1343019 & 688340 & 4.8 & 5.1745 & TRN \\
\hline CHEMBL1329719 & 688340 & 6.0 & 4.95 & TRN \\
\hline CHEMBL1304595 & 688340 & 4.65 & 4.4517 & TRN \\
\hline CHEMBL587884 & 688340 & 5.35 & 4.9188 & TST \\
\hline CHEMBL1517364 & 688340 & 4.3 & 4.8032 & TRN \\
\hline CHEMBL1443378 & 688340 & 6.0 & 5.3564 & TST \\
\hline CHEMBL1537628 & 688340 & 6.5 & 5.037 & TST \\
\hline CHEMBL1484067 & 688340 & 6.15 & 5.2407 & TRN \\
\hline CHEMBL1544951 & 688340 & 4.55 & 4.9678 & TST \\
\hline CHEMBL1426122 & 688340 & 5.0 & 5.3248 & TST \\
\hline CHEMBL3209414 & 688340 & 6.0 & 5.317 & TST \\
\hline CHEMBL1602767 & 688340 & 7.0501 & 5.5414 & TRN \\
\hline CHEMBL1337483 & 688340 & 4.55 & 5.1035 & TRN \\
\hline CHEMBL1539579 & 688340 & 5.5 & 4.9985 & TST \\
\hline CHEMBL1605246 & 688340 & 4.35 & 5.0004 & TRN \\
\hline CHEMBL1535421 & 688340 & 4.6 & 4.9919 & TRN \\
\hline CHEMBL1377536 & 688340 & 7.4001 & 5.1573 & TRN \\
\hline CHEMBL1467309 & 688340 & 4.4 & 4.8471 & TRN \\
\hline CHEMBL1460331 & 688340 & 6.05 & 4.941 & TRN \\
\hline CHEMBL1561159 & 688340 & 4.45 & 4.8188 & TRN \\
\hline CHEMBL1560165 & 688340 & 4.55 & 4.8172 & TRN \\
\hline CHEMBL1368496 & 688340 & 5.25 & 4.9342 & TRN \\
\hline CHEMBL1428285 & 688340 & 4.95 & 5.2561 & TRN \\
\hline CHEMBL1515979 & 688340 & 5.6 & 5.1281 & TRN \\
\hline
\end{tabular}




\begin{tabular}{|c|c|c|c|c|}
\hline \multirow[b]{2}{*}{ CHEMBL1530738 } & \multicolumn{4}{|c|}{ Supplemental Table S2.txt } \\
\hline & 688340 & 5.2 & 4.9611 & TST \\
\hline CHEMBL1326904 & 688340 & 6.95 & 5.3012 & TRN \\
\hline CHEMBL1530266 & 688340 & 5.15 & 4.9783 & TST \\
\hline CHEMBL1370209 & 688340 & 4.95 & 5.5062 & TST \\
\hline CHEMBL1443982 & 688340 & 5.1 & 4.5316 & TRN \\
\hline CHEMBL1452608 & 688340 & 4.8 & 5.025 & TST \\
\hline CHEMBL1487665 & 688340 & 7.0501 & 5.0835 & TST \\
\hline CHEMBL1414432 & 688340 & 5.6 & 4.8161 & TRN \\
\hline CHEMBL1368607 & 688340 & 4.5 & 4.9878 & TRN \\
\hline CHEMBL1404207 & 688340 & 4.55 & 4.7906 & TRN \\
\hline CHEMBL1528749 & 688340 & 4.65 & 4.779 & TRN \\
\hline CHEMBL1334475 & 688340 & 4.4 & 5.1582 & TRN \\
\hline CHEMBL1467063 & 688340 & 5.2 & 5.0842 & TRN \\
\hline CHEMBL1531094 & 688340 & 4.6 & 4.5379 & TRN \\
\hline CHEMBL1386806 & 688340 & 4.65 & 4.9993 & TRN \\
\hline CHEMBL1443449 & 688340 & 4.45 & 5.0312 & TRN \\
\hline CHEMBL1355535 & 688340 & 4.65 & 4.8075 & TRN \\
\hline CHEMBL1470357 & 688340 & 4.75 & 5.0297 & TST \\
\hline CHEMBL1315524 & 688340 & 4.4 & 4.9373 & TRN \\
\hline CHEMBL1383244 & 688340 & 4.9 & 4.8384 & TRN \\
\hline CHEMBL1580565 & 688340 & 6.1 & 5.3056 & TRN \\
\hline CHEMBL1425216 & 688340 & 6.5501 & 5.1224 & TRN \\
\hline CHEMBL1359352 & 688340 & 5.5 & 5.329 & TRN \\
\hline CHEMBL1425483 & 688340 & 4.65 & 4.9097 & TST \\
\hline CHEMBL1593376 & 688340 & 7.0 & 5.2158 & TRN \\
\hline CHEMBL1444299 & 688340 & 6.15 & 5.2031 & TRN \\
\hline CHEMBL1588832 & 688340 & 4.5 & 4.6521 & TRN \\
\hline CHEMBL1484679 & 688340 & 4.55 & 5.1346 & TRN \\
\hline CHEMBL1358403 & 688340 & 4.8 & 4.8187 & TRN \\
\hline CHEMBL1506972 & 688340 & 4.55 & 4.6659 & TRN \\
\hline CHEMBL1503279 & 688340 & 4.4 & 5.0773 & TRN \\
\hline CHEMBL3194447 & 688340 & 4.7 & 5.1052 & TRN \\
\hline CHEMBL1457403 & 688340 & 4.4 & 4.8519 & TRN \\
\hline CHEMBL1431885 & 688340 & 5.2 & 5.2885 & TST \\
\hline CHEMBL1480400 & 688340 & 4.45 & 5.1691 & TRN \\
\hline CHEMBL1407865 & 688340 & 5.6 & 5.1248 & TRN \\
\hline CHEMBL1452565 & 688340 & 4.65 & 5.0319 & TRN \\
\hline CHEMBL3212151 & 688340 & 6.5 & 4.908 & TST \\
\hline CHEMBL1465264 & 688340 & 5.05 & 5.0181 & TST \\
\hline CHEMBL1348104 & 688340 & 4.65 & 5.1293 & TRN \\
\hline CHEMBL1340834 & 688340 & 5.45 & 4.6429 & TRN \\
\hline CHEMBL1470712 & 688340 & 4.75 & 4.9234 & TRN \\
\hline CHEMBL3197100 & 688340 & 5.05 & 5.2478 & TRN \\
\hline CHEMBL1324264 & 688340 & 7.5003 & 5.4259 & TRN \\
\hline CHEMBL1505063 & 688340 & 6.4 & 5.1999 & TST \\
\hline CHEMBL1377258 & 688340 & 4.95 & 4.8646 & TRN \\
\hline CHEMBL1569858 & 688340 & 4.5 & 4.6296 & TRN \\
\hline CHEMBL1516050 & 688340 & 6.1 & 5.1201 & TRN \\
\hline
\end{tabular}




\begin{tabular}{|c|c|c|c|c|c|}
\hline \multicolumn{6}{|c|}{ Supplemental Table S2.txt } \\
\hline CHEMBL1602869 & 688340 & 6.1 & 5.2238 & TST & \\
\hline CHEMBL1305904 & 688340 & 5.45 & 5.2052 & TST & \\
\hline CHEMBL1421278 & 688340 & 4.45 & 4.8344 & TRN & \\
\hline CHEMBL1355180 & 688340 & 4.6 & 4.9182 & TRN & \\
\hline CHEMBL1361892 & 688340 & 5.25 & 5.2058 & TRN & \\
\hline CHEMBL1335460 & 688340 & 5.4 & 5.0418 & TRN & \\
\hline CHEMBL1317513 & 688340 & 4.5 & 4.6783 & TRN & \\
\hline CHEMBL1341532 & 688340 & 5.4 & 4.6049 & TRN & \\
\hline CHEMBL1341097 & 688340 & 4.55 & 5.0769 & TRN & \\
\hline CHEMBL1611107 & 688340 & 5.3 & 5.2409 & TRN & \\
\hline CHEMBL1406667 & 688340 & 4.55 & 4.9537 & TRN & \\
\hline CHEMBL1459152 & 688340 & 4.4 & 4.5702 & TRN & \\
\hline CHEMBL1313543 & 688340 & 4.5 & 4.8241 & TRN & \\
\hline CHEMBL1374747 & 688340 & 5.2 & 5.3576 & TRN & \\
\hline CHEMBL1582182 & 688340 & 6.45 & 5.2281 & TRN & \\
\hline CHEMBL1429182 & 688340 & 6.95 & 5.1463 & TRN & \\
\hline CHEMBL1467294 & 688340 & 4.8 & 4.5239 & TRN & \\
\hline CHEMBL1358353 & 688340 & 6.9 & 5.2001 & TRN & \\
\hline CHEMBL1583928 & 688340 & 4.45 & 4.761 & TRN & \\
\hline CHEMBL1423211 & 688340 & 5.3 & $4.8580 e$ & 00000000005 & TRN \\
\hline CHEMBL1472940 & 688340 & 4.5 & 5.2107 & TST & \\
\hline CHEMBL1432803 & 688340 & 7.6003 & 5.0944 & TST & \\
\hline CHEMBL1424460 & 688340 & 4.85 & 5.0617 & TRN & \\
\hline CHEMBL1353171 & 688340 & 5.35 & 4.9214 & TST & \\
\hline CHEMBL1393837 & 688340 & 4.65 & 5.0831 & TRN & \\
\hline CHEMBL1993978 & 688340 & 5.3 & 5.1199 & TRN & \\
\hline CHEMBL1314500 & 688340 & 6.15 & 5.1707 & TRN & \\
\hline CHEMBL1350252 & 688340 & 4.4 & 4.9426 & TRN & \\
\hline CHEMBL1424381 & 688340 & 4.55 & 5.3628 & TRN & \\
\hline CHEMBL1304947 & 688340 & 4.95 & 4.9905 & TRN & \\
\hline CHEMBL1439591 & 688340 & 4.6 & 4.758 & TRN & \\
\hline CHEMBL1578997 & 688340 & 4.65 & 4.5692 & TRN & \\
\hline CHEMBL1452185 & 688340 & 5.05 & 4.9954 & TRN & \\
\hline CHEMBL1545998 & 688340 & 5.35 & 5.1097 & TRN & \\
\hline CHEMBL1984719 & 688340 & 5.1 & 5.0656 & TRN & \\
\hline CHEMBL1586998 & 688340 & 5.25 & 5.0113 & TRN & \\
\hline CHEMBL1331812 & 688340 & 6.95 & 5.6965 & TST & \\
\hline CHEMBL1315896 & 688340 & 7.0501 & 5.7143 & TRN & \\
\hline CHEMBL1605451 & 688340 & 5.0 & 5.5484 & TRN & \\
\hline CHEMBL1551307 & 688340 & 5.2 & 5.0607 & TRN & \\
\hline CHEMBL210298 & 688340 & 5.25 & 5.1073 & TRN & \\
\hline CHEMBL1495086 & 688340 & 5.0 & 5.0662 & TST & \\
\hline CHEMBL1536401 & 688340 & 6.0 & 5.0765 & TRN & \\
\hline CHEMBL1445410 & 688340 & 4.5 & 4.8864 & TRN & \\
\hline CHEMBL1321711 & 688340 & 4.35 & 5.3658 & TRN & \\
\hline CHEMBL1452307 & 688340 & 4.6 & 4.8388 & TRN & \\
\hline CHEMBL3191434 & 688340 & 4.45 & 4.7976 & TRN & \\
\hline CHEMBL1447185 & 688340 & 4.9 & 4.992 & TRN & \\
\hline
\end{tabular}




\begin{tabular}{|c|c|c|c|c|c|}
\hline \\
\hline CHEMBL1605760 & 688340 & 5.2 & 5.3673 & TRN & \\
\hline CHEMBL1576604 & 688340 & 4.6 & 5.2088 & TRN & \\
\hline CHEMBL1528246 & 688340 & 4.55 & 5.0584 & TRN & \\
\hline CHEMBL1584564 & 688340 & 5.2 & 4.7711 & TST & \\
\hline CHEMBL1392448 & 688340 & 6.4 & 5.5117 & TRN & \\
\hline CHEMBL1972346 & 688340 & 4.5 & 5.0388 & TRN & \\
\hline CHEMBL1505952 & 688340 & 5.25 & 5.3041 & TRN & \\
\hline CHEMBL1301591 & 688340 & 4.7 & 5.0304 & TRN & \\
\hline CHEMBL1483721 & 688340 & 4.45 & 5.1074 & TST & \\
\hline CHEMBL1436577 & 688340 & 4.4 & 5.0451 & TRN & \\
\hline CHEMBL125044 & 688340 & 5.5 & 5.2819 & TRN & \\
\hline CHEMBL1334048 & 688340 & 4.45 & 5.1785 & TST & \\
\hline CHEMBL1540868 & 688340 & 4.5 & 4.7191 & TRN & \\
\hline CHEMBL1502876 & 688340 & 4.55 & 4.9174 & TRN & \\
\hline CHEMBL3198399 & 688340 & 7.0 & 5.2657 & TST & \\
\hline CHEMBL1558285 & 688340 & 4.7 & 4.7694 & TRN & \\
\hline CHEMBL1472499 & 688340 & 4.75 & 4.811 & TRN & \\
\hline CHEMBL1995177 & 688340 & 4.6 & 4.8584 & TST & \\
\hline CHEMBL1303244 & 688340 & 4.4 & 5.3837 & TST & \\
\hline CHEMBL1343300 & 688340 & 5.05 & 5.24299 & 9999999999 & TRN \\
\hline CHEMBL1419513 & 688340 & 5.15 & 5.4855 & TRN & \\
\hline CHEMBL1603523 & 688340 & 5.05 & 4.8952 & TST & \\
\hline CHEMBL1534959 & 688340 & 4.55 & 4.8752 & TRN & \\
\hline CHEMBL1570676 & 688340 & 6.1 & 4.6758 & TRN & \\
\hline CHEMBL1495661 & 688340 & 5.0 & 5.1635 & TST & \\
\hline CHEMBL1459569 & 688340 & 4.55 & 4.8815 & TRN & \\
\hline CHEMBL1362703 & 688340 & 4.7 & 5.3479 & TRN & \\
\hline CHEMBL1586529 & 688340 & 4.35 & 5.3803 & TST & \\
\hline CHEMBL1417918 & 688340 & 4.6 & 5.1138 & TRN & \\
\hline CHEMBL1610810 & 688340 & 5.05 & 4.7091 & TST & \\
\hline CHEMBL1509835 & 688340 & 5.3 & 5.2098 & TST & \\
\hline CHEMBL1376456 & 688340 & 4.65 & 5.0405 & TRN & \\
\hline CHEMBL1376516 & 688340 & 4.85 & 5.0953 & TST & \\
\hline CHEMBL1493891 & 688340 & 4.85 & 4.7927 & TRN & \\
\hline CHEMBL1326175 & 688340 & 5.3 & 4.9383 & TRN & \\
\hline CHEMBL1453143 & 688340 & 5.0 & 5.4987 & TST & \\
\hline CHEMBL1451635 & 688340 & 7.0501 & 5.3603 & TRN & \\
\hline CHEMBL1335324 & 688340 & 4.5 & 5.1351 & TRN & \\
\hline CHEMBL1518264 & 688340 & 4.6 & 4.7802 & TST & \\
\hline CHEMBL1482883 & 688340 & 4.8 & 4.7588 & TRN & \\
\hline CHEMBL1366999 & 688340 & 4.5 & 4.7483 & TST & \\
\hline CHEMBL1480976 & 688340 & 5.25 & 5.0919 & TRN & \\
\hline CHEMBL1452924 & 688340 & 5.4 & 4.8922 & TRN & \\
\hline CHEMBL1328610 & 688340 & 4.6 & 5.0351 & TRN & \\
\hline CHEMBL1425564 & 688340 & 5.05 & 5.1875 & TRN & \\
\hline CHEMBL1456831 & 688340 & 5.2 & 5.6705 & TRN & \\
\hline CHEMBL1344991 & 688340 & 5.4 & 5.0783 & TST & \\
\hline CHEMBL1377018 & 688340 & 5.0 & 4.9174 & TRN & \\
\hline
\end{tabular}




\begin{tabular}{|c|c|c|c|c|}
\hline & & & pplemen & al $\mathrm{T}$ \\
\hline CHEMBL1596305 & 688340 & 4.5 & 4.9848 & TRN \\
\hline CHEMBL1352344 & 688340 & 4.4 & 4.9463 & TST \\
\hline CHEMBL1536200 & 688340 & 6.35 & 5.13 & TST \\
\hline CHEMBL1478755 & 688340 & 4.6 & 4.5779 & TRN \\
\hline CHEMBL195455 & 688340 & 5.1 & 5.0269 & TRN \\
\hline CHEMBL1269633 & 688340 & 4.4 & 4.8329 & TRN \\
\hline CHEMBL1611892 & 688340 & 4.5 & 4.5439 & TRN \\
\hline CHEMBL2006168 & 688340 & 5.55 & 5.2517 & TRN \\
\hline CHEMBL3198983 & 688340 & 4.45 & 5.1243 & TRN \\
\hline CHEMBL1429886 & 688340 & 5.0 & 4.7296 & TRN \\
\hline CHEMBL3212266 & 688340 & 5.65 & 5.1434 & TRN \\
\hline CHEMBL1580587 & 688340 & 4.55 & 5.0914 & TRN \\
\hline CHEMBL3192053 & 688340 & 5.6 & 5.1235 & TRN \\
\hline CHEMBL1453730 & 688340 & 4.6 & 4.5385 & TRN \\
\hline CHEMBL1387474 & 688340 & 4.5 & 4.9244 & TST \\
\hline CHEMBL1485593 & 688340 & 4.95 & 4.9105 & TRN \\
\hline CHEMBL1608319 & 688340 & 4.55 & 4.7561 & TRN \\
\hline CHEMBL1542498 & 688340 & 6.35 & 5.2589 & TRN \\
\hline CHEMBL1316324 & 688340 & 4.9 & 4.7896 & TST \\
\hline CHEMBL1332369 & 688340 & 4.6 & 4.9808 & TRN \\
\hline CHEMBL1478306 & 688340 & 4.5 & 5.0122 & TRN \\
\hline CHEMBL1351172 & 688340 & 5.3 & 4.8715 & TST \\
\hline CHEMBL1501977 & 688340 & 6.2 & 5.2331 & TST \\
\hline CHEMBL1581746 & 688340 & 4.45 & 4.7544 & TRN \\
\hline CHEMBL1454202 & 688340 & 5.0 & 5.0908 & TRN \\
\hline CHEMBL1502672 & 688340 & 4.65 & 4.8864 & TRN \\
\hline CHEMBL1458441 & 688340 & 4.6 & 4.8374 & TRN \\
\hline CHEMBL1609603 & 688340 & 4.6 & 4.7638 & TRN \\
\hline CHEMBL1608764 & 688340 & 6.1 & 5.0693 & TST \\
\hline CHEMBL3193363 & 688340 & 4.5 & 4.9685 & TST \\
\hline CHEMBL1354523 & 688340 & 4.35 & 5.2315 & TST \\
\hline CHEMBL1610998 & 688340 & 6.1 & 4.9273 & TST \\
\hline CHEMBL1607591 & 688340 & 4.35 & 4.6762 & TRN \\
\hline CHEMBL1430660 & 688340 & 4.6 & 4.9424 & TRN \\
\hline CHEMBL1505348 & 688340 & 5.15 & 5.6645 & TST \\
\hline CHEMBL1500265 & 688340 & 4.6 & 4.7016 & TRN \\
\hline CHEMBL1373577 & 688340 & 4.5 & 4.6781 & TRN \\
\hline CHEMBL1483647 & 688340 & 5.1 & 5.0395 & TST \\
\hline CHEMBL402053 & 688340 & 4.6 & 4.8877 & TRN \\
\hline CHEMBL1997413 & 688340 & 5.0 & 4.9642 & TRN \\
\hline CHEMBL1403297 & 688340 & 4.4 & 4.628 & TST \\
\hline CHEMBL1990734 & 688340 & 4.45 & 4.8621 & TST \\
\hline CHEMBL3196407 & 688340 & 4.45 & 4.8578 & TRN \\
\hline CHEMBL1399332 & 688340 & 4.55 & 4.7793 & TRN \\
\hline CHEMBL1524903 & 688340 & 5.75 & 5.3989 & TRN \\
\hline CHEMBL1555925 & 688340 & 5.15 & 5.1556 & TST \\
\hline CHEMBL1584834 & 688340 & 6.95 & 5.0478 & TST \\
\hline CHEMBL1469086 & 688340 & 4.4 & 5.0695 & TRN \\
\hline
\end{tabular}




\begin{tabular}{|c|c|c|c|c|c|}
\hline \multicolumn{6}{|c|}{ Supplemental Table S2.txt } \\
\hline CHEMBL1377006 & 688340 & 4.95 & 4.9429 & TRN & \\
\hline CHEMBL468155 & 688340 & 6.25 & 4.7921 & TRN & \\
\hline CHEMBL1534195 & 688340 & 4.4 & 5.2826 & TRN & \\
\hline CHEMBL1311384 & 688340 & 4.9 & 5.4721 & TST & \\
\hline CHEMBL1411111 & 688340 & 4.55 & 4.7753 & TRN & \\
\hline CHEMBL3197798 & 688340 & 5.25 & 4.6198 & TRN & \\
\hline CHEMBL1379751 & 688340 & 4.55 & 5.0275 & TRN & \\
\hline CHEMBL1304251 & 688340 & 4.4 & 5.1552 & TRN & \\
\hline CHEMBL1477831 & 688340 & 4.65 & 4.8962 & TRN & \\
\hline CHEMBL1349231 & 688340 & 4.65 & 4.9709 & TRN & \\
\hline CHEMBL1329801 & 688340 & 4.4 & 4.7211 & TRN & \\
\hline CHEMBL1535451 & 688340 & 5.35 & 5.1003 & TRN & \\
\hline CHEMBL1378190 & 688340 & 4.7 & 5.2117 & TRN & \\
\hline CHEMBL1302469 & 688340 & 6.05 & 4.7154 & TST & \\
\hline CHEMBL1332241 & 688340 & 4.6 & 4.8843 & TRN & \\
\hline CHEMBL1326973 & 688340 & 5.2 & 5.0036 & TST & \\
\hline CHEMBL1462073 & 688340 & 4.4 & 5.1275 & TRN & \\
\hline CHEMBL1570505 & 688340 & 5.3 & 5.1008 & TRN & \\
\hline CHEMBL1500910 & 688340 & 4.5 & 5.1566 & TRN & \\
\hline CHEMBL1414220 & 688340 & 4.5 & 4.8291 & TRN & \\
\hline CHEMBL1489596 & 688340 & 4.45 & 5.0119 & TRN & \\
\hline CHEMBL1341882 & 688340 & 4.4 & 4.9873 & TST & \\
\hline CHEMBL1357873 & 688340 & 4.4 & 4.9179 & TRN & \\
\hline CHEMBL1484395 & 688340 & 4.4 & 4.6875 & TRN & \\
\hline CHEMBL3190262 & 688340 & 5.5 & 4.7668 & TRN & \\
\hline CHEMBL1400534 & 688340 & 4.5 & 5.0242 & TRN & \\
\hline CHEMBL1401108 & 688340 & 4.55 & 5.0541 & TRN & \\
\hline CHEMBL1538168 & 688340 & 7.0 & 5.4859 & TRN & \\
\hline CHEMBL3208789 & 688340 & 5.05 & 4.9958 & TST & \\
\hline CHEMBL1330888 & 688340 & 7.0501 & 5.2437 & TRN & \\
\hline CHEMBL1341743 & 688340 & 5.4 & 4.9972 & TRN & \\
\hline CHEMBL1428785 & 688340 & 4.45 & 5.124 & TST & \\
\hline CHEMBL1322936 & 688340 & 4.0 & 5.36299 & 99999999995 & TRN \\
\hline CHEMBL3196373 & 688340 & 4.5 & 4.8019 & TRN & \\
\hline CHEMBL1351436 & 688340 & 4.55 & 4.7083 & TRN & \\
\hline CHEMBL1370892 & 688340 & 7.0501 & 5.38299 & 9999999999 & TRN \\
\hline CHEMBL1372392 & 688340 & 4.55 & 4.7179 & TRN & \\
\hline CHEMBL1541549 & 688340 & 4.6 & 5.1137 & TRN & \\
\hline CHEMBL1323693 & 688340 & 5.6 & 5.1645 & TRN & \\
\hline CHEMBL1493105 & 688340 & 7.0 & 5.3149 & TRN & \\
\hline CHEMBL1441363 & 688340 & 4.65 & 4.6773 & TRN & \\
\hline CHEMBL1378523 & 688340 & 4.95 & 4.8298 & TRN & \\
\hline CHEMBL1407479 & 688340 & 4.55 & 4.55399 & 9999999999 & TRN \\
\hline CHEMBL1591743 & 688340 & 4.55 & 4.8075 & TRN & \\
\hline CHEMBL1311206 & 688340 & 6.0 & 5.0423 & TRN & \\
\hline CHEMBL3209608 & 688340 & 4.7 & 5.0213 & TRN & \\
\hline CHEMBL1375570 & 688340 & 4.4 & 4.9691 & TST & \\
\hline CHEMBL1459125 & 688340 & 5.05 & 4.8138 & TRN & \\
\hline
\end{tabular}




\begin{tabular}{|c|c|c|c|c|c|}
\hline \\
\hline CHEMBL1455263 & 688340 & 4.7 & 4.7592 & TRN & \\
\hline CHEMBL1528816 & 688340 & 9.699 & 5.0232 & TRN & \\
\hline CHEMBL1329421 & 688340 & 6.5 & 5.2018 & TRN & \\
\hline CHEMBL1345433 & 688340 & 4.6 & 5.0682 & TST & \\
\hline CHEMBL1613709 & 688340 & 4.5 & 5.2657 & TRN & \\
\hline CHEMBL1445119 & 688340 & 4.4 & 5.2573 & TRN & \\
\hline CHEMBL1499899 & 688340 & 4.7 & 5.0037 & TRN & \\
\hline CHEMBL1368977 & 688340 & 5.4 & 4.8324 & TST & \\
\hline CHEMBL1991736 & 688340 & 4.85 & 4.7328 & TRN & \\
\hline CHEMBL1313134 & 688340 & 4.4 & 4.9453 & TST & \\
\hline CHEMBL1341948 & 688340 & 7.0 & 4.9938 & TST & \\
\hline CHEMBL1326482 & 688340 & 4.55 & 4.8262 & TRN & \\
\hline CHEMBL1493254 & 688340 & 4.5 & 4.5376 & TST & \\
\hline CHEMBL1494559 & 688340 & 4.6 & 4.9261 & TRN & \\
\hline CHEMBL1484010 & 688340 & 4.4 & 5.0635 & TRN & \\
\hline CHEMBL1455308 & 688340 & 6.0 & 4.8316 & TST & \\
\hline CHEMBL1559657 & 688340 & 4.65 & 5.3669 & TST & \\
\hline CHEMBL1349409 & 688340 & 6.1 & 4.6339 & TST & \\
\hline CHEMBL1404169 & 688340 & 4.5 & 5.07600 & 00000000005 & TST \\
\hline CHEMBL1427593 & 688340 & 7.0 & 5.0524 & TRN & \\
\hline CHEMBL1492144 & 688340 & 6.2 & 5.3861 & TRN & \\
\hline CHEMBL1421603 & 688340 & 4.3 & 4.8347 & TST & \\
\hline CHEMBL1971410 & 688340 & 4.55 & 4.7204 & TRN & \\
\hline CHEMBL466004 & 688340 & 4.45 & 5.357 & TRN & \\
\hline CHEMBL1434767 & 688340 & 4.45 & 4.8972 & TRN & \\
\hline CHEMBL 3214167 & 688340 & 4.7 & 4.7838 & TRN & \\
\hline CHEMBL1521955 & 688340 & 6.3 & 5.2618 & TRN & \\
\hline CHEMBL1581149 & 688340 & 4.4 & 4.6496 & TRN & \\
\hline CHEMBL1419815 & 688340 & 4.9 & 5.1454 & TRN & \\
\hline CHEMBL1461097 & 688340 & 5.5 & 5.3819 & TRN & \\
\hline CHEMBL1507826 & 688340 & 7.0501 & 5.4184 & TRN & \\
\hline CHEMBL1567158 & 688340 & 5.05 & 5.3644 & TRN & \\
\hline CHEMBL1323463 & 688340 & 5.6 & 5.2509 & TRN & \\
\hline CHEMBL1387575 & 688340 & 5.15 & 5.1638 & TRN & \\
\hline CHEMBL1409717 & 688340 & 4.45 & 5.0679 & TRN & \\
\hline CHEMBL1368857 & 688340 & 4.35 & 5.0095 & TRN & \\
\hline CHEMBL1300735 & 688340 & 4.75 & 5.0177 & TRN & \\
\hline CHEMBL1334891 & 688340 & 5.0 & 4.9101 & TST & \\
\hline CHEMBL1569416 & 688340 & 5.15 & 4.9486 & TRN & \\
\hline CHEMBL1450564 & 688340 & 4.7 & 5.0604 & TST & \\
\hline CHEMBL1575408 & 688340 & 7.0 & 5.3039 & TRN & \\
\hline CHEMBL1568913 & 688340 & 4.6 & 4.606 & TRN & \\
\hline CHEMBL1468423 & 688340 & 5.3 & 5.2028 & TST & \\
\hline CHEMBL1341561 & 688340 & 5.05 & 4.6368 & TRN & \\
\hline CHEMBL1451294 & 688340 & 4.9 & 4.9276 & TRN & \\
\hline CHEMBL1360723 & 688340 & 4.35 & 4.7729 & TST & \\
\hline CHEMBL1390395 & 688340 & 6.4 & 4.9889 & TST & \\
\hline CHEMBL1560102 & 688340 & 4.4 & 4.9409 & TST & \\
\hline
\end{tabular}




\begin{tabular}{|c|c|c|c|c|}
\hline & & & upplement & al $\mathrm{T}$ \\
\hline CHEMBL1304514 & 688340 & 4.6 & 4.6932 & TRN \\
\hline CHEMBL1600335 & 688340 & 3.55 & 5.2982 & TRN \\
\hline CHEMBL1339050 & 688340 & 4.6 & 5.1306 & TRN \\
\hline CHEMBL1581102 & 688340 & 4.55 & 5.1011 & TRN \\
\hline CHEMBL1511779 & 688340 & 5.55 & 5.229 & TRN \\
\hline CHEMBL3191622 & 688340 & 5.05 & 4.729 & TRN \\
\hline CHEMBL1477120 & 688340 & 4.55 & 4.8765 & TRN \\
\hline CHEMBL1455137 & 688340 & 4.45 & 4.9324 & TRN \\
\hline CHEMBL1472308 & 688340 & 6.0 & 5.1262 & TRN \\
\hline CHEMBL1511893 & 688340 & 4.6 & 4.8338 & TRN \\
\hline CHEMBL3199045 & 688340 & 4.4 & 4.6259 & TRN \\
\hline CHEMBL1325644 & 688340 & 4.4 & 5.042 & TRN \\
\hline CHEMBL1609500 & 688340 & 5.95 & 5.1488 & TRN \\
\hline CHEMBL1576791 & 688340 & 4.45 & 4.6913 & TRN \\
\hline CHEMBL1344298 & 688340 & 4.35 & 5.5977 & TST \\
\hline CHEMBL1392316 & 688340 & 4.45 & 5.1308 & TRN \\
\hline CHEMBL1459863 & 688340 & 5.35 & 5.2141 & TST \\
\hline CHEMBL1488729 & 688340 & 5.4 & 4.9704 & TST \\
\hline CHEMBL1481622 & 688340 & 5.4 & 5.0441 & TRN \\
\hline CHEMBL1601851 & 688340 & 4.7 & 4.9941 & TRN \\
\hline CHEMBL1477271 & 688340 & 6.05 & 5.2463 & TRN \\
\hline CHEMBL1578024 & 688340 & 4.65 & 4.6407 & TST \\
\hline CHEMBL1366241 & 688340 & 6.15 & 5.3654 & TRN \\
\hline CHEMBL1522060 & 688340 & 5.5 & 5.691 & TRN \\
\hline CHEMBL1606809 & 688340 & 4.55 & 4.2735 & TRN \\
\hline CHEMBL1411673 & 688340 & 5.1 & 4.9414 & TRN \\
\hline CHEMBL1506399 & 688340 & 5.9 & 5.0514 & TRN \\
\hline CHEMBL1458537 & 688340 & 4.4 & 4.873 & TRN \\
\hline CHEMBL1493772 & 688340 & 4.45 & 4.8584 & TRN \\
\hline CHEMBL1487834 & 688340 & 5.2 & 4.9261 & TST \\
\hline CHEMBL1446458 & 688340 & 5.1 & 4.9748 & TRN \\
\hline CHEMBL1348968 & 688340 & 6.15 & 5.1302 & TRN \\
\hline CHEMBL1423902 & 688340 & 4.75 & 5.0896 & TST \\
\hline CHEMBL1522115 & 688340 & 4.5 & 4.604 & TRN \\
\hline CHEMBL1364312 & 688340 & 5.05 & 5.1878 & TRN \\
\hline CHEMBL1355270 & 688340 & 4.95 & 4.7252 & TRN \\
\hline CHEMBL1603411 & 688340 & 6.95 & 5.4363 & TRN \\
\hline CHEMBL1484622 & 688340 & 5.0 & 5.1381 & TRN \\
\hline CHEMBL1582739 & 688340 & 4.65 & 5.0327 & TRN \\
\hline CHEMBL1337505 & 688340 & 5.55 & 5.1847 & TST \\
\hline CHEMBL1375872 & 688340 & 4.0 & 5.2184 & TST \\
\hline CHEMBL1303045 & 688340 & 4.5 & 5.0342 & TRN \\
\hline CHEMBL1433665 & 688340 & 6.8 & 4.9533 & TRN \\
\hline CHEMBL1505049 & 688340 & 4.6 & 5.2443 & TST \\
\hline CHEMBL1584646 & 688340 & 4.8 & 4.7778 & TRN \\
\hline CHEMBL1428545 & 688340 & 7.2 & 5.0553 & TST \\
\hline CHEMBL3209895 & 688340 & 4.5 & 5.1649 & TRN \\
\hline CHEMBL1397312 & 688340 & 4.55 & 4.9398 & TRN \\
\hline
\end{tabular}




\begin{tabular}{|c|c|c|c|c|}
\hline \multicolumn{5}{|c|}{ Supplemental Table S2.txt } \\
\hline CHEMBL1443233 & 688340 & 6.5501 & 5.3074 & TRN \\
\hline CHEMBL1307065 & 688340 & 4.5 & 4.9983 & TRN \\
\hline CHEMBL1359846 & 688340 & 4.95 & 5.1797 & TRN \\
\hline CHEMBL1341064 & 688340 & 4.8 & 4.8742 & TRN \\
\hline CHEMBL1529203 & 688340 & 5.0 & 4.5866 & TRN \\
\hline CHEMBL1498549 & 688340 & 6.05 & 5.0284 & TST \\
\hline CHEMBL1457914 & 688340 & 4.55 & 5.0663 & TRN \\
\hline CHEMBL3211598 & 688340 & 7.0 & 4.9347 & TRN \\
\hline CHEMBL1449753 & 688340 & 7.0 & 5.3305 & TST \\
\hline CHEMBL1514892 & 688340 & 5.35 & 5.4472 & TRN \\
\hline CHEMBL1312121 & 688340 & 4.7 & 5.6831 & TRN \\
\hline CHEMBL1603023 & 688340 & 5.1 & 5.0933 & TST \\
\hline CHEMBL1382247 & 688340 & 4.5 & 4.9699 & TRN \\
\hline CHEMBL1302170 & 688340 & 5.4 & 5.0141 & TST \\
\hline CHEMBL1501132 & 688340 & 5.55 & 5.1657 & TRN \\
\hline CHEMBL1313696 & 688340 & 4.55 & 4.7746 & TRN \\
\hline CHEMBL1495498 & 688340 & 4.65 & 4.987 & TRN \\
\hline CHEMBL1568979 & 688340 & 4.35 & 4.9865 & TST \\
\hline CHEMBL1346110 & 688340 & 4.5 & 4.7325 & TST \\
\hline CHEMBL1539510 & 688340 & 4.4 & 4.9307 & TRN \\
\hline CHEMBL1530182 & 688340 & 5.0 & 4.9208 & TRN \\
\hline CHEMBL3194477 & 688340 & 5.1 & 4.9876 & TRN \\
\hline CHEMBL1310451 & 688340 & 4.55 & 5.3308 & TRN \\
\hline CHEMBL1366681 & 688340 & 4.45 & 4.8051 & TRN \\
\hline CHEMBL1471653 & 688340 & 7.0 & 5.1673 & TRN \\
\hline CHEMBL1369673 & 688340 & 7.0501 & 5.3838 & TRN \\
\hline CHEMBL1368717 & 688340 & 5.15 & 4.9182 & TST \\
\hline CHEMBL1335753 & 688340 & 5.0 & 5.5143 & TST \\
\hline CHEMBL1421517 & 688340 & 4.4 & 5.0178 & TRN \\
\hline CHEMBL1563060 & 688340 & 4.4 & 5.1652 & TRN \\
\hline CHEMBL1323853 & 688340 & 4.5 & 5.0348 & TRN \\
\hline CHEMBL1327768 & 688340 & 5.25 & 4.8911 & TRN \\
\hline CHEMBL1333752 & 688340 & 4.8 & 4.7751 & TRN \\
\hline CHEMBL1466905 & 688340 & 5.45 & 5.0998 & TRN \\
\hline CHEMBL1509718 & 688340 & 4.55 & 4.6427 & TST \\
\hline CHEMBL1354156 & 688340 & 4.5 & 5.0627 & TST \\
\hline CHEMBL1302012 & 688340 & 4.5 & 5.0702 & TRN \\
\hline CHEMBL1329661 & 688340 & 4.65 & 5.1584 & TRN \\
\hline CHEMBL1576398 & 688340 & 5.05 & 5.0217 & TRN \\
\hline CHEMBL1332506 & 688340 & 4.9 & 4.9265 & TRN \\
\hline CHEMBL1379687 & 688340 & 4.55 & 5.0135 & TRN \\
\hline CHEMBL1603700 & 688340 & 4.55 & 4.6669 & TST \\
\hline CHEMBL1493541 & 688340 & 5.05 & 5.0895 & TST \\
\hline CHEMBL1967431 & 688340 & 4.9 & 5.0034 & TST \\
\hline CHEMBL1353732 & 688340 & 4.4 & 5.0569 & TRN \\
\hline CHEMBL1367717 & 688340 & 5.15 & 4.6111 & TRN \\
\hline CHEMBL1489701 & 688340 & 5.15 & 5.0097 & TST \\
\hline CHEMBL1471716 & 688340 & 4.95 & 4.823 & TRN \\
\hline
\end{tabular}




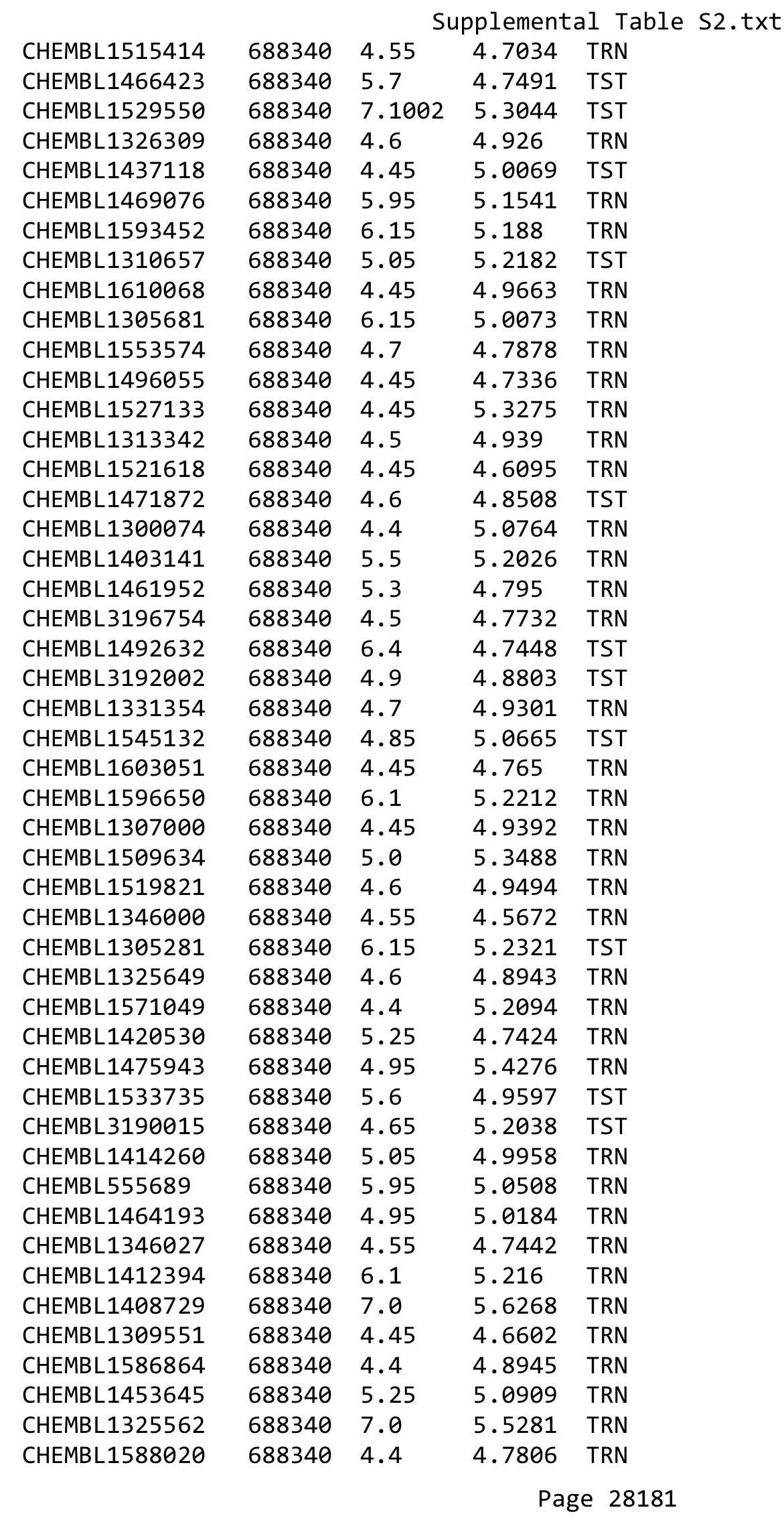




\begin{tabular}{|c|c|c|c|c|}
\hline \multicolumn{5}{|c|}{ Supplemental Table S2.txt } \\
\hline CHEMBL3199883 & 688340 & 4.6 & 4.6151 & TRN \\
\hline CHEMBL1408901 & 688340 & 5.8 & 4.9612 & TRN \\
\hline CHEMBL1343177 & 688340 & 5.2 & 5.1719 & TRN \\
\hline CHEMBL1334211 & 688340 & 6.0 & 5.1836 & TRN \\
\hline CHEMBL1319115 & 688340 & 4.45 & 4.6582 & TRN \\
\hline CHEMBL1421577 & 688340 & 4.5 & 4.8638 & TRN \\
\hline CHEMBL1554821 & 688340 & 4.65 & 4.7667 & TST \\
\hline CHEMBL3189474 & 688340 & 4.55 & 4.9098 & TRN \\
\hline CHEMBL1329787 & 688340 & 4.4 & 5.3701 & TRN \\
\hline CHEMBL1593105 & 688340 & 4.5 & 5.4283 & TRN \\
\hline CHEMBL1328269 & 688340 & 4.25 & 5.2925 & TRN \\
\hline CHEMBL1490504 & 688340 & 7.0 & 4.6726 & TRN \\
\hline CHEMBL1612619 & 688340 & 4.7 & 4.9069 & TRN \\
\hline CHEMBL1535340 & 688340 & 5.15 & 5.0884 & TRN \\
\hline CHEMBL1403600 & 688340 & 3.35 & 4.9802 & TRN \\
\hline CHEMBL1569727 & 688340 & 5.7 & 5.3821 & TRN \\
\hline CHEMBL1547481 & 688340 & 5.65 & 4.7271 & TRN \\
\hline CHEMBL1568573 & 688340 & 6.5 & 5.0169 & TRN \\
\hline CHEMBL1354213 & 688340 & 4.5 & 5.0394 & TRN \\
\hline CHEMBL1584083 & 688340 & 6.15 & 5.1631 & TRN \\
\hline CHEMBL1434712 & 688340 & 4.9 & 4.5896 & TRN \\
\hline CHEMBL1384508 & 688340 & 4.4 & 4.784 & TRN \\
\hline CHEMBL1336123 & 688340 & 4.6 & 5.0139 & TST \\
\hline CHEMBL1560454 & 688340 & 4.65 & 5.318 & TRN \\
\hline CHEMBL3199695 & 688340 & 4.45 & 5.1489 & TRN \\
\hline CHEMBL1541034 & 688340 & 4.55 & 4.9207 & TRN \\
\hline CHEMBL1375329 & 688340 & 4.45 & 4.7968 & TST \\
\hline CHEMBL1531374 & 688340 & 4.55 & 5.1203 & TST \\
\hline CHEMBL1319026 & 688340 & 4.85 & 4.91 & TRN \\
\hline CHEMBL1336119 & 688340 & 4.45 & 4.681 & TST \\
\hline CHEMBL1509500 & 688340 & 4.55 & 4.9403 & TST \\
\hline CHEMBL1359564 & 688340 & 5.0 & 4.9496 & TRN \\
\hline CHEMBL1563210 & 688340 & 5.05 & 5.0802 & TRN \\
\hline CHEMBL3189851 & 688340 & 5.55 & 5.0079 & TST \\
\hline CHEMBL1573095 & 688340 & 3.75 & 5.0632 & TRN \\
\hline CHEMBL1382649 & 688340 & 5.5 & 5.0181 & TRN \\
\hline CHEMBL1454250 & 688340 & 5.25 & 5.2197 & TRN \\
\hline CHEMBL1461985 & 688340 & 4.0 & 5.2717 & TST \\
\hline CHEMBL1611555 & 688340 & 4.6 & 4.9421 & TRN \\
\hline CHEMBL1392789 & 688340 & 4.8 & 4.7391 & TRN \\
\hline CHEMBL1507732 & 688340 & 4.5 & 4.8303 & TRN \\
\hline CHEMBL1575008 & 688340 & 4.45 & 5.2245 & TST \\
\hline CHEMBL1481366 & 688340 & 4.4 & 5.1391 & TRN \\
\hline CHEMBL1443836 & 688340 & 6.5 & 5.184 & TST \\
\hline CHEMBL1471662 & 688340 & 5.3 & 5.1125 & TRN \\
\hline CHEMBL1596586 & 688340 & 4.4 & 4.6618 & TRN \\
\hline CHEMBL1605953 & 688340 & 4.65 & 4.6884 & TRN \\
\hline CHEMBL1430666 & 688340 & 4.65 & 5.0876 & TRN \\
\hline
\end{tabular}




\begin{tabular}{|c|c|c|c|c|}
\hline \multicolumn{5}{|c|}{ Supplemental Table S2.txt } \\
\hline CHEMBL1396262 & 688340 & 5.85 & 5.3454 & TRN \\
\hline CHEMBL1359388 & 688340 & 5.2 & 5.4483 & TST \\
\hline CHEMBL1411039 & 688340 & 4.65 & 4.8213 & TRN \\
\hline CHEMBL1492878 & 688340 & 4.35 & 5.4215 & TST \\
\hline CHEMBL1345135 & 688340 & 4.6 & 4.9531 & TRN \\
\hline CHEMBL1535030 & 688340 & 4.4 & 5.0207 & TRN \\
\hline CHEMBL187845 & 688340 & 4.5 & 5.0794 & TRN \\
\hline CHEMBL1580668 & 688340 & 4.55 & 5.1667 & TRN \\
\hline CHEMBL1547901 & 688340 & 4.4 & 4.5269 & TST \\
\hline CHEMBL1380352 & 688340 & 4.5 & 4.8071 & TST \\
\hline CHEMBL1429570 & 688340 & 5.4 & 4.9433 & TRN \\
\hline CHEMBL1572909 & 688340 & 5.3 & 5.0295 & TRN \\
\hline CHEMBL1494575 & 688340 & 5.85 & 5.2487 & TRN \\
\hline CHEMBL1380513 & 688340 & 5.4 & 5.3245 & TRN \\
\hline CHEMBL1595144 & 688340 & 4.45 & 5.5122 & TRN \\
\hline CHEMBL1376140 & 688340 & 5.25 & 5.0685 & TRN \\
\hline CHEMBL3192227 & 688340 & 6.15 & 5.1025 & TST \\
\hline CHEMBL1967099 & 688340 & 4.45 & 5.1963 & TRN \\
\hline CHEMBL65675 & 688340 & 4.4 & 5.0832 & TRN \\
\hline CHEMBL1592214 & 688340 & 7.0 & 5.5917 & TRN \\
\hline CHEMBL3209740 & 688340 & 5.6 & 5.5608 & TRN \\
\hline CHEMBL1469058 & 688340 & 5.4 & 4.694 & TST \\
\hline CHEMBL582491 & 688340 & 4.55 & 4.7044 & TRN \\
\hline CHEMBL1421779 & 688340 & 6.6499 & 4.8387 & TST \\
\hline CHEMBL1557023 & 688340 & 5.55 & 5.4397 & TRN \\
\hline CHEMBL1519818 & 688340 & 6.0 & 4.9189 & TRN \\
\hline CHEMBL1505347 & 688340 & 6.9 & 5.484 & TRN \\
\hline CHEMBL1485496 & 688340 & 5.2 & 5.2616 & TST \\
\hline CHEMBL 3190747 & 688340 & 4.55 & 5.0392 & TRN \\
\hline CHEMBL1995112 & 688340 & 4.6 & 4.8651 & TRN \\
\hline CHEMBL1488038 & 688340 & 5.2 & 5.2172 & TRN \\
\hline CHEMBL1462659 & 688340 & 4.4 & 5.0006 & TRN \\
\hline CHEMBL1318149 & 688340 & 4.85 & 5.0894 & TRN \\
\hline CHEMBL1464991 & 688340 & 4.7 & 4.8505 & TRN \\
\hline CHEMBL1518949 & 688340 & 5.05 & 4.6297 & TST \\
\hline CHEMBL1329414 & 688340 & 4.95 & 4.629 & TRN \\
\hline CHEMBL 1434510 & 688340 & 5.05 & 5.2126 & TRN \\
\hline CHEMBL1433737 & 688340 & 6.3 & 5.4737 & TRN \\
\hline CHEMBL1547690 & 688340 & 6.2 & 5.1792 & TRN \\
\hline CHEMBL1530257 & 688340 & 4.55 & 4.8791 & TRN \\
\hline CHEMBL1494973 & 688340 & 5.3 & 4.4984 & TRN \\
\hline CHEMBL1403410 & 688340 & 6.35 & 5.4853 & TRN \\
\hline CHEMBL1489566 & 688340 & 7.1002 & 4.7363 & TRN \\
\hline CHEMBL1579873 & 688340 & 4.55 & 4.7106 & TRN \\
\hline CHEMBL1522968 & 688340 & 6.35 & 4.8774 & TST \\
\hline CHEMBL1331760 & 688340 & 4.6 & 4.7471 & TRN \\
\hline CHEMBL1579486 & 688340 & 4.55 & 5.2927 & TST \\
\hline CHEMBL1582170 & 688340 & 4.6 & 5.5241 & TST \\
\hline
\end{tabular}




\begin{tabular}{|c|c|c|c|c|}
\hline \\
\hline CHEMBL1547938 & 688340 & 4.7 & 4.5859 & TRN \\
\hline CHEMBL1354292 & 688340 & 4.0 & 5.2077 & TRN \\
\hline CHEMBL1305147 & 688340 & 7.0 & 5.192 & TRN \\
\hline CHEMBL18096 & 688340 & 5.6 & 4.9104 & TRN \\
\hline CHEMBL1362588 & 688340 & 4.8 & 5.1896 & TRN \\
\hline CHEMBL1550431 & 688340 & 4.55 & 4.8316 & TST \\
\hline CHEMBL1482115 & 688340 & 4.55 & \multicolumn{2}{|c|}{ 4.9639999999999995 } \\
\hline CHEMBL1361121 & 688340 & 7.0 & 4.6298 & TST \\
\hline CHEMBL1323546 & 688340 & 4.55 & 5.1057 & TRN \\
\hline CHEMBL1536662 & 688340 & 4.95 & 5.2406 & TST \\
\hline CHEMBL1375457 & 688340 & 5.6 & 5.2748 & TRN \\
\hline CHEMBL1571903 & 688340 & 6.0 & 5.4678 & TRN \\
\hline CHEMBL1333659 & 688340 & 4.55 & 4.9971 & TRN \\
\hline CHEMBL1310308 & 688340 & 4.4 & 5.1022 & TRN \\
\hline CHEMBL3189203 & 688340 & 4.6 & 5.1448 & TRN \\
\hline CHEMBL1543411 & 688340 & 4.4 & 4.9007 & TST \\
\hline CHEMBL3190153 & 688340 & 6.8 & 5.2628 & TRN \\
\hline CHEMBL1359797 & 688340 & 4.5 & 4.933 & TRN \\
\hline CHEMBL1350524 & 688340 & 6.8499 & 5.3343 & TST \\
\hline CHEMBL1522306 & 688340 & 5.05 & 4.9986 & TRN \\
\hline CHEMBL1499282 & 688340 & 5.05 & 4.92 & TST \\
\hline CHEMBL1348354 & 688340 & 4.55 & 4.9053 & TRN \\
\hline CHEMBL 3194877 & 688340 & 5.3 & \multicolumn{2}{|c|}{5.053999999999999} \\
\hline CHEMBL3189413 & 688340 & 5.0 & 5.1013 & TRN \\
\hline CHEMBL1324728 & 688340 & 5.35 & 5.0787 & TRN \\
\hline CHEMBL3198971 & 688340 & 5.75 & 5.3021 & TRN \\
\hline CHEMBL1600550 & 688340 & 4.85 & 4.9073 & TRN \\
\hline CHEMBL1574125 & 688340 & 4.55 & 5.2111 & TRN \\
\hline CHEMBL1345124 & 688340 & 4.55 & 5.3059 & TRN \\
\hline CHEMBL3199843 & 688340 & 4.0 & 4.6534 & TST \\
\hline CHEMBL1356373 & 688340 & 4.4 & 5.0016 & TRN \\
\hline CHEMBL1372780 & 688340 & 4.45 & 4.6158 & TRN \\
\hline CHEMBL1466744 & 688340 & 5.3 & 5.3213 & TRN \\
\hline CHEMBL1438780 & 688340 & 5.25 & 5.2066 & TRN \\
\hline CHEMBL1577965 & 688340 & 4.5 & 5.1468 & TRN \\
\hline CHEMBL1613433 & 688340 & 4.55 & 5.1785 & TRN \\
\hline CHEMBL1358375 & 688340 & 4.55 & 4.9168 & TST \\
\hline CHEMBL1420185 & 688340 & 6.1 & 4.6307 & TRN \\
\hline CHEMBL1483941 & 688340 & 4.4 & 4.5591 & TRN \\
\hline CHEMBL1394624 & 688340 & 6.0 & 4.6995 & TRN \\
\hline CHEMBL1474091 & 688340 & 4.7 & 4.7272 & TRN \\
\hline CHEMBL1495877 & 688340 & 4.75 & 5.1446 & TST \\
\hline CHEMBL1524336 & 688340 & 4.55 & 4.7693 & TRN \\
\hline CHEMBL1572547 & 688340 & 4.8 & 5.077 & TRN \\
\hline CHEMBL1536456 & 688340 & 4.85 & 4.9621 & TRN \\
\hline CHEMBL1405642 & 688340 & 4.4 & 4.957 & TRN \\
\hline CHEMBL1318778 & 688340 & 4.65 & 4.8378 & TRN \\
\hline CHEMBL1342068 & 688340 & 4.55 & 5.3241 & TRN \\
\hline
\end{tabular}




\begin{tabular}{|c|c|c|c|c|}
\hline \multicolumn{5}{|c|}{ Supplemental Table S2.txt } \\
\hline CHEMBL1438324 & 688340 & 4.75 & 5.0382 & TRN \\
\hline CHEMBL1380174 & 688340 & 5.05 & 5.1291 & TRN \\
\hline CHEMBL1325077 & 688340 & 4.75 & 5.2646 & TRN \\
\hline CHEMBL1466191 & 688340 & 5.45 & 5.0741 & TRN \\
\hline CHEMBL1312714 & 688340 & 4.9 & 4.7551 & TRN \\
\hline CHEMBL1327172 & 688340 & 4.7 & 4.7554 & TRN \\
\hline CHEMBL1581581 & 688340 & 4.6 & 4.8748 & TRN \\
\hline CHEMBL1704267 & 688340 & 5.45 & 4.7815 & TRN \\
\hline CHEMBL1576330 & 688340 & 4.65 & 4.544 & TRN \\
\hline CHEMBL76904 & 688340 & 4.65 & 4.9631 & TRN \\
\hline CHEMBL1348923 & 688340 & 4.95 & 5.0073 & TST \\
\hline CHEMBL1401270 & 688340 & 4.55 & 4.8387 & TRN \\
\hline CHEMBL1485277 & 688340 & 4.8 & 4.7185 & TRN \\
\hline CHEMBL1384995 & 688340 & 4.4 & 5.0028 & TRN \\
\hline CHEMBL1609020 & 688340 & 5.0 & 5.4003 & TRN \\
\hline CHEMBL1304262 & 688340 & 6.1 & 5.2437 & TRN \\
\hline CHEMBL1443932 & 688340 & 5.0 & 4.859 & TRN \\
\hline CHEMBL1535341 & 688340 & 5.45 & 5.4161 & TRN \\
\hline CHEMBL1528809 & 688340 & 5.1 & 5.3692 & TRN \\
\hline CHEMBL1490489 & 688340 & 4.4 & 5.1319 & TST \\
\hline CHEMBL1498509 & 688340 & 5.2 & 4.8781 & TST \\
\hline CHEMBL1500905 & 688340 & 4.5 & 4.8473 & TST \\
\hline CHEMBL1564991 & 688340 & 5.1 & 4.8473 & TST \\
\hline CHEMBL1343424 & 688340 & 4.55 & 4.8088 & TRN \\
\hline CHEMBL1319682 & 688340 & 4.75 & 4.9022 & TRN \\
\hline CHEMBL1353879 & 688340 & 4.55 & 4.9099 & TST \\
\hline CHEMBL1522852 & 688340 & 4.55 & 4.5482 & TRN \\
\hline CHEMBL1525701 & 688340 & 4.5 & 5.0135 & TRN \\
\hline CHEMBL 3192786 & 688340 & 4.5 & 4.8017 & TRN \\
\hline CHEMBL1457302 & 688340 & 4.75 & 4.9803 & TRN \\
\hline CHEMBL1315232 & 688340 & 5.35 & 4.944 & TRN \\
\hline CHEMBL1382573 & 688340 & 6.15 & 5.374 & TRN \\
\hline CHEMBL1354460 & 688340 & 4.4 & 5.3183 & TRN \\
\hline CHEMBL1314156 & 688340 & 6.1 & 5.1418 & TRN \\
\hline CHEMBL1334040 & 688340 & 4.65 & 4.6443 & TST \\
\hline CHEMBL1485535 & 688340 & 6.15 & 5.1991 & TRN \\
\hline CHEMBL1391373 & 688340 & 4.5 & 4.6719 & TRN \\
\hline CHEMBL1469802 & 688340 & 5.05 & 5.17 & TRN \\
\hline CHEMBL1338527 & 688340 & 4.5 & 4.9617 & TRN \\
\hline CHEMBL1323993 & 688340 & 4.0 & 5.3392 & TRN \\
\hline CHEMBL1967770 & 688340 & 4.85 & 5.1389 & TRN \\
\hline CHEMBL1590644 & 688340 & 4.4 & 5.5567 & TRN \\
\hline CHEMBL1465959 & 688340 & 4.0 & 5.2236 & TST \\
\hline CHEMBL1467867 & 688340 & 4.4 & 4.6956 & TRN \\
\hline CHEMBL1483945 & 688340 & 4.55 & 4.6612 & TRN \\
\hline CHEMBL3197042 & 688340 & 5.45 & 4.7942 & TRN \\
\hline CHEMBL1416403 & 688340 & 4.45 & 4.8764 & TRN \\
\hline CHEMBL1361488 & 688340 & 4.4 & 4.9581 & TRN \\
\hline
\end{tabular}




\begin{tabular}{|c|c|c|c|c|}
\hline \multicolumn{5}{|c|}{ splemental T } \\
\hline CHEMBL1425660 & 688340 & 4.6 & 4.8658 & TRN \\
\hline CHEMBL3195409 & 688340 & 5.4 & 5.0701 & TRN \\
\hline CHEMBL1549743 & 688340 & 4.4 & 4.5347 & TST \\
\hline CHEMBL1513608 & 688340 & 4.7 & 4.79 & TRN \\
\hline CHEMBL1518584 & 688340 & 4.35 & 5.3072 & TRN \\
\hline CHEMBL1303824 & 688340 & 5.2 & 5.1907 & TRN \\
\hline CHEMBL1416049 & 688340 & 4.4 & 5.193 & TST \\
\hline CHEMBL1991885 & 688340 & 4.45 & 4.9325 & TST \\
\hline CHEMBL1424665 & 688340 & 5.4 & 4.4146 & TRN \\
\hline CHEMBL1443806 & 688340 & 4.65 & 4.7652 & TRN \\
\hline CHEMBL591412 & 688340 & 4.6 & 4.537 & TRN \\
\hline CHEMBL1444407 & 688340 & 4.4 & 5.1877 & TST \\
\hline CHEMBL3199763 & 688340 & 4.45 & 5.0645 & TRN \\
\hline CHEMBL1306123 & 688340 & 7.0501 & 5.239 & TRN \\
\hline CHEMBL1608203 & 688340 & 4.45 & 4.888 & TRN \\
\hline CHEMBL1472542 & 688340 & 6.15 & 4.9845 & TRN \\
\hline CHEMBL1302670 & 688340 & 4.35 & 4.796 & TST \\
\hline CHEMBL1498677 & 688340 & 4.65 & 4.8787 & TRN \\
\hline CHEMBL1508648 & 688340 & 6.45 & 5.2841 & TRN \\
\hline CHEMBL1573754 & 688340 & 4.6 & 5.0728 & TRN \\
\hline CHEMBL1526061 & 688340 & 4.6 & 4.7626 & TRN \\
\hline CHEMBL1434416 & 688340 & 5.2 & 5.2434 & TRN \\
\hline CHEMBL3193133 & 688340 & 5.15 & 4.9819 & TRN \\
\hline CHEMBL3211998 & 688340 & 4.55 & 4.9021 & TRN \\
\hline CHEMBL1541008 & 688340 & 4.5 & 4.8231 & TRN \\
\hline CHEMBL1343631 & 688340 & 5.25 & 5.2713 & TST \\
\hline CHEMBL1329284 & 688340 & 4.4 & 4.9323 & TRN \\
\hline CHEMBL1402996 & 688340 & 5.4 & 4.8423 & TRN \\
\hline CHEMBL1326978 & 688340 & 4.5 & 4.8599 & TRN \\
\hline CHEMBL1303314 & 688340 & 4.55 & 4.8933 & TRN \\
\hline CHEMBL1322714 & 688340 & 4.5 & 4.9399 & TRN \\
\hline CHEMBL1340814 & 688340 & 4.4 & 4.9541 & TST \\
\hline CHEMBL1352020 & 688340 & 4.75 & 4.659 & TRN \\
\hline CHEMBL1577661 & 688340 & 4.7 & 4.8017 & TRN \\
\hline CHEMBL1433747 & 688340 & 4.4 & 5.3558 & TRN \\
\hline CHEMBL1479100 & 688340 & 6.95 & 4.8688 & TRN \\
\hline CHEMBL1405622 & 688340 & 4.5 & 4.7754 & TST \\
\hline CHEMBL1598180 & 688340 & 5.1 & 4.7697 & TRN \\
\hline CHEMBL1464470 & 688340 & 6.45 & 5.1207 & TRN \\
\hline CHEMBL1380319 & 688340 & 5.05 & 5.3028 & TRN \\
\hline CHEMBL1339632 & 688340 & 5.9 & 5.1985 & TRN \\
\hline CHEMBL1505688 & 688340 & 5.2 & 5.0436 & TRN \\
\hline CHEMBL1420556 & 688340 & 5.35 & 4.9961 & TST \\
\hline CHEMBL1301195 & 688340 & 4.55 & 5.182 & TRN \\
\hline CHEMBL1528776 & 688340 & 5.45 & 4.82 & TRN \\
\hline CHEMBL 3427333 & 688340 & 4.4 & 4.7597 & TRN \\
\hline CHEMBL1422465 & 688340 & 4.7 & 4.8397 & TST \\
\hline CHEMBL1433263 & 688340 & 4.85 & 4.8017 & TRN \\
\hline
\end{tabular}




\begin{tabular}{|c|c|c|c|c|}
\hline \multicolumn{5}{|c|}{ Supplemental Table S2.txt } \\
\hline CHEMBL1308642 & 688340 & 5.0 & 5.0167 & TST \\
\hline CHEMBL1355493 & 688340 & 4.7 & 4.9864 & TRN \\
\hline CHEMBL1455979 & 688340 & 4.45 & 5.1788 & TRN \\
\hline CHEMBL1492702 & 688340 & 7.1002 & 5.1942 & TST \\
\hline CHEMBL1984240 & 688340 & 5.85 & 4.7049 & TRN \\
\hline CHEMBL1424694 & 688340 & 6.1 & 5.0928 & TRN \\
\hline CHEMBL1444082 & 688340 & 4.6 & 4.7472 & TRN \\
\hline CHEMBL1481074 & 688340 & 6.95 & 4.8689 & TST \\
\hline CHEMBL1605872 & 688340 & 4.95 & 4.9401 & TRN \\
\hline CHEMBL1439364 & 688340 & 4.5 & 4.8047 & TRN \\
\hline CHEMBL1395952 & 688340 & 5.2 & 4.7901 & TRN \\
\hline CHEMBL1589746 & 688340 & 4.4 & 4.9258 & TRN \\
\hline CHEMBL1566871 & 688340 & 4.35 & 4.6505 & TRN \\
\hline CHEMBL1346727 & 688340 & 5.3 & 5.0657 & TST \\
\hline CHEMBL1564313 & 688340 & 5.05 & 4.7247 & TST \\
\hline CHEMBL1589162 & 688340 & 7.0 & 5.1305 & TRN \\
\hline CHEMBL1569742 & 688340 & 4.65 & 5.0282 & TRN \\
\hline CHEMBL1392101 & 688340 & 7.4001 & 5.4106 & TRN \\
\hline CHEMBL1352439 & 688340 & 6.35 & 5.1346 & TST \\
\hline CHEMBL1500125 & 688340 & 6.4 & 5.2648 & TST \\
\hline CHEMBL1424920 & 688340 & 5.65 & 5.0934 & TRN \\
\hline CHEMBL1307530 & 688340 & 4.75 & 4.8685 & TRN \\
\hline CHEMBL1401234 & 688340 & 6.45 & 5.1167 & TRN \\
\hline CHEMBL1433755 & 688340 & 4.4 & 4.8631 & TRN \\
\hline CHEMBL1522536 & 688340 & 4.45 & 4.9391 & TST \\
\hline CHEMBL1475769 & 688340 & 4.5 & 5.2272 & TRN \\
\hline CHEMBL1235760 & 688340 & 4.35 & 5.3935 & TRN \\
\hline CHEMBL1308813 & 688340 & 5.0 & 5.1692 & TRN \\
\hline CHEMBL1511937 & 688340 & 4.45 & 5.1276 & TST \\
\hline CHEMBL1590711 & 688340 & 4.6 & 5.3938 & TRN \\
\hline CHEMBL3192724 & 688340 & 4.6 & 5.1948 & TRN \\
\hline CHEMBL 3195076 & 688340 & 4.7 & 4.9225 & TRN \\
\hline CHEMBL1524482 & 688340 & 4.6 & 5.0442 & TRN \\
\hline CHEMBL1376127 & 688340 & 6.25 & 5.0912 & TRN \\
\hline CHEMBL1457701 & 688340 & 6.2 & 4.9668 & TRN \\
\hline CHEMBL1492564 & 688340 & 4.55 & 4.785 & TST \\
\hline CHEMBL1579618 & 688340 & 4.6 & 5.073 & TRN \\
\hline CHEMBL8739 & 688340 & 4.5 & 5.1235 & TRN \\
\hline CHEMBL1404941 & 688340 & 4.5 & 4.7742 & TST \\
\hline CHEMBL1402802 & 688340 & 5.2 & 4.9761 & TST \\
\hline CHEMBL1522640 & 688340 & 4.4 & 5.0502 & TRN \\
\hline CHEMBL1306479 & 688340 & 4.85 & 5.1731 & TST \\
\hline CHEMBL1565805 & 688340 & 4.85 & 5.3297 & TST \\
\hline CHEMBL1572436 & 688340 & 5.05 & 5.0341 & TRN \\
\hline CHEMBL1404559 & 688340 & 4.6 & 4.4809 & TRN \\
\hline CHEMBL1560226 & 688340 & 5.0 & 5.1135 & TRN \\
\hline CHEMBL1386796 & 688340 & 5.05 & 4.8465 & TRN \\
\hline CHEMBL1579084 & 688340 & 4.7 & 4.9314 & TST \\
\hline
\end{tabular}




\begin{tabular}{|c|c|c|c|c|c|}
\hline \multicolumn{6}{|c|}{ Supplemental Table S2.txt } \\
\hline CHEMBL1502636 & 688340 & 5.8 & 5.1898 & TRN & \\
\hline CHEMBL1563835 & 688340 & 4.9 & 4.9249 & TRN & \\
\hline CHEMBL1339285 & 688340 & 7.0501 & 4.9506 & TRN & \\
\hline CHEMBL1493630 & 688340 & 4.4 & 5.2118 & TRN & \\
\hline CHEMBL1323042 & 688340 & 5.45 & 5.1126 & TRN & \\
\hline CHEMBL1299705 & 688340 & 4.6 & 4.8719 & TRN & \\
\hline CHEMBL1528316 & 688340 & 4.6 & 4.8597 & TRN & \\
\hline CHEMBL1480014 & 688340 & 4.85 & 4.9223 & TRN & \\
\hline CHEMBL1605463 & 688340 & 5.1 & 5.0108 & TRN & \\
\hline CHEMBL1401242 & 688340 & 5.1 & 4.7172 & TRN & \\
\hline CHEMBL1334376 & 688340 & 4.5 & 5.0532 & TRN & \\
\hline CHEMBL1565541 & 688340 & 4.75 & 4.8418 & TRN & \\
\hline CHEMBL1537277 & 688340 & 4.65 & 5.1153 & TRN & \\
\hline CHEMBL3192246 & 688340 & 5.2 & 4.5987 & TRN & \\
\hline CHEMBL1312231 & 688340 & 4.8 & 4.9722 & TRN & \\
\hline CHEMBL1982441 & 688340 & 4.5 & 4.7618 & TRN & \\
\hline CHEMBL2005247 & 688340 & 4.6 & 5.0761 & TRN & \\
\hline CHEMBL1410347 & 688340 & 4.5 & 5.2794 & TRN & \\
\hline CHEMBL1606754 & 688340 & 4.55 & 4.7112 & TRN & \\
\hline CHEMBL1573121 & 688340 & 4.55 & 4.6342 & TRN & \\
\hline CHEMBL1408276 & 688340 & 4.75 & 4.7588 & TRN & \\
\hline CHEMBL3190468 & 688340 & 4.6 & 4.5542 & TRN & \\
\hline CHEMBL1597667 & 688340 & 6.05 & 4.9911 & TRN & \\
\hline CHEMBL1314747 & 688340 & 5.0 & 5.1579 & TRN & \\
\hline CHEMBL1509368 & 688340 & 4.65 & 4.7518 & TRN & \\
\hline CHEMBL1370047 & 688340 & 4.65 & 4.6892 & TST & \\
\hline CHEMBL1597425 & 688340 & 4.5 & 4.9755 & TRN & \\
\hline CHEMBL1550788 & 688340 & 4.4 & 4.7735 & TRN & \\
\hline CHEMBL1525515 & 688340 & 5.0 & 5.1593 & TRN & \\
\hline CHEMBL1528576 & 688340 & 4.55 & 4.50899 & 99999999995 & TRN \\
\hline CHEMBL1979957 & 688340 & 5.1 & 4.8393 & TRN & \\
\hline CHEMBL1399829 & 688340 & 5.0 & 5.1077 & TRN & \\
\hline CHEMBL1431844 & 688340 & 4.4 & 5.1564 & TRN & \\
\hline CHEMBL1572107 & 688340 & 4.55 & 5.0065 & TRN & \\
\hline CHEMBL1576256 & 688340 & 3.9 & 5.0498 & TST & \\
\hline CHEMBL1408342 & 688340 & 4.35 & 4.9616 & TRN & \\
\hline CHEMBL1499415 & 688340 & 4.45 & 4.8758 & TRN & \\
\hline CHEMBL468590 & 688340 & 4.55 & 4.9434 & TRN & \\
\hline CHEMBL1585062 & 688340 & 5.5 & 5.13899 & 9999999999 & TRN \\
\hline CHEMBL3191593 & 688340 & 5.0 & 5.033 & TRN & \\
\hline CHEMBL522990 & 688340 & 4.5 & 5.034 & TST & \\
\hline CHEMBL1514835 & 688340 & 4.35 & 5.1388 & TST & \\
\hline CHEMBL1563662 & 688340 & 4.6 & 5.3486 & TRN & \\
\hline CHEMBL1451006 & 688340 & 6.15 & 5.3456 & TRN & \\
\hline CHEMBL1603883 & 688340 & 6.15 & 5.1851 & TRN & \\
\hline CHEMBL1340954 & 688340 & 4.6 & 4.7448 & TRN & \\
\hline CHEMBL3190491 & 688340 & 6.05 & 4.8796 & TST & \\
\hline CHEMBL1584217 & 688340 & 4.4 & 5.0201 & TRN & \\
\hline
\end{tabular}




\begin{tabular}{|c|c|c|c|c|}
\hline \multicolumn{5}{|c|}{ Supplemental Table S2.txt } \\
\hline CHEMBL1471670 & 688340 & 4.5 & 4.944 & TRN \\
\hline CHEMBL1571034 & 688340 & 6.1 & 5.0941 & TRN \\
\hline CHEMBL1544394 & 688340 & 5.2 & 5.1893 & TRN \\
\hline CHEMBL1537073 & 688340 & 4.95 & 5.275 & TRN \\
\hline CHEMBL1455019 & 688340 & 4.5 & 5.2578 & TRN \\
\hline CHEMBL1382614 & 688340 & 5.35 & 4.9957 & TRN \\
\hline CHEMBL1356043 & 688340 & 6.1 & 5.1373 & TST \\
\hline CHEMBL1535893 & 688340 & 4.6 & 4.9252 & TRN \\
\hline CHEMBL1341590 & 688340 & 4.6 & 4.7607 & TRN \\
\hline CHEMBL1467766 & 688340 & 4.45 & 5.4671 & TRN \\
\hline CHEMBL1453051 & 688340 & 5.75 & 5.1912 & TRN \\
\hline CHEMBL1563936 & 688340 & 4.5 & 5.01 & TRN \\
\hline CHEMBL1539714 & 688340 & 7.0501 & 5.3613 & TRN \\
\hline CHEMBL1587708 & 688340 & 4.65 & 4.6824 & TRN \\
\hline CHEMBL3197346 & 688340 & 4.45 & 4.8935 & TRN \\
\hline CHEMBL1500636 & 688340 & 4.75 & 4.7379 & TRN \\
\hline CHEMBL1383287 & 688340 & 6.45 & 5.4051 & TRN \\
\hline CHEMBL1537068 & 688340 & 5.45 & 4.7721 & TST \\
\hline CHEMBL1367872 & 688340 & 4.65 & 4.6881 & TRN \\
\hline CHEMBL1604679 & 688340 & 4.4 & 5.2127 & TRN \\
\hline CHEMBL3195824 & 688340 & 4.7 & 4.8383 & TRN \\
\hline CHEMBL1470548 & 688340 & 4.55 & 5.227 & TRN \\
\hline CHEMBL1415635 & 688340 & 5.45 & 4.9642 & TRN \\
\hline CHEMBL1392890 & 688340 & 4.65 & 4.8455 & TRN \\
\hline CHEMBL1389755 & 688340 & 4.85 & 4.6764 & TRN \\
\hline CHEMBL1407916 & 688340 & 5.0 & 5.3497 & TRN \\
\hline CHEMBL1305314 & 688340 & 4.85 & 4.886 & TRN \\
\hline CHEMBL1349535 & 688340 & 4.85 & 4.9116 & TRN \\
\hline CHEMBL1560092 & 688340 & 4.45 & 4.9023 & TRN \\
\hline CHEMBL1578561 & 688340 & 4.5 & 4.9274 & TRN \\
\hline CHEMBL1991921 & 688340 & 4.4 & 5.0035 & TST \\
\hline CHEMBL1325821 & 688340 & 6.5 & 5.3468 & TRN \\
\hline CHEMBL1549316 & 688340 & 4.9 & 5.0151 & TRN \\
\hline CHEMBL1303188 & 688340 & 4.45 & 5.035 & TRN \\
\hline CHEMBL1352800 & 688340 & 4.6 & 4.7568 & TRN \\
\hline CHEMBL1384510 & 688340 & 6.15 & 5.1839 & TST \\
\hline CHEMBL1541090 & 688340 & 5.0 & $4.8610 e$ & 0000000001 \\
\hline CHEMBL 2005317 & 688340 & 6.15 & 5.0573 & TRN \\
\hline CHEMBL1409188 & 688340 & 3.8 & 5.0146 & TST \\
\hline CHEMBL1591369 & 688340 & 4.55 & 4.9993 & TRN \\
\hline CHEMBL1608198 & 688340 & 4.35 & 5.6364 & TRN \\
\hline CHEMBL3191083 & 688340 & 4.5 & 5.0938 & TRN \\
\hline CHEMBL1546405 & 688340 & 4.8 & 4.7377 & TRN \\
\hline CHEMBL1500080 & 688340 & 4.6 & 5.2123 & TRN \\
\hline CHEMBL1532816 & 688340 & 4.45 & 4.8679 & TRN \\
\hline CHEMBL1523249 & 688340 & 4.6 & 5.1954 & TST \\
\hline CHEMBL1573261 & 688340 & 4.55 & 5.1346 & TRN \\
\hline CHEMBL1600745 & 688340 & 4.0 & 5.3266 & TST \\
\hline
\end{tabular}




\begin{tabular}{|c|c|c|c|c|c|}
\hline \multicolumn{6}{|c|}{ Supplemental Table S2.txt } \\
\hline CHEMBL1310284 & 688340 & 4.65 & 4.9709 & TRN & \\
\hline CHEMBL1309572 & 688340 & 4.4 & 5.277 & TRN & \\
\hline CHEMBL1453475 & 688340 & 5.6 & 4.9842 & TRN & \\
\hline CHEMBL1360134 & 688340 & 3.95 & 5.1804 & TST & \\
\hline CHEMBL1516859 & 688340 & 4.55 & 4.5271 & TRN & \\
\hline CHEMBL1468344 & 688340 & 4.35 & 5.1818 & TST & \\
\hline CHEMBL1389645 & 688340 & 4.6 & 5.0594 & TST & \\
\hline CHEMBL1365833 & 688340 & 4.55 & 5.0184 & TRN & \\
\hline CHEMBL1562633 & 688340 & 4.5 & 4.8723 & TRN & \\
\hline CHEMBL1382672 & 688340 & 4.4 & 4.8415 & TRN & \\
\hline CHEMBL1473696 & 688340 & 4.7 & 4.6529 & TRN & \\
\hline CHEMBL1558533 & 688340 & 5.2 & 5.0165 & TRN & \\
\hline CHEMBL1537503 & 688340 & 4.5 & 4.7905 & TST & \\
\hline CHEMBL1300729 & 688340 & 5.4 & 4.9051 & TRN & \\
\hline CHEMBL3196750 & 688340 & 4.5 & 4.8393 & TRN & \\
\hline CHEMBL1377047 & 688340 & 5.25 & 4.7589 & TST & \\
\hline CHEMBL1489071 & 688340 & 4.5 & 5.048 & TST & \\
\hline CHEMBL1572010 & 688340 & 4.55 & 5.0284 & TST & \\
\hline CHEMBL1541522 & 688340 & 5.35 & 5.2111 & TRN & \\
\hline CHEMBL1527982 & 688340 & 4.75 & 4.9682 & TRN & \\
\hline CHEMBL1358194 & 688340 & 4.55 & 4.9957 & TRN & \\
\hline CHEMBL1418939 & 688340 & 4.6 & 4.7149 & TRN & \\
\hline CHEMBL1583281 & 688340 & 5.35 & 5.3424 & TST & \\
\hline CHEMBL1500908 & 688340 & 5.55 & 5.0533 & TST & \\
\hline CHEMBL1339225 & 688340 & 4.65 & 5.1698 & TRN & \\
\hline CHEMBL1565212 & 688340 & 5.35 & 4.91 & TRN & \\
\hline CHEMBL1387953 & 688340 & 4.8 & 5.0253 & TRN & \\
\hline CHEMBL1545995 & 688340 & 4.65 & 4.8395 & TRN & \\
\hline CHEMBL1408125 & 688340 & 4.4 & 4.8951 & TST & \\
\hline CHEMBL1587560 & 688340 & 5.2 & 4.8164 & TRN & \\
\hline CHEMBL78257 & 688340 & 4.5 & 5.13299 & 9999999999 & TST \\
\hline CHEMBL107231 & 688340 & 4.35 & 4.8556 & TRN & \\
\hline CHEMBL1316002 & 688340 & 5.4 & 5.13399 & 99999999995 & TRN \\
\hline CHEMBL1554441 & 688340 & 6.4 & 5.4454 & TRN & \\
\hline CHEMBL1368166 & 688340 & 5.4 & 4.8834 & TRN & \\
\hline CHEMBL1504875 & 688340 & 4.6 & 5.0777 & TRN & \\
\hline CHEMBL1503188 & 688340 & 4.55 & 4.7956 & TRN & \\
\hline CHEMBL1475513 & 688340 & 4.6 & 5.0937 & TRN & \\
\hline CHEMBL1573618 & 688340 & 4.55 & 4.6442 & TRN & \\
\hline CHEMBL1577491 & 688340 & 5.15 & 5.085 & TRN & \\
\hline CHEMBL1314447 & 688340 & 4.0 & 4.954 & TST & \\
\hline CHEMBL1585952 & 688340 & 5.0 & 5.0346 & TRN & \\
\hline CHEMBL1488435 & 688340 & 4.35 & 4.8857 & TST & \\
\hline CHEMBL1403828 & 688340 & 7.5003 & 4.9851 & TRN & \\
\hline CHEMBL1332361 & 688340 & 4.95 & 5.1672 & TRN & \\
\hline CHEMBL1598177 & 688340 & 8.4559 & 5.2777 & TRN & \\
\hline CHEMBL1469527 & 688340 & 5.2 & 5.3193 & TRN & \\
\hline CHEMBL1515912 & 688340 & 4.55 & 5.3081 & TRN & \\
\hline
\end{tabular}




\begin{tabular}{|c|c|c|c|c|}
\hline \multicolumn{5}{|c|}{ Supplemental Table S2.txt } \\
\hline CHEMBL1428559 & 688340 & 4.0 & 5.146 & TRN \\
\hline CHEMBL1369893 & 688340 & 5.0 & 4.7207 & TRN \\
\hline CHEMBL1392124 & 688340 & 4.0 & 5.2015 & TRN \\
\hline CHEMBL1403808 & 688340 & 4.8 & 4.7709 & TRN \\
\hline CHEMBL1345379 & 688340 & 6.3 & 5.1449 & TRN \\
\hline CHEMBL3209818 & 688340 & 6.15 & 5.3301 & TRN \\
\hline CHEMBL1318932 & 688340 & 3.8 & 5.2123 & TST \\
\hline CHEMBL3196551 & 688340 & 5.0 & 5.0319 & TST \\
\hline CHEMBL1313527 & 688340 & 4.6 & 4.9204 & TRN \\
\hline CHEMBL1980204 & 688340 & 4.5 & 4.7229 & TRN \\
\hline CHEMBL1389400 & 688340 & 4.5 & 4.685 & TRN \\
\hline CHEMBL1396690 & 688340 & 4.55 & 5.2531 & TRN \\
\hline CHEMBL1554276 & 688340 & 4.55 & 5.2043 & TRN \\
\hline CHEMBL1538476 & 688340 & 4.45 & 5.2164 & TRN \\
\hline CHEMBL1489910 & 688340 & 4.9 & 5.1238 & TST \\
\hline CHEMBL1541255 & 688340 & 4.5 & 5.0564 & TRN \\
\hline CHEMBL1553278 & 688340 & 4.3 & 5.3122 & TRN \\
\hline CHEMBL1594354 & 688340 & 5.25 & 5.105 & TST \\
\hline CHEMBL1597264 & 688340 & 4.4 & 4.9363 & TRN \\
\hline CHEMBL1425404 & 688340 & 4.05 & 4.9454 & TRN \\
\hline CHEMBL1583365 & 688340 & 4.8 & 4.9989 & TRN \\
\hline CHEMBL1530566 & 688340 & 4.95 & 5.0802 & TST \\
\hline CHEMBL1506096 & 688340 & 4.9 & 5.36 & TRN \\
\hline CHEMBL1475836 & 688340 & 7.3002 & 5.3113 & TRN \\
\hline CHEMBL1592780 & 688340 & 5.55 & 5.2781 & TRN \\
\hline CHEMBL1508037 & 688340 & 4.45 & 4.8977 & TRN \\
\hline CHEMBL1401002 & 688340 & 4.8 & 5.0993 & TST \\
\hline CHEMBL1546369 & 688340 & 4.45 & 4.9897 & TRN \\
\hline CHEMBL1319917 & 688340 & 5.1 & 4.64 & TRN \\
\hline CHEMBL1450129 & 688340 & 4.65 & 5.065 & TRN \\
\hline CHEMBL1506082 & 688340 & 4.55 & 4.9374 & TRN \\
\hline CHEMBL1454577 & 688340 & 4.95 & 4.8967 & TRN \\
\hline CHEMBL1421791 & 688340 & 6.8499 & 5.1095 & TST \\
\hline CHEMBL1412507 & 688340 & 5.0 & 5.0751 & TST \\
\hline CHEMBL1521615 & 688340 & 4.55 & 4.8137 & TRN \\
\hline CHEMBL1480297 & 688340 & 5.3 & 5.3502 & TRN \\
\hline CHEMBL1316907 & 688340 & 4.5 & 5.4774 & TRN \\
\hline CHEMBL1443822 & 688340 & 5.45 & 4.9191 & TRN \\
\hline CHEMBL125812 & 688340 & 6.2 & 5.3146 & TRN \\
\hline CHEMBL1565403 & 688340 & 4.6 & 4.7717 & TRN \\
\hline CHEMBL1389530 & 688340 & 5.7 & 4.9089 & TRN \\
\hline CHEMBL1587958 & 688340 & 5.25 & 5.2713 & TRN \\
\hline CHEMBL1425596 & 688340 & 6.35 & 5.0506 & TST \\
\hline CHEMBL1972915 & 688340 & 4.45 & 4.7748 & TRN \\
\hline CHEMBL1574148 & 688340 & 4.65 & 4.8582 & TST \\
\hline CHEMBL1441532 & 688340 & 5.45 & 5.2679 & TRN \\
\hline CHEMBL1594286 & 688340 & 4.4 & 4.9185 & TRN \\
\hline CHEMBL3209267 & 688340 & 4.8 & 4.4927 & TRN \\
\hline
\end{tabular}




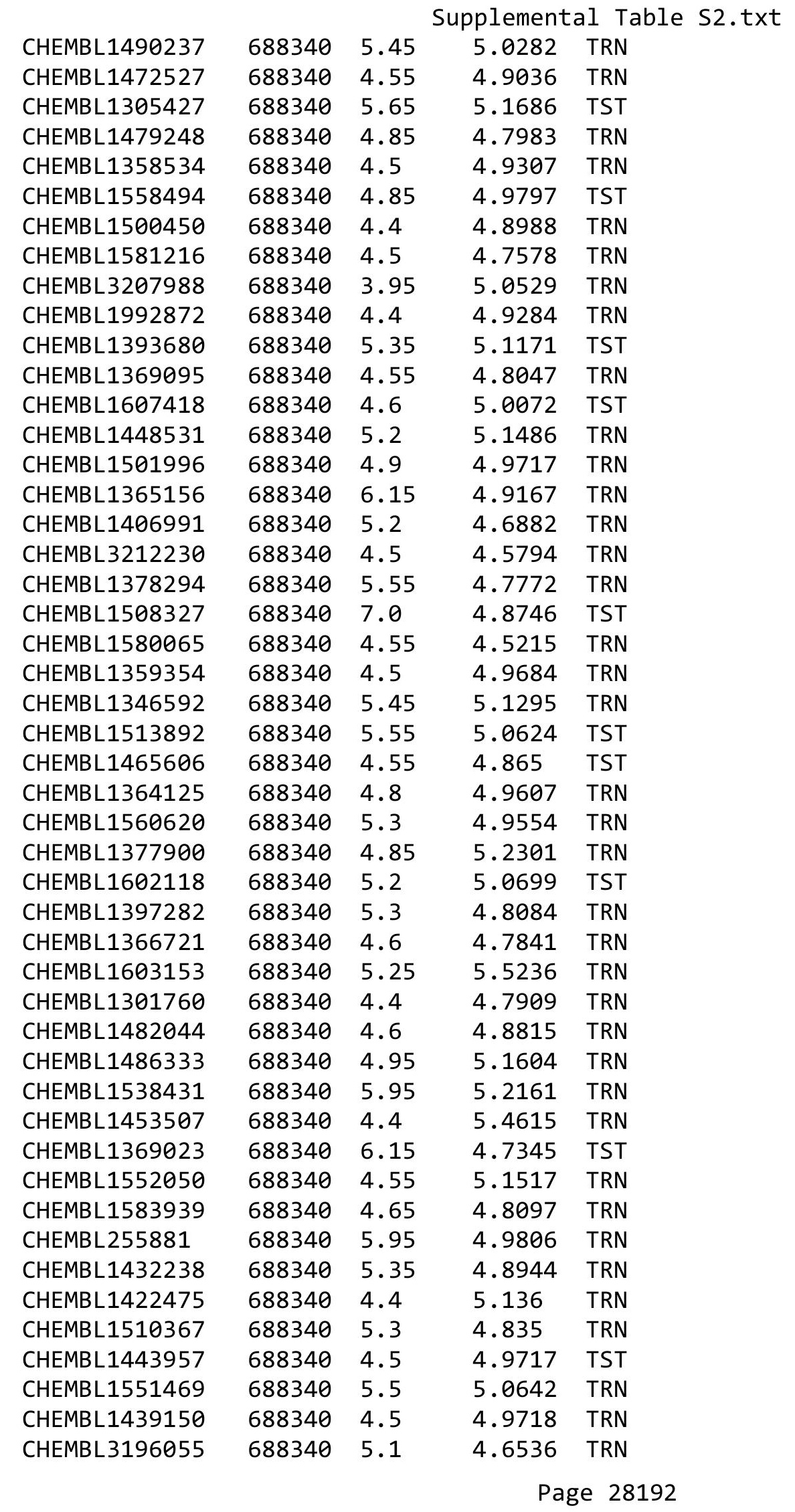




\begin{tabular}{|c|c|c|c|c|}
\hline \multicolumn{5}{|c|}{ Supplemental Table S2.txt } \\
\hline CHEMBL1354721 & 688340 & 4.55 & 4.7669 & TRN \\
\hline CHEMBL 3196054 & 688340 & 4.55 & 4.751 & TRN \\
\hline CHEMBL1379304 & 688340 & 4.0 & 5.2422 & TRN \\
\hline CHEMBL1609110 & 688340 & 4.4 & 4.8396 & TRN \\
\hline CHEMBL1519789 & 688340 & 5.35 & 5.1678 & TST \\
\hline CHEMBL1433083 & 688340 & 4.05 & 4.9717 & TRN \\
\hline CHEMBL1977487 & 688340 & 4.95 & 5.3044 & TRN \\
\hline CHEMBL1446569 & 688340 & 4.5 & 4.7815 & TRN \\
\hline CHEMBL1566702 & 688340 & 4.45 & 5.1189 & TST \\
\hline CHEMBL1490118 & 688340 & 4.55 & 4.7239 & TRN \\
\hline CHEMBL 3196452 & 688340 & 4.9 & 4.6897 & TRN \\
\hline CHEMBL1323612 & 688340 & 4.8 & 5.0243 & TRN \\
\hline CHEMBL1581838 & 688340 & 5.7 & 4.7725 & TRN \\
\hline CHEMBL 1474003 & 688340 & 6.0 & 4.9818 & TRN \\
\hline CHEMBL1462157 & 688340 & 4.4 & 4.9688 & TRN \\
\hline CHEMBL1344431 & 688340 & 4.5 & 5.2178 & TRN \\
\hline CHEMBL1475376 & 688340 & 6.15 & 5.1953 & TRN \\
\hline CHEMBL 3197060 & 688340 & 4.5 & 5.0192 & TRN \\
\hline CHEMBL1447010 & 688340 & 4.45 & 4.95 & TRN \\
\hline CHEMBL1489152 & 688340 & 4.4 & 4.8466 & TRN \\
\hline CHEMBL1366206 & 688340 & 8.9586 & 4.7576 & TST \\
\hline CHEMBL1432627 & 688340 & 4.4 & 5.0586 & TRN \\
\hline CHEMBL1495441 & 688340 & 7.0 & 5.1229 & TRN \\
\hline CHEMBL1404248 & 688340 & 5.05 & 5.1837 & TST \\
\hline CHEMBL1338252 & 688340 & 4.5 & 4.7184 & TRN \\
\hline CHEMBL 3195626 & 688340 & 4.7 & 4.8695 & TRN \\
\hline CHEMBL1789996 & 688340 & 4.6 & 4.7355 & TST \\
\hline CHEMBL1439990 & 688340 & 4.5 & 4.9867 & TRN \\
\hline CHEMBL1430236 & 688340 & 5.85 & 4.9461 & TRN \\
\hline CHEMBL1561833 & 688340 & 4.45 & 4.9766 & TRN \\
\hline CHEMBL1336680 & 688340 & 5.0 & 4.9808 & TRN \\
\hline CHEMBL1352056 & 688340 & 4.6 & 4.9568 & TRN \\
\hline CHEMBL1384169 & 688340 & 7.0 & 5.2274 & TRN \\
\hline CHEMBL1312873 & 688340 & 4.45 & 4.823 & TST \\
\hline CHEMBL1336808 & 688340 & 5.4 & 5.053 & TRN \\
\hline CHEMBL1531622 & 688340 & 4.65 & 4.9269 & TRN \\
\hline CHEMBL1301971 & 688340 & 4.4 & 4.9791 & TST \\
\hline CHEMBL1987928 & 688340 & 5.95 & 5.197 & TRN \\
\hline CHEMBL1582299 & 688340 & 4.4 & 4.9382 & TRN \\
\hline CHEMBL1539846 & 688340 & 4.4 & 5.2411 & TRN \\
\hline CHEMBL1315183 & 688340 & 4.5 & 4.811 & TRN \\
\hline CHEMBL1518581 & 688340 & 4.65 & 4.7564 & TRN \\
\hline CHEMBL1500850 & 688340 & 4.65 & 4.8682 & TRN \\
\hline CHEMBL1595462 & 688340 & 4.35 & 5.0115 & TST \\
\hline CHEMBL1416967 & 688340 & 4.9 & 5.1888 & TRN \\
\hline CHEMBL1395360 & 688340 & 5.35 & 5.0327 & TRN \\
\hline CHEMBL1424300 & 688340 & 5.0 & 5.1569 & TRN \\
\hline CHEMBL 3195357 & 688340 & 4.5 & 5.0506 & TRN \\
\hline
\end{tabular}




\begin{tabular}{|c|c|c|c|c|c|}
\hline \multicolumn{6}{|c|}{ Supplemental Table S2.txt } \\
\hline CHEMBL1599696 & 688340 & 4.65 & 5.4012 & TRN & \\
\hline CHEMBL1341934 & 688340 & 6.9 & 5.1551 & TRN & \\
\hline CHEMBL1471888 & 688340 & 4.4 & 4.6777 & TRN & \\
\hline CHEMBL1342473 & 688340 & 4.4 & 4.8176 & TRN & \\
\hline CHEMBL1502356 & 688340 & 4.4 & 5.1307 & TST & \\
\hline CHEMBL1363788 & 688340 & 4.55 & 5.0962 & TRN & \\
\hline CHEMBL1539325 & 688340 & 5.2 & 4.9964 & TRN & \\
\hline CHEMBL1547977 & 688340 & 5.5 & 5.36299 & 99999999995 & TRN \\
\hline CHEMBL1496732 & 688340 & 5.1 & 4.8145 & TRN & \\
\hline CHEMBL3194984 & 688340 & 6.2 & 4.9207 & TRN & \\
\hline CHEMBL1468867 & 688340 & 5.25 & 5.2584 & TST & \\
\hline CHEMBL1511037 & 688340 & 4.8 & 4.5421 & TRN & \\
\hline CHEMBL1381135 & 688340 & 5.4 & 4.8446 & TRN & \\
\hline CHEMBL 3195658 & 688340 & 6.15 & 4.8704 & TST & \\
\hline CHEMBL1992589 & 688340 & 5.35 & 5.0476 & TRN & \\
\hline CHEMBL1464204 & 688340 & 4.4 & 5.2707 & TST & \\
\hline CHEMBL1588198 & 688340 & 5.05 & 4.9743 & TRN & \\
\hline CHEMBL1541918 & 688340 & 4.8 & 4.9341 & TRN & \\
\hline CHEMBL1359914 & 688340 & 5.0 & 4.8944 & TRN & \\
\hline CHEMBL1541346 & 688340 & 4.7 & 4.6066 & TRN & \\
\hline CHEMBL1335492 & 688340 & 4.75 & 4.8122 & TST & \\
\hline CHEMBL1582353 & 688340 & 4.55 & 4.9193 & TRN & \\
\hline CHEMBL1310205 & 688340 & 5.05 & 5.3265 & TRN & \\
\hline CHEMBL1492904 & 688340 & 4.5 & 5.1299 & TST & \\
\hline CHEMBL1466972 & 688340 & 4.65 & 5.1145 & TRN & \\
\hline CHEMBL1531853 & 688340 & 4.65 & 4.7418 & TRN & \\
\hline CHEMBL1557002 & 688340 & 4.8 & 4.8708 & TRN & \\
\hline CHEMBL1458518 & 688340 & 4.55 & 4.936 & TRN & \\
\hline CHEMBL1320367 & 688340 & 4.5 & 4.9938 & TRN & \\
\hline CHEMBL1408463 & 688340 & 4.45 & 4.7871 & TRN & \\
\hline CHEMBL1441118 & 688340 & 4.6 & 4.5045 & TRN & \\
\hline CHEMBL1535885 & 688340 & 4.6 & 5.0827 & TRN & \\
\hline CHEMBL1306960 & 688340 & 4.45 & 4.9597 & TST & \\
\hline CHEMBL1323341 & 688340 & 5.2 & 5.2884 & TST & \\
\hline CHEMBL1603074 & 688340 & 4.55 & 4.9541 & TRN & \\
\hline CHEMBL1542356 & 688340 & 4.35 & 5.0414 & TRN & \\
\hline CHEMBL1438598 & 688340 & 4.55 & 4.5627 & TRN & \\
\hline CHEMBL1489138 & 688340 & 4.65 & 4.8822 & TRN & \\
\hline CHEMBL1586498 & 688340 & 4.45 & 4.8378 & TRN & \\
\hline CHEMBL1355687 & 688340 & 4.45 & 5.3641 & TRN & \\
\hline CHEMBL1521999 & 688340 & 4.5 & 5.1491 & TST & \\
\hline CHEMBL1522652 & 688340 & 6.25 & 5.142 & TRN & \\
\hline CHEMBL1416961 & 688340 & 4.4 & 4.8647 & TRN & \\
\hline CHEMBL1974389 & 688340 & 4.65 & 4.9897 & TST & \\
\hline CHEMBL1545071 & 688340 & 4.55 & 4.8649 & TRN & \\
\hline CHEMBL1330161 & 688340 & 4.5 & 4.6856 & TRN & \\
\hline CHEMBL1378054 & 688340 & 4.5 & 5.0956 & TRN & \\
\hline CHEMBL1558463 & 688340 & 4.35 & 5.3597 & TRN & \\
\hline
\end{tabular}




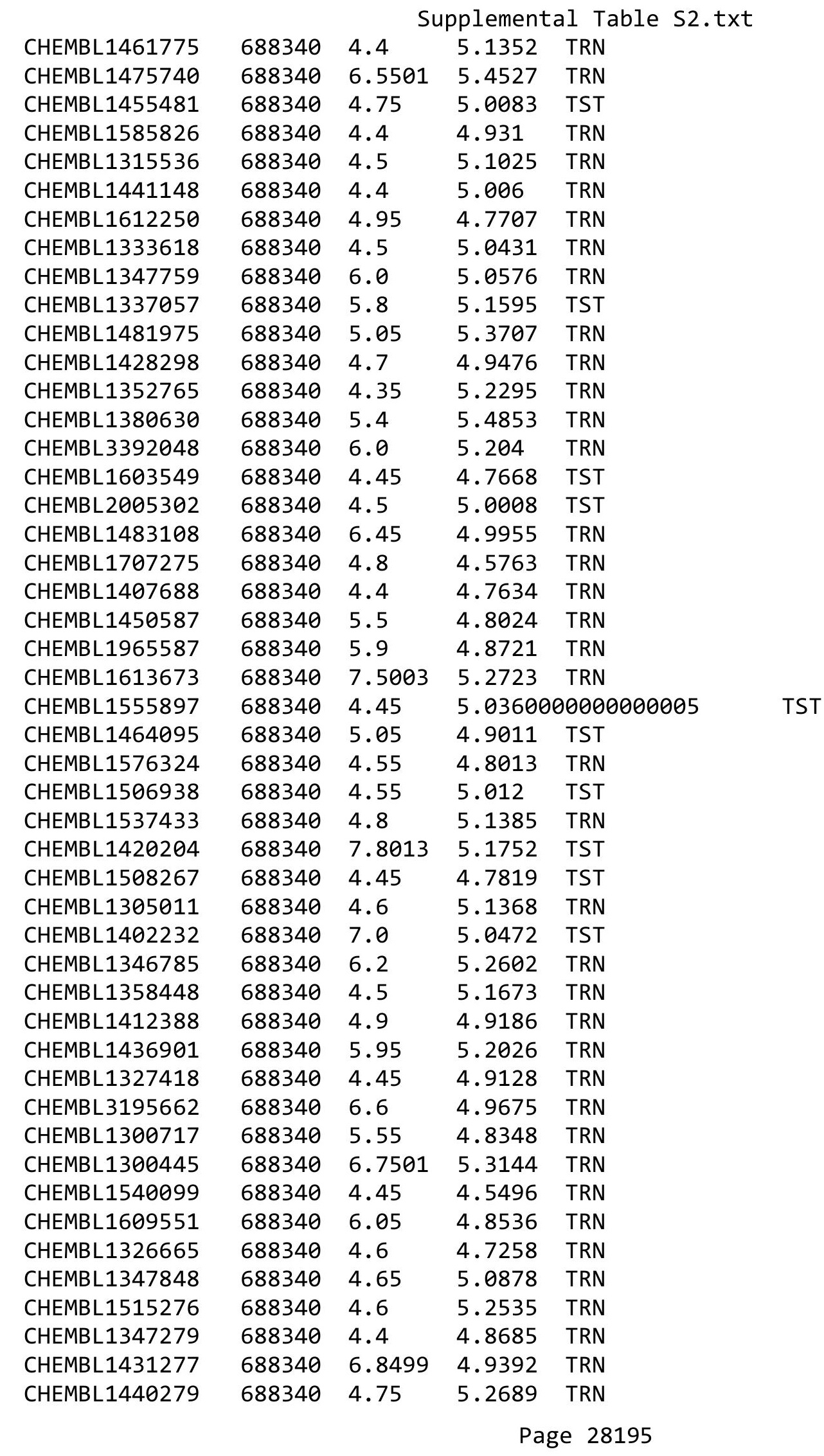




\begin{tabular}{|c|c|c|c|c|}
\hline \multicolumn{5}{|r|}{ al Table S } \\
\hline CHEMBL1383265 & 688340 & 7.0 & 4.8871 & TRN \\
\hline CHEMBL1598091 & 688340 & 4.6 & 4.9104 & TRN \\
\hline CHEMBL1499436 & 688340 & 4.9 & 4.86600 & 00000000005 \\
\hline CHEMBL1350090 & 688340 & 6.8499 & 5.1062 & TRN \\
\hline CHEMBL1453441 & 688340 & 4.55 & 5.1656 & TRN \\
\hline CHEMBL1342308 & 688340 & 5.1 & 4.745 & TST \\
\hline CHEMBL1465850 & 688340 & 4.6 & 4.7305 & TST \\
\hline CHEMBL1312300 & 688340 & 4.5 & 5.08 & TRN \\
\hline CHEMBL1449317 & 688340 & 5.6 & 4.8716 & TRN \\
\hline CHEMBL1301562 & 688340 & 5.45 & 4.9285 & TRN \\
\hline CHEMBL 1604473 & 688340 & 4.45 & 4.9315 & TRN \\
\hline CHEMBL1464984 & 688340 & 4.65 & 4.5227 & TRN \\
\hline CHEMBL1317502 & 688340 & 4.75 & 4.9698 & TRN \\
\hline CHEMBL1558597 & 688340 & 5.35 & 5.0285 & TRN \\
\hline CHEMBL3199408 & 688340 & 4.4 & 5.1984 & TRN \\
\hline CHEMBL1332799 & 688340 & 4.55 & 4.645 & TRN \\
\hline CHEMBL1536994 & 688340 & 4.9 & 4.9917 & TRN \\
\hline CHEMBL1492585 & 688340 & 4.55 & 4.474 & TRN \\
\hline CHEMBL3190318 & 688340 & 7.1002 & 4.942 & TRN \\
\hline CHEMBL3191643 & 688340 & 4.45 & 5.1233 & TRN \\
\hline CHEMBL1319391 & 688340 & 5.6 & 4.7381 & TRN \\
\hline CHEMBL1488613 & 688340 & 6.2 & 4.9619 & TRN \\
\hline CHEMBL1425914 & 688340 & 4.65 & 4.8953 & TRN \\
\hline CHEMBL1314085 & 688340 & 4.4 & 4.8602 & TRN \\
\hline CHEMBL 1558643 & 688340 & 4.35 & 4.9894 & TRN \\
\hline CHEMBL1458247 & 688340 & 5.0 & 4.8944 & TST \\
\hline CHEMBL3209028 & 688340 & 6.1 & 5.1093 & TRN \\
\hline CHEMBL1531251 & 688340 & 4.65 & 4.9787 & TST \\
\hline CHEMBL1528178 & 688340 & 4.5 & 5.0666 & TST \\
\hline CHEMBL1559542 & 688340 & 4.6 & 4.8785 & TRN \\
\hline CHEMBL3145303 & 688340 & 4.6 & 5.0533 & TRN \\
\hline CHEMBL1433421 & 688340 & 4.6 & 4.6952 & TRN \\
\hline CHEMBL1424274 & 688340 & 6.0 & 5.2503 & TST \\
\hline CHEMBL1300859 & 688340 & 4.4 & 4.7341 & TRN \\
\hline CHEMBL3199393 & 688340 & 4.6 & 4.8748 & TRN \\
\hline CHEMBL1312650 & 688340 & 5.05 & 5.0307 & TRN \\
\hline CHEMBL600922 & 688340 & 4.5 & 4.626 & TRN \\
\hline CHEMBL1439348 & 688340 & 4.35 & 4.9187 & TRN \\
\hline CHEMBL1492049 & 688340 & 4.95 & 5.1694 & TST \\
\hline CHEMBL1530870 & 688340 & 7.0 & 5.4912 & TST \\
\hline CHEMBL358546 & 688340 & 4.45 & 5.0802 & TRN \\
\hline CHEMBL1344292 & 688340 & 5.1 & 4.9789 & TST \\
\hline CHEMBL1384692 & 688340 & 4.35 & 5.0708 & TRN \\
\hline CHEMBL1327994 & 688340 & 4.5 & 4.9861 & TRN \\
\hline CHEMBL1365706 & 688340 & 4.45 & 4.7232 & TRN \\
\hline CHEMBL1485916 & 688340 & 4.6 & 5.1393 & TRN \\
\hline CHEMBL1497012 & 688340 & 4.55 & 4.8177 & TRN \\
\hline CHEMBL1304105 & 688340 & 6.8 & 4.8386 & TRN \\
\hline
\end{tabular}




\begin{tabular}{|c|c|c|c|c|}
\hline \\
\hline IEMBL1529182 & 688340 & 4.7 & 5.1371 & TST \\
\hline CHEMBL1390102 & 688340 & 4.8 & 4.6028 & \\
\hline HEMBL1369639 & 88340 & 4.5 & 659 & \\
\hline HEMBL1592897 & 88340 & 5.0 & .375 & \\
\hline HEMBL1528684 & 88340 & 4.6 & 9053 & \\
\hline HEMBL1514131 & 588340 & 4.65 & 5.041 & \\
\hline HEMBL1573780 & 588340 & 6.8499 & 4.9122 & \\
\hline HEMBL1535530 & 88340 & 5.2 & 5.2644 & \\
\hline HEMBL1519983 & 588340 & 4.5 & 4.6911 & \\
\hline HEMBL1401306 & 688340 & & 5.2734 & \\
\hline HEMBL1506630 & 688340 & 5.2 & 5.2453 & \\
\hline HEMBL1539954 & 688340 & 4.4 & 5.0542 & \\
\hline HEMBL1459947 & 588340 & 6.9 & 5.1976 & \\
\hline HEMBL1311844 & 688340 & & & \\
\hline HEMBL1329521 & 688340 & 4.55 & 4.8094 & \\
\hline HEMBL1557939 & 688340 & 6.15 & 5.2317 & \\
\hline HEMBL: & 688340 & 4.4 & 4.9951 & \\
\hline HEMBL3192160 & 688340 & 6.0 & 5.007 & \\
\hline HEMBL1312549 & 688340 & 4.5 & & \\
\hline HEMBL] & 688340 & 4. & 5.0979 & \\
\hline 09901 & 688 & 5.5 & 4.6385 & \\
\hline AEMBL & 688 & 5.4 & 5.2169 & \\
\hline AEMBL: & 688340 & & & \\
\hline AEMBL: & 6883 & & & \\
\hline HEMBL & 688340 & & & \\
\hline 00670 & 688 & 4.6 & 4.8684 & \\
\hline 17714 & 40 & 4.4 & 99 & \\
\hline 308679 & $68 \varepsilon$ & & & \\
\hline HEMBL1425727 & 688340 & & 4.6952 & \\
\hline HEMBL1441395 & 6883 & & 57 & \\
\hline 12 & 40 & 4.55 & 4.8386 & \\
\hline HEMBL: & & 5.5 & & \\
\hline AEMBL1400175 & 688340 & & 5.1062 & \\
\hline HEMBL1421792 & 688340 & & 5.5323 & \\
\hline HEMBL: & 68 & & 4.9983 & \\
\hline 59 & 40 & 4.6 & 4.856 & \\
\hline HEMBL1386057 & 688340 & 4.55 & 4.7273 & \\
\hline HEMBL1596382 & 688340 & 5. & 5.0733 & \\
\hline CHEMBL1560380 & 688340 & 4. & 17 & \\
\hline CHEMBL: & 688 & 4 . & 4.6532 & \\
\hline CHEMBL1332165 & 688340 & 5.05 & 4.6328 & \\
\hline CHEMBL1996150 & 688340 & 4.4 & 4.8711 & \\
\hline CHEMBL1474799 & 688340 & 4. & 4.912 & \\
\hline CHEMBL1566191 & 688340 & & 4.8031 & \\
\hline CHEMBL1308363 & 688340 & 4.45 & 4.998 & \\
\hline CHEMBL1522641 & 688340 & 4.65 & 4.8868 & \\
\hline CHEMBL1531256 & 688340 & 4.4 & 4.9186 & \\
\hline 497180 & 688340 & 8.102 & 5.5447 & \\
\hline
\end{tabular}

Page 28197 


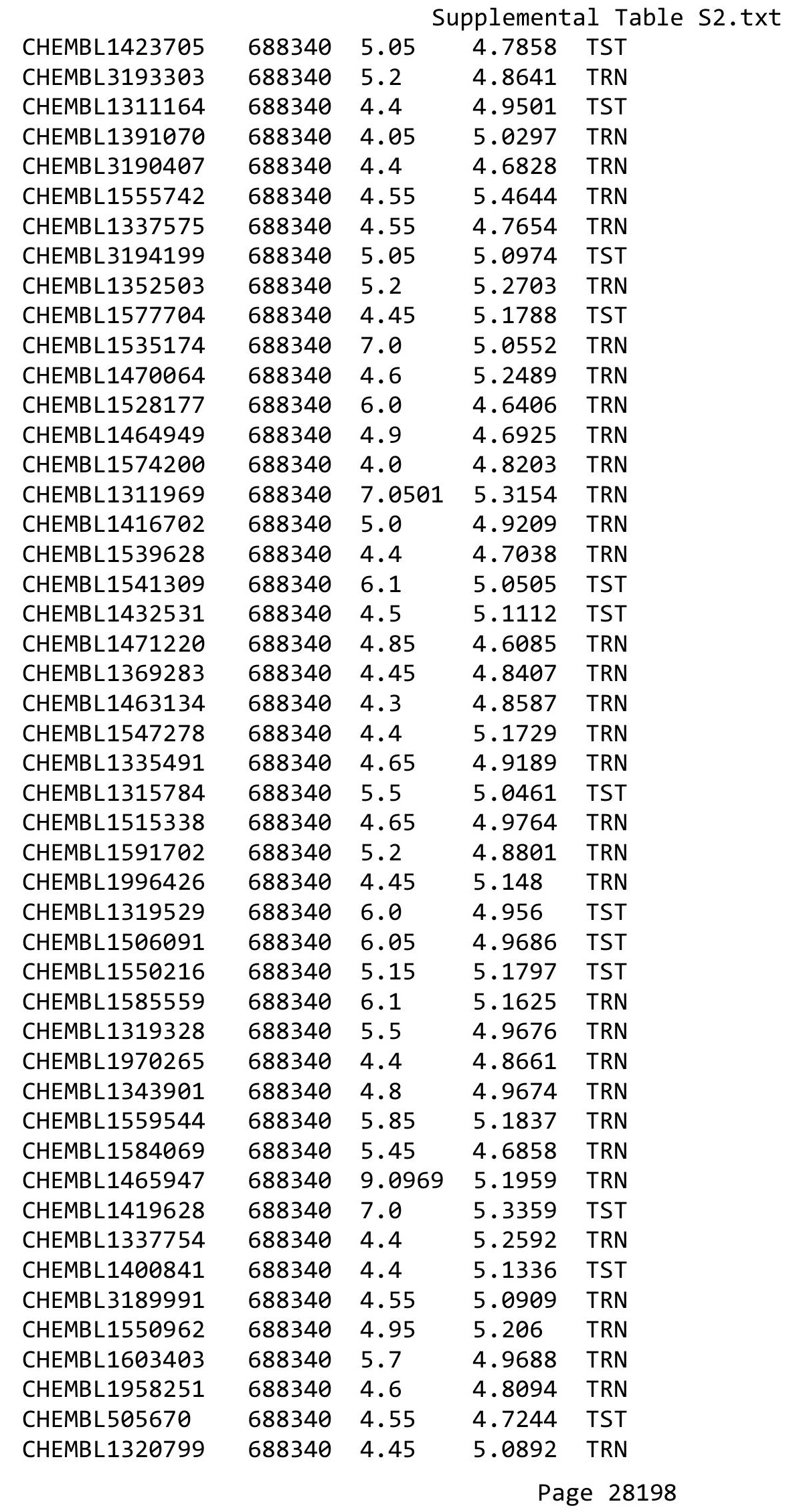




\begin{tabular}{|c|c|c|c|c|c|}
\hline \multicolumn{6}{|c|}{ Supplemental Table S2.txt } \\
\hline CHEMBL1558955 & 688340 & 4.4 & 5.1508 & TRN & \\
\hline CHEMBL1319293 & 688340 & 6.1 & 5.2448 & TRN & \\
\hline CHEMBL1390904 & 688340 & 6.7501 & 5.0836 & TRN & \\
\hline CHEMBL1540103 & 688340 & 4.6 & 4.8302 & TRN & \\
\hline CHEMBL1580377 & 688340 & 4.55 & 4.7962 & TRN & \\
\hline CHEMBL1517708 & 688340 & 4.7 & 4.9572 & TRN & \\
\hline CHEMBL1449004 & 688340 & 4.4 & 4.4052 & TRN & \\
\hline CHEMBL1466790 & 688340 & 4.55 & 4.6788 & TST & \\
\hline CHEMBL1411772 & 688340 & 7.0 & 5.5283 & TRN & \\
\hline CHEMBL1537995 & 688340 & 4.5 & 4.4974 & TRN & \\
\hline CHEMBL3198618 & 688340 & 4.75 & 5.05399 & 9999999999 & TRN \\
\hline CHEMBL1341575 & 688340 & 4.6 & 4.6705 & TRN & \\
\hline CHEMBL1606122 & 688340 & 4.9 & 4.8339 & TST & \\
\hline CHEMBL1433480 & 688340 & 4.7 & 4.9477 & TST & \\
\hline CHEMBL1349715 & 688340 & 7.0 & 5.3016 & TST & \\
\hline CHEMBL1331006 & 688340 & 5.05 & 4.82100 & 0000000001 & TST \\
\hline CHEMBL1386883 & 688340 & 5.45 & 4.852 & TST & \\
\hline CHEMBL1572753 & 688340 & 4.85 & 4.7602 & TRN & \\
\hline CHEMBL1371113 & 688340 & 5.15 & 4.8469 & TST & \\
\hline CHEMBL1420418 & 688340 & 5.05 & 4.6488 & TST & \\
\hline CHEMBL3197520 & 688340 & 4.6 & 4.8163 & TRN & \\
\hline CHEMBL1534543 & 688340 & 4.9 & 5.3973 & TRN & \\
\hline CHEMBL1486644 & 688340 & 5.6 & 5.2584 & TRN & \\
\hline CHEMBL1512375 & 688340 & 4.5 & 5.2623 & TRN & \\
\hline CHEMBL1585318 & 688340 & 4.5 & 4.7854 & TST & \\
\hline CHEMBL1530582 & 688340 & 5.15 & 5.7522 & TST & \\
\hline CHEMBL1533940 & 688340 & 4.45 & 4.8924 & TRN & \\
\hline CHEMBL1513161 & 688340 & 6.6 & 5.4761 & TRN & \\
\hline CHEMBL1302857 & 688340 & 4.75 & 5.0512 & TRN & \\
\hline CHEMBL1589723 & 688340 & 4.5 & 4.8756 & TRN & \\
\hline CHEMBL1566645 & 688340 & 4.5 & 4.8756 & TST & \\
\hline CHEMBL1320319 & 688340 & 4.55 & 4.4674 & TST & \\
\hline CHEMBL1369813 & 688340 & 5.0 & 5.2249 & TRN & \\
\hline CHEMBL1530840 & 688340 & 4.5 & 4.9393 & TRN & \\
\hline CHEMBL1610842 & 688340 & 6.15 & 4.8357 & TST & \\
\hline CHEMBL1514720 & 688340 & 5.85 & 5.2932 & TRN & \\
\hline CHEMBL1388951 & 688340 & 5.1 & 4.9692 & TRN & \\
\hline CHEMBL3192010 & 688340 & 4.7 & 4.9724 & TRN & \\
\hline CHEMBL1408704 & 688340 & 4.5 & 4.9543 & TRN & \\
\hline CHEMBL1591174 & 688340 & 4.4 & 4.8869 & TST & \\
\hline CHEMBL1310171 & 688340 & 4.5 & 4.9457 & TRN & \\
\hline CHEMBL1309790 & 688340 & 5.2 & 5.1526 & TRN & \\
\hline CHEMBL3199557 & 688340 & 5.55 & 5.1084 & TST & \\
\hline CHEMBL186174 & 688340 & 5.4 & 5.1305 & TST & \\
\hline CHEMBL1510314 & 688340 & 4.55 & 4.8165 & TRN & \\
\hline CHEMBL1461459 & 688340 & 4.6 & 5.1609 & TRN & \\
\hline CHEMBL1421480 & 688340 & 5.15 & 4.8983 & TST & \\
\hline CHEMBL1392359 & 688340 & 5.65 & 4.7098 & TST & \\
\hline
\end{tabular}




\begin{tabular}{|c|c|c|c|c|}
\hline \multicolumn{5}{|c|}{ Supplemental Table S2.txt } \\
\hline CHEMBL3190389 & 688340 & 4.5 & 4.7549 & TRN \\
\hline CHEMBL1440062 & 688340 & 5.15 & 5.0334 & TST \\
\hline CHEMBL1462686 & 688340 & 4.65 & 5.0267 & TST \\
\hline CHEMBL1361025 & 688340 & 6.1 & 4.9865 & TRN \\
\hline CHEMBL1586643 & 688340 & 7.0 & 5.2867 & TRN \\
\hline CHEMBL1395909 & 688340 & 6.5 & 4.937 & TRN \\
\hline CHEMBL3196567 & 688340 & 4.4 & 5.1065 & TST \\
\hline CHEMBL1572727 & 688340 & 4.55 & 4.6568 & TRN \\
\hline CHEMBL1555108 & 688340 & 4.45 & 4.8655 & TRN \\
\hline CHEMBL1311120 & 688340 & 5.7 & 4.9952 & TRN \\
\hline CHEMBL1600483 & 688340 & 4.6 & 5.0635 & TST \\
\hline CHEMBL1458501 & 688340 & 6.15 & 5.3877 & TRN \\
\hline CHEMBL1310886 & 688340 & 4.5 & 4.8294 & TRN \\
\hline CHEMBL1461005 & 688340 & 3.15 & 5.1306 & TRN \\
\hline CHEMBL3192632 & 688340 & 5.0 & 4.7979 & TRN \\
\hline CHEMBL1394889 & 688340 & 4.45 & 5.0237 & TRN \\
\hline CHEMBL1368085 & 688340 & 5.05 & 5.079 & TST \\
\hline CHEMBL1311468 & 688340 & 6.45 & 5.072 & TRN \\
\hline CHEMBL1496214 & 688340 & 4.6 & 4.9571 & TRN \\
\hline CHEMBL600862 & 688340 & 4.45 & 4.3817 & TRN \\
\hline CHEMBL1593106 & 688340 & 4.5 & 5.1785 & TRN \\
\hline CHEMBL1305650 & 688340 & 5.25 & 5.5822 & TRN \\
\hline CHEMBL1441072 & 688340 & 7.0501 & 5.4819 & TST \\
\hline CHEMBL1361824 & 688340 & 6.1 & 4.5872 & TRN \\
\hline CHEMBL1374266 & 688340 & 4.45 & 5.471 & TRN \\
\hline CHEMBL1402272 & 688340 & 5.0 & 5.2141 & TRN \\
\hline CHEMBL1583687 & 688340 & 4.5 & 4.9331 & TRN \\
\hline CHEMBL1307871 & 688340 & 5.3 & 5.1053 & TST \\
\hline CHEMBL1611802 & 688340 & 4.5 & 4.8468 & TRN \\
\hline CHEMBL1455014 & 688340 & 5.1 & 5.1132 & TRN \\
\hline CHEMBL1601133 & 688340 & 4.45 & 4.5078 & TRN \\
\hline CHEMBL1326833 & 688340 & 6.1 & 4.9762 & TRN \\
\hline CHEMBL1311416 & 688340 & 5.8 & 4.9056 & TRN \\
\hline CHEMBL1565057 & 688340 & 4.45 & 4.6212 & TRN \\
\hline CHEMBL1594573 & 688340 & 5.1 & 5.4379 & TRN \\
\hline CHEMBL1450043 & 688340 & 6.15 & 5.3131 & TRN \\
\hline CHEMBL1300803 & 688340 & 5.05 & 5.0071 & TRN \\
\hline CHEMBL1365326 & 688340 & 4.35 & 5.225 & TST \\
\hline CHEMBL1465161 & 688340 & 5.55 & 5.2405 & TST \\
\hline CHEMBL3192125 & 688340 & 4.4 & 4.8434 & TST \\
\hline CHEMBL1322322 & 688340 & 5.5 & 4.9971 & TST \\
\hline CHEMBL1598432 & 688340 & 4.55 & 4.8668 & TRN \\
\hline CHEMBL1524942 & 688340 & 4.55 & 5.066 & TRN \\
\hline CHEMBL1431650 & 688340 & 4.5 & 4.8989 & TRN \\
\hline CHEMBL1466080 & 688340 & 4.4 & 5.024 & TRN \\
\hline CHEMBL1496795 & 688340 & 5.35 & 4.9887 & TRN \\
\hline CHEMBL1503379 & 688340 & 6.5 & 5.0937 & TST \\
\hline CHEMBL1464509 & 688340 & 4.45 & 5.1183 & TST \\
\hline
\end{tabular}




\begin{tabular}{|c|c|c|c|c|}
\hline & & & pplement & T \\
\hline CHEMBL1597441 & 688340 & 4.5 & 4.8822 & TST \\
\hline CHEMBL 3214446 & 688340 & 4.7 & 4.7814 & TRN \\
\hline CHEMBL1529341 & 688340 & 4.4 & 4.7486 & TRN \\
\hline CHEMBL1569745 & 688340 & 5.15 & 5.3785 & TRN \\
\hline CHEMBL1321200 & 688340 & 5.2 & 4.8832 & TST \\
\hline CHEMBL1454584 & 688340 & 5.95 & 5.22 & TST \\
\hline CHEMBL1310358 & 688340 & 3.45 & 5.2038 & TRN \\
\hline CHEMBL 3192453 & 688340 & 4.45 & 5.0185 & TRN \\
\hline CHEMBL1421047 & 688340 & 4.55 & 4.8941 & TRN \\
\hline CHEMBL1601579 & 688340 & 5.05 & 5.1973 & TRN \\
\hline CHEMBL1327336 & 688340 & 4.4 & 4.7674 & TRN \\
\hline CHEMBL1380664 & 688340 & 5.6 & 4.958 & TST \\
\hline CHEMBL1452778 & 688340 & 4.55 & 4.9964 & TRN \\
\hline CHEMBL1373685 & 688340 & 4.35 & 5.1604 & TRN \\
\hline CHEMBL1302275 & 688340 & 5.35 & 4.8861 & TRN \\
\hline CHEMBL1410416 & 688340 & 4.8 & 4.7357 & TRN \\
\hline CHEMBL1315099 & 688340 & 4.5 & 5.1901 & TRN \\
\hline CHEMBL1545060 & 688340 & 6.7001 & 5.3016 & TRN \\
\hline CHEMBL1427685 & 688340 & 4.5 & 5.0508 & TST \\
\hline CHEMBL1447542 & 688340 & 4.4 & 5.0871 & TRN \\
\hline CHEMBL1461060 & 688340 & 4.4 & 5.2014 & TST \\
\hline CHEMBL1583329 & 688340 & 6.25 & 5.114 & TST \\
\hline CHEMBL1531803 & 688340 & 4.45 & 5.0234 & TRN \\
\hline CHEMBL539676 & 688340 & 4.95 & 5.0173 & TRN \\
\hline CHEMBL1414448 & 688340 & 4.45 & 4.7224 & TST \\
\hline CHEMBL1429151 & 688340 & 4.6 & 5.2111 & TRN \\
\hline CHEMBL1309624 & 688340 & 4.65 & 5.2996 & TRN \\
\hline CHEMBL1549674 & 688340 & 4.5 & 4.9932 & TRN \\
\hline CHEMBL1419792 & 688340 & 4.4 & 4.7377 & TRN \\
\hline CHEMBL3210259 & 688340 & 4.4 & 5.006 & TRN \\
\hline CHEMBL1579777 & 688340 & 5.0 & 4.9917 & TST \\
\hline CHEMBL3190693 & 688340 & 5.05 & 4.7295 & TRN \\
\hline CHEMBL1501366 & 688340 & 7.0501 & 5.0646 & TST \\
\hline CHEMBL 3198546 & 688340 & 4.4 & 5.047 & TRN \\
\hline CHEMBL1479892 & 688340 & 4.4 & 4.9684 & TRN \\
\hline CHEMBL1546973 & 688340 & 4.55 & 4.9249 & TST \\
\hline CHEMBL503470 & 688340 & 4.65 & 4.5458 & TST \\
\hline CHEMBL1566134 & 688340 & 4.6 & 5.2128 & TST \\
\hline CHEMBL1473325 & 688340 & 4.5 & 5.1557 & TRN \\
\hline CHEMBL1436792 & 688340 & 6.0 & 5.1461 & TRN \\
\hline CHEMBL1483655 & 688340 & 5.05 & 4.8591 & TST \\
\hline CHEMBL1387940 & 688340 & 5.7 & 5.3651 & TRN \\
\hline CHEMBL1538241 & 688340 & 4.6 & 5.1226 & TST \\
\hline CHEMBL1559618 & 688340 & 4.6 & 5.0344 & TST \\
\hline CHEMBL1369964 & 688340 & 4.6 & 4.5758 & TRN \\
\hline CHEMBL1441231 & 688340 & 4.6 & 5.1861 & TRN \\
\hline CHEMBL1455957 & 688340 & 5.3 & 5.0282 & TST \\
\hline CHEMBL 3144857 & 688340 & 5.05 & 5.2202 & TRN \\
\hline
\end{tabular}




\begin{tabular}{|c|c|c|c|c|c|}
\hline \\
\hline CHEMBL1398584 & 688340 & 4.4 & 5.2145 & TRN & \\
\hline CHEMBL1545168 & 688340 & 4.5 & 5.1897 & TST & \\
\hline CHEMBL1523466 & 688340 & 5.55 & 5.0164 & TRN & \\
\hline CHEMBL1508569 & 688340 & 4.75 & 5.0009 & TRN & \\
\hline CHEMBL1556530 & 688340 & 4.6 & 4.7629 & TRN & \\
\hline CHEMBL1305965 & 688340 & 4.0 & 4.848 & TST & \\
\hline CHEMBL1607115 & 688340 & 5.05 & 5.1171 & TRN & \\
\hline CHEMBL1304175 & 688340 & 4.95 & 5.1516 & TRN & \\
\hline CHEMBL1422103 & 688340 & 5.35 & 5.2076 & TRN & \\
\hline CHEMBL1438907 & 688340 & 4.65 & 4.792 & TRN & \\
\hline CHEMBL1331644 & 688340 & 5.05 & 4.9759 & TRN & \\
\hline CHEMBL1507819 & 688340 & 4.7 & 5.1792 & TRN & \\
\hline CHEMBL1606282 & 688340 & 6.1 & 5.042 & TRN & \\
\hline CHEMBL3212912 & 688340 & 7.0 & 4.9448 & TRN & \\
\hline CHEMBL3195627 & 688340 & 4.7 & 5.0054 & TRN & \\
\hline CHEMBL1540295 & 688340 & 4.05 & 5.218 & TRN & \\
\hline CHEMBL1311146 & 688340 & 5.35 & 5.28100 & 0000000001 & TRN \\
\hline CHEMBL1489920 & 688340 & 4.5 & 4.9941 & TRN & \\
\hline CHEMBL3209979 & 688340 & 6.9 & 5.1946 & TRN & \\
\hline CHEMBL1608962 & 688340 & 5.45 & 5.1908 & TRN & \\
\hline CHEMBL1583037 & 688340 & 4.75 & 5.1737 & TST & \\
\hline CHEMBL1361686 & 688340 & 4.35 & 5.1887 & TRN & \\
\hline CHEMBL1475563 & 688340 & 4.9 & 5.0123 & TRN & \\
\hline CHEMBL1321077 & 688340 & 7.1002 & 5.1772 & TST & \\
\hline CHEMBL1395775 & 688340 & 4.55 & 5.0672 & TRN & \\
\hline CHEMBL1550476 & 688340 & 4.65 & 4.9424 & TRN & \\
\hline CHEMBL1527223 & 688340 & 4.0 & 5.1904 & TRN & \\
\hline CHEMBL1559782 & 688340 & 5.2 & 5.0873 & TST & \\
\hline CHEMBL1991888 & 688340 & 4.5 & 4.8061 & TST & \\
\hline CHEMBL1420066 & 688340 & 4.4 & 5.1844 & TRN & \\
\hline CHEMBL1462628 & 688340 & 4.55 & 4.8139 & TST & \\
\hline CHEMBL1342859 & 688340 & 5.45 & 5.1085 & TRN & \\
\hline CHEMBL1458013 & 688340 & 4.4 & 5.2666 & TRN & \\
\hline CHEMBL1527350 & 688340 & 6.1 & 4.8683 & TST & \\
\hline CHEMBL1359872 & 688340 & 4.55 & 4.7748 & TRN & \\
\hline CHEMBL1435586 & 688340 & 6.95 & 5.0413 & TRN & \\
\hline CHEMBL1521746 & 688340 & 5.75 & 5.1464 & TRN & \\
\hline CHEMBL1519408 & 688340 & 5.05 & 4.7786 & TRN & \\
\hline CHEMBL3199168 & 688340 & 6.25 & 4.7809 & TRN & \\
\hline CHEMBL1381159 & 688340 & 5.15 & 5.0558 & TRN & \\
\hline CHEMBL1496802 & 688340 & 4.35 & 5.4228 & TRN & \\
\hline CHEMBL1452686 & 688340 & 4.75 & 5.2677 & TST & \\
\hline CHEMBL1571532 & 688340 & 6.15 & 4.9091 & TST & \\
\hline CHEMBL1521600 & 688340 & 5.05 & 4.8596 & TRN & \\
\hline CHEMBL1599946 & 688340 & 4.9 & 4.7758 & TRN & \\
\hline CHEMBL1542757 & 688340 & 7.0 & 4.9079 & TST & \\
\hline CHEMBL3199897 & 688340 & 5.45 & 4.7005 & TRN & \\
\hline CHEMBL1558901 & 688340 & 5.15 & 5.1831 & TST & \\
\hline
\end{tabular}




\begin{tabular}{|c|c|c|c|c|c|}
\hline \\
\hline CHEMBL3192759 & 688340 & 4.3 & 5.0274 & TRN & \\
\hline CHEMBL3191236 & 688340 & 4.5 & 4.6948 & TRN & \\
\hline CHEMBL1507021 & 688340 & 4.55 & 4.8312 & TRN & \\
\hline CHEMBL1327112 & 688340 & 4.55 & 4.7504 & TRN & \\
\hline CHEMBL24510 & 688340 & 5.05 & 4.9991 & TST & \\
\hline CHEMBL1448047 & 688340 & 4.4 & 4.9119 & TST & \\
\hline CHEMBL1524951 & 688340 & 5.5 & 5.1797 & TST & \\
\hline CHEMBL1541886 & 688340 & 5.4 & 4.8647 & TST & \\
\hline CHEMBL1505153 & 688340 & 5.5 & 4.6121 & TRN & \\
\hline CHEMBL1439964 & 688340 & 7.0 & 5.052 & TST & \\
\hline CHEMBL1376653 & 688340 & 4.5 & 4.85 & TRN & \\
\hline CHEMBL1413495 & 688340 & 4.5 & 4.8578 & TRN & \\
\hline CHEMBL1333731 & 688340 & 4.95 & 5.4248 & TRN & \\
\hline CHEMBL1965786 & 688340 & 4.7 & 4.8033 & TRN & \\
\hline CHEMBL1329272 & 688340 & 4.5 & 5.1795 & TRN & \\
\hline CHEMBL1593630 & 688340 & 7.5003 & 5.0714 & TRN & \\
\hline CHEMBL1438106 & 688340 & 4.35 & 5.0063 & TST & \\
\hline CHEMBL1583239 & 688340 & 6.6 & 5.5633 & TRN & \\
\hline CHEMBL1514341 & 688340 & 4.0 & 5.1411 & TRN & \\
\hline CHEMBL1381215 & 688340 & 4.75 & 5.0211 & TRN & \\
\hline CHEMBL1539052 & 688340 & 5.7 & 5.3498 & TST & \\
\hline CHEMBL1425249 & 688340 & 7.0 & 5.2824 & TRN & \\
\hline CHEMBL1521960 & 688340 & 4.8 & 4.8969 & TST & \\
\hline CHEMBL1613732 & 688340 & 5.3 & 4.7994 & TRN & \\
\hline CHEMBL1380943 & 688340 & 4.5 & 4.9247 & TST & \\
\hline CHEMBL1490332 & 688340 & 5.2 & 5.115 & TRN & \\
\hline CHEMBL1382733 & 688340 & 5.25 & 5.0704 & TST & \\
\hline CHEMBL1396996 & 688340 & 4.6 & 5.0907 & TRN & \\
\hline CHEMBL1449773 & 688340 & 5.0 & 5.0679 & TRN & \\
\hline CHEMBL3189748 & 688340 & 4.75 & 4.9416 & TST & \\
\hline CHEMBL1378258 & 688340 & 5.25 & 4.8052 & TRN & \\
\hline CHEMBL1504892 & 688340 & 4.45 & 5.0929 & TST & \\
\hline CHEMBL1405505 & 688340 & 4.35 & 5.12299 & 7999999999 & TRN \\
\hline CHEMBL1573575 & 688340 & 4.7 & 4.7465 & TRN & \\
\hline CHEMBL1579592 & 688340 & 4.5 & 4.8024 & TRN & \\
\hline CHEMBL1388989 & 688340 & 5.7 & 4.8852 & TRN & \\
\hline CHEMBL3196541 & 688340 & 5.15 & 5.1463 & TRN & \\
\hline CHEMBL1385563 & 688340 & 6.3 & 4.7228 & TST & \\
\hline CHEMBL1373059 & 688340 & 4.55 & 4.9491 & TST & \\
\hline CHEMBL1364547 & 688340 & 8.2007 & 4.8352 & TST & \\
\hline CHEMBL1369313 & 688340 & 4.95 & 4.9656 & TST & \\
\hline CHEMBL1548331 & 688340 & 6.5 & 4.9268 & TST & \\
\hline CHEMBL1529460 & 688340 & 4.4 & 4.9078 & TST & \\
\hline CHEMBL1371906 & 688340 & 5.25 & 5.43 & TST & \\
\hline CHEMBL1550649 & 688340 & 4.0 & 5.1844 & TRN & \\
\hline CHEMBL 3190149 & 688340 & 4.6 & 5.0296 & TST & \\
\hline CHEMBL1441861 & 688340 & 4.6 & 4.9204 & TRN & \\
\hline CHEMBL1309890 & 688340 & 5.3 & 4.6258 & TRN & \\
\hline
\end{tabular}




\begin{tabular}{|c|c|c|c|c|}
\hline & & & pplemen & al $\mathrm{T}$ \\
\hline CHEMBL1598520 & 688340 & 5.2 & 4.8641 & TRN \\
\hline CHEMBL1500830 & 688340 & 4.4 & 4.7377 & TRN \\
\hline CHEMBL1492629 & 688340 & 6.0 & 5.3383 & TST \\
\hline CHEMBL1317951 & 688340 & 4.95 & 5.2108 & TRN \\
\hline CHEMBL1544161 & 688340 & 5.3 & 5.1788 & TRN \\
\hline CHEMBL1482498 & 688340 & 4.35 & 5.4401 & TRN \\
\hline CHEMBL1473982 & 688340 & 5.0 & 5.2734 & TRN \\
\hline CHEMBL1494800 & 688340 & 4.55 & 4.65 & TRN \\
\hline CHEMBL1339387 & 688340 & 4.4 & 4.852 & TRN \\
\hline CHEMBL1490686 & 688340 & 7.0501 & 5.1844 & TRN \\
\hline CHEMBL1556721 & 688340 & 4.45 & 5.0112 & TST \\
\hline CHEMBL1549242 & 688340 & 4.5 & 5.3331 & TRN \\
\hline CHEMBL1505107 & 688340 & 5.2 & 4.7725 & TRN \\
\hline CHEMBL1566217 & 688340 & 5.5 & 5.1187 & TST \\
\hline CHEMBL1348572 & 688340 & 5.15 & 4.9113 & TST \\
\hline CHEMBL1469245 & 688340 & 4.4 & 4.5491 & TRN \\
\hline CHEMBL1383575 & 688340 & 4.45 & 4.9854 & TRN \\
\hline CHEMBL1425789 & 688340 & 4.45 & 4.9834 & TRN \\
\hline CHEMBL1464561 & 688340 & 5.5 & 4.8196 & TRN \\
\hline CHEMBL1344367 & 688340 & 6.5 & 5.2524 & TST \\
\hline CHEMBL1350256 & 688340 & 5.25 & 5.0533 & TST \\
\hline CHEMBL1530147 & 688340 & 5.05 & 4.9455 & TRN \\
\hline CHEMBL1340355 & 688340 & 7.0501 & 5.197 & TRN \\
\hline CHEMBL 3195635 & 688340 & 4.75 & 4.76 & TRN \\
\hline CHEMBL1449346 & 688340 & 6.35 & 5.0362 & TRN \\
\hline CHEMBL1489984 & 688340 & 5.05 & 5.1283 & TRN \\
\hline CHEMBL1987516 & 688340 & 4.5 & 4.9151 & TRN \\
\hline CHEMBL1312391 & 688340 & 6.15 & 4.7597 & TST \\
\hline CHEMBL1411323 & 688340 & 4.4 & 5.2548 & TRN \\
\hline CHEMBL1301587 & 688340 & 3.95 & 4.8314 & TRN \\
\hline CHEMBL1613116 & 688340 & 4.55 & 4.9293 & TRN \\
\hline CHEMBL1558986 & 688340 & 5.25 & 5.2054 & TST \\
\hline CHEMBL1342915 & 688340 & 4.8 & 4.7511 & TRN \\
\hline CHEMBL1400905 & 688340 & 6.0 & 5.0195 & TRN \\
\hline CHEMBL1396835 & 688340 & 4.6 & 5.0631 & TRN \\
\hline CHEMBL1528931 & 688340 & 4.5 & 4.8196 & TRN \\
\hline CHEMBL1299995 & 688340 & 5.55 & 4.9774 & TRN \\
\hline CHEMBL2369159 & 688340 & 4.8 & 5.0188 & TRN \\
\hline CHEMBL1303845 & 688340 & 4.55 & 4.7931 & TRN \\
\hline CHEMBL1537841 & 688340 & 4.45 & 4.9385 & TST \\
\hline CHEMBL1553222 & 688340 & 7.5498 & 5.0252 & TRN \\
\hline CHEMBL1405310 & 688340 & 5.15 & 4.901 & TST \\
\hline CHEMBL1512390 & 688340 & 4.6 & 5.0905 & TRN \\
\hline CHEMBL1588136 & 688340 & 6.25 & 5.4568 & TRN \\
\hline CHEMBL1342036 & 688340 & 6.9 & 5.2414 & TRN \\
\hline CHEMBL1492143 & 688340 & 4.4 & 4.6857 & TRN \\
\hline CHEMBL1487890 & 688340 & 5.55 & 5.2203 & TST \\
\hline CHEMBL1332953 & 688340 & 5.65 & 4.9031 & TRN \\
\hline
\end{tabular}




\begin{tabular}{|c|c|c|c|c|}
\hline & & & pplement & al $\mathrm{Ta}$ \\
\hline CHEMBL3193230 & 688340 & 6.6 & 5.1199 & TRN \\
\hline CHEMBL1485809 & 688340 & 4.9 & 4.9988 & TST \\
\hline CHEMBL1557219 & 688340 & 4.55 & 5.0454 & TRN \\
\hline CHEMBL1591913 & 688340 & 4.5 & 4.7244 & TRN \\
\hline CHEMBL1527642 & 688340 & 6.0 & 5.2701 & TRN \\
\hline CHEMBL1382485 & 688340 & 4.85 & 4.7743 & TRN \\
\hline CHEMBL1428581 & 688340 & 5.35 & 5.6805 & TRN \\
\hline CHEMBL1591615 & 688340 & 5.95 & 5.1411 & TRN \\
\hline CHEMBL1509389 & 688340 & 5.05 & 4.7962 & TRN \\
\hline CHEMBL1505180 & 688340 & 4.6 & 4.7439 & TST \\
\hline CHEMBL1393417 & 688340 & 5.0 & 5.1401 & TST \\
\hline CHEMBL1519022 & 688340 & 4.8 & 5.1496 & TRN \\
\hline CHEMBL1439023 & 688340 & 4.5 & 4.7965 & TRN \\
\hline CHEMBL 3194475 & 688340 & 7.0 & 5.0233 & TST \\
\hline CHEMBL1547866 & 688340 & 5.95 & 4.9873 & TST \\
\hline CHEMBL1509992 & 688340 & 5.55 & 4.9138 & TRN \\
\hline CHEMBL1478482 & 688340 & 5.25 & 5.2484 & TRN \\
\hline CHEMBL1321449 & 688340 & 4.55 & 4.8294 & TRN \\
\hline CHEMBL1526848 & 688340 & 5.95 & 5.1788 & TRN \\
\hline CHEMBL1320509 & 688340 & 5.3 & 5.2788 & TRN \\
\hline CHEMBL1463472 & 688340 & 6.15 & 5.3267 & TRN \\
\hline CHEMBL1333636 & 688340 & 4.5 & 4.8448 & TRN \\
\hline CHEMBL1348065 & 688340 & 4.55 & 4.7756 & TRN \\
\hline CHEMBL1453281 & 688340 & 4.4 & 5.4261 & TST \\
\hline CHEMBL1586809 & 688340 & 4.8 & 4.6334 & TRN \\
\hline CHEMBL1482938 & 688340 & 4.0 & 4.9354 & TRN \\
\hline CHEMBL1325489 & 688340 & 4.65 & 4.6673 & TST \\
\hline CHEMBL1539127 & 688340 & 7.0 & 4.9778 & TRN \\
\hline CHEMBL1570659 & 688340 & 5.45 & 5.4263 & TRN \\
\hline CHEMBL1340620 & 688340 & 7.15 & 5.3394 & TRN \\
\hline CHEMBL1468874 & 688340 & 4.65 & 4.6751 & TRN \\
\hline CHEMBL1451649 & 688340 & 4.55 & 4.584 & TRN \\
\hline CHEMBL1579186 & 688340 & 4.65 & 4.9071 & TST \\
\hline CHEMBL1515267 & 688340 & 4.4 & 4.6283 & TRN \\
\hline CHEMBL3191801 & 688340 & 4.4 & 4.9402 & TRN \\
\hline CHEMBL1435733 & 688340 & 5.55 & 5.2984 & TRN \\
\hline CHEMBL1435831 & 688340 & 5.5 & 5.3247 & TRN \\
\hline CHEMBL1586194 & 688340 & 5.5 & 5.2833 & TRN \\
\hline CHEMBL1412585 & 688340 & 4.6 & 4.6874 & TRN \\
\hline CHEMBL483768 & 688340 & 4.55 & 4.8609 & TRN \\
\hline CHEMBL1302638 & 688340 & 4.6 & 4.5968 & TST \\
\hline CHEMBL1552025 & 688340 & 4.55 & 4.9834 & TRN \\
\hline CHEMBL1582703 & 688340 & 4.65 & 4.8313 & TRN \\
\hline CHEMBL1338474 & 688340 & 4.85 & 4.9609 & TRN \\
\hline CHEMBL1520328 & 688340 & 5.35 & 4.4398 & TST \\
\hline CHEMBL1498977 & 688340 & 4.7 & 4.7763 & TRN \\
\hline CHEMBL3199006 & 688340 & 4.5 & 5.0828 & TRN \\
\hline CHEMBL1553733 & 688340 & 4.65 & 4.7281 & TRN \\
\hline
\end{tabular}




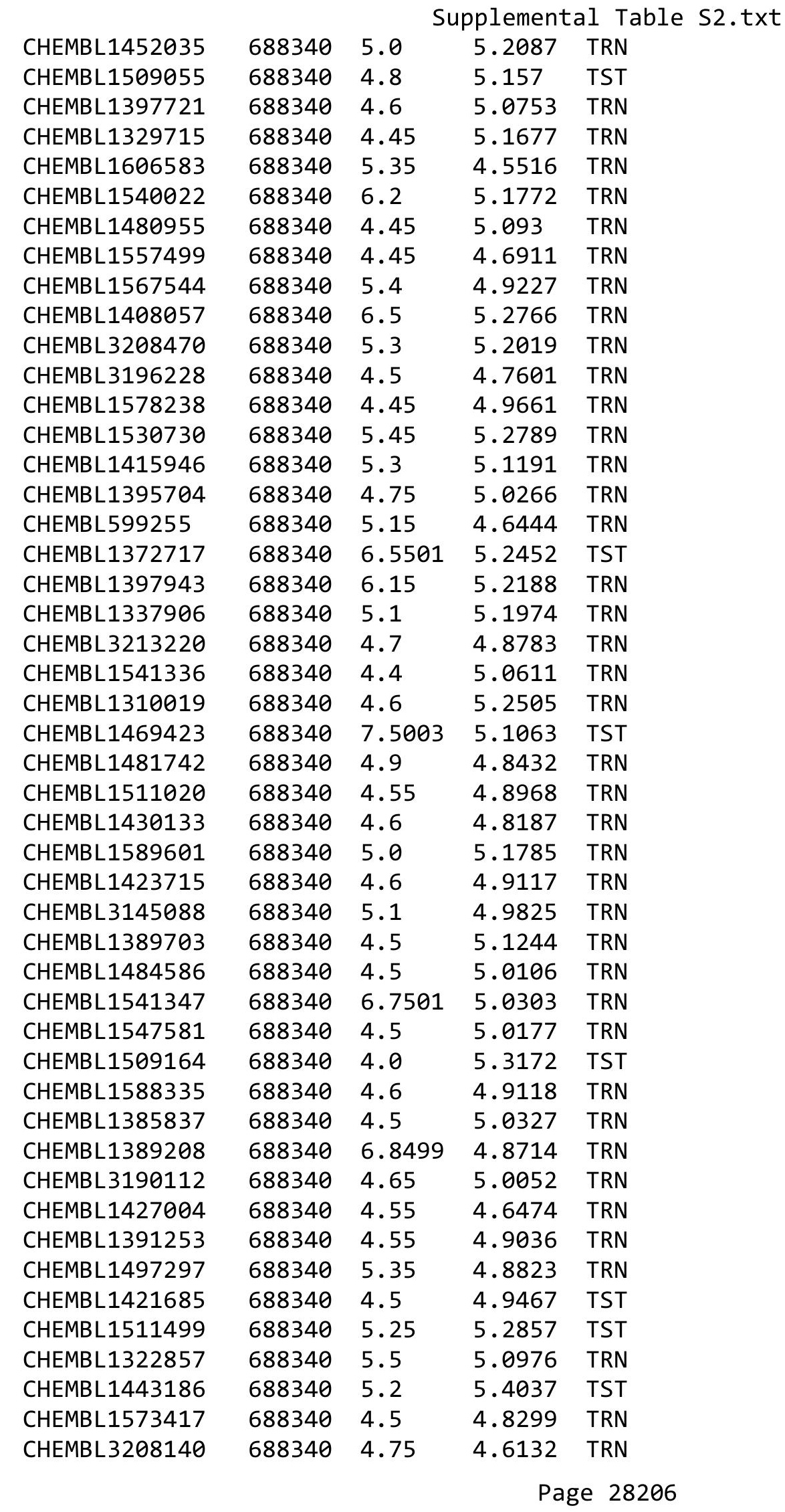




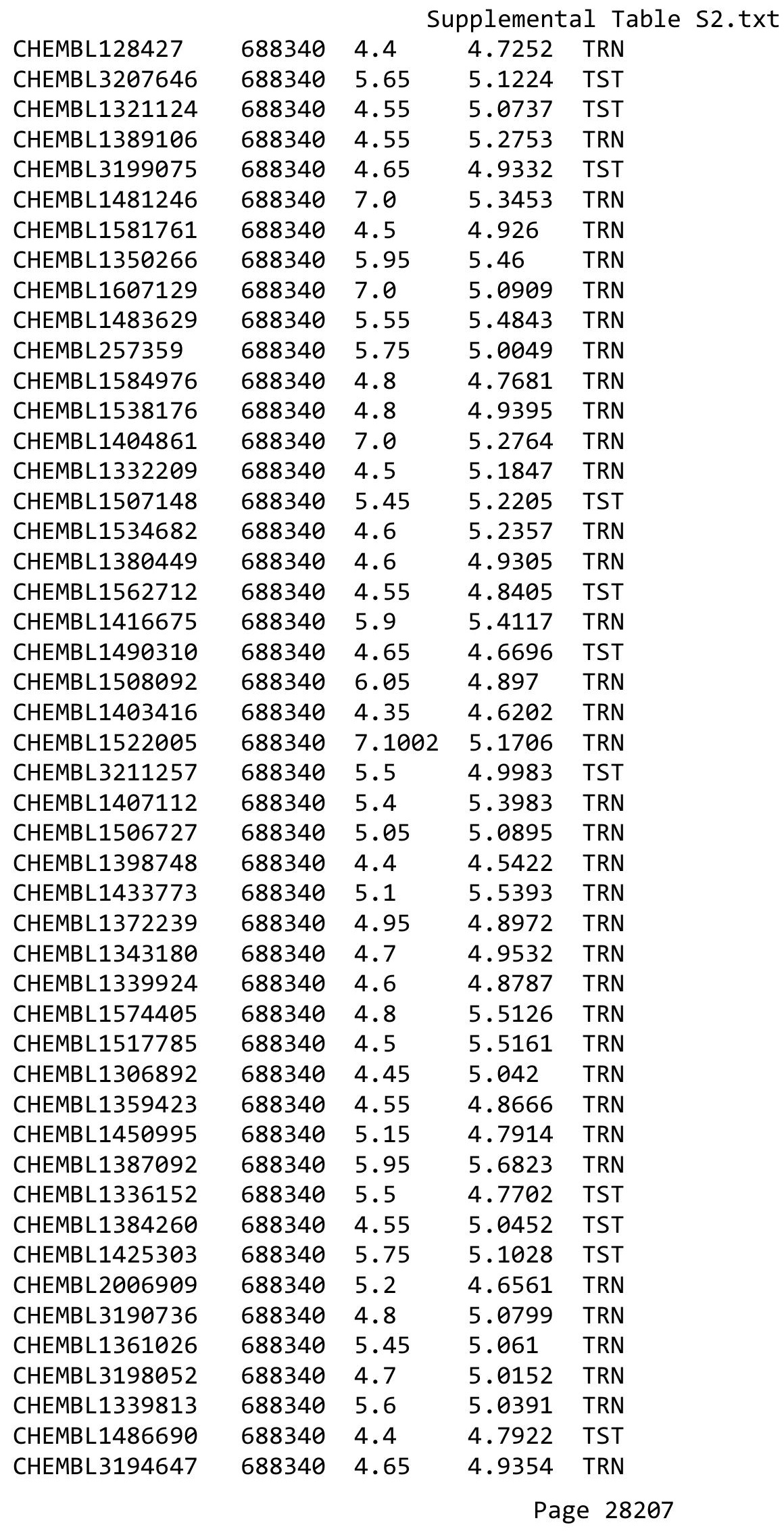




\begin{tabular}{|c|c|c|c|c|c|}
\hline \multicolumn{6}{|c|}{ Supplemental Table S2.txt } \\
\hline CHEMBL1363095 & 688340 & 6.25 & 5.2792 & TRN & \\
\hline CHEMBL1420471 & 688340 & 4.65 & 5.3454 & TRN & \\
\hline CHEMBL1548392 & 688340 & 5.45 & 5.0831 & TST & \\
\hline CHEMBL1315344 & 688340 & 4.5 & 4.9997 & TRN & \\
\hline CHEMBL522983 & 688340 & 6.15 & 5.1107 & TRN & \\
\hline CHEMBL1332071 & 688340 & 5.05 & 5.2804 & TRN & \\
\hline CHEMBL1473676 & 688340 & 5.25 & 4.507 & TRN & \\
\hline CHEMBL1361412 & 688340 & 7.0501 & 4.9991 & TRN & \\
\hline CHEMBL1576094 & 688340 & 4.55 & 4.8321 & TRN & \\
\hline CHEMBL1551382 & 688340 & 7.0501 & 5.0037 & TRN & \\
\hline CHEMBL1375468 & 688340 & 4.85 & 5.1659 & TRN & \\
\hline CHEMBL1464399 & 688340 & 4.5 & 4.9399 & TRN & \\
\hline CHEMBL1400666 & 688340 & 4.95 & 4.9009 & TST & \\
\hline CHEMBL1609419 & 688340 & 4.4 & 4.9579 & TRN & \\
\hline CHEMBL1418126 & 688340 & 4.7 & 4.8085 & TRN & \\
\hline CHEMBL1520582 & 688340 & 4.7 & 4.7651 & TST & \\
\hline CHEMBL1592854 & 688340 & 4.4 & 5.0108 & TRN & \\
\hline CHEMBL1484733 & 688340 & 4.4 & 4.5255 & TRN & \\
\hline CHEMBL1554853 & 688340 & 4.55 & 4.88399 & 99999999995 & TRN \\
\hline CHEMBL3191025 & 688340 & 5.0 & 5.2354 & TRN & \\
\hline CHEMBL1358848 & 688340 & 5.35 & 5.3086 & TRN & \\
\hline CHEMBL1487212 & 688340 & 4.65 & 4.8603 & TST & \\
\hline CHEMBL1392335 & 688340 & 4.6 & 4.8557 & TRN & \\
\hline CHEMBL1443990 & 688340 & 4.7 & 5.2413 & TRN & \\
\hline CHEMBL1606092 & 688340 & 5.2 & 5.0738 & TRN & \\
\hline CHEMBL 2001685 & 688340 & 4.4 & 4.9239 & TST & \\
\hline CHEMBL1450202 & 688340 & 4.85 & 5.1125 & TST & \\
\hline CHEMBL1375878 & 688340 & 4.95 & 5.2063 & TRN & \\
\hline CHEMBL1512246 & 688340 & 6.1 & 5.1406 & TRN & \\
\hline CHEMBL1498788 & 688340 & 4.4 & 4.5272 & TRN & \\
\hline CHEMBL1451156 & 688340 & 4.4 & 4.9751 & TRN & \\
\hline CHEMBL1493493 & 688340 & 4.45 & 4.9187 & TRN & \\
\hline CHEMBL1436517 & 688340 & 4.35 & 5.1322 & TRN & \\
\hline CHEMBL1595032 & 688340 & 5.5 & 4.9232 & TRN & \\
\hline CHEMBL1591147 & 688340 & 5.95 & 5.1739 & TRN & \\
\hline CHEMBL1608806 & 688340 & 3.85 & 5.1485 & TRN & \\
\hline CHEMBL 3212270 & 688340 & 6.05 & 4.8567 & TRN & \\
\hline CHEMBL1382700 & 688340 & 5.0 & 4.9605 & TRN & \\
\hline CHEMBL 3211593 & 688340 & 4.95 & 5.0595 & TRN & \\
\hline CHEMBL1401439 & 688340 & 5.4 & 5.1263 & TRN & \\
\hline CHEMBL3191682 & 688340 & 5.1 & 4.8714 & TRN & \\
\hline CHEMBL1386565 & 688340 & 5.0 & 5.0401 & TST & \\
\hline CHEMBL3196606 & 688340 & 5.05 & 5.055 & TRN & \\
\hline CHEMBL1306614 & 688340 & 4.75 & 4.751 & TRN & \\
\hline CHEMBL3213819 & 688340 & 4.4 & 4.9872 & TRN & \\
\hline CHEMBL1376997 & 688340 & 6.15 & 4.9864 & TRN & \\
\hline CHEMBL1511179 & 688340 & 5.4 & 4.6493 & TRN & \\
\hline CHEMBL3192432 & 688340 & 4.4 & 4.8054 & TRN & \\
\hline
\end{tabular}




\begin{tabular}{|c|c|c|c|c|}
\hline \multicolumn{5}{|c|}{ Supplemental Table S2.txt } \\
\hline CHEMBL1539235 & 688340 & 4.85 & 5.2917 & TRN \\
\hline CHEMBL1549749 & 688340 & 4.4 & 5.1088 & TST \\
\hline CHEMBL1458412 & 688340 & 4.8 & 4.6392 & TRN \\
\hline CHEMBL 3207380 & 688340 & 6.0 & 5.0589 & TST \\
\hline CHEMBL1470983 & 688340 & 4.85 & 5.1975 & TRN \\
\hline CHEMBL1337695 & 688340 & 6.1 & 5.1047 & TRN \\
\hline CHEMBL1489888 & 688340 & 4.65 & 5.1087 & TRN \\
\hline CHEMBL1520909 & 688340 & 4.5 & 5.1092 & TST \\
\hline CHEMBL1568631 & 688340 & 5.5 & 4.8663 & TRN \\
\hline CHEMBL1509671 & 688340 & 4.55 & 4.8608 & TRN \\
\hline CHEMBL1460269 & 688340 & 5.05 & 5.0968 & TRN \\
\hline CHEMBL1408935 & 688340 & 4.55 & 5.1709 & TRN \\
\hline CHEMBL1612543 & 688340 & 4.5 & 5.0319 & TRN \\
\hline CHEMBL1586195 & 688340 & 4.55 & 5.0597 & TRN \\
\hline CHEMBL1398680 & 688340 & 5.6 & 4.8738 & TRN \\
\hline CHEMBL1577177 & 688340 & 5.1 & 5.0035 & TRN \\
\hline CHEMBL1499283 & 688340 & 6.3 & 4.7926 & TRN \\
\hline CHEMBL1537414 & 688340 & 7.0 & 5.3364 & TRN \\
\hline CHEMBL1455274 & 688340 & 5.25 & 5.2587 & TRN \\
\hline CHEMBL1304312 & 688340 & 5.25 & 5.1061 & TRN \\
\hline CHEMBL1314216 & 688340 & 4.4 & 5.0748 & TRN \\
\hline CHEMBL1430451 & 688340 & 4.5 & 5.0063 & TRN \\
\hline CHEMBL1522530 & 688340 & 6.5 & 5.025 & TRN \\
\hline CHEMBL1564195 & 688340 & 4.55 & 4.9316 & TRN \\
\hline CHEMBL1605583 & 688340 & 4.4 & 5.1716 & TRN \\
\hline CHEMBL1330886 & 688340 & 7.0501 & 5.2166 & TST \\
\hline CHEMBL1531317 & 688340 & 5.1 & 5.0475 & TRN \\
\hline CHEMBL1497129 & 688340 & 5.35 & 4.9583 & TRN \\
\hline CHEMBL 3196658 & 688340 & 5.15 & 4.9474 & TRN \\
\hline CHEMBL1514615 & 688340 & 4.6 & $5.2570 e$ & 0000000001 \\
\hline CHEMBL1472413 & 688340 & 4.4 & 4.5717 & TRN \\
\hline CHEMBL1433888 & 688340 & 4.5 & 4.9444 & TRN \\
\hline CHEMBL1565044 & 688340 & 5.95 & 5.0882 & TST \\
\hline CHEMBL1527563 & 688340 & 4.45 & 4.9137 & TRN \\
\hline CHEMBL1460750 & 688340 & 4.65 & 4.8264 & TRN \\
\hline CHEMBL1522666 & 688340 & 4.4 & 5.315 & TST \\
\hline CHEMBL3192179 & 688340 & 4.85 & 5.0735 & TRN \\
\hline CHEMBL1492245 & 688340 & 4.35 & 5.3639 & TRN \\
\hline CHEMBL1565960 & 688340 & 5.35 & 4.8066 & TRN \\
\hline CHEMBL1400585 & 688340 & 4.45 & 4.8647 & TRN \\
\hline CHEMBL1569896 & 688340 & 5.55 & 5.1322 & TRN \\
\hline CHEMBL1609978 & 688340 & 4.4 & 5.1594 & TST \\
\hline CHEMBL1430983 & 688340 & 5.6 & 5.0782 & TRN \\
\hline CHEMBL1576629 & 688340 & 6.7001 & 5.4102 & TRN \\
\hline CHEMBL1450458 & 688340 & 4.9 & 4.6914 & TRN \\
\hline CHEMBL1583375 & 688340 & 6.15 & 4.6517 & TRN \\
\hline CHEMBL3211351 & 688340 & 7.0 & 5.08 & TRN \\
\hline CHEMBL1556698 & 688340 & 5.0 & 5.0773 & TRN \\
\hline
\end{tabular}




\begin{tabular}{|c|c|c|c|c|c|}
\hline \multicolumn{6}{|c|}{ Supplemental Table S2.txt } \\
\hline CHEMBL1971875 & 688340 & 4.45 & 4.8269 & TRN & \\
\hline CHEMBL1572892 & 688340 & 5.95 & 5.2595 & TRN & \\
\hline CHEMBL1368710 & 688340 & 5.0 & 5.5101 & TRN & \\
\hline CHEMBL1598181 & 688340 & 5.85 & 4.9794 & TRN & \\
\hline CHEMBL1601300 & 688340 & 5.35 & 5.165 & TRN & \\
\hline CHEMBL1540935 & 688340 & 5.05 & 5.1831 & TRN & \\
\hline CHEMBL1410071 & 688340 & 6.95 & 4.9459 & TST & \\
\hline CHEMBL1586371 & 688340 & 4.4 & 5.4995 & TRN & \\
\hline CHEMBL1511175 & 688340 & 4.55 & 4.9901 & TRN & \\
\hline CHEMBL1568818 & 688340 & 4.45 & 4.5128 & TRN & \\
\hline CHEMBL1511898 & 688340 & 4.65 & 5.2242 & TST & \\
\hline CHEMBL3198912 & 688340 & 5.55 & 4.6266 & TST & \\
\hline CHEMBL1455554 & 688340 & 4.65 & 5.29 & TRN & \\
\hline CHEMBL1379278 & 688340 & 4.55 & 5.1462 & TRN & \\
\hline CHEMBL1366945 & 688340 & 4.65 & 5.1331 & TRN & \\
\hline CHEMBL1603435 & 688340 & 4.45 & 5.2196 & TST & \\
\hline CHEMBL1302019 & 688340 & 4.55 & 4.9469 & TRN & \\
\hline CHEMBL1563539 & 688340 & 4.9 & 5.1995 & TRN & \\
\hline CHEMBL1446232 & 688340 & 4.45 & 5.3622 & TRN & \\
\hline CHEMBL3214069 & 688340 & 6.15 & 5.0757 & TRN & \\
\hline CHEMBL1503680 & 688340 & 5.9 & 4.968 & TRN & \\
\hline CHEMBL1479809 & 688340 & 5.0 & 5.0024 & TRN & \\
\hline CHEMBL1406529 & 688340 & 4.55 & 4.7839 & TST & \\
\hline CHEMBL1337281 & 688340 & 4.4 & 5.3511 & TRN & \\
\hline CHEMBL1520266 & 688340 & 5.25 & 4.8635 & TST & \\
\hline CHEMBL1373070 & 688340 & 4.75 & 5.0939 & TRN & \\
\hline CHEMBL3192926 & 688340 & 4.5 & 4.5854 & TRN & \\
\hline CHEMBL1392545 & 688340 & 4.55 & 5.1868 & TRN & \\
\hline CHEMBL1553118 & 688340 & 4.4 & 5.3478 & TRN & \\
\hline CHEMBL1392104 & 688340 & 4.5 & 5.1458 & TRN & \\
\hline CHEMBL1369330 & 688340 & 7.0 & 5.0664 & TRN & \\
\hline CHEMBL1323185 & 688340 & 5.5 & 5.1431 & TST & \\
\hline CHEMBL1465410 & 688340 & 4.55 & 4.8418 & TRN & \\
\hline CHEMBL1975855 & 688340 & 4.55 & 4.95100 & 00000000005 & TRN \\
\hline CHEMBL1500471 & 688340 & 4.85 & 4.6919 & TRN & \\
\hline CHEMBL3195481 & 688340 & 4.45 & 5.178 & TRN & \\
\hline CHEMBL1414891 & 688340 & 4.4 & 4.8593 & TRN & \\
\hline CHEMBL1350236 & 688340 & 7.0 & 5.3686 & TST & \\
\hline CHEMBL1344682 & 688340 & 4.65 & 5.1122 & TST & \\
\hline CHEMBL 3191454 & 688340 & 7.0 & 4.8122 & TRN & \\
\hline CHEMBL1365768 & 688340 & 5.4 & 4.8813 & TRN & \\
\hline CHEMBL1382394 & 688340 & 4.8 & 4.7018 & TST & \\
\hline CHEMBL1365487 & 688340 & 4.6 & 4.5983 & TRN & \\
\hline CHEMBL1481540 & 688340 & 4.55 & 5.1566 & TRN & \\
\hline CHEMBL1370838 & 688340 & 5.0 & 4.8968 & TST & \\
\hline CHEMBL1977010 & 688340 & 4.6 & 4.829 & TST & \\
\hline CHEMBL1367112 & 688340 & 5.2 & 5.4775 & TRN & \\
\hline CHEMBL1508717 & 688340 & 4.4 & 5.1608 & TRN & \\
\hline
\end{tabular}




\begin{tabular}{|c|c|c|c|c|}
\hline \multicolumn{5}{|c|}{ Iement } \\
\hline CHEMBL1420866 & 688340 & 4.4 & 4.9354 & TST \\
\hline CHEMBL1334310 & 688340 & 4.55 & 4.7132 & TRN \\
\hline CHEMBL1583881 & 688340 & 5.5 & 4.9318 & TST \\
\hline CHEMBL1516577 & 688340 & 6.15 & 5.2094 & TRN \\
\hline CHEMBL3214310 & 688340 & 5.5 & 4.8512 & TRN \\
\hline CHEMBL1354766 & 688340 & 4.55 & \multicolumn{2}{|c|}{4.8660000000000005} \\
\hline CHEMBL1431318 & 688340 & 4.45 & 4.9479 & TRN \\
\hline CHEMBL1999947 & 688340 & 4.4 & 4.8288 & TRN \\
\hline CHEMBL1450963 & 688340 & 5.25 & 5.1773 & TRN \\
\hline CHEMBL1331791 & 688340 & 4.55 & 5.2131 & TRN \\
\hline CHEMBL604100 & 688340 & 4.55 & 4.9676 & TRN \\
\hline CHEMBL1365258 & 688340 & 5.4 & 5.2983 & TRN \\
\hline CHEMBL1459764 & 688340 & 4.55 & 4.8271 & TRN \\
\hline CHEMBL1572566 & 688340 & 4.85 & 5.1627 & TRN \\
\hline CHEMBL1608996 & 688340 & 7.0 & 5.1923 & TRN \\
\hline CHEMBL1469008 & 688340 & 4.4 & 4.8133 & TRN \\
\hline CHEMBL1554232 & 688340 & 4.45 & 5.1113 & TST \\
\hline CHEMBL1523036 & 688340 & 5.5 & 4.8919 & TRN \\
\hline CHEMBL1524661 & 688340 & 4.5 & 4.8339 & TST \\
\hline CHEMBL1588255 & 688340 & 6.9 & 5.2659 & TRN \\
\hline CHEMBL1355990 & 688340 & 4.75 & 4.749 & TRN \\
\hline CHEMBL1388552 & 688340 & 5.15 & 5.356 & TRN \\
\hline CHEMBL1432443 & 688340 & 4.7 & 4.8167 & TRN \\
\hline CHEMBL1464450 & 688340 & 4.6 & 5.0434 & TST \\
\hline CHEMBL1383920 & 688340 & 5.3 & 5.2616 & TST \\
\hline CHEMBL1477068 & 688340 & 4.4 & 5.0813 & TST \\
\hline CHEMBL1522443 & 688340 & 4.5 & 5.0272 & TRN \\
\hline CHEMBL1384981 & 688340 & 4.95 & 5.1529 & TST \\
\hline CHEMBL1478636 & 688340 & 4.55 & 5.1572 & TRN \\
\hline CHEMBL1383174 & 688340 & 5.0 & 5.1331 & TRN \\
\hline CHEMBL1595409 & 688340 & 5.6 & 4.958 & TRN \\
\hline CHEMBL3207969 & 688340 & 7.0 & 4.9905 & TST \\
\hline CHEMBL3199060 & 688340 & 5.65 & 4.8736 & TRN \\
\hline CHEMBL1423044 & 688340 & 4.5 & 5.3289 & TST \\
\hline CHEMBL1371841 & 688340 & 4.4 & 5.318 & TRN \\
\hline CHEMBL1449416 & 688340 & 5.25 & 4.9667 & TST \\
\hline CHEMBL1586905 & 688340 & 4.35 & 5.5407 & TRN \\
\hline CHEMBL1546962 & 688340 & 5.5 & 5.3149 & TST \\
\hline CHEMBL1370409 & 688340 & 5.25 & 5.2747 & TST \\
\hline CHEMBL1395774 & 688340 & 7.0 & 5.4794 & TRN \\
\hline CHEMBL1562761 & 688340 & 4.55 & 5.0625 & TRN \\
\hline CHEMBL1563624 & 688340 & 4.4 & 4.8726 & TST \\
\hline CHEMBL1423692 & 688340 & 4.5 & 4.9301 & TST \\
\hline CHEMBL1460757 & 688340 & 6.8499 & 5.0439 & TST \\
\hline CHEMBL1433975 & 688340 & 4.65 & 4.9004 & TRN \\
\hline CHEMBL1559077 & 688340 & 5.95 & 5.1915 & TST \\
\hline CHEMBL1991573 & 688340 & 5.45 & 4.8884 & TRN \\
\hline CHEMBL1468556 & 688340 & 4.7 & 4.6107 & TRN \\
\hline
\end{tabular}




\begin{tabular}{|c|c|c|c|c|c|}
\hline \\
\hline CHEMBL1607487 & 688340 & 4.5 & 4.8599 & TST & \\
\hline CHEMBL1481109 & 688340 & 4.75 & 5.0943 & TRN & \\
\hline CHEMBL1449995 & 688340 & 4.4 & 4.7763 & TRN & \\
\hline CHEMBL1550301 & 688340 & 3.95 & 5.0171 & TST & \\
\hline CHEMBL1560045 & 688340 & 4.4 & 5.0642 & TRN & \\
\hline CHEMBL1391223 & 688340 & 7.0501 & 5.2311 & TRN & \\
\hline CHEMBL1389124 & 688340 & 4.9 & 4.8908 & TRN & \\
\hline CHEMBL1403052 & 688340 & 5.25 & 5.5649 & TRN & \\
\hline CHEMBL1531669 & 688340 & 4.55 & 4.8483 & TRN & \\
\hline CHEMBL1304419 & 688340 & 5.0 & 4.687 & TRN & \\
\hline CHEMBL3196949 & 688340 & 4.6 & 4.852 & TRN & \\
\hline CHEMBL1580578 & 688340 & 4.4 & 5.2862 & TST & \\
\hline CHEMBL1314115 & 688340 & 5.15 & 5.1138 & TRN & \\
\hline CHEMBL1481390 & 688340 & 4.6 & 4.5928 & TRN & \\
\hline CHEMBL1401494 & 688340 & 4.65 & 5.2758 & TRN & \\
\hline CHEMBL1994094 & 688340 & 4.75 & 5.0357 & TRN & \\
\hline CHEMBL1456904 & 688340 & 5.9 & 4.8815 & TRN & \\
\hline CHEMBL1563502 & 688340 & 4.6 & 5.0083 & TRN & \\
\hline CHEMBL1405648 & 688340 & 4.75 & 5.2091 & TRN & \\
\hline CHEMBL1416187 & 688340 & 5.45 & 5.4476 & TRN & \\
\hline CHEMBL1563582 & 688340 & 5.55 & 5.0051 & TRN & \\
\hline CHEMBL1610525 & 688340 & 4.85 & 4.9744 & TST & \\
\hline CHEMBL1518208 & 688340 & 4.4 & 4.8437 & TRN & \\
\hline CHEMBL1601202 & 688340 & 4.6 & 5.1492 & TRN & \\
\hline CHEMBL1394128 & 688340 & 6.1 & 5.021 & TRN & \\
\hline CHEMBL1401564 & 688340 & 4.45 & 5.1037 & TRN & \\
\hline CHEMBL1438656 & 688340 & 6.15 & 5.1119 & TRN & \\
\hline CHEMBL1385512 & 688340 & 4.4 & 5.0539 & TST & \\
\hline CHEMBL1565460 & 688340 & 4.4 & 5.1148 & TRN & \\
\hline CHEMBL1332699 & 688340 & 5.5 & 4.8998 & TST & \\
\hline CHEMBL1335920 & 688340 & 4.65 & 4.7435 & TRN & \\
\hline CHEMBL1536209 & 688340 & 4.45 & 5.1903 & TST & \\
\hline CHEMBL1528775 & 688340 & 4.5 & 5.0867 & TST & \\
\hline CHEMBL1471058 & 688340 & 6.05 & 5.2939 & TST & \\
\hline CHEMBL1559260 & 688340 & 4.6 & 4.9181 & TST & \\
\hline CHEMBL1386112 & 688340 & 5.85 & 4.7436 & TRN & \\
\hline CHEMBL1540644 & 688340 & 4.3 & 5.34399 & э999999999 & TRN \\
\hline CHEMBL1495714 & 688340 & 4.5 & 4.7901 & TRN & \\
\hline CHEMBL1551001 & 688340 & 4.9 & 4.8644 & TRN & \\
\hline CHEMBL1409526 & 688340 & 4.6 & 5.0451 & TRN & \\
\hline CHEMBL1493946 & 688340 & 4.7 & 4.9784 & TRN & \\
\hline CHEMBL1610916 & 688340 & 5.2 & 4.713 & TRN & \\
\hline CHEMBL1391291 & 688340 & 4.6 & 4.8363 & TRN & \\
\hline CHEMBL1601904 & 688340 & 4.6 & 4.9784 & TRN & \\
\hline CHEMBL1605956 & 688340 & 4.5 & 5.0997 & TRN & \\
\hline CHEMBL3196947 & 688340 & 5.3 & 5.2933 & TRN & \\
\hline CHEMBL1423428 & 688340 & 4.8 & 4.9218 & TRN & \\
\hline CHEMBL1377130 & 688340 & 4.75 & 4.8591 & TRN & \\
\hline
\end{tabular}




\begin{tabular}{|c|c|c|c|c|}
\hline & & & pplemen & al $\mathrm{T}$ \\
\hline CHEMBL1448704 & 688340 & 6.1 & 5.1923 & TRN \\
\hline CHEMBL1329920 & 688340 & 6.5 & 5.1471 & TRN \\
\hline CHEMBL1302756 & 688340 & 4.55 & 4.7979 & TRN \\
\hline CHEMBL3207641 & 688340 & 6.05 & 5.2505 & TRN \\
\hline CHEMBL1565093 & 688340 & 4.5 & 4.85 & TRN \\
\hline CHEMBL1601217 & 688340 & 4.6 & 4.7364 & TRN \\
\hline CHEMBL1497535 & 688340 & 4.35 & 4.7954 & TRN \\
\hline CHEMBL370611 & 688340 & 4.95 & 5.1031 & TRN \\
\hline CHEMBL1341944 & 688340 & 4.0 & 5.4941 & TRN \\
\hline CHEMBL3191812 & 688340 & 4.45 & 4.9032 & TRN \\
\hline CHEMBL1985165 & 688340 & 4.4 & 4.8601 & TRN \\
\hline CHEMBL1359127 & 688340 & 5.2 & 4.8875 & TRN \\
\hline CHEMBL1515407 & 688340 & 4.45 & 4.8821 & TST \\
\hline CHEMBL1580710 & 688340 & 4.55 & 4.5106 & TRN \\
\hline CHEMBL 2007484 & 688340 & 6.05 & 4.8497 & TRN \\
\hline CHEMBL1401532 & 688340 & 4.0 & 4.9561 & TRN \\
\hline CHEMBL1523651 & 688340 & 6.8 & 4.8267 & TRN \\
\hline CHEMBL1419214 & 688340 & 4.4 & 5.183 & TRN \\
\hline CHEMBL1584687 & 688340 & 5.75 & 4.9036 & TRN \\
\hline CHEMBL1424231 & 688340 & 4.75 & 4.7975 & TRN \\
\hline CHEMBL1327249 & 688340 & 4.6 & 5.1045 & TRN \\
\hline CHEMBL3209497 & 688340 & 4.85 & 4.9161 & TRN \\
\hline CHEMBL1312363 & 688340 & 4.85 & 4.8431 & TRN \\
\hline CHEMBL1307515 & 688340 & 5.0 & 5.1162 & TRN \\
\hline CHEMBL3192905 & 688340 & 4.8 & 5.05 & TRN \\
\hline CHEMBL1451931 & 688340 & 4.65 & 4.8286 & TRN \\
\hline CHEMBL3191363 & 688340 & 4.85 & 5.0026 & TRN \\
\hline CHEMBL1512144 & 688340 & 4.55 & 4.8638 & TRN \\
\hline CHEMBL3193869 & 688340 & 6.15 & 4.6784 & TST \\
\hline CHEMBL3195873 & 688340 & 5.0 & 5.098 & TRN \\
\hline CHEMBL1343722 & 688340 & 4.4 & 5.2166 & TRN \\
\hline CHEMBL1548492 & 688340 & 4.4 & 4.3952 & TRN \\
\hline CHEMBL1496608 & 688340 & 5.5 & 4.9762 & TRN \\
\hline CHEMBL1450350 & 688340 & 5.85 & 5.0486 & TRN \\
\hline CHEMBL1386455 & 688340 & 4.5 & 5.1113 & TRN \\
\hline CHEMBL1312222 & 688340 & 4.6 & 4.7547 & TRN \\
\hline CHEMBL1364021 & 688340 & 5.15 & 4.6744 & TST \\
\hline CHEMBL1344691 & 688340 & 6.05 & 5.3944 & TRN \\
\hline CHEMBL1471295 & 688340 & 4.85 & 4.8481 & TRN \\
\hline CHEMBL1407275 & 688340 & 4.5 & 4.9248 & TRN \\
\hline CHEMBL29542 & 688340 & 4.6 & 5.1024 & TRN \\
\hline CHEMBL 3211445 & 688340 & 4.4 & 4.7703 & TRN \\
\hline CHEMBL1389553 & 688340 & 7.0 & 4.6294 & TRN \\
\hline CHEMBL1396801 & 688340 & 4.5 & 5.0196 & TRN \\
\hline CHEMBL1575297 & 688340 & 6.15 & 5.3444 & TRN \\
\hline CHEMBL1318640 & 688340 & 6.1 & 5.5135 & TRN \\
\hline CHEMBL1374749 & 688340 & 4.55 & 5.2321 & TRN \\
\hline CHEMBL3190198 & 688340 & 5.2 & 4.7948 & TRN \\
\hline
\end{tabular}




\begin{tabular}{|c|c|c|c|c|c|}
\hline & & & & & \\
\hline CHEMBL1967566 & 688340 & 4.9 & 5.074 & TRN & \\
\hline CHEMBL1513983 & 688340 & 6.05 & 5.1283 & TRN & \\
\hline CHEMBL1511618 & 688340 & 4.55 & 5.2057 & TRN & \\
\hline CHEMBL1540266 & 688340 & 4.6 & 4.9767 & TRN & \\
\hline CHEMBL1354754 & 688340 & 4.4 & 4.9975 & TRN & \\
\hline CHEMBL146710 & 688340 & 4.8 & 4.9649 & TST & \\
\hline CHEMBL1336005 & 688340 & 4.5 & 5.0049 & TRN & \\
\hline CHEMBL1444756 & 688340 & 4.5 & 5.0239 & TRN & \\
\hline CHEMBL1445006 & 688340 & 5.6 & 5.2821 & TRN & \\
\hline CHEMBL1084720 & 688340 & 4.45 & 4.8675 & TRN & \\
\hline CHEMBL1373297 & 688340 & 5.3 & 5.1208 & TRN & \\
\hline CHEMBL1580619 & 688340 & 4.9 & 4.8379 & TRN & \\
\hline CHEMBL1406081 & 688340 & 4.5 & 4.9474 & TRN & \\
\hline CHEMBL3208998 & 688340 & 5.65 & 5.432 & TRN & \\
\hline CHEMBL1474583 & 688340 & 4.7 & 4.8401 & TRN & \\
\hline CHEMBL1078979 & 688340 & 5.5 & 4.9927 & TST & \\
\hline CHEMBL1591383 & 688340 & 5.2 & 5.109 & TRN & \\
\hline CHEMBL1522086 & 688340 & 8.0506 & 5.0507 & TRN & \\
\hline CHEMBL1432615 & 688340 & 4.6 & 4.7706 & TRN & \\
\hline CHEMBL1425024 & 688340 & 4.4 & 4.8748 & TRN & \\
\hline CHEMBL 3197141 & 688340 & 4.95 & 4.7724 & TRN & \\
\hline CHEMBL1359707 & 688340 & 4.4 & 5.2688 & TST & \\
\hline CHEMBL1407806 & 688340 & 5.1 & 4.811 & TST & \\
\hline CHEMBL1457131 & 688340 & 4.55 & 4.7927 & TRN & \\
\hline CHEMBL3198931 & 688340 & 5.15 & 4.712 & TRN & \\
\hline CHEMBL1475913 & 688340 & 5.8 & 5.2896 & TRN & \\
\hline CHEMBL1484796 & 688340 & 5.35 & 5.0314 & TST & \\
\hline CHEMBL1522314 & 688340 & 4.55 & 4.9567 & TRN & \\
\hline CHEMBL1469810 & 688340 & 4.4 & 4.6028 & TRN & \\
\hline CHEMBL1317496 & 688340 & 7.0 & 5.006 & TRN & \\
\hline CHEMBL1408143 & 688340 & 5.0 & 4.7395 & TRN & \\
\hline CHEMBL1396469 & 688340 & 4.5 & 5.0309 & TST & \\
\hline CHEMBL1561585 & 688340 & 6.4 & 5.0199 & TRN & \\
\hline CHEMBL1516672 & 688340 & 4.9 & 5.2443 & TRN & \\
\hline CHEMBL1469680 & 688340 & 4.0 & 5.0666 & TST & \\
\hline CHEMBL1391174 & 688340 & 4.4 & 4.8212 & TST & \\
\hline CHEMBL1506499 & 688340 & 4.55 & 4.6982 & TRN & \\
\hline CHEMBL1532909 & 688340 & 4.6 & 4.9654 & TST & \\
\hline CHEMBL1583408 & 688340 & 5.0 & 5.1664 & TRN & \\
\hline CHEMBL1327058 & 688340 & 6.1 & 5.0653 & TST & \\
\hline CHEMBL1485453 & 688340 & 4.95 & 5.3832 & TRN & \\
\hline CHEMBL1476255 & 688340 & 5.25 & 5.1897 & TRN & \\
\hline CHEMBL1433388 & 688340 & 4.9 & 4.8826 & TRN & \\
\hline CHEMBL3195234 & 688340 & 4.5 & 4.8767 & TRN & \\
\hline CHEMBL1385108 & 688340 & 4.55 & 4.8598 & TRN & \\
\hline CHEMBL1578607 & 688340 & 5.65 & 4.9928 & TRN & \\
\hline CHEMBL1331367 & 688340 & 5.6 & 5.1652 & TST & \\
\hline CHEMBL1328916 & 688340 & 7.0 & 5.33899 & 99999999995 & TRN \\
\hline & & & & 28214 & \\
\hline
\end{tabular}




\begin{tabular}{|c|c|c|c|c|c|}
\hline \multicolumn{6}{|c|}{ Supplemental Table S2.txt } \\
\hline CHEMBL1467796 & 688340 & 4.8 & 5.1207 & TRN & \\
\hline CHEMBL1594330 & 688340 & 5.9 & 5.0712 & TST & \\
\hline CHEMBL1486877 & 688340 & 4.65 & 4.9723 & TRN & \\
\hline CHEMBL1463647 & 688340 & 4.4 & 5.4976 & TRN & \\
\hline CHEMBL1502347 & 688340 & 8.301 & 5.0429 & TST & \\
\hline CHEMBL1397432 & 688340 & 4.5 & 4.9238 & TRN & \\
\hline CHEMBL1475476 & 688340 & 4.55 & 5.1706 & TRN & \\
\hline CHEMBL1381605 & 688340 & 4.75 & 5.0312 & TRN & \\
\hline CHEMBL 3190822 & 688340 & 4.65 & 4.7914 & TST & \\
\hline CHEMBL1551311 & 688340 & 4.5 & 4.7078 & TRN & \\
\hline CHEMBL1420683 & 688340 & 5.0 & 4.5915 & TST & \\
\hline CHEMBL1414818 & 688340 & 6.95 & 4.9686 & TST & \\
\hline CHEMBL1442556 & 688340 & 4.4 & 5.0669 & TRN & \\
\hline CHEMBL1572924 & 688340 & 4.55 & 4.8801 & TRN & \\
\hline CHEMBL1420015 & 688340 & 4.5 & 5.1674 & TRN & \\
\hline CHEMBL1405257 & 688340 & 4.6 & 4.7189 & TRN & \\
\hline CHEMBL56542 & 688340 & 4.9 & 4.8744 & TRN & \\
\hline CHEMBL1600205 & 688340 & 4.45 & 4.6753 & TRN & \\
\hline CHEMBL1562724 & 688340 & 4.6 & 4.9624 & TRN & \\
\hline CHEMBL 260311 & 688340 & 6.0 & 5.1864 & TRN & \\
\hline CHEMBL1343708 & 688340 & 5.15 & 5.1659 & TRN & \\
\hline CHEMBL1327512 & 688340 & 5.15 & 5.2105 & TRN & \\
\hline CHEMBL1583199 & 688340 & 4.5 & 4.7076 & TRN & \\
\hline CHEMBL 2000592 & 688340 & 4.65 & 4.7408 & TRN & \\
\hline CHEMBL1387856 & 688340 & 4.95 & 4.9937 & TRN & \\
\hline CHEMBL1458694 & 688340 & 5.8 & 5.6909 & TRN & \\
\hline CHEMBL1370986 & 688340 & 4.45 & 4.855 & TRN & \\
\hline CHEMBL1550134 & 688340 & 4.55 & 5.3398 & TRN & \\
\hline CHEMBL1583137 & 688340 & 5.0 & 4.6815 & TRN & \\
\hline CHEMBL 2006519 & 688340 & 4.45 & 4.6746 & TRN & \\
\hline CHEMBL1358482 & 688340 & 4.35 & 5.0466 & TRN & \\
\hline CHEMBL1595618 & 688340 & 5.25 & 5.2356 & TRN & \\
\hline CHEMBL1418505 & 688340 & 5.75 & 5.0865 & TRN & \\
\hline CHEMBL1441493 & 688340 & 6.2 & 5.1931 & TRN & \\
\hline CHEMBL1325624 & 688340 & 6.1 & 5.2953 & TRN & \\
\hline CHEMBL1348432 & 688340 & 4.45 & 4.8219 & TRN & \\
\hline CHEMBL1553877 & 688340 & 5.0 & 5.0507 & TRN & \\
\hline CHEMBL1365818 & 688340 & 5.2 & 5.0882 & TRN & \\
\hline CHEMBL1558440 & 688340 & 5.2 & 5.0135 & TRN & \\
\hline CHEMBL1312757 & 688340 & 4.5 & 4.7939 & TRN & \\
\hline CHEMBL1364659 & 688340 & 6.8499 & 5.041 & TRN & \\
\hline CHEMBL1394267 & 688340 & 7.0501 & 5.0307 & TRN & \\
\hline CHEMBL1415846 & 688340 & 5.2 & 5.267 & TRN & \\
\hline CHEMBL1589300 & 688340 & 5.25 & $4.7330 e$ & 00000000005 & TRN \\
\hline CHEMBL3213952 & 688340 & 4.4 & 4.7524 & TST & \\
\hline CHEMBL1401774 & 688340 & 4.65 & 5.1864 & TRN & \\
\hline CHEMBL1342867 & 688340 & 4.8 & 4.992 & TRN & \\
\hline CHEMBL1318750 & 688340 & 4.4 & 5.4187 & TRN & \\
\hline
\end{tabular}




\begin{tabular}{|c|c|c|c|c|c|}
\hline \multirow[b]{2}{*}{ CHEMBL1538864 } & \multirow[b]{2}{*}{688340} & \\
\hline & & 4.5 & 4.9762 & TRN & \\
\hline CHEMBL1549618 & 688340 & 4.6 & 4.8128 & TRN & \\
\hline CHEMBL1342884 & 688340 & 4.55 & 4.8632 & TRN & \\
\hline CHEMBL1494284 & 688340 & 5.5 & 4.9626 & TRN & \\
\hline CHEMBL1505196 & 688340 & 4.5 & 5.0107 & TRN & \\
\hline CHEMBL1577681 & 688340 & 6.15 & 5.1199 & TRN & \\
\hline CHEMBL1606059 & 688340 & 5.2 & 5.01399 & 9999999999 & TST \\
\hline CHEMBL1388813 & 688340 & 6.5 & 4.8995 & TST & \\
\hline CHEMBL1445744 & 688340 & 5.25 & 5.1116 & TRN & \\
\hline CHEMBL1535938 & 688340 & 4.55 & 5.0376 & TST & \\
\hline CHEMBL1526910 & 688340 & 4.65 & 4.9405 & TST & \\
\hline CHEMBL1361920 & 688340 & 5.35 & 5.0121 & TRN & \\
\hline CHEMBL1305986 & 688340 & 4.45 & 4.7648 & TRN & \\
\hline CHEMBL1364802 & 688340 & 4.65 & 4.8691 & TRN & \\
\hline CHEMBL1349923 & 688340 & 5.2 & 5.4024 & TRN & \\
\hline CHEMBL1477919 & 688340 & 4.45 & 4.763 & TRN & \\
\hline CHEMBL1455298 & 688340 & 6.15 & 5.0751 & TST & \\
\hline CHEMBL1528208 & 688340 & 5.45 & 4.992 & TST & \\
\hline CHEMBL1573875 & 688340 & 4.45 & 5.0409 & TRN & \\
\hline CHEMBL1317161 & 688340 & 4.45 & 4.7559 & TRN & \\
\hline CHEMBL1480762 & 688340 & 2.6 & 5.2781 & TST & \\
\hline CHEMBL1358939 & 688340 & 4.6 & 4.5006 & TRN & \\
\hline CHEMBL1373589 & 688340 & 4.6 & 4.9774 & TRN & \\
\hline CHEMBL1424585 & 688340 & 5.75 & 5.1158 & TRN & \\
\hline CHEMBL1392167 & 688340 & 4.45 & 5.0582 & TRN & \\
\hline CHEMBL1358733 & 688340 & 4.5 & 5.5889 & TRN & \\
\hline CHEMBL3195970 & 688340 & 4.0 & 5.1378 & TRN & \\
\hline CHEMBL1384550 & 688340 & 4.55 & 4.5961 & TRN & \\
\hline CHEMBL1484752 & 688340 & 4.55 & 4.8878 & TRN & \\
\hline CHEMBL47986 & 688340 & 4.8 & 5.0997 & TST & \\
\hline CHEMBL3197816 & 688340 & 5.25 & 4.8523 & TRN & \\
\hline CHEMBL1333315 & 688340 & 4.4 & 5.2471 & TRN & \\
\hline CHEMBL1324051 & 688340 & 5.6 & 4.4228 & TRN & \\
\hline CHEMBL3189699 & 688340 & 4.4 & 4.6656 & TRN & \\
\hline CHEMBL1589286 & 688340 & 4.4 & 5.3734 & TRN & \\
\hline CHEMBL1427517 & 688340 & 4.4 & 5.0607 & TST & \\
\hline CHEMBL1563612 & 688340 & 5.05 & 5.2046 & TRN & \\
\hline CHEMBL1456789 & 688340 & 6.05 & 5.24299 & 9999999999 & TRN \\
\hline CHEMBL1380940 & 688340 & 6.1 & 4.8887 & TST & \\
\hline CHEMBL1489384 & 688340 & 4.95 & 5.1988 & TRN & \\
\hline CHEMBL1496211 & 688340 & 6.15 & 5.0602 & TRN & \\
\hline CHEMBL1516742 & 688340 & 4.95 & 5.0189 & TST & \\
\hline CHEMBL1598485 & 688340 & 5.85 & 5.0006 & TRN & \\
\hline CHEMBL1300046 & 688340 & 4.5 & 5.0708 & TRN & \\
\hline CHEMBL454060 & 688340 & 4.4 & 4.7592 & TRN & \\
\hline CHEMBL1479261 & 688340 & 4.85 & 5.0557 & TST & \\
\hline CHEMBL3195575 & 688340 & 4.4 & 5.1558 & TST & \\
\hline CHEMBL1502367 & 688340 & 4.7 & 5.1804 & TST & \\
\hline & & & & 2821 & \\
\hline
\end{tabular}




\begin{tabular}{|c|c|c|c|c|}
\hline \multicolumn{5}{|c|}{ Supplemental Table S2.txt } \\
\hline CHEMBL533293 & 688340 & 5.1 & 4.6582 & TST \\
\hline CHEMBL1356047 & 688340 & 5.55 & 5.0748 & TRN \\
\hline CHEMBL1369590 & 688340 & 5.0 & 4.7555 & TRN \\
\hline CHEMBL1345002 & 688340 & 5.5 & 5.0501 & TRN \\
\hline CHEMBL199387 & 688340 & 4.85 & 4.8697 & TRN \\
\hline CHEMBL1450928 & 688340 & 4.7 & 5.2217 & TRN \\
\hline CHEMBL1607788 & 688340 & 4.4 & 4.9988 & TRN \\
\hline CHEMBL1579120 & 688340 & 4.55 & 5.0063 & TRN \\
\hline CHEMBL1540666 & 688340 & 4.5 & 4.8595 & TRN \\
\hline CHEMBL1540308 & 688340 & 6.15 & 5.0918 & TRN \\
\hline CHEMBL1579137 & 688340 & 4.7 & 4.8411 & TRN \\
\hline CHEMBL1460655 & 688340 & 5.4 & 4.976 & TST \\
\hline CHEMBL1998863 & 688340 & 4.7 & 4.9246 & TRN \\
\hline CHEMBL1556611 & 688340 & 4.4 & 5.138 & TRN \\
\hline CHEMBL1458057 & 688340 & 5.65 & 5.3313 & TRN \\
\hline CHEMBL1486928 & 688340 & 4.6 & 4.9603 & TRN \\
\hline CHEMBL1390780 & 688340 & 4.55 & 4.6881 & TRN \\
\hline CHEMBL3210789 & 688340 & 4.4 & 4.9933 & TRN \\
\hline CHEMBL1511358 & 688340 & 6.95 & 5.085 & TRN \\
\hline CHEMBL1501487 & 688340 & 5.15 & 5.1699 & TST \\
\hline CHEMBL1471441 & 688340 & 5.5 & 4.9693 & TRN \\
\hline CHEMBL1334367 & 688340 & 4.35 & 5.0941 & TRN \\
\hline CHEMBL1351804 & 688340 & 7.0 & 5.1426 & TRN \\
\hline CHEMBL1449886 & 688340 & 4.7 & 5.1271 & TRN \\
\hline CHEMBL1543194 & 688340 & 4.75 & 4.8632 & TRN \\
\hline CHEMBL3193815 & 688340 & 4.85 & 5.0358 & TST \\
\hline CHEMBL1607053 & 688340 & 4.75 & 5.2203 & TST \\
\hline CHEMBL1333519 & 688340 & 5.15 & 5.067 & TRN \\
\hline CHEMBL1591260 & 688340 & 5.05 & 4.6181 & TRN \\
\hline CHEMBL1316890 & 688340 & 4.75 & 5.2902 & TRN \\
\hline CHEMBL1368681 & 688340 & 4.55 & 4.6106 & TST \\
\hline CHEMBL1975756 & 688340 & 5.4 & 5.1043 & TRN \\
\hline CHEMBL1483809 & 688340 & 4.45 & 4.6933 & TRN \\
\hline CHEMBL1502211 & 688340 & 4.4 & 4.8574 & TRN \\
\hline CHEMBL1404853 & 688340 & 4.4 & 5.1293 & TRN \\
\hline CHEMBL1551746 & 688340 & 7.9508 & 5.2338 & TRN \\
\hline CHEMBL1378477 & 688340 & 5.1 & 5.0228 & TST \\
\hline CHEMBL1447781 & 688340 & 4.55 & 4.8373 & TRN \\
\hline CHEMBL1511738 & 688340 & 4.35 & 5.3116 & TST \\
\hline CHEMBL1391742 & 688340 & 5.15 & 4.79 & TRN \\
\hline CHEMBL1330354 & 688340 & 6.1 & 5.1298 & TST \\
\hline CHEMBL1413045 & 688340 & 4.4 & 4.927 & TRN \\
\hline CHEMBL1573856 & 688340 & 5.25 & 5.1404 & TST \\
\hline CHEMBL1397830 & 688340 & 4.55 & 4.8259 & TRN \\
\hline CHEMBL1560016 & 688340 & 4.85 & 4.8536 & TRN \\
\hline CHEMBL1553706 & 688340 & 4.4 & 4.9995 & TRN \\
\hline CHEMBL3192324 & 688340 & 4.4 & 5.1858 & TST \\
\hline CHEMBL1566957 & 688340 & 4.9 & 4.9003 & TST \\
\hline
\end{tabular}




\begin{tabular}{|c|c|c|c|c|}
\hline \multicolumn{5}{|c|}{ Supplemental Table S2.txt } \\
\hline CHEMBL1513138 & 688340 & 4.6 & 4.6857 & TRN \\
\hline CHEMBL1566131 & 688340 & 4.05 & 5.5208 & TRN \\
\hline CHEMBL1327907 & 688340 & 5.75 & 4.9178 & TRN \\
\hline CHEMBL1330584 & 688340 & 5.05 & 4.9569 & TRN \\
\hline CHEMBL1547260 & 688340 & 5.15 & 4.8814 & TST \\
\hline CHEMBL1386096 & 688340 & 4.4 & 5.2388 & TRN \\
\hline CHEMBL1299964 & 688340 & 4.55 & 4.9871 & TRN \\
\hline CHEMBL1590386 & 688340 & 5.55 & 5.1679 & TRN \\
\hline CHEMBL1439870 & 688340 & 4.6 & 5.3368 & TST \\
\hline CHEMBL1562463 & 688340 & 6.0 & 4.8858 & TST \\
\hline CHEMBL1426549 & 688340 & 4.6 & 4.9018 & TRN \\
\hline CHEMBL1403081 & 688340 & 5.2 & 4.9844 & TST \\
\hline CHEMBL3208108 & 688340 & 5.2 & 5.0664 & TST \\
\hline CHEMBL1479466 & 688340 & 4.45 & 5.0529 & TRN \\
\hline CHEMBL1320263 & 688340 & 6.25 & 5.2046 & TST \\
\hline CHEMBL1518821 & 688340 & 5.4 & 5.3786 & TRN \\
\hline CHEMBL1981949 & 688340 & 4.35 & 5.0433 & TRN \\
\hline CHEMBL1598118 & 688340 & 4.55 & 4.9739 & TRN \\
\hline CHEMBL1373412 & 688340 & 5.35 & 5.2102 & TRN \\
\hline CHEMBL1521357 & 688340 & 4.4 & 4.7108 & TRN \\
\hline CHEMBL1419228 & 688340 & 4.85 & 5.0379 & TRN \\
\hline CHEMBL1388922 & 688340 & 4.7 & 4.7637 & TRN \\
\hline CHEMBL1494634 & 688340 & 6.95 & 5.6053 & TRN \\
\hline CHEMBL1339505 & 688340 & 4.9 & 5.1415 & TRN \\
\hline CHEMBL1489329 & 688340 & 4.65 & 5.0541 & TRN \\
\hline CHEMBL454843 & 688340 & 6.1 & 4.85 & TST \\
\hline CHEMBL1536775 & 688340 & 4.75 & 4.999 & TST \\
\hline CHEMBL1461448 & 688340 & 4.65 & 5.0762 & TST \\
\hline CHEMBL1583708 & 688340 & 4.4 & 4.454 & TRN \\
\hline CHEMBL1331403 & 688340 & 4.55 & 4.7504 & TRN \\
\hline CHEMBL1613281 & 688340 & 4.35 & 5.2781 & TRN \\
\hline CHEMBL1595065 & 688340 & 4.5 & 4.7198 & TRN \\
\hline CHEMBL1355495 & 688340 & 4.55 & 5.2736 & TRN \\
\hline CHEMBL1332647 & 688340 & 4.6 & 5.1532 & TST \\
\hline CHEMBL1455170 & 688340 & 4.55 & 4.9065 & TRN \\
\hline CHEMBL1546809 & 688340 & 5.45 & 5.2346 & TRN \\
\hline CHEMBL1446462 & 688340 & 4.75 & 5.0514 & TRN \\
\hline CHEMBL1435484 & 688340 & 4.5 & 4.8181 & TRN \\
\hline CHEMBL1566898 & 688340 & 4.5 & 5.0397 & TRN \\
\hline CHEMBL1379601 & 688340 & 5.4 & 4.7961 & TRN \\
\hline CHEMBL1571889 & 688340 & 4.55 & 5.0951 & TST \\
\hline CHEMBL1375814 & 688340 & 6.4 & 5.3036 & TRN \\
\hline CHEMBL3194049 & 688340 & 4.65 & 5.0638 & TST \\
\hline CHEMBL1300694 & 688340 & 7.3497 & 4.6221 & TRN \\
\hline CHEMBL1498658 & 688340 & 4.45 & 4.3999 & TRN \\
\hline CHEMBL1437435 & 688340 & 5.65 & 4.8919 & TRN \\
\hline CHEMBL1326677 & 688340 & 6.15 & 4.8992 & TST \\
\hline CHEMBL84010 & 688340 & 5.6 & 4.8749 & TRN \\
\hline
\end{tabular}




\begin{tabular}{|c|c|c|c|c|c|}
\hline \\
\hline CHEMBL2001895 & 688340 & 4.4 & 4.6382 & TST & \\
\hline CHEMBL1578948 & 688340 & 4.65 & 4.5045 & TRN & \\
\hline CHEMBL1509070 & 688340 & 4.5 & 4.9852 & TRN & \\
\hline CHEMBL1594507 & 688340 & 4.6 & 5.03100 & 0000000001 & TRN \\
\hline CHEMBL1399399 & 688340 & 7.0 & 5.4002 & TRN & \\
\hline CHEMBL1520610 & 688340 & 4.0 & 5.1832 & TST & \\
\hline CHEMBL1354133 & 688340 & 4.55 & 5.0217 & TRN & \\
\hline CHEMBL1571632 & 688340 & 4.35 & 5.1401 & TST & \\
\hline CHEMBL1611654 & 688340 & 4.5 & 5.314 & TST & \\
\hline CHEMBL1368967 & 688340 & 5.25 & 4.9986 & TST & \\
\hline CHEMBL1512837 & 688340 & 4.4 & 4.8828 & TST & \\
\hline CHEMBL1341879 & 688340 & 5.45 & 5.0387 & TRN & \\
\hline CHEMBL3191815 & 688340 & 5.0 & 5.221 & TST & \\
\hline CHEMBL1505774 & 688340 & 4.45 & 4.7471 & TRN & \\
\hline CHEMBL1610071 & 688340 & 4.6 & 5.1485 & TST & \\
\hline CHEMBL1439614 & 688340 & 4.45 & 4.9309 & TRN & \\
\hline CHEMBL1603206 & 688340 & 4.0 & 5.0135 & TRN & \\
\hline CHEMBL1514645 & 688340 & 4.75 & 4.7724 & TRN & \\
\hline CHEMBL1457620 & 688340 & 4.0 & 4.9324 & TRN & \\
\hline CHEMBL1515203 & 688340 & 4.85 & 5.1475 & TST & \\
\hline CHEMBL1507171 & 688340 & 4.55 & 4.8051 & TST & \\
\hline CHEMBL1430560 & 688340 & 5.8 & 4.9308 & TST & \\
\hline CHEMBL3195157 & 688340 & 6.15 & 4.78600 & 00000000005 & TRN \\
\hline CHEMBL1505229 & 688340 & 4.5 & 4.7913 & TRN & \\
\hline CHEMBL1559081 & 688340 & 7.0 & 5.4567 & TRN & \\
\hline CHEMBL1353005 & 688340 & 5.25 & 4.7804 & TST & \\
\hline CHEMBL 2002597 & 688340 & 5.2 & 5.0238 & TRN & \\
\hline CHEMBL1412370 & 688340 & 4.85 & 4.6706 & TRN & \\
\hline CHEMBL1350573 & 688340 & 4.4 & 4.9295 & TRN & \\
\hline CHEMBL1993029 & 688340 & 4.7 & 4.7566 & TRN & \\
\hline CHEMBL1389918 & 688340 & 4.0 & 5.4021 & TST & \\
\hline CHEMBL1424412 & 688340 & 4.9 & 5.1932 & TRN & \\
\hline CHEMBL1405908 & 688340 & 4.4 & 4.9677 & TST & \\
\hline CHEMBL1379452 & 688340 & 7.0 & 4.8473 & TST & \\
\hline CHEMBL3194666 & 688340 & 5.35 & 4.9708 & TRN & \\
\hline CHEMBL1372484 & 688340 & 5.35 & 5.4123 & TRN & \\
\hline CHEMBL1364360 & 688340 & 6.35 & 5.3549 & TST & \\
\hline CHEMBL1533677 & 688340 & 5.1 & 4.8521 & TRN & \\
\hline CHEMBL1515906 & 688340 & 4.6 & 4.9615 & TRN & \\
\hline CHEMBL1458224 & 688340 & 6.9 & 4.9963 & TRN & \\
\hline CHEMBL1438232 & 688340 & 4.4 & 4.96 & TRN & \\
\hline CHEMBL1309575 & 688340 & 4.4 & 4.9504 & TRN & \\
\hline CHEMBL1544447 & 688340 & 4.65 & 4.9464 & TRN & \\
\hline CHEMBL1496790 & 688340 & 4.55 & 4.7653 & TRN & \\
\hline CHEMBL1432446 & 688340 & 4.4 & 4.8288 & TRN & \\
\hline CHEMBL1510117 & 688340 & 4.5 & 4.8768 & TRN & \\
\hline CHEMBL1536907 & 688340 & 4.6 & 4.8597 & TST & \\
\hline CHEMBL1321664 & 688340 & 4.45 & 4.8991 & TRN & \\
\hline
\end{tabular}




\begin{tabular}{|c|c|c|c|c|c|}
\hline \multicolumn{6}{|c|}{ Supplemental Table S2.txt } \\
\hline CHEMBL1610610 & 688340 & 4.45 & 5.0521 & TRN & \\
\hline CHEMBL1429803 & 688340 & 8.0506 & 5.4115 & TRN & \\
\hline CHEMBL3210625 & 688340 & 4.5 & 5.1328 & TRN & \\
\hline CHEMBL1584191 & 688340 & 6.2 & 5.2998 & TST & \\
\hline CHEMBL1446904 & 688340 & 4.6 & 4.6899 & TRN & \\
\hline CHEMBL1413405 & 688340 & 4.6 & 4.8174 & TRN & \\
\hline CHEMBL1576422 & 688340 & 4.4 & 5.0017 & TRN & \\
\hline CHEMBL1342998 & 688340 & 5.05 & 5.0206 & TST & \\
\hline CHEMBL1398503 & 688340 & 4.4 & 4.8225 & TST & \\
\hline CHEMBL1524976 & 688340 & 4.45 & 4.8254 & TRN & \\
\hline CHEMBL1448251 & 688340 & 5.3 & 5.1511 & TRN & \\
\hline CHEMBL1526016 & 688340 & 4.9 & 4.8962 & TRN & \\
\hline CHEMBL1304089 & 688340 & 4.45 & 4.8403 & TRN & \\
\hline CHEMBL1518995 & 688340 & 4.6 & 4.6696 & TRN & \\
\hline CHEMBL3194066 & 688340 & 4.65 & 4.9154 & TRN & \\
\hline CHEMBL1506698 & 688340 & 4.5 & 4.5677 & TST & \\
\hline CHEMBL1382825 & 688340 & 6.95 & 4.9634 & TST & \\
\hline CHEMBL1573200 & 688340 & 4.75 & 5.1473 & TRN & \\
\hline CHEMBL3209238 & 688340 & 4.35 & 5.3344 & TRN & \\
\hline CHEMBL1307573 & 688340 & 4.5 & 4.8976 & TST & \\
\hline CHEMBL1428500 & 688340 & 6.1 & 5.2594 & TST & \\
\hline CHEMBL1423821 & 688340 & 4.5 & 5.3256 & TST & \\
\hline CHEMBL1567139 & 688340 & 4.75 & 4.89199 & 99999999995 & TRN \\
\hline CHEMBL1398562 & 688340 & 5.3 & 5.5677 & TRN & \\
\hline CHEMBL1491273 & 688340 & 5.25 & 4.7693 & TRN & \\
\hline CHEMBL1325974 & 688340 & 5.4 & 5.3307 & TRN & \\
\hline CHEMBL1433851 & 688340 & 6.15 & 5.1686 & TRN & \\
\hline CHEMBL1342063 & 688340 & 4.6 & 4.7726 & TRN & \\
\hline CHEMBL1338207 & 688340 & 6.2 & 5.2021 & TRN & \\
\hline CHEMBL104916 & 688340 & 6.15 & 4.8411 & TRN & \\
\hline CHEMBL1550302 & 688340 & 6.1 & 5.13399 & 99999999995 & TRN \\
\hline CHEMBL1446704 & 688340 & 4.5 & 4.9744 & TRN & \\
\hline CHEMBL1487509 & 688340 & 4.6 & 5.083 & TRN & \\
\hline CHEMBL1317680 & 688340 & 5.0 & 5.1065 & TRN & \\
\hline CHEMBL1446463 & 688340 & 4.8 & 4.8647 & TRN & \\
\hline CHEMBL1527600 & 688340 & 4.55 & 5.2626 & TRN & \\
\hline CHEMBL1429566 & 688340 & 6.05 & 4.8745 & TRN & \\
\hline CHEMBL1542407 & 688340 & 6.15 & 5.05699 & 99999999995 & TRN \\
\hline CHEMBL1609437 & 688340 & 5.15 & 4.9441 & TRN & \\
\hline CHEMBL606532 & 688340 & 4.55 & 4.8098 & TRN & \\
\hline CHEMBL1511981 & 688340 & 4.7 & 4.6828 & TRN & \\
\hline CHEMBL 70501 & 688340 & 4.4 & 5.1245 & TST & \\
\hline CHEMBL1539023 & 688340 & 4.65 & 4.9195 & TRN & \\
\hline CHEMBL1608853 & 688340 & 5.5 & 4.7549 & TRN & \\
\hline CHEMBL1487754 & 688340 & 4.45 & 5.1804 & TRN & \\
\hline CHEMBL1492376 & 688340 & 4.55 & 4.6922 & TRN & \\
\hline CHEMBL3198364 & 688340 & 4.55 & 4.7708 & TRN & \\
\hline CHEMBL1453225 & 688340 & 5.15 & 4.9323 & TRN & \\
\hline
\end{tabular}




\begin{tabular}{|c|c|c|c|c|c|}
\hline \multicolumn{6}{|c|}{ Supplemental Table S2.txt } \\
\hline CHEMBL1596248 & 688340 & 4.95 & 4.792 & TRN & \\
\hline CHEMBL1371261 & 688340 & 5.2 & 5.3579 & TRN & \\
\hline CHEMBL1611355 & 688340 & 5.7 & 5.2405 & TST & \\
\hline CHEMBL1549453 & 688340 & 4.5 & 5.0565 & TRN & \\
\hline CHEMBL1329337 & 688340 & 4.6 & 4.7486 & TRN & \\
\hline CHEMBL1890899 & 688340 & 4.4 & 4.7364 & TRN & \\
\hline CHEMBL1385623 & 688340 & 4.5 & 4.6001 & TRN & \\
\hline CHEMBL1365118 & 688340 & 4.8 & 4.8669 & TRN & \\
\hline CHEMBL1408115 & 688340 & 5.4 & 5.485 & TRN & \\
\hline CHEMBL1346297 & 688340 & 4.9 & 5.0006 & TRN & \\
\hline CHEMBL1454531 & 688340 & 5.45 & 5.1098 & TRN & \\
\hline CHEMBL1441208 & 688340 & 4.4 & 5.4758 & TST & \\
\hline CHEMBL1309084 & 688340 & 4.6 & 4.9046 & TRN & \\
\hline CHEMBL1510059 & 688340 & 4.95 & 5.2971 & TST & \\
\hline CHEMBL1310672 & 688340 & 4.6 & 4.7512 & TRN & \\
\hline CHEMBL1530482 & 688340 & 2.9 & 5.2988 & TRN & \\
\hline CHEMBL3189946 & 688340 & 5.45 & 5.09699 & 99999999995 & TRN \\
\hline CHEMBL1562381 & 688340 & 4.85 & 4.6502 & TRN & \\
\hline CHEMBL1469601 & 688340 & 4.7 & 5.276 & TRN & \\
\hline CHEMBL1393428 & 688340 & 4.6 & 5.0002 & TRN & \\
\hline CHEMBL1572691 & 688340 & 5.2 & 5.0669 & TRN & \\
\hline CHEMBL1609564 & 688340 & 4.65 & 4.9876 & TST & \\
\hline CHEMBL1400873 & 688340 & 5.45 & 5.5138 & TRN & \\
\hline CHEMBL1577994 & 688340 & 4.45 & 5.1455 & TRN & \\
\hline CHEMBL1411420 & 688340 & 4.4 & 4.8266 & TRN & \\
\hline CHEMBL1363517 & 688340 & 4.6 & 5.0786 & TRN & \\
\hline CHEMBL1604759 & 688340 & 4.0 & 5.0773 & TST & \\
\hline CHEMBL1484139 & 688340 & 4.65 & 4.9246 & TRN & \\
\hline CHEMBL1458900 & 688340 & 4.5 & 4.843 & TRN & \\
\hline CHEMBL1390041 & 688340 & 5.15 & 5.0071 & TRN & \\
\hline CHEMBL 3209887 & 688340 & 6.95 & 5.2618 & TRN & \\
\hline CHEMBL1306806 & 688340 & 5.05 & 5.2438 & TST & \\
\hline CHEMBL1459455 & 688340 & 4.5 & 4.9569 & TRN & \\
\hline CHEMBL1334732 & 688340 & 4.7 & 4.8181 & TRN & \\
\hline CHEMBL1453842 & 688340 & 5.05 & 5.3025 & TST & \\
\hline CHEMBL1304567 & 688340 & 4.85 & 5.2212 & TRN & \\
\hline CHEMBL1427274 & 688340 & 4.65 & 5.43 & TRN & \\
\hline CHEMBL1580211 & 688340 & 5.45 & 5.2265 & TRN & \\
\hline CHEMBL1447788 & 688340 & 6.8 & 5.0325 & TST & \\
\hline CHEMBL1354903 & 688340 & 4.6 & 4.7758 & TRN & \\
\hline CHEMBL1611661 & 688340 & 4.5 & 5.0308 & TRN & \\
\hline CHEMBL1522720 & 688340 & 5.5 & 4.7815 & TRN & \\
\hline CHEMBL1361699 & 688340 & 5.8 & 4.6392 & TRN & \\
\hline CHEMBL1537481 & 688340 & 4.7 & 4.8552 & TRN & \\
\hline CHEMBL1485109 & 688340 & 4.85 & 5.1263 & TST & \\
\hline CHEMBL1368514 & 688340 & 4.8 & 4.7182 & TRN & \\
\hline CHEMBL1369348 & 688340 & 4.35 & 5.1775 & TRN & \\
\hline CHEMBL1453972 & 688340 & 4.85 & 4.8897 & TRN & \\
\hline
\end{tabular}




\begin{tabular}{|c|c|c|c|c|}
\hline & & & & \\
\hline CHEMBL1492525 & 688340 & 4.7 & 5.0696 & TST \\
\hline CHEMBL1325254 & 688340 & 4.45 & 5.2952 & TRN \\
\hline CHEMBL1572280 & 688340 & 4.5 & 4.5147 & TST \\
\hline CHEMBL1440071 & 688340 & 4.45 & 5.351 & TRN \\
\hline CHEMBL1604925 & 688340 & 4.55 & 4.9159 & TST \\
\hline CHEMBL1493462 & 688340 & 7.0 & 5.5856 & TST \\
\hline CHEMBL1456656 & 688340 & 4.6 & 5.2124 & TST \\
\hline CHEMBL1731995 & 688340 & 5.35 & 4.8114 & TRN \\
\hline CHEMBL1577193 & 688340 & 4.75 & 4.95100 & 00000000005 \\
\hline CHEMBL1340628 & 688340 & 4.8 & 4.4695 & TRN \\
\hline CHEMBL1573297 & 688340 & 5.4 & 5.1915 & TST \\
\hline CHEMBL1420872 & 688340 & 4.4 & 5.4091 & TRN \\
\hline CHEMBL1425597 & 688340 & 4.85 & 5.1391 & TRN \\
\hline CHEMBL1568399 & 688340 & 4.85 & 5.20299 & 9999999999 \\
\hline CHEMBL1307862 & 688340 & 5.2 & 4.8824 & TRN \\
\hline CHEMBL1449447 & 688340 & 4.6 & 5.5377 & TRN \\
\hline CHEMBL1384735 & 688340 & 4.9 & 4.7289 & TRN \\
\hline CHEMBL1418328 & 688340 & 4.7 & 5.0727 & TST \\
\hline CHEMBL1357023 & 688340 & 6.95 & 5.4945 & TRN \\
\hline CHEMBL252966 & 688340 & 5.05 & 5.1502 & TRN \\
\hline CHEMBL1370315 & 688340 & 4.6 & 4.8691 & TRN \\
\hline CHEMBL1526078 & 688340 & 5.35 & 5.1611 & TRN \\
\hline CHEMBL1460862 & 688340 & 5.7 & 5.1668 & TRN \\
\hline CHEMBL1373738 & 688340 & 5.4 & 5.4865 & TRN \\
\hline CHEMBL1319766 & 688340 & 5.65 & 5.3805 & TRN \\
\hline CHEMBL1600511 & 688340 & 6.15 & 5.0158 & TST \\
\hline CHEMBL1482857 & 688340 & 7.0501 & 5.3188 & TRN \\
\hline CHEMBL1301092 & 688340 & 5.6 & 4.8422 & TST \\
\hline CHEMBL1438096 & 688340 & 4.4 & 4.7282 & TRN \\
\hline CHEMBL1437911 & 688340 & 5.15 & 5.4491 & TST \\
\hline CHEMBL1543707 & 688340 & 4.4 & 4.8766 & TRN \\
\hline CHEMBL1583580 & 688340 & 4.55 & 4.7121 & TRN \\
\hline CHEMBL1344978 & 688340 & 7.0 & 5.0977 & TST \\
\hline CHEMBL1382910 & 688340 & 4.75 & 5.1632 & TRN \\
\hline CHEMBL1522356 & 688340 & 4.6 & 4.7886 & TST \\
\hline CHEMBL1316538 & 688340 & 6.95 & 5.4884 & TST \\
\hline CHEMBL1318999 & 688340 & 5.45 & 5.4088 & TRN \\
\hline CHEMBL1586061 & 688340 & 5.15 & 4.9737 & TST \\
\hline CHEMBL1457034 & 688340 & 4.85 & 5.0337 & TRN \\
\hline CHEMBL1303152 & 688340 & 5.05 & 4.8649 & TRN \\
\hline CHEMBL1587863 & 688340 & 4.5 & 4.9295 & TRN \\
\hline CHEMBL1606828 & 688340 & 4.55 & 4.7979 & TRN \\
\hline CHEMBL1409936 & 688340 & 6.5501 & 5.0649 & TRN \\
\hline CHEMBL1347656 & 688340 & 4.5 & 5.0575 & TRN \\
\hline CHEMBL1341945 & 688340 & 4.35 & 5.0121 & TST \\
\hline CHEMBL1441026 & 688340 & 4.45 & 4.8213 & TRN \\
\hline CHEMBL1530139 & 688340 & 4.4 & 5.0111 & TRN \\
\hline CHEMBL1609996 & 688340 & 4.55 & 4.8308 & TRN \\
\hline
\end{tabular}




\begin{tabular}{|c|c|c|c|c|c|}
\hline \multirow[b]{2}{*}{ CHEMBL1498395 } & \multicolumn{5}{|c|}{ Supplemental Table S2.txt } \\
\hline & 688340 & 4.65 & 4.8484 & TST & \\
\hline CHEMBL1577622 & 688340 & 4.55 & 4.7251 & TRN & \\
\hline CHEMBL1390729 & 688340 & 4.55 & 5.0277 & TRN & \\
\hline CHEMBL1567386 & 688340 & 4.55 & 4.9061 & TST & \\
\hline CHEMBL1335431 & 688340 & 6.2 & 5.4663 & TRN & \\
\hline CHEMBL1534636 & 688340 & 5.05 & 5.1632 & TRN & \\
\hline CHEMBL1389510 & 688340 & 4.4 & 4.7792 & TRN & \\
\hline CHEMBL1324193 & 688340 & 4.4 & 4.9404 & TRN & \\
\hline CHEMBL1450770 & 688340 & 6.4 & 4.8627 & TST & \\
\hline CHEMBL1489428 & 688340 & 7.0501 & 5.2696 & TRN & \\
\hline CHEMBL1410534 & 688340 & 4.45 & 4.5624 & TRN & \\
\hline CHEMBL1548794 & 688340 & 4.55 & 4.9768 & TRN & \\
\hline CHEMBL1345573 & 688340 & 7.0501 & 4.9992 & TRN & \\
\hline CHEMBL1556941 & 688340 & 6.0 & 5.3587 & TRN & \\
\hline CHEMBL1350204 & 688340 & 5.3 & 5.4425 & TRN & \\
\hline CHEMBL1408240 & 688340 & 4.65 & 4.8435 & TRN & \\
\hline CHEMBL1511356 & 688340 & 4.6 & 4.9819 & TRN & \\
\hline CHEMBL1612648 & 688340 & 4.6 & 4.8502 & TRN & \\
\hline CHEMBL 3211170 & 688340 & 4.8 & 5.1888 & TST & \\
\hline CHEMBL1539727 & 688340 & 4.8 & 4.74 & TRN & \\
\hline CHEMBL1399278 & 688340 & 4.6 & 4.8003 & TRN & \\
\hline CHEMBL1580112 & 688340 & 4.4 & 5.1329 & TRN & \\
\hline CHEMBL1487597 & 688340 & 4.45 & 5.0037 & TST & \\
\hline CHEMBL3198304 & 688340 & 4.45 & 4.7615 & TRN & \\
\hline CHEMBL1353011 & 688340 & 4.45 & 5.0849 & TRN & \\
\hline CHEMBL1432386 & 688340 & 4.4 & 5.3068 & TRN & \\
\hline CHEMBL363207 & 688340 & 4.7 & 5.0864 & TST & \\
\hline CHEMBL1341642 & 688340 & 5.0 & 4.83 & TST & \\
\hline CHEMBL1331680 & 688340 & 5.05 & 4.9773 & TRN & \\
\hline CHEMBL1377552 & 688340 & 4.7 & 4.4 & TRN & \\
\hline CHEMBL1597550 & 688340 & 4.6 & 4.7698 & TRN & \\
\hline CHEMBL1595202 & 688340 & 4.65 & 4.9265 & TST & \\
\hline CHEMBL598903 & 688340 & 4.4 & 4.7014 & TST & \\
\hline CHEMBL3199302 & 688340 & 4.6 & 5.0947 & TST & \\
\hline CHEMBL1328303 & 688340 & 6.45 & 5.3508 & TST & \\
\hline CHEMBL1572995 & 688340 & 4.6 & 5.2285 & TRN & \\
\hline CHEMBL1521532 & 688340 & 4.7 & 5.1242 & TRN & \\
\hline CHEMBL1478652 & 688340 & 4.7 & 4.84699 & 99999999995 & TRN \\
\hline CHEMBL1321884 & 688340 & 4.65 & 4.8571 & TRN & \\
\hline CHEMBL1567290 & 688340 & 4.55 & 4.7623 & TRN & \\
\hline CHEMBL1424204 & 688340 & 5.25 & 4.9313 & TST & \\
\hline CHEMBL1528111 & 688340 & 4.4 & 4.9985 & TST & \\
\hline CHEMBL1367305 & 688340 & 4.5 & 5.0769 & TRN & \\
\hline CHEMBL1515894 & 688340 & 4.05 & 5.345 & TRN & \\
\hline CHEMBL1393131 & 688340 & 5.35 & 4.69300 & 00000000005 & TRN \\
\hline CHEMBL1343499 & 688340 & 6.2 & 4.8585 & TST & \\
\hline CHEMBL1360393 & 688340 & 4.45 & 4.8977 & TRN & \\
\hline CHEMBL1457677 & 688340 & 6.9 & 5.1777 & TRN & \\
\hline
\end{tabular}




\begin{tabular}{|c|c|c|c|c|c|}
\hline \multicolumn{6}{|c|}{ Supplemental Table S2.txt } \\
\hline CHEMBL1509284 & 688340 & 4.75 & 5.1483 & TRN & \\
\hline CHEMBL1555363 & 688340 & 6.2 & 5.3558 & TRN & \\
\hline CHEMBL1476264 & 688340 & 5.45 & 4.8848 & TRN & \\
\hline CHEMBL1453402 & 688340 & 4.4 & 4.7903 & TRN & \\
\hline CHEMBL1375050 & 688340 & 6.5501 & 4.7494 & TRN & \\
\hline CHEMBL3199560 & 688340 & 5.4 & 4.8911 & TRN & \\
\hline CHEMBL1311453 & 688340 & 5.05 & 4.806 & TRN & \\
\hline CHEMBL1354730 & 688340 & 6.8499 & 5.0409 & TST & \\
\hline CHEMBL1353150 & 688340 & 6.0 & 5.2095 & TST & \\
\hline CHEMBL1444907 & 688340 & 5.3 & 4.94600 & 0000000001 & TRN \\
\hline CHEMBL1474066 & 688340 & 5.15 & 5.3161 & TRN & \\
\hline CHEMBL1422327 & 688340 & 4.55 & 4.8191 & TRN & \\
\hline CHEMBL1357139 & 688340 & 4.55 & 4.7263 & TRN & \\
\hline CHEMBL1430260 & 688340 & 4.65 & 4.8416 & TRN & \\
\hline CHEMBL1487709 & 688340 & 5.25 & 5.2677 & TRN & \\
\hline CHEMBL1422028 & 688340 & 6.5501 & 5.0328 & TRN & \\
\hline CHEMBL1373994 & 688340 & 4.55 & 5.2777 & TRN & \\
\hline CHEMBL3191273 & 688340 & 4.4 & 5.01 & TRN & \\
\hline CHEMBL1603072 & 688340 & 5.0 & 4.8229 & TRN & \\
\hline CHEMBL1305766 & 688340 & 4.45 & 4.9544 & TST & \\
\hline CHEMBL1401325 & 688340 & 4.7 & 4.7647 & TRN & \\
\hline CHEMBL1525541 & 688340 & 5.45 & 5.2909 & TST & \\
\hline CHEMBL1414105 & 688340 & 4.45 & 5.002 & TRN & \\
\hline CHEMBL1423619 & 688340 & 4.95 & 4.9528 & TRN & \\
\hline CHEMBL1456372 & 688340 & 4.7 & 5.1913 & TRN & \\
\hline CHEMBL1483886 & 688340 & 4.5 & 5.0665 & TRN & \\
\hline CHEMBL1418203 & 688340 & 6.15 & 5.2999 & TRN & \\
\hline CHEMBL1586006 & 688340 & 4.35 & 5.3121 & TRN & \\
\hline CHEMBL1464826 & 688340 & 8.699 & 5.1803 & TRN & \\
\hline CHEMBL1388156 & 688340 & 6.5 & 5.0577 & TST & \\
\hline CHEMBL1593697 & 688340 & 6.0 & 5.23 & TRN & \\
\hline CHEMBL1503325 & 688340 & 4.55 & 5.0723 & TRN & \\
\hline CHEMBL1568327 & 688340 & 4.75 & 5.3818 & TRN & \\
\hline CHEMBL1569553 & 688340 & 7.0 & 5.1306 & TST & \\
\hline CHEMBL1432991 & 688340 & 4.95 & 5.1043 & TRN & \\
\hline CHEMBL1443299 & 688340 & 5.2 & 5.4229 & TRN & \\
\hline CHEMBL1396848 & 688340 & 6.15 & 5.3569 & TRN & \\
\hline CHEMBL1317166 & 688340 & 5.4 & 5.0685 & TRN & \\
\hline CHEMBL1332531 & 688340 & 5.2 & 5.2784 & TST & \\
\hline CHEMBL1382312 & 688340 & 4.55 & 5.1023 & TRN & \\
\hline CHEMBL1309348 & 688340 & 4.5 & 4.7531 & TRN & \\
\hline CHEMBL1995715 & 688340 & 5.0 & 4.9824 & TRN & \\
\hline CHEMBL1408812 & 688340 & 5.2 & 5.0715 & TST & \\
\hline CHEMBL1512263 & 688340 & 6.5501 & 5.2198 & TRN & \\
\hline CHEMBL1344015 & 688340 & 4.5 & 4.7084 & TRN & \\
\hline CHEMBL1570390 & 688340 & 5.3 & 4.6066 & TST & \\
\hline CHEMBL3145205 & 688340 & 4.55 & 5.0608 & TRN & \\
\hline CHEMBL1559514 & 688340 & 4.4 & 5.2775 & TRN & \\
\hline
\end{tabular}




\begin{tabular}{|c|c|c|c|c|}
\hline \multicolumn{5}{|c|}{ Supplemental Table } \\
\hline CHEMBL1511573 & 688340 & 4.55 & 4.8575 & TST \\
\hline CHEMBL1435780 & 688340 & 4.45 & 4.7573 & TRN \\
\hline CHEMBL1510799 & 688340 & 4.0 & 5.3715 & TRN \\
\hline CHEMBL1575286 & 688340 & 4.55 & 4.7745 & TRN \\
\hline CHEMBL1348825 & 688340 & 4.5 & 4.8498 & TST \\
\hline CHEMBL1536585 & 688340 & 4.4 & 4.7705 & TST \\
\hline CHEMBL1326086 & 688340 & 4.5 & 4.8433 & TRN \\
\hline CHEMBL1380667 & 688340 & 4.4 & 5.2616 & TST \\
\hline CHEMBL 3190620 & 688340 & 4.55 & 4.9632 & TRN \\
\hline CHEMBL1556596 & 688340 & 4.65 & 5.011 & TRN \\
\hline CHEMBL 3211294 & 688340 & 4.9 & 5.118 & TRN \\
\hline CHEMBL1498500 & 688340 & 4.85 & 4.9725 & TRN \\
\hline CHEMBL1304881 & 688340 & 7.0501 & 5.562 & TRN \\
\hline CHEMBL1389810 & 688340 & 4.4 & 4.6023 & TRN \\
\hline CHEMBL1301534 & 688340 & 4.6 & 4.9944 & TRN \\
\hline CHEMBL1411015 & 688340 & 7.4498 & 4.9407 & TRN \\
\hline CHEMBL1431114 & 688340 & 6.15 & 4.7524 & TST \\
\hline CHEMBL3144936 & 688340 & 5.55 & 5.2404 & TRN \\
\hline CHEMBL1399069 & 688340 & 9.2218 & 5.5149 & TST \\
\hline CHEMBL1497609 & 688340 & 4.4 & 5.3444 & TST \\
\hline CHEMBL3197928 & 688340 & 6.45 & 4.9068 & TRN \\
\hline CHEMBL 393287 & 688340 & 4.75 & 5.0537 & TRN \\
\hline CHEMBL1351637 & 688340 & 4.6 & 4.6689 & TRN \\
\hline CHEMBL1459091 & 688340 & 4.4 & 5.0744 & TRN \\
\hline CHEMBL1610797 & 688340 & 4.4 & 5.4358 & TRN \\
\hline CHEMBL1446266 & 688340 & 4.55 & 4.7628 & TST \\
\hline CHEMBL3190073 & 688340 & 4.6 & 5.0348 & TRN \\
\hline CHEMBL1339270 & 688340 & 4.7 & 4.6657 & TRN \\
\hline CHEMBL1476978 & 688340 & 4.6 & 5.0332 & TRN \\
\hline CHEMBL1467504 & 688340 & 5.0 & 4.9922 & TST \\
\hline CHEMBL1312358 & 688340 & 6.8499 & 5.1713 & TST \\
\hline CHEMBL1568910 & 688340 & 4.6 & 5.0047 & TRN \\
\hline CHEMBL1519910 & 688340 & 4.65 & 5.164 & TRN \\
\hline CHEMBL1466912 & 688340 & 4.5 & 5.1419 & TRN \\
\hline CHEMBL1491679 & 688340 & 5.65 & 5.265 & TRN \\
\hline CHEMBL3190757 & 688340 & 5.45 & 4.8355 & TST \\
\hline CHEMBL 1470330 & 688340 & 4.45 & 4.9058 & TRN \\
\hline CHEMBL1420425 & 688340 & 6.9 & 5.1938 & TST \\
\hline CHEMBL1458486 & 688340 & 4.5 & 4.7439 & TRN \\
\hline CHEMBL1530440 & 688340 & 5.0 & 4.9818 & TRN \\
\hline CHEMBL1389803 & 688340 & 5.0 & 5.2881 & TRN \\
\hline CHEMBL1579209 & 688340 & 4.6 & 4.8881 & TRN \\
\hline CHEMBL1524035 & 688340 & 6.3 & 5.4149 & TRN \\
\hline CHEMBL1507590 & 688340 & 4.45 & 5.2391 & TRN \\
\hline CHEMBL1304499 & 688340 & 4.55 & 4.5287 & TRN \\
\hline CHEMBL1409622 & 688340 & 4.8 & 5.3735 & TRN \\
\hline CHEMBL1303540 & 688340 & 4.6 & 4.9964 & TST \\
\hline CHEMBL3199737 & 688340 & 4.4 & 5.055 & TRN \\
\hline
\end{tabular}




\begin{tabular}{|c|c|c|c|c|c|}
\hline \\
\hline CHEMBL1416455 & 688340 & 6.5 & 5.2542 & TRN & \\
\hline CHEMBL1396656 & 688340 & 4.05 & 5.1352 & TST & \\
\hline CHEMBL1431724 & 688340 & 4.6 & 4.5305 & TRN & \\
\hline CHEMBL1442861 & 688340 & 4.4 & 4.6685 & TRN & \\
\hline CHEMBL1529204 & 688340 & 3.35 & 5.3832 & TRN & \\
\hline CHEMBL1354438 & 688340 & 4.55 & 5.0095 & TRN & \\
\hline CHEMBL1309127 & 688340 & 5.0 & 4.7438 & TRN & \\
\hline CHEMBL1502883 & 688340 & 4.8 & 4.9644 & TRN & \\
\hline CHEMBL1386245 & 688340 & 6.2 & 5.3032 & TRN & \\
\hline CHEMBL1340318 & 688340 & 4.0 & 5.4413 & TST & \\
\hline CHEMBL1426673 & 688340 & 7.0 & 5.102 & TRN & \\
\hline CHEMBL1572851 & 688340 & 7.0501 & 5.3111 & TRN & \\
\hline CHEMBL1323932 & 688340 & 7.0 & 5.3605 & TRN & \\
\hline CHEMBL1574396 & 688340 & 5.85 & 5.3116 & TRN & \\
\hline CHEMBL1444047 & 688340 & 4.9 & 5.2171 & TRN & \\
\hline CHEMBL3194347 & 688340 & 5.2 & 5.0815 & TRN & \\
\hline CHEMBL1330230 & 688340 & 5.75 & 4.8629 & TST & \\
\hline CHEMBL1968695 & 688340 & 4.4 & 4.7374 & TST & \\
\hline CHEMBL1510862 & 688340 & 5.3 & 5.3587 & TRN & \\
\hline CHEMBL1370630 & 688340 & 4.75 & 4.8453 & TRN & \\
\hline CHEMBL1518504 & 688340 & 7.0501 & 5.1077 & TRN & \\
\hline CHEMBL1413958 & 688340 & 4.55 & 4.8533 & TST & \\
\hline CHEMBL1535981 & 688340 & 5.05 & 4.7258 & TRN & \\
\hline CHEMBL1350054 & 688340 & 5.55 & 4.836 & TST & \\
\hline CHEMBL1474688 & 688340 & 5.2 & 5.3385 & TRN & \\
\hline CHEMBL1527363 & 688340 & 4.65 & 5.0703 & TRN & \\
\hline CHEMBL1395409 & 688340 & 5.25 & 5.2617 & TRN & \\
\hline CHEMBL1329974 & 688340 & 5.0 & 4.94600 & 0000000001 & TRN \\
\hline CHEMBL1381868 & 688340 & 4.85 & 4.9712 & TRN & \\
\hline CHEMBL1491598 & 688340 & 4.6 & 5.1344 & TRN & \\
\hline CHEMBL1378153 & 688340 & 4.4 & 5.3377 & TRN & \\
\hline CHEMBL1511984 & 688340 & 4.4 & 5.2451 & TRN & \\
\hline CHEMBL1535290 & 688340 & 4.5 & 4.9102 & TRN & \\
\hline CHEMBL1427775 & 688340 & 5.65 & 5.1705 & TRN & \\
\hline CHEMBL1473150 & 688340 & 4.4 & 4.8379 & TRN & \\
\hline CHEMBL1302848 & 688340 & 5.2 & 5.29299 & 9999999999 & TRN \\
\hline CHEMBL1351799 & 688340 & 4.5 & 4.8868 & TRN & \\
\hline CHEMBL1517185 & 688340 & 4.55 & 5.1631 & TST & \\
\hline CHEMBL1420031 & 688340 & 5.4 & 4.7462 & TRN & \\
\hline CHEMBL1523771 & 688340 & 4.5 & 4.6845 & TRN & \\
\hline CHEMBL1409320 & 688340 & 6.15 & 5.0042 & TST & \\
\hline CHEMBL1478447 & 688340 & 5.15 & 5.392 & TRN & \\
\hline CHEMBL1311997 & 688340 & 5.0 & 5.2784 & TRN & \\
\hline CHEMBL1302522 & 688340 & 4.5 & 4.6169 & TRN & \\
\hline CHEMBL1483169 & 688340 & 4.75 & 4.8052 & TRN & \\
\hline CHEMBL1485374 & 688340 & 4.4 & 4.8577 & TRN & \\
\hline CHEMBL1492331 & 688340 & 5.1 & 5.1372 & TST & \\
\hline CHEMBL3195053 & 688340 & 4.45 & 4.7491 & TRN & \\
\hline
\end{tabular}




\begin{tabular}{|c|c|c|c|c|}
\hline \multicolumn{5}{|c|}{ olemental I } \\
\hline CHEMBL1603597 & 688340 & 4.4 & 4.9819 & TRN \\
\hline CHEMBL1367718 & 688340 & 4.55 & 4.9216 & TRN \\
\hline CHEMBL3193676 & 688340 & 4.5 & 5.2259 & TST \\
\hline CHEMBL1527963 & 688340 & 4.55 & 5.052 & TRN \\
\hline CHEMBL1352340 & 688340 & 4.7 & 4.8488 & TRN \\
\hline CHEMBL1470633 & 688340 & 4.7 & 5.1546 & TST \\
\hline CHEMBL1357528 & 688340 & 7.0501 & 5.0892 & TST \\
\hline CHEMBL1481493 & 688340 & 4.5 & 4.8501 & TRN \\
\hline CHEMBL1334926 & 688340 & 4.7 & 5.33200 & 0000000001 \\
\hline CHEMBL1515473 & 688340 & 4.6 & 4.619 & TRN \\
\hline CHEMBL1586116 & 688340 & 4.45 & 4.716 & TRN \\
\hline CHEMBL1465926 & 688340 & 5.25 & 5.0656 & TRN \\
\hline CHEMBL 2002980 & 688340 & 5.65 & 4.9282 & TST \\
\hline CHEMBL1077150 & 688340 & 5.15 & 5.3859 & TRN \\
\hline CHEMBL1485395 & 688340 & 5.05 & 5.2156 & TRN \\
\hline CHEMBL3199718 & 688340 & 4.5 & 5.2202 & TST \\
\hline CHEMBL1974362 & 688340 & 5.0 & 5.0483 & TRN \\
\hline CHEMBL1506390 & 688340 & 4.35 & 4.9907 & TST \\
\hline CHEMBL1482964 & 688340 & 4.75 & 4.7768 & TRN \\
\hline CHEMBL1368505 & 688340 & 4.65 & 4.9442 & TRN \\
\hline CHEMBL1359621 & 688340 & 4.4 & 5.0026 & TRN \\
\hline CHEMBL1453120 & 688340 & 4.55 & 4.9465 & TRN \\
\hline CHEMBL1463936 & 688340 & 5.6 & 4.6511 & TRN \\
\hline CHEMBL1487583 & 688340 & 5.6 & 5.1002 & TRN \\
\hline CHEMBL1503161 & 688340 & 5.0 & 5.4486 & TRN \\
\hline CHEMBL1611270 & 688340 & 4.5 & 4.7419 & TRN \\
\hline CHEMBL1566380 & 688340 & 6.6 & 5.1031 & TRN \\
\hline CHEMBL1398158 & 688340 & 4.45 & 4.9749 & TST \\
\hline CHEMBL1387184 & 688340 & 4.85 & 4.8488 & TRN \\
\hline CHEMBL1419032 & 688340 & 4.7 & 5.0912 & TST \\
\hline CHEMBL1381716 & 688340 & 6.5501 & 5.2307 & TRN \\
\hline CHEMBL1459104 & 688340 & 4.8 & 4.9792 & TRN \\
\hline CHEMBL1587109 & 688340 & 4.65 & 4.6762 & TRN \\
\hline CHEMBL1560960 & 688340 & 4.35 & 5.3089 & TST \\
\hline CHEMBL1332397 & 688340 & 5.2 & 5.3504 & TRN \\
\hline CHEMBL1609652 & 688340 & 4.55 & 4.7993 & TRN \\
\hline CHEMBL1403665 & 688340 & 4.5 & 4.7157 & TRN \\
\hline CHEMBL1392861 & 688340 & 4.6 & 5.055 & TRN \\
\hline CHEMBL1465054 & 688340 & 4.55 & 5.0754 & TRN \\
\hline CHEMBL1573230 & 688340 & 4.45 & 4.9203 & TRN \\
\hline CHEMBL3195944 & 688340 & 4.55 & 4.9259 & TRN \\
\hline CHEMBL1359792 & 688340 & 4.55 & 4.9201 & TRN \\
\hline CHEMBL1362898 & 688340 & 4.4 & 5.2599 & TST \\
\hline CHEMBL3192059 & 688340 & 6.2 & 4.8913 & TST \\
\hline CHEMBL1611209 & 688340 & 4.45 & 4.7825 & TRN \\
\hline CHEMBL1092114 & 688340 & 4.3 & 5.2247 & TST \\
\hline CHEMBL1472183 & 688340 & 7.0501 & 5.1356 & TST \\
\hline CHEMBL1467310 & 688340 & 6.05 & 4.9193 & TST \\
\hline
\end{tabular}




\begin{tabular}{|c|c|c|c|c|c|}
\hline \\
\hline CHEMBL1609016 & 688340 & 4.5 & 5.4228 & TRN & \\
\hline CHEMBL1977188 & 688340 & 4.45 & 4.8372 & TST & \\
\hline CHEMBL1439998 & 688340 & 4.55 & 4.9582 & TRN & \\
\hline CHEMBL3194670 & 688340 & 4.85 & 4.7956 & TRN & \\
\hline CHEMBL1363882 & 688340 & 6.0 & 4.9403 & TRN & \\
\hline CHEMBL1597984 & 688340 & 5.3 & 4.8506 & TRN & \\
\hline CHEMBL1359429 & 688340 & 4.35 & 5.1512 & TRN & \\
\hline CHEMBL1440916 & 688340 & 6.2 & 4.9723 & TRN & \\
\hline CHEMBL3189600 & 688340 & 4.4 & 4.7495 & TRN & \\
\hline CHEMBL1393749 & 688340 & 6.1 & 5.1152 & TST & \\
\hline CHEMBL1489351 & 688340 & 5.6 & 4.6489 & TST & \\
\hline CHEMBL1602066 & 688340 & 5.05 & 4.8566 & TRN & \\
\hline CHEMBL1318809 & 688340 & 5.25 & 5.4923 & TRN & \\
\hline CHEMBL1306245 & 688340 & 4.75 & 5.008 & TRN & \\
\hline CHEMBL1566945 & 688340 & 5.6 & 4.8054 & TRN & \\
\hline CHEMBL1571839 & 688340 & 4.75 & 4.7613 & TRN & \\
\hline CHEMBL3209274 & 688340 & 4.9 & 5.1594 & TST & \\
\hline CHEMBL1407094 & 688340 & 4.7 & 4.8105 & TRN & \\
\hline CHEMBL1453943 & 688340 & 6.1 & 5.3157 & TRN & \\
\hline CHEMBL1601345 & 688340 & 4.5 & 4.5567 & TRN & \\
\hline CHEMBL1561378 & 688340 & 4.4 & 5.371 & TRN & \\
\hline CHEMBL1452684 & 688340 & 5.05 & 4.8118 & TRN & \\
\hline CHEMBL1312316 & 688340 & 4.45 & 4.9832 & TRN & \\
\hline CHEMBL1531496 & 688340 & 4.55 & 5.0573 & TST & \\
\hline CHEMBL1434247 & 688340 & 4.45 & 4.7451 & TST & \\
\hline CHEMBL1476707 & 688340 & 4.5 & 4.7603 & TRN & \\
\hline CHEMBL1611696 & 688340 & 4.65 & 5.1344 & TRN & \\
\hline CHEMBL1323323 & 688340 & 4.35 & 5.2018 & TST & \\
\hline CHEMBL1480774 & 688340 & 4.5 & 4.8232 & TST & \\
\hline CHEMBL3191942 & 688340 & 6.0 & 4.9873 & TRN & \\
\hline CHEMBL1888528 & 688340 & 4.6 & 4.90300 & 30000000005 & TRN \\
\hline CHEMBL358580 & 688340 & 5.25 & 4.735 & TRN & \\
\hline CHEMBL1354146 & 688340 & 4.55 & 4.763 & TST & \\
\hline CHEMBL1447584 & 688340 & 4.65 & 5.3132 & TRN & \\
\hline CHEMBL1302581 & 688340 & 4.45 & 4.9658 & TST & \\
\hline CHEMBL1371701 & 688340 & 4.5 & 4.8792 & TRN & \\
\hline CHEMBL1388777 & 688340 & 4.55 & 5.2345 & TRN & \\
\hline CHEMBL1504653 & 688340 & 5.85 & 4.9602 & TST & \\
\hline CHEMBL1505636 & 688340 & 4.5 & 4.8726 & TRN & \\
\hline CHEMBL1472411 & 688340 & 4.55 & 4.9783 & TST & \\
\hline CHEMBL1992447 & 688340 & 4.65 & 4.8471 & TRN & \\
\hline CHEMBL1484227 & 688340 & 4.4 & 4.7505 & TRN & \\
\hline CHEMBL1567604 & 688340 & 5.2 & 5.1552 & TRN & \\
\hline CHEMBL1501237 & 688340 & 5.8 & 4.9586 & TST & \\
\hline CHEMBL1462800 & 688340 & 4.5 & 5.1274 & TRN & \\
\hline CHEMBL 3196558 & 688340 & 4.65 & 4.8794 & TRN & \\
\hline CHEMBL1496236 & 688340 & 6.05 & 5.2622 & TRN & \\
\hline CHEMBL1320578 & 688340 & 4.5 & 5.0406 & TRN & \\
\hline
\end{tabular}




\begin{tabular}{|c|c|c|c|c|}
\hline & & & & \\
\hline CHEMBL1430724 & 688340 & 5.2 & 5.0356 & TRN \\
\hline CHEMBL1385557 & 688340 & 4.5 & 4.8937 & TRN \\
\hline CHEMBL1459983 & 688340 & 5.05 & 4.9846 & TRN \\
\hline CHEMBL1508858 & 688340 & 4.65 & 4.4802 & TRN \\
\hline CHEMBL1450874 & 688340 & 4.0 & 5.0556 & TRN \\
\hline CHEMBL1493796 & 688340 & 5.15 & 5.2362 & TST \\
\hline CHEMBL1378797 & 688340 & 7.8508 & 4.9962 & TRN \\
\hline CHEMBL1483525 & 688340 & 5.5 & 5.0464 & TRN \\
\hline CHEMBL1314566 & 688340 & 4.05 & 5.1475 & TRN \\
\hline CHEMBL1412435 & 688340 & 4.35 & 5.5313 & TRN \\
\hline CHEMBL1500335 & 688340 & 4.4 & 5.2975 & TRN \\
\hline CHEMBL3195354 & 688340 & 4.4 & 5.0085 & TST \\
\hline CHEMBL1456256 & 688340 & 4.9 & 5.2924 & TRN \\
\hline CHEMBL1477145 & 688340 & 4.6 & 5.3098 & TRN \\
\hline CHEMBL1471613 & 688340 & 4.6 & 4.6873 & TRN \\
\hline CHEMBL1557957 & 688340 & 4.4 & 4.9557 & TST \\
\hline CHEMBL1513083 & 688340 & 4.75 & 4.8667 & TST \\
\hline CHEMBL1607306 & 688340 & 4.55 & 4.8393 & TRN \\
\hline CHEMBL187460 & 688340 & 4.75 & 4.7702 & TRN \\
\hline CHEMBL1579037 & 688340 & 5.1 & 4.9599 & TRN \\
\hline CHEMBL3193848 & 688340 & 4.55 & 5.0716 & TRN \\
\hline CHEMBL1381523 & 688340 & 6.3 & 4.9691 & TRN \\
\hline CHEMBL1550923 & 688340 & 4.55 & 4.8725 & TRN \\
\hline CHEMBL1299666 & 688340 & 4.75 & 4.8095 & TRN \\
\hline CHEMBL1598101 & 688340 & 4.75 & 4.8103 & TST \\
\hline CHEMBL1325671 & 688340 & 4.3 & 4.83899 & 99999999995 \\
\hline CHEMBL 3144988 & 688340 & 5.5 & 5.3076 & TST \\
\hline CHEMBL1419404 & 688340 & 4.25 & 5.0159 & TST \\
\hline CHEMBL1328615 & 688340 & 4.45 & 4.7892 & TST \\
\hline CHEMBL1513683 & 688340 & 4.45 & 4.8354 & TRN \\
\hline CHEMBL1610014 & 688340 & 4.65 & 4.9924 & TRN \\
\hline CHEMBL1594918 & 688340 & 4.4 & 4.6098 & TRN \\
\hline CHEMBL1479651 & 688340 & 6.15 & 4.9149 & TST \\
\hline CHEMBL1506123 & 688340 & 4.55 & 4.6629 & TRN \\
\hline CHEMBL1495539 & 688340 & 6.25 & 4.8536 & TRN \\
\hline CHEMBL1559410 & 688340 & 4.55 & 4.5198 & TRN \\
\hline CHEMBL1383600 & 688340 & 4.4 & 5.433 & TRN \\
\hline CHEMBL1306005 & 688340 & 5.5 & 4.864 & TRN \\
\hline CHEMBL1485507 & 688340 & 4.6 & 5.3881 & TRN \\
\hline CHEMBL 2018847 & 688340 & 4.6 & 4.8616 & TST \\
\hline CHEMBL1537532 & 688340 & 6.95 & 5.3066 & TRN \\
\hline CHEMBL1597167 & 688340 & 5.2 & 5.1512 & TST \\
\hline CHEMBL1991779 & 688340 & 4.6 & 4.8814 & TRN \\
\hline CHEMBL1330214 & 688340 & 4.6 & 4.5471 & TRN \\
\hline CHEMBL1370307 & 688340 & 5.2 & 5.2855 & TST \\
\hline CHEMBL1492369 & 688340 & 4.95 & 5.4697 & TST \\
\hline CHEMBL1506728 & 688340 & 4.6 & 5.2913 & TRN \\
\hline CHEMBL3197556 & 688340 & 4.2 & 5.1965 & TRN \\
\hline
\end{tabular}




\begin{tabular}{|c|c|c|c|c|c|}
\hline \multicolumn{6}{|c|}{ Supplemental Table S2.txt } \\
\hline CHEMBL1299445 & 688340 & 4.45 & 4.9423 & TST & \\
\hline CHEMBL1575082 & 688340 & 4.55 & 5.2236 & TRN & \\
\hline CHEMBL3199119 & 688340 & 4.75 & 5.0354 & TRN & \\
\hline CHEMBL1299346 & 688340 & 4.4 & 4.6872 & TRN & \\
\hline CHEMBL1451347 & 688340 & 4.55 & 4.9377 & TRN & \\
\hline CHEMBL1428316 & 688340 & 6.2 & 5.1648 & TRN & \\
\hline CHEMBL1414023 & 688340 & 4.7 & 4.9674 & TRN & \\
\hline CHEMBL1482566 & 688340 & 4.4 & 4.8432 & TRN & \\
\hline CHEMBL1374840 & 688340 & 6.1 & 5.2138 & TST & \\
\hline CHEMBL1371148 & 688340 & 4.5 & 4.881 & TRN & \\
\hline CHEMBL1597062 & 688340 & 4.35 & 4.9807 & TRN & \\
\hline CHEMBL1555377 & 688340 & 6.15 & 5.3755 & TRN & \\
\hline CHEMBL1477396 & 688340 & 4.6 & 5.1509 & TRN & \\
\hline CHEMBL1371777 & 688340 & 5.05 & 4.6139 & TRN & \\
\hline CHEMBL1544365 & 688340 & 5.15 & 5.2202 & TRN & \\
\hline CHEMBL1563475 & 688340 & 5.5 & 5.25799 & 9999999999 & TST \\
\hline CHEMBL1300112 & 688340 & 5.6 & 4.9926 & TST & \\
\hline CHEMBL1522300 & 688340 & 4.55 & 5.081 & TRN & \\
\hline CHEMBL1485294 & 688340 & 4.55 & 5.1354 & TRN & \\
\hline CHEMBL1605274 & 688340 & 5.35 & 4.8963 & TRN & \\
\hline CHEMBL1436898 & 688340 & 4.9 & 5.018 & TRN & \\
\hline CHEMBL1460931 & 688340 & 5.2 & 5.2053 & TRN & \\
\hline CHEMBL1422741 & 688340 & 4.7 & 4.9991 & TRN & \\
\hline CHEMBL1305066 & 688340 & 4.5 & 5.0266 & TST & \\
\hline CHEMBL1607559 & 688340 & 5.45 & 5.2177 & TST & \\
\hline CHEMBL1377316 & 688340 & 5.0 & 4.6066 & TRN & \\
\hline CHEMBL1354807 & 688340 & 4.45 & 5.1407 & TRN & \\
\hline CHEMBL1479175 & 688340 & 4.35 & 5.16700 & 0000000001 & TRN \\
\hline CHEMBL1317111 & 688340 & 4.5 & 4.7402 & TRN & \\
\hline CHEMBL3194209 & 688340 & 4.5 & 4.9554 & TRN & \\
\hline CHEMBL1365170 & 688340 & 5.25 & 4.6212 & TRN & \\
\hline CHEMBL1369968 & 688340 & 3.65 & 5.3584 & TRN & \\
\hline CHEMBL1568790 & 688340 & 5.7 & 4.8972 & TST & \\
\hline CHEMBL3192207 & 688340 & 4.0 & 5.1184 & TST & \\
\hline CHEMBL1442776 & 688340 & 4.5 & 4.6595 & TRN & \\
\hline CHEMBL1563671 & 688340 & 6.8499 & 5.016 & TRN & \\
\hline CHEMBL1495550 & 688340 & 4.55 & 4.8998 & TRN & \\
\hline CHEMBL1596362 & 688340 & 4.5 & 4.9547 & TRN & \\
\hline CHEMBL1324999 & 688340 & 5.0 & 4.6675 & TRN & \\
\hline CHEMBL1351990 & 688340 & 4.6 & 5.0952 & TST & \\
\hline CHEMBL1561881 & 688340 & 6.5 & 5.051 & TRN & \\
\hline CHEMBL1466562 & 688340 & 4.45 & 5.0342 & TST & \\
\hline CHEMBL1303072 & 688340 & 4.6 & 5.1955 & TRN & \\
\hline CHEMBL1562395 & 688340 & 4.6 & 5.29799 & 9999999999 & TRN \\
\hline CHEMBL1373506 & 688340 & 4.4 & 5.29200 & 0000000001 & TRN \\
\hline CHEMBL1503146 & 688340 & 3.55 & 4.9756 & TRN & \\
\hline CHEMBL1373110 & 688340 & 4.8 & 5.0268 & TRN & \\
\hline CHEMBL1410750 & 688340 & 5.0 & 5.0646 & TST & \\
\hline
\end{tabular}




\begin{tabular}{|c|c|c|c|c|c|}
\hline & & & & & \\
\hline CHEMBL1585112 & 688340 & 4.5 & 4.5311 & TST & \\
\hline CHEMBL1508048 & 688340 & 4.5 & 4.8081 & TRN & \\
\hline CHEMBL1372283 & 688340 & 4.4 & 4.9419 & TST & \\
\hline CHEMBL1447306 & 688340 & 4.55 & $5.0310 e$ & $\partial 000000001$ & TST \\
\hline CHEMBL1343752 & 688340 & 5.95 & 5.2461 & TRN & \\
\hline CHEMBL1410591 & 688340 & 5.25 & 4.9677 & TRN & \\
\hline CHEMBL1409105 & 688340 & 5.1 & 5.033 & TRN & \\
\hline CHEMBL1595575 & 688340 & 4.05 & 5.0619 & TRN & \\
\hline CHEMBL1379695 & 688340 & 5.05 & 5.0286 & TST & \\
\hline CHEMBL1373527 & 688340 & 4.45 & 5.0687 & TRN & \\
\hline CHEMBL1505401 & 688340 & 4.6 & 5.314 & TRN & \\
\hline CHEMBL1339447 & 688340 & 5.2 & 4.7936 & TRN & \\
\hline CHEMBL1583798 & 688340 & 4.7 & 4.8489 & TRN & \\
\hline CHEMBL1597278 & 688340 & 4.5 & 4.853 & TST & \\
\hline CHEMBL3191151 & 688340 & 4.8 & 5.1095 & TRN & \\
\hline CHEMBL1349668 & 688340 & 5.1 & 5.4006 & TST & \\
\hline CHEMBL3190456 & 688340 & 5.9 & 4.8661 & TRN & \\
\hline CHEMBL1472901 & 688340 & 6.6 & 5.3316 & TRN & \\
\hline CHEMBL3198384 & 688340 & 6.1 & 4.9603 & TRN & \\
\hline CHEMBL1338538 & 688340 & 5.3 & 5.1003 & TST & \\
\hline CHEMBL1966691 & 688340 & 4.3 & 5.3154 & TRN & \\
\hline CHEMBL1454640 & 688340 & 4.55 & 4.8031 & TRN & \\
\hline CHEMBL1441512 & 688340 & 5.35 & 5.4349 & TST & \\
\hline CHEMBL1435703 & 688340 & 5.75 & 4.9957 & TRN & \\
\hline CHEMBL1402886 & 688340 & 5.0 & 5.0858 & TRN & \\
\hline CHEMBL1532137 & 688340 & 4.65 & 4.9339 & TRN & \\
\hline CHEMBL1489036 & 688340 & 4.4 & 5.1063 & TRN & \\
\hline CHEMBL1597126 & 688340 & 5.4 & 5.3568 & TRN & \\
\hline CHEMBL3195336 & 688340 & 5.75 & 4.7942 & TST & \\
\hline CHEMBL 2000581 & 688340 & 4.8 & 5.0577 & TST & \\
\hline CHEMBL1549646 & 688340 & 4.6 & 5.1316 & TST & \\
\hline CHEMBL1301807 & 688340 & 4.35 & 5.0983 & TRN & \\
\hline CHEMBL1359306 & 688340 & 4.0 & 4.757 & TRN & \\
\hline CHEMBL1999610 & 688340 & 4.85 & 4.9667 & TRN & \\
\hline CHEMBL1300628 & 688340 & 4.7 & 5.2787 & TRN & \\
\hline CHEMBL1577859 & 688340 & 4.55 & 4.7948 & TRN & \\
\hline CHEMBL1581012 & 688340 & 5.15 & 5.1467 & TRN & \\
\hline CHEMBL1490692 & 688340 & 5.9 & 4.9575 & TST & \\
\hline CHEMBL197131 & 688340 & 4.5 & 4.9022 & TRN & \\
\hline CHEMBL1476798 & 688340 & 5.1 & 4.8468 & TRN & \\
\hline CHEMBL1395243 & 688340 & 5.95 & 5.1284 & TST & \\
\hline CHEMBL1456080 & 688340 & 4.4 & 5.2635 & TRN & \\
\hline CHEMBL1559149 & 688340 & 4.45 & 5.2904 & TST & \\
\hline CHEMBL1335451 & 688340 & 3.95 & 5.08899 & 99999999995 & TRN \\
\hline CHEMBL1533918 & 688340 & 4.55 & 5.5556 & TST & \\
\hline CHEMBL1592279 & 688340 & 6.5 & 5.5025 & TRN & \\
\hline CHEMBL1312929 & 688340 & 4.4 & 5.3377 & TST & \\
\hline CHEMBL1982945 & 688340 & 5.25 & 4.9273 & TRN & \\
\hline & & & & 28231 & \\
\hline
\end{tabular}




\begin{tabular}{|c|c|c|c|c|}
\hline \multicolumn{5}{|c|}{ Supplemental Table s2.txt } \\
\hline CHEMBL1353099 & 688340 & 7.0 & 4.9202 & TRN \\
\hline CHEMBL1368260 & 688340 & 5.3 & 4.981 & TRN \\
\hline CHEMBL1587403 & 688340 & 7.0 & 4.994 & TST \\
\hline CHEMBL1347572 & 688340 & 4.45 & 5.0601 & TST \\
\hline CHEMBL1534106 & 688340 & 4.8 & 5.0356 & TRN \\
\hline CHEMBL3195265 & 688340 & 5.65 & 4.8436 & TST \\
\hline CHEMBL1578694 & 688340 & 4.4 & 5.318 & TRN \\
\hline CHEMBL1303333 & 688340 & 4.4 & 4.8517 & TRN \\
\hline CHEMBL1492041 & 688340 & 4.45 & 4.8086 & TRN \\
\hline CHEMBL1383792 & 688340 & 8.0 & 5.4933 & TRN \\
\hline CHEMBL1411449 & 688340 & 4.45 & 4.9992 & TRN \\
\hline CHEMBL1357258 & 688340 & 4.6 & 5.0556 & TRN \\
\hline CHEMBL1564706 & 688340 & 4.35 & 5.1303 & TRN \\
\hline CHEMBL1410674 & 688340 & 4.45 & 5.2066 & TRN \\
\hline CHEMBL1323320 & 688340 & 4.65 & 4.8769 & TRN \\
\hline CHEMBL1446511 & 688340 & 4.6 & 4.7368 & TRN \\
\hline CHEMBL1457137 & 688340 & 4.4 & 5.1368 & TRN \\
\hline CHEMBL1380684 & 688340 & 4.5 & 5.07 & TST \\
\hline CHEMBL1299778 & 688340 & 5.55 & 4.3443 & TRN \\
\hline CHEMBL1336751 & 688340 & 6.1 & 4.98600 & 0000000001 \\
\hline CHEMBL1965236 & 688340 & 5.15 & 4.9285 & TST \\
\hline CHEMBL1548008 & 688340 & 5.55 & 5.1979 & TRN \\
\hline CHEMBL1548127 & 688340 & 6.95 & 5.1296 & TRN \\
\hline CHEMBL1340723 & 688340 & 4.5 & 4.9518 & TRN \\
\hline CHEMBL1497269 & 688340 & 4.4 & 4.6532 & TRN \\
\hline CHEMBL1392872 & 688340 & 5.5 & 5.3794 & TST \\
\hline CHEMBL1543455 & 688340 & 7.0 & 5.0726 & TST \\
\hline CHEMBL581677 & 688340 & 5.1 & 4.8579 & TRN \\
\hline CHEMBL1392511 & 688340 & 4.4 & 5.2654 & TRN \\
\hline CHEMBL1567252 & 688340 & 4.4 & 5.0825 & TRN \\
\hline CHEMBL1329206 & 688340 & 4.55 & 5.007 & TRN \\
\hline CHEMBL1443113 & 688340 & 4.95 & 4.7942 & TRN \\
\hline CHEMBL1462225 & 688340 & 4.65 & 5.4953 & TST \\
\hline CHEMBL1339850 & 688340 & 5.65 & 5.1609 & TRN \\
\hline CHEMBL1299600 & 688340 & 4.85 & 4.9559 & TST \\
\hline CHEMBL1411125 & 688340 & 4.55 & 5.284 & TRN \\
\hline CHEMBL1353794 & 688340 & 5.45 & 4.7898 & TRN \\
\hline CHEMBL1466860 & 688340 & 4.6 & 4.8558 & TRN \\
\hline CHEMBL1369680 & 688340 & 4.45 & 4.9663 & TRN \\
\hline CHEMBL 3196340 & 688340 & 4.55 & 5.0294 & TST \\
\hline CHEMBL1456081 & 688340 & 4.85 & 4.7635 & TRN \\
\hline CHEMBL1350422 & 688340 & 5.3 & 5.1242 & TRN \\
\hline CHEMBL3213810 & 688340 & 4.65 & 4.7863 & TRN \\
\hline CHEMBL1336936 & 688340 & 7.4498 & 5.2989 & TST \\
\hline CHEMBL1507881 & 688340 & 4.85 & 4.8924 & TRN \\
\hline CHEMBL1432375 & 688340 & 5.1 & 5.4738 & TST \\
\hline CHEMBL3211762 & 688340 & 5.7 & 5.0204 & TST \\
\hline CHEMBL1974091 & 688340 & 7.0501 & 4.9571 & TST \\
\hline
\end{tabular}




\begin{tabular}{|c|c|c|c|c|c|}
\hline \multirow{2}{*}{ CHEMBL1322790 } & \\
\hline & 688340 & 4.5 & 4.7991 & TRN & \\
\hline CHEMBL1470918 & 688340 & 7.0 & 5.0309 & TST & \\
\hline CHEMBL3195640 & 688340 & 6.2 & 5.1442 & TRN & \\
\hline CHEMBL1411601 & 688340 & 5.5 & 4.7213 & TRN & \\
\hline CHEMBL1307473 & 688340 & 4.6 & 4.9786 & TST & \\
\hline CHEMBL1325118 & 688340 & 4.7 & 5.2579 & TRN & \\
\hline CHEMBL1557479 & 688340 & 4.35 & 4.9061 & TST & \\
\hline CHEMBL514882 & 688340 & 7.2 & 5.3028 & TST & \\
\hline CHEMBL1307362 & 688340 & 6.5501 & 4.9653 & TRN & \\
\hline CHEMBL1408151 & 688340 & 5.05 & 5.1493 & TRN & \\
\hline CHEMBL1321942 & 688340 & 6.0 & 5.4146 & TRN & \\
\hline CHEMBL1369690 & 688340 & 4.65 & 4.8419 & TRN & \\
\hline CHEMBL3193098 & 688340 & 4.5 & 4.8343 & TRN & \\
\hline CHEMBL1301714 & 688340 & 5.0 & 5.1308 & TRN & \\
\hline CHEMBL1384217 & 688340 & 4.4 & 4.8892 & TST & \\
\hline CHEMBL1375356 & 688340 & 4.55 & 5.3532 & TRN & \\
\hline CHEMBL3189680 & 688340 & 5.6 & 5.3423 & TST & \\
\hline CHEMBL1535910 & 688340 & 4.65 & 5.0803 & TST & \\
\hline CHEMBL1409094 & 688340 & 4.55 & 4.645 & TRN & \\
\hline CHEMBL3189238 & 688340 & 4.45 & 5.0365 & TRN & \\
\hline CHEMBL1452090 & 688340 & 4.65 & 4.7338 & TRN & \\
\hline CHEMBL1486176 & 688340 & 4.6 & 4.7781 & TRN & \\
\hline CHEMBL1432894 & 688340 & 4.7 & 4.8157 & TST & \\
\hline CHEMBL1421710 & 688340 & 4.45 & 4.5852 & TST & \\
\hline CHEMBL3193616 & 688340 & 7.0 & 4.848 & TRN & \\
\hline CHEMBL1427784 & 688340 & 5.2 & 5.1337 & TRN & \\
\hline CHEMBL1521902 & 688340 & 5.25 & 4.8643 & TRN & \\
\hline CHEMBL1376772 & 688340 & 4.6 & 4.91100 & 00000000005 & TRN \\
\hline CHEMBL1511060 & 688340 & 6.95 & 5.3418 & TRN & \\
\hline CHEMBL3214026 & 688340 & 4.6 & 4.9783 & TRN & \\
\hline CHEMBL3208775 & 688340 & 4.65 & 4.8685 & TRN & \\
\hline CHEMBL1587422 & 688340 & 4.45 & 5.0613 & TRN & \\
\hline CHEMBL1382538 & 688340 & 4.4 & 4.8424 & TST & \\
\hline CHEMBL254255 & 688340 & 4.8 & 5.0732 & TRN & \\
\hline CHEMBL1328145 & 688340 & 4.65 & 4.7689 & TRN & \\
\hline CHEMBL1336866 & 688340 & 4.5 & 4.8929 & TRN & \\
\hline CHEMBL1416160 & 688340 & 4.65 & 4.6736 & TRN & \\
\hline CHEMBL1972470 & 688340 & 4.5 & 4.8078 & TRN & \\
\hline CHEMBL1580295 & 688340 & 4.9 & 4.9347 & TRN & \\
\hline CHEMBL1421468 & 688340 & 4.6 & 4.9315 & TRN & \\
\hline CHEMBL1502708 & 688340 & 5.25 & 5.307 & TST & \\
\hline CHEMBL1326357 & 688340 & 5.0 & 5.1873 & TRN & \\
\hline CHEMBL378062 & 688340 & 5.05 & 5.1583 & TRN & \\
\hline CHEMBL1427213 & 688340 & 4.9 & 4.9714 & TRN & \\
\hline CHEMBL1450018 & 688340 & 4.45 & 4.7766 & TRN & \\
\hline CHEMBL1466886 & 688340 & 4.5 & 5.0737 & TRN & \\
\hline CHEMBL1986027 & 688340 & 4.4 & 5.0217 & TRN & \\
\hline CHEMBL3193853 & 688340 & 4.8 & 4.6877 & TRN & \\
\hline & & & & 28233 & \\
\hline
\end{tabular}




\begin{tabular}{|c|c|c|c|c|}
\hline \multicolumn{5}{|c|}{ Supplemental Ta } \\
\hline CHEMBL1534402 & 688340 & 6.1 & 5.0018 & TST \\
\hline CHEMBL1502020 & 688340 & 4.5 & 4.8942 & TRN \\
\hline CHEMBL1582747 & 688340 & 4.5 & 5.0433 & TRN \\
\hline CHEMBL1343938 & 688340 & 4.4 & 5.0197 & TRN \\
\hline CHEMBL1546445 & 688340 & 4.55 & 4.6609 & TRN \\
\hline CHEMBL1434495 & 688340 & 8.2518 & 5.2627 & TRN \\
\hline CHEMBL1604132 & 688340 & 4.4 & 5.0161 & TRN \\
\hline CHEMBL1434699 & 688340 & 4.7 & 4.8125 & TRN \\
\hline CHEMBL1385193 & 688340 & 4.65 & 4.918 & TST \\
\hline CHEMBL1474549 & 688340 & 4.75 & 4.9678 & TRN \\
\hline CHEMBL1317664 & 688340 & 5.35 & 5.1975 & TST \\
\hline CHEMBL1602888 & 688340 & 4.4 & 5.3009 & TRN \\
\hline CHEMBL1994599 & 688340 & 4.85 & 5.0931 & TRN \\
\hline CHEMBL1496382 & 688340 & 7.0 & 5.2697 & TST \\
\hline CHEMBL1421172 & 688340 & 5.45 & 4.7335 & TRN \\
\hline CHEMBL1422443 & 688340 & 4.55 & 4.9663 & TRN \\
\hline CHEMBL1415253 & 688340 & 4.4 & 4.8309 & TRN \\
\hline CHEMBL1416437 & 688340 & 4.6 & 5.1461 & TRN \\
\hline CHEMBL1429000 & 688340 & 4.5 & 4.7787 & TRN \\
\hline CHEMBL1443329 & 688340 & 5.35 & 4.6357 & TRN \\
\hline CHEMBL1493604 & 688340 & 5.45 & 4.6886 & TRN \\
\hline CHEMBL1316584 & 688340 & 4.0 & 5.2394 & TRN \\
\hline CHEMBL1395653 & 688340 & 4.4 & 5.0892 & TRN \\
\hline CHEMBL1515297 & 688340 & 4.6 & 4.6702 & TRN \\
\hline CHEMBL1603524 & 688340 & 5.5 & 5.3832 & TRN \\
\hline CHEMBL1368597 & 688340 & 5.2 & 4.7846 & TRN \\
\hline CHEMBL1483385 & 688340 & 4.35 & 5.1507 & TST \\
\hline CHEMBL1486409 & 688340 & 5.55 & 5.396 & TRN \\
\hline CHEMBL1550966 & 688340 & 4.4 & 5.4675 & TST \\
\hline CHEMBL1529170 & 688340 & 4.4 & 5.3004 & TST \\
\hline CHEMBL3195093 & 688340 & 4.6 & 4.7887 & TRN \\
\hline CHEMBL1564633 & 688340 & 4.4 & 5.0251 & TST \\
\hline CHEMBL1592354 & 688340 & 4.4 & 4.8799 & TRN \\
\hline CHEMBL1432990 & 688340 & 4.4 & 5.3953 & TRN \\
\hline CHEMBL1357373 & 688340 & 7.0501 & 5.5472 & TRN \\
\hline CHEMBL1409552 & 688340 & 4.5 & 4.9606 & TRN \\
\hline CHEMBL1495138 & 688340 & 5.6 & 5.154 & TRN \\
\hline CHEMBL3196823 & 688340 & 4.6 & 5.0717 & TRN \\
\hline CHEMBL1528814 & 688340 & 5.9 & 5.171 & TRN \\
\hline CHEMBL1454358 & 688340 & 4.55 & 4.8162 & TRN \\
\hline CHEMBL1475539 & 688340 & 4.55 & 5.0509 & TRN \\
\hline CHEMBL 259355 & 688340 & 5.25 & 5.1626 & TRN \\
\hline CHEMBL1583825 & 688340 & 4.45 & 4.5443 & TRN \\
\hline CHEMBL1385454 & 688340 & 5.15 & 4.9412 & TRN \\
\hline CHEMBL1541241 & 688340 & 4.55 & 4.6732 & TRN \\
\hline CHEMBL1470867 & 688340 & 5.35 & 5.046 & TRN \\
\hline CHEMBL1414400 & 688340 & 4.7 & 4.9419 & TRN \\
\hline CHEMBL1471964 & 688340 & 6.05 & 5.2791 & TST \\
\hline
\end{tabular}




\begin{tabular}{|c|c|c|c|c|}
\hline \multicolumn{5}{|c|}{ Supplemental Table S2.txt } \\
\hline CHEMBL1528664 & 688340 & 5.15 & 4.8549 & TRN \\
\hline CHEMBL1467410 & 688340 & 4.5 & 5.143 & TRN \\
\hline CHEMBL3198876 & 688340 & 4.75 & 4.9559 & TRN \\
\hline CHEMBL 2001331 & 688340 & 6.15 & 5.1232 & TRN \\
\hline CHEMBL1223397 & 688340 & 4.4 & 5.0986 & TRN \\
\hline CHEMBL1563924 & 688340 & 4.8 & 4.9489 & TRN \\
\hline CHEMBL1309656 & 688340 & 4.55 & 4.8136 & TST \\
\hline CHEMBL1556525 & 688340 & 5.05 & 4.8489 & TRN \\
\hline CHEMBL1501589 & 688340 & 5.1 & 4.9456 & TRN \\
\hline CHEMBL1537686 & 688340 & 6.0 & 5.032 & TRN \\
\hline CHEMBL1486549 & 688340 & 4.6 & 5.2108 & TRN \\
\hline CHEMBL1393375 & 688340 & 4.85 & 5.1013 & TST \\
\hline CHEMBL1381433 & 688340 & 5.2 & 5.0726 & TRN \\
\hline CHEMBL1392025 & 688340 & 4.6 & 4.94 & TRN \\
\hline CHEMBL1488334 & 688340 & 6.2 & 5.3272 & TST \\
\hline CHEMBL1522077 & 688340 & 5.55 & 5.3643 & TRN \\
\hline CHEMBL1609337 & 688340 & 4.4 & 5.2318 & TST \\
\hline CHEMBL1583496 & 688340 & 5.2 & 5.3467 & TRN \\
\hline CHEMBL3190806 & 688340 & 4.65 & 5.2243 & TRN \\
\hline CHEMBL1511448 & 688340 & 6.15 & 5.1544 & TST \\
\hline CHEMBL1575089 & 688340 & 5.0 & 5.0676 & TST \\
\hline CHEMBL1443357 & 688340 & 5.2 & 5.349 & TST \\
\hline CHEMBL1503745 & 688340 & 5.35 & 4.9556 & TST \\
\hline CHEMBL1379170 & 688340 & 5.1 & 5.1086 & TRN \\
\hline CHEMBL1380987 & 688340 & 4.4 & 4.8718 & TRN \\
\hline CHEMBL1402057 & 688340 & 4.4 & 4.6991 & TRN \\
\hline CHEMBL1502500 & 688340 & 4.95 & 5.4348 & TRN \\
\hline CHEMBL1582831 & 688340 & 4.4 & 4.6324 & TRN \\
\hline CHEMBL1367677 & 688340 & 4.5 & 4.4445 & TRN \\
\hline CHEMBL1508566 & 688340 & 5.8 & 5.193 & TRN \\
\hline CHEMBL1502940 & 688340 & 4.5 & 4.8046 & TRN \\
\hline CHEMBL1317966 & 688340 & 4.75 & 4.9586 & TRN \\
\hline CHEMBL1589116 & 688340 & 4.65 & 4.7801 & TRN \\
\hline CHEMBL1394029 & 688340 & 4.4 & 5.1382 & TRN \\
\hline CHEMBL1425511 & 688340 & 4.5 & 4.6963 & TST \\
\hline CHEMBL1431064 & 688340 & 5.35 & 5.26 & TRN \\
\hline CHEMBL3196056 & 688340 & 4.5 & 4.846 & TRN \\
\hline CHEMBL1530040 & 688340 & 4.35 & 5.2372 & TST \\
\hline CHEMBL1342821 & 688340 & 4.6 & 4.6785 & TRN \\
\hline CHEMBL1507667 & 688340 & 5.1 & 4.9141 & TRN \\
\hline CHEMBL1299450 & 688340 & 4.6 & 4.51699 & 99999999995 \\
\hline CHEMBL1530039 & 688340 & 5.8 & 5.2519 & TST \\
\hline CHEMBL1580232 & 688340 & 6.15 & 5.1663 & TRN \\
\hline CHEMBL1439004 & 688340 & 4.5 & 5.2001 & TST \\
\hline CHEMBL1416409 & 688340 & 5.5 & 5.1558 & TRN \\
\hline CHEMBL210208 & 688340 & 6.6 & 4.833 & TST \\
\hline CHEMBL1572320 & 688340 & 6.2 & 5.401 & TST \\
\hline CHEMBL1509261 & 688340 & 4.55 & 5.5291 & TST \\
\hline
\end{tabular}




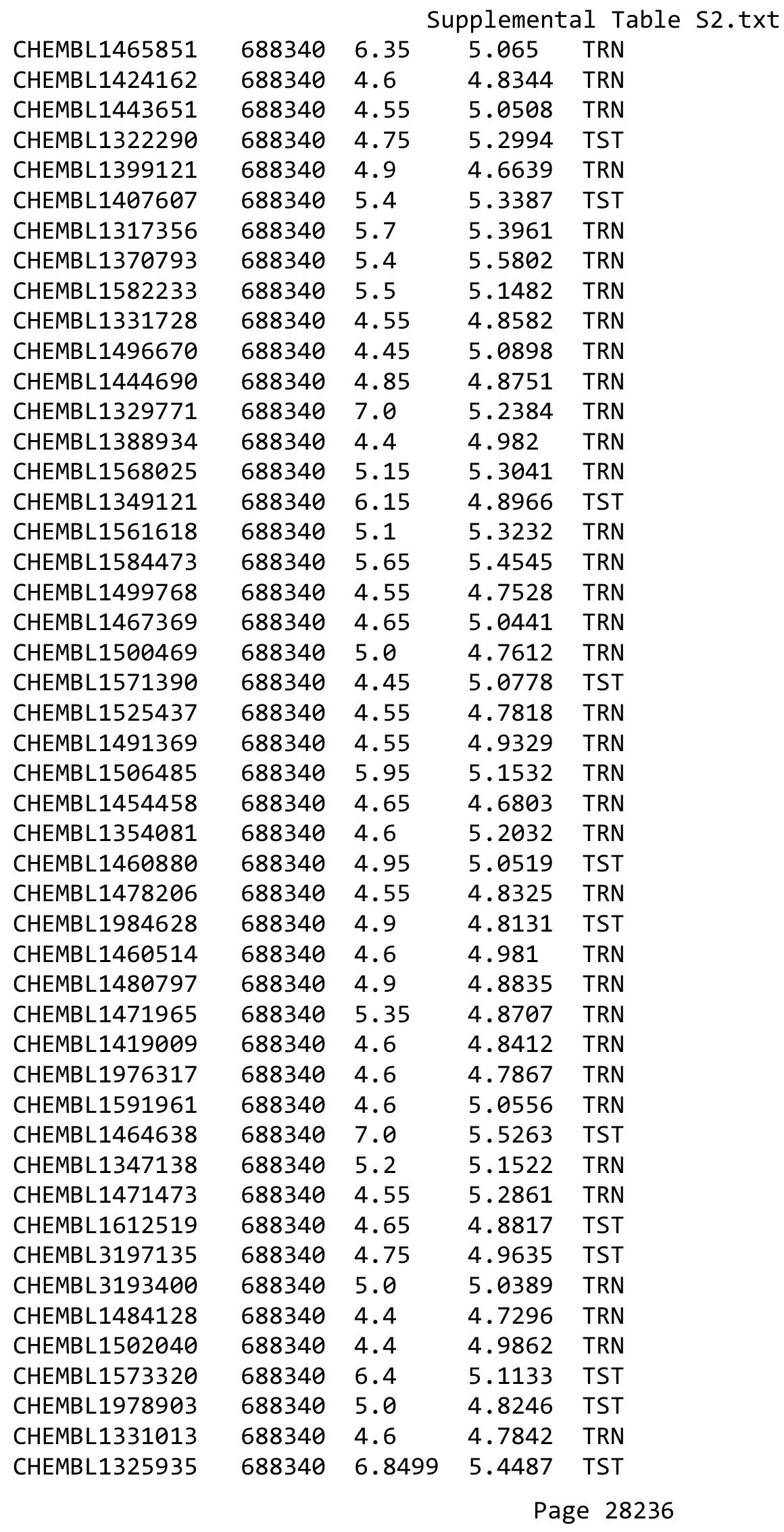




\begin{tabular}{|c|c|c|c|c|}
\hline & & & upplement & $d+1$ \\
\hline CHEMBL1573346 & 688340 & 6.8 & 5.2856 & TRN \\
\hline CHEMBL1407786 & 688340 & 4.6 & 5.1036 & TRN \\
\hline CHEMBL1340457 & 688340 & 6.1 & 5.0075 & TRN \\
\hline CHEMBL1097120 & 688340 & 4.7 & 5.0659 & TRN \\
\hline CHEMBL1602905 & 688340 & 5.1 & 4.5001 & TRN \\
\hline CHEMBL1528003 & 688340 & 5.45 & 4.8427 & TRN \\
\hline CHEMBL1438684 & 688340 & 4.5 & 4.8101 & TRN \\
\hline CHEMBL1443546 & 688340 & 4.4 & 4.7353 & TST \\
\hline CHEMBL1387713 & 688340 & 4.35 & 5.2295 & TRN \\
\hline CHEMBL1541779 & 688340 & 4.85 & 4.8329 & TRN \\
\hline CHEMBL1419235 & 688340 & 4.6 & 4.9588 & TRN \\
\hline CHEMBL1509196 & 688340 & 4.5 & 4.6576 & TRN \\
\hline CHEMBL1566917 & 688340 & 4.0 & 5.6571 & TRN \\
\hline CHEMBL1536034 & 688340 & 5.2 & 4.9582 & TST \\
\hline CHEMBL1503821 & 688340 & 4.5 & 4.7887 & TRN \\
\hline CHEMBL1525161 & 688340 & 4.55 & 4.8772 & TRN \\
\hline CHEMBL 3214085 & 688340 & 4.85 & 4.9932 & TST \\
\hline CHEMBL1345952 & 688340 & 4.35 & 4.8808 & TRN \\
\hline CHEMBL 3189514 & 688340 & 4.6 & 4.7494 & TST \\
\hline CHEMBL1305801 & 688340 & 7.0 & 5.0432 & TRN \\
\hline CHEMBL1364759 & 688340 & 6.15 & 4.5213 & TST \\
\hline CHEMBL1408285 & 688340 & 5.15 & 5.0027 & TST \\
\hline CHEMBL1418462 & 688340 & 4.65 & 4.7387 & TRN \\
\hline CHEMBL1450897 & 688340 & 4.85 & 4.8995 & TRN \\
\hline CHEMBL175266 & 688340 & 5.55 & 5.0667 & TRN \\
\hline CHEMBL3194916 & 688340 & 4.7 & 4.9932 & TRN \\
\hline CHEMBL 261394 & 688340 & 4.5 & 4.716 & TRN \\
\hline CHEMBL139935 & 688340 & 4.9 & 4.68 & TRN \\
\hline CHEMBL1375160 & 688340 & 4.45 & 4.8598 & TRN \\
\hline CHEMBL1982577 & 688340 & 4.55 & 4.7881 & TRN \\
\hline CHEMBL1370619 & 688340 & 4.55 & 4.9352 & TRN \\
\hline CHEMBL1466137 & 688340 & 4.55 & 4.7539 & TST \\
\hline CHEMBL1574055 & 688340 & 4.65 & 5.0645 & TRN \\
\hline CHEMBL1304093 & 688340 & 4.85 & 4.9023 & TRN \\
\hline CHEMBL1396762 & 688340 & 4.5 & 4.8812 & TST \\
\hline CHEMBL1354909 & 688340 & 4.6 & 4.8417 & TRN \\
\hline CHEMBL1382827 & 688340 & 4.9 & 5.2571 & TRN \\
\hline CHEMBL1611460 & 688340 & 5.25 & 5.1241 & TRN \\
\hline CHEMBL1336709 & 688340 & 4.85 & 5.3854 & TRN \\
\hline CHEMBL1360566 & 688340 & 4.35 & 4.9744 & TRN \\
\hline CHEMBL1499021 & 688340 & 5.0 & 4.7058 & TRN \\
\hline CHEMBL1425928 & 688340 & 5.2 & 5.227 & TRN \\
\hline CHEMBL1427421 & 688340 & 4.5 & 4.8952 & TRN \\
\hline CHEMBL1467134 & 688340 & 4.5 & 4.6678 & TRN \\
\hline CHEMBL1379329 & 688340 & 4.65 & 5.1103 & TRN \\
\hline CHEMBL 2007422 & 688340 & 5.7 & 4.8167 & TRN \\
\hline CHEMBL1451590 & 688340 & 4.4 & 4.9446 & TRN \\
\hline CHEMBL1375487 & 688340 & 4.5 & 5.048 & TRN \\
\hline
\end{tabular}




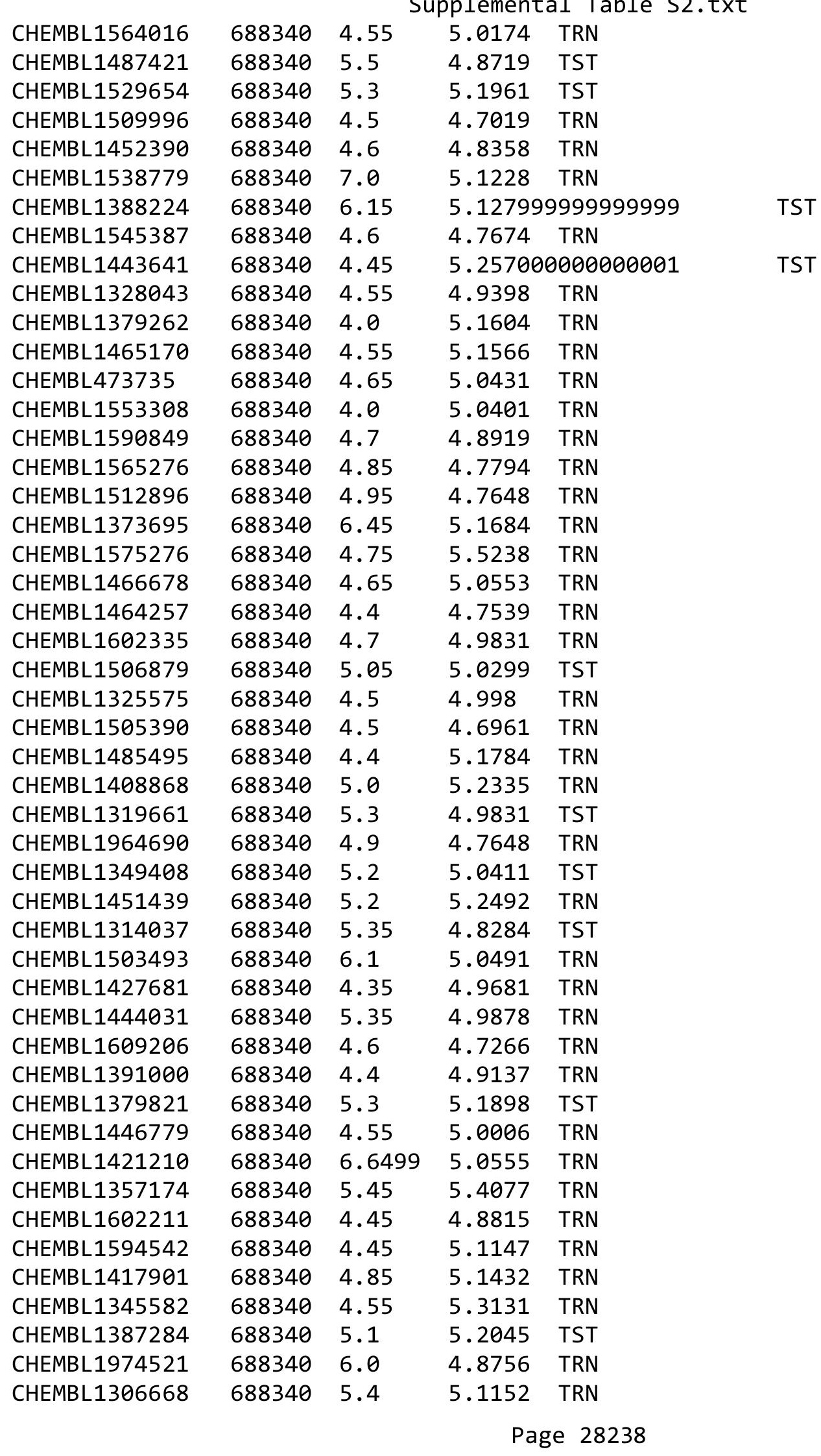




\begin{tabular}{|c|c|c|c|c|c|}
\hline \\
\hline CHEMBL1411940 & 688340 & 5.4 & 5.4248 & TRN & \\
\hline CHEMBL1453421 & 688340 & 4.75 & 4.9505 & TRN & \\
\hline CHEMBL1313358 & 688340 & 5.1 & 5.2121 & TRN & \\
\hline CHEMBL1410272 & 688340 & 4.45 & 4.9664 & TRN & \\
\hline CHEMBL1605629 & 688340 & 4.05 & 5.1549 & TST & \\
\hline CHEMBL1580365 & 688340 & 4.45 & 5.0738 & TRN & \\
\hline CHEMBL1613093 & 688340 & 4.4 & 4.7771 & TRN & \\
\hline CHEMBL1510771 & 688340 & 6.15 & 5.0149 & TRN & \\
\hline CHEMBL1371186 & 688340 & 4.4 & 4.9762 & TST & \\
\hline CHEMBL1548882 & 688340 & 4.85 & 4.7475 & TRN & \\
\hline CHEMBL3211609 & 688340 & 6.1 & 5.2478 & TRN & \\
\hline CHEMBL1333943 & 688340 & 7.0501 & 5.0783 & TRN & \\
\hline CHEMBL1336922 & 688340 & 5.0 & 5.0031 & TST & \\
\hline CHEMBL1564502 & 688340 & 4.5 & 4.8584 & TRN & \\
\hline CHEMBL1591575 & 688340 & 4.6 & 4.8386 & TRN & \\
\hline CHEMBL1550963 & 688340 & 6.15 & 5.114 & TRN & \\
\hline CHEMBL1422096 & 688340 & 4.5 & 4.5966 & TST & \\
\hline CHEMBL1302869 & 688340 & 5.1 & 5.024 & TRN & \\
\hline CHEMBL1549627 & 688340 & 6.0 & 4.9324 & TRN & \\
\hline CHEMBL1442524 & 688340 & 4.95 & 4.8598 & TRN & \\
\hline CHEMBL1577976 & 688340 & 5.45 & 4.5842 & TRN & \\
\hline CHEMBL1386676 & 688340 & 4.45 & 4.6356 & TRN & \\
\hline CHEMBL1572605 & 688340 & 4.4 & 4.934 & TST & \\
\hline CHEMBL1561940 & 688340 & 4.6 & 4.7112 & TRN & \\
\hline CHEMBL1334969 & 688340 & 4.4 & 4.8162 & TRN & \\
\hline CHEMBL1555820 & 688340 & 4.4 & 5.3675 & TRN & \\
\hline CHEMBL1589331 & 688340 & 4.45 & 4.814 & TRN & \\
\hline CHEMBL1585734 & 688340 & 5.35 & 5.3519 & TRN & \\
\hline CHEMBL1469704 & 688340 & 4.45 & 5.2439 & TRN & \\
\hline CHEMBL1460266 & 688340 & 5.25 & 5.0142 & TST & \\
\hline CHEMBL1366977 & 688340 & 4.5 & 5.1686 & TST & \\
\hline CHEMBL1421023 & 688340 & 4.55 & 4.4711 & TRN & \\
\hline CHEMBL1490097 & 688340 & 7.0501 & 5.1852 & TRN & \\
\hline CHEMBL1322369 & 688340 & 5.1 & 5.1158 & TST & \\
\hline CHEMBL1609444 & 688340 & 4.65 & 5.2601 & TRN & \\
\hline CHEMBL1392457 & 688340 & 7.0 & 5.4715 & TRN & \\
\hline CHEMBL1496630 & 688340 & 4.55 & 4.8329 & TRN & \\
\hline CHEMBL1441618 & 688340 & 7.0 & 4.8864 & TST & \\
\hline CHEMBL1534490 & 688340 & 4.65 & 5.0336 & TST & \\
\hline CHEMBL1372991 & 688340 & 5.25 & 4.9771 & TRN & \\
\hline CHEMBL1612846 & 688340 & 6.0 & 4.944 & TRN & \\
\hline CHEMBL3193150 & 688340 & 4.5 & 4.9697 & TST & \\
\hline CHEMBL1513249 & 688340 & 4.9 & 5.24100 & 00000000005 & TRN \\
\hline CHEMBL1505341 & 688340 & 4.55 & 4.7106 & TRN & \\
\hline CHEMBL1384602 & 688340 & 4.45 & 4.9277 & TRN & \\
\hline CHEMBL1387845 & 688340 & 4.65 & 4.8157 & TRN & \\
\hline CHEMBL1503050 & 688340 & 5.25 & 5.1723 & TST & \\
\hline CHEMBL1454037 & 688340 & 4.6 & 4.8445 & TST & \\
\hline
\end{tabular}




\begin{tabular}{|c|c|c|c|c|}
\hline \multicolumn{5}{|c|}{ Supplemental Table S2.txt } \\
\hline CHEMBL1582179 & 688340 & 5.15 & 4.7879 & TRN \\
\hline CHEMBL1589900 & 688340 & 4.5 & 4.8214 & TRN \\
\hline CHEMBL1426405 & 688340 & 6.35 & 4.9631 & TRN \\
\hline CHEMBL1395570 & 688340 & 5.05 & 4.9527 & TRN \\
\hline CHEMBL3210411 & 688340 & 6.0 & 5.2601 & TRN \\
\hline CHEMBL1608729 & 688340 & 5.05 & 4.8587 & TST \\
\hline CHEMBL1458386 & 688340 & 4.55 & 5.0877 & TRN \\
\hline CHEMBL1334135 & 688340 & 4.6 & 5.0341 & TRN \\
\hline CHEMBL1426492 & 688340 & 6.05 & 5.1492 & TRN \\
\hline CHEMBL1517826 & 688340 & 4.6 & 5.1334 & TRN \\
\hline CHEMBL1310454 & 688340 & 4.4 & 4.6093 & TRN \\
\hline CHEMBL1449899 & 688340 & 4.65 & 5.1685 & TRN \\
\hline CHEMBL1560100 & 688340 & 6.1 & 5.2649 & TRN \\
\hline CHEMBL1435152 & 688340 & 4.6 & 5.0659 & TRN \\
\hline CHEMBL1342281 & 688340 & 4.5 & 4.4533 & TRN \\
\hline CHEMBL1600490 & 688340 & 4.75 & 4.7498 & TRN \\
\hline CHEMBL1603855 & 688340 & 4.65 & 5.1454 & TRN \\
\hline CHEMBL1596566 & 688340 & 4.6 & 4.9436 & TRN \\
\hline CHEMBL1981541 & 688340 & 4.8 & 4.998 & TST \\
\hline CHEMBL1415838 & 688340 & 5.35 & 4.9436 & TRN \\
\hline CHEMBL1481192 & 688340 & 4.5 & 4.728 & TRN \\
\hline CHEMBL1339192 & 688340 & 4.35 & 4.8171 & TRN \\
\hline CHEMBL1565114 & 688340 & 4.6 & 4.9932 & TRN \\
\hline CHEMBL1545873 & 688340 & 5.05 & 4.9992 & TRN \\
\hline CHEMBL1557557 & 688340 & 4.8 & 4.9976 & TRN \\
\hline CHEMBL1582609 & 688340 & 5.1 & 5.0507 & TRN \\
\hline CHEMBL3196468 & 688340 & 4.7 & 4.6054 & TST \\
\hline CHEMBL3190426 & 688340 & 5.0 & 5.1797 & TRN \\
\hline CHEMBL1320611 & 688340 & 5.05 & 5.2584 & TRN \\
\hline CHEMBL1423725 & 688340 & 4.6 & 4.8538 & TST \\
\hline CHEMBL1451525 & 688340 & 4.4 & 4.899 & TRN \\
\hline CHEMBL1581100 & 688340 & 7.0501 & 5.2853 & TST \\
\hline CHEMBL1548826 & 688340 & 5.2 & 5.1142 & TRN \\
\hline CHEMBL1451059 & 688340 & 5.5 & 5.1464 & TRN \\
\hline CHEMBL1527171 & 688340 & 4.35 & 5.6567 & TRN \\
\hline CHEMBL1429479 & 688340 & 4.45 & 5.0886 & TRN \\
\hline CHEMBL1544912 & 688340 & 5.0 & 4.7236 & TRN \\
\hline CHEMBL1431440 & 688340 & 4.5 & 4.7634 & TRN \\
\hline CHEMBL1495809 & 688340 & 4.4 & 4.9271 & TST \\
\hline CHEMBL1584662 & 688340 & 4.6 & 4.8174 & TRN \\
\hline CHEMBL1575517 & 688340 & 6.25 & 5.0384 & TRN \\
\hline CHEMBL1324639 & 688340 & 4.4 & 5.1562 & TST \\
\hline CHEMBL1392394 & 688340 & 5.45 & 5.0427 & TRN \\
\hline CHEMBL1579199 & 688340 & 4.5 & 5.0794 & TRN \\
\hline CHEMBL1509388 & 688340 & 6.95 & 5.1389 & TRN \\
\hline CHEMBL1307432 & 688340 & 4.8 & 5.1114 & TRN \\
\hline CHEMBL1344384 & 688340 & 4.0 & 4.8756 & TST \\
\hline CHEMBL574779 & 688340 & 4.45 & 5.1311 & TRN \\
\hline
\end{tabular}




\begin{tabular}{|c|c|c|c|c|c|}
\hline & & & & & \\
\hline CHEMBL1362916 & 688340 & 6.8 & 4.7472 & TRN & \\
\hline CHEMBL1575310 & 688340 & 5.4 & 4.7348 & TRN & \\
\hline CHEMBL1459189 & 688340 & 4.0 & 4.8931 & TST & \\
\hline CHEMBL1328730 & 688340 & 4.95 & 5.2405 & TRN & \\
\hline CHEMBL1431707 & 688340 & 5.3 & 5.2631 & TST & \\
\hline CHEMBL1389844 & 688340 & 5.35 & 4.7232 & TRN & \\
\hline CHEMBL1462078 & 688340 & 5.45 & 5.0001 & TRN & \\
\hline CHEMBL3197876 & 688340 & 4.55 & 5.0582 & TRN & \\
\hline CHEMBL1419128 & 688340 & 4.55 & 4.8188 & TRN & \\
\hline CHEMBL1437290 & 688340 & 6.1 & 5.32799 & 9999999999 & TRN \\
\hline CHEMBL1532838 & 688340 & 4.6 & 4.8575 & TRN & \\
\hline CHEMBL1300508 & 688340 & 4.45 & 5.29899 & 99999999995 & TRN \\
\hline CHEMBL1459360 & 688340 & 4.75 & 5.0604 & TST & \\
\hline CHEMBL1385357 & 688340 & 4.35 & 4.4202 & TST & \\
\hline CHEMBL1589022 & 688340 & 5.0 & 5.419 & TST & \\
\hline CHEMBL1548817 & 688340 & 4.4 & 5.5037 & TRN & \\
\hline CHEMBL3191725 & 688340 & 4.5 & 4.8751 & TRN & \\
\hline CHEMBL1496902 & 688340 & 4.4 & 5.1206 & TRN & \\
\hline CHEMBL1460576 & 688340 & 2.4 & 5.1077 & TRN & \\
\hline CHEMBL1521165 & 688340 & 4.5 & 4.9374 & TRN & \\
\hline CHEMBL1417165 & 688340 & 4.65 & 4.94 & TRN & \\
\hline CHEMBL1485978 & 688340 & 5.3 & 5.2976 & TRN & \\
\hline CHEMBL1434171 & 688340 & 5.65 & 4.4579 & TRN & \\
\hline CHEMBL1509051 & 688340 & 5.55 & 4.8156 & TRN & \\
\hline CHEMBL479368 & 688340 & 4.45 & 4.6912 & TRN & \\
\hline CHEMBL1556805 & 688340 & 4.4 & 4.5346 & TRN & \\
\hline CHEMBL1406312 & 688340 & 4.6 & 4.8728 & TST & \\
\hline CHEMBL1317811 & 688340 & 3.95 & 5.2488 & TRN & \\
\hline CHEMBL1458944 & 688340 & 5.35 & 4.7698 & TRN & \\
\hline CHEMBL3199211 & 688340 & 6.6499 & 5.1055 & TRN & \\
\hline CHEMBL1548323 & 688340 & 4.55 & 5.3659 & TST & \\
\hline CHEMBL1602077 & 688340 & 4.75 & 5.0087 & TRN & \\
\hline CHEMBL1437464 & 688340 & 5.45 & 4.9467 & TRN & \\
\hline CHEMBL3191619 & 688340 & 5.55 & 4.9611 & TRN & \\
\hline CHEMBL1548384 & 688340 & 4.55 & 4.5748 & TRN & \\
\hline CHEMBL3192136 & 688340 & 4.75 & 5.1149 & TRN & \\
\hline CHEMBL1357603 & 688340 & 4.45 & 4.6549 & TST & \\
\hline CHEMBL1302815 & 688340 & 4.75 & 4.9509 & TRN & \\
\hline CHEMBL1577950 & 688340 & 4.65 & 4.7614 & TRN & \\
\hline CHEMBL1605735 & 688340 & 4.55 & 4.8257 & TRN & \\
\hline CHEMBL1451032 & 688340 & 4.5 & 4.9137 & TRN & \\
\hline CHEMBL1387590 & 688340 & 6.1 & 5.0696 & TRN & \\
\hline CHEMBL1356849 & 688340 & 4.4 & 5.1301 & TRN & \\
\hline CHEMBL1432872 & 688340 & 4.4 & 5.0418 & TRN & \\
\hline CHEMBL1346689 & 688340 & 5.3 & 4.9804 & TRN & \\
\hline CHEMBL1471762 & 688340 & 4.35 & 4.9606 & TRN & \\
\hline CHEMBL1431490 & 688340 & 5.4 & 5.0126 & TRN & \\
\hline CHEMBL1562688 & 688340 & 5.15 & 4.6919 & TST & \\
\hline
\end{tabular}




\begin{tabular}{|c|c|c|c|c|c|}
\hline \\
\hline CHEMBL1594074 & 688340 & 4.6 & 5.091 & TRN & \\
\hline CHEMBL1471728 & 688340 & 4.6 & 4.6927 & TRN & \\
\hline CHEMBL1494882 & 688340 & 4.5 & 5.3748 & TRN & \\
\hline CHEMBL1427908 & 688340 & 5.0 & 5.0618 & TST & \\
\hline CHEMBL1419637 & 688340 & 5.4 & 4.9245 & TRN & \\
\hline CHEMBL1479475 & 688340 & 4.75 & 4.838 & TRN & \\
\hline CHEMBL1575071 & 688340 & 7.0501 & 5.3451 & TRN & \\
\hline CHEMBL1374546 & 688340 & 4.35 & 5.1868 & TRN & \\
\hline CHEMBL1417376 & 688340 & 4.8 & 4.6941 & TRN & \\
\hline CHEMBL1411788 & 688340 & 4.4 & 5.1811 & TRN & \\
\hline CHEMBL1489240 & 688340 & 5.5 & 4.6442 & TRN & \\
\hline CHEMBL1445219 & 688340 & 5.15 & 4.8372 & TRN & \\
\hline CHEMBL1398118 & 688340 & 4.55 & 4.9023 & TRN & \\
\hline CHEMBL1509021 & 688340 & 6.8 & 5.3298 & TRN & \\
\hline CHEMBL1377864 & 688340 & 4.9 & 4.8214 & TRN & \\
\hline CHEMBL1589808 & 688340 & 4.7 & 4.9212 & TST & \\
\hline CHEMBL1479098 & 688340 & 4.4 & 4.8163 & TST & \\
\hline CHEMBL1348263 & 688340 & 4.65 & 5.0677 & TRN & \\
\hline CHEMBL1344618 & 688340 & 4.8 & 5.147 & TRN & \\
\hline CHEMBL1600643 & 688340 & 5.45 & 4.9541 & TST & \\
\hline CHEMBL1568795 & 688340 & 4.55 & 4.9367 & TST & \\
\hline CHEMBL1456728 & 688340 & 4.5 & 4.9256 & TRN & \\
\hline CHEMBL3190702 & 688340 & 4.75 & 4.8485 & TRN & \\
\hline CHEMBL1378784 & 688340 & 5.3 & 5.0153 & TRN & \\
\hline CHEMBL1322436 & 688340 & 5.4 & 5.3214 & TRN & \\
\hline CHEMBL1542463 & 688340 & 5.7 & 4.9328 & TST & \\
\hline CHEMBL1389205 & 688340 & 5.2 & 5.0275 & TRN & \\
\hline CHEMBL1444840 & 688340 & 4.55 & 4.7586 & TRN & \\
\hline CHEMBL3194979 & 688340 & 5.1 & 5.0491 & TST & \\
\hline CHEMBL3191541 & 688340 & 4.85 & 4.7101 & TRN & \\
\hline CHEMBL1323515 & 688340 & 4.45 & 4.9087 & TST & \\
\hline CHEMBL1600260 & 688340 & 4.3 & 4.636 & TRN & \\
\hline CHEMBL1411801 & 688340 & 5.2 & 5.16799 & 9999999999 & TRN \\
\hline CHEMBL3208847 & 688340 & 5.7 & 5.0661 & TST & \\
\hline CHEMBL1391484 & 688340 & 4.6 & 5.2033 & TST & \\
\hline CHEMBL1480950 & 688340 & 5.0 & 5.0275 & TRN & \\
\hline CHEMBL1327267 & 688340 & 4.7 & 5.2867 & TRN & \\
\hline CHEMBL1520432 & 688340 & 5.95 & 4.7721 & TRN & \\
\hline CHEMBL1302343 & 688340 & 6.05 & 4.7252 & TRN & \\
\hline CHEMBL1550702 & 688340 & 5.0 & 4.9808 & TRN & \\
\hline CHEMBL3189477 & 688340 & 4.5 & 4.7086 & TRN & \\
\hline CHEMBL1543384 & 688340 & 4.55 & 4.871 & TST & \\
\hline CHEMBL1531118 & 688340 & 6.1 & 4.8553 & TST & \\
\hline CHEMBL1573892 & 688340 & 4.5 & 5.0224 & TST & \\
\hline CHEMBL1506510 & 688340 & 4.5 & 4.6088 & TRN & \\
\hline CHEMBL 3214318 & 688340 & 6.4 & 5.1085 & TST & \\
\hline CHEMBL1343814 & 688340 & 4.55 & 4.7817 & TRN & \\
\hline CHEMBL3208497 & 688340 & 4.85 & 4.7313 & TRN & \\
\hline
\end{tabular}




\begin{tabular}{|c|c|c|c|c|}
\hline \multicolumn{5}{|c|}{ Supplemental Table S2.txt } \\
\hline CHEMBL1604668 & 688340 & 5.65 & 4.9542 & TRN \\
\hline CHEMBL3193332 & 688340 & 5.0 & 4.7587 & TRN \\
\hline CHEMBL3193504 & 688340 & 5.5 & 5.1474 & TRN \\
\hline CHEMBL1549166 & 688340 & 4.55 & 5.0871 & TST \\
\hline CHEMBL1590883 & 688340 & 4.6 & 5.0044 & TRN \\
\hline CHEMBL1440190 & 688340 & 5.0 & 4.8954 & TRN \\
\hline CHEMBL1500799 & 688340 & 4.4 & 5.1333 & TRN \\
\hline CHEMBL1328605 & 688340 & 4.7 & 4.996 & TRN \\
\hline CHEMBL 3198724 & 688340 & 5.2 & 4.8292 & TRN \\
\hline CHEMBL3209614 & 688340 & 4.95 & 4.8448 & TRN \\
\hline CHEMBL1541861 & 688340 & 4.6 & 4.6743 & TST \\
\hline CHEMBL1544814 & 688340 & 6.9 & 5.0035 & TRN \\
\hline CHEMBL1546677 & 688340 & 4.55 & 5.2098 & TST \\
\hline CHEMBL1576998 & 688340 & 5.15 & 4.8982 & TRN \\
\hline CHEMBL1429432 & 688340 & 5.0 & 4.7493 & TST \\
\hline CHEMBL1492174 & 688340 & 4.6 & 4.9734 & TRN \\
\hline CHEMBL1489391 & 688340 & 5.25 & 5.2912 & TRN \\
\hline CHEMBL1412725 & 688340 & 5.2 & 5.2425 & TRN \\
\hline CHEMBL1307394 & 688340 & 4.9 & 4.7966 & TRN \\
\hline CHEMBL1450744 & 688340 & 5.55 & 5.0916 & TRN \\
\hline CHEMBL1462335 & 688340 & 4.5 & 4.9693 & TRN \\
\hline CHEMBL1362972 & 688340 & 5.2 & 4.9411 & TST \\
\hline CHEMBL1385125 & 688340 & 4.4 & 4.8733 & TST \\
\hline CHEMBL1505561 & 688340 & 6.5501 & 5.0431 & TRN \\
\hline CHEMBL1535408 & 688340 & 5.0 & 5.2682 & TRN \\
\hline CHEMBL1510389 & 688340 & 5.05 & 4.85 & TRN \\
\hline CHEMBL1601178 & 688340 & 7.0 & 5.4514 & TRN \\
\hline CHEMBL1397123 & 688340 & 4.8 & 4.774 & TRN \\
\hline CHEMBL1612945 & 688340 & 4.45 & 4.9813 & TST \\
\hline CHEMBL1375332 & 688340 & 4.95 & 4.7685 & TST \\
\hline CHEMBL1491620 & 688340 & 4.75 & 5.3583 & TRN \\
\hline CHEMBL405070 & 688340 & 5.8 & 5.2279 & TST \\
\hline CHEMBL1334351 & 688340 & 4.5 & 5.2101 & TRN \\
\hline CHEMBL1520811 & 688340 & 4.9 & 5.1265 & TRN \\
\hline CHEMBL1584680 & 688340 & 4.5 & 4.9645 & TRN \\
\hline CHEMBL165188 & 688340 & 4.4 & 4.9676 & TRN \\
\hline CHEMBL1331751 & 688340 & 4.4 & 5.0195 & TRN \\
\hline CHEMBL1541448 & 688340 & 4.85 & 4.8319 & TRN \\
\hline CHEMBL1303448 & 688340 & 8.0506 & 5.5532 & TST \\
\hline CHEMBL1424873 & 688340 & 7.0 & 5.3434 & TRN \\
\hline CHEMBL1503122 & 688340 & 4.8 & 5.1342 & TRN \\
\hline CHEMBL3196877 & 688340 & 4.6 & 4.9564 & TRN \\
\hline CHEMBL580155 & 688340 & 4.6 & 5.2336 & TRN \\
\hline CHEMBL1606655 & 688340 & 4.45 & 5.0556 & TRN \\
\hline CHEMBL1593931 & 688340 & 4.6 & 5.0737 & TRN \\
\hline CHEMBL1488132 & 688340 & 5.4 & 4.9959 & TRN \\
\hline CHEMBL1370314 & 688340 & 4.4 & 4.832 & TRN \\
\hline CHEMBL1519992 & 688340 & 5.1 & 4.9115 & TRN \\
\hline
\end{tabular}




\begin{tabular}{|c|c|c|c|c|c|}
\hline \multicolumn{6}{|c|}{ Supplemental Table S2.txt } \\
\hline CHEMBL1393485 & 688340 & 4.65 & 4.8911 & TRN & \\
\hline CHEMBL1481353 & 688340 & 4.4 & 4.7605 & TRN & \\
\hline CHEMBL3191245 & 688340 & 4.7 & 4.9087 & TRN & \\
\hline CHEMBL1978331 & 688340 & 5.65 & 5.271 & TRN & \\
\hline CHEMBL1380020 & 688340 & 4.75 & 4.7105 & TRN & \\
\hline CHEMBL1487875 & 688340 & 4.5 & 5.0862 & TRN & \\
\hline CHEMBL1604543 & 688340 & 4.4 & 4.8873 & TRN & \\
\hline CHEMBL1300035 & 688340 & 5.65 & 5.0019 & TRN & \\
\hline CHEMBL1546102 & 688340 & 4.6 & 4.6501 & TRN & \\
\hline CHEMBL3191765 & 688340 & 5.45 & 4.7486 & TST & \\
\hline CHEMBL1392599 & 688340 & 4.6 & 5.1087 & TRN & \\
\hline CHEMBL1380475 & 688340 & 4.5 & 5.1583 & TRN & \\
\hline CHEMBL1461326 & 688340 & 6.6499 & 5.1597 & TST & \\
\hline CHEMBL1586019 & 688340 & 4.65 & 4.809 & TRN & \\
\hline CHEMBL1564848 & 688340 & 4.45 & 4.8917 & TST & \\
\hline CHEMBL1532262 & 688340 & 4.5 & 4.8568 & TST & \\
\hline CHEMBL1304490 & 688340 & 4.6 & 4.9862 & TRN & \\
\hline CHEMBL1560529 & 688340 & 4.45 & 4.9965 & TRN & \\
\hline CHEMBL 3145244 & 688340 & 4.5 & 4.9562 & TRN & \\
\hline CHEMBL1322449 & 688340 & 4.7 & 4.79899 & 99999999995 & TRN \\
\hline CHEMBL1541076 & 688340 & 4.4 & 5.1813 & TST & \\
\hline CHEMBL1439136 & 688340 & 4.55 & 4.9498 & TST & \\
\hline CHEMBL1469661 & 688340 & 6.45 & 5.103 & TST & \\
\hline CHEMBL1427918 & 688340 & 4.6 & 4.9841 & TST & \\
\hline CHEMBL1390514 & 688340 & 4.8 & 4.7244 & TRN & \\
\hline CHEMBL1608207 & 688340 & 4.8 & 4.7676 & TRN & \\
\hline CHEMBL1312275 & 688340 & 4.4 & 5.1419 & TRN & \\
\hline CHEMBL199925 & 688340 & 4.55 & 5.0035 & TRN & \\
\hline CHEMBL1581002 & 688340 & 7.0 & 5.2259 & TST & \\
\hline CHEMBL1578778 & 688340 & 5.15 & 5.5693 & TRN & \\
\hline CHEMBL1525755 & 688340 & 4.5 & 4.9501 & TST & \\
\hline CHEMBL1312239 & 688340 & 4.5 & 4.92899 & 9999999999 & TRN \\
\hline CHEMBL1606701 & 688340 & 4.45 & 5.2288 & TRN & \\
\hline CHEMBL1503931 & 688340 & 4.35 & 5.1507 & TST & \\
\hline CHEMBL1501321 & 688340 & 6.1 & 5.0997 & TST & \\
\hline CHEMBL1589567 & 688340 & 4.5 & 4.504 & TRN & \\
\hline CHEMBL1567148 & 688340 & 5.05 & 5.022 & TRN & \\
\hline CHEMBL1447267 & 688340 & 4.5 & 5.0737 & TRN & \\
\hline CHEMBL1608300 & 688340 & 4.45 & 4.8284 & TRN & \\
\hline CHEMBL1576053 & 688340 & 4.4 & 5.1001 & TST & \\
\hline CHEMBL1401666 & 688340 & 6.1 & 5.2548 & TRN & \\
\hline CHEMBL1607586 & 688340 & 4.5 & 4.9264 & TRN & \\
\hline CHEMBL1381567 & 688340 & 4.75 & 4.8897 & TRN & \\
\hline CHEMBL1375386 & 688340 & 7.0501 & 5.1375 & TRN & \\
\hline CHEMBL1418757 & 688340 & 5.4 & 4.9971 & TST & \\
\hline CHEMBL1383754 & 688340 & 4.55 & 4.895 & TRN & \\
\hline CHEMBL1536067 & 688340 & 6.45 & 4.9676 & TST & \\
\hline CHEMBL1401838 & 688340 & 5.8 & 4.9187 & TRN & \\
\hline
\end{tabular}




\begin{tabular}{|c|c|c|c|c|c|}
\hline \\
\hline CHEMBL1489513 & 688340 & 5.3 & 5.1012 & TRN & \\
\hline CHEMBL1463669 & 688340 & 6.1 & 5.0633 & TRN & \\
\hline CHEMBL1995948 & 688340 & 5.0 & 4.8769 & TRN & \\
\hline CHEMBL1393569 & 688340 & 4.65 & 4.7277 & TRN & \\
\hline CHEMBL1537553 & 688340 & 4.4 & 5.0349 & TST & \\
\hline CHEMBL1386696 & 688340 & 5.5 & 4.6952 & TRN & \\
\hline CHEMBL1345211 & 688340 & 4.5 & 5.4967 & TST & \\
\hline CHEMBL1300013 & 688340 & 5.2 & 5.0221 & TRN & \\
\hline CHEMBL1528512 & 688340 & 4.95 & 4.7248 & TRN & \\
\hline CHEMBL1547594 & 688340 & 6.5 & 4.5982 & TRN & \\
\hline CHEMBL1456052 & 688340 & 4.8 & 4.8606 & TRN & \\
\hline CHEMBL578294 & 688340 & 4.8 & 4.7059 & TRN & \\
\hline CHEMBL3144999 & 688340 & 5.0 & 4.8949 & TRN & \\
\hline CHEMBL3195168 & 688340 & 4.4 & 4.7581 & TRN & \\
\hline CHEMBL1300881 & 688340 & 4.55 & 4.7667 & TRN & \\
\hline CHEMBL1339932 & 688340 & 7.0 & 5.3288 & TST & \\
\hline CHEMBL1534964 & 688340 & 6.15 & 5.2292 & TRN & \\
\hline CHEMBL1473052 & 688340 & 4.95 & 5.2449 & TRN & \\
\hline CHEMBL1463304 & 688340 & 5.55 & 5.3426 & TRN & \\
\hline CHEMBL1440804 & 688340 & 4.5 & 5.0775 & TRN & \\
\hline CHEMBL1603886 & 688340 & 4.55 & 4.7541 & TRN & \\
\hline CHEMBL1430296 & 688340 & 4.4 & 4.7611 & TRN & \\
\hline CHEMBL1491255 & 688340 & 4.85 & 4.8057 & TST & \\
\hline CHEMBL1347728 & 688340 & 4.95 & 5.19799 & 99999999995 & TRN \\
\hline CHEMBL1493191 & 688340 & 5.35 & 4.8576 & TRN & \\
\hline CHEMBL1452967 & 688340 & 6.95 & 5.2044 & TRN & \\
\hline CHEMBL3197612 & 688340 & 4.7 & 4.7523 & TRN & \\
\hline CHEMBL1569375 & 688340 & 4.85 & 4.6594 & TRN & \\
\hline CHEMBL3197065 & 688340 & 4.85 & 4.5508 & TRN & \\
\hline CHEMBL1501398 & 688340 & 4.5 & 4.7327 & TRN & \\
\hline CHEMBL1392921 & 688340 & 4.85 & 4.673 & TRN & \\
\hline CHEMBL1488813 & 688340 & 4.55 & 4.8118 & TST & \\
\hline CHEMBL1360173 & 688340 & 4.65 & 4.7782 & TRN & \\
\hline CHEMBL1431644 & 688340 & 4.95 & 5.095 & TST & \\
\hline CHEMBL1351543 & 688340 & 4.55 & 4.6405 & TRN & \\
\hline CHEMBL1533397 & 688340 & 5.5 & 4.8071 & TRN & \\
\hline CHEMBL3197223 & 688340 & 5.15 & 4.9675 & TRN & \\
\hline CHEMBL1405484 & 688340 & 4.65 & 4.7797 & TRN & \\
\hline CHEMBL1501498 & 688340 & 5.65 & 5.2021 & TRN & \\
\hline CHEMBL3192718 & 688340 & 6.15 & 5.2115 & TST & \\
\hline CHEMBL1515086 & 688340 & 6.2 & 5.1735 & TRN & \\
\hline CHEMBL1477166 & 688340 & 5.0 & 5.2981 & TRN & \\
\hline CHEMBL1972143 & 688340 & 4.85 & 4.9084 & TRN & \\
\hline CHEMBL1350518 & 688340 & 4.6 & 5.0576 & TST & \\
\hline CHEMBL1429064 & 688340 & 5.0 & 4.5681 & TRN & \\
\hline CHEMBL1469002 & 688340 & 4.75 & 5.0602 & TST & \\
\hline CHEMBL1325670 & 688340 & 5.05 & 4.8906 & TRN & \\
\hline CHEMBL1439414 & 688340 & 4.5 & 4.9195 & TRN & \\
\hline & & & & 282 & \\
\hline
\end{tabular}




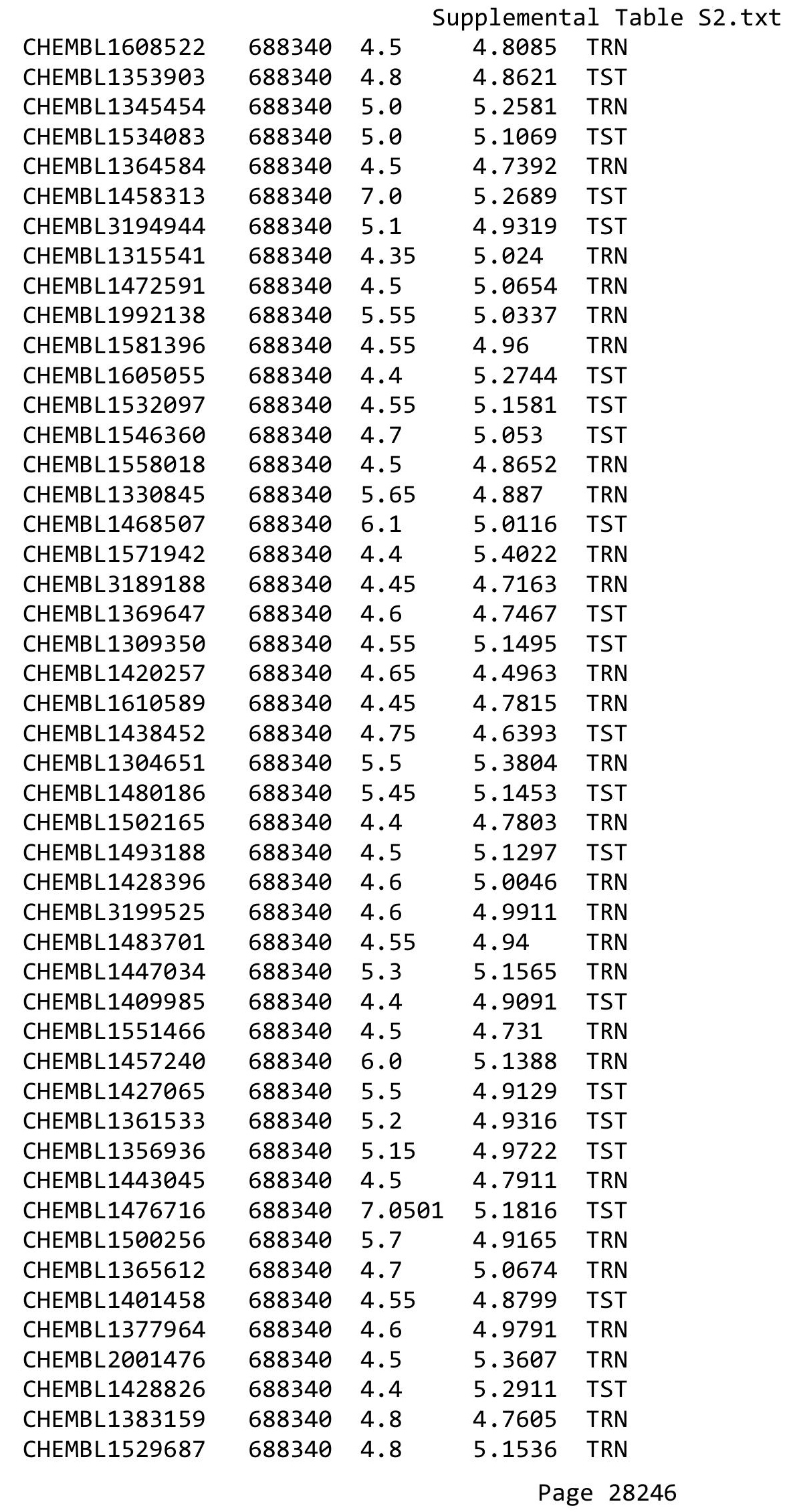




\begin{tabular}{|c|c|c|c|c|}
\hline \multicolumn{5}{|c|}{ Supplemental Table S2.txt } \\
\hline CHEMBL1432404 & 688340 & 5.3 & 5.0086 & TRN \\
\hline CHEMBL1550363 & 688340 & 5.75 & 5.3062 & TRN \\
\hline CHEMBL1479196 & 688340 & 4.7 & 4.9933 & TRN \\
\hline CHEMBL1599935 & 688340 & 6.0 & 4.4585 & TRN \\
\hline CHEMBL1340902 & 688340 & 4.8 & 4.8998 & TRN \\
\hline CHEMBL1345497 & 688340 & 6.45 & 5.3755 & TRN \\
\hline CHEMBL1517854 & 688340 & 6.15 & 5.4565 & TRN \\
\hline CHEMBL1486134 & 688340 & 4.55 & 4.7188 & TRN \\
\hline CHEMBL1588628 & 688340 & 4.5 & 4.8668 & TST \\
\hline CHEMBL1478161 & 688340 & 3.25 & 5.1411 & TST \\
\hline CHEMBL1603775 & 688340 & 5.4 & 5.1315 & TRN \\
\hline CHEMBL1378659 & 688340 & 6.05 & 5.3238 & TRN \\
\hline CHEMBL1459642 & 688340 & 5.3 & 4.777 & TST \\
\hline CHEMBL1416195 & 688340 & 4.4 & 5.1086 & TST \\
\hline CHEMBL1504853 & 688340 & 4.5 & 4.7501 & TRN \\
\hline CHEMBL1502562 & 688340 & 4.4 & 5.2353 & TST \\
\hline CHEMBL1499794 & 688340 & 4.4 & 4.9372 & TRN \\
\hline CHEMBL1541962 & 688340 & 5.35 & 5.1914 & TST \\
\hline CHEMBL1555317 & 688340 & 4.5 & 4.8342 & TRN \\
\hline CHEMBL1382360 & 688340 & 5.3 & 4.7962 & TRN \\
\hline CHEMBL1521108 & 688340 & 4.0 & 5.151 & TRN \\
\hline CHEMBL1600456 & 688340 & 4.55 & 4.8591 & TRN \\
\hline CHEMBL1544404 & 688340 & 4.8 & 4.7536 & TST \\
\hline CHEMBL3211193 & 688340 & 4.75 & 4.8351 & TRN \\
\hline CHEMBL1321620 & 688340 & 4.8 & 4.859 & TRN \\
\hline CHEMBL1385904 & 688340 & 6.15 & 5.0283 & TRN \\
\hline CHEMBL1417018 & 688340 & 4.75 & 5.1751 & TRN \\
\hline CHEMBL1572403 & 688340 & 4.55 & 4.7683 & TRN \\
\hline CHEMBL3213728 & 688340 & 5.05 & 4.8113 & TRN \\
\hline CHEMBL1609019 & 688340 & 5.25 & 5.2232 & TRN \\
\hline CHEMBL1507170 & 688340 & 6.45 & 4.9335 & TRN \\
\hline CHEMBL1499638 & 688340 & 4.6 & 5.0839 & TRN \\
\hline CHEMBL1444351 & 688340 & 4.5 & 4.5964 & TST \\
\hline CHEMBL1563978 & 688340 & 4.8 & 4.9171 & TRN \\
\hline CHEMBL1399385 & 688340 & 6.25 & 4.802 & TST \\
\hline CHEMBL1348741 & 688340 & 4.4 & 4.9636 & TST \\
\hline CHEMBL1440636 & 688340 & 4.4 & 4.9227 & TRN \\
\hline CHEMBL1490561 & 688340 & 5.25 & 5.0891 & TRN \\
\hline CHEMBL1342766 & 688340 & 4.8 & 4.8679 & TRN \\
\hline CHEMBL1609090 & 688340 & 4.5 & 4.8797 & TST \\
\hline CHEMBL1401153 & 688340 & 5.3 & 4.9916 & TST \\
\hline CHEMBL1610365 & 688340 & 5.65 & 5.0154 & TRN \\
\hline CHEMBL1589941 & 688340 & 4.45 & 5.077 & TRN \\
\hline CHEMBL1563302 & 688340 & 5.1 & 4.9059 & TRN \\
\hline CHEMBL1595319 & 688340 & 4.55 & 4.7158 & TRN \\
\hline CHEMBL1299902 & 688340 & 5.35 & 5.2518 & TRN \\
\hline CHEMBL1572976 & 688340 & 4.65 & 5.1856 & TST \\
\hline CHEMBL1327465 & 688340 & 5.8 & 5.103 & TRN \\
\hline
\end{tabular}




\begin{tabular}{|c|c|c|c|c|c|}
\hline \\
\hline CHEMBL1344739 & 688340 & 4.4 & 4.7263 & TRN & \\
\hline CHEMBL1485275 & 688340 & 6.0 & 5.1985 & TRN & \\
\hline CHEMBL1573157 & 688340 & 5.05 & 4.947 & TRN & \\
\hline CHEMBL1591691 & 688340 & 4.4 & 4.6317 & TRN & \\
\hline CHEMBL1347733 & 688340 & 4.8 & 4.6838 & TRN & \\
\hline CHEMBL1311676 & 688340 & 4.55 & 4.869 & TRN & \\
\hline CHEMBL2000988 & 688340 & 7.0 & 4.7642 & TST & \\
\hline CHEMBL1433552 & 688340 & 4.45 & 4.8372 & TRN & \\
\hline CHEMBL1439425 & 688340 & 4.45 & 5.2111 & TST & \\
\hline CHEMBL1475629 & 688340 & 6.0 & 4.9771 & TRN & \\
\hline CHEMBL1579771 & 688340 & 4.55 & 4.82100 & 0000000001 & TRN \\
\hline CHEMBL1422733 & 688340 & 4.7 & 5.0687 & TST & \\
\hline CHEMBL1307718 & 688340 & 5.9 & 5.3364 & TRN & \\
\hline CHEMBL1375623 & 688340 & 4.4 & 5.061 & TRN & \\
\hline CHEMBL1393376 & 688340 & 4.4 & 5.0129 & TRN & \\
\hline CHEMBL3193457 & 688340 & 4.4 & 4.8872 & TRN & \\
\hline CHEMBL1384991 & 688340 & 7.0 & 5.2456 & TST & \\
\hline CHEMBL1345143 & 688340 & 4.6 & 4.9052 & TRN & \\
\hline CHEMBL1425537 & 688340 & 4.45 & 4.9465 & TST & \\
\hline CHEMBL1509384 & 688340 & 4.55 & 5.1945 & TRN & \\
\hline CHEMBL1363130 & 688340 & 5.35 & 5.2475 & TRN & \\
\hline CHEMBL1314181 & 688340 & 5.05 & 5.0722 & TRN & \\
\hline CHEMBL1350516 & 688340 & 5.6 & 5.3413 & TRN & \\
\hline CHEMBL1579251 & 688340 & 6.4 & 5.0911 & TRN & \\
\hline CHEMBL1447363 & 688340 & 4.4 & 5.1152 & TRN & \\
\hline CHEMBL1559307 & 688340 & 4.45 & 4.8181 & TRN & \\
\hline CHEMBL1512924 & 688340 & 7.0 & 5.0864 & TST & \\
\hline CHEMBL1369401 & 688340 & 4.6 & 4.7751 & TRN & \\
\hline CHEMBL1467889 & 688340 & 4.4 & 5.13299 & 9999999999 & TST \\
\hline CHEMBL1417354 & 688340 & 5.3 & 4.9015 & TST & \\
\hline CHEMBL1526590 & 688340 & 7.0 & 5.0014 & TRN & \\
\hline CHEMBL1436078 & 688340 & 4.6 & 4.7251 & TRN & \\
\hline CHEMBL3192197 & 688340 & 4.4 & 4.7274 & TRN & \\
\hline CHEMBL1488097 & 688340 & 4.75 & 4.8468 & TRN & \\
\hline CHEMBL1523644 & 688340 & 4.65 & 5.0026 & TRN & \\
\hline CHEMBL1611573 & 688340 & 4.45 & 4.7871 & TST & \\
\hline CHEMBL3213886 & 688340 & 5.05 & 4.9455 & TRN & \\
\hline CHEMBL1457030 & 688340 & 4.3 & 5.4689 & TRN & \\
\hline CHEMBL1333249 & 688340 & 4.6 & 4.9689 & TRN & \\
\hline CHEMBL380979 & 688340 & 4.4 & 4.8916 & TRN & \\
\hline CHEMBL1469237 & 688340 & 8.301 & 5.3177 & TRN & \\
\hline CHEMBL1408535 & 688340 & 4.95 & 4.7528 & TRN & \\
\hline CHEMBL1602983 & 688340 & 4.4 & 5.0936 & TRN & \\
\hline CHEMBL1544975 & 688340 & 4.4 & 4.7793 & TRN & \\
\hline CHEMBL1525009 & 688340 & 4.65 & 4.9552 & TST & \\
\hline CHEMBL1445449 & 688340 & 5.35 & 4.6545 & TRN & \\
\hline CHEMBL1576239 & 688340 & 4.85 & 4.7842 & TRN & \\
\hline CHEMBL1429003 & 688340 & 4.65 & 4.921 & TST & \\
\hline
\end{tabular}




\begin{tabular}{|c|c|c|c|c|c|}
\hline \multicolumn{6}{|c|}{ Supplemental Table S2.txt } \\
\hline CHEMBL3199206 & 688340 & 6.0 & 4.9221 & TRN & \\
\hline CHEMBL1590146 & 688340 & 6.1 & 5.1082 & TRN & \\
\hline CHEMBL1321154 & 688340 & 4.45 & 4.9402 & TRN & \\
\hline CHEMBL3195483 & 688340 & 4.4 & 4.9419 & TRN & \\
\hline CHEMBL1509079 & 688340 & 5.5 & 5.3472 & TST & \\
\hline CHEMBL1530352 & 688340 & 4.55 & 4.6486 & TRN & \\
\hline CHEMBL3192552 & 688340 & 4.4 & 5.2261 & TRN & \\
\hline CHEMBL1566210 & 688340 & 5.4 & 5.3671 & TST & \\
\hline CHEMBL1345512 & 688340 & 4.6 & 4.5603 & TST & \\
\hline CHEMBL1380663 & 688340 & 6.8499 & 4.9312 & TRN & \\
\hline CHEMBL1300360 & 688340 & 4.55 & 4.7257 & TRN & \\
\hline CHEMBL1370666 & 688340 & 5.15 & 5.0552 & TST & \\
\hline CHEMBL1316472 & 688340 & 4.55 & 4.5992 & TRN & \\
\hline CHEMBL1370760 & 688340 & 4.5 & 4.6179 & TRN & \\
\hline CHEMBL1413820 & 688340 & 4.4 & 4.9529 & TST & \\
\hline CHEMBL 3211860 & 688340 & 6.5 & 5.2053 & TRN & \\
\hline CHEMBL1362574 & 688340 & 5.35 & 5.006 & TST & \\
\hline CHEMBL1412421 & 688340 & 4.0 & 5.1211 & TST & \\
\hline CHEMBL1539815 & 688340 & 4.6 & 4.8258 & TRN & \\
\hline CHEMBL1549553 & 688340 & 6.5 & 4.9572 & TST & \\
\hline CHEMBL1395434 & 688340 & 4.4 & 5.1109 & TST & \\
\hline CHEMBL1311754 & 688340 & 4.5 & 4.8501 & TRN & \\
\hline CHEMBL1452303 & 688340 & 7.0501 & 5.0715 & TST & \\
\hline CHEMBL1346640 & 688340 & 4.65 & 4.4836 & TRN & \\
\hline CHEMBL1320399 & 688340 & 7.6498 & 5.6196 & TRN & \\
\hline CHEMBL1606222 & 688340 & 4.55 & 5.0622 & TRN & \\
\hline CHEMBL3212836 & 688340 & 4.4 & 4.8156 & TRN & \\
\hline CHEMBL1404018 & 688340 & 6.6499 & 5.1078 & TRN & \\
\hline CHEMBL1483800 & 688340 & 4.4 & 4.7814 & TRN & \\
\hline CHEMBL1599087 & 688340 & 6.15 & 5.3313 & TRN & \\
\hline CHEMBL1528944 & 688340 & 4.4 & 4.8749 & TRN & \\
\hline CHEMBL1371749 & 688340 & 4.55 & 5.2709 & TRN & \\
\hline CHEMBL1534289 & 688340 & 4.95 & 4.8489 & TRN & \\
\hline CHEMBL1361563 & 688340 & 7.0 & 5.1979 & TRN & \\
\hline CHEMBL1348975 & 688340 & 5.15 & 5.4151 & TRN & \\
\hline CHEMBL1450704 & 688340 & 4.0 & 4.9531 & TRN & \\
\hline CHEMBL1394338 & 688340 & 4.55 & 5.2941 & TRN & \\
\hline CHEMBL1331821 & 688340 & 5.15 & 5.0924 & TRN & \\
\hline CHEMBL1438389 & 688340 & 6.15 & 5.1117 & TST & \\
\hline CHEMBL1323974 & 688340 & 4.4 & 5.1611 & TST & \\
\hline CHEMBL1584059 & 688340 & 6.15 & 4.9859 & TRN & \\
\hline CHEMBL1361994 & 688340 & 6.45 & 5.0634 & TST & \\
\hline CHEMBL3392069 & 688340 & 5.15 & 4.995 & TST & \\
\hline CHEMBL1562161 & 688340 & 4.5 & 4.93199 & 99999999995 & TRN \\
\hline CHEMBL1498236 & 688340 & 4.65 & 4.3279 & TRN & \\
\hline CHEMBL1386511 & 688340 & 4.65 & 4.5064 & TRN & \\
\hline CHEMBL1405008 & 688340 & 7.0 & 5.2966 & TRN & \\
\hline CHEMBL3209768 & 688340 & 5.2 & 5.1266 & TST & \\
\hline
\end{tabular}




\begin{tabular}{|c|c|c|c|c|c|}
\hline \\
\hline CHEMBL1440987 & 688340 & 4.4 & 5.1396 & TRN & \\
\hline CHEMBL1564831 & 688340 & 5.35 & 5.3185 & TRN & \\
\hline CHEMBL1511965 & 688340 & 6.5 & 5.1264 & TRN & \\
\hline CHEMBL1426709 & 688340 & 5.2 & 4.8043 & TST & \\
\hline CHEMBL1442278 & 688340 & 4.5 & 4.6999 & TRN & \\
\hline CHEMBL1604640 & 688340 & 5.0 & 5.0128 & TST & \\
\hline CHEMBL1540378 & 688340 & 6.0 & 5.4458 & TRN & \\
\hline CHEMBL1307929 & 688340 & 4.4 & 5.4086 & TST & \\
\hline CHEMBL1301986 & 688340 & 4.45 & 5.0304 & TRN & \\
\hline CHEMBL1306561 & 688340 & 6.05 & 5.2539 & TRN & \\
\hline CHEMBL1536030 & 688340 & 5.5 & 5.3423 & TRN & \\
\hline CHEMBL1578306 & 688340 & 5.05 & 5.0178 & TRN & \\
\hline CHEMBL1584238 & 688340 & 4.4 & 4.8284 & TRN & \\
\hline CHEMBL1519105 & 688340 & 5.35 & 5.2748 & TRN & \\
\hline CHEMBL1346567 & 688340 & 4.65 & 4.9817 & TRN & \\
\hline CHEMBL1439507 & 688340 & 5.05 & 5.0326 & TRN & \\
\hline CHEMBL1391905 & 688340 & 6.05 & 5.49200 & 0000000001 & TRN \\
\hline CHEMBL1337502 & 688340 & 5.15 & 4.7443 & TRN & \\
\hline CHEMBL1419283 & 688340 & 4.4 & 5.0732 & TST & \\
\hline CHEMBL1302540 & 688340 & 4.4 & 5.2248 & TRN & \\
\hline CHEMBL1304604 & 688340 & 5.2 & 5.0942 & TRN & \\
\hline CHEMBL1393898 & 688340 & 4.55 & 4.9179 & TST & \\
\hline CHEMBL463175 & 688340 & 6.2 & 5.1221 & TRN & \\
\hline CHEMBL1482670 & 688340 & 4.5 & 4.9698 & TRN & \\
\hline CHEMBL1570105 & 688340 & 5.2 & 5.2488 & TST & \\
\hline CHEMBL1442410 & 688340 & 5.0 & 4.8344 & TST & \\
\hline CHEMBL1570131 & 688340 & 4.95 & 4.9866 & TRN & \\
\hline CHEMBL1369236 & 688340 & 4.45 & 4.996 & TRN & \\
\hline CHEMBL1400699 & 688340 & 4.7 & 5.2555 & TRN & \\
\hline CHEMBL1333336 & 688340 & 4.6 & 4.7984 & TRN & \\
\hline CHEMBL1324822 & 688340 & 4.4 & 4.6624 & TST & \\
\hline CHEMBL1464696 & 688340 & 5.2 & 5.3709 & TST & \\
\hline CHEMBL1560594 & 688340 & 5.2 & 4.8868 & TRN & \\
\hline CHEMBL1430661 & 688340 & 4.55 & 4.89 & TRN & \\
\hline CHEMBL3199796 & 688340 & 4.4 & 4.7992 & TRN & \\
\hline CHEMBL1379408 & 688340 & 4.95 & 4.8761 & TRN & \\
\hline CHEMBL1546947 & 688340 & 4.55 & 4.8826 & TRN & \\
\hline CHEMBL1512513 & 688340 & 4.6 & 4.77 & TRN & \\
\hline CHEMBL1544017 & 688340 & 5.0 & 5.1457 & TRN & \\
\hline CHEMBL3198994 & 688340 & 4.85 & 4.78 & TRN & \\
\hline CHEMBL1325830 & 688340 & 5.8 & 5.3674 & TST & \\
\hline CHEMBL3196782 & 688340 & 5.0 & 4.8138 & TST & \\
\hline CHEMBL1434806 & 688340 & 4.75 & 4.7582 & TRN & \\
\hline CHEMBL1396113 & 688340 & 4.4 & 5.0738 & TRN & \\
\hline CHEMBL1375320 & 688340 & 5.15 & 4.7218 & TST & \\
\hline CHEMBL1573323 & 688340 & 4.65 & 4.9679 & TST & \\
\hline CHEMBL1323352 & 688340 & 4.45 & 5.3662 & TRN & \\
\hline CHEMBL1446259 & 688340 & 4.5 & 5.0667 & TRN & \\
\hline
\end{tabular}




\begin{tabular}{|c|c|c|c|c|c|}
\hline \\
\hline CHEMBL1467860 & 688340 & 5.1 & 4.9772 & TRN & \\
\hline CHEMBL1491251 & 688340 & 4.55 & 4.6733 & TRN & \\
\hline CHEMBL1303599 & 688340 & 4.45 & 5.043 & TST & \\
\hline CHEMBL40274 & 688340 & 6.2 & 5.4667 & TST & \\
\hline CHEMBL1369780 & 688340 & 7.0 & 5.3878 & TST & \\
\hline CHEMBL1486366 & 688340 & 6.0 & 4.6971 & TRN & \\
\hline CHEMBL1511663 & 688340 & 4.85 & 5.0979 & TST & \\
\hline CHEMBL1503392 & 688340 & 4.4 & 4.5803 & TRN & \\
\hline CHEMBL1340626 & 688340 & 4.5 & 4.9148 & TRN & \\
\hline CHEMBL1376137 & 688340 & 4.45 & 4.7531 & TRN & \\
\hline CHEMBL1428998 & 688340 & 4.6 & 5.1952 & TRN & \\
\hline CHEMBL1441350 & 688340 & 5.0 & 4.9525 & TRN & \\
\hline CHEMBL1313306 & 688340 & 4.4 & 4.96899 & 9999999999 & TST \\
\hline CHEMBL1443015 & 688340 & 5.1 & 5.2011 & TRN & \\
\hline CHEMBL1586988 & 688340 & 5.45 & 5.3614 & TRN & \\
\hline CHEMBL1579785 & 688340 & 5.15 & 4.8892 & TST & \\
\hline CHEMBL1990582 & 688340 & 4.55 & 4.8319 & TRN & \\
\hline CHEMBL1418297 & 688340 & 7.0 & 5.2629 & TRN & \\
\hline CHEMBL1597427 & 688340 & 4.6 & 4.5279 & TRN & \\
\hline CHEMBL1443946 & 688340 & 4.55 & 4.4889 & TRN & \\
\hline CHEMBL1549629 & 688340 & 5.0 & 4.9808 & TRN & \\
\hline CHEMBL1415993 & 688340 & 5.2 & 5.1409 & TRN & \\
\hline CHEMBL1498940 & 688340 & 4.85 & 5.20200 & 2000000001 & TRN \\
\hline CHEMBL1587588 & 688340 & 4.4 & 5.0203 & TRN & \\
\hline CHEMBL1526217 & 688340 & 4.85 & 4.8405 & TRN & \\
\hline CHEMBL1411921 & 688340 & 5.05 & 4.9991 & TRN & \\
\hline CHEMBL1517380 & 688340 & 4.5 & 5.0668 & TRN & \\
\hline CHEMBL1469929 & 688340 & 4.4 & 4.9501 & TRN & \\
\hline CHEMBL1343916 & 688340 & 4.65 & 4.8212 & TRN & \\
\hline CHEMBL1539170 & 688340 & 4.55 & 5.0955 & TRN & \\
\hline CHEMBL1356328 & 688340 & 4.7 & 4.9131 & TRN & \\
\hline CHEMBL1328323 & 688340 & 4.55 & 5.1315 & TRN & \\
\hline CHEMBL1481906 & 688340 & 4.4 & 5.2049 & TRN & \\
\hline CHEMBL1413554 & 688340 & 4.4 & 5.0899 & TRN & \\
\hline CHEMBL3194215 & 688340 & 4.35 & 4.9965 & TRN & \\
\hline CHEMBL1449018 & 688340 & 4.75 & 4.8789 & TRN & \\
\hline CHEMBL1372524 & 688340 & 4.4 & 4.9356 & TRN & \\
\hline CHEMBL1510118 & 688340 & 5.35 & 5.033 & TRN & \\
\hline CHEMBL1361204 & 688340 & 4.95 & 5.2343 & TRN & \\
\hline CHEMBL1453011 & 688340 & 5.6 & 4.9936 & TRN & \\
\hline CHEMBL120734 & 688340 & 4.9 & 4.6917 & TRN & \\
\hline CHEMBL1391159 & 688340 & 5.2 & 4.7903 & TRN & \\
\hline CHEMBL1346951 & 688340 & 4.7 & 4.8238 & TRN & \\
\hline CHEMBL1302413 & 688340 & 4.95 & 5.0511 & TRN & \\
\hline CHEMBL1499253 & 688340 & 4.6 & 5.0871 & TRN & \\
\hline CHEMBL1349895 & 688340 & 5.25 & 5.4598 & TRN & \\
\hline CHEMBL1356520 & 688340 & 5.0 & 5.1377 & TRN & \\
\hline CHEMBL1342528 & 688340 & 4.5 & 4.6748 & TRN & \\
\hline
\end{tabular}




\begin{tabular}{|c|c|c|c|c|c|}
\hline \multicolumn{6}{|c|}{ Supplemental Table S2.txt } \\
\hline CHEMBL3194550 & 688340 & 4.55 & 4.9382 & TRN & \\
\hline CHEMBL1551785 & 688340 & 4.45 & 4.9233 & TRN & \\
\hline CHEMBL1413073 & 688340 & 4.5 & 5.082 & TRN & \\
\hline CHEMBL3197264 & 688340 & 4.5 & 4.8649 & TRN & \\
\hline CHEMBL1555615 & 688340 & 5.4 & 5.2861 & TST & \\
\hline CHEMBL1546390 & 688340 & 4.4 & 5.4892 & TRN & \\
\hline CHEMBL1564222 & 688340 & 5.4 & 5.0932 & TRN & \\
\hline CHEMBL1344242 & 688340 & 4.3 & 5.3764 & TRN & \\
\hline CHEMBL1611613 & 688340 & 5.4 & 5.1643 & TRN & \\
\hline CHEMBL1535100 & 688340 & 7.0 & 5.2272 & TRN & \\
\hline CHEMBL 3212364 & 688340 & 4.5 & 4.9437 & TRN & \\
\hline CHEMBL1361023 & 688340 & 5.0 & 4.9624 & TRN & \\
\hline CHEMBL1587758 & 688340 & 4.75 & 4.8538 & TRN & \\
\hline CHEMBL1450586 & 688340 & 4.5 & 5.2086 & TST & \\
\hline CHEMBL1392215 & 688340 & 4.4 & 4.9794 & TST & \\
\hline CHEMBL1501432 & 688340 & 4.6 & 4.9127 & TST & \\
\hline CHEMBL1534066 & 688340 & 6.5501 & 5.3077 & TRN & \\
\hline CHEMBL 3189941 & 688340 & 4.45 & 5.0725 & TRN & \\
\hline CHEMBL1597622 & 688340 & 4.45 & 4.5991 & TRN & \\
\hline CHEMBL1610037 & 688340 & 4.5 & 4.5723 & TRN & \\
\hline CHEMBL109037 & 688340 & 6.8 & 5.4998 & TST & \\
\hline CHEMBL1543209 & 688340 & 7.1002 & 5.3981 & TRN & \\
\hline CHEMBL1436698 & 688340 & 4.8 & 5.4417 & TRN & \\
\hline CHEMBL1344176 & 688340 & 4.7 & 5.0221 & TRN & \\
\hline CHEMBL1425721 & 688340 & 4.5 & 5.0006 & TRN & \\
\hline CHEMBL1391385 & 688340 & 5.85 & 5.7108 & TRN & \\
\hline CHEMBL1428802 & 688340 & 6.15 & 5.3352 & TRN & \\
\hline CHEMBL1497149 & 688340 & 4.4 & 4.5993 & TRN & \\
\hline CHEMBL339304 & 688340 & 4.4 & 4.9765 & TRN & \\
\hline CHEMBL1340534 & 688340 & 7.0 & 5.3988 & TST & \\
\hline CHEMBL1470382 & 688340 & 5.45 & 4.5767 & TRN & \\
\hline CHEMBL1401497 & 688340 & 4.0 & 5.0195 & TRN & \\
\hline CHEMBL1510209 & 688340 & 4.45 & 4.7671 & TRN & \\
\hline CHEMBL1418601 & 688340 & 5.0 & 4.6266 & TRN & \\
\hline CHEMBL1482304 & 688340 & 4.65 & 4.7089 & TRN & \\
\hline CHEMBL1309344 & 688340 & 5.6 & 5.3581 & TRN & \\
\hline CHEMBL1424151 & 688340 & 5.0 & 4.9271 & TRN & \\
\hline CHEMBL1573719 & 688340 & 4.4 & 5.0505 & TST & \\
\hline CHEMBL1422132 & 688340 & 4.45 & 4.7826 & TRN & \\
\hline CHEMBL1359870 & 688340 & 7.0 & 5.3537 & TRN & \\
\hline CHEMBL1371234 & 688340 & 5.2 & 5.0118 & TST & \\
\hline CHEMBL1320379 & 688340 & 4.8 & 4.8986 & TRN & \\
\hline CHEMBL1386969 & 688340 & 4.55 & 4.7035 & TRN & \\
\hline CHEMBL1407561 & 688340 & 4.65 & 4.8089 & TRN & \\
\hline CHEMBL1393729 & 688340 & 4.6 & 4.7553 & TRN & \\
\hline CHEMBL1372751 & 688340 & 4.6 & 4.9108 & TRN & \\
\hline CHEMBL1383240 & 688340 & 4.45 & 4.86600 & 00000000005 & TRN \\
\hline CHEMBL1363482 & 688340 & 4.45 & 4.9899 & TST & \\
\hline
\end{tabular}




\begin{tabular}{|c|c|c|c|c|}
\hline \\
\hline CHEMBL1545332 & 688340 & 4.8 & 4.919 & TRN \\
\hline CHEMBL1390925 & 688340 & 4.5 & 4.788 & TRN \\
\hline CHEMBL1456220 & 688340 & 5.0 & 5.3881 & TRN \\
\hline CHEMBL1562862 & 688340 & 4.5 & 5.3922 & TRN \\
\hline CHEMBL1501204 & 688340 & 4.75 & 5.0043 & TRN \\
\hline CHEMBL1312156 & 688340 & 4.4 & 5.1057 & TRN \\
\hline CHEMBL1342410 & 688340 & 4.65 & 4.7551 & TRN \\
\hline CHEMBL3199652 & 688340 & 5.25 & 4.9779 & TRN \\
\hline CHEMBL3210983 & 688340 & 4.45 & 4.9393 & TRN \\
\hline CHEMBL1513029 & 688340 & 4.4 & 5.5614 & TRN \\
\hline CHEMBL1402979 & 688340 & 5.3 & 4.7934 & TST \\
\hline CHEMBL484640 & 688340 & 5.4 & 5.2159 & TST \\
\hline CHEMBL1448371 & 688340 & 4.5 & 4.9259 & TST \\
\hline CHEMBL1556215 & 688340 & 4.45 & 5.1386 & TRN \\
\hline CHEMBL1361425 & 688340 & 7.0 & 5.2747 & TST \\
\hline CHEMBL1478283 & 688340 & 5.4 & 5.0801 & TRN \\
\hline CHEMBL1611046 & 688340 & 6.5 & 4.9202 & TRN \\
\hline CHEMBL1426619 & 688340 & 4.6 & 5.1534 & TRN \\
\hline CHEMBL1374970 & 688340 & 4.55 & 4.8245 & TRN \\
\hline CHEMBL1550336 & 688340 & 4.5 & 5.1118 & TRN \\
\hline CHEMBL1405015 & 688340 & 4.4 & 4.9448 & TRN \\
\hline CHEMBL1459161 & 688340 & 4.75 & 4.7476 & TRN \\
\hline CHEMBL1468333 & 688340 & 5.2 & 4.7141 & TRN \\
\hline CHEMBL1435274 & 688340 & 4.9 & 4.8368 & TRN \\
\hline CHEMBL1518130 & 688340 & 7.0501 & 5.5103 & TRN \\
\hline CHEMBL1481775 & 688340 & 5.3 & 5.3049 & TRN \\
\hline CHEMBL1412169 & 688340 & 4.5 & 4.9072 & TST \\
\hline CHEMBL1536493 & 688340 & 5.45 & 5.3514 & TRN \\
\hline CHEMBL1452373 & 688340 & 4.55 & 5.1786 & TST \\
\hline CHEMBL1349022 & 688340 & 4.55 & 4.8672 & TRN \\
\hline CHEMBL1577715 & 688340 & 4.6 & 4.8901 & TRN \\
\hline CHEMBL1527537 & 688340 & 4.55 & 4.5904 & TRN \\
\hline CHEMBL 1446220 & 688340 & 6.15 & 5.7209 & TRN \\
\hline CHEMBL 3145038 & 688340 & 4.7 & 5.2937 & TRN \\
\hline CHEMBL1299440 & 688340 & 6.05 & 5.442 & TRN \\
\hline CHEMBL1427637 & 688340 & 4.5 & 4.8098 & TRN \\
\hline CHEMBL1485949 & 688340 & 4.5 & 4.7601 & TRN \\
\hline CHEMBL1495510 & 688340 & 4.4 & 5.4699 & TRN \\
\hline CHEMBL1441897 & 688340 & 4.85 & 4.663 & TRN \\
\hline CHEMBL3199899 & 688340 & 4.4 & 4.6622 & TST \\
\hline CHEMBL1369635 & 688340 & 5.1 & 5.308 & TRN \\
\hline CHEMBL1570920 & 688340 & 4.55 & 4.8315 & TST \\
\hline CHEMBL1322960 & 688340 & 5.7 & 4.8458 & TRN \\
\hline CHEMBL1375200 & 688340 & 5.25 & 5.3142 & TRN \\
\hline CHEMBL1569397 & 688340 & 4.5 & 4.9948 & TRN \\
\hline CHEMBL1529509 & 688340 & 4.65 & 4.8942 & TRN \\
\hline CHEMBL1541446 & 688340 & 4.5 & 4.8938 & TRN \\
\hline CHEMBL1421469 & 688340 & 5.2 & 5.087 & TST \\
\hline
\end{tabular}




\begin{tabular}{|c|c|c|c|c|c|}
\hline \\
\hline CHEMBL1588410 & 688340 & 6.2 & 4.966 & TST & \\
\hline CHEMBL1309430 & 688340 & 5.0 & 4.8839 & TRN & \\
\hline CHEMBL1306379 & 688340 & 4.5 & 4.9864 & TRN & \\
\hline CHEMBL3193990 & 688340 & 4.55 & 5.0644 & TRN & \\
\hline CHEMBL3197767 & 688340 & 6.1 & 4.7829 & TRN & \\
\hline CHEMBL1432438 & 688340 & 4.75 & 5.0064 & TRN & \\
\hline CHEMBL1311084 & 688340 & 4.95 & 5.273 & TST & \\
\hline CHEMBL1576206 & 688340 & 4.6 & 4.9297 & TRN & \\
\hline CHEMBL1596480 & 688340 & 4.6 & 4.9239 & TRN & \\
\hline CHEMBL1486645 & 688340 & 4.0 & 4.9784 & TRN & \\
\hline CHEMBL1588434 & 688340 & 4.5 & 4.8221 & TRN & \\
\hline CHEMBL1487639 & 688340 & 5.4 & 4.899 & TRN & \\
\hline CHEMBL1379065 & 688340 & 4.4 & 4.9934 & TRN & \\
\hline CHEMBL1465765 & 688340 & 5.0 & 5.121 & TRN & \\
\hline CHEMBL1543622 & 688340 & 7.0501 & 4.9601 & TRN & \\
\hline CHEMBL1427282 & 688340 & 4.8 & 5.0244 & TST & \\
\hline CHEMBL1489407 & 688340 & 4.4 & 4.8108 & TRN & \\
\hline CHEMBL1496117 & 688340 & 4.55 & 5.0423 & TRN & \\
\hline CHEMBL3193271 & 688340 & 7.0 & 5.2325 & TRN & \\
\hline CHEMBL1379681 & 688340 & 4.5 & 5.2593 & TRN & \\
\hline CHEMBL1336069 & 688340 & 6.3 & 5.5349 & TRN & \\
\hline CHEMBL1468944 & 688340 & 5.45 & 5.4051 & TRN & \\
\hline CHEMBL1529465 & 688340 & 4.5 & 4.8567 & TRN & \\
\hline CHEMBL1570775 & 688340 & 6.1 & 5.1169 & TRN & \\
\hline CHEMBL1368809 & 688340 & 4.45 & 5.0841 & TST & \\
\hline CHEMBL1577300 & 688340 & 4.95 & 4.9909 & TRN & \\
\hline CHEMBL1455367 & 688340 & 4.6 & 5.1462 & TST & \\
\hline CHEMBL1444318 & 688340 & 6.5 & 5.065 & TRN & \\
\hline CHEMBL1318110 & 688340 & 4.5 & 5.082 & TST & \\
\hline CHEMBL1560370 & 688340 & 4.55 & 5.1879 & TST & \\
\hline CHEMBL3195471 & 688340 & 4.4 & 4.6693 & TRN & \\
\hline CHEMBL1497844 & 688340 & 5.7 & 4.8596 & TST & \\
\hline CHEMBL1351231 & 688340 & 4.4 & 5.008 & TRN & \\
\hline CHEMBL1571288 & 688340 & 4.55 & 5.17899 & 9999999999 & TRN \\
\hline CHEMBL1304872 & 688340 & 5.35 & 5.4196 & TRN & \\
\hline CHEMBL1301723 & 688340 & 5.2 & 4.6942 & TST & \\
\hline CHEMBL1563637 & 688340 & 4.35 & 5.1628 & TRN & \\
\hline CHEMBL1546688 & 688340 & 4.4 & 5.0017 & TRN & \\
\hline CHEMBL1485459 & 688340 & 6.5 & 5.2901 & TRN & \\
\hline CHEMBL1601167 & 688340 & 6.95 & 5.0868 & TST & \\
\hline CHEMBL1339613 & 688340 & 4.55 & 4.8838 & TRN & \\
\hline CHEMBL1302823 & 688340 & 4.55 & 4.9944 & TRN & \\
\hline CHEMBL1311985 & 688340 & 5.45 & 5.2649 & TRN & \\
\hline CHEMBL1481318 & 688340 & 5.15 & 5.1077 & TST & \\
\hline CHEMBL1432986 & 688340 & 7.0 & 5.4924 & TRN & \\
\hline CHEMBL183322 & 688340 & 7.0 & 5.211 & TRN & \\
\hline CHEMBL1480616 & 688340 & 5.45 & 5.0265 & TST & \\
\hline CHEMBL1310969 & 688340 & 4.85 & 5.3557 & TRN & \\
\hline
\end{tabular}




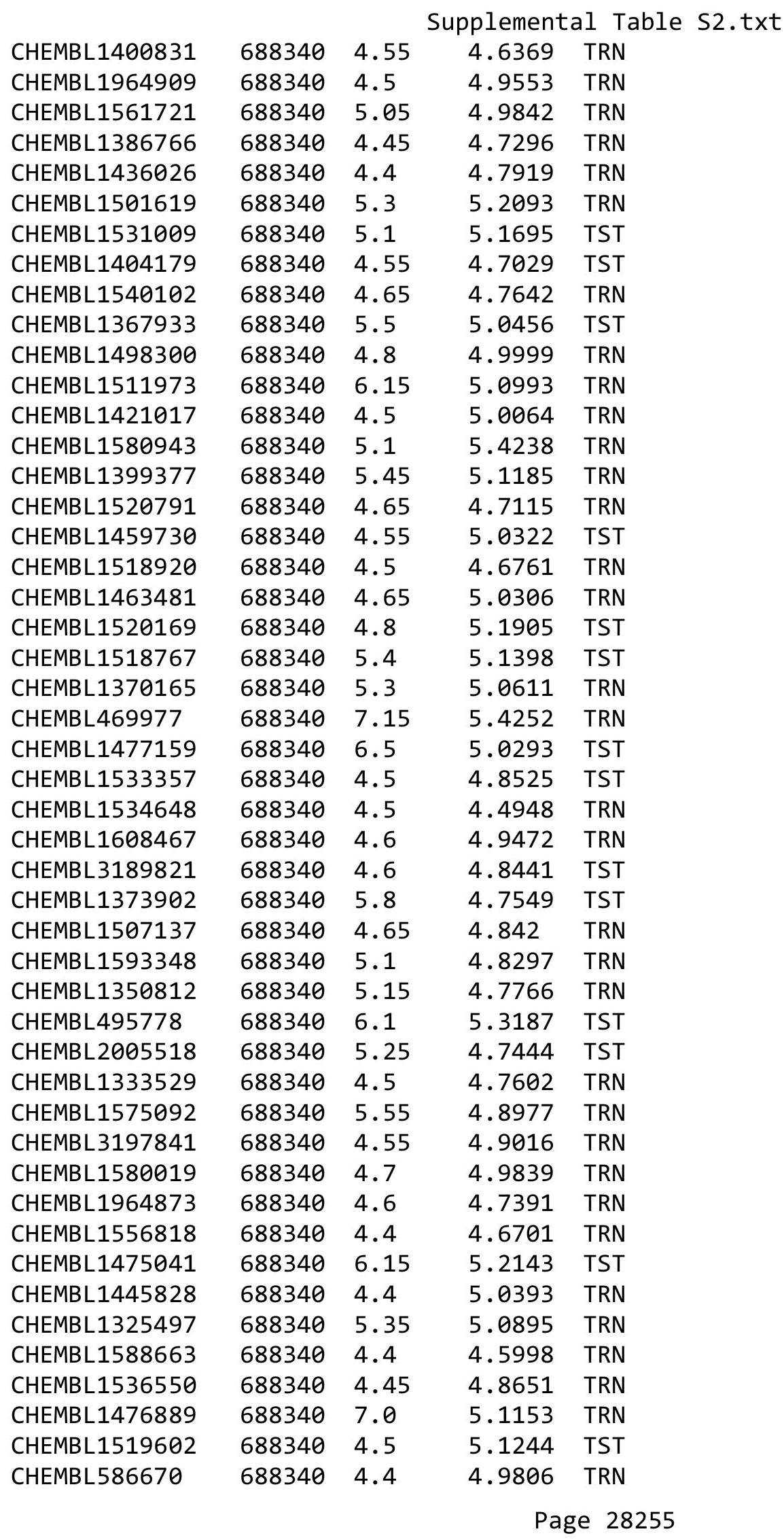




\begin{tabular}{|c|c|c|c|c|}
\hline & & & pplemen & al $\mathrm{T}$ \\
\hline CHEMBL1606824 & 688340 & 5.1 & 5.2287 & TRN \\
\hline CHEMBL1396811 & 688340 & 6.5 & 5.1406 & TRN \\
\hline CHEMBL1595894 & 688340 & 6.1 & 5.1015 & TRN \\
\hline CHEMBL1344248 & 688340 & 4.55 & 4.934 & TRN \\
\hline CHEMBL1447384 & 688340 & 5.2 & 5.4612 & TST \\
\hline CHEMBL1533288 & 688340 & 6.0 & 4.9092 & TST \\
\hline CHEMBL1478701 & 688340 & 5.15 & 5.088 & TST \\
\hline CHEMBL1498452 & 688340 & 5.5 & 5.1871 & TST \\
\hline CHEMBL 3189780 & 688340 & 4.6 & 4.8317 & TRN \\
\hline CHEMBL1450271 & 688340 & 5.0 & 5.1708 & TST \\
\hline CHEMBL1351403 & 688340 & 4.65 & 4.775 & TRN \\
\hline CHEMBL1981200 & 688340 & 4.45 & 4.6806 & TRN \\
\hline CHEMBL1326873 & 688340 & 4.5 & 5.2787 & TRN \\
\hline CHEMBL1505698 & 688340 & 6.2 & 5.1041 & TRN \\
\hline CHEMBL1539148 & 688340 & 4.45 & 5.0376 & TRN \\
\hline CHEMBL1587430 & 688340 & 4.45 & 4.8872 & TST \\
\hline CHEMBL1539927 & 688340 & 4.7 & 4.9638 & TST \\
\hline CHEMBL1379347 & 688340 & 4.65 & 5.0377 & TST \\
\hline CHEMBL1364729 & 688340 & 4.75 & 4.8988 & TST \\
\hline CHEMBL1489578 & 688340 & 5.7 & 5.301 & TRN \\
\hline CHEMBL1480005 & 688340 & 5.45 & 4.9454 & TRN \\
\hline CHEMBL3211705 & 688340 & 4.55 & 4.9973 & TRN \\
\hline CHEMBL1473828 & 688340 & 4.65 & 5.0117 & TRN \\
\hline CHEMBL1407151 & 688340 & 5.1 & 4.9445 & TRN \\
\hline CHEMBL1452442 & 688340 & 5.1 & 5.1809 & TRN \\
\hline CHEMBL1322742 & 688340 & 4.6 & 4.5592 & TRN \\
\hline CHEMBL1472935 & 688340 & 6.15 & 5.3614 & TRN \\
\hline CHEMBL1421400 & 688340 & 5.05 & 5.0759 & TST \\
\hline CHEMBL1334549 & 688340 & 4.4 & 5.6192 & TRN \\
\hline CHEMBL1576676 & 688340 & 5.5 & 5.0839 & TST \\
\hline CHEMBL1584262 & 688340 & 6.5 & 5.218 & TRN \\
\hline CHEMBL1453680 & 688340 & 4.4 & 4.5988 & TRN \\
\hline CHEMBL1423507 & 688340 & 4.4 & 4.8269 & TRN \\
\hline CHEMBL1351970 & 688340 & 5.2 & 4.802 & TST \\
\hline CHEMBL3191022 & 688340 & 5.65 & 4.9587 & TRN \\
\hline CHEMBL1396705 & 688340 & 6.45 & 5.176 & TRN \\
\hline CHEMBL1516912 & 688340 & 4.55 & 4.6247 & TRN \\
\hline CHEMBL1503159 & 688340 & 6.0 & 5.1219 & TST \\
\hline CHEMBL 71271 & 688340 & 4.65 & 5.1215 & TST \\
\hline CHEMBL1336741 & 688340 & 6.8 & 5.1393 & TRN \\
\hline CHEMBL1981242 & 688340 & 4.4 & 4.9618 & TRN \\
\hline CHEMBL1493247 & 688340 & 4.4 & 5.1114 & TST \\
\hline CHEMBL1343848 & 688340 & 4.55 & 4.8477 & TRN \\
\hline CHEMBL1319104 & 688340 & 4.5 & 4.5664 & TRN \\
\hline CHEMBL1531911 & 688340 & 5.5 & 5.3705 & TRN \\
\hline CHEMBL1600619 & 688340 & 4.5 & 4.9546 & TST \\
\hline CHEMBL1515996 & 688340 & 5.1 & 4.961 & TRN \\
\hline CHEMBL3195856 & 688340 & 4.6 & 4.8347 & TST \\
\hline
\end{tabular}




\begin{tabular}{|c|c|c|c|c|c|}
\hline & & \multicolumn{4}{|c|}{ Supplemental Table s2.txt } \\
\hline CHEMBL1566561 & 688340 & 4.75 & 4.8065 & TST & \\
\hline CHEMBL1396318 & 688340 & 5.15 & 5.0656 & TST & \\
\hline CHEMBL1516827 & 688340 & 4.65 & 4.5873 & TRN & \\
\hline CHEMBL1436573 & 688340 & 6.15 & 5.2447 & TRN & \\
\hline CHEMBL1470588 & 688340 & 4.45 & 4.9591 & TST & \\
\hline CHEMBL3194633 & 688340 & 4.6 & 4.8468 & TRN & \\
\hline CHEMBL 3195218 & 688340 & 5.15 & 4.9581 & TRN & \\
\hline CHEMBL1494576 & 688340 & 5.85 & 5.4584 & TRN & \\
\hline CHEMBL1335904 & 688340 & 4.4 & 4.8914 & TRN & \\
\hline CHEMBL1584908 & 688340 & 4.55 & 4.6524 & TST & \\
\hline CHEMBL1544555 & 688340 & 4.65 & 4.9327 & TRN & \\
\hline CHEMBL1433669 & 688340 & 4.6 & 5.0411 & TRN & \\
\hline CHEMBL1998824 & 688340 & 4.55 & 4.7562 & TRN & \\
\hline CHEMBL1470749 & 688340 & 4.5 & 4.745 & TRN & \\
\hline CHEMBL1562672 & 688340 & 4.65 & 4.6094 & TRN & \\
\hline CHEMBL3198962 & 688340 & 4.85 & 4.6948 & TRN & \\
\hline CHEMBL1477961 & 688340 & 5.65 & 5.3772 & TRN & \\
\hline CHEMBL1486361 & 688340 & 5.15 & 5.2328 & TST & \\
\hline CHEMBL1467007 & 688340 & 4.65 & 4.8444 & TST & \\
\hline CHEMBL1309931 & 688340 & 4.55 & 4.8576 & TRN & \\
\hline CHEMBL1351323 & 688340 & 4.6 & 5.2167 & TRN & \\
\hline CHEMBL1516663 & 688340 & 4.65 & 5.1199 & TRN & \\
\hline CHEMBL1475080 & 688340 & 4.45 & 4.6105 & TRN & \\
\hline CHEMBL1534025 & 688340 & 4.85 & 5.0799 & TRN & \\
\hline CHEMBL1977435 & 688340 & 5.05 & 4.9858 & TST & \\
\hline CHEMBL1460424 & 688340 & 5.0 & 5.2046 & TRN & \\
\hline CHEMBL1371776 & 688340 & 4.85 & 4.7801 & TRN & \\
\hline CHEMBL3190989 & 688340 & 4.8 & 4.7998 & TRN & \\
\hline CHEMBL1497288 & 688340 & 5.6 & 5.4041 & TRN & \\
\hline CHEMBL1487646 & 688340 & 4.65 & 4.7954 & TRN & \\
\hline CHEMBL1563029 & 688340 & 4.5 & 5.2301 & TRN & \\
\hline CHEMBL1534748 & 688340 & 6.3 & 4.9689 & TRN & \\
\hline CHEMBL1454256 & 688340 & 4.5 & 4.8866 & TRN & \\
\hline CHEMBL408982 & 688340 & 5.15 & 5.1627 & TRN & \\
\hline CHEMBL1517848 & 688340 & 4.7 & 5.0808 & TRN & \\
\hline CHEMBL1602304 & 688340 & 4.55 & 4.7934 & TRN & \\
\hline CHEMBL1533621 & 688340 & 4.4 & 4.5702 & TRN & \\
\hline CHEMBL1413826 & 688340 & 4.55 & 4.846 & TRN & \\
\hline CHEMBL1404929 & 688340 & 4.8 & 4.9792 & TRN & \\
\hline CHEMBL3192714 & 688340 & 8.0506 & 5.0603 & TST & \\
\hline CHEMBL3196524 & 688340 & 4.45 & 4.85800 & 00000000005 & TRN \\
\hline CHEMBL1498281 & 688340 & 4.55 & 4.7965 & TRN & \\
\hline CHEMBL1411082 & 688340 & 5.5 & 4.9414 & TRN & \\
\hline CHEMBL1452317 & 688340 & 4.35 & 5.1233 & TST & \\
\hline CHEMBL1337420 & 688340 & 4.5 & 4.3367 & TRN & \\
\hline CHEMBL1331355 & 688340 & 5.1 & 5.1442 & TRN & \\
\hline CHEMBL1299256 & 688340 & 5.6 & 5.1358 & TST & \\
\hline CHEMBL1539986 & 688340 & 4.35 & 4.8587 & TST & \\
\hline
\end{tabular}




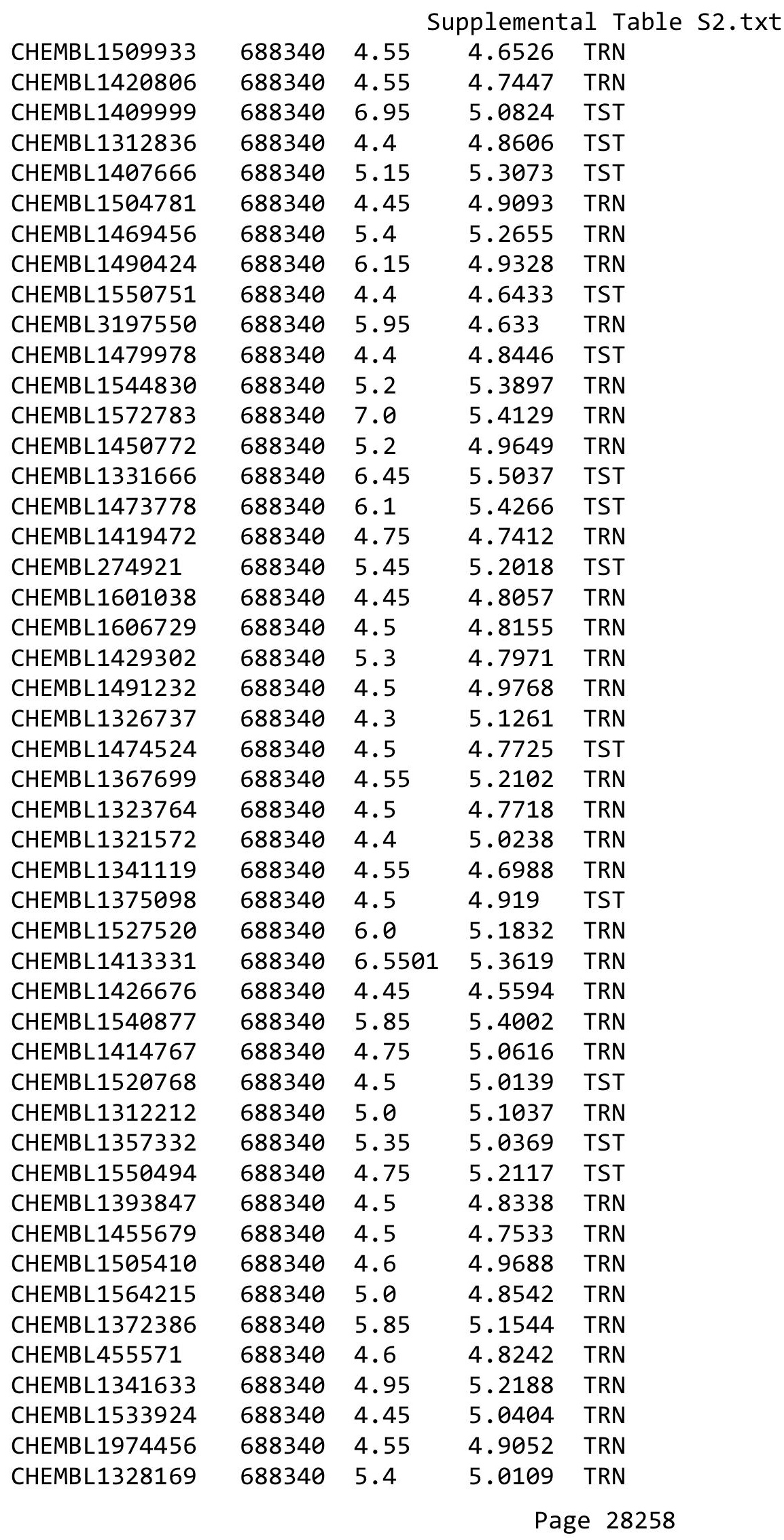




\begin{tabular}{|c|c|c|c|c|}
\hline \multicolumn{5}{|c|}{ Supplemental Table S2.txt } \\
\hline CHEMBL1431353 & 688340 & 5.25 & 5.2432 & TRN \\
\hline CHEMBL1360330 & 688340 & 5.3 & 4.8764 & TRN \\
\hline CHEMBL1384388 & 688340 & 4.95 & 4.9211 & TRN \\
\hline CHEMBL1442604 & 688340 & 4.5 & 4.785 & TRN \\
\hline CHEMBL1384137 & 688340 & 4.55 & 4.7942 & TRN \\
\hline CHEMBL1540272 & 688340 & 4.85 & 4.88 & TRN \\
\hline CHEMBL1410944 & 688340 & 5.4 & 5.4506 & TRN \\
\hline CHEMBL1520891 & 688340 & 4.8 & 5.0334 & TRN \\
\hline CHEMBL1312969 & 688340 & 4.6 & 4.5909 & TRN \\
\hline CHEMBL1474014 & 688340 & 4.45 & 4.7654 & TRN \\
\hline CHEMBL1313513 & 688340 & 4.5 & 4.9425 & TRN \\
\hline CHEMBL1496857 & 688340 & 4.7 & 4.7153 & TRN \\
\hline CHEMBL1513284 & 688340 & 4.45 & 5.4594 & TRN \\
\hline CHEMBL1449793 & 688340 & 4.4 & 4.9615 & TST \\
\hline CHEMBL1350596 & 688340 & 4.6 & 5.0322 & TRN \\
\hline CHEMBL1407745 & 688340 & 5.5 & 5.3045 & TRN \\
\hline CHEMBL3197450 & 688340 & 4.7 & 4.7845 & TRN \\
\hline CHEMBL1335732 & 688340 & 4.4 & 4.8816 & TRN \\
\hline CHEMBL1307149 & 688340 & 4.4 & 5.1361 & TRN \\
\hline CHEMBL1548928 & 688340 & 4.45 & 4.9674 & TST \\
\hline CHEMBL1345913 & 688340 & 6.5501 & 5.187 & TST \\
\hline CHEMBL1404761 & 688340 & 4.7 & 4.6231 & TRN \\
\hline CHEMBL1601853 & 688340 & 4.45 & 4.9159 & TRN \\
\hline CHEMBL1321163 & 688340 & 4.4 & 4.731 & TRN \\
\hline CHEMBL2003310 & 688340 & 4.55 & 5.0424 & TST \\
\hline CHEMBL1540117 & 688340 & 7.0 & 4.8833 & TRN \\
\hline CHEMBL1360548 & 688340 & 5.2 & 5.0891 & TRN \\
\hline CHEMBL1339274 & 688340 & 4.4 & 5.222 & TRN \\
\hline CHEMBL1538926 & 688340 & 5.5 & 5.2624 & TRN \\
\hline CHEMBL1386255 & 688340 & 5.75 & 5.3318 & TST \\
\hline CHEMBL1527498 & 688340 & 4.55 & 5.2024 & TRN \\
\hline CHEMBL1503081 & 688340 & 4.95 & 5.0033 & TRN \\
\hline CHEMBL1353921 & 688340 & 6.15 & 4.8863 & TST \\
\hline CHEMBL1549783 & 688340 & 6.15 & 5.0615 & TRN \\
\hline CHEMBL1543663 & 688340 & 4.65 & 4.8172 & TRN \\
\hline CHEMBL1370848 & 688340 & 4.5 & 4.9709 & TST \\
\hline CHEMBL1386435 & 688340 & 8.6021 & 4.9642 & TRN \\
\hline CHEMBL1475489 & 688340 & 4.75 & 5.0948 & TRN \\
\hline CHEMBL1553064 & 688340 & 6.6 & 5.0821 & TRN \\
\hline CHEMBL1456567 & 688340 & 5.75 & 5.1981 & TST \\
\hline CHEMBL1531851 & 688340 & 4.75 & 5.0612 & TRN \\
\hline CHEMBL1345879 & 688340 & 5.25 & 5.0846 & TRN \\
\hline CHEMBL1359376 & 688340 & 6.45 & 5.0076 & TST \\
\hline CHEMBL1383451 & 688340 & 4.75 & 4.9499 & TRN \\
\hline CHEMBL3191908 & 688340 & 4.6 & 5.0486 & TRN \\
\hline CHEMBL1543627 & 688340 & 4.7 & 4.7979 & TST \\
\hline CHEMBL1580925 & 688340 & 5.2 & 5.0024 & TST \\
\hline CHEMBL1379884 & 688340 & 7.0 & 5.7455 & TST \\
\hline
\end{tabular}




\begin{tabular}{|c|c|c|c|c|}
\hline \multirow[b]{2}{*}{ CHEMBL1588926 } & & & pplement & al $\mathrm{Ta}$ \\
\hline & 688340 & 5.3 & 4.83 & TRN \\
\hline CHEMBL1586179 & 688340 & 6.9 & 4.8251 & TST \\
\hline CHEMBL1473882 & 688340 & 4.4 & 5.2614 & TRN \\
\hline CHEMBL1341223 & 688340 & 4.4 & 5.2683 & TRN \\
\hline CHEMBL1322221 & 688340 & 4.85 & 4.9047 & TRN \\
\hline CHEMBL1537745 & 688340 & 5.45 & 5.2854 & TST \\
\hline CHEMBL1411392 & 688340 & 4.3 & 5.1514 & TRN \\
\hline CHEMBL1325236 & 688340 & 4.75 & 4.9776 & TST \\
\hline CHEMBL1386085 & 688340 & 4.7 & 4.8917 & TST \\
\hline CHEMBL1367461 & 688340 & 4.45 & 4.9504 & TRN \\
\hline CHEMBL1602799 & 688340 & 4.7 & 4.8942 & TRN \\
\hline CHEMBL1502514 & 688340 & 4.35 & 5.0848 & TRN \\
\hline CHEMBL1375019 & 688340 & 4.55 & 4.7919 & TST \\
\hline CHEMBL1595889 & 688340 & 4.3 & 4.8184 & TST \\
\hline CHEMBL1393718 & 688340 & 6.2 & 5.1083 & TRN \\
\hline CHEMBL1370738 & 688340 & 4.5 & 4.9119 & TRN \\
\hline CHEMBL1540895 & 688340 & 4.75 & 4.7816 & TRN \\
\hline CHEMBL1470745 & 688340 & 4.65 & 4.9063 & TRN \\
\hline CHEMBL1310951 & 688340 & 3.8 & 5.0507 & TRN \\
\hline CHEMBL1432640 & 688340 & 4.55 & 4.7341 & TRN \\
\hline CHEMBL1472249 & 688340 & 5.7 & 4.9503 & TRN \\
\hline CHEMBL1498819 & 688340 & 4.55 & 5.1506 & TRN \\
\hline CHEMBL1366038 & 688340 & 4.45 & 4.8826 & TST \\
\hline CHEMBL1316816 & 688340 & 4.55 & 4.7177 & TRN \\
\hline CHEMBL1301445 & 688340 & 4.8 & 4.8859 & TST \\
\hline CHEMBL1505827 & 688340 & 5.55 & 5.1546 & TRN \\
\hline CHEMBL1434966 & 688340 & 4.55 & 4.7701 & TRN \\
\hline CHEMBL1332240 & 688340 & 4.7 & 5.1563 & TRN \\
\hline CHEMBL1434926 & 688340 & 4.6 & 4.9824 & TRN \\
\hline CHEMBL1317569 & 688340 & 4.95 & 4.9665 & TRN \\
\hline CHEMBL1467986 & 688340 & 4.4 & 4.7026 & TRN \\
\hline CHEMBL1526019 & 688340 & 4.4 & 4.72 & TRN \\
\hline CHEMBL3210666 & 688340 & 4.35 & 4.9869 & TRN \\
\hline CHEMBL1383746 & 688340 & 4.55 & 5.2038 & TRN \\
\hline CHEMBL1489694 & 688340 & 4.55 & 4.8871 & TRN \\
\hline CHEMBL1490140 & 688340 & 7.0 & 5.1316 & TST \\
\hline CHEMBL1366610 & 688340 & 4.55 & 4.9023 & TRN \\
\hline CHEMBL1552416 & 688340 & 7.0 & 5.4632 & TRN \\
\hline CHEMBL1491452 & 688340 & 5.85 & 5.1652 & TRN \\
\hline CHEMBL1481083 & 688340 & 4.8 & 4.6456 & TRN \\
\hline CHEMBL1568449 & 688340 & 4.35 & 5.2575 & TRN \\
\hline CHEMBL1581251 & 688340 & 5.55 & 4.9507 & TRN \\
\hline CHEMBL1608575 & 688340 & 5.15 & 4.9546 & TRN \\
\hline CHEMBL1343020 & 688340 & 5.35 & 5.1414 & TRN \\
\hline CHEMBL1453604 & 688340 & 5.35 & 5.3712 & TRN \\
\hline CHEMBL1602622 & 688340 & 5.15 & 4.9735 & TRN \\
\hline CHEMBL1403806 & 688340 & 4.6 & 5.0272 & TRN \\
\hline CHEMBL1978327 & 688340 & 4.45 & 4.6929 & TRN \\
\hline
\end{tabular}




\begin{tabular}{|c|c|c|c|c|}
\hline \multicolumn{5}{|c|}{ Supplemental Table } \\
\hline CHEMBL1311879 & 688340 & 4.95 & 4.8694 & TRN \\
\hline CHEMBL3207754 & 688340 & 6.05 & 4.9433 & TST \\
\hline CHEMBL1379237 & 688340 & 4.4 & 4.9647 & TRN \\
\hline CHEMBL1467133 & 688340 & 5.1 & 4.7744 & TRN \\
\hline CHEMBL1603095 & 688340 & 4.6 & 4.8397 & TRN \\
\hline CHEMBL3210873 & 688340 & 4.85 & 4.8334 & TRN \\
\hline CHEMBL1609674 & 688340 & 4.65 & 4.98 & TST \\
\hline CHEMBL3190849 & 688340 & 4.55 & 4.8306 & TRN \\
\hline CHEMBL1585462 & 688340 & 4.5 & 5.1224 & TST \\
\hline CHEMBL1310918 & 688340 & 5.7 & 5.5628 & TRN \\
\hline CHEMBL1366284 & 688340 & 4.6 & 5.0134 & TRN \\
\hline CHEMBL1446178 & 688340 & 5.2 & 5.25 & TRN \\
\hline CHEMBL1350986 & 688340 & 4.55 & 4.7841 & TRN \\
\hline CHEMBL1572193 & 688340 & 4.55 & 4.8282 & TST \\
\hline CHEMBL1379615 & 688340 & 5.85 & 4.9491 & TRN \\
\hline CHEMBL1383055 & 688340 & 8.9586 & 4.9627 & TRN \\
\hline CHEMBL1399909 & 688340 & 4.5 & 5.1056 & TRN \\
\hline CHEMBL1550856 & 688340 & 4.45 & 4.7229 & TRN \\
\hline CHEMBL1417460 & 688340 & 6.0 & 5.5066 & TRN \\
\hline CHEMBL1538142 & 688340 & 4.8 & 5.3102 & TRN \\
\hline CHEMBL1430147 & 688340 & 4.6 & 4.8542 & TRN \\
\hline CHEMBL1312059 & 688340 & 5.2 & 4.9411 & TST \\
\hline CHEMBL1492707 & 688340 & 4.5 & 4.7935 & TRN \\
\hline CHEMBL1510636 & 688340 & 5.75 & 5.0855 & TRN \\
\hline CHEMBL1466517 & 688340 & 5.1 & 4.9456 & TRN \\
\hline CHEMBL1439318 & 688340 & 4.6 & 4.9447 & TRN \\
\hline CHEMBL1329826 & 688340 & 5.5 & 5.2554 & TRN \\
\hline CHEMBL3193706 & 688340 & 7.0 & 4.8323 & TRN \\
\hline CHEMBL1611223 & 688340 & 4.55 & 4.7466 & TRN \\
\hline CHEMBL1421913 & 688340 & 4.55 & 5.0679 & TRN \\
\hline CHEMBL3194097 & 688340 & 5.6 & 4.8676 & TRN \\
\hline CHEMBL1508847 & 688340 & 5.95 & 5.0809 & TRN \\
\hline CHEMBL1592834 & 688340 & 4.35 & 5.1143 & TRN \\
\hline CHEMBL1579664 & 688340 & 6.95 & 4.9684 & TRN \\
\hline CHEMBL1586928 & 688340 & 6.1 & 5.4572 & TRN \\
\hline CHEMBL1527994 & 688340 & 4.8 & 4.6427 & TRN \\
\hline CHEMBL1313283 & 688340 & 4.85 & 4.9699 & TST \\
\hline CHEMBL1521296 & 688340 & 5.0 & 4.8331 & TRN \\
\hline CHEMBL1325591 & 688340 & 4.35 & 4.8927 & TRN \\
\hline CHEMBL1550685 & 688340 & 5.25 & 4.7324 & TST \\
\hline CHEMBL1417082 & 688340 & 6.4 & 5.426 & TRN \\
\hline CHEMBL1536856 & 688340 & 4.5 & 4.5522 & TRN \\
\hline CHEMBL1603060 & 688340 & 4.95 & 5.6251 & TRN \\
\hline CHEMBL1449929 & 688340 & 4.95 & 4.8348 & TST \\
\hline CHEMBL1374573 & 688340 & 5.6 & 4.9992 & TRN \\
\hline CHEMBL1520863 & 688340 & 4.0 & 5.1377 & TRN \\
\hline CHEMBL1474084 & 688340 & 6.2 & 5.4016 & TRN \\
\hline CHEMBL1469594 & 688340 & 4.6 & 4.9167 & TRN \\
\hline
\end{tabular}




\begin{tabular}{|c|c|c|c|c|c|}
\hline \multicolumn{6}{|c|}{ plemental Table } \\
\hline CHEMBL1454267 & 688340 & 4.35 & 5.1341 & TST & \\
\hline CHEMBL1471583 & 688340 & 4.5 & 4.6638 & TRN & \\
\hline CHEMBL1465739 & 688340 & 4.55 & 4.8464 & TRN & \\
\hline CHEMBL1464773 & 688340 & 4.55 & 5.2017 & TRN & \\
\hline CHEMBL1347725 & 688340 & 5.7 & 5.4012 & TRN & \\
\hline CHEMBL1327279 & 688340 & 4.85 & 4.9625 & TRN & \\
\hline CHEMBL1423100 & 688340 & 5.2 & 5.2435 & TRN & \\
\hline CHEMBL1463529 & 688340 & 6.8499 & 4.6166 & TRN & \\
\hline CHEMBL1525676 & 688340 & 4.4 & 4.9076 & TRN & \\
\hline CHEMBL1552913 & 688340 & 4.5 & 4.6541 & TRN & \\
\hline CHEMBL1335494 & 688340 & 4.85 & 4.3495 & TRN & \\
\hline CHEMBL1408362 & 688340 & 5.35 & 5.1634 & TST & \\
\hline CHEMBL1382181 & 688340 & 5.0 & 5.045 & TRN & \\
\hline CHEMBL1594732 & 688340 & 6.3 & 5.0346 & TRN & \\
\hline CHEMBL1485363 & 688340 & 4.7 & 4.6895 & TRN & \\
\hline CHEMBL1611158 & 688340 & 5.0 & 5.2837 & TRN & \\
\hline CHEMBL1329283 & 688340 & 4.55 & 4.9124 & TRN & \\
\hline CHEMBL1567939 & 688340 & 5.25 & 4.8461 & TST & \\
\hline CHEMBL1318994 & 688340 & 5.95 & 5.2638 & TST & \\
\hline CHEMBL1560211 & 688340 & 4.4 & 4.9185 & TRN & \\
\hline CHEMBL1506360 & 688340 & 5.0 & 5.1755 & TRN & \\
\hline CHEMBL1605691 & 688340 & 4.85 & 5.03 & TST & \\
\hline CHEMBL3210571 & 688340 & 5.2 & 5.1614 & TST & \\
\hline CHEMBL 3208756 & 688340 & 4.35 & 5.301 & TST & \\
\hline CHEMBL1977867 & 688340 & 4.65 & 5.0919 & TRN & \\
\hline CHEMBL1602503 & 688340 & 5.05 & 5.4226 & TRN & \\
\hline CHEMBL1451752 & 688340 & 5.0 & 4.5485 & TRN & \\
\hline CHEMBL1598737 & 688340 & 5.55 & 5.11100 & 0000000001 & TRN \\
\hline CHEMBL1537076 & 688340 & 7.0501 & 4.9813 & TRN & \\
\hline CHEMBL1457207 & 688340 & 7.0 & 5.1788 & TST & \\
\hline CHEMBL1422439 & 688340 & 5.9 & 4.865 & TRN & \\
\hline CHEMBL1416215 & 688340 & 5.5 & 5.0764 & TST & \\
\hline CHEMBL 3197662 & 688340 & 4.4 & 4.8936 & TRN & \\
\hline CHEMBL1607799 & 688340 & 4.65 & 5.0818 & TST & \\
\hline CHEMBL1363249 & 688340 & 4.45 & 4.7689 & TRN & \\
\hline CHEMBL1478187 & 688340 & 4.55 & 4.6733 & TRN & \\
\hline CHEMBL1374916 & 688340 & 4.5 & 4.935 & TRN & \\
\hline CHEMBL1326689 & 688340 & 5.45 & 5.4553 & TRN & \\
\hline CHEMBL1435944 & 688340 & 4.4 & 5.3073 & TRN & \\
\hline CHEMBL1571717 & 688340 & 4.5 & 4.838 & TRN & \\
\hline CHEMBL1400269 & 688340 & 4.5 & 5.1146 & TRN & \\
\hline CHEMBL1579883 & 688340 & 5.2 & 5.4008 & TRN & \\
\hline CHEMBL1393972 & 688340 & 4.4 & 5.0844 & TRN & \\
\hline CHEMBL 1437526 & 688340 & 6.45 & 5.311 & TST & \\
\hline CHEMBL1377223 & 688340 & 4.5 & 5.0709 & TRN & \\
\hline CHEMBL1538753 & 688340 & 4.6 & 4.8416 & TRN & \\
\hline CHEMBL 264947 & 688340 & 5.4 & 5.6271 & TRN & \\
\hline CHEMBL1993929 & 688340 & 4.85 & 4.8187 & TST & \\
\hline
\end{tabular}




\begin{tabular}{|c|c|c|c|c|}
\hline \multicolumn{5}{|c|}{ Supplemental Table S2.txt } \\
\hline CHEMBL1367925 & 688340 & 4.85 & 4.6377 & TRN \\
\hline CHEMBL 3214388 & 688340 & 4.55 & 4.9291 & TRN \\
\hline CHEMBL1315969 & 688340 & 4.55 & 4.7832 & TRN \\
\hline CHEMBL1511755 & 688340 & 6.95 & 5.2492 & TRN \\
\hline CHEMBL1348142 & 688340 & 5.0 & 5.0687 & TRN \\
\hline CHEMBL1414291 & 688340 & 5.2 & 5.0281 & TST \\
\hline CHEMBL1542069 & 688340 & 5.2 & 4.7054 & TRN \\
\hline CHEMBL1509617 & 688340 & 4.7 & 4.8463 & TST \\
\hline CHEMBL1349666 & 688340 & 4.3 & 4.8064 & TRN \\
\hline CHEMBL19117 & 688340 & 4.45 & 4.8858 & TRN \\
\hline CHEMBL1343332 & 688340 & 4.4 & 5.3611 & TST \\
\hline CHEMBL 2004884 & 688340 & 5.2 & 4.8658 & TRN \\
\hline CHEMBL1518061 & 688340 & 4.65 & 5.2296 & TRN \\
\hline CHEMBL1496959 & 688340 & 4.85 & 4.8617 & TRN \\
\hline CHEMBL1391581 & 688340 & 6.1 & 5.0297 & TRN \\
\hline CHEMBL1335364 & 688340 & 4.55 & 4.8617 & TRN \\
\hline CHEMBL1483539 & 688340 & 5.0 & 5.0937 & TST \\
\hline CHEMBL1534110 & 688340 & 4.6 & 4.6789 & TRN \\
\hline CHEMBL1405694 & 688340 & 3.75 & 5.0557 & TST \\
\hline CHEMBL1420291 & 688340 & 4.6 & 5.0735 & TRN \\
\hline CHEMBL1556878 & 688340 & 6.15 & 5.3331 & TRN \\
\hline CHEMBL3211496 & 688340 & 7.1002 & 4.9243 & TST \\
\hline CHEMBL1535052 & 688340 & 5.5 & 5.0366 & TST \\
\hline CHEMBL1421702 & 688340 & 5.7 & 4.9326 & TST \\
\hline CHEMBL1596674 & 688340 & 5.0 & 4.8964 & TRN \\
\hline CHEMBL1306872 & 688340 & 6.95 & 4.9881 & TRN \\
\hline CHEMBL1306089 & 688340 & 4.4 & 4.8318 & TRN \\
\hline CHEMBL1401398 & 688340 & 4.4 & 5.083 & TRN \\
\hline CHEMBL317469 & 688340 & 4.9 & 5.0254 & TRN \\
\hline CHEMBL1364028 & 688340 & 5.25 & 5.3902 & TST \\
\hline CHEMBL1376492 & 688340 & 4.55 & 4.8717 & TRN \\
\hline CHEMBL1573400 & 688340 & 5.2 & 5.1943 & TRN \\
\hline CHEMBL1601173 & 688340 & 7.1002 & 5.1983 & TRN \\
\hline CHEMBL1560871 & 688340 & 4.4 & 5.1489 & TRN \\
\hline CHEMBL1592664 & 688340 & 4.5 & 4.9246 & TRN \\
\hline CHEMBL1433066 & 688340 & 4.95 & 5.2852 & TST \\
\hline CHEMBL362919 & 688340 & 4.5 & 4.9577 & TST \\
\hline CHEMBL1503548 & 688340 & 4.55 & 4.8533 & TRN \\
\hline CHEMBL1539861 & 688340 & 5.15 & 5.3116 & TRN \\
\hline CHEMBL1417799 & 688340 & 5.5 & 5.2851 & TRN \\
\hline CHEMBL1607514 & 688340 & 4.6 & 4.9148 & TRN \\
\hline CHEMBL1605270 & 688340 & 6.0 & 5.3548 & TRN \\
\hline CHEMBL1328588 & 688340 & 4.6 & 5.2671 & TRN \\
\hline CHEMBL1398964 & 688340 & 6.0 & 4.6951 & TRN \\
\hline CHEMBL1380613 & 688340 & 4.5 & 4.7976 & TST \\
\hline CHEMBL1443442 & 688340 & 4.65 & 4.8067 & TRN \\
\hline CHEMBL1349027 & 688340 & 6.95 & 4.91 & TRN \\
\hline CHEMBL1519401 & 688340 & 4.4 & 5.2462 & TRN \\
\hline
\end{tabular}




\begin{tabular}{|c|c|c|c|c|c|}
\hline & & & & & \\
\hline CHEMBL1545939 & 688340 & 4.4 & 5.3551 & TST & \\
\hline CHEMBL1509676 & 688340 & 5.2 & 4.7364 & TRN & \\
\hline CHEMBL1554653 & 688340 & 4.4 & 5.0656 & TRN & \\
\hline CHEMBL1560833 & 688340 & 5.5 & 4.8467 & TRN & \\
\hline CHEMBL1346772 & 688340 & 5.75 & 5.57799 & 9999999999 & TRN \\
\hline CHEMBL1492595 & 688340 & 5.15 & 5.1872 & TST & \\
\hline CHEMBL1988767 & 688340 & 4.4 & 4.4052 & TRN & \\
\hline CHEMBL1496996 & 688340 & 5.85 & 5.3302 & TST & \\
\hline CHEMBL1470733 & 688340 & 5.55 & 4.9741 & TRN & \\
\hline CHEMBL1358716 & 688340 & 5.85 & 5.5784 & TRN & \\
\hline CHEMBL1338419 & 688340 & 4.55 & 4.7357 & TRN & \\
\hline CHEMBL1455740 & 688340 & 5.25 & 5.4035 & TRN & \\
\hline CHEMBL1345994 & 688340 & 4.65 & 5.1029 & TRN & \\
\hline CHEMBL1368512 & 688340 & 3.9 & 4.7569 & TST & \\
\hline CHEMBL1483832 & 688340 & 4.55 & 4.9279 & TRN & \\
\hline CHEMBL1606688 & 688340 & 5.95 & 4.8892 & TST & \\
\hline CHEMBL1313372 & 688340 & 4.4 & 5.2357 & TRN & \\
\hline CHEMBL1571801 & 688340 & 5.4 & 4.8166 & TRN & \\
\hline CHEMBL3195322 & 688340 & 5.2 & 4.6222 & TRN & \\
\hline CHEMBL1579284 & 688340 & 4.55 & 4.9832 & TRN & \\
\hline CHEMBL1301923 & 688340 & 5.2 & 5.1394 & TST & \\
\hline CHEMBL1372190 & 688340 & 3.8 & 4.6369 & TST & \\
\hline CHEMBL1503382 & 688340 & 6.5 & 5.0949 & TRN & \\
\hline CHEMBL1598785 & 688340 & 4.4 & 4.4462 & TRN & \\
\hline CHEMBL1587715 & 688340 & 5.0 & 4.7806 & TRN & \\
\hline CHEMBL1514095 & 688340 & 5.35 & 5.2355 & TRN & \\
\hline CHEMBL1578515 & 688340 & 4.4 & 4.9818 & TRN & \\
\hline CHEMBL1565856 & 688340 & 4.4 & 5.301 & TRN & \\
\hline CHEMBL1425287 & 688340 & 5.2 & 5.2706 & TST & \\
\hline CHEMBL1457115 & 688340 & 4.85 & 5.2159 & TRN & \\
\hline CHEMBL1391362 & 688340 & 4.6 & 5.2162 & TRN & \\
\hline CHEMBL1587685 & 688340 & 5.2 & 5.294 & TRN & \\
\hline CHEMBL1474221 & 688340 & 8.4949 & 5.4871 & TRN & \\
\hline CHEMBL1527752 & 688340 & 4.85 & 4.8679 & TST & \\
\hline CHEMBL1384014 & 688340 & 4.4 & 4.7271 & TRN & \\
\hline CHEMBL3211140 & 688340 & 4.8 & 5.0557 & TRN & \\
\hline CHEMBL1300395 & 688340 & 4.4 & 4.8821 & TST & \\
\hline CHEMBL1522373 & 688340 & 5.5 & 4.8218 & TRN & \\
\hline CHEMBL1538360 & 688340 & 4.75 & 4.8313 & TST & \\
\hline CHEMBL1424486 & 688340 & 4.4 & 4.6332 & TRN & \\
\hline CHEMBL1586599 & 688340 & 4.75 & 4.5067 & TST & \\
\hline CHEMBL1493537 & 688340 & 5.7 & 5.3255 & TRN & \\
\hline CHEMBL3199509 & 688340 & 4.6 & 5.2599 & TRN & \\
\hline CHEMBL1313434 & 688340 & 4.5 & 5.2441 & TRN & \\
\hline CHEMBL1586499 & 688340 & 4.55 & 5.3134 & TST & \\
\hline CHEMBL1509159 & 688340 & 5.7 & 5.1607 & TRN & \\
\hline CHEMBL1393605 & 688340 & 4.6 & 4.86600 & 20000000005 & TRN \\
\hline CHEMBL1465375 & 688340 & 6.05 & 5.3319 & TST & \\
\hline & & & & 28264 & \\
\hline
\end{tabular}




\begin{tabular}{|c|c|c|c|c|c|}
\hline \multicolumn{6}{|c|}{ Supplemental Table S2.txt } \\
\hline CHEMBL1482750 & 688340 & 5.05 & 4.7942 & TST & \\
\hline CHEMBL1369150 & 688340 & 4.5 & 5.0726 & TST & \\
\hline CHEMBL1446805 & 688340 & 4.45 & 4.7606 & TRN & \\
\hline CHEMBL1562870 & 688340 & 4.5 & 5.2912 & TRN & \\
\hline CHEMBL1325000 & 688340 & 6.95 & 5.1299 & TST & \\
\hline CHEMBL1611070 & 688340 & 7.0 & 4.9392 & TST & \\
\hline CHEMBL1590421 & 688340 & 4.7 & 4.6493 & TRN & \\
\hline CHEMBL1575904 & 688340 & 5.05 & 4.5589 & TST & \\
\hline CHEMBL1406354 & 688340 & 6.7001 & 5.4453 & TRN & \\
\hline CHEMBL504977 & 688340 & 4.55 & 4.7136 & TRN & \\
\hline CHEMBL1524564 & 688340 & 4.55 & 4.9714 & TRN & \\
\hline CHEMBL1461928 & 688340 & 4.7 & 5.1494 & TRN & \\
\hline CHEMBL1379384 & 688340 & 4.65 & 5.0097 & TRN & \\
\hline CHEMBL1380958 & 688340 & 4.95 & 4.9592 & TRN & \\
\hline CHEMBL22062 & 688340 & 4.65 & 4.9384 & TRN & \\
\hline CHEMBL1518015 & 688340 & 4.4 & 4.9763 & TST & \\
\hline CHEMBL1377148 & 688340 & 4.5 & 5.0171 & TRN & \\
\hline CHEMBL1438476 & 688340 & 4.65 & 4.7717 & TRN & \\
\hline CHEMBL1447756 & 688340 & 3.0 & 4.8132 & TRN & \\
\hline CHEMBL1417026 & 688340 & 4.45 & 5.0296 & TRN & \\
\hline CHEMBL1611821 & 688340 & 6.5 & 5.2918 & TRN & \\
\hline CHEMBL1597805 & 688340 & 5.05 & 4.5431 & TST & \\
\hline CHEMBL1471193 & 688340 & 4.5 & 4.5037 & TRN & \\
\hline CHEMBL1445725 & 688340 & 4.7 & 4.8525 & TRN & \\
\hline CHEMBL1411396 & 688340 & 4.5 & 4.8132 & TRN & \\
\hline CHEMBL1971142 & 688340 & 6.05 & 5.0471 & TRN & \\
\hline CHEMBL1540045 & 688340 & 5.0 & 5.2087 & TRN & \\
\hline CHEMBL1386851 & 688340 & 4.6 & 4.8946 & TST & \\
\hline CHEMBL1440661 & 688340 & 4.75 & 4.8326 & TRN & \\
\hline CHEMBL1556741 & 688340 & 6.45 & 5.3604 & TRN & \\
\hline CHEMBL1604802 & 688340 & 4.6 & 4.8306 & TRN & \\
\hline CHEMBL1558120 & 688340 & 7.0 & 5.1849 & TST & \\
\hline CHEMBL1564952 & 688340 & 5.4 & 5.5183 & TRN & \\
\hline CHEMBL1407368 & 688340 & 4.4 & 5.0848 & TRN & \\
\hline CHEMBL1374762 & 688340 & 5.05 & 5.2211 & TRN & \\
\hline CHEMBL1357923 & 688340 & 5.2 & 5.0664 & TRN & \\
\hline CHEMBL1484234 & 688340 & 4.55 & 4.9032 & TST & \\
\hline CHEMBL1529425 & 688340 & 4.5 & 4.6597 & TRN & \\
\hline CHEMBL1581739 & 688340 & 7.4001 & 5.0018 & TST & \\
\hline CHEMBL1555517 & 688340 & 4.75 & 5.0355 & TRN & \\
\hline CHEMBL3190763 & 688340 & 5.5 & 5.1385 & TRN & \\
\hline CHEMBL3198301 & 688340 & 4.4 & 4.9684 & TRN & \\
\hline CHEMBL1545240 & 688340 & 4.75 & 4.8641 & TRN & \\
\hline CHEMBL3194354 & 688340 & 4.65 & 4.605 & TST & \\
\hline CHEMBL1587620 & 688340 & 4.55 & 4.6528 & TRN & \\
\hline CHEMBL1364869 & 688340 & 4.6 & 5.1263 & TST & \\
\hline CHEMBL1494946 & 688340 & 4.4 & 5.2013 & TRN & \\
\hline CHEMBL1429171 & 688340 & 4.45 & 4.45100 & 00000000005 & TRN \\
\hline & & & & 28265 & \\
\hline
\end{tabular}




\begin{tabular}{|c|c|c|c|c|}
\hline \multirow[b]{2}{*}{ CHEMBL1448834 } & \multicolumn{4}{|c|}{ Supplemental Table S2.txt } \\
\hline & 688340 & 4.4 & 5.0997 & TST \\
\hline CHEMBL1592853 & 688340 & 5.25 & 5.1422 & TST \\
\hline CHEMBL1541408 & 688340 & 4.6 & 4.9163 & TRN \\
\hline CHEMBL1522879 & 688340 & 4.5 & 5.3792 & TRN \\
\hline CHEMBL1557484 & 688340 & 4.4 & 4.7344 & TRN \\
\hline CHEMBL1463457 & 688340 & 5.25 & 4.832 & TRN \\
\hline CHEMBL1472954 & 688340 & 4.4 & 4.8598 & TRN \\
\hline CHEMBL1489943 & 688340 & 4.4 & 4.7799 & TST \\
\hline CHEMBL1341205 & 688340 & 4.6 & 5.6501 & TST \\
\hline CHEMBL1496129 & 688340 & 4.95 & 5.2127 & TRN \\
\hline CHEMBL1581427 & 688340 & 4.5 & 5.2226 & TST \\
\hline CHEMBL1568665 & 688340 & 4.45 & 5.0662 & TRN \\
\hline CHEMBL1358512 & 688340 & 5.15 & 5.5013 & TST \\
\hline CHEMBL1459277 & 688340 & 5.2 & 5.0183 & TRN \\
\hline CHEMBL591598 & 688340 & 5.3 & 4.7393 & TRN \\
\hline CHEMBL1606297 & 688340 & 4.5 & 5.4355 & TRN \\
\hline CHEMBL1551077 & 688340 & 6.9 & 5.8007 & TRN \\
\hline CHEMBL 3195461 & 688340 & 4.5 & 4.6895 & TRN \\
\hline CHEMBL1437334 & 688340 & 4.6 & 5.2175 & TST \\
\hline CHEMBL1564306 & 688340 & 5.45 & 4.8452 & TST \\
\hline CHEMBL1605654 & 688340 & 4.0 & 5.1794 & TRN \\
\hline CHEMBL1387110 & 688340 & 7.5498 & 4.9346 & TST \\
\hline CHEMBL1485447 & 688340 & 5.55 & 4.9867 & TRN \\
\hline CHEMBL1587868 & 688340 & 5.5 & 4.9484 & TRN \\
\hline CHEMBL1417168 & 688340 & 4.8 & 5.0215 & TRN \\
\hline CHEMBL1420010 & 688340 & 4.4 & 5.1674 & TST \\
\hline CHEMBL3191039 & 688340 & 4.4 & 4.9145 & TRN \\
\hline CHEMBL1360080 & 688340 & 4.6 & 5.1506 & TST \\
\hline CHEMBL1439895 & 688340 & 4.5 & 4.9817 & TRN \\
\hline CHEMBL1565385 & 688340 & 5.5 & 4.8304 & TST \\
\hline CHEMBL1374016 & 688340 & 4.5 & 4.9245 & TRN \\
\hline CHEMBL1499578 & 688340 & 5.4 & 5.11 & TST \\
\hline CHEMBL3209612 & 688340 & 4.35 & 4.9882 & TRN \\
\hline CHEMBL1505129 & 688340 & 4.5 & 5.3222 & TRN \\
\hline CHEMBL1598874 & 688340 & 5.2 & 4.8082 & TRN \\
\hline CHEMBL1485835 & 688340 & 4.5 & 5.0255 & TST \\
\hline CHEMBL1441165 & 688340 & 7.0 & 5.1618 & TRN \\
\hline CHEMBL1454215 & 688340 & 4.75 & 5.035 & TRN \\
\hline CHEMBL1406195 & 688340 & 5.5 & 5.073 & TRN \\
\hline CHEMBL1564743 & 688340 & 4.65 & 4.9126 & TRN \\
\hline CHEMBL1384553 & 688340 & 4.6 & 5.5463 & TST \\
\hline CHEMBL1312353 & 688340 & 5.05 & 4.886 & TRN \\
\hline CHEMBL3197491 & 688340 & 4.65 & 4.6264 & TRN \\
\hline CHEMBL1566068 & 688340 & 4.45 & 4.4747 & TRN \\
\hline CHEMBL 1451342 & 688340 & 5.2 & 5.2964 & TRN \\
\hline CHEMBL1318764 & 688340 & 5.05 & 5.0555 & TRN \\
\hline CHEMBL1351405 & 688340 & 7.5003 & 5.5644 & TRN \\
\hline CHEMBL1403089 & 688340 & 4.6 & 4.9384 & TRN \\
\hline
\end{tabular}




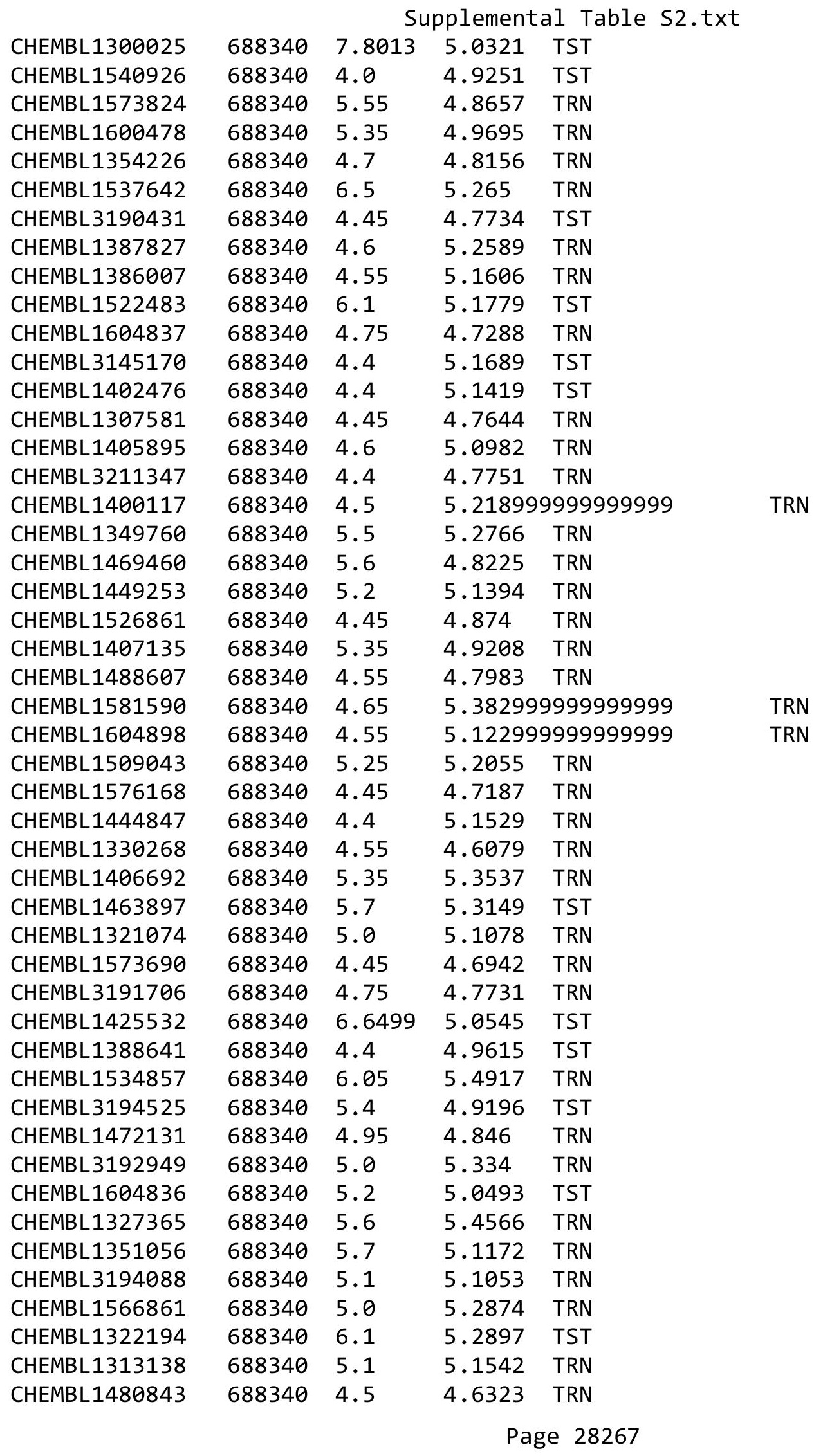




\begin{tabular}{|c|c|c|c|c|c|}
\hline \multicolumn{6}{|c|}{ Supplemental Table S2.txt } \\
\hline CHEMBL1416056 & 688340 & 4.55 & 5.0094 & TST & \\
\hline CHEMBL1412206 & 688340 & 7.0501 & 5.1775 & TRN & \\
\hline CHEMBL1321932 & 688340 & 4.55 & 4.7715 & TRN & \\
\hline CHEMBL1418962 & 688340 & 4.55 & 4.6078 & TRN & \\
\hline CHEMBL1998001 & 688340 & 5.2 & 4.6803 & TRN & \\
\hline CHEMBL1327255 & 688340 & 4.5 & 4.98 & TRN & \\
\hline CHEMBL1474037 & 688340 & 4.7 & 4.8564 & TRN & \\
\hline CHEMBL1575911 & 688340 & 4.4 & 4.6608 & TRN & \\
\hline CHEMBL1319488 & 688340 & 4.55 & 4.5616 & TRN & \\
\hline CHEMBL1520275 & 688340 & 5.2 & 4.9171 & TRN & \\
\hline CHEMBL1325440 & 688340 & 5.8 & 4.8526 & TRN & \\
\hline CHEMBL1361876 & 688340 & 6.1 & 5.2768 & TRN & \\
\hline CHEMBL1327372 & 688340 & 5.95 & 5.2039 & TRN & \\
\hline CHEMBL1423897 & 688340 & 7.0501 & 5.1681 & TST & \\
\hline CHEMBL1389669 & 688340 & 5.5 & 4.9357 & TRN & \\
\hline CHEMBL1517569 & 688340 & 4.5 & 5.1081 & TST & \\
\hline CHEMBL1485816 & 688340 & 6.2 & 5.0633 & TRN & \\
\hline CHEMBL1529187 & 688340 & 5.25 & 5.5135 & TRN & \\
\hline CHEMBL1455924 & 688340 & 4.4 & 5.3647 & TRN & \\
\hline CHEMBL1461246 & 688340 & 5.15 & 5.0043 & TRN & \\
\hline CHEMBL1526729 & 688340 & 4.65 & 4.6536 & TST & \\
\hline CHEMBL1309723 & 688340 & 5.5 & 5.1458 & TRN & \\
\hline CHEMBL1598423 & 688340 & 4.6 & 5.2753 & TRN & \\
\hline CHEMBL1299717 & 688340 & 5.1 & 5.004 & TRN & \\
\hline CHEMBL1500840 & 688340 & 4.5 & 4.9082 & TRN & \\
\hline CHEMBL1538140 & 688340 & 4.55 & 4.8824 & TRN & \\
\hline CHEMBL1587544 & 688340 & 4.75 & 4.8969 & TRN & \\
\hline CHEMBL1572534 & 688340 & 4.6 & 4.7757 & TRN & \\
\hline CHEMBL1545664 & 688340 & 4.45 & 4.8349 & TRN & \\
\hline CHEMBL1396399 & 688340 & 4.7 & 5.13299 & 9999999999 & TRN \\
\hline CHEMBL1552905 & 688340 & 4.7 & 5.2503 & TRN & \\
\hline CHEMBL1537659 & 688340 & 4.1 & 4.7636 & TRN & \\
\hline CHEMBL1321457 & 688340 & 4.4 & 4.9702 & TRN & \\
\hline CHEMBL3196094 & 688340 & 4.55 & 4.8163 & TRN & \\
\hline CHEMBL1418596 & 688340 & 4.55 & 5.2186 & TST & \\
\hline CHEMBL1360930 & 688340 & 8.0506 & 5.2359 & TRN & \\
\hline CHEMBL1491137 & 688340 & 4.6 & 5.2949 & TRN & \\
\hline CHEMBL1332961 & 688340 & 4.5 & 4.9549 & TRN & \\
\hline CHEMBL1305610 & 688340 & 4.4 & 5.1911 & TRN & \\
\hline CHEMBL3214589 & 688340 & 5.5 & 4.9569 & TST & \\
\hline CHEMBL1459974 & 688340 & 5.25 & 5.4637 & TST & \\
\hline CHEMBL1575701 & 688340 & 4.6 & 4.9827 & TST & \\
\hline CHEMBL1335302 & 688340 & 4.4 & 5.3966 & TRN & \\
\hline CHEMBL1580967 & 688340 & 6.15 & 5.2746 & TRN & \\
\hline CHEMBL1303477 & 688340 & 4.55 & 4.8013 & TRN & \\
\hline CHEMBL1417011 & 688340 & 4.45 & 5.3941 & TRN & \\
\hline CHEMBL1377266 & 688340 & 4.45 & 5.1521 & TST & \\
\hline CHEMBL1413557 & 688340 & 4.5 & 4.7942 & TRN & \\
\hline
\end{tabular}




\begin{tabular}{|c|c|c|c|c|c|}
\hline \\
\hline CHEMBL1608199 & 688340 & 4.5 & 5.0397 & TRN & \\
\hline CHEMBL1494318 & 688340 & 4.5 & 5.0279 & TST & \\
\hline CHEMBL1472648 & 688340 & 5.2 & 4.9927 & TST & \\
\hline CHEMBL1375934 & 688340 & 4.5 & 4.9797 & TRN & \\
\hline CHEMBL1486686 & 688340 & 4.4 & 5.0258 & TRN & \\
\hline CHEMBL1315692 & 688340 & 4.8 & 4.8024 & TRN & \\
\hline CHEMBL1491911 & 688340 & 4.7 & 4.5773 & TST & \\
\hline CHEMBL1306065 & 688340 & 4.6 & 4.7115 & TRN & \\
\hline CHEMBL1391706 & 688340 & 4.65 & 5.224 & TRN & \\
\hline CHEMBL1323459 & 688340 & 4.6 & 4.9077 & TRN & \\
\hline CHEMBL1435087 & 688340 & 6.05 & 5.6769 & TRN & \\
\hline CHEMBL3194671 & 688340 & 4.5 & 4.922 & TST & \\
\hline CHEMBL1565636 & 688340 & 4.5 & 5.2277 & TRN & \\
\hline CHEMBL1373282 & 688340 & 4.6 & 5.0388 & TST & \\
\hline CHEMBL1448607 & 688340 & 4.4 & 5.1604 & TST & \\
\hline CHEMBL1601752 & 688340 & 4.6 & 4.9598 & TST & \\
\hline CHEMBL1342307 & 688340 & 6.5 & 5.1655 & TRN & \\
\hline CHEMBL3198585 & 688340 & 4.4 & 4.8253 & TRN & \\
\hline CHEMBL1403023 & 688340 & 5.6 & 5.2221 & TRN & \\
\hline CHEMBL1392310 & 688340 & 4.6 & 5.05699 & э9999999995 & TRN \\
\hline CHEMBL1344969 & 688340 & 4.85 & 5.0093 & TRN & \\
\hline CHEMBL1502443 & 688340 & 4.55 & 4.9443 & TRN & \\
\hline CHEMBL1599215 & 688340 & 4.55 & 5.2002 & TRN & \\
\hline CHEMBL1352493 & 688340 & 4.55 & 4.7317 & TRN & \\
\hline CHEMBL1306943 & 688340 & 4.5 & 4.8522 & TST & \\
\hline CHEMBL1323744 & 688340 & 4.9 & 4.6864 & TRN & \\
\hline CHEMBL1466087 & 688340 & 4.55 & 5.011 & TRN & \\
\hline CHEMBL1461822 & 688340 & 4.9 & 5.2113 & TST & \\
\hline CHEMBL1329621 & 688340 & 4.55 & 5.1404 & TRN & \\
\hline CHEMBL1509343 & 688340 & 7.0 & 4.8694 & TRN & \\
\hline CHEMBL1457407 & 688340 & 4.45 & 5.002 & TRN & \\
\hline CHEMBL1416235 & 688340 & 4.45 & 4.857 & TRN & \\
\hline CHEMBL1448387 & 688340 & 6.0 & 5.1498 & TST & \\
\hline CHEMBL1448233 & 688340 & 4.6 & 5.2848 & TRN & \\
\hline CHEMBL1491172 & 688340 & 5.35 & 5.428 & TRN & \\
\hline CHEMBL1374632 & 688340 & 7.0 & 5.1634 & TRN & \\
\hline CHEMBL1348355 & 688340 & 5.8 & 5.0775 & TRN & \\
\hline CHEMBL1370028 & 688340 & 5.15 & 4.9397 & TRN & \\
\hline CHEMBL1300209 & 688340 & 4.5 & 5.0488 & TST & \\
\hline CHEMBL1586067 & 688340 & 5.0 & 4.8139 & TRN & \\
\hline CHEMBL1302985 & 688340 & 5.05 & 4.9825 & TRN & \\
\hline CHEMBL1551718 & 688340 & 4.4 & 5.0061 & TRN & \\
\hline CHEMBL1423904 & 688340 & 4.45 & 5.1617 & TRN & \\
\hline CHEMBL1316676 & 688340 & 6.5 & 5.4473 & TRN & \\
\hline CHEMBL 2003808 & 688340 & 4.55 & 4.7782 & TRN & \\
\hline CHEMBL1352182 & 688340 & 4.4 & 5.1902 & TRN & \\
\hline CHEMBL1521059 & 688340 & 5.2 & 5.1749 & TRN & \\
\hline CHEMBL1384158 & 688340 & 4.4 & 4.6361 & TRN & \\
\hline
\end{tabular}




\begin{tabular}{|c|c|c|c|c|c|}
\hline \multicolumn{6}{|c|}{ Supplemental Table S2.txt } \\
\hline CHEMBL1426999 & 688340 & 6.15 & 5.2087 & TRN & \\
\hline CHEMBL1497249 & 688340 & 5.15 & 5.2248 & TRN & \\
\hline CHEMBL1299317 & 688340 & 7.0 & 5.4466 & TRN & \\
\hline CHEMBL1475392 & 688340 & 6.95 & 5.3906 & TRN & \\
\hline CHEMBL1468781 & 688340 & 6.3 & 5.3374 & TST & \\
\hline CHEMBL1470322 & 688340 & 5.8 & 5.141 & TRN & \\
\hline CHEMBL1453291 & 688340 & 5.45 & 4.9425 & TRN & \\
\hline CHEMBL1434433 & 688340 & 6.15 & 4.9318 & TRN & \\
\hline CHEMBL1504543 & 688340 & 5.15 & 5.1605 & TRN & \\
\hline CHEMBL1337908 & 688340 & 4.9 & 5.1406 & TRN & \\
\hline CHEMBL1497459 & 688340 & 4.45 & 5.151 & TST & \\
\hline CHEMBL1547217 & 688340 & 4.4 & 4.8762 & TRN & \\
\hline CHEMBL1349471 & 688340 & 5.5 & 4.6588 & TST & \\
\hline CHEMBL1996233 & 688340 & 4.45 & 4.7866 & TRN & \\
\hline CHEMBL1458711 & 688340 & 5.3 & 5.3735 & TRN & \\
\hline CHEMBL1439750 & 688340 & 4.7 & 4.8943 & TRN & \\
\hline CHEMBL1478150 & 688340 & 6.4 & 5.2208 & TRN & \\
\hline CHEMBL1350615 & 688340 & 5.0 & 4.8645 & TRN & \\
\hline CHEMBL1393655 & 688340 & 4.75 & 5.1047 & TRN & \\
\hline CHEMBL1477671 & 688340 & 4.4 & 5.11600 & 20000000005 & TST \\
\hline CHEMBL1563823 & 688340 & 4.8 & 4.9371 & TST & \\
\hline CHEMBL1341419 & 688340 & 4.7 & 5.0739 & TRN & \\
\hline CHEMBL454211 & 688340 & 4.45 & 4.9385 & TRN & \\
\hline CHEMBL1380452 & 688340 & 4.55 & 4.8536 & TRN & \\
\hline CHEMBL1410180 & 688340 & 5.4 & 5.1692 & TRN & \\
\hline CHEMBL1322829 & 688340 & 4.6 & 5.2934 & TRN & \\
\hline CHEMBL1489217 & 688340 & 4.55 & 4.9486 & TST & \\
\hline CHEMBL1593726 & 688340 & 4.4 & 5.2528 & TRN & \\
\hline CHEMBL1442665 & 688340 & 5.5 & 4.92399 & 99999999995 & TRN \\
\hline CHEMBL1312922 & 688340 & 6.25 & 4.998 & TST & \\
\hline CHEMBL1478371 & 688340 & 7.0 & 5.2558 & TRN & \\
\hline CHEMBL1447458 & 688340 & 7.0 & 5.0787 & TRN & \\
\hline CHEMBL1395733 & 688340 & 4.5 & 4.8514 & TRN & \\
\hline CHEMBL1469124 & 688340 & 4.45 & 5.2075 & TST & \\
\hline CHEMBL1574631 & 688340 & 4.35 & 4.8899 & TRN & \\
\hline CHEMBL1526955 & 688340 & 4.5 & 4.96399 & 99999999995 & TST \\
\hline CHEMBL 1450380 & 688340 & 4.5 & 4.7617 & TRN & \\
\hline CHEMBL1406615 & 688340 & 4.65 & 4.9017 & TRN & \\
\hline CHEMBL1377208 & 688340 & 4.55 & 4.9862 & TRN & \\
\hline CHEMBL1549103 & 688340 & 6.15 & 5.0327 & TRN & \\
\hline CHEMBL3190951 & 688340 & 5.0 & 5.0218 & TRN & \\
\hline CHEMBL1580558 & 688340 & 5.25 & 4.9192 & TST & \\
\hline CHEMBL1336082 & 688340 & 4.4 & 4.803 & TRN & \\
\hline CHEMBL1455839 & 688340 & 4.5 & 4.8368 & TST & \\
\hline CHEMBL1535315 & 688340 & 4.75 & 5.056 & TRN & \\
\hline CHEMBL1307729 & 688340 & 4.45 & 5.023 & TRN & \\
\hline CHEMBL1479544 & 688340 & 5.4 & 5.4522 & TRN & \\
\hline CHEMBL1392538 & 688340 & 4.5 & 5.1024 & TRN & \\
\hline
\end{tabular}




\begin{tabular}{|c|c|c|c|c|}
\hline \multicolumn{5}{|c|}{ Supplemental Table s2.txt } \\
\hline CHEMBL1354505 & 688340 & 4.7 & 5.2716 & TRN \\
\hline CHEMBL1498393 & 688340 & 4.7 & 4.7668 & TRN \\
\hline CHEMBL1323935 & 688340 & 4.65 & 4.6329 & TRN \\
\hline CHEMBL3198961 & 688340 & 4.75 & 4.7411 & TRN \\
\hline CHEMBL1491546 & 688340 & 5.4 & 5.3354 & TST \\
\hline CHEMBL1596139 & 688340 & 4.45 & 5.1816 & TRN \\
\hline CHEMBL1422976 & 688340 & 5.5 & 4.9814 & TRN \\
\hline CHEMBL1358008 & 688340 & 4.75 & 4.8011 & TRN \\
\hline CHEMBL1479272 & 688340 & 4.75 & 4.7866 & TRN \\
\hline CHEMBL1411534 & 688340 & 4.6 & 4.9967 & TRN \\
\hline CHEMBL1354173 & 688340 & 4.55 & 4.787 & TRN \\
\hline CHEMBL1331439 & 688340 & 4.7 & 4.8765 & TRN \\
\hline CHEMBL1968316 & 688340 & 4.85 & 4.8672 & TRN \\
\hline CHEMBL1463062 & 688340 & 4.9 & 5.4039 & TST \\
\hline CHEMBL1325399 & 688340 & 3.25 & 4.7899 & TST \\
\hline CHEMBL1577830 & 688340 & 6.35 & 5.5399 & TRN \\
\hline CHEMBL463563 & 688340 & 4.85 & 5.0196 & TST \\
\hline CHEMBL1540581 & 688340 & 4.4 & 4.8029 & TRN \\
\hline CHEMBL1455361 & 688340 & 5.4 & 4.8594 & TRN \\
\hline CHEMBL1419995 & 688340 & 6.45 & 4.9197 & TST \\
\hline CHEMBL1576587 & 688340 & 4.8 & 4.8576 & TRN \\
\hline CHEMBL1410381 & 688340 & 5.4 & 4.6521 & TRN \\
\hline CHEMBL3196003 & 688340 & 5.25 & 4.9859 & TRN \\
\hline CHEMBL1360902 & 688340 & 7.0501 & 5.0618 & TRN \\
\hline CHEMBL1493763 & 688340 & 4.45 & 5.2469 & TRN \\
\hline CHEMBL173530 & 688340 & 4.5 & 5.0898 & TRN \\
\hline CHEMBL1419497 & 688340 & 4.45 & 5.0489 & TRN \\
\hline CHEMBL1345147 & 688340 & 4.55 & 4.819 & TRN \\
\hline CHEMBL1477926 & 688340 & 5.4 & 4.6966 & TRN \\
\hline CHEMBL1598489 & 688340 & 7.0501 & 5.1424 & TST \\
\hline CHEMBL1587684 & 688340 & 5.05 & 5.295 & TRN \\
\hline CHEMBL1357201 & 688340 & 4.0 & 5.2319 & TRN \\
\hline CHEMBL1412368 & 688340 & 5.25 & 5.1009 & TST \\
\hline CHEMBL1367346 & 688340 & 5.45 & 5.4961 & TRN \\
\hline CHEMBL1545122 & 688340 & 5.45 & 4.8504 & TST \\
\hline CHEMBL1309258 & 688340 & 4.6 & 4.8436 & TRN \\
\hline CHEMBL1359877 & 688340 & 5.3 & 5.0881 & TRN \\
\hline CHEMBL1368792 & 688340 & 4.45 & 4.882 & TRN \\
\hline CHEMBL3189562 & 688340 & 5.95 & 4.6866 & TRN \\
\hline CHEMBL1612042 & 688340 & 5.35 & 4.6558 & TRN \\
\hline CHEMBL1606510 & 688340 & 4.45 & 4.9477 & TST \\
\hline CHEMBL1569851 & 688340 & 4.55 & 4.671 & TRN \\
\hline CHEMBL1420318 & 688340 & 4.6 & 4.8309 & TRN \\
\hline CHEMBL1417203 & 688340 & 4.4 & 4.9493 & TRN \\
\hline CHEMBL1578271 & 688340 & 4.4 & $5.1270 e$ & 0000000001 \\
\hline CHEMBL1318116 & 688340 & 4.4 & 5.065 & TRN \\
\hline CHEMBL1402532 & 688340 & 5.55 & 5.0912 & TST \\
\hline CHEMBL1362824 & 688340 & 4.4 & 4.987 & TRN \\
\hline
\end{tabular}




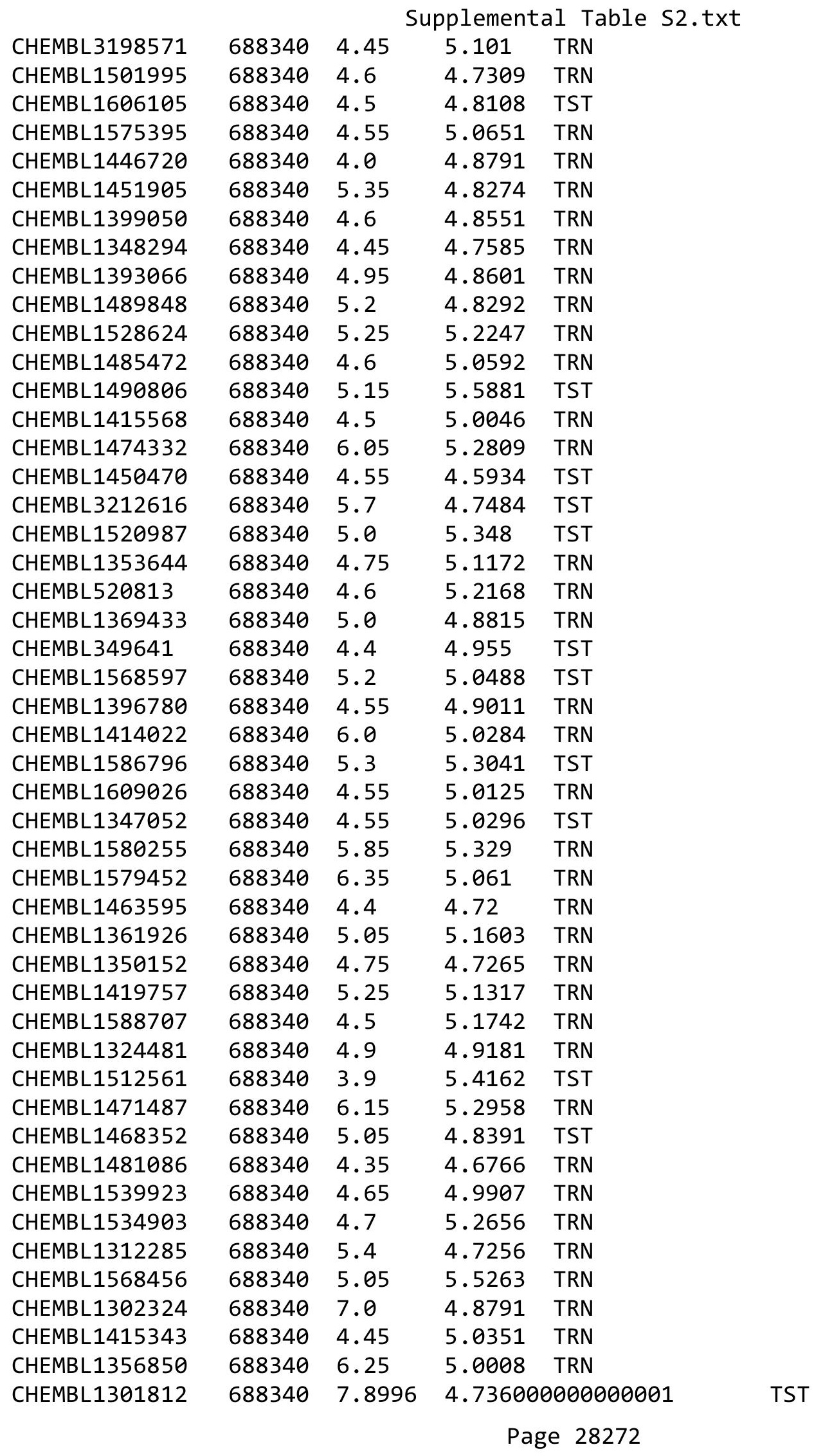




\begin{tabular}{|c|c|c|c|c|}
\hline \multicolumn{5}{|c|}{ Supplemental Table S2.txt } \\
\hline CHEMBL1494656 & 688340 & 4.55 & 4.757 & TRN \\
\hline CHEMBL1561817 & 688340 & 4.55 & 4.7524 & TRN \\
\hline CHEMBL1303302 & 688340 & 4.4 & 5.1746 & TRN \\
\hline CHEMBL1523528 & 688340 & 4.75 & 4.8434 & TRN \\
\hline CHEMBL1306268 & 688340 & 5.6 & 4.9856 & TRN \\
\hline CHEMBL1521909 & 688340 & 4.55 & 4.7459 & TRN \\
\hline CHEMBL1522627 & 688340 & 6.15 & 5.2805 & TRN \\
\hline CHEMBL1814509 & 688340 & 4.5 & 4.6883 & TRN \\
\hline CHEMBL1337788 & 688340 & 6.45 & 5.0348 & TRN \\
\hline CHEMBL131871 & 688340 & 4.8 & 4.7273 & TRN \\
\hline CHEMBL1362276 & 688340 & 4.55 & 4.8723 & TRN \\
\hline CHEMBL1988401 & 688340 & 5.2 & 4.9464 & TST \\
\hline CHEMBL1549300 & 688340 & 5.3 & 5.2321 & TRN \\
\hline CHEMBL1374689 & 688340 & 6.25 & 5.0473 & TRN \\
\hline CHEMBL1600011 & 688340 & 4.55 & 4.5866 & TRN \\
\hline CHEMBL1489604 & 688340 & 5.7 & 5.2336 & TST \\
\hline CHEMBL1588620 & 688340 & 3.55 & 5.0102 & TRN \\
\hline CHEMBL1310227 & 688340 & 4.55 & 4.9355 & TRN \\
\hline CHEMBL1498652 & 688340 & 4.6 & 4.9687 & TST \\
\hline CHEMBL1406554 & 688340 & 4.5 & 4.5889 & TRN \\
\hline CHEMBL1438530 & 688340 & 4.6 & 4.9014 & TRN \\
\hline CHEMBL1466462 & 688340 & 4.5 & 4.3028 & TRN \\
\hline CHEMBL1424892 & 688340 & 4.8 & 4.9978 & TRN \\
\hline CHEMBL1372852 & 688340 & 4.4 & 5.2075 & TRN \\
\hline CHEMBL1400955 & 688340 & 4.65 & 4.6998 & TRN \\
\hline CHEMBL1430816 & 688340 & 4.6 & 4.7754 & TRN \\
\hline CHEMBL1425943 & 688340 & 6.15 & 4.9736 & TRN \\
\hline CHEMBL1314326 & 688340 & 5.45 & 5.1536 & TST \\
\hline CHEMBL1532090 & 688340 & 5.2 & 5.147 & TST \\
\hline CHEMBL1414070 & 688340 & 6.3 & 5.6593 & TRN \\
\hline CHEMBL1323747 & 688340 & 4.55 & 4.8431 & TRN \\
\hline CHEMBL3196544 & 688340 & 4.95 & 5.0336 & TRN \\
\hline CHEMBL1300063 & 688340 & 4.75 & 4.5372 & TRN \\
\hline CHEMBL1584212 & 688340 & 4.35 & 4.7799 & TRN \\
\hline CHEMBL3189667 & 688340 & 6.95 & 5.0607 & TRN \\
\hline CHEMBL1321734 & 688340 & 5.6 & 5.1684 & TRN \\
\hline CHEMBL1304744 & 688340 & 4.5 & 5.0456 & TST \\
\hline CHEMBL1374245 & 688340 & 6.0 & 4.82 & TRN \\
\hline CHEMBL1359772 & 688340 & 4.4 & 5.1574 & TST \\
\hline CHEMBL1585479 & 688340 & 4.7 & 4.7959 & TRN \\
\hline CHEMBL526952 & 688340 & 4.4 & 4.9572 & TRN \\
\hline CHEMBL3208922 & 688340 & 4.6 & 4.7953 & TST \\
\hline CHEMBL1315311 & 688340 & 4.4 & 5.3334 & TRN \\
\hline CHEMBL1386164 & 688340 & 5.1 & 5.4035 & TRN \\
\hline CHEMBL1382225 & 688340 & 5.1 & 4.7013 & TRN \\
\hline CHEMBL1975746 & 688340 & 4.8 & 4.9875 & TST \\
\hline CHEMBL1509570 & 688340 & 4.4 & 5.2814 & TRN \\
\hline CHEMBL1558941 & 688340 & 4.1 & 5.092 & TST \\
\hline
\end{tabular}




\begin{tabular}{|c|c|c|c|c|}
\hline \multicolumn{5}{|c|}{ Supplemental Table S2.txt } \\
\hline CHEMBL1345130 & 688340 & 5.4 & 4.7837 & TST \\
\hline CHEMBL1440113 & 688340 & 5.2 & 5.2241 & TRN \\
\hline CHEMBL1323553 & 688340 & 5.25 & 4.8719 & TRN \\
\hline CHEMBL1484012 & 688340 & 4.7 & 5.1415 & TRN \\
\hline CHEMBL80658 & 688340 & 6.0 & 4.8445 & TRN \\
\hline CHEMBL1359372 & 688340 & 5.4 & 5.1368 & TST \\
\hline CHEMBL1438712 & 688340 & 4.65 & 5.0078 & TRN \\
\hline CHEMBL1422005 & 688340 & 4.65 & 4.9999 & TRN \\
\hline CHEMBL1989372 & 688340 & 4.5 & 4.8895 & TST \\
\hline CHEMBL1323674 & 688340 & 5.5 & 5.047 & TRN \\
\hline CHEMBL1537620 & 688340 & 4.55 & 5.0267 & TRN \\
\hline CHEMBL1477897 & 688340 & 5.15 & 4.7356 & TRN \\
\hline CHEMBL1609245 & 688340 & 4.6 & 4.8903 & TRN \\
\hline CHEMBL1441348 & 688340 & 4.45 & 5.2143 & TRN \\
\hline CHEMBL1600862 & 688340 & 4.6 & 4.7938 & TST \\
\hline CHEMBL3199429 & 688340 & 5.05 & 4.8859 & TRN \\
\hline CHEMBL1438936 & 688340 & 4.7 & 5.1628 & TRN \\
\hline CHEMBL1566928 & 688340 & 4.6 & 4.578 & TRN \\
\hline CHEMBL1556716 & 688340 & 5.0 & 5.3708 & TRN \\
\hline CHEMBL1328068 & 688340 & 6.25 & 4.8475 & TRN \\
\hline CHEMBL1389429 & 688340 & 4.45 & 5.0913 & TRN \\
\hline CHEMBL1579324 & 688340 & 5.2 & 5.1337 & TST \\
\hline CHEMBL1345083 & 688340 & 5.25 & 5.1458 & TRN \\
\hline CHEMBL1359694 & 688340 & 4.35 & 4.6522 & TRN \\
\hline CHEMBL1579161 & 688340 & 4.35 & 5.0625 & TST \\
\hline CHEMBL1483614 & 688340 & 6.1 & 5.0604 & TRN \\
\hline CHEMBL1568775 & 688340 & 4.0 & 4.9903 & TRN \\
\hline CHEMBL1607082 & 688340 & 5.5 & 5.1392 & TST \\
\hline CHEMBL1541992 & 688340 & 5.1 & 5.1541 & TRN \\
\hline CHEMBL1559045 & 688340 & 6.1 & 5.1607 & TST \\
\hline CHEMBL1471883 & 688340 & 5.15 & 4.7242 & TRN \\
\hline CHEMBL1570841 & 688340 & 6.1 & 5.0309 & TST \\
\hline CHEMBL3192506 & 688340 & 4.75 & 4.9168 & TRN \\
\hline CHEMBL1303243 & 688340 & 4.65 & 5.1006 & TRN \\
\hline CHEMBL1299661 & 688340 & 5.2 & 4.989 & TRN \\
\hline CHEMBL1511241 & 688340 & 4.4 & 5.1865 & TRN \\
\hline CHEMBL1383969 & 688340 & 7.0 & 5.5056 & TRN \\
\hline CHEMBL3197950 & 688340 & 6.15 & 4.9797 & TRN \\
\hline CHEMBL1535793 & 688340 & 4.7 & 4.6722 & TRN \\
\hline CHEMBL1399879 & 688340 & 4.7 & 4.9653 & TRN \\
\hline CHEMBL1428362 & 688340 & 4.5 & 4.876 & TRN \\
\hline CHEMBL1603053 & 688340 & 4.6 & 4.7114 & TRN \\
\hline CHEMBL1336011 & 688340 & 5.0 & 4.8375 & TRN \\
\hline CHEMBL1407928 & 688340 & 4.85 & 4.9296 & TST \\
\hline CHEMBL1361818 & 688340 & 4.65 & 4.8974 & TRN \\
\hline CHEMBL1538023 & 688340 & 4.7 & 4.9144 & TRN \\
\hline CHEMBL1602141 & 688340 & 4.45 & 4.8276 & TRN \\
\hline CHEMBL1442772 & 688340 & 4.4 & 4.8363 & TRN \\
\hline
\end{tabular}




\begin{tabular}{|c|c|c|c|c|c|}
\hline \multicolumn{6}{|c|}{ Supplemental Table S2.txt } \\
\hline CHEMBL1413593 & 688340 & 5.45 & 4.9707 & TRN & \\
\hline CHEMBL1374177 & 688340 & 4.6 & 5.3879 & TST & \\
\hline CHEMBL1431469 & 688340 & 7.0 & 5.0061 & TRN & \\
\hline CHEMBL3191913 & 688340 & 4.9 & 4.8675 & TRN & \\
\hline CHEMBL1444221 & 688340 & 4.5 & 4.7859 & TRN & \\
\hline CHEMBL1413071 & 688340 & 4.55 & 5.0409 & TRN & \\
\hline CHEMBL1595554 & 688340 & 4.95 & 5.0666 & TRN & \\
\hline CHEMBL1407421 & 688340 & 4.35 & 5.2102 & TST & \\
\hline CHEMBL1315179 & 688340 & 5.2 & 5.26200 & 00000000005 & TRN \\
\hline CHEMBL1418929 & 688340 & 6.0 & 4.8547 & TRN & \\
\hline CHEMBL1462127 & 688340 & 6.45 & 5.3216 & TRN & \\
\hline CHEMBL1579024 & 688340 & 6.2 & 5.05699 & 99999999995 & TST \\
\hline CHEMBL1346564 & 688340 & 4.6 & 4.9 & TRN & \\
\hline CHEMBL1359460 & 688340 & 4.4 & 5.1058 & TST & \\
\hline CHEMBL1463689 & 688340 & 4.4 & 4.8273 & TRN & \\
\hline CHEMBL1526156 & 688340 & 4.4 & 5.0958 & TRN & \\
\hline CHEMBL1480324 & 688340 & 5.8 & 5.1409 & TRN & \\
\hline CHEMBL1569500 & 688340 & 4.45 & 5.0509 & TRN & \\
\hline CHEMBL1467523 & 688340 & 4.4 & 4.9588 & TRN & \\
\hline CHEMBL599013 & 688340 & 4.4 & 4.7706 & TRN & \\
\hline CHEMBL1576942 & 688340 & 4.7 & 5.0392 & TST & \\
\hline CHEMBL1478573 & 688340 & 4.65 & 5.0593 & TRN & \\
\hline CHEMBL1588577 & 688340 & 4.65 & 5.1817 & TRN & \\
\hline CHEMBL1612272 & 688340 & 5.35 & 5.04899 & 99999999995 & TRN \\
\hline CHEMBL1377973 & 688340 & 4.55 & 5.1126 & TST & \\
\hline CHEMBL1444604 & 688340 & 5.95 & 4.5955 & TRN & \\
\hline CHEMBL1363965 & 688340 & 4.6 & 4.9064 & TST & \\
\hline CHEMBL1545766 & 688340 & 7.0 & 5.224 & TRN & \\
\hline CHEMBL1483607 & 688340 & 4.55 & 5.1163 & TRN & \\
\hline CHEMBL1362466 & 688340 & 5.55 & 5.0742 & TST & \\
\hline CHEMBL1483757 & 688340 & 4.5 & 5.0579 & TST & \\
\hline CHEMBL1508981 & 688340 & 5.05 & 5.2168 & TST & \\
\hline CHEMBL1562824 & 688340 & 5.9 & 4.75899 & 99999999995 & TRN \\
\hline CHEMBL1303524 & 688340 & 4.95 & 4.6175 & TRN & \\
\hline CHEMBL1515875 & 688340 & 4.4 & 4.9439 & TRN & \\
\hline CHEMBL1432897 & 688340 & 4.0 & 5.1972 & TST & \\
\hline CHEMBL1613606 & 688340 & 4.4 & 5.12799 & 9999999999 & TRN \\
\hline CHEMBL1583382 & 688340 & 4.05 & 4.8204 & TRN & \\
\hline CHEMBL1452680 & 688340 & 5.15 & 5.2121 & TRN & \\
\hline CHEMBL1613592 & 688340 & 5.15 & 5.2219 & TRN & \\
\hline CHEMBL1301488 & 688340 & 4.65 & 4.8987 & TRN & \\
\hline CHEMBL375107 & 688340 & 4.5 & 5.2285 & TST & \\
\hline CHEMBL572203 & 688340 & 4.5 & 4.9788 & TRN & \\
\hline CHEMBL1348904 & 688340 & 6.95 & 5.5448 & TRN & \\
\hline CHEMBL3195487 & 688340 & 5.5 & 5.1246 & TRN & \\
\hline CHEMBL1478258 & 688340 & 4.6 & 4.7696 & TRN & \\
\hline CHEMBL1437820 & 688340 & 4.4 & 5.2713 & TRN & \\
\hline CHEMBL3211961 & 688340 & 4.4 & 4.7214 & TRN & \\
\hline
\end{tabular}




\begin{tabular}{|c|c|c|c|c|c|}
\hline \multicolumn{6}{|c|}{ Supplemental Table S2.txt } \\
\hline CHEMBL1385951 & 688340 & 4.55 & 5.0773 & TRN & \\
\hline CHEMBL1356324 & 688340 & 4.55 & 4.8989 & TRN & \\
\hline CHEMBL1379197 & 688340 & 4.6 & 5.1549 & TST & \\
\hline CHEMBL1328661 & 688340 & 4.85 & 5.1486 & TRN & \\
\hline CHEMBL1601846 & 688340 & 6.5 & 5.2011 & TST & \\
\hline CHEMBL456881 & 688340 & 4.55 & 4.901 & TRN & \\
\hline CHEMBL1586534 & 688340 & 5.6 & 4.8168 & TRN & \\
\hline CHEMBL1336077 & 688340 & 5.0 & 4.76699 & 99999999995 & TRN \\
\hline CHEMBL1407655 & 688340 & 4.5 & 4.9955 & TRN & \\
\hline CHEMBL1461215 & 688340 & 5.6 & 5.2717 & TRN & \\
\hline CHEMBL1449331 & 688340 & 5.5 & 5.0853 & TRN & \\
\hline CHEMBL1531900 & 688340 & 5.2 & 5.044 & TRN & \\
\hline CHEMBL3191560 & 688340 & 4.5 & 5.0724 & TST & \\
\hline CHEMBL1324986 & 688340 & 5.3 & 5.4118 & TRN & \\
\hline CHEMBL1967938 & 688340 & 5.3 & 4.8382 & TRN & \\
\hline CHEMBL1397682 & 688340 & 6.15 & 5.0793 & TRN & \\
\hline CHEMBL1508258 & 688340 & 4.8 & 4.8423 & TRN & \\
\hline CHEMBL1362933 & 688340 & 4.5 & 4.9456 & TRN & \\
\hline CHEMBL3198369 & 688340 & 4.55 & 5.0689 & TST & \\
\hline CHEMBL1378605 & 688340 & 5.6 & 5.0606 & TRN & \\
\hline CHEMBL3194910 & 688340 & 4.65 & 5.0932 & TRN & \\
\hline CHEMBL1580981 & 688340 & 4.6 & 4.9094 & TST & \\
\hline CHEMBL3189968 & 688340 & 5.2 & 4.7915 & TRN & \\
\hline CHEMBL1452259 & 688340 & 6.5501 & 5.4263 & TRN & \\
\hline CHEMBL1577002 & 688340 & 4.45 & 4.8955 & TRN & \\
\hline CHEMBL1271322 & 688340 & 6.0 & 4.7249 & TRN & \\
\hline CHEMBL1348530 & 688340 & 4.45 & 5.0014 & TRN & \\
\hline CHEMBL1537338 & 688340 & 4.35 & 4.8272 & TST & \\
\hline CHEMBL1410112 & 688340 & 6.9 & 5.0402 & TRN & \\
\hline CHEMBL3212232 & 688340 & 4.8 & 4.8862 & TST & \\
\hline CHEMBL1428920 & 688340 & 6.15 & 5.3519 & TST & \\
\hline CHEMBL1577184 & 688340 & 4.65 & 4.9322 & TST & \\
\hline CHEMBL1313979 & 688340 & 4.95 & 5.09 & TRN & \\
\hline CHEMBL1609150 & 688340 & 4.45 & 4.6111 & TRN & \\
\hline CHEMBL1594446 & 688340 & 5.9 & 5.03600 & 00000000005 & TRN \\
\hline CHEMBL1521576 & 688340 & 4.55 & 4.8672 & TRN & \\
\hline CHEMBL1969543 & 688340 & 4.5 & 5.1131 & TRN & \\
\hline CHEMBL1492129 & 688340 & 8.301 & 5.0683 & TST & \\
\hline CHEMBL1598606 & 688340 & 5.0 & 5.2064 & TRN & \\
\hline CHEMBL1435335 & 688340 & 6.05 & 5.2188 & TRN & \\
\hline CHEMBL534743 & 688340 & 4.4 & 4.7863 & TRN & \\
\hline CHEMBL1418335 & 688340 & 4.6 & 5.09 & TRN & \\
\hline CHEMBL1420170 & 688340 & 4.75 & 4.9579 & TRN & \\
\hline CHEMBL1393703 & 688340 & 4.9 & 4.9253 & TST & \\
\hline CHEMBL1301654 & 688340 & 5.25 & 5.3289 & TST & \\
\hline CHEMBL1483226 & 688340 & 4.4 & 4.9658 & TRN & \\
\hline CHEMBL1419722 & 688340 & 5.55 & 5.5406 & TRN & \\
\hline CHEMBL1503327 & 688340 & 5.0 & 4.9604 & TST & \\
\hline
\end{tabular}




\begin{tabular}{|c|c|c|c|c|}
\hline \multicolumn{5}{|c|}{ Supplemental Table S2.txt } \\
\hline CHEMBL1387386 & 688340 & 6.95 & 4.9288 & TST \\
\hline CHEMBL3196037 & 688340 & 4.4 & 5.1544 & TRN \\
\hline CHEMBL1457806 & 688340 & 7.0 & 4.857 & TST \\
\hline CHEMBL1386918 & 688340 & 4.75 & 4.9487 & TRN \\
\hline CHEMBL1609709 & 688340 & 6.8499 & 5.1285 & TST \\
\hline CHEMBL1538015 & 688340 & 5.0 & 5.2818 & TRN \\
\hline CHEMBL1394288 & 688340 & 4.4 & 4.9858 & TRN \\
\hline CHEMBL1364771 & 688340 & 4.75 & 4.7015 & TRN \\
\hline CHEMBL1374331 & 688340 & 6.2 & 5.2985 & TRN \\
\hline CHEMBL1445568 & 688340 & 5.0 & 5.2611 & TRN \\
\hline CHEMBL1367877 & 688340 & 4.95 & 5.0441 & TST \\
\hline CHEMBL1563492 & 688340 & 4.55 & 4.9803 & TRN \\
\hline CHEMBL1485617 & 688340 & 4.75 & 4.9652 & TST \\
\hline CHEMBL1310763 & 688340 & 4.45 & 5.3943 & TRN \\
\hline CHEMBL1522575 & 688340 & 4.05 & 5.0566 & TST \\
\hline CHEMBL1607292 & 688340 & 5.05 & 5.1208 & TRN \\
\hline CHEMBL1517375 & 688340 & 4.4 & 5.0366 & TRN \\
\hline CHEMBL1350290 & 688340 & 4.65 & 4.644 & TRN \\
\hline CHEMBL1499914 & 688340 & 4.45 & 5.0594 & TRN \\
\hline CHEMBL1480378 & 688340 & 4.5 & 4.7091 & TRN \\
\hline CHEMBL1332656 & 688340 & 5.45 & 4.9019 & TRN \\
\hline CHEMBL1345334 & 688340 & 4.65 & 5.078 & TRN \\
\hline CHEMBL1550019 & 688340 & 4.75 & 5.0827 & TST \\
\hline CHEMBL3191960 & 688340 & 4.5 & 4.8638 & TRN \\
\hline CHEMBL1451159 & 688340 & 4.45 & 4.5752 & TRN \\
\hline CHEMBL1567974 & 688340 & 4.4 & 5.1036 & TRN \\
\hline CHEMBL3194408 & 688340 & 4.5 & 5.0146 & TST \\
\hline CHEMBL1503920 & 688340 & 4.65 & 5.0377 & TRN \\
\hline CHEMBL1504315 & 688340 & 4.7 & 4.7201 & TRN \\
\hline CHEMBL1478565 & 688340 & 4.6 & 4.7644 & TRN \\
\hline CHEMBL1409509 & 688340 & 5.65 & 5.3961 & TRN \\
\hline CHEMBL1483048 & 688340 & 4.65 & 4.992 & TRN \\
\hline CHEMBL1428059 & 688340 & 5.9 & 5.0523 & TRN \\
\hline CHEMBL1551205 & 688340 & 5.2 & 5.2941 & TRN \\
\hline CHEMBL1360881 & 688340 & 5.15 & 4.9916 & TST \\
\hline CHEMBL1495707 & 688340 & 4.4 & 4.8933 & TRN \\
\hline CHEMBL1453375 & 688340 & 4.45 & 4.9185 & TRN \\
\hline CHEMBL1423650 & 688340 & 5.2 & 5.0058 & TRN \\
\hline CHEMBL1379424 & 688340 & 4.4 & 4.7113 & TRN \\
\hline CHEMBL1311222 & 688340 & 5.7 & 5.0615 & TST \\
\hline CHEMBL1416169 & 688340 & 4.9 & 4.8483 & TRN \\
\hline CHEMBL1401707 & 688340 & 5.2 & 4.9176 & TRN \\
\hline CHEMBL1456425 & 688340 & 4.55 & 4.941 & TRN \\
\hline CHEMBL1312208 & 688340 & 5.2 & 5.1294 & TRN \\
\hline CHEMBL1324140 & 688340 & 5.2 & 5.4321 & TST \\
\hline CHEMBL1461485 & 688340 & 4.55 & 4.9082 & TRN \\
\hline CHEMBL1549675 & 688340 & 6.25 & 4.938 & TST \\
\hline CHEMBL1437976 & 688340 & 5.2 & 5.0502 & TRN \\
\hline
\end{tabular}




\begin{tabular}{|c|c|c|c|c|c|}
\hline \multicolumn{6}{|c|}{ Supplemental Table S2.txt } \\
\hline CHEMBL1400818 & 688340 & 7.0 & 5.385 & TRN & \\
\hline CHEMBL1552533 & 688340 & 4.95 & 5.2371 & TST & \\
\hline CHEMBL1554744 & 688340 & 5.15 & 4.9885 & TRN & \\
\hline CHEMBL1443088 & 688340 & 4.4 & 4.9333 & TRN & \\
\hline CHEMBL1455522 & 688340 & 4.4 & 4.6831 & TRN & \\
\hline CHEMBL1342722 & 688340 & 7.8013 & 5.3145 & TRN & \\
\hline CHEMBL1343603 & 688340 & 4.75 & 4.7405 & TST & \\
\hline CHEMBL1478082 & 688340 & 4.4 & 4.7937 & TRN & \\
\hline CHEMBL1389332 & 688340 & 4.35 & 4.9998 & TRN & \\
\hline CHEMBL1453409 & 688340 & 5.1 & 5.1274 & TRN & \\
\hline CHEMBL1560245 & 688340 & 4.65 & 4.9738 & TRN & \\
\hline CHEMBL1606013 & 688340 & 4.85 & 5.0981 & TRN & \\
\hline CHEMBL1501577 & 688340 & 5.05 & 4.9736 & TRN & \\
\hline CHEMBL1567645 & 688340 & 4.35 & 5.4686 & TRN & \\
\hline CHEMBL1324129 & 688340 & 5.15 & 5.0403 & TRN & \\
\hline CHEMBL1375788 & 688340 & 4.65 & $4.9060 e$ & 0000000001 & TST \\
\hline CHEMBL1300484 & 688340 & 4.55 & 5.0662 & TST & \\
\hline CHEMBL1493670 & 688340 & 4.4 & 5.2127 & TRN & \\
\hline CHEMBL1429533 & 688340 & 6.9 & 5.2773 & TRN & \\
\hline CHEMBL1321103 & 688340 & 6.4 & 5.3772 & TST & \\
\hline CHEMBL1539174 & 688340 & 6.15 & 5.1468 & TRN & \\
\hline CHEMBL1412910 & 688340 & 6.15 & 4.7891 & TRN & \\
\hline CHEMBL 3214478 & 688340 & 4.35 & 5.2186 & TRN & \\
\hline CHEMBL1303780 & 688340 & 7.0 & 4.9412 & TST & \\
\hline CHEMBL1366034 & 688340 & 6.8499 & 5.4473 & TRN & \\
\hline CHEMBL1591069 & 688340 & 5.2 & 5.3316 & TRN & \\
\hline CHEMBL1547473 & 688340 & 4.4 & 4.8529 & TST & \\
\hline CHEMBL1537522 & 688340 & 4.95 & 4.7315 & TRN & \\
\hline CHEMBL1590276 & 688340 & 4.6 & 5.075 & TRN & \\
\hline CHEMBL1605851 & 688340 & 4.4 & 4.9601 & TST & \\
\hline CHEMBL307341 & 688340 & 4.5 & 4.845 & TST & \\
\hline CHEMBL1547272 & 688340 & 4.4 & 5.3177 & TRN & \\
\hline CHEMBL1381181 & 688340 & 4.4 & 5.0188 & TST & \\
\hline CHEMBL1400929 & 688340 & 5.5 & 5.0449 & TRN & \\
\hline CHEMBL1303399 & 688340 & 4.45 & 4.8865 & TRN & \\
\hline CHEMBL1433770 & 688340 & 4.65 & 5.0038 & TRN & \\
\hline CHEMBL3198048 & 688340 & 4.55 & 4.8446 & TST & \\
\hline CHEMBL1452618 & 688340 & 5.4 & 5.1425 & TRN & \\
\hline CHEMBL1578649 & 688340 & 5.5 & 5.0537 & TRN & \\
\hline CHEMBL1596184 & 688340 & 5.6 & 5.0275 & TRN & \\
\hline CHEMBL1336376 & 688340 & 4.8 & 4.8529 & TRN & \\
\hline CHEMBL1331109 & 688340 & 7.0 & 4.9957 & TRN & \\
\hline CHEMBL1328679 & 688340 & 4.4 & 5.2026 & TRN & \\
\hline CHEMBL1978150 & 688340 & 4.6 & 5.0868 & TRN & \\
\hline CHEMBL1305146 & 688340 & 4.4 & 4.779 & TST & \\
\hline CHEMBL3190321 & 688340 & 5.35 & 5.0315 & TRN & \\
\hline CHEMBL1598719 & 688340 & 4.65 & 4.9824 & TRN & \\
\hline CHEMBL1992764 & 688340 & 4.65 & 4.8592 & TST & \\
\hline
\end{tabular}




\begin{tabular}{|c|c|c|c|c|c|}
\hline \multirow[b]{2}{*}{ CHEMBL1392829 } & \multirow[b]{2}{*}{688340} & \\
\hline & & 4.4 & 4.7407 & TRN & \\
\hline CHEMBL1466269 & 688340 & 4.4 & 5.1984 & TST & \\
\hline CHEMBL3199741 & 688340 & 4.6 & 4.7465 & TST & \\
\hline CHEMBL1384410 & 688340 & 4.85 & 4.7648 & TRN & \\
\hline CHEMBL1417225 & 688340 & 4.65 & 4.6765 & TRN & \\
\hline CHEMBL1454986 & 688340 & 4.95 & 4.8144 & TRN & \\
\hline CHEMBL3213174 & 688340 & 5.2 & 4.8938 & TST & \\
\hline CHEMBL1441207 & 688340 & 5.75 & 5.224 & TRN & \\
\hline CHEMBL1538414 & 688340 & 6.25 & 5.2109 & TST & \\
\hline CHEMBL1541064 & 688340 & 4.95 & 5.2775 & TST & \\
\hline CHEMBL1455405 & 688340 & 6.25 & 5.3668 & TRN & \\
\hline CHEMBL3145034 & 688340 & 4.4 & 5.0402 & TRN & \\
\hline CHEMBL1483975 & 688340 & 4.8 & 5.0862 & TRN & \\
\hline CHEMBL1391127 & 688340 & 5.2 & 5.2124 & TRN & \\
\hline CHEMBL1440449 & 688340 & 4.2 & 5.4629 & TRN & \\
\hline CHEMBL1998038 & 688340 & 6.2 & 5.1853 & TRN & \\
\hline CHEMBL1519950 & 688340 & 4.95 & 5.2584 & TRN & \\
\hline CHEMBL1376200 & 688340 & 5.0 & 4.9574 & TST & \\
\hline CHEMBL1386122 & 688340 & 4.5 & 4.92 & TRN & \\
\hline CHEMBL1574478 & 688340 & 5.3 & 4.8881 & TRN & \\
\hline CHEMBL1517745 & 688340 & 4.5 & 5.5163 & TST & \\
\hline CHEMBL1453411 & 688340 & 4.55 & 5.0197 & TRN & \\
\hline CHEMBL1490443 & 688340 & 4.05 & 5.0618 & TST & \\
\hline CHEMBL1387773 & 688340 & 4.4 & 5.0154 & TRN & \\
\hline CHEMBL1462124 & 688340 & 4.45 & 5.103 & TRN & \\
\hline CHEMBL1390523 & 688340 & 6.35 & 5.0313 & TRN & \\
\hline CHEMBL1516868 & 688340 & 4.4 & 5.15799 & 99999999995 & TRN \\
\hline CHEMBL1332140 & 688340 & 5.1 & 4.8169 & TRN & \\
\hline CHEMBL1454289 & 688340 & 7.0 & 5.0905 & TRN & \\
\hline CHEMBL1528091 & 688340 & 4.4 & 5.1397 & TRN & \\
\hline CHEMBL1337744 & 688340 & 4.65 & 4.6849 & TST & \\
\hline CHEMBL1431820 & 688340 & 6.9 & 5.5031 & TRN & \\
\hline CHEMBL1311563 & 688340 & 5.7 & 5.2118 & TRN & \\
\hline CHEMBL 2006856 & 688340 & 5.3 & 4.992 & TRN & \\
\hline CHEMBL1546384 & 688340 & 6.45 & 5.2026 & TRN & \\
\hline CHEMBL1453081 & 688340 & 5.25 & 5.2294 & TST & \\
\hline CHEMBL1315505 & 688340 & 4.65 & 4.812 & TST & \\
\hline CHEMBL1316320 & 688340 & 4.65 & 4.7326 & TRN & \\
\hline CHEMBL1357601 & 688340 & 6.1 & 5.1874 & TRN & \\
\hline CHEMBL1413873 & 688340 & 7.0 & 5.3256 & TRN & \\
\hline CHEMBL1482398 & 688340 & 4.4 & 5.0377 & TRN & \\
\hline CHEMBL1967385 & 688340 & 4.55 & 5.0977 & TRN & \\
\hline CHEMBL1564555 & 688340 & 4.4 & 5.4412 & TST & \\
\hline CHEMBL81935 & 688340 & 4.8 & 4.9085 & TST & \\
\hline CHEMBL1319055 & 688340 & 6.1 & 4.915 & TST & \\
\hline CHEMBL1574477 & 688340 & 5.45 & 5.0857 & TRN & \\
\hline CHEMBL1500285 & 688340 & 4.4 & 5.119 & TST & \\
\hline CHEMBL1486136 & 688340 & 6.2 & 4.9385 & TST & \\
\hline & & & & 2827 & \\
\hline
\end{tabular}




\begin{tabular}{|c|c|c|c|c|}
\hline & & & pplement & al $\mathrm{T}$ \\
\hline CHEMBL1310976 & 688340 & 4.6 & 5.0887 & TRN \\
\hline CHEMBL1380121 & 688340 & 6.1 & 4.6345 & TRN \\
\hline CHEMBL1356342 & 688340 & 4.55 & 5.2323 & TST \\
\hline CHEMBL3191677 & 688340 & 4.55 & 4.953 & TRN \\
\hline CHEMBL1374536 & 688340 & 5.05 & 5.0562 & TRN \\
\hline CHEMBL1318284 & 688340 & 4.45 & 5.1571 & TST \\
\hline CHEMBL1564484 & 688340 & 5.35 & 5.0498 & TRN \\
\hline CHEMBL1367206 & 688340 & 4.8 & 4.9516 & TRN \\
\hline CHEMBL429095 & 688340 & 4.55 & 5.265 & TST \\
\hline CHEMBL1455192 & 688340 & 4.55 & 4.9129 & TRN \\
\hline CHEMBL1387693 & 688340 & 4.8 & 4.705 & TRN \\
\hline CHEMBL1603539 & 688340 & 6.05 & 5.2383 & TRN \\
\hline CHEMBL1418440 & 688340 & 4.6 & 5.0199 & TRN \\
\hline CHEMBL1559734 & 688340 & 4.55 & 5.0693 & TST \\
\hline CHEMBL1501714 & 688340 & 4.7 & 5.0454 & TRN \\
\hline CHEMBL1477028 & 688340 & 4.55 & 4.7492 & TRN \\
\hline CHEMBL1395998 & 688340 & 5.1 & 4.9158 & TRN \\
\hline CHEMBL1495778 & 688340 & 5.5 & 4.7863 & TRN \\
\hline CHEMBL1427977 & 688340 & 6.15 & 5.1258 & TRN \\
\hline CHEMBL1438556 & 688340 & 8.4949 & 5.4735 & TST \\
\hline CHEMBL1609276 & 688340 & 5.45 & 5.0941 & TRN \\
\hline CHEMBL1392137 & 688340 & 4.55 & 4.9258 & TRN \\
\hline CHEMBL1400151 & 688340 & 4.55 & 4.7424 & TRN \\
\hline CHEMBL1484657 & 688340 & 5.3 & 4.5199 & TRN \\
\hline CHEMBL1566021 & 688340 & 4.55 & 5.0431 & TRN \\
\hline CHEMBL1310815 & 688340 & 5.15 & 5.3221 & TRN \\
\hline CHEMBL1595525 & 688340 & 4.55 & 4.6082 & TRN \\
\hline CHEMBL1433732 & 688340 & 4.5 & 5.0986 & TRN \\
\hline CHEMBL1497274 & 688340 & 5.4 & 5.148 & TRN \\
\hline CHEMBL1496297 & 688340 & 4.65 & 5.0646 & TRN \\
\hline CHEMBL1312430 & 688340 & 4.4 & 5.0201 & TST \\
\hline CHEMBL1544882 & 688340 & 5.5 & 4.9982 & TRN \\
\hline CHEMBL1311446 & 688340 & 7.4001 & 5.246 & TST \\
\hline CHEMBL1336400 & 688340 & 4.5 & 4.8769 & TST \\
\hline CHEMBL1988072 & 688340 & 4.95 & 5.0761 & TRN \\
\hline CHEMBL1431861 & 688340 & 5.0 & 4.9816 & TST \\
\hline CHEMBL1300836 & 688340 & 4.5 & 5.1097 & TRN \\
\hline CHEMBL1361727 & 688340 & 4.4 & 5.1408 & TRN \\
\hline CHEMBL1589354 & 688340 & 4.35 & 4.891 & TRN \\
\hline CHEMBL 3210157 & 688340 & 5.4 & 4.9575 & TST \\
\hline CHEMBL1585702 & 688340 & 5.2 & 4.9429 & TRN \\
\hline CHEMBL3189678 & 688340 & 4.3 & 5.2157 & TRN \\
\hline CHEMBL1309744 & 688340 & 5.25 & 4.7309 & TST \\
\hline CHEMBL1381480 & 688340 & 4.5 & 4.9645 & TRN \\
\hline CHEMBL1301068 & 688340 & 7.0 & 5.2875 & TRN \\
\hline CHEMBL1308170 & 688340 & 4.6 & 5.0757 & TRN \\
\hline CHEMBL1370921 & 688340 & 4.8 & 5.3376 & TRN \\
\hline CHEMBL1533336 & 688340 & 4.5 & 5.0186 & TRN \\
\hline
\end{tabular}




\begin{tabular}{|c|c|c|c|c|}
\hline \multicolumn{5}{|c|}{ plemental Table S2.t } \\
\hline CHEMBL3196561 & 688340 & 6.0 & 4.9263 & TRN \\
\hline CHEMBL1300993 & 688340 & 6.15 & 5.1560 & 0000000001 \\
\hline CHEMBL1377184 & 688340 & 4.55 & 5.3341 & TRN \\
\hline CHEMBL1421079 & 688340 & 4.6 & 5.5318 & TRN \\
\hline CHEMBL1346960 & 688340 & 4.5 & 4.6991 & TRN \\
\hline CHEMBL1346786 & 688340 & 5.2 & 4.9548 & TRN \\
\hline CHEMBL1433461 & 688340 & 4.45 & 5.0612 & TRN \\
\hline CHEMBL1310668 & 688340 & 5.5 & 5.0511 & TRN \\
\hline CHEMBL1512450 & 688340 & 9.5229 & 5.6107 & TRN \\
\hline CHEMBL1463919 & 688340 & 4.55 & 4.9924 & TRN \\
\hline CHEMBL1471037 & 688340 & 4.5 & 4.9019 & TST \\
\hline CHEMBL1514949 & 688340 & 4.6 & 5.0333 & TRN \\
\hline CHEMBL1601480 & 688340 & 4.65 & 5.1137 & TST \\
\hline CHEMBL1598344 & 688340 & 5.45 & 5.4172 & TRN \\
\hline CHEMBL1472545 & 688340 & 5.15 & 5.148 & TST \\
\hline CHEMBL1596131 & 688340 & 4.7 & 5.149 & TRN \\
\hline CHEMBL1393129 & 688340 & 4.5 & 4.8757 & TRN \\
\hline CHEMBL1468323 & 688340 & 4.65 & 4.6236 & TRN \\
\hline CHEMBL1589093 & 688340 & 4.4 & 4.8236 & TRN \\
\hline CHEMBL1546282 & 688340 & 4.6 & 4.6976 & TRN \\
\hline CHEMBL1511671 & 688340 & 5.55 & 5.1162 & TRN \\
\hline CHEMBL1511610 & 688340 & 7.0 & 4.8806 & TST \\
\hline CHEMBL1511238 & 688340 & 6.15 & 5.2231 & TST \\
\hline CHEMBL1459954 & 688340 & 5.35 & 5.0082 & TRN \\
\hline CHEMBL1509846 & 688340 & 5.55 & 4.6568 & TRN \\
\hline CHEMBL1587132 & 688340 & 5.3 & 5.0223 & TST \\
\hline CHEMBL1469890 & 688340 & 4.55 & 4.8286 & TRN \\
\hline CHEMBL1500718 & 688340 & 4.4 & 5.0207 & TRN \\
\hline CHEMBL1427214 & 688340 & 4.7 & 5.2518 & TST \\
\hline CHEMBL1409193 & 688340 & 4.45 & 4.8845 & TRN \\
\hline CHEMBL1553178 & 688340 & 4.5 & 4.9901 & TRN \\
\hline CHEMBL1422316 & 688340 & 5.45 & 5.2963 & TST \\
\hline CHEMBL1413334 & 688340 & 5.9 & 5.2122 & TRN \\
\hline CHEMBL1548704 & 688340 & 5.5 & 4.8042 & TST \\
\hline CHEMBL1346203 & 688340 & 7.4498 & 5.7203 & TRN \\
\hline CHEMBL1481914 & 688340 & 5.3 & 4.8761 & TRN \\
\hline CHEMBL1537846 & 688340 & 4.55 & 4.9802 & TST \\
\hline CHEMBL1425253 & 688340 & 6.1 & 5.5566 & TRN \\
\hline CHEMBL1318225 & 688340 & 4.35 & 5.1242 & TST \\
\hline CHEMBL1479396 & 688340 & 6.8499 & 5.2016 & TRN \\
\hline CHEMBL1406057 & 688340 & 4.55 & 4.8898 & TRN \\
\hline CHEMBL1381526 & 688340 & 7.0501 & 4.9899 & TST \\
\hline CHEMBL3196327 & 688340 & 4.45 & 5.0441 & TST \\
\hline CHEMBL1571071 & 688340 & 4.4 & 5.1126 & TRN \\
\hline CHEMBL1309306 & 688340 & 5.0 & 4.8521 & TRN \\
\hline CHEMBL1483286 & 688340 & 6.45 & 5.0732 & TST \\
\hline CHEMBL1544695 & 688340 & 5.35 & 5.0153 & TST \\
\hline CHEMBL1505751 & 688340 & 5.25 & 4.8566 & TRN \\
\hline
\end{tabular}

TRN 


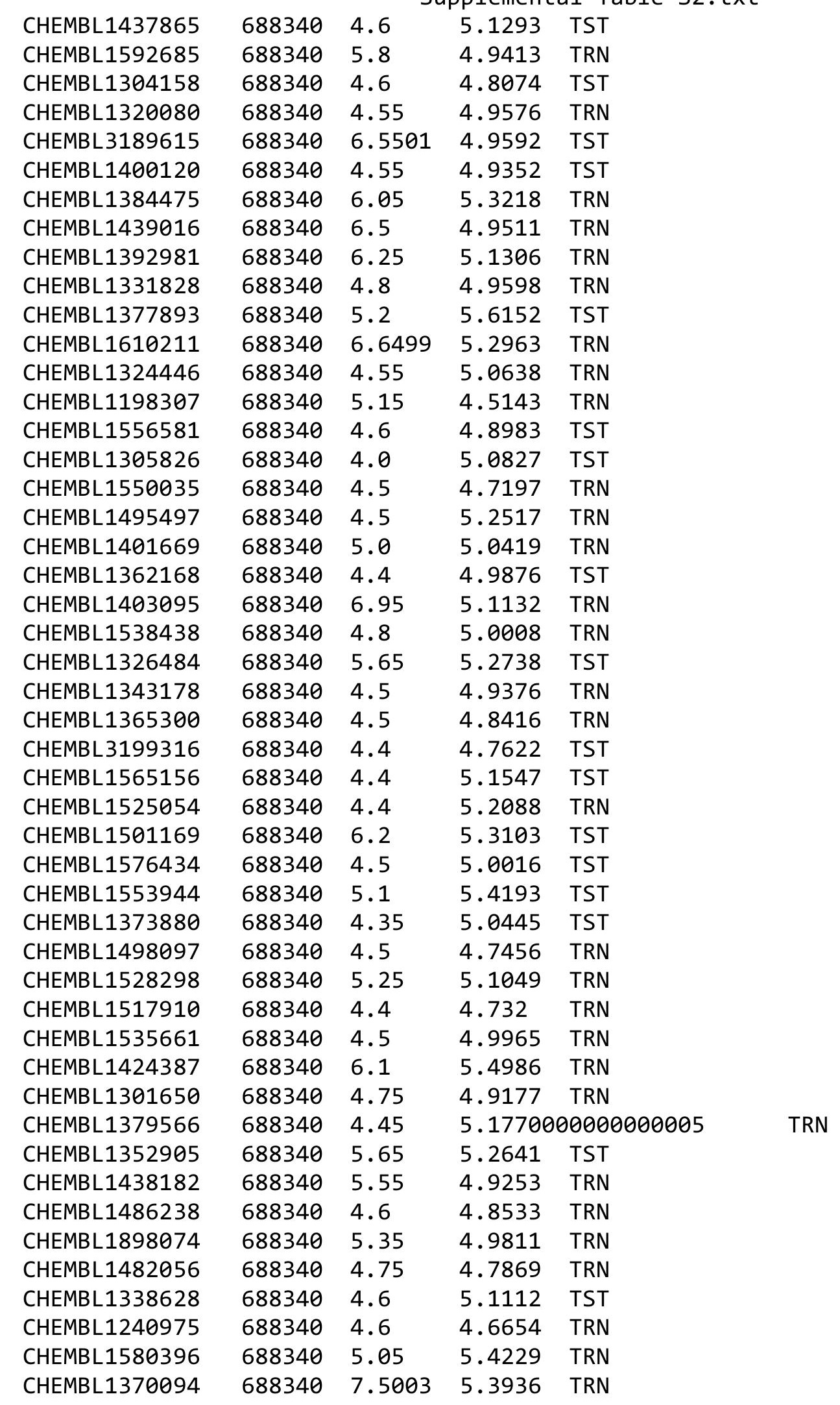

Page 28282 


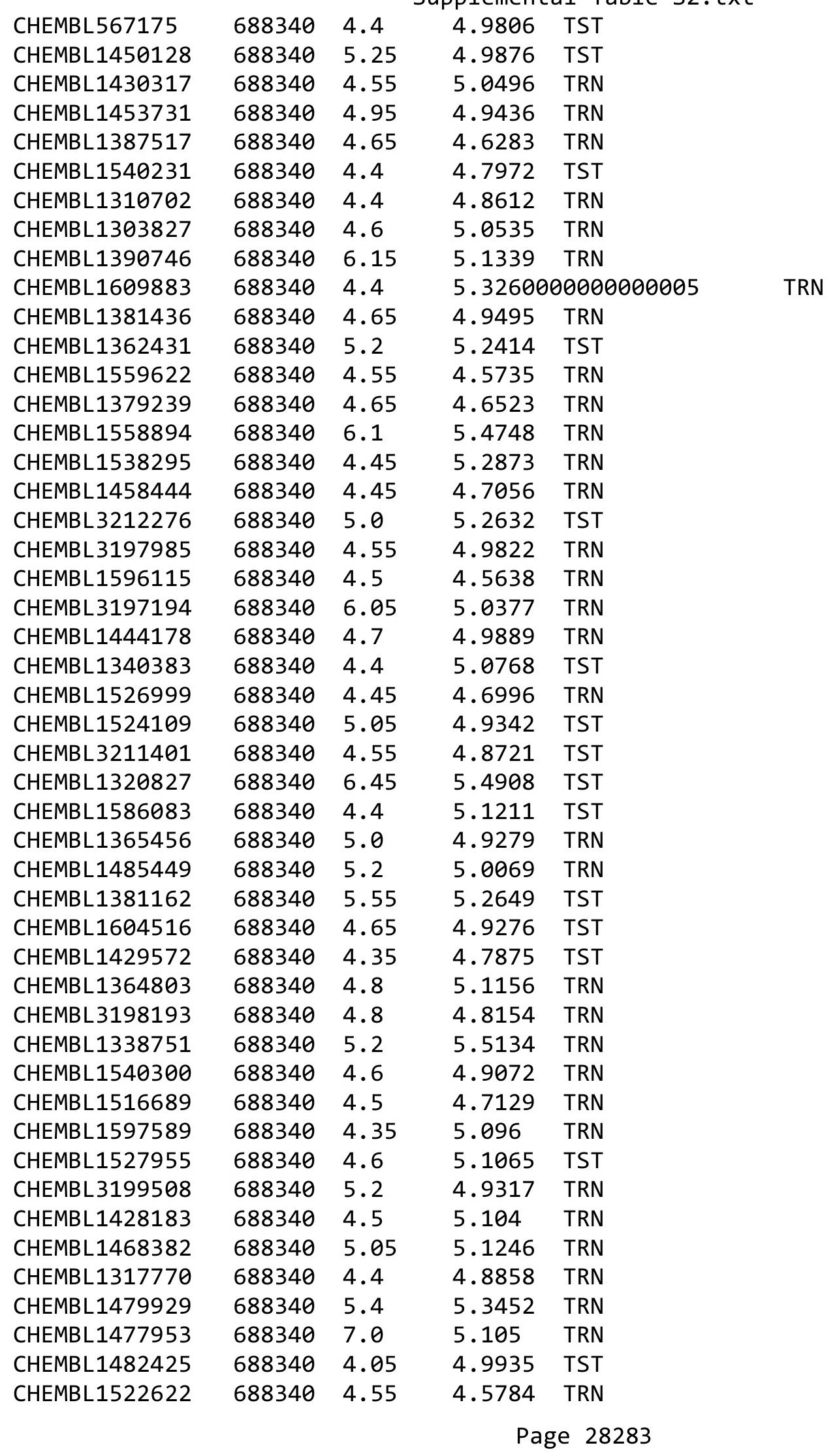




\begin{tabular}{|c|c|c|c|c|}
\hline \multicolumn{5}{|c|}{ Supplemental Table } \\
\hline CHEMBL1436833 & 688340 & 6.5 & 5.3043 & TRN \\
\hline CHEMBL1342613 & 688340 & 4.55 & 4.7436 & TRN \\
\hline CHEMBL1487175 & 688340 & 4.0 & 5.0089 & TRN \\
\hline CHEMBL1356800 & 688340 & 4.6 & 5.2551 & TRN \\
\hline CHEMBL1426644 & 688340 & 7.0501 & 5.0764 & TRN \\
\hline CHEMBL1473687 & 688340 & 5.85 & 5.4015 & TRN \\
\hline CHEMBL1531748 & 688340 & 6.0 & 5.4694 & TRN \\
\hline CHEMBL1461574 & 688340 & 4.4 & 4.9362 & TRN \\
\hline CHEMBL1572540 & 688340 & 5.3 & 5.0953 & TST \\
\hline CHEMBL1586350 & 688340 & 4.8 & 4.8355 & TRN \\
\hline CHEMBL1507672 & 688340 & 4.45 & 4.8147 & TRN \\
\hline CHEMBL1535102 & 688340 & 4.5 & 5.2699 & TRN \\
\hline CHEMBL1300609 & 688340 & 4.4 & 4.8412 & TRN \\
\hline CHEMBL1489980 & 688340 & 4.45 & 5.0249 & TRN \\
\hline CHEMBL1514903 & 688340 & 4.3 & 4.8284 & TRN \\
\hline CHEMBL1405834 & 688340 & 5.45 & 4.6066 & TRN \\
\hline CHEMBL1303228 & 688340 & 5.0 & 5.2274 & TRN \\
\hline CHEMBL1575531 & 688340 & 4.55 & 4.9161 & TST \\
\hline CHEMBL1590108 & 688340 & 4.4 & 5.0808 & TRN \\
\hline CHEMBL1493914 & 688340 & 6.3 & 5.0283 & TST \\
\hline CHEMBL1346274 & 688340 & 4.4 & 4.6347 & TRN \\
\hline CHEMBL1491189 & 688340 & 4.85 & 5.0675 & TST \\
\hline CHEMBL1591983 & 688340 & 4.8 & 5.276 & TRN \\
\hline CHEMBL1333103 & 688340 & 4.5 & 5.2479 & TRN \\
\hline CHEMBL3199421 & 688340 & 4.4 & 4.9265 & TRN \\
\hline CHEMBL1333049 & 688340 & 4.65 & 4.9075 & TRN \\
\hline CHEMBL1385094 & 688340 & 4.65 & 4.834 & TRN \\
\hline CHEMBL1401421 & 688340 & 4.4 & 5.2744 & TRN \\
\hline CHEMBL1481350 & 688340 & 5.65 & 4.956 & TRN \\
\hline CHEMBL1461779 & 688340 & 4.4 & 5.4653 & TST \\
\hline CHEMBL1513243 & 688340 & 4.5 & 5.1878 & TRN \\
\hline CHEMBL1530399 & 688340 & 4.45 & 4.9222 & TST \\
\hline CHEMBL1555881 & 688340 & 4.4 & 5.0152 & TST \\
\hline CHEMBL1576043 & 688340 & 7.699 & 5.1965 & TRN \\
\hline CHEMBL3212346 & 688340 & 4.6 & 4.7468 & TRN \\
\hline CHEMBL584841 & 688340 & 4.55 & 4.8638 & TRN \\
\hline CHEMBL 1475368 & 688340 & 6.95 & 5.4638 & TRN \\
\hline CHEMBL1540504 & 688340 & 6.25 & 5.2431 & TRN \\
\hline CHEMBL1562866 & 688340 & 4.8 & 5.0771 & TRN \\
\hline CHEMBL1605419 & 688340 & 4.55 & 4.6362 & TRN \\
\hline CHEMBL1589837 & 688340 & 4.75 & 4.832 & TRN \\
\hline CHEMBL 1454860 & 688340 & 4.65 & 4.5236 & TRN \\
\hline CHEMBL3190092 & 688340 & 5.2 & 4.837 & TRN \\
\hline CHEMBL1500507 & 688340 & 5.95 & 4.8164 & TRN \\
\hline CHEMBL1364014 & 688340 & 5.05 & 4.7832 & TRN \\
\hline CHEMBL1515544 & 688340 & 4.45 & 4.9632 & TST \\
\hline CHEMBL1310006 & 688340 & 7.0501 & 5.0736 & TRN \\
\hline CHEMBL1334412 & 688340 & 5.3 & 5.1569 & TRN \\
\hline
\end{tabular}




\begin{tabular}{|c|c|c|c|c|c|}
\hline \multicolumn{6}{|c|}{ Supplemental Table S2.txt } \\
\hline CHEMBL1591754 & 688340 & 5.45 & 5.0378 & TRN & \\
\hline CHEMBL1323177 & 688340 & 4.0 & 5.2172 & TRN & \\
\hline CHEMBL1485743 & 688340 & 5.9 & 4.9562 & TRN & \\
\hline CHEMBL1366627 & 688340 & 5.6 & 4.881 & TRN & \\
\hline CHEMBL1514811 & 688340 & 5.25 & 4.9795 & TRN & \\
\hline CHEMBL1317071 & 688340 & 6.35 & 5.0039 & TRN & \\
\hline CHEMBL1393166 & 688340 & 5.2 & 5.597 & TRN & \\
\hline CHEMBL1361844 & 688340 & 5.0 & 5.0375 & TRN & \\
\hline CHEMBL1601128 & 688340 & 4.55 & 5.0134 & TRN & \\
\hline CHEMBL1322481 & 688340 & 6.1 & 5.2263 & TST & \\
\hline CHEMBL1425192 & 688340 & 7.0 & 5.1036 & TRN & \\
\hline CHEMBL1519937 & 688340 & 4.95 & 5.2766 & TST & \\
\hline CHEMBL1382279 & 688340 & 4.85 & 4.6985 & TRN & \\
\hline CHEMBL1399873 & 688340 & 5.3 & 4.7634 & TRN & \\
\hline CHEMBL1313024 & 688340 & 4.55 & 4.934 & TST & \\
\hline CHEMBL1331380 & 688340 & 4.5 & 4.9769 & TRN & \\
\hline CHEMBL1365648 & 688340 & 5.95 & 5.4444 & TRN & \\
\hline CHEMBL1517008 & 688340 & 4.7 & 5.0118 & TRN & \\
\hline CHEMBL1541894 & 688340 & 4.4 & 5.1058 & TRN & \\
\hline CHEMBL1471645 & 688340 & 5.8 & 4.9365 & TST & \\
\hline CHEMBL1325336 & 688340 & 4.65 & 5.0505 & TRN & \\
\hline CHEMBL1440471 & 688340 & 5.15 & 4.6461 & TRN & \\
\hline CHEMBL1466573 & 688340 & 7.0 & 5.0636 & TRN & \\
\hline CHEMBL1430927 & 688340 & 4.75 & 5.102 & TRN & \\
\hline CHEMBL1325742 & 688340 & 4.4 & 4.8969 & TRN & \\
\hline CHEMBL1311860 & 688340 & 4.4 & $5.2070 e$ & 0000000001 & TRN \\
\hline CHEMBL1449992 & 688340 & 4.6 & 4.9911 & TRN & \\
\hline CHEMBL1484865 & 688340 & 4.55 & 4.5548 & TRN & \\
\hline CHEMBL1447076 & 688340 & 4.85 & 4.5744 & TRN & \\
\hline CHEMBL1589205 & 688340 & 4.7 & 5.2631 & TRN & \\
\hline CHEMBL1381306 & 688340 & 5.2 & 5.3442 & TRN & \\
\hline CHEMBL1368971 & 688340 & 4.85 & 4.9245 & TRN & \\
\hline CHEMBL1388992 & 688340 & 5.2 & 5.4109 & TRN & \\
\hline CHEMBL1305207 & 688340 & 5.75 & 5.1975 & TRN & \\
\hline CHEMBL1580844 & 688340 & 5.4 & 4.8609 & TRN & \\
\hline CHEMBL1328361 & 688340 & 4.4 & 4.8072 & TST & \\
\hline CHEMBL1495845 & 688340 & 5.35 & 5.0074 & TST & \\
\hline CHEMBL1412709 & 688340 & 4.5 & 4.5513 & TRN & \\
\hline CHEMBL3207613 & 688340 & 5.2 & 5.0959 & TST & \\
\hline CHEMBL1534387 & 688340 & 4.45 & 5.0702 & TRN & \\
\hline CHEMBL1377970 & 688340 & 5.5 & 4.6837 & TRN & \\
\hline CHEMBL1505392 & 688340 & 5.0 & 5.0769 & TST & \\
\hline CHEMBL3197309 & 688340 & 4.55 & 5.0199 & TRN & \\
\hline CHEMBL1509715 & 688340 & 4.85 & 5.0139 & TST & \\
\hline CHEMBL444478 & 688340 & 6.0 & 5.0544 & TST & \\
\hline CHEMBL1543214 & 688340 & 6.9 & 5.1085 & TRN & \\
\hline CHEMBL1543678 & 688340 & 5.05 & 4.9453 & TST & \\
\hline CHEMBL1309115 & 688340 & 4.55 & 5.0611 & TRN & \\
\hline
\end{tabular}




\begin{tabular}{|c|c|c|c|c|}
\hline & & & pplemen & al $\mathrm{T}$ \\
\hline CHEMBL1995252 & 688340 & 4.4 & 4.8412 & TRN \\
\hline CHEMBL1584122 & 688340 & 5.7 & 5.3744 & TRN \\
\hline CHEMBL1589993 & 688340 & 5.4 & 5.2351 & TRN \\
\hline CHEMBL1447396 & 688340 & 5.0 & 4.8688 & TST \\
\hline CHEMBL1583817 & 688340 & 5.6 & 5.2116 & TRN \\
\hline CHEMBL3190945 & 688340 & 4.4 & 5.1999 & TRN \\
\hline CHEMBL3196965 & 688340 & 4.35 & 5.0968 & TRN \\
\hline CHEMBL1400733 & 688340 & 4.4 & 4.9685 & TRN \\
\hline CHEMBL1527598 & 688340 & 4.55 & 5.0649 & TST \\
\hline CHEMBL1341913 & 688340 & 4.5 & 4.9763 & TRN \\
\hline CHEMBL1352673 & 688340 & 4.35 & 5.0288 & TRN \\
\hline CHEMBL1472478 & 688340 & 4.6 & 4.7899 & TRN \\
\hline CHEMBL1473353 & 688340 & 4.5 & 5.146 & TST \\
\hline CHEMBL1362510 & 688340 & 4.0 & 5.1802 & TRN \\
\hline CHEMBL1487017 & 688340 & 4.5 & 4.9747 & TRN \\
\hline CHEMBL1484046 & 688340 & 6.15 & 5.2276 & TRN \\
\hline CHEMBL1470039 & 688340 & 5.35 & 5.353 & TST \\
\hline CHEMBL1606036 & 688340 & 4.4 & 5.1126 & TRN \\
\hline CHEMBL1386188 & 688340 & 4.05 & 5.1264 & TRN \\
\hline CHEMBL1447809 & 688340 & 4.5 & 4.8087 & TRN \\
\hline CHEMBL1502856 & 688340 & 4.6 & 5.178 & TRN \\
\hline CHEMBL1567824 & 688340 & 4.85 & 4.9139 & TRN \\
\hline CHEMBL1353503 & 688340 & 4.45 & 5.1375 & TRN \\
\hline CHEMBL1563961 & 688340 & 6.5 & 4.9643 & TRN \\
\hline CHEMBL1505422 & 688340 & 6.1 & 5.303 & TST \\
\hline CHEMBL1565743 & 688340 & 5.15 & 5.0642 & TST \\
\hline CHEMBL1385704 & 688340 & 4.5 & 5.0195 & TRN \\
\hline CHEMBL1493400 & 688340 & 4.45 & 4.902 & TRN \\
\hline CHEMBL1345572 & 688340 & 6.35 & 5.1433 & TRN \\
\hline CHEMBL1376055 & 688340 & 4.45 & 5.5002 & TRN \\
\hline CHEMBL1353805 & 688340 & 4.7 & 5.141 & TST \\
\hline CHEMBL1400839 & 688340 & 7.0 & 5.0944 & TST \\
\hline CHEMBL1322356 & 688340 & 4.4 & 5.0593 & TRN \\
\hline CHEMBL1446279 & 688340 & 4.6 & 4.7642 & TRN \\
\hline CHEMBL1427920 & 688340 & 5.6 & 5.0232 & TST \\
\hline CHEMBL1553180 & 688340 & 5.0 & 5.4373 & TRN \\
\hline CHEMBL1371528 & 688340 & 4.4 & 5.2755 & TRN \\
\hline CHEMBL3195702 & 688340 & 4.75 & 5.0177 & TRN \\
\hline CHEMBL1339315 & 688340 & 7.0 & 5.1124 & TST \\
\hline CHEMBL1499561 & 688340 & 4.4 & 4.9445 & TST \\
\hline CHEMBL401317 & 688340 & 4.45 & 4.729 & TRN \\
\hline CHEMBL3199691 & 688340 & 4.5 & 4.8717 & TST \\
\hline CHEMBL1599781 & 688340 & 4.35 & 5.1017 & TRN \\
\hline CHEMBL1537118 & 688340 & 4.4 & 4.7203 & TST \\
\hline CHEMBL1599463 & 688340 & 5.5 & 5.0666 & TST \\
\hline CHEMBL1389414 & 688340 & 4.55 & 5.104 & TRN \\
\hline CHEMBL1567855 & 688340 & 6.0 & 4.8689 & TST \\
\hline CHEMBL1345764 & 688340 & 4.95 & 4.8842 & TRN \\
\hline
\end{tabular}




\begin{tabular}{|c|c|c|c|c|c|}
\hline & & & & & \\
\hline CHEMBL1361410 & 688340 & 5.9 & 5.0674 & TRN & \\
\hline CHEMBL3214575 & 688340 & 7.0 & 5.2232 & TRN & \\
\hline CHEMBL1417779 & 688340 & 5.6 & 5.2727 & TRN & \\
\hline CHEMBL1341201 & 688340 & 5.35 & 5.2698 & TST & \\
\hline CHEMBL1455977 & 688340 & 7.0 & 5.561 & TST & \\
\hline CHEMBL1356058 & 688340 & 4.7 & 4.897 & TRN & \\
\hline CHEMBL3196996 & 688340 & 4.45 & 5.1228 & TRN & \\
\hline CHEMBL1467136 & 688340 & 6.1 & 4.7639 & TST & \\
\hline CHEMBL1499710 & 688340 & 4.45 & 5.1718 & TRN & \\
\hline CHEMBL1486180 & 688340 & 4.55 & 4.9569 & TRN & \\
\hline CHEMBL1474885 & 688340 & 4.55 & 4.8404 & TRN & \\
\hline CHEMBL1578433 & 688340 & 6.5 & 4.9576 & TRN & \\
\hline CHEMBL1444241 & 688340 & 4.7 & 5.1701 & TST & \\
\hline CHEMBL1524466 & 688340 & 4.65 & 4.9528 & TST & \\
\hline CHEMBL1397926 & 688340 & 4.0 & 5.4543 & TRN & \\
\hline CHEMBL1269896 & 688340 & 4.4 & 4.88899 & 9999999999 & TRN \\
\hline CHEMBL1350435 & 688340 & 4.6 & 4.3696 & TRN & \\
\hline CHEMBL1581256 & 688340 & 5.05 & 5.13700 & 00000000005 & TST \\
\hline CHEMBL1577150 & 688340 & 7.4498 & 5.2181 & TST & \\
\hline CHEMBL1485284 & 688340 & 4.55 & 4.4018 & TST & \\
\hline CHEMBL1509747 & 688340 & 4.5 & 4.896 & TRN & \\
\hline CHEMBL1305387 & 688340 & 4.9 & 5.12799 & 9999999999 & TRN \\
\hline CHEMBL3193670 & 688340 & 4.55 & 4.6908 & TRN & \\
\hline CHEMBL1458003 & 688340 & 4.95 & 4.9952 & TRN & \\
\hline CHEMBL530038 & 688340 & 6.1 & 4.934 & TST & \\
\hline CHEMBL1431725 & 688340 & 4.5 & 5.0758 & TRN & \\
\hline CHEMBL3199033 & 688340 & 4.5 & 4.8139 & TRN & \\
\hline CHEMBL1317747 & 688340 & 5.2 & 5.7017 & TRN & \\
\hline CHEMBL3211452 & 688340 & 4.4 & 4.8811 & TST & \\
\hline CHEMBL1440595 & 688340 & 5.55 & 5.0261 & TST & \\
\hline CHEMBL1600284 & 688340 & 4.5 & 4.9107 & TRN & \\
\hline CHEMBL1986541 & 688340 & 4.4 & 4.6809 & TRN & \\
\hline CHEMBL1423421 & 688340 & 4.65 & 4.9112 & TRN & \\
\hline CHEMBL1524070 & 688340 & 4.5 & 5.1869 & TRN & \\
\hline CHEMBL1317663 & 688340 & 4.6 & 4.8548 & TRN & \\
\hline CHEMBL1344545 & 688340 & 6.4 & 5.2542 & TRN & \\
\hline CHEMBL1419374 & 688340 & 4.7 & 4.9235 & TRN & \\
\hline CHEMBL1315495 & 688340 & 4.55 & 4.8588 & TRN & \\
\hline CHEMBL1480782 & 688340 & 4.75 & 4.7681 & TST & \\
\hline CHEMBL1343701 & 688340 & 4.7 & 4.976 & TRN & \\
\hline CHEMBL1412994 & 688340 & 5.4 & 4.9788 & TST & \\
\hline CHEMBL1354147 & 688340 & 4.5 & 5.0718 & TRN & \\
\hline CHEMBL1408160 & 688340 & 4.95 & 4.8554 & TRN & \\
\hline CHEMBL1604303 & 688340 & 4.65 & 4.872 & TRN & \\
\hline CHEMBL1493383 & 688340 & 4.4 & 4.9503 & TST & \\
\hline CHEMBL1507719 & 688340 & 4.6 & 5.1402 & TRN & \\
\hline CHEMBL1567937 & 688340 & 7.0 & 5.4233 & TST & \\
\hline CHEMBL1379380 & 688340 & 4.55 & 4.9032 & TRN & \\
\hline & & & & 28287 & \\
\hline
\end{tabular}




\begin{tabular}{|c|c|c|c|c|}
\hline \multicolumn{5}{|c|}{ Supplemental Table S2.txt } \\
\hline CHEMBL1389271 & 688340 & 6.7001 & 4.9697 & TRN \\
\hline CHEMBL1429672 & 688340 & 6.15 & 4.893 & TST \\
\hline CHEMBL1380386 & 688340 & 4.65 & 4.9658 & TRN \\
\hline CHEMBL1451084 & 688340 & 4.45 & 4.9233 & TST \\
\hline CHEMBL1416147 & 688340 & 4.55 & 5.3177 & TST \\
\hline CHEMBL1543567 & 688340 & 4.9 & 4.7552 & TRN \\
\hline CHEMBL1531750 & 688340 & 5.05 & 4.7999 & TRN \\
\hline CHEMBL1399852 & 688340 & 5.25 & 5.2812 & TST \\
\hline CHEMBL1332328 & 688340 & 5.2 & 5.1772 & TST \\
\hline CHEMBL1344657 & 688340 & 5.0 & 5.1997 & TST \\
\hline CHEMBL1410686 & 688340 & 4.55 & 4.9076 & TRN \\
\hline CHEMBL1367060 & 688340 & 4.55 & 5.0007 & TST \\
\hline CHEMBL1411737 & 688340 & 3.95 & 5.0731 & TRN \\
\hline CHEMBL1385138 & 688340 & 4.4 & 5.244 & TRN \\
\hline CHEMBL1460927 & 688340 & 4.35 & 4.8102 & TST \\
\hline CHEMBL1546284 & 688340 & 4.5 & 4.9642 & TRN \\
\hline CHEMBL1500165 & 688340 & 4.5 & 4.7844 & TRN \\
\hline CHEMBL1424852 & 688340 & 6.4 & 5.2148 & TRN \\
\hline CHEMBL1361392 & 688340 & 4.4 & 4.5067 & TRN \\
\hline CHEMBL1464320 & 688340 & 5.4 & 4.9074 & TST \\
\hline CHEMBL1466801 & 688340 & 5.25 & 5.3133 & TST \\
\hline CHEMBL3193844 & 688340 & 4.4 & 4.9177 & TRN \\
\hline CHEMBL1390024 & 688340 & 5.25 & 5.273 & TRN \\
\hline CHEMBL1582927 & 688340 & 4.55 & 4.9815 & TRN \\
\hline CHEMBL1506847 & 688340 & 4.8 & 5.1561 & TRN \\
\hline CHEMBL1482950 & 688340 & 5.0 & 4.8481 & TRN \\
\hline CHEMBL1401449 & 688340 & 5.95 & 5.3061 & TRN \\
\hline CHEMBL1317035 & 688340 & 6.8499 & 5.5751 & TRN \\
\hline CHEMBL3196453 & 688340 & 4.65 & 4.734 & TRN \\
\hline CHEMBL1546404 & 688340 & 6.1 & 4.8094 & TRN \\
\hline CHEMBL1432145 & 688340 & 5.25 & 4.9132 & TRN \\
\hline CHEMBL1557849 & 688340 & 4.65 & 5.0831 & TRN \\
\hline CHEMBL1500317 & 688340 & 4.4 & 5.1593 & TRN \\
\hline CHEMBL1592920 & 688340 & 6.0 & 5.1711 & TRN \\
\hline CHEMBL1457560 & 688340 & 6.15 & 4.7539 & TRN \\
\hline CHEMBL1520181 & 688340 & 7.0 & 4.9108 & TST \\
\hline CHEMBL1467181 & 688340 & 4.4 & 5.0989 & TRN \\
\hline CHEMBL1451216 & 688340 & 6.1 & 5.2261 & TST \\
\hline CHEMBL1475245 & 688340 & 4.55 & 4.9473 & TRN \\
\hline CHEMBL1591773 & 688340 & 4.55 & 4.7827 & TRN \\
\hline CHEMBL1476932 & 688340 & 4.55 & 4.9234 & TRN \\
\hline CHEMBL1362151 & 688340 & 6.45 & 5.1503 & TRN \\
\hline CHEMBL1579003 & 688340 & 4.5 & 4.8694 & TRN \\
\hline CHEMBL1611344 & 688340 & 2.9 & 5.0064 & TRN \\
\hline CHEMBL1437856 & 688340 & 5.1 & 4.9541 & TRN \\
\hline CHEMBL1574295 & 688340 & 4.45 & 4.862 & TRN \\
\hline CHEMBL1409111 & 688340 & 7.0 & 5.1663 & TRN \\
\hline CHEMBL1356511 & 688340 & 7.0 & 5.2682 & TRN \\
\hline
\end{tabular}




\begin{tabular}{|c|c|c|c|c|c|}
\hline & & & & & \\
\hline CHEMBL1441772 & 688340 & 5.15 & 5.24 & TRN & \\
\hline CHEMBL1374595 & 688340 & 5.5 & 4.8751 & TST & \\
\hline CHEMBL1470395 & 688340 & 4.5 & 4.8828 & TRN & \\
\hline CHEMBL1344599 & 688340 & 5.3 & 5.2747 & TRN & \\
\hline CHEMBL1330349 & 688340 & 6.3 & 5.2925 & TRN & \\
\hline CHEMBL1601228 & 688340 & 5.35 & 5.2599 & TRN & \\
\hline CHEMBL1468076 & 688340 & 4.55 & 4.7328 & TRN & \\
\hline CHEMBL1409331 & 688340 & 6.15 & 5.1454 & TST & \\
\hline CHEMBL1392632 & 688340 & 4.35 & 4.9604 & TST & \\
\hline CHEMBL1521731 & 688340 & 4.5 & 4.8456 & TRN & \\
\hline CHEMBL1362048 & 688340 & 6.1 & 5.2369 & TRN & \\
\hline CHEMBL1410186 & 688340 & 5.7 & 5.1128 & TRN & \\
\hline CHEMBL1303939 & 688340 & 4.9 & 4.8678 & TRN & \\
\hline CHEMBL1491786 & 688340 & 3.9 & 5.04899 & 99999999995 & TST \\
\hline CHEMBL1540844 & 688340 & 9.5229 & 5.1415 & TST & \\
\hline CHEMBL1433291 & 688340 & 4.4 & 5.0156 & TRN & \\
\hline CHEMBL1323936 & 688340 & 6.3 & 5.2496 & TST & \\
\hline CHEMBL1457241 & 688340 & 4.5 & 4.8187 & TRN & \\
\hline CHEMBL1708832 & 688340 & 4.5 & 5.0013 & TRN & \\
\hline CHEMBL1459090 & 688340 & 5.0 & 5.182 & TRN & \\
\hline CHEMBL1391078 & 688340 & 4.6 & 4.7894 & TRN & \\
\hline CHEMBL1493784 & 688340 & 3.9 & 4.7405 & TRN & \\
\hline CHEMBL1463818 & 688340 & 4.8 & 5.2277 & TRN & \\
\hline CHEMBL1360351 & 688340 & 4.6 & 5.1262 & TST & \\
\hline CHEMBL1579112 & 688340 & 4.4 & 4.968 & TRN & \\
\hline CHEMBL1305810 & 688340 & 4.8 & 4.918 & TST & \\
\hline CHEMBL1575337 & 688340 & 5.0 & 5.223 & TRN & \\
\hline CHEMBL3195996 & 688340 & 5.6 & 5.1321 & TRN & \\
\hline CHEMBL3198769 & 688340 & 4.4 & 5.0925 & TRN & \\
\hline CHEMBL 3214252 & 688340 & 3.95 & 4.7957 & TRN & \\
\hline CHEMBL1337614 & 688340 & 4.85 & 4.7852 & TRN & \\
\hline CHEMBL1506267 & 688340 & 7.0501 & 5.1259 & TRN & \\
\hline CHEMBL1585105 & 688340 & 4.45 & 4.9545 & TRN & \\
\hline CHEMBL3213767 & 688340 & 4.35 & 4.9482 & TST & \\
\hline CHEMBL1381310 & 688340 & 5.5 & 5.0807 & TRN & \\
\hline CHEMBL1455711 & 688340 & 4.6 & 5.2407 & TRN & \\
\hline CHEMBL1556044 & 688340 & 5.05 & 5.0177 & TST & \\
\hline CHEMBL1350167 & 688340 & 4.65 & 5.0236 & TRN & \\
\hline CHEMBL1308344 & 688340 & 4.35 & 5.5015 & TRN & \\
\hline CHEMBL1492819 & 688340 & 5.05 & 4.7929 & TRN & \\
\hline CHEMBL1451273 & 688340 & 5.45 & 4.657 & TRN & \\
\hline CHEMBL1404857 & 688340 & 4.5 & 4.8831 & TRN & \\
\hline CHEMBL1387823 & 688340 & 6.5 & 5.4777 & TRN & \\
\hline CHEMBL1559620 & 688340 & 4.5 & 5.0036 & TRN & \\
\hline CHEMBL1323348 & 688340 & 5.2 & 5.1522 & TST & \\
\hline CHEMBL1447837 & 688340 & 4.6 & 5.1535 & TRN & \\
\hline CHEMBL1544070 & 688340 & 5.25 & 5.1583 & TRN & \\
\hline CHEMBL1398001 & 688340 & 4.5 & 5.0488 & TRN & \\
\hline
\end{tabular}




\begin{tabular}{|c|c|c|c|c|}
\hline \multicolumn{5}{|c|}{ Supplemental Table S2.txt } \\
\hline CHEMBL1490449 & 688340 & 4.6 & 4.9477 & TST \\
\hline CHEMBL1511964 & 688340 & 4.6 & 4.7178 & TRN \\
\hline CHEMBL1522152 & 688340 & 4.6 & 4.7729 & TRN \\
\hline CHEMBL1421707 & 688340 & 6.15 & 5.3001 & TRN \\
\hline CHEMBL3189307 & 688340 & 4.7 & 5.1498 & TRN \\
\hline CHEMBL1552216 & 688340 & 5.4 & 5.056 & TRN \\
\hline CHEMBL1510808 & 688340 & 5.2 & 4.6516 & TRN \\
\hline CHEMBL1310336 & 688340 & 4.5 & 4.6757 & TRN \\
\hline CHEMBL1566185 & 688340 & 5.2 & 5.1627 & TRN \\
\hline CHEMBL1350814 & 688340 & 4.6 & 4.9858 & TST \\
\hline CHEMBL1506079 & 688340 & 4.7 & 4.7287 & TRN \\
\hline CHEMBL 3193295 & 688340 & 4.4 & 4.8236 & TRN \\
\hline CHEMBL1596208 & 688340 & 5.2 & 5.2068 & TRN \\
\hline CHEMBL1406990 & 688340 & 5.5 & 5.1805 & TST \\
\hline CHEMBL1342299 & 688340 & 5.5 & 4.947 & TST \\
\hline CHEMBL1483925 & 688340 & 5.05 & 5.21299 & 9999999999 \\
\hline CHEMBL1482369 & 688340 & 5.3 & 4.9739 & TST \\
\hline CHEMBL1360793 & 688340 & 4.4 & 4.8516 & TRN \\
\hline CHEMBL3195717 & 688340 & 4.55 & 4.5456 & TRN \\
\hline CHEMBL 256097 & 688340 & 4.5 & 4.8603 & TRN \\
\hline CHEMBL1513630 & 688340 & 5.15 & 4.9088 & TRN \\
\hline CHEMBL1586814 & 688340 & 4.45 & 5.125 & TRN \\
\hline CHEMBL1350248 & 688340 & 6.15 & 4.9091 & TRN \\
\hline CHEMBL1496289 & 688340 & 4.6 & 5.2367 & TRN \\
\hline CHEMBL1534751 & 688340 & 5.45 & 5.0753 & TRN \\
\hline CHEMBL1306459 & 688340 & 4.4 & 5.2276 & TST \\
\hline CHEMBL1599920 & 688340 & 4.55 & 4.6972 & TRN \\
\hline CHEMBL1583499 & 688340 & 4.55 & 5.0117 & TRN \\
\hline CHEMBL1352543 & 688340 & 4.6 & 4.5701 & TRN \\
\hline CHEMBL1330852 & 688340 & 5.05 & 4.8245 & TRN \\
\hline CHEMBL1389089 & 688340 & 5.35 & 5.2472 & TST \\
\hline CHEMBL1613658 & 688340 & 5.35 & 5.1159 & TRN \\
\hline CHEMBL1430473 & 688340 & 6.5 & 5.1528 & TRN \\
\hline CHEMBL1433293 & 688340 & 4.4 & 5.1719 & TRN \\
\hline CHEMBL1476610 & 688340 & 5.2 & 5.0179 & TST \\
\hline CHEMBL1558519 & 688340 & 4.4 & 5.0051 & TRN \\
\hline CHEMBL1430743 & 688340 & 4.35 & 5.1161 & TST \\
\hline CHEMBL1561247 & 688340 & 4.65 & 5.1546 & TRN \\
\hline CHEMBL1378035 & 688340 & 5.5 & 5.5358 & TST \\
\hline CHEMBL1501579 & 688340 & 4.5 & 4.8097 & TRN \\
\hline CHEMBL1458080 & 688340 & 4.65 & 5.0119 & TRN \\
\hline CHEMBL1307798 & 688340 & 5.35 & 4.9455 & TRN \\
\hline CHEMBL1570425 & 688340 & 5.35 & 4.7281 & TRN \\
\hline CHEMBL1449094 & 688340 & 4.55 & 4.7592 & TRN \\
\hline CHEMBL1403262 & 688340 & 6.45 & 5.3635 & TRN \\
\hline CHEMBL1500249 & 688340 & 6.7501 & 5.2708 & TST \\
\hline CHEMBL1612603 & 688340 & 5.4 & 4.8875 & TRN \\
\hline CHEMBL1318714 & 688340 & 5.25 & 5.4803 & TST \\
\hline
\end{tabular}




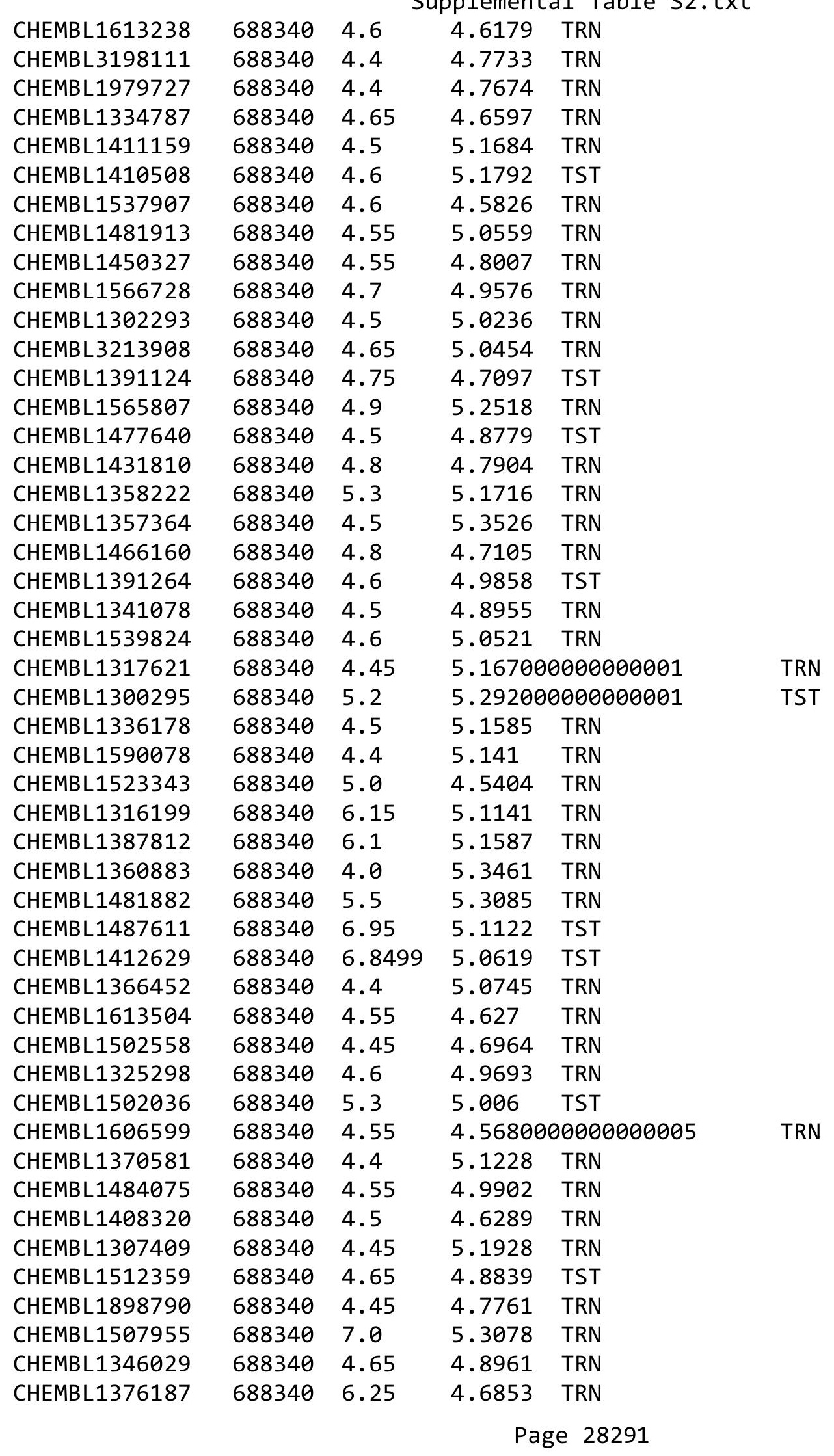




\begin{tabular}{|c|c|c|c|c|}
\hline & & & pplement & al $\mathrm{Ta}$ \\
\hline CHEMBL1310865 & 688340 & 4.5 & 4.7043 & TRN \\
\hline CHEMBL1486581 & 688340 & 4.9 & 4.9776 & TRN \\
\hline CHEMBL1561953 & 688340 & 4.0 & 5.3576 & TST \\
\hline CHEMBL 3214058 & 688340 & 5.9 & 5.2723 & TST \\
\hline CHEMBL1573433 & 688340 & 5.7 & 5.6387 & TRN \\
\hline CHEMBL1452843 & 688340 & 5.25 & 5.1082 & TRN \\
\hline CHEMBL1438406 & 688340 & 4.6 & 4.9388 & TRN \\
\hline CHEMBL1309290 & 688340 & 6.15 & 4.8357 & TST \\
\hline CHEMBL1594464 & 688340 & 4.55 & 4.6451 & TRN \\
\hline CHEMBL1339534 & 688340 & 4.4 & 4.8628 & TRN \\
\hline CHEMBL1437372 & 688340 & 4.4 & 5.2695 & TRN \\
\hline CHEMBL1318818 & 688340 & 4.8 & 4.6404 & TRN \\
\hline CHEMBL1366730 & 688340 & 6.1 & 5.0009 & TRN \\
\hline CHEMBL 3192174 & 688340 & 4.5 & 4.6152 & TRN \\
\hline CHEMBL1556692 & 688340 & 5.0 & 5.2047 & TRN \\
\hline CHEMBL1334118 & 688340 & 5.0 & 5.0872 & TRN \\
\hline CHEMBL1364811 & 688340 & 4.5 & 4.9083 & TRN \\
\hline CHEMBL1514443 & 688340 & 6.5 & 5.1542 & TST \\
\hline CHEMBL1576270 & 688340 & 6.8499 & 5.0726 & TRN \\
\hline CHEMBL1520377 & 688340 & 4.9 & 4.9835 & TRN \\
\hline CHEMBL3192311 & 688340 & 6.1 & 5.1989 & TRN \\
\hline CHEMBL1514309 & 688340 & 5.6 & 5.3409 & TRN \\
\hline CHEMBL1505649 & 688340 & 4.4 & 5.0101 & TRN \\
\hline CHEMBL 3197080 & 688340 & 4.5 & 5.0 & TRN \\
\hline CHEMBL1387917 & 688340 & 6.5501 & 4.9145 & TRN \\
\hline CHEMBL3195505 & 688340 & 4.4 & 4.8876 & TRN \\
\hline CHEMBL1527382 & 688340 & 5.0 & 5.2126 & TST \\
\hline CHEMBL1514291 & 688340 & 4.55 & 4.9165 & TRN \\
\hline CHEMBL1594634 & 688340 & 4.65 & 4.6008 & TRN \\
\hline CHEMBL1365741 & 688340 & 4.45 & 5.2891 & TRN \\
\hline CHEMBL1519638 & 688340 & 4.55 & 4.9465 & TST \\
\hline CHEMBL1590468 & 688340 & 7.0 & 4.8697 & TST \\
\hline CHEMBL 1458330 & 688340 & 4.4 & 4.815 & TRN \\
\hline CHEMBL89445 & 688340 & 4.55 & 4.7532 & TRN \\
\hline CHEMBL1418251 & 688340 & 6.8499 & 5.0068 & TRN \\
\hline CHEMBL1519494 & 688340 & 5.05 & 4.8466 & TRN \\
\hline CHEMBL1540340 & 688340 & 4.55 & 4.8226 & TRN \\
\hline CHEMBL1523536 & 688340 & 5.15 & 5.0243 & TST \\
\hline CHEMBL1326706 & 688340 & 6.8 & 5.1302 & TST \\
\hline CHEMBL1583231 & 688340 & 7.0501 & 4.8734 & TRN \\
\hline CHEMBL1452044 & 688340 & 5.2 & 5.2105 & TRN \\
\hline CHEMBL3210063 & 688340 & 5.3 & 4.8066 & TST \\
\hline CHEMBL1414489 & 688340 & 4.4 & 4.9978 & TRN \\
\hline CHEMBL1564529 & 688340 & 5.0 & 5.0863 & TST \\
\hline CHEMBL1571706 & 688340 & 4.0 & 5.0648 & TST \\
\hline CHEMBL1580947 & 688340 & 4.4 & 5.0538 & TRN \\
\hline CHEMBL1527692 & 688340 & 4.35 & 4.895 & TST \\
\hline CHEMBL1510229 & 688340 & 5.2 & 5.101 & TRN \\
\hline
\end{tabular}




\begin{tabular}{|c|c|c|c|c|}
\hline \multicolumn{5}{|c|}{ Supplemental Table S2.txt } \\
\hline CHEMBL1354394 & 688340 & 5.95 & 4.904 & TRN \\
\hline CHEMBL1529213 & 688340 & 4.65 & 4.6455 & TRN \\
\hline CHEMBL3197304 & 688340 & 5.65 & 4.8771 & TST \\
\hline CHEMBL1543754 & 688340 & 6.2 & 5.1632 & TRN \\
\hline CHEMBL 1328210 & 688340 & 5.2 & 5.1874 & TST \\
\hline CHEMBL1386030 & 688340 & 4.5 & 5.4713 & TST \\
\hline CHEMBL1444260 & 688340 & 4.45 & 5.1549 & TRN \\
\hline CHEMBL1369782 & 688340 & 5.05 & 4.916 & TRN \\
\hline CHEMBL1380031 & 688340 & 6.0 & 5.3607 & TST \\
\hline CHEMBL1384084 & 688340 & 4.7 & 5.2324 & TST \\
\hline CHEMBL1375451 & 688340 & 6.45 & 5.2499 & TRN \\
\hline CHEMBL1606838 & 688340 & 5.0 & 4.8178 & TRN \\
\hline CHEMBL1459486 & 688340 & 4.75 & 4.9916 & TST \\
\hline CHEMBL1350463 & 688340 & 5.0 & 5.1974 & TST \\
\hline CHEMBL1578998 & 688340 & 5.05 & 5.1267 & TRN \\
\hline CHEMBL3192587 & 688340 & 4.55 & 4.8475 & TRN \\
\hline CHEMBL1436660 & 688340 & 5.2 & 5.0748 & TRN \\
\hline CHEMBL1564403 & 688340 & 4.55 & 4.9537 & TRN \\
\hline CHEMBL3198659 & 688340 & 4.85 & 4.7379 & TST \\
\hline CHEMBL1403276 & 688340 & 5.2 & 4.7488 & TRN \\
\hline CHEMBL3197342 & 688340 & 4.6 & 4.9608 & TRN \\
\hline CHEMBL1429308 & 688340 & 7.6003 & 5.2893 & TST \\
\hline CHEMBL1408323 & 688340 & 4.55 & 4.8297 & TST \\
\hline CHEMBL1314869 & 688340 & 4.45 & 5.2737 & TST \\
\hline CHEMBL1400878 & 688340 & 5.0 & 5.1784 & TRN \\
\hline CHEMBL3198210 & 688340 & 4.4 & 4.7698 & TRN \\
\hline CHEMBL1592164 & 688340 & 4.4 & 4.8596 & TRN \\
\hline CHEMBL1312512 & 688340 & 3.95 & 5.2224 & TST \\
\hline CHEMBL1341616 & 688340 & 4.4 & 5.0264 & TRN \\
\hline CHEMBL1351979 & 688340 & 4.75 & 4.6526 & TRN \\
\hline CHEMBL1491331 & 688340 & 4.85 & 5.4461 & TRN \\
\hline CHEMBL1532812 & 688340 & 4.6 & 5.3962 & TRN \\
\hline CHEMBL1374927 & 688340 & 5.2 & 4.855 & TRN \\
\hline CHEMBL1318829 & 688340 & 4.85 & 4.7206 & TRN \\
\hline CHEMBL1605684 & 688340 & 6.2 & 5.0876 & TRN \\
\hline CHEMBL1469075 & 688340 & 4.6 & 4.7871 & TRN \\
\hline CHEMBL400585 & 688340 & 4.5 & 5.0834 & TST \\
\hline CHEMBL1324258 & 688340 & 5.15 & 5.0496 & TST \\
\hline CHEMBL1414529 & 688340 & 4.4 & 4.9718 & TST \\
\hline CHEMBL1494158 & 688340 & 4.95 & 5.1149 & TRN \\
\hline CHEMBL1574267 & 688340 & 7.0 & 5.0169 & TRN \\
\hline CHEMBL1517115 & 688340 & 4.6 & 4.9579 & TRN \\
\hline CHEMBL1333512 & 688340 & 4.45 & 4.8663 & TRN \\
\hline CHEMBL1300826 & 688340 & 5.45 & 5.0804 & TRN \\
\hline CHEMBL1534896 & 688340 & 5.25 & 5.5877 & TRN \\
\hline CHEMBL1511896 & 688340 & 4.6 & 4.8538 & TRN \\
\hline CHEMBL1576822 & 688340 & 5.25 & 5.2395 & TST \\
\hline CHEMBL1416440 & 688340 & 4.4 & 4.9514 & TST \\
\hline
\end{tabular}




\begin{tabular}{|c|c|c|c|c|}
\hline \multirow[b]{2}{*}{ CHEMBL1441851 } & \multicolumn{4}{|c|}{ Supplemental Table S2.tx } \\
\hline & 688340 & 5.2 & 5.2547 & TST \\
\hline CHEMBL1461102 & 688340 & 4.55 & 4.7714 & TRN \\
\hline CHEMBL1586238 & 688340 & 4.4 & 4.7194 & TRN \\
\hline CHEMBL1595920 & 688340 & 5.15 & 5.0282 & TRN \\
\hline CHEMBL1472103 & 688340 & 4.6 & 5.1323 & TRN \\
\hline CHEMBL3209647 & 688340 & 4.6 & 5.1921 & TRN \\
\hline CHEMBL1439180 & 688340 & 3.95 & 5.1337 & TRN \\
\hline CHEMBL1426282 & 688340 & 5.2 & 4.8643 & TRN \\
\hline CHEMBL1596516 & 688340 & 4.6 & 4.6869 & TRN \\
\hline CHEMBL1578845 & 688340 & 4.65 & 5.4775 & TRN \\
\hline CHEMBL1304083 & 688340 & 5.15 & 5.6179 & TST \\
\hline CHEMBL1446377 & 688340 & 4.55 & 4.7955 & TST \\
\hline CHEMBL101815 & 688340 & 4.7 & 4.7337 & TRN \\
\hline CHEMBL1421593 & 688340 & 5.15 & 5.1245 & TRN \\
\hline CHEMBL3212872 & 688340 & 4.6 & 4.7682 & TRN \\
\hline CHEMBL1312111 & 688340 & 4.55 & 4.9543 & TRN \\
\hline CHEMBL1558156 & 688340 & 4.55 & 4.9421 & TRN \\
\hline CHEMBL1979849 & 688340 & 5.8 & 4.9915 & TRN \\
\hline CHEMBL1550064 & 688340 & 4.4 & 4.8577 & TRN \\
\hline CHEMBL3192326 & 688340 & 4.6 & 4.76 & TRN \\
\hline CHEMBL1452538 & 688340 & 5.3 & 5.1474 & TRN \\
\hline CHEMBL1501990 & 688340 & 4.6 & 5.0993 & TRN \\
\hline CHEMBL1497895 & 688340 & 4.85 & 5.2992 & TST \\
\hline CHEMBL1370877 & 688340 & 4.4 & 5.1778 & TRN \\
\hline CHEMBL1304930 & 688340 & 5.45 & 5.3275 & TST \\
\hline CHEMBL3194857 & 688340 & 4.65 & 5.1107 & TRN \\
\hline CHEMBL1425257 & 688340 & 5.65 & 4.7607 & TRN \\
\hline CHEMBL1345946 & 688340 & 4.45 & 5.2354 & TST \\
\hline CHEMBL1439141 & 688340 & 6.15 & 5.2104 & TRN \\
\hline CHEMBL1334970 & 688340 & 4.9 & 4.8956 & TRN \\
\hline CHEMBL1484484 & 688340 & 5.6 & 4.8506 & TRN \\
\hline CHEMBL1527175 & 688340 & 4.7 & 4.8523 & TRN \\
\hline CHEMBL1516385 & 688340 & 4.4 & 4.862 & TRN \\
\hline CHEMBL1450635 & 688340 & 4.65 & 4.9472 & TRN \\
\hline CHEMBL1332600 & 688340 & 4.7 & 4.8763 & TRN \\
\hline CHEMBL1380914 & 688340 & 4.55 & 4.9274 & TRN \\
\hline CHEMBL1576847 & 688340 & 4.6 & 4.9689 & TRN \\
\hline CHEMBL1342965 & 688340 & 6.45 & 5.1882 & TRN \\
\hline CHEMBL1533462 & 688340 & 5.05 & 4.9031 & TRN \\
\hline CHEMBL1567624 & 688340 & 4.85 & 4.6707 & TRN \\
\hline CHEMBL1481141 & 688340 & 5.15 & 4.8415 & TRN \\
\hline CHEMBL1524663 & 688340 & 4.55 & 4.8751 & TRN \\
\hline CHEMBL1512339 & 688340 & 4.5 & 5.0271 & TRN \\
\hline CHEMBL1340480 & 688340 & 4.7 & 5.0064 & TRN \\
\hline CHEMBL1301191 & 688340 & 6.15 & 5.1241 & TST \\
\hline CHEMBL1460711 & 688340 & 4.6 & 4.9805 & TST \\
\hline CHEMBL1496958 & 688340 & 7.0 & 5.3405 & TRN \\
\hline CHEMBL1332070 & 688340 & 4.65 & 4.6028 & TRN \\
\hline
\end{tabular}




\begin{tabular}{|c|c|c|c|c|c|}
\hline & & \multicolumn{4}{|c|}{ Supplemental Table S2.txt } \\
\hline CHEMBL523844 & 688340 & 4.65 & 4.6585 & TRN & \\
\hline CHEMBL1569435 & 688340 & 4.4 & 4.6099 & TRN & \\
\hline CHEMBL570844 & 688340 & 4.45 & 4.6542 & TRN & \\
\hline CHEMBL1314261 & 688340 & 6.1 & 5.2176 & TRN & \\
\hline CHEMBL1556861 & 688340 & 4.7 & 4.9469 & TRN & \\
\hline CHEMBL3196678 & 688340 & 5.05 & 4.7468 & TRN & \\
\hline CHEMBL1370958 & 688340 & 5.55 & 4.9946 & TST & \\
\hline CHEMBL1464803 & 688340 & 4.7 & 4.9006 & TRN & \\
\hline CHEMBL1371495 & 688340 & 5.55 & 4.8088 & TST & \\
\hline CHEMBL1381749 & 688340 & 6.4 & 5.2198 & TRN & \\
\hline CHEMBL1398855 & 688340 & 4.8 & 5.033 & TRN & \\
\hline CHEMBL1479165 & 688340 & 4.85 & 5.1841 & TRN & \\
\hline CHEMBL1522353 & 688340 & 7.0 & 4.9181 & TRN & \\
\hline CHEMBL1969761 & 688340 & 4.4 & 4.7435 & TRN & \\
\hline CHEMBL1584863 & 688340 & 4.9 & 5.4157 & TST & \\
\hline CHEMBL3191242 & 688340 & 4.85 & 4.8825 & TRN & \\
\hline CHEMBL1311300 & 688340 & 5.9 & 5.3735 & TRN & \\
\hline CHEMBL2005973 & 688340 & 4.45 & 4.7443 & TST & \\
\hline CHEMBL1372101 & 688340 & 4.5 & 4.728 & TRN & \\
\hline CHEMBL1303865 & 688340 & 4.55 & 4.8273 & TRN & \\
\hline CHEMBL1525848 & 688340 & 4.6 & 5.4533 & TRN & \\
\hline CHEMBL1359521 & 688340 & 4.6 & 4.8947 & TRN & \\
\hline CHEMBL1533567 & 688340 & 5.75 & 5.1419 & TRN & \\
\hline CHEMBL1377250 & 688340 & 4.5 & 4.7368 & TRN & \\
\hline CHEMBL1312641 & 688340 & 4.85 & 4.7515 & TRN & \\
\hline CHEMBL1528076 & 688340 & 4.7 & 4.6975 & TRN & \\
\hline CHEMBL1362351 & 688340 & 5.0 & 5.3098 & TRN & \\
\hline CHEMBL1613638 & 688340 & 4.65 & 5.0037 & TRN & \\
\hline CHEMBL1531309 & 688340 & 4.7 & 4.7354 & TST & \\
\hline CHEMBL1303619 & 688340 & 4.55 & 4.9471 & TRN & \\
\hline CHEMBL1333451 & 688340 & 6.0 & 4.7515 & TST & \\
\hline CHEMBL1342848 & 688340 & 6.1 & 5.2083 & TST & \\
\hline CHEMBL1566075 & 688340 & 4.6 & 5.0599 & TRN & \\
\hline CHEMBL1988851 & 688340 & 5.45 & 4.7838 & TRN & \\
\hline CHEMBL1524936 & 688340 & 5.2 & 5.2139 & TST & \\
\hline CHEMBL1386310 & 688340 & 5.5 & 5.0485 & TRN & \\
\hline CHEMBL1563926 & 688340 & 5.2 & 5.3624 & TRN & \\
\hline CHEMBL1511401 & 688340 & 6.2 & 5.2181 & TRN & \\
\hline CHEMBL1374915 & 688340 & 5.05 & 4.9229 & TRN & \\
\hline CHEMBL1432276 & 688340 & 4.6 & 5.319 & TRN & \\
\hline CHEMBL1594989 & 688340 & 2.95 & 4.8317 & TRN & \\
\hline CHEMBL2369261 & 688340 & 4.55 & 5.0412 & TST & \\
\hline CHEMBL1594320 & 688340 & 4.4 & 4.9224 & TRN & \\
\hline CHEMBL1460614 & 688340 & 5.0 & 5.08899 & 99999999995 & TRN \\
\hline CHEMBL1440571 & 688340 & 4.6 & 5.0333 & TRN & \\
\hline CHEMBL1390247 & 688340 & 6.0 & 5.3966 & TRN & \\
\hline CHEMBL1391526 & 688340 & 5.05 & 5.4462 & TRN & \\
\hline CHEMBL1612230 & 688340 & 4.55 & 5.2061 & TRN & \\
\hline
\end{tabular}




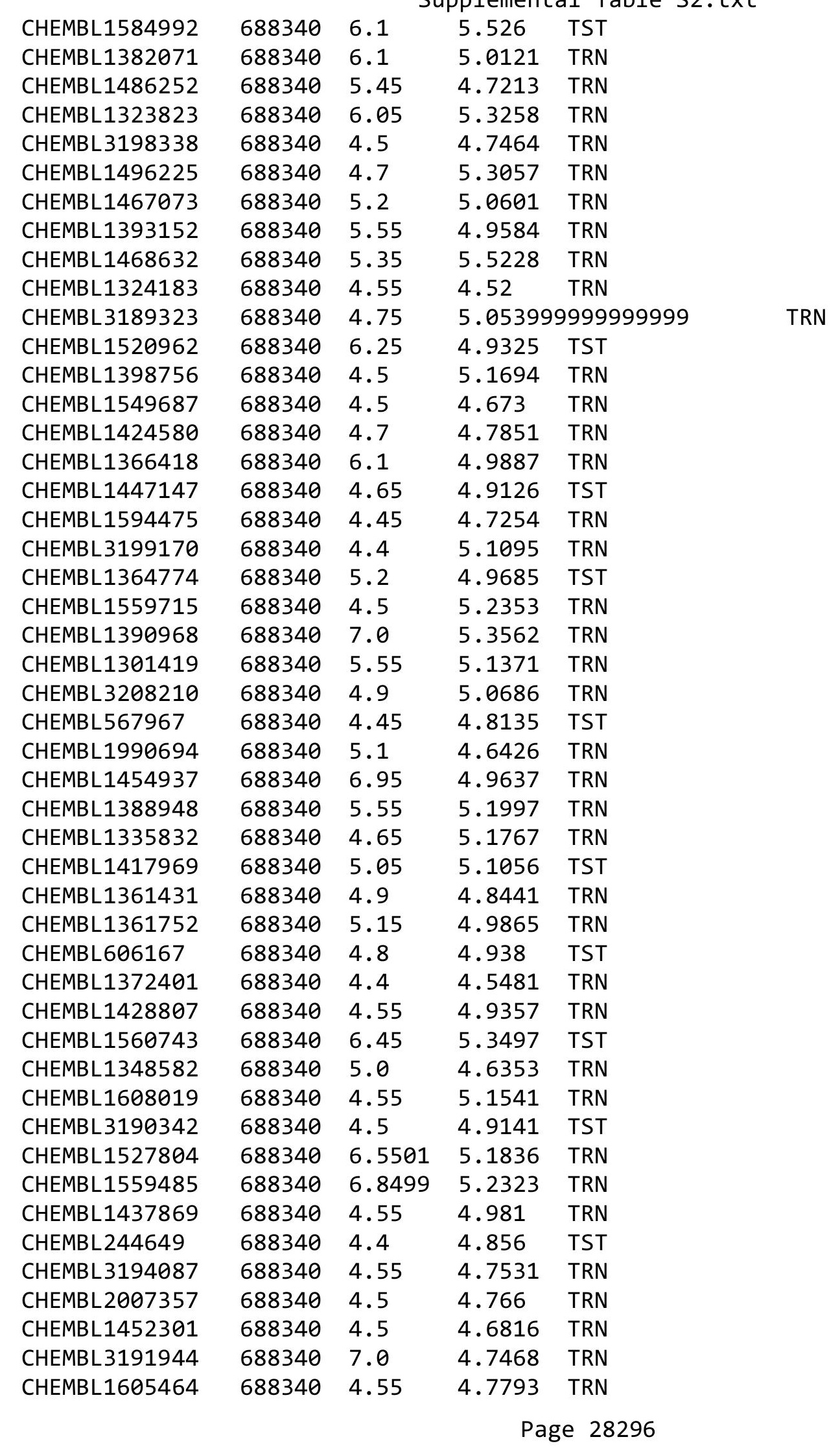




\begin{tabular}{|c|c|c|c|c|c|}
\hline \multicolumn{6}{|c|}{ Supplemental Table S2.txt } \\
\hline CHEMBL1561110 & 688340 & 4.35 & 5.1661 & TST & \\
\hline CHEMBL1436630 & 688340 & 4.55 & 4.8434 & TRN & \\
\hline CHEMBL1591870 & 688340 & 5.35 & 4.7531 & TRN & \\
\hline CHEMBL1320061 & 688340 & 4.85 & 4.86100 & 0000000001 & TRN \\
\hline CHEMBL1362601 & 688340 & 5.0 & 5.1533 & TRN & \\
\hline CHEMBL1577840 & 688340 & 5.5 & 4.8531 & TST & \\
\hline CHEMBL1455542 & 688340 & 4.7 & 4.6952 & TST & \\
\hline CHEMBL1538172 & 688340 & 5.65 & 4.974 & TST & \\
\hline CHEMBL1562310 & 688340 & 6.95 & 4.8355 & TRN & \\
\hline CHEMBL1562033 & 688340 & 4.4 & 4.7167 & TRN & \\
\hline CHEMBL1968789 & 688340 & 4.75 & 4.7877 & TRN & \\
\hline CHEMBL1374237 & 688340 & 4.8 & 4.8867 & TST & \\
\hline CHEMBL1392532 & 688340 & 4.5 & 4.8585 & TRN & \\
\hline CHEMBL1588930 & 688340 & 4.65 & 4.6483 & TRN & \\
\hline CHEMBL1386325 & 688340 & 5.35 & 5.4407 & TRN & \\
\hline CHEMBL1462340 & 688340 & 4.4 & 5.1341 & TST & \\
\hline CHEMBL1530741 & 688340 & 4.85 & 4.9792 & TRN & \\
\hline CHEMBL1588274 & 688340 & 4.5 & 5.0281 & TRN & \\
\hline CHEMBL191015 & 688340 & 4.6 & 4.8222 & TRN & \\
\hline CHEMBL1375228 & 688340 & 7.0501 & 5.2789 & TST & \\
\hline CHEMBL1378538 & 688340 & 4.85 & 5.0861 & TRN & \\
\hline CHEMBL3196786 & 688340 & 5.4 & 5.0835 & TRN & \\
\hline CHEMBL1470627 & 688340 & 5.2 & 5.1803 & TST & \\
\hline CHEMBL1472461 & 688340 & 7.0501 & 5.0793 & TRN & \\
\hline CHEMBL1537530 & 688340 & 5.4 & 5.1896 & TST & \\
\hline CHEMBL1533502 & 688340 & 5.15 & 5.2065 & TRN & \\
\hline CHEMBL1481575 & 688340 & 4.7 & 5.1192 & TRN & \\
\hline CHEMBL1565806 & 688340 & 5.4 & 4.9501 & TRN & \\
\hline CHEMBL1373124 & 688340 & 4.65 & 4.8363 & TRN & \\
\hline CHEMBL1601854 & 688340 & 4.65 & 5.1043 & TST & \\
\hline CHEMBL1488072 & 688340 & 4.6 & 5.14 & TRN & \\
\hline CHEMBL581910 & 688340 & 4.4 & 4.9071 & TST & \\
\hline CHEMBL1448633 & 688340 & 6.05 & 5.38899 & 9999999999 & TRN \\
\hline CHEMBL1430857 & 688340 & 5.0 & 5.3584 & TST & \\
\hline CHEMBL1472061 & 688340 & 5.45 & 5.1687 & TST & \\
\hline CHEMBL1505130 & 688340 & 4.85 & 4.9565 & TRN & \\
\hline CHEMBL1499252 & 688340 & 5.4 & 5.1459 & TRN & \\
\hline CHEMBL1461634 & 688340 & 5.15 & 4.8028 & TRN & \\
\hline CHEMBL1465287 & 688340 & 4.7 & 4.7333 & TRN & \\
\hline CHEMBL1558011 & 688340 & 6.5501 & 4.851 & TRN & \\
\hline CHEMBL1546561 & 688340 & 6.4 & 4.9953 & TRN & \\
\hline CHEMBL1510817 & 688340 & 4.65 & 4.8846 & TST & \\
\hline CHEMBL1477547 & 688340 & 4.5 & 5.0532 & TRN & \\
\hline CHEMBL1406817 & 688340 & 4.6 & 4.8881 & TRN & \\
\hline CHEMBL1525288 & 688340 & 5.05 & 5.2364 & TRN & \\
\hline CHEMBL 1456140 & 688340 & 4.4 & 4.89 & TRN & \\
\hline CHEMBL1604687 & 688340 & 4.65 & 4.9911 & TST & \\
\hline CHEMBL1432599 & 688340 & 4.85 & 5.1456 & TRN & \\
\hline
\end{tabular}




\begin{tabular}{|c|c|c|c|c|c|}
\hline \multicolumn{6}{|c|}{ Supplemental Table S2.txt } \\
\hline CHEMBL1485331 & 688340 & 6.15 & 4.7506 & TST & \\
\hline CHEMBL1538427 & 688340 & 4.5 & 4.8013 & TRN & \\
\hline CHEMBL1532412 & 688340 & 4.8 & 4.9335 & TRN & \\
\hline CHEMBL1586485 & 688340 & 4.4 & 4.955 & TRN & \\
\hline CHEMBL1544371 & 688340 & 6.0 & 4.724 & TRN & \\
\hline CHEMBL1482594 & 688340 & 4.6 & 5.0194 & TRN & \\
\hline CHEMBL1539491 & 688340 & 4.8 & 4.7934 & TST & \\
\hline CHEMBL1427167 & 688340 & 5.4 & 5.3037 & TRN & \\
\hline CHEMBL1475055 & 688340 & 6.15 & 5.2632 & TST & \\
\hline CHEMBL1370567 & 688340 & 4.45 & 4.938 & TRN & \\
\hline CHEMBL607979 & 688340 & 5.15 & 5.1063 & TRN & \\
\hline CHEMBL1488203 & 688340 & 5.1 & 4.9905 & TRN & \\
\hline CHEMBL1303711 & 688340 & 4.55 & 4.7072 & TRN & \\
\hline CHEMBL1613161 & 688340 & 5.0 & 5.1236 & TST & \\
\hline CHEMBL1391113 & 688340 & 9.0969 & 5.1017 & TST & \\
\hline CHEMBL1497851 & 688340 & 4.5 & 5.2495 & TRN & \\
\hline CHEMBL1319489 & 688340 & 5.15 & 4.9852 & TRN & \\
\hline CHEMBL1451674 & 688340 & 7.0501 & 5.2226 & TRN & \\
\hline CHEMBL 3209760 & 688340 & 7.0 & 4.9468 & TST & \\
\hline CHEMBL1573436 & 688340 & 4.6 & 4.5474 & TRN & \\
\hline CHEMBL1486265 & 688340 & 4.5 & 5.0776 & TST & \\
\hline CHEMBL1367682 & 688340 & 4.5 & 4.96899 & & TST \\
\hline CHEMBL1985606 & 688340 & 4.65 & 4.8292 & TST & \\
\hline CHEMBL1467588 & 688340 & 5.25 & 4.8992 & TRN & \\
\hline CHEMBL1602693 & 688340 & 4.0 & 4.9971 & TST & \\
\hline CHEMBL1467552 & 688340 & 5.15 & 5.223 & TRN & \\
\hline CHEMBL1425176 & 688340 & 4.6 & 5.0101 & TST & \\
\hline CHEMBL1484216 & 688340 & 4.95 & 5.3867 & TRN & \\
\hline CHEMBL1493596 & 688340 & 5.4 & 5.2545 & TST & \\
\hline CHEMBL1611096 & 688340 & 4.5 & 4.9033 & TRN & \\
\hline CHEMBL1507769 & 688340 & 4.4 & 5.3713 & TST & \\
\hline CHEMBL1560122 & 688340 & 6.45 & 5.5053 & TRN & \\
\hline CHEMBL1454035 & 688340 & 6.15 & 4.9332 & TRN & \\
\hline CHEMBL1531209 & 688340 & 4.65 & 4.9635 & TST & \\
\hline CHEMBL1512623 & 688340 & 4.4 & 5.1874 & TRN & \\
\hline CHEMBL1582878 & 688340 & 4.55 & 4.9527 & TRN & \\
\hline CHEMBL1497918 & 688340 & 4.4 & 5.2013 & TRN & \\
\hline CHEMBL1411938 & 688340 & 5.1 & 5.1887 & TRN & \\
\hline CHEMBL1542926 & 688340 & 4.9 & 4.7763 & TST & \\
\hline CHEMBL1326546 & 688340 & 4.5 & 4.8571 & TRN & \\
\hline CHEMBL1392676 & 688340 & 4.55 & 4.7087 & TST & \\
\hline CHEMBL1467332 & 688340 & 4.4 & 4.8352 & TRN & \\
\hline CHEMBL1498947 & 688340 & 5.05 & 5.041 & TST & \\
\hline CHEMBL1320230 & 688340 & 5.9 & 4.9597 & TRN & \\
\hline CHEMBL1509593 & 688340 & 4.3 & 5.2039 & TRN & \\
\hline CHEMBL1597665 & 688340 & 4.75 & 4.9422 & TRN & \\
\hline CHEMBL1457666 & 688340 & 6.1 & 5.1449 & TRN & \\
\hline CHEMBL1421719 & 688340 & 7.0 & 5.0568 & TST & \\
\hline
\end{tabular}




\begin{tabular}{|c|c|c|c|c|c|}
\hline \multicolumn{6}{|c|}{ Supplemental Table S2.txt } \\
\hline CHEMBL1524257 & 688340 & 4.65 & 4.8337 & TRN & \\
\hline CHEMBL1492678 & 688340 & 4.4 & 5.0575 & TRN & \\
\hline CHEMBL1317243 & 688340 & 4.55 & 5.0964 & TRN & \\
\hline CHEMBL1309164 & 688340 & 4.55 & 4.7495 & TRN & \\
\hline CHEMBL1544663 & 688340 & 4.0 & 5.2562 & TST & \\
\hline CHEMBL1570792 & 688340 & 7.0 & 5.581 & TRN & \\
\hline CHEMBL1600431 & 688340 & 4.55 & 4.9654 & TST & \\
\hline CHEMBL1350317 & 688340 & 4.6 & 4.7876 & TRN & \\
\hline CHEMBL1430122 & 688340 & 4.75 & 4.9063 & TRN & \\
\hline CHEMBL1376624 & 688340 & 5.4 & 5.5313 & TST & \\
\hline CHEMBL1517087 & 688340 & 5.95 & 5.0488 & TRN & \\
\hline CHEMBL1300344 & 688340 & 4.65 & 4.9674 & TRN & \\
\hline CHEMBL1435652 & 688340 & 5.3 & 5.268 & TRN & \\
\hline CHEMBL1538396 & 688340 & 4.5 & 4.8245 & TRN & \\
\hline CHEMBL1509314 & 688340 & 4.55 & 4.7181 & TRN & \\
\hline CHEMBL1324374 & 688340 & 5.0 & 4.8534 & TST & \\
\hline CHEMBL1491200 & 688340 & 4.3 & 5.5602 & TRN & \\
\hline CHEMBL1403734 & 688340 & 4.55 & 4.923 & TRN & \\
\hline CHEMBL3189665 & 688340 & 4.55 & 4.8781 & TRN & \\
\hline CHEMBL3199008 & 688340 & 4.55 & 5.1202 & TRN & \\
\hline CHEMBL1585882 & 688340 & 5.25 & 5.0431 & TST & \\
\hline CHEMBL1514698 & 688340 & 6.15 & 5.2072 & TRN & \\
\hline CHEMBL1376825 & 688340 & 4.55 & 4.7805 & TRN & \\
\hline CHEMBL1578729 & 688340 & 4.55 & 5.1563 & TRN & \\
\hline CHEMBL 3195564 & 688340 & 4.85 & 5.0055 & TST & \\
\hline CHEMBL1513981 & 688340 & 4.55 & 4.9758 & TRN & \\
\hline CHEMBL1594273 & 688340 & 5.7 & 5.1376 & TRN & \\
\hline CHEMBL1606460 & 688340 & 4.95 & 4.8503 & TRN & \\
\hline CHEMBL1482458 & 688340 & 6.5501 & 5.1191 & TRN & \\
\hline CHEMBL 3145060 & 688340 & 6.1 & 5.0594 & TRN & \\
\hline CHEMBL1417070 & 688340 & 5.1 & 4.8738 & TRN & \\
\hline CHEMBL1505956 & 688340 & 4.45 & 4.7819 & TST & \\
\hline CHEMBL1469647 & 688340 & 4.5 & 4.465 & TRN & \\
\hline CHEMBL1530775 & 688340 & 4.45 & 5.0234 & TRN & \\
\hline CHEMBL1564881 & 688340 & 5.4 & 5.53606 & 00000000005 & TRN \\
\hline CHEMBL1334134 & 688340 & 4.55 & 5.008 & TRN & \\
\hline CHEMBL1305269 & 688340 & 5.7 & 4.7229 & TRN & \\
\hline CHEMBL1528188 & 688340 & 5.0 & 5.1687 & TRN & \\
\hline CHEMBL1592658 & 688340 & 4.55 & 5.1496 & TRN & \\
\hline CHEMBL1509338 & 688340 & 5.25 & 4.8398 & TST & \\
\hline CHEMBL1322068 & 688340 & 4.4 & 4.5708 & TST & \\
\hline CHEMBL1370233 & 688340 & 4.95 & 4.8441 & TRN & \\
\hline CHEMBL1602502 & 688340 & 4.55 & 4.902 & TRN & \\
\hline CHEMBL1526171 & 688340 & 5.45 & 5.2258 & TRN & \\
\hline CHEMBL1398719 & 688340 & 4.55 & 4.9399 & TRN & \\
\hline CHEMBL1359287 & 688340 & 4.65 & 4.8397 & TRN & \\
\hline CHEMBL1552053 & 688340 & 4.45 & 4.7935 & TRN & \\
\hline CHEMBL1333827 & 688340 & 7.0501 & 4.7681 & TST & \\
\hline
\end{tabular}




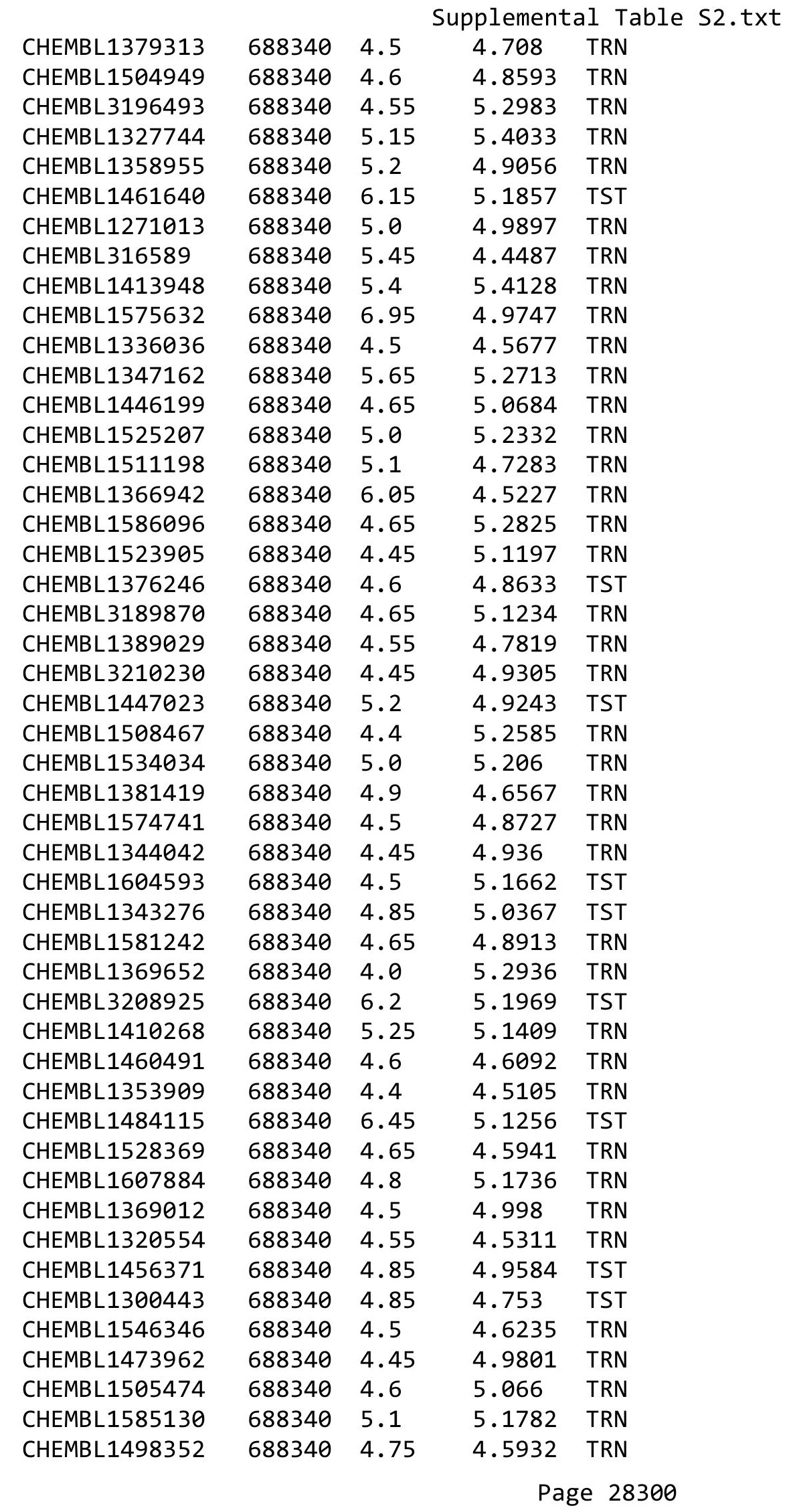




\begin{tabular}{|c|c|c|c|c|c|}
\hline \\
\hline CHEMBL1372629 & 688340 & 6.0 & 5.1007 & TRN & \\
\hline CHEMBL1393809 & 688340 & 5.0 & 5.2518 & TST & \\
\hline CHEMBL1459229 & 688340 & 4.9 & 4.9985 & TST & \\
\hline CHEMBL1303203 & 688340 & 4.6 & 4.8961 & TRN & \\
\hline CHEMBL1583914 & 688340 & 4.45 & 5.0489 & TST & \\
\hline CHEMBL1325273 & 688340 & 5.6 & 4.7313 & TST & \\
\hline CHEMBL1513339 & 688340 & 7.0 & 5.3739 & TST & \\
\hline CHEMBL1349438 & 688340 & 5.95 & 5.1819 & TRN & \\
\hline CHEMBL1312716 & 688340 & 4.8 & 4.9599 & TRN & \\
\hline CHEMBL1507308 & 688340 & 4.6 & 4.9186 & TRN & \\
\hline CHEMBL1527590 & 688340 & 5.4 & 4.6637 & TST & \\
\hline CHEMBL512261 & 688340 & 4.65 & 5.1631 & TRN & \\
\hline CHEMBL1455120 & 688340 & 7.0 & 5.2274 & TRN & \\
\hline CHEMBL1319129 & 688340 & 5.5 & 5.1587 & TRN & \\
\hline CHEMBL1430051 & 688340 & 4.85 & 4.6875 & TRN & \\
\hline CHEMBL1344596 & 688340 & 4.6 & 4.6533 & TST & \\
\hline CHEMBL1320665 & 688340 & 4.55 & 5.0628 & TRN & \\
\hline CHEMBL1603365 & 688340 & 6.1 & 5.2806 & TRN & \\
\hline CHEMBL1386684 & 688340 & 5.15 & 4.6381 & TRN & \\
\hline CHEMBL1600699 & 688340 & 5.2 & 5.0139 & TST & \\
\hline CHEMBL1313496 & 688340 & 4.0 & 5.3163 & TRN & \\
\hline CHEMBL1319397 & 688340 & 5.2 & 5.1826 & TST & \\
\hline CHEMBL1485713 & 688340 & 4.45 & 5.171 & TRN & \\
\hline CHEMBL1423198 & 688340 & 4.4 & 4.8622 & TRN & \\
\hline CHEMBL1610857 & 688340 & 5.15 & 4.9356 & TRN & \\
\hline CHEMBL1540785 & 688340 & 5.3 & 5.0656 & TST & \\
\hline CHEMBL1366408 & 688340 & 5.0 & 5.01699 & 99999999995 & TST \\
\hline CHEMBL1582193 & 688340 & 4.5 & 4.9736 & TRN & \\
\hline CHEMBL1576960 & 688340 & 4.5 & 5.0062 & TRN & \\
\hline CHEMBL1431274 & 688340 & 5.75 & 5.5359 & TRN & \\
\hline CHEMBL3194905 & 688340 & 4.4 & 5.2166 & TST & \\
\hline CHEMBL1584560 & 688340 & 4.7 & 5.3337 & TRN & \\
\hline CHEMBL1606376 & 688340 & 5.3 & 5.2582 & TRN & \\
\hline CHEMBL1529861 & 688340 & 4.6 & 5.0513 & TRN & \\
\hline CHEMBL1350915 & 688340 & 4.75 & 4.8528 & TRN & \\
\hline CHEMBL1505114 & 688340 & 5.45 & 5.3132 & TRN & \\
\hline CHEMBL1402682 & 688340 & 4.95 & 4.8866 & TRN & \\
\hline CHEMBL1328592 & 688340 & 5.85 & 4.8236 & TRN & \\
\hline CHEMBL1582114 & 688340 & 4.55 & 5.1203 & TRN & \\
\hline CHEMBL3194445 & 688340 & 4.55 & 4.6695 & TRN & \\
\hline CHEMBL1557739 & 688340 & 4.0 & 5.4592 & TRN & \\
\hline CHEMBL1379840 & 688340 & 6.8 & 5.3089 & TRN & \\
\hline CHEMBL1360753 & 688340 & 4.0 & 4.9067 & TST & \\
\hline CHEMBL1981657 & 688340 & 4.95 & 5.1268 & TST & \\
\hline CHEMBL1491686 & 688340 & 4.4 & 4.9315 & TRN & \\
\hline CHEMBL1596655 & 688340 & 4.7 & 5.081 & TST & \\
\hline CHEMBL1483810 & 688340 & 4.6 & 4.9988 & TRN & \\
\hline CHEMBL3190916 & 688340 & 7.0501 & 4.9992 & TST & \\
\hline
\end{tabular}

Page 28301 


\begin{tabular}{|c|c|c|c|c|c|}
\hline \multicolumn{6}{|c|}{ plemental } \\
\hline CHEMBL1442893 & 688340 & 4.7 & 5.2209 & TRN & \\
\hline CHEMBL1508001 & 688340 & 6.1 & 4.9068 & TRN & \\
\hline CHEMBL1330691 & 688340 & 4.6 & 5.0009 & TST & \\
\hline CHEMBL443231 & 688340 & 4.65 & 5.0326 & TRN & \\
\hline CHEMBL1587396 & 688340 & 6.15 & 5.0595 & TST & \\
\hline CHEMBL1582329 & 688340 & 4.7 & 4.7964 & TRN & \\
\hline CHEMBL3198017 & 688340 & 4.5 & 4.7673 & TRN & \\
\hline CHEMBL1561770 & 688340 & 4.95 & 5.1121 & TRN & \\
\hline CHEMBL1584438 & 688340 & 4.35 & 5.0542 & TST & \\
\hline CHEMBL1448410 & 688340 & 5.1 & 5.0108 & TRN & \\
\hline CHEMBL1533459 & 688340 & 4.65 & 4.9812 & TRN & \\
\hline CHEMBL1398866 & 688340 & 5.95 & 5.2509 & TST & \\
\hline CHEMBL1375732 & 688340 & 4.8 & 5.1304 & TRN & \\
\hline CHEMBL1309195 & 688340 & 6.8499 & 5.0739 & TST & \\
\hline CHEMBL1516329 & 688340 & 4.9 & 4.8961 & TRN & \\
\hline CHEMBL1509477 & 688340 & 4.5 & 4.6331 & TRN & \\
\hline CHEMBL1331440 & 688340 & 4.4 & 5.3495 & TRN & \\
\hline CHEMBL1434526 & 688340 & 5.15 & 5.0027 & TST & \\
\hline CHEMBL1317189 & 688340 & 6.05 & 5.0686 & TRN & \\
\hline CHEMBL1598935 & 688340 & 4.65 & 5.0265 & TRN & \\
\hline CHEMBL1299616 & 688340 & 5.05 & 4.9901 & TRN & \\
\hline CHEMBL3207809 & 688340 & 4.0 & 4.8056 & TRN & \\
\hline CHEMBL1570107 & 688340 & 4.55 & 5.0822 & TST & \\
\hline CHEMBL1389455 & 688340 & 4.45 & 4.8989 & TRN & \\
\hline CHEMBL3189907 & 688340 & 5.2 & 4.8209 & TRN & \\
\hline CHEMBL1364166 & 688340 & 4.65 & 4.6536 & TRN & \\
\hline CHEMBL1570584 & 688340 & 4.55 & 4.9768 & TRN & \\
\hline CHEMBL1394023 & 688340 & 4.5 & 4.8334 & TRN & \\
\hline CHEMBL1540725 & 688340 & 6.8499 & 5.1002 & TST & \\
\hline CHEMBL1510083 & 688340 & 4.4 & 4.9513 & TRN & \\
\hline CHEMBL3199586 & 688340 & 4.4 & 4.6934 & TRN & \\
\hline CHEMBL1565009 & 688340 & 5.2 & 5.4831 & TST & \\
\hline CHEMBL1477786 & 688340 & 4.65 & 4.71899 & 9999999999 & TRN \\
\hline CHEMBL1608616 & 688340 & 4.6 & 4.7452 & TST & \\
\hline CHEMBL1543776 & 688340 & 4.85 & 5.1331 & TRN & \\
\hline CHEMBL1324784 & 688340 & 6.1 & 5.3038 & TST & \\
\hline CHEMBL1409034 & 688340 & 5.2 & 5.1468 & TRN & \\
\hline CHEMBL1408923 & 688340 & 4.4 & 4.8648 & TST & \\
\hline CHEMBL1407610 & 688340 & 4.8 & 4.9085 & TST & \\
\hline CHEMBL1531052 & 688340 & 5.2 & 5.3491 & TST & \\
\hline CHEMBL3190306 & 688340 & 4.4 & 5.2911 & TRN & \\
\hline CHEMBL3196751 & 688340 & 4.6 & 5.05699 & 99999999995 & TRN \\
\hline CHEMBL1463618 & 688340 & 5.15 & 5.3807 & TST & \\
\hline CHEMBL1447556 & 688340 & 5.2 & 5.0897 & TST & \\
\hline CHEMBL1586400 & 688340 & 4.5 & 4.8002 & TST & \\
\hline CHEMBL1084441 & 688340 & 4.6 & 4.7256 & TRN & \\
\hline CHEMBL1575194 & 688340 & 7.0501 & 4.956 & TRN & \\
\hline CHEMBL1396768 & 688340 & 4.6 & 5.0518 & TST & \\
\hline
\end{tabular}




\begin{tabular}{|c|c|c|c|c|}
\hline & & & & al Table S2 \\
\hline CHEMBL1486248 & 688340 & 2.8 & 5.2146 & TRN \\
\hline CHEMBL1611196 & 688340 & 6.45 & 5.029 & TST \\
\hline CHEMBL1598103 & 688340 & 7.0 & 5.2962 & TRN \\
\hline CHEMBL1400394 & 688340 & 4.4 & 5.4893 & TST \\
\hline CHEMBL1513584 & 688340 & 4.5 & 5.476 & TST \\
\hline CHEMBL1595909 & 688340 & 4.45 & 4.7953 & TRN \\
\hline CHEMBL1395533 & 688340 & 4.45 & 4.8081 & TRN \\
\hline CHEMBL1362935 & 688340 & 6.0 & 5.0681 & TST \\
\hline CHEMBL1427636 & 688340 & 5.2 & 5.0649 & TST \\
\hline CHEMBL1311266 & 688340 & 4.55 & 4.8988 & TRN \\
\hline CHEMBL1598766 & 688340 & 5.15 & 5.0673 & TRN \\
\hline CHEMBL3212844 & 688340 & 4.4 & 5.0994 & TST \\
\hline CHEMBL1541890 & 688340 & 4.6 & 4.8652 & TRN \\
\hline CHEMBL1604084 & 688340 & 4.65 & 4.8438 & TST \\
\hline CHEMBL1612318 & 688340 & 4.4 & 5.5095 & TST \\
\hline CHEMBL1422221 & 688340 & 4.4 & 4.9935 & TRN \\
\hline CHEMBL1460977 & 688340 & 5.2 & 5.5281 & TRN \\
\hline CHEMBL1461947 & 688340 & 4.4 & 4.8681 & TRN \\
\hline CHEMBL1585774 & 688340 & 5.0 & 5.1164 & TRN \\
\hline CHEMBL3210321 & 688340 & 6.05 & 4.8462 & TRN \\
\hline CHEMBL1555215 & 688340 & 4.5 & 4.6433 & TRN \\
\hline CHEMBL1464352 & 688340 & 4.6 & 4.8167 & TRN \\
\hline CHEMBL1390797 & 688340 & 5.4 & 4.9123 & TRN \\
\hline CHEMBL1507290 & 688340 & 5.0 & 5.0118 & TRN \\
\hline CHEMBL1434435 & 688340 & 4.8 & 4.8431 & TRN \\
\hline CHEMBL1497298 & 688340 & 5.05 & 4.9286 & TST \\
\hline CHEMBL1598071 & 688340 & 4.9 & 5.2119 & TRN \\
\hline CHEMBL1612225 & 688340 & 5.8 & 5.2749 & TRN \\
\hline CHEMBL3208791 & 688340 & 5.2 & 4.97199 & 99999999995 \\
\hline CHEMBL1566599 & 688340 & 5.0 & 4.9989 & TST \\
\hline CHEMBL1573000 & 688340 & 5.05 & 4.7895 & TST \\
\hline CHEMBL1521025 & 688340 & 5.95 & 5.4467 & TRN \\
\hline CHEMBL1350010 & 688340 & 5.55 & 4.8606 & TRN \\
\hline CHEMBL1474076 & 688340 & 4.95 & 5.2342 & TST \\
\hline CHEMBL1563542 & 688340 & 4.4 & 4.8844 & TRN \\
\hline CHEMBL1610215 & 688340 & 4.7 & 4.7844 & TRN \\
\hline CHEMBL1328414 & 688340 & 4.4 & 5.3814 & TRN \\
\hline CHEMBL3193554 & 688340 & 4.55 & 4.9755 & TRN \\
\hline CHEMBL1332581 & 688340 & 4.4 & 4.9955 & TRN \\
\hline CHEMBL3193949 & 688340 & 4.7 & 5.1356 & TRN \\
\hline CHEMBL1402360 & 688340 & 4.4 & 5.1485 & TST \\
\hline CHEMBL1328106 & 688340 & 4.7 & 5.1917 & TRN \\
\hline CHEMBL1350760 & 688340 & 5.6 & 5.5557 & TRN \\
\hline CHEMBL1518060 & 688340 & 5.5 & 5.0879 & TST \\
\hline CHEMBL1325586 & 688340 & 4.65 & 4.9118 & TRN \\
\hline CHEMBL1469246 & 688340 & 5.05 & 4.9482 & TRN \\
\hline CHEMBL1306007 & 688340 & 4.75 & 4.9617 & TST \\
\hline CHEMBL1487147 & 688340 & 4.5 & 5.0686 & TRN \\
\hline
\end{tabular}




\begin{tabular}{|c|c|c|c|c|c|}
\hline \multicolumn{6}{|c|}{ Supplemental Table S2.txt } \\
\hline CHEMBL1432564 & 688340 & 4.4 & 4.6557 & TRN & \\
\hline CHEMBL1306215 & 688340 & 4.5 & 4.8307 & TST & \\
\hline CHEMBL1519870 & 688340 & 4.4 & 4.751 & TRN & \\
\hline CHEMBL1584135 & 688340 & 6.15 & 4.9101 & TRN & \\
\hline CHEMBL1979721 & 688340 & 4.5 & 5.1241 & TRN & \\
\hline CHEMBL1346909 & 688340 & 5.0 & 4.8585 & TRN & \\
\hline CHEMBL1496046 & 688340 & 4.6 & 4.7399 & TRN & \\
\hline CHEMBL1500816 & 688340 & 4.55 & 4.6847 & TST & \\
\hline CHEMBL3193946 & 688340 & 4.65 & 5.0762 & TST & \\
\hline CHEMBL1568020 & 688340 & 4.6 & 4.9242 & TRN & \\
\hline CHEMBL1612897 & 688340 & 5.05 & 5.0686 & TST & \\
\hline CHEMBL1565350 & 688340 & 4.65 & 4.6563 & TRN & \\
\hline CHEMBL1527027 & 688340 & 4.55 & 4.8559 & TRN & \\
\hline CHEMBL1411494 & 688340 & 4.5 & 4.7448 & TRN & \\
\hline CHEMBL1353661 & 688340 & 5.15 & 4.7372 & TST & \\
\hline CHEMBL1359873 & 688340 & 4.75 & 4.8198 & TRN & \\
\hline CHEMBL1454592 & 688340 & 6.1 & 5.4814 & TRN & \\
\hline CHEMBL175434 & 688340 & 4.6 & 4.6818 & TRN & \\
\hline CHEMBL1403225 & 688340 & 7.0501 & 5.3976 & TRN & \\
\hline CHEMBL40439 & 688340 & 5.5 & 4.8167 & TRN & \\
\hline CHEMBL1579526 & 688340 & 6.2 & 5.0034 & TST & \\
\hline CHEMBL1574988 & 688340 & 5.55 & 5.2454 & TRN & \\
\hline CHEMBL1598830 & 688340 & 4.6 & 4.9207 & TRN & \\
\hline CHEMBL3199935 & 688340 & 5.35 & 4.934 & TRN & \\
\hline CHEMBL1458874 & 688340 & 5.05 & 5.0962 & TST & \\
\hline CHEMBL1331610 & 688340 & 4.4 & 5.2371 & TRN & \\
\hline CHEMBL1407633 & 688340 & 4.4 & 5.0225 & TRN & \\
\hline CHEMBL1479883 & 688340 & 4.65 & 4.9149 & TRN & \\
\hline CHEMBL1409001 & 688340 & 5.6 & 5.1722 & TST & \\
\hline CHEMBL1348630 & 688340 & 4.75 & 4.7194 & TRN & \\
\hline CHEMBL1468899 & 688340 & 6.05 & 5.2385 & TRN & \\
\hline CHEMBL1517823 & 688340 & 5.9 & 5.0922 & TST & \\
\hline CHEMBL1591895 & 688340 & 5.2 & 5.3488 & TRN & \\
\hline CHEMBL1385207 & 688340 & 5.2 & 5.1542 & TRN & \\
\hline CHEMBL1518805 & 688340 & 5.35 & 5.5014 & TST & \\
\hline CHEMBL1548474 & 688340 & 4.4 & 5.3883 & TRN & \\
\hline CHEMBL3199590 & 688340 & 6.0 & 4.7058 & TRN & \\
\hline CHEMBL355014 & 688340 & 4.55 & 4.7991 & TRN & \\
\hline CHEMBL1349844 & 688340 & 4.5 & 5.2389 & TRN & \\
\hline CHEMBL1561461 & 688340 & 4.4 & 4.7399 & TRN & \\
\hline CHEMBL1342833 & 688340 & 4.6 & 5.3303 & TRN & \\
\hline CHEMBL1337673 & 688340 & 6.8 & 5.0409 & TST & \\
\hline CHEMBL1418185 & 688340 & 5.5 & 5.0414 & TRN & \\
\hline CHEMBL1458323 & 688340 & 5.2 & 5.1942 & TRN & \\
\hline CHEMBL1374282 & 688340 & 5.2 & 5.00899 & 99999999995 & TRN \\
\hline CHEMBL1571480 & 688340 & 5.5 & 5.0131 & TRN & \\
\hline CHEMBL1347485 & 688340 & 6.5501 & 5.2948 & TST & \\
\hline CHEMBL1303362 & 688340 & 5.55 & 5.0033 & TRN & \\
\hline
\end{tabular}




\begin{tabular}{|c|c|c|c|c|}
\hline \multicolumn{5}{|c|}{ Supplemental Table S2.txt } \\
\hline CHEMBL1527161 & 688340 & 4.45 & 4.9325 & TRN \\
\hline CHEMBL1459361 & 688340 & 5.0 & 5.0398 & TRN \\
\hline CHEMBL1576938 & 688340 & 4.55 & 4.9004 & TRN \\
\hline CHEMBL1606141 & 688340 & 4.65 & 5.2613 & TRN \\
\hline CHEMBL1384406 & 688340 & 4.55 & 4.895 & TRN \\
\hline CHEMBL3194604 & 688340 & 5.35 & 5.0976 & TST \\
\hline CHEMBL1521873 & 688340 & 4.55 & 4.895 & TRN \\
\hline CHEMBL1528590 & 688340 & 5.2 & 5.0939 & TRN \\
\hline CHEMBL1609687 & 688340 & 4.6 & 5.1883 & TRN \\
\hline CHEMBL1410670 & 688340 & 5.4 & 5.1289 & TRN \\
\hline CHEMBL1469875 & 688340 & 6.95 & 5.3016 & TST \\
\hline CHEMBL1323267 & 688340 & 4.5 & 4.9868 & TRN \\
\hline CHEMBL1602379 & 688340 & 4.6 & 4.9566 & TST \\
\hline CHEMBL1496462 & 688340 & 3.4 & 4.7902 & TST \\
\hline CHEMBL1578212 & 688340 & 4.9 & 4.6686 & TRN \\
\hline CHEMBL3192824 & 688340 & 4.55 & 5.0327 & TRN \\
\hline CHEMBL1585740 & 688340 & 4.5 & 5.1173 & TRN \\
\hline CHEMBL 2003564 & 688340 & 5.3 & 4.9137 & TRN \\
\hline CHEMBL1611868 & 688340 & 4.55 & 4.7827 & TRN \\
\hline CHEMBL1587394 & 688340 & 5.5 & 4.9847 & TRN \\
\hline CHEMBL1445713 & 688340 & 4.55 & 4.7125 & TRN \\
\hline CHEMBL1420825 & 688340 & 4.5 & 5.0857 & TST \\
\hline CHEMBL1422452 & 688340 & 4.95 & 5.165 & TST \\
\hline CHEMBL1612890 & 688340 & 5.25 & 5.0052 & TRN \\
\hline CHEMBL1575399 & 688340 & 4.75 & 4.9672 & TRN \\
\hline CHEMBL1552641 & 688340 & 4.45 & 5.2025 & TRN \\
\hline CHEMBL1371126 & 688340 & 6.8499 & 5.0856 & TRN \\
\hline CHEMBL1448835 & 688340 & 7.0 & 5.5606 & TRN \\
\hline CHEMBL3199318 & 688340 & 4.5 & 4.819 & TST \\
\hline CHEMBL1388226 & 688340 & 4.5 & 4.6025 & TRN \\
\hline CHEMBL1566756 & 688340 & 6.15 & 4.9767 & TRN \\
\hline CHEMBL1493051 & 688340 & 4.8 & 5.0978 & TRN \\
\hline CHEMBL1310044 & 688340 & 4.5 & 5.069 & TRN \\
\hline CHEMBL3189545 & 688340 & 4.5 & 4.684 & TRN \\
\hline CHEMBL1332770 & 688340 & 4.6 & 4.8146 & TRN \\
\hline CHEMBL1601417 & 688340 & 4.45 & 4.8883 & TRN \\
\hline CHEMBL 264945 & 688340 & 4.4 & 5.1441 & TST \\
\hline CHEMBL1413808 & 688340 & 4.4 & 5.0387 & TRN \\
\hline CHEMBL3189395 & 688340 & 4.85 & 4.9618 & TRN \\
\hline CHEMBL1379488 & 688340 & 5.65 & 5.1445 & TRN \\
\hline CHEMBL1451157 & 688340 & 6.45 & 5.425 & TRN \\
\hline CHEMBL1416133 & 688340 & 5.0 & 5.1715 & TST \\
\hline CHEMBL1322604 & 688340 & 4.55 & 4.9947 & TRN \\
\hline CHEMBL1314669 & 688340 & 5.9 & 4.8423 & TST \\
\hline CHEMBL1370390 & 688340 & 5.05 & 4.8459 & TRN \\
\hline CHEMBL329673 & 688340 & 4.7 & 4.83 & TST \\
\hline CHEMBL1978373 & 688340 & 5.1 & 4.9629 & TRN \\
\hline CHEMBL1342337 & 688340 & 4.55 & 4.6991 & TRN \\
\hline
\end{tabular}




\begin{tabular}{|c|c|c|c|c|}
\hline \multicolumn{5}{|c|}{ Supplemental Table S2.txt } \\
\hline CHEMBL1517794 & 688340 & 5.6 & 4.9346 & TST \\
\hline CHEMBL1359365 & 688340 & 5.4 & 4.7677 & TST \\
\hline CHEMBL1981398 & 688340 & 5.0 & 5.0574 & TST \\
\hline CHEMBL1555481 & 688340 & 5.85 & 4.9579 & TST \\
\hline CHEMBL1453154 & 688340 & 5.2 & 5.1689 & TRN \\
\hline CHEMBL1565749 & 688340 & 5.15 & 4.9628 & TST \\
\hline CHEMBL1324111 & 688340 & 4.45 & 4.8154 & TST \\
\hline CHEMBL1537450 & 688340 & 4.6 & 4.5926 & TST \\
\hline CHEMBL1303396 & 688340 & 5.45 & 4.9796 & TRN \\
\hline CHEMBL1393721 & 688340 & 5.3 & 5.3941 & TRN \\
\hline CHEMBL1384446 & 688340 & 4.55 & 5.0405 & TST \\
\hline CHEMBL1461140 & 688340 & 4.65 & 5.13 & TRN \\
\hline CHEMBL1575705 & 688340 & 5.6 & 5.1628 & TRN \\
\hline CHEMBL1439116 & 688340 & 5.25 & 5.0031 & TST \\
\hline CHEMBL1497238 & 688340 & 4.4 & 5.2683 & TRN \\
\hline CHEMBL1560074 & 688340 & 4.4 & 4.8202 & TST \\
\hline CHEMBL1564066 & 688340 & 4.55 & 4.7961 & TRN \\
\hline CHEMBL3193247 & 688340 & 4.5 & 4.8591 & TST \\
\hline CHEMBL1535742 & 688340 & 4.65 & 4.8841 & TRN \\
\hline CHEMBL3208474 & 688340 & 6.1 & 4.9937 & TST \\
\hline CHEMBL1460209 & 688340 & 3.9 & 5.2511 & TST \\
\hline CHEMBL1306562 & 688340 & 7.0 & 4.9038 & TRN \\
\hline CHEMBL3392033 & 688340 & 4.6 & 4.7584 & TST \\
\hline CHEMBL1544534 & 688340 & 5.45 & 5.0038 & TST \\
\hline CHEMBL1317103 & 688340 & 4.35 & 5.0351 & TRN \\
\hline CHEMBL1408737 & 688340 & 4.7 & 5.1586 & TST \\
\hline CHEMBL1451122 & 688340 & 4.35 & 4.925 & TST \\
\hline CHEMBL1466068 & 688340 & 4.5 & 4.6634 & TRN \\
\hline CHEMBL1538903 & 688340 & 5.0 & 5.0231 & TRN \\
\hline CHEMBL1562453 & 688340 & 5.2 & 5.0041 & TRN \\
\hline CHEMBL1451850 & 688340 & 4.4 & 5.1091 & TST \\
\hline CHEMBL1411001 & 688340 & 4.75 & 4.9582 & TST \\
\hline CHEMBL1389512 & 688340 & 5.05 & 4.8752 & TRN \\
\hline CHEMBL1313554 & 688340 & 4.75 & 5.1527 & TRN \\
\hline CHEMBL1488875 & 688340 & 4.4 & 4.9621 & TRN \\
\hline CHEMBL1304056 & 688340 & 3.4 & 4.971 & TST \\
\hline CHEMBL61559 & 688340 & 4.95 & 4.9094 & TRN \\
\hline CHEMBL1473682 & 688340 & 7.0 & 5.5989 & TRN \\
\hline CHEMBL1365226 & 688340 & 4.85 & 4.9964 & TRN \\
\hline CHEMBL1406054 & 688340 & 5.4 & 4.9239 & TRN \\
\hline CHEMBL1493522 & 688340 & 5.25 & 4.9885 & TST \\
\hline CHEMBL3193483 & 688340 & 5.45 & 5.1337 & TST \\
\hline CHEMBL1474199 & 688340 & 6.15 & 4.9069 & TRN \\
\hline CHEMBL445420 & 688340 & 5.5 & 5.2079 & TST \\
\hline CHEMBL1463622 & 688340 & 4.35 & 5.1916 & TRN \\
\hline CHEMBL1572522 & 688340 & 4.4 & 5.1051 & TST \\
\hline CHEMBL1517327 & 688340 & 4.5 & 4.8491 & TRN \\
\hline CHEMBL3209088 & 688340 & 6.1 & 4.7602 & TST \\
\hline
\end{tabular}




\begin{tabular}{|c|c|c|c|c|c|}
\hline \multicolumn{6}{|c|}{ Supplemental Table S2.txt } \\
\hline CHEMBL1512376 & 688340 & 5.05 & 5.1259 & TRN & \\
\hline CHEMBL1528662 & 688340 & 4.65 & 5.1736 & TRN & \\
\hline CHEMBL1365340 & 688340 & 4.5 & 5.0109 & TRN & \\
\hline CHEMBL1496303 & 688340 & 4.4 & 4.8052 & TRN & \\
\hline CHEMBL1571295 & 688340 & 5.95 & 5.1217 & TST & \\
\hline CHEMBL1361660 & 688340 & 4.4 & 5.0195 & TRN & \\
\hline CHEMBL1443443 & 688340 & 4.7 & 4.5275 & TST & \\
\hline CHEMBL1418782 & 688340 & 5.45 & 4.8511 & TRN & \\
\hline CHEMBL1606716 & 688340 & 4.75 & 4.9857 & TRN & \\
\hline CHEMBL1576982 & 688340 & 5.2 & 5.2383 & TRN & \\
\hline CHEMBL1492521 & 688340 & 5.5 & 5.0193 & TST & \\
\hline CHEMBL1501156 & 688340 & 5.25 & 5.3687 & TRN & \\
\hline CHEMBL502774 & 688340 & 4.6 & 4.8061 & TRN & \\
\hline CHEMBL1421718 & 688340 & 4.5 & 4.7649 & TRN & \\
\hline CHEMBL1422133 & 688340 & 4.6 & 4.8501 & TRN & \\
\hline CHEMBL1460615 & 688340 & 5.15 & 5.2231 & TST & \\
\hline CHEMBL1308238 & 688340 & 5.2 & 4.8681 & TST & \\
\hline CHEMBL1353095 & 688340 & 4.5 & 4.9621 & TRN & \\
\hline CHEMBL1422889 & 688340 & 5.15 & 4.7437 & TRN & \\
\hline CHEMBL1525097 & 688340 & 5.2 & 5.5595 & TRN & \\
\hline CHEMBL1412459 & 688340 & 5.0 & 5.4001 & TRN & \\
\hline CHEMBL1573116 & 688340 & 4.4 & 4.8632 & TRN & \\
\hline CHEMBL1375499 & 688340 & 5.1 & 4.9207 & TRN & \\
\hline CHEMBL1491683 & 688340 & 4.55 & 5.0077 & TRN & \\
\hline CHEMBL 3189243 & 688340 & 4.6 & 5.1144 & TST & \\
\hline CHEMBL1506471 & 688340 & 5.45 & 4.6334 & TRN & \\
\hline CHEMBL1432378 & 688340 & 5.65 & 4.976 & TRN & \\
\hline CHEMBL1539006 & 688340 & 4.55 & 4.92899 & 9999999999 & TRN \\
\hline CHEMBL3192281 & 688340 & 4.45 & 5.0823 & TRN & \\
\hline CHEMBL1415426 & 688340 & 4.55 & 4.9783 & TRN & \\
\hline CHEMBL1536391 & 688340 & 5.35 & 4.9441 & TRN & \\
\hline CHEMBL1437155 & 688340 & 4.4 & 4.5045 & TRN & \\
\hline CHEMBL1329858 & 688340 & 4.4 & 5.3198 & TST & \\
\hline CHEMBL1442536 & 688340 & 6.5 & 5.1604 & TST & \\
\hline CHEMBL1597878 & 688340 & 4.45 & 5.0473 & TRN & \\
\hline CHEMBL1490716 & 688340 & 4.45 & 4.8468 & TRN & \\
\hline CHEMBL1509065 & 688340 & 4.5 & 4.9269 & TRN & \\
\hline CHEMBL1548111 & 688340 & 4.45 & 4.8507 & TRN & \\
\hline CHEMBL1613634 & 688340 & 4.6 & 4.5909 & TRN & \\
\hline CHEMBL1607609 & 688340 & 5.2 & 5.2478 & TST & \\
\hline CHEMBL 3190843 & 688340 & 4.85 & 4.9369 & TRN & \\
\hline CHEMBL1321514 & 688340 & 4.35 & 4.9791 & TRN & \\
\hline CHEMBL1423477 & 688340 & 5.25 & 5.1897 & TRN & \\
\hline CHEMBL1306676 & 688340 & 4.4 & 4.8844 & TRN & \\
\hline CHEMBL1543112 & 688340 & 5.0 & 5.2009 & TRN & \\
\hline CHEMBL1477980 & 688340 & 4.35 & 4.9705 & TST & \\
\hline CHEMBL1362768 & 688340 & 4.3 & 5.3773 & TST & \\
\hline CHEMBL1494194 & 688340 & 4.45 & 4.8093 & TRN & \\
\hline
\end{tabular}




\begin{tabular}{|c|c|c|c|c|c|}
\hline & & \multicolumn{4}{|c|}{ Supplemental Table S2.txt } \\
\hline CHEMBL1347959 & 688340 & 4.4 & 4.8713 & TRN & \\
\hline CHEMBL1345633 & 688340 & 4.9 & 4.7642 & TST & \\
\hline CHEMBL1335040 & 688340 & 4.55 & 5.0021 & TRN & \\
\hline CHEMBL1481651 & 688340 & 4.55 & 4.6834 & TRN & \\
\hline CHEMBL1558288 & 688340 & 4.75 & 5.0493 & TRN & \\
\hline CHEMBL1525076 & 688340 & 5.55 & 5.2707 & TRN & \\
\hline CHEMBL1974450 & 688340 & 5.25 & 4.7971 & TRN & \\
\hline CHEMBL1382616 & 688340 & 4.5 & 4.5918 & TRN & \\
\hline CHEMBL1383497 & 688340 & 5.5 & 4.8699 & TRN & \\
\hline CHEMBL1325207 & 688340 & 5.15 & 4.9767 & TRN & \\
\hline CHEMBL1581354 & 688340 & 4.4 & 4.9309 & TRN & \\
\hline CHEMBL1978479 & 688340 & 4.6 & 4.8907 & TST & \\
\hline CHEMBL1352250 & 688340 & 4.65 & 5.4859 & TRN & \\
\hline CHEMBL1567378 & 688340 & 4.55 & 5.24299 & 9999999999 & TST \\
\hline CHEMBL1440488 & 688340 & 4.5 & 4.893 & TRN & \\
\hline CHEMBL1310478 & 688340 & 6.15 & 4.7544 & TRN & \\
\hline CHEMBL1566994 & 688340 & 4.45 & 4.8281 & TRN & \\
\hline CHEMBL1431285 & 688340 & 4.5 & 4.718 & TRN & \\
\hline CHEMBL1555499 & 688340 & 4.65 & 5.0623 & TRN & \\
\hline CHEMBL1529285 & 688340 & 5.1 & 4.9965 & TRN & \\
\hline CHEMBL602363 & 688340 & 4.4 & 4.5833 & TST & \\
\hline CHEMBL1610364 & 688340 & 4.0 & 5.087 & TRN & \\
\hline CHEMBL1348039 & 688340 & 5.25 & 5.2479 & TRN & \\
\hline CHEMBL1458698 & 688340 & 4.55 & 4.8334 & TRN & \\
\hline CHEMBL1592296 & 688340 & 6.95 & 5.0715 & TRN & \\
\hline CHEMBL1597738 & 688340 & 4.4 & 5.0592 & TRN & \\
\hline CHEMBL1533811 & 688340 & 5.05 & 5.1392 & TST & \\
\hline CHEMBL1383666 & 688340 & 4.7 & 4.8548 & TRN & \\
\hline CHEMBL1588976 & 688340 & 4.55 & 4.8766 & TRN & \\
\hline CHEMBL1491588 & 688340 & 5.2 & 5.0942 & TRN & \\
\hline CHEMBL1462781 & 688340 & 4.4 & 5.2933 & TRN & \\
\hline CHEMBL1491268 & 688340 & 4.35 & 4.9005 & TRN & \\
\hline CHEMBL1364246 & 688340 & 4.9 & 4.9696 & TRN & \\
\hline CHEMBL567531 & 688340 & 5.15 & 4.9244 & TRN & \\
\hline CHEMBL1337641 & 688340 & 4.4 & 5.232 & TST & \\
\hline CHEMBL1576064 & 688340 & 4.4 & 4.7202 & TRN & \\
\hline CHEMBL1511410 & 688340 & 5.5 & 5.2401 & TRN & \\
\hline CHEMBL3190479 & 688340 & 5.45 & 5.069 & TRN & \\
\hline CHEMBL1506350 & 688340 & 4.7 & 5.0588 & TRN & \\
\hline CHEMBL1470626 & 688340 & 5.45 & 4.7517 & TRN & \\
\hline CHEMBL1546030 & 688340 & 4.4 & 4.9257 & TST & \\
\hline CHEMBL1464880 & 688340 & 5.65 & 5.2113 & TST & \\
\hline CHEMBL1570106 & 688340 & 4.35 & 5.0208 & TST & \\
\hline CHEMBL1585127 & 688340 & 4.5 & 5.04 & TRN & \\
\hline CHEMBL1344028 & 688340 & 6.6 & 5.4351 & TRN & \\
\hline CHEMBL1603477 & 688340 & 4.6 & 5.0677 & TRN & \\
\hline CHEMBL1535136 & 688340 & 5.6 & 5.0344 & TST & \\
\hline CHEMBL1436916 & 688340 & 4.4 & 5.0354 & TRN & \\
\hline
\end{tabular}




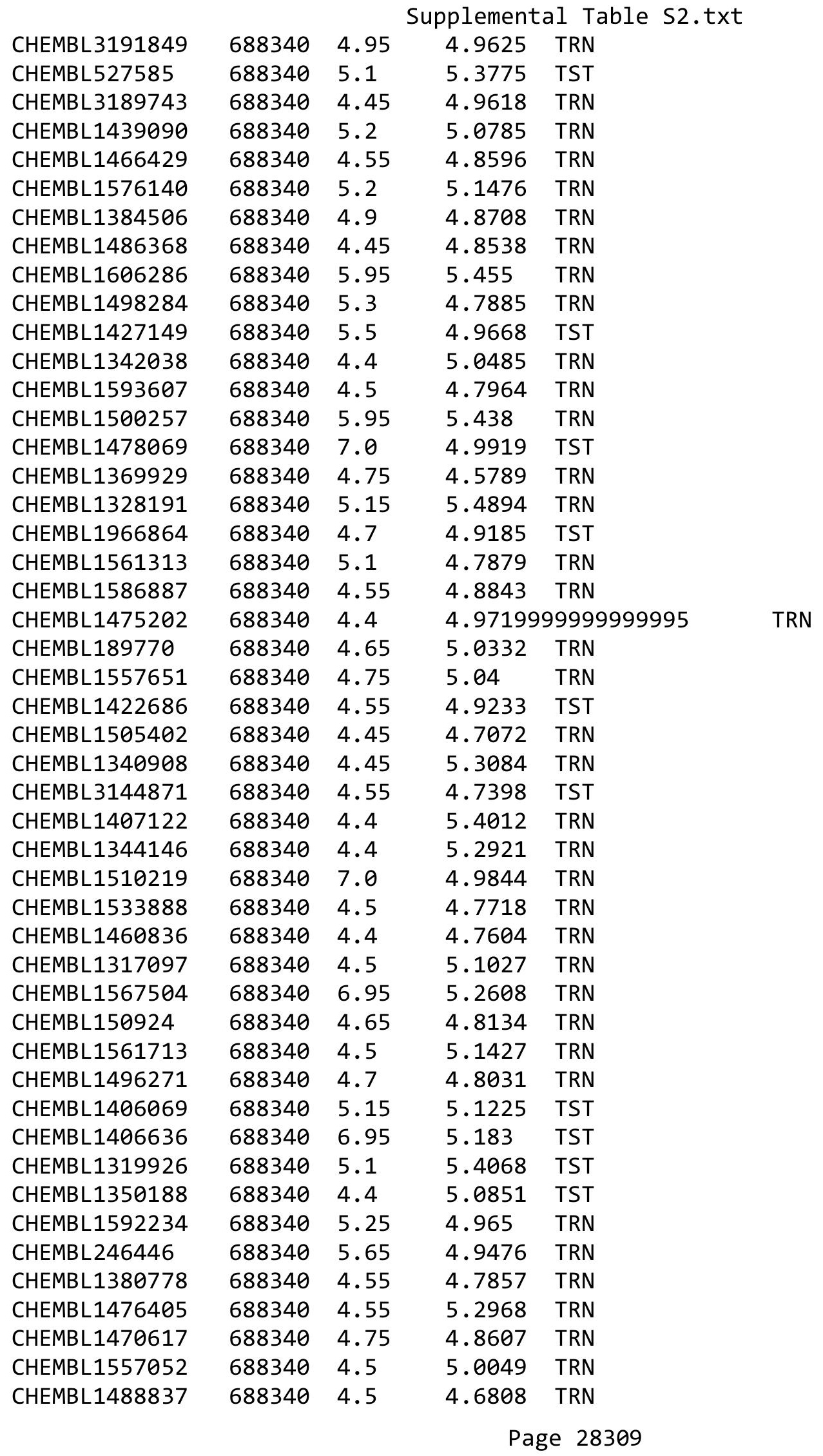




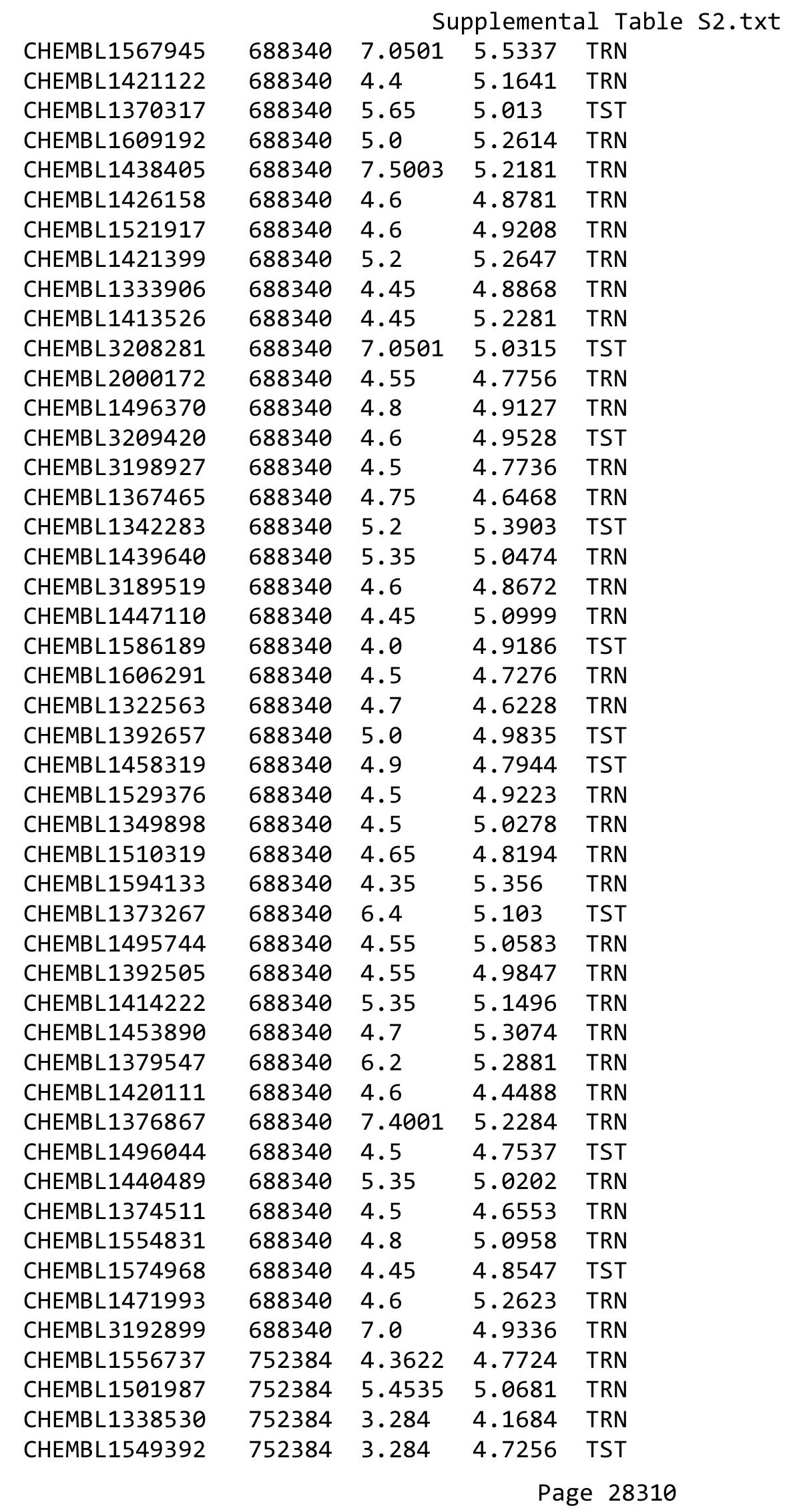




\begin{tabular}{|c|c|c|c|c|c|c|}
\hline \multicolumn{7}{|c|}{ Supplemental Table S2.txt } \\
\hline CHEMBL1506185 & 752384 & 6.2676 & 5.263 & TRN & & \\
\hline CHEMBL1382847 & 752384 & 3.284 & 4.3872 & TRN & & \\
\hline CHEMBL1352113 & 752384 & 5.0438 & 4.9775 & TRN & & \\
\hline CHEMBL1492819 & 752384 & 4.4035 & 4.9986 & TRN & & \\
\hline CHEMBL1544136 & 752384 & 4.9289 & 4.3727 & TRN & & \\
\hline CHEMBL1576762 & 752384 & 4.4883 & 5.0054 & TRN & & \\
\hline CHEMBL1468268 & 752384 & 4.5349 & 3.9598 & TRN & & \\
\hline CHEMBL1481417 & 752384 & 4.9821 & 5.1854 & TRN & & \\
\hline CHEMBL1392013 & 752384 & 3.284 & 3.7838 & TRN & & \\
\hline CHEMBL1377181 & 752384 & 4.5014 & 4.6475 & TRN & & \\
\hline CHEMBL1566994 & 752384 & 3.284 & 3.1362 & TRN & & \\
\hline CHEMBL1401891 & 752384 & 5.0209 & 4.901 & TST & & \\
\hline CHEMBL1421993 & 752384 & 4.9115 & 4.6414 & TRN & & \\
\hline CHEMBL1566748 & 752384 & 4.2904 & 4.534 & TRN & & \\
\hline CHEMBL1461518 & 752384 & 4.4025 & 3.9832 & TRN & & \\
\hline CHEMBL1500251 & 752384 & 5.3675 & 5.8695 & TRN & & \\
\hline CHEMBL1468698 & 752384 & 5.1107 & 4.402 & TRN & & \\
\hline CHEMBL1734544 & 752384 & 4.5906 & 3.1675 & TRN & & \\
\hline CHEMBL1413510 & 752384 & 5.8539 & 5.9432 & TRN & & \\
\hline CHEMBL1306714 & 752384 & 5.7167 & 4.6868 & TRN & & \\
\hline CHEMBL1383461 & 752384 & 4.8726 & 4.7022 & TRN & & \\
\hline CHEMBL1512176 & 752384 & 3.284 & 3.4704 & TRN & & \\
\hline CHEMBL1345866 & 752384 & 5.8386 & 4.3677 & TRN & & \\
\hline CHEMBL3189519 & 752384 & 3.284 & 4.2753 & TRN & & \\
\hline CHEMBL1498441 & 752384 & 4.6811 & 4.6065 & TRN & & \\
\hline CHEMBL1524257 & 752384 & 5.7399 & 5.6371 & TRN & & \\
\hline CHEMBL1575701 & 752384 & 5.7496 & 4.7601 & TRN & & \\
\hline CHEMBL1709562 & 752384 & 5.4214 & 4.7157 & TRN & & \\
\hline CHEMBL 391877 & 752384 & 4.6925 & 4.2316 & TRN & & \\
\hline CHEMBL1340574 & 752384 & 3.284 & 4.8721 & TST & & \\
\hline CHEMBL1732287 & 752384 & 3.284 & 3.5818 & TRN & & \\
\hline CHEMBL1399913 & 752384 & 4.6455 & 4.864 & TRN & & \\
\hline CHEMBL1520159 & 752384 & 3.284 & 4.1971 & TRN & & \\
\hline CHEMBL1564866 & 752384 & 5.5735 & 3.9944 & TRN & & \\
\hline CHEMBL1345100 & 752384 & 4.82100 & $\partial 0000000$ & $\partial 1$ & 4. 3469999999999995 & TST \\
\hline CHEMBL1719807 & 752384 & 5.055 & 4.3714 & TRN & & \\
\hline CHEMBL1502018 & 752384 & 3.284 & 4.7259 & TRN & & \\
\hline CHEMBL1339275 & 752384 & 3.284 & 3.6567 & TRN & & \\
\hline CHEMBL1493011 & 752384 & 3.284 & 4.6888 & TRN & & \\
\hline CHEMBL1455256 & 752384 & 4.3195 & 4.7199 & TST & & \\
\hline CHEMBL1353828 & 752384 & 4.4445 & 4.4614 & TRN & & \\
\hline CHEMBL1473205 & 752384 & 5.3605 & 4.9212 & TRN & & \\
\hline CHEMBL1392 & 752384 & 4.9535 & 4.8346 & TRN & & \\
\hline CHEMBL1469444 & 752384 & 4.3518 & 4.6607 & TRN & & \\
\hline CHEMBL1598570 & 752384 & 3.284 & 3.4256 & TRN & & \\
\hline CHEMBL1329425 & 752384 & 4.6627 & 4.0198 & TRN & & \\
\hline CHEMBL1367154 & 752384 & 4.9263 & 4.0269 & TRN & & \\
\hline CHEMBL1405416 & 752384 & 3.284 & 4.1556 & TST & & \\
\hline
\end{tabular}




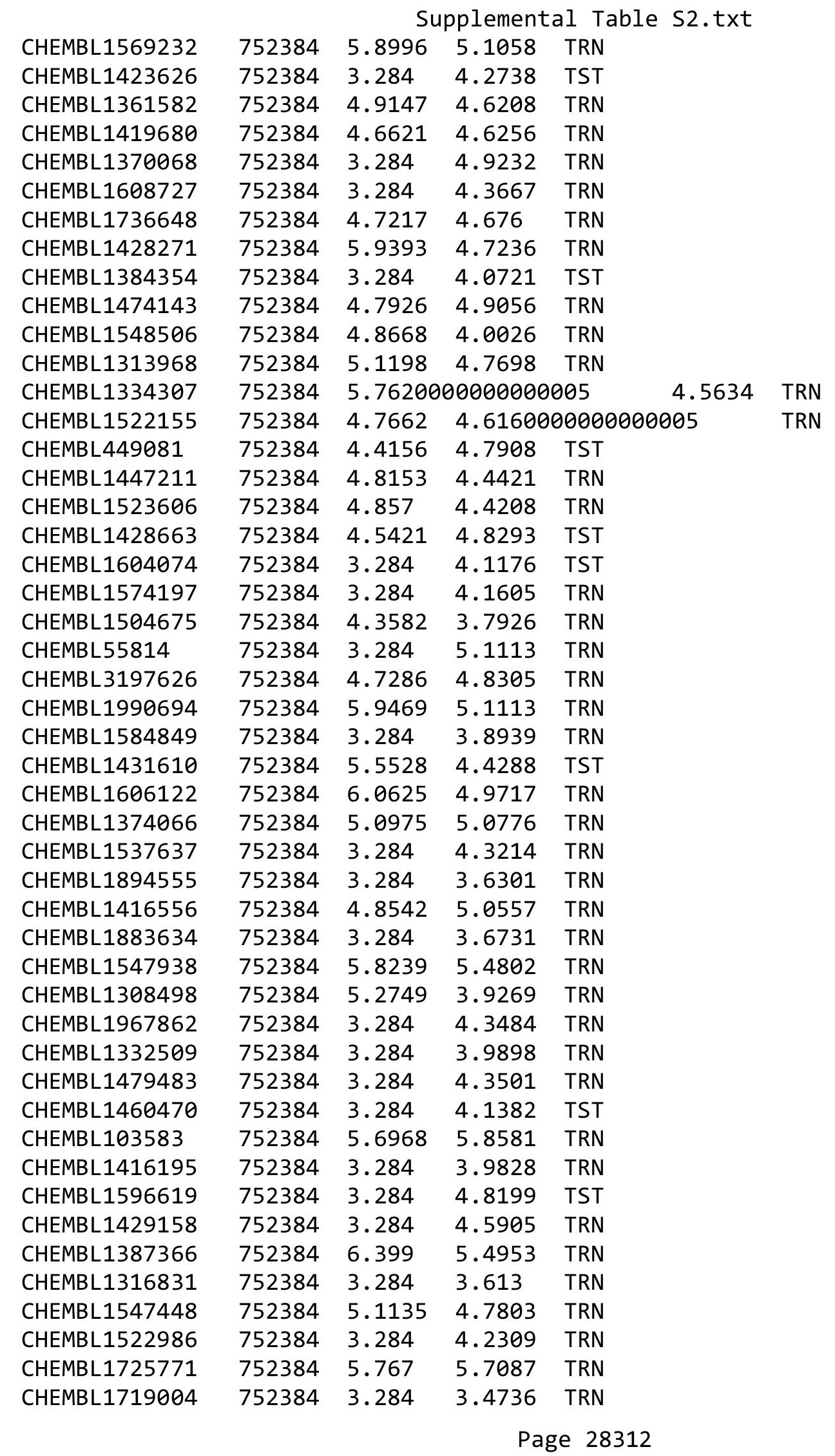




\begin{tabular}{|c|c|c|c|c|c|c|}
\hline & & \multicolumn{5}{|c|}{ Supplemental Table S2.txt } \\
\hline CHEMBL3197637 & 752384 & 3.284 & 3.8987 & TST & & \\
\hline CHEMBL1460757 & 752384 & 5.4802 & 4.2771 & TST & & \\
\hline CHEMBL1706454 & 752384 & 3.284 & 4.356 & TST & & \\
\hline CHEMBL1518626 & 752384 & 4.9248 & 4.2043 & TST & & \\
\hline CHEMBL1398345 & 752384 & 6.1543 & 5.7487 & TST & & \\
\hline CHEMBL1351902 & 752384 & 3.284 & 4.7369 & TST & & \\
\hline CHEMBL1390636 & 752384 & 4.6205 & 4.4272 & TST & & \\
\hline CHEMBL1430473 & 752384 & 3.284 & 4.1925 & TST & & \\
\hline CHEMBL1451725 & 752384 & 3.284 & 4.87 & TST & & \\
\hline CHEMBL1412067 & 752384 & 6.0762 & 5.9309 & TST & & \\
\hline CHEMBL1372920 & 752384 & 5.5969 & 5.414 & TST & & \\
\hline CHEMBL1608156 & 752384 & \multicolumn{3}{|c|}{ 4.7669999999999995 } & 4.5235 & TST \\
\hline CHEMBL1429070 & 752384 & 5.4498 & 5.1996 & TST & & \\
\hline CHEMBL1329597 & 752384 & 3.284 & 5.2799 & TST & & \\
\hline CHEMBL1385512 & 752384 & 5.3036 & 4.6211 & TST & & \\
\hline CHEMBL3609086 & 1513935 & 9.6517 & 9.7691 & TRN & & \\
\hline CHEMBL3609242 & 1513935 & 9.0168 & 9.0604 & TRN & & \\
\hline CHEMBL3609251 & 1513935 & 9.5935 & 9.6509 & TST & & \\
\hline CHEMBL3609221 & 1513935 & 9.0996 & 9.1559 & TRN & & \\
\hline CHEMBL3609093 & 1513935 & 10.3188 & 9.1559 & TRN & & \\
\hline CHEMBL 3609092 & 1513935 & 9.2882 & 8.8548 & TST & & \\
\hline CHEMBL3609083 & 1513935 & 9.4976 & 9.8828 & TST & & \\
\hline CHEMBL3609024 & 1513935 & 6.0362 & 8.7502 & TRN & & \\
\hline CHEMBL 3609256 & 1513935 & 10.0757 & 9.6322 & TRN & & \\
\hline CHEMBL3609224 & 1513935 & 10.3188 & 9.1559 & TRN & & \\
\hline CHEMBL3609089 & 1513935 & 9.5186 & 8.9206 & TST & & \\
\hline CHEMBL3609031 & 1513935 & 7.4685 & 8.7502 & TRN & & \\
\hline CHEMBL3609047 & 1513935 & 9.308 & 9.7691 & TRN & & \\
\hline CHEMBL 3609243 & 1513935 & 7.7447 & 7.6195 & TRN & & \\
\hline CHEMBL3609075 & 1513935 & 9.7144 & 9.1559 & TRN & & \\
\hline CHEMBL3609049 & 1513935 & 9.5498 & 9.5252 & TST & & \\
\hline CHEMBL 3609067 & 1513935 & \multicolumn{3}{|c|}{9.011000000000001} & 9.6543 & TST \\
\hline CHEMBL 3609030 & 1513935 & 9.3979 & 8.7502 & TRN & & \\
\hline CHEMBL3609042 & 1513935 & 10.0809 & 9.1559 & TRN & & \\
\hline CHEMBL3609060 & 1513935 & 9.6517 & 9.8828 & TST & & \\
\hline CHEMBL3609050 & 1513935 & 7.3947 & 9.1559 & TRN & & \\
\hline CHEMBL 3609080 & 1513935 & 7.9281 & 9.1559 & TRN & & \\
\hline CHEMBL3609263 & 1513935 & 10.2007 & 9.9892 & TRN & & \\
\hline CHEMBL 3609048 & 1513935 & 10.2518 & 9.1559 & TRN & & \\
\hline CHEMBL3609023 & 1513935 & 9.6655 & 9.2024 & TST & & \\
\hline CHEMBL3608317 & 1513935 & 7.9957 & 7.8519 & TRN & & \\
\hline CHEMBL 3609226 & 1513935 & 9.0921 & 9.1559 & TRN & & \\
\hline CHEMBL3609084 & 1513935 & 9.8665 & 9.7365 & TRN & & \\
\hline CHEMBL3609277 & 1513935 & 9.2403 & 9.2024 & TST & & \\
\hline CHEMBL3609072 & 1513935 & 9.0039 & 9.5252 & TST & & \\
\hline CHEMBL3609043 & 1513935 & 9.8894 & 9.1559 & TRN & & \\
\hline CHEMBL3609232 & 1513935 & 9.9208 & 9.1559 & TRN & & \\
\hline CHEMBL3609228 & 1513935 & 8.3969 & 9.1559 & TRN & & \\
\hline
\end{tabular}

Page 28313 


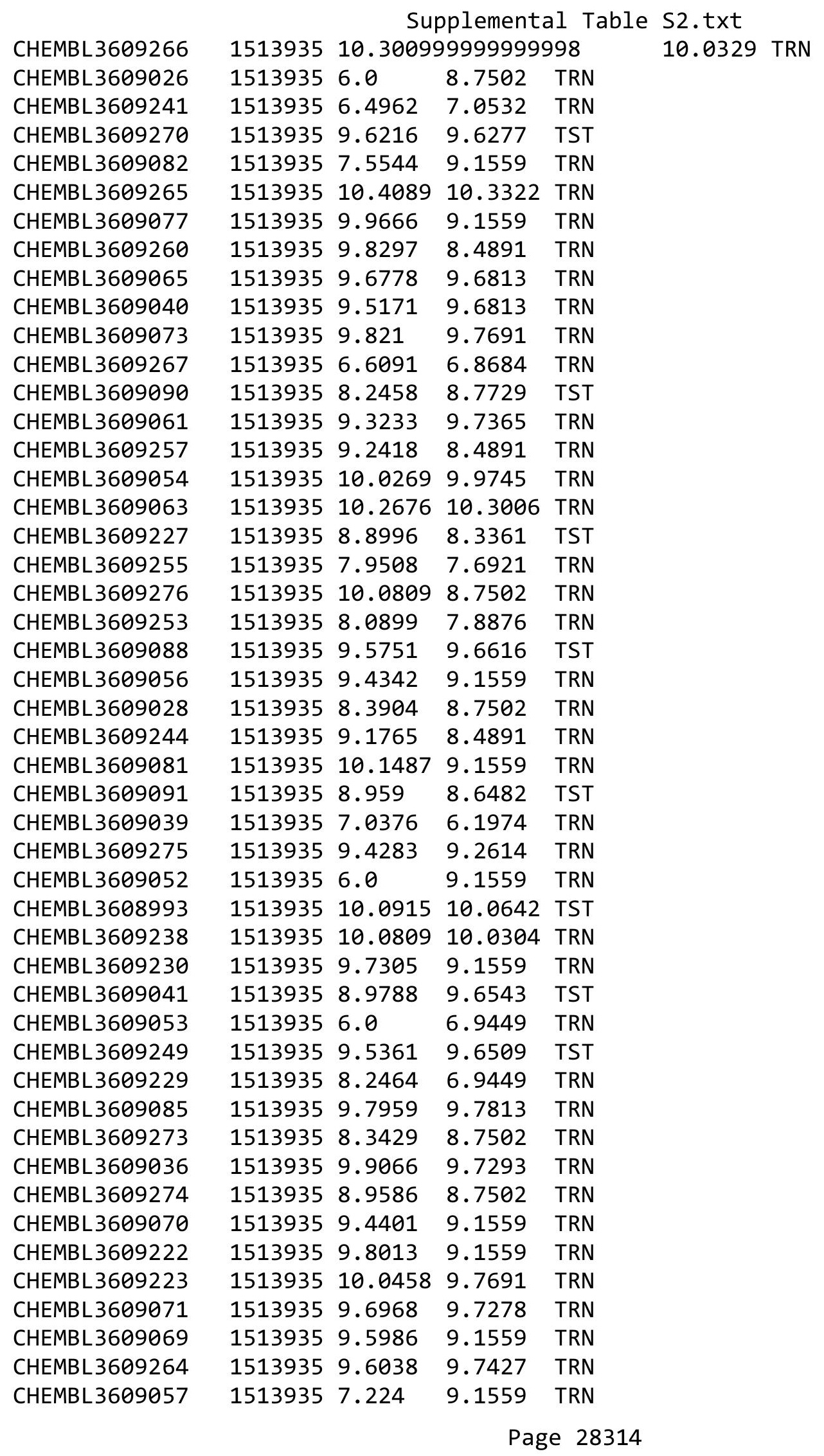




\begin{tabular}{|c|c|c|c|c|c|c|}
\hline \multicolumn{7}{|c|}{ Supplemental Table S2.txt } \\
\hline CHEMBL3609254 & 1513935 & 6.0 & 8.4891 & TRN & & \\
\hline CHEMBL3609058 & 1513935 & 10.2366 & 9.1559 & TRN & & \\
\hline CHEMBL3609269 & 1513935 & 7.71 & 7.9234 & TRN & & \\
\hline CHEMBL3609045 & 1513935 & 9.5817 & 9.7278 & TRN & & \\
\hline CHEMBL 3609064 & 1513935 & 6.0 & 6.1974 & TRN & & \\
\hline CHEMBL3609059 & 1513935 & 7.4089 & 9.1559 & TRN & & \\
\hline CHEMBL3609066 & 1513935 & 7.8697 & 7.8519 & TRN & & \\
\hline CHEMBL3609234 & 1513935 & 8.2757 & 9.1559 & TRN & & \\
\hline CHEMBL3609025 & 1513935 & 7.5513 & 7.2251 & TST & & \\
\hline CHEMBL3609044 & 1513935 & 9.1972 & 9.1559 & TRN & & \\
\hline CHEMBL3609250 & 1513935 & 8.02 & 8.0385 & TRN & & \\
\hline CHEMBL3609239 & 1513935 & 9.5884 & 9.4953 & TST & & \\
\hline CHEMBL3609259 & 1513935 & 8.0926 & 8.4891 & TRN & & \\
\hline CHEMBL3609248 & 1513935 & 9.9586 & 9.7278 & TRN & & \\
\hline CHEMBL3609022 & 1513935 & 9.8794 & 9.8916 & TRN & & \\
\hline CHEMBL3609078 & 1513935 & 9.4365 & 9.6678 & TRN & & \\
\hline CHEMBL3609237 & 1513935 & 9.9136 & 9.8828 & TST & & \\
\hline CHEMBL3608995 & 1513935 & 10.1549 & 9.1559 & TRN & & \\
\hline CHEMBL3609055 & 1513935 & 9.7122 & 9.6678 & TRN & & \\
\hline CHEMBL3609258 & 1513935 & 8.5467 & 8.4891 & TRN & & \\
\hline CHEMBL3609074 & 1513935 & 10.0506 & 9.5252 & TST & & \\
\hline CHEMBL3608994 & 1513935 & 10.3372 & 10.3006 & TRN & & \\
\hline CHEMBL3609094 & 1513935 & 8.507 & 8.3988 & TRN & & \\
\hline CHEMBL 3609029 & 1513935 & 9.1688 & 9.1176 & TRN & & \\
\hline CHEMBL3609252 & 1513935 & 6.0 & 8.4891 & TRN & & \\
\hline CHEMBL3609262 & 1513935 & 8.8447 & 9.7099 & TST & & \\
\hline CHEMBL3609032 & 1513935 & 8.7077 & 8.7502 & TRN & & \\
\hline CHEMBL3609271 & 1513935 & 10.2518 & 8.7502 & TRN & & \\
\hline CHEMBL 3609027 & 1513935 & 6.0 & 6.5896 & TRN & & \\
\hline CHEMBL3608996 & 1513935 & 8.7033 & 8.6363 & TRN & & \\
\hline CHEMBL3608318 & 1513935 & 9.6055 & 9.6016 & TST & & \\
\hline CHEMBL3609051 & 1513935 & 8.5114 & 8.3361 & TST & & \\
\hline CHEMBL3608997 & 1513935 & 10.1805 & 9.6543 & TST & & \\
\hline CHEMBL 3609087 & 1513935 & 9.55600 & 000000000 & 01 & 9.55 & TST \\
\hline CHEMBL3609236 & 1513935 & 9.6536 & 9.1559 & TRN & & \\
\hline CHEMBL3609235 & 1513935 & 9.5114 & 9.1559 & TRN & & \\
\hline CHEMBL3609245 & 1513935 & 9.5935 & 8.4891 & TRN & & \\
\hline CHEMBL3609272 & 1513935 & 10.2596 & 8.7502 & TRN & & \\
\hline CHEMBL3608991 & 1513935 & 9.426 & 8.4891 & TRN & & \\
\hline CHEMBL3609046 & 1513935 & 9.7375 & 9.5252 & TST & & \\
\hline CHEMBL3609038 & 1513935 & 9.9101 & 10.3006 & TRN & & \\
\hline CHEMBL3608999 & 1513935 & 8.9172 & 9.1559 & TRN & & \\
\hline CHEMBL3609247 & 1513935 & 8.3134 & 8.4891 & TRN & & \\
\hline CHEMBL 3609220 & 1513935 & 8.6676 & 9.1559 & TRN & & \\
\hline CHEMBL3609033 & 1513935 & 10.3665 & 8.7502 & TRN & & \\
\hline CHEMBL3609034 & 1513935 & 9.51 & 8.7502 & TRN & & \\
\hline CHEMBL3609240 & 1513935 & 9.4976 & 9.5213 & TST & & \\
\hline CHEMBL3609268 & 1513935 & 9.9626 & 9.6731 & TRN & & \\
\hline
\end{tabular}


Supplemental Table S2.txt

\begin{tabular}{|c|c|c|c|c|c|c|}
\hline CHEMBL 3609261 & 1513935 & 9.8894 & 8.4891 & TST & & \\
\hline CHEMBL 3608998 & 1513935 & 10.0915 & 9.1559 & TRN & & \\
\hline CHEMBL 3609068 & 1513935 & 10.0862 & 9.1559 & TRN & & \\
\hline CHEMBL 3609037 & 1513935 & 9.9355 & 9.962 & TRN & & \\
\hline CHEMBL 3609062 & 1513935 & 10.1367 & 10.1028 & TRN & & \\
\hline CHEMBL3609035 & 1513935 & 9.7545 & 10.0404 & TST & & \\
\hline CHEMBL 3609225 & 1513935 & 9.2549 & 9.5252 & TST & & \\
\hline CHEMBL 3609095 & 1513935 & 10.3372 & 10.061 & TST & & \\
\hline CHEMBL 3609231 & 1513935 & 9.1931 & 9.6678 & TRN & & \\
\hline CHEMBL 3609233 & 1513935 & 8.0964 & 9.1559 & TRN & & \\
\hline CHEMBL 3608992 & 1513935 & 9.9547 & 9.9115 & TST & & \\
\hline CHEMBL 3609079 & 1513935 & 9.3045 & 9.1559 & TRN & & \\
\hline CHEMBL 3609246 & 1513935 & 8.7825 & 8.4891 & TST & & \\
\hline CHEMBL 3609076 & 1513935 & 8.317 & 8.3361 & TST & & \\
\hline CHEMBL 1270612 & 675629 & \multicolumn{3}{|c|}{7.292000000000001} & 7.3531 & TRN \\
\hline CHEMBL1270710 & 675629 & 7.181 & 7.2302 & TRN & & \\
\hline CHEMBL1270711 & 675629 & 7.237 & 7.2501 & TRN & & \\
\hline CHEMBL1270815 & 675629 & \multicolumn{3}{|c|}{7.0920000000000005} & 6.9367 & TRN \\
\hline CHEMBL1270816 & 675629 & 7.886 & 8.4194 & TRN & & \\
\hline CHEMBL 1270918 & 675629 & 7.42 & 7.8178 & TRN & & \\
\hline CHEMBL1270919 & 675629 & 6.983 & 7.266 & TRN & & \\
\hline CHEMBL1271017 & 675629 & 7.77 & 7.4978 & TRN & & \\
\hline CHEMBL 1271018 & 675629 & 7.678 & 7.6973 & TRN & & \\
\hline CHEMBL1271122 & 675629 & 7.678 & 7.5878 & TRN & & \\
\hline CHEMBL 1271123 & 675629 & 7.061 & 7.2385 & TRN & & \\
\hline CHEMBL1271225 & 675629 & 6.68 & 6.862 & TST & & \\
\hline CHEMBL 1271226 & 675629 & 7.721 & 7.2932 & TST & & \\
\hline CHEMBL1271227 & 675629 & \multicolumn{3}{|c|}{6.827000000000001} & 7.2286 & $1 \mathrm{~K}$ \\
\hline CHEMBL1271327 & 675629 & 7.013 & 6.6697 & TRN & & \\
\hline CHEMBL 1271328 & 675629 & 5.755 & 5.5173 & TST & & \\
\hline CHEMBL1271435 & 675629 & \multicolumn{3}{|c|}{6.757000000000001} & 6.3463 & TRN \\
\hline CHEMBL 1271436 & 675629 & \multicolumn{3}{|c|}{5.8629999999999995} & 6.2931 & TST \\
\hline CHEMBL1269902 & 675629 & 7.638 & 7.6645 & TST & & \\
\hline CHEMBL1269903 & 675629 & 7.699 & 7.8885 & TST & & \\
\hline CHEMBL1270009 & 675629 & 7.284 & 7.6926 & TST & & \\
\hline CHEMBL1270010 & 675629 & \multicolumn{3}{|c|}{8.222000000000001} & 7.99 & TST \\
\hline CHEMBL 1270116 & 675629 & 8.301 & 8.1469 & TST & & \\
\hline CHEMBL1270117 & 675629 & \multicolumn{3}{|c|}{8.097000000000001} & 7.9248 & $|S|$ \\
\hline CHEMBL1270223 & 675629 & 8.301 & 7.8631 & TST & & \\
\hline CHEMBL1270224 & 675629 & \multicolumn{3}{|c|}{8.222000000000001} & 7.8873 & TRN \\
\hline CHEMBL1270318 & 675629 & 7.229 & 6.8692 & TRN & & \\
\hline CHEMBL 1270319 & 675629 & 8.155 & 8.4928 & TRN & & \\
\hline CHEMBL1270418 & 675629 & \multicolumn{3}{|c|}{5.3389999999999995} & 6.183 & TRN \\
\hline CHEMBL1270419 & 675629 & 8.699 & 8.4128 & TRN & & \\
\hline CHEMBL 1270512 & 675629 & 7.495 & 7.1423 & TRN & & \\
\hline CHEMBL1270513 & 675629 & 8.523 & 8.7262 & TRN & & \\
\hline CHEMBL1270613 & 675629 & 7.602 & 7.8453 & TRN & & \\
\hline CHEMBL1270614 & 675629 & 7.921 & 7.6109 & TRN & & \\
\hline
\end{tabular}




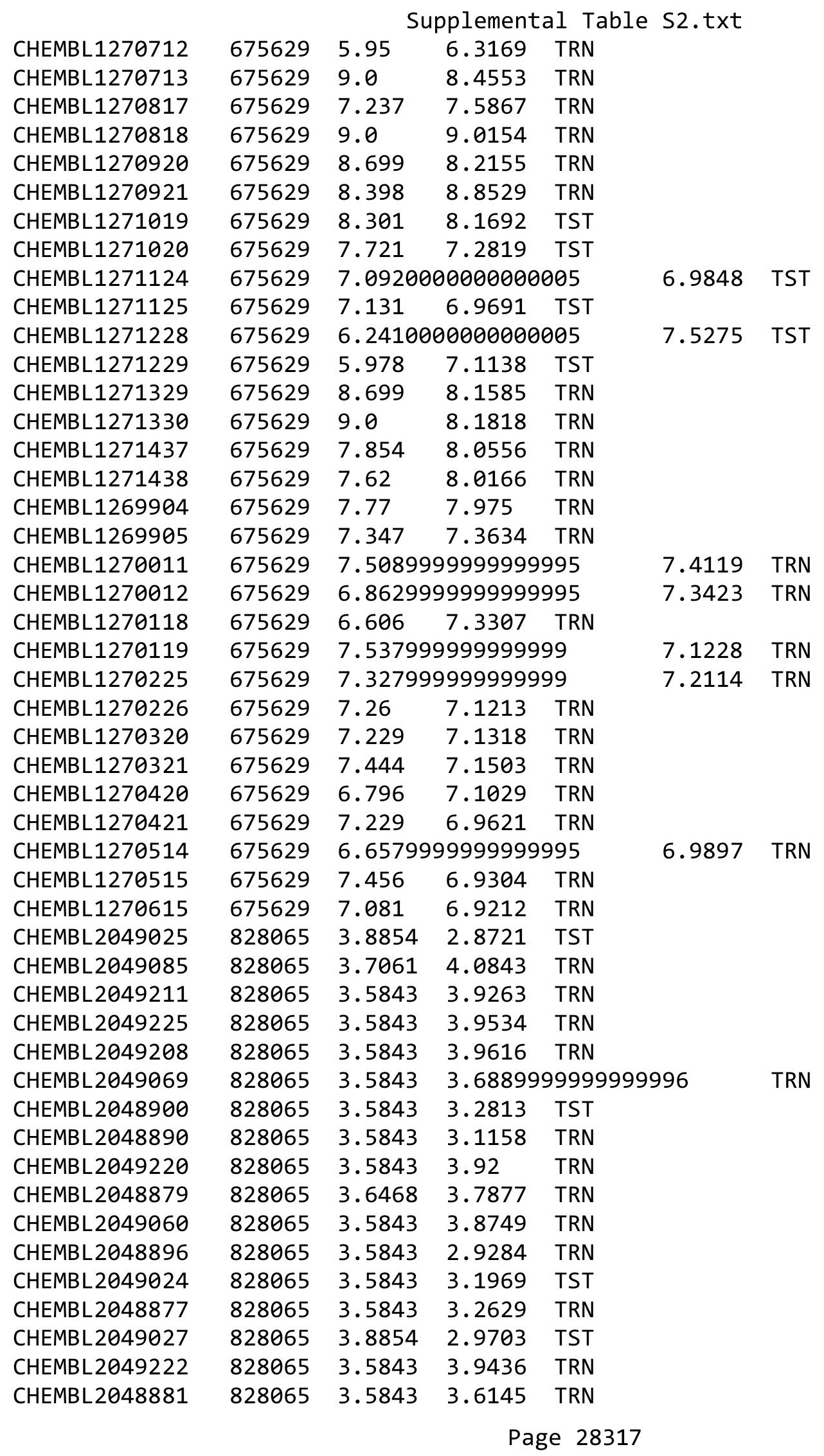




\begin{tabular}{|c|c|c|c|c|c|}
\hline \multicolumn{6}{|c|}{ Supplemental Table S2.txt } \\
\hline CHEMBL 2048887 & 828065 & 3.5843 & 3.1673 & TRN & \\
\hline CHEMBL 2049223 & 828065 & 3.5843 & 4.0664 & TRN & \\
\hline CHEMBL 2049053 & 828065 & 3.6805 & 3.9104 & TRN & \\
\hline CHEMBL 2048897 & 828065 & 3.5658 & 3.1431 & TRN & \\
\hline CHEMBL 2049083 & 828065 & 3.5843 & 4.1023 & TRN & \\
\hline CHEMBL291083 & 828065 & 3.8854 & 2.7583 & TST & \\
\hline CHEMBL 2049215 & 828065 & 3.5843 & 3.8866 & TRN & \\
\hline CHEMBL 2049026 & 828065 & 3.8854 & 2.8788 & TST & \\
\hline CHEMBL 2049080 & 828065 & 3.5843 & 4.0762 & TRN & \\
\hline CHEMBL 2049087 & 828065 & 3.676 & 3.9537 & TRN & \\
\hline CHEMBL 2049072 & 828065 & 3.5843 & 3.8118 & TRN & \\
\hline CHEMBL 2049064 & 828065 & 3.5843 & 3.8372 & TRN & \\
\hline CHEMBL 2049045 & 828065 & 3.5843 & 3.9664 & TRN & \\
\hline CHEMBL 2049221 & 828065 & 3.5843 & 4.0465 & TRN & \\
\hline CHEMBL 2048894 & 828065 & 3.5843 & 3.0876 & TRN & \\
\hline CHEMBL 2048899 & 828065 & 3.8854 & 2.9194 & TST & \\
\hline CHEMBL 2048883 & 828065 & 3.5843 & 3.3934 & TRN & \\
\hline CHEMBL150924 & 828065 & 3.5843 & 3.1051 & TST & \\
\hline CHEMBL 2049071 & 828065 & 3.5843 & 3.6775 & TRN & \\
\hline CHEMBL 2049040 & 828065 & 3.8854 & 2.8064 & TST & \\
\hline CHEMBL 2049061 & 828065 & 3.5843 & 4.4784 & TRN & \\
\hline CHEMBL 2049052 & 828065 & 3.6782 & 3.8319 & TRN & \\
\hline CHEMBL 2048895 & 828065 & 3.5843 & 3.2196 & TRN & \\
\hline CHEMBL 2049079 & 828065 & 3.5843 & 4.136 & TRN & \\
\hline CHEMBL 2049207 & 828065 & 3.7333 & 4.0667 & TRN & \\
\hline CHEMBL 2049210 & 828065 & 9.8861 & 4.3873 & TRN & \\
\hline CHEMBL 2049214 & 828065 & 3.5843 & 3.8856 & TRN & \\
\hline CHEMBL 2048875 & 828065 & 3.5843 & 3.4843 & TRN & \\
\hline CHEMBL1369462 & 828065 & 3.5843 & 3.1382 & TST & \\
\hline CHEMBL 2049022 & 828065 & 3.5843 & 3.1602 & TST & \\
\hline CHEMBL 2048886 & 828065 & 3.5843 & 3.2173 & TRN & \\
\hline CHEMBL 2048901 & 828065 & 3.5843 & 3.3193 & TST & \\
\hline CHEMBL 2049056 & 828065 & 3.5843 & 3.8167 & TRN & \\
\hline CHEMBL 2049088 & 828065 & 3.6499 & 4.0282 & TRN & \\
\hline CHEMBL 2049032 & 828065 & 3.8854 & 3.3298 & TST & \\
\hline CHEMBL 2049036 & 828065 & 3.8854 & 2.96199 & 99999999997 & TST \\
\hline CHEMBL 2049057 & 828065 & 3.5843 & 4.1904 & TRN & \\
\hline CHEMBL 2049031 & 828065 & 3.8854 & 3.0416 & TST & \\
\hline CHEMBL 2049033 & 828065 & 3.8854 & 2.9644 & TST & \\
\hline CHEMBL 2048888 & 828065 & 3.5843 & 3.655 & TRN & \\
\hline CHEMBL 2048898 & 828065 & 3.5658 & 3.0446 & TRN & \\
\hline CHEMBL 2048891 & 828065 & 3.5843 & 3.0854 & TRN & \\
\hline CHEMBL 2049062 & 828065 & 3.5843 & 3.7607 & TRN & \\
\hline CHEMBL 2049023 & 828065 & 3.5843 & 3.156 & TST & \\
\hline CHEMBL 2049029 & 828065 & 3.8854 & 2.9891 & TST & \\
\hline CHEMBL 2048893 & 828065 & 3.5843 & 3.0059 & TRN & \\
\hline CHEMBL 2049205 & 828065 & 3.5843 & 3.9333 & TRN & \\
\hline CHEMBL 2049218 & 828065 & 3.5843 & 3.8016 & TRN & \\
\hline
\end{tabular}




\begin{tabular}{|c|c|c|c|c|c|}
\hline \multicolumn{6}{|c|}{ Supplemental Table S2.txt } \\
\hline CHEMBL 2049058 & 828065 & 3.5843 & 3.8033 & TRN & \\
\hline CHEMBL 2049048 & 828065 & 3.5843 & 3.9786 & TRN & \\
\hline CHEMBL 2049216 & 828065 & 3.5843 & 3.819 & TRN & \\
\hline CHEMBL 2049035 & 828065 & 3.8854 & 2.9147 & TST & \\
\hline CHEMBL 2049043 & 828065 & 3.5843 & 3.5656 & TRN & \\
\hline CHEMBL 2048882 & 828065 & 3.5843 & 3.6219 & TRN & \\
\hline CHEMBL 2049075 & 828065 & 3.5843 & 3.9161 & TRN & \\
\hline CHEMBL 2049049 & 828065 & 3.5843 & 3.9353 & TRN & \\
\hline CHEMBL 2049059 & 828065 & 3.5843 & 3.7479 & TRN & \\
\hline CHEMBL 2048880 & 828065 & 3.5843 & 3.5554 & TRN & \\
\hline CHEMBL 2049224 & 828065 & 3.5843 & 4.0209 & TRN & \\
\hline CHEMBL 2049204 & 828065 & 9.8861 & 4.6022 & TRN & \\
\hline CHEMBL 2049074 & 828065 & 3.5843 & 3.8174 & TRN & \\
\hline CHEMBL 2049051 & 828065 & 3.5843 & 3.9301 & TRN & \\
\hline CHEMBL 2049084 & 828065 & 3.5843 & 4.0579 & TRN & \\
\hline CHEMBL 2049067 & 828065 & 3.5843 & 3.8383 & TRN & \\
\hline CHEMBL 2049021 & 828065 & 3.5843 & 2.9247 & TST & \\
\hline CHEMBL 2049203 & 828065 & 3.5843 & 3.998 & TRN & \\
\hline CHEMBL 2049046 & 828065 & 3.5843 & 3.8713 & TRN & \\
\hline CHEMBL 2049039 & 828065 & 3.8854 & 2.9364 & TST & \\
\hline CHEMBL 2049044 & 828065 & 9.8861 & 4.0242 & TRN & \\
\hline CHEMBL 2048884 & 828065 & 3.5843 & 3.4765 & TRN & \\
\hline CHEMBL 2049063 & 828065 & 3.6595 & 3.9373 & TRN & \\
\hline CHEMBL 2049028 & 828065 & 3.8854 & 2.9656 & TST & \\
\hline CHEMBL 2049050 & 828065 & 3.727 & 3.9678 & TRN & \\
\hline CHEMBL 2048889 & 828065 & 3.5843 & 3.3773 & TRN & \\
\hline CHEMBL 2049082 & 828065 & 3.5843 & 3.9681 & TRN & \\
\hline CHEMBL 2049070 & 828065 & 3.5843 & 3.6677 & TRN & \\
\hline CHEMBL 2049042 & 828065 & 3.8854 & 2.9075 & TST & \\
\hline CHEMBL2049037 & 828065 & 3.8854 & 2.8497 & TST & \\
\hline CHEMBL 2049041 & 828065 & 3.8854 & 3.1255 & TST & \\
\hline CHEMBL 2049055 & 828065 & 3.5843 & 3.6897 & TRN & \\
\hline CHEMBL 2048878 & 828065 & 3.5843 & 3.35600 & 00000000003 & TRN \\
\hline CHEMBL 2049065 & 828065 & 3.5843 & 4.2743 & TRN & \\
\hline CHEMBL 2049030 & 828065 & 3.8854 & 3.0169 & TST & \\
\hline CHEMBL 2049066 & 828065 & 3.5843 & 3.8029 & TRN & \\
\hline CHEMBL 2048874 & 828065 & 3.5843 & 3.417 & TRN & \\
\hline CHEMBL 2049202 & 828065 & 3.5843 & 4.3719 & TRN & \\
\hline CHEMBL 2049209 & 828065 & 3.5843 & 3.9312 & TRN & \\
\hline CHEMBL2049054 & 828065 & 3.6595 & 3.679 & TRN & \\
\hline CHEMBL 2049090 & 828065 & 3.5843 & 3.8121 & TRN & \\
\hline CHEMBL 2049091 & 828065 & 3.5843 & 3.9394 & TRN & \\
\hline CHEMBL 2049212 & 828065 & 3.5843 & 3.966 & TRN & \\
\hline CHEMBL 2049078 & 828065 & 3.5843 & 3.6972 & TRN & \\
\hline CHEMBL 2049077 & 828065 & 3.5843 & 3.8328 & TRN & \\
\hline CHEMBL 2049201 & 828065 & 3.5843 & 3.8612 & TRN & \\
\hline CHEMBL 2049081 & 828065 & 3.5843 & 3.9908 & TRN & \\
\hline CHEMBL 2049034 & 828065 & 3.8854 & 2.9311 & TST & \\
\hline
\end{tabular}




\begin{tabular}{|c|c|c|c|c|c|}
\hline & & \multicolumn{4}{|c|}{ Supplemental Table S2.txt } \\
\hline CHEMBL2049219 & 828065 & 3.5843 & 3.8896 & TRN & \\
\hline CHEMBL 2049200 & 828065 & 3.5843 & 3.9178 & TRN & \\
\hline CHEMBL2049076 & 828065 & 3.5843 & 3.9634 & TRN & \\
\hline CHEMBL 2049089 & 828065 & 3.6116 & 3.8091 & TRN & \\
\hline CHEMBL 2049073 & 828065 & 3.5843 & 3.927 & TRN & \\
\hline CHEMBL 2049047 & 828065 & 3.5843 & 3.8587 & TRN & \\
\hline CHEMBL 2048885 & 828065 & 3.5843 & 3.6609 & TRN & \\
\hline CHEMBL2048892 & 828065 & 3.5843 & 3.2631 & TRN & \\
\hline CHEMBL 2046470 & 828065 & 3.5843 & 3.8011 & TRN & \\
\hline CHEMBL2049199 & 828065 & 3.5843 & 4.3097 & TRN & \\
\hline CHEMBL 2049206 & 828065 & 3.5843 & 3.8992 & TRN & \\
\hline CHEMBL 2048902 & 828065 & 3.8854 & 2.8781 & TST & \\
\hline CHEMBL 2048876 & 828065 & 3.5843 & 3.4964 & TRN & \\
\hline CHEMBL 2049213 & 828065 & 3.5843 & 3.8321 & TST & \\
\hline CHEMBL 2049068 & 828065 & 3.5843 & 3.7145 & TST & \\
\hline CHEMBL 2049086 & 828065 & 3.5843 & 4.0448 & TST & \\
\hline CHEMBL 2049038 & 828065 & 3.8854 & 2.9638 & TST & \\
\hline CHEMBL 2049217 & 828065 & 3.5843 & 3.7976 & TST & \\
\hline CHEMBL1516477 & 688545 & 4.85 & 5.1585 & TST & \\
\hline CHEMBL1256995 & 688545 & 5.3 & 5.2568 & TRN & \\
\hline CHEMBL1476170 & 688545 & 4.55 & 4.962 & TRN & \\
\hline CHEMBL 286722 & 688545 & 7.8508 & 5.5043 & TRN & \\
\hline CHEMBL309176 & 688545 & 4.6 & 5.4206 & TRN & \\
\hline CHEMBL 22304 & 688545 & 5.15 & 5.2468 & TRN & \\
\hline CHEMBL1480516 & 688545 & 4.7 & 4.9451 & TRN & \\
\hline CHEMBL261634 & 688545 & 4.5 & 5.2676 & TST & \\
\hline CHEMBL445102 & 688545 & 4.9 & 4.7183 & TRN & \\
\hline CHEMBL1517187 & 688545 & 4.55 & 4.68199 & 99999999995 & TST \\
\hline CHEMBL1435381 & 688545 & 4.75 & 4.68199 & 99999999995 & TST \\
\hline CHEMBL1506225 & 688545 & 6.0 & 6.1811 & TRN & \\
\hline CHEMBL544713 & 688545 & 4.95 & 5.0265 & TRN & \\
\hline CHEMBL1255966 & 688545 & 6.0 & 4.9959 & TRN & \\
\hline CHEMBL1515691 & 688545 & 5.85 & 5.2319 & TST & \\
\hline CHEMBL1373007 & 688545 & 6.45 & 5.1552 & TST & \\
\hline CHEMBL398673 & 688545 & 5.6 & 5.3169 & TST & \\
\hline CHEMBL182461 & 688545 & 5.1 & 5.4498 & TRN & \\
\hline CHEMBL1552095 & 688545 & 4.7 & 4.9398 & TRN & \\
\hline CHEMBL1400543 & 688545 & 6.0 & 5.7178 & TRN & \\
\hline CHEMBL1402894 & 688545 & 4.8 & 5.0407 & TRN & \\
\hline CHEMBL113830 & 688545 & 5.1 & 5.3755 & TRN & \\
\hline CHEMBL1356870 & 688545 & 7.6003 & 6.1212 & TRN & \\
\hline CHEMBL1256654 & 688545 & 4.65 & 5.2279 & TRN & \\
\hline CHEMBL1256659 & 688545 & 4.95 & 4.9122 & TRN & \\
\hline CHEMBL326967 & 688545 & 4.85 & 4.4601 & TRN & \\
\hline CHEMBL1256147 & 688545 & 5.1 & 5.2112 & TRN & \\
\hline CHEMBL1397559 & 688545 & 5.1 & 5.2527 & TRN & \\
\hline CHEMBL1598680 & 688545 & 4.75 & 5.25799 & 9999999999 & TRN \\
\hline CHEMBL137743 & 688545 & 4.75 & 4.8097 & TRN & \\
\hline
\end{tabular}




\begin{tabular}{|c|c|c|c|c|}
\hline \multicolumn{5}{|c|}{ Supplemental Table S2.txt } \\
\hline CHEMBL327708 & 688545 & 4.55 & 4.8628 & TRN \\
\hline CHEMBL34704 & 688545 & 4.75 & 5.6411 & TST \\
\hline CHEMBL1256873 & 688545 & 4.5 & 5.3769 & TST \\
\hline CHEMBL1256019 & 688545 & 5.3 & 5.4785 & TRN \\
\hline CHEMBL1256666 & 688545 & 5.55 & 4.9675 & TRN \\
\hline CHEMBL1324405 & 688545 & 4.8 & 5.3889 & TRN \\
\hline CHEMBL1319469 & 688545 & 6.0 & 6.0591 & TRN \\
\hline CHEMBL64119 & 688545 & 4.8 & 5.1402 & TRN \\
\hline CHEMBL 8618 & 688545 & 5.1 & 5.1725 & TRN \\
\hline CHEMBL1256878 & 688545 & 4.85 & 4.9503 & TRN \\
\hline CHEMBL122270 & 688545 & 4.85 & 5.6222 & TRN \\
\hline CHEMBL293349 & 688545 & 4.8 & 4.7015 & TRN \\
\hline CHEMBL 277120 & 688545 & 4.6 & 5.0813 & TRN \\
\hline CHEMBL1321005 & 688545 & 5.05 & 4.9105 & TRN \\
\hline CHEMBL1256656 & 688545 & 4.5 & 4.3885 & TRN \\
\hline CHEMBL536803 & 688545 & 4.65 & 4.7414 & TRN \\
\hline CHEMBL1255733 & 688545 & 4.9 & 5.2095 & TST \\
\hline CHEMBL1554717 & 688545 & 4.6 & 4.8937 & TRN \\
\hline CHEMBL556001 & 688545 & 4.75 & 4.9114 & TRN \\
\hline CHEMBL 2449003 & 688545 & 6.0 & 6.3608 & TRN \\
\hline CHEMBL216504 & 688545 & 5.4 & 5.0819 & TST \\
\hline CHEMBL1320485 & 688545 & 4.8 & 5.3915 & TRN \\
\hline CHEMBL1315457 & 688545 & 5.4 & 4.9193 & TST \\
\hline CHEMBL903 & 688545 & 5.05 & 4.9144 & TRN \\
\hline CHEMBL1256667 & 688545 & 5.05 & 4.8114 & TST \\
\hline CHEMBL1257125 & 688545 & 8.5528 & 7.0131 & TRN \\
\hline CHEMBL1256839 & 688545 & 4.85 & 4.6854 & TRN \\
\hline CHEMBL1257041 & 688545 & 5.1 & 5.3645 & TRN \\
\hline CHEMBL124267 & 688545 & 4.5 & 4.8567 & TRN \\
\hline CHEMBL1256647 & 688545 & 5.85 & 5.1815 & TRN \\
\hline CHEMBL1256625 & 688545 & 4.45 & 5.0981 & TRN \\
\hline CHEMBL3216928 & 688545 & 5.65 & 5.6536 & TRN \\
\hline CHEMBL 88584 & 688545 & 5.75 & 5.1033 & TRN \\
\hline CHEMBL1435477 & 688545 & 6.9 & 5.8695 & TRN \\
\hline CHEMBL112816 & 688545 & 5.0 & 5.335 & TRN \\
\hline CHEMBL23957 & 688545 & 8.0 & 4.9649 & TST \\
\hline CHEMBL1256660 & 688545 & 5.0 & 5.154 & TRN \\
\hline CHEMBL1255935 & 688545 & 4.95 & 5.0939 & TRN \\
\hline CHEMBL 26915 & 688545 & 4.75 & 4.7077 & TRN \\
\hline CHEMBL296586 & 688545 & 5.15 & 5.1314 & TRN \\
\hline CHEMBL76897 & 688545 & 7.9508 & 6.5815 & TRN \\
\hline CHEMBL1554131 & 688545 & 5.1 & 5.4549 & TRN \\
\hline CHEMBL 7917 & 688545 & 4.75 & 4.3401 & TRN \\
\hline CHEMBL1365455 & 688545 & 5.4 & 5.2087 & TRN \\
\hline CHEMBL604119 & 688545 & 4.9 & 4.3166 & TST \\
\hline CHEMBL 310310 & 688545 & 7.8996 & 6.7883 & TRN \\
\hline CHEMBL1354398 & 688545 & 6.0 & 6.1566 & TRN \\
\hline CHEMBL1405759 & 688545 & 4.45 & 5.1633 & TRN \\
\hline
\end{tabular}




\begin{tabular}{|c|c|c|c|c|}
\hline \multicolumn{5}{|c|}{ Supplemental Table S2.txt } \\
\hline CHEMBL333985 & 688545 & 4.55 & 5.2579 & TST \\
\hline CHEMBL53898 & 688545 & 4.95 & 5.0808 & TRN \\
\hline CHEMBL433461 & 688545 & 4.6 & 5.0062 & TST \\
\hline CHEMBL1256624 & 688545 & 4.5 & $5.5370 e$ & 0000000001 \\
\hline CHEMBL93403 & 688545 & 4.95 & 4.5719 & TRN \\
\hline CHEMBL286136 & 688545 & 5.1 & 4.426 & TRN \\
\hline CHEMBL 299052 & 688545 & 4.85 & 5.5631 & TRN \\
\hline CHEMBL1256835 & 688545 & 4.85 & 4.4612 & TRN \\
\hline CHEMBL188 & 688545 & 5.7 & 5.2014 & TRN \\
\hline CHEMBL1255650 & 688545 & 5.65 & 5.3 & TRN \\
\hline CHEMBL1456417 & 688545 & 4.85 & 5.1975 & TRN \\
\hline CHEMBL573214 & 688545 & 5.65 & 4.8482 & TRN \\
\hline CHEMBL1200450 & 688545 & 5.4 & 5.1133 & TRN \\
\hline CHEMBL1356280 & 688545 & 4.85 & 5.1266 & TRN \\
\hline CHEMBL1355710 & 688545 & 4.95 & 5.1755 & TRN \\
\hline CHEMBL104264 & 688545 & 6.3 & 4.5728 & TRN \\
\hline CHEMBL1554789 & 688545 & 6.0 & 5.6726 & TRN \\
\hline CHEMBL 286077 & 688545 & 5.0 & 5.2169 & TRN \\
\hline CHEMBL 244948 & 688545 & 4.65 & 5.1163 & TRN \\
\hline CHEMBL1590980 & 688545 & 4.75 & 4.7199 & TRN \\
\hline CHEMBL323356 & 688545 & 4.8 & 5.0303 & TRN \\
\hline CHEMBL10247 & 688545 & 4.95 & 5.4133 & TRN \\
\hline CHEMBL1489918 & 688545 & 4.5 & 5.1519 & TST \\
\hline CHEMBL63329 & 688545 & 7.1002 & 5.4522 & TRN \\
\hline CHEMBL263972 & 688545 & 6.4 & 5.4693 & TRN \\
\hline CHEMBL1256910 & 688545 & 4.5 & 4.8013 & TRN \\
\hline CHEMBL1256797 & 688545 & 4.8 & 4.6872 & TRN \\
\hline CHEMBL1442153 & 688545 & 6.0 & 5.6081 & TRN \\
\hline CHEMBL1256770 & 688545 & 4.7 & 4.3549 & TRN \\
\hline CHEMBL1256916 & 688545 & 5.0 & 5.0367 & TRN \\
\hline CHEMBL1256686 & 688545 & 4.75 & 5.0842 & TST \\
\hline CHEMBL539947 & 688545 & 5.4 & 5.375 & TRN \\
\hline CHEMBL1318166 & 688545 & 5.85 & 5.2179 & TST \\
\hline CHEMBL316966 & 688545 & 5.3 & 5.2962 & TRN \\
\hline CHEMBL 278332 & 688545 & 4.7 & 5.1042 & TRN \\
\hline CHEMBL2373602 & 688545 & 4.5 & 4.8728 & TRN \\
\hline CHEMBL546257 & 688545 & 4.55 & 5.0946 & TRN \\
\hline CHEMBL478 & 688545 & 4.8 & 4.6745 & TRN \\
\hline CHEMBL1257083 & 688545 & 4.85 & 4.9457 & TRN \\
\hline CHEMBL15192 & 688545 & 5.05 & 5.2649 & TRN \\
\hline CHEMBL49247 & 688545 & 5.1 & 5.1892 & TRN \\
\hline CHEMBL1256360 & 688545 & 4.9 & 4.6563 & TRN \\
\hline CHEMBL1256737 & 688545 & 5.25 & 5.1772 & TRN \\
\hline CHEMBL 2028085 & 688545 & 4.8 & 4.6335 & TRN \\
\hline CHEMBL1528648 & 688545 & 4.75 & 4.6599 & TST \\
\hline CHEMBL541585 & 688545 & 4.7 & 4.4839 & TRN \\
\hline CHEMBL1316314 & 688545 & 4.5 & 5.5605 & TRN \\
\hline CHEMBL481537 & 688545 & 4.7 & 5.4879 & TRN \\
\hline
\end{tabular}

TRN 


\begin{tabular}{|c|c|c|c|c|c|}
\hline \multirow[b]{2}{*}{ CHEMBL1531863 } & \multicolumn{5}{|c|}{ Supplemental Table S2.txt } \\
\hline & 688545 & 8.3979 & 6.6037 & TRN & \\
\hline CHEMBL1316222 & 688545 & 4.8 & 4.835 & TRN & \\
\hline CHEMBL545184 & 688545 & 4.65 & 5.4398 & TRN & \\
\hline CHEMBL1565861 & 688545 & 4.85 & 5.5526 & TRN & \\
\hline CHEMBL17331 & 688545 & 4.75 & 5.19600 & 0000000001 & TST \\
\hline CHEMBL1972346 & 688545 & 4.8 & 5.153 & TRN & \\
\hline CHEMBL56393 & 688545 & 5.3 & 4.8634 & TRN & \\
\hline CHEMBL1595524 & 688545 & 6.35 & 5.6826 & TRN & \\
\hline CHEMBL326958 & 688545 & 5.1 & 5.3224 & TRN & \\
\hline CHEMBL1626274 & 688545 & 5.15 & 5.0958 & TRN & \\
\hline CHEMBL1256148 & 688545 & 4.95 & 4.9705 & TRN & \\
\hline CHEMBL28862 & 688545 & 4.65 & 5.6622 & TRN & \\
\hline CHEMBL1200938 & 688545 & 4.8 & 4.9991 & TRN & \\
\hline CHEMBL1494294 & 688545 & 4.95 & 5.3394 & TRN & \\
\hline CHEMBL1256957 & 688545 & 4.5 & 5.0293 & TRN & \\
\hline CHEMBL1256663 & 688545 & 4.55 & 4.9216 & TRN & \\
\hline CHEMBL1529009 & 688545 & 4.85 & 4.7277 & TRN & \\
\hline CHEMBL1329033 & 688545 & 4.85 & 4.7942 & TRN & \\
\hline CHEMBL539027 & 688545 & 4.75 & 5.2084 & TRN & \\
\hline CHEMBL1256923 & 688545 & 5.0 & 4.7537 & TRN & \\
\hline CHEMBL80155 & 688545 & 4.75 & 5.1761 & TRN & \\
\hline CHEMBL1256869 & 688545 & 4.85 & 4.4144 & TRN & \\
\hline CHEMBL305881 & 688545 & 4.85 & 5.3894 & TRN & \\
\hline CHEMBL157351 & 688545 & 4.8 & 4.9845 & TRN & \\
\hline CHEMBL107201 & 688545 & 4.8 & 4.9492 & TRN & \\
\hline CHEMBL1256851 & 688545 & 4.85 & 5.2077 & TRN & \\
\hline CHEMBL1512470 & 688545 & 4.75 & 5.3557 & TRN & \\
\hline CHEMBL1256911 & 688545 & 4.45 & 4.68199 & 99999999995 & TRN \\
\hline CHEMBL1336469 & 688545 & 4.75 & 4.5031 & TRN & \\
\hline CHEMBL1318078 & 688545 & 5.0 & 5.6736 & TRN & \\
\hline CHEMBL1256760 & 688545 & 4.7 & 5.1021 & TST & \\
\hline CHEMBL576349 & 688545 & 5.05 & 5.3999 & TRN & \\
\hline CHEMBL310798 & 688545 & 5.1 & 5.4689 & TRN & \\
\hline CHEMBL1366846 & 688545 & 4.95 & 4.8657 & TRN & \\
\hline CHEMBL45244 & 688545 & 8.1024 & 5.1458 & TRN & \\
\hline CHEMBL1257076 & 688545 & 4.95 & 5.3894 & TRN & \\
\hline CHEMBL1256698 & 688545 & 5.05 & 5.25 & TRN & \\
\hline CHEMBL1526455 & 688545 & 4.75 & 4.6025 & TRN & \\
\hline CHEMBL1256727 & 688545 & 4.75 & 4.93 & TRN & \\
\hline CHEMBL1553768 & 688545 & 4.6 & 4.7821 & TRN & \\
\hline CHEMBL21823 & 688545 & 6.25 & 6.1907 & TRN & \\
\hline CHEMBL123 & 688545 & 4.6 & 5.2492 & TRN & \\
\hline CHEMBL1255662 & 688545 & 5.15 & 5.8146 & TRN & \\
\hline CHEMBL347862 & 688545 & 5.65 & 5.6646 & TRN & \\
\hline CHEMBL513116 & 688545 & 4.75 & 4.7097 & TRN & \\
\hline CHEMBL26320 & 688545 & 5.05 & 5.8439 & TRN & \\
\hline CHEMBL276727 & 688545 & 5.5 & 5.3896 & TRN & \\
\hline CHEMBL1526543 & 688545 & 5.1 & 4.7401 & TST & \\
\hline
\end{tabular}




\begin{tabular}{|c|c|c|c|c|}
\hline \multicolumn{5}{|c|}{ Supplemental Table S2.txt } \\
\hline CHEMBL1256720 & 688545 & 4.7 & 4.5019 & TRN \\
\hline CHEMBL50267 & 688545 & 4.8 & 5.49200 & 0000000001 \\
\hline CHEMBL394171 & 688545 & 4.85 & 5.0515 & TRN \\
\hline CHEMBL1255832 & 688545 & 4.5 & 5.1965 & TRN \\
\hline CHEMBL320820 & 688545 & 7.0 & 5.0779 & TST \\
\hline CHEMBL1180496 & 688545 & 4.9 & 4.8551 & TRN \\
\hline CHEMBL1208858 & 688545 & 4.85 & 4.9396 & TST \\
\hline CHEMBL1333019 & 688545 & 5.1 & 5.6208 & TRN \\
\hline CHEMBL330129 & 688545 & 4.5 & 5.4416 & TRN \\
\hline CHEMBL56731 & 688545 & 4.7 & 5.4029 & TRN \\
\hline CHEMBL39 & 688545 & 4.65 & 4.9444 & TRN \\
\hline CHEMBL1256996 & 688545 & 6.0 & 4.9077 & TRN \\
\hline CHEMBL1256844 & 688545 & 4.85 & 4.9082 & TRN \\
\hline CHEMBL428768 & 688545 & 4.7 & 4.7412 & TRN \\
\hline CHEMBL1317234 & 688545 & 5.05 & 5.3359 & TST \\
\hline CHEMBL355496 & 688545 & 4.85 & 5.4287 & TRN \\
\hline CHEMBL429023 & 688545 & 5.8 & 4.8544 & TRN \\
\hline CHEMBL1284 & 688545 & 5.25 & 5.2502 & TRN \\
\hline CHEMBL1363347 & 688545 & 6.35 & 6.6021 & TRN \\
\hline CHEMBL1256775 & 688545 & 5.1 & 5.1152 & TRN \\
\hline CHEMBL1453208 & 688545 & 5.1 & 4.9427 & TRN \\
\hline CHEMBL500996 & 688545 & 5.45 & 5.2506 & TRN \\
\hline CHEMBL105457 & 688545 & 6.5 & 5.1984 & TST \\
\hline CHEMBL541543 & 688545 & 4.75 & 4.8821 & TST \\
\hline CHEMBL90472 & 688545 & 4.75 & 4.8853 & TRN \\
\hline CHEMBL1365553 & 688545 & 5.0 & 5.276 & TST \\
\hline CHEMBL67535 & 688545 & 4.75 & 4.7243 & TRN \\
\hline CHEMBL 3084891 & 688545 & 8.1487 & 6.8281 & TRN \\
\hline CHEMBL 56 & 688545 & 5.15 & 4.9309 & TRN \\
\hline CHEMBL1367076 & 688545 & 4.75 & 4.6699 & TRN \\
\hline CHEMBL428496 & 688545 & 5.55 & 5.1817 & TST \\
\hline CHEMBL1256924 & 688545 & 4.7 & 4.9335 & TRN \\
\hline CHEMBL 2374259 & 688545 & 5.1 & 4.6338 & TRN \\
\hline CHEMBL197027 & 688545 & 4.75 & 4.9566 & TST \\
\hline CHEMBL429095 & 688545 & 5.0 & 5.8032 & TRN \\
\hline CHEMBL30432 & 688545 & 4.95 & 4.8527 & TRN \\
\hline CHEMBL153036 & 688545 & 6.0 & 5.7295 & TRN \\
\hline CHEMBL542493 & 688545 & 5.3 & 5.3454 & TRN \\
\hline CHEMBL1256693 & 688545 & 4.85 & 4.6371 & TRN \\
\hline CHEMBL66 & 688545 & 4.55 & 5.5079 & TRN \\
\hline CHEMBL1173475 & 688545 & 4.7 & 4.957 & TRN \\
\hline CHEMBL1553700 & 688545 & 5.05 & 4.8276 & TRN \\
\hline CHEMBL1224512 & 688545 & 4.6 & 4.987 & TRN \\
\hline CHEMBL336467 & 688545 & 5.6 & 5.9438 & TST \\
\hline CHEMBL1256998 & 688545 & 4.85 & 4.6353 & TRN \\
\hline CHEMBL8747 & 688545 & 4.7 & 5.2985 & TRN \\
\hline CHEMBL1256186 & 688545 & 4.8 & 4.8368 & TST \\
\hline CHEMBL1529217 & 688545 & 4.65 & 4.8685 & TST \\
\hline
\end{tabular}




\begin{tabular}{|c|c|c|c|c|}
\hline \multicolumn{5}{|c|}{ Supplemental Table S2.txt } \\
\hline CHEMBL293749 & 688545 & 4.8 & 5.1859 & TRN \\
\hline CHEMBL1257003 & 688545 & 4.7 & 4.519 & TRN \\
\hline CHEMBL8867 & 688545 & 5.25 & 5.5862 & TRN \\
\hline CHEMBL479014 & 688545 & 4.6 & 5.0207 & TST \\
\hline CHEMBL1256687 & 688545 & 5.1 & 4.9368 & TRN \\
\hline CHEMBL1355762 & 688545 & 6.45 & 5.9023 & TRN \\
\hline CHEMBL1357401 & 688545 & 4.85 & 5.0369 & TRN \\
\hline CHEMBL 249669 & 688545 & 4.7 & 4.6491 & TRN \\
\hline CHEMBL1436438 & 688545 & 5.0 & 5.0 & TRN \\
\hline CHEMBL1357247 & 688545 & 7.4001 & 5.4708 & TRN \\
\hline CHEMBL 376103 & 688545 & 5.0 & 5.7277 & TRN \\
\hline CHEMBL1527442 & 688545 & 4.8 & 4.735 & TST \\
\hline CHEMBL 288096 & 688545 & 4.85 & 5.5137 & TRN \\
\hline CHEMBL1570350 & 688545 & 4.8 & 4.4664 & TRN \\
\hline CHEMBL1255837 & 688545 & 5.9 & 5.0614 & TRN \\
\hline CHEMBL1372588 & 688545 & 5.8 & 5.7383 & TRN \\
\hline CHEMBL34730 & 688545 & 5.05 & 5.2545 & TRN \\
\hline CHEMBL605003 & 688545 & 5.1 & 4.9559 & TRN \\
\hline CHEMBL 323542 & 688545 & 4.6 & 4.7862 & TRN \\
\hline CHEMBL 251904 & 688545 & 6.45 & 5.9081 & TRN \\
\hline CHEMBL1200717 & 688545 & 5.15 & 4.9637 & TST \\
\hline CHEMBL1256678 & 688545 & 5.5 & 4.8197 & TRN \\
\hline CHEMBL 273807 & 688545 & 7.5498 & 5.2689 & TRN \\
\hline CHEMBL1257002 & 688545 & 4.85 & 4.7379 & TRN \\
\hline CHEMBL 260374 & 688545 & 4.7 & 4.8365 & TST \\
\hline CHEMBL1256776 & 688545 & 4.9 & 4.6829 & TRN \\
\hline CHEMBL431504 & 688545 & 4.75 & 5.5648 & TST \\
\hline CHEMBL1487371 & 688545 & 4.9 & 5.1579 & TRN \\
\hline CHEMBL1426948 & 688545 & 4.8 & 4.668 & TRN \\
\hline CHEMBL72365 & 688545 & 4.6 & 4.6343 & TRN \\
\hline CHEMBL1256914 & 688545 & 5.15 & 5.5538 & TRN \\
\hline CHEMBL1256577 & 688545 & 4.85 & 4.7792 & TRN \\
\hline CHEMBL 79824 & 688545 & 4.95 & 5.1708 & TST \\
\hline CHEMBL16410 & 688545 & 5.6 & 4.9409 & TRN \\
\hline CHEMBL1585944 & 688545 & 5.95 & 4.99 & TRN \\
\hline CHEMBL 297784 & 688545 & 4.9 & 4.8225 & TRN \\
\hline CHEMBL1597612 & 688545 & 4.75 & 5.3558 & TST \\
\hline CHEMBL1527722 & 688545 & 5.05 & 5.4026 & TRN \\
\hline CHEMBL1320310 & 688545 & 4.75 & 4.8658 & TST \\
\hline CHEMBL 8488 & 688545 & 7.0501 & 5.4423 & TRN \\
\hline CHEMBL56543 & 688545 & 4.8 & 4.9807 & TRN \\
\hline CHEMBL116600 & 688545 & 5.6 & 5.2326 & TST \\
\hline CHEMBL14276 & 688545 & 4.75 & 4.5881 & TRN \\
\hline CHEMBL1079460 & 688545 & 4.85 & 4.5727 & TRN \\
\hline CHEMBL1329790 & 688545 & 4.7 & 5.2913 & TRN \\
\hline CHEMBL47814 & 688545 & 4.85 & 5.4546 & TRN \\
\hline CHEMBL 1256754 & 688545 & 5.55 & 5.3681 & TRN \\
\hline CHEMBL305195 & 688545 & 5.15 & 5.5562 & TRN \\
\hline
\end{tabular}




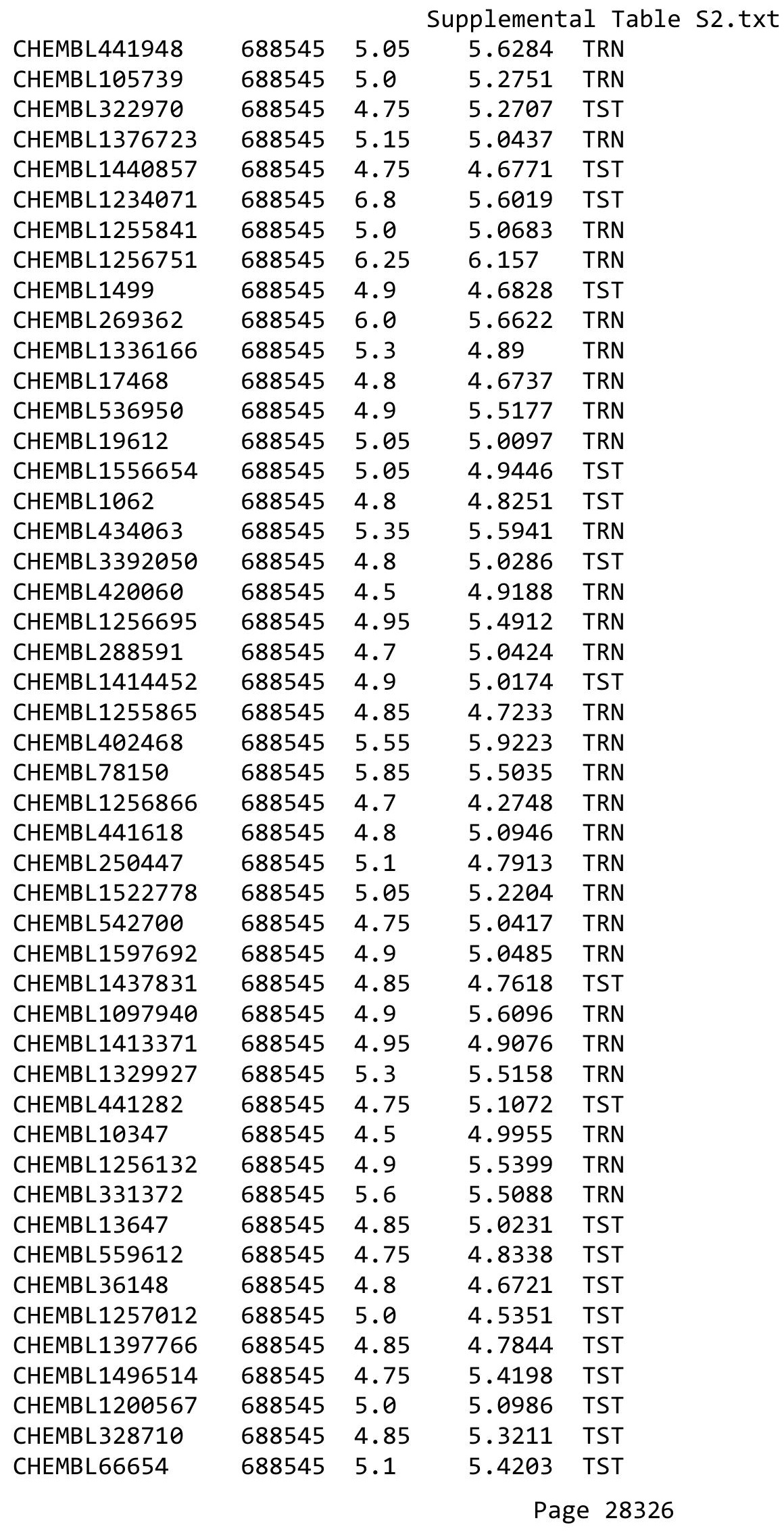




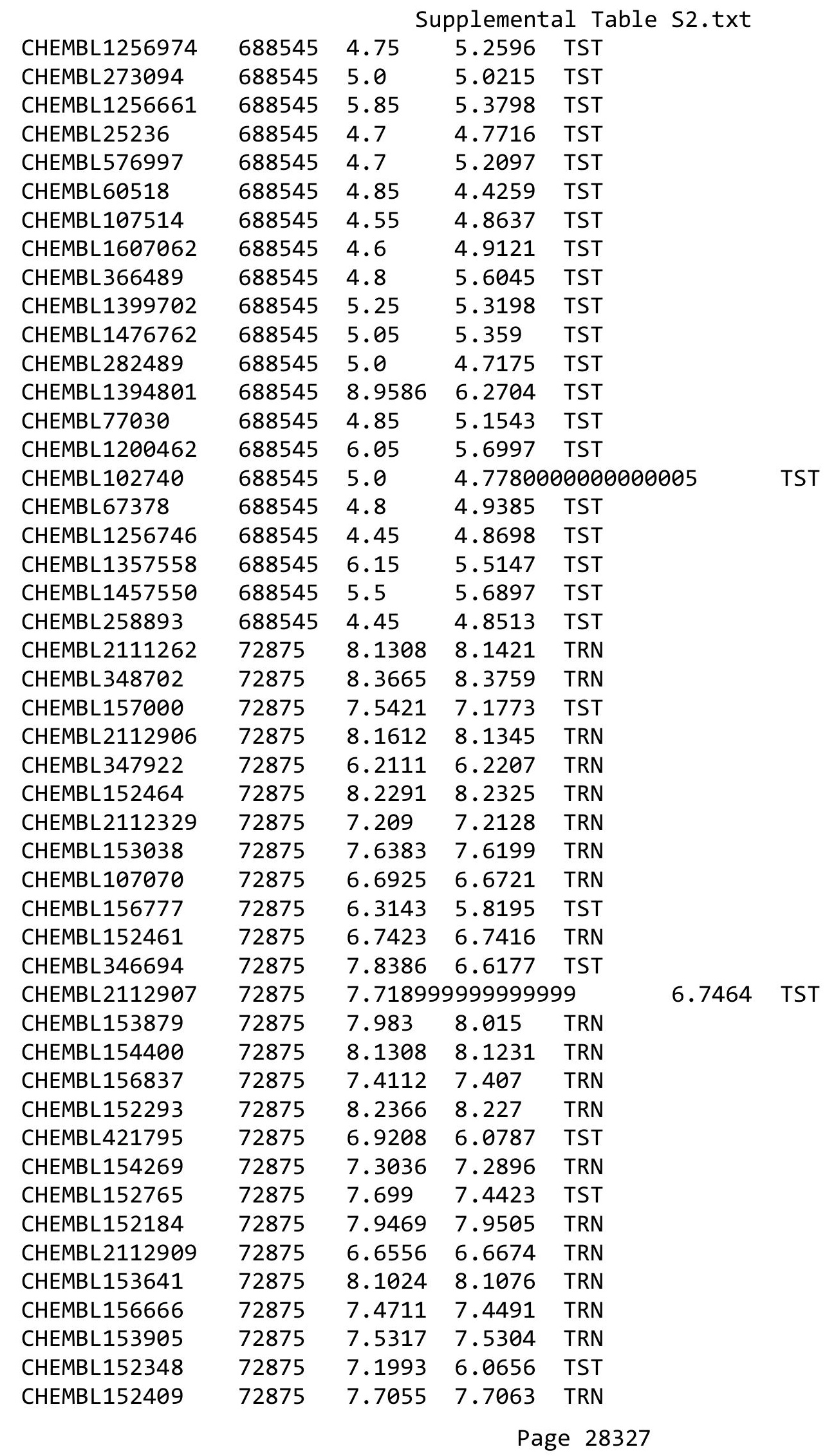




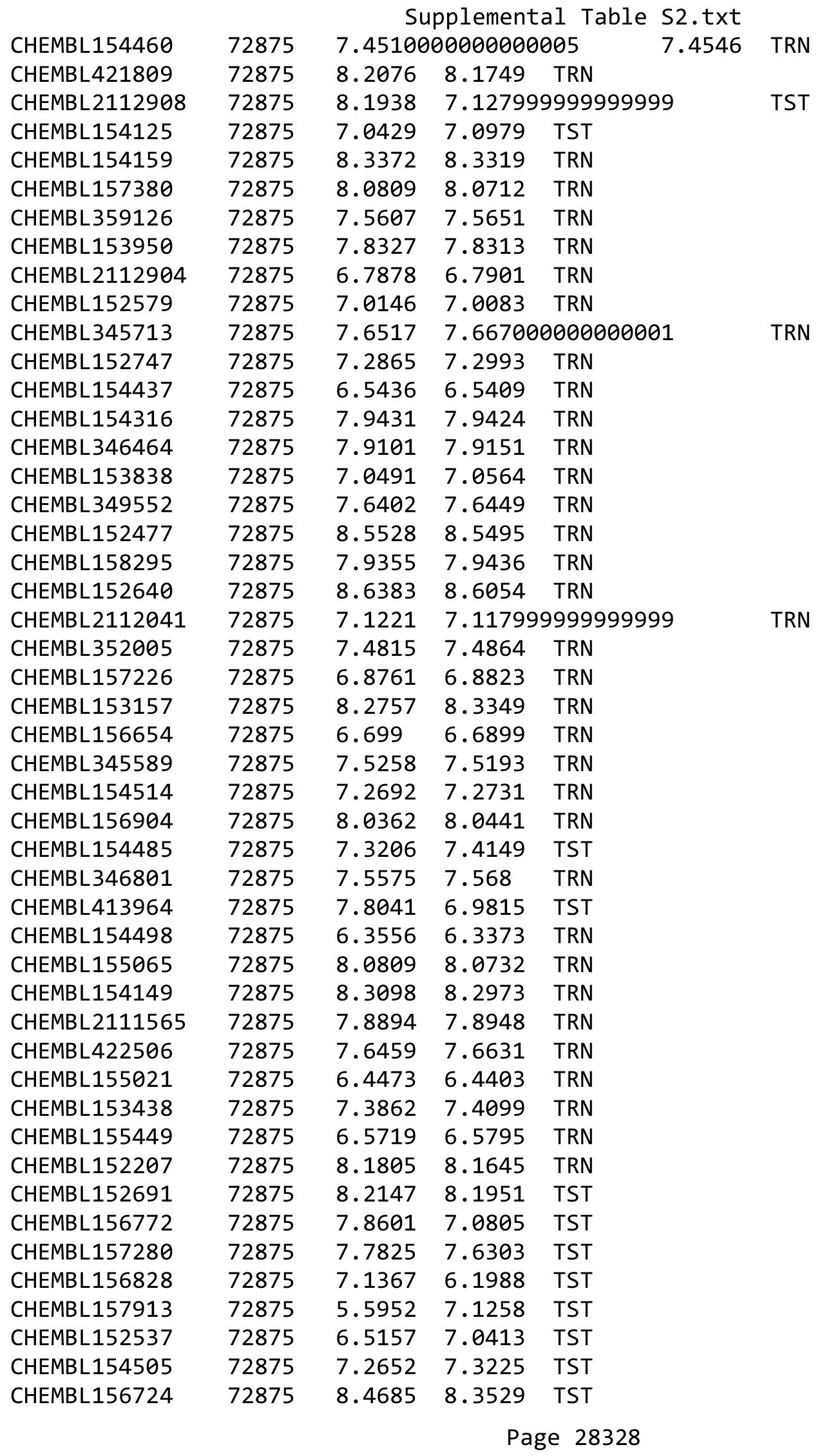


Supplemental Table S2.txt

\begin{tabular}{|c|c|c|c|c|c|}
\hline CHEMBL 3187121 & 1301793 & 3.9318 & 4.2624 & TRN & \\
\hline CHEMBL 3187872 & 1301793 & 7.4318 & 6.5242 & TRN & \\
\hline CHEMBL3182280 & 1301793 & 3.9318 & 4.0699 & TRN & \\
\hline CHEMBL 3188524 & 1301793 & 3.9318 & 3.7561 & TRN & \\
\hline CHEMBL3183725 & 1301793 & 3.9318 & 3.8773 & TRN & \\
\hline CHEMBL3187493 & 1301793 & 3.9318 & 3.6308 & TRN & \\
\hline CHEMBL 3188297 & 1301793 & 3.9318 & 4.1127 & TRN & \\
\hline CHEMBL 3187528 & 1301793 & 3.9318 & 3.7762 & TRN & \\
\hline CHEMBL 3188146 & 1301793 & 3.9318 & 4.0436 & TRN & \\
\hline CHEMBL3187241 & 1301793 & 3.9318 & 3.8299 & TRN & \\
\hline CHEMBL3183227 & 1301793 & 3.9318 & 4.3819 & TRN & \\
\hline CHEMBL3183586 & 1301793 & 3.9318 & 4.4175 & TRN & \\
\hline CHEMBL3187975 & 1301793 & 3.9318 & 3.7876 & TRN & \\
\hline CHEMBL 3183682 & 1301793 & 3.9318 & 3.9234 & TRN & \\
\hline CHEMBL3182177 & 1301793 & 3.9318 & 3.9111 & TRN & \\
\hline CHEMBL3185831 & 1301793 & 3.9318 & 3.786 & TRN & \\
\hline CHEMBL3186429 & 1301793 & 3.9318 & 3.4321 & TRN & \\
\hline CHEMBL3185694 & 1301793 & 3.9318 & 4.1569 & TRN & \\
\hline CHEMBL 3185857 & 1301793 & 3.9318 & 4.3707 & TRN & \\
\hline CHEMBL3182383 & 1301793 & 3.9318 & 3.7074 & TRN & \\
\hline CHEMBL 3185423 & 1301793 & 6.7545 & 6.0743 & TRN & \\
\hline CHEMBL 3187517 & 1301793 & 3.9318 & 4.7116 & TST & \\
\hline CHEMBL3184611 & 1301793 & 3.9318 & \multicolumn{2}{|c|}{4.0889999999999995} & TRN \\
\hline CHEMBL 3184558 & 1301793 & 3.9318 & 4.1715 & TRN & \\
\hline CHEMBL 3183804 & 1301793 & 3.9318 & 4.2536 & TST & \\
\hline CHEMBL 3184327 & 1301793 & 3.9318 & 5.5466 & TRN & \\
\hline CHEMBL3186785 & 1301793 & 3.9318 & 3.8263 & TRN & \\
\hline CHEMBL3183417 & 1301793 & 3.9318 & 4.1056 & TRN & \\
\hline CHEMBL3182966 & 1301793 & 3.9318 & 3.9212 & TRN & \\
\hline CHEMBL3186180 & 1301793 & 3.9318 & \multicolumn{2}{|c|}{3.6639999999999997} & TST \\
\hline CHEMBL 3186748 & 1301793 & 3.9318 & 4.916 & TST & \\
\hline CHEMBL3183966 & 1301793 & 3.9318 & 3.9486 & TST & \\
\hline CHEMBL 3182557 & 1301793 & 3.9318 & 4.7302 & TRN & \\
\hline CHEMBL3182163 & 1301793 & 3.9318 & 4.0003 & TRN & \\
\hline CHEMBL 3187538 & 1301793 & 3.9318 & 3.9159 & TRN & \\
\hline CHEMBL 3184277 & 1301793 & 3.9318 & 3.5682 & TRN & \\
\hline CHEMBL3182201 & 1301793 & 3.9318 & 4.072 & TRN & \\
\hline CHEMBL 3182548 & 1301793 & 3.9318 & 4.6106 & TST & \\
\hline CHEMBL3186476 & 1301793 & 3.9318 & 4.3443 & TRN & \\
\hline CHEMBL 3182255 & 1301793 & 3.9318 & 2.5765 & TST & \\
\hline CHEMBL1583316 & 1301793 & 3.9318 & 3.7482 & TRN & \\
\hline CHEMBL3187752 & 1301793 & 3.9318 & \multicolumn{2}{|c|}{3.8289999999999997} & TRN \\
\hline CHEMBL 3187107 & 1301793 & 3.9318 & 3.5578 & TST & \\
\hline CHEMBL1523428 & 1301793 & 6.1965 & 4.0837 & TST & \\
\hline CHEMBL3189013 & 1301793 & 3.9318 & 3.9457 & TRN & \\
\hline CHEMBL 3188207 & 1301793 & 3.9318 & 3.9021 & TRN & \\
\hline CHEMBL3182703 & 1301793 & 3.9318 & 3.7544 & TRN & \\
\hline CHEMBL3185613 & 1301793 & 6.2549 & 5.4992 & TST & \\
\hline
\end{tabular}


Supplemental Table S2.txt

\begin{tabular}{|c|c|c|c|c|}
\hline HEMBL3185202 & L301793 & 3.9318 & 3.7945 & TRN \\
\hline CHEMBL3184876 & 301793 & 7.1302 & 5.1081 & TRN \\
\hline HEMBL1438842 & 301793 & 7.4225 & 1175 & TST \\
\hline HEMBL 3188754 & 301793 & 3.9318 & 3.7026 & ST \\
\hline HEMBL3183962 & 301793 & 3.9318 & .2864 & $\mathrm{~T}$ \\
\hline HEMBL3187814 & 301793 & 3.9318 & 4.2042 & ST \\
\hline HEMBL3186610 & 301793 & 3.9318 & 4.8846 & RN \\
\hline AEMBL3188640 & 301793 & 3.9318 & 4.2651 & ST \\
\hline HEMBL3185558 & 301793 & 3.9318 & 3.5676 & RN \\
\hline HEMBL293498 & 28212 & 7.47 & 7.3175 & $\mathrm{RN}$ \\
\hline HEMBL58119 & 28212 & 8.24 & 8.2256 & $\mathrm{RN}$ \\
\hline HEMBL351433 & 28212 & 3 & 8.2894 & RN \\
\hline HEMBL433931 & 28212 & 47 & 7.4838 & RN \\
\hline HEMBL423825 & 628212 & 7.02 & 7.0517 & RN \\
\hline HEMBL 293271 & 28212 & 5.94 & 5.8986 & TRN \\
\hline HEMBL58506 & 28212 & 7.25 & 7.2788 & TRN \\
\hline HEMBL58453 & 628212 & 6.73 & 6.7346 & RN \\
\hline HEMBL167287 & 628212 & & 5.2223 & $\mathrm{RN}$ \\
\hline HEMBL58952 & 628212 & 7.33 & 7.2826 & TRN \\
\hline HEMBL354989 & 28212 & & 8.5485 & TRN \\
\hline HEMBL167851 & 28212 & 7.06 & 6.9687 & TRN \\
\hline HEMBL352425 & 28212 & 7.32 & 7.3779 & RN \\
\hline HEMBL 298626 & 28212 & 6.36 & 6.3025 & $\mathrm{RN}$ \\
\hline HEMBL58811 & 628212 & 7.53 & 7.5975 & TRN \\
\hline HEMBL 58493 & 282 & & 6.1582 & TRN \\
\hline HEMBL59279 & 28212 & 7.87 & 7.7459 & TRN \\
\hline CHEMBL291565 & 28212 & 48 & 4.5465 & TRN \\
\hline HEMBL164233 & 28212 & 3.07 & 3.0379 & TRN \\
\hline IEMBL349465 & 628212 & 5.18 & 5.1769 & TRN \\
\hline HEMBL165335 & 28212 & & 4.2096 & TRN \\
\hline CHEMBL167459 & 628212 & 5 & 5.1701 & TRN \\
\hline CHEMBL352555 & 628212 & & 3.7962 & TRN \\
\hline CHEMBL60982 & 28212 & 5.61 & 5.5674 & TRN \\
\hline CHEMBL59131 & 628212 & 7.6 & 7.7333 & TST \\
\hline HEMBL 59160 & 628212 & 5.23 & 6.0437 & TST \\
\hline HEMBL291319 & 628212 & & 7.1541 & TST \\
\hline CHEMBL16 & 628212 & 5.18 & 5.8034 & TST \\
\hline CHEMBL293814 & 628212 & 7.6 & 7.689 & TST \\
\hline CHEMBL432516 & 628212 & 5.97 & 7.2303 & TST \\
\hline CHEMBL353986 & 28212 & & 4.1342 & TRN \\
\hline CHEMBL1099270 & 628212 & 3.07 & 3.0751 & TRN \\
\hline CHEMBL1095240 & 628212 & 3.24 & 3.2035 & TRN \\
\hline CHEMBL1099292 & 628212 & 3.97 & 3.9784 & TRN \\
\hline CHEMBL1099293 & 628212 & 4.3 & 4.3343 & TRN \\
\hline CHEMBL1094610 & 628212 & 4.36 & 4.3751 & TRN \\
\hline CHEMBL520711 & 628212 & 4 & 3.9898 & TRN \\
\hline CHEMBL292197 & 628212 & 4.9 & 5.6965 & TST \\
\hline CHEMBL1098926 & 628212 & 4.21 & 4.1775 & TRN \\
\hline
\end{tabular}

Page 28330 


\begin{tabular}{|c|c|c|c|c|c|}
\hline & & \multicolumn{4}{|c|}{ Supplemental Table S2.txt } \\
\hline CHEMBL1095586 & 628212 & 4.54 & 4.5112 & TRN & \\
\hline CHEMBL1095567 & 628212 & 4.43 & 4.4307 & TRN & \\
\hline CHEMBL1095587 & 628212 & 3.91 & 3.9063 & TRN & \\
\hline CHEMBL1096911 & 628212 & 4.15 & 4.1476 & TRN & \\
\hline CHEMBL420367 & 628212 & 7.34 & 7.3182 & TRN & \\
\hline CHEMBL69674 & 628212 & 6.8 & 6.785 & TRN & \\
\hline CHEMBL348749 & 628212 & 4.64 & 3.8277 & TST & \\
\hline CHEMBL68175 & 628212 & 4.5 & 3.9547 & TST & \\
\hline CHEMBL 308222 & 628212 & 6.17 & 5.8635 & TST & \\
\hline CHEMBL66704 & 628212 & 5.66 & 5.423999 & 99999999995 & TST \\
\hline CHEMBL163883 & 628212 & 4.13 & 4.2443 & TST & \\
\hline CHEMBL69775 & 628212 & 4.9 & 4.6355 & TST & \\
\hline CHEMBL304317 & 628212 & 4.32 & 3.8175 & TST & \\
\hline CHEMBL69517 & 628212 & 4.92 & 5.0011 & TRN & \\
\hline CHEMBL420740 & 628212 & 6.84 & 6.7251 & TRN & \\
\hline CHEMBL307994 & 628212 & 6.8 & 6.8687 & TRN & \\
\hline CHEMBL65800 & 628212 & 5.61 & 5.6271 & TRN & \\
\hline CHEMBL65881 & 628212 & 7.11 & 7.0173 & TRN & \\
\hline CHEMBL66155 & 628212 & 7.92 & 8.0331 & TRN & \\
\hline CHEMBL304294 & 628212 & 7.64 & 7.5996 & TRN & \\
\hline CHEMBL1094595 & 628212 & 4.25 & 4.1696 & TST & \\
\hline CHEMBL1094596 & 628212 & 5.65 & 5.5905 & TST & \\
\hline CHEMBL1096897 & 628212 & 4.87 & 4.8733 & TST & \\
\hline CHEMBL165976 & 628212 & 6.64 & 6.5611 & TRN & \\
\hline CHEMBL164075 & 628212 & 6.32 & 6.3884 & TRN & \\
\hline CHEMBL82396 & 628212 & 6.74 & 6.9286 & TRN & \\
\hline CHEMBL67451 & 628212 & 5.78 & 5.8343 & TRN & \\
\hline CHEMBL3601113 & 1509385 & 5.1574 & 5.3265 & TRN & \\
\hline CHEMBL 3601710 & 1509385 & 5.1118 & 4.9325 & TRN & \\
\hline CHEMBL 3601714 & 1509385 & 4.9255 & 5.1138 & TRN & \\
\hline CHEMBL3601117 & 1509385 & 5.0419 & 5.1007 & TRN & \\
\hline CHEMBL 3601223 & 1509385 & 5.4957 & 5.4961 & TRN & \\
\hline CHEMBL3601127 & 1509385 & 5.6334 & 5.5914 & TRN & \\
\hline CHEMBL3601234 & 1509385 & 3.301 & 3.4246 & TRN & \\
\hline CHEMBL3601724 & 1509385 & 3.301 & 4.3332 & TST & \\
\hline CHEMBL3601107 & 1509385 & 5.4998 & 5.5159 & TRN & \\
\hline CHEMBL 3601120 & 1509385 & 5.1441 & 5.1626 & TRN & \\
\hline CHEMBL 3601861 & 1509385 & 5.2752 & 5.1744 & TRN & \\
\hline CHEMBL 3601224 & 1509385 & 5.2094 & 5.3415 & TRN & \\
\hline CHEMBL3601712 & 1509385 & 5.4123 & 5.4752 & TRN & \\
\hline CHEMBL3601123 & 1509385 & 5.0077 & 4.5129 & TRN & \\
\hline CHEMBL3601232 & 1509385 & 5.5361 & 5.0391 & TRN & \\
\hline CHEMBL3601236 & 1509385 & 5.4828 & 5.136 & TRN & \\
\hline CHEMBL3601715 & 1509385 & 5.5222 & 5.5211 & TRN & \\
\hline CHEMBL 3601230 & 1509385 & 5.2232 & 5.4337 & TRN & \\
\hline CHEMBL3601106 & 1509385 & 5.4828 & 5.5887 & TRN & \\
\hline CHEMBL3601709 & 1509385 & 5.21899 & 999999999 & 5.2945 & TRN \\
\hline CHEMBL3601231 & 1509385 & 5.4313 & 5.2556 & TRN & \\
\hline
\end{tabular}


Supplemental Table S2.txt

\begin{tabular}{|c|c|c|c|c|c|}
\hline CHEMBL3600393 & 1509385 & 5.5566 & 5.5182 & TRN & \\
\hline CHEMBL3601238 & 1509385 & 5.5352 & 5.0447 & TRN & \\
\hline CHEMBL3601722 & 1509385 & 4.5244 & 4.7791 & TST & \\
\hline CHEMBL3601111 & 1509385 & 5.206 & 5.0465 & TRN & \\
\hline CHEMBL3601229 & 1509385 & 5.5711 & 5.7627 & TRN & \\
\hline CHEMBL3601239 & 1509385 & 4.5119 & 4.7483 & TST & \\
\hline CHEMBL3601243 & 1509385 & 5.0712 & 5.077 & TRN & \\
\hline CHEMBL 3601704 & 1509385 & 5.3014 & 5.4277 & TRN & \\
\hline CHEMBL3601118 & 1509385 & 3.301 & 4.2027 & TRN & \\
\hline CHEMBL3601707 & 1509385 & 4.9948 & 4.7233 & TRN & \\
\hline CHEMBL3601711 & 1509385 & 5.5085 & 5.5834 & TRN & \\
\hline CHEMBL3601237 & 1509385 & 5.3644 & 5.1771 & TRN & \\
\hline CHEMBL3601705 & 1509385 & 6.0585 & 5.9768 & TRN & \\
\hline CHEMBL 3601114 & 1509385 & 5.1912 & 5.1876 & TRN & \\
\hline CHEMBL3601108 & 1509385 & 5.5588 & 5.2068 & TRN & \\
\hline CHEMBL3601706 & 1509385 & 5.3249 & 5.8347 & TRN & \\
\hline CHEMBL3601109 & 1509385 & 3.301 & 3.4258 & TRN & \\
\hline CHEMBL3601119 & 1509385 & 5.0411 & 5.2587 & TRN & \\
\hline CHEMBL3601727 & 1509385 & 5.0758 & 5.0425 & TST & \\
\hline CHEMBL3601235 & 1509385 & 3.301 & 3.5815 & TRN & \\
\hline CHEMBL3601242 & 1509385 & 5.4114 & 5.5783 & TRN & \\
\hline CHEMBL3601112 & 1509385 & 4.71 & 4.8988 & TRN & \\
\hline CHEMBL3601121 & 1509385 & 5.1375 & 5.1538 & TRN & \\
\hline CHEMBL3601116 & 1509385 & 5.2068 & 5.04899 & 79999999995 & TRN \\
\hline CHEMBL 3601728 & 1509385 & 5.2237 & 5.3186 & TRN & \\
\hline CHEMBL3601122 & 1509385 & 5.029 & 5.1244 & TRN & \\
\hline CHEMBL3601713 & 1509385 & 5.3728 & 5.3621 & TST & \\
\hline CHEMBL3601725 & 1509385 & 5.3929 & 5.3604 & TST & \\
\hline CHEMBL3601115 & 1509385 & 4.5068 & 4.0624 & TRN & \\
\hline CHEMBL 3601718 & 1509385 & 5.3879 & 5.3316 & TRN & \\
\hline CHEMBL3601708 & 1509385 & 5.2538 & 5.1771 & TRN & \\
\hline CHEMBL3601233 & 1509385 & 5.0416 & 4.7086 & TST & \\
\hline CHEMBL3601726 & 1509385 & 5.1721 & 5.0811 & TST & \\
\hline CHEMBL3601228 & 1509385 & 6.1599 & 6.1017 & TST & \\
\hline CHEMBL3601110 & 1509385 & 4.5578 & 4.7271 & TST & \\
\hline CHEMBL3601244 & 1509385 & 5.3987 & 5.3867 & TST & \\
\hline CHEMBL 3601716 & 1509385 & 5.6151 & 5.3612 & TST & \\
\hline CHEMBL3601125 & 1509385 & 4.7635 & 5.0617 & TST & \\
\hline CHEMBL3601226 & 1509385 & 5.9944 & 5.8763 & TST & \\
\hline CHEMBL3601723 & 1509385 & 5.5634 & 5.3364 & TST & \\
\hline CHEMBL 3601227 & 1509385 & 6.0031 & 5.99700 & 0000000001 & TST \\
\hline CHEMBL399530 & 954869 & 5.2986 & 4.8531 & TRN & \\
\hline CHEMBL 2137530 & 954869 & 4.8245 & 4.9373 & TRN & \\
\hline CHEMBL135561 & 954869 & 4.8561 & 4.6505 & TRN & \\
\hline CHEMBL1643959 & 954869 & 3.2616 & 3.3022 & TRN & \\
\hline CHEMBL1909414 & 954869 & 3.4408 & 3.3318 & TRN & \\
\hline CHEMBL189584 & 954869 & 4.3638 & 4.6743 & TRN & \\
\hline CHEMBL92309 & 954869 & 3.6161 & 2.8967 & TST & \\
\hline
\end{tabular}


Supplemental Table S2.txt

\begin{tabular}{|c|c|c|c|c|c|}
\hline CHEMBL 222102 & 954869 & 4.5762 & 4.3523 & TRN & \\
\hline CHEMBL585951 & 954869 & 6.5197 & 6.5129 & TRN & \\
\hline CHEMBL515416 & 954869 & 4.1097 & 4.2235 & TRN & \\
\hline CHEMBL 2144069 & 954869 & 4.0627 & 3.9355 & TRN & \\
\hline CHEMBL 3392440 & 954869 & 3.761 & 3.7339 & TRN & \\
\hline CHEMBL191334 & 954869 & 3.8895 & 3.7919 & TRN & \\
\hline CHEMBL3199475 & 954869 & 3.7911 & 4.3908 & TRN & \\
\hline CHEMBL217354 & 954869 & 6.522 & 6.5559 & TRN & \\
\hline CHEMBL 258844 & 954869 & 4.3035 & 4.3116 & TRN & \\
\hline CHEMBL514499 & 954869 & 7.9104 & 7.5225 & TRN & \\
\hline CHEMBL 373751 & 954869 & 3.2165 & 3.6884 & TRN & \\
\hline CHEMBL393929 & 954869 & 4.4068 & 4.2393 & TRN & \\
\hline CHEMBL483847 & 954869 & 4.593 & 4.3806 & TRN & \\
\hline CHEMBL 255342 & 954869 & 3.4343 & 3.792 & TRN & \\
\hline CHEMBL1516890 & 954869 & 3.8479 & 4.0353 & TRN & \\
\hline CHEMBL1230020 & 954869 & 3.3826 & 3.3845 & TRN & \\
\hline CHEMBL 202721 & 954869 & 5.1901 & 5.4852 & TRN & \\
\hline CHEMBL1357247 & 954869 & 3.1598 & 3.0515 & TRN & \\
\hline CHEMBL1242367 & 954869 & 4.6951 & 4.2007 & TRN & \\
\hline CHEMBL240954 & 954869 & 3.375 & 3.6979 & TST & \\
\hline CHEMBL 2134202 & 954869 & 4.2175 & 4.6549 & TRN & \\
\hline CHEMBL1788116 & 954869 & 4.8187 & 4.4007 & TRN & \\
\hline CHEMBL1673039 & 954869 & 4.3859 & 4.4873 & TRN & \\
\hline CHEMBL1186585 & 954869 & 4.9764 & 5.1408 & TRN & \\
\hline CHEMBL577784 & 954869 & 5.7221 & 5.7805 & TRN & \\
\hline CHEMBL1190711 & 954869 & 4.2079 & 4.6951 & TRN & \\
\hline CHEMBL192566 & 954869 & 7.9129 & 8.0617 & TST & \\
\hline CHEMBL483849 & 954869 & 2.0185 & 2.2397 & TST & \\
\hline CHEMBL1256459 & 954869 & 6.9619 & 7.2381 & TRN & \\
\hline CHEMBL3349342 & 954869 & 4.9761 & 4.4111 & TRN & \\
\hline CHEMBL1590308 & 954869 & 2.705 & 3.3913 & TST & \\
\hline CHEMBL 2005886 & 954869 & \multicolumn{2}{|c|}{5.111000000000001} & 4.8884 & TRN \\
\hline CHEMBL180127 & 954869 & 4.61 & 4.5772 & TRN & \\
\hline CHEMBL9470 & 954869 & 6.4616 & 5.7684 & TST & \\
\hline CHEMBL1970879 & 954869 & 3.6697 & 3.7348 & TRN & \\
\hline CHEMBL1404918 & 954869 & 3.2797 & 3.0477 & TRN & \\
\hline CHEMBL392695 & 954869 & 6.5453 & 5.7555 & TRN & \\
\hline CHEMBL300389 & 954869 & 7.2294 & 7.2416 & TRN & \\
\hline CHEMBL573107 & 954869 & 5.4253 & 5.4748 & TRN & \\
\hline CHEMBL 3186408 & 954869 & 3.3823 & 3.7675 & TST & \\
\hline CHEMBL220241 & 954869 & 5.7948 & 5.4846 & TRN & \\
\hline CHEMBL 379975 & 954869 & 4.8817 & 5.1443 & TRN & \\
\hline CHEMBL102714 & 954869 & 3.3093 & 3.3585 & TRN & \\
\hline CHEMBL188678 & 954869 & 4.9098 & 5.0334 & TRN & \\
\hline CHEMBL512504 & 954869 & 4.4988 & 4.8734 & TRN & \\
\hline CHEMBL509032 & 954869 & 5.6198 & $5.10800 t$ & 00000000005 & TRN \\
\hline CHEMBL210618 & 954869 & 3.3233 & 3.407 & TRN & \\
\hline CHEMBL 379300 & 954869 & 5.5025 & 6.1192 & TRN & \\
\hline
\end{tabular}

Page 28333 


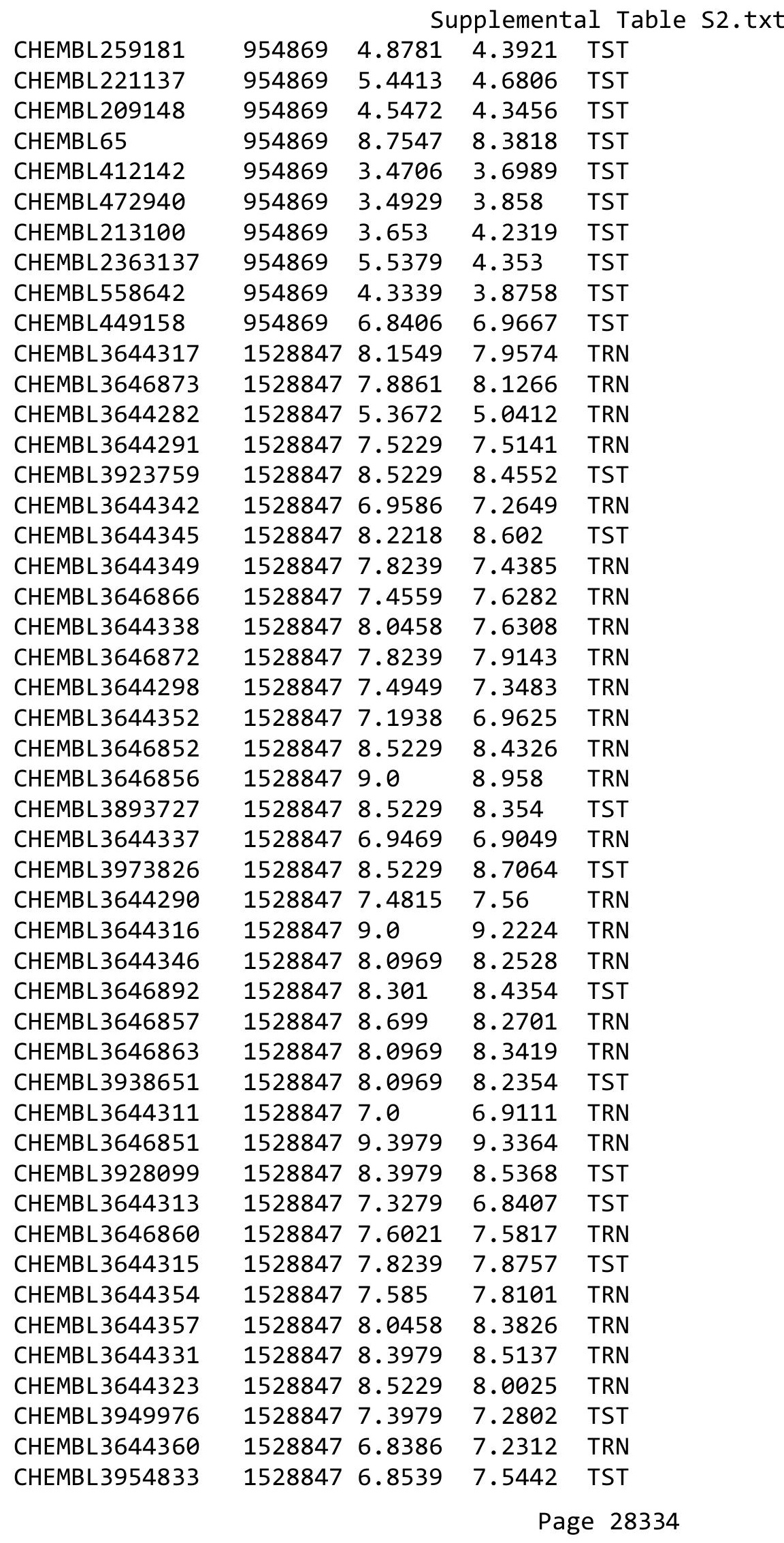


Supplemental Table S2.txt

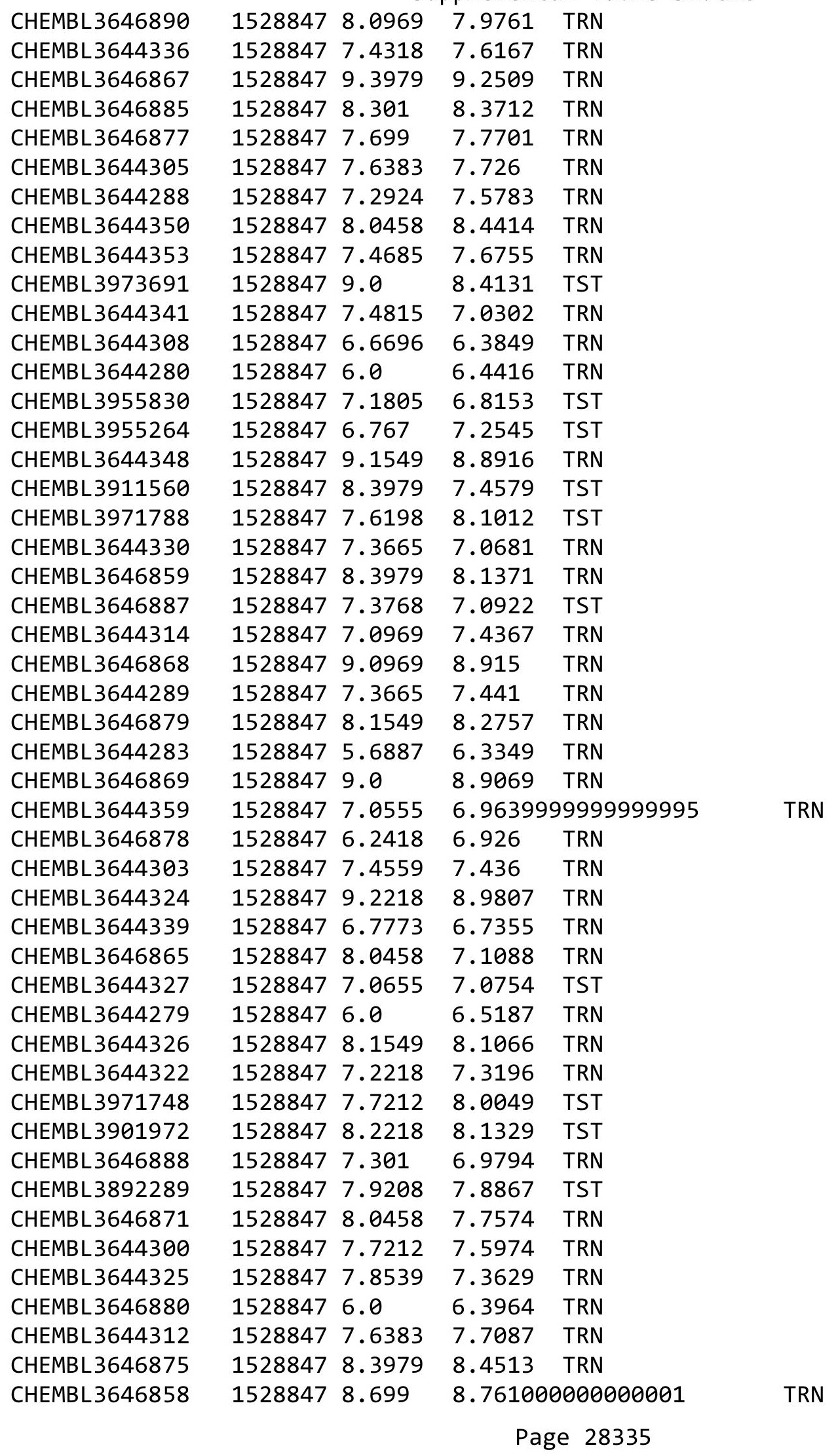


Supplemental Table S2.txt

\begin{tabular}{|c|c|c|c|c|c|}
\hline CHEMBL3644294 & 1528847 & 7.6383 & 7.7288 & TRN & \\
\hline CHEMBL3644320 & 1528847 & 6.0 & 6.445 & TRN & \\
\hline CHEMBL3646884 & 1528847 & 6.0 & 6.5439 & TRN & \\
\hline CHEMBL3955282 & 1528847 & 9.1549 & 9.0854 & TST & \\
\hline CHEMBL3644351 & 1528847 & 8.2218 & 8.272 & TRN & \\
\hline CHEMBL3646861 & 1528847 & 7.4559 & 7.8796 & TRN & \\
\hline CHEMBL3644296 & 1528847 & 8.5229 & 8.2045 & TRN & \\
\hline CHEMBL3644306 & 1528847 & 7.8239 & 7.8888 & TRN & \\
\hline CHEMBL3646881 & 1528847 & 8.3979 & 8.1851 & TRN & \\
\hline CHEMBL3901055 & 1528847 & 6.0 & 8.1383 & TST & \\
\hline CHEMBL3644285 & 1528847 & 5.5291 & 5.7654 & TRN & \\
\hline CHEMBL3646874 & 1528847 & 7.3468 & 7.5968 & TRN & \\
\hline CHEMBL3644307 & 1528847 & 7.5229 & 7.7355 & TRN & \\
\hline CHEMBL 3646864 & 1528847 & 7.5229 & 8.0172 & TST & \\
\hline CHEMBL3644355 & 1528847 & 8.2218 & 8.7614 & TRN & \\
\hline CHEMBL3646891 & 1528847 & 8.2218 & 7.9201 & TRN & \\
\hline CHEMBL3646850 & 1528847 & 7.7212 & 7.1627 & TRN & \\
\hline CHEMBL 3646870 & 1528847 & 8.699 & 8.8091 & TRN & \\
\hline CHEMBL3646889 & 1528847 & 8.3979 & 8.1335 & TRN & \\
\hline CHEMBL3644340 & 1528847 & 6.7352 & 6.8925 & TRN & \\
\hline CHEMBL3644297 & 1528847 & 8.3979 & 7.5783 & TRN & \\
\hline CHEMBL3646883 & 1528847 & 6.4377 & 7.5051 & TST & \\
\hline CHEMBL3900116 & 1528847 & 8.301 & 8.3811 & TST & \\
\hline CHEMBL3644286 & 1528847 & 5.5203 & 5.2464 & TRN & \\
\hline CHEMBL3644284 & 1528847 & 6.2733 & 5.796 & TRN & \\
\hline CHEMBL3644332 & 1528847 & 7.9208 & 8.345 & TRN & \\
\hline CHEMBL3644356 & 1528847 & 9.0 & 9.113 & TST & \\
\hline CHEMBL3644302 & 1528847 & 7.4318 & 7.5783 & TST & \\
\hline CHEMBL3644361 & 1528847 & 8.5229 & 8.2308 & TST & \\
\hline CHEMBL 2000340 & 737370 & 5.1085 & 4.7434 & TST & \\
\hline CHEMBL1491222 & 737370 & 4.8539 & 5.1793 & TRN & \\
\hline CHEMBL1350780 & 737370 & 4.9914 & 5.0043 & TRN & \\
\hline CHEMBL1479876 & 737370 & 4.7905 & 4.6422 & TST & \\
\hline CHEMBL1542039 & 737370 & 5.0414 & 4.453 & TRN & \\
\hline CHEMBL1568646 & 737370 & 5.1864 & \multicolumn{2}{|c|}{4.7589999999999995} & TRN \\
\hline CHEMBL1611543 & 737370 & 4.8894 & 4.6621 & TRN & \\
\hline CHEMBL1335224 & 737370 & 5.2 & 4.5196 & TRN & \\
\hline CHEMBL1991908 & 737370 & 4.7747 & 4.3159 & TRN & \\
\hline CHEMBL1505604 & 737370 & 5.1972 & 4.9446 & TRN & \\
\hline CHEMBL1522846 & 737370 & 5.0022 & 4.6458 & TST & \\
\hline CHEMBL3145282 & 737370 & 4.9245 & 4.4945 & TST & \\
\hline CHEMBL1580083 & 737370 & 5.8125 & 4.749 & TRN & \\
\hline CHEMBL1702699 & 737370 & 4.5986 & 4.5554 & TST & \\
\hline CHEMBL1424951 & 737370 & 5.0931 & 4.615 & TRN & \\
\hline CHEMBL1362566 & 737370 & 4.7747 & 4.9178 & TRN & \\
\hline CHEMBL319244 & 737370 & 6.0506 & 4.8153 & TRN & \\
\hline CHEMBL1534218 & 737370 & 3.0969 & 4.5427 & TRN & \\
\hline CHEMBL3193664 & 737370 & 5.1791 & 4.9471 & TRN & \\
\hline
\end{tabular}

Page 28336 


\begin{tabular}{|c|c|c|c|c|c|c|}
\hline & & \multicolumn{5}{|c|}{ Supplemental Table S2.txt } \\
\hline CHEMBL1607268 & 737370 & 4.4989 & 4.5308 & TRN & & \\
\hline CHEMBL1724535 & 737370 & 4.8894 & 4.8559 & TRN & & \\
\hline CHEMBL1567267 & 737370 & 4.4168 & 4.4255 & TRN & & \\
\hline CHEMBL1558863 & 737370 & 3.0969 & 4.4547 & TRN & & \\
\hline CHEMBL1531686 & 737370 & 3.0969 & 4.77 & TRN & & \\
\hline CHEMBL1537810 & 737370 & 6.041 & 4.7392 & TRN & & \\
\hline CHEMBL1564522 & 737370 & 5.1772 & 4.5127 & TRN & & \\
\hline CHEMBL1334904 & 737370 & 4.4295 & 4.7033 & TRN & & \\
\hline CHEMBL1613445 & 737370 & 5.1475 & 4.6736 & TST & & \\
\hline CHEMBL1969303 & 737370 & 5.1851 & 4.7645 & TRN & & \\
\hline CHEMBL1611796 & 737370 & 4.9281 & 4.8624 & TRN & & \\
\hline CHEMBL1516637 & 737370 & 4.9281 & 4.4617 & TRN & & \\
\hline CHEMBL1528581 & 737370 & 5.8729 & 5.1964 & TRN & & \\
\hline CHEMBL1400298 & 737370 & \multicolumn{3}{|c|}{5.0680000000000005} & 5.2523 & TRN \\
\hline CHEMBL1417692 & 737370 & 5.1169 & 4.5646 & TRN & & \\
\hline CHEMBL1600587 & 737370 & 4.7447 & 4.7442 & TRN & & \\
\hline CHEMBL1466340 & 737370 & 4.8041 & 4.6428 & TRN & & \\
\hline CHEMBL1417204 & 737370 & 5.0477 & 4.431 & TRN & & \\
\hline CHEMBL1594685 & 737370 & 5.3354 & 4.4998 & TRN & & \\
\hline CHEMBL1480798 & 737370 & 5.8069 & 4.9879 & TRN & & \\
\hline CHEMBL112597 & 737370 & \multicolumn{3}{|c|}{4.9830000000000005} & 5.0579 & TRN \\
\hline CHEMBL1346233 & 737370 & 3.0969 & 4.6788 & TRN & & \\
\hline CHEMBL190880 & 737370 & 4.8477 & 4.4332 & TRN & & \\
\hline CHEMBL1443448 & 737370 & 3.0969 & 4.6916 & TRN & & \\
\hline CHEMBL1372421 & 737370 & 3.0969 & 4.8894 & TRN & & \\
\hline CHEMBL1418103 & 737370 & 5.0079 & 4.5607 & TRN & & \\
\hline CHEMBL1590745 & 737370 & 4.7399 & 4.4886 & TRN & & \\
\hline CHEMBL1305642 & 737370 & 5.0227 & 4.8879 & TRN & & \\
\hline CHEMBL1309573 & 737370 & 5.1451 & 4.925 & TRN & & \\
\hline CHEMBL1376872 & 737370 & 4.3757 & 4.5331 & TRN & & \\
\hline CHEMBL3191811 & 737370 & 5.0066 & 4.7791 & TRN & & \\
\hline CHEMBL1324256 & 737370 & 5.0625 & 4.523 & TRN & & \\
\hline CHEMBL1986073 & 737370 & 5.0 & 4.84399 & 9999999999 & & TRN \\
\hline CHEMBL1360793 & 737370 & 4.9318 & 5.1409 & TRN & & \\
\hline CHEMBL1509327 & 737370 & 5.1487 & 4.7355 & TST & & \\
\hline CHEMBL1342156 & 737370 & 5.0128 & 4.9937 & TRN & & \\
\hline CHEMBL1465511 & 737370 & 3.0969 & 4.4751 & TRN & & \\
\hline CHEMBL1386649 & 737370 & 4.9208 & 4.2315 & TRN & & \\
\hline CHEMBL1492961 & 737370 & 5.3344 & 4.2331 & TRN & & \\
\hline CHEMBL1402909 & 737370 & 4.8125 & 4.6266 & TST & & \\
\hline CHEMBL1981677 & 737370 & 4.5214 & 4.6596 & TST & & \\
\hline CHEMBL1414009 & 737370 & 4.4191 & 4.5166 & TRN & & \\
\hline CHEMBL1483562 & 737370 & 3.0969 & 4.9905 & TRN & & \\
\hline CHEMBL3199006 & 737370 & 5.4389 & 4.7604 & TRN & & \\
\hline CHEMBL1535938 & 737370 & 4.9066 & 4.4331 & TRN & & \\
\hline CHEMBL1517763 & 737370 & 4.5735 & 4.6839 & TRN & & \\
\hline CHEMBL1499214 & 737370 & 5.1864 & 4.5795 & TST & & \\
\hline CHEMBL1499436 & 737370 & 4.8356 & 4.7006 & TRN & & \\
\hline
\end{tabular}


Supplemental Table S2.txt

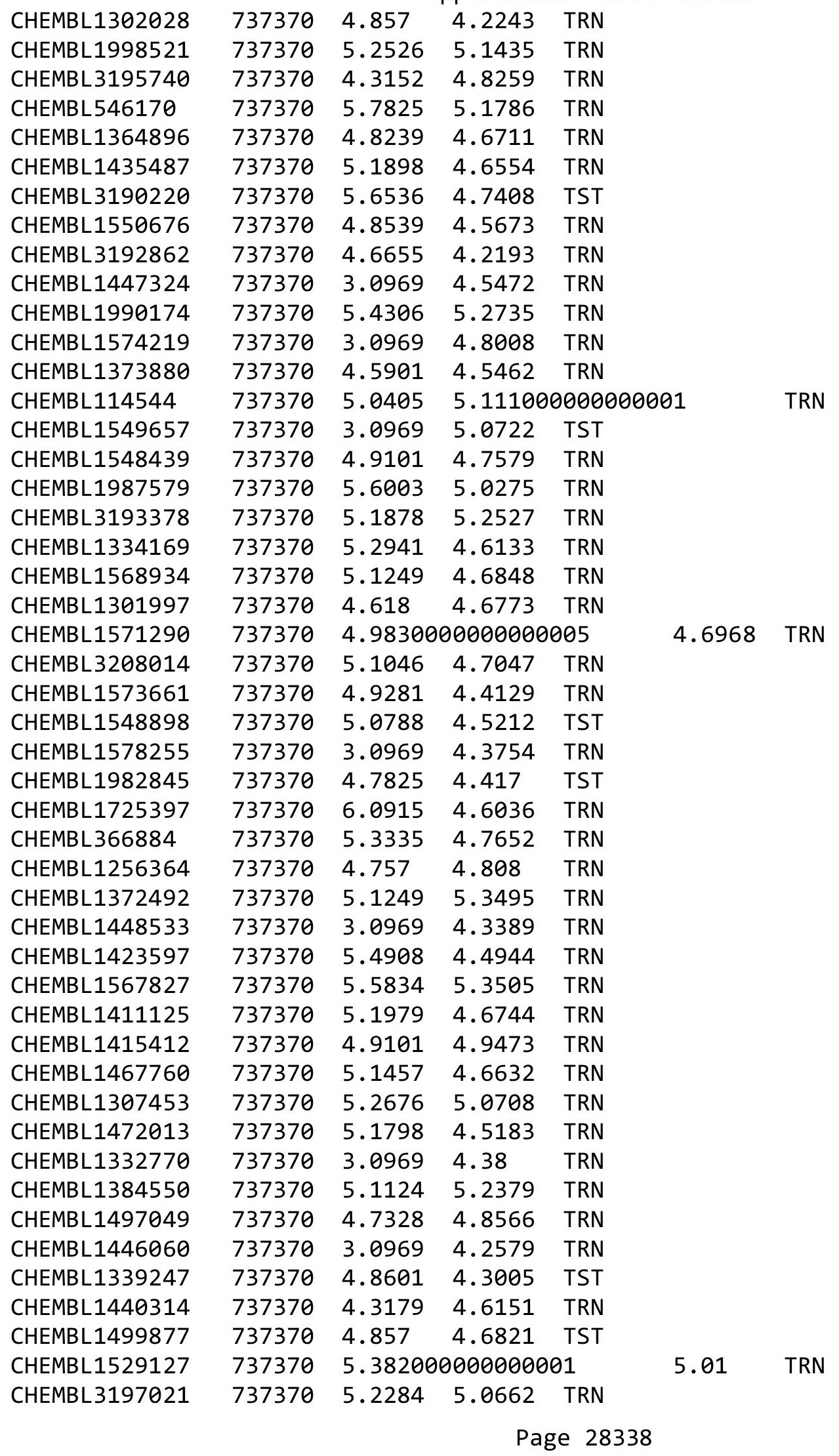


Supplemental Table S2.txt

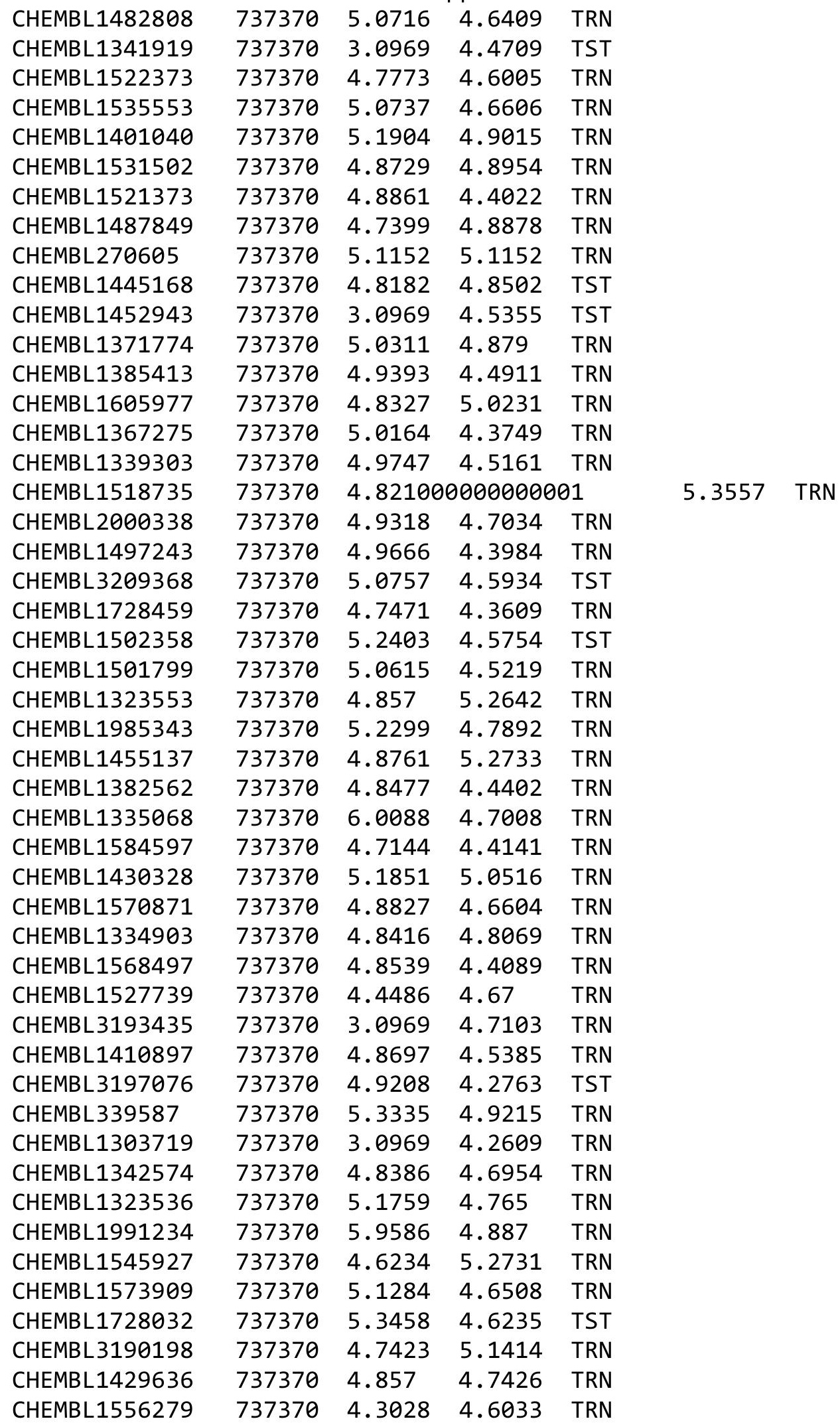

Page 28339 


\begin{tabular}{|c|c|c|c|c|c|}
\hline \multirow[b]{2}{*}{ CHEMBL1309018 } & \multicolumn{5}{|c|}{ Supplemental Table S2.txt } \\
\hline & 737370 & 4.2314 & 4.5857 & TRN & \\
\hline CHEMBL1366864 & 737370 & 4.6968 & 4.7593 & TRN & \\
\hline CHEMBL1533959 & 737370 & 4.9281 & 4.6111 & TRN & \\
\hline CHEMBL 3198576 & 737370 & 5.1284 & 5.0896 & TRN & \\
\hline CHEMBL1346860 & 737370 & 4.8894 & 4.4809 & TRN & \\
\hline CHEMBL1610463 & 737370 & 4.251 & 4.6788 & TRN & \\
\hline CHEMBL1547420 & 737370 & 5.2652 & 4.772 & TRN & \\
\hline CHEMBL1518291 & 737370 & 5.011 & 4.9192 & TRN & \\
\hline CHEMBL1964873 & 737370 & 5.1361 & 4.7536 & TRN & \\
\hline CHEMBL1509946 & 737370 & 3.0969 & 4.6414 & TST & \\
\hline CHEMBL1972435 & 737370 & 3.0969 & 4.2308 & TRN & \\
\hline CHEMBL 2002262 & 737370 & 3.0969 & 4.7639 & TRN & \\
\hline CHEMBL1515506 & 737370 & 5.0061 & 4.6553 & TRN & \\
\hline CHEMBL1539236 & 737370 & 3.0969 & 4.4052 & TRN & \\
\hline CHEMBL528694 & 737370 & 6.1938 & 5.2226 & TRN & \\
\hline CHEMBL1487635 & 737370 & 5.3556 & 5.2415 & TRN & \\
\hline CHEMBL1446802 & 737370 & 3.0969 & 4.7652 & TST & \\
\hline CHEMBL3190594 & 737370 & 5.3036 & 5.496 & TRN & \\
\hline CHEMBL1311956 & 737370 & 4.8996 & 4.5061 & TRN & \\
\hline CHEMBL1340619 & 737370 & 4.9666 & 5.0101 & TRN & \\
\hline CHEMBL1596903 & 737370 & 4.8962 & 4.9631 & TRN & \\
\hline CHEMBL1600326 & 737370 & 3.0969 & 4.6054 & TRN & \\
\hline CHEMBL 2004351 & 737370 & 3.0969 & 4.3273 & TRN & \\
\hline CHEMBL1525315 & 737370 & 5.1018 & 4.7923 & TRN & \\
\hline CHEMBL1444114 & 737370 & 5.8601 & 4.9314 & TRN & \\
\hline CHEMBL3209659 & 737370 & 5.0835 & 4.2672 & TRN & \\
\hline CHEMBL1377964 & 737370 & 5.2218 & 4.7042 & TRN & \\
\hline CHEMBL1440293 & 737370 & 5.4012 & 4.7517 & TST & \\
\hline CHEMBL1352760 & 737370 & 4.5544 & 4.9233 & TRN & \\
\hline CHEMBL3196363 & 737370 & 4.5607 & 4.8815 & TRN & \\
\hline CHEMBL1301453 & 737370 & 5.0991 & 5.2494 & TRN & \\
\hline CHEMBL548615 & 737370 & 5.0846 & 5.1439 & TRN & \\
\hline CHEMBL1487300 & 737370 & 5.1096 & 4.544 & TRN & \\
\hline CHEMBL1420031 & 737370 & 3.0969 & 4.4625 & TRN & \\
\hline CHEMBL3194477 & 737370 & 4.9101 & 4.9503 & TST & \\
\hline CHEMBL1504370 & 737370 & 3.0969 & 4.6242 & TST & \\
\hline CHEMBL 2003964 & 737370 & 5.9101 & 4.883 & TRN & \\
\hline CHEMBL1338033 & 737370 & 5.0691 & 4.3903 & TRN & \\
\hline CHEMBL 2094484 & 737370 & 5.4921 & 5.2163 & TRN & \\
\hline CHEMBL1310701 & 737370 & 3.0969 & 4.4734 & TRN & \\
\hline CHEMBL1312672 & 737370 & 3.0969 & 4.4063 & TRN & \\
\hline CHEMBL1578521 & 737370 & 4.8239 & 4.3864 & TRN & \\
\hline CHEMBL1485665 & 737370 & 4.8327 & 4.588 & TRN & \\
\hline CHEMBL1596226 & 737370 & 4.9586 & 4.42899 & 9999999999 & TST \\
\hline CHEMBL1573201 & 737370 & 4.757 & 4.6881 & TRN & \\
\hline CHEMBL1542861 & 737370 & 4.6091 & 4.438 & TRN & \\
\hline CHEMBL1519298 & 737370 & 3.0969 & 4.2082 & TRN & \\
\hline CHEMBL1872457 & 737370 & 4.8794 & 4.8405 & TRN & \\
\hline
\end{tabular}




\begin{tabular}{|c|c|c|c|c|c|c|}
\hline \multirow[b]{2}{*}{ CHEMBL1341741 } & & \multicolumn{5}{|c|}{ Supplemental Table S2.txt } \\
\hline & 737370 & 3.0969 & 4.3292 & TRN & & \\
\hline CHEMBL1347795 & 737370 & 4.82100 & 00000000 & $\partial 1$ & 4.5513 & TRN \\
\hline CHEMBL1547295 & 737370 & 3.0969 & 4.4246 & TST & & \\
\hline CHEMBL1308151 & 737370 & 4.6696 & 4.9619 & TRN & & \\
\hline CHEMBL1427430 & 737370 & 5.0297 & 4.3374 & TRN & & \\
\hline CHEMBL3193227 & 737370 & 4.9031 & 4.6251 & TRN & & \\
\hline CHEMBL1348169 & 737370 & 5.1618 & 4.9561 & TST & & \\
\hline CHEMBL1424746 & 737370 & 5.1349 & 4.40300 & 20000 & 005 & TRN \\
\hline CHEMBL1517511 & 737370 & 3.0969 & 4.7206 & TST & & \\
\hline CHEMBL1365235 & 737370 & 4.9666 & 4.7075 & TRN & & \\
\hline CHEMBL1379833 & 737370 & 3.0969 & 4.4257 & TRN & & \\
\hline CHEMBL3197092 & 737370 & 5.8794 & 5.157 & TRN & & \\
\hline CHEMBL1497982 & 737370 & 4.8633 & 4.5248 & TST & & \\
\hline CHEMBL1976317 & 737370 & 5.4868 & 4.9444 & TRN & & \\
\hline CHEMBL 3209000 & 737370 & 3.0969 & 4.8393 & TRN & & \\
\hline CHEMBL1998940 & 737370 & 4.7799 & 4.6942 & TST & & \\
\hline CHEMBL3192087 & 737370 & 3.0969 & 4.3414 & TRN & & \\
\hline CHEMBL1441619 & 737370 & 5.2857 & 4.6904 & TRN & & \\
\hline CHEMBL1392620 & 737370 & 5.1051 & 4.5872 & TRN & & \\
\hline CHEMBL1565662 & 737370 & 4.7721 & 4.7058 & TRN & & \\
\hline CHEMBL 2000686 & 737370 & 5.1169 & 5.0222 & TRN & & \\
\hline CHEMBL1528569 & 737370 & 5.2168 & 4.7435 & TRN & & \\
\hline CHEMBL1488192 & 737370 & 4.6556 & 4.5838 & TRN & & \\
\hline CHEMBL1390543 & 737370 & 4.3206 & 4.558 & TRN & & \\
\hline CHEMBL1425921 & 737370 & 5.1986 & 4.966 & TRN & & \\
\hline CHEMBL1558070 & 737370 & 5.1113 & 4.8154 & TST & & \\
\hline CHEMBL1527929 & 737370 & 5.0186 & 4.7356 & TST & & \\
\hline CHEMBL1535134 & 737370 & 5.1226 & 4.5601 & TRN & & \\
\hline CHEMBL1487938 & 737370 & 4.5129 & 4.6785 & TRN & & \\
\hline CHEMBL3208631 & 737370 & 5.2097 & 4.5375 & TRN & & \\
\hline CHEMBL1345877 & 737370 & 3.0969 & 4.4962 & TST & & \\
\hline CHEMBL 2000633 & 737370 & 5.27 & 5.1973 & TRN & & \\
\hline CHEMBL1323696 & 737370 & 4.8268 & 4.4358 & TRN & & \\
\hline CHEMBL1579210 & 737370 & 3.0969 & 4.4915 & TST & & \\
\hline CHEMBL1460748 & 737370 & 4.7773 & 4.801 & TRN & & \\
\hline CHEMBL1599458 & 737370 & 5.1343 & 4.9786 & TRN & & \\
\hline CHEMBL1563323 & 737370 & 4.4908 & 4.5783 & TRN & & \\
\hline CHEMBL1354031 & 737370 & 4.4437 & 4.2435 & TRN & & \\
\hline CHEMBL1988579 & 737370 & 3.0969 & 4.8189 & TST & & \\
\hline CHEMBL1348306 & 737370 & 5.34200 & 30000000 & 005 & 4.4855 & TST \\
\hline CHEMBL1474553 & 737370 & 4.2284 & 5.2288 & TRN & & \\
\hline CHEMBL1390785 & 737370 & 4.9318 & 4.6631 & TRN & & \\
\hline CHEMBL1716112 & 737370 & 4.98300 & 30000000 & 005 & 4.6892 & TST \\
\hline CHEMBL1463930 & 737370 & 4.4828 & 4.5137 & TRN & & \\
\hline CHEMBL1432815 & 737370 & 5.0278 & 4.2552 & TRN & & \\
\hline CHEMBL1337538 & 737370 & 4.8182 & 4.8424 & TRN & & \\
\hline CHEMBL1409219 & 737370 & 5.1129 & 4.5366 & TRN & & \\
\hline CHEMBL1466699 & 737370 & 5.3468 & 4.7307 & TRN & & \\
\hline
\end{tabular}


Supplemental Table S2.txt

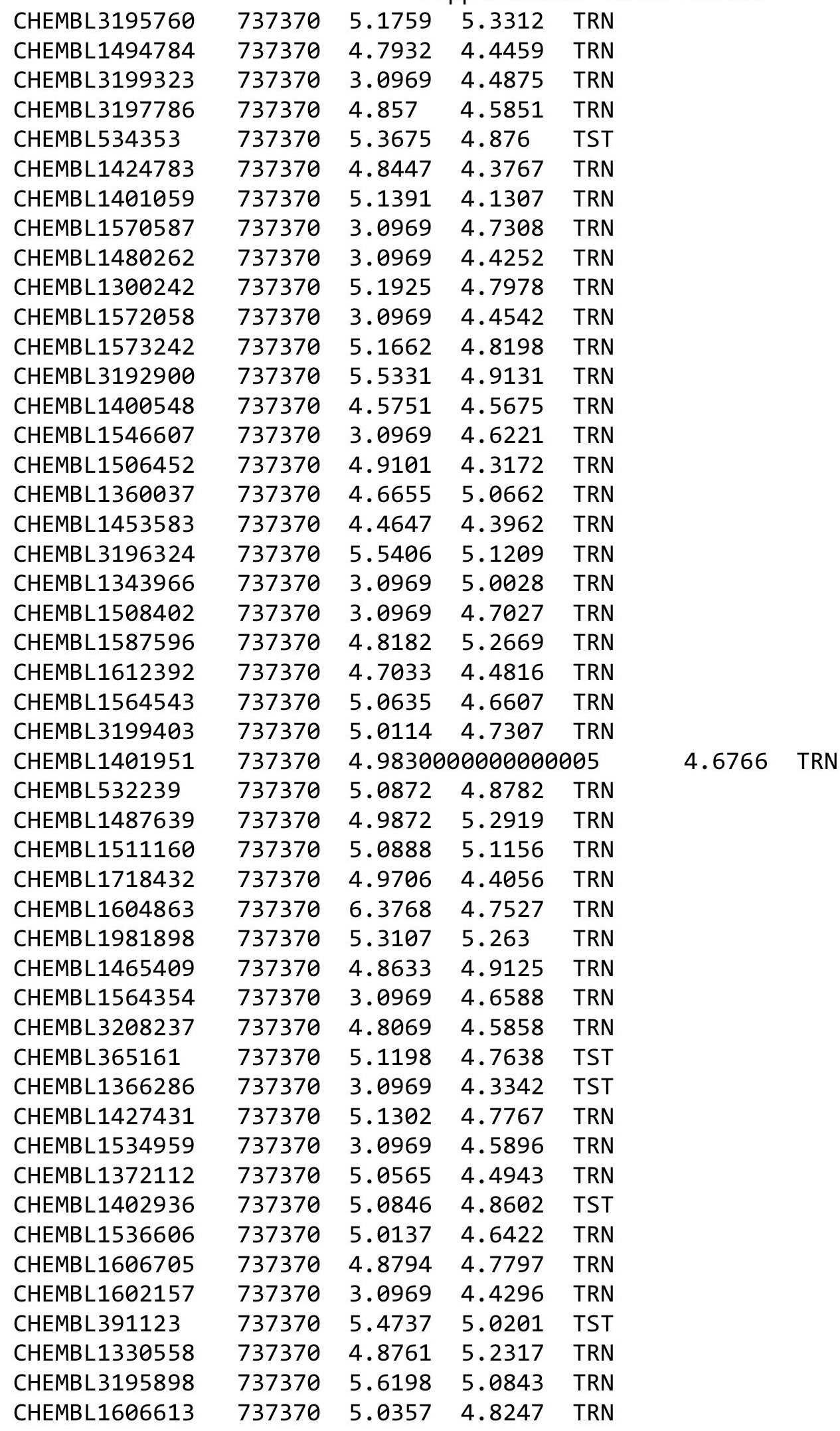

Page 28342 


\begin{tabular}{|c|c|c|c|c|}
\hline & & & oplement & al Ta \\
\hline CHEMBL1431928 & 737370 & 4.4498 & 4.8461 & TRN \\
\hline CHEMBL1469904 & 737370 & 5.2541 & 5.0119 & TRN \\
\hline CHEMBL1306267 & 737370 & 4.8327 & 5.0018 & TRN \\
\hline CHEMBL1604350 & 737370 & 3.0969 & 4.5095 & TRN \\
\hline CHEMBL1565444 & 737370 & 5.2269 & 5.3268 & TRN \\
\hline CHEMBL1333929 & 737370 & 5.0395 & 4.5474 & TRN \\
\hline CHEMBL3195564 & 737370 & 5.0269 & 4.9177 & TRN \\
\hline CHEMBL1577986 & 737370 & 4.9066 & 4.6864 & TST \\
\hline CHEMBL1396209 & 737370 & 5.3307 & 4.4752 & TST \\
\hline CHEMBL1538474 & 737370 & 3.0969 & 4.2906 & TST \\
\hline CHEMBL1504035 & 737370 & 3.0969 & 4.2444 & TRN \\
\hline CHEMBL1996281 & 737370 & 4.9957 & 4.5495 & TRN \\
\hline CHEMBL1309127 & 737370 & 5.2013 & 5.1174 & TRN \\
\hline CHEMBL3189151 & 737370 & 3.0969 & 4.9357 & TRN \\
\hline CHEMBL1447391 & 737370 & 4.9393 & 4.7995 & TST \\
\hline CHEMBL3209511 & 737370 & 4.7352 & 4.5916 & TST \\
\hline CHEMBL3192206 & 737370 & 4.4401 & 4.7107 & TRN \\
\hline CHEMBL1544633 & 737370 & 5.6055 & 5.1209 & TRN \\
\hline CHEMBL1319676 & 737370 & 5.0825 & 4.8244 & TRN \\
\hline CHEMBL1979957 & 737370 & 4.3152 & 4.7624 & TRN \\
\hline CHEMBL1333386 & 737370 & 5.1656 & 5.1206 & TRN \\
\hline CHEMBL1419335 & 737370 & 5.8097 & 4.7703 & TRN \\
\hline CHEMBL1403085 & 737370 & 3.0969 & 4.6634 & TRN \\
\hline CHEMBL1985582 & 737370 & 4.9101 & 4.4309 & TRN \\
\hline CHEMBL1341560 & 737370 & 4.9957 & 4.6445 & TRN \\
\hline CHEMBL455284 & 737370 & 5.6021 & 5.2537 & TRN \\
\hline CHEMBL3192616 & 737370 & 5.2967 & 4.978 & TRN \\
\hline CHEMBL3193533 & 737370 & 5.0635 & 4.5302 & TRN \\
\hline CHEMBL1538775 & 737370 & 4.6271 & 4.4773 & TRN \\
\hline CHEMBL1608985 & 737370 & 4.9547 & 4.9346 & TRN \\
\hline CHEMBL1541379 & 737370 & 3.0969 & 4.5932 & TRN \\
\hline CHEMBL1382870 & 737370 & 4.2832 & 4.4182 & TRN \\
\hline CHEMBL1362565 & 737370 & 5.1079 & 4.5212 & TST \\
\hline CHEMBL1563766 & 737370 & 4.5969 & 5.0371 & TRN \\
\hline CHEMBL3212519 & 737370 & 5.015 & 4.6398 & TRN \\
\hline CHEMBL428064 & 737370 & 5.466 & 5.0562 & TRN \\
\hline CHEMBL586602 & 737370 & 4.9469 & 4.5068 & TST \\
\hline CHEMBL1431684 & 737370 & 3.0969 & 4.3766 & TRN \\
\hline CHEMBL1984876 & 737370 & 5.6271 & 5.1428 & TRN \\
\hline CHEMBL1369124 & 737370 & 5.1409 & 4.3348 & TRN \\
\hline CHEMBL586937 & 737370 & 4.9788 & 4.9624 & TRN \\
\hline CHEMBL1565623 & 737370 & 4.9066 & 4.3943 & TRN \\
\hline CHEMBL1328473 & 737370 & 5.2907 & 4.8192 & TRN \\
\hline CHEMBL1430673 & 737370 & 5.1965 & 4.5301 & TRN \\
\hline CHEMBL1299997 & 737370 & 5.0106 & 4.6727 & TRN \\
\hline CHEMBL1389886 & 737370 & 4.8996 & 4.567 & TRN \\
\hline CHEMBL1400005 & 737370 & 4.9747 & 4.6513 & TRN \\
\hline CHEMBL3209440 & 737370 & 4.3925 & 4.2855 & TRN \\
\hline
\end{tabular}




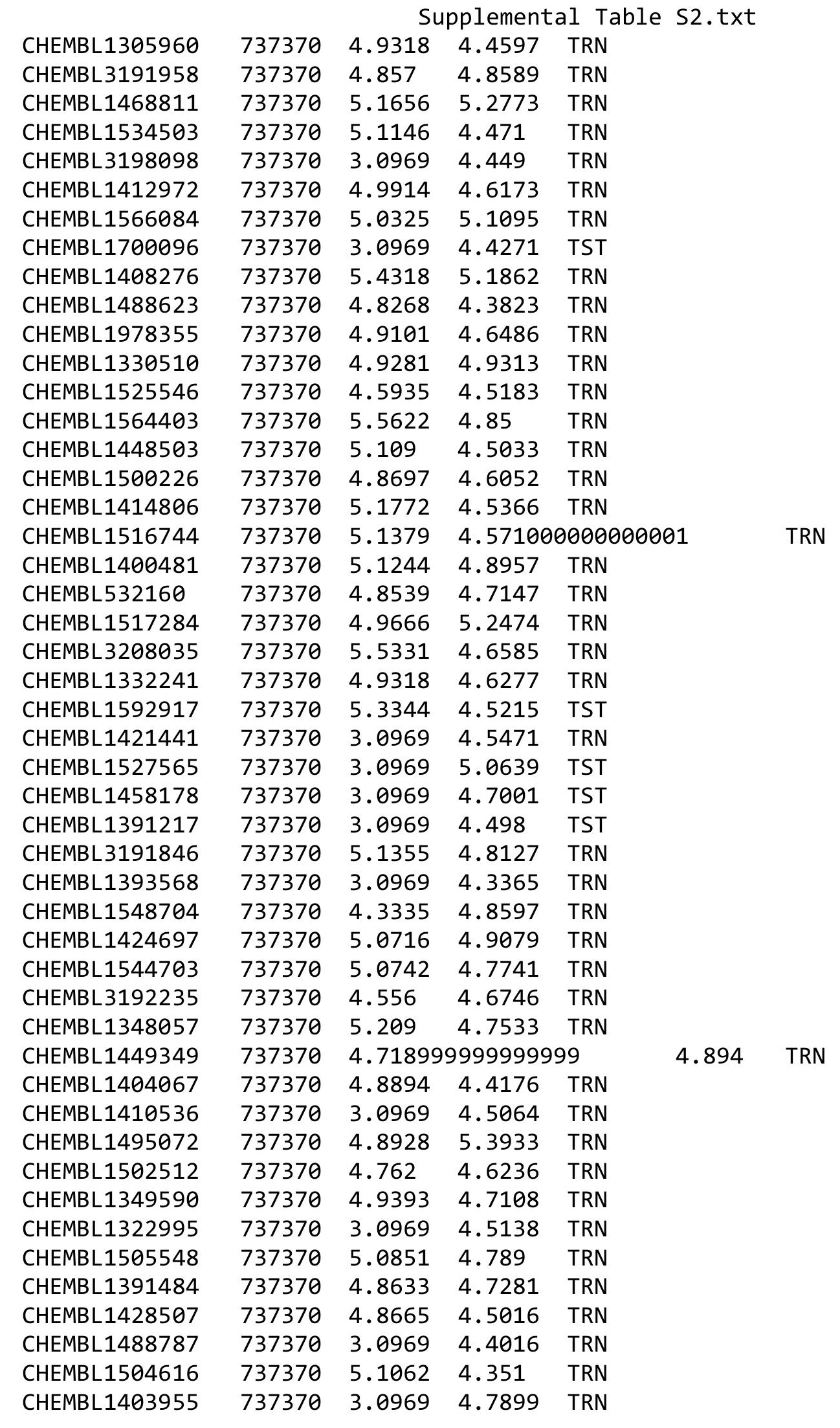

Page 28344 


\begin{tabular}{|c|c|c|c|c|c|}
\hline & & \multicolumn{4}{|c|}{ Supplemental Table S2.txt } \\
\hline CHEMBL1407826 & 737370 & 3.0969 & 4.6188 & TRN & \\
\hline CHEMBL1709004 & 737370 & 4.8962 & 4.4363 & TST & \\
\hline CHEMBL1448982 & 737370 & 4.5482 & 4.9321 & TRN & \\
\hline CHEMBL1709936 & 737370 & 4.3197 & 4.4492 & TRN & \\
\hline CHEMBL1421316 & 737370 & 5.4056 & 4.6534 & TST & \\
\hline CHEMBL1553074 & 737370 & 4.9031 & 4.864 & TRN & \\
\hline CHEMBL1341553 & 737370 & 4.9393 & 4.5934 & TRN & \\
\hline CHEMBL1586895 & 737370 & 3.0969 & 4.4985 & TRN & \\
\hline CHEMBL1339270 & 737370 & 5.1379 & 5.20100 & 00000000005 & TRN \\
\hline CHEMBL1426358 & 737370 & 4.9508 & 4.8595 & TRN & \\
\hline CHEMBL1427790 & 737370 & 4.8761 & 4.7734 & TST & \\
\hline CHEMBL1518463 & 737370 & 3.0969 & 4.38 & TST & \\
\hline CHEMBL1477337 & 737370 & 4.9431 & 4.9638 & TRN & \\
\hline CHEMBL1374947 & 737370 & 5.1824 & 4.7586 & TRN & \\
\hline CHEMBL1478237 & 737370 & 5.1284 & 4.7179 & TRN & \\
\hline CHEMBL 2369281 & 737370 & 3.0969 & 4.3999 & TRN & \\
\hline CHEMBL1544797 & 737370 & 5.5607 & 4.8235 & TRN & \\
\hline CHEMBL 3197070 & 737370 & 5.0825 & 5.0917 & TRN & \\
\hline CHEMBL1463564 & 737370 & 4.7852 & 4.4287 & TRN & \\
\hline CHEMBL256042 & 737370 & 5.1445 & 5.1119 & TRN & \\
\hline CHEMBL579102 & 737370 & 5.0726 & 4.6201 & TRN & \\
\hline CHEMBL1526851 & 737370 & 5.0458 & 5.2761 & TRN & \\
\hline CHEMBL1469171 & 737370 & 5.0191 & 4.7068 & TRN & \\
\hline CHEMBL1462968 & 737370 & 5.1073 & 4.7643 & TRN & \\
\hline CHEMBL1437888 & 737370 & 5.1662 & 4.5468 & TST & \\
\hline CHEMBL1335846 & 737370 & 5.4237 & 4.4635 & TST & \\
\hline CHEMBL 3194451 & 737370 & 3.0969 & 4.6638 & TRN & \\
\hline CHEMBL1488408 & 737370 & 4.9136 & 4.7106 & TST & \\
\hline CHEMBL1324894 & 737370 & 4.7905 & 4.6289 & TRN & \\
\hline CHEMBL1511526 & 737370 & 3.0969 & 4.4503 & TRN & \\
\hline CHEMBL1433015 & 737370 & 4.8539 & 4.4128 & TRN & \\
\hline CHEMBL2003511 & 737370 & 5.4763 & 4.7066 & TRN & \\
\hline CHEMBL1597580 & 737370 & 5.4377 & 4.7744 & TRN & \\
\hline CHEMBL1303953 & 737370 & 3.0969 & 4.9942 & TRN & \\
\hline CHEMBL1533823 & 737370 & 5.8861 & 4.5805 & TRN & \\
\hline CHEMBL1359006 & 737370 & 4.7986 & 4.5991 & TRN & \\
\hline CHEMBL1544508 & 737370 & 5.1107 & 4.8347 & TRN & \\
\hline CHEMBL1984130 & 737370 & 3.0969 & 4.4078 & TRN & \\
\hline CHEMBL1309188 & 737370 & 4.4547 & 4.3124 & TRN & \\
\hline CHEMBL1548542 & 737370 & 4.9747 & 4.4837 & TST & \\
\hline CHEMBL1973341 & 737370 & 4.52 & 4.7381 & TRN & \\
\hline CHEMBL1322695 & 737370 & 4.9318 & 4.5421 & TRN & \\
\hline CHEMBL1467766 & 737370 & 5.1232 & 4.7249 & TRN & \\
\hline CHEMBL1716494 & 737370 & 4.8894 & 4.46 & TRN & \\
\hline CHEMBL1541834 & 737370 & 4.9208 & 5.1447 & TRN & \\
\hline CHEMBL1343952 & 737370 & 5.1759 & 4.5239 & TRN & \\
\hline CHEMBL1522618 & 737370 & 5.9666 & 5.0582 & TRN & \\
\hline CHEMBL1376861 & 737370 & 3.0969 & 4.3865 & TRN & \\
\hline
\end{tabular}




\begin{tabular}{|c|c|c|c|c|c|c|}
\hline & & \multicolumn{5}{|c|}{ Supplemental Table S2.txt } \\
\hline CHEMBL1523610 & 737370 & 4.8665 & 4.3914 & TRN & & \\
\hline CHEMBL1562359 & 737370 & 3.0969 & 5.0142 & TST & & \\
\hline CHEMBL1451911 & 737370 & 3.0969 & 4.2411 & TRN & & \\
\hline CHEMBL1301278 & 737370 & 5.1024 & 4.7465 & TRN & & \\
\hline CHEMBL1495189 & 737370 & 4.3585 & 4.9517 & TST & & \\
\hline CHEMBL1398450 & 737370 & 4.8416 & 4.2771 & TRN & & \\
\hline CHEMBL1608578 & 737370 & 3.0969 & 4.6023 & TRN & & \\
\hline CHEMBL3193391 & 737370 & 3.0969 & 4.6755 & TRN & & \\
\hline CHEMBL1481697 & 737370 & 4.8416 & 4.596 & TRN & & \\
\hline CHEMBL3210072 & 737370 & 4.9957 & 5.072 & TRN & & \\
\hline CHEMBL3213030 & 737370 & 4.4202 & 4.842 & TRN & & \\
\hline CHEMBL260148 & 737370 & 3.0969 & 4.5097 & TST & & \\
\hline CHEMBL3209159 & 737370 & 4.7212 & 4.6297 & TRN & & \\
\hline CHEMBL1468055 & 737370 & 5.0311 & 4.7347 & TST & & \\
\hline CHEMBL1576094 & 737370 & 4.76699 & 9999999 & 995 & 4.4157 & TRN \\
\hline CHEMBL 2005744 & 737370 & 4.7375 & 5.1182 & TRN & & \\
\hline CHEMBL1567898 & 737370 & 4.5157 & 4.4038 & TST & & \\
\hline CHEMBL1596681 & 737370 & 3.0969 & 4.3619 & TST & & \\
\hline CHEMBL1305525 & 737370 & 3.0969 & 4.2578 & TST & & \\
\hline CHEMBL1600146 & 737370 & 4.9245 & 4.6918 & TRN & & \\
\hline CHEMBL1535457 & 737370 & 4.7959 & 4.5104 & TRN & & \\
\hline CHEMBL1339562 & 737370 & 3.0969 & 4.5694 & TRN & & \\
\hline CHEMBL 3212447 & 737370 & 4.3002 & 4.3448 & TRN & & \\
\hline CHEMBL3189322 & 737370 & 4.6459 & 4.3602 & TRN & & \\
\hline CHEMBL19980 & 737370 & 5.8729 & 4.3717 & TST & & \\
\hline CHEMBL1338045 & 737370 & 5.1302 & 4.4149 & TRN & & \\
\hline CHEMBL1486520 & 737370 & 4.8539 & 4.5463 & TRN & & \\
\hline CHEMBL1549419 & 737370 & 4.8153 & 4.8428 & TRN & & \\
\hline CHEMBL1370810 & 737370 & 4.8327 & 4.5636 & TRN & & \\
\hline CHEMBL1556583 & 737370 & 4.7959 & 4.2873 & TRN & & \\
\hline CHEMBL1347600 & 737370 & 5.15799 & 99999999 & 995 & 4.5109 & TST \\
\hline CHEMBL1447284 & 737370 & 5.1029 & 5.095 & TRN & & \\
\hline CHEMBL1404953 & 737370 & 4.8697 & 4.6554 & TRN & & \\
\hline CHEMBL3109023 & 737370 & 5.6271 & 4.6484 & TRN & & \\
\hline CHEMBL3194419 & 737370 & 5.061 & 4.5452 & TRN & & \\
\hline CHEMBL1584502 & 737370 & 5.1694 & 4.4242 & TRN & & \\
\hline CHEMBL1410068 & 737370 & 4.8386 & 4.994 & TST & & \\
\hline CHEMBL1352555 & 737370 & 5.1561 & 4.5448 & TRN & & \\
\hline CHEMBL1968356 & 737370 & 5.4168 & 4.4563 & TRN & & \\
\hline CHEMBL1967775 & 737370 & 4.3893 & 4.875 & TRN & & \\
\hline CHEMBL1517686 & 737370 & 3.0969 & 4.6038 & TRN & & \\
\hline CHEMBL1534922 & 737370 & 3.0969 & 4.4719 & TRN & & \\
\hline CHEMBL591126 & 737370 & 4.9747 & 5.1856 & TRN & & \\
\hline CHEMBL1306124 & 737370 & 5.1397 & 4.3127 & TRN & & \\
\hline CHEMBL1373688 & 737370 & 4.8268 & 4.5148 & TRN & & \\
\hline CHEMBL1965132 & 737370 & 5.1911 & 4.7393 & TRN & & \\
\hline CHEMBL1328386 & 737370 & 3.0969 & 4.5426 & TRN & & \\
\hline CHEMBL1490942 & 737370 & 4.8697 & 4.4012 & TRN & & \\
\hline
\end{tabular}




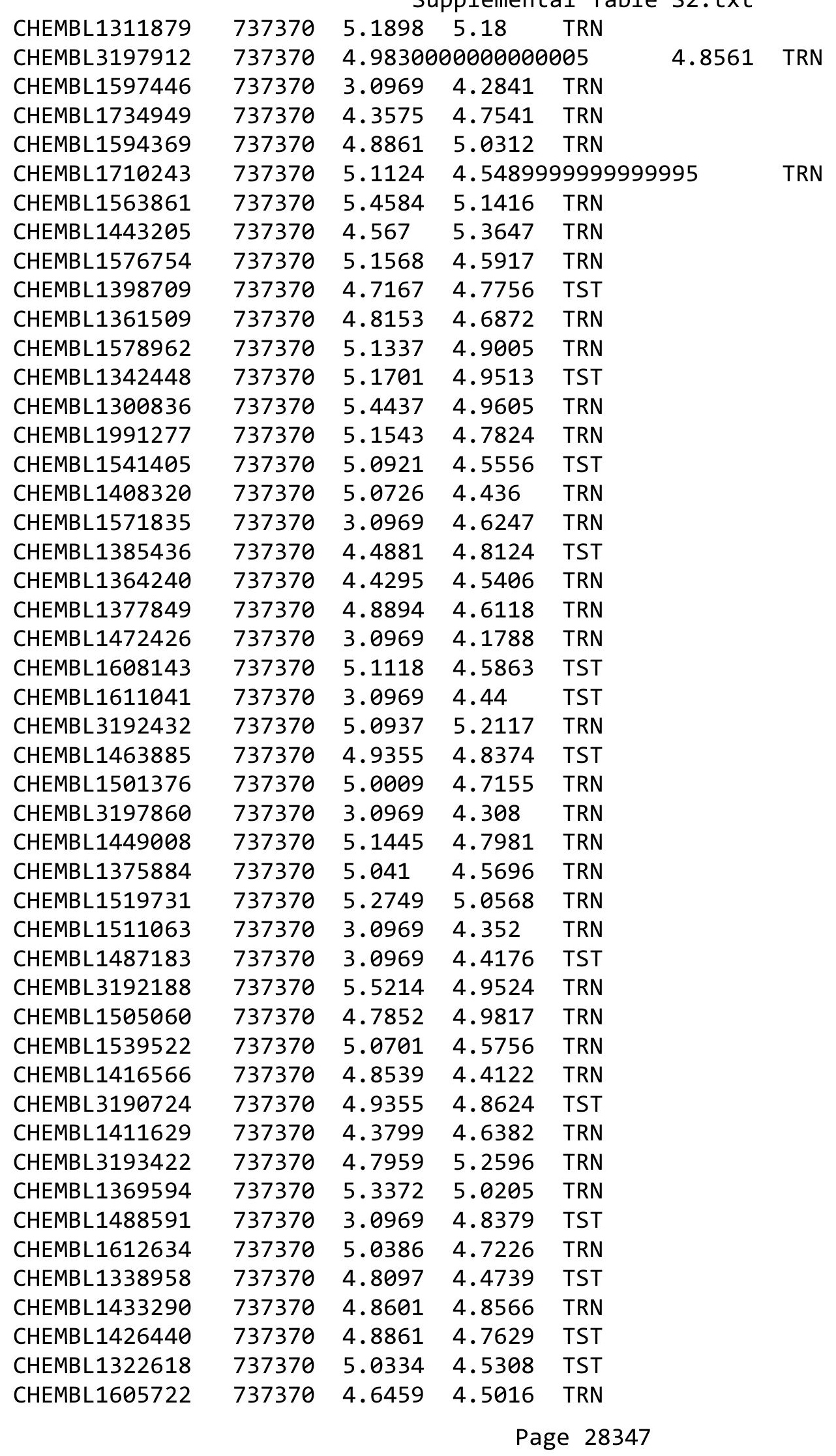




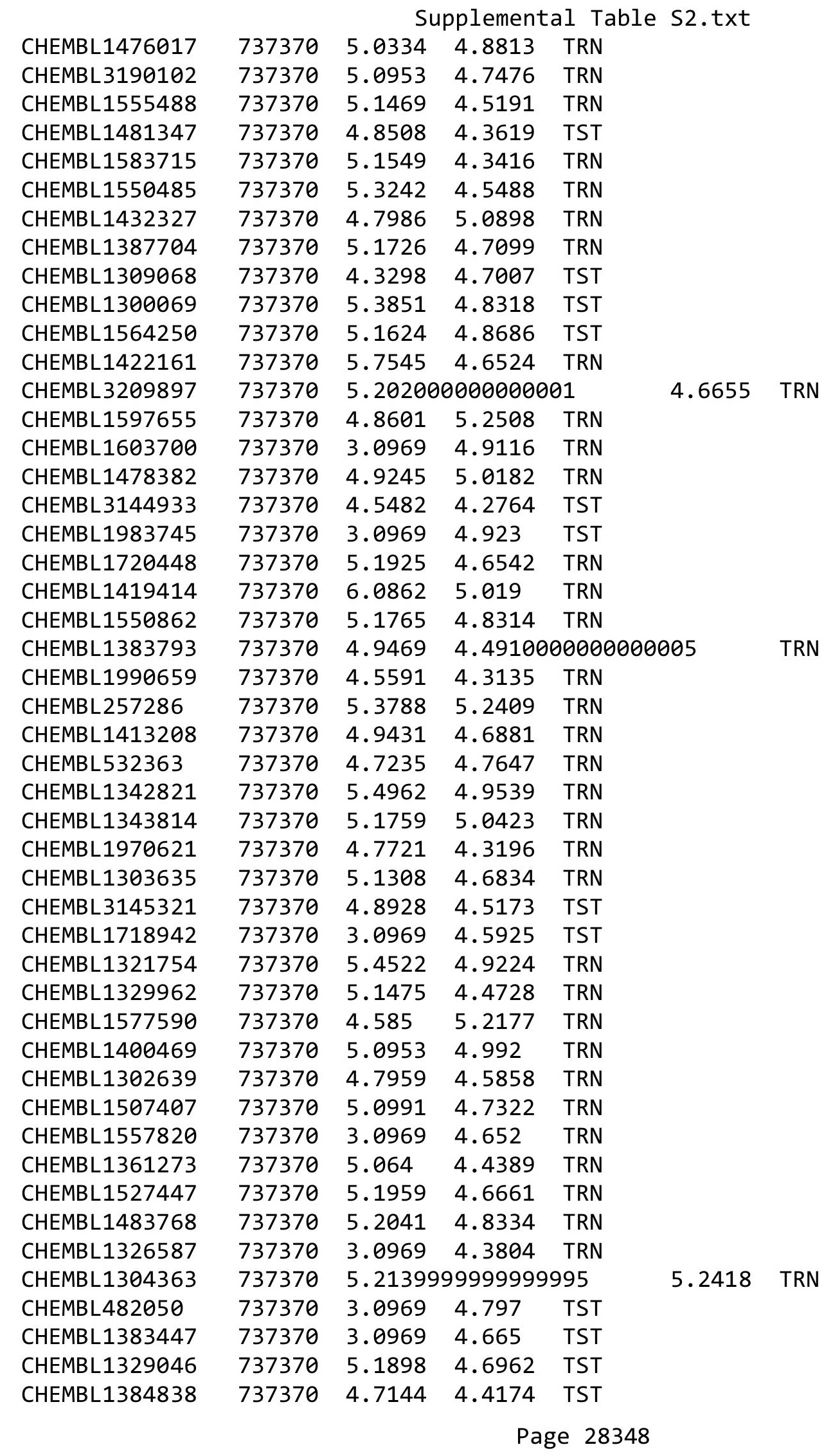


Supplemental Table S2.txt

\begin{tabular}{|c|c|c|c|c|}
\hline HEM & 370 & 4.8827 & & 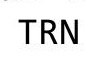 \\
\hline 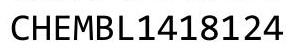 & 37370 & 4.4067 & & \\
\hline IFMR I - & 70 & & & \\
\hline HEMBL & 370 & & & \\
\hline AEMBL1429164 & 37370 & 969 & 896 & \\
\hline HEMBL453 & 37370 & 41 & 592 & \\
\hline HEMBL19 & 7370 & & & \\
\hline AEMBL14 & & & & \\
\hline HEMBL1550076 & 37370 & 1249 & 904 & \\
\hline HEMBL196 & 37370 & 06 & 904 & \\
\hline HEMBL 320 & & 447 & 502 & \\
\hline IEM & 70 & & 891 & \\
\hline AEMBL15 & & & & \\
\hline HEMBL1477528 & 37370 & 969 & 995 & - \\
\hline HEMBL159 & & & & TST \\
\hline AEMBL14 & 70 & 59 & & \\
\hline HEMBL15 & 70 & & & ST \\
\hline HEMBL15 & 70 & & & \\
\hline HFMBI 158 & & & & ביד \\
\hline HEMBL143 & & & & $1 \mathrm{I}$ \\
\hline HEMBL 31 & 70 & & & ST \\
\hline HEMBL13 & & & & \\
\hline HEMBL188 & 70 & & & \\
\hline HEMPI 153 & & & & 15 \\
\hline JEMBL14 & & & & ISI \\
\hline HEMBL14 & 70 & & & ST \\
\hline HFMBI 15 & 70 & & & ST \\
\hline HEMPI 2 & 70 & & & \\
\hline HEMBL19 & & & & 15 \\
\hline HEMBL142 & & & 57 & TST \\
\hline HEMBL14 & & & 09 & IST \\
\hline HEM & & & & ST \\
\hline 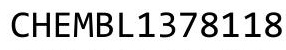 & & & & $T C T$ \\
\hline HEMBL 363 & & & & TST \\
\hline HEMBL157 & 70 & & 21 & ГST \\
\hline AEMPI 13 & 70 & & & ST \\
\hline 9 & & & & ST \\
\hline HEMBL 144 & & & & TST \\
\hline HEMBL 32 & & & 17 & TS \\
\hline+2 & & & & IST \\
\hline 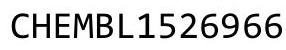 & 70 & & & \\
\hline & 70 & & 369 & ST \\
\hline HEMBL13ऽ & 37370 & & & TS \\
\hline HEMBL15 & 70 & & 84 & TS \\
\hline CHFMRI 1544114 & & & & 31 \\
\hline HEMBL58 & 30 & & 196 & \\
\hline HEMBL137 & 37370 & 69 & 4.317 & ST \\
\hline CHEMBL170495 & 737370 & 4.7496 & 4.8053 & $S T$ \\
\hline
\end{tabular}

Page 28349 


\begin{tabular}{|c|c|c|c|c|c|}
\hline & & \multicolumn{4}{|c|}{ Supplemental Table S2.txt } \\
\hline CHEMBL3192267 & 737370 & 5.0511 & 4.6575 & TST & \\
\hline CHEMBL3193428 & 737370 & 5.0985 & 4.8428 & TST & \\
\hline CHEMBL3209308 & 737370 & 4.6402 & 4.5571 & TST & \\
\hline CHEMBL1422386 & 737370 & 3.0969 & 4.6888 & TST & \\
\hline CHEMBL1483596 & 737370 & 4.8665 & 4.7752 & TST & \\
\hline CHEMBL1438319 & 737370 & 4.8601 & 4.8245 & TST & \\
\hline CHEMBL1501755 & 737370 & 5.1203 & 4.4143 & TST & \\
\hline CHEMBL1509145 & 737370 & 4.6308 & 4.6017 & TST & \\
\hline CHEMBL1321238 & 737370 & 4.9508 & 4.9215 & TST & \\
\hline CHEMBL1439210 & 737370 & 5.1593 & 5.1227 & TST & \\
\hline CHEMBL1968789 & 737370 & 4.3429 & 4.7844 & TST & \\
\hline CHEMBL1587831 & 737370 & 4.8327 & 4.5777 & TST & \\
\hline CHEMBL1986557 & 737370 & 4.9355 & 4.8585 & TST & \\
\hline CHEMBL1546223 & 737370 & 5.15 & 4.8055 & TST & \\
\hline CHEMBL3209146 & 737370 & 4.699 & 4.2947 & TST & \\
\hline CHEMBL1583292 & 737370 & 5.3686 & 4.6052 & TST & \\
\hline CHEMBL1457644 & 737370 & 4.644 & 5.1188 & TST & \\
\hline CHEMBL1539808 & 737370 & 5.1415 & 4.3097 & TST & \\
\hline CHEMBL1509061 & 737370 & 4.5391 & 4.3743 & TST & \\
\hline CHEMBL1457472 & 737370 & 3.0969 & 4.7322 & TST & \\
\hline CHEMBL1378931 & 737370 & 5.7852 & 4.7014 & TST & \\
\hline CHEMBL 2094567 & 737370 & 5.4868 & 5.3025 & TST & \\
\hline CHEMBL1329069 & 737370 & 5.2083 & 4.4946 & TST & \\
\hline CHEMBL1527214 & 737370 & 4.5591 & 5.0493 & TST & \\
\hline CHEMBL1565344 & 737370 & 4.9431 & 4.5513 & TST & \\
\hline CHEMBL1330307 & 737370 & 4.9101 & 5.4069 & TST & \\
\hline CHEMBL607553 & 737370 & 5.1073 & 4.9694 & TST & \\
\hline CHEMBL3197433 & 737370 & 5.3686 & 5.0086 & TST & \\
\hline CHEMBL1517752 & 737370 & 5.1325 & 4.7054 & TST & \\
\hline CHEMBL1494117 & 688256 & 4.6678 & 4.1551 & TRN & \\
\hline CHEMBL1450526 & 688256 & 5.1284 & 4.6196 & TRN & \\
\hline CHEMBL1428894 & 688256 & 4.5111 & 4.1579 & TRN & \\
\hline CHEMBL463175 & 688256 & 4.1248 & 2.9293 & TST & \\
\hline CHEMBL1582199 & 688256 & 3.0 & 3.4802 & TRN & \\
\hline CHEMBL1351369 & 688256 & 4.01399 & 99999999 & 3.1599 & TRN \\
\hline CHEMBL1452421 & 688256 & 4.4375 & 3.8469 & TRN & \\
\hline CHEMBL 2000517 & 688256 & 3.0 & 3.3154 & TRN & \\
\hline CHEMBL3208475 & 688256 & 4.1076 & 4.0003 & TRN & \\
\hline CHEMBL1507162 & 688256 & 3.0 & 3.3076 & TRN & \\
\hline CHEMBL1488681 & 688256 & 3.0 & 3.7868 & TRN & \\
\hline CHEMBL1989179 & 688256 & 3.0 & 3.1274 & TRN & \\
\hline CHEMBL1353960 & 688256 & 3.0 & 3.3465 & TST & \\
\hline CHEMBL548540 & 688256 & 5.0709 & 4.6277 & TRN & \\
\hline CHEMBL3195360 & 688256 & 3.0 & 3.1225 & TRN & \\
\hline CHEMBL3196561 & 688256 & 3.0 & 3.24300 & 00000000003 & TRN \\
\hline CHEMBL3192400 & 688256 & 3.0 & 3.7032 & TRN & \\
\hline CHEMBL1312320 & 688256 & 4.0972 & 3.7432 & TST & \\
\hline CHEMBL1540680 & 688256 & 3.0 & 3.5803 & TRN & \\
\hline
\end{tabular}




\begin{tabular}{|c|c|c|c|c|c|c|}
\hline \multicolumn{7}{|c|}{ Supplemental Table S2.txt } \\
\hline CHEMBL1437947 & 688256 & 3.0 & 2.9094 & TRN & & \\
\hline CHEMBL1498431 & 688256 & 4.2841 & 3.9382 & TRN & & \\
\hline CHEMBL1560760 & 688256 & 3.0 & 3.2887 & TST & & \\
\hline CHEMBL 3193432 & 688256 & 3.0 & 3.0403 & TRN & & \\
\hline CHEMBL 3189743 & 688256 & 3.0 & 3.1335 & TRN & & \\
\hline CHEMBL1344470 & 688256 & 3.0 & 3.6029 & TRN & & \\
\hline CHEMBL1369893 & 688256 & 4.4629 & 4.6845 & TRN & & \\
\hline CHEMBL 3197343 & 688256 & 3.0 & 3.6102 & TRN & & \\
\hline CHEMBL1583585 & 688256 & \multicolumn{3}{|c|}{4.0280000000000005} & 3.9643 & \\
\hline CHEMBL1407632 & 688256 & 3.0 & 2.978 & TRN & & \\
\hline CHEMBL1969851 & 688256 & 3.0 & 3.9337 & TST & & \\
\hline CHEMBL1490352 & 688256 & 3.0 & 3.0064 & TRN & & \\
\hline CHEMBL1485259 & 688256 & 4.223 & 3.8205 & TRN & & \\
\hline CHEMBL1582741 & 688256 & 4.372 & 4.2926 & TRN & & \\
\hline CHEMBL3195409 & 688256 & 3.0 & 3.404 & TRN & & \\
\hline CHEMBL1440549 & 688256 & 4.4563 & 4.0802 & TRN & & \\
\hline CHEMBL1306708 & 688256 & 3.0 & 3.1393 & TRN & & \\
\hline CHEMBL1523147 & 688256 & 3.0 & 4.0339 & TST & & \\
\hline CHEMBL1463795 & 688256 & 3.0 & 3.0001 & TST & & \\
\hline CHEMBL1549102 & 688256 & 3.0 & 3.07 & TST & & \\
\hline CHEMBL1384253 & 688256 & 3.0 & 3.4888 & TRN & & \\
\hline CHEMBL1585209 & 688256 & 4.2217 & 3.949 & TRN & & \\
\hline CHEMBL1564070 & 688256 & 3.0 & 3.4643 & TRN & & \\
\hline CHEMBL1348582 & 688256 & 4.5956 & 4.3015 & TRN & & \\
\hline CHEMBL1307453 & 688256 & 4.0139 & 3.5089 & TRN & & \\
\hline CHEMBL1564638 & 688256 & 3.0 & 3.0553 & TRN & & \\
\hline CHEMBL1405150 & 688256 & 4.1814 & 4.6868 & TRN & & \\
\hline CHEMBL1982195 & 688256 & 3.0 & 3.0222 & TRN & & \\
\hline CHEMBL1334319 & 688256 & 3.0 & 3.3547 & TRN & & \\
\hline CHEMBL1339591 & 688256 & 3.0 & 3.3716 & TRN & & \\
\hline CHEMBL505670 & 688256 & 4.7734 & 4.0604 & TRN & & \\
\hline CHEMBL52347 & 688256 & 3.0 & 3.4922 & TRN & & \\
\hline CHEMBL1479139 & 688256 & 3.0 & 3.0689 & TRN & & \\
\hline CHEMBL3191647 & 688256 & 3.0 & 3.3161 & TRN & & \\
\hline CHEMBL1459612 & 688256 & 3.0 & 3.1286 & TRN & & \\
\hline CHEMBL1547177 & 688256 & 3.0 & 3.0796 & TRN & & \\
\hline CHEMBL1492003 & 688256 & 3.0 & 3.0535 & TRN & & \\
\hline CHEMBL1995910 & 688256 & 4.5968 & 3.8633 & TRN & & \\
\hline CHEMBL1451931 & 688256 & 4.4423 & 4.1236 & TRN & & \\
\hline CHEMBL1428250 & 688256 & 3.0 & 3.0724 & TST & & \\
\hline CHEMBL363535 & 688256 & 4.1037 & 3.4971 & TRN & & \\
\hline CHEMBL1964909 & 688256 & 4.2358 & 3.4724 & TRN & & \\
\hline CHEMBL1495682 & 688256 & 3.0 & 3.1573 & TRN & & \\
\hline CHEMBL1309890 & 688256 & 4.6016 & 4.3332 & TRN & & \\
\hline CHEMBL1971033 & 688256 & 4.4536 & 3.9364 & TRN & & \\
\hline CHEMBL1448013 & 688256 & 3.0 & 3.1623 & TRN & & \\
\hline CHEMBL 1443120 & 688256 & 3.0 & 2.8339 & TRN & & \\
\hline CHEMBL463686 & 688256 & 4.322 & 3.7475 & TST & & \\
\hline
\end{tabular}




\begin{tabular}{|c|c|c|c|c|}
\hline \multicolumn{5}{|c|}{ Supplemental Table s2.txt } \\
\hline CHEMBL1372672 & 688256 & 3.0 & 3.2156 & TRN \\
\hline CHEMBL1353752 & 688256 & 4.4605 & 3.5338 & TRN \\
\hline CHEMBL 3194876 & 688256 & 3.0 & 3.3132 & TRN \\
\hline CHEMBL1541391 & 688256 & 3.0 & 3.3791 & TRN \\
\hline CHEMBL1495714 & 688256 & 3.0 & 3.5456 & TST \\
\hline CHEMBL1437787 & 688256 & 3.0 & 2.8794 & TST \\
\hline CHEMBL3196124 & 688256 & 4.1228 & 3.6653 & TRN \\
\hline CHEMBL1443791 & 688256 & 4.0707 & 3.7139 & TRN \\
\hline CHEMBL1574127 & 688256 & 4.0176 & 3.5039 & TRN \\
\hline CHEMBL1365988 & 688256 & 4.2581 & 4.3312 & TRN \\
\hline CHEMBL1584153 & 688256 & 3.0 & 3.242 & TRN \\
\hline CHEMBL 3197141 & 688256 & 4.3368 & 3.8516 & TRN \\
\hline CHEMBL1338143 & 688256 & 3.0 & 2.8322 & TRN \\
\hline CHEMBL487356 & 688256 & 3.0 & 3.3848 & TRN \\
\hline CHEMBL1566748 & 688256 & 3.0 & 3.4511 & TRN \\
\hline CHEMBL1429632 & 688256 & 3.0 & 3.3607 & TST \\
\hline CHEMBL1462825 & 688256 & 4.1393 & 3.7631 & TRN \\
\hline CHEMBL155563 & 688256 & 4.1698 & 4.003 & TRN \\
\hline CHEMBL1484632 & 688256 & 3.0 & 3.2366 & TRN \\
\hline CHEMBL1361046 & 688256 & 4.5345 & 4.3739 & TRN \\
\hline CHEMBL1461538 & 688256 & 3.0 & 3.2409 & TRN \\
\hline CHEMBL1570980 & 688256 & 3.0 & 3.4185 & TRN \\
\hline CHEMBL1998566 & 688256 & 3.0 & 3.3598 & TRN \\
\hline CHEMBL1453852 & 688256 & 3.0 & 3.258 & TST \\
\hline CHEMBL1328373 & 688256 & 4.2262 & 3.568 & TST \\
\hline CHEMBL1309993 & 688256 & 3.0 & 2.9492 & TRN \\
\hline CHEMBL3208443 & 688256 & 3.0 & 3.5659 & TRN \\
\hline CHEMBL584442 & 688256 & 4.077 & 3.8862 & TST \\
\hline CHEMBL140 & 688256 & 3.0 & 2.8608 & TRN \\
\hline CHEMBL1367178 & 688256 & 3.0 & 3.3798 & TRN \\
\hline CHEMBL1349727 & 688256 & 4.4488 & 3.9636 & TRN \\
\hline CHEMBL1337281 & 688256 & 3.0 & 2.8198 & TRN \\
\hline CHEMBL1610311 & 688256 & 3.0 & 2.9129 & TST \\
\hline CHEMBL 3856090 & 688256 & 4.3557 & 3.3188 & TST \\
\hline CHEMBL1613285 & 688256 & 3.0 & 3.9302 & TRN \\
\hline CHEMBL1528330 & 688256 & 4.1227 & 4.0797 & TRN \\
\hline CHEMBL1546767 & 688256 & 4.6797 & 4.6082 & TRN \\
\hline CHEMBL1452090 & 688256 & 4.6065 & 4.6353 & TRN \\
\hline CHEMBL1544313 & 688256 & 3.0 & 2.3144 & TRN \\
\hline CHEMBL1470135 & 688256 & 4.4536 & 4.154 & TRN \\
\hline CHEMBL1498342 & 688256 & 4.0791 & 3.8233 & TRN \\
\hline CHEMBL 3145107 & 688256 & 4.3092 & 3.5767 & TST \\
\hline CHEMBL1306267 & 688256 & 4.3668 & 3.5171 & TRN \\
\hline CHEMBL1600082 & 688256 & 3.0 & 3.2147 & TRN \\
\hline CHEMBL 3194149 & 688256 & 4.0601 & 3.22399 & 99999999998 \\
\hline CHEMBL1529511 & 688256 & 3.0 & 3.1198 & TRN \\
\hline CHEMBL 3194188 & 688256 & 3.0 & 2.7678 & TRN \\
\hline CHEMBL1363152 & 688256 & 3.0 & 2.2894 & TRN \\
\hline
\end{tabular}

TRN 


\begin{tabular}{|c|c|c|c|c|c|}
\hline \multicolumn{6}{|c|}{ Supplemental Table S2.txt } \\
\hline CHEMBL1608223 & 688256 & 3.0 & 2.8082 & TRN & \\
\hline CHEMBL1306923 & 688256 & 4.1431 & 3.9247 & TRN & \\
\hline CHEMBL1990342 & 688256 & 3.0 & 3.0029 & TRN & \\
\hline CHEMBL1349147 & 688256 & 4.0144 & 3.5606 & TRN & \\
\hline CHEMBL1498210 & 688256 & 3.0 & 2.8681 & TST & \\
\hline CHEMBL1386684 & 688256 & 3.0 & 4.3083 & TRN & \\
\hline CHEMBL1607451 & 688256 & 3.0 & 3.0291 & TST & \\
\hline CHEMBL1583082 & 688256 & 3.0 & 4.0916 & TRN & \\
\hline CHEMBL1449883 & 688256 & 4.4178 & 4.3763 & TRN & \\
\hline CHEMBL1520551 & 688256 & 3.0 & 2.7672 & TRN & \\
\hline CHEMBL1091723 & 688256 & 3.0 & 3.2226 & TRN & \\
\hline CHEMBL1350274 & 688256 & 3.0 & 3.4036 & TRN & \\
\hline CHEMBL1391743 & 688256 & 3.0 & 3.9674 & TRN & \\
\hline CHEMBL1410753 & 688256 & 3.0 & 3.1215 & TST & \\
\hline CHEMBL3191025 & 688256 & 3.0 & 3.3381 & TRN & \\
\hline CHEMBL1883149 & 688256 & 4.3793 & 3.156 & TST & \\
\hline CHEMBL1458674 & 688256 & 3.0 & 2.8293 & TST & \\
\hline CHEMBL3191011 & 688256 & 4.2931 & 3.4777 & TST & \\
\hline CHEMBL 3192541 & 688256 & 3.0 & 3.2874 & TST & \\
\hline CHEMBL 2006503 & 688256 & 3.0 & 4.282 & TST & \\
\hline CHEMBL1360140 & 688256 & 3.0 & 3.2555 & TST & \\
\hline CHEMBL1584752 & 688256 & 4.4436 & 3.9018 & TST & \\
\hline CHEMBL1575658 & 688256 & 3.0 & 2.8625 & TST & \\
\hline CHEMBL1408792 & 688256 & 3.0 & 3.04100 & 00000000004 & TST \\
\hline CHEMBL1405483 & 688256 & 4.0149 & 2.5819 & TST & \\
\hline CHEMBL1537553 & 688256 & 3.0 & 3.7497 & TST & \\
\hline CHEMBL1300243 & 688256 & 4.8451 & 3.0189 & TST & \\
\hline CHEMBL1561847 & 688256 & 4.0584 & 3.25600 & 00000000002 & TST \\
\hline CHEMBL1303641 & 737059 & 5.3947 & 4.5006 & TST & \\
\hline CHEMBL1344750 & 737059 & 5.2865 & 4.5071 & TRN & \\
\hline CHEMBL1350949 & 737059 & 5.055 & 4.9779 & TRN & \\
\hline CHEMBL1303193 & 737059 & 5.51 & 4.84 & TRN & \\
\hline CHEMBL1302170 & 737059 & 5.1445 & 4.203 & TST & \\
\hline CHEMBL1601599 & 737059 & 4.9208 & 4.3523 & TRN & \\
\hline CHEMBL1600311 & 737059 & 5.0092 & 4.8603 & TRN & \\
\hline CHEMBL1585011 & 737059 & 3.7959 & 4.6891 & TST & \\
\hline CHEMBL1538417 & 737059 & 6.1261 & 4.9084 & TRN & \\
\hline CHEMBL1612672 & 737059 & 3.7959 & 4.5966 & TRN & \\
\hline CHEMBL3197404 & 737059 & 6.0814 & 4.4717 & TRN & \\
\hline CHEMBL1612974 & 737059 & 3.7959 & 5.1884 & TRN & \\
\hline CHEMBL1461131 & 737059 & 5.1675 & 4.5239 & TRN & \\
\hline CHEMBL1543131 & 737059 & 5.7235 & 5.1528 & TRN & \\
\hline CHEMBL1455256 & 737059 & 4.9508 & 4.5662 & TST & \\
\hline CHEMBL1523528 & 737059 & 3.7959 & 4.1285 & TRN & \\
\hline CHEMBL3197123 & 737059 & 3.7959 & 4.4621 & TST & \\
\hline CHEMBL1498210 & 737059 & 5.5544 & 5.6185 & TRN & \\
\hline CHEMBL1484223 & 737059 & 3.7959 & 4.3939 & TRN & \\
\hline CHEMBL1332522 & 737059 & 7.6021 & 6.1943 & TRN & \\
\hline
\end{tabular}


Supplemental Table S2.txt

\begin{tabular}{|c|c|c|c|c|c|c|}
\hline CHEMBL1489356 & 737059 & 3.7959 & 4.1832 & TST & & \\
\hline CHEMBL1599946 & 737059 & 7.6021 & 6.3342 & TRN & & \\
\hline CHEMBL1327785 & 737059 & 3.7959 & 4.4179 & TRN & & \\
\hline CHEMBL1487918 & 737059 & 4.9245 & 4.585 & TST & & \\
\hline CHEMBL1470077 & 737059 & 5.2573 & 4.5448 & TST & & \\
\hline CHEMBL1558301 & 737059 & 5.0057 & 4.6547 & TRN & & \\
\hline CHEMBL1319963 & 737059 & 5.1373 & 4.9107 & TRN & & \\
\hline CHEMBL1340574 & 737059 & 4.9547 & 4.4581 & TST & & \\
\hline CHEMBL1564591 & 737059 & 3.7959 & 4.5677 & TRN & & \\
\hline CHEMBL1347334 & 737059 & 3.7959 & 5.1076 & TRN & & \\
\hline CHEMBL1596619 & 737059 & 5.2218 & 4.4698 & TST & & \\
\hline CHEMBL1483129 & 737059 & 3.7959 & 4.6649 & TRN & & \\
\hline CHEMBL1581326 & 737059 & 5.1726 & 5.558 & TRN & & \\
\hline CHEMBL1536042 & 737059 & 3.7959 & 4.5392 & TRN & & \\
\hline CHEMBL1406829 & 737059 & 5.1343 & 4.5437 & TST & & \\
\hline CHEMBL1462078 & 737059 & 5.0168 & 4.9481 & TRN & & \\
\hline CHEMBL1348043 & 737059 & 5.2182 & 5.0206 & TST & & \\
\hline CHEMBL1540360 & 737059 & 3.7959 & 4.6478 & TRN & & \\
\hline CHEMBL1583872 & 737059 & 6.1918 & 6.4357 & TRN & & \\
\hline CHEMBL1313968 & 737059 & 4.9172 & 4.1284 & TRN & & \\
\hline CHEMBL1576762 & 737059 & 5.0395 & 4.4039 & TRN & & \\
\hline CHEMBL1439036 & 737059 & 3.7959 & 4.308 & TST & & \\
\hline CHEMBL3209591 & 737059 & 5.4134 & 4.5338 & TRN & & \\
\hline CHEMBL1564313 & 737059 & 6.1555 & 5.8221 & TST & & \\
\hline CHEMBL1575470 & 737059 & 5.2749 & 5.6485 & TRN & & \\
\hline CHEMBL1596391 & 737059 & 5.062 & 4.5098 & TST & & \\
\hline CHEMBL1351229 & 737059 & 3.7959 & 4.1334 & TRN & & \\
\hline CHEMBL1497574 & 737059 & 3.7959 & 4.4847 & TRN & & \\
\hline CHEMBL1508252 & 737059 & 4.8928 & 4.9506 & TRN & & \\
\hline CHEMBL1561204 & 737059 & 3.7959 & 4.4943 & TRN & & \\
\hline CHEMBL515248 & 737059 & 5.0511 & 4.2956 & TRN & & \\
\hline CHEMBL1542902 & 737059 & 3.7959 & 4.2615 & TRN & & \\
\hline CHEMBL1335315 & 737059 & 3.7959 & 4.3575 & TRN & & \\
\hline CHEMBL1576289 & 737059 & 3.7959 & 4.208 & TRN & & \\
\hline CHEMBL1587121 & 737059 & 5.6536 & 5.0004 & TRN & & \\
\hline CHEMBL1391382 & 737059 & 3.7959 & 4.2699 & TRN & & \\
\hline CHEMBL1390427 & 737059 & 5.5935 & 4.5437 & TRN & & \\
\hline CHEMBL1409207 & 737059 & 5.2284 & 4.2002 & TRN & & \\
\hline CHEMBL1447647 & 737059 & 3.7959 & 4.6126 & TRN & & \\
\hline CHEMBL61559 & 737059 & 5.2 & 4.3121 & TRN & & \\
\hline CHEMBL1582024 & 737059 & 5.3947 & 5.2255 & TRN & & \\
\hline CHEMBL1497386 & 737059 & \multicolumn{3}{|c|}{4.9830000000000005} & 4.4679 & TS \\
\hline CHEMBL1458524 & 737059 & 6.2487 & 5.2485 & TRN & & \\
\hline CHEMBL1541209 & 737059 & 3.7959 & 4.1548 & TRN & & \\
\hline CHEMBL1327648 & 737059 & 4.8125 & 4.6724 & TRN & & \\
\hline CHEMBL1527994 & 737059 & 5.1512 & 4.169 & TRN & & \\
\hline CHEMBL1309683 & 737059 & 3.7959 & 4.3618 & TST & & \\
\hline CHEMBL1546414 & 737059 & 4.9788 & 4.6277 & TRN & & \\
\hline
\end{tabular}

Page 28354 
Supplemental Table S2.txt

\begin{tabular}{|c|c|c|c|c|c|c|}
\hline CHEMBL1489587 & 737059 & 4.9872 & 4.2356 & TRN & & \\
\hline CHEMBL3195117 & 737059 & 3.7959 & 4.525 & TST & & \\
\hline CHEMBL1486503 & 737059 & 3.7959 & 4.1345 & TRN & & \\
\hline CHEMBL1530303 & 737059 & 3.7959 & 4.531000 & 0000000 & & TRN \\
\hline CHEMBL1335827 & 737059 & 3.7959 & 4.3482 & TST & & \\
\hline CHEMBL1390056 & 737059 & 5.0595 & 4.1059 & TRN & & \\
\hline CHEMBL1499258 & 737059 & 3.7959 & 4.3139 & TRN & & \\
\hline CHEMBL1442271 & 737059 & 6.0521 & 4.2802 & TST & & \\
\hline CHEMBL1418110 & 737059 & 5.3197 & 5.1381 & TRN & & \\
\hline CHEMBL1334439 & 737059 & 3.7959 & 4.2691 & TRN & & \\
\hline CHEMBL1300876 & 737059 & 5.1878 & 4.152 & TST & & \\
\hline CHEMBL1382443 & 737059 & 3.7959 & 4.3551 & TRN & & \\
\hline CHEMBL1548690 & 737059 & 5.1361 & 4.5486 & TRN & & \\
\hline CHEMBL1613508 & 737059 & 4.8508 & 4.4197 & TRN & & \\
\hline CHEMBL1472546 & 737059 & 3.7959 & 4.5139 & TRN & & \\
\hline CHEMBL1466743 & 737059 & 3.7959 & 4.3139 & TST & & \\
\hline CHEMBL1444791 & 737059 & 3.7959 & 4.0441 & TST & & \\
\hline CHEMBL1604160 & 737059 & 3.7959 & 4.1577 & TST & & \\
\hline CHEMBL1610433 & 737059 & 3.7959 & 5.2266 & TRN & & \\
\hline CHEMBL1533772 & 737059 & 3.7959 & 4.7512 & TRN & & \\
\hline CHEMBL1447432 & 737059 & 6.317 & 5.5778 & TRN & & \\
\hline CHEMBL1975147 & 737059 & 5.2027 & 5.1672 & TRN & & \\
\hline CHEMBL1537386 & 737059 & 5.0625 & 4.5005 & TST & & \\
\hline CHEMBL1350504 & 737059 & 5.4101 & 4.2688 & TRN & & \\
\hline CHEMBL1477556 & 737059 & 3.7959 & 4.3654 & TRN & & \\
\hline CHEMBL1340089 & 737059 & 3.7959 & 4.7803 & TRN & & \\
\hline CHEMBL1506185 & 737059 & 5.0516 & 4.4116 & TRN & & \\
\hline CHEMBL1992540 & 737059 & 3.7959 & 4.3929 & TRN & & \\
\hline CHEMBL1327074 & 737059 & 3.7959 & 4.3356 & TRN & & \\
\hline CHEMBL1327254 & 737059 & 6.2182 & 4.9312 & TRN & & \\
\hline CHEMBL1399533 & 737059 & 6.1391 & 4.4062 & TRN & & \\
\hline CHEMBL1492716 & 737059 & 3.7959 & 4.5768 & TRN & & \\
\hline CHEMBL1424929 & 737059 & 3.7959 & 4.5597 & TRN & & \\
\hline CHEMBL1891759 & 737059 & 3.7959 & 4.2087 & TST & & \\
\hline CHEMBL1466046 & 737059 & 4.9914 & 4.5478 & TRN & & \\
\hline CHEMBL1506234 & 737059 & 3.7959 & 4.8515 & TRN & & \\
\hline CHEMBL1611002 & 737059 & 5.5406 & 5.2997 & TRN & & \\
\hline CHEMBL1365898 & 737059 & 5.0894 & 4.4621 & TST & & \\
\hline CHEMBL1419164 & 737059 & 5.24799 & 999999999 & 99 & 4.3845 & TRN \\
\hline CHEMBL1309478 & 737059 & 3.7959 & 4.0844 & TRN & & \\
\hline CHEMBL1463795 & 737059 & 5.4672 & 5.2169 & TRN & & \\
\hline CHEMBL1367178 & 737059 & 4.98300 & 000000000 & 305 & 4.5399 & I א \\
\hline CHEMBL1312189 & 737059 & 3.7959 & 4.2134 & TST & & \\
\hline CHEMBL1386978 & 737059 & 3.7959 & 4.4531 & TRN & & \\
\hline CHEMBL1987895 & 737059 & 3.7959 & 4.0883 & TRN & & \\
\hline CHEMBL1898721 & 737059 & 3.7959 & 4.3255 & TRN & & \\
\hline CHEMBL1971611 & 737059 & 5.0315 & 4.5639 & TRN & & \\
\hline CHEMBL1407632 & 737059 & 5.0391 & 4.5798 & TRN & & \\
\hline
\end{tabular}


Supplemental Table S2.txt

\begin{tabular}{|c|c|c|c|c|c|}
\hline CHEMBL1989414 & 737059 & 5.7375 & 5.0497 & TRN & \\
\hline CHEMBL1388509 & 737059 & 4.9957 & 4.9227 & TRN & \\
\hline CHEMBL1517883 & 737059 & 3.7959 & 4.5746 & TRN & \\
\hline CHEMBL1348406 & 737059 & 5.4634 & 4.6508 & TRN & \\
\hline CHEMBL3189462 & 737059 & 5.0146 & 4.7711 & TRN & \\
\hline CHEMBL1559707 & 737059 & 5.5482 & 5.312 & TRN & \\
\hline CHEMBL1986889 & 737059 & 3.7959 & 4.8141 & TRN & \\
\hline CHEMBL1531133 & 737059 & 5.8539 & 5.0235 & TRN & \\
\hline CHEMBL1600976 & 737059 & 3.7959 & 4.5605 & TRN & \\
\hline CHEMBL1541316 & 737059 & 3.7959 & 5.0418 & TRN & \\
\hline CHEMBL1420142 & 737059 & 5.5884 & 4.4172 & TRN & \\
\hline CHEMBL1306714 & 737059 & 5.059 & 4.5899 & TST & \\
\hline CHEMBL1580066 & 737059 & 3.7959 & 4.2782 & TRN & \\
\hline CHEMBL1472080 & 737059 & 4.8601 & 4.7673 & TRN & \\
\hline CHEMBL1322871 & 737059 & 5.0931 & 4.3294 & TRN & \\
\hline CHEMBL1299502 & 737059 & 3.7959 & 4.1324 & TRN & \\
\hline CHEMBL1465435 & 737059 & 4.8894 & 4.1459 & TRN & \\
\hline CHEMBL1577981 & 737059 & 5.5391 & 4.9737 & TRN & \\
\hline CHEMBL1571034 & 737059 & 5.0685 & 4.5476 & TST & \\
\hline CHEMBL1401397 & 737059 & 5.2518 & 4.7186 & TRN & \\
\hline CHEMBL1606122 & 737059 & 3.7959 & 4.5717 & TST & \\
\hline CHEMBL1378294 & 737059 & 4.9914 & 5.5456 & TRN & \\
\hline CHEMBL3212655 & 737059 & 3.7959 & 4.5457 & TRN & \\
\hline CHEMBL1504421 & 737059 & 5.1649 & 5.0726 & TRN & \\
\hline CHEMBL1304179 & 737059 & 5.0048 & 4.7719 & TRN & \\
\hline CHEMBL1453231 & 737059 & 5.0958 & 4.5077 & TST & \\
\hline CHEMBL1331680 & 737059 & 4.9066 & 4.5357 & TRN & \\
\hline CHEMBL1547184 & 737059 & 3.7959 & 4.5596 & TRN & \\
\hline CHEMBL1428271 & 737059 & 4.8761 & 4.5114 & TRN & \\
\hline CHEMBL1550816 & 737059 & 3.7959 & 4.4058 & TRN & \\
\hline CHEMBL1539363 & 737059 & 3.7959 & 4.5527 & TRN & \\
\hline CHEMBL1346219 & 737059 & 4.8996 & 4.4434 & TST & \\
\hline CHEMBL1607959 & 737059 & 3.7959 & 4.2169 & TRN & \\
\hline CHEMBL1328361 & 737059 & 5.4763 & 4.1847 & TST & \\
\hline CHEMBL1988851 & 737059 & 3.7959 & 4.7534 & TRN & \\
\hline CHEMBL1566684 & 737059 & 5.0958 & 4.2257 & TRN & \\
\hline CHEMBL1604962 & 737059 & 5.5918 & 5.1315 & TRN & \\
\hline CHEMBL1984584 & 737059 & 4.9666 & 4.442 & TRN & \\
\hline CHEMBL1430184 & 737059 & 3.7959 & 4.4078 & TRN & \\
\hline CHEMBL1468500 & 737059 & 3.7959 & 4.3229 & TST & \\
\hline CHEMBL1454879 & 737059 & 5.3478 & 4.6943 & TRN & \\
\hline CHEMBL1511298 & 737059 & 5.0496 & 4.6597 & TRN & \\
\hline CHEMBL1526126 & 737059 & 5.0367 & 5.3148 & TRN & \\
\hline CHEMBL1353754 & 737059 & 3.7959 & 4.3541 & TST & \\
\hline CHEMBL1503122 & 737059 & 3.7959 & 4.3416 & TRN & \\
\hline CHEMBL1306708 & 737059 & \multicolumn{3}{|c|}{4.9830000000000005} & 4.478 \\
\hline CHEMBL1335787 & 737059 & 5.0701 & 4.5182 & TST & \\
\hline CHEMBL1999014 & 737059 & 3.7959 & 4.6785 & TRN & \\
\hline
\end{tabular}




\begin{tabular}{|c|c|c|c|c|c|}
\hline \multirow[b]{2}{*}{ CHEMBL1352344 } & \multicolumn{5}{|c|}{ Supplemental Table S2.txt } \\
\hline & 737059 & 3.7959 & 4.4026 & TRN & \\
\hline CHEMBL1491798 & 737059 & 5.266 & 4.1935 & TRN & \\
\hline CHEMBL1419714 & 737059 & 3.7959 & 4.7126 & TRN & \\
\hline CHEMBL1602160 & 737059 & 6.0 & 5.4981 & TRN & \\
\hline CHEMBL1446608 & 737059 & 5.0511 & 4.483006 & 00000000005 & TST \\
\hline CHEMBL1483471 & 737059 & 5.2518 & 5.2185 & TRN & \\
\hline CHEMBL1492044 & 737059 & 6.3575 & 4.358006 & 00000000005 & TST \\
\hline CHEMBL1418656 & 737059 & 5.2668 & 4.4474 & TRN & \\
\hline CHEMBL 236615 & 737059 & 3.7959 & 4.7215 & TRN & \\
\hline CHEMBL3212445 & 737059 & 3.7959 & 4.316 & TST & \\
\hline CHEMBL1480005 & 737059 & 5.0372 & 4.4863 & TRN & \\
\hline CHEMBL1369513 & 737059 & 3.7959 & 4.9333 & TRN & \\
\hline CHEMBL1565600 & 737059 & 5.0752 & 4.4883 & TRN & \\
\hline CHEMBL1332059 & 737059 & 5.0057 & 4.6808 & TST & \\
\hline CHEMBL1406758 & 737059 & 5.0 & 5.0741 & TRN & \\
\hline CHEMBL1498530 & 737059 & 5.7696 & 4.7523 & TRN & \\
\hline CHEMBL2006258 & 737059 & 5.5901 & 5.6347 & TRN & \\
\hline CHEMBL1471761 & 737059 & 5.0809 & 5.1758 & TRN & \\
\hline CHEMBL1349197 & 737059 & 3.7959 & 4.478 & TST & \\
\hline CHEMBL1423165 & 737059 & 5.1215 & 4.4692 & TRN & \\
\hline CHEMBL1440262 & 737059 & 5.1337 & 4.394 & TRN & \\
\hline CHEMBL1370844 & 737059 & 3.7959 & 4.1969 & TRN & \\
\hline CHEMBL3192206 & 737059 & 3.7959 & 4.2746 & TST & \\
\hline CHEMBL1496666 & 737059 & 5.4225 & 4.4742 & TST & \\
\hline CHEMBL1547938 & 737059 & 4.8633 & 4.3677 & TRN & \\
\hline CHEMBL1323013 & 737059 & 4.8327 & 4.8347 & TRN & \\
\hline CHEMBL1995681 & 737059 & 5.466 & 4.2407 & TST & \\
\hline CHEMBL1342798 & 737059 & 5.0862 & 4.1736 & TRN & \\
\hline CHEMBL1991303 & 737059 & 3.7959 & 4.3397 & TRN & \\
\hline CHEMBL1308455 & 737059 & 3.7959 & 4.2674 & TRN & \\
\hline CHEMBL1410838 & 737059 & 3.7959 & 4.2223 & TRN & \\
\hline CHEMBL1724937 & 737059 & 5.3391 & 4.7165 & TRN & \\
\hline CHEMBL533293 & 737059 & 7.6021 & 6.2904 & TRN & \\
\hline CHEMBL1550089 & 737059 & 3.7959 & 4.2423 & TRN & \\
\hline CHEMBL1439668 & 737059 & 4.9245 & 4.4799 & TST & \\
\hline CHEMBL1549128 & 737059 & 3.7959 & 5.0297 & TST & \\
\hline CHEMBL1982477 & 737059 & 3.7959 & $4.36600 t$ & 00000000005 & TRN \\
\hline CHEMBL1995041 & 737059 & 3.7959 & 4.3641 & TRN & \\
\hline CHEMBL1437947 & 737059 & 4.9666 & 4.9519 & TRN & \\
\hline CHEMBL1353112 & 737059 & 6.0186 & 5.4091 & TRN & \\
\hline CHEMBL1964615 & 737059 & 3.7959 & 4.2972 & TST & \\
\hline CHEMBL1308255 & 737059 & 3.7959 & 4.1238 & TRN & \\
\hline CHEMBL1979622 & 737059 & 3.7959 & 5.0209 & TRN & \\
\hline CHEMBL1329915 & 737059 & 4.9318 & 4.5522 & TST & \\
\hline CHEMBL1471789 & 737059 & 3.7959 & 4.1973 & TRN & \\
\hline CHEMBL1990748 & 737059 & 4.8447 & 4.3971 & TRN & \\
\hline CHEMBL1531654 & 737059 & 3.7959 & 4.3686 & TRN & \\
\hline CHEMBL1349390 & 737059 & 3.7959 & 4.3868 & TRN & \\
\hline
\end{tabular}


Supplemental Table S2.txt

\begin{tabular}{|c|c|c|c|c|}
\hline IE & & 36 & & \\
\hline UГМ I 17201 & & & 4.24 & \\
\hline 82 & & & & \\
\hline HEMBL200 & 9 & 224 & 2297 & \\
\hline AEMBL1323828 & 37059 & 208 & 0017 & \\
\hline HEMBL1548928 & 37059 & 3.7959 & 3361 & \\
\hline HEMBL139 & 59 & 959 & & \\
\hline AFMBI 198 & & & & \\
\hline AEMBL1582888 & 59 & 1296 & 5936 & \\
\hline HEMBL1600766 & 37059 & 487 & 5944 & \\
\hline AEMBL1463574 & 59 & & 66 & \\
\hline IEMBL15C & 59 & 55 & & \\
\hline AEMBL13 & & & & \\
\hline HEMBL141 & 59 & 959 & 3245 & \\
\hline AEMBL13 & & & & \\
\hline IEMBL14 & 59 & 959 & 32 & \\
\hline HEMBL14 & 59 & & & \\
\hline HEMBL 31 & & & & \\
\hline HEMBL14 & & & & \\
\hline AEMBL13 & & & & \\
\hline IE/MBLI3 & 59 & 33 & 03 & \\
\hline AEMBL14 & & & & \\
\hline HEMBL13 & 59 & & & \\
\hline IEMBL16 & & & & \\
\hline HEMBL $20 €$ & & & & \\
\hline HEMBL14 & 9 & 9 & 18 & \\
\hline HEMBL15 & & & & \\
\hline HFMBI 15 & & & & \\
\hline HEMBL13\& & & & & \\
\hline HEMBL144 & & & & KN \\
\hline HEMBL13 & & & & RN \\
\hline HEMBL1S & & & & Niv \\
\hline AEMBL13 & & & 67 & RN \\
\hline HEMBL1996555 & & & & RN \\
\hline HEMBL1352607 & & & 322 & TRN \\
\hline HEMBL13 & & 57 & 86 & \\
\hline HEMRI 1 & & 9 & & RN \\
\hline HEMBL15 & & & & RN \\
\hline HEMBL1310204 & & 3251 & & TRN \\
\hline IEMBL13 & & & 746 & RN \\
\hline HEMBL19 & & 57 & 798 & \\
\hline HEMBL 143 & & & & RN \\
\hline HEMBL1389510 & 59 & 4.9431 & 4119 & TST \\
\hline HEMBL1372672 & 59 & 7959 & 807 & ГRN \\
\hline MPI 3 & & & & \\
\hline HEMBL19 & & & 3264 & \\
\hline CHEMBL199894e & & & .5147 & \\
\hline SHEMBL160248s & 737059 & 3.7959 & 4.4487 & - \\
\hline
\end{tabular}

Page 28358 


\begin{tabular}{|c|c|c|c|c|c|}
\hline & & \multicolumn{4}{|c|}{ Supplemental Table S2.txt } \\
\hline CHEMBL1388372 & 737059 & 6.0088 & 4.455 & TRN & \\
\hline CHEMBL1457844 & 737059 & 3.7959 & 5.2689 & TRN & \\
\hline CHEMBL1340454 & 737059 & 5.04 & 5.0713 & TRN & \\
\hline CHEMBL1561538 & 737059 & 3.7959 & 4.084 & TST & \\
\hline CHEMBL1507424 & 737059 & 3.7959 & 4.9121 & TRN & \\
\hline CHEMBL1587433 & 737059 & 5.0472 & 4.6708 & TRN & \\
\hline CHEMBL1404787 & 737059 & 3.7959 & 4.2801 & TRN & \\
\hline CHEMBL1466913 & 737059 & 3.7959 & 4.4496 & TRN & \\
\hline CHEMBL1508769 & 737059 & 3.7959 & 4.2917 & TRN & \\
\hline CHEMBL1089894 & 737059 & 3.7959 & 4.04899 & 99999999995 & TRN \\
\hline CHEMBL1580969 & 737059 & 3.7959 & 4.2009 & TRN & \\
\hline CHEMBL1467088 & 737059 & 4.8697 & 4.5053 & TRN & \\
\hline CHEMBL 2006684 & 737059 & 3.7959 & 5.0483 & TRN & \\
\hline CHEMBL1415999 & 737059 & 3.7959 & 4.4642 & TRN & \\
\hline CHEMBL1424559 & 737059 & 4.9031 & 4.6742 & TRN & \\
\hline CHEMBL1336788 & 737059 & 3.7959 & 4.5798 & TRN & \\
\hline CHEMBL1402546 & 737059 & 5.3344 & 4.5417 & TST & \\
\hline CHEMBL3195681 & 737059 & 6.4449 & 5.8482 & TRN & \\
\hline CHEMBL1352283 & 737059 & 4.9393 & 4.5494 & TST & \\
\hline CHEMBL1367521 & 737059 & 3.7959 & 4.401 & TST & \\
\hline CHEMBL1574521 & 737059 & 5.7932 & 4.2972 & TRN & \\
\hline CHEMBL1440883 & 737059 & 3.7959 & 4.3195 & TRN & \\
\hline CHEMBL1549568 & 737059 & 3.7959 & 4.7774 & TST & \\
\hline CHEMBL1344297 & 737059 & 3.7959 & 4.1783 & TRN & \\
\hline CHEMBL2005139 & 737059 & 5.5482 & 5.0529 & TST & \\
\hline CHEMBL1564153 & 737059 & 3.7959 & 4.41 & TRN & \\
\hline CHEMBL2003304 & 737059 & 5.4214 & 4.6053 & TRN & \\
\hline CHEMBL1472131 & 737059 & 5.7721 & 4.9475 & TRN & \\
\hline CHEMBL1448013 & 737059 & 3.7959 & 4.5568 & TRN & \\
\hline CHEMBL1565500 & 737059 & 5.058 & 5.5543 & TRN & \\
\hline CHEMBL1983530 & 737059 & 3.7959 & 4.3976 & TST & \\
\hline CHEMBL1439189 & 737059 & 3.7959 & 4.5079 & TST & \\
\hline CHEMBL1305230 & 737059 & 3.7959 & 4.5899 & TST & \\
\hline CHEMBL1995565 & 737059 & 5.3134 & 4.2636 & TST & \\
\hline CHEMBL1516758 & 737059 & 5.1759 & 4.6414 & TST & \\
\hline CHEMBL1526494 & 737059 & 3.7959 & 4.189 & TST & \\
\hline CHEMBL1384436 & 737059 & 3.7959 & 4.4006 & TST & \\
\hline CHEMBL1543673 & 737059 & 3.7959 & 4.5786 & TST & \\
\hline CHEMBL1682065 & 727385 & 4.6778 & 4.5656 & TST & \\
\hline CHEMBL1685079 & 727385 & 4.9208 & 4.7737 & TRN & \\
\hline CHEMBL1685077 & 727385 & 4.4949 & 4.6841 & TRN & \\
\hline CHEMBL1682026 & 727385 & 4.2924 & 4.3807 & TRN & \\
\hline CHEMBL1682069 & 727385 & 3.0 & 3.6883 & TST & \\
\hline CHEMBL1685083 & 727385 & 4.7212 & 4.7465 & TRN & \\
\hline CHEMBL1682038 & 727385 & 4.3872 & 4.5821 & TRN & \\
\hline CHEMBL1682068 & 727385 & 4.8239 & 4.0942 & TST & \\
\hline CHEMBL1682057 & 727385 & 4.2007 & 4.7125 & TRN & \\
\hline CHEMBL1682047 & 727385 & 4.1192 & 4.0921 & TRN & \\
\hline
\end{tabular}




\begin{tabular}{|c|c|c|c|c|}
\hline & & & pplement & al $\mathrm{T}$ \\
\hline CHEMBL1682050 & 727385 & 4.7959 & 4.8743 & TRN \\
\hline CHEMBL1682053 & 727385 & 4.3372 & 4.4614 & TRN \\
\hline CHEMBL1682051 & 727385 & 4.7447 & 4.9429 & TRN \\
\hline CHEMBL1682070 & 727385 & 3.0 & 4.0176 & TST \\
\hline CHEMBL218227 & 727385 & 6.2218 & 4.5696 & TST \\
\hline CHEMBL1682030 & 727385 & 4.8861 & 4.9894 & TRN \\
\hline CHEMBL1682063 & 727385 & 4.301 & 4.0591 & TRN \\
\hline CHEMBL1682055 & 727385 & 4.9586 & 4.9607 & TRN \\
\hline CHEMBL1682044 & 727385 & 4.4089 & 4.5508 & TRN \\
\hline CHEMBL1682040 & 727385 & 4.6198 & 4.5907 & TRN \\
\hline CHEMBL1682034 & 727385 & 4.0362 & 4.4565 & TRN \\
\hline CHEMBL1685080 & 727385 & 5.301 & 5.0318 & TRN \\
\hline CHEMBL1682029 & 727385 & 4.8539 & 4.9446 & TRN \\
\hline CHEMBL1682039 & 727385 & 4.7696 & 4.7002 & TRN \\
\hline CHEMBL1682046 & 727385 & 4.1192 & 4.0128 & TRN \\
\hline CHEMBL1682056 & 727385 & 4.7959 & 4.2306 & TRN \\
\hline CHEMBL1682042 & 727385 & 4.5376 & 4.6598 & TRN \\
\hline CHEMBL1685075 & 727385 & 4.6021 & 4.7194 & TRN \\
\hline CHEMBL1685084 & 727385 & 4.4685 & 4.4713 & TRN \\
\hline CHEMBL1682058 & 727385 & 4.284 & 4.2423 & TRN \\
\hline CHEMBL1682036 & 727385 & 4.7696 & 4.6699 & TRN \\
\hline CHEMBL1682049 & 727385 & 4.7447 & 4.8215 & TRN \\
\hline CHEMBL1682060 & 727385 & 4.7447 & 4.9343 & TRN \\
\hline CHEMBL1682067 & 727385 & 4.2441 & 4.1258 & TST \\
\hline CHEMBL1682045 & 727385 & 4.2366 & 4.195 & TRN \\
\hline CHEMBL1682032 & 727385 & 4.2757 & 4.5331 & TRN \\
\hline CHEMBL1685076 & 727385 & 4.8539 & 4.7726 & TRN \\
\hline CHEMBL1682041 & 727385 & 4.5229 & 4.5583 & TRN \\
\hline CHEMBL1682043 & 727385 & 4.8239 & 4.7652 & TRN \\
\hline CHEMBL1682061 & 727385 & 4.2291 & 4.6938 & TRN \\
\hline CHEMBL1682028 & 727385 & 4.7959 & 4.8161 & TRN \\
\hline CHEMBL1682035 & 727385 & 4.6021 & 4.5348 & TRN \\
\hline CHEMBL1682066 & 727385 & 5.0969 & 4.0368 & TST \\
\hline CHEMBL1682064 & 727385 & 4.1675 & 4.0417 & TST \\
\hline CHEMBL1682052 & 727385 & 4.2596 & 4.4193 & TST \\
\hline CHEMBL1685082 & 727385 & 5.1549 & 4.885 & TRN \\
\hline CHEMBL1682037 & 727385 & 4.5229 & 4.5661 & TRN \\
\hline CHEMBL1685081 & 727385 & 4.4559 & 4.8236 & TRN \\
\hline CHEMBL1682048 & 727385 & 5.0458 & 4.8546 & TRN \\
\hline CHEMBL1682031 & 727385 & 6.4318 & 4.9453 & TRN \\
\hline CHEMBL1682062 & 727385 & 4.3565 & 4.2837 & TRN \\
\hline CHEMBL1685078 & 727385 & 5.0458 & 4.8146 & TST \\
\hline CHEMBL1682054 & 727385 & 4.2676 & 4.4578 & TST \\
\hline CHEMBL1682059 & 727385 & 4.4949 & 4.7402 & TST \\
\hline CHEMBL1682027 & 727385 & 4.7447 & 4.8555 & TST \\
\hline CHEMBL1682033 & 727385 & 3.0 & 4.1787 & TST \\
\hline CHEMBL 289492 & 176323 & 5.585 & 5.4935 & TRN \\
\hline CHEMBL 288241 & 176323 & 3.0 & 3.415 & TRN \\
\hline
\end{tabular}




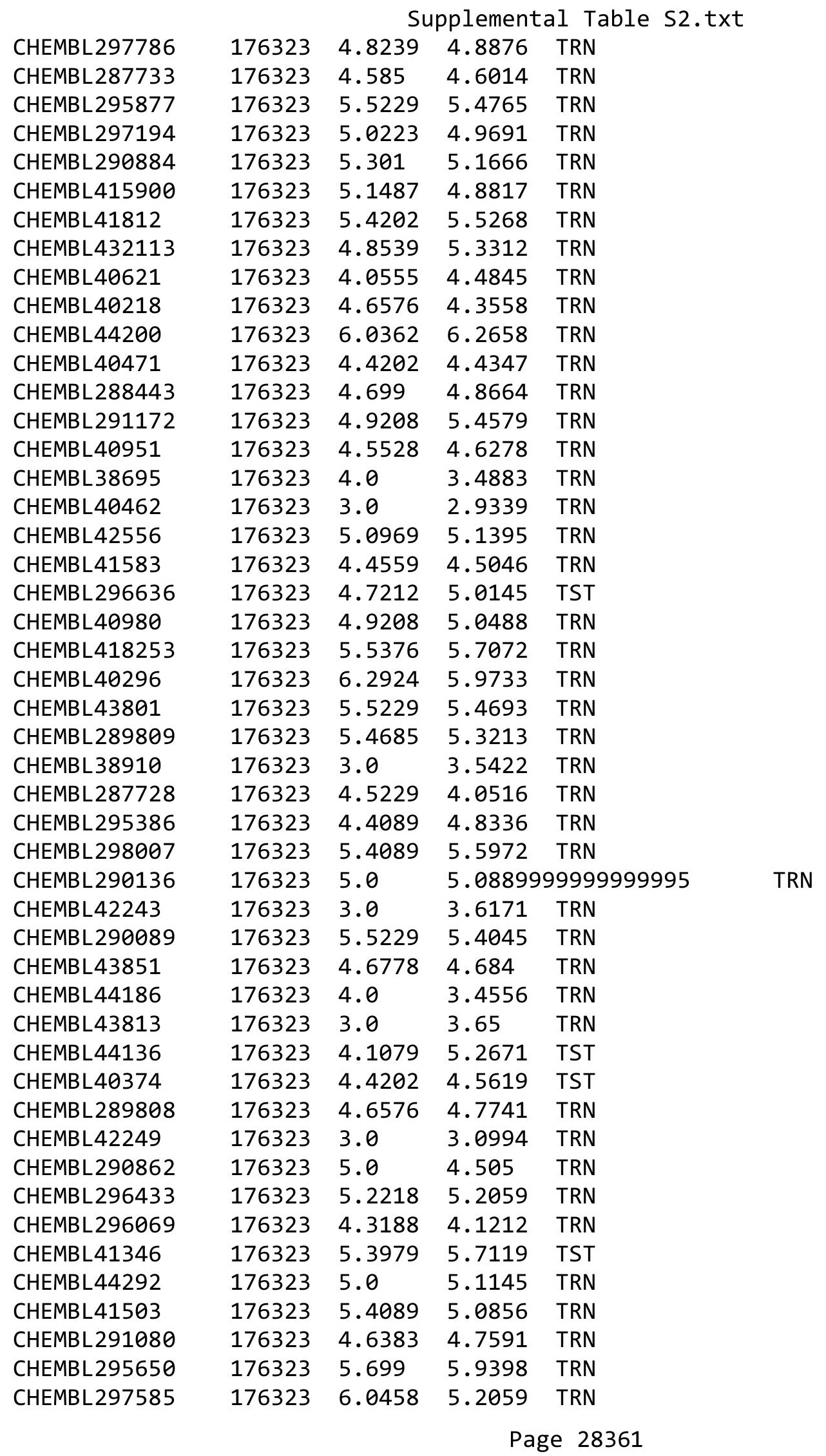




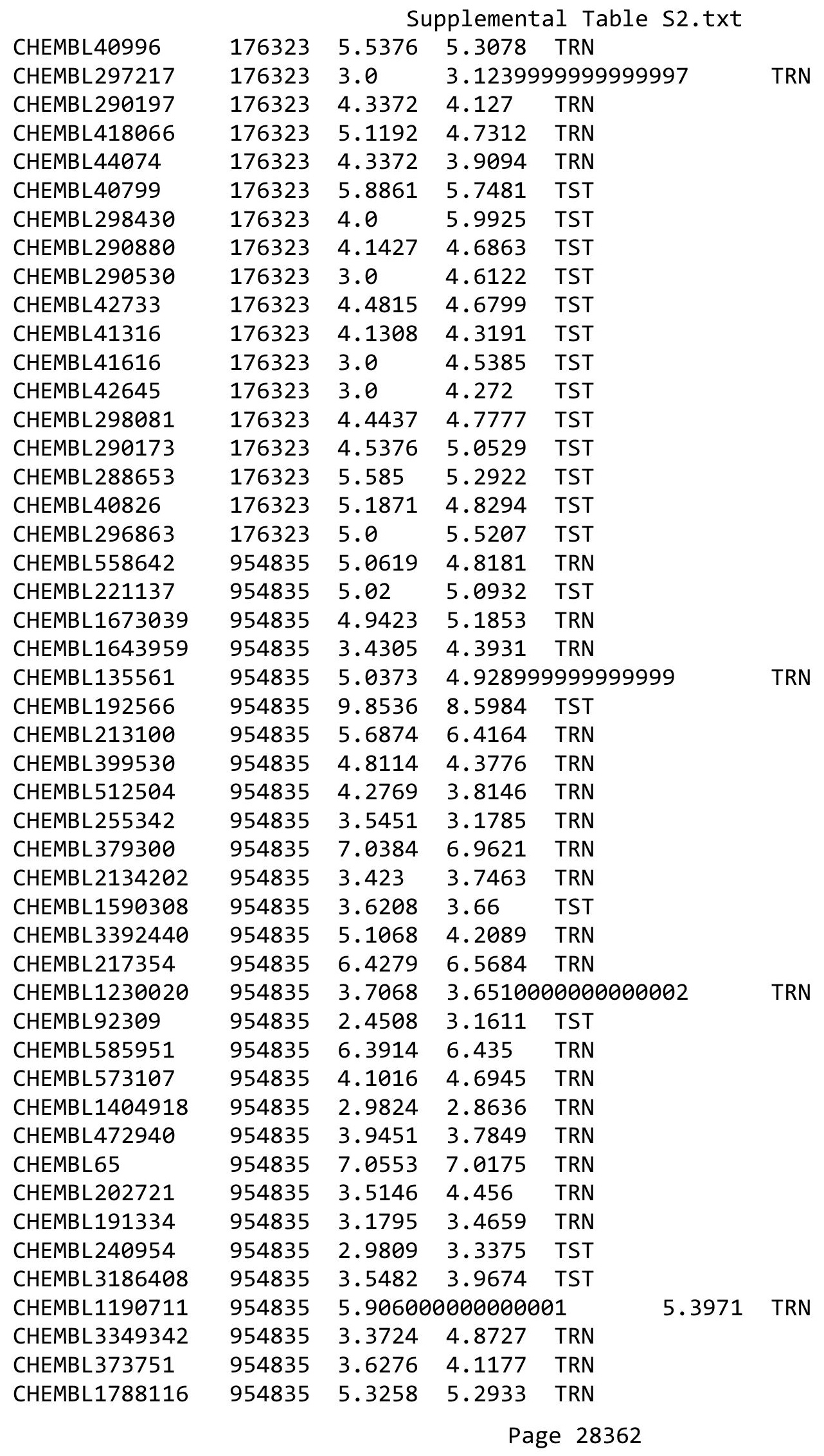




\begin{tabular}{|c|c|c|c|c|c|}
\hline \multirow[b]{2}{*}{ CHEMBL188678 } & \multicolumn{5}{|c|}{ Supplemental Table S } \\
\hline & 954835 & 4.2313 & 3.9983 & TRN & \\
\hline CHEMBL509032 & 954835 & 6.1104 & 6.3708 & TRN & \\
\hline CHEMBL577784 & 954835 & 5.1647 & 5.0255 & TRN & \\
\hline CHEMBL222102 & 954835 & 3.6116 & 3.4506 & TRN & \\
\hline CHEMBL1516890 & 954835 & 4.1055 & 3.9995 & TRN & \\
\hline CHEMBL220241 & 954835 & 6.6067 & 5.3003 & TRN & \\
\hline CHEMBL 2144069 & 954835 & 4.6911 & 4.9009 & TRN & \\
\hline CHEMBL 2137530 & 954835 & 4.7346 & 4.7496 & TRN & \\
\hline CHEMBL1357247 & 954835 & 3.4609 & 3.5311 & TRN & \\
\hline CHEMBL514499 & 954835 & 8.2081 & 7.6507 & TRN & \\
\hline CHEMBL1242367 & 954835 & 3.9122 & 4.8689 & TRN & \\
\hline CHEMBL379975 & 954835 & 3.9719 & 4.3092 & TRN & \\
\hline CHEMBL483847 & 954835 & 5.4876 & 4.7022 & TRN & \\
\hline CHEMBL 9470 & 954835 & 5.1036 & 5.9947 & TST & \\
\hline CHEMBL1970879 & 954835 & 5.7068 & 6.1391 & TRN & \\
\hline CHEMBL1909414 & 954835 & 3.4673 & 3.221 & TRN & \\
\hline CHEMBL2363137 & 954835 & 5.519 & 5.2534 & TRN & \\
\hline CHEMBL 3199475 & 954835 & 5.8277 & 4.5618 & TRN & \\
\hline CHEMBL 259181 & 954835 & 4.9066 & 4.8876 & TRN & \\
\hline CHEMBL1186585 & 954835 & 3.7862 & 3.6868 & TRN & \\
\hline CHEMBL1256459 & 954835 & 7.9654 & 8.0625 & TRN & \\
\hline CHEMBL 300389 & 954835 & 8.0567 & 7.5853 & TRN & \\
\hline CHEMBL483849 & 954835 & 1.6533 & 1.8534 & TST & \\
\hline CHEMBL449158 & 954835 & 6.7118 & 7.002000 & 0000000001 & TST \\
\hline CHEMBL189584 & 954835 & 3.7881 & 4.1625 & TRN & \\
\hline CHEMBL412142 & 954835 & 4.2527 & 4.4541 & TRN & \\
\hline CHEMBL180127 & 954835 & 4.5493 & 4.5007 & TRN & \\
\hline CHEMBL102714 & 954835 & 2.8356 & 3.2434 & TST & \\
\hline CHEMBL 210618 & 954835 & 3.5068 & 3.2947 & TST & \\
\hline CHEMBL392695 & 954835 & 4.53 & 5.6086 & TST & \\
\hline CHEMBL 2005886 & 954835 & 6.3719 & 6.2566 & TST & \\
\hline CHEMBL515416 & 954835 & 4.1585 & 4.9961 & TST & \\
\hline CHEMBL393929 & 954835 & 4.5281 & 3.6858 & TST & \\
\hline CHEMBL 258844 & 954835 & 5.0663 & 4.8825 & TST & \\
\hline CHEMBL209148 & 954835 & 5.6737 & 4.9853 & TST & \\
\hline CHEMBL 3717967 & 1536917 & 6.9957 & 6.1559 & TRN & \\
\hline CHEMBL3719101 & 1536917 & 11.0 & 10.6886 & TRN & \\
\hline CHEMBL 3718497 & 1536917 & 11.0 & 10.3662 & TRN & \\
\hline CHEMBL 3719358 & 1536917 & 6.9957 & 5.3842 & TRN & \\
\hline CHEMBL 3717158 & 1536917 & 6.9957 & 8.0875 & TRN & \\
\hline CHEMBL 3716195 & 1536917 & 6.9957 & 5.8978 & TST & \\
\hline CHEMBL3715095 & 1536917 & 6.9957 & 6.8311 & TRN & \\
\hline CHEMBL3719100 & 1536917 & 11.0 & 9.1824 & TRN & \\
\hline CHEMBL 3715443 & 1536917 & 11.0 & 10.2061 & TRN & \\
\hline CHEMBL 3718076 & 1536917 & 6.3002 & 7.3685 & TRN & \\
\hline CHEMBL 3716889 & 1536917 & 11.0 & 11.0121 & TRN & \\
\hline CHEMBL 3717796 & 1536917 & 6.0 & 6.9035 & TRN & \\
\hline CHEMBL 3715080 & 1536917 & 6.9957 & 5.9649 & TRN & \\
\hline
\end{tabular}

Page 28363 
Supplemental Table S2.txt

\begin{tabular}{|c|c|c|c|c|c|}
\hline CHEMBL3716225 & 1536917 & 6.3002 & 6.3697 & TRN & \\
\hline CHEMBL3717133 & 1536917 & 6.9957 & 8.4131 & TRN & \\
\hline CHEMBL3719258 & 1536917 & 11.0 & 10.9199 & TRN & \\
\hline CHEMBL 3715009 & 1536917 & 6.9957 & 5.9225 & TRN & \\
\hline CHEMBL 3717201 & 1536917 & 11.0 & 11.9488 & TRN & \\
\hline CHEMBL 3716882 & 1536917 & 6.9957 & 5.1651 & TST & \\
\hline CHEMBL3717790 & 1536917 & 11.0 & 9.6135 & TRN & \\
\hline CHEMBL3719374 & 1536917 & 11.0 & 10.4649 & TRN & \\
\hline CHEMBL 3718828 & 1536917 & 6.9957 & 6.7913 & TRN & \\
\hline CHEMBL3718618 & 1536917 & 6.0 & 7.4426 & TRN & \\
\hline CHEMBL 3717251 & 1536917 & 6.9957 & 7.5995 & TRN & \\
\hline CHEMBL3715918 & 1536917 & 6.9957 & 9.1806 & TRN & \\
\hline CHEMBL 3717963 & 1536917 & 11.0 & 9.6845 & TRN & \\
\hline CHEMBL3717905 & 1536917 & 11.0 & 10.1487 & TRN & \\
\hline CHEMBL 3714813 & 1536917 & 6.9957 & 9.9262 & TST & \\
\hline CHEMBL3715656 & 1536917 & 11.0 & 10.1305 & TRN & \\
\hline CHEMBL3719364 & 1536917 & 11.0 & 9.9172 & TST & \\
\hline CHEMBL3717453 & 1536917 & 6.9957 & 7.9982 & TRN & \\
\hline CHEMBL 3718288 & 1536917 & 6.9957 & 8.0383 & TST & \\
\hline CHEMBL 3718192 & 1536917 & 11.0 & 10.3965 & TST & \\
\hline CHEMBL 3714827 & 1536917 & 6.9957 & 6.2705 & TRN & \\
\hline CHEMBL3717936 & 1536917 & 6.3002 & 5.888999 & 9999999999 & TRN \\
\hline CHEMBL3715459 & 1536917 & 6.9957 & 5.8615 & TRN & \\
\hline CHEMBL 3715870 & 1536917 & 6.9957 & 9.7665 & TST & \\
\hline CHEMBL 3716784 & 1536917 & 6.0 & 8.5108 & TRN & \\
\hline CHEMBL 3716680 & 1536917 & 6.3002 & 6.1564 & TRN & \\
\hline CHEMBL3717641 & 1536917 & 11.0 & 9.9856 & TRN & \\
\hline CHEMBL3718413 & 1536917 & 6.0 & 7.084 & TRN & \\
\hline CHEMBL 3714785 & 1536917 & 11.0 & 10.2857 & TRN & \\
\hline CHEMBL3716123 & 1536917 & 11.0 & 9.5026 & TRN & \\
\hline CHEMBL3716159 & 1536917 & 11.0 & 9.4685 & TRN & \\
\hline CHEMBL3716121 & 1536917 & 6.9957 & 7.814 & TRN & \\
\hline CHEMBL3718802 & 1536917 & 6.9957 & 6.6895 & TRN & \\
\hline CHEMBL 3716561 & 1536917 & 11.0 & 9.2532 & TRN & \\
\hline CHEMBL3719137 & 1536917 & 6.9957 & 6.4041 & TRN & \\
\hline CHEMBL3715192 & 1536917 & 11.0 & 11.0638 & TRN & \\
\hline CHEMBL3715923 & 1536917 & 11.0 & 9.6112 & TRN & \\
\hline CHEMBL 3716184 & 1536917 & 11.0 & 7.9249 & TRN & \\
\hline CHEMBL 3716446 & 1536917 & 11.0 & 9.0054 & TST & \\
\hline CHEMBL3716433 & 1536917 & 6.9957 & 7.6979 & TRN & \\
\hline CHEMBL3718436 & 1536917 & 6.9957 & 8.1171 & TRN & \\
\hline CHEMBL 3717753 & 1536917 & 11.0 & 10.2391 & TRN & \\
\hline CHEMBL3718719 & 1536917 & 6.9957 & 8.3072 & TRN & \\
\hline CHEMBL 3716728 & 1536917 & 11.0 & 11.7513 & TRN & \\
\hline CHEMBL3718999 & 1536917 & 11.0 & 10.9229 & TRN & \\
\hline CHEMBL 3717473 & 1536917 & 6.9957 & 9.9241 & TST & \\
\hline CHEMBL 3717600 & 1536917 & 11.0 & 9.1801 & TRN & \\
\hline CHEMBL 3718036 & 1536917 & 6.9957 & 8.7521 & TRN & \\
\hline
\end{tabular}

Page 28364 


\begin{tabular}{|c|c|c|c|c|c|}
\hline \multicolumn{6}{|c|}{ Supplemental Table S2.txt } \\
\hline CHEMBL3715817 & 1536917 & 11.0 & 9.9822 & TRN & \\
\hline CHEMBL 3718012 & 1536917 & 6.9957 & 7.801 & TST & \\
\hline CHEMBL3715879 & 1536917 & 6.9957 & 7.8043 & TST & \\
\hline CHEMBL3715679 & 1536917 & 6.9957 & 9.3948 & TRN & \\
\hline CHEMBL 3716050 & 1536917 & 6.9957 & 6.9555 & TRN & \\
\hline CHEMBL 3718720 & 1536917 & 6.0 & 8.6388 & TRN & \\
\hline CHEMBL3716365 & 1536917 & 6.0 & 8.343 & TRN & \\
\hline CHEMBL3716722 & 1536917 & 11.0 & 8.61399 & 9999999999 & TRN \\
\hline CHEMBL 3715265 & 1536917 & 6.9957 & 8.29 & TRN & \\
\hline CHEMBL3718005 & 1536917 & 11.0 & 7.0347 & TST & \\
\hline CHEMBL 3715540 & 1536917 & 6.9957 & 9.3221 & TRN & \\
\hline CHEMBL 3714783 & 1536917 & 11.0 & 9.1409 & TRN & \\
\hline CHEMBL3718818 & 1536917 & 6.9957 & 6.1375 & TRN & \\
\hline CHEMBL3717983 & 1536917 & 6.9957 & 8.3406 & TRN & \\
\hline CHEMBL3718290 & 1536917 & 6.9957 & 6.7887 & TRN & \\
\hline CHEMBL 3718528 & 1536917 & 11.0 & 11.1128 & TRN & \\
\hline CHEMBL3718792 & 1536917 & 6.3002 & 5.9171 & TRN & \\
\hline CHEMBL3719139 & 1536917 & 6.3002 & 5.9027 & TRN & \\
\hline CHEMBL3717809 & 1536917 & 11.0 & 9.9032 & TRN & \\
\hline CHEMBL 3715594 & 1536917 & 6.9957 & 6.9219 & TRN & \\
\hline CHEMBL3719143 & 1536917 & 6.0 & 6.9221 & TRN & \\
\hline CHEMBL3719080 & 1536917 & 11.0 & 9.9025 & TRN & \\
\hline CHEMBL3715088 & 1536917 & 11.0 & 10.3651 & TRN & \\
\hline CHEMBL3718852 & 1536917 & 6.3002 & 11.7383 & TST & \\
\hline CHEMBL3715690 & 1536917 & 6.9957 & 5.6394 & TRN & \\
\hline CHEMBL3718711 & 1536917 & 6.3002 & 9.5653 & TST & \\
\hline CHEMBL 3717471 & 1536917 & 6.9957 & 9.219 & TRN & \\
\hline CHEMBL3716527 & 1536917 & 11.0 & 11.5086 & TRN & \\
\hline CHEMBL 3716848 & 1536917 & 6.3002 & 7.0743 & TRN & \\
\hline CHEMBL3719125 & 1536917 & 6.3002 & 6.4613 & TRN & \\
\hline CHEMBL 3717561 & 1536917 & 6.9957 & 8.1487 & TRN & \\
\hline CHEMBL3717016 & 1536917 & 6.9957 & 6.6009 & TRN & \\
\hline CHEMBL3716958 & 1536917 & 11.0 & 10.9222 & TRN & \\
\hline CHEMBL3717001 & 1536917 & 6.3002 & 7.5572 & TRN & \\
\hline CHEMBL 3718244 & 1536917 & 11.0 & 11.3363 & TST & \\
\hline CHEMBL3716857 & 1536917 & 6.9957 & 8.8819 & TRN & \\
\hline CHEMBL3716157 & 1536917 & 6.9957 & 7.0754 & TRN & \\
\hline CHEMBL3716729 & 1536917 & 6.3002 & 4.9195 & TST & \\
\hline CHEMBL3714806 & 1536917 & 11.0 & 9.7993 & TRN & \\
\hline CHEMBL 3718080 & 1536917 & 11.0 & 10.024 & TRN & \\
\hline CHEMBL3718113 & 1536917 & 6.9957 & 6.9802 & TRN & \\
\hline CHEMBL 3717415 & 1536917 & 6.9957 & 7.4759 & TRN & \\
\hline CHEMBL3718332 & 1536917 & 6.9957 & 7.4797 & TST & \\
\hline CHEMBL3716619 & 1536917 & 6.9957 & 8.7557 & TRN & \\
\hline CHEMBL 3718174 & 1536917 & 6.9957 & 8.3767 & TST & \\
\hline CHEMBL3717755 & 1536917 & 6.0 & 8.7935 & TST & \\
\hline CHEMBL3715055 & 1536917 & 6.9957 & 10.7423 & TST & \\
\hline CHEMBL3717795 & 1536917 & 11.0 & 9.3042 & TST & \\
\hline
\end{tabular}




\begin{tabular}{|c|c|c|c|c|c|}
\hline \multicolumn{6}{|c|}{ Supplemental Table S2.txt } \\
\hline CHEMBL 3717853 & 1536917 & 11.0 & 7.8719 & TST & \\
\hline CHEMBL 3716280 & 1536917 & 11.0 & 9.1878 & TST & \\
\hline CHEMBL 3714871 & 1536917 & 6.3002 & 5.8165 & TST & \\
\hline CHEMBL 3716528 & 1536917 & 11.0 & 9.5925 & TST & \\
\hline CHEMBL3717086 & 1536917 & 6.0 & 8.5596 & TST & \\
\hline CHEMBL 3716024 & 1536917 & 11.0 & 8.9046 & TST & \\
\hline CHEMBL 3718350 & 1536917 & 11.0 & 7.4092 & TST & \\
\hline CHEMBL3718393 & 1536917 & 6.9957 & 8.0916 & TST & \\
\hline CHEMBL3719155 & 1536917 & 4.9996 & 8.5222 & TST & \\
\hline CHEMBL201105 & 330757 & 5.7496 & 5.5918 & TRN & \\
\hline CHEMBL 382503 & 330757 & 6.0177 & 6.074 & TRN & \\
\hline CHEMBL202497 & 330757 & 3.2464 & 4.3456 & TST & \\
\hline CHEMBL370815 & 330757 & 3.5622 & 3.5408 & TRN & \\
\hline CHEMBL370343 & 330757 & 4.1308 & 3.9833 & TRN & \\
\hline CHEMBL 373070 & 330757 & 6.0315 & 6.1975 & TRN & \\
\hline CHEMBL 377926 & 330757 & 6.3372 & 6.3385 & TRN & \\
\hline CHEMBL201050 & 330757 & 3.2815 & 3.6778 & TRN & \\
\hline CHEMBL 200992 & 330757 & 5.9469 & 6.0479 & TRN & \\
\hline CHEMBL 202008 & 330757 & 3.8268 & 3.8782 & TRN & \\
\hline CHEMBL202019 & 330757 & 6.4685 & 6.6184 & TRN & \\
\hline CHEMBL 380764 & 330757 & 6.0044 & 6.1558 & TRN & \\
\hline CHEMBL 202404 & 330757 & 6.7212 & 6.2127 & TRN & \\
\hline CHEMBL201252 & 330757 & 5.9355 & 5.8871 & TRN & \\
\hline CHEMBL201759 & 330757 & 5.5952 & 5.6174 & TRN & \\
\hline CHEMBL201245 & 330757 & 4.3565 & 4.7298 & TST & \\
\hline CHEMBL 370452 & 330757 & 4.2291 & 3.9926 & TRN & \\
\hline CHEMBL201846 & 330757 & 4.3872 & 4.1946 & TRN & \\
\hline CHEMBL201855 & 330757 & 6.5376 & 6.4003 & TRN & \\
\hline CHEMBL201229 & 330757 & 5.9318 & 5.8323 & TRN & \\
\hline CHEMBL 383490 & 330757 & 6.1367 & 6.1638 & TRN & \\
\hline CHEMBL 202467 & 330757 & 6.6021 & 6.6891 & TRN & \\
\hline CHEMBL203588 & 330757 & 6.1739 & 6.2791 & TRN & \\
\hline CHEMBL 381676 & 330757 & 4.2596 & 4.102 & TRN & \\
\hline CHEMBL383096 & 330757 & 5.9208 & 6.0889 & TRN & \\
\hline CHEMBL382903 & 330757 & 3.1018 & 3.5095 & TST & \\
\hline CHEMBL202488 & 330757 & 6.3872 & 6.2036 & TRN & \\
\hline CHEMBL370601 & 330757 & 3.719 & 5.2347 & TST & \\
\hline CHEMBL370189 & 330757 & 3.31699 & 99999999 & 3.3474 & TRN \\
\hline CHEMBL379464 & 330757 & 3.6799 & 4.52800 & 00000000005 & TST \\
\hline CHEMBL440043 & 330757 & 3.9706 & 3.93399 & 99999999997 & TST \\
\hline CHEMBL382813 & 330757 & 5.7011 & 5.9028 & TRN & \\
\hline CHEMBL204145 & 330757 & 5.2741 & 5.49799 & 9999999999 & TRN \\
\hline CHEMBL202179 & 330757 & 2.9666 & 3.977 & TST & \\
\hline CHEMBL202016 & 330757 & 3.9355 & 3.8832 & TST & \\
\hline CHEMBL378578 & 330757 & 3.6216 & 3.8223 & TRN & \\
\hline CHEMBL264476 & 330757 & 3.3325 & 3.6766 & TRN & \\
\hline CHEMBL203691 & 330757 & 3.7878 & 3.8307 & TRN & \\
\hline CHEMBL202168 & 330757 & 6.4089 & 6.3389 & TRN & \\
\hline
\end{tabular}




\begin{tabular}{|c|c|c|c|c|c|}
\hline \multicolumn{6}{|c|}{ Supplemental Table S2.txt } \\
\hline CHEMBL201153 & 330757 & 3.5186 & 3.3257 & TRN & \\
\hline CHEMBL 381381 & 330757 & 5.3028 & 5.3162 & TRN & \\
\hline CHEMBL383009 & 330757 & 6.4089 & 6.1331 & TRN & \\
\hline CHEMBL 202333 & 330757 & 3.6478 & 3.6792 & TRN & \\
\hline CHEMBL 202022 & 330757 & 6.2007 & 6.0745 & TRN & \\
\hline CHEMBL370451 & 330757 & 4.0555 & 4.0653 & TRN & \\
\hline CHEMBL 202772 & 330757 & 3.7747 & 3.9442 & TST & \\
\hline CHEMBL 202144 & 330757 & 5.4283 & 5.7804 & TRN & \\
\hline CHEMBL 202073 & 330757 & 4.2007 & 4.7868 & TST & \\
\hline CHEMBL201233 & 330757 & 5.4776 & 5.6829 & TRN & \\
\hline CHEMBL383613 & 330757 & 3.9431 & 4.3249 & TST & \\
\hline CHEMBL201397 & 330757 & 5.5935 & 5.695 & TRN & \\
\hline CHEMBL425580 & 330757 & 5.8297 & 5.5873 & TRN & \\
\hline CHEMBL 204498 & 330757 & 6.1675 & 6.1374 & TRN & \\
\hline CHEMBL371323 & 330757 & 3.8182 & 4.7603 & TST & \\
\hline CHEMBL 202230 & 330757 & 3.9281 & 4.6304 & TST & \\
\hline CHEMBL 377710 & 330757 & 4.4318 & 4.0421 & TRN & \\
\hline CHEMBL 202285 & 330757 & 3.4672 & 3.4326 & TRN & \\
\hline CHEMBL 202147 & 330757 & 5.8861 & 5.7414 & TRN & \\
\hline CHEMBL202161 & 330757 & 4.1871 & 4.1907 & TRN & \\
\hline CHEMBL402264 & 330757 & 3.8097 & 3.8862 & TST & \\
\hline CHEMBL201995 & 330757 & 6.8539 & 6.7255 & TRN & \\
\hline CHEMBL 202543 & 330757 & 3.4685 & 3.4521 & TRN & \\
\hline CHEMBL 202487 & 330757 & 5.5003 & 5.9741 & TRN & \\
\hline CHEMBL201996 & 330757 & 6.3768 & 6.32700 & 0000000001 & TRN \\
\hline CHEMBL 202205 & 330757 & 3.4976 & 4.4775 & TST & \\
\hline CHEMBL381992 & 330757 & 3.4935 & 3.5619 & TRN & \\
\hline CHEMBL 202654 & 330757 & 6.1871 & 6.0024 & TRN & \\
\hline CHEMBL 202266 & 330757 & 5.5575 & 6.2655 & TST & \\
\hline CHEMBL201244 & 330757 & 6.4559 & 4.6644 & TST & \\
\hline CHEMBL382998 & 330757 & 5.5272 & 5.4804 & TRN & \\
\hline CHEMBL 202276 & 330757 & 6.699 & 6.7362 & TRN & \\
\hline CHEMBL370368 & 330757 & 3.6144 & 4.3175 & TST & \\
\hline CHEMBL 2151486 & 851667 & 6.301 & 6.1149 & TRN & \\
\hline CHEMBL2151619 & 851667 & 6.1675 & 5.9528 & TRN & \\
\hline CHEMBL 2151622 & 851667 & 4.0 & 4.7063 & TRN & \\
\hline CHEMBL 2151468 & 851667 & 5.8539 & 5.4801 & TRN & \\
\hline CHEMBL 2151488 & 851667 & 4.0 & 4.7716 & TRN & \\
\hline CHEMBL 2151466 & 851667 & 4.0 & 3.5738 & TRN & \\
\hline CHEMBL2151635 & 851667 & 5.7212 & 5.3578 & TST & \\
\hline CHEMBL 2151482 & 851667 & 4.0 & 3.8474 & TRN & \\
\hline CHEMBL 2151616 & 851667 & 6.2676 & 5.6488 & TRN & \\
\hline CHEMBL 2151477 & 851667 & 4.0 & 3.3697 & TST & \\
\hline CHEMBL 2151469 & 851667 & 4.0 & 4.1039 & TRN & \\
\hline CHEMBL2151476 & 851667 & 4.0 & 3.7033 & TST & \\
\hline CHEMBL 2151632 & 851667 & 4.0 & 4.0009 & TST & \\
\hline CHEMBL 2151484 & 851667 & 6.0223 & 6.0945 & TRN & \\
\hline CHEMBL 2151470 & 851667 & 4.0 & 3.8528 & TRN & \\
\hline
\end{tabular}




\begin{tabular}{|c|c|c|c|c|c|}
\hline \multicolumn{6}{|c|}{ Supplemental Table S2.txt } \\
\hline CHEMBL2151496 & 851667 & 4.0 & 3.6655 & TRN & \\
\hline CHEMBL2151502 & 851667 & 6.0 & 6.1747 & TRN & \\
\hline CHEMBL2151628 & 851667 & 7.3279 & 6.8647 & TRN & \\
\hline CHEMBL 2151494 & 851667 & 6.284 & 6.1151 & TRN & \\
\hline CHEMBL2151625 & 851667 & 4.0 & 4.5595 & TRN & \\
\hline CHEMBL 2151640 & 851667 & 6.0 & 5.2357 & TST & \\
\hline CHEMBL2151045 & 851667 & 5.6198 & 4.8902 & TST & \\
\hline CHEMBL 2151483 & 851667 & 4.0 & 3.7794 & TST & \\
\hline CHEMBL2151493 & 851667 & 6.2291 & 6.5381 & TRN & \\
\hline CHEMBL2151617 & 851667 & 6.284 & 6.3382 & TRN & \\
\hline CHEMBL2151490 & 851667 & 4.0 & 3.9741 & TRN & \\
\hline CHEMBL2151626 & 851667 & 4.0 & 3.6906 & TRN & \\
\hline CHEMBL 2151630 & 851667 & 5.9208 & 4.9777 & TST & \\
\hline CHEMBL 2151621 & 851667 & 6.063 & 5.6939 & TRN & \\
\hline CHEMBL2151489 & 851667 & 4.0 & 4.1633 & TRN & \\
\hline CHEMBL2151624 & 851667 & 6.699 & 6.2187 & TRN & \\
\hline CHEMBL2151620 & 851667 & 6.4318 & 6.8647 & TRN & \\
\hline CHEMBL 2151495 & 851667 & 4.0 & 4.54899 & 99999999995 & TRN \\
\hline CHEMBL 2151497 & 851667 & 6.7447 & 6.5614 & TRN & \\
\hline CHEMBL 2151475 & 851667 & 5.4949 & 5.2483 & TRN & \\
\hline CHEMBL 2151627 & 851667 & 4.0 & 3.9761 & TRN & \\
\hline CHEMBL2151623 & 851667 & 6.0044 & 5.9444 & TRN & \\
\hline CHEMBL 2151485 & 851667 & 6.0132 & 5.9012 & TRN & \\
\hline CHEMBL 2151481 & 851667 & 4.0 & 4.0973 & TST & \\
\hline CHEMBL2151618 & 851667 & 5.6576 & 5.8293 & TRN & \\
\hline CHEMBL 2151491 & 851667 & 4.0 & 3.8265 & TRN & \\
\hline CHEMBL2151629 & 851667 & 4.0 & 5.0757 & TRN & \\
\hline CHEMBL 2151500 & 851667 & 6.0 & 6.1751 & TRN & \\
\hline CHEMBL 2151634 & 851667 & 4.0 & 4.3046 & TST & \\
\hline CHEMBL 2151479 & 851667 & 4.0 & 3.7159 & TST & \\
\hline CHEMBL2151498 & 851667 & 5.8239 & 5.8471 & TRN & \\
\hline CHEMBL2151480 & 851667 & 4.0 & 3.8346 & TST & \\
\hline CHEMBL2151499 & 851667 & 6.3872 & 5.9107 & TRN & \\
\hline CHEMBL 2151474 & 851667 & 5.1675 & 5.3119 & TRN & \\
\hline CHEMBL 2151487 & 851667 & 6.0 & 6.1772 & TRN & \\
\hline CHEMBL2151492 & 851667 & 4.0 & 3.8578 & TRN & \\
\hline CHEMBL 2151467 & 851667 & 4.0 & 3.6396 & TRN & \\
\hline CHEMBL2151472 & 851667 & 5.6198 & 5.1609 & TRN & \\
\hline CHEMBL2151471 & 851667 & 5.1487 & 5.5121 & TRN & \\
\hline CHEMBL 2151478 & 851667 & 4.0 & 3.1997 & TST & \\
\hline CHEMBL2151501 & 851667 & 5.9586 & 6.0412 & TRN & \\
\hline CHEMBL 2151473 & 851667 & 5.6021 & 5.433 & TRN & \\
\hline CHEMBL2151465 & 851667 & 4.0 & 4.5672 & TRN & \\
\hline CHEMBL2151631 & 851667 & 4.0 & 3.5845 & TST & \\
\hline CHEMBL 2151633 & 851667 & 5.8239 & 5.4512 & TST & \\
\hline CHEMBL 213100 & 954866 & 3.948 & 3.9458 & TRN & \\
\hline CHEMBL3186408 & 954866 & 3.6684 & 3.6669 & TST & \\
\hline CHEMBL221137 & 954866 & 4.6277 & 4.3791 & TST & \\
\hline
\end{tabular}




\begin{tabular}{|c|c|c|c|c|c|}
\hline & & \multicolumn{4}{|c|}{ Supplemental Table S2.txt } \\
\hline CHEMBL1186585 & 954866 & 4.1545 & 4.1124 & TRN & \\
\hline CHEMBL3349342 & 954866 & 4.0214 & 4.0076 & TRN & \\
\hline CHEMBL515416 & 954866 & 4.3881 & 4.3618 & TRN & \\
\hline CHEMBL1516890 & 954866 & 4.7818 & 4.7364 & TRN & \\
\hline CHEMBL 220241 & 954866 & 3.9355 & 3.9076 & TRN & \\
\hline CHEMBL255342 & 954866 & 3.3004 & 3.3021 & TRN & \\
\hline CHEMBL240954 & 954866 & 3.5178 & 4.2807 & TST & \\
\hline CHEMBL 2134202 & 954866 & 3.3284 & 3.3651 & TRN & \\
\hline CHEMBL1909414 & 954866 & 4.3598 & 4.333 & TRN & \\
\hline CHEMBL483847 & 954866 & 3.6266 & 3.6655 & TRN & \\
\hline CHEMBL9470 & 954866 & 5.3383 & 5.6431 & TST & \\
\hline CHEMBL135561 & 954866 & 4.5663 & 4.5838 & TRN & \\
\hline CHEMBL1256459 & 954866 & 6.6834 & 6.7039 & TRN & \\
\hline CHEMBL102714 & 954866 & 3.1097 & 3.1433 & TRN & \\
\hline CHEMBL217354 & 954866 & 6.7671 & 6.7692 & TRN & \\
\hline CHEMBL373751 & 954866 & 3.0077 & 3.0288 & TRN & \\
\hline CHEMBL180127 & 954866 & 3.5934 & 3.59899 & 99999999998 & TRN \\
\hline CHEMBL1357247 & 954866 & 2.6587 & 2.6568 & TRN & \\
\hline CHEMBL1590308 & 954866 & 2.8811 & 2.9707 & TST & \\
\hline CHEMBL202721 & 954866 & 5.1092 & 5.1307 & TRN & \\
\hline CHEMBL472940 & 954866 & 3.4387 & 3.4207 & TRN & \\
\hline CHEMBL189584 & 954866 & 4.9505 & 4.956 & TRN & \\
\hline CHEMBL 1230020 & 954866 & 3.6551 & 3.6321 & TRN & \\
\hline CHEMBL 2005886 & 954866 & 4.3762 & 4.3634 & TRN & \\
\hline CHEMBL558642 & 954866 & 4.1002 & 4.088 & TRN & \\
\hline CHEMBL379975 & 954866 & 6.1764 & 6.216 & TRN & \\
\hline CHEMBL514499 & 954866 & 6.4773 & 6.4599 & TRN & \\
\hline CHEMBL 2363137 & 954866 & 4.1717 & 4.1601 & TRN & \\
\hline CHEMBL399530 & 954866 & 4.9744 & 4.9954 & TRN & \\
\hline CHEMBL192566 & 954866 & 7.2965 & 8.7905 & TST & \\
\hline CHEMBL573107 & 954866 & 5.4841 & 5.4868 & TRN & \\
\hline CHEMBL1673039 & 954866 & 4.7578 & 4.73300 & 00000000005 & TRN \\
\hline CHEMBL509032 & 954866 & 4.4095 & 4.4179 & TRN & \\
\hline CHEMBL1404918 & 954866 & 3.1356 & 3.12899 & 99999999996 & TRN \\
\hline CHEMBL188678 & 954866 & 5.4073 & 5.4355 & TRN & \\
\hline CHEMBL449158 & 954866 & 5.9605 & 6.4934 & TST & \\
\hline CHEMBL1643959 & 954866 & 3.2481 & 3.2876 & TRN & \\
\hline CHEMBL585951 & 954866 & 6.0918 & 6.1156 & TRN & \\
\hline CHEMBL483849 & 954866 & 2.3479 & 2.3153 & TST & \\
\hline CHEMBL412142 & 954866 & 3.4082 & 3.3836 & TRN & \\
\hline CHEMBL1190711 & 954866 & 5.4656 & 5.4433 & TRN & \\
\hline CHEMBL92309 & 954866 & 2.9399 & 3.3046 & TST & \\
\hline CHEMBL222102 & 954866 & 4.9318 & 4.9274 & TRN & \\
\hline CHEMBL3392440 & 954866 & 4.0776 & 4.0888 & TRN & \\
\hline CHEMBL 2144069 & 954866 & 4.96 & 4.9587 & TRN & \\
\hline CHEMBL392695 & 954866 & 4.5661 & 4.5816 & TRN & \\
\hline CHEMBL209148 & 954866 & 4.4997 & 4.5174 & TRN & \\
\hline CHEMBL210618 & 954866 & 4.5538 & 4.5841 & TRN & \\
\hline
\end{tabular}




\begin{tabular}{|c|c|c|c|c|c|c|}
\hline & & \multicolumn{5}{|c|}{ Supplemental Table s2.txt } \\
\hline CHEMBL258844 & 954866 & 3.3458 & 3.3205 & TRN & & \\
\hline CHEMBL1242367 & 954866 & 4.6379 & 4.6199 & TRN & & \\
\hline CHEMBL259181 & 954866 & 5.2324 & 5.2407 & TRN & & \\
\hline CHEMBL1788116 & 954866 & 3.3245 & 3.347 & TRN & & \\
\hline CHEMBL1970879 & 954866 & 4.6776 & 4.654 & TRN & & \\
\hline CHEMBL512504 & 954866 & 6.403 & 6.3623 & TRN & & \\
\hline CHEMBL3199475 & 954866 & 4.6546 & 4.3919 & TST & & \\
\hline CHEMBL65 & 954866 & 9.1513 & 9.8654 & TST & & \\
\hline CHEMBL393929 & 954866 & 4.2206 & 4.8129 & TST & & \\
\hline CHEMBL379300 & 954866 & 6.4363 & 5.7743 & TST & & \\
\hline CHEMBL577784 & 954866 & 4.6868 & 5.6169 & TST & & \\
\hline CHEMBL191334 & 954866 & 5.4153 & 3.867 & TST & & \\
\hline CHEMBL300389 & 954866 & 7.1254 & 6.8265 & TST & & \\
\hline CHEMBL 2137530 & 954866 & 5.26 & 5.0186 & TST & & \\
\hline CHEMBL1650359 & 715074 & 7.3605 & 6.9085 & TRN & & \\
\hline CHEMBL1650401 & 715074 & 7.2495 & 7.2009 & TRN & & \\
\hline CHEMBL1650370 & 715074 & 7.7423 & 7.4699 & TRN & & \\
\hline CHEMBL1650385 & 715074 & 8.2076 & 7.394 & TST & & \\
\hline CHEMBL1650397 & 715074 & 7.2358 & 7.6258 & TRN & & \\
\hline CHEMBL1650367 & 715074 & 7.1986 & 7.5503 & TRN & & \\
\hline CHEMBL 222384 & 715074 & 6.767 & 6.9101 & TRN & & \\
\hline CHEMBL1650352 & 715074 & 6.8996 & 6.7608 & TRN & & \\
\hline CHEMBL1650396 & 715074 & 7.9136 & 7.8449 & TRN & & \\
\hline CHEMBL1650143 & 715074 & 6.8041 & 6.8236 & TRN & & \\
\hline CHEMBL1650349 & 715074 & 8.3565 & 8.2006 & TRN & & \\
\hline CHEMBL1650400 & 715074 & 7.2807 & 7.4233 & TRN & & \\
\hline CHEMBL1650371 & 715074 & 6.7959 & 7.1834 & TRN & & \\
\hline CHEMBL1650164 & 715074 & 6.5544 & 6.2325 & TRN & & \\
\hline CHEMBL 222474 & 715074 & $7.3420 e$ & 30000000 & 205 & 7.319 & TRN \\
\hline CHEMBL1650382 & 715074 & 7.8069 & 7.062 & TST & & \\
\hline CHEMBL1650361 & 715074 & 7.5986 & 7.7528 & TRN & & \\
\hline CHEMBL1650144 & 715074 & 6.8827 & 6.4263 & TRN & & \\
\hline CHEMBL1650362 & 715074 & 7.3575 & 7.4961 & TRN & & \\
\hline CHEMBL1650172 & 715074 & 6.9957 & 7.1459 & TRN & & \\
\hline CHEMBL1650393 & 715074 & 7.6946 & 7.6171 & TST & & \\
\hline CHEMBL1650341 & 715074 & 5.7206 & 6.4991 & TST & & \\
\hline CHEMBL1650374 & 715074 & 7.6345 & 7.54 & TRN & & \\
\hline CHEMBL1650372 & 715074 & 6.8697 & 6.7722 & TRN & & \\
\hline CHEMBL1650355 & 715074 & 8.4437 & 8.5104 & TRN & & \\
\hline CHEMBL1650351 & 715074 & 7.2291 & 7.4857 & TRN & & \\
\hline CHEMBL1650358 & 715074 & 7.1469 & 7.1612 & TRN & & \\
\hline CHEMBL1650377 & 715074 & 7.9469 & 8.0142 & TRN & & \\
\hline CHEMBL222718 & 715074 & 6.2749 & 6.2178 & TRN & & \\
\hline CHEMBL1650366 & 715074 & 7.4584 & 7.312 & TRN & & \\
\hline CHEMBL1650373 & 715074 & 7.61799 & 99999999 & 99 & 7.8053 & TRN \\
\hline CHEMBL1650173 & 715074 & 6.8962 & 6.8238 & TRN & & \\
\hline CHEMBL1650363 & 715074 & 6.8761 & 7.0717 & TRN & & \\
\hline CHEMBL1650394 & 715074 & 7.1925 & 7.3354 & TST & & \\
\hline
\end{tabular}


Supplemental Table S2.txt

\begin{tabular}{|c|c|c|c|c|}
\hline CHEMBL1650357 & 715074 & 7.9586 & 7.8477 & TRN \\
\hline CHEMBL1650142 & 715074 & 7.3251 & 7.1574 & TRN \\
\hline CHEMBL1650347 & 715074 & 5.8931 & 6.2731 & TST \\
\hline CHEMBL1650174 & 715074 & 6.1244 & 6.4159 & TRN \\
\hline CHEMBL1650369 & 715074 & 6.9872 & 6.8898 & TRN \\
\hline CHEMBL1650379 & 715074 & 8.4815 & 8.2253 & TRN \\
\hline CHEMBL225460 & 715074 & 6.7696 & 5.63399 & 79999999995 \\
\hline CHEMBL1650365 & 715074 & 7.9172 & 7.7164 & TRN \\
\hline CHEMBL1650398 & 715074 & 7.4935 & 7.4041 & TRN \\
\hline CHEMBL1650383 & 715074 & 7.3288 & 6.7744 & TST \\
\hline CHEMBL1650378 & 715074 & 7.9914 & 7.7683 & TRN \\
\hline CHEMBL1650364 & 715074 & 7.7773 & 7.9776 & TRN \\
\hline CHEMBL1650176 & 715074 & 6.8477 & 6.5778 & TST \\
\hline CHEMBL1650388 & 715074 & 7.6615 & 7.1784 & TST \\
\hline CHEMBL426565 & 715074 & 7.9172 & 7.61 & TRN \\
\hline CHEMBL1650356 & 715074 & 8.4437 & 8.2602 & TRN \\
\hline CHEMBL1650380 & 715074 & 7.8386 & 7.9509 & TRN \\
\hline CHEMBL1650381 & 715074 & 7.2291 & 7.50799 & 9999999999 \\
\hline CHEMBL1650386 & 715074 & 8.0044 & 6.9858 & TST \\
\hline CHEMBL1650390 & 715074 & 7.9957 & 7.5933 & TST \\
\hline CHEMBL1650350 & 715074 & 7.7375 & 7.9169 & TRN \\
\hline CHEMBL1650376 & 715074 & 8.2676 & 8.2697 & TRN \\
\hline CHEMBL1650384 & 715074 & 8.5229 & 7.6904 & TST \\
\hline CHEMBL1650368 & 715074 & 7.5969 & 7.295 & TRN \\
\hline CHEMBL1650399 & 715074 & 7.7986 & 7.6247 & TRN \\
\hline CHEMBL1650391 & 715074 & 7.8996 & 7.3058 & TST \\
\hline CHEMBL1650152 & 715074 & 5.3531 & 5.8087 & TRN \\
\hline CHEMBL1650375 & 715074 & 6.9586 & 7.2909 & TRN \\
\hline CHEMBL1650389 & 715074 & 7.6383 & 6.7797 & TST \\
\hline CHEMBL1650387 & 715074 & 8.0969 & 7.4668 & TST \\
\hline CHEMBL1940943 & 798934 & 6.0362 & 6.0584 & TRN \\
\hline CHEMBL1941079 & 798934 & 6.699 & 6.7027 & TRN \\
\hline CHEMBL1940914 & 798934 & 5.0 & 5.0121 & TRN \\
\hline CHEMBL1941057 & 798934 & 5.0 & 5.0189 & TRN \\
\hline CHEMBL1941060 & 798934 & 5.0 & 4.9869 & TRN \\
\hline CHEMBL1940915 & 798934 & 5.0 & 4.9909 & TRN \\
\hline CHEMBL1940918 & 798934 & 5.0 & 5.1849 & TRN \\
\hline CHEMBL1941067 & 798934 & 5.0 & 5.5392 & TST \\
\hline CHEMBL1940933 & 798934 & 5.0 & 5.053 & TRN \\
\hline CHEMBL1941058 & 798934 & 5.0 & 4.9761 & TRN \\
\hline CHEMBL1940931 & 798934 & 6.699 & 6.6878 & TRN \\
\hline CHEMBL1940913 & 798934 & 5.0 & 5.0267 & TRN \\
\hline CHEMBL1940923 & 798934 & 5.0 & 5.2788 & TST \\
\hline CHEMBL1941068 & 798934 & 6.2518 & 6.2543 & TRN \\
\hline CHEMBL1940936 & 798934 & 5.0 & 5.0023 & TRN \\
\hline CHEMBL1941053 & 798934 & 7.2596 & 7.2663 & TRN \\
\hline CHEMBL1940941 & 798934 & 7.6576 & 7.6372 & TRN \\
\hline CHEMBL1941081 & 798934 & 5.0 & 5.0068 & TRN \\
\hline
\end{tabular}




\begin{tabular}{|c|c|c|c|c|}
\hline \multicolumn{5}{|c|}{ Supplemental Table S2.txt } \\
\hline CHEMBL1940939 & 798934 & 5.0 & 4.999 & TRN \\
\hline CHEMBL1941072 & 798934 & 6.4437 & 5.6844 & TST \\
\hline CHEMBL1941069 & 798934 & 6.3098 & 5.8524 & TST \\
\hline CHEMBL1940925 & 798934 & 7.0915 & 6.8789 & TRN \\
\hline CHEMBL1941061 & 798934 & 7.6576 & 7.6763 & TRN \\
\hline CHEMBL1940921 & 798934 & 6.1249 & 6.0871 & TRN \\
\hline CHEMBL1941054 & 798934 & 6.6198 & 6.603 & TRN \\
\hline CHEMBL1940920 & 798934 & 5.0 & 5.008 & TRN \\
\hline CHEMBL1940942 & 798934 & 5.0 & 4.9986 & TRN \\
\hline CHEMBL1940949 & 798934 & 6.7696 & 6.7305 & TRN \\
\hline CHEMBL1940926 & 798934 & 7.6198 & 7.7501 & TRN \\
\hline CHEMBL1940922 & 798934 & 5.0 & 4.9836 & TRN \\
\hline CHEMBL1940917 & 798934 & 6.3872 & 6.3482 & TRN \\
\hline CHEMBL1941080 & 798934 & 5.0 & 5.0047 & TRN \\
\hline CHEMBL1938422 & 798934 & 5.0 & 4.9754 & TRN \\
\hline CHEMBL1940940 & 798934 & 5.0 & 5.0273 & TRN \\
\hline CHEMBL1941051 & 798934 & 5.0 & 4.9895 & TRN \\
\hline CHEMBL1940928 & 798934 & 5.0 & 5.0084 & TRN \\
\hline CHEMBL1941076 & 798934 & 6.9586 & 6.96 & TRN \\
\hline CHEMBL1941050 & 798934 & 6.9586 & 6.9645 & TRN \\
\hline CHEMBL1941064 & 798934 & 7.7212 & 7.727 & TRN \\
\hline CHEMBL1940947 & 798934 & 6.0 & 5.9255 & TRN \\
\hline CHEMBL1940935 & 798934 & 5.0 & 5.0084 & TRN \\
\hline CHEMBL1940944 & 798934 & 5.585 & 5.6441 & TRN \\
\hline CHEMBL1940930 & 798934 & 7.8861 & 7.9026 & TRN \\
\hline CHEMBL1940919 & 798934 & 6.5086 & 6.3467 & TRN \\
\hline CHEMBL1941074 & 798934 & 7.0605 & 7.0717 & TRN \\
\hline CHEMBL1941055 & 798934 & 7.0223 & 7.0418 & TRN \\
\hline CHEMBL1941073 & 798934 & 6.7696 & 5.8489 & TST \\
\hline CHEMBL1941078 & 798934 & 7.7959 & 7.8218 & TRN \\
\hline CHEMBL1941071 & 798934 & 6.1249 & 6.1212 & TRN \\
\hline CHEMBL1941075 & 798934 & 6.7447 & 6.9282 & TST \\
\hline CHEMBL1941056 & 798934 & 5.0 & 4.9821 & TRN \\
\hline CHEMBL1940927 & 798934 & 7.7959 & 7.7952 & TRN \\
\hline CHEMBL1941082 & 798934 & 5.0 & 6.7437 & TST \\
\hline CHEMBL1941066 & 798934 & 5.0 & 4.9807 & TRN \\
\hline CHEMBL1941070 & 798934 & 5.0 & 4.9921 & TRN \\
\hline CHEMBL1940929 & 798934 & 7.3768 & 7.3784 & TRN \\
\hline CHEMBL1941083 & 798934 & 5.0 & 4.1985 & TST \\
\hline CHEMBL1941063 & 798934 & 7.7696 & 7.8395 & TRN \\
\hline CHEMBL1941062 & 798934 & 7.0862 & 6.157 & TST \\
\hline CHEMBL1940924 & 798934 & 6.8861 & 5.4301 & TST \\
\hline CHEMBL1941065 & 798934 & 5.0 & 4.2387 & TST \\
\hline CHEMBL1941052 & 798934 & 7.7696 & 6.5654 & TST \\
\hline CHEMBL1941077 & 798934 & 7.6576 & 6.5407 & TST \\
\hline CHEMBL1940932 & 798934 & 5.0 & 5.6605 & TST \\
\hline CHEMBL1940916 & 798934 & 5.0 & 4.8474 & TST \\
\hline CHEMBL1940934 & 798934 & 6.1938 & 5.9882 & TST \\
\hline
\end{tabular}


Supplemental Table S2.txt

\begin{tabular}{|c|c|c|c|c|c|c|}
\hline CHEMBL1941059 & 798934 & 6.0915 & 6.5243 & TST & & \\
\hline CHEMBL 3972969 & 1640186 & 8.0904 & 8.1569 & TRN & & \\
\hline CHEMBL3956658 & 1640186 & 8.0141 & 8.0557 & TRN & & \\
\hline CHEMBL 3974641 & 1640186 & 7.5317 & 7.5872 & TST & & \\
\hline CHEMBL 3912108 & 1640186 & 8.7375 & 8.5087 & TRN & & \\
\hline CHEMBL120413 & 1640186 & 7.209 & 7.1005 & TST & & \\
\hline CHEMBL 3972799 & 1640186 & 9.1494 & 9.0849 & TRN & & \\
\hline CHEMBL 3960154 & 1640186 & 9.1439 & 9.136000 & 000000000 & & TST \\
\hline CHEMBL194810 & 1640186 & 7.7595 & 8.0302 & TRN & & \\
\hline CHEMBL 3968842 & 1640186 & 8.4989 & 8.5228 & TRN & & \\
\hline CHEMBL371106 & 1640186 & 7.4389 & 7.5891 & TRN & & \\
\hline CHEMBL 3910588 & 1640186 & 9.0867 & 9.1063 & TRN & & \\
\hline CHEMBL3928201 & 1640186 & 7.6383 & 7.7352 & TST & & \\
\hline CHEMBL316053 & 1640186 & 7.3696 & 7.3852 & TST & & \\
\hline CHEMBL197547 & 1640186 & 7.3468 & 7.3897 & TRN & & \\
\hline CHEMBL564248 & 1640186 & 8.7799 & 8.8864 & TRN & & \\
\hline CHEMBL436293 & 1640186 & 7.0788 & 6.8744 & TRN & & \\
\hline CHEMBL 3986101 & 1640186 & 8.9626 & 9.0383 & TRN & & \\
\hline CHEMBL194186 & 1640186 & 9.1175 & 9.0854 & TRN & & \\
\hline CHEMBL1235423 & 1640186 & 7.5058 & 7.2286 & TST & & \\
\hline CHEMBL 3959350 & 1640186 & 7.4145 & 7.295 & TRN & & \\
\hline CHEMBL 3966335 & 1640186 & 6.0453 & 6.2876 & TST & & \\
\hline CHEMBL198421 & 1640186 & 6.5702 & 6.6584 & TRN & & \\
\hline CHEMBL48813 & 1640186 & 8.7167 & 8.8552 & TST & & \\
\hline CHEMBL383361 & 1640186 & 9.0083 & 9.0057 & TRN & & \\
\hline CHEMBL 3961484 & 1640186 & 9.0 & 8.9454 & TRN & & \\
\hline CHEMBL381866 & 1640186 & 8.3224 & 8.4162 & TRN & & \\
\hline CHEMBL198654 & 1640186 & 8.2314 & 8.2377 & TRN & & \\
\hline CHEMBL196539 & 1640186 & 9.0685 & 9.0723 & TRN & & \\
\hline CHEMBL 3955803 & 1640186 & \multicolumn{3}{|c|}{8.767000000000001} & 8.7095 & TRN \\
\hline CHEMBL 3958789 & 1640186 & 8.4672 & 8.526 & TRN & & \\
\hline CHEMBL 3957468 & 1640186 & 7.7773 & 7.9238 & TRN & & \\
\hline CHEMBL196669 & 1640186 & 5.2083 & 5.1325 & TRN & & \\
\hline CHEMBL194889 & 1640186 & 6.2865 & 6.2532 & TRN & & \\
\hline CHEMBL 3942651 & 1640186 & 5.4034 & 5.6332 & TST & & \\
\hline CHEMBL370176 & 1640186 & 6.7235 & 6.8756 & TRN & & \\
\hline CHEMBL 3904655 & 1640186 & 8.5513 & 8.469 & TRN & & \\
\hline CHEMBL372568 & 1640186 & 6.3497 & 6.4504 & TRN & & \\
\hline CHEMBL 3907419 & 1640186 & 8.5072 & 8.4053 & TRN & & \\
\hline CHEMBL196162 & 1640186 & 8.3883 & 7.9983 & TRN & & \\
\hline CHEMBL 3979386 & 1640186 & \multicolumn{3}{|c|}{8.982999999999999} & 8.9395 & TRN \\
\hline CHEMBL93087 & 1640186 & 7.0904 & 7.3071 & TST & & \\
\hline CHEMBL196589 & 1640186 & 7.1129 & 7.261 & TRN & & \\
\hline CHEMBL3305961 & 1640186 & 7.6055 & 7.5498 & TRN & & \\
\hline CHEMBL196492 & 1640186 & 8.3382 & 8.2543 & TRN & & \\
\hline CHEMBL 364284 & 1640186 & 9.6478 & 9.8158 & TRN & & \\
\hline CHEMBL190142 & 1640186 & 8.7959 & 8.5072 & TRN & & \\
\hline CHEMBL3304291 & 1640186 & 8.1878 & 8.2592 & TRN & & \\
\hline
\end{tabular}

Page 28373 


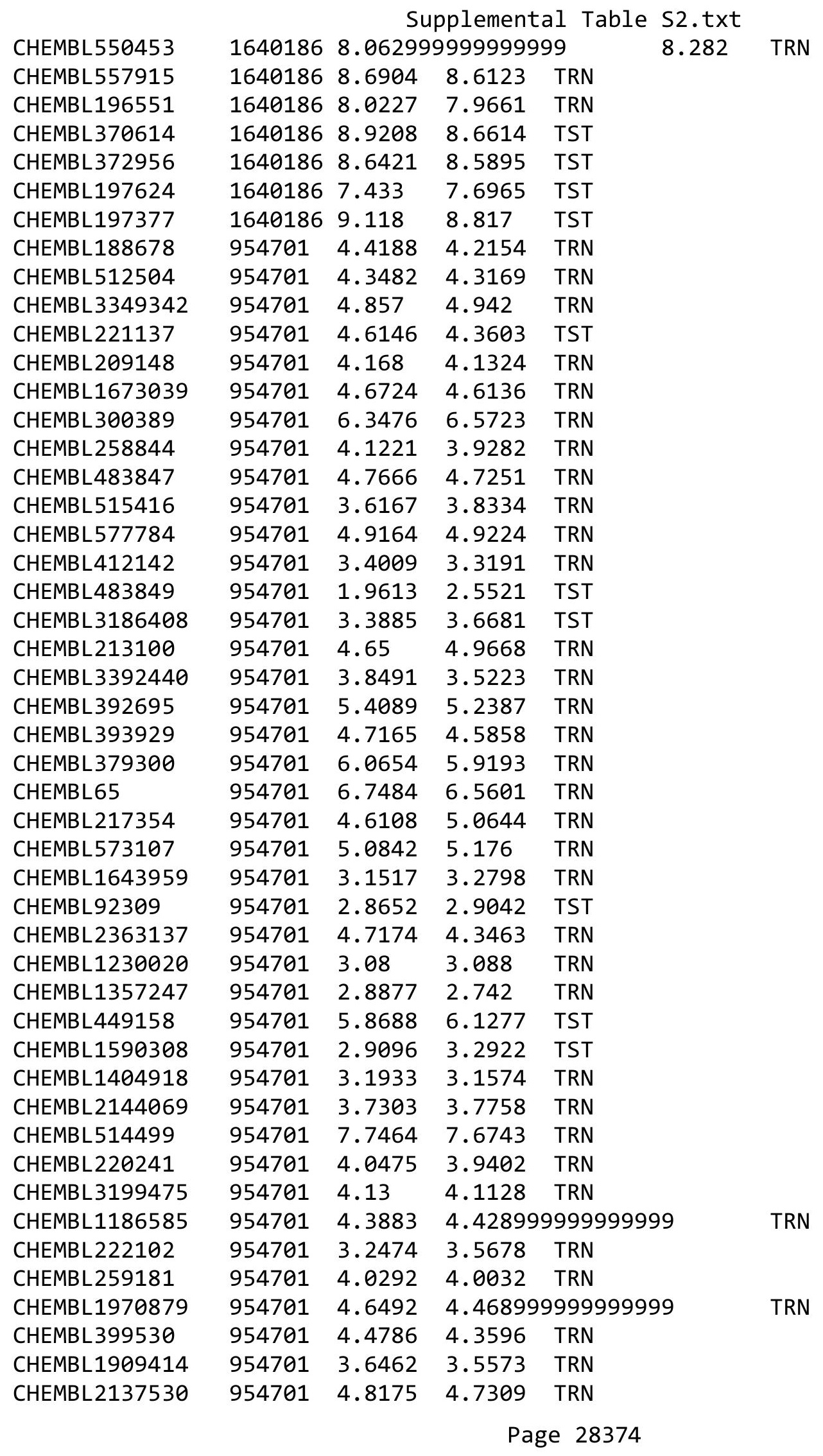




\begin{tabular}{|c|c|c|c|c|c|c|}
\hline & & \multicolumn{5}{|c|}{ Supplemental Table S2.txt } \\
\hline CHEMBL472940 & 954701 & 4.1516 & 3.9999 & TRN & & \\
\hline CHEMBL210618 & 954701 & 2.9228 & 3.1199 & TRN & & \\
\hline CHEMBL189584 & 954701 & 5.0579 & 5.0357 & TRN & & \\
\hline CHEMBL1190711 & 954701 & 5.1567 & 4.8922 & TRN & & \\
\hline CHEMBL373751 & 954701 & 3.3132 & 3.799 & TRN & & \\
\hline CHEMBL558642 & 954701 & 3.0624 & 2.9774 & TRN & & \\
\hline CHEMBL585951 & 954701 & \multicolumn{3}{|c|}{5.6979999999999995} & 5.5417 & TRN \\
\hline CHEMBL102714 & 954701 & 3.0217 & 3.2351 & TRN & & \\
\hline CHEMBL1242367 & 954701 & 4.387 & 4.3172 & TRN & & \\
\hline CHEMBL1256459 & 954701 & 6.1668 & 6.4393 & TRN & & \\
\hline CHEMBL2134202 & 954701 & 4.3576 & 4.592 & TRN & & \\
\hline CHEMBL192566 & 954701 & 7.7491 & 7.1248 & TST & & \\
\hline CHEMBL180127 & 954701 & 3.9887 & 4.2049 & TRN & & \\
\hline CHEMBL 202721 & 954701 & 4.0136 & 4.0654 & TRN & & \\
\hline CHEMBL191334 & 954701 & 3.5257 & 3.583 & TST & & \\
\hline CHEMBL135561 & 954701 & 3.9501 & 4.1963 & TST & & \\
\hline CHEMBL1788116 & 954701 & 3.8238 & 4.1223 & TST & & \\
\hline CHEMBL379975 & 954701 & 4.2967 & \multicolumn{3}{|c|}{4.428999999999999} & TST \\
\hline CHEMBL9470 & 954701 & 5.5275 & 5.1842 & TST & & \\
\hline CHEMBL 255342 & 954701 & 4.7581 & 3.6922 & TST & & \\
\hline CHEMBL1516890 & 954701 & 4.3057 & 4.0374 & TST & & \\
\hline CHEMBL240954 & 954701 & 2.9967 & 3.563 & TST & & \\
\hline CHEMBL509032 & 954701 & 5.6595 & 5.4248 & TST & & \\
\hline CHEMBL 2005886 & 954701 & 4.3818 & 4.7833 & TST & & \\
\hline CHEMBL3652351 & 1535129 & 7.7328 & 8.3217 & TRN & & \\
\hline CHEMBL3652303 & 1535129 & 6.0 & 6.3563 & TRN & & \\
\hline CHEMBL3901124 & 1535129 & 10.7011 & 10.6472 & TST & & \\
\hline CHEMBL3652313 & 1535129 & 6.9706 & 7.0711 & TRN & & \\
\hline CHEMBL3652315 & 1535129 & 7.1487 & 7.3552 & TRN & & \\
\hline CHEMBL3652375 & 1535129 & 7.1844 & 7.0666 & TRN & & \\
\hline CHEMBL 3652337 & 1535129 & 7.6576 & \multicolumn{3}{|c|}{7.656000000000001} & TRN \\
\hline CHEMBL3652391 & 1535129 & 7.3655 & 7.3943 & TST & & \\
\hline CHEMBL3652294 & 1535129 & 7.4815 & 7.2625 & TRN & & \\
\hline CHEMBL3652329 & 1535129 & 7.2941 & 7.4017 & TRN & & \\
\hline CHEMBL3652404 & 1535129 & 10.7825 & 10.236 & TRN & & \\
\hline CHEMBL3652306 & 1535129 & 7.4921 & 7.6131 & TRN & & \\
\hline CHEMBL3652357 & 1535129 & 7.3686 & 7.3266 & TRN & & \\
\hline CHEMBL3652364 & 1535129 & 7.4271 & 7.5135 & TRN & & \\
\hline CHEMBL3652332 & 1535129 & 7.1415 & 7.2175 & TRN & & \\
\hline CHEMBL3652341 & 1535129 & 6.0 & 7.1136 & TRN & & \\
\hline CHEMBL3652397 & 1535129 & 7.2041 & 7.0532 & TRN & & \\
\hline CHEMBL3927234 & 1535129 & 7.1445 & 6.9991 & TST & & \\
\hline CHEMBL3652299 & 1535129 & 7.3152 & 7.6945 & TRN & & \\
\hline CHEMBL3652310 & 1535129 & 6.8996 & 7.3079 & TRN & & \\
\hline CHEMBL3652290 & 1535129 & \multicolumn{3}{|c|}{7.2620000000000005} & 7.2607 & TRN \\
\hline CHEMBL3652389 & 1535129 & 7.8633 & 7.7792 & TRN & & \\
\hline CHEMBL3652368 & 1535129 & 7.8827 & 7.9985 & TST & & \\
\hline CHEMBL3652339 & 1535129 & 7.3788 & 7.2499 & TRN & & \\
\hline
\end{tabular}

Page 28375 
Supplemental Table S2.txt

\begin{tabular}{|c|c|c|c|c|c|c|}
\hline CHEMBL 3652322 & 1535129 & 7.1818 & 7.2455 & TST & & \\
\hline CHEMBL 3652298 & 1535129 & 6.0 & 6.0614 & TRN & & \\
\hline CHEMBL3652319 & 1535129 & 7.1649 & 7.1948 & TRN & & \\
\hline CHEMBL 3652349 & 1535129 & 7.4647 & 7.3077 & TRN & & \\
\hline CHEMBL 3652373 & 1535129 & 7.5436 & 7.0793 & TRN & & \\
\hline CHEMBL3652354 & 1535129 & 7.7773 & 7.7521 & TRN & & \\
\hline CHEMBL 3652352 & 1535129 & 7.6055 & 7.8438 & TRN & & \\
\hline CHEMBL3652277 & 1535129 & 8.3883 & 8.7766 & TRN & & \\
\hline CHEMBL 3652358 & 1535129 & 8.2426 & 7.9046 & TRN & & \\
\hline CHEMBL3652346 & 1535129 & 7.2062 & 7.1576 & TRN & & \\
\hline CHEMBL 3652410 & 1535129 & 9.9747 & 10.0605 & TRN & & \\
\hline CHEMBL 3652387 & 1535129 & 7.4895 & 7.3225 & TRN & & \\
\hline CHEMBL 3652302 & 1535129 & 7.8239 & 7.4482 & TRN & & \\
\hline CHEMBL 3652292 & 1535129 & 7.3298 & 7.2836 & TST & & \\
\hline CHEMBL 3652380 & 1535129 & 7.4045 & 7.2865 & TRN & & \\
\hline CHEMBL 3652320 & 1535129 & 7.0711 & 7.0191 & TRN & & \\
\hline CHEMBL3652331 & 1535129 & 7.6253 & 8.1536 & TRN & & \\
\hline CHEMBL 3652376 & 1535129 & 7.0438 & 7.0138 & TRN & & \\
\hline CHEMBL 3652293 & 1535129 & 7.8182 & 7.831 & TRN & & \\
\hline CHEMBL 3652374 & 1535129 & 7.4461 & 7.5094 & TRN & & \\
\hline CHEMBL3652279 & 1535129 & 7.6596 & 7.3951 & TRN & & \\
\hline CHEMBL 3652409 & 1535129 & 9.9355 & 10.1263 & TRN & & \\
\hline CHEMBL 3652288 & 1535129 & 7.4949 & 6.9201 & TRN & & \\
\hline CHEMBL 3931018 & 1535129 & 7.2269 & 7.4286 & TST & & \\
\hline CHEMBL3652316 & 1535129 & 7.21399 & 99999999 & 95 & 7.4132 & TRN \\
\hline CHEMBL 3929066 & 1535129 & 7.7747 & 8.0045 & TRN & & \\
\hline CHEMBL 3652360 & 1535129 & 7.75700 & 00000000 & 1 & 7.7879 & TRN \\
\hline CHEMBL 3652385 & 1535129 & 7.4634 & 7.0373 & TRN & & \\
\hline CHEMBL 3652284 & 1535129 & 7.011 & 6.6776 & TRN & & \\
\hline CHEMBL 3652378 & 1535129 & 8.2062 & 8.071 & TRN & & \\
\hline CHEMBL 3652281 & 1535129 & 7.7375 & 8.2291 & TRN & & \\
\hline CHEMBL 3652309 & 1535129 & 7.7282 & 7.2536 & TRN & & \\
\hline CHEMBL 3652403 & 1535129 & 9.8894 & 9.5404 & TRN & & \\
\hline CHEMBL 3639511 & 1535129 & 7.466 & 7.0978 & TRN & & \\
\hline CHEMBL 3652399 & 1535129 & 7.4881 & 8.2127 & TRN & & \\
\hline CHEMBL3652382 & 1535129 & 7.699 & 7.4385 & TRN & & \\
\hline CHEMBL 3652367 & 1535129 & 7.4935 & 7.2285 & TRN & & \\
\hline CHEMBL3969771 & 1535129 & 7.2041 & 7.064 & TRN & & \\
\hline CHEMBL 3652328 & 1535129 & 7.2233 & 7.5492 & TRN & & \\
\hline CHEMBL 3652317 & 1535129 & 8.0472 & 8.2912 & TRN & & \\
\hline CHEMBL 3652396 & 1535129 & 7.3507 & 7.228 & TRN & & \\
\hline CHEMBL 3652359 & 1535129 & 7.6308 & 7.3305 & TST & & \\
\hline CHEMBL 3652280 & 1535129 & 7.2652 & 7.2946 & TRN & & \\
\hline CHEMBL 3652314 & 1535129 & 7.1746 & 6.8986 & TRN & & \\
\hline CHEMBL 3652336 & 1535129 & 7.3883 & 7.1112 & TRN & & \\
\hline CHEMBL 3652344 & 1535129 & 7.6478 & 7.7088 & TRN & & \\
\hline CHEMBL 3652338 & 1535129 & 7.0353 & 7.1457 & TRN & & \\
\hline CHEMBL 3652369 & 1535129 & 7.5287 & 7.5436 & TRN & & \\
\hline
\end{tabular}

Page 28376 
Supplemental Table S2.txt

\begin{tabular}{|c|c|c|c|c|c|}
\hline CHEMBL 3652347 & 1535129 & 7.5654 & 7.7681 & TRN & \\
\hline CHEMBL3652289 & 1535129 & 8.1129 & 7.9837 & TRN & \\
\hline CHEMBL3652408 & 1535129 & 11.3925 & 11.0142 & TRN & \\
\hline CHEMBL 3652296 & 1535129 & 7.3757 & 7.3213 & TRN & \\
\hline CHEMBL3652355 & 1535129 & 7.5817 & 7.6824 & TST & \\
\hline CHEMBL3652335 & 1535129 & 6.0 & 6.2512 & TRN & \\
\hline CHEMBL3652282 & 1535129 & 6.9031 & 6.8838 & TRN & \\
\hline CHEMBL3652330 & 1535129 & 7.6861 & 7.5799 & TRN & \\
\hline CHEMBL3652361 & 1535129 & 8.0315 & 7.8899 & TST & \\
\hline CHEMBL3652283 & 1535129 & 7.5817 & 7.4584 & TRN & \\
\hline CHEMBL3652297 & 1535129 & 8.1296 & 7.9939 & TRN & \\
\hline CHEMBL 3652340 & 1535129 & 7.2503 & 7.3822 & TRN & \\
\hline CHEMBL 3652343 & 1535129 & 6.0 & 6.3157 & TRN & \\
\hline CHEMBL3652327 & 1535129 & 7.0716 & 7.0304 & TRN & \\
\hline CHEMBL3652363 & 1535129 & 7.0915 & 7.3902 & TRN & \\
\hline CHEMBL3652348 & 1535129 & 7.2993 & 7.2605 & TRN & \\
\hline CHEMBL3652377 & 1535129 & 7.6144 & 7.6308 & TST & \\
\hline CHEMBL3652392 & 1535129 & 7.7545 & 7.3125 & TST & \\
\hline CHEMBL3652334 & 1535129 & 7.295 & 7.2442 & TRN & \\
\hline CHEMBL3652388 & 1535129 & 7.2941 & 7.4068 & TRN & \\
\hline CHEMBL3652350 & 1535129 & 7.2549 & 7.1257 & TRN & \\
\hline CHEMBL3639512 & 1535129 & 7.4486 & 7.2121 & TRN & \\
\hline CHEMBL3652383 & 1535129 & 8.0004 & 7.8682 & TRN & \\
\hline CHEMBL 3652345 & 1535129 & 7.2581 & 7.1699 & TRN & \\
\hline CHEMBL3652372 & 1535129 & 7.4449 & 7.4082 & TRN & \\
\hline CHEMBL3652325 & 1535129 & 7.0429 & 6.9798 & TRN & \\
\hline CHEMBL3652379 & 1535129 & 7.3915 & 7.2348 & TRN & \\
\hline CHEMBL3652312 & 1535129 & 6.0 & 6.1621 & TRN & \\
\hline CHEMBL3652333 & 1535129 & 7.6968 & 7.5178 & TRN & \\
\hline CHEMBL3652401 & 1535129 & 7.7496 & 8.0978 & TRN & \\
\hline CHEMBL3652386 & 1535129 & 7.3019 & 7.4734 & TRN & \\
\hline CHEMBL3652356 & 1535129 & 7.3354 & 7.4974 & TST & \\
\hline CHEMBL3652326 & 1535129 & 7.3478 & \multicolumn{2}{|c|}{7.127000000000001} & TRN \\
\hline CHEMBL3652295 & 1535129 & 6.0 & 6.055 & TRN & \\
\hline CHEMBL3652381 & 1535129 & 7.6459 & 7.3979 & TST & \\
\hline CHEMBL3652384 & 1535129 & 8.0362 & 7.9119 & TST & \\
\hline CHEMBL3652308 & 1535129 & 6.0 & 6.1907 & TST & \\
\hline CHEMBL3652394 & 1535129 & 7.5302 & 7.5327 & TST & \\
\hline CHEMBL3916507 & 1535129 & 7.3585 & 7.1074 & TST & \\
\hline CHEMBL3652353 & 1535129 & 7.7595 & \multicolumn{2}{|c|}{7.667000000000001} & TST \\
\hline CHEMBL3652405 & 1535129 & 9.9626 & 9.3743 & TST & \\
\hline CHEMBL3652291 & 1535129 & 7.71 & 7.6046 & TST & \\
\hline CHEMBL3652362 & 1535129 & 7.9666 & 7.9905 & TST & \\
\hline CHEMBL3652323 & 1535129 & 7.0701 & 7.0433 & TST & \\
\hline CHEMBL3652393 & 1535129 & 7.3028 & 7.3737 & TST & \\
\hline CHEMBL3652366 & 1535129 & 7.3391 & 7.2175 & TST & \\
\hline CHEMBL3652407 & 1535129 & 11.1152 & 10.776 & TST & \\
\hline CHEMBL3652321 & 1535129 & 7.0526 & 7.1504 & TST & \\
\hline
\end{tabular}


Supplemental Table S2.txt

\begin{tabular}{|c|c|c|c|c|c|}
\hline CHEMBL 3652371 & 1535129 & 7.3904 & 7.4246 & TST & \\
\hline CHEMBL 3652365 & 1535129 & 7.1965 & 7.2858 & TST & \\
\hline CHEMBL 3652318 & 1535129 & 7.75200 & 30000000 & 1 & 7.5485 \\
\hline CHEMBL 3652324 & 1535129 & 6.9393 & 6.9459 & TST & \\
\hline CHEMBL3652390 & 1535129 & 7.6517 & 7.556 & TST & \\
\hline CHEMBL1917631 & 785711 & 7.8539 & 6.7124 & TST & \\
\hline CHEMBL1917780 & 785711 & 7.7959 & 7.6911 & TST & \\
\hline CHEMBL1917623 & 785711 & 7.7212 & 7.7185 & TRN & \\
\hline CHEMBL1917611 & 785711 & 7.6778 & 7.6445 & TRN & \\
\hline CHEMBL1917396 & 785711 & 6.7375 & 7.8854 & TST & \\
\hline CHEMBL1917778 & 785711 & 7.3665 & 6.7175 & TST & \\
\hline CHEMBL1917784 & 785711 & 7.3372 & 7.8479 & TST & \\
\hline CHEMBL1917577 & 785711 & 8.0 & 7.8042 & TRN & \\
\hline CHEMBL1917794 & 785711 & 7.6198 & 7.6212 & TRN & \\
\hline CHEMBL1917806 & 785711 & 7.2441 & 7.2947 & TRN & \\
\hline CHEMBL1917791 & 785711 & 7.3565 & 7.3652 & TRN & \\
\hline CHEMBL1917802 & 785711 & 8.5229 & 8.6752 & TRN & \\
\hline CHEMBL1917600 & 785711 & 8.301 & 8.2783 & TRN & \\
\hline CHEMBL1917595 & 785711 & 8.5376 & 8.4688 & TRN & \\
\hline CHEMBL1917586 & 785711 & 8.5229 & 8.5243 & TRN & \\
\hline CHEMBL1917635 & 785711 & 7.6021 & 7.3132 & TST & \\
\hline CHEMBL1917411 & 785711 & 7.7696 & 7.4855 & TST & \\
\hline CHEMBL1917397 & 785711 & 5.8327 & 6.9321 & TST & \\
\hline CHEMBL1917805 & 785711 & 7.5229 & 7.5978 & TRN & \\
\hline CHEMBL1917787 & 785711 & 6.5482 & 6.5287 & TRN & \\
\hline CHEMBL1917393 & 785711 & 7.6198 & 7.621 & TRN & \\
\hline CHEMBL1917394 & 785711 & 7.0362 & 7.0333 & TRN & \\
\hline CHEMBL1917409 & 785711 & 8.3098 & 8.352 & TRN & \\
\hline CHEMBL1917628 & 785711 & 7.9208 & 6.4413 & TST & \\
\hline CHEMBL1917580 & 785711 & 8.4559 & 8.494 & TRN & \\
\hline CHEMBL1917797 & 785711 & 7.9208 & 7.9166 & TRN & \\
\hline CHEMBL1917410 & 785711 & 7.3665 & 7.3784 & TRN & \\
\hline CHEMBL1917587 & 785711 & 8.301 & 8.3189 & TRN & \\
\hline CHEMBL1917785 & 785711 & 7.0605 & 8.0787 & TST & \\
\hline CHEMBL1917619 & 785711 & 7.2676 & 7.3017 & TRN & \\
\hline CHEMBL1917598 & 785711 & 8.5086 & 8.3981 & TRN & \\
\hline CHEMBL1917390 & 785711 & 7.2218 & 7.2048 & TRN & \\
\hline CHEMBL1917576 & 785711 & 7.5528 & 7.6787 & TRN & \\
\hline CHEMBL1917606 & 785711 & 8.301 & 8.2899 & TRN & \\
\hline CHEMBL1917395 & 785711 & 6.9957 & 7.0079 & TRN & \\
\hline CHEMBL1917403 & 785711 & 5.9508 & 5.9721 & TRN & \\
\hline CHEMBL1917798 & 785711 & 7.7212 & 7.6885 & TRN & \\
\hline CHEMBL1917594 & 785711 & 8.6778 & 8.6499 & TRN & \\
\hline CHEMBL1917788 & 785711 & 7.1871 & 7.1918 & TRN & \\
\hline CHEMBL1917790 & 785711 & 7.2596 & 7.273 & TRN & \\
\hline CHEMBL1917588 & 785711 & 8.1549 & 8.1226 & TRN & \\
\hline CHEMBL1917405 & 785711 & 6.2211 & 6.2304 & TRN & \\
\hline CHEMBL1917637 & 785711 & 8.1549 & 6.9894 & TST & \\
\hline
\end{tabular}


Supplemental Table S2.txt

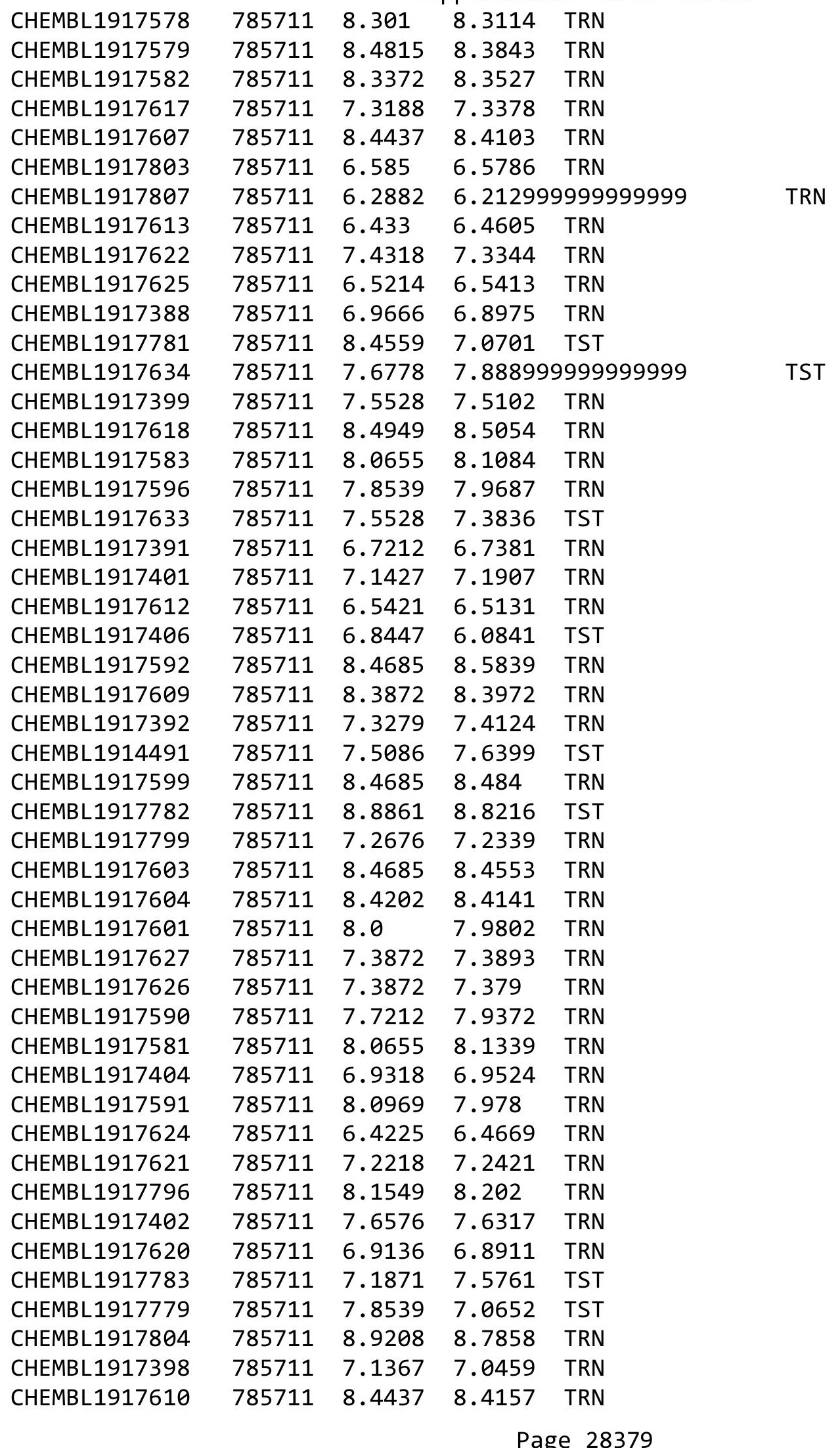




\begin{tabular}{|c|c|c|c|c|c|}
\hline \multicolumn{6}{|c|}{ Supplemental Table S2.txt } \\
\hline CHEMBL1917793 & 785711 & 8.0 & 7.9813 & TRN & \\
\hline CHEMBL1917616 & 785711 & 7.284 & 7.267 & TRN & \\
\hline CHEMBL1917585 & 785711 & 8.2218 & 8.3241 & TRN & \\
\hline CHEMBL1917597 & 785711 & 8.301 & 8.3219 & TRN & \\
\hline CHEMBL1917400 & 785711 & 7.3872 & 7.3848 & TRN & \\
\hline CHEMBL1917408 & 785711 & 8.3665 & 8.3001 & TRN & \\
\hline CHEMBL1917593 & 785711 & 8.3979 & 8.3139 & TRN & \\
\hline CHEMBL1917389 & 785711 & 7.5376 & 7.5675 & TRN & \\
\hline CHEMBL1917789 & 785711 & 5.3206 & 5.2939 & TRN & \\
\hline CHEMBL1917407 & 785711 & 7.6021 & 7.6194 & TRN & \\
\hline CHEMBL1917584 & 785711 & 8.699 & 8.5346 & TRN & \\
\hline CHEMBL1917615 & 785711 & 7.2596 & 7.2746 & TRN & \\
\hline CHEMBL1917632 & 785711 & 7.4815 & 7.5596 & TST & \\
\hline CHEMBL1917629 & 785711 & 7.6021 & 7.2046 & TST & \\
\hline CHEMBL1917605 & 785711 & 8.3768 & 8.4035 & TRN & \\
\hline CHEMBL1917387 & 785711 & 7.5528 & 7.59200 & 00000000005 & TRN \\
\hline CHEMBL1917602 & 785711 & 8.3565 & 8.3764 & TRN & \\
\hline CHEMBL1917614 & 785711 & 7.0655 & 7.0832 & TRN & \\
\hline CHEMBL1917630 & 785711 & 7.6383 & 7.5293 & TST & \\
\hline CHEMBL1917638 & 785711 & 8.0969 & 7.8078 & TST & \\
\hline CHEMBL1917608 & 785711 & 8.7212 & 8.7378 & TRN & \\
\hline CHEMBL1917589 & 785711 & 8.2218 & 8.235 & TRN & \\
\hline CHEMBL1917800 & 785711 & 7.7447 & 7.749 & TRN & \\
\hline CHEMBL1917636 & 785711 & 8.301 & 7.2004 & TST & \\
\hline CHEMBL1917801 & 785711 & 7.9208 & 7.0257 & TST & \\
\hline CHEMBL1917575 & 785711 & 8.0458 & 8.3197 & TST & \\
\hline CHEMBL1917786 & 785711 & 6.1267 & 6.4329 & TST & \\
\hline CHEMBL1917795 & 785711 & 7.6778 & 8.1849 & TST & \\
\hline CHEMBL1917792 & 785711 & 7.9208 & 7.2379 & TST & \\
\hline CHEMBL1917412 & 785711 & 7.8239 & 7.9409 & TST & \\
\hline CHEMBL1917810 & 785711 & 8.301 & 7.989 & TST & \\
\hline CHEMBL1830760 & 769241 & 7.9586 & 7.9507 & TRN & \\
\hline CHEMBL1830767 & 769241 & 7.2924 & 7.2924 & TRN & \\
\hline CHEMBL1830764 & 769241 & 7.1675 & 7.1712 & TRN & \\
\hline CHEMBL1830732 & 769241 & 6.1864 & 6.1699 & TST & \\
\hline CHEMBL1830766 & 769241 & 6.5901 & 7.0868 & TST & \\
\hline CHEMBL1830737 & 769241 & 6.2076 & 6.2658 & TST & \\
\hline CHEMBL1830721 & 769241 & 5.3775 & 5.3354 & TRN & \\
\hline CHEMBL1830761 & 769241 & 6.8041 & 6.8055 & TRN & \\
\hline CHEMBL1830730 & 769241 & 4.0 & 3.9988 & TRN & \\
\hline CHEMBL1830741 & 769241 & 4.0 & 5.5751 & TST & \\
\hline CHEMBL1830746 & 769241 & 5.4685 & 5.4722 & TRN & \\
\hline CHEMBL1830758 & 769241 & 5.7878 & 5.7732 & TRN & \\
\hline CHEMBL1830727 & 769241 & 6.2125 & 6.1843 & TRN & \\
\hline CHEMBL1830719 & 769241 & 6.1124 & 6.0892 & TRN & \\
\hline CHEMBL1830720 & 769241 & 6.0391 & 6.1062 & TRN & \\
\hline CHEMBL286346 & 769241 & 7.6383 & 4.8858 & TST & \\
\hline CHEMBL1830734 & 769241 & 5.1549 & 5.7925 & TST & \\
\hline
\end{tabular}




\begin{tabular}{|c|c|c|c|c|c|c|}
\hline \multirow{3}{*}{$\begin{array}{l}\text { CHEMBL481537 } \\
\text { CHEMBL1830729 }\end{array}$} & \multirow{3}{*}{$\begin{array}{l}769241 \\
769241\end{array}$} & \multicolumn{5}{|c|}{ Supplemental Table S2.txt } \\
\hline & & \multicolumn{4}{|c|}{8.03154 .1080000000000005} & \multirow[t]{2}{*}{ TST } \\
\hline & & 5.2607 & 5.2568 & TRN & & \\
\hline CHEMBL1830762 & 769241 & 5.6576 & 5.644 & TRN & & \\
\hline CHEMBL1830717 & 769241 & 4.0 & 4.001 & TRN & & \\
\hline CHEMBL1830752 & 769241 & 7.4949 & 7.506 & TRN & & \\
\hline CHEMBL1830718 & 769241 & 4.0 & 3.992 & TRN & & \\
\hline CHEMBL1830728 & 769241 & 5.3371 & 5.3427 & TRN & & \\
\hline CHEMBL1830725 & 769241 & 4.0 & 4.0076 & TRN & & \\
\hline CHEMBL1830763 & 769241 & 6.3125 & 6.3142 & TRN & & \\
\hline CHEMBL1830753 & 769241 & \multicolumn{3}{|c|}{6.821000000000001} & 6.8151 & TRN \\
\hline CHEMBL1830743 & 769241 & 6.3107 & 6.3044 & TRN & & \\
\hline CHEMBL1830723 & 769241 & 4.0 & 4.0016 & TRN & & \\
\hline CHEMBL1830731 & 769241 & 4.0 & 4.5474 & TST & & \\
\hline CHEMBL1830749 & 769241 & 5.4949 & 5.4947 & TRN & & \\
\hline CHEMBL1830733 & 769241 & 6.4214 & 6.607 & TST & & \\
\hline CHEMBL1830726 & 769241 & 5.4607 & 5.4817 & TRN & & \\
\hline CHEMBL1830724 & 769241 & 4.0 & 3.9986 & TRN & & \\
\hline CHEMBL1830759 & 769241 & 7.0555 & 7.0768 & TRN & & \\
\hline CHEMBL1830739 & 769241 & 5.2366 & 5.8294 & TST & & \\
\hline CHEMBL1830754 & 769241 & 6.0259 & 6.0356 & TRN & & \\
\hline CHEMBL1830745 & 769241 & 5.9586 & 5.9984 & TRN & & \\
\hline CHEMBL1830750 & 769241 & 5.7701 & 5.7878 & TRN & & \\
\hline CHEMBL1830742 & 769241 & 5.3625 & 5.3601 & TRN & & \\
\hline CHEMBL1830740 & 769241 & 4.0 & 4.9206 & TST & & \\
\hline CHEMBL1830755 & 769241 & \multicolumn{3}{|c|}{6.752000000000001} & 6.7427 & TRN \\
\hline CHEMBL1830736 & 769241 & 4.0 & 4.4913 & TST & & \\
\hline CHEMBL1830757 & 769241 & 6.1524 & 6.1461 & TRN & & \\
\hline CHEMBL1830735 & 769241 & 5.5686 & 5.4458 & TST & & \\
\hline CHEMBL1830756 & 769241 & 7.3468 & 7.3525 & TRN & & \\
\hline CHEMBL1830744 & 769241 & 6.8761 & 6.845 & TRN & & \\
\hline CHEMBL1830748 & 769241 & 6.8182 & 6.7948 & TRN & & \\
\hline CHEMBL1830738 & 769241 & 6.4179 & 6.6781 & TST & & \\
\hline CHEMBL1830765 & 769241 & 6.057 & 6.0652 & TRN & & \\
\hline CHEMBL1830747 & 769241 & 6.5735 & 6.5935 & TRN & & \\
\hline CHEMBL1830722 & 769241 & 5.3122 & 5.3161 & TRN & & \\
\hline CHEMBL1830751 & 769241 & 6.4609 & 6.4382 & TRN & & \\
\hline CHEMBL 2113082 & 306801 & 7.5086 & 7.4752 & TRN & & \\
\hline CHEMBL176077 & 306801 & 8.7959 & 8.8612 & TRN & & \\
\hline CHEMBL193330 & 306801 & 8.7447 & 8.7773 & TRN & & \\
\hline CHEMBL46905 & 306801 & 8.6021 & 7.2726 & TST & & \\
\hline CHEMBL193442 & 306801 & 8.2218 & 8.6078 & TRN & & \\
\hline CHEMBL194601 & 306801 & 8.699 & 8.2256 & TRN & & \\
\hline CHEMBL195129 & 306801 & 8.7212 & 8.988 & TRN & & \\
\hline CHEMBL175559 & 306801 & 6.0 & 6.6771 & TRN & & \\
\hline CHEMBL195433 & 306801 & 9.0458 & 9.0336 & TRN & & \\
\hline CHEMBL 373347 & 306801 & 8.699 & 8.7554 & TST & & \\
\hline CHEMBL 2112050 & 306801 & 7.1079 & 6.6148 & TRN & & \\
\hline CHEMBL 2113080 & 306801 & 8.7696 & 8.3491 & TRN & & \\
\hline
\end{tabular}

Page 28381 


\begin{tabular}{|c|c|c|c|c|}
\hline & & & oplement & al Table S? \\
\hline CHEMBL364977 & 306801 & 8.6383 & 8.957 & TRN \\
\hline CHEMBL195348 & 306801 & 6.0 & 8.1066 & TRN \\
\hline CHEMBL368683 & 306801 & 8.585 & 7.1092 & TST \\
\hline CHEMBL364508 & 306801 & 9.0458 & 9.1403 & TRN \\
\hline CHEMBL367992 & 306801 & 6.0 & 7.0969 & TRN \\
\hline CHEMBL194384 & 306801 & 7.9208 & 8.2686 & TRN \\
\hline CHEMBL365820 & 306801 & 8.8239 & 8.2502 & TRN \\
\hline CHEMBL123611 & 306801 & 9.0 & 7.1528 & TST \\
\hline CHEMBL363373 & 306801 & 6.0 & 8.2537 & TRN \\
\hline CHEMBL365732 & 306801 & 8.7212 & 8.9777 & TRN \\
\hline CHEMBL2113079 & 306801 & 8.8861 & 8.4697 & TRN \\
\hline CHEMBL3706810 & 306801 & 9.1549 & 8.3724 & TRN \\
\hline CHEMBL369073 & 306801 & 8.5229 & 7.3406 & TRN \\
\hline CHEMBL2096696 & 306801 & 6.0 & 7.3823 & TRN \\
\hline CHEMBL 382108 & 306801 & 9.0 & 8.7878 & TRN \\
\hline CHEMBL364068 & 306801 & 8.6576 & 8.8593 & TRN \\
\hline CHEMBL124317 & 306801 & 6.9031 & 7.2487 & TST \\
\hline CHEMBL2112049 & 306801 & 7.3872 & 7.0247 & TRN \\
\hline CHEMBL364673 & 306801 & 8.3372 & 8.6321 & TRN \\
\hline CHEMBL 2112987 & 306801 & 7.5528 & 7.0668 & TRN \\
\hline CHEMBL3706813 & 306801 & 8.7959 & 8.2031 & TRN \\
\hline CHEMBL362466 & 306801 & 8.6021 & 8.4436 & TRN \\
\hline CHEMBL 295832 & 306801 & 8.0 & 7.0905 & TST \\
\hline CHEMBL2096695 & 306801 & 6.0 & 6.8739 & TRN \\
\hline CHEMBL 363840 & 306801 & 9.1549 & 7.9265 & TRN \\
\hline CHEMBL2113076 & 306801 & 8.9208 & 8.3518 & TRN \\
\hline CHEMBL195044 & 306801 & 8.8539 & 9.0942 & TRN \\
\hline CHEMBL192240 & 306801 & 8.9586 & 8.7187 & TRN \\
\hline CHEMBL175679 & 306801 & 8.0458 & 7.2881 & TRN \\
\hline CHEMBL193575 & 306801 & 8.9586 & 8.369 & TRN \\
\hline CHEMBL277131 & 306801 & 9.1549 & 9.0051 & TRN \\
\hline CHEMBL364263 & 306801 & 8.0 & 7.4716 & TRN \\
\hline CHEMBL3706812 & 306801 & 9.0 & 8.367 & TRN \\
\hline CHEMBL195555 & 306801 & 8.8539 & 7.898 & TST \\
\hline CHEMBL362465 & 306801 & 7.9208 & 7.0453 & TST \\
\hline CHEMBL193526 & 306801 & 8.5686 & 8.754 & TST \\
\hline CHEMBL194141 & 306801 & 8.301 & 8.6653 & TST \\
\hline CHEMBL195790 & 306801 & 8.3979 & 8.6216 & TST \\
\hline CHEMBL175634 & 306801 & 8.8539 & 8.4721 & TST \\
\hline CHEMBL363166 & 306801 & 8.3979 & 8.2448 & TST \\
\hline CHEMBL3706811 & 306801 & 8.7447 & 8.3634 & TST \\
\hline CHEMBL 215152 & 809259 & 4.6 & 4.9615 & TRN \\
\hline CHEMBL2006765 & 809259 & 4.6 & 5.0841 & TRN \\
\hline CHEMBL1986590 & 809259 & 4.6 & 4.4343 & TRN \\
\hline CHEMBL1870106 & 809259 & 4.6 & 5.25799 & 9999999999 \\
\hline CHEMBL406845 & 809259 & 4.6 & 4.3637 & TRN \\
\hline CHEMBL1980246 & 809259 & 4.6 & 4.2418 & TRN \\
\hline CHEMBL1983980 & 809259 & 6.3 & 5.6839 & TRN \\
\hline
\end{tabular}




\begin{tabular}{|c|c|c|c|c|c|}
\hline \multicolumn{6}{|c|}{ Supplemental Table S2.txt } \\
\hline CHEMBL482538 & 809259 & 3.0 & 3.6917 & TRN & \\
\hline CHEMBL1999484 & 809259 & 4.7 & 4.825 & TRN & \\
\hline CHEMBL1973399 & 809259 & 3.0 & 3.3604 & TRN & \\
\hline CHEMBL1984296 & 809259 & 5.6 & 5.0774 & TST & \\
\hline CHEMBL1986899 & 809259 & 4.6 & 4.7785 & TRN & \\
\hline CHEMBL1996837 & 809259 & 3.0 & 3.4476 & TRN & \\
\hline CHEMBL1984038 & 809259 & 4.6 & 4.6028 & TRN & \\
\hline CHEMBL1964718 & 809259 & 3.0 & 3.6949 & TST & \\
\hline CHEMBL1993661 & 809259 & 5.0 & 5.5308 & TRN & \\
\hline CHEMBL1968705 & 809259 & 4.6 & 4.9228 & TRN & \\
\hline CHEMBL1964441 & 809259 & 4.6 & 5.0505 & TRN & \\
\hline CHEMBL1991410 & 809259 & 4.6 & 4.5727 & TRN & \\
\hline CHEMBL1986684 & 809259 & 3.0 & 3.7752 & TRN & \\
\hline CHEMBL546797 & 809259 & 5.7 & 4.7503 & TST & \\
\hline CHEMBL1978271 & 809259 & 4.6 & 4.8722 & TRN & \\
\hline CHEMBL 2007266 & 809259 & 4.6 & 5.0104 & TRN & \\
\hline CHEMBL202721 & 809259 & 4.6 & 4.584 & TRN & \\
\hline CHEMBL 2000568 & 809259 & 4.6 & 4.1597 & TRN & \\
\hline CHEMBL2007097 & 809259 & 4.3 & 3.8723 & TRN & \\
\hline CHEMBL1825138 & 809259 & 4.6 & 5.0351 & TST & \\
\hline CHEMBL1973516 & 809259 & 4.6 & 5.2201 & TRN & \\
\hline CHEMBL1974328 & 809259 & 4.8 & 4.6972 & TRN & \\
\hline CHEMBL509032 & 809259 & 6.4 & 4.9243 & TRN & \\
\hline CHEMBL143703 & 809259 & 3.0 & 2.9198 & TRN & \\
\hline CHEMBL 388311 & 809259 & 7.2 & 6.3852 & TRN & \\
\hline CHEMBL1964948 & 809259 & 4.6 & 4.761 & TRN & \\
\hline CHEMBL 2002202 & 809259 & 4.0 & 3.7129 & TRN & \\
\hline CHEMBL1973013 & 809259 & 5.9 & 4.966 & TRN & \\
\hline CHEMBL1989834 & 809259 & 3.9 & 3.3263 & TRN & \\
\hline CHEMBL1987430 & 809259 & 4.6 & 4.8293 & TRN & \\
\hline CHEMBL1993413 & 809259 & 4.6 & 4.3389 & TRN & \\
\hline CHEMBL205415 & 809259 & 4.6 & 5.015 & TRN & \\
\hline CHEMBL1975927 & 809259 & 4.6 & 4.7249 & TRN & \\
\hline CHEMBL1986943 & 809259 & 4.6 & 5.2237 & TRN & \\
\hline CHEMBL 289959 & 809259 & 3.0 & 3.0916 & TRN & \\
\hline CHEMBL1997119 & 809259 & 4.6 & 3.3516 & TRN & \\
\hline CHEMBL1977138 & 809259 & 5.8 & 5.8373 & TRN & \\
\hline CHEMBL 2000879 & 809259 & 4.2 & 3.4928 & TST & \\
\hline CHEMBL1978448 & 809259 & 4.6 & 4.703 & TST & \\
\hline CHEMBL1980329 & 809259 & 6.3 & 5.7913 & TRN & \\
\hline CHEMBL2004515 & 809259 & 5.0 & 4.6342 & TRN & \\
\hline CHEMBL1992042 & 809259 & 6.2 & 5.845 & TRN & \\
\hline CHEMBL1986265 & 809259 & 4.6 & 4.8978 & TRN & \\
\hline CHEMBL1967211 & 809259 & 3.0 & 3.3009 & TRN & \\
\hline CHEMBL1991734 & 809259 & 6.3 & 5.0454 & TST & \\
\hline CHEMBL21156 & 809259 & 4.6 & 5.0957 & TST & \\
\hline CHEMBL1380050 & 809259 & 3.0 & 3.40199 & 99999999997 & TRN \\
\hline CHEMBL1994724 & 809259 & 4.6 & 4.747 & TRN & \\
\hline
\end{tabular}




\begin{tabular}{|c|c|c|c|c|c|}
\hline & & & & & \\
\hline CHEMBL1989267 & 809259 & 5.6 & 5.4364 & TRN & \\
\hline CHEMBL1991782 & 809259 & 3.3 & 3.1078 & TRN & \\
\hline CHEMBL2002105 & 809259 & 4.6 & 4.1458 & TRN & \\
\hline CHEMBL1983348 & 809259 & 6.0 & 5.6031 & TST & \\
\hline CHEMBL1970290 & 809259 & 4.6 & 5.3776 & TRN & \\
\hline CHEMBL1968394 & 809259 & 3.0 & 3.1946 & TRN & \\
\hline CHEMBL1993877 & 809259 & 4.6 & 4.5068 & TRN & \\
\hline CHEMBL1974480 & 809259 & 6.0 & 5.5912 & TRN & \\
\hline CHEMBL1996500 & 809259 & 4.6 & 4.4878 & TRN & \\
\hline CHEMBL1980671 & 809259 & 3.0 & $3.5860 e$ & 00000000003 & TRN \\
\hline CHEMBL1986177 & 809259 & 4.6 & 4.6931 & TRN & \\
\hline CHEMBL1989708 & 809259 & 4.6 & 5.0861 & TRN & \\
\hline CHEMBL1976420 & 809259 & 4.6 & 4.6149 & TRN & \\
\hline CHEMBL1981744 & 809259 & 4.6 & 5.0257 & TRN & \\
\hline CHEMBL1989423 & 809259 & 4.2 & 3.0932 & TST & \\
\hline CHEMBL1985367 & 809259 & 4.6 & 4.029 & TRN & \\
\hline CHEMBL1996510 & 809259 & 4.6 & 5.1042 & TRN & \\
\hline CHEMBL 2000029 & 809259 & 5.7 & 5.484 & TRN & \\
\hline CHEMBL1995172 & 809259 & 4.2 & 3.8993 & TST & \\
\hline CHEMBL 2001584 & 809259 & 4.6 & 4.7532 & TRN & \\
\hline CHEMBL1973961 & 809259 & 4.6 & 4.9152 & TRN & \\
\hline CHEMBL1971227 & 809259 & 5.8 & 5.2681 & TST & \\
\hline CHEMBL1967998 & 809259 & 5.9 & 5.5708 & TRN & \\
\hline CHEMBL1978562 & 809259 & 5.6 & 5.9417 & TRN & \\
\hline CHEMBL1994977 & 809259 & 4.6 & 4.6665 & TRN & \\
\hline CHEMBL1974875 & 809259 & 4.0 & 3.7018 & TRN & \\
\hline CHEMBL 2005478 & 809259 & 5.8 & 5.8111 & TRN & \\
\hline CHEMBL1996646 & 809259 & 5.6 & 5.7271 & TRN & \\
\hline CHEMBL1979773 & 809259 & 4.6 & 4.6239 & TRN & \\
\hline CHEMBL1989471 & 809259 & 4.6 & 4.8443 & TST & \\
\hline CHEMBL1992723 & 809259 & 3.0 & 2.9231 & TRN & \\
\hline CHEMBL1996702 & 809259 & 4.6 & 5.2873 & TRN & \\
\hline CHEMBL 2007124 & 809259 & 4.6 & 4.5087 & TRN & \\
\hline CHEMBL1978195 & 809259 & 4.6 & 4.9117 & TRN & \\
\hline CHEMBL 2006439 & 809259 & 4.6 & 4.6916 & TRN & \\
\hline CHEMBL1985681 & 809259 & 4.6 & 5.3183 & TRN & \\
\hline CHEMBL1991674 & 809259 & 4.6 & 5.0042 & TRN & \\
\hline CHEMBL1982711 & 809259 & 5.8 & 4.6599 & TRN & \\
\hline CHEMBL262623 & 809259 & 3.0 & 3.2717 & TRN & \\
\hline CHEMBL1984842 & 809259 & 4.6 & 4.3979 & TRN & \\
\hline CHEMBL 2004118 & 809259 & 4.6 & 4.8551 & TRN & \\
\hline CHEMBL1996345 & 809259 & 4.6 & 4.6128 & TRN & \\
\hline CHEMBL 2004025 & 809259 & 6.2 & 5.8156 & TRN & \\
\hline CHEMBL1996048 & 809259 & 6.4 & 4.8934 & TRN & \\
\hline CHEMBL50894 & 809259 & 4.6 & 4.6755 & TRN & \\
\hline CHEMBL1995211 & 809259 & 4.6 & 3.9204 & TRN & \\
\hline CHEMBL1965033 & 809259 & 4.6 & 4.7965 & TRN & \\
\hline CHEMBL461876 & 809259 & 4.6 & 5.1075 & TRN & \\
\hline & & & & 28384 & \\
\hline
\end{tabular}




\begin{tabular}{|c|c|c|c|c|c|}
\hline \multicolumn{6}{|c|}{ Supplemental Table S2.txt } \\
\hline CHEMBL1982753 & 809259 & 5.7 & 4.6193 & TRN & \\
\hline CHEMBL 2006299 & 809259 & 4.6 & 4.8964 & TRN & \\
\hline CHEMBL1972346 & 809259 & 6.3 & 4.8691 & TST & \\
\hline CHEMBL1971519 & 809259 & 4.3 & 3.9884 & TRN & \\
\hline CHEMBL1997335 & 809259 & 4.6 & 4.9742 & TRN & \\
\hline CHEMBL1965169 & 809259 & 4.6 & 4.7955 & TRN & \\
\hline CHEMBL1081312 & 809259 & 4.6 & 4.8279 & TRN & \\
\hline CHEMBL1965170 & 809259 & 4.6 & 5.3366 & TRN & \\
\hline CHEMBL1994808 & 809259 & 4.0 & 3.875 & TRN & \\
\hline CHEMBL1393571 & 809259 & 3.0 & 3.5782 & TRN & \\
\hline CHEMBL 2005792 & 809259 & 4.6 & \multicolumn{2}{|c|}{4.2330000000000005} & TRN \\
\hline CHEMBL1991867 & 809259 & 3.0 & 3.8029 & TRN & \\
\hline CHEMBL1972355 & 809259 & 6.3 & 5.9924 & TST & \\
\hline CHEMBL1997892 & 809259 & 4.6 & 5.1487 & TRN & \\
\hline CHEMBL 2001641 & 809259 & 4.6 & 4.408 & TRN & \\
\hline CHEMBL1997193 & 809259 & 6.4 & 5.6951 & TST & \\
\hline CHEMBL1964902 & 809259 & 4.6 & 4.6215 & TRN & \\
\hline CHEMBL1973868 & 809259 & 4.6 & \multicolumn{2}{|c|}{ 4. 388999999999999} & TRN \\
\hline CHEMBL1983715 & 809259 & 4.6 & 5.1796 & TRN & \\
\hline CHEMBL 2002992 & 809259 & 4.6 & 4.5099 & TRN & \\
\hline CHEMBL1982700 & 809259 & 4.6 & 4.6386 & TRN & \\
\hline CHEMBL10 & 809259 & 4.6 & 4.3327 & TRN & \\
\hline CHEMBL1980763 & 809259 & 4.6 & 4.9711 & TRN & \\
\hline CHEMBL1977634 & 809259 & 4.6 & 4.7124 & TRN & \\
\hline CHEMBL1977931 & 809259 & 4.2 & 3.8801 & TRN & \\
\hline CHEMBL1976872 & 809259 & 3.0 & 3.4281 & TRN & \\
\hline CHEMBL1969156 & 809259 & 3.0 & 2.8526 & TRN & \\
\hline CHEMBL 2007479 & 809259 & 4.6 & 4.6137 & TRN & \\
\hline CHEMBL1998953 & 809259 & 4.6 & 3.7501 & TRN & \\
\hline CHEMBL1971606 & 809259 & 4.6 & 4.8435 & TRN & \\
\hline CHEMBL1999120 & 809259 & 3.0 & 3.9445 & TST & \\
\hline CHEMBL1972220 & 809259 & 5.9 & 5.3449 & TRN & \\
\hline CHEMBL1972583 & 809259 & 3.0 & 3.1366 & TRN & \\
\hline CHEMBL1981215 & 809259 & 4.6 & 4.8472 & TRN & \\
\hline CHEMBL 2003785 & 809259 & 4.4 & 4.3581 & TRN & \\
\hline CHEMBL1973720 & 809259 & 4.6 & 5.2442 & TRN & \\
\hline CHEMBL354676 & 809259 & 3.0 & 3.1125 & TRN & \\
\hline CHEMBL1999414 & 809259 & 4.6 & 5.2351 & TRN & \\
\hline CHEMBL1967336 & 809259 & 4.6 & 4.8843 & TRN & \\
\hline CHEMBL 2001923 & 809259 & 4.6 & 5.0099 & TRN & \\
\hline CHEMBL1983070 & 809259 & 4.6 & 4.498 & TRN & \\
\hline CHEMBL 2003514 & 809259 & 4.6 & 4.7299 & TRN & \\
\hline CHEMBL1970340 & 809259 & 4.2 & 4.1425 & TRN & \\
\hline CHEMBL1967992 & 809259 & 4.6 & 4.8125 & TRN & \\
\hline CHEMBL1989043 & 809259 & 4.6 & 4.5024 & TRN & \\
\hline CHEMBL 2006450 & 809259 & 4.6 & 4.7266 & TRN & \\
\hline CHEMBL1967538 & 809259 & 3.0 & 3.5902 & TRN & \\
\hline CHEMBL 2001987 & 809259 & 4.6 & 4.5341 & TRN & \\
\hline
\end{tabular}




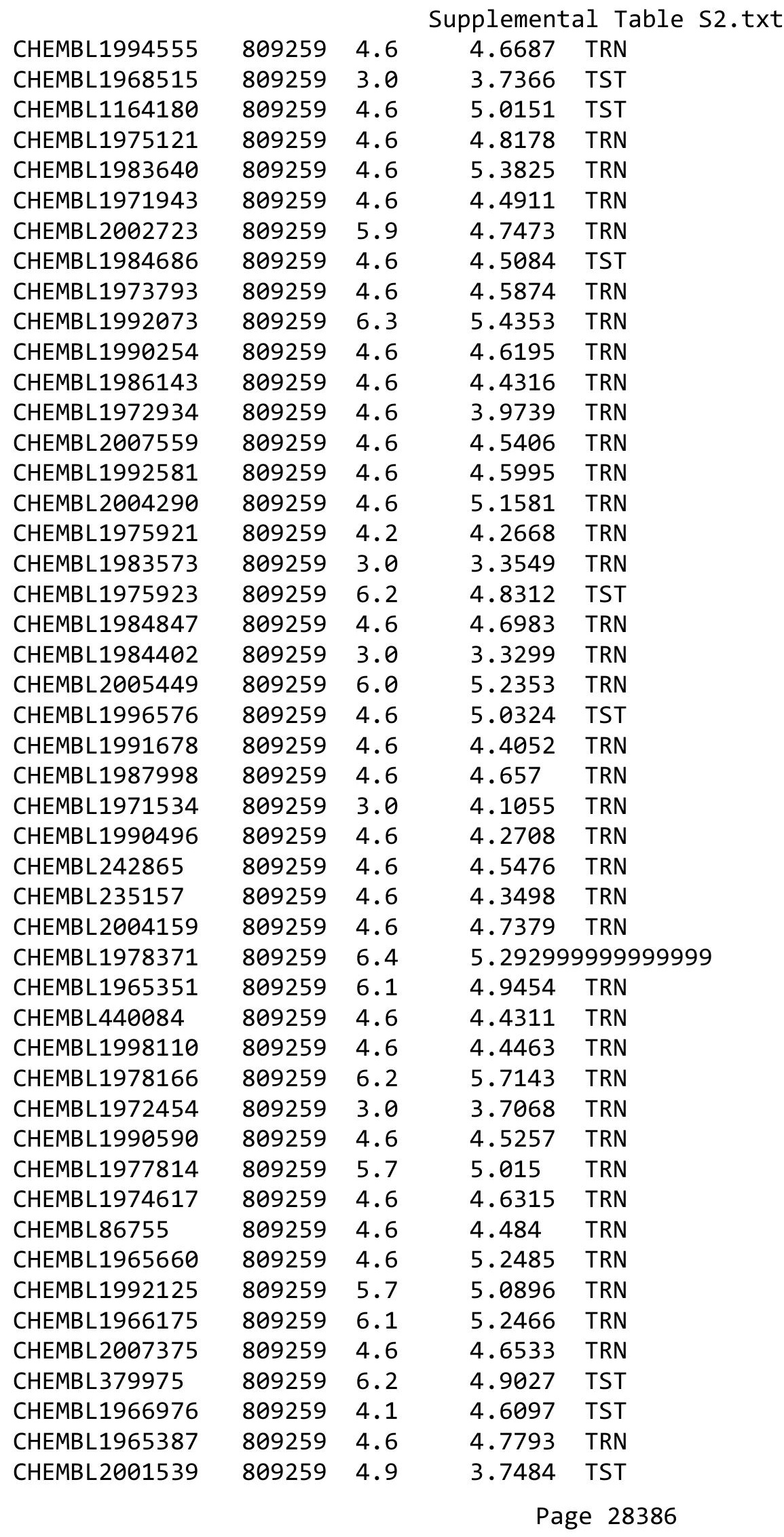




\begin{tabular}{|c|c|c|c|c|c|}
\hline \\
\hline CHEMBL388978 & 809259 & 8.4 & 6.4393 & TST & \\
\hline CHEMBL1997041 & 809259 & 5.2 & 4.632 & TRN & \\
\hline CHEMBL550418 & 809259 & 4.6 & 4.8245 & TRN & \\
\hline CHEMBL398951 & 809259 & 4.6 & 4.8284 & TST & \\
\hline CHEMBL1971289 & 809259 & 4.6 & 5.2106 & TST & \\
\hline CHEMBL1988437 & 809259 & 4.6 & 5.0383 & TRN & \\
\hline CHEMBL1421720 & 809259 & 6.0 & 5.3848 & TRN & \\
\hline CHEMBL1233887 & 809259 & 4.6 & 4.9112 & TRN & \\
\hline CHEMBL1968130 & 809259 & 4.0 & 3.7878 & TRN & \\
\hline CHEMBL1996649 & 809259 & 4.6 & 5.2499 & TRN & \\
\hline CHEMBL1986756 & 809259 & 4.6 & 4.9531 & TRN & \\
\hline CHEMBL1949855 & 809259 & 4.8 & 4.3859 & TRN & \\
\hline CHEMBL3109278 & 809259 & 4.7 & 5.3767 & TRN & \\
\hline CHEMBL1727312 & 809259 & 3.0 & 3.0684 & TRN & \\
\hline CHEMBL1990223 & 809259 & 4.6 & 4.8576 & TRN & \\
\hline CHEMBL 2004438 & 809259 & 4.6 & 4.4006 & TRN & \\
\hline CHEMBL1964382 & 809259 & 4.6 & 4.6997 & TST & \\
\hline CHEMBL101311 & 809259 & 4.6 & 4.8104 & TRN & \\
\hline CHEMBL191003 & 809259 & 4.6 & 4.8263 & TRN & \\
\hline CHEMBL1973359 & 809259 & 6.3 & 5.4726 & TST & \\
\hline CHEMBL1988581 & 809259 & 7.3 & 6.1383 & TST & \\
\hline CHEMBL2005699 & 809259 & 4.6 & 4.6936 & TRN & \\
\hline CHEMBL 2006564 & 809259 & 4.6 & 5.1704 & TRN & \\
\hline CHEMBL1979690 & 809259 & 6.1 & 5.4432 & TRN & \\
\hline CHEMBL 234085 & 809259 & 4.8 & 5.0243 & TRN & \\
\hline CHEMBL1978167 & 809259 & 4.6 & 5.2295 & TRN & \\
\hline CHEMBL418203 & 809259 & 4.6 & 5.4216 & TST & \\
\hline CHEMBL 225519 & 809259 & 4.6 & 4.5404 & TRN & \\
\hline CHEMBL1994159 & 809259 & 4.2 & 3.4338 & TRN & \\
\hline CHEMBL1976376 & 809259 & 4.6 & 4.5087 & TRN & \\
\hline CHEMBL1988622 & 809259 & 3.0 & 3.193 & TRN & \\
\hline CHEMBL1983575 & 809259 & 5.8 & 5.5169 & TRN & \\
\hline CHEMBL1968868 & 809259 & 4.6 & 4.9912 & TRN & \\
\hline CHEMBL1981047 & 809259 & 4.6 & 4.6243 & TRN & \\
\hline CHEMBL1998470 & 809259 & 4.6 & 4.7892 & TRN & \\
\hline CHEMBL1976196 & 809259 & 6.0 & 5.2889 & TRN & \\
\hline CHEMBL1997197 & 809259 & 4.6 & 4.3376 & TRN & \\
\hline CHEMBL1975903 & 809259 & 4.6 & 4.2534 & TRN & \\
\hline CHEMBL1983630 & 809259 & 4.4 & 3.5351 & TRN & \\
\hline CHEMBL1522508 & 809259 & 3.0 & 3.70399 & 99999999997 & TRN \\
\hline CHEMBL1973795 & 809259 & 3.0 & 2.9326 & TRN & \\
\hline CHEMBL1988805 & 809259 & 4.6 & 4.4386 & TRN & \\
\hline CHEMBL458997 & 809259 & 4.7 & 4.9152 & TRN & \\
\hline CHEMBL1969942 & 809259 & 4.6 & 4.5997 & TRN & \\
\hline CHEMBL1982660 & 809259 & 4.6 & 4.8879 & TRN & \\
\hline CHEMBL1978567 & 809259 & 4.6 & 4.4463 & TRN & \\
\hline CHEMBL1976290 & 809259 & 3.0 & 3.571 & TRN & \\
\hline CHEMBL1995765 & 809259 & 4.7 & 4.0957 & TRN & \\
\hline & & & & 28387 & \\
\hline
\end{tabular}




\begin{tabular}{|c|c|c|c|c|}
\hline \multicolumn{5}{|c|}{ Ipplemental Table S } \\
\hline CHEMBL1984760 & 809259 & 4.6 & 4.7731 & TRN \\
\hline CHEMBL1997846 & 809259 & 4.6 & 4.6249 & TRN \\
\hline CHEMBL424872 & 809259 & 4.6 & 5.2485 & TST \\
\hline CHEMBL360847 & 809259 & 4.6 & 5.153 & TRN \\
\hline CHEMBL1995811 & 809259 & 6.2 & 5.8098 & TRN \\
\hline CHEMBL1983111 & 809259 & 6.3 & 5.6112 & TRN \\
\hline CHEMBL1995916 & 809259 & 3.0 & 3.4588 & TRN \\
\hline CHEMBL1988141 & 809259 & 6.5 & 6.2205 & TST \\
\hline CHEMBL1992937 & 809259 & 4.6 & 4.7826 & TRN \\
\hline CHEMBL451401 & 809259 & 4.5 & 3.5862 & TRN \\
\hline CHEMBL1977134 & 809259 & 4.6 & 4.7664 & TRN \\
\hline CHEMBL1970873 & 809259 & 3.0 & 3.4833 & TRN \\
\hline CHEMBL1985206 & 809259 & 4.6 & 4.5561 & TRN \\
\hline CHEMBL1991078 & 809259 & 6.6 & 5.7189 & TRN \\
\hline CHEMBL1977749 & 809259 & 4.6 & 4.8251 & TST \\
\hline CHEMBL 2002450 & 809259 & 3.1 & 3.4966 & TRN \\
\hline CHEMBL1975212 & 809259 & 4.4 & 3.5657 & TRN \\
\hline CHEMBL2001613 & 809259 & 4.7 & 4.4921 & TRN \\
\hline CHEMBL261849 & 809259 & 4.6 & 4.6234 & TST \\
\hline CHEMBL1983923 & 809259 & 4.6 & 4.9083 & TST \\
\hline CHEMBL1993904 & 809259 & 4.6 & 4.6561 & TST \\
\hline CHEMBL1997275 & 809259 & 4.6 & 4.7218 & TST \\
\hline CHEMBL1967513 & 809259 & 4.6 & 4.8149 & TST \\
\hline CHEMBL1980376 & 809259 & 3.0 & 3.8265 & TST \\
\hline CHEMBL 2000724 & 809259 & 4.6 & 4.4868 & TST \\
\hline CHEMBL1982413 & 809259 & 6.1 & 5.465 & TST \\
\hline CHEMBL1987535 & 809259 & 4.6 & 5.0056 & TST \\
\hline CHEMBL1983393 & 809259 & 4.6 & 4.4219 & TST \\
\hline CHEMBL1981792 & 809259 & 4.6 & 4.7643 & TST \\
\hline CHEMBL 2002586 & 809259 & 4.6 & 4.4595 & TST \\
\hline CHEMBL1987815 & 809259 & 4.3 & 3.4341 & TST \\
\hline CHEMBL 2006674 & 809259 & 4.6 & 5.3783 & TST \\
\hline CHEMBL383264 & 809259 & 4.6 & 5.003 & TST \\
\hline CHEMBL1992371 & 809259 & 4.6 & 4.9109 & TST \\
\hline CHEMBL1984236 & 809259 & 4.6 & 4.5124 & TST \\
\hline CHEMBL 2007421 & 809259 & 6.8 & 5.2652 & TST \\
\hline CHEMBL1973138 & 809259 & 4.6 & 4.6515 & TST \\
\hline CHEMBL2002599 & 809259 & 4.6 & 4.7077 & TST \\
\hline CHEMBL1992673 & 809259 & 3.0 & 4.5301 & TST \\
\hline CHEMBL1969151 & 809259 & 4.6 & 5.28299 & 99999999995 \\
\hline CHEMBL1967252 & 809259 & 4.8 & 4.3006 & TST \\
\hline CHEMBL1993335 & 809259 & 6.1 & 5.9894 & TST \\
\hline CHEMBL1981492 & 809259 & 3.0 & 3.78 & TST \\
\hline CHEMBL 2007574 & 809259 & 4.6 & 4.8784 & TST \\
\hline CHEMBL1988692 & 809259 & 4.6 & 4.751 & TST \\
\hline CHEMBL 2004637 & 809259 & 4.6 & 5.0896 & TST \\
\hline CHEMBL1993374 & 809259 & 5.9 & 4.5397 & TST \\
\hline CHEMBL1998680 & 809259 & 4.6 & 4.785 & TST \\
\hline
\end{tabular}




\begin{tabular}{|c|c|c|c|c|c|}
\hline \multicolumn{6}{|c|}{ Supplemental Table S2.txt } \\
\hline CHEMBL592030 & 809259 & 4.6 & 4.7993 & TST & \\
\hline CHEMBL1605605 & 809259 & 4.6 & 4.1556 & TST & \\
\hline CHEMBL1997007 & 809259 & 4.6 & 4.6969 & TST & \\
\hline CHEMBL1970352 & 809259 & 4.6 & 5.3816 & TST & \\
\hline CHEMBL 2002690 & 809259 & 4.6 & 4.331 & TST & \\
\hline CHEMBL1980167 & 809259 & 6.0 & 5.5288 & TST & \\
\hline CHEMBL1975503 & 809259 & 3.0 & 3.333 & TST & \\
\hline CHEMBL377408 & 809259 & 4.6 & 4.9947 & TST & \\
\hline CHEMBL278041 & 809259 & 4.6 & 4.4633 & TST & \\
\hline CHEMBL3647646 & 1528905 & 8.1555 & 7.8081 & TRN & \\
\hline CHEMBL3647613 & 1528905 & 8.3737 & 8.0827 & TRN & \\
\hline CHEMBL3647622 & 1528905 & 7.7055 & 7.6504 & TRN & \\
\hline CHEMBL3647593 & 1528905 & 8.5581 & 7.9094 & TRN & \\
\hline CHEMBL3647624 & 1528905 & 8.6144 & 8.3332 & TRN & \\
\hline CHEMBL 3647663 & 1528905 & 8.8239 & 7.2896 & TRN & \\
\hline CHEMBL3647597 & 1528905 & 6.0 & 7.0603 & TRN & \\
\hline CHEMBL 2180768 & 1528905 & 7.7075 & 7.5964 & TRN & \\
\hline CHEMBL3647586 & 1528905 & 7.3372 & 6.0063 & TST & \\
\hline CHEMBL3639464 & 1528905 & 8.4202 & 9.0137 & TRN & \\
\hline CHEMBL 3647642 & 1528905 & 7.5317 & 7.2471 & TRN & \\
\hline CHEMBL3647615 & 1528905 & 8.4698 & 8.2339 & TRN & \\
\hline CHEMBL3647630 & 1528905 & 9.8894 & 8.7994 & TRN & \\
\hline CHEMBL3647651 & 1528905 & 8.6459 & 7.7736 & TRN & \\
\hline CHEMBL3647608 & 1528905 & 8.2652 & 6.6285 & TST & \\
\hline CHEMBL 3647645 & 1528905 & 7.7328 & 7.6776 & TRN & \\
\hline CHEMBL3647605 & 1528905 & 7.7375 & 6.7039 & TST & \\
\hline CHEMBL3647657 & 1528905 & 8.0334 & 7.9242 & TRN & \\
\hline CHEMBL3647649 & 1528905 & 8.6364 & 7.4965 & TRN & \\
\hline CHEMBL3647664 & 1528905 & 8.1249 & 7.3965 & TRN & \\
\hline CHEMBL3647611 & 1528905 & 8.6108 & 6.6682 & TST & \\
\hline CHEMBL3925068 & 1528905 & 6.0 & 6.7975 & TRN & \\
\hline CHEMBL3647636 & 1528905 & 8.4976 & 7.9536 & TRN & \\
\hline CHEMBL3647659 & 1528905 & 8.9031 & 7.6808 & TRN & \\
\hline CHEMBL3647632 & 1528905 & $7.7570 e$ & j00000006 & 7.9615 & TRN \\
\hline CHEMBL3647606 & 1528905 & $7.8210 e$ & 30000000 & 6.7439 & TST \\
\hline CHEMBL3647643 & 1528905 & 6.0 & 7.41100 & 00000000005 & TRN \\
\hline CHEMBL3647620 & 1528905 & 8.7122 & 7.8912 & TRN & \\
\hline CHEMBL3647589 & 1528905 & 7.9208 & 6.5768 & TST & \\
\hline CHEMBL 3647640 & 1528905 & 6.0 & 7.3728 & TRN & \\
\hline CHEMBL 2180769 & 1528905 & 8.8794 & 8.0314 & TRN & \\
\hline CHEMBL3647614 & 1528905 & 7.6882 & 7.8754 & TRN & \\
\hline CHEMBL3647634 & 1528905 & 8.2958 & 8.3879 & TRN & \\
\hline CHEMBL3647652 & 1528905 & 6.5003 & 7.7179 & TST & \\
\hline CHEMBL3647635 & 1528905 & 8.8894 & 8.0621 & TRN & \\
\hline CHEMBL 3647585 & 1528905 & 6.8239 & 5.865 & TRN & \\
\hline CHEMBL 3647627 & 1528905 & 6.0 & 7.7285 & TRN & \\
\hline CHEMBL3647621 & 1528905 & 8.5622 & 8.6435 & TRN & \\
\hline CHEMBL3647617 & 1528905 & 8.4881 & 8.0218 & TRN & \\
\hline
\end{tabular}


Supplemental Table S2.txt

\begin{tabular}{|c|c|c|c|c|c|c|}
\hline CHEMBL 3647658 & 1528905 & 7.6253 & 8.1486 & TRN & & \\
\hline CHEMBL3647618 & 1528905 & 8.1158 & 8.1115 & TRN & & \\
\hline CHEMBL 3647623 & 1528905 & 8.0783 & 8.4838 & TRN & & \\
\hline CHEMBL3647653 & 1528905 & \multicolumn{3}{|c|}{7.962999999999999} & 7.8298 TST & \\
\hline CHEMBL3647616 & 1528905 & 8.3862 & 8.1925 & TRN & & \\
\hline CHEMBL3647626 & 1528905 & 8.8894 & 8.5829 & TRN & & \\
\hline CHEMBL 3647637 & 1528905 & 9.0232 & 8.3056 & TRN & & \\
\hline CHEMBL 3647670 & 1528905 & 6.0 & 6.5515 & TST & & \\
\hline CHEMBL 3647591 & 1528905 & 6.0 & 6.5137 & TST & & \\
\hline CHEMBL3647660 & 1528905 & 6.0 & 6.5563 & TST & & \\
\hline CHEMBL3647628 & 1528905 & 6.0 & 8.3513 & TRN & & \\
\hline CHEMBL3647639 & 1528905 & 7.6498 & 7.1319 & TRN & & \\
\hline CHEMBL 3647629 & 1528905 & 8.5287 & 8.7773 & TRN & & \\
\hline CHEMBL 3647610 & 1528905 & 8.8416 & 6.7798 & TST & & \\
\hline CHEMBL3647590 & 1528905 & 7.4878 & 6.7713 & TRN & & \\
\hline CHEMBL3647594 & 1528905 & 6.0 & 8.1157 & TRN & & \\
\hline CHEMBL3647587 & 1528905 & \multicolumn{3}{|c|}{5.757000000000001} & 6.093999999999999 & TRN \\
\hline CHEMBL3647609 & 1528905 & 8.4572 & 6.7342 & TST & & \\
\hline CHEMBL3647604 & 1528905 & 7.8861 & 6.5769 & TST & & \\
\hline CHEMBL3647650 & 1528905 & 6.9136 & 7.5212 & TRN & & \\
\hline CHEMBL3647672 & 1528905 & 8.3726 & 8.0294 & TRN & & \\
\hline CHEMBL3647625 & 1528905 & 8.1129 & 8.3131 & TRN & & \\
\hline CHEMBL3647599 & 1528905 & 6.0 & 6.5858 & TRN & & \\
\hline CHEMBL3647638 & 1528905 & 8.5003 & 7.6493 & TRN & & \\
\hline CHEMBL 3647601 & 1528905 & 7.3419 & 7.6289 & TRN & & \\
\hline CHEMBL3647607 & 1528905 & 7.567 & 6.6111 & TST & & \\
\hline CHEMBL 3647644 & 1528905 & 7.9547 & 7.5403 & TRN & & \\
\hline CHEMBL 3647612 & 1528905 & 8.4498 & 7.4861 & TST & & \\
\hline CHEMBL3647619 & 1528905 & 8.1308 & 8.2191 & TST & & \\
\hline CHEMBL 3647602 & 1528905 & 6.0 & 7.072 & TRN & & \\
\hline CHEMBL 3647631 & 1528905 & 8.1824 & 8.1303 & TRN & & \\
\hline CHEMBL3647596 & 1528905 & 6.6028 & 6.8361 & TST & & \\
\hline CHEMBL 3647671 & 1528905 & 9.585 & 9.0071 & TST & & \\
\hline CHEMBL3647641 & 1528905 & 6.0 & 7.3831 & TRN & & \\
\hline CHEMBL 3647588 & 1528905 & 7.041 & 6.9846 & TRN & & \\
\hline CHEMBL3186611 & 1301575 & 4.3143 & 3.5265 & TST & & \\
\hline CHEMBL3186861 & 1301575 & 5.0462 & 5.1555 & TRN & & \\
\hline CHEMBL473542 & 1301575 & 4.9788 & 4.5549 & TRN & & \\
\hline CHEMBL3188325 & 1301575 & 4.8589 & 5.0565 & TRN & & \\
\hline CHEMBL 3185555 & 1301575 & 3.1549 & 4.3484 & TRN & & \\
\hline CHEMBL3185734 & 1301575 & 3.1549 & 4.1557 & TRN & & \\
\hline CHEMBL3187721 & 1301575 & 3.1549 & 3.1502 & TRN & & \\
\hline CHEMBL 3187525 & 1301575 & 3.1549 & 3.5428 & TRN & & \\
\hline CHEMBL1543340 & 1301575 & 3.1549 & 3.3487 & TST & & \\
\hline CHEMBL489693 & 1301575 & 3.1549 & 3.5358 & TRN & & \\
\hline CHEMBL3186408 & 1301575 & 4.3575 & 3.534 & TST & & \\
\hline CHEMBL502910 & 1301575 & 4.6413 & 4.2077 & TRN & & \\
\hline CHEMBL 3183210 & 1301575 & 3.1549 & 3.4093 & TST & & \\
\hline
\end{tabular}

Page 28390 
Supplemental Table S2.txt

\begin{tabular}{|c|c|c|c|c|c|}
\hline CHEMBL 2032070 & 1301575 & 3.1549 & 3.1046 & TRN & \\
\hline CHEMBL578502 & 1301575 & 4.8573 & 4.78 & TRN & \\
\hline CHEMBL3189091 & 1301575 & 4.8297 & 4.878 & TRN & \\
\hline CHEMBL472736 & 1301575 & 5.0353 & 5.3656 & TRN & \\
\hline CHEMBL3184792 & 1301575 & 4.223 & 3.4775 & TRN & \\
\hline CHEMBL3183946 & 1301575 & 3.1549 & 3.3835 & TRN & \\
\hline CHEMBL3182935 & 1301575 & 4.8887 & 5.0251 & TRN & \\
\hline CHEMBL3184857 & 1301575 & 4.5154 & 4.6112 & TRN & \\
\hline CHEMBL489305 & 1301575 & 4.8765 & 4.7638 & TRN & \\
\hline CHEMBL3186925 & 1301575 & 4.76 & 4.4165 & TRN & \\
\hline CHEMBL578905 & 1301575 & 4.6047 & 4.2268 & TRN & \\
\hline CHEMBL3183984 & 1301575 & 5.5361 & 5.172999 & 9999999999 & TRN \\
\hline CHEMBL3185954 & 1301575 & 4.2981 & 3.8409 & TRN & \\
\hline CHEMBL3182390 & 1301575 & 4.6714 & 4.7172 & TRN & \\
\hline CHEMBL3187661 & 1301575 & 4.2511 & 3.5065 & TRN & \\
\hline CHEMBL3184404 & 1301575 & 3.1549 & 3.2354 & TRN & \\
\hline CHEMBL502336 & 1301575 & 5.0521 & 5.2059 & TRN & \\
\hline CHEMBL490302 & 1301575 & 4.9278 & 4.8277 & TRN & \\
\hline CHEMBL3185869 & 1301575 & 4.7187 & 4.993 & TRN & \\
\hline CHEMBL3182975 & 1301575 & 3.1549 & 3.3762 & TRN & \\
\hline CHEMBL1403744 & 1301575 & 4.5274 & 4.3394 & TST & \\
\hline CHEMBL3184519 & 1301575 & 3.1549 & 2.7357 & TRN & \\
\hline CHEMBL473338 & 1301575 & 4.5051 & 4.3247 & TRN & \\
\hline CHEMBL 3187616 & 1301575 & 3.1549 & 3.384 & TRN & \\
\hline CHEMBL474124 & 1301575 & 5.0794 & 5.0114 & TRN & \\
\hline CHEMBL3182396 & 1301575 & 3.1549 & 3.4153 & TRN & \\
\hline CHEMBL3182398 & 1301575 & 4.5933 & 4.5803 & TRN & \\
\hline CHEMBL1576149 & 1301575 & 3.1549 & 3.0456 & TRN & \\
\hline CHEMBL1347347 & 1301575 & 3.1549 & 3.745 & TRN & \\
\hline CHEMBL3185577 & 1301575 & 3.1549 & 3.1001 & TRN & \\
\hline CHEMBL3188820 & 1301575 & 4.6411 & 4.769 & TRN & \\
\hline CHEMBL3182979 & 1301575 & 3.1549 & 3.1171 & TRN & \\
\hline CHEMBL3186625 & 1301575 & 5.0675 & 4.9313 & TRN & \\
\hline CHEMBL491280 & 1301575 & 3.1549 & 3.3334 & TRN & \\
\hline CHEMBL3182536 & 1301575 & 4.3021 & 4.0811 & TRN & \\
\hline CHEMBL3182920 & 1301575 & 3.1549 & 3.2053 & TRN & \\
\hline CHEMBL3186570 & 1301575 & 3.1549 & 3.1769 & TST & \\
\hline CHEMBL 3182880 & 1301575 & 5.24799 & 999999999 & 5.2394 & TRN \\
\hline CHEMBL3182643 & 1301575 & 3.1549 & 3.0583 & TRN & \\
\hline CHEMBL3184415 & 1301575 & 4.6788 & 4.6151 & TRN & \\
\hline CHEMBL3183431 & 1301575 & 3.1549 & 3.1098 & TRN & \\
\hline CHEMBL3187580 & 1301575 & 4.1592 & 3.6738 & TRN & \\
\hline CHEMBL3185112 & 1301575 & 4.6312 & 4.6519 & TRN & \\
\hline CHEMBL 84010 & 1301575 & 3.1549 & 3.1358 & TST & \\
\hline CHEMBL3183317 & 1301575 & 4.8477 & 5.0038 & TRN & \\
\hline CHEMBL3185499 & 1301575 & 4.4955 & 4.3327 & TRN & \\
\hline CHEMBL3185543 & 1301575 & 4.3239 & 4.1373 & TRN & \\
\hline CHEMBL3183416 & 1301575 & 4.7975 & 4.9578 & TRN & \\
\hline
\end{tabular}

Page 28391 
Supplemental Table S2.txt

\begin{tabular}{|c|c|c|c|c|}
\hline CHEMBL 3182980 & 1301575 & 3.1549 & 3.2772 & TRN \\
\hline CHEMBL3182750 & 1301575 & 3.1549 & 3.6056 & TRN \\
\hline CHEMBL3186235 & 1301575 & 3.1549 & 3.0958 & TRN \\
\hline CHEMBL 3182344 & 1301575 & 3.1549 & 3.3914 & TRN \\
\hline CHEMBL415711 & 1301575 & 4.1822 & 3.2142 & TST \\
\hline CHEMBL3189117 & 1301575 & 3.1549 & 2.7985 & TST \\
\hline CHEMBL 3184406 & 1301575 & 4.9504 & 5.0009 & TRN \\
\hline CHEMBL 3184515 & 1301575 & 3.1549 & 3.2638 & TRN \\
\hline CHEMBL489304 & 1301575 & 4.8658 & 4.4403 & TRN \\
\hline CHEMBL3184216 & 1301575 & 5.1733 & 5.2701 & TRN \\
\hline CHEMBL472735 & 1301575 & 5.1415 & 5.3209 & TRN \\
\hline CHEMBL490493 & 1301575 & 4.739 & 4.7132 & TRN \\
\hline CHEMBL 3182727 & 1301575 & 4.7464 & 4.5361 & TRN \\
\hline CHEMBL 3187471 & 1301575 & 5.5867 & 5.2216 & TRN \\
\hline CHEMBL1436964 & 1301575 & 3.1549 & 3.58100 & 00000000004 \\
\hline CHEMBL3188038 & 1301575 & 4.6763 & 4.7163 & TRN \\
\hline CHEMBL3185600 & 1301575 & 4.6202 & 4.4272 & TRN \\
\hline CHEMBL1403890 & 1301575 & 4.5354 & 3.4624 & TST \\
\hline CHEMBL1165723 & 1301575 & 3.1549 & 3.4462 & TRN \\
\hline CHEMBL3185080 & 1301575 & 3.1549 & 3.1689 & TRN \\
\hline CHEMBL490301 & 1301575 & 3.1549 & 3.3985 & TRN \\
\hline CHEMBL1347328 & 1301575 & 4.5519 & 4.2477 & TRN \\
\hline CHEMBL 3185446 & 1301575 & 5.2351 & 4.7549 & TRN \\
\hline CHEMBL3181884 & 1301575 & 5.2076 & 5.3008 & TRN \\
\hline CHEMBL514665 & 1301575 & 4.4901 & 4.7332 & TST \\
\hline CHEMBL3183778 & 1301575 & 4.8268 & 4.9516 & TST \\
\hline CHEMBL 3187287 & 1301575 & 3.1549 & 3.0077 & TST \\
\hline CHEMBL 3188122 & 1301575 & 4.5704 & 4.5882 & TST \\
\hline CHEMBL3185784 & 1301575 & 4.4374 & 4.6962 & TST \\
\hline CHEMBL 3186962 & 1301575 & 4.6847 & 4.3796 & TST \\
\hline CHEMBL 3188682 & 1301575 & 4.5085 & 3.8963 & TST \\
\hline CHEMBL1464975 & 1301575 & 3.1549 & 3.5454 & TST \\
\hline CHEMBL 3188380 & 1301575 & 4.539 & 3.7986 & TST \\
\hline CHEMBL3183450 & 1301575 & 3.1549 & 3.2779 & TST \\
\hline CHEMBL 3188635 & 1301575 & 5.0438 & 4.4677 & TST \\
\hline CHEMBL475546 & 1301575 & 4.7402 & 4.7841 & TST \\
\hline CHEMBL1340868 & 1301575 & 3.1549 & 3.2144 & TST \\
\hline CHEMBL473541 & 1301575 & 4.7378 & 4.4872 & TST \\
\hline CHEMBL3946352 & 1641222 & 8.6021 & 7.8947 & TRN \\
\hline CHEMBL 3892242 & 1641222 & 6.9788 & 7.5961 & TRN \\
\hline CHEMBL3899399 & 1641222 & 7.3655 & 7.62 & TRN \\
\hline CHEMBL3969189 & 1641222 & 7.3401 & 6.9498 & TRN \\
\hline CHEMBL3942283 & 1641222 & 6.8508 & 7.0541 & TRN \\
\hline CHEMBL3973298 & 1641222 & 6.9431 & 8.0884 & TRN \\
\hline CHEMBL 3891887 & 1641222 & 8.2291 & 8.8164 & TRN \\
\hline CHEMBL3956812 & 1641222 & 8.1079 & 7.6655 & TRN \\
\hline CHEMBL3950795 & 1641222 & 8.7747 & 7.8379 & TRN \\
\hline CHEMBL3920008 & 1641222 & 8.0706 & 9.0636 & TRN \\
\hline
\end{tabular}

Page 28392 
Supplemental Table S2.txt

\begin{tabular}{|c|c|c|c|c|}
\hline CHEMBL3954564 & 1641222 & 8.6576 & 7.1672 & TRN \\
\hline CHEMBL3898552 & 1641222 & 8.0862 & 8.5174 & TST \\
\hline CHEMBL3909857 & 1641222 & 7.6737 & 6.9902 & TST \\
\hline CHEMBL3913320 & 1641222 & 9.0969 & 9.0564 & TRN \\
\hline CHEMBL3913026 & 1641222 & 8.0362 & 8.0124 & TRN \\
\hline CHEMBL3893423 & 1641222 & 6.8013 & 7.6288 & TRN \\
\hline CHEMBL3889477 & 1641222 & 7.9788 & 7.3254 & TST \\
\hline CHEMBL3913944 & 1641222 & 8.4437 & 7.3519 & TRN \\
\hline CHEMBL3921177 & 1641222 & 7.2269 & 7.7047 & TRN \\
\hline CHEMBL3952967 & 1641222 & 7.4672 & 7.4231 & TRN \\
\hline CHEMBL3920939 & 1641222 & 7.6737 & 7.3729 & TRN \\
\hline CHEMBL3909657 & 1641222 & 7.75700 & 00000006 & 7.9431 \\
\hline CHEMBL3935539 & 1641222 & 8.6778 & 8.8201 & TRN \\
\hline CHEMBL3941153 & 1641222 & 8.9208 & 8.5642 & TRN \\
\hline CHEMBL3982257 & 1641222 & 7.8297 & 7.5966 & TRN \\
\hline CHEMBL3972404 & 1641222 & 8.6383 & 8.9066 & TRN \\
\hline CHEMBL3943136 & 1641222 & 7.3298 & 7.2467 & TRN \\
\hline CHEMBL3959616 & 1641222 & 8.5686 & 7.37 & TST \\
\hline CHEMBL3904308 & 1641222 & 6.4724 & 7.8999 & TST \\
\hline CHEMBL3909712 & 1641222 & 7.9318 & 8.3243 & TRN \\
\hline CHEMBL3959537 & 1641222 & 8.699 & 8.4063 & TRN \\
\hline CHEMBL3976211 & 1641222 & 8.5376 & 8.0784 & TRN \\
\hline CHEMBL3964696 & 1641222 & 7.3665 & 7.1705 & TRN \\
\hline CHEMBL3962435 & 1641222 & 7.6861 & 7.9424 & TRN \\
\hline CHEMBL 3894780 & 1641222 & 9.2757 & 8.7915 & TRN \\
\hline CHEMBL3933567 & 1641222 & 6.2118 & 6.8659 & TRN \\
\hline CHEMBL3941272 & 1641222 & 7.644 & 8.4606 & TRN \\
\hline CHEMBL3913257 & 1641222 & 8.6778 & 8.506 & TRN \\
\hline CHEMBL3959512 & 1641222 & 7.52 & 8.5364 & TST \\
\hline CHEMBL 3914994 & 1641222 & 6.8996 & 7.112999 & 99999999995 \\
\hline CHEMBL3923317 & 1641222 & 7.8041 & 7.4693 & TRN \\
\hline CHEMBL3891575 & 1641222 & 8.7447 & 8.7247 & TRN \\
\hline CHEMBL3919575 & 1641222 & 8.1675 & 8.5112 & TRN \\
\hline CHEMBL3984224 & 1641222 & 8.8539 & 8.6325 & TRN \\
\hline CHEMBL3975242 & 1641222 & 8.0605 & 7.7235 & TST \\
\hline CHEMBL3955174 & 1641222 & 9.0969 & 8.8347 & TRN \\
\hline CHEMBL3966727 & 1641222 & 6.1656 & 6.7243 & TRN \\
\hline CHEMBL3953412 & 1641222 & 7.58 & 8.0191 & TRN \\
\hline CHEMBL3906372 & 1641222 & 6.6799 & 7.1787 & TST \\
\hline CHEMBL3963975 & 1641222 & 7.6517 & 7.4083 & TRN \\
\hline CHEMBL3952361 & 1641222 & 9.1739 & 8.2398 & TST \\
\hline CHEMBL3934698 & 1641222 & 7.3179 & 6.7433 & TRN \\
\hline CHEMBL3919643 & 1641222 & 8.9586 & 8.3298 & TRN \\
\hline CHEMBL3911837 & 1641222 & 7.8894 & 8.709 & TRN \\
\hline CHEMBL3915072 & 1641222 & 8.2668 & 7.885 & TRN \\
\hline CHEMBL3975729 & 1641222 & 7.8996 & 8.1811 & TRN \\
\hline CHEMBL3890603 & 1641222 & 7.7077 & 7.5683 & TRN \\
\hline CHEMBL3924468 & 1641222 & 6.0 & 7.5361 & TRN \\
\hline
\end{tabular}


Supplemental Table S2.txt

\begin{tabular}{|c|c|c|c|c|}
\hline 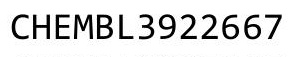 & 222 & 8.0 & & \\
\hline HEMBL3987165 & 541222 & 8.3665 & 2141 & \\
\hline HEMBL3904977 & 641222 & 8.1805 & 4976 & \\
\hline 050 & 222 & & 8397 & \\
\hline IEMBL3 & 222 & 78 & 517 & \\
\hline HEMBL3981950 & 641222 & 8.6383 & 6785 & \\
\hline HEMBL3944499 & 641222 & 8.5686 & 9707 & \\
\hline HEMBL3\& & 222 & 685 & 5083 & \\
\hline IEMBL3 & 222 & 86 & 703 & \\
\hline IEMBL3 & 222 & 208 & 4356 & \\
\hline HEMBL3982476 & 222 & 6.3152 & 9022 & \\
\hline AEMBL3939815 & 222 & 8.0 & 0188 & \\
\hline HEMBL 392 & 222 & 18 & 1457 & \\
\hline HEMBL3S & & 51 & 2833 & \\
\hline HEMBL3 & 22 & 7. & 5316 & \\
\hline HEMBL3S & 22 & 61 & 365 & \\
\hline HEMBL3929848 & 22 & 6. & 6.8708 & \\
\hline HEMBL3\& & 22 & $\partial 8$ & 157 & \\
\hline HEMBL3S & & & & \\
\hline HEMBL3 & 22 & & 3923 & D \\
\hline HEMBL3S & 22 & & 9381 & \\
\hline HEMBL39 & 22 & 8. & 5647 & RN \\
\hline HEMBL3S & 22 & 99 & 1034 & \\
\hline HEMBL3S & & & 698 & \\
\hline HEM & 22 & 6. & 7282 & RN \\
\hline HEMBL3\& & & 39 & 2985 & RN \\
\hline HEMBL 394 & 22 & 6. & 2928 & ГRN \\
\hline HEMBL39 & 22 & $\partial 5$ & 9732 & \\
\hline HEM & 22 & & 111 & ST \\
\hline HEME & 22 & & 7324 & RN \\
\hline HEMBL38 & & & 3849 & ST \\
\hline HEMBL3957462 & 22 & 6. & 7353 & $\mathrm{RN}$ \\
\hline HEMBL38 & 22 & & 102 & RN \\
\hline 4 & & & 923 & ST \\
\hline HEMBL38 & 22 & & 5551 & RN \\
\hline HEMBL 392 & & 8.3468 & 5367 & RN \\
\hline HEMBL39 & 22 & 6 & 3885 & RN \\
\hline HEMBL39 & 22 & & 647 & RN \\
\hline 2 & & & 119 & RN \\
\hline HEMBL39 & & 6.0 & 3659 & RN \\
\hline HEMBL 389 & 22 & 9. & 793 & RN \\
\hline HEMBL 39 & 22 & & 302 & RN \\
\hline HEMBL3\& & & & 7.3566 & \\
\hline CHEMBL 39 & & & 8.1308 & RN \\
\hline HEMBL 398 & & 7.4461 & 7.0542 & ST \\
\hline HEMBL 392 & 22 & 7.4237 & .5968 & RN \\
\hline HEN & & & & \\
\hline & & & & \\
\hline
\end{tabular}

Page 28394 
Supplemental Table S2.txt

\begin{tabular}{|c|c|c|c|c|c|}
\hline CHEMBL3960097 & 1641222 & 8.1002 & 8.8778 & TST & \\
\hline CHEMBL3925096 & 1641222 & 7.9788 & 8.3861 & TRN & \\
\hline CHEMBL3974765 & 1641222 & 7.6946 & 7.7893 & TRN & \\
\hline CHEMBL3946564 & 1641222 & 8.1427 & 8.0072 & TST & \\
\hline CHEMBL3957203 & 1641222 & 7.8861 & 7.5511 & TRN & \\
\hline CHEMBL 3983954 & 1641222 & 9.2218 & 8.6806 & TRN & \\
\hline CHEMBL3969773 & 1641222 & 7.8297 & 7.7929 & TRN & \\
\hline CHEMBL 3937520 & 1641222 & 8.5086 & 8.039 & TRN & \\
\hline CHEMBL3919971 & 1641222 & 8.0575 & 8.0104 & TRN & \\
\hline CHEMBL3961910 & 1641222 & 7.8827 & 7.7689 & TRN & \\
\hline CHEMBL 3956276 & 1641222 & 7.6402 & 7.5667 & TRN & \\
\hline CHEMBL3890436 & 1641222 & 7.9788 & 8.44 & TRN & \\
\hline CHEMBL 3974897 & 1641222 & 8.9355 & 8.3242 & TRN & \\
\hline CHEMBL 3897043 & 1641222 & 9.2218 & 8.5801 & TRN & \\
\hline CHEMBL 3948364 & 1641222 & 7.5467 & 7.3326 & TST & \\
\hline CHEMBL3931159 & 1641222 & 7.3251 & 7.4385 & TRN & \\
\hline CHEMBL3945535 & 1641222 & 8.6021 & 7.504 & TRN & \\
\hline CHEMBL3949001 & 1641222 & 6.1612 & 7.05399 & 9999999999 & TRN \\
\hline CHEMBL3956387 & 1641222 & 8.2007 & 7.7006 & TRN & \\
\hline CHEMBL 3907150 & 1641222 & 8.3478 & 7.6394 & TST & \\
\hline CHEMBL3973001 & 1641222 & 8.6576 & 8.515 & TRN & \\
\hline CHEMBL3981928 & 1641222 & 7.6198 & 7.8418 & TST & \\
\hline CHEMBL3896620 & 1641222 & 7.8125 & 7.76399 & 9999999999 & TST \\
\hline CHEMBL3982892 & 1641222 & 7.4225 & 8.3646 & TST & \\
\hline CHEMBL 3966461 & 1641222 & 8.699 & 8.0418 & TST & \\
\hline CHEMBL3892411 & 1641222 & 6.0 & 7.3151 & TRN & \\
\hline CHEMBL3976895 & 1641222 & 8.5528 & 8.6673 & TRN & \\
\hline CHEMBL3955016 & 1641222 & 7.7423 & 8.3038 & TRN & \\
\hline CHEMBL3910750 & 1641222 & 8.0605 & 8.3568 & TRN & \\
\hline CHEMBL 3898773 & 1641222 & 8.3188 & 8.1518 & TRN & \\
\hline CHEMBL3937597 & 1641222 & 8.2757 & 7.9767 & TRN & \\
\hline CHEMBL3930642 & 1641222 & 6.5735 & 6.2161 & TRN & \\
\hline CHEMBL3898221 & 1641222 & 6.0472 & 7.237 & TRN & \\
\hline CHEMBL3984341 & 1641222 & 6.7645 & 7.2247 & TRN & \\
\hline CHEMBL3930697 & 1641222 & 7.3904 & 8.2881 & TST & \\
\hline CHEMBL3960253 & 1641222 & 7.9318 & 7.5603 & TRN & \\
\hline CHEMBL3933381 & 1641222 & 8.3242 & 8.0893 & TST & \\
\hline CHEMBL3975121 & 1641222 & 7.4908 & 8.0112 & TST & \\
\hline CHEMBL3947012 & 1641222 & 7.3936 & 7.6561 & TRN & \\
\hline CHEMBL3973924 & 1641222 & 7.4157 & 8.3854 & TST & \\
\hline CHEMBL3974113 & 1641222 & 7.5784 & 7.9415 & TST & \\
\hline CHEMBL3950100 & 1641222 & 8.9208 & 8.7931 & TRN & \\
\hline CHEMBL3946443 & 1641222 & 8.4202 & 8.0419 & TRN & \\
\hline CHEMBL3950297 & 1641222 & 8.7212 & 8.2429 & TST & \\
\hline CHEMBL3981044 & 1641222 & 7.52 & 7.3225 & TRN & \\
\hline CHEMBL3897543 & 1641222 & 7.6615 & 6.8965 & TRN & \\
\hline CHEMBL 3977368 & 1641222 & 7.8268 & 8.394 & TRN & \\
\hline CHEMBL3959123 & 1641222 & 9.5528 & 9.696 & TRN & \\
\hline
\end{tabular}


Supplemental Table S2.txt

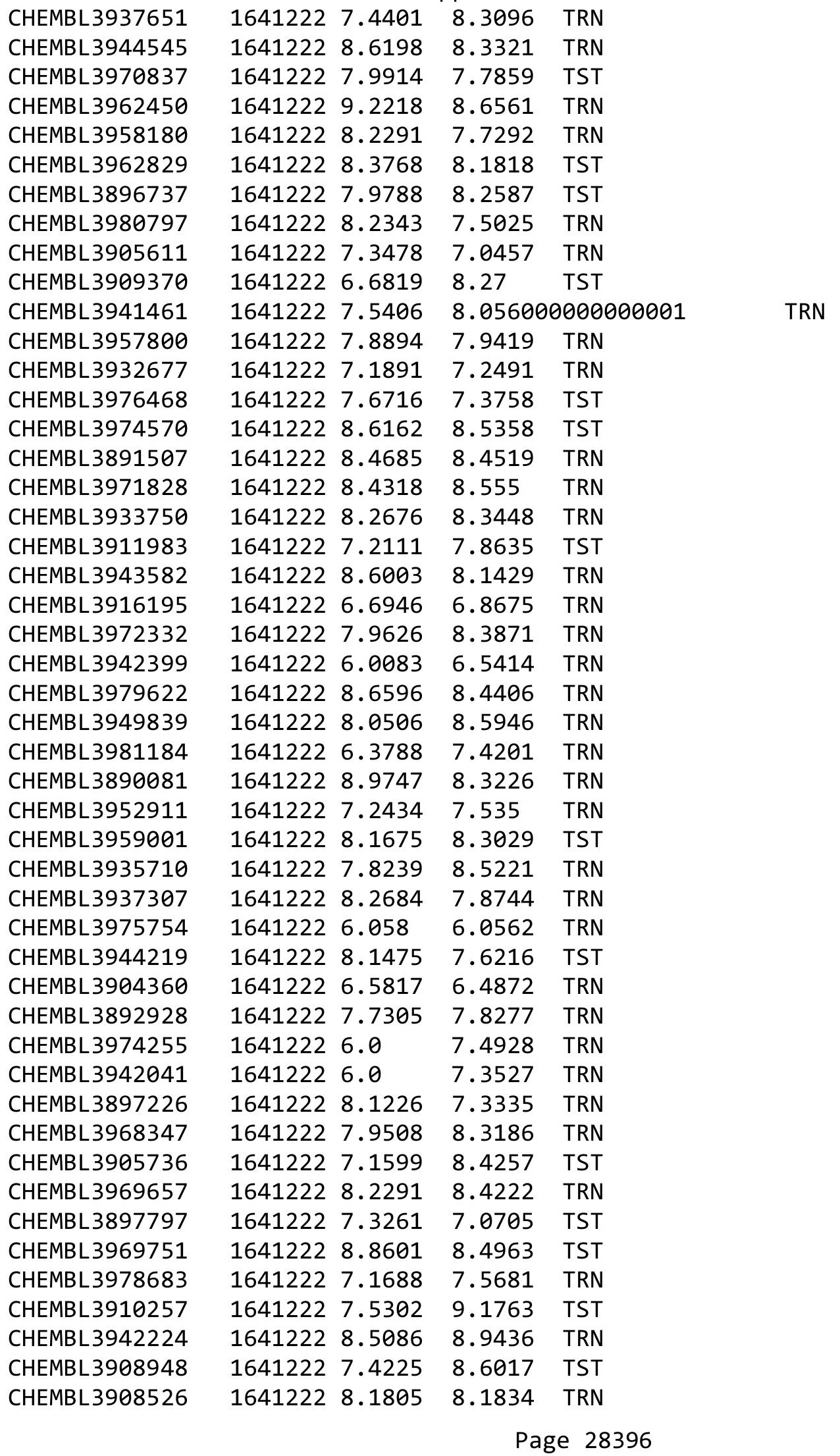


Supplemental Table S2.txt

\begin{tabular}{|c|c|c|c|c|c|}
\hline CHEMBL3917765 & 1641222 & 8.4685 & 8.2489 & TRN & \\
\hline CHEMBL3968967 & 1641222 & 6.0645 & 6.6038 & TRN & \\
\hline CHEMBL3926560 & 1641222 & 7.6289 & 7.5459 & TRN & \\
\hline CHEMBL3968838 & 1641222 & 8.0862 & 7.7269 & TRN & \\
\hline CHEMBL3945515 & 1641222 & 8.0186 & 8.3215 & TRN & \\
\hline CHEMBL 3958282 & 1641222 & 9.0969 & 8.0902 & TRN & \\
\hline CHEMBL3930314 & 1641222 & 7.9318 & 8.2747 & TRN & \\
\hline CHEMBL3920243 & 1641222 & 6.382999 & 99999999 & 7.2693 & TRN \\
\hline CHEMBL3941641 & 1641222 & 8.3098 & 7.5849 & TRN & \\
\hline CHEMBL3979897 & 1641222 & 6.0395 & 6.6744 & TRN & \\
\hline CHEMBL 3900940 & 1641222 & 6.9586 & 7.0658 & TRN & \\
\hline CHEMBL3972187 & 1641222 & 7.2426 & 7.2421 & TST & \\
\hline CHEMBL 3898097 & 1641222 & 9.5229 & 8.7307 & TRN & \\
\hline CHEMBL 3924017 & 1641222 & 8.6021 & 8.6385 & TRN & \\
\hline CHEMBL 3904164 & 1641222 & 7.821006 & 00000000 & 7.3959 & TRN \\
\hline CHEMBL3913313 & 1641222 & 6.8297 & 7.13299 & 9999999999 & TRN \\
\hline CHEMBL3927186 & 1641222 & 8.8601 & 9.6601 & TST & \\
\hline CHEMBL3961602 & 1641222 & 7.2676 & 7.5453 & TST & \\
\hline CHEMBL3914723 & 1641222 & 7.752006 & 300000006 & 7.8752 & 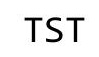 \\
\hline CHEMBL 3922214 & 1641222 & 7.5171 & 7.1752 & TST & \\
\hline CHEMBL3965537 & 1641222 & 7.757006 & 00000000 & 7.983 & TST \\
\hline CHEMBL3979771 & 1641222 & 7.1068 & 7.2032 & TRN & \\
\hline CHEMBL3973783 & 1641222 & 8.2147 & 8.3513 & TRN & \\
\hline CHEMBL3910079 & 1641222 & 8.7959 & 8.7962 & TRN & \\
\hline CHEMBL 3951722 & 1641222 & 8.3279 & 7.8755 & TRN & \\
\hline CHEMBL3924069 & 1641222 & 9.0458 & 9.1166 & TRN & \\
\hline CHEMBL3917846 & 1641222 & 6.7825 & 6.8105 & TRN & \\
\hline CHEMBL3929064 & 1641222 & 6.7471 & 8.6485 & TST & \\
\hline CHEMBL3986474 & 1641222 & 7.6655 & 8.0155 & TST & \\
\hline CHEMBL 3948483 & 1641222 & 9.5528 & 8.8377 & TRN & \\
\hline CHEMBL3912305 & 1641222 & 7.7878 & 8.2683 & TST & \\
\hline CHEMBL3915718 & 1641222 & 8.8539 & 9.1949 & TRN & \\
\hline CHEMBL3973180 & 1641222 & 7.6737 & 7.8707 & TRN & \\
\hline CHEMBL3951837 & 1641222 & 6.0 & 6.88399 & 99999999995 & TRN \\
\hline CHEMBL3975907 & 1641222 & 8.4685 & 7.6734 & TRN & \\
\hline CHEMBL3985850 & 1641222 & 9.0458 & 7.3147 & TRN & \\
\hline CHEMBL3889962 & 1641222 & 7.4449 & 7.87299 & 9999999999 & ובנו \\
\hline CHEMBL3928837 & 1641222 & 8.4949 & 8.51 & TRN & \\
\hline CHEMBL3950050 & 1641222 & 6.4584 & 6.3467 & TRN & \\
\hline CHEMBL3898891 & 1641222 & 7.2351 & 7.4947 & TRN & \\
\hline CHEMBL3957622 & 1641222 & 7.4935 & 8.026 & TRN & \\
\hline CHEMBL3922921 & 1641222 & 7.8297 & 8.0794 & TRN & \\
\hline CHEMBL3978829 & 1641222 & 8.5686 & 8.37 & TRN & \\
\hline CHEMBL3913978 & 1641222 & 7.9208 & 7.8731 & TRN & \\
\hline CHEMBL3936792 & 1641222 & 9.5229 & 8.2453 & TRN & \\
\hline CHEMBL3935409 & 1641222 & 7.8539 & 8.0635 & TRN & \\
\hline CHEMBL3972806 & 1641222 & 8.2596 & 8.4096 & TRN & \\
\hline CHEMBL3977592 & 1641222 & 8.4437 & 8.076 & TRN & \\
\hline
\end{tabular}


Supplemental Table S2.txt

\begin{tabular}{|c|c|c|c|c|c|}
\hline CHEMBL3914432 & 1641222 & 7.2284 & 7.8991 & TRN & \\
\hline CHEMBL 3982163 & 1641222 & 8.2757 & 7.8721 & TRN & \\
\hline CHEMBL3895638 & 1641222 & 8.163 & 7.8478 & TST & \\
\hline CHEMBL 3914037 & 1641222 & 8.7011 & 7.9194 & TRN & \\
\hline CHEMBL3966835 & 1641222 & 6.2692 & 6.8321 & TST & \\
\hline CHEMBL3940205 & 1641222 & 8.6073 & 8.5353 & TST & \\
\hline CHEMBL 3951774 & 1641222 & 8.7447 & 8.6267 & TRN & \\
\hline CHEMBL 3957763 & 1641222 & 8.585 & 8.1007 & TRN & \\
\hline CHEMBL 3949954 & 1641222 & 8.6383 & 7.6783 & TST & \\
\hline CHEMBL3973150 & 1641222 & 9.301 & 8.3716 & TRN & \\
\hline CHEMBL3898927 & 1641222 & 8.426 & 7.6249 & TRN & \\
\hline CHEMBL3925212 & 1641222 & 7.1618 & 6.2054 & TRN & \\
\hline CHEMBL 3898343 & 1641222 & 7.8928 & 8.4872 & TRN & \\
\hline CHEMBL 3898400 & 1641222 & 7.8297 & 8.3776 & TRN & \\
\hline CHEMBL3910162 & 1641222 & 7.9957 & 7.6374 & TRN & \\
\hline CHEMBL3917166 & 1641222 & 8.8928 & 9.0854 & TRN & \\
\hline CHEMBL3924647 & 1641222 & 7.8794 & 7.923999 & 79999999995 & \\
\hline CHEMBL 3963787 & 1641222 & 8.4437 & 8.3023 & TRN & \\
\hline CHEMBL3950424 & 1641222 & 8.1397 & 9.0056 & TST & \\
\hline CHEMBL3916780 & 1641222 & 7.7471 & 7.2718 & TST & \\
\hline CHEMBL3922310 & 1641222 & 7.0645 & 8.1928 & TST & \\
\hline CHEMBL3947265 & 1641222 & 6.6021 & 8.0726 & TST & \\
\hline CHEMBL 3985541 & 1641222 & 8.041 & 8.2371 & TRN & \\
\hline CHEMBL3900865 & 1641222 & 8.7959 & 8.3919 & TRN & \\
\hline CHEMBL 3928582 & 1641222 & 7.7905 & 7.9103 & TST & \\
\hline CHEMBL3986141 & 1641222 & 8.6198 & \multicolumn{2}{|c|}{8.216000000000001} & \\
\hline CHEMBL 3982573 & 1641222 & 8.98299 & 999999999 & 7.577999999999999 & TRN \\
\hline CHEMBL 3929228 & 1641222 & 8.4318 & 8.4504 & TRN & \\
\hline CHEMBL3922550 & 1641222 & 8.7959 & 8.4211 & TRN & \\
\hline CHEMBL 3906725 & 1641222 & 7.295 & 6.8206 & TST & \\
\hline CHEMBL 3986652 & 1641222 & 8.4685 & 8.3829 & TRN & \\
\hline CHEMBL3928441 & 1641222 & 6.0 & 7.7667 & TRN & \\
\hline CHEMBL3925631 & 1641222 & 7.1605 & 7.2836 & TRN & \\
\hline CHEMBL3945153 & 1641222 & 9.1612 & 8.846 & TRN & \\
\hline CHEMBL 3927264 & 1641222 & 8.5129 & 8.3818 & TRN & \\
\hline CHEMBL3912862 & 1641222 & 8.6757 & 8.5206 & TRN & \\
\hline CHEMBL3922370 & 1641222 & 8.7212 & 8.2807 & TRN & \\
\hline CHEMBL3939663 & 1641222 & 7.7212 & 8.1213 & TRN & \\
\hline CHEMBL3928905 & 1641222 & 8.0376 & 7.7502 & TRN & \\
\hline CHEMBL 3912560 & 1641222 & 7.1085 & 7.4557 & TRN & \\
\hline CHEMBL3919164 & 1641222 & 8.5528 & 7.3784 & TST & \\
\hline CHEMBL3943674 & 1641222 & 9.6576 & 8.7138 & TRN & \\
\hline CHEMBL3981218 & 1641222 & 7.5986 & 6.7648 & TRN & \\
\hline CHEMBL3901887 & 1641222 & 8.7696 & 8.3497 & TRN & \\
\hline CHEMBL3939647 & 1641222 & 7.3757 & 7.4145 & TRN & \\
\hline CHEMBL3946492 & 1641222 & 8.1367 & 8.2927 & TRN & \\
\hline CHEMBL3967744 & 1641222 & 6.5969 & 7.0216 & TRN & \\
\hline CHEMBL3900755 & 1641222 & 8.7212 & 8.4738 & TRN & \\
\hline
\end{tabular}

Page 28398 
Supplemental Table S2.txt

\begin{tabular}{|c|c|c|c|c|c|}
\hline CHEMBL3909008 & 1641222 & 8.0969 & 8.2728 & TST & \\
\hline CHEMBL3982320 & 1641222 & 6.0 & 8.1734 & TRN & \\
\hline CHEMBL3958270 & 1641222 & 8.1361 & 8.0648 & TRN & \\
\hline CHEMBL3959991 & 1641222 & 8.317 & 8.0126 & TRN & \\
\hline CHEMBL3890539 & 1641222 & 6.9469 & 7.6883 & TRN & \\
\hline CHEMBL3984022 & 1641222 & 8.1549 & 8.0043 & TRN & \\
\hline CHEMBL3974966 & 1641222 & 8.7447 & 8.1051 & TRN & \\
\hline CHEMBL3927239 & 1641222 & 7.5918 & 7.9051 & TRN & \\
\hline CHEMBL3903872 & 1641222 & 7.7878 & 7.677000 & 0000000005 & TRN \\
\hline CHEMBL3919220 & 1641222 & 6.8356 & 7.1876 & TST & \\
\hline CHEMBL 3937865 & 1641222 & 9.0969 & 9.0127 & TRN & \\
\hline CHEMBL3913364 & 1641222 & 8.7696 & 8.6915 & TRN & \\
\hline CHEMBL3946613 & 1641222 & 9.0458 & 8.4861 & TRN & \\
\hline CHEMBL 3960788 & 1641222 & 6.7447 & 6.2543 & TRN & \\
\hline CHEMBL 3961770 & 1641222 & 8.3768 & 8.0271 & TRN & \\
\hline CHEMBL 3898398 & 1641222 & 7.5607 & 7.6438 & TRN & \\
\hline CHEMBL3950007 & 1641222 & 8.2291 & 7.5839 & TRN & \\
\hline CHEMBL3911338 & 1641222 & 6.0 & 7.8028 & TRN & \\
\hline CHEMBL3983096 & 1641222 & 8.2924 & 8.4783 & TRN & \\
\hline CHEMBL3906204 & 1641222 & 8.6198 & 8.3211 & TRN & \\
\hline CHEMBL3953684 & 1641222 & 8.0809 & 7.5816 & TRN & \\
\hline CHEMBL3898724 & 1641222 & 8.0177 & 8.5943 & TRN & \\
\hline CHEMBL3894480 & 1641222 & 7.5834 & 7.8357 & TRN & \\
\hline CHEMBL 3967277 & 1641222 & 7.7011 & 7.1519 & TRN & \\
\hline CHEMBL3914404 & 1641222 & 8.301 & 8.4559 & TRN & \\
\hline CHEMBL3902827 & 1641222 & 6.8268 & 7.1896 & TRN & \\
\hline CHEMBL3985486 & 1641222 & 7.4855 & 6.8653 & TRN & \\
\hline CHEMBL3944664 & 1641222 & 8.9208 & 7.1121 & TRN & \\
\hline CHEMBL3954685 & 1641222 & 7.1518 & 7.8223 & TST & \\
\hline CHEMBL3917977 & 1641222 & 7.3028 & 7.2422 & TST & \\
\hline CHEMBL3893171 & 1641222 & 9.1549 & 7.8043 & TRN & \\
\hline CHEMBL 3898843 & 1641222 & 8.4089 & 8.7692 & TRN & \\
\hline CHEMBL3912327 & 1641222 & 8.3768 & 8.8688 & TST & \\
\hline CHEMBL3912309 & 1641222 & 7.8697 & 8.1887 & TRN & \\
\hline CHEMBL3958683 & 1641222 & 7.9957 & 7.9231 & TRN & \\
\hline CHEMBL3906801 & 1641222 & 7.15799 & 999999999 & 7.5169 & TST \\
\hline CHEMBL3927763 & 1641222 & 8.7696 & 8.257 & TRN & \\
\hline CHEMBL3920151 & 1641222 & 7.1409 & 7.6375 & TRN & \\
\hline CHEMBL3986592 & 1641222 & 6.3665 & 7.9657 & TST & \\
\hline CHEMBL3920569 & 1641222 & 8.1612 & 7.1748 & TRN & \\
\hline CHEMBL3916967 & 1641222 & 9.0458 & 8.6004 & TRN & \\
\hline CHEMBL3955318 & 1641222 & 8.3768 & 8.0859 & TRN & \\
\hline CHEMBL3971075 & 1641222 & 6.6021 & 6.5627 & TST & \\
\hline CHEMBL3970643 & 1641222 & 8.1308 & 7.8828 & TRN & \\
\hline CHEMBL3934505 & 1641222 & 7.8928 & 8.2845 & TRN & \\
\hline CHEMBL3946488 & 1641222 & 8.585 & 8.4399 & TRN & \\
\hline CHEMBL3970699 & 1641222 & 7.3063 & 8.1641 & TRN & \\
\hline CHEMBL 3891514 & 1641222 & 8.699 & 8.5723 & TRN & \\
\hline
\end{tabular}




\begin{tabular}{|c|c|c|c|c|c|c|c|}
\hline \multicolumn{7}{|c|}{ Supplemental Table S2.txt } & \\
\hline CHEMBL3968368 & 1641222 & 7.9469 & 7.5134 & TST & & & \\
\hline CHEMBL3971283 & 1641222 & 8.266 & 7.9772 & TRN & & & \\
\hline CHEMBL3961028 & 1641222 & 7.9747 & 7.4107 & TRN & & & \\
\hline CHEMBL 3898335 & 1641222 & 6.76200 & 0000000 & 205 & 7.4071 & TST & \\
\hline CHEMBL3920822 & 1641222 & 8.2366 & 7.6391 & TST & & & \\
\hline CHEMBL3960261 & 1641222 & 9.0506 & 8.9699 & TRN & & & \\
\hline CHEMBL3892170 & 1641222 & 9.0 & 8.7719 & TRN & & & \\
\hline CHEMBL3905454 & 1641222 & 6.1113 & 6.2905 & TRN & & & \\
\hline CHEMBL3920150 & 1641222 & 6.0 & 7.9537 & TRN & & & \\
\hline CHEMBL3944759 & 1641222 & 6.7282 & 6.3433 & TRN & & & \\
\hline CHEMBL3972013 & 1641222 & 8.3605 & 7.3519 & TST & & & \\
\hline CHEMBL 3943049 & 1641222 & 7.4134 & 7.1213 & TRN & & & \\
\hline CHEMBL3902741 & 1641222 & 9.1249 & 8.4148 & TRN & & & \\
\hline CHEMBL 3923248 & 1641222 & 7.9281 & 8.8812 & TRN & & & \\
\hline CHEMBL3949532 & 1641222 & 6.0 & 6.6947 & TRN & & & \\
\hline CHEMBL3948204 & 1641222 & 8.5686 & 8.0781 & TRN & & & \\
\hline CHEMBL3902811 & 1641222 & 6.9318 & 7.6506 & TST & & & \\
\hline CHEMBL3912411 & 1641222 & 8.0969 & 8.3643 & TST & & & \\
\hline CHEMBL3909630 & 1641222 & 9.0 & 8.1878 & TST & & & \\
\hline CHEMBL3942802 & 1641222 & 8.7696 & 8.0438 & TRN & & & \\
\hline CHEMBL3892479 & 1641222 & 9.3372 & 9.0514 & TST & & & \\
\hline CHEMBL3891491 & 1641222 & 8.4202 & 8.1196 & TST & & & \\
\hline CHEMBL3890037 & 1641222 & 7.1965 & 6.8252 & TRN & & & \\
\hline CHEMBL3901268 & 1641222 & 8.3747 & 8.0781 & TRN & & & \\
\hline CHEMBL3967697 & 1641222 & 6.2588 & 7.0868 & TST & & & \\
\hline CHEMBL3915621 & 1641222 & 7.2874 & 7.7811 & TST & & & \\
\hline CHEMBL3899697 & 1641222 & 7.8665 & 8.4021 & TST & & & \\
\hline CHEMBL3897501 & 1641222 & 7.3089 & 6.7742 & TST & & & \\
\hline CHEMBL3918317 & 1641222 & 7.15799 & 99999999 & 995 & 7.2917 & TRN & \\
\hline CHEMBL3960999 & 1641222 & 8.0915 & 8.3292 & TRN & & & \\
\hline CHEMBL3969258 & 1641222 & 6.6003 & 7.0237 & TRN & & & \\
\hline CHEMBL3942713 & 1641222 & 8.4318 & 7.664 & TRN & & & \\
\hline CHEMBL3904070 & 1641222 & 9.699 & 8.6327 & TRN & & & \\
\hline CHEMBL3898991 & 1641222 & 6.7545 & 6.9475 & TRN & & & \\
\hline CHEMBL3911205 & 1641222 & 7.7328 & 7.7268 & TRN & & & \\
\hline CHEMBL3978107 & 1641222 & 6.2262 & 7.2227 & TRN & & & \\
\hline CHEMBL3958517 & 1641222 & 8.4685 & 8.0453 & TRN & & & \\
\hline CHEMBL3985005 & 1641222 & 6.5391 & 8.3965 & TST & & & \\
\hline CHEMBL3934340 & 1641222 & 8.4202 & 7.3365 & TST & & & \\
\hline CHEMBL3925934 & 1641222 & 8.1079 & 7.9986 & TRN & & & \\
\hline CHEMBL3919764 & 1641222 & 9.0458 & 7.9763 & TRN & & & \\
\hline CHEMBL 3955680 & 1641222 & 6.0 & 6.2768 & TRN & & & \\
\hline CHEMBL3955736 & 1641222 & 6.38299 & 99999999 & 99 & 7.7154 & TST & \\
\hline CHEMBL3978949 & 1641222 & 8.4318 & 8.8413 & TRN & & & \\
\hline CHEMBL3973943 & 1641222 & 8.1135 & 8.7019 & TRN & & & \\
\hline CHEMBL3986926 & 1641222 & 6.1169 & 6.7206 & TRN & & & \\
\hline CHEMBL3980466 & 1641222 & 8.8539 & 8.1598 & TRN & & & \\
\hline CHEMBL3891690 & 1641222 & 8.09100 & 000000006 & & 7.632 & 9999999999 & TRN \\
\hline
\end{tabular}


Supplemental Table S2.txt

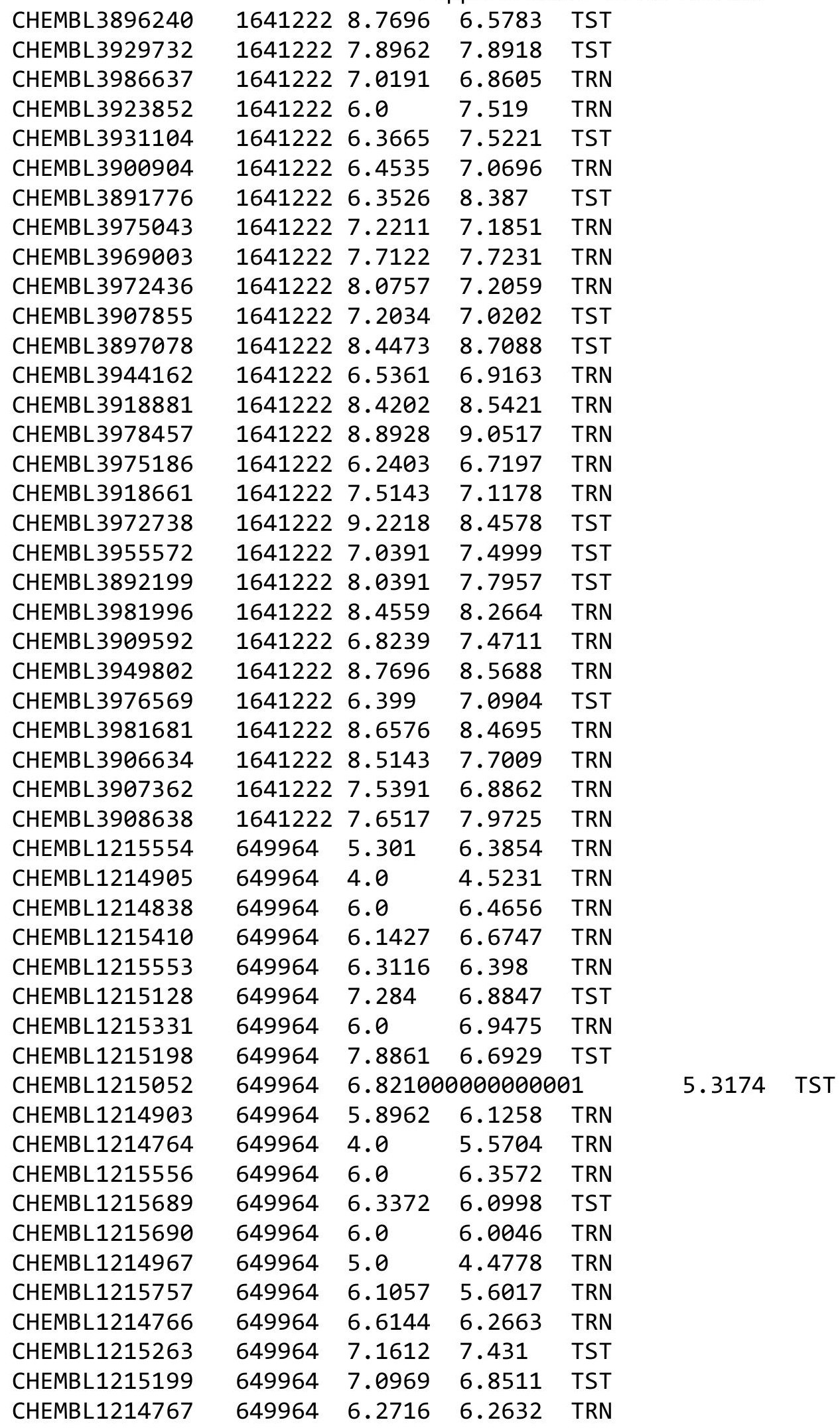

Page 28401 


\begin{tabular}{|c|c|c|c|c|c|}
\hline & & & & & \\
\hline CHEMBL1215758 & 649964 & 6.0 & 5.5893 & TRN & \\
\hline CHEMBL1214841 & 649964 & 7.2518 & 6.7616 & TRN & \\
\hline CHEMBL1215051 & 649964 & 5.8894 & 5.3402 & TST & \\
\hline CHEMBL1215625 & 649964 & 6.0 & 6.6068 & TRN & \\
\hline CHEMBL1214971 & 649964 & 6.3556 & 5.6161 & TRN & \\
\hline CHEMBL1215486 & 649964 & 8.3979 & 7.1942 & TRN & \\
\hline CHEMBL1215050 & 649964 & 5.7986 & 5.8017 & TRN & \\
\hline CHEMBL1214968 & 649964 & 6.3872 & 5.1103 & TRN & \\
\hline CHEMBL1215756 & 649964 & 4.0 & 5.0934 & TRN & \\
\hline CHEMBL1215693 & 649964 & 7.4949 & 6.6632 & TST & \\
\hline CHEMBL1215262 & 649964 & 6.8697 & 6.7036 & TST & \\
\hline CHEMBL1215626 & 649964 & 7.6021 & 6.8294 & TST & \\
\hline CHEMBL1214687 & 649964 & 5.0119 & 5.1512 & TRN & \\
\hline CHEMBL1215555 & 649964 & 6.0711 & 6.4879 & TRN & \\
\hline CHEMBL1215265 & 649964 & 6.2573 & 6.3966 & TRN & \\
\hline CHEMBL1214970 & 649964 & 5.4377 & 4.8116 & TRN & \\
\hline CHEMBL1214906 & 649964 & 4.0 & 3.99399 & 99999999998 & TRN \\
\hline CHEMBL1215129 & 649964 & 7.585 & 6.5452 & TST & \\
\hline CHEMBL1214765 & 649964 & 5.8416 & 6.2594 & TRN & \\
\hline CHEMBL1214969 & 649964 & 6.1175 & 5.1388 & TRN & \\
\hline CHEMBL1215197 & 649964 & 8.2218 & 7.285 & TST & \\
\hline CHEMBL1215053 & 649964 & 6.4168 & 6.4769 & TRN & \\
\hline CHEMBL1215411 & 649964 & 6.8962 & 6.7599 & TRN & \\
\hline CHEMBL1215196 & 649964 & 8.699 & 7.1983 & TST & \\
\hline CHEMBL1214904 & 649964 & 5.0 & 6.152 & TRN & \\
\hline CHEMBL1215054 & 649964 & 5.5969 & 5.5654 & TRN & \\
\hline CHEMBL1215755 & 649964 & 7.0809 & 6.7066 & TRN & \\
\hline CHEMBL1214688 & 649964 & 6.7447 & 6.6378 & TRN & \\
\hline CHEMBL1215264 & 649964 & 5.3625 & 6.1415 & TRN & \\
\hline CHEMBL1214840 & 649964 & 6.5467 & 6.5452 & TRN & \\
\hline CHEMBL1215408 & 649964 & 7.6778 & 6.9444 & TRN & \\
\hline CHEMBL1215487 & 649964 & 8.1549 & 7.37 & TRN & \\
\hline CHEMBL1215488 & 649964 & 6.8239 & 7.1487 & TRN & \\
\hline CHEMBL1215130 & 649964 & 7.8539 & 7.2585 & TST & \\
\hline CHEMBL1215409 & 649964 & 7.8239 & 6.9663 & TRN & \\
\hline CHEMBL1215485 & 649964 & 7.0506 & 6.2586 & TRN & \\
\hline CHEMBL 258844 & 955078 & 3.4702 & 3.5366 & TRN & \\
\hline CHEMBL483847 & 955078 & 3.4574 & 3.3543 & TRN & \\
\hline CHEMBL412142 & 955078 & 3.2787 & 3.0719 & TRN & \\
\hline CHEMBL514499 & 955078 & 7.0642 & 6.6815 & TRN & \\
\hline CHEMBL3392440 & 955078 & 3.3635 & 3.3728 & TRN & \\
\hline CHEMBL 220241 & 955078 & 3.2755 & 3.2088 & TRN & \\
\hline CHEMBL558642 & 955078 & 4.0051 & 4.0495 & TRN & \\
\hline CHEMBL 213100 & 955078 & 3.5479 & 3.47899 & 99999999996 & TRN \\
\hline CHEMBL 300389 & 955078 & 5.043 & 4.9513 & TRN & \\
\hline CHEMBL 9470 & 955078 & 5.6139 & 6.0038 & TST & \\
\hline CHEMBL65 & 955078 & 8.7156 & 8.6079 & TRN & \\
\hline CHEMBL1186585 & 955078 & 4.7787 & 4.7589 & TRN & \\
\hline
\end{tabular}

Page 28402 


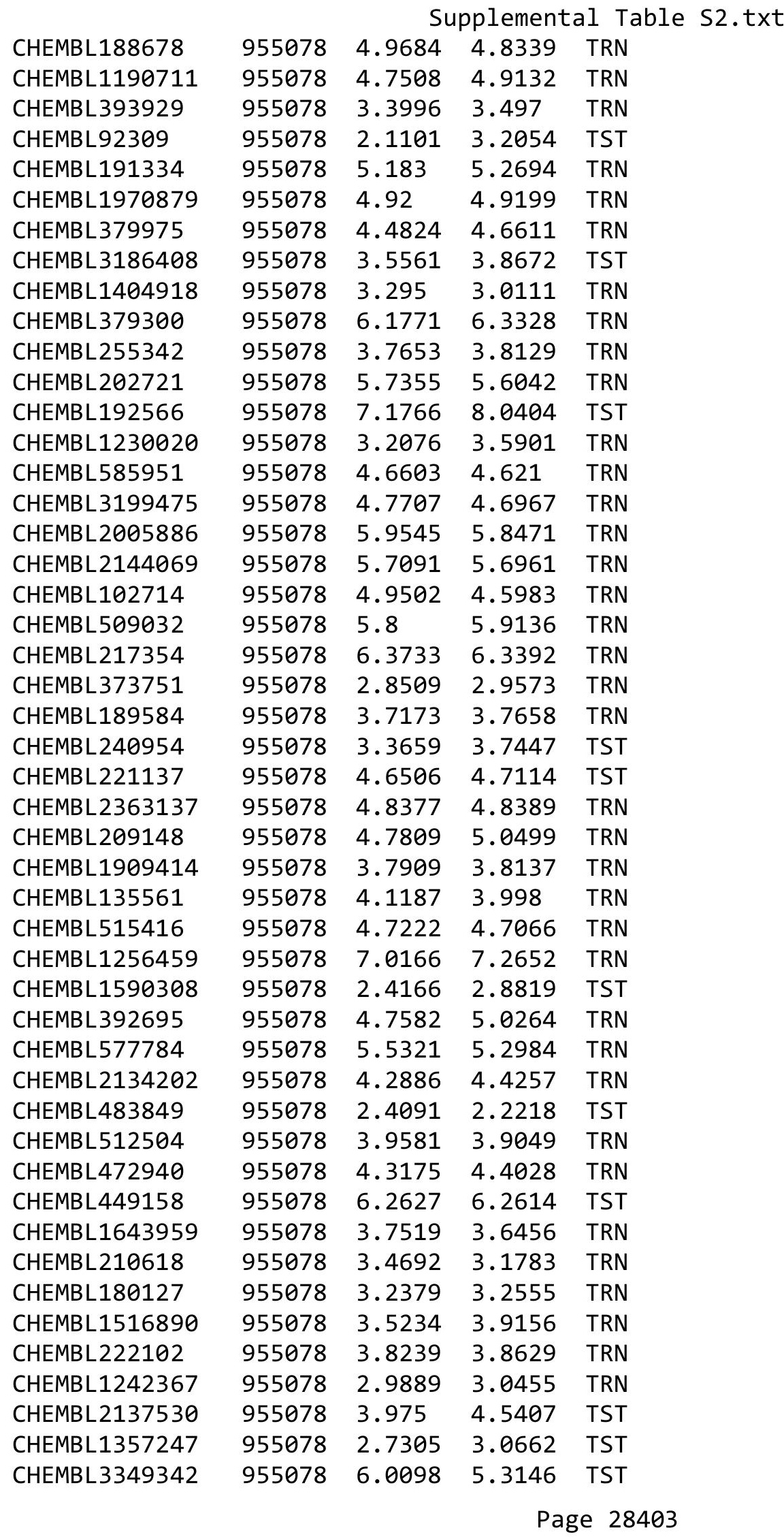




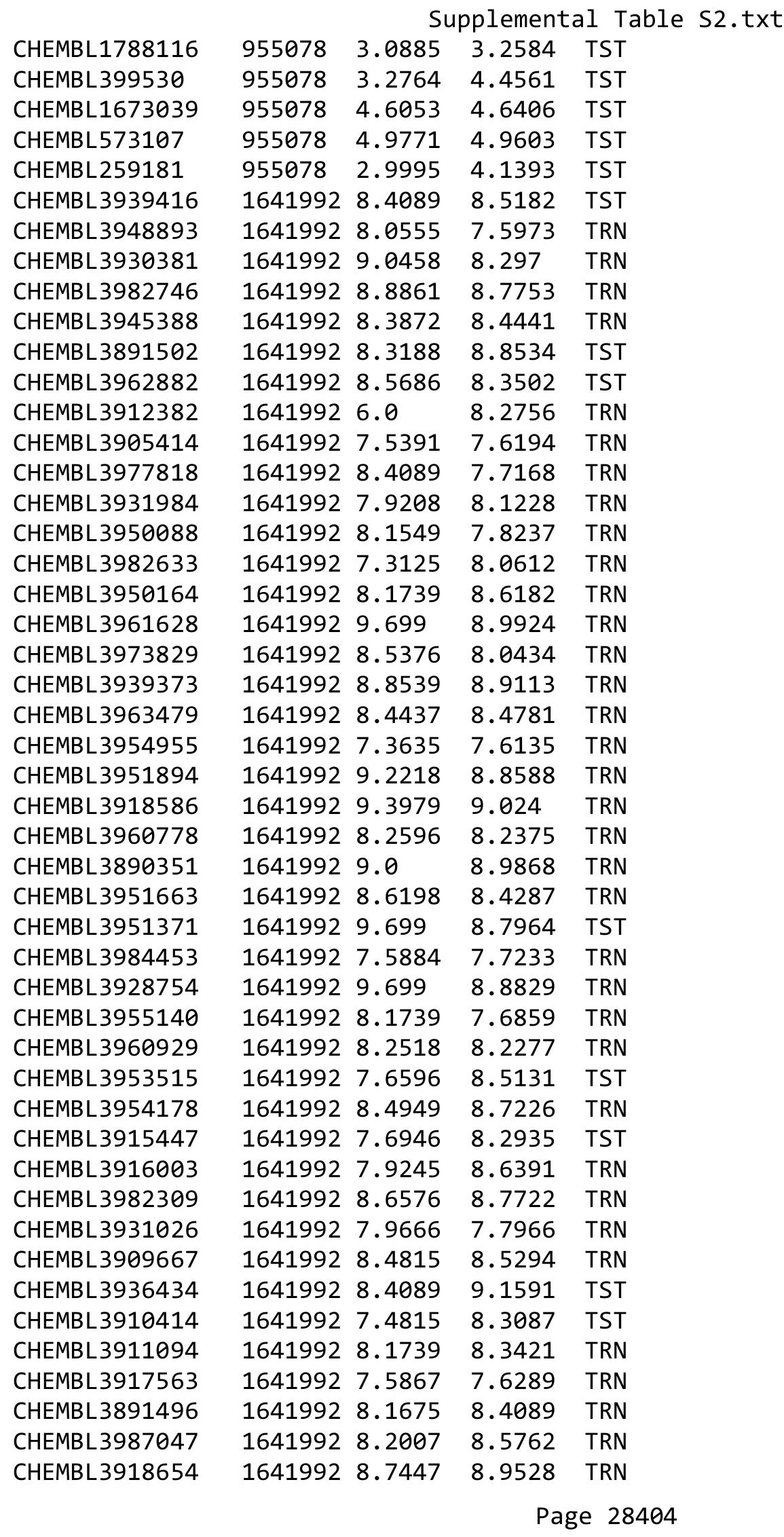


Supplemental Table S2.txt

\begin{tabular}{|c|c|c|c|c|c|}
\hline CHEMBL3911451 & 1641992 & 7.9586 & 8.703 & TRN & \\
\hline CHEMBL3938572 & 1641992 & 8.1805 & 8.2261 & TRN & \\
\hline CHEMBL3962914 & 1641992 & 8.585 & 8.5756 & TRN & \\
\hline CHEMBL3959905 & 1641992 & 8.7212 & 9.1759 & TST & \\
\hline CHEMBL3963282 & 1641992 & 9.0458 & 9.0422 & TST & \\
\hline CHEMBL3920978 & 1641992 & 9.2218 & 8.8213 & TRN & \\
\hline CHEMBL3984609 & 1641992 & 8.9586 & 8.8132 & TRN & \\
\hline CHEMBL3962273 & 1641992 & 7.2823 & 8.1269 & TRN & \\
\hline CHEMBL3941895 & 1641992 & 7.0 & 7.6764 & TRN & \\
\hline CHEMBL 3922224 & 1641992 & 8.8239 & 9.1287 & TST & \\
\hline CHEMBL3976909 & 1641992 & 9.2218 & 8.8904 & TRN & \\
\hline CHEMBL3916360 & 1641992 & 9.301 & 8.621 & TRN & \\
\hline CHEMBL3954081 & 1641992 & 7.9393 & 8.47200 & 0000000001 & TRN \\
\hline CHEMBL3904107 & 1641992 & 7.9431 & 7.9414 & TRN & \\
\hline CHEMBL 3974070 & 1641992 & 7.6126 & 9.0368 & TST & \\
\hline CHEMBL3941117 & 1641992 & 8.4685 & 8.4536 & TRN & \\
\hline CHEMBL3932181 & 1641992 & 9.3979 & 8.7691 & TRN & \\
\hline CHEMBL3941138 & 1641992 & 7.7799 & 9.1135 & TST & \\
\hline CHEMBL3972126 & 1641992 & 9.1549 & 9.0344 & TRN & \\
\hline CHEMBL3922470 & 1641992 & 9.0458 & 8.4003 & TST & \\
\hline CHEMBL3958776 & 1641992 & 9.1549 & 8.9513 & TRN & \\
\hline CHEMBL3968035 & 1641992 & 8.5086 & 8.9397 & TRN & \\
\hline CHEMBL3897511 & 1641992 & 8.5376 & 8.40299 & 9999999999 & TST \\
\hline CHEMBL3939024 & 1641992 & 8.5528 & 8.4645 & TST & \\
\hline CHEMBL3941853 & 1641992 & 8.7212 & 9.0133 & TST & \\
\hline CHEMBL3977649 & 1641992 & 9.1549 & 8.4633 & TRN & \\
\hline CHEMBL3925511 & 1641992 & 7.9957 & 8.229 & TRN & \\
\hline CHEMBL3939360 & 1641992 & 8.9586 & 9.0156 & TRN & \\
\hline CHEMBL3963909 & 1641992 & 8.2518 & 8.201 & TRN & \\
\hline CHEMBL3926541 & 1641992 & 7.7235 & 8.3697 & TST & \\
\hline CHEMBL3957152 & 1641992 & 8.4685 & 8.4974 & TRN & \\
\hline CHEMBL3938331 & 1641992 & 7.4815 & 7.8182 & TRN & \\
\hline CHEMBL3940165 & 1641992 & 8.2757 & 8.7252 & TST & \\
\hline CHEMBL3952855 & 1641992 & 8.2366 & 7.7851 & TRN & \\
\hline CHEMBL3973972 & 1641992 & 7.7696 & 9.1582 & TRN & \\
\hline CHEMBL3961732 & 1641992 & 8.699 & 8.1506 & TRN & \\
\hline CHEMBL 3974414 & 1641992 & 8.3372 & 8.4465 & TRN & \\
\hline CHEMBL3925881 & 1641992 & 8.1938 & 8.6001 & TRN & \\
\hline CHEMBL3923628 & 1641992 & 9.3979 & 8.2338 & TRN & \\
\hline CHEMBL3912036 & 1641992 & 8.5528 & 8.7086 & TRN & \\
\hline CHEMBL3966584 & 1641992 & 8.8239 & 8.7052 & TST & \\
\hline CHEMBL3929316 & 1641992 & 8.5686 & 8.8384 & TRN & \\
\hline CHEMBL3968179 & 1641992 & 8.5086 & 8.2243 & TRN & \\
\hline CHEMBL3901048 & 1641992 & 7.0 & 7.746 & TRN & \\
\hline CHEMBL3965128 & 1641992 & 9.5229 & 8.4073 & TRN & \\
\hline CHEMBL3933630 & 1641992 & 8.7447 & 8.9265 & TST & \\
\hline CHEMBL3930776 & 1641992 & 9.1549 & 8.316 & TRN & \\
\hline CHEMBL3971110 & 1641992 & 9.0458 & 8.9641 & TST & \\
\hline
\end{tabular}


Supplemental Table S2.txt

\begin{tabular}{|c|c|c|c|c|c|}
\hline CHEMBL3892083 & 1641992 & 8.3279 & 8.2161 & TRN & \\
\hline CHEMBL3891167 & 1641992 & 8.3372 & 8.3971 & TRN & \\
\hline CHEMBL3910558 & 1641992 & 7.8153 & 8.0536 & TRN & \\
\hline CHEMBL3934235 & 1641992 & 7.5452 & 7.8564 & TRN & \\
\hline CHEMBL3918542 & 1641992 & 8.1739 & 8.0706 & TRN & \\
\hline CHEMBL3936009 & 1641992 & 8.9208 & 9.0956 & TST & \\
\hline CHEMBL3922969 & 1641992 & 8.1938 & 8.3395 & TRN & \\
\hline CHEMBL3932135 & 1641992 & 8.1367 & 8.5312 & TRN & \\
\hline CHEMBL3965094 & 1641992 & 8.2757 & 8.9194 & TRN & \\
\hline CHEMBL3939458 & 1641992 & 8.3188 & 8.7353 & TRN & \\
\hline CHEMBL3912122 & 1641992 & 9.0 & 8.3435 & TRN & \\
\hline CHEMBL3954600 & 1641992 & 8.6383 & 9.0899 & TST & \\
\hline CHEMBL3915482 & 1641992 & 8.7447 & 8.263 & TST & \\
\hline CHEMBL3891339 & 1641992 & 7.2676 & 7.71899 & 9999999999 & TRN \\
\hline CHEMBL3987030 & 1641992 & 8.6778 & 8.3234 & TRN & \\
\hline CHEMBL3963313 & 1641992 & 8.9586 & 8.8159 & TRN & \\
\hline CHEMBL3963669 & 1641992 & 9.0 & 8.6625 & TRN & \\
\hline CHEMBL 3948697 & 1641992 & 8.5229 & 8.4124 & TRN & \\
\hline CHEMBL3936654 & 1641992 & 7.6162 & 8.4281 & TST & \\
\hline CHEMBL3907929 & 1641992 & 9.1549 & 8.8462 & TRN & \\
\hline CHEMBL3940120 & 1641992 & 8.6778 & 8.3959 & TRN & \\
\hline CHEMBL 3941419 & 1641992 & 7.2351 & 7.6754 & TST & \\
\hline CHEMBL3915035 & 1641992 & 8.6198 & 8.9301 & TST & \\
\hline CHEMBL3959748 & 1641992 & 8.1427 & 8.8876 & TST & \\
\hline CHEMBL604760 & 610564 & 7.699 & 7.5903 & TRN & \\
\hline CHEMBL601677 & 610564 & 7.301 & 7.1486 & TRN & \\
\hline CHEMBL605374 & 610564 & 6.7959 & 7.1334 & TRN & \\
\hline CHEMBL602291 & 610564 & 5.5528 & 6.9224 & TST & \\
\hline CHEMBL599556 & 610564 & 7.5229 & 7.471 & TRN & \\
\hline CHEMBL602142 & 610564 & 7.3979 & 7.635 & TRN & \\
\hline CHEMBL179532 & 610564 & 7.1549 & 7.2507 & TRN & \\
\hline CHEMBL602669 & 610564 & 7.301 & 6.961 & TRN & \\
\hline CHEMBL603081 & 610564 & 7.3979 & 7.8496 & TRN & \\
\hline CHEMBL602290 & 610564 & 6.6778 & 7.0905 & TRN & \\
\hline CHEMBL602877 & 610564 & 7.3979 & 7.5026 & TRN & \\
\hline CHEMBL600425 & 610564 & 7.699 & 7.6302 & TRN & \\
\hline CHEMBL604956 & 610564 & 7.5229 & 7.4588 & TRN & \\
\hline CHEMBL608565 & 610564 & 6.8861 & 6.4928 & TRN & \\
\hline CHEMBL601030 & 610564 & 7.5229 & 7.5907 & TRN & \\
\hline CHEMBL594318 & 610564 & 7.0 & \multicolumn{2}{|c|}{7.0760000000000005} & TST \\
\hline CHEMBL605578 & 610564 & 6.4437 & 6.716 & TRN & \\
\hline CHEMBL598099 & 610564 & 7.3979 & 7.32700 & 0000000001 & TRN \\
\hline CHEMBL602267 & 610564 & 7.5229 & 7.7563 & TRN & \\
\hline CHEMBL597104 & 610564 & 7.5229 & 7.4479 & TRN & \\
\hline CHEMBL601239 & 610564 & 7.0 & 7.0301 & TRN & \\
\hline CHEMBL601226 & 610564 & 7.0 & 7.4369 & TST & \\
\hline CHEMBL599557 & 610564 & 7.699 & 7.5147 & TRN & \\
\hline CHEMBL604945 & 610564 & 7.699 & 7.4705 & TRN & \\
\hline
\end{tabular}




\begin{tabular}{|c|c|c|c|c|c|}
\hline \multirow[b]{2}{*}{ CHEMBL600406 } & \multicolumn{5}{|c|}{ Supplemental Table s2.txt } \\
\hline & 610564 & 7.5229 & 7.9076 & TRN & \\
\hline CHEMBL600222 & 610564 & 7.699 & 7.7321 & TRN & \\
\hline CHEMBL600204 & 610564 & 7.5229 & 7.5918 & TRN & \\
\hline CHEMBL602063 & 610564 & 7.1549 & 7.2702 & TRN & \\
\hline CHEMBL600205 & 610564 & 2.8601 & 5.7266 & TRN & \\
\hline CHEMBL602079 & 610564 & 7.1549 & 6.4421 & TRN & \\
\hline CHEMBL600223 & 610564 & 7.5229 & 7.7321 & TRN & \\
\hline CHEMBL603237 & 610564 & 7.3979 & 7.5474 & TRN & \\
\hline CHEMBL605997 & 610564 & 7.3979 & 7.2249 & TRN & \\
\hline CHEMBL597513 & 610564 & 7.3979 & 7.5474 & TRN & \\
\hline CHEMBL602870 & 610564 & 7.2218 & 6.7832 & TRN & \\
\hline CHEMBL601436 & 610564 & 7.1549 & 6.9023 & TRN & \\
\hline CHEMBL608866 & 610564 & 6.8861 & 6.3647 & TRN & \\
\hline CHEMBL600206 & 610564 & 7.2218 & 7.4993 & TST & \\
\hline CHEMBL606202 & 610564 & 7.5229 & 7.6315 & TRN & \\
\hline CHEMBL603703 & 610564 & 7.2218 & 7.2273 & TRN & \\
\hline CHEMBL175177 & 610564 & 5.9586 & 6.8731 & TST & \\
\hline CHEMBL610921 & 610564 & 7.5229 & 7.3105 & TRN & \\
\hline CHEMBL601001 & 610564 & 7.699 & 7.4772 & TRN & \\
\hline CHEMBL602876 & 610564 & 6.6778 & 7.069 & TST & \\
\hline CHEMBL600005 & 610564 & 7.3979 & 7.3338 & TRN & \\
\hline CHEMBL600814 & 610564 & 6.5376 & 5.83200 & 0000000001 & TRN \\
\hline CHEMBL605557 & 610564 & 7.699 & 7.5398 & TRN & \\
\hline CHEMBL601437 & 610564 & 7.0969 & 6.9894 & TRN & \\
\hline CHEMBL604947 & 610564 & 7.0458 & 6.4339 & TRN & \\
\hline CHEMBL604336 & 610564 & 7.699 & 7.3958 & TRN & \\
\hline CHEMBL603918 & 610564 & 7.3979 & 7.2116 & TST & \\
\hline CHEMBL600673 & 610564 & 7.1549 & 7.6031 & TRN & \\
\hline CHEMBL602869 & 610564 & 6.9208 & 7.157 & TRN & \\
\hline CHEMBL386508 & 610564 & 7.7959 & 7.0692 & TRN & \\
\hline CHEMBL605366 & 610564 & 6.6198 & 6.7522 & TRN & \\
\hline CHEMBL602095 & 610564 & 7.0458 & 6.955 & TRN & \\
\hline CHEMBL601031 & 610564 & 7.3979 & 7.5144 & TRN & \\
\hline CHEMBL606427 & 610564 & 7.301 & 6.9738 & TRN & \\
\hline CHEMBL600613 & 610564 & 7.699 & 7.8404 & TRN & \\
\hline CHEMBL601238 & 610564 & 7.3979 & 6.9151 & TRN & \\
\hline CHEMBL601862 & 610564 & 6.9586 & 7.3994 & TRN & \\
\hline CHEMBL610631 & 610564 & 7.301 & 7.36600 & 00000000005 & TST \\
\hline CHEMBL601010 & 610564 & 7.301 & 7.3694 & TST & \\
\hline CHEMBL600408 & 610564 & 6.6021 & 6.5007 & TST & \\
\hline CHEMBL604128 & 610564 & 7.3979 & 7.6099 & TST & \\
\hline CHEMBL605164 & 610564 & 7.0969 & 6.8186 & TST & \\
\hline CHEMBL216000 & 610564 & 7.5229 & 6.7805 & TST & \\
\hline CHEMBL190558 & 610564 & 7.699 & 7.34 & TST & \\
\hline CHEMBL601435 & 610564 & 6.7959 & 7.3715 & TST & \\
\hline CHEMBL589140 & 610564 & 6.7959 & 7.4564 & TST & \\
\hline CHEMBL600427 & 610564 & 7.699 & 7.6564 & TST & \\
\hline CHEMBL178126 & 610564 & 7.3979 & 6.94 & TST & \\
\hline
\end{tabular}




\begin{tabular}{|c|c|c|c|c|c|}
\hline & & \multicolumn{4}{|c|}{ Supplemental Table s2.txt } \\
\hline CHEMBL3392440 & 954801 & 3.4357 & 3.4592 & TRN & \\
\hline CHEMBL3199475 & 954801 & 3.6004 & 3.9439 & TRN & \\
\hline CHEMBL1643959 & 954801 & 3.3835 & 3.3379 & TRN & \\
\hline CHEMBL1516890 & 954801 & 4.6486 & 3.6133 & TRN & \\
\hline CHEMBL209148 & 954801 & 4.4886 & 4.1678 & TRN & \\
\hline CHEMBL1590308 & 954801 & 2.9763 & 3.0177 & TST & \\
\hline CHEMBL3186408 & 954801 & 3.1756 & 3.4293 & TST & \\
\hline CHEMBL1256459 & 954801 & 6.6199 & 6.7966 & TRN & \\
\hline CHEMBL217354 & 954801 & 7.0423 & 5.609 & TRN & \\
\hline CHEMBL512504 & 954801 & 4.2341 & 4.4204 & TRN & \\
\hline CHEMBL 2144069 & 954801 & 4.3361 & 4.5839 & TRN & \\
\hline CHEMBL412142 & 954801 & 3.8314 & 3.6035 & TRN & \\
\hline CHEMBL259181 & 954801 & 3.0777 & 4.0677 & TRN & \\
\hline CHEMBL 9470 & 954801 & 4.4493 & 5.37799 & 9999999999 & TST \\
\hline CHEMBL 2134202 & 954801 & 4.3383 & 3.9386 & TRN & \\
\hline CHEMBL191334 & 954801 & 2.8892 & 3.81699 & 99999999997 & TRN \\
\hline CHEMBL573107 & 954801 & 5.3175 & 4.7148 & TRN & \\
\hline CHEMBL221137 & 954801 & 4.4666 & 4.2659 & TST & \\
\hline CHEMBL 2137530 & 954801 & 4.2442 & 4.3694 & TRN & \\
\hline CHEMBL577784 & 954801 & 4.9048 & 4.812 & TRN & \\
\hline CHEMBL 2363137 & 954801 & 4.1701 & 4.3664 & TRN & \\
\hline CHEMBL1788116 & 954801 & 3.8908 & 3.9692 & TRN & \\
\hline CHEMBL65 & 954801 & 7.091 & 7.6143 & TRN & \\
\hline CHEMBL483847 & 954801 & 3.5905 & 3.8441 & TRN & \\
\hline CHEMBL202721 & 954801 & 3.46199 & 99999999 & 4.5729 & TRN \\
\hline CHEMBL3349342 & 954801 & 4.6345 & 4.7174 & TRN & \\
\hline CHEMBL379300 & 954801 & 6.0073 & 6.0506 & TRN & \\
\hline CHEMBL509032 & 954801 & 5.5825 & 5.2422 & TRN & \\
\hline CHEMBL240954 & 954801 & 3.2867 & 3.2663 & TST & \\
\hline CHEMBL1404918 & 954801 & 2.4366 & 2.4479 & TRN & \\
\hline CHEMBL483849 & 954801 & 2.8015 & 1.8086 & TST & \\
\hline CHEMBL373751 & 954801 & 3.1816 & 3.3261 & TRN & \\
\hline CHEMBL585951 & 954801 & 5.0468 & 5.725 & TRN & \\
\hline CHEMBL1242367 & 954801 & 3.8579 & 3.8127 & TRN & \\
\hline CHEMBL1673039 & 954801 & 4.5109 & 4.437 & TRN & \\
\hline CHEMBL189584 & 954801 & 5.8641 & 4.2135 & TRN & \\
\hline CHEMBL1190711 & 954801 & 4.2886 & 4.6249 & TRN & \\
\hline CHEMBL 258844 & 954801 & 3.2836 & 3.9175 & TRN & \\
\hline CHEMBL1970879 & 954801 & 3.3332 & 4.3535 & TRN & \\
\hline CHEMBL 2005886 & 954801 & 5.2531 & 5.0408 & TRN & \\
\hline CHEMBL1357247 & 954801 & 2.8122 & 2.6959 & TRN & \\
\hline CHEMBL399530 & 954801 & 4.4864 & 4.1567 & TRN & \\
\hline CHEMBL222102 & 954801 & 3.3846 & 3.3549 & TRN & \\
\hline CHEMBL449158 & 954801 & 6.4378 & 6.4197 & TST & \\
\hline CHEMBL392695 & 954801 & 5.4869 & 4.8006 & TRN & \\
\hline CHEMBL515416 & 954801 & 3.3103 & 4.1249 & TRN & \\
\hline CHEMBL472940 & 954801 & 3.1581 & 3.2034 & TRN & \\
\hline CHEMBL180127 & 954801 & 3.9581 & 3.8326 & TRN & \\
\hline
\end{tabular}




\begin{tabular}{|c|c|c|c|c|c|c|}
\hline \multicolumn{7}{|c|}{ Supplemental Table S2.txt } \\
\hline CHEMBL92309 & 954801 & 2.1365 & 2.5318 & TST & & \\
\hline CHEMBL102714 & 954801 & 2.9614 & 3.1223 & TRN & & \\
\hline CHEMBL 210618 & 954801 & 3.2875 & 3.0121 & TRN & & \\
\hline CHEMBL1186585 & 954801 & 4.4892 & 3.9832 & TRN & & \\
\hline CHEMBL213100 & 954801 & 5.5544 & 4.7045 & TRN & & \\
\hline CHEMBL1230020 & 954801 & 3.22899 & 99999999 & 996 & 3.5891 & TRN \\
\hline CHEMBL514499 & 954801 & 6.915 & 6.70299 & 9999999999 & & TRN \\
\hline CHEMBL1909414 & 954801 & 3.4532 & 3.5494 & TRN & & \\
\hline CHEMBL188678 & 954801 & 4.8145 & 3.9936 & TST & & \\
\hline CHEMBL192566 & 954801 & 5.8242 & 7.7272 & TST & & \\
\hline CHEMBL379975 & 954801 & 3.8308 & 4.5697 & TST & & \\
\hline CHEMBL135561 & 954801 & 3.9954 & 4.0287 & TST & & \\
\hline CHEMBL393929 & 954801 & 4.5623 & 3.4928 & TST & & \\
\hline CHEMBL558642 & 954801 & 3.2342 & 3.7302 & TST & & \\
\hline CHEMBL 300389 & 954801 & 6.2894 & 6.4416 & TST & & \\
\hline CHEMBL220241 & 954801 & 4.3024 & 4.3796 & TST & & \\
\hline CHEMBL 255342 & 954801 & 3.5037 & 3.2196 & TST & & \\
\hline CHEMBL3218018 & 1641064 & 6.5376 & 6.4625 & TRN & & \\
\hline CHEMBL3218289 & 1641064 & 6.0 & 5.8837 & TRN & & \\
\hline CHEMBL 3218027 & 1641064 & 6.9208 & 6.9344 & TRN & & \\
\hline CHEMBL3218008 & 1641064 & 5.1296 & 5.3245 & TRN & & \\
\hline CHEMBL3218025 & 1641064 & 5.9586 & 5.8067 & TRN & & \\
\hline CHEMBL 3218028 & 1641064 & 5.6882 & 5.559 & TRN & & \\
\hline CHEMBL 3944452 & 1641064 & 5.8416 & 5.95200 & 0000000001 & & TRN \\
\hline CHEMBL 3218294 & 1641064 & 6.0 & 6.1096 & TRN & & \\
\hline CHEMBL 3218013 & 1641064 & 6.8539 & 6.7777 & TRN & & \\
\hline CHEMBL3218019 & 1641064 & 6.1675 & 6.1922 & TRN & & \\
\hline CHEMBL 3978510 & 1641064 & 5.426 & 5.4903 & TST & & \\
\hline CHEMBL3218009 & 1641064 & 7.699 & 7.4893 & TRN & & \\
\hline CHEMBL 3218021 & 1641064 & 6.0 & 6.0003 & TRN & & \\
\hline CHEMBL 3218006 & 1641064 & 6.0 & 5.9047 & TRN & & \\
\hline CHEMBL 3894166 & 1641064 & 4.7049 & 4.6166 & TRN & & \\
\hline CHEMBL 3914256 & 1641064 & 6.2757 & 5.5722 & TST & & \\
\hline CHEMBL 3218020 & 1641064 & 5.4634 & 5.442 & TRN & & \\
\hline CHEMBL 3218285 & 1641064 & 6.0 & 6.0134 & TRN & & \\
\hline CHEMBL3915031 & 1641064 & 5.71 & 6.1398 & TST & & \\
\hline CHEMBL3218012 & 1641064 & 6.5528 & 6.5742 & TRN & & \\
\hline CHEMBL 3218015 & 1641064 & 7.0 & 7.1249 & TRN & & \\
\hline CHEMBL 3973907 & 1641064 & 5.8327 & 5.7475 & TRN & & \\
\hline CHEMBL 3218024 & 1641064 & 7.2218 & 7.1596 & TRN & & \\
\hline CHEMBL 3954084 & 1641064 & 4.7595 & 4.886 & TRN & & \\
\hline CHEMBL3966306 & 1641064 & 7.1549 & 7.1217 & TST & & \\
\hline CHEMBL3218016 & 1641064 & 6.8861 & 6.7881 & TRN & & \\
\hline CHEMBL3218299 & 1641064 & 6.4202 & 6.4625 & TRN & & \\
\hline CHEMBL 3903548 & 1641064 & 6.0 & 5.8778 & TST & & \\
\hline CHEMBL 3890560 & 1641064 & 5.0783 & 6.4416 & TST & & \\
\hline CHEMBL3916739 & 1641064 & 6.0 & 5.6809 & TST & & \\
\hline CHEMBL 3218292 & 1641064 & 7.1549 & 7.1757 & TRN & & \\
\hline
\end{tabular}

Page 28409 
Supplemental Table S2.txt

\begin{tabular}{|c|c|c|c|c|}
\hline CHEMBL 3218010 & 1641064 & 4.5074 & 4.7016 & TRN \\
\hline CHEMBL3218276 & 1641064 & 7.8239 & 7.8432 & TRN \\
\hline CHEMBL3963188 & 1641064 & 4.6017 & 4.5167 & TRN \\
\hline CHEMBL 3217759 & 1641064 & 6.9586 & 7.0304 & TRN \\
\hline CHEMBL3958434 & 1641064 & 6.0177 & 6.0233 & TRN \\
\hline CHEMBL3926492 & 1641064 & 6.3098 & 5.9854 & TST \\
\hline CHEMBL3218274 & 1641064 & 7.1549 & 7.2594 & TRN \\
\hline CHEMBL3218023 & 1641064 & 6.7212 & 6.6745 & TRN \\
\hline CHEMBL 3932202 & 1641064 & 6.4559 & 6.0838 & TST \\
\hline CHEMBL3963845 & 1641064 & 6.4202 & 5.9937 & TST \\
\hline CHEMBL3218017 & 1641064 & 6.6198 & 6.5971 & TRN \\
\hline CHEMBL3218007 & 1641064 & 6.3279 & 6.2334 & TRN \\
\hline CHEMBL3218280 & 1641064 & 6.0 & 5.9726 & TRN \\
\hline CHEMBL3218275 & 1641064 & 8.699 & 8.7361 & TRN \\
\hline CHEMBL3218287 & 1641064 & 6.0 & 6.0929 & TRN \\
\hline CHEMBL3218022 & 1641064 & 6.9208 & 6.9428 & TRN \\
\hline CHEMBL3218026 & 1641064 & 6.9208 & 6.9886 & TRN \\
\hline CHEMBL3218005 & 1641064 & 6.0 & 5.9358 & TRN \\
\hline CHEMBL 3987124 & 1641064 & 6.2366 & 5.4483 & TST \\
\hline CHEMBL3935950 & 1641064 & 6.3979 & 6.1386 & TST \\
\hline CHEMBL 3923247 & 1641064 & 6.6198 & 6.4579 & TST \\
\hline CHEMBL3218014 & 1641064 & 6.7447 & 6.8317 & TRN \\
\hline CHEMBL 3889585 & 1641064 & 4.923 & 5.0383 & TST \\
\hline CHEMBL3218011 & 1641064 & 6.0 & 6.1176 & TRN \\
\hline CHEMBL3218286 & 1641064 & 6.0 & 5.9267 & TRN \\
\hline CHEMBL1964290 & 809118 & 4.6 & 4.5812 & TRN \\
\hline CHEMBL 213505 & 809118 & 4.6 & 6.1931 & TRN \\
\hline CHEMBL 202721 & 809118 & 4.6 & 4.7634 & TRN \\
\hline CHEMBL1987034 & 809118 & 4.6 & 6.7179 & TRN \\
\hline CHEMBL1993941 & 809118 & 8.5 & 8.5803 & TRN \\
\hline CHEMBL 377383 & 809118 & 4.6 & 4.6871 & TRN \\
\hline CHEMBL2005886 & 809118 & 7.6 & 5.6503 & TRN \\
\hline CHEMBL481491 & 809118 & 5.7 & 4.7882 & TST \\
\hline CHEMBL1682345 & 809118 & 4.6 & 4.6158 & TRN \\
\hline CHEMBL1973142 & 809118 & 4.6 & 5.4951 & TRN \\
\hline CHEMBL388311 & 809118 & 6.2 & 7.4007 & TRN \\
\hline CHEMBL1973145 & 809118 & 8.5 & 7.7382 & TRN \\
\hline CHEMBL1982924 & 809118 & 4.6 & 4.7534 & TRN \\
\hline CHEMBL2005936 & 809118 & 4.6 & 4.4507 & TRN \\
\hline CHEMBL1807515 & 809118 & 7.0 & 5.6728 & TRN \\
\hline CHEMBL1964948 & 809118 & 4.6 & 4.2539 & TRN \\
\hline CHEMBL1971141 & 809118 & 6.4 & 6.5794 & TRN \\
\hline CHEMBL1995813 & 809118 & 4.6 & 5.2886 & TRN \\
\hline CHEMBL1979718 & 809118 & 4.6 & 4.6316 & TRN \\
\hline CHEMBL206236 & 809118 & 4.6 & 4.578 & TRN \\
\hline CHEMBL1989834 & 809118 & 3.4 & 3.9321 & TRN \\
\hline CHEMBL523823 & 809118 & 4.6 & 5.1482 & TST \\
\hline CHEMBL1973178 & 809118 & 8.3 & 7.7191 & TRN \\
\hline
\end{tabular}




\begin{tabular}{|c|c|c|c|c|c|}
\hline CHEMBL1987430 & 809118 & 4.6 & 4.4685 & TRN & \\
\hline CHEMBL244378 & 809118 & 6.5 & 6.1977 & TRN & \\
\hline CHEMBL1988778 & 809118 & 8.5 & 8.7187 & TRN & \\
\hline CHEMBL 2001957 & 809118 & 4.6 & 4.7307 & TRN & \\
\hline CHEMBL1969372 & 809118 & 4.6 & 4.853 & TRN & \\
\hline CHEMBL1993413 & 809118 & 4.6 & 4.3381 & TRN & \\
\hline CHEMBL1990583 & 809118 & 4.6 & 5.1513 & TRN & \\
\hline CHEMBL1986943 & 809118 & 6.7 & 6.375 & TRN & \\
\hline CHEMBL289959 & 809118 & 3.2 & 2.9321 & TRN & \\
\hline CHEMBL2006263 & 809118 & 4.6 & 4.7708 & TST & \\
\hline CHEMBL1993584 & 809118 & 4.6 & 4.2558 & TRN & \\
\hline CHEMBL1986263 & 809118 & 6.4 & 5.659 & TRN & \\
\hline CHEMBL 2000114 & 809118 & 4.6 & 4.9923 & TRN & \\
\hline CHEMBL210618 & 809118 & 4.6 & 4.6275 & TRN & \\
\hline CHEMBL1986265 & 809118 & 4.6 & 4.4247 & TST & \\
\hline CHEMBL1975647 & 809118 & 6.0 & 5.0885 & TRN & \\
\hline CHEMBL1968380 & 809118 & 4.6 & 4.7492 & TRN & \\
\hline CHEMBL1967211 & 809118 & 3.0 & 3.9748 & TRN & \\
\hline CHEMBL1964644 & 809118 & 4.6 & 4.4408 & TRN & \\
\hline CHEMBL1991734 & 809118 & 5.9 & 5.5511 & TST & \\
\hline CHEMBL1981782 & 809118 & 4.6 & 4.6144 & TRN & \\
\hline CHEMBL1977681 & 809118 & 4.6 & 5.3155 & TRN & \\
\hline CHEMBL1970142 & 809118 & 8.0 & 8.3415 & TRN & \\
\hline CHEMBL1990912 & 809118 & 4.6 & 4.5969 & TRN & \\
\hline CHEMBL1991782 & 809118 & 3.3 & 3.1944 & TRN & \\
\hline CHEMBL 2002105 & 809118 & 4.5 & 4.2154 & TRN & \\
\hline CHEMBL1983348 & 809118 & 4.6 & 6.1426 & TRN & \\
\hline CHEMBL1968394 & 809118 & 3.0 & 3.6493 & TRN & \\
\hline CHEMBL1988163 & 809118 & 5.6 & 6.001 & TRN & \\
\hline CHEMBL1995592 & 809118 & 6.8 & 6.0569 & TST & \\
\hline CHEMBL1974480 & 809118 & 6.0 & 5.1653 & TRN & \\
\hline CHEMBL1980671 & 809118 & 5.6 & 4.9945 & TRN & \\
\hline CHEMBL 2006493 & 809118 & 4.6 & 4.6962 & TST & \\
\hline CHEMBL1986177 & 809118 & 4.6 & 4.4382 & TRN & \\
\hline CHEMBL1983449 & 809118 & 4.6 & 4.4165 & TRN & \\
\hline CHEMBL1992323 & 809118 & 4.6 & 4.6061 & TRN & \\
\hline CHEMBL1969735 & 809118 & 4.6 & 4.5004 & TRN & \\
\hline CHEMBL 2003524 & 809118 & 5.7 & 5.0353 & TST & \\
\hline CHEMBL 2002649 & 809118 & 4.6 & 5.7505 & TRN & \\
\hline CHEMBL1989423 & 809118 & 3.2 & 3.6157 & TST & \\
\hline CHEMBL1985367 & 809118 & 4.6 & 4.8086 & TST & \\
\hline CHEMBL1996510 & 809118 & 4.6 & 5.1021 & TST & \\
\hline CHEMBL437747 & 809118 & 4.6 & 5.5381 & TRN & \\
\hline CHEMBL1995172 & 809118 & 3.5 & 4.2655 & TST & \\
\hline CHEMBL 2001584 & 809118 & 4.6 & 4.2534 & TRN & \\
\hline CHEMBL507936 & 809118 & 8.2 & \multicolumn{2}{|c|}{6.497000000000001} & TRN \\
\hline CHEMBL104264 & 809118 & 4.6 & 4.8339 & TST & \\
\hline \multirow[t]{2}{*}{ CHEMBL1967998 } & 809118 & 8.2 & \multirow{2}{*}{\multicolumn{2}{|c|}{$\begin{array}{c}7.367999999999999 \\
\text { Page } 28411\end{array}$}} & TRN \\
\hline & & & & & \\
\hline
\end{tabular}




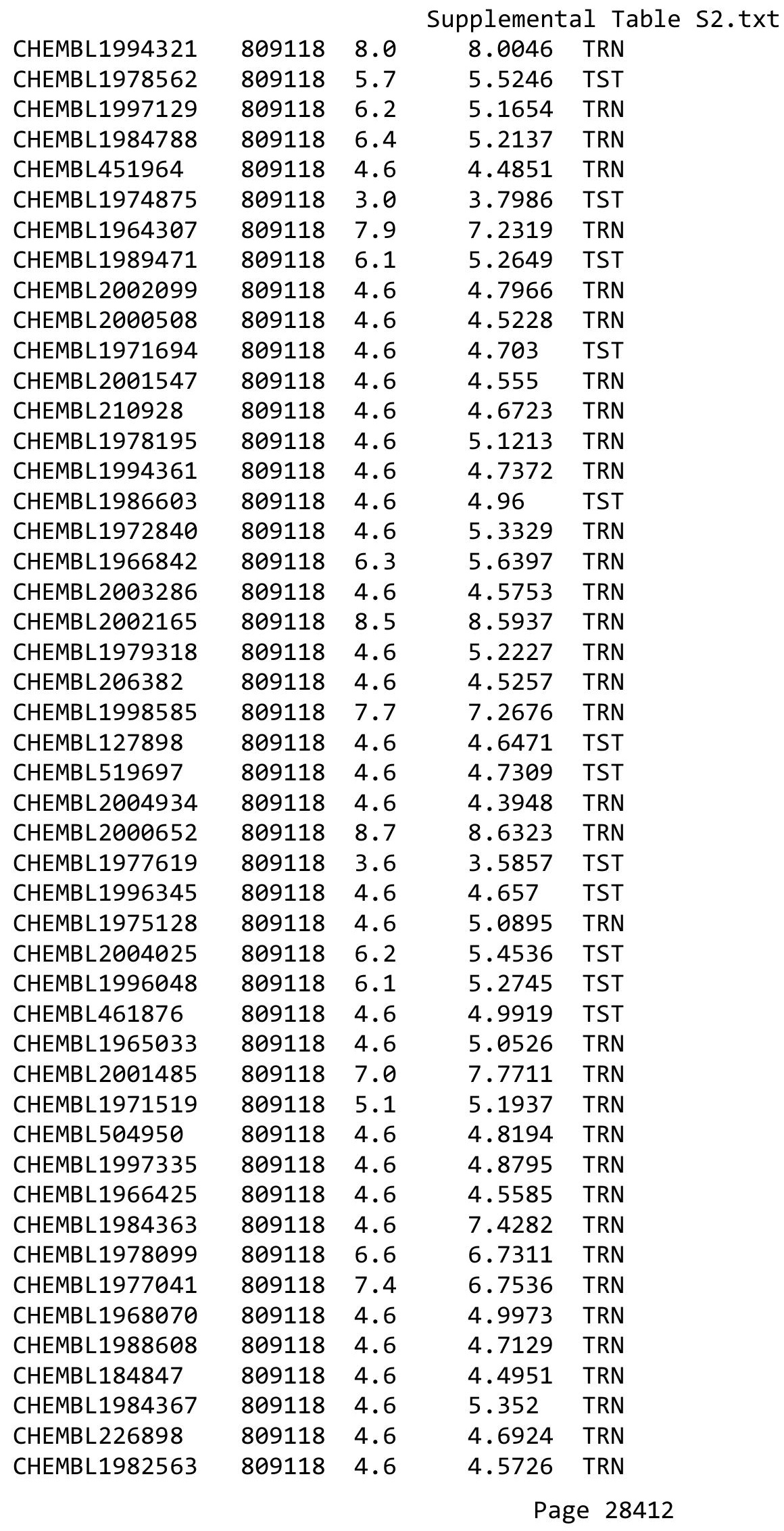




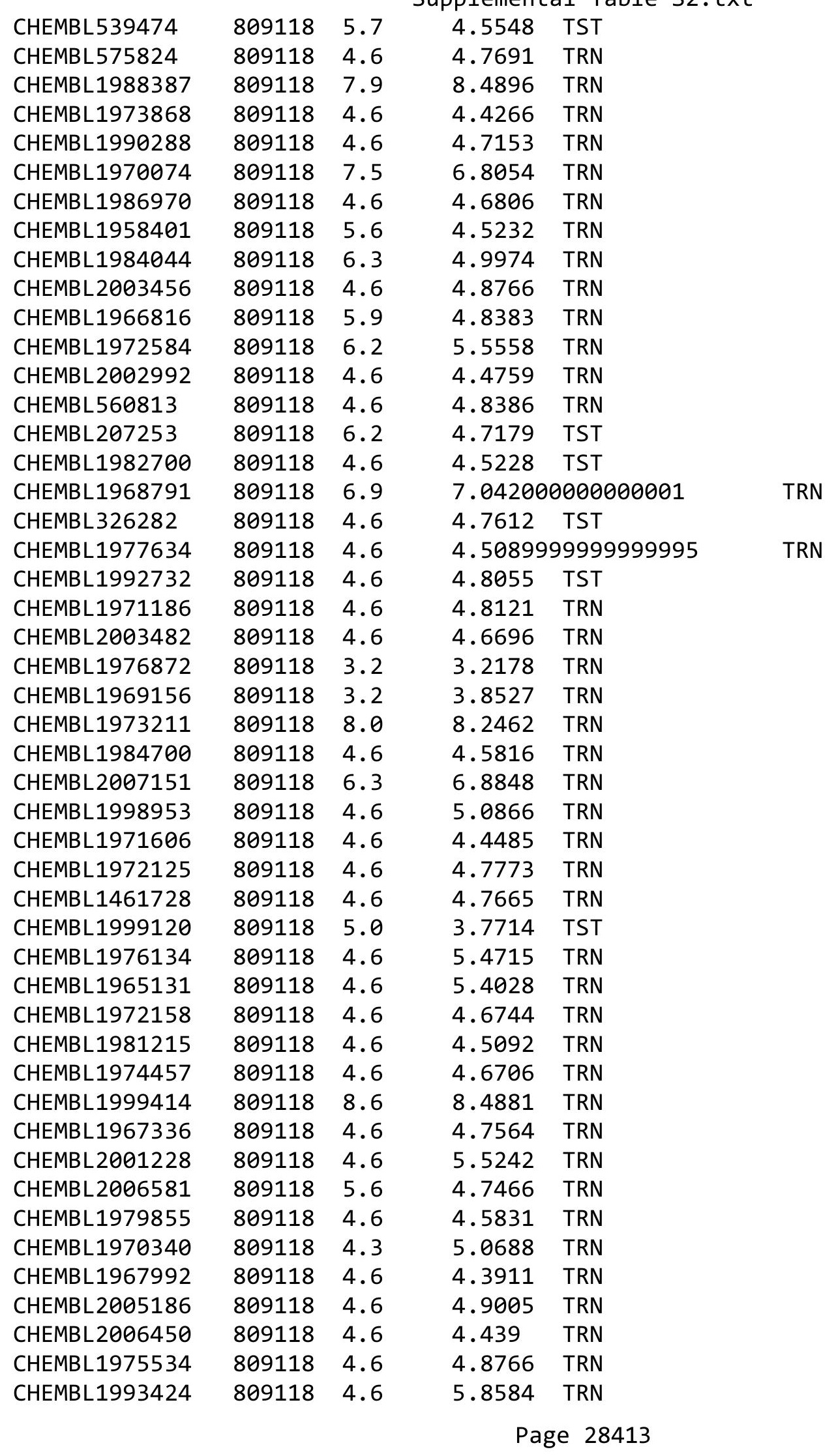




\begin{tabular}{|c|c|c|c|c|}
\hline \multicolumn{5}{|c|}{ lemental Table s } \\
\hline CHEMBL1966703 & 809118 & 4.6 & 4.8066 & TST \\
\hline CHEMBL 2001987 & 809118 & 4.6 & 4.5055 & TRN \\
\hline CHEMBL1969561 & 809118 & 4.6 & 4.6462 & TRN \\
\hline CHEMBL1994555 & 809118 & 4.6 & 4.9841 & TST \\
\hline CHEMBL1975121 & 809118 & 4.6 & 4.3896 & TRN \\
\hline CHEMBL1983640 & 809118 & 8.3 & 7.6208 & TRN \\
\hline CHEMBL1997023 & 809118 & 4.6 & 4.2766 & TST \\
\hline CHEMBL1964687 & 809118 & 7.7 & 5.7479 & TRN \\
\hline CHEMBL1971943 & 809118 & 4.6 & 5.2804 & TRN \\
\hline CHEMBL1999918 & 809118 & 4.6 & 5.1938 & TRN \\
\hline CHEMBL 1974254 & 809118 & 8.6 & 8.7292 & TRN \\
\hline CHEMBL1997924 & 809118 & 7.4 & 6.6421 & TRN \\
\hline CHEMBL1988537 & 809118 & 4.6 & 5.1372 & TST \\
\hline CHEMBL1969049 & 809118 & 4.6 & 4.3045 & TRN \\
\hline CHEMBL 2005828 & 809118 & 6.3 & 6.4423 & TRN \\
\hline CHEMBL1978267 & 809118 & 4.6 & 5.6062 & TRN \\
\hline CHEMBL1998611 & 809118 & 5.7 & 5.6343 & TRN \\
\hline CHEMBL485556 & 809118 & 4.6 & 5.53799 & 9999999999 \\
\hline CHEMBL1975900 & 809118 & 4.6 & 4.2209 & TRN \\
\hline CHEMBL 255822 & 809118 & 4.6 & 4.5928 & TRN \\
\hline CHEMBL1972221 & 809118 & 4.6 & 4.7861 & TRN \\
\hline CHEMBL 2006778 & 809118 & 8.4 & 7.7229 & TRN \\
\hline CHEMBL378627 & 809118 & 4.6 & 4.5949 & TRN \\
\hline CHEMBL1996979 & 809118 & 6.5 & 5.2767 & TRN \\
\hline CHEMBL1997025 & 809118 & 6.1 & 4.956 & TRN \\
\hline CHEMBL1968406 & 809118 & 4.6 & 5.6798 & TRN \\
\hline CHEMBL1975921 & 809118 & 3.0 & 4.6474 & TRN \\
\hline CHEMBL1982476 & 809118 & 8.8 & 8.5151 & TRN \\
\hline CHEMBL1998545 & 809118 & 4.6 & 4.4565 & TRN \\
\hline CHEMBL1986869 & 809118 & 4.6 & 4.6226 & TRN \\
\hline CHEMBL1975923 & 809118 & 4.9 & 5.081 & TST \\
\hline CHEMBL 2005449 & 809118 & 5.9 & 5.6855 & TRN \\
\hline CHEMBL1987998 & 809118 & 4.6 & 4.4417 & TST \\
\hline CHEMBL 2006010 & 809118 & 4.6 & 4.6058 & TRN \\
\hline CHEMBL1682558 & 809118 & 4.6 & 4.5514 & TRN \\
\hline CHEMBL1971534 & 809118 & 3.0 & 4.3761 & TRN \\
\hline CHEMBL1990496 & 809118 & 4.6 & 4.2903 & TRN \\
\hline CHEMBL 242865 & 809118 & 4.6 & 5.8359 & TRN \\
\hline CHEMBL1997623 & 809118 & 6.9 & 6.8438 & TRN \\
\hline CHEMBL 2002479 & 809118 & 4.6 & 4.2914 & TRN \\
\hline CHEMBL 2002480 & 809118 & 4.0 & 4.4194 & TRN \\
\hline CHEMBL1993166 & 809118 & 4.6 & 4.4969 & TRN \\
\hline CHEMBL1967094 & 809118 & 4.6 & 5.1195 & TRN \\
\hline CHEMBL1966035 & 809118 & 4.6 & 4.6216 & TRN \\
\hline CHEMBL 2003341 & 809118 & 4.6 & 4.4182 & TRN \\
\hline CHEMBL1992645 & 809118 & 4.6 & 4.6125 & TST \\
\hline CHEMBL1982992 & 809118 & 4.6 & 4.6063 & TRN \\
\hline CHEMBL1998110 & 809118 & 4.6 & 4.3478 & TRN \\
\hline
\end{tabular}




\begin{tabular}{|c|c|c|c|c|c|}
\hline \multirow[b]{2}{*}{ CHEMBL1999590 } & \multirow[b]{2}{*}{809118} & \\
\hline & & 4.6 & 5.2681 & TST & \\
\hline CHEMBL1981079 & 809118 & 4.6 & 4.5899 & TRN & \\
\hline CHEMBL1978166 & 809118 & 7.4 & 7.6199 & TRN & \\
\hline CHEMBL1972276 & 809118 & 4.6 & 4.9781 & TRN & \\
\hline CHEMBL1980489 & 809118 & 4.6 & 4.329 & TRN & \\
\hline CHEMBL 2000832 & 809118 & 4.6 & 5.2228 & TRN & \\
\hline CHEMBL1967116 & 809118 & 8.8 & 8.8879 & TRN & \\
\hline CHEMBL1972454 & 809118 & 3.0 & 4.056 & TST & \\
\hline CHEMBL1990590 & 809118 & 4.6 & 4.5153 & TRN & \\
\hline CHEMBL1970709 & 809118 & 4.6 & 4.855 & TRN & \\
\hline CHEMBL1974617 & 809118 & 3.0 & 4.7051 & TRN & \\
\hline CHEMBL1965660 & 809118 & 4.6 & 4.7856 & TRN & \\
\hline CHEMBL1992125 & 809118 & 5.7 & 5.5223 & TRN & \\
\hline CHEMBL1998112 & 809118 & 4.6 & 4.8097 & TRN & \\
\hline CHEMBL1993996 & 809118 & 8.9 & 8.7696 & TRN & \\
\hline CHEMBL1969126 & 809118 & 4.6 & 4.5511 & TRN & \\
\hline CHEMBL1980896 & 809118 & 7.6 & 6.0019 & TRN & \\
\hline CHEMBL1970104 & 809118 & 6.5 & 5.9251 & TRN & \\
\hline CHEMBL1991429 & 809118 & 4.6 & 5.9498 & TRN & \\
\hline CHEMBL1964777 & 809118 & 4.6 & 4.55699 & 99999999995 & TRN \\
\hline CHEMBL1971149 & 809118 & 4.6 & 4.6326 & TRN & \\
\hline CHEMBL1999714 & 809118 & 4.6 & 4.1393 & TRN & \\
\hline CHEMBL1987533 & 809118 & 4.6 & 4.6416 & TRN & \\
\hline CHEMBL1994040 & 809118 & 4.6 & 4.7498 & TRN & \\
\hline CHEMBL388978 & 809118 & 8.1 & 8.1947 & TST & \\
\hline CHEMBL579246 & 809118 & 4.6 & 4.7809 & TRN & \\
\hline CHEMBL398951 & 809118 & 4.6 & 4.9286 & TST & \\
\hline CHEMBL1982506 & 809118 & 5.8 & 5.0601 & TST & \\
\hline CHEMBL2004716 & 809118 & 7.8 & 8.2353 & TRN & \\
\hline CHEMBL1968127 & 809118 & 4.6 & 4.6973 & TRN & \\
\hline CHEMBL1975233 & 809118 & 4.6 & 4.7838 & TRN & \\
\hline CHEMBL1985406 & 809118 & 4.6 & 4.3414 & TRN & \\
\hline CHEMBL207400 & 809118 & 4.6 & 4.5197 & TST & \\
\hline CHEMBL 2000894 & 809118 & 4.6 & 4.9366 & TST & \\
\hline CHEMBL1421720 & 809118 & 4.6 & 4.5363 & TRN & \\
\hline CHEMBL1968130 & 809118 & 4.1 & 3.9676 & TRN & \\
\hline CHEMBL1982135 & 809118 & 4.6 & 5.7365 & TRN & \\
\hline CHEMBL1976090 & 809118 & 4.6 & 4.6613 & TRN & \\
\hline CHEMBL1993243 & 809118 & 7.5 & 6.8964 & TRN & \\
\hline CHEMBL 2004771 & 809118 & 4.6 & 5.2507 & TRN & \\
\hline CHEMBL1992922 & 809118 & 4.6 & 5.0298 & TRN & \\
\hline CHEMBL399021 & 809118 & 6.0 & 6.402 & TRN & \\
\hline CHEMBL1997597 & 809118 & 4.6 & 4.7906 & TRN & \\
\hline CHEMBL1969537 & 809118 & 4.6 & 4.8683 & TST & \\
\hline CHEMBL1976093 & 809118 & 4.6 & 4.6672 & TRN & \\
\hline CHEMBL1996543 & 809118 & 4.6 & 4.502 & TRN & \\
\hline CHEMBL1975256 & 809118 & 4.6 & 4.8408 & TST & \\
\hline CHEMBL508928 & 809118 & 7.5 & 7.1569 & TRN & \\
\hline & & & & 28415 & \\
\hline
\end{tabular}




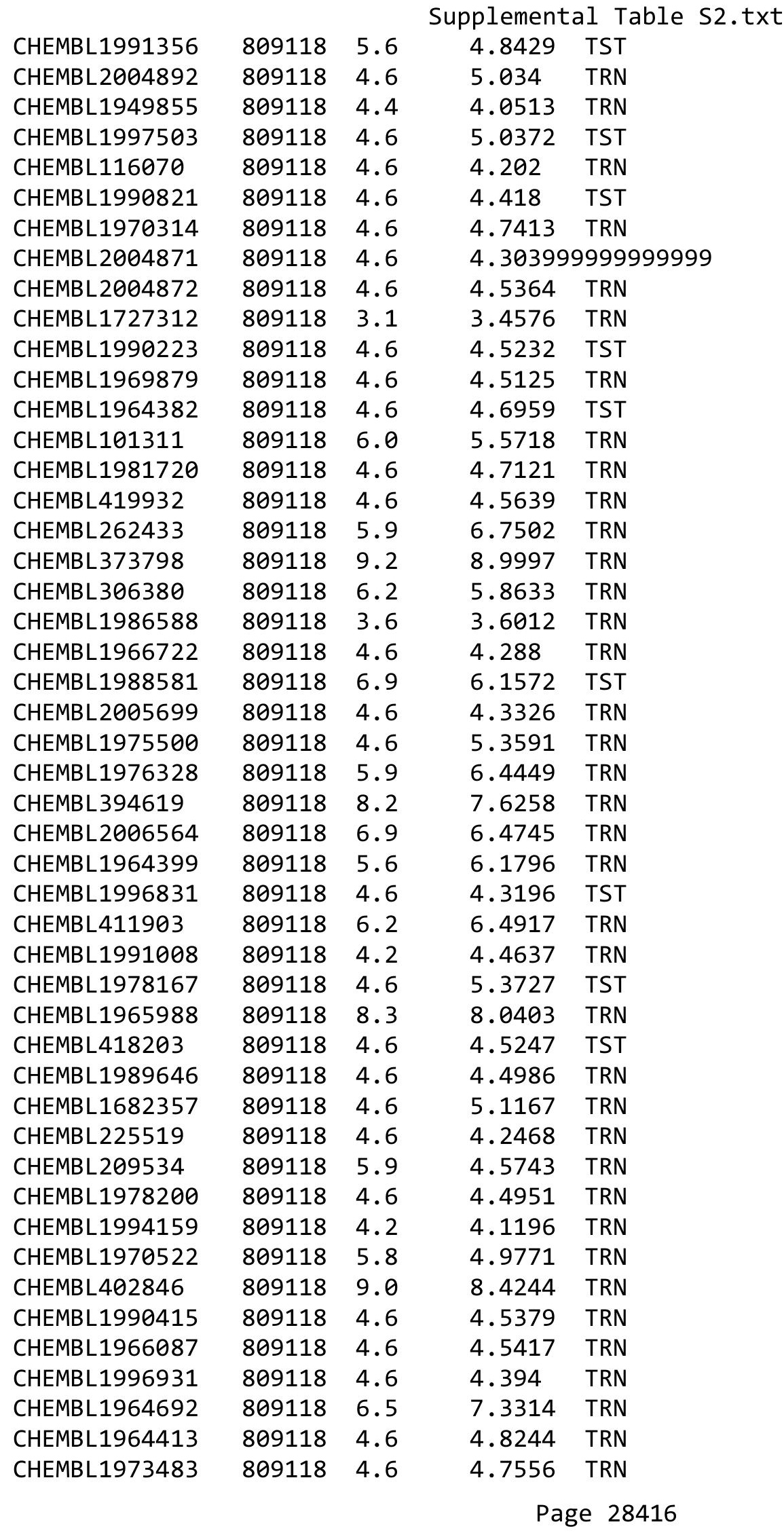

TRN 


\begin{tabular}{|c|c|c|c|c|}
\hline \multirow[b]{2}{*}{ CHEMBL1998470 } & \multicolumn{4}{|c|}{ Supplemental Ta } \\
\hline & 809118 & 4.6 & 4.578 & TRN \\
\hline CHEMBL1995428 & 809118 & 6.2 & 5.7111 & TRN \\
\hline CHEMBL1984432 & 809118 & 4.6 & 5.0236 & TRN \\
\hline CHEMBL 219722 & 809118 & 8.2 & 7.6985 & TRN \\
\hline CHEMBL1975903 & 809118 & 4.6 & 5.7096 & TRN \\
\hline CHEMBL1997340 & 809118 & 4.6 & 4.6908 & TRN \\
\hline CHEMBL1522508 & 809118 & 3.3 & 3.8939 & TRN \\
\hline CHEMBL1989474 & 809118 & 4.6 & 4.673 & TRN \\
\hline CHEMBL1090360 & 809118 & 6.0 & 5.8729 & TRN \\
\hline CHEMBL1988805 & 809118 & 4.6 & 4.7101 & TST \\
\hline CHEMBL458997 & 809118 & 5.8 & 6.0925 & TRN \\
\hline CHEMBL1971021 & 809118 & 4.6 & 5.2475 & TRN \\
\hline CHEMBL 227271 & 809118 & 4.6 & 4.8523 & TRN \\
\hline CHEMBL583144 & 809118 & 4.6 & 4.4112 & TRN \\
\hline CHEMBL1974310 & 809118 & 4.6 & 5.1105 & TRN \\
\hline CHEMBL1969942 & 809118 & 4.6 & 5.0417 & TRN \\
\hline CHEMBL1978567 & 809118 & 4.6 & 4.3478 & TRN \\
\hline CHEMBL1982660 & 809118 & 4.6 & 4.9327 & TRN \\
\hline CHEMBL1994693 & 809118 & 4.6 & 5.7734 & TRN \\
\hline CHEMBL1982957 & 809118 & 6.4 & 5.9043 & TRN \\
\hline CHEMBL1725279 & 809118 & 6.9 & 5.737 & TST \\
\hline CHEMBL 2002346 & 809118 & 6.7 & 5.6382 & TRN \\
\hline CHEMBL1975138 & 809118 & 4.6 & 4.2163 & TRN \\
\hline CHEMBL424872 & 809118 & 6.2 & 4.666 & TRN \\
\hline CHEMBL1971947 & 809118 & 7.8 & 7.4753 & TRN \\
\hline CHEMBL412142 & 809118 & 4.6 & 4.9269 & TST \\
\hline CHEMBL1980704 & 809118 & 4.6 & 4.5927 & TST \\
\hline CHEMBL 2003271 & 809118 & 4.6 & 5.0054 & TRN \\
\hline CHEMBL1972365 & 809118 & 3.6 & 4.5897 & TRN \\
\hline CHEMBL1966808 & 809118 & 4.6 & 4.3294 & TRN \\
\hline CHEMBL1996255 & 809118 & 8.9 & 8.7867 & TRN \\
\hline CHEMBL2004447 & 809118 & 4.6 & 4.7429 & TRN \\
\hline CHEMBL1983111 & 809118 & 7.2 & 7.2954 & TST \\
\hline CHEMBL1973860 & 809118 & 4.6 & 4.4844 & TRN \\
\hline CHEMBL260135 & 809118 & 5.6 & 4.7962 & TRN \\
\hline CHEMBL 220241 & 809118 & 4.6 & 4.9209 & TRN \\
\hline CHEMBL1988141 & 809118 & 6.6 & 5.545 & TST \\
\hline CHEMBL1982610 & 809118 & 4.6 & 4.7283 & TST \\
\hline CHEMBL1977134 & 809118 & 7.2 & 6.5 & TRN \\
\hline CHEMBL1999496 & 809118 & 4.6 & 4.7895 & TRN \\
\hline CHEMBL1970873 & 809118 & 3.4 & 3.8193 & TRN \\
\hline CHEMBL 2006933 & 809118 & 4.6 & 4.9573 & TST \\
\hline CHEMBL1985206 & 809118 & 4.6 & 5.1482 & TST \\
\hline CHEMBL1988300 & 809118 & 7.3 & 6.7539 & TRN \\
\hline CHEMBL1991078 & 809118 & 4.8 & 5.5741 & TRN \\
\hline CHEMBL1987359 & 809118 & 4.6 & 4.5828 & TST \\
\hline CHEMBL1977749 & 809118 & 4.6 & 4.9816 & TST \\
\hline CHEMBL1975212 & 809118 & 5.7 & 5.1693 & TRN \\
\hline
\end{tabular}




\begin{tabular}{|c|c|c|c|c|c|}
\hline \multicolumn{6}{|c|}{ Supplemental Table S2.txt } \\
\hline CHEMBL 2000685 & 809118 & 4.6 & 4.3924 & TRN & \\
\hline CHEMBL 2001613 & 809118 & 4.4 & 4.1485 & TRN & \\
\hline CHEMBL1997275 & 809118 & 4.6 & 5.4133 & TRN & \\
\hline CHEMBL1993904 & 809118 & 6.1 & 5.4107 & TRN & \\
\hline CHEMBL1980376 & 809118 & 4.8 & 4.725 & TRN & \\
\hline CHEMBL1967513 & 809118 & 4.6 & 4.6075 & TRN & \\
\hline CHEMBL 2000724 & 809118 & 4.6 & 4.4758 & TRN & \\
\hline CHEMBL1985311 & 809118 & 8.3 & 8.0007 & TRN & \\
\hline CHEMBL1989265 & 809118 & 4.6 & 4.7717 & TST & \\
\hline CHEMBL1982413 & 809118 & 4.6 & 5.0275 & TST & \\
\hline CHEMBL1969502 & 809118 & 4.6 & 5.817 & TRN & \\
\hline CHEMBL1965910 & 809118 & 5.9 & 6.223 & TRN & \\
\hline CHEMBL1682553 & 809118 & 4.6 & 4.9021 & TRN & \\
\hline CHEMBL1971430 & 809118 & 4.6 & 4.5304 & TRN & \\
\hline CHEMBL1983963 & 809118 & 8.7 & 7.3569 & TRN & \\
\hline CHEMBL1997764 & 809118 & 5.7 & 4.9054 & TRN & \\
\hline CHEMBL 2000271 & 809118 & 4.6 & 5.5922 & TRN & \\
\hline CHEMBL562488 & 809118 & 3.6 & 3.89600 & 00000000004 & TRN \\
\hline CHEMBL1981792 & 809118 & 4.6 & 4.7014 & TRN & \\
\hline CHEMBL1987535 & 809118 & 4.6 & 4.8824 & TRN & \\
\hline CHEMBL354676 & 809118 & 3.2 & 3.6229 & TRN & \\
\hline CHEMBL1985092 & 809118 & 4.6 & 4.5358 & TRN & \\
\hline CHEMBL 2004692 & 809118 & 4.6 & 4.7586 & TST & \\
\hline CHEMBL1981410 & 809118 & 4.6 & 5.9724 & TRN & \\
\hline CHEMBL 2002586 & 809118 & 4.6 & 5.04899 & 99999999995 & TRN \\
\hline CHEMBL1987815 & 809118 & 3.0 & 3.9395 & TST & \\
\hline CHEMBL1996234 & 809118 & 4.6 & 5.0687 & TRN & \\
\hline CHEMBL383264 & 809118 & 4.6 & 4.8617 & TRN & \\
\hline CHEMBL 2007421 & 809118 & 4.6 & 5.4693 & TRN & \\
\hline CHEMBL1991434 & 809118 & 4.6 & 4.7036 & TST & \\
\hline CHEMBL1967544 & 809118 & 4.6 & 4.75 & TRN & \\
\hline CHEMBL1973138 & 809118 & 4.6 & 4.3153 & TRN & \\
\hline CHEMBL223367 & 809118 & 7.7 & 4.8438 & TST & \\
\hline CHEMBL1992673 & 809118 & 4.7 & 4.5247 & TRN & \\
\hline CHEMBL340384 & 809118 & 6.4 & 5.183 & TST & \\
\hline CHEMBL1969151 & 809118 & 6.3 & 5.82600 & 20000000005 & TRN \\
\hline CHEMBL1996587 & 809118 & 4.6 & 4.7978 & TRN & \\
\hline CHEMBL1981492 & 809118 & 4.1 & 4.2146 & TRN & \\
\hline CHEMBL1993335 & 809118 & 6.2 & 6.1311 & TST & \\
\hline CHEMBL1988692 & 809118 & 6.1 & 6.0049 & TRN & \\
\hline CHEMBL 2007574 & 809118 & 4.6 & 4.9674 & TRN & \\
\hline CHEMBL1964804 & 809118 & 4.6 & 4.5579 & TRN & \\
\hline CHEMBL443962 & 809118 & 4.6 & 5.28100 & 0000000001 & TRN \\
\hline CHEMBL 2000354 & 809118 & 4.6 & 4.5706 & TRN & \\
\hline CHEMBL1965507 & 809118 & 4.6 & 5.074 & TRN & \\
\hline CHEMBL274064 & 809118 & 4.6 & 4.8587 & TRN & \\
\hline CHEMBL1998680 & 809118 & 4.6 & 4.3922 & TRN & \\
\hline CHEMBL1967564 & 809118 & 4.6 & 4.5696 & TRN & \\
\hline
\end{tabular}




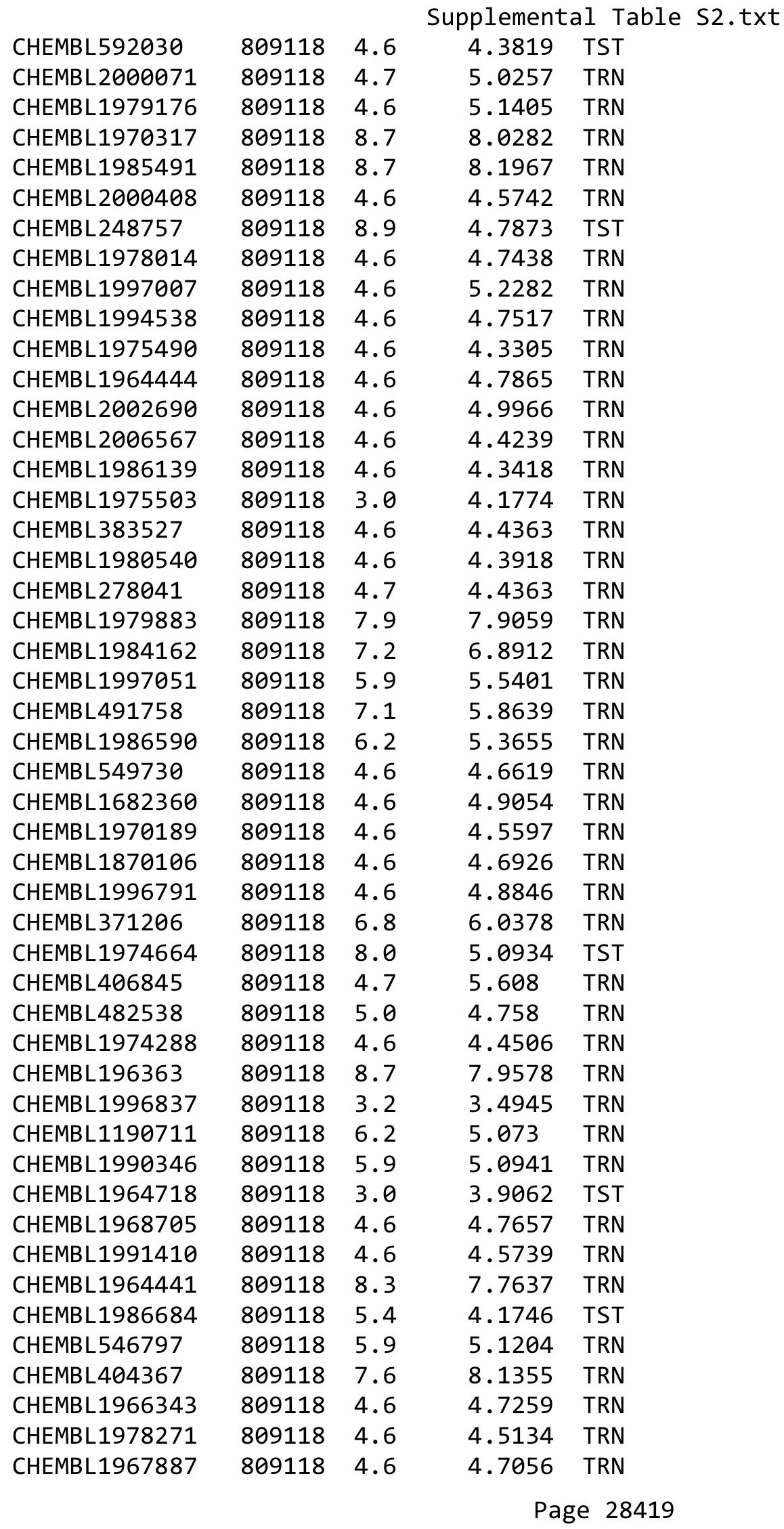




\begin{tabular}{|c|c|c|c|c|c|}
\hline CHEMBL 2007266 & 809118 & 7.8 & \multicolumn{2}{|c|}{7.547000000000001} & \multirow[t]{2}{*}{ TRN } \\
\hline CHEMBL 2000568 & 809118 & 4.6 & 5.2089 & TRN & \\
\hline CHEMBL 2000335 & 809118 & 6.9 & 7.2794 & TRN & \\
\hline CHEMBL2007097 & 809118 & 4.4 & 4.2377 & TRN & \\
\hline CHEMBL1988717 & 809118 & 8.2 & 7.2366 & TRN & \\
\hline CHEMBL1974328 & 809118 & 6.0 & 5.6414 & TST & \\
\hline CHEMBL509032 & 809118 & 6.4 & 6.9315 & TRN & \\
\hline CHEMBL143703 & 809118 & 3.2 & 3.5984 & TRN & \\
\hline CHEMBL1973808 & 809118 & 4.6 & 4.6426 & TRN & \\
\hline CHEMBL 2000429 & 809118 & 4.6 & 4.5398 & TRN & \\
\hline CHEMBL1972576 & 809118 & 4.6 & 4.9362 & TRN & \\
\hline CHEMBL1990254 & 809118 & 4.6 & 4.4556 & TRN & \\
\hline CHEMBL1992342 & 809118 & 4.6 & 5.0326 & TRN & \\
\hline CHEMBL1988173 & 809118 & 4.6 & 4.0282 & TRN & \\
\hline CHEMBL1973013 & 809118 & 6.3 & 5.2549 & TRN & \\
\hline CHEMBL1164265 & 809118 & 6.4 & 5.6057 & TST & \\
\hline CHEMBL1989805 & 809118 & 4.6 & 4.3961 & TST & \\
\hline CHEMBL1965423 & 809118 & 4.6 & 4.9314 & TRN & \\
\hline CHEMBL1983025 & 809118 & 7.5 & 7.7212 & TRN & \\
\hline CHEMBL1975927 & 809118 & 8.3 & 6.401 & TRN & \\
\hline CHEMBL 205415 & 809118 & 4.6 & 4.3872 & TRN & \\
\hline CHEMBL1977135 & 809118 & 4.6 & 4.4159 & TRN & \\
\hline CHEMBL 2001920 & 809118 & 4.6 & 4.5189 & TST & \\
\hline CHEMBL 2002322 & 809118 & 4.6 & 4.5184 & TRN & \\
\hline CHEMBL1980904 & 809118 & 8.5 & \multicolumn{2}{|c|}{8.447000000000001} & TRN \\
\hline CHEMBL1977138 & 809118 & 6.6 & 5.1279 & TST & \\
\hline CHEMBL 2002323 & 809118 & 4.6 & 4.5486 & TRN & \\
\hline CHEMBL1241473 & 809118 & 7.9 & \multicolumn{2}{|c|}{6.5360000000000005} & TRN \\
\hline CHEMBL2000879 & 809118 & 4.3 & 4.2179 & TST & \\
\hline CHEMBL1978448 & 809118 & 4.8 & 4.5277 & TST & \\
\hline CHEMBL1972258 & 809118 & 4.6 & 4.5117 & TRN & \\
\hline CHEMBL 2004513 & 809118 & 5.9 & 4.7972 & TRN & \\
\hline CHEMBL1969483 & 809118 & 6.2 & 6.0292 & TRN & \\
\hline CHEMBL1980329 & 809118 & 5.9 & 6.5127 & TRN & \\
\hline CHEMBL 2004515 & 809118 & 4.9 & 4.9854 & TRN & \\
\hline CHEMBL2001257 & 809118 & 7.6 & 7.4326 & TRN & \\
\hline CHEMBL1992042 & 809118 & 4.6 & 4.9927 & TST & \\
\hline CHEMBL 2005548 & 809118 & 4.6 & 4.5608 & TRN & \\
\hline CHEMBL271441 & 809118 & 9.1 & 9.0849 & TRN & \\
\hline CHEMBL1992536 & 809118 & 4.6 & 4.8888 & TRN & \\
\hline CHEMBL21156 & 809118 & 4.6 & 4.7962 & TST & \\
\hline CHEMBL1380050 & 809118 & 3.0 & 4.1827 & TRN & \\
\hline CHEMBL1992740 & 809118 & 4.6 & 4.8946 & TRN & \\
\hline CHEMBL1994724 & 809118 & 4.6 & 4.4129 & TRN & \\
\hline CHEMBL1989267 & 809118 & 7.1 & 6.8182 & TRN & \\
\hline CHEMBL2002373 & 809118 & 4.6 & 4.2474 & TRN & \\
\hline CHEMBL439340 & 809118 & 4.6 & 4.7859 & TRN & \\
\hline CHEMBL2006188 & 809118 & 4.6 & 4.6417 & TRN & \\
\hline
\end{tabular}




\begin{tabular}{|c|c|c|c|c|}
\hline & & & & $a+1 a$ \\
\hline CHEMBL1970290 & 809118 & 4.6 & 5.3347 & TRN \\
\hline CHEMBL1967531 & 809118 & 6.7 & 6.7952 & TRN \\
\hline CHEMBL1970913 & 809118 & 4.6 & 4.6134 & TRN \\
\hline CHEMBL1973893 & 809118 & 4.6 & 4.8301 & TRN \\
\hline CHEMBL1997534 & 809118 & 4.6 & 4.3833 & TRN \\
\hline CHEMBL1993877 & 809118 & 5.9 & 5.70799 & 9999999999 \\
\hline CHEMBL1985095 & 809118 & 4.6 & 5.3394 & TST \\
\hline CHEMBL1996500 & 809118 & 4.6 & 4.4122 & TRN \\
\hline CHEMBL273187 & 809118 & 9.5 & 9.2376 & TRN \\
\hline CHEMBL1991180 & 809118 & 4.6 & 5.3083 & TST \\
\hline CHEMBL1682540 & 809118 & 4.6 & 4.5931 & TRN \\
\hline CHEMBL1976420 & 809118 & 5.8 & 4.9476 & TST \\
\hline CHEMBL1986979 & 809118 & 8.8 & 8.9493 & TRN \\
\hline CHEMBL413779 & 809118 & 7.6 & 4.877 & TST \\
\hline CHEMBL1994864 & 809118 & 4.6 & 4.4329 & TRN \\
\hline CHEMBL1981744 & 809118 & 4.6 & 4.5279 & TRN \\
\hline CHEMBL 2002446 & 809118 & 8.5 & 6.885 & TST \\
\hline CHEMBL497151 & 809118 & 4.6 & 4.1164 & TRN \\
\hline CHEMBL 2000029 & 809118 & 5.8 & 4.6444 & TRN \\
\hline CHEMBL1973961 & 809118 & 4.6 & 4.7225 & TRN \\
\hline CHEMBL 246970 & 809118 & 4.6 & 4.7284 & TRN \\
\hline CHEMBL340921 & 809118 & 6.0 & 4.6861 & TST \\
\hline CHEMBL1994977 & 809118 & 4.6 & 4.5556 & TRN \\
\hline CHEMBL373598 & 809118 & 7.4 & 4.7499 & TST \\
\hline CHEMBL1999718 & 809118 & 4.6 & 4.6625 & TRN \\
\hline CHEMBL 2000078 & 809118 & 5.9 & 6.0019 & TRN \\
\hline CHEMBL1276446 & 809118 & 6.6 & 6.0859 & TST \\
\hline CHEMBL 2005478 & 809118 & 5.8 & 5.4875 & TST \\
\hline CHEMBL1996646 & 809118 & 6.5 & 6.8541 & TRN \\
\hline CHEMBL1979773 & 809118 & 4.6 & 4.1706 & TRN \\
\hline CHEMBL1977346 & 809118 & 4.6 & 5.3154 & TRN \\
\hline CHEMBL 2003657 & 809118 & 4.6 & 5.1129 & TRN \\
\hline CHEMBL1971649 & 809118 & 4.6 & 6.6989 & TRN \\
\hline CHEMBL1992723 & 809118 & 4.1 & 3.9488 & TRN \\
\hline CHEMBL 2005482 & 809118 & 6.8 & 6.3254 & TRN \\
\hline CHEMBL1996702 & 809118 & 4.6 & 5.4832 & TRN \\
\hline CHEMBL1997909 & 809118 & 7.1 & 6.0736 & TRN \\
\hline CHEMBL 2007124 & 809118 & 4.6 & 4.5966 & TRN \\
\hline CHEMBL 2006439 & 809118 & 4.8 & 5.9103 & TRN \\
\hline CHEMBL1985681 & 809118 & 6.9 & 5.9942 & TST \\
\hline CHEMBL1969190 & 809118 & 4.6 & 6.6266 & TRN \\
\hline CHEMBL1973937 & 809118 & 7.8 & 7.5189 & TRN \\
\hline CHEMBL1991674 & 809118 & 6.7 & 5.3082 & TRN \\
\hline CHEMBL1982711 & 809118 & 4.7 & 5.0139 & TRN \\
\hline CHEMBL 262623 & 809118 & 3.0 & 4.8722 & TRN \\
\hline CHEMBL1984842 & 809118 & 4.6 & 4.4516 & TRN \\
\hline CHEMBL1969102 & 809118 & 8.6 & 8.8524 & TRN \\
\hline CHEMBL 2004118 & 809118 & 5.8 & 5.381 & TRN \\
\hline
\end{tabular}




\begin{tabular}{|c|c|c|c|c|c|}
\hline \multicolumn{6}{|c|}{ Supplemental Table S2.txt } \\
\hline CHEMBL1682346 & 809118 & 4.6 & 4.8947 & TRN & \\
\hline CHEMBL 2007044 & 809118 & 4.6 & 4.9889 & TST & \\
\hline CHEMBL 2001998 & 809118 & 6.4 & 5.3706 & TST & \\
\hline CHEMBL1994241 & 809118 & 5.7 & 5.0792 & TRN & \\
\hline CHEMBL223460 & 809118 & 7.8 & 4.8021 & TST & \\
\hline CHEMBL1998829 & 809118 & 4.6 & 4.8925 & TRN & \\
\hline CHEMBL50894 & 809118 & 6.0 & 5.1523 & TRN & \\
\hline CHEMBL1995211 & 809118 & 4.6 & 4.6118 & TRN & \\
\hline CHEMBL1988838 & 809118 & 6.5 & 6.5 & TRN & \\
\hline CHEMBL1981725 & 809118 & 7.5 & 6.8227 & TRN & \\
\hline CHEMBL1982753 & 809118 & 4.6 & 5.2501 & TST & \\
\hline CHEMBL375284 & 809118 & 8.6 & 7.1019 & TRN & \\
\hline CHEMBL 2006299 & 809118 & 4.6 & 4.3989 & TRN & \\
\hline CHEMBL1972346 & 809118 & 4.6 & 4.7456 & TST & \\
\hline CHEMBL1965169 & 809118 & 4.6 & 4.9232 & TST & \\
\hline CHEMBL1081312 & 809118 & 6.4 & 6.1919 & TRN & \\
\hline CHEMBL1965170 & 809118 & 8.4 & 8.907 & TRN & \\
\hline CHEMBL1982866 & 809118 & 4.6 & 4.6939 & TRN & \\
\hline CHEMBL1393571 & 809118 & 3.0 & 3.9903 & TRN & \\
\hline CHEMBL 2005792 & 809118 & 4.6 & 4.4317 & TRN & \\
\hline CHEMBL1968926 & 809118 & 4.6 & 4.4128 & TRN & \\
\hline CHEMBL365617 & 809118 & 5.9 & 4.9368 & TRN & \\
\hline CHEMBL1984206 & 809118 & 5.8 & 4.5203 & TRN & \\
\hline CHEMBL462120 & 809118 & 6.7 & 4.7316 & TRN & \\
\hline CHEMBL1991577 & 809118 & 4.6 & 4.5139 & TRN & \\
\hline CHEMBL1991867 & 809118 & 3.2 & 3.9299 & TST & \\
\hline CHEMBL 2007592 & 809118 & 4.6 & 4.5022 & TRN & \\
\hline CHEMBL1965570 & 809118 & 6.7 & 7.83 & TRN & \\
\hline CHEMBL1972355 & 809118 & 5.7 & 5.7155 & TST & \\
\hline CHEMBL1997892 & 809118 & 4.6 & 5.0461 & TRN & \\
\hline CHEMBL 2001641 & 809118 & 4.4 & 4.3486 & TRN & \\
\hline CHEMBL1997193 & 809118 & 6.4 & 5.1286 & TST & \\
\hline CHEMBL210963 & 809118 & 4.6 & 4.5897 & TRN & \\
\hline CHEMBL1964902 & 809118 & 4.6 & 4.3507 & TRN & \\
\hline CHEMBL1082440 & 809118 & 4.6 & 5.0015 & TST & \\
\hline CHEMBL1614705 & 809118 & 4.6 & 4.806 & TRN & \\
\hline CHEMBL1972362 & 809118 & 4.6 & 4.98300 & 00000000005 & TRN \\
\hline CHEMBL1984633 & 809118 & 4.6 & 4.4672 & TRN & \\
\hline CHEMBL1965845 & 809118 & 4.6 & 5.0606 & TRN & \\
\hline CHEMBL 2007372 & 809118 & 4.6 & 4.5406 & TRN & \\
\hline CHEMBL1983715 & 809118 & 7.6 & 6.8078 & TRN & \\
\hline CHEMBL1971017 & 809118 & 4.6 & 5.1867 & TRN & \\
\hline CHEMBL 2006715 & 809118 & 6.1 & 5.7327 & TRN & \\
\hline CHEMBL1986597 & 809118 & 6.0 & 5.2842 & TRN & \\
\hline CHEMBL1990482 & 809118 & 4.6 & 4.578 & TRN & \\
\hline CHEMBL1990904 & 809118 & 4.6 & 4.6205 & TRN & \\
\hline CHEMBL 2000104 & 809118 & 4.6 & 5.1017 & TRN & \\
\hline CHEMBL 2005475 & 809118 & 4.6 & 5.3407 & TRN & \\
\hline
\end{tabular}




\begin{tabular}{|c|c|c|c|c|c|}
\hline \multicolumn{6}{|c|}{ Supplemental Table S2.txt } \\
\hline CHEMBL183844 & 809118 & 4.6 & 6.1339 & TRN & \\
\hline CHEMBL220057 & 809118 & 8.4 & 8.6958 & TRN & \\
\hline CHEMBL1682545 & 809118 & 4.6 & 4.96899 & 9999999999 & TRN \\
\hline CHEMBL 383541 & 809118 & 4.6 & 4.4271 & TRN & \\
\hline CHEMBL 2001224 & 809118 & 4.6 & 4.7737 & TRN & \\
\hline CHEMBL10 & 809118 & 4.6 & 4.4225 & TRN & \\
\hline CHEMBL1976732 & 809118 & 4.6 & 4.5799 & TRN & \\
\hline CHEMBL1969506 & 809118 & 4.6 & 4.7928 & TRN & \\
\hline CHEMBL1980763 & 809118 & 6.3 & 5.4438 & TRN & \\
\hline CHEMBL1964937 & 809118 & 4.6 & 4.6227 & TRN & \\
\hline CHEMBL1980163 & 809118 & 4.6 & 4.1877 & TRN & \\
\hline CHEMBL590109 & 809118 & 5.6 & 4.6459 & TST & \\
\hline CHEMBL1977931 & 809118 & 4.2 & 4.3109 & TRN & \\
\hline CHEMBL1970879 & 809118 & 6.1 & 5.0362 & TRN & \\
\hline CHEMBL1989856 & 809118 & 4.6 & 5.011 & TST & \\
\hline CHEMBL 2005899 & 809118 & 4.6 & 4.9507 & TRN & \\
\hline CHEMBL1682552 & 809118 & 4.6 & 4.8557 & TRN & \\
\hline CHEMBL259850 & 809118 & 4.6 & 4.4412 & TRN & \\
\hline CHEMBL 2007479 & 809118 & 4.6 & 4.4664 & TRN & \\
\hline CHEMBL 229799 & 809118 & 4.6 & 5.318 & TRN & \\
\hline CHEMBL105739 & 809118 & 7.7 & 6.20200 & 0000000001 & TRN \\
\hline CHEMBL1682359 & 809118 & 4.6 & 4.5547 & TRN & \\
\hline CHEMBL1972220 & 809118 & 8.0 & 9.0114 & TRN & \\
\hline CHEMBL379300 & 809118 & 4.6 & 5.2486 & TRN & \\
\hline CHEMBL203673 & 809118 & 4.6 & 4.5283 & TRN & \\
\hline CHEMBL1972583 & 809118 & 3.0 & 3.6938 & TRN & \\
\hline CHEMBL 2003785 & 809118 & 4.5 & 4.6631 & TST & \\
\hline CHEMBL1973720 & 809118 & 6.9 & 6.3385 & TRN & \\
\hline CHEMBL1969523 & 809118 & 5.9 & 6.0491 & TRN & \\
\hline CHEMBL 207995 & 809118 & 4.6 & 5.1058 & TRN & \\
\hline CHEMBL 2001923 & 809118 & 4.6 & 4.5365 & TRN & \\
\hline CHEMBL1986781 & 809118 & 4.6 & 4.8775 & TRN & \\
\hline CHEMBL1983070 & 809118 & 4.6 & 4.6193 & TRN & \\
\hline CHEMBL526133 & 809118 & 4.6 & 4.4559 & TRN & \\
\hline CHEMBL 2003514 & 809118 & 4.6 & 4.4313 & TRN & \\
\hline CHEMBL1966836 & 809118 & 8.4 & 8.3201 & TRN & \\
\hline CHEMBL1989043 & 809118 & 4.6 & 5.0572 & TRN & \\
\hline CHEMBL1967538 & 809118 & 3.2 & 3.6186 & TRN & \\
\hline CHEMBL1979057 & 809118 & 4.6 & 4.4159 & TRN & \\
\hline CHEMBL1981045 & 809118 & 4.6 & 4.3785 & TRN & \\
\hline CHEMBL387971 & 809118 & 7.8 & 6.5006 & TST & \\
\hline CHEMBL1975418 & 809118 & 4.6 & 5.0546 & TRN & \\
\hline CHEMBL1992796 & 809118 & 5.6 & 4.6891 & TRN & \\
\hline CHEMBL1968515 & 809118 & 3.0 & 4.2889 & TST & \\
\hline CHEMBL1164180 & 809118 & 6.5 & 5.8838 & TST & \\
\hline CHEMBL223257 & 809118 & 7.0 & 4.648 & TST & \\
\hline CHEMBL1999428 & 809118 & 5.6 & 5.1947 & TRN & \\
\hline CHEMBL1967560 & 809118 & 4.6 & 4.9992 & TRN & \\
\hline
\end{tabular}




\begin{tabular}{|c|c|c|c|c|}
\hline & & & 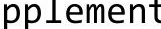 & al Ta \\
\hline CHEMBL1516890 & 809118 & 4.6 & 5.1728 & TRN \\
\hline CHEMBL 211378 & 809118 & 7.8 & 6.6995 & TRN \\
\hline CHEMBL1982465 & 809118 & 8.1 & 8.3854 & TRN \\
\hline CHEMBL 2001751 & 809118 & 4.6 & 5.7578 & TRN \\
\hline CHEMBL 2003420 & 809118 & 4.6 & 4.5858 & TRN \\
\hline CHEMBL1984586 & 809118 & 4.6 & 6.3614 & TRN \\
\hline CHEMBL1999774 & 809118 & 4.6 & 4.5323 & TST \\
\hline CHEMBL 272938 & 809118 & 9.2 & 9.3291 & TRN \\
\hline CHEMBL1972659 & 809118 & 4.6 & 4.7072 & TST \\
\hline CHEMBL 2002723 & 809118 & 5.7 & 5.2012 & TST \\
\hline CHEMBL1973395 & 809118 & 4.6 & 5.2972 & TRN \\
\hline CHEMBL 272453 & 809118 & 6.8 & 7.2071 & TRN \\
\hline CHEMBL1987143 & 809118 & 3.6 & 4.499 & TRN \\
\hline CHEMBL1970217 & 809118 & 4.6 & 4.4066 & TRN \\
\hline CHEMBL1971801 & 809118 & 4.6 & 4.4607 & TRN \\
\hline CHEMBL1968850 & 809118 & 4.6 & 4.8573 & TRN \\
\hline CHEMBL 2005528 & 809118 & 4.6 & 4.9422 & TST \\
\hline CHEMBL1984686 & 809118 & 4.6 & 4.5517 & TRN \\
\hline CHEMBL185569 & 809118 & 7.2 & 6.6108 & TRN \\
\hline CHEMBL1969843 & 809118 & 4.6 & 4.6853 & TRN \\
\hline CHEMBL 2007002 & 809118 & 4.6 & 4.777 & TRN \\
\hline CHEMBL1987007 & 809118 & 4.6 & 5.4703 & TRN \\
\hline CHEMBL1973793 & 809118 & 4.6 & 4.7102 & TST \\
\hline CHEMBL1969588 & 809118 & 6.8 & 5.4345 & TRN \\
\hline CHEMBL1984711 & 809118 & 7.6 & 5.9443 & TRN \\
\hline CHEMBL1992073 & 809118 & 5.8 & 4.9469 & TRN \\
\hline CHEMBL484390 & 809118 & 4.6 & 4.5426 & TST \\
\hline CHEMBL1979252 & 809118 & 4.6 & 4.4291 & TRN \\
\hline CHEMBL1986143 & 809118 & 4.6 & 4.4345 & TRN \\
\hline CHEMBL1972934 & 809118 & 4.9 & 4.4048 & TRN \\
\hline CHEMBL 2007559 & 809118 & 4.6 & 4.9201 & TRN \\
\hline CHEMBL1992581 & 809118 & 5.8 & 5.7259 & TRN \\
\hline CHEMBL1682341 & 809118 & 4.6 & 4.4076 & TRN \\
\hline CHEMBL 2004290 & 809118 & 8.2 & 8.5497 & TRN \\
\hline CHEMBL1986499 & 809118 & 5.6 & 4.7858 & TRN \\
\hline CHEMBL1972937 & 809118 & 4.6 & 4.6806 & TRN \\
\hline CHEMBL1972250 & 809118 & 5.6 & 5.0122 & TST \\
\hline CHEMBL 2000393 & 809118 & 4.6 & 5.688 & TST \\
\hline CHEMBL403402 & 809118 & 8.8 & 8.7391 & TRN \\
\hline CHEMBL1089101 & 809118 & 5.7 & 4.8723 & TRN \\
\hline CHEMBL1983573 & 809118 & 5.2 & 4.2457 & TRN \\
\hline CHEMBL 2004311 & 809118 & 6.2 & 5.388 & TRN \\
\hline CHEMBL1992634 & 809118 & 4.6 & 5.489 & TRN \\
\hline CHEMBL1242373 & 809118 & 4.6 & 5.9592 & TRN \\
\hline CHEMBL1984847 & 809118 & 4.6 & 4.6018 & TST \\
\hline CHEMBL1984402 & 809118 & 4.1 & 4.1416 & TST \\
\hline CHEMBL316264 & 809118 & 4.6 & 4.3965 & TRN \\
\hline CHEMBL1988075 & 809118 & 8.0 & 8.0362 & TRN \\
\hline
\end{tabular}




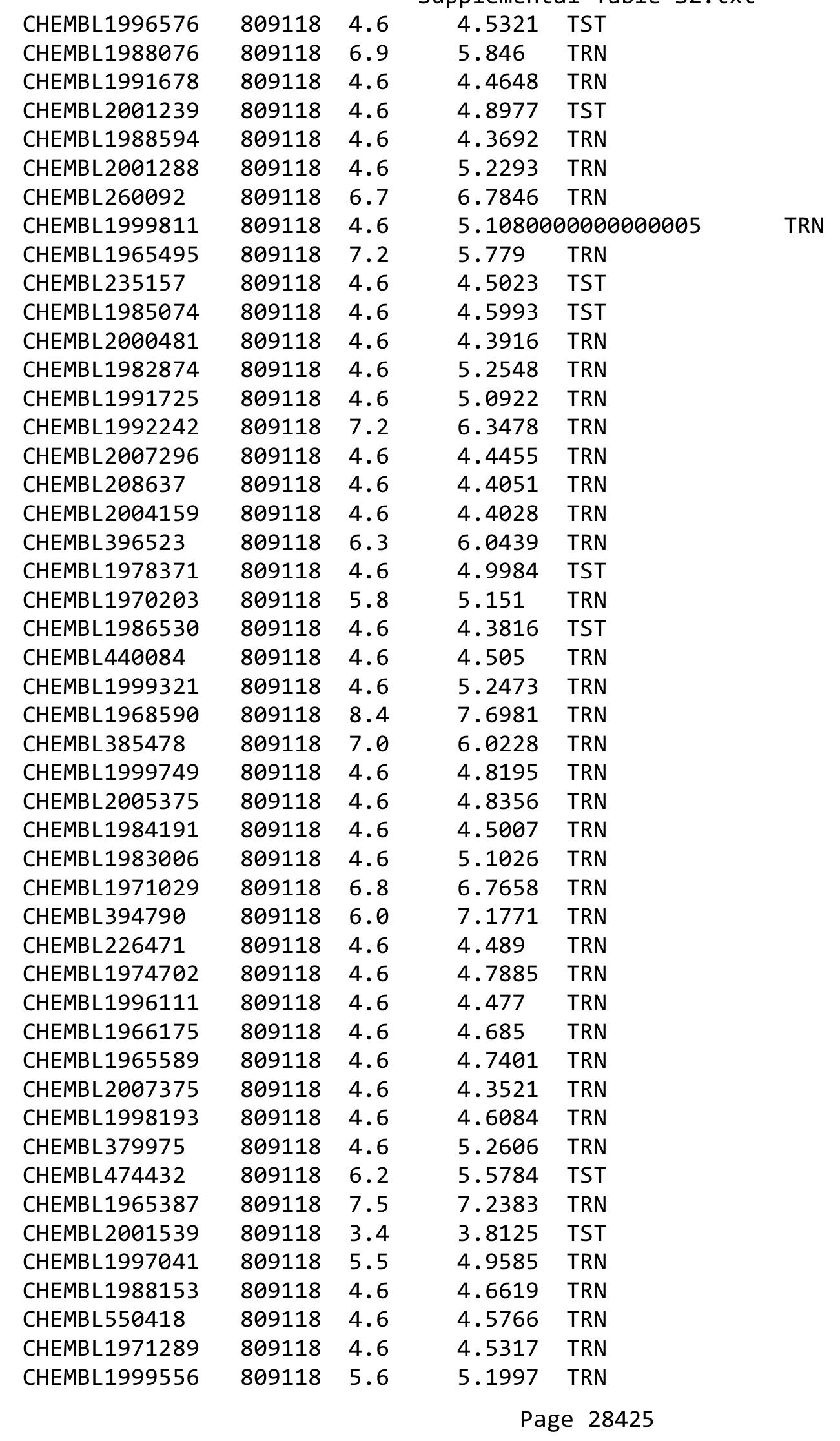




\begin{tabular}{|c|c|c|c|c|}
\hline \multicolumn{5}{|c|}{ Supplemental Table S2.txt } \\
\hline CHEMBL1988437 & 809118 & 7.1 & 7.4336 & TRN \\
\hline CHEMBL1968245 & 809118 & 4.6 & 4.3846 & TRN \\
\hline CHEMBL1979577 & 809118 & 8.1 & 7.9646 & TRN \\
\hline CHEMBL1998121 & 809118 & 4.6 & 4.8739 & TRN \\
\hline CHEMBL1233887 & 809118 & 4.6 & 4.3781 & TST \\
\hline CHEMBL1992607 & 809118 & 4.1 & 4.789 & TRN \\
\hline CHEMBL1991800 & 809118 & 4.6 & 4.7814 & TRN \\
\hline CHEMBL52387 & 809118 & 4.6 & 4.6196 & TST \\
\hline CHEMBL379835 & 809118 & 4.6 & 4.5438 & TST \\
\hline CHEMBL1979357 & 809118 & 4.6 & 4.425 & TRN \\
\hline CHEMBL1980802 & 809118 & 6.8 & 4.7023 & TST \\
\hline CHEMBL1996649 & 809118 & 8.6 & 8.2889 & TRN \\
\hline CHEMBL1996817 & 809118 & 6.5 & 5.2898 & TRN \\
\hline CHEMBL1979554 & 809118 & 4.6 & 4.5983 & TRN \\
\hline CHEMBL1986756 & 809118 & 4.6 & 4.5221 & TRN \\
\hline CHEMBL409349 & 809118 & 8.4 & 8.0589 & TRN \\
\hline CHEMBL2004355 & 809118 & 6.7 & 4.7033 & TRN \\
\hline CHEMBL468280 & 809118 & 4.6 & 4.7303 & TST \\
\hline CHEMBL1990884 & 809118 & 6.4 & 5.5921 & TRN \\
\hline CHEMBL3109278 & 809118 & 8.6 & $6.7360 e$ & 2000000001 \\
\hline CHEMBL 256835 & 809118 & 4.6 & 4.6213 & TRN \\
\hline CHEMBL1980142 & 809118 & 4.6 & 4.5724 & TRN \\
\hline CHEMBL41783 & 809118 & 4.6 & 4.6565 & TRN \\
\hline CHEMBL2004438 & 809118 & 7.6 & 5.9819 & TRN \\
\hline CHEMBL 2006276 & 809118 & 4.6 & 4.6752 & TRN \\
\hline CHEMBL191003 & 809118 & 5.9 & 6.1502 & TRN \\
\hline CHEMBL 271381 & 809118 & 7.1 & 6.5319 & TRN \\
\hline CHEMBL 2006785 & 809118 & 4.6 & 4.7678 & TRN \\
\hline CHEMBL1982466 & 809118 & 8.1 & 8.5247 & TRN \\
\hline CHEMBL1973359 & 809118 & 5.9 & 5.1932 & TST \\
\hline CHEMBL1994638 & 809118 & 8.8 & 8.8578 & TRN \\
\hline CHEMBL1995740 & 809118 & 4.6 & 4.7179 & TRN \\
\hline CHEMBL1985888 & 809118 & 8.6 & 8.154 & TRN \\
\hline CHEMBL1996390 & 809118 & 4.6 & 4.4611 & TRN \\
\hline CHEMBL1979690 & 809118 & 7.8 & 7.4681 & TRN \\
\hline CHEMBL234085 & 809118 & 4.6 & 4.5328 & TRN \\
\hline CHEMBL1995832 & 809118 & 4.6 & 4.5287 & TRN \\
\hline CHEMBL1969042 & 809118 & 4.6 & 5.2762 & TRN \\
\hline CHEMBL2000345 & 809118 & 5.9 & 5.0719 & TRN \\
\hline CHEMBL1999931 & 809118 & 4.6 & 5.4431 & TRN \\
\hline CHEMBL1976376 & 809118 & 4.6 & 6.1013 & TRN \\
\hline CHEMBL1991640 & 809118 & 4.6 & 4.8624 & TST \\
\hline CHEMBL1988622 & 809118 & 3.0 & 3.9855 & TRN \\
\hline CHEMBL1983575 & 809118 & 7.5 & 5.398 & TRN \\
\hline CHEMBL1968868 & 809118 & 4.6 & 4.5449 & TRN \\
\hline CHEMBL1375418 & 809118 & 4.6 & 4.474 & TRN \\
\hline CHEMBL 302449 & 809118 & 5.8 & 6.4162 & TST \\
\hline CHEMBL 2007064 & 809118 & 7.0 & 6.0061 & TRN \\
\hline
\end{tabular}




\begin{tabular}{|c|c|c|c|c|c|}
\hline \multirow{3}{*}{$\begin{array}{l}\text { CHEMBL1981047 } \\
\text { CHEMBL } 229968\end{array}$} & \multirow{3}{*}{$\begin{array}{l}809118 \\
809118\end{array}$} & \multicolumn{4}{|c|}{ Supplemental Table S2.txt } \\
\hline & & 6.8 & 5.3229 & 99999999995 & TRN \\
\hline & & 4.6 & 5.0664 & TRN & \\
\hline CHEMBL1976196 & 809118 & 4.6 & 4.5319 & TST & \\
\hline CHEMBL 2002432 & 809118 & 6.2 & 5.649 & TRN & \\
\hline CHEMBL1976240 & 809118 & 4.6 & 4.3829 & TRN & \\
\hline CHEMBL1997197 & 809118 & 4.6 & 4.5048 & TRN & \\
\hline CHEMBL1983630 & 809118 & 4.2 & 4.0904 & TRN & \\
\hline CHEMBL1968151 & 809118 & 4.6 & 4.3927 & TRN & \\
\hline CHEMBL1979093 & 809118 & 6.3 & 6.6331 & TRN & \\
\hline CHEMBL1381197 & 809118 & 4.6 & 4.6038 & TRN & \\
\hline CHEMBL1973795 & 809118 & 3.0 & 3.4768 & TRN & \\
\hline CHEMBL1987009 & 809118 & 4.6 & 5.2161 & TRN & \\
\hline CHEMBL379218 & 809118 & 4.6 & 4.8968 & TRN & \\
\hline CHEMBL 2003817 & 809118 & 4.6 & 4.9866 & TRN & \\
\hline CHEMBL336961 & 809118 & 4.6 & 4.6714 & TRN & \\
\hline CHEMBL1994830 & 809118 & 4.6 & 4.1702 & TRN & \\
\hline CHEMBL1987054 & 809118 & 7.0 & 7.0403 & TRN & \\
\hline CHEMBL1970083 & 809118 & 7.7 & 7.8071 & TRN & \\
\hline CHEMBL226403 & 809118 & 4.6 & 4.4527 & TRN & \\
\hline CHEMBL 2005631 & 809118 & 8.5 & 8.73 & TRN & \\
\hline CHEMBL1994938 & 809118 & 7.3 & 6.8959 & TRN & \\
\hline CHEMBL1977223 & 809118 & 4.6 & 4.5752 & TRN & \\
\hline CHEMBL1995765 & 809118 & 4.8 & 4.2905 & TST & \\
\hline CHEMBL1976290 & 809118 & 3.0 & 3.5382 & TRN & \\
\hline CHEMBL1966279 & 809118 & 4.6 & 4.5187 & TRN & \\
\hline CHEMBL1236126 & 809118 & 5.7 & 4.6672 & TST & \\
\hline CHEMBL1997846 & 809118 & 4.8 & 4.8601 & TRN & \\
\hline CHEMBL1984760 & 809118 & 6.0 & 5.2257 & TRN & \\
\hline CHEMBL2004419 & 809118 & 4.6 & 4.6693 & TRN & \\
\hline CHEMBL1991728 & 809118 & 4.6 & 4.592 & TRN & \\
\hline CHEMBL360847 & 809118 & 4.6 & 4.9784 & TST & \\
\hline CHEMBL1995811 & 809118 & 4.6 & 4.6717 & TRN & \\
\hline CHEMBL1975787 & 809118 & 5.7 & 5.2026 & TRN & \\
\hline CHEMBL1995916 & 809118 & 3.0 & 4.2819 & TRN & \\
\hline CHEMBL 2002407 & 809118 & 4.6 & 4.8431 & TRN & \\
\hline CHEMBL1972489 & 809118 & 4.6 & 4.6237 & TRN & \\
\hline CHEMBL1994074 & 809118 & 5.9 & 4.7345 & TRN & \\
\hline CHEMBL1992937 & 809118 & 6.1 & 5.3232 & TST & \\
\hline CHEMBL451401 & 809118 & 4.8 & 4.0728 & TRN & \\
\hline CHEMBL1985566 & 809118 & 4.6 & 4.5379 & TRN & \\
\hline CHEMBL1972119 & 809118 & 4.6 & 4.5984 & TRN & \\
\hline CHEMBL1986328 & 809118 & 4.6 & 4.3677 & TST & \\
\hline CHEMBL95692 & 809118 & 4.6 & 4.5843 & TRN & \\
\hline CHEMBL1090356 & 809118 & 4.9 & 6.2583 & TRN & \\
\hline CHEMBL 2002450 & 809118 & 3.0 & 3.6681 & TST & \\
\hline CHEMBL1986507 & 809118 & 8.7 & 7.8609 & TST & \\
\hline CHEMBL1976455 & 809118 & 4.6 & 4.7858 & TST & \\
\hline CHEMBL261849 & 809118 & 7.4 & 4.4258 & TST & \\
\hline
\end{tabular}




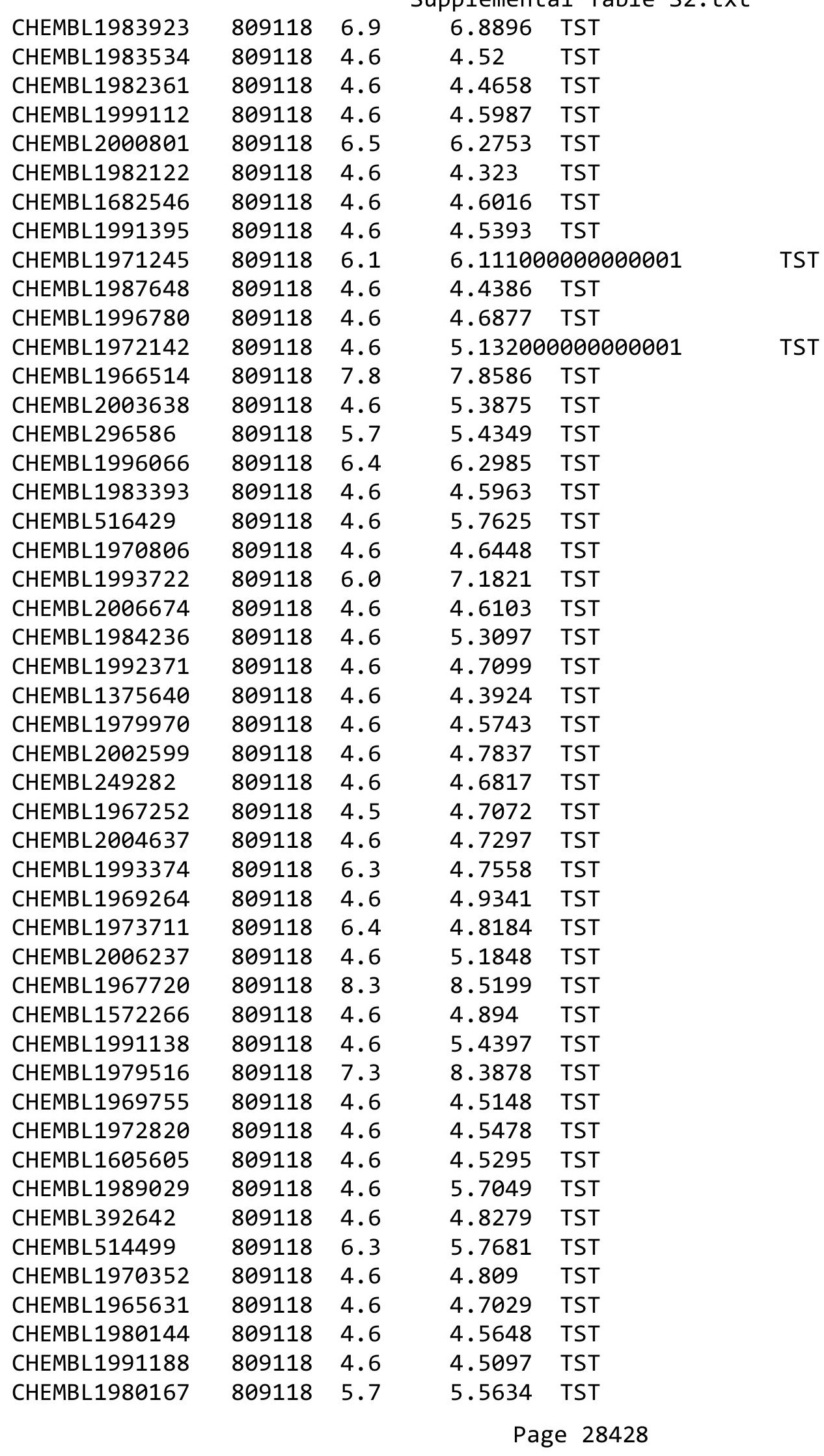




\begin{tabular}{|c|c|c|c|c|c|}
\hline \\
\hline CHEMBL1972849 & 809118 & 4.6 & 4.6019 & TST & \\
\hline CHEMBL377408 & 809118 & 6.2 & 4.8323 & TST & \\
\hline CHEMBL215152 & 809118 & 4.6 & 5.4705 & TST & \\
\hline CHEMBL231209 & 809118 & 4.6 & 6.9099 & TST & \\
\hline CHEMBL1976220 & 809118 & 6.1 & 7.2408 & TST & \\
\hline CHEMBL 2006765 & 809118 & 4.6 & 5.5767 & TST & \\
\hline CHEMBL259922 & 809118 & 7.6 & 5.0354 & TST & \\
\hline CHEMBL1997617 & 809118 & 7.8 & 7.2814 & TST & \\
\hline CHEMBL1969301 & 809118 & 4.6 & 4.5967 & TST & \\
\hline CHEMBL1982383 & 809118 & 4.6 & 4.9059 & TST & \\
\hline CHEMBL17370 & 809118 & 4.6 & 4.3473 & TST & \\
\hline CHEMBL1980246 & 809118 & 5.8 & 4.7954 & TST & \\
\hline CHEMBL374044 & 809118 & 9.0 & 9.2282 & TST & \\
\hline CHEMBL1987910 & 809118 & 6.7 & 6.5859 & TST & \\
\hline CHEMBL1983932 & 809118 & 4.6 & 5.2938 & TST & \\
\hline CHEMBL1983980 & 809118 & 5.8 & 5.5163 & TST & \\
\hline CHEMBL1999484 & 809118 & 7.2 & 7.016 & TST & \\
\hline CHEMBL404366 & 809118 & 9.5 & 8.2577 & TST & \\
\hline CHEMBL1973399 & 809118 & 3.2 & 3.5323 & TST & \\
\hline CHEMBL1966069 & 809118 & 4.6 & 4.4175 & TST & \\
\hline CHEMBL1986899 & 809118 & 7.0 & 5.0861 & TST & \\
\hline CHEMBL1991285 & 809118 & 6.0 & 5.5235 & TST & \\
\hline CHEMBL1997822 & 809118 & 7.4 & 7.1452 & TST & \\
\hline CHEMBL243088 & 809118 & 6.5 & 6.1506 & TST & \\
\hline CHEMBL1984038 & 809118 & 4.6 & 4.3127 & TST & \\
\hline CHEMBL1974416 & 809118 & 5.9 & 5.0739 & TST & \\
\hline CHEMBL1993661 & 809118 & 6.8 & 7.1817 & TST & \\
\hline CHEMBL1997872 & 809118 & 4.6 & 5.5233 & TST & \\
\hline CHEMBL 2408540 & 972800 & 5.5901 & 5.5515 & TRN & \\
\hline CHEMBL 2408545 & 972800 & 5.7033 & 5.5011 & TRN & \\
\hline CHEMBL 2408541 & 972800 & 4.5462 & 4.6466 & TRN & \\
\hline CHEMBL 2408537 & 972800 & 5.6757 & 5.6163 & TRN & \\
\hline CHEMBL2408526 & 972800 & 4.7886 & 4.6204 & TRN & \\
\hline CHEMBL 2408557 & 972800 & 4.6706 & 3.9136 & TST & \\
\hline CHEMBL 2408547 & 972800 & 5.5817 & 5.5984 & TRN & \\
\hline CHEMBL 2408531 & 972800 & 5.5302 & 5.40799 & 99999999995 & TRN \\
\hline CHEMBL 2408523 & 972800 & 4.9562 & 4.8847 & TRN & \\
\hline CHEMBL2408555 & 972800 & 5.4449 & 5.5675 & TRN & \\
\hline CHEMBL 2408364 & 972800 & 3.3979 & 3.4669 & TRN & \\
\hline CHEMBL 2408524 & 972800 & 4.8722 & 4.4765 & TST & \\
\hline CHEMBL2408529 & 972800 & 5.0101 & 5.2033 & TRN & \\
\hline CHEMBL 2408522 & 972800 & 5.51 & 5.4464 & TRN & \\
\hline CHEMBL2408536 & 972800 & 5.4248 & 5.3555 & TRN & \\
\hline CHEMBL 2408518 & 972800 & 4.4265 & 4.2942 & TRN & \\
\hline CHEMBL 2408360 & 972800 & 3.3979 & 3.9245 & TST & \\
\hline CHEMBL2408516 & 972800 & 3.3979 & 3.5793 & TST & \\
\hline CHEMBL 2408365 & 972800 & 4.8969 & 4.9316 & TRN & \\
\hline CHEMBL2408549 & 972800 & 4.7773 & 4.6837 & TST & \\
\hline & & & & 28429 & \\
\hline
\end{tabular}


Supplemental Table S2.txt

\begin{tabular}{|c|c|c|c|c|c|}
\hline CHEMBL 2408548 & 972800 & 5.0969 & 5.0656 & TRN & \\
\hline CHEMBL 2408535 & 972800 & 4.8193 & 4.9934 & TRN & \\
\hline CHEMBL 2408520 & 972800 & 4.9281 & 5.1059 & TRN & \\
\hline CHEMBL 2408542 & 972800 & 4.7395 & 4.262 & TST & \\
\hline CHEMBL 2408528 & 972800 & 5.4976 & 5.562 & TRN & \\
\hline CHEMBL 2408361 & 972800 & 4.6178 & 4.6864 & TRN & \\
\hline CHEMBL 2408558 & 972800 & 3.3979 & 3.0824 & TST & \\
\hline CHEMBL 2408553 & 972800 & 5.4168 & 5.5596 & TRN & \\
\hline CHEMBL 2408513 & 972800 & 4.7849 & 4.8007 & TRN & \\
\hline CHEMBL 2408543 & 972800 & 4.8438 & 4.8212 & TRN & \\
\hline CHEMBL 2408539 & 972800 & 5.6271 & 5.6863 & TRN & \\
\hline CHEMBL 2408521 & 972800 & 4.9108 & 4.8914 & TRN & \\
\hline CHEMBL 2408552 & 972800 & 5.2549 & 5.365 & TRN & \\
\hline CHEMBL 2408530 & 972800 & 4.978 & 4.9608 & TRN & \\
\hline CHEMBL 2408517 & 972800 & 4.997 & 4.958 & TRN & \\
\hline CHEMBL 2408519 & 972800 & 5.2381 & 5.3769 & TRN & \\
\hline CHEMBL 2408525 & 972800 & 4.8371 & 4.9669 & TRN & \\
\hline CHEMBL 2408512 & 972800 & 5.1643 & 5.1515 & TRN & \\
\hline CHEMBL 2408527 & 972800 & 5.4976 & 5.2519 & TRN & \\
\hline CHEMBL 2408359 & 972800 & 3.3979 & 4.2356 & TST & \\
\hline CHEMBL 2408556 & 972800 & 3.3979 & 3.0615 & TST & \\
\hline CHEMBL 2408532 & 972800 & 4.8844 & 5.0705 & TST & \\
\hline CHEMBL 2408550 & 972800 & 5.45100 & 00000000 & 205 & 5.2384 \\
\hline CHEMBL 2408551 & 972800 & 4.8066 & 4.852 & TRN & \\
\hline CHEMBL 2408538 & 972800 & 5.2874 & 5.3798 & TRN & \\
\hline CHEMBL 2408546 & 972800 & 5.7235 & 5.4315 & TRN & \\
\hline CHEMBL 2408534 & 972800 & 5.0434 & 5.2595 & TRN & \\
\hline CHEMBL 2408544 & 972800 & 5.4283 & 5.5813 & TRN & \\
\hline CHEMBL 2408362 & 972800 & 3.3979 & 4.2685 & TST & \\
\hline CHEMBL 2408515 & 972800 & 4.9983 & 4.5089 & TST & \\
\hline CHEMBL 2408363 & 972800 & 4.8407 & 4.8075 & TRN & \\
\hline CHEMBL 2408514 & 972800 & 5.433 & 5.2001 & TRN & \\
\hline CHEMBL 2408533 & 972800 & 4.7196 & 4.6933 & TST & \\
\hline CHEMBL 2408554 & 972800 & 5.4437 & 5.4049 & TRN & \\
\hline CHEMBL 2408559 & 972800 & 3.3979 & 3.7936 & TST & \\
\hline CHEMBL 251389 & 688504 & 4.4 & 4.4891 & TRN & \\
\hline CHEMBL 263116 & 688504 & 4.9 & 5.0035 & TRN & \\
\hline CHEMBL 242080 & 688504 & 4.3 & 4.4858 & TRN & \\
\hline CHEMBL1499545 & 688504 & 5.1 & 5.3762 & TRN & \\
\hline CHEMBL1492884 & 688504 & 4.3 & 4.453 & TRN & \\
\hline CHEMBL220845 & 688504 & 4.5 & 4.2815 & TRN & \\
\hline CHEMBL57394 & 688504 & 4.4 & 4.5039 & TRN & \\
\hline CHEMBL1569493 & 688504 & 6.0 & 6.0606 & TRN & \\
\hline CHEMBL1517425 & 688504 & 4.3 & 4.225 & TRN & \\
\hline CHEMBL1527567 & 688504 & 4.4 & 4.4396 & TRN & \\
\hline CHEMBL440287 & 688504 & 4.4 & 4.6593 & TRN & \\
\hline CHEMBL1304981 & 688504 & 4.3 & 4.5066 & TST & \\
\hline CHEMBL137035 & 688504 & 6.3 & 4.9529 & TRN & \\
\hline
\end{tabular}




\begin{tabular}{|c|c|c|c|c|}
\hline \multicolumn{5}{|c|}{ lemental Ta } \\
\hline CHEMBL1221925 & 688504 & 4.3 & 4.5159 & TRN \\
\hline CHEMBL1393325 & 688504 & 4.3 & 4.6414 & TRN \\
\hline CHEMBL402063 & 688504 & 4.3 & 5.3678 & TST \\
\hline CHEMBL1489064 & 688504 & 4.3 & 4.3439 & TRN \\
\hline CHEMBL 348107 & 688504 & 7.2 & 4.6657 & TRN \\
\hline CHEMBL167423 & 688504 & 4.3 & 4.2229 & TRN \\
\hline CHEMBL1486465 & 688504 & 4.8 & 4.635 & TRN \\
\hline CHEMBL1330518 & 688504 & 4.3 & 4.5135 & TRN \\
\hline CHEMBL1562104 & 688504 & 5.5 & 5.4596 & TRN \\
\hline CHEMBL1366408 & 688504 & 4.4 & 4.6031 & TRN \\
\hline CHEMBL 1448387 & 688504 & 4.6 & 4.5886 & TRN \\
\hline CHEMBL1450607 & 688504 & 4.6 & 4.7048 & TRN \\
\hline CHEMBL1414154 & 688504 & 4.3 & 4.228 & TRN \\
\hline CHEMBL1364985 & 688504 & 4.3 & 4.7111 & TRN \\
\hline CHEMBL1338613 & 688504 & 4.4 & 4.4158 & TST \\
\hline CHEMBL1609459 & 688504 & 5.0 & 5.2213 & TRN \\
\hline CHEMBL1391326 & 688504 & 5.1 & 4.5801 & TRN \\
\hline CHEMBL280998 & 688504 & 4.9 & 4.4923 & TRN \\
\hline CHEMBL1585396 & 688504 & 4.3 & 4.599 & TRN \\
\hline CHEMBL1565705 & 688504 & 4.1 & 4.4252 & TRN \\
\hline CHEMBL1530684 & 688504 & 4.4 & 4.5754 & TRN \\
\hline CHEMBL1407826 & 688504 & 4.5 & 4.9082 & TST \\
\hline CHEMBL1526319 & 688504 & 4.4 & 4.329 & TRN \\
\hline CHEMBL1559341 & 688504 & 4.6 & 4.3892 & TRN \\
\hline CHEMBL1303139 & 688504 & 5.3 & 5.1764 & TRN \\
\hline CHEMBL1545634 & 688504 & 6.5 & 6.4970 & 2000000001 \\
\hline CHEMBL1485360 & 688504 & 4.9 & 4.7724 & TST \\
\hline CHEMBL8739 & 688504 & 4.3 & 4.3816 & TRN \\
\hline CHEMBL1576086 & 688504 & 4.4 & 4.6045 & TRN \\
\hline CHEMBL1574328 & 688504 & 4.8 & 4.8835 & TRN \\
\hline CHEMBL1451833 & 688504 & 4.3 & 4.6878 & TST \\
\hline CHEMBL195953 & 688504 & 4.4 & 4.3557 & TRN \\
\hline CHEMBL28319 & 688504 & 4.4 & 4.4708 & TRN \\
\hline CHEMBL1408847 & 688504 & 5.3 & 5.2931 & TRN \\
\hline CHEMBL1535689 & 688504 & 4.5 & 4.3104 & TRN \\
\hline CHEMBL1612246 & 688504 & 4.4 & 4.7405 & TRN \\
\hline CHEMBL 84685 & 688504 & 4.6 & 4.5288 & TRN \\
\hline CHEMBL1558796 & 688504 & 4.4 & 4.6346 & TRN \\
\hline CHEMBL552741 & 688504 & 4.8 & 4.6512 & TRN \\
\hline CHEMBL144530 & 688504 & 4.5 & 4.251 & TRN \\
\hline CHEMBL1522486 & 688504 & 4.9 & 4.7606 & TRN \\
\hline CHEMBL230156 & 688504 & 4.4 & 4.3287 & TRN \\
\hline CHEMBL445957 & 688504 & 4.4 & 4.5373 & TRN \\
\hline CHEMBL 8320 & 688504 & 4.5 & 4.5784 & TRN \\
\hline CHEMBL 935 & 688504 & 4.5 & 4.5318 & TRN \\
\hline CHEMBL175193 & 688504 & 4.1 & 4.2257 & TRN \\
\hline CHEMBL58835 & 688504 & 4.4 & 4.6134 & TRN \\
\hline CHEMBL1519327 & 688504 & 6.4 & 6.3972 & TRN \\
\hline
\end{tabular}

TRN 


\begin{tabular}{|c|c|c|c|c|c|}
\hline \multirow{2}{*}{ CHEMBL1319452 } & \multirow{2}{*}{688504} & \multirow[b]{2}{*}{4.7} & \\
\hline & & & 4.6215 & TRN & \\
\hline CHEMBL1200471 & 688504 & 6.6 & 6.6639 & TRN & \\
\hline CHEMBL443949 & 688504 & 4.5 & 4.5553 & TRN & \\
\hline CHEMBL194400 & 688504 & 4.3 & 4.3803 & TRN & \\
\hline CHEMBL329673 & 688504 & 4.2 & 4.4804 & TRN & \\
\hline CHEMBL1452158 & 688504 & 4.3 & 4.454 & TRN & \\
\hline CHEMBL1485974 & 688504 & 4.4 & 4.388 & TRN & \\
\hline CHEMBL1449018 & 688504 & 4.6 & 4.6917 & TRN & \\
\hline CHEMBL70971 & 688504 & 4.9 & 4.6716 & TRN & \\
\hline CHEMBL36296 & 688504 & 4.3 & 4.5237 & TRN & \\
\hline CHEMBL1309179 & 688504 & 5.0 & 4.8706 & TRN & \\
\hline CHEMBL1496957 & 688504 & 4.8 & 4.8512 & TRN & \\
\hline CHEMBL1562553 & 688504 & 4.3 & 4.5974 & TRN & \\
\hline CHEMBL44072 & 688504 & 4.4 & 4.4818 & TRN & \\
\hline CHEMBL454173 & 688504 & 4.6 & 4.7535 & TST & \\
\hline CHEMBL1418603 & 688504 & 4.3 & 4.2443 & TRN & \\
\hline CHEMBL1518369 & 688504 & 4.4 & 4.4996 & TRN & \\
\hline CHEMBL1524617 & 688504 & 5.3 & 5.2404 & TST & \\
\hline CHEMBL1526721 & 688504 & 5.4 & 5.1199 & TRN & \\
\hline CHEMBL1369243 & 688504 & 4.3 & 4.4515 & TRN & \\
\hline CHEMBL192627 & 688504 & 4.4 & 4.7201 & TRN & \\
\hline CHEMBL105712 & 688504 & 5.1 & 5.0259 & TRN & \\
\hline CHEMBL1344952 & 688504 & 4.3 & 4.2358 & TRN & \\
\hline CHEMBL1600998 & 688504 & 5.4 & 5.4446 & TRN & \\
\hline CHEMBL1489568 & 688504 & 4.3 & 4.3541 & TRN & \\
\hline CHEMBL1331245 & 688504 & 4.3 & 4.3164 & TRN & \\
\hline CHEMBL85811 & 688504 & 4.3 & 4.25899 & 99999999995 & TRN \\
\hline CHEMBL334255 & 688504 & 4.8 & 5.095 & TRN & \\
\hline CHEMBL162598 & 688504 & 4.3 & 4.64 & TST & \\
\hline CHEMBL1430204 & 688504 & 4.4 & 4.4961 & TRN & \\
\hline CHEMBL1142 & 688504 & 4.5 & 4.5126 & TRN & \\
\hline CHEMBL1569226 & 688504 & 5.3 & 5.1664 & TRN & \\
\hline CHEMBL1580759 & 688504 & 4.5 & 4.4133 & TST & \\
\hline CHEMBL1566504 & 688504 & 4.4 & 4.4868 & TST & \\
\hline CHEMBL418068 & 688504 & 4.3 & 4.5019 & TST & \\
\hline CHEMBL224282 & 688504 & 4.3 & 4.3174 & TST & \\
\hline CHEMBL1419151 & 688504 & 4.0 & 4.7554 & TST & \\
\hline CHEMBL1549844 & 688504 & 4.8 & 4.7988 & TST & \\
\hline CHEMBL509531 & 688504 & 4.8 & 4.9083 & TST & \\
\hline CHEMBL140 & 688504 & 4.3 & 4.4612 & TST & \\
\hline CHEMBL153062 & 688504 & 4.3 & 4.7018 & TST & \\
\hline CHEMBL1409985 & 688504 & 5.4 & 5.2427 & TST & \\
\hline CHEMBL1308088 & 688504 & 5.0 & 4.8454 & TST & \\
\hline CHEMBL486193 & 688504 & 4.3 & 4.7913 & TST & \\
\hline CHEMBL1492104 & 688504 & 4.8 & 4.9411 & TST & \\
\hline CHEMBL1456906 & 688504 & 4.1 & 4.5856 & TST & \\
\hline CHEMBL1602699 & 688504 & 5.3 & 5.3442 & TST & \\
\hline CHEMBL462576 & 688504 & 4.3 & 4.6738 & TST & \\
\hline & & & & 28432 & \\
\hline
\end{tabular}




\begin{tabular}{|c|c|c|c|c|c|}
\hline \multirow[b]{2}{*}{ CHEMBL1471289 } & \multicolumn{5}{|c|}{ Supplemental Table s2.txt } \\
\hline & 688504 & 4.6 & 4.4639 & 99999999995 & TST \\
\hline CHEMBL1447588 & 688504 & 5.0 & 5.1085 & TST & \\
\hline CHEMBL388676 & 688504 & 5.4 & 4.9033 & TST & \\
\hline CHEMBL1462419 & 688504 & 4.3 & 4.6761 & TST & \\
\hline CHEMBL 3251188 & 1342912 & 4.5654 & 5.0362 & TRN & \\
\hline CHEMBL3251538 & 1342912 & 4.9666 & 4.5742 & TRN & \\
\hline CHEMBL3251185 & 1342912 & 4.7122 & 4.8923 & TRN & \\
\hline CHEMBL165312 & 1342912 & 5.4881 & 5.8216 & TRN & \\
\hline CHEMBL145735 & 1342912 & 4.4789 & 4.5319 & TRN & \\
\hline CHEMBL164947 & 1342912 & 5.2366 & 5.2086 & TRN & \\
\hline CHEMBL168077 & 1342912 & 5.6716 & 5.1886 & TRN & \\
\hline CHEMBL167761 & 1342912 & 5.2097 & 5.4048 & TRN & \\
\hline CHEMBL167845 & 1342912 & 5.4789 & 5.2658 & TRN & \\
\hline CHEMBL 297403 & 1342912 & 5.0241 & 5.3279 & TRN & \\
\hline CHEMBL352718 & 1342912 & 4.4935 & 4.8732 & TRN & \\
\hline CHEMBL166236 & 1342912 & 5.1759 & 4.6688 & TRN & \\
\hline CHEMBL1688696 & 1342912 & 4.8356 & 4.9424 & TRN & \\
\hline CHEMBL164489 & 1342912 & 4.8069 & 5.1353 & TRN & \\
\hline CHEMBL3251189 & 1342912 & 4.6126 & 4.6517 & TRN & \\
\hline CHEMBL484621 & 1342912 & 4.3768 & 4.5144 & TRN & \\
\hline CHEMBL3251531 & 1342912 & 3.0 & 3.0542 & TST & \\
\hline CHEMBL99951 & 1342912 & 7.7696 & 5.4965 & TRN & \\
\hline CHEMBL352923 & 1342912 & 5.4045 & 5.5613 & TRN & \\
\hline CHEMBL417907 & 1342912 & 4.7696 & 5.0585 & TRN & \\
\hline CHEMBL3251537 & 1342912 & 4.7905 & 4.7208 & TRN & \\
\hline CHEMBL167762 & 1342912 & 5.3251 & 5.7142 & TRN & \\
\hline CHEMBL3251535 & 1342912 & 5.1481 & 4.9706 & TRN & \\
\hline CHEMBL3251536 & 1342912 & 4.7447 & 4.5639 & TRN & \\
\hline CHEMBL289577 & 1342912 & 5.4214 & 5.7368 & TRN & \\
\hline CHEMBL102148 & 1342912 & 5.5287 & 5.5355 & TRN & \\
\hline CHEMBL3251194 & 1342912 & 4.1726 & 4.6523 & TRN & \\
\hline CHEMBL168138 & 1342912 & 4.4711 & 4.7397 & TST & \\
\hline CHEMBL1233459 & 1342912 & 5.0088 & 5.3724 & TRN & \\
\hline CHEMBL356487 & 1342912 & 5.3298 & 5.1185 & TRN & \\
\hline CHEMBL3251534 & 1342912 & 5.5607 & 5.6488 & TRN & \\
\hline CHEMBL3251191 & 1342912 & 5.3778 & 5.7834 & TRN & \\
\hline CHEMBL3251186 & 1342912 & 5.3809 & 5.1125 & TRN & \\
\hline CHEMBL3251193 & 1342912 & 2.0 & 2.4942 & TRN & \\
\hline CHEMBL 145656 & 1342912 & 4.556 & 4.8465 & TRN & \\
\hline CHEMBL279962 & 1342912 & 5.6498 & 5.3561 & TRN & \\
\hline CHEMBL353802 & 1342912 & 2.0 & 2.5452 & TST & \\
\hline CHEMBL3251187 & 1342912 & 4.8827 & 4.7729 & TRN & \\
\hline CHEMBL3251527 & 1342912 & 5.3307 & 5.3702 & TRN & \\
\hline CHEMBL352553 & 1342912 & 5.3799 & 5.3954 & TRN & \\
\hline CHEMBL297809 & 1342912 & 5.2306 & 5.3279 & TRN & \\
\hline CHEMBL145466 & 1342912 & 3.2097 & 2.6335 & TST & \\
\hline CHEMBL3251529 & 1342912 & 5.4908 & 4.5502 & TST & \\
\hline CHEMBL3251533 & 1342912 & 4.2933 & 4.5722 & TRN & \\
\hline
\end{tabular}


Supplemental Table S2.txt

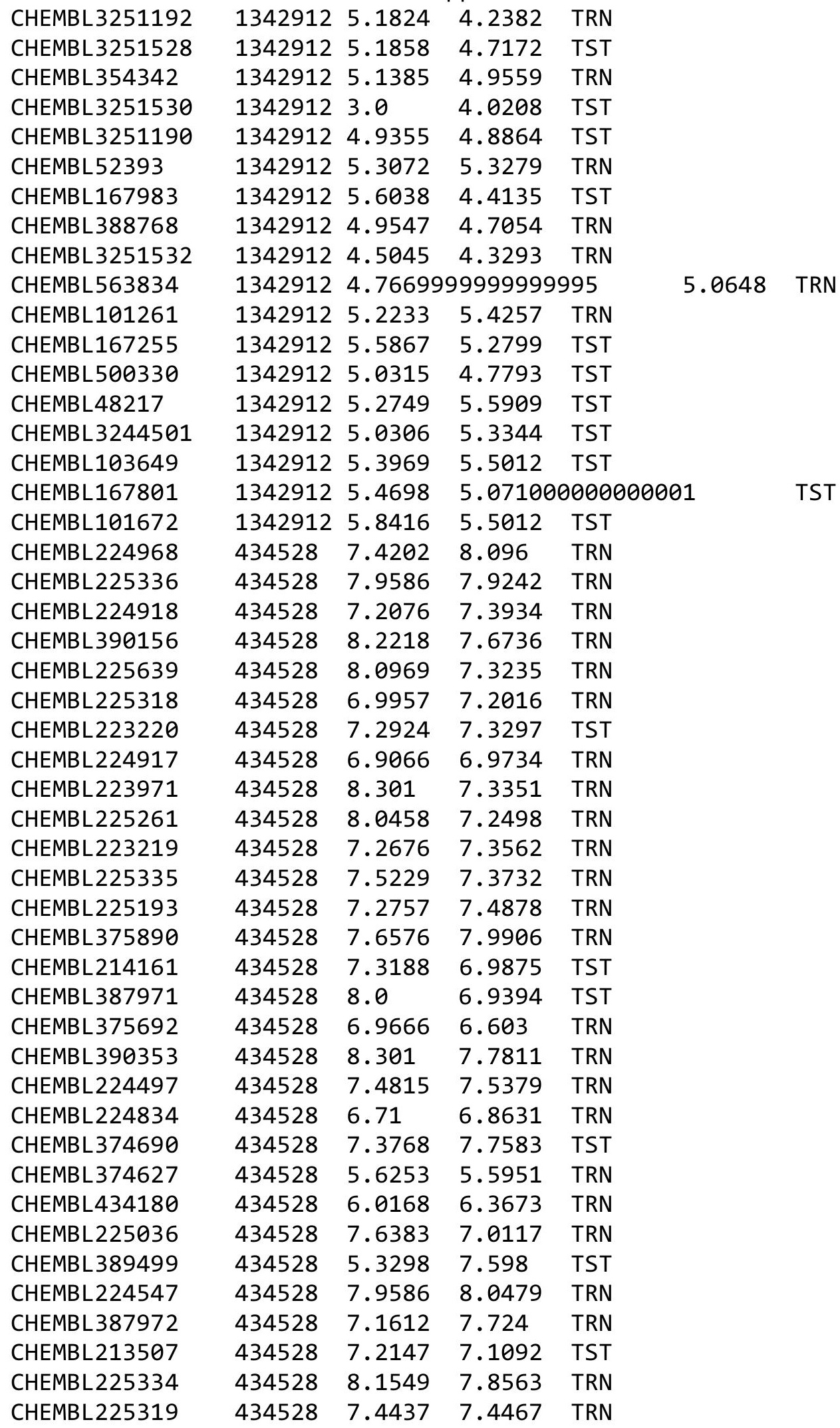

Page 28434 


\begin{tabular}{|c|c|c|c|c|c|}
\hline & & \multicolumn{4}{|c|}{ Supplemental Table S2.txt } \\
\hline CHEMBL225311 & 434528 & 8.5229 & 8.3741 & TRN & \\
\hline CHEMBL224889 & 434528 & 7.699 & 7.2184 & TRN & \\
\hline CHEMBL224027 & 434528 & 7.6198 & 7.4017 & TRN & \\
\hline CHEMBL224496 & 434528 & 7.3768 & 7.5339 & TRN & \\
\hline CHEMBL225090 & 434528 & 7.0706 & 7.688 & TRN & \\
\hline CHEMBL225192 & 434528 & 5.0991 & 6.2991 & TRN & \\
\hline CHEMBL223999 & 434528 & 7.9586 & 8.07200 & 0000000001 & TRN \\
\hline CHEMBL223551 & 434528 & 3.301 & 6.7244 & TST & \\
\hline CHEMBL 225278 & 434528 & 7.9586 & 7.6855 & TRN & \\
\hline CHEMBL441369 & 434528 & 6.15 & 6.1978 & TST & \\
\hline CHEMBL426009 & 434528 & 7.4437 & 7.5623 & TRN & \\
\hline CHEMBL223998 & 434528 & 7.3188 & 7.5934 & TRN & \\
\hline CHEMBL225248 & 434528 & 6.7986 & 7.4266 & TST & \\
\hline CHEMBL390735 & 434528 & 7.3565 & 7.9509 & TRN & \\
\hline CHEMBL223997 & 434528 & 7.1249 & 7.0179 & TRN & \\
\hline CHEMBL225240 & 434528 & 7.0757 & 7.2477 & TRN & \\
\hline CHEMBL223604 & 434528 & 7.3979 & 8.6048 & TST & \\
\hline CHEMBL387929 & 434528 & 7.1079 & 7.0683 & TRN & \\
\hline CHEMBL445404 & 434528 & 7.3188 & 7.4615 & TRN & \\
\hline CHEMBL376779 & 434528 & 7.3468 & 7.7542 & TST & \\
\hline CHEMBL375491 & 434528 & 7.301 & 6.9271 & TST & \\
\hline CHEMBL223943 & 434528 & 6.0 & 6.6515 & TST & \\
\hline CHEMBL218329 & 424022 & 5.3665 & 5.2324 & TRN & \\
\hline CHEMBL434563 & 424022 & 5.3665 & 4.9102 & TST & \\
\hline CHEMBL218681 & 424022 & 6.0969 & 5.6296 & TRN & \\
\hline CHEMBL218284 & 424022 & 5.2076 & 5.4488 & TRN & \\
\hline CHEMBL383878 & 424022 & 5.301 & 5.1889 & TST & \\
\hline CHEMBL375848 & 424022 & 5.9208 & 4.9832 & TST & \\
\hline CHEMBL375071 & 424022 & 5.2076 & 5.53 & TRN & \\
\hline CHEMBL218153 & 424022 & 5.4815 & 5.0968 & TST & \\
\hline CHEMBL220481 & 424022 & 5.5086 & 5.0124 & TST & \\
\hline CHEMBL139800 & 424022 & 3.8539 & 5.2774 & TRN & \\
\hline CHEMBL383993 & 424022 & 6.6383 & 5.7442 & TRN & \\
\hline CHEMBL221531 & 424022 & 5.3468 & 5.272 & TRN & \\
\hline CHEMBL 220930 & 424022 & 5.0223 & 4.621 & TRN & \\
\hline CHEMBL218048 & 424022 & 5.2757 & 5.3415 & TST & \\
\hline CHEMBL218689 & 424022 & 5.8861 & 5.3356 & TST & \\
\hline CHEMBL 220877 & 424022 & 5.4949 & 5.5074 & TRN & \\
\hline CHEMBL137817 & 424022 & 5.4815 & 5.17 & TRN & \\
\hline CHEMBL221234 & 424022 & 5.4815 & 4.7277 & TRN & \\
\hline CHEMBL220983 & 424022 & 3.7696 & 4.5533 & TRN & \\
\hline CHEMBL218385 & 424022 & 5.1079 & 5.6163 & TRN & \\
\hline CHEMBL218335 & 424022 & 5.6576 & 5.4326 & TRN & \\
\hline CHEMBL218680 & 424022 & 4.9208 & 5.6516 & TRN & \\
\hline CHEMBL218496 & 424022 & 6.0223 & 5.5954 & TRN & \\
\hline CHEMBL218388 & 424022 & 3.7696 & 4.9273 & TST & \\
\hline CHEMBL220818 & 424022 & 5.2218 & 4.7387 & TRN & \\
\hline CHEMBL218050 & 424022 & 5.5686 & 5.5387 & TRN & \\
\hline
\end{tabular}


Supplemental Table S2.txt

\begin{tabular}{|c|c|c|c|c|}
\hline CHEMBL 218437 & 424022 & 5.1367 & 5.2287 & TRN \\
\hline CHEMBL341729 & 424022 & 5.5528 & 5.3372 & TRN \\
\hline CHEMBL 218332 & 424022 & 5.7696 & 5.7735 & TRN \\
\hline CHEMBL 221235 & 424022 & 5.9586 & 5.3852 & TRN \\
\hline CHEMBL385113 & 424022 & 5.7959 & 5.621 & TRN \\
\hline CHEMBL 220878 & 424022 & 6.2291 & 5.6932 & TRN \\
\hline CHEMBL 221967 & 424022 & 5.2441 & 5.5429 & TRN \\
\hline CHEMBL218438 & 424022 & 5.0655 & 5.5748 & TRN \\
\hline CHEMBL138524 & 424022 & 5.4815 & 5.19600 & 0000000001 \\
\hline CHEMBL217931 & 424022 & 5.1135 & 4.8571 & TRN \\
\hline CHEMBL221966 & 424022 & 5.2366 & 5.5732 & TRN \\
\hline CHEMBL386160 & 424022 & 4.7447 & 5.6776 & TRN \\
\hline CHEMBL 218548 & 424022 & 5.9586 & 5.5247 & TRN \\
\hline CHEMBL 218630 & 424022 & 5.2007 & 5.7078 & TRN \\
\hline CHEMBL218739 & 424022 & 5.2441 & 5.3168 & TRN \\
\hline CHEMBL 218330 & 424022 & 5.2366 & 4.9822 & TST \\
\hline CHEMBL218337 & 424022 & 6.1739 & 5.3236 & TST \\
\hline CHEMBL 221581 & 424022 & 5.8239 & 5.4888 & TRN \\
\hline CHEMBL139805 & 424022 & 5.0 & 5.0968 & TRN \\
\hline CHEMBL385631 & 424022 & 3.8539 & 4.6836 & TRN \\
\hline CHEMBL 218495 & 424022 & 5.3872 & 5.482 & TRN \\
\hline CHEMBL 221432 & 424022 & 3.7959 & 4.5896 & TRN \\
\hline CHEMBL374279 & 424022 & 5.5528 & 4.9384 & TST \\
\hline CHEMBL 221741 & 424022 & 5.0 & 4.8146 & TST \\
\hline CHEMBL 221740 & 424022 & 6.301 & 5.4017 & TRN \\
\hline CHEMBL 218436 & 424022 & 5.5686 & 5.2665 & TRN \\
\hline CHEMBL139856 & 424022 & 5.3372 & 4.869 & TST \\
\hline CHEMBL 218333 & 424022 & 5.5086 & 5.3081 & TRN \\
\hline CHEMBL 218331 & 424022 & 4.8539 & 5.3172 & TRN \\
\hline CHEMBL138710 & 424022 & 5.699 & 5.1597 & TST \\
\hline CHEMBL426212 & 424022 & 5.3188 & 5.075 & TST \\
\hline CHEMBL441861 & 424022 & 5.301 & 4.6612 & TRN \\
\hline CHEMBL462688 & 559248 & 7.4437 & 8.3351 & TST \\
\hline CHEMBL461658 & 559248 & 7.1487 & 6.2096 & TST \\
\hline CHEMBL467654 & 559248 & 7.2441 & 7.233 & TRN \\
\hline CHEMBL512963 & 559248 & 5.4962 & 5.6432 & TRN \\
\hline CHEMBL460146 & 559248 & 7.7959 & 7.8888 & TST \\
\hline CHEMBL468259 & 559248 & 4.301 & 3.9909 & TST \\
\hline CHEMBL469093 & 559248 & 4.301 & 4.4624 & TRN \\
\hline CHEMBL462499 & 559248 & 4.301 & 4.3015 & TST \\
\hline CHEMBL469298 & 559248 & 6.0635 & 6.108 & TRN \\
\hline CHEMBL462040 & 559248 & 6.983 & 7.0188 & TRN \\
\hline CHEMBL467852 & 559248 & 4.301 & 4.2814 & TRN \\
\hline CHEMBL513165 & 559248 & 4.301 & 4.6571 & TRN \\
\hline CHEMBL466405 & 559248 & 7.2676 & 7.3539 & TRN \\
\hline CHEMBL511589 & 559248 & 8.2218 & 8.3038 & TRN \\
\hline CHEMBL467843 & 559248 & 6.7696 & 6.6806 & TRN \\
\hline CHEMBL462068 & 559248 & 7.2676 & 6.9748 & TRN \\
\hline
\end{tabular}




\begin{tabular}{|c|c|c|c|c|c|}
\hline \multicolumn{6}{|c|}{ Supplemental Table S2.txt } \\
\hline CHEMBL468261 & 559248 & 6.2676 & 5.9976 & TRN & \\
\hline CHEMBL467841 & 559248 & 6.7167 & 6.3105 & TRN & \\
\hline CHEMBL468268 & 559248 & 7.4318 & 7.3849 & TRN & \\
\hline CHEMBL465990 & 559248 & 8.699 & 8.7716 & TRN & \\
\hline CHEMBL459320 & 559248 & 7.9586 & 8.0578 & TST & \\
\hline CHEMBL459733 & 559248 & 7.3665 & 7.4306 & TRN & \\
\hline CHEMBL467634 & 559248 & 7.585 & 7.5395 & TRN & \\
\hline CHEMBL517566 & 559248 & 9.0 & 9.0308 & TRN & \\
\hline CHEMBL511221 & 559248 & 7.4949 & 7.5146 & TRN & \\
\hline CHEMBL460980 & 559248 & 7.6021 & 7.6949 & TST & \\
\hline CHEMBL467639 & 559248 & 7.9208 & 7.7954 & TRN & \\
\hline CHEMBL462041 & 559248 & 6.9469 & 7.1532 & TRN & \\
\hline CHEMBL462067 & 559248 & 7.4685 & 7.6531 & TRN & \\
\hline CHEMBL513156 & 559248 & 4.301 & 4.2761 & TRN & \\
\hline CHEMBL511234 & 559248 & 5.7696 & 5.6307 & TRN & \\
\hline CHEMBL460373 & 559248 & 8.5229 & 8.5086 & TRN & \\
\hline CHEMBL467431 & 559248 & 7.4949 & 7.6462 & TRN & \\
\hline CHEMBL512425 & 559248 & 6.2291 & 6.1347 & TRN & \\
\hline CHEMBL462270 & 559248 & 4.301 & 6.1873 & TST & \\
\hline CHEMBL467851 & 559248 & 8.5229 & 8.6177 & TRN & \\
\hline CHEMBL466404 & 559248 & 7.2757 & 7.1961 & TRN & \\
\hline CHEMBL467842 & 559248 & 4.301 & 4.4335 & TRN & \\
\hline CHEMBL466826 & 559248 & 5.0 & 3.0764 & TST & \\
\hline CHEMBL467007 & 559248 & 8.3979 & 8.4215 & TRN & \\
\hline CHEMBL512298 & 559248 & 8.5229 & 8.5806 & TRN & \\
\hline CHEMBL469302 & 559248 & 9.0 & 8.9023 & TRN & \\
\hline CHEMBL466180 & 559248 & 8.699 & 8.6259 & TRN & \\
\hline CHEMBL466825 & 559248 & 4.301 & 4.44300 & 00000000005 & TRN \\
\hline CHEMBL516769 & 559248 & 9.301 & 9.3574 & TRN & \\
\hline CHEMBL469297 & 559248 & 8.5229 & 8.4588 & TRN & \\
\hline CHEMBL462042 & 559248 & 7.1135 & 7.0447 & TRN & \\
\hline CHEMBL511391 & 559248 & 9.301 & 9.3481 & TRN & \\
\hline CHEMBL460145 & 559248 & 7.4815 & 8.0633 & TST & \\
\hline CHEMBL465986 & 559248 & 7.8539 & 7.9459 & TRN & \\
\hline CHEMBL516503 & 559248 & 6.9245 & 7.0754 & TST & \\
\hline CHEMBL511548 & 559248 & 5.5719 & 5.4142 & TRN & \\
\hline CHEMBL469308 & 559248 & 6.6556 & 6.5896 & TRN & \\
\hline CHEMBL518363 & 559248 & 4.301 & 4.0595 & TST & \\
\hline CHEMBL466602 & 559248 & 4.301 & 4.1986 & TRN & \\
\hline CHEMBL468470 & 559248 & 8.7959 & 8.4669 & TST & \\
\hline CHEMBL462276 & 559248 & 8.0458 & 8.6107 & TST & \\
\hline CHEMBL517044 & 559248 & 8.0458 & 8.1927 & TST & \\
\hline CHEMBL393929 & 954962 & 3.5791 & 3.5791 & TRN & \\
\hline CHEMBL1673039 & 954962 & 4.8004 & 4.8006 & TRN & \\
\hline CHEMBL 3186408 & 954962 & 3.5265 & 3.8751 & TST & \\
\hline CHEMBL 255342 & 954962 & 3.759 & 3.7585 & TRN & \\
\hline CHEMBL472940 & 954962 & 2.6177 & 2.6179 & TRN & \\
\hline CHEMBL180127 & 954962 & 4.3413 & 4.3417 & TRN & \\
\hline
\end{tabular}

Page 28437 


\begin{tabular}{|c|c|c|c|c|c|c|}
\hline \multicolumn{7}{|c|}{ Supplemental Table S2.txt } \\
\hline CHEMBL379975 & 954962 & 4.4054 & 4.4054 & TRN & & \\
\hline CHEMBL449158 & 954962 & 6.31 & 6.494 & TST & & \\
\hline CHEMBL3349342 & 954962 & 4.4225 & 4.423 & TRN & & \\
\hline CHEMBL412142 & 954962 & 4.4967 & 4.4969 & TRN & & \\
\hline CHEMBL573107 & 954962 & 5.2789 & 5.2784 & TRN & & \\
\hline CHEMBL577784 & 954962 & 4.2944 & 4.2944 & TRN & & \\
\hline CHEMBL192566 & 954962 & 7.7724 & 8.0377 & TST & & \\
\hline CHEMBL102714 & 954962 & 3.16399 & 999999999 & 997 & 3.1645 & TRN \\
\hline CHEMBL1190711 & 954962 & 4.074 & 4.0741 & TRN & & \\
\hline CHEMBL222102 & 954962 & 4.0629 & 4.0641 & TRN & & \\
\hline CHEMBL202721 & 954962 & 4.7578 & 4.7571 & TRN & & \\
\hline CHEMBL3199475 & 954962 & 3.6845 & 3.6843 & TRN & & \\
\hline CHEMBL1242367 & 954962 & 4.8313 & 4.8313 & TRN & & \\
\hline CHEMBL1590308 & 954962 & 3.3708 & 3.9872 & TST & & \\
\hline CHEMBL399530 & 954962 & 3.8227 & 3.8228 & TRN & & \\
\hline CHEMBL188678 & 954962 & 3.7821 & 3.7809 & TRN & & \\
\hline CHEMBL512504 & 954962 & 4.4223 & 4.4225 & TRN & & \\
\hline CHEMBL3392440 & 954962 & 3.7691 & 3.7691 & TRN & & \\
\hline CHEMBL2144069 & 954962 & 4.2397 & 4.2399 & TRN & & \\
\hline CHEMBL221137 & 954962 & 4.4418 & 4.3824 & TST & & \\
\hline CHEMBL1970879 & 954962 & 3.8302 & 3.83 & TRN & & \\
\hline CHEMBL300389 & 954962 & 6.8854 & 6.8859 & TRN & & \\
\hline CHEMBL1788116 & 954962 & 4.9584 & 4.9585 & TRN & & \\
\hline CHEMBL1909414 & 954962 & 3.5595 & 3.5585 & TRN & & \\
\hline CHEMBL 2005886 & 954962 & 4.3674 & 4.3675 & TRN & & \\
\hline CHEMBL 209148 & 954962 & 4.6968 & 4.6967 & TRN & & \\
\hline CHEMBL9470 & 954962 & 4.7291 & 5.3388 & TST & & \\
\hline CHEMBL191334 & 954962 & 3.3662 & 3.367 & TRN & & \\
\hline CHEMBL258844 & 954962 & 4.5438 & 4.5441 & TRN & & \\
\hline CHEMBL217354 & 954962 & 5.5944 & 5.5939 & TRN & & \\
\hline CHEMBL1230020 & 954962 & 3.0807 & 3.0805 & TRN & & \\
\hline CHEMBL 379300 & 954962 & 6.6052 & 6.6052 & TRN & & \\
\hline CHEMBL210618 & 954962 & 3.0734 & 3.0731 & TRN & & \\
\hline CHEMBL65 & 954962 & 7.4796 & 7.4797 & TRN & & \\
\hline CHEMBL240954 & 954962 & 3.4994 & 3.4039 & TST & & \\
\hline CHEMBL1256459 & 954962 & 7.086 & 7.0858 & TRN & & \\
\hline CHEMBL220241 & 954962 & 5.0546 & 5.0546 & TRN & & \\
\hline CHEMBL92309 & 954962 & 3.6394 & 3.0478 & TST & & \\
\hline CHEMBL259181 & 954962 & 4.2757 & 4.2759 & TRN & & \\
\hline CHEMBL1643959 & 954962 & 3.6127 & 3.6121 & TRN & & \\
\hline CHEMBL392695 & 954962 & 5.58799 & 999999999 & 99 & 5.5878 & TRN \\
\hline CHEMBL483847 & 954962 & 3.9923 & 3.992 & TRN & & \\
\hline CHEMBL515416 & 954962 & 4.585 & 4.5852 & TRN & & \\
\hline CHEMBL1516890 & 954962 & 3.6231 & 3.6233 & TRN & & \\
\hline CHEMBL2363137 & 954962 & 4.8966 & 4.8967 & TRN & & \\
\hline CHEMBL1186585 & 954962 & 3.5546 & 3.555 & TRN & & \\
\hline CHEMBL 373751 & 954962 & 3.4688 & 3.4689 & TRN & & \\
\hline CHEMBL189584 & 954962 & 3.615 & 3.6154 & TRN & & \\
\hline
\end{tabular}


Supplemental Table S2.txt

\begin{tabular}{|c|c|c|c|c|c|}
\hline CHEMBL 2134202 & 954962 & 3.9677 & 3.9674 & TRN & \\
\hline CHEMBL585951 & 954962 & 5.9642 & \multicolumn{2}{|c|}{5.9639999999999995} & TRN \\
\hline CHEMBL483849 & 954962 & 2.5353 & 2.129 & TST & \\
\hline CHEMBL509032 & 954962 & 4.5883 & 4.5904 & TST & \\
\hline CHEMBL 2137530 & 954962 & 4.0468 & 4.5509 & TST & \\
\hline CHEMBL 213100 & 954962 & 4.173 & 3.8455 & TST & \\
\hline CHEMBL1404918 & 954962 & 2.7288 & \multicolumn{2}{|c|}{2.6210000000000004} & TST \\
\hline CHEMBL135561 & 954962 & 4.1331 & 4.2914 & TST & \\
\hline CHEMBL514499 & 954962 & 7.6073 & 6.7833 & TST & \\
\hline CHEMBL1357247 & 954962 & 3.7496 & \multicolumn{2}{|c|}{3.0869999999999997} & TST \\
\hline CHEMBL558642 & 954962 & 4.1164 & 3.9086 & TST & \\
\hline CHEMBL3775465 & 1561969 & 6.2676 & 6.3168 & TRN & \\
\hline CHEMBL3774392 & 1561969 & 6.7423 & 6.6333 & TRN & \\
\hline CHEMBL164087 & 1561969 & 4.6799 & 4.6471 & TRN & \\
\hline CHEMBL 3775782 & 1561969 & 3.9821 & 4.1728 & TRN & \\
\hline CHEMBL3775894 & 1561969 & 7.0969 & 6.9545 & TRN & \\
\hline CHEMBL3775636 & 1561969 & 5.0969 & 5.2019 & TST & \\
\hline CHEMBL 2098433 & 1561969 & 4.9626 & 4.9461 & TRN & \\
\hline CHEMBL3774437 & 1561969 & 4.7825 & \multicolumn{2}{|c|}{5.156000000000001} & TRN \\
\hline CHEMBL3775130 & 1561969 & 6.1135 & 6.0797 & TRN & \\
\hline CHEMBL 3774672 & 1561969 & 4.6615 & 4.6011 & TRN & \\
\hline CHEMBL3775933 & 1561969 & 6.0458 & 5.9953 & TRN & \\
\hline CHEMBL3775040 & 1561969 & 6.8327 & 6.7099 & TRN & \\
\hline CHEMBL3774798 & 1561969 & 4.9393 & 4.9293 & TST & \\
\hline CHEMBL 3770256 & 1561969 & 5.7696 & 4.7378 & TST & \\
\hline CHEMBL3774537 & 1561969 & 6.9914 & 6.8486 & TRN & \\
\hline CHEMBL 3774747 & 1561969 & 6.0458 & 6.0113 & TRN & \\
\hline CHEMBL 3775802 & 1561969 & 5.1612 & 4.4806 & TST & \\
\hline CHEMBL3775814 & 1561969 & 6.9281 & 7.0657 & TRN & \\
\hline CHEMBL3775454 & 1561969 & 5.3872 & 5.3929 & TRN & \\
\hline CHEMBL3775899 & 1561969 & 6.8996 & 6.8693 & TRN & \\
\hline CHEMBL3774692 & 1561969 & 6.699 & 5.8941 & TRN & \\
\hline CHEMBL 3774749 & 1561969 & 4.7773 & 4.6113 & TRN & \\
\hline CHEMBL3775362 & 1561969 & 6.5229 & 5.4564 & TST & \\
\hline CHEMBL 3774710 & 1561969 & 5.8539 & 5.7024 & TRN & \\
\hline CHEMBL2098408 & 1561969 & 4.8794 & 4.7885 & TRN & \\
\hline CHEMBL3774457 & 1561969 & 6.341 & 6.6913 & TRN & \\
\hline CHEMBL3775668 & 1561969 & 6.8447 & 6.8201 & TRN & \\
\hline CHEMBL3775956 & 1561969 & 6.2218 & 6.3091 & TRN & \\
\hline CHEMBL3775095 & 1561969 & 6.0223 & 5.5067 & TST & \\
\hline CHEMBL3774701 & 1561969 & 6.1805 & 6.4106 & TRN & \\
\hline CHEMBL3775121 & 1561969 & 6.9586 & 6.83 & TRN & \\
\hline CHEMBL3775987 & 1561969 & 4.3686 & 4.5287 & TST & \\
\hline CHEMBL3774688 & 1561969 & 4.2321 & 4.5991 & TST & \\
\hline CHEMBL3774456 & 1561969 & 6.8601 & 6.7706 & TRN & \\
\hline CHEMBL3774418 & 1561969 & 3.0 & 4.1749 & TST & \\
\hline CHEMBL3775135 & 1561969 & 6.2218 & 6.2244 & TRN & \\
\hline CHEMBL3774940 & 1561969 & 6.8416 & 6.8313 & TRN & \\
\hline
\end{tabular}


Supplemental Table S2.txt

\begin{tabular}{|c|c|c|c|c|c|}
\hline CHEMBL3775295 & 1561969 & 3.0 & 4.4721 & TST & \\
\hline CHEMBL3775637 & 1561969 & 4.5143 & 4.9301 & TRN & \\
\hline CHEMBL 3775548 & 1561969 & 6.8928 & 6.8484 & TRN & \\
\hline CHEMBL 3775953 & 1561969 & 6.75700 & 00000000 & 1 & 6.8663 \\
\hline CHEMBL 3775451 & 1561969 & 6.8665 & 6.8296 & TRN & \\
\hline CHEMBL 3775615 & 1561969 & 4.8069 & 5.2031 & TST & \\
\hline CHEMBL 3774665 & 1561969 & 6.9626 & 7.2928 & TRN & \\
\hline CHEMBL 3774765 & 1561969 & 5.2147 & 5.0101 & TST & \\
\hline CHEMBL 2094865 & 1561969 & 4.7773 & 4.8176 & TRN & \\
\hline CHEMBL 3775277 & 1561969 & 6.8386 & 6.801 & TRN & \\
\hline CHEMBL 3775545 & 1561969 & 6.9101 & 6.8126 & TRN & \\
\hline CHEMBL 3775977 & 1561969 & 6.8601 & 6.9546 & TRN & \\
\hline CHEMBL 3775493 & 1561969 & 5.0088 & 4.6892 & TST & \\
\hline CHEMBL 3775145 & 1561969 & 6.4089 & 6.2324 & TRN & \\
\hline CHEMBL 3774922 & 1561969 & 6.0555 & 6.1521 & TRN & \\
\hline CHEMBL3775500 & 1561969 & 5.7447 & 5.5877 & TRN & \\
\hline CHEMBL3775453 & 1561969 & 4.8827 & 5.0118 & TST & \\
\hline CHEMBL 3775516 & 1561969 & 6.8013 & 6.9003 & TRN & \\
\hline CHEMBL 3775823 & 1561969 & 6.3862 & 6.5654 & TRN & \\
\hline CHEMBL1964290 & 809198 & 6.3 & 5.2718 & TRN & \\
\hline CHEMBL 2001398 & 809198 & 4.2 & 4.5717 & TRN & \\
\hline CHEMBL2003768 & 809198 & 4.0 & 3.7955 & TRN & \\
\hline CHEMBL213505 & 809198 & 6.1 & 5.5931 & TRN & \\
\hline CHEMBL202721 & 809198 & 4.2 & 4.3426 & TRN & \\
\hline CHEMBL1987034 & 809198 & 7.7 & 8.2882 & TRN & \\
\hline CHEMBL1993941 & 809198 & 6.1 & 6.0311 & TRN & \\
\hline CHEMBL 377383 & 809198 & 4.0 & 4.2739 & TRN & \\
\hline CHEMBL 2005886 & 809198 & 5.5 & 5.7149 & TRN & \\
\hline CHEMBL481491 & 809198 & 4.0 & 4.4526 & TST & \\
\hline CHEMBL1973142 & 809198 & 4.0 & 4.5781 & TRN & \\
\hline CHEMBL388311 & 809198 & 6.6 & 6.4095 & TRN & \\
\hline CHEMBL1998765 & 809198 & 4.2 & 4.2757 & TRN & \\
\hline CHEMBL1973145 & 809198 & 4.0 & 4.6249 & TRN & \\
\hline CHEMBL1982924 & 809198 & 4.0 & 4.5875 & TRN & \\
\hline CHEMBL 2005936 & 809198 & 4.0 & 4.671 & TRN & \\
\hline CHEMBL1807515 & 809198 & 6.5 & 6.0705 & TRN & \\
\hline CHEMBL1964948 & 809198 & 4.2 & 4.4051 & TRN & \\
\hline CHEMBL1971141 & 809198 & 4.0 & 4.2876 & TRN & \\
\hline CHEMBL1995813 & 809198 & 5.4 & 5.6313 & TRN & \\
\hline CHEMBL 206236 & 809198 & 4.0 & 3.8933 & TRN & \\
\hline CHEMBL1987430 & 809198 & 4.2 & 4.2657 & TRN & \\
\hline CHEMBL 244378 & 809198 & 7.0 & 7.7749 & TRN & \\
\hline CHEMBL2001957 & 809198 & 5.3 & 5.1646 & TRN & \\
\hline CHEMBL1969372 & 809198 & 5.2 & 4.5818 & TRN & \\
\hline CHEMBL1993413 & 809198 & 4.2 & 3.7836 & TRN & \\
\hline CHEMBL1986943 & 809198 & 6.3 & 5.8275 & TRN & \\
\hline CHEMBL 2006263 & 809198 & 5.6 & 4.4962 & TST & \\
\hline CHEMBL2001646 & 809198 & 5.0 & 5.183 & TRN & \\
\hline
\end{tabular}




\begin{tabular}{|c|c|c|c|c|}
\hline & & & 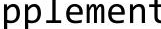 & \\
\hline CHEMBL1993584 & 809198 & 4.0 & 4.0627 & TRN \\
\hline CHEMBL1986263 & 809198 & 6.3 & 6.2026 & TRN \\
\hline CHEMBL 2000114 & 809198 & 4.0 & 4.4098 & TRN \\
\hline CHEMBL 210618 & 809198 & 4.0 & 4.1197 & TRN \\
\hline CHEMBL1986265 & 809198 & 4.2 & 4.4301 & TRN \\
\hline CHEMBL1975647 & 809198 & 5.1 & 4.2477 & TRN \\
\hline CHEMBL1968380 & 809198 & 5.1 & 4.9651 & TRN \\
\hline CHEMBL1964644 & 809198 & 4.0 & 3.8463 & TRN \\
\hline CHEMBL1991734 & 809198 & 5.9 & 6.0033 & TST \\
\hline CHEMBL1981782 & 809198 & 4.0 & 4.1842 & TRN \\
\hline CHEMBL1977681 & 809198 & 4.0 & 4.2661 & TRN \\
\hline CHEMBL1970142 & 809198 & 5.4 & 5.8788 & TRN \\
\hline CHEMBL1990912 & 809198 & 4.0 & 4.3279 & TRN \\
\hline CHEMBL1983348 & 809198 & 5.3 & 5.3001 & TRN \\
\hline CHEMBL1988163 & 809198 & 6.8 & 7.5323 & TRN \\
\hline CHEMBL 2000934 & 809198 & 4.6 & 4.2462 & TRN \\
\hline CHEMBL1980671 & 809198 & 4.6 & 4.4829 & TRN \\
\hline CHEMBL 2006493 & 809198 & 4.0 & 3.9579 & TST \\
\hline CHEMBL1986177 & 809198 & 4.2 & 4.6427 & TRN \\
\hline CHEMBL1996923 & 809198 & 4.0 & 4.1495 & TST \\
\hline CHEMBL1983449 & 809198 & 4.0 & 3.838 & TRN \\
\hline CHEMBL1992323 & 809198 & 4.0 & 3.9955 & TRN \\
\hline CHEMBL1969735 & 809198 & 5.2 & 4.9607 & TRN \\
\hline CHEMBL 2002649 & 809198 & 5.7 & 5.1222 & TRN \\
\hline CHEMBL1985367 & 809198 & 4.2 & 4.6438 & TST \\
\hline CHEMBL1996510 & 809198 & 6.0 & 4.5537 & TRN \\
\hline CHEMBL1995172 & 809198 & 4.1 & 3.7739 & TST \\
\hline CHEMBL 2001584 & 809198 & 4.2 & 4.1703 & TRN \\
\hline CHEMBL1967998 & 809198 & 7.6 & 7.3764 & TRN \\
\hline CHEMBL1994321 & 809198 & 6.4 & 5.9778 & TRN \\
\hline CHEMBL1978562 & 809198 & 4.2 & 4.7014 & TRN \\
\hline CHEMBL1997129 & 809198 & 6.0 & 5.4534 & TRN \\
\hline CHEMBL1984788 & 809198 & 4.0 & 4.0769 & TRN \\
\hline CHEMBL1996604 & 809198 & 4.0 & 3.9933 & TRN \\
\hline CHEMBL1989471 & 809198 & 5.5 & 4.7542 & TST \\
\hline CHEMBL 2000508 & 809198 & 4.0 & 4.8826 & TRN \\
\hline CHEMBL1971694 & 809198 & 4.0 & 4.1388 & TST \\
\hline CHEMBL 2001547 & 809198 & 4.0 & 4.7987 & TRN \\
\hline CHEMBL 210928 & 809198 & 4.0 & 4.2738 & TRN \\
\hline CHEMBL1978195 & 809198 & 4.2 & 4.8341 & TRN \\
\hline CHEMBL1986603 & 809198 & 4.0 & 4.1991 & TST \\
\hline CHEMBL1977148 & 809198 & 5.0 & 4.8612 & TRN \\
\hline CHEMBL1966842 & 809198 & 5.7 & 5.5562 & TRN \\
\hline CHEMBL 2003286 & 809198 & 4.0 & 4.2931 & TRN \\
\hline CHEMBL1992306 & 809198 & 7.1 & 5.4457 & TRN \\
\hline CHEMBL 2002165 & 809198 & 6.2 & 6.1313 & TRN \\
\hline CHEMBL 2001668 & 809198 & 4.0 & 4.0187 & TST \\
\hline CHEMBL1979318 & 809198 & 4.0 & 4.1254 & TST \\
\hline
\end{tabular}




\begin{tabular}{|c|c|c|c|c|}
\hline & & & p] & \\
\hline CHEMBL206382 & 809198 & 4.0 & 4.0329 & TRN \\
\hline CHEMBL1998585 & 809198 & 6.6 & 6.8144 & TRN \\
\hline CHEMBL127898 & 809198 & 5.4 & 4.2021 & TST \\
\hline CHEMBL519697 & 809198 & 5.7 & 4.6864 & TRN \\
\hline CHEMBL 2004934 & 809198 & 4.0 & 4.423 & TRN \\
\hline CHEMBL1973516 & 809198 & 7.0 & 6.7869 & TRN \\
\hline CHEMBL1996345 & 809198 & 4.2 & 4.4397 & TST \\
\hline CHEMBL1975128 & 809198 & 4.0 & 4.5557 & TRN \\
\hline CHEMBL 2004025 & 809198 & 4.2 & 4.8838 & TRN \\
\hline CHEMBL1996048 & 809198 & 4.3 & 4.7148 & TST \\
\hline CHEMBL1970369 & 809198 & 4.0 & 3.9354 & TRN \\
\hline CHEMBL1976158 & 809198 & 4.5 & 4.9228 & TST \\
\hline CHEMBL461876 & 809198 & 5.7 & 5.5139 & TRN \\
\hline CHEMBL1965033 & 809198 & 4.2 & 4.4484 & TRN \\
\hline CHEMBL 2001485 & 809198 & 5.0 & 5.8952 & TRN \\
\hline CHEMBL1997335 & 809198 & 6.0 & 6.1726 & TRN \\
\hline CHEMBL1966425 & 809198 & 5.4 & 5.3268 & TRN \\
\hline CHEMBL1984363 & 809198 & 4.0 & 4.1725 & TRN \\
\hline CHEMBL1978099 & 809198 & 6.2 & 6.0038 & TRN \\
\hline CHEMBL1988608 & 809198 & 4.0 & 4.4665 & TRN \\
\hline CHEMBL184847 & 809198 & 5.0 & 4.5398 & TRN \\
\hline CHEMBL1971132 & 809198 & 4.2 & 4.3196 & TRN \\
\hline CHEMBL1984367 & 809198 & 4.0 & 3.8275 & TRN \\
\hline CHEMBL178737 & 809198 & 4.0 & 4.7283 & TST \\
\hline CHEMBL226898 & 809198 & 7.5 & 5.8757 & TRN \\
\hline CHEMBL1982563 & 809198 & 5.3 & 5.0218 & TRN \\
\hline CHEMBL1991377 & 809198 & 4.2 & 4.4121 & TRN \\
\hline CHEMBL539474 & 809198 & 5.2 & 5.1996 & TRN \\
\hline CHEMBL575824 & 809198 & 4.0 & 4.5939 & TRN \\
\hline CHEMBL1988387 & 809198 & 6.2 & 6.3228 & TRN \\
\hline CHEMBL1973868 & 809198 & 4.2 & 4.2308 & TRN \\
\hline CHEMBL1972462 & 809198 & 4.2 & 4.0962 & TRN \\
\hline CHEMBL1974803 & 809198 & 5.1 & 5.2424 & TRN \\
\hline CHEMBL1970074 & 809198 & 5.9 & 5.1386 & TRN \\
\hline CHEMBL1986970 & 809198 & 4.0 & 3.8419 & TRN \\
\hline CHEMBL 2005112 & 809198 & 4.0 & 4.4832 & TST \\
\hline CHEMBL1958401 & 809198 & 4.0 & 4.1173 & TRN \\
\hline CHEMBL1984044 & 809198 & 4.0 & 3.9667 & TRN \\
\hline CHEMBL 2003456 & 809198 & 4.0 & 4.0091 & TRN \\
\hline CHEMBL1966816 & 809198 & 5.1 & 4.7385 & TRN \\
\hline CHEMBL 2002992 & 809198 & 4.1 & 4.2218 & TRN \\
\hline CHEMBL560813 & 809198 & 4.0 & 4.4844 & TRN \\
\hline CHEMBL207253 & 809198 & 4.0 & 4.2643 & TST \\
\hline CHEMBL1982700 & 809198 & 4.2 & 4.1653 & TST \\
\hline CHEMBL1990635 & 809198 & 5.1 & 4.8529 & TST \\
\hline CHEMBL1968791 & 809198 & 5.2 & 4.8829 & TRN \\
\hline CHEMBL 2002682 & 809198 & 5.2 & 5.3607 & TRN \\
\hline CHEMBL1977634 & 809198 & 4.2 & 4.1879 & TRN \\
\hline
\end{tabular}




\begin{tabular}{|c|c|c|c|c|}
\hline & & & Supplement & \\
\hline CHEMBL1971186 & 809198 & 5.9 & 4.802 & TRN \\
\hline CHEMBL 2003482 & 809198 & 4.0 & 3.9565 & TRN \\
\hline CHEMBL1973211 & 809198 & 6.7 & 6.1956 & TRN \\
\hline CHEMBL1984700 & 809198 & 5.5 & 4.9799 & TRN \\
\hline CHEMBL1998953 & 809198 & 4.3 & 4.3369 & TRN \\
\hline CHEMBL1971606 & 809198 & 4.2 & 4.1262 & TRN \\
\hline CHEMBL1972125 & 809198 & 4.2 & 4.2925 & TRN \\
\hline CHEMBL1461728 & 809198 & 4.0 & 4.1391 & TRN \\
\hline CHEMBL1976134 & 809198 & 5.2 & 4.5647 & TRN \\
\hline CHEMBL1965131 & 809198 & 4.0 & 4.4767 & TRN \\
\hline CHEMBL1972158 & 809198 & 4.0 & 4.3585 & TRN \\
\hline CHEMBL1981215 & 809198 & 4.2 & 4.3929 & TRN \\
\hline CHEMBL 2006580 & 809198 & 4.0 & 4.2733 & TRN \\
\hline CHEMBL1999414 & 809198 & 6.9 & 6.6688 & TRN \\
\hline CHEMBL1967336 & 809198 & 4.2 & 4.0655 & TRN \\
\hline CHEMBL 2001228 & 809198 & 4.2 & 4.9826 & TRN \\
\hline CHEMBL 2006481 & 809198 & 4.0 & 3.9128 & TRN \\
\hline CHEMBL1979855 & 809198 & 4.0 & 4.079 & TRN \\
\hline CHEMBL1970340 & 809198 & 3.6 & 4.1885 & TRN \\
\hline CHEMBL1967992 & 809198 & 4.2 & 4.1269 & TRN \\
\hline CHEMBL 2005186 & 809198 & 4.0 & 4.3461 & TRN \\
\hline CHEMBL1995927 & 809198 & 4.0 & 4.0554 & TRN \\
\hline CHEMBL1981671 & 809198 & 4.2 & 4.2049 & TRN \\
\hline CHEMBL2006450 & 809198 & 4.2 & 4.0759 & TRN \\
\hline CHEMBL1975534 & 809198 & 4.0 & 4.3082 & TRN \\
\hline CHEMBL1993424 & 809198 & 6.5 & 7.0463 & TRN \\
\hline CHEMBL1966703 & 809198 & 4.0 & 4.27 & TST \\
\hline CHEMBL 2001987 & 809198 & 4.2 & 4.4865 & TRN \\
\hline CHEMBL1969561 & 809198 & 4.0 & 3.8885 & TRN \\
\hline CHEMBL1994555 & 809198 & 5.7 & 5.0307 & TRN \\
\hline CHEMBL1983640 & 809198 & 4.2 & 5.1136 & TRN \\
\hline CHEMBL1997023 & 809198 & 4.0 & 4.1525 & TST \\
\hline CHEMBL1964687 & 809198 & 5.5 & 5.2342 & TRN \\
\hline CHEMBL1971943 & 809198 & 4.4 & 4.5016 & TRN \\
\hline CHEMBL1974254 & 809198 & 5.2 & 5.4271 & TRN \\
\hline CHEMBL1997924 & 809198 & 6.9 & 6.6101 & TRN \\
\hline CHEMBL1988537 & 809198 & 4.0 & 4.3833 & TST \\
\hline CHEMBL1969049 & 809198 & 4.0 & 4.2749 & TRN \\
\hline CHEMBL 2005828 & 809198 & 4.0 & 4.8327 & TRN \\
\hline CHEMBL 2002240 & 809198 & 4.0 & 4.1626 & TRN \\
\hline CHEMBL1978267 & 809198 & 4.2 & 4.7976 & TRN \\
\hline CHEMBL1971485 & 809198 & 4.2 & 4.9201 & TRN \\
\hline CHEMBL1991143 & 809198 & 4.0 & 4.0937 & TST \\
\hline CHEMBL1998611 & 809198 & 5.6 & 4.3699 & TRN \\
\hline CHEMBL1975900 & 809198 & 4.0 & 3.8941 & TRN \\
\hline CHEMBL1992334 & 809198 & 4.2 & 4.0805 & TRN \\
\hline CHEMBL255822 & 809198 & 5.2 & 4.4619 & TRN \\
\hline CHEMBL1972221 & 809198 & 5.1 & 4.381 & TRN \\
\hline
\end{tabular}




\begin{tabular}{|c|c|c|c|c|c|}
\hline \multirow[b]{2}{*}{ CHEMBL 2006778} & \\
\hline & 809198 & 6.4 & 6.2181 & TRN & \\
\hline CHEMBL378627 & 809198 & 4.0 & 4.519 & TRN & \\
\hline CHEMBL1996979 & 809198 & 5.3 & 5.4547 & TRN & \\
\hline CHEMBL1997025 & 809198 & 4.0 & 4.2281 & TRN & \\
\hline CHEMBL1968406 & 809198 & 5.7 & 5.6075 & TRN & \\
\hline CHEMBL1975921 & 809198 & 4.9 & 4.1649 & TRN & \\
\hline CHEMBL1984274 & 809198 & 5.7 & 4.9439 & TST & \\
\hline CHEMBL1998545 & 809198 & 4.0 & 3.9636 & TRN & \\
\hline CHEMBL1986869 & 809198 & 4.0 & 3.8915 & TRN & \\
\hline CHEMBL 2004033 & 809198 & 4.2 & 4.5381 & TST & \\
\hline CHEMBL1975923 & 809198 & 5.7 & 5.2346 & TST & \\
\hline CHEMBL 2005449 & 809198 & 5.9 & 5.4057 & TRN & \\
\hline CHEMBL1987998 & 809198 & 4.2 & 4.4331 & TRN & \\
\hline CHEMBL 2006010 & 809198 & 4.0 & 4.0981 & TRN & \\
\hline CHEMBL1682558 & 809198 & 4.0 & 4.2196 & TRN & \\
\hline CHEMBL1990496 & 809198 & 5.6 & 4.7634 & TRN & \\
\hline CHEMBL 2002799 & 809198 & 4.2 & 4.1256 & TST & \\
\hline CHEMBL242865 & 809198 & 6.0 & 6.437 & TRN & \\
\hline CHEMBL 2002479 & 809198 & 5.5 & 5.4426 & TRN & \\
\hline CHEMBL1967094 & 809198 & 4.0 & 3.8408 & TRN & \\
\hline CHEMBL1966035 & 809198 & 4.0 & 3.6096 & TRN & \\
\hline CHEMBL 2003341 & 809198 & 4.0 & 4.0934 & TRN & \\
\hline CHEMBL1982992 & 809198 & 4.0 & 5.0253 & TRN & \\
\hline CHEMBL1998110 & 809198 & 4.2 & 4.0671 & TRN & \\
\hline CHEMBL1999590 & 809198 & 5.1 & 4.8463 & TST & \\
\hline CHEMBL1981079 & 809198 & 5.9 & 5.4193 & TRN & \\
\hline CHEMBL1978166 & 809198 & 6.2 & 6.66706 & 0000000001 & TRN \\
\hline CHEMBL1972276 & 809198 & 4.0 & 3.8768 & TRN & \\
\hline CHEMBL1980489 & 809198 & 4.0 & 3.7623 & TRN & \\
\hline CHEMBL 2000832 & 809198 & 7.2 & 6.0293 & TRN & \\
\hline CHEMBL1967116 & 809198 & 7.0 & 6.5756 & TRN & \\
\hline CHEMBL1972454 & 809198 & 5.2 & 4.8003 & TRN & \\
\hline CHEMBL1990590 & 809198 & 4.2 & 4.3365 & TRN & \\
\hline CHEMBL1977814 & 809198 & 4.2 & 4.2461 & TST & \\
\hline CHEMBL513846 & 809198 & 5.3 & 4.6568 & TRN & \\
\hline CHEMBL86755 & 809198 & 4.2 & 4.5333 & TRN & \\
\hline CHEMBL1970709 & 809198 & 4.0 & 3.9542 & TRN & \\
\hline CHEMBL1974617 & 809198 & 4.1 & 4.1455 & TRN & \\
\hline CHEMBL1965660 & 809198 & 6.6 & 5.5716 & TRN & \\
\hline CHEMBL1992125 & 809198 & 6.1 & 5.6128 & TRN & \\
\hline CHEMBL1998112 & 809198 & 4.0 & 4.34 & TRN & \\
\hline CHEMBL1969126 & 809198 & 4.0 & 4.6606 & TRN & \\
\hline CHEMBL1980896 & 809198 & 5.4 & 4.7216 & TRN & \\
\hline CHEMBL1975208 & 809198 & 4.0 & 4.0371 & TST & \\
\hline CHEMBL1970104 & 809198 & 5.4 & 5.0052 & TRN & \\
\hline CHEMBL1991429 & 809198 & 6.5 & 6.1223 & TRN & \\
\hline CHEMBL1964777 & 809198 & 4.0 & 4.8873 & TRN & \\
\hline CHEMBL1971149 & 809198 & 4.0 & 4.6587 & TRN & \\
\hline & & & & 28444 & \\
\hline
\end{tabular}




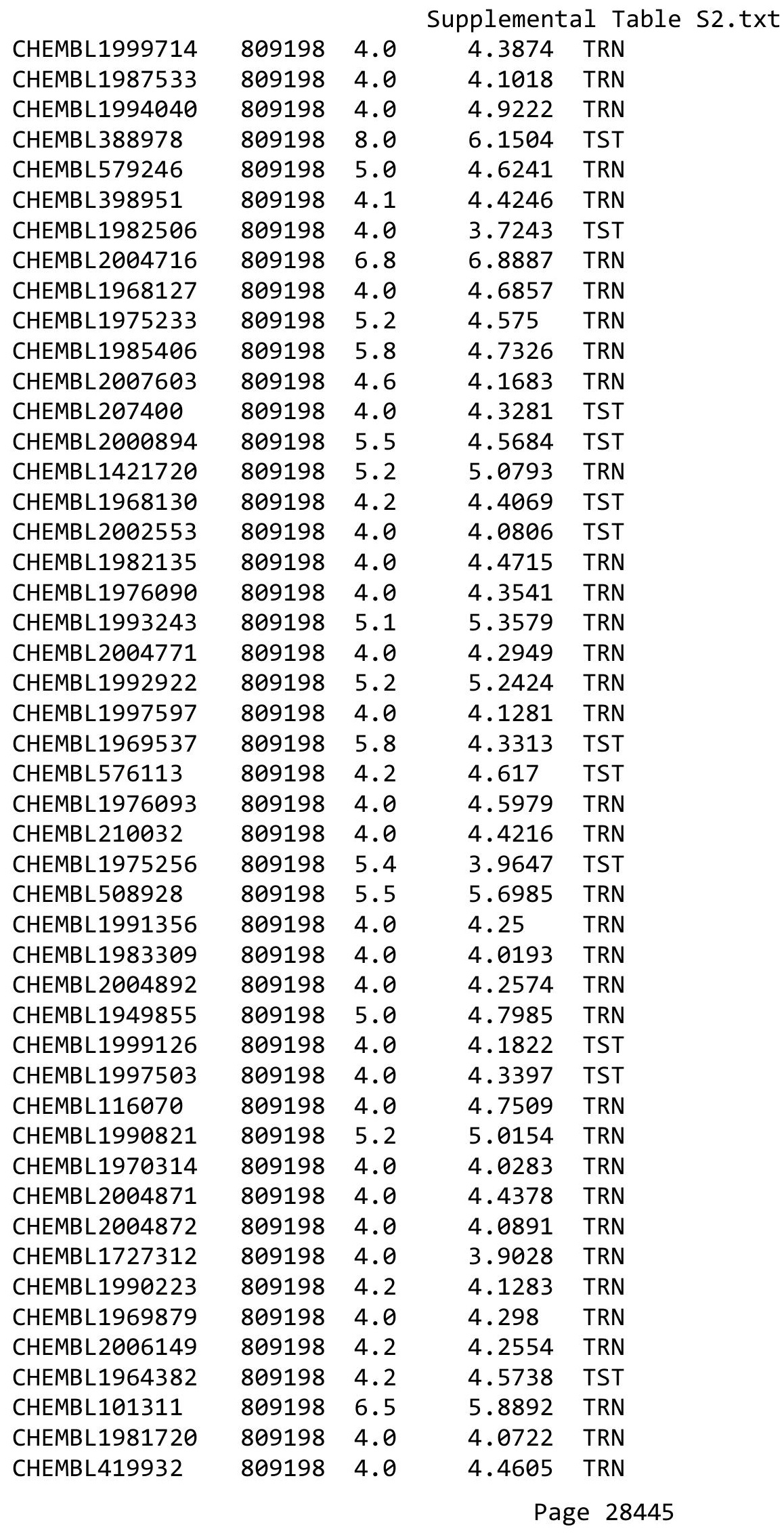




\begin{tabular}{|c|c|c|c|c|}
\hline & & & & al Table S \\
\hline CHEMBL262433 & 809198 & 5.3 & 5.3135 & TRN \\
\hline CHEMBL306380 & 809198 & 5.7 & 5.4229 & TRN \\
\hline CHEMBL1966722 & 809198 & 5.5 & 5.3342 & TST \\
\hline CHEMBL1988581 & 809198 & 6.4 & 6.4194 & TST \\
\hline CHEMBL 2005699 & 809198 & 4.2 & 4.1698 & TRN \\
\hline CHEMBL1975500 & 809198 & 6.2 & 5.9083 & TRN \\
\hline CHEMBL394619 & 809198 & 5.9 & 5.6439 & TRN \\
\hline CHEMBL 2006564 & 809198 & 7.2 & 6.3309 & TRN \\
\hline CHEMBL1996831 & 809198 & 5.7 & 4.3388 & TST \\
\hline CHEMBL411903 & 809198 & 5.2 & 5.63 & TRN \\
\hline CHEMBL1978167 & 809198 & 4.2 & 4.0929 & TRN \\
\hline CHEMBL1965988 & 809198 & 6.4 & 6.2659 & TRN \\
\hline CHEMBL418203 & 809198 & 6.1 & 5.5967 & TST \\
\hline CHEMBL1989646 & 809198 & 4.0 & 4.4816 & TRN \\
\hline CHEMBL225519 & 809198 & 5.6 & 4.8101 & TRN \\
\hline CHEMBL1978200 & 809198 & 5.4 & 4.967 & TRN \\
\hline CHEMBL 2006631 & 809198 & 4.0 & 4.4125 & TRN \\
\hline CHEMBL1970522 & 809198 & 4.0 & 4.1415 & TRN \\
\hline CHEMBL1990415 & 809198 & 4.0 & 4.3853 & TRN \\
\hline CHEMBL1966087 & 809198 & 4.0 & 3.9425 & TRN \\
\hline CHEMBL1964692 & 809198 & 6.7 & 6.1337 & TRN \\
\hline CHEMBL1996931 & 809198 & 4.0 & 3.9852 & TRN \\
\hline CHEMBL1971223 & 809198 & 4.2 & 4.0149 & TRN \\
\hline CHEMBL1964413 & 809198 & 4.0 & 3.6115 & TRN \\
\hline CHEMBL1973483 & 809198 & 5.3 & 4.2268 & TRN \\
\hline CHEMBL1998470 & 809198 & 4.2 & 4.0597 & TRN \\
\hline CHEMBL1995428 & 809198 & 4.2 & 5.1979 & TRN \\
\hline CHEMBL1970735 & 809198 & 4.0 & 4.3529 & TRN \\
\hline CHEMBL1975903 & 809198 & 5.6 & 5.3061 & TRN \\
\hline CHEMBL1997340 & 809198 & 4.0 & 3.9536 & TRN \\
\hline CHEMBL 2004365 & 809198 & 5.5 & 4.481 & TST \\
\hline CHEMBL1522508 & 809198 & 4.0 & 3.8029 & TRN \\
\hline CHEMBL1989474 & 809198 & 4.0 & 4.3397 & TRN \\
\hline CHEMBL1090360 & 809198 & 6.6 & 5.8541 & TRN \\
\hline CHEMBL 210887 & 809198 & 5.1 & 4.3971 & TRN \\
\hline CHEMBL1988805 & 809198 & 4.2 & 4.6066 & TST \\
\hline CHEMBL458997 & 809198 & 5.5 & 5.9136 & TRN \\
\hline CHEMBL1971021 & 809198 & 5.2 & 4.86 & TRN \\
\hline CHEMBL 227271 & 809198 & 5.9 & 5.9414 & TRN \\
\hline CHEMBL583144 & 809198 & 5.7 & 4.53100 & 0000000001 \\
\hline CHEMBL1974310 & 809198 & 4.0 & 5.1147 & TRN \\
\hline CHEMBL1969942 & 809198 & 4.2 & 4.471 & TRN \\
\hline CHEMBL1978567 & 809198 & 4.2 & 4.0671 & TRN \\
\hline CHEMBL1994693 & 809198 & 5.4 & 4.8389 & TRN \\
\hline CHEMBL1982957 & 809198 & 6.2 & 5.6311 & TRN \\
\hline CHEMBL1725279 & 809198 & 5.3 & 5.1021 & TST \\
\hline CHEMBL1975138 & 809198 & 5.4 & 4.9945 & TST \\
\hline CHEMBL 424872 & 809198 & 4.3 & 4.2029 & TRN \\
\hline
\end{tabular}




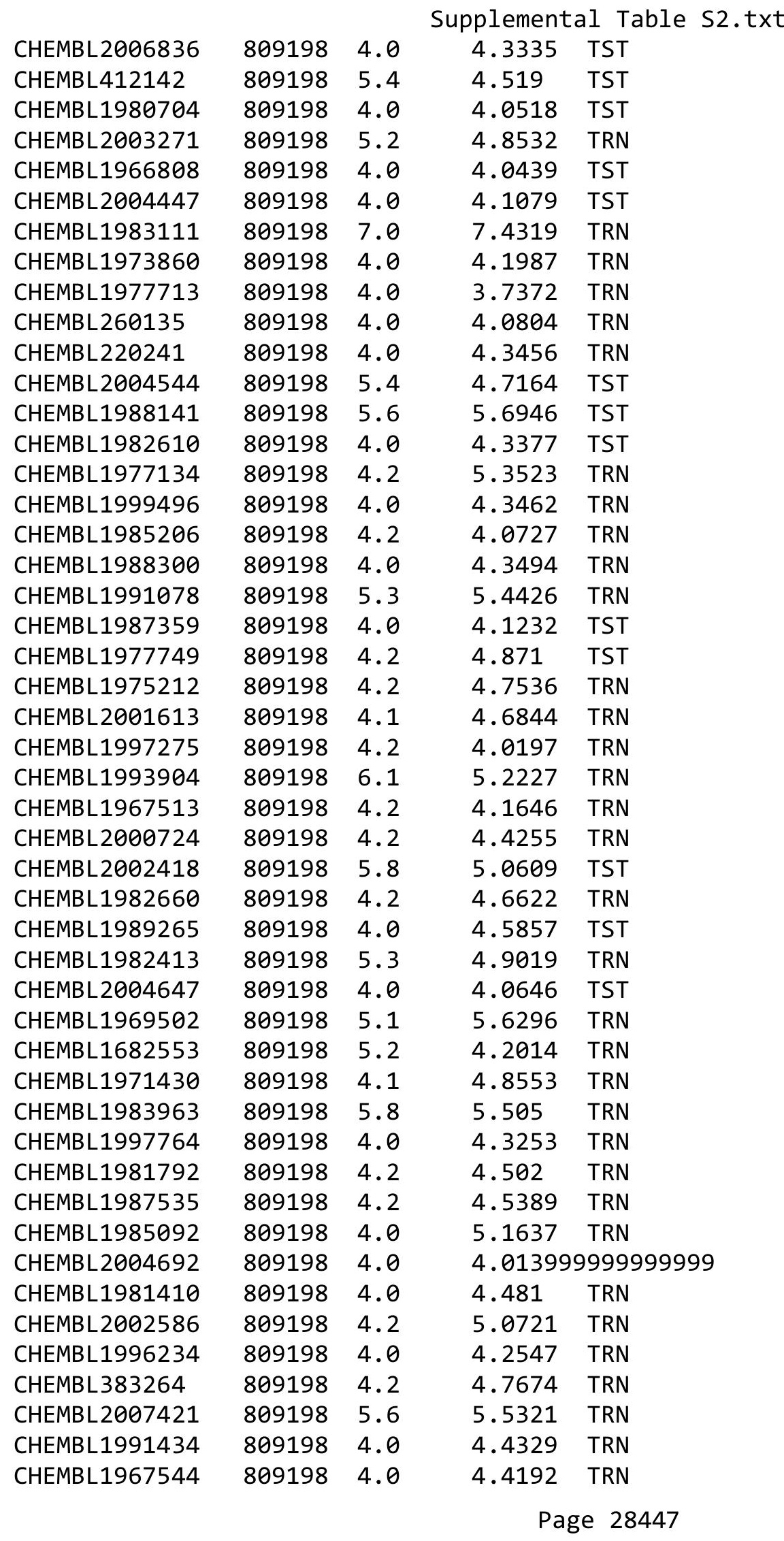




\begin{tabular}{|c|c|c|c|c|c|}
\hline \\
\hline CHEMBL1973138 & 809198 & 4.2 & 4.1493 & TRN & \\
\hline CHEMBL223367 & 809198 & 5.1 & 5.0983 & TST & \\
\hline CHEMBL340384 & 809198 & 6.0 & 4.89199 & 99999999995 & TST \\
\hline CHEMBL1969151 & 809198 & 4.2 & 5.2994 & TRN & \\
\hline CHEMBL1996587 & 809198 & 4.0 & 4.3434 & TRN & \\
\hline CHEMBL1981492 & 809198 & 4.0 & 4.1871 & TRN & \\
\hline CHEMBL1993335 & 809198 & 4.2 & 4.6851 & TRN & \\
\hline CHEMBL1988692 & 809198 & 4.2 & 4.2987 & TRN & \\
\hline CHEMBL 2007574 & 809198 & 6.4 & 4.7494 & TRN & \\
\hline CHEMBL1964804 & 809198 & 4.0 & 4.3528 & TRN & \\
\hline CHEMBL443962 & 809198 & 4.0 & 3.8233 & TST & \\
\hline CHEMBL 2000354 & 809198 & 5.1 & 4.4996 & TRN & \\
\hline CHEMBL1965507 & 809198 & 4.0 & 4.9865 & TRN & \\
\hline CHEMBL 274064 & 809198 & 4.0 & 4.8618 & TRN & \\
\hline CHEMBL1998680 & 809198 & 4.2 & 4.1614 & TRN & \\
\hline CHEMBL1967564 & 809198 & 4.0 & 4.1442 & TRN & \\
\hline CHEMBL592030 & 809198 & 4.3 & 5.1305 & TST & \\
\hline CHEMBL 2000071 & 809198 & 4.0 & 5.1697 & TRN & \\
\hline CHEMBL1979176 & 809198 & 4.0 & 4.1605 & TRN & \\
\hline CHEMBL1970317 & 809198 & 6.2 & 5.5993 & TRN & \\
\hline CHEMBL 2000408 & 809198 & 5.5 & 4.9754 & TRN & \\
\hline CHEMBL248757 & 809198 & 4.0 & 4.6747 & TST & \\
\hline CHEMBL1978014 & 809198 & 4.0 & 4.0517 & TRN & \\
\hline CHEMBL 2002736 & 809198 & 4.2 & 4.0933 & TRN & \\
\hline CHEMBL1997007 & 809198 & 5.4 & 4.7852 & TRN & \\
\hline CHEMBL1994538 & 809198 & 4.1 & 4.4034 & TRN & \\
\hline CHEMBL1983195 & 809198 & 5.4 & 4.6588 & TST & \\
\hline CHEMBL1975490 & 809198 & 5.8 & 5.5706 & TRN & \\
\hline CHEMBL1964444 & 809198 & 4.2 & 4.435 & TRN & \\
\hline CHEMBL1989957 & 809198 & 4.0 & 4.0185 & TRN & \\
\hline CHEMBL 2002690 & 809198 & 4.2 & 4.4204 & TRN & \\
\hline CHEMBL1986139 & 809198 & 4.0 & 4.2837 & TRN & \\
\hline CHEMBL1980540 & 809198 & 4.0 & 4.359 & TRN & \\
\hline CHEMBL 278041 & 809198 & 4.2 & 4.7999 & TRN & \\
\hline CHEMBL1979883 & 809198 & 6.7 & 6.3663 & TRN & \\
\hline CHEMBL1984162 & 809198 & 5.8 & 6.4354 & TRN & \\
\hline CHEMBL1997051 & 809198 & 6.4 & 5.6408 & TRN & \\
\hline CHEMBL491758 & 809198 & 5.2 & 5.38899 & 9999999999 & TRN \\
\hline CHEMBL1986590 & 809198 & 4.2 & 4.2188 & TRN & \\
\hline CHEMBL549730 & 809198 & 4.0 & 3.517 & TRN & \\
\hline CHEMBL1970189 & 809198 & 4.0 & 4.4857 & TST & \\
\hline CHEMBL1870106 & 809198 & 4.2 & 4.3206 & TRN & \\
\hline CHEMBL1996791 & 809198 & 4.0 & 4.3343 & TRN & \\
\hline CHEMBL371206 & 809198 & 6.6 & 5.8988 & TRN & \\
\hline CHEMBL1974664 & 809198 & 4.0 & 4.7894 & TRN & \\
\hline CHEMBL406845 & 809198 & 4.3 & 4.6508 & TRN & \\
\hline CHEMBL1974288 & 809198 & 4.0 & 4.2341 & TRN & \\
\hline CHEMBL1984296 & 809198 & 5.4 & 5.1171 & TST & \\
\hline
\end{tabular}




\begin{tabular}{|c|c|c|c|c|}
\hline & & & & al Table \\
\hline CHEMBL196363 & 809198 & 6.3 & 6.2884 & TRN \\
\hline CHEMBL1190711 & 809198 & 4.0 & 4.5412 & TRN \\
\hline CHEMBL1968705 & 809198 & 4.4 & 4.7852 & TRN \\
\hline CHEMBL1964441 & 809198 & 6.4 & 5.8764 & TRN \\
\hline CHEMBL1991410 & 809198 & 4.2 & 4.03100 & 0000000001 \\
\hline CHEMBL546797 & 809198 & 4.2 & 4.2246 & TRN \\
\hline CHEMBL404367 & 809198 & 6.2 & 5.3218 & TRN \\
\hline CHEMBL1966343 & 809198 & 4.0 & 4.2932 & TRN \\
\hline CHEMBL1978271 & 809198 & 4.2 & 4.2281 & TRN \\
\hline CHEMBL1967887 & 809198 & 4.0 & 4.8639 & TRN \\
\hline CHEMBL2007266 & 809198 & 4.2 & 4.3911 & TRN \\
\hline CHEMBL1985469 & 809198 & 4.2 & 4.1166 & TST \\
\hline CHEMBL 2000568 & 809198 & 4.1 & 4.0373 & TRN \\
\hline CHEMBL1994308 & 809198 & 4.2 & 4.0689 & TRN \\
\hline CHEMBL 2000335 & 809198 & 6.8 & 6.324 & TRN \\
\hline CHEMBL1977604 & 809198 & 4.0 & 4.5276 & TST \\
\hline CHEMBL1988717 & 809198 & 5.6 & 5.7995 & TRN \\
\hline CHEMBL1974328 & 809198 & 5.8 & 6.1094 & TRN \\
\hline CHEMBL509032 & 809198 & 6.8 & 7.17 & TRN \\
\hline CHEMBL1973808 & 809198 & 4.0 & 4.1285 & TRN \\
\hline CHEMBL 2000429 & 809198 & 6.0 & 4.9241 & TRN \\
\hline CHEMBL1972576 & 809198 & 5.4 & 4.7848 & TRN \\
\hline CHEMBL1992555 & 809198 & 4.0 & 4.3416 & TRN \\
\hline CHEMBL1992342 & 809198 & 4.0 & 4.2312 & TRN \\
\hline CHEMBL1988173 & 809198 & 6.3 & 5.2815 & TST \\
\hline CHEMBL1973013 & 809198 & 5.3 & 5.2174 & TRN \\
\hline CHEMBL1164265 & 809198 & 5.9 & 5.3601 & TST \\
\hline CHEMBL535331 & 809198 & 4.0 & 4.0151 & TRN \\
\hline CHEMBL1989805 & 809198 & 5.9 & 4.5797 & TST \\
\hline CHEMBL1982980 & 809198 & 5.3 & 4.6384 & TRN \\
\hline CHEMBL1965423 & 809198 & 5.3 & 5.1852 & TRN \\
\hline CHEMBL1983025 & 809198 & 6.3 & 6.1123 & TRN \\
\hline CHEMBL1975927 & 809198 & 5.3 & 5.7136 & TRN \\
\hline CHEMBL205415 & 809198 & 4.2 & 4.1469 & TRN \\
\hline CHEMBL1977135 & 809198 & 4.0 & 3.9624 & TRN \\
\hline CHEMBL2001920 & 809198 & 5.3 & 4.4081 & TRN \\
\hline CHEMBL1977138 & 809198 & 5.7 & 5.8768 & TST \\
\hline CHEMBL1241473 & 809198 & 6.6 & 7.3606 & TRN \\
\hline CHEMBL1978448 & 809198 & 4.4 & 4.7274 & TRN \\
\hline CHEMBL 2004513 & 809198 & 4.0 & 4.2511 & TRN \\
\hline CHEMBL1972258 & 809198 & 4.0 & 3.9454 & TRN \\
\hline CHEMBL1969483 & 809198 & 6.6 & 4.796 & TRN \\
\hline CHEMBL1980329 & 809198 & 6.4 & 5.3821 & TRN \\
\hline CHEMBL 2001257 & 809198 & 6.8 & 6.1278 & TRN \\
\hline CHEMBL1992042 & 809198 & 4.2 & 5.0084 & TRN \\
\hline CHEMBL1987793 & 809198 & 5.4 & 5.2283 & TRN \\
\hline CHEMBL1992536 & 809198 & 4.0 & 3.9053 & TRN \\
\hline CHEMBL 21156 & 809198 & 4.2 & 4.7984 & TST \\
\hline
\end{tabular}




\begin{tabular}{|c|c|c|c|c|}
\hline & & & ient & al Ta \\
\hline CHEMBL1992740 & 809198 & 5.4 & 4.4726 & TRN \\
\hline CHEMBL1994724 & 809198 & 4.2 & 4.3959 & TRN \\
\hline CHEMBL1989267 & 809198 & 5.8 & 5.7149 & TRN \\
\hline CHEMBL 2002373 & 809198 & 4.0 & 4.535 & TRN \\
\hline CHEMBL439340 & 809198 & 4.0 & 4.2623 & TRN \\
\hline CHEMBL1974574 & 809198 & 4.2 & 4.6298 & TST \\
\hline CHEMBL 2006188 & 809198 & 4.0 & 4.1082 & TRN \\
\hline CHEMBL1967531 & 809198 & 5.6 & 5.4471 & TRN \\
\hline CHEMBL1970913 & 809198 & 4.0 & 4.217 & TRN \\
\hline CHEMBL1973893 & 809198 & 5.2 & 4.4239 & TRN \\
\hline CHEMBL1995736 & 809198 & 4.0 & 4.2738 & TRN \\
\hline CHEMBL1997534 & 809198 & 5.2 & 4.8119 & TRN \\
\hline CHEMBL1993877 & 809198 & 4.2 & 4.8174 & TRN \\
\hline CHEMBL1996500 & 809198 & 4.1 & 4.718 & TRN \\
\hline CHEMBL1985095 & 809198 & 5.6 & 4.895 & TST \\
\hline CHEMBL1998551 & 809198 & 4.0 & 4.2977 & TRN \\
\hline CHEMBL1977374 & 809198 & 4.0 & 4.3469 & TRN \\
\hline CHEMBL1973363 & 809198 & 6.0 & 5.0577 & TRN \\
\hline CHEMBL1682540 & 809198 & 4.0 & 4.0348 & TRN \\
\hline CHEMBL1976420 & 809198 & 4.4 & 5.2985 & TRN \\
\hline CHEMBL1998253 & 809198 & 4.2 & 4.3583 & TST \\
\hline CHEMBL1981744 & 809198 & 4.2 & 4.31 & TRN \\
\hline CHEMBL1994864 & 809198 & 4.0 & 3.9083 & TRN \\
\hline CHEMBL 2002446 & 809198 & 4.0 & 4.3383 & TRN \\
\hline CHEMBL497151 & 809198 & 5.1 & 4.4831 & TRN \\
\hline CHEMBL 2000029 & 809198 & 5.3 & 4.6165 & TRN \\
\hline CHEMBL1973961 & 809198 & 4.2 & 4.4187 & TRN \\
\hline CHEMBL246970 & 809198 & 5.2 & 5.3163 & TRN \\
\hline CHEMBL340921 & 809198 & 5.4 & 4.6251 & TST \\
\hline CHEMBL1994977 & 809198 & 4.2 & 4.0149 & TRN \\
\hline CHEMBL2001149 & 809198 & 5.9 & 4.9219 & TRN \\
\hline CHEMBL1999718 & 809198 & 4.0 & 4.1804 & TRN \\
\hline CHEMBL 2000078 & 809198 & 4.2 & 5.1132 & TRN \\
\hline CHEMBL 2005478 & 809198 & 4.2 & 4.3668 & TRN \\
\hline CHEMBL1276446 & 809198 & 5.8 & 6.0736 & TST \\
\hline CHEMBL1996646 & 809198 & 5.7 & 4.9787 & TRN \\
\hline CHEMBL1979773 & 809198 & 4.2 & 4.6784 & TRN \\
\hline CHEMBL1977346 & 809198 & 4.0 & 4.4709 & TRN \\
\hline CHEMBL1971649 & 809198 & 4.0 & 4.1256 & TRN \\
\hline CHEMBL 2005482 & 809198 & 6.1 & 5.4261 & TRN \\
\hline CHEMBL1996702 & 809198 & 5.8 & 6.3527 & TRN \\
\hline CHEMBL1997909 & 809198 & 4.2 & 4.8171 & TRN \\
\hline CHEMBL 2007124 & 809198 & 4.2 & 4.8952 & TRN \\
\hline CHEMBL1998435 & 809198 & 4.0 & 3.9541 & TRN \\
\hline CHEMBL 2006439 & 809198 & 4.1 & 4.2861 & TRN \\
\hline CHEMBL 2006156 & 809198 & 5.4 & 4.495 & TST \\
\hline CHEMBL1985681 & 809198 & 4.2 & 4.5401 & TST \\
\hline CHEMBL1969190 & 809198 & 5.2 & 5.4391 & TRN \\
\hline
\end{tabular}




\begin{tabular}{|c|c|c|c|c|c|}
\hline \multicolumn{6}{|c|}{ Supplemental Table S2.txt } \\
\hline CHEMBL 2002660 & 809198 & 4.2 & 4.3828 & TRN & \\
\hline CHEMBL1973937 & 809198 & 6.3 & 5.6553 & TRN & \\
\hline CHEMBL1991674 & 809198 & 5.6 & 5.0401 & TRN & \\
\hline CHEMBL1982711 & 809198 & 5.7 & 5.0646 & TRN & \\
\hline CHEMBL262623 & 809198 & 4.1 & 4.1321 & TRN & \\
\hline CHEMBL1987982 & 809198 & 4.0 & 4.8194 & TST & \\
\hline CHEMBL1984842 & 809198 & 5.3 & 4.9755 & TRN & \\
\hline CHEMBL 2004118 & 809198 & 4.2 & 4.6212 & TRN & \\
\hline CHEMBL1996795 & 809198 & 4.2 & 4.596 & TST & \\
\hline CHEMBL 2007044 & 809198 & 4.0 & 4.4987 & TRN & \\
\hline CHEMBL1994241 & 809198 & 5.1 & 4.6007 & TRN & \\
\hline CHEMBL223460 & 809198 & 5.2 & 4.9312 & TST & \\
\hline CHEMBL1998829 & 809198 & 4.0 & 4.5042 & TRN & \\
\hline CHEMBL50894 & 809198 & 4.5 & 4.5757 & TST & \\
\hline CHEMBL1995211 & 809198 & 5.5 & 5.1192 & TRN & \\
\hline CHEMBL1988838 & 809198 & 6.8 & 6.9985 & TRN & \\
\hline CHEMBL1981725 & 809198 & 7.4 & 6.8548 & TRN & \\
\hline CHEMBL1982753 & 809198 & 4.4 & 4.8221 & TRN & \\
\hline CHEMBL 2006299 & 809198 & 4.2 & 3.9854 & TRN & \\
\hline CHEMBL1972346 & 809198 & 6.0 & 5.2835 & TST & \\
\hline CHEMBL1965169 & 809198 & 4.2 & 4.0658 & TRN & \\
\hline CHEMBL1991818 & 809198 & 5.5 & 4.7629 & TST & \\
\hline CHEMBL1081312 & 809198 & 5.6 & 5.7176 & TRN & \\
\hline CHEMBL1965170 & 809198 & 4.2 & 4.81800 & 00000000005 & TRN \\
\hline CHEMBL1982866 & 809198 & 4.0 & 4.271 & TRN & \\
\hline CHEMBL 2005792 & 809198 & 5.5 & 5.0488 & TRN & \\
\hline CHEMBL1968926 & 809198 & 4.0 & 4.1631 & TRN & \\
\hline CHEMBL462120 & 809198 & 4.0 & 4.5324 & TRN & \\
\hline CHEMBL1986503 & 809198 & 4.2 & 4.4482 & TST & \\
\hline CHEMBL1965570 & 809198 & 5.1 & 5.4876 & TRN & \\
\hline CHEMBL 2007592 & 809198 & 4.0 & 4.0493 & TST & \\
\hline CHEMBL1972355 & 809198 & 5.4 & 5.6401 & TRN & \\
\hline CHEMBL1997892 & 809198 & 4.2 & 4.4281 & TRN & \\
\hline CHEMBL 2001641 & 809198 & 4.1 & 4.0395 & TRN & \\
\hline CHEMBL1997193 & 809198 & 4.2 & 4.7411 & TST & \\
\hline CHEMBL210963 & 809198 & 4.0 & 4.4511 & TRN & \\
\hline CHEMBL1964902 & 809198 & 4.2 & 4.1831 & TRN & \\
\hline CHEMBL1082440 & 809198 & 4.0 & 4.4932 & TST & \\
\hline CHEMBL1614705 & 809198 & 4.0 & 4.5365 & TRN & \\
\hline CHEMBL1984633 & 809198 & 4.0 & 4.0803 & TRN & \\
\hline CHEMBL1965845 & 809198 & 4.0 & 4.4954 & TRN & \\
\hline CHEMBL 2007372 & 809198 & 4.0 & 4.6557 & TRN & \\
\hline CHEMBL1983715 & 809198 & 6.3 & 7.159 & TRN & \\
\hline CHEMBL 2006715 & 809198 & 7.8 & 5.7381 & TRN & \\
\hline CHEMBL1986597 & 809198 & 4.0 & 3.9406 & TRN & \\
\hline CHEMBL1990482 & 809198 & 4.0 & 3.9521 & TRN & \\
\hline CHEMBL1990904 & 809198 & 5.6 & 5.0111 & TRN & \\
\hline CHEMBL2005475 & 809198 & 4.0 & 3.6308 & TRN & \\
\hline
\end{tabular}




\begin{tabular}{|c|c|c|c|c|}
\hline \multicolumn{5}{|c|}{ Supplemental Table S2.txt } \\
\hline CHEMBL402846 & 809198 & 5.8 & 5.1105 & TRN \\
\hline CHEMBL1997349 & 809198 & 5.4 & 4.7149 & TST \\
\hline CHEMBL183844 & 809198 & 4.0 & 4.4476 & TRN \\
\hline CHEMBL220057 & 809198 & 6.0 & 5.3127 & TRN \\
\hline CHEMBL1682545 & 809198 & 5.3 & 4.1935 & TRN \\
\hline CHEMBL383541 & 809198 & 5.9 & 4.4739 & TRN \\
\hline CHEMBL 2001224 & 809198 & 4.0 & 4.5218 & TRN \\
\hline CHEMBL10 & 809198 & 4.3 & 4.4778 & TRN \\
\hline CHEMBL1976732 & 809198 & 5.1 & 4.3981 & TRN \\
\hline CHEMBL1969506 & 809198 & 5.7 & 4.4067 & TRN \\
\hline CHEMBL1964937 & 809198 & 4.0 & 4.6324 & TRN \\
\hline CHEMBL1980763 & 809198 & 4.2 & 4.6452 & TRN \\
\hline CHEMBL1980163 & 809198 & 4.0 & 3.8098 & TRN \\
\hline CHEMBL1977931 & 809198 & 4.4 & 4.0587 & TRN \\
\hline CHEMBL2005899 & 809198 & 4.0 & 3.4732 & TRN \\
\hline CHEMBL1682552 & 809198 & 5.4 & 4.0414 & TRN \\
\hline CHEMBL1972568 & 809198 & 4.0 & 3.7749 & TRN \\
\hline CHEMBL 2007479 & 809198 & 4.2 & 4.1964 & TRN \\
\hline CHEMBL229799 & 809198 & 6.5 & 6.2275 & TRN \\
\hline CHEMBL105739 & 809198 & 4.0 & 4.6359 & TRN \\
\hline CHEMBL1972220 & 809198 & 6.1 & 5.7998 & TRN \\
\hline CHEMBL 379300 & 809198 & 4.0 & 5.7278 & TRN \\
\hline CHEMBL1973720 & 809198 & 4.2 & 5.6636 & TRN \\
\hline CHEMBL1969523 & 809198 & 4.0 & 4.9979 & TRN \\
\hline CHEMBL1988995 & 809198 & 4.0 & 4.4454 & TRN \\
\hline CHEMBL 2001923 & 809198 & 4.2 & 4.8275 & TST \\
\hline CHEMBL1986781 & 809198 & 5.6 & 4.841 & TRN \\
\hline CHEMBL1983070 & 809198 & 7.2 & 4.7637 & TRN \\
\hline CHEMBL526133 & 809198 & 4.0 & 4.2804 & TRN \\
\hline CHEMBL 2003514 & 809198 & 4.2 & 3.7387 & TRN \\
\hline CHEMBL1989043 & 809198 & 6.7 & 5.1708 & TRN \\
\hline CHEMBL1979057 & 809198 & 5.0 & 3.9502 & TRN \\
\hline CHEMBL 387971 & 809198 & 4.0 & 3.9989 & TRN \\
\hline CHEMBL1164180 & 809198 & 6.1 & 5.449 & TST \\
\hline CHEMBL1999428 & 809198 & 4.0 & 3.6475 & TRN \\
\hline CHEMBL1967560 & 809198 & 4.0 & 4.2518 & TRN \\
\hline CHEMBL1997611 & 809198 & 5.6 & 4.7347 & TST \\
\hline CHEMBL1516890 & 809198 & 4.0 & 4.6243 & TRN \\
\hline CHEMBL 211378 & 809198 & 5.3 & 4.8147 & TRN \\
\hline CHEMBL1982465 & 809198 & 6.0 & 5.7222 & TRN \\
\hline CHEMBL 2001751 & 809198 & 6.9 & 6.1852 & TRN \\
\hline CHEMBL 2003420 & 809198 & 4.0 & 3.9171 & TRN \\
\hline CHEMBL1984586 & 809198 & 4.0 & 4.6008 & TRN \\
\hline CHEMBL1972659 & 809198 & 4.0 & 4.3124 & TST \\
\hline CHEMBL 2002723 & 809198 & 5.3 & 5.0071 & TST \\
\hline CHEMBL 272453 & 809198 & 4.0 & 4.5297 & TRN \\
\hline CHEMBL1970217 & 809198 & 4.0 & 4.3769 & TRN \\
\hline CHEMBL 2005528 & 809198 & 4.0 & 4.2737 & TST \\
\hline
\end{tabular}




\begin{tabular}{|c|c|c|c|c|c|}
\hline \\
\hline CHEMBL1984686 & 809198 & 5.2 & 4.4121 & TRN & \\
\hline CHEMBL185569 & 809198 & 5.1 & 4.2703 & TRN & \\
\hline CHEMBL1969843 & 809198 & 4.0 & 3.6513 & TRN & \\
\hline CHEMBL2007002 & 809198 & 5.3 & 4.9023 & TRN & \\
\hline CHEMBL1987007 & 809198 & 4.0 & 3.9467 & TRN & \\
\hline CHEMBL1973793 & 809198 & 4.2 & 4.3899 & TST & \\
\hline CHEMBL1969588 & 809198 & 6.5 & 5.8383 & TRN & \\
\hline CHEMBL1984711 & 809198 & 5.6 & 5.4146 & TRN & \\
\hline CHEMBL1992073 & 809198 & 4.7 & 4.8258 & TRN & \\
\hline CHEMBL484390 & 809198 & 5.4 & 4.7753 & TRN & \\
\hline CHEMBL1983255 & 809198 & 5.0 & 4.6214 & TST & \\
\hline CHEMBL1979252 & 809198 & 4.0 & 4.0007 & TRN & \\
\hline CHEMBL1986143 & 809198 & 4.2 & 3.8855 & TRN & \\
\hline CHEMBL2007559 & 809198 & 4.2 & 4.9465 & TRN & \\
\hline CHEMBL1992581 & 809198 & 4.2 & 4.3363 & TRN & \\
\hline CHEMBL 2004290 & 809198 & 4.2 & 5.098 & TRN & \\
\hline CHEMBL1986499 & 809198 & 4.0 & 4.2126 & TRN & \\
\hline CHEMBL1972937 & 809198 & 4.0 & 4.0952 & TRN & \\
\hline CHEMBL2000393 & 809198 & 5.3 & 5.3521 & TST & \\
\hline CHEMBL2004311 & 809198 & 5.1 & 4.9937 & TRN & \\
\hline CHEMBL1992634 & 809198 & 5.8 & 5.0604 & TRN & \\
\hline CHEMBL1242373 & 809198 & 5.4 & 5.4299 & TRN & \\
\hline CHEMBL56543 & 809198 & 5.4 & 4.5888 & TRN & \\
\hline CHEMBL1984847 & 809198 & 7.6 & 4.6349 & TRN & \\
\hline CHEMBL316264 & 809198 & 4.0 & 4.6377 & TRN & \\
\hline CHEMBL1988075 & 809198 & 5.7 & 5.2194 & TRN & \\
\hline CHEMBL1996576 & 809198 & 4.2 & 4.2444 & TST & \\
\hline CHEMBL1988076 & 809198 & 6.2 & 4.8795 & TRN & \\
\hline CHEMBL1991678 & 809198 & 5.2 & 4.7436 & TRN & \\
\hline CHEMBL2001239 & 809198 & 5.8 & 5.6999 & TST & \\
\hline CHEMBL1988594 & 809198 & 4.0 & 4.6273 & TRN & \\
\hline CHEMBL 2001288 & 809198 & 4.0 & 4.0438 & TRN & \\
\hline CHEMBL1999811 & 809198 & 5.5 & 4.6419 & TRN & \\
\hline CHEMBL235157 & 809198 & 4.2 & 4.207 & TST & \\
\hline CHEMBL1985074 & 809198 & 4.0 & $4.2410 e$ & 00000000005 & TST \\
\hline CHEMBL2000481 & 809198 & 5.2 & $4.9910 e$ & 20000000005 & TRN \\
\hline CHEMBL1982874 & 809198 & 5.4 & 5.0347 & TRN & \\
\hline CHEMBL1991725 & 809198 & 4.0 & 3.8763 & TRN & \\
\hline CHEMBL1992242 & 809198 & 4.0 & 4.2596 & TRN & \\
\hline CHEMBL2007296 & 809198 & 4.0 & 4.0017 & TRN & \\
\hline CHEMBL208637 & 809198 & 4.0 & 4.2267 & TRN & \\
\hline CHEMBL396523 & 809198 & 7.1 & 7.4064 & TRN & \\
\hline CHEMBL2004159 & 809198 & 4.2 & 3.8915 & TRN & \\
\hline CHEMBL1978371 & 809198 & 5.6 & 5.1404 & TST & \\
\hline CHEMBL1970203 & 809198 & 4.0 & 4.3485 & TRN & \\
\hline CHEMBL1986530 & 809198 & 4.0 & 4.4949 & TST & \\
\hline CHEMBL440084 & 809198 & 4.6 & 4.5378 & TRN & \\
\hline CHEMBL1999321 & 809198 & 4.0 & 3.7227 & TRN & \\
\hline
\end{tabular}




\begin{tabular}{|c|c|c|c|c|}
\hline \multirow[b]{2}{*}{ CHEMBL1968590 } & \multicolumn{4}{|c|}{ Supplemental Table S2.txt } \\
\hline & 809198 & 4.0 & 5.019 & TRN \\
\hline CHEMBL 2005375 & 809198 & 4.0 & 4.5347 & TRN \\
\hline CHEMBL1984191 & 809198 & 4.0 & 4.6354 & TRN \\
\hline CHEMBL1972183 & 809198 & 4.0 & 3.9807 & TST \\
\hline CHEMBL1966501 & 809198 & 4.2 & 4.4204 & TRN \\
\hline CHEMBL1971029 & 809198 & 7.1 & 7.5237 & TRN \\
\hline CHEMBL 394790 & 809198 & 5.8 & 5.4385 & TRN \\
\hline CHEMBL2001451 & 809198 & 5.4 & 4.4321 & TRN \\
\hline CHEMBL226471 & 809198 & 4.0 & 4.7717 & TRN \\
\hline CHEMBL1974702 & 809198 & 5.3 & 4.3014 & TRN \\
\hline CHEMBL1996111 & 809198 & 4.0 & 4.043 & TRN \\
\hline CHEMBL1966175 & 809198 & 4.2 & 4.563 & TRN \\
\hline CHEMBL1965589 & 809198 & 5.3 & 4.9338 & TRN \\
\hline CHEMBL 2007375 & 809198 & 4.2 & 3.9848 & TRN \\
\hline CHEMBL1998193 & 809198 & 4.0 & 3.8486 & TRN \\
\hline CHEMBL379975 & 809198 & 5.8 & 5.2391 & TRN \\
\hline CHEMBL474432 & 809198 & 4.1 & 4.6324 & TST \\
\hline CHEMBL1973016 & 809198 & 4.2 & 4.2363 & TRN \\
\hline CHEMBL1965387 & 809198 & 4.2 & 4.2889 & TRN \\
\hline CHEMBL2001539 & 809198 & 4.6 & 3.8716 & TST \\
\hline CHEMBL1988153 & 809198 & 4.0 & 4.3164 & TRN \\
\hline CHEMBL550418 & 809198 & 5.5 & 5.5435 & TRN \\
\hline CHEMBL1972584 & 809198 & 6.0 & 5.8903 & TRN \\
\hline CHEMBL1971289 & 809198 & 4.2 & 4.8029 & TRN \\
\hline CHEMBL1988437 & 809198 & 4.4 & 4.5659 & TST \\
\hline CHEMBL1979577 & 809198 & 6.9 & 6.1925 & TRN \\
\hline CHEMBL1998121 & 809198 & 4.0 & 5.092 & TRN \\
\hline CHEMBL1233887 & 809198 & 4.2 & 3.8133 & TRN \\
\hline CHEMBL1991800 & 809198 & 5.1 & 5.0971 & TRN \\
\hline CHEMBL52387 & 809198 & 4.0 & 4.4271 & TST \\
\hline CHEMBL 2003689 & 809198 & 4.2 & 4.1916 & TRN \\
\hline CHEMBL379835 & 809198 & 4.0 & 4.067 & TST \\
\hline CHEMBL1979357 & 809198 & 4.0 & 4.0272 & TRN \\
\hline CHEMBL1996649 & 809198 & 6.5 & 6.3599 & TRN \\
\hline CHEMBL1996817 & 809198 & 5.8 & 5.2969 & TRN \\
\hline CHEMBL1986756 & 809198 & 4.2 & 4.251 & TRN \\
\hline CHEMBL3197315 & 809198 & 4.0 & 3.9309 & TST \\
\hline CHEMBL468280 & 809198 & 4.0 & 4.1382 & TST \\
\hline CHEMBL1990884 & 809198 & 4.0 & 5.0055 & TRN \\
\hline CHEMBL3109278 & 809198 & 4.4 & 4.2616 & TRN \\
\hline CHEMBL 256835 & 809198 & 4.0 & 4.7882 & TRN \\
\hline CHEMBL1970006 & 809198 & 4.0 & 4.2809 & TST \\
\hline CHEMBL1974998 & 809198 & 4.2 & 4.2232 & TRN \\
\hline CHEMBL1980142 & 809198 & 4.0 & 4.169 & TRN \\
\hline CHEMBL41783 & 809198 & 4.0 & 4.4238 & TRN \\
\hline CHEMBL 2004438 & 809198 & 4.2 & 4.3872 & TRN \\
\hline CHEMBL 2006276 & 809198 & 4.0 & 4.3358 & TRN \\
\hline CHEMBL191003 & 809198 & 7.6 & 6.2176 & TRN \\
\hline
\end{tabular}




\begin{tabular}{|c|c|c|c|c|}
\hline & & & pplement & \\
\hline CHEMBL271381 & 809198 & 5.9 & 6.1064 & TRN \\
\hline CHEMBL 2006785 & 809198 & 4.0 & 4.2825 & TRN \\
\hline CHEMBL1982466 & 809198 & 5.5 & 5.8426 & TRN \\
\hline CHEMBL1973359 & 809198 & 5.9 & 6.2099 & TST \\
\hline CHEMBL 249697 & 809198 & 5.1 & 4.7027 & TST \\
\hline CHEMBL1995740 & 809198 & 5.1 & 5.4582 & TRN \\
\hline CHEMBL1979690 & 809198 & 7.3 & 7.2956 & TRN \\
\hline CHEMBL 234085 & 809198 & 4.2 & 4.5608 & TRN \\
\hline CHEMBL1995832 & 809198 & 5.9 & 5.1832 & TRN \\
\hline CHEMBL1998414 & 809198 & 4.0 & 3.8381 & TRN \\
\hline CHEMBL1969042 & 809198 & 5.5 & 4.8667 & TRN \\
\hline CHEMBL 2000345 & 809198 & 5.1 & 4.6547 & TRN \\
\hline CHEMBL1999931 & 809198 & 5.8 & 5.4988 & TRN \\
\hline CHEMBL1976376 & 809198 & 4.2 & 4.1464 & TRN \\
\hline CHEMBL1983575 & 809198 & 5.2 & 6.2731 & TRN \\
\hline CHEMBL1968868 & 809198 & 4.2 & 4.4868 & TRN \\
\hline CHEMBL1375418 & 809198 & 5.2 & 4.2985 & TRN \\
\hline CHEMBL 2007064 & 809198 & 4.0 & 4.823 & TRN \\
\hline CHEMBL1981047 & 809198 & 5.4 & 6.2743 & TRN \\
\hline CHEMBL229968 & 809198 & 6.2 & 6.0452 & TRN \\
\hline CHEMBL1976196 & 809198 & 4.2 & 4.7924 & TST \\
\hline CHEMBL1976240 & 809198 & 4.0 & 4.3294 & TRN \\
\hline CHEMBL1997197 & 809198 & 5.3 & 4.5197 & TRN \\
\hline CHEMBL1979093 & 809198 & 5.2 & 5.5084 & TRN \\
\hline CHEMBL1968151 & 809198 & 4.0 & 4.0988 & TST \\
\hline CHEMBL1987009 & 809198 & 4.0 & 4.1751 & TRN \\
\hline CHEMBL 379218 & 809198 & 6.0 & 5.4256 & TRN \\
\hline CHEMBL 2003817 & 809198 & 4.0 & 4.192 & TRN \\
\hline CHEMBL1994830 & 809198 & 4.0 & 4.4223 & TRN \\
\hline CHEMBL226403 & 809198 & 4.1 & 4.505 & TRN \\
\hline CHEMBL 2005631 & 809198 & 7.0 & 6.6823 & TRN \\
\hline CHEMBL1994938 & 809198 & 5.1 & 5.6298 & TRN \\
\hline CHEMBL1977223 & 809198 & 4.0 & 4.7515 & TRN \\
\hline CHEMBL1966279 & 809198 & 4.0 & 4.4946 & TRN \\
\hline CHEMBL1236126 & 809198 & 4.0 & 4.2704 & TRN \\
\hline CHEMBL1984760 & 809198 & 5.3 & 4.9828 & TRN \\
\hline CHEMBL1997846 & 809198 & 4.2 & 4.3049 & TRN \\
\hline CHEMBL 2004419 & 809198 & 4.0 & 4.9787 & TRN \\
\hline CHEMBL 360847 & 809198 & 5.6 & 4.4885 & TST \\
\hline CHEMBL2007073 & 809198 & 4.2 & 3.9953 & TRN \\
\hline CHEMBL1995811 & 809198 & 4.2 & 4.6592 & TRN \\
\hline CHEMBL1972489 & 809198 & 4.0 & 4.1519 & TRN \\
\hline CHEMBL1994074 & 809198 & 4.0 & 4.1242 & TRN \\
\hline CHEMBL1992937 & 809198 & 5.8 & 4.1443 & TST \\
\hline CHEMBL1972119 & 809198 & 4.0 & 4.0296 & TRN \\
\hline CHEMBL1986328 & 809198 & 5.4 & 4.5338 & TST \\
\hline CHEMBL95692 & 809198 & 4.0 & 4.7224 & TRN \\
\hline CHEMBL1090356 & 809198 & 6.5 & 5.7596 & TRN \\
\hline
\end{tabular}




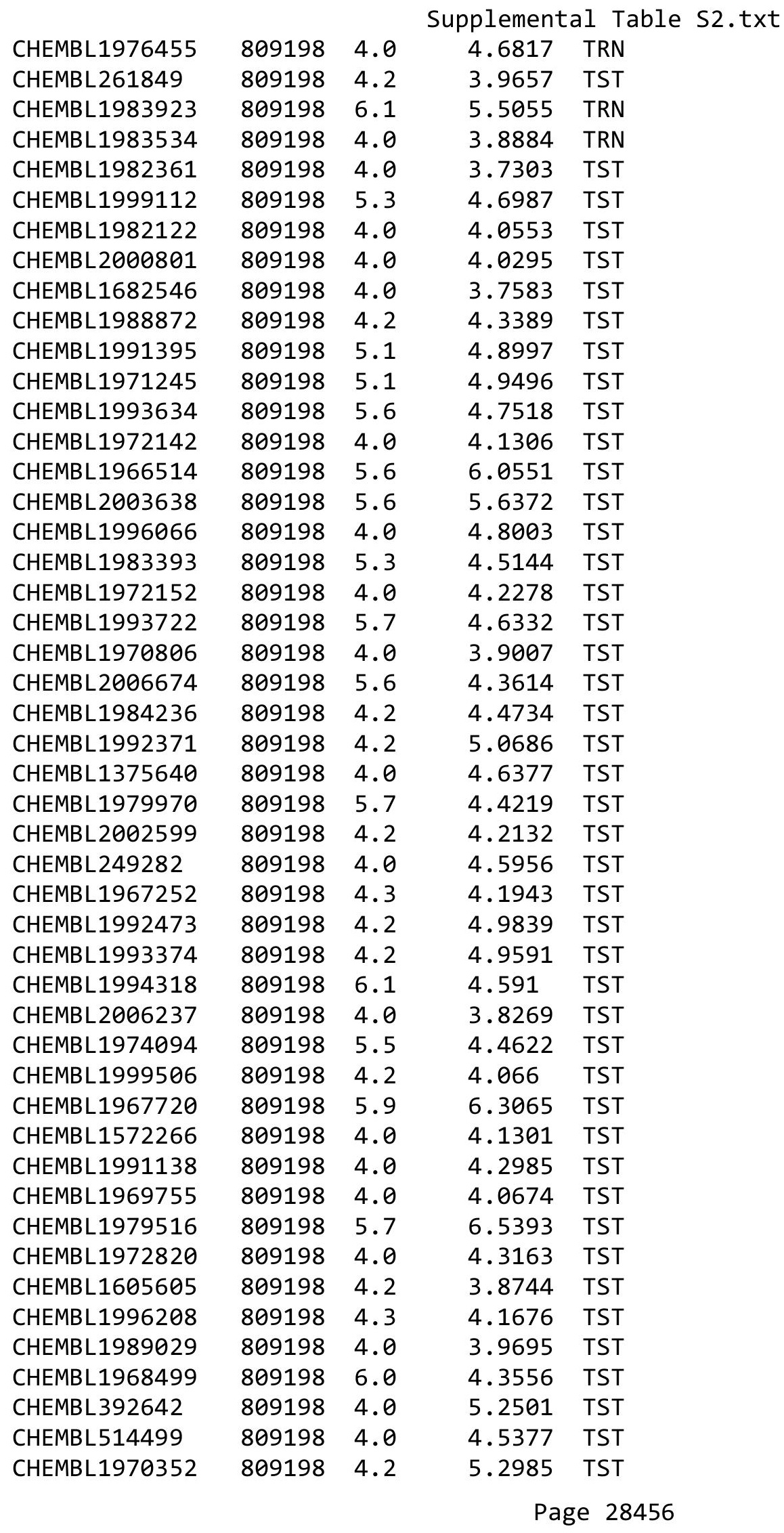




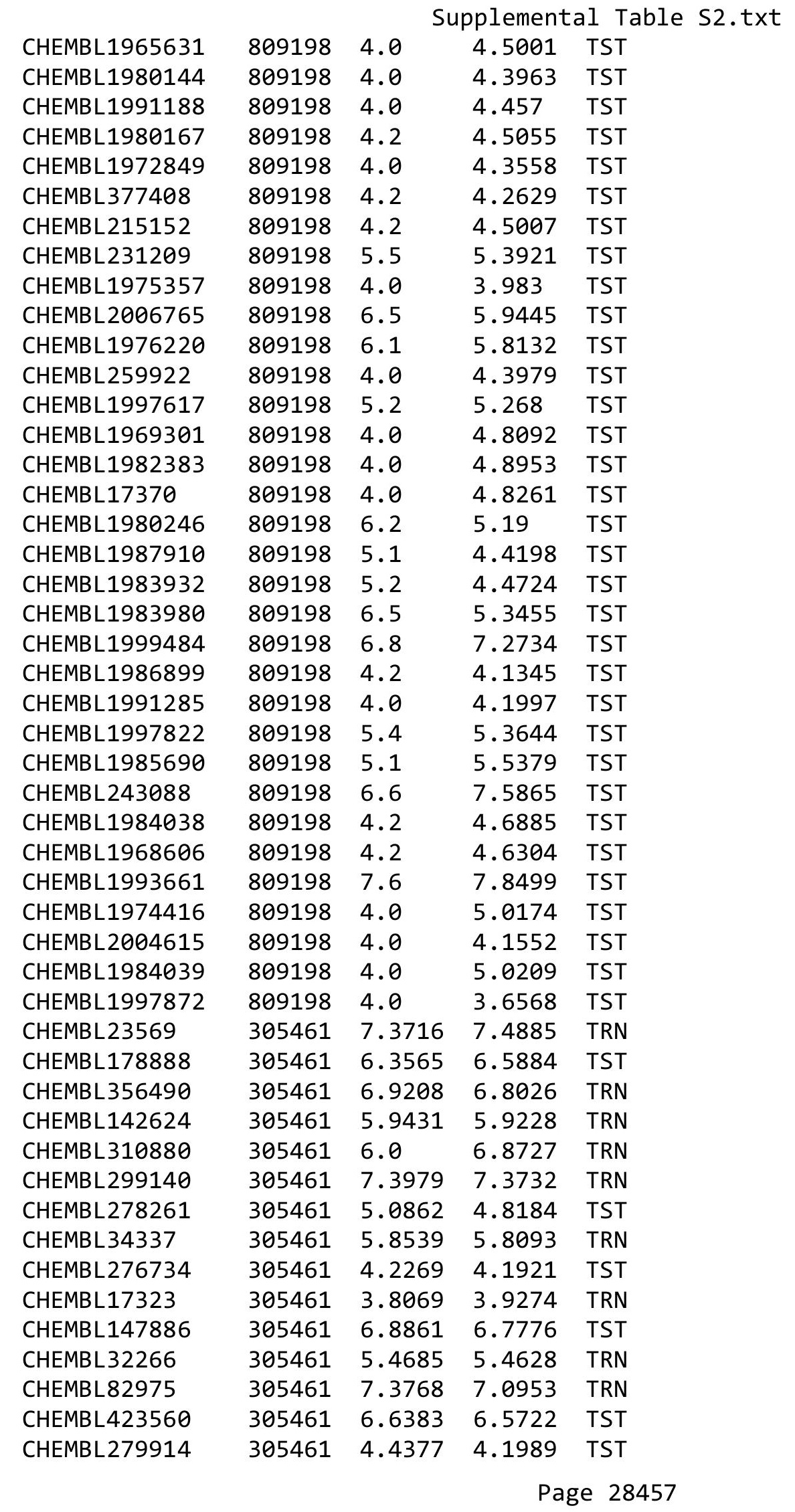




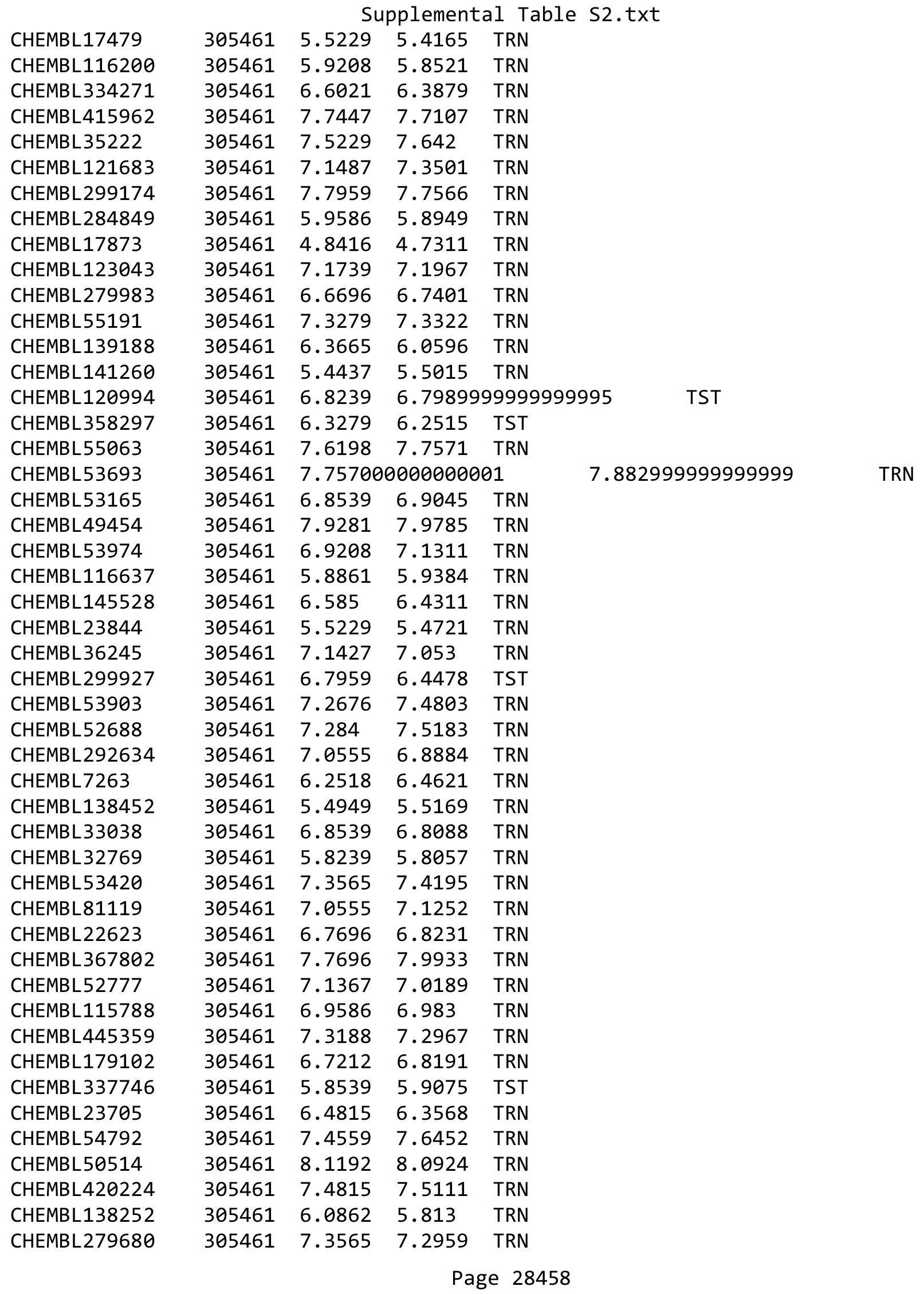


Supplemental Table S2.txt

\begin{tabular}{|c|c|c|c|c|c|}
\hline CHEMBL312348 & 305461 & 7.2549 & 7.3511 & TRN & \\
\hline CHEMBL141218 & 305461 & 5.4202 & 5.21299 & 9999999999 & TRN \\
\hline CHEMBL178512 & 305461 & 5.4559 & 5.5851 & TST & \\
\hline CHEMBL 7488 & 305461 & 6.5376 & 6.7426 & TRN & \\
\hline CHEMBL 296382 & 305461 & 6.4949 & 6.341 & TRN & \\
\hline CHEMBL 286700 & 305461 & 5.6778 & 5.8503 & TRN & \\
\hline CHEMBL264386 & 305461 & 7.8861 & 7.5215 & TRN & \\
\hline CHEMBL55928 & 305461 & 7.2218 & 7.1491 & TRN & \\
\hline CHEMBL180476 & 305461 & 6.7696 & 6.12299 & 9999999999 & TST \\
\hline CHEMBL 81820 & 305461 & 7.2757 & 7.3405 & TRN & \\
\hline CHEMBL121264 & 305461 & 6.857 & 7.0081 & TST & \\
\hline CHEMBL283518 & 305461 & 8.1192 & 8.2187 & TRN & \\
\hline CHEMBL141708 & 305461 & 5.6778 & 5.5966 & TRN & \\
\hline CHEMBL121433 & 305461 & 7.4685 & 7.4228 & TST & \\
\hline CHEMBL52698 & 305461 & 7.0605 & 7.1858 & TRN & \\
\hline CHEMBL283515 & 305461 & 4.6383 & 4.5496 & TST & \\
\hline CHEMBL 23288 & 305461 & 5.7212 & 5.8617 & TRN & \\
\hline CHEMBL113999 & 305461 & 6.0458 & 5.9737 & TRN & \\
\hline CHEMBL 80065 & 305461 & 7.4572 & 7.5827 & TRN & \\
\hline CHEMBL 33187 & 305461 & 5.5376 & 5.4774 & TRN & \\
\hline CHEMBL179131 & 305461 & 6.6383 & 6.5215 & TST & \\
\hline CHEMBL120939 & 305461 & 5.8327 & 6.1758 & TST & \\
\hline CHEMBL54913 & 305461 & 7.0862 & 7.0015 & TRN & \\
\hline CHEMBL 33208 & 305461 & 5.4815 & 5.5098 & TRN & \\
\hline CHEMBL123122 & 305461 & 7.3279 & 7.5407 & TST & \\
\hline CHEMBL 23021 & 305461 & 6.8928 & 7.1328 & TRN & \\
\hline CHEMBL17431 & 305461 & 4.7773 & 4.9577 & TRN & \\
\hline CHEMBL 275893 & 305461 & 4.0814 & 4.3509 & TRN & \\
\hline CHEMBL17430 & 305461 & 5.2757 & 5.1609 & TRN & \\
\hline CHEMBL52836 & 305461 & 6.699 & 6.6527 & TRN & \\
\hline CHEMBL23960 & 305461 & 3.8633 & 3.8686 & TST & \\
\hline CHEMBL 264548 & 305461 & 6.9355 & 6.8925 & TST & \\
\hline CHEMBL301105 & 305461 & 7.301 & 7.3466 & TRN & \\
\hline CHEMBL54618 & 305461 & 6.8539 & 6.9157 & TRN & \\
\hline CHEMBL 279679 & 305461 & 7.7595 & 7.5345 & TRN & \\
\hline CHEMBL33136 & 305461 & 6.5528 & 6.3763 & TRN & \\
\hline CHEMBL54523 & 305461 & 6.3768 & 6.4135 & TRN & \\
\hline CHEMBL116816 & 305461 & 5.9586 & 5.9917 & TRN & \\
\hline CHEMBL32635 & 305461 & 6.6198 & 6.6784 & TRN & \\
\hline CHEMBL 278110 & 305461 & 4.4647 & 3.8497 & TST & \\
\hline CHEMBL178684 & 305461 & 5.7878 & 6.0656 & TST & \\
\hline CHEMBL140705 & 305461 & 6.585 & 6.2763 & TRN & \\
\hline CHEMBL 80066 & 305461 & 7.4318 & 7.5504 & TRN & \\
\hline CHEMBL417746 & 305461 & 6.6778 & 6.8035 & TRN & \\
\hline CHEMBL 292143 & 305461 & 7.0655 & 7.284 & TST & \\
\hline CHEMBL 79347 & 305461 & 7.4437 & 7.371 & TRN & \\
\hline CHEMBL55179 & 305461 & 6.699 & 6.8748 & TRN & \\
\hline CHEMBL57682 & 305461 & 6.0 & 6.3601 & TST & \\
\hline
\end{tabular}




\begin{tabular}{|c|c|c|c|c|c|}
\hline \multicolumn{6}{|c|}{ Supplemental Table s2.txt } \\
\hline CHEMBL54732 & 305461 & 7.2366 & 7.0996 & TRN & \\
\hline CHEMBL53318 & 305461 & 6.9208 & 7.0854 & TRN & \\
\hline CHEMBL137981 & 305461 & 7.7447 & 7.8914 & TST & \\
\hline CHEMBL115474 & 305461 & 6.1805 & 6.2016 & TRN & \\
\hline CHEMBL52947 & 305461 & 6.5528 & 6.4523 & TRN & \\
\hline CHEMBL68439 & 305461 & 3.9355 & 4.0047 & TRN & \\
\hline CHEMBL54733 & 305461 & 6.585 & 6.7491 & TRN & \\
\hline CHEMBL32583 & 305461 & 5.8962 & 5.7262 & TRN & \\
\hline CHEMBL23532 & 305461 & 8.6778 & 8.5658 & TRN & \\
\hline CHEMBL142741 & 305461 & 6.5528 & 6.5889 & TRN & \\
\hline CHEMBL178119 & 305461 & 4.644 & 5.175 & TRN & \\
\hline CHEMBL57624 & 305461 & 8.5686 & 7.1565 & TRN & \\
\hline CHEMBL23297 & 305461 & 4.7905 & 4.4548 & TST & \\
\hline CHEMBL32708 & 305461 & 6.4559 & 6.2525 & TRN & \\
\hline CHEMBL145005 & 305461 & 4.9281 & 5.0335 & TRN & \\
\hline CHEMBL 32220 & 305461 & 6.3665 & 6.3406 & TRN & \\
\hline CHEMBL333791 & 305461 & 6.9626 & 7.0969 & TST & \\
\hline CHEMBL23867 & 305461 & 7.5287 & 7.3342 & TRN & \\
\hline CHEMBL32113 & 305461 & 7.2441 & 7.3596 & TRN & \\
\hline CHEMBL292212 & 305461 & 6.699 & 6.7058 & TRN & \\
\hline CHEMBL120826 & 305461 & 6.7959 & 7.1496 & TST & \\
\hline CHEMBL22561 & 305461 & 4.8356 & 4.4207 & TST & \\
\hline CHEMBL281803 & 305461 & 6.3904 & 6.1579 & TRN & \\
\hline CHEMBL115804 & 305461 & 7.3665 & 7.5546 & TRN & \\
\hline CHEMBL342555 & 305461 & 5.1308 & 5.3837 & TRN & \\
\hline CHEMBL283311 & 305461 & 4.9101 & 4.9133 & TST & \\
\hline CHEMBL121319 & 305461 & 6.6198 & 6.7397 & TST & \\
\hline CHEMBL178904 & 305461 & 6.8928 & 7.0152 & TST & \\
\hline CHEMBL300886 & 305461 & 6.284 & 6.6276 & TST & \\
\hline CHEMBL54538 & 305461 & 8.1367 & 8.118 & TRN & \\
\hline CHEMBL117750 & 305461 & 7.7212 & 7.8817 & TRN & \\
\hline CHEMBL55727 & 305461 & 8.1427 & 8.123 & TRN & \\
\hline CHEMBL300603 & 305461 & 7.7696 & 7.7978 & TRN & \\
\hline CHEMBL35569 & 305461 & 5.4815 & 5.7018 & TRN & \\
\hline CHEMBL23416 & 305461 & 7.2924 & 7.4016 & TRN & \\
\hline CHEMBL121868 & 305461 & 6.585 & 6.9286 & TST & \\
\hline CHEMBL55656 & 305461 & 6.7959 & 6.9328 & TST & \\
\hline CHEMBL120821 & 305461 & 7.1308 & 7.6041 & TST & \\
\hline CHEMBL68673 & 305461 & 4.2007 & 4.0124 & TRN & \\
\hline CHEMBL292427 & 305461 & 7.2676 & 7.3229 & TRN & \\
\hline CHEMBL121348 & 305461 & 7.3279 & 7.1825 & TST & \\
\hline CHEMBL32754 & 305461 & 5.5376 & 5.6844 & TRN & \\
\hline CHEMBL116614 & 305461 & 6.8539 & 6.567 & TRN & \\
\hline CHEMBL114833 & 305461 & 5.7959 & 5.8062 & TRN & \\
\hline CHEMBL325434 & 305461 & 7.585 & 7.7047 & TRN & \\
\hline CHEMBL32190 & 305461 & 7.4815 & 7.3197 & TRN & \\
\hline CHEMBL145068 & 305461 & 6.2147 & 6.28700 & 0000000001 & TRN \\
\hline CHEMBL23846 & 305461 & 4.9208 & 4.4894 & TST & \\
\hline
\end{tabular}




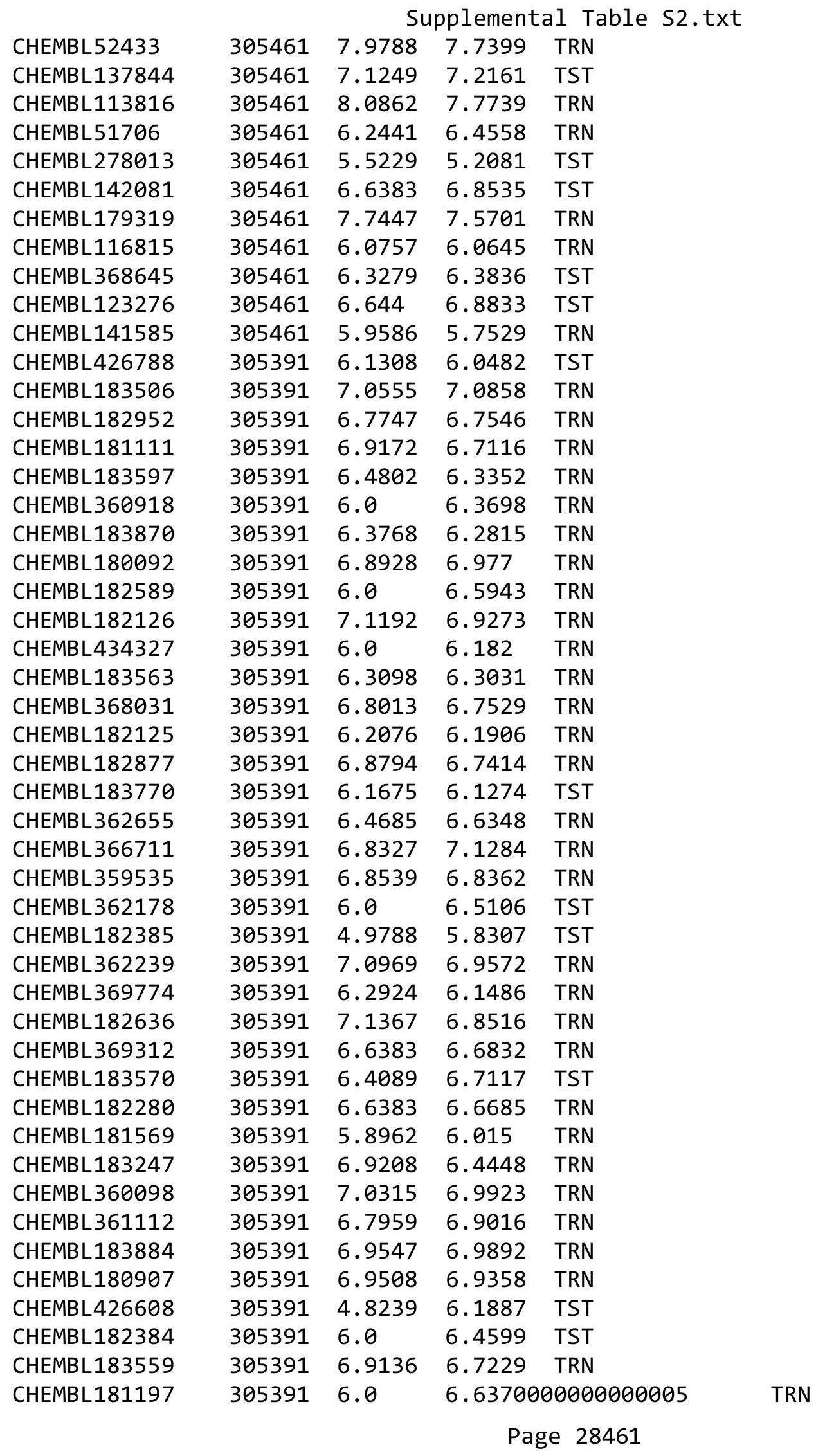




\begin{tabular}{|c|c|c|c|c|c|}
\hline \multicolumn{6}{|c|}{ Supplemental Table S2.txt } \\
\hline CHEMBL183680 & 305391 & 6.9666 & 7.0823 & TRN & \\
\hline CHEMBL359814 & 305391 & 6.2596 & 6.3042 & TRN & \\
\hline CHEMBL360249 & 305391 & 6.4377 & 6.5258 & TST & \\
\hline CHEMBL182733 & 305391 & 6.6576 & 6.7399 & TRN & \\
\hline CHEMBL180283 & 305391 & 6.4547 & 6.474 & TST & \\
\hline CHEMBL183699 & 305391 & 6.9208 & 6.3793 & TRN & \\
\hline CHEMBL182447 & 305391 & 7.2924 & 7.3257 & TRN & \\
\hline CHEMBL360082 & 305391 & 6.0 & 5.9716 & TRN & \\
\hline CHEMBL181146 & 305391 & 7.0969 & 7.3281 & TRN & \\
\hline CHEMBL183272 & 305391 & 7.3665 & 7.2463 & TRN & \\
\hline CHEMBL180486 & 305391 & 6.7747 & 6.7962 & TST & \\
\hline CHEMBL183226 & 305391 & 7.1135 & 7.0228 & TRN & \\
\hline CHEMBL183904 & 305391 & 6.6696 & 6.9255 & TRN & \\
\hline CHEMBL182693 & 305391 & 6.1267 & 5.7863 & TST & \\
\hline CHEMBL181106 & 305391 & 7.2076 & 7.0202 & TRN & \\
\hline CHEMBL183444 & 305391 & 6.7167 & 6.6308 & TST & \\
\hline CHEMBL181377 & 305391 & 6.7959 & 6.8731 & TRN & \\
\hline CHEMBL360765 & 305391 & 6.6421 & 6.7242 & TRN & \\
\hline CHEMBL179875 & 305391 & 6.9469 & 6.6992 & TRN & \\
\hline CHEMBL183485 & 305391 & 7.0555 & 7.0081 & TRN & \\
\hline CHEMBL360677 & 305391 & 6.7305 & 6.75 & TRN & \\
\hline CHEMBL182732 & 305391 & 6.0 & 6.0302 & TRN & \\
\hline CHEMBL183295 & 305391 & 6.9508 & 6.8159 & TST & \\
\hline CHEMBL 360772 & 305391 & 7.2218 & 6.4252 & TST & \\
\hline CHEMBL183111 & 305391 & 6.7825 & 6.6865 & TRN & \\
\hline CHEMBL360487 & 305391 & 5.4437 & 6.0428 & TST & \\
\hline CHEMBL182784 & 305391 & 6.3279 & 6.2708 & TRN & \\
\hline CHEMBL183781 & 305391 & 6.5229 & 6.5559 & TRN & \\
\hline CHEMBL361628 & 305391 & 6.0 & 6.3608 & TST & \\
\hline CHEMBL183017 & 305391 & 7.0458 & 6.914 & TRN & \\
\hline CHEMBL181343 & 305391 & 6.6021 & 6.2537 & TRN & \\
\hline CHEMBL183139 & 305391 & 6.1192 & 5.7906 & TST & \\
\hline CHEMBL183598 & 305391 & 7.585 & 7.4008 & TRN & \\
\hline CHEMBL 362260 & 305391 & 6.0 & 6.2573 & TRN & \\
\hline CHEMBL426426 & 305391 & 6.0458 & 6.0193 & TRN & \\
\hline CHEMBL180097 & 305391 & 4.9208 & 5.7388 & TST & \\
\hline CHEMBL183780 & 305391 & 6.8996 & 6.75799 & 9999999999 & TST \\
\hline CHEMBL180653 & 305391 & 6.6383 & 6.6034 & TRN & \\
\hline CHEMBL181271 & 305391 & 6.5229 & 6.7068 & TST & \\
\hline CHEMBL182333 & 305391 & 6.0 & 6.3291 & TRN & \\
\hline CHEMBL180412 & 305391 & 7.2924 & 7.2426 & TRN & \\
\hline CHEMBL182453 & 305391 & 6.8539 & 6.9361 & TRN & \\
\hline CHEMBL225197 & 430066 & 5.2007 & 4.7845 & TST & \\
\hline CHEMBL 225253 & 430066 & 2.301 & 2.3472 & TRN & \\
\hline CHEMBL222210 & 430066 & 5.3468 & 5.3716 & TRN & \\
\hline CHEMBL387956 & 430066 & 5.0862 & 5.0843 & TRN & \\
\hline CHEMBL224848 & 430066 & 2.301 & 3.2258 & TRN & \\
\hline CHEMBL225405 & 430066 & 5.301 & 5.3167 & TRN & \\
\hline
\end{tabular}




\begin{tabular}{|c|c|c|c|c|c|}
\hline \multicolumn{6}{|c|}{ Supplemental Table S2.txt } \\
\hline CHEMBL222208 & 430066 & 5.1871 & 5.0726 & TRN & \\
\hline CHEMBL417155 & 430066 & 5.301 & 4.6091 & TST & \\
\hline CHEMBL222910 & 430066 & 4.0757 & 3.2258 & TRN & \\
\hline CHEMBL376544 & 430066 & 5.4815 & 5.4397 & TRN & \\
\hline CHEMBL225585 & 430066 & 2.301 & 2.2837 & TRN & \\
\hline CHEMBL373877 & 430066 & 5.8861 & 5.8229 & TRN & \\
\hline CHEMBL374202 & 430066 & 3.9508 & 3.7078 & TST & \\
\hline CHEMBL221785 & 430066 & 3.7496 & 3.7397 & TRN & \\
\hline CHEMBL222042 & 430066 & 3.5622 & 3.5246 & TRN & \\
\hline CHEMBL1438 & 430066 & 2.699 & 2.7572 & TST & \\
\hline CHEMBL224836 & 430066 & 4.2924 & 4.3088 & TRN & \\
\hline CHEMBL 225140 & 430066 & 2.301 & 2.3845 & TRN & \\
\hline CHEMBL445584 & 430066 & 3.301 & 3.32800 & 00000000003 & TRN \\
\hline CHEMBL390536 & 430066 & 3.301 & 3.3049 & TRN & \\
\hline CHEMBL 225170 & 430066 & 5.9586 & 6.0319 & TRN & \\
\hline CHEMBL225495 & 430066 & 5.6576 & 5.7031 & TRN & \\
\hline CHEMBL425125 & 430066 & 5.3188 & 5.1295 & TST & \\
\hline CHEMBL388171 & 430066 & 4.9586 & 4.8252 & TRN & \\
\hline CHEMBL 309487 & 430066 & 2.301 & 2.7031 & TST & \\
\hline CHEMBL222105 & 430066 & 5.3665 & 5.3748 & TRN & \\
\hline CHEMBL221365 & 430066 & 2.301 & 2.2133 & TRN & \\
\hline CHEMBL225408 & 430066 & 5.6021 & 5.6017 & TRN & \\
\hline CHEMBL 373380 & 430066 & 5.1612 & 5.0897 & TRN & \\
\hline CHEMBL 373470 & 430066 & 4.4559 & 4.416 & TRN & \\
\hline CHEMBL221456 & 430066 & 3.5229 & 3.5246 & TRN & \\
\hline CHEMBL287713 & 430066 & 5.0458 & 5.0726 & TRN & \\
\hline CHEMBL376872 & 430066 & 4.5229 & 4.51 & TRN & \\
\hline CHEMBL 225648 & 430066 & 2.301 & 2.3047 & TRN & \\
\hline CHEMBL39043 & 430066 & 5.301 & 4.6091 & TST & \\
\hline CHEMBL225189 & 430066 & 6.6576 & 6.6246 & TRN & \\
\hline CHEMBL 39010 & 430066 & 3.9872 & 3.84899 & 99999999998 & TST \\
\hline CHEMBL288505 & 430066 & 4.4089 & 4.0201 & TST & \\
\hline CHEMBL 222263 & 430066 & 3.3487 & 3.1494 & TST & \\
\hline CHEMBL 222770 & 430066 & 3.9508 & 4.2092 & TRN & \\
\hline CHEMBL 275861 & 430066 & 2.301 & 2.1883 & TRN & \\
\hline CHEMBL225389 & 430066 & 4.4437 & 4.4995 & TRN & \\
\hline CHEMBL221361 & 430066 & 2.699 & 2.6373 & TRN & \\
\hline CHEMBL 288861 & 430066 & 3.7905 & 3.4359 & TST & \\
\hline CHEMBL376661 & 430066 & 4.8861 & 4.8252 & TRN & \\
\hline CHEMBL 374113 & 430066 & 5.2924 & 5.3566 & TRN & \\
\hline CHEMBL540451 & 430066 & 5.2757 & 5.2997 & TRN & \\
\hline CHEMBL376560 & 430066 & 4.5229 & 4.3652 & TST & \\
\hline CHEMBL388327 & 430066 & 4.9586 & 4.3652 & TST & \\
\hline CHEMBL225586 & 430066 & 2.301 & 2.3473 & TRN & \\
\hline CHEMBL49026 & 158036 & 4.41 & 4.425 & TRN & \\
\hline CHEMBL46337 & 158036 & 9.22 & 9.1632 & TRN & \\
\hline CHEMBL298303 & 158036 & 8.68 & 8.6732 & TRN & \\
\hline CHEMBL299659 & 158036 & 9.66 & 9.5544 & TRN & \\
\hline
\end{tabular}




\begin{tabular}{|c|c|c|c|c|c|}
\hline \multicolumn{6}{|c|}{ Supplemental Table S2.txt } \\
\hline CHEMBL 300512 & 158036 & 6.01 & 5.9579 & TRN & \\
\hline CHEMBL49936 & 158036 & 6.92 & 6.9207 & TRN & \\
\hline CHEMBL51680 & 158036 & 6.74 & 6.8069 & TRN & \\
\hline CHEMBL 3350208 & 158036 & 6.44 & 7.7811 & TST & \\
\hline CHEMBL 300035 & 158036 & 4.89 & 4.8788 & TRN & \\
\hline CHEMBL 299375 & 158036 & 8.43 & 8.5659 & TRN & \\
\hline CHEMBL51921 & 158036 & 5.45 & 5.4868 & TRN & \\
\hline CHEMBL49288 & 158036 & 8.31 & 8.3548 & TRN & \\
\hline CHEMBL 263523 & 158036 & 8.06 & 9.7157 & TST & \\
\hline CHEMBL301728 & 158036 & 7.45 & 4.7337 & TST & \\
\hline CHEMBL51362 & 158036 & 6.44 & 8.2787 & TST & \\
\hline CHEMBL423661 & 158036 & 5.35 & 5.337000 & 0000000001 & TRN \\
\hline CHEMBL51521 & 158036 & 8.0 & 7.9468 & TRN & \\
\hline CHEMBL 2311136 & 158036 & 7.68 & 7.9168 & TRN & \\
\hline CHEMBL417012 & 158036 & 5.58 & 5.6275 & TRN & \\
\hline CHEMBL 297576 & 158036 & 4.41 & 4.3282 & TRN & \\
\hline CHEMBL48996 & 158036 & 6.11 & 5.3232 & TST & \\
\hline CHEMBL52130 & 158036 & 9.0 & 8.9658 & TRN & \\
\hline CHEMBL 297931 & 158036 & 7.96 & 8.6126 & TRN & \\
\hline CHEMBL50812 & 158036 & 4.72 & 5.6452 & TST & \\
\hline CHEMBL 298903 & 158036 & 5.1 & 5.5169 & TRN & \\
\hline CHEMBL 295414 & 158036 & 9.47 & 10.2549 & TST & \\
\hline CHEMBL52483 & 158036 & 7.15 & 9.1171 & TST & \\
\hline CHEMBL51073 & 158036 & 4.42 & 4.5087 & TRN & \\
\hline CHEMBL433088 & 158036 & 6.8 & 6.8366 & TRN & \\
\hline CHEMBL3350206 & 158036 & 8.3 & 10.4311 & TST & \\
\hline CHEMBL52051 & 158036 & 8.54 & 8.5513 & TRN & \\
\hline CHEMBL3350218 & 158036 & 7.92 & 10.9592 & TST & \\
\hline CHEMBL48180 & 158036 & 8.3 & 9.6227 & TST & \\
\hline CHEMBL52494 & 158036 & 5.97 & 5.5451 & TRN & \\
\hline CHEMBL407010 & 158036 & 6.3 & 6.282999 & 99999999995 & TRN \\
\hline CHEMBL52495 & 158036 & 6.09 & 6.0863 & TRN & \\
\hline CHEMBL3350203 & 158036 & 7.59 & 10.8935 & TST & \\
\hline CHEMBL49004 & 158036 & 7.74 & 7.7695 & TRN & \\
\hline CHEMBL3350197 & 158036 & 8.3 & 10.6613 & TST & \\
\hline CHEMBL408723 & 158036 & 8.66 & 8.6359 & TRN & \\
\hline CHEMBL48491 & 158036 & 5.36 & 5.4422 & TRN & \\
\hline CHEMBL 277655 & 158036 & 7.32 & 7.3511 & TRN & \\
\hline CHEMBL49643 & 158036 & 5.92 & 5.8053 & TRN & \\
\hline CHEMBL 300858 & 158036 & 8.47 & 8.5081 & TRN & \\
\hline CHEMBL 296811 & 158036 & 5.43 & 5.4695 & TRN & \\
\hline CHEMBL 77621 & 158036 & 4.74 & 4.6497 & TRN & \\
\hline CHEMBL444834 & 158036 & 6.38 & 6.4053 & TRN & \\
\hline CHEMBL407853 & 158036 & 7.15 & 7.1659 & TRN & \\
\hline CHEMBL 265557 & 158036 & 7.1 & 7.075 & TRN & \\
\hline CHEMBL 297192 & 158036 & 7.68 & 7.4679 & TRN & \\
\hline CHEMBL300714 & 158036 & 5.34 & 5.2383 & TRN & \\
\hline CHEMBL 300050 & 158036 & 9.62 & 9.0113 & TRN & \\
\hline
\end{tabular}




\begin{tabular}{|c|c|c|c|c|c|}
\hline \multicolumn{6}{|c|}{ Supplemental Table S2.txt } \\
\hline CHEMBL301365 & 158036 & 8.85 & 8.8353 & TRN & \\
\hline CHEMBL48693 & 158036 & 7.92 & 6.8774 & TST & \\
\hline CHEMBL1575482 & 688284 & 4.3866 & 4.5321 & TRN & \\
\hline CHEMBL1508109 & 688284 & 5.4377 & 5.1802 & TST & \\
\hline CHEMBL1390419 & 688284 & 4.1674 & 5.0727 & TST & \\
\hline CHEMBL1425551 & 688284 & 4.4728 & 4.7724 & TST & \\
\hline CHEMBL1309121 & 688284 & 5.0255 & 4.8215 & TRN & \\
\hline CHEMBL1427857 & 688284 & 4.1056 & 4.3439 & TST & \\
\hline CHEMBL1329322 & 688284 & 4.6872 & 4.6962 & TST & \\
\hline CHEMBL1465386 & 688284 & 4.6774 & 4.5328 & TRN & \\
\hline CHEMBL1540525 & 688284 & 4.2474 & 4.1483 & TRN & \\
\hline CHEMBL3207825 & 688284 & 4.0025 & 4.3072 & TRN & \\
\hline CHEMBL1574127 & 688284 & 4.0457 & 4.3788 & TST & \\
\hline CHEMBL1559282 & 688284 & 4.3239 & 4.0253 & TRN & \\
\hline CHEMBL1484046 & 688284 & 4.2318 & 4.3696 & TRN & \\
\hline CHEMBL1370806 & 688284 & 4.7397 & 5.2514 & TRN & \\
\hline CHEMBL3192540 & 688284 & 4.2423 & 4.84 & TRN & \\
\hline CHEMBL1542429 & 688284 & 5.2291 & 4.9793 & TRN & \\
\hline CHEMBL1522654 & 688284 & 5.0991 & 5.5934 & TRN & \\
\hline CHEMBL1546981 & 688284 & 4.498 & 4.4774 & TRN & \\
\hline CHEMBL1404669 & 688284 & 4.1208 & 5.3419 & TST & \\
\hline CHEMBL1462218 & 688284 & 7.0 & 6.3022 & TRN & \\
\hline CHEMBL1299355 & 688284 & 5.06 & 5.0333 & TRN & \\
\hline CHEMBL1303316 & 688284 & 4.8758 & 4.9404 & TRN & \\
\hline CHEMBL1583406 & 688284 & 4.2054 & 4.2802 & TRN & \\
\hline CHEMBL1510581 & 688284 & 4.5133 & 5.045 & TRN & \\
\hline CHEMBL1500165 & 688284 & 5.3635 & 5.33799 & 9999999999 & TRN \\
\hline CHEMBL1399882 & 688284 & 4.3043 & 4.9275 & TST & \\
\hline CHEMBL1563786 & 688284 & 4.8005 & 4.32 & TRN & \\
\hline CHEMBL1500641 & 688284 & 4.3093 & 4.4646 & TRN & \\
\hline CHEMBL1448792 & 688284 & 5.0141 & 4.5329 & TRN & \\
\hline CHEMBL1524886 & 688284 & 4.9259 & 4.9528 & TRN & \\
\hline CHEMBL1596931 & 688284 & 4.4811 & 4.43199 & 99999999995 & TRN \\
\hline CHEMBL1326643 & 688284 & 5.317 & 6.0211 & TRN & \\
\hline CHEMBL1378174 & 688284 & 5.2055 & 5.4435 & TRN & \\
\hline CHEMBL1319512 & 688284 & 4.5354 & 4.6535 & TRN & \\
\hline CHEMBL3196869 & 688284 & 4.6724 & 4.8749 & TRN & \\
\hline CHEMBL370611 & 688284 & 5.5317 & 5.1495 & TRN & \\
\hline CHEMBL402300 & 688284 & 4.0211 & 4.8316 & TST & \\
\hline CHEMBL1550861 & 688284 & 4.337 & 4.3259 & TRN & \\
\hline CHEMBL1420660 & 688284 & 4.0771 & 4.9235 & TRN & \\
\hline CHEMBL1487498 & 688284 & 4.6227 & 4.6251 & TST & \\
\hline CHEMBL1418928 & 688284 & 5.2248 & 5.0837 & TRN & \\
\hline CHEMBL1483180 & 688284 & 4.919 & 4.7705 & TRN & \\
\hline CHEMBL1451429 & 688284 & 4.8162 & 5.072 & TRN & \\
\hline CHEMBL1600606 & 688284 & 4.7091 & 4.4669 & TRN & \\
\hline CHEMBL35888 & 688284 & 4.9017 & 4.8895 & TRN & \\
\hline CHEMBL1459907 & 688284 & 5.9914 & 5.9122 & TRN & \\
\hline
\end{tabular}


Supplemental Table S2.txt

\begin{tabular}{|c|c|c|c|c|c|}
\hline CHEMBL1340299 & 688284 & 4.6983 & 5.5034 & TST & \\
\hline CHEMBL1574404 & 688284 & 4.6807 & 4.6877 & TRN & \\
\hline CHEMBL1610589 & 688284 & 5.0097 & 4.5161 & TRN & \\
\hline CHEMBL1462499 & 688284 & 4.3944 & 4.3035 & TRN & \\
\hline CHEMBL1399371 & 688284 & 4.1903 & 4.9172 & TST & \\
\hline CHEMBL3209978 & 688284 & 4.0938 & 4.7459 & TRN & \\
\hline CHEMBL1388169 & 688284 & 5.1427 & 5.0216 & TRN & \\
\hline CHEMBL 3213454 & 688284 & 4.9119 & 4.0406 & TRN & \\
\hline CHEMBL1443361 & 688284 & 4.9187 & 4.9095 & TRN & \\
\hline CHEMBL3208162 & 688284 & 3.8902 & 4.4273 & TRN & \\
\hline CHEMBL1606502 & 688284 & 5.5498 & 5.3458 & TRN & \\
\hline CHEMBL1576913 & 688284 & 4.0015 & 4.3739 & TST & \\
\hline CHEMBL1540273 & 688284 & 4.5352 & 4.7171 & TRN & \\
\hline CHEMBL1350103 & 688284 & 4.1225 & 4.746 & TRN & \\
\hline CHEMBL1975179 & 688284 & 5.4295 & 4.391 & TST & \\
\hline CHEMBL1382785 & 688284 & 5.2733 & 5.2036 & TRN & \\
\hline CHEMBL1305379 & 688284 & 4.7433 & 4.888 & TRN & \\
\hline CHEMBL1242180 & 688284 & 4.0533 & 4.8595 & TST & \\
\hline CHEMBL1321345 & 688284 & 4.6012 & 5.0349 & TRN & \\
\hline CHEMBL1401676 & 688284 & 4.0743 & 4.8554 & TRN & \\
\hline CHEMBL1996030 & 688284 & 4.285 & 4.2812 & TST & \\
\hline CHEMBL1576399 & 688284 & 4.2631 & 4.3408 & TRN & \\
\hline CHEMBL1364176 & 688284 & 5.5272 & 5.25 & TST & \\
\hline CHEMBL1600959 & 688284 & 4.3452 & 4.5569 & TRN & \\
\hline CHEMBL1416046 & 688284 & 5.2636 & 5.417999 & 9999999999 & TRN \\
\hline CHEMBL1393480 & 688284 & 4.4069 & 5.022 & TRN & \\
\hline CHEMBL1594736 & 688284 & 4.6615 & 4.8318 & TST & \\
\hline CHEMBL1580518 & 688284 & 4.967 & 4.9805 & TRN & \\
\hline CHEMBL1603977 & 688284 & 4.6442 & 4.6303 & TST & \\
\hline CHEMBL1326616 & 688284 & 5.1096 & 4.9676 & TRN & \\
\hline CHEMBL1299222 & 688284 & 3.9442 & 4.0929 & TRN & \\
\hline CHEMBL1301548 & 688284 & 4.37 & 4.4167 & TRN & \\
\hline CHEMBL1326397 & 688284 & 4.8564 & 4.8713 & TST & \\
\hline CHEMBL1380472 & 688284 & 4.2272 & 4.6983 & TRN & \\
\hline CHEMBL1302825 & 688284 & 4.8533 & 4.8372 & TRN & \\
\hline CHEMBL1612489 & 688284 & 4.2928 & 4.8016 & TRN & \\
\hline CHEMBL1492010 & 688284 & 7.0 & 6.2181 & TRN & \\
\hline CHEMBL1597894 & 688284 & 4.6592 & 4.7418 & TRN & \\
\hline CHEMBL1352058 & 688284 & 4.6371 & 4.7548 & TRN & \\
\hline CHEMBL1370991 & 688284 & 7.0 & 5.8026 & TRN & \\
\hline CHEMBL1611789 & 688284 & 5.1457 & 4.7495 & TRN & \\
\hline CHEMBL1608069 & 688284 & 5.76200 & 000000000 & 5.6223 & $1 \mathrm{KI}$ \\
\hline CHEMBL1609417 & 688284 & 5.4168 & 4.9797 & TRN & \\
\hline CHEMBL1567691 & 688284 & 5.2457 & 4.7738 & TRN & \\
\hline CHEMBL1445020 & 688284 & 4.1336 & 4.1634 & TRN & \\
\hline CHEMBL1518016 & 688284 & 5.15 & 5.154 & TRN & \\
\hline CHEMBL1563937 & 688284 & 4.9045 & 5.1473 & TRN & \\
\hline CHEMBL1310309 & 688284 & 4.6121 & 4.917 & TRN & \\
\hline
\end{tabular}


Supplemental Table s2.txt

\begin{tabular}{|c|c|c|c|c|c|}
\hline CHEMBL1416512 & 688284 & 4.6108 & 4.4871 & TRN & \\
\hline CHEMBL3193655 & 688284 & 4.1404 & 4.1555 & TRN & \\
\hline CHEMBL1304445 & 688284 & 5.1409 & 4.5396 & TRN & \\
\hline CHEMBL1549097 & 688284 & 4.856 & 4.8495 & TRN & \\
\hline CHEMBL1566496 & 688284 & 4.2129 & 4.6055 & TST & \\
\hline CHEMBL1450885 & 688284 & 4.6908 & 4.5589 & TST & \\
\hline CHEMBL1503946 & 688284 & 4.3159 & 4.5415 & TRN & \\
\hline CHEMBL1546729 & 688284 & 5.3316 & 4.621 & TST & \\
\hline CHEMBL1384526 & 688284 & 7.0 & 5.5903 & TRN & \\
\hline CHEMBL1399298 & 688284 & 5.6108 & 5.4821 & TRN & \\
\hline CHEMBL1608243 & 688284 & 4.8395 & 5.0442 & TRN & \\
\hline CHEMBL1511502 & 688284 & 5.2984 & 5.5086 & TRN & \\
\hline CHEMBL1428114 & 688284 & 4.8765 & 4.853 & TST & \\
\hline CHEMBL1309220 & 688284 & 5.5058 & 5.3194 & TST & \\
\hline CHEMBL1372559 & 688284 & 4.1996 & 4.3566 & TST & \\
\hline CHEMBL1505651 & 688284 & 4.8745 & 5.13 & TRN & \\
\hline CHEMBL1538544 & 688284 & 3.9786 & 4.1979 & TRN & \\
\hline CHEMBL1550828 & 688284 & 4.7317 & 5.6552 & TRN & \\
\hline CHEMBL1532614 & 688284 & 5.1007 & 4.80699 & & TRN \\
\hline CHEMBL1597669 & 688284 & 7.0 & 6.11700 & 0000000001 & TRN \\
\hline CHEMBL1459332 & 688284 & 4.4482 & 5.1295 & TRN & \\
\hline CHEMBL1374083 & 688284 & 7.0 & 4.9996 & TST & \\
\hline CHEMBL1540300 & 688284 & 4.83 & 4.8713 & TRN & \\
\hline CHEMBL1352990 & 688284 & \multicolumn{3}{|c|}{5.218999999999999} & TRN \\
\hline CHEMBL1350596 & 688284 & 4.7471 & 4.9675 & TRN & \\
\hline CHEMBL1359070 & 688284 & 4.1158 & 4.5627 & TST & \\
\hline CHEMBL1571174 & 688284 & 5.1198 & 5.1796 & TRN & \\
\hline CHEMBL1338022 & 688284 & 4.198 & 4.4108 & TRN & \\
\hline CHEMBL1520994 & 688284 & 4.2284 & 4.4045 & TRN & \\
\hline CHEMBL1369634 & 688284 & 5.6968 & 5.1073 & TRN & \\
\hline CHEMBL 3214202 & 688284 & 4.6794 & 4.6087 & TRN & \\
\hline CHEMBL3214187 & 688284 & 4.1601 & 4.1951 & TRN & \\
\hline CHEMBL1349140 & 688284 & 4.0455 & 4.3671 & TRN & \\
\hline CHEMBL1415339 & 688284 & 4.9423 & 4.6662 & TRN & \\
\hline CHEMBL1491588 & 688284 & 4.6019 & 4.4279 & TRN & \\
\hline CHEMBL1322258 & 688284 & 5.1911 & 4.3309 & TST & \\
\hline CHEMBL1497026 & 688284 & 4.3612 & 5.0748 & TRN & \\
\hline CHEMBL1568922 & 688284 & 4.2207 & 5.2106 & TST & \\
\hline CHEMBL1448279 & 688284 & 4.4224 & 4.5584 & TRN & \\
\hline CHEMBL1506533 & 688284 & 5.8297 & 5.6793 & TRN & \\
\hline CHEMBL1423308 & 688284 & 4.791 & 4.9833 & TRN & \\
\hline CHEMBL1521602 & 688284 & 4.8164 & 4.3174 & TRN & \\
\hline CHEMBL1462573 & 688284 & 4.7937 & 4.3689 & TRN & \\
\hline CHEMBL1312990 & 688284 & 4.6919 & 4.7495 & TRN & \\
\hline CHEMBL1454652 & 688284 & 4.5032 & 4.4739 & TRN & \\
\hline CHEMBL1550488 & 688284 & 5.2916 & 5.5736 & TRN & \\
\hline CHEMBL1313434 & 688284 & 4.2818 & 4.162 & TRN & \\
\hline CHEMBL1300250 & 688284 & 5.5735 & 5.5345 & TRN & \\
\hline
\end{tabular}




\begin{tabular}{|c|c|c|c|c|c|}
\hline \multicolumn{6}{|c|}{ Supplemental Table S2.txt } \\
\hline CHEMBL1532925 & 688284 & 5.5467 & 5.0736 & TRN & \\
\hline CHEMBL1379170 & 688284 & 4.9923 & 5.0031 & TRN & \\
\hline CHEMBL1464272 & 688284 & 4.4068 & 4.4847 & TRN & \\
\hline CHEMBL1439633 & 688284 & 4.533 & 4.75 & TRN & \\
\hline CHEMBL1496897 & 688284 & 4.0255 & 4.8773 & TST & \\
\hline CHEMBL3194460 & 688284 & 4.8745 & 5.0821 & TRN & \\
\hline CHEMBL1493353 & 688284 & 4.9374 & 4.9131 & TST & \\
\hline CHEMBL1392396 & 688284 & 7.0 & 6.1677 & TRN & \\
\hline CHEMBL1406171 & 688284 & 4.4684 & 4.6387 & TRN & \\
\hline CHEMBL1603993 & 688284 & 4.9987 & 4.9155 & TRN & \\
\hline CHEMBL1549018 & 688284 & 4.1669 & 5.2511 & TST & \\
\hline CHEMBL1546136 & 688284 & 4.687 & 4.6019 & TRN & \\
\hline CHEMBL1386804 & 688284 & 5.3197 & 5.652 & TRN & \\
\hline CHEMBL1335999 & 688284 & 4.7284 & 4.4268 & TRN & \\
\hline CHEMBL1503251 & 688284 & 4.8807 & 4.9772 & TRN & \\
\hline CHEMBL1389299 & 688284 & 4.574 & 4.6912 & TST & \\
\hline CHEMBL1423356 & 688284 & 5.1746 & 4.834 & TRN & \\
\hline CHEMBL1421228 & 688284 & 3.9639 & 4.5071 & TST & \\
\hline CHEMBL1604631 & 688284 & 4.8049 & 5.4674 & TRN & \\
\hline CHEMBL1412254 & 688284 & 5.0395 & 5.1262 & TRN & \\
\hline CHEMBL 240331 & 688284 & 4.8867 & 4.7539 & TRN & \\
\hline CHEMBL1550377 & 688284 & 4.3784 & 4.3072 & TRN & \\
\hline CHEMBL3191785 & 688284 & 4.3409 & 4.6504 & TRN & \\
\hline CHEMBL1324741 & 688284 & 5.1925 & 4.8312 & TRN & \\
\hline CHEMBL1342138 & 688284 & 4.9255 & 5.0394 & TRN & \\
\hline CHEMBL3196931 & 688284 & 4.7219 & 4.6787 & TRN & \\
\hline CHEMBL1597358 & 688284 & 5.1046 & 5.3585 & TST & \\
\hline CHEMBL1470629 & 688284 & 4.2159 & 4.808 & TST & \\
\hline CHEMBL1426255 & 688284 & 4.2779 & 5.0769 & TST & \\
\hline CHEMBL1302576 & 688284 & 4.6326 & 4.796 & TRN & \\
\hline CHEMBL1569574 & 688284 & 4.8294 & 4.7926 & TRN & \\
\hline CHEMBL1425332 & 688284 & 4.1505 & 4.5104 & TST & \\
\hline CHEMBL1486854 & 688284 & 5.279 & 4.7054 & TST & \\
\hline CHEMBL1408736 & 688284 & 4.1489 & 4.17399 & 99999999995 & TRN \\
\hline CHEMBL1336420 & 688284 & 5.2924 & 5.5192 & TRN & \\
\hline CHEMBL1320177 & 688284 & 4.8052 & 4.9259 & TRN & \\
\hline CHEMBL1505117 & 688284 & 5.8761 & 5.4665 & TRN & \\
\hline CHEMBL1349476 & 688284 & 4.6728 & 4.5397 & TRN & \\
\hline CHEMBL1383053 & 688284 & 5.3645 & 4.8212 & TRN & \\
\hline CHEMBL1492299 & 688284 & 4.35 & 4.6172 & TRN & \\
\hline CHEMBL1412367 & 688284 & 4.997 & 5.28600 & 00000000005 & TRN \\
\hline CHEMBL1564658 & 688284 & 4.2354 & 4.5889 & TST & \\
\hline CHEMBL1430358 & 688284 & 4.0386 & 4.4824 & TST & \\
\hline CHEMBL1382834 & 688284 & 5.7545 & 4.4856 & TST & \\
\hline CHEMBL1411307 & 688284 & 4.6794 & 4.6163 & TST & \\
\hline CHEMBL1569694 & 688284 & 4.5173 & 4.6553 & TRN & \\
\hline CHEMBL1404254 & 688284 & 4.7678 & 4.8678 & TRN & \\
\hline CHEMBL1343343 & 688284 & 5.9469 & 5.4787 & TRN & \\
\hline
\end{tabular}


Supplemental Table S2.txt

\begin{tabular}{|c|c|c|c|c|c|}
\hline CHEMBL1544163 & 688284 & 3.9062 & 4.7161 & TST & \\
\hline CHEMBL1459601 & 688284 & 4.7773 & 4.3086 & TRN & \\
\hline CHEMBL1416076 & 688284 & 4.3279 & 4.7792 & TRN & \\
\hline CHEMBL1376311 & 688284 & 4.9923 & 4.9009 & TRN & \\
\hline CHEMBL1568925 & 688284 & 4.4947 & 4.8904 & TRN & \\
\hline CHEMBL1522027 & 688284 & 4.9551 & 4.8864 & TRN & \\
\hline CHEMBL1490352 & 688284 & 3.9485 & 4.0053 & TST & \\
\hline CHEMBL1301069 & 688284 & 4.9626 & 5.1082 & TRN & \\
\hline CHEMBL3192108 & 688284 & 4.8771 & 4.6366 & TRN & \\
\hline CHEMBL1453076 & 688284 & 4.1216 & 5.0342 & TST & \\
\hline CHEMBL1373511 & 688284 & 5.0306 & 5.1068 & TRN & \\
\hline CHEMBL1444633 & 688284 & 4.6275 & 4.0999 & TRN & \\
\hline CHEMBL 3194740 & 688284 & 5.091 & 5.5815 & TRN & \\
\hline CHEMBL1426714 & 688284 & 4.0014 & 4.7177 & TRN & \\
\hline CHEMBL3198017 & 688284 & 4.5423 & 4.4256 & TST & \\
\hline CHEMBL3212531 & 688284 & 4.4369 & 4.763 & TRN & \\
\hline CHEMBL1599447 & 688284 & 5.5157 & 5.3945 & TRN & \\
\hline CHEMBL1409045 & 688284 & 4.3577 & 4.55 & TRN & \\
\hline CHEMBL1340083 & 688284 & 4.7945 & 5.1363 & TRN & \\
\hline CHEMBL1400396 & 688284 & 4.934 & 4.7445 & TRN & \\
\hline CHEMBL1410601 & 688284 & 5.0066 & 4.8314 & TRN & \\
\hline CHEMBL1343730 & 688284 & 5.0353 & 4.19600 & 0000000001 & TRN \\
\hline CHEMBL1331729 & 688284 & 5.1244 & 4.9126 & TRN & \\
\hline CHEMBL1452717 & 688284 & 5.1186 & 4.95 & TRN & \\
\hline CHEMBL3194385 & 688284 & 4.3047 & 4.2233 & TRN & \\
\hline CHEMBL1328326 & 688284 & 4.5439 & 4.7643 & TRN & \\
\hline CHEMBL1401270 & 688284 & 4.819 & 5.0906 & TRN & \\
\hline CHEMBL1544493 & 688284 & 5.6861 & 5.1474 & TRN & \\
\hline CHEMBL1501536 & 688284 & 5.06 & \multicolumn{2}{|c|}{4.861000000000001} & TRN \\
\hline CHEMBL1498329 & 688284 & 4.1127 & 4.8947 & TST & \\
\hline CHEMBL1420929 & 688284 & 4.787 & 5.063 & TST & \\
\hline CHEMBL1500368 & 688284 & 4.391 & 4.4863 & TRN & \\
\hline CHEMBL1607746 & 688284 & 4.3578 & 4.4329 & TRN & \\
\hline CHEMBL1343459 & 688284 & 4.5536 & 5.5558 & TRN & \\
\hline CHEMBL1374226 & 688284 & 5.2154 & 4.8656 & TRN & \\
\hline CHEMBL1580706 & 688284 & 4.8362 & 4.6956 & TRN & \\
\hline CHEMBL1608439 & 688284 & 5.0381 & 5.0252 & TRN & \\
\hline CHEMBL1972962 & 688284 & 3.9589 & 4.9754 & TRN & \\
\hline CHEMBL1563770 & 688284 & 4.4662 & 5.0157 & TRN & \\
\hline CHEMBL1334710 & 688284 & 4.8748 & 4.5529 & TRN & \\
\hline CHEMBL1340157 & 688284 & 4.2309 & 4.4562 & TST & \\
\hline CHEMBL1577360 & 688284 & 5.1568 & 4.7191 & TST & \\
\hline CHEMBL3196542 & 688284 & 5.0969 & 4.5991 & TRN & \\
\hline CHEMBL1598797 & 688284 & 5.6596 & 5.1006 & TRN & \\
\hline CHEMBL1594974 & 688284 & 5.6517 & 5.3725 & TST & \\
\hline CHEMBL1521921 & 688284 & 5.0991 & 5.7007 & TRN & \\
\hline CHEMBL1370875 & 688284 & 4.3982 & 4.6314 & TST & \\
\hline CHEMBL1376727 & 688284 & 4.8038 & 4.3862 & TRN & \\
\hline
\end{tabular}

Page 28469 


\begin{tabular}{|c|c|c|c|c|c|c|}
\hline \multirow[b]{2}{*}{ CHEMBL358546 } & & \multicolumn{5}{|c|}{ Supplemental Table S2.txt } \\
\hline & 688284 & 5.0804 & 4.3995 & TRN & & \\
\hline CHEMBL1559011 & 688284 & 4.9045 & 5.0666 & TRN & & \\
\hline CHEMBL1303779 & 688284 & 4.5246 & 4.6584 & TRN & & \\
\hline CHEMBL1445410 & 688284 & 4.8918 & 4.9597 & TRN & & \\
\hline CHEMBL1492041 & 688284 & 4.7014 & 5.1694 & TRN & & \\
\hline CHEMBL1432871 & 688284 & 4.708 & 4.9136 & TRN & & \\
\hline CHEMBL1373562 & 688284 & 4.8526 & 4.9401 & TRN & & \\
\hline CHEMBL1411696 & 688284 & 4.1264 & 4.9554 & TRN & & \\
\hline CHEMBL1521618 & 688284 & 5.7212 & 5.7743 & TRN & & \\
\hline CHEMBL1412811 & 688284 & 4.7018 & 4.8636 & TRN & & \\
\hline CHEMBL3193530 & 688284 & 4.6904 & 4.666 & TRN & & \\
\hline CHEMBL3195656 & 688284 & 4.8404 & 5.4539 & TRN & & \\
\hline CHEMBL1329538 & 688284 & 4.0614 & 4.28 & TST & & \\
\hline CHEMBL1573427 & 688284 & \multicolumn{3}{|c|}{5.752000000000001} & 5.3111 & TST \\
\hline CHEMBL1445192 & 688284 & 4.1148 & 4.9865 & TST & & \\
\hline CHEMBL1361920 & 688284 & 4.1388 & 4.8522 & TRN & & \\
\hline CHEMBL1596275 & 688284 & 7.0 & 5.6237 & TRN & & \\
\hline CHEMBL1584251 & 688284 & 5.0862 & 4.8168 & TRN & & \\
\hline CHEMBL1499004 & 688284 & 4.5011 & 4.6773 & TRN & & \\
\hline CHEMBL1331665 & 688284 & 4.7142 & 4.5486 & TRN & & \\
\hline CHEMBL1603398 & 688284 & 4.7962 & 4.7838 & TRN & & \\
\hline CHEMBL1446296 & 688284 & 4.6423 & 4.3231 & TRN & & \\
\hline CHEMBL1424930 & 688284 & 4.5063 & 4.1269 & TST & & \\
\hline CHEMBL1587465 & 688284 & 4.3558 & 4.7278 & TRN & & \\
\hline CHEMBL3191340 & 688284 & 4.4026 & 4.8927 & TRN & & \\
\hline CHEMBL1534853 & 688284 & 5.1586 & 4.5064 & TST & & \\
\hline CHEMBL1447816 & 688284 & 4.5272 & 5.1901 & TST & & \\
\hline CHEMBL1422363 & 688284 & 5.4908 & 5.2164 & TRN & & \\
\hline CHEMBL1572805 & 688284 & 5.0348 & 4.936 & TRN & & \\
\hline CHEMBL1505824 & 688284 & 5.1931 & 5.8594 & TRN & & \\
\hline CHEMBL365342 & 688284 & 4.3143 & 4.6399 & TRN & & \\
\hline CHEMBL1505115 & 688284 & 5.0926 & 5.2564 & TRN & & \\
\hline CHEMBL1509881 & 688284 & 4.399 & 4.2825 & TRN & & \\
\hline CHEMBL1596266 & 688284 & 4.7778 & 5.4004 & TST & & \\
\hline CHEMBL1494363 & 688284 & 4.2777 & 4.793 & TST & & \\
\hline CHEMBL1490789 & 688284 & 5.0721 & 5.0721 & TRN & & \\
\hline CHEMBL1508357 & 688284 & 4.1394 & 4.5715 & TST & & \\
\hline CHEMBL1582819 & 688284 & 4.3611 & 4.3953 & TRN & & \\
\hline CHEMBL1388016 & 688284 & 5.2426 & 5.0867 & TRN & & \\
\hline CHEMBL1345856 & 688284 & 4.8489 & 4.7378 & TRN & & \\
\hline CHEMBL1412158 & 688284 & 7.0 & 6.9074 & TRN & & \\
\hline CHEMBL1421908 & 688284 & 4.8327 & 5.0583 & TRN & & \\
\hline CHEMBL1573288 & 688284 & 4.5511 & 5.1527 & TRN & & \\
\hline CHEMBL3209088 & 688284 & 4.7854 & 4.4402 & TRN & & \\
\hline CHEMBL259516 & 688284 & 4.7416 & 4.2399 & TRN & & \\
\hline CHEMBL1485041 & 688284 & 4.3515 & 4.6034 & TRN & & \\
\hline CHEMBL1450758 & 688284 & 5.4547 & 5.0614 & TRN & & \\
\hline CHEMBL3196058 & 688284 & 4.8254 & 4.5693 & TRN & & \\
\hline
\end{tabular}

Page 28470 
Supplemental Table S2.txt

\begin{tabular}{|c|c|c|c|c|c|c|}
\hline CHEMBL1406745 & 688284 & 4.1779 & 4.8293 & TST & & \\
\hline CHEMBL1518422 & 688284 & 5.0443 & 5.4097 & TRN & & \\
\hline CHEMBL484385 & 688284 & 4.0219 & 4.1651 & TRN & & \\
\hline CHEMBL1587282 & 688284 & 4.8564 & 4.2099 & TRN & & \\
\hline CHEMBL1409585 & 688284 & 4.2026 & 4.0945 & TRN & & \\
\hline CHEMBL1372672 & 688284 & 4.18199 & 99999999 & 995 & 4.1918 & TST \\
\hline CHEMBL1510565 & 688284 & 4.1882 & 4.5329 & TRN & & \\
\hline CHEMBL1530329 & 688284 & 4.9805 & 5.0854 & TRN & & \\
\hline CHEMBL1483318 & 688284 & 4.6743 & 4.3437 & TRN & & \\
\hline CHEMBL1416763 & 688284 & 4.6131 & 4.4346 & TRN & & \\
\hline CHEMBL1451046 & 688284 & 5.2314 & 4.9569 & TRN & & \\
\hline CHEMBL1347805 & 688284 & 4.7908 & 4.8279 & TRN & & \\
\hline CHEMBL1566014 & 688284 & 5.1152 & 5.1201 & TRN & & \\
\hline CHEMBL1559133 & 688284 & 4.167 & 4.4082 & TRN & & \\
\hline CHEMBL1506414 & 688284 & 7.0 & 6.8187 & TRN & & \\
\hline CHEMBL1367693 & 688284 & 5.2 & 5.3273 & TRN & & \\
\hline CHEMBL1573337 & 688284 & 5.1965 & 5.4151 & TRN & & \\
\hline CHEMBL1368362 & 688284 & 5.5157 & 4.8794 & TRN & & \\
\hline CHEMBL1444958 & 688284 & 4.298 & 4.0783 & TRN & & \\
\hline CHEMBL1586481 & 688284 & 4.5889 & 4.7321 & TST & & \\
\hline CHEMBL1506947 & 688284 & 4.2674 & 3.9567 & TRN & & \\
\hline CHEMBL1517055 & 688284 & 2.7876 & 4.5236 & TRN & & \\
\hline CHEMBL1972470 & 688284 & 7.0 & 5.6295 & TRN & & \\
\hline CHEMBL1532396 & 688284 & 5.066 & 4.587 & TRN & & \\
\hline CHEMBL1993746 & 688284 & 4.791 & 4.8253 & TRN & & \\
\hline CHEMBL1420830 & 688284 & 4.0775 & 4.6048 & TST & & \\
\hline CHEMBL1384089 & 688284 & 4.9076 & 5.0788 & TRN & & \\
\hline CHEMBL1424352 & 688284 & 4.2464 & 4.4557 & TRN & & \\
\hline CHEMBL1453327 & 688284 & 4.9559 & 4.9939 & TRN & & \\
\hline CHEMBL1418212 & 688284 & 4.8677 & 4.8116 & TRN & & \\
\hline CHEMBL1538553 & 688284 & 7.0 & 6.2365 & TRN & & \\
\hline CHEMBL1431695 & 688284 & 4.3918 & 4.2353 & TRN & & \\
\hline CHEMBL1466597 & 688284 & 5.2565 & 5.0424 & TRN & & \\
\hline CHEMBL1323276 & 688284 & 5.0477 & 4.4391 & TRN & & \\
\hline CHEMBL1410111 & 688284 & 4.7905 & 5.5253 & TRN & & \\
\hline CHEMBL1358236 & 688284 & 4.4686 & 5.2018 & TST & & \\
\hline CHEMBL1581595 & 688284 & 5.1805 & 5.0365 & TRN & & \\
\hline CHEMBL1499655 & 688284 & 4.2938 & 4.598 & TRN & & \\
\hline CHEMBL1421503 & 688284 & 4.672 & 4.6784 & TRN & & \\
\hline CHEMBL1429266 & 688284 & 4.087 & 4.2964 & TRN & & \\
\hline CHEMBL1334197 & 688284 & 5.1524 & 5.2237 & TRN & & \\
\hline CHEMBL1524101 & 688284 & 4.4891 & 5.5263 & TST & & \\
\hline CHEMBL1403877 & 688284 & 4.2555 & 4.5161 & TST & & \\
\hline CHEMBL1383046 & 688284 & 5.2197 & 5.0559 & TRN & & \\
\hline CHEMBL1532785 & 688284 & 4.6992 & 4.8367 & TST & & \\
\hline CHEMBL1404524 & 688284 & 5.8268 & 4.9871 & TRN & & \\
\hline CHEMBL1525442 & 688284 & 4.3624 & 4.8542 & TST & & \\
\hline CHEMBL1345564 & 688284 & 4.4917 & 4.3223 & TRN & & \\
\hline
\end{tabular}

Page 28471 


\begin{tabular}{|c|c|c|c|c|c|c|}
\hline & & \multicolumn{5}{|c|}{ Supplemental Table S2.txt } \\
\hline CHEMBL1511189 & 688284 & 4.3576 & 4.809 & TRN & & \\
\hline CHEMBL1340682 & 688284 & 4.8145 & 5.3021 & TRN & & \\
\hline CHEMBL1416999 & 688284 & 5.0386 & 4.8972 & TRN & & \\
\hline CHEMBL1349938 & 688284 & 5.6576 & 5.5453 & TRN & & \\
\hline CHEMBL1398798 & 688284 & 5.0297 & 4.7062 & TRN & & \\
\hline CHEMBL1484062 & 688284 & 4.5484 & 4.5525 & TRN & & \\
\hline CHEMBL1302562 & 688284 & 4.8703 & 4.7514 & TRN & & \\
\hline CHEMBL1583856 & 688284 & 4.2084 & 4.7447 & TST & & \\
\hline CHEMBL1517842 & 688284 & 4.5057 & 4.7585 & TRN & & \\
\hline CHEMBL1522044 & 688284 & 4.4289 & 5.3314 & TST & & \\
\hline CHEMBL1311557 & 688284 & 4.458 & 4.2161 & TRN & & \\
\hline CHEMBL1602659 & 688284 & 4.5781 & 4.5996 & TRN & & \\
\hline CHEMBL1538427 & 688284 & 3.8278 & 4.4375 & TRN & & \\
\hline CHEMBL1491705 & 688284 & 4.8986 & 4.8169 & TRN & & \\
\hline CHEMBL1411184 & 688284 & 4.1912 & 4.2784 & TRN & & \\
\hline CHEMBL1566227 & 688284 & 4.025 & 4.7485 & TRN & & \\
\hline CHEMBL1549438 & 688284 & 4.6438 & 4.9245 & TRN & & \\
\hline CHEMBL1521393 & 688284 & 5.1555 & 5.0751 & TRN & & \\
\hline CHEMBL1531735 & 688284 & 4.2191 & 4.4555 & TST & & \\
\hline CHEMBL495123 & 688284 & 4.6012 & 5.1248 & TST & & \\
\hline CHEMBL1439918 & 688284 & 4.8697 & 5.0051 & TRN & & \\
\hline CHEMBL1438343 & 688284 & 4.6176 & 4.779 & TRN & & \\
\hline CHEMBL1612335 & 688284 & 4.9296 & 5.0714 & TRN & & \\
\hline CHEMBL 3213802 & 688284 & 4.7144 & 4.8361 & TRN & & \\
\hline CHEMBL1517956 & 688284 & 4.5321 & 4.971 & TRN & & \\
\hline CHEMBL1559253 & 688284 & 4.2061 & 4.8415 & TST & & \\
\hline CHEMBL1506237 & 688284 & 5.1096 & 4.6789 & TRN & & \\
\hline CHEMBL1557150 & 688284 & 4.0834 & 3.9604 & TRN & & \\
\hline CHEMBL1462722 & 688284 & 5.82100 & 30000000 & 01 & 5.1657 & TRN \\
\hline CHEMBL1392095 & 688284 & 5.2628 & 5.1258 & TRN & & \\
\hline CHEMBL1458446 & 688284 & 4.0401 & 4.2483 & TRN & & \\
\hline CHEMBL1172911 & 688284 & 4.4109 & 5.2028 & TRN & & \\
\hline CHEMBL1334768 & 688284 & 5.6536 & 4.9888 & TST & & \\
\hline CHEMBL1463795 & 688284 & 3.99899 & 99999999 & 997 & 5.2695 & TST \\
\hline CHEMBL1337281 & 688284 & 4.8817 & 4.2896 & TRN & & \\
\hline CHEMBL1485746 & 688284 & 4.041 & 5.3606 & TST & & \\
\hline CHEMBL1531181 & 688284 & 4.0364 & 4.0059 & TRN & & \\
\hline CHEMBL1425326 & 688284 & 4.8199 & 4.6863 & TRN & & \\
\hline CHEMBL1468555 & 688284 & 5.2062 & 5.3773 & TRN & & \\
\hline CHEMBL1482233 & 688284 & 4.997 & 5.3969 & TRN & & \\
\hline CHEMBL1467658 & 688284 & 4.6627 & 4.8786 & TRN & & \\
\hline CHEMBL1382690 & 688284 & 4.8447 & 5.0916 & TRN & & \\
\hline CHEMBL3213378 & 688284 & 4.8548 & 4.5784 & TRN & & \\
\hline CHEMBL1443822 & 688284 & 4.3711 & 4.4932 & TRN & & \\
\hline CHEMBL1583484 & 688284 & 4.7602 & 4.9718 & TRN & & \\
\hline CHEMBL1342344 & 688284 & 7.0 & 6.6616 & TRN & & \\
\hline CHEMBL1389111 & 688284 & 4.6351 & 4.6925 & TRN & & \\
\hline CHEMBL1313460 & 688284 & 5.8386 & 5.6743 & TRN & & \\
\hline
\end{tabular}




\begin{tabular}{|c|c|c|c|c|c|}
\hline \multicolumn{6}{|c|}{ Supplemental Table S2.txt } \\
\hline CHEMBL1301428 & 688284 & 5.9136 & 5.8587 & TRN & \\
\hline CHEMBL1361530 & 688284 & 7.0 & 6.579 & TRN & \\
\hline CHEMBL1412089 & 688284 & 4.537 & 4.8889 & TRN & \\
\hline CHEMBL1564294 & 688284 & 5.9031 & 5.1024 & TST & \\
\hline CHEMBL1522631 & 688284 & 4.6123 & 4.5174 & TRN & \\
\hline CHEMBL1312100 & 688284 & 4.5258 & 4.7335 & TRN & \\
\hline CHEMBL3212774 & 688284 & 4.8811 & 4.5982 & TRN & \\
\hline CHEMBL1535307 & 688284 & 7.0 & 6.3008 & TRN & \\
\hline CHEMBL1401972 & 688284 & 5.6517 & 5.5429 & TRN & \\
\hline CHEMBL1597242 & 688284 & 5.4473 & 5.2557 & TRN & \\
\hline CHEMBL1309891 & 688284 & 5.5143 & 5.36600 & 00000000005 & TRN \\
\hline CHEMBL1391193 & 688284 & 4.4111 & 4.6295 & TRN & \\
\hline CHEMBL1345948 & 688284 & 4.1464 & 4.4814 & TRN & \\
\hline CHEMBL1306242 & 688284 & 5.8386 & 5.8295 & TRN & \\
\hline CHEMBL1312212 & 688284 & 4.8022 & 5.2053 & TST & \\
\hline CHEMBL1381738 & 688284 & 4.7496 & 5.2387 & TRN & \\
\hline CHEMBL1609854 & 688284 & 4.6718 & 4.4217 & TRN & \\
\hline CHEMBL1522248 & 688284 & 4.6794 & 4.4642 & TST & \\
\hline CHEMBL1324861 & 688284 & 4.5989 & 4.3145 & TRN & \\
\hline CHEMBL3193592 & 688284 & 4.02 & 4.4914 & TST & \\
\hline CHEMBL1422754 & 688284 & 3.9221 & 4.9365 & TST & \\
\hline CHEMBL1365970 & 688284 & 4.8368 & 4.6573 & TST & \\
\hline CHEMBL1509383 & 688284 & 4.8649 & 5.1284 & TST & \\
\hline CHEMBL1531785 & 688284 & 4.5024 & 4.5991 & TRN & \\
\hline CHEMBL1545601 & 688284 & 4.8677 & 4.5908 & TRN & \\
\hline CHEMBL1428695 & 688284 & 4.1873 & 4.7336 & TRN & \\
\hline CHEMBL1307249 & 688284 & 4.3903 & 5.06 & TRN & \\
\hline CHEMBL1529282 & 688284 & 4.8948 & 4.3385 & TRN & \\
\hline CHEMBL3194162 & 688284 & 4.8019 & 4.9014 & TRN & \\
\hline CHEMBL1332301 & 688284 & 5.51 & 5.0434 & TRN & \\
\hline CHEMBL1337645 & 688284 & 4.0458 & 4.1152 & TRN & \\
\hline CHEMBL1498326 & 688284 & 5.4547 & 5.01 & TRN & \\
\hline CHEMBL1536935 & 688284 & 5.4134 & 4.8964 & TRN & \\
\hline CHEMBL1559236 & 688284 & 4.3106 & 4.8462 & TRN & \\
\hline CHEMBL1546060 & 688284 & 5.1746 & 4.9772 & TRN & \\
\hline CHEMBL1567877 & 688284 & 4.4445 & 4.3916 & TST & \\
\hline CHEMBL610508 & 688284 & 4.4536 & 5.1359 & TRN & \\
\hline CHEMBL1576730 & 688284 & 5.0391 & 4.1298 & TRN & \\
\hline CHEMBL1328483 & 688284 & 4.1004 & 3.926 & TRN & \\
\hline CHEMBL1352830 & 688284 & 5.4486 & 5.0411 & TST & \\
\hline CHEMBL1459884 & 688284 & 5.2197 & 5.5205 & TRN & \\
\hline CHEMBL1406203 & 688284 & 5.1878 & 5.5916 & TRN & \\
\hline CHEMBL1586918 & 688284 & 4.857 & 5.00899 & 99999999995 & TRN \\
\hline CHEMBL3188273 & 688284 & 5.2048 & 4.7313 & TRN & \\
\hline CHEMBL1500012 & 688284 & 5.1637 & 4.8076 & TRN & \\
\hline CHEMBL3199859 & 688284 & 4.3401 & 3.4502 & TRN & \\
\hline CHEMBL1365924 & 688284 & 5.3507 & 5.1667 & TRN & \\
\hline CHEMBL3193147 & 688284 & 4.4675 & 4.5328 & TRN & \\
\hline
\end{tabular}




\begin{tabular}{|c|c|c|c|c|c|c|}
\hline & & \multicolumn{5}{|c|}{ Supplemental Table S2.txt } \\
\hline CHEMBL1326739 & 688284 & 5.061 & 4.6323 & TRN & & \\
\hline CHEMBL1350468 & 688284 & 4.869 & 4.9939 & TRN & & \\
\hline CHEMBL3194330 & 688284 & 4.4645 & 4.4223 & TRN & & \\
\hline CHEMBL1609015 & 688284 & 4.9842 & 4.5916 & TST & & \\
\hline CHEMBL1507773 & 688284 & 4.145 & 5.566 & TST & & \\
\hline CHEMBL1528280 & 688284 & 4.994 & 4.9586 & TRN & & \\
\hline CHEMBL1477039 & 688284 & 4.8871 & 4.8351 & TRN & & \\
\hline CHEMBL1313454 & 688284 & 5.2027 & 5.1435 & TRN & & \\
\hline CHEMBL1424612 & 688284 & 3.9779 & 4.2224 & TRN & & \\
\hline CHEMBL1410893 & 688284 & 5.0009 & 4.2205 & TST & & \\
\hline CHEMBL1467528 & 688284 & 4.8404 & 4.2895 & TRN & & \\
\hline CHEMBL1477545 & 688284 & 4.6613 & 5.1624 & TRN & & \\
\hline CHEMBL1471440 & 688284 & \multicolumn{3}{|c|}{5.327000000000001} & .5678 & TRN \\
\hline CHEMBL3194565 & 688284 & 4.6059 & 4.9939 & TRN & & \\
\hline CHEMBL3189482 & 688284 & 4.4531 & 4.2821 & TRN & & \\
\hline CHEMBL1972864 & 688284 & 5.585 & 4.4638 & TST & & \\
\hline CHEMBL1487339 & 688284 & 4.9961 & 5.0214 & TRN & & \\
\hline CHEMBL3196767 & 688284 & 3.9892 & 4.7249 & TRN & & \\
\hline CHEMBL1385924 & 688284 & 4.4831 & 4.5884 & TRN & & \\
\hline CHEMBL1384598 & 688284 & 5.3585 & 4.5224 & TRN & & \\
\hline CHEMBL1461040 & 688284 & 4.3355 & 4.5421 & TST & & \\
\hline CHEMBL1413212 & 688284 & 4.3228 & 4.1286 & TST & & \\
\hline CHEMBL1354011 & 688284 & 4.7537 & 4.7812 & TRN & & \\
\hline CHEMBL1444370 & 688284 & 7.0 & 5.8505 & TRN & & \\
\hline CHEMBL1335310 & 688284 & 5.9208 & 5.6154 & TRN & & \\
\hline CHEMBL1390936 & 688284 & 4.9867 & 5.49700 & 0000000001 & & TRN \\
\hline CHEMBL1600341 & 688284 & 5.0182 & 4.8506 & TRN & & \\
\hline CHEMBL1612364 & 688284 & 4.9147 & 4.8598 & TRN & & \\
\hline CHEMBL1463945 & 688284 & 4.2204 & 4.8362 & TRN & & \\
\hline CHEMBL1301728 & 688284 & 4.7242 & 4.857 & TRN & & \\
\hline CHEMBL3189941 & 688284 & 5.2255 & 4.7138 & TST & & \\
\hline CHEMBL1510425 & 688284 & 7.0 & 6.2554 & TRN & & \\
\hline CHEMBL1329717 & 688284 & \multicolumn{3}{|c|}{4.4319999999999995} & 4.6767 & TRN \\
\hline CHEMBL1366418 & 688284 & 4.7462 & 4.3529 & TRN & & \\
\hline CHEMBL1441993 & 688284 & 4.7921 & 4.7931 & TRN & & \\
\hline CHEMBL1480141 & 688284 & 4.6028 & 5.1255 & TRN & & \\
\hline CHEMBL1606599 & 688284 & 4.1287 & 4.7908 & TST & & \\
\hline CHEMBL3199191 & 688284 & \multicolumn{3}{|c|}{4.5169999999999995} & 4.5016 & TRN \\
\hline CHEMBL1306254 & 688284 & 4.2057 & 4.4877 & TRN & & \\
\hline CHEMBL3196880 & 688284 & 4.7089 & 4.6137 & TRN & & \\
\hline CHEMBL1456123 & 688284 & 4.1482 & 4.8744 & TST & & \\
\hline CHEMBL1542385 & 688284 & 4.3376 & 4.6289 & TRN & & \\
\hline CHEMBL1403911 & 688284 & 4.2054 & 4.0906 & TRN & & \\
\hline CHEMBL1470969 & 688284 & 4.8604 & 4.6812 & TRN & & \\
\hline CHEMBL1568341 & 688284 & 5.1439 & 5.6949 & TRN & & \\
\hline CHEMBL1460607 & 688284 & 4.3373 & 4.4468 & TRN & & \\
\hline CHEMBL1348358 & 688284 & 4.8969 & 5.0245 & TRN & & \\
\hline CHEMBL1571704 & 688284 & 4.5375 & 4.747 & TRN & & \\
\hline
\end{tabular}


Supplemental Table S2.txt

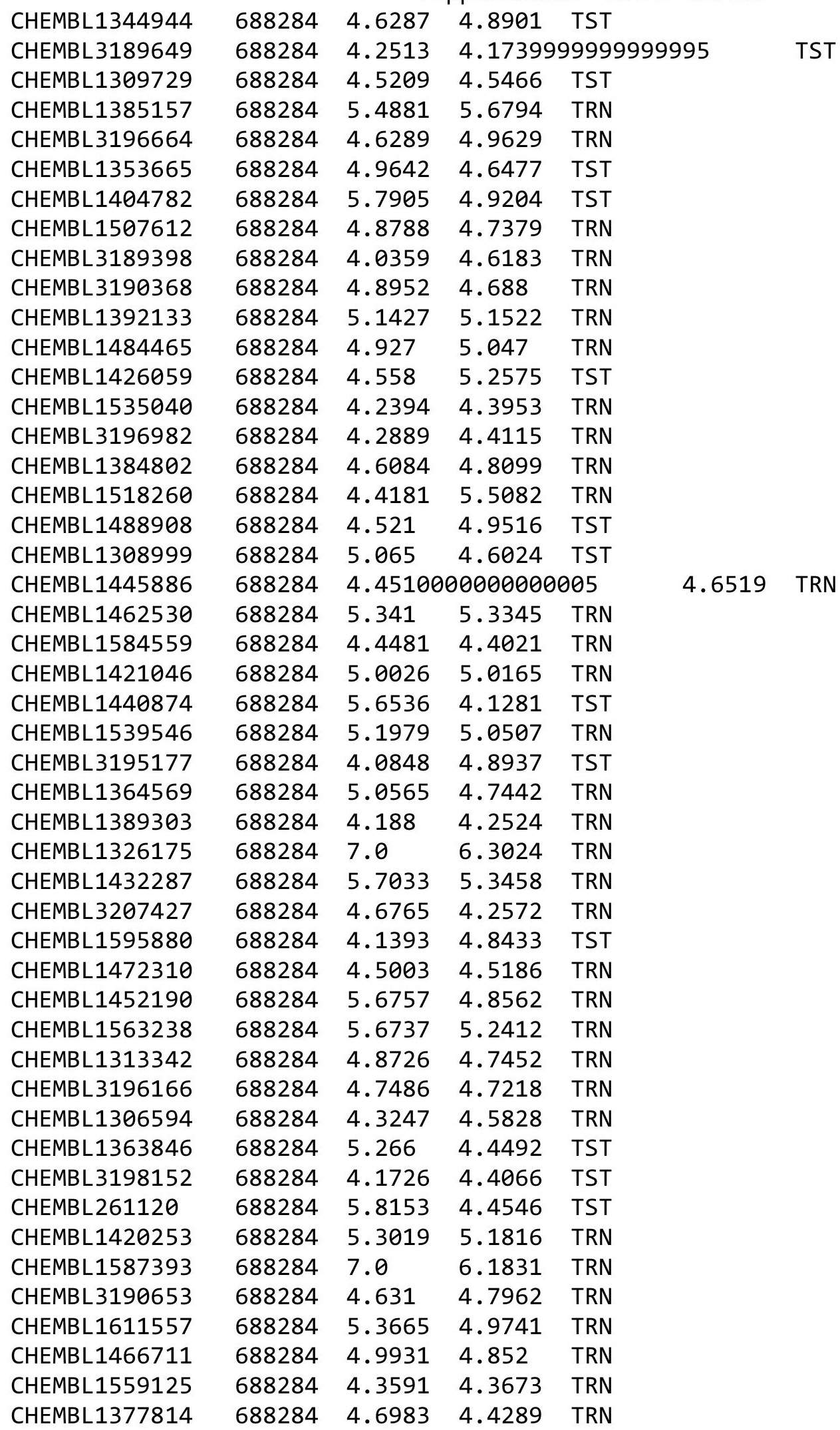

Page 28475 
Supplemental Table S2.txt

\begin{tabular}{|c|c|c|c|c|}
\hline CHEMBL1461628 & 688284 & 5.3915 & 5.5183 & TRN \\
\hline CHEMBL1429516 & 688284 & 5.5986 & 5.3777 & TRN \\
\hline CHEMBL1325983 & 688284 & 4.7567 & 4.7189 & TRN \\
\hline CHEMBL1570461 & 688284 & 4.8222 & 4.1899 & TST \\
\hline CHEMBL1523277 & 688284 & 4.3022 & 5.0606 & TST \\
\hline CHEMBL1544759 & 688284 & 4.2109 & 4.7148 & TST \\
\hline CHEMBL1392012 & 688284 & 4.5664 & 4.7759 & TRN \\
\hline CHEMBL1334246 & 688284 & 5.0168 & 5.1806 & TRN \\
\hline CHEMBL1606181 & 688284 & 5.1169 & 4.3745 & TST \\
\hline CHEMBL1504067 & 688284 & 4.0925 & 4.6578 & TRN \\
\hline CHEMBL1574720 & 688284 & 5.3188 & 5.4318 & TRN \\
\hline CHEMBL1328777 & 688284 & 4.7562 & 5.034 & TRN \\
\hline CHEMBL1431264 & 688284 & 4.1725 & 5.0858 & TRN \\
\hline CHEMBL1555850 & 688284 & 4.6149 & 5.2044 & TRN \\
\hline CHEMBL3214200 & 688284 & 4.6156 & 4.8224 & TRN \\
\hline CHEMBL1379652 & 688284 & 5.5901 & 5.9338 & TRN \\
\hline CHEMBL1420727 & 688284 & 5.5784 & 5.5884 & TRN \\
\hline CHEMBL1613716 & 688284 & 4.9488 & 5.231 & TST \\
\hline CHEMBL1516831 & 688284 & 5.2676 & 5.7831 & TRN \\
\hline CHEMBL1428761 & 688284 & 4.5482 & 4.7354 & TRN \\
\hline CHEMBL3191622 & 688284 & 4.2956 & 4.633 & TRN \\
\hline CHEMBL1547143 & 688284 & 4.1767 & 4.4017 & TST \\
\hline CHEMBL1336870 & 688284 & 4.5624 & 4.5271 & TRN \\
\hline CHEMBL1549237 & 688284 & 5.2588 & 4.7584 & TRN \\
\hline CHEMBL1373359 & 688284 & 5.2218 & 5.5071 & TRN \\
\hline CHEMBL1524353 & 688284 & 4.8595 & 4.5499 & TST \\
\hline CHEMBL1353530 & 688284 & 3.9977 & 4.8925 & TST \\
\hline CHEMBL1456330 & 688284 & 4.8303 & 5.2983 & TST \\
\hline CHEMBL1416158 & 688284 & 4.2642 & 4.8158 & TRN \\
\hline CHEMBL1580779 & 688284 & 5.1073 & 5.5297 & TRN \\
\hline CHEMBL1414863 & 688284 & 4.8395 & 4.7527 & TRN \\
\hline CHEMBL1572197 & 688284 & 4.6265 & 4.8402 & TRN \\
\hline CHEMBL1430555 & 688284 & 4.3118 & 4.3588 & TRN \\
\hline CHEMBL1550612 & 688284 & 4.4916 & 4.7737 & TST \\
\hline CHEMBL1374735 & 688284 & 4.8099 & 5.0498 & TRN \\
\hline CHEMBL1400008 & 688284 & 3.987 & 5.2935 & TST \\
\hline CHEMBL1337033 & 688284 & 4.6486 & 5.1458 & TRN \\
\hline CHEMBL3198160 & 688284 & 4.6828 & 4.4822 & TRN \\
\hline CHEMBL1307689 & 688284 & 4.3571 & 4.2436 & TRN \\
\hline CHEMBL1347923 & 688284 & 4.4238 & 4.4055 & TRN \\
\hline CHEMBL1973265 & 688284 & 4.5722 & 4.5755 & TRN \\
\hline CHEMBL1321385 & 688284 & 5.7696 & $5.73600 e$ & 0000000001 \\
\hline CHEMBL3211571 & 688284 & 4.0447 & 4.495 & TST \\
\hline CHEMBL1977983 & 688284 & 4.3112 & 4.4923 & TRN \\
\hline CHEMBL1456389 & 688284 & 5.4134 & 5.4746 & TRN \\
\hline CHEMBL1501247 & 688284 & 4.9739 & 4.4033 & TRN \\
\hline CHEMBL1412001 & 688284 & 4.5306 & 4.7801 & TRN \\
\hline CHEMBL1444178 & 688284 & 5.091 & 4.385 & TRN \\
\hline
\end{tabular}




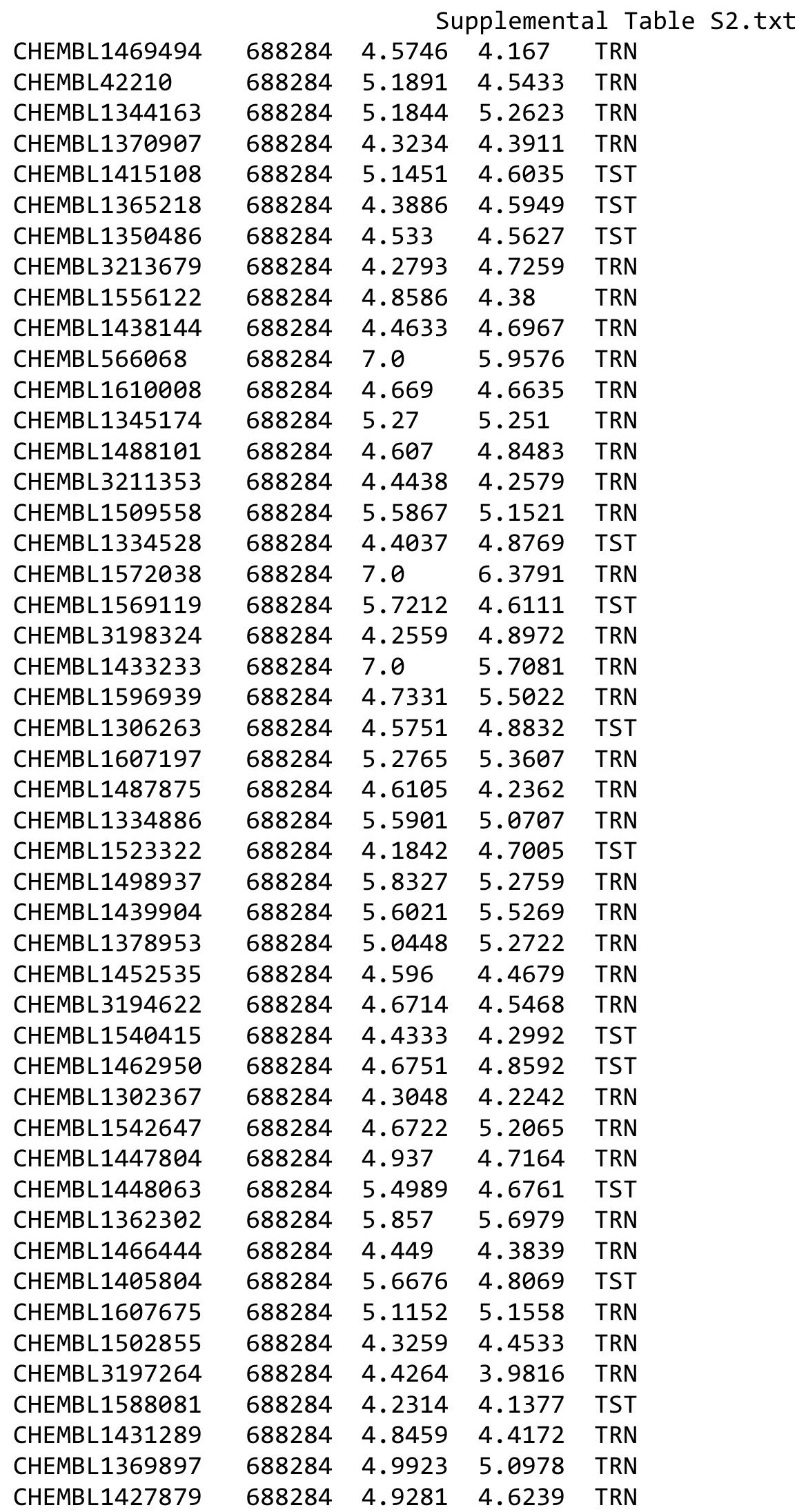

Page 28477 


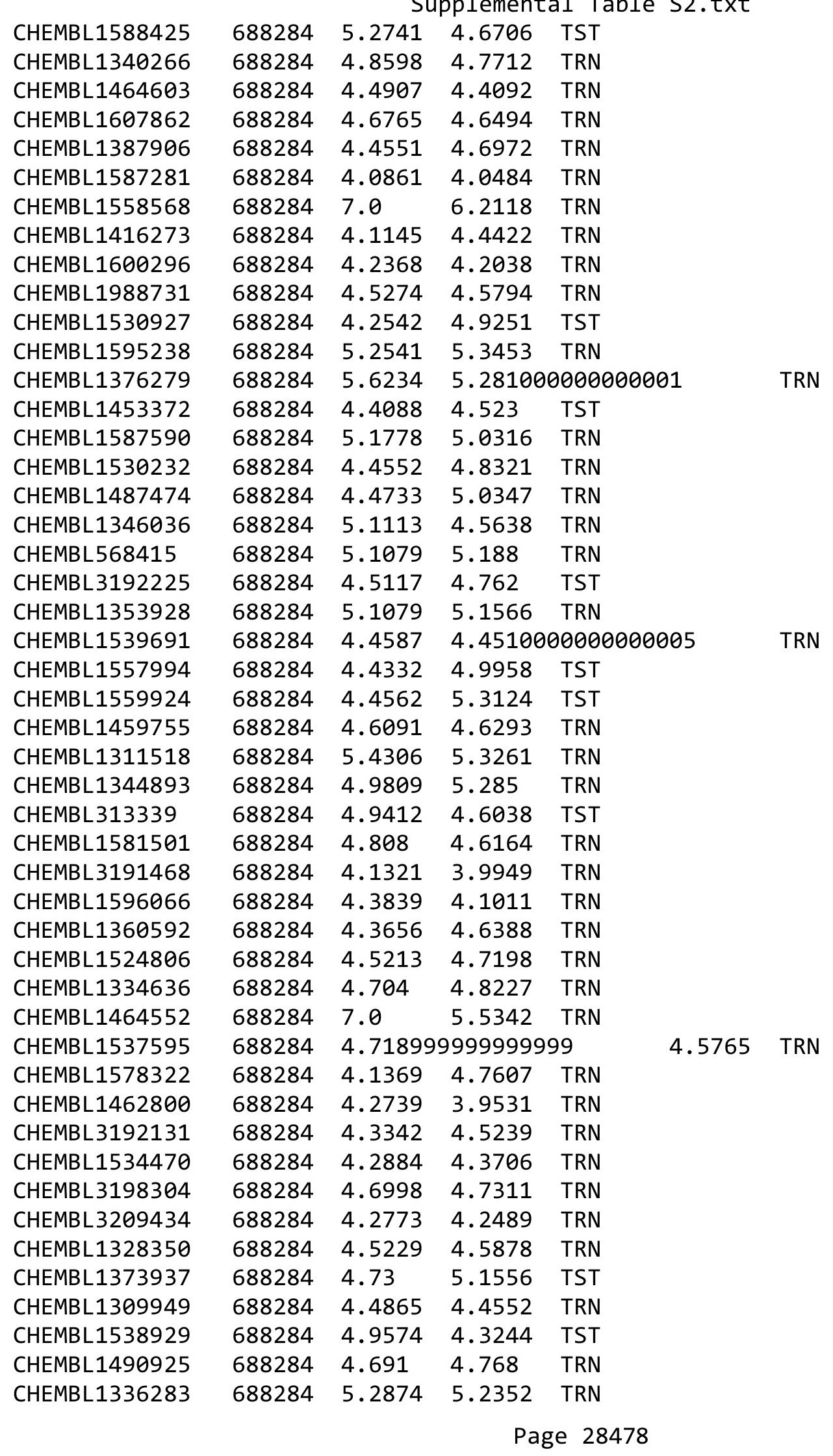




\begin{tabular}{|c|c|c|c|c|c|}
\hline & & \multicolumn{4}{|c|}{ Supplemental Table S2.txt } \\
\hline CHEMBL1389678 & 688284 & 5.8539 & 6.0349 & TRN & \\
\hline CHEMBL1433128 & 688284 & 4.3418 & 4.2357 & TRN & \\
\hline CHEMBL1306708 & 688284 & 4.1414 & 4.7698 & TST & \\
\hline CHEMBL1370800 & 688284 & 4.1224 & 4.04899 & 99999999995 & TRN \\
\hline CHEMBL1341852 & 688284 & 5.6021 & 5.3067 & TRN & \\
\hline CHEMBL1467732 & 688284 & 5.0472 & 4.7311 & TRN & \\
\hline CHEMBL1310833 & 688284 & 5.7122 & 5.775 & TRN & \\
\hline CHEMBL1588112 & 688284 & 5.4112 & 5.2222 & TRN & \\
\hline CHEMBL1402497 & 688284 & 5.5229 & 5.92299 & 9999999999 & TRN \\
\hline CHEMBL3145306 & 688284 & 4.945 & 4.9178 & TRN & \\
\hline CHEMBL1555443 & 688284 & 4.7062 & 4.6948 & TRN & \\
\hline CHEMBL1323245 & 688284 & 4.8841 & 4.6417 & TRN & \\
\hline CHEMBL1352422 & 688284 & 4.7948 & 4.7594 & TRN & \\
\hline CHEMBL1560130 & 688284 & 4.7219 & 4.6214 & TRN & \\
\hline CHEMBL3145323 & 688284 & 4.4566 & 4.0886 & TRN & \\
\hline CHEMBL1544987 & 688284 & 4.3077 & 4.4165 & TRN & \\
\hline CHEMBL1548072 & 688284 & 5.0467 & 4.8192 & TRN & \\
\hline CHEMBL 3194536 & 688284 & 4.754 & 4.7689 & TRN & \\
\hline CHEMBL1391880 & 688284 & 5.7144 & 6.5939 & TRN & \\
\hline CHEMBL1422308 & 688284 & 4.7625 & 4.364 & TST & \\
\hline CHEMBL1350038 & 688284 & 5.4202 & 5.1226 & TRN & \\
\hline CHEMBL1563236 & 688284 & 5.5346 & 5.3429 & TRN & \\
\hline CHEMBL1492585 & 688284 & 3.9577 & 4.9662 & TST & \\
\hline CHEMBL1487453 & 688284 & 5.0915 & 4.9401 & TRN & \\
\hline CHEMBL1536779 & 688284 & 4.7102 & 4.5375 & TST & \\
\hline CHEMBL1482916 & 688284 & 5.5817 & 4.125 & TST & \\
\hline CHEMBL2006817 & 688284 & 4.9423 & 4.9689 & TRN & \\
\hline CHEMBL1537058 & 688284 & 4.7703 & 5.0375 & TRN & \\
\hline CHEMBL1463178 & 688284 & 4.4535 & 4.5797 & TRN & \\
\hline CHEMBL1516643 & 688284 & 5.1785 & 5.2306 & TRN & \\
\hline CHEMBL1613560 & 688284 & 5.4921 & 5.6081 & TRN & \\
\hline CHEMBL1485062 & 688284 & 4.8268 & 4.6558 & TRN & \\
\hline CHEMBL1339421 & 688284 & 4.6527 & 4.7858 & TRN & \\
\hline CHEMBL1611017 & 688284 & 4.3389 & 4.1214 & TRN & \\
\hline CHEMBL1550659 & 688284 & 7.0 & 6.5848 & TRN & \\
\hline CHEMBL3211190 & 688284 & 4.5732 & 4.8412 & TRN & \\
\hline CHEMBL3209438 & 688284 & 4.2776 & 4.46899 & 9999999999 & TST \\
\hline CHEMBL1550153 & 688284 & 7.0 & 5.8251 & TRN & \\
\hline CHEMBL1571825 & 688284 & 4.5865 & 4.7912 & TRN & \\
\hline CHEMBL1587117 & 688284 & 4.6061 & 5.3914 & TRN & \\
\hline CHEMBL1505052 & 688284 & 4.0216 & 4.888 & TST & \\
\hline CHEMBL1577321 & 688284 & 4.4931 & 4.5621 & TRN & \\
\hline CHEMBL1462324 & 688284 & 4.4648 & 4.5507 & TRN & \\
\hline CHEMBL1506682 & 688284 & 4.3174 & 5.15 & TST & \\
\hline CHEMBL1568219 & 688284 & 4.5484 & 4.6438 & TST & \\
\hline CHEMBL1344869 & 688284 & 4.8983 & 5.072 & TRN & \\
\hline CHEMBL1420916 & 688284 & 5.2976 & 4.9686 & TRN & \\
\hline CHEMBL1488462 & 688284 & 4.4347 & 4.4635 & TRN & \\
\hline
\end{tabular}




\begin{tabular}{|c|c|c|c|c|}
\hline & & & oplement & al $\mathrm{Tc}$ \\
\hline CHEMBL1527373 & 688284 & 4.6338 & 4.8654 & TRN \\
\hline CHEMBL1494419 & 688284 & 4.8642 & 5.0243 & TRN \\
\hline CHEMBL1564246 & 688284 & 4.2968 & 4.3994 & TRN \\
\hline CHEMBL3193804 & 688284 & 4.8041 & 4.7193 & TRN \\
\hline CHEMBL1555607 & 688284 & 4.5433 & 4.9365 & TRN \\
\hline CHEMBL3194814 & 688284 & 5.5031 & 4.6689 & TRN \\
\hline CHEMBL1505420 & 688284 & 4.325 & 4.3372 & TRN \\
\hline CHEMBL1568805 & 688284 & 3.9595 & 4.1406 & TRN \\
\hline CHEMBL1389922 & 688284 & 4.3901 & 4.3379 & TRN \\
\hline CHEMBL1485608 & 688284 & 4.46 & 4.6912 & TRN \\
\hline CHEMBL1486430 & 688284 & 4.7528 & 5.2382 & TRN \\
\hline CHEMBL3197999 & 688284 & 3.9951 & 4.6932 & TRN \\
\hline CHEMBL1466719 & 688284 & 5.9172 & 5.2418 & TRN \\
\hline CHEMBL1339990 & 688284 & 4.2314 & 4.3168 & TRN \\
\hline CHEMBL1323944 & 688284 & 4.6413 & 4.7427 & TRN \\
\hline CHEMBL1383166 & 688284 & 4.1911 & 4.734 & TRN \\
\hline CHEMBL1493955 & 688284 & 4.6341 & 4.5181 & TST \\
\hline CHEMBL1581404 & 688284 & 5.8508 & 5.6516 & TRN \\
\hline CHEMBL1444437 & 688284 & 5.857 & 5.1752 & TRN \\
\hline CHEMBL1310907 & 688284 & 4.4225 & 4.2324 & TRN \\
\hline CHEMBL1557531 & 688284 & 4.6319 & 4.8992 & TRN \\
\hline CHEMBL1580656 & 688284 & 5.4584 & 5.0491 & TRN \\
\hline CHEMBL1519296 & 688284 & 4.7314 & 5.0213 & TRN \\
\hline CHEMBL3191457 & 688284 & 4.1029 & 4.1747 & TRN \\
\hline CHEMBL3209055 & 688284 & 4.7359 & 4.4541 & TRN \\
\hline CHEMBL 3193432 & 688284 & 4.0648 & 4.5641 & TST \\
\hline CHEMBL1544818 & 688284 & 4.8002 & 4.702 & TRN \\
\hline CHEMBL1418225 & 688284 & 5.091 & 4.8397 & TST \\
\hline CHEMBL1409953 & 688284 & 5.8041 & 6.2865 & TRN \\
\hline CHEMBL1447794 & 688284 & 5.4134 & 5.0391 & TRN \\
\hline CHEMBL1575082 & 688284 & 4.5352 & 4.8363 & TRN \\
\hline CHEMBL1392578 & 688284 & 4.1435 & 4.4427 & TRN \\
\hline CHEMBL 2002634 & 688284 & 4.505 & 4.2653 & TRN \\
\hline CHEMBL1305726 & 688284 & 5.0101 & 5.197 & TRN \\
\hline CHEMBL1371004 & 688284 & 4.4614 & 5.345 & TRN \\
\hline CHEMBL1546411 & 688284 & 4.4479 & 4.465 & TRN \\
\hline CHEMBL1438342 & 688284 & 3.8195 & 4.2171 & TRN \\
\hline CHEMBL1594374 & 688284 & 4.6882 & 4.0858 & TST \\
\hline CHEMBL1481220 & 688284 & 7.0 & 6.3572 & TRN \\
\hline CHEMBL1562923 & 688284 & 4.5948 & 4.7431 & TRN \\
\hline CHEMBL1490445 & 688284 & 7.0 & 6.2751 & TRN \\
\hline CHEMBL1492661 & 688284 & 5.1694 & 4.5964 & TST \\
\hline CHEMBL3191438 & 688284 & 4.302 & 4.5282 & TRN \\
\hline CHEMBL1530356 & 688284 & 4.8038 & 4.9849 & TRN \\
\hline CHEMBL1499872 & 688284 & 7.0 & 6.2173 & TRN \\
\hline CHEMBL1459866 & 688284 & 5.5622 & 5.9829 & TRN \\
\hline CHEMBL1424064 & 688284 & 4.957 & 5.8391 & TRN \\
\hline CHEMBL1306312 & 688284 & 4.6934 & 4.6124 & TRN \\
\hline
\end{tabular}




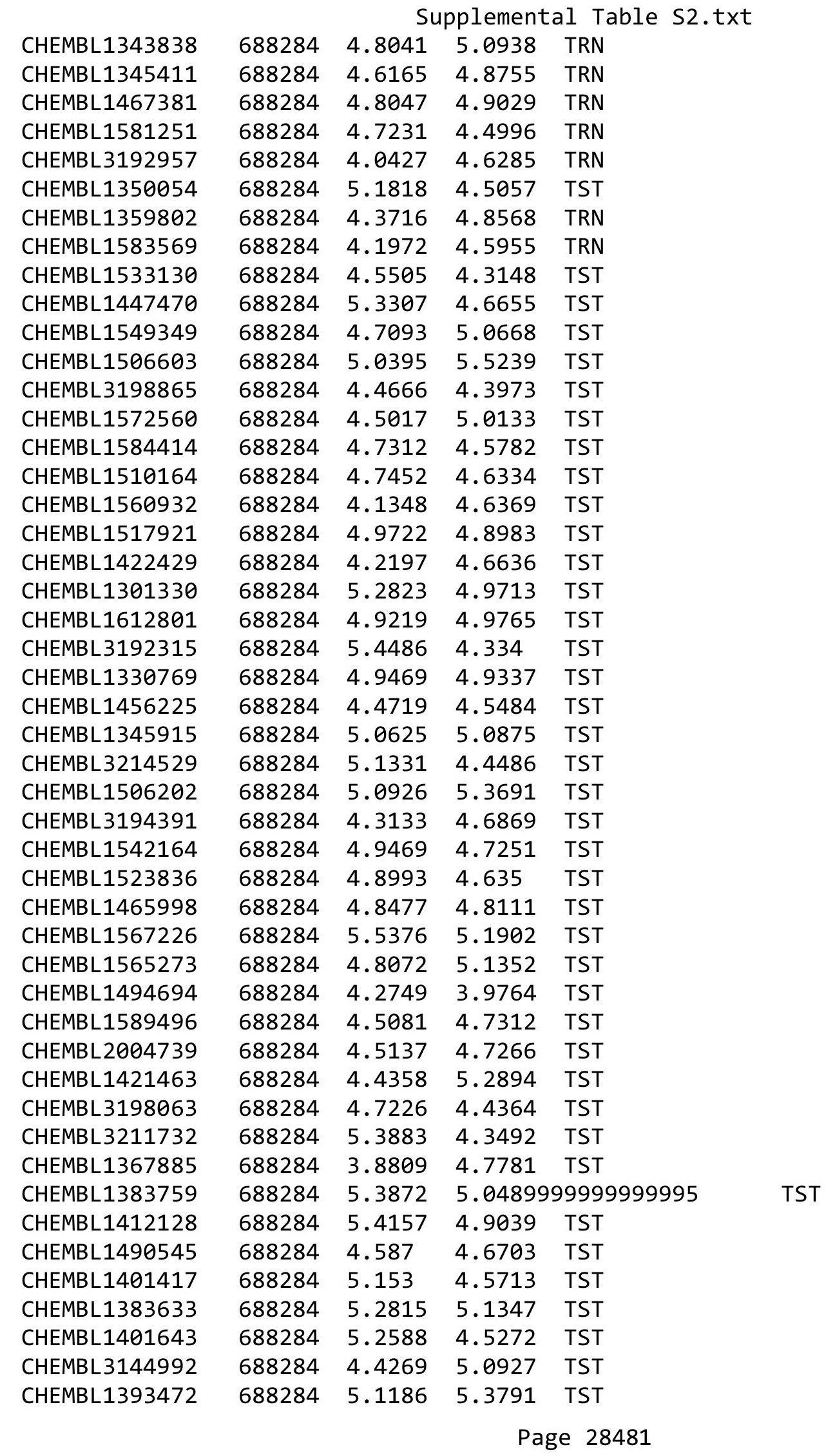


Supplemental Table S2.txt

\begin{tabular}{|c|c|c|c|c|c|c|c|}
\hline CHEMBL3213053 & 688284 & 4.6921 & 4.9665 & TST & & & \\
\hline CHEMBL1509933 & 688284 & 4.6008 & 5.107 & TST & & & \\
\hline CHEMBL1377928 & 688284 & 4.7459 & 5.528 & TST & & & \\
\hline CHEMBL1430137 & 688284 & 5.8153 & 5.1558 & TST & & & \\
\hline CHEMBL1367375 & 688284 & 4.9606 & 4.5919 & TST & & & \\
\hline CHEMBL 300389 & 954940 & 7.0871 & 7.0871 & TRN & & & \\
\hline CHEMBL573107 & 954940 & 3.9638 & 3.9638 & TRN & & & \\
\hline CHEMBL373751 & 954940 & 3.6824 & 3.6824 & TRN & & & \\
\hline CHEMBL1256459 & 954940 & 6.9356 & 6.9356 & TRN & & & \\
\hline CHEMBL1230020 & 954940 & \multicolumn{3}{|c|}{3.2260000000000004} & \multirow{24}{*}{\multicolumn{2}{|c|}{3.2260000000000004}} & TRN \\
\hline CHEMBL512504 & 954940 & 4.8504 & 4.8504 & TRN & & & \\
\hline CHEMBL180127 & 954940 & 4.7571 & 4.7571 & TRN & & & \\
\hline CHEMBL192566 & 954940 & 4.2129 & 7.5335 & TST & & & \\
\hline CHEMBL1190711 & 954940 & 2.7273 & 2.7273 & TRN & & & \\
\hline CHEMBL 3186408 & 954940 & 3.0005 & 2.6566 & TST & & & \\
\hline CHEMBL 221137 & 954940 & 3.1923 & 4.7861 & TST & & & \\
\hline CHEMBL393929 & 954940 & 3.6782 & 3.6782 & TRN & & & \\
\hline CHEMBL1516890 & 954940 & 6.0124 & 6.0124 & TRN & & & \\
\hline CHEMBL 2137530 & 954940 & 4.8548 & 4.8548 & TRN & & & \\
\hline CHEMBL 2134202 & 954940 & 4.1834 & 4.1834 & TRN & & & \\
\hline CHEMBL1788116 & 954940 & 2.7896 & 2.7896 & TRN & & & \\
\hline CHEMBL135561 & 954940 & 4.0981 & 4.0981 & TRN & & & \\
\hline CHEMBL189584 & 954940 & 3.8471 & 3.8471 & TRN & & & \\
\hline CHEMBL412142 & 954940 & 3.3235 & 3.3235 & TRN & & & \\
\hline CHEMBL102714 & 954940 & 5.9171 & 5.9171 & TRN & & & \\
\hline CHEMBL 9470 & 954940 & 5.4864 & 5.6877 & TST & & & \\
\hline CHEMBL585951 & 954940 & 5.4821 & 5.4821 & TRN & & & \\
\hline CHEMBL240954 & 954940 & 3.0203 & 3.6517 & TST & & & \\
\hline CHEMBL 202721 & 954940 & 4.8115 & 4.8115 & TRN & & & \\
\hline CHEMBL1673039 & 954940 & 4.4833 & 4.4833 & TRN & & & \\
\hline CHEMBL 220241 & 954940 & 3.0366 & 3.0366 & TRN & & & \\
\hline CHEMBL217354 & 954940 & 8.5847 & 8.5847 & TRN & & & \\
\hline CHEMBL1909414 & 954940 & 4.0536 & 4.0536 & TRN & & & \\
\hline CHEMBL483849 & 954940 & \multicolumn{3}{|c|}{3.4610000000000003} & \multirow{11}{*}{\multicolumn{2}{|c|}{ 1.483 TST }} & \\
\hline CHEMBL515416 & 954940 & 4.8078 & 4.8078 & TRN & & & \\
\hline CHEMBL92309 & 954940 & 0.4525 & 1.8047 & TST & & & \\
\hline CHEMBL472940 & 954940 & 2.2988 & 2.2988 & TRN & & & \\
\hline CHEMBL514499 & 954940 & 7.246 & 7.246 & TRN & & & \\
\hline CHEMBL1242367 & 954940 & 3.7489 & 3.7489 & TRN & & & \\
\hline CHEMBL1357247 & 954940 & 2.6048 & 2.6048 & TRN & & & \\
\hline CHEMBL1186585 & 954940 & 4.4687 & 4.4687 & TRN & & & \\
\hline CHEMBL191334 & 954940 & 4.8035 & 4.8035 & TRN & & & \\
\hline CHEMBL3392440 & 954940 & 3.2039 & 3.2039 & TRN & & & \\
\hline CHEMBL449158 & 954940 & 6.1886 & 7.875 & TST & & & \\
\hline CHEMBL577784 & 954940 & \multicolumn{3}{|c|}{5.462999999999999} & \multirow{4}{*}{\multicolumn{2}{|c|}{5.462999999999999}} & RN \\
\hline CHEMBL1643959 & 954940 & 2.9193 & 2.9193 & TRN & & & \\
\hline CHEMBL258844 & 954940 & 3.2205 & 3.2205 & TRN & & & \\
\hline CHEMBL1970879 & 954940 & 3.7391 & 3.7391 & TRN & & & \\
\hline
\end{tabular}

Page 28482 


\begin{tabular}{|c|c|c|c|c|c|}
\hline \multirow[b]{2}{*}{ CHEMBL399530 } & \\
\hline & 954940 & 4.7855 & 4.7855 & TRN & \\
\hline CHEMBL188678 & 954940 & 3.9112 & 3.9112 & TRN & \\
\hline CHEMBL222102 & 954940 & 3.2688 & 3.2688 & TRN & \\
\hline CHEMBL 259181 & 954940 & 2.9213 & 2.9213 & TRN & \\
\hline CHEMBL558642 & 954940 & 2.8725 & 2.8725 & TRN & \\
\hline CHEMBL3349342 & 954940 & 3.5799 & 3.5799 & TRN & \\
\hline CHEMBL65 & 954940 & 7.8374 & 7.8374 & TRN & \\
\hline CHEMBL 2005886 & 954940 & 4.4832 & 4.4832 & TRN & \\
\hline CHEMBL3199475 & 954940 & 3.5385 & 3.5385 & TRN & \\
\hline CHEMBL209148 & 954940 & 4.8476 & 4.8476 & TRN & \\
\hline CHEMBL1404918 & 954940 & 2.9932 & 2.9932 & TRN & \\
\hline CHEMBL509032 & 954940 & 3.8992 & 3.8992 & TRN & \\
\hline CHEMBL379975 & 954940 & 4.2412 & 4.2412 & TRN & \\
\hline CHEMBL 255342 & 954940 & 3.3636 & 3.8777 & TST & \\
\hline CHEMBL213100 & 954940 & 3.7975 & 3.5157 & TST & \\
\hline CHEMBL392695 & 954940 & 6.0264 & 5.6033 & TST & \\
\hline CHEMBL483847 & 954940 & 3.4413 & 3.8439 & TST & \\
\hline CHEMBL2144069 & 954940 & 3.2446 & 4.289 & TST & \\
\hline CHEMBL 379300 & 954940 & 6.808 & 6.3546 & TST & \\
\hline CHEMBL210618 & 954940 & 2.9806 & 3.4476 & TST & \\
\hline CHEMBL 2363137 & 954940 & 4.6383 & 5.4491 & TST & \\
\hline CHEMBL1590308 & 954940 & 3.5914 & 3.4319 & TST & \\
\hline CHEMBL1270026 & 674726 & 6.9586 & 6.5663 & TRN & \\
\hline CHEMBL1270727 & 674726 & 7.0 & 6.6917 & TRN & \\
\hline CHEMBL1270241 & 674726 & 6.5229 & 6.5694 & TRN & \\
\hline CHEMBL1270136 & 674726 & 5.9208 & 6.42200 & 0000000001 & TRN \\
\hline CHEMBL1270629 & 674726 & 7.3979 & 7.3896 & TRN & \\
\hline CHEMBL1271037 & 674726 & 6.4815 & 7.3089 & TRN & \\
\hline CHEMBL1270337 & 674726 & 7.3979 & 6.98799 & 99999999995 & TRN \\
\hline CHEMBL1270239 & 674726 & 7.0 & 6.7554 & TST & \\
\hline CHEMBL1271245 & 674726 & 7.301 & 7.0448 & TRN & \\
\hline CHEMBL1270526 & 674726 & 7.5229 & 7.6163 & TRN & \\
\hline CHEMBL1270729 & 674726 & 7.0 & 7.2978 & TST & \\
\hline CHEMBL1270529 & 674726 & 7.2218 & 6.9251 & TRN & \\
\hline CHEMBL1271140 & 674726 & 6.4318 & 6.5031 & TST & \\
\hline CHEMBL1269920 & 674726 & 7.1549 & 7.1167 & TRN & \\
\hline CHEMBL1270028 & 674726 & 6.3979 & 6.8198 & TRN & \\
\hline CHEMBL1270027 & 674726 & 6.2757 & 6.5682 & TRN & \\
\hline CHEMBL1269921 & 674726 & 7.699 & 7.5271 & TRN & \\
\hline CHEMBL1270833 & 674726 & 5.5031 & 6.5752 & TRN & \\
\hline CHEMBL1270240 & 674726 & 7.1549 & 6.8505 & TRN & \\
\hline CHEMBL1270133 & 674726 & 6.3872 & 6.5496 & TRN & \\
\hline CHEMBL1271343 & 674726 & 6.7959 & 6.4378 & TRN & \\
\hline CHEMBL1270334 & 674726 & 7.5229 & 7.8377 & TRN & \\
\hline CHEMBL1271244 & 674726 & 7.5686 & 7.0833 & TST & \\
\hline CHEMBL1270436 & 674726 & 6.5229 & 7.0347 & TRN & \\
\hline CHEMBL1271346 & 674726 & 8.0 & 7.66700 & 2000000001 & TRN \\
\hline CHEMBL1271452 & 674726 & 8.0 & 7.6993 & TRN & \\
\hline & & & & 28483 & \\
\hline
\end{tabular}




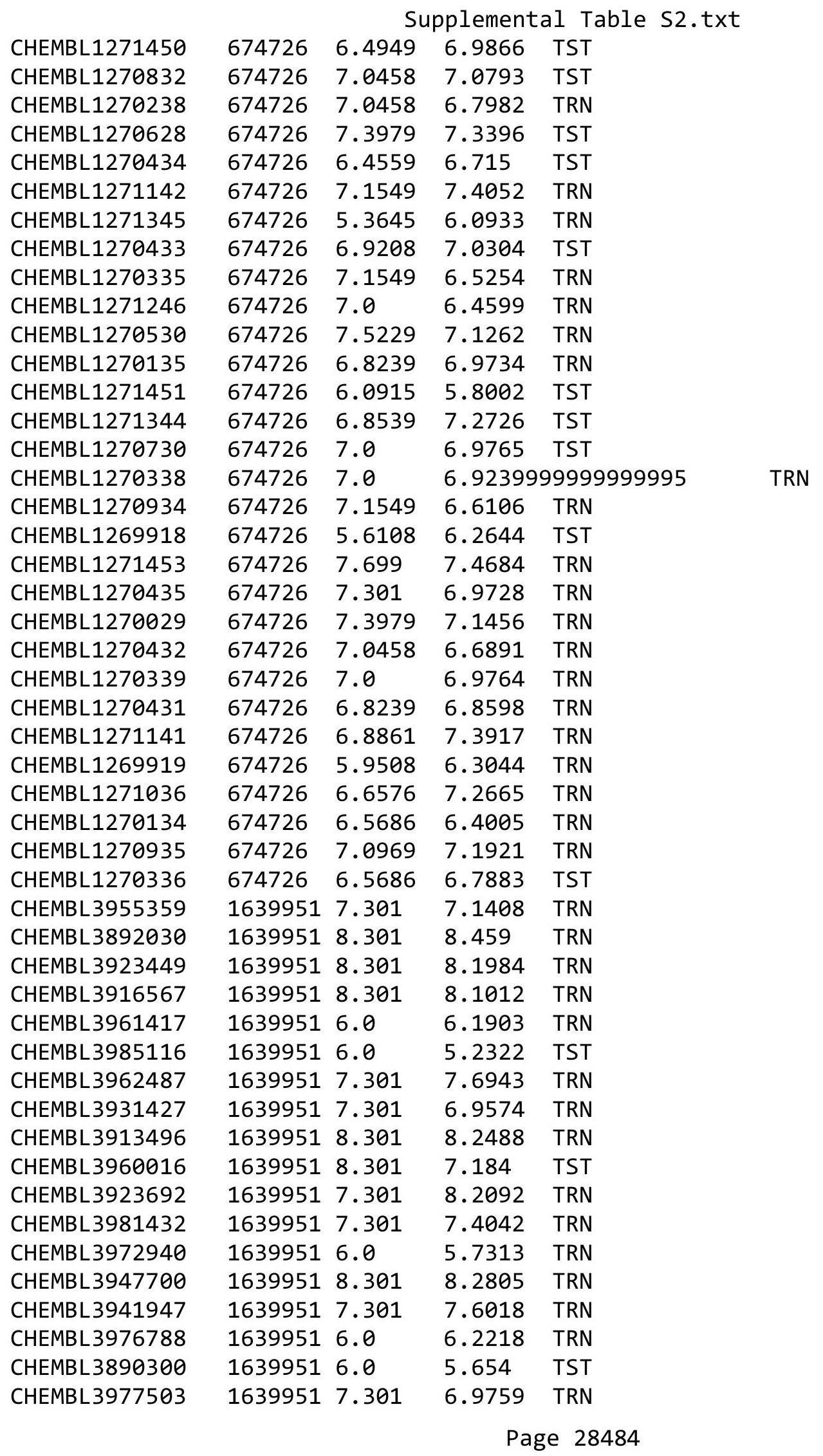


Supplemental Table S2.txt

CHEMBL3916225

CHEMBL 3959195

CHEMBL3940489

CHEMBL3959638

CHEMBL3936151

CHEMBL 3907230

CHEMBL3968519

CHEMBL3906936

CHEMBL 3976226

CHEMBL3925803

CHEMBL 3955083

CHEMBL 3921390

CHEMBL3958898

CHEMBL3957171

CHEMBL 3893416

CHEMBL3938869

CHEMBL3928601

CHEMBL 3983466

CHEMBL3909572

CHEMBL 3958466

CHEMBL3937048

CHEMBL 3924442

CHEMBL 3924998

CHEMBL 3941402

CHEMBL 3959495

CHEMBL3968522

CHEMBL 3934134

CHEMBL3921689

CHEMBL3932115

CHEMBL3891059

CHEMBL3955486

CHEMBL3949434

CHEMBL 3898088

CHEMBL3895129

CHEMBL3986404

CHEMBL3965625

CHEMBL 3959254

CHEMBL3943570

CHEMBL3909603

CHEMBL 3983938

CHEMBL 3933359

CHEMBL3952465

CHEMBL3939828

CHEMBL3939133

CHEMBL3964605

CHEMBL3968233

CHEMBL 3986082

CHEMBL 3930406
16399517.301

16399518.301

16399516.0

16399518.301

16399517.301

16399517.301

16399518.301

16399518.301

16399518.301

16399518.301

16399517.301

16399516.0

16399517.301

16399518.301

16399517.301

16399517.301

16399517.301

16399516.0

16399516.0

16399518.301

16399517.301

16399516.0

16399517.301

16399518.301

16399517.301

16399517.301

16399516.0

16399517.301

16399517.301

16399516.0

16399516.0

16399517.301

16399517.301

16399517.301

16399517.301

16399516.0

16399518.301

16399518.301

16399516.0

16399517.301

16399516.0

16399517.301

16399517.301

16399517.301

16399517.301

16399517.301

16399516.0

16399517.301
7.1331 TRN

6.9395 TST

7.2057 TST

8.4213 TRN

7.5171 TRN

6.2333 TRN

7.7173 TST

8.2275 TRN

8.0033 TRN

8.2832 TRN

7.4079 TRN

6.7613 TRN

6.617000000000001 TST

6.8198 TST

7.2436 TRN

6.8996 TRN

7.1435 TRN

7.1192 TST

6.2432 TRN

8.3254 TRN

7.1791 TRN

5.4501 TST

6.8012 TRN

8.0848 TRN

7.4673 TRN

6.9346 TRN

6.5151 TRN

6.8141 TRN

6.7583 TRN

6.6283 TRN

6.7089 TRN

7.2368 TST

6.9031 TST

7.7228 TRN

7.2341 TRN

6.7238 TST

7.4298 TST

7.3572 TRN

7.41 TST

7.728 TRN

6.1416 TRN

7.098 TRN

7.1101 TRN

6.8382 TRN

6.4294 TST

7.3398 TRN

6.5109 TRN

6.8769 TST

Page 28485 
Supplemental Table S2.txt

\begin{tabular}{|c|c|c|c|c|}
\hline CHEMBL3952693 & 1639951 & 8.301 & 7.3501 & TST \\
\hline CHEMBL3933130 & 1639951 & 7.301 & 7.4426 & TST \\
\hline CHEMBL3923645 & 1639951 & 6.0 & 5.8974 & TRN \\
\hline CHEMBL3961005 & 1639951 & 7.301 & 7.3586 & TRN \\
\hline CHEMBL3920036 & 1639951 & 7.301 & 7.5448 & TRN \\
\hline CHEMBL3927849 & 1639951 & 6.0 & 5.9791 & TRN \\
\hline CHEMBL3956820 & 1639951 & 6.0 & 6.2537 & TRN \\
\hline CHEMBL3945860 & 1639951 & 8.301 & 6.754 & TST \\
\hline CHEMBL3895458 & 1639951 & 6.0 & 6.1119 & TRN \\
\hline CHEMBL3914599 & 1639951 & 7.301 & 7.4071 & TRN \\
\hline CHEMBL3945028 & 1639951 & 6.0 & 6.5002 & TRN \\
\hline CHEMBL3946590 & 1639951 & 6.0 & 6.1988 & TRN \\
\hline CHEMBL3986135 & 1639951 & 6.0 & 7.4017 & TST \\
\hline CHEMBL3977030 & 1639951 & 8.301 & 7.5501 & TST \\
\hline CHEMBL3937297 & 1639951 & 8.301 & 8.3773 & TRN \\
\hline CHEMBL3893058 & 1639951 & 6.0 & 5.1943 & TST \\
\hline CHEMBL3935851 & 1639951 & 7.301 & 7.5429 & TST \\
\hline CHEMBL3906715 & 1639951 & 7.301 & 7.1239 & TRN \\
\hline CHEMBL3897525 & 1639951 & 8.301 & 8.5849 & TRN \\
\hline CHEMBL3958678 & 1639951 & 7.301 & 6.693 & TST \\
\hline CHEMBL3938621 & 1639951 & 8.301 & 7.2168 & TST \\
\hline CHEMBL3910031 & 1639951 & 6.0 & 6.6059 & TRN \\
\hline CHEMBL3920114 & 1639951 & 8.301 & 8.2824 & TRN \\
\hline CHEMBL3959774 & 1639951 & 7.301 & 7.5862 & TRN \\
\hline CHEMBL3916828 & 1639951 & 7.301 & 6.4156 & TST \\
\hline CHEMBL3971560 & 1639951 & 6.0 & 5.9686 & TRN \\
\hline CHEMBL3909744 & 1639951 & 8.301 & 7.61799 & 9999999999 \\
\hline CHEMBL3940839 & 1639951 & 8.301 & 8.2942 & TRN \\
\hline CHEMBL3939671 & 1639951 & 8.301 & 8.4365 & TRN \\
\hline CHEMBL3968956 & 1639951 & 8.301 & 8.6886 & TRN \\
\hline CHEMBL3917294 & 1639951 & 7.301 & 7.3457 & TRN \\
\hline CHEMBL3947712 & 1639951 & 6.0 & 7.2135 & TST \\
\hline CHEMBL3924098 & 1639951 & 7.301 & 6.8368 & TRN \\
\hline CHEMBL3909626 & 1639951 & 7.301 & 7.6015 & TST \\
\hline CHEMBL3895424 & 1639951 & 7.301 & 6.4413 & TRN \\
\hline CHEMBL3893846 & 1639951 & 7.301 & 7.2925 & TRN \\
\hline CHEMBL3962203 & 1639951 & 7.301 & 7.3758 & TRN \\
\hline CHEMBL3934095 & 1639951 & 7.301 & 7.1245 & TRN \\
\hline CHEMBL3914189 & 1639951 & 7.301 & 6.9677 & TRN \\
\hline CHEMBL3944791 & 1639951 & 7.301 & 7.2166 & TRN \\
\hline CHEMBL3904460 & 1639951 & 8.301 & 7.8674 & TRN \\
\hline CHEMBL3921482 & 1639951 & 8.301 & 7.9604 & TRN \\
\hline CHEMBL3918761 & 1639951 & 8.301 & 8.4301 & TRN \\
\hline CHEMBL3914180 & 1639951 & 8.301 & 8.0357 & TRN \\
\hline CHEMBL3974328 & 1639951 & 6.0 & 6.3563 & TRN \\
\hline CHEMBL3945353 & 1639951 & 7.301 & 6.5236 & TST \\
\hline CHEMBL3922278 & 1639951 & 7.301 & 6.9483 & TRN \\
\hline CHEMBL3917442 & 1639951 & 8.301 & 8.2614 & TRN \\
\hline
\end{tabular}




\begin{tabular}{|c|c|c|c|c|c|}
\hline \multicolumn{6}{|c|}{ Supplemental Table S2.txt } \\
\hline CHEMBL3891130 & 1639951 & 6.0 & 7.4097 & TST & \\
\hline CHEMBL3943734 & 1639951 & 7.301 & 7.0808 & TRN & \\
\hline CHEMBL3928696 & 1639951 & 7.301 & 7.7847 & TST & \\
\hline CHEMBL3896067 & 1639951 & 7.301 & 7.0091 & TRN & \\
\hline CHEMBL3959160 & 1639951 & 6.0 & 6.1331 & TRN & \\
\hline CHEMBL3923250 & 1639951 & 6.0 & 6.5909 & TST & \\
\hline CHEMBL3923153 & 1639951 & 7.301 & 7.2273 & TRN & \\
\hline CHEMBL3958481 & 1639951 & 6.0 & 6.25700 & 0000000001 & TRN \\
\hline CHEMBL 3959857 & 1639951 & 8.301 & 7.3429 & TST & \\
\hline CHEMBL 3947643 & 1639951 & 6.0 & 5.9867 & TRN & \\
\hline CHEMBL3971050 & 1639951 & 8.301 & 8.3647 & TRN & \\
\hline CHEMBL3968192 & 1639951 & 6.0 & 6.3786 & TRN & \\
\hline CHEMBL3921861 & 1639951 & 6.0 & 5.9435 & TRN & \\
\hline CHEMBL3924380 & 1639951 & 6.0 & 6.5182 & TRN & \\
\hline CHEMBL3964556 & 1639951 & 7.301 & 7.269 & TRN & \\
\hline CHEMBL3916953 & 1639951 & 6.0 & 6.2137 & TRN & \\
\hline CHEMBL3961472 & 1639951 & 8.301 & 8.3029 & TRN & \\
\hline CHEMBL3896122 & 1639951 & 7.301 & 7.1985 & TRN & \\
\hline CHEMBL3919051 & 1639951 & 7.301 & 7.2071 & TRN & \\
\hline CHEMBL3905501 & 1639951 & 6.0 & 6.3973 & TRN & \\
\hline CHEMBL3958721 & 1639951 & 7.301 & 7.2061 & TRN & \\
\hline CHEMBL 3942161 & 1639951 & 8.301 & 7.9554 & TRN & \\
\hline CHEMBL3945177 & 1639951 & 7.301 & 7.4025 & TRN & \\
\hline CHEMBL3919145 & 1639951 & 7.301 & 7.3549 & TST & \\
\hline CHEMBL3972712 & 1639951 & 7.301 & 7.6186 & TRN & \\
\hline CHEMBL3957416 & 1613064 & 6.7595 & 6.6974 & TRN & \\
\hline CHEMBL3958006 & 1613064 & 7.4559 & 7.5471 & TRN & \\
\hline CHEMBL3896779 & 1613064 & 6.9914 & 7.0638 & TRN & \\
\hline CHEMBL3969056 & 1613064 & 7.9586 & 8.0631 & TRN & \\
\hline CHEMBL3963723 & 1613064 & 6.0969 & 6.5161 & TST & \\
\hline CHEMBL3948084 & 1613064 & 6.8153 & 6.7929 & TRN & \\
\hline CHEMBL3971413 & 1613064 & 6.7033 & 6.7754 & TRN & \\
\hline CHEMBL3925158 & 1613064 & 6.0888 & 5.6619 & TST & \\
\hline CHEMBL3939985 & 1613064 & 7.699 & 7.8096 & TRN & \\
\hline CHEMBL3921555 & 1613064 & 7.0506 & 6.7107 & TRN & \\
\hline CHEMBL3970330 & 1613064 & 7.7212 & 7.8728 & TRN & \\
\hline CHEMBL3968839 & 1613064 & 6.1925 & 6.1412 & TRN & \\
\hline CHEMBL3921129 & 1613064 & 7.6383 & 7.4565 & TRN & \\
\hline CHEMBL 3943512 & 1613064 & 6.3778 & 6.4798 & TST & \\
\hline CHEMBL3930316 & 1613064 & 6.3915 & 7.6654 & TST & \\
\hline CHEMBL3957801 & 1613064 & 6.2933 & 7.3383 & TST & \\
\hline CHEMBL3904257 & 1613064 & 7.2757 & 7.1934 & TRN & \\
\hline CHEMBL3890751 & 1613064 & 7.5229 & 7.525 & TRN & \\
\hline CHEMBL 3921446 & 1613064 & 5.0 & 5.2033 & TRN & \\
\hline CHEMBL3950549 & 1613064 & 7.4949 & 7.9539 & TST & \\
\hline CHEMBL3899132 & 1613064 & 7.4202 & 7.5057 & TRN & \\
\hline CHEMBL3930506 & 1613064 & 7.8539 & 7.9556 & TRN & \\
\hline CHEMBL3964380 & 1613064 & 6.1068 & 6.0136 & TRN & \\
\hline
\end{tabular}


Supplemental Table S2.txt

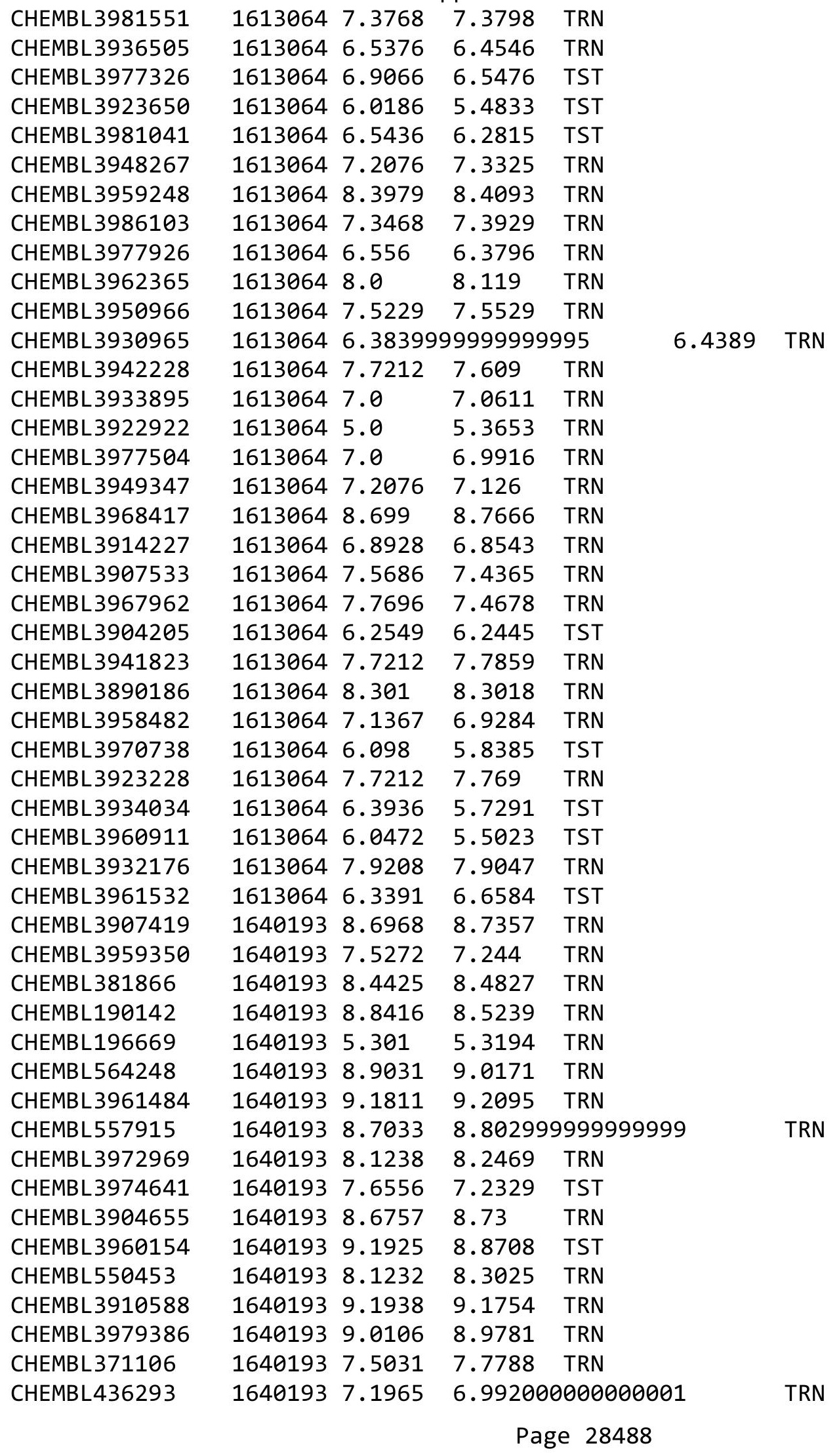


Supplemental Table S2.txt

\begin{tabular}{|c|c|c|c|c|c|}
\hline CHEMBL120413 & 1640193 & 7.3675 & 7.256 & TST & \\
\hline CHEMBL 370176 & 1640193 & 6.9788 & 7.0832 & TRN & \\
\hline CHEMBL1235423 & 1640193 & 7.6925 & 7.4016 & TST & \\
\hline CHEMBL316053 & 1640193 & 7.7545 & 7.3193 & TST & \\
\hline CHEMBL3966335 & 1640193 & 6.0035 & 6.2247 & TST & \\
\hline CHEMBL197624 & 1640193 & 7.6091 & 7.5711 & TRN & \\
\hline CHEMBL48813 & 1640193 & 8.8386 & 8.607999 & 9999999999 & TST \\
\hline CHEMBL198421 & 1640193 & 6.6345 & 6.749 & TRN & \\
\hline CHEMBL3942651 & 1640193 & 5.426 & 5.702999 & 9999999999 & TST \\
\hline CHEMBL370614 & 1640193 & 9.104 & 8.9891 & TRN & \\
\hline CHEMBL3958789 & 1640193 & 8.6904 & 8.6051 & TRN & \\
\hline CHEMBL194810 & 1640193 & 7.75200 & 000000000 & 8.0036 & TRN \\
\hline CHEMBL3955803 & 1640193 & 8.9172 & 8.7861 & TRN & \\
\hline CHEMBL3968842 & 1640193 & 8.6271 & 8.7954 & TRN & \\
\hline CHEMBL196551 & 1640193 & 8.0362 & 8.0651 & TRN & \\
\hline CHEMBL194186 & 1640193 & 9.1637 & 9.2899 & TRN & \\
\hline CHEMBL93087 & 1640193 & 7.1555 & 7.2102 & TST & \\
\hline CHEMBL3957468 & 1640193 & 7.9355 & 8.0994 & TRN & \\
\hline CHEMBL 3956658 & 1640193 & 8.1013 & 8.3618 & TRN & \\
\hline CHEMBL197377 & 1640193 & 9.262 & 9.0019 & TRN & \\
\hline CHEMBL 364284 & 1640193 & 9.6615 & 9.7419 & TRN & \\
\hline CHEMBL196539 & 1640193 & 9.1818 & 9.2095 & TRN & \\
\hline CHEMBL197547 & 1640193 & 7.3904 & 7.3867 & TRN & \\
\hline CHEMBL3928201 & 1640193 & 7.8182 & 7.4888 & TST & \\
\hline CHEMBL196589 & 1640193 & 7.2381 & 7.3981 & TRN & \\
\hline CHEMBL194889 & 1640193 & 6.4012 & 6.2607 & TRN & \\
\hline CHEMBL372568 & 1640193 & 6.3556 & 6.5098 & TRN & \\
\hline CHEMBL198654 & 1640193 & 8.1707 & 8.274 & TRN & \\
\hline CHEMBL3912108 & 1640193 & 8.9136 & 8.7503 & TRN & \\
\hline CHEMBL3304291 & 1640193 & 8.4763 & 8.5291 & TRN & \\
\hline CHEMBL 372956 & 1640193 & 8.9547 & 8.5307 & TRN & \\
\hline CHEMBL3305961 & 1640193 & 7.7375 & 7.8406 & TRN & \\
\hline CHEMBL196162 & 1640193 & 8.5591 & 7.9046 & TRN & \\
\hline CHEMBL196492 & 1640193 & 8.3372 & \multicolumn{2}{|c|}{7.9479999999999995} & TS \\
\hline CHEMBL3972799 & 1640193 & 9.1925 & 9.0617 & TST & \\
\hline CHEMBL383361 & 1640193 & 9.1314 & 9.2307 & TST & \\
\hline CHEMBL3986101 & 1640193 & 9.057 & 9.0895 & TST & \\
\hline CHEMBL3930807 & 1642116 & 6.7036 & 7.0313 & TRN & \\
\hline CHEMBL3936028 & 1642116 & 6.3548 & 7.4941 & TRN & \\
\hline CHEMBL3916255 & 1642116 & 7.9872 & 7.971 & TRN & \\
\hline CHEMBL3946983 & 1642116 & 7.308 & 7.3258 & TRN & \\
\hline CHEMBL3935206 & 1642116 & 8.2366 & 7.8323 & TRN & \\
\hline CHEMBL3984996 & 1642116 & 7.2125 & 7.5902 & TRN & \\
\hline CHEMBL3973703 & 1642116 & 7.5467 & 7.3077 & TRN & \\
\hline CHEMBL3952854 & 1642116 & 8.3872 & 7.4997 & TRN & \\
\hline CHEMBL 3922495 & 1642116 & 7.3242 & 6.9938 & TRN & \\
\hline CHEMBL 3918429 & 1642116 & 7.6904 & 8.2478 & TRN & \\
\hline CHEMBL3968469 & 1642116 & 7.9586 & 7.7178 & TRN & \\
\hline
\end{tabular}

Page 28489 
Supplemental Table S2.txt

\begin{tabular}{|c|c|c|c|c|c|}
\hline CHEMBL 3895228 & 1642116 & 7.9208 & 7.1833 & TRN & \\
\hline CHEMBL3963316 & 1642116 & 6.7496 & 7.3814 & TRN & \\
\hline CHEMBL3903525 & 1642116 & 8.0177 & 8.5443 & TRN & \\
\hline CHEMBL3945091 & 1642116 & 7.8665 & 8.4082 & TRN & \\
\hline CHEMBL3898171 & 1642116 & 7.056 & 7.2949 & TRN & \\
\hline CHEMBL3897862 & 1642116 & 7.2396 & 7.7783 & TRN & \\
\hline CHEMBL3965458 & 1642116 & 8.6021 & 7.5447 & TRN & \\
\hline CHEMBL3968098 & 1642116 & 6.6548 & 6.7809 & TRN & \\
\hline CHEMBL3900364 & 1642116 & 6.0 & 6.6216 & TRN & \\
\hline CHEMBL3896990 & 1642116 & 6.8072 & 6.6616 & TST & \\
\hline CHEMBL3972177 & 1642116 & 6.8499 & 6.7767 & TRN & \\
\hline CHEMBL3918487 & 1642116 & 9.1549 & 8.3397 & TRN & \\
\hline CHEMBL 3972823 & 1642116 & 6.5894 & 7.0212 & TRN & \\
\hline CHEMBL 3948481 & 1642116 & 6.0 & 7.2152 & TRN & \\
\hline CHEMBL3953670 & 1642116 & 6.5524 & $6.91200 t$ & 0000000001 & TRN \\
\hline CHEMBL3974511 & 1642116 & 7.9281 & 7.9568 & TRN & \\
\hline CHEMBL3969306 & 1642116 & 7.3635 & 7.9458 & TRN & \\
\hline CHEMBL3905931 & 1642116 & 7.055 & 6.4968 & TST & \\
\hline CHEMBL3937051 & 1642116 & 8.7447 & 7.7929 & TRN & \\
\hline CHEMBL3915658 & 1642116 & 7.433 & 7.7029 & TRN & \\
\hline CHEMBL3951812 & 1642116 & 7.82100 & $20000000 t$ & 7.3252 & TRN \\
\hline CHEMBL3969957 & 1642116 & 7.3526 & 7.5755 & TRN & \\
\hline CHEMBL3986681 & 1642116 & 6.0 & 7.1521 & TRN & \\
\hline CHEMBL3920295 & 1642116 & 7.4318 & 7.0056 & TRN & \\
\hline CHEMBL3919391 & 1642116 & 7.6882 & 8.1779 & TRN & \\
\hline CHEMBL3945147 & 1642116 & 7.1979 & 7.15 & TRN & \\
\hline CHEMBL3982524 & 1642116 & 6.9073 & 7.7704 & TRN & \\
\hline CHEMBL3900197 & 1642116 & 7.1512 & 7.6801 & TRN & \\
\hline CHEMBL3919417 & 1642116 & 6.5931 & 7.1278 & TST & \\
\hline CHEMBL3986841 & 1642116 & 7.8356 & 7.1959 & TRN & \\
\hline CHEMBL3966926 & 1642116 & 7.8356 & 7.6253 & TRN & \\
\hline CHEMBL3940625 & 1642116 & 7.3645 & 7.2762 & TRN & \\
\hline CHEMBL3932617 & 1642116 & 6.9722 & 6.9738 & TST & \\
\hline CHEMBL3985937 & 1642116 & 7.3188 & 6.604 & TST & \\
\hline CHEMBL3910468 & 1642116 & 7.684 & 6.7054 & TRN & \\
\hline CHEMBL3915090 & 1642116 & 6.0 & 6.9925 & TRN & \\
\hline CHEMBL3934832 & 1642116 & 9.3979 & 8.7306 & TRN & \\
\hline CHEMBL3930436 & 1642116 & 7.7878 & 7.322 & TRN & \\
\hline CHEMBL3911518 & 1642116 & 7.5058 & 7.3732 & TRN & \\
\hline CHEMBL3981504 & 1642116 & 7.015 & 6.91299 & 9999999999 & TRN \\
\hline CHEMBL3968149 & 1642116 & 6.9682 & 6.849 & TST & \\
\hline CHEMBL3986907 & 1642116 & 7.9281 & 7.9122 & TRN & \\
\hline CHEMBL3905510 & 1642116 & 6.8545 & 6.6191 & TST & \\
\hline CHEMBL3904595 & 1642116 & 6.7007 & 7.0889 & TRN & \\
\hline CHEMBL3946399 & 1642116 & 8.0655 & 7.7178 & TRN & \\
\hline CHEMBL3910656 & 1642116 & 6.0 & 7.059 & TST & \\
\hline CHEMBL3975413 & 1642116 & 8.7696 & 7.9181 & TRN & \\
\hline CHEMBL3959188 & 1642116 & 8.5686 & 7.9536 & TRN & \\
\hline
\end{tabular}

Page 28490 
Supplemental Table S2.txt

\begin{tabular}{|c|c|c|c|c|}
\hline CHEMBL3902921 & 1642116 & 7.7167 & 7.6403 & TRN \\
\hline CHEMBL3979779 & 1642116 & 6.9842 & 6.9118 & TST \\
\hline CHEMBL3905076 & 1642116 & 7.6882 & 8.5077 & TRN \\
\hline CHEMBL3932592 & 1642116 & 7.5058 & 7.74100 & 30000000005 \\
\hline CHEMBL 3941506 & 1642116 & 6.5367 & 7.11100 & 0000000001 \\
\hline CHEMBL 3902735 & 1642116 & 7.2716 & 6.9571 & TRN \\
\hline CHEMBL 3908287 & 1642116 & 7.0696 & 6.7047 & TRN \\
\hline CHEMBL 3936226 & 1642116 & 6.9066 & 7.2161 & TRN \\
\hline CHEMBL3941217 & 1642116 & 6.965 & 6.9077 & TRN \\
\hline CHEMBL 3924411 & 1642116 & 7.6498 & 7.3421 & TRN \\
\hline CHEMBL 3936193 & 1642116 & 7.289 & 6.5818 & TRN \\
\hline CHEMBL 3973752 & 1642116 & 8.1871 & 7.8339 & TRN \\
\hline CHEMBL3970926 & 1642116 & 6.0 & 6.5424 & TRN \\
\hline CHEMBL3925954 & 1642116 & 6.9359 & 7.3548 & TRN \\
\hline CHEMBL 3978729 & 1642116 & 8.2518 & 7.7328 & TRN \\
\hline CHEMBL 3978508 & 1642116 & 8.8539 & 7.9715 & TRN \\
\hline CHEMBL3901880 & 1642116 & 7.2269 & 7.1113 & TRN \\
\hline CHEMBL3931118 & 1642116 & 7.2865 & 7.7842 & TRN \\
\hline CHEMBL3890139 & 1642116 & 7.3615 & 7.0615 & TRN \\
\hline CHEMBL 3913580 & 1642116 & 7.0315 & 7.3562 & TRN \\
\hline CHEMBL3960115 & 1642116 & 8.1308 & 7.9493 & TRN \\
\hline CHEMBL 3980707 & 1642116 & 7.0334 & 6.9686 & TRN \\
\hline CHEMBL 3946424 & 1642116 & 7.7328 & 7.8101 & TST \\
\hline CHEMBL3899901 & 1642116 & 8.1367 & 7.6532 & TST \\
\hline CHEMBL 3899083 & 1642116 & 7.8697 & 7.4486 & TST \\
\hline CHEMBL3964278 & 1642116 & 7.3675 & 7.0889 & TST \\
\hline CHEMBL 3957187 & 1642116 & 7.2248 & 8.255 & TST \\
\hline CHEMBL3920764 & 1642116 & 8.1675 & 7.1672 & TST \\
\hline CHEMBL3920453 & 1642116 & 7.6421 & 6.5876 & TST \\
\hline CHEMBL 3914074 & 1642116 & 6.6959 & 6.53799 & 9999999999 \\
\hline CHEMBL3919716 & 1642116 & 7.1302 & 8.1364 & TST \\
\hline CHEMBL 3929508 & 1642116 & 7.1397 & 7.2967 & TST \\
\hline CHEMBL3973657 & 1642116 & 7.1018 & 7.6901 & TST \\
\hline CHEMBL3957074 & 1642116 & 6.0 & 7.1561 & TST \\
\hline CHEMBL3899236 & 1642116 & 6.4852 & 7.4489 & TST \\
\hline CHEMBL1525735 & 736830 & 5.5421 & 5.8231 & TRN \\
\hline CHEMBL1299637 & 736830 & 5.4342 & 5.4262 & TST \\
\hline CHEMBL1387232 & 736830 & 3.699 & 4.3686 & TRN \\
\hline CHEMBL1433943 & 736830 & 5.289 & 5.4284 & TRN \\
\hline CHEMBL1472304 & 736830 & 5.5346 & 4.8896 & TST \\
\hline CHEMBL1705002 & 736830 & 8.4078 & 7.5592 & TRN \\
\hline CHEMBL1333821 & 736830 & 5.5482 & 5.1951 & TST \\
\hline CHEMBL1595779 & 736830 & 5.4976 & 5.371 & TST \\
\hline CHEMBL1492752 & 736830 & 6.1694 & 6.1859 & TRN \\
\hline CHEMBL1388113 & 736830 & 5.5702 & 5.4058 & TST \\
\hline CHEMBL1706542 & 736830 & 3.699 & 3.6468 & TRN \\
\hline CHEMBL1728408 & 736830 & 3.699 & 3.815 & TRN \\
\hline CHEMBL1525546 & 736830 & 3.699 & 4.4352 & TST \\
\hline
\end{tabular}




\begin{tabular}{|c|c|c|c|c|c|}
\hline \multirow[b]{2}{*}{ CHEMBL1384893 } & & \multicolumn{4}{|c|}{ Supplemental Table s2.txt } \\
\hline & 736830 & 4.8827 & 4.7657 & TRN & \\
\hline CHEMBL1333593 & 736830 & 5.2343 & 5.3921 & TRN & \\
\hline CHEMBL1710033 & 736830 & 6.0 & 6.2499 & TRN & \\
\hline CHEMBL1735926 & 736830 & 5.7696 & 5.9612 & TRN & \\
\hline CHEMBL1338507 & 736830 & 3.699 & 3.3973 & TRN & \\
\hline CHEMBL1713298 & 736830 & 8.4078 & 8.0654 & TRN & \\
\hline CHEMBL1325227 & 736830 & 3.699 & 4.564 & TST & \\
\hline CHEMBL1299281 & 736830 & 5.3215 & 5.046 & TRN & \\
\hline CHEMBL1346782 & 736830 & 6.0 & 4.8976 & TRN & \\
\hline CHEMBL1525854 & 736830 & 5.2857 & 4.371 & TRN & \\
\hline CHEMBL1417851 & 736830 & 4.9469 & 6.8273 & TST & \\
\hline CHEMBL3145330 & 736830 & 3.699 & 4.6308 & TST & \\
\hline CHEMBL1530557 & 736830 & 5.5072 & 5.9228 & TRN & \\
\hline CHEMBL1370183 & 736830 & 5.2381 & 5.5292 & TRN & \\
\hline CHEMBL1708215 & 736830 & 3.699 & 3.565 & TRN & \\
\hline CHEMBL1698647 & 736830 & 3.699 & 4.3678 & TRN & \\
\hline CHEMBL1714566 & 736830 & 3.699 & 4.6011 & TRN & \\
\hline CHEMBL1699379 & 736830 & 3.699 & 3.6053 & TRN & \\
\hline CHEMBL1732490 & 736830 & 8.4078 & 7.3637 & TRN & \\
\hline CHEMBL1321508 & 736830 & 5.6536 & 5.6176 & TRN & \\
\hline CHEMBL1500188 & 736830 & 6.2549 & 5.7217 & TST & \\
\hline CHEMBL1532328 & 736830 & 5.5072 & 5.6434 & TRN & \\
\hline CHEMBL1412853 & 736830 & 6.0 & 5.5322 & TRN & \\
\hline CHEMBL1733280 & 736830 & 5.2396 & 5.3237 & TRN & \\
\hline CHEMBL1699128 & 736830 & 7.4976 & 6.3963 & TRN & \\
\hline CHEMBL1700643 & 736830 & 4.8894 & 5.1847 & TRN & \\
\hline CHEMBL1723575 & 736830 & 3.699 & 3.8961 & TRN & \\
\hline CHEMBL1607187 & 736830 & 6.3645 & 6.2516 & TRN & \\
\hline CHEMBL1481570 & 736830 & 3.699 & 3.7089 & TRN & \\
\hline CHEMBL1727785 & 736830 & 4.82100 & 00000000 & 3.89 & TRN \\
\hline CHEMBL1364793 & 736830 & 6.0 & 6.1583 & TRN & \\
\hline CHEMBL1719472 & 736830 & 4.757 & 4.2587 & TRN & \\
\hline CHEMBL1461631 & 736830 & 6.6345 & 6.8175 & TRN & \\
\hline CHEMBL1411639 & 736830 & 5.6162 & 5.8465 & TRN & \\
\hline CHEMBL1329930 & 736830 & 5.1118 & 5.3837 & TRN & \\
\hline CHEMBL1732890 & 736830 & 5.3134 & 4.5458 & TRN & \\
\hline CHEMBL1299751 & 736830 & 5.3726 & 5.32600 & 00000000005 & TRN \\
\hline CHEMBL1319304 & 736830 & 6.1129 & 5.3446 & TRN & \\
\hline CHEMBL1482357 & 736830 & 4.7122 & 4.086 & TRN & \\
\hline CHEMBL1717353 & 736830 & 5.1871 & 5.0362 & TRN & \\
\hline CHEMBL1466495 & 736830 & 5.1325 & 5.2031 & TST & \\
\hline CHEMBL1586616 & 736830 & 5.4306 & 5.8775 & TST & \\
\hline CHEMBL1481689 & 736830 & 3.699 & 4.3115 & TST & \\
\hline CHEMBL1723582 & 736830 & 3.699 & 3.4056 & TRN & \\
\hline CHEMBL1312200 & 736830 & 5.2226 & 5.4476 & TRN & \\
\hline CHEMBL1729147 & 736830 & 3.699 & 4.13 & TRN & \\
\hline CHEMBL1377340 & 736830 & 5.2306 & 5.6391 & TST & \\
\hline CHEMBL1706382 & 736830 & 3.699 & 3.5466 & TRN & \\
\hline
\end{tabular}




\begin{tabular}{|c|c|c|c|c|c|}
\hline \multicolumn{6}{|c|}{ Supplemental Table S2.txt } \\
\hline CHEMBL1704728 & 736830 & 6.6144 & 6.4922 & TRN & \\
\hline CHEMBL1524014 & 736830 & 7.0074 & 6.6517 & TRN & \\
\hline CHEMBL65374 & 736830 & 5.8297 & 5.9506 & TRN & \\
\hline CHEMBL1320366 & 736830 & 3.699 & 3.7355 & TRN & \\
\hline CHEMBL1464332 & 736830 & 5.2652 & 5.3276 & TRN & \\
\hline CHEMBL1729457 & 736830 & 3.699 & 4.2751 & TRN & \\
\hline CHEMBL1569954 & 736830 & 6.0 & 5.1145 & TRN & \\
\hline CHEMBL1569988 & 736830 & 5.5467 & 5.0862 & TRN & \\
\hline CHEMBL1411903 & 736830 & 3.699 & 4.6042 & TRN & \\
\hline CHEMBL1574961 & 736830 & 5.8182 & 5.2132 & TRN & \\
\hline CHEMBL1334593 & 736830 & 5.1146 & 5.4962 & TST & \\
\hline CHEMBL1434502 & 736830 & 5.0434 & 5.2707 & TRN & \\
\hline CHEMBL1718692 & 736830 & 3.699 & 3.9153 & TRN & \\
\hline CHEMBL1703491 & 736830 & 6.8356 & 5.3273 & TRN & \\
\hline CHEMBL1708434 & 736830 & 5.4202 & 4.506 & TRN & \\
\hline CHEMBL1567684 & 736830 & 5.1713 & 5.1092 & TRN & \\
\hline CHEMBL1488993 & 736830 & 4.8959 & 4.7019 & TRN & \\
\hline CHEMBL1700026 & 736830 & 3.699 & 3.5163 & TRN & \\
\hline CHEMBL1731586 & 736830 & 3.699 & 4.1939 & TRN & \\
\hline CHEMBL1445206 & 736830 & 3.699 & 3.9749 & TST & \\
\hline CHEMBL1372398 & 736830 & 5.8539 & 5.4084 & TRN & \\
\hline CHEMBL1411091 & 736830 & 3.699 & 4.1108 & TST & \\
\hline CHEMBL1732337 & 736830 & 6.585 & 6.5822 & TRN & \\
\hline CHEMBL1342760 & 736830 & 5.4634 & 4.5745 & TRN & \\
\hline CHEMBL1719980 & 736830 & 4.7595 & 4.5842 & TRN & \\
\hline CHEMBL1715638 & 736830 & 3.699 & 3.5224 & TRN & \\
\hline CHEMBL1736791 & 736830 & 3.699 & 4.5663 & TRN & \\
\hline CHEMBL1698552 & 736830 & 3.699 & 3.819 & TRN & \\
\hline CHEMBL1721926 & 736830 & 5.699 & 5.9062 & TRN & \\
\hline CHEMBL1491541 & 736830 & 4.9136 & 4.8929 & TST & \\
\hline CHEMBL1595790 & 736830 & 7.0227 & 6.1893 & TST & \\
\hline CHEMBL1721360 & 736830 & 3.699 & 3.5619 & TRN & \\
\hline CHEMBL1571150 & 736830 & 5.3655 & 5.3672 & TRN & \\
\hline CHEMBL1487136 & 736830 & 7.3655 & 7.2208 & TRN & \\
\hline CHEMBL1717950 & 736830 & 3.699 & 3.72300 & 00000000003 & TRN \\
\hline CHEMBL3199186 & 736830 & 3.699 & 4.0916 & TST & \\
\hline CHEMBL 1542713 & 736830 & 5.4989 & 5.3431 & TRN & \\
\hline CHEMBL599890 & 736830 & 4.7852 & 4.7322 & TST & \\
\hline CHEMBL1480238 & 736830 & 6.3675 & 6.1874 & TRN & \\
\hline CHEMBL1360862 & 736830 & 5.0088 & 4.747 & TRN & \\
\hline CHEMBL1373066 & 736830 & 4.8416 & 5.1739 & TRN & \\
\hline CHEMBL1445071 & 736830 & 5.4572 & 4.7743 & TST & \\
\hline CHEMBL1701407 & 736830 & 6.0 & 7.3126 & TRN & \\
\hline CHEMBL1719188 & 736830 & 6.1135 & 5.6801 & TRN & \\
\hline CHEMBL1735377 & 736830 & 3.699 & 4.3211 & TST & \\
\hline CHEMBL1361156 & 736830 & 3.699 & 4.9433 & TRN & \\
\hline CHEMBL1726725 & 736830 & 3.699 & 3.4066 & TRN & \\
\hline CHEMBL1433326 & 736830 & 3.699 & 4.1189 & TRN & \\
\hline
\end{tabular}




\begin{tabular}{|c|c|c|c|c|c|}
\hline \multicolumn{6}{|c|}{ Supplemental Table S2.txt } \\
\hline CHEMBL3192230 & 736830 & 5.2652 & 5.4482 & TRN & \\
\hline CHEMBL1710228 & 736830 & 3.699 & 4.1691 & TRN & \\
\hline CHEMBL1325856 & 736830 & 5.6021 & 5.8939 & TST & \\
\hline CHEMBL1332003 & 736830 & 3.699 & 3.8489 & TRN & \\
\hline CHEMBL1341697 & 736830 & 5.3565 & 5.528 & TST & \\
\hline CHEMBL1706268 & 736830 & 5.2314 & 5.0102 & TRN & \\
\hline CHEMBL1453730 & 736830 & 5.2013 & 5.3612 & TST & \\
\hline CHEMBL1424982 & 736830 & 3.699 & 3.5595 & TRN & \\
\hline CHEMBL1705298 & 736830 & 5.5045 & 5.3318 & TST & \\
\hline CHEMBL1327276 & 736830 & 5.5045 & 5.2991 & TST & \\
\hline CHEMBL1721154 & 736830 & 3.699 & 4.1565 & TRN & \\
\hline CHEMBL1565083 & 736830 & 5.5114 & 5.6059 & TST & \\
\hline CHEMBL1525940 & 736830 & 5.1925 & 4.5231 & TRN & \\
\hline CHEMBL1706800 & 736830 & 6.426 & 5.496 & TRN & \\
\hline CHEMBL1446570 & 736830 & 5.5003 & 5.9352 & TRN & \\
\hline CHEMBL1400601 & 736830 & 4.9547 & 5.15600 & 0000000001 & TRN \\
\hline CHEMBL1485417 & 736830 & 5.8761 & 6.2025 & TRN & \\
\hline CHEMBL1703685 & 736830 & 6.0044 & 6.4173 & TRN & \\
\hline CHEMBL1434007 & 736830 & 3.699 & 4.298 & TRN & \\
\hline CHEMBL1726092 & 736830 & 3.699 & 4.1017 & TRN & \\
\hline CHEMBL1335978 & 736830 & 5.2848 & 5.3626 & TRN & \\
\hline CHEMBL1732803 & 736830 & 5.4056 & 5.5018 & TST & \\
\hline CHEMBL1405985 & 736830 & 5.6326 & 5.8849 & TRN & \\
\hline CHEMBL1573795 & 736830 & 5.7545 & 4.2114 & TRN & \\
\hline CHEMBL1712964 & 736830 & 3.699 & 4.1836 & TRN & \\
\hline CHEMBL1700826 & 736830 & 3.699 & 3.3275 & TRN & \\
\hline CHEMBL1702900 & 736830 & 6.7696 & 6.3739 & TRN & \\
\hline CHEMBL1537124 & 736830 & 5.3188 & 5.5218 & TRN & \\
\hline CHEMBL1608707 & 736830 & 5.0159 & 5.2623 & TST & \\
\hline CHEMBL1541475 & 736830 & 3.699 & 3.81 & TRN & \\
\hline CHEMBL1720257 & 736830 & 5.5901 & 5.6951 & TRN & \\
\hline CHEMBL1700405 & 736830 & 6.2899 & 6.4283 & TRN & \\
\hline CHEMBL1308276 & 736830 & 5.7595 & 5.7974 & TST & \\
\hline CHEMBL1531328 & 736830 & 6.0 & 5.5454 & TRN & \\
\hline CHEMBL1597561 & 736830 & 5.3188 & 5.3651 & TST & \\
\hline CHEMBL1716972 & 736830 & 3.699 & 3.8347 & TRN & \\
\hline CHEMBL1387990 & 736830 & 4.7595 & 4.4648 & TST & \\
\hline CHEMBL1305007 & 736830 & 3.699 & 3.6301 & TRN & \\
\hline CHEMBL1424118 & 736830 & 5.4647 & 4.9928 & TST & \\
\hline CHEMBL1382232 & 736830 & 3.699 & 3.19199 & 99999999997 & TRN \\
\hline CHEMBL1426966 & 736830 & 5.2596 & 5.1361 & TST & \\
\hline CHEMBL1501470 & 736830 & 3.699 & 4.4672 & TST & \\
\hline CHEMBL1369425 & 736830 & 5.2757 & 4.8276 & TRN & \\
\hline CHEMBL1704929 & 736830 & 3.699 & 4.0977 & TRN & \\
\hline CHEMBL1701049 & 736830 & 3.699 & 3.7549 & TRN & \\
\hline CHEMBL1306769 & 736830 & 5.8097 & 5.3475 & TRN & \\
\hline CHEMBL1717116 & 736830 & 5.4401 & 5.7453 & TRN & \\
\hline CHEMBL1554526 & 736830 & 5.5467 & 5.9278 & TRN & \\
\hline
\end{tabular}




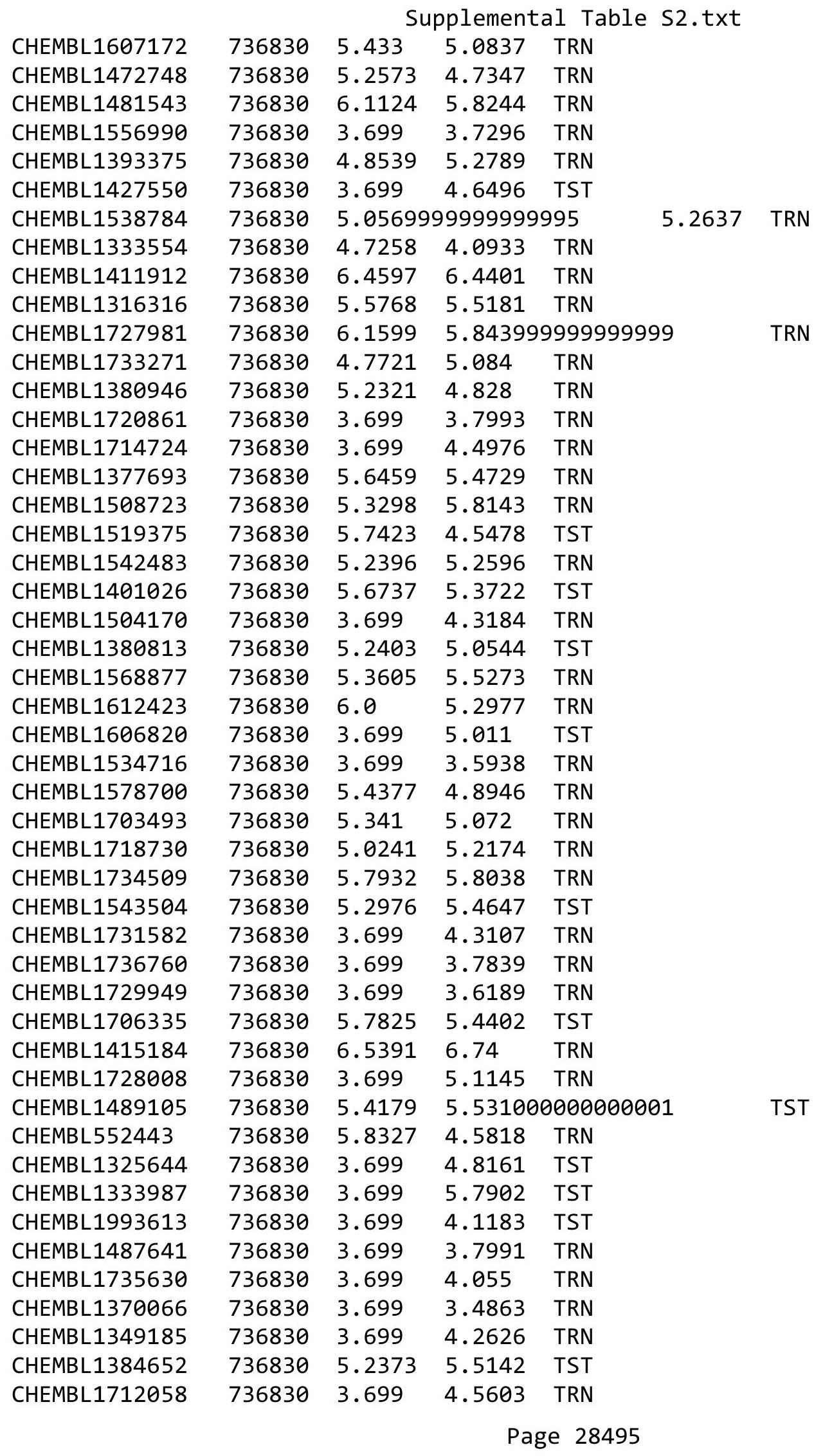




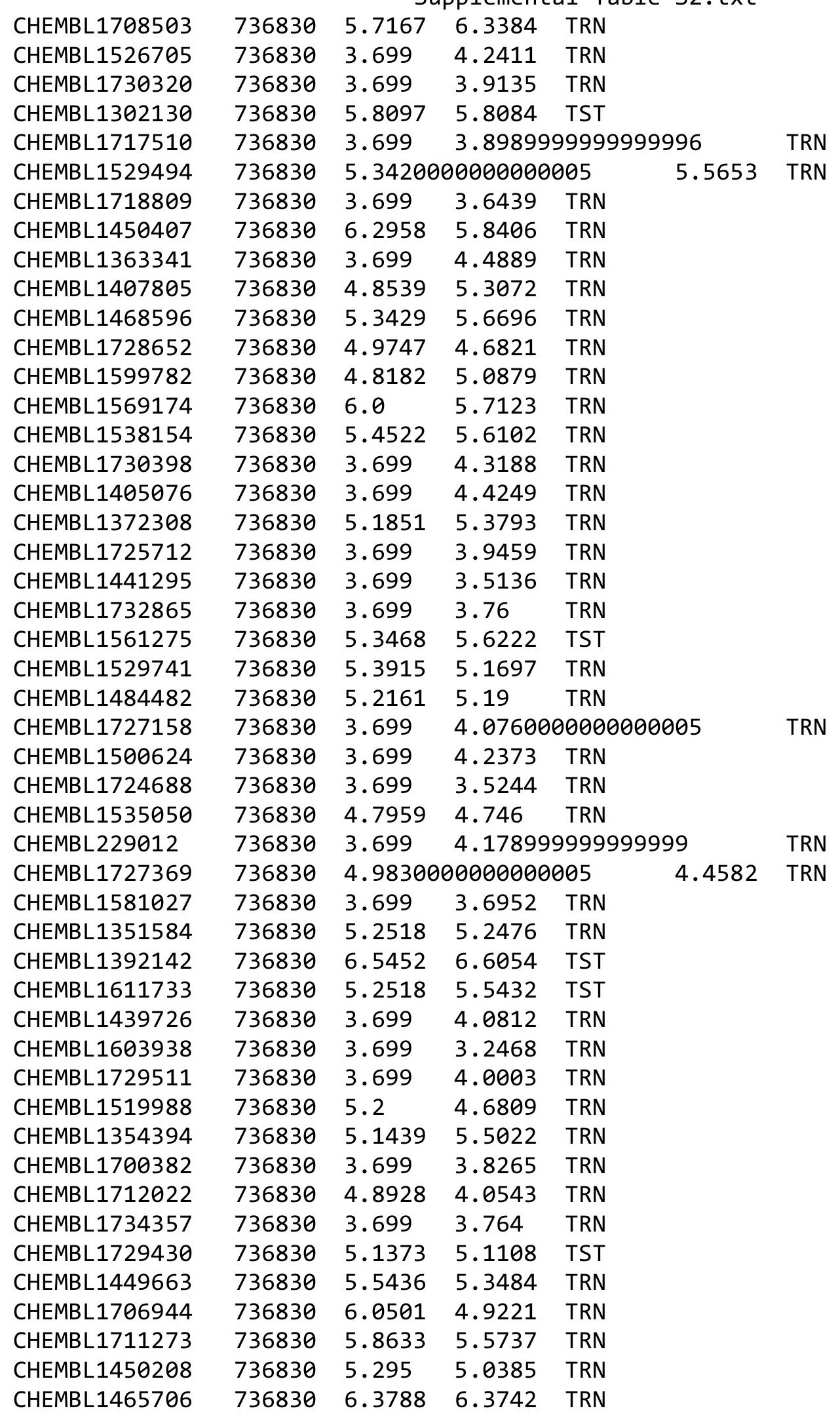

Page 28496 
Supplemental Table S2.txt

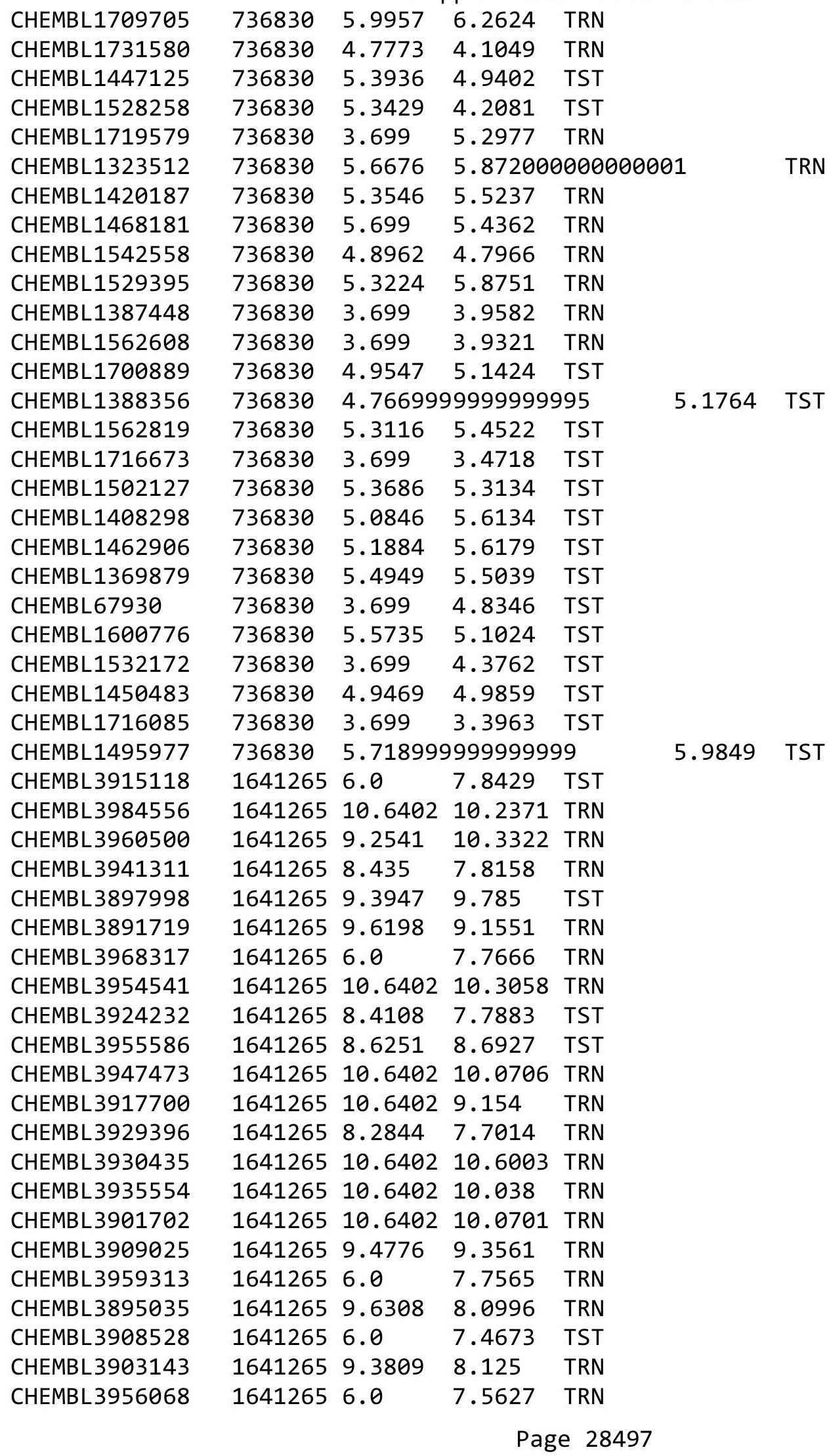


Supplemental Table S2.txt

\begin{tabular}{|c|c|c|c|c|}
\hline & 265 & & & \\
\hline HEMBL3 & 641265 & 10.6402 & 7.6568 & \\
\hline & 265 & & & \\
\hline 8 & 265 & 778 & & \\
\hline IEMBL & 641265 & 6.0 & 327 & \\
\hline IEMBL3 & 641265 & 9.4202 & 268 & \\
\hline 71 & 265 & 5402 & 104 & \\
\hline 13 & 265 & 6.0 & & \\
\hline IEMBL & 265 & 10.6 & 714 & \\
\hline IEMBL3 & 265 & 5402 & 4032 & \\
\hline IEMBL 35 & 265 & 9.3354 & & \\
\hline+33 & 265 & 402 & 278 & \\
\hline & & & & \\
\hline 13 & 265 & 9. & & \\
\hline 217 & 265 & 6.0 & 02 & \\
\hline 24 & 5 & 8. & 65 & \\
\hline 89 & 5 & 6. & 49 & \\
\hline & & & 955 & \\
\hline 64 & 265 & 6. & 032 & \\
\hline 29 & & & & \\
\hline 38 & 162 & 8. & 31 & \\
\hline 82 & & 7. & 73 & \\
\hline 55 & & 5402 & 794 & \\
\hline 182 & 265 & & 201 & \\
\hline 14 & 5 & 6. & & \\
\hline & 5 & & & \\
\hline & & & 798 & \\
\hline & & & 84 & \\
\hline 56 & 65 & 6. & & \\
\hline & & & & \\
\hline 76 & 55 & 9.2 & 777 & \\
\hline 41 & 5 & & 3825 & \\
\hline & 55 & & & \\
\hline & 164 & & 559 & \\
\hline 328 & 164 & 6 . & & \\
\hline & & 10 & & \\
\hline & & & 38 & \\
\hline & & 10. & & \\
\hline 613 & 164 & 9.1002 & 069 & $\mathrm{TR}$ \\
\hline 33 & 265 & 6 . & 62 & TR \\
\hline & 16 & 10.6 & 3702 & \\
\hline & & & & \\
\hline & 265 & 6. & 602 & 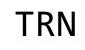 \\
\hline 57954 & 1641265 & 10.6402 & 8.1659 & $\Gamma R$ \\
\hline & 65 & & & \\
\hline & & & & \\
\hline & 16 & 0.0 & 7.3519 & \\
\hline HEMBL3921788 & 1641265 & 8.5677 & 7.9062 & \\
\hline
\end{tabular}

Page 28498 


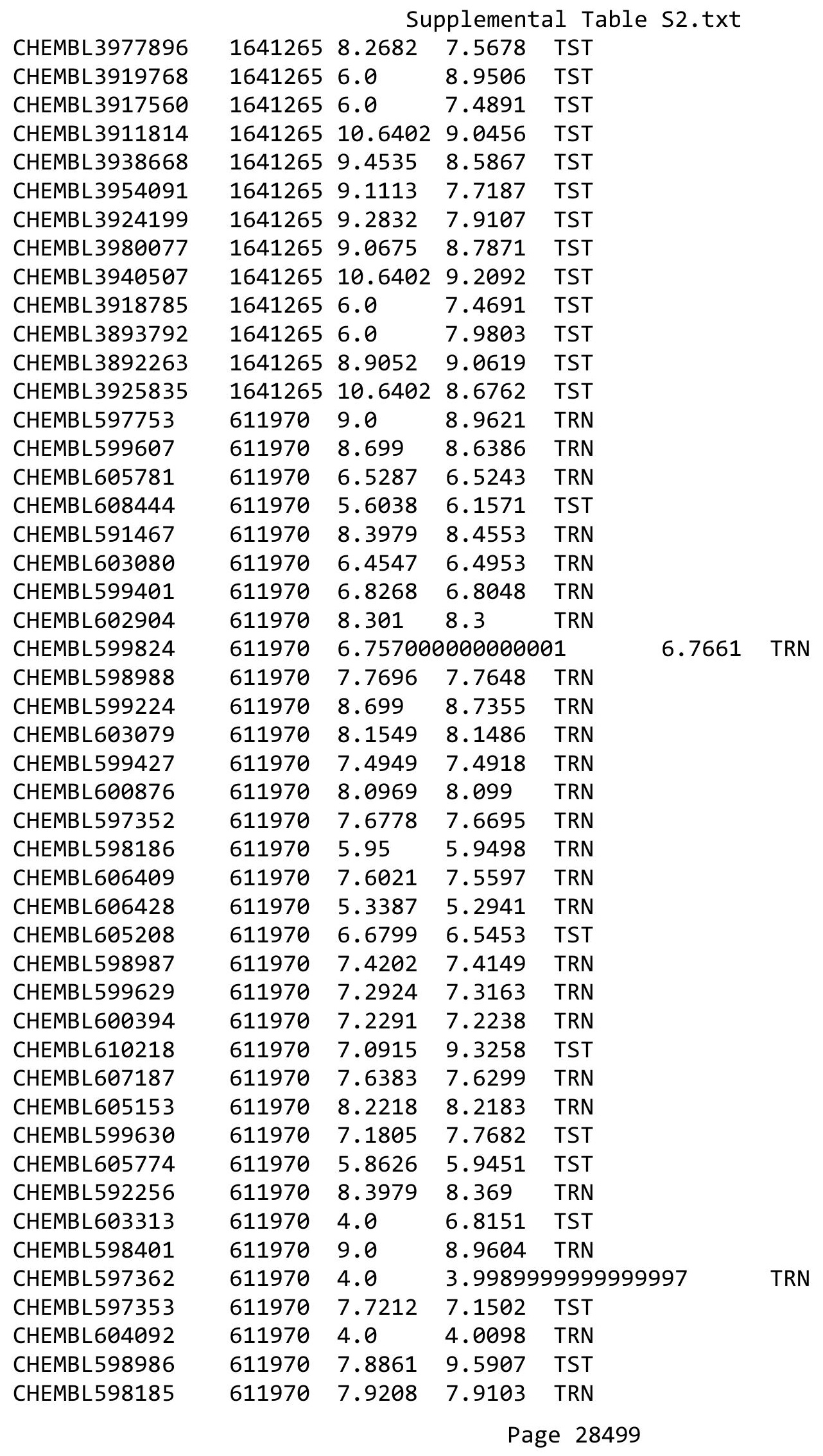




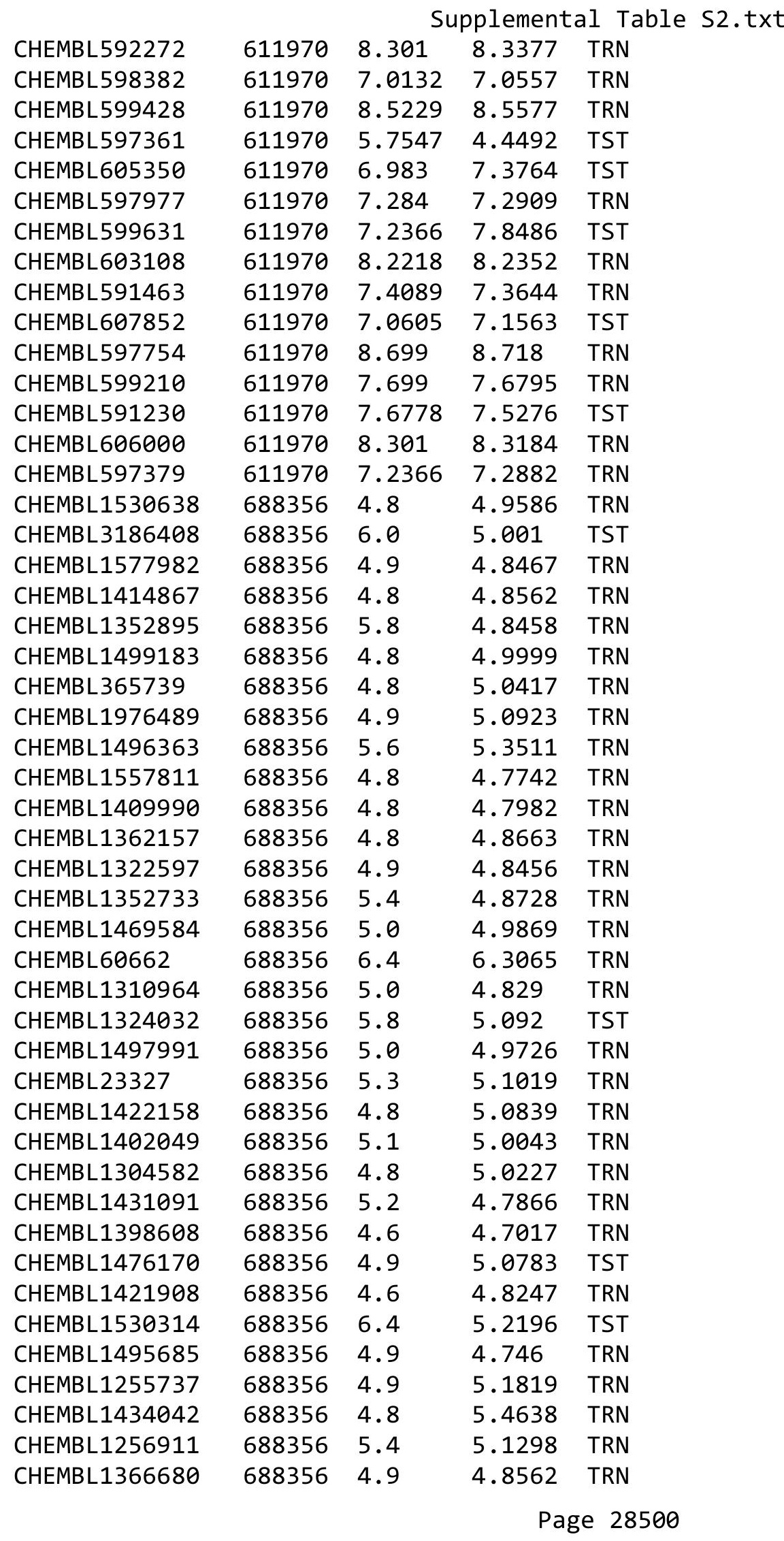




\begin{tabular}{|c|c|c|c|c|}
\hline & & & & \\
\hline CHEMBL1173475 & 688356 & 5.6 & 5.3586 & TRN \\
\hline CHEMBL1608811 & 688356 & 4.8 & 4.7231 & TRN \\
\hline CHEMBL65 & 688356 & 4.6 & 4.9489 & TRN \\
\hline CHEMBL18238 & 688356 & 5.3 & 6.2179 & TRN \\
\hline CHEMBL1374763 & 688356 & 4.9 & 4.9564 & TRN \\
\hline CHEMBL1439172 & 688356 & 4.9 & 5.504 & TRN \\
\hline CHEMBL1529647 & 688356 & 5.1 & 4.8181 & TRN \\
\hline CHEMBL363332 & 688356 & 6.0 & 5.1768 & TRN \\
\hline CHEMBL1256775 & 688356 & 4.4 & 5.0812 & TRN \\
\hline CHEMBL1552708 & 688356 & 5.4 & 6.1292 & TRN \\
\hline CHEMBL1329597 & 688356 & 4.8 & 4.9056 & TRN \\
\hline CHEMBL516616 & 688356 & 5.1 & 5.1381 & TST \\
\hline CHEMBL3212923 & 688356 & 4.8 & 4.9744 & TRN \\
\hline CHEMBL1318643 & 688356 & 4.6 & 6.4401 & TRN \\
\hline CHEMBL1547481 & 688356 & 4.8 & 4.8202 & TRN \\
\hline CHEMBL1316980 & 688356 & 5.1 & 6.2177 & TRN \\
\hline CHEMBL584759 & 688356 & 4.9 & 5.194 & TRN \\
\hline CHEMBL1414842 & 688356 & 4.9 & 4.7641 & TRN \\
\hline CHEMBL1370146 & 688356 & 4.8 & 4.8774 & TRN \\
\hline CHEMBL1391184 & 688356 & 4.7 & 4.7487 & TRN \\
\hline CHEMBL404613 & 688356 & 6.7001 & 5.1277 & TST \\
\hline CHEMBL1523150 & 688356 & 4.6 & 4.8913 & TRN \\
\hline CHEMBL1551254 & 688356 & 5.2 & 5.0438 & TST \\
\hline CHEMBL 275516 & 688356 & 5.0 & 4.894 & TST \\
\hline CHEMBL1391136 & 688356 & 5.0 & 4.8185 & TRN \\
\hline CHEMBL1488420 & 688356 & 4.5 & 4.8062 & TRN \\
\hline CHEMBL512908 & 688356 & 4.8 & 5.0782 & TRN \\
\hline CHEMBL1471205 & 688356 & 4.2 & 4.8233 & TRN \\
\hline CHEMBL1358065 & 688356 & 5.0 & 4.9566 & TRN \\
\hline CHEMBL1229712 & 688356 & 5.2 & 4.7632 & TRN \\
\hline CHEMBL 3304020 & 688356 & 4.9 & 5.1248 & TRN \\
\hline CHEMBL1327989 & 688356 & 4.6 & 4.9724 & TRN \\
\hline CHEMBL1521681 & 688356 & 5.0 & 5.008 & TRN \\
\hline CHEMBL1515691 & 688356 & 6.1 & 5.0775 & TRN \\
\hline CHEMBL1601218 & 688356 & 4.7 & 5.0419 & TST \\
\hline CHEMBL1407886 & 688356 & 5.3 & 4.9616 & TST \\
\hline CHEMBL1430325 & 688356 & 4.8 & 4.9387 & TRN \\
\hline CHEMBL1481974 & 688356 & 5.0 & 5.0536 & TRN \\
\hline CHEMBL1530216 & 688356 & 5.0 & 4.8176 & TRN \\
\hline CHEMBL1379686 & 688356 & 4.9 & 4.7805 & TRN \\
\hline CHEMBL1524631 & 688356 & 5.4 & 4.8523 & TRN \\
\hline CHEMBL1517669 & 688356 & 4.9 & 4.7548 & TRN \\
\hline CHEMBL1596619 & 688356 & 4.5 & 4.9687 & TST \\
\hline CHEMBL1236872 & 688356 & 10.5 & 6.8681 & TRN \\
\hline CHEMBL1359564 & 688356 & 4.6 & 4.8248 & TRN \\
\hline CHEMBL1570111 & 688356 & 5.1 & 4.8507 & TRN \\
\hline CHEMBL605003 & 688356 & 5.6 & 5.1061 & TST \\
\hline CHEMBL1533917 & 688356 & 5.0 & 4.8118 & TRN \\
\hline
\end{tabular}




\begin{tabular}{|c|c|c|c|c|}
\hline & & & ipplement & al Table S \\
\hline CHEMBL1544947 & 688356 & 5.5 & 4.9232 & TRN \\
\hline CHEMBL1393783 & 688356 & 5.3 & 5.0449 & TST \\
\hline CHEMBL72365 & 688356 & 4.9 & 5.2778 & TST \\
\hline CHEMBL1445121 & 688356 & 5.5 & 4.9077 & TST \\
\hline CHEMBL1317415 & 688356 & 5.2 & 5.2005 & TST \\
\hline CHEMBL1374334 & 688356 & 4.8 & 5.0373 & TST \\
\hline CHEMBL429095 & 688356 & 5.2 & 5.0159 & TST \\
\hline CHEMBL1505922 & 688356 & 4.8 & 4.8835 & TST \\
\hline CHEMBL 340807 & 688356 & 4.8 & 4.8881 & TST \\
\hline CHEMBL1315725 & 688356 & 5.0 & 5.0391 & TST \\
\hline CHEMBL 1574278 & 688356 & 4.6 & 4.8393 & TST \\
\hline CHEMBL1320482 & 688356 & 5.9 & 4.8478 & TST \\
\hline CHEMBL546257 & 688356 & 4.9 & 5.0164 & TST \\
\hline CHEMBL493229 & 538786 & 6.66 & 6.5078 & TRN \\
\hline CHEMBL493663 & 538786 & 4.91 & 4.9818 & TRN \\
\hline CHEMBL493461 & 538786 & 5.73 & 6.1284 & TRN \\
\hline CHEMBL494667 & 538786 & 6.41 & 6.2833 & TRN \\
\hline CHEMBL493664 & 538786 & 4.85 & 4.8299 & TRN \\
\hline CHEMBL523335 & 538786 & 5.64 & 4.9624 & TST \\
\hline CHEMBL494678 & 538786 & 7.23 & 6.7169 & TRN \\
\hline CHEMBL492631 & 538786 & 7.17 & 6.1132 & TRN \\
\hline CHEMBL494679 & 538786 & 6.6 & 5.313 & TST \\
\hline CHEMBL489663 & 538786 & 5.33 & 5.4636 & TRN \\
\hline CHEMBL493261 & 538786 & 5.1 & 5.5094 & TRN \\
\hline CHEMBL495341 & 538786 & 6.52 & 5.4044 & TST \\
\hline CHEMBL493100 & 538786 & 5.01 & 5.3935 & TST \\
\hline CHEMBL493099 & 538786 & 5.95 & 5.1961 & TST \\
\hline CHEMBL499631 & 538786 & 5.75 & 5.4525 & TST \\
\hline CHEMBL449021 & 538786 & 5.62 & 6.2403 & TRN \\
\hline CHEMBL506187 & 538786 & 6.61 & 6.6959 & TRN \\
\hline CHEMBL494890 & 538786 & 6.61 & 6.5071 & TRN \\
\hline CHEMBL494585 & 538786 & 5.44 & 5.6812 & TST \\
\hline CHEMBL494687 & 538786 & 4.63 & 5.3239 & TRN \\
\hline CHEMBL495342 & 538786 & 6.03 & 5.8396 & TRN \\
\hline CHEMBL455016 & 538786 & 5.29 & 5.6546 & TRN \\
\hline CHEMBL447151 & 538786 & 4.64 & 4.998 & TRN \\
\hline CHEMBL449157 & 538786 & 4.74 & 4.6209 & TRN \\
\hline CHEMBL492489 & 538786 & 5.33 & 5.2436 & TRN \\
\hline CHEMBL495265 & 538786 & 5.06 & 5.0862 & TRN \\
\hline CHEMBL493477 & 538786 & 6.2 & 5.5252 & TST \\
\hline CHEMBL446896 & 538786 & 7.18 & 5.45700 & 0000000001 \\
\hline CHEMBL502104 & 538786 & 6.93 & 6.51 & TRN \\
\hline CHEMBL492869 & 538786 & 5.87 & 5.9936 & TRN \\
\hline CHEMBL444484 & 538786 & 6.47 & 6.3527 & TRN \\
\hline CHEMBL444782 & 538786 & 7.33 & 7.1834 & TRN \\
\hline CHEMBL492663 & 538786 & 5.44 & 5.1562 & TRN \\
\hline CHEMBL505061 & 538786 & 7.16 & 6.9729 & TRN \\
\hline CHEMBL492662 & 538786 & 6.45 & 6.3808 & TRN \\
\hline
\end{tabular}




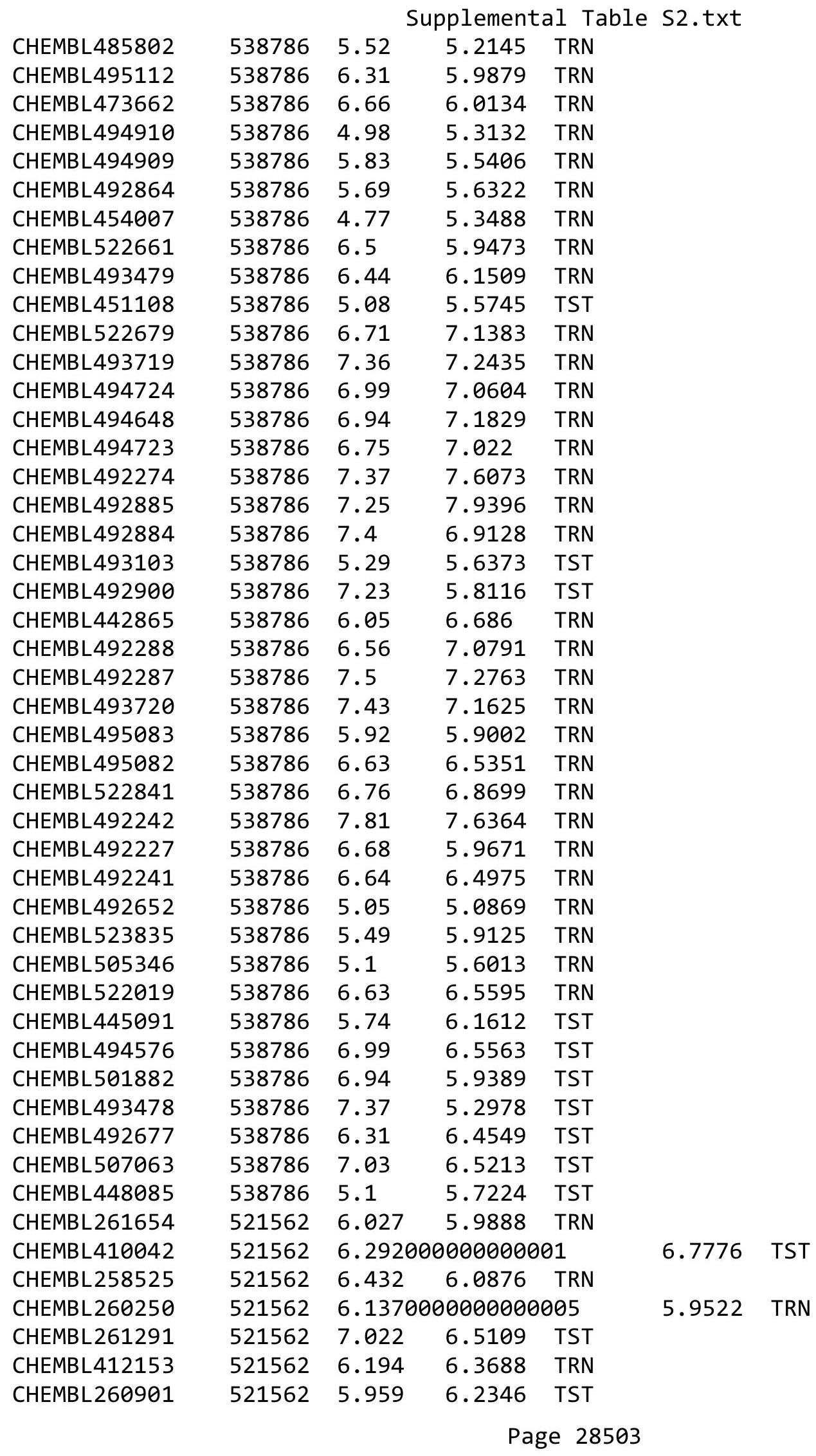




\begin{tabular}{|c|c|c|c|c|c|c|}
\hline \multirow[b]{2}{*}{ CHEMBL259626 } & \multicolumn{6}{|c|}{ suppsemerticas } \\
\hline & 521562 & 7.097 & 6.8707 & TRN & & \\
\hline CHEMBL259625 & 521562 & 5.854 & 6.0956 & TRN & & \\
\hline CHEMBL260023 & 521562 & 6.149 & 5.8841 & TRN & & \\
\hline CHEMBL436700 & 521562 & 7.347 & 7.352 & TRN & & \\
\hline CHEMBL410922 & 521562 & 5.046 & 5.7602 & TRN & & \\
\hline CHEMBL259619 & 521562 & \multicolumn{3}{|c|}{6.167000000000001} & 5.6172 & TRN \\
\hline CHEMBL261653 & 521562 & 6.301 & 5.9693 & TRN & & \\
\hline CHEMBL261151 & 521562 & 6.301 & 5.8334 & TST & & \\
\hline CHEMBL409107 & 521562 & 5.602 & 5.5975 & TRN & & \\
\hline CHEMBL258524 & 521562 & 5.886 & \multicolumn{3}{|c|}{6.8870000000000005} & TRN \\
\hline CHEMBL262589 & 521562 & \multicolumn{3}{|c|}{5.1370000000000005} & 5.5947 & TST \\
\hline CHEMBL260249 & 521562 & 6.187 & 6.3241 & TRN & & \\
\hline CHEMBL409358 & 521562 & 6.398 & 6.4064 & TRN & & \\
\hline CHEMBL261100 & 521562 & 5.62 & 5.9525 & TRN & & \\
\hline CHEMBL260074 & 521562 & 6.886 & 7.0983 & TST & & \\
\hline CHEMBL260073 & 521562 & 6.959 & 6.9757 & TRN & & \\
\hline CHEMBL409157 & 521562 & 6.347 & 6.41200 & 00006 & & TRN \\
\hline CHEMBL260706 & 521562 & 6.796 & 6.7915 & TRN & & \\
\hline CHEMBL259415 & 521562 & \multicolumn{3}{|c|}{6.337000000000001} & 6.8433 & TST \\
\hline CHEMBL259414 & 521562 & \multicolumn{3}{|c|}{6.1610000000000005} & 6.7049 & TST \\
\hline CHEMBL260029 & 521562 & \multicolumn{3}{|c|}{6.377000000000001} & 6.7464 & TST \\
\hline CHEMBL259827 & 521562 & 6.699 & 6.5709 & TST & & \\
\hline CHEMBL428781 & 521562 & 7.678 & 7.1916 & TRN & & \\
\hline CHEMBL261232 & 521562 & 5.699 & 6.2205 & TRN & & \\
\hline CHEMBL261231 & 521562 & 7.585 & 7.6708 & TRN & & \\
\hline CHEMBL261573 & 521562 & 6.456 & 6.5502 & TST & & \\
\hline CHEMBL410075 & 521562 & 6.032 & 6.0819 & TRN & & \\
\hline CHEMBL261187 & 521562 & 6.114 & 6.3427 & TRN & & \\
\hline CHEMBL260971 & 521562 & 6.114 & 5.9362 & TRN & & \\
\hline CHEMBL259408 & 521562 & 7.284 & 6.8123 & TRN & & \\
\hline CHEMBL411105 & 521562 & 6.721 & 6.6466 & TRN & & \\
\hline CHEMBL260003 & 521562 & \multicolumn{3}{|c|}{5.6579999999999995} & 6.1617 & TRN \\
\hline CHEMBL260076 & 521562 & 6.347 & 6.4851 & TRN & & \\
\hline CHEMBL261102 & 521562 & 7.125 & 6.5946 & TST & & \\
\hline CHEMBL261099 & 521562 & 6.027 & 6.4367 & TST & & \\
\hline CHEMBL410722 & 521562 & 5.824 & 6.4723 & TST & & \\
\hline CHEMBL260903 & 521562 & 6.229 & 6.3034 & TST & & \\
\hline CHEMBL260705 & 521562 & \multicolumn{3}{|c|}{7.071000000000001} & 6.9047 & TRN \\
\hline CHEMBL411868 & 521562 & 5.959 & 6.0063 & TRN & & \\
\hline CHEMBL 258785 & 521562 & 7.721 & 7.379 & TRN & & \\
\hline CHEMBL261019 & 521562 & \multicolumn{3}{|c|}{7.0360000000000005} & 6.3699 & TST \\
\hline CHEMBL261018 & 521562 & \multicolumn{3}{|c|}{6.167000000000001} & 5.8898 & TRN \\
\hline CHEMBL261572 & 521562 & \multicolumn{3}{|c|}{6.327999999999999} & 6.1424 & TRN \\
\hline CHEMBL411442 & 521562 & 6.0 & 6.399 & TRN & & \\
\hline CHEMBL260648 & 521562 & \multicolumn{3}{|c|}{6.377000000000001} & 5.9989 & TRN \\
\hline CHEMBL405892 & 521562 & 6.699 & 6.8725 & TRN & & \\
\hline CHEMBL260970 & 521562 & 6.886 & 6.7029 & TRN & & \\
\hline \multirow[t]{2}{*}{ CHEMBL260969 } & 521562 & 5.921 & 6.2226 & TRN & & \\
\hline & & \multicolumn{5}{|c|}{ Page 28504} \\
\hline
\end{tabular}




\begin{tabular}{|c|c|c|c|c|c|c|}
\hline & & \multicolumn{5}{|c|}{ Supplemental Table S2.txt } \\
\hline CHEMBL407966 & 521562 & 6.569 & 6.5477 & TRN & & \\
\hline CHEMBL261434 & 521562 & 7.26 & 6.6587 & TST & & \\
\hline CHEMBL261433 & 521562 & 6.20799 & 99999999 & 99 & 6.5075 & TST \\
\hline CHEMBL261149 & 521562 & 6.699 & 6.5447 & TST & & \\
\hline CHEMBL411104 & 521562 & 6.585 & 6.3809 & TST & & \\
\hline CHEMBL 259776 & 521562 & 6.921 & 6.9701 & TRN & & \\
\hline CHEMBL410043 & 521562 & 6.03600 & 00000000 & 005 & 6.2537 & TRN \\
\hline CHEMBL259236 & 521562 & 6.456 & 6.0748 & TRN & & \\
\hline CHEMBL260907 & 521562 & 7.921 & 7.4464 & TRN & & \\
\hline CHEMBL260906 & 521562 & 7.131 & 6.4276 & TST & & \\
\hline CHEMBL261337 & 521562 & 6.229 & 5.9571 & TRN & & \\
\hline CHEMBL260902 & 521562 & 6.678 & 7.0256 & TRN & & \\
\hline CHEMBL408717 & 521562 & 7.53799 & 99999999 & & 7.6212 & TRN \\
\hline CHEMBL 260514 & 521562 & 6.959 & 7.2832 & TRN & & \\
\hline CHEMBL409156 & 521562 & 7.102 & 6.8034 & TRN & & \\
\hline CHEMBL 259001 & 521562 & 7.319 & 7.3981 & TRN & & \\
\hline CHEMBL407411 & 521562 & 7.00899 & 99999999 & 995 & 7.1529 & TRN \\
\hline CHEMBL 260022 & 521562 & 7.26 & 7.6089 & TRN & & \\
\hline CHEMBL258995 & 521562 & 7.041 & 7.2615 & TRN & & \\
\hline CHEMBL 260804 & 521562 & 6.638 & 6.91799 & 999999999 & & TRN \\
\hline CHEMBL 261742 & 521562 & 7.796 & 7.3759 & TRN & & \\
\hline CHEMBL258956 & 521562 & 7.013 & 6.99299 & 999999999 & & TRN \\
\hline CHEMBL260756 & 521562 & 7.53799 & 99999999 & 99 & 7.4787 & TRN \\
\hline CHEMBL259199 & 521562 & 7.31 & 7.1637 & TRN & & \\
\hline CHEMBL 259407 & 521562 & 6.721 & 6.7876 & TRN & & \\
\hline CHEMBL406221 & 521562 & 7.796 & 7.2751 & TRN & & \\
\hline CHEMBL1522050 & 752591 & 7.317 & 7.5136 & TRN & & \\
\hline CHEMBL1577023 & 752591 & 6.0 & 6.3471 & TRN & & \\
\hline CHEMBL1878737 & 752591 & 6.2823 & 6.5449 & TRN & & \\
\hline CHEMBL295234 & 752591 & 5.5575 & 7.3397 & TST & & \\
\hline CHEMBL1724644 & 752591 & 6.8013 & 6.1597 & TRN & & \\
\hline CHEMBL1557985 & 752591 & 5.1409 & 5.3146 & TRN & & \\
\hline CHEMBL1325241 & 752591 & 5.9626 & 6.0219 & TST & & \\
\hline CHEMBL1329712 & 752591 & 6.3224 & 6.5156 & TRN & & \\
\hline CHEMBL1429919 & 752591 & 5.8508 & 6.1318 & TRN & & \\
\hline CHEMBL1256360 & 752591 & 6.4056 & 6.4189 & TST & & \\
\hline CHEMBL1449091 & 752591 & 6.6144 & 6.6933 & TRN & & \\
\hline CHEMBL1426242 & 752591 & 6.8761 & 6.6627 & TRN & & \\
\hline CHEMBL1590854 & 752591 & 6.0964 & 6.1789 & TRN & & \\
\hline CHEMBL1306990 & 752591 & 5.5243 & 5.3452 & TRN & & \\
\hline CHEMBL1600429 & 752591 & 5.2299 & 5.0733 & TRN & & \\
\hline CHEMBL1348147 & 752591 & 5.8356 & 5.6464 & TRN & & \\
\hline CHEMBL1528906 & 752591 & 8.1135 & 7.9498 & TRN & & \\
\hline CHEMBL1364979 & 752591 & 5.9031 & 6.3518 & TST & & \\
\hline CHEMBL1368962 & 752591 & 5.7595 & 5.7041 & TRN & & \\
\hline CHEMBL1436649 & 752591 & 5.9706 & 5.5833 & TRN & & \\
\hline CHEMBL1322514 & 752591 & 7.567 & 7.3791 & TRN & & \\
\hline CHEMBL1598434 & 752591 & 7.4023 & 6.6431 & TRN & & \\
\hline
\end{tabular}


Supplemental Table S2.txt

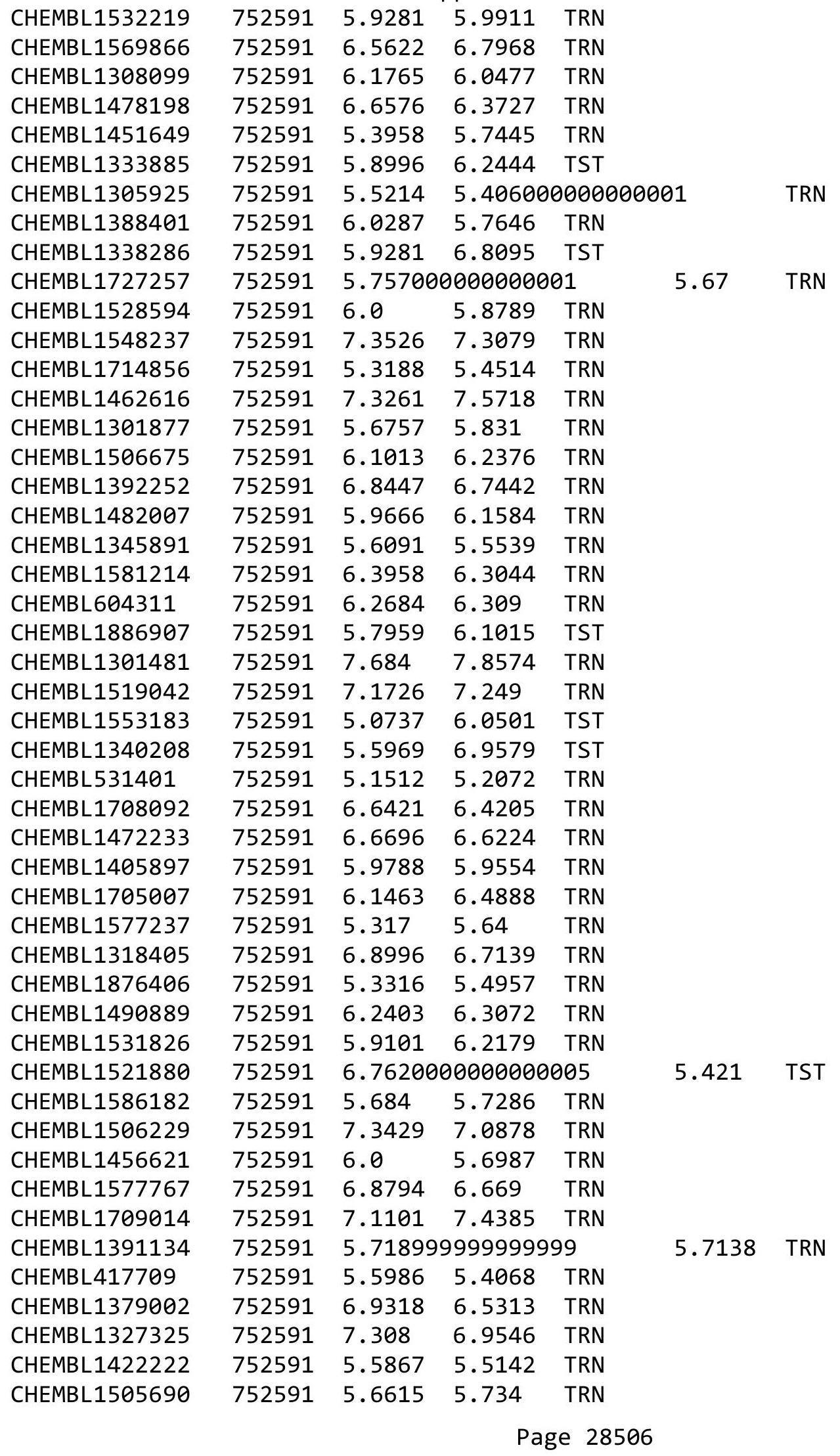




\begin{tabular}{|c|c|c|c|c|c|c|}
\hline \multirow[b]{2}{*}{ CHEMBL1722488 } & \multicolumn{6}{|c|}{ Supplemental Table S2.txt } \\
\hline & 752591 & 6.0964 & 6.4443 & TRN & & \\
\hline CHEMBL1422244 & 752591 & 5.71 & 5.9758 & TRN & & \\
\hline CHEMBL1479957 & 752591 & 7.466 & 7.5043 & TRN & & \\
\hline CHEMBL1383213 & 752591 & 6.5986 & 6.6088 & TRN & & \\
\hline CHEMBL1346173 & 752591 & 5.4437 & 5.374 & TRN & & \\
\hline CHEMBL1424697 & 752591 & 5.0921 & 5.8239 & TST & & \\
\hline CHEMBL1562748 & 752591 & 7.3799 & 7.2125 & TRN & & \\
\hline CHEMBL1570111 & 752591 & 7.0915 & 7.1701 & TRN & & \\
\hline CHEMBL1500954 & 752591 & 5.032 & 6.9193 & TST & & \\
\hline CHEMBL1570251 & 752591 & 5.5452 & 5.3992 & TRN & & \\
\hline CHEMBL1337858 & 752591 & 6.4647 & 6.2887 & TRN & & \\
\hline CHEMBL1545591 & 752591 & 6.6536 & 6.6456 & TRN & & \\
\hline CHEMBL1728955 & 752591 & 6.4522 & 5.5829 & TST & & \\
\hline CHEMBL1524289 & 752591 & 5.1296 & 5.5681 & TRN & & \\
\hline CHEMBL1325250 & 752591 & 5.3883 & 5.6776 & TRN & & \\
\hline CHEMBL1704973 & 752591 & 5.5735 & 5.7584 & TRN & & \\
\hline CHEMBL1575889 & 752591 & 7.0899 & 5.6748 & TST & & \\
\hline CHEMBL1464795 & 752591 & 5.5058 & 5.5145 & TRN & & \\
\hline CHEMBL1415227 & 752591 & 5.4763 & 5.3322 & TRN & & \\
\hline CHEMBL1387056 & 752591 & 5.0575 & 5.2982 & TRN & & \\
\hline CHEMBL1459608 & 752591 & 5.2426 & 5.6287 & TRN & & \\
\hline CHEMBL531322 & 752591 & 6.308 & 6.63 & TRN & & \\
\hline CHEMBL1370616 & 752591 & 6.2472 & 6.1319 & TRN & & \\
\hline CHEMBL1559831 & 752591 & 6.6716 & 6.5314 & TRN & & \\
\hline CHEMBL1351178 & 752591 & 6.0004 & 6.0777 & TRN & & \\
\hline CHEMBL1457704 & 752591 & 6.2111 & 6.6627 & TRN & & \\
\hline CHEMBL1424678 & 752591 & 6.0 & 5.6733 & TRN & & \\
\hline CHEMBL1538061 & 752591 & 7.5376 & 7.5732 & TRN & & \\
\hline CHEMBL1327806 & 752591 & 6.5157 & 6.3585 & TRN & & \\
\hline CHEMBL1376574 & 752591 & 6.0119 & 5.7783 & TRN & & \\
\hline CHEMBL1393806 & 752591 & 5.8894 & 5.6751 & TRN & & \\
\hline CHEMBL1406272 & 752591 & 5.8794 & 5.7155 & TRN & & \\
\hline CHEMBL1612392 & 752591 & 5.2534 & 5.2218 & TRN & & \\
\hline CHEMBL3211107 & 752591 & 6.2314 & 5.4227 & TST & & \\
\hline CHEMBL1319108 & 752591 & 7.098 & 6.6387 & TRN & & \\
\hline CHEMBL1562838 & 752591 & 8.3335 & 7.4624 & TRN & & \\
\hline CHEMBL1330871 & 752591 & 7.2161 & 7.1002 & TRN & & \\
\hline CHEMBL1439691 & 752591 & 7.4202 & 7.2966 & TRN & & \\
\hline CHEMBL1506379 & 752591 & 7.3468 & 7.5303 & TRN & & \\
\hline CHEMBL1361693 & 752591 & 5.4306 & 6.2476 & TST & & \\
\hline CHEMBL1450612 & 752591 & 5.8539 & 5.9706 & TRN & & \\
\hline CHEMBL1396351 & 752591 & 5.0768 & 5.9358 & TST & & \\
\hline CHEMBL1483308 & 752591 & 5.3635 & 5.3287 & TRN & & \\
\hline CHEMBL1531486 & 752591 & 5.38200 & 30000000 & $\partial 1$ & 5.3869 & TRN \\
\hline CHEMBL1497287 & 752591 & 5.1858 & 6.1719 & TST & & \\
\hline CHEMBL1559039 & 752591 & 6.2434 & 6.2323 & TRN & & \\
\hline CHEMBL1585368 & 752591 & 7.3098 & 7.3118 & TRN & & \\
\hline CHEMBL1444240 & 752591 & 8.0883 & 8.2287 & TRN & & \\
\hline
\end{tabular}

Page 28507 
Supplemental Table S2.txt

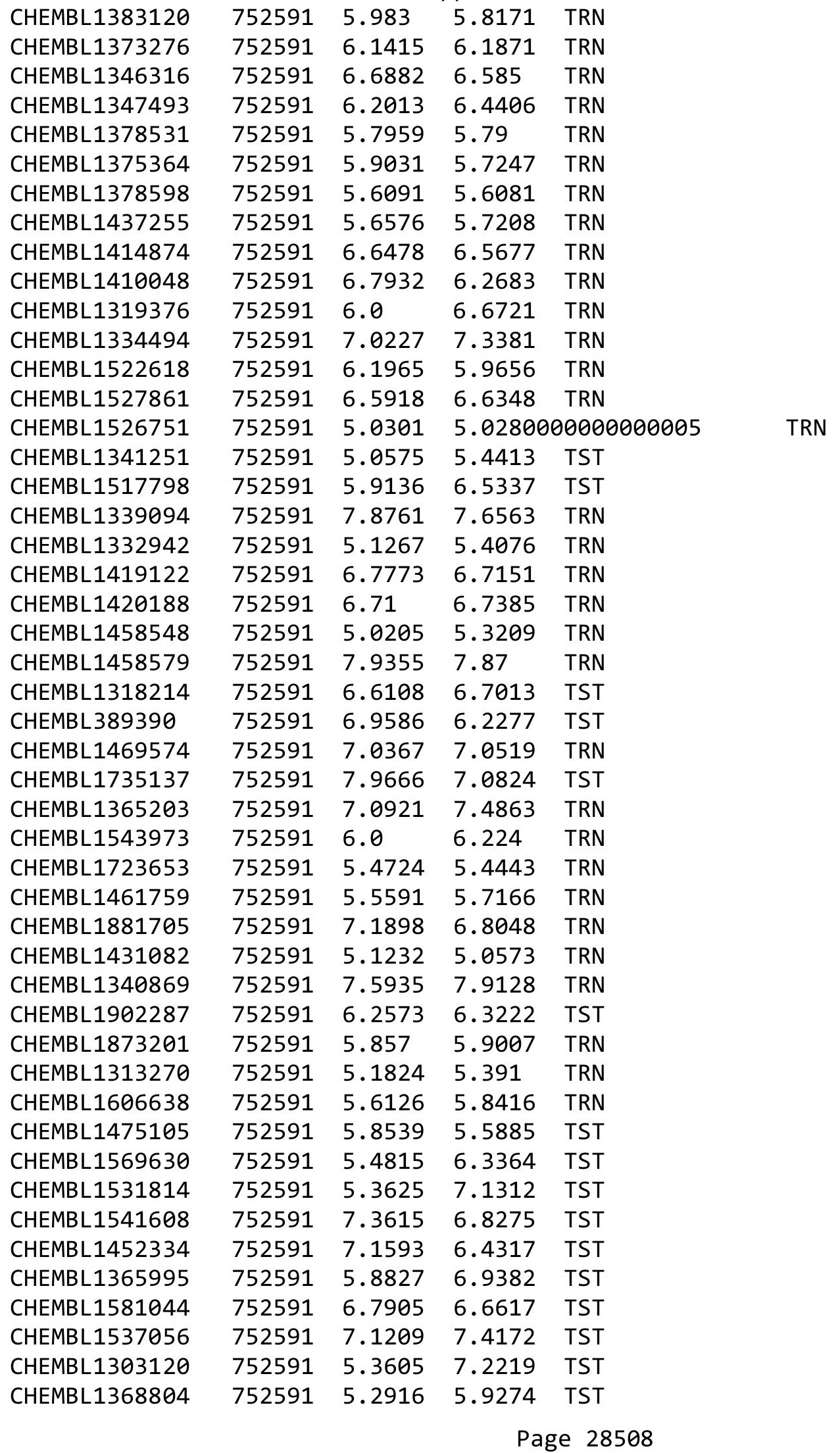


Supplemental Table S2.txt

\begin{tabular}{|c|c|c|c|c|c|c|}
\hline CHEMBL1491674 & 752591 & 7.4056 & 7.4188 & TST & & \\
\hline CHEMBL1573444 & 752591 & 5.2161 & 5.6014 & TST & & \\
\hline CHEMBL1604735 & 752591 & 5.2062 & 6.2531 & TST & & \\
\hline CHEMBL1539906 & 752591 & 5.3152 & 7.3643 & TST & & \\
\hline CHEMBL1479163 & 752591 & 7.4214 & 7.4537 & TST & & \\
\hline CHEMBL1401186 & 752591 & 6.0 & 6.1439 & TST & & \\
\hline CHEMBL1581826 & 752591 & 6.15799 & 99999999 & 995 & 5.2203 & TST \\
\hline CHEMBL1484690 & 752591 & 7.6925 & 6.8951 & TST & & \\
\hline CHEMBL1373386 & 752591 & 6.6696 & 6.8518 & TST & & \\
\hline CHEMBL1518070 & 752591 & 5.7696 & 6.3674 & TST & & \\
\hline CHEMBL266197 & 213817 & 5.6383 & 5.636 & TRN & & \\
\hline CHEMBL6517 & 213817 & 4.3979 & 4.404 & TRN & & \\
\hline CHEMBL267678 & 213817 & 5.0 & 4.9331 & TRN & & \\
\hline CHEMBL6417 & 213817 & 3.0 & 2.9776 & TRN & & \\
\hline CHEMBL 266064 & 213817 & 4.7696 & 5.61 & TST & & \\
\hline CHEMBL 267456 & 213817 & 4.3979 & 4.3888 & TRN & & \\
\hline CHEMBL 266798 & 213817 & 4.3979 & 4.4006 & TRN & & \\
\hline CHEMBL269075 & 213817 & 4.6778 & 4.6708 & TRN & & \\
\hline CHEMBL6215 & 213817 & 3.0 & 5.2067 & TST & & \\
\hline CHEMBL6229 & 213817 & 5.6021 & 5.905 & TST & & \\
\hline CHEMBL6442 & 213817 & 5.0 & 5.0071 & TRN & & \\
\hline CHEMBL 263080 & 213817 & 4.1871 & 4.1736 & TRN & & \\
\hline CHEMBL6249 & 213817 & 5.4559 & 5.4723 & TRN & & \\
\hline CHEMBL6381 & 213817 & 4.3979 & 4.4049 & TRN & & \\
\hline CHEMBL268099 & 213817 & 5.0 & 5.0033 & TRN & & \\
\hline CHEMBL6369 & 213817 & 4.699 & 4.707 & TRN & & \\
\hline CHEMBL269056 & 213817 & 4.7447 & 5.7172 & TST & & \\
\hline CHEMBL6370 & 213817 & 4.8239 & 4.8115 & TRN & & \\
\hline CHEMBL268667 & 213817 & 4.3979 & 4.4005 & TRN & & \\
\hline CHEMBL6278 & 213817 & 5.0 & 4.9925 & TRN & & \\
\hline CHEMBL 269598 & 213817 & 4.3372 & 4.3453 & TRN & & \\
\hline CHEMBL 269497 & 213817 & 4.3979 & 4.412 & TRN & & \\
\hline CHEMBL6762 & 213817 & 4.3979 & 4.4023 & TRN & & \\
\hline CHEMBL 269495 & 213817 & 4.7212 & 5.8418 & TST & & \\
\hline CHEMBL6258 & 213817 & 4.3979 & 4.394 & TRN & & \\
\hline CHEMBL 266460 & 213817 & 4.3979 & 4.4098 & TRN & & \\
\hline CHEMBL 266799 & 213817 & 4.4089 & 5.2738 & TST & & \\
\hline CHEMBL6542 & 213817 & 6.0 & 6.0015 & TRN & & \\
\hline CHEMBL6523 & 213817 & 4.699 & 5.5225 & TST & & \\
\hline CHEMBL 6275 & 213817 & 4.3979 & 4.4213 & TRN & & \\
\hline CHEMBL6248 & 213817 & \multicolumn{3}{|c|}{6.757000000000001} & 5.9119 & S \\
\hline CHEMBL 262570 & 213817 & 5.0 & 4.9993 & TRN & & \\
\hline CHEMBL 269570 & 213817 & 5.0 & 5.0112 & TRN & & \\
\hline CHEMBL 268567 & 213817 & 4.3979 & 4.4105 & TRN & & \\
\hline CHEMBL 266429 & 213817 & 4.7212 & 4.7195 & TRN & & \\
\hline CHEMBL 268530 & 213817 & 4.3979 & 4.3727 & TRN & & \\
\hline CHEMBL6324 & 213817 & 4.3979 & 4.387 & TRN & & \\
\hline CHEMBL6371 & 213817 & 5.5686 & 5.5553 & TRN & & \\
\hline
\end{tabular}




\begin{tabular}{|c|c|c|c|c|c|}
\hline \multicolumn{6}{|c|}{ Supplemental Table S2.txt } \\
\hline CHEMBL266198 & 213817 & 4.3979 & 4.4019 & TRN & \\
\hline CHEMBL6316 & 213817 & 4.3979 & 4.4104 & TRN & \\
\hline CHEMBL267127 & 213817 & 5.4559 & 5.9499 & TST & \\
\hline CHEMBL6264 & 213817 & 5.0 & 5.0218 & TRN & \\
\hline CHEMBL 263081 & 213817 & 5.699 & 5.6853 & TRN & \\
\hline CHEMBL6534 & 213817 & 4.3979 & 4.4045 & TRN & \\
\hline CHEMBL 6430 & 213817 & 4.2291 & 5.345 & TST & \\
\hline CHEMBL 266572 & 213817 & 5.6778 & 4.5002 & TST & \\
\hline CHEMBL6612 & 213817 & 5.0 & 4.994 & TRN & \\
\hline CHEMBL 267938 & 213817 & 5.0 & 5.0009 & TRN & \\
\hline CHEMBL6320 & 213817 & 4.3979 & 5.2521 & TST & \\
\hline CHEMBL 6257 & 213817 & 5.8861 & 5.875 & TRN & \\
\hline CHEMBL267914 & 213817 & 4.8239 & 4.8375 & TRN & \\
\hline CHEMBL 267125 & 213817 & 5.0 & 4.9994 & TRN & \\
\hline CHEMBL266708 & 213817 & 4.3979 & 4.4077 & TRN & \\
\hline CHEMBL 268070 & 213817 & 5.0 & 5.019 & TRN & \\
\hline CHEMBL 6830 & 213817 & 6.1135 & 5.0033 & TST & \\
\hline CHEMBL428508 & 213817 & 4.3979 & 3.9444 & TST & \\
\hline CHEMBL3577549 & 1496999 & 4.5082 & 4.5041 & TRN & \\
\hline CHEMBL3577539 & 1496999 & 5.6253 & 5.4094 & TRN & \\
\hline CHEMBL3577537 & 1496999 & 5.0809 & 4.959 & TRN & \\
\hline CHEMBL3577519 & 1496999 & 4.5077 & 4.4986 & TRN & \\
\hline CHEMBL 3577524 & 1496999 & 5.5361 & 5.5377 & TRN & \\
\hline CHEMBL3577531 & 1496999 & 4.6897 & 4.6458 & TRN & \\
\hline CHEMBL 3577546 & 1496999 & 4.6696 & 4.5135 & TRN & \\
\hline CHEMBL3577543 & 1496999 & 4.9126 & 5.1346 & TRN & \\
\hline CHEMBL3577552 & 1496999 & 6.1135 & 5.7258 & TRN & \\
\hline CHEMBL3577530 & 1496999 & 4.6021 & 4.44 & TST & \\
\hline CHEMBL3577527 & 1496999 & 5.6038 & 5.6363 & TRN & \\
\hline CHEMBL 3577534 & 1496999 & 5.7986 & 5.6265 & TRN & \\
\hline CHEMBL3577550 & 1496999 & 5.0985 & 5.2519 & TRN & \\
\hline CHEMBL 3577533 & 1496999 & 5.7496 & 5.8067 & TRN & \\
\hline CHEMBL3577511 & 1496999 & 6.2076 & 6.2484 & TRN & \\
\hline CHEMBL3577525 & 1496999 & 4.4477 & 5.0802 & TST & \\
\hline CHEMBL 3577521 & 1496999 & 4.8416 & 4.6822 & TRN & \\
\hline CHEMBL3577506 & 1496999 & 5.0605 & 5.1927 & TRN & \\
\hline CHEMBL 3577538 & 1496999 & 4.9126 & 4.9152 & TRN & \\
\hline CHEMBL3577529 & 1496999 & 4.6484 & 4.6766 & TST & \\
\hline CHEMBL 3577508 & 1496999 & 5.2076 & 5.2833 & TST & \\
\hline CHEMBL 3577512 & 1496999 & 5.0691 & 4.8882 & TRN & \\
\hline CHEMBL3577514 & 1496999 & 5.2676 & 5.4294 & TST & \\
\hline CHEMBL 3577513 & 1496999 & 5.2782 & 5.4951 & TST & \\
\hline CHEMBL3577532 & 1496999 & 5.7986 & 5.66799 & 9999999999 & TRN \\
\hline CHEMBL3577505 & 1496999 & 6.1427 & 5.9157 & TRN & \\
\hline CHEMBL3577542 & 1496999 & 5.2125 & 4.9085 & TST & \\
\hline CHEMBL 3577548 & 1496999 & 5.3468 & 5.5767 & TRN & \\
\hline CHEMBL 3577547 & 1496999 & 4.5441 & 4.5898 & TRN & \\
\hline CHEMBL3577516 & 1496999 & 5.6517 & 5.7192 & TRN & \\
\hline
\end{tabular}

Page 28510 
Supplemental Table S2.txt

$\begin{array}{lllll}\text { CHEMBL3577515 } & 1496999 & 5.5482 & 5.547000000000001\end{array}$ TRN

